
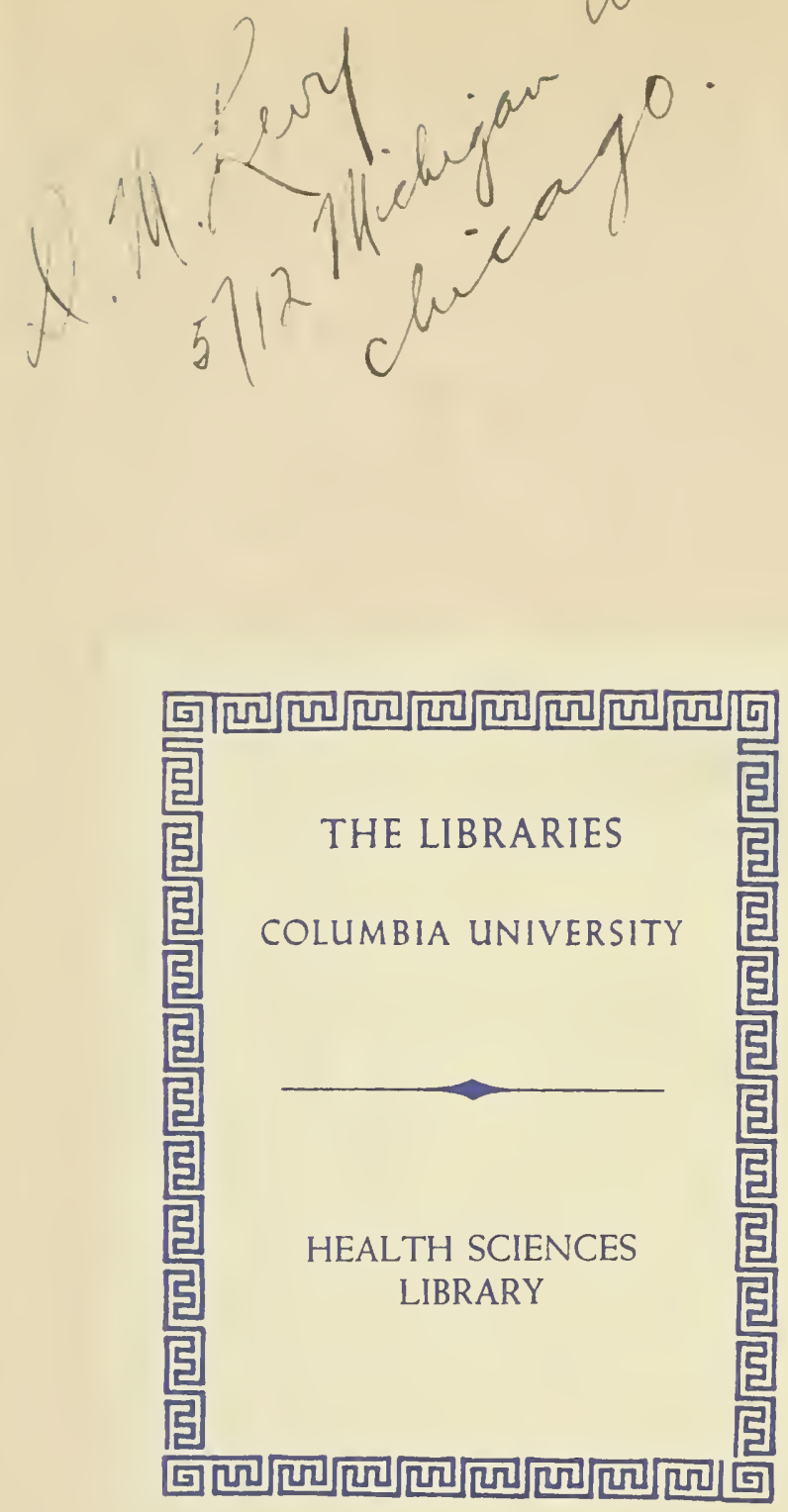


Digitized by the Internet Archive in 2010 with funding from Columbia University Libraries 

TEXT-BOOK OF ANATOMY 
PUBLISHED BY THE JOINT COMMITTEE OF HENRY FROWDE AND HODDER \& STOUGHTON AT THE OXFORD PRESS WAREHOUSE, FALCON SQUARE, LONDON, E.C. 


\section{CUNNINGHAM'S TEXT-BOOK}

OF

A N A T O M Y

EDITED BY

ARTHUR ROBINSON, M.D., F.R.C.S. ED.

PROFESSOR OF ANATOMY, UNIVERSITY OF EDINBURGH

FOURTH EDITION, ENLARGED AND REWRITTEN

ILLUSTRATED BY II 24 FIGURES FROM ORIGINAL DRAWINGS

637 OF WHICH ARE PRINTED IN COLORS,

AND TWO PLATES

NEW YORK

WILLIAM WOOD AND COMPANY

MDCCCCXIV 


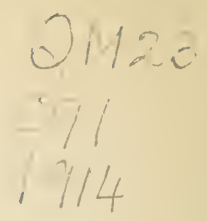

FIRST EDITION 1902.

SECOND EDITION 1905.

THIRD EDITION 1909.

FOURTH EDITION 1914. 
TO

Zir Tralliam Turner, 登, 代.B.

F.R.S., M.B., LL.D., D.C.L., D.Se

IN RECOGNITION OF

HIS EMINENCE AS AN ANATOMIST

AND HIS ITFLUENCE AS A TEACHER

\section{THIS VOLUME}

IS DEDICATED

BY THOSE OF HIS FORHER PUPILS AND ASSISTANTS

WHO HAVE CONTRIBUTED

TO ITS PAGES 


\section{PREFACE TO THE FOURTH EDITION.}

THE fourth edition of Cunningham's Text-book of Anatomy has lacked during its preparation the able guidance of its original editor, but the various contributors have attempted to maintain the standard of excellence which was Professor Cunningham's ideal.

The deaths of Professor Cunningham, Professor Birmingham, and Professor A. H. Young have necessitated changes in the authorship of several of the articles. Every section has been fully revised; some have been partially and others have been completely rewritten.

In the majority of the sections numerous additional illustrations have been added, or the original illustrations have been replaced by new figures better adapted to their purpose, and colour has been largely used, particulariy in diagrams.

The sections originally written by Professor Cunningham were the Central Nervous System, the Respiratory System, and the Ductless Glands. The account of the Central Nervous System has been revised and largely rewritten by Professor Elliot Smith of Manchester. The Respiratory System has been revised and partly rewritten by Professor Berry of Melbourne; and the section dealing with the Ductless Glands has been rewritten by Professor A. Campbell Geddes of Dublin.

The description of the Alimentary System, originally written by Professor Birmingham, has been revised and partially rewritten by Professor Waterston of King's College, London.

With regard to the sections dealing with General Embryology and the Vascular System, in the original preparation of which I was associated with my senior colleague and friend, Professor A. H. Young, I have completely rewritten the account of General Embryology, and have revised and partially rewritten the account of the Vascular System.

It may be found, where the sections written by various authors overlap one another, that there occur, in this as in previous editions, different accounts of certain phenomena concerning which our knowledge is still in an indefinite stage, and it must be understood that the authors of the various sections are solely responsible for the opinions expressed in their own sections.

The Basle anatomical terminology has been adopted throughout, except in those cases where the results of recent researches have shown that the terms of that nomenclature are incorrect, or where the terms themselves did not conform with the principles of the terminology.

It is scarcely necessary, to-day, to urge reasons for the use of the Basle nomenclature, for it is now generally recognised, not only that it is based on 
sound general principles, but also that it is, at the same time, less cumbrous and more definitely instructive than the terminology previously in use in this country.

One of the recognised functions of a preface is to give the editor the opportunity of expressing his thanks to those who have assisted in the production of the work, and I gladly avail myself of this function.

My thanks are due to all the authors for their courtesy and consideration. To Mr. J. Keogh Murphy, F.R.C.S., for the preparation of an extremely useful glossary and index, and for ever-ready help and many valuable suggestions. To Dr. E. B. Jamieson for assistance in the revision of the text, and for the preparation of specimens from which some of the new illustrations were made.

I am also greatly indebted to Professor Keibel, and to Mr. Gustav Fischer of Jena for permission to copy eight figures from Normentaflen zur Entwicklungsgeschichte des Menschen; to Professor Gustav Retzius for permission to use figures from his monographs; and to Professors Mall, Felix, and Tandler for permission to utilise the results of their work in the preparation of diagrams.

Most of the new figures in this edition have been drawn by Mr. J. T. Murray with his usual skill and appreciation, and the remainder have been prepared by Mr. Frank Butterworth from designs made by the authors of the articles in which the figures appear.

ARTHUR ROBINSON.

EDInburgh, April 1913. 


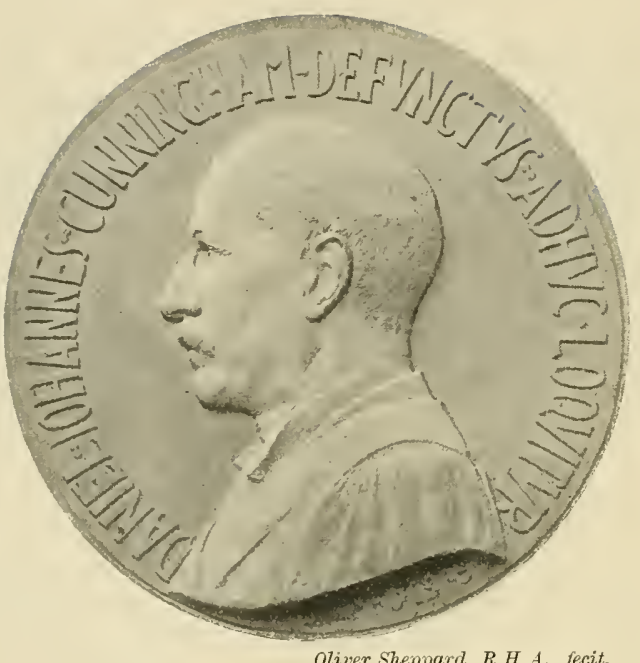

\section{DANIEL JOHANNES CUNNINGHAM ADHUC LOQUITUR.}

DeMoxstrator of ANATOMY, UNIVERsity OF EDINBURgh, 1874-1882. Professor of Anatomy, Royal College of Surgeons, Dublin, 1882-1883. Professor of Anatomit, Trinity College, Dublin, 1883-1903. Professor of Anatomy, University of Edinborgh, 1903-1909. 


\section{LIST OF CONTRIBUTORS}

RICHARD J. A. BERRY, M.D., F.R.C.S. Ed.,

Professor of Anatomy, University of Melbourne.

(The Respiratory System.)

A. FRANCIS DIXON, M.B., D.Sc. (Dubl.),

Professor of Anatomy, Trinity College, Dublin.

(The Urino-genital System.)

A. CAMPBELL GEDDES, M.D.,

Professor of Anatomy, Royal College of Surgeons of Ireland.

(The Ductless Glands.)

DAVID HEPBURN, M.D., F.R.S.E.,

Professor of Anatomy, University College, Cardiff.

(Arthrology.)

ROBERT HOWDEN, M.A., M.B.,

Professor of Anatomy, University of Durham.

(The Organs of Sense and the Integument.)

A. M. PATERSON, M.D., F.R.C.S.,

Professor of Anatomy, University of Liverpool.

(Myology, The Spinal and Cerebral Nerves, The Sympathetic Nervous System.)

ARTHUR ROBINSON, M.D., F.R.C.S.Ed.,

Professor of Anatomy, University of Edinburgh.

(General Embryology, The Vascular System.)

G. ELLIOT SMITH, M.D., F.R.S.,

Professor of Anatomy, University of Manchester.

(The Central Nervous System.)

HAROLD J. STILES, M.B., F.R.C.S. Ed.,

Surgeon to the Royal Hospital for Sick Children, Edinburgh.

(Surface and Surgical Anatomy.)

ARTHUR THOMSON, M.A., M.B., F.R.C.S.,

Professor of Human Anatomy, University of Oxford.

(Osteology.)

DAVID WATERSTON, M.A., M.D., F.R.C.S. Ed.,

Professor of Anatomy, University of London.

(The Digestive System.)

The New Index and Glossary are the work of Mr. J. Krocin Morphy, M.C. Cantab., F.R.C.S. 


\section{CONTENTS.}

Glossary of Variations between Ixternational and Old Terminology

PAGW:

$\mathrm{XV}$

1

\section{GENERAL EMBRYOLOGY.}

The Animal Cells .

Reproduction of Cells

Amitotic and Mitotic Division of Cells

The Ovum

Its Structure

Its Maturation.

The Spermatozoon .

Fertilisation

Segmentation

Formation of Blastula

Ectoderm and Entoderm Embryonic Area

Extra-Embryonic Cœlom

Differentiation of the Embryonic Arez

Neural Groove

Formation of Notochord and Secondary Mesoderm

The Paraxial Mesoderm . Mesodermic Somites.

Early Stages in Development of the Nervous System

Nerve Ganglia and Chromaffin Tissues

Differentiation of the Neural Tube . Fute of Walls of Primitive Brain Vesicles

Fate of Cavities of Primitive Brain

Folding off of the Embryo

\section{OSTEOLOGY.}

The Skeleton .

Composition of Bone

Structure of Bone

Ossification and Growth of Bones

The Vertebral Column

A Typical Vertebra

Cervical Vertebræ

Thoracic Vertebræ

Lumbar Vertebræ

False or Fixed Vertebræ

The Sacrum

The Coccyx

The Vertebral Column as a whole

Professor ARthur Robinson.

\begin{tabular}{r|} 
PAGE \\
7 \\
8 \\
\\
9 \\
13 \\
13 \\
15 \\
17 \\
20 \\
21 \\
21 \\
21 \\
22 \\
22 \\
\\
23
\end{tabular}

23

24

28

28

30

32

33

33

36

37

Formation of the Embryo

PAGE

Development of the Limbs . $\quad 39$

Primitive Alimentary Canal . . . 41

The Fore-Gut-Pharynx and Stomatodæum .

Visceral Clefts and Arches $\quad 42$

Rudiments of Respiratory System . 44

External Ear, Tympanic Cavity, and Auditory Tube . . . 44

The Tongue . . . . . 45

Derivatives of the Mid-Gut . . . 47

The Hind-Gut, Anal Passage, and Postanal Gut

Derivatives of the StomatodæumThe Nose and Mouth . . 48

The Internal Ear . . . . . 50

Protection and Nutrition of the Embryo during its Intra-uterine Existence 53

Fœtal Membranes and Appendages . 53

Chorion. . . . 53

Amnion . . . . . $\quad 54$

Body-Stalk . . . . . . 54

Allantois . . . . . 54

Umbilical Cord $\quad$. $\quad . \quad$. $\quad 55$

Yolk-Sac or Umbilical Vesicle. . $\quad 55$

The Placenta . . . . . . 56

Primitive Vascular System and Fœtal Circulation

Summary of the External Features of the Human Embryo and Fotus at different periods of Development .

Professor Arthur Thomson.

81
Development of the Vertebral Column . 102

The Cartilaginous Column . . . 102

Ossification of the Vertebræ . . . 104

The Sternum . . . . . . . 106

The Ribs . . . . . . . 109

The Costal Cartilages . . . . . 113

The Thorax as a whole . . . . 113

The Bones of the Skull . . . . 115

Frontal Bone . . . . . . 115

Parietal Bones . . . . . . 118

Occipital Bone. . . . . 120

Temporal Bones . . . . $\quad$. 125

Sphenoid Bone. . . . . 133 
Ethmoid Bone

Inferior Conchæe

The Lacrimal Bones

The Vomer

Nasal Bones

Sutural Bones

Bones of the Face

Maxillæ

Palate Bones

Zygomatic Bones

Niandible.

The Hyoid Bone

The Skull as a whole

The Skull from the Front

The Skull from the Side

Posterior Aspect of the Skull

Upper Aspect of Skull

Base of the Skull

The Skull in Sectiou

Upper Surface of the Base of the Skull

Medial Sagittal Section of the Skull

Nasal Fossæ

Nasal Septum

Air-sinuses in connexion with the Nasal Fossæ .

Frontal Seetions of the Skull

Horizontal Section of the Skull

Sexual Differences in the Skull

The Skull at Birth

Differences due to Age

Bones of the Upper Extremity

Clavicle

Scapula

Humerus

THE ARTICULATIONS OR JOINTS.

Syndesmology

Synarthroses

Diarthroses or Movable Joints .

Structures which enter into the Formation of Joints

The Different Kinds of Movement at Joints

The Development of Joints

Morphology of Ligaments

Ligaments of the Vertebral Columm and Skull

Articulation between the Atlas and Epistropheus

Articulation between the Atlas and the Cranium

Mandibular Joint

Cranial Ligaments not directly associated with Articulations

The Joints of the Thorax

Joints of the Heads of the Ribs

Costo-transrerse Joints

Articulations between the Ribs and their Cartilages

Interchondral Joints

Sterno-costal Joints

Sternal Articulations

The Articulations of the Superior Extremity .

THE MUSCULAR SYSTEM.

The Mruscular System

Fascire

Description of the Muscles

\section{Ũlna}

Radius

The Carpus

The Carpus as a whole

The Metacarpus

The Phalanges

Sesamoid Bones

Bones of the Lower Limb

The Pelric Girdle and the Lower Extremity.

The Hip Bone

The Pelvis

The Femur

The Patella

The Tibia .

The Fibula

Tarsus

Talus

Calcaneus

Naricular Bone of the Foot

Cuneiform Bones

Cuboid Bone

The Tarsus as a whole

The Metatarsus.

Phalanges of the Foot

Sesamoid Bones of the Foot

Atppendices-

Architecture of the Bones of the Skeleton

Tariations in the Skeleton

Serial Homologies of the Tertebræ

Measurements and Indices employed in Physical Anthropology

Derelopment of the Chondro-cranium and IIorphology of the Skull

Morphology of the Limbs

\section{Professor David Hepburx.}

Articulations of the Claricle .

317

Sterno-cla vicular Joint

317

Acromio-clavicular Joint

Ligaments of the Scapula

318

Shoulder-joint

Elbow-joint

The Radio-ulnar Joints

The Radio-carpal Joint

Carpal Joints

Intermetacarpal Joints

Carpo-metacarpal Joints

Metacarpo-phalangeal Joints

Interphalangeal Joints

Articulationsand Ligaments of the Pelvis Lumbo-sacral Joints Sacro-iliac Joint

Symphysis Pubis

iculations of the Inferior Extremity

The Hip-joint

The Knee-joint

The Tibio-tibular Joints

The Joints of the Foot

The Ankle-joint

The Intertarsal Joints

The Tarso-metatarsal Joints

Intermetatasal Joints

Ifetatarso-phalangeal Joints

Interphalangeal Joints

320

323

326

328

329

332

332

333

334

334

335

335

337

339

$3: 39$

342

349

351

351

354

359

360

360

361

Professor A. Mrefitile Paterson. 
Fasciae of the Back

The Superticial Muscles of the Back

The Fascice and Muscles of the Pectoral Region

Fascie of the Pectoral liegion

Muscles of the Pectoral Region

Fascice and Muscles of the Shoulder

Muscles of the Shoulder

Fascia and Muscles of the Arm

Fascia and Muscles of the Forearm and Hand

The Muscles of the Frout and Miedial Aspect of the Forearm.

Superficial Muscles

Intermediate Layer.

Deep Layer

Short II uscles of the Hand

Muscles of the Thumb

Muscles of the Little Finger .

The Interosseous Muscles of the Hand

The Muscles on the Dorsal Surfiace of the Forear'm

Superficial Muscles .

Deep Muscles

The Lower Limb

Fasciæ and Muscles of the Thigh and Buttock .

Fascia of the Thigh and Buttock .

Muscles of the Thigh and Buttock

The Muscles on the Anterior Aspect of the Thigh

The Muscles on the Medial Side of the Thigh

The Muscles of the Buttock

The Muscles on the Posterior Aspect of the Thigh

The Fasciæ and Mruscles of the Leg and Foot

Fasciæ of the Leg and Foot

The Muscles on the Front of the Leg and Dorsum of the Foot

369

369

373

373

378

382

385

385

388

388

391

392

393

394

395

396

398

402

402

402

405

405

411

414

418

422

422

424

THE CENTRAL NERVOUS SYSTEM.

Elements of the Central Nervous SYSTEM .

Outline of Development of the Central Nervous System

Neurone Theory

Nerve Components

Nerve-cells

Nerve-fibres

Neuroglia

The Nature of the Brain

The Spinal Medulua

Internal Structure of Spinal Medulla

Characters presented by the Spinal Medulla in its Different Regions.

Component Parts of the Gray Matter of the Spinal Medulla.

Component Parts of the White Matter. of the Spinal Medulla

The Excephalox or Braty

General Apjearance of the Brain

Parts of Encephalon derived from the Hind-brain

Medulla ObIongata

Pons

The Fourth Ventricle

Internal Structure of Medulla Oblongata and Pons

Internal Structure of the Pons

499

503

505

506

508

511

512

517

523

524

527

531

539

539

543

543

548

549

551

565
The Muscles on the Lateral Sicle of the Leg

The Muscles on the Posterior Aspect of the Leg.

The Muscles in the Sole of the Foot . 432

Axial Muscles . . . . 437

The Fascic and Muscles of the Back . 437

The Fascic of the Back . . . . 437

'The Muscles of the Back . . . . 438

First Group . . . . . . . 438

Second Group . . . . . . . 439

Third Group . . . . . . 442

Fourth Group . . . . . 444

The Fasciæ and MIuscles of the Head and Neck

Fasciæ of the Head and Neck : . 446

The Muscles of the Head . . . . 448

Superficial Mnscles . . . . . 448

The Muscles of the Scalp . . . . 448

The Muscles of the Face . . . 450

The Fasciæ and Muscles of the Orbit . 452

Muscles of Mastication . . . . . 454

The Muscles of the Neck . . . 458

The Muscles of the Hyoid Bone . . 458

The Muscles of the Tongue . . . 462

The Muscles of the Pharynx . . . 464

The Muscles of the Soft Palate . . 466

Deep Lateral and Prævertebral Muscles of the Neck

The Iluscles of the Thorax

Muscles of Respiration . . 470

Fasciæ and Muscles of the AbdominalWall 474

Fasciæ of the Abdominal WVall . . 474

The Muscles of the Abdominal Wall . 476

Fasciæ and Muscles of the Perineum and Pelvis

The Muscles of the Perin

The Fasciæ of the Pelvis 486

Muscles of the Pelvis . . . . 493

The Development and Morphology of the Skeletal Muscles

495

Professor G. Elitot Smith.

The Cerebellum

The Structure and Connexions of the Cerebellum

The Mesencephalon

570

Internal Structure of the Mesencephalon

The Deep Connexions of the Cerebral Nerves attached to the Medulla Oblongata, Pons, and Mesencephalon

Prosencephalon or Fore-brain .

Development of Parts derived from Fore-brain

Parts derived from the Diencephalon

Thalamus

Hypothalamic Region

Pineal Body

Trigonum Habenulæ

Corpora Mamillaria

Hypophysis

Third Ventricle

Cerebral Connexions of the Optic Tract

Parts derived from the Telencephalon .

Cerebral Hemispheres

The Connexions of the Olfactory 
The Cerebral Commissures and the Septum Pellucidum

The Corpus Callosum

The Lateral Ventricle

Basal Ganglia of the Cerebral Hemisphere

Intimate Structure of Cerebral Hemisphere

The Cerebral Cortex .

The Neopallium

The White Matter of the Cerebral Hemispheres.

THE PERIPHERAL NERVOUS SYSTEM

SPINAL NERTES

Development of the Peripheral Nerves.

Development of the Sympathetic System.

Development of the Cerebral Nerves

The Spinal Nerves.

Posterior Rami of the Spinal Nerves

Posterior Rami of the Cervical Nerves

Posterior Rami of the Thoracic Nerves .

Posterior Rami of the Lumbar Nerves

Posterior Rami of the Sacral and Coccygeal Nerves

Morphology of the Posterior Rami Anterior Rami of the Spinal Nerves

Cervical Nerves

Cervical Plexus

Phrenic Nerve

Morphology of the Cervical Plexus.

Brachial Plexus

Branches of Brachial Plexus .

Anterior Thoracic Nerves

Musculo-cutaneous Nerve

Median Nerve

Ulnar Nerve

Medial Cutaneous Nerve of the Forearm

Medial Cutaneous Nerve of the Arm

Axillary Nerve.

Radial Nerve

Superficial Ramus of Radial Nerve.

Deep Ramus of Radial Nerre

Subscapular Nerves

Thoracic Nerves

Lumbo-sacral Plexus

Lumbar Plexus

Obturator Nerve

Femoral Nerve.

Sacral Plexus

Sciatic Nerve

The Nerves of Distribution from the Sacral Plexus
The Sulci and Grri of the Cerebral Hemispheres

The Acoustic Area and Fibre Tracts

The Visual Area and Fibre Tracts.

The Parietal Region of the Brain

The Frontal Region .

Weight of the Brain.

Meninges of the Encephalon and Spinal Miedulla

Dura Mater

Arachnoidea

Pia Mater .

\section{3}

657

658

662

665

667

667

667

670

673

Professor A. Mielvillie Patersox.

Common Peroneal Nerre . . . 730

Deep Peromeal Nerve . . . 730

Superficial Peroneal Nerre . . 731

Tibial Nerve . . . . . 732

Medial Plantar Nerve . . : 734

Lateral Plantar Nerve . . . 734

Pudendal Plexus . . . . . 735

Pudendal Nerve . . . 738

Morphology of the Pudendal Plezus . $\quad 740$

Morphology of the Limb-plexuses. . 741

Distribution of Spinal Nerves to Mruscles and Skin of Limbs

Variations in Position of the Limbplexuses

Significance of the Limb-plexuses.

SyMPathetic Nervous Systeys : 753

Cervical Part of Sympathetic Trunk : $\quad 756$

Superior Cervical Ganglion . . . 756

Middle Cervical Ganglion . . 759

Inferior Cervical Ganglion . . 759

Thoracic Part of Sympathetic Trunk . 759

Abdominal Part of Sympathetic Trunk 761

Pelvic Part of Sympathetic Trunk . 762

Sympathetic Plexuses . . . . 763

Coliac and Pelvic Plexuses . . $\quad 763$

Cerebrat Nerves . . . . 767

Olfactory Nerves . . . . 767

Optic Nerre . . . . . 768

Oculo-motor Nerve . . . . $\quad 769$

Trochlear Nerve . . . . 770

Trigeminal Nerve . . . . 771

Abducens Nerve . . . . 781

Facial Nerve . . . . . 781

Acoustic Nerve . . . . . 784

Glossopharyngeal Nerve : . $\quad 785$

Yagus Nerve . . . . 786

789

Accessory Nerve : $\quad . \quad 791$

Hypoglossal Nerre . . . . 791

Development of Cerebral Nerves . . $\quad 795$

Morphology of Cerebral Nerves . . 796

ORGANS OF SENSE AND THE INTEGUMENT.

Professor Robert Howdex.

OLFACTORY ORGAN

799

800

801

806

806

807

808

810

814

819

821

824

825

827

External Ear.

827

Auricle

External Acoustic Meatus

827

Tympanic Cavity

Tympanic Antrum and Mastoid Aircells

Auditory Tube

Auditory Ossicles

Internal Ear' 
Appendages of the Skiu .

Derelopment of the Skin and its Appendages .

861
Endings of Nerves of General Sensation

Special End Organs

Professor Arthur Robinson.

$$
\text { Innominate Teins }
$$

962

870

873

878

880

882

882

884

884

884

885

$\$ 87$

887

888

888

888

888

891

891

900

902

905

909

909

910

914

916

917

918

919

921

Radial Artery

Ulnar Artery

The Arterial Arches of the Wrist and Hand

Branches of Descending Thoracic Aorta

Visceral Branches of the Descending Thoracic Aorta

Parietal Branches of the Descending Thoracic Aorta

Branches of Abdominal Aorta

The Paired Visceral Branches of the Abdominal Aorta

The Unpaired or Single Visceral Branches of the Abdominal Aorta

Parietal Branches of the Abdominal Aorta

Common Iliac Arteries

Hypogastric Artery

Branches of the Posterior Division .

Branches of the Anterior Division .

Visceral Branches

Parietal Branches of the Anterior Division

The Arteries of the Lower Extremity

The External Iliac Artery

The Femoral Artery

Popliteal Artery

Posterior Tibial Artery

Plantar Arteries

Anterior Tilial Artery

THE YeIXs

The Pulmonary Veins

Systemic Veins

Coronary Sinus and Veins of Heart

Superior Vena Cava and its Tributaries

Azygos Veins

924

927
Veins of the Head and Neck.

The Veins of the Scalp

Veins of the Orbit, Nose, and Infratemporal Region

Venous Sinuses and Veins of the Cranium, and its Contents . . 969

Diploic and Meningeal Veins . . 969

Veins of the Brain . . . 970

Sinuses of the Dura Mater . . 972

Veins of the Spinal Medulla . $\quad .977$

Veins of the Superior Extremity . . 977

Deep Veins of the Upper Extremity 977

Axillary Vein . • . . . 977

The Superficial Veins of the Superior Extremity . . . . 978

Inferior Vena Cava and its Tribntaries 980

Common Iliac Veins . . . 983

Veins of the Lower Extremity . . 985

Deep Veins of the Lower Extremity 986

Superficial Veins of the Lower Extremity

The Portal System . . . . 988

Mesenteric and Splenic Veins . . 992

The LTMPH VAscular StsteMI . . 993

The Terminal Lymph Vessels 996

Lymph Glands of the Head . . . 998

Lymph Glands of the Neck . . . 1000

Lymph Vessels of the Head and Neck . 1003

Lymph Glands of the Superior Extremity . . . 1006

Lymph Vessels of the Superior Extremity

The Lymph Glands of the Thorax .

The Lymph Vessels of the Thorax 1013

Lymph Glands and Vessels of the Inferior Extremity . . . .

Lymph Vessels of the Inferior Extremity Lymph Glands of the Pelvis and Abdomen .

Lymph Vessels of the Pelvic Viscera

Lymph Glands of the Abdomen . .

DevelopMeNT OF THE BLOOD-VASCULAR

SYSTEMI . . . . . 1025

The Primitive Aortæ and Primitive Heart

The Primitive Veins : . 1026

Development of Heart, of first part of Aorta, and of Pnlmonary Artery .

Division of Heart into its different Chambers, and Division of Aortic Bulb

The Aortic Arches-Formation of Chief Arteries

Primitive Dorsal Aortæ-Formation of Descending Aorta

Branches of Primitive Dorsal Aortæ

Arteries of Limbs

Development of the Veins

The Vitelline and Umbilical Vंeins.

Formation of the Portal System.

The Anterior Cardinal Veins . .

The Posterior Cardinal Veins, the Subcardinal Veins, and the Inferjor Vena Cava

Veins of Limbs .
1025

1013

1014

1015

1017

1019

1031 
Morphology of the VAscular Ststem The Segmental Arteries and their Anastomoses .

Aorta, Pulmonary Artery, and other Chief Stem Vessels

The Limb Arteries

Morphology of the Veins .

ABNoRMalities aND Vartations OF THE VASCULar SYstem

Abnormalities of the Heart

Abnormalities of Arteries

\section{THE RESPIRATORY SYSTEMI}

The Organs of Respiration and Voice

The Larynx

Cartilages of the Larynx

Articulations, Ligaments, and Membranes of the Larynx

Cavity of the Larynx

Muscles of the Larynx

Trachea .

\section{THE DIGESTIVE SYSTEM.}

Digestive System, General Arrangement of 1104 Mouth

Palate and Isthmus Faucium

Teeth

$$
\text { Permanent Teeth }
$$

Deciduous Teeth

Structure of the Teeth

Tongue

Glands

Salivary Glands

The Pharynx .

The Palatine Tonsils

The Esophagus

Structure of the Esophagus

The Abdominal Cavity .

Subdivisions of the Abdominal Cavity .

The Peritoneum

Stomach .

Relations and Connexions of Stomach

Position of Stomach .

Structure of the Stomach

THE URINO-GENITAL SYSTEM.

The URinary Organs .

The Kidneys .

The Ureters

The Urinary Bladder

The Urethra (Female)

The Male Reproductive Organs

The Testis

The Deferent Duct

Descent of the Testis

Spermatic Funiculus

Scrotum .

Penis

Prostate .

Bulbo-urethral Glands

The Male Urethra

The Female Reproductive Organs

THE DUCTLESS GLANDS.

The Chromaphil and Cortical Systems

The Suprarenal Glands

Ductless Glands of Entodermal Origin

The Thyreoid Gland

The Parathyreoid Glands
PAGE
1042

1042

1046

1047

1047

1049

1050

1050

1061

1061

1062

1065

1068

1072

1078

1106

1110

1113

1115

1121

1122

1124

1131

1133

1140

1145

1150

1153

1155

1158

1160

1163

1169

1172

1174

1257

1257

1265

1271

1284

1286

1286

1289

1295

1296

1297

1298

1301

1304

1304

1310

1341

1343

$13 \pm 7$

1347

1348
The Branches of the Aorta

PAGE

The Arteries of the Head and Neck. 1053

The Arteries of the Upper Limb . 1054

The Iliac Arteries and their Branches 1055

The Arteries of the Lower Limb . 1056

Abnormalities of Veins . . . . 1057

The Superior Vena Cara . . . 1057

The Veins of the Upper Extremity . 1058

The Inferior Vena Cava . . . 1058

The Veins of the Lower Extremity . 1059

Abnormalities of the Lymph Vessels . 1059

Professor Richard J. A. Berrt.

Bronchi . . . . . 1082

Thoracic Cavity . . . . . 1083

Pleuræ . . . . . . 1084

Mediastina . . . . . . 1089

The Lungs . . . . . 1091

Root of the Lung . . . . 1096

Structure of the Lungs . . . 1098

Development of the Respiratory Apparatus 1099

Professor David Waterston.

Intestines . . 1177

Structure of Intestines . . . 1178

Duodenum . . . . . . 1182

Liver . . . . . 1187

Structure of Liver . . . . 1198

Vessels of Liver . . . . 1199

Gall-Bladder and Bile Passages . . 1201

Pancreas. . . . . 1203

Jejunum and Ileım . . . . 1208

Large Intestine . . . . . 1210

Cæenm and Vermiform Process . . 1213

Colon . . . . . . . 1219

Rectum . . . . . . . 1224

Anal Canal . . . . . . . 1228

Peritoneum . . . . . . 1234

Development of Digestive System. . 1244

Development of the Teeth . . . 1244

Morphology of Teeth . . . . 1248

Development of the Pharynx . . 1248

of the Esophagus, Stomach, and

Intestines 1249

of the Peritoneum . . . . 1252

of the Liver and Pancreas _ . 1254

Professor A. Francis Dixon.

Ovary . . . . . . 1310

Uterine Tubes . . . . 1314

Uterus . . . . . . . 1316

Vagina . . . . . . . 1321

Female External Genital Organs . $\quad 1324$

Larger Vestibular Glands . . 1327

Development of the Urino-genital Organs . . . . 1327

The Wolffian Duct and Embryonic Secretoly Organ 1329

The Ureter and Permanent Kidney 1331

The Urethra . . . . . 1332

Sexual Glinds and Generative Ducts 1333

External Genital Organs . . . 1335

The Mammary Glands . . . . 1336

Development of the Mamme $\quad$. 1339

Professor A. Chapbetr, Gendes.

The Thymus.

1350

Ductless Glands associated with the Tascular System . 
SURFACE AND SURGICAL ANATOMY.

Harold J. Stiles, F.R.C.S. Ed.

Head and Neck . . . . . PASE

Cranium . . . . 1357

Face. $: 51374$

Neck . . . . . . 1385

Thorax . . . . 1395

The Lungs and Plenres . . . 1398

The Heart and Great Vessels . . 1403

Abdomen . . . . 1407

The Anterior Abdominal Wall • 1407

Abdominal Cavity . . . . 1411

The Abdominal Viscera . . . 1415

Male Perineum . . . . . 1427

Prostate . . . . . . . 1429

Female Pelvis . . . . 1434

Back . . . 1436

The Upper Extremity . . . . 1444

Shonlder . . . . . 1444

Axilla . . . . . . 1446

Arm . . . . . . 1447

Elbow . . . . . . 1449

Forearm and Hand . . . . 1450

The Lower Extremity . . . . 1455

The Buttock . . . . . 1455

The Back of the Thigh . . . 1456

The Popliteal Fossa . . . . 1457

The Front of the Thigh . . . 1458

The Knee. . . . 1460

The Leg . . . . . . 1461

The Foot and Ankle : : 1463

INDEX. 


\title{
A GLOSSARY
}

OF THE

\section{INTERNATIONAL (B.N.A.)}

\section{ANATOMICAL TERMINOLOGY}

\author{
GENERAL TERMS.
}

\section{- Terms indicating Situation and Direction.}

\begin{tabular}{|c|c|}
\hline Longitudinalis & Longitudinal \\
\hline Verticalis & Vertical \\
\hline Anterior . & Anterior $\}$ \\
\hline Ventral & Veutral) \\
\hline Dorsal & Dorsal \\
\hline Cranial & Cranial) \\
\hline Caudal & Caudal \\
\hline Superior & Superior ? \\
\hline Inferior & Inferior $f$ \\
\hline Proximalis & Proximal) \\
\hline Distalis & Distal $\int$ \\
\hline Sagittalis & Sagittal \\
\hline Frontalis & Frontal \\
\hline Horizontalis & Horizontal \\
\hline Medianus & Mediau \\
\hline Medialis & Medial $\}$ \\
\hline & \\
\hline Intermedius & Intermed \\
\hline Superficialis & Superficial? \\
\hline Profundus & Deep \\
\hline Externus & External \\
\hline Internus & Internal \\
\hline Ulnaris & Ulnar ? \\
\hline Radialis & Radial $f$ \\
\hline Tibial & Tibial \\
\hline Fibular & Fibular \\
\hline
\end{tabular}

Referring to the long axis of the body.

$\int$ Referring to the position of the long axis of the body in the 1 ereet posture.

Referring to the front and back of the body or the limbs.

$\int$ Referring to the anterior and posterior aspects, respectively, of the body, and to the flexor and extensor aspects of the limbs, respectively.

(Referring to position nearer the head or the tail end of the long axis. Used only in reference to parts of the head, neck, or trunk. Cephatic is sometimes used instead of cranial.

f Used in reference to the head, neek, and trunk. Equivalent to L cranial and caudal respectively.

U Used only in reference to the limbs. Proximal, nearer the $\{$ attaclied end. Distal, nearer the free end.

S Used in reference to planes parallel with the sagittal suture of $\{$ the skull, i.e. vertical antero-posterior planes.

$\int$ Used in reference to planes parallel with the coronal suture of ( the skull, i.e. vertical transverse planes.

Used in reference to planes at right angles to rertical planes.

fReferring to the median rertical antero-posterior plane of the $\{$ body.

fReferring to structures relatively nearer to or further away from $\{$ the merlian plane.

f Referring to structures situated between more medial and more $\{\quad$ lateral structures.

fReferring to structures nearer to and further away from the surfaee.

Refering, with few exceptions, to the walls of eavities and hollow organs. Not to be used as synonymous with medial and lateral.

Used in reference to the medial and lateral borlers, respectively, of the forealm and hand.

i Used in reference to the medial and lateral borders, respectively,

1 of the leg and foot. 
THE BONES.

B.X.A. Tenuratogy.

\section{Vertebræ}

Fovea costalis

superior

Fovea costalis inferior

Forea costalis transversalis

Radix arcus rertebre

Atlas

Fovea dentis

\section{Epistropheus}

Dens

\section{Sternum}

Corpus sterni

Processus xiphoideus

Incisura jugularis

Planum sternale

\section{Ossa Cranii.}

\section{0 s frontale}

Spina frontalis

Processus zygomaticus

Facies cerebralis

Facies frontalis

Pars orbitalis

\section{Os parietale}

Lineæ temporales

Sulcus transversus

Sulcus sagittalis

\section{Os occipitale}

Canalis hypoglossi

Foramen occipitale magnum

Canalis condyloideus

Sulcus transversus

Sulcus sagittalis

Clivus

Linea unchæ suprema

Linea nuchæ superior

Linea nuchæ inferior

\section{Os sphenoidale}

Crista infratemporalis

Sulcus chiasmatis

Crista sphenoidalis

Spina angularis

Lamina merlialis processus pterygoidei

Lamina lateralis processus pterygoidei

Canalis pterygoideus [Vidii]

Fossa bypophyseos
Or.D TemannulouY.

\section{Vertebræ}

incomplete facet for head of rib, upjer

Incomplete facet for head of rib, lower

Facet for tubercle of the rib

Pedicle

Atlas

Facet for odontoid process

\section{Axis}

Odontoid process

\section{Sternum}

Gladiolus

Ensiform process

Supra-sternal notch

Anterior surface

\section{Bones of Skull.}

\section{Frontal}

Nasal spine

External angular process

Internal surface

Frontal surface

Orbital plate

\section{Parietal}

Temporal ridges

Groove for lateral sinus

Groove for sup. longitudinal simus

\section{Occipital}

Anterior condyloid foramen

Foramen magnum

Posterior condyloid foramen

Groove for lateral sinus

Groove for sup. loug. siuus

Median part of upjer surface of basi-occipital

Highest curved line

Snperior curved line

Inferior curved line

\section{Sphenoid}

Pterygoid ridge

Optic groove

Ethmoidal crest

Spinous process

Internal pterygoid jlate

Exterual pterygoid plate

Vidian canal

Pituitary fossa
B.N.A. Terilixologi.

Sulcus caroticus

Conchr sphenoidales

Hamulus pterygroidens

Canalis pharyugeus

Tuberculum sellae

Fissura orbitalis superior

Os temporale

Canalis facialis [Fallopii]

Hiatus eanalis facialis

Tagina processus styloidei

Incisura mastoidea

Impressio trigemini

Eminentia arcuata

Sulcus sigmoideus

Fissura petrotympanica

Fossa mandibularis

Semicanalis tubx auditivæ

Os ethmoidale

Labyrinthus ethmoidalis

Lamina papyracea

Processins uncinatus

\section{Os lacrimale}

Hamulns lacrimalis

Crista lacrimalis posterior

\section{Os nasale}

Sulcus ethmoidalis

\section{Maxilla}

Facies anterior

Facies infratemporalis

Sinus maxillaris

Processus frontalis

Processus zygomaticus

Cauales alveolares

Canalis naso-lacrimalis

Os incisivum

Foramen incisivum

\section{Os palatinum}

Pars perpendicularis

Crista conchalis

Crista ethmoidalis

Pars horizontalis
Old Terminology.

Caveruons groove

Sphenoidal turbinal bones

Hamular process

Pterygo-palatine canal

Olivary eminence

Sphenoidal fissure

\section{Temporal Bone}

Aqueduct of Fal lopius

Hiatus Fallopii

Taginal process of tympanic plate

Digastric fossa

Impression for Gasserian gauglion

Eminence for sup. semicirenlar canal

Sigmoid fossa

Glaserian fissure

Glenoid cavity

Enstachian tube

\section{Ethmoid}

Lateral mass

Os planum

Unciform process

\section{Lachrymal Bone}

Hamular process

Lachrymal crest

\section{Nasal Bone}

Groove for nasal nerve

\section{Superior Maxillary} Bone

Facial or external surface

Zygomatic surface

Antrum of Highmore

Nasal process

Malar process

Posterior dental canals

Lachrymal groove

Premaxilla

Anterior palatine foramen

\section{Palate Bone}

Vertical plate

Inferior turbinate crest

Superior turbinate crest

Horizontal plate 
B.N.A. TERMTNOLOGY.

Os zygomaticum

Processus temporalis

Processus frontosphenoidalis

Foramen zygomatico-orbitale

Foramen zygomaticofaciale

\section{Mandibula}

\section{Spina mentalis}

Linea obliqua

Linea mylohyoidea

Incisura mandibulæ

Foramen mandibulare

Canalis mandibulæ

Protuberantia mentalis

\section{The Skull as a Whole.}

Ossa suturarum

Foveolæ granulares (Pacchioni)

Fossa pterygo-palatina

Canalis pterygopalatinus

Foramen lacerum

\section{Choanæ}

Fissura orbitalis superior

Fissura orbitalis inferior

OLd Terminologr.

Malar Bone

Zygomatic process

Frontal process

Temporo-malar canal

Malar foramen

\section{Inferior Maxillary} Bone

Genial tuberele or spine

External oblique line

Internal oblique line

Sigmoid notch

Inferior dental foramen

Inferior dental canal

Mental process

Wormian bones

Pacchionian depressions

Spheno-maxillary fossa

Posterior palatine canal

Foramen lacerum medium

Posterior nares

Sphenoidal fissure

Spheno-maxillary fissure

\section{Upper Extremity.}

Clavicula

Tuberositas coracoidea

Tuberositas costalis

\section{Scapula}

Incisura scapularis Angulus lateralis

Angulus medialis

\section{Humerus}

Sulcus intertubercularis

Crista tuberculi majoris

Crista tuberculi minoris

Facies anterior medialis

Facies anterior lateralis

Margo medialis

Margo lateralis

Sulcus nervi radialis

Capitulum

Epicondylus medialis

Epicondylus lateralis

\section{Ulna}

Incisura semilumaris

Scapula

Supra-scapular notch Anterior or lateral angle

\section{Humerus}

Bicipital groove

External lip

Internal lip

Internal surface

External surface

Interual border

External border

II usculo-spiral groove

Capitellum

Internal condyle

Exterual condyle

\section{Ulna}

Greater sigmoid
Superior angle cavity
B.N.A. TERMNOLOGY.

Incisura radialis

Crista interossea

Facies dorsalis

Facies volaris

Facies medialis

MIargo dorsalis

Margo volaris

\section{Radius}

Tuberositas radii

Incisura ulnaris

Crista interossea

Facies dorsalis

Facies volaris

Facies lateralis

Margo dorsalis

Margo volaris

\section{Carpus}

Os naviculare

Os lunatum

Os triquetrum

Os multangulum majus

Os multangulum minus

Os capitatum

Os hamatum

\section{Lower Extremity.}

Os coxæ

Linea glutæa anterior

Linea glutæa posterior

Spina ischiadica

Incisura ischiadica major

Incisura ischiadica minor

Tuberculum pubicum

Ramus inferior ossis pubis

Old Termenologr.

Lesser sigmoid cavity

External or interosseous border

Posterior surface

Anterior surface

Internal surface

Posterior border

Anterior border

\section{Radius}

Bicipital tuberosity

Sigmoid cavity

Internal or interosseous border

Posterior surface

Anterior surface

External surface

Posterior border

Anterior border

Carpus

Scaphoid

Semilunar

Cuneiform

Trapezium

Trapezoid

Os magnum

Unciform

Innominate Bone

Niddle curved line

Superior eurved line

Spine of the ischium

Great sacro-sciatic notch

Lesser sacro-sciatic notch

Spine of pubis

Descendiug ramns of pubis

Ramus superior ossis pubis

Ramus superior ossis ischii

Ramus inferior ossis ischii

Pecten ossis pubis

Facies sympliyseos

\section{Pelvis}

Pelvis major

Pelvis minor

Alertura pelvis minoris superior

Linea terminalis

Apertura pelvis minoris inferior

\section{Femur}

Fossa trochanterica

Linea intertrochanterica

Crista intertroclianterica
Ascending ramus of pubis

Body of ischium

liamus of ischinm

l'ubic part of iliopectineal line

Symphysis mbis

Pelvis

False pelvis

True pelvis

l'elric inlet

Margin of inlet of true pelvis

Pelvic outlet

\section{Femur}

Digital fossa

spiral line

Post. intertrochanteric line 
B.N.A. TERMLNology.

Condylus medialis

Condrlus lateralis

Epicondrlus medialis

Ejicondylus lateralis

Tibia

Condylus medialis

Condylus lateralis

Eminentia inter-

condyloidea

Tuberositas tibice

Malleolus medialis

Fibula

Aper capituli fibulæ

Malleolus lateralis
OLd TERMIYLOGY.

Inner condyle

Outer condyle

Inner tuberosity

Onter tuberosity

\section{Tibia}

Internal tuberosity

External tuberosity

Spine

Tubercle

Iuternal malleolus

Fibula

Styloid process

External malleolus

B. N.A. Terminolog.

Old Terminology.

\section{Bones of the Foot.}

Talus

\section{Calcaneus}

Tuber calcanei

Processus medialis tuberis calcanei

Processus lateralis

tuberis calcanei

Os cuneiforme primum

Os cuneiforme secundum

Os cuneiforme tertium

\section{Astragalus \\ Os calcis}

Tuberasity of os calcis Inner | tuberosities Outer $\{$ of os calcis

\section{Inner cuneiform}

\section{Middle cuneiform}

Outer cuneiform

\section{THE LIGAMENTS.}

\section{Ligaments of the Spine.}

Lig. longitudinale anterius

Lig. longitudinale posterius

Lig. flava

Membrana tectoria

Articulatio atlanto epistrophica

Lig. alaria

Lig. apicis dentis

Anterior common ligament

Posterior common ligament

Ligamenta subflava

Posterior occipito-axial ligament

Joint between the atlas and the axis

Odontoid or check ligaments

Suspensory ligament

\section{The Ribs.}

Lig. capituli costæ radiatum

Lig. sterno - costale interarticulare

Lig. sterno - costalia radiata

Lig. costoxiphoidea

Anterior costo - vertebral or stellate ligament

Interarticular chondro - sternal ligament

Anterior and posterior chondro-sterual ligament

Chondro-xiphoid ligaments

\section{The Jaw.}

Lig. temporo-mandibulare

Lig. spheno-mandibulare

Lig. stylo - mandibulare

External lateral ligament of the jaw

Internal lateral ligament of the jaw

Stylo-maxillary ligament

\section{Upper Extremity.}

Lig. costo-claviculare Labrum glenoidale Articulatio radio ulnaris proximalis

Lis. collaterale ulnare

\section{Lig. collaterale} radiale

Lig. annulare radii

Chorda obliqua

Articulatio radio . ulnaris distalis

Superior radio - uluar joint

Internal lateral ligament of elbow-joint,

External lateral ligament

Orbicular ligament

Oblique ligament of ulna

Inferior radio - ulnar joint
Discus articularis

Recessus sacciformis

Lig. radio - carpeum volare

Lig. radio - carpeum dorsale

Lig. collaterale carpi ulnare

Lig. collaterale carpi radiale

Articulationes intercarpeæ

Lig. accessoria volaria

Lig. capitulorum ossium metacarpalium transversa

Lig. collateralia

\section{The Lower Extremity.}

Lig. arcuatum

Lig. sacro-tuberosum

\section{Processus falci- formis}

Lig. sacro-spinosum

Labrum glenoidale

Zona orbicularis

Ligamentum ilio femorale

Lig. ischio-capsulare

Lig. pubo-capsulare

Lig. popliteum obliquum

Triangular fibrocartilage

Membrana sacci. formis

Anterior ligament of the radio-carpaljoint

Posterior ligament of the radio - carpal joint

Internal lateral ligament of the wristjoint

External lateral ligament of the wrist-joint

Carpal joints

Palmal ligaments of the metacarpo phalangeal joints

Transverse metacar pal ligament

Lateral phalangeal ligaments

Subpubic ligament

Great sacro - sciatic ligament

Falciform process

Small sacro - sciatic ligament

Cotyloid ligament

Zonular band

$Y$-shaped ligament

Ischio-capsular band Pubo-femoral ligament Ligament of Winslow

Lig. collaterale fibulare

Lig. collaterale tibiale

Lig. popliteum arcuatum

Meniscus lateralis
Long external lateral ligament

Interual lateral ligament

Arcuate popliteal ligament

External semilunar cartilage 
B.N.A. Terminology.

Meniscus medialis

Plica synovialis patellaris

Plice alares

Articulatio tibio-fibularis

Lig. capituli fibulæe

Syndesmosis tibio-fibularis

Lig. deltoidenm

Lig. talo-fibulare anterius

Lig. talo-fibulare posterius
Old Terminology.

Internal semilunar cartilage

Lig. mucosum

Ligamenta alaria

Superior tibio-fibular articulation

Anterior and posterior superior tibio-fibular ligaments

Inferior tibio-fibular articulation

Internal lateral ligainent of ankle

Anterior fasciculus of external lateral ligament

Posterior fasciculus of external lateral ligament
B.N.A. TERMINOLOGY.

Lig. calcaneo-fibulare

Lig. talo - calcancum laterale

Lig. talo - calcaneum mediale

Lig. calcaneo - naviculare plantare

Lig. talo-naviculare

Parscalcaneonavicularis lig.

Parscalcaneo-bifurcuboidea catum
Otd Termiñology.

Jiddle fasciculus of external lateral ligament

External caleaneoastragaloid ligament

Internal calcaneoastragaloid liga. ment

Inferior calcaneo navicular ligament

Astragalo - scaphoid ligament

Superior calcaneo - scaphoid ligament

Iuternal calcaneo-cuboid ligrament

\section{THE MUSCLES.}

Muscles of the Back.

\section{Superficial.}

Levator scapulæ

Levator anguli scapulæ

\section{Muscles of the Chest.}

Serratus anterior

Serratus magnus

\section{Muscles of Upper Extremity.}

Biceps brachii

Lacertus fibrosns

Brachialis

Triceps brachii

Caput mediale

Caput laterale

Pronator teres

Caput ulnare

Brachio-radialis

Supinator

Extensor carpi radialis longus

Extensor carpi radialis brevis

Extensor indicis proprius

Extensor digiti quinti proprius

Abduetor pollicis longus

Abductor pollicis brevis

Extensor pollicis brevis

Extensor pollicis longus

Lig. carpi transversum

Lig. carpi dorsale

\section{Muscles of Lower Extremity.}

Tensor fasciæ latæ Canalis addnctorius (Hunteri)
Trigonum femorale (fossa Scarpre major)

Canalis femoralis

Annulus femoralis

II. quadriceps

femoris-

Riectus femoris

Vastus lateralis

Vastus intermedins

Tastus medialis

II. articularis genu

Tibialis anterior

Tendo calcaneus

Tibialis posterior

Quadratus jlante

Lig. transversum cruris

Lig. cruciatum eruris

Lig. laciniatum

Retinaculum musculoruin peroneor'um superius

Retiuaculuru musculorum peronitorum inferius

Scarpa's triangle

Crural canal

Crural ring

Guadriceps-

Rectus femoris

Vastus externus

Crurens

Tastus internus

Subcrureus

Tibialis anticus

Tendo Achillis

Tibialis posticus

Accessorius

Upler anterior annular ligament

Lower anterior annular litament

Interual annular ligament

External annular ligament

\section{Axial Muscles.}

Muscles of the Back.

Serratus posterior superior

Serratus posterior inferior

Spleuius cervicis

siacro-spinalis

Ilio-costalis -

Lumborum

Dorsi

C'ervicis

Longissimus-

I) ursi

Cervicis

Cinpitis
Serratus posticus superior

Serratus posticus inferior

Splenins colli

Erector sjuine

Ilio-costalis -

Sacro-Iumbalis

Accessorius

Cervicalis asceudens

Longissimus-

1)orsi

Transversalis cervicis Trachelo-mastoid 
B. N.A. Terminology.

\section{Spinalis- \\ Dorsi \\ Cerricis \\ Capitis}

Semispinalis -

Dorsi

Cervicis

Capitis

Multifidus

\section{Muscles of Head and Neck.}

Epicranius

Galea aponeurotica

\section{Procerus}

Pars transversa (nasalis)

Pars alaris (nasalis) Amicularis anterior

Amricularis posterior Auricularis superior

Orbicularis oculi

Pars lacrimalis

Triangularis

Quadratus labii superioris-

Caput zygomaticum

Caput infraorbitale

Caput angulare

Zygomaticus

Caninus

Quadratus labii inferioris

Mentalis

Platysma

Sterno-thyreoid

Thyreo-hyoid

Attrahens aurem

Retraheus aurem

Attollens aurem

Orbicularis palpebrarum

\section{Tensor tarsi}

Zygomaticus minor oris oris alrque nasi

Zygomaticus major oris

Levator menti

Platysma myoides

Sterno-thyroid

Thyro-hyoid
OlD TERMIAOLOGY.

\section{Spinalis \\ Dorsi \\ Colli \\ Capuitis}

Semispinalis -

1)orsi

Colli

Complexus

Mnltifidus spinæ

Deep Lateral Muscles of Neck.

\section{B.N.A. Terminolocy.}

Scalenus anterior

Scalenus posterior

Longus capitis

Rectus eapitis anterior

Old Terminology.

Scalemus anticus

Scalenus posticus

Rectus capitis anticus major

Rectus capitis anticus minor

\section{Muscles of Thorax.}

Transversus thoracis

Diaphragma, pars lumbalis

Crus mediale Crus intermedium Crus laterale

Arcus lumbocostalis medialis (Halleri)

Arcus lumbo. costalis lateralis (Halleri)

Triangularis sterni Diaphragm, lumbar part-

Crus and origin from internal arcuate ligaments

Ligamentum arcuatum internum

Ligamentum arcuatum externum

Depressor anguli oris

Levator labii superi-

Levator labii superi-

Levator anguli oris

Depressor labii inferi-

\section{Muscles and Fascia of the Orbit.}

Fascia bulbi

Septum orbitale

Rectus lateralis

Rectus medialis
Capsule of Tenon

Palpebral ligaments

Rectus externus

Rectus internus

\section{Muscles of the Tongue.}

Genio-glossus

Longitudiualis superior

Longitudinalis inferior

Transversus lingure

Verticalis lingure
Genio-hyo-glossus

Superior lingualis

Inferior lingualis

Transverse fibres Vertical fibres

\section{Muscles of the Abdomen.}

Ligamentum inguinale (Pouparti)

Ligamentum lacunare (Gimbernati)

Fibræ intercrurales

Ligamentum inguinale reflexum (Collesi)

Annulus inguinalis subcutaneus Crus superins Crus inferius

Falx (aponeurotica) inguinalis

II. transversus ab. dominis

Linea semicircularis (Douglasi)

Annulus inguinalis abdominalis

Poupart's ligament

Gimbernat's ligament

Intercolumnar fibres

Triangular fascia

\section{External abdominal ring}

Internal pillar

External pillar

Conjoined tendon

Transversalis muscle

Fold of Douglas

Internal abdominal
ring

\section{Perineum and Pelvis.}

Transversus perinei superficialis

II. sphincter urethræ membranaceæ

Diaphragma urogenitale

Fascia diaphragmatis urogen italis superior

Fascia diaphragmatis urogenitalis inferior

Arcus tendineus fascire pelvis

\section{Muscles of the Pharynx.}

Pharyngo-palatinus

Ii. uvulæ

Levator veli palatini

Tensor veli palatini

Glosso-palatimus
Palato-pharyngeus

Azygos uvulæ

Levator palati

Tensor palati

Palato-glossus
Ligamenta pubo prostatica

Fascia diaphragmatis pelvis superior

Fascia diaphragmatis pelvis inferior
Transversus perinei

Compressor urethræ

Deep transverse muscle and compressor urethræ

Deep layer of triangular ligament

Superficial layer of the triangular ligament

White line of pelvis

Anterior and lateral true ligaments of bladder

Visceral layer of pelvic fascia

Anal fascia 


\section{THE NERVOUS SYSTEY.}

\section{Spinal Medulla.}

B.N.A. Terminology.

Fasciculus anterior proprius (Flechsig)

Fasciculus lateralis proprius

\section{Nucleus dorsalis}

Pars thoracalis

Sulcus intermedius posterior
Old Termayolog.

Anterior ground or basis bundle

Lateral ground bundle

Clarke's column

Dorsal part of spiual medulla

Paramedian furrow
B.N.A. Terminologx.

Columnxanteriores, etc. Fasciculus cerebro spinalis anterior

Fasciculus cerebro. spinalis lateralis (pyramidalis)

Fasciculus cerebello. spinalis

Fasciculus antero-later. alis superficialis
Old Termiyology.

Anterior grey horns, etc.

Direct pyramidal tract

\section{Crossed pyramidal} tract

\section{Direct cerebellar tract}

Gowers' tract

he Brain or EncephaIon is divided into parts as follows :-

$\left.\begin{array}{rl}\text { RHOMBENCEPHALON }= & \text { Myelencephalon (medulla oblongata) (after-brain) } \\ & \text { Metencephalon (pous and cerebellum) (hind-brain) }\end{array}\right\}$ Posterior primary vesicle.

Metencephalon (pous and cerebellum) (hind-brain) Posterior primary vesicle.

(fore-brain)

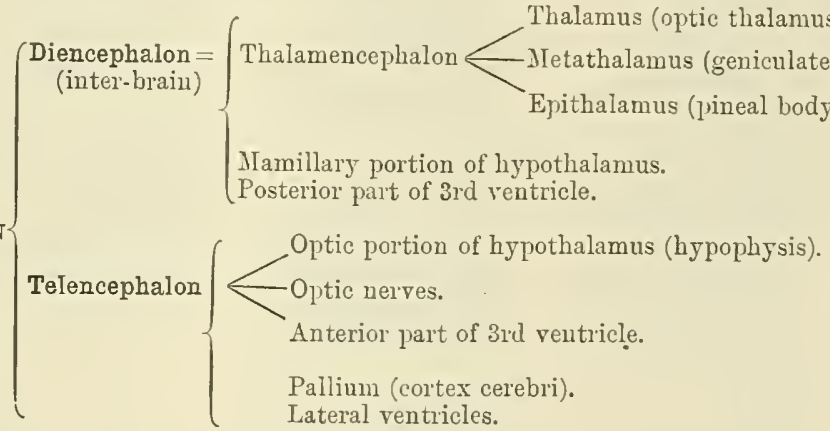

\section{Brain.}

\section{Rhombencephalon}

Eminentia medialis

Ala cinerea

Area acustica

Nucleus nervi abducentis

Nuclei n. acustici

Fasciculus longitudinalis medialis

Corpus trapezoideum

Incisura cerebelli anteriol

Incisura cerebelli posterior

Sulcus horizontalis cerebelli

Lobulus centralis

Folium vermis

Tuber vermis

Lobulus quadrangularis

Brachium conjumetivum cerebelli

Brachium pontis

Restiform body

Lobulus semilnuaris superior

Lobulus semilunaris inferior
Eminentia teres

Trigonum vagi

Trigonum acnsticum

Nucleus of 6 th nerve

Auditory nucleus

Posterior longitudinal bundle

Corpus trapezoides

Semilunar notch (of cerebellum

Marsupial noteh

Great horizontal fis. sure

Lobus centralis

Folium cacuminis

Tuber valvulæ

Quadrate lobule

Superior cercbellar peduucle

Middle cerebellan peduncle

Inferior cerebellar peduncle

Postero - superior lobule

Postero-inferiol lobule

\section{Cerebrum}

Pedunculus cerebri

Colliculus superior

Colliculus inferior

Aquæductus cerebri

Foramen interven. triculare

Hypothalamus

Sulcus hypothalamicus

Massa intermedia

Fasciculus thalamomamillaris

Pars opereularis

Thalamus

Pallium

Gyri transitivi

Fissura cerebri lateralis

Gyrus temporalis superior

Gyrus temporalis medius

Gyrus temporalis in. feriol

Sulcus centralis (Ro. landi)

Sulcus temporalis superior
Crus cerebri

Anterior corpus quadrigeminmu

Posterior corpus quadrigeminum

Iter e tertio ad quartum ventriculum, or aqued. of Sylvius

Foramen of Meuro

Subthalamic region

Sulcus of Momro

Middle commissure

Bundle of Vicqd'Azyr

Pars basilaris

Optic thalamus

Cortex cerebri

Annectant gyri

Fissure of Sylvius

First temporal gyrus

Second temporal gyrus

Third temporal gyrus

Fissure of Rolando

Parallel sulcus 


\section{B. X.A. Terminologr.}

Sulcus temporalis medius

Sulcus temporalis inferior

Gyrus fusiformis

Sulcus interparietalis Sulcus corporis callosi Sulcus cinguli

Fissura hippocampi

Gryrus cinguli

Stria terminalis

Trigonum collaterale

Hippocampus campi

Fascia dentata hippocampi

Columna fornicis

Septum pellucidum

Cornu inferius

Commissura hippocampi

Nuclens lentiformis

Pars frontalis capsulæ internæe

Pars occipitalis capsulæ internæ thalamica

Radiatio corporis callosi

Pars frontalis

Pars occipitalis
Suleus eireularis

Digitationes hippo .

Radiatio occipito -

OLd Temmixologr.

Second temporal sulcus

Limiting sulcus of Reil

Occipito-temporal sulcus

Occipito-temporal convolution

Intraparietal sulcus

Callosal sulcus

Calloso-marginal fissure

Dentate fissure

Callosal convolution

Tænia semicircularis

Trigonum ventriculi

Hippocampus major

Pes hippocampi

Gyrus dentatus

Anterior pillar of fornix

Descending horn of lateral ventricle

Lyra

Lenticular nucleus

Anterior limb (of internal capsule)

Posterior limb (of internal capsule)

Optic radiation

Radiation of corpus callosum

Forceps minor

Forceps major

\section{Membranes of Brain.}

Cisterna cerebello-me- Cisterna magna dullaris

Cisterna interpeduncularis

Granulationes arachnoi- Pacchionian bodies deales

Tela chorioidea ven- Velum interpositum triculi tertii

Tela chorioidea ven- Tela choroidea inferior triculi quarti

\section{Cerebral Nerves.}

$\mathrm{N}$. oculomotorius

$\mathrm{N}$. trochlearis

N. trigeminus

$$
\begin{aligned}
& \text { Ganglion semi- } \\
& \text { lunare (Gasseri) } \\
& \text { F. naso-ciliaris }
\end{aligned}
$$

N. maxillaris

N. meningeus (medius)

N. zygomaticus

Rami alveolares superiores pos teriores

Rami alveolares superiores medii

Fourth nerve

Fifth nerve

Gasserian ganglion

Nasal nerve

Superior maxillary nerve

Recurrent meningeal nerve

Temporo-malar nerve

Posterior superior dental

Middle superior dental
B.N.A. Terminologr.

Rami alveolares superiores anteriores

Ganglion sphenopalatiuum

N. palatinus medius

N. mandibularis

Nerrus spinosus

$\mathrm{N}$. alveolaris inferior

N. abducens

$\mathrm{N}$. facialis

$\mathrm{N}$. intermedius

N. acusticus

Ganglion superius

N. recmrrens

Ganglion jugulare

Ganglion nodosum

Plexns csophageus anterior

Plexus œsophageus posterior

Nervus accessorius

Ramus internus

Ramus externus

\section{Spinal Nerves.}

Rami posteriores

Rami anteriores

N. cutaneus colli

Nn. supraclaviculares anteriores

Nu. supraclaviculares medii

Nn. supraclaviculares posteriores

N. dor'salis scapulæ

Nn. intercosto. brachiales

$\mathrm{N}$. thoracalis longus

$\mathrm{N}$. thoraco-dorsalis

Old Terminology.

Anterior superior dental

Meckel's gaugliou

External palatine nerve

Inferior maxillary nerve

Recurrent nerve

Inferior dental

Sixth nerve

Seventh nerve

Pars intermedia of Wrisberg

Eighth or auditory nerve

Jugular ganglion of 9 th nerve

Recurrent laryngeal nerve

$\underset{\text { root }}{\operatorname{Ganglion}}$ of

Ganglion of vagus trunk

Plexus gulæ

Spinal accessory

Accessory portion of spinal accessory nerve

Spinal portion

Posterior primary divisions

Anterior primary divisions

Transverse superficial cervical nerve

Suprasternal nerves

Supraclavicular nerves

Supra - acromial nerves

Nerve to the rhomboids

Intercosto - humeral nerve

Nerve of Bell

Long subscapular nerve

N. cutanens brachii medialis

N. cutaneus brachii lateralis

Fasciculus lateralis

Fasciculns medialis

T. cutaneus antibrachii lateralis

N. cutaneus antibrachii medialis

Ramus volaris

Ramus ulnaris

$\mathrm{N}$. axillaris
Lesser internal cutaneous nelve

Cutaneous branch of circumflex nerve

Onter cord (of plexus)

Inner cord

Cutaneous branch of musculo-cutaneous nerve

Internal cutaneous nerve

Anterior branch

Posterior branch

Circumflex nerve 
B.N.A. TERMINoLOGY,

$\mathrm{N}$. interosseus volaris

Ramus palmaris $N$. mediani

Nn. digitales volares proprii

Ramus dorsalis manus

Ramus cutaneus pal. maris

N. radialis

N. cutaneus brachii posterior

N. cutanens antibrachii dorsalis

Ramus superficialis

$\mathrm{N}$. interosseus dorsalis

Nn. digitales dorsales

N. ilio-hypogastricus

Ramus cutaneus
lateralis

Ramus cutaneus anterior
OLD TERMINOLOGY.

Anterior interosseous

$\mathrm{Palmar}$ cutaneous branch of the median nerve

Collateral palmar digital branches of median nerve

Dorsal cutaneous branch of nlnal nerve

Palmar cutaneons branch of ulnar nerve

Muscůlo-spiral nerve

Internal cutaneous branch of nuus. culo-spiral nerve

External cutaneous branches of musculo-spiral nerve

Radial nerve

Posterior interosseous nerve

Dorsal digital nerves

Ilio - hypogastric nerve

Iliae branch of ilio-hypogastric nerve

Hypogastric branch of ilio-hypo. gastric nerve
B. N.A. TERMINOLOGY.

N. genito femoralis

T. $\ln \mathrm{mbo}$ - in guinalis

N. spermaticus extermus

N. cutaneus femoris

lateralis

I. femoralis

X. saphenus

Ramus infrapatellaris

N. ischiadicus

ז. peronæus com munis

Ramus anasto moticus pero. næus

N. peronæus superficialis

$\mathrm{N}$. peroneus pro-

$\mathrm{N}$. tibialis fundus

N. cutaneus suræ

$\mathrm{I}$. suralis medialis

X. plantaris medialis

$\mathrm{X}$. plantaris lateralis

N. pudendus
OLD TERMIYOLOGI.

Genito-crural nerve

Crural branch of genito - crural nerve

Genital branch of genito - crural nerve

External cutane. ons nerve

Anterior erural nerve

Long saplenous nerve

Patellar branch of long saphenous nerre

Great sciatic nerve

External popliteal nerve

Nerrus communicans fibularis

\section{Musculo-cutaneous} nerve

Anterior tibial nerve

Internal popliteal and posterior tibial nerves

Nervus communicans tibialis

Short saphenous nerve

Interual plantar

External plantar

Pudic nerve

\section{THE HEART AND BLOOD-TESSELS.}

\section{Heart.}

\section{Atrium}

Auricula cordis

Incisura cordis

Trabeculæ carneæ

Tuberculum inter. venosum

Sulcus longitudinalis anterior

Sulcus coronarius

Limbus fossæ ovalis

Valvula venæ cavæe

Valvula sinus coronarii

\section{Arteries.}

Siuus aortæ

A. profunda lingure

A. maxillaris externa

A. alveolaris inferior

Ramus meningeus accessorius

A. buccinatoria

A. alveolaris superior posterior

Aa. alveolares su periores anteriores

Ramus carotico-tympanicus
A. chorioidea

Auricle

Auricular appendix

Notch at apex of heart

Columnæ carneæ

Interveuous tubercle of Lower

Anterior interventricular groove

Auriculo - ventricular groove

Annulus oralis

Eustachian valve

Valve of Thebesius

Sinuses of Talsalva

Ranine artery

Facial artery

Inferior dental artery

Small meningeal artery

Buccal artery

Posterior superior den tal artery

Anterior superior dental arteries

Tympanic branch of int. carotid phrenica calis prema scajulie alis superior inferior aris

\section{A. auditiva interna}

Rami ad pontem

A. pericardiaco-

Rami intercostales

Truncus thyreo-cervi-

A. transversa scapulie

A. intercostalis su-

A. transversa colli

1. thoracalis suprema

A. thoraco-acromialis

A. thoracalis lateralis

A. circum $\mathrm{flexa}$

A. profunda bracliii

A. collateralis radi-

1. collatemalis uluaris

A. collateralis ulnaris Inastomotica magna

Ramus carpeus vol- Anterior radial earpal

Anterior choroidal artery

Anditory artery

Transverse arteries (branches of basilar artery)

Arteria comes nervi plirenici

Anterior intercostal arteries

Thyroid axis

Suprascapular artery Superior intercostal

Transiersalis colli

Superior thoracic artery

Acromio - thoracic artery

Loug thoracic artery

Dorsalis scapula

Superior profunda Anterior branch of stlperior profunda

Inferior profuncli 
B.N.A. Termyologr.

liamus carpens lorsalis

Ait. metacarpex dorsales

A. rolaris indicis radialis

Areus volaris superficialis

Areus rolaris profundus

A. interossea dorsalis

A. interossea recurrens

\section{A. interossea rolaris}

Ramns carpeus dorsalis Ramns carpens volaris Aa. digitales volares communes

Aa. digitales volares proprise

Arterixe intestinales

A. suprarenalis media

A. hypogastrica

A. umbilicalis

A. pudenda interna

A. epigastrica inferior

A. spermatica externa

Aa. pudendæe externe

A. circumflexa femoris medialis

A. circumflexa femoris lateralis

A. genu suprema

A. genu superior lateralis

A. genu superior medialis

A. genu media

A. genu inferior lateralis

A. genu inferior medialis

A. malleolaris anterior lateralis

A. malleolaris anterior medialis

A. peronæa

Ramus perforans

A. malleolaris posterior lateralis
OLD Termyologr.

Posterior radial carpal

Dorsal interosseous arteries

Radialis indicis

Superficial pialmar arch

Deep palmar arch

Posterior interosseous artery

Posteriol interosseous recurrent artery

Anterior interosseous artery

Posterior ulnar carpal

Anterior ulnar carpal

Palmar digital arteries

Collateral digital arteries

Intestinal branches of sup. mesenteric

Middle capsular artery

Internal iliac artery

Obliterated hypogastric

Internal pudic artery

Deep epigastric artery

Cremasteric artery

Superficial and deep external pndic arteries

Internal circumfles artery

External circumflex artery

Anastomotica magna

Superior external articular artery

Superior internal articular artery

Azygos articnlar artery

Inferior external articular artery

Inferior internal articular artery

External malleolar artery

Internal malleolar artery

Peroneal artery

Anterior peroneal artery

Posterior peroneal artery
B. N. A. Terminotogr.

A. malleolaris posterior medialis

Rami calcanei laterales

Rami calcanei mediales

A. plantaris medialis

A. plantaris lateralis

Aa. metatarsæ plantares

Aa. digitales plantares

OLd Terminologx.

Internal malleolar artery

External calcanean artery

Internal calcanean artery

Internal plantar artery

External plantar artery

Digital branches

Collateral digital branches

\section{Veins.}

$V$. cordis magna

Great cardiac vein

r. obliqua atrii sinistri

Lig. venæ ca $\nabla \rightsquigarrow$ sinistræ

Tv. cordis minimæ

Sinus transversus

Confluens sinuum

Plexus basilaris

Sinus sagittalis superior

Sinus sagittalis inferior

Simus spheno-parietalis

V. cerebri internæ

$\mathrm{V}$, cerebri magna

$\mathrm{V}$. terminalis

T. basalis

V. transversa scapulæ

T. thoraco-acromialis

Vv. transversæ colli

V. thoracalis lateralis

V. azygos

V. hemiazygos

$\mathrm{V}$. lemiazygos accessoria

V. hypogastrica

$V$. epigastrica inferior

V. saphena magna

V. saphena parva

Oblique vein of Marshail

Vestigial fold of Marshall

Veins of Thebesins

Lateral sinus

Torcular Herophili

Basilar sinus

Snperior longitudinal sinus

Inferior longitudinal sinus

Sinns alæ parvæ

Veins of Galen

Vena magna Galeni

Vein of the corpus striatum

Basilar vein

Suprascapular vein

Acromio - thoracic vein

Transversalis colli veins

Long thoracic vein

Vena azygos major

Vena azygos minor inferior

Vena azygos minor superior

Internal iliac vein

Deep epigastric vein

Internal saphenons vein

External saphenous vein

\section{Lymphatics.}

Cisterma chyli

Receptaculum chyli

\section{THE VISCERA.}

\section{Digestive Apparatus.}

\section{Arcus glosso-pala- tinus \\ Areus pharyngo-pala- tinus}

(i1. lingrualis anterior

Ductus submaxillaris

Gl. parotis accessoria

Ductus parotidens (Stenonis)
Dentes præmolares

Dens serotinus

Papillæ vallatæ fauces

Posterior pillar of fallces

Cland of Nulin

Wharton's duet

Soeia paratidis

Stenson's duct
Recessus pharyngeus

Tela submucosa

Plicæe circulares

G]. intestinales

Valvula coli

Columnæ rectales
Bicnspid teeth

Wisdom tooth

Cireumvallate papillæ

Lateral recess of pharynx

Pharyngeal aponemrosis

Valvulæ comniventes

Crypts of Lieberkuhn

Ileo-cæcal valve

Columns of Morgagni 
B.N.A. TERMINOLOGY.

Plicæ transversales recti

Valvula spiralis

Noduli lymphatici aggregati (Peyeri)

Intestinum jejunum

Intestinum ileum

Noduli lymphatici lienales (Malpighii)

\section{Respiratory Apparatus.}

\section{Larynx}

Prominentia laryngea Incisura thyreoidea superior

M. ary-epiglotticus

M. vocalis

M. thyreo - epiglotticus

Appendix ventriculi laryngis

Plica rocalis

Plica ventricularis

Ligamentum ventriculare

Ligamentum vocale

\section{Glottis}

Rima vestibuli

Cartilago thyreoidea

Membrana hyothyreoidea

Cartilago corniculata (Santorini)

Tuberculum epiglotticum

Pars intermembranacea (rimæglottidis)

Pars intercartilaginea (rimæ glottidis)

Conus elasticus (membranæ elasticæ laryngis)

Glandula thyreoidea
Old Terminologi.

Valves of Houston

Valve of Heister

Peyer's patches

Jejuntum

Ileum

Malpighian corr puscles

Adam's apple

Superior thyroid notch

Aryteno-epiglottidean muscle

Internal thyro-arytenoid muscle

Thyro - epiglottidean muscle

Laryngeal sac

True vocal cord

False vocal cord

Superior thyro - arytenoid ligament

Inferior thyro-arytenoid ligament

Glottis vera

Glottis spuria

Thyroid cartilage

Thyro-hyoid membrane

Cartilage of Santorini

Cushion of epiglottis

Glottis vocalis

Glottis respiratoria

Crico - thyroid membrane

Thyroid gland
B.N.A. Terminology.

Glomus caroticum

Nose

Concha nasalis suprema (Santorini)

Concha nasalis siperior

Concha nasalis media

Concha nasalis inferior

\section{Urogenital Apparatus.}

Corpuscula renis

Paradidymis

Appendix testis

Ductus deferens

Gl. urethrales

Glandula bulbo-ure-

thralis (Comperi)

Folliculi oophori Graafian follicles resiculosi

Cumulus oophorus

Tuba uterina

Epoophoron

Appendices vesiculosi

Ductus epoopliori longitudinalis

Orificium internum uteri

Orificium externum

Processus vaginalis

Glandula vestibularis Bartholin's gland major

\section{Peritoneum.}

Bursa omeutalis

Foramen epiploicum

Lig. phrenico - colicum

Excavatio rectouterina (cavum Douglasi)

Lig. gastro-lienale
OLd Terminologr.

ntercarotid gland or body

Highest turbinate bone

Superior turbinate bone

Middle turbinate bone

Inferior turbinate bone

Malpighian corpuscles Orgau of Giraldés Hydatid of Morgagni (male)

Vas deferens

Glauds of Littré

Cowper's gland

Discus proligerus

Fallopian tube

Parovarium

Hydatids of Morgagni (female)

Gärtuer's duct

Internal os (of uterus)

Exterual os

Canal of Nuck

Lesser peritoneal sac

Foramen of Winslow Costo-colic ligament

Pouch of Douglas

Gastro-splenic omentum

\section{THE SENSE ORGANS.}

\section{The Eye.}

Sclera

Lamina elastica anterior (Bowmani)

Lamina elastica posterior (Descemeti)

Spatia anguli iridis

Angulus iridis

Zonula ciliaris

Septum orbitale

Fascia bulbi

Commissura palpebrarum lateralis

Commissura palpebrarum medialis

Tarsus superior

Tarsus inferior

Lig. palpebrale modiale

Raphe palpebralis lateralis
Sclerotic coat

Bowman's membrane

Descemet's membraue

Spaces of Fontana

Irido-corneal junction

Zonule of Zinu

Palpebral ligament

Capsule of Tenon

Exterual canthus

Interual canthus

Superior tarsal plate

Inferior tarsal plate

Interual tarsal ligiament

External tarsal ligament
Tarsal glands

Meibomian glands

The Ear.

Canalis semicircularis lateralis

Ductus remniens

Ductus cochlearis

liecessus sphrericus

Fiecessus ellipticus

Paries jugularis

Paries labyrinthica

Fenestra restibuli

Fenestra cochle:

l'aries mastoilea

Antrum tympanicum

Paries carotica

l'rocessus lateralis

Processus anterior

Anterior wall
External semicireular canal

Canalis reuniens

Membranous cochlea

Fovea hemispherica

Forea hemi-elliptica

Floor of tympanum

inner wall

Fenestra ovalis

lenestri rotunda

Posterior wall

Mastoil an truun

Processus brevis (of malleus)

Processus gracilis 



\section{TEXT-BOOK OF ANATOMY.}

\section{INTRODUCTION.}

Anatomy is a comprehensive term, which includes several closely related branches of study. Primarily it is employed to indicate the study of the several parts which build up the body, and the relationship which these present to each other. But the structure of an individual is not the same at all stages of its life, for many changes occur during the period of its existence. The orum and the spermatozoon, which are the starting-points of every individual, are very different from the finished organism as represented by the adult, and the series of changes through which the organism passes until its structure is perfected and full growth is attained constitute the phenomena of development. The general term "development" includes not only the various and striking structural changes which occur during the intra-uterine life of the individual, to the study of which the term embryology is more specially applied, but also many growth processes which occur after birth, such as the later stages in the ossification and growth of the bones, the eruption of the two series of teeth, the adjustment of the vascular system to its new requirements, etc. The actual observation of the processes by which the parts of the body are gradually formed, and of the structural arrangements by means of which a temporary connexion is established between the orum and the mother, through which an interchange of nutritive and other matters between the two takes place, renders embryology one of the most interesting of all the departments of anatomy. The term ontogeny also is used to denote the derelopment of the individual. There is, however, another form of development, slower, but just as certain in its processes, which affects not only the individual, but all the members of the animal group to which it belongs. The theory of descent or evolution leads us to believe that between man of the present day and his remote ancestors there is a wide structural gap, which, if the geological record were perfect, would be seen to be completely occupied by long-lost intermediate forms. In the process of evolution, therefore, structural changes have gradually taken place which have modified the entire race. These evolutionary phases constitute the ancestral history or phylogeny of the individual. Ontogeny and phylogeny are intertwined in a remarkable manner, and present certain extraordinary relationships. In other words, the ancestral evolutionary derelopment appears to be so stamped upon an individual that it repeats certain of the phylogenetic stages with more or less clearness during the process of its own individual development. Thus, at an early period in the embryology of man we recognise evanescent gill-ponches comparable with those of a fish, whilst a study of the derelopment of his heart shows that it passes through transitory structural conditions similar, in many respects, to the permanent 
condition of the heart in certain of the lower animals. It is in connexion with this that the phrase has arisen that every animal in its individual development or ontogeny climbs up its own genealogical tree-a saying which, taking it even in the broadest sense, is only partially true.

The broader conceptions of anatomy, which are obtained by taking a general survey of the structural aspects of the entire animal kingdom, constitute morphology. The morphologist investigates the laws of form and structure, and in his generalisations he gives attention to detail only in so far as this is necessary for the proper establishment of his views. The knowledge of anatomy which is required by the student of medicine is different. It is essentially one of detail, and often details important from the practical and utilitarian points of view have little or no morphological value. This want of balance in the interest attached to anatomical facts, according to the aspect from which they are examined, so far from being unfortunate, affords the teacher the means of making the study of anatomy at once fascinating and instructive. Almost every fact which is brought under the notice of the student can be accompanied by a morphological or a practical application. It is this that lightens a study which, presented to the student of medicine in any other way, would be at once dry and tedious.

Certain terms employed in morphology require early and definite explanation. These are homology, serial homology, and homoplasy. The same organ repeated in two different animals is said to present a case of homology. But this morphological identity between these two organs must be proved beyond dispute before the homology between them can be allowed. In deciding this identity the great and essential test is that the two organs in question should have a similar developmental origin. Thus, the fore-limb of a quadruped is homologous with the upper limb of man; the puny collar-bone of a tiger, the fibrous thread which is the only representative of this bone in the horse, and the strongly marked clavicle of the ape or man, are all, strictly speaking, homologous with one another. Homologous organs in different animals usually present a similar position and a similar structure, but not invariably so. It is not uncommon for a muscle to wander somewhat from its original position, and many cases could be quoted in which parts have become completely transformed in structure, either from disuse or for the purpose of meeting some special demand in the animal economy. In the study of the muscles and ligaments instances of this will be brought under the notice of the reader.

Often organs which perform totally different functions are yet perfectly homologous. Thus the wing of a bat or the wing of a bird, both of which are subservient to flight, are homologous with the upper limb of man, the office of which is the different one of prehension. Identity or correspondence in the function performed by two organs in two different animals is not taken into consideration in deciding questions of homology. The gills of a fish and the lungs of a higher vertebrate perform very much the same physiological office, and yet they are not homologous. The term analogy is often used to express functional correspondence of this kind.

In the construction of vertebrates and certain other animal groups a series of similar parts are repeated along a longitudinal axis, one after the other. Thus the series of vertebræ which build up the backbone, the series of ribs which gird round each side of the chest, the series of intercostal muscles which fill up the intervals between the ribs, the series of nerves which arise from the brain and spinal medulla, are all examples of this. An animal exhibiting such a condition of parts is said to present the segmental type of organisation, and in the early stages of development this segmentation is much more strongly marked, and is to be seen in parts which 
subsequently lose all trace of such a subdivision. The parts thus repeated are said to be serially homologous. But there are other instances of serial homology besides those which are manifestly produced by segmentation. The upper limb is serially homologous with the lower limb: each is composed of parts which, to a large extent, are repeated in the other, and the correct adjustment of this comparison between the several parts of the upper and lower limbs constitutes one of the most difficult and yet interesting problems of morphology.

Homoplasy is a term which has been introduced to express a form of correspondence between organs in different animals which cannot be included under the term homology. Two animal groups, which originally have sprung from the same stem-form, may independently develop a similar structural character which is altogether absent in the ancestor common to both. Thus the common ancestor of man and the carnivora in all probability possessed a smooth brain, and jet the human brain and the carnivore brain are both richly convoluted. Not only this, but certain anatomists seek to reconcile the convolutionary pattern of the one with the convolutionary pattern of the other. What correspondence there is does not, in every instance, constitute a case of homology, because there is not in every case a community of origin. Correspondence of this kind is included under the term "homoplasy." Another example is afforded by the heart of the mammal and that of the bird. In both of these groups the ventricular portion of the heart consists of a right and a left chamber, and yet the ventricular septum in the one is not homologous with the corresponding septum in the other, because the common ancestor from which both have sprung possessed a heart with a single ventricular cavity, and the double-chambered condition has been a subsequent and independent development in the two groups.

Systematic Anatomy.-The human body is composed of a combination of several systems of organs, and the several parts of each system not only present a certain similarity in structure, but also fulfil special functions. Thus we hare-

1. The skeletal system, composed of the bones and certain cartilaginous and membranous parts associated with them, the knowledge of which is known as osteology.

2. The articulatory system, which includes the joints or articulations, the knowledge of which is termed arthrology.

3. The muscular system, comprising the muscles, the knowledge of which constitutes myology.

4. The nervous system, in which are included the brain, the spinal medulla, the ganglia of the spinal and cerebral nerves, the sympathetic ganglia, and the various nerves proceeding from and entering these. The knowledge of these parts is expressed by the term neurology. In this system the organs of sense may also be included.

5. The blood vascular and lymphatic system, including the heart, blood-ressels, the lymph vessels, and the lymph glands. Angeiology is the term applied to the knowledge of this system.

6. The respiratory system, in which we place the lungs, windpipe, and laryux.

7. The digestive system, which consists of the alimentary canal and its associated glands, and parts such as the tongue, teeth, liver, pancreas, etc.

8. The urogenital system, composed of the urinary organs and the reproductive organs-the latter differing in the two sexes.

The term splanchnology denotes the knowledge of the organs included in the respiratory, digestive, and urogenital systems.

9. The integumentary system consists of the skin, nails, hair, ete. The knowledge of this system is termed dermatology. 
These numerous organs which form the various systems are themselves built up of tissues, the ultimate elements of which can be studied only by the aid of the microscope. The knowledge of these elements and of the manner in which they are grouped together to form the various tissues of the body forms an important branch of anatomy, which is termed histology.

The structure of the human body may be studied in two different ways. The several parts may be considered with reference to their relative positions, either as they are met with in the course of an ordinary dissection, or as they are seen on the surface of a section through the body. This is the topographical method. On the other hand, the several systems of organs may be treated separately and in sequence. This constitutes the systematic method, and it is the plan which is adhered to in this treatise.

Descriptive Terms.-Anatomy is a descriptive science founded on observation, and in order that precision and accuracy may be attained it is necessary that we should be provided with a series of well-defined descriptive terms. It must

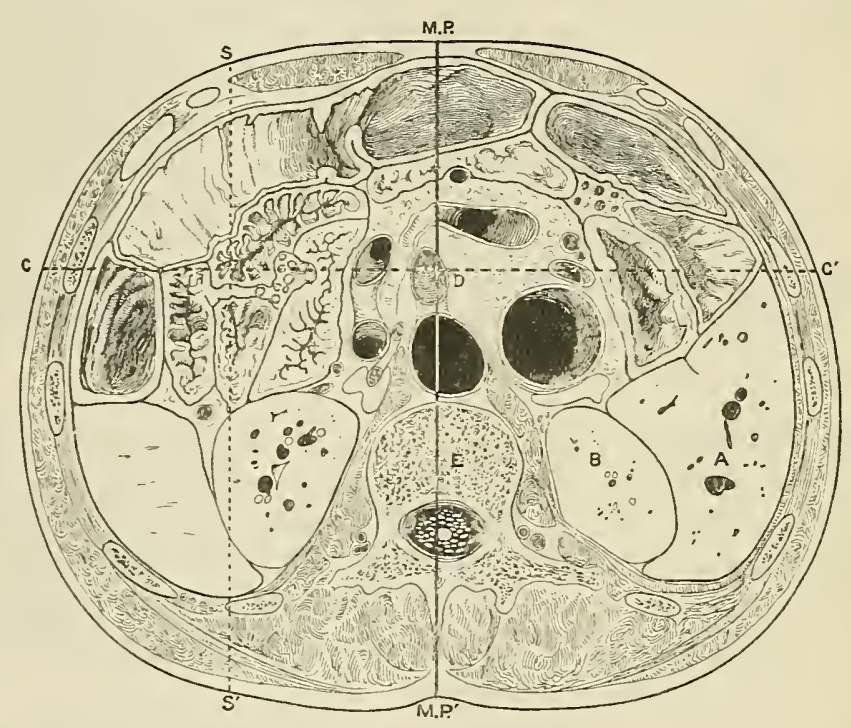

Fig. 1. - Horizontal Section through the Trunk at the Level of the First lumbar Vertebra.

be clearly understood that all descriptions are framed on the supposition that the body is in the erect position, with the arms by the side, and the hands held so that the palms look forwards and the thumbs laterally. An imaginary plane of section, passing longitudinally through the body so as to divide it accurately into a right and a left half, is called the median plane, Fig. 1 (M.P.). When the right and left halves of the body are studied it will be found that both are to a large extent formed of similar parts. The right and left limbs are alike; the right and left halves of the brain are the same; there are a right and a left kidney and a right and a left lung, and so on. So far the organs are said to be symmetrically arranged. But still a large amount of asymmetry may be observed. Thus, the chief bulk of the liver lies to the right side of the median plane, and the spleen is an organ which belongs wholly to the left half of the body. Indeed, it is well to state that perfect symmetry never does exist. There always will be, and always must be, a certain want of balance between symmetrically placed parts of the body. Thus the right upper limb is, as a rule, constructed upon a heavier and more massive plan than the left, and even in those organs where the symmetry appears most 
perfect, as for instance the brain and spinal medulla, it requires only a closer study to reveal many points of difference between the right and left halves.

The line on the front of the body along which the median plane reaches the surface is termed the anterior median line; whilst the corresponding line behind is called the posterior median line.

It is convenient to employ other terms to indicate other imaginary planes of section through the body. The term; sagittal, therefore, is used to denote any plane which cuts through the body along a path which is parallel to the median plane $\left(\mathrm{S} \mathrm{S}^{\prime}\right)$; and the term coronal or frontal is given to any vertical plane which passes through the body in a path which cuts the median plane at right angles $\left(\mathrm{C} \mathrm{C}^{\prime}\right)$. The term horizontal, as applied to a plane of section, requires no explanation.

Any structure which lies nearer to the median plane than another is said to be medial to it; and any structure placed further from the median plane than another is said to lie lateral to it. Thus in Fig. $1, \mathrm{~A}$ is lateral to B; whilst $\mathrm{B}$ is medial to $\mathrm{A}$.

The terms internal and external are applied to the walls of hollow cavities or organs; thus, the ribs possess external surfaces, that is, surfaces away from the cavity of the thorax, and internal surfaces adjacent to the cavity.

The terms anterior and ventral are synonymous, and are used to indicate a structure (D) which lies nearer to the front or ventral surface of the body than another structure $(\mathrm{E})$ which is placed nearer to the back or dorsal surface of the body, and which is thus said to be posterior or dorsal. In some respects it would be well to discard the terms "anterior" and "posterior" in favour of "ventral" and "dorsal," seeing that the former are only applicable to man in the erect attitude, and cannot be applied to an animal in the prone or quadrupedal position. They are, however, so deeply ingrained into the descriptive language of the human anatomist that they cannot be entirely discarded. A similar objection may be raised to the terms superior and inferior, which are employed to indicate the relative levels at which two structures lie with reference to the upper and lower ends of the body. The equivalent terms of cephalic or cranial and preaxial are, therefore, sometimes used in place of "superior," and caudal and postaxial in place of "inferior."

The terms proximal and distal should be applied only in the description of the limbs. They denote relative nearness to or distance from the root of the limb. Thus, the hand is distal to the forearm, whilst the arm or brachium is proximal to the forearm. 



\title{
HUMAN EMBRYOLOGY.
}

\author{
By A. H. Young and Arthur Robinson. \\ Rewritten by ARthur Robinson.
}

THE ontogenetic or developmental history of every human individual is separable into two main periods, pre-natal and post-natal.

It is to the knowledge of the phenomena of the earlier or pre-natal period that the term human embryology is applied, and as pre-natal development takes place in an organ called the uterus, it is frequently spoken of as intra-uterine development.

The period of pre-natal development extends through nine lunar months, and may be divided into three sub-periods: (1) the pre-embryonic period, during which the zygote, from which the embryo is formed, shows no definite separation into embryonic and non-embryonic portions. This period lasts about fourteen days; (2) the period of the embryo, in which the zygote is definitely separated into embryonic and non-embryonic portions, but the embryonic part has not jet assumed a clearly human form. This period terminates at the end of the second month; (3) the fœtal period, which commences at the end of the second month, when the embryo assumes a definitely human form and is called, thenceforth, a fœtus. The fotal period ends at birth, when the fœtus becomes a child and postnatal development commences.

Only the general phenomena of the pre-natal period of derelopment are considered in this section; the details of the pre-and post-natal development of the various organs and systems will be dealt with in the sections deroted to the descriptions of their adult conditions.

\section{THE STRUCTURE OF ANIMAL CELLS.}

The human body is formed by the multiplication and differentiation of animal cells, therefore it is essential that the student should possess a knowledge of the main features and capabilities of such cells before he commences the study of the details of human embryology.

Animal cells differ from each other in minor points of structure, in association with the positions they occupy and the functions they perform; nevertheless, they all possess some common and essential structural features, and, in the younger stages of their history, some common capabilities.

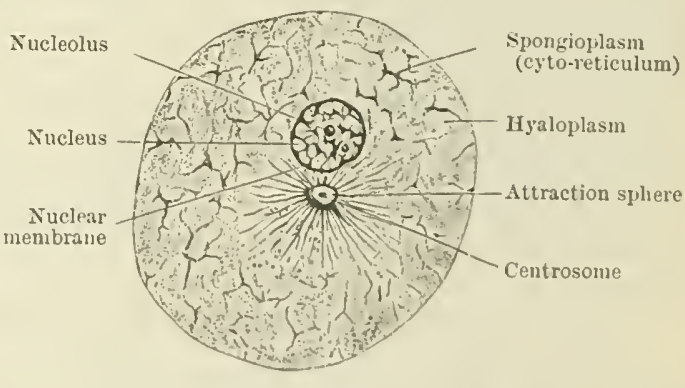

Fig. 2,-Diagram of an Axmal Cell.

The following are the constitment parts of a typical animal cell :-

The cell body :- containing
(a) The nucleus ;
(b) The nucleolus;
(c) The centrosome;
(d) The centrioles;
(e) The mitochondria.

All the essential parts of the cell consist of a substance called protoplasm.

In its simplest form protoplasm is the semilluid, viscous, irrituble, and con- 
tractile substance which forms the "physical basis of life." It consists of C., H., N., O., and S., combined together in different ways and in differing proportions to form various modifications of protoplasm which possess definite physical and chemical characteristics, and receive, therefore, different names.

The cell body consists of a kind of protoplasm called cytoplasm, separable into two parts; the spongioplasm or cyto-reticulum, which forms a network or spongework; and a more fluid part, the hyaloplasm or cytolymph, which occupies the interstices of the reticulum.

The nucleus lies in the cytoplasm. It consists of a form of protoplasm, called karyoplasm, which is separable into a more fibrillar part, the karyo-reticulum, and a more fluid part, the karyo-lymph or nuclear juice. The reticulum also consists of two parts, the achromatic or non-stainable part formed of a substance called linin, and a part called chromatin, which is readily stainable.

Chromatin varies in appearance at various stages of the cell life. During the resting periods, which intervene between the periods of cell division, it is broken up into small particles which either are embedded in or are in close association with the linin network.

When cell division commences the chromatin particles are aggregated to form a thread-like strand, which ultimately breaks up into a number of segments called chromosomes. The chromosomes are always of definite number in the body cells of any given species of animal. In the human subject the typical number is probably 24 .

According to Winiwarter's recent observations the number of chromosomes in each oocyte I (see p. 12) is 48, and in each spermatocyte I (see p. 12) it is 47 . Each mature ovum (see p. 13), therefore, has 24 chromosomes, but some spermatids (see p. 17) have 24 and others 23 . If a spermatozoon (see p. 17) with 24 chromosomes unites with a mature ovum a female results, but if a spermatozoon with 23 chromosomes unites with a mature ovum a male results.

During the resting period the nucleus is bounded by a distinct nuclear membrane, which is continuous on the one hand with the karyo-reticulum, and on the other with the cyto-reticulum.

The nucleolus is a spherical vesicle which lies in the karyo-lymph during the resting periods of the cell. It disappears entirely during the periods of division. The protoplasm of which it is formed is called pyrenin. In some cases several nucleoli are present.

The nodes of the karyo-reticulum are sometimes called false nucleoli.

The centrosome is a clear spherical area of the cytoplasm which lies usually in the neighbourhood of the nucleus. Around it the granules of the cytoplasm are arranged in radial lines, and in its interior lie one or two minute, deeply staining bodies, the centrioles. The centrosome appears to play a very important part in cell multiplication; and, in the more ordinary form of cell division, it divides before the division of the cell takes place, but in certain cases it disappears before the cell divides.

The mitochondria are minute particles. They are demonstrable in the majority of cells by means of certain stains, after special methods of fixation and preservation have been used. They are believed to play an important part in the economy and life-history of the cells, and they form a very definite part of the structure of the spermatozoon or male gamete.

\section{THE LIFE-HISTORY AND CAPABILITIES OF ANIMAL CELLS.}

Every animal cell is formed by the division of a pre-existing cell called the mother cell. The mother cell divides into two equal parts-the daughter cells, each of which, under ordinary conditions, possesses all the capabilities of its mother.

Reproduction of Cells.-Ordinary tissue cells increase in number by the division of the pre-existing cells into equal parts, each of which possesses similar capabilities. Every new cell has a definite life-history; it grows, performs its proper function, and ceases to exist, either by dividing into two daughter cells, or by dying and breaking up into fragments which disappear.

Whilst the multiplication rate exceeds the death-rate in any given tissue or organ, that tissue or organ grows. When the multiplication rate and the death- 
rate are equal, the tissue or organ is in a state of equilibrium. As soon as the death-rate exceeds the multiplication rate, decay and atrophy set in; and when the decay and atrophy have proceeded to such an extent that an important tissue or organ can no longer perform its proper functions, general death ensues.

General decay and death are, therefore, the natural results of the loss of multiplication power of the cells of the body, but life may persist after multiplication power is lost, so long as the cells last produced retain their capabilities, and death may result whilst multiplication power of the cells is retained, if the newly produced cells are incapable of performing their proper functions. Nevertheless, speaking generally, it may be said that cell multiplication is a vital necessity, and it takes place in two ways-(1) by amitotic and (2) by mitotic division of pre-existing cells.

Amitotic Division.-The phenomena of amitotic division, so far as they are known, are much simpler than those of mitotic division. First the nucleus is constricted and divided; then the cell body is constricted and divided, and two similar daughter cells, each half the size of the mother cell, are produced. The part played by the centrosome during the process is not definitely known, but each daughter cell eventually possesses a centrosome. The apparently simple process of amitotic division occurs at some periods of growth, and the more complicated process of mitotic division at other periods, but the laws which govern the alternations are unknown.

Mitotic Division; Mitosis, or Karyokinesis.-Mitotic or karyokinetic division is not only the more complicated, but it appears also to be the more important form of cell division. It takes place in all rapidly growing tissues, especially in the embryonic and fotal stages of life, and it is the main form of cell division which occurs in the eariiest enibryonic periods. There are, however, two forms of mitosis, the homotype and the heterotype. Of the two, homotype is so much the more common that it may be looked upon as the ordinary form, for heterotype mitosis appears to be limited to one of the two cell divisions which occur during the maturation of the germ cells, and to some of the cell divisions which are associated with the production of malignant tumours.

Homotype Mitosis. - The phenomena of homotype mitosis occur in four phases, (1)

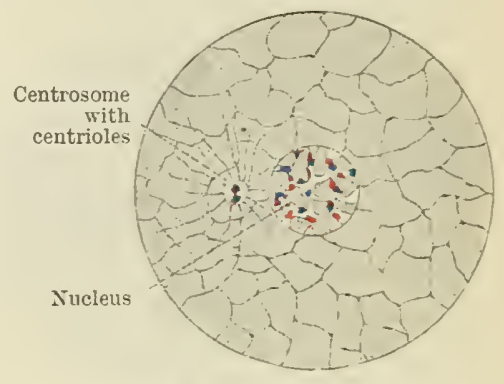

Fig. 3.-Schema of Aimal Cell ix Piestixg Stige.

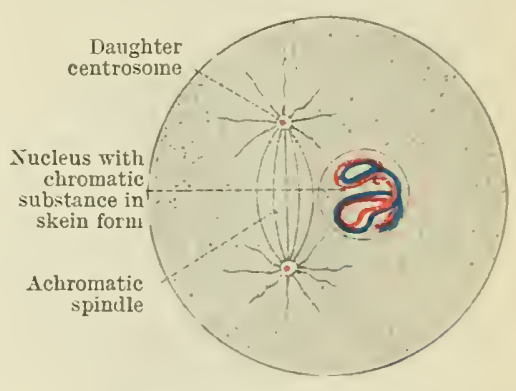

Fig. 4.-SChEMA OF ANIMAL C'ELL IS EARLY Part of Prophase of HoMotipe Mitosis.

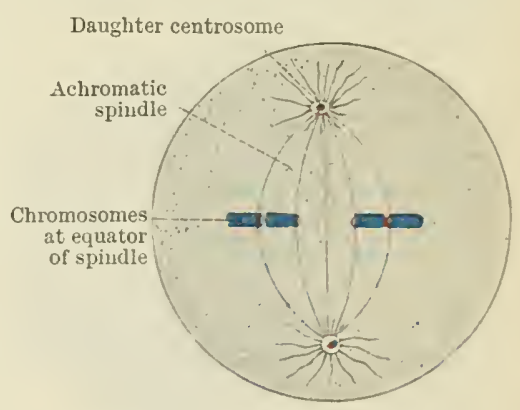

Fig. 5.-Schema of ANimal Cell at ComPLETIOA OF PrOIHASE OF HUMOTYPE, Mitosis. the prophase, (2) the metaphase, (3) the anaphase, and ( \pm ) the telophase.

The Prophase.-During the prophase both the centrosome and the nucleus undergo very obvious transformations.

The centrosome and its contained centriole divide into two parts, of which one passes to one pole and the other to the opposite pole of the nucleus.

The nuclear transformations concern the uucleolus, the chromatic sulustance, and the nucleolar membrane.

The nucleolus disappears. In some cases it passes from the nucleus into the cytoplasm, where it breaks up; in other cases the details of its disappearance are entirely unknown. 
The chromatic substance is aggregated to form first a fine and afterwards a thicker thread or spirem. At the same time, a spindle of achromatic fibrils appears between the two daughter centrosomes, and the nuclear membrane disappears.

As soon as the achromatic spindle is definitely estahlished the chromatic thread breaks up into a number of segments, the chromosomes, which arrange themselves around the equator of the achromatic spindle.

The chromosomes may be V-shaped, rod-like, cuboidal or spheroidal, and each

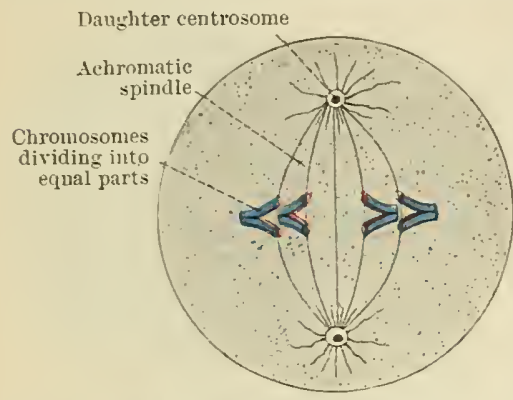

Fig. 6.--Schema of ANimal Cell ix MetaPHASE OF HoMotYPE Mitosis.

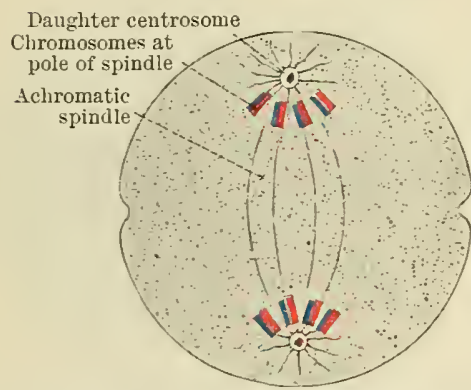

Fig, 7.-Schema of Aximal Cell at Exd of Axaphase of Homotype Mitosis.

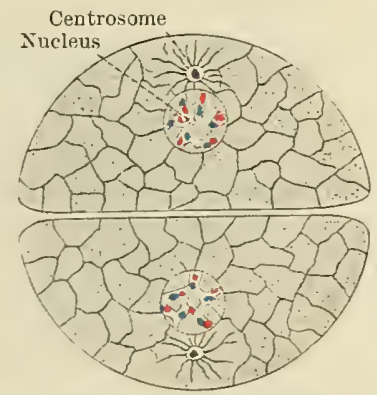

Fig. 8.-Schema of Aximal Cell at Exd of Telophase of Homotype Mitosis. The cell has divided into two daughter cells. Rerl and blue indicate the original paternal and materual derivatives.

typical number of chromosomes, and a portion of the achromatic spindle. may be a single structure, or it may consist of tro or four parts which are closely bound together. There is evidence which tends to support the belief that, whether the chromosome appears to consist of one, two, or more segments, its constituent particles are derived partly from the maternal and partly from the paternal ancestor of the cell; and it is believed that the maternal and paternal portions undergo similar division during the last three phases of mitosis. In any case, whether the chromosomes are single or compound structures, each becomes attached to, or very closely associated with, one of the fibrils of the achromatic spindle.

At the end of the prophase the nucleus as such, and the nucleolus, have entirely disappeared, and the cell body contains in their place two centrosomes, an achromatic spindle, and the chromosomes. The centrosomes lie at the opposite poles of the achromatic spindle with the granules of the protoplasin grouped radially around them, and the chromosomes are grouped round the equator of the achromatic spindle.

The Metaphase.-During the metaphase each chromosome divides into two equal parts, the rods or loops dividing longitudinally; and the division, in all cases, commences at the point where the chromosome is in relation with the fibrils of the achromatic spindle.

The Anaphase.-In the anaphase the halves of the chromosomes, i.e. daughter chromosomes, move towards the opposite poles of the achromatic spindle, and when they reach the vicinity of the daughter centrosomes the anaphase ends and the telophase begins.

The T'elophase. - At the end of the anaphase, or the commencement of the telophase, a constriction appears around the periphery of the cell, at the level of the equator of the achromatic spindle. After its appearance the constriction gradually deepens until the cell is completely divided into two halves, the daughter cells, each of which contains the

The Resting Stage.-During the resting stage, which lasts for a variable period, a nucleus is formed in each daughter cell by the appearance of a nuclear membrane around the chromosomes, as they repass first to the thread-like and then to the granular form of chromatic substance, and by the reappearance of a nucleolus. The cell increases in size also.

The Period of Cell Life.-The period of cell life varies, but in all cases it ultimately ends in death; for a time comes when cells no longer transmit to their 
descendants the power of division, or the capability of growth and function. If it were not so, growth and function, or at least maintenance and function, would continue uninterruptedly, and in the absence of accident or disease individual life would continue for ever, and "old age" would be unknown.

It appears, therefore, that the ancestors of certain tissue cells are capable of producing only a certain number of descendants, which grow to the normal size and perform their proper functions for a more or less fixed period, whilst in other cases the power of division appears to be transmitted continuously, but the more remote descendants become less and less capable of performing their proper functions. The result in both cases is the same; gradual decay, terminating in death.

Heterotype IMitosis.-In ordinary or homotype mitosis the chromosomes are divided into equal parts, and, when the process of cell division is completed, each daughter cell possesses the same number and same kind of chromosomes as the mother cell from which it was derived (Figs. 3-8). In heterotype mitosis, the number of chromosomes is reduced during the cell division, and each daughter cell possesses only half the number of chromosomes that was present in the mother cell.

The details of the division of the chromosomes during heterotype mitosis differ in different groups of animals, but the end is the same in all cells in which the process occurs, and is the reduction of the number of the chromosomes in the daughter cells to half the number typical for the ordinary cells of the animal.

The most typical form of heterotype mitosis is seen during the first maturation division of many germ cells, in which, during the spirem or thread-like stage of the chromatic substance, careful examination of the thread shows that it consists of a number of alternate segments attached end to end, the number of segments corresponding with the number of the chromosomes typical for the ordinary cells of the animal. Towards the end of the prophase, the segments of the thread become attached together in pairs which form a number of twin chromosomes. These arrange themselves around the equator of the achromatic spindle, and it is obvious that the number of twin chromosomes is only half the number of the chromosomes originally present in the cell (Figs. 12 and 13).

The total number of chromatic segments is still the same, for each twin chromosome consists of two ordinary chromosomes attached side to side.

The process of reduction takes place during the metaphase, when the two segments of each twin chromosome become separated from each other. During the anaphase the separated segments pass to the opposite poles of the achromatic spindle, and when the telophase is completed the number of chromosones in each daughter cell is half that which was present in the mother cell (Figs. 12-19).

In some cases, at the commencement of heterotype mitosis, the chromosomes are not arranged in pairs as twins, but in groups of four, called tetrads, each tetrad consisting of a pair of dyads. In these cases the two drads of each tetrad are separated from each other during the metaphase, and when the telophase is completed each daughter cell possesses only half the number of chromatic particles which were present in the mother cell.

It is known that a cell which contains only half the typical number of chromosomes can divide once, therefore from each original cell which underwent heterotype mitosis four granddaughter cells may be produced. It is still uncertain, however, whether or not cells which contain only half the typical number of chromosomes can further subdivide, or whether they can continue to lire and function. So far as the observations made can be relied upon, it appears that such cells either die or they unite with another cell containing half the typical number of chromosomes to produce a new cell which contains the typical number of chromosomes and which possesses also the capability of reproducing itself by division.

The Gametes.-The gametes are the germ elements by whose union, in pairs, new individuals are produced.

They are of two kinds, female gametes or ova and male gametes or spermatozoa. Both female and male gametes are modified cells, fy means of which hereditary characteristics are transmitted from generation to generation, and they are derived from cells called primitive germ cells, whose origrin will he considered in association with the development of the germinal layers. 
The germ cells reach their full development in special sex glands, the ova in the ovaries of the female and the spermatozoa in the testes of the male.

After the descendants of the primitive germ cells have increased, by ordinary

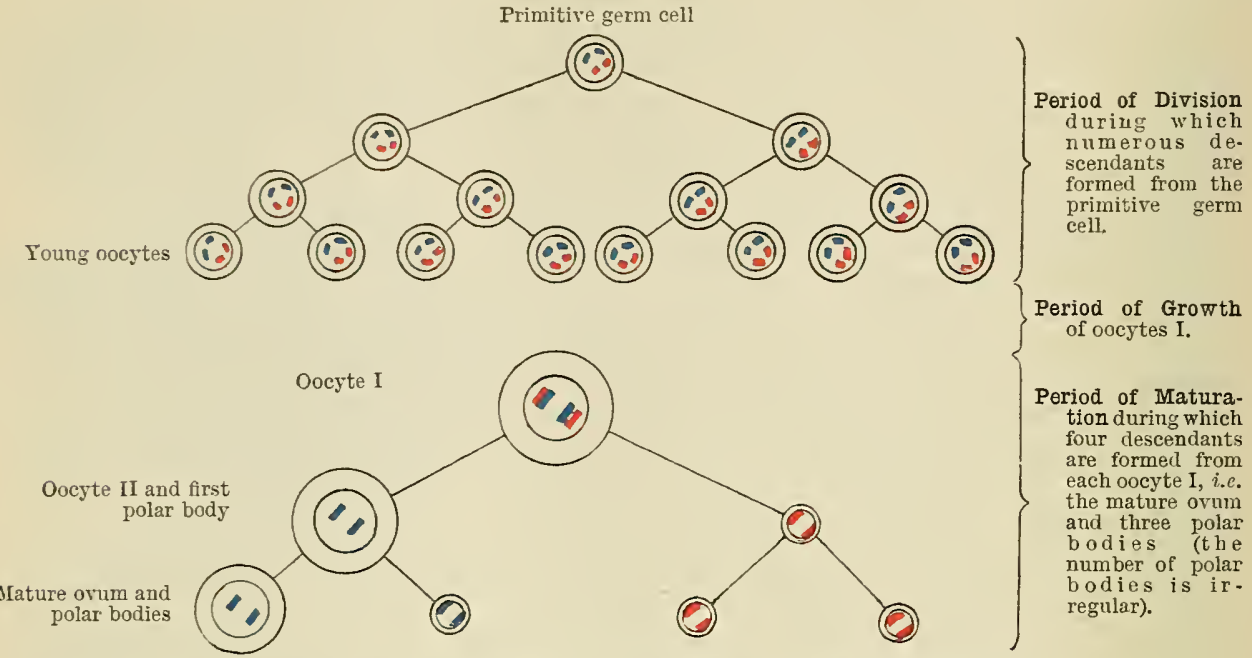

Fig. 9. - Schema of the Detelopiental History of the Matere Ovem.

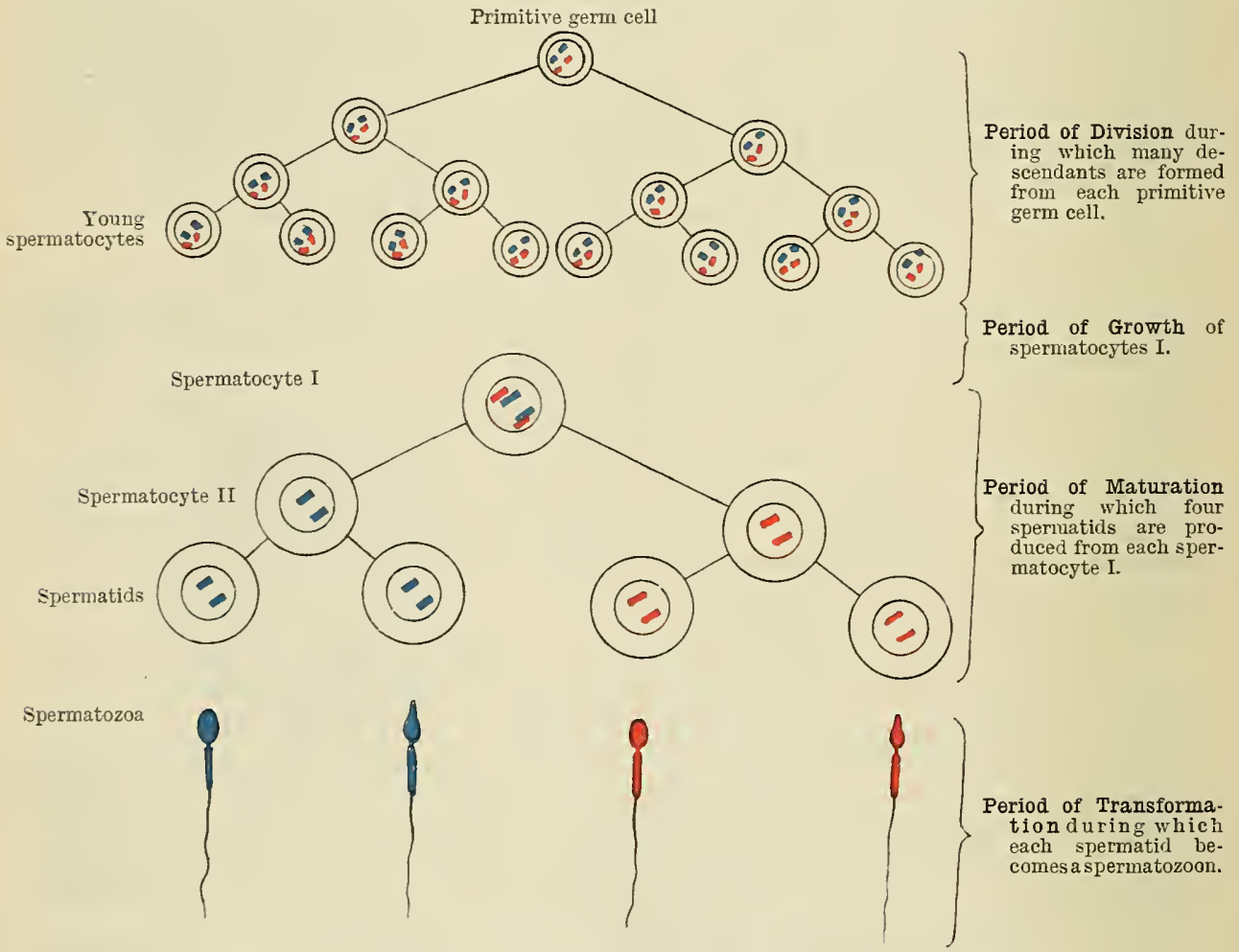

Fig. 10.-Schema of the Detelopyental History of Spermatozoa.

cell division, to a number which is probably fixed and unchangeable, but which is not definitely known, they begin to increase in size, that is, they enter upon a period of growth, and at this time the female germ cells are called oocytes of the first order, oocytes I, and the male germ cells are called spermatocytes of the first order, spermatocytes I. Both the oocytes I and the spermatocytes I possess all the essential 
parts of a typical animal cell, and, in addition, each has special peculiarities which differentiate it both from the germ-cells of the opposite sex and also from ordinary animal cells. Therefore the oocyte and the spermatocyte must be considered separately; but before this is done it must be noted that each oocrte I and each spermatocyte I is capable of producing only four descendants. The mitotic cell divisions by which the descendants are produced are called the maturation divisions, and they result, in the case of the oocyte, in the formation of one large functional cell-the mature ovum, and three small impotent cells-the polar bodies; whilst in the case of the spermatocyte the four descendants are of equal size and each becomes transformed into a potent spermatozoon.

\section{THE OVUM.}

An ovum presents all the characteristic structural features of an animal cell, but it is peculiar on account of its relatively large size, the large size of its nucleus, and the possession of an investing membrane, the oolemma. As the young ora or oocytes of the first order enter upon their period of growth, each is enclosed by a single layer of special cells, the stratum granulosum, which constitute, together with the oocyte, a primary ovarian follicle (O.T. Graafian follicle). The cells of the stratum granulosum multiply rapidly until they form a layer, several cells thick. At the same time, the oocyte increases in size and becomes surrounded by the membrane, called the oolemma, which intervenes between it and the innermost cells of the stratum granulosum.

Whilst the growth of the oocyte and the thickening of the oolemma are still proceeding, a fluid-filled cavity appears in the stratum granulosum. Whether the cavity is due to the imbibition of fluid or to the dehiscence of the cells of the stratum granulosum is still uncertain, but, after its appearance, the cavity with its surrounding walls and the enclosed oocyte is spoken of as a vesicular ovarian follicle. The cavity of the vesicular follicle gradually increases, and, as it grows, it separates the oocyte and the cells of the stratum

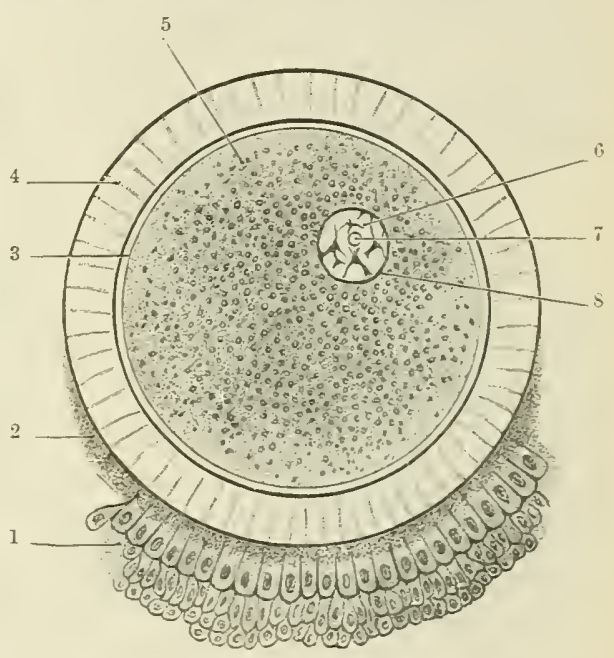

Fig. 11.-The Oruy AXd ITs Coverixgs (Diagrammatic).

The corona radiata, which completely surrounds the ovum, is ouly represented in the lower part of the figure.

1. Corona radiata. 2. Granular layer.

3. Vitelline membrane. granulosum immediately around the oocyte from the remainder of the cells of the stratum, except in a small area where the two parts of the stratum granulosum still remain in direct continuity. When this condition is attained the cells of the stratum granulosum which immediately surround the oolemma are spoken of as the ovular cumulus; they enclose the oocyte, and, together with it, they form a bold promontory which projects into the cavity of the follicle.

When its full growth is attained each oocyte $I$ is a comparatively large cell, which measures $200 \mu$ in diameter. It consists of a cell body which is surrounded by a definite enclosing membrane, the oolemma, and it contains (1) a nucleus, ( 2 ) a centrosome, (3) numerous granules called deutoplasmic or yolk granules, and (4) mitochondria.

The Oolemma. - The limiting membrane or oolemma is also called the sona pellucida, on account of its appearance under low magnifying powers, and the zona striata, because it is pierced by numerous radial canals which are visible when highly magnified. It is a strong, elastic membrane, which not only protects the oocyte from pressure, but probably also prevents the impregnated oocyte or zygote 
from coming into close contact with the maternal tissues until it has attained the proper stage of derelopment.

The exact origin of the oolemma is unknown. It must be formed either by the action of the cells of the stratum granulosum, or by the action of the oocyte, or by

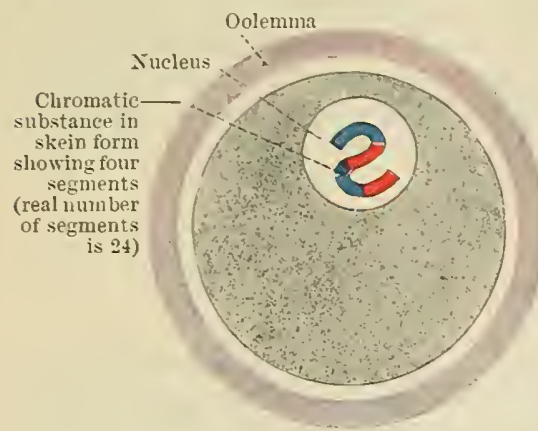

Fig. 12. -Schema of́ Maturation of OVUM, Early Part of Prophase of First Division.

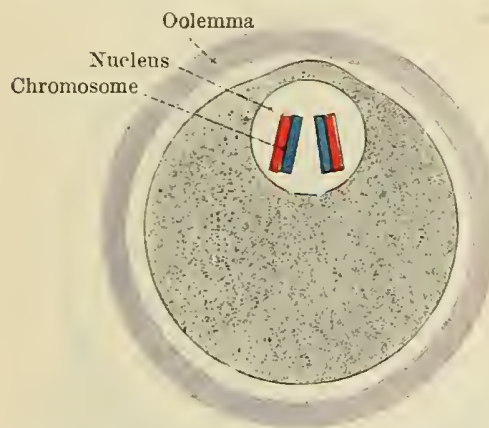

Fig. 13. - Schema of Maturation of Ovum in Prophase of First Division. The chromatic thread has divided into twin chromosomes. Each twin may be assumed to consist of a maternal and a paternal part.

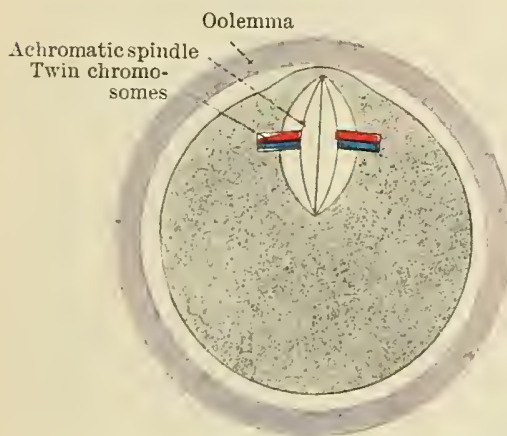

Fig. 14.- Schema of Maturation of Oveji at Exd of Prophase of First Division. The twin chromosomes lie at the equator of the achromatic spindle. (1) an achromatic reticulum, the linin; (2) chromatic substance, which is embedded in or closely connected with the strands of the linin; and (3) the nuclear juice, which fills the meshes of the reticulum; and it contains usually one, but sometimes several nucleoli.

The Centrosome.-The centrosome is not always very evident. It is usually present during the growth stage of the oocyte, and it disappears when the first maturation division commences. It may contain one or two centrioles, and it 
lies in the region of the larger deutoplasmic granules by which its presence is frequently obscured.

The Mitochondria.--These minute particles can be demonstrated by suitable methods of fixation and staining.

The Maturation of the Ovum.-The process of maturation consists of two mitotic divisions, of which the first is heterotypical, and results in the reduction of the number of chromosomes, and the second is homotypical. The phenomena of the two divisions differ in some of their details from those of ordinary cell divisions, therefore a short account of them is necessary.

In the prophase of the first maturation division, the centrosome, the nucleolus, and the nucleus vanish, and an achromatic spindle appears at one pole of the oocste, where. it lies, at first, parallel with the surface; and the chromosomes are gathered around its equator. The number of the chromosomes is only half the typical number, and they are probably twin chromosomes (p. 11). There are no centrosomes at the poles of the spindle. After a short time the spindle rotates until it lies at right angles to its original position, and one pole, surromnded by a small amount of the cytoplasm, forms a projection, the first polar projection, on the surface of the oocyte (Fig. 14).

During the metaphase the twin chromosomes divide. In the anaphase the daughter chromosomes travel to the opposite poles of the spindle, and at the end of the anaphase one-half of the daughter chromosomes lies in the first polar projection and the other half in the body of the oocyte (Fig. 16).

In the telophase the first polar projection is separated from the body of the oocyte and oocyte I ceases to exist, being converted into an oocyte of the second order, or oocrte II, and the first polar body, each of which contains half the typical number of chromosomes.

The second maturation division occurs without the intervention of a resting stage, i.e. without the reappearance of a nucleus in oocyte II. A new achromatic spindle appears with the danghter chromosomes at its equator; it rotates, and one pole, surrounded by a small amount of cytoplasm, projects on the surface of the oocyte as the second polar projection (Fig. 17). In the metaphase the daughter chromosomes diride homotypically into equal parts, and during the anaphase the grand-daughter chromosomes move towards the poles of the spindle,

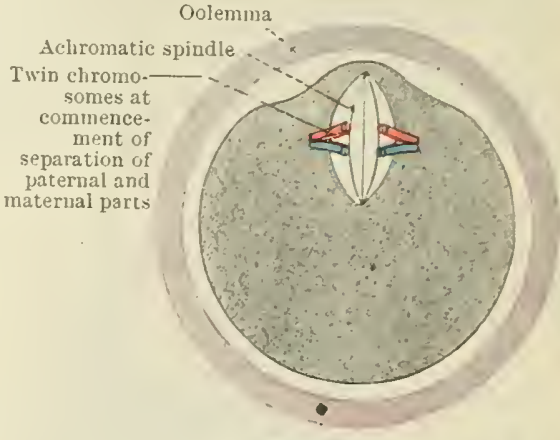

Fig. 15.-SCHEMA OF MatCRATION OF OrUa IN Mietaphase of First Difisiox. One pole of the spindle projects into the first polar bud, and the materual and paternal parts of the chromosomes are separating from eacli other.

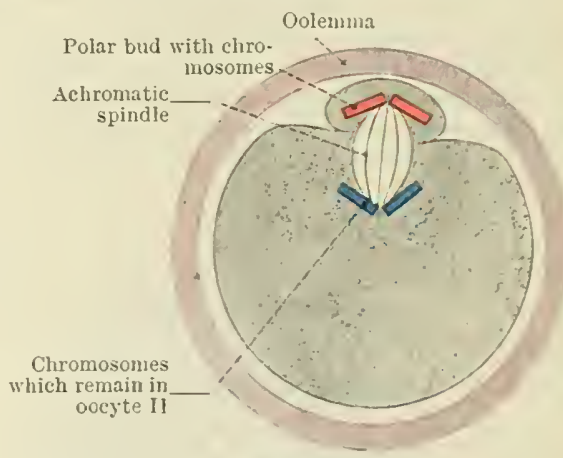

FIG. 16.-SCHEMA OF MATCRATIIX OF OVUM AT ExD OF THE ANAPHASE OF THE FIRST IOIVIsiox. Two chromosomes (paterual or maternal) lie in the first polar bud and two in the larger part of the ovmm which becomes oocyte 11 .

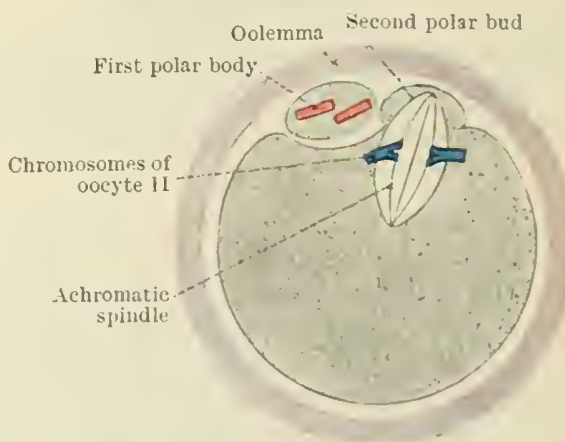

Fil. 17. - Sched.t UF MATURATLON OF OVUM AT THE (')MAEXIENE.XT OF THE METALHASE OH THE SECOND DIVISIUX. one-half entering the second polar projection and the other half remaining in the body of the oocyte. During the telophase the second polar projection is separated as the second polar body and the larger remaining part of the oocjte II becomes the mature ovum (Figs. 17 and 18). 
Simultaneonsly with the division of the oocyte II into the second polar body and the mature ormm, the first polar body may divide into two parts. When this occurs four cells are present within the oolemma at the end of the maturation, i.e. the relatively large mature orum and the three polar bodies (Fig. 19).

The details of the maturation of the human ovum are unknown, and the above account is based upon the phenomena which occur in other mammals. In some animals only one polar body is formed, and in others the first does not divide into two parts simultaneonsly with the formation of the second. The significance of these differences is not at present fully understood.

Each of the four descendants of the oocyte I contains half the typical number of

Second polar bud with chromosomes Chromosomes of second polar bud

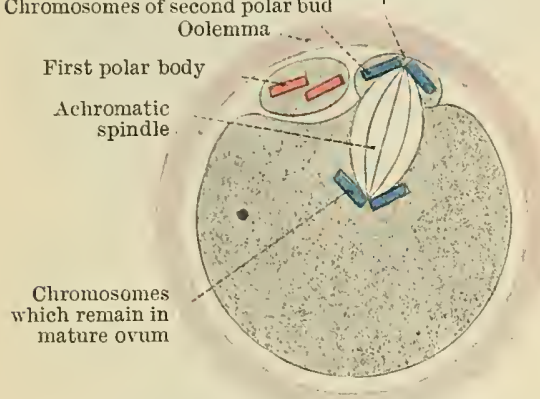

Fig. 18.-Scheira OF Matoration of OVUM at ENd of ANaphase of Second Division. The chromosomes of oocyte II have separated into equal parts which have passed to the opposite poles of the spindle.

Second polar body Parts of first polar body

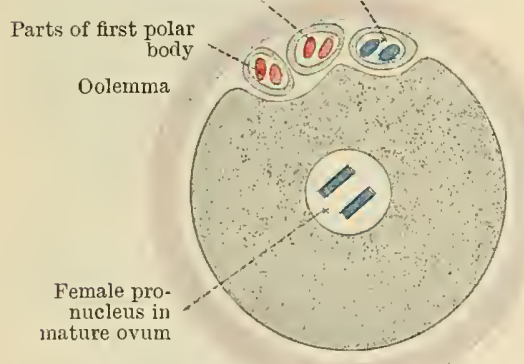

Fic. 19. - Schema of Maturation of Ovum. ENd of Telophase of SEcond Division where the four descendants of oocyte I are the mature ovum, with half the original number of chromosomes, and three polar bodies.

the tubules of the testes or male sex converted into spermatozoa.

They differ from the oocytes $I$ in three important respects: (1) they have no protective membrane corresponding with the oolemma of the oocyte; (2) they are not enclosed in follicles; (3) the spermatocytes are not surrounded by definite encircling layers of cells similar to the cells of the stratum granulosum.

As the spermatocytes lie in the walls of the tubules of the testes they are intermingled with other cells, the supporting and nurse cells, amidst which they undergo their maturation divisions, and their descendants become embedded in the nurse cells, where they are converted into spermatozoa. To a certain extent, therefore, the nurse cells may be looked upon as corresponding with the cells of the ovular. cumulus which surround the growing oocyte.

After it has reached its full growth each spermatocyte I, like each oocyte I, can produce only four descendants, and the descendants, as in the case of the oocyte I, 
are formed by two successive mitotic divisions, of which the first is heterotypical and produces reduction of the chromosomes, and the second is homotypical.

The two divisions differ from the corresponding divisions of the oocytes in three important respects: (1) centrosomes are present; (2) the four grand-daughter cells produced are of equal size and presumably of equal value, so far as capability of uniting with a mature ovum to form a zygote is concerned; (3) each of the four grand-daughter cells possesses two centrosomes.

In the prophase of the first or heterotype division the nucleus and nucleolus disappear in the ordinary way. The centrosome divides, and an achromatic spindle appears, which has the daughter centrosomes at its poles and half the typical number of chromosomes at its equator. The chromosomes are twin chromosomes. During the metaphase the two segments of each twin chromosome separate from each other. In the anaphase they travel to the opposite poles of the achromatic spindle, and consequently, when the cell divides in the telophase, each daughter cell or spermatocyte II contains a centrosome and half the typical number of chromosomes.

The second maturation division, which takes place without the intervention of a resting stage, is of the homotype form. The centrosome divides, a new achromatic spindle appears, and the daughter chromosomes gather at its equator. In the metaphase the chromosomes divide into equal parts, which travel to the opposite poles of the spindle during the anaphase, and when the telophase is completed the granddaughter cells, which are called spermatids, possess a centrosome and half the typical number of chromosomes. In the resting stage which follows, the chromatic particles become enclosed in a new-formed nucleus, and the centrosome, if it has not already divided, separates into two parts, one which lies nearer the nucleus and is called the anterior centrosome, and another, farther from the nucleus, termed the posterior centrosome (Fig. 22). Numerous mitochondria are present, and an indefinite structure, called the accessory body, is also found in the cell protoplasm. A spermatid, therefore, differs from a typical animal cell not only because it possesses the chromatic substance of only half the typical number of chromosomes, but also because it possesses an accessory body and two centrosomes.

From Spermatid to Spermatozoon.-The reader will have noted that the female gametes become mature and ready for conjugation with male gametes directly after the second maturation division is completed. In the case of the male germ cells, however, the spermatids which result from the second maturation division have still to undergo a complicated process of transformation before they become converted to spermatozoa or mature male gametes. The process of transformation takes place in association with the nurse cells in which the developing spermatozoa become embedded.

The details of the process of transformation are difficult to follow, and the knowledge regarding them is still to some extent indefinite. Certain points, however, are well established; but before they are considered it is necessary that the reader should be acquainted with the anatomy of an adult spermatozoon.

\section{THE SPERMATOZOON.}

A spermatozoon is a minute organism consisting of a head, a neck, a body, a tail, and an end-piece. Its total length is about $50 \mu$, that is, its length is about the same as the diameter of the nucleus of the ovum.

The head has the form of a laterally compressed ovoid. It is separable into anterior and posterior portions, and the anterior portion is more or less completely covered by a head-cap, which culminates in a sharp ridge. The length of the head is about $4 \cdot 5 \mu$.

The neck is an extremely short constricted region which intervenes between the head and the body. At its anterior end, where it joins the head, there is a deeply staining anterior centrosome, and at its posterior end a similarly deepstaining posterior centrosome, from which a deep-staining axial filament extends posteriorly through the body and tail into the eud-piece (Fig. 21). 
The Body.-The body is a little longer than the head, and its constituent parts

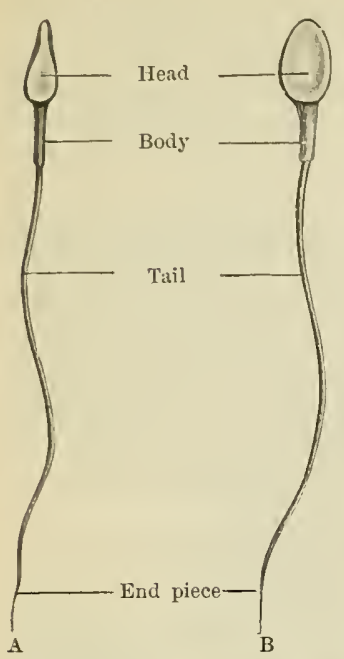
(after Retzius).

A, Side riew ; B, Front riew.

are: (1) a portion of the axial filament; (2) a portion of the axial sheath; (3) the spiral sheath; (4) the mitochondrial sheath; (5) the end-ring.

The axial sheath is a thin layer of protoplasm immediately surrounding the axial filament.

The spiral sheath consists of a spiral fibril embedded in indifferent protoplasm, and the mitochondrial sheath, which surrounds the spiral sheath, is formed by protoplasm containing numerous mitochondria.

The end-ring closes the posterior ends of the spiral and mitochondrial sheaths, and it is perforated by the axial filament and its sheath as they pass from the body into the tail.

The tail is $28-29 \mu$ long. It consists of prolongations of the axial filament and its sheath, and it ends in the short thin end-piece.

The Transformation of the Spermatid into the Spermatozoon.-As the transformation progresses the nucleus of the spermatid becomes the head of the spermatozoon. The axial filament grows out from the posterior centrosome of the spermatid, which divides into two parts, one of which becomes the posterior centrosome of the neck of the spermatozoon, whilst the other becomes the end-ring of the body of the spermatozoon.

The anterior centrosome of the spermatid becomes

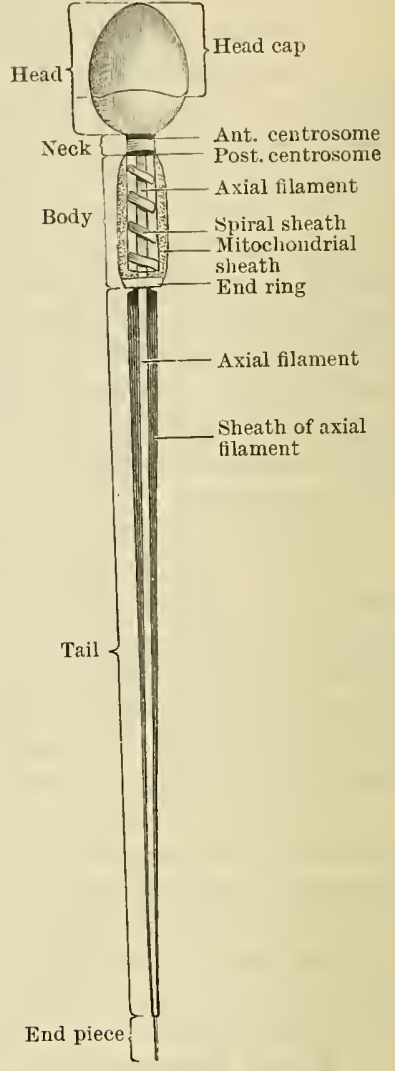

Fig. 21.-Structure of a Human Spermatozoon (after Meeves).
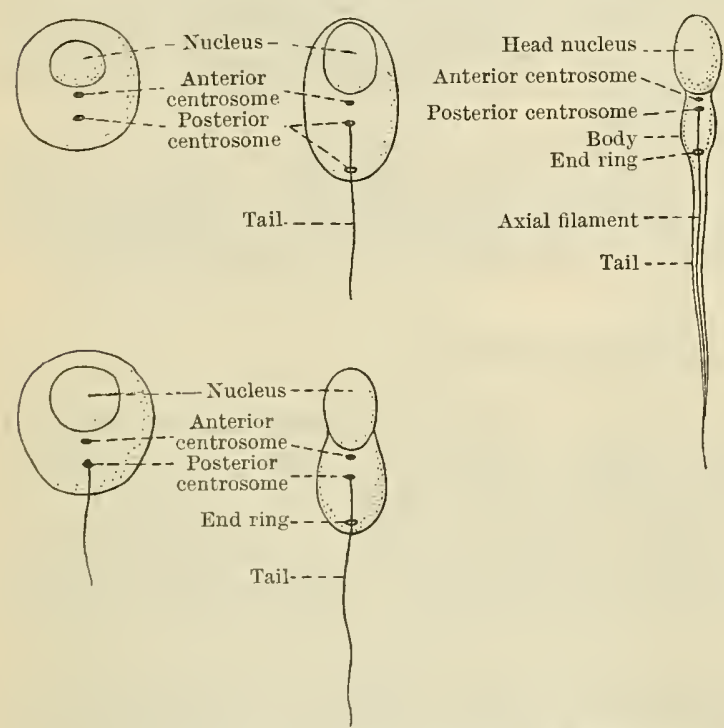

Fig. 22.-Schema of Transformation of Spermatid ryto Speraratuzoon (after Meeves, modified).

the anterior centrosome of the neck of the spermatozoon. The cytoplasm of the spermatid forms the axial sheath, the indifferent protoplasm of the spiral sheath and mitochondrial sheath. The origin of the spiral filament and the origin of the head-cap are uncertain, but it is stated that, in some animals, the head-cap is formed from the accessory body, which is not shown in Fig. 22.

The Object of the Reduction of the Chromosomes. - The most striking phenomenon of the process of the maturation of the gametes is the reduction of the chromosomes. The constancy of the reduction tends to emphasise its importance, but, as we have no definite knowledge of the functions of the chromatic substance, the object of the reduction can only be surmised. The evidence which has been accumulated tends to the 
conclusion that the particles of the chromatic substance are the bearers of hereditary tendencies and capabilities. ${ }^{1}$ If this is the case, then they are the means by which ancestral possessions, in the morphological sense, are transmitted from generation to generation. There is evidence also, first ascertained by Mendel and substantiated and increased in recent years by his followers, which lends probability to the belief that the tendency carriers form two main groups: (1) those which carry certain tendencies; (2) those which carry opposite tendencies. The bearers of tendencies and the bearers of their opposites are allelomorphic or alternative to each other, and are called allelomorphs. Thus the particles which bear tallness and dwarfness respectively are allelomorphs, that is, they are alternative to each other.

Further, the facts which are known suggest the idea that in the primitive germ cells, and their descendants which contain the typical number of chromosomes, the character-bearing particles are arranged in pairs of which both elements may bear the same tendencies, or one may bear one tendency and the other the opposite.

For example, if red and blue be supposed to be opposite tendencies carried by differcnt particles or allelomorphs, then the germ cells of any given animal, male or female, may contain either a pair of red-bearing particles, a pair of blue-bearing particles, or a red and a blue bearing particle associated together as a pair.

The reduction of the chromosomes during the maturation divisions of the germ cells is an admitted fact, and it is believed that the reduction is a necessary preliminary to the union of a male and a female gamete to form a zygote from which a new individual may arise. It is assumed that the purpose of the reduction is the segregation of the different tendency bearers from each other in order that they may enter into new combinations. If this assumption is correct, then every mature germ element or gamete contains only one element of any given pair of tendency bearers, in the suppositious case under consideration, either the red or the blue bearer, but not both; and the object of the reducing division is the segregation of the allelomorphs in order that they may enter into new and possibly into different combinations, producing new and possibly varied results.

If, in the case of any given group of animals, the mature germ cells of some of both sexes contain the blue-bearing particles and others the red-bearing particles, it necessarily follows that three possible results may ensue when impregnation occurs, that is when two mature germ cells unite to form a zygote.

(1) A female gamete bearing red tendency particles may fuse with a male gamete bearing red tendency particles; (2) a female gamete bearing blue tendency particles may meet and fuse with a male gamete bearing blue tendency particles; (3) a female gamete bearing red tendeney particles may meet and fuse with a male gamete bearing blue tendency particles. The constitution of the zygotes formed may be stated as follows:-

\section{RR BB RB,}

and the character of the individual developed from the zygote will vary according to the combination. If two red tendency bearing gametes meet, the individual will be red; if two blue tendency bearing gametes meet, the individual produced will be blue; but when a gamete bearing red teudency particles unites will a gamete bearing blue tendency particles the individual will be either red or blue or a combination of the two, the result depending upon the relative potency or dominance of the two tendencies.

Further exposition of this interesting subject would be out of place in a textbook of anatomy, but it is of such great importance in association with the transmission of hereditary characteristics and liereditary diseases that every medical student should make himself familiar with its possibilities by consulting the works of Bateson, Punnet, and other writers and observers who are attempting to solve the complicated problems which it presents.

1 It must be understood that this function, if it exists, does not prevent the chromatic particles possessing other functions, and that there is no evidence that the potency of a temency depends upon amount of chromatic substance. 


\section{Fertilisation.}

Fertilisation is the term applied to the union of the male with the female gamete to form a zygote which contains the typical number of chromosomes (Fig. 23).

The meeting of the gametes and their union take place, normally, in the upper part of the uterine tube.

The details of the process are unknown in the case of the human subject, but in many animals it has been noted that as the spermatozoon approaches the ovum the latter shows sigus of exeitement, and a small prominence, called the cone of attraction, appears on its surface. At the same time its pronucleus undergoes changes of form. As the two gametes meet the spermatozoon pierces the oolemma which surrounds the ovum and passes through the cone of attraction into the body of the ovum.

In some cases apparently only the head, neck, and body of the spermatozoon effect an entrance, but in others the whole spermatozoon enters the body of the ovum.

If the entrance occurs before the second polar body is formed, the parts of the
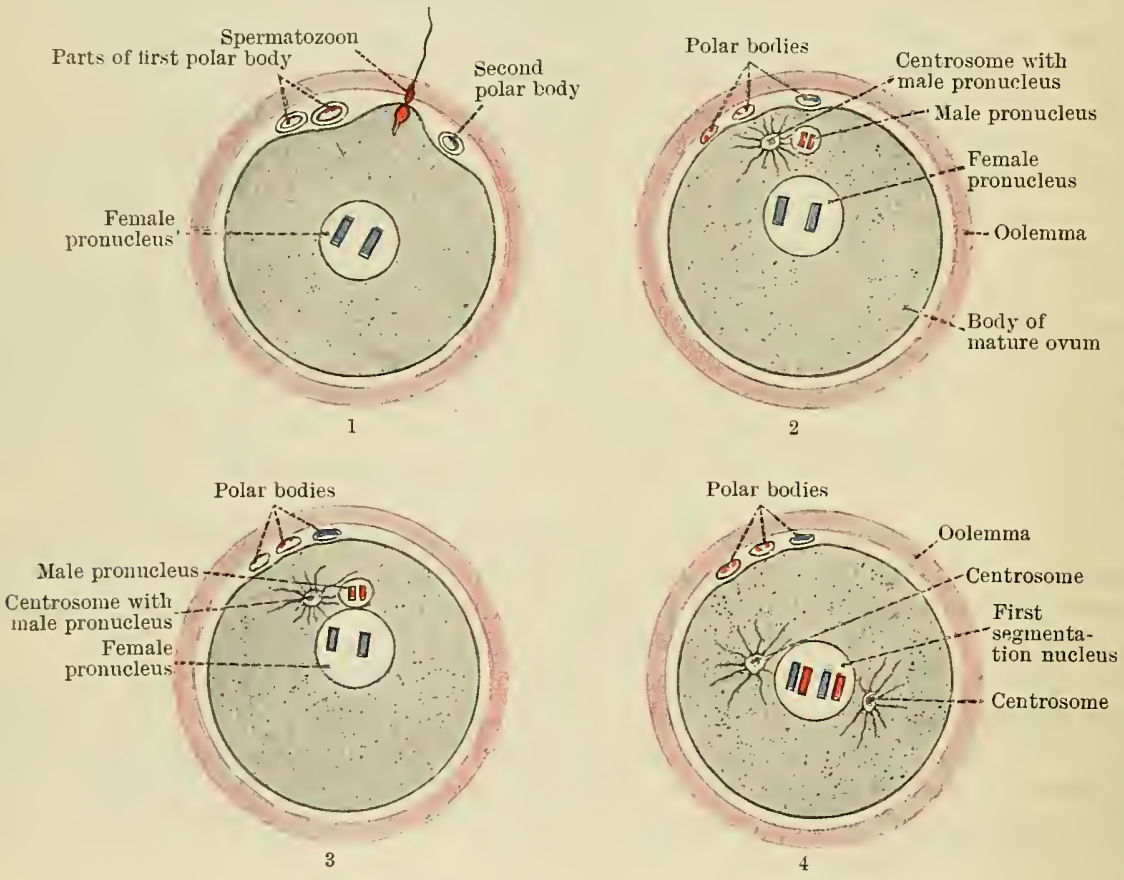

Fig. 23.- Schema of the Fertilisation of the Matere Ovem and the Formation of the Zygote.

spermatozoon which have entered remain quiescent till that event has occurred, then they disappear and are replaced by a nucleus which contains half the typical number of chromosomes and is accompanied by two centrosomes. At this period the impregnated ovum contains two pronuelei, both of which contain half the typical number of chromosomes; but the female pronucleus has no accompanying centrosomes.

Shortly after the appearance of the male pronucleus the two pronuclei unite and then the zygote, formed by the union of the male and female gametes, consists of a cell body enclosing a nucleus called the first segmentation nucleus; and two centrosomes.

The first segmentation nucleus is the product of the union of the male and the female pronuclei. It contains the typical number of chromosomes, half being derived from the male and half from the female gamete; and it is accompanied by two centrosomes, both of which appear to be derived from the male gamete, though their exact origin has not yet been definitely established. The zygote and the polar hodies which are still present are enclosed within the oolemma. 


\section{SEgMENTATION.}

Immediately after its formation the zygote is separated, by a series of consecutive mitotic divisions, into a large number of cells which are grouped together in the form of a solid spherical mass, called a morula on account of the mulberrylike appearance of its surface. This period of division is called the period of segmentation (Figs. 24-27).

The segmentation divisions are of the homotype form, and there is evidence which tends to the conclusion that the earliest divisions, by which the zygote is divided first into two and then into four parts, are quantitatively and qualitatively equal. After a time, however, the divisions result in the formation of cells of different sizes and different capabilities, definite and circumscribed functions being allocated to certain groups of cells and their descendants. It is probable that at this time cells are set apart which are the progenitors of the germ cells of the next generation, and which therefore retain all the capabilities of their ancestors. These cells are the means by which the species is reproduced and the hereditary tendencies are transmitted from generation to generation. At the same time other cells are set apart for the production of the tissues and organs of the individual which will be produced from the zygote, and in which the germ cells and their descendants will be lodged and protected till they attain their maturity.

After the morula is established one of the first definite changes which occurs in its constitution is the differentiation of its cells into an outer layer and an inner mass (Fig. 26).

In the human subject, as in many other mammals, the cells of the outer layer constitute the trophoblast or trophoblastic ectoderm, which plays a most important part in the nutrition of the embryo and foetus. They enter into the formation of the chorion, or outermost envelope of the growing zygote, which is subsequently differentiated into a placental and a nonplacental portion and which serves, in the first instance, both as a protective and a nutritive covering.

In many mammals the cells of the immer mass soon separate into two main groups, the ecto-mesoderm and the entoderm; but it appears probable that, in the human subject, they differentiate into three groups, ecto-mesoderm, primary mesoderm, anch entoderm.

In the majority of mammals, immediately before or as the differentiation of the inner mass occurs, a cavity appears in the zygote. As soon as the cavity appears the morula is converted into a blastula and the cavity enlarges until it separates the inner mass from the outer layer, except at one pole of the zygote, where the inner mass and the onter layer remain in contact. The cavity is called the segmentation cavity. It
would appear, however, from the evidence at present

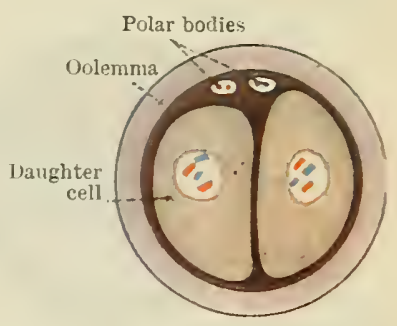

Fig. 24.-SegMextation of Zigote. 2-Cell Stage.

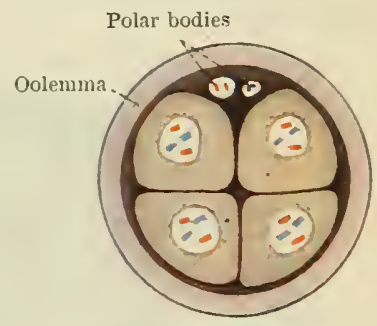

Fig. 25.-Segmextatiox of Zigote. 1.Cell Stage.

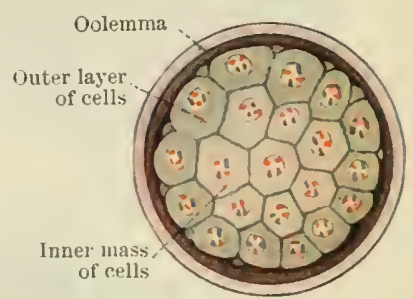

Fig. 26. -SEGMextatiox OF ZYGote. Morula Stage.

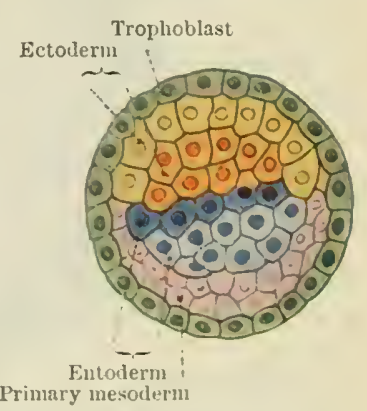

Fig, 27.-DIFFEREXTIITIU⿴囗十 UF ZÝote AND C'LlLs (Hypothetical). available, that this primitive cavity never exists in the human sulject, for as the main part of the inner mass separates from the outer layer the cells of the primary mesoderm segment of the inner mass proliferate rapidly and form a jelly-like tissue which completely fills the space which would otherwise lecome the segmentation cavity. At the same time the ecto-mesodermal and entodermal segments of the 
inner mass hecome converted into hollow vesicles by the appearance of cavities in their interiors (Fig. 29).

When the abore-mentioned changes have occurred the zygote consists of three spheres, one large and two small. The large sphere is bounded by the tropho-

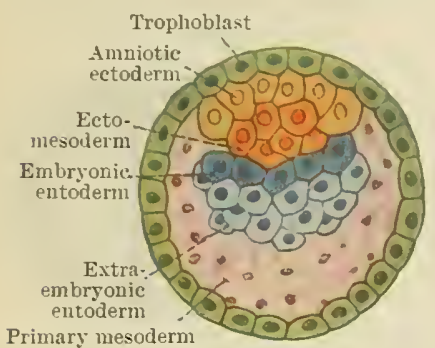

Fig. 2S.-Frrther Differestiatios (1) ZYGOTE (Hypothetical).

Plasmodial trophoblast

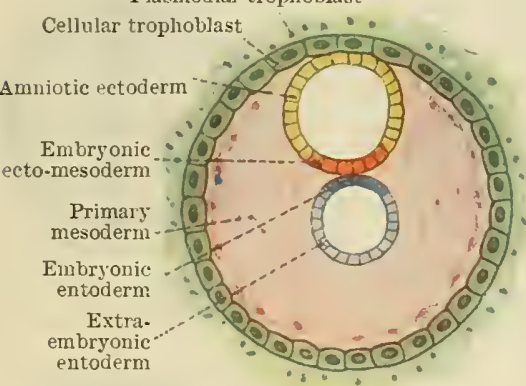

Fig. 29.-SCHEMA OF Differextiatios OF Zrgote (Bryce's Ovum).

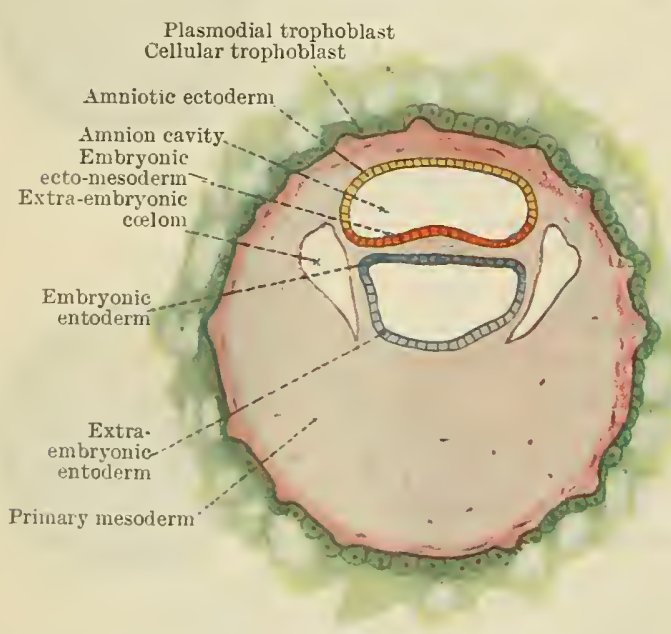

Fig. 30.-ScheMA of Differextitiox of Zygote (Peter's Ovum). mass (Fig. 29). defined. blast, and it contains the two small spheres and the jelly-like mass of primary mesoderm derived from the primary mesoderm segment of the inner

The two small vesicles lie ex-centrically in the interior of the larger vesicle. The larger and more external of the two is the ecto-mesodermal vesicle. It is separated from the trophoblast, peripherally, and the entodermal vesicle, centrally, by the surrounding mesoderm.

The early appearance of the mesoderm in the zygote and its insinuation at so early a period between the ectoderm and the entoderm are peculiarities limited to the human subject. In most mammals the mesoderm does not appear until the embryonic area and its primitive streak are

The Embryonic Area.-The area where the two inner. vesicles lie in apposition with each other is the region of the zygote from which the embryo will be formed; it is called, therefore, the embryonic area, and at the time of its definition it consists of three layers, ectoderm, primary mesoderm, and entoderm. It is uncertain whether the mesoderm which is present in the area at this period takes part in the formation of the embryo or is replaced at a later period by mesoderm derived from the cells of the ecto-mesodermal vesicle; the latter certainly forms a large part of the mesoderm of the embryo.

The Extra-Embryonic Cœlom. - The extra-embryonic cœlom is a space which appear's as two clefts, one on either side of the embryonic area, in the primary mesoderm (Fig. 30). The clefts fuse together round the periphery of the embryonic area, and the single space so formed expands rapidly until the mesoderm which originally filled the greater part of the larger vesicle becomes converted into a thin layer which lines the inner surface of the trophoblast and covers the outer surfaces of the epithelial walls of the extra-embryonic parts of the two inner vesicles (Fig. 32).

The extra-embryonic coelom does not extend into the embryonic area, and it never completely separates the ecto-mesodermal vesicle from the inner surface of the trophoblast; on the contrary, the primary mesoderm on the outer surface of the ecto-mesodermal resicle retains its continuity with the mesoderm on the inner surface of the trophoblast until the termination of intrauterine life, and 
it takes part, as will be seen later, in the formation of the umbilical cord, which connects the fotus with the placenta.

The Differentiation of the Embryonic Area.-As the embryonic area is the area of contact between the ecto-mesodermal and the entodermal vesicles it is, at first, circular in outline. As growth continues the area becomes oval, and a linear streak, the primitive streak, appears in that part of the oval which becomes the posterior part of the area (Fig. 31).

At the same time the position of the mesodermal elements of the wall of the ecto-mesodermal vesicle is revealed, for the primitive streak is a thickened ridge of cells which grows from the ecto-mesoderm and projects against the entoderm in the posterior part of the embryonic area, pushing aside the primitive mesoderm which intervened between the adjacent parts of the walls of the ecto-mesodermal and the entodermal vesicles. The deeper cells of the ridge, those next the entoderm, are the mesodermal elements of the primitive ecto-mesoderm, and, by proliferation, they form the larger part, if not the whole, of the embryonic mesoderm and also an organ, called the notochord. The mesoderm produced from the primitive streak may be termed the secondary mesoderm.

Immediately after the formation of the primitive streak a groore, the neural groove, appears in the anterior part of the embryonic area. It is formed by the longitudinal folding of a thickened plate of ectoderm, the neural plate, which is the rudiment of the whole of the central and peripheral portions of the nervous system, except perhaps the olfactory nerves, and the end organs of the sensory nerves. From it also are derived the cells of the primitive sheaths of the nerve-fibres and the chromaffin cells of the supra-renal glands and other chromaffin bodies.

The lateral walls of the neural groove are called the neural folds.

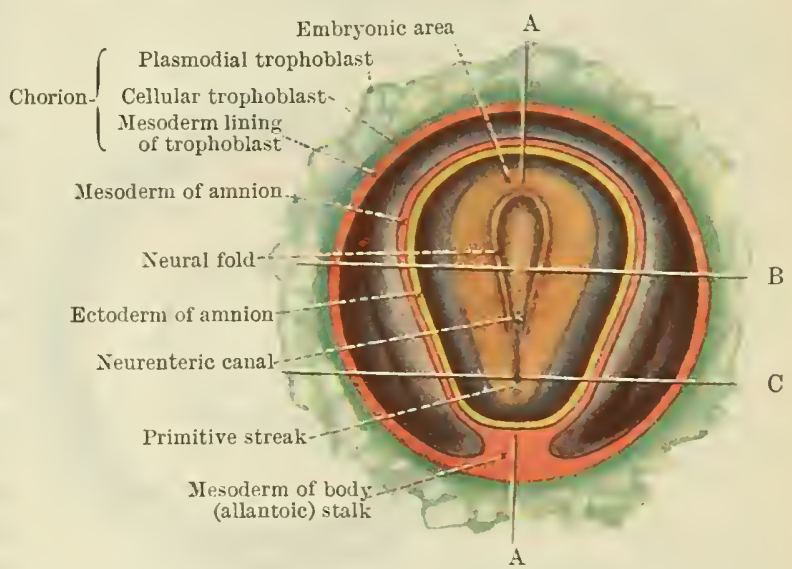

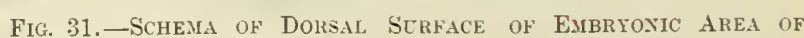
ZTgOTE AFTER THE REMOVAL OF PART OF THE CHORION AXD PART OF THE AMNIOX.

Almost from the first the anterior ends of the neural folds are united together a short distance posterior to the anterior end of the embryonic area. Their posterior ends, which remain separate for a time, embrace the anterior part of the primitive streak. In the meantime, however, a groove, the primitive groove, has appeared on the surface of the primitive streak. The anterior end of the primitive groove deepens until it forms a perforation which passes through the anterior end of the streak and the subjacent entoderm into the cavity of the entodermal vesicle. As this perforation passes from the floor of the posterior part of the neural groove into that part of the entodermal resicle which afterwards becomes the primitive enteron or alimentary canal, it is called the neurenteric canal. This canal is but a transitory passage, and it disappears lefore the nemral groove is converted into a neural tube.

After the appearance of the primitive groove and the neurenteric canal the posterior ends of the neural folds converge across the anterior part of the primitive streak and groove and fuse together posterior to the neurenteric canal. The primitive streak is thus divided into two portions. (1) An anterior portion which lies at first in the floor of the neural groore, and, later, in the floor or ventral wall of the posterior end of the spinal medulla; and (2) a posterior portion which remains on the surface and afterwards takes part in the formation of the median portion of the posterior end of the hody, forming the perineum, and the median part of the ventral wall of the body, from the perinem posteriorly to the umbilicus 
anteriorly. It is through the perineal section of the posterior part of the primitive streak that, at a later period of embryonic life, the anal and urogenital orifices

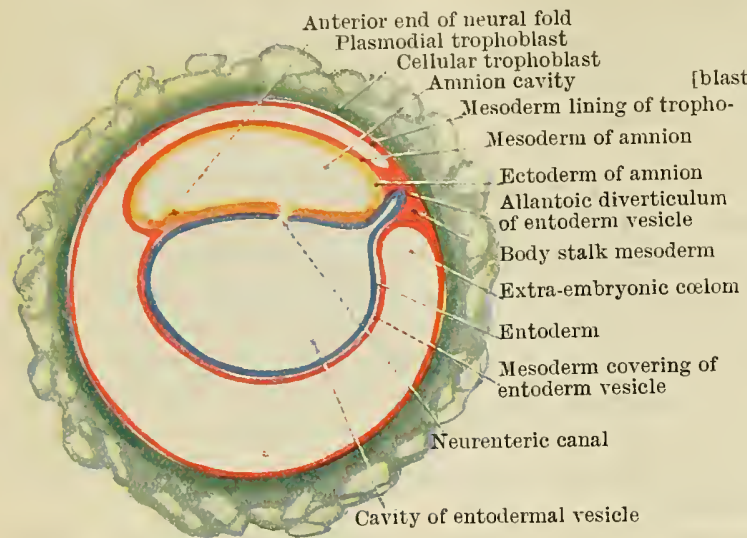

Fig. 32.-Schema of SagitTal Secrion of Zygote along LINE A IN FIG. 31.

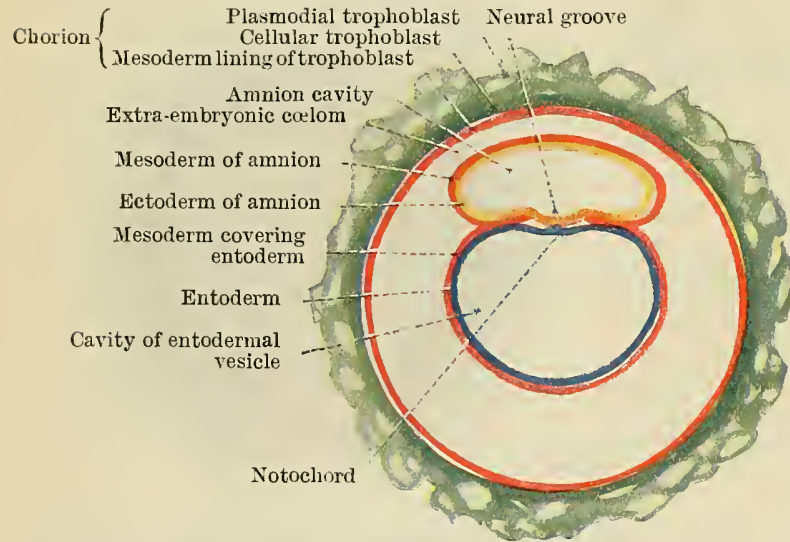

Fig. 33. - Schema of Transverse Section of Zygote along Line B in Fig. 31.

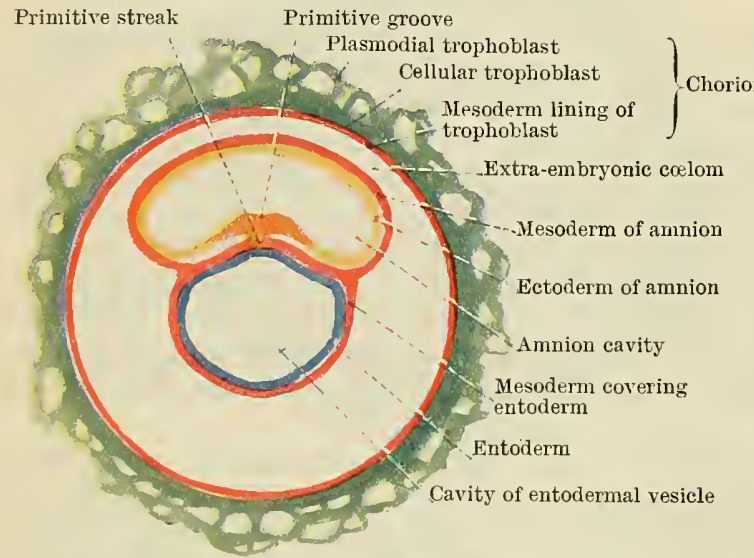

Fig. 34.-Schema of Transverse Section of Zygote along LINE C IN Fig. 31. by continued proliferation from the front end of the primitive streak, they are at once intercalated in the dorsal wall of the entodermal sac, where they remain, forming a part of the dorsal wall of the entodermal cavity (Fig. 33), for a

The Formation of the Notochord and the Secondary Mesoderm. - The notochord and the secondary mesoderm are formed from the primitive streak; thenotochord fromits anterior extremity and the secondary mesoderm from its lateral margins and posterior end.

As soon as the primitive streak is established its anterior end becomes a node or centre of growth by means of which the length and, to a certain extent, the breadth of the body are increased. The portions of the body formed by the activity of the anterior end of the streak are (1) the dorsal portion, from the back part of the roof of the nose, anteriorly, to the posterior end of the trunk, (2) the perineum, (3) pelvis, and (4) the ventral wall of the body from the perineum to the umbilicus. Nevertheless, the primitive streak undergoes little or no increase in length; indeed, as growth continues, it becomes relatively shorter as contrasted with the total length of the embryonic region, for the new material, formed by its borders and its anterior extremity, is transformed into the tissues of embryo as rapidly as it is created.

The Notochord.-The notochord or primitive skeletal axis is formed by the proliferation of cells from the anterior end of the primitive streak. On its first appearance it is a narrow process of cells, the head process, which projects forwards from the anterior boundary of the neurenteric canal, between the ectoderm and the entoderm. Shortly after its appearance the head process wedges its way between the entoderm cells, and from that period onwards, as the posterior parts are formed, 
considerable time. At a later period the notochordal cells are excalated from the entoderm, and then they form a cylindrical rod of cells which occupies the median plane, lying between the floor of the ectodermal neural groove and the entodermal roof of the primitive alimentary canal, which, in the meantime, has been more or less moulded off from the dorsal part of the entodermal sac (Fig. 37). For a still longer time the caudal end of the notochord remains connected with the anterior end of the primitive streak and its cephalic end is continuous with the entoderm of a small portion of the embryonic area, which lies immediately in front of the anterior end of the neural groove, and becomes bilaminar by the disappearance of the primary mesoderm. This region, because it afterwards forms the loundary membrane between the anterior end of the primitive entodermal canal and the primitive buccal cavity or stomatodæum, is called the bucco-pharyngeal membrane (Fig. 55, p. 42). It disappears about the third week of embryonic life, and immediately afterwards the anterior end of the notochord separates from the entoderm, but the posterior end remains continuous with the primitive streak until the formation of the neural tube is completed.

After a time the cylindrical notochordal rod is surrounded by secondary mesoderm which becomes converted into the vertebral column of the adult, and as the vertebral column is formed the notochord is enlarged in the regions of the intervertebral fibro-cartilages and for a time assumes a nodulated appearance (Fig. 60).

Ultimately it disappears as a distinct structure, but remnants of it are lielieved to exist as the pulpy centres of the intervertebral fibro-cartilages. The extension of the notochord into the region of the head is of interest from a morphological, and possibly also from a practical point of view. It extends through the base of the cranium from the anterior border of the foramen magnum into the posterior part of the body of the sphenoid bone. Its presence in this region suggests that the posterior part of the skull was primitively of vertebral nature. As it passes through the occipital portion of the skull it pierces the basilar portion of the occipital region first from within outwards and then in the reverse direction. It lies, therefore, for a short distance, on the ventral surface of the rudiment of the occipital bone, in the dorsal wall of the pharynx, and it is possible that some of the tumours which form in the dorsal wall of the pharymx are due to the proliferation of remnants of this pharyngeal portion of the notochord.

The Differentiation of the Secondary Mesoderm. - It has already licen noted that a portion of the inner mass of the human zygote becomes convertecl directly into mesoderm which may be called, for convenience, primary mesoderm. It was stated also that the wall of the larger of the two inner vesicles of the zygote consists of ecto-mesoderm, that term being intended to convey the illea that the cells of the wall of the larger inner vesicle were the progenitors of both ectodermal and mesodermal cells.

As soon as the larger of the two inner vesicles is formel two areas of its wall are defined: (1) the part in contact with the smaller inner or entodermal vesicle and (2) the remainder. As future events prove, the cells of the larger area, which is not in contact with the entodermal vesicle, simply proluce ectodermal descendants which line the inner surface of a sac-like covering of the embryo termed the ammion; they are, therefore, the predecessors of the amniotic ectoderm.

The cells of the larger inner vesicle, which lie adjacent to the smaller entoderm vesicle, and are merely separated from the entolerm ly it thin layer of primary mesoderm, take part in the formation of the embryo; forming, with the entoderm, the embryonie area from which the embryo is evolved. These cells are the forcrunners of both ectoderm and mesoderm, and as the mesoler'm developel from them is differentiated after the formation of the primary mesoderm it may be termed secondary mesoderm or primitive streak mesoderm: the litter term lieing applied because it is differentiated in a linear regron ealled the primitive streak (p. 23). It is the formation and fate of this primitive streak mesodern which is now to be considered.

At first the embryonic area is circular in ontline, at il later perionl it hecomes ovoid, and in the narrower or candal portion of the ovoid arcal a lincar thiekening 


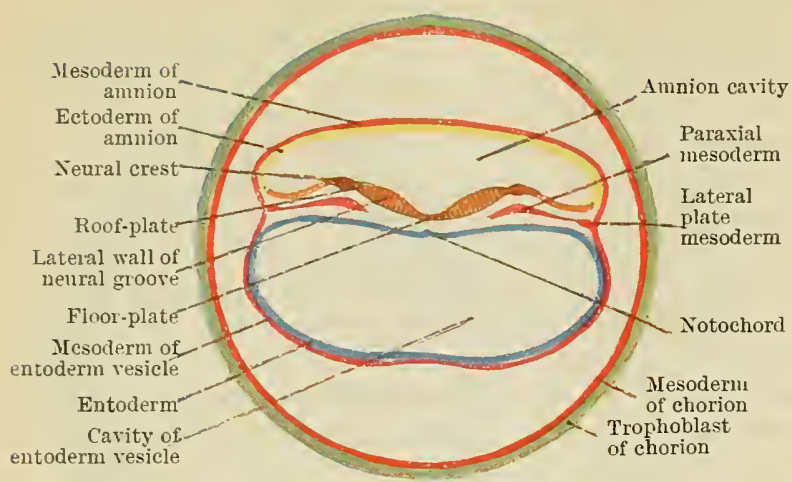

Fig. 35. -Transterse Section of a Zygote, showing early stage of embryonic secondary mesoderm before the appearance of the embryonic parts of colom.

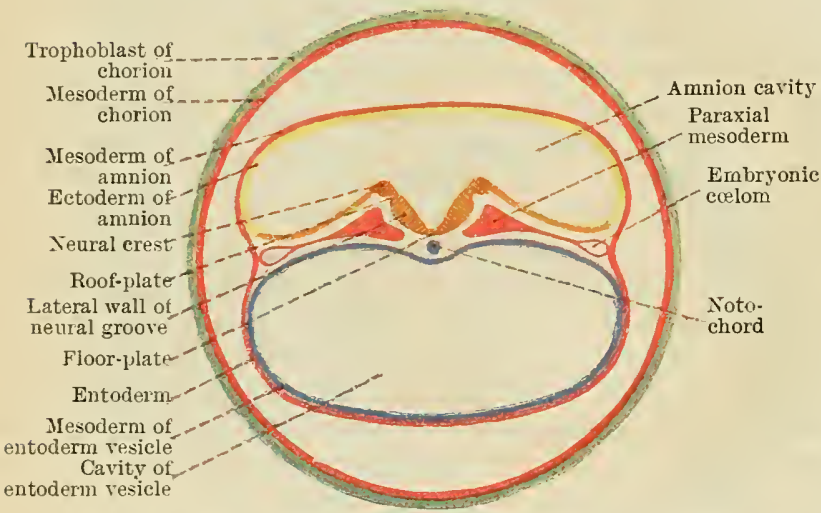

Fic. 36.-Trassverse Section of a Zygote, showing early stage of derelopment of embryonic coelom and differentiation of mesoderm.

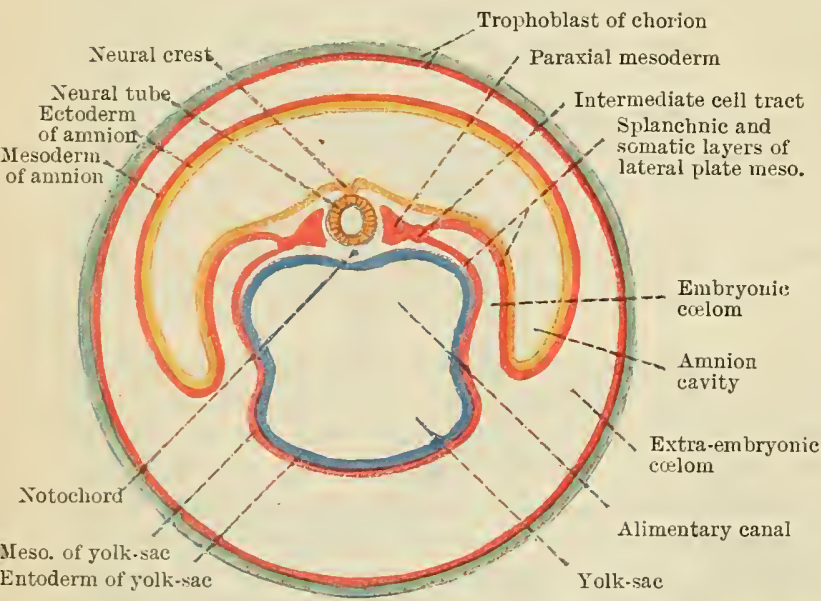

Fig. 37.-Trditsverse Section of a Zigote, showing union of intra- and extra-embryonic parts of cœlom and separation of embryonic mesoderm into paraxial bars, intermediate tracts, and lateral plates, with separation of lateral plates into somatic and splanchnic layers by the intra-embryonic part of the cœlom. appears; this is the primitive streak(Figs. 31, 34). Itisformed by the proliferation of the ectomesodermal cells of the wall of the larger inner vesicle. The deeper cells of the streak, which displace the primary mesoderm from the median plane, and thus come into contact with the entoderm, are the rudiments of the secondary or primitive streak mesoderm (Fig. 34). The superficial cells form part of the surface ectoderm of the embryo.

At the anterior end of the primitive streak the mesodermal elements of the streak fuse with the subjacent entoderm and through the fused mass a perforation, the neurenteric canal (p. 23), is formed (Fig. $32)$.

The canal itself soon disappears, but the cells of its walls form a nodal growing point, and by their proliferation the length and breadth of the embryonic area are increased. The mesoderm cells proliferated from the cephalic border of the nodal point are the rudiments of the notochord, which has already been considered ( $\mathrm{p}$. 24).

It is uncertain whether or not the mesodermal cells budded off from the nodal point blend with the cells of the primary mesoderm, but there can be little doubt that they form by far the greater part, if not the whole, of the permanent mesoderm of the embryo.

Either by displacement or by union with the primary mesoderm the secondary mesoderm forms a continuous sheet of cells, in the embryonic area, on each side of the median plane.

Each of the lateral sheets is thickest where it abuts against the notochord and the wall of the neural groove, and thinnest at its peripheral margin, where it is continuous with the primary mesoderm of the extra-embryonic area (Fig. $35)$. 
At the cephalic end of the embryonic area the medial margins of the mesodermal sheets fuse together across the inedian plane, forming a transverse bar of mesodermal cells which may be called the pericardial mesoderm (Fig. 48), because the pericardial sac, which envelops the heart, is afterwards developed from it. The area in which this mesoderm lies may be named the pericardial region of the embryonic area (Fig. 48).

Between the bar of pericardial mesoderm, the cephalic end of the neural groove, and the medial margins of the mesodermal plates lies a small segment of the embryonic area from which the primary mesoderm entirely disapyears, leaving the ectoderm and entoderm in contact. This is the bucco-pharyngeal area. It afterwards becomes the bucco-pharyngeal membrane (Figs. 50, 55), which separates the primitive mouth or stomatodxum from the cephalic end of the primitive entodermal alimentary canal. As already stated, the bucco-pharyngeal membrane disappears during the third week, when the stomatodæum and the primitive alimentary canal become continuous with each other.

Between the buccopharyngeal area and the cephalic end of the primitive streak the medial margins of the mesodermal plates are separated from one another by the notochord and the neural groove (Fig. 36), and still more caudally they are united with the sides of the streak (Fig. 34).

After the permanent mesodermal plates are definitely established a series of clefts appear in their peripheral margins. The clefts on each side soon fuse together to form the bilateral rudiments of the embryonic cœlom (Fig. 36).

The septum of cells at the lateral horder of the embryonic area on each side, which, for a time, separates the embryonic from the extra-embryonic colom, soon disappears, and the coelom then forms a continuous cavity (Fig. 37).

The embryonic cœlom also extends medially, lut the medial extension ceases whilst the cavity is still at some distance from the median plane, except at the cephalic end of the embryonic area, where the two lateral halves of the embryonic coelom become continuous with each other through the interior of the pericardial mesodermal bar (Figs. 49, 55).

As the embryonic ccelom is forming and extending, a longitudinal constriction appears in each lateral half of the mesoderm, a short clistance from its medial border. This constriction separates each plate into three parts : (1) a medial bar, the paraxial mesoderm, which lies at the side of the neural groove and the notochord (Fin. $37)$; (2) the constricted portion, which is called the intermediate cell tract; and (3) the part lateral to the constriction, which is called the lateral plate (Fig. 37 ).

The embryonic cœlom is confined, as a rule, in the human sulject, to the lateral plate, which it divides into a superticial layer, next the ectoderm, the somatic mesoderm, and a deeper layer, next the entoderm, the splanchnic mesoderm.

The medial borders of the somatic and splanchnic mesoderm are continuous 
with each other round the medial border of the cœlom. The lateral border of the somatic mesoderm is continuous, at the margin of the embryonic area, with the mesoderm which covers the outer surface of the amnion, and the lateral border of the splanchnic layer is continuous with the mesoderm on the wall of the extra-embryonic or yolk-sac portion of the entodermal sac.

The Paraxial Mesoderm. - Each paraxial mesodermal bar soon assumes the form

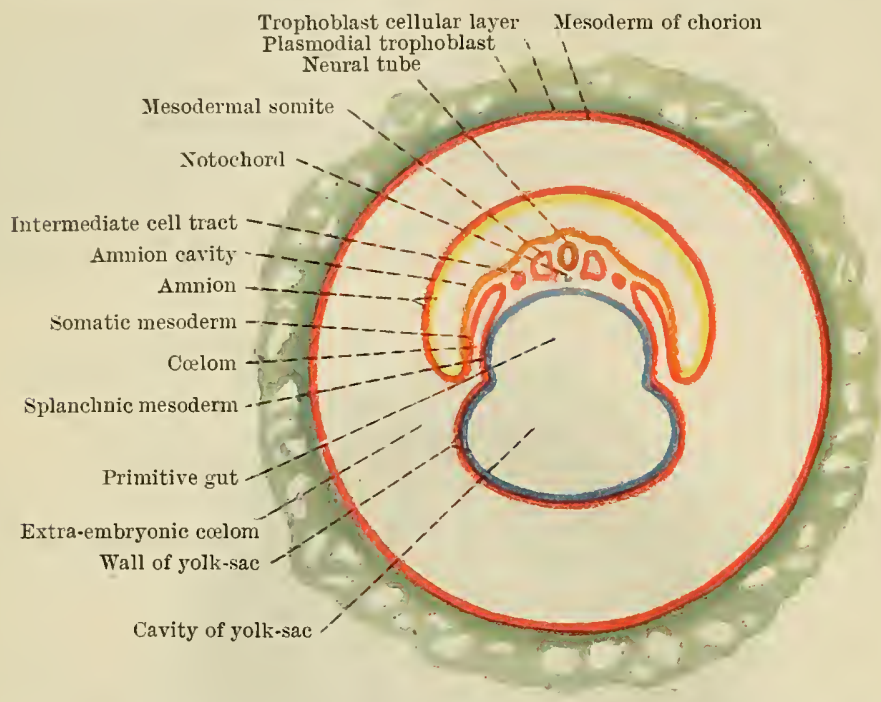

Fig. 39.-Transverse Section of the Zygote shown in Fig. 38, showing the differentiation of the mesoderm.

of a triangular prism with the apex directed ventro-medially, towards the notochord, and the base dorso-laterally, towards the surface ectoderm.

The cephalic portion of each paraxial bar, as far caudalwards as the middle of the hind-brain, remains unsegmented, but the remainder is cut into a number of

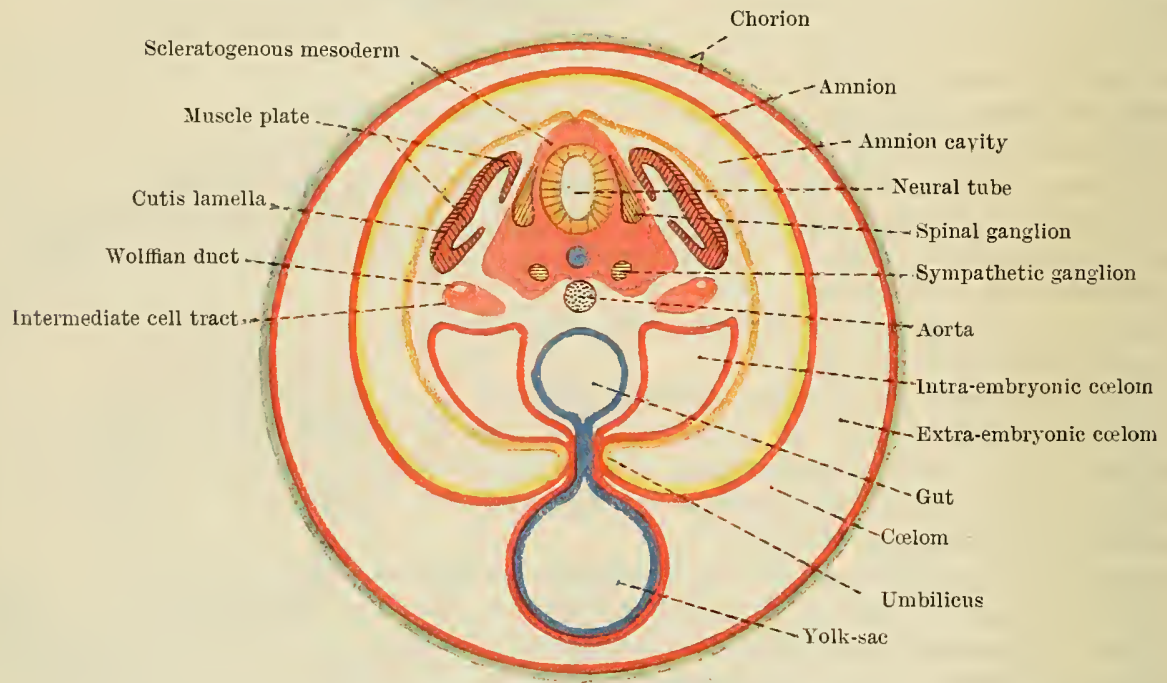

Fit: 40.- Schema of a Transverse Section of a Zygote, showing differentiation of mesoderm and extension of amuion.

segments, the mesodermal somites, by a series of transverse clefts (Fig. 38). The first cleft appears in the region of the hind-brain, and the others are formed successively, each caudal to its predecessor. Only three or four somites lie in the 
region of the head; the remainder are in the body area of the embrionic region. The segmentation of the paraxial bars commences before their elongation is completed, and the posterior somites are separated off as the paraxial bars are extended by the continued proliferation from the nodal point at the anterior end of the primitive streak.

When they are first defined the somites are solid masses of cells, but in a short time a cavity - the cœlom of the somite or myocœle-is developed in each mass.

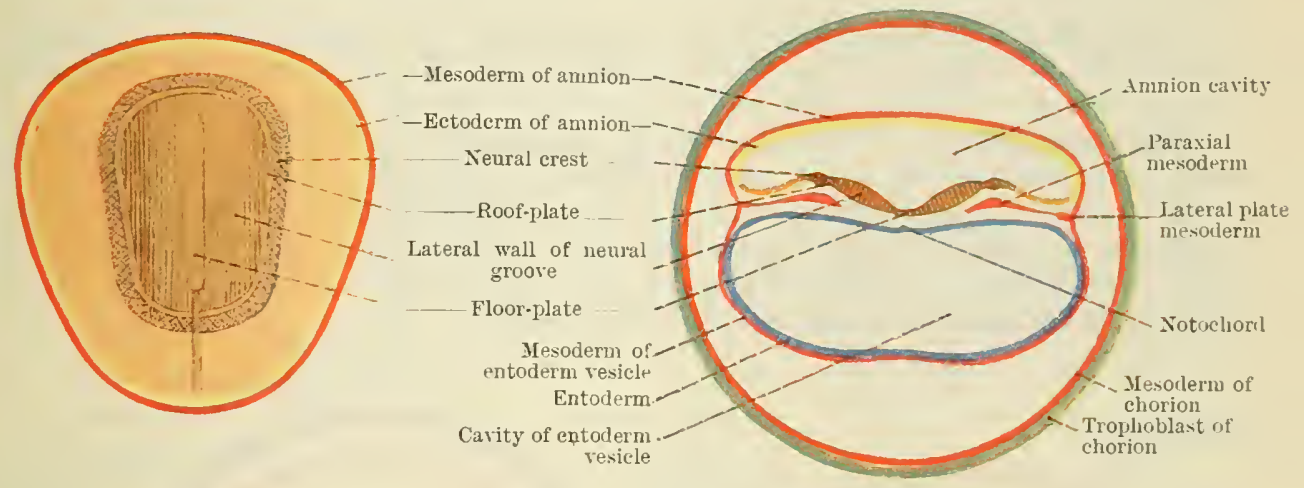

B

FIti. 41.

A

A. Transverse section of a zygote, showing the constituent parts.

B. Diagram of embryonic area showing parts of neural plate and primitive streak.

The apical portion of the hollow mesodermal somite is its scleratogenous segment. The cells of the scleratogenous section of the somite undergo rapid proliferation. Some of the newly formed scleratogenous cells invade the myocole; others migrate towards the notochord; finally, the scleratogenous cells separate from the remainder of the somite, and as they increase in number they migrate along the sides of

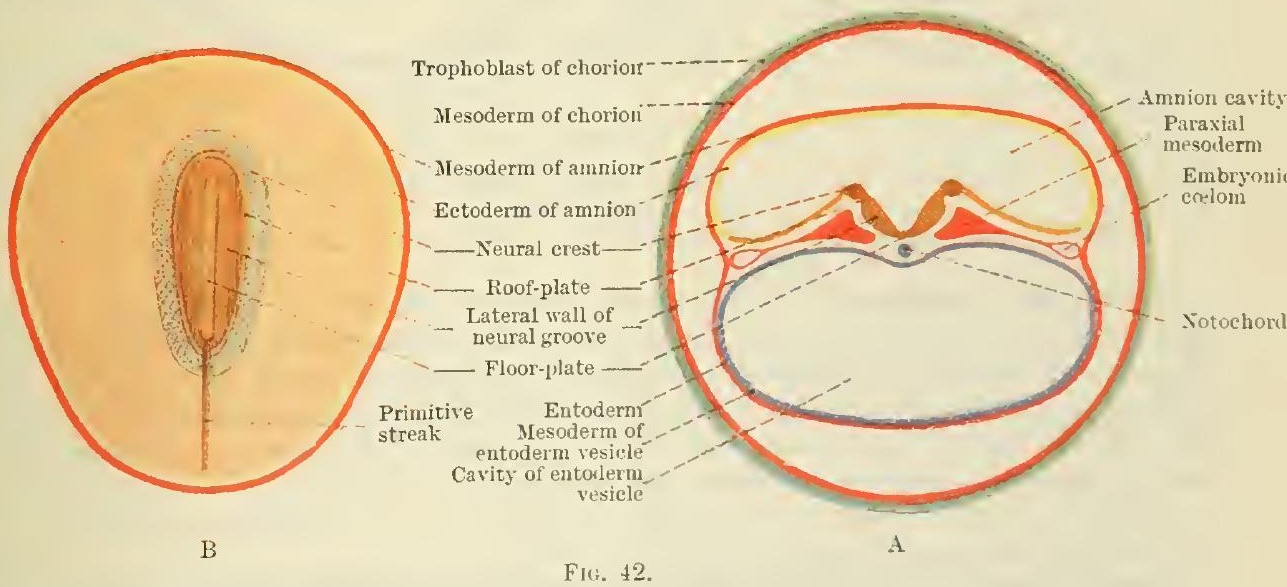

A. Diagram of a transverse section of a zygote, showing the formation of a neural groove iu the embryonic area.

B. Diagram of a surface view of the embryonic area of the same zyote.

the notochord and the neural tube, which has been formed in the meantime from the neural groove, and join with their fellows of the opposite side, and with their cephalic and caudal neighbours. In this way is formed, around the neural tube and the notochord, a continuous sheath of mesoderm, the membranous vertebral column, from which are differentiated, in later stages, the vertebral column and its ligaments, and the membranes of the brain and the spinal medulla. 
After the separation of the scleratogenous segments of the mesodermal somites, the remainders of the somites, each of which consists of a flat plate with incurved dorsal and ventral margins, constitute the muscle plates from which the striped muscle fibres are derived.

In the opinion of some observers the outermost portion of each of the above-described plates is developed into subcutaneous comnective tisstie cells; consequently it is spoken of as the cutis lamella. According to this riew the muscle cells are formed from their innermost cells and the incurved margins of the plates.

The Intermediate Cell Tracts. - The intermediate cell tracts are the rudinents of the internal organs of the genital system and the temporary and permanent urinary system, with the exception of the urinary bladder and the urethra.

The Lateral Plates.-From the cells of the lateral plates are formed the lining endothelial cells of the great serous cavities of the body-the pleuræ, the pericardium, and the peritoneum; the majority of the connective tissues, with the exception of those of the vertebral column and the head, the greater part or all the mesoderm of the limbs, and, probably, the unstriped muscle fibres of the walls of the alimentary canal and the blood-ressels.

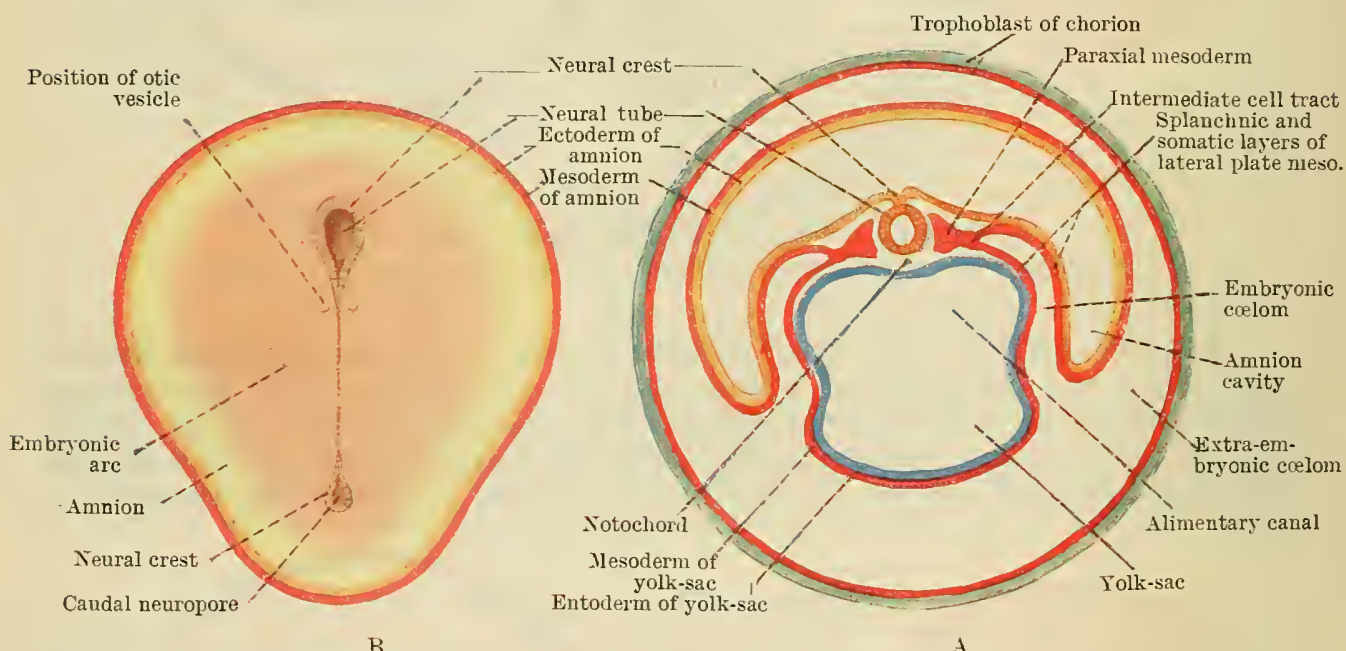

F1G. 43.

A. Diagram of a transverse section of a zygote, in which the neural tube has formed but has not separated from the surface ectoderm.

B. Diagram of embryonic area of same zygote. Compare with surface view of embryo in Fig. $3 S$.

The Cephalic Mesoderm. - It has already been noted that the mesoderm of the head becomes segmented only in the region of the caudal part of the hind-brain, where four cephatic mesodermal somites are formed on each side. From the scleratogenous portions of these somites are developed the occipital part of the skull and the corresponding portions of the membranes of the brain, and from their muscle plates the intrinsic muscles of the tongue.

The unsegmented part of the cephalic mesoderm gives rise to the remaining muscles and connective tissues of the head region.

Early Stages of the Development of the Nervous System.-No definite trace of the nervous system is present until the primitive streak has formed and the embryonic area has passed from a circular to an elongated form. Then an area of thickened ectoderm, the neural plate, appears in the anterior part of the area. It commences a short distance posterior to the anterior end of the area, and its posterior extremity embraces the anterior end of the primitive streak. Its lateral margins fade gradually into the surrounding ectoderm, and in the earliest stages cannot be definitely defined: but, as the elongation of the plate continues coincidently with the elongation of the embryonic area, the lateral margins of the plate are elevated as the mesoderm beneath them thickens, and so they become distinct. 
life both apertures are closed and, for a time, the neural canal becomes a completely closed cavity.

As the margins of the nemral groove rise and converge they carry with them the adjacent ectoderm to which they are attached, and which forms part of the surface corering of the embryo; consequently, when the lateral margins of the folds meet and unite, the tube, which is completed by their fusion, is embedded in the body of the embryo, but, for a time, its dorsal wall is attached to the surface ectoderm by a ridge of cells, formed by the fused lateral margins of the neural plate. This ridge is called the neural crest (Figs. 41-44).

The neural crest is the rudiment of the cerebral and spinal nerve ganglia, the sympathetic ganglia, the chromaffin cells of the chromaffin organs, and the cellular sheaths of the peripheral nerves; whilst the walls of the neural tube become transformed into the various constituent parts of the central nervous system, the brain and spinal medulla, the retinæ of the eye-balls, and the optic nerves. ${ }^{1}$

The Formation of the Nerve Ganglia, the Chromaffin Tissues, and the Primitive Nerve Sheaths.-The primitive ganglia grow as cell buds from the neural crest which, for a time, connects the dorsal wall of the neural tube with the surface ectoderm. In the body region they correspond in number with the spinal nerves and with the primitive segments into which the mesoderm becomes divided, but in the cephalic region their arrangement is more irregular, and some of the ganglia of the cerebral nerves receive additional cell elements from the surface ectoderm.

Simultaneously with the appearance of the cell buds which form the primitive ganglia, the neural crest disappears, and directly after the ganglia are formed they lose their connexion with both the neural tube and the surface ectoderm and become isolated cell clumps. At this period, therefore, the nervous system consists of the neural tube and the primitive ganglia.

After the primitive ganglia have lost their connexion with the neural tube they increase in size by the proliferation of their constituent cells, and they migrate ventrally along the sides of the neural tube, but the migration ceases before the ventral ends of the ganglia reach the level of the ventral wall of the tuhe. As the migration proceeds, clumps of cells are budded off from the ventral ends of the ganglia. These secondary cell buds are the rudiments of the sympathetic ganglion cells and of the chromaffin tissue which is found in the sympathetic nerve plexuses, the medulla of the suprarenal glands, and in the carotid glands. In the first instance the secondary cell buds which form the sympathetic ganglia wander ventrally and medially, from the ventral ends of the primitive ganglia, until they attain the positions afterwards occupied by the ganglia of the sympathetic trunks on the ventro-lateral aspects of the vertebral column. From the primary sympathetic ganglia, buds of cells are given off which wander still further ventrally to become the cells of the ganglia of the cardiac, coeliac, and other great ganglionic nerve plexuses, as well as to form the chromaffin cells of the chromaffin organs.

The exact manner in which the cells of the primitive sheaths of the nerves originate from the primitive ganglia is not known, but it has been shown by Harrison, in the case of the frog, that if the primitive ganglia are destroyed, the primitive sheaths of the nerves are not formed. Presumably, therefore, in the frog the cellular sheaths of the nerves are derived from cells produced by the primitive ganglia, and it may be assumed that they have a similar origin in the human subject.

After the rudiments of the sympathetic system, the chromaffin cells, and the cellular sheaths of the nerves have separated, the remains of the primitive ganglia become the permanent spinal and cerebral nerve ganglia.

In the early stages these ganglia are completely isolated structures which lie along the sides of the neural tube between the lateral walls of the tube medially, and the mesoderin somites laterally.

Some lime after the ganglia of the cerebral and spinal nerves become isolated,

1 It is stated that some of the sympathetic nerve-cells are derived from the ventral parts of the lateral walls of the neural tube, but the evidence on this point is not entirely satisfactory. 
their cells give off processes which become nerre-fibres. These fibres grow out both from the dorsal and the ventral ends of the ganglia, and, together with the ganglia, they form, in the cranial region, certain of the cerebral nerves, and, in the spinal region, the posterior roots of the spinal nerves.

The fibres which grow out of the dorsal ends of the ganglia enter the walls of the neural tube, and by their means the ganglia regain connexion with the tube.

The fibres which grow out from the ventral end of each spinal ganglion unite with the fibres of the corresponding anterior nerve-root, which, in the meantime, has grown out from the cells of the ventral part of the lateral wall of the spinal portion of the neural tube, and form with them a spinal nerve-trunk.

The Differentiation of the Neural Tube.-Before the neural groove is converted into a closed tube, an expansion of its anterior part indicates the separation of the neural rudiment into cerebral and spinal sections, the dilated portion being the rudiment of the brain and undilated part the rudiment of the spinal medulla.

Whilst the cerebral portion is still unclosed, three secondary dilatations of its walls indicate its separation into three sections, the primitive fore-brain, the mid-brain, and the hind-brain; the primitive fore-brain being the most cephalward or anterior and the hind-brain the most caudal or posterior of the three (Fig. 38).

Shortly after the three segments of the brain are defined, and before it becomes a closed tube, a vesicular evagination forms at the cephalic end of each lateral wall of the primitive fore-brain region. These evaginations are the primary optic vesicles, and they are the rudiments of the optic nerves, the retinæ, and the posterior epithelium of the ciliary body, and the iris of the eje-ball.

When the cerebral portions of the neural folds meet and fuse dorsally the cerebral dilatations become the primitive brain vesicles, each resicle possessing its own cavity and walls, but the cavities of the three vesicles are continuous with one another, and the cavity of the hind-brain vesicle is continuous, caudally, with the central canal of the spinal part of the neural tube.

After the primitive brain vesicles are formed, a diverticulum grows out from the cephalic end of the primitive fore-brain vesicle. This is the rudiment of the secondary fore-brain. Its cephalic end soon divides into two lateral halves, which are the rudiments of the cerebral hemispheres of the adult brain (Fig. 45).

After their formation the cerebral hemispheres expand rapidly in all directions. They soon overlap the primitive fore-brain and mid-brain (Fig. 63), and, eventually, the hind-brain also, and each gives off from the cephalic end of its ventral wall a secondary diverticulum, the olfactory diverticulum, which becomes converted later into the olfactory bulb and olfactory tract.

When they first appear the rudiments of the cerebral hemispheres are connected together, across the median plane, by a part of the cephalic end of the wall of the secondary fore-brain dilatation, which is called the lamina terminalis. This primitive connexion between the two cerebral hemispheres persists throughout the whole of life, and it is supplemented, at a later period, by the formation of two secondary commissures, the corpus callosum aud the fornix, which grow across the space between the cerebral hemispheres and commect their medial walls together.

The Fate of the Walls of the Primitive Brain Vesicles.-The primitive hind-brain, which is also called the rhombencephalon, is separated in the later stages of development into two parts. (1) A caudal portion which is connected with the medulla spinalis, and which becomes the medulla oblongata or myelencephalon of the adult brain. (2) A cephalic portion called the metencephalon, which is continuous at one end with the medulla olilongata and at the other with the mid-brain. The ventral wall of this portion of the primitive hind-brain is ultimately converted into the pons, and its dorsal wall differentiates into two parts-a caudal part which becomes the cerebellum; and a cephalic part which is converted into the anterior medullary velum and the brachia conjunctiva. The brachia conjunctiva connect the cerebellum with the corpora quadrigemina, which are developed from the dorsal part of the mid-brain. 'The pons and cerebellum form the metencephalon of the adult, whilst the brachia conjunctivia and the 
anterior medullary velum constitute parts of the isthmus rhombencephali (Figs. $45,63)$.

The rentral portion of the primitive mid-brain is converted into the tro peduncles of the cerebrum of the adult brain, and the dorsal portion, as already mentioned, is transformed into four rounded elerations, the corpora quadrigemina.

The transformations which take place in the region of the primitise fore-brain or prosencephalon are numerous and complicated; therefore its rentral, lateral, and dorsal walls require separate consideration.

Br the expansion of its cephalic (anterior) extremity is formed the secondary fore-brain, which becomes divided, as already explained, into the two secondars resicles which are the rudiments of the cerebral hemispheres of the completed brain.

After the formation of the rudiments of the cerebral hemispheres, which
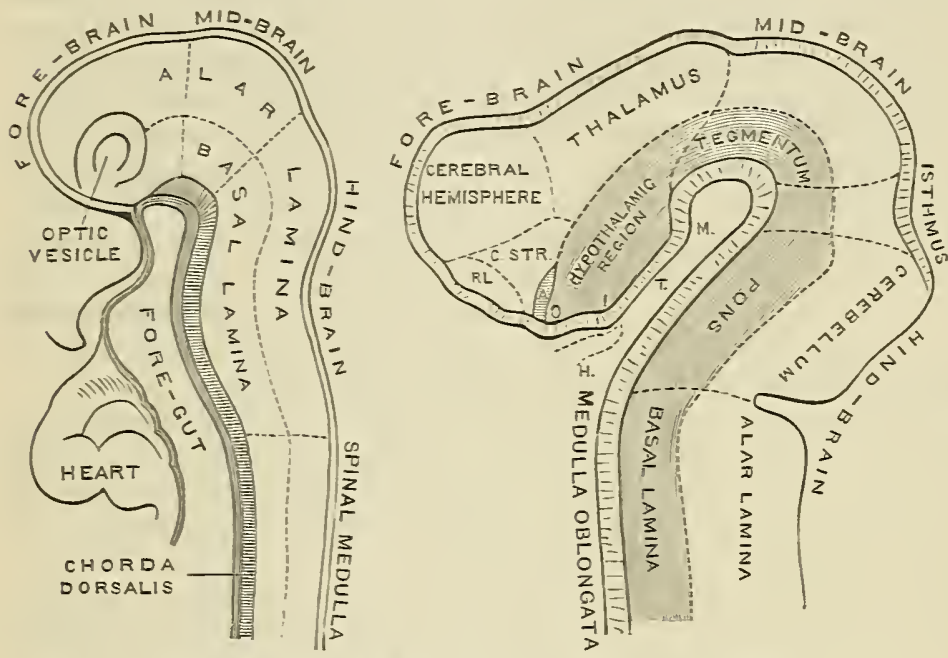

Fig. 15.-Diagrays to ILlestrate the AIAR ATD BASAL Lamix. In both cases the embryonic brain is represented in mesial section (His).

A. The different subdirisions of the brain are marked off from each other br dotted lines, and the dotted line running in the long axis of the neural tube indicates the separation of the alar from the basal lamina of the lateral wall.

B. Medial section through the brain of a human embryo at the end of the first month. Dotted lines rark off the different regions and also the alar and basal laminæ from each other.

H, Buccal part of hypophrsis cerebri : RL, Olfactory lobe ; C.STR, Corpus striatum :

A, Entrance to optic stalk; 0 , Optic recess; I. Infundibular recess; T, Tuber cinereum: M. Mamillary eminence. cerebral hemispheres and is called the anterior commissure, whilst the other is the optic chiasma in which the medial fibres of the optic nerres decussate.

From the cephalic or anterior end of the rentral wall of the diencephalon a diverticulum is projected rentrally towards the dorsal wall of the primitire mouth. The rentral end of this direrticulum becomes the posterior lobe of the hypophysis (O.T. pituitary body) of the adult, the dorsal end becomes the tuber cinereum, and the intermediate part is the infundibulum which connects the tuber cinereum of the adult brain with the posterior lobe of the hrpophrsis.

Caudal to the hrpophrseal direrticulum a single eleration appears in the rentral wall of the diencephalon. It is the corpus mamillare, which afterwards separates into the paired corpora mamillaria of the adult brain.

Still more caudally the rentral wall of the diencephalon takes part in the formation of the substantia perforata posterior, which lies between the two peduncles of the cerebrum and is partly dereloped from the cephalic or anterior end of the rentral wall of the primitire mid-brain.

The greater part of the dorsal wall of the diencephalon is ultimatels reduced to a single larer of epithelial cells, but near its caudal end a direrticulum is projected dorsalls. This is the epiphysis or pineal body, which remains quite 
rudimentary in man as contrasted with many other animals. At a later period two transverse bands of fibres appear in the dorsal wall of the diencephalon, one in front of and the other immediately behind the root of the epiphyseal recess. The anterior band is the dorsal or habenular commissure, and the posterior is the posterior commissure of the adult brain.

These structures, collectively, together with a small diverticulum of the epitlielial roof, which appears anterior to the dorsal commissure, and is called the supra-pineal recess, constitute the so-called epithalamus.

Each lateral wall of the diencephalon is differentiated into a dorsal and a ventral part. The dorsal part forms a large gray mass called the thalamus, and on the posterior end of the thalamus are developed two rounded elevations, the medial and the lateral geniculate bodies, which constitute the meta-

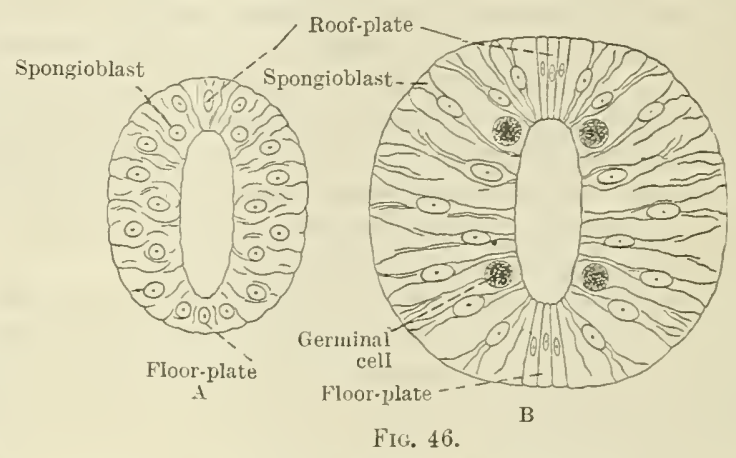

A. Diagram of a transvense section of a spinal medulla which has not differentiated into groups of cells.

B. Diagram of a transverse section of a spinal medulla showing positions of germinal cells. thalamus of the adult brain.

The ventral or basal portion of the lateral wall of the diencephalon, together with the adjacent part of the ventral wall, forms the hypothalamus of the fully developed brain.

The Fate of the Spinal Portion of the Primitive Neural Tube--The spinal portion of the neural tube, during the first three months of intra-nterine life, develops equally in its whole extent, but after that period a longer cephalic or anterior (superior in the erect posture) and a shorter caudal portion are recognisable. The cephalic portion undergoes still further development and is converted into

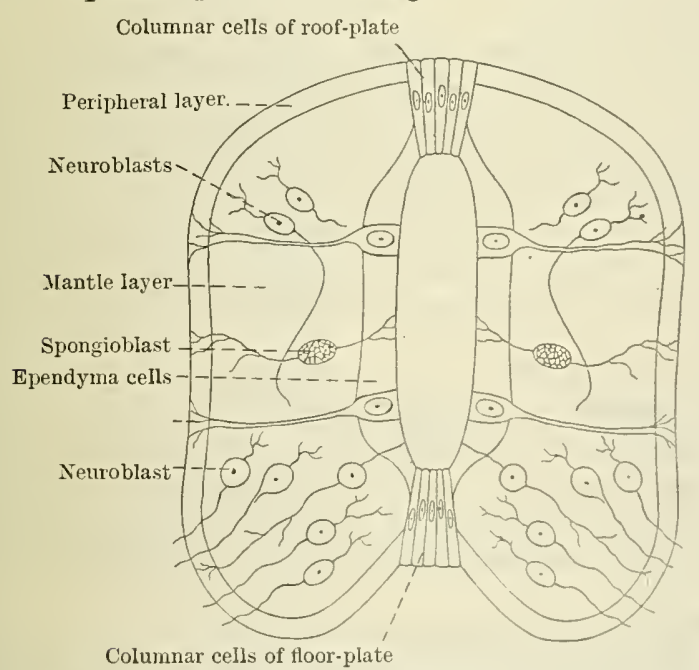

Fig. 47.-Showing Elements of Central Nemodo sistem. the spinal medulla of the adult, but in the smaller caudal or posterior portion retrogressive changes occur, and it is transformed into the non-functional filum terminale of the completed medulla spinalis.

Histological Differentiation of the Walls of the Neural Tube. - In the earliest stages of its development the walls of the neural tube consist of a mass of nucleated protoplasm more or less distinctly differentiated into cell areas of columnar form which extend between and are comuected with an internal limiting membrane, hounding the neural canal, and an external limiting membrane, which surrouncts the whole tube. At this time the outline of a transrerse section of the primitive neural tube is
somewhat ovoid. The cavity of the tube is compressed laterally into a dorsosomewhat ovoid. The cavity of the tube is compressed cleft, which is hounded by dorsal, rentral, and lateral walls. In the dorsal and ventral walls, called respectively the roof-and Hoor-plates, the colummar character of the primitive epithelial elements of the medulla spinalis is retained throughout the whole of life, hut the peripheral parts of the cells are convertert into fibrils.

In the lateral walls of the embryonic medulla spinalis some of the cells suon 
assume a spherical form. These spherical cells have large deeply staining nuclei, and they are termed germinal cells.

For many years it was believed that the germinal cells were the predecessors of the primitive nerve elements or neuroblasts, and that the remaining cells, called spongioblasts, lecame transformed into the reticular sustentacular tissue of the central nervous system. It appears, however, from the results of more recent researches, that some of the descendants of the germinal cells become spongioblasts whilst others become neuroblasts or primitive nerve-cells. Moreover, there appear to be two groups of primitive germ cells; the descendants of one group are directly transformed into the ependymal or lining cells of the central canal, whilst those of the other group form in the first instance indifferent cells, some of whose descendants become neuroblasts and others spongioblasts. The fate of the cells present before the germinal cells appear is uncertain, but they probably take part in the formation of the spongioblastic tissue.

It is believed, therefore, that all the nerve-cells are the descendants of the germinal cells, and that the spongioblasts which become developed into the cells of the neuroglia or sustentacular reticulum are derived partly from the nongerminal cells of the primitive neural tube and, partly, they are descendants of the germinal cells.

As differentiation proceeds three layers and two membranes are gradually defined in the walls of the neural tube: (1) a central layer of columnar ependyma cells immediately surrounding the central canal; (2) an intermediate or mantle layer consisting of neuroblasts and their processes, the nerve-fibres, intermingled with spongioblasts; (3) a peripheral reticular layer consisting, at first, of processes of the bodies of the spongioblasts. The membranes are an external limiting membrane, surrounding the exterior of the tube, formed by the fused outer ends of the spongioblastic cells, and an internal limiting membrane bounding the central canal and continuous with the inner ends of the ependyma cells. Throughout the whole of the spinal medulla and the brain, the ependyma cells become transformed into the columnar ciliated cells which line the cavities of the adult brain and spinal medulla. The mantle layer becomes converted into the gray matter of the adult central nervous system.

The peripheral reticular layer, in the spinal region, becomes permeated by nerve-fibres, which are merely processes of the nerve-cells, and it is thus converted into the white matter of the adult spinal medulla. In the brain region it is either transformed in the same way into white matter, or it remains in a more rudimentary condition as a thin peripheral layer of neuroglia on the surface of the gray matter. On the other hand, in the brain region white matter is formed internal to the gray matter by the growth of nerve-fibres which insinuate themselves between the mantle layer externally and the bodies of the ependyma cells internally.

As the histological differentiation of the walls of the neural tube is proceeding each lateral wall is divided into a dorsal part, the alar lamina, and a ventral part, the basal lamina, by a sulcus-like dilatation of the central canal called the sulcus limitans. After the limiting sulci are formed the parts of the walls of the neural tube are a roof-plate, a floor-plate, and two lateral walls, each of which consists of an alar lamina, essentially sensory in function, and a basal lamina, essentially motor in function (Fig. 44).

The Fate of the Cavities of the Primitive Brain.-The cavity of the spinal portion of the primitive neural tube becomes the central canal of the spinal medulla of the adult. The cavities of the primitive brain vesicles are transformed into the ventricles, foramina, and aqueduct of the adult brain. The cavities of the telencephalic divisions of the secondary fore-brain become the right and left lateral ventricles of the adult brain. The cavity of the undivided portion of the secondary fore-brain vesicle, together with the cavity of the primary fore-brain, become the third ventricle or cavity of the diencephalon, and the apertures of communication between the third ventricle and the cerebral hemispheres are the interventricular foramina (O.T. foramina of Monro).

The cavity of the hind-brain vesicle becomes the fourth ventricle, and the 
cavity of the primitive mid-brain is converted into the aqueductus cerebri, which connects the third with the fourth ventricle.

After the anterior and posterior neuropores (p. 31) are closed, the cavity of the neural tube is, for a time, a completely enclosed space. Subsequently the mesoderm, which in the meantime has surrounded the tube, becomes differentiated, in its immediate neighbourhood, into three membranes. The innermost of the three is closely connected with the walls of the neural tube and is called the pia mater. The outermost, known as the dura mater, is dense and resistant, and the intermediate membrane is a thin lamella called the arachnoid.

As the membranes are formed, spaces are differentiated between them. The space between the dura mater and the arachnoid is the subdural space, and that between the arachnoid and the pia mater is the subarachnoid space.

After a time a median perforation, the median aperture of the fourth ventricle (O.T. foramen of Magendie), and two lateral perforations pierce the dorsal wall of the fourth ventricle and the pia mater which covers it, and thus the fourth ventricle becomes comnected with the subarachnoid space. It is stated also that a perforation passes through the medial wall and the covering pia mater of a portion of each lateral ventricle which is called its inferior horn, throwing those portions of the lateral ventricles also into communication with the subarachnoid space.

\section{THE FORMATION OF THE EMBRYO.}

The transformation of the relatively flat embryonic area into the form of the embryo is due, in the first instance, to the rapid extension of the median part of the area, as contrasted with the slower growth of its margins, and the later modelling of the various parts of the embryo is due to different rates of growth in different parts of the embryonic region.

By the rapid proliferation of cells from the nodal growing point, at the cephalic end of the primitive streak, the cephalo-caudal length of the

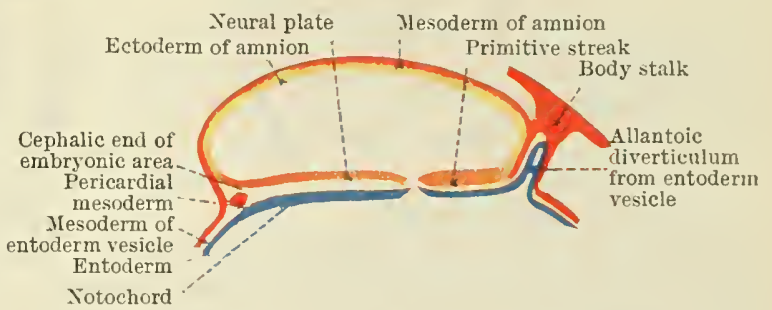

Fig. 48. - Schema of SagitTal Section of Embrtoxic ARea axd Aminos before the Foldixg of the Area has comanced. area is increased, whilst the cephalic and caudal ends of the area remain relatively fixed, consequently the area becomes folded longitudinally. At the same time, the cephalic end of the neural groove is pushed away from the nodal point until it lies at first dorsal and then cephalad to the cephalic border of the area. As a result of this move-

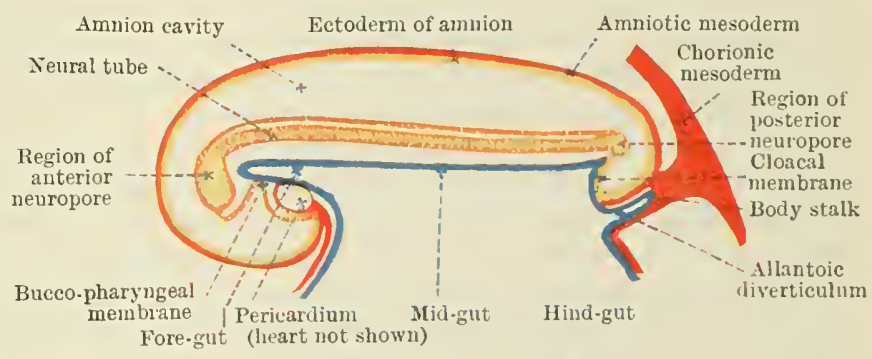

Fig. 49.-Schema of SigitTal Section of Eabrtoxic Area shortuy AFTER THE FOLDIXG HAS COMMENCED. The pericardial mesoderu is earried into the ventral wall of the fore-gut and the coelom has extended through it. The cephalic end of the neural tube and the caudal part of the primitive streak are bent ventrully, anl the latter now forms the cloacal nembrane. ment the bucco-pharyngeal and the pericardial areas become reversed in position, and a cephalic or head fold is formed. This is bounded dorsally by what is now the ceplialic portion of the embryo, ventrally by the reversed pericardial region, and its cephalic end is formed by the extremity of the head region and the bucco-pharyugeal membrane. 
The growth at the nodal point not only produces a head fold, but at the same time it forces the cephalic end of the primitive streak caudally over the caudal end of the embryonic area, thus forming a tail fold.

As the head and tail folds of the embryo are produced by the longitudinal increase of the embryonic area, transverse growth of the area results in the formation of right and left lateral folds (Figs. 37, 39), and as the various folds are formed the embryo rises like a mushroom into the interior of the amnion cavity.

The portion of the entodermal sac which is enclosed within the hollow embryo, formed by the folding of the embryonic area, is the primitive entodermal alimentary canal. The part which remains outside the embryo is the yolk sac, and the passage of communication between the two is the vitello-intestinal duct.

That portion of the primitive entodermal alimentary canal which lies in the head fold is termed the fore-gut, the part in the tail fold is the hind-gut, and the intermediate portion which is in free communication with the yolk-sac is the mid-gut.

As the extension of the embryonic area and its folding proceed the margin of the area which remains relatively stationary becomes the margin of an orifice, on

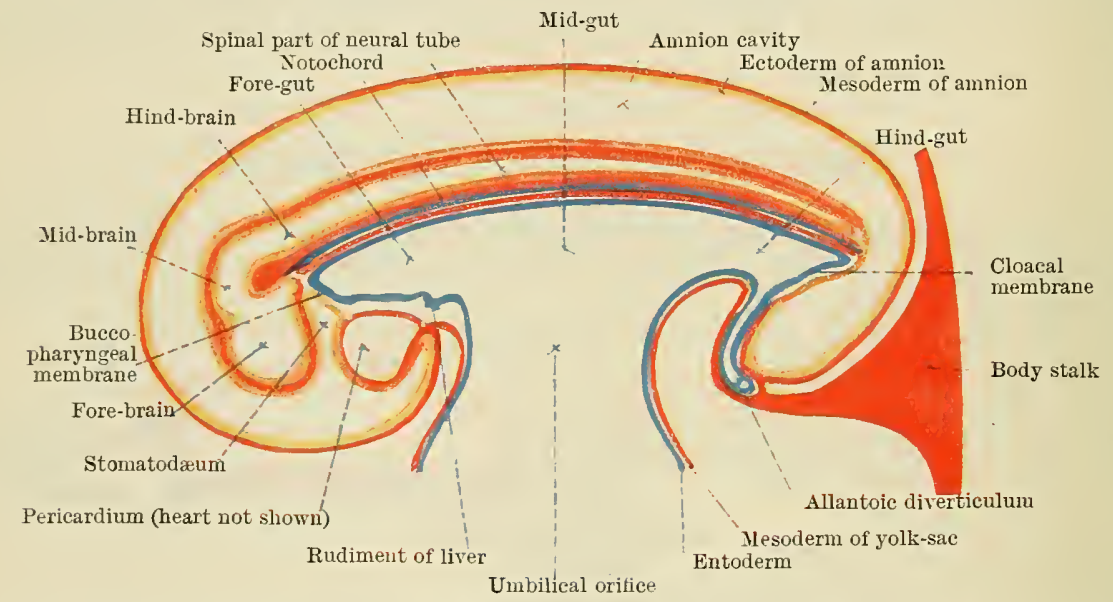

Fig. 50. - Schema of Sagittal Section of Embryo after the Folding has defined both the ForeGUT AND HIND-GUT AREAS.

the ventral aspect of the embryo, through which the primitive alimentary canal of the embryo and the intra-embryonic part of the colom communicate, respectively, with the yolk sac and the extra-embryonic portion of the coelom. This orifice is the primitive umbilical orifice.

Not only does the primitive alimentary canal communicate with the yolk sac, and the intra-embryonic with the extra-embryonic colom, at the margin of the umbilical orifice, but also the body walls of the embryo, formed by the somatopleure, becomes continuous, at the same margin, with the wall of the amnion.

The young embryo is connected also with the inner surface of the chorion by a band of tissue formed by the median portion of the caudal part of the wall of the amnion sac. The mesoderm in this region is thickened, and contains in its interior a diverticulum, allantoic aiverticulum, which is primarily derived from the entodermal sac, but is afterwards connected with the hind-gut. This strand, which contains the blood-vessels passing between the embryo and the chorion, was called by $H$ is the body stalk. The term is not altogether fortunate, for it appears that the stalk takes no direct part in the formation of the body of the embryo. On the other hand, its mesodermal and entodermal constituents represent a diverticulum from the wall of the hind-gut, known as the allantois which, in many animals, attains a large size, and it might with advantage be termed the allantoic stalk.

At first the umbilical orifice is relatively large as contrasted with the total size 
of the embryo, but as the embryo rapidly extends in all directions from the margin of the orifice, the latter soon becomes relatively small. Ultimately the various parts of the margin of the orifice are approximated until they fuse together, closing the opening and forming a cicatrix on the ventral wall of the abdomen which is known as the umbilicus or navel.

\section{THE EMBRYO.}

Whilst the embryonic area is being folded into the form of the embryo, the neural groove on the surface of the area is being converted into the neural tube. After the neural tube is completely closed and separated from the surface, during the third week, the embryo is an elongated organism possessing a larger cephalic end, a smaller caudal end attached by the body stalk to the chorion (Fig. 49), a continuous and unbroken dorsal surface, a ventral surface separated into cephalic and caudal portions by the umbilical orifice, two lateral surfaces right and left, and it contains within its interior three cavities: (1) The cavity of the neural tube, which becomes the cavities of the brain and the spinal medulla (Fig. 50); (2) the primitive alimentary canal, which is a portion of the entodermal vesicle constricted off during the folding of the embryonic area (Figs. 37, 40); (3) the embryonic colom. The colom consists of right and left portions which communicate at the margin of the umbilicus with the extra-embryonic colom, and with each other through the pericardial portion of the cclom in the ventral wall of the fore-gut of the embryo (Figs. 49, 90).

At this period the embryo is easily distinguished from the remainder of the zygote, and it is so far developed that indications of its general plan of organisation are discernible.

It has, as jet, no limbs, but the general contour of the head and body are defined. It possesses a notochord or primitive skeletal axis, afterwards replaced by the permanent vertebral column. On the dorsal aspect of the notochord lies the neural tube, which is the rudiment of the future brain and the spinal medulla.

At the sides of the neural tube and the notochord are the mesodermal somites and the nerve ganglia (Figs. 40, 43).

Ventral to the notochord is the primitive alimentary canal (Fig. 50), closed at its cephalic end by the bucco-pharyngeal membrane, and at its caudal end by what was originally the caudal portion of the primitive streak, but which is now called the cloacal membrane because it separates the caudal end of the hind-gut, which becomes the entodermal cloaca, from the amniotic cavity (Fig. 50).

At the sides of the primitive alimentary canal are the right and left lateral parts of the coelom, and between the dorsal angle of each half of the colom and the mesodermal somites of the same side lies the intermediate cell tract which is the rudiment of the greater part of the genito-urinary system (Figs. 39, 40).

Ventral to the fore-gut is the pericardial mesoderm, traversed by the pericardial portion of the colom, which is connected dorsally, on each side with the corresponding lateral portions of the colom; and rentral to the hind-grut is the cloacal membrane. Between the pericardial region at the one end and the cloacal membrane at the other lies the umbilical oritice, through which the mid-gut communicates with the yolk sac, the intra-embryonic part of the calom with the extra-embryonic colom, and the allantoic diverticulum with the cloaca (Figs. $39,50)$.

\section{THE LIMBS.}

When it is first defined the embryo is entirely deroid of limbs (Fig. 51). During the third week a superficial ridge appears on each side, along the line of the intermediate cell tract in the interior. This is the Wolffan ridge, and upon it the rudiments of the fore and hind limbs, the limb buds, are formed, as secondary elevations, the fore-limb buds preceding the hind-limb buds in time of appearance (Fig. 52). 
Shortly after it has appeared, each limb bud assumes a semilunar outline; it projects at right angles from the surface of the body, and it possesses dorsal and rentral surfaces, and cephalic or preaxial, and caudal or postaxial borders. The

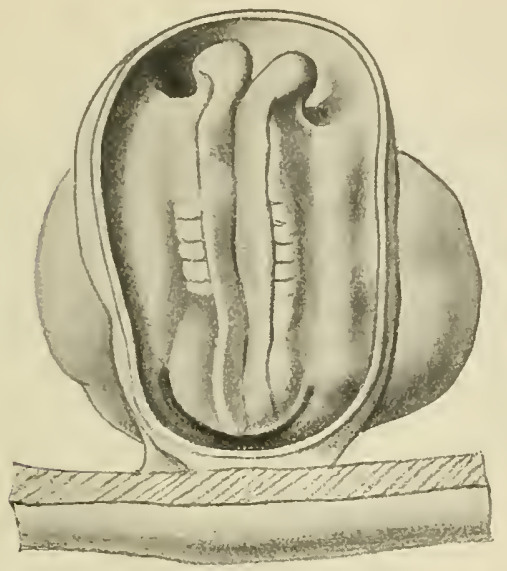

Fig. 51.-View of Dorsal Aspect of A HOMAN EMBRYO-1.38 mm. LONG, before the appearance of the limbs. (From Keibel and Elze, Normaltufeln.)

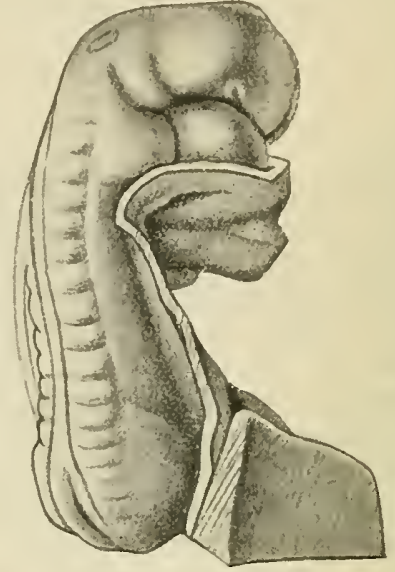

Fig. 52.-Dorsal Lateral View of a Human Embrio - $2.4 \mathrm{~mm}$. LoNG. The Wolffian ridge is seen at the lateral border of the mesodermal somites. (Keibel and Elze, Normaltafeln.)

bud is the rudiment of the distal segment of the future limb, the hand in the case of the fore-limb, and the foot in the case of the hind-limb.

As the limb-rudiment increases in length the more proximal segments of the limb are differentiated, the forearm and arm in the case of the fore-limb, and the

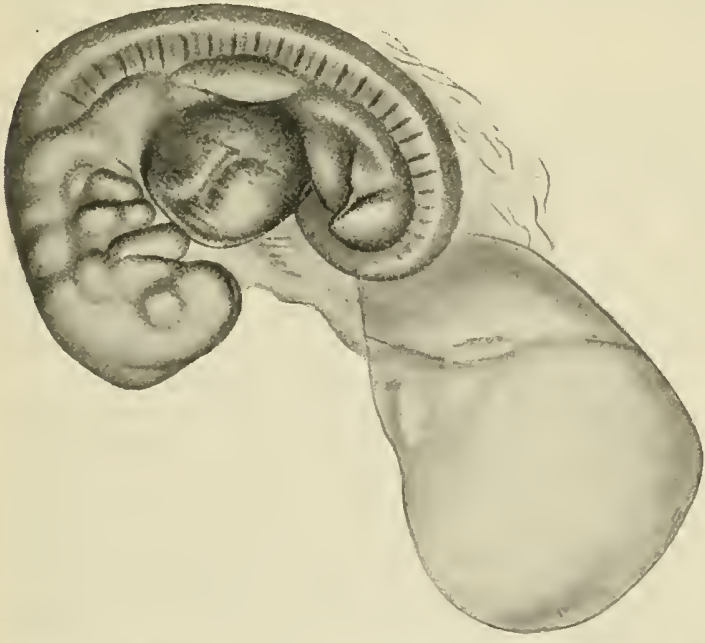

Fig. こ̌.-Lateral View of a Human Embryo-2.1 mm. greatest length, showing limb buds projecting from the Wolffian ridge. (Keibel and Elze, Normaltafeln.)

ment of each limb is, at first, a flat plate terminal or distal segates into a rounded margin, but it soon differentiates into a proximal or basal part and a more flattened marginal portion. It is along the line where these two parts are continuous that the rudiments of the digits appear. They become evident as small elevations on the dorsal surface of the limb bud about the fifth week; they extend peripherally, and by the sixth week the fingers project beyond the margins of the hand segment, but the toes do not attain to a corresponding stage of development until the early part of the seventh week. 
The nails are later developments. They appear at the third month and reach the ends of the digits at the sixth month.

Each limb bud is essentially an extension of a definite number of segments of the body. It consists, at first, of a core of mesoderm covered by ectoderm. As it grows the anterior branches of the spinal nerves of the corresponding segments are prolonged into it, together with a number of bloodvessels. The nerves remain as the nerves of the fully developed limb, but the blood-ressels are reduced in number and are modified until a smaller number of permanent main trunks is established.

The greater part, if not the whole, of the mesodermal core of the primitive limb-rudiment seems to be produced by the somatic mesoderm of the lateral plate. As the development proceeds it is differentiated into the cartilaginous, muscular, and other connective tissue elements which are the rudiments of the skeletal framerrork and the muscles and fasciæ of the adult limb.

It is not yet decided whether or not the muscle elements of the mesodermal core are derived from the lateral plate mesoderm or from muscle cells which have migrated into the limb, from the muscle plates of the segments from which

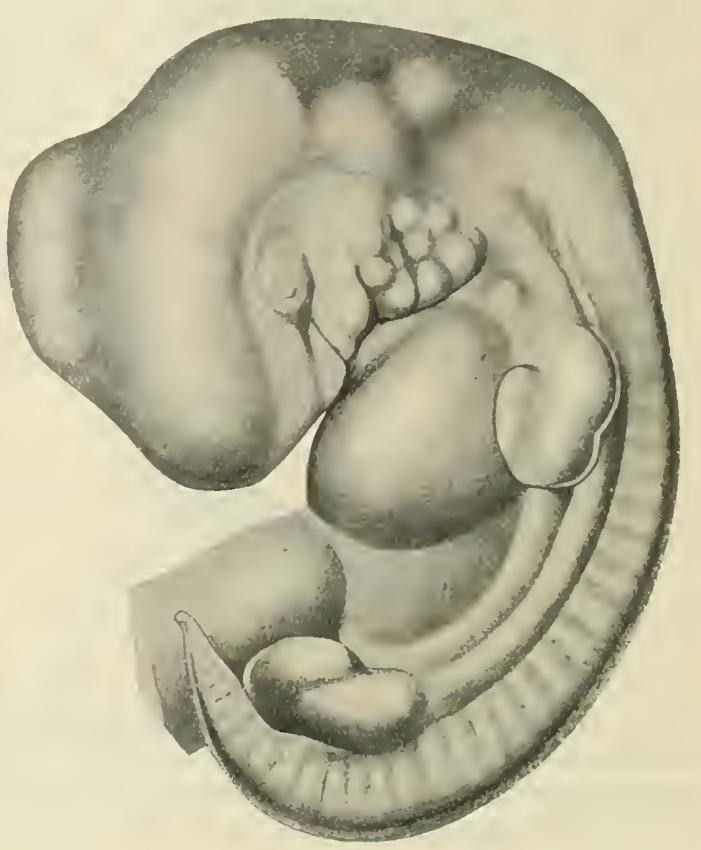

Fig. 54.-Lateral Vien of a Hemax Embryo-9.5 min. LosG. (Keibel and Elze, Normaltafeln.)

Note that the limb rudiments no longer project at right angles from the side of the body but that they are bent ventrally. the limb is formed and from which muscles of the body wall are developed; and although it is generally believed that the bone which replaces the cartilaginous skeletal rudiments is produced by mesodermal cells, it has been asserted that the bone-producing cells originate in the ectoderm and migrate from the surface into the interior.

THE EARLIER MODIFICATIONS OF THE PRIMITIVE ENTODERMAL ALIMENTARY CANAL AND THE FORMATION OF THE STOMATOD EUM AND PROCTODEUM.

The greater part of the permanent alimentary canal is derived from the entodermal sac and is therefore lined by entoderm cells. This part is enclosed in the embryo as the latter is folded off from the remainder of the zygote (Fig. 50), but its cephalic and caudal portions are formed by the enclosure of part of the external space and are, therefore, lined by ectoderm.

The cephalic part is a portion of a space called the stomatodæum which lies, at first, between the ventrally bent extremity of the head and the bulging pericardial region (Fig. 50). At a later period it is enclosed laterally by the rudiments of the maxillæ or upper jaws, and caudally by the mandibular rudiments.

When it first appears the stomatodieum is separated from the cephalic end of the entodermal portion of the primitive canal by the bucco-pharyngeal membrane, but when that septum disappears, during the third week, the stomatodium communicates with the fore-gut. Subsequently it is seprated into nasal and oral portions, and the latter forms that portion of the mouth in which the gums and teeth are dereloped.

The caudal part of the permanent canal is formed by the elevation of a surface 
The first of these bars is the rudiment of the maxillary and mandibular regions. It is called the mandibular arch. The second is the hyoid arch, and the remainder are the branchial arches proper.

When they first appear the arches extend from the level of the dorsal wall of the fore-gut to the pericardium but, as growth proceeds, and the neck is dereloped between the head and the pericardium, the ventral ends of the arches of opposite sides meet in the ventral wall of the primitive pharynx. The growth of the mandi-

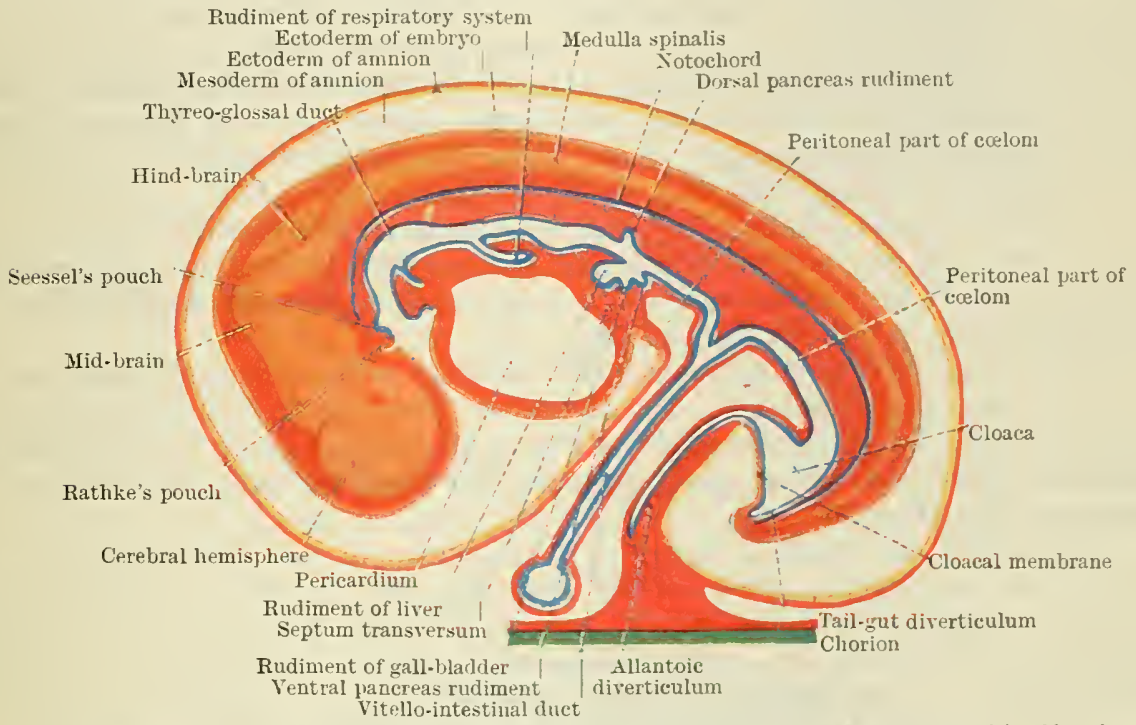

Fig. 57.--Scheyd of a Losgitudixal Section of as Embryo. (After Mall, moditied.) Showing dorsal and ventral divertricula for alimentary canal. The heart is not shown.

bular and the hyoid arches soon greatly exceeds that of the branchial arches proper, and the latter gradually recede from the surface until, on each side, they lie at the bottom of a depression, the precervical sinus, which is overlapped by the caudal border of the hyoid arch. As the overgrowth of the hyoid arch continues the opening of the precervical sinus on the surface is reduced to a narrow channel, the precervical duct. $\Delta$ fterwards this is obliterated, the sinus becomes the precervical vesicle,

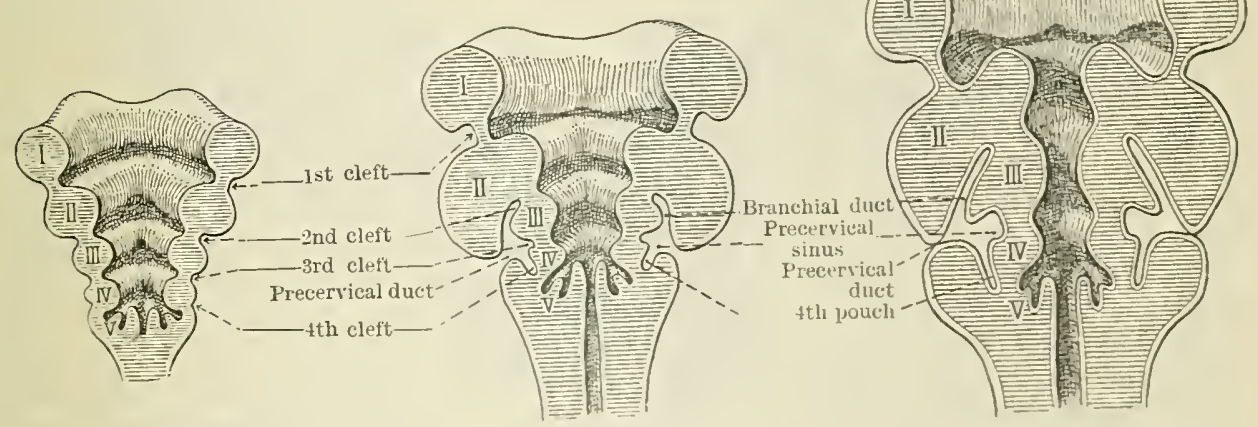

FIG. 58. - SCHEMA showing the formation of the precervical sinus, the branchial ducts, and the precervical suleus.

and the position of the original aperture of the precervical duct is indicated by a sulcus, the precervical sulcus which soon disappears. The precervical resicle lies at the side of the third plaryngeal ponch, and it is associated with the second and fourth pouches by narrow canals, the branchial ducts, which are the remains of the branchial clefts. Ultimately the precervical resicle and the branchial ducts disappear, but it bas been suggested that before the vesicle disappears a part of the lobe of the thymus of the same side is formed from its wall. 
The portion of the wall of the primitive pharynx which lies between each pair of risceral arches and separates the clefts externally from the pouches internally is called the separating membrane. In the earliest stages it consists of ectoderm, mesoderm, and entoderm; then, for a time, the mesoderm disappears to re-appear agaiu between the two epithelial strata at a still later period.

Round the margins of the dorsal part of the first pharyngeal or mandibular cleft are formed a series of tubercles which develop into the auricle of the external ear, and the cavity of the cleft becomes the external acoustic meatus (see p. 52). The first pharyngeal pouch and the adjacent part of the cavity of the primitive pharynx becomes the tympanic cavity and the auditory (O.T. Eustachian) tube. A part of the cavity of the second pharyngeal or hyoid pouch is represented in the adult by the supra-tonsillar recess, which lies in the side wall of the pharynx above the palatine tonsil (Fig. 56).

The third pharyngeal pouch opens like the first and second directly into the cavity of the fore-gut, but the fourth and fifth pouches lie in the lateral wall of a common recess which opens by a single aperture, the pharyngo-branchial duct, into the cavity of the primitive pharynx (Fig. 56).

The carities of the third, fourth, and fifth pouches ultimately disappear, but before the disappearance takes place diverticula which at first are hollow but afterwards become solid are given off from the ventro-lateral parts of each, and solid epithelial outgrowths are formed from the dorso-lateral walls of the third and fourth pouches (Fig. 56).

The ventral diverticulum from the third pouch, on each side, forms the main part of the corresponding lobe of the thymus, and the ventral diverticulum of the fourth pouch either takes part in the formation of the thymus or it entirely disappears. The rudiment of the thymus is formed in the neck, but as the gland differentiates it extends and it migrates caudally, until its cephalic end lies near the caudal end of the thyreoid gland, at the level of the sixth ring of the trachea, and its caudal end is in the thorax at the level of the fourth costal cartilage.

The epithelial bodies derived from the third and fourth pharyngeal pouches form the struetures known in the adult as the parathyreoid bodies. That derived from the third pouch migrates caudally more rapidly than its fellow formed from the fourth pouch; consequently the parathyreoid derived from the fourth pharyngeal pouch lies at the middle of the dorsal border of the lateral lobe of the adult thyreoid gland, and the parathyreoid formed from the third pharyngeal pouch is situated at the caudal end of the lateral lobe of the thyreoid gland and close to the cephalic end of the thymus.

The diverticulum formed from the ventral part of the fifth pharyngeal pouch is the ultimo-branchial body. After it separates from the pouch it becomes solid and is associated with the corresponding lobe of the thyreoid gland, but, apparently, in the human subject, it takes no part in the formation of that gland.

Derivatives of the Ventral Wall.-The diverticulum from the ventral wall of the primitive fore-gut, which is situated nearest the cephalic or anterior end of the gut, is the rudiment of the thyreoid gland. It commences in the median plane, between the ventral ends of the mandibular and hyoid arches, and grows ventrally into the substance of the neck, then turns caudally, ventral to the cartilages which form in the second, third, and fourth arches, from which the hyoid bone and the cartilages of the larynx are developed. When the caudal end of the diverticulum reaches the region where the cephalic or anterior portion of the trachea will be formed it becomes bilobed, and thus is differentiated into the isthmus and the lateral lobes of the permanent gland. The stalk of the diverticulum, which extends from what becomes the oral part of the primitive pharynx to the isthmus of the gland, is the thyreoglossal duct. Its cephalic end remains as the foramen cæcum, which is situated in the dorsum of the tongue at the junction of the ventral two-thirds with the dorsal third. The caudal end sometimes persists and is transformed into the third or pyramidal lobe of the thyreoid gland, which is attached to the dorsal border of the isthmus (Figs. 56, 61).

The more caudally situated diverticulum from the ventral wall of the fore-gut is the rudiment of the respiratory system (Figs. 59, 60). When it first appears 
it has the form of a longitudinal groove bounded at its cranial end and laterally by an elevated ridge, named by His the furcula (Fig. 59). The caudal end of the groove soon dilates into a pouch, and then the pouch and groove are separated ly a constriction, which passes from the caudal towards the cranial end, from the more dorsal part of the fore-gut, which becomes the esophagus. The eonstricting process ceases lefore the separation reaches the cranial extremity of the respiratory rudiment, which remains, therefore, in communication with the pharynx and forms the permanent laryngeal aperture. The tube formed by the separation of the groove is differentiated into the larynx and the trachea, and the caudal terminal dilatation soon divides into two lateral lobes, each of which is the rudiment of the bronchi and the lung of the corresponding side.

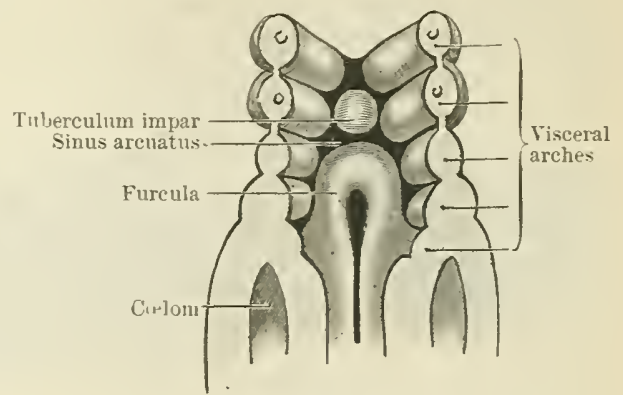

Fig. 59.-Tiew of Floor of Primtive Pharyax, showing the furcula with the groose, from which arise the cavities of the larynx, the trachea, the bronchi. and the alveoli of the lungs.

The Tongue.-The tongue is formed by four separate rudiments which lie in the ventral part of the cranial end of the primitive pharynx. Two of these are elevations formed on the caudal surfaces of the ventral ends of the mandibular arches,

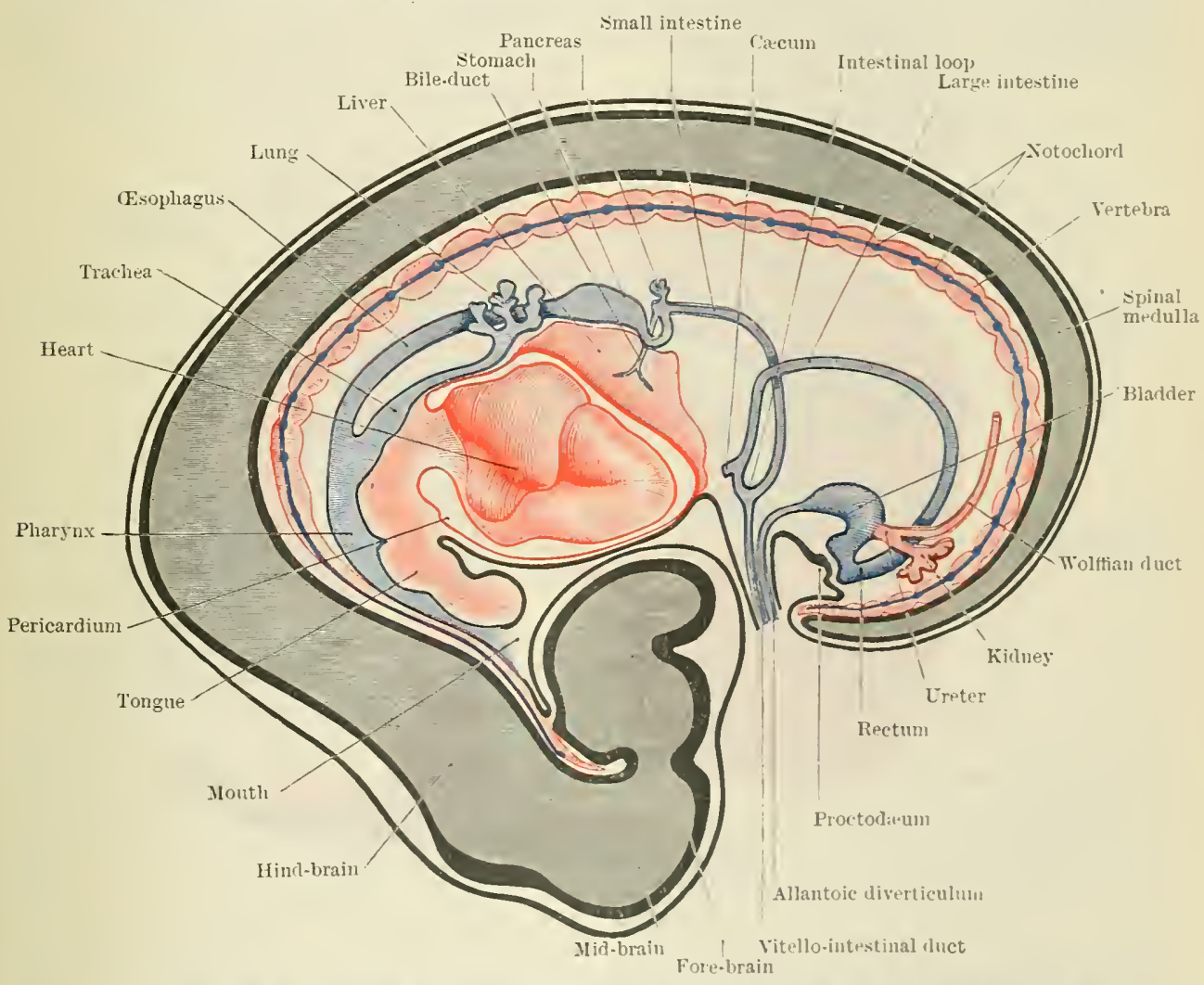

Fig. 60.-Further Developmext of the Alimentary Caxil, as seen is a Humax Embiro ABOUT FISE WEEKS OLD (Diagrammatic).

The tongue is well formed, the trachea and cesophagus are separated, the bronchi have commenced to branch : the duodenal curve is well formed, and the crecum lias appeared in the loop of the mid-gut. The cloaca is partially separated into genito-urinary and rectal portions.

one on each side. The third is a median eleration, the tuberculum impar, which is situated immediately caudal to the onjoined ventral ends of the mandilular arches, 
and the fourth, called the copula, formed by the conjoined ventral ends of the second arches, is separated from the tuberculum impar by the orifice of the thyreoid rudiment (Fig. 61).

The two lateral elevations on the mandibular arches unite to form the greater part of the rentral or anterior two-thirds of the tongue, upon which all the papillæ

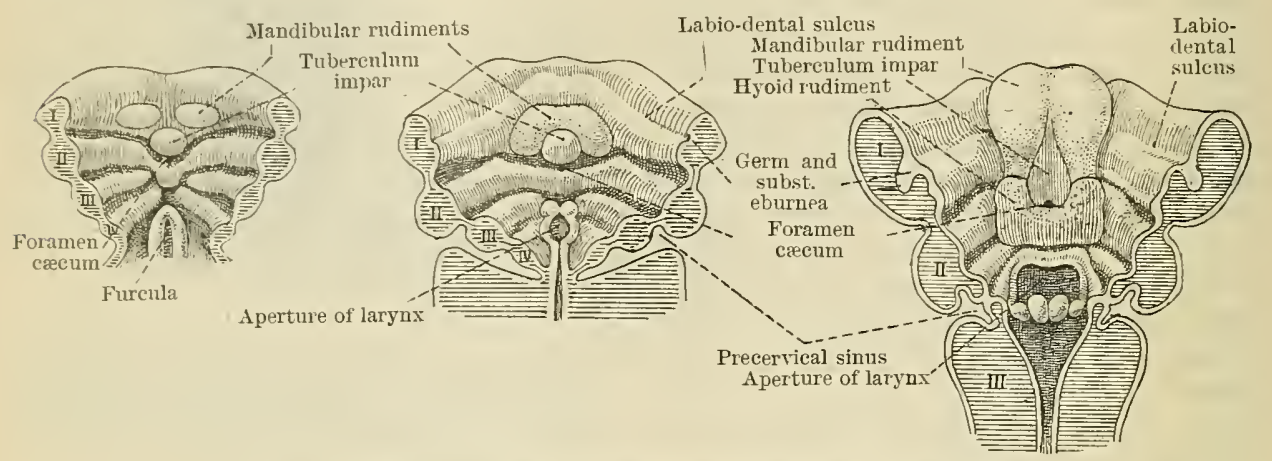

Fig. 61.-SCHEMA showing stages in the development of the tongue.

are developed. The tuberculum impar either disappears or it forms the median part of the anterior two-thirds of the organ. The posterior or dorsal third of the tongue, which lies in the ventral or anterior wall of the permanent pharynx, is formed from the copula of the second arches. It follows from what has been said

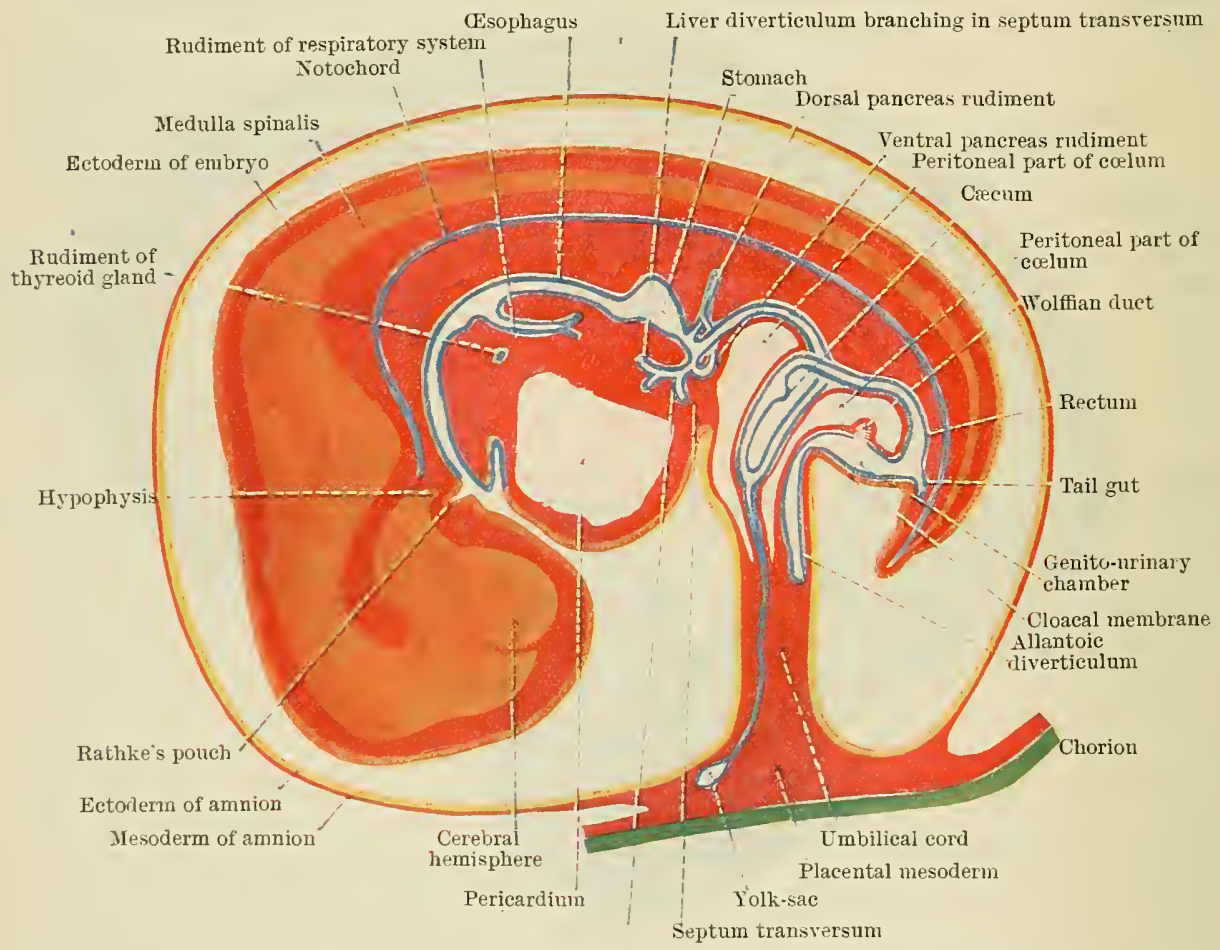

FIG. 62.-SChEMa showing further stages in the development of the diverticula from the primitive gut and modifications of the mid-gut and the mirl-gut regions. The heart is not shown. (After Mall, morlified.)

that the commencement of the thyreoid rudiment, which persists in the adult as the foramen cæcum of the tongue, must lie at the junction of the dorsal third with the ventral two-thirds. In many cases it appears to lie in the dorsal end of the ventral two-thirds, a position which may be associated with the fact that in some cases the rudiment of the thyreoid passes through the substance of the tuberculum 
impar and not from between the tuberculum impar and the ventral ends of the hyoid arches.

Derivative of the Dorsal Wall (Seessel's Pouch). - The dorsal diverticulum from the cranial end of the fore-gut, to which the above term is applied, enters the base of the occipital region of the primitive head. The ultimate fate of the pouch is unknown in the human subject, but it has been suggested that it is represented by a depression in the mucous membrane of the cranial part of the pharynx, close to the pharyngeal tonsil, which is known as the pharyngeal bursa.

The reader who has followed this description will have noted that from the cranial portion of the fore-gut are formed the caudal or inferior part of the mouth (with the exception of the lips, teeth, and gums), the pharynx, the thyreoid gland, the thymus, the parathyreoids, the respiratory organs, and the cesophagus. The more caudally situated portion of the fore-gut is differentiated into the stomach and the first and second parts of the duodenum.

The stomach is formed from the part of the fore-gut immediately adjacent to

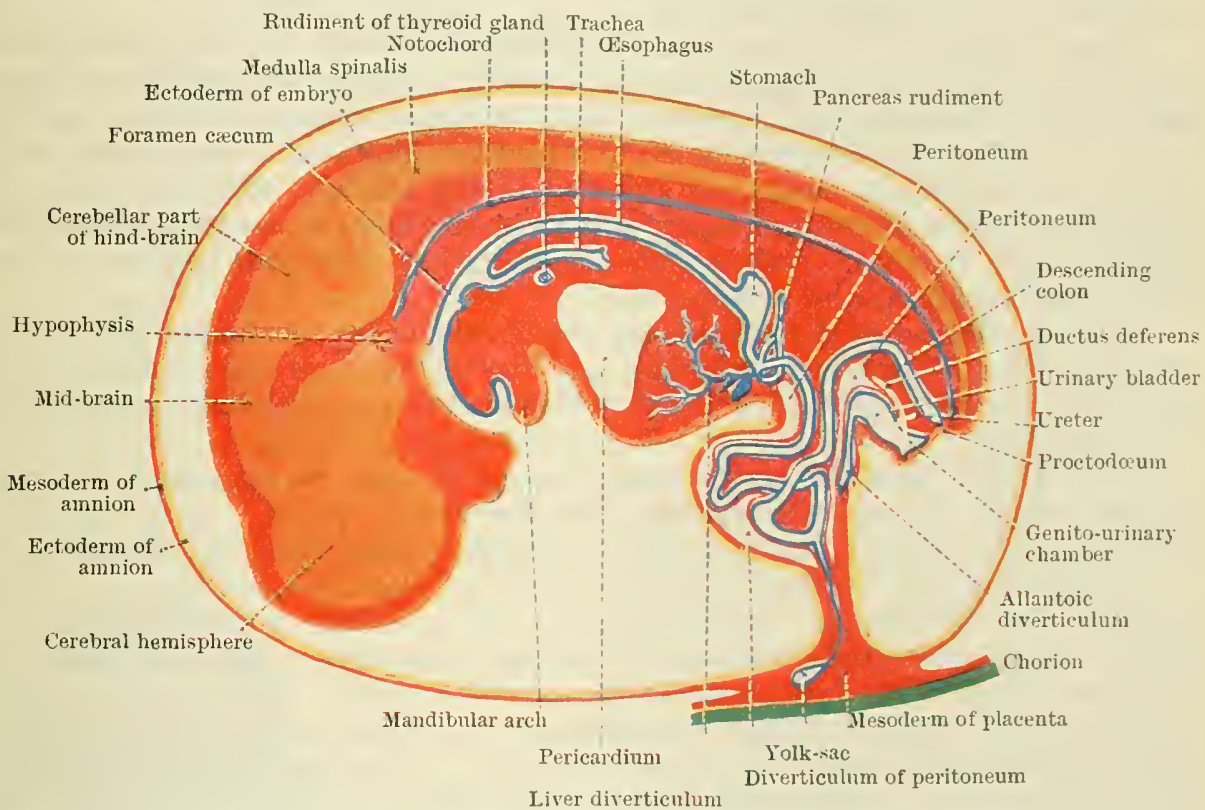

FIG. 63.-Schema showing complete separation of cloaca into dorsal and ventral parts and the temporary ventral hernia of a portion of the gut through the umbilical orifice. The heart is not shown. (After Mall, modified.)

the osophagus, and the duodenum from the more caudally placed portion, which is directly continuous with the mid-gut.

The Liver and Pancreas.-When the embryo is about three weeks old and lias attained a length of $2.5 \mathrm{~mm}$. a ventral diverticulum appears in the rentral wall of the duodenal part of the fore-gut, and when the age of the embryo is ahout four weeks and its length increased to alout $4 \mathrm{~mm}$. a diverticulum is formed in the dorsal wall a little nearer the cranial end. The rentral pouch is the rudiment of the liver, the gall bladder, the bile-ducts, and a portion of the pancreas, and the remainder of the pancreas is formed from the dorsal diverticulum (Figs. 57. 6:, 63).

The Derivatives of the Mid-Gut.-The mid-gut is transformed into small intestine and part of the large intestine. The exact amount of intestine formed from this portion of the primitive gut is not definitely known, but it is generally believed that it is the rudiment of the terminal part of the duodenum, the jejumum, the ileum, the cecum and its vermiform process, the ascending colon, the right colic flexure, and the transverse colon. It is possible that the left colic flexure and a portion if not the whole of the descending colon may also be dereloped from this part of the gut.

It has already been noted that the mid-gnt is simply that part of the entodermal 
portion of the primitive alimentary tract which lies between the more definitely enclosed fore-gut and hind-gut, and that it is in free communication with the yolk-sac.

As development proceeds this portion of the alimentary canal becomes converted into a $U$-shaped tube which possesses a cranial and a caudal limb, and a ventral extremity which is connected with the yolk-sac by a narrowed and elongated canal, the vitello-intestinal duct (Fig. 57).

Upon the caudal limb of the loop, about the middle of its dorso-ventral height, an enlargement appears which is the rudiment of the cæcum and vermiform process of the adult. After this rudiment has formed the caudal limb of the loop undergoes rotation, being carried first to the left, then cranially, and finally to the right. As it is carried to the right it crosses the cranial (later ventral) aspect of the cranial limb of the loop, and when the rotation is completed the regions of the jejunum and ileum, the cæcum, the ascending and the transverse colon are defined.

After the rotation has occurred the tubular intestine formed from the mid-gut undergoes rapid elongation and is thrown into a number of coils.

When the embryo has attained the length of $10 \mathrm{~mm}$., and is a little over a month old, the greater portion of the coiled gut passes through the umbilical orifice into an expansion of the colom formed in the proximal part of the umbilical cord (see p. 47) (Fig. 63), which has replaced the allantoic or body-stalk as the medium by which the embryo is attached to the chorion. The herniated coils remain in the root of the umbilical cord until the embryo is about $40 \mathrm{~mm}$. long, and about ten weeks old, when they return to the abdomen, and the cœlomic space in the umbilical cord disappears.

The Derivatives of the Hind-Gut.-When the caudal portion of the hind-gut is first enclosed its terminal extremity and its ventral wall are bounded by the caudal portion of the primitive streak, which is bent ventrally during the foldingoff of the embryo.

The terminal part of this portion of the gut becomes expanded, forming a chamber called the entodermal cloaca, into the ventral parts of which the ducts of the primitive kidneys, the pronephric or Wolffian ducts, open, one on each side.

The ventral part of the cephalic end of the cloaca is continuous with the allantoic diverticulum, and the dorsal part with a tubular portion of gut which forms the descending and possibly also the iliac and pelvic portions of the colon. The exact origin of the latter part of the primitive gut is uncertain, but it must be formed either from the mid- or hind-gut. As the temporary tail is formed and projected first caudally and then ventrally, by the growth energy of the nodal point situated at the caudal end of the neural tube, a diverticulum of the caudal end of the dorsal part of the cloaca is prolonged into it, forming the tail gut. This soon becomes shut off from the cloaca. But it entirely disappears before the temporary tail is absorbed into the caudal end of the body (Figs. 57, 62, 63).

At a later period the cloaca itself is separated into a dorsal part, the rectum, and a ventral part, the urino-genital chamber, by the formation of a septum, which commences in the angle between the allantoic diverticulum and the ventral wall of the cloaca, and is prolonged caudally till it reaches and fuses with the internal surface of the cloacal membrane, which thus becomes separated into urino-genital and anal portions, both of which disappear about the eighth week.

In both sexes the urino-genital section of the cloaca is separable into three parts: (1) a cranial part, which is converted into the urachus or middle umbilical ligament; (2) an intermediate part, which becomes the urinary bladder; and (3) a caudal part, which, in the female, is transformed into the urethra and the vestibule of the vagina, and in the male it is developed into the urethra.

Derivatives of the Stomatodæum. - When the stomatodæum is first definitely established, it is bounded cranially by the caudal surface of the ventrally bent terminal part of the head, caudally by the conjoined ventral ends of the mandibular arches, and laterally by the dorsal partis of the mandibular arches and the maxillary processes, which grow ventrally from the dorsal parts of the mandibular arches. The space is open ventrally, and it is closed dorsally by the bucco-pharyngeal membrane, which separates it from the fore-gut (Fig. 55). 
The bucco-pharyngeal membrane disappears about the third week, and about the twenty-first day a diverticulum from the stomatodæum is projected into the caudal surface of the head, from the angle immediately ventral to the point where that surface originally joined the external surface of the bucco-pharyngeal membrane. The diverticulum is Rathke's pouch. The cranial extremity of the pouch comes into relation with the hypophyseal diverticulum from the floor of the third ventricle, and dilates. The stalk which connects the dilated terminal part of the diverticulum with the stomatodæum disappears, and the terminal vesicle becomes the anterior lobe of the hypophysis (O.T. pituitary body) (Figs. 57, 62, 63).

The Separation of the Stomatodæum into Nose and Mouth.-In the cephalic boundary of the stomatodæal space lies the ventral end of the head, which is

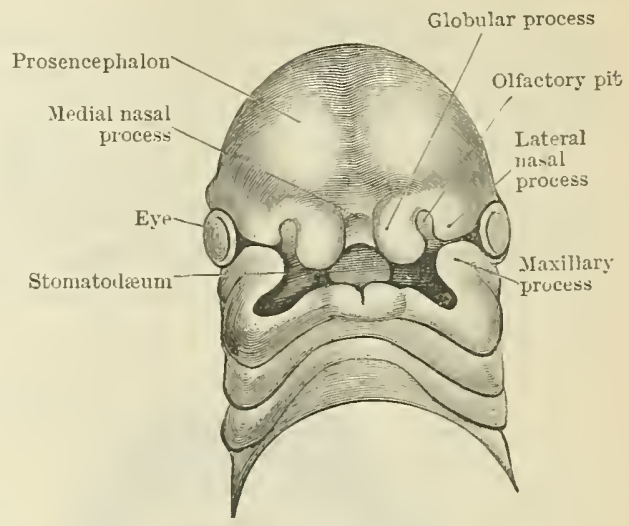

Fig. 64. - ANTERIor VIEW OF Bucxdaries OF Stomatodech before Completiox of Prim. TIVE UPPER LIP. called the fronto-nasal process.

Upon the fronto-nasal process, on either sicle of the median plane, is situater it shallow pit, the olfactory pit, and by the pits the process is divicled into a median part, the median nasal process, and two lateral parts, the lateral nasal processes. Further, the margin of the median process is divided ly a median eleft into right and left globular processes (Fig. 64).

The orifices of the olfactory pits are directed laterally, therefore the lateral nasal processes lie dorsal to the median nasal process in the cranial boundary of the stomatodral space, and as their margins increase in height the pits deepen (Fig. 69).

At this period the cranial houndary of the stomatodrem is clivided ly the median sulcus and the olfactory pits in to four projections - the two globular processes,

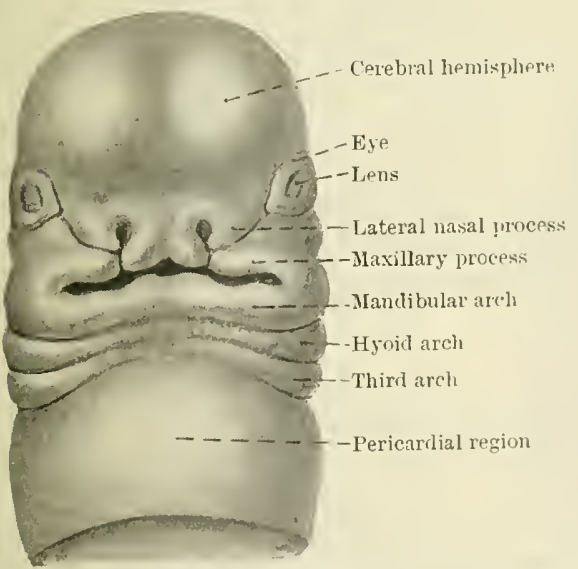

Fig. 65. -Suhema OF ANTERIOR View OH the HEAT OF a Human EMbryo showing the Completion of the Primtive Upper Lip. each of which lies between the median suleus and an olfactory pit, and the two lateral nasal processes, which form the dorso-lateral horders of the olfactory pits. The lateral houndaries are formenl by the maxillary processes and the dorsal parts of the mandibular bars, and the camdal boundary is formed by the medially turned and conjoinerl ventral parts of the mandibular hars. Immediately cranial to the maxillary process, on each side, is the projecting eye: and leading from it, hetween the maxillary process and the lateral nasal process, is the naso-lacrimal sulcus.

As growth proceeds and each maxillary process srows ventrally, its extremity fuses with the ciudial or posterior forder of the lateral nasal proeess, and then, carrying the lateral nasal process with it, it fuses with the ghobular process of the sime sille.

After the fusion of the maxillary processes, and the posterior or ciutul borders of the lateral nasal processes, with the glolular processes has occurrecl, the olfactory pits are completely separater, for a time, from the stomatodiem, and they lie in the ledge which now forms the cranlill boundary of the stomatodæum. This ledge consists of the two globular processes, fused into a single mass, and the two maxillary processes, the camclal or posterior ${ }^{1}$ edges of the lateral nasal 
processes heing shut off from the margin of the ledge ly the maxillary processes (Fig. 65).

After the ledge is completed the dorsal ends of the olfactory pits are separated from the stomatodieum hy a thin membrane, but this soon disappears, and the pits open again into the stomatodæal space, through apertures which are caller the primitive choanæ.

After the formation of the primitive choance a ledge grows from the medial surface of each maxillary process towards the median plane, caurlal to the choana. These ledges, the palatine processes, meet and fuse during the third month of fotal life, the fusion commencing ventrally and being completed dorsally in the region of the urula. As the ledges meet and fuse, the stomatodrum is separated into a

Anterior nasal orifice

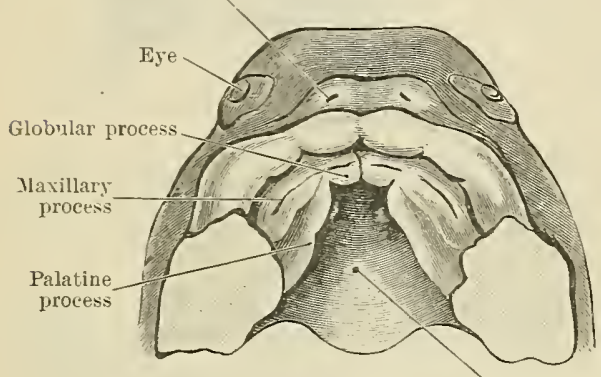

Hypophyseal depression

Fif. 66. - PORTIOX OF THE HEAD OF a HUMAX

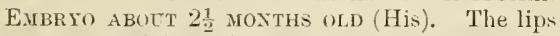
are separated from the gums, and the line of the common dental germ is visible in the latter. The palatine processes are growing inwards from the maxillary processes.

Urino-genital System. - The formation of the internal parts of the urino-genital system from the intermediate cell tract, the urino-genital chamber, and the differentiation of the external genitals in the region of the cloacal membrane are described in the account of the urino-genital system.

The development of the auditory organ is so intimately associated with the development of the pharyngeal portion of the primitive gut that a short consideration of the chief phenomena may with adrantage be introduced here; but for the details of the development of the internal, middle, and external portions of the ear the student must refer to the account of the development given in association with the description of the auditory organ.

\section{THE INTERNAL EAR, THE TYMPANUM AND AUDITORY TUBE,} AND THE EXTERNAL EAR.

In the human subject, as in other mammals, the auditory organ consists of the internal ear or labyrinth, the middle ear or tympanum, with which is associated the auditory tube (O.T. Eustachian); and the external ear, which consists of the external acoustic meatus with the auricle at its lateral end.

The internal ear itself consists of two parts - the cochlea, which is the true organ of hearing, and the vestibule and the three semicircular canals connected with it, which are associated with the recognition of alterations in the position of the head, and, therefore, with the recognition and maintenance of equilibrium.

The whole of the internal ear is lined with ectodermal epithelium, the auditory epithelium, which is derived from the surface of the head of the embryo. It is recognisable in embryos of about $2.6 \mathrm{~mm}$. (Fig. 67) as a thickened and slightly depressed plate of ectodermal cells which lies on the surface of the head, in the region of the hind-hrain, dorsal to the second branchial cleft. As development 
proceeds the plate is gradually invaginated into the substance of the head, and is

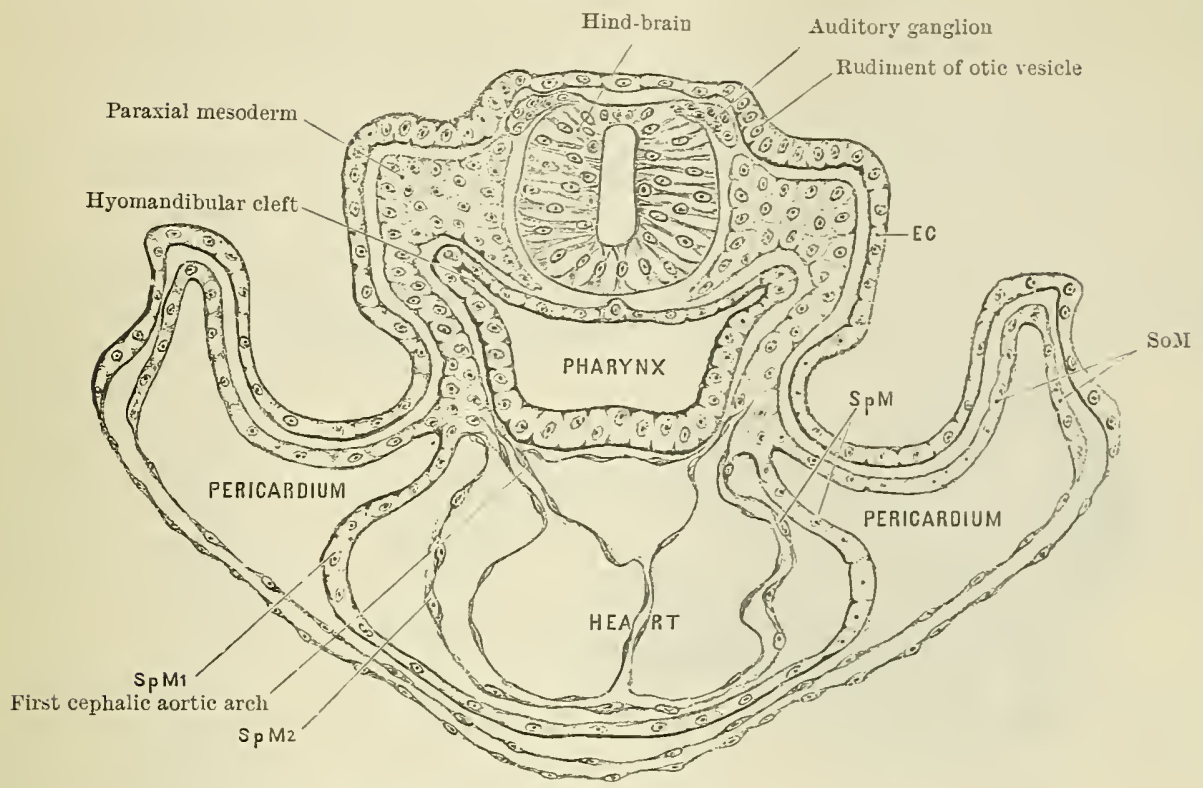

Fig. 67.-Transverse Section of a Rit Eubryo.

Showing the relation of the paraxial mesoderm of the head to the lateral plates, the conmencement of the formation of the otic resicles and hyomandibular clefts, and the relation of the primitive heart to the pericardium and fore-gut.
EC. Ectoderm.
SoMI. Somatic mesoderm.
SpM. Splanchnic mesoderm.

transformed into a pear-shaped vesicle, the otic vesicle, which remains for a time in communication with the exterior by means of a short tubular stalk, the recessus labyrinthi, which is subsequently converted into the ductus endolymphaticus.

After it is separated from the surface the otic vesicle alters its position until its ventral end lies in close relation to the dorsal wall of the pharynx, and, at the same time, it undergoes alteration of shape. The ventral part of the vesicle grows towards the median plane, along the ventral wall of the hind-brain. It forms the cavity and the lining epithelium of the cochlea; but it remains in connexion with the dorsal part by means of a narrow tube, the canalis reuniens, and as it grows in length it becomes converted into a spiral tube.

The portion of the dorsal section of the primitive vesicle, which lies to the lateral side

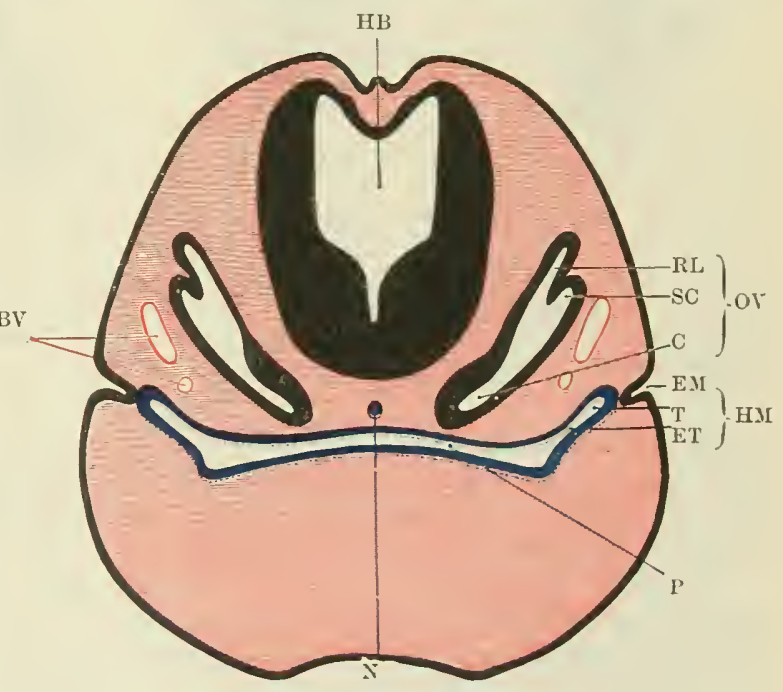

Fig. 68.-Transverse Section throdgh the Head OF AX EMBRYO.

Showing the rudiments of the three parts of the ear and their relation to the hyomandibular cleft.
Br. Blooil-ressels.
C. Cochlea.
EM. Ext. acoustic meatus.
E'T. Auditory tube.
HB. Hind-brain.
H.I. Hyomandibular cleft.

of the ductus endolymphaticus, first expauds and then hecomes compressed and 
constricted into the form of three flat purse-like diverticula which, by the partial obliteration of their cavities, become converted into the three semicircular canals (see Sense Organs). The more ventral part of the dorsal section of the vesicle is divided, by a constriction of its lateral wall, into a dorsal part, the utricle, which remains in connexion with the semicircular canals, and a ventral part, the saccule, which is united to the cochlea by the canalis remiens. The apex of the constriction which separates the utricle from the saccule passes gradually into the mouth of the ductus endolymphaticus, which is thus transformed into a Y-shaped tube connecting the utricle with the saccule. At a later period the closed extremity of the ductus endolymphaticus, which was originally connected with the surface of the head, becomes dilated and forms the saccus endolymphaticus. This is found,

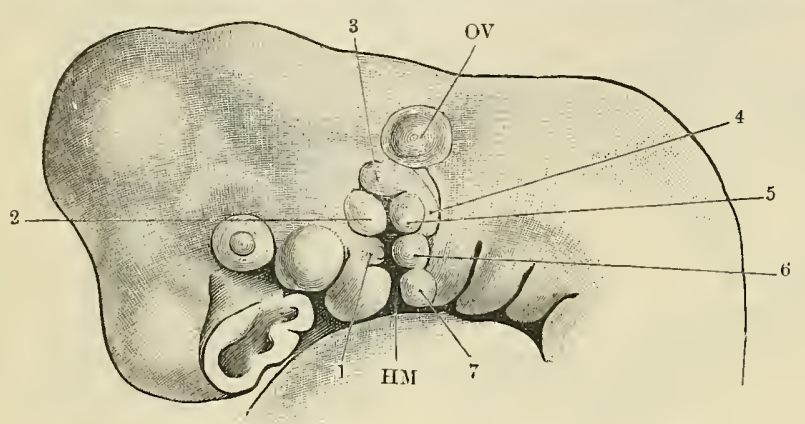

3
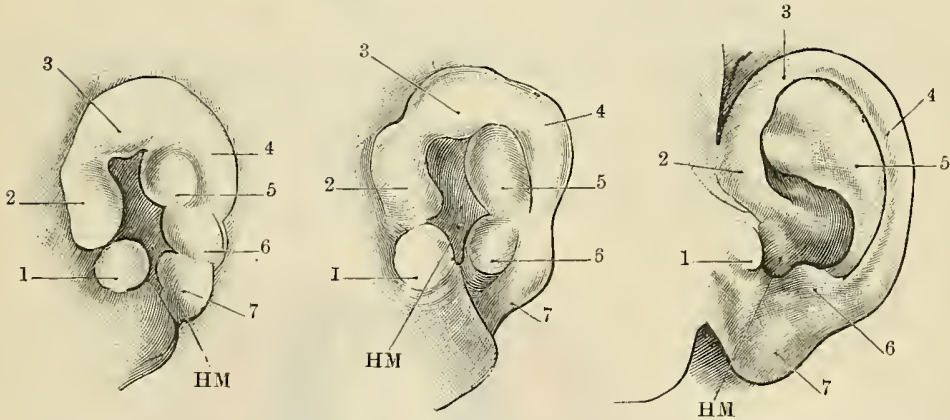

Fig. 69.-FigUres, MOdified From His, ILlUSTRATING THE Formation of THE PINNA.

1. Tuberculum tragicum = Tragus.

2.,$\quad$ anterius helicis

$\left.\begin{array}{ll}\text { 2. } & \text { anterius helicis } \\ \text { 4. Cauda helicis } & \text { intermedium helicis }\end{array}\right\}$ Helix.

5. Tuberculum anthelicis = Antihelix.
6. Tubereulum antitragieum $=$ Antitragus.

7. Tuberculum lobulare = Lobule. HM. Hyomandibular cleft.

OV. Otic vesicle. in the adult, in the posterior fossa of the skull, lying in relation with the posterior surface of the petrous part of the temporal bone.

The tympanum and the auditory tube (O.T. Eustachian) are developed from the first visceral pouch.

The ventral part of the pouch disappears at an early stage. The dorsal extremity expands and is converted into the cavity of the tympanum, whilst the stalk of connexion with the pharynx is gradually constricted off from its lateral towards its medial end, and is converted into the auditory tube. The constriction commences when the embryo has attained a length of about $20 \mathrm{~mm}$., that is about the beginning of the eighth week, and is completed about the end of the week when the embryo is about $25 \mathrm{~mm}$. long.

After the auditory tube is defined it grows rapidly in length, and cartilage appears in its walls during the fourth month.

As the tympanic cavity increases in size the auditory ossicles-stapes, incus, and malleus, which are differentiated from the dorsal ends of the cartilages of the first and second branchial arches, are invaginated into it.

The membrana tympani, which separates the tympanum from the external acoustic meatus, is formed from the separating membrane which intervenes between the first branchial pouch and the first cleft. It consists, therefore, of an external covering of ectoderm, an internal lining of entoderm, and an intervening layer, of fibrous tissue, derived from the mesoderm.

The external ear is developed from the cavity and the boundaries of the first branchial cleft. The cavity of the cleft is transformed into the cavity of the external acoustic meatus, and on the mandibular and on the hyoid margins of the 
cleft three eminences appear. From the eminences on the two arches, and the skin immediately posterior to the eminences on the hyoid arch, are formed the various parts of the amicle, but the exact part played by the individual eminences in the human subject is as yet a matter of some doubt.

\section{THE PROTECTION AND NUTRITION OF THE EMBRYO DURING ITS INTRA-UTERINE EXISTENCE.}

Whilst it is passing down the uterine tube, and for a brief period after it enters the uterus, the zygote, or impregnated ovum, depends for its nutrition upon the yolk granules (deutoplasm) embedded in its cytoplasm, and upon the fluid medium surrounding it which is secreted by the walls of the uterine tube and the uterus.

As the human ovum is very small, and as it contains but little deutoplasm, its nutrition is practically dependent, almost from the first, upon external sources of supply. The urgent necessity for the formation of adequate arrangements whereby the external sources may be utilised leads to the early establishment of an intimate connexion between the zygote and the mother, which is one of the characteristic features of the development of the human embryo.

During the third week after fertilisation, as the embryo is beginning to be moulded from the embryonic region, and before the paraxial mesoderm commences to separate into mesodermal somites, a primitive heart and the rudiments of some well-defined blood-vessels are distinguishahle in the embryo; but the details of the development of the vascular system and the establishment of the embryonic circulation cannot be well understood until the formation and structure of a group of closely associated extra-embryonic organs or appendages, derired from the zygote, has been considered.

This group includes the chorion, the placenta, the amnion, the umbilical cord, and the yolk-sac.

\section{THE MEMBRANES AND APPENDAGES.}

The Chorion.-It has already been noted that when the zygote becomes a blastula it consists of three vesicles, a large vesicle enclosing two smaller vesicles and a mass of primary mesoderm (Fig. 29).

The wall of the large vesicle is composed of trophoblast (trophoblastic ectoderm), and its inner surface is in direct contact with the primary mesoderm.

A little later a cavity, the extra-embryonic cœlom, appears in the primary mesoderm, separating it into two layers, one lining the inner surface of the trophoblast and the other covering the outer surfaces of the two imner vesicles (Figs. $70,71)$.

As soon as the extra-embryonic coelom is established the chorion is formed; it consists of the trophoblast and its inner covering of mesoderm.

In the meantime the trophoblast has differentiated into two layers, an inner cellular layer, and an outer plasmodial layer. In the plasmodial layer cell territories are not defined, and it consists, therefore, of nucleated protoplasm.

The differentiation of the trophoblast into two layers occur's after the zygote has become embedded in the mucous membrane of the uterus which is modified for its reception and, after the modification has occurred, is called the decidua.

As development proceeds the trophoblast increases in thickness and it invades the decidua. As this invasion occur's the plasmodial layer of the trophoblast becomes permeated with spaces which are continuous with the lumina of the maternal blood-vessels in the decidua, and are filled with maternal blood.

By means of the spaces the plasmodial trophoblast is separated into branching processes which intervene between the blood-filled spaces. The processes are the primary chorionic villi, and they soon develoy, cellular interiors (Fig. 72).

After a time the primary villi are invaded by the chorionic mesoderm, and are thus converted into the secondary chorionic villi, which become vascularised by the 
growth of fotal vessels into the fœetal mesodermal cores. The secondary villi, therefore, consist of a mesodermal core covered by a layer of cellular trophoblast and a layer of plasmodium, the latter lying outside the former. Still later the

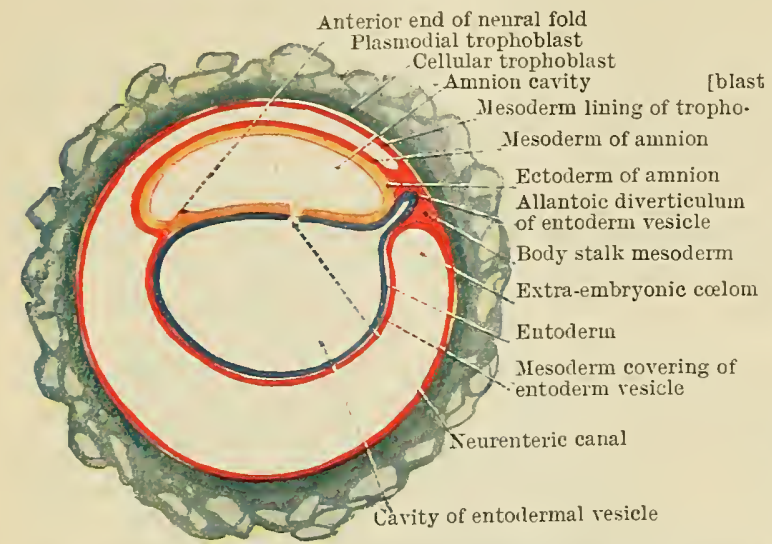

Fig. 70.-Schejia of Sagittal. Section of Zygote aloxg Line A.

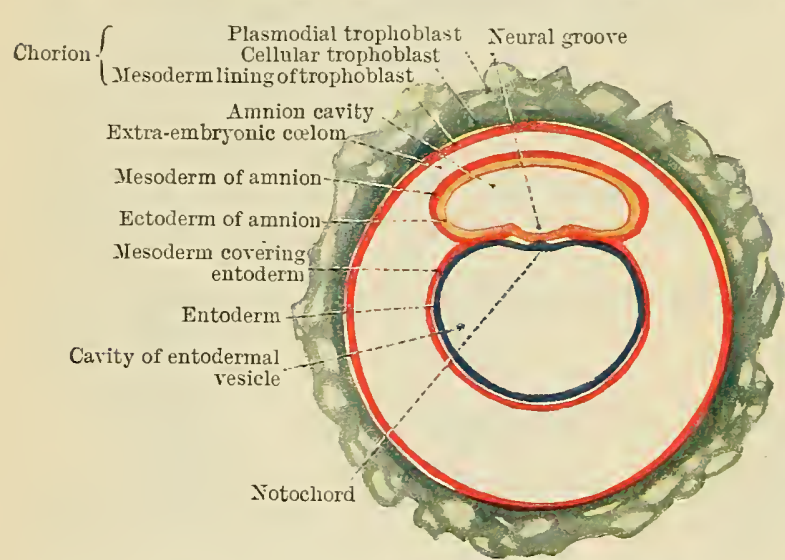

Fig. 71. - ScheMa of TraNsverse Section of Zigote AloNG LINE B (Fig. 31). secondary villi send out numerous branches into the blood spaces, and thus increase greatly in complexity (Figs. 75, 76, 77).

As development progresses still further a part of the chorion is converted into the fotal portion of an organ called the placenta, and thus the chorion is divided into placental and non-placental regions. Upon the placental part the villi continue to increase, but they disappear entirely from the nonplacental part, which is then called the chorion læve (Fig. 77).

The Amnion, the BodyStalk (Allantoic Stalk), and the Umbilical Cord. - The ammion is formed from that portion of the wall of the larger of the two inner vesicles of the zygote, the ecto-mesodermal vesicle (p. 22), which does not take part in the formation of the embryo. It consists of ectoderm cells covered externally by a layer of extra-embryonic mesoderm, and it is continuous with the margin of the embryonic area (Figs. $70,71)$.

The cavity of the ectomesodermal vesicle, enclosed between the amnion and the embryonic area, is the cavity of the amnion; it is filled with fluid, which raises the amnion in the form of a cupola over the embryonic region (Fig. 70).

The Body-Stalk (Allantoic Stalk). - It has been noted already that the mesoderm of the median part of the posterior portion of the amnion becomes thickened.
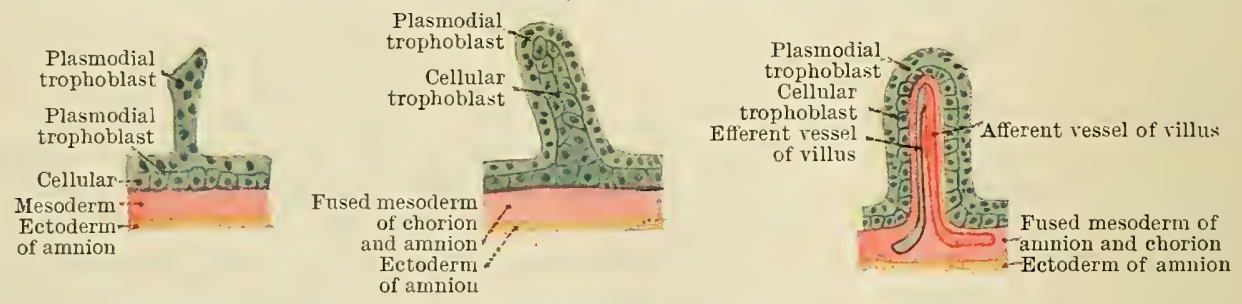

Fig, 72. -Schema of Three Stages ix the formatios of a Chorionic Tillus.

In the thickened strand lies the allantoic diverticulum of the entodermal vesicle (Fig. 70), whilst through it, on either side of the allantoic diverticulum, pass the umbilical arteries and veins, by means of which blood is conveyed between the embryo and the chorion.

This strand of the wall of the amnion vesicle, with its contents, was termed by His the body-stalk. Apparently it takes no direct part in the formation of the 
embryo, and as it contaius the rudimentary allantoic diverticulum and represents the much more highly developed allantois of other forms, it might, with advantage, be named the allantoic stalk. For the present purpose it is important to note that the blood-vessels which pass through the body-stalk enter or leave the body through the umbilical orifice, which is, at first, a relatively large aperture (Fig. 50).

As the embryonic area is folded into the form of the embryo the amnion increases in extent, filling more and more of the extra-embryonic coelom, and the embryo rises into the interior of its cavity. In other words, the walls of the amnion bulge ventrally round the cranial and caudal extremities and the lateral borders of the embryo (Figs. 75, 76, 77). As the distension of the amnion still continues, the rentral bulging round the margin of the umbilical orifice becomes more pronounced, the yolk-sac is forced farther and farther away from the embryo, the vitello-intestinal duct is elongated, and it is surrounded by a hollow tube. The cavity of the tube is an elongated part of the extra-embryonic colom, and its walls are formed by the amnion (Figs. 57,62,63).

The caudal wall of the tube necessarily consists of the elongated body-stalk (allantoic stalk).

As the distension of the amnion still continues, the walls of the tube are forced against the vitello-intestinal duct, and the amniotic mesoderm fuses with the mesoderm of the vitello-intestinal duct.

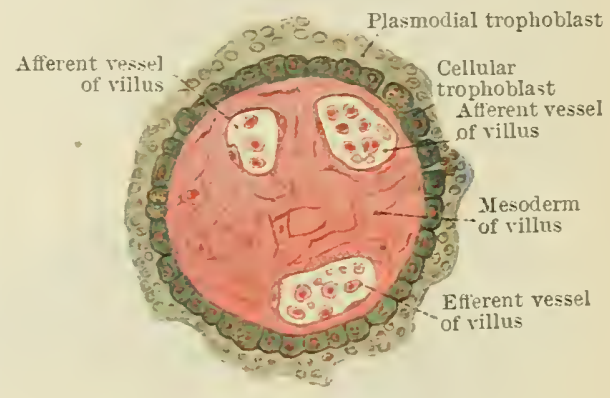

Fig. 73.-Schema of a Trasiserse Sectior of a Secoxdary Chorionic Villes. A loop of the afferent vessel has been cut at two points. When the fusion is completed, a solid cord, the umbilical cord, is formed (Figs. $77,78,80)$. It consists of an external covering of amniotic ectoderm, and a core of mesoderm in which lie the two umbilical arteries of the body-stalk, a single umbilical vein formed by the fusion of the two primitive reins, and the remains of the vitello-intestinal duct and the ritelline vessels. The proximal end of the umbilical cord is connected with the embryo; the distal end is attached to the chorion, and in its neighbourhood lies the now relatively small resicular folk-sac (Fig. 62).

As the amnion grows still larger, all that part of its outer surface which does not take part in the formation of the umbilical cord is ultimately pressed into contact with the inner surface of the chorion, with which it fuses, and the cavity of the extra-embryonic part of the cœlom is obliterated (Fig. 78).

The outer wall of the zygote now consists of the fused chorion and amnion, and it contains in its interior the amniotic carity and the embryo, which is attached to the chorion by the umbilical cord.

When it is first formed the umbilical cord is comparatively short, but as the amniotic carity increases the cord elongates, untii it attains a length of from 18 to 20 inches, a condition which allows the embryo to float freely in the fluid in the amniotic cavity, whilst its nutrition is provided for by the flow and return of blood, through the umbilical cord, to and from the placenta, where interchanges take place between the maternal and the fœital blood.

The Yolk-Sac or Umbilical Vesicle. - When the embryonic area is folded into the form of the embryo, the entodermal resicle is differentiated into three parts: (1) a part enclosed in the embryo, where it forms the primitive entodermal alimentary canal; (2) a part which lies external to the emhryo in the extraembryonic colom-this is the yolk-sac or umbilical vesicle; (3) the third portion is the vitello-intestinal duct, which connects the primitive alimentary canal and the yolk-sac together (Figs. 40, 62).

The walls and the carity of the yolk sac are, therefore, continuous with the walls of the primitive alimentary canal, and the structural features of the two are identical, each consisting of an internal layer of entodermal cells and an external layer of splanchnic mesoderm.

Free communication between the rolk-sac and the primitive alimentary canal 
appears to exist in the human subject till the embryo is three weeks old and about $2.5 \mathrm{~mm}$. long. During the fourth week the vitello-intestinal duct is elongated into a relatively long narrow tube, which is lodged in the umbilical cord, and the yolk-sac, which has become a relatively small vesicle, is placed between the outer surface of the amnion and the imner surface of the chorion, in the region of the placenta (Fig. 62). Duriug the latter part of the fourth or the early part of the fifth week, when the embryo has attained a length of about $5 \mathrm{~mm}$., the vitellointestinal duct separates from the intestine and commences to undergo atrophy, but remmants of it may be found in the umbilical cord up to the third month.

The yolk-sac itself persists until birth, when it is, relatively, a very minute object which lies either between the amnion and the placenta or between the amnion and the chorion læve.

At a very early period, before the paraxial mesoderm has commenced to divide into mesodermal somites, a number of arteries, the primitive vitelline arteries, are distributed to the yolk-sac from the primitive arterial trunks of the embryo, the primitive aortæ, and the blood is returned from the yolk-sac to the embryo by a pair of vitelline veins (Fig. 81).

After a time the arteries are reduced to a single pair, and after the two primitive dorsal aortæ have fused into a single trunk, the pair of vitelline arteries also becomes converted into a single trunk, which passes throurgh the umbilical orifice along the vitello-intestinal duct to the yolk-sac (Fig. 83).

The vitelline veins also pass through the umbilical orifice on their way to the heart of the embryo, and they become connected together, in the interior of the body of the embryo, by transverse anastomoses, which are described in the account of the development of the vascular system.

After the umbilical cord is formed, the extra-embryonic parts of the vitelline veins disappear, and can no longer be traced in the cord. The same fate overtakes the extra-embryonic and a portion of the intra-embryonic part of the vitelline artery, and the remainder of the artery persists as the superior mesenteric.

\section{THE PLACEN'TA.}

The placenta is an organ developed for the purpose of providing first the embryo and later the foetus with food and oxygen, and for removing the effete products produced by the metabolic processes which take place in the growing organism. It is formed partly from the zygote and partly from the mucous membrane of the uterus of the mother.

In the placenta the blood-vessels of the embryo of the earlier stages and the foetus of the later stages and the blood of the mother are brought into close relationship with one another, so that free interchanges may readily, take place between the two blood streams; and the modifications and transformations of the uterine mucous membrane and the chorion of the zygote, by which this intimate relationship is attained, constitute the phenomena of the development of the placenta.

The details of the development of the human zygote for the first ten or twelve days after the fertilisation of the ovum are not known, but the knowledge of what happens in other mammals justifies the belief that during that time the zygote is formed, in the uterine end of the uterine tube, by the union of a spermatozoon with the mature ovum. During the first ten to fourteen days after its formation it passes along the uterine tube, towards the uterus, whilst, at the same time, it undergoes the divisions which convert it into a morula.

The Formation of the Placenta.-Before the zygote reaches the uterus the mucous membrane which lines the cavity of that organ undergoes changes, in preparation for its reception and retention, and when the changes are completed the modified mucous membrane is known as the uterine decidua.

The changes which take place are, for the most part, hypertrophic in character; the vascularity of the mucous membrane is increased, mainly by the dilatation of its capillaries; the tubular glands of the membrane are elongated, they become 
tortuous, and dilatations form in their walls a short distance from their outer closed extremities. At the same time the interglandular tissue increases in amount, and as a result of the various processes the decidua is thicker, softer, more spong 5 , and more vascular than the mucous membrane from which it was evolred.

Partly on account of the dilatation of the deep part of the glands and partly on account of differences in texture of the internal as contrasted with the external part of the decidua, the membrane may be looked upon as consisting of three layers. (1) An internal layer, next the cavity, the stratum compactum. (2) An intermediate layer, the stratum spongiosum, formed largely by the dilated parts of the glands. (3) An external layer, the unchanged layer, in which lie the comparatively unaltered outer ends of the glands.

When the zygote, in the morula stage, reaches the uterus, from the tenth to the fourteenth day, it acts as a parasite, eats its way through the epithelium on the surface of the decidua, and implants itself in the stratum compactum.

The zygote may penetrate the decidua at any point of the wall of the uterine cavity, but it usually enters at some point of the dorsal or the ventral wall. The entrance generally takes place - between the mouths of adjacent glands, which are pushed aside, and the zygote becomes at once surrounded by the interglandular tissue of the stratum compactum of the decidua. The aperture through which it passes may be closed by a fibrinous plug or its margins may conrerge rapidly and fuse together.

The portion of the decidua in which the zygote is embedded is thicker than the other parts of the membrane, and it is separated by the zygote into an internal part, the decidua capsularis, and an external part, the decidua basalis. The junction of the decidua

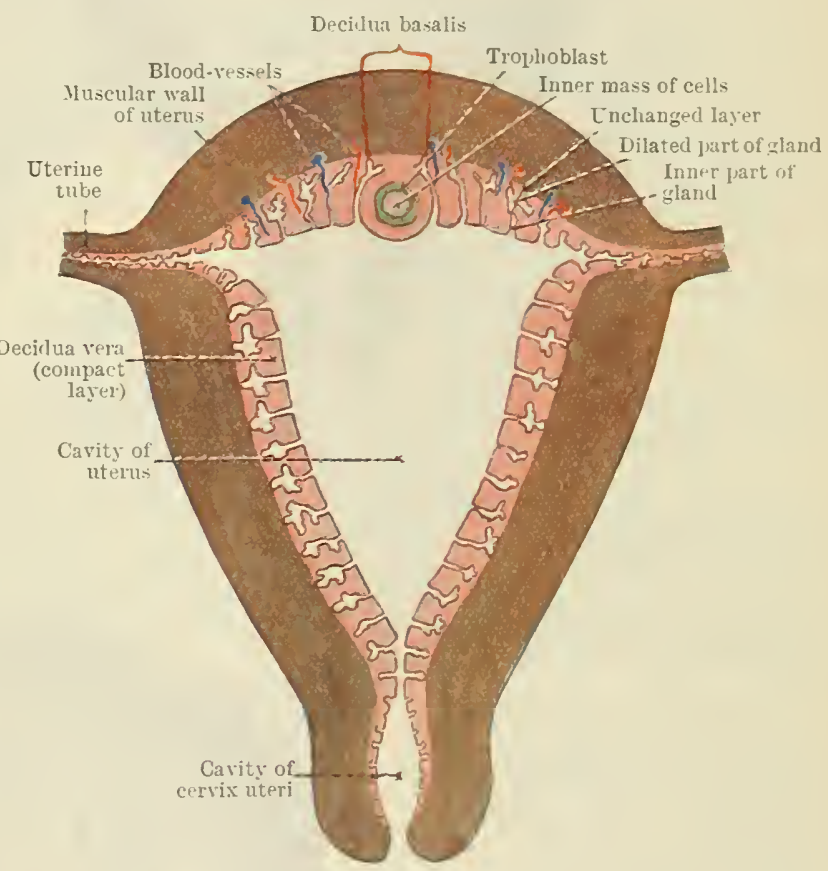

Fig. 74.-Scheara of a Froxtal Sectins uf the Utterds. showing the various parts of the decidua and a zygote emberled in the decidua. capsularis with the decidua basalis is the decidua marginalis, and the remainder of the decidua, by far the larger portion, is the decidua vera.

As soon as the zygote becomes embedded in the decidua its trophohlast unclerAs soon as the zygote becomes embedid proliferation. The superficial part of the growing tropholiast hecomes
goes rapid
converted into a mass of mucleated protoplasm, the plasmodial or syncytial layer, but the inner part remains more or less distinctly cellular.

The plasmodial portion of the trophoblast invades and destroys the surromding maternal tissue, and at the same time spaces appear in it. sulstance. As the plasmodium destroys the walls of the dilated maternal blood-ressels, channels are made through which the maternal hlood flows into the slaces in the plasmodium, and thus matermal blood begins to circulate in the tissue of the zygote.

In the meantime the extra-embryonic crelom has appeitred in the primary mesoderm of the zygote, and the outer layer of the mesockrm has associated itseif with the trophoblast to form the chorion.

The spaces in the plasmodim enlitrge rapidly after the waternil blood 
begins to circulate within them and the plasmodium becomes divided into

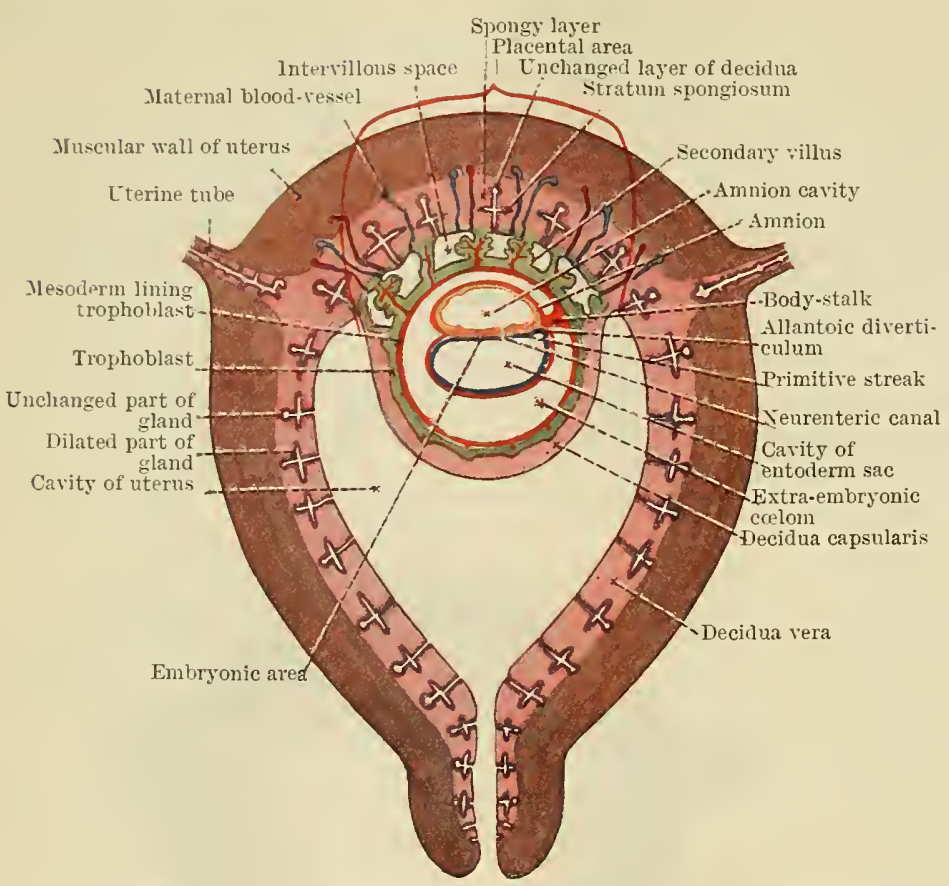

Fig. 75... Schema of a Section of a Pregrant Uterts after the formation of the INTERVILlots SPACES. three series of parts. (1) The parts which lie between adjacent blood spaces, the primary chorionic villi. (2) The parts which lie in contactwith the mesoderm of the chorion, and which form with the mesoderm the chorion plate. (3) The parts which cover the maternal tissues and form the outer bounclaries of the blood spaces, the basal layer. The blood spaces themselves are called the intervillous spaces (Figs. 76, 79).

After a time each primary villus differentiates into a cellular core and plasmodial periphery, and thereafter the villi are invaded by the mesoderm of the chorion and are thus converted into secondary villi (Fig. 76).

The first-formed villi are non-vascular, but by the time the secondary villi have developed the umbilical arteries have grown through the body-stalk (allantoic stalk) into the mesoderm of the chorion, and branches from them enter the mesodermal cores of the villi, which thus become vascular.

When the secondary villi are fully developed each consists of a vascular mesodermal core continuous with the mesoderm of the chorion. The mesodermal core iscovered

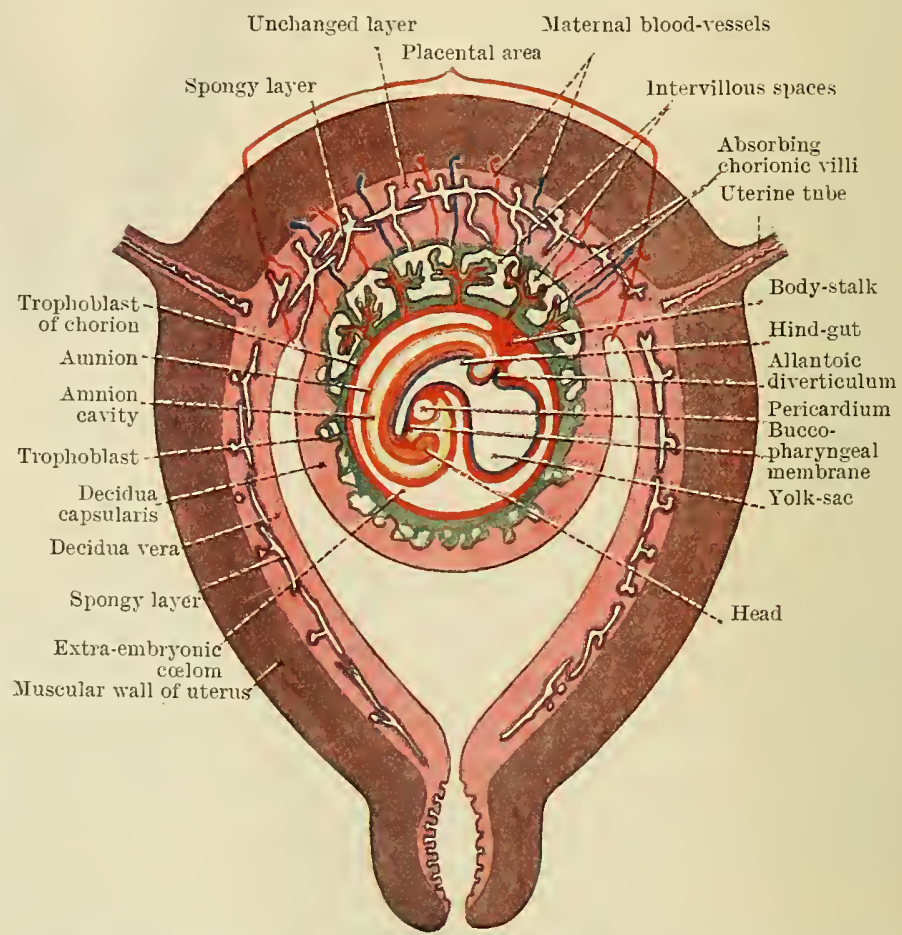

Fig. 76. - Schema of a Frontal Section of a Pregnist Uterus at the PERIOD OF the Formation OF THE EMrRyo. Tote extension of amnion as contrasted with stage shown in Fig. 75 . 
by a layer of cellular trophoblast, Langhan's layer, which lies next the mesoderm, and a layer of plasmodium external to the cellular layer. The proximal end of each villus is continuous with the chorion plate of the intervillous spaces, formed by the chorion, and the distal extremity is connected by the plasmodial basal layer of the trophoblast, which forms the outer boundary of the intervillous spaces and which is fused with the maternal decidual tissue.

After a time branches are projected from the sides of the seeondary villi into the intervillous spaces. In this way tro sets of secondary rilli are differentiated, (1) the anchoring villi (Fig. 79), which cross from the chorion to the

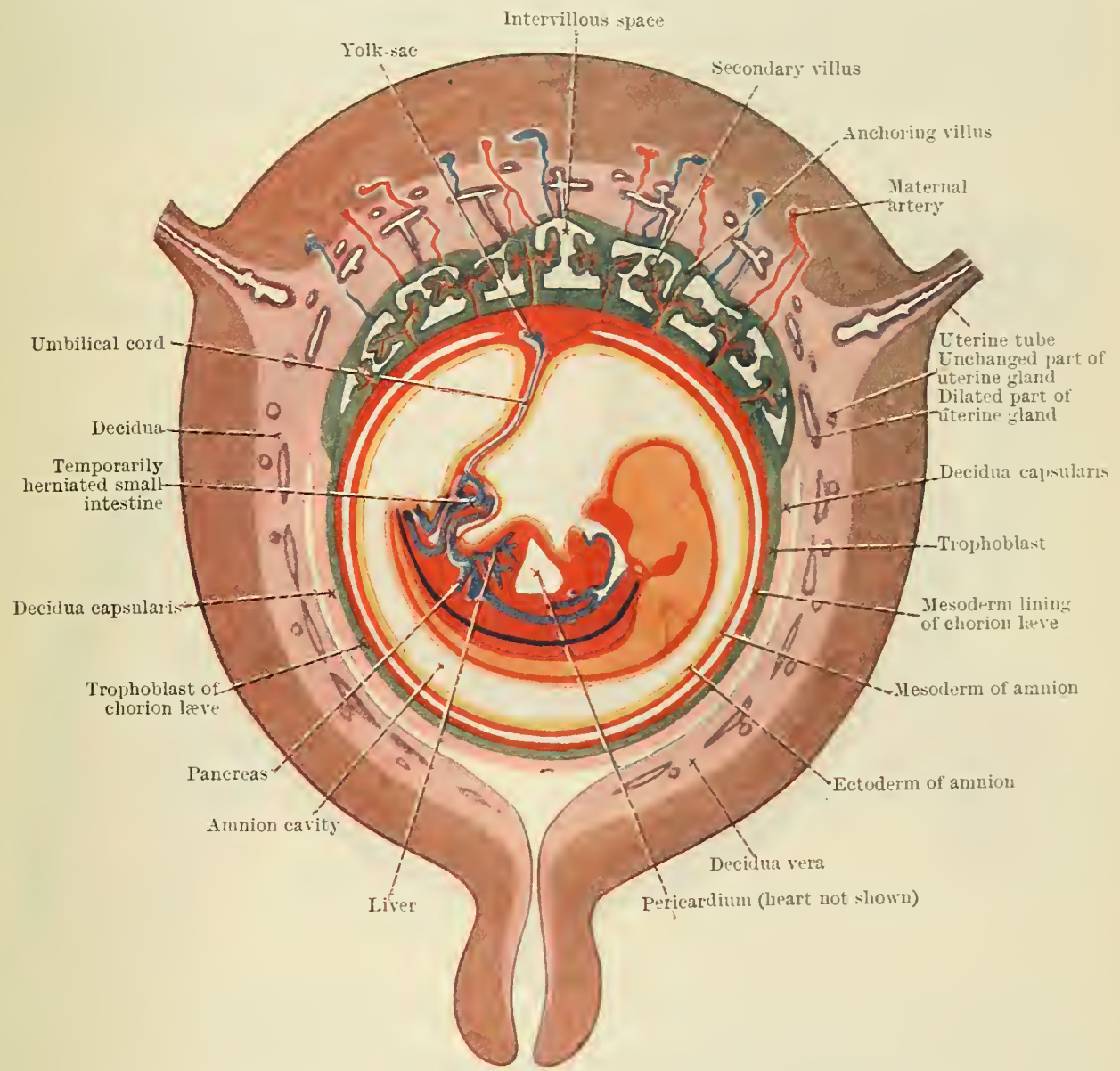

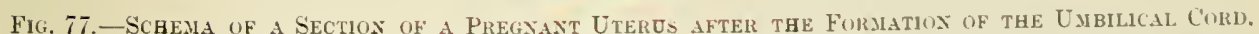
Note that the expanding amnion has almost obliterated the extra-embryonic colom which lies between it and the chorion.

basal layer of trophoblast and are attached to the latter ly cell columms, which are the remains of the primary villi which have not been penetrated by the foctal mesoderm, and (2) free or absorbing villi (Fig. 76), which extend fiom the sides of the original secondary villi into the blood, in the intervillous spaces.

Whilst the trophoblastic invasion of the compact layer of the decidui is proceeding, not only are the interglandular elements of the decidua destroyed, but the walls of the glands also, and, as a consequence, some of the glands in the decidua basaiis open for a time into the interrillous spaces, and become filled with blood which passes from the spaces into the gland cavities. In many cases, however, before the glands are destroyed their walls are converted into solid strands of cells, and thus the cavities of their more caternal undestroyed portions are converted into elosed spaces.

In the early stages the trophoblast is differentiated in a similar manner over 
the whole of the surface of the zygote, and thus, for a time, the whole of the surface of the chorion is covered with villi. As the embryo grows, and the amnion and the extra-embryonic coelom are distended, the zygote increases in size, and the capsular portion of the decidua is stretched till its vascular supply is interfered with and the villi associated with it undergo atrophy and disappear. When these degenerative changes have occurred, the portion of the chorion in association with the thinned decidua capsularis presents a relatively smooth surface, and is known as the chorion læve. Whilst the decidua capsularis is being stretched and thinned, and the associated portion of the chorion is being reduced to the condition of a non-villous region, the decidua basalis increases in thickness; at the same time the villi associated with it increase in size and in the complexity of their branches. The portion of the chorion from which these large villi spring is termed the chorion frondosum. It is this portion of the chorion which takes

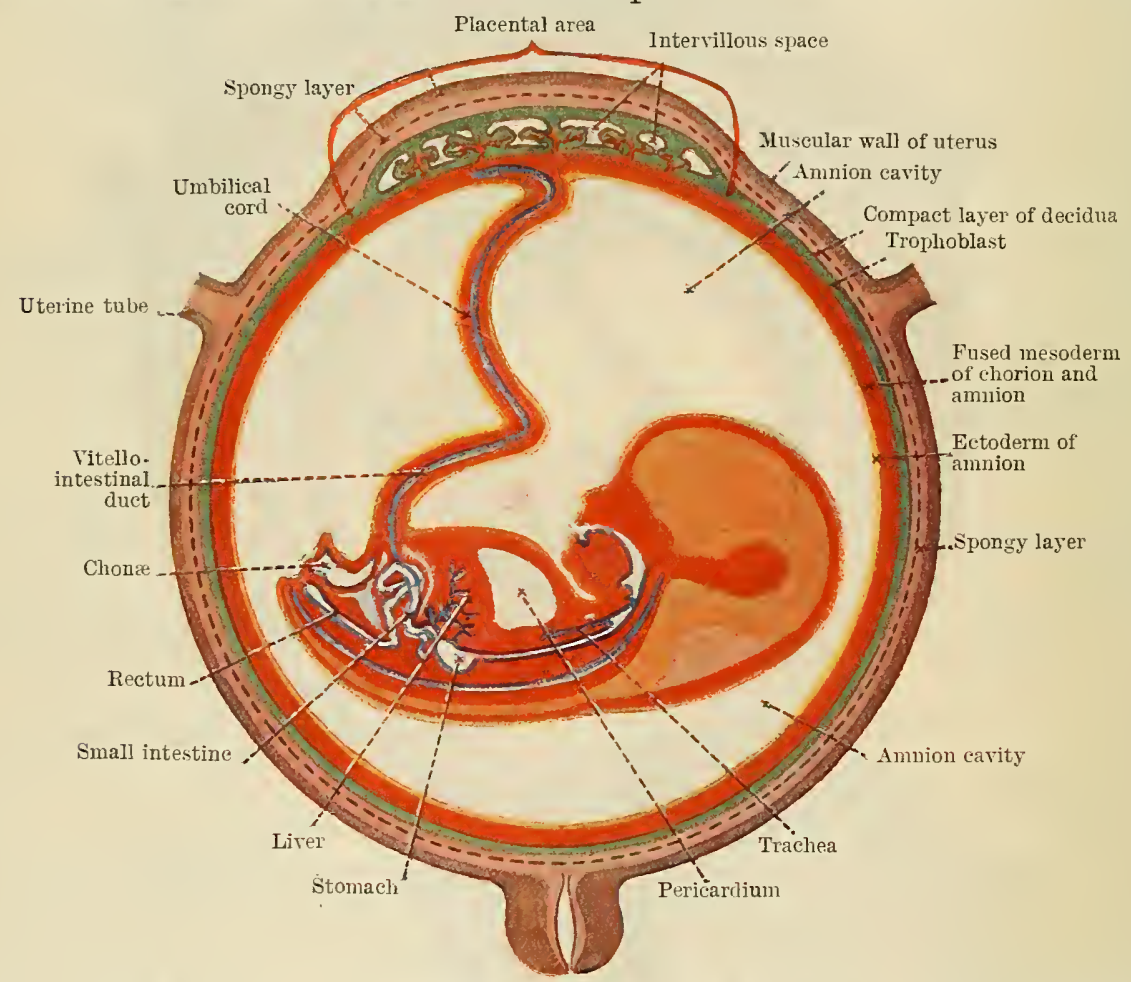

Fig. 78. - Schema of a Section of a Pregiant Uterds after Fusion of Amion and Chorion.

part in the formation of the so-called fotal portion of the placenta, the maternal part of that organ being formed by the decidua basilis.

The placenta, therefore, is formed partly by the zygote and partly by maternal tissues, but the interchanges between the foetal and the maternal blood take place in the tissue of the zygote through the trophoblast which covers the surfaces of the villi.

As the growth of the embryo and the distension of the ammion continue, the outer surface of the amnion is gradually forced against the inner surface of the chorion, with which it fuses. When this fusion is completed the extraembryonic celom is obliterated and the zygote contains only one extra-embryonic cavity, the amniotic cavity, in which the foetus floats in the amnion fluid (Fig. 78).

At this period the amnion cavity is bounded by a wall formed by the fused amnion chorion and decidua. In the meantime the chorion has differentiated into the chorion læve, fused with the decidua capsularis, and the chorion frondosum, fused with the decidua basilis. As the distension of the amnion proceeds to a still greater extent, the part of the wall of the cavity formed by the fused amnion chorion læve and the decidua capsularis projects more and more into the cavity 
of the uterus, until it is forced against the surrounding wall of the uterine cavity, where it fuses with the decidua vera, and thus the cavity of the uterus is obliterated. This fusion takes place towards the end of the second month, and as soon as it has occurred the discoid mass of placental tissue is continuous at its margin with the fused amnion, chorion, and decidua vera (Fig. 78).

After the second month the foetus lies in the amnion carity, which is bounded by the fused chorion and uterine wall, except at the lower end of the uterus, where, over the orificium internum, the cavity of the body of the uterus communicates with the cavity of the neck of the uterus; there the amniotic cavity is bounded by a membrane formed by the fused amnion chorion lreve and the decidua cajsularis only.

And at the end of pregnancy this portion of the rnembrane is ruptured by the increased pressure of the amnion fluid produced by the contraction of the muscular wall of the uterus (Fig. 88).

Unchanged part of uterine gland
Iuscular wall of uterus

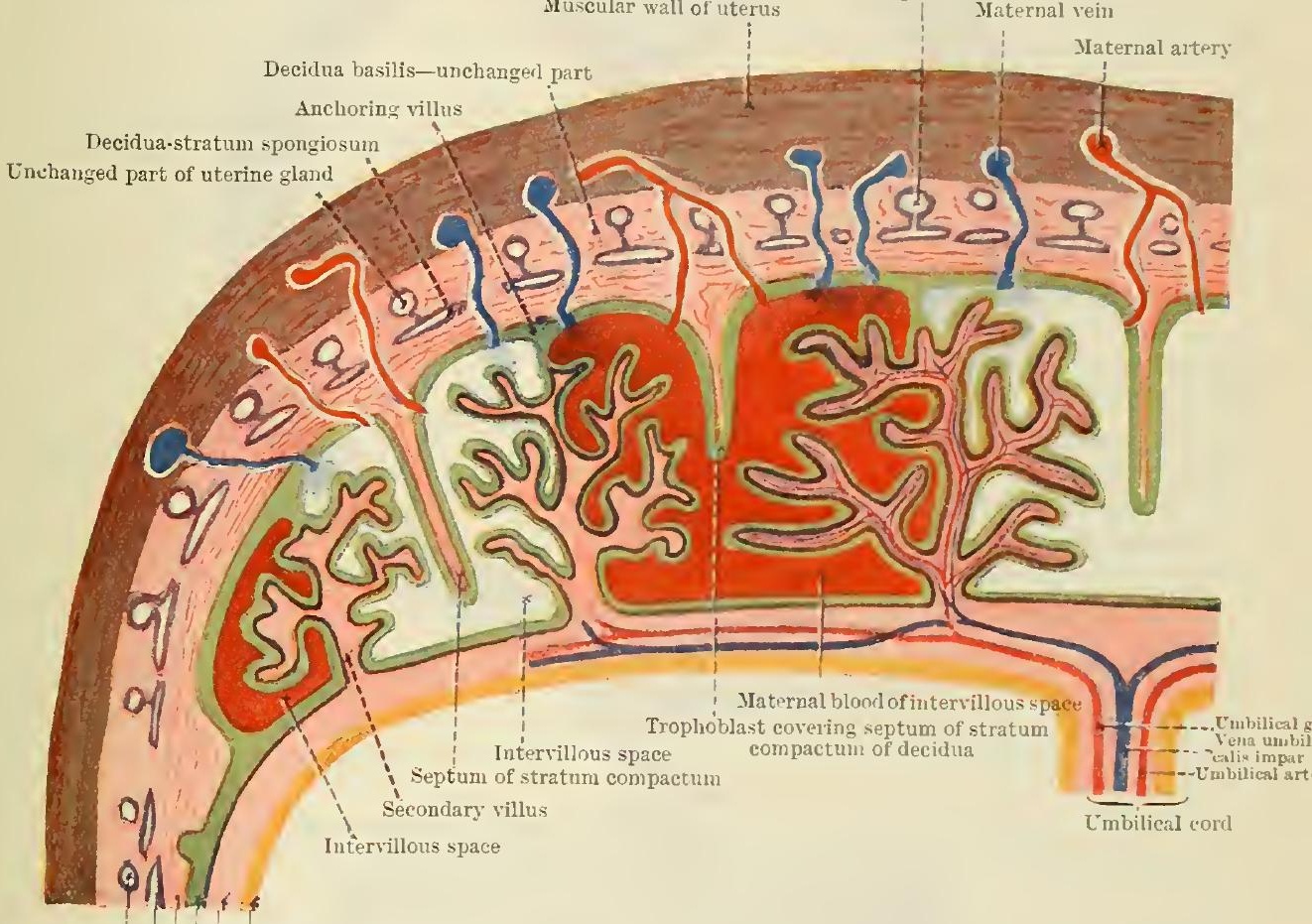

Unchanged layer | Ectoderm of amnion

Spongy layer Fused mesoderm of amnion and chorion

Compact layer Trophoblast of clioriou

Fig. 79.-Schesh of Structere of Cumpleted Placexta.

Completion of the Placenta.-It has already been stated that each sccondary villus consists of a vascular mesodermal core corered by a cellular and a plasmodial layer of trophoblast, the latter lying next the maternal hlood in the intervillous spaces. As development proceeds and the intervillous spaces become larger, the villi become longer and more complicated, and at the same time the cellular layer of the trophoblast largely disappears, nutil in the majority of the villi the plasmodial layer alone covers the rascular mesolermal core.

In still later stages, degenerative changes occur not only in the villi, but also in the chorionic plate of the intervillous spaces and in the basal trophoblast which closes the spaces externally. One of the results of the degenerative processes is the deposit of fitrinoid material in the place originally occupied by the trophoblast; the object of this process is still unlinown: another is the adhesion of the fibrinous layers on the surfaces of adjacent rilli, and the fusion of the villi thus connected into masses of intermingled fibrinuus and rascular tissue.

When the chorionic part of the placenta is completed it consists of (1) the 
chorion plate closing the intervillous spaces internally; (2) the villi; (3) the intervillous spaces; and ( 4 ) the basal layer of the trophoblast, which closes the intervillous spaces externally, and is perforated by the maternal ressels passing to and from the spaces.

The maternal portion of the completed placenta consists from within outwards of (1) the basal layer of the decidua; (2) the remains of the spongy layer of the decidua: and (3) the unchanged layer.

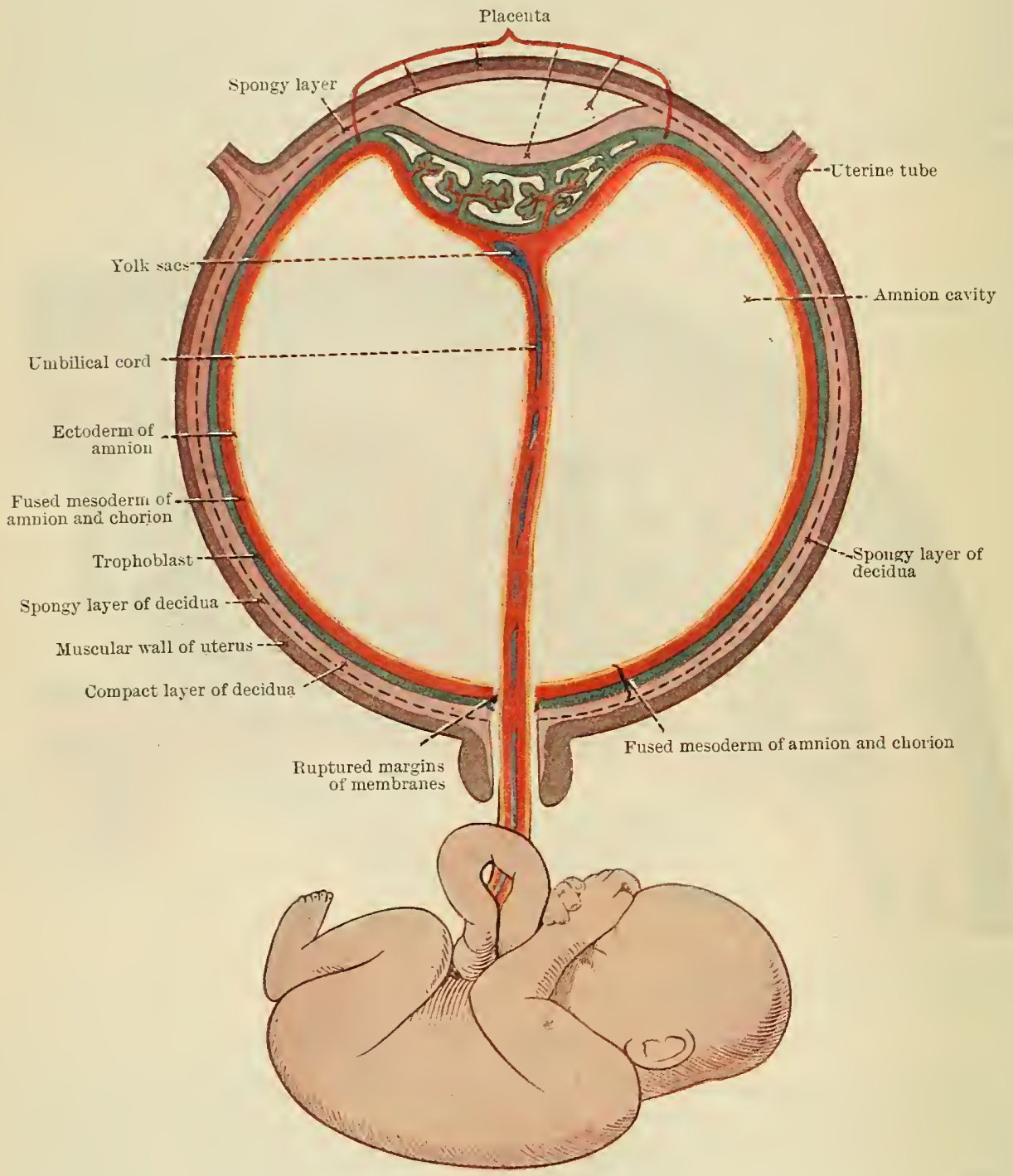

Fig. S0. - Schema OF Pregnayt Utercs immediately after Birth of the Child, showing commencing separation of the placenta. Part of the umbilical cord is shown in section and part in surface view. The blue streaks in the former part indicate the position occupied by the vitello-intestinal duct in earlier stages.

The basal layer of the decidua is the remains of the compact part of the decidua basalis of earlier stages. It is fused internally with the basal plate of the trophoblast, and is continuous externally with the spongy layer. The spongy layer consists of a series of cleft-like spaces. These spaces are the compressed remains of the earlier dilated portions of the glands of the stratum spongiosum from which the epithelial lining has, to a great extent, disappeared. The spongy layer is continuous externally with the unchanged layer, in which lie the unaltered outer parts of the glands and the intervening interglandular tissue. 
The maternal blood-ressels pass from the muscular wall of the uterus into the sulmucous tissue, and thence into the placenta, where they traverse the maternal portion and the basal plate of the decidua and open into the intervillons spaces. The arteries usually open on or near the septa and the reins in the intermediate areas.

In addition, however; to the constituent parts alrealy lescribed, the chorionic part of the placenta contains some strands of maternal tissue, and in the maternal part there are portions of trophoblast.

The parts of the decidua found in the chorionic part of the placenta are a series of fibrous strands, the remains of parts of the stratum compactum which were not destroyed by the trophoblastic invasion. They are continuous extemally with fibrous strands of the maternal part of the placenta, and serve to separate the placenta into a series of lobes, from 15 to 20 in number.

The portions of trophoblast met with in the maternal part of the placenta are variable pieces of plasmodium which appear to have wanclered from the general mass. They may be found in any of the strata of the maternal part, and eren in the submucous tissue.

At the end of preguancy, when intra-nterine life terminates, the fused ammion chorion and clecidua capsularis are ruptured in the region of the internal orifice of the uterus, and the amniotic fluid is expelled through the vagina. Next the foetus is extruded, and as soon as it is born it becomes a child. After the child is horn it remains attached to the placenta by the umbilical corl (Fig. 80 , which is usually ligatured in tro places and then clivided, between the ligatures, lig a medical man or an attendant. Afterwards the placenta is expelled fiom the uterus.

Detachment of the placenta is probably caused by contraction of the muscular substance of the uterus, and it takes place by rupture of the strands of the spongy layer of the decidua (Fig. S0). As the detached placenta is expelled the decidua vera is torn through along the line of the spongy layer, and the fused ammion and chorion læve and the inner part of the deciclua rera, which are attiched to the margin of the placenta and which constitute the membranes, are expelled with it.

At birth the placenta weighs about $500 \mathrm{grm}$., it has a diameter of about 16 to $20 \mathrm{~cm}$., and is about $3 \mathrm{~cm}$. thick. Its inner surface is covered with the amnion which fused with the chorion towards the end of the seconcl month of pregnancr. Its outer surface is rough, it is formed by the remains of the spongy layer of the decidua, and is divided into a number of areas by a series of fissures which correspond in position with the septa by which the organ is dirided into lolues.

\section{THE PRIMITIVE VASCULAR STSTEM AND THE} FETAL CIRCULATION.

As the zygote uravels along the uterine tube, from the ovarian towards the uterine end, it exists either upon the yolk granules derired from the orusn or upon substances absorbed from the fluids by which it is surrounded. After it enters the uterus it must depend, for a time, upon the same sources of nutriment, but as it penetrates the decidua it is probable that the cells of the trophoblast actually devour the cells of the decidua which they invade. This source of food is only sufficient for a short period, whilst the zygote remains relatively small, and substances absorbed by its surface cells can be transmitted easily to all parts.

Whilst the period exists, howerer, not only are the decidual tisines utilised as a food-supply, but fluids are absorbed from them and transmitted into the interior. of the zygote to fill the expanding cavities of the amnion and the coelous.

In all probability the fluids passed into the zygote contain nutritive materials which suftice for the requirements of the embryonic and non-enthryonic parts of the zygote so long as both consist of comparatively thin layers of cells, hut when the embryonic area increases in thickness, and hegins to he monlded into the embryo, its association with adjacent Huids lrecomes less intinate, and as the development of its various parts progresses, a supply of food and oxygen is required which is greater than can be provided by osmosis from the adjacent thid media. Thus an imperative necessity arises for a method of food-suply adequate to meet the increasing requirements upon which the continued derelopment and gruwth depend. 
To meet this necessity the blood vascular system is formed. The system is essentially an irrigation system. In its earliest stages it consists of a series of ressels, the blood-ressels, all of which contain a corpuscle-laden fluid, called blood. The blood is kept circulating, in the early stages, by the rhythmical contraction of the walls of the ressels, but, after a short time, parts of the ressels are dereloped into a muscular organ called the heart. After the heart is established the continuance of the circulation of the blood depends upon the regular contractions of the muscular substance of its walls.

The corpuscular portions of the blood and the walls of the blood-vessels are formed from the cells of the zygote, but it is obvious, in the early stages at all events, that the fluid portion of the blood must be obtained from the mother. It is necessary, therefore, both for this purpose and for the facilitation of interchanges hetween the fœtal and maternal blood streams, that the fœtal blood-ressels should be brought into close association with the maternal blood at an early period. It is for this purpose, among others, that large spaces appear in the trophoblast, become filled with blood from maternal vessels which have been opened up by the destructive action of the trophoblast cells, and are afterwards invaded by the chorionis villi, which carry in their interiors branches of the blood-vessels of the embryo. As soon as the intimate relationship between the chorionic villi and the maternal blood is established fluids can readily pass from the maternal to the fotal vessels, and there can be no doubt that both food and oxycen pass from the maternal to the foetal blood through and by the agency of the trophoblastic epithelium, whilst, at the same time, waste products of fotal metabolism pass from the fœetal to the maternal blood.

The germs of the vascular system are a series of cells arranged in strands which constitute, collectively, the angioblast. They appear between the entodermal and the mesodermal layers of the wall of the yolk-sac, and, therefore, entirely outside the embryo; but it is not certain whether they are derived from the mesoderm or from the entoderm.

Origin of Blood Corpuscles.-After a time the angioblast separates into two parts, (1) the peripheral cells of the strands which form the endothelial walls of the primitive blood-vessels, and (2) the central cells which become the primitive blood corpuscles or mesamœboids (Minot).

The mesamœeboids are colourless cells with large nuclei and a relatively small amount of protoplasm; from them are formed, either by transformation or division, the erythrocytes, which are coloured blood corpuscles, and also nucleated colourless corpuscles. The erythrocytes are nucleated cells with a homogeneous protoplasm which contains the substance, called hæmoglobin, upon which the yellowish-red colour of the cells depends, and from them are derived the fully developed red corpuscles.

The primitive erythrocytes, the ichthyoid cells of Minot, are transitory structures in mammals, but they are the permanent red blood cells of the ichthyopsida (fishes and amphibia). They are succeeded by the sauroid blood cells (Minot), which represent the permanent corpuscles of reptiles and birds, and which are distinguishable from the ichthyoid cells by their smaller size and more deeply-staining nuclei.

The sauroid blood cells are replaced by the blood plastids, which are young nonnucleated red corpuscles. According to some observers the blood plastids are sauroid cells which have lost their nuclei, whilst other investigators believe the blood plastids to be the nuclei of sauroid cells. Whatever their origin, they become converted into permanent red blood corpuscles by transformation from the spherical to a cup-shaped and later to a biconcave form.

The young red blood cells are therefore the ichthyoid cells, those progressively older are sauroid cells, blood plastids, and blood corpuscles.

The colourless, nucleated corpuscles-white blood corpuscles-are much less numerous than the coloured corpuscles in the adult blood. They appear to be derived from the mesamcboids, though it is possible that they are also formed by ordinary mesoderm cells, and as regards those formed from mesamoeboids it is not certain whether a mesamœboid cell can by division produce both erythrocytes and white corpuscles, or whether it must produce one or the other. 
The primitive mesamoboids are formed in the wall of the yolk-sac, and there some of them produce erythrocytes; manj, however, migrate into the embryo, where some of them take part in the formation of the walls of the embryonic blood-vessels, and others become enclosed in the liver, the lymph glands, and the bone marrow, where they become foci for the formation of blood corpuscles.

During the first two months the primitive forms of red blood cells predominate. In the second month the sauroid cells increase considerably in number, and from the third month the blood plastids become more and more numerous, until, at the eighth month (Minot), the majority of the blood cells are blood plastids undergoing conversion into blood corpuscles. At this time the colourless cells are present in a very distinct minority.

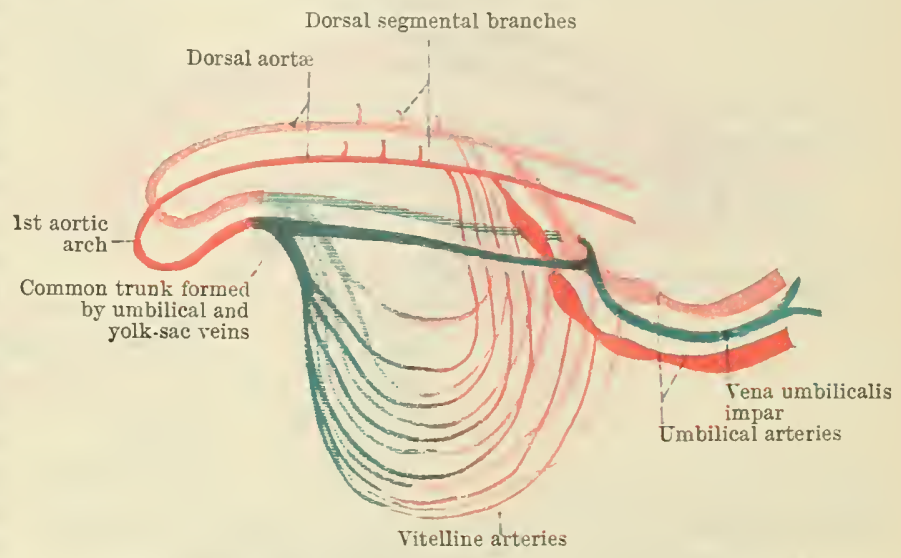

Fig. 81.-Schema of Circulation of ax Embrto, 1.35 My. lowg, mith Six Somites. (After Felix, modified.)

Formation of the Primitive Blood Vascular System of the Embryo.-The earliest stage of the formation of the heart and blood-vessels in the human subject are not known, but, judging by what occurs in other mammals, it is probable that the firstformed vessels appear in the splanchnic mesoderm of the pericardial region before the embryonic area begins to fold. It is presumed that they are formed by angioblastic cells which have migrated into the embryonic area from the walls of the yolk-sac. From their seat of origin they extend towards the caudal end of the embryonic area, one on either side of the notochord, and from the caudal end of the embryonic region they pass along the body-stalk into the chorion.

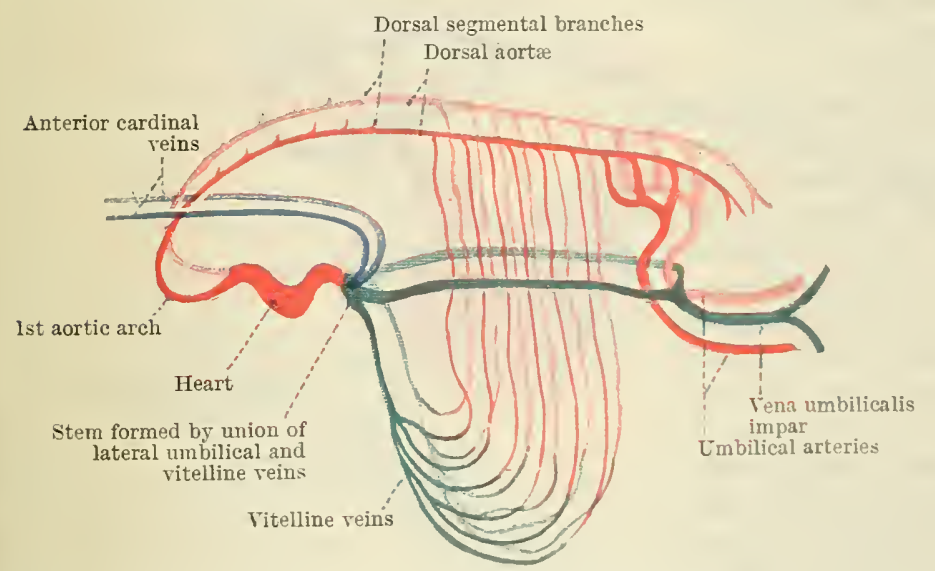

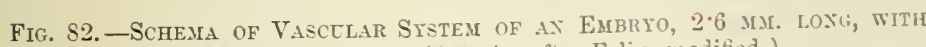
Focrtees Somtes. (Arteries after Felix, modified.)

As the cephalic end of the embryonic area is folded to enclose the fore-gut, the corresponding parts of the primitive arteries are bent into a $\subset$-shaped form. The ventral limb of the $\subset$, which lies in the dorsal wall of the pericardium and the rentral wall of the fore-gut, is the primicive ventral aorta. The bend of the $\subset$ is the first aortic arch, which passes along the lateral margin of the bucco-pharyngeal membrane. The dorsal limb of the $\subset$ is the cranial part of the primitive dorsal aorta. The primitive dorsal aorta passes posteriorly into the tail and gives off in the region of the tail fold the primitive umbilical artery, which runs along the body-stalk to the chorion.

The caudal parts of the primitive ventral aortie are the rudiments of the heart. At first they lie, quite separate from each other, in the dorsal wall of the pericardium. but soon they approach one another and fuse together to form a single tubular 
heart. The more cranially situated parts of the primitive ventral aortæ remain separate and take part in the formation of ventral roots of the aortic arches. Before the single heart is formed other blood-vessels have appeared, which return blood from the chorion and the yolk-sac to the heart. These vessels are the primitive veins. Two veins pass from the chorion into the body-stalk, where

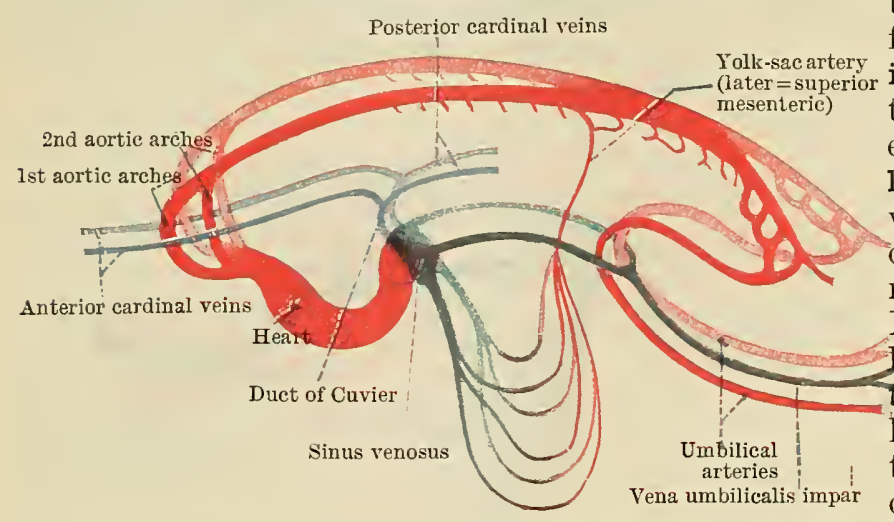
they fuse together to form the vena umbilicalis impar. This divides, at the caudal end of the embryo, into the two lateral umbilical veins, which run to the heart one along each lateral margin of the embryo. In an embryo $1.3 \mathrm{~mm}$. Jong (Eternod), in which the paraxial mesoderm had not yet commenced to segment into mesodermal somites, each lateral umbilical vein received, as it entered

the embryo, a large

Fig. 83.-Schema of Vascular System of aN EMbryo With tWentrTHREE SOMITES. (Arteries after Felix, modified.)

efferent vein from the yolk-sac. This condition, if regular, is very transitory. After a very short time the comnexion of the vitelline veins with the caudal ends of the lateral umbilical veins is lost, and the blood is returned from the yolk-sac directly to the heart by two vitelline veins, one on each side, which run along the sides of the vitello-intestinal duct and receive the lateral umbilical veins close to the heart (Fig. 81).

In the meantime a number of branches have been developed from both the dorsal and the ventral walls of the primitive dorsal aortæ; the former are the somatic pre-segmental and segmental arteries, and the latter are the primitive vitelline arteries.

In a human embryo which has developed six distinct mesodermal somites the vitelline arteries form a plexus on the sides of the hind-gut area of the wall of the entodermal vesicle, from which the umbilical arteries appear to spring (Felix). The plexus is represented in Fig. 81 by the bulbous dilatations. The vessels which enter this plexus arise from the ventral aspects of the primitive dorsal aortæ, some distance from their caudal ends. It is probable, however, that the caudal ends of the primitive dorsal aortæ are comnected with the caudal part of the plexus at the points of origin of the umbilical arteries, though

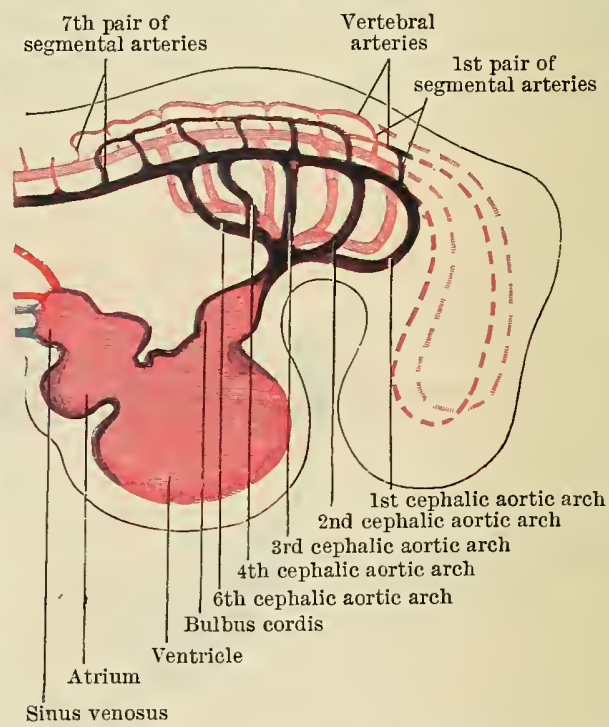

Fig. 84.-Diagram showing stage of five aortic arches. the connexions are not visible in the sections of the embryo mentioned (Fig. 81).

Practically the same condition is present in an embryo $1.6 \mathrm{~mm}$. long possessing fourteen distinct somites, except that the main rootlets of the umbilical artery, on each side, are situated farther caudalwards than in the younger embryo, and lie in the region of the most caudal somites (Fig. 82).

Further Development of the Arterial System.-When the embryo possesses twenty-three mesodermal somites, but is still devoid of limbs, the arterial system has 
advanced considerably in development. Two aortic arches, on each side, now connect the cephalic end of the heart with the primitive dorsal aorta. The umbilical artery and vitelline arteries are quite separate, and each umbilical artery springs, by a number of roots which anastomose together, from the caudal part of the corresponding dorsal aorta. The vitelline arteries are still numerous, but that which rises opposite the twelfth mesodermal somite is becoming the main artery of the yolk-sac; eventually its proximal part is transformed into the superior mesenteric artery of the foetus.

When the embryo has attained a length of $5 \mathrm{~mm}$., and is about five weeks old, it possesses about thirty-eight mesodermal somites, and five aortic arches are present on each side. Commencing from the cranial end, they are the first, second, third, fourth, and sixth; the fifth arch appears subsequently between the

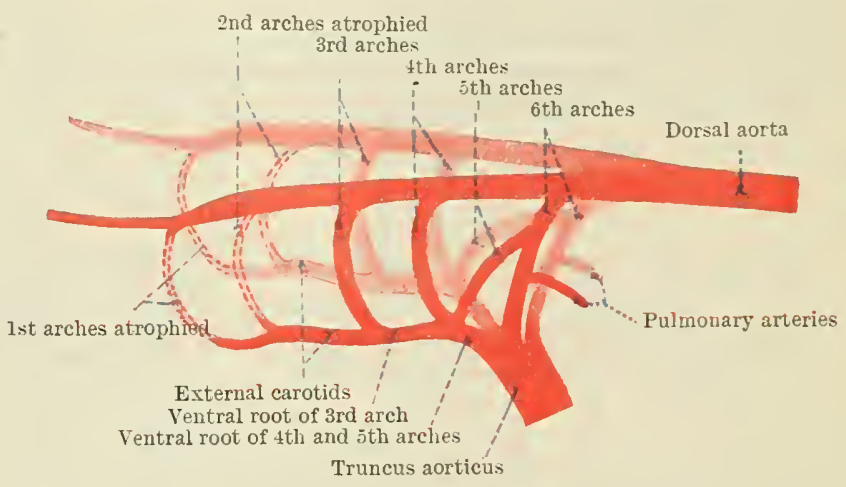

Fig. 85. - Schema of Aortic Arches of Ax Embryo, 9 Mir. Loxg. (After Tandeln, modified.) The second and third arches have atrophied and the transitory fifth has appeared.

fourth and the sixth. Ail five arches pass to the corresponding dorsal aorta, but the three most caudal, on each side, spring from the cranial end of the heart, which is now called the aortic trunk, whilst the two most cranial rise from a common stem which constitutes their ventral roots, and which springs, also, from the aortic trunk (Fig. 84). A little later the aortic trunk gives off only two branches on each side, (1) a stem common to the first five arches, for the fifth has now appeared, and (2) the sixth arch (Fig. 85). The fifth arch is very transitory. Whilst it is present

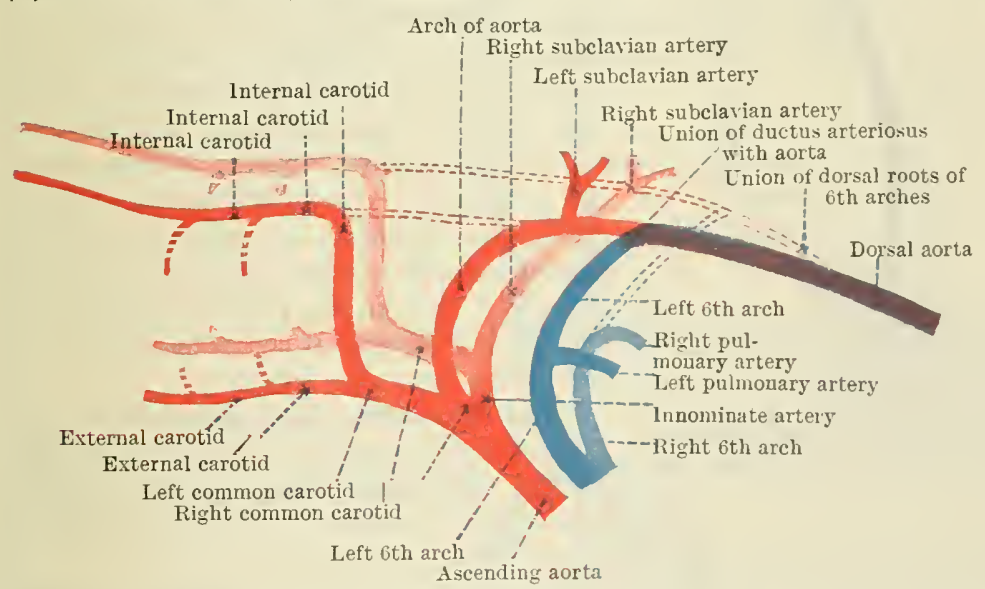

Fig. 86. - Schema of parti of the Artertal System of a Fetus seex from the Left SIDE. Parts of the first and secoud arches, the dorsal roots of the third arches, the dorsal part of the right sixth arch, and the dorsal roots of the right fourth and fiftl arches have atrophied. The position of the fifth arch is not indicated; see Fig. 84. it runs from the common rentralstem, caudal to the fourth arch, to the dorsal part of the sixth arch. It soon disappears, and no traces of it are left in the adult (Fig. S5).

The portion of the common rentral stem which lies caudal to each of the arches is called, the ventral root of the arch, and the parts of the primitive dorsal aortie which lie canclal to the dorsal ends of the arches are called their dorsal roots.

The first two arches, on each side, disappear, and their ventral roots become the external carotid arteries of the actult. The ventral root of the thirc arch becomes the common carotid, whilst the third areli and the dorsal roots of the first and second arches are transformed into the internal carotid. The rentral root of the fourth arch on the right side becomes the innominate artery, and the right fourth arch forms the proximal part of the right subclavian artery. The remainder of the 
right subclavian is developed from the seventh right somatic segmental artery. The ventral root of the left fourth arch and the arch itself form the arch of the aorta. The fifth arch, as already stated, is quite transitory; it leaves no remains, therefore it is not necessary to speak of any part of the ventral stem as its ventral root. The ventral part of the sixth arch on the right side becomes the extra-pulmonary part of the corresponding pulmonary artery. On the left side it disappears. On the right side the dorsal part disappears, but on the left side it persists, till birth, as the ductus arteriosus, which connects the pulmonary artery with the aorta, and after birth it is converted into the ligamentum arteriosum. The truncus arteriosus is cleft into two parts by a spiral septum; one part, which remains continuous with

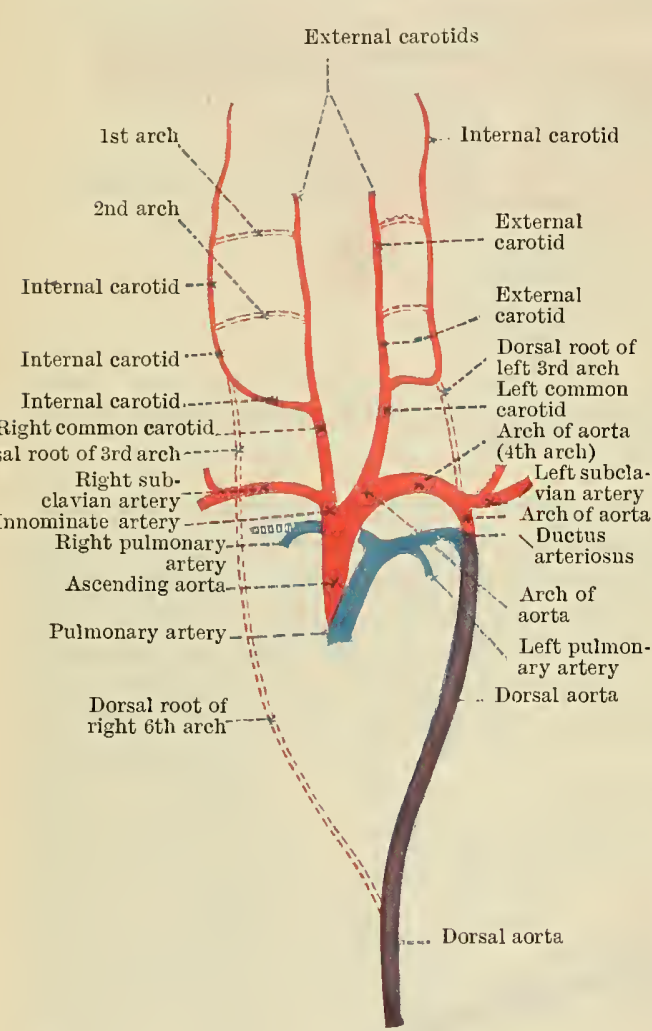

Fig. 87.-SChema of Part OF the VAscular System or a Fotus seex from the Front. Showing the origin of the positions of the first and second arches, the dorsal roots of the third arches on both sides, and the dorsal roots of the fourth and fifth arches on the right side are shown in dotted lines. The positions of the fifth arches are not shown.

veins, which convey the blood from the yolk-sac.

the ventral roots of the fourth arches and therefore with the innominate artery and the aortic arch, becomes the ascending aorta, and the other, which remains associated with the sixth arches, becomes the stem of the pulmonary artery.

Whilst the changes mentioned have been taking place in the cephalic part of the arterial system, the primitive dorsal aortæ have fused together from a point immediately caudal to their seventh dorsal branches to a point immediately cranial to the origins of the umbilical branches from their ventral aspects, and their ventral branches have fused together into single stems, some of which have been converted into the coeliac, the superior mesenteric, and the inferior mesenteric arteries. The fusion of the dorsal aortæ commences in embryos about $2.5 \mathrm{~mm}$. long. When the embryo has attained a length of $5 \mathrm{~mm}$. the fusion has extended to the caudal ends of the aortæ and the single stem is continued into the rudimentary tail as the caudal artery, which afterwards becomes the middle sacral artery. After the fusion is completed the umbilical arteries spring from the ventral aspect of the single dorsal aorta. (For the further history of the arterial system, see under Vascular System.)

The Primitive Venous System.-The first definite venous trunks to appear are the umbilical veins, returning blood from the chorion, and the vitelline

Two umbilical veins enter the body-stalk and unite to form the vena umbilicalis impar (Fig. 81). This divides, at the posterior margin of the umbilicus, into the right and left lateral umbilical veins, which run round the lateral margins of the umbilical orifice, in the lateral margins of the body wall of the embryo. At the cranial margin of the umbilicus they turn medially, enter a transverse bar of mesoderm which forms the caudal boundary of the pericardium and is known as the septum transversum, and pass through it into the caudal end of the heart (Figs. 81, 82).

The blood from the yolk-sac passes, for a short time, into the lateral umbilical veins at the posterior margin of the umbilicus. This is a very transitory arrangement, and it is soon replaced by the formation of two proper vitelline veins, one on each side, which ascend, along the vitello-intestinal duct, to the cranial margin 
of the umbilicus, where they enter the septum transversum, in which each vitelline vein joins the corresponding umbilical vein, forming a common vitello-intestinal trunk, which enters the sinus venosus (Fig. 81).

This trunk also receives the primitive head vein, or anterior cardinal vein, which returns the blood from the cranial part of the embryo (Fig. 82).

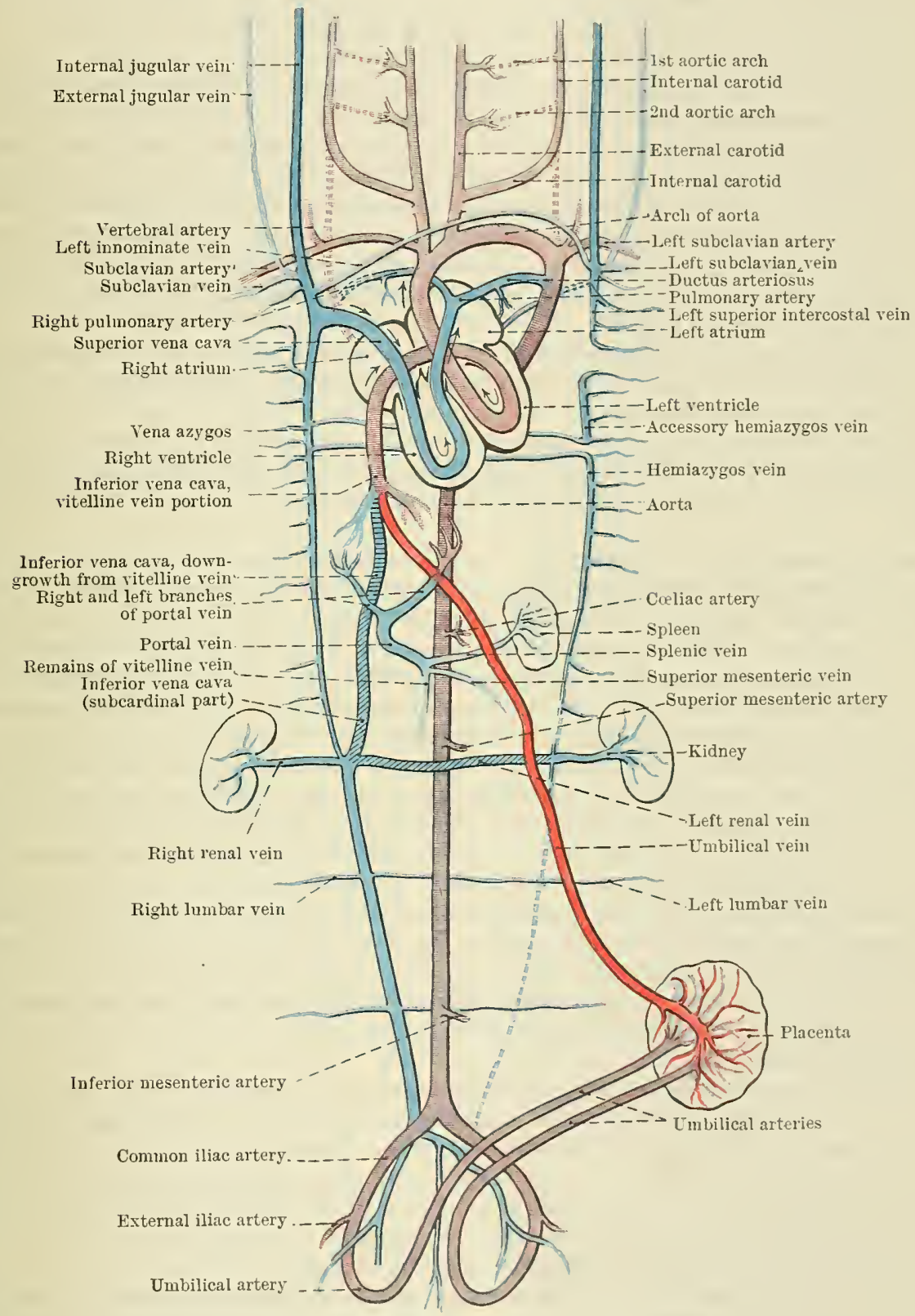

Fig. 88.-Diagram of the Fotal Circulatiox.

A little later two veins are formed, one on each sicle, which return blood from the body wall and the primitive limbs. They are the posterior cardinal veins, and as soon as they are established they join the caudal ends of the anterior cardinal veins to form the ducts of Cuvier, which then open dircetly into the posterior part of the heart which is called the sinus renosus (Fig. S3). Shortly afterwards the common stems of the vitello-umbilical reins are absorbed into the sinus venosus, forming its right and left horns. When this has happened six reins open into 
the sinus venosus, three on each side-the two ducts of Cuvier, the two vitelline reins, and the two lateral umbilical reins (Fig. 83).

The anterior cardinal reins and their tributaries, and cross anastomoses which form between them, are transformed into some of the cranial blood sinuses, the internal jugnlar reins, the innominate veins, and the cephalic (upper) part of the superior rena cara. The right duct of Curier becomes the caudal part of the superior rena cara, and the left is converted into the oblique vein of the left atrium (O.T. oblique vein of Marshall) (Fig. 88).

A portion of the abdominal part of the right posterior cardinal vein is replaced by the right subcardinal vein, and from this and a transverse anastomosis between it and the opposite subcardinal vein is formed that part of the inferior vena cava which extends from the renal veins to the liver, and a part of the left renal vein. From the remains of the cardinal veins and transverse anastomoses between them are formed (1) the azygos, the hemiazygos, and the accessory hemiazygos veins; (2) the inferior rena cava, caudal to the renal veins; (3) the common iliac veins; (4) the hypogastric veins; and (5) the parts of the left lumbar veins which pass clorsal to the aorta (Fig. 88).

The cephalic end of the inferior vena cava is formed from the cephalic extremity of the right vitelline rein and a caudal outgrowth from it which unites with the right subcardinal vein (Fig. 88).

Details of the history of the transformations of the cardinal veins, the vitelline and umbilical reins, and the formation of the cranial part of the inferior vena cava are given in the account of the further stage of the development of the vascular system.

The Primitive Heart. - The primitive heart is formed in the dorsal wall of the pericardium, ventral to the fore-gut, by the fusion of the caudal parts of the primitive ventral aortæ, and shortly after its formation it is divided into five primitive chambers. The most caudal of the five, which receives the main primitive veins, is the sinus venosus, the second is the atrium, the third the ventricle, the fourth is the bulbus cordis, and the fifth and most cranial is the truncus aorticus, which discharges its contents into the ventral roots of the aortic arches (Fig. 84).

During the period which intervenes between the time when the embryo is $8 \mathrm{~mm}$. and $17 \mathrm{~mm}$. long, that is between the fifth and the eighth weeks, the greater part of the sinus venosus is absorbed into the atrium; the ventricle and the atrium are each divided into right and left chambers by the formation of an interatrial and an interventricular septum; the bulbus cordis is absorbed partly into the ventricle and partly into the truncus aorticus, and the truncus aorticus is separated into the ascending part of the aorta and the stem of the pulmonary artery. When these changes are completed the heart consists of right and left atria and right and left ventricles. The ventricles are entirely separated from one another by the interventricular septum, but there is an orifice of communication between the right and left atria (Fig. 88).

The right atrium receives blood from the superior and inferior venæ cavæ, and from the walls of the heart, by the coronary sinus, which is a remnant of the transverse part and left horn of the sinus venosus. The blood which enters through the superior vena cava and by the coronary sinus, passes through the right atrioventricular orifice into the right ventricle, but the whole, or the greater part, of the blood which enters by the inferior vena cava passes through the foramen ovale, which lies in the interatrial septum, into the left atrium.

The blood which enters the right ventricle is ejected into the pulmonary artery. A small portion of it passes by the right and left branches of the artery into the lungs, and is returned to the left atrium by the pulmonary veins, but by far the greater part passes through the ductus arteriosus into the aorta, which it enters at a point immediately beyond the origin of the left subclavian artery (Fig. 88).

The blood which passes into the left atrium, through the foramen ovale, mixes, in the left atrium, with a small amount of blood which is returned by the pulmonary veins; then it passes through the left atrio-ventricular orifice into the left ventricle, by which it is forced into the aorta. Some of this blood passes into the innominate artery, and so, by its right subclavian branch, to the right upper 
extremity, and by its right common carotid branch to the right side of the head and neck; another part enters the left common carotid artery and is distributed to the left side of the head and neck, and some passes through the left subclavian artery to the left upper limh. The remainder mixes with the blood which enters the aorta, from the right ventricle, through the pulmonary artery and the ductus arteriosus. Part of this mixed blood is distributed to the body and the viscera, and the remainder passes through the umbilical arteries to the placenta (Fig. 88).

The Fotai Circulation. - When the foetal circulation is thus filly established, purified oxygenated blood, returning from the placenta, euters the liody of the foetus by the umbilical vein and passes to the liver. Srome of it enters the liver, but the greater part passes, through a channel called the ductus venosus, to the inferior vena cava, where it mixes with the renous bloor returning from the lower limbs and the abdominal region, including the liver. This inixed, but, as contrasted with the blood in the superior vena cava, comparatively pure linond enters the right atrium and passes through it and through the foramen ovale into the left atrium, thence to the left ventricle and through the left ventricle into the aorta. A portion of this comparatively pure blood is distributed to the head and neck and the upper limbs. The remainder unites with the stream of renous blood poured into the aorta through the ductus arteriosus. Part of it is distributed to the body and the lower limbs, and part is sent to the placenta to be purified and oxygenated (Fig. S8).

The remaining part of the blood stream is formed by the biood returned from the head and neck, the upper part of the body and the upper limbs, hy the superior vena cava, and from the walls of the heart by the coronary sinus. It is the most renous and impure blood in the body. After entering the right atrium it passes into the right ventricle, and thence into the pulmonary artery. A very small part of it is passed to the lungs, by the right and left branches of the pulmonary artery; the remainder goes through the ductus arteriosus into the aorta, where, beyond the origin of the left subclavian artery, it mixes with the snuch purer blood which entered the aorta from the left ventricle.

At birth, when the placental circulation ceases, the lungs become the organs through which oxygen enters and carbonic aeid leaves the blood; the foramen ovale in the interatrial septum closes, and the ductus arteriosus is obliterated. The course of the circulation and the condition of the blood in the different regions is, therefore, considerably altered.

On account of the cessation of the placental circulation all the hloor which enters the right atrium is entirely venous, and, as the foramen orale is closed, it all passes into the right ventriele, which forces it into the pulmonary artery. As the ductus arteriosus is closed, all the blood which enters the pulmonary artery must now pass through the lungs, where it is rerated, and whence it is returned, by the pulmonary veins, as oxygenated blood, to the left atrium. It passes from the left atrium to the left ventriele, which forces it through the aorta and its branches to all parts of the head, neck, body, and limbs; and now, for the first time, all parts receive blool of the same quality.

\section{THE COLOM.}

It has already been pointed out that there are two parts of the colom, the extra-embryonic and the intra-embryonic. Both are clefts separating an outer from an inner layer of mesoderm.

The Extra-embryonic Cœlom.-The extra-embryonic culonn appears in the primary mesoderm and separates it into a parietal and a viseeral layer. The parietal layer covers the inner surface of the trophohlast and forms with it the chorion. It covers also the outer surface of the ammion. The visceral liyer covers the onter surface of the extra-embryonic portion of the wall of the entoderulal carity.

The extra-embryonic and intra-embryonic parts of the corlom are at first separate from one another (Fig. 36), then they become enntinuous, for a time, in the region of the umbilical orifice (Fig. 37 ), but are separated from one onother again 
when the umbilical urifice closes. The extra-embryonic portion is entirely obliterated when the outer surface of the expanding amnion fuses with the inner surface of the chorion (compare Figs. 77 and 78 ).

The Intra-embryonic Cœlom.-The intra-embryonic colom appears as a series of cleft-like spaces in the margin of the embryonic mesoderm. The spaces fuse together to form a $\cap$-shaped cavity (Fig. 89) which separates the peripheral part of the embryonic mesoderm into a parietal or somatic, and a visceral or splanchnic,

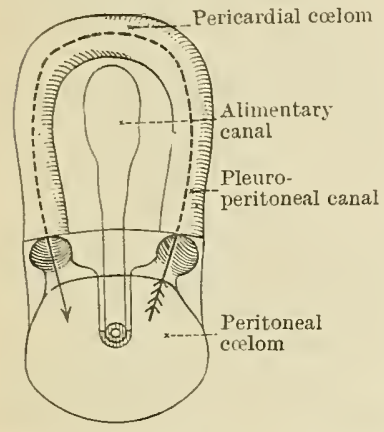

Fig. S9. - SCHEXIA UF INTRA

EMBRYONIC CELOM SEEN FRON ABOVE BEFORE THE FOLDING OF THE EMrRponic AREA.

wall of the fore-gut (Fig. 90). The mesoderm which originally formed its peri-
" The carried ventrally and caudally into the ventral pheral boundary, but whe mesoderm which originally formed its periorifice, becomes thickened, and forms the septum transversum (Figs. 90, 91, 93).
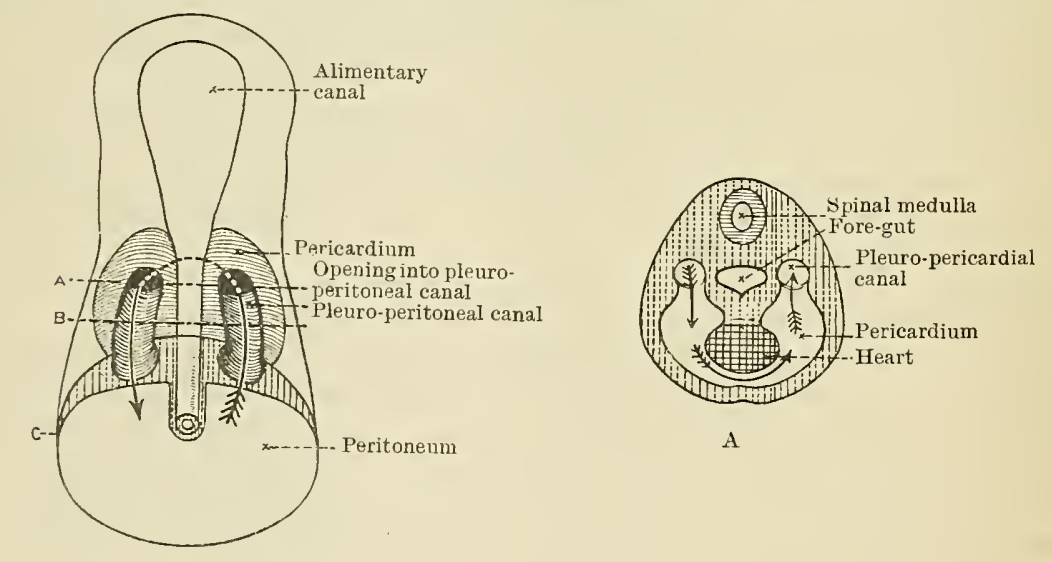

A

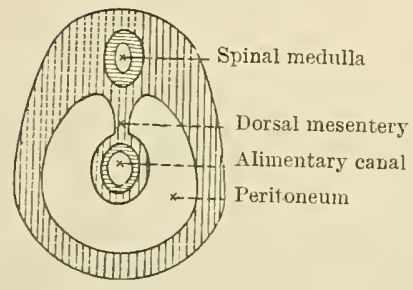

C and it has no direct communication with the extraembryonic colom, but the candal part of each stem of the cavity, on account of the disappearance of its lateral wall, soon opens, laterally, into the extraembryonic colom.

The transverse portion of the $\cap$-shaped cavity, which extends across the cephalic end of the embryonic area and connects the two limbs together, is the pericardial cavity. The adjacent part of each lateral limb of the cavity, the pleuro-pericardial canal, becomes a pleural cavity, and the lateral parts of the remaining portions unite ventrally, as the umbilical orifice closes, to form the single peritoneal cavity.

As the head fold forms, the pericardial part of the cavity is carried ventrally and caudally into the ventral

D

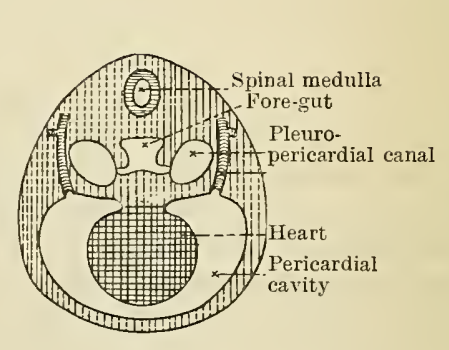

$\mathrm{B}$ maroin of the cephalic part of the embryonic region,

Fig. 90.- Schemata of Embryonic Ćelon after folding of Embrgonic Ared but before the Separatiox of the Various Parts. D from above; $\mathrm{A}, \mathrm{B}$, and $\mathrm{C}$ at levels of line $\mathrm{A}$, $\mathrm{B}$, and $\mathrm{C}$ in Fig. $\mathrm{D}$.

At the cephalic end of its dorsal wall, on each side, the pericardial cavity is still continuous with the two lateral parts of the celom; and each lateral part, which 
lies dorsal to the pericardium, and between the fore-gut medially and the body laterally, is still a pleuro-pericardial canal.

The Separation of the Pericardial, Pleural, and Peritoneal Parts of the

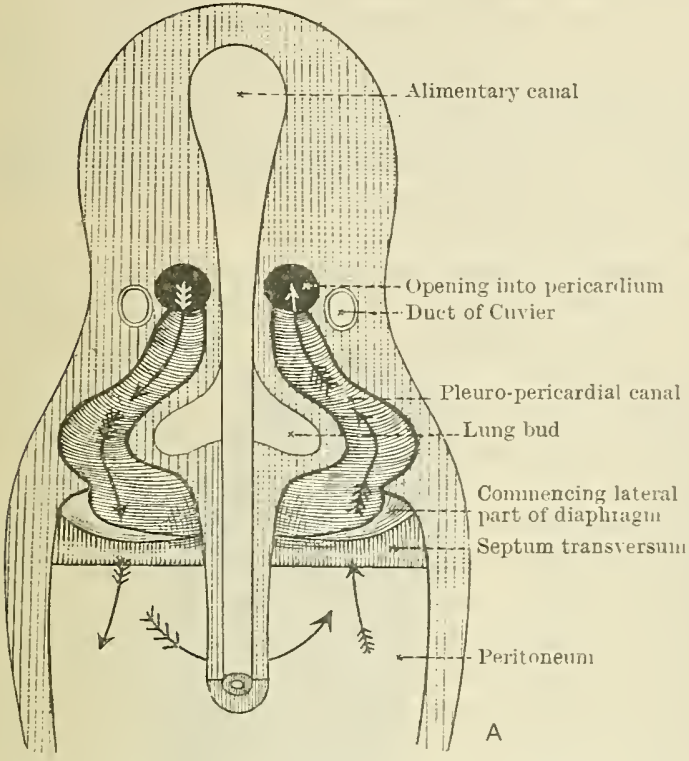

Fig, 91.--SCHEMA of LATER ŚTAGE of DIFFEIRENTIATIO) of C'ELous. A, from above. B, transverse section cut level of lung bud in $A$.
Cœlom.-In the lateral wall of each pleuro-pericardial canal, near its cephalic end, lies the duct of Cuvier, passing towards the heart; and a lung bud containing a primitive bronchial tube grows from the medial wall into the cavity of each pleuro-

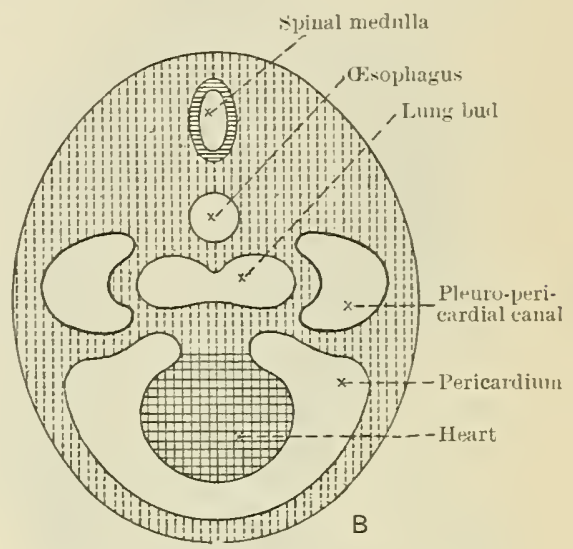

Fu, 92.-SCHEMA OF a TRASStERSE S̈HTIUN AT THF, LEVEL, or THF; LCXG BT'D IN FIG. 91.

pericardial canal (Fig. 91). As the lung buds grow the cavities of the pleuropericardial canals increase in size, and each passes ventrally, round the side of

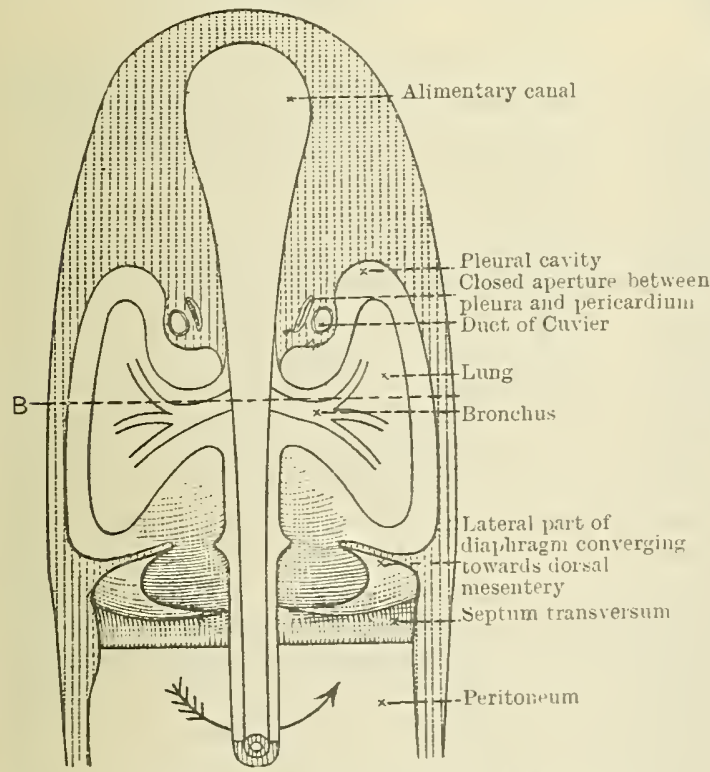

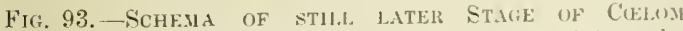
Differextiation. The pleuræ are separated from the pericardia, but still commuicate with the peritonem. the pericardium towards the rentral wall of the body, until it is separated from its fellow of the opposite side only by a median mesoderm-filled interval, which becomes the anterior mediastinum and the anterior part of the superior mediastinum (Fig. 9t). At the same time the cavity of each pleuro-pericardial canal, and the growing lung bud in its interior, grow towards the cephalic end of the embryo (Fig.

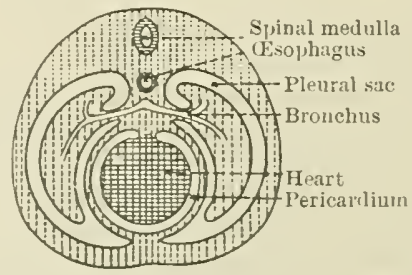

FIl, 94. - StHEMA of Thuxisterse SHCTIU: (IF E.MBRTO AT LEVEL OF Lisk: B. Fig. 93, showing ventral exteusion of the plenra.

93). As it passes cephalwards the growing lung lies to the lateral side of the duct of Cuvier, which is thus forced against the cephalic end of the pleuropericardial canal, compressing it torrards the median plane, against the sides 
of the trachea and the resophagus, until its cavity is obliterated. When this occurs the pericardial carity is entirely shut off from the remainder of the colom, and becomes a completely closed space (Fig. 93).

As the closure of the pericardial cavity is taking place two wing-like folds of mesoderm, connected ventrally with the septum transversum and laterally with the hody walls, appear, caudal to the lumgs (Figs. 91, 93). These folds are the rudiments of the lateral parts of the diaphragm, and each passes medially until it fuses with the mesoderm of the side wall of the fore-gut and its dorsal mesentery. When this fusion is completed the cavity of the portion of the cœlom surrounding the lung, the original pleuro-pericardial canal, is separated from the more caudal part of the calom, which now becomes the peritoneal cavity.

Only the broad outlines of the processes by which the pleuro-peritoneal canals are separated from the pericardium and the peritoneum are mentioned in the preceding paragraphs. The details of the processes are too complicated for description in an orlinary text-book of anatomy.

The Formation of the Diaphragm.-There are four main parts of the diaphragm, a ventral, a dorsal, and a right and a left lateral.

The ventral part is formed from the septum transversum, which is gradually differentiated into a caudal, an intermediate, and a cephalic part. The caudal part is transformed into (1) the mesodermal tissue of the liver, which grows towards the abdomen, (2) the falciform and coronary ligaments, and (3) the small omentum. The cephalic part becomes the candal or diaphragmatic wall of the pericardium. The intermediate part is transformed into the ventral portion of the diaphragm.

The dorsal part of the diaphragm is developed from the mesoderm of the dorsal mesentery of the fore-gut. Each lateral part is derived from a lateral ingrowth which springs ventrally from the septum transversum and laterally from the body wall. The two lateral portions grow towards the median plane till they fuse with the dorsal portion; but in some cases, especially on the left sicle, the fusion is not completed. In such cases an aperture of communication remains, between the pleural and the peritoneal cavities, throngh which a portion of the abdominal contents may pass into the pleural sac, constituting a diaphragmatic hernia.

\section{SUMMARY OF THE EX'TERNAL FEATURES OF THE HUMAN EMBRYO AND FETUS AT DIFFERENT PERIODS OF DEVELOPMENT.}

During the first fourteen days after the impregnation of the ovum the human zygote descends through the uterine tube, assumes the morula condition, enters the uterus, penetrates into the decidua compacta, and differentiates into three vesicles and a mass of primitive mesoderm; but, probably, it is not until the beginning of the third week, if Bryce's calculations are correct, that a definite embryonic area is present. By that time the zygote is an ovoid vesicle measuring 2.4 by $1.8 \mathrm{~mm}$. Its wall is formed by the trophoblast, and it contains two inner vesicles, the ecto-mesodermal and the entodermal vesicles. The inner vesicles are surrounded by a mass of primary mesoderm in which the extra-embryonic portion of the colom is beginning to appear. At this period the embryonic area is the region where the walls of the two inner vesicles lie in relation with one another, and it is $19 \mathrm{~mm}$. long (Fig. 30).

By the eighteenth or nineteenth day the area has attained a length of $1.17 \mathrm{~mm}$. and it is $.6 \mathrm{~mm}$. broad. It is pierced, about the centre of its length, by the neurenteric canal ; the primitive streak has appeared on the dorsal surface of the area ; the primitive groove is distinct, and the neural groove is indicated. The body-stalk is bent dorsally, at right angles with the area, and it contains the allantoic diverticulum, which has already been projected from the wall of the entodermal vesicle (Fig. 95).

During the next twenty-four hours the length of the embryonic area increases to 1.54 $\mathrm{mm}$; the neurenteric canal is moved caudally, to a point well behind the middle of the length of the area, and the posterior part of the area is bent ventrally, forming the posterior boundary of the hind-gut region and indicating the position of the future cloacal menbrane. The head fold has begun to form, and the pericardial region lies in the ventral wall of the rudimentary fore-gut (Fig. 96).

By the middle of the third week the head and tail folds are distinctly formed and 
the length of the embryo is $1.9 \mathrm{~mm}$, the neural folds are well developed, the neural groove is still completely open, and six pairs of mesodermal somites are visible (Fig. 97).

In the next few days the length increases to $2.5 \mathrm{~mm}$., the neural groove closes except in the cranial and caudal regions, the number of mesodermal somites is increased to fourteen pairs, and the cranial region begins to bend ventrally as the cervical flexure forms (Fig. 98).

By the end of the first month the greatest length of the embryo is about $2.6 \mathrm{~mm}$., the head is bent at right angles to the body, the Wolffan ridges hare appeared along the ventral margins of the mesodermal somites and indications of the limb rudiments

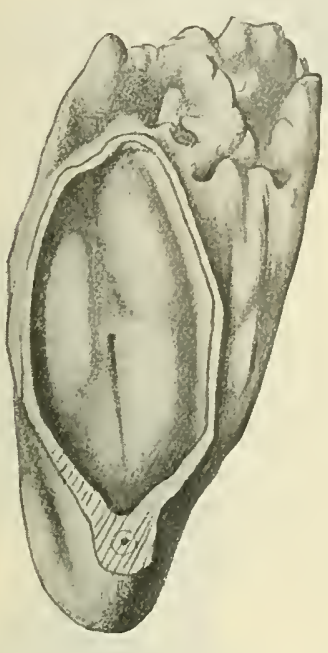

Fig. 95.-Frassi's ZrGote. Estimated to be 18-19 days old (Bryce). The embryonic area is $1 \cdot 17$ $\mathrm{mm}$. long and $6 \mathrm{~mm}$. broad. Copied from Lormaltafeln, Keibel and Elze, representing a reconstruction. The chorion is not shown. The upper part of the amuion is cut away, and the dorsal aspect of the embryonic area is seen from above. In the centre of the area is the neurenteric canal and caudal (inferior in the Fig.) to it is the primitive groove. Cephalwards of the neurenteric canal is the neural groove, in the middle of the neural plate. At the lower (caudicl) end of the Fig. is seen a section of the body stalk containing the allantoic diverticulum, and the nolulated area seen at the upper and right lateral part of the Fig. is a portion of the yolk-sac.

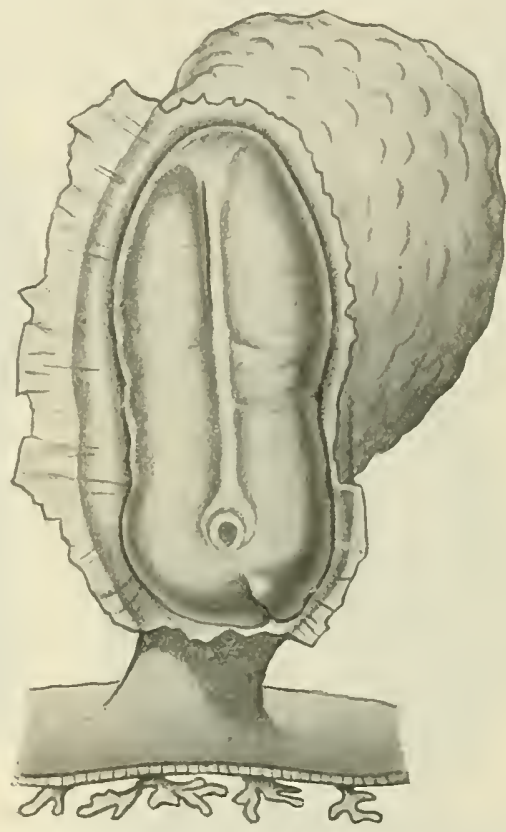

F19. 96. -SPEE's ZYGote. (From Keibel and Elze's Normaltafeln.) Length of embryonic area $1.54 \mathrm{~mm}$. Estimated age 19-20 days (Bryce). At the lower end of the Fig. (caudal end of the embryo) is seen a portion of the chorion attaclied to the embryo by the body stalk. A portion of the amnion is still attached to the margin of the embryonic area, and the dorsal surface of the elubryonic area is exposed. In the median plane of the area is the neural groove, and at the cauclal end of the groove is the neureuteric canal. The caudal part of the area is bent ventrally, and upon it is the remains of the primitive groove. The yolk-sac is seen at the upper and right part of the Fig.

are present. The rudiments of the otic vesicles have appeared as slight depressions in the region of the hind-brain. The anterior and posterior neuropores are still open (Fig. 99).

In the latter part of the fourth or the beginning of the fifth weck the embryo attains a length of about $5 \mathrm{~mm}$., when measured from the vertex of the head to the base of the tail, the mesodermal somites increase to thirty-five; the rudiments of the fore- and hindlimbs become quite distinct; the otic resicles sink into the interior of the head but remain connected with the surface by the ductus endolymphaticus, the tail becomes a very definite appendage, and the bulgings cansed by the otic vosicles are quite obvions on the surface of the head. The cervical flexure remains acute, and the head bends at right angles upon itself in the region of the hind-brain, forming the cephalic flexure, with the result that the frontal extremity of the head is tumed caudally (Fig. 100).

By the end of the fifth week the length of the entryo has increased to $11 \mathrm{~mm}$. (CR) ${ }^{1}$

1 CR indicates the crown-rump or crown-breech measurement which corresponcls with tbe sitting height (Mall). 
Mall. Fortr-three mesoderwal somites are present, but onlr about twentr-one are risible on the surface. During the fifth week the lens of the ere appears as a thickening of the surface ectoderm: sinks into the interior of the ereball: becomes a resicle and separates from the suriace. The three segments of the fore-limb become risible, and the rudiments of the fincers appear. The lind-limb is less adranced; the thich serment is not distinct, and the rudiments of the toes are not ret risitle. The third and fourth visceral arches disappear from the surface and lie in the depths of the precervical sinus, a depression betreen the neck and the auterior part oi the bods; this is orerlapped, superficially, br the caudal wargin of the second arch, which grow s tailwards and forms the operculum of

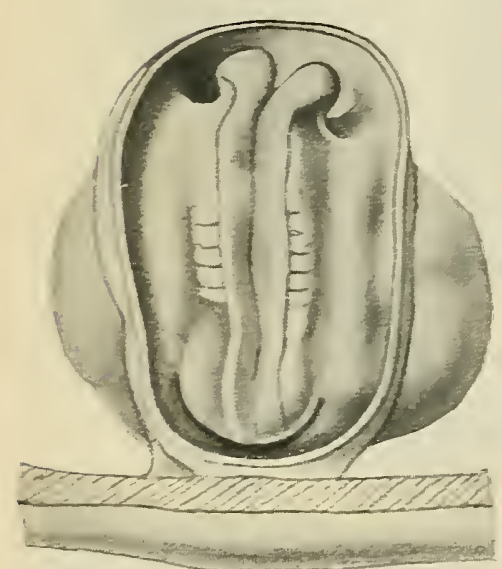

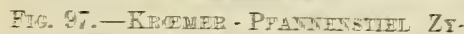
GOTE. (Frota Eeibel aud Elze's Mormantateln.) The embryonic region is folded into the form of an

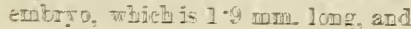
it is prsibily about three $x$ telis old. A: the lower ed of the Fig. (the caudal sud of the embryol are seen portions of the chorion asd bodystalk. The cereloral Iortion of the zeural rarizuent is defined. Six pairt of twesodermal somites are present, bat there are no sigus of linute:

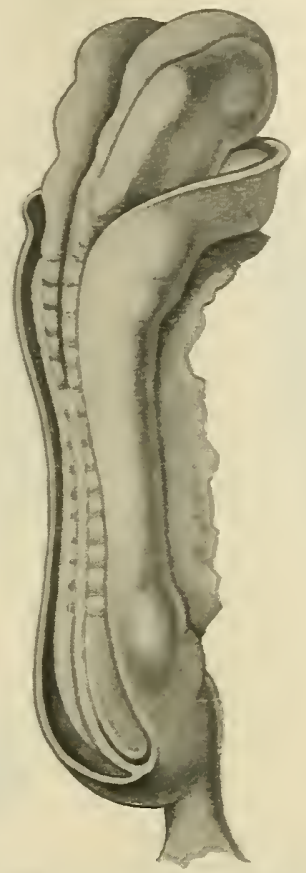

Fig. 95. - Balle': Emerto. (From Keibel and Elze's Tormalitafum.) Length after hardeniog in alentol 2.5 mm. The nemral groore is ciosed from the sirth somite to wilinin a short distance of the candal $\in$ d. bot it is open anteriorly. The hind-, rnid-, and forebrain regions and the optic resicle can be distinguister. At the lower end of the Fig. is the bady-stalk, aud a: the right side a part of the rolk-sac.

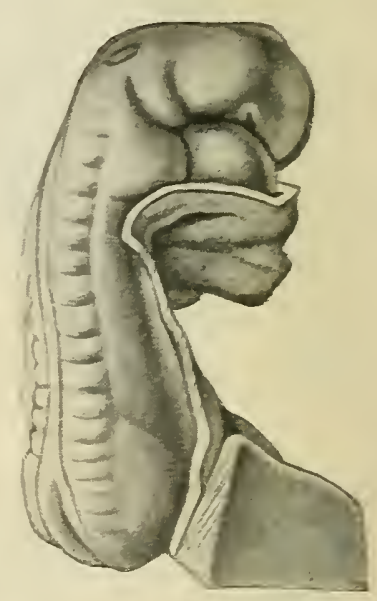

Fig. 99.-Pfarrenstiel's EM. BRIG. (From Keibel and Elze: Tormaltafeln.) Leagth of embryo about $2.6 \mathrm{~mm}$. The radiment of the otic Tesicle is seen in the Fig. abore the second branchial cleft. The heart and pericardium from the bulging eminence below the head and the Wolffian ridge is seen at the lateral border of the mesodermal somites.

the sinti: (Fies. 101, 102). During the fifth week the head grows rapidly, and becomes relatively very lareve as contrasted with the bods.

During this week also the olfactory pits appear, and grow dorsally in the roof of the stornatodreum, separating the median from the lateral nasal processes; the median process is dirided into the two globular processes; and the masillart processes of the mandibular arches, growing towards the median plane, fuse with the lateral nasal and the globular processes, so completing the lateral parts of the primitire cranial lip (Figs. 61, 65, 66).

The nodular outgrowths which form the rudiments of the auricles appear on the margins of the hro-mandibular cleft and fuse together, and by the end of the week traces of the tragus, the helir, and the antitragus are risible (Fig. 103).

By the serenth week the embryo has attained a length of $17 \mathrm{~mm}$. (CP). The cerrical flexure has begnan in unfold. The rudinents of the erelids have appeared. The globular processes have fused together, tut there is still a distinct notch in the middle of the cephalic on upper lip. The margins of the auricles are now well defined; the hands are 


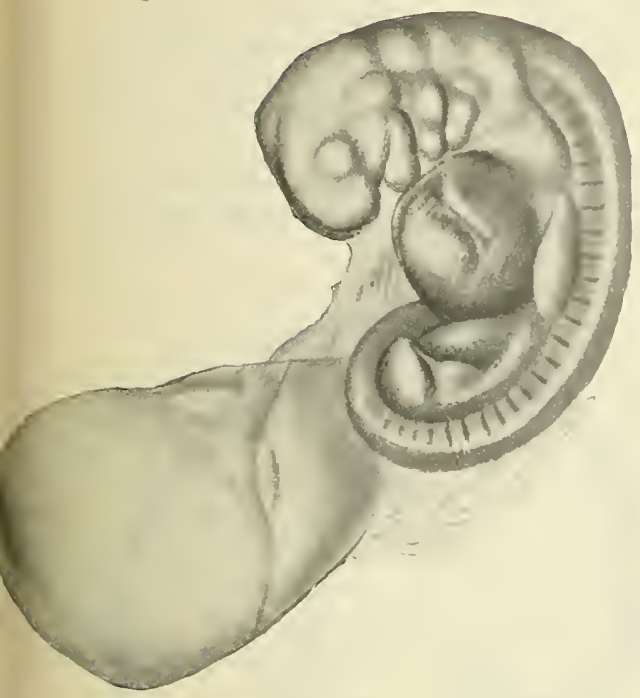

IG. 100.-SIDE VIEW of AN EMbRYo, measuring about $5 \mathrm{~mm}$. from the root of the neck to the base of the tail, and about $47 \mathrm{~mm}$. from the crown or mid-brain region to the base of the tail, that is to the breech or rump. (From Keibel and Elze's Normaltafeln.) The neural tube is closed. The limb buds are quite distinct, and the maxillary process of the mandibular bar has grown forward below the eye (dorsal to the eye in the Fig.).

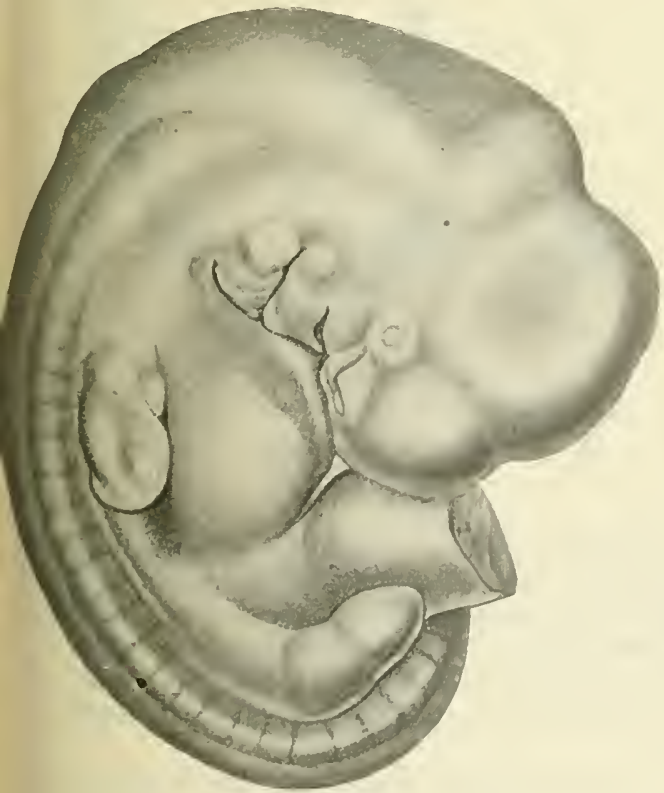

102.-EnbRYo, $7 \cdot 2 \mathrm{~mm}$. (CR), and $8 \mathrm{~mm}$. greatest length. (From Keibel and Elze's Normaltafeln.) The limbs have begun to fold ventrally. The secoud arch lias completely overlapped the third and fourth which now lie in the precervical sinus, and the sinus still opens on the surface at the posterior border of the second arch. The lens of the eyeball is very evident, and rudiments of the aurivle of the external ear have appeared on the mandibular or first, and the hyoid or second arch.

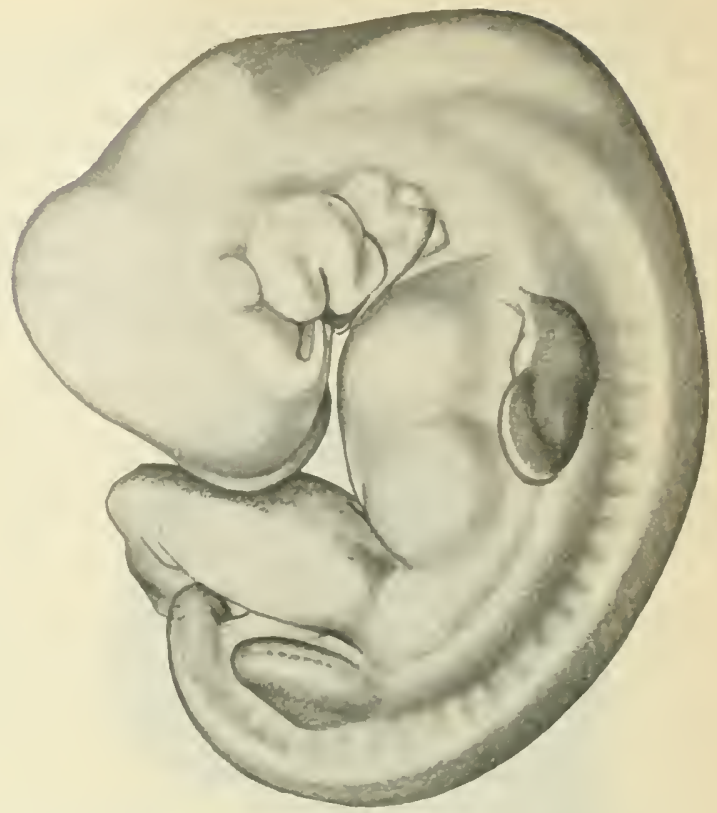

Fig. 101. - EMBRY of $7 \cdot 2$ M.M., CR MEASCrEMExt, 8.5 mu. greatest length. (From Keibel and Elze's Limrmalta feln.) The fore-limb is listinctly in alsance of the himl-limb. 'The second brauchial arch has begun to overlap the thiri anil fourth and to enclose the precervical sinns. The tip of the maxillary process is in contact with the lateral and medial nasal processes at the margins of the olfactory pit.

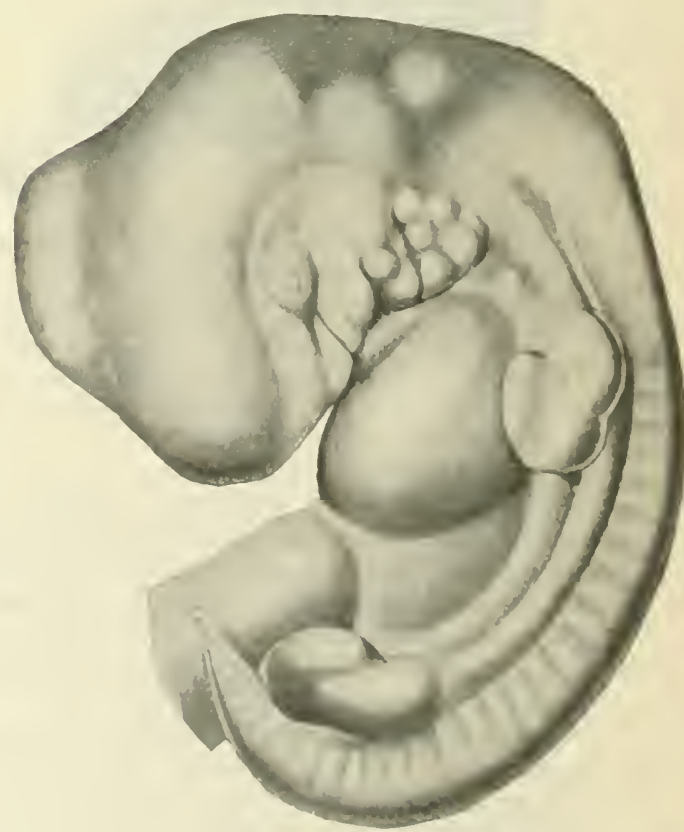

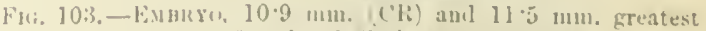
length. (From Kibihel and kize's . Vormallufiln. The precervical simus is closed aul alditional ruliments of the nuriele of the external ear are present on the first smel serond arches. The anterior nares are no longer vi-ible from the side. 
folded medially; the tips of the fingers are free, and the palms rest on the cranial part of the distended abdomen. The thighs and the toes have appeared, and the tail has begnn to fuse with the caudal end of the body (Fig. 104).

At the end of the eighth week, when the embryo becomes a fœtus, it has attained a length of about $25 \mathrm{~mm}$. (CR). The auricles project from the sides of the head, the tail has almost disappeared from the surface, and the toes are free from one another. The cervical flexure is now very slight, and although the head is still relatively large, the disproportion between it and the body has begun to decrease (Fig. 105).

Third Month.- The head grows less rapidly, and, though it is still large, it is relatively smaller in proportion to the whole body. The eyelids close, and their margins fuse

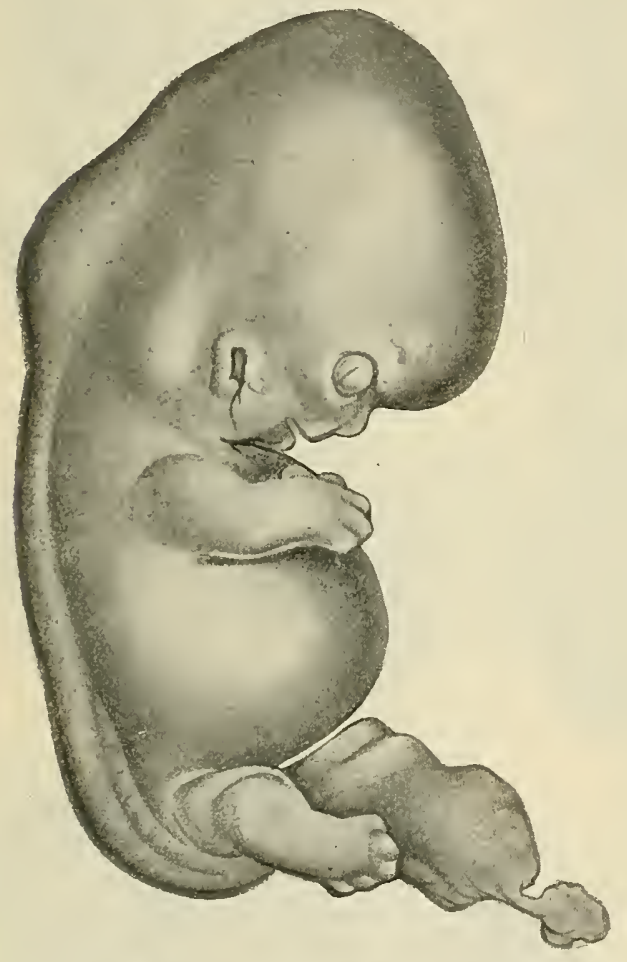

Fig. 104.-Eubryo (CR) greatest length $18.5 \mathrm{~mm}$. Probably between seven and eight weeks old. (From Keibel and Elze's Normaltafeln.) The abdomen is very prominent on account of the rapid increase of the liver. The digits of the hand and foot are distinct but not separated from one another. The margin auricle of the external ear is completed. The eyelids have begun to form.

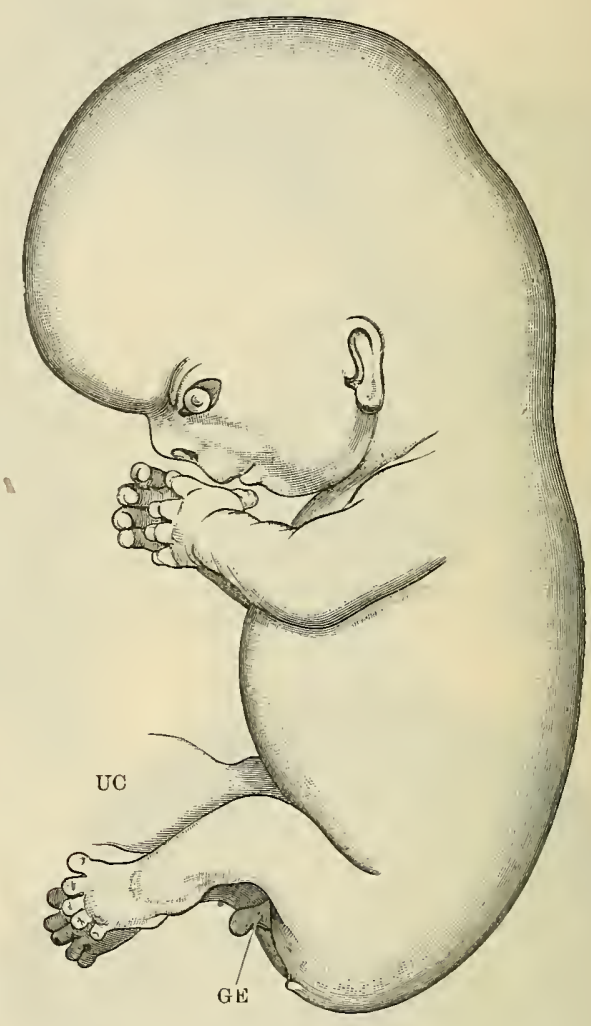

Fig. 105.-Human Fetus etght axd a half WEEKS OLD. (After His.)

GE. Genital eminence ; UC. Umbilical cord.

together. The neck increases in length. The various parts of the limbs assume their definite proportions, and nails appear on the fingers and toes. The proctodæum is formed and the external generative organs are differentiated, so that the sex can be distinguished on external examination. The skin is a rosy colour, thin and delicate, but more consistent than in the preceding stages. By the end of the third month the total length of the foetus,

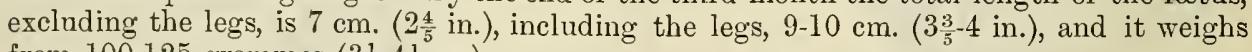
from 100-125 grammes $\left(3 \frac{1}{2}-4 \frac{1}{2}\right.$ oz.).

Fourth Month. - In the fourth month the skin becomes firmer, and fine hairs are developed. The disproportion between the fore- and hind-limbs disappears. If the fœtus is born at this period it may live for a few hours. Its total length from vertex to heels is $16-20 \mathrm{~cm} .\left(6 \frac{2}{5}-8 \mathrm{in}\right.$.), from vertex to coccyx $12-13 \mathrm{~cm}$. $\left(4 \frac{4}{5}-5 \frac{1}{5} \mathrm{in}.\right)$, and it weighs from 230-260 grammes ( $8 \frac{1}{8}-9 \frac{1}{5}$ oz.).

Fifth Month. -The skin becomes firmer, the hairs are more developed, and sebaceous matter appears on the surface of the body. The legs are longer than the arms, and the umbilicus is farther from the pubis. At the end of the month the total length of the 


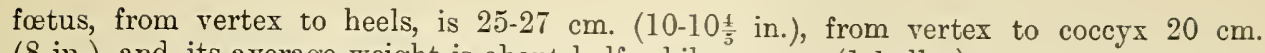
(8 in.), and its average weight is about half a kilogramme ( $\left.1 \frac{1}{10} \mathrm{lbs}.\right)$.

Sixth Month.-The skin is wrinkled and of a dirty reddish colour. The hairs are stronger and darker. The deposit of sebaceous matter is greater, especially in the axillæ and groins. The eyelashes and eyebrows appear. At the end of the month the

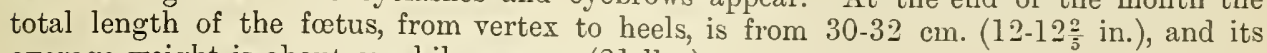
average weight is about one kilogramme $\left(2 \frac{1}{5} \mathrm{lbs}\right.$.).

Seventh Month. - The skin is still a dirty red colour, but it is lighter than in the previous month. The body is more plump on account of a greater deposit of subcutaneous fat. The eyelids re-open, and the foetus is capable of living if born at this period. Its total length at the end of the month, measured from vertex to heels, is 35 - 36 $\mathrm{cm}$. (14-14 $\frac{2}{5} \mathrm{in}$.), and its weight is about one and a half kilogrammes ( $3 \frac{1}{3} \mathrm{lbs}$.).

Eighth Month.-The skin is completely covered with sebaceous deposit, which is thickest on the head and in the axillæa and groins, and its colour changes to a bright flesh tint. The umbilicus is farther from the pubis, but it is not yet at the centre of the body. The total length of the fœtus, from vertex to heels, is $40 \mathrm{~cm}$. (16 in.), and its weight varies from 2 to $2 \frac{1}{2}$ kilogrammes $\left(4 \frac{1}{2}-5 \frac{1}{2} l \mathrm{lbs}\right.$.).

Ninth Month. - The hair begins to disappear from the body, but it remains long and abundant on the head. The skin becomes paler, the plumpness increases, and the umbilicus reaches the centre of the body. At the end of the ninth month, when the fotus is born, it measures about $50 \mathrm{~cm}$. from vertex to heels $(20 \mathrm{in}$.), and it weighs from $3-3 \frac{1}{2}$ kilogrammes $\left(6 \frac{6}{10}-7 \frac{7}{10}\right.$ lbs.).

The age of a fœtus may be estimated, approximately, by Hasse's rule, viz., Up to the fifth month the length in centimeters, the lower limbs being included, equals the square of the age in months, and after the fifth month the length in centimeters equals the age multiplied by five. 



\title{
O S T E O L O G Y.
}

\author{
THE SKELETON.
}

\author{
By Artiun Thomson, F.R.C.S. \\ Professor of Anatomy, Lniversity of Orford.
}

The term skeleton (from the Greek, $\sigma \kappa \epsilon \lambda \epsilon \tau o$ s, dried) is applied to the parts which remain after the softer tissues of the body have been disintegrated or removed, and includes not only the bones, but also the cartilages and ligaments which bind them together. In the restricted sense of the word the skeleton denotes the osseous framework of the body. It is in this sense that it is generally employed in human anatomy.

The skeleton serves to support the softer structures which are grouped around it, and also affords protection to many of the delicate organs which are lodged within its cavities. By the articulation of its several parts, its segments are converted into levers which constitute the passive portion of the locomotory system. Recent research has also proved that certain cells found in bone-marrow are intimately associated with the development and production of some of the corpuscles of the blood.

Bone may be regarded as white fibrous tissue which, having become calcified, has undergone subsequent ehanges, so as to be converted into true osseous tissue. Most probably all bone is of membranous origin, but it may pass through a stage in which cartilage plays an important part in its development. In many instances the cartilage persists, and is not converted into bone, as in the case of the articular cartilage which clothes the joint surfaces, the nasal septum, the cartilages of the nose, and the cartilages of the ribs. A persistence of the membranous condition is met with in man in the case of the tentorium cerebelli, which in some groups of animals (Carnivora) is converted into a bony partition.

Skeletal structures may be derived from each of the three layers of the trilaminar blastoderm. The exo-skeleton includes structures of ectodermal, and some of mesodermal origin, in the shape of hair, nails, feathers, teeth, scales, armourplates, etc., whilst the endo-skeleton, with which we are more particularly concerned, is largely derived from the mesodermal tissue, but also includes the notochord, an entodermal structure which forms the primitive endo-skeleton, around which the axial skeleton is subsequently developed in the Vertebrata. The endo-skeleton is divisible into an axial portion, appertaining to the trunk and head, and an appendicular part associated with the limbs. It also includes the splanchnic skeleton, which comprises certain bones developed in the substance of some of the viscera, such as the os cordis and os penis of certain mammals. In man, perhaps, the cartilaginous framework of the trachea and bronchi may be referred to this system.

The number of the bones of the slieleton of man varies according to age. Owing to a process of fusion taking place during growtl, the 11 muber in the adlult is less than the number in the child. The following table does not include the sesamoid bones, which are frequently dereloped in tendons, the most constant ossicles of this description being those in relation to the metrearpo-phalangeal joint of the thumb, and the metatarso-phalangeal joint of the great trig. 
The table represents the number of bones distinct and separable during adult life :-

\begin{tabular}{|c|c|c|c|c|}
\hline \multirow{6}{*}{ Axial skeleton } & & Single Bones. & Pairs. & Total. \\
\hline & The vertebral columm & 26 & & \\
\hline & The skull . & 6 & 8 & 22 \\
\hline & The sternum & 1 & & 1 \\
\hline & The ribs & - & 12 & 24 \\
\hline & & 1 & & 1 \\
\hline Appendicular skeleton & The lipper limbs & $\cdots$ & 32 & 64 \\
\hline \multirow[t]{2}{*}{ The ossicles of the ear } & . & $\cdots$ & 3 & 6 \\
\hline & & 34 & 86 & 206 \\
\hline
\end{tabular}

Bones are often classified according to their shape. Thus long bones, that is to say, bones of elongated cylindrical form, are more or less characteristic of the limbs. Broad or flat bones are plate-like, and serve as protective coverings to the structures they overlie; the bones of the cranial vault display this particular form. Other bones, such as the carpus and tarsus, are termed short bones; whilst the bones of the cranial base, the face, and the vertebræ, are frequently referred to as irregular bones.

Various descriptive terms are applied to the prominences commonly met with on a bone, such as tuberosity, eminence, protuberance, process, tubercle, spine, ridge, crest, and line. These may be articular in their nature, or may serve as points or lines of muscular and ligamentous attachment. The surface of the bone may be excavated into pits, depressions, fossce, cavities, furrows, grooves, and notches. These may be articular or non-articular, the latter serving for the reception of organs, tendons, ligaments, vessels, and nerves. In some instances the substance of the bone is hollowed out to form an air space, sinus, or antrum. Bones are traversed by foramina and canals; these may be for the entrance and exit of nutrient vessels, or for the transmission of vessels and nerves from one region to another. A cleft, hiatus, or fissure serves the same purpose. Channels of this kind are usually placed in the line of a suture, or correspond to the line of fusion of the primitive portions of the bone which they pierce.

Composition of Bone.-Bone is composed of a combination of organic and inorganic substances in about the proportion of one to two.

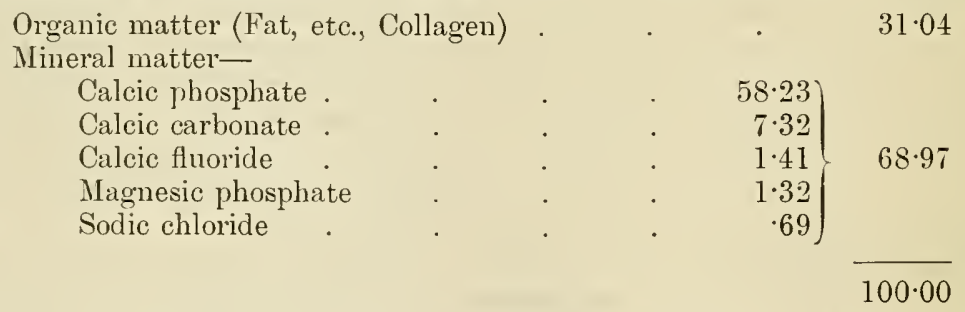

The animal matter may be removed by boiling or charring. According to the completeness with which the fibrous elements have been withdrawn, so the brittleness of the bone increases. When subjected to high temperatures the earthy matter alone remains. By soaking a bone in acid the salts may be dissolved out, leaving only the organic part. The shape of the bone is still retained, though it has now become soft, and can be bent about in any direction. The toughness and elasticity of bone depends therefore on its organic constituents, whilst its hardness is due to its mineral matter.

Bone may be examined either in the fresh or dry condition. In the former state it retains all its organic parts, which include the fibrous tissue in and around it, the blood-vessels and their contents, together with the cellular elements found within the substance of the bone itself, and the marrow which occupies the lacunar spaces and marrow cavity. In the dried or macerated bone most of these have disappeared, though a considerable portion of the organic matter still remains, even in bones of great antiquity and in a more or less fossil condition. Considering its nature and the amount of material employed, bone possesses a remarkable strength, equal to nearly twice that of oak, whilst it is capable of resisting a 
greater crushing strain; it is stated that a cubic inch of bone will support a weight of over two tons. Its elasticity is remarkable, and is of the greatest service in enabling it to withstand the shocks to which it is so frequently subjected. In regions where wood is scarce the natives use the ribs of large mammals as a substitute in the construction of their bows. Its hardness and density vary in different parts of the skeleton, and its permanency and durability exceed that of any other tissue of the body, except the enamel and dentine of the teeth. The osseous remains of a race over eighty centuries old are now being excarated in Egypt.

Structure of Bone (Macroscopic).-To obtain an idea of the structure of a bone it is necessary to examine it both in the fresh or recent condition and in the macerated state. In the former the bone is covered by a membrane which is with difficulty torn off, owing to the abundance of fine fibrils which enter the substance of the bone from its deep surface. This membrane, called the periosteum, overlies the bone, except where the bone is coated with cartilage. This cartilage may form a bond of union between contiguous bones or, in the case of bones united to each other by movable joints, may be moulded into smooth articular surfaces called the articular cartilages. The attachment of the various ligaments and muscles can also be studied, and it will be noticed that where tendon or ligament is attached, the bone is often roughened to form a ridge or eminence; where fleshy muscular fibres are attached, the bone is, as a rule, smooth. In the macerated condition, when the cartilage and fibrous elements have been destroyed, it is possible, howerer, to determine with considerable accuracy the parts of the bone corered with articular cartilage, since the bone here is smooth and conforms generally to the curves of the articular areas of the joint; these areas are referred to as the articular surfaces of the bone. The bone stripped of its periosteal correring displays a dense surface finely pitted for the entrance of the processes derived from the periosteum, which thus establish a connexion between the bony substance and that vascular layer; here and there, more particularly in the neighbourhood of the articular extremities, these pits increase in size and number and allow of the transmission of small blood-vessels. If careful examination is made, one or two foramina of larger size will usually be noticed. These vascular foramina or canals allow the passage of arteries of considerable size into the interior of the bone, and are called the canales nutricii or nutrient canals or fnomina of the bone. There are also corresponding channels for the escape of reins from the interior.

In order more fully to ascertain the structure of bone it will be necessary to study it in section. Taking first a long bone, such as one meets with in the extremities, one notices on longitudinal section, that the bone is not of the same density throughout, for, whilst the external layers are solid and compact, the interior is made up of loose spongy bone called substantia spongiosa (cancellous tissue). Further, it will be observed that in certain situations this spongy substance is absent, so that there is a hollow in the interior of the bone called the medullary cavity. In the recent condition this cavity is filled with the marrow and is hence often called the marrow cavity. This marrow, which fills not only the marrow cavity but also the interstices between the cancellous fibres, consists largely of fat cells together with sorne marrow cells proper supported by a kind of retiform tissue. The appearance and constituents of this marrow differ in diflerent situations. In the medullary cavity of long bones the marrow, as above described, is known as medulla ossium flara (yellow marrow). In other situations, viz., in the diploë of the cranial bones (to be hereafter described), in the spongy tissue of such bones as the rertebre, the sternum, and the ribs, the marrow is more fluid, less fatty, and is characterised by the presence of marrow-cells proper, which resemble in some respects colourless blood corpuscles. In addition to these, however, there are small reddish-coloured cells, akin to the nucleated red corpuscles of the blood of the embryo. These cells (erythroblasts) are concerned in the formation of the coloured corpuscles of the blood. Marrow which displays these characteristic appearances is listinguished from the yellow variety, already described, by being called the medulla ussium $v^{*} u b r a$ (red marrow). The narrow met with in the cancellous tissue of the cranial bones of aged individuals often undergoes degenerative chinges and is sometinies referred to as gelatinous marrow. 
A better idea of the disposition of the bony framework of a long bone can be obtained by the examination of a section of a macerated specimen. Here the marrow has been destroyed and the osseous architecture of the bone is consequently better displayed.

Within the shaft is seen the marrow cavity extending towards, but not reaching, either extremity of the bone. This cavity is surrounded on all sides by a loose spicular network of bone, which gradually increases in compactness until it reaches the circumference of the shaft, where it forms a dense surrounding wall. In the shaft of a long bone the thickness of this onter layer is not the same throughout, but tends to diminish as we approach the extremities, nor is it of uniform thickness on all sides of the bone. All the long bones display curves in varying degree, and it is a uniform rule that the thicker dense bone is found along the concave surface of the curse, thus assisting in materially strengthening the bone. Towards the extremities of the long bone the structure and arrangement of the bone undergoes a change. There is no marrow cavity, the spongy tissue is not so open and irregular, and the external wall is much thinner than in the shaft; indeed in many instances it is little thicker thau stout paper. A closer examination of the arrangement of this spongy tissue throughout the bone suggests a regularity in its arrangement which might escape notice: and if, in place of one bone only being examined, sections of other bones are also inspected, it will be observed that the spicules of this tissue are so arranged as best to withstand the strains and stresses to which the bone is habitually subjected.

From what has been said it will be obvious that the arrangements above described are those best adapted to secure the maximum of strength with the minimum of material, and a consequent reduction in the weight of the skeleton. The same description applies, with some modification, to bones of flattened form. Taking as an example the expanded plate-like bones of the cranial vault, their structure, as displayed on section, exhibits the following appearance: The onter and inner surfaces are formed by two compact and dense layers, having sandwiched between them a layer of spongy tissue called the diploë, containing red marrow. Note that there is no medullary cavity, though in certain situations and at certain periods of life the substance of the diploë may become absorbed and converted, by the evagination of the mucous membrane of the respiratory tract, into air-spaces or air-sinuses.

Structure of Bone (Microscopic).-True bone differs from calcified cartilage or membrane in that it not merely consists of the deposition of earthy salts within its matrix, but displays a definite arrangement of its organic and inorganic parts. Compact bone merely differs from loose or spongy bone in the denseness of its tissue, the characteristic feature of which is the arrangement of the osseous lamellæ to form what are called Haversian systems. These consist of a central or Haversian canal, which contains the vessels of the bone. Around this the osseous lamellæ are arranged concentrically, separated here and there by interspaces called lacunæ, in which the bone corpuscles are lodged. Passing from these lacunæ are many fine channels called canaliculi. These are disposed radially to the Haversian canal, and pass through the osseous lamellæ. They are occupied by the slender processes of the bone corpuscles. Each Haversian system consists of from three to ten concentric rings of osseous lamellæ.

In addition to the lamellæ of the Haversian systems there are others which are termed the interstitial lamellæ; these occupy the intervals between adjoining Haversian systems, and consist of Haversian systems which have undergone a process of partial absorption. Towards the surface of the bone, and subjacent to the periosteal membrane which surrounds the shaft, there are lamellæ arranged circumferentially; these are sometimes referred to as the outer fundamental lamellæ. The periosteal membrane which surrounds the bone, and which plays so important a part in its development, sends in processes through the various Haversian systems, which carry with them vessels and cells, thus forming an organic meshwork around which the earthy salts are deposited.

Ossification of Bone.-For an account of the earlier development of the skeleton the reader is referred to the section on Embryology. Concerning the 
subsequent changes which take place, these are dependent on the conversion of the scleratogenous tissue into membrane and cartilage. A characteristic of this tissue is that it contains elements which become formed into bone-producing cells, called osteoblasts. These are met with in the connective tissue from which the membrane bones are formed, whilst they also appear in the deeper layers of the investing tissue of the cartilage (perichondrium), and so lead to its conversion into the boneproducing layer or periosteum. All true bone, therefore, may probably be regarded as of membranous origin, though its appearance is preceded in some instances by the deposition of cartilage; in this case calcification of the cartilage is an essential stage in the process of bone formation, but the ultimate conversion into true bone, with characteristic Haversian systems, leads to the absorption and disappearance of this primitive ealcified cartilage. In considering the development of bone an inspection of the skeleton of a foetus will enable the student to realise that much of what is bone in the adult is preformed in cartilage, whilst a part of the fully developed skeleton is represented only by membrane: hence, in regard to this ossification, bones have been described as of cartilaginous and membranous origin. If the development of a long bone is traced through successive stages from the cartilaginous condition in which it is preformed, it will be noticed that ossification first begins in the shaft. This ossific centre is referred to as the diaphysis, and, since it is the first to appear, is also spoken of as the primary centre of ossification. As yet, the extremities of the shaft are cartilaginous knobs, but at a later stage one or more ossific centres appear in these cartilaginous extremities. These centres, which are independent of the diaphysis and appear much later, at variable periods, are termed epiphyses or secondary centres. If there are more than one such centre at the extremity of a bone, these associated centres unite, and at a later stage the osseous mass so formed joins with the shaft or diaphysis, and in this way the formation of the bone is completed. Complete fusion by osseous union of the epiphyses with the diaphyses occurs at variable periods in the life of the individual. Prior to this taking place, the two are bonded together by a cartilaginous layer which marks the position of the epiphyseal line. If the bone is macerated at this stage of growth, the epiphysis falls away from the diaphysis. In the case of the articular ends of bone it will be noticed that the surfaces exposed by the separation of the epiphysis from the diaphysis are not plane and smooth, but often irregular, notched, and deeply pitted, so that when the two are brought together they interlock, and, as it were, dovetail into each other. In this way the extremities of the bone as yet ununited by osseous growth are, during youth and adolescence, able to withstand the shocks and jars to which during life they are habitually subjected. A long bone has been taken as the simplest example, but it by no means follows that these secondary centres or epiphyses are confined to the articular extremities of long bones. They are met with not only in relation to the articular surfaces of bones of varied form, but also occur where bones may be subjected to unusual pressure or to the strain of particular muscles. For this reason epiphyses of this nature have been called pressure and traction epiphyses (Parsons). There occur, however, secondary independent centres of ossification, which cannot be so accounted for. Possibly these are of phylogenetic interest only, and may accordingly be classed as Atavistic.

Ossification in Membrane.-Membrane bones are such as have developed from fibrous tissue without having passed through a cartilaginous stage. Of this nature are the bones of the cranial vault and the majority of the bones of the face, viz., the maxillæ, zygomatic (malar), nasal, lacrimal, and palate bones, as well as the vomer. The medial lamina of the pterygoid process (internal pterygoid plate) is also of membranous origin. In the course of the development of a bone from membrane, as, for example, the parietal bone, the fibrous tissue corresponding to the position of the primary centre becomes osteogenetic, because here appear the bone-forming cells (osteoblasts), which rapidly surround themselves with a bony deposit more or less spicular in arrangement. As growth goes on these osteoblasts become embedded in the ossifying matrix, and remain as the corpuscles of the future bone, the spaces in which they are lodged corresponding to the lacune and canaliculi of the fully developed osseous tissue. From the primary centre ossifica- 
tion spreads eccentrically towards the margins of the bone, where ultimately the sutures are formed. Here the growth rendered necessary by the expansion of the cranium takes place through the agency of an intervening layer of vascular connective tissue rich in osteoblasts; but in course of time the activity of this is reduced until only a thin layer of intermediate tissue persists along the line of the suture; this may eventually become absorbed, leading to the obliteration of the suture by the osseous union of the contiguous bones. Whilst the expansion of the bone in all directions is thus provided for, its increase in thickness is determined by the activity of the underlying and overlying strata. These form the periosteum, and furnish the lamelle which constitute the inner and outer compact osseous layers.

Ossification in Cartilage.--Cartilage bones are those which are preformed in cartilage, and include most of the bones of the skeleton. Their growth is often described as endochondral and ectochondral, the former term implying the deposition of membrane bone in the centre of the cartilage, while the latter signifies a deposit of membrane bone on the surface of the cartilage, the osteogenetic layer on the surface of the cartilage being named the perichondrium till once bone has been formed, when it is called the periosteum.

In a cartilage bone changes of a similar nature occur. The cartilage, which may be regarded histologically as white fibrous tissue + chondro-sulphuric acid and a certain amount of lime salts, undergoes the following changes :-First, the cartilage cells being arranged in rows, become enlarged; secondly, the matrix between the cartilage cells becomes calcified by the deposition of an additional amount of lime salts; thirdly, the rows of cells become confluent; and, fourthly, into the spaces so formed extend the blood-vessels derived from the vaseular layer of the periosteum. Accompanying these vessels are osteoblasts and osteoclasts, the former building up true bone at the expense of the calcified cartilage, the latter causing an absorption of the newly formed bone, and leading to its conversion into a marrow cavity, so that in due course all the cartilage or its products disappear. At the same time that this is taking place within the cartilage, the perichondrium is undergoing conversion into the periosteum, an investing membrane, the deeper stratum of which, highly vascular, furnishes a layer of osteoblast cells which serve to develop the circumferential lamellæ of the bone. It is by the accrescence of these layers externally, and their absorption internally through the action of the osteoclast cells, that growth takes place transversely. A transverse section of the shaft of a long bone shows this very clearly. Centrally there is the marrow cavity, formed primarily by the absorption of the calcified cartilage; around this the spongy tissue produced by the partial erosion of the primary periosteal bone is disposed, whilst externally there is the dense envelope made up of the more recent periosteal growth.

Growth of Bone.-The above description, whilst explaining the growth of bone circumferentially, fails to account for its growth in length; hence the necessity in long bones for some arrangement whereby ossification may take place at one or both extremities of the shaft. This zone of growth is situated where the ossified shaft becomes continuous with the cartilaginous epiphysis. In addition, within these epiphysial cartilages calcification of the cartilage takes place centrally, just as in the diaphysis. The two parts of the bone, viz., the diaphysis and epiphysis, are thus separated by a layer of cartilage, sometimes called the cartilage of conjugation, as yet uncalcified, but extremely active in growth owing to the invasion of vessels and cells from a vascular zone which surrounds the epiphysis. The nucleus of the epiphysis becomes converted into true bone, which grows eccentrically. This arrangement provides for the growth of the shaft towards the epiphysis, and the growth of the epiphysis towards the shaft; so that as long as the active intervening layer of cartilage persists, extension of growth in a longitudinal direction is possible. As might be expected, experience proves that growth takes place more actively, and is continued for a longer time, at the end of the bone where the epiphysis is the last to unite. In consequence, surgeons sometimes term this the "growing end of the bone." Subsequently, however, at variable periods the intervening layer of cartilage becomes calcified, and true bony growth occurs within it, thus leading to complete osseous union between the shaft and epiphysis. When this has taken place all further growth in a longitudinal 
direction ceases. In cases where the epiphysis enters into the formation of a joint, the cartilage over the articular area persists and undergoes neither calcification nor ossification.

Vascular, Lymph, and Nervous Supply of Bone.-From what has been said it will be gathered that the vascular supply of the bone is derived from the vessels of the periosteum. These consist of fine arteries which enter the surface of the diaphysis and epiphysis; but in addition there is a larger trunk which enters the diaphysis and reaches the medullary cavity. This is called the nutrient artery of the bone. The direction taken by this vessel varies in different bones. In the upper limb the artery runs distally in the case of the humerus and proximally in the radius and ulna; in the lower limb the nutrient vessel of the femur is directed towards the proximal extremity of the shaft, whilst in the tibia and fibula. it follows a distal course. The direction of the nutrient artery in the bone is a mechanical result of the unequal growth of the two extremities of the bone. During the greater part of intra-uterine life the principal nutrient arteries of the long bones are directed towards the distal extremity of the limb. In the process of development the point of entrance of the artery is turned away from the epiphysis which furnishes the greatest amount of bone, and thus, together with the nutrient canal, acquires an obliquity directed towards the extremity of the bone which develops last (Piollet, J. de l'Anat. et de la Phys., 1905, p. 57).

It may assist the memory to point out that when all the joints are flexed, as in the position occupied by the fœetus in utero, the direction taken by the ressels is the same, and corresponds to a line passing from the head towards the tail-end of the embryo. Consequently, in the upper limb the vessels run towards the elbow, whilst in the lower limb they pass from the knee.

The veins which permeate the spongy texture of the bone are large and thinwalled. They do not accompany the arteries, and, as a rule, in long bones they escape through large openings near the articular surfaces. In flat bones they occupy channels within the diploë, and drain into an adjacent sinus, or form communications with the superficial veins of the scalp.

The lymph vessels are mainly periosteal, but enter the bone along with the blood-vessels and become perivascular.

The nerves which accompany the arteries are probably destined for the supply of the coats of these vessels. Whether they end in the bony tissue or not is unknown.

The attention of anatomists has long been directed to the elucidation of the laws which regulate bone-growth. Our present knowledge of the subject may be briefly summarised in the following generalisations:-

1. In bones with a shaft and two epiphyses, the epiphysis towards which the nutrient artery is directed is the first to unite with the shaft.

2. In bones with a shaft and two epiphyses, as a rule the epiphysis which commences to ossify latest unites soonest with the shaft. (The fibula is a notable exception to this rule.)

3. In bones with a shaft and one epiphysis the nutrient artery is directed towards the end of the bone which has no epiphysis. (This arrangenent holds good in the case of the clavicle, the metacarpus, metatarsus, and phalanges.)

4. When an epiphysis is ossified from more than one centre, coalescence takes place between the separate ossific nuclei before the epiphysis unites with the shatt.

Highly suggestive, too, are the following propositions-That ossitication first commences in the epiphysis which ultimately acquires the largest relative 1roportion to the rest of the bone, and that the ossification of the epiphysis is also correlated with its functional importance. In cases of long bones with only one epiphysis, the epiphysis is placed at the encl of the bone where there is most movement.

\section{COLUIM NA VERTEBRALIS.}

The vertebral column of man cousists of thirty-three superposed segments or vertebræ. In the adult, certain of these vertebrie have become fused together in the process of growth to foru bones, the segmental arrangement of which 
is somewhat obscured, though even in their fully developed condition sufficient evidence remains to demonstrate their compound nature. The vertebrie so blended are termed the fixed or false vertebræ, whilst those between which osseous union has not taken place are described as the movable or true vertebræ. This fusion of the vertebral segments is met with at either extremity of the rertebral column, more particularly below, where the column is Inodified to adapt it for union with the girdle of the lower limb, and also in the region of man's degenerated caudal appendage. But a partial union of the vertebral segments also takes place above, between the two highest vertebre, in association with the mechanism necessary to provide for the movements of the head on the column.

For descriptive purposes the vertebral column is subdivided according to the regions through which it passes. Thus the vertebræ are described as cervical (vertebræ cervicales), thoracic (vertebræ thoracales), lumbar (vertebræ lumbales), sacral (vertebræ sacrales), and coccygeal (vertebræ caudales), according as they lie in the regions of the neck, thorax, loins, pelvis, and tail. The number of vertebræ met with in these regions is fairly constant, though, as will be hereafter pointed out, variations may occur in the number of the members of the different series. The vertebræ in man are thus apportioned - 7 cervical, 12 thoracic, 5 lumbar, 5 sacral, and 4 or 5 coccygeal ; the three former groups comprise the true or movable vertebræ, the two latter the false or fixed vertebræ. The vertebral formula may be thus expressed :-

Movable or True Vertebræ.

Cervical. Thoracic. Lumbar. $\begin{array}{lll}7 & 12 & 5\end{array}$
Fixed or False Vertebræ.

Sacral. Coccygeal.

$5 \quad 4=33$.

The vertebræ, though displaying great diversity of characters in the regions above enumerated, yet preserve certain features in common. All possess a solid part, corpus vertebræ or body (centrum); all have articular processes by which they articulate with their fellows; most have muscular processes developed in connexion with them; whilst the majority display a vertebral foramen formed by the union of a bony arcus vertebræ (vertebral arch) with the body. These common characters may best be studied by selecting for description an intermediate member of the series. For this purpose one of the middle or lower thoracic vertebræ may be chosen.

A typical vertebra may be described as consisting of a body composed of a mass of spongy bone, more or less cylindrical in form. The size and shape of the body is liable to considerable variation according to the vertebra examined. The superior and inferior surfaces of the body are very slightly concave dorsoventrally and from side to side, due to the thickening of the bone around its margins. In the recent condition these surfaces afford attachment for the intervertebral fibro-cartilages, which are placed like pads between the bodies of the movable members of the series. The circumference of the body, formed as it is of more compact bone than the interior, is usually slightly concave from above downwards, though the dorsal surface becomes flat, where the body forms the anterior boundary of the rertebral foramen, at which point it is usually slightly concave from sicle to side. The vertical surfaces of the body are pierced here and there by foramina for the passage of nutrient vessels, more particularly on the dorsal surface, where a depression of considerable size receives the openings of the canals through which some of the veins which drain the body of the bone escape. Connected with the body posteriorly there is a bony vertebral arch, which, by its union with the body, encloses a foramen of variable size, the vertebral foramen. When the vertebræ are placed on the top of each other these foramina form, with the uniting ligaments, a continuous canal-vertebral canal-in which the spinal medulla with its coverings is lodged. The vertebral arch, which is formed by the union of the roots of the vertebral arches (pedicles) and laminæ, besides enclosing the vertebral foramen, also supports the spinous and transverse processes, which may be regarded as a series of levers to which muscles are 
attached, whilst others are articular and assist in uniting the different vertebra together by means of a series of movable joints. The roots of the vertebral arches (O.T. pedicles) are the bars of bone which pass from the dorsum of the body of the vertebræ on either side to the points where the articular processes are united to the arch. These roots are compressed laterally, and have rounded superior and inferior borders. Since the vertical breadth of the roots is not as great as the thickness of the body to which they are attached, it follows that when the vertebræ are placed one above the other a series of intervals is left between the roots of the vertebral arches of the different vertebræ. These spaces, enclosed anteriorly by the bodies of the vertebræ and their intervertebral fibrocartilages and posteriorly by the coaptation of the articular processes, form a series of holes communicating with the rertebral canal; these are called the intervertebral foramina, and allow the transmission of spinal nerves and vessels. As each intervertebral foramen is bounded above and below by one of the roots of the vertebral arch, the grooved surfaces in correspondence with the upper and lower borders of the roots are called the incisurae vertebrales superior et inferior (upper and lower intervertebral notches). Posteriorly, the two roots of the vertebral arch are united by two somewhat flattened plates of bone-the laminæ, which converge towards the median plane, and become fused with the root of the projecting spinous process. The breadth of the laminæ and their
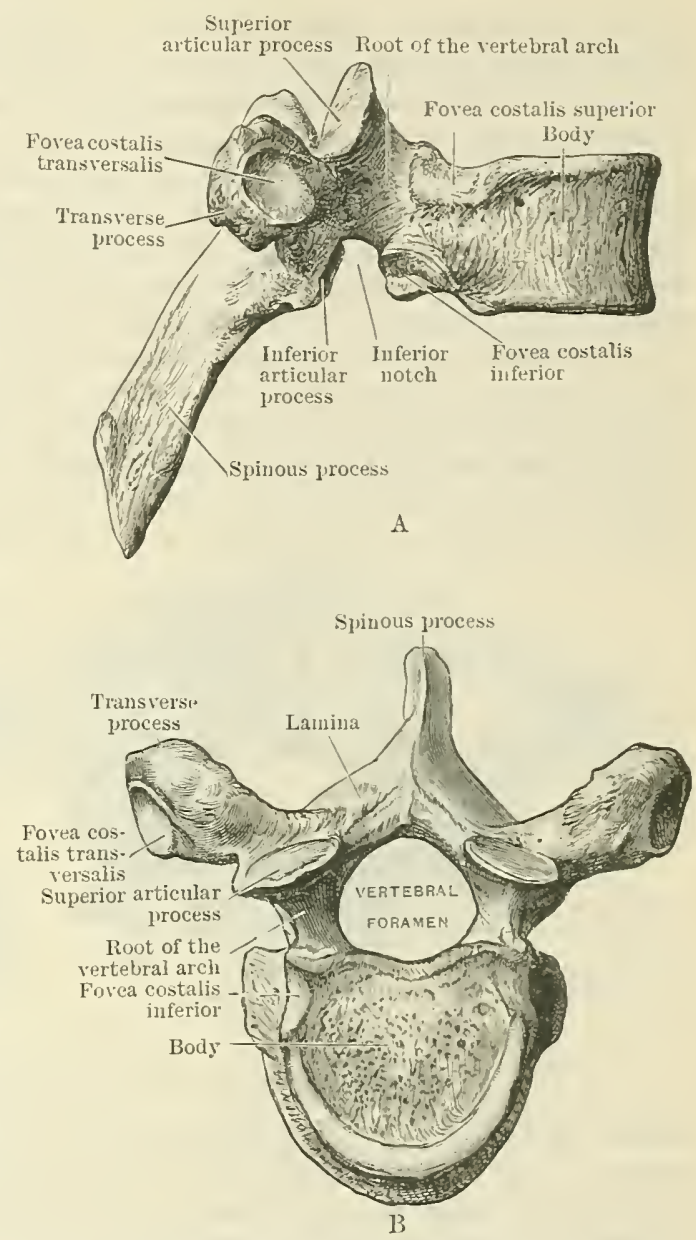

Fig. 106.-Firth THuracic Tertebla, (A) as viewerl from the right sicle, $(B)$ as viewed from above. sloping arrangement are such, that, when the vertebræ are articulated together, they leave little space between them, thus enclosing fairly completely the vertebral canal, of which they form the posterior wall. The edges and inner surfaces of the lamina are rough for the attachment of the ligaments which bind them together.

The muscular processes are three in number, viz., two processus transversione on either side-and one central or median, the processus spinosus. The transverse processes project laterally on either side from the arch at the point where the root of the rertebral arch joins the lamina. The spinous process extends backwards in the median plane from the point of fusion of the lamince. The spinous processes display much variety of length and form.

The articular processes (zygapophyses), four in number, are arranged in pairsone superior, the other inferior; the former are placed on the upper part of the arch where the roots of the arch (pedicles) and laminie join, the latter on the lower part of the arch in correspondence with the superior. Whilst differing much in the direction of their articular surfaces, the upper have generally a backward tendency, whilst the lower incline forwards. 


\section{THE TRUE OR MOVABLE VERTEBRAE.}

\section{Vertebrae Cervicales.}

The cervical vertebræ, seven in number, can be readily distinguished from all the other vertebræ by the fact that their transverse processes are pierced by a foramen. The two highest, and the lowest, require special description; the remaining four conform to a common type.

Their bodies, the smallest of all the true vertebræ, are oblong in shape, the transverse diameter being much longer than the antero-posterior width. The superior surface, which slopes from behind forwards and downwards, is concave from side to side, owing to the marked projection of its lateral margins. Its anterior lip is rounded off, whilst its posterior edge is sharply defined.

The inferior surface, which is more or less saddle-shaped, is directed downwards and backwards. It is convex from side to side, and concave from before backwards, with a slight rounding off of the projecting anterior lip. The vertical diameter of the body is small in proportion to its width. The anterior surface is flat in the middle line, but furrowed laterally. The posterior surface, which is rough and pierced by many small foramina, is flat from side to side and above down-
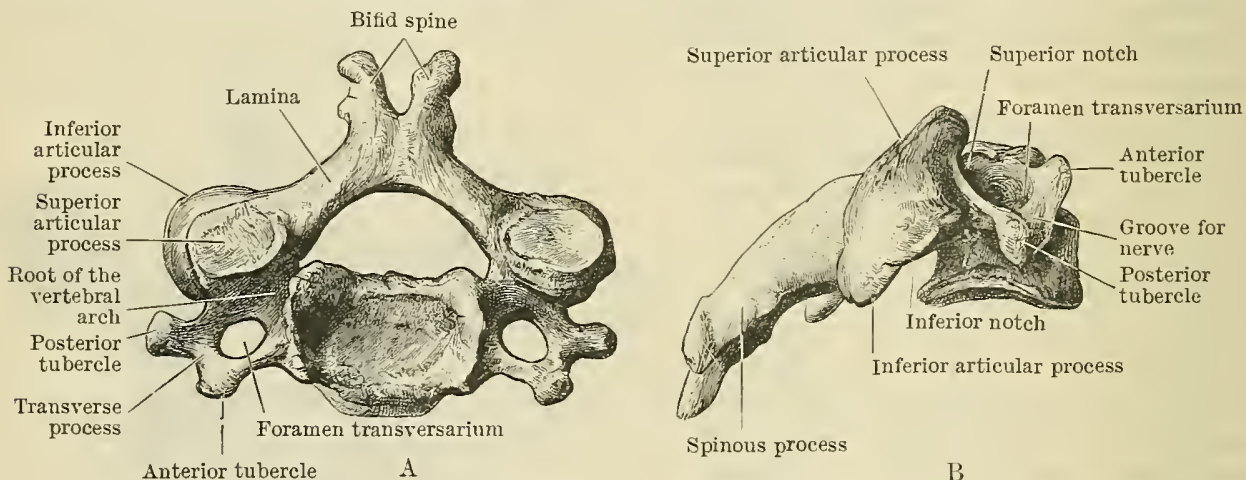

Fig. 107.-Fourth Cervical Vertebra, (A) from above, and (B) from the right side.

wards; it forms part of the anterior wall of the vertebral foramen. The lateral aspects of the body, particularly in their upper parts, are fused with the costal parts of the transverse processes, and form the medial wall of the foramen transversarium. The roots of the vertebral arches, which spring from the posterior half of the lateral aspects of the body, abont equidistant from their superior and inferior margins, are directed horizontally backwards and laterally. The superior and inferior notches are nearly equal in depth. The laminæ are long, and about as wide as the body of the bone is thick. The vertebral canal is laryer than in the thoracic and lumbar regions; its shape is triangular, or more nearly semilunar. The transverse processes, so called, are pierced by the foramen transversarium (vertebrarterial or transverse foramen). They consist of two parts - the part behind the foramen, which springs from the vertebral arch and is the true transverse process, and the part in front, which is homologous with the ribs in the thoracic portion of the column. These two processes, united laterally by a bridge of bone, which thus converts the interval between them into a foramen, terminate in two tubercles, known as the tubercula anterius et posterius (anterior and posterior tubercles). The general direction of these processes is laterally, slightly forwards, and a little downwards, the anterior tubercles lying medial to the posterior. The two tubercles are separated above by a groove directed laterally, downwards, and forwards; along this the spinal nerve trunk passes. The foramen transversarium is often subdivided by a spicule of bone, and is traversed by the vertebral artery and vein in the upper six vertebræ. The spinous processes, which are directed backwards, are short, compressed vertically, and bifid. The articular processes are supported on cylindrical masses of bone fused with the arch where the roots 
of the vertebral arches and the laminæ join. These cylinders are sliced away obliquely above and below, so that the superior articular facets, more or less circular in form, are directed upwards and backwards, whilst the corresponding inferior surfaces are turned downwards and forwards.

The Atlas or First Cervical Vertebra.-This bone may be readily recognised by the absence of the body and spinous process. It consists of two lateral masses, which support the articular and transverse processes. The lateral inasses are themselves united by two curved bars of bone, the anterior and posterior arches, of which the former is the stouter and shorter. Each lateral mass is irregularly six-sided, and so placed that it lies closer to its fellow of the opposite side in front than behind. Its upper surface is excavated to form an elongated oval facet called the fovea articularis superior, which is concave from before backwards, and inclined obliquely medially; not infrequently this articular surface displays indications of division into two parts. These facets are for the reception of the condyles of the occipital bone.

The foveæ articulares inferiores (inferior articular facets) are placed on the inferior surfaces of the lateral masses. Of circular form, they display a slight sideto-side concavity, though flat in the antero-posterior direction. Their disposition is such that their surfaces incline downwards and slightly medially. They rest on the superior articular processes of the second cervical vertebra or epistropheus. Springing from the anterior and medial aspects of the lateral masses, and uniting them in front, is a curved bar of bone, the arcus anterior (anterior arch); compressed on either side, this is thickened centrally so as to form on its anterior aspect the rounded tuberculum anterius (anterior

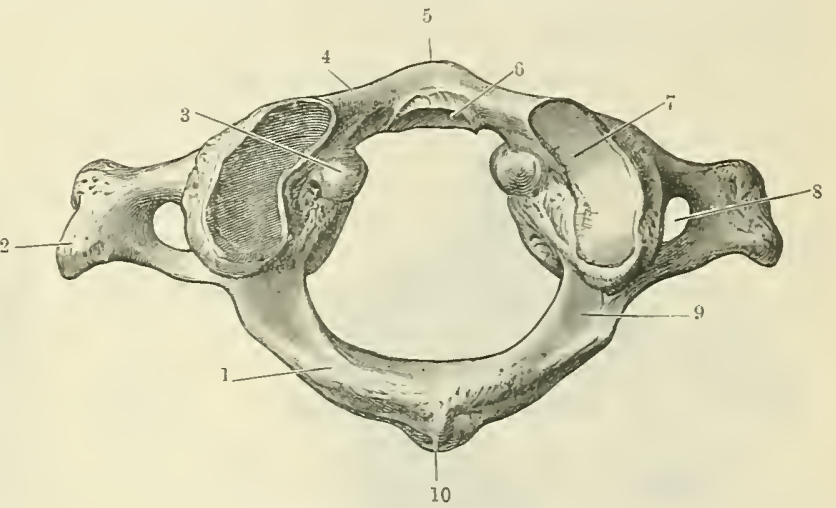

FIG. 108. -THE ATLAS FroM ABOTE.

1. Posterior alch.

2. Transverse process.

3. Tubercle for transverse ligament.

4. Anterior arch.

5. Anterior tubercle.
6. Surface for articulation with dens.

7. Superior articular surface.

8. Foramen for vertebral artery.

9. Groove for vertebral artery.

10. Posterior tubercle.

tubercle). In correspondence with this, on the posterior surface of this arch is a circular facet (fovea dentis) for articulation with the dens of the epistropheus.

The medial surface of the lateral mass is rough and irregular, displaying a little tubercle for the attachment of the transverse ligament of the atlas, which passes across the space inchded between the two lateral masses and the anterior arch, thus holding the dens of the epistropheus in position. Behind each tubercle there is usually a deep pit, opening into the bottom of which are the canals for the nutrient vessels.

Laterally to the lateral mass, and principally from its upper half, the trausverse process arises by two roots which inclucle between them the foramen transversarium. The transverse process is long, obliquely compressed, and down-turned; the anterior and posterior tubercles have fused to form one mass.

The posterior arch arises in part from the posterior surface of the lateral mass, and in part from the posterior root of the transverse process. Compressed from above downwards anteriorly, where it bounds a groove which curves around the posterior aspect of the superior articular process, which groore is also continuous laterally with the foramen transversarium, the posterior arch hecomes thicker medially, at which point it displays posteriorly a rough irregrular projection-the tuberculum posterius (posterior tubercle), the feeble representative of the spinous process. A prominent little tubercle, arising from the posteriur extremity of the superior articular process, overhangs the groove ahove mentioned, and not in- 
frequently becomes developed so as to form a bridge of bone across it, converting the groove into a canal through which the vertebral artery aud the posterior ramus. of the suboccipital nerve pass - a condition normally met with in many animals. It is noteworthy that the grooves traversed by the two highest spinal nerves lie behind the articular processes, in place of in front, as in other parts of the column.

The ring formed by the lateral masses and the anterior and posterior arches is of irregular outline. The anterior part, cut off from the rest by the transverse ligament, serves for the lodgment of the dens of the epistropheus; the larger part behind corresponds to the upper part of the vertebral canal.

Epistropheus or Second Cervical Vertebra.-This is characterised by the presence of the tooth-like dens (O.T. odontoid process) which projects upwards from the superior surface of the body. Slightly constricted where it joins the body, the dens tapers to a blunt point superiorly, on the sides of which there are surfaces for the attachment of the alar ligaments. When the atlas and epistropheus are articulated this process lies behind the anterior arch of the atlas, and displays on its anterior surface an oval or circular facet which rests on that on the posterior surface of the anterior arch of the atlas. On the posterior aspect of the neck of the dens there is a shallow groove in which lies the transverse ligament of the atlas, which holds it in position.

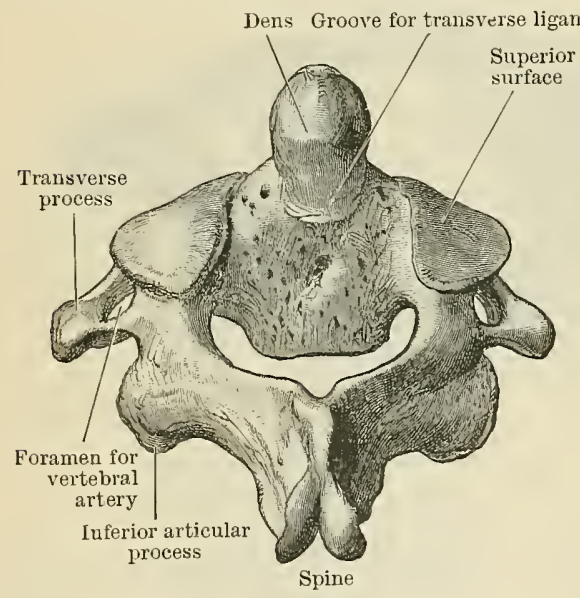

A

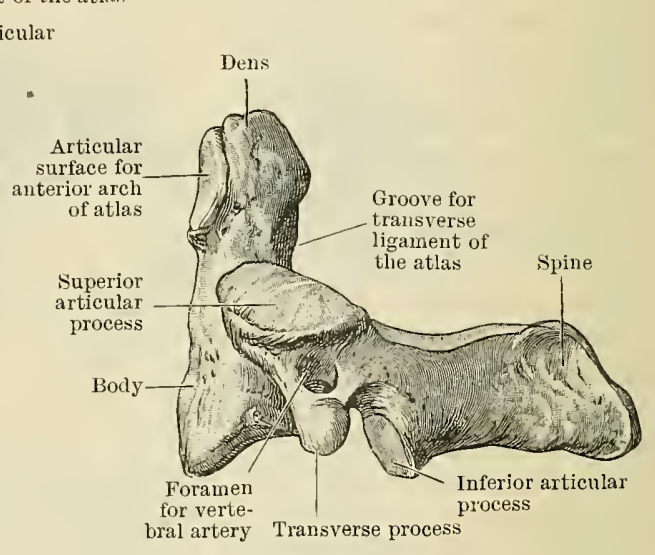

B

Fig. 109.-Epistropheus (O.T. Axis), (A) from behind and above, (B) from the left side.

The anterior surface of the body has a raised triangular surface, which ends superiorly in a ridge passing upwards to the neck of the dens. The roots of the vertebral arches are concealed above by the superior articular processes; inferiorly, they are deeply grooved. The laminæ-prismatic on section-are thick and strong, ending in a stout, broad, and bifid spinous process, the under surface of which is deeply grooved, whilst its sides meet superiorly in a ridge. Placed over the roots of the vertebral arches and the anterior root of the transverse processes are the superior articular surfaces. These are more or less circular in shape, slightly convex from before backwards, flat from side to side, and are directed upwards and a little laterally. They are channelled inferiorly by the foramina transversaria, which turn laterally beneath them. The grooves by which the second cervical nerves leave the vertebral canal cross the laminæ immediately behind the superior articular processes. The inferior articular processes agree in form and position with those of the remaining members of the series, and are placed behind the inferior intervertebral notches. The transverse process is markedly down-turned, with a single pointed extremity.

The sixth cervical vertebra often displays an enlargement of the anterior tubercle on the transverse process, called the carotid tubercle from the circumstance that the carotid artery may be conveniently compressed against it. It is necessary to add, however, that the tubercle is not always well developed. 
The seventh cervical vertebra (vertebra prominens) receives the latter name, from the outstanding nature of its spinous process, which ends in a single broad tubercle This forms a well-marked surface projection at the back of the root of the neck. The transverse processes are broad, being flattened from above downwards; they project considerably beyond those of the sixth. The maximum width between their extremities agrees with that between the transverse processes of the atlas, these two constituting the widest members of the cervical series. The anterior tubercle is very small and is placed near the body. The foramen transversarium is small and does not as a rule transmit the vertebral artery. Usually a small vein passes through it. Not infrequently the costal element is separate from the true transverse process, thus constituting a cervical rib.

\section{Vertebrae Thoracales.}

The thoracic vertebræ, twelve in number, are distinguished by having facets on the sides of their bodies for the heads of the ribs, and in most.instances also articular surfaces on their transverse processes for the tubercles of the ribs (Fig. 124, p. 111).

The body is described as characteristically heart-shaped, though in the upper and lower members of the series it undergoes transition to the typical forms of the cervical, and lumbar vertebræ, respectively. Its antero-posterior and transverse widths are nearly equal; the latter is greatest in line with the facets for the heads of the ribs. The bodies are slightly thicker behind than in front, thus adapting themselves to the anterior concavity which the column displays in this region. The bodies of the second to the ninth thoracic vertebræ inclusive, each possess four foveæ costales or costal facets, a superior pair placed on the superior margin of the body, close to the junction of the root of the vertebral arch with the body, and an inferior pair situated on the inferior edge, close to and in front of the inferior intervertebral grooves.

When contiguous vertebræ are articulated, the upper pair of facets of the lower vertebra coincide with the lower facets of the higher vertebra, and, together with the intervening intervertebral fibro-cartilage, form an articular cup for the reception of the head of a rib. Of these facets on the body the upper pair are the primary articular surfaces for the head of the rib; the lower are only acquired secondarily. Moreover, these facets, though apparently placed on the body, are in reality developerl on the sides of the roots of the vertebral arches behind the line of union of the roots with the body (neurocentral synchondrosis), as will be explained hereafter.

The roots of the vertebral arches (O.T. pedicles) are short and thick, and directed posteriorly and slightly upwards. The superior vertebral notch is faintly marked; the inferior is deep. The laminæ are broad, flat, and sloping, having sharp superior and inferior margins. When the vertebre are superposed the latter overlap the former in an imbricated manner. The vertebral foramen is smaller than in the cervical and lumbar regions, and nearly circular in shape.

The spinous processes vary in length and direction, being shorter and more horizontal in the upper and lower members of the series, longest and most oblique in direction towards the middle of this part of the colımn. Nearly all have a downward inclination, and are so arranged that they overlap one another. Triangular in section where they spring from the vertebral arch, they hecome laterally compressed towards their extremities, which are capped by more or less distinct tubercles. The transverse processes are directed backwards and laterally, and a little upwards. They gradually decrease in size and length from ahove downwards. Each has a somewhat expanded extremity, the anterior surface of which, in the case of the upper ten vertebræ, is hollowed out in the form of a circular facet for articulation with the tubercle of the rib which rests in the upper facet of the vertelura to which the transverse process belongs. The superior articular processes are vertical, and have their surfaces directed backwards, slightly upwards, and a little laterally; the inferior, correspondingly forwards, (lownwards, and medially.

Certain of the thoracic vertebre display characters by which they can readily 
be recognised. These are the first, tenth, eleventh, and twelfth, and sometimes

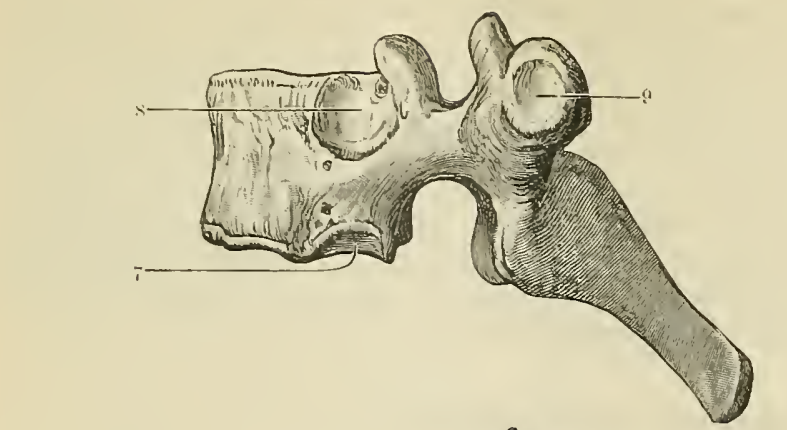

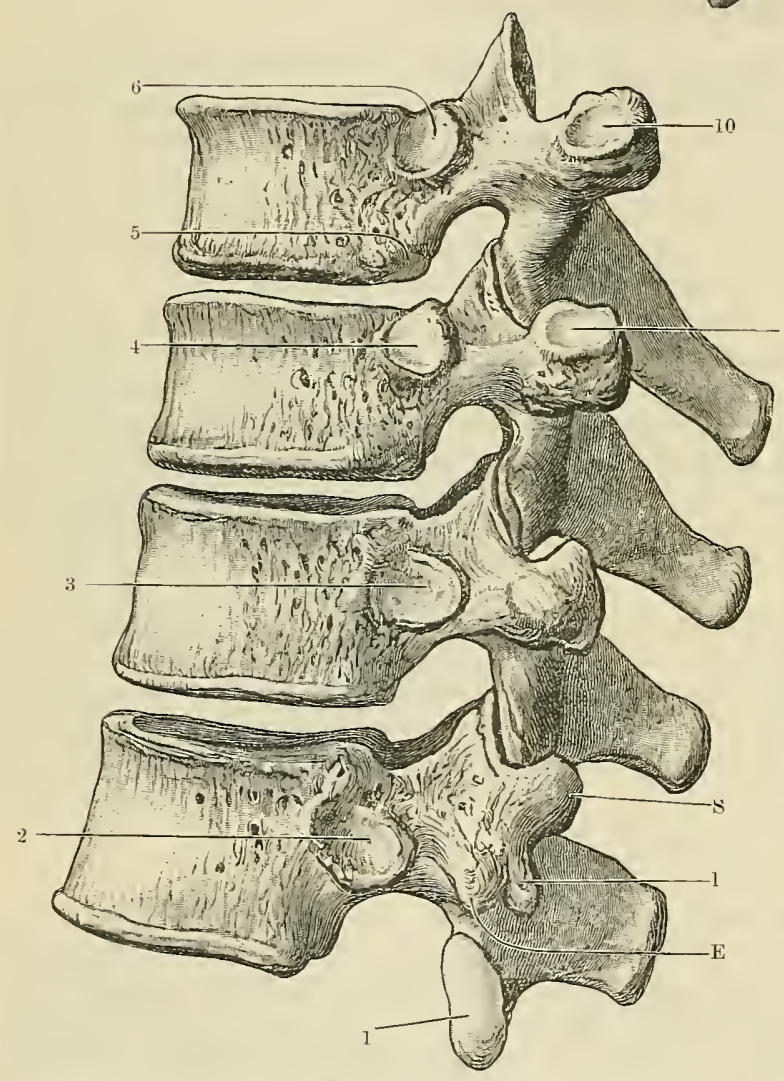

Fig. 110.--First, Ninth, Tenth, Eleventh, And Twelfth Thoracic Vertebre from the LeFt Side.

1. Inferior articular process with laterally turned facet.

2. Single facet for head of XIIth rib; 10. Facet on transverse process for no facet on transverse process.

3. Single facet for head of XIth rib no facet on transverse process.

4. Single facet for head of Xth rib.

5 . Occasional facet for liead of Xth rib.

6. Facet for head of IXth rib.

7. Facet for head of IInd rib.

8. Single facet for head of Ist rib.

\section{the ninth.}

The first thoracic vertebra resembles the seventh cervical in the shape of its body, and the length and direction of its spine. There is a cirenlar facet on either side of the body for the head of the first rib, and one facet on each side at the inferior border of its body, to complete the socket for the head of the second rib. Its transverse processes are long, and the superior intervertebral notch is better marked than in other members of the thoracic series. The superior articular surfaces are directed backwards and upwards, not laterally as in the lower members of the series.

The ninth thoracic vertebra occasionally has only the upper pair of facets on its body; at other times it conforms to the usual type.

The tenth thoracic vertebra may have only one complete costal facet on each side for the Xth rib, though sometimes thearticular socket may be completed by the ninth dorsal vertebra. The facet on the transverse process is generally small, and sometimes absent.

The eleventh thoracic vertebra has a complete circular facet on the lateral sicle of each root of the vertebral arch for articulation with the XIth rib. Its transverse processes are short and stunted, and have no facets.

The twelfth thoracic

11. Facet on transverse process for vertebra has a single facet tuberosity of Xth rib, in this on each root of the vertebral particular instance well arch for the XIIth rib. Its
marked. S. Superior Tubercles Mamillary. transverse processes, short 1. Inferior $\begin{gathered}\text { corre- } \\ \text { sponding }\end{gathered}$ Accessory. and stunted, have no facets,

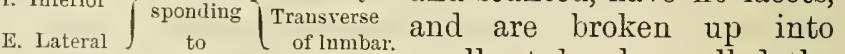
smaller tubercles, called the lateral, superior, and inferior tubercles. These are homologous with the trans-
verse, mamillary, and accessory processes of the lumbar vertebræ. Indications of these processes may also be met with in the tenth and eleventh thoracic vertebræ. The twelfth thoracic vertebra may usually be distinguished 
from the eleventh by the arrangement of its inferior articular processes, which resemble those of the lumbar series in being turned laterally; but the eleventh occasionally displays the same arrangement, in which case it is not always easy to distinguish between them.

\section{Vertebrae Lumbales.}

The lumbar vertebræ, five in number, are the largest of the movable vertebræ. They have no costal articular facets, nor are their transverse processes pierced by a foramen. In this way they can be readily distinguished from the members of
the cervical and thoracic series.

The body is kidneyshaped in outline, and of large size, exhibiting a gradual transition from the thoracic form in the higher segments. The transverse diameter is usually about a half greater than the anteroposterior width. The anterior vertical thickness is slightly greater than the posterior, being thus adapted to the anterior convex curve of the column in this region. The roots of vertebral arches (O.T. pedicles), directed horizontally backwards, are short and stout; the superior notches are shallow, but deeper than in the thoracic region; the inferior grooves are deep. The laminæ are broad and nearly vertical, sloping but little. They support on their inferior margins the inferiorarticular processes. The vertebral foramen is large and triangular.

The spinous processes, spatula shaped, with a thickened posterior margin, project backwards and slightly down wards. The transverse processes, more slender than in the thoracic region, pass horizontally laterally, with a
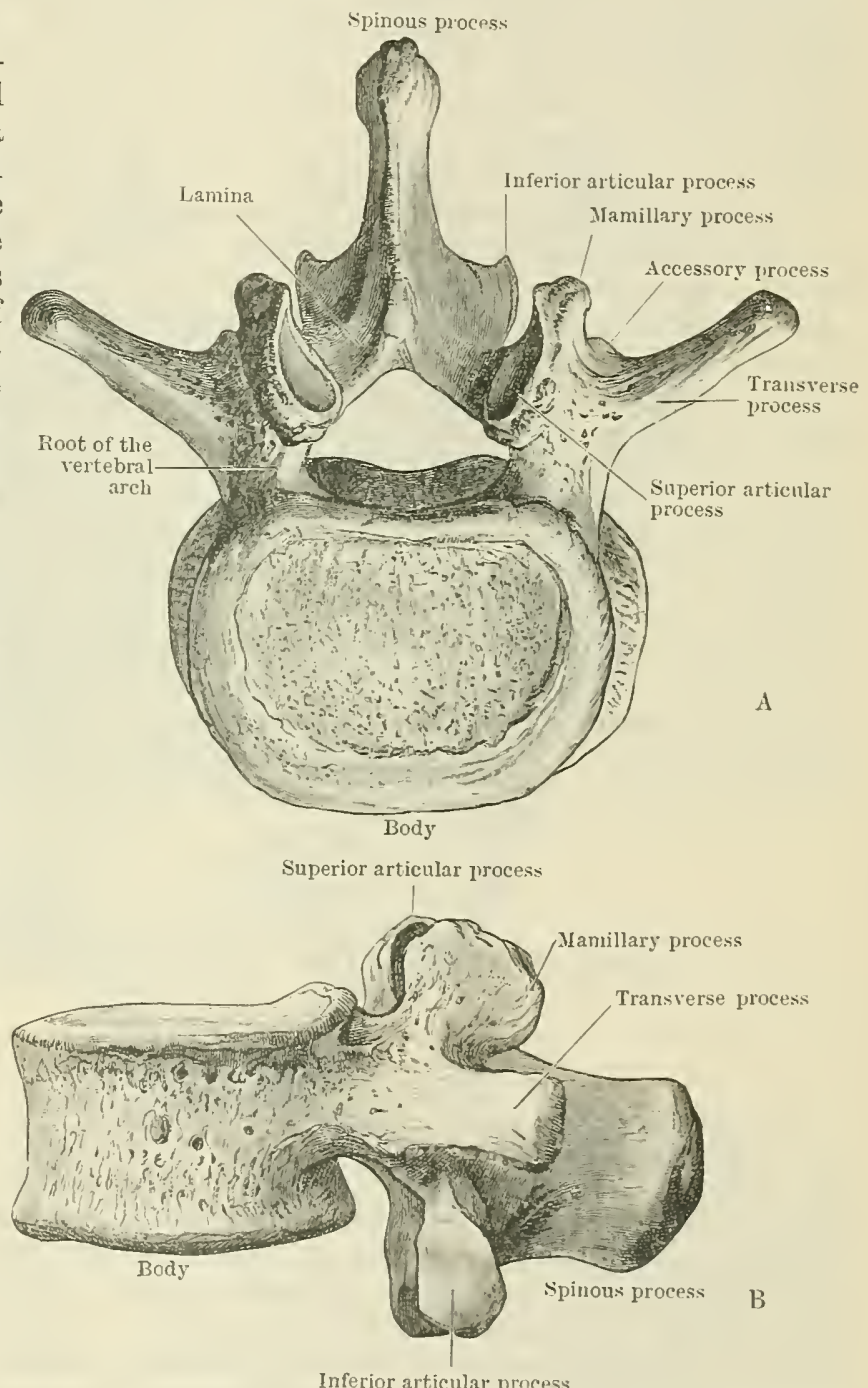

Fig. 111.-Third Lumbar Vertebra, (A) from alove, and (B) from the left sicle. slight backward inclination and usually with an upward tilt. Arising from the junction of the roots of the rertebral arches with the laminre in the higher members of the series, they tend to advance so as to become fused with the lateral side of the root and posterior aspect of the body in the lower two lumbar vertebra. In these latter rertebra the superior intervertebral grooves are carried obliquely across the superior surfaces of the bases of the transverse processes. The transverse processes lie in line with the lateral tubercles of the lower thoracic vertebre, with 
which they are serially homologous, and are to be regarded as representing the costal element. Placed on their bases posteriorly, and just lateral to and inferior to the superior articular processes, are the small accessory processes, which are in series with the inferior tubercles of the lower thoracic vertebræ. The superior articular processes are stout, oval, curved plates of bone, fused in front with the roots and laminæ, and having their concave articular surfaces vertical and turned medially. Laterally, and on their posterior edge, the bone rises in the form of an elongated oval tubercle, the processus mamillaris (mamillary process); these are in correspondence with the superior tubercles of the lower thoracic transverse processes.

The inferior articular processes lie on either side of the root of the spinous process, supported on the inferior margin of the laminæ. Their articular surfaces, oval in outline, convex from side to side, and plane from above downwards, are turned laterally. The inferior articular processes are much closer together than the superior; so that when the vertebræ are articulated the superior articular processes of the lower vertebra embrace the inferior articular processes of the higher vertebra.

The fifth lumbar vertebra is characterised by the size of its body, which is the largest of all the vertebræ. Further, the inferior surface of the body is cut away at the expense of its posterior part: hence the thickness of the body in front much exceeds the vertical diameter behind. By its articulation with the first sacral segment the inferior border of the body of this bone assists in the formation of the sacro-vertebral angle. The transverse process is pyramidal in form, and stouter than those of the other lumbar vertebræ. It arises by a broad base from the side of the back of the body, as well as from the pedicle, and is directed outwards and a little backwards and upwards. Its upper surface is slightly grooved by the superior intervertebral notch. A deep notch separates it posteriorly from the superior articular processes, which are less in-turned than in the other members of the series, their articular surfaces being directed more backwards than inwards, and displaying less concavity. The inferior articular processes are further apart than is the case with the other members of the series: they lie in line with the superior. The spinous process is shorter and narrower than the other lumbar spines, particularly so in the female. The vertebral canal is somewhat compressed at its lateral angles.

\section{THE FALSE OR FIXED VERTEBRAE.}

\section{Os Sacrum.}

The sacrum, of roughly triangular shape, is formed normally by the fusion of five vertebræ. The anterior surface of the bone is slightly hollow from side to side and concave from above downwards, the curve being usually most pronounced opposite the third sacral segment. The central part corresponds to the bodies of the sacral vertebræ, the lines of fusion of which are indicated by a series of four parallel ridges which cross the medial part of the bone at gradually diminishing intervals from above downwards; laterally, these ridges disappear on either side on the medial walls of the four foramina sacralia anteriora (anterior sacral foramina). The size of these holes decreases from above downwards. The upper and under border of each foramen is formed by a stout bar of bone, of which there are five on each side, corresponding in number with the vertebræ present. These unite laterally so as to form the pars lateralis (O.T. lateral mass), thus enclosing the foramina to the lateral side, though here the edge is not abrupt, but sloped so as to pass gradually into the canal. The large anterior branches of the sacral nerves pass through these foramina and occupy the shallow grooves. The bone is broadest across the first sacral vertebra, tends to narrow opposite the second, and again usually increases in width opposite the third. When this condition is well marked, the edge has a notched appearance (sacral notch) which 
assists in the interlocking of the sacro-iliac joint; this feature is common in the Simiidæ and some of the lower races of mankind (Paterson). The surface of bone between and lateral to the first, second, third, and fourth foramina affords attachment to the fibres of origin of the piriformis, which may in some instances extend on to the bodies of the second and third segments (Adolphi), whilst on the edge lateral to and below the fourth foramen the coccygeus is inserted.

The posterior surface is rough and irregular. Convex from above dornwwards, it displays in the median plane the crista sacralis media, a crest whereon are seen four elongated tubercles-the spines of the upper four sacral vertebræ. Lateral to these the bone forms a groove-the sacral groove-the floor of which is made up of the confluent laminæ of the corresponding vertebræ. In line with the intervals between the spines, and wider apart above than below, another series of tubercles is to be

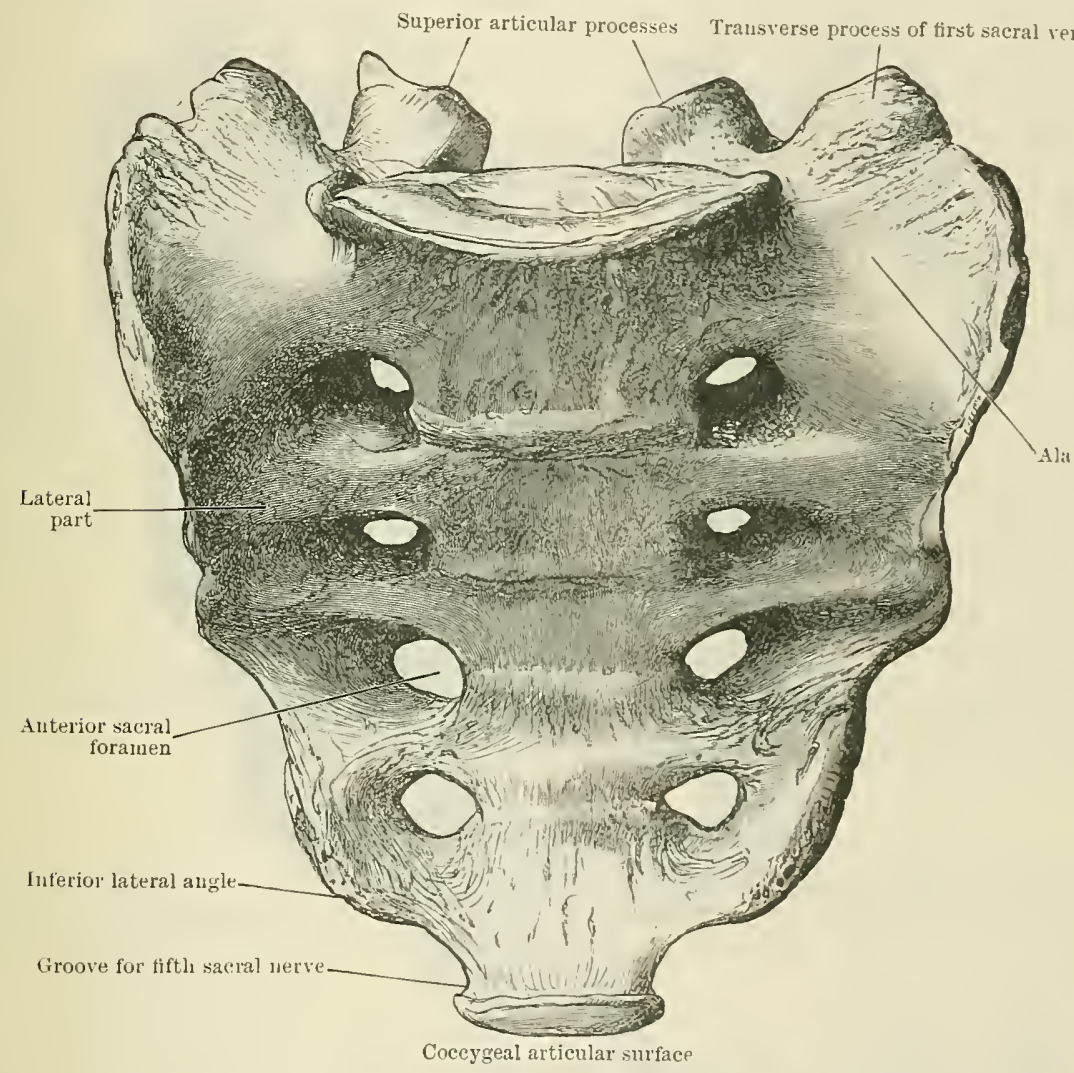

FIG. 112.-ThE S.ACROM (anterior view).

seen. These are due to the fusion of the articular processes of the sacral vertebrit, which thus form faint interrupted ridges on either side of the bone (cristæ sacrales articulares). Normally, the spine of the lowest sacral segment is absent, and the laminæ do not coalesce inedially, thus leaving a gap in which the sacral canal is exposed (hiatus sacralis); whilst inferiorly the tubercles corresponding to the inferior articular processes of the last sacral vertebra form little down-projecting processes-the sacral cornua-by means of which the sacrum is in part united to the coccyx. Just wide of the articular tubercles are the posterior sacral foramina, for the transmission of the posterior branches of the sacral nerves. These are in correspondence with the anterior foramina, so that a probe can be passed directly through both openings; but be it noted that the posterior are much smaller, and their margins much sharper, than is the case with the anterior. The surface of the pars lateralis (lateral mass) literal to the posterior socral foramina is rough and irregular, owing to the presence of four more or less elevated tubercles, which constitute the lateral rilges on either sile of the bone (cristæ sacrales 
laterales), and which are serially homologous with the true transverse processes of the lumbar vertebrie. The posterior surface of the bone furnishes an extensive surface for the origin of the sacro-spinalis, whilst the edge of the bone lateral to the third and fourth foramen gives attachment to the glutæus maximus.

The base of the bone displays features more in accordance with a typical vertebra. Centrally, and in front, is placed the body, the superior surface of which articulates with the last lumbar vertebra through the medium of an intervertebral fibro-cartilage. The anterior margin is thin and projecting, overhanging the general concavity of the jelvic surface of the bone, and forming what is called the promontory. Posterior to the body, the sacral canal, of triangular form but slightly compressed dorso-ventrally, is seen, whilst still more posteriorly is the short spinous

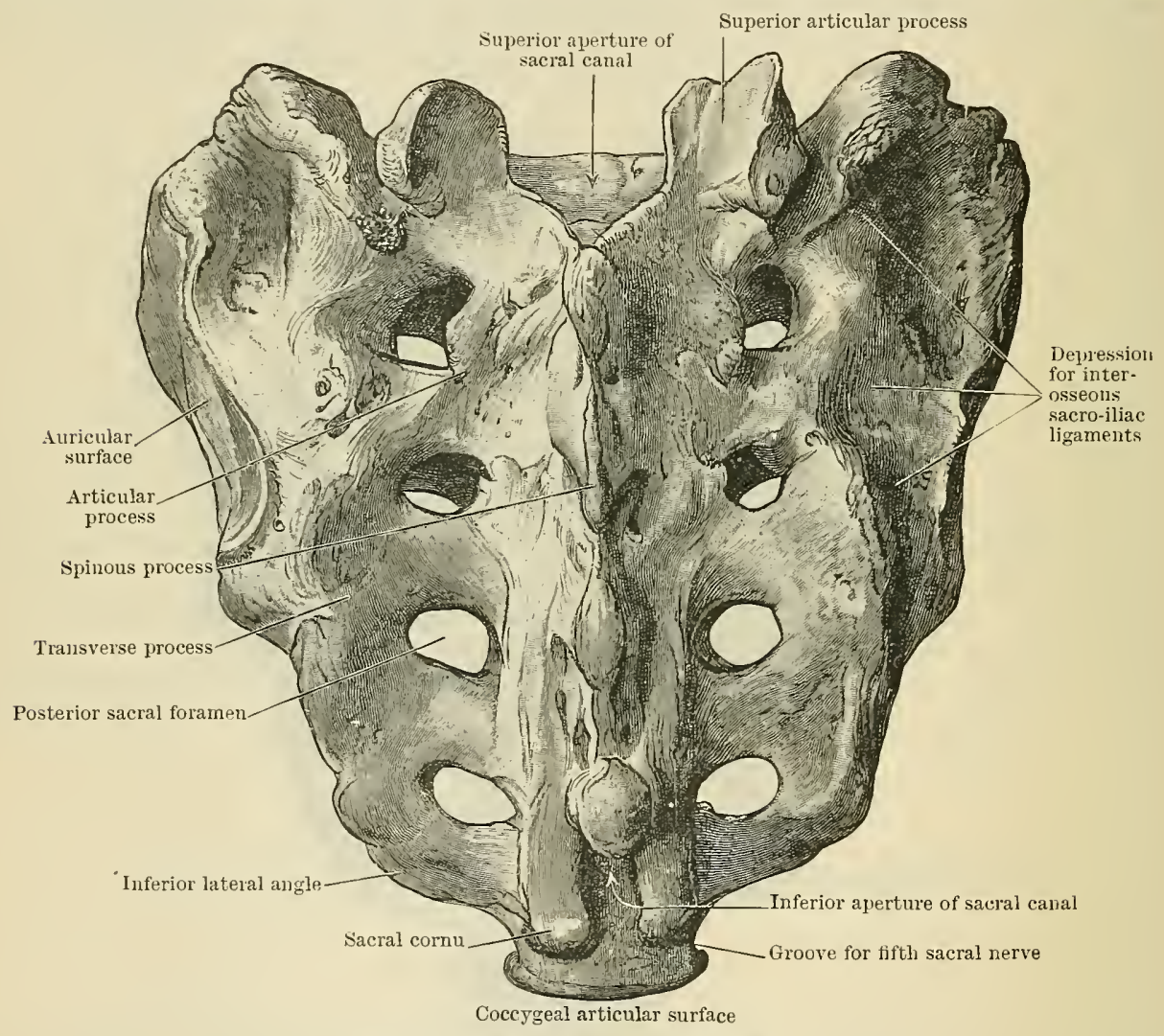

Fig. 113.-The Sacrum (posterior view).

process, forming the highest tubercle of the median crest. Spreading out from the sides, and partly from the back of the body on either side, is a fan-shaped mass of bone, the upper surface of which is slightly concave from side to side, and convex from above and behind downwards and forwards. This, the ala sacralis, corresponds to the thick upper border of the lateral part, and is formed, as will be explained hereafter, by elements which correspond to the roots of the vertebral arches (O.T. pedicles) and the transverse processes of the sacral vertebræ, together with superadded structures - the sacral ribs. The lateral margin of the lateral part, as seen from above, is sharp and laterally convex, terminating posteriorly in a prominent tuberclethe highest of the series of elevations seen on the posterior surface of the bone, which have been already described as serially homologous with the true transverse processes of the lumbar vertebræ. Fused with the dorsal surface of each lateral part, and separated from it laterally by a narrow but deep notch, is the superior articular process. This supports a vertical articular surface, which is of circular or oval form, and concave from side to side, having a general direction backwards and a little medially.

The borders of the sacrum are thick above, where they articulate with the ilia, 
thin and tapering below, where they furnish attachments for the powerful sacrotuberous ligaments (O.T. great sacro-sciatic). The iliac articular surfaces are described as auricular in shape (facies auricularis), and overlie the lateral parts formed by the first three sacral vertebræ, though this arrangement is liable to considerable variation. Posterior to the auricular surface the bone is rough and pitted by three distinct depressions for the attachment of the strong sacro-iliac ligaments. Inferiorly, the edge formed by the lateral parts of the fourth and fifth sacral vertebræ becomes gradually thinner, and at the inferior lateral angle changes its direction and sweeps medially towards the body of the fifth sacral segment.

The apex, or lower end of the sacrum, is formed by the small oval body of the fifth sacral vertebra, which articulates with the coccyx.

The sacral canal follows the curve of the bone; more or less triangular in shape above, it becomes compressed and flattened dorso-ventrally below. Inferiorly, its posterior wall is deficient owing to the imperfect ossification of the lamince of the fifth, and, it may be, of the fourth sacral segments. Passing obliquely downwards and laterally from this canal into the lateral parts on either side are the four pairs of intervertebral foramina, each of which is connected laterally with a V-shaped canal which terminates in front and behind in the anterior and posterior sacral foramina. The posterior limb of the $V$ is shorter and narrower than the anterior.

The female sacrum is proportionately broader than the male, its curves are liable to great individual variation; usually it is flattened above, and somewhat abruptly curved below, as contrasted with the male sacrum, in which the curve is more uniformly distributed throughout the bone. In the female the absolute depth of the curve is less than in the male. The iliac articular surface of the female sacrum is smaller than, and of a different shape from, that of the male; in the majority of cases it only extends over two sacral segnents, whereas in the male it invariably includes a part, and at times the whole of the third segment (Derry).

The variation in the proportions of the breadth to the length of the sacrum is expressed by the formula $\frac{\text { breadth } \times 100}{\text { length }}=$ Sacral Index. Sacra with an index above 100 are platyhieric and are generally characteristic of the higher races, those with an index below 100 are dolichohieric and are more commonly met with in the lower races of men. The average European index is 112.4 for males and $116 \cdot 8$ for females.

\section{Os Coccygis.}

The coccyx consists of four-sometimes five, less frequently three-rudimentary vertebræ, which tend to become fused. The first piece is larger than the others; it has an oval hollow facet on its superior surface, which articulates with the body of the last sacral segment. Posteriorly, two processes, cornua coccygea, which lie in series with the articular processes of the sacrum, extend upwards and unite with the sacral cornua, thus bridging over the notch for the exit of the fifth sacral nerve, and converting it into a foramen, the last of the intervertebral
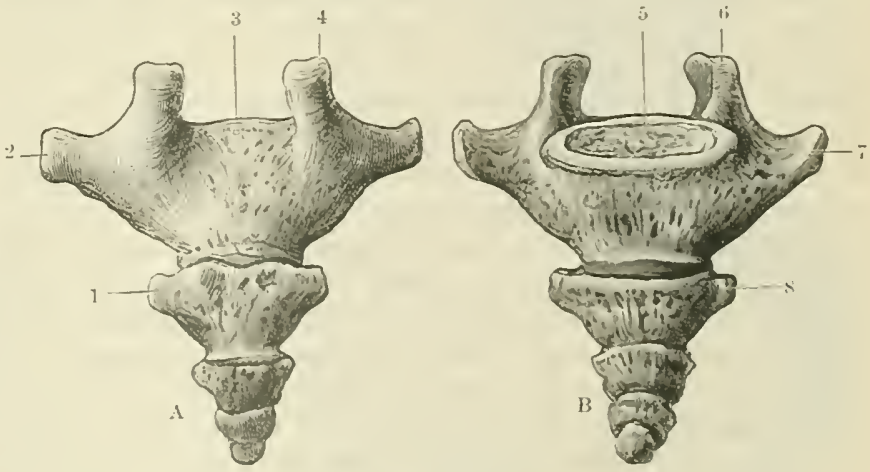

Fll. 114. The Cocryx.

A. Posteriol surface. B. Anterior Surface. series. From the lateral sides of the body project rudimentary transverse processes, which may, or may not, unite with the sacrum close to the lower lateral angles; in the latter case the fifth anterior sacral foramina are enclosed. Inferiorly, the body of the bone articulates with the succeeding rertebra. 'l'he' second coccygeal veriebra displays 
slight traces of a transverse process and the rudiments of roots of the vertebral arch. The succeeding segments are mere rounded or oval-shaped nodules of bone.

Fusion between the lower elements occurs normally in middle life, whilst union between the first and second segments occurs somewhat later. It is not unusual, however, to find that the first coccygeal vertebra remains separate from the others. Though very variable, as a rule, fusion occurs more commonly in the male, and at an earlier age, than in the female. Szawlowski has recorded a case in which a curved process arose from the ventral surface of the first coccygeal segment. He regards this as possibly the homologne of a ventral arch (Anat. Anz. Jena, vol. xx. p. 320).

From the posterior surface of the coccyx the glutæus maximus arises, whilst to it is attached the filum terminale of the spinal medulla. To its lateral borders are attached the coccygei and levatores ani muscles, and from its tip spring the fibres of the sphincter ani externus.

\section{THE VERTEBRAL COLUMN AS A WHOLE.}

When all the vertebræ are articulated together, the resulting column displays certain characteristic features. The division of the column into a true or movable part, comprising the members of the cervical, thoracic, and lumbar series, and a false or fixed portion, including the sacrum and coccyx, can now be readily recognised. The vertebræ are so disposed that the bodies form an interrupted column of solid parts anteriorly, which constitutes the axis of support for the head and trunk; whilst the vertebral arches posteriorly provide a canal for the lodgment and protection of the spinal medulla and its membranes. In the movable part of the column both the anterior supporting axis and the vertebral canal are liable to changes in their disposition, owing to the movements of the head and trunk. Like the bodies and vertebral arches, the spinous and transverse processes are also superposed, and fall in line, forming three series of interrupted ridgesone (the spinous) placed centrally and behind, the others (the transverse) placed laterally. In this way two vertebral grooves are formed which lie between the central and lateral ridges. The floor of each groove is formed by the laminæ and articular processes, and in these grooves are lodged the muscles which serve to support and control the movements of the column.

Further, the column so constituted is seen to display certain curves in an antero-posterior direction. These curves are, of course, subject to very great variation according to the position of the trunk and head, and can only be satisfactorily studied in a fresh specimen; but if care is exercised in the articulation of the vertebræ, the following characteristic features may be observed, assuming, of course, that the column is erect and the head so placed that the axis of vision is directed towards the horizon. There is a forward curve in the cervical region, which gradually merges with the backward thoracic curve; this becomes continuous below with an anterior convexity in the lumbar region, which ends more or less abruptly at the union of the fifth lumbar with the first sacral vertebra, where the sacrum slopes suddenly backwards, causing the column to form a marked projection-the sacro-vertebral angle. Below this, the anterior concavity of the front of the sacrum is directed downwards as well as forwards. Of these four curves, two-the thoracic and sacral-are primary, they alone exist during foetal life; whilst the cervical and lumbar forward curves only make their appearance after birth-the former being associated with the extension and elevation of the head, whilst the latter is developed in connexion with the use of the hind limb in the hyper-extended position, which in man is correlated with the assumption of the erect posture; this curve, therefore, only appears after the child has begun to walk. For these reasons the cervical and lumbar curves are described as secondary and compensatory.

Not infrequently there is a slight lateral curvature in the thoracic region, the convexity of the curve being usually directed towards the right side. This may be associated with a greater use of the muscles of the right upper limb, or may depend on the pressure exercised by the upper part of the thoracic aorta on the 
vertebræ of the thoracic region, thus causing a slight lateral displacement, together with a flattening of the sicle of the fifth thoracic vertebra (impressio aortica) as was first pointed out by Wood (Journ. Anat. and Physiol. vol. iii.). Above and below this curve there are slight compensatory curves in the opposite direction.

The line which unites the tips of the spinous processes is not a repetition of the curves formed by the bodies. This is due to the fact that the length and direction of the spinous processes vary much in different regions; thus in the neck, with the exception of the second, sixth, and seventh, they are all short (absent in the case of the atlas). In the thoracic region the spinous processes, though long, are obliquely placed - a circumstance which much reduces their prominence; that of the seventh thoracic vertebra is usually the longest and most slanting. Below this point their length gradually decreases, and their position more nearly approaches the horizontal. In the loins the spinous processes have all a slight downward direction.

The spinous processes of the upper three or four sacral vertebræ form an osseous ridge with interrupted tubercles. The ridge formed by the vertebral spines is an important determinant of the surface form, as it corresponds to the medial furrow of the back, and here the individual spines may be felt and counted from the seventh cervical down to the sacral region. This is best done when the back is well bent forwards.

Taken as a whole, the spinous processes of the movable vertebræ in man have a downward inclination-a character which he shares with the anthropoid apes and a few other animals. This character serves to distinguish his column from those of lower mammals in which the spines of the lumbar vertebræ are directed headwards towards the "centre of motion," which is usually situated near the caudal extremity of the thorax, where a vertebra is placed the direction of whose spine is vertical to the horizontally disposed column; this vertebra is often referred to as the anticlinal vertebra.

As viewed from the front, the vertebral bodies increase in width from the second cervical to the first thoracic; thence a reduction in breadth takes place to the level of the fourth thoracic, below which there is a gradual increase in their transverse diameters until the sacrum is reached. Here a rapid reduction in width takes place, terminating inferiorly in the nodules of the coccyx.

The transverse processes of the atlas are wide and outstanding. The succeeding four cervical vertebræ have transverse processes of nearly equal width; the seventh, however, displays a marked increase in its transverse diameter, and is about equal in width to the first thoracic vertebra. Below this a gradual and regular diminution in width characterises the transverse processes of the thoracic vertebræ, until in the case of the eleventh and twelfth they are merely represented by the small lateral tubercles. In the

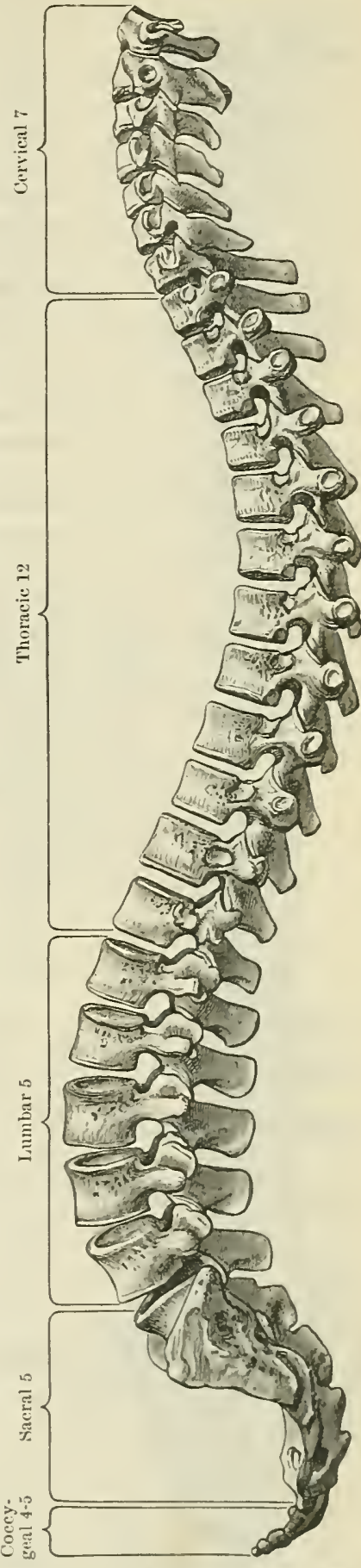

Fig. 115.-VERTEBRaL Coldar FROM THE LEFT SIDE. lumbar region the transverse processes again appear outstanding, and of nearly equal length.

The transverse diameter of the lateral part of the first sacral vertebra forms the widest part of the column. Below this, a decrease in width occurs until the 
level of the third sacral segment is reached, at which point the transverse diameter is somewhat abruptly diminished, a reduction in width which is further suddenly

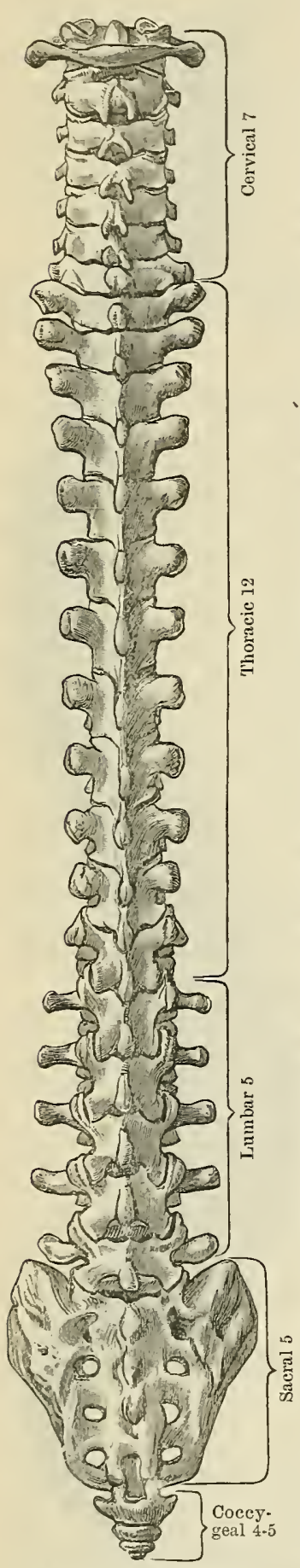

FiG. 116.—VERTEBRAL COLUMN AS SEEN FROM BEHIND accentuated opposite the fifth sacral segment.

As viewed from the side, the bodies display a gradual increase in their antero-posterior width until the second lumbar vertebra is reached, below which, this diameter is slightly reduced. In the sacral region the reduction in this diameter is great in the first and second sacral segments, more gradual and less marked in the last three segments. The facets for the heads of the ribs in the upper thoracic region lie on the sides of the bodies; those for the tenth, eleventh, and twelfth are placed farther back on the roots of the vertebral arches.

The intervertebral foramina increase in size from above downwards in the movable part of the column, being largest in the lumbar region. In the sacral region they decrease in size from above downwards. In the cervical region the two highest cervical nerves pass out behind the articular processes of the atlas and epistropheus, and lie, therefore, behind the corresponding transverse processes of these vertebræ. The succeeding cervical nerves pass out through the intervertebral foramina, which are placed between the transverse processes and anterior to the articular processes. In the thoracic and lumbar vertebræ the intervertebral foramina lie anterior to both the articular and transverse processes. The arrangement of these foramina in the sacrum has been already sufficiently explained.

The vertebral canal for the lodgment of the spinal medulla and its meninges is largest in the cervical and lumbar regions, in both of which it assumes a triangular form; whilst it is narrow and circular in the thoracic region. These facts are correlated with the movements of the column which are most free in those regions where the canal is largest, i.e. the neck and loins.

The average length of the vertebral column is from 70 to 73 centimetres, or from $27 \frac{1}{2}$ to $28 \frac{3}{4}$ inches. Of this the cervical part measures from 13 to $14 \mathrm{~cm}$; the thoracic, 27 to $29 \mathrm{~cm}$.; lumbar, 17 to $18 \mathrm{~cm}$.; and the sacro-coccygeal, 12 to $15 \mathrm{~cm}$. The individual differences in the length of the column are less than one might expect, the variation in height of different individuals being often largely dependent on the length of the lower limbs. In the female the average length of the column is about 60 centimetres, or $23 \frac{3}{4}$ inches, and the curve in the lnmbar region is usnally more pronounced.

\section{DEVELOPIMENT OF THE VERTEBRAL COLUMN.}

\section{The Cartilaginous Column.}

As has been already stated (p. 37), the neural tube and the notochord are enveloped by a continuous sheath of mesodermal tissue which forms the membranous vertebral column. It is by the chondrification of this that the cartilaginous column is developed. This process commences about the end of the first or the beginning of the second month of foetal life. In correspondence with each vertebral segment, two symmetrical nodules of cartilage appear on either side of the notochord; these rapidly surround and constrict it. By their fusion they constitute the body of a 
cartilaginous vertebra, and are so disposed that they alternate in position with the muscle plates which are lying on either side. In this way a vertebral body corresponds in position to the posterior half of the anterior myotome, and the anterior half of the posterior myotome, the intermyotomic intervals, which contain the connective tissue plates separating the muscle segments, lie in line laterally with the mid-points of the sides of the cartilaginous vertebræ. It is by chondrification of these intersegmental layers that in certain regions the ribs are ultimately developed. Meanwhile, the scleratogenous tissue between the chondrifying vertebral bodies undergoes little change and persists as the intervertebral fibro-cartilage. Here the embedded notochord undergoes but slight compression and enlarges, so that if a length of the column be examined in longitudinal section the notochord displays a moniliform appearance, the constricted parts corresponding to the bodies, the enlarged portions to the fibro-cartilages. The former disappear at a later stage when ossification begins, but the latter persist in the adult as the pulpy core in the centre of the intervertebral fibro-cartilage.

The portions of the scleratogenous tissue which lie lateral to the notochord have next to be considered; these extend dorsalwards around the vertebral canal, and ventralwards beneath the notochord. The former is sometimes called the vertebral bow, the latter the hypochordal bow. The vertebral bow begins to chondrify on either side, and forms the lateral portions of the cartilaginous vertebral

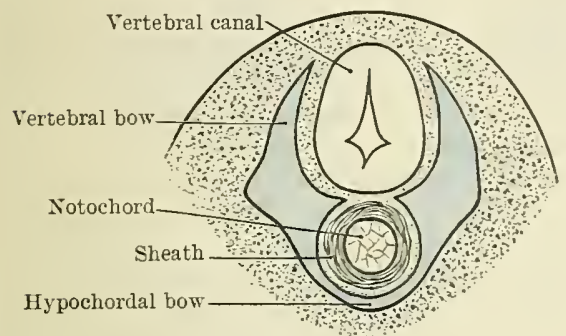

A

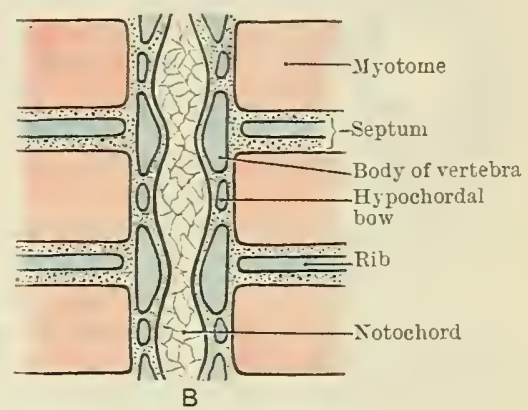

B

Fig. 117.-The Defelopuest of the Nembrayous Basis of a Vertebra (after Keith).

$A$, in transverse section. $B$, in horizontal section, showing the relation of the vertebræ to the primitive segments.

arch, the extremities of which usually unite dorsally about the fourth month of fœtal life; if from defective development this union should fail to occur a deformity known as spina bifida is the result.

From the cartilaginous vertebral arch, so formed, arise the chondrified rudiments of the spinous, transverse, and articular processes.

The chondrification of the vertebral arch is variously described as being independent of the body or an extension from it; in any case, union between it and the body is rapidly effected.

The scleratogenous tissue between the cartilaginous vertebral arches which does not undergo chondrification persists as the ligaments uniting the vertebral laminæ.

As regards the so-called hypochordal bow, for the most part it disappears. By some it is regarded as being represented by a fibrous strand in the intervertebral fibro-cartilage in front of the rertebra to which it belongs. It is, however, noteworthy that in the case of the atlas vertebra there is an exception to this arrangement; for here the hypochordal bow chondrifies and subsequently by ossification forms the anterior arch of that bone-an arch which lies ventral to, and embraces the dens of the epistropheus (q.v. p. 91).

It is only in the thoracic region that the ribs, developed as stated above by the chondrification of the intersegmental septa, attain their full dimensions. In the cervical, lumbar, and sacral regions they exist only in a rudimentary or modified form, as has been described elsewhere. In the construction of the chest wall the ribs are supported ventrally by the sternum, as to the development of which there is some difference of opinion. Puge has described this bone as formed by the fusion of two cartilaginous bands produced by the coalescence of the expanded ends of the first five 
or seven cartilaginous ribs. Paterson, on the other hand, regards the sternum as arising independently of the ribs by the union of a right and left sternal bar in the median ventral line. There are also reasons for supposing that the presternum is intimately associated with the development of the ventral part of the shoulder girdle.

Ossification of the Vertebræ.-The vertebræ are developed by ossification of the cartilage which surrounds the notochord and which passes dorsally over the sides of the vertebral canal. The centres for the bodies first appear in the lower thoracic vertebræ about the tenth week. An oval nucleus develops in each body. At first it is placed dorsal to the notochord, but subsequently surrounds and causes the disappearance of that structure. Occasionally, however, the primitive centre appears to be formed by the coalescence of two primary nuclei. Support is given to this view by the occasional occurrence of vertebre in which the body is developed in two lateral halves, or in cases where only one-half of the body persists (Turner); normally, however, it is impossible to make out this division. From these single nuclei the bodies are developed, the process extending up and down the column until, by the fifth month, all the centra possess ossific nodules, except the coccygeal segments. About the seventh week a single centre appears in the vertebral arch on either side. These commence first to ossify in the upper cervical region and extend rapidly downwards throughout the column. They first appear near the bases of the superior articular processes, and extend backwards into the laminæ, laterally into

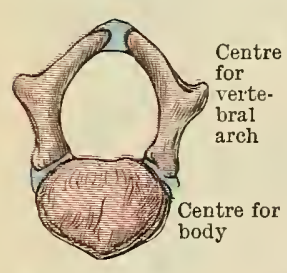

FIG. 118.-OSSIFICATION OF VERTEBRE. the transverse processes, and forwards into the roots of the vertebral arches. These latter project anteriorly and form a considerable portion of the postero-lateral aspects of the body, from which, however, they are separated by a cartilaginous strip--theneuro-central synchondrosis -which does not entirely disappear until about the fifth or sixth year. It is important to note that in the thoracic region the costal facets lie behind the neuro-central synchondrosis, and are therefore borne on the lateral aspects of the roots of the vertebral arches. Fusion of the laminæ in the median plane posteriorly begins, after birth, in the lumbar region and extends upwards, so that by the fifteenth month or thereabouts the arches in the cervical region are completed posteriorly. In the sacral region ossification is slower, the vertebral canal not being enclosed till the seventh to the tenth year. The spinous processes are cartilaginous at birth, but these become ossified by the extension into them of the bony laminæ.

At puberty certain secondary centres or epiphyses make their appearance; these are five in number. One caps the summit of the spinous process, except in the cervical region. A single epiphysis on either side appears at the extremity of the transverse process, and in the thoracic region assists in forming the articular surface for the tubercle of the rib. Two epiphysial plates are formed - one for the superior, and the second for the inferior surface of the body, including also that part which lies posterior to the neuro-central synchondrosis and is formed by the root of the vertebral arch ; from these the thickened circumference of both upper and lower aspects of the body are derived. Fusion of these centres with the rest of the bone is not complete till the twenty-fifth year.

In the cervical region independent centres are described as occurring in the anterior roots of the transverse processes of the sixth and seventh vertebræ. These correspond to the costal element, and may occasionally persist in the form of cervical ribs. Elsewhere they are formed by lateral extensions from the root of the vertebral arch.

In the lumbar region the transverse process of the first lumbar vertebra is occasionally associated with an independent costal centre, which may blend with it, or persist as a lumbar rib. The mamillary processes are derived from separate epiphyses. The vertebral arch of the fifth lumbar vertebra is occasionally developed from two centres on either side, as is demonstrated by the fact that the arch is sometimes divided by a synchondrodial joint running obliquely across between the superior and inferior articular processes on either side. (See ante, p. 91; also Fortschritte auf dem Gebiete der Röntgenstrahlen. Ergänzungsheft i.; "die Entwickelung des menschlichen Knochengerüstes während des fötalen Lebens," von Lambertz.) At the eighteenth year there are two epiphyses at the end of the costo-transverse process of the fifth lumbar vertebra; one caps the transverse element, the other caps the costal element (Fawcett).

Atlas.-The lateral masses, transverse processes, and posterior arch are developed from two centres-one on either side-which correspond with the centres from which the vertebral arches of the other members of the series are developed. These make their appearance about the seventh week, and do not unite posteriorly till after the third year. Their point of union is sometimes preceded by the formation of a distinct spinal 
nucleus (Quain). The transverse processes are completed by epiphyses about the eighteenth year (Fawcett). The anterior arch is developed from centres variously described as single or double, which appear in one of the hypochordal arches of cartilage described by Froriep (Arch. f. Anat. u. Physiol., Anat. Abth. 1886) which here persists. In this cartilage ossification commences during the first year of life. Union with the lateral masses is delayed till six or eight years after birth. The lateral extremities of the anterior arch assist in forming the anterior part of the superior articular processes.

Epistropheus. - The epistropheus ossifies from five primitive centres. Of these, two -one on either side-appear about the seventh week, and form the articular and transverse processes, together with the laminæ and spinous process. One, or it may be two, nuclei appear in the inferior part of the body about the fifth month. The superior part of the body, including a small part of the superior articular process, and the base of the dens,

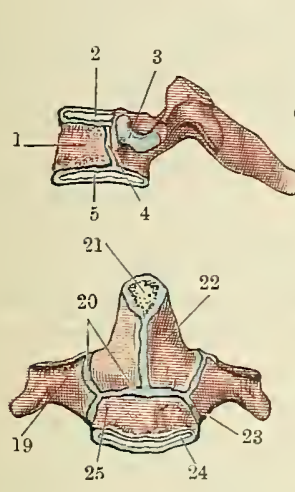

Cervical vertebra.

1. Centre for body.

2. Superior epiphysial plate.

3. Anterior bar of transverse process developed by lateral exteusion from root of vertebral arch.

4. Neuro-central synchondrosis.

5. Inferior epiphysial plate.

6. Body.

Lumbar vertebra.

7. Superior epiphysial plate.

8. Epiphysis for mamillary process.

9. Epiphysis for transverse process.

10. Epiphysis for spinous process.

11. Neuro-central synchondrosis.

12. Inferior epiphysial plate.

\section{Thoracic vertebra.}

13. Centre for body.

14. Superior epiphysial plate, appears about puberty ; unites at 25 th year.

15. Neuro-central synchondrosis does not ossify till 5 th or 6 th year.

16. Appears at puberty; unites at 25 th year.

17. Appears at puberty; unites at 25 th year.

18. Appears about 6 th week.

\section{Epistropheus.}

19. Centre for transverse process and vertebral arch; appears about \&th week.

20. Synchondroses close about 3rd year.

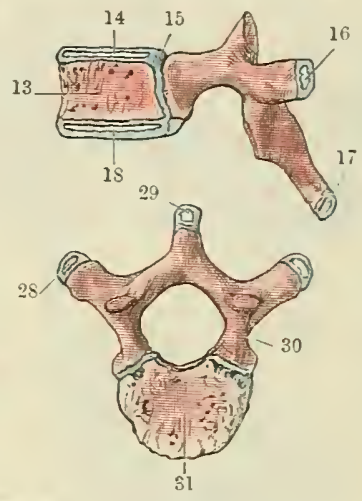

16
2

\section{.}

Fig. 119.-Ossification OF Vertebra.

21. Centre for summit of dens ; appears $3 \mathrm{rd}$ to 5 th year, fuses $S$ th to 12 th year.

22. Appears about 5th or 6 th month; unites with opposite side 7 th to 8 th month.

23. Synchondrosis closes from 4 th to 6 th year.

24. Inferior epipbysial plate; appears about puberty; unites about 25 th year.

25. Single or double centre for body; appears about 5 th month.

\section{Atlas.}

26. Posterior arch and lateral masses dereloped from a single centre on either side, which appears about 7 th week. In this figure the posterior arch is represented complete by the union posteriorly of its posterior elements.

27. Anterior arch and portion of superior articular surface developed from single or double centre, appearing during lst year.

\section{Thoracic vertebra.}

28. Epiphysis for transverse process; appears about puberty, unites about 25 th year.

29. Epiphysis appears about puberty; unites about 25 th or 27 th year.

30. Centre for vertebral arch on either side ; appears about 6 th or 7 th week, the lamina unite from birth to 15 th month. The arch is here shown complete posteriorly.

31. Centre for body; appears about 6 th week, unites with vertebral arch from 5 th to 6 th year.

are developed from two laterally-placed nuclei which appear shortly after, and fuse together at the seventh or eighth month, so that at birth the bone consists of four pieces. Fusion between these parts takes place in the following order:-The dens unites with the body and lateral parts about the third or fourth rear; ninion between the two lateral portions posteriorly and the body and lateral parts anteriorly, is complete at from four to six rears.

The summit of the dens is developed from a separatc centre, oceasionally double, which appears from the third to the fifth ycar, and fuses with the rest of the bone from the eighth to the twelfth year. About puberty an anmular epiphysis is developed on the inferior surface of the body, with which it is completely united during the twentieth to the twenty-fifth year. Some authorities state that a few granules between the base of the dens and the superior surface of the body represcnt the superior epiphysial plate; but 
as fusion between the dens and the body occurs before the time for the appearance of these secondary epiphysial plates, this can hardly be regarded as correct. The line of fusion of the dens with the body is defined by a small disc of cartilage which persists within the substance of the bone till an advanced period of life.

A pair of epiphyses placed over the tubercles of the spinous process, if not always present, are at least frequent.

Sacrum.-Each of the sacral segments is ossified from three centres: one for the body, and two for the rertebral arch-that for the body, which makes its appearance in the first three sacral vertebræ about the end of the third month, about the fifth to the eighth month for the last two segments. From the two centres for the vertebral arches, which make their appearance about the fifth or sixth month in the higher segments, the laminæ, articular processes, and the posterior half of the alæ on either side are developed. The sacral canal is not enclosed till the seventh to the tenth year, the laminæ usually failing to meet in the lowest segment, and occasionally, to a greater or less extent, in some of the higher segments. The anterior portion of the lateral parts is developed from separate centres which represent the costal elements (Gegenbauer). These appear about the sixth to the eighth month, and may develop in relation to the upper four sacral segments; more usually they are met with in comnexion with the first three, and exceptionally they may be found only in the upper two. It is by fusion of these

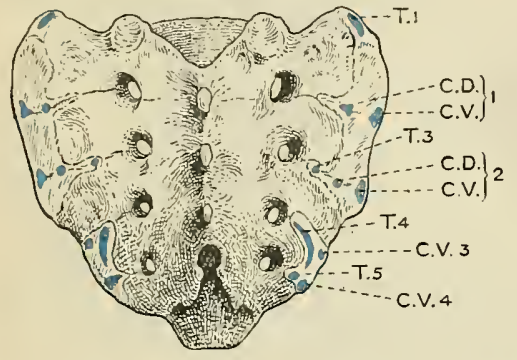

Fig. 120.-DiagraM (after Fawcett) OF THE ARrangement of the Costal and TransVERSE EPIPHYSEs aT THE Eighteenth YEAR.

T., Epiphysis of transverse process.

C.V., Ventral epiphysis of costal process.

C.D., Dorsal epiphysis.

The numbers indicate the segments to which the epiphyses belong. with the posterior arches that the lateral parts, which support the hip bones, are formed. The costal elements fuse about the second to the fifth year with the vertebral arches, prior to their union with the bodies; and the segments of the lateral parts unite with each other sooner than the union of the bodies is effected. The latter only takes place after puberty by the fusion of the epiphysial plates, a pair of which make their appearance between the bodies of each segment. The lower segments begin to unite together about the eighteenth year, but fusion between the first and secoud sacral vertebræ is not completed till the twenty-fifth year or after. In addition to the foregoing there are costal and transverse epiphyses. According to Fawcett they are arranged as follows. Costal epiphyses: The costal processes of the I. and II. sacral segments bear at their lateral ends inferiorly two such epiphyses, one dorsal and one ventral; these, by their fusion

and expansion mainly in an upward direction, form a plate-the auricular facet. The III. and IV. costal processes have only one epiphysis each, viz., the ventral. All these appear about the eighteenth year. Transverse epiphyses : Epiphyses are developed on all the transverse processes of the sacral vertebræ except the II. Those of the IV. and V. play an important part in the moulding of the lower lateral region of the sacrum. Thus, the transverse epiphysis of the IV. segment becomes comma-shaped by downward and lateral growth, the head of the comma fuses with the costal epiphysis of the III. sacral segment, which in turn unites with the epiphysis of the transverse process of the V. segment, the nitimate result being a Z-like arrangement on the posterior and inferior aspect of the sacrum. The extremities of the superior spinous processes are occasionally developed from independent epiphyses. On making a median section of an adult bone the persistence of the intervertebral fibro-cartilages between the bodies is indicated by a series of oval cavities.

Coccygeal Vertebræ.-These are cartilaginous at birth. Each has a separate centre; the first appears from the first to the fourth year, the second from the sixth to the tenth year, the third and fourth segments at or about puberty. Secondary centres, for the coccygeal cornua and epiphysial plates for the bodies are also described. Fusion of the various segments begins below and proceeds upwards, but is liable to great individual variation. In advanced life the coccyx is often ossified to the sacrum.

\section{THE STERNUM.}

The sternum occupies the middle of the upper part of the thoracic wall anteriorly. It is connected laterally with the cartilages of the first seven ribs, and supports, superiorly, the clavicles. It consists of three parts, named respectively 
the manubrium or handle; the corpus sterni or body; and the processus xiphoideus (or xiphoid cartilage). Of these the body is formed by the fusion in early life of four segments or sternebræ.

The manubrium or superior part, usually separate throughout life from the rest of the bone, though occasionally fused with it, is of a flattened triangular form. The anterior surface, slightly saddle-shaped, affords attachment to the fibres of the pectoralis major and sterno-mastoid muscles. It is bounded above by a thick border, the lateral parts of which are hollowed out obliquely to form the facets (incisuræ claviculares) for the sternal ends of the clavicles; around the facets, which have an upward, lateral, and slightly backward direction, the bone is faintly lipped. In the interval between these two facets there is a slight notch (incisura jugularis) which forms the floor of the characteristic hollow seen at the root of the neck anteriorly-the suprasternal notch. The lateral borders are excavated immediately below the clavicular facets for the reception of the cartilages of the first ribs. Below this, the margin of the bone slopes medially, and is sharp, except inferiorly, where it presents a facet which supports a part of the second costal cartilage. Around this the bone is usually lipped anteriorly. The upper angles correspond to the ridge separating the clavicular facets from the first costal facets: whilst the lower angle, which may be regarded as cut across transversely, forms the surface which is united by cartilage to the body of the sternum. The anterior edge of this surface is usually prominent. The posterior aspect of the manubrium is smoother than the anterior, is pierced by numerous foramina, and is slightly concave from side to side and above downwards. Here are attached some of the fibres of the sterno-hyoid and sterno-thyreoid muscles.

The body or middle part of the sternum, usually twice the length and from half to two-thirds the width of the manubrium, displays evidence of its composite nature. If the planum sternale, (anterior surface) which is slightly convex from above downwards, and faintly concave from side to side, is carefully examined, three ill-marked ridges may be seen crossing it transversely; these correspond to the lines of fusion between the four primitive segments. To this surface of the bone the great pectoral muscles are extensively attached on either side of the

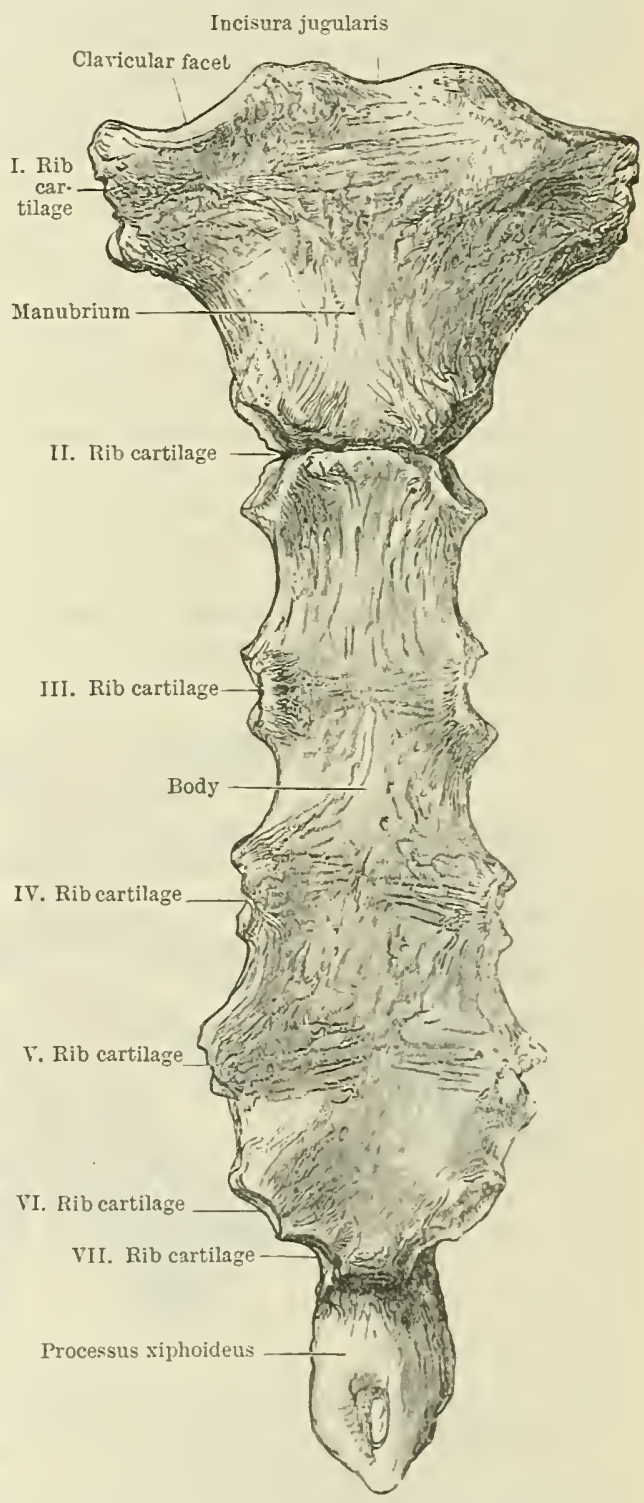

Fig. 121.-The Sterndor (anterior view). median plane. The lateral borders are thick and interrupted at points corresponding to the transverse lines already mentioned by $U$-shaped hollows, the edges of which are more or less projecting. These are for the reception of the cartilages of the third, fourth, and fifth ribs. The superior border is united to the manubrium above, and forms with it an angle of variable degree-the angulus sterni (sternal angle). A small facet is formed at the expense of the lateral extremity of this 
border, and in conjunction with the facet on the inferior edge of the manubrium forms a recess on either side, in line with the articulation between the manubrium and body, into which the cartilage of the second rib fits. The inferior border of the body is curved, and is united in the middle line with the xiphoid process, whilst on either side it is pitted to receive the cartilages of the sixth and seventh ribs, the latter being in part supported by the xiphoid process. The middle line of the body of the sternum anteriorly corresponds to the floor of the medial surface furrow, which runs down the front of the chest in the interval between the two great pectoral muscles. The posterior surface is slightly concave from above downwards, and displays faint indications of three transverse lines in correspondence with those placed anteriorly. It is in relation with the pleura and pericardium, and affords attachment at its inferior extremity to the transversus thoracis muscle.

The xiphoid process displays many varieties of form and structure. It is a pointed process of cartilage, supported by a core of bone connected above with the inferior end of the body of the sternum, and having its lower extremity, to which the linea alba is attached, free. It lies somewhat posterior to the plaue of the anterior surface of the manubrium, and forms a floor to the $V$-shaped interval between the cartilages of the seventh ribs. In this way a depression is formed, the surface hollow in correspondence with which is called the pit of the stomach or infrasternal depression. To the sides of this process are attached the aponeuroses of the abdominal muscles, whilst posteriorly the fibres of the diaphragm and transversus thoracis muscles derive attachment from it. It remains partly cartilaginous until middle life, at which time it generally undergoes ossification, particularly at its upper part, becoming fused with the body. Of varied form, it may be met with of spatula-shape, bifid, circular, pierced in the centre, or twisted and deflected to one or other side, or turned forward.

The sternum as a whole is broadest above, where the first rib cartilages are attached. It becomes narrow opposite the second rib cartilages, but again expands until the level of the fifth rib cartilage is reached, below which it is rapidly

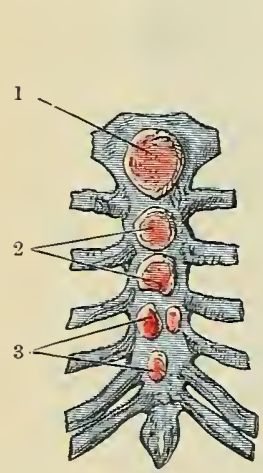

At birth.

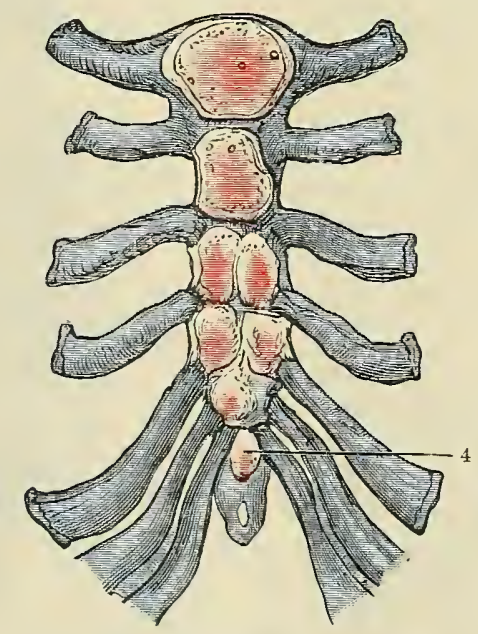

At 3 years.

Fig. 122.-OSSIFICATION OF THE STERNUM.

In this figure the second as well as the third segment of the body possesses two centres.

1. Appears about 5 th or 6 th month. 2. Appear about 7 th month unite from 20 to 25. 3. Appear about 8 th or 9 th month; third segment unites with second about puberty ; fourth segment unites with third in early childhood. 4. Appears about 3rd year or later. reduced in width and ends below in the pointed xiphoid process. Its position in the body is oblique from above downwards and forwards; its axis, if prolonged upwards, would touch the vertebral column opposite the third or fourth cervical vertebra. Though liable to changes in position by the rising and falling of the chest wall, its upper extremity corresponds to the level of the lower border of the second thoracic vertebra, whilst the lower end of the xiphoid process usually falls in line with the fibro-cartilage between the tenth and eleventh thoracic vertebræ.

In women the sternum as a whole is usually narrower and shorter than in men, and its position less oblique. On the other hand, Paterson has shown that the male manubrimm is proportionately wider and shorter than the female, whilst the male body is proportionately longer and narrower than the female.

Ossification.-The cartilaginous sternum, developed from the fusion medially of two cartilaginous bands uniting the anterior extremities of the cartilages of the first eight ribs, according to the researches of Ruge and more recently of Eggeling, begins 
to ossify about the sixth month of fœetal life. About this time a single centre appears in the manubrium; at birth this is well developed. Two centres placed vertically have also been recorded. Secondary epiphyses have been described in connexion with the clavicular facets; these do not unite with the rest of the mannbrium till adult life is reached. The body, formed by the fusion of four segments, is ossified from independent centres, either single or double, for each segment. These appear-the highest as early as the sixth month of intrauterine life-in some cases eren before the manubrium has begun to ossify (Lambertz), the lowest towards the end of full term. The common arrangement met with at birth is a single centre for the first, and double centres for each of the succeeding segments. Union between these segments occurs rather irregularly, and is liable to much variation. The fourth unites with the third segment in early childhood, the third with the second about puberty, whilst the fusion of the second with the first segment may not be complete till the twentieth or twenty-fifth year.

The xiphoid process usually ossifies from a single centre, which may appear as early as the third year, though often very much later. The xipboid process usually unites with the body about forty or fifty, and in exceptional cases osseous mnion between the body and manubrium may occur in advanced life.

According to Paterson the mambrium or presternum is dereloped in association with the shoulder girdle and becomes only secondarily associated with the ventrally growing ribs.

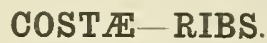

The ribs, of which there are twelve pairs, form a series of curved osseous bands which support the thoracic wall; posteriorly they articulate with the thoracic vertebræ, anteriorly each rib is provided with a costal cartilage. The first seven ribs articulate with the sternum by means of their cartilages, and are termed the costæ veræ, true or vertebro-sternal ribs. The lower five ribs are not so supported, and are described as the costæ spuriæ (false ribs). Of these the eighth, ninth, and tenth are united by their cartilages to the cartilage of the seventh rib, and are called the vertebro-chondral ribs, whilst the last two ribs are free at their anterior extremities, and are named the floating or vertebral ribs.

A typical rib consists of a capitulum costæ (head), a collum costæ (neck), a tuberculum costæ (tubercle), and a corpus costæ (shaft), on which, near its posterior end, is the angulus costæ (angle).

The head, placed on the posterior or vertebral end of the bone, is somewhat expanded. Medially, its articular surface is wedge-shaped and divided into two parts, a superior and inferior, by a ridge or crest (crista capituli), to which the interarticular ligament of the head of the rib is attached. Of these two facets the inferior is usually the larger, and articulates with the superior facet on the body of the vertebra in numerical correspondence with it, whilst the superior facet is for the corresponding area on the inferior part of the body of the vertebra above. The head is supported by a more or less constricted bar of bone, the neck, which lies anterior to the transverse process of the lower of the two vertebræ with which the rib articulates, and thus assists in the formation of the costo-transverse cleft. The neck is continuous with the shaft laterally; at which point there is a well-marked tubercle on its posterior surface. The anterior surface of the neck is smooth; its posterior aspect is rough, and pierced by numerous small holes for vessels. Here is attached the ligament of the neck of the rib. Not uncommonly the superior border of the neck is lipped and ridged (crista colli costæ), especially in the case of the sixth, seventh, and eighth ribs, and affords attachment to the anterior costo-trausverse ligament. The inferior border is continuous with the costal groove laterally.

The tubercle consists of an articular and a non-articular part; the former is medial and inferior to the latter. Its articular surface, of rounded or oval shape, is directed downwards, posteriorly, and a little medially, and rests npon a facet on the transverse process of the vertebra in numerical correspondence with the rib. The non-articular part, most prominent in the upper ribs, has the fibres of the ligament of the tubercle of the rib attached to it. It is usually separated from the superior border of the neck and shaft by a groore, in which lies the lateral dirision of the posterior branch of a thoracic nerve.

The shaft is thin, flattened, and band-like. Its length varies much; 
the seventh and eighth, which are usually the longest, are from two and a half to three times the length of the first and twelfth ribs respectively. The shafts are curved so as to adapt them to the form of the thoracic wall. More acute in the upper members of the series, where the shafts are shorter, the curve opens out in the middle and lower parts of the thorax, where the diameters of that cavity are greater. The curve, however, is not uniform. Including the whole length of the bone, it will be seen to be most accentuated towards the posterior part, where, in correspondence with the point at which the bend is most pronounced, there is a rough ridge placed obliquely across the outer surface of the shaft for the attachment of the slips of the ilio-costalis muscle; this is the angulus costæ. The distance between the angle and the tubercle is greatest on the eighth rib; above that, the width

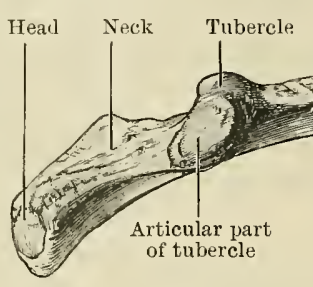
between these two points gradually decreases until, in the case of the first rib, the two coincide. Below the level of the eighth rib the distance slightly diminishes in conformity with the general narrowing of the thorax below that level. Towards the anterior extremity of the rib where the digitations of the serratus anterior and external oblique muscles are attached to its outer surface the curve of the shaft is somewhat more pronounced, and is referred to as the anterior angle.

Combined with this curve, there is in many of the ribs a twist. This may best be understood if the student will take a strip of stiff paper and bend it in the form of the curve of the rib. If, after he has done this, he pulls down the anterior end and turns up the posterior end of the strip, he will have imparted to the strip of paper a twist similar to that met with in the rib. This appearance is best seen in the middle members of the series, notably in the seventh and eighth ribs, above and below which it gradually becomes less marked. It is the occurrence of this twist which prevents the extremities of the ribs, together with the shaft, from resting on the same plane surface. To this rule there are certain notable exceptions, viz., the first and second, the twelfth, and not infrequently the eleventh.

The shaft has two surfaces, inner and outer, and two borders, a superior and an inferior. The outer surface, which is smooth, conforms to the general vertical convexity of the thorax, being directed upwards in the first rib, upwards and outwards in the higher ribs, outwards in the middle series, and outwards and slightly downwards in the tenth, eleventh, and twelfth. The inner surfaces are arranged conversely and are covered by the parietal pleura. Towards the sternal end of the middle ribs, where the downward twist is most marked, there is often an oblique line across the outer surface. This is sometimes referred to as the anterior angle. The upper border of the shaft is thick and rounded behind, thinner and sharper in front; to it are attached the fibres of the internal and Angle

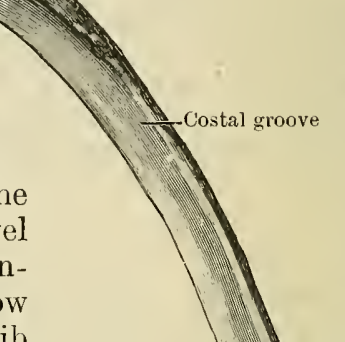

(

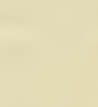

.
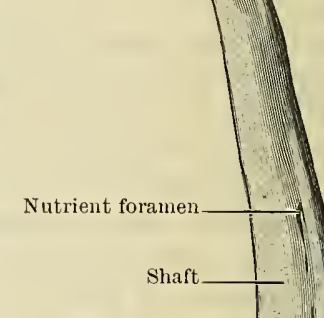
external intercostal muscles. The lower border is grooved behind at the expense of the inner surface, and is overhung laterally by a sharp margin. Anteriorly this sulcus costalis (costal groove) fades away, and its lips coalesce to form a rounded edge. The intercostal vessels and nerve are lodged in this groove, whilst its lips afford 
attachment to the external and internal intercostal muscles respectively. On the floor of the groove may also be seen the openings of the canals for the transmission of the nutrient vessels, which are directed towards the vertebral end of the rib.

The anterior or sternal extremity of the shaft, often slightly enlarged, displays an elongated oval pit into which the costal cartilage is sunk.

Peculiar Ribs.-The first, second, tenth, eleventh, and twelfth ribs all display characters by which they can be readily recognised.

The first rib can be easily distinguished from the others by its size, curvature, and flattened form, as well as by the great proportionate width of its shaft. 'The head, which is of small size, has a single oval or circular facet, which is directed medially and slightly backwards for articulation with the side of the body of the first thoracic vertebra. The neck is flattened fromabove downwards,

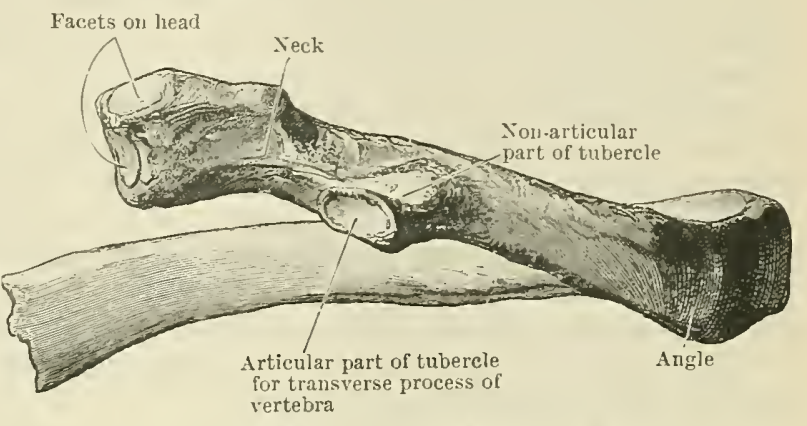

Fig. 124.-Fifth Right Rib as seen from Behind. and is slightly down-turned towards the end which supports the head. Its anterior border is rounded and smooth; its posterior edge rough for the attachment of ligaments. At the point where the neck joins the shaft posteriorly, a prominent tubercle curves upwards and backwards.

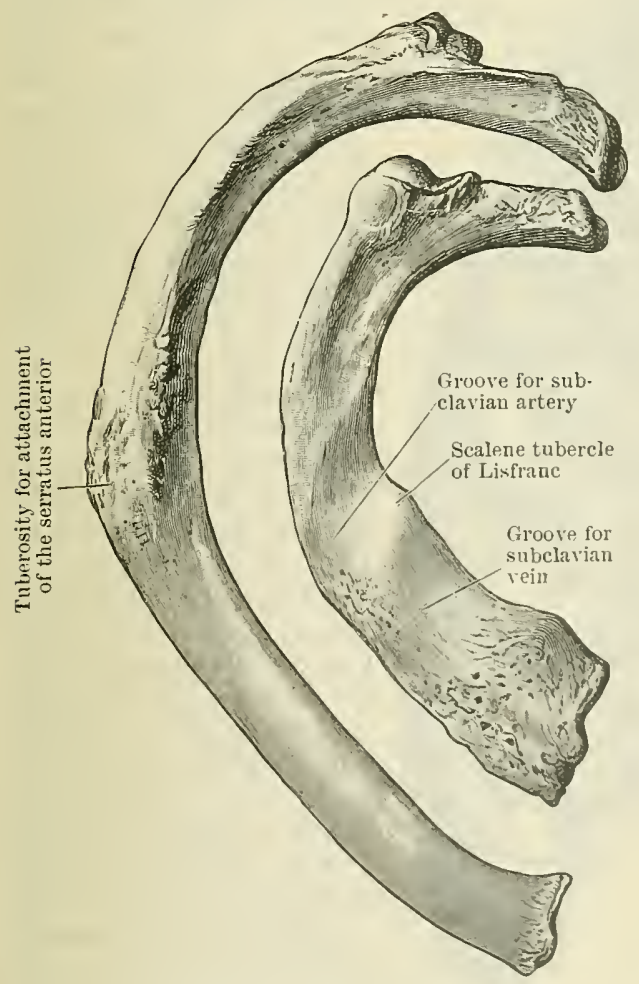

Fig. 125.-First and SEcond Right Ribs as SEEN FROM ABOVE.
The inner and under surface of this process has a small circular facet which rests on a corresponding articular surface on the transverse process of the first thoracic rertebra. The angle coincides with the tubercle, and thus assists in emphasising its prominence. The surfaces of the body of the rib are directed upwards and downwards, its borders inwards and outwards. If the tinger is run along the thin inner border, a distinct spine or tubercle can be readily felt about an inch or an inch and a quarter from its anterior extremity. This is the tuberculum scaleni (scalene tubercle of Lisfranc), which also forms an eleration on the upper surface of the shaft and affords an attachment for the scalenus anterior muscle. There is a shallow, oblique groove crossing the superior surface of the shaft in front of this, for the lodgment of the subclavian vein; whilst behind the tubercle there is another groove, usually better marked, and passing obliquely forwards for the subclavian artery (sulcus subclaviæ). In this groove, hehind and helow the artery, is loiged that part of the first thoracic nerve which contributes to the formativu of the brachial plexus. Aceording to Wood Jones the development of the groove lepends upon the size of the nerve
passing over it. The space on the upper surface of the ril, between this latter passing orer it. The space on the "pper sture posteriorly is somewhat rough, and affords attachment to the fibres of the scalenus medius muscle. In many specimens these features are 
but faintly marked. The anterior extremity of the rib is thickened and often expanded for the reception of its costal cartilage, which is not infrequently ossified. Here on the upper surface are attached the costo-clavicular ligament and the subclavius muscle. The inferior surface of the rib is smooth and is covered by pleura. The onter convex border, thin in front, is usually thick and rough behind the subclavian groove, where it has attached to it the fibres of the first digitation of the serratus anterior. Along this edge, also, are attached the external and internal intercostal muscles of the first intercostal space. The inner concave border is thin, and has connected with it the aponeurotic expansion known as Sibson's fascia.

The second rib may be distinguished by the size of its curve; the absence of any twist on its shaft, so that it can be laid flat on the table; the oblique direction of the surfaces of its shaft, the lateral being directed upwards and outwards, whilst the inner is turned downwards and inwards; and the presence of a well-marked, rough, oval area about the middle of its lateral surface and lower border for part of the first, and the whole of the second digitation of the serratus anterior muscle. The head has two facets, and the angle is close to the tubercle posteriorly.

The tenth rib has usually only a single articular facet on the head, and may or may not have a facet on the tubercle.

The eleventh and twelfth ribs are recognised by their length. Their heads, usually large in proportion to their shafts, support a single facet for articulation with the eleventh and twelfth thoracic vertebræ respectively. The tubercles are illdeveloped and have no articular facets. The angle is faintly marked on the

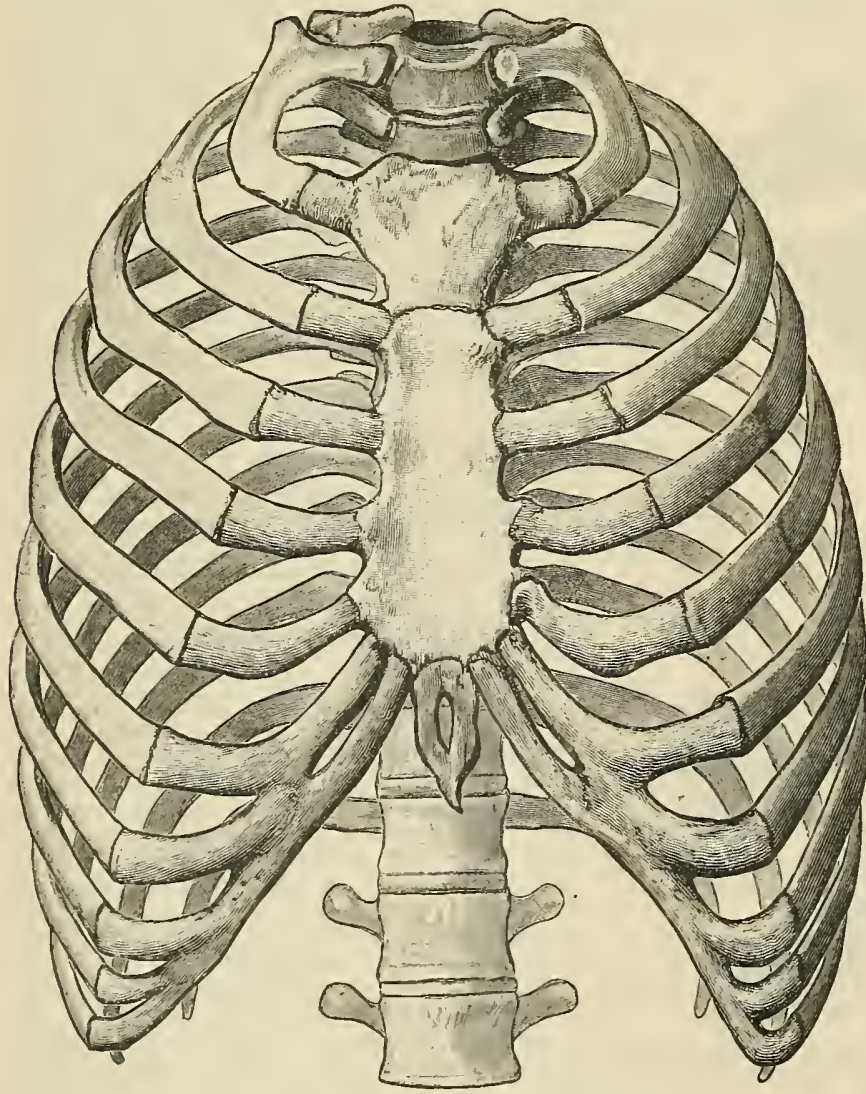

Fig. 126. -The 'Thorax as seen from the Front. eleventh, scarcely perceptible on the twelfth. Their anterior extremities are narrow and pointed and tipped with cartilage. The costal groove is absent in the twelfth, and but slightly seen in the eleventh. The twelfth is considerably shorter than the eleventh rib.

Ossification. - Ossification begins in the cartilaginous ribs about thesixth week, and rapidly extends along the shaft, so that by the end of the third month it has reached the permanent costal cartilage. The sixth and seventh ribs are the earliest to ossify; the first rib being the last (Lambertz). At puberty, or before, secondary centres appear. One for the head. In the first rib there is one epiphysis for the tubercle. In the second to the sixth ribs inclusive there are two epiphyses for the tubercle, one for the ar ticular part and one for the non-articular part. In the remaining ribs which have articular tubercles there is only one epiphysis (Fawcett). By the twenty-fifth year fusion between these and the shaft is complete. 


\section{THE COSTAL CARTILAGES.}

The costal cartilages, of which there are twelve pairs, are bars of hyaline cartilage united to the anterior extremities of the ribs, into which they are recessed and held in position by the periosteum. Through these cartilages the first seven ribs are connected directly with the sternum by means of synovial joints corresponding to the notches along the margins of the breast bone. To this there is an exception in the case of the first rib, the cartilage of which is directly blended with the manubrium sterni. The eighth, ninth, and tenth are connected indirectly with the sternum by their union with each other, and their articulation, through the medium of the eighth, with the seventh rib cartilage, whilst the eleventh and twelfth cartilages tip the ribs to which they belong, and lie free in the muscles of the flank. The costal cartilages increase in length from the first to the seventh, below which they become shorter. The first inclines obliquely downwards and medially to unite with the superior angle of the manubrium. The second lies more or less horizontally. The third to the seventh gradually become more and more curved, inclining downward from the extremities of their respective ribs, and then turning upwards to reach the sternum. The tenth cartilage articulates by means of a synovial joint with the ninth, the ninth with the eighth, and the eighth with the seventh. There are also surfaces for the articulation of the seventh with the sixth, and sometimes for the sixth with the fifth.

\section{THE THORAX AS A WHOLE.}

The bony and cartilaginous thorax is barrel-shaped, being narrower above than below, and compressed from before backwards. Its posterior wall is longer than its anterior, and its transverse width, which reaches its maximum opposite the eighth or ninth rib, is much in excess of its sagittal diameter. This is largely owing to the forward projection of the thoracic part of the vertebral column into the thoracic cavity.

The anterior wall is formed by the ribs and rib cartilages, together with the sternum. The posterior wall comprises the thoracic part of the vertebral column and the ribs as far as their angles. Owing to the posterior curve of the ribs, and the projection forwards of the vertebral bodies, the antero-posterior

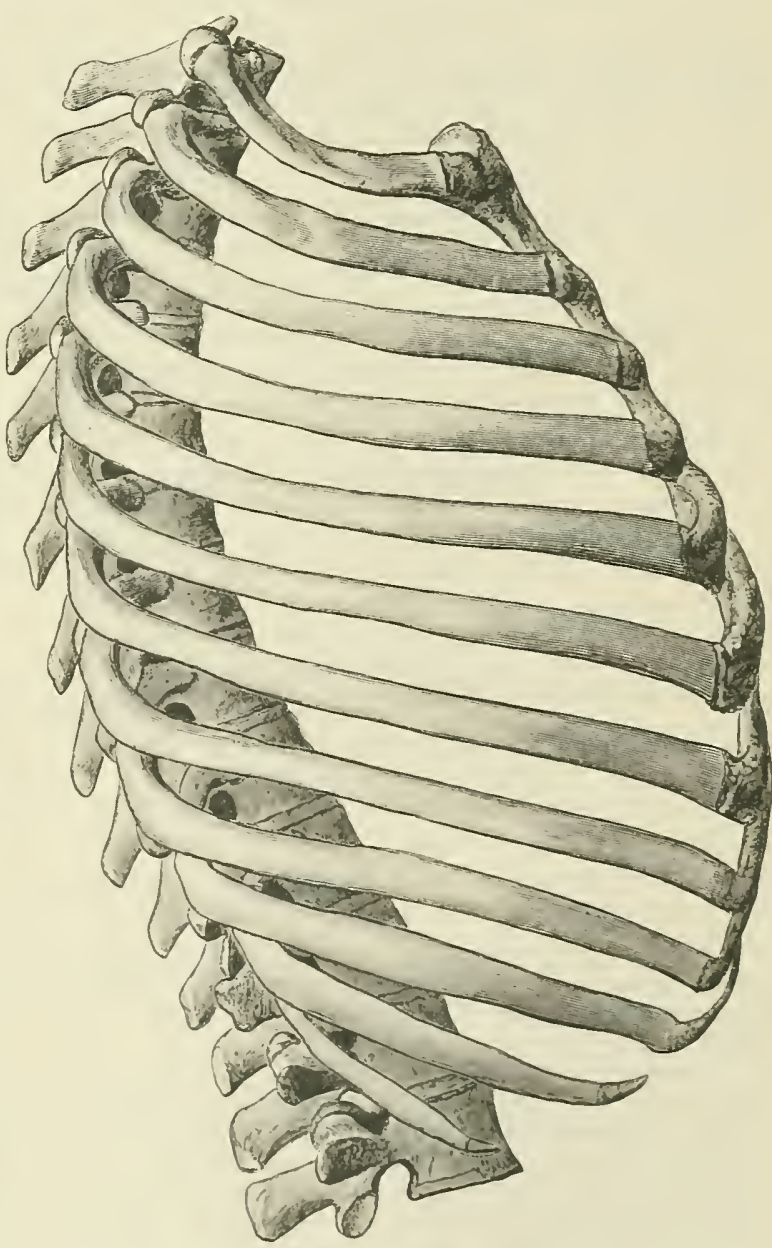

Fig. 127.-The Thurax as seex from the Right Side. diameter of the thoracic cavity is considerably greater on either side of the medial plane than in the median plane, thus allowing for the lodgment of the rounded 
posterior borders of the lungs. For the same reason the furrow on either side of the spinous processes of the thoracic vertebræ is converted into a broad groove (vertebral groove), the floor of which is in part formed by the ribs as far as their angles. The grooves so formed are each occupied by the fleshy mass of the sacrospinalis muscle.

The lateral walls are formed by the costal arches. The ribs, which run obliquely from above downwards and forwards, do not lie parallel to each other, but spread somewhat, so that the intervals between them (intercostal spaces) are wider in front than behind.

The superior aperture or inlet formed by the body of the first thoracic vertebra behind, the arches of the first rib on either side, and the upper border of the manubrium sterni in front, is contracted and of reniform shape, measuring on an arerage from 10 to $12 \mathrm{~cm}$. transversely and $5 \mathrm{~cm}$. in an antero-posterior direction. The plane of the inlet is oblique from behind downwards and forwards, so that in expiration the superior border of the sternum lies on a level with the fibru-cartilage between the second and third thoracic vertebræ.

The inferior aperture, of large size, is bounded in the median plane behind by the trrelfth thoracic vertebra; passing thence the twelfth ribs slope laterally, inferiorly, and forwards. From these a line carried horizontally forwards from their tips touches the end of the eleventh rib, and then curving slightly superiorly reaches the cartilage of the tenth rib. Here it follows the confluent margins of the cartilages of the tenth, ninth, eighth, and seventh ribs, finally reaching the xiphoid process, where it forms with the costal margin of the opposite side the infrasternal angle, the summit of which coincides with the xiphi-sternal articulation; in expiration this joint usually lies on a level with the intervertebral fibro-cartilage between the ninth and tenth thoracic vertebræ, and corresponds with the surface depression familiarly known as the pit of the stomach. The inferior aperture of the thorax is occupied by the vault of the diaphragm.

In the fotal condition the form of the thorax differs from that of the adult. It is laterally compressed-in this respect resembling the simian type. Its antero-posterior diameter is relatively greater than in the adult. At birth changes in form take place dependent on the expansion of the lungs; during subsequent growth, the further expansion of the thoracic cavity in a transverse direction is correlated with the assumption of the erect posture, and the use of the fore-limbs as prehensile organs.

Sexual Differences. - The thorax of the female is usually described as being proportionately shorter and rounder than the male. It also tends to narrowness in the lower segment. It is hardly necessary to point out that the natural form is often modified by the use of tight or ill-fitting corsets.

The Thoracic Index $=\frac{\text { Transverse diameter } \times 100}{\text { Antero-posterior diameter }}$ taken at the level of the junction of the xiphoid process with the body expresses the proportions of these diameters. That of the female is on an average lower than the male, indicating a more rounded form.

\section{THE SKULL.}

(In riew of the vast amount of accurate knowledge the medical student is now called upon to acquire, it is, in the opinion of the writer of this article, desirable that less stress should be laid upon the details of the disarticulated bones of the skull and more emphasis placed on the study of the skull as a whole.

It has hitherto been the custom to disarticulate the bones of the skull, imposing on the student the task of again reconstructing it, much after the manuer of a Chinese puzzle. In this way a minute acquaintance with the forms and articulations of the individual bones became necessary, and the student's memory was burdened with a mass of detail of little or no practical or scientific value, for in regard to the latter aspect of the subject the points of phylogenetic and ontogenetic interest are best illustrated by a consideration of the details of the evolution of the skull and the development and ossification of its parts. With possibly the exception of the temporal bones and the mandible, the author loolds that most of the useful information relating to the skull can best be studied in the complete cranium, or in sections of it made in different planes. By this method the student acquires a more intimate knowledge of its structure and topography, and is consequently better equipped to deal with the regions he may have to explore in the living. 
With this object in view, the writer of this article has given more space to the description of the skull as a whole and in section than is usually the case. Such a plan has doubtless given rise to some repetition; at the same time it renders more complete, and, it is hoped, also more useful from a practical standpoint, the account supplied.

It must, however, be borne in mind that a text-book of Anatomy serves the double purpose of a "Manual" of instruction and a work of reference. In view of this, the author has furnished a detailed account of the disarticulated cranial bones, such as has been hitherto supplied in works of a like kind.

The student, however, must not assume on this account that this section of the article should be neglected. He will find most of the more important details described in the article on the skull as a whole; but he would do well to supplement his knowledge by a reference to the more detailed accomnt for information regarding the development, ossification, and rariations of the individual bones.

In this edition additional figures hare been introduced, with the object of displaying additional points in the development and ossification of the skull.)

\section{THE BONES OF THE SKULL (Ossa Cranii). ${ }^{1}$}

The term skull (cranium) is commonly employed to signify the entire skeleton of the head. This comprises the bony envelope which surrounds the brain (cranium cerebrale), and the osseous structures which support the face (ossa faciei).

The cranium cerebrale is composed of the occipital, the sphenoid, the ethmoid, the frontal, the two parietals, and the two temporals, the inferior nasal conchx (O.T. inferior turbinated bones), the lacrimals, the nasal, and the vomer-fifteen bones in all.

The bones of the face (cranium viscerale, ossa faciei) include the following:One single, viz., the mandible, and six bones, arranged in pairs, viz., the maxillæ, zygomatic (O.T. malar), palate-seven bones in all.

The hyoid bone is usually described along with the skull. If, in addition, the bones of the middle ear, three on each side (malleus, incus, and stapes), be included, the skeleton of the head consists of twenty-nine bones.

\section{THE SEPARATE BONES OF THE SKULL \\ Os Frontale.}

The frontal bone, situated in the anterior part of the cranium, is a single bone formed by the fusion in early life of two symmetrical halres. It consists of a frontal part, which corresponds to the region of the forehead; an orbital part, which enters into the structure of the roof of the orbits; and a nasal part, which assists in forming the roof of the nasal fossæ.

Pars Frontalis. - The frontal part is the shell-like portion of the bone which rises upwards above the orbital arches. Its external surface is rounded from side to side and from above downwards. This convexity is most pronounced about $1 \frac{1}{4}$ inches above the orbital arches on either side of the median plane, constituting what are known as the frontal tuberosities. These mark the original sites of the centres from which the bone ossifies. The inferior margin of this part is formed on either side of the median plane by the curved supraorbital margin, the lateral and medial extremities of which constitute the zygomatic process (O.T. external angular) and the medial angular process, respectively. The latter, which descends to a lower lerel than the former, articulates with the lacrimal bone, and is separated from its fellow by a rough articular surface - the nasal notch for the nasal and maxillary bones. The curve of the supraorbital margin varies in different individuals and races; towards its medial third

1 In catalogues of craniological collections the terms used are as follows:Skull = entire skeleton of head, including the mandible.

Cranium = the skull, minus the mandible.

Calvaria = that part of the skmll which remains after the bones of the face have been remored or destroyed. 
it is crossed by a groove, often ( 25 per cent, Krause) converted into a foramen-the supraorbital notch or foramen. Through this there pass the supraorbital nerve and artery. Sometimes (16 per cent, Loja) a series of grooves, radiating upwards and laterally, indicate the course of the nerve (Dixon). Above the supraorbital margin the character of the bone displays marked differences in the two sexes: in the male, above the interval between the two medial angular processes, there is usually a well-marked prominence, called the glabella; from this the fulness extends laterally above the supraorbital margin, varying in degree and extent, and forming the elerations known as the arcus superciliares (superciliary arches). The prominence of these naturally reacts on the character of the supraorbital margins, which are thicker and more rounded in the male than in the female. Passing upwards over the glabella, the remains of the suture which originally separated the two halves of the frontal bone can usually be seen; above this point all trace of the suture is generally obliterated.

Extending from the zygomatic process is a well-marked ridge, which

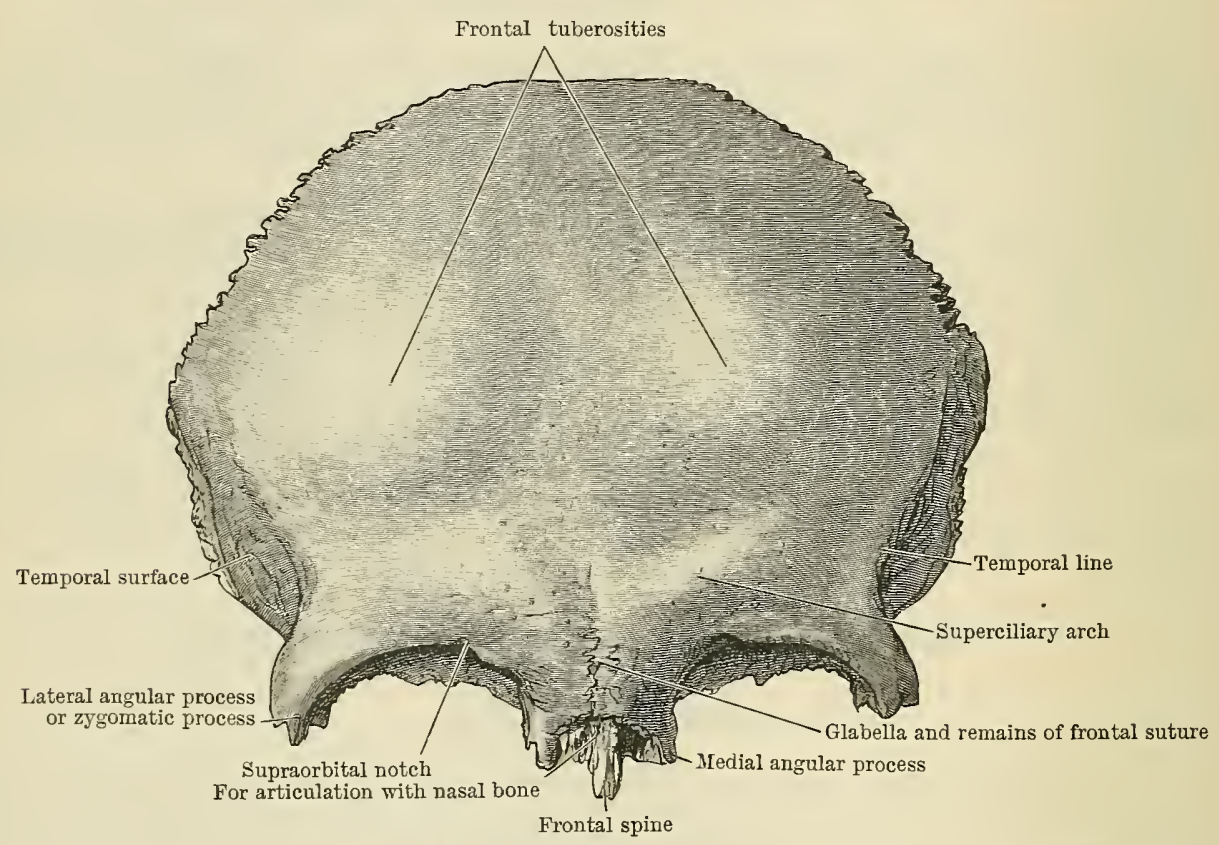

Fig. 128. - The Frontal Bone (Anterior View).

curves upwards and slightly medially, then, turning backwards, it arches across the lateral aspect of the bone. This is the linea temporalis, which serves to separate the anterior surface of the frontal portion of the bone from its temporal aspect. The latter (facies temporalis) forms the floor of the upper and anterior part of the temporal fossa, and serves for the attachment of the temporal muscle.

Pars Orbitalis. - The orbital part of the bone consists of two transversely curved plates, each having the form of a sextant; their medial edges, which are irregular and formed of cellular. bone, lie parallel to each other, and are separated in their posterior half by the incisura ethmoidalis (ethmoidal notch), in which the ethmoid bone is lodged. The edges of the notch on either side are grooved in front and behind by the anterior and posterior ethmoidal foramina, which are completed when the ethmoid is in situ. The anterior transmits the anterior ethmoidal branch of the naso-ciliary nerve (O.T. nasal) and the anterior ethmoidal vessels; the posterior, the posterior ethmoidal vessels. Anterior to the ethmoidal notch is the nasal notch, from the centre of which the nasal process projects downwards and forwards to terminate in the frontal spine, which lies between, and articulates with the nasal bones and perpendicular part of the 
ethmoid. On either side of the root of this process the pars nasalis (nasal part) of the bone is grooved obliquely from above downwards and forwards, and enters into the formation of the narrow roof of the nasal cavity. Anteriorly the nasal notch is limited by a rough $U$-shaped serrated surface, the medial part of which articulates with the nasal bones, whilst on either side the frontal processes of the maxillæ are united with it. Behind this, amid the broken cells, the passages leading into the frontal sinuses are readily distinguished, and here the medial edges of the orbital plates articulate with the lacrimal bones. The orbital part is thin and brittle. Anteriorly it is bounded by the supraorbital margin, just within which, midway between the medial angular process and the supraorbital notch, there is a small shallow depression (fovea trochlearis), often displaying a spicule of bone arising from its edge (spina trochlearis), which affords attachment to the pulley of the superior oblique inuscle of the eyeball. Laterally the orbital part is overhung by the supraorbital margin and the zygomatic process, and in the hollow so produced (fossa glandulæ lacrimalis) the lacrimal gland is lodged. The extremity of the zygomatic process articulates with the frontal process of the zygomatic bone.

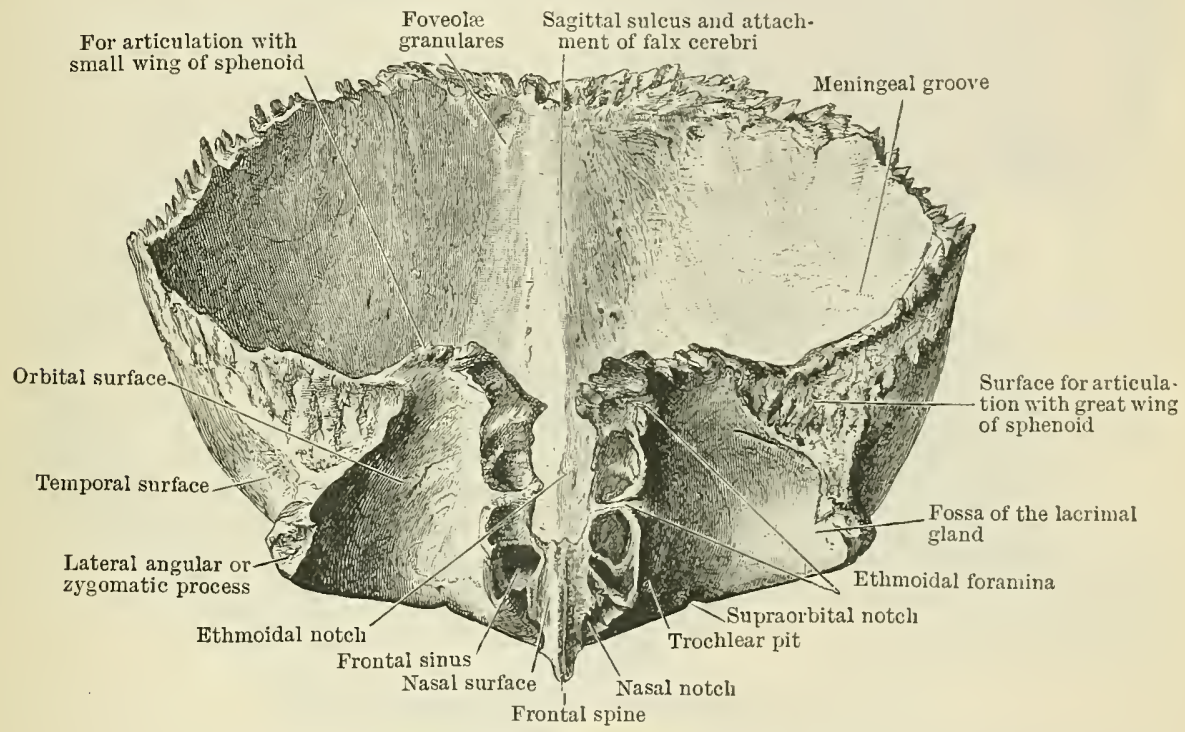

Fig. 129.-The Frontal Bone as seen from below.

Behind this the irregular edge of the orbital surface is united with the great wing of the sphenoid by a triangular area, which also extends on to the inferior aspect of the temporal surface of the frontal bone. The apex of the orbital surface, for the space of about half an inch, articnlates with the small wing of the sphenoid.

The cerebral surface of the bone forms a fossa in which lie the anterior and inferior parts of the frontal lobes of the cerebrum, the gyri of which impress their form on the inner table of the bone. Here, too, on either side of the median plane, may be seen depressions called foveolæ granulares, for the lodgment of arachnoideal granulations (O.T. Pacchionian bodies). Descending from the centre of the upper margin of the bone is a vertical groove, the sagittal sulcus; narrowing below, this ends in a ridge - the frontal crest-which nearly reaches the anterior part of the ethmoidal notch, where it terminates in a small orifice, the foramen cæcum, placed usually in the suture between the anterior part of the ethmoid and the frontal. This foramen may, or may not, transmit a small rein from the nose to the commencement of the superior sagittal sinus. This sinus, which is interposed between the layers of the falx cerebri, is at first attached to the frontal crest, but subsequently occupies the sagittal sulcus. Deeply concave from side to side and from above downwards, the lateral aspects of the fossa are seen to be traversed by small grooves for the anterior branches of the middle meningeal arteries. Below, the 
orbital parts bulge into the floor of the fossa, so that the ethmoidal notch appears recessed between them. On either side of the notch faint grooves for the meningeal branches of the ethmoidal vessels may be seen. The circumference of the fossa is formed by the serrated edges of the bone which articulate with the parietals above, and on either side below with the great and small wings of the sphenoid.

Connexions.-The frontal articulates with twelve bones, viz., posteriorly with the parietals and sphenoid; laterally with the zygomatic bones; inferiorly and medially with the nasals, maxillæ, lacrimals, and ethmoid.

Ossification.-Ossification begins in membrane from one centre for each half. This makes its appearance about the sisth or seventb week in the region above the processus

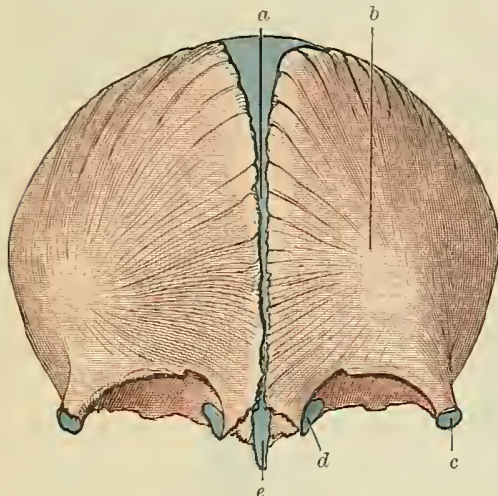

Fig. 130.-Ossification of the Frontal BONE.

$a$, Metopic suture still open. $b$, Position of primary centre. $c$, Centre for zygomatic process. $d$, Centre for region of trochlea. $e$, Centres for nasal spine. zygomaticus. From these the two halves of the frontal part of the bone are developed, and by extension medially and posteriorly from their lower part the orbital parts are also formed. Serres, Rambaud and Remault, and $v$. Ihering describe the occurrence of three pairs of secondary centres somewhat later: one pair for the frontal spine on either side of the foramen creum; a centre on either side in correspondence with the position of each trochlear pit; and a centre for each zygomatic process. Fusion between these secondary and the primary centres is usually complete about the sixth or seventh month of fœtal life. At birth the two symmetrical halves of the bone are separated by the metopic suture, obliteration of which, commencing as a rule on a level with the frontal tubera, gradually takes place, so that about the fifth or sixth year it is more or less completely closed, traces only of the suture being left above and below. In about 8 per cent of Europeans, however, the suture persists in the adult (see ante). At birth the supraorbital notches lie near the middle of the supraorbital margins.

Traces of the frontal sinuses may be met with about the second year, but it is only about the age of seven that they can be definitely recognised. From that time they increase in size till the age of puberty, subsequent to which time they attain their maximum development.

\section{Ossa Parietalia.}

The parietal bones, two in number, are placed on either side of the vault of the cranium, articulating with the frontal anteriorly, the occipital posteriorly, and the temporals and sphenoid inferiorly. Each bone possesses a parietal and cerebral surface, four borders, and four angles.

The parietal surface, convex from above downwards and from before backwards, displays towards its centre a more or less pronounced elevation, the tuber parietale (parietal tuberosity). This marks the position of the primitive ossific centre, and not infrequently corresponds to the point of maximum width of the head. At a variable distance from the inferior border of the bone, and more or less parallel to it, two curved lines can usually be distinguished. The linea temporalis superior (superior temporal line) serves for the attachment of the temporal fascia; the linea temporalis inferior (inferior temporal line) defines the attachment of the temporal muscle, the extent and development of which necessarily determine the position of the line. The surface below the lines enters into the formation of the floor of the temporal fossa, and is called the planum temporale; it also affords origin to the temporal muscle, and is often faintly marked by grooves which indicate the course of the middle temporal artery.

Above the superior temporal line the bone is covered only by the tissues of the scalp. Near its superior border, and about an inch from its occipital angle, is the small parietal foramen, through which pass a small arteriole and an emissary vein. 
The cerebral surface is concave from side to side and from above downwards. It is moulded over the surface of portions of the frontal, parietal, occipital, and temporal lobes of the cerebrum, and displays impressions corresponding to the arrangement of the gyri of these portions of the brain. It also presents a series of wellmarked grooves for the lodgment of the renous sinuses which accompany the branches of the middle meningeal artery ( $\mathrm{F}$. Wood Jones); these radiate from the sphenoidal angle of the bone, the best marked running upwards at some little distance behind and parallel to its anterior border. Within the superior margin is a series of depressions for arachnoideal granulations, and here also the bone is channelled so as to form a groove (sulcus sagittalis), which is completed by articulation with its fellow of the opposite side. Writhin this groove lies the superior sagittal venous sinus, and to its edges the falx cerebri is attached. Close to the mastoid angle there is also a curved groove, the transverse sulcus, in which the bighest portion or bend of the transverse venous sinus is lodged.

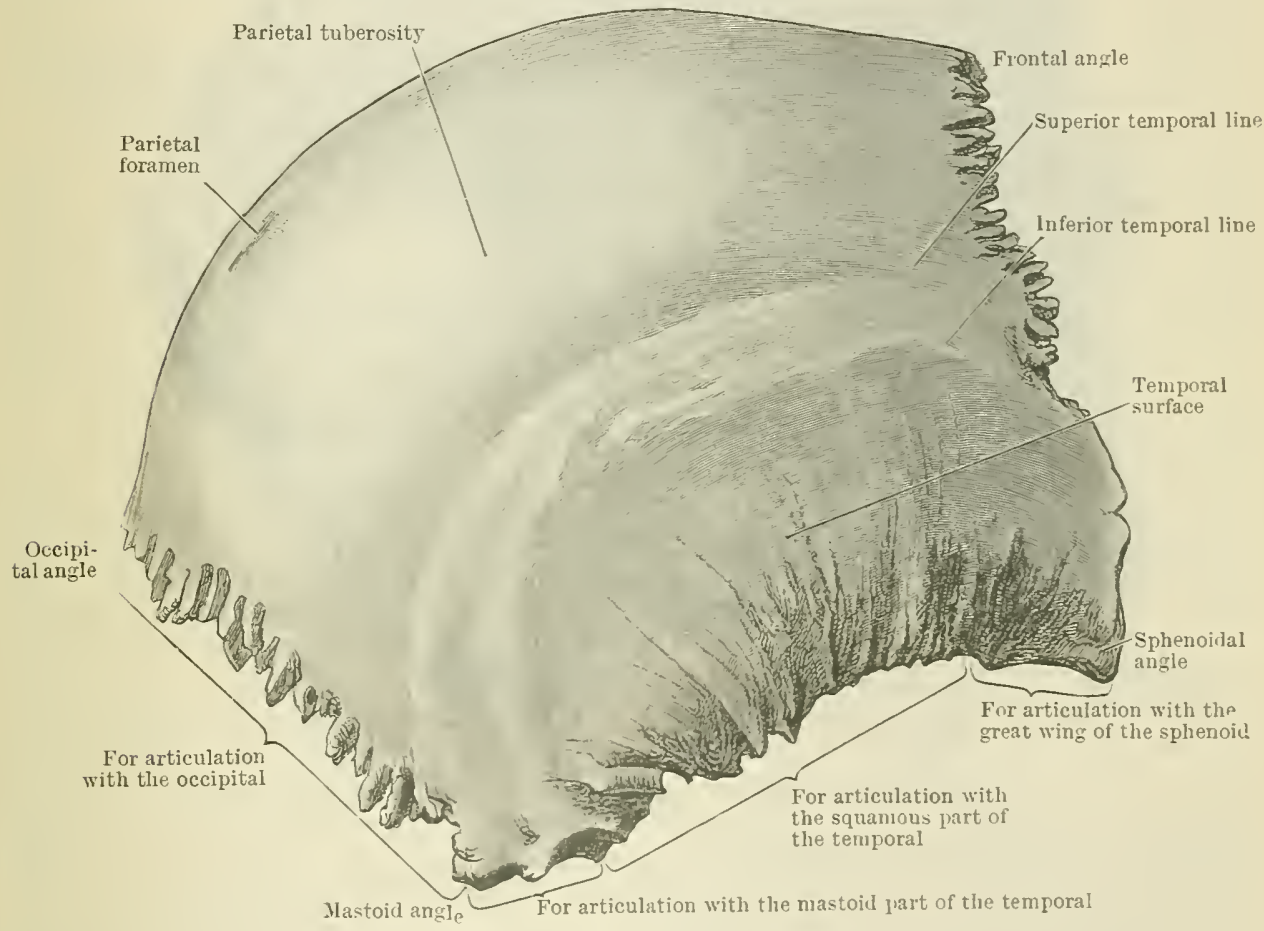

Fig. 131. - The Right Parietal Bone (Parietal Surface).

The anterior, superior, and posterior borders are deeply serrated. The anterior border articulates with the frontal bone, forming with it the coronal suture. In the superior part of this suture the frontal bone overlaps the parietal, while the parietal overlies the frontal below. The posterior border is united with the occipital bone to form the lambdoid suture. The superior border articulates with its fellow of the opposite side by means of the sagittal suture; in the interval between the two parietal foramina this suture is msually simple in its outline. The frontal angle is almost rectangular, and corresponds to the site of the anterior fontanelle. The occipital angle, usually more or less rounded, corresponds in position to the posterior fontanelle. The inferior border (margo squamosus) is curved, and shorter than the others: it lies between the sphenoidal and mastoid angles. Sharp and bevelled at the expense of its outer table, it displays a fluted arrangement, and articulates with the squama temporalis of the temporal bone. The sphenoidal angle, pointed and prominent, articulates with the great wing of the sphenoid. It is wedged into the angle formed by the union of that bone with the frontal, and is bevelled at the expense of its immer talle anterincly, 
whilst inferiorly it is thinned at the expense of its outer table. The mastoid angle is a truncated angle lying between the inferior and posterior borders. It is deeply serrated, and articulates with the mastoid process of the temporal bone. Not infrequently there is a channel in this suture which transmits an emissary vein.

Connexions. - The parietal bone articulates with its fellow, with the frontal, occipital, mastoid and squama temporalis of the temporal, and with the sphenoid. Occasionally the

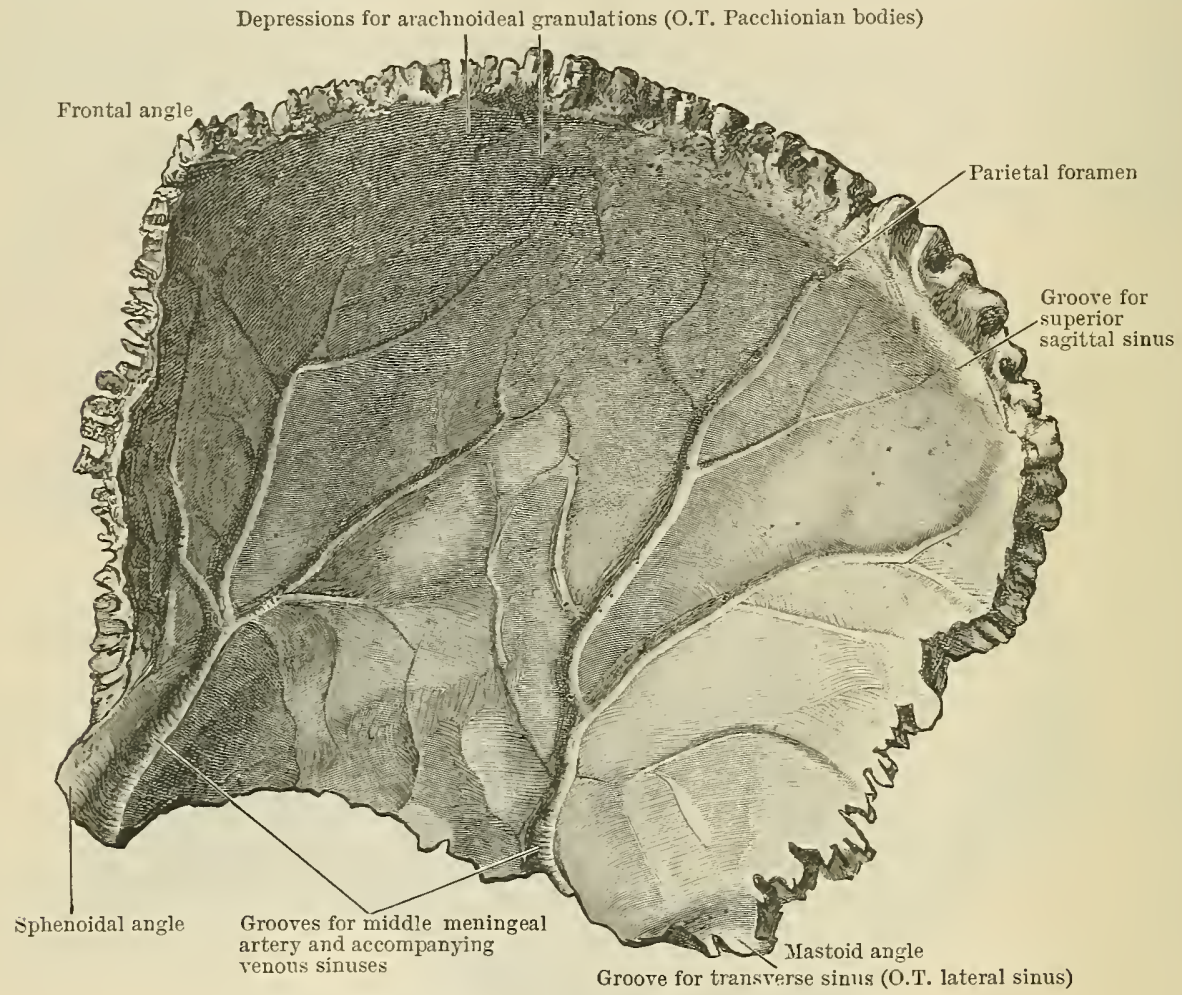

Fig. 132. -The Right Parietal Bone (Cerebral Surface).

sphenoidal angle may not reach the great wing of the sphenoid, being separated from it by the articulation of the squama temporalis of the temporal with the frontal (Appendix B).

Ossification.-Ossification takes place in membrane by two centres which appear, one superior to the other, abont the end of the second month (Toldt); these gradually unite during the fourth month and correspond in position to the future tuber parietale; from this ossification spreads in a radial manner towards the edges of the bone, where, however, the membranons condition still for some time persists, constituting the foutanelles. These correspond in position to the angles of the bone. Ossification is also somewhat delayed in the region of the parietal foramina, constitnting what is known as the sagittal fontanelle, a membranous interval which is not infrequently apparent even at birth.

\section{Os Occipitale.}

The occipital bone, placed at the posterior and lower part of the cranium, consists of four parts, arranged around a large oval hole, called the foramen occipitale magnum or foramen magnum. At birth these parts are all separate. The expanded curved plate posterior to the foramen is the squama occipitalis or tabular part. The thick rod-like portion anterior to the foramen is the basilar part. On either side the foramen is bounded by the lateral or exoccipital parts. 
The squamous or tabular part in shape somewhat resembles a Gothic arch, and is curved from side to side and from above downwards. It forms inferiorly a small portion of the middle of the posterior boundary of the foramen magnum, and unites, on either side of that, with the lateral parts of the bone. About the centre of the parietal surface of the squama there is a prominence-the protuberantia occipitalis externa (external occipital protuberance), which raries considerably in its distinctness and projection, and serves for the attachment of the ligamentum nuchæ. From the protuberance on either side two lines curve out towards the lateral angles of the bone. These are known respectirely as the linea nuchæ suprema and linea nuchæ superior (highest and superior curved lines). To the upper of these the galea aponeurotica (O.T. epicranial aponeurosis) is attached, whilst the lower serves for the origin of the trapezius and occipitalis muscles and the insertion of the sternomastoid and splenius capitis muscles. The tro lines together serve to divide the external surface of the squama occipitalis into an upper or occipital plane (planum occipitale), covered by the hairy scalp, and a lower or nuchal plane (planum nuchale), serving for the attachment of the fleshy muscles of the back of the neck. As a rule the occipital part bulges backwards beyond the external occipital protuberance; exceptionally, however, the latter process is the most outstanding part of the bone.

The nuchal plane, irregular and rough, is divided into two lateral halves by a medial ridge - the crista occipitalis externa (external occipital crest), which stretches from the external occipital protuberance above to the posterior border of the foramen magnum below. Crossing the nuchal plane transversely, about its middle, is the inferior nuchal line, which passes laterally and forwards on either side towards the lateral margins of the bone. The areas thus marked out serve for the attachment of the semispinalis capitis (O.T. complexus), obliquus capitis superior, and rectus capitis posterior major and minor muscles.

The cerebral surface of the squamous part, concave from side to side and from above downwards, is subdivided into four fossæ by a crucial arrangement of grooved ridges called the eminentia cruciata. In the upper pair of fosse are lodged the occipital lobes of the cerebrum, whilst the lobes of the cerebellum occupy the lower pair. Near the centre of the eminence is the protuberantia occipitalis interna (internal occipital protuberance), an irregular elevation, the sides of which are variously channelled according to the disposition of the grooves. Leading from this to the posterior margin of the foramen magnum is a sharp and well-defined ridge, the internal occipital crest, which serves for the attachment of the falx cerebelli, a process of dura mater which separates the two cerebellar hemispheres. Passing upwards from the internal occipital protuberance there is usually a well-marked ridge, to one or other side of which, more frequently the right (with the bone in the normal position and viewed from behind), there is a well-defined groove, the sulcus sagittalis, the lateral lip of which is generally less prominent. Placed in this groove is the superior sagittal venous sinus, and attached to the lips is the falx cerebri. At right angles to the foregoing, and at the level of the internal occipital protuberance, with which they become confluent, are two transverse grooves, the sulci transversi. These grooves, which have more or less prominent edges, lie between the upper and lower pairs of fossæ, and serve for the attachment of the tentorinm cerebelli as well as the lodgment of the transverse sinuses. Commonly the right transrerse groore is confluent with the groove to the right side of the median ridge, but exceptions to this rule are not infrequent. The angle formed by the union of the renous sinuses lodged in these grooves constitutes the confluens sinuum (O.T. torcular Herophili), which may accordingly be placed to one or other sicle of the internal occipital protuberance, more frequently the right; in some cases, however, it may occuply a central position.

The superior angle, more or less sharp and pointed, is wedged in between the two parietal bones, its position corresponding to the site of the posterior fontanelle. The lateral angles articulate on either side with the posterior extremity of the mastoid portion of the temporal bone. The superior borders, much serrated, articulate with the parietal bones forming the lambdoid suture; and the lateral borders, extending from the lateral angles to the jugular process inferiorly, are connected with the medial sides of the mastoid portions of the temporals.

The lateral (or exoccipital) parts of the occipital bone are placed on 
either side of the foramen magnum; on their under surface they bear the condyli occipitales by means of which the skull articulates with the atlas. Of elongated oval form, the condyles are so disposed that their anterior extremities, in line with the anterior margin of the foramen magnum, lie closer together than their posterior ends, which extend as far back as the middle of the lateral borders of the foramen. Convex from before backwards, they are skewed so that their surfaces, which are nearly plane from side to side, are directed slightly laterally. Each is supported on a boss of bone, pierced by the canalis hypoglossi (hypoglossal canal), which opens obliquely from within laterally and forwards on the floor of a fossa called the fossa condyloidea, situated just lateral to the anterior part of the condyle. The canal transmits the hypoglossal nerve, together with a meningeal branch of the ascending pharyngeal

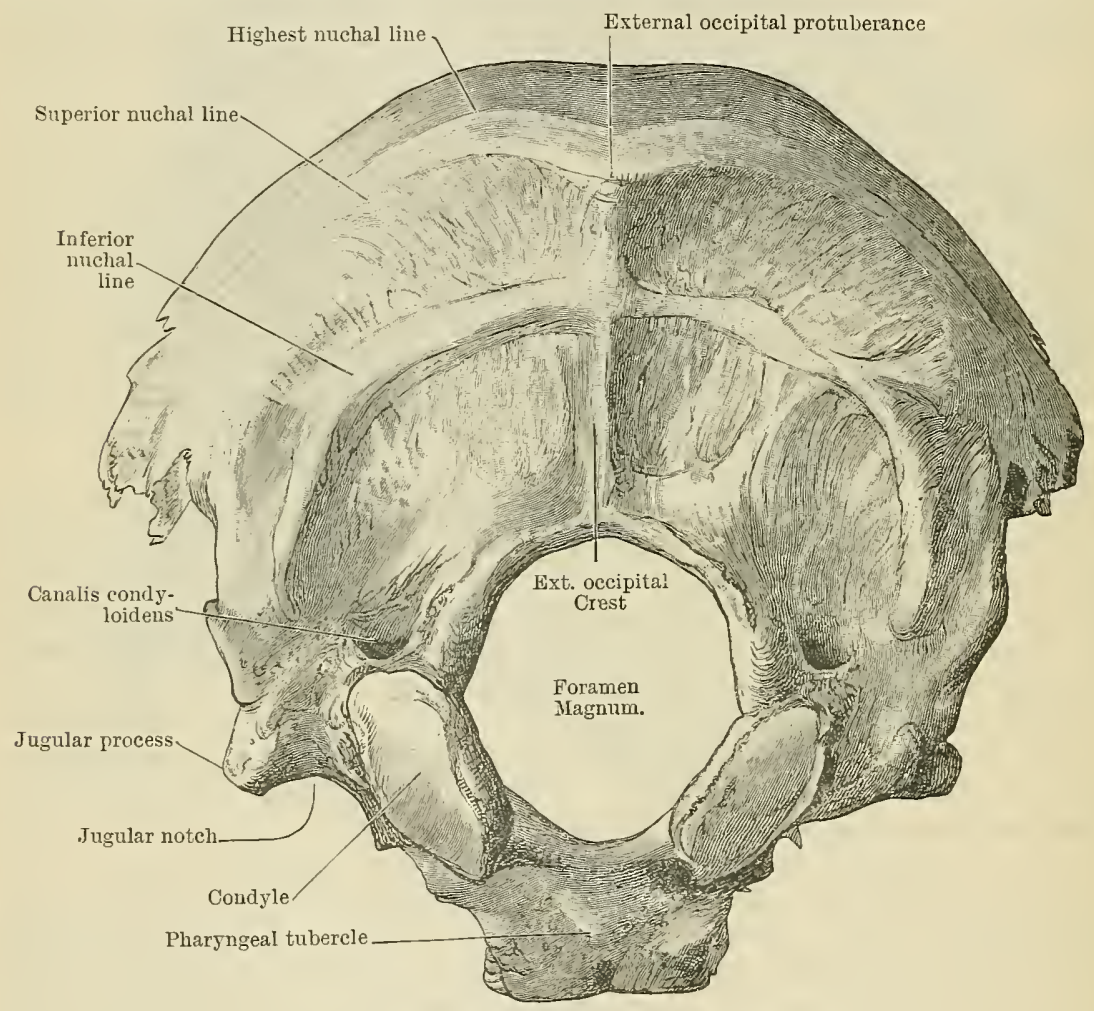

Fig. 133.-The Occipital Bone as Seen from Below.

artery and its companion veins. Behind the condyle is placed the fossa condyloidea, in the floor of which the canalis condyloideus (condyloid canal) frequently opens. Through this a vein passes which joins the transverse sinus. The fossæ lodge the posterior margins of the superior articular processes of the atlas in extension of the head. The edge of the foramen magnum immediately posterior to the condyle is often grooved for the passage of the vertebral artery around it. Jutting laterally from the posterior half of the condyle is a stout bar of bone, serially homologous with the vertebral transverse process-this is the processus jugularis; deeply notched in front (jugular notch) its anterior border is free and rounded, and forms the posterior boundary of the jugular foramen. Curving laterally from this margin, in line with the hypoglossal canal, there is often a small pointed projection, the processus intrajugulare, which serves to divide the jugular foramen into two compartments. Laterally the jugular process articulates by means of a synchondrosis with the jugular surface of the petrous part of the temporal bone. Its posterior border is confluent with the inferior and lateral portion of the occipital squama, and its under surface is rough and tubercular for the attachment of the 
rectus capitis lateralis muscle. The superior aspect of the lateral part displays on either side of the foramen magnum an elevated surface of oval form, the tuberculum jugulare; this corresponds to the part of the bone which bridges over the canal for the hypoglossal nerve. Its upper surface in many instances displays an oblique groove running across it; in this are lodged the glosso-pharyngeal, vagus, and accessory nerves. The jugular process is deeply grooved superiorly for the lower part of the transverse blood sinus, or sigmoid sinus, which here turns round the anterior free edge of the process into the jugular foramen. Joining this, close to its medial edge, is the opening of the canalis condyloideus when it exists.

The basilar part of the occipital bone extends forwards and upwards from the foramen magnum. Its anterior extremity is usually sawn across, as,

Groove for superior sagitta] simus and falx cerebri Superior angle

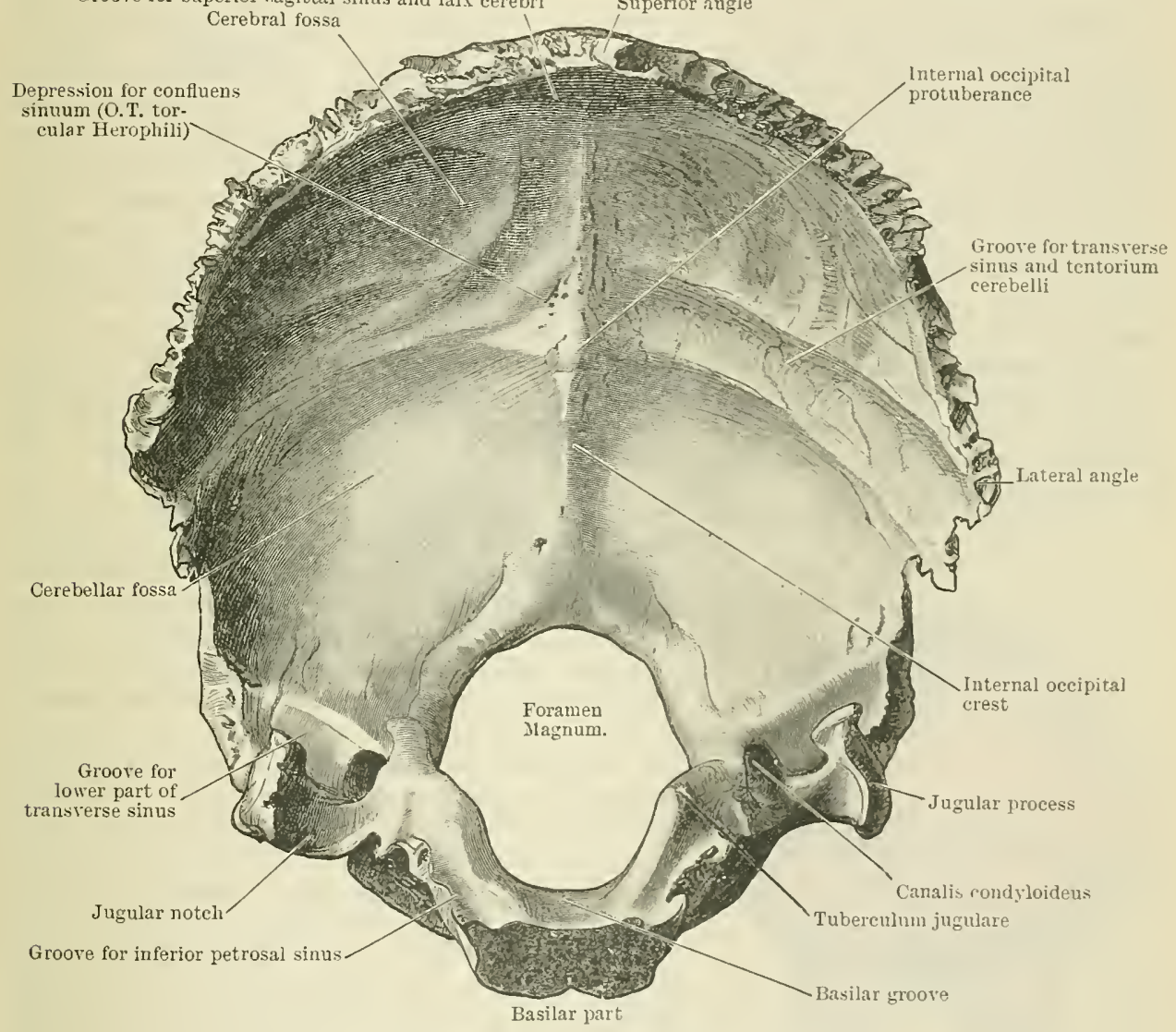

Fig. 131,-Occipital Bone (Cerebral Surface).

after adult life, it is necessary to sever it in this way from the sphenoid, the cartilage uniting the two bones having by that time become completely ossified. Broad and thin posteriorly, it narrows laterally and thickens vertically anteriorly, where on section it displays a quadrilateral form. Projecting from its inferior surface some little distance anterior to the foramen magnum is the pharyngeal tubercle to which the fibrous raphe of the pharynx is attached; on either side of this the longus capitis and rectus capitis anterior muscles are inserted. The superior surface forms a broad and shallow groove which slopes upwards and forwards from the thin anterior margin of the foramen magnum; in this rests the medulla oblongata. On either side its lateral edges are faintly groored for the inferior petrosal venous sinuses, below which the lateral aspect of the bone is rough for the cartilage which unites it to the sicles and apex of the petrous part of the temporal bone.

The foramen magnum, of oral shape, so disposed that its long axis lies in the 
sagittal plane, is of variable size and form. The plane of its outlet differs somewhat in individual skulls; in most instances it is directed inferiorly and slightly forwards. Anteriorly the condyles encroach upon it, and narrow to some extent its transrerse diameter. To its margins are attached the ligaments which unite it with the atlas"and epistropheus. Through it pass the lower part of the medulla oblongata where it becomes continuous with the spinal medulla, the two vertebral arteries, the accessory nerves, and the blood-ressels of the meninges of the superior part of the spinal medulla.

Connexions. - The occipital bone articulates with the two parietals in front and above, with the sphenoid in front and below, with the two temporals on either side, and with the atlas by means of its condyles.

Ossification.-The major part of the bone ossifies in cartilage, the upper part of the squamous part (interparietal) alone developing in membrane. The basilar part begins to ossify about the sixth week of fotal life by the appearance of two centres, one in front of the other; the anterior, according to Albrecht, constitutes the basiotic, the posterior the basi-occipital. These two centres - which there is some reason to believe may themselves be formed by the fusion of pairs placed laterally-rapidly unite, so that the occurrence of one centre alone is frequently described. From this the fore part of the margin of the foramen magnum is formed, together with a portion of the anterior end of the occipital condyle on either side. It helps also to close up the front of the hypoglossal canal. Uniou with the condylic parts is complete about the fourth or fifth year. Ankylosis between the basi-occipital and the sphenoid takes place about the twenty-fifth year.

The lateral, condylic, or exoccipital parts begin to ossify from a single centre about the end of the second month of foetal life. The notch for the hypoglossal canal appears about the third month. From this centre is formed the posterior three-fourths of the occipital condyle. The exoccipital is usually completely fused with the squamous part by the third year or earlier.

As already noted, the squamous part consists of two parts-the one above the occipital

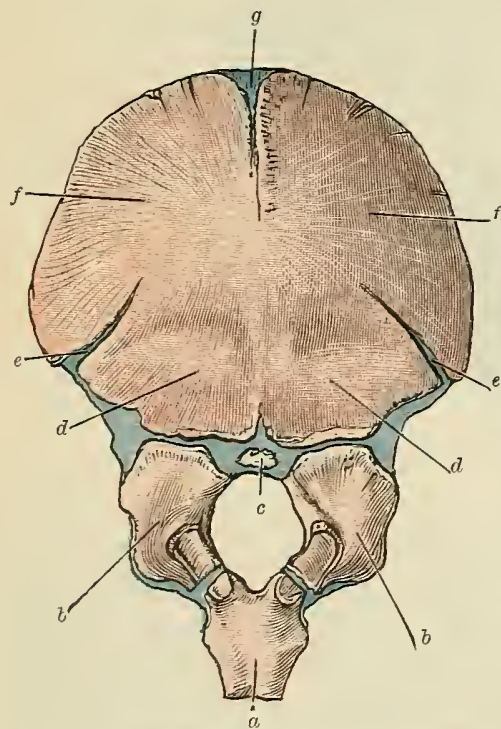

Fig. 135.--OSSIfication of THE OCCIPITAL BoNe.

$a$, Basilar centre ; $b$, Exoccipital ; $c$, Ossicle of Kerkring; $d$, Supra-occipital (from cartilage); $e$, Fissure between supra-occipital and interparietal ; $f$, Interparietal (from membrane); $g$, Fissure between interparietals. The supra-occipital forms a small part of the
median part of the posterior border of the foramen magnum, though here a small independent centre, known as the ossicle of Kerkring, is occasionally met with. Other independent centres are sometimes seen between the supra-occipital and the exoccipitals. membrane, the latter in cartilage. In a three-months fœetus this difference is very characteristic. The cartilaginous part (supra-occipital) begins to ossify from two centres (four according to Mall) about the sixth or seventh week, which rapidly join to form an elongated strip placed transversely in the region of the occipital protuberance. The centres for the superior part (interparietal) appear later. According to Maggi (Arch. Ital. Biol. tome 26, fas. 2, p. 301), they are four in number, of which two placed on either side of the median plane appear about the second month. The other pair, placed laterally, are seen about the third month; fusion between these takes place early, but their disposition and arrangement explain the anomalies to which this part of the bone is subject. The medial pair may persist as separate ossicles, or fuse to form the pre-interparietals, whilst the lateral pair may remain independent of the supra-occipital as a single or double interparietal bone, the former, owing to the frequency of its occurrence in Peruvian skulls, being sometimes called the "os Incce." Union between the supraoccipital and the interparietal elements occurs about the third or fourth month; but evidence of their separation is frequently met with even in the adult by the persistence of a transverse suture running inwards from each lateral angle of the squamous part, or, as above mentioned, there may be an os Incæ. crest, the other below it; the former develops in 
At birth the occipital consists of four parts-the interparietal and supra-occipital combined, the basi-occipital, and the exoccipitals-one on either side.

\section{Ossa Temporalia.}

The temporal bone lies about the centre of the inferior half of either side of the skull, and enters largely into the formation of the cranial base. It is placed between the occipital behind, the parietal above, the sphenoid in front, and the occipital and sphenoid medially and below. At birth it consists of three parts - a superior and lateral part, the squama temporalis or squamous portion; a medial and posterior portion, the petro-mastoid, which contains the parts specially associated with the sense of hearing, together with the organ associated with equilibration; and an inferior or tympanic part, from which the floor and anterior wall of the external acoustic meatus is formed.

The squamous part consists of a thin shell-like plate of bone placed vertically, having a medial (cerebral) and a lateral (temporal) surface and a semicircular upper border. Inferiorly, behind, and medially it is fused in early life with the petro-mastoid portion by means of the squamoso-mastoid and the petro-squamosal sutures, traces of which are often met with in the adult bone; whilst below and in front it is separated from the tympanic and petrous parts by the petro-tympanic fissure. Its temporal surface, smooth and slightly convex, enters into the formation of the floor of the temporal fossa, and affords attachment to the temporal muscle. Near its posterior part it is crossed by one or more ascending grooves for the branches of the middle temporal artery. In front and below there springs from it the processus zygomaticus. This arises by a broad attachment, the surfaces of which are inferior and superior; curving laterally and forwards, it then becomes twisted and narrow, so that its sides are turned medially and laterally and its edges directed upwards and downwards. Anteriorly it ends in an oblique serrated extremity which articulates with the temporal process of the zygomatic bone. Posteriorly the edges of the zygomatic process separate and are termed its roots. The superior edge, which becomes the posterior root, sweeps back over the external acoustic meatus, and is continuous with the supra-mastoid crest, which curves backwards and slightly upwards, and serves to define the limit of the temporal fossa posteriorly. Internally this ridge corresponds to the level of the floor of the middle cerebral fossa. The inferior edge turns medially and constitutes the anterior root; the inferior surface of this forms a transversely disposed rounded ridge, the tuberculum articulare (O.T. articular eminence), behind which there is a deep hollow, the fossa mandibularis, limited posteriorly by the tympanic plate, and crossed at its deepest part by an oblique fissure, the petrotympanic fissure. This cleft, which is closed externally, transmits about its middle the tympanic branches of the internal maxillary artery, and lodges the anterior process of the malleus. At its medial end the lips of this fissure are frequently separated by a thin scale of bone, a downgrowth from the tegmen tympani of the petrous part, which here separates the tympanic from the squamous elements, forming in its descent the major part of the lateral wall of the osseous auditory tube, which lies just medial to it. Between this scale of bone and the posterior edge of the fissure there is a canaliculus, which transmits the chorda tympani nerve. The part of the mandibular fossa in front of the petro-tympanic fissure as well as the articular tubercle articulate with the condyle of the mandible, through the medium of the interposed articular disc. Posteriorly the part of the fossa behind the fissure is non-articular and lodges a portion of the parotid gland. At the angle formed by the divergence of the two roots of the zygoma, in correspondence with the lateral part of the articular tubercle, there is a rounded tubercle: to this are attached the fibres of the temporo-mandibular ligament of the mandibular joint. In front of the medial end of the articular tubercle there is a small triangular surface, limited anteriorly by the edge of the anterior root, and medially by a thick serrated margin which articulates with the temporal aspect of the great wing of the sphenoid; this area forms part of the roof of the infra-temporal (O.T. zygomatic) fossa. Just anterior to the external acoustic meatus and projecting 
downwards from the inferior surface of the posterior root there is a conical process, called the post-glenoid tubercle, which forms a prominent anterior lip to the lateral extremity of the petro-tympanic fissure; it is the representative in man of a process which is developed in some mammals and prevents the backward displacement of the mandible. By some anatomists it is referred to as the middle root of the zygomatic process.

The zygomatic process by its inferior margin and medial surface gives origin to the masseter muscle, whilst attached to its superior edge are the layers of the temporal fascia. Behind the external acoustic meatus, and below the supramastoid crest, the squainous element extends downwards as a pointed process, which assists in forming the roof and posterior wall of the external acoustic meatus, where it unites inferiorly with the tympanic part and forms the lateral wall of a hollow within called the tympanic antrum. In the adult this process is occasionally

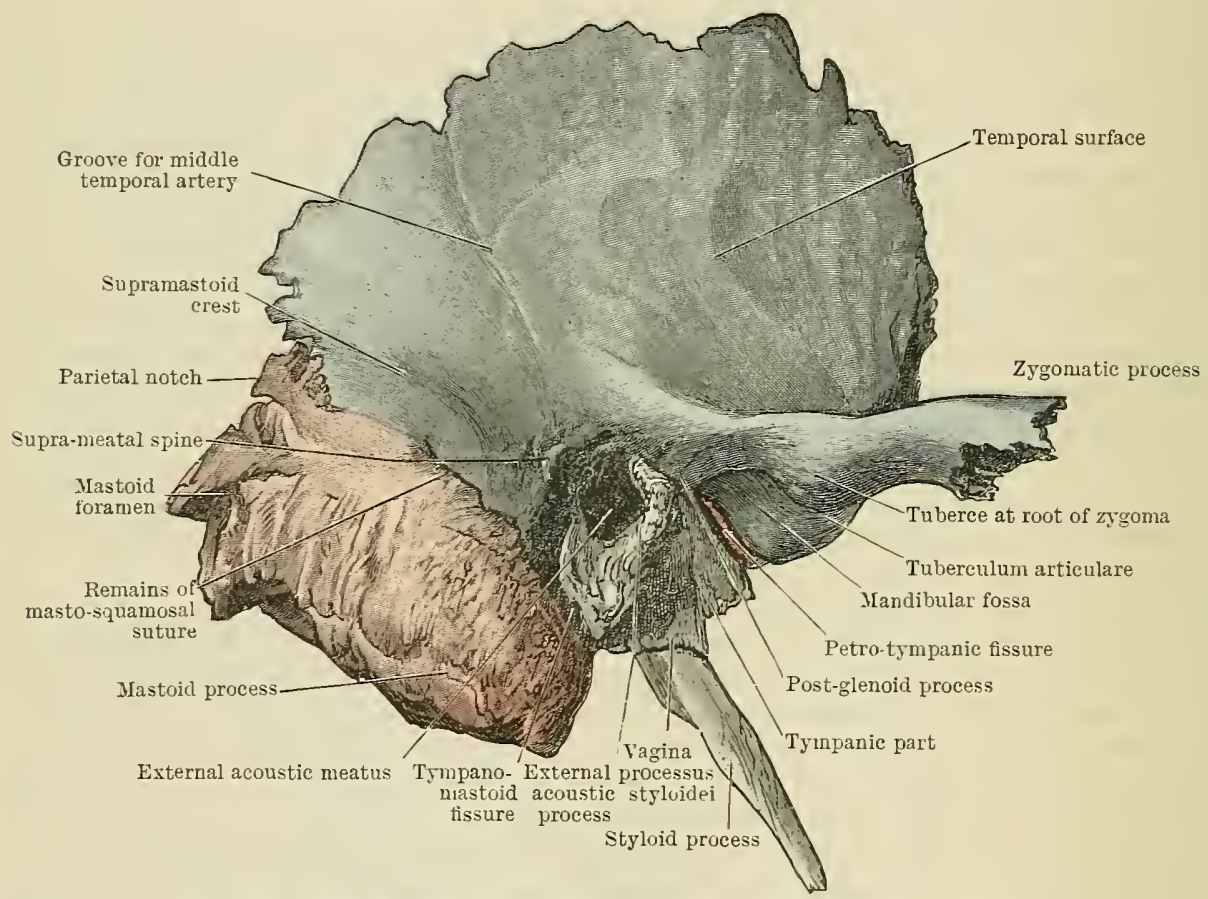

Fig. 136. - The Right Temporal Bone seen from the Parietal Side.

The squamo-zygomatic part is coloured blue; the petro-mastoid, red. The tympanic part and styloid process are left uncoloured.

sharply defined posteriorly by an oblique irregular fissure, the remains of the mastosquamosal suture. Immediately above and behind the external acoustic meatus there is often a little projecting spur of bone, the spina suprameatum (suprameatal spine).

The angular recess between this process and the supramastoid crest is of interest surgically, and is known as Macewen's triangle. The same authority has pointed out that the masto-squamosal suture frequently remains open till puberty and occasionally after, and may be of importance as a channel along which infective processes may extend.

The cerebral surface of the squamous part, less extensive than the parittal asfect owing to the bevelling of the parietal border, is marked by the impression of the gyri of the temporal lobe of the cerebrum, and is limited below by the petrosquamosal suture, the remains of which can frequently be seen. It is crossed in front by an ascending groove for the middle meningeal artery and its accompanying venous sinuses, branches from which course backwards over the bone in grooves more or less parallel to its parietal border.

The parietal border of the squamous part is curved, sharp, and scale-like, being 
bevelled at the expense of its inner table, except in front, where the margin is thick and stout. Here it articulates with the great wing of the sphenoid, its union with that bone extending to near the anterior part of the summit of the curve, behind which it is united to the parietal, overlapping the squamous border of that bone; posteriorly the free margin of the squamous part ends at an angle formed between it and the mastoid process called the incisura parietalis.

Pars Tympanica.-The tympanic part of the temporal bone forms the anterior, lower, and part of the posterior wall of the external acoustic meatus. Bounded in front and above by the petro-tympanic fissure, it forms the posterior wall of the non-articular part of the mandibular fossa. Fused medially with the petrous part, its lower edge, sharp and well defined medially, splits to enclose the root of the projecting styloid process, and is hence called the vagina processus styloidei (sheath of the styloid process). Laterally it unites with the anterior part of the

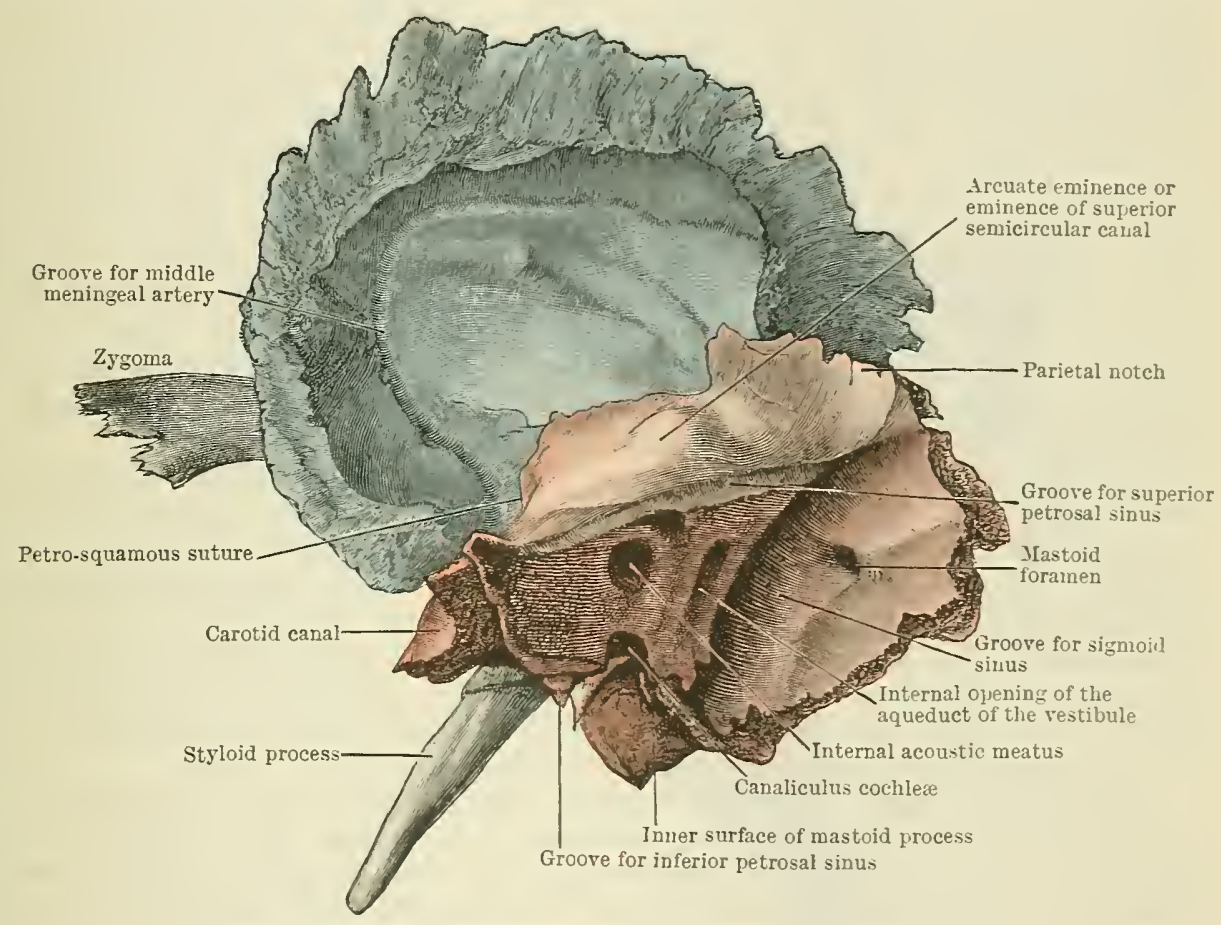

Fig. 137.-The Right Temporal Bone (Cerebral aspect).

The squamo-zygomatic part is coloured blue; the petro-mastoid part, red.

The styloid process is left uncoloured.

mastoid process, and higher up with the descending process of the squamous part, from both of which it is separated by the tympano-mastoid fissure, through which the auricular branch of the vagus escapes. Its free border, which forms the anterior, lower, and part of the posterior border of the external acoustic meatus, is usually somewhat thickened and rough, and serves for the attachment of the cartilaginous part of the external acoustic meatus.

The meatus acusticus externus (external acoustic meatus) is directed obliquely inwards and a little forwards, and describes a slight curve, the convexity of which is directed upwards; of oval form, its long axis, close to its orifice, is nearly vertical, but, as it passes inwards, inclines somewhat forwards so as to give a twist to the canal. The depth of the canal to the attachment of the membrana tympani averages from 14 to $16 \mathrm{~mm}$. The superior margin of the outer orifice overhangs considerably the lower edge, but owing to the obliquity of the inner aperture, to which the membrana tympani is attached, the superior wall of the osseous canal only exceeds the length of the lower wall by one or two millimetres.

Pars Petrosa et Pars Mastoidea.-The petro-mastoid part of the temporal 
bone, of pyramidal form, is fused to the medial aspect of the tympanic and squamosal portions, extending behind them, however, to form the well-marked and prominent mastoid process, which lies posterior to the external acoustic meatus. This process forms a nipple-like projection, the size of which differs considerably in different iudividuals. Usually larger in the male than in the female, its rough lateral surface and inferior border serve for the insertions of the sterno-mastoid, splenius capitis, and longissimus capitis muscles. Within and below its poiuted extremity there is a deep groove (incisura mastoidea), usually well marked, which gives origin to the posterior belly of the digastric muscle; whilst lying to the medial side of this, and separated from it by a more or less well-defined rough ridge, there can oftentimes be seen a narrow, shallow furrow, which indicates the course of the occipital artery. The medial surface of the mastoid portion forms, in part, the lateral wall of the posterior cranial fossa, in which the cerebellar lobes are lodged. Coursing across this aspect of the bone there is a broad curved groove, the convexity of which is directed forwards and lies in the angle formed by the base of the petrous part and its fusion with the mastoid portion. The depth to which the bone is here channelled varies considerably, and is important from a surgical standpoint, as herein lies the sigmoid portion of the transverse venous sinus. Anteriorly the mastoid is fused with the descending process of the squamosal above, and below, where it is united with the tympanic, it enters into the formation of the posterior wall of the external acoustic meatus and the cavity of the tympanum. Above, its free margin is rough and serrated, and articulates with the mastoid angle of the parietal; behind and below it articulates by a jagged suture with the occipital. Traversing this suture, or near it, is the mastoid foramen, which transmits a vein from the transverse sinus to the cutaneous occipital vein, together with a small branch of the occipital artery.

The petrous part (pyramis) of the petro-mastoid is of the form of an elongated three-sided pyramid. By its base it is united obliquely to the inner sides of the squamosal and tympanic parts. Its apex is directed medially, forwards, and a little upwards. Its three surfaces are arranged as follows :- The anterior looks upwards, slightly forwards, and a little laterally, and forms part of the floor of the middle cranial fossa. The posterior is directed backwards and medially, and forms part of the anterior wall of the posterior cranial fossa. The inferior is seen on the under surface of the base of the skull, and is directed downwards. The borders or augles are named respectively anterior, superior, and posterior.

The anterior angle is short, and forms an acute angle with the anterior part of the squamous part; within this angle is wedged the spinous part of the great wing of the sphenoid. Here, too, the osseous part of the auditory tube (canalis musculotubarius) may be seen leading backwards and laterally from the summit of the angle to reach the anterior part of the cavity of the tympanum in the interior of the bone. On looking into it, the canal is seen to be divided into two unequal parts by an osseous partition, the septum tubæ. The upper compartment, the smaller of the two (semicanalis $\mathrm{m}$. tensoris tympani), lodges the tensor tympani muscle, whilst the lower (semicanalis tubæ auditivæ) forms the osseous part of a channel (the auditory tube), which serves to conduct air from the pharynx to the tympanum.

The posterior angle is in part articular and in part non-articular. Posteriorly and laterally it corresponds to the upper margin of an area on the inferior surface with which the extremity of the jugular process of the occipital articulates. In front of that it is irregularly notched, and forms the free anterior edge of the jugular foramen, medial to which it has a sharp curved border, often grooved, reaching to the apex. This groove, which is completed by articulation with the lateral side of the basi-occipital, lodges the inferior petrosal venous sinus.

The superior angle is a twisted edge which is continuous with the upper margin of the sulcus for the transverse sinus posteriorly, and anteriorly and medially reaches the apex of the bone. Running along it there is usually a well-marked groove for the superior petrosal venous simus, and near its medial extremity it is slightly notched for the passage of the trigeminal nerve. Along the entire length of this border the tentorium cerebelli is attached. 
On the inferior surface of the petrous part, which is bounded in front by the anterior border medially, the tympanic plate laterally, and behind by the posterior. border, the following structures are to be noted:-Springing from and surrounded by its sheath is the slender and pointed processus styloideus, the length of which varies much. Projecting downwards and slightly forwards and medially, it affords attachments for the stylo-glossus, stylo-hyoid, and stylo-pharyngeus muscles, as well as the stylo-hyoid and stylo-mandibular ligaments. Just tehind it, and between it and the mastoid process, is the foramen stylomastoideum, which lies at the anterior end of the mastoid groove, and transmits the facial nerve and the stylo-mastoid artery. Just medial to the styloid process there is a deep, smooth, excavated hollow, the fossa jugularis, which is converted into a foramen (jugular) by articulation with the occipital bone. Behind and lateral to the fossa there is a small quadrilateral surface of variable size, which is united to the extremity of the jugular process of the exoccipital by a synchondrosis. Inside the fossa, on its lateral aspect, or placed on its lateral border, is the opening of a small canal (canaliculus mastoideus), which passes outwards to open into the canalis facialis, and transmits the auricular branch of the vagus, which ultimately escapes through the petro-mastoid fissure (vide ante). In front of the jugular fossa and separated from it by a sharp crest, and just medial to the tympanic plate, is the circular opening of the inferior orifice of the canalis caroticus (carotid canal). Directed at first upwards, this canal bends at a right angle and turns forwards and inwards, lying parallel to the anterior angle; reaching the anterior part of the apex of the bone, it opens in front by an oblique ragged orifice.

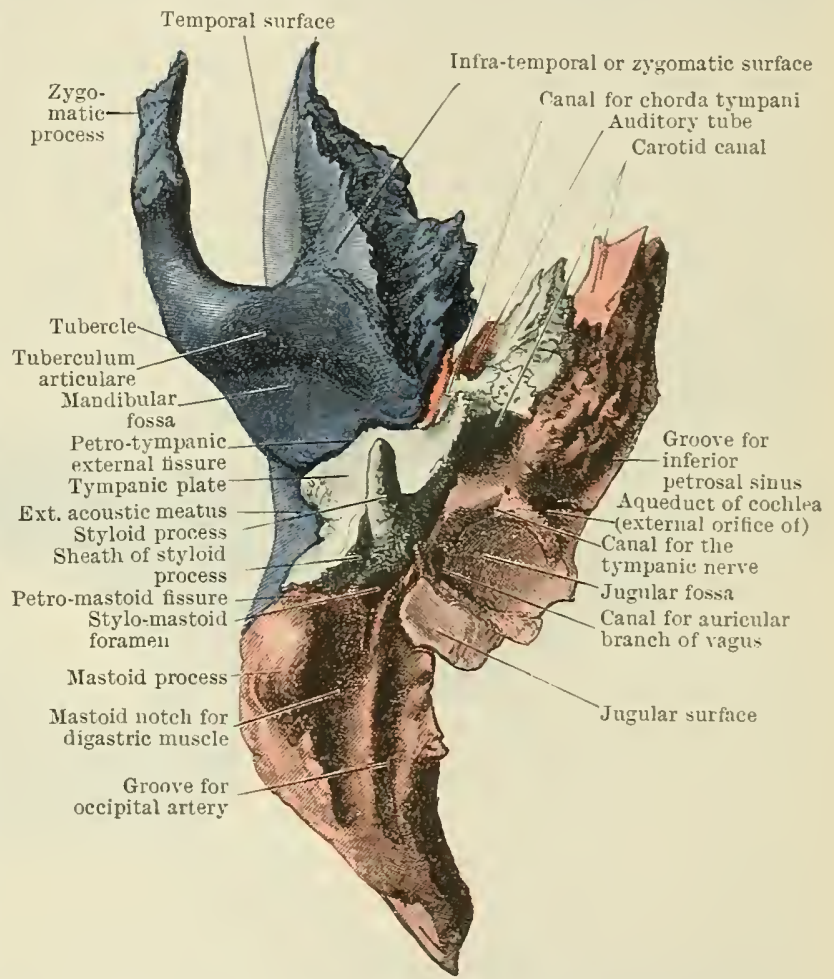

Fig. 13S.-The Right Temporal Bone seen from below.

The squamo-zygomatic part is coloured blue; the petro-mastoid, reil. The tympanic portion and styloid process are left uncoloured.

Through the canal the internal carotid artery, accompanied by a plexus of sympathetic nerves, passes into the cranium. On the ridge of bone separating the jugular fossa from the carotid canal is the opening of a small canal (canaliculus tympanicus), through which the tympanic nerve of the glosso-pharyngeal passes to reach the tympanum. Within the orifice of the carotid canal other small openings (canaliculi carotici tympanici) may be noticed which afford passage to the tympanic branches of the internal carotid artery and carotid sympathetic plexus. Occupying the interval posteriorly and medially between the jugular fossa and the carotid canal is a V-shaped depression (fossula fenestræ cochleæ), on the floor of which and close to the posterior border is the orifice of the apertura externa aquæductus cochleæ (aqueduct of the cochlea). In the fossa is lodged the petrous ganglion of the glosso-pharyngeal nerve, and the aqueduct transmits a tubular prolongation of the dura mater, which forms a channel of communication between the perilymph of the cochlea and the subarachnoid space. A small vein also passes through it. In front of and medial to the orifice of the carotid canal the under surface of the 
apex of the bone corresponds to a rough quadrilateral surface which forms the floor of the carotid canal, and also serves for the attachment of the cartilaginous part of the auditory tube as well as the origin of the levator veli palatini muscle; elsewhere it has attached to it the dense fibrous tissue which fills up the cleft (petro-basilar fissure) between it and the basilar part of the occipital bone.

The anterior surface bears the impress of the gyri of the under surface of the temporal lobe of the cerebrum, which rests upon it; in addition, there is a distinct but shaliow depression (impressio trigemini) near the apex, corresponding to the roof of the carotid canal; in this is lodged the semilunar ganglion on the sensory root of the trigeminal nerve. Lateral to the middle of the upper surface, and close to its posterior border, is the elevation (eminentia arcuata), more or less pronounced, which marks the position of the superior semicircular canal, here developed within the substance of the bone. A little

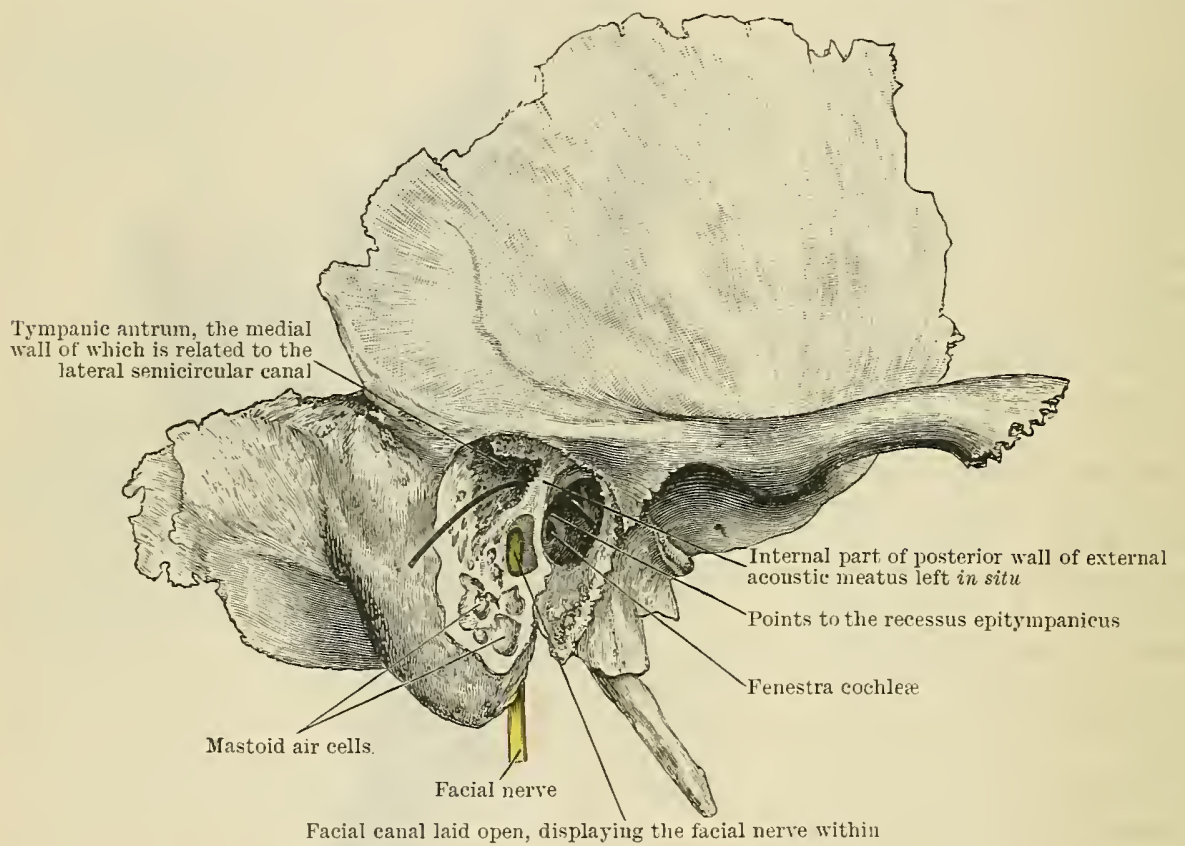

Fig. 139.

Preparation to display the position and relations of the tympanic antrum. The greater part of the posterior wall of the external acoustic meatus has been removed, leaving only a bridge of bone at its inner extremity ; under this a bristle is lisplayed, passing from the tympanic antrum throngh the iter to the cavity of the tympanum

in front of this, and in line with the angle formed by the anterior border and the squamous part, is the slit-like opening of the hiatus canalis facialis, within the projecting lip of which two small orifices can usually be seen. These are the openings of the canalis facialis; if a bristle be passed through the more medial of the two openings it will be observed to pass into the bottom of the internal acoustic meatus, if into the more lateral, it will pass thiough the facial canal, and, provided the channel be clear, will appear on the under surface of the bone at the stylo-mastoid, foramen. Leading forwards and medially from the hiatus towards the anterior border is a groove; in this lies the great superficial petrosal nerve, which passes out of the hiatus. A small branch of the middle meningeal artery also enters the bone here. A little lateral to the hiatus is another small opening (apertura superior canalis tympanici), often difficult to see; from this a groove runs forwards which channels the upper surface of the roof of the canal for the tensor tympani muscle. Through this foramen and along this groove passes the lesser superficial petrosal nerve. Behind this, and in front of the arcuate eminence, the bone is usually thin (as may be seen by holding it up to the light falling through the external acoustic meatus), roofing in the cavity 
within the bone called the tympanum and forming the tegmen tympani. Laterally the line of fusion of the petrous with the squamous part is often indicated by a faint and irregular petro-squamous fissure.

Posterior Surface.-The most conspicuous object on the posterior surface of the petrous part of the bone is the meatus acusticus internus (internal acoustic meatus), about $8 \mathrm{~mm}$. deep in the adult. This has an oblique oval aperture, and leads outwards and slightly downwards into the substance of the bone, giving passage to the acoustic and facial nerves, together with the nervus intermedius and the auditory branch of the basilar artery. The canal appears to end blindly; but if it be large, or still better, if part of it be cut away, its fundus will be seen to be crossed by a horizontal ridge, the falciform crest, which divides it into two fossæ, the floors of which (laminæ cribrosæ) are pierced by numerous small foramina for the branches of the acoustic nerve and the vessels passing to the membranous labyrinth, whilst in the anterior and upper part of the higher fossa the orifice of the canalis facialis, through which the facial nerve passes, is seen leading in the direction of the hiatus canalis facialis (vide supra). Lateral to the internal acoustic meatus and above it, close to the superior border, an irregular depression, often faintly marked, with one or two small foramina opening into it, is to be noticed. This is the fossa subarcuata, best seen

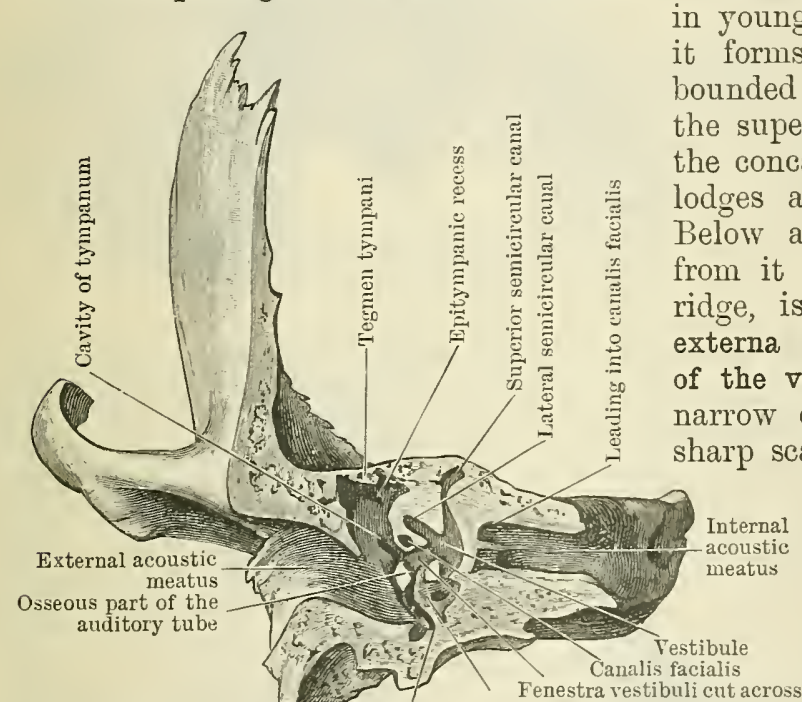

Superior opening of the canal for the tympanic branch of glosso-pharyngeal

Fig. 140.-Vertical Transverse Section throdgh the LefT Temporal Bone (Anterior Half of Section). in young bones (see Fig. $143 \mathrm{C}$ ), where it forms a distinct recess, which is bounded above by the bulging caused by the superior semicircular canal, within the concavity of which it is placed; it lodges a process of the dura mater. Below and lateral to this, separated from it by a smooth, elevated curved ridge, is the opening of the apertura externa aquæductus vestibuli (aqueduct of the vestibule), often concealed in a narrow curved fissure overhung by a sharp scale of bone. In this is lodged the saccus endolymphaticus, the remains of the stalk of the otocyst, together with a small vein. The ridge above it corresponds to the upper half of the posterior semicircular canal.

Connexions. - The temporal bonearticulates with the zygomatic, sphenoid, parietal, and occipital bones, and by a movable joint with the mandible. Occasionally the temporal articulates with the frontal, as happens normally in the anthropoid apes; although the region of the pterion is characterised by an X-like form, in the lower races of man there is no evidence that the occurrence of a fronto-squamosal suture is more frequent in the lower than the higher races, its occurrence being due to the manner of fusion of the so-called epipteric ossicles with the surrounding bones.

Ossification.-The temporal bone of man represents the fused periotic, squamosal, and tympanic elements; the two latter are membrane or investing bones, whilst the former is developed in cartilage around the auditory capsule. The cartilages of the I. and II. visceral arches are also intimately associated with its development, as will be elsewhere explained (Appendix E). The human temporal bone is charicterised by the large proportionate size of the squamosal, the comparatively small size of the tympanic, the absence of an anditory bulla, and the exceptional development of the mastoid process.

Ossification commences in the ear capsule in the fifth month, and proceeds so rapidly that by the end of the sixth month the inclividual centres are more or less fused. Of these, one, the Pro-otic (Huxley), which appears in the ricinity of the eminentia arcuata, is the most definite in position and form; from this a lamina of bone of spiral form is developed, which covers in the medial limb of the superior semicircular canal, and forms the roof of the internal acoustic meatus, together with the commencement of the 
facial canal. Reaching forwards, it extends to the apex of the petrous part; whilst laterally it forms part of the medial wall of the tympanum, surrounds the fenestra vestibuli, and encloses within its substance portions of the cochlea, vestibule, and superior semicircular canal. Another centre, the Opisthotic, appears in the vicinity of the promontory on the medial wall of the tympanum, surrounds the fenestra cochleæ, forms the floor of the restibule, and extends medially to complete the floor of the internal acoustic meatus. Surrounding the cochlea inferiorly and laterally, it completes the floor of the tympanum, and ultimately blends with the anterior and under part of the tympanic ring. The carotid canal at first groores it, and is then subsequently surrounded by it. According to Lambertz the lamina spiralis of the cochlea ossifies in membrane. The roof of the tympanum is formed from a separate centre, the Pterotic, which extends backwards towards the superior semicircular canal, and encloses the tympanic part of the facial canal; laterally this centre unites by suture with the squamosal, and sends down a thin process, which appears between the lips of the petro-tympanic fissure, and forms the lateral wall of the auditory tube. Nuclei, either single or multiple, Epiotic, appear in the base of the petrous part, and envelop the

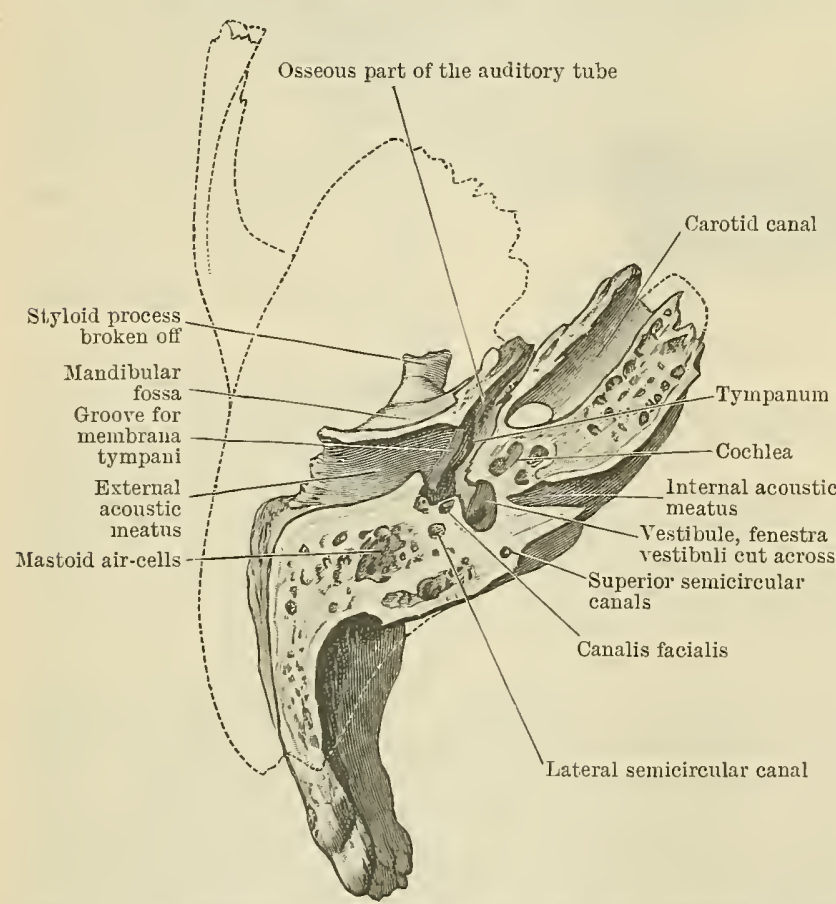

Fig. 142.-Horizontal Section through the Left Temporal Bone (Lower Half of Section).

the end of the second month. Situated near the root of lhe zygoma, it extends forwards and laterally into that process, medially to form the floor of the infra-temporal fossa, and upwards into the squamosal. From this latter there is a downward and backward exten-

posterior and lateral semitension from this part that the mastoid process is ultimately developed. The styloid process, an independent development from the upper end of the cartilage of the second visceral arch, is ossified from two centres. The upper or basal appears before birth, and rapidly unites with the petromastoid, the tympanic plate encircling it in front. This represents the tympanohyal of comparative anatomy. At birth, or subsequent to it, another centre appears in the cartilage below the above: this is the stylohyal. Ankylosis usually occurs in adult life between the tympanohyal and stylohyal, the union of the two constituting the socalled styloid process of human anatomy.

The centre from which the squamo-zygomatic develops appears in membrane about 
sion, which forms the post-auditory process; this ultimately blends with the posterior limb of the tympanic ring, being separated from it in the adult by the petro-mastoid fissure. It forms the lateral wall of the tympanic antrum, and constitutes the anterior and upper part of the mastoid process in the adult. About the third month a centre appears in the outer membranous wall of the tympanum: from this the tympanic ring is dereloped. Incomplete above, it displays two free extremities. Of these, the anterior is somewhat enlarged, and unites in front with the mandibular portion of the squamo-zygomatic, being separated from it by the petro-tympanic fissure and the downgrowth from the tegmen tympani ; the posterior joins the post-auditory process of the squamo-zygomatic above mentioned. Below, it blends medially with the portion of the petro-mastoid which forms the floor of the tympanum and ensheathes the tympanohyal behind. From the medial surface of the ring below there is an extension medially and forwards which forms the floor of the osseous part of the auditory tube, as well as the lateral wall and half the floor of the carotid canal. From the lateral side of the lower part of this ring two tubercles arise;

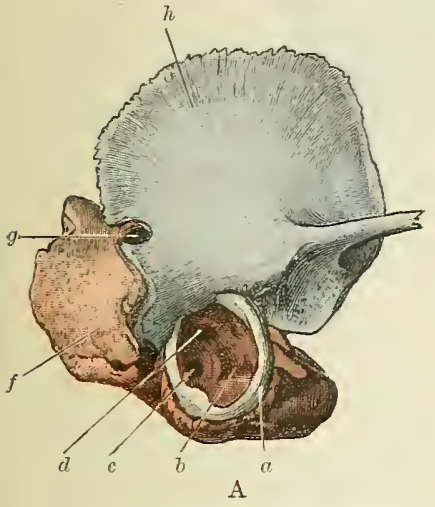

A

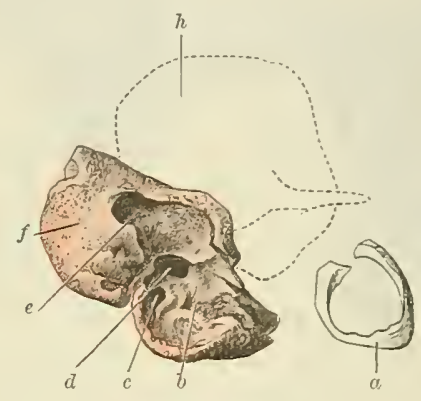

B

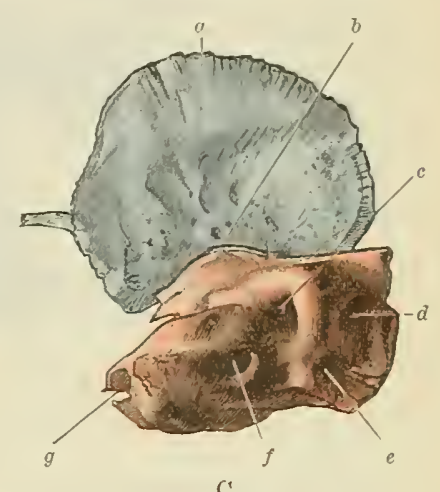

C

The squamo-zygomatic part is coloured blue; the petro-mastoid red. The tympanic ring is left uncoloured.

Fig. 143. - A. The Parietal Surface of the Right Temporal Boje at Birth. B. The Same With the SQuamo-zigonatic Portion ReMoved.

(The lettering is the same in both $\mathrm{A}$ and B.) $a$. Tympanic ring. $b$, Medial wall of tympanum. c , Fenestra cochlex. d, Fenestra vestibuli. e, Tympanic antrum. $f$, Mastoid process. $g$. Masto-squamosal suture, with foramen for transmission of vessels. $h$, Squamo-zygomatic, remored in figure B to show how its descending process forms the lateral wall of tlie tympanic antrum.
C. Cerebral Strface of the Right Temporal Boje at Birth.

$a$, Squamo-zygomatic. $b$, Petrosquamosal suture aud foramen (just above the end of the lead line). $c$, Subarcuate fossa. $d$, Aquaductus vestibuli. $e$, Aquxductus cochleæ. $f$, Internal acoustic meatus. g, Upper end of carotid canal.

these grow laterally, and so form the floor of the external acoustic meatus. The interval between them remains unossified till about the age of five or six, after which closure takes place. This deficiency may, however, persist even in adult life (see Appendix B, Temporal).

At birth the temporal bone can usually be separated into its component parts. 'The lateral surface of the petrous part not only forms the medial wall of the tympanmm, but is hollowed out behind and above to form the inner side of the tympanic antrum, the outer wall of which is completed by the post-auditory process of the squamo-zygomatic. As yet the mastoid process is undeveloped. It only assumes its nipple-like form about the second year. Towards puberty its spongy substance becomes permeated with air spaces, which are in communication with and extensions from the tympanic antrum. Occasionally this pneumatic condition is met with in early childhood. The external acoustic meatus is unossified in front and below, the outgrowth from the tympanic ring occurring subsequent to birth. The mandihular fossa is shallow and everted; the jugrular fossa is ill-marked; whilst the subarcuate fossa is represented ly a deep pit, the so-called floccular fossa of comparative anatomy. The hiatus of the facial canal is an open groove, displaying at either end the openings of the medial and lateral portions of the facial canial.

\section{Os Sphenoidale.}

The sphenoid bone lies in front of the basilar part of the occipital medially, and the temporals on either side. It enters into the formation of the cranial, orbital, and nasal eavities, as well as the temporal, infra-temporal, and pterygo- 
palatine fossæ. It consists of a body with three pairs of expanded processes, the great wings, the small wings, and the pterygoid processes.

The corpus (body), more or less cubical in form, is hollow, and contains within it the two large sphenoidal air sinuses. These are separated by a partition, which

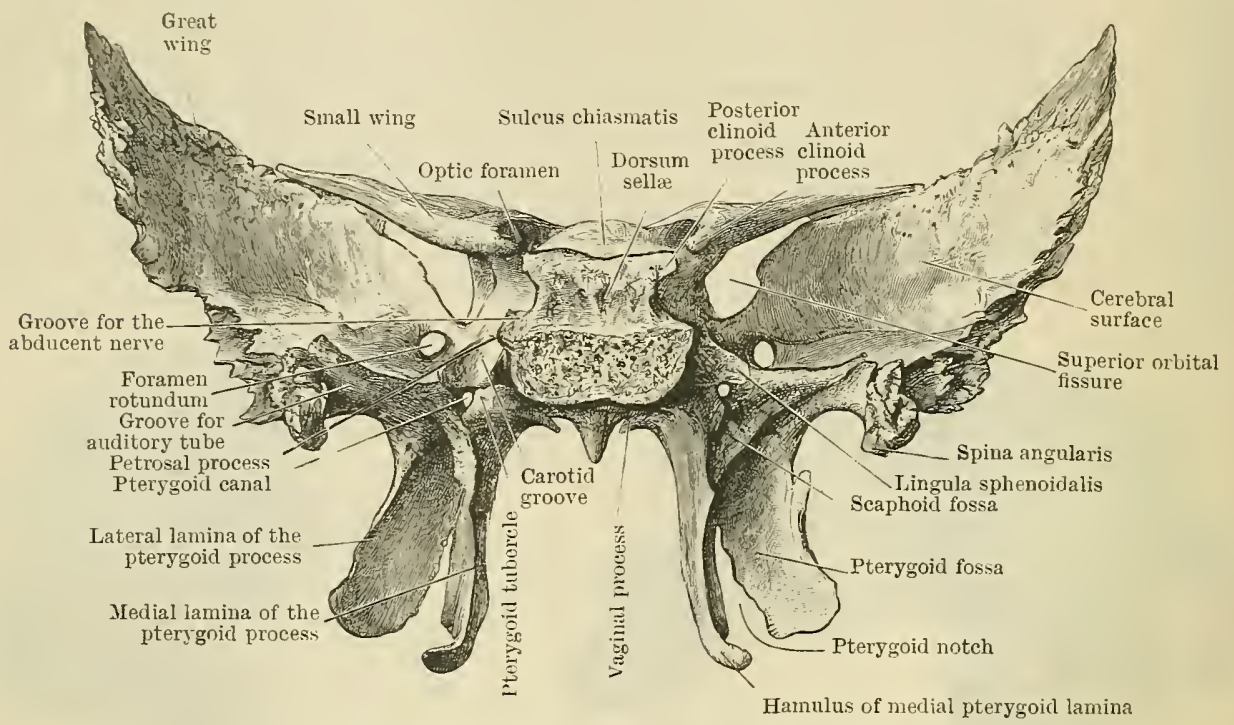

Fig. 144.-ThE SPHENOID SEEN FROM BEHIND.

is usually deflected to one or other side of the median plane. Each sinus extends laterally for a short distance into the root of the great wing, and downwards and laterally towards the base of the pterygoid process of the same side. They

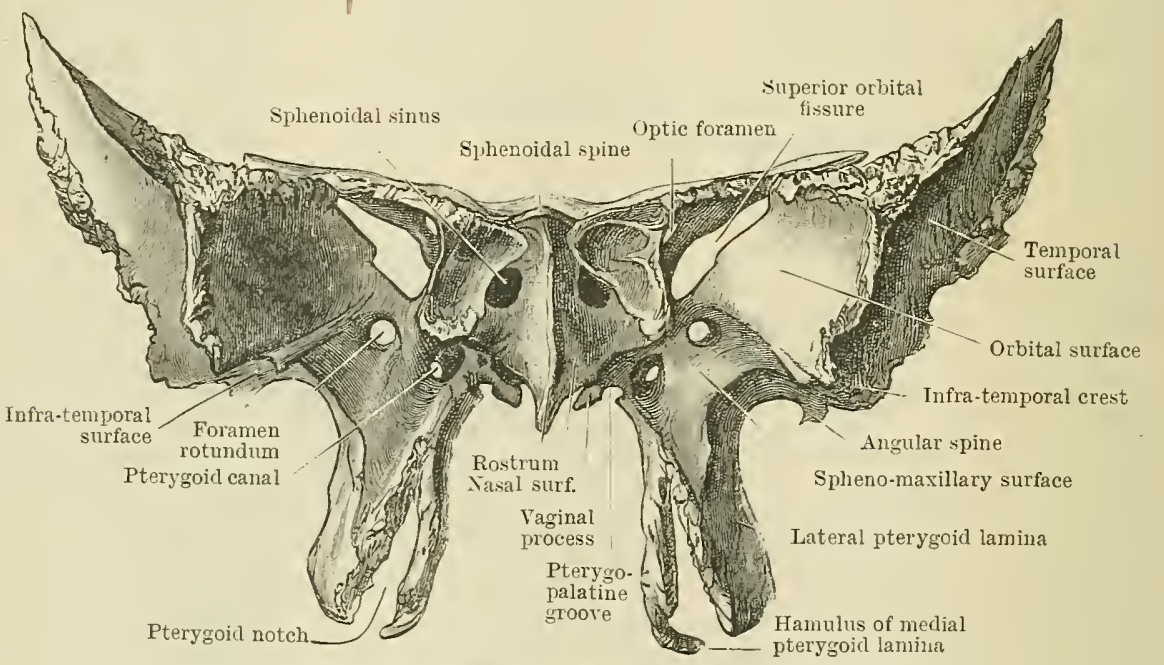

Fig. 145.-The SPHexold SEeN Fron THE FroNt.

communicate by apertures with the upper and back part of the nasal cavities. In the adult the posterior aspect of the body displays a sawn surface due to its separation from the basi-occipital, with which in the adult it is firmly ankylosed. The superior surface, from the anterior angles of which the small wings arise, displays an appearance comparable to that of an oriental saddle. Over its middle there is a deep depression, the sella turcica or fossa hypophyseos, in which is lodged the hypophysis (O.T. pituitary body). Behind, this is overhung by a sloping ridge, the dorsum sellæ, the posterior surface of which is inclined upwards, and is in continuation with 
the basilar groove of the occipital bone, supporting the pons and the basilar artery. Anteriorly and laterally the angles of this ridge project orer the fossa hypophyseos in the form of prominent tubercles, called the processus clinoidei posteriores (posterior clinoid processes). To these are altached the tentorium cerebelli and interchinoid ligaments. In front of the sella turcica there is a transverse elevation, the tuberculum sellæ, towards the lateral extremities of which, and somewhat behind, there are oftentimes little spurs of bone, the processus clinoidei medii (middle clinoid processes). In front of the tuberculum sellie is the sulcus chiasmatis, which passes laterally on either side to become continuous, between the roots of the small wings, with the optic foramina.

This groove is liable to considerable variations, and apparently does not always serve for the lodgment of the optic chiasma. (Lawrence, "Proc. Soc. Anat.," Journ. Anat. and Physiol. *ol. xxviii. p. 18.)

In front of the sulcus chiasmatis, from which it is often separated by a thin sharp edge, the superior surface continues forwards on the same plane as the upper surfaces of the small wings, and terminates an teriorly in a ragged edge, which articulates with the cribriform plate of the ethmoid, and has often projecting from it, medially, a pointed process, the sphenoidal spine. The lateral aspects of the body are fused with the great wings, and in part also with the roots of the pterygoid processes. Curving along the side of the body, superior to its attachment to the great wing, is an $\zeta$-shaped groove, the sulcus caroticus (carotid groove), which marks the position and course of the internal carotid artery. Posteriorly, the hinder margin of this groove, formed by the salient lateral edge of the posterior surface of the body, articulates with the apex of the petrous portion of the temporal bone, and is hence called the petrosal process; just above this, on the lateral border of the dorsum sellæ, there is often a groove for the abducent nerve.

The anterior surface of the body displays a rertical medial crista sphenoidalis (sphenoidal crest), continuous above with the sphenoidal spine, and below with the pointed projection called the sphenoidal rostrum. This crest articulates in front with the perpendicular plate of the ethmoid. On either side of the median plane are seen the irregular openings leading into the sphenoidal air sinuses, the thin anterior walls of which are in part formed by the absorption of the sphenoidal conchæ (O.T. turbinated bones) with which in early life they are in contact. With exception of a broad groove leading downwards from the apertures above mentioned, which enters into the formation of the roof of the nasal fossa of the corresponding side, the lateral aspects of this surface of the bone are elsewhere in articulation with the labyrinths of the ethmoid and the orbital processes of the palate bones. The sphenoidal rostrum is continued posteriorly for some distance along the inferior surface of the body, where it forms a prominent keel which fits into the recess formed by the alæe of the vomer. The edges of the latter serve to separate the rostrum from the incurved vaginal processes at the roots of the medial plates of the pterygoid processes. Posteriorly the under surface of the body of the sphenoid is rougher, and covered by the mucous membrane of the roof of the pharynx; here, occasionally, a median depression may be seen which marks the position of the inferior extremity of a foetal chanuel, called the canalis craniopharyngeus.

Alæ Parvæ.-The small wings are two flattened triangular plates of bone which project forwards and laterally from the anterior and upper part of the body of the bone, with which they are united by two roots which enclose between them the optic foramina for the transmission of the optic nerves and ophthalmic arteries. Of these roots, the posterior springs from the body just wide of the tuberculum selle, separating the carotid groove behind from the optic foramen in front; laterally this root is confluent with the recurved posterior angle of the small wing, forming the projection known as the processus clinoideus anterior (anterior clinoid process), which overhangs the anterior part of the body of the bone and affords an attachment to the tentorium cerebelli and interclinoid ligaments. The anterior root, broad and compressed, unites the upper surface of the small wing with the anterior and upper part of the body. Laterally the lateral 
angle terminates in a pointed process which reaches the region of the pterion and there articulates with the frontal, and may come in contact with the great wing. The superior aspect is smooth, and forms in part the floor of the anterior cranial fossa. 'The inferior surface constitutes part of the posterior portion of the upper wall of the orbit, and also serves to roof in the superior orbital fissure (O.T. sphenoidal fissure), which separates the small wing from the great wing below. The anterior edge is ragged and irregular, and articulates with the orbital parts of the frontal. The posterior margin, sharp and sickle-shaped, separates the anterior from the middle cranial fossa, and corresponds to the position of the stem of the lateral cerebral fissure on the surface of the cerebrum.

Alæ Magnæ.-The great wings, as seen from above, are of a somewhat crescentic shape and form a considerable portion of the floor of the middle cranial fossa. If the medial convex edge of the crescent be divided into fifths, the posterior fifth extends backwards and laterally beyond the body of the bone, presenting a free posterior edge, which forms the anterior boundary of the foramen lacerum. This border ends behind in the horn of the crescent, from which a pointed process projects downwards, called the spina angularis; this is wedged into the angle between the petrous and squamous parts of the temporal bone. The medial surface of the posterior border and spine is furrowed for the cartilaginous part of the auditory tube (sulcus tubæ), whilst on the medial side of the spine the course of the chorda tympani nerve is indicated by a groove (Lucas). The second fifth of the convex border of the crescent is fused to the side of the body and united below with the root of the pterygoid process. The angle formed by the union of the great wing with the side of the body posteriorly corresponds to the hinder end of the carotid groove, the lateral lip of which is formed by a projecting lamina called the lingula. The remaining three-fifths of the convex border is divisible into two nearly equal parts; the medial is a free, curved, sharp margin, which forms the inferior margin of the superior orbital fissure, the cleft which separates the great wing from the small wing, and which establishes a wide channel of communication between the middle cranial fossa and the cavity of the orbit, transmitting the oculomotor, trochlear, ophthalmic division of the trigeminal, and the abducent nerves, together with the ophthalmic veins. Wide of the superior orbital fissure this edge becomes broad and serrated, articulating with the frontal bone medially, and at the part corresponding to the anterior horn of the crescent, by a surface of variable width, it unites with the sphenoidal angle of the parietal bone. The lateral border corresponds to the concave side of the crescent, and is serrated for articulation with the squamous part of the temporal, being thin and bevelled at the expense of its parietal surface above and laterally, and broad and thick behind as it passes towards the angular spine. The superior or cerebral surface is concave from behind forwards, and in its anterior part from side to side also; it forms a considerable part of the floor of the middle cranial fossa, and bears the impress of the convolutions of the extremity of the temporal lobe of the cerebrum which rests upon it; towards its lateral side it is grooved obliquely by an anterior branch of the middle meningeal artery. The following foramina pierce the great wing: close to and in front of the alar spine is the foramen spinosum for the transmission of the middle meningeal artery and its companion vein, together with the nervus spinosus from the mandibular division of the trigeminal nerve. In front of and medial to this, and close to the posterior free border, is the foramen ovale, of large size and elongated form. This gives passage to the motor root and mandibular sensory division of the trigeminal nerve, and admits the accessory meningeal branch of the middle meningeal artery; a small emissary vein from the cavernous sinus usually passes through this foramen, and occasionally also the small superficial petrosal nerve. Near the anterior part of the root of the great wing, and just below the sphenoidal fissure, is the foramen rotundum, of smaller size and circular form. Through this the maxillary division of the trigeminal nerve escapes from the cranium. Occasionally there is a small canal-the foramen of Vesalius-which pierces the root of the great wing to the medial side of the foramen ovale. This opens below into the scaphoid fossa at the base of the medial pterygoid lamina, and transmits a 
small vein. Occasionally there is a small foramen (canaliculus innominatus) to the medial side of the foramen spinosum for the transmission of the small superficial petrosal nerve.

The lateral surface of the great wing enters into the formation of the walls of the orbital, temporal, infra-temporal, and pterygo-palatine fossæ by three welldefined areas; of these the upper two, the orbital and the temporal, are separated by an oblique jagged ridge, the margo zygomaticus (zygomatic border), for articulation with the fronto-sphenoidal process of the zygomatic bone. Occasionally the lower part of this ridge articulates with the zygomatic process of the maxilla. The facies orbitalis (orbital surface) lies to the medial side of this crest and is directed forwards and a little medially; of quadrilateral shape, it forms the posterior and lateral wall of the orbit; plane and smooth, it is bounded posterioriy by the sharp inferior free margin of the superior orbital fissure, towards the medial extremity of which a pointed spine (spina recti lateralis), for the attachment of the inferior common ligament of origin of the ocular muscles, can usually be seen. It is limited superiorly by the edge of a rough triangular area which articulates with the frontal bone; anteriorly by the zygomatic border; whilst inferiorly a free, well-defined oblique margin constitutes the posterior and lateral boundary of the fissura orbitalis inferior (inferior orbital fissure), which separates this part of the bone from the orbital surface of the maxilla. Below this border there is a grooved surface which leads medially toward the orifice of the foramen rotundum. In the articulated skull this forms part of the posterior wall of the pterygo-palatine fossa.

To the lateral side of the zygomatic border, which bounds it in front, is the facies temporalis (temporal area), concavo-convex from before backwards. It slopes medially below, where it is separated from the spheno-maxillary area by a wellmarked muscular ridge, the crista infratemporalis (infra-temporal crest). Behind, the temporal surface is bounded by the margin of the great wing which articulates with the squamous part of the temporal (margo squamosus), and above by the edge which unites it with the sphenoidal angle of the parietal and the frontal bone. The temporal surface enters into the formation of the floor of the fossa of the same name, and affords an extensive attachment to the fibres of origin of the temporal muscle. The facies sphenomaxillaris (spheno-maxillary surface), the third of the areas above referred to, is situated below the infra-temporal crest, and corresponds to the under surface of the posterior half of the great wing; it extends as far back as the angular spine and posterior border. Opening on it are seen the orifices of the foramen spinosum and ovale. It is slightly concave from side to side, and is confluent medially with the lateral surface of the lateral pterygoid plate. In front it is bounded by a ridge which curves upwards and laterally from the anterior part of the lateral pterygoid plate to join the infra-temporal crest. In the articulated skull this ridge forms the posterior boundary of the pterygomaxillary fissure. The spheno-maxillary surface overhangs the infra-temporal fossa, and affords an origin for the superior head of the extermal pterygoid muscle.

The processus pterygoidei (pterygoid processes) spring from the inferior surface of the lateral aspect of the body as well as the under side of the root of the great wings, and pass vertically downwards. Each consists of two laminæ, the laminæ processus pterygoidei lateralis et medialis, fused together anteriorly, and enclosing between them posteriorly the fossa pterygoidea (pterygoid fossa).

The lateral pterygoid plate, thin and expanded, is directed obliquely backwards and laterally, its lower part being often somewhat everted. Its hinder edge is sharp, and often has projecting from it one or two spines, to one of which (processus pterygospinosus) the pterygo-spinous ligament, which stretches towards the angular spine, is attached. Laterally it furnishes an origin for the inferior head of the external pterygoid muscle, and on its medial side, where it forms the lateral wall of the pterygoid fossa, it supplies an attachment for the internal pterygoid muscle.

The medial pterygoid plate is narrower and somewhat stonter. By its medial aspect it forms the posterior part of the lateral wall of the nasal cavities; laterally it is directed torwards the pterygoid fossa. Its posterior edge ends 
below in the hamulus pterygoideus (pterygoid hooklet), which, reaching a lower level than the lateral plate, curres backwards and laterally, furnishing a groove in which the tendon of the tensor veli palatini muscle glides; superiorly, the sharp posterior margin of the medial plate bifurcates, so as to enclose the shallow scaphoid fossa from which the tensor veli palatini muscle arises, and wherein may occasionally be seen the inferior aperture of the foramen Vesalii. To the medial edge of this fossa, as well as to the posterior border of the medial pterygoid plate, the pharyngo-basilar fascia (pharyngeal aponeurosis) is attached. Here, too, the cartilage of the auditory tube is supported on a slight projection, and the pharyngo-palatinus muscle receives an origin, whilst the superior constrictor of the pharynx arises from the inferior third of the same border and from the pterygoid hooklet. Superiorly and medially the medial plate forms an incurved lamina of bone, the processus vaginalis (vaginal process), which is applied to the under surface of the lateral aspect of the body reaching medially, towards the root of the rostrum, from which, however, it is separated by a groove, in which, in the articulated skull, the ala of the vomer is lodged. The angle formed by the raginal process and the medial edge of the scaphoid fossa forms a projection called the pterygoid tubercle, immediately above which is the posterior aperture of the canalis pterygoideus, through which the nerve and artery of the canal (O.T. Vidian) are transmitted. On its under surface the vaginal process displays a groove (sulcus pterygopalatinus) which in the articulated skull is converted into the pharyngeal canal by its union with the palate bone. In front, at its root, the pterygoid process displays a broad smooth surface (facies sphenomaxillaris), which is confluent above with the root of the great wing around the foramen rotundum, and forms the posterior wall of the pterygo-palatine fossa. Here, to the medial side of the foramen rotundum, is seen the anterior opening of the pterygoid canal. Below, the pterygoid laminæ are separated by an angular cleft, the fissura pterygoidea (pterygoid notch); in this is lodged the pyramidal process of the palate bone, the margins of which articulate with the serrated edges of the recess.

Connexions.-The sphenoid articulates with the occipital, temporals, parietals, frontal, ethmoid, sphenoidal conchæ, vomer, palate and zygomatic bones, and occasionally with the maxillæ.

Ossification.-The sphenoid of man is formed by the fusion of two parts, the presphenoid and the post-sphenoid, each associated with certain processes. In most mammals the orbito-sphenoids or small wings fuse with the pre-sphenoid, whilst the alisphenoids or great wings, together with the medial pterygoid lamina, ankylose with the post-sphenoid. The ossification of these several parts takes place in cartilage, with the exception of the medial pterygoid lamina, which is developed from an independent centre in the connective tissue of the lateral wall of the oral cavity (Hertwig).

At the end of the second month a centre appears in the root of the great wing between the foramen ovale and foramen rotundnm; from this the ossification spreads laterally and

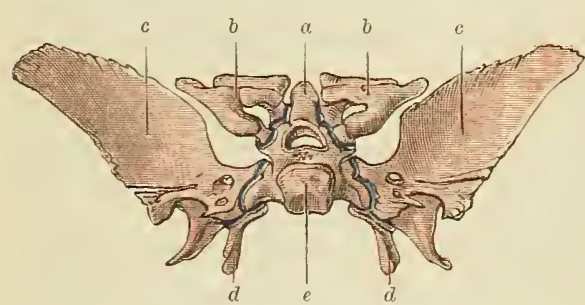

Fig. 146.-Ossification of the Sphexoid. $a$, Pre-sphenoid ; $b$, Orbito-sphenoids ; $c$, Alisphenoids $d$, Medial pterygoid laminz ; $e$, Basi-sphenoid. backwards and also downwards into the lateral pterygoid lamina. According to Fawcett the pterygoid laminæ or the common root of the two laminæe in the adult is practically the only part of the ala temporalis preformed in cartilage; the whole of the lateral pterygoid lamina and that part of the alisphenoid projected into the orbital and temporal fossæ are ossified in membrane; so too are the foramen ovale and foramen spinosum. Meanwhile two centres appear about the same time in the basi-sphenoid in relation to the floor of the sella turcica and on either side of the craniopharyngeal canal, aronnd which they ossify, ultimately leading to the obliteration of this channel. Somewhat later a sphenotic centre appears on either side, from which the lateral aspect of the body and the lingula are developed. Fusion between these four centres is usually complete by the sixth month.

In the pre-sphenoid a pair of lateral nuclei make their appearance about the middle of the third month, just lateral to the optic foramina; from each of these the orbito- 
sphenoids (small wings) and their roots are developed. About the same time another pair of centres, placed medial to the optic foramina, constitute the body of the presphenoid. At first the superior surface of the bodr of the pre-sphenoid is exposed in the interval between the orbito-sphenoids, but by the ultimate coalescence of the medial borders of the orbito-sphenoids to form the jugum sphenoidale the body of the pre-sphenoid is almost completely covered over superiorly. By the coalescence of these in front, and their ultimate union with the basi-sphenoid behind, a cartilaginous interval is enclosed, of triangular shape, which, howerer, becomes gradually reduced in size by the ingrowth of its margins so as to form two medially placed foramina, as may be frequently observed in young bones-one opening on the surface of the olivary eminence, the other being placed anteriorly. (Lawrence, "Proc. Soc. Anat." Jouin. Anat. and Physiol. rol. xxviii. p. 19.)

As has been seen, the medial pterygoid laminæ are developed in membrane and are the first parts of the sphenoid to ossify. (Fawcett, Anat. Anz., vol.xxri. 1905, p. 280.) Each is derived from a single nucleus which appears about the ninth or tenth week, and fuses with the inferior surface of the great wing, there forming a groove which is converted into the pharyngeal canal when the alisphenoid and medial pterygoid laminæ fuse later with the body of the post-sphenoid. The hamulus, howerer, chondrifies before it ossifies during the third month. Fawcett also regards the external pterygoid plate as of membranous origin.

At birth the sphenoid consists of three parts : one comprising the orbito-sphenoids together with the body of the pre-sphenoid and the basi-sphenoid, the others consisting of the alisphenoids, one on either side. Fusion of the latter with the former occurs near the end of the first year. The dorsum sellæ at birth consists of a cartilaginous plate which separates the body of the post-sphenoid from the basi-occipital. This slowly ossifies, but the cartilage does not entirely disappear till the age of twenty-fire, by which time bonyankylosis of the basi-cranial axis is complete. For a considerable time the under surface of the body of the pre-sphenoid displays a bullate appearance, with the sides of which the sphenoidal conchæ articulate. It is only after the serenth or eighth jear is reached that the cancellous tissue within this part of the bone becomes absorbed to form the sphenoidal sinuses.

The conchæ sphenoidales (sphenoidal conchæ), or bones of Bertin, best studied in childhood, are formed by the fusion of four distinct ossicles (Cleland), the centres for which appear in the later months of ntero-gestation. Each bone consists of a hollow, three-sided pyramid, the apex of which is in contact with the fore-part of the raginal process of the medial pterygoid lamina, whilst the base fits on to the posterior surface of the lateral mass of the ethmoid. The inferior surface of each forms the roof of the corresponding nasal fossa, and completes the formation of the spheno-palatine foramen, whilst the lateral aspect is united with the palate bone and forms the medial wall of the pterygo-palatine fossa, and occasionally constitutes a part of the orbital wall posterior to the lamina papyracea of the ethmoid. The superior surfuce of the sphenoidal concha is applied to the fore and under surface of the body of the pre-sphenoid on either side of the rostrum. It is by the absorption of this wall that the sphenoidal sinuses are ultimately opened up. The base of the pyramid forms the aperture through which each of these sinuses opens into the nasal fossce in the adnlt. Up to the age of five these ossicles remain independent, but subsequently, owing to their firm ankylosis with the surrounding bones, they are merely represented in the adult disarticulated skull by the irregular fragments adherent to the separated border's of the ethmoid, palate, and sphonoid bones.

\section{Os Ethmoidale.}

The ethmoid bone lies in front of the sphenoid, and occupies the interval between the orbital parts of the frontal, thus entering into the formation of the anterior cranial fossa as well as the medial walls of the orbits and the roof medial and lateral walls of the nasal carities. The bone, which is extremely light, consists of two cellular parts-the labyrinthi ethmoidales (ethmoidal labyrinths), which are united superiorly to a median lamina perpendicularis (perpendicular plate) by a thin horizontal lamina which, from its perforated condition, is called the lamina cribrosa (cribriform plate). The general arrangement of the parts of the bone resembles the capital letter $T$; the median plate corresponds to the vertical limb, the cribriform plate to the horizontal limb of the $T$, whilst the ethmoidal labyrinths may lue 
regarded as comparable to the enlarged down-turned extremities of the horizontal limb of the letter.

The study of this bone will be much facilitated by cutting through the cribriform plate on one side of the perpendicular plate, thus removing the ethmoidal labyrinth of one side and

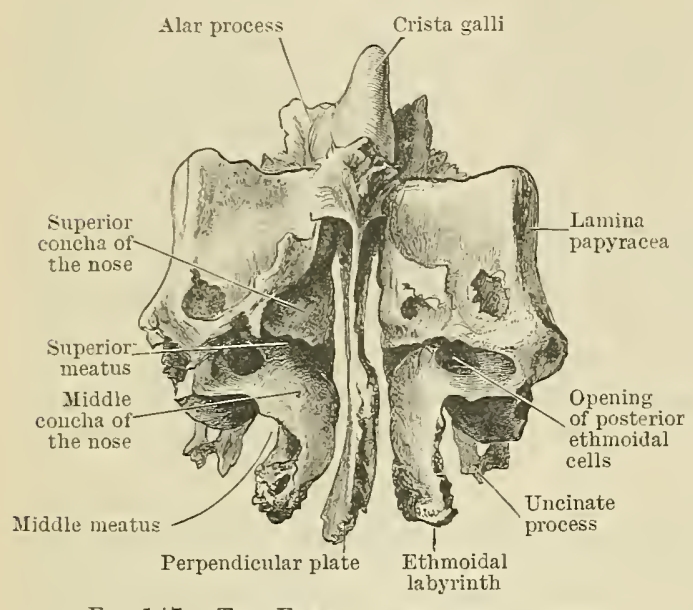

Fig. 147.-The Ethmoid SEeN From Behind. exposing more fully the central perpendicular lamina.

The perpendicular plate, of irregular pentagonal shape, forms the superior part of the nasal septum. Its superior border projectsabove the level of the cribriform plate so as to form a crest, which is much elevated anteriorly, where it terminates in a thick, vertical, triangular process, called the crista galli, the interior of which is filled with fine spongy bone, but is occasionally pneumatic. The superior edge of this process is sharp and pointed, and affords attachment to the falx cerebri. In front of this process there is a groove which separates the processus alares (alar processes) which project from the crista galli on either side. By articulation with the frontal bone this groove is converted into a canal, the foramen cæcum; this, however, is not always blind, but frequently transmits a vein to the roof of the nose. The posterior border of the perpendicular plate is thin, and articulates with the crest of the sphenoid. The posterior inferior border in the adult is ankylosed with the vomer; and the anterior inferior border, which is usually thicker than the others, unites with the cartilaginous nasal septum. The anterior superior border articulates with the spine of the frontal bone and with the median crest formed by the union of the two nasal bones. The perpendicular plate, which is usually deflected to one or other side, has generally smooth surfaces, except above, where they are channelled by short and shallow grooves leading to the

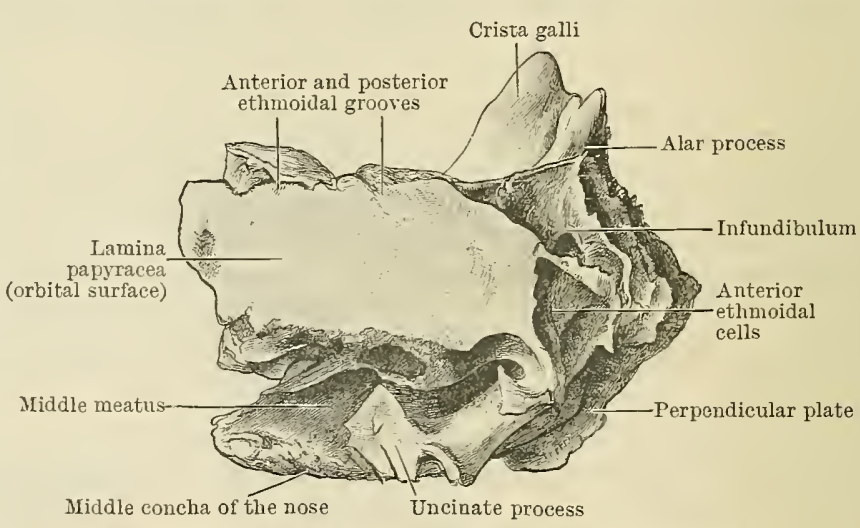

Fig. 148.-The Ethuoid seen from the Right Side. foramina which pierce the cribriform plate; these are for the lodgment of the olfactory nerves.

The ethmoidal labyrinth is composed of exceedingly thin bone, enclosing a large number of air-cells; these are arranged in three groups-an anterior, a middle, and a posterior, the walls of which have been broken in front, above, behind, and below, in the process of disarticulation. Laterally they are closed in by a thin oblong lamina, the lamina papyracea or orbital plate, which forms a part of the medial wall of the orbit, and articulates above with the orbital part of the frontal, which here roofs in the ethmoidal cells. (The line of this suture is pierced by two canals, the anterior and posterior ethmoidal foramina, both of which transmit small ethmoidal vessels, whilst the anterior also gives passage to the naso-ciliary nerve.) In front the lamina papyracea articulates 
with the lacrimal bone; whilst below, by its union with the orbital surface of the maxilla, the air-sinuses in both situations are completed. Posteriorly the lamina papyracea articulates with the sphenoid, and at its posterior inferior angle for a variable distance with the orbital process of the palate bone, both of which serve to close in the air-cells. The medial aspect of the ethmoidal labyrinth displays the convoluted conchæ of the nose, usually two in number, though occasionally there may be three-rarely more. In cases where there are two ethmo-turbinals ${ }^{1}$ they are separated posteriorly by a deep groove. A channel is thus formed in the back part of the lateral and upper aspect of the nasal fossæ, called the superior meatus, which is roofed in by the concha nasalis superior (superior concha), whilst its floor

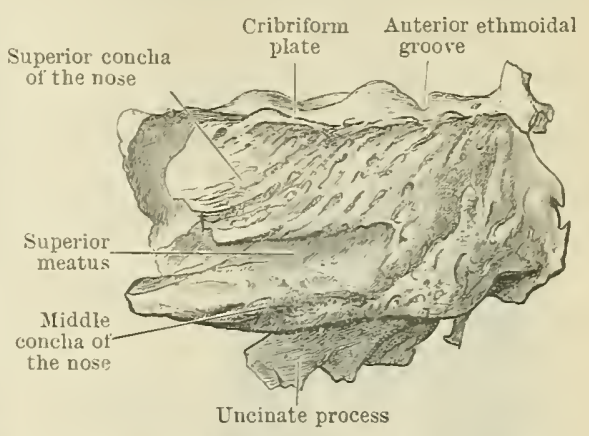
is formed by the superior surface of the

Fig. 149.-SEction SHOWING THE NaSAL ASPECT OF THE LEFT LABYRINTH OF THE ETHMOID. concha nasalis media (middle concha). The posterior ethmoidal cells open into this meatus. In front of the superior meatus, which only grooves the posterior half of this aspect of the bone, the surface is rounded from above downwards and before backwards, and forms the medial wall of the anterior and middle ethmoidal cells. Running obliquely from above downwards and backwards over the medial surface of the superior concha, are a number of fine grooves continuous above with the foramina in the cribriform plate; these are fewer and more scattered in front, do not pass on to the middle concha, and are for the olfactory nerves.

The middle concha is nearly twice the length of the superior. Its anterior extremity is united for a short distance to the ethmoidal crest on the

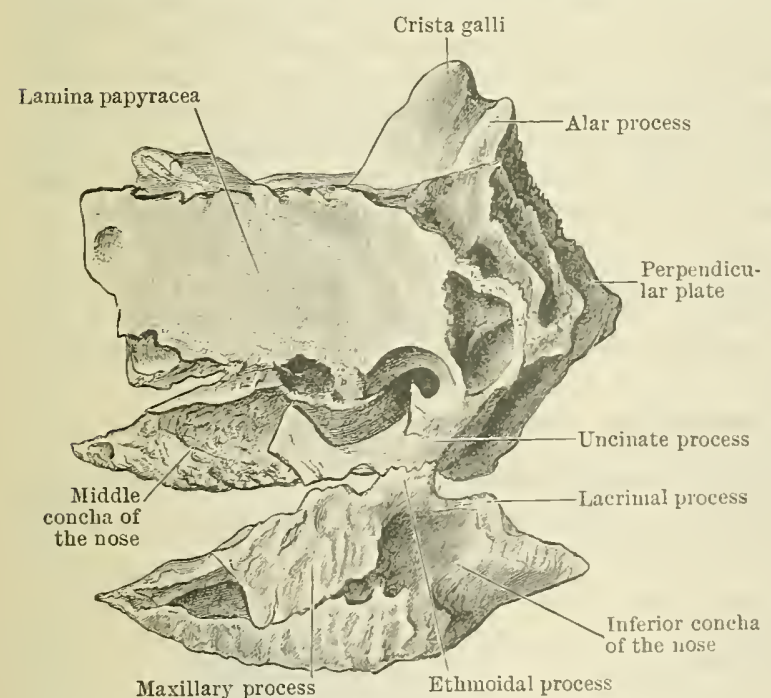

Fig. 150.-Showing the ARticulatiox of the INfeirior CUNChA WITH THE ETHMOID. medial side of the frontal process of the maxilla. By its thickened, free convoluted border it overhangs a deep groove which runs along the inferior surface of the ethmoidal labyrinth. This is the middle meatus of the nose. It receives the openings of the middle ethmoidal cells, which project into the meatus, forming a rounded elevation called the ethmoidal bulla. In front and below this is a groove, the hiatus semilunaris, which by articulation above with adjacent bones is converted into a canal, the infundibulum, which runs upwards and forwards and forms a channel of communication with the frontal sinus and the an terior ethmoidal cells. Curving downwards, backwards, and a little laterally from the roof of the anterior part of this meatus in front of the infundibulum is the processus uncinatus. This bridges across the irregular opening on the medial wall of the maxillary sinus, and articulates inferiorly with the ethmoidal process of the inferior concha. The posterior extremity of the middle concha articulates with the ethmoidal crest on the perpendicular part of the palate bone.

The lamina cribrosa (cribriform plate) is the horizontal lamina which con-

1 So called to distinguish then from the maxillo-turbinals and naso-turbinals of comparaive anatomy. 
nects the ethmoidal labyrinths with the perpendicular plate. It occupies the interval between the orbital parts of the frontal bone, roofing in the nasal cavities inferiorly, and superiorly forming on either side of the crista galli two shallow

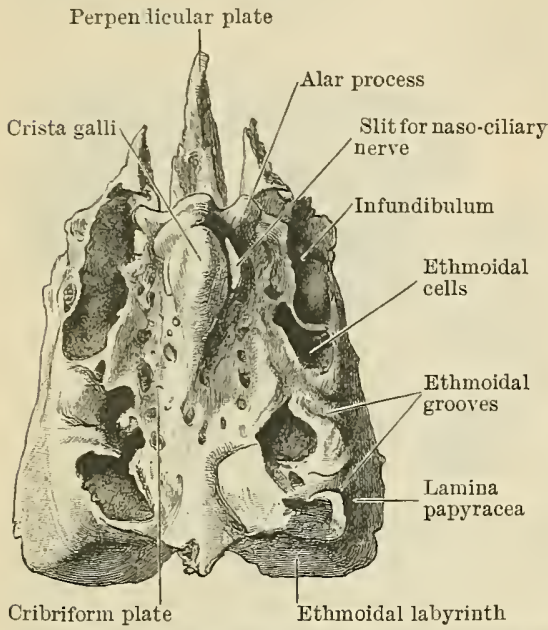

Fig. 151.-The EthMoID SEeN FRoM ABOve. olfactory grooves in which, in the recent condition, the olfactory lobes of the cerebrum are lodged. Numerous foramina for the transmission of the olfactory nerves pierce this part of the bone; those to the medial and lateral sides of the groove are the largest and most regular in their arrangement. Along the lateral edges of the cribriform plate two notches can usually be distinguished; when articulated with the frontal bone these form the medial openings of the ethmoidal foramina. Leading forwards from the anterior of these there is often a groove which crosses to the side of the crista galli, where it ends in a slit which allows of the transmission of the naso-ciliary nerve to the nose. Posteriorly the cribriform plate articulates with the spine of the sphenoid.

Connexions.-The ethmoid articulates with the sphenoid and sphenoidal conchæ, the frontal, the two nasals, two maxillæ, two lacrimals, two inferior conchæ, two palates, and the vomer.

Ossification takes place in the cartilage of the nasal capsule. Each lateral mass has one centre, which appears about the fourth or fifth month in the neighbourhood of the lamina papyracea. According to Fawcett ossification first commences in a process which passes outside the naso-lacrimal duct to reach the frontal process of the maxilla. From this the laminæ around the ethmoidal air-cells are formed, which are complete at birth, the air-sinuses in this instance not being formed by the absorption of cancellous bone. From these centres the conchæ are also developed, and these too are ossified at the ninth month.

At birth the ossified lateral masses are united to the cartilaginous septum by a fibrous layer. Two centres make their appearance in the septal cartilage on either side of the root of the crista galli about the end of the first year; from these, the crista galli and the vertical plate are ossified, as well as the medial part of the cribriform plate, the lateral portions of which are derived from a medial extension of the lateral mass.

Ossification is usually complete about the fifth or sixth year. About the twenty-fifth year bony union has taken place between the cribriform plate and the sphenoid, but ankylosis between the vertical plate and the vomer is not usual till the fortieth or fortyfiftl year.

\section{Conchre Nasales Inferiores.}

The inferior conchæ (O.T. inferior turbinated bones) are two shell-like laminæ of bone lying along the lower part of the lateral wall of the nasal cavity on either

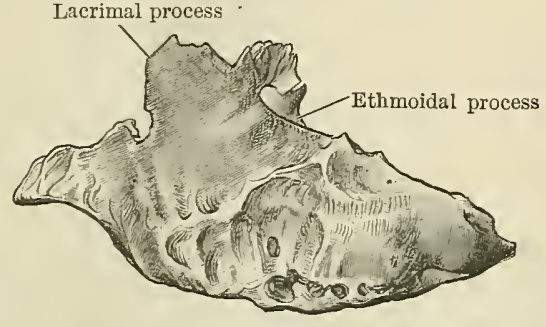

A

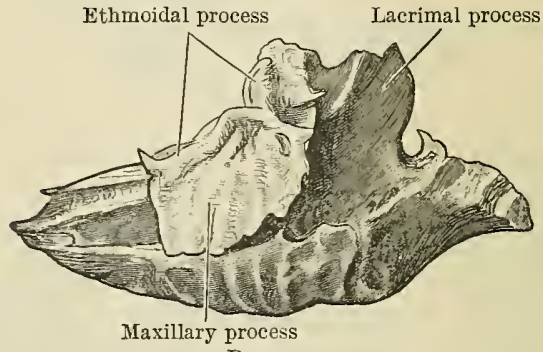

$\mathrm{B}$

Fig. 152,-The Right Inferior Concha. A, Medial Surface; B, Lateral Surface.

side. Of elongated form, the bone displays two curved borders enclosing a medial and lateral surface.

The superior or attached border is thin and sharp in front and behind, where 
it articulates with the inferior conchal crests on the medial surface of the body of the maxilla and the perpendicular part of the palate bone respectively. Between these two articulations the central part of the superior border rises in the form of a sharp crest, the anterior part of which forms the upstanding processus lacrimalis (lacrimal process) which articulates above with the descending process of the lacrimal bone, as well as with the edges of the naso-lacrimal groove of the maxilla, thus completing the osseous canal of the naso-lacrimal duct. The posterior end of this crest is elevated in the form of an irregular projection called the processus ethmoidalis (ethmoidal process). This unites with the uncinate process of the ethmoid bone (see Fig. 150). Spreading downwards from the middle of the superior border, on its lateral side, is a thin irregular plate of bone, the processus maxillaris (maxillary process), which partially conceals the lateral concave surface of the bone, and, by its union with the medial wall of the maxillary sinus, assists in the completion of the partition which separates that cavity from the inferior nasal meatus.

The inferior or free border, gently curved from before backwards and slightly out-turned, is rounded and full, and formed of bone which is deeply pitted and of a somewhat cellular character. The anterior and posterior extremities of the bone, formed by the convergence of the superior and inferior borders, are thin and sharp; as a rule the posterior end is the more pointed of the two. The medial surface projects into the nasal cavity ; convex from above downwards, and slightly curved from before backwards, it forms the floor of the middle meatus. It is rough and pitted, and displays some scattered and longitudinally directed vascular grooves. The lateral surface overhangs the inferior meatus of the nose. Concave from above downwards, and to some extent from before backwards, it is directed towards the lateral wall of the nasal cavity. It is smooth in front, where it corresponds to the opening of the canal for the naso-lacrimal duct; behind and towards its inferior border it is irregular and pitted. In the disarticulated bone this surface is in part concealed by the downward projecting maxillary process.

Connexions. - The inferior concha articulates with the maxilla, lacrimal, ethmoid, and palate bones.

Ossification.-The inferior concha (the maxillo-turbinal of comparative anatomy) is derived from the cartilage forming the lateral wall of the nasal cajssule, the upjer portion of which forms the ethmo-turbinals. It ossifies, howerer, from a separate centre, which appears about the fifth month of fœetal life, and later contracts a union by a horizontal lamella on its lateral side with the maxilla.

\section{Ossa Lacrimalia.}

The lacrimal bone, a thin scale of bone about the size of a finger-nail, forms part of the medial orbital wall behind the frontal process of the maxilla. Irregularly quadrangular, it has two surfaces - a medial and lateral-and four borders.

Its lateral or orbital surface has a vertical ridge, the crista lacrimalis posterior (posterior lacrimal crest), running downwards upon it. In front of this is the sulcus lacrimalis (lacrimal groove) for the lodgment of the lacrimal sac. The medial wall of this groove descends below the level of the bulk of the bone, and forms the descending process, which helps to complete the osseous canal for the naso-lacrimal duct, and articulates inferiorly with the inferior concha. The inferior end of the lacrimal crest terminates in a hooklike projection, the hamulus lacrimalis (lacrimal hooklet). which curves round the posterior and lateral edge of the naso-lacrimal notch of the maxilla, and thus defines the upper aperture of the canal for the naso-lacrimal duct. To the free edge of the crest behind the lacrimal groove are attached the reflected portion of the tendo oculi and the lacrimal part of the orlicularis oculi, the crest being sometimes thickened at the site of this attachment. The

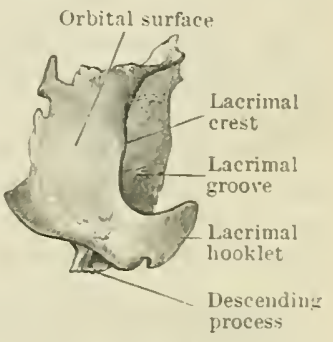

Fig. 153.-Right LachimaL Boxe (Orbital Surface). part of the bone behind the lacrimal crest is smooth and continuous with the surface of the lamina papyracea of the ethmoid. The medial surface is irregular and 
cellular above; it closes in some of the anterior ethmoidal cells and helps to complete the infundibulum. Where it is smoother it forms a part of the lateral wall of the middle meatus of the nose immediately behind the frontal process of the maxilla, and above the inferior concha. The superior border articulates with the orbital part of the frontal; the anterior edge with the posterior border of the frontal process of the maxilla, with which it completes the lacrimal groove for the lodgment of the lacrimal sac. The inferior margin articulates with the orbital surface of the maxilla, and in front by its descending process with the inferior concha. Posteriorly the bone articulates with the anterior border of the lamina papyracea of the ethmoid.

Connexions.- The lacrimal bone articulates with four bones-the frontal, ethmoid, inferior concha, and the maxilla.

Ossification.-The lacrimal is developed from a single centre, which makes its appearance about the end of the second or the beginning of the third month of intrauterine life in the membrane around the cartilaginous nasal capsule.

\section{Vomer.}

The vomer or ploughshare bone, a bone of irregular quadrilateral shape, is placed in the posterior part of the nasal septum. It has four borders and two

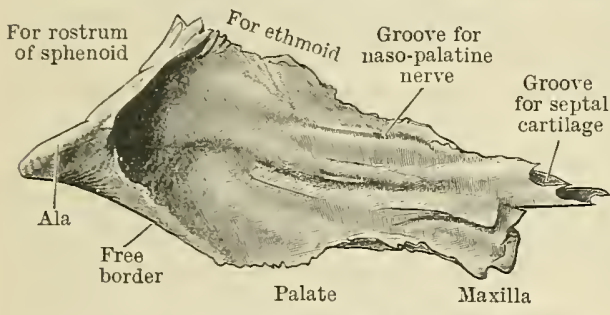

FIG. 154.-THE VOMER AS SEEN FroM THE Right SidE. surfaces. The superior border, which can readily be distinguished by the presence on either side of an everted lip or ala, slopes from behind upwards and forwards, and articulates with the inferior surface of the body of the sphenoid, the pointed rostrum of which is received into the groove formed by the projecting alæ. Laterally these alæ are wedged in between the sphenoidal processes of the palate bones in front, and the vaginal processes at the root of the medial laminæ of the pterygoid processes behind. The posterior border, which slopes from behind downwards and forwards, is free, and forms a sharp, slightly curved edge; this constitutes the posterior margin of the nasal septum, and serves to separate the openings of the choanæ (O.T. posterior nares). The inferior border, more or less horizontal in direction, articulates with the nasal crest formed by the maxillie and palate bones. The anterior edge is the longest; it slopes obliquely from above downwards and forwards. In its upper half it is ankylosed to the perpendicular plate of the ethmoid; in its lower half this margin is grooved for the reception of the septal cartilage of the nose. The anterior extremity of the bone forms a trun-

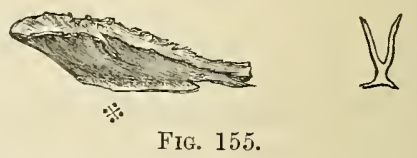

Vomer at Birth displaying its formation by two Osseons Laminæ united inferiorly. The figure to the right exhibits the appearance of the bone, in vertical section, at the point marked $\ddot{*}$ in the left figure. cated angle, which articulates with the posterior border of the incisor crest of the maxillæ, and sends downwards a pointed process which passes between the incisor foramina. The right and left surfaces of the bone are smooth and covered by mucous membrane. It is not uncommon to find them deflected to one or other side. A few vascular grooves may be noticed scattered over these surfaces, and one, usually more distinct than the others, running obliquely downwards and forwards, indicates the course of the naso-palatine nerve.

Connexions. - The vomer articulates with the sphenoid, the ethmoid, the palates, and the maxillæ. In front it supports the septal cartilage.

Ossification.-The vomer commences to ossify in membrane at the end of the second month. A nucleus appears on each side of the middle line below the nasal septum medial to the plane of the anterior paraseptal cartilages and posterior to them. During the third month the nuclei, which have increased in height and length, 
fuse at their lower edges, and by forward growth invade the posterior end of each anterior paraseptal cartilage, thus forming a deep groove in which the septal cartilage is lodged (Fawcett). As growth goes on the groove becomes reduced by the further fusion of the lateral plates and the absorption of the cartilage, until the age of puberty, by which time the lateral laminæ have united to form a median plate, the primitively divided condition of which is now only represented by the eversion of the alæ and the grooving along the anterior border. According to Fawcett, the ossification of the Jacobsonian cartilage produces a hitherto undescribed element in the formation of the osseous nasal septum.

\section{Ossa Nasalia.}

The nasal bones, two in number, iie in the interval between the frontal processes of the maxillæ, there forming the root or bridge of the nose. Each bone is of elongated quadrangular form, having two surfaces-an inner and outer-and four borders. The outer surface, somewhat constricted about its middle, is convex from side to side, and slightly concavo-convex from above downwards. Near its centre there is usually the opening of a nutrient canal.

The inner surface is not so extensive as the outer, as the superior and anterior articular borders encroach somewhat upon it above. Concave from side to side, and also from above downwards, it is covered, in the recent

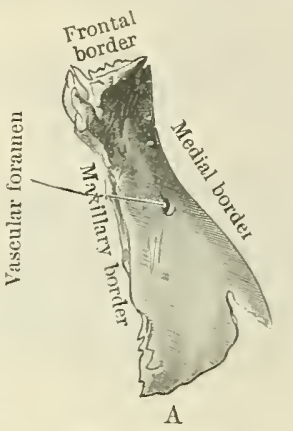

Fig. 156. -ThE Right NASAL Bonf.

A, Lateral side ; B, Medial side.

condition, by the mucous membrane of the nose. Running downwards along this surface is a narrow groove (sulcus ethmoidalis) which transmits the anterior terminal branch of the naso-ciliary nerve. The anterior or medial border, narrow below, is thick above, and, in conjunction with its fellow at the opposite side, with which it articulates, forms a median crest posteriorly, which is united to the spine of the frontal, the perpendicular plate of the ethmoid, and the septal cartilage of the nose, in that order from above downwards. The posterior or lateral border, usually the longest, is serrated and bevelled to fit on to the anterior edge of the frontal process of the maxilla. The superior border forms a wide toothed surface, which articulates with the medial part of the nasal notch of the frontal bone anteriorly; whilst, posteriorly, it rests in contact with the root of the nasal process of the same bone. The inferior border is thin and sharp, and is connected below with the lateral cartilage of the nose, and is usually deeply notched near its medial extremity.

Connexions. - The nasal bone articulates with its fellow of the opposite side, with the frontal above, posteriorly with the perpendicular plate of the ethmoid and with the frontal process of the maxilla. It is also united to the septal and lateral cartilages of the nose.

Ossification.-The nasal bones are each developed from a single centre, which makes its appearance about the end of the second month in the membrane covering the anterior part of the cartilaginons nasal capsule. Subsequent to birth the underlying cartilaginous stratum disappears, persisting, however, below in the form of the lateral nasal cartilage, and behind as the septal cartilage of the nose.

\section{Ossa Suturarum (O.T. Wormian).}

Along the line of the cranial sutures and in the region of the fontanelles, isolated bones of irregular form and variable size are occasionally met with. These are the once socalled Wormian bones, named after the Danish anatomist Wormins. They are now called ossa suturarum (sutural bones). Their presence depends on the fact that they are either developed from distinct ossific nuclei, or it may be from a division of the primary ossific deposit. Their occurrence may also be associated with certain pathological conditions 
which modify the development of the bone. They usually include the whole thickness of the cranial wall, or they may ouly involve the outer or inner tables of the cranial bones. They are most frequent in the region of the lambda and the lambdoid suture. They occur commonly about the pterion, and in this situation are called epipteric bones (Flower). By their fusion with one or other of the adjacent bones they here lead to the occurrence of a fronto-squimosal suture. Their presence has also been noted along the line of the sagittal suture, and sometimes in metopic sknlls in the inter-frontal suture. They are occasionally met with at the asterion and more rarely at the obelion. They appear less frequently in the face, but their presence has been noted around the lacrimal bone, and also at the extremity of the inferior orbital fissure, where they may form an independent nodnle wedged in between the great wing of the sphenoid, the zygomatic, and the maxillary bones.

\section{OSSA FACIEI.}

The bones of the face, seven in number, comprise two maxillæ, two palates, two zygomatics, with the mandible or lower jaw.

\section{The Maxillae.}

The maxillæ, of which there are two, unite to form the upper jaw. Each consists of a body, with which are connected four projections, named respectively the zygomatic, frontal, alveolar, and palatine processes.

The body (corpus) is of pyramidal form, and contains within it a hollow called the maxillary sinus. It has four surfaces-an anterior or facial, an infra-temporal or postero-lateral, an orbital or supero-lateral, and a nasal or medial-and four processes-the malar, frontal, alveolar, and palatine.

Surfaces.-The facies anterior (anterior surface) is confluent below with the alveolar process. Above, it is separated from the orbital aspect by the margo infraorbitalis (infra-orbital margin), whilst medially it is limited by the free margin of the nasal notch, which ends below in the pointed spina nasalis anterior (anterior nasal spine). Posteriorly it is separated from the infra-temporal surface by

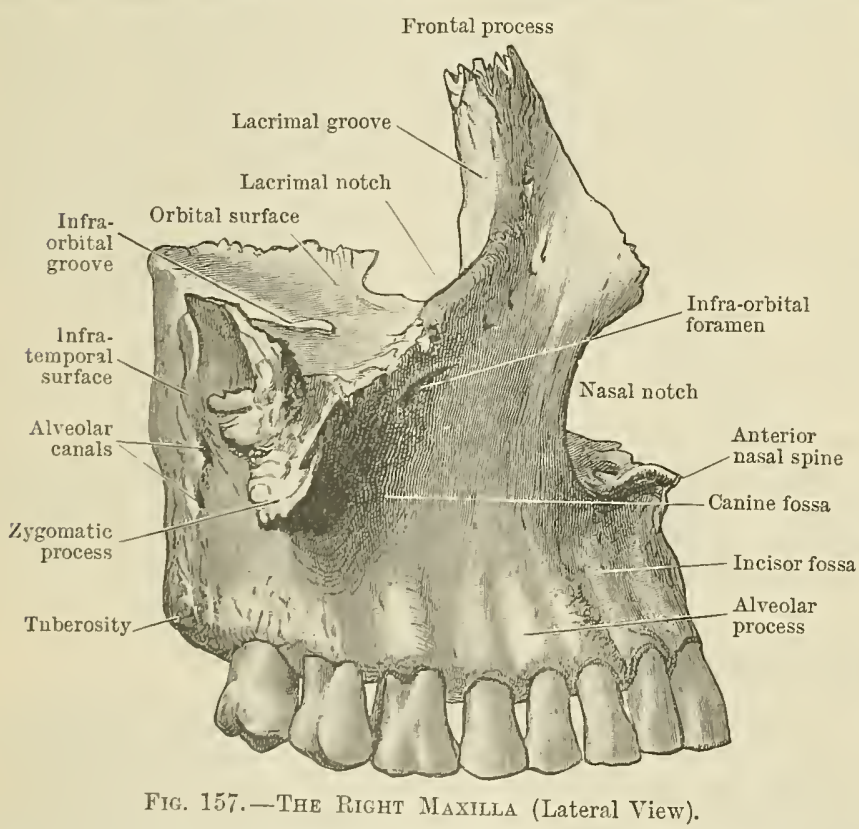
the inferior border of the zygomatic process. The facial aspect of the bone is ridged by the sockets of the teeth (juga alveolaria). The ridge corresponding to the root of the canine tooth is usually the most pronounced; medial to this, and overlying the roots of the incisor teeth, is the shallow incisive or myrtiform fossa, whilst placed laterally, on a higher level, is the deeper canine fossa, the floor of which is formed in part by the projecting zygomatic process. Above this, and near the infra-orbital margin, is the infra-orbital foramen, the external opening of the infra-orbital canal, which transmits the infra-orbital nerve and artery. 
The infra-temporal

or postero-lateral surface is separated above from the orbital aspect by a of the inferior orbital fissure in the articulated skull. Inferiorly and anteriorly it is separated from the anterior surface by the zygomatic process and its free lower border. Medially it is limited by a sharp, irregular margin with which the palate bone articulates. This surface is more or less convex, and is directed towards the infra-temporal and pterygo-palatine fossæ. It is pierced in a downward direction by the apertures of the alveolar canals (foramina alveolaria), two or more in number, which transmit the corresponding nerves and vessels to the molar teeth. Its lower part, slightly more prominent where it overrounded free edge, which forms the anterior margin

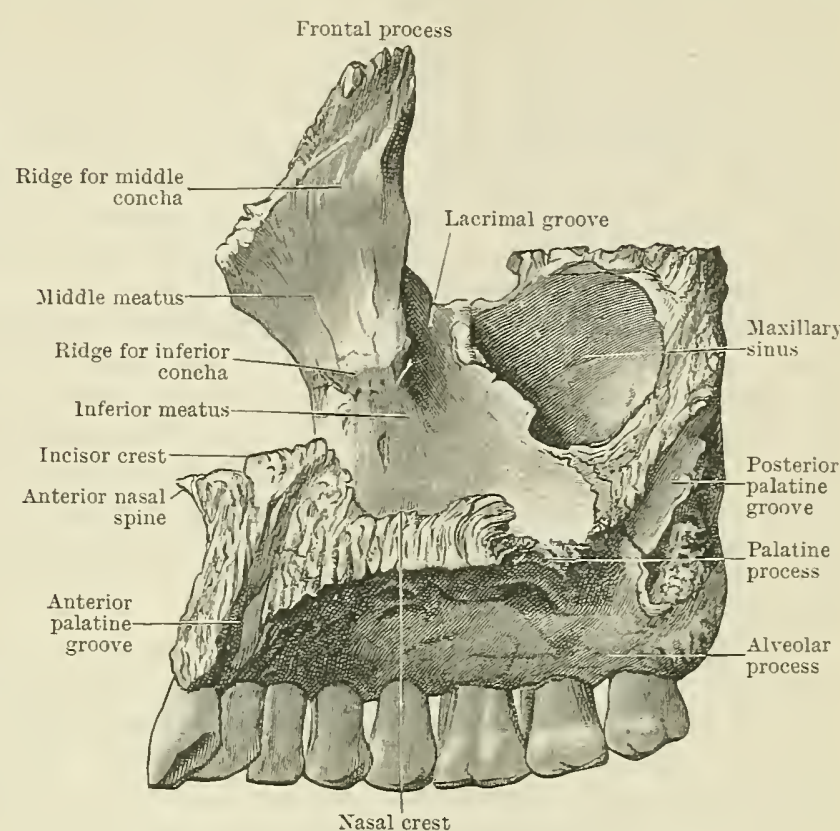

Fig. 158.-The Right Maxilla (Medial Aspect). hangs the root of the wisdom molar, is often called the tuber maxillare (maxillary tuberosity).

The planum orbitale (orbital surface), smooth and plane, is triangular in shape and forms part of the floor of the orbit. Its anterior edge corresponds to the infra-orbital margin; its posterior border coincides with the anterior boundary of the inferior orbital fissure. Its thin medial edge, which may be regarded as the base of the triangle, is notched in front to form the sulcus lacrimalis (lacrimal groove), behind which it articulates with the lacrimal bone for a short distance, then for a greater length with the lamina papyracea of the ethmoid, and terminates posteriorly in a surface for articulation with the orbital process of the palate bone. Its lateral angle corresponds to the base of the zygomatic process. Traversing its substance is the infra-orbital canal, the anterior opening of which has been already noticed on the anterior aspect of the body. Behind, however, owing to deficiency of its roof, the canal forms a groove which lips the eage of the bone which constitutes the anterior boundary of the inferior orbital fissure. If this canal be laid open, the orifices of the middle and anterior alveolar canals will be seen, which transmit the corresponding vessels and nerves to the premolar and incisor teeth.

The facies nasalis (nasal surface) of the body is directed medially towards the nasal cavity. Below, it is confluent with the superior surface of the palatine process; anteriorly it is limited by the sharp edge of the nasal notch; above and anteriorly it is continuous with the medial surface of the frontal process; behind this it is deeply channelled by the lacrimal groove, which is converted in to a canal by articulation with the lacrimal and inferior conchal hones. The channel so formed conveys the naso-lacrimal duct from the orbital cavity above to the inferior nasal meatus below. Behind this groove the upper edge of this area corresponds to the medial margin of the orbital surface, and articulates from before backwards with the lacrimal, lamina papyracea of the ethmoid, and the orbital process of the palate bone. The posterior border, rough for articulation with the palate bone, is traversed obliquely from above downwards and slightly medially by a groove, which, by articulation with the palate bone, is converted into the pterygo-palatine canal, which transmits 
the greater palatine artery and posterior palatine nerve. Towards its upper and posterior part the nasal surface of the body displays the irregular, more or less triangular, opening of the sinus maxillaris (maxillary sinus). This aperture which, in the articulated skull opens into the middle meatus of the nose, is much reduced in size by articulation with the lacrimal, ethmoid, palate, and inferior conchal bones. In front of the lacrimal groove the nasal surface is ridged horizontally by the crista conchalis (inferior conchal crest), to which the inferior conchal bone is attached. Below this the bone forms the lateral wall of the inferior nasal meatus, receiving the termination of the lacrimal groove. Above, and for some little distance also on the medial side of the frontal process, it constitutes the smooth lateril wall of the atrium of the middle meatus.

Processes. - The processus zygomaticus (zygomatic process), which is placed on the antero-lateral surface of the body, is confluent anteriorly with the facial surface of the body; posteriorly, where it is concave from side to side, with the infra-temporal surface; whilst superiorly, where it is rough and articular, it forms the apex of the triangular orbital surface, and supports the zygomatic bone. Inferiorly, its anterior and posterior surfaces meet to form an arched border, which fuses with the alveolar process opposite the root of the first molar tooth, and serves to separate the anterior from the infra-temporal surfaces of the body.

The processus frontalis (frontal process) rises from the upper and anterior part of the body. It has two surfaces-one lateral, the other medial. The lateral is divided into two by a vertical ridge (crista lacrimalis anterior), which is the upward extension of the infra-orbital margin. The narrow strip of bone behind this ridge is hollowed out, and leads into the lacrimal groove below. Posteriorly the edge of the frontal process here articulates with the lacrimal, and so forms the fossa for the lodgment of the lacrimal sac (fossa sacci lacrimalis). In front of the vertical crest, to which the tendo oculi is attached, the lateral surface is confluent below with the facial surface of the body, and forms the side of the root of the nose. Here may often be seen a vascular groove entering the bone. Its anterior edge is rough, or grooved, for articulation with the nasal bone. Superiorly the summit of the process is serrated for articulation with the nasal notch of the frontal bone. The medial surface of the frontal process is directed towards the nasal cavity. It is crossed obliquely from below upwards and backwards by a ridge-the agger nasi or ethmoidal crest which is considered to be a vestige of the naso-turbinal which is wet with in some mammals. Below this the bone is smooth and forms the upper part of the atrium of the middle meatus, whilst the ridge itself articulates posteriorly with the forepart of the middle conchal bone, formed by the inferior concha of the ethmoid bone.

The processus alveolaris (alveolar process) projects from the inferior surface of the body of the bone below the level of the palatal process. Of curved form, it completes, with its fellow of the opposite side, the alveolar arch, in which are embedded, in sockets or alveoli, the roots of the teeth of the maxilla; ordinarily in the adult, when dentition is complete, each alveolar process supports eight teeth. Piercing the medial surface of the alveolar border behind the incisor teeth two small vascular foramina are usually visible. When any or all the teeth are shed the alveoli become absorbed, and the process may under these circumstances be reduced to the level of the plane of the palatine process. Posteriorly the alveolar process ends below the maxillary tuberosity of the body; anteriorly it shares in the formation of the intermaxillary suture.

The processus palatinus (palatine process), of the form of a quadrant, lies in the horizontal plane; it has two surfaces-superior and inferior-and three borders, a straight medial, a more or less straight posterior, and a curved lateral, by which latter it is attached to the medial side of the body and alveolar process as far back as the interval between the second and third molar teeth. Its under surface, together with that of its fellow, forms the anterior three-fourths of the vaulted hard palate; it is rough and pitted for the glands of the mucous membrane of the roof of the mouth, and is grooved on either side, near the alveolar margin, by a channel which passes forward from the pterygo-palatine canal and transmits the 
posterior palatine nerve and greater palatine artery. Its superior surface, smooth and concave from side to side, forms the floor of the corresponding nasal cavity. Its medial border, broad and serrated, rises in a ridge superiorly, so as to form with its fellow of the opposite side the crista nasalis (nasal crest), which is grooved superiorly to receive the inferior border of the romer. In front of its articulation with the vomer this ridge rises somewhat higher, being named the incisor crest, anterior to which it projects beyond the free border of the nasal notch, and together with its fellow forms the pointed projection called the anterior nasal spine. These parts support the septal cartilage of the nose. Immediately to the lateral side of the incisor crest the superior surface of the palatine process is pierced by a foramen which leads downwards, forwards, and a little medially, to open into a broad groove on the medial border of the bone immediately behind the central incisor tooth. When the two maxillæ are articulated, the two grooves form the oval foramen incisivum, into which the two afore-mentioned foramina open like the limbs of a $Y$; these are called the foramina of Stensen, and represent the channels by which in lower forms the organs of Jacobson open into the mouth. In man they afford a means of establishing an anastomosis between the ressels of the mouth and nose. In front and behind these, and lying within the fossa and in the line of the suture, are the smaller foramina of Scarpa, which transmit the naso-palatine nerves, the right nerve usually passing through the posterior foramen, the left through the anterior. The posterior border of the palatine process, which is sharp and thin, falls in line with the interval between the second and third molar, and articulates with the horizontal part of the palate bone.

The sinus maxillaris (maxillary sinus) lies within the body of the bone, and is of corresponding prramidal form, its base being directed towards the nasal carity, with the middle meatus of which it communicates, its summit extending laterally into the root of the zygomatic process. It is closed in laterally and abore by the thin walls which form the anterior, infra-temporal, and orbital surfaces of the body. Inferiorly it overlies the alveolar process in which the molar teeth are implanted, more particularly the first and second, the sockets of which are separated from it by a thin layer of bone.

The angles and corners of this cavity are frequently groined by narrow ridges of bone, one superiorly corresponds to the relief formed by the infra-orbital canal. A vascular and nervous groove is often exposed, curving along the floor of the maxillary sinus just above the alveoli of the teeth. The interior of the carity is lined by an extension from the mucous membrane of the nose.

Connexions.-The maxilla articulates with the nasal, frontal, lacrimal, and ethmoid bones above, laterally with the zygomatic, and occasionally with the sphenoid, posteriorly and medially with the palate, whilst on its medial side it unites with its fellow of the opposite side, and also supports the inferior concha and the romer.

Ossification.-The maxillæ (proper) are developed in the connectire tissue around the oral aperture of the embryo. Ossification commences in membrane from one centre in the neighbourhood of the canine tooth germ. From this centre growth takes place rapidly in several directions, riz., upwards on the lateral side of the nasal capsule to form the hinder part of the processus frontalis, backwards to form the processus zjgomaticus, downwards to form the lateral wall of the processus alreolaris, and inwards to form the processus palatinus. From the latter a process descends downward on the medial side of the teeth to form the medial wall of the processus alveolaris. At first a large gap intervenes between the greater part of the processus palatinus and the processus zygomaticus, but bridges of bone ultimately connect the two, separating the rarious tooth germs, and so forming the tooth sockets. About the fourth month the maxilla invades a small lateral cartilaginous process of the nasal capsule (Mihalliovics), and incorporates it within itself. The infra-orbital nerve is at first placed considcrably above the facies orbitalis of the maxilla, and only comes in contact with it in the second month when a groove is formed on the bone, which by the njprising of its lateral wall and its folding over medialwards finally encloses the nerve and forms the infra-orbital canal and foramen. This account of the ossification of the maxilla, which differs considerably from that given in previous editions, is based on the work of Mall and Fawcett. In the early stages of the derelopment of the bone the alveolar groove, in which the teeth are 
developed, lies close below the infra-orbital groove, and it is not till later that they become scparited by the growth of the maxillary sinus, which first makes its

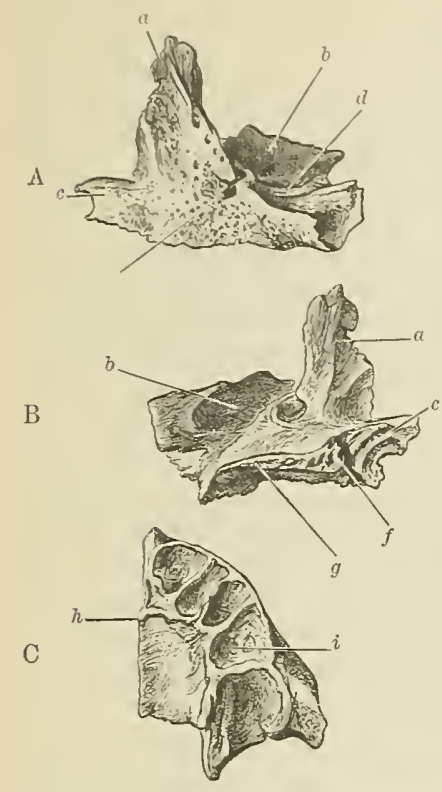

FIG. 159.-OSSIFICATION OF THE Maxilla.

A, Lateral side ; B, Medial side ; C, Under side. $a$, Nasal process; $b$, Orbital plate; $c$, Anterior nasal spine; $d$, Infra-orbital groove; $e$, Infra-orbital foramen; $f$, Anterior palatine groove ; $g$, Palatine process; $h$, Premaxillary suture ; $i$, Alveolar process.

palatine foramen to the interval obliquely laterally and forwards, from the anterior cases of alveolar cleft palate the adjacent bones fail to unite along the line of the suture. In some instances, however, the cleft passes outwards between the central and lateral incisor teeth, and this condition suggests the explanation that the premaxillary element is derived from two centres-a lateral and a medial. The researches of Albrecht and Warinski support this view. The latter anatomist further observes that the lateral cleavage may lead to a division of the dental germ of the lateral incisor tooth, and so explain the occurrence of the supernumerary incisor which is occasionally met with. In this way the different varieties of cleft palate are readily explained; medial cleft palate being due to failure of union between the two premaxillary bones. Lateral cleft palate may be of two types: the cleft in one case passing forward between the central and lateral incisor, and being due to the non-union of the two elements from which the premaxilla is primarily developed; the other, in which the cleft passes between the lateral incisor and the canine, or between the lateral incisor and a supernumerary incisor, owing to the imperfect fusion of the premaxilla laterally with the maxilla.

\section{Ossa Palatina.}

The palate bone, of irregular shape, assists in the formation of the lateral wall of the posterior part of the nasal cavity, the posterior portion of the hard palate, the orbit, the pterygo-palatine, the infra-temporal, and the pterygoid fossæ. It consists of horizontal and vertical parts, united to each other like the limbs of the letter L. At their point of union there is an irregular outstanding process, called the pyramidal process, whilst capping the summit of the vertical part and separated by a deep cleft are two irregular pieces of bone, called the sphenoidal and orbital processes. 
where it articulates with the anterior part of the medial pterygoid lamina, expands below into the pyramidal process. The inferior border of the vertical part is con-

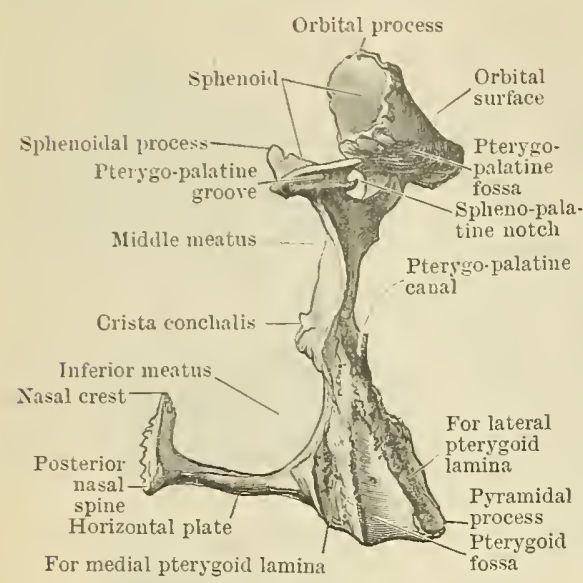

Fig. 161.-The Right Palate Bone. As seen from behind. fluent with the lateral edge of the horizontal part; posteriorly, and immediately in front of the tuberosity, it is notched by the lower extremity of the larger palatine foramen. The superior border supports the orbital and sphenoidal processes; the formerthe anterior-is separated from the latter by a notch (incisura sphenopalatina), which is converted into the spheno-palatine foramen by the articulation of the palate bone with the inferior surface of the sphenoid. Through this communication between the pterygo-palatine fossa and nasal cavity pass the spheno-palatine artery and the nasal branches of the spheno-palatine ganglion.

The processus pyramidalis (pyramidal process) is directed backwards and laterally from the angle formed by the perpendicular and horizontal parts, and presents, on its posterior surface, a central smooth vertical groove, bounded on either side by rough articular furrows which unite above in a $V$-shaped manner with the upper thin posterior edge. These latter articulate with the anterior parts of the lower portions of the medial and lateral pterygoid laminæ, while the central groove fits into the wedge-like interval between the two pterygoid laminæ, thus entering into the formation of the pterygoid fossa. The lateral surface of the pyramidal process is rough above, where it is confluent with the lateral surface of the perpendicular part which articulates with the tuberosity of the maxilla; below, there is a small, smooth, triangular area which appears between the tuberosity of the maxilla and the lateral surface of the lateral pterygoid lamina, and so enters into the medial wall of the infra-temporal fossa. Passing through the pyramidal process in a vertical direction are the foramina palatina minora (lesser palatine foramina) for the transmission of the smaller palatine nerves and vessels.

The processus orbitalis (orbital process), shaped like a hollow cube, surmounts the anterior part of the vertical plate. The open mouth of the cube is usually directed backwards and medially towards the anterior part of the body of the sphenoid, with the cavity of which it commonly communicates; the anterior part of the cube articulates with the medial end of the angle formed by the orbital plate and infra-temporal surface of the maxilla. Of the remaining four surfaces, one directed forwards and medially articulates with the ethmoid. The others are non-articular: the superior enters into the formation of the floor of the orbit; the lateral is directed towards the pterygo-palatine fossa; whilst the inferior, which is confluent with the medial surface of the vertical part, is of variable extent, and overhangs the superior meatus of the nose.

The processus sphenoidalis (sphenoidal process), much smaller than the orbital, curves upwards, medially, and backwards from the posterior part of the summit of the perpendicular part. Its superior surface, which is grooved, articulates with the anterior part of the inferior surface of the body of the sphenoid and the root of the medial pterygoid lamina, thereby converting the groove into the pharyngeal canal, which transmits an artery of the same name together with a pharyngeal branch from the spheno-palatine ganglion. Its lateral side enters into the formation of part of the medial wall of the pterygo-palatine fossa. Its medial curved aspect is directed towards the nasal cavity, whilst its medial edge is in contact with the ala of the vomer.

Connexions.-The palate bone articulates with its fellow of the opposite side, with the ethmoid, vomer, sphenoid, maxilla, and inferior concha. 
Ossification.-The palate bone ossifies in membrane at the side of the nasal segment of the bucco-nasal cavity, medial to the descending palatine nerves, at a time when each half of the developing palatine shelf is hanging down by the side of the tongue. When the palatine shelf becomes horizontal, as it does in the fifth week, bone extends into it to form the horizontal plate. From this common centre all parts of the palate bone develope but the orbital process may be ossified from an independent centre, which either fuses with the palate bone, or with the sphenoid, or with the ethmoid.

\section{Ossa Zygomatica.}

The zygomatic bone (O.T. malar) underlies the most prominent part of the cheek, and is hence often called the cheek-bone. Placed to the lateral side of the orbital cavity, it forms the sharp lateral border of that hollow, and serves to separate that space from the temporal and infra-temporal fossæ which lie behind; below, it rests upon and is united to the maxilla; behind, it enters into the formation of the zygomatic arch, which bridges across the temporal fossa.

As viewed from the lateral side, the bone is convex from side to side, and has four processes, of which three are prominent. These are the fronto-sphenoidal

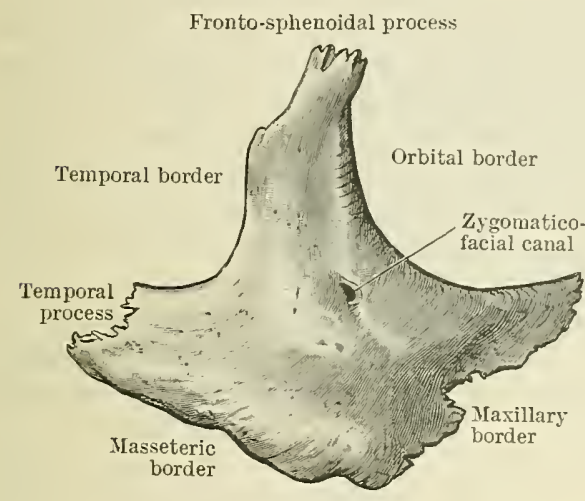

A

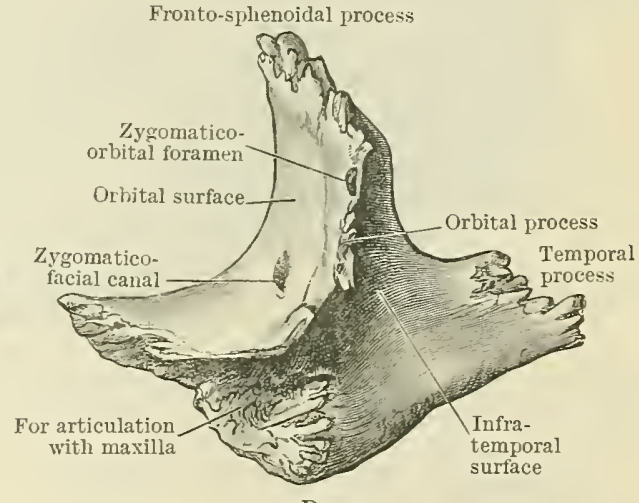

B

Fig. 162.-The Right Zrgomatic Bose. A, Lateral Side; B, Medial Side.

(processus frontosphenoidalis), the marginal or pointed extremity of the maxillary border, and the temporal (processus temporalis). The most elevated part of the convex malar surface (facies malaris) forms the malar tuberosity.

The temporal process ends posteriorly in an oblique edge, which articulates with the extremity of the zygomatic process of the temporal boue. The frontosphenoidal process, the most prominent of the three, is united superiorly to the zygomatic process of the frontal bone. The edge between the frontal and temporal processes is thin and sharp; it affords attachment to the temporal fascia, and near its upper end there is usually a pronounced angle (processus marginalis), formed by a sudden change in the direction of the border of the bone. It is just below this point that the zygomatico-temporal branch of the zygomatic nerve becomes cutaneous. The inferior margin of the temporal process is somerrat thicker and rounded; it extends downwards and forwards torards the inferior angle, where the bone articulates with the maxilla, and is there confluent with the ridge which separates the facial from the infra-temporal aspect of the maxilla. This edge of the bone is sometimes called the masseteric border, since it affords attachment to the fibres of origin of the masseter muscle. Sweeping dowmwards, in front of the fronto-sphenoidal process, is a curved edge which terminates inferiorly in a pointed process. This border forms the lateral and, in part, the inferior margin of the orbital cavity. Between the anterior extremity of the masseteric edge and the pointed anterior angle there is an irregular suture by which the bone is joined to the maxilla. The opening of the foramen zygomaticofaciale (zygomatico- 
facial foramen) is seen on the lateral surface of the bone; its size and position are very variable.

The medial aspect of the bone is distinguished by a curved elevated crest, called the orbital process, which extends medially and backwards, and is confluent laterally with the orbital margin. This process has two surfaces-one anterior, which forms a part of the lateral and lower wall of the orbit, and one posterior, which is directed towards the temporal fossa above and the infra-temporal fossa below. The free edge of the orbital process is thin and serrated; a little below its middle it is usually interrupted by a non-articular notch, which corresponds to the anterior extremity of the inferior orbital fissure. The part above this articulates with the great wing of the sphenoid, the portion below with the orbital surface of the maxilla. Behind the orbital process the medial surface of the bone is concave from side to side, and extends backwards along the medial aspect of the temporal process and upwards over the posterior half of the medial side of the frontal process, thus entering into the formation of the infra-temporal and temporal fossæ respectively. The orbital surface of the orbital process usually displays the openings of two canals (foramina zygomatico-orbitalia)-one which traverses the bone below the orbital margin and appears on the front of the bone as already described, the other which passes obliquely upwards and laterally through the orbital process and appears in the temporal fossa, to the medial side of the frontal

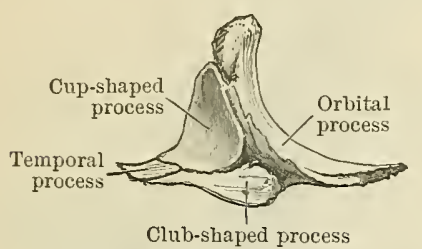

Fig. 163.-Medial Surface of The Zigomatic Bone at Birth. process (foramen zygomaticotemporale). The former transmits the zygomatico-facial branch, the latter the zygomatico-temporal branch of the zygomatic nerve. Just under the orbital margin and a short distance below the zygomatico-frontal sutures there is usually a small tubercle serving for the lateral attachment of the ligamentum palpebrarum. (Whitnall, J. A. and P., vol. xlv.)

Below the orbital process there is a rough triangular area, bounded laterally by the maxillary border. This articulates with the zygomatic process of the maxilla, and occasionally forms the lateral wall of the maxillary sinus.

Connexions.-The zygomatic bone articulates with the frontal, sphenoid, maxilla, and teniporal bones.

Ossification.-The zygomatic ossifies in membrane. Its basis appears about the tenth week as a thin ossifying lamina which corresponds to the orbital margin, attached to which there is a backward expansion corresponding to the body of the bone; from this posteriorly there extends the element of the temporal process. On the medial side, and lying within the angle formed by the orbital and temporal elements, there appears a secondary thickening, which develops into a cup-shaped layer which fits into the recess and ultimately forms the surface of the bone directed to the temporal fossa. Below the orbital margin on the medial side, and extending backwards towards the temporal process, is another secondary thickening, which forms a club-shaped nodule, the thick end of which is directed forwards, whilst posteriorly it forms, in part, the lower margin of the body and temporal process. The overlap of these several parts leads to the formation of grooves which may persist in the adult as sutures. (Karl Toldt, junr., Sitzsbr. des Akad. des Wiss., Wien, July 1902.) Regarding the ossification of this bone there are great differences of opinion; not a few anatomists describe it as developed from a single centre. Support, however, is given to its origin from multiple centres owing to the frequency with which in the adult it is met with in a divided condition.

\section{Mandibula.}

The mandible or lower jaw, of horse-shoe shape, with the extremities upturned, is the only movable bone of the face. Stout and strong, it supports the teeth of the lower dental arch, and articulates with the base of the cranium, by the joints, on either side, between its condyles and the mandibular fossæ of the 
temporal bones. The anterior or horizontal part, which contains the teeth, is called the corpus mandibulæ (body); the posterior or vertical portions constitute the rami mandibulæ.

The body displays in the median plane, in front, a faint vertical ridge, the symphysis, which indicates the line of fusion of the two symmetrical halves from which the bone is primarily developed. Inferiorly this ridge divides so as to enclose, in well-marked specimens, a triangular area-the protuberantia mentalis (mental protuberance), the centre of which is somewhat depressed, thus emphasising the inferior angles, which are known as the tubera mentalia (mental tubercles). The lateral surface is crossed by a faint, elevated ridge, the linea obliqua (oblique line), which runs upwards and backwards from the mental tubercle to the lower part of the anterior border of the ramus, with which it is confluent. From this ridge arise the $\mathrm{m}$. quadratuslabiiinferioris and the triangular muscle. A littleabove this, midway between the upper and lower borders of the mandible, and in line with the root of the second premolar tooth, the bone ispierced by the mental foramen; this is the anterior opening of the inferior

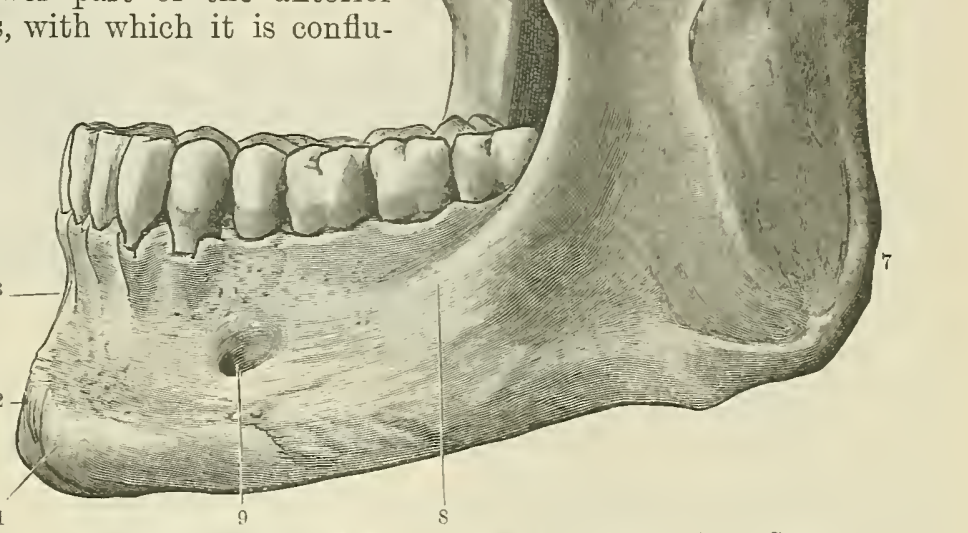

Fig. 161.-The Maxdible as seen from the Left Side.
1. Mental tubercle.
2. Mental protuberance.
3. Symphysis.
7. Angle.
8. Oblique line.
9. Mental foramen.

alveolar canal, which traverses the body of the bone. Through this aperture the mental vessels and nerves reach the surface. The upper border supports the sixteen teeth of the mandible. It is thick behind and thinner in front, in correspondence with the size of the roots of the teeth. Anteriorly the sockets of the incisor and canine teeth produce a series of vertical elevations (juga alveolaria), of which that corresponding to the canine tooth is the most prominent. When this is outstanding it gives rise to a hollowing of the surface between it and the symphysis, often referred to as the incisor fossa; frequently, however, this is only faintly marked. Below the oblique line the bone is full and rounded, and ends below in the basis mandibulæ (base). This slopes laterally at the sides, and forwards in front, where it is thick and hollowed out on either side of the symphysis to form the digastric fossæ, to which the anterior bellies of the digastric muscles are attached; narrowing somewhat behind this, the base again expands opposite the molar teeth, and finally becoming reduced in width, terminates posteriorly at the angle formed between it and the posterior border of the ramus. The medial surface of the body is crossed by the linea mylohyoidea (mylo-hyoid line). This slants from above downwards and forwards towards the lower part of the symphysis. It serves for the origin of the mylo-hyoid muscle, and also, just behind the last molar tooth, furnishes an attachment to the superior constrictor of the pharynx. Below the posterior part of this ridge the surface is hollowed to form a fossa for the lodgment of the submaxillary gland. Above the anterior part of the mylo-hyoid line the bone is smooth and usually convex. Here the sublingual gland lies in relation to it. In the angle formed by the convergence of the two mylo-hyoid lines, and in 
correspondence with the back of the lower part of the symphysis, there is a raised tubercle surmounted by two laterally placed spines, the spinæ mentales (mental spines). Occasionally these are again subdivided into an upper and lower pair, or it may be that the lower pair may fuse to form a rough median ridge. To the upper pair of spines the genio-glossi muscles are attached, whilst the lower pair serve for the origin of the genio-hyoid muscles. Immediately above the tubercle there is a median foramen for the transmission of a nutrient vessel, and close to the alveolar border opposite the intervals between the central and lateral incisors, there are two little vascular canals.

The ramus mandibulæ passes upwards from the posterior part of the bone, forming by the junction of its posterior border with the base of the body the angulus mandibulæ (angle), which is usually rounded and more or less everted. The lateral surface of the ramus affords attachment to the masseter muscle, and when that muscle is powerfully developed the bone

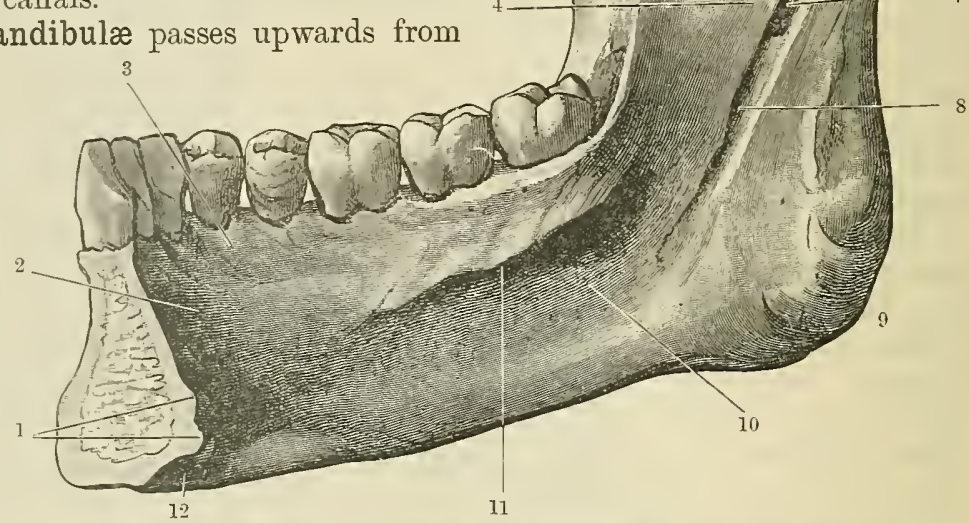

Fig. 165.-The Medial Side of the Right Half of the Mandible.

1. Mental spines.

2. Surface in relation to the sublingual gland. 3. Alveolar border. 4. Lingula.
5. Coronoid process.

6. Condyloid processes.

7. Mandibular foramen.

8. Mylo-hyoid groove.

9. Angle.
10. Fossa for submaxillary gland.

11. Mylo-hyoid line.

12. Digastric fossa.

is usually marked by a series of oblique curved ridges, best seen towards the angle. About the middle of the deep or medial surface is the large opening (foramen mandibulare) of the inferior alveolar canal, which runs downwards and forwards to reach the body, and transmits the inferior alveolar vessels and nerves. This aperture is overhung in front by a pointed scale of bone, the lingula mandibulæ, to the edges of which the spheno-mandibular ligament of the mandibular articulation is attached. Behind the lingula and leading downwards and forwards for an inch or so from the opening of the inferior alveolar canal is the sulcus mylohyoideus (mylo-hyoid groove), along which the mylo-hyoid artery and nerve pass. Behind and below this groove the medial surface of the angle is rough for the attachment of the internal pterygoid muscle. Superiorly the ramus supports the coronoid process in front, and the condyloid process behind, the two being separated by the wide incisura mandibulæ (mandibular notch), over which there pass in the recent condition the vessels and nerve to the masseter muscle. The coronoid process, of variable length and beak-shaped, is limited behind by a thin curved margin, which forms the anterior boundary of the mandibular notch. In front its anterior edge is convex from above downwards and forwards, and becomes confluent below with the anterior border of the ramus and the oblique line. To the medial side of this edge there is a grooved elongated triangular surface, the medial margin of which, commencing above near the summit of the coronoid process, leads downwards along the medial side of the root of the last molar tooth towards the mylo-hyoid line. Behind this ridge the thickness of the ramus is much reduced. The temporal muscle is inserted into the margins and medial surface of the coronoid process. The posterior border of the ramus is continued upwards to support the capitulum mandibulæ (condyle), below which it is somewhat constricted to form the collum mandibulæ (neck), which is compressed from 
before backwards, and bounds the mandibular notch posteriorly. To the medial side of the neck, immediately below the condyle, there is a little depression (fovea pterygoidea) for the insertion of the external pterygoid muscle. The convex surface of the condyle is transversely elongated, and so disposed that its long axis is inclined nearly horizontally from within laterally and a little forwards. The convexity of the condyle is more marked in its anteroposterior than in its transverse diameter, and tends slightly to overhang the mandibular notch. The medial and lateral ends of the condyle terminate in

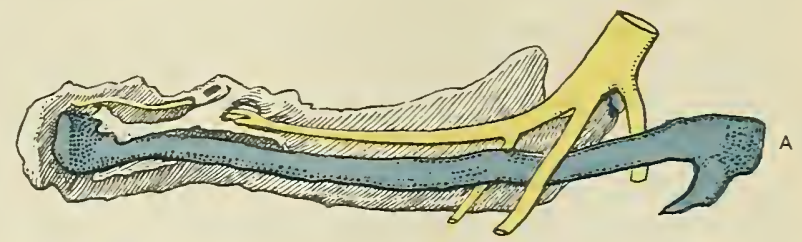
tubercles which serve for the attachment of part of the capsular ligament of the joint.

Ossification.-Its derelopment is intimately associated with Meckel's cartilage, the cartilaginous bar of the first visceral or mandibular arch. Meckel's cartilages, of which there are two, are connected proxi-

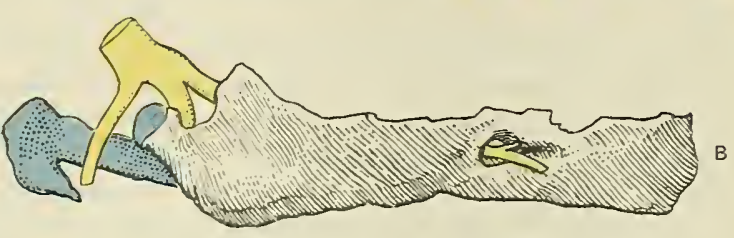
mally with the periotic capsule and cranial base. These distal ends meet but do not fuse in the region of the symphysis. Ossification takes place chiefly from membrane, in part from primordial cartilage (Meckel's cartilage), and also in part from accessory (metaplastic) cartilages, which have no comnexion with Meckel's cartilage, but arise in the membrane from which the greater part of the bone is formed. Before ossification commences three structures are seen lying side by side in the mandibular arch of the embryo. These are, from within laterally, Meckel's cartilage, the inferior alreolar nerve which anteriorly divides into its two terminal branches, viz, the incisor and mental nerves, and a dense connective tissue which stretches from before backwards from close to the mid-line anteriorly to near the acoustic region posteriorly. Ossification in membrane commences about the fortieth to forty-fifth day in the angle between the incisor and mental nerves; it extends rapidly backwards under the mental nerve which grooves its upper surface, and is ultimately enclosed within the mental foramen. At the same time the outer alveolar wall is formed by the extension of this ossifying membrane bone, from which later, about the third month, is dereloped by backward growth the angle and ramus, the latter surmounted by a well-defined coronoid process. About the forty-fifth day the inner alveolar wall, the so-called splenial element, is formed by an ingrowth from the anterior part of the floor of the mental groove. This passes below the incisor nerve and passes up between it and Neckel's cartilage, which it subsequently overlaps, extending rapidly forwards and backwards to end posteriorly in the lingula anterior to the point of origin of the mylo-hyoid nerre. The mandible, in point of time, is the second bone to ossify, being preceded only by the clavicle. Ossification in Meckel's cartilage.-This commences a little later than the first formation of the coronoid process, opposite the first and second incisor with germs, not by independent ossification, but by invasion of osteoblasts from the neighbouring membrane bone. The cartilage becomes surrounded by shelves of bone projected medially both above and below it from the main membrane bone. A bony tube is thus formed which extends from near the mid-line anteriorly to the second milk tooth posteriorly. Within these limits Meckel's cartilage becomes incorporated within the mandible. The extreme anterior end of the cartilage does not, however, undergo ossification, and the hinder end, save that part concerned in the formation of the malleus and incus, degenerates and ultimately disappears. Ossification in accessory curtilages.-These appear at the following sites: one, 
a carrot-like mass, at the condyle; the large end forms the condyle; the tapering end is wedged into the ossifying ramus inder the root of the coronoid process. This cartilage appear's about the eleventh week. About the thirteenth week a strip of cartilage appears along the anterior border of the coronoid process. Along the anterior end of the alveolar walls close to the middle line, and turning down the symphysial surface of the mandible to end below in the recrion of the future digastric impression, another mass of cartilage appears about the fomrteenth week. All the above cartilages are ossified by invasion from the surrounding membrane bone and are not therefore independent centres. It is possible that the symphysial cartilages may be occasionally independently ossified and thus give rise to the ossa mentalia when they exist. From what has been stated it thus appears that under normal conditions each half of the mandible ossifies from one centre only. The above account is based on the researches of Low ${ }^{1}$ and Fawcett. ${ }^{2}$

In a third or fourth month fœtus the cartilage can be traced from the under surface of the fore part of the tympanic ring downwards and forwards to reach the jaw, to which it is attached at the opening of the mandibular canal ; from this it may be traced forwards as a narrow strip applied to the medial surface of the mandible, which it sensibly grooves. The proximal end of this furrow remains permanently as the mylo-hyoid groove. The part of the cartilage between the tympanic ring and the jaw disappears, and its sheath becomes converted into fibrous tissue, and persists in the adult as the so-called internal lateral (spheno-mandibular) ligament of the temporo-maxillary articulation, its proximal end through the Gaserian fissure being continuous with the slender process of the mallens, with the development of which bone it is intimately associated. I. Chaine (Comptes Rendus, Biologie, 1903) takes exception to this view and regards the sphenomandibular ligament as the remmant of a muscular slip.

At birth the mandible consists of two lateral halves united at the symphysis by fibrous tissne; towards the end of the first, or during the second year, osseous union between the two halves is complete. In infancy the jaw is shallow and the rami proportionately small ; further, owing to the obliquity of the ramus the angle is large, averaging abont $150^{\circ}$. The mental foramen lies near the lower border of the bone. Coincident with the eruption of the teeth and the use of the jaw in mastication, the rami rapidly increases in size, and the angle becomes more acute. After the completion of the permanent dentition it approaches more nearly a right angle varying from $110^{\circ}$ to $120^{\circ}$. The body of the bone is stout and deep, whind the mental foramen usually lies midway between the upper and lower borders. As age advances, owing to the loss of the teeth and the consequent shrinkage and absorption of the alveolar border of the bone, the body becomes narrow and attenuated, and the mental foramen now lies close to the upper border. At the same time the angle opens out again $\left(130^{\circ}\right.$ to $\left.140^{\circ}\right)$, in this respect resembling the infantile condition. In old age the coronoid process and the condyle form a more open angle with each other than in the adult.

\section{Os Hyoideum.}

The hyoid bone, though placed in the neck, is developmentally connected with the skull. It lies between the mandible above and the larynx below,

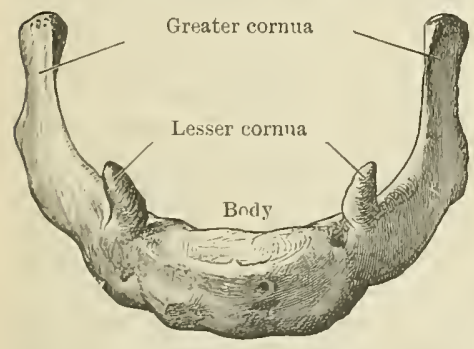

Fig. 167.-The Hyord BONE AS SEEN FROM THE FRONT. attachment of the mylo-hyoid muscles. Its posterior surface, deeply hollowed, is concave from side to side and from above downwards. Herein lie a quantity of

and is connected with the root of the tongue. Of $U$-shaped form, as its name implies (Greek $v$ and $\epsilon \hat{i} \delta$, like), it consists in the adult of a central part, or body, with which are united two long processes extending backwards - the greater cornua -one on either side. At the point where these are ossified with the body, the lesser cornua, which project upwards and backwards, are placed.

The body is arched from side to side and compressed from before backwards, so that its surfaces slope downwards and forwards. Its anterior surface displays a slight median ridge, on either side of which the bone is marked by the 1 . Journal of Anteriny and Physiulogy, vol. xliv. p. 82. 2 Graduation Thesis, Elinburgh, 1906. 
fat and a bursa which separates this aspect from the thyreo-hyoid membrane. The upper border, usually described with the anterior surface, is broad; it is separated from the anterior aspect by a transrerse ridge, behind which are the impressions for the attachment of the genio-hyoid muscles. Its posterior edge is thin and sharp; to this, above, are attached the genio-glossi, whilst behind and below the thyreo-hyoid membrane is connected with it. The inferior border is well defined and narrow; it serves for the attachment of the omo-hyoid, sterno-hyoid, thyreohyoid, and stylo-hyoid muscles.

The greater cornua are connected on either side with the lateral parts of the body. At first, union is effected by synchondroses, which, however, ultimately ossify. These cornua curve backwards, as well as upwards, and terminate in more or less rounded and expanded extremities. Compressed laterally, they serve for the attachments laterally of the thyreo-hyoid and hyo-glossi muscles, and the middle constrictor of the pharynx from below upwards, whilst medially they are connected with the lateral expansions of the thyreo-hyoid membrane, the free edges of which are somewhat thickened, and connect the extremities of the great cornua with the ends of the superior cornua of the thyreoid cartilage below.

The lesser cornua, frequently cartilaginous in part, are about the size of grains of wheat. They rest upon the upper surface of the bone at the junctions of the greater cornua with the body. In jouth they are separated from, but in advanced life become ossified with, the rest of the bone, from which they are directed upwards, backwards, and a little laterally. Their summits are connected with the stylohyoid ligaments; they also serve for the attachment of muscles.

Connexions.-The hyoid is slung from the styloid processes of the temporal bones by the stylo-hyoid ligaments. Inferiorly it is connected with the thyreoid cartilage of the larynx by the thyreo-hyoid ligaments and membrane. Posteriorly it is intimately associated with the epiglottis.

Ossification.-In considering the development of the hyoid bone it is necessary to refer to the arrangement and disposition of the cartilaginous bars of the second and third visceral arches. That of the second visceral arch, the hyoid bar-or Reichert's cartilage, as it is sometimes called -is united above to the petrous part of the temporal, whilst ventrally it is joined to its fellow of the opposite side by an independent median cartilage. Chondrification of the third visceral arch only occur's towards its ventral extremity, forming what is known as the thyreo-hyoid bar. This also unites with the median cartilage above mentioned. In these cartilaginous processes ossific centres appear in certain definite situations. Towards the end of fotal life a single centre (by some authorities regarded as primarily double) appears in the median cartilage, and forms the body of the bone (basihyal). About the same time ossification begins in the lower ends of the thyreo-hyoid bars, and from these the greater cornua are developed (thyreo-hyals). During the first year the lower ends of the hyoid bars begin to ossify and form the lesser cormua (cerato-hyals). The cephalic ends of the same cartilages meanwhile ossify to form the styloid process (stylohyal) on either sicle and one of the anditory ossicles called the stapes, whilst the intervening portions of cartilage undergo resorption and become conrerted into the fibrous tissue of the stylo-hyoid ligaments, which in the adult connect the lesser cornua with the styloid processes of the temporal bone. The greater cornua fuse with the body in middle life; the lesser coruua only at a more advanced period. Variations in the course of development lead to interesting anomalies of the hyoid apparatus. The lesser cornua may be unduly long or the stylo-hyoid ligament may be bony; in this case the cartilage has not undergone resorption, but has passed on to the further stage of ossification, thus forming an epihyal element comparable to that in the dog. The ossified stylo-hyoid ligament, as felt through the pharyngeal wall, may be mistaken for a foreign body. (Farmer, G. WV. S., Brit. Med. Journ. 1900, vol. i. p. 1405.)

\section{THE SKULL AS A WHOLE.}

The skull as a whole may be studied as seen from the front (norma frontalis), from the side (norma lateralis), from the back (norma occipitalis), from above (norma verticalis), and from below (norma basalis). 


\section{The Skull from the Front (Norma Frontalis).}

In front, the smooth convexity of the frontal bone limits this region above, whilst inferiorly, when the lower jaw is disarticulated, the teeth of the upper jaw form its lower boundary. The large openings of the orbits are seen on either side; whilst placed centrally, and at a somewhat lower level, is the apertura piriformis (anterior nasal aperture) leading into the nasal cavity.

The frontal region, conver from above downwards and from side to side, is limited laterally by two ridges, which are the anterior extremities of 'the temporal lines. Superiorly the fulness of the bone blends with the convexity of the vertex. Inferiorly the frontal bone forms on either side the arched superior border of the orbit (margo supraorbitalis). The space between these borders corresponds to the root of the nose, and here are seen the sutures which unite the frontal with the nasal bones medially, and with the frontal process of the maxilla on either side, called the naso-frontal and fronto-maxillary sutures, respectively. The supra-orbital margin is thin and sharp laterally, but becomes thick and more rounded towards its medial side, where it forms the medial angular process and unites with the frontal process of the maxilla and the lacrimal bone on the medial wall of the orbit. This arched border is interrupted towards the medial side by a notch (incisura supraorbitalis), sometimes converted into a foramen, for the transmission of the supra-orbital nerve and artery. In the median plane, just above the naso-frontal suture, there is often the remains of a median suture (sutura frontalis), which marks the fusion of the two halves from which the bone is primarily ossified. Here also a prominence, of variable extent-the glabella-is met with; from this there passes out on either side above and over the orbital margin a projection called the superciliary arch.

The orbital fossæ, of more or less conical form, display a tendency to assume the shape of four-sided pyramids by the flattening of the superior, inferior, and lateral walls. The base, which is directed forwards and a little laterally, corresponds to the orbital aperture. The shape of this is liable to individual and racial variations, being nearly circular in the Mongoloid type, whilst it displays a more or less quadrangular form in Australoid skulls. The superior margin, as has been already stated, is formed by the frontal bone between the zygomatic and medial angular, processes. The lateral and about half the inferior margins are formed by the sharp curved edge between the facial and orbital surfaces of the zygomatic bone. The medial border and the remainder of the inferior margin are determined by the lateral surface of the frontal process of the maxilla, and the sharp edge separating the facial from the orbital surface of the same bone. Three sutures interrupt the continuity of the orbital margin-zygomatico-frontal laterally, the fronto-maxillary medially, both lying about the same level, and the zygomatico-maxillary inferiorly. The apex of the space is directed backwards and medially, so that the medial walls of the two orbits lie nearly parallel to each other, whilst the lateral walls are so disposed as to form almost a right angle with each other. The depth of the orbit measures, on an average, about two inches $(5 \mathrm{~cm}$.$) . At the apex there are two openings; the larger, known as the superior$ orbital fissure (O.T. sphenoidal), passes from the apex of the space laterally and a little upwards for the distance of three-quarters of an inch or so, between the roof and lateral wall of the orbit. The medial third of this fissure is broad and of circular form. Laterally it is considerably reduced in width. Through this the oculomotor, trochlea, ophthalmic division of the trigeminal, and the abducent nerves enter the orbit, whilst the ophthalmic veins pass backwards through it. Above and medial to the medial end of the sphenoidal fissure there is a smaller circular opening, the optic foramen, for the transmission of the optic nerve and ophthalmic artery.

The roof of the orbit, which is very thin and brittle towards its centre, is formed in front by the orbital part of the frontal bone and behind by a small triangular piece of the small wing of the sphenoid, which surrounds the optic foramen and forms the upper border of the superior orbital fissure. Laterally 
this surface is separated from the lateral wall by the superior orbital fissure

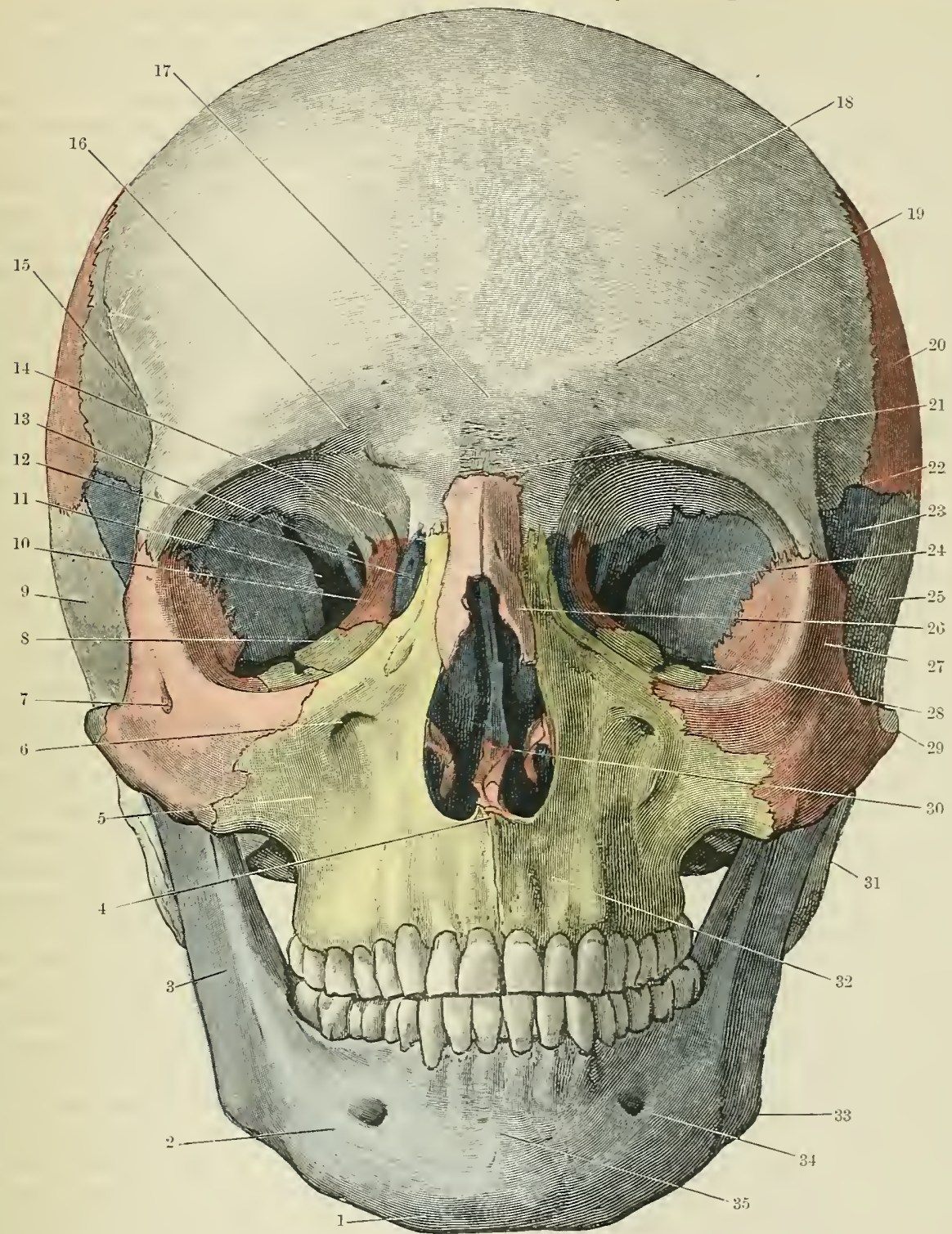

Fig. 168. - The FroNt of The SKLLL.

The uasal bones, lamina paprracea of the ethmoid, vomer, inferior conchr, zygomatic, and parietal bones are coloured red. The sphenoid, lacrimal, perpendicular part and middle conche of the ethmoid, anil inferior conchie are coloured blue. The mixillie are coloured yellow. The frontal and temporal bones are left incoloured.

1. Mental protuberance.

2. Body of mandible.

3. Ramus of mandible.

4. Anterior nasal spine.

5. Canine fossa.

6. Infra-orbital foramen.

7. Zygomatico-facial foramen.

8. Orbital surface of maxilla.

9. Temporal fossa.

10. Lamina papyracea of ethıoid.

11. Superior orbital tissure.

12. Lacrimal bone and groove.

13. Optic foramen.
14. Ethmoirlal foranina.

15. Temporal line.

16. Supra-orbital noteh.

17. Glabella.

18. Frontal tuberosity.

19. Superciliary arch.

20. Parietal bone.

21. Naso-frontal suture.

22. Pterion.

23. Great wing of sphenoil.

24. Orbital surface of great wing of sphenoil.

25. Squamous part of the temporal.

26. Left nasal bone.

27. Zygomatic bone.

28. Inferior orbital fissure.

29. Zygomatic arch.

30. Apertura piriformis, displaying nasal septum and inferior and middle conche.

31. Mastoid process.

32. Incisor fossa.

33. Angle of jaw:

34. Mental foramen

3う. Symphysis menti.

posteriorly, anteriorly by an irregular suture between the orbital part of the 
frontal and the upper margin of the orbital surface of the great wing of the sphenoid, lateral to which the zygomatic process of the frontal articulates with the zyomatic bone, often forming a ridge which limits the fossa for the lodgment of the lacrimal gland inferiorly (Whitnall). Medially the roof is marked off from the medial wall by a suture, more or less horizontal in direction, between the orbital plate of the frontal and the following bones in order from before backwards, viz., the frontal process of the maxilla, the lacrimal bone, and the lamina papyracea of the ethmoid. In the suture between the last-mentioned bone and the frontal there are two foramina, the anterior and posterior ethmoidal foramina; both transmit ethmoidal ressels - the anterior affording passage to the anterior ethmoidal branch of the naso-ciliary nerve as well. The roof is concave from side to side, and to some extent also from before backwards. About midway between the fronto-maxillary suture and the supra-orbital notch or foramen, but within the margin of the orbit, there is a small depression, occasionally associated with a spine (fovea vel spina trochlearis), for the attachment of the cartilaginous pulley of the superior oblique muscle of the eyeball. Under cover of the zygomatic process the roof is more deeply excavated, forming a shallow fossa for the lodgment of the lacrimal gland (fossa glandulæ lacrimalis). In front, the roof separates the orbit from the frontal sinus, and along its medial border it is in relation with the ethmoidal air-cells. The relation to these air spaces is variable, depending on the development and size of the sinuses. The rest of the roof, which is very thin, forms by its upper surface part of the floor of the anterior cranial fossa, in which are lodged the frontal lobes of the cerebrum.

The floor of the orbit is formed by the orbital surface of the maxilla, together with part of the orbital surface of the zygomatic bone, and a small triangular piece of bone, the orbital process of the palate, which is wedged in posteriorly. Laterally, for three-quarters of its length posteriorly, it is separated from the lateral wall, which is here formed by the great wing of the sphenoid, by a cleft called the inferior orbital fissure. Through this there pass the maxillary division of the trigeminal nerve on its way to the infra-orbital canal, the zygomatic branch of the maxillary nerve, the infra-orbital vessels, a branch connecting the inferior ophthalmic vein with the pterygoid plexus, and some twigs from the sphenopalatine ganglion. By means of this fissure the orbit communicates with the pterygo-palatine fossa behind, and the infra-temporal fossa to the lateral side, thongh in the recent condition the fissure is bridged over by the involuntary orbitalis muscle of Müller. Medially the floor is limited from behind forwards by the suture between the following bones, viz., the orbital process of the palate below with the body of the sphenoid above and behind, and the lamina papyracea of the ethmoid above and in front-anterior to which the orbital surface of the maxilla below articulates with the lamina papyracea of the ethmoid and the lacrimal above and in front. At the anterior extremity of this line of sutures the medial edge of the orbital plate of the maxilla is notched and free between the point where it articulates with the lacrimal posteriorly and the part from which its frontal process rises. Here it forms the lateral edge of a canal, down which the membranous naso-lacrimal duct passes to the nose. The floor of the orbit is thin behind and at the sides, but thicker in front, where it blends with the orbital margin. Passing in a sagittal direction through its substance is the infra-orbital canal, the roof of which is usually deficient behind, where it becomes continuous with a broad, shallow groove, which leads forwards from the anterior margin of the inferior orbital fissure. This canal (canalis infraorbitalis) opens on the anterior surface of the maxilla immediately below the orbital margin (foramen infraorbitale) and transmits the maxillary division of the trigeminal nerve, together with the infra-orbital vessels. The floor forms a thin partition which separates the orbit from the maxillary sinus, which lies beneath it. Medially it completes the lower ethmoidal air-cells, and separates the orbit from the middle meatus of the nasal cavity.

The lateral wall of the orbit, which is the strongest, is formed by the orbital surface of the great wing of the sphenoid and the superior part of the orbital surface of the zygomatic bone. Above it, behind, is the superior orbital fissure, whilst below, 
and extending much farther forward, is the inferior orbital fissure. The posterior portion of this wall, formed by the great wing of the sphenoid, serves as a partition between the orbit and the anterior extremity of the middle cranial fossa, in which is lodged the pole of the temporal lobe of the cerebrum. In front of this, and behind the line of the spheno-zygomatic suture, this wall is strengthened on its outer aspect by its confluence with the cranial wall. Still more anteriorly, the lateral wall separates the orbit from the temporal fossa. The anterior margin of the lateral wall is stout and formed by the zygomatic bone, behind which, formed in part by the orbital process of the zygomatic bone and the zygomatic edge of the great wing of the sphenoid, it forms a fairly thick partition between the orbit in front and the temporal fossa behind. Crossing this surface from above downwards, close to the anterior extremity of the inferior orbital fissure, is the suture between the zygomatic bone and the great wing of the sphenoid (sutura sphenozygomatica). This wall is pierced in front by one or two small canals (foramina zygomatico-orbitalia), which traverse the zJgomatic bone and allow the transmission of the zygomatico-temporal and zJgomatico-facial branches of the zygomatic portion of the maxillary division of the trigeminal nerve. A small tubercle, which can be more readily felt than seen, is situated just within the orbital margin near the middle of the fore part of this wall, and indicates the site of attachment of the ligamentum palpebrarum laterale (Thitnall).

The medial wall of the orbit is formed from before backwards by a small part of the frontal process of the maxilla, by the lacrimal, and by the lamina papyracea of the ethmoid, posterior to which is a small part of the lateral aspect of the body of the sphenoid in front of the optic foramen. Above, the orbital part of the frontal bone forms a continuous suture from before backwards with the bones just enumerated; whilst below, the lacrimal and the lamina papyracea of the ethmoid articulate with the orbital plate of the maxilla; posteriorly the hinder extremity of the lamina papyracea and the anterior part of the body of the sphenoid articulate with the orbital process of the palate. The orbital surface of the lacrimal bone is divided into two by a rertical ridge - the lacrimal crest (crista lacrimalis posterior) - which forms in front the posterior half of a hollow, the fossa sacci lacrimalis (lacrimal fossa), the anterior part of which is completed by the channelled posterior border of the frontal process of the maxilla. In the lacrimal fossa is lodged the lacrimal sac, whilst passing from it and occupying the canal, of which the upper opening is at present seen, is the membranous nasolacrimal duct. The lower part of the lacrimal fossa separates the orbit from the anterior part of the middle meatus of the nasal cavity. To the medial side of the upper part of the lacrimal fossa lie the anterior ethmoidal cells, the passage leading from the nose to the frontal sinus (infundibulum ethmoidale), whilst the part of the bone behind the lacrimal crest forms the thin partition between the orbit and the ethmoidal cells. Behind, where the body of the sphenoid forms part of the medial wall of the orbit, the sphenoidal air sinus is in relation to the apex of that space, though here the partition wall between the two carities is much thicker.

The skeleton of the face on its anterior surface is formed by the two maxillæ, the frontal processes of which have been already seen to pass up to articulate with the medial angular processes of the frontal bone, thus forning the lower halves of the medial margins of the orbit. Joined to the maxille laterally are the zygomatic bones, which are supported by their union with the temporal bones posteriorly through the medium of the zygomatic arches. The suture which separates the zygomatic from the maxilla (sutura zygomaticomaxillaris) commences above about the centre of the inferior orbital margin and passes obliquely downward and laterally, its inferior end lying in vertical line with the lateral orbital margin. The two maxillie are separated by the nasal cavities, which here open anteriorly. Abore, the two nasal bones are wedged in between the frontal processes of the maxillie: whilst below the apertura piriformis, the maxilla themselres are united in the middle line by the intermaxillary suture (sutura intermaxillaris).

The apertura piriformis (piriform aperture) (O.T. nasal aperture or anterior nares), which lies below and in part between the orbits, is of variable 
shape and size-usually piriform, it tends to be long and narrow in Europeans, as contrasted with the shorter and wider form met with in the negroid races. Its edges are formed below and on either side by the free curved margin of the body and the frontal process of the maxilla; and above, and partly at the sides, by the free border of the nasal bones. In the median plane, inferiorly, corresponding to the upper end of the intermaxillary suture there is an outstanding processthe anterior nasal spine, formed by the coalescence of spicules from both maxillæ; arising from this, and passing backwards and upwards, is a thin bony partition - the osseous septum of the nose. Often deflected to one or other side, it divides the cavity of the nose (cavum nasi) into a right and left half. Projecting into these chambers from their lateral walls can be seen the medial surfaces and free borders of the middle and inferior conchr, the spaces below and between which form the inferior and middle meatuses of the nose, respectively.

Below the orbit, and to the lateral side of the piriform aperture, the anterior or facial surface of the body of the maxilla is seen; this is continuous inferiorly with the lateral surface of the alveolar process, in which are embedded the roots of the upper teeth.

A horizontal line drawn round the jaw on the level of a point midway between the lower border of the piriform aperture and the alveolar edge corresponds to the plane of the hard palate. Below that the alveolar process separates the cavity of the mouth from the front of the face; whilst above, the large air space, the maxillary sinus, lies within the body of the maxilla.

The zygomatic bone forms the lower half of the lateral and lateral half of the lower border of the orbit. Its lateral aspect corresponds to the point of greatest width of the face, the modelling of which depends on the flatness or projection of this bone.

When the mandible or lower jaw is in position, and the teeth in both jaws are complete, the lower dental arch will be seen to be smaller in all its diameters than the upper, so that when the jaws are closed the upper teeth slightly overlap the lower both in front and at the sides. Exceptionally, a departure from this arrangement is met with.

\section{Lateral Aspect of the Skull (Norma Lateralis).}

Viewing the lateral aspect of the skull, in the first instance without the lower jaw, it is seen to be formed in part by the bones of the cranium, and in part by the bones of the face. A line drawn from the fronto-nasal suture to the tip of the mastoid process serves to define roughly the boundary between these portions of the skull. Of ovoid shape, the cranium is formed above by the frontal, parietal, and occipital bones from before backwards; whilst below, included within these are the sphenoid and temporal bones. The sutures between these several bones are arranged as follows: Commencing at the zygomatic process of the frontal, the suture between that bone and the zygomatic bone is first seen; tracing this backwards and a little upwards, the lower edge of the frontal next articulates with the upper margin of the great wing of the sphenoid for a distance varying from three-quarters of an inch to one inch. Here the posterior border of the frontal turns upwards and slightly backwards, forming with the parietal the sutura coronalis (coronal suture). The lower border of the parietal bone, which is placed immediately behind the frontal, articulates anteriorly with the posterior part of the superior border of the great wing of the sphenoid. The extent of this suture (sutura sphenoparietalis) is liable to very great individual variation - at times being broad, in other instances being pointed and narrow, whilst occasionally the parietal does not articulate with the sphenoid at all. Behind the spheno-parietal suture the parietal articulates with the squamous part of the temporal (sutura squamosa), the posterior extremity of which is about one inch behind the external acoustic meatus. Here the suture alters its character and direction, and in place of being scaly, becomes toothed and irregular, uniting, for the space of an inch or so, the mastoid angle of the parietal with the mastoid process of the temporal bone. This suture (sutura parietomastoidea) is more or less horizontal in direction, and lies in line and on a level with the superior border of the zygomatic arch. At a point about two inches behind the external acoustic 
meatus the posterior border of the parietal bone turns obliquely upwards and backwards, and forms with the squamous part of the occipital bone the strongly denticulated sutura lambdoidea (lambdoid suture). Inferiorly this suture is continued obliquely downwards between the occipital bone and the posterior border of the mastoid portion of the temporal, where it forms the sutura occipitomastoidea

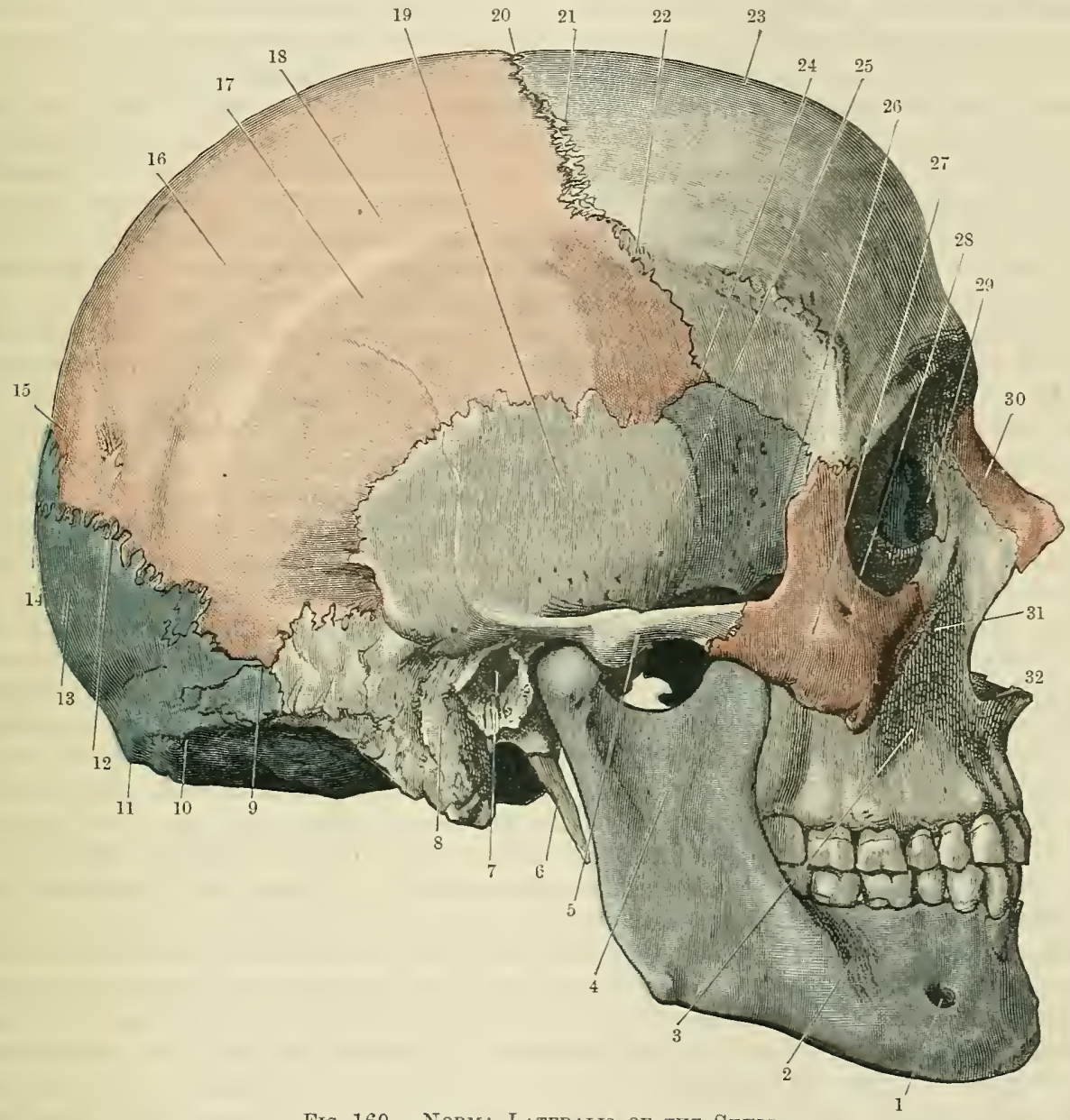

Fig. 169.-Norma Lateralis of the Skell.

The occipital, sphenoid, ethmoid, and lacrimal bones and the mandible are coloured blue. The parietal, zygomatic, and nasal bones are coloured red. The temporal, frontal, and maxillary bones are left nncoloured.
1. Mental foramen.
12. Lambdoid suture.
13. Occipital bone.
14. Lambda.
22. Stephauion.
3. Maxilla.
4. Ramus of mandible.
15. Obelion placed between the two
23. Frontal bone.
5. Zygomatic arch.
6. Styloid process. parietal foramina.
16. Parietal bone.
24. Pterion.
25. Temporal fossa.
7. External acoustic meatus.
17. Lower temporal line.
18. Upper temporal line.
9. Asterion.
10. Superior nuchal line of occipital
bone.
11. External occipital protuberance.
19. Squamous part of temporal bone.
20. Bregma.
26. Great wing of sphenoid.
27. Zygomatic bone.
28. Zygomatico-facial foramen.
29. Lacrimal bone.
21. Coronal suture.
30. Nasal bone.
31. Infra-orbital foramen.
32. Piriform aperture and anterior nasal spine.

(occipito-mastoid suture), much simpler and less serrated than the two previously mentioned. These three sutures just described meet in triradiate fashion at a point called the asterion.

Anteriorly the curve of the squamous suture is continued downward between the anterior edge of the squamous part of the temporal and the posterior border of the great wing of the sphenoid; inferiorly it lies in plane with the middle of the zygomatic arch. 
The sutures around the summit of the great wing of the sphenoid are arranged like the letter $H$ placed obliquely, the cross-piece of the $H$ corresponding to the spheno-parietal suture. When this is short, and becomes a mere point of contact, the arrangement then resembles the letter $X$. This region is named the pterion.

Curving over the lateral region of the calvaria in a longitudinal direction is the temporal line. This is often double. The lower line marks the limit of the attachment of the temporal muscle, whilst the upper ridge defines the attachment of the temporal fascia. Commencing in front at the zygomatic process of the frontal, the line sweeps upwards and backwards across the inferior part of that bone, and then crossing the coronal suture-at a point called the stephanion -it passes on to the parietal, over which it curves in the direction of its mastoid angle. Here it is continued on to the temporal bone, where it sweeps forward to form the supra-mastoid crest, which serves to separate the squamous from the mastoid portion of the temporal bone laterally. Carried forwards, this ridge is seen to become continuous with the upper border of the zygomatic arch over the external acoustic meatus. In front, the temporal ridge separates the temporal fossa from the region of the forehead; above and behind, it bounds the temporal fossa which lies within its concavity, and serves to separate that hollow from the surface of the calvaria which is overlain by the scalp. Above the level of the temporal lines the surfaces of the frontal and parietal bones are smooth, the latter exhibiting an elevation of varying prominence and position, but usually situated about the centre of the bone, called the tuber parietale (parietal tuberosity). A slight hollowing of the surface of the parietal behind and parallel to the coronal suture is not uncommon, and is referred to as the post-coronal depression.

As seen in profile, the part of the calvaria behind and below the lambdoid suture is formed by the squamous part of the occipital bone. In line with the zygomatic arch this outline is interrupted by the external occipital protuberance or inion. The projection of this point is variable; but its position can usually be easily determined in the living. Passing forwards from it, and blending anteriorly with the posterior border of the mastoid process of the temporal bone, is a rough crest, the linea nuchæ superior (superior or nuchal curved line), a little above which there is often a much fainter line, the linea nuchæ suprema (highest curved line); this affords attachment to the galea aponeurotica. These two lines serve to separate the part of the cranium above, which is covered by scalp, from that below, which serves for the attachment of the fleshy muscles of the back of the neck, the latter surface (planum nuchale) being rough and irregular as contrasted with the smooth superior part (planum occipitale). The fulness of these two parts of the occipital bone varies much. There is frequently a pronounced bulging of the planum occipitale, and the position of the lambda can often be easily determined in the living; similarly the planum nuchale may be either comparatively flat or else full and rounded. These differences are of course associated with corresponding differences in the development of the cerebral and cerebellar lobes, which are lodged in relation to the cerebral aspect of these parts of the bone. The further description of the planum nuchale is best deferred till the external aspect of the base of the skull is studied.

Fossa Temporalis.-Within the limits of the temporal lines the side of the cranium slopes forwards, inwards, and downwards, thus leaving a considerable in terval between its lower part and the zygomatic arch. This space or hollow is called the temporal fossa; bounded above and behind by the temporal lines, its inferior limit is defined by the level of the zygomatic arch. Deepest opposite the angle formed by the frontal and temporal processes of the zygomatic bone, the fossa becomes shallow towards its circumference.

Its floor or medial wall, which is slightly concavo-convex from before backwards about mid-level, is formed above by the temporal surface of the frontal, behind by the sphenoidal angle of the parietal, as well as the lower portion of that bone, below the temporal line; below and in front by the temporal surface of the great wing of the sphenoid, and behind and below by the squamous portion of the temporal bone. Inferiorly, the floor is limited in front by the free inferior border of the great wing of the sphenoid, which forms the upper boundary of the pterygo- 
palatine fossa; behind that, by a rough ridge, the infra-temporal crest, which crosses the lateral surface of the great wing of the sphenoid, to become continuous posteriorly with a ridge on the lower surface of the squamous part of the temporal, from which the anterior root of the zygomatic process springs. Anteriorly the temporal fossa is separated from the orbit by the zygomatic process of the frontal above, and by the orbital process of the zygomatic and its junction with the lateral border of the great wing of the sphenoid between its orbital and temporal surfaces.

Laterally and in front, the fossa is overhung by the backward projection of the fronto-sphenoidal process of the zygomatic bone, and it is under cover of this, and within the angle formed by the frontal and orbital processes of the zygomatic bone, that we see the opening of the zygomatico-temporal foramen, which pierces the orbital plate of the zygomatic bone and transmits the zygomatico-temporal branch of the zygomatic nerve-a filament of the maxillary division of the trigeminal nerve. The anterior part of the inferior orbital fissure opens into the lower part of the temporal fossa, and thus establishes a communication between it and the orbit. If the floor of the fossa be carefully examined, some more or less distinct vascular grooves may be seen. One passing upwards over the posterior part of the squamous temporal, immediately in front of and above the external acoustic meatus, is for the middle temporal artery; two others, usually less distinct, pass up, one over the temporal surface of the great wing of the sphenoid, the other over the anterior part of the squamous part of the temporal ; these are for the anterior and posterior deep temporal branches of the internal maxillary artery. Inferiorly the temporal fossa communicates with the infratemporal fossa, beneath the zygomatic arch, the two being separated by an imaginary horizontal plane passing medially at the level of that bony bridge. The fossa contains the temporal muscle with its vessels and nerves, together with the zygomatico-temporal branch of the zygomatic nerve and some fat; all of which are enclosed by the fascia which stretches over the space from the upper temporal line above to the superior border of the zygomatic arch below. The extent and depth of the fossa depends on the size of the temporal muscle, the development of which is correlated with the size and weight of the lower jaw.

Springing from the front and lower part of the squamous part of the temporal is the zygomatic process of that bone; it has two roots, an anterior and a posterior, between and below which are placed the fossa mandibularis (mandibular fossa) in front, and the opening of the external acoustic meatus behind. Of compressed triangular form, the process at first has its surfaces directed upwards and downwards, but curving laterally and forwards, it twists on itself, so that its narrowed surfaces are now turned laterally and medially, and its edges upwards and downwards; passing forwards, it expands somewhat, and ends in an oblique serrated surface, which unites with the temporal process of the zygomatic bone completing the zygomatic arch. It is the superior edge of this bridge of bone which forms the posterior root. The inferior border, turning medially, forms the anterior root, and serves to separate the temporal from the infra-temporal surface of the squamous part of the temporal, blending in front with the infra-temporal crest on the lateral surface of the great wing of the sphenoid. The under surface of this root is convex from before backwards, and is thrown into relief by the mandibular fossa, which passes up behind it. In this way a downward projection, which is called the tuberculum articulare (O.T. eminentia articularis), is formed.

The spina angularis of the sphenoid (angular spine) lies immediately to the medial side of the articular part of the mandibular fossa. Its size and projection vary. It is well to remember its relation to the condyloid process of the mandible when that bone is in position; lying, as it does, to the medial side and a little in front of that process, it affords attachment to the spheno-mandibular ligament of the mandibular articulation. As will be seen hereafter, the anterior extremity of the osseous part of the auditnry tube lies just to its medial side.

A noteworthy feature about the articular part of the mandibular fossa is the thinness of the bony plate which serves to separate it from the middle cranial fossa above. The vaginal process is a crest of bone which rums obliquely forwards from the front and medial side of the mastoid process, just below the 
exterual acoustic meatus, to the angular spine of the sphenoid. Passing downwards and slightly forwards from the centre of this, and ensheathed by it in front and at the sides, is the pointed styloid process, the length of which is extremely variable.

In the recess between the posterior root of the zygoma and the upper curved edge of the meatus there is usually a depression, though in some instances this may be replaced by a slight bulging of the bone. If from the posterior root of the zygoma a vertical line be let fall, tangential to the posterior edge of the meatus, a small triangular area is mapped off which has been named by Macewen the suprameatal triangle. Surgically this is of importance, as it is the spot selected in which to trephine the bone to reach the tympanic antrum.

In the suture between the posterior border of the mastoid part of the temporal and the squamous part of the occipital, there is usually a foramen (mastoid) for the transmission of an emissary vein from the transverse sinus within the cranium to the cutaneous occipital rein of the scalp; this opening, which may be double, varies greatly in size, and is usually placed on a level with the external acoustic meatus.

Fossa Infratemporalis. - The side of the cranium in front of the anterior root of the zygomatic process of the temporal bone is deeply hollowed, forming the infra-temporal fossa. The student must bear in mind that, in examining this space, the ramus and coronoid process of the mandible form its lateral wall; but this bone for the present being withdrawn, enables us to get a better view of the boundaries of the space. In front its anterior wall is formed by the convex posterior or infra-temporal surface of the maxilla, which rises behind the socket for the last molar tooth to form the tuber maxillare (maxillary tuberosity). Anteriorly, the infra-temporal surface of the maxilla is separated from its anterior aspect by the rounded inferior margin of the zygomatic process which supports the zygomatic bone. This latter curves laterally and backwards, forming part of the upper and anterior wall of the fossa. On the medial surface of this wall will be seen the suture uniting the zygomatic and maxillary bones (sutura zygomaticomaxillaris), which runs obliquely upwards and medially to reach the lateral extremity of the inferior orbital fissure, the inferior border of which forms the superior boundary of the infra-temporal surface of the maxilla. On this aspect of the bone are to be seen the openiugs of the foramina alveolaria, two or more in number, which transmit the nerves and vessels to the upper molar teeth. The medial wall of the infra-temporal fossa is formed by the lateral surface of the lateral pterygoid lamina, the width and shape of which varies greatly; its posterior border is thin and sharp, and often furnished with spiny points, to one of which the pterygo-spinous ligament, which stretches from this border to the angular spine of the sphenoid, is attached. It occasionally happens that this ligament becomes ossified. Anteriorly the lateral pterygoid lamina is separated from the maxilla above by an interval called the pterygo-maxillary fissure. Below this the bones are apparently fused, but a careful inspection of the skull, together with an examination of the disarticulated bones, will enable the student to realise that, wedged in between the two bones at this point, is a part of one of the smaller bones of the face, the pyramidal process of the palate bone (O.T. tuberosity of palate bone).

The inferior border of the lateral pterygoid lamina is usually curved and slightly everted. Superiorly, where the lateral pterygoid lamina is generally narrower, it sweeps upwards to become continuous with the broad inferior surface of the great wing of the sphenoid; this, which overhangs in part the infra-temporal fossa superiorly, is limited laterally by the infra-temporal crest, which separates its infra-temporal from its temporal surface. The infra-temporal surface of the great wing of the sphenoid is limited in front and below by the edge which forms the superior boundary of the inferior orbital fissure, whilst behind it reaches as far back as the medial extremity of the petro-tympanic fissure, where it terminates in the angular spine. It is from this point that the suture (sutura sphenosquamosa) curves forward and upwards to reach the region of the pterion. The infra-temporal surface of the great wing of the sphenoid, and the lateral surface of the lateral pterygoid plate, alike afford extensive attachments for the external pterygoid muscle, whilst the former is pierced by minute canals for the transmission of emissary veins. Occasionally a larger vascular foramen is present (foramen Vesalii), 
through which a vein runs from the cavernous sinus within the cranium to the pterygoid venous plexus situated in the infra-temporal fossa. Immediately behind the root of the external pterygoid plate there is a large oval hole, the foramen ovale, and behind that, and in line with the angular spine, is the smaller foramen spinosum. These two foramina cannot usually be seen in a side view of the skull, and are better studied when the base is examined; they are mentioned, however, because they transmit structures which here pass to and from the cranium, viz., the mandibular division of the trigeminal nerve, together with its motor root, and the accessory meningeal artery through the foramen ovale, and the middle meningeal artery and its companion vein through the foramen spinosum. A part of the squamous part of the temporal also forms a small portion of the roof of this fossa; it consists of a triangular area immediately in front of the tuberculum articulare, and between it and the anterior root of the zygomatic process of the temporal, which is here curving medially and forwards, to become continuous with the infra-temporal crest. Medially this surface is continuous with the infra-temporal surface of the great wing of the sphenoid, separated from it, howerer, by the posterior part of the spheno-squamosal suture.

When the mandible is in position, the infra-temporal fossa is concealed by the ramus of the mandible, the medial surface of which, in its upper half, forms the lateral wall of that space. Viewed from the lateral side, the ramus of the mandible displays considerable differences in different skulls. These are mainly due to variations in its width and in the nature of the angle which it forms at its fusion with the body of the bone. A considerable interval separates the posterior border of the ramus from the front of the mastoid process. Within this space may be seen the free inferior edge of the tympanic plate (vaginal process), from which, just below the external acoustic meatus, the styloid process of the temporal bone is observed passing downwards and slightly forwards. The width and height of the coronoid process vary much, oftentimes reaching the level of the top of the condyle. Its extremity, when the lower jaw is closed, lies just within the anterior part of the zygomatic arch; at other times it rises to a much higher level, so that its point may be seen above the level of the upper border of the zygomatic arch. The posterior edge of the coronoid process forms the anterior border of the mandibular notch, and limits in front the interval left between the lower border of the posterior half of the zygomatic arch and the upper hollowed edge of the ramus. On looking into this interval, the floor of the infra-temporal fossa may be seen, formed anteriorly by the lateral pterygoid lamina; whilst posteriorly it is possible to pass a probe right across the base of the skull from one mandibular notch to the other, the shaft of the probe lying immediately behind the pterygoid processes of the sphenoid, and crossing the foramina ovalia, through which the mandibular divisions of the trigeminal nerves pass.

The ramus and coronoid process are so placed as to occupy a position intermediate between the zygomatic arch laterally and the lateral pterygoid lamina medially; their medial surface, therefore, forms the lateral wall of the infra-temporal fossa. On a level with the surface of the crowns of the teeth of the mandible, and situated about the middle of this aspect of the ramus, is the mandibular foramen, the superior opening of the canalis mandibulæ (mandibular canal), which traverses the body of the bone. Throngh this foramen there pass the inferior alveolar branch of the mandibular division of the trigeminal nerve, together with the inferior alveolar artery and its reins. As will now be seen, when the mandible is in position, the infra-temporal fossa is closed in laterally by the ramus of the mandible. In front there is an interval between the anterior border of the ramus and the infra-temporal surface of the maxilla, through which pass the buccinator branch of the trigeninal nerve and the communicating rein between the pterygoid plexus and the anterior facial vein. Abore, in the interval between the mandibular notch and the inferior border of the zygomatic arch, there pass from the fossa the vessels and nerves which supply the masseter muscle. Between the posterior border of the ramus and the styloid process there enter and leave the large vessels which are found within the space. Superiorly, under cover of the zygomatic arch, the infra-temporal fossa communicates with the 
temporal fossa, whilst inferiorly it is continuous with the infra-maxillary region. Medially, on the floor of the fossa there is an $\Gamma$-shaped fissure, the horizontal limb of which corresponds to the inferior orbital fissure, forming a channel of communication between the fossa and the orbit, through which passes the zygomatic branch of the maxillary division of the trigeminal nerve; whilst the vertical cleft is the pterygo-maxillary fissure, which leads into a small fossa placed between the front of the root of the pterygoid process of the sphenoid and the back of the maxilla, called the pterygo-palatine fossa.

The following foramina open into the infra-temporal fossa-the foramen ovale, foramen spinosum, foramina alveolaria, mandibular foramen, minute foramina for the transmission of emissary veins; of these one of large size is occasionally present, the foramen of Vesalius.

Fossa Pterygopalatina. - This space, which corresponds to the angular

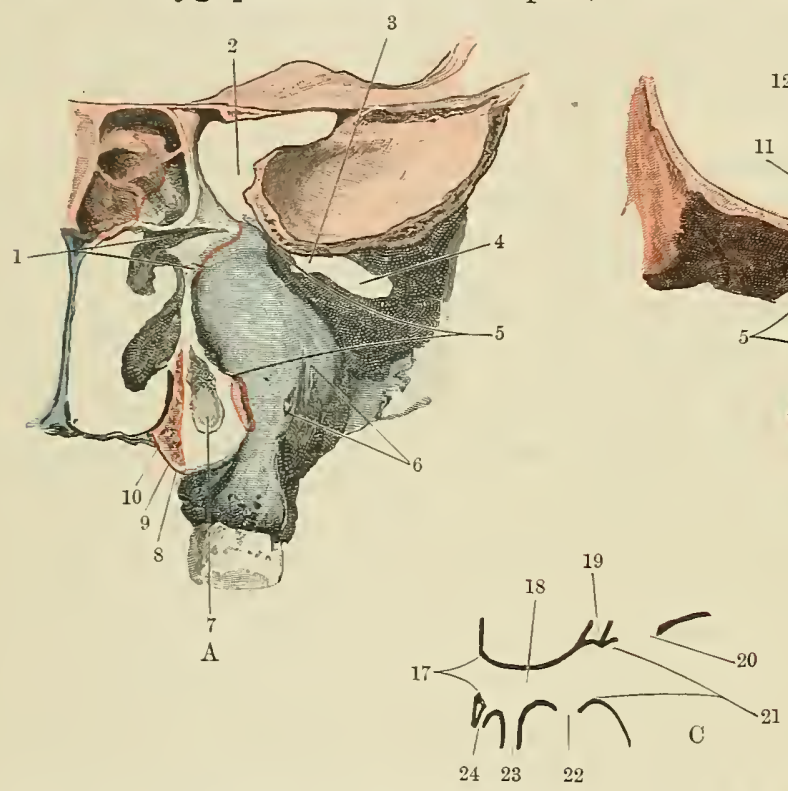

Fig. 170.-Coroxal Section throdgh the Ptertgo-palatuse Fossa of the Right Side.

The sphenoid is coloured red. The maxilla, vomer, middle, and inferior conchæ are coloured blue. The palate bone is left uncoloured.

A. Anterior Wall. B. Posterior Wall. C. Diagrammatic representation of a horizontal section across the

1. Spheno-palatine foramen.

2. Apex of orbital cavity.

3. Inferior orbital tissure.

4. Inferior orbital fissure.

5. Pterygo-maxillary fissure.

6. Alveolar foramina.

7. Part of pterygoid fossa.

\section{fossa.}

$\begin{array}{ll}\text { 8, 9, 10. Pterygo-palatine and lesser } & \text { 17. Spheno-palatine foramen. } \\ \text { palatine canals. } & \text { 18. Pterygo-palatine fossa. } \\ \text { 11. Foramen rotundum. } & \text { 19. Infra-orbital groove. } \\ \text { 12. Superior orbital fissure. } & \text { 20. Inferior orbital fissure. } \\ \text { 13. Optic foramen. } & \text { 21. Pterygo-maxillary fissure. } \\ \text { 11. Sphenoidal sinus. } & \text { 22. Foramen rotundum. } \\ \text { 15. Pharyngeal canal. } & \text { 23. Pterygoid canal. } \\ \text { 16. Pterygoid canal. } & \text { 24. Pharyngeal canal. }\end{array}$

interval between the pterygo-maxillary and inferior orbital fissures, and which lies between the maxilla in front and the root of the pterygoid process behind, is bounded medially by the perpendicular part of the palate bone, which separates it from the nasal cavity, with which, however, it communicates by means of the spheno-palatine foramen, which lies between the orbital and sphenoidal processes of the palate bone and the inferior surface of the body of the sphenoid. Opening into this fossa, above and behind, are the foramen rotundum, the pterygoid canal and the pharyngeal canal, in that order from lateral to medial side, whilst below is the superior orifice of the pterygo-palatine canal, together with openings of the lesser palatine canals. Its roof is formed by the under surface of the body of the sphenoid and the orbital process of the palate bone. Anteriorly it lies in relation to the apex of the orbit, with which it communicates by means of the inferior orbital fissure; whilst laterally, as already stated, it communicates with the infra-temporal fossa through the pterygo-maxillary fissure. 


\section{Posterior Aspect of the Skull (Norma Occipitalis).}

The view of the cranium as seen from behind includes the posterior halves of the two parietal bones above, the squamous part of the occipital bone below, and the mastoid portions of the temporal bones on either side, inferiorly. The shape of this aspect of the skull varies much, but ordinarily the greatest width corresponds to the level of the parietal tuberosities. The sutures on this view of the calvaria display a triradiate arrangement, one limb of which is vertical, and corresponds to the posterior part of the interparietal or sagittal suture. The other two limbs pass laterally and downwards in the direction of the mastoid processes, uniting the two parietal bones in front with the occipital bone behind; these constitute the $\Lambda$-shaped lambdoid suture. The point of confluence of the sagittal and lambdoid sutures is called the lambda. This can generally be felt in the living, owing to the tendency of the squamous part of the occipital to project slightly, immediately below this spot. About one inch and a quarter above the lambda the two small parietal foramina are seen, through which pass the small emissary veins of Santorini, which connect the intra-cranial venous system with the superficial veins of the scalp. These small holes lie about $\frac{5}{16}$ of an inch apart on either side of the sagittal suture, which here, for the space of about an inch, displays a simplicity of outline in striking contrast with its serrated arrangement elsewhere. The term obelion is applied to a point on the sagittal suture in line with the two parietal foramina. The lambdoid suture is characterised by great irregularity of outline, and not infrequently chains of separated ossicles are met with in it, the ossa suturarum (sutural bones). The squamous part of the occipital bone is divided into two parts by the superior nuchal or curved line, the central part of which forms the external occipital protuberance or inion. The part above, called the planum occipitale or occipital surface comes within our present consideration; the part below, called the planum nuchale or the nuchal surface, though seen in perspective, had best be considered when the base is examined. A little above the level of the superior curved line the occipital surface is crossed on either side by a faint lunated line, the linea nuchæ suprema (highest nuchal or curved line), to which are attached the occipitales muscles and the galea aponeurotica. The projection of the occipital surface varies much in individual skulls; most frequently it overhangs the external occipital protuberance, forming a distinct boss ; exceptionally, however, the latter may be the most projecting part of the bone. The extremity of the superior nuchal line on either side corresponds to the position of the asterion (p. 285). Lateral to these points the outline of the skull is determined by the downward projection of the mastoid processes, the medial surfaces of which are deeply grooved by the mastoid notches for the attachment of the posterior bellies of the digastric muscles, thus causing these processes to appear more pointed when viewed from this aspect.

\section{Upper Aspect of Skull (Norma Verticalis).}

This is the view of the calvaria as seen from above. It is liable to great diversities of form. Thus its shape may vary from an elongated oval to an outline more nearly circular. These differences have been classified, and form important distinctions from a craniometrical standpoint, the rounder varieties being termed the brachycephalic, whilst the elongated belong to the dolichocephalic group. Another noteworthy point in this view is the fact that in some instances the zygomatic arches are seen, whilst in others they are concealed by the overhang and bulge of the sides of the anterior part of the cranium. The former condition is described as phænozygous, the latter as cryptozygous, and each is more or less closely associated with the long or round varieties of head-form respectively.

The sutures displayed have a T-shaped arrangement. Placed medially between the two parietal bones is the sagittal suture. This is finely denticulated, except in the region of the obelion, though, of course, this will not be apparent if obliteration of the suture has taken place through fusion of the two parietal bones. Posteriorly the sagittal suture unites with the lambdoid suture at the lambda, which marks in the adult the position of the posterior fontanelle of the fotus. Anteriorly it terminates by joining the transverse suture which separates the frontal bone 
anteriorly from the parietals posteriorly; this latter is called the coronal suture, and the point of junction between the sagittal and coronal sutures is known as the bregma; this corresponds in position to the anterior fontanelle of the fotus. The summit of the vault of the calvaria corresponds to a variable point in the line of the sagittal suture, and is named the vertex. The coronal suture is less denticulated centrally than laterally. Occasionally there is a persistence of the suture (metopic) which unites the two halves of the frontal bone; under these conditions the line of the sagittal suture is carried forward to the fronto-nasal suture, and a skull displaying this peculiarity is described as metopic. Behind the coronal suture may occasionally be seen the post-coronal depression, and in some instances the vault of the calvaria forms a broad, slightly elevated crest along the line of the sagittal suture. On either side the temporal ridges can be seen curving over the lateral and superior aspects of the parietal bones. As the lower of these crosses the coronal suture in front it marks a spot known as the stephanion, useful as affording a fixed point from which to estimate the bi-stephanic diameter. The interval between the temporal ridges on either side will vary according to the form of the skull and the derelopment of the temporal muscle. In this view of the calvaria a small part of the lambdoid suture on either side of the lambda is visible posteriorly.

\section{Basis Cranii Externa (Norma Basalis).}

The external or inferior aspect of the base of the cranium-i.e. the skull without the mandible-includes a description of the under surfaces of the skeleton of the face (cranium viscerale) and the cranium (cranium cerebrale). The former includes the hard palate formed by the maxillæ and palate bones, the superior alveolar arch, and the bodies of the maxillæ as seen from below; whilst laterally, and united with the bodies of the maxillæ, the zygomatic bones are displayed, curving backwards to form the anterior halves of the zygomatic arches. In the median plane, passing from the upper surface of the hard palate, is the osseous septum of the nose, here formed by the vomer, which is united above to the under surface of the body of the sphenoid.

The under surface of the cranium is pierced by the foramen occipitale magnum for the transmission of the spinal medulla and its membranes. In front of this a stout bar of bone extends forwards in the median plane, formed by the union of the body of the sphenoid in front with the basilar part of the occipital bone behind. In adult skulls all trace of the fusion of these two bones has disappeared; when union is incomplete, it indicates that the skull is that of a person below the age of twenty-five. The sphenoid comprises that part of the calvaria which forms the roof and sides of the apertures which lie on either side of the nasal septum above the hard palate-the choanæ. Laterally the under surfaces of the great wings of the sphenoid extend as far forward as the posterior border of the inferior orbital fissure; whilst posteriorly they reach as far as the angular spine, lateral to which the spheno-squamosal suture, separating the great wing of the sphenoid from the squamous portion of the temporal, curves forwards and upwards, medial to the tuberculum articulare, to reach the floor of the temporal fossa, along which its course has been already traced (p. 168). On a level with the front of the foramen magnum the jugular process of the occipital bone forms an irregular curved border, which sweeps laterally to terminate at a point just medial to the root of the styloid process. Here, in line with the spheno-squamosal suture, from which, however, it is separated by a considerable interval, its extremity turns backwards, and may be traced at first medial to, and then turning upwards, behind the mastoid process of the temporal bone, separated from this latter by the occipito-mastoid suture. The bone behind the foramen magnum, which is included between the two occipito-mastoid sutures, comprises the nuchal surface of the squamous portion of the occipital bone, an area which is limited behind by the superior nuchal line, which separates it from the occipital surface of the same bone. The remaining portions of the base of the calvaria, as at present exposed, are formed by the squamous and tympanic portions of the temporal bone, together with the petro-mastoid part of the same bone, the latter of which is wedged in between the great wing of 


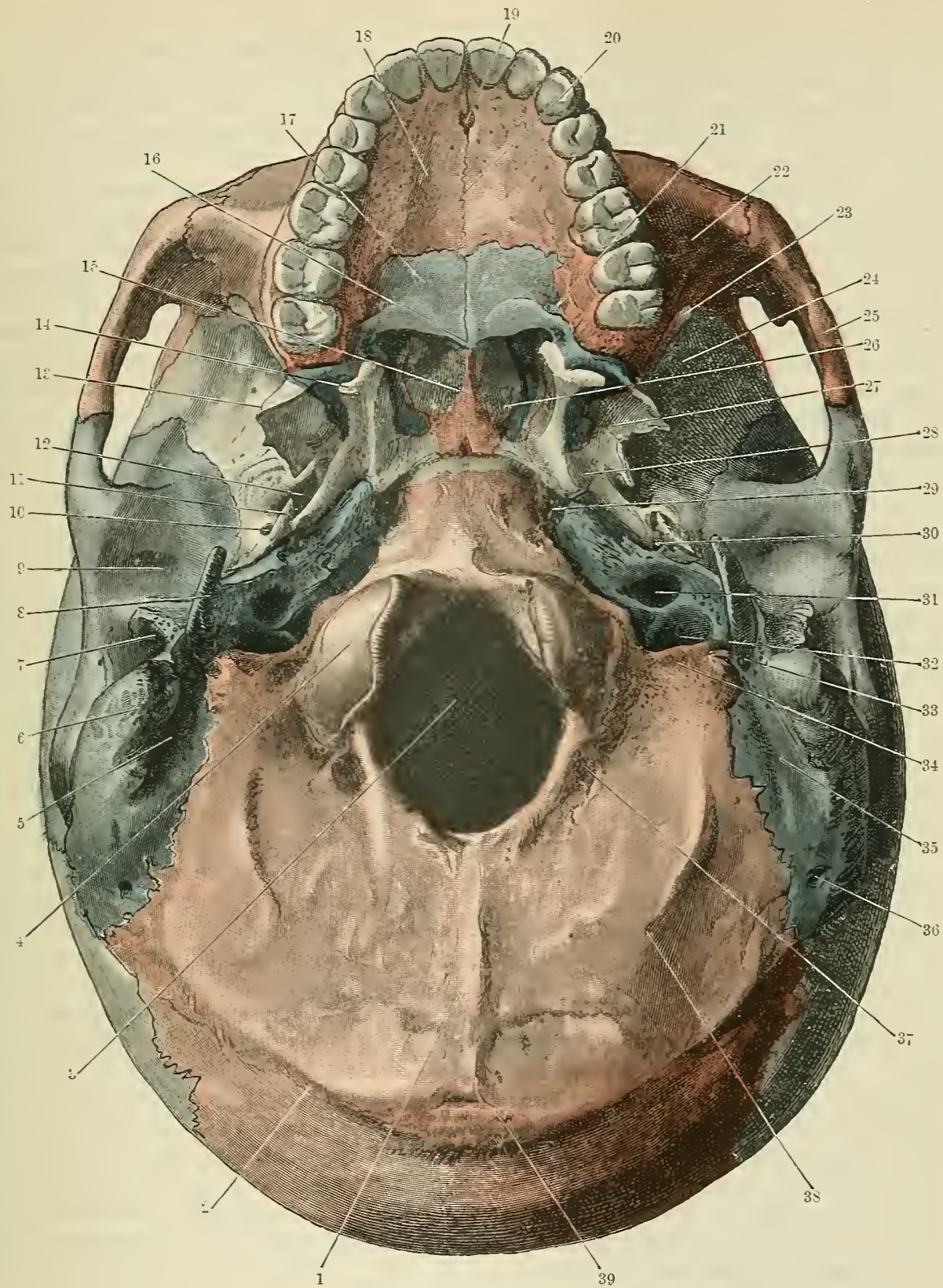

Fig. 171.-Isferior Sorface of Base of Skell.

The occipital, romer, maxillary, and zygomatic bones are coloured red. The temporal and palate bones, blue. The sphenoid and parietal bones, and the teeth, are left uncoloured.

1. External occipital crest. 13. Lateral pterygoid lamina.

2. Superior nuchal line of the occipital bone.

3. Foramen magnum.

4. Occipital coudyle.

5. Mastoid notch.

6. Mastoid process.

7. Exterual acoustic meatus.

8. Styloid process.

9. Nandibular fossa.

10. Foramen spinosum.

11. Angular spine of the sphenoid.

12. Foramen ovale.
14. Hamulus of medial pterygoid lamina.

15. Nasal septum.

16. Posterior nasal spine.

17. Horizontal part of palate boue.

18. Palatine process of maxilla.

19. Incisive foramen.

20. Intermaxillary suture.

21. Greater palatine foramen.

22. Zygomatic process of maxilla.

23. Inferior orbital fissure.

24. Infra-temporal fossa.

25. Zygomatic arch.
26. Left choana.

27. Pterygoid fossa.

2S. Scaphoid fossa.

29. Foramen lacerum.

30. Opening of osseous part of auditory tube.

31. Carotid canal.

32. Jugular fossa.

33. Stylo-mastoid foramen.

34. Jugular process of occipital bone.

35. Groove for occipital artery.

36. Mastoid foramen.

37. Canalis condyloideus.

38. Inferior nuchal line of occipital bone.

39. External occipital prutuberance. 
the sphenoid in front and the occipital bone behind. Stretching forwards from the squamous part of the temporal in front is seen the zygomatic process which, by its union with the zygomatic bone, completes the formation of the zygomatic arch.

Palatum Durum.-Studying next the various parts in detail, the hard palate may be first examined. Of horse-shoe shape as a rule, it presents many varieties of outline and size. Formed by the palatine processes of the maxillæ in front and the horizontal parts of the palate bones behind, its circumference in front and at the sides corresponds to the superior alveolar arch, in which are embedded the sixteen teeth of the two maxillæ; posteriorly the edge of the hard palate is thin, presenting in the median plane a pointed process, the posterior nasal spine, on either side of which the posterior free border is sharp and lunated. The vault of the palate, which is concave from side to side, and from before backwards, varies in depth according to the projection and development of the alveolar processes. When the teeth are shed and the alveoli are absorbed, the palate becomes shallow and flat. Running throughout its entire length in the median plane is the median palatine suture, which separates the palatine processes of the maxillæ in front and the horizontal parts of the palate bones behind. A little behind the central incisor teeth, and in the line of this suture, is a little pit, the foramen incisivum. At the bottom of this may be seen the openings of some small canals, varying in number from one to four; these are usually described as arranged in two pairs, the one pair placed side by side, the other lying in the median plane in front and behind. The former are called the foramina of Stenson, and transmit the terminal twigs of the greater palatine arteries which ascend to reach the nasal cavities. The latter, called the foramina of Scarpa, open, the anterior into the left, the posterior into the right nasal cavity, and afford passage for the fine filaments of the left and right naso-palatine nerves, respectively. About half an inch (12 mm.) in front of the posterior nasal spine the median palatine suture is crossed at right angles by the transverse palatine suture. This, which indicates the line of union of the palatine processes of the maxillæ with the horizontal parts of the palate bones, passes transversely laterally on either side until it reaches the medial aspect of the base of the alveolar process, along which it turns backward, to disappear within the foramen palatinum majus (greater palatine foramen), the aperture of which lies just medial to the root of the dens serotinus (wisdom molar). Through this there pass the greater palatine artery and the large posterior palatine nerve. Leading from this foramen is a groove which curves forward immediately to the medial side of the alveolar arch; not infrequently the medial edge of this groove forms a thin and sharp ridge on the surface of the palate. In this groove are lodged the afore-mentioned vessels and nerves. The surface of the palate in front of the transverse suture is rough, pitted for the palatine glands, and pierced by numerous smali vascular foramina; the part of the palate behind the suture, formed by the under surface of the horizontal part of the palate bone, is much smoother. From this there rises, just posterior to the greater palatine foramen, a thin sharp crest, which curves medially immediately in front of the posterior free edge; to this are attached some of the tendinous fibres of the tensor veli palatini muscle.

Pterygoid Processes.-Buttressed against the posterior extremities of the alveolar arch are the pterygoid processes of the sphenoid. If carefully examined, these will be seen not to lie in actual contact with the maxillæ, but to be separated from them by the triangular wedge-shaped pyramidal processes of the palate bones. It is these latter which are pierced by the foramina palatina minora (lesser palatine canals), which lie just behind the greater palatine foramen, and through which pass the lesser palatine nerves. As here displayed, the pterygoid processes of the sphenoid lie on either side of the opening of the choanæ (O.T. posterior nares); each consists of two lamina, a medial and a lateral; the latter is the broader, and is directed backwards and slightly laterally. Its lateral surface has been already studied in connexion with the infra-temporal fossa (p. 168). Medially it is separated from the medial pterygoid lamina by the pterygoid fossa, wherein is lodged a considerable part of the internal pterygoid muscle. The floor of the fossa is formed in greater part by the coalescence of the two pterygoid laminæ; but at the level of 
the hard palate the pyramidal process of the palate bone appears wedged in between the two plates, and so enters into the formation of the floor of the pterygoid fossa. The medial pterygoid lamina separates the nasal cavity from the pterygoid fossa; to the posterior edge of the medial pterygoid lamina are attached the pharyngeal aponeurosis, the superior constrictor of the pharynx, and the pharyngopalatinus muscle. Above, the posterior border of this plate is channelled to form the small fossa scaphoidea (scaphoid fossa), which curves laterally over the summit of the pterygoid fossa, and furnishes a surface for the origin of the tensor veli palatini muscle. The sharp medial margin of this fossa, continuous below with the posterior border of the medial pterygoid lamina, extends upwards, and on either side of the body of the sphenoid forms a blunt pointed process, 'the pterygoid tubercle, which extends backwards towards the apex of the petrous part of the temporal bone. Just lateral to this, and concealed by it, is the posterior extremity of the canalis pterygoideus, through which pass the artery and nerve of the canal. The medial surface of the medial pterygoid lamina is directed towards the nasal cavity. Superiorly this surface curves medially to meet the inferior surface of the body of the sphenoid, forming on either side a lipped edge, the vaginal process, between which the alæ of the vomer, which here forms the nasal septum, are wedged. Between the two a small interval, however, is occasionally left, which forms on either side the basi-pharyngeal canal. A little lateral to the line of union of the vaginal process with the vomer is the opening of the pharyngeal canal. This lies between the inferior surface of the vaginal process and the sphenoidal process of the palate bone, which here articulates with the inferior surface of the body of the sphenoid. The pharyngeal branch of the spheno-palatine ganglion and the pterygo-palatine artery pass through this canal. Inferiorly the pterygoid processes project below the level of the hard palate. The medial plate ends in a slender recurved process, called the hamulus pterygoideus, which turns backwards and laterally (this is frequently broken off in skulls which have been roughly handled). It reaches as low as the level of the alveolar margin, and lies just within and behind the posterior extremity of the alveolar process. It can readily be felt in the living by placing the finger against the soft palate behind and just within the gum around the root of the dens serotinus (O.T. wisdom tooth). On the front of and below this process the tendon of the tensor veli palatini muscle glides in a groove.

The choanæ (O.T. posterior nares) lie between the two pterygoid processes. Of a shape much resembling two Gothic windows, their bases or inferior boundaries are formed by the horizontal part of the palate bone. Laterally they are bounded by the medial surfaces of the medial pterygoid laminæ, whilst above, the lateral side of the arch is formed by the vaginal processes of the same laminæ; medially they are separated by the thin vertical posterior border of the vomer, whilst above the everted alæ of the same bone form the medial sides of the arch. The plane of these apertures is not vertical but oblique, corresponding usually to a line drawn from the bregma above through the last molar tooth of the upper jaw below. Their size varies considerably, but the height is usually equal to twice the width.

The region of the cranium which lies lateral to the maxilla and lateral pterygoid lamina corresponds to the infra-temporal fossa, which has been already described, as it is seen from the side (Lateral Aspect of the Skull, p. 168). Viewed from below, the infra-temporal fossa is bounded in front by the infra-temporal surface of the body of the maxilla and the medial surface of the zygomatic bone. The roof, which is traversed by the spheno-squamosal suture, is formed in front by the inferior surface of the great wing of the sphenoid, and behind by a small triangular surface of the under side of the squamous part of the temporal bone, immediately in front of the tuberculum articulare.

Circumscribed laterally and behind by the anterior root of the zygoma, which curves forward to become continuous in front with the infra-temporal crest crossing the lateral surface of the great wing of the sphenoid, the roof of the fossa is separated from its anterior wall by the inferior orbital fissure, which is so inclined that with its fellow of the opposite side it forms an angle of $90^{\circ}$. Superiorly the infra-temporal fossa communicates freely with the temporal fossa medial to the 
zygomatic arch, though the student must bear in mind the fact that when the mandible is in position the lateral limits of the space are very much reduced (p. 168).

The under surface of the great wing of the sphenoid is here V-shaped. The angle corresponds to the spine, the lateral limb to the spheno-squamosal suture, whilst the medial limb corresponds to a narrow cleft, the fissura spheno-petrosa, which separates it from the petrous portion of the temporal bone, to which it is united in the recent condition by a synchondrosis. Along the line of this latter fissure the edges of the adjacent bones (sphenoid and petrous part of the temporal)are bevelled so as to form a groove, which extends from the root of the medial pterygoid lamina medially, to the medial side of the base of the angular spine laterally, where the groove ends by entering an osseous canal. In the groove (sulcus tubæ auditivæ) the cartilaginous part of the auditory tube is lodged, whilst the osseous canal includes the bony part of the same tube, together with the tensor tympani muscle, which is lodged in a separate compartment immediately above it. The anterior extremity of the cartilaginous part of the auditory tube is supported by the posterior edge of the medial pterygoid lamina, which is often notched for its reception. Between the root of the lateral pterygoid lamina and the angular spine there are two foramina which lie immediately in front of the sulcus tubæ auditivæ. Of these the larger and anterior is the foramen ovale, through which pass the motor root and mandibular division of the trigeminal nerve, together with the accessory meningeal artery. The smaller, which, from its position immediately in front of the angular spine, is called the foramen spinosum, transmits the middle meningeal artery and vein, and sympathetic plexus surrounding the artery. The lesser superficial petrosal nerve here passes through the base of the skull to join the otic ganglion either through a small foramen (canalis innominatus) placed between the foramen ovale and the foramen spinosum, or through the foramen ovale or through the spheno-petrosal fissure. The position of the suture between the basi-occipital and basi-sphenoid corresponds to a line connecting the tips of the pterygoid tubercles at the root of the medial pterygoid laminæ.

Occasionally in the centre of this line there is a small pit with a foramen leading from it. This probably represents the lower end of the cranio-pharyngeal canal.

The under surface of the basilar part of the occipital bone (basi-occipital) stretches between the body of the sphenoid in front and the anterior margin of the foramen magnum behind; projecting from its centre is a slight elevation, the pharyngeal tubercle, to which the pharyngeal raphe, together with the central part of the anterior atlanto-occipital membrane, is attached. It should be noted, that when the atlas is in position the pharyngeal tubercle lies in line with the tubercle on the anterior arch of that bone. Curving laterally and backwards from the pharyngeal tubercle, on either side, is an irregular ridge (crista muscularis), in front and behind which are attached the longus capitis and rectus capitis anterior muscles. On either side of the basi-occipital, in front, there is an irregular opening of variable size; this is placed between the root of the pterygoid process anteriorly, the apex of the petrous portion of the temporal bone laterally, and the lateral edge of the basi-occipital and basi-sphenoid medially. It is called the foramen lacerum. Opening into it in front, just lateral to the pterygoid tubercle, is the pterygoid canal, whilst, in correspondence with the apex of the petrous part of the temporal, the large orifice of the carotid canal may be seen entering it behind and from the lateral side. In the recent condition the lower part of the foramen lacerum is occupied by fibro-cartilage, over the apper surface of which the internal carotid artery and greater superficial petrosal nerve pass to reach their respective foramina, whilst a small meningeal branch of the ascending pharyngeal occasionally enters the cranium through it. Leading laterally from the foramen lacerum in the direction of the angular spine of the sphenoid is the spheno-petrosal fissure, which lies at the bottom of the sulcus tubæ auditivæ, and disappears from view within the bony part of the auditory tube. Passing backwards from the foramen lacerum there is a fissure between the lateral sicle of the basi-occipital and the posterior and medial border of the petrous part of the temporal bone. This, which is called the petro-occipital fissure, opens posteriorly into the jugular foramen. In the recent 
condition the fissure is filled up with cartilage. The under surface of the petrous bone included between these two fissures is rough and irregular, and affords attachments near its apex to two small muscles, the levator veli palatini and the tensor tympani. Immediately behind the angular spine the petrous part of the temporal is pierced by a circular hole, the inferior opening of the canalis caroticus (carotid canal). This passes upwards, and then turns medially and forwards towards the apex of the bone, where it may again be seen opening into the lateral and upper side of the foramen lacerum. Laterally the wall of the vertical part of this canal, which is usually very thin, separates it from the cavity of the tympanum, as may be seen by holding the skull up to the light and looking into the external acoustic meatus. The carotid canal transmits the internal carotid artery, together with the sympathetic plexus around it. It is noteworthy that the two carotid canals lie in line with the anterior edges of the two external acoustic meatuses.

The jugular foramen is an opening of irregular shape and variable size placed between the petrous part of the temporal in front and the jugular process of the occipital bone behind. The former is excavated into a hollow called the jugular fossa, which forms a roof to the upper and lateral part of the space, whilst the latter, by a curved edge, either rounded or sharp, constitutes its posterior border. There is often considerable difference in the size of the jugular foramina; that on the right side (with the skull in its normal position) is usually the larger. The foramen is occasionally subdivided into two by spicules of bone which bridge across it. Lodged within the fossa is the bulb of the internal jugular vein, in front of which the inferior petrosal sinus passes down to join the internal jugular vein below the foramen. Effecting an exit between the two veins, in order from before backwards, are the glosso-pharyngeal, vagus, and accessory nerves. Small meningeal branches from the ascending pharyngeal and occipital arteries also enter the foramen. The two jugular foramina lie in line with a line drawn through the centres of the two external acoustic meatuses. Following the direction of a line connecting the angular spine of the sphenoid and the mastoid process of the temporal, and placed immediately lateral to the apertures of the carotid canal and jugular foramen, is the vaginal process of the tympanic plate of the temporal bone, the edge of which is sharp and thin, and serves to separate the inferior surface of the petrous part of the temporal from the non-articular part of the mandibular fossa. Springing from this crest immediately lateral to the jugular fossa, and in line with the middle of the external acoustic meatus, is the styloid process of the temporal bone. Its relation to the jugular foramen is of great importance as the internal jugular vein lies close to its medial side.

Immediately behind the root of the styloid process, medial to and in line with the front of the mastoid process, is the stylo-mastoid foramen, which is the inferior aperture of the canalis facialis. Through it the facial nerve passes out and the stylo-mastoid branch of the posterior auricular artery passes in. The medial surface of the mastoid process is deeply grooved at its base for the origin of the posterior belly of the digastric muscle. Medial to this, and running along, just wide of the occipito-mastoid suture, is a shallow groore in which the occipital artery is lodged. Just medial to the stylo-mastoid foramen is the synchondrosis between the extremity of the jugular process of the occipital bone and the petrous part of the temporal. The jugular process is a bar of bone which limits the jugular fossa posteriorly and abuts on the occipital condyles medially; its under surface is convex from before backwards and affords attachment to the rectus capitis lateralis muscle. The occipital condyles are placed between the jugular processes and the foramen magnum. Limited in front by a rounded thickening which becomes confluent with the anterior border of the foramen magnum, they form by their medial sides the lateral boundaries of that aperture on its anterior half. Laterally they are continuous with the jugular processes, in front of which they overhang a fossa which is pierced behind by the canalis hypoglossi, through which passes the hypoglossal nerve, together with a small vein and occasionally a small meningeal branch derived from the ascending pharyngeal artery.

The posterior condylic fossæ are situated just behind the posterior extremities of the condyles. Not infrequently the floor of each is pierced by the condyloid canal, 
through which the posterior condylic vein emerges. The base of the skull behind the jugular processes and condyles of the occipital bone is formed by the nuchal surfice of the squamous part of that bone. Posteriorly this surface is bounded by the superior nuchal or curved line, in the centre of which is placed the projecting extermal occipital protuberance. Laterally the squamous part of occipital bone is separated from the mastoid portion of the temporal bone by the occipito-mastoid suture, which curves backwards and laterally, from the extremity of the jugular process in front, around the base of the mastoid process behind. In front and in the median plane this plate of bone is pierced by the foramen occipitale magnum, the anterior half of which has been already seen to lie between the occipital condyles. Usually of oval form, though in some cases it tends to approach the circular, the plane of this opening is inclined downwards and slightly forwards. The extreme anterior edge of the foramen is sometimes called the basion, whilst the extreme posterior margin is termed the opisthion. The lower border of the medulla oblongata, where it becomes continuous with the spinal medulla, is lodged within the formen, together with the meninges which cover it, whilst the vertebral arteries and the spinal portions of the accessory nerves pass upwards through it. The anterior and posterior spinal arteries, some small veins, and the roots of the first cervical nerves, also traverse it from above downwards.

The student will, no doubt, experience considerable difficulty in bearing in mind the relative positions of the various forminina and processes which he has studied on the under surface of the base of the skull.

If a line be drawn on either side from the incisive foramen in front, through the stylomastoid foramina posteriorly, it will be found to cut or pass near to the following objects :-On the hard palate it will lie close to the greater and smaller palatine foramina. It will then pass between the hamulus and the lateral pterygoid lamina, overlying the foramen ovale, the foramen spinosum, the opening of the osseous part of the auditory tube and the angular spine of the sphenoid; behind this it will cut through the root of the styloid process and define laterally the limits of the jugular fossa. After passing through the stylo-mastoid foramen, if the line be prolonged backwards it will usually be found to pass over the mastoid foramen in the occipitomastoid suture. Another line of much value is one drawn across the base of the skull from the centre of one external acoustic meatus to the other. This will be found to pass through the root of the styloid process, the jugular foramen, the hypoglossal canal; it then crosses the front of the occipital condyles, and corresponds with the anterior edge of the foramen magnum.

A line which may be found useful is one drawn from the stylo-mastoid foramen of one side to the greater palatine foramen of the opposite side. This will be seen to overlie, from behind forwards, the lateral part of the jugular foramen and the inferior opening of the carotid canal. The line indicates the direction of the carotid canal, and cuts the foramen lacerum anteriorly; in front of this it issually corresponds to the position of the posterior aperture of the pharyngeal canal.

Mandible and Atlas in Position.-The examination of the base of the skull is incomplete unless the student examines it with the mandible and atlas in position. The relation of the ramus of the mandible to the infra-temporal fossa has been already sufficiently studied (p. 169); one or two points, however, may be emphasised. The angular spine of the sphenoid lies just medial to the condyle of the mandible when that structure is in position in the articular part of the mandibular fossa, and it is noteworthy that immediately to the medial side of the angular spine is the commencement of the osseous part of the auditory tube. The root of the styloid process occupies the centre of the interval between the mandibular ramus and the front of the mastoid process.

Anteriorly the arcade formed by the body of the mandible adds greatly to the depth of the hard palate. In this space are lodged the tongue and the structures which form the floor of the month. The medial surface of each side of the body of the mandible is traversed by the mylo-hyoid line, which commences posteriorly just behind the root of the last molar tooth and runs downwards and forwards towards the symphysis in front.

When the atlas is in articulation with the occipital bone it is well to recognise the relation of its transverse processes to the surrounding structures. The extremities of these processes lie in line with the ends of the jugnlar processes of the occipital bone, and thus come to be placed just medial to and immediately below and slightly in front of the tips of the mastoid processes. They can thus be easily felt in the living subject. Anteriorly they are separated by a short interval from the styloid processes, and the stylo-mastoid foramina lie immediately in front and 
slightly to the lateral side of their extremities. The student will note that there is no hole in the jugular process of the occipital bone corresponding to the arterial foramen in the transverse process of the atlas through which the vertebral artery passes. The course of this vessel over the upper surface of the posterior arch behind the superior articular processes of the atlas will be seen to coincide with the posterior condylic fossæ and the margins of the foramen magnum immediately medial thereto, where a slight grooving of the edge often indicates the course of the artery. In front the anterior tubercle of the atlas falls in line with the pharyngeal tubercle on the under surface of the basi-occipital, and the student must not overlook the fact that the anterior surface of the cervical column does not coincide with the anterior margin of the foramen magnum, but lies nearly half an inch in front of that, in a frontal plane passing immediately in front of the external acoustic meatuses. Behind, the upper surface of the posterior arch of the atlas overlaps the posterior margin of the foramen magnum, and it is by the apposition of these two surfaces that extension is checked at the oceipito-atlantal articulation.

\section{THE SKULL IN SECTION.}

By the removal of the skull-cap the cerebral aspect of the cranial cavity is exposed. The deep surface of the cranial vault is grooved medially for the superior sagittal sinus, on either side of which are seen numerons depressions for the lodgment of arachnoideal granulations. On holding the bone up to the light, the floor of these little hollows is oftentimes seen to be very thin. A short distance in front of the lambda, and on either side of the sagittal suture, are the cerebral openings of the parietal foramina. The inner tables of the frontal and parietal bones are grooved for the meningeal arteries. The principal branch of the middle meningeal runs more or less parallel to and at a variable distance behind the line of the coronal suture. Along the bottom of these grooves small foramina may be seen for the passage of nutrient arteries to the bone, and the floor of the sagittal sinus is likewise pierced by small apertures for the transmission of veins.

\section{Basis Cranii Interna.}

Cranial Fossæ.-The upper surface of the base of the skull is divided into three fossæ, of which the cerebrum occupies the anterior and middle, whilst in the posterior is lodged the cerebellum.

The anterior fossa is defined posteriorly by the sharp, thin edge of the small wings of the sphenoid, which curve laterally and slightly upwards, as well as backwards, to reach the region of the pterion laterally. The floor is formed from before backwards, in the median plane, by the superior surface of the ethmoid and the anterior part of the body of the sphenoid; laterally it is constituted by the orbital parts of the frontal and the small wings of the sphenoid. On these the inferior surface of the frontal lobes of the cerebrum rests. In front the fossa is divicled in the median plane by the frontal crest, to which the falx cerebri is attached. This is confluent below with the anterior part of the crista galli, from which, however, it is separated by the foramen cæcum, which nsually transmits a small vein from the nose. On either side of the crista galli there are grooves which vary considerably in depth and width: therein are lodged the olfactory lobes. The floor and sides of the groove are pierced by numerous foramina; of these the largest number transmit the olfactory nerves to the nasal cavity. In front an elongated slit, placed on either sicle of the crista, affords a passage to the nose for the anterior ethmoidal branch of the naso-ciliary nerve and a small branch of the anterior ethmoidal artery which accompanies it. To the lateral side of the olfactory groove and the cribriform plate, the anterior fossæ communicate on either side by means of the two ethmoidal foramina with the cavities of the orbits. The anterior foramen transmits the anterior ethmoidal nerve and the anterior ethmoidal artery; the posterior affords passage to the posterior ethmoidal artery and nerves (O.T. spheno-ethmoidal nerve of Luschka). Lateral to the olfactory groove, the floor of the fossa, which here corresponds to the roof of the orbit, is very thin, as may 
be seen by holding the skull up to the light; it is convex from side to side, and bears the impress of the gyri of the under surface of the frontal lobes of the cerebrum, which rest upon it. In front and at the side there are a number of vascular grooves for the branches of the anterior and middle meningeal arteries respectively.

The middle fossa, which in form may be compared to the wings of a bird united by the body, is bounded in front by the curved thin posterior edge of the small wings of the sphenoid; posteriorly, by the line of attachment of the tentorium cerebelli, extending from the posterior clinoid process along the superior angle of the petrous portion of the temporal bone. The median part of the fossa, which is narrow, corresponds to the sella turcica and the tuberculum sellæ of the sphenoid. It is limited anteriorly by a line connecting the anterior margins of the two optic foramina, and is overhung behind by the dorsum sellæ. In this area are lodged the structures which lie within the interpeduncular ossa on the base of the brain. The floor of the lateral parts of the fossa on each side is formed by the great wing of the sphenoid in front, the squamous part of the temporal bone to the lateral side, and the superior surface of the petrous part of the temporal behind. In the hollows so formed the temporal lobes of the cerebrum are lodged. On either side of the tuberculum sellæ are seen the optic foramina; these pass into the orbital cavities and transmit the optic nerves and ophthalmic arteries. Immediately behind these openings the anterior and middle clinoid processes are sometimes united, so as to enclose a foramen. Through this the internal carotid artery passes upwards. Leading backwards from this, along the side of the body of the sphenoid, is the carotid groove, which turns downwards near the apex of the petrous part of the temporal, to become continuous with the carotid canal, which here opens on the posterior wall of an irregular aperture, placed between the side of the body of the sphenoid and the summit of the petrous part of the temporal, called the foramen lacerum. Through the medial angle of this opening the carotid artery accompanied by its plexus of veins and sympathetic nerves passes upwards. Running through the fibrous tissue, which in life blocks up this opening, the greater superficial petrosal nerve coming from the hiatus facialis passes downwards and forwards to reach the posterior orifice of the canalis pterygoideus, which is placed on the anterior and inferior border of the foramen lacerum. A small meningeal branch of the ascending pharyngeal artery also passes upwards through this foramen. In front and to the lateral side of the foramen lacerum, and separated from it by a narrow bar of bone, is the foramen ovale; through this pass both roots of the mandibular nerve, the accessory meningeal artery, and some emissary veins. Somewhat lateral and posterior to this is the foramen spinosum for the transmission of the middle meningeal vessels, together with a recurrent branch (nervus spinosus) from the mandibular nerve. Leading from the lateral extremity of the foramen lacerum there is a groove which passes laterally, backwards, and slightly upwards on the superior surface of the petrous part of the temporal to end in the hiatus facialis (a cleft opening into the canalis facialis), which gives passage to the greater superficial petrosal branch derived from the ganglion geniculi on the facial nerve, together with the small petrosal branch of the middle meningeal artery. Just lateral to the hiatus facialis there is another small foramen for the transmission of the lesser superficial petrosal nerve. Overhung by the posterior border of the lesser wing of the sphenoid is the superior orbital fissure, the cleft which separates the small from the great wings of the sphenoid, and which opens anteriorly into the hollow of the orbit; through this pass the oculomotor, trochlear, ophthalmic division of the trigeminal, and abducent nerves, together with the ophthalmic veins as well as the sympathetic filament to the ciliary ganglion and the small orbital branch of the middle meningeal artery. Just below its medial extremity is the foramen rotundum for the passage of the maxillary nerve to the pterygo-palatine fossa. Behind this, and between it and the foramen ovale, the foramen Vesalii may occasionally be seen, through which a vein passes to reach the pterygoid plexus.

The lateral parts of the middle fossa are moulded in conformity with the gyri of the temporal lobes, but towards its medial part the splitting of the dura mater in the region of the cavernous sinus serves to separate the cranial base from the under surface of the cerebrum. As may be seen by transmitted light, 


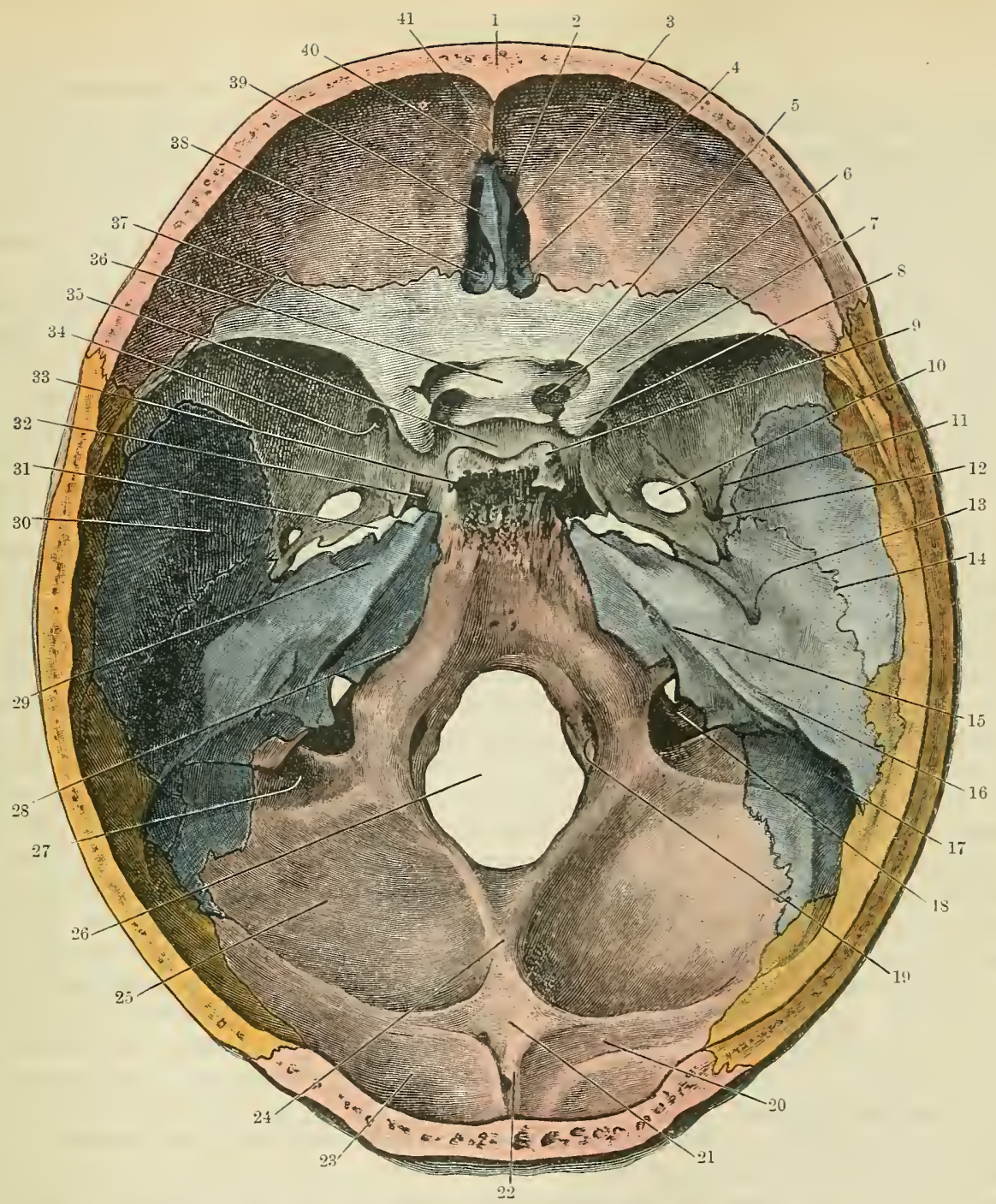

Fig. 172.-BASE OF THE SKULL SEEN FROM ABOVE.

The frontal and occipital boues are coloured red ; the ethmoid and temporal bones, blue ; the parietal, orange; ant the sphenoisl is left unculoured.

\section{Frontal bone.}

2. Slit for anterior ethmoiclal nerve.

3. Anterior ethinoidal foramen.

4. Posterior ethmoidal foramen.

5. Optic foramen.

6. Foramen for internal carotid artery formed by anterior and middle clinoid process.

7. Small wing of sphenoid.

8. Anterior clinoid process, in this case united on its merlial side to the middle clinoid processes.

9. Posterior clinoid process.

10. Foramen ovale.

11. Groove for middle meningeal artery.

12. Foramen spinosum.

13. Hiatus canalis facialis.

14. Line of petro-squanosal suture.

15. Internal acoustic meatus.

16. Groove for superior petrosal sinus.

17. Groove for sigmoid part of transverse sinus.

18. Jugular foramen.

19. Canalis hypoglossi.

20. Groove for transverse sinus.

21. Internal occipital protuberance.

22. Ridge for attachment of falx cerebri.

23. Fossa for the lodgment of the occipital lobes of the brain.
24. Ridge for the attachment of the falx cerebelli.

25. Fossa for the lodgment of the left cerebellar. bemisphere.

26. Foramen occipitale magnun.

27. Groove for the sigmoid sinus turning into the jugular foramell.

28. Groove for the inferior petrosal sinus running along the line of suture between the petrous part of the temporal and the hasi-occipital.

29. Depression for the senilunar ganglion.

30. Middle cranial fossa for lodgnient of the temporal lobes of the brain.

31. Foramen Iacerum.

32. Carotid groove.

33. Dorsum sellæ of sphenoil.

34. Leads into foramen rotundum.

35. Sella turcica.

36. Tuberculum sellie of the sphenojd.

37. Anterior cranial fossa for lodgment of frontal lobes of the brain.

38. Cribriform plate of ethmoid.

39. Crista galli of ethmoid.

40. Foramen cxeum.

11. Crest for attachment of falx cerebri. 
the floor of the lateral parts of the fossa is thin as it overlies the temporal, infratemporal, and mandibular fossæ. The grooves for the lodgment of the branches of the middle meningeal artery leading from the foramen spinosum are readily seen; one, coursing backwards a little below the line of the squamoso-parietal suture, is specially well marked. Amongst other features may be noticed the depression for the lodgment of the semilunar ganglion overlying the apex of the petrous part of the temporal; behind and to the lateral side of the hiatus facialis, the arcuate eminence, indicating the position of the superior semicircular canal; and immediately anterior and slightly to the lateral side of this the tegmen tympani, which roofs in the cavity of the tympanum, the thinness of which can readily be demonstrated if light be allowed to fall through the external acoustic meatus.

The posterior fossa is larger and deeper than the others. In front it is limited by a line on either side leading backwards and laterally from each posterior clinoid process along the superior border of the petrous part of the temporal bone, where laterally and posteriorly it becomes confluent with the superior lip of the transverse groove for the transverse sinus, ending posteriorly in the middle line at the internal occipital protuberance. Along the line thus indicated the process of dura mater called the tentorium cerebelli, which roofs in the posterior fossa, is attached. The floor of the fossa, in which the cerebellar lobes, the pons, and medulla oblongata are lodged, is formed by the petrous and mastoid portions of the temporal bone, with part of the body of the sphenoid and the basilar portion of the occipital bone wedged in between them. Above the mastoid part of the temporal a small part of the mastoid angle of the parietal enters into the constitution of the lateral wall of the fossa. Behind and within these the lateral parts and inferior portions of the squamous part of the occipital complete the floor. In the median plane the floor of the fossa is pierced by the foramen magnum, in which lies the lower part of the medulla oblongata, together with its membranes, and through which pass upwards the vertebral arteries and the accessory nerves. On either side of the foramen magnum, and a little in front of a transverse line passing through its centre, is the opening of the canalis hypoglossi for the passage of the hypoglossal nerve, a small meningeal branch from the ascending pharyngeal artery and an emissary vein. Overhanging the opening of the canalis hypoglossi there is a thickened rounded bridge of bone, to the lateral side of which is placed the irregular opening of the jugular foramen. The size of this is apt to vary on the two sides, and the lumen is frequently subdivided by a spicule of bone which runs across it; the posterior and lateral rounded part of the foramen is occupied by the transverse sinus, which here joins the internal jugular vein. A meningeal branch from the ascending pharyngeal or occipital artery also enters the skull through this compartment. The anterior and medial part of the foramen is confluent with the groove for the inferior petrosal sinus, which turns downwards in front of the spicule above referred to. The interval between the portions of the foramen occupied by the two veins allows the transmission of the glosso-pharyngeal, vagus, and accessory nerves in this order from before backwards. About a quarter of an inch above and to the lateral side of the anterior part of the foramen jugnlare the posterior surface of the petrous portion of the temporal bone is pierced by the internal acoustic meatus, through which the facial and acoustic nerves, together with the nervus intermedius, and the auditory branch of the basilar artery, leave the cranial cavity. Behind the juguiar foramen and close to the margin of the foramen magnum the opening of the canalis condyloideus, when present, may be seen. This gives passage to a vein which joins the vertebral vein inferiorly. The inner aperture of the mastoid foramen is noticed opening into the groove for the transverse sinus, a little below the level of the superior border of the petrous part of the temporal. Through it passes an emissary vein which joins the occipital vein laterally; the mastoid branch of the occipital artery also enters the cranial cavity through this foramen.

The posterior fossa is divided into two halves posteriorly by the internal occipital crest, to which the falx cerebelli is attached, the floors of the hollows on either side of which are often exceedingly thin and are for the lodgment of the hemispheres of the cerebellum. The grooves for the following blood sinuses are usually distinctthe superior petrosal running along the superior angle of the petrous part of the 
temporal, the inferior petrosal lying along the line of suture between the petrous part of the temporal and the basilar part of the occipital bone; the occipital sinus grooving the internal occipital crest; and the transverse sinus curving forwards and laterally from the internal occipital protuberance, across the cerebral surface of the squamous part of the occipital, to reach the mastoid angle of the parietal bone, in front of which it turns downwards and medially to reach the jugular foramen, describing a sigmoid curve, and grooving deeply the inner surface of the mastoid and posterior aspect of the petrous portions of the temporal bone. Before it terminates at the jugular foramen it again reaches the occipital bone and channels the upper surface of the jugular process of that bone. Slight grooves for meningeal arteries are also seen-some pass upwards, whilst others turn downwards and are occupied by branches from the posterior offsets of the middle meningeal arteries.

\section{Median Sagittal Section of the Skull.}

Such a section should be made a little to one or other side of the median plane, so as to pass through the nasal cavity lateral to the septum; one-half will then display the nasal septum in position, whilst in the other the lateral wall of the nasal cavity of that side will be exposed.

The form of the cranial cavity is, of course, subject to many variations dependent on individual and racial peculiarities. The following details are, however, worthy of note. The posterior border of the foramen magnum (opisthion), and consequently the floor of the posterior cranial fossa, occupies the same horizontal plane as the hard palate. The anterior border of the foramen magnum (basion) lies a little higher, so that the plane of the foramen is, in the higher races at least, oblique, and is directed downwards and slightly forwards. From the basion a line passing upwards and forwards to reach the suture between the sphenoid and ethmoid passes through the basi-cranial axis formed by the basi-occipital, the basi-sphenoid, and the presphenoid. The basi-cranial axis is wedge-shaped on section posteriorly, whilst anteriorly it is of considerable width, and has within it the large sphenoidal air sinus. Its upper surface leads upwards and forwards with a varying degree of obliquity from the basion to the overhanging edge of the dorsum sellæ, in front of which the sella tuncica, the floor of which is quite thin, is well seen in the section.

From the tuberculum sellæ the floor of the anterior fossa follows a more or less horizontal direction, corresponding pretty closely to the level of the axis of the orbital cavity. The roof of the orbit is seen to bulge upwards to a considerable extent into the floor of the anterior fossa; whilst the floor of the middle fossa sinks to a level corresponding to that of the under surface of the basi-cranial axis, where it forms the roof of the choanæ. The maxinum length of the skull is measured from the glabella (a point between the superciliary arches) to the occipital point posteriorly. It is noteworthy that the maximum occipital point does not necessarily correspond to the external occipital protuberance (inion). The greatest vertical height usually corresponds to the distance from the basion to the bregma (point of union of the sagittal with the coronal suture), though to this rule there are many exceptions. On looking into the posterior fossa the hypoglossal canals and jugular foramina and the internal acoustic meatus are seen in line, sloping from below upwards. The internal acoustic meatus lies in a vertical plane, passing through the basion. The grooves for the middle meningeal artery and its branches are very obvious. The anterior groove curves forwards and laterally, and reaching the cerebral surface of the pterion, passes towards the vertex at a variable distance behind and more or less parallel to the coronal suture. From this grooves pass forwards across the suture to reach the frontal bone. Another groove curves upwards and backwards a little below the line of the parieto-squamosal suture. From this an upwardly directed branch radiates on the cerebral surface of the parietal bone, in the region of the parietal tuberosity, whilst a lower branch passes backwards some little distance above the lambdoid suture, and gives offsets which curve downwards and medially over the cerebral surface of the squama occipitalis of the occipital bone.

Cavum Nasi. - In the section through the nasal cavity the structures which form its lateral wall can now be studied. These are-the nasal bone; the frontal process of the maxilla; the lacrimal bone; the lahyrinth of the ethmoid, comprising the superior and middle conchal bones; the perpendicular part of the palate bone; the inferior conchal bone; and the medial surface of the medial pterygoid lamina. 
The roof as seen in the section is formed by the nasal and frontal bones, the cribriform plate of the ethmoid, the body of the sphenoid and the sphenoidal conchæ, the sphenoidal process of the palate and the ala of the vomer. The floor, which is

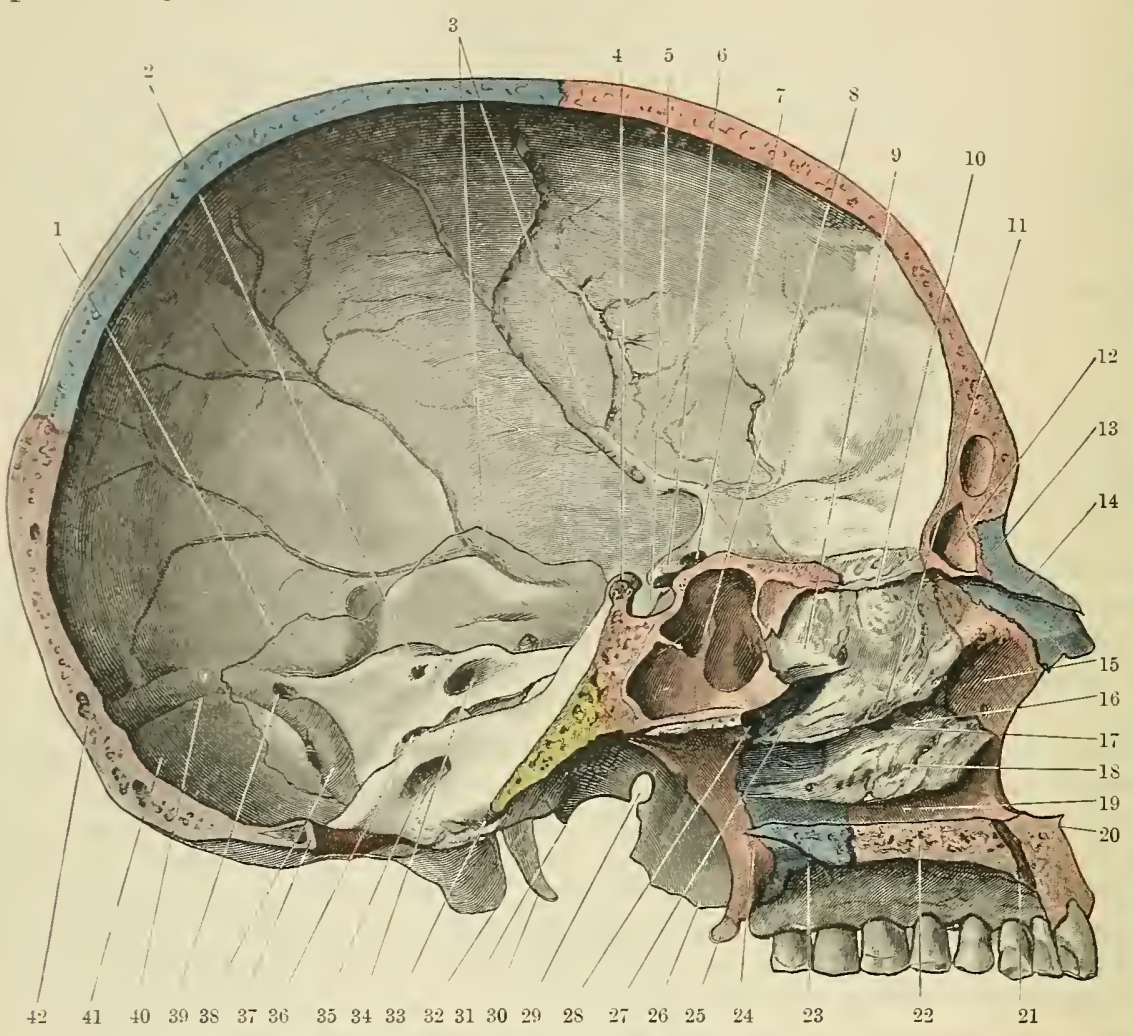

Fig. 173.-Nedial Aspect of the Left Half of the Skull Sagittally divided.

The frontal, maxillary, and sphenoid bones are coloured red; the parietal nasal and palate bones, blue; the basilar part of occipital, yellow, and squama occipitalis, purple. The ethmoid and inferior concha, together with the left ala of the vomer, are left uncoloured.

1. Suture between parietal and temporal bones.

2. Remains of the subarcuate fossa.

3. Grooves for branches of the middle meningeal artery:

4. Dorsum sellæ.

5. Sella tureica.

6. Anterior clinoid process.

7. Optic foramen.

8. Sphenoidal sinus.

9. Nasal surface of superior concha.

10. Cribriform plate of ethmoid.

11. Nasal surface of middle concha.

12. Frontal sinus.

13. Nasal hone near spine of frontal.

14. Nasal bone.

15. Frontal process of maxilla.

16. Midrle meatus of nose.

17. Directed towards opening of maxillary simus.

18. Nasal surface of inferior coucha.

19. Inferior meatus of nose.

20. Anterior nasal spine.

21. Foramen incisivum.

22. Palatine process of maxilla.

23. Horizontal part of palate bone.
24. Posterior nasal spine.

25. Hamulus of medial pterygoid lamina.

26. Lateral pterygoid lamina.

27. Superior meatus of nose.

28. Spheno-palatine foramen.

29. Pterygo-spinous ligament almost completely ossified to enclose a foramen.

30. Styloid process of temporal bone.

3I. Angular spine of sphenoir.

32. Mastoid process.

33. Basion (mid-point of anterior border of foramen nagnum).

34. Internal acoustic meatus.

35. Canalis hypoglossi.

36. Groove for inferior petrosal sinus leading into jugular foramen.

37. Oyisthion (mid-point of posterior border of foramen magnum).

38. Groove for sigmoid sinus.

39. Opening of mastoid foramen.

40. For transverse sinus and attachment of tentorium cerebelli.

41. Fossa for lodgment of cerebellar henisphere.

42. Internal occipital protuberance.

nearly horizontal from before backwards, is formed by the palatine processes of the maxillæe and palate bones. On sagittal section the nasal cavity appears somewhat triangular in shape with the angles cut off; the base corresponds to the floor; the apertura piriformis and choana to the truncated anterior and posterior 
angles, respectively; the superior angle is cut off by the cribriform plate; whilst the sides correspond to the frontal and nasal bones anteriorly, and the sphenoidal conchæ, sphenoidal process of the palate, and the ala of the vomer posteriorly. The cavity is therefore deep towards its middle, but gradually becomes shallower in front and behind where the piriform aperture and choana are situated. The piriform opening of the nose, which is of half-heart shape, is larger than that of the choanæ (O.'I'. posterior nares), and is directed forwards and downwards; the choanæ are of rhomboidal form, and slope backwards and downwards. The inferior meatus is the channel which is overhung by the inferior concha, and its floor is formed by the side-to-side concavity of the upper surface of the hard palate. Opening into it above, under cover of the anterior part of the inferior concha, is the canal for the naso-lacrimal duct; whilst its floor is pierced in front near the middle line by the canalis incisivus. The middle meatus is the hollow between the middle and inferior conchæ; it slopes from above downwards and backwards, and is overhung by the free curved edge of the middle conchæ, beneath which there is a passage called the infundibulum, leading upwards and forwards to open superiorly into the frontal sinus, as well as into some of the anterior ethmoidal cells. Under cover of the centre of the middle concha and continuous with the infundibulum in front there is a curved groove, the hiatus semilunaris, into which open one or more orifices from the maxillary sinus. Above this groove there is a rounded eminence, the bulla ethmoidalis, overlying the middle ethmoidal cells, which usually open on its surface. The superior meatus, about half the length of the middle meatus, is placed between the superior and middle conchæ in the posterior and upper part of the cavity; it receives the openings of the posterior ethmoidal cells. Near its posterior extremity the spheno-palatine foramen pierces its lateral wall, and brings it in relation with the pterrgopalatine fossa. The sphenoidal sinus opens on the roof of the nose, abore the level of the superior conchæ, into a depression called the spheno-ethmoidal recess.

Septum Nasi.- If the opposite half of the section in which the osseous nasal septum is retained be now studied, it will be seen to be formed by the crests of the maxillary and palate bones below, on which rests the romer, the posterior border of which being free, forms the posterior edge of the nasal septum, which slopes obliquely upwards and backwards towards the inferior surface of the body of the sphenoid. Here the vomer articulates with the rostrum of the sphenoid. In front of this the romer articulates with the perpendicular part of the ethmoid, and between them anteriorly there is an angular recess into which the cartilaginous septum fits. Superiorly and anteriorly the osseous septum is completed by the articulation of the perpendicular part of the ethmoid with the nasal spine of the frontal, together with the nasal crest formed by the union of the nasal bones: whilst posteriorly and superiorly the perpendicular plate of the ethmoid articulates with the median ethmoidal crest of the sphenoid. In most instances the osseous septum is not perfectly vertical, but is deflected towards one or other side.

Air-sinuses in Connexion with the Nasal Cavities.-Connected with the nasal cavities are a number of air-sinuses. These are found within the body of the sphenoid, the labyrinth of the ethmoid, the orbital process of the palate bone, the body of the maxilla, and the superciliary arch of the frontal bone.

The sphenoidal sinus, of variable size, occupies the interior of the body of the sphenoid. In some cases it extends towards the roots of the pterygoid processes. In front it is formed in part by the absorption of the sphenoidal conchæ and is divided up into two cavities by a sagittally placed partition, which, however, is frequently displaced to one or other side. It opens anteriorly into the roof of the nose in the region of the spheno-ethmoidal recess.

The ethmoidal sinuses are placed between the lateral aspects of the upper part of the nasal cavities, and the cavities of the orbits, from which they are separated by thin and papery walls. These air-spaces are completed by the articulation of the ethmoid with the maxilla, lacrimal, frontal, sphenoid, and palate bones, and are divided into three groups - an anterior, middle, and posterior. The latter communicates with the superior meatus: the anterior and middle open either independently or in conjunction with the infundibulum into the middle meatus. 
The sinus in the orbital process of the palate bone either communicates with the sphenoidal sinus, or else assists in closing in some of the posterior ethmoidal cells. Its communication with the nasal carity is through one or other of these spaces.

The maxillary sinus lies to the lateral side of the nasal cavity, occupying the body of the maxilla. Its walls, which are relatively thin, are directed upwards to the orbit, forwards to the face, backwards to the infra-temporal and pterygo-palatine fosse, and medially to the nose. In the latter situation the perpendicular part

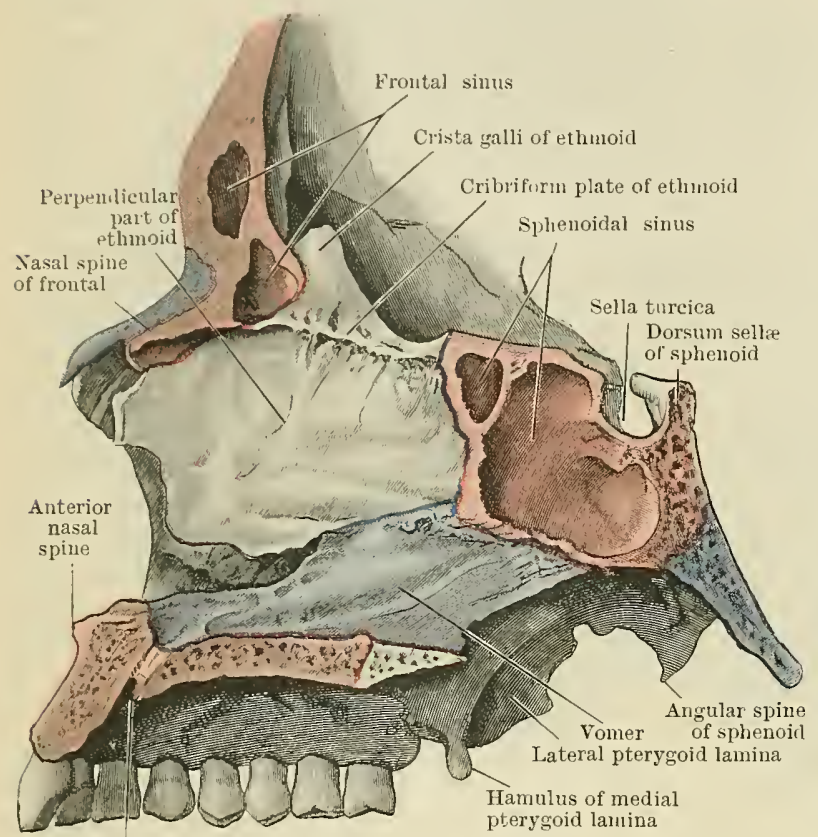

Foramen iucisivum

Fig. 174.- The Nasal Septum as seen from the Left Side.

The frontal, maxillary, and sphenoid bones are coloured red ; the nasal, vomer, and basi-occipital blue; the perpendicular part of the ethmoid and the horizontal part of the palate bone are left uncoloured.

of the palate bone, the uncinate process of the ethmoid, the maxillary process of the inferior concha, and a small part of the lacrimal bone assist in the formation of the thin osseous partition which separates it from the nasal cavity. The floor corresponds to the alveolar border of the maxilla, and differs from the other walls in being stout and thick; it is, however, deeply pitted inferiorly by the alveoli for the teeth. The sinus opens by a narrow orifice in the floor of the hiatus semilunaris into the middle meatus. Occasionally there are two openings.

The frontal sinuses lie, one on either side, between the inner and outer tables of the frontal bone over the root of the nose, and extend laterally under the superciliary arches. The partition which separates them is usually central, though it may be deflected to one or other side. They communicate with the nose through a passage called the infundibulum, which opens inferiorly into the anterior part of the iniddle meatus, below the ethmoidal bulla and continuous with the hiatus semilunaris.

The fact should not be overlooked that the air-spaces within the temporal bone, viz., the tympanic cavity and the mastoid air-cells, are brought into communication with the naso-pharynx through the auditory tubes. Further details regarding the air-sinuses and the mode of their growth will be found under the description of the individual bones.

\section{Frontal Sections.}

The relations of many parts of the cranium are best displayed in a series of frontal (coronal) sections.

By sawing off a thin slice from the front of the lower part of the frontal bone above, and carrying the section downwards through the medial wall of the orbit and the frontal process of the maxilla, into the piriform aperture below, a number of important relations are revealed (see Fig. 175). In the frontal region the extent and arrangement of the frontal sinuses are displayed. The partition between the two sinuses, be it noted, is usually complete and central in position, though it may occasionally be perforated or oblique. The sinuses are hardly ever symmetrical, the right being usually the smaller of the two. (Logan Turner, Edin. Med. Journ. 1898.)

The infundibulum on either side, leading from the frontal sinus above to the middle 
meatus below, is seen with the middle concha medial to it, and the anterior ethmoidal cells to its lateral side abore. If the section passes through the canal for the nasolacrimal duct the continuity of that channel leading from the orbit above to the inferior meatus of the nose below is clearly shown. Its medial wall above, by which it is separated from the cavity of the nose, is formed by the thin lacrimal bone; below, it passes under cover of the inferior concha to open into the anterior part of the inferior meatus. It is

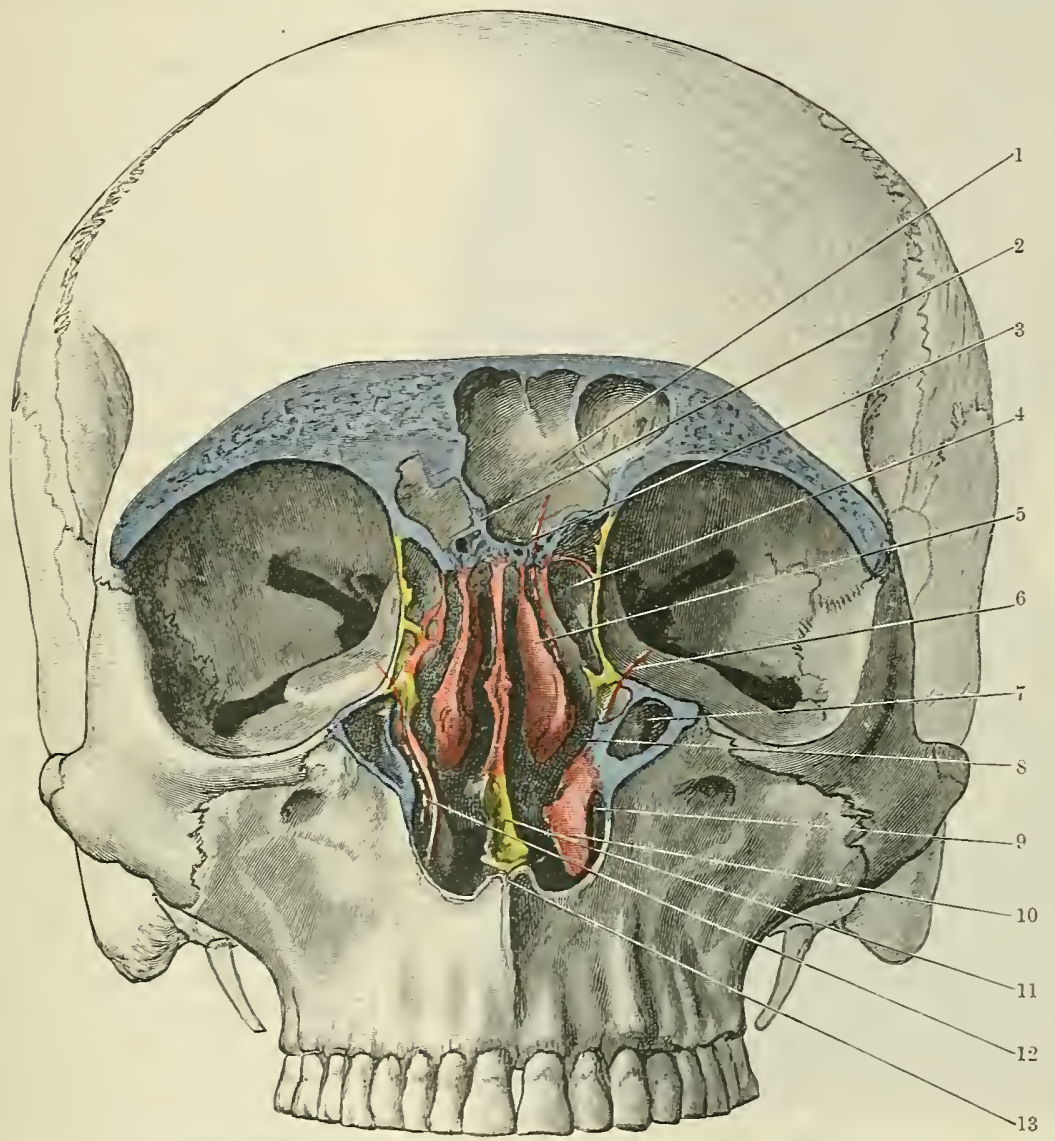

Fig. 175.-Part of the Frontal, Nasal, and Maxiltary Bones remoted in order to DISPLAY THE RELATIOX OF THE VARIOUS CAVITIES EXPOSED.

The frontal aud maxillary bones, where cut, are coloured blue ; the ethmoid and the inferior concha red ; the lacrinal and vomer yellow.

1. Frontal sinus.

2. Septum of frontal sinus deflected towards the right.

3. Infundibulum leading from sinus to middle meatus.

4. Anterior ethrooidal air-sinnses.

5. Middle concha.

6. Red line in upper part of osseous canal for masolacrimal duct, laid open throughout its entire length on the right side.
7. Carity of maxillary sinus laid open.

8. Middle meatus of nose.

9. Inferior meatus of nose.

10. Inferior concha.

11. Nasal septum.

12. Canal for naso-lacrimal duct laid open throughout its entire length.

13. Anterior nasal spine.

separated from the maxillary sinus laterally by a thin lamina of bone. The cavity of the maxillary sinus is seen to extend upwards and forwards so as to pass over the lateral side as well as slightly in front of the canal for the naso-lacrimal duct.

The lower margins of the middle conchæ lie pretty nearly on a level with the most dependent parts of the orbital margins, whilst the lower borders of the inferior conchre are placed a little above the lower margin of the piriform opening on a lerel with the lowest point of the zygomatico-maxillary suture.

Such a section will rereal any deflection of the nasal septum should it exist, and will also show that but a narrow cleft separates the upper part of the septım, on either side, from the medial surface of the superior conchre.

The next section (Fig. 176) passes through the anterior part of the temporal fossa just 
behind the zygomatic process of the frontal bone above; inferiorly it passes through the alveolar process of the maxilla in the interval between the first and second molar

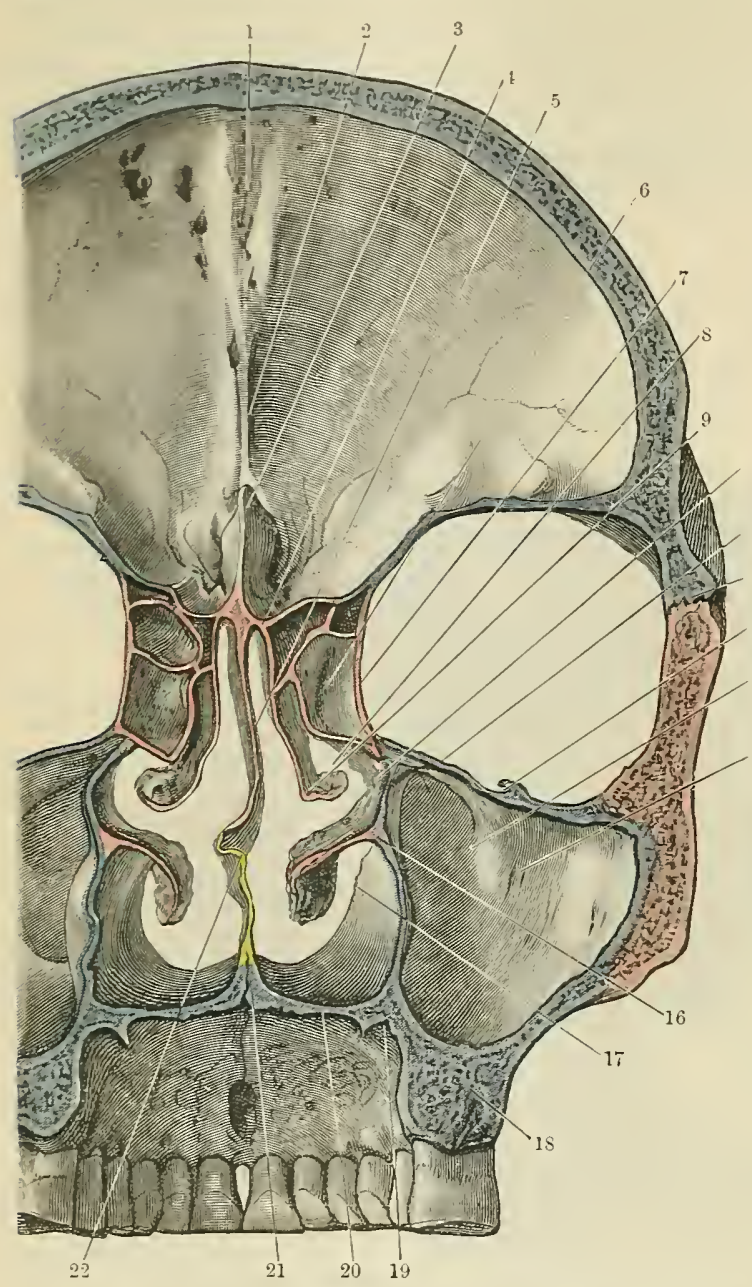

Fig. 176.-FroNtal Section PASSING INFERIORLY THROUgh the Istertal between the First and Second IIolar Teeth.

The frontal aud naxillary bones, where cut, are coloured blue; the ethmoid, inferior conchæ, and zygonatics red; the vomer yellow.

1. Groove for sagittal sinus.

12. Zygomatico-frontal suture.

2. Crest for attachment of falx 13. Infra-orbital groove. cerebri.

3. Crista galli of ethmoid.

4. Cribriform plate of ethmoid.

5. Perpendicular part of ethmoid, assisting in the formation of the nasal septum.

6. Labyrinth of ethmoid consistiug of the ethmoidal cells.

7. Lamina papyracea of ethmoid.

8. Middle meatus of nose.

9. Middle concha.

10. Opening from midule meatus into maxillary sinus.

11. Orbital surface of maxilla. teeth. The cranial, orbital, nasal, and maxillary cavities are all exposed, together with the roof of the mouth.

The anterior cranial fossa is deepest in its centre, where its floor is formed by the cribriform plate of the ethmoid; this corresponds to the level of the zygomatico-frontal suture laterally. On either side the floor of the fossa bulges upwards, owing to the arching of the roof of the orbit. Of the orbital walls, the 10 lateral is the thickestand stoutest; the superior, medial, and inferior walls, which separate the orbit from the cranial cavity, the ethmoidal cells, and the maxillary sinus, respectively, are all thin. The cavity of the maxillary sinus lying to the lateral side of the nasal cavity is well seen. Its roof, which separates it from the orbital cavity, is thin and traversed by the infraorbital canal. Its medial wall, with which the inferior concha articulates, is very slender, and forms the lateral walls of both the middle and inferior meatuses of the nose. Its lateral wall is stouter where it arches up to bracket the temporal process of the zygomatic bone. Its floor, which rests upon the superior surface of the alveolar border of the maxilla, sinks below the lerel of the hard palate. The fangs of the teeth sometimes project into the floor of the cavity.

The nasal cavities are narrow above, where they lie between the orbital cavities, from which they are separated by the cells within the labyrinth of the ethmoid. The roof which corresponds to the cribriform plate is narrow, and lies between the septum medially and the labyrinth on either side.

At the level of the orbital floor the nasal cavities expand laterally, the middle meatus running longitudinally in the angle formed by the labyrinth of the ethmoid with the body of the maxilla, overhung by the middle concha. This channel is seen to have the ethmoidal cells superior to it, the orbital cavity above and to the lateral side, the maxillary sinus laterally, whilst its floor is formed by the superior surface of the inferior concha.

The inferior meatus, much more roomy, runs along under cover of the inferior 
concha. Laterally it is related to the maxillary sinus, whilst its floor is formed by the concave superior surface of the hard palate.

The hard palate is arched below, whilst its superior surface is concave upwards on either side of the median crest which supports the nasal septum. The sides of the arch below correspond to the medial surfaces of the alveolar processes and fall in line with the lateral walls of the nasal cavities superiorly. The summit of the arch lies a quarter of an inch above the level of the floor of the maxillary sinus.

The next section (Fig. 17i) passes through the pterygo-palatine and temporal fossæ inferiorly, and cuts the cranial vault about half an inch in front of the bregma. The floor of the anterior cranial fossa is seen to be formed by the upper surface of the body and small wings of the sphenoid, and is almost horizontal. At the median plane the sphenoidal sinuses are exposed, separated by a thin bony partition, on either side of which the openings by which they communicate with the nasal cavities are seen. The section passes in front of the optic foramen, the groove of which may be seen on the under surface of the small wing of the sphenoid close to the body, and lays open the superior orbital fissure which here leads forwards into the orbit, and which, inferiorly and laterally, is continuous with the cleft between the maxilla and the lower edge of the great wing of the sphenoid-the inferior orbital fissure. This also leads into the orbit.

The nasal cavities, now much diminished in height, are roofed in above by the under-surface of the body of the sphenoid and the ale of the romer, whilst the lateral walls are seen to be formed by the thin perpendicular parts of the palate bones, lateral to which the rounded posterior surface of the maxilla is directed backwards, here forming the anterior wall of the pterygo-palatine fossa - the space which lies between the anterior part of the pterygoid process behind and the maxilla anteriorly. As will be seen, the medial wall of this space is formed by the perpendicular part of the palate, which is, however, deficient above immediately below the inferior surface of the body of the sphenoid. In the interval between the orbital process, which lies in front of the section, and the sphenoidal process, which lies behind,

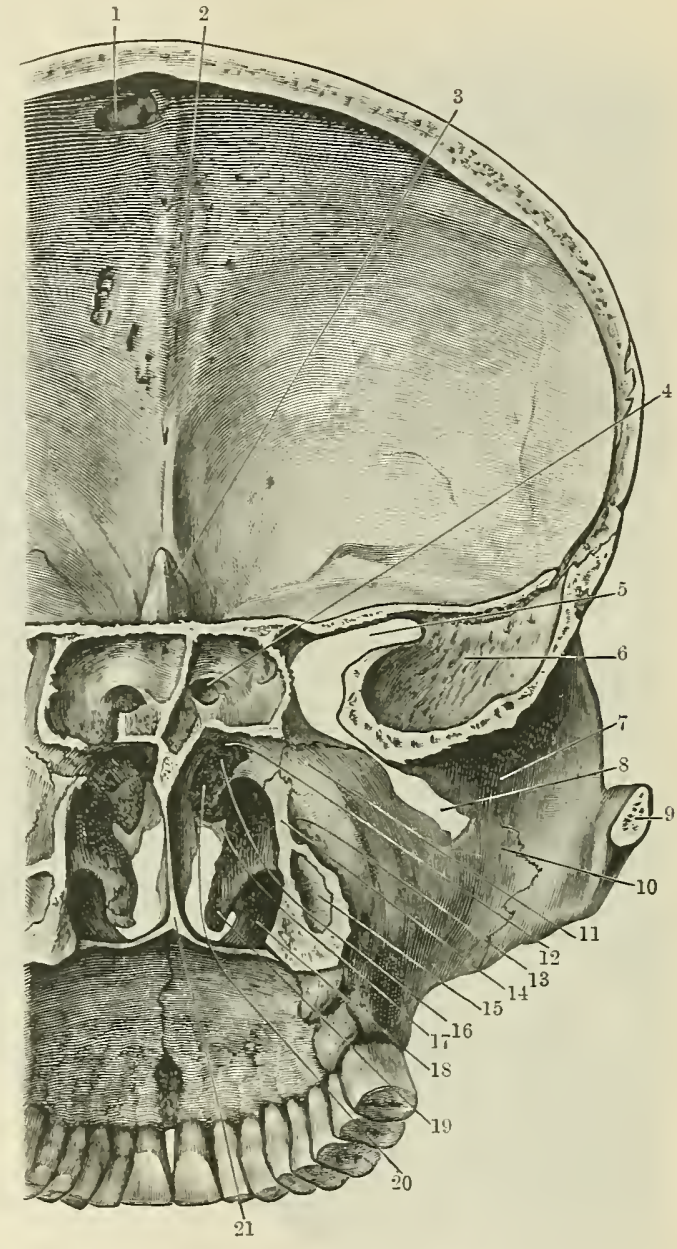

Fig. 17\%.-Froxtal Sectiox PASsixg throtgh the Pterigo-Palatiae Fossa.

1. Depression for arach-10. Zygomatic process of noideal granulation.

2. Groove for sagittal sinus, 11. Surface of maxilla which

3. Crista galli of ethmoid.

4. Opening of sphenoidal sinus into superior meatus of nose through 12. Spheno-palatineforamen. spheno-ethmoidal re- 13. Opening of pterygo-palacess.

5. Superior orbital fissure.

6. Part of midclle fossa formed by cerebral surface of great wing 16. Superior meatus of nose. of sphenoil. 17. Middle meatus of nose.

7. Zygomatic crest of great 18. Inferior meatus of nose. wing of sphenoid. 19. Inferior concha.

8. Inferior orbital fissure. 20. Middle concha.

9. Zygomatic process of 21. Maxillarycrestand vomer temporal. forming nasal septum. this forms the spheno-palatine foramen. Laterally the section has passed through the inferior orbital fissure, which is continuous above with the pterygo-palatine fossa. Inferiorly the section passes through the line of fusion of the pterygoid processes with the pyramidal process of the palate 
bone and the minion of the latter with the maxilla. Just above this the opening of the pterygo-palatine canal, which leads from the pterygo-palatine fossa to the uncler surface of the hard palate, is visible; whilst inferiorly a small portion of the lower part of the

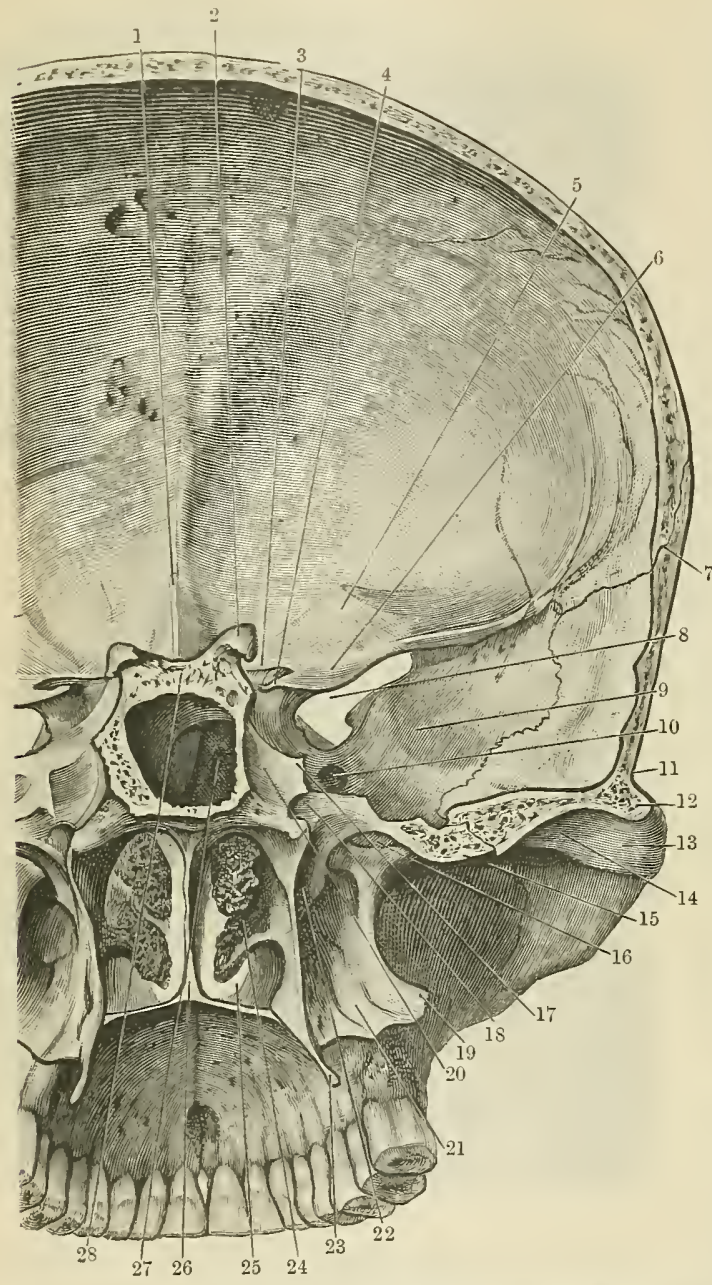

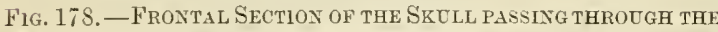
Mandibular Fossa Jest behind the Tuberculum Articulare.

1. Crista galli of ethmoid.

2. Posterior clinoid process.

3. Optic foramen.

4. Anterior clinoid process.

5. Orbital part of frontal.

6. Small wing of sphenoid.

7. Suture between squamous part of the temporal, and parietal bones.

8. Superior orbital fissure.

9. Cerebral surface of great wing of sphenoid.

10. Foramen rotundum.

11. Squamous part of temporal.

12. Posterior root of zygomatic process.

13. Tubereulum articulare.

14. Mandibular fossa.
15. Great wing of sphenoid in front of spine.

16. Foramen ovale.

17. Lingula.

18. Auterior margin of foramen lacerum and opening of pterygoid canal.

19. Postero-lateral margiu of lateral pterygoid lamina.

20. Groove for carotid artery.

21. Pterygoid fossa.

22. Scaphoid fossa.

23. Hamulus of medial ptery goid lamina.

24. Inferior concha

25. Inferior meatus of the nose.

26. Nasal septum.

27. Opening of sphenoidal sinus

28. Dorsum sellæ. pterygoid fossa is cut through. Within the choanæ the middle and inferior conchre are seen; the inferior border of the former corresponds to the level of the superior border of the zygomatic arch, whilst the attached edge of the latter to the perpendicular part of the palate lies in the same horizontal plane as the inferior margins of that arch. Note also that the medial pterygoid lamince lie considerably within the lines of the medial surfaces of the alveolar border, and reach some little distance below the level of the hard palate.

The next section (Fig. 178) passes through the mandibular fossa just behind the tuberculum articulare; superiorly, it cuts the vault half an inch behind the bregma. The middle cranial fossa is shown in section, the floor of which descends as low as the level of the iuferior surface of the body of the sphenoid, corresponding laterally to a horizontal plane passing through the superior edge of the posterior root of the zygoma. The body of the sphenoid rises a finger's breadth above this in the median plane; the cavity within it is exposed, whilst on either side and below is seen the groove for the internal carotid artery, leading upwards from the medial part of the foramen lacerum, which is here divided. To the lateral side of the groove is seen the prominent edge of the lingula, immediately below which is the posterior aperture of the pterygoid canal, the inferior edge of which is in part concealed by the pterygoid tubercle. Immediately lateral to the foramen lacerum the foramen ovale is seen separated from the surface of the section by a narrow bridge of bone. Here it is seen to overlie the root of the lateral pterygoid lamina. The section passes just in front of the foramen spinosum, and here is visible the stont suture between the great wing of the sphenoid and the squamous part of the temporal bone. The mandibular fossa of the temporal bone is cut on either side, and in its deepest part is separated from the middle cranial fossa by but a thin lamina of bone. The thinness of the squamous part of the temporal and the manuer in which it is sutured to the parietal is also well displayed. 
The next figure (Fig. 179) displays the anterior surface of the section immediately behind that above described. In the centre is seen the body of the sphenoid, and the posterior wall of the sinus is now exposed; on either side the apex of the petrons part of the temporal abuts upon the side of the body of the sphenoid, and the large orifice of the carotid canal is seen opening on to the posterior wall of the foramen lacerum, which is here divided. In the recess between the lateral wall of the carotid canal and the spine of the sphenoid is the groove leading into the osseous part of theauditory tube, in front of which the base is pierced by the foramen spinosum. Lateral to the angular spine, the mandibular fossa is divided and its thin roof displayed. Crossing it transversely is seen the petrotympanic fissure which divides the fossa into an articular and non-articular part. The floor of the middle cranial fossa is here seen to be formed by the upward slope of the anterior surface of the petrous part of the temporal, which is pierced by the hiatus facialis, and the foramen for the lesser superficial petrosal nerve. On the upper surface of the summit of the petrous part of the temporal the depression for the lodgment of the semilunar ganglion is well seen on either side.

The last section, the anterior surface of which Fig. 180 is a representation, passes vertically through the base immediately in front of the root of the styloid process. In the median plane the basi-occipital is divided a little in front of the anterior extremities of the occipital condyles; its upper surface is concare from side to side and forms a wide groove for the medulla oblongata and pons. On either side there is a narrow interval between the lateral edge of the basi-occipital and the posterior border of the petrous part of the temporal, which in life is occupied by dense fibrous tissue; rmming along the upper surface of this suture is the inferior petrosal sinus. Laterally the section passes through the

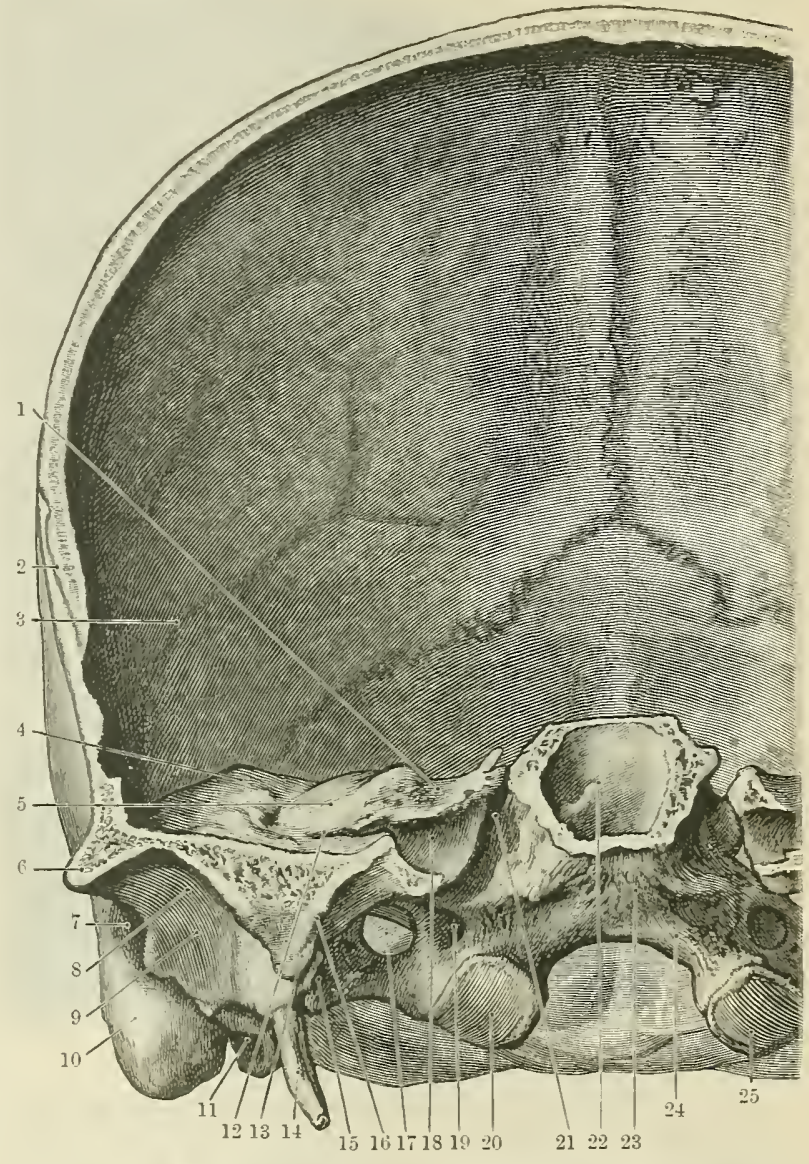

Fig. 179.-Axterior Strface of the Section of the SkLll IMNEDIATELY BEHIXD THE PRECEDLYG SECTIOX.

1. Impressio trigemini on apex of 13. Angular spine of the sphenoid. petrons bone.

2. Squamo-parietal suture.

3. Groove for posterior branch of middle meningeal artery.

4. Eminence of superior semi- 16. Position of osseous opening of circular canal (eminentia auditory tube.

arcuata). 17 . Jugular foramen.

5. Hiatus facialis. 1S. Medial wall of open carotid

6. Posterior root of zygomatic canal. process of temporal. 19 . Canalis hypoglossi.

7. Leads into external acoustic 20. Condyle of occipital bone. meatus. 21. Petro-occipital suture.

8. Mandibular fossa. 22. Posterior wall of splienoidal

9. Tympanic plate.

10. Mastoid process. 23. Position of pharyngeal tnbercle.

11. Learling into stylo-mastoid 24. Anterior margin of foramen foramen.

12. Roof of carotid canal. 25. Occipital condyle. temporal bone, dividing the cavity of the tympanum and laying open the external acoustic meatus. To the medial side of the tympanic wall the cochlea is exposed, whilst abore and lateral to it the canalis facialis is twice dirided, the section passing posterior to the angle formed by its genu. Below the cochlea, and separated from it and the medial part of the floor of the tympanum, the carotid canal is in part exposed. Abore the tympanum is the epitympanic recess ("attic") leading into the tympanic antrum, the whole being 
roofed in br the thin tegmen tympani, which separates it from the middle cranial fossa. The obliquity of the medial end of the external aconstic meatus, together with the

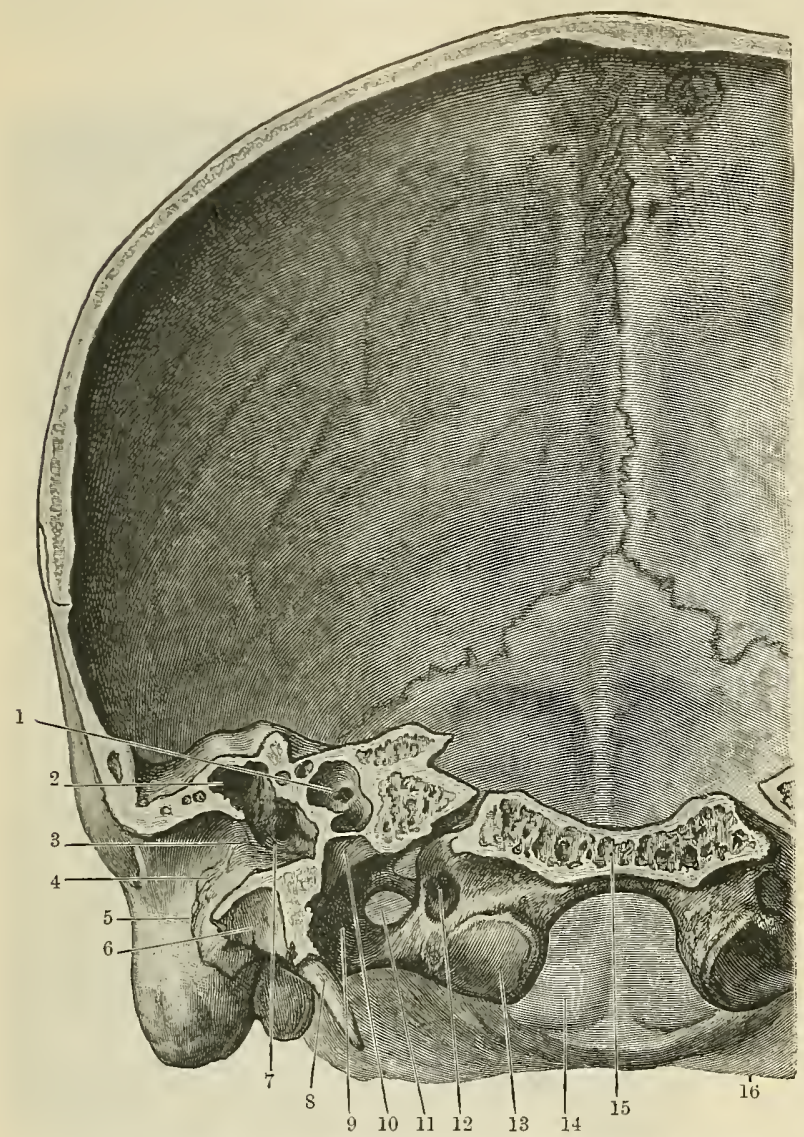

Fig. 180.-Vertical Sectiox throdgh the SkUll imaedately in FroNt of the root of the Strloid Process.

1. Cochlea.

2. Entrance to the antrum.

3. Sulcus tympanicus.

4. Tympanic bone.

5. Auricular fissure.

6. Part of mandibular fossa.

7. Tympanic cavity (floor).

8. Styloid process.

9. Jugular fossa.
10. Inferior opening of carotid canal.

11. Jugular foramen.

12. Canalis hypoglossi.

13. Occipital condyle.

14. Foramen magnum.

15. Basi-occipital. bone.
16. Squamous part of occipital groove for the attachment of the tympanic membrane is well seen, and the thickness of the upper wall of that passage is also noteworthy. The floor of the meatus, formed by the tympanic plate, which separates it from the mandibular fossa, is much thinner, but in the region of the root of the styloid process there is a massing together of dense bone.

\section{HORIZONTAL SECTION.}

Figure 181 represents a horizontal section passing through the face a little below the level of the inferior orbital margin, cutting through the root of each pterygoid process posteriorly. The nasal cavities and the maxillary sinuses are thus exposed. The nasal cavity is divided slightly below the inferior edge of the middle cocha along the line of the middle meatus. The thin partition, which here separates the nose from the maxillary sinus, is cut through, and the aperture into the sinus laid open. In front of this, the canal for the naso-lacrimal duct is cut across, and its relations to the maxillary sinus in front and to the lateral side, and to the nose medially, are well displayed. The form of the maxillary sinus, as exposed, is triangular, the summit of the triangle being directed laterally towards the root of the zygomatic process. Its anterior wall, which is here stout, is pierced obliquely by the infra-orbital canal which at this point reaches the facial surface of the maxilla at the infra-orbital foramen. Its posterior wall, thin and convex backwards, is directed towards the infra-temporal fossa laterally, and to the pterygo-palatine fossa medially, where it lies in front of the pterygoid processes. The latter fossa has been cut across and is seen to correspond to the interval between the posterior and superior surface of the maxilla, and the anterior aspect of the root of the pterygoid process. Laterally, it is seen to communicate with the infra-temporal fossa by means of the pterygomaxillary fissure which is here cut across ; medially, it opens into the nose by the sphenopalatine foramen, which is also divided. On one side the anterior orifice of the pterygoid canal is seen opening on to the posterior wall of the fossa. On the other side, the canal has been laid open, by removing its lower wall, so as to expose its whole length as it leads backward to the anterior edge of the foramen lacerum. In the middle line, the nasal septum, here formed by the romer and perpendicular part of the ethmoid, is shown in section. A line passing through the inferior orbital fissures cuts the zygomatic arch where the zygomatic process of the temporal articulates with the zygomatic bone. 


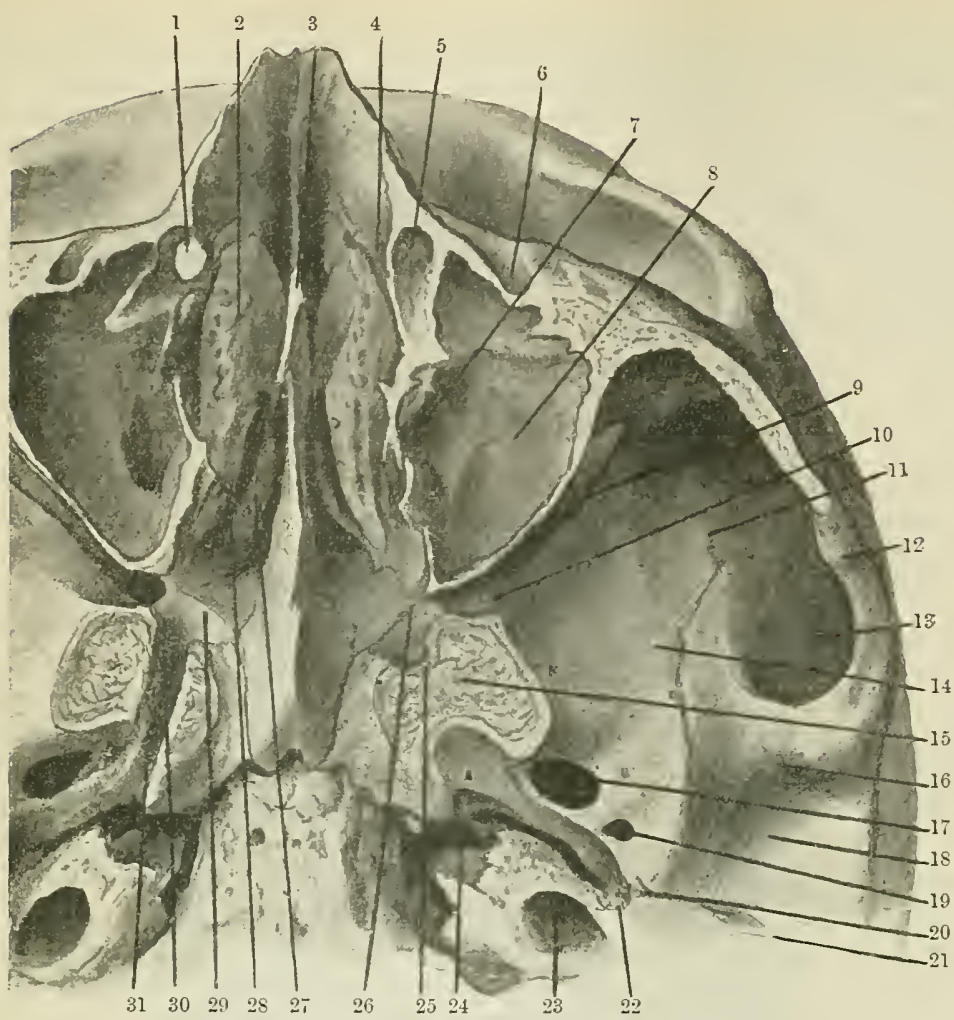

Fig. 181.-Horizontal Section of the Skell a little below the LEVEL of the INFERIOR ORBITAL MaRgIN.

1. Canal for naso-lacrimal duct.

2. Midale concha.

3. Nasal septum.

4. Middle meatus of nose.

5. Naso-lacrimal cluct.

6. Infra-orbital canal.

7. Opening into maxillary sinus from the middle meatus of the nose.

8. Roof of maxillary sims.

9. Inferior orbital fissure.

10. Passing through pterygo-maxillary fissure into pterygo-palatine fossa and ending opposite opening of foramen rotundum.

11. Infra-temporal crest of great wing of sphenoid.

12. Zygomatic arch.

13. Squamous part of temporal.

14. Under surface of great wing of sphenoid.

15. Cut pterygoid process.

16. Tuberculum articulare.

17. Foramen ovale.
18. Mandibular fossa.

19. Foramen sliuosum.

20. Spine of sphenoid.

21. Petro-squamosal fissure.

22. Opening of bony canal of auditory tube.

23. Carotid caual.

24. Upper opening of carotid canal (foramen lacerum).

25. Anterior opening of pterygoir canal.

26. Roof of pterygo-palatine fossa just above spheno-palatine foramen.

27. Superior concha.

28. Superior meatus of the nose.

29. Placed iu position of spheno-palatine foramen.

30. Placed in the pterygo-palatine fossa near the upper part of the pterygomaxillary fissure.

31. Pterygoid canal laid open.

\section{SEXUAL DIFFERENCES IN THE SKULL.}

Whilst it is a matter of difficulty, in all cases, to determine with certainty the sex of a skull, the following points of difference are usually fairly characteristic. The female skull is, as a rule, smaller than the male. In point of cranial capacity it averages about a tenth less than the male of corresponding race. Undue stress must not be laid on these facts, since the female in bulk and stature measures on an arerage less than the male. It is lighter, smoother as regards the derelopment of its muscular ridges, and possesses less prominent mastoid processes. In the frontal region, the superciliary arches are less pronounced, and this imparts a thinness and sharpness to the upper orbital margin, which is fairly characteristic, and can best be appreciated by running the finger along that edge of bone. For the same reason, the forehead apjears more rertical and the projections of the 
frontal tuberositics more outstanding, though it is stated that the frontal and occipital regions are less capacious proportionately than in the male. The vertex in the female is said to be more flattened, and the height of the skull consequently somewhat reduced. In the male the edge of the tympanic plate is generally sharp, and divides to form the sheath of the styloid process, whilst in the female the corresponding border is described as being rounder and more tubercular.

Whilst it is true that no one of these differences is sufficiently characteristic to enable us to pronounce with certainty on the matter of sex, it is the case that, taken together, they usually justify us in arriving at a conclusion which, as a rule, may be regarded as fairly accurate. In some instances, however, it is impossible to express any definite opinion.

\section{THE SKULL AT BIRTH.}

The skull at birth is remarkable for the small size of its facial portion and the proportionately great development of its calvarial part, the former constituting only about one-eighth of the mass of the latter.

The bones of the cranial vault have not as yet the serrated edges which they exhibit at a later stage of growth, but are at present separated from each other by a narrow linear membranous interval, corresponding in position to the lines of the sutures by which they are ultimately united. At certain points, where these membranous sutures meet or intersect, there are areas, of varying outline, in which the space between the edges of the surrounding bones is formed of membrane ouly. This membrane corresponds to the overlying pericranium and the underlying dura mater. The larger of these membranous intervals, called fonticuli or fontanelles, are met with in correspondence with the angles of the parietal bone. Of these, two are placed medially, at either end of the sagittal suture.

The fonticulus frontalis, or anterior medial fontanelle, formed by the convergence of four sutures, is the lozenge-shaped membranous interval between the rounded frontal angles of the parietal bones posteriorly and the sloping edges of the two halves of the frontal bone anteriorly, which are still separated from each other by the metopic suture. This space closes about the first half of the second year or later.

The fonticulus occipitalis, or posterior medial fontanelle, at this stage is represented by a triradiate membranous interval interposed between the two parietals in front and the more or less pointed angular superior extremity of the occipital squama behind and below. The anterior limb of the triradiate area corresponds to the posterior more open part of the sagittal suture, whilst the lateral extensions slope outwards and downwards between the edges of the occipital squama and the posterior margins of the parietal boues on either side; variations in the outline of this fontanelle may be met with, owing to the persistence of the suture which separates the interparietal elements of the occipital bone into two halves. Closure of the occipital fonticulus takes place about the second month after birth.

The lateral fonticuli are situated at the sphenoidal angles of the parietal bone. The fonticulus sphenoidalis, or antero-lateral fontanelle, corresponds to the region of the pterion, and is the irregular membranous interval between the sphenoidal angle of the parietal above, the posterior edge of the frontal anteriorly, and the margins of the great wing of the sphenoid and the pars squamosa of the temporal bone below; it closes from two to three months after birth.

The fonticulus mastoideus, or postero-lateral fontanelle, lies between the mastoid angle of the parietal superiorly and the mastoid portion of the petro-mastoid element of the temporal bone in front, the edge of the ex-occipital part of the occipital bone below, and the anterior margin of the supra-occipital element of the same bone behind. The site of this fontanelle corresponds to what is known as the asterion in the adult; it closes in from twelve months to two years after birth.

In any of these fonticuli independent ossicles of bone, called ossa suturarum, are liable to appear, and assist in the closure of the membranous area. At birth such an ossicle may appear in the fonticulus occipitalis, constituting what has been termed a pre-interparietal. And in the region of the pterion such ossicles have been described as epipteric bones; but it is doubtful if such independent ossicles have any 
morphological significance, and are not more readily accounted for on the assumption that they are mere irregularities in the ossification of the occluding membrane.

The sagittal fonticulus is occasionally seen in the skull at birth as a transverse fissure or angular cleft, notching the sagittal margins of the parietal bones, transversely to the line of the sagittal suture, and in correspondence with the position of the parietal foramina, the medial margins of which may, as yet, be unossified and formed merely by the membranous layer uniting the two bones. Frequently at birth all evidence of the previous existence of this fonticulus is absent.

Most striking at birth is the occurrence of outstanding bosses, tubera parietalia, on the surface of the parietal bones. These overlie the position of the primary ossific centres from which these bones are originally developed, and correspond to

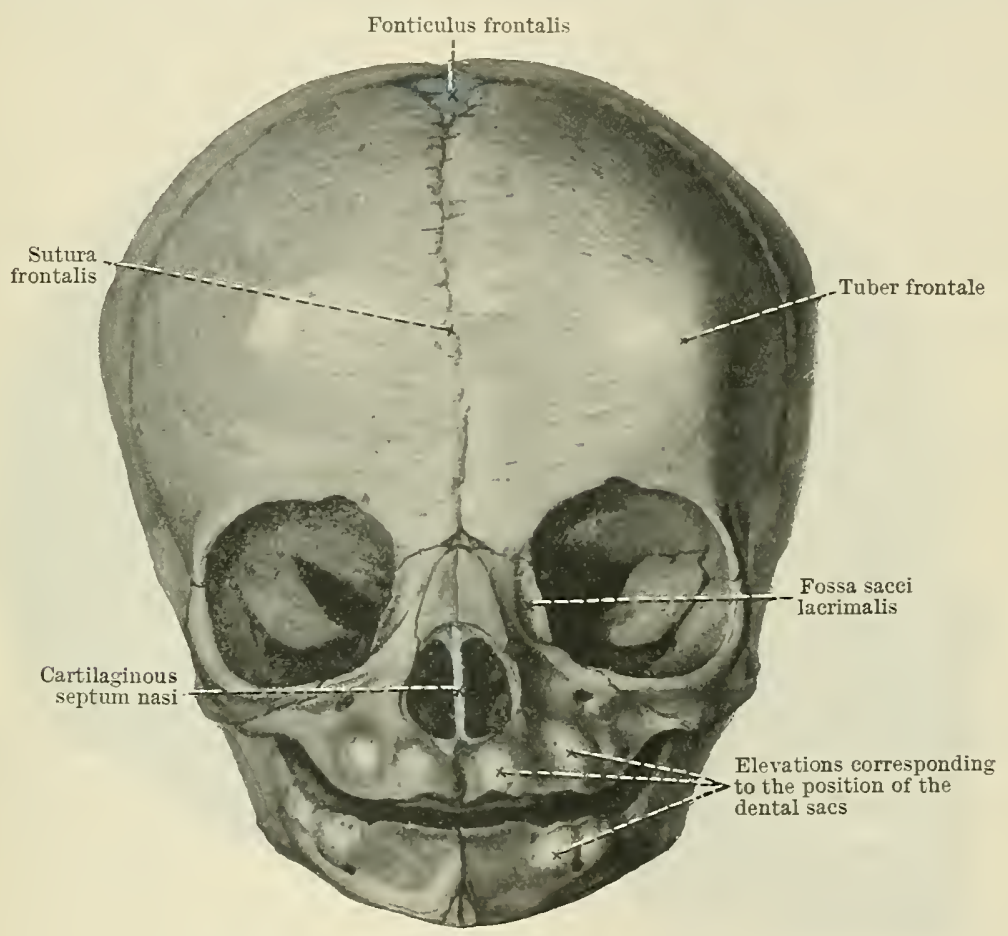

Fig. 182.-Froytal Aspect of the Skull at Birth.

the greatest maximum width of the calvaria. They mark the position of what in the adult are known as the tubera parietalia, though, be it noted, that in the adult condition these reliefs need not necessarily correspond to the greater breadth of the head.

In like manner the sites of the centres from which the lateral portions of the frontal pad of the frontal bone are dereloped are readily recognised by the presence of the frontal bosses, which impart to the child's forehead its bulging appearance, and correspond in later life to the position of the frontal tuberosities. As yet the two halves of the frontal part of the frontal bone are ununited, being separated by the frontal or metopic suture (sutura frontalis), which lies in direct continuation anteriorly with the line of the sagittal suture. The frontal suture is, as a rule, more or less completely fused by the sixth year.

The size of the infant's skull at birth varies considerably, and is to a large extent dependent on the bulk and derelopment of the child. The size of the skull in female infants is absolutely smaller than in the case of male children, though not necessarily proportionately smaller, since the weight of female children at birth is on the average absolutely less than male foetuses at full term. 
In viewing the skeleton of the face the observer is struck with the large proportionate size of the orbital and nasal apertures. The former are circular in outline, with sharp crisp margins. Under cover of the zygomatic process of the frontal bone the roof and lateral wall of the orbit is deeply recessed. The fossa sacci lacrimalis is oftentimes directed more towards the facial aspect than towards the orbital cavity. The superior and inferior orbital fissures are proportionately large, and the latter, in the macerated skull, forms a wide channel of communication with the fossa infratemporalis. The nasal aperture, apertura piriformis, is cordate in form, and exhibits a greater proportionate width than is met with in the adult; its inferior margin is not far beneath the level of the inferior orbital margins. The vertical depth of the maxillæ is small, and as yet the processus alveolaris is imperfectly developed, its inferior edge lying but little below the level of the inferior border of the arcus zygomaticus. Sunk in the alveolar border at this

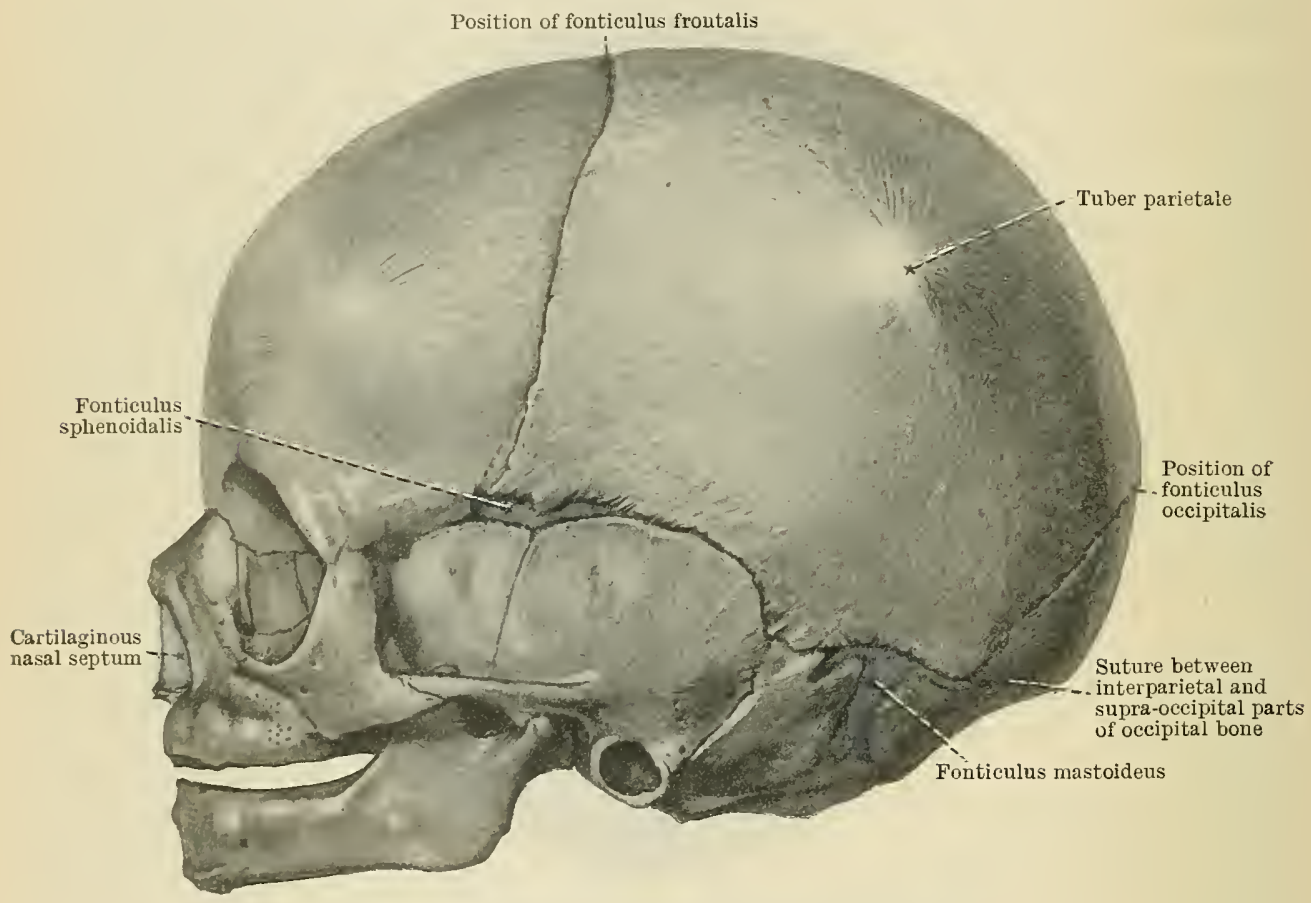

Fig. 183. - Lateral Aspect of the SkUll d'T Birth.

stage may be seen the relatively large hollows in which the dental sacs are lodged. Within the body of the maxilla the maxillary sinus is represented by a shallow groove, disposed in relation to the middle meatus of the nose. For this reason the space separating the orbital floor from the palatine surface of the bone is small, but is later increased to its adult proportions by the enlargement of the maxillary sinus and the consequent expansion of the body of the maxilla.

Viewed from the inferior surface, the hard palate is shallow, owing to the poor development of the alveolar border. The sutures between the ossa incisiva and the processus palatini of the maxillæ are readily recognisable, and the vertical height of the choanæ is seen to be relatively small, owing to the perpendicular parts of the palate bones not having reached their adult proportions.

The mandible consists of two parts united, medially in front, by fibrous tissue to form the symphysis. The alveolar border is deeply grooved for the reception of the dental sacs, whilst the remaining substance of the body of the bone is but slightly developed. The foramen mentale pierces the bone about midway between its superior and inferior borders. 
The ramus is proportionately wide, and forms with the body an angle which is very obtuse.

The coronoid process rises considerably above the level of the capitulum, and comes into close relationship with the crista infratemporalis.

The capitulum, which is proportionately more expanded than in the adult, occupies the somewhat laterally directed shallow mandibular fossa of the temporal bone.

On viewing the lateral aspect of the skull, the meatus auditorius externus, as such, is not seen; it is replaced by the slender annulus tympanicus, which supports the tympanic membrane. This ring of bone, incomplete above, is united by its extremities superiorly to the under surface and lateral aspect of the squamozygomatic part of the temporal bone. The ring itself is disposed so that it slopes downwards, forwards, and medially; as yet it fails to enter into the formation of the posterior wall of the fossa mandibularis, and only at a later stage does it grow laterally to form the floor of the external acoustic meatus. Through the ring the labyrinthic wall of the cavum tympani is seen; exposed on this surface are the promontory, the fenestra vestibuli, and the fenestra cochleæ.

Posterior to the tympanic ring the sutura squamosomastoidea, still open, is seen separating the pars mastoidea from the squama temporalis of the temporal bone. On turning the skull over so that its inferior surface is exposed, the partes laterales of the occipital bone are seen separated in front from the pars basilaris by a suture, which runs through the occipital condyle on either side. Posteriorly an open suture, which curves backward and laterally on each side of the posterior margin of the foramen ovale, separates them from that part of the squama occipitalis which is developed in cartilage. The squama occipitalis at this stage exhibits a lateral cleft on each side, passing backwards from the fonticulus mastoidea, which serves to indicate the line of union of the parts which are developed in cartilage and membrane respectively. The latter, the superior, sometimes separate, constitutes the os interparietale.

\section{DIFFERENCES DUE TO AGE.}

At birth the face is proportionately small as compared with the cranium, constituting about one-eighth of the bulk of the latter. In the adult the face equals at least half the cranium. About the age of puberty the development and expansion of some of the airsinuses, more particularly the frontal sinus, lead to characteristic differences in form in both the head and face.

The eruption of the teeth in early life and adolescence enables us to determine the age with fair accuracy. After the completion of the permanent dentition, the wear of the teeth may assist us in hazarding an approximate estimate. The condition of the sutures, too, may guide us, synostosis of the coronal and sagittal sutures not as a rule taking place till late in life. Complete obliteration of the synchondrosis between the occipital bone and sphenoid may be regarded as an indication of maturity. In old age the skull usually becomes lighter and the cranial bones thinner. The alveolar borders of the maxillæ and mandibles become absorbed owing to the loss of the teeth. This gires rise to a flattening of the vault of the hard palate and an alteration in the form of the mandible, whereby the mandibular angle becomes more obtuse.

\section{THE BONES OF THE UPPER EXTREMITY.}

\section{Clavicula.}

The clavicle, or collar bone, one of the elements in the formation of the shoulder girdle, consists of a curved shaft, the extremities of which are enlarged. The medial end, since it articulates with the sternum, is called the sternal extremity; the lateral extremity, from its union with the acromion process of the scapula, is known as the acromial end.

The extremitas sternalis (sternal end) is enlarged, and rests upon the disc 
of fibro-cartilage which is interposed between it and the clavicular facet on the upper and lateral angle of the manubrium sterni. It is also supported by a small part of the medial end of the cartilage of the first rib. Its articular surface, usually broader from above downwards than from side to side, displays an antero-posterior conrexity, whilst tending to be slightly concave in a vertical direction. The edge around the articular area, which serves for the attachment of the capsule of the

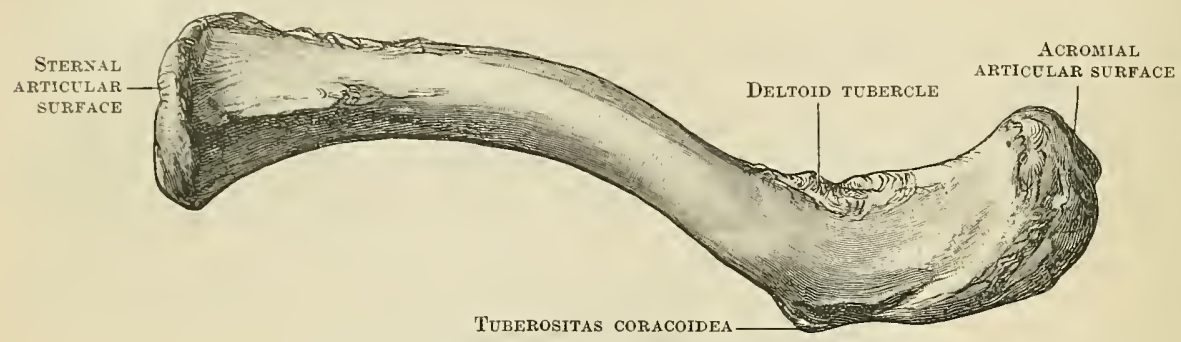

Fig. 184. -The Right Clavicle seen From above.

sterno-clavicular articulation, is sharp and well defined, except below where it is rounded.

The shaft exhibits a double curve, being bent forwards in the medial twothirds of its extent, whilst in its lateral third it displays a backward curve. Of rounded or prismatic form towards its sternal end, it becomes compressed and flattened at its acromial extremity. It may be described as possessing two surfaces, a superior and an inferior, separated by anterior and posterior borders, which

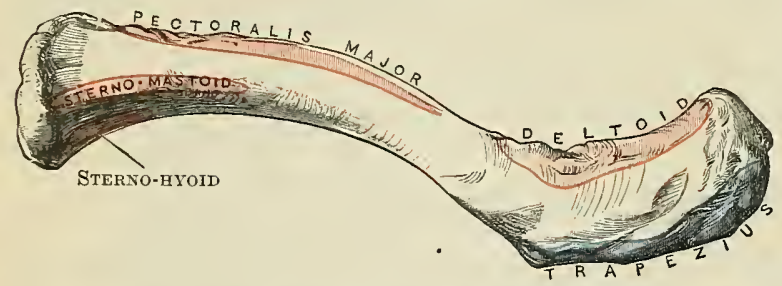

Fig. 185.-The UpPer SURface of the Right Clavicle With Muscle Attachments. are well defined towards the lateral extremity of the bone, but become wider and less well marked medially where they conform more to the cylindrical shape of the bone. The superior surface, which is smooth and subcutaneous throughout its whole length, is directed upwards and forwards. The anterior border, which separates the superior from the inferior surface in front, is rough and tubercular towards its medial end for the attachment of the clavicular fibres of the pectoralis major, whilst laterally, where it becomes continuous with the anterior margin of the acromial end, it is better defined, and bears the imprint of the origin of the fibres of the deltoid muscle; here, not uncommonly, a projecting spur of bone, called the deltoid tubercle, may be seen. The posterior border is broad medially,

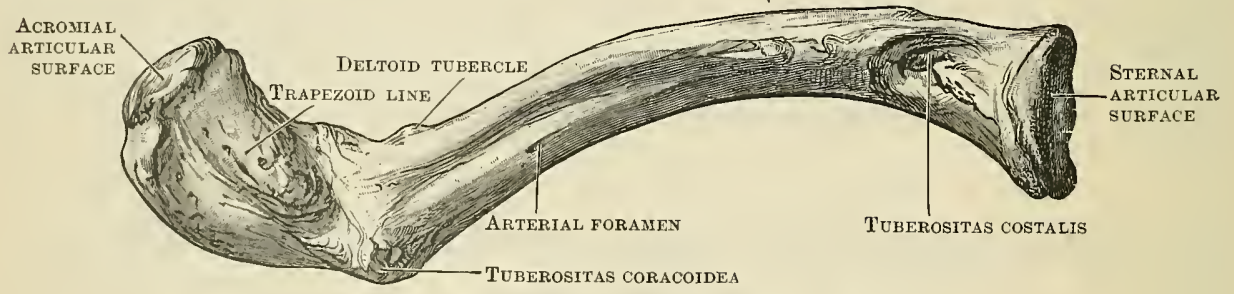

Fig. 186.-The Right Clavicle SEen From Below.

where it is lipped superiorly to furnish an attachment for the clavicular fibres of the sterno-mastoid muscle; behind and below this the sterno-hyoid and sterno-thyreoid muscles are attached to the bone. Laterally, the posterior border becomes more rounded, and is confluent with the posterior edge of the acromial end at a point where there is a marked outgrowth of bone from its inferior surface, the tuberositas coracoidea. Into the lateral third of this border are inserted the 
upper and anterior fibres of the trapezius muscle. The inferior surface, inclined downwards and backwards, is marked close to the sternal end by an irregular elongated impression (tuberositas costalis), often deeply pitted, for the attachment of the costoclavicular ligament, which unites it to the cartilage of the first rib. Lateral to this the shaft is channelled by a groove which terminates close

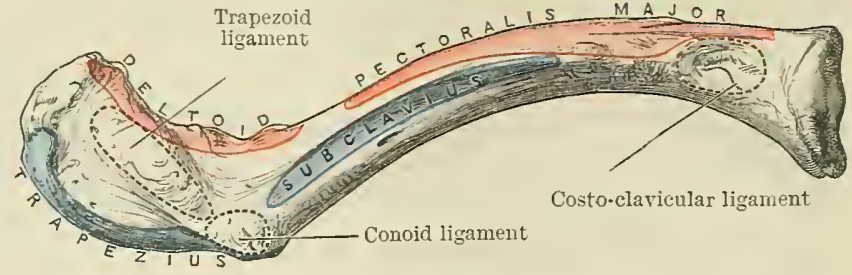

Fig, 187.-The Uxder Surface of the Right Claticle mith the ATtaChMENTS OF THE MUScles MAPPED OUT.

to the coracoid impression; into this groove the subclavius muscle is inserted.

The acromial end of the bone is flattened and compressed from above downwards, and expanded from before backwards; its anterior edge is sharp and well defined, and gives attachment to the deltoid muscle, which also spreads orer part of its upper surface. Its posterior margin is rougher and more tubercular, and provides a surface for the insertion of the trapezius. The area between these two muscular attachments is smooth and subcutaneous. The lateral edge of this forward-turned part of the bone is provided with an oval facet (facies articularis acromialis) for articulation with the acromion of the scapula; the margins around this articular area serve for the attachment of the capsule of the joint. The inferior surface of the acromial end of the bone is traversed obliquely from behind forwards and laterally by a rough ridge or line called the trapezoid ridge. The posterior extremity of this ridge, as it abuts on the posterior border of the bone, forms a prominent process, the tuberositas coracoidea; to each of these, respectively, are attached the trapezoid and conoid portions of the coracoclavicular ligament.

The morphology of the claricle is of special interest. Its presence is associated with the freer use and greater range of movement of the fore-limb, such as are necessary for its employment for more specialised actions than those of mere progression. In consequence of these requirements, the limb, and with it the scapula, become further removed from the trunk, and so the support which the blade bone receired through the union of its coracoid element with the sternum, as in birds and reptiles, and to some extent in the lowest mammals, is withdrawn. Some substitute, however, is necessary to meet the altered conditions, and in consequence a new element is introduced in the form of a clavicle. The origin of this bone appears to be intimately associated with the precoracoid element met with in amphibia or reptiles but whereas the precoracoid is alwars laid down in cartilage, which, however, not infrequently disappears, the claricle develops in the membrane overlying the precoracoid cartilage. In the course of its derelopment it may become intimately associated with the remains of that cartilage. Thus, it is probable that the articular discs at the sterno-clavicular and acromio-clavicular joints, as well as the sternal articular end of the clavicle, represent persistent portions of the primitive cartilage, whilst it is possible that the supra-sterual ossicles occasionally present may be also derived from it. In this way, in its most specialised form, a secondary support is established between the sternum and scapula, which serves as a morable fulcrum, and greatly enhances the range of movement of the shoulder girdle.

Nutrient Foramina.-The foramina for the larger nutrient vessels, offsets of the transverse scapular artery, of which there may be one or two directed laterally, are usually found about the middle of the posterior border, or, it may be, opening into the floor of the groove for the subclavius muscle.

Ossification.-The clavicle in man is remarkable in commencing to ossify before any other bone in the body; this occurs as early as the fifth or sixth week of fœtal life. The shaft is ossified from two primitive centres (Mall). These are preceded by a curved rod of connective tissue on the interior of which are dereloped two masses of a peculiar precartilaginous nature, one, the sternal, placed medially, lies above and overlaps in front the acromial mass, which is placed laterally. In each of these near their approximated ends a centre of ossification appears. These, subsequent to the fusion of the 
two independent precartilaginous masses, coalesce and form a bridge of bone uniting the two primary ossific centres. At a later stage cartilage cells appear in the medial

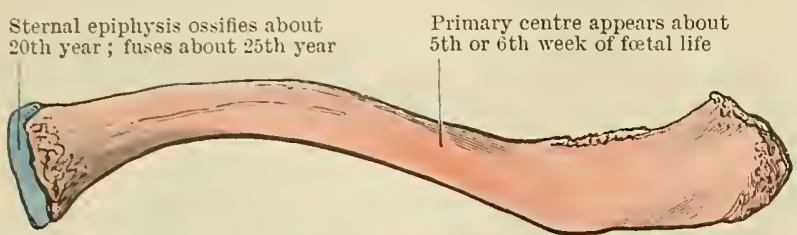

Fig. 188. - Ossification of the Clavicle. extremity of the sternal precartilaginous mass and still later in the lateral end of the acromial mass. By the growth and subsequent ossification of the cartilage so formed the clavicle increases in length (Fawcett).

A secondary centre ox epiphysis appears at the sternal end about the age of twenty or later, and fusion rapidly occurring between it and the shaft, ossification is completed at the age of twenty-five or thereabouts.

\section{The Scapula.}

The scapula, or shoulder blade, is of triangular shape and flattened form. It has two surfaces, costal or ventral, and dorsal. From the latter there springs a triangular process called the spine, which ends laterally in the acromion;

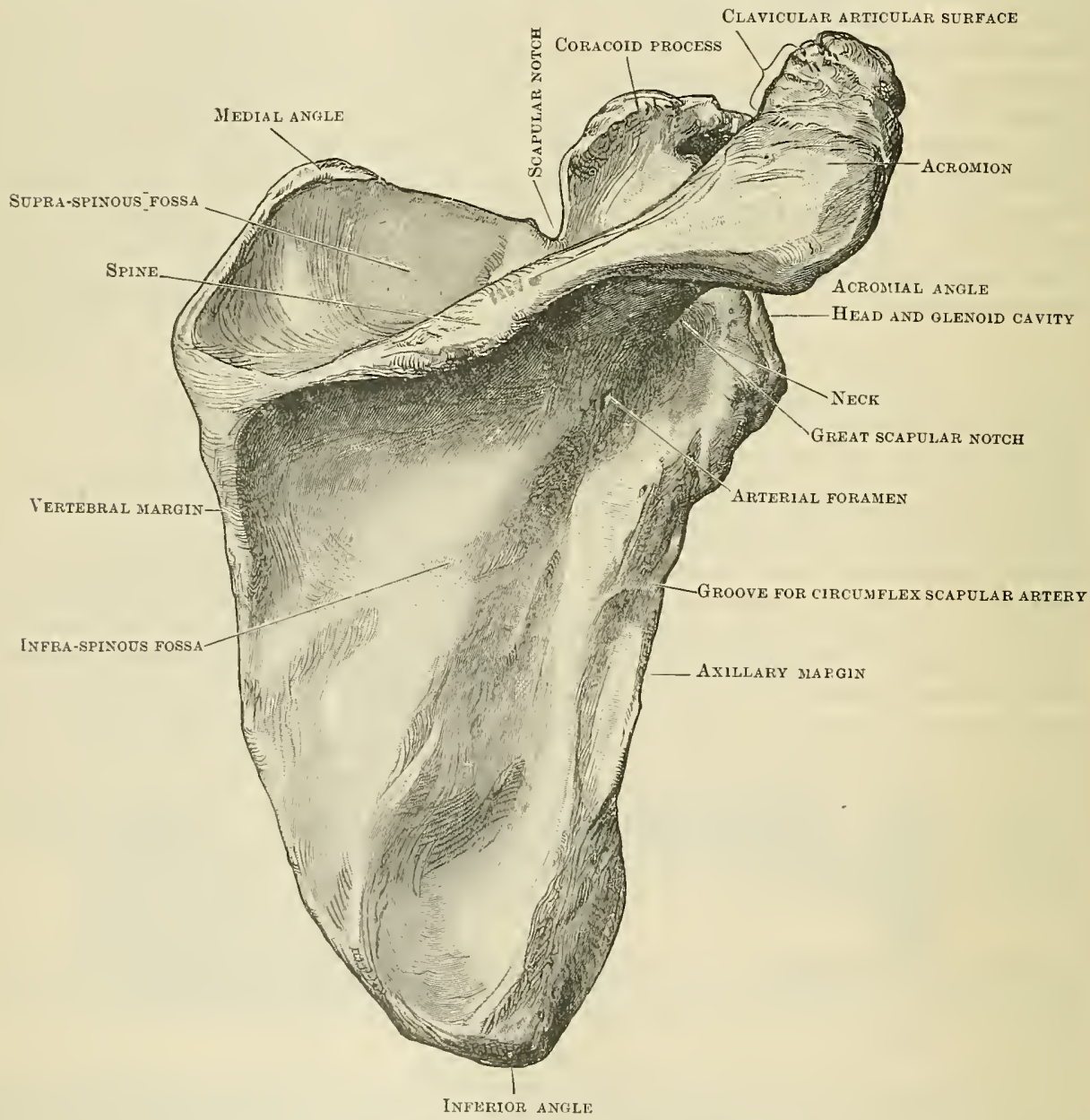

Fig. 189.-The Dorsal Surface of the Right Scapula.

whilst from its superior margin there arises a beak-like projection called the coracoid process. The bone overlies the postero-lateral aspect of the thoracic framework, reaching from the second to the seventh rib. 
The body of the bone, which is thin and translucent, except along its margins and where the spine springs from it, has three margins and three angles. Of these margins the vertebral (margo vertebralis) is the longest; it stretches from the medial angle above to the inferior angle below. Of curved or somewhat irregular outline, it affords a narrow surface for the insertion of the levator scapulæ, rhomboideus minor, and rhomboideus major muscles.

The superior margin, which is thin and sharp, is the shortest of the three. It runs from the medial angle towards the root of the coracoid process, before reaching which, however, it is interrupted by the scapular notch, which lies very close to the medial side of the base of that process. This notch, which is converted into a foramen by a ligament, or occasionally by a spicule of bone, transmits the suprascapular nerve, whilst the transierse scapular artery runs above it. Attached to the superior margin, close to the notch, is the posterior belly of the omo-hyoid. The axillary margin, so called from its relation to the hollow of the axilla (armpit), is much stouter than either of the others; it extends from the lateral angle above to the inferior angle below. The upper inch or so of this border, which lies immediately below the glenoid articular cavity, is rough and tubercular (tuberositas infraglenoidalis), and affords attachment to the long head of the triceps. Below this it is usually crossed by a groove which marks the position of the circumflex scapular artery.

The medial angle is sharp and more or less rectangular; the inferior angle is blunter and more acute; whilst the lateral angle corresponds to that part of the bone which is sometimes called the head,

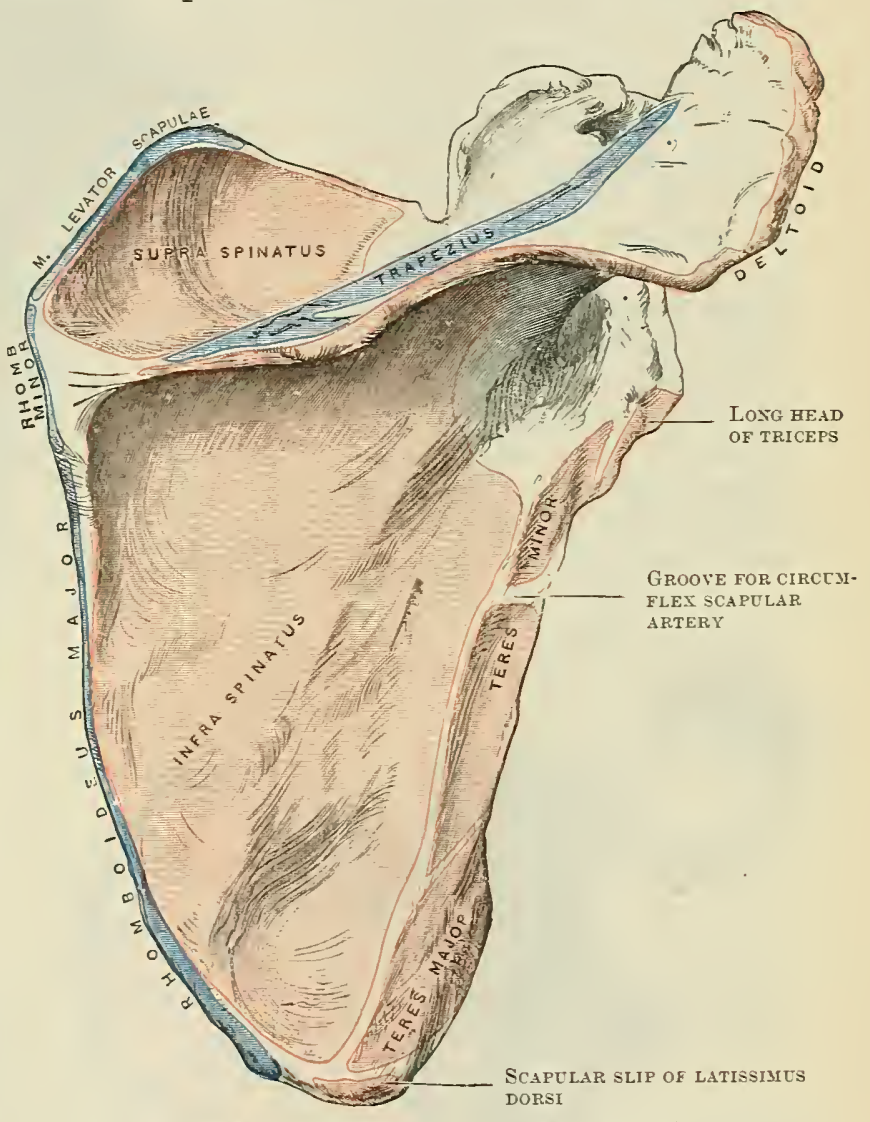

Fig. 190.-The Dorsal Surface of the Right Scapula With THE ATTACHMENTS OF THE MUSCles Mapped oUT. and which supports the glenoid cavity and the coracoid process.

The glenoid cavity is a piriform articular area, slightly concave from abore downwards and from side to side ; its border is but slightly raised above the general surface and affords attachment in the recent condition to the labrum glenoidale, which helps to deepen the socket in which the head of the humerus rests. Below, the margin of the glenoid cavity is confluent with the infra-glenoidal tuberosity, whilst, above, it blends with a tubercle (tuberositas supraglenoidalis), to which the long head of the biceps muscle is attached. Springing from the upper part of the head, in line with the superior margin, is the processus coracoideus (coracoid process). The base of this is limited laterally by the glenoid edge, whilst medially it is separated from the superior margin by the scapular notch. Rising upwards for a short space, it bends on itself at nearly a right angle, and ends in a process which is directed laterally and slightly forwards, overhanging the glenoid cavity above and in front. Compressed from above downwards, it has attached to its upper surface near its angle the conoid ligament, lateral to which there is a rough area for the trapezoid ligament. Attached to its dorsal border is the coraco- 
acromial ligament, whilst at its extremity and towards the front of its rentral border, is the combined origin of the biceps and coracobrachialis, together with the insertion of the pectoralis minor. The colIum scapulæ (neck) is that somewhat constricted part of the bone which supports the head; it corresponds in front and behind to a line drawn from the scapular notch to the infra-glenoidal tuberosity.

The body of the bone has two surfaces, a dorsal (facies dorsalis) and a costal (facies costalis). The former is divided into two fossæ by an outstanding process of triangular form, called the spina scapulæ. The attached border of this crosses the dorsal surface of the body obliquely in a direction

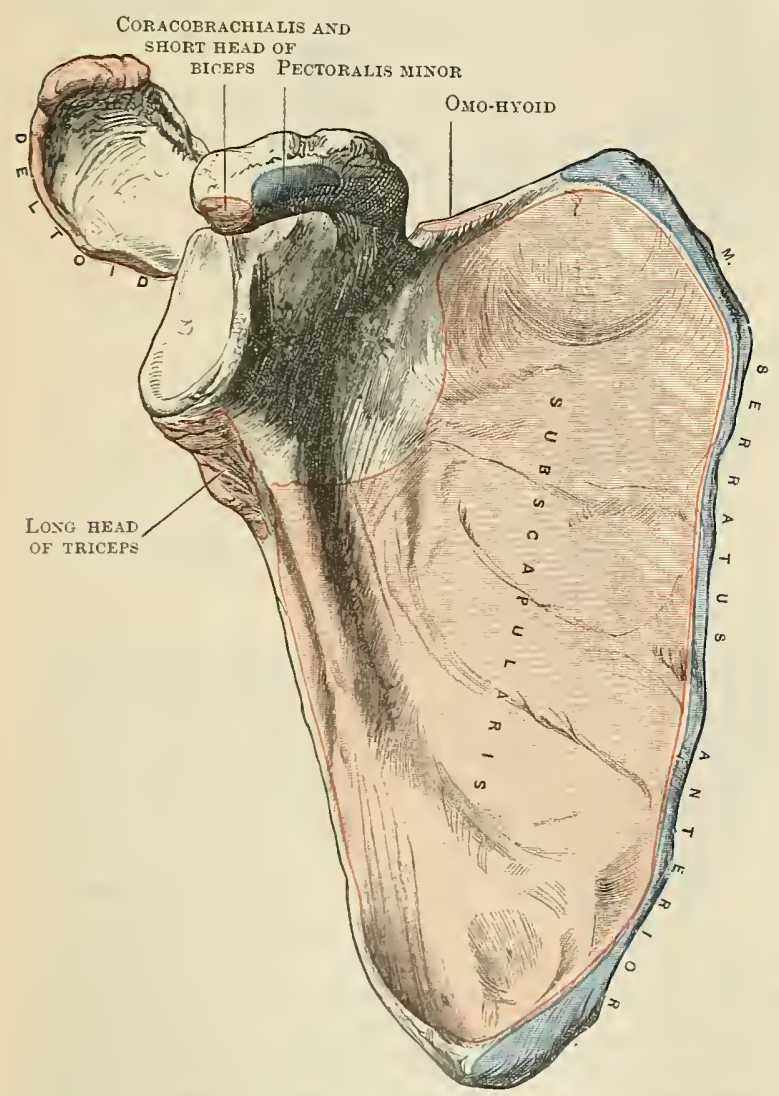

Fig. 192. - Costal Surface of the Right Scapdla with the AtTACHMENTS OF MUSCles MAPPED OUT.

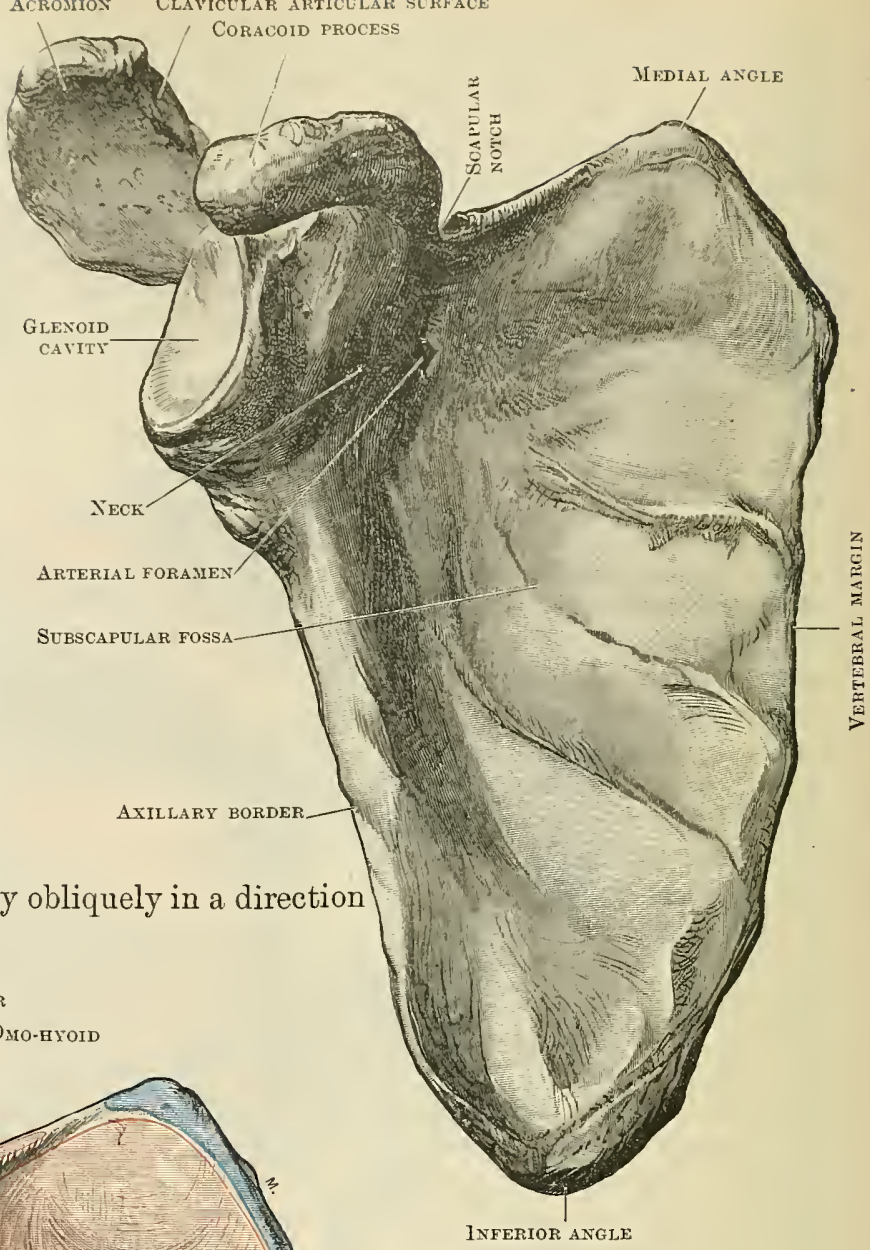

Fig. 191.-The Right Scapula SEEN FROM THE FRONT.

laterally and slightly upwards, extending from the vertebral border, near the lower limit of its upper fourth, towards the centre of the posterior glenoid edge, from which, however, it is separated by the great scapular notch, which here corresponds to the dorsal aspect of the neck. Within this notch the transverse scapular vessels and the supra-scapular nerve pass to the infra-spinous fossa. The surfaces of the spine, which are directed upwards and downwards, are concave, the upper entering into the formation of the supra-spinous fossa, which lies above it, the lower forming the upper wall of the infra-spinous fossa, which lies below it. The two fossæ are in communication 
with each other round the free lateral concave border of the spine, where that curves over the great scapular notch. The dorsal free border of the spine is subcutaneous throughout its entire length. Its upper and lower edges are strongly lipped, and serve - the superior, for the insertion of the trapezius; the inferior, for the origin of the deltoid. The intervening surface varies in width-broad and triangular where it becomes confluent with the vertebral border, it displays a smooth surface, over which the tendinous fibres of the trapezius play; narrowing rapidly, it forms a surface of varying width which blends laterally with a flattened process, the two forming a compressed plate of bone which arches across the great scapular notch above and behind, and then curves, upwards, forwards, and laterally to overhang the glenoid cavity. The medial border of this process is continuous with the upper margin of the spine, and is gently curved. The lateral border, more curved than the medial, with which it is united in front, is confluent with the inferior edge of the spine, with which it forms an abrupt bend,termed the acromial angle. The bone included between these two borders is called the acromion. Of compressed form, it much resembles the acromial end of the clavicle, with which it articulates by means of a surface (facies articularis acromii) which is placed on its medial border near its anterior extremity. The superior surface of the acromion, which is broad and expanded, is subcutaneous, and is directed upwards and dorsally, and in the normal position of the bone laterally as well. Its medial edge, where not in contact with the clavicle, has attached to it the fibres of the trapezius, whilst its lateral margin affords origin to the central part of the deltoid. At its anterior extremity it is connected with the coracoid process by means of the coracoacromial ligament. Its inferior surface is smooth and overhangs the shoulder-joint.

The supra-spinous fossa, of much less extent than the infra-spinous, is placed above the spine, the upper surface of which assists in forming its curved floor; in it is lodged the supraspinatus muscle. The scapular notch opens into it above, whilst below and laterally it communicates with the infra-spinous fossa by the great scapular notch, through which the transverse scapular artery and suprascapular nerve pass to reach the infra-spinous fossa.

The infra-spinous fossa, overhung by the spine above, is of triangular form. The axillary margin of the bone limits it in front, whilst the vertebral margin bounds it behind ; the greater part of this surface affords origin to the infraspinatus muscle, excepting a well-defined area which skirts the axillary margin and inferior angle of the bone, and which affords an attachment to the fibres of origin of the teres minor. This muscle extends along the dorsal surface of the axillary margin in its superior two-thirds, reaching nearly as high as the glenoid edge; whilst a crescentic surface, which occupies the inferior third of the axillary border and curves backward round the dorsal aspect of the inferior angle, furnishes an origin for the teres major muscle. Here also, near the inferior angle, are occasionally attached some of the fibres of the latissimus dorsi muscle.

The facies costalis (costal aspect) of the body is hollow from above downwards and from side to side, the greatest depth being in correspondence with the spring of the spine from the dorsal surface. Its medial boundary, which is formed by the anterior lipped edge of the vertebral margin, affords attachment to the fibres of insertion of the serratus anterior along the greater part of its extent. The area of insertion of this muscle is, however, considerably increased over the ventral aspects of the medial and inferior angles respectively. Running down from the head and neck above to the inferior angle below, there is a stout rounded ridge of bone, which imparts a fulness to the costal aspect of the axillary margin and increases the depth of the costal hollow; to this, as well as to the floor of the fossa, the subscapularis muscle is attached. The tendinous intersections of this muscle leave their imprint on this surface of the bone in a series of three or four rough lines which converge towards the neck.

The scapula of man is characterised by the greater proportionate length of its base or vertebral margin as compared with lower forms. This proportion is expressed by what is termed the scapular index (Appendix D). The greater size of the acromion is also a distinctive feature. The double ossification of the coracoid occurs only in mammals. It is probable that the centre for the upper and anterior part of the 
coracoid process represents the epicorncoid or precoracoid of lower forms, whilst the subcoracoid centre (metacoracoid) which assists in the formation of the glenoid carity is the reduced and restigial remains of the stout coracoid clement met with in Ornithorhynchus, which articulates with the steruum.

Nutrient Foramina.-Foramina for the passage of nutrient vessels are seen in different parts of the bone; the most constant in position is one which opens into the infra-spinons fossa, about an inch or so from the seapular notch. Others are met with on the upper and under surfaces of the spine, on the costal aspect near its deepest part, and also around the glenoid margin.

Connexions. - The scapula is not directly connected with the trunk, but articulates with the lateral end of the clavicle, in nnion with which it forms the shoulder girdle, supporting the humerns on its glenoid surface. Placed on the upper and back part of the thorax, it covers the ribs from the second to the seventh inclusive. Possessed of a wide range of movement, it alters its position according to the attitude of the limb, rising or falling, being drawn inwards or outwards, or being rotated upon itself according as the arm is moved in varions directions. These changes in position can easily be determined by recognising the altered relations of the subcutaneous and bony prominences, more especially the former, which include the spine, the acromion, and the inferior half of the vertebral border.

Ossification.--Ossification begins in the body of the cartilaginous scapula about the end of the second month of fotal life. At birth the head, neck, body, spine, and base of the coracoid process are well defined; the rertebral margin, inferior angle, glenoid cavity, acromion, and coracoid process, are still cartilaginous. The centre for the upper and anterior part of the coracoid appears in the first year, and fusion along an oblique line leading from the upper edge of the glenoid cavity to the conoid tubercle is complete about the fifteenth year. A separate centre (subcoracoid), which ultimately includes the superior part

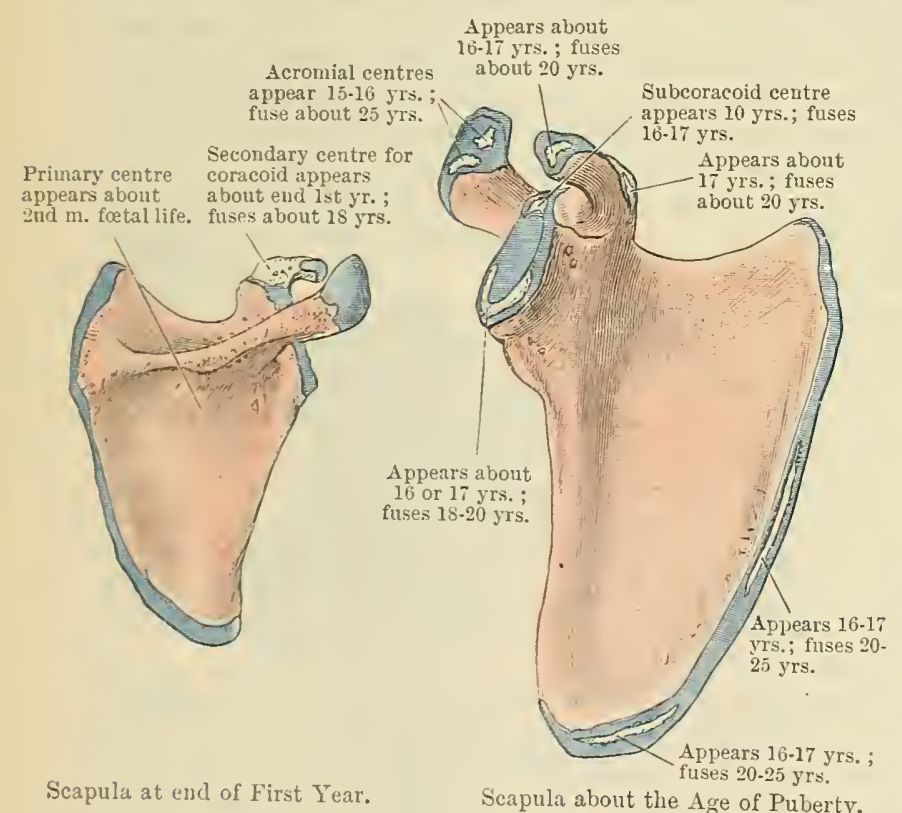

Fis: 193.-OSSIFICATION OF THE SCAPCLA. of the glenoid cavity and lateral part of the coracoid process, makes its appearance about the tenth year, and fuses with the surrounding bone about sixteen or seventeen. Up till the age of puberty the acromion remains cartilaginous; centres, two or more in number, then make their appearance, which coalesce and ultimately unite with the spine about the twenty-fifth year. Failure of union may, however, persist throughout life (see Appendix B-Variations).

Ossification commences in the cartilage in the inferior angle abont puberty, and independently and a little later, along the rertebral margin, fusion with the body occurring at from twenty to twenty-five years.

Small scale-like epiphyses make their appearance on the superior surface and at the
plate devity of the coracoid, and are completed about the twentieth year. A thin epiphysial plate develops over the inferior part of the glenoid cavity about sixteen or seventeen, fusion

\section{The Humerus.}

The humerus, or bone of the upper arm, articulates proximally with the scapula and distally with the bones of the forearm, the radius and ulna. Its proximal end comprises the head and larger and smaller tubercles; its shaft, which is longer than any of the other bones of the upper extremity, is cylindrical proximally and flattened distally. At the distal extremity, which is expanded to form the epicondyles on either side, it supports the trochlear and capitular articular surfaces for the ulna
and radius respectively. 
The proximal extremity is the thickest and stoutest part of the bone. The caput humeri (head), which forms about one-third of a spheroid and is covered with

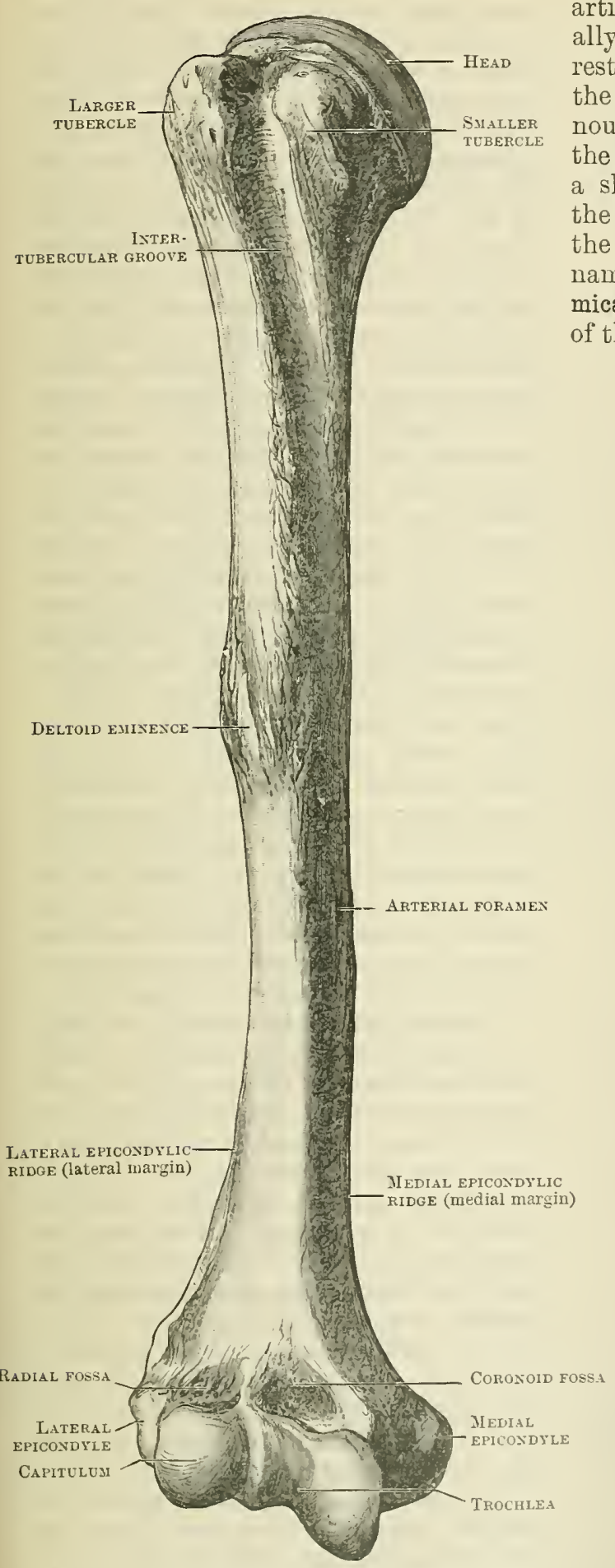

Fig. 194.-ANterior VilN of the Right Humerus. articular cartilage, is directed proximally, medially, and slightly dorsally, and rests in the glenoid cavity of the scapula; the convexity of its surface is most pronounced in its posterior half. Separating the head from the tubercles laterally is a shallow groove, which fades away on the surface of the boue which supports the articular part inferiorly. This is named the collum anatomicum (anatomical neck) and serves for the attachment of the capsule of the shoulder-joint. The

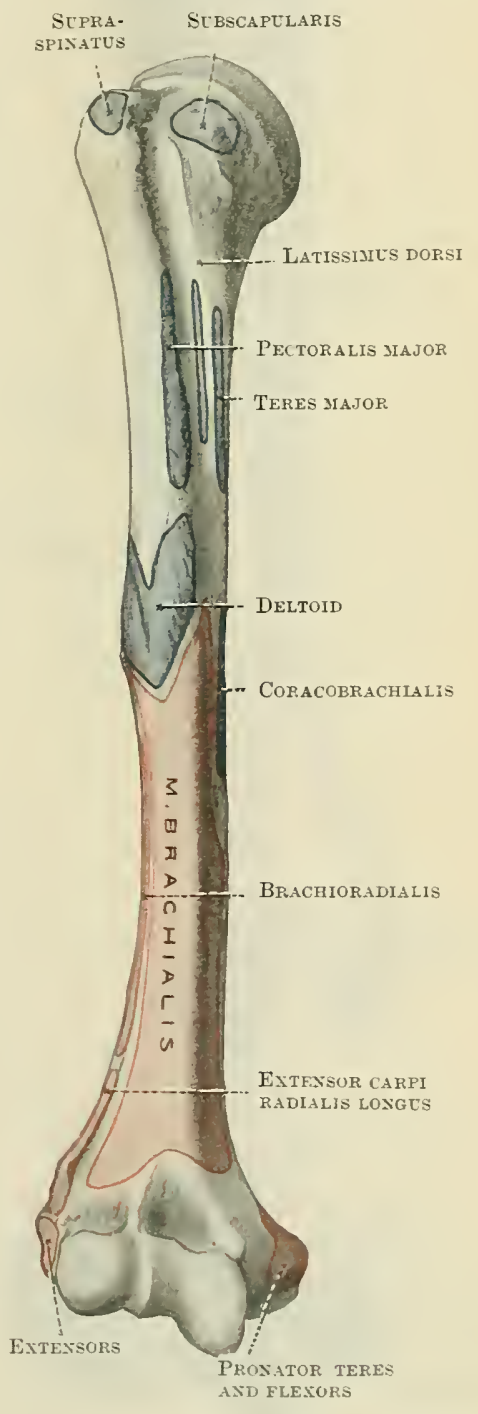

Fig. 195. - The Axterior SURfaces (1F THE HUMERUS MITH MesctlaR ATTICHMEXTS MAPPED OCT.

articular edge of the gronve opposite the smaller tubercle is usually potehed for the attachment of the superior gleno-humeral ligament. The tuberculum majus (larger 
tubercle) abuts on the lateral side of the head and becomes contiuuous with the shaft distally. Its proximal surface forms a quadraut, which is subdivided into

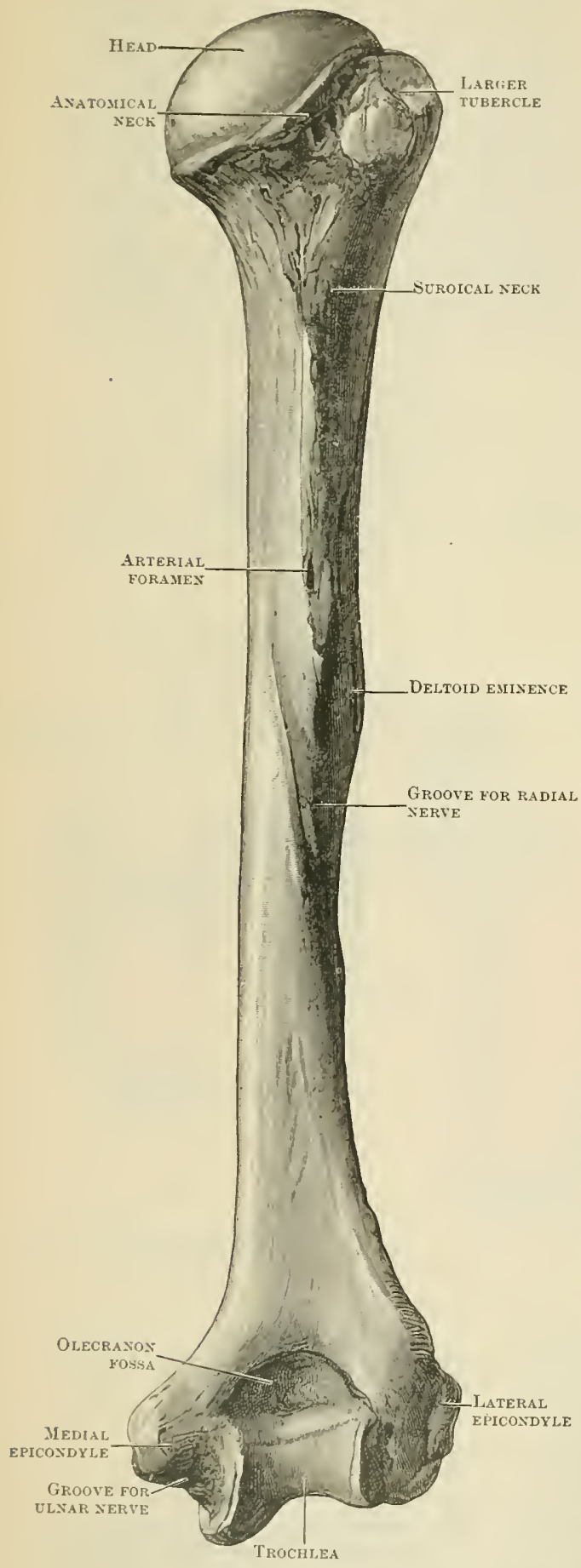

Fig. 196.-Posterior SUrface of the Right Humerus. three more or less smooth areas of unequal size. Of these the proximal and anterior is for the insertion of the supraspinatus muscle, the middle for the infraspinatus, whilst the most distal and posterior serves for the insertion of the teres minor muscle. The lateral surface of this tubercle, which bulges beyond the line of the shaft, is rough and pierced by numerous vascular foramina. Anteriorly the larger tubercle is separated from the tuberculum minus (smaller tubercle) by a well-defined furrow, called the sulcus intertubercularis (intertubercular groove) (O.T. bicipital groove). The transverse humeral ligament stretches across the groove between the two tubercles, thus converting the groove into a canal in which the tendon of the long head of the biceps and the ascending articular branch of the anterior circumflex artery of the humerus are lodged. The smaller tubercle lies in front of the lateral half of the head; it forms a pronounced elevation, which fades into the shaft distally. The surface of this tubercle is faceted above and in front for the insertion of the subscapularis muscle, whilst laterally it forms the prominent medial lip of the inter-tubercular groove. Distal to the head and tubercles the shaft of the bone rapidly contracts, and is here named the collum chirurgicum (surgical neck) owing to its liability to fracture at this spot.

The corpus humeri (shaft, or body) is cylindrical in its proximal half. On it the inter-tubercular groove may be traced distally and slightly medially, along its anterior surface. The edges of the groove, which are termed its lips, are confluent proximally with the larger and smaller tubercles, respectively. Here they are prominent, and form the cristæ tuberculi majoris et minoris (crests of the larger and smaller tubercles). Distally the lips of the intertubercular groove gradually fade away, the medial more rapidly than the lateral, which latter may usually be traced distally to a rough elevation placed on the lateral anterior surface of the shaft about its middle, called the deltoid tuberosity. Into the lateral lip of the intertubercular groove are inserted the fibres of the pectoralis major muscle; hence it is sometimes described as the pectoral ridge. To the floor of the groove the latissimus dorsi is attached; whilst the teres major muscle is inserted into the medial lip. 
The tuberositas deltoidea (deltoid tuberosity) to which the powerful deltoid muscle is attached, is a rough, slightly elevated V-shaped surface, placed on the lateral anterior surface of the shaft about its middle. The anterior limb of the $V$ is parallel to the axis of the shaft, and is continuous proximally with the lateral lip of the intertubercular groove, whilst the posterior limb of the $V$ winds obliquely round the lateral anterior surface of the bone towards the posterior surface, where it becomes continuous with a slightly elevated and occasionally rough ridge which leads proximally along the posterior of the bone towards the larger tubercle; from this latter ridge the lateral head of the triceps muscle arises.

The medial anterior surface of the shaft about its middle inclines to form a rounded border, on which there is often a rough linear impression marking the insertion of the coracobrachialis muscle. Distal to this the shaft becomes compressed and expanded laterally, ending distally on either side in the epicondyles. Its surfaces are now anterior and posterior, being separated from each other by two clearly defined borders, the medial and lateral margins, or epicondylic ridges. Of these, the medial (margo medialis) is the more curved and less prominent, and is continuous proximally with the surface to which the coracobrachialis is attached, whilst distally it ends by blending with the medial epicondyle. The lateral (margo lateralis) is straighter and more projecting; its edge is usually distinctly lipped. Confluent with the lateral epicondyle distally, it may be traced proximally to near the deltoid tuberosity, where it turns backwards more or less parallel to the posterior oblique border of that impression, to be lost on the posterior surface of the shaft. The interval between this border and the deltoid eminence is thus converted into a shallow oblique furrow, which winds round the lateral surface of the bone just distal to its middle; this constitutes the sulcus $\mathrm{n}$. radialis (groove for the radial nerve) along which the radial (O.T. musculo-spinal) nerve, together with the profunda brachii artery, passes from the back to reach the front of the arm. To the epicondylic ridges are attached the intermuscular septa, whilst the lateral in its proximal two-thirds furnishes a surface for the origin of the brachioradialis muscle, and in its distal third for the extensor carpi radialis longus muscle.

The anterior surface of the distal half of the shaft is of elongated triangular form, the base corre-

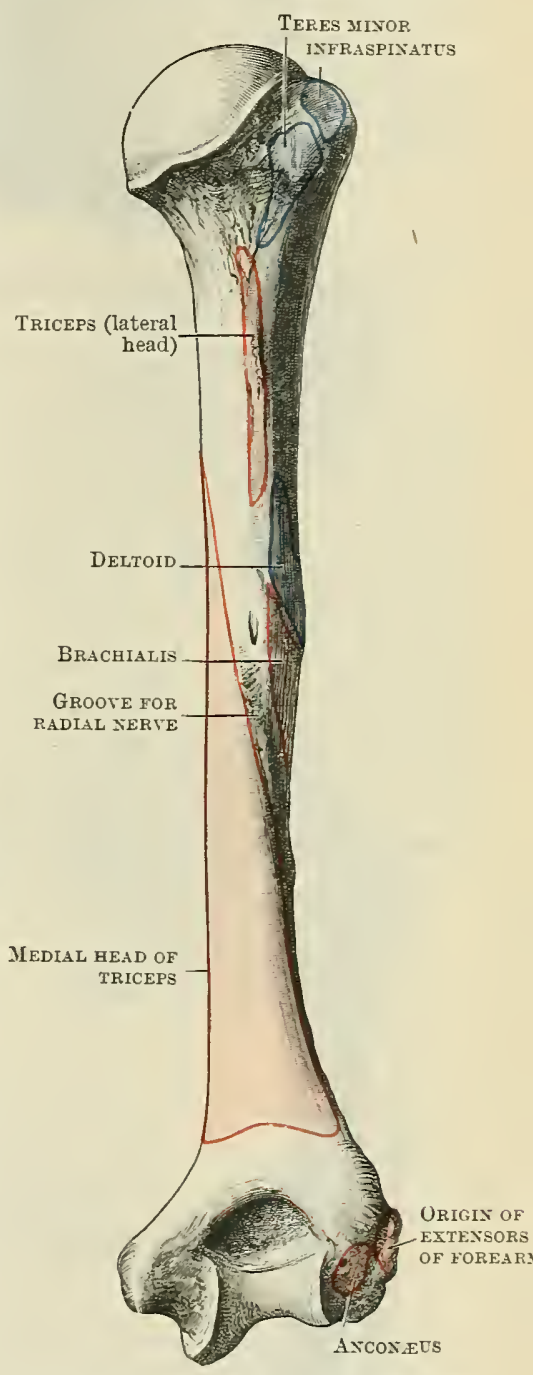

Fig. 197.-Posterior SURFace of the Right HUMERUS WITH ATTaChMENTS OF MUSCLES MAPPED OUT. sponding to the distal extremity of the bone. Running down the centre of this is a broad, rounded, elevated ridge, most pronounced proximally, where it joins the deltoid tuberosity, and sloping on either side towards the epicondrlic ridges; it is into the lateral of these slopes that the groove for the radial nerve flows. Distally the elevated surface spreads out, and becomes confluent with the epicondyles. The epicondylus medialis (medial epicondyle) is the more prominent of the two, and furnishes a surface for the origin of the pronator teres, and the superficial flexor muscles of the forearm. The epicondylus lateralis (lateral epicondyle), stunted and but little projecting, serves for the attachment of the common tendon of origin of the extensor muscles. The brachialis muscle has an extensive origin from the anterior surface of the distal half of the shaft, including between its proximal slips the insertion of the deltoid. 
The posterior surface of the distal half of the shaft is smooth and rounded from

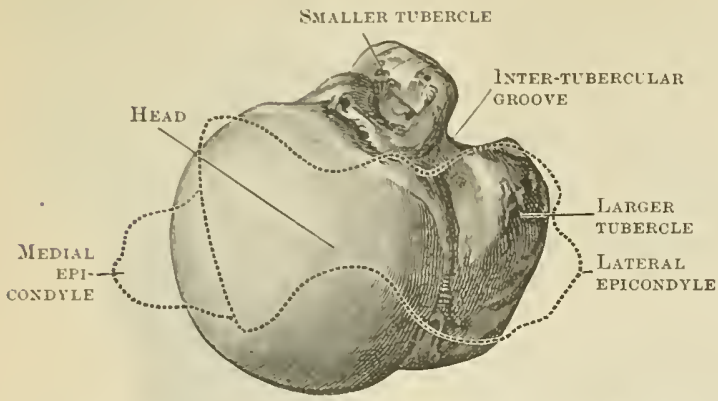

Fig. 19S.-Proximal Aspect of the Head of tiHe Right HUMERUS (with the outline of the distal extremity in relation thereto shown in dotted line).

The distal extremity of the humerus is furnished with two articular surfaces (the condyles proper), the lateral of which, called the capitulum, for articulation with the proximal surface of the head of the radius, is a rounded eminence, placed on the anterior surface and distal border, but not extending on to the posterior surface of the distal end of the bone. Proximal to it, in front, there is a shallow depression (fossa radialis), into which the margin of the head of the radius sinks when the elbow is strongly flexed. A shallow groove separates the capitulum medially from the

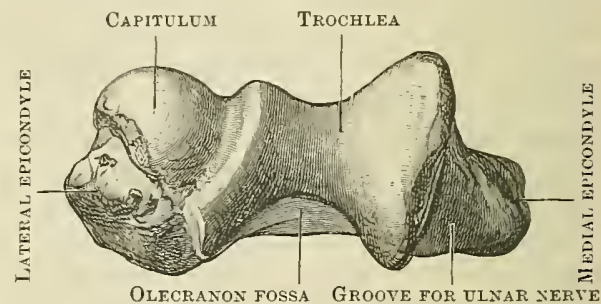

Fig. 199.-Distal Aspect of the Distal Ex-. TREMTt of the Right HuMerus.

trochlea, which is a grooved articular surface, with prominent edges winding spirally

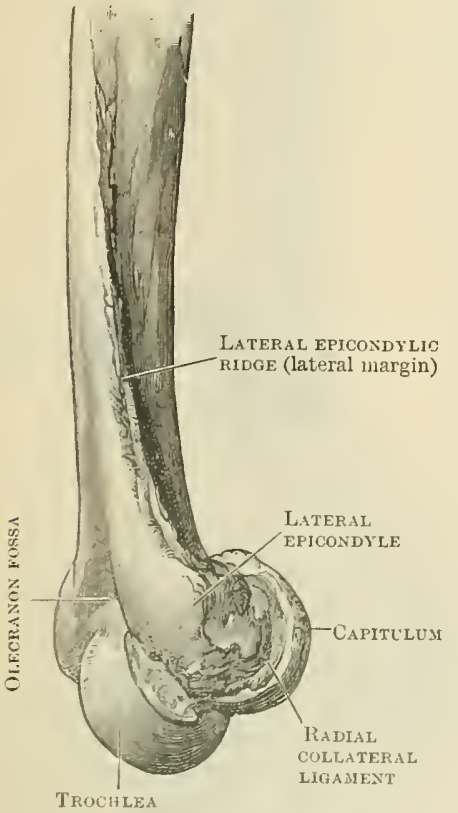

Fig. 200.-The Distal FND of The Right HUMERUS SEEN FrOM THE Lateral Side. radial and coronoid fossæ in front attached to the proximal margins of the the proximal border and later foment is connected with spiral curves from behind forwards and medially, and its axis is slightly oblique to the long axis of the shaft. The medial lip is the more salient of the two, and forms a sharp and well-defined margin to the articular area; its cartilage-covered surface is slightly convex. Thelateral lip, much less prominent, is rounded off into the articular groove which separates it from the capitulum, posterior to which, however, it is carried up as a more or less definite crest. It is by means of the trochlea that the humerus articulates with the semilunar notch of the ulna. On the anterior surface of the bone, immediately proximal to the trochlea, is a depression-the fossa coronoidea (coronoid fossa) - into which the coronoid process of the ulna slips in flexion of the joint, whilst in a corresponding position on the posterior aspect of the distal end of the shaft there is a hollow, called the fossa olecrani (olecranon fossa), just proximal to the trochlea posteriorly. Into this the olecranon process sinks when the elbow is extended. The two fossæ are separated by a thin translucent layer of bone which may be deficient, thus leading to the formation of a foramen between the two hollows in the macerated bone. The anterior part of the capsule of the elbowal edges of the olecranon fossa behind. The strong 
ulnar and radial collateral ligaments of the elbow joint are attached proximally to the medial and lateral epicondyles respectively. The proportionate length of the humerus to the body height is as 1 is to $4 \cdot 93-5 \cdot 25$.

Nutrient foramina are usually to be seen, one at or near the surface for the insertion of the coraco-brachialis, the other usually close to the posterior border of the deltoid tuberosity; both have a distal direction. Numerous vascular foramina are scattered along the line of the anatomical neck, the larger ones being situated near the proximal end of the inter-tubercular groore. The vascularity of the bone is here intimately associated with the activity of its growth in this situation.

Connexions. - The humerus articulates proximaliy with the scapula, and distally with the radius and ulna. Embedded, as the humerus is, in the substance of the arm, its shaft and head are surrounded on all sides. It is only at its distal part that it comes into direct relation with the surface, the medial epicondyle forming a characteristic projection on the medial side of the elbow; whilst the lateral epicondyle, less prominent, and the lateral epicondylic ridge can best be recognised when the elbow is bent.

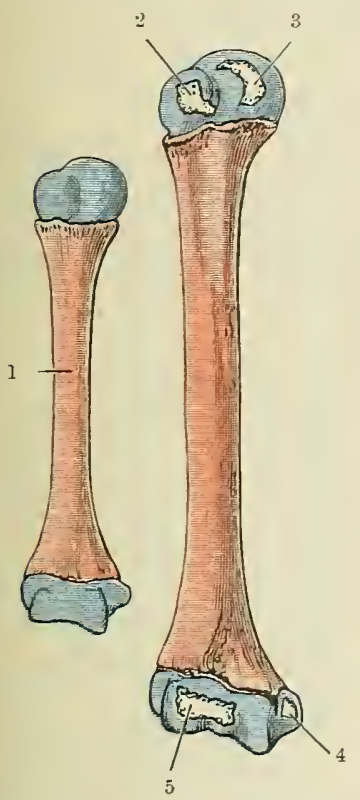

At birth. About 5 years.
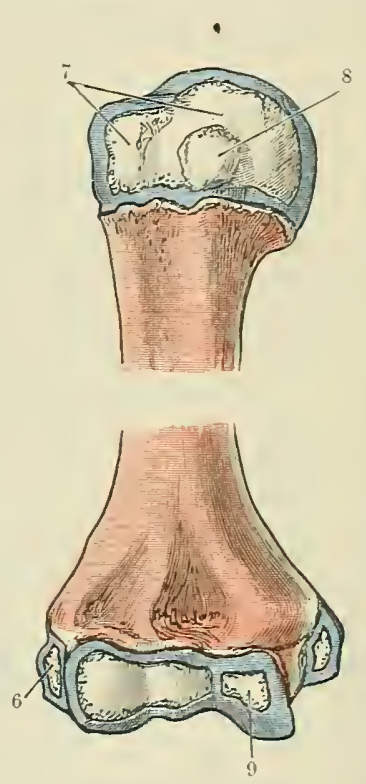

About 12 jears.
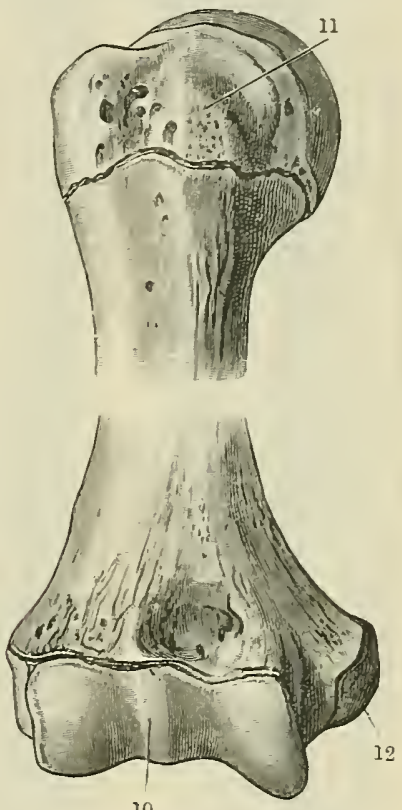

10

Ahout 16 years.

Fig. 201.-OSsification of the Huneres.

1. Appears early in 2nd month foetal life.

2. For larger tubercle, appears 2 to 3 years.

3. For head, appears within first 6 months.

4. For medial epicondyle, apyears about 5 years.

5. For capitnlum, appears 2 to 3 years.

6. Appears about 12 years.
7. Centres for head and larger tubercle coalesce about
5 years. 5 years.

Sexual differences.-Dwight (American Journ. of Anat. vol. iv. 1904) has shown that the head of the humerus in the female is proportionately smaller than that of the male.

Ossification. - At birth the shaft of the humerus is usually the only part of the bone ossified, if we except the occasional presence ( 22 per cent) of an ossific centre in the head. (H. R. Spencer, Journ. Anat. and Physiol. vol. xxv. p. 552.) The centre for the shaft makes its appearance early in the second month of intra-uterine life. Within the first six months after birth a centre usually appears for the head; this is succeeded by one for the larger tubercle during the second or third year. These soon coalesce; and a third centre for the smaller tubercle begins to appear about the end of the third year, or may be delayed till the fourth or fifth year. These three centres are all blended by the seventh year, and form an epiphysis, which ultimately unites with the shaft about the age of twenty-five. It may be noticed that the proximal end of the diaphysis is conical and pointed in the centre, over which the epiphysis fits as a cap, an arrangement which thus tends to prevent its displacement before union has occurred. The first centre to appear in the distal extremity is that for the capitulum about the second or third year. This extends medially, and forms the lateral half.of the trochlear surface, the centre for the medial half not making its appearance till the eleventh or twelfth year. 
Separate centres are dereloped in commexion with the epicondyles; that for the lateral appears about the twelfth year, and, rapidly coalescing with the centres for the capitulum and trochlea, forms an epiphysis, which unites with the shaft about the sixteenth or

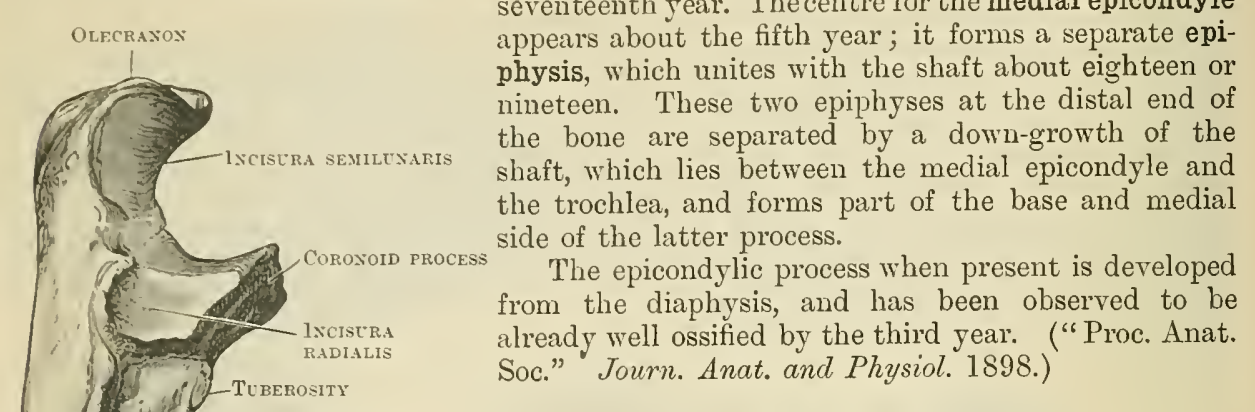

The Ulna.

Of the two bones of the forearm, the ulna, which is placed medially, is the longer. It consists of a large proximal extremity supporting the olecranon and the coronoid process; a body or shaft tapering distally; and a small rounded distal end called the head.

Proximal Extremity. - The olecranon lies in line with the shaft. Its dorsal surface, more or less triangular in form, is smooth and subcutaneous and covered by a bursa. Its proximal aspect, which forms with the posterior surface a nearly rectangular projection-the tip of the elbow furnishes a surface for the insertion of the tendon of the triceps brachii muscle, together with a smooth area which is overlain by the same tendon, but separated from it by a bursal sac. To the volar crescentic border of this process are attached the fibres of the posterior part of the capsule and a portion of the ulnar collateral ligament of the elbow-joint. The volar surface is articular, and enters into the formation of the semilunar notch.

The processus coronoideus (coronoid process) is a bracket-like process, which juts forwards from the volar and proximal part of the shaft, and is fused with the olecranon proximally. By its proximal surface it enters into the formation of the semilunar notch, whilst its volar aspect, which is separated from its proximal side by a sharp irregular margin, slopes distally and dorsally to become confluent with the volar surface of the shaft. Of triangular shape, this area, which is rough and tubercular, terminates inferiorly in an oval elevated tubercle (tuberositas ulnæ), into which the tendon of the brachialis muscle is inserted. Of the lateral margins of the coronoid process, the medial is usually the better defined. Proximally, where it joins the proximal border, there is generally a salient tubercle, to which one of the heads of origin of the flexor digi-

Fig. 202.-The Right ULNA AS VIEWED FROM THE LATERAL SIDE.

torum sublimis muscle is attached, whilst distal to this point the medial border furnishes origins for the pronator teres, and occasionally for the flexor pollicis 
longus muscles, from above downwards. The smooth medial surface of the coronoid process merges with the olecranon dorsally, and with the medial surface of the shaft distally.

The incisura semilunaris (O.T. greater sigmoid cavity), for articulation with the trochlea of the humerus, is a semicircular notch, the proximal part of which is formed by the volar surface of the olecranon, whilst distally it is completed by the proximal surface of the coronoid process. Constricted towards its deepest part by the notching of its lateral borders, the articular surface is occasionally crossed by a narrow impression which serves to define the olecranon proximally from the coronoid distally. The articular area is divided into a medial portion, slightly concave transversely, and a lateral part, transversely convex to a slight degree, by a longitudinal smooth ridge which extends from the most prominent part of the border of the olecranon proximally to the most outstanding point of the coronoid process distally. The margins of the semilunar notch are sharp and well defined, and serve, with the exception of the area occupied by the radial notch, for the attachment of the capsule of the elbow-joint.

The radial notch (O.T. lesser sigmoid cavity), placed on the radial side of the coronoid process, is an oblong articular surface for the reception of the head of the radius. It encroaches on the distal and lateral part of the semilunar notch, so as to narrow it considerably. Separated from it by a rectangular curved edge, it displays a surface which is plane from above downwards, and concave from before backwards. Its volar extremity is narrower and more pointed than its dorsal, and becomes confluent with the anterior edge of the coronoid process, at which point the annular ligament, which retains the head of the radius in position, is attached in front. Its dorsal border, wider and more outstanding, lies in line, and is continuous with the interosseous margin of the shaft. Dorsal to this border, the annular ligament is attached posteriorly.

The shaft of the ulna (corpus ulnæ), which is nearly straight, or but slightly curred, is stout and thick proximally,

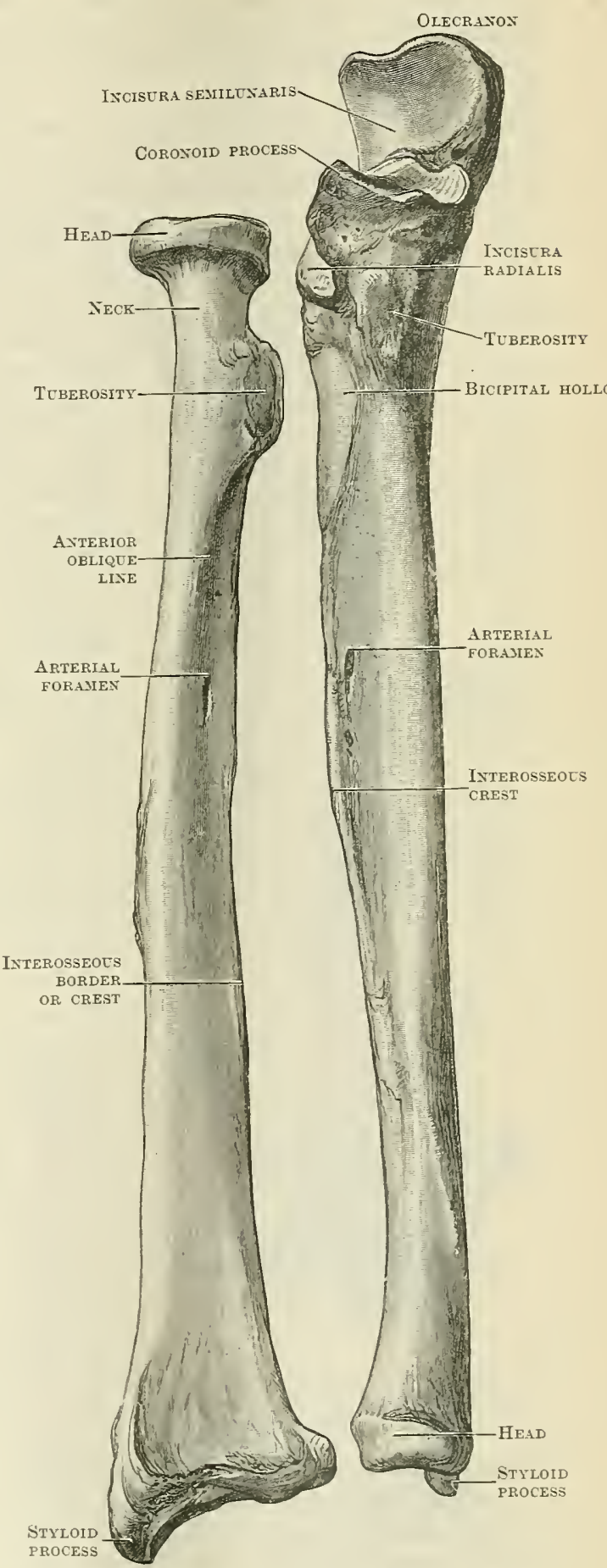

Fig. 203. - The Right Radius axd Ulya seey FrOM THE TOLAR ASPECT. gradually tapering towards its distal extremity. It may be divided into three surfaces, a volar (O.T. anterior), a dorsal or posterior, and a medial, by three well-defined borders, an interosseous crest, a dorsal margin, which latter is 
subcutaneous throughout its whole length, and a volar margin (O.T. anterior border).

The crista interossea (interosseous crest) is crisp and sharp in the proximal three-fourths of the shaft, but becomes faint and ill-defined in the distal fourth. To this, with the exception only of the part which forms the dorsal boumdary of the hollow in which the tuberosity of the radius is disposed when the two bones are articulated, is attached the interosseous membrane which connects the two bones of the forearm. The margo dorsalis (dorsal margin), of sinuous outline, curving laterally above, and slightly medially below, is continuous

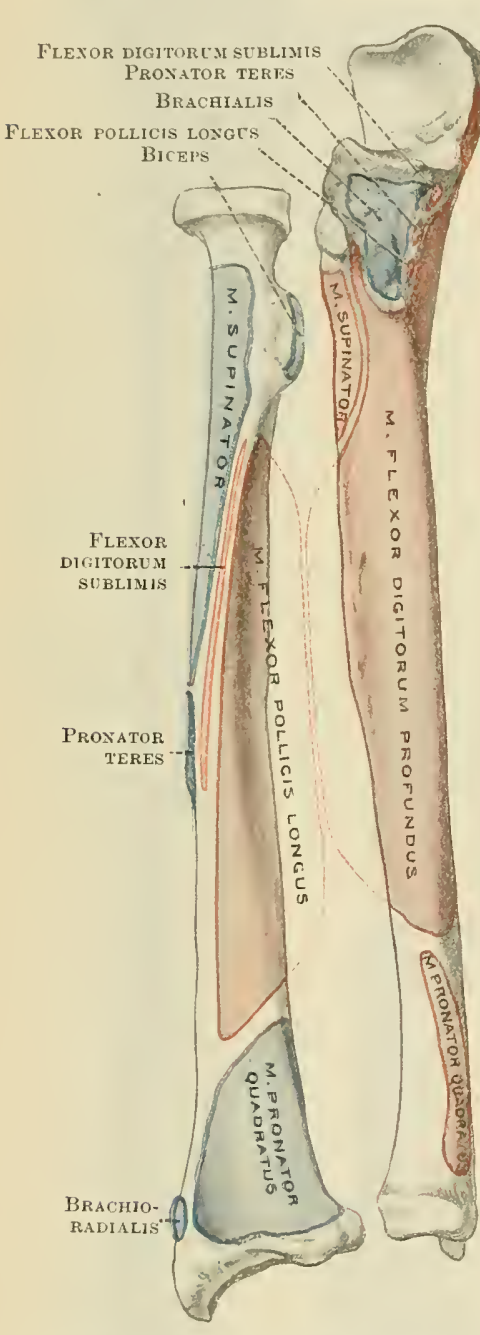

Fig. 204.- Tolar Aspect of Bones of THE Right Foreari With MUSCULAR ATTACHMENTS MAPPED OUT. proximally with the triangular subcutaneous area on the back of the olecranon, being formed by the confluence of the borders which bound that surface; well marked above, it becomes faint and more rounded below, but may be traced distally to the dorsal surface of the base of the styloid process. To this border is attached an aponeurosis common to the flexor carpi ulnaris, extensor carpi ulnaris, and flexor digitorum profundus muscles. A noteworthy feature in connexion with this part of the shaft is the fact that it is subcutaneous, and can easily be felt beneath the skin throughout its whole length.

The volar or anterior surface corresponds to the front and medial side of the shaft. It is described as consisting of two surfaces, a volar and a medial, which are separated by a rounded volar margin, which extends from the tuberosity proximally towards the styloid process distally. The prominence of this ridge varies in different bones, being well marked in bones of a pronounced type, but corresponding merely to the rounding of the surfaces in poorly developed specimens. The volar aspect of the bone affords an extensive origin to the flexor digitorum profundus muscle, which clothes its volar and medial surfaces in its proximal threefourths, reaching as far back as the dorsal border, and extending proximally as high as the medial side of the olecranon process. Immediately distal to the radial notch there is a hollow triangular area, limited dorsally by the proximal part of the interosseous crest, and defined in front by an oblique line which extends distally and backwards from the lateral margin of the coronoid process. In this hollow the tuberosity of the radius rests when the forearm is in the prone position, and to its floor are attached the fibres of origin of the supinator muscle. The distal fourth of the shaft is crossed by the fibres of the pronator quadratus muscle, which derives its origin from a more or less well-defined crest, which winds spirally distally and backwards towards the volar surface of the root of the styloid process, and is continuous proximally with the volar margin.

The dorsal surface of the shaft lies dorsally between the dorsal margin and the interosseous crest. At its proximal part it is placed behind the semilunar and radial notches, extending on to the lateral side of the olecranon. Here an area corresponding to the proximal third of the length of the bone is marked off distally by an oblique ridge which leaves the interosseous crest about an inch or more distal to the dorsal edge of the radial notch. Into this somewhat triangular surface the fibres of the anconæus are inserted. Distal to this the 
posterior surface is subdivided by a faint longitudinal ridge, the bone between which and the interosseous crest furnishes origins for the abductor pollicis longus, extensor pollicis longus, and extensor indicis proprius muscles, in order proximodistally. The surface of bone between the dorsal margin and the afore-mentioned longitudinal line is smooth and overlain by the extensor carpi ulnaris muscle, which does not arise from it.

The distal extremity of the ulna presents a rounded head (capitulum ulnæ), from which, on its medial and dorsal aspect, there projects distally a cylindrical pointed process called the styloid process. To the extremity of this latter is attached the ulnar collateral ligament of the carpus, whilst on the volar aspect it has connected with it the antero-medial portion of the capsule of the wrist-joint. The antero-lateral half of the circumference of the head is furnished with a smooth narrow convex articular surface, which fits into the ulnar notch of the radius. Its distal surface, flat and semilunar in shape, and separated from the root of the styloid process by a well-marked groove, rests on the upper surface of the triangular articular disc of the wrist, the apex of which is attached to the groove just mentioned. The margins of the head, to the volar side and dorsal to the radial articular surface, have attached to them the volar and dorsal inferior radioulnar ligaments. The dorsal and medial surface of the styloid process is channelled by a groove which separates it from the dorsal surface of the head, and extends proximally some little way upon the dorsal surface of the distal end of the shaft. In this is lodged the tendon of the extensor carpi ulnaris muscle. The proportionate length of the ulna to the body height is as 1 is to $6 \cdot 26-6 \cdot 66$.

Nutrient Foramina.-A foramen, having a proximal direction, for the nutrient artery of the shaft opens on the volar surface of the bone from two to three inches distal to the tuberosity. Vascular canals of large size are seen proximal and dorsal to the radial notch, just dorsal to the notched lateral border of the semilunar notch. At the distal end of the bone similar openings are seen in the groove between the styloid process and the distal articular surface of the head.

Connexions. - The ulna articulates proximally with the trochlea of the humerus. On the lateral side it is in contact with the radins at both proximal and distal ends, the proximal radioulnar articulation being formed by the head of the radius and the radial notch of the nIna, the distal radio-ulnar joint comprising the head of the nlna, which fits into the ulnar notch of the radius. Between these two joints the shafts of the bones are united by the interosseons membrane. The distal surface of the head of the ulna does not articulate with the carpus, but rests on the proximal surface of the interposed articular disc. The ulna is superficial throughout its entire extent. Superiorly the olecranon process can be readily recognised, particularly when the elbow is bent, as in this position the olecranon is withdrawn from the olecranon fossa of the humerus in which it rests when the joint is extended. Distal to this the subcutaneous triangular area on the back of the olecranon can be easily determined, and from it the posterior border of the bone can readily be traced along the line of the "nlnar furrow" to the styloid process. With the hand supine this latter process can be felt to the medial side and slightly behind the wrist. When the hand is pronated, the distal end of the radius rolls round the distal extremity of the ulna, and the antero-lateral surface of the head of the latter bone now forms a wellmarked projection on the dorsum of the wrist in line with the cleft between the little and ring finger's.

Ossification.-The ulna is ossified from one primary and two or more secondary centres. The centre for the shaft appears early in the second month of foetal life. At birth the shaft and a considerable part of the proximal extremity, including the coronoid process, are ossified, as well as part of the distal extremity. The olecranon and

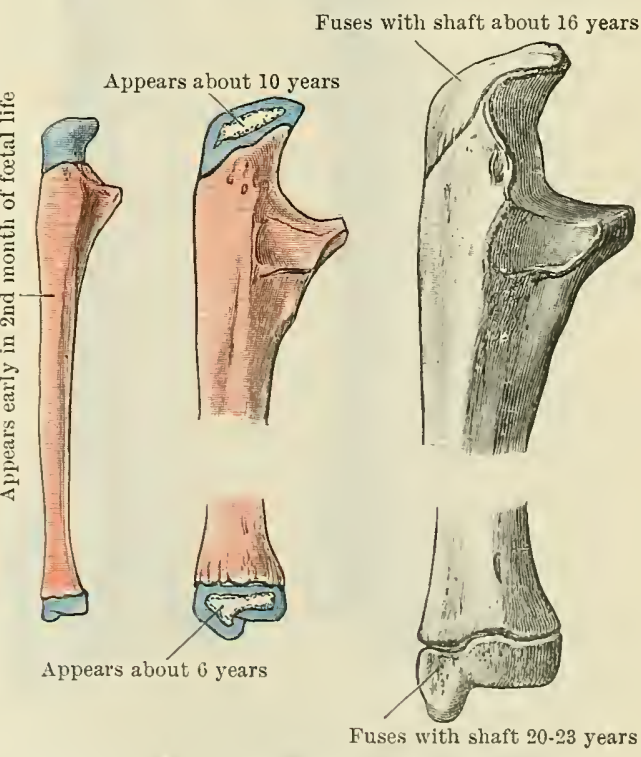

At Birth. About 12 years. About 16 years. the distal surface of the head and the styloid process are cartilaginous. About ten years of age a secondary centre appears in the cartilage at the proximal end of the bone, and 
forms an epiphysis which unites with the shaft about sixteen. In this connexion Fawcett (Proc. Anat. Soc. Great Britain and Ireland, 1904, p. xxrii) has described the occurrence

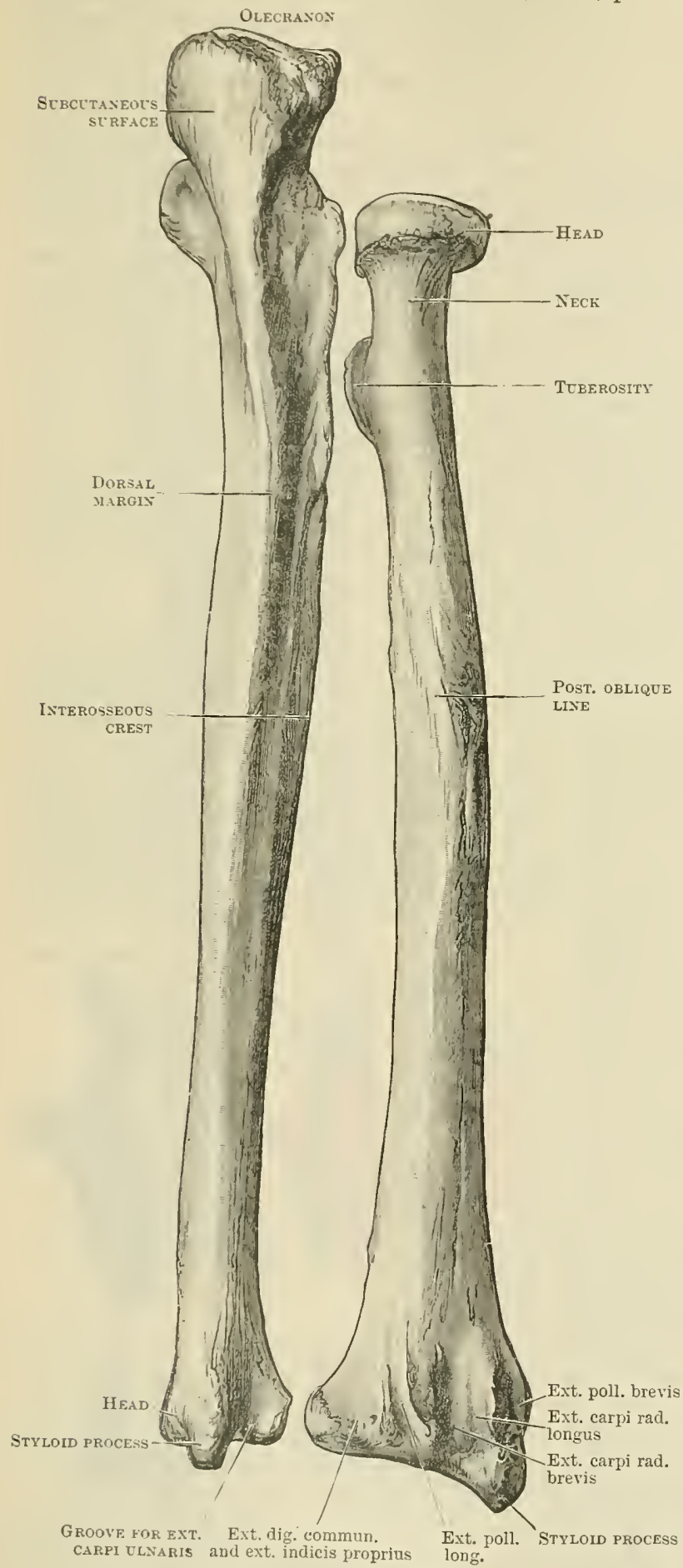

Fig. 206.-The Right Rudius and Ulia seen from the Dorsal. ASPECT. of two ossific centres in the olecranon. One, the more rolar, the "beak centre," enters into the formation of the proximal end of the articular surface of the semilunar notch, the other centre, not in any way forming it. A scale-like centre appears in the cartilage of the head about the sixth year, from which the distal surface of that part of the bone is developed, and by the extension of which the styloid process is also ossified; this epiphysis does not uuite with the shaft till the twentieth or twenty-third year. Independent centres for the styloid process and for the extreme edge of the olecranon have also been described. The student may here be warned that the epiphysial line between the shaft and superior or olecranon epiphysis does not correspond to the constricted part of the semilunar notch, but lies considerably above it.

\section{The Radius.}

The radius, or lateral bone of the forearm, is shorter than the ulna, with which it is united on the medial side. Proximally it articulates with the humerus, and distally it supports the carpus. It consists of a head, a neck, a tuberosity, a shaft, and an expanded distal extremity. The shaft is narrow proximally, but increases in all its diameters distally.

Proximal Extremity. - The capitulum (head) is disc-shaped and provided with a shallow concave surface (fovea capituli radii) proximally for articulation with the capitulum of the humerus. The circumference of the head (circumferentiaarticularis) is smooth and is embraced by the annular ligament. On the medial side it is usually much broader, and displays an articular surface, plane in the proximo-distal direction, 
which rolls within the radial notch of the ulna in the movements of pronation and supination. The character of the lateral half of the circumference differs from the medial, in being narrower, and rounded from above downwards.

The collum radii (neck) is the constricted part of the shaft which supports the head, the overhang of the latter being greatest towards the lateral and dorsal side. Distal to the neck, on the medial side, there is an outstanding oval prominence, the tuberositas radii (radial tuberosity). The dorsal part of this is rough for the insertion of the biceps tendon, whilst the volar half is smooth and covered by a bursa which intervenes between it and the tendon.

The shaft (corpus radii), which has a lateral curve and is narrow proximally and broad distally, is wedge-shaped on section. The edge of the wedge forms the sharp medial interosseous crest of the bone (crista interossea), whilst its base corresponds to the thick and rounded lateral border over which the volar or anterior surface becomes confluent with the dorsal or posterior surface.

The interosseous crest, faint proximally where it lies in line with the dorsal margin of the tuberosity, becomes sharp and prominent in the middle third of the bone. Distal to this it splits into two faint lines, which lead to either side of the ulnar notch on the distal end of the bone, thus including between them a narrow triangular area into which the deeper fibres of the pronator quadratus muscle are inserted. To this crest, as well as to the clorsal of the two divergent lines, the interosseous inembrane is attached.

The lateral surface (once described as the lateral border) is thick and rounded proximally, but becomes thinner and more prominent distally, where it merges with the base of the styloid process. About its middle the anterior and posterior oblique lines become confluent with it, and here, placed between them, is a rough elongated impression which marks the insertion of the pronator teres muscle. Proximal to this, and on the lateral surface of the neck, the supinator muscle is inserted, whilst distally this surface is overlain by the tendons of the brachio-radialis and the extensor carpi radialis longus and brevis muscles.

The volar or anterior surface

ExTENSOR DIGITORUM COMHUNIS

ABDUCTOR POLLICIS LOXGUS AND EXTEXSOR POLLICIS BREFIS

AND EXTENSOR INDICIS PROPRIUS

Fig. 207.-Dorsal Aspect of Bones of Right ForeARM WTTH ATTACHMENTS OF MCSCLES MAPPED OCT. (facies volaris) is crossed obliquely by a line which runs from the tuberosity proximally, distally, and laterally towards the middle of the lateral

surface of the shaft. This, often called the anterior oblique line, serves for the attachment of the radial head of origin of the flexor digitorum sublimis muscle. Proximal to it, the volar aspect of the bone has the fibres of the supinator muscle inserted into it, whilst distally and medial to it, extending as far distally as the distal limit of the middle third of the bone, is an extensire surface for the origin of the flexor pollicis longus muscle. In the distal fourth of the bone, where the rolar aspect of the shaft is broad and flat, there is a surface for the insertion of the pronator quadratus muscle, which also extends dorsally to the interosseous ridge.

The dorsal or posterior surface (facies dorsalis) is also crossed by an oblique line, less distinct than the anterior. This serves to define the proximal 
limit of the origin of the abductor pollicis longus muscle. Proximal to this, the dorsal aspect of the neck and proximal part of the shaft is overlain by the fibres of the supinator muscle which become attached to this surface of the bone in its lateral half. Distal to the posterior oblique line the dorsal surface in the proximal part of its medial half gives origin to the abductor pollicis longus and the extensor pollicis brevis muscles in that order proximo-distally.

The distal extremity, which tends to be turned slightly forward, has a somewhat triangular form. Its distal carpal articular surface, concave from before backwards, and slightly so from side to side, is divided into two facets by a slight antero-posterior ridge, best marked at its extremities where the volar and dorsal margins are notched; the lateral of these areas, of triangular shape, is for articulation with the navicular, whilst the medial, quadrilateral in form, is for the os lunatum. The volar border, prominent and turned forward, is rough at its edge, where it serves for the attachment of the volar part of the capsule of the wrist-joint. The dorsal border is rough, rounded, and tubercular, and is grooved by many tendons; of these grooves the best marked is one which passes obliquely across its dorsal surface. This is for the tendon of the extensor pollicis longus muscle. The lateral lip of this groove is often very prominent, and forms an outstanding tubercle. To the medial side of this oblique groove there is a broad shallow furrow in which the tendons of the extensor digitorum communis and extensor indicis proprius muscles are lodged, whilst to its lateral side, and between it and the styloid process, there is another broad groove, subdivided by a faint ridge into two, for the passage of the tendons of the extensor carpi radialis brevis medially and the extensor carpi radialis longus laterally. The styloid process lies to the lateral side of the distal extremity; broad at its base, it becomes narrow and pointed distally where by its medial cartilage-covered surface it forms the summit of the distal triangular articular area. The lateral surface of this process is crossed obliquely distally and forwards by a shallow groove, the volar lip of which is sharp and well marked, and serves to separate it from the volar surface of the bone, whilst the dorsal lip is often emphasised by a small tubercle above. The tendon of the brachio-radialis muscle is inserted into the proximal part of either lip, and also spreads out on to the floor of the groove, whilst the tendons of the abductor pollicis longus and the extensor pollicis brevis muscles lie within the groove. To the tip of the styloid process is attached the radial collateral ligament of the wrist. On the medial side of the distal extremity is placed the incisura ulnaris (ulnar notch) for the reception of the head of the ulna. Concave from before backwards, and plane proximo-distally, it forms by its inferior margin a rectangular edge which separates it from the distal carpal surface. To this edge the base of the articular disc is attached, a structure which serves to separate the distal articular surface of the head of the ulna from the carpus. The volar and dorsal edges of the ulnar notch, more or less prominent, serve for the attachment of ligaments.

The proportionate length of the radius to the body height is as 1 is to $6 \cdot 70-7 \cdot 11$.

Nutrient Foramina.-The openings of several small nutrient canals may be seen in the region of the neck. That for the shaft, which has a proximal direction, is usually placed on the volar surface of the bone, medial to the anterior oblique line, and from an inch and a half to two inches distal to the tuberosity. The dorsal surface of the distal extremity of the bone is pierced by many small vascular foramina.

Connexions. - The radius articulates with the capitulum of the humerns in the flexed position of the elbow, with the ulna to its medial side by the proximal and distal radio-ulnar joints, and with the navicular and lunate bones of the carpus distally. Proximally, the head of the bone can be felt in the intermuscular depression on the lateral side of the back of the elbow; here the bone is only covered by the skin, superficial fascia, and the thin common tendinous origin of the extensor muscles, as well as the ligaments which support it. Its position can best be ascertained by pronating and supinating the bones of the forearm, when the head will be felt rotating beneath the finger. The distal end of the bone is overlain on the volar and dorsal aspects by the flexor and extensor tendons, but its general form can be readily made out. The styloid process lying to the lateral side of the wrist in line with the extended thumb can easily be recognised; note that it reaches a more distal level than the corresponding process of the ulna. The lateral border of the lower third of the shaft can be distinctly felt, as here the bone is only overlain by
tendons.

Ossification.-The centre for the shaft makes its appearance early in the second 


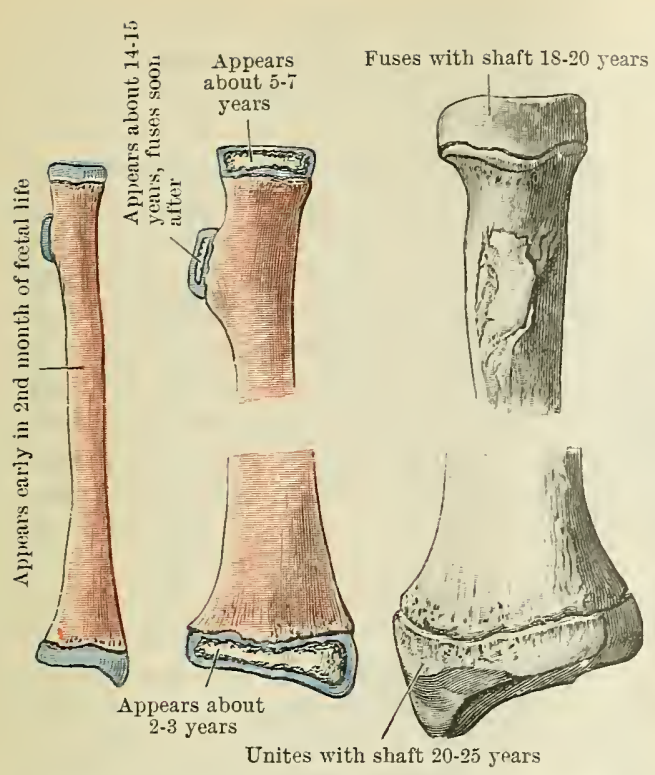

month of intra-uterine life. At birth the shaft is well formed; its proximal and distal extremities are capped with cartilage, and the tuberosity is beginning to appear. A secondary centre appears in the cartilage of the distal extremity about the second or third year; this does not unite with the shaft until the twentieth or twenty-fifth year, somewhat earlier in the female. From this the carpal and ulnar articular surfaces are formed. The centre for the head appears from the fifth to the seventh year, and fuses with the neck about the age of eighteen or twenty. It forms the capitular articular surface and combines with the neck to form the area for articulation with the radial notch of the ulna. A scale-like

At Birth. About 12 years. About 16 years.

Fig. 208.-The Ossification of the Radius.

epiphysis capping the summit of the tuberosity has been described; this appears about the fourteenth or fifteenth year, and rapidly fuses with that process.

\section{THE BONES OF THE HAND.}

The bones of the hand, twenty-seven in number, may be conveniently divided into three groups :-

(1) The bones of the wrist or carpus-eight in number.

(2) The bones of the palm or metacarpus - five in number.

(3) The bones of the fingers and thumb or phalanges-fourteen in number.

\section{The Carpus.}

The ossa carpi (carpal bones) are arranged in two rows: the first, or proximal row, comprises from radial to ulnar side, the navicular (O.T. scaphoid), os lunatum (O.T. semi-lunar), os triquetrum (O.T. cuneiform), and os pisiforme or pisiform; the second or distal row includes the greater multangular (O.T. trapezium), lesser multangular (O.T. trapezoid), os capitatum (O.T. os magnum), and
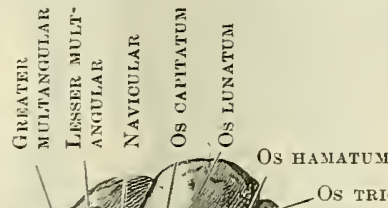

PAL
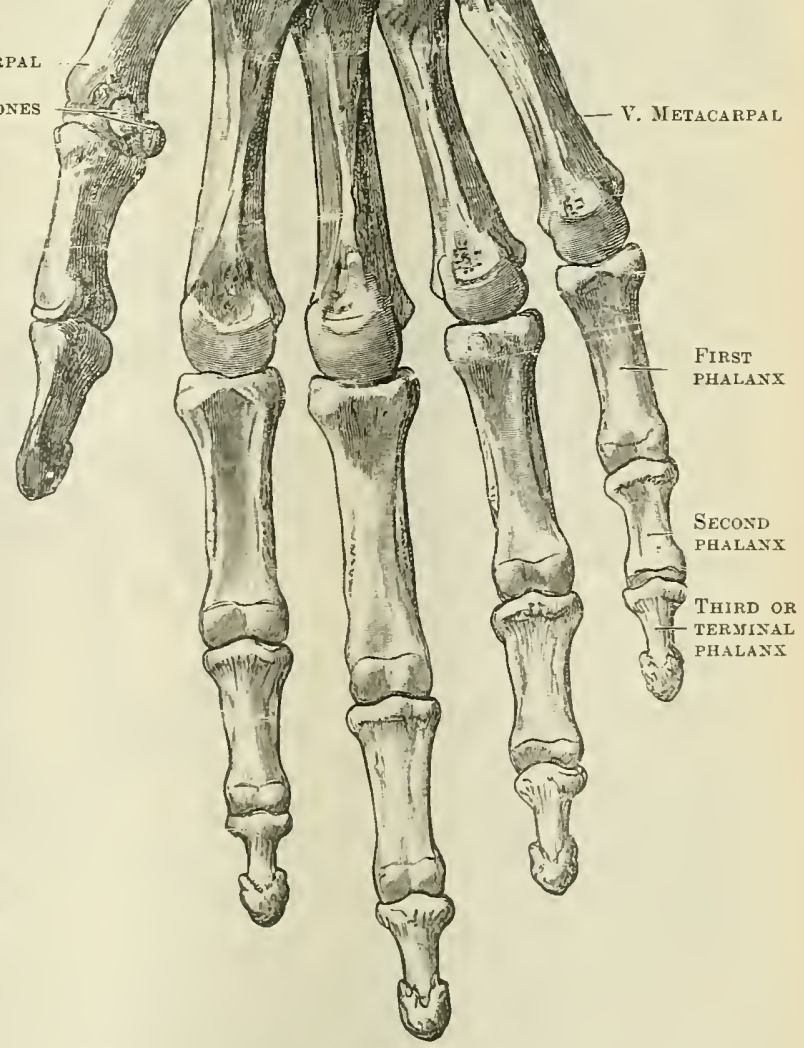

Fig. 209.-The BoNes of the Right Wrist aNd Hayd SEEN FROM THE TOLAR ASPECT. 
os hamatum (O.T. unciform). Irregularly six-sided, each of these bones possesses non-articular volar and dorsal surfaces. In addition, the marginal bones are nonarticular along their ulnar and radial aspects according as they form the medial or lateral members of the series.

Navicular Bone (O.T. Scaphoid). - This is the largest as well as the most lateral

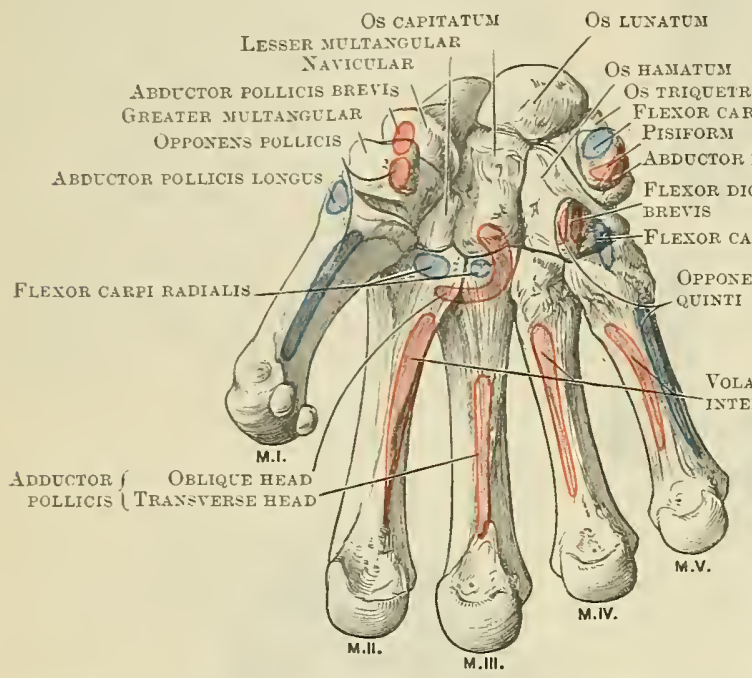

Fig. 210. - Tolar ASPECt of Bones of the Right Carpes and Metacarpes with Mescular attachments mapped oUt.

bone of the first row. Its volar surface, rough for the attachment of ligaments, is irregularly triangular. The distal angle on the lateral side forms a projection called the tuberosity; this can be felt at the base of the root of the thumb. Its proximal surface is convex from side to side and before backwards for articulation with the radius. This area extends considerably over the dorsal surface of the bone. Its distal surface is convex from before backwards, and extends on to the dorsal aspect of the bone, slightly convex from side to side; it is divisible into two areas, the lateral for articulation with the greater multangular, the medial for the lesser multangular. The lateral surface is narrow and rounded and forms a non-articular border, which extends from the radial articular surface proximally to the tuberosity distally. The medial surface is hollowed out in front for articulation with the head of the capitate bone. Proximal to this it displays a small semilunarshaped facet for the os lunatum. The dorsal non-articular surface lies between the lateral articular surface proximally and the surface for the greater and lesser multangular bones distally. It is obliquely grooved for the attachment of the dorsal ligaments of the wrist. The navicular articulates with five bones - the radius, the os lunatum, the capitate, the lesser multangular, and the greater multangular.

Os Lunatum (O.T. Semilunar Bone).- So called from its deeply

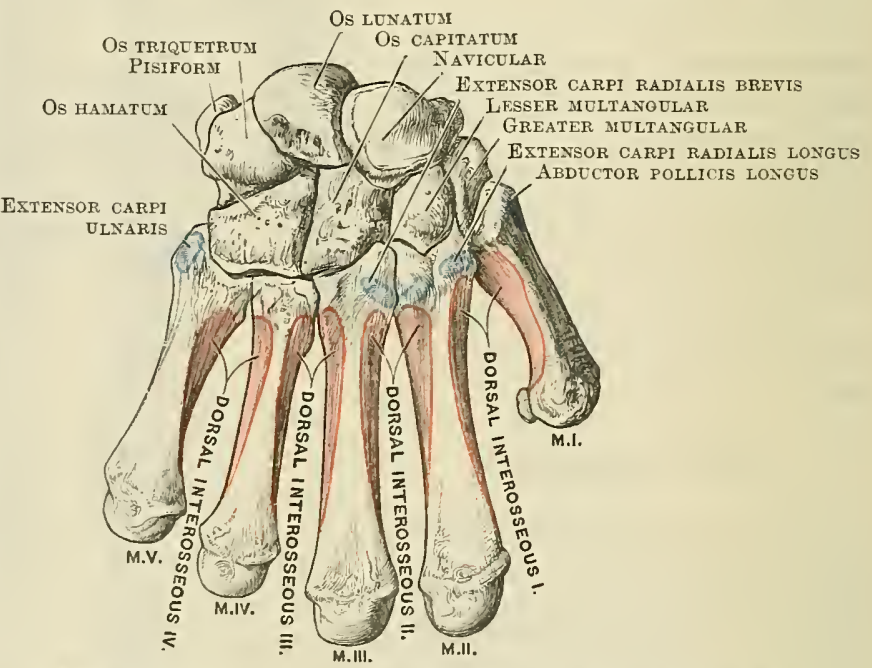

Fig. 211.-Dorsal Aspect of Bones of the Right Carpes and Mietacarpes with Muscular Attachuents mapped odt. excavated form, the os lunatum lies between the navicular on the lateral side and the os triquetrum on the medial. Its volar surface, of rhombic form and considerable size, is rough for the attachment of ligaments; its proximal surface, convex from side to side and from before backwards, articulates with the radius and in part with the distal surface of the articular disc of the wrist. Its distal aspect, deeply 
hollowed from before backwards, is divided into two articular areas, of which the lateral is the larger; this is for the head of the capitate bone; the medial, narrow from side to side, articulates with the os hamatum. Its lateral surface, crescentic in shape, serves for articulation with the navicular, and also for the attachment of the interosseous ligaments which connect it with that bone. Its medial surface, of quadrilateral form, is cartilage-covered for articulation with the os triquetrum, and the edge which separates this from the proximal surface has attached to it the interosseous ligament which unites these two bones. The rough dorsal non-articular surface is much smaller than the volar; by this means the volar and dorsal surfaces of the bone can readily be determined. The os lunatum articulates with five bones- the navicular, the radius, the os triquetrum, the os hamatum, and the capitate bone.

Os Triquetrum (O.T. Cuneiform). - This bone may be recognised by the small oval or circular facet on its volar surface for the pisiform. This is placed towards the distal part of the volar surface, which is elsewhere rough for ligaments. The bone is placed obliquely, so that its surfaces cannot be accurately described as distal, proximal, etc.; but for convenience of description, the method already adopted is adhered to. The proximal surface has a convex rhombic surface for articulation with the distal surface of the articular disc in adduction of the hand, though ordinarily it does not appear to be in contact with that structure. To the medial side of this it is rough for ligaments. The distal surface is elongated and concavo-convex from radial to ulnar side; here the bone articulates with the os hamatum. The lateral surface, broader in front than behind, articulates with the os lunatum. The medial surface, rounded and rough, is confluent proximally and dorsally with the proximal and dorsal aspects of the bone.

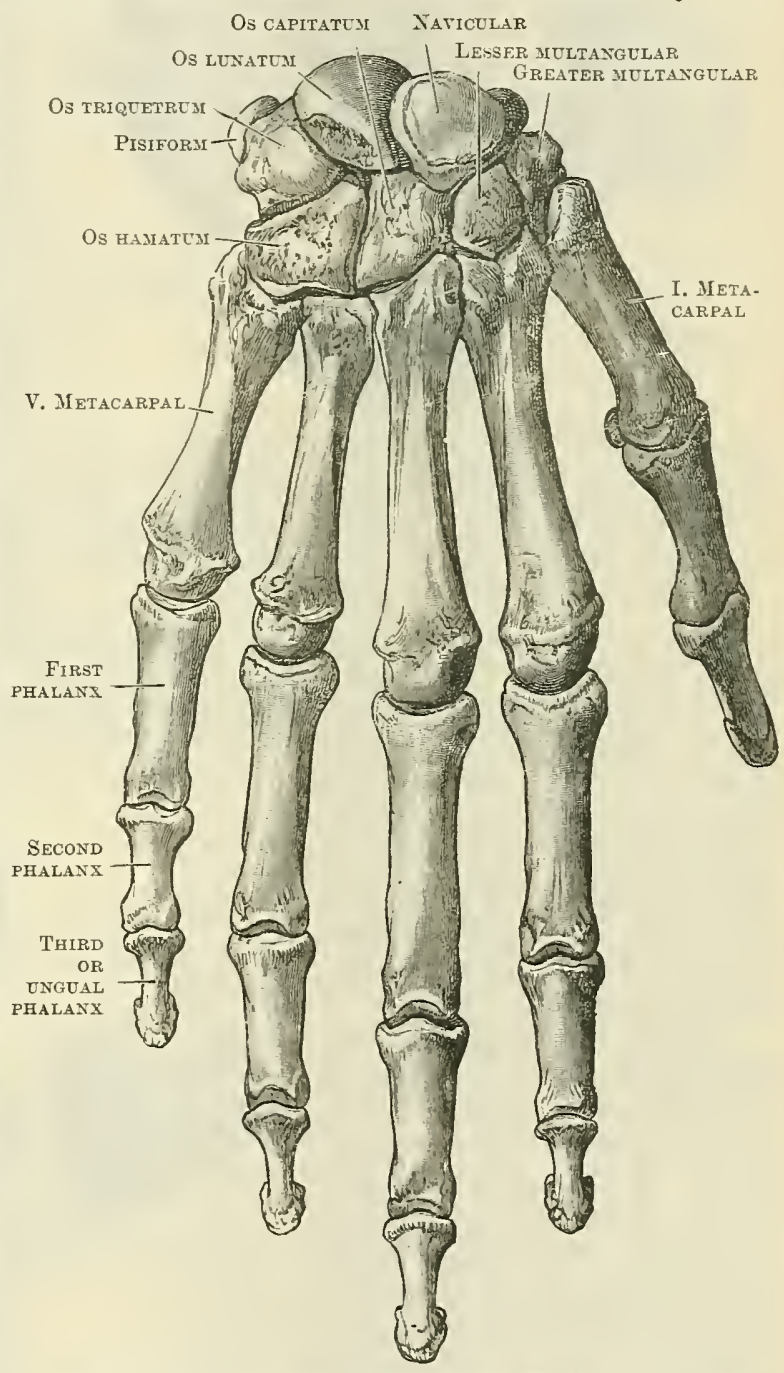

Fig. 212. -The Bones of the Right Wrist and Haxd SEEN FRON THE DORSAL ASPECT.

The dorsal surface, rounded and smooth laterally, is ridged and grooved medially for the attachment of ligaments. The os triquetrum articulates with three bones, viz., the pisiform, the os hamatum, and the os lunatum.

Os Pisiforme (O.T. Pisiform Bone).-A bout the size and shape of a large pea, the pisiform bone rests on the volar surface of the os triquetrum, with which it articulates by an oval or circular facet on its dorsal aspect. The rounded mass of the rest of the bone is non-articular, and inclines distally and laterally so as to overhang the articular facet in front and laterally. The mass of the bone is usually separated from the articular surface by a small but distinct groove. Into the summit of the bone the tendon of the flexor carpi ulnaris muscle is 
inserted, and here also the transverse carpal ligament is attached. The ulnar artery and nerve are in immediate relation with the lateral side of the bone.

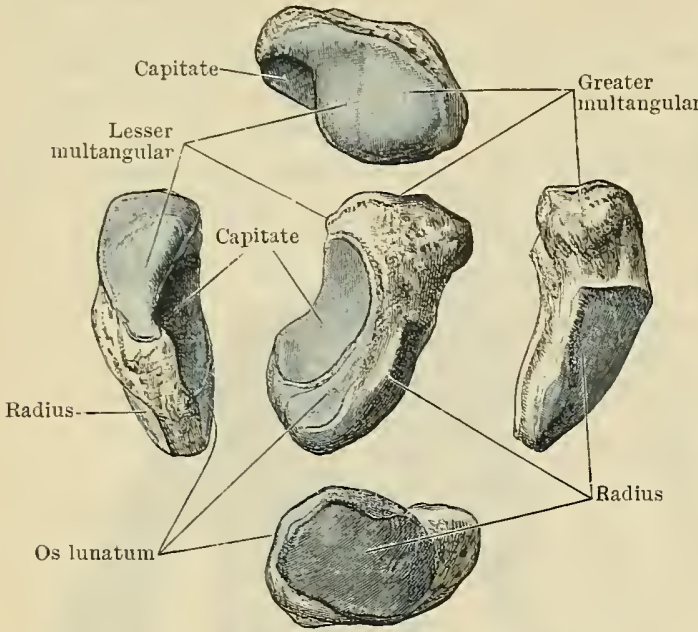

Fig, 213.-The Right Navicular Bone.

NotE.-The bone is represented in the centre of the figure in the position which it occupies in the right hand viewed from the volar aspect. The views on either side, and above and below, represent respectively the corresponding surfaces of the bone turned towards the reader. concave proximo-distally, and very slightly convex from volar to dorsal side, and is for articulation with the lesser multangular; the distal, small and circular, and not always present, is for articulation with the lateral side of the base of the second metacarpal bone. The dorsal surface, of irregular outline, is rough for the attachment of ligaments. The greater multangular articulates with four bones, the navicular, lesser multangular, and the first and second metacarpal bones.

Lesser Multangular (O.T. Trapezoid Bone).-With the exception of the pisiform, this is the smallest of the carpal bones. Its rough volar surface is small and pentagonal in outline. By a small oblong surface on its proximal aspect it articulates with the navicular. Distally, by a somewhat saddle-shaped surface, it articulateswith the base of the second metacarpal. Separated from this by a rough $V$-shaped impression prolonged from its volar aspect, is the surface on the lateral side for articulation with the greater mult-

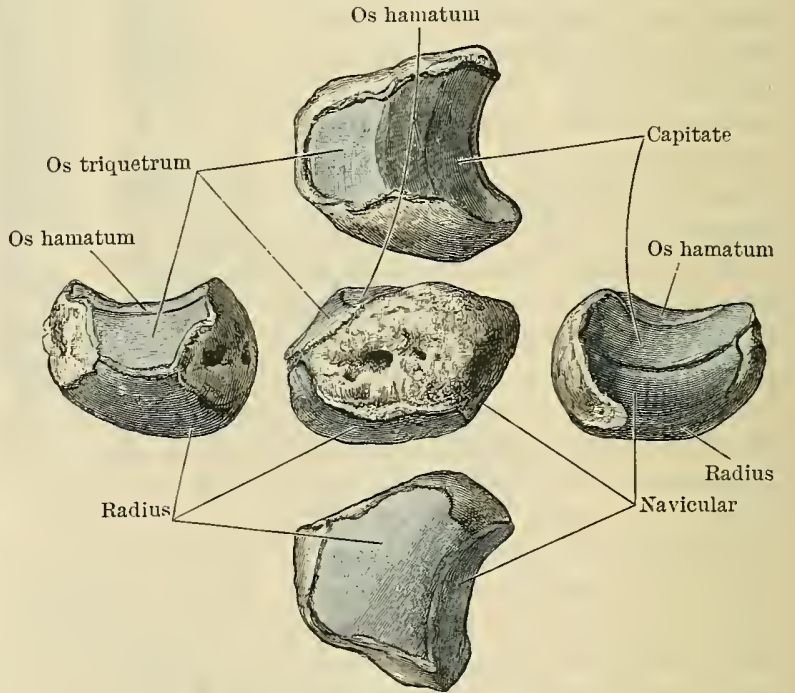

Fig. 214.-The Right Os Lunatur.

NотE.-The bone is represented in the centre of the figure in the position which it occupies in the right hand viewed from the volar aspect. The views on either side, and above and below, represent respectively the corresponding surfaces of the bone turned towards the reader.

angular ; this appears as if obliquely grooved from before backwards and distally. The inecical facet for articulation with the capitate is narrow proximo-distally, and deeply curved from before backwards. The dorsal surface of the bone, which is rough and non-articular, is much larger than the volar aspect. The mass of the bone, 
dorsally, is directed distally and towards the medial side. The lesser multangular articulates with four bones-the greater multangular, navicular, and capitate bones, and the second metacarpal.

Capitate Bone (O.T. Os Magnum). -This is the largest of the carpal bones. Its volar surface is rough and rounded. The proximal portion of the bone forms the head, and is furnished with convex articular facets which fit in to the hollows on the medial surface of the navicular and distal surface of the os lunatum; that for the latter is medial to and separated by a slight ridge from the navicular articular area. The distal surface, narrow towards its volar border and broad dorsally, is subdivided usually into three facets by two ridges-that towards the lateral side is for the base of the second metacarpal;
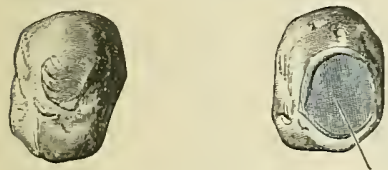

Os triquetrum

Fig. 216.-The Right Pisiform BoNE.

Note.-The figure to the left represents the volar aspect of the bone; that to the right the dorsal view. the inter$m e d i a t e$ facet is for the third metacarpal ; whilst the medial facet of the three,

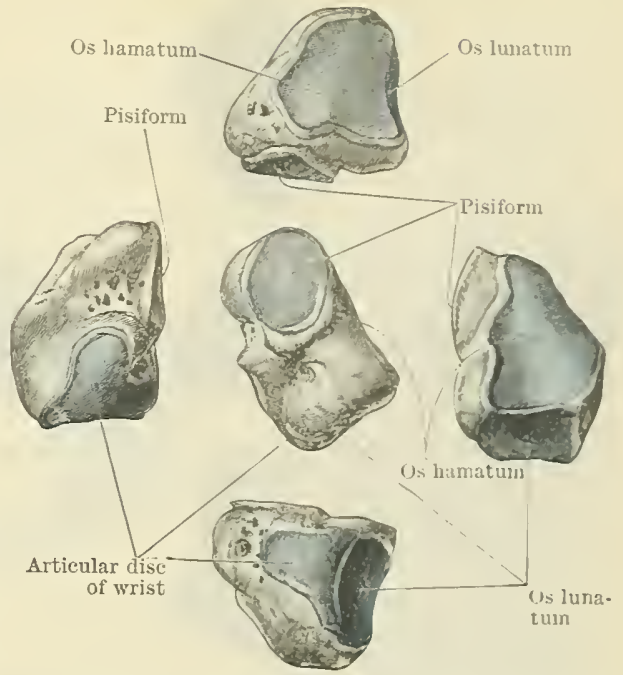

Fig. 215.-The Right Os Triquetrics.

Note.-The bone is represented in the centre of the figure in the position which it occupies in the right hand viewed from the volar aspect. The riews on either side, and above and below, represent resuectively the corresponding surfaces of the bone turned towards the reader.

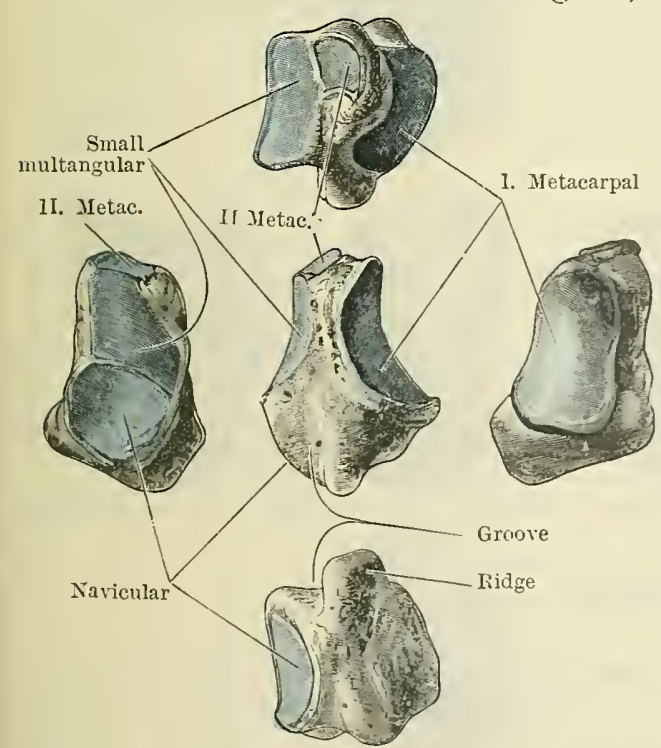

Fig. 217.-The Right Greatrir Multangular Bone.

NoTE.-The bone is represented in the centre of the figure in the position which it occupies in the right hand viewed from the volar aspect. The views on either side, and above and below, represent respectively the corresponding surfaces of the bone turned towards the reader. r surface on the head bJ a rough line, to which the interosseous ligament connecting it with the naricular is attached. The medial side of the body has an elongated articular surface, usually deeply notched in front; or it may be divided anteriorly into a small circular area near the dorsal edge, and a larger posterior part. This latter articulates either singly or doubly with the os hamatum, the interosseous ligament which unites the two bones being attached either to the notch or to the surface separating the two articular facets. The dorsal surface is rough for ligaments; it is somewhat constricted below the head, the articular surface of which sweeps round its proximal border.

The capitate bone articulates with seven bones-the os hamatum, the os lunatum, the navicular, the small multangular, and the second, thirl, and fourth metacarpal bones; occasionally the fourth metacarpal does not articulate with the capitate.

Os Hamatum (O.'1'. Unciform Bone).-The os hamatum can be readily 
medial aspect of its rolar surface. To this is attached the transverse carpal

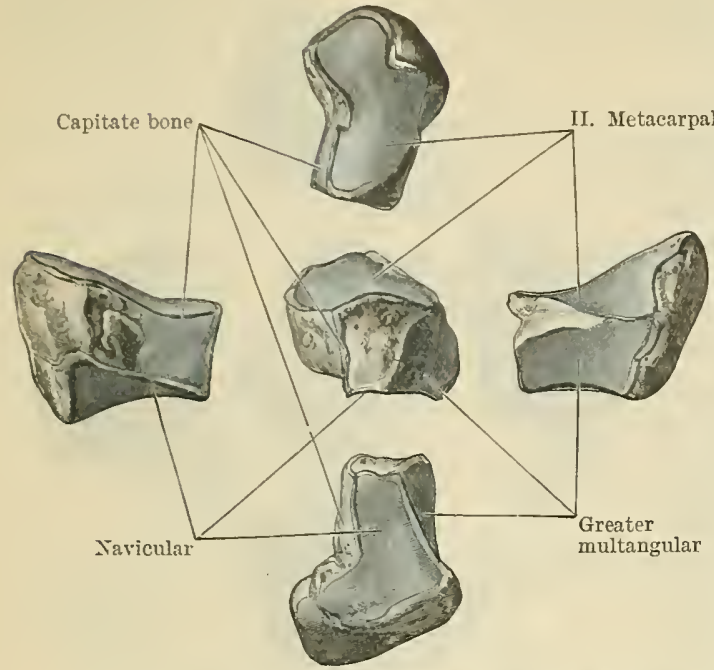

Fig. 218.-The Right Lesser Multajgular Bone.

Note.-The bone is represented in the centre of the figure in the position which it occupies in the right hand viewed from the volar aspect. The views on either side, and above and below, represent respectively the corresponding surfaces of the bone turued towards the reader. the fourth, and the medial with the fifth metacarpal bone. The dorsal surface, more or less triangular in shape, is rough for ligaments.

The os hamatum articulates with five bones-viz., the capitate, os Iunatum, os triquetrum, and the fourth and fifth metacarpals.

\section{The Carpus as a Whole.}

When the carpal bones are articulated together they form a bony mass, the dorsal surface of which is convex from side to side. Anteriorly they present a grooved appearance, con cave from side to side. This arrangement is further emphasised by the forward projection, onthe medial side, of the pisiform and hamulus of the os hamatum, whilst laterally the tuberosity of the navicular and the ridge of the greater multangular help to deepen the furrow by their elevation. ligament as well as some of the fibres of origin of the short muscles of the little finger. The medial side of the hamulus is sometimes grooved by the deep branch of the ulnarnerve. (Anderson, W., "Proc. Anat. Soc." Journ. Anat. and Physiol.vol.xxviii.p.11.) Thevolar surface, rough for ligaments, is somewhat triangular in shape. Proximally and towards the medial side there is an elongated articular surface for the os triquetrum, convex proximally and concave distally. The lateral aspect of the bone is provided with a plane elongated facet, occasionally divided into two for articulation with the capitate bone (see above). Where the proximal and lateral surfaces meet, the angle is blunt, and has a narrow facet which articulates with the os lunatum. Distally there are two articular facets separated by a ridge; these are for articulation, the lateral with

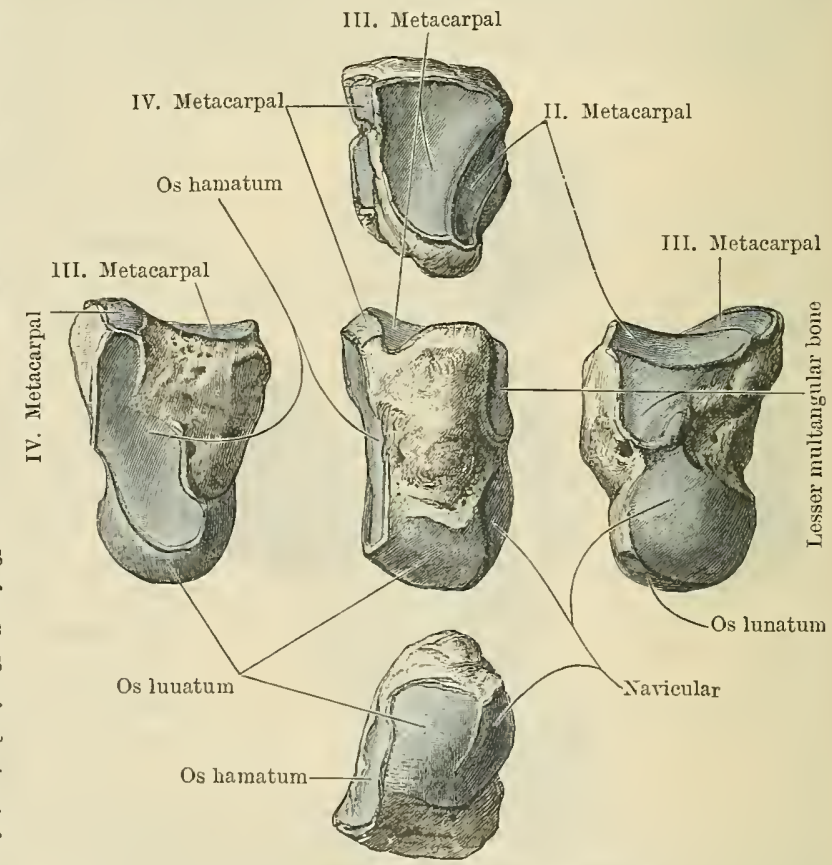

Fig. 219.-The Right Capitate Bone.

NoTE. - The bone is represented in the centre of the figure in the position which it occupies in the right hand viewed from the volar aspect. The views on either side, and above and below, represent respectively the corresponding surfaces of the bone turned towards the reader. 
four points the transverse carpal ligament is attached, which stretches across from

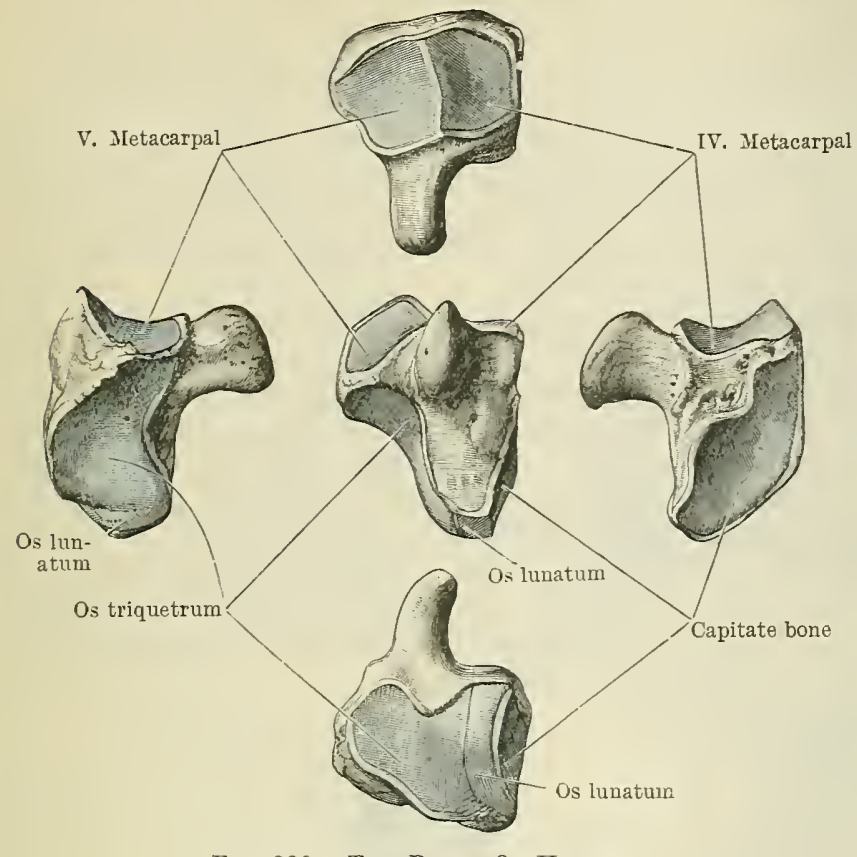

Fig. 220.-The Right Os Haiatum.

NOTE.-The bone is represented in the centre of the figure in the position which it occupies in the right hand viewed from the volar aspect. The views on either side, and above and below, represent respectively the corresponding surfaces of the bone turned towards the reader. side to side, and thus converts the furrow into a canal through which the flexor tendons pass to reach the fingers.

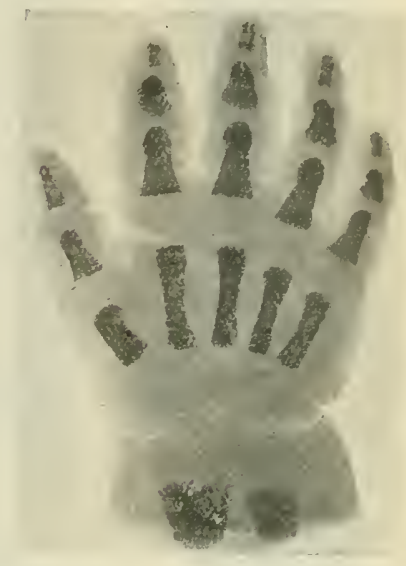

Fig. 221.-Radiograph of the HaNd at Birth.

It will be noticed that whilst the primary centres for the metacarpus and phalanges are well ossified, the carpus is still entirely cartilaginous.

Compare this with the tarsus at birth, in which the tarsus is shown in part already ossified.

Ossification.-At birth the carpus is entirely cartilaginous. An exceptional case is figured by Lambertz, in which the centres for the capitate and triquetral bones were alreadr present. The same authority states that it is not uncommon to meet with these centres in the second month after birth. According to Debierre (Journ. de l'Anat. et de la Physiol. vol. xxii. 1886, p. 285̃), ossification takes place approximately as follows :-

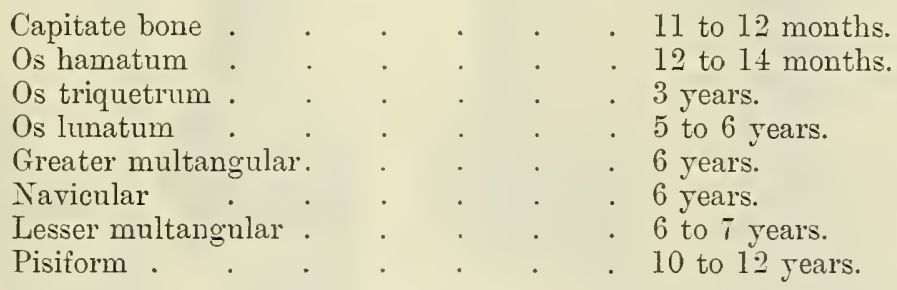

The same observer failed to note the appearance of a separate centre for the hamulus of the os hamatum, and records the occurrence of two centres for the pisiform.

\section{The IMetacarpus.}

The metacarpal bones form the skeleton of the palm, articulating proximally with the carpus, whilst by their distal extremities or heads they support the bones of the digits. Five in number, one for each digit, they lie side by side and slightly divergent from each other, being separated by intervals, termed interosseous spaces. Distinguished numerically from the lateral to the medial side, they all display certain common characters; each possesses a body or shaft, a base or carpal extremity, and a head or phalangeal end.

The shafts, which are slightly curved towards the volar aspect, are narrowest towards their middle. The dorsal surface of each is marked by two divergent lines which pass distally from the dorsum of the base to tubercles on either side of the 
head. The surface included between the two lines is smooth and of elongated triangular form. On either side of these lines two broad shallow grooves wind

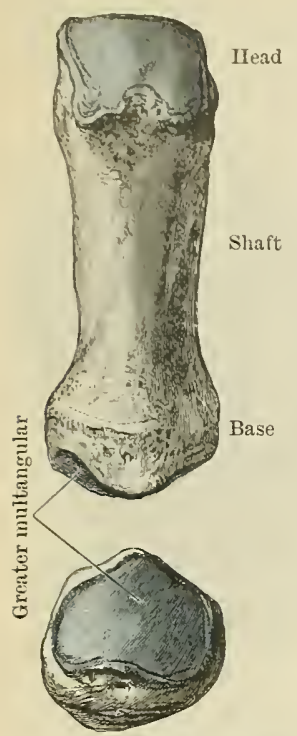

Fig. 222.-FIRST Right Metacarpal Bone. spirally on to the volar surface, where they are separated by a sharp ridge which is continuous with a somewhat triangular surface which corresponds to the volar aspect of the base. The grooved surfaces on either side of the shaft furnish origins for the interossei muscles. Close to the volar crest is the opening of the nutrient canal, which is directed towards the proximal extremity, except in the case of the first metacarpal bone.

The capitulum (head) is provided with a surface for articulation with the proximal phalanx. This area curves farther over its volar than its dorsal aspect. Convex from before backwards and from side to side, it is wider anteriorly than posteriorly; notched on its volar aspect, its edges form two prominent tubercles, which are sometimes grooved for the small sesamoid bones which may occasionally be found on the volar surface of the joint. On either side of the head of the bone there is a deep pit, behind which is a prominent tubercle; to these are attached the collateral ligaments of the metacarpo-phalangeal joints.

The bases, all more or less wedge-shaped in form, articulate with the carpus; they differ in size and shape according to their articulation.

Of the five metacarpal bones, the first, viz., that of the thumb, is the shortest and stoutest, the second is the longest, whilst the third, fourth, and fifth display a gradual reduction in length.

The four medial bones articulate by their bases with each other, and are united at their distal extremities by ligaments. They are so arranged as to conform to the hollow of the palm, being concave from side to side anteriorly, and convex posteriorly. The first metacarpal differs from the others in being free at its distal extremity, whilst its proximal end possesses only a carpal articular facet.

The first metacarpal bone is the shortest and stoutest of the series. Its shaft is compressed from before backwards. Its head, of large size, is but slightly convex from side to side,
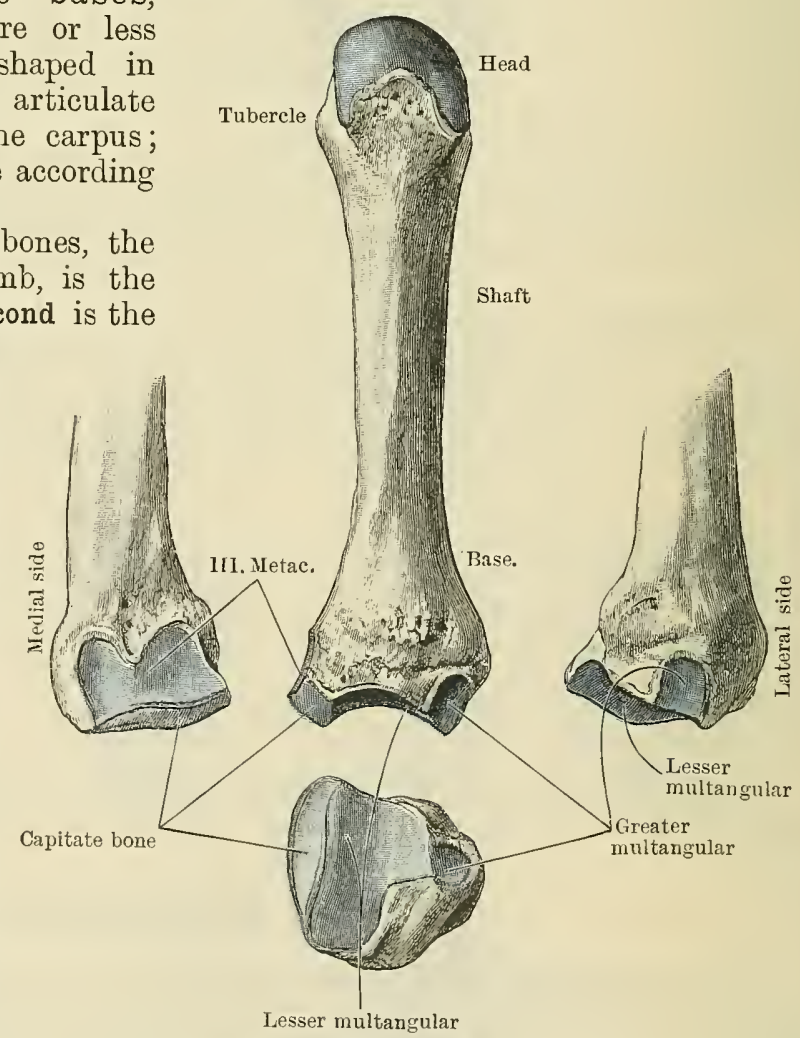

Fig. 223.-Second Right Metacarpal Bone.

and is grooved on its volar aspect for the sesamoid bones. The base is provided with a saddle-shaped surface for articulation with the greater multangular, and has no lateral facets. Laterally there is a slight tubercle to which the abductor pollicis 
longus muscle is attached. The canal for the nutrient artery is directed towards the head of the bone.

The second metacarpal bone is recognised by its length and its broad and deeply notched base for articulation with the small multangular. It has a small half-oval facet for the large multangular on the lateral side of its base, whilst on its medial aspect it presents a narrow vertical strip for the capitate, in front of which there are two half-oval surfaces for the third metacarpal. To the dorsal aspect of the base is attached the tendon of the extensor carpi radialis longus muscle, whilst the flexor carpi radialis is inserted into the volar surface.

The third metacarpal bone can usually be recognised by the pointed styloid process which springs from the dorsum of its base, and is directed

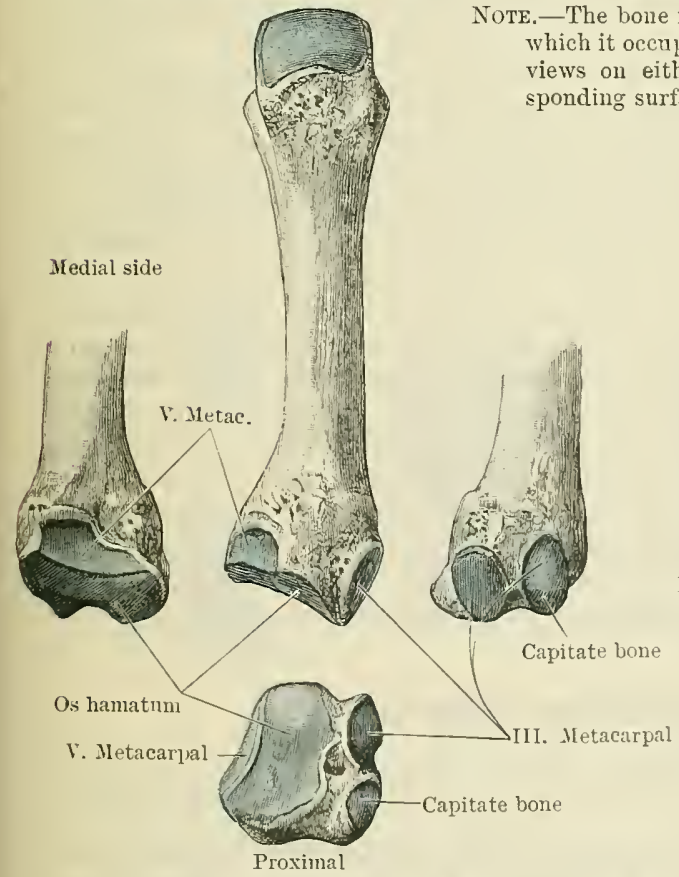

Fig. 225.-Fourth Right Metacarpal Bone.

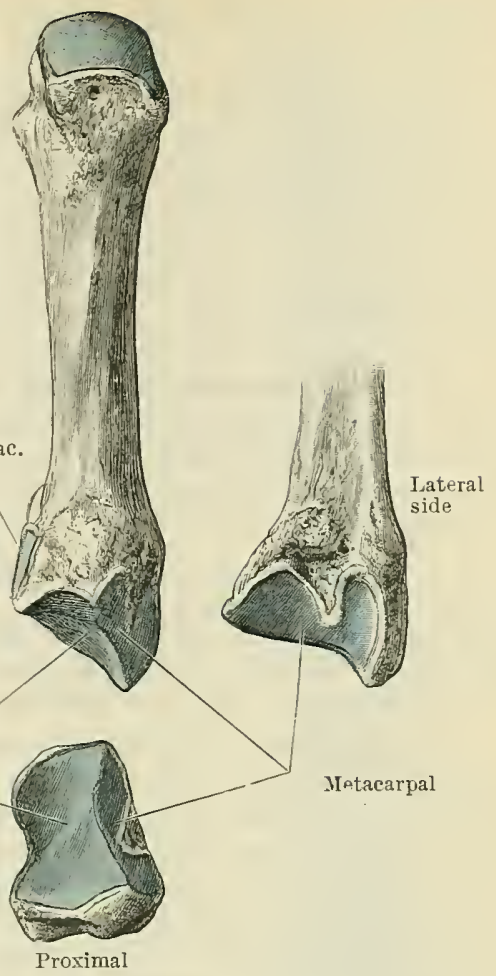

Fig. 221.-Third Right Metacarpal Bone.
bone is represented in the centre of the figure in the position occupies in the right hand viewed from the volar aspect. The views on either side, and below, represent respectively the corresponding surfaces of the bone turned towards the reader.

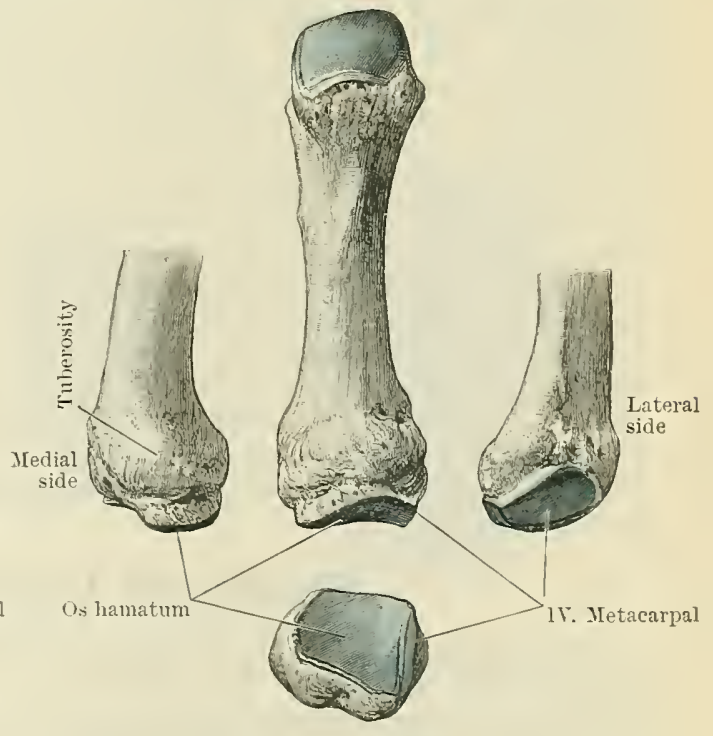

Fig. 226.--Fifth Right Metacarpal Bone.

NoтE. - The bone in each figure is represented in the centre of the figure in the position which it occupies in the right hand viewed from the volar aspect. The views on either side, and below, represent respectively the corresponding surfaces of the bone turned towards the reader.

towards the radial side. Superiorly there is a facet on the base for the capitate. To the lateral side there are two half-oral facets for the second metacarpal. To the medial side there are usually two small oval or nearly circular facets for the 
fourth metacarpal. The extensor carpi radialis brevis muscle is inserted into the dorsum of the base.

The fourth metacarpal bone may be recognised by a method of exclusion. It is unlike either the first, second, or third, and differs from the fifth, which it resembles in size, by having articular surfaces on both sides of its base. Proximally there is a quadrilateral surface on its base for articulation with the os hamatum. On its lateral side there are ustally two small oral facets for the third metacarpal. Of these facets the dorsal one not infrequently has a narrow surface for articulation with the capitate. On the medial side there is a narrow articular strip for the base of the fifth metacarpal.

The fifth metacarpal bone can be recognised by its size and the fact that it has only one lateral articular facet on its base, namely, that on its lateral side for the fourth metacarpal. The carpal articular surface is saddle-shaped, and there is a tubercle on the medial side of the base for the insertion of the extensor carpi ulnaris muscle.

As has been already pointed out, the openings of the arterial canals are usually seen on the volar surfaces of the metacarpals, those of the four medial bones being directed proximally towards the base or carpal end, differing in this respect from that of the first metacarpal, which is directed distally towards the head or phalangeal extremity. The opening of the latter canal usually lies to the medial side of the volar aspect of the shaft.

Ossification.-The metacarpal bones are developed from primary and secondary centres; but there is a remarkable difference between the mode of growth of the first and the remaining four metacarpals, for whilst the shaft and head of the first metacarpal are developed from the primary ossific centre, and its base from a secondary epiphysis, in the case of the second, third, fourth, and fifth metacarpals the shafts and bases are developed from the primary centres, the heads in these instances being derived from the secondary epiphyses. In this respect, therefore, as will be seen hereafter, the metacarpal bone of the thumb resembles the phalanges in the manner of its growth, a circumstance which has given rise to considerable discussion as to whether the thumb is to be regarded as possessing three phalanges and no metacarpal, or one metacarpal and two phalanges. Broom (Anat. Anz. vol. 28), by a reference to reptilian forms, offers an explanation in regard to the difference in the mode of ossification of the first metacarpal on the ground that the most morable joint is that between the first metacarpal and the carpus, whereas on the other digits the most movable joints are those between the metacarpals and phalanges. In consequence those ends of the bones which enter into the formation of the joints where movement is most free are the ends where the epiphyses will appear. This is in accordance with the law to be suggested in connexion with the fibula. The primary centres for the shafts and bases of the second, third, fourth, and fifth metacarpals appear in that order during the ninth or tenth week of intra-uterine life, some little time after the terminal phalanges have begun to ossify; that for the shaft and head of the metacarpal bone of the thumb a little later. At birth the shafts of the bones are well formed. The secondary centres from which the heads of the second, third, fourth, and fifth metacarpals and the base of the first are developed, appear about the third year, and usually completely fuse with the shafts about the age of twenty. There may be an independent centre for the styloid process of the third metacarpal, and there is usually a scale-like epiphysis on the head of the first metacarpal which makes its appearauce about eight or ten, and rapidly unites with the head. The occurrence of a basal epiphysis in the second metacarpal bone has been noticed.

\section{Phalanges Digitorum Manus.}

The phalanges or finger bones are fourteen in number-three for each finger, and two for the thumb.

Named numerically in order from the proximal toward the distal ends of the fingers, the phalanx prima (first phalanx), the longest and stoutest of the three, has a semi-cylindrical shaft which is curved slightly forwards. The volar surface is flat, and bounded on either side by two sharp borders to which the sheath of the flexor tendons is attached. The dorsal surface, convex from side to side, is overlain by the extensor tendons. The proximal end, considerably enlarged, has a simple oval concave surface, which rests on the head of its corresponding metacarpal bone. On either side of this the bone displays a tubercular form, and affords attachment to 
the collateral ligaments of the metacarpo-phalangeal joint, and also to the interossei muscles. The distal end is much smaller than the proximal; the convex articular surface is divided into two condyles by a central groove running from before backward. The phalanx secunda (second phalanx) resembles the first in general form, but is of smaller size. It differs, however, in the form of its proximal articular surface, which is not a simple oval concavity, but is an oval area divided into two small, nearly circular concavities by a central ridge passing from volar to dorsal edge; these articulate with the condylic surfaces of the proximal phalanx. Into the margins of its volar surface near the proximal end are inserted the split portions of the tendon of the flexor digitorum sublimis, whilst on the dorsal aspect of the proximal end the central slip of the extensor digitorum communis muscle is attached. The phalanx tertia (third, terminal, or ungual phalanx) is the smallest of the three; it is easily recognised by the spatula-shaped surface on its distal extremity which supports the nail. The articular surface on its proximal end resembles that on the proximal end of the second phalanx, but is smaller. On the volar aspect of this end of the bone there is a rough surface for the insertion of the tendon of the flexor digitorum profundus muscle. The dorsal surface of the same extremity has attached to it the terminal portions of the tendon of the extensor digitorum communis muscle. The phalanges of the thumb resemble in the arrangement of their parts the first and third phalanges of the fingers.

The arterial canals, usually two in number, placed on either side of the palmar aspect and nearer the distal than the proximal end of the bone, are directed towards the finger-tips.

Ossification.-The phalanges are ossified from primary

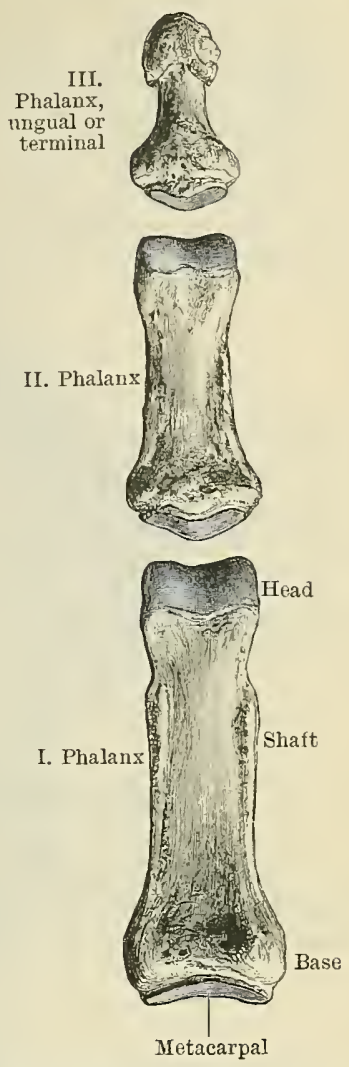

Fig. 227.-The Phalanges of THE Fingers (Volar Aspect). and secondary centres. From the former, which appear as early as the ninth week of
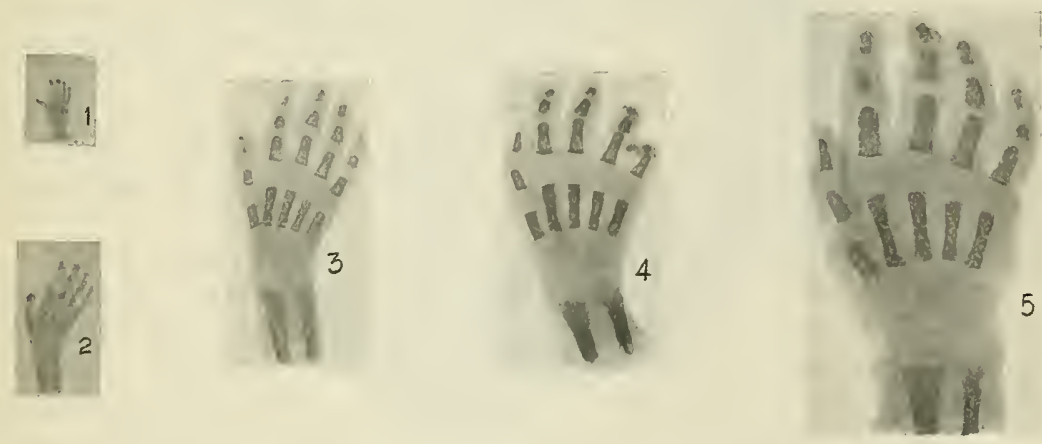

Fig, 228.-Radiographs of Fettal Hands.

1. About ten weeks. Here the ossific nuclei of the terminal phalanges and the four medial metacarpal bones are seen.

2. A little later. The centre for the metacarpal for the thumb is now present, as also the centres for the proximal row of phalanges. The centres of the medial row of phalanges have appeared in the case of the middle and ring fingers.

3. During the third month. All the primary centres for the metacarpal bones and phalanges are now developed.

4. About the fourth to fifth month.

5. About the sixth to seventh month.

fotal life, the shaft and distal extremities are developed; whilst the latter, which begin to appear about the third year, form the proximal epiphyses which unite with the shafts 
from eighteen to twenty. Dixey (Proc. Roy. Soc. xxx. and xxxi.) has pointed out that the primary centre in the distal phalanges commences to ossify in the distal part of the bone rather than towards the centre of the shaft. This observation has been confirmed by Lambertz, who further demonstrates the fact that ossification commences earlier in the distal phalanges than in any of the other bones of the hand. Of the other phalanges, those of the first row, beginning with that of the third finger, next ossify, subsequent to the appearance of ossific centres in the shafts of the metacarpal bones, whilst the second or middle row of the phalanges is the last to ossify about the end of the third month. Sewell has recorded a case in which the proximal phalanx had a distal as well as a proximal epiphysis.

\section{Ossa Sesamoidea.}

Two little oval nodules (sesamoid bones), which play in grooves on the volar aspect of the articular surface of the head of the first metacarpal bone, are constantly met with in the tendons and ligaments of that metacarpo-phalangeal articulation. Similar nodules, though of smaller size, are sometimes formed in the corresponding joints of the other fingers, more particularly the index and little finger; as Thilenius has pointed out (Norph. Arbeiten, vol. v.), these are but the persistence of cartilaginous elements which have a phylogenetic interest.

\section{THE LOWER LIMB.}

\section{THE PELVIC GIRDLE AND THE INFERIOR EXTREMITY.}

The pelvic girdle is formed by the articulation of the two hip bones with the sacrum dorsally, and their union with each other ventraily, at the joint called the symphysis pubis.

\section{Os Coxae.}

The hip bone (os coxæ) (O.T. innominate) is the largest of the "flat" bones of the skeleton. It consists of three parts - the ilium, the ischium, and the os pubisprimarily distinct, but fused together in the process of growth to form one large irregular bone. The coalescence of these elements takes place in and around the acetabulum, a large circular articular hollow which is placed on the lateral side of the bone. The expanded wing-like part above this is the ilium; the stout V-shaped portion below and behind it constitutes the ischium; while the <-shaped part to the medial side, and in front and below, forms the os pubis. The two latter portions of the bone enclose between them a large aperture of irregular outline, called the foramen obturatum (obturator foramen), which is placed in front and below, and to the medial side of the acetabulum.

The ilium, almost a quadrant in form, consists of an expanded plate of bone, having a curved superior border, the crista iliaca (iliac crest). Viewed from the side, this forms a curve corresponding to the circumference of the circle of which the bone is the quadrant; viewed from above, however, it will be seen to display a double bend-convex anteriorly and laterally, and concave posteriorly and laterally. The iliac crest is stout and thick, and for descriptive purposes is divided into a labium externum (external lip), a labium internum (internal lip), and an intermediate surface (linea intermedia), which is broad behind, narrowest about its middle, and wider again in front. About $2 \frac{1}{2}$ inches from the anterior extremity of the crest the external lip is usually markedly prominent and forms a projecting tubercle, which can readily be felt in the living. Attached to these surfaces and lips anteriorly are the muscles of the flank, whilst from them posteriorly the latissimus dorsi, quadratus lumborum, and sacro-spinalis muscles derive their origins. The crest ends in front in a pointed process, the spina iliaca anterior superior (anterior superior iliac spine). To this the lateral extremity of Poupart's inguinal ligament is attached, as well as the sartorius muscle, which also arises from the edge of bone immediately below it, whilst from the same process and from the 
anterior end of the external lip of the iliac crest the tensor fasciæ latæ muscle takes origin.

The anterior border of the ilium stretches from the anterior superior iliac spine to the margin of the acetabulum below. Above, it is thin; but below, it forms a thick blunt process, the spina iliaca anterior inferior (anterior inferior iliac spine). From this the rectus femoris muscle arises, whilst the stout fibres of the

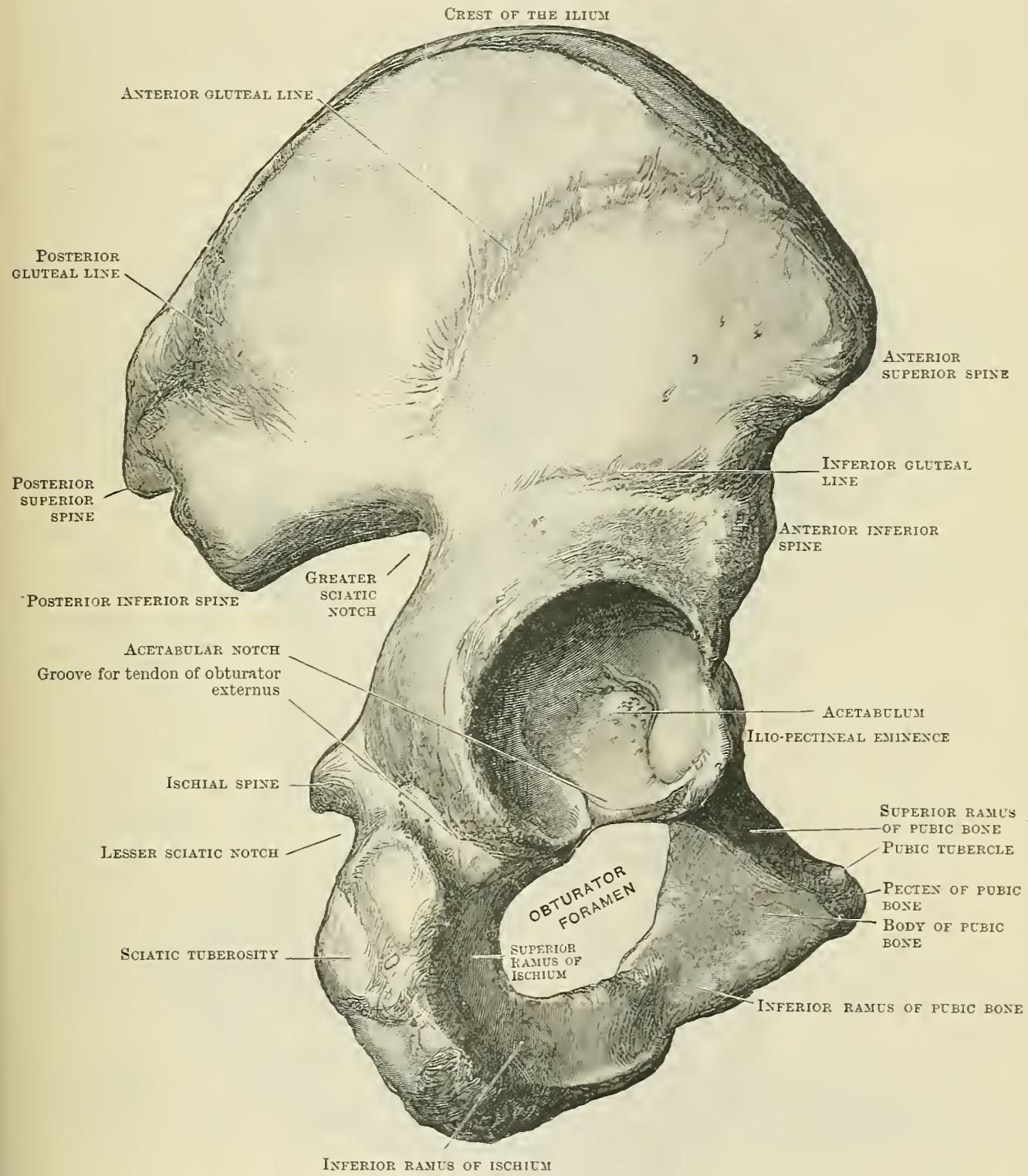

Fig. 229.-The Right Hip Bone SEex from the Lateral side.

ilio-femoral ligament of the hip-joint are attached to it immediately above the acetabular margin. Posteriorly, the crest terminates in the spina iliaca posterior superior (posterior superior iliac spine). Below this, the posterior border of the bone is sharp and irregularly notched, terminating in a prominent angle, the spina iliaca posterior inferior (posterior inferior iliac spine), in front of which the edge of the bone becomes thick and rounded, and forms a wide notch which sweeps forwards and downwards to join the mass of bone behind the acetabulum, where it becomes fused with the ischium; this is called the incisura ischiadica major (greater sciatic notch). 
The ilium has two surfaces, medial and lateral. The lateral surface is divided into two parts, viz., a lower acetabular, and an upper gluteal part. The lower forms a little less than the upper two-fifths of the acetabular hollow, and is separated from the larger gluteal surface above by the upper prominent margin of the articular carity. The gluteal surface, broad and expanded, is concavo-convex from behind forward. It is traversed by three rongh gluteal (O.T. curved) lines, well seen in strongly developed bones, but often faint and indistinct in feebly marked specimens. Of these the linea glutæa inferior (inferior gluteal line) curves backwards from a point immediately above the anterior inferior spine towards the greater sciatic notch posteriorly; the bone between this and the acetabular margin is marked by a rough shallow groove, from which the reflected head of the rectus femoris muscle

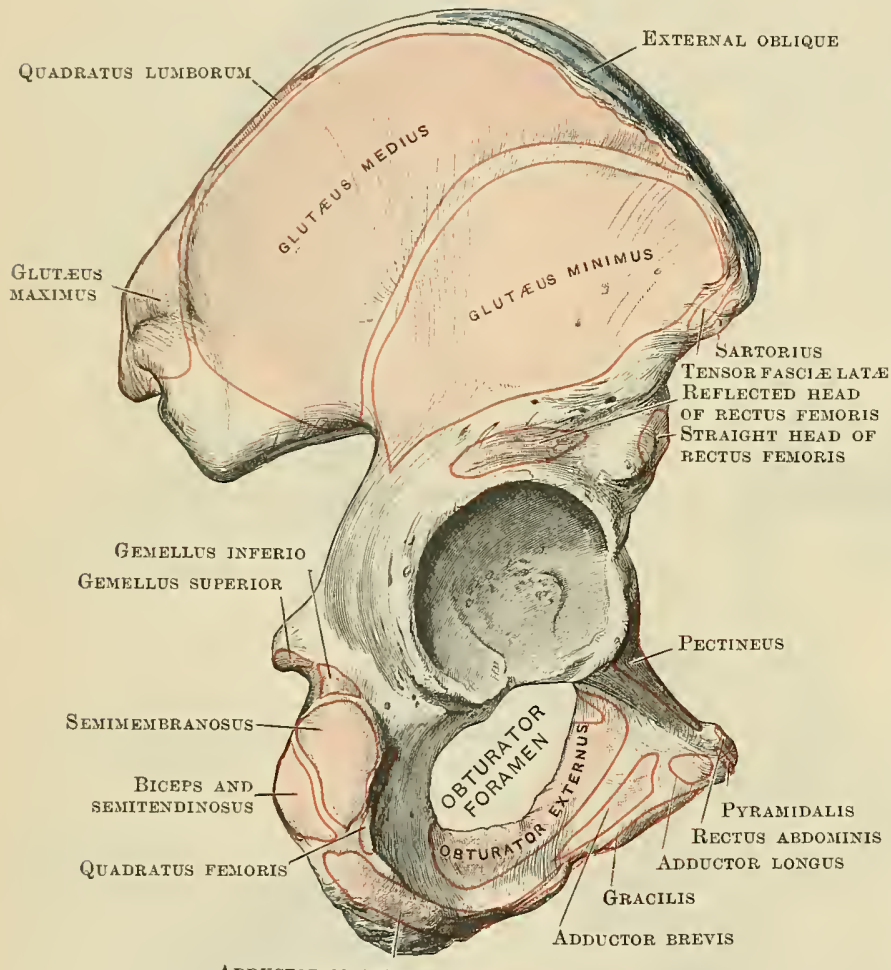

ADDECTOR MAONUS

Fig. 230.-Lateral Aspect of the Right Hip Bone with the Attachients of the Muscles mapped out. arises. The linea glutæa anterior(anteriorgluteal line) commences at the crest of the ilium, about one inch and a half behind theanterior superior iliac spine, and sweeps backwards and downwards towards the upper and posterior part of the greater sciatic notch. The surface between this line and the preceding furnishes an extensive origin for the glutæus minimus muscle. The linea glutæa posterior (posterior gluteal line) leaves the iliac crest about two and a half inches in front of the posterior superior iliac spine, and bends downwards and slightly forwards in a direction anterior to the posterior inferior spine. The area between this and the anterior gluteal line is for the origin of the glutæus medius muscle, whilst the rough surface immediately above and behind it is for some of the fibres of origin of the glutæus maximus muscle.

The medial surface of the ilium is divided into two areas which present very characteristic differences. The posterior or sacral part, which is rough, displays, in front, a somewhat smooth, auricular surface (facies auricularis) which is cartilagecoated in the recent condition, and articulates with the sacrum.

This area is said to be proportionately smaller in the female, whilst curving round in front of its anterior margin there is often a groove, for the attachment of the fibres of the anterior sacro-iliac ligaments, called the pre-auricular sulcus. According to Derry this groove is better marked in the female, and may be regarded as characteristic of that sex.

Above and behind this there is an elevated irregular area, the tuberosity (tuberositas iliaca), which is here and there deeply pitted for the attachment of the strong interosseous and posterior sacro-iliac ligaments. Above this the bone becomes confluent with the inner lip of the iliac crest, and here it affords an origin to the sacrospinalis and multifidus muscles, and some of the fibres of the quadratus lumborum. The anterior part of the medial aspect of the bone is smooth and extensive; it 
is subdivided by an oblique ridge, called the ilio-pectineal line (linea arcuata), which passes forwards and distally, from the most prominent point of the auricular surface towards the medial side of the ilio-pectineal eminence, which is placed just above and in front of the acetabulum and marks the fusion of the

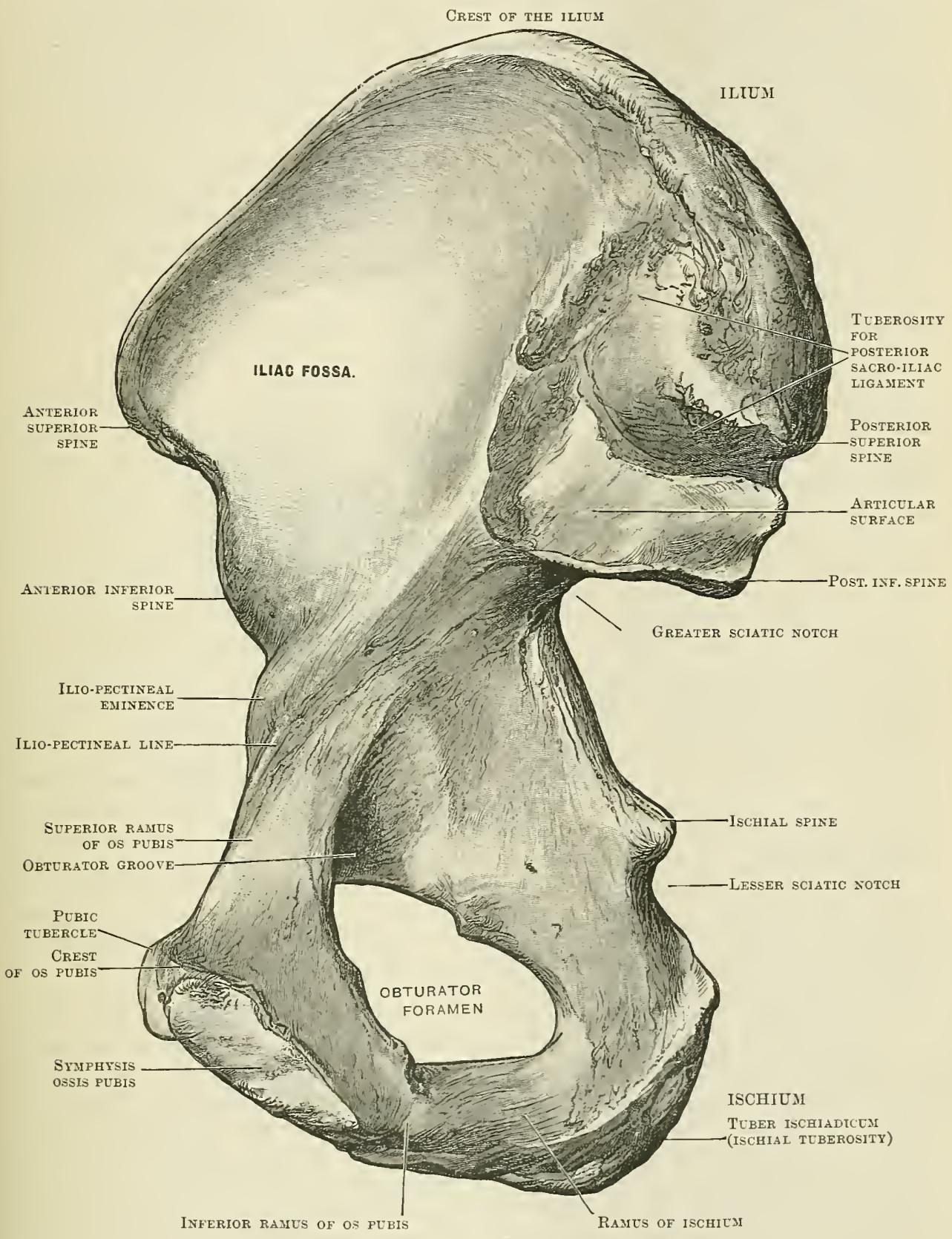

Fig. 231.-The Right Hip Bone (Medial Aspect).

ilium with the os pubis. Above this the bone forms the shallow iliac fossa, from the floor of which the iliacus muscle arises, whilst leading from the fossa, below and in front, there is a shallow furrow, passing over the superior acetabular margin, between the anterior inferior iliac spine on the lateral side and the ilio-pectineal eminence medially, for the lodgment of the tendinous and fleshy part of the ilio-psoas muscle. If held up to the light the floor of the deepest part 
of the iliac fossa will be seen to be formed of but a thin layer of bone. A nutrient foramen of large size is seen piercing the bone towards the posterior part of the fossa. Below and behind the ilio-pectineal line the medial surface of the ilium forms a small portion of the wall of the small pelvis; the bone here is smooth, and rounded off posteriorly into the greater sciatic notch, where it becomes confluent with the medial aspect of the ischium. This part of the bone is proportionately longer in the female than in the male, and forms with the ischium a more open angle. Just anterior to the greater sciatic notch there are usually the openings of one or two large vascular foramina. From this surface arise some of the posterior fibres of the obturator internus muscle.

The ischium constitutes the lower and posterior part of the hip bone. Superiorly its body (corpus) forms somewhat more than the inferior two-fifths of the acetabulum together with the bone supporting it behind and medially. Below this, the superior ramus passes downwards and posteriorly as a stout three-sided piece of bone, from the inferior extremity of which a compressed bar of bone, called the inferior ramus, extends forwards at an acute angle. This latter unites in front and above with the inferior ramus of the pubis, and encloses the aperture called the obturator foramen.

Superiorly, and on the lateral aspect of the ischium, the acetabular surface is separated from the bone below by a sharp and prominent margin, which is, however, deficient in front, where it corresponds to the acetabular notch (O.T. cotyloid notch) leading into the articular hollow; the floor of this notch is entirely formed by the ischium. Below the prominent acetabular margin there is a wellmarked groove in which the tendon of the obturator externus lies. Beneath this the antero-lateral surface of the superior and inferior rami furnish surfaces for the attachments of the obturator externus, quadratus femoris, and adductor magnus muscles. The postero-lateral surface of the ischium forms the convex surface on the back of the acetabulum. The medial border of this is sharp and well defined, andis confluent above with the border of the ilium, which sweeps round the great sciatic notch. From this border, on a level with the lower edge of the acetabulum, there springs a pointed process, the spina ischiadica (ischial spine), to which are attached the sacro-spinous ligament and the superior gemellus muscle. Inferior to this, the postero-lateral surface narrows rapidly, its medial border just below the spine being hollowed out to form the incisura ischiadica minor (lesser sciatic notch). The lower part of this surface and the angle formed by the two rami are capped by an irregularly rough piriform mass called the tuber ischiadicum (ischial tuberosity). This is divided by an oblique ridge into two areas, the upper and lateral for the tendon of origin of the semimembranosus muscle, the lower and medial for the conjoined heads of the biceps and semitendinosus muscles. Its prominent medial lip serves for the attachment of the sacro-tuberous ligament, whilst its lateral edge furnishes an origin for the quadratus femoris muscle; in front and below, the adductor magnus muscle is attached to it.

The medial surface of the body and superior ramus of the ischium form in part the wall of the small pelvis. Smooth and slightly concave from before backwards, and nearly plane from above downwards, it is widest opposite the level of the ischial spine. Below this, its posterior edge is rounded and forms a groove leading to the lesser sciatic notch, along and over which the tendon of the obturator internus passes. To part of this surface the fibres of the obturator internus are attached, whilst the medial aspect of the spine supplies points of origin for the coccygeus and levator ani muscles, as well as furnishing an attachment to the "white line" of the pelvic fascia. The medial surface of the inferior ramus of the ischium is smooth, and so rounded that its inferior edge tends to be everted. To this, as well as to its margin, is attached the crus penis, together with the ischio-cavernosus, obturator internus, transversus perinei, and sphincter muscle of the membranous urethra. In the female, structures in correspondence with these are found.

The anterior part of the hip bone is formed by the os pubis; it is by means of the union of this bone with its fellow of the opposite side that the pelvic girdle is completed in front.

The pubis (os pubis) consists of two rami-a superior (ramus superior ossis 
pubis) and an inferior (ramus inferior ossis pubis). The broad part of the bone formed by the fusion of these two rami is the body.

The body of the os pubis has two surfaces. Of these the posterior or posterosuperior is smooth, and forms the anterior part of the wall of the small pelvis; hereto are attached the levator ani muscle and pubo-prostatic ligaments, and on it rests the bladder. The anterior or antero-inferior surface is rougher, and furnishes origins for the gracilis, adductor longus, adductor brevis, and some of the fibres of the obturator externus muscles. The medial border is provided with an elongated oval cartilage-covered surface by means of which it is united to its fellow of the opposite side, the joint being called the facies symphyseos (symphyseal surface) of the pubic bone. The superior border, thick and rounded, projects somewhat, so as to overhang the anterior surface. It is called the crest. Internally this forms with the medial border or symphysis the angle, whilst laterally it terminates in a pointed process, the tuberculum pubicum (pubic tubercle). From

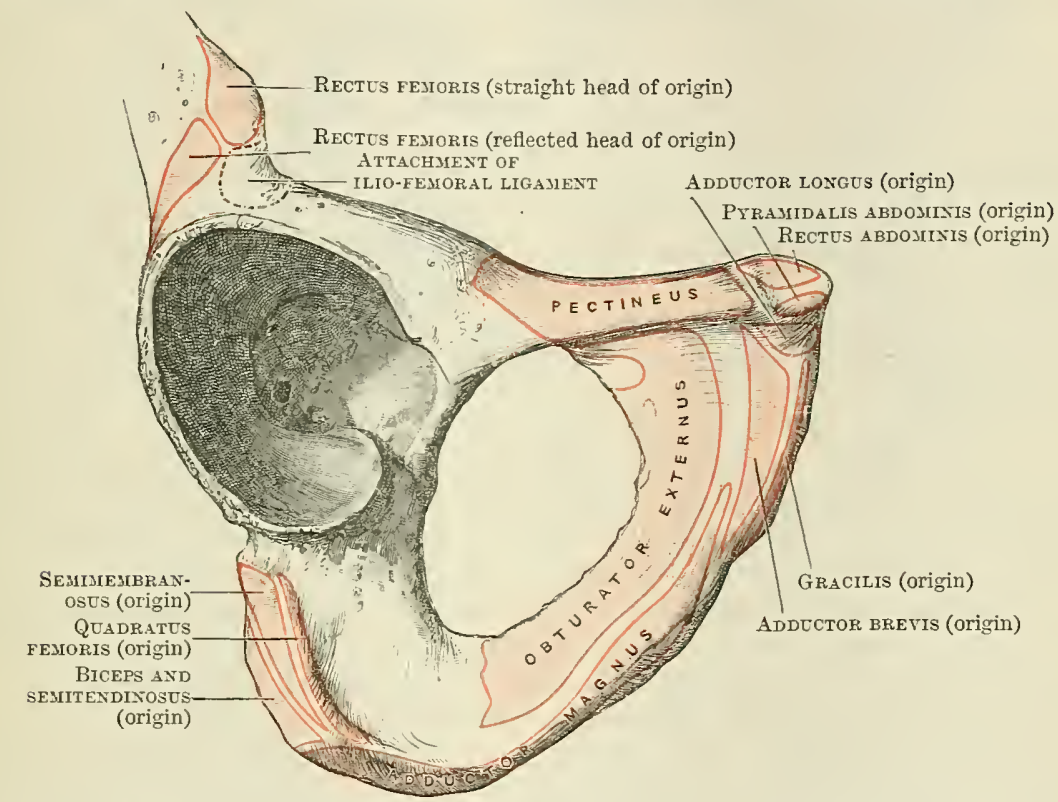

Fig. 232.-Muscle Attachments to the Lateral Surface of the Os Pubis axd Ischida.

the crest arise the rectus abdominis and pyramidalis muscles, and to the tubercle is attached the medial end of the inguinal ligament. Passing upwards and laterally from the lateral side of the body towards the acetabulum, of which it forms about the anterior fifth, is the superior ramus. This has three surfaces: an antero-superior, an antero-inferior, and an internal or posterior. The antero-superior surface is triangular in form. Its apex corresponds to the pubic tubercle; its anterior inferior border to the crista obturatoria (obturator crest), leading from the pubic tubercle to the upper border of the acetabular notch; whilst its sharp postero-superior border trends upwards and laterally from the tubercle, and is continuous with the iliac portion of the ilio-pectineal line just medial to the ilio-pectineal eminence, forming as it passes along the superior ramus the pubic portion of that same line (pecten ossis pubis). On this line, just medial to the ilio-pectineal eminence, there is often a short sharp crest which marks the insertion of the psoas minor. The base of the triangle corresponds to the ilio-pectineal eminence above and the upper margin of the acetabular notch below. Slightly hollow from side to side, and convex from before backwards, this surface provides an origin for, and is in part overlain by, the pectineus muscle. The posterior or postero-superior surface of the superior ramus is smooth, concave from side to side, and slightly rounded from above downwards; by its sharp inferior curved border it completes the obturator foramen, as seen from behind. The 
antero-inferior surface forms the roof of the broad sulcus obturatorius (obturator groove) which passes obliquely downwards and forwards between the lower margin of the antero-superior surface in front and the inferior sharp border of the medial surface behind. The inferior ramus of the os pubis passes downwards and laterally from the lower part of the body. Flattened and compressed, it unites with the inferior ramus of the ischium, and thus encloses the obturator foramen, whilst in correspondence with its fellow of the opposite side it completes the formation of the pubic arch. Anteriorly it furmishes origins for the gracilis, adductor brevis, and adductor magnus muscles, as well as some of the fibres of the obturator externus muscle. Its medial surface is smooth, whilst its lower border, rounded or more or less everted, has attached to it the anterior part of the crus penis and the arcuate (O.T. subpubic) ligament.

The acetabulum is the nearly circular hollow in which the head of the thigh bone fits. As has been already stated, it is formed by the fusion of the ilium and ischium and os pubis in the following proportions: the ilium a little less than twofifths, the ischium somewhat more than two-fifths, the os pubis constituting the remaining one-fifth. It is so placed as to be directed downwards, laterally, and forwards, and is surrounded by a prominent margin, to which the capsule and glenoid lip of the hip-joint are attached. Opposite the obturator foramen this margin is interrupted by the incisura acetabuli (acetabular notch); immediately lateral to the ilio-pectineal eminence the margin is slightly hollowed, whilst occasionally there is a feeble notching of the border above and behind. These irregularities in the outline of the margin correspond to the lines of fusion of the ilium and pubis and the ilium and ischium respectively. The floor of the acetabulum is furnished with a horseshoe-shaped articular surface, which lines the circumference of the hollow, except in front, where it is interrupted by the acetabular notch. It is broad above; narrower in front and below. Within this articular surface there is a more or less circular rough area (fossa acetabuli) continuous in front and below with the floor of the acetabular notch. This, somewhat depressed below the surface of the articular area, lodges a quantity of fat, and provides accommodation for the intra-articular ligament of the joint. As may be seen by holding the bone up to the light, the floor of this part of the acetabulum is not usually of great thickness. The major part of the non-articular area is formed by the ischium, which also forms the floor of the acetabular notch.

The foramen obturatum (obturator foramen) lies in front of, below, and medial to the acetabulum. The margins of this opening, which are formed in front and above by the os pubis, and behind and below by the ischium, are sharp and thin, except above, where the under surface of the superior ramus of the pubis is channelled by the obturator groove. Below, and on either side of this groove, two tubercles can usually be seen. The one, situated on the edge of the ischium, just in front of the cotyloid notch, is named the posterior obturator tubercle; the other, placed on the lower border of the posterior surface of the superior ramus of the os pubis, is called the anterior obturator tubercle. Between these two tubercles there passes a ligamentous band, which converts the groove into a canal along which the obturator vessels and nerve pass. Elsewhere in the fresh condition the obturator membrane stretches across the opening from margin to margin. The form of the foramen varies much, being oval in some specimens, in others more nearly triangular; its relative width in the female is greater than in the male.

Nutrient foramina for the ilium are seen on the floor of the iliac fossa, just in front of the auricular surface; on the pelvic aspect of the bone, close to the greater sciatic notch; and on the gluteal surface laterally, near the centre of the anterior gluteal line. For the ischium, on its pelvic surface, and also laterally on the groove below the acetabulum. For the pubis, on the surface of the body, and deeply also from the acetabular fossa.

Connexions. - The hip bone articulates with the sacrum behind, with the femur to the lateral side and below, and with its fellow of the opposite side medially and in front. Each of its three parts comes into direct relation with the surface. Above, the iliac crest assists in forming the iliac furrow, which serves to separate the region of the flank from that of the buttock. In front, the anterior superior iliac spine forms a definite landmark; whilst behind, the posterior superior iliac spines will be found to correspond with dimples situated on either side of the median plane of the root of the back. The symphysis, the crest, and tubercle of 
the pubis can all be distinguished in front, though overlain by a considerable quantity of fat, whilst the position of the tuberosities of the ischia, when uncovered by the great gluteal muscles in the flexed position of the thigh, can readily be ascertained. In the perineal region the outline of the pubic and ischial rami can easily be determined by digital examination.

Ossification commences in the ilium about the ninth week of intra-uterine life: about the fourth month a centre appears below the acetabulum for the ischium, the os pubis being developed from a centre which appears in front of the acetabulum about the fifth or sixth month. At birth the form of the ilium is well defined; the body and part of the tuberosity of the ischium are ossified, as well as the superior ramus and part of the body of the os pubis. All three parts enter into the formation of the sides of the acetabulum, and by the third yearhaveconverged to form the bottom of that hollow, being separated from each other by a triradiate piece of cartilage, in which, about the twelfth year, independent ossific centres make their appearance, which. may or may not become fused with the adjacent bones. In the latter case they unite to form an independent ossicle, the os acetaluli, which subsequently fuses with and forms the acetabular part of the os pubis. By the age of sixteen the ossification of the acetabulum is usually completed, whilst the rami of the ischium and os pubis commonly unite about the tenth

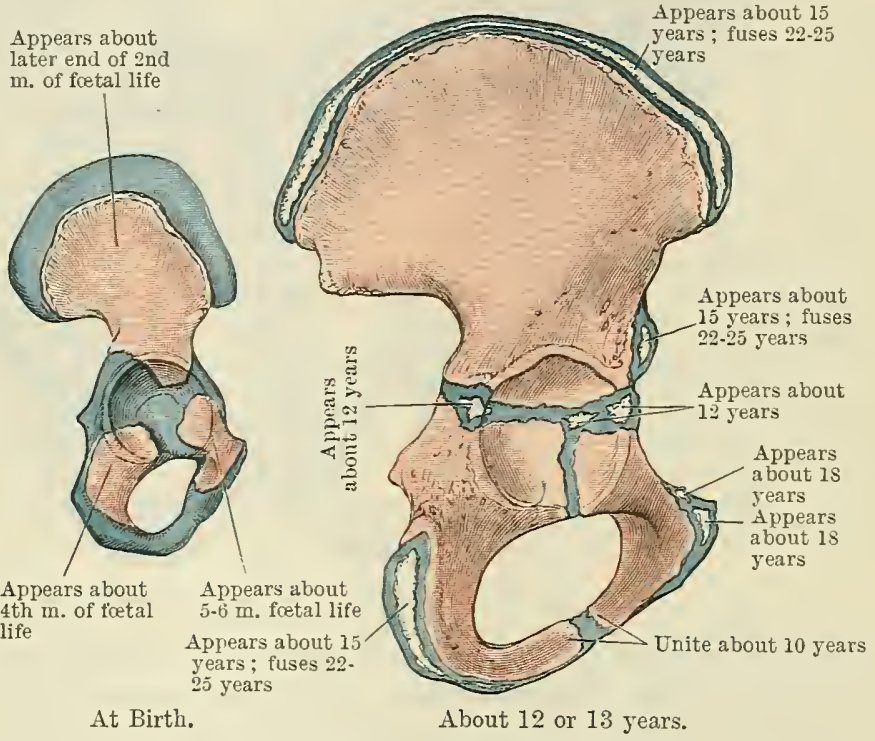

Fig. 233.-Ossification of the Hip Bone.

year. Secondary centres, seven in number, make their appearance abont the age of puberty, and are found in the following situations: one for the anterior inferior iliac spine ; one for the ventral two-thirds of the iliac crest and the anterior stperior iliac spine which grows backwards, one for the posterior superior iliac spine and dorsal third of the iliac crest which grows forwards-these two unite about the twentieth year; a scale-like epiphysis over the tuberosity of the ischium; a separate epiphysis for the spine of the ischium; (?) a point for the tubercle and another for the angle of the os pubis. Fusion between these and the primary centres is usually complete between the twenty-second and twenty-fifth years. Le Damany states that the proportionate depth of the acetabular cavity at the sixth month of fotal life is greater than at birth. In the third year a rapid increase in its depth again takes place correlated with the assumption of the erect position.

Parsons (Journ. Anat. and Physiol. vol. xxxrii. p. 315) regards the ischial epiphysis as the homologue of the hypo-ischium in reptiles, and suggests that the epiphysis over the angle of the pubis may represent the epipubic bone of marsupials.

\section{The Pelvis.}

The pelvis is formed by the union of the hip bones with each other in front, and with the sacrum behind. In man the dwarfed caudal vertebræ (coccygeal) are curved forwards and so encroach upon the limits of the pelvic cavity inferiorly. The pelvis is divided into two parts by the ilio-pectineal lines, which curve forwards from the upper part of the lateral parts of the sacrum behind to the roots of the tubercles of the os pubis in front. The part above is called the pelvis major (large pelvis), and serves by the expanded iliac fossie to support the abdominal contents; the part below, the pelvis minor (small pelvis), contains the pelvic viscera, and in the female forms the bony canal through which at full term the fotus is expelled. 
The small pelvis is bounded in front by the symphysis pubis in the median plane, and by the body and rami of the os pulis on either side, laterally by the smooth medial surfices of the ischia and ischial rami, together with a small part of the ilium helow the iliac portion of the ilio-pectiveal line. Springing from the posterior margin of the ischium are the inturned ischial spines. Behind, the broad curved

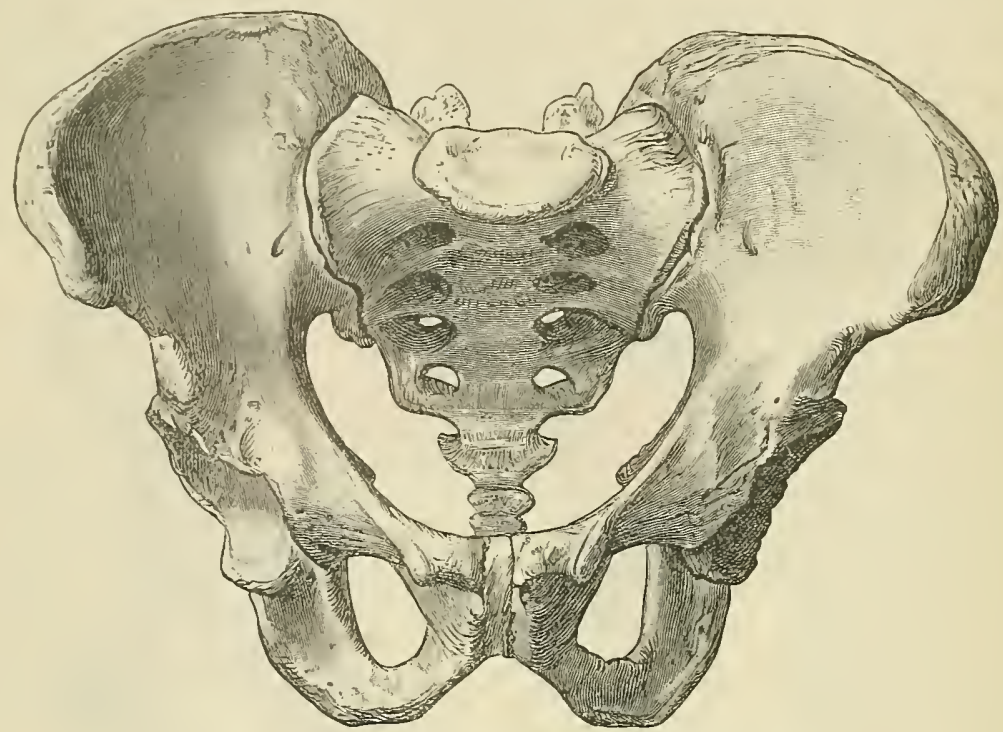

Fig, 234.-The Male Pelvis seen from the front.

anterior surface of the sacrum, and below it, the small and irregular coccyx, form its posterior wall. Between the sides of the sacrum behind, and the ischium and ilium in front and above, there is a wide interval, called the greater sciatic notch, which is, however, bridged across in the recent condition by the sacro-tuberous and sacro-spinous ligaments, which thus convert it into two foramina-the larger above

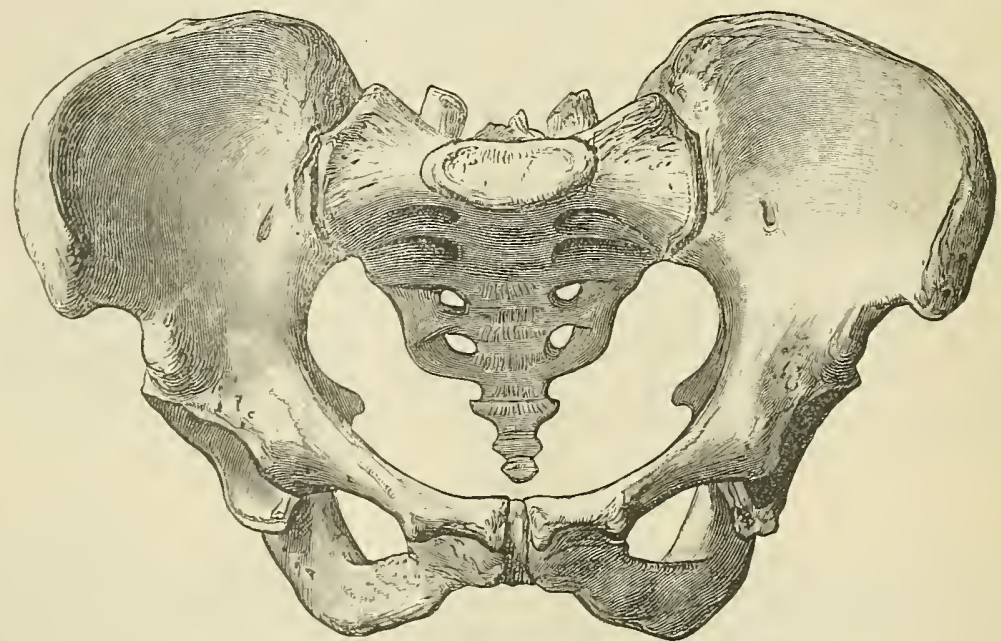

Fig. 235.-The Female Pelis seen from the front.

the spine of the ischium, the greater sciatic foramen; the lower and smaller below the spine, called the lesser sciatic foramen.

Apertura Pelvis Superior.-The upper opening of the small pelvis is bounded in front by the symphysis pubis, with the body of the pubis on either side; laterally by the ilio-pectineal lines; and behind by the sacral promontory. The circumference of this aperture is often called the brim of the small pelvis; in the male it is 
heart-shaped, in the female more oval. The antero-posterior or conjugate diameter is measured from the sacro-vertebral angle to the symphysis pubis; the oblique diameter from the sacro-iliac joint of one side to the ilio-pectineal eminence of the other; whilst the transverse diameter is taken across the greatest width of the pelvic aperture.

Apertura Pelvis Inferior. - The lower opening is bounded anteriorly by the arcus pubis (pubic arch), formed in front and above by the bodies of the ossa pubis, with the symphysis between them, and the inferior pubic rami below and on either side. These latter are continuous with the ischial rami, which pass backwards and laterally to the ischial tuberosities, which are placed on either side of this aperture. In the median plane behind, the tip of the coccyx projects forward; and in the recent condition the interval between this and the ischial tuberosities is bridged across by the sacro-tuberous ligament, the inferior edge of which necessarily assists in determining the shape of the outlet.

As the anterior wall of the cavity, formed by the symphysis pubis, measures from $1 \frac{1}{2}$ to 2 inches, whilst the posterior wall, made up of the sacrum and coccyx, is from 5 to 6 inches in length, it follows that the planes of the inlet and outlet are not parallel, but placed at an angle to each other. The term axis of the pelvis is given to lines drawn at right angles to the centres of these planes. Thus, with the pelvis in its true position, when the figure is erect, the axis of the upper opening corresponds to a line drawn downwards and backwards from the umbilicus towards the tip of the coccyx below, whilst the axis of the lower opening is directed downwards and slightly backwards, or downwards and a little forwards, varying according to the length of the coccyx. Between these two planes the axis of the cavity, as it passes through planes of varying degrees of obliquity, describes a curve repeating fairly closely the curve of the sacrum and coccyx.

Position of the Pelvis.-The position of the pelvis in the living, when the figure is erect, may be approximately represented by placing it so that the anterior superior iliac spines and the symphysis pubis lie in the same vertical plane. Under these conditions the plane of the upper opening is oblique, and forms with a horizontal line an angle of from $50^{\circ}$ to $60^{\circ}$. The position of the pelvis depends upon the length of the ilio-femoral ligaments of the hip-joint, being more oblique when these are short, as usually happens in women in whom the anterior superior iliac spines tend to lie in a plane slightly in advance of that occupied by the symphysis pubis. In cases where the ilio-femoral ligament is long a greater amount of extension of the hip-joint is permitted, and this leads to a lessening of the obliquity of the pelvis. This condition, which is more typical of men, results in the anterior superior iliac spines lying in a plane slightly posterior to the plane of the symphysis, whilst the angle formed by the plane of the inlet and the horizontal is thereby reduced. Bearing in mind the oblique position of the pelvis, it will now be seen that the front of the sacrum is directed downwards more than forwards, and that the sacral promontory is raised as much as from $3 \frac{1}{2}$ to 4 inches above the upper border of the symphysis pubis, lying higher than the level of a line connecting the two anterior superior iliac spines. From the manner in which the sacrum articulates with the ilia, it will be noticed that the weight of the trunk is transmitted downwards through the thickest and strongest part of the bone (see Architecture, Appendix A) to the upper part of the acetalula, where these rest on the heads of the femora.

Sexual Differences.-The female pelvis is lighter in its construction than that of the male; its surfaces are smoother, and the indications of muscular attachments less marked. Its height is less and the splay of its walls not so pronounced as in the male, so that the female pelvis has been well described as a short segment of a long cone as contrasted with the male pelvis, which is a long segment of a short cone. The cavity of the small pelvis in the female is more roomy, and the ischial spines not so nuch inturned. The pubic arch is wide and rounded, and will usually admit a right-angled set-square being placed within, so that the summit touches the inferior surface of the symphysis pubis, whilst the sides lie in contact with the ischial rami. In the male the arch is narrow and angular, forming an angle of from $65^{\circ}$ to $70^{\circ}$. The greater sciatic notch in the female is wide and shallow. The distance from the posterior edge of the body of the ischium to the posterior inferior iliac spine is longer, measuring on an average $50 \mathrm{~mm}$. (2 inches) in the female, as contrasted with $40 \mathrm{~mm}$. ( $1 \frac{5}{8}$ inches) in the male. The angle formed by the ischial and iliac borders is more contracted and acute in the male as compared with the 
female, in whom it is wider and more open. In the female the acetabulum is proportionately smaller than in the male.

The upper opening in the female is large and oval or reniform, as compared with the cribbed and leart-shaped aperture in the male. The sacro-vertebral angle is more pronounced in the female, and the obliquity of the upper opening greater. The sacrum is shorter and wider. The posterior superior iliac spines lie wider apart; the pubic crests are longer; and the pubic tubercles are separated by a greater interval than in man The outlet is larger; the tuberosities of the ischia are farther apart; and the coccyx does not project forward so much. The curve of the sacrum is liable to very great individual variation. As a rule the curve is more uniform in the male, whilst in the female it tends to be flatter above and more accentuated below. There is a greater proportionate width between the acetabular hollows in the female than in the male. Of nuch importance from the standpoint of the obstetrician are the various diameters of the small pelvis. In regard to this it is worthy of note that the plane of "greatest pelvic expansion" extends from the union between the second and third sacral vertebræ behind, to the middle of the symphysis pubis in front, its lateral boundaries on either side corresponding with the mid-point of the medial surface of the acetabulum; whilst the plane of "least pelvic diameter" lies somewhat lower, and is defined by lines passing through the sacro-coccygeal articulation, the ischial spines, and the lower third of the symphysis pubis (Norris). Subjoined is a table showing the principal average measurements in the two sexes:-

PELVIS MAJOR.

\begin{tabular}{|l|c|l|}
\hline & \multicolumn{1}{|c|}{ Males. } & \multicolumn{1}{c|}{ Females. } \\
\hline $\begin{array}{l}\text { Maximum distance between the iliac crests } \\
\text { Distance between the anterior superior iliac } \\
\text { spines }\end{array}$ & $\begin{array}{l}11 \frac{1}{8} \text { in., or } 282 \mathrm{~mm} . \\
9 \frac{1}{2} \text { in., or } 240 \mathrm{~mm} .\end{array}$ & $\begin{array}{l}10 \frac{3}{4} \text { in., or } 273 \mathrm{~mm} . \\
9 \frac{3}{4} \text { in., or } 250 \mathrm{~mm} .\end{array}$ \\
$\begin{array}{l}\text { Distance between the last lumbar spine and } \\
\text { the front of the symphysis pubis }\end{array}$ & 7 in., or $176 \mathrm{~mm}$. & $7 \frac{1}{8}$ in., or $180 \mathrm{~mm}$. \\
\hline
\end{tabular}

PELVIS MINOR.

\begin{tabular}{|c|c|c|c|c|c|c|}
\hline & \multicolumn{2}{|c|}{ Males. } & \multicolumn{4}{|c|}{ Females. } \\
\hline & \multirow{2}{*}{$\begin{array}{l}\text { Upper } \\
\text { Opening. }\end{array}$} & \multirow{2}{*}{$\begin{array}{l}\text { Lower } \\
\text { Opening. }\end{array}$} & \multirow{2}{*}{$\begin{array}{c}\text { Upper } \\
\text { Opening. }\end{array}$} & \multicolumn{2}{|c|}{ Cavity. } & \multirow{2}{*}{$\begin{array}{l}\text { Lower } \\
\text { Opening. }\end{array}$} \\
\hline & & & & Greatest. & Least. & \\
\hline $\begin{array}{l}\text { Antero-posterior (conju- } \\
\text { gate) diameter } \\
\text { Oblique diameter . } \\
\text { Transverse diameter }\end{array}$ & $\begin{array}{l}4 \text { in., or } \\
101 \mathrm{~mm} . \\
4 \frac{3}{4} \text { in., or } \\
120 \mathrm{~mm} \text {. } \\
5 \text { in., or } \\
127 \mathrm{~mm} .\end{array}$ & $\begin{array}{l}3 \frac{3}{4} \mathrm{in} ., \text { or } \\
95 \mathrm{~mm} \text {. } \\
3 \frac{1}{2} \mathrm{in} ., \text { or } \\
88 \mathrm{~mm} \text {. } \\
3 \frac{1}{2} \mathrm{in} . \text {, or } \\
88 \mathrm{~mm} .\end{array}$ & $\begin{array}{l}4 \frac{3}{8} \text { in., or } \\
110 \mathrm{~mm} \text {. } \\
5 \text { in., or } \\
125 \mathrm{~mm} \text {. } \\
5 \frac{1}{4} \text { in., or } \\
135 \mathrm{~mm} \text {. }\end{array}$ & $\begin{array}{c}5 \text { in., or } \\
127 \mathrm{~mm} . \\
\ldots \\
4 \frac{7}{8} \text { in., or } \\
125 \mathrm{~mm} \text {. }\end{array}$ & $\begin{array}{c}4 \frac{3}{8} \text { in., or } \\
110 \mathrm{~mm} . \\
\ldots \\
4 \frac{3}{8} \text { in., or } \\
110 \mathrm{~mm} \text {. }\end{array}$ & $\begin{array}{l}4 \frac{1}{2} 1 \mathrm{n} . \text {, or } \\
115 \mathrm{~mm} \text {. } \\
4 \frac{1}{2} \text { in., or } \\
115 \mathrm{~mm} \text {. } \\
4 \frac{3}{8} \text { in., or } \\
110 \mathrm{~mm} \text {. }\end{array}$ \\
\hline
\end{tabular}

Growth of the Pelvis.-From the close association of the pelvic girdle with the lower limb we find that its growth takes place concurrently with the development of that member. At birth the lower limbs measure but a fourth of the entire body length; consequently at that time the pelvis, as compared with the head and trunk, is relatively small. At this period of life the bladder in both sexes is in greater part an abdominal organ, whilst in the female the uterus has not yet sunk into the small pelvic cavity, and the ovaries and uterine tubes rest in the iliac fossæ. The sacro-vertebral angle, though readily recognised, is as yet but faintly marked. Coincident with the remarkable growth of the lower limbs and the assumption of the erect position when the child begins to walk, striking changes take place in the form and size of the pelvis. These consist in a greater expansion of the iliac bones necessarily associated with the growth of the muscles which control the movements of the hip, together with a marked increase in the sacro-vertebral angle due to the development of a forward lumbar curve; at the same time, the weight of the trunk being thrown on the sacrum causes the elements of that bone to sink to a lower level between the hip bones. The cavity of the small pelvis increases in size proportionally, and the viscera afore-mentioned now begin to sink down and have assumed a position within the pelvis by the fifth or sixth year. The extension of the thighs in the upright position necessarily brings about a more pronounced pelvic obliquity, whilst the stoutness and thickness of the ilium over the upper part of the acetabulum is much increased to withstand the pressure to which it is obviously subjected. Coincident with this is the gradual development 

of the iliac portion of the ilio-pectineal line, which serves in the adult to separate sharply
the large from the small pelvis. This part of the bone is remarkably strong, as will be shown

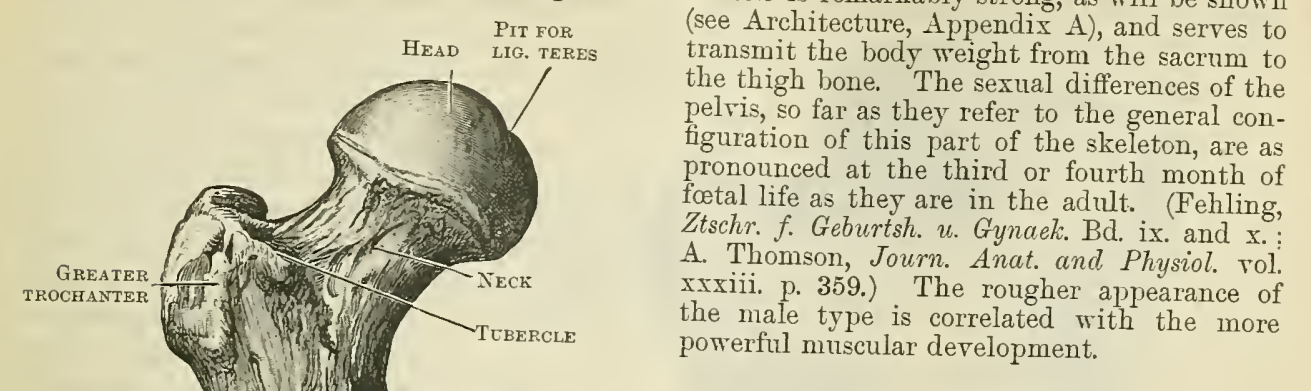

\section{The Femur.}

The femur or thigh bone is remarkable for its length, being the longest

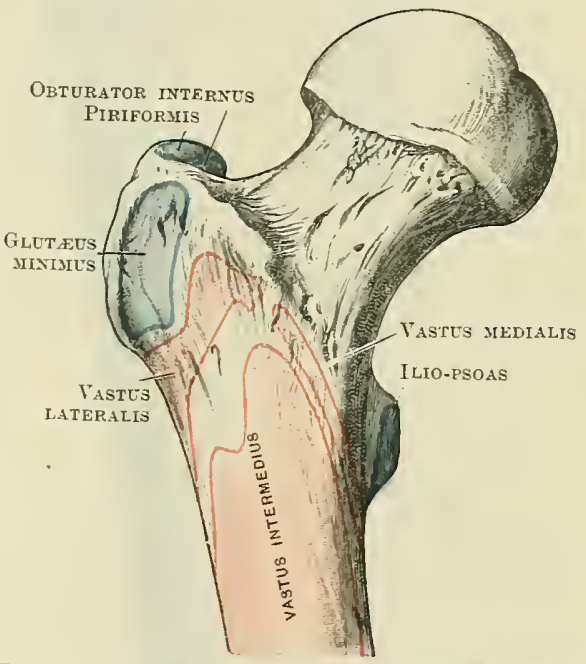

Fig. 237.-ANTerior Aspect of Prosimal PorTIOx of the Right Fendr mith AtTAChMENTS OF MUSCles MAPPED OUT.

bone in the body. Proximally the femora are separated by the width of the pelvis. Distally they articulate with the tibiæ and patellæ. In the military position of attention, with the knees close together, the shafts of the thigh bones occupy an oblique position.

For descriptive purposes the bone is divided into a proximal extremity, com-

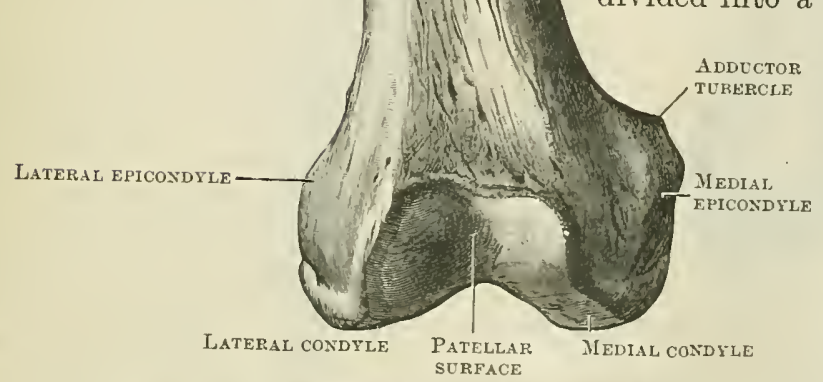
prising the head, neck, and two trochanters; a shaft; and a distal extremity, forming the expansions known as the condyles.

The caput femoris (head) is the hemispherical articular surface which fits into the acetabulum. Its pole medially, and slightly forwards. A little below the summit, and usually somewhat 
behind it, is a hollow oval pit (fovea capitis femoris) for the attachment of the ligannentum teres. Piercing the floor of this depression are seen several foramina

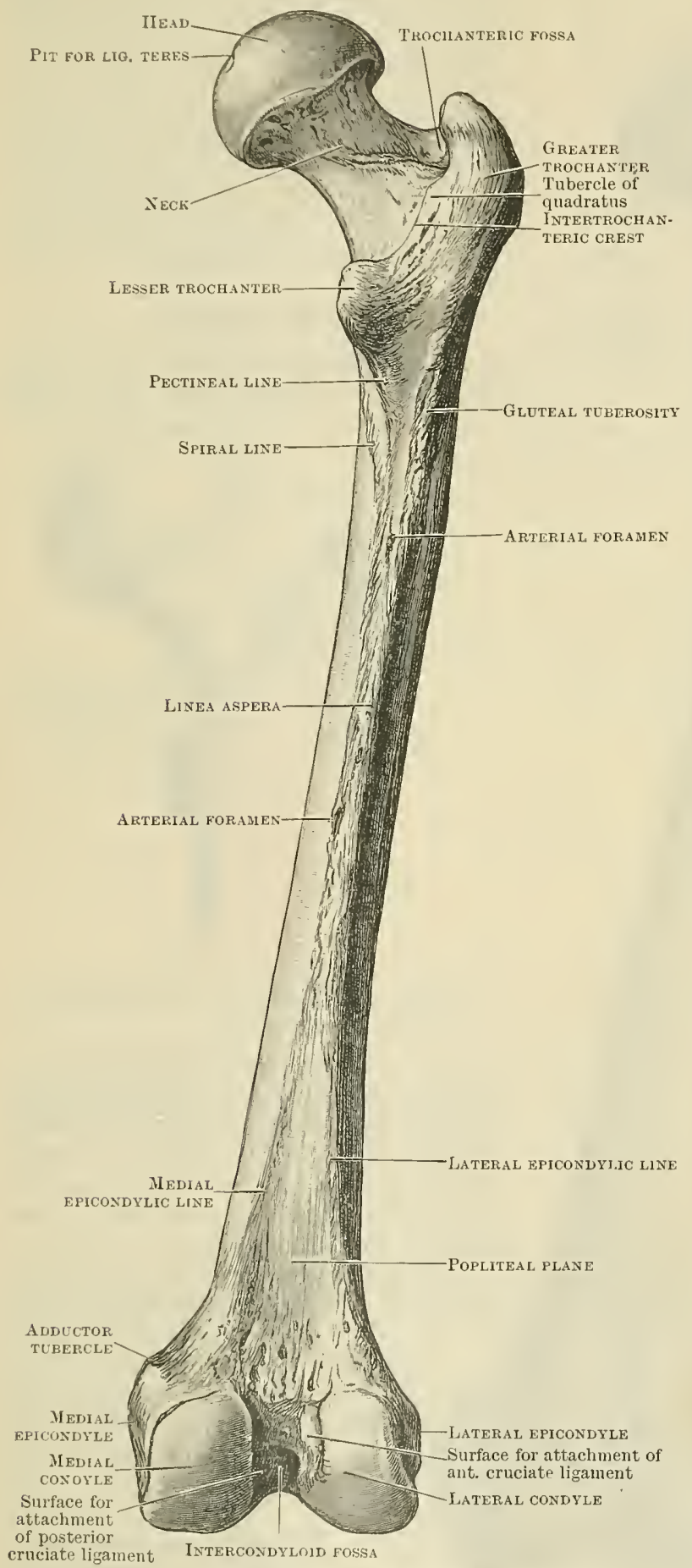

Fig. 238.-The Right FeMur seen from Behind. through which vessels pass to supply the head of the bone; the proximal epiphysis thus having a double blood supply, viz., from the neck distally, and through the medium of the ligamentum teres proximally. The circumference of the head forms a lip with a wavy outline, more prominent proximally and dorsally than in front. The head is supported by a stout compressed bar of bone, the collum femoris (neck), which forms with the proximal end of the shaft an angle of about 125 degrees, and is directed proximally, medially, and a little forwards. Its vertical width exceeds its antero-posterior thickness. Constricted about its middle, it expands medially to support the head, whilst laterally, where it joins the shaft, its vertical diameter is much increased. Anteriorly it is clearly defined from the shaft by a rough ridge which commences above on a prominence, sometimes called the tubercle of the femur, and passes obliquely downwards and medially. This constitutes the upper part of the linea intertrochanterica (intertrochanteric line), and serves for the attachment of the ilio-femoral ligament of the hip-joint. Posteriorly where the neck unites with the shaft, there is a full rounded ridge passing from the trochanter major proximally to the trochanter minor distally; this is the crista intertrochanterica (intertrochanteric crest). A little proximal to the middle of this ridge there is usually a fulness which serves to indicate the proximal limit of attachment of the quadratus femoris muscle, and is called the tubercle for the quadratus. Laterally the 
neck is embedded in the medial surface of the trochanter major, by which, at its proximal and dorsal part, it is.to some extent overhung. Here is situated the trochanteric fossa, into which the tendon of the obturator externus is inserted. Passing nearly horizontally across the back of the neck there is a faint groove leading into this depression; in this the tendon of the obturator externus muscle lies. Distally the neck becomes confluent with the trochanter minor behind, and is continuous with the medial surface of the shaft in front. The neck is pierced by many vascular canals, most numerous at the proximal and dorsal part. Some are directed proximally towards the head, whilst others pass in the direction of the trochanter major.

The trochanter major (greater trochanter) is a large quadrangular process which caps the proximal and lateral part of the shaft, and overhangs the root of the neck above and behind. Its lateral surface, of rounded irregular form, slopes proximally and medially, and is separated from the lateral surface of the shaft distally by a more or less horizontal ridge. Crossing it obliquely from the posterior superior to the anterior inferior angle is a rough line which serves for the insertion of the

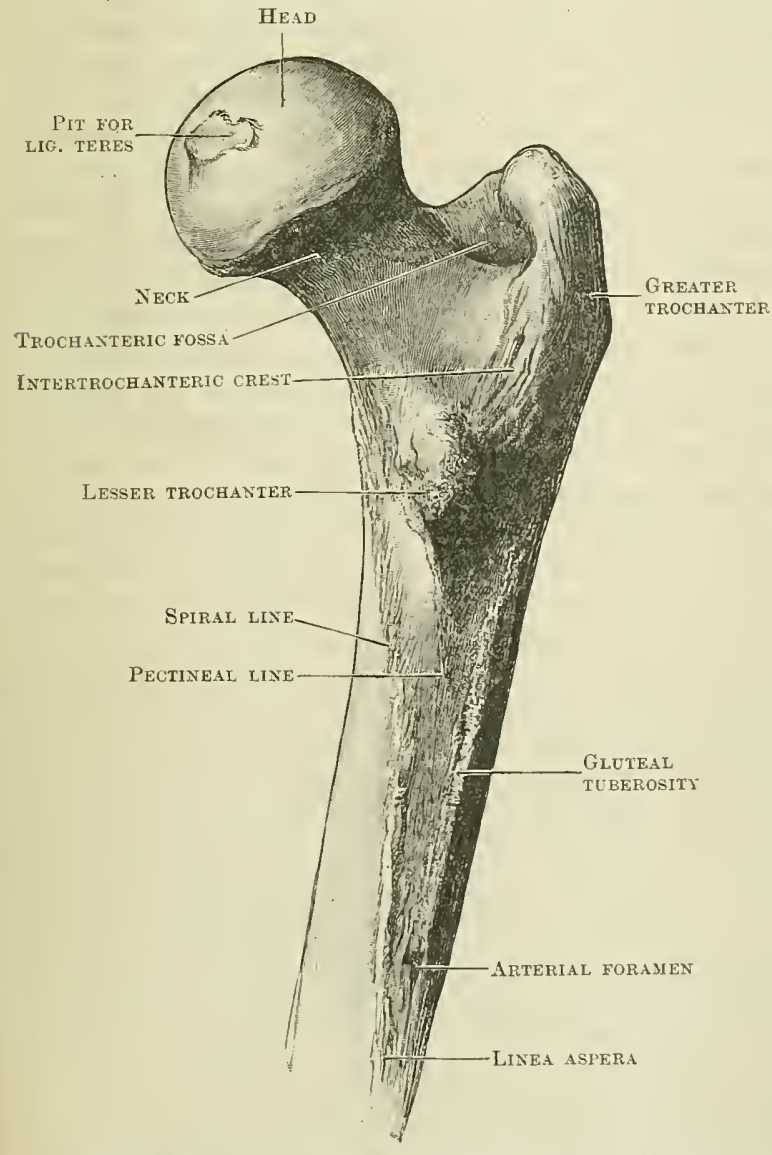

Fig. 240.-Dorsal View of the Proximal Exd of THE RIGHT FEMUR.

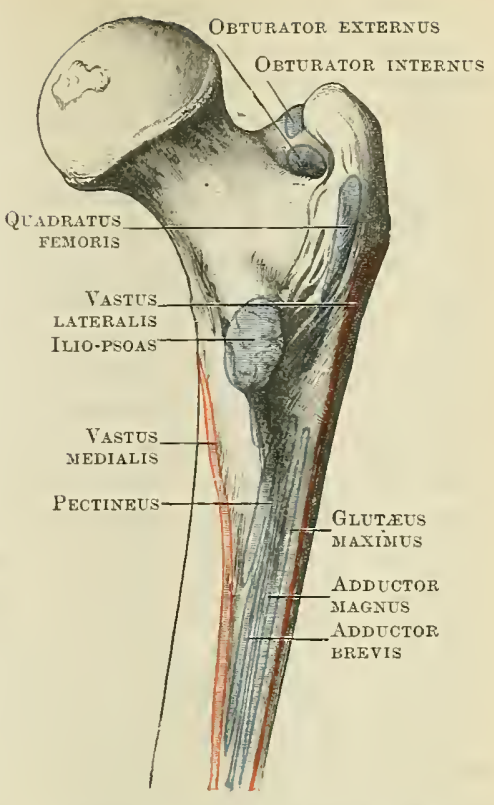

Fig. 239. - Dorsal Aspect of the Proximal Portion of the Pight Femur with the Attachuents of MUSCLES MAPPED OUT.

glutæus medius muscle; proximally and distally to this the surface of the bone is smoother and is overlain by bursæ. The ventral surface, somewhat oblong in shape, and inclined obliquely from below upwards and medially, is elevated from the general aspect of the shaft below, from which it is separated in front by an oblique line leading upwards and medially to the tubercle at the proximal end of the superior part of the intertrochanteric line. This surface serves for the insertion of the glutæus minimus. The proximal border is curved and elevated; into it are inserted the tendons of the obturator internus and gemelli muscles medially and in front, and the piriformis muscle proximally and dorsally. The dorsal border is thick and rounded, and forms the upper part, of the intertrochanteric crest. The angle formed by the proximal and dorsal borders is sharp and pointed, and forms the tip of the trochanter overhanging the trochanteric fossa, which lies immediately distal and medial to its medial surface. 
The lesser trochanter (trochanter minor) is an elevated pyramidal process situated at the dorsal side of the medial and proximal part of the shaft, where that becomes continuous with the distal and dorsal part of the neck. Confluent above with the intertrochanteric crest, it gradually fades away into the dorsal aspect of the shaft below. The combined tendon of the ilio-psoas is inserted into this process and into the bone immediately below it.

The shaft (corpus femoris), which is characterised by its great length, is cylinlrical in form. As viewed from the front, it is straight or but slightly curved; as seen in profile, it is bent forwards, the curve being most pronounced in its proximal part. The shaft is thinnest at some little distance proximal to its middle; distal to this it gradually increases in width to support the condyles; its anteroposterior diameter, however, is not much increased distally. Its surfaces are generally smooth and rounded, except behind, where, running longitudinally along the centre of its curved dorsal aspect, there is a rough-lipped ridge, the linea aspera. Most salient towards the middle of the shaft, the linea aspera consists of a medial lip and a lateral lip, with a narrow intervening rough surface. Proximally, about 2 to $2 \frac{1}{2}$ inches from the trochanter minor, the linea aspera is formed by the convergence of three lines. Of these the lateral is a rough, somewhat elevated, ridge, which commences proximally, on the back of the shaft, lateral to and on a level with the trochanter minor, and becomes continuous distally with the lateral lip of the linea aspera. This serves for the bony insertion of the glutrus maximus, and is occasionally developed into an outstanding process called the trochanter tertius. The medial lip of the linea aspera is confluent proximally with a line which winds round the shaft upwards and forwards in tront of the trochanter minor to become continuous with the rough ridge which serves to define the neck from the shaft anteriorly (see p. 240). The whole constitutes what is known as the spiral line, and extends from the anterior part of the trochanter major proximally to the linea aspera distally. Intermediate in position between the spiral line in front and medially, and the gluteal ridge laterally, there is a third line, the pectineal line, which passes distally from the trochanter minor and fades away into the surface between the two lips of the linea aspera. Into this the pectineus muscle is inserted. About the junction of the middle with the distal third of the shaft the two lips of the linea aspera separate from one another, each passing in the direction of the epicondyle of the corresponding side. The lines so formed are called the medial and lateral epicondylic lines, respectively, and enclose between them a smooth triangular area corresponding to the back of the distal third of the shaft; this, called the planum popliteum (popliteal surface), forms the floor of the proximal part of the popliteal fossa. The continuity of the proximal part of the medial epicondylic line is but faintly marked, being interrupted by a wide and faint groove along which the popliteal artery passes to enter the fossa of that name. Distally, where the line ends on the proximal and medial surface of the medial epicondyle, there is a little spur of bone called the adductor tubercle, to which the tendon of the adductor magnus is attached, and behind which the medial head of the gastrocnemius muscle talies origin.

The linea aspera affords extensive linear attachments to many of the muscles of the thigh. The vastus medialis arises from the spiral line proximally and the medial lip of the linea aspera distally. This muscle overlies but does not take origin from the medial aspect of the shaft. The adductor longus is inserted into the medial lip about the middle third of the length of the shaft. The adductor magnns is inserted into the intermediate part of the line, extending to the level of the trochanter minor, where it lies medial to the insertion of the glutrus maximus. Distally, its insertion passes on to the medial epicondylic ridge, reaching as far as the adductor tubercle. The adductor brevis muscle is inserted into the linea aspera proximally, between the pectineus and adductor longus muscles medially and the adductor magnus laterally. Distal to the insertion of the glutæns maximus the short head of the biceps arises from the lateral lip as well as from the lateral epicondylic line; in front these also serve for the origin of the vastus lateralis muscle. There is frequently a small tubercle which marks the distal attachment of the lateral intermuscular septum on the lateral condylic line, about two inches from the condyle. This is known as the lateral epicondyle. Immediately proximal to this there is often a groove for a large muscular artery which pievces the septum at this point (Frazer).

The canals for the nutrient arteries of the shaft, which have a proximal direction, are usually two in number, and are placed on or near the linea aspera - the proximal one about the level of the junction of the middle and proximal third of the bone, the distal some three or four inches distal 
to this-usually on the medial side of the shaft, immediately in front of the medial lip of the linea aspera.

The anterior and lateral aspects of the shaft are covered by, and furnish surfaces for, the origins of the vastus lateralis and vastus intermedius. The medial aspect is covered by the vastus medialis.

The distal extremity of the femur comprises the two condyles and epicondyles. The condyles are two recurved processes of bone, each provided with an

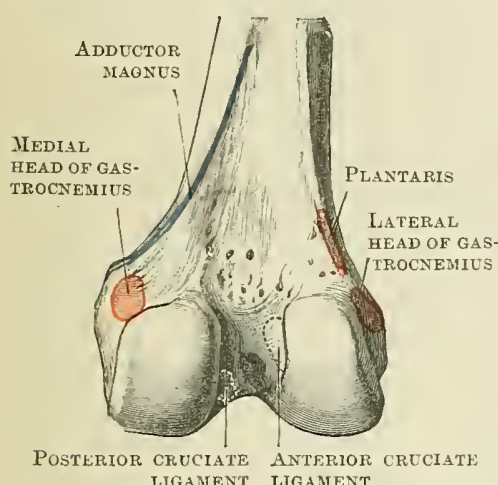

LIGAMEN'T LIGAMENT

Fig. 241.-Posterior Aspect of Distal Portion of the Pight Fender with ATTACHMENTS OF MUSCles MaPPED OठT. lateral and medial condyles respectively, the latter being more deeply excarated, and displaying an oval surface near its distal and anterior part for the attachment of the posterior eruciate ligament of the knee-joint. On the posterior and proximal part of the medial surface of the lateral condyle there is a corresponding surface for the attachment of the anterior cruciate ligament. The floor of the notch, which is pierced by numerous vascular canals, slopes proximally and dorsally towards the popliteal surface on the back of the shaft, from which it is separated by a slight ridge (linea intercondyloidea) to which the posterior part of the capsule of the knee-joint is attached.

Epicondyles.-The cutaneous aspect of each condyle (i.e. the lateral surface of the lateral condyle and the medial surface of the medial condyle) presents an elevated rough surface called the epicondyle, the medial (epicondylus medialis) projecting more prominently from the line of the shaft; capped proximally by the adductor tubercle, it affords attachment near its most prominent point to the fibres of the tibial collateral ligament of the knee-joint. The epicondylus lateralis (lateral epicondyle), less pronounced and lying more in line with the lateral surface of the shaft, is channelled behind by a curved groove, the distal rounded lip of which serves to separate it from the distal articular surface. This groove ends in front in a pit which is placed just distal to the most salient point of the

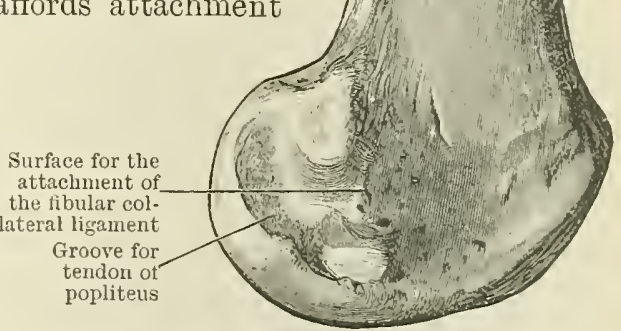

Fig. 242.-Distal End of the Righx Fesur (Lateral Side). tuberosity; hereto is attached the tendon of the popliteus muscle, which overlies the distal lip of the groove, which is often indented for it in the extended position of the joint, but slips into and occupies the groove when the joint is flexed. Dorsal to the most prominent part of the lateral epicondyle, and just proximal to the pit for the attachment of the popliteus, the fibular collateral ligament of the knee-joint is attached, whilst proximal to that there is a circumscribed area for the origin of the tendinous part of the lateral head of the gastrocnemius muscle. 
The articular surface on the distal extremity is divisible into three partsthat which corresponds to the distal surface of the shaft and is formed by the coalescence of the two condyles in front; and those which overlie the distal and posterior aspects of each of those processes. The former is separated from the latter by two shallow oblique grooves which traverse the articular surface from before backwards, on either side, in the direction of the anterior part of the intercondyloid fossa. These furrows are the impressions in which fit the anterior parts of the medial and lateral menisci of the knee-joint, respectively, when the knee-joint is extended. The anterior articular area or facies patellaris (patellar surface) is adapted for articulation with the patella. Convex proximo-distally, it displays a broad and shallow central groove, bounded on either side by two slightly convex surfaces. Of the two sides, the lateral is the wider and more prominent, and rises on the front of the bone to a more proximal level than the medial, thus tending to prevent lateral dislocation of the patella. The condylar or tibial surfaces are convex from side to side, and convex from before backwards. Sweeping round the distal surface and posterior extremities of the condyles, they describe a spiral curve more open in front than behind. The medial condylar articular surface is narrower

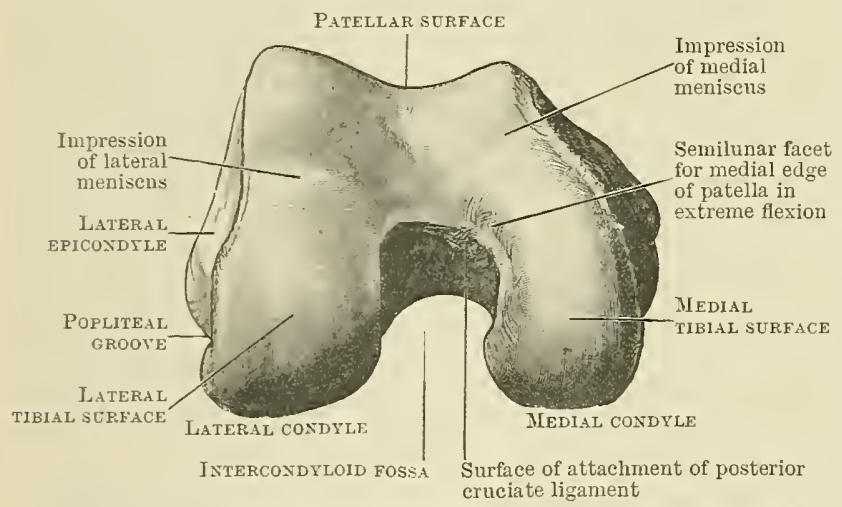

Fig. 243.-Distal Aspect of Distal Exd of the Right Femur. than the lateral, and when its distal aspect is viewed it is seen to describe a curve around a vertical axis. Along the lateral edge of this, and in front, where it bounds the intercondyloid fossa, is a semilunar articular area, best seen when the bone is coated with cartilage. This articulates with the medial edge of the patella in extreme flexion of the joint. The articular surface of the lateral condyle is inclined obliquely from before backwards and slightly laterally. The surfaces of the condyles proximal to the articular area posteriorly are continuous with the popliteal surface of the shaft. The bone from which the medial head of the muscle springs is often elevated in the form of a tubercle placed on the distal part of the popliteal surface of the shaft, just proximal to the medial condyle.

The proportionate length of the femur to the body height is as 1 is to $3 \cdot 53-3 \cdot 92$.

Arterial Foramina.-Numerous vascular canals are seen in the region of the neck, at the bottom of the trochanteric fossa, in the fossa for the ligamentum teres, on the intertrochauteric crest, and on the lateral surface of the greater trochanter. The nutrient arteries for the shaft pierce the bone in a proximal direction on or near the linea aspera. Both back and front of the distal end of the shaft display the openings of numerous vascular canals, and the floor of the intercondyloid fossa is also similarly pierced.

Connexions.- The femur articulates with the hip bone proximally and the tibia and patella distally. The lateral surface of the greater trochanter determines the point of greatest hip width in the male, being covered only by the skin and superficial fascia and the aponeurotic insertion of the glutæus maximus. In the erect position the tip of the trochanter corresponds to the level of the centre of the hip-joint. When the thigh is flexed the trochanter major sinks under cover of the anterior fibres of the glutens maximus. In women the hip width is usually greatest at some little distance distal to the trochanter, due to the accumulation of fat in this region. The shaft of the bone is surrounded on all sides by muscles. Its forward curve, however, is accountable to some extent for the fulness of the front of the thigh. The exposed surfaces of the condyles determine to a large extent the form of the knee. In flexion the articular edges can easily be recognised on either side of and distal to the patella.

Sexual Differences.-According to Dwight, the head of the femur in the female is proportionately smaller than that of the male.

Ossification.-The shaft begins to ossify early in the second month of fotal life, and at birth displays enlargements at both ends, which are capped with cartilage. If at birth the distal cartilaginous end be sliced away, a small ossific nucleus for the distal epiphysis will usually be seen. This, as a rule, makes its appearance towards the latter end of the ninth 
month of fœtal life, and is of service from a medico-legal standpoint in deternining the age of the fœtus. According to Hartman, it is absent in about 12 per cent of children at term, and may appear as early as the eighth month of fœtal life in about 7 per cent. The proximal extremity, entirely cartilaginous at birth, comprises the head, neck, and trochanter major. A centre appears for the head during the early part of the first year. It is worthy of note that this epiphysis has a double blood-supply - one through the neck, the other through the ligamentum teres. That for the trochanter major begins to ossify about the second or third year, whilst the neck is developed as a proximal extension of the shaft, which is, however, not confined to the neck alone, but forms the distal circumference of the articular head, as may be seen in bones up to the age of twelve or sixteen; after that, the separate epiphysis of the head begins to overlap it so as to corer it entirely when fusion is com-

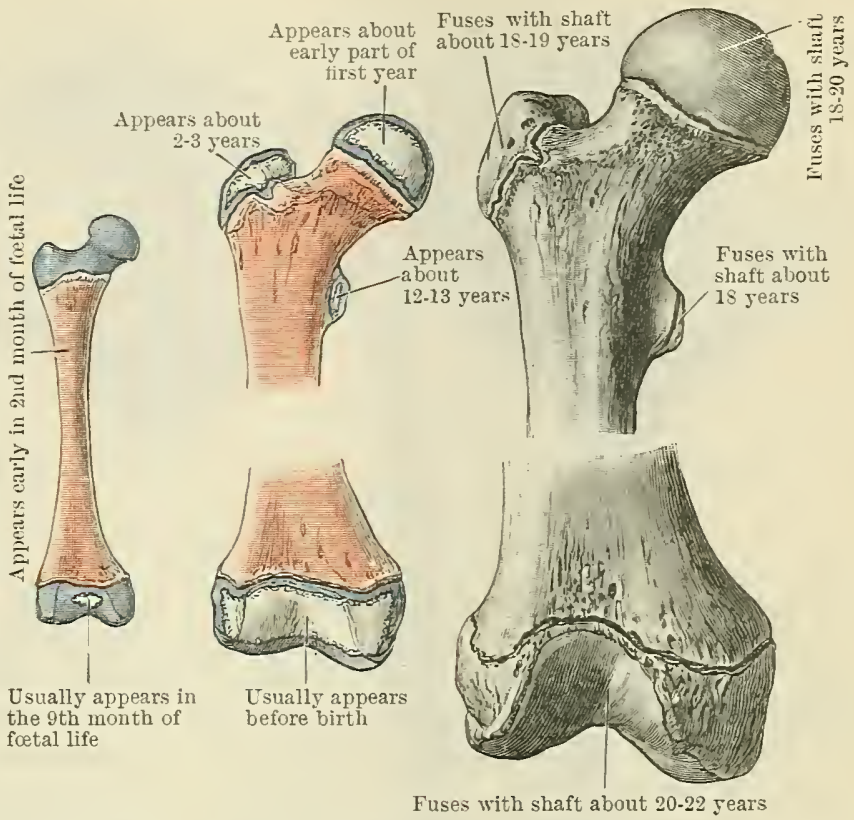

At birth. About 12 years. About 16 years.

Fig. 244.-OSsification OF the Feivor. plete at the age of eighteen or twenty.

The epiphysis of the greater trochanter unites with the shaft and neck about eighteen or nineteen, whilst the epiphysis for the trochanter minor, which usually makes its appearance about the twelfth or thirteenth year, is usually completely fused with the shaft about the age of eighteen. The epiphysis for the distal end, although the first to ossify, is not completely united to the shaft until from about the twentieth to the twenty-second jear. It is worthy of note that the line of fusion of the shaft and distal epiphysis passes through the adductor tubercle, a point which can easily be determined in the living. The distal end is the so-called "growing end of the bone."

\section{The Patella.}

The patella, the largest of the sesamoid bones, overlies the front of the kneejoint in the tendon of the quadriceps extensor. Of compressed form and somewhat triangular slrape, its distal angle forms a peak, called the apex patellæ, whilst its proximal edge, or base (basis patellæ), broad, thick, and sloping forwards and a little distally, is divided into two areas by a transverse line or groove; the anterior area so defined serves for the attachment of the common tendon of the quadriceps extensor muscle, whilst the posterior, of compressed triangular shape, is covered by synovial membrane. The medial and lateral borders, of curved outline, receive the insertions of the vastus medialis and lateralis muscles, respectively, the attachment of the vastus medialis being more extensive than that of the vastus lateralis. The anterior surface of the boue, slightly convex in both diameters, has a fibrous appearance, due to its longitudinal striation, and is pierced here and there by the openings of vascular canals. Oftentimes at the superior lateral angle there is a well-defined area for the tendinous insertion of the vastus lateralis. The posterior or articular surface is divided into two unequal parts (of which the lateral is the wider) by a vertical elevation which glides in the furrow of the trochlear surface of the femur, and in extreme flexion passes to occupy the intercondyloid fossa. The lateral of the two femoral surfaces is slightly concave in both its diameters; the medial, though slightly concave proximo-distally, is 
usually plane, or somewhat convex transversely. Occasionally, in the macerated bone, indications of a third vertical area are to be noted along the medial edge of the posterior aspect. This defines the part of the articular surface which rests on
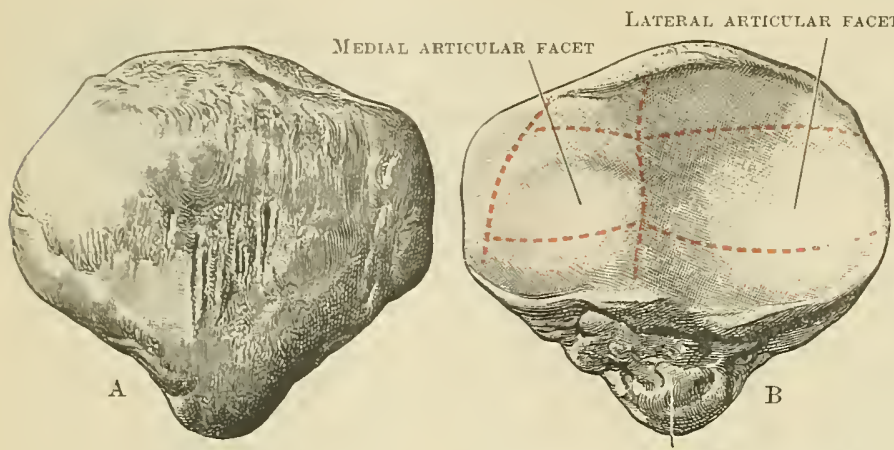

Fig. 245.-The Right Patella.

A. Anterior Surface.

B. Posterior Surface. the lateral border of the medial condyle in extreme flexion. In the recent condition, when the femoral surface is coated with cartilage, a more complex arrangement of facets may be in some cases displayed (as indicated in Fig. 244). Lamont (Journal of Anat. and Physiol., 1910, vol. xliv. p. 149) has shown that these areas undergo considerable variation in

their arrangement in races who habitually adopt the squatting posture.

Distal to the femoral articular area the posterior surface of the apex is rough and irregular: the greater part of this is covered by synovial membrane, the ligamentum patellie being attached to its summit and margins, reaching some little distance round the borders on to the anterior aspect of this part of the bone.

Ossification.-The patella is laid down in cartilage about the third month of fotal life. At birth it is cartilaginous, and the tendon of the quadriceps is continuous with the ligamentum patellæ over its anterior surface, and can easily be dissected off. About the third year an ossific centre appears in it and spreads more particularly over its deeper surface. Two centres, vertically disposed, have also been described. Ossification is usually completed by the age of puberty.

\section{The Tibia.}

The tibia is the medial bone of the leg. It is much stouter and stronger than its neighbour the fibula, with which it is united proximally and distally. By its proximal expanded extremity it supports the condyles of the femur, while distally it shares in the formation of the ankle-joint, articulating with the proximal surface and medial side of the talus.

The proximal extremity comprises the medial and lateral condyles (0.T.tuberosities), the intercondyloid eminence (O.T. spine), and the tuberosity (O.T. tubercle). Each con-

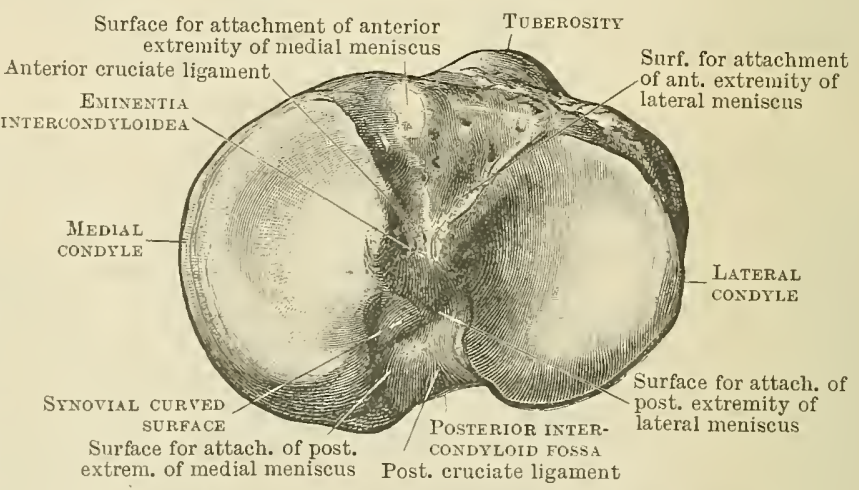

Fig. 246.-The Proximal Surface of the Proximal Extremity OF the Right Tibia. dyle is provided on its proximal aspect with an articular surface (facies articularis superior), which supports the corresponding femoral condyle, as well as the interposed meniscus. Of these two condylic surfaces the medial is the larger. Of oval shape, its long axis is placed antero-posteriorly; slightly concave from before backwards and from side to side, its circumference rises in the form of a sharp and well-defined edge. The lateral condylic surface is smaller and rounder. Slightly concave from side to side, and gently convex from before backwards, its circumfer- 
ence is well defined in front, but is rounded off behind, thus markedly increasing the convexity of its posterior part. Between the two condylic surfaces the bone is raised in the centre to form the intercondyloid eminence which consists of two intercondyloid tubercles separated by an oblique groove, in the anterior part of which lies the anterior cruciate ligament. The medial tubercle (tuberculum intercondyloideum mediale), the higher, is prolonged backwards and laterally by an oblique ridge to which part of the posterior cornu of the lateral meniscus is attached. The lateral tubercle (tuberculum intercondyloideum laterale) is more pointed and not so elevated. In front and behind the intercondyloid eminence the articular areas are separated by two irregular V-shaped surfaces, the intercondyloid fossæ. The anterior intercondyloid fossa, the larger and wider, furnishes areas for the attachment of the menisci on either side, and for the anterior cruciate ligament immediately in front of the intercondyloid eminence. The floor of this space is pierced by many nutrient foramina. The posterior intercondyloid fossa is concave from side to side, and slopes downwards and backwards. The lateral meniscus is attached near its apex to a surface which rises on to the back of the intercondyloid eminence; the medial meniscus is fixed to a groove which runs along its medial edge, and the posterior cruciate ligament derives an attachment from the smooth posterior rounded surface.

The lateral condyle is the smaller of the two. It overhangs the shaft to a greater extent than the medial, though this is obscured in the living by its articulation with the fibula. The facet for the fibula, often small and indistinct, is placed postero-laterally ou the distal surface of its most projecting part. Antero-laterally the imprint caused by the attachment of the trachis iliotibialis (O.T. ilio-tibial band) is often quite distinct. Curring distally and forwards from the fibular facet there is often a definite ridge for the attachment of the expansion of the biceps tendon;

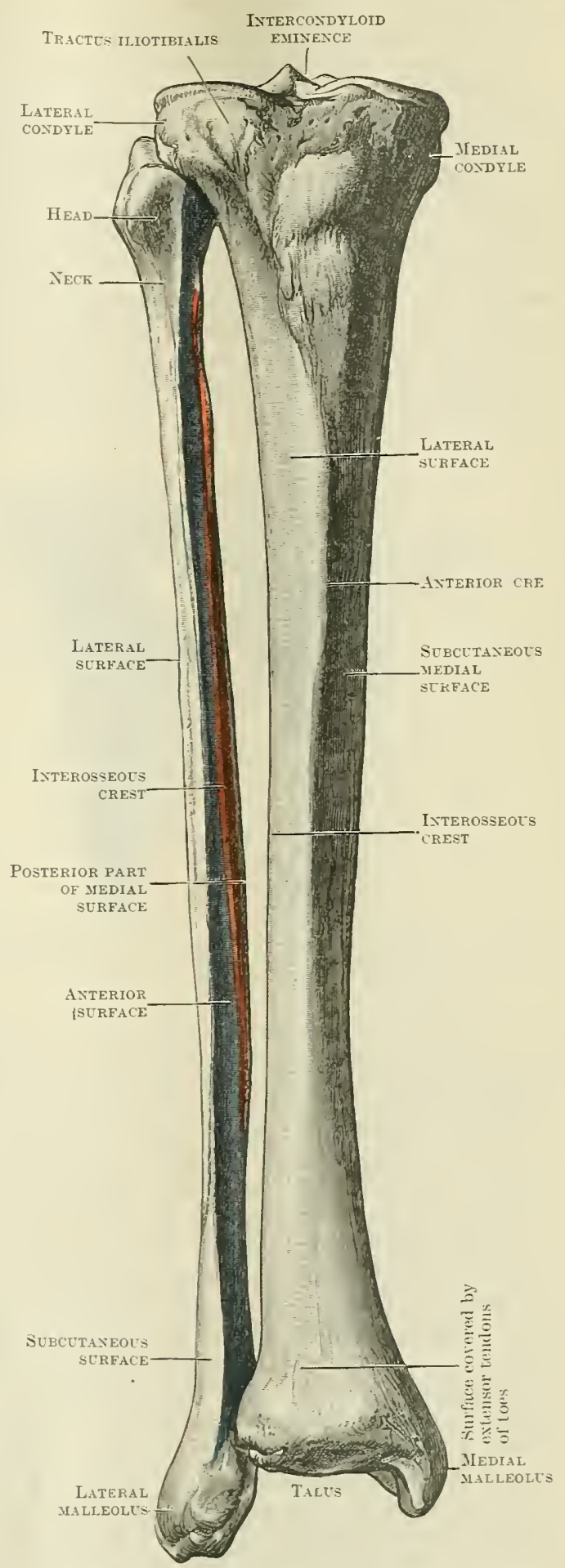

Fig. 247.-The Right Tibia atd Fibula as sees FROM THE FRONT.

The anterior part of the medial surface of the fibula is coloured blue. The posterior part of the medial surface of the fibula is coloured red. The lateral or peroneal surface of the fibula is left uncoloured. 
distal to this the areas for the origins of the peronæus longus and extensor digitorum longus are often crisply defined. The circumference of the medial condyle is groovecl postero-medially for the insertion of the tendon of the semi-membranosus.

In front of the condyles, and about an inch distal to the level of the condylic surfaces, there is an oval elevation called the tuberosity of the tibia. The proximal half of this is smooth and covered by a bursa, while the distal part is rough and serves for the attachment of the ligamentum patellæ.

Considered in its entirety, the proximal extremity of the tibia is broader transversely than antero-posteriorly, and is inclined backwards so as to overhang the shaft posteriorly.

The corpus tibiæ (shaft) is irregularly three-sided, possessing a medial, a lateral, and a posterior surface, separated by an anterior crest, a medial margin, and a lateral or interosseous crest. It is narrowest about the junction of its middle and distal thirds, and expands proximally and distally to support the extremities. Running along the front of the bone there is a gently-curved, prominent margin, the crista anterior, confluent proximally with the tuberosity, but fading away distally

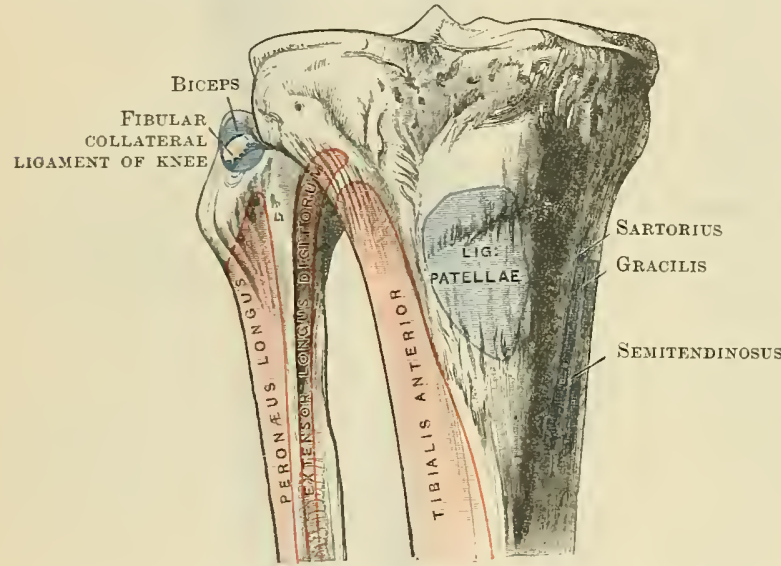

Fig. 248. - Anterior aspect of the Prosinal Portions of the Bones of the Right Leg with Attachments of Moscles MAPPED OET.

the tendons of the sartorius, gracilis, and semitendinosus muscles overlie it, as they pass towards their insertions. This surface is limited posteriorly by the medial margin, which passes from the medial and distal surface of the medial condyle proximally to the posterior border of the medial malleolus distally. This margin is rounded and indefinite proximally and distally, being usually best marked about its middle third. To the lateral side of the anterior crest is the lateral surface of the bone; it is limited behind by a straight vertical ridge, the crista interossea (interosseous crest), to which the interosseous membrane, which occupies the interval between the tibia and the fibula, is attached. This ridge commences near the middle of the lateral and distal surface of the lateral condyle, and terminates about two inches from the distal extremity by dividing into two lines, which separate and enclose between them the surface for articulation with the distal end of the fibula, and the area of attachment of the interosseous ligament, which here unites the two bones. In its proximal two-thirds the lateral surface provides an extensive origin for the tibialis anterior. Distally, where the anterior crest is no longer well defined, the lateral surface turns forward on to the front of the shaft, and is limited by the anterior margin of the distal articular surface. Over this the tendon of the tibialis anterior, and the combined fleshy and tendinous parts of the extensor hallucis proprius and extensor digitorum communis muscles pass obliquely distally. The posterior surface of the shaft lies between the interosseous crest laterally and the medial margin on the medial side. Its contours are liable to considerable variation according to the clegree of lateral compression of the bone. It is usually full 
and rounded proximally, and flat distally. Proximally it is crossed by the linea poplitea (popliteal line), which runs distally and medially, from the fibular facet to the medial border on a level with the junction of the middle with the proximal third of the shaft. To this line the deep transverse fascia is attached, whilst distal to it, as well as from the medial border of the bone distally, the soleus muscle takes origin. Into the bulk of the triangular area proximal to it the popliteus muscle is inserted. Arising from the middle of the popliteal line there is a vertical ridge, which passes distally and divides the posterior aspect of the shaft into two surfaces-a lateral for the tibial origin of the tibialis posterior muscle, and a medial for the flexor digitorum longus muscle. The distal third of this surface of the shaft is free from muscular attachments, but is overlain by the tendons of the above muscles, together with that of the flexor hallucis longus. A large nutrient canal, having a distal direction, opens on the posterior surface of the shaft a little distal to the popliteal line and just lateral to the vertical ridge which springs from it.

The distal extremity of the tibia displays an expanded quadrangular form. It is furnished with a saddle-shaped articular surface on its distal surface (facies articularis inferior), which is concave from before backwards and slightly convex from side to side. This rests upon the proximal articular surface of the body of the talus, and is bounded in front and behind by well-defined borders. The anterior border is the rounder and thicker, and is oftentimes channelled by a groove for the attachment of the anterior ligament of the joint; further, it is occasionally provided with a pressure facet caused by the locking of the bone against the neck of the talus in extreme flexion. Laterally the edge of the articular area corresponds to the base of the triangle formed by the splitting of the interosseous ridge into two parts. Where these two lines join it, both in front and behind, the bone is elevated into the form of tubercles, in the hollow between which incisura fibularis) the distal end of the fibula is lodged, being held in position by powerful ligaments. The cartilage-covered surface occasionally extends for some little distance proximal to the base of the triangle. Medially there is a process projecting distally, and called the medial malleolus, the medial aspect of which is subcutaneous and forms the projection of the medial ankle. Its lateral surface is furnished with a piriform facet (facies articularis malleolaris), confluent with the cartilagecovered area on the distal extremity of the shaft; this articulates with a corresponding area on the medial surface of the body of the talus. Distally the malleolus is pointed in front, but notched behind for the attachment of the tibial collateral ligament of the ankle. Running obliquely along the posterior surface of the malleolus there is a broad groove (sulcus malleolaris) in which the tendons of the tibialis posterior and flexor digitorum longus muscles are lodged; whilst a little to the fibular side of this, and running distally orer the posterior surface of the distal extremity of the bone, there is another groove, often faintly marked, for the lodgment of the tendon of the flexor hallucis longus muscle.

The proportionate length of the tibia to the body height is as 1 is to $4 \cdot 32-4 \cdot 80$.

Arterial Foramina. - Nutrient canals are seen piercing the proximal extremity of the bone around its circumference and proximal to the tuberosity. The floors of the intercondyloid fossæ are also similarly pierced, and there is usually a canal of large size opening on the summit of the intercondyloid eminence. Two or three foramina of fair size are seen running proximally into the substance of the bone a little distal to and to the medial side of the tuberosity, while the principal vessel for the shaft passes distally into the bone on its posterior surface, about the level of the junction of the proximal and middle thirds. The medial surface of the medial malleolus, as well as the anterior and posterior borders of the distal extremity, are likewise pitted by the orifices of small vascular channels.

Connexions.-Proximally the tibia supports the condyles of the feruur, and is connected in front with the patella by means of the patellar ligament. Articulating laterally with the fibula proximally and distally, it is united to that bone throughont nearly its entire length by the interosseous membrane. The crest and medial surface can be readily examined, as they are subcutaneous, except proximally, where the medial surface is overlain by the thin tendinous aponeuroses of the muscles passing over the medial side of the knee. The form of the distal part of the knee in front is determined by the condyles on either side crossed centrally by the ligamentum patellæ. Distally the medial malleolus forms the projection of the medial ankle, which is wider, not so low, less pointed, and placed in advance of the projection of the lateral ankle. The front and 
back of the distal end of the bone are crossed by tendons, which mask to a certain extent its form.

Ossification.- The shaft begins to ossify early in the second month of intra-uterine life. It birth it is well formed, and capped proximally and distally by pieces of cartilage,

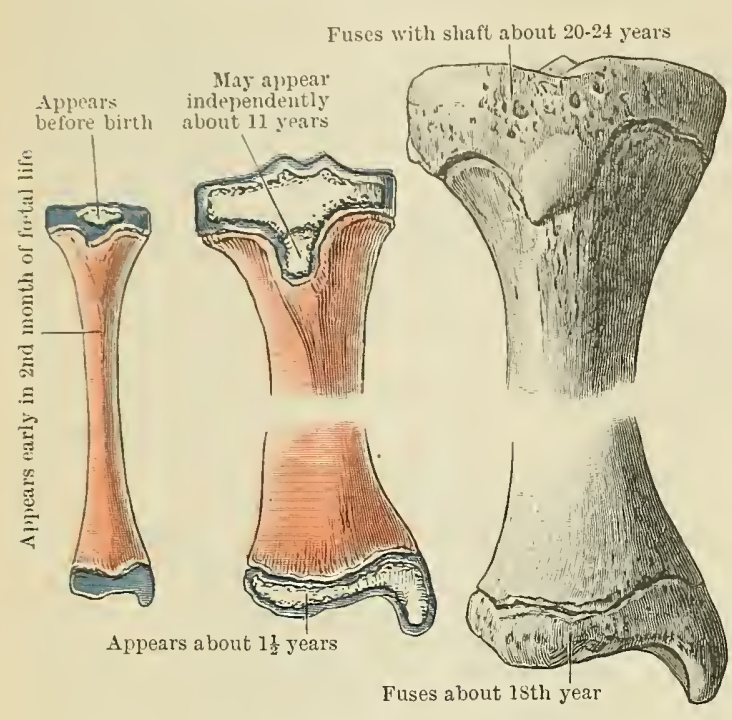

At birth. About 12 years. About 16 years. in the proximal of which the centre for the proximal epiphysis has already usually made its appearance. From this the condyles and tuberosity are developed, though sometimes an independent centre for the latter appears about the eleventh or twelfth years, rapidly joining with the already well-developed mass of the rest of the epiphysis. Complete fusion between the proximal epiphysis and the shaft does not take place until the twentieth or the twenty-fourth year. The centre for the distal articular surface and the medial malleolus makes its appearance about the end of the second year, and union with the shaft is usually complete by the age of eighteen. Lambertz notes the occasional presence of an accessory nucleus in the malleolus. The proximal end is the so-called "growing end of the bone."

Fra. 249.-Ossification of the Tibia.

\section{The Fibula.}

The fibula is a slender bone with two enlarged ends. It lies to the lateral side of the tibia, with which it is firmly united by ligaments, and nearly equals that bone in length.

The first difficnlty which the student has to overcome is to determine which is the proximal and which the distal extremity of the bone. This can easily be done by recognising the fact that there is a deep pit on the medial aspect of the distal extremity immediately behind the triangular articular surface. Holding the bone vertically with the distal extremity downwards and so turned that the triangular articular area lies in front of the notch already spoken of, the subcutaneous non-articular aspect of the distal extremity will point to the side to which the bone belongs.

The proximal extremity or head of the fibula (capitulum fibulæ), of irregular rounded form, is bevelled on its medial surface so as to adapt it to the form of the distal surface of the lateral condyle of the tibia. At the border, where this surface becomes confluent with the lateral aspect of the head, there is a pointed upstanding eminence called the apex capituli fibulæ (apex of the head); to this the short fibular collateral ligament is attached, as well as a piece of the tendon of the biceps, which is inserted into its anterior part. Immediately to the medial side of this, and occupying the summit of the medial sloping surface, there is an articular area (facies articularis capituli), of variable size and more or less triangular shape. This serves for articulation with the lateral condyle of the tibia. The long fibular collateral ligament, together with the remainder of the tendon of the biceps muscle which surrounds it, is attached to the lateral and proximal side of the head in front of the apex capituli. In front and behind the head there are usually prominent tubercles. The anterior of these is associated with the origin of the peronæus longus muscle; the posterior, whilst furnishing an origin for the upper fibres of the soleus, serves to deepen the groove, behind the proximal tibio-fibular articulation, in which the tendon and fleshy part of the popliteus muscle play. The constricted portion of the shaft distal to the head 
is often referred to as the neck; around the lateral side of this the common peroneal

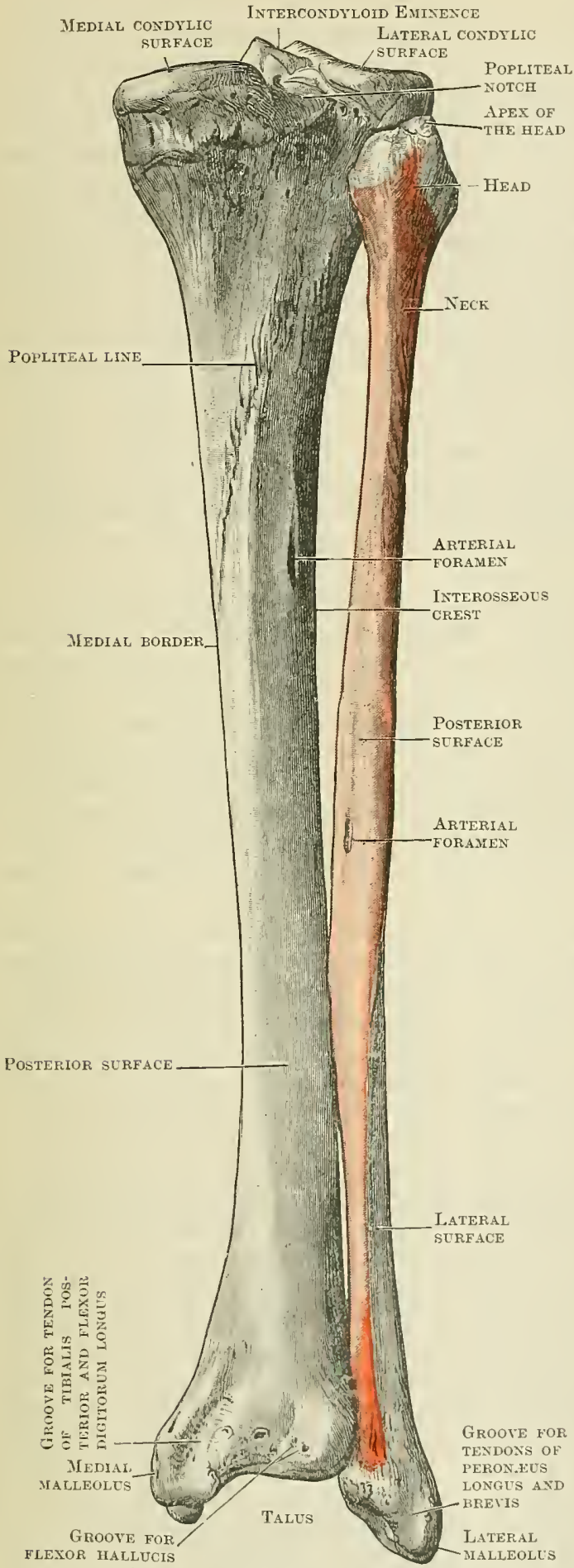
Lito

Fig. 250.-The Right Tibia and Fibula seen frod BEHIND.

The Posterior surface of the fibula is coloured red ; the lateral surface is left uncoloured. nerve winds.

\section{SHAFT.}

The shaft of the fibula (corpus fibulæ) presents mally varieties of shape and form, being ridged and channelled in such a way as greatly to increase the difficulties of the student in recognising the various surfaces described. The most important point is first to determine the position of the interosseous ridge. Holding the bone in the position which it normally occupies in the leg, it

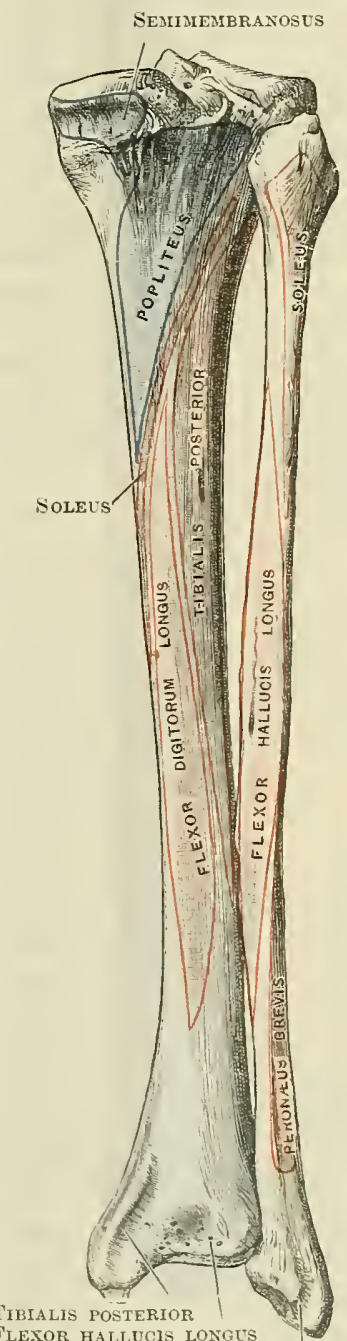

Flexor HaLuels LONGTS

PERONiEUS LONGUS AND BREVIS

Fig. 251.-POSTERIOR ASPECT OF THE BONES OF THE LEg WITH ATtACH MEXTS OF MUSCLES MAPPED OET.

will be noticed that the lateral surface of the distal extremity is limited in 


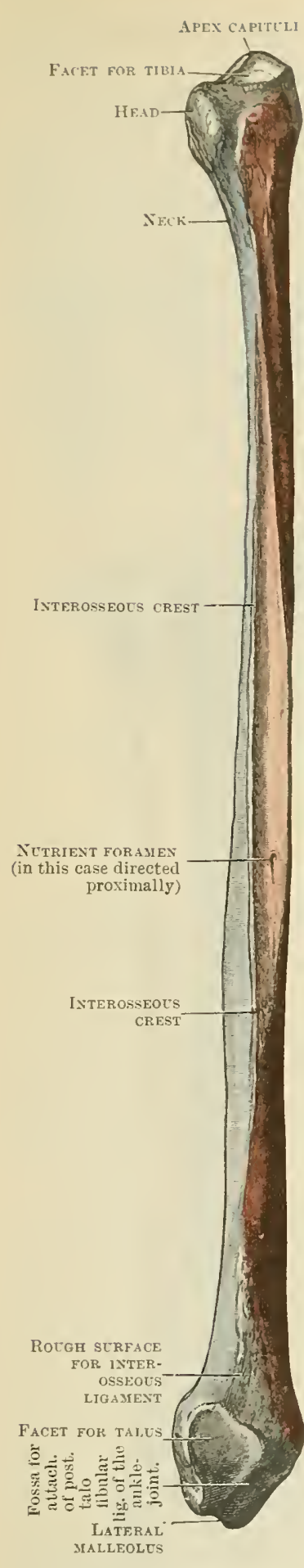

Fig. 252,-Pight FIBULA AS SEEN FROM THE MEDIAL SIDE.

The anterior part of the medial surface is coloured blue; the posterior part of the medial surface is coloured red. front and behind by two lines, which converge and enclose between them a triangular subcutaneous area which lies immediately proximal to the lateral malleolus. From the summit of the triangle so formed a welldefined ridge may be traced along the front of the shaft to reach the anterior aspect of the head. This is the anterior crest, and must not be mistaken for the interosseous crest, which is now easy to find, for the next ridge which lies just medial to the anterior crest, or towards the tibial side on the anterior aspect of the bone, is the line to which the interosseous membrane is attached. As a rule these two lines are separated by a considerable interval in the distal half of the bone, but tend to run much closer together proximally; indeed it is not uncommon to find that they coalesce to form a single crest. Let it therefore be clear that the interosseous line is that which lies just medial to the ridge which springs from the malleolar subcutaneous triangular surface, notwithstanding the differences in width of the surface which separates the lines, or their occasional coalescence above.

The position of the anterior crest enables us at once to separate the medial surface of the bone from its lateral surface. In addition, there is the posterior surface.

Starting then at the interosseous crest, and passing forwards, the anterior part of the medial surface is the first met with; this, as has been said, may be either of considerable width or almost linear. From this arises the extensor digitorum communis, together with the peronæus tertius and the extensor hallicis longus muscles.

The anterior crest serves for the attachment of the intermuscular septum, which separates the foregoing group of muscles from that which lies along the lateral side of the shaft, viz., the peronæus longus and brevis muscles. The surface from which these arise is limited behind by the lateral crest, which is usually sharp and well defined distally, where it is continuous with the bone immediately proximal to the pit on the medial surface of the distal extremity, whilst it tends to be less distinct and more rounded proximally, where it runs into the base of. the apex capituli. In its proximal third or fourth this crest is often rough and tubercular where it serves for the origin of the soleus. The lateral or peroneal surface is somewhat twisted, being directed rather forwards proximally, but tending to turn backwards distally, where it becomes continuous with the groove which courses along the back of the lateral malleolus and which lodges the tendons of the peronæus longus and brevis muscles. The remainder of the shaft is included between the lateral crest behind and the interosseous crest in front and medially. Here arise the several muscles whose action in part is to extend the ankle. This surface is cut up by a curved ridge often the most prominent and outstanding on the bone, and hence frequently mistaken by the student for the interosseous ridge; it serves to define the area for the origin of the tibialis posterior, and arises distally 
from the posterior border of the interosseous crest at the junction of the middle and distal thirds of the shaft, curves a little backwards, and passing proximally ends at the medial side of the posterior surface of the head. This is called the medial crest; and the surface so mapped off between it and the interosseous crest is the posterior part of the medial surface. The crest itself serves for the attachment of the aponeurosis which covers the tibialis posterior muscle. The remainder of the posterior aspect of the shaft, which, proximally, is directed backwards, is so twisted that distally it is directed medially. It lies between the medial and lateral crests, and is known as the posterior surface. From this, in its proximal part, the soleus muscle arises; whilst more distally, the flexor hallucis longus muscle derives an extensive origin. Both of these muscles, together with the tibialis posterior, act as extensors of the ankle, On this aspect of the bone, at or near the middle of the shaft, and just behind the prominent medial crest, is the opening of the nutrient canal, which has a distal direction.

The distal extremity of the fibula, or lateral malleolus, is of pyramidal form. Its medial surface is furnished with a triangular articular area (facies articularis malleoli), plane from before backwards, and slightly convex proximodistally, which articulates with a corresponding surface on the lateral side of the body of the talus. Behind this there is a deep pit, to which the posterior talo-fibular ligament is attached. Proximal to the articular facet there is a rough triangular area, from the summit of which the iuterosseous crest arises; to this are attached the strong fibres of the distal interosseous ligament which binds together the opposed surfaces of the tibia and fibula. The lateral surface of the distal extremity forms the elevation of the lateral malleolus which determines the shape of the projection of the lateral ankle. Rounded from side to side and proximodistally, it terminates in a pointed process, which reaches a more distal level than the corresponding process of the tibia, from which it also differs in being narrower and more pointed and being placed in a plane nearer the heel. Proximally, this surface, which is subcutaneous, is continuous with the triangular subcutaneous area so clearly defined by the convergence of the lines which unite to form the anterior crest. The anterior border and tip of the lateral malleolus furnish attachments to the anterior talo-fibular and calcaneo-fibular ligaments. The posterior surface of the lateral malleolus, broad proximally, where it is confluent with the lateral or peroneal surface, is reduced in width distally by the presence of the pit which lies to its medial side. This aspect of the bone is grooved (sulcus malleolaris) by the tendons of the peronæus longus and brevis muscles, which curve round the posterior and distal aspects of the malleolus.

The proportionate length of the fibula to the body height is as 1 is to $4 \cdot 37-4 \cdot 82$.

Arterial Foramina.-Numerous minute vascular canals are seen piercing the lateral surface of the head, and one or two of larger size are seen on the medial surface immediately anterior to the proximal articular facet. The canal for the nutrient artery of the shaft, which has a distal direction, is situated on the posterior surface of the bone about its middle. The lateral surface of the lateral malleolus displays the openings of many small canals, and one or two larger openings are to be noted at the bottom of the pit behind the distal articular surface.

Connexions.-The head and lateral malleolus, and part of the shaft immediately proximal to the latter, are subcutaneous. The remainder of the shaft is covered on all sides by the muscles which surround it. Proximally the bone plays no part in the formation of the knee-joint, but distally it assists materially in strengthening the ankle-joint by its union with the tibia and its articulation with the talus. In position the bone is not parallel to the axis of the tibia, but oblique to it, its proximal extremity lying posterior and lateral to a vertical line passing through the lateral malleolus.

Ossification. - The shaft begins to ossify about the middle of the second month of fotal life. At the end of the third month there is but little difference in size between it and the tibia, and at birth the fibula is much larger in proportion to the size of the tibia than in the adult. Its extremities are cartilaginous, the distal extremity not being as long as the medial malleolar cartilage of the tibia. It is in this, however, that an ossific centre first appears about the end of the second year, which increases rapidly in size, and unites with the shaft in about nineteen years. The centre for the proximal epiphysis begins to ossify about the third or fourth year, and union with the shaft is 
not complete until a period somewhat later than that for the distal epiphysis. The mode

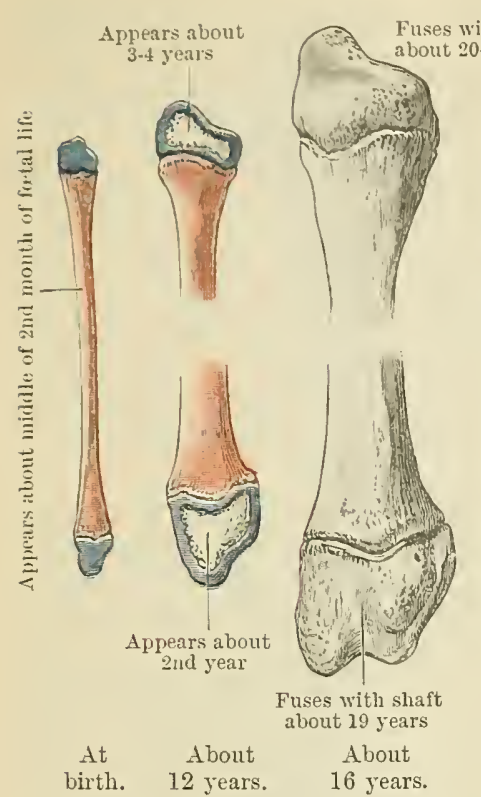

Fig. 253.-Ossification of Fibula. of ossification of the distal extremity is an exception to the general rule that epiphyses which are the first to ossify are the last to unite with the shaft. This may possibly be accounted for by the fact that the distal end is functionally more important than the rudimentary proximal end, since in man alone, of all vertebrates, does the lateral malleolus reach beyond the level of the medial malleolus. Its early union with the shaft is doubtless required to ensure the stability of the ankle-joint necessitated by the assumption of the erect position.

In its earlier stages of development it has been stated, on the authority of Leboneq, Gegenbaur, and others, that the fibula as well as the tibia is in contact with the femmr. This is, however, denied by Grumbaum " Proc. Anat. Soc.," Journ. Anat. and Physiol., vol. xxvi. p. 22), who states that after the sixth week the fibula is not in contact with the femur, and that prior to that date it is impossible to differentiate the tissue which is to form femur from that which forms fibula.

\section{BONES OF THE FOOT.}

The bones of the foot, twenty-six in number, are arranged in three groups: the tarsal, seven in number; the metatarsal, five in number; the phalanges, fourteen in number.

Comparing the foot with the hand, the student will be struck with the great proportionate size of the tarsus as compared with the carpus, and the reduction in size of the bones of the toes as compared with the fingers. The size of the metatarsal segment more nearly equals that of the metacarpus.

\section{The Tarsus.}

The tarsus consists of seven bones (ossa tarsi)-the talus or astragalus; calcaneus, navicular or scaphoid, three cuneiforms, and the cuboid. Of irregular form and varying size, they may be described as roughly cubical, presenting for examination dorsal and plantar surfaces, as well as anterior or distal, posterior or proximal, medial, and lateral aspects.

\section{The Talus.}

The talus (O.T. astragalus) is the bone through which the body weight is transmitted from the leg to the foot. Proximally the tibia rests upon it, whilst on either sicle it articulates with the medial and lateral malleolar processes of the tibia and fibula respectively; distally it overlies the calcaneus, and anteriorly it articulates with the navicular. For descriptive purposes the bone is divisible into three parts - the corpus tali (body) blended in front with the collum tali (neck), which supports the caput tali (head).

The proximal surface of the body is provided with a saddle-shaped articular surface (trochlea tali), broader in front than behind, for articulation with the distal surface of the tibia. The medial edge of the trochlea is straight; whilst the lateral border, which is sharp in front and more rounded behind, is curved medially posteriorly, where it is bevelled to form a narrow, elongated, triangular facet, which is in contact with the transverse or distal tibio-fibular ligament during flexion of the ankle. (Fawcett, Ed. Med. Journ., 1895.) Over the lateral border the cartilagecovered surface is continuous laterally with an extensive area of the form of a quadrant. This is concave from above downwards, and articulates with the medial surface of the lateral malleolus. The distal angle of this area is prominent and somewhat everted, and sometimes referred to as the processus lateralis tali (lateral 
process). The medial aspect of the body has a comma-shaped facet, confluent with the superior articular surface, over the medial edge of the trochlea; this articulates with the lateral surface of the medial malleolus. Distal to this facet

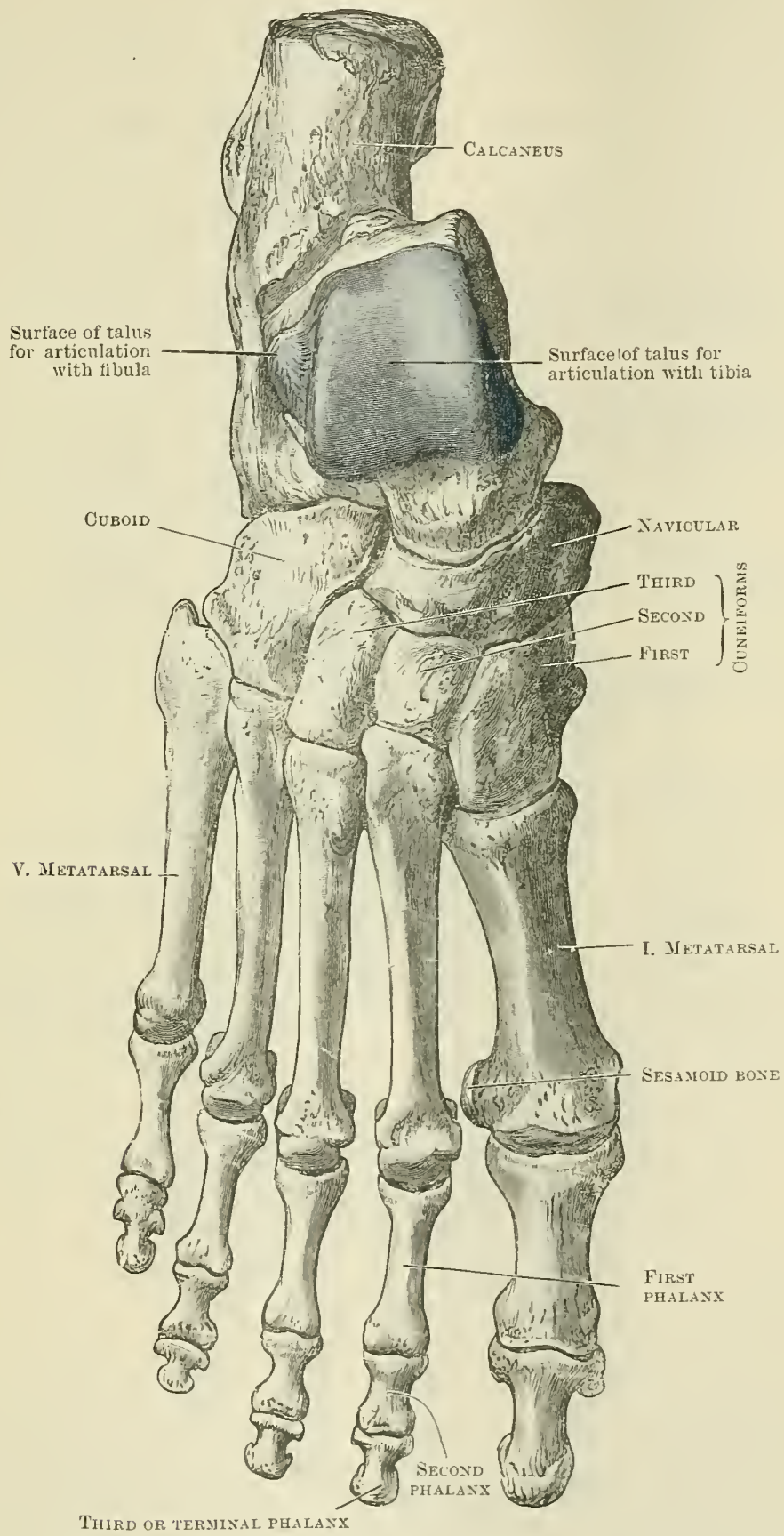

Fig. 254.-Dorsil Surface of the Boses of rhe Right Foor.

the bone is rough and pitted by numerons small openings, and just below the tail of the comma there is a circular impression for the attachment of the deep fibres of the deltoid ligament (talo-tibial fibres). On the distal surface of the body there is a deep concave facet, called the posterior calcanean facet (facies calcanea articularis posterior), which is of more or less oval or oblong form and is 
placed obliquely from behind forwards and laterally; this, rests upon a corresponding surface on the dorsal aspect of the calcaneus. In front of this, and crossing the bone from the medial side laterally and forwards, is a deep furrow (sulcus tali),

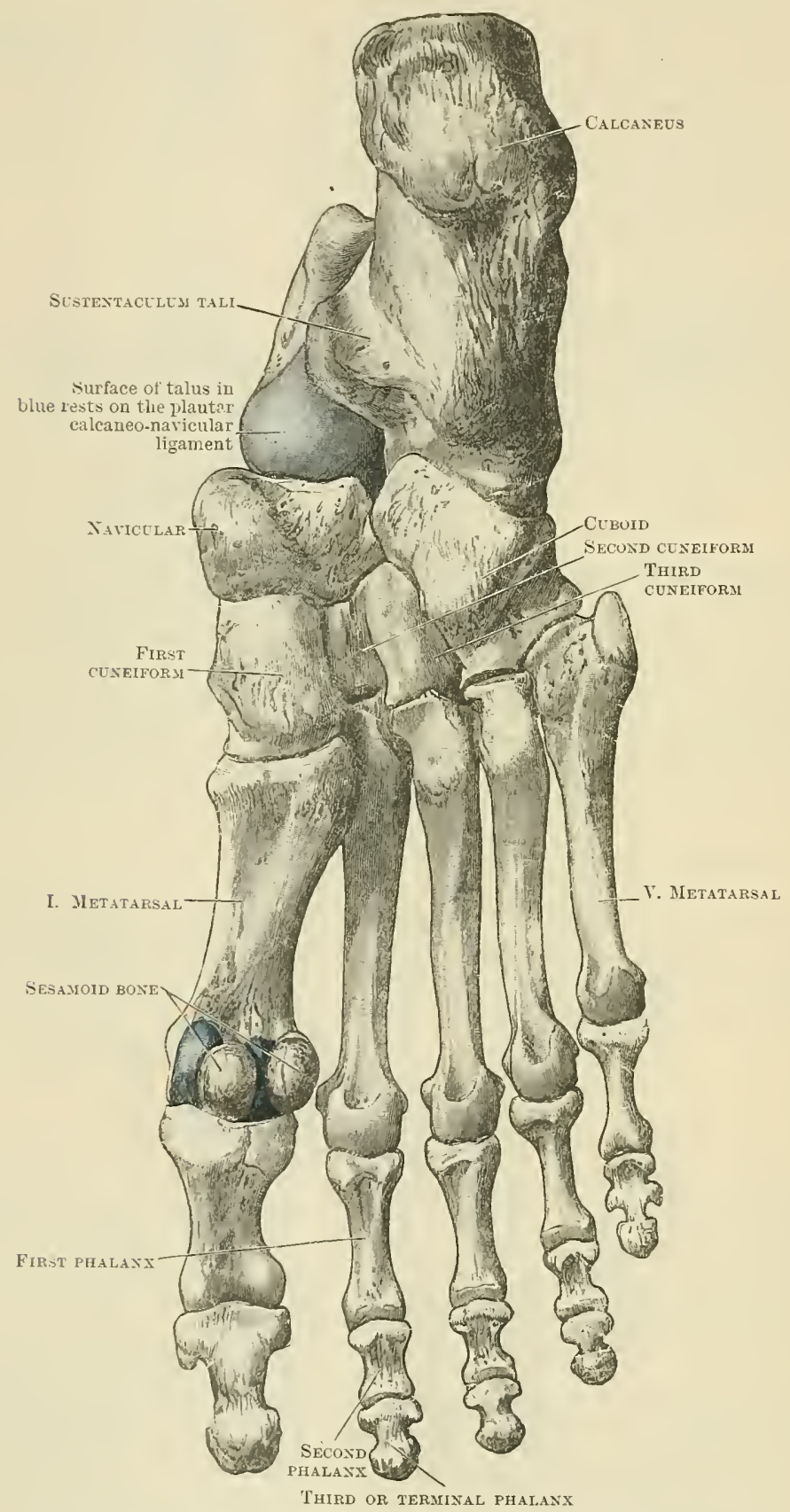

Fig. 255.-Plantar Surface of the Bones of the Right Foot.

the floor of which is pierced by numerous large canals. It serves for the attachment of the strong interosseous ligament which unites the talus with the calcaneus, and separates the facet already described from a smaller oval articular area having a slightly convex surface, which lies immediately in front of it. This is called the middle calcanean facet (facies articularis calcanea media), and articulates with 
the dorsal surface of the sustentaculum tali of the calcaneus. Posteriorly the body is provided with two tubercles, separated by a groove; the lateral of these (processus posterior tali) is usually the larger, and is occasionally a separate ossicle (os trigonum). To it is attached the posterior talo-fibular ligament of the anklejoint. The groove, which winds obliquely from above downwards and medially over the posterior surface of the bone, lodges the tendon of the flexor hallucis longus muscle.

The head, of oval form, is directed forwards and medially. Its anterior surface

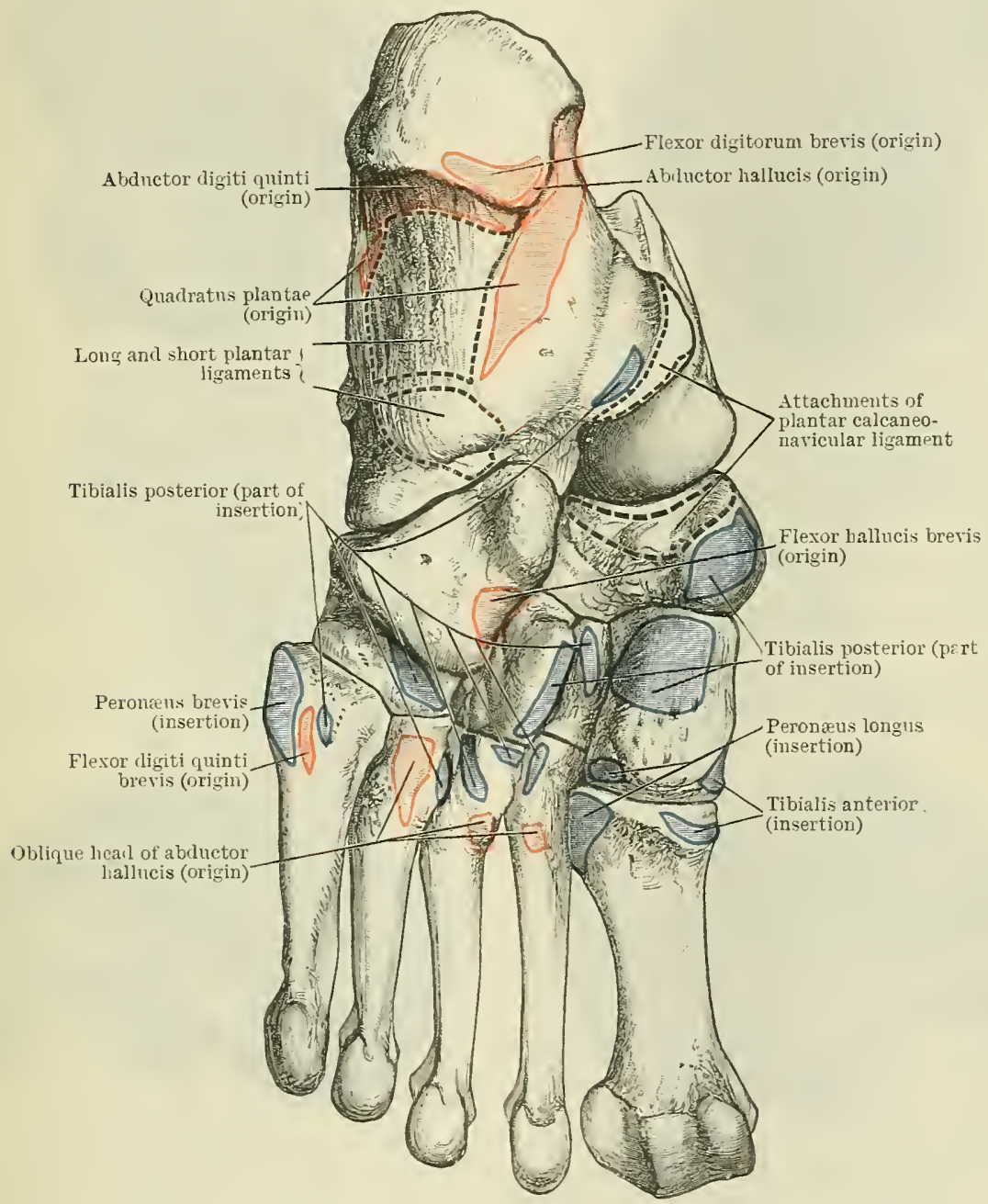

Fig. 256.-Mirscle-Attachments to Left Tarses aid Metatarses (Plantar Aspect).

is convex from side to side and from above downwards, and articulates with the navicular bone (facies articularis navicularis). Inferiorly this surface is confluent with the middle calcanean facet, but in well-marked specimens, or when the bones are articulated, it will be seen that a small area in front of, and lateral to, the middle calcanean facet rests upon an articular surface on the dorsal surface of the anterior portion of the calcaneus, and is called the anterior calcanean facet (facies articularis calcanea anterior). On the medial and distal surface of the head there is a cartilage-covered surface which does not articulate with any bone, but rests on the dorso-lateral surface of the plantar calcaneo-navicular ligament, and is supported on the medial side by the tendon of the tibialis posterior muscle. (Fawcett, Ed. Med. Journ., 1895, p. 987.) 
The neck, best seen on dorsal surface, passes from the front of the body and
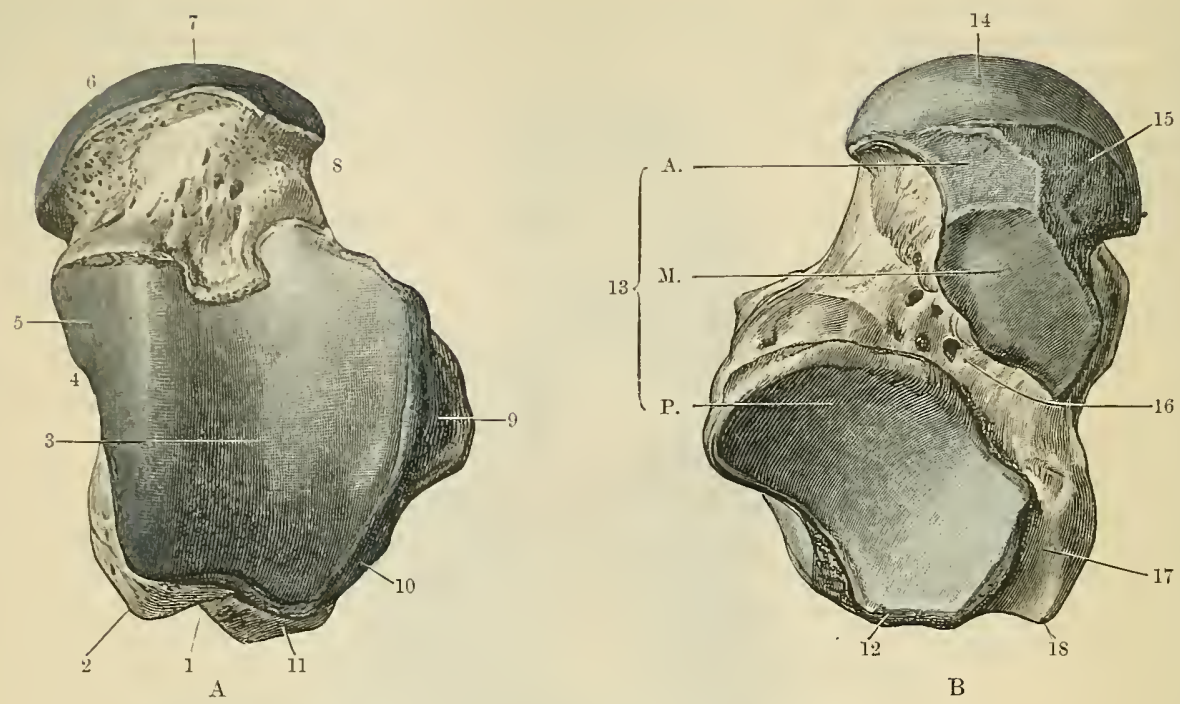

Fig, 257.-The Right Talus. A. Dorsal surface; B. Plantar surface.

1. Groove for FLEx. HALLdis. LONG. 2. HEDIAL TUBERCLE.

3. TROCHLEA.

4. BODT.

5. For articulation with MEDIAL MALLEOLUS.

6. HEAD.

7. For articulation With Navicular, 8. NECK.
9. For articulation with lateral MALLEOLUS.

10. SURFACE AOAINST WHICH THE POSTERIOR TALO-FIBULAR LIGA. HENT RESTS.

11. PRocessus POSTERIOR.

12. Processus posterior.

13. Posterior, MIDDLE, AND ANTERIOR FACETS FOR CALCANEDS.
14. For articulation with NaviCULAR.

15. Surface restixg on PLANTar CALCANEO-NAVICULAR LIGA. DENT.

16. INTEROSSEOUS GROOVE.

17. GROOVE FOR FLEXOR HALLUCIS LONGUS.

18. Medial tUBERCle.

inclines towards the medial side. It is confluent with the medial surface in front
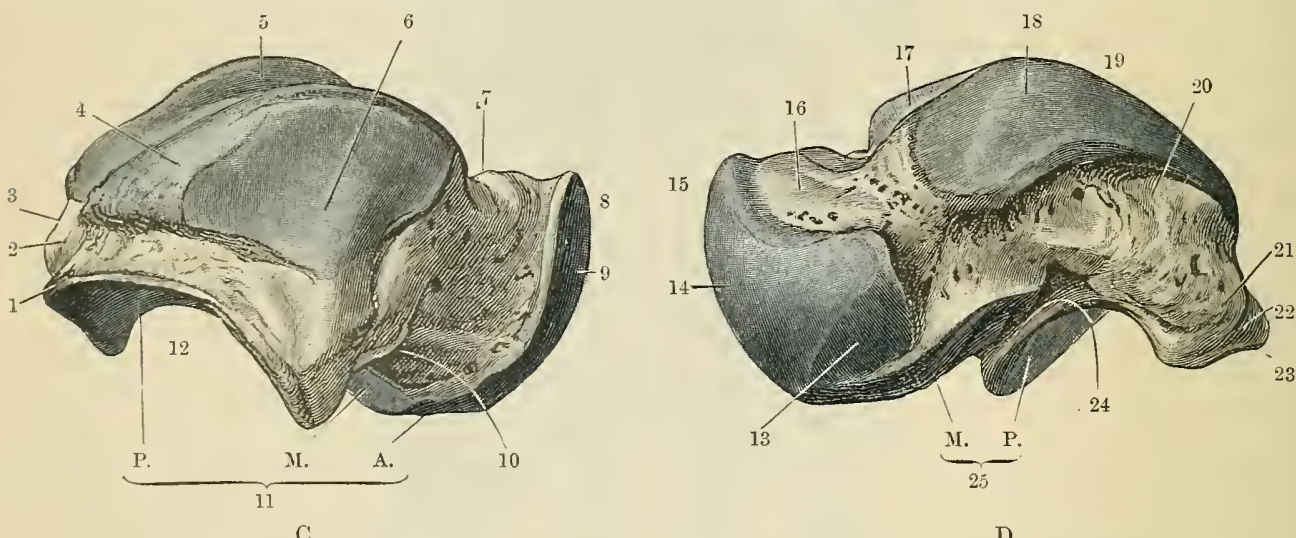

C

$\mathrm{D}$

Fig. 258.-The Right Talus. C. Seen from the lateral side; D. Seen from the medial side.

1. PrOCESSUS POSTERIOR.

2. GROOVE FOR FLEXOR HALLUCIS

I.ONGUS.

3. MEDIAL TÜBEHCLE.

4. SURFACE AGAINST WHICH THE POSTERIOR TALO-FIBULAR LIGAJIENT RESTS.

5. TROCHLEA FOR TIBIA.

6. FOR ARTICULATION WITH

6. FOR ARTTCULATION.

$\begin{array}{ll}\text { 7. NEATERAL MaLlEolU's. } & \text { 8. HEad. }\end{array}$

9. FOR ARTICULATION WITH NAVICULAR.
10. INTEROSSEOUS GROOVE.

11. ANTERIOR, IIIDDLE, AND POSTERIOR FACETS FOR CAL. CANEUS.

12. BODY.

13. SURFACE RESTING ON PLANTAR CALCANEO - NAVICULAR LIGAMENT.

11. For articulation with Navi15. CULAR.

15. HEAD.

17. TrOCHLEA FOR TIBLA.
18. For articulation with medial IALLEOLUS.

19. BODY

20. IMPRESSION FOR DELTOID LIGAMEENT.

21. MEDIAL TLBERCLE.

22. GROOVE FOR FLEXOR HALLUCIS LONGUS.

23. PROCESSUS POSTERIOR.

21. INTEROSSEOUS GROOVE.

25. Posterior aNd MiDdle facets FOR CALCANEUS.

of the medial malleolar facet, and laterally forms a wide groove, which becomes continuous on the plantar surface with the lateral end of the interosseous groove. 


\section{The Calcaneus.}

The calcaneus is the largest of the tarsal bones. It supports the talus on its dorsal surface and articulates with the cuboid anteriorly. On the plantar aspect and behind, its posterior extremity, or tuberosity (tuber calcanei), forms the heel, on which so large a proportion of the body weight rests. The long axis of the bone inclines forwards and a little laterally.

The dorsal surface of the calcaneus is divisible into two parts-a posterior nonarticular part and an anterior articular portion. The length of the former varies according to the projection of the heel ; rounded from side to side, it is slightly concave from before backwards. In front of this there is a convex articular area of variable shape (facies articularis posterior), sometimes nearly circular, at other times oval and occasionally almost triangular. This is directed upwards and forwards, and articulates with the posterior calcanean facet on the plantar surface of the talus. Anterior to this facet the bone is deeply excavated, forming a fossa from

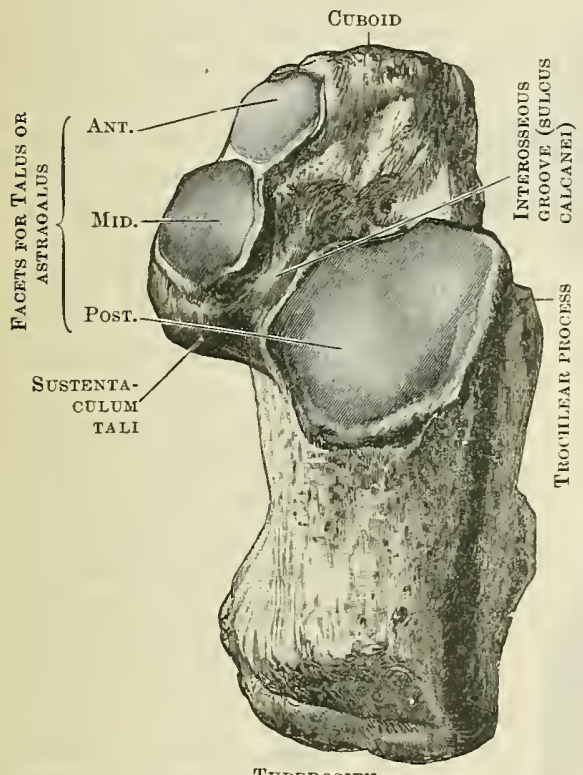

TUBEROSITY

A

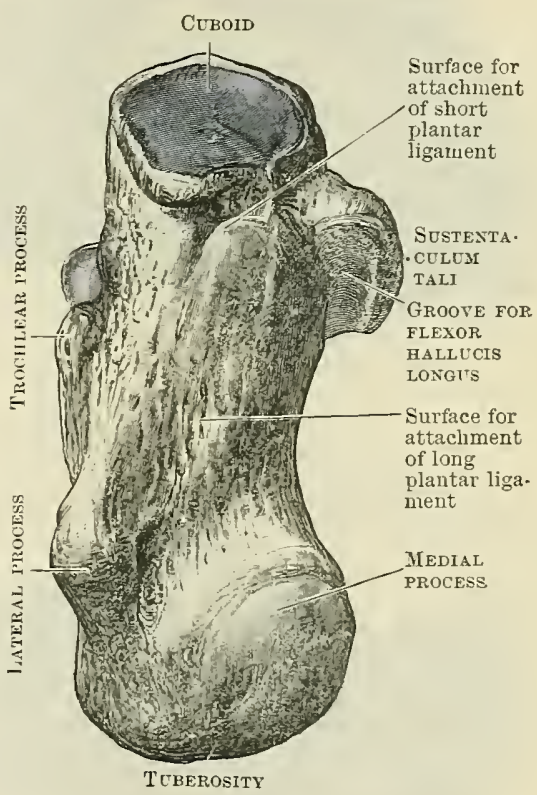

B

Fig. 259.-The Right Calcanecs. A. Seen from above; B. Seen from below.

which a groove (sulcus calcanei) leads backwards and medially around the anteromedial border of the articular surface. When the calcaneus is placed in contact with the talus, this groove coincides with the sulcus on the plantar surface of the talus, and so forms a canal or tunnel (sinus tarsi) in which the strong interosseous ligament which unites the two bones is lodged. To the front and medial side of this groove there is an elongated articular facet directed obliquely from behind forwards and laterally, and concave in the direction of its long axis. This is frequently divided into two smaller oval areas by an intermediate nonarticular surface. Of these facets the posterior (facies articularis media) articulates with the middle calcanean facet on the plantar surface of the talus, whilst the anterior (facies articularis anterior) supports the plantar surface of the head of the talus (facies articularis calcanei anterior). The lateral side of the anterior extremity of the dorsal surface of the bone is rough, and to this is attached the origin of the short extensor muscle of the toes.

The plantar surface of the bone is slightly concave from before backwards, and convex from side to side. The plantar aspect of the tuberosity is provided with two tubercles, a medial (processus medialis tuberis calcanei) and a lateral (processus lateralis tuberis calcanei), of which the former is the larger. From this the short flexor of the toes and the abductor hallucis muscle arise, whilst from both tubercles 
spring the fibres of origin of the abductor digiti quinti muscle. On the anterior part of the plantar surface there is an elevated elongated tubercle, which terminates somewhat abruptly just behind the anterior border of this aspect of the bone, giving rise at times to a notch. From the former spring the fibres of the long plantar ligament, whilst the latter serves for the attachment of the deeper fibres of the plantar calcaneo-cuboid ligament. The two heads of origin of the quadratus plantæ muscle arise from the bone on either side of the long plantar ligament.

The medial surface of the calcaneus is crossed obliquely, from above downwards and forwards, by a broad groove of considerable depth; along this pass many of the structures which enter the sole of the foot from the back of the leg. The

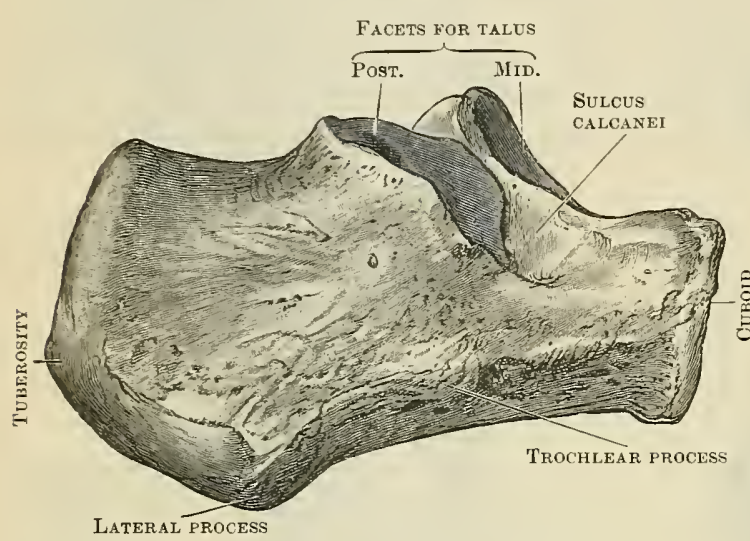

C

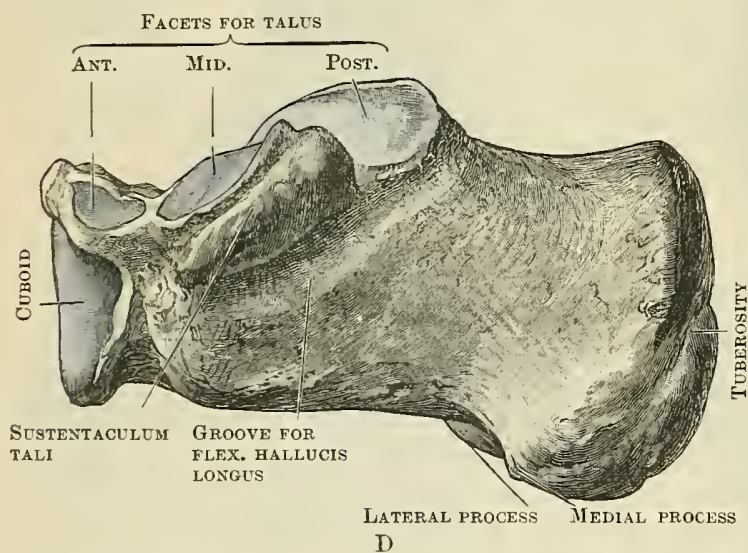

Fig. 260.-The Right Calcaneus. C. Seen from the lateral side; D. Seen from the medial side. groove is overhung in front and above by a projecting bracketlike process, called the sustentaculum tali. The plantar surface of the sustentaculum is channelled by a groove, in which is lodged the tendon of the flexor hallucis longus muscle; whilst its medial border, to which is attached a part of the deltoid ligament(tibio-calcanean fibres) of the ankle, is overlain by the tendon of the flexor digitorum longus. To the anterior border of the sustentaculum isattached the plantar calcaneo-navicular ligament, and placed on its dorsal surface is the articular facet already alluded to (facies articularis media). Posteriorly the medial surface of the bone is limited inferiorly by the projection of the medial process of the tuber calcanei, and above by the medial lipped edge of the tuberosity.

The lateral surface, broad behind and narrower in front, is of flattened form. Springing from it, just below the lateral end of the sinus tarsi, is the trochlear process, often indistinctly marked. To this the fibres of the inferior retinaculum of the peroneal tendons are attached; whilst in grooves, above and below it, pass the tendons of the peronæus brevis and longus muscles respectively. To the upper and posterior part of this surface are attached the fibres of the calcaneo-fibular ligament of the ankle.

The anterior extremity is furnished with a saddle-shaped surface on its anterior aspect for articulation with the cuboid. This facet is concave from above downwards, and slightly convex from side to side; its edges are sharply defined, except medially, and serve for the attachment of ligaments.

The posterior extremity, called the tuber calcanei (tuberosity), forms the projection of the heel. Of oval form and rounded surface, it rests upon the two processes or tubercles inferiorly and is divisible into three areas. Of these the highest is smooth and crescentic, and is covered by a bursa; the intermediate is also fairly smooth, and is defined inferiorly by an irregular line, sometimes a definite ridge, 
the edges of which are striated. Into this surface the tendo calcaneus is inserted. The lowest surface is rough and striated, and is confluent below with the medial and lateral processes; this is overlain by the dense layer of tissue which forms the pad of the heel.

\section{Os Naviculare Pedis.}

The navicular bone (O.T. scaphoid), of compressed piriform shape, is placed on the medial side of the foot, between the head of the talus posteriorly and the three cuneiform bones anteriorly. The bone derives its name from the oval or boat-shaped hollow on its proximal surface, which rests upon the head of the talus. Its distal aspect is furnished with a semilunar articular area, which is subdivided by two faint ridges into three wedge-shaped facets for articulation, medio-laterally, with the first, second, and third cuneiform bones. The dorsal surface of the bone, convex from side to side, is rough for the attachment of the ligaments on the dorsal aspect of the foot. On its plantar aspect the bone is irregularly concave ; projecting downwards and backwards from its lateral side there is often a prominent spur of bone, the plantar process, to which is attached the

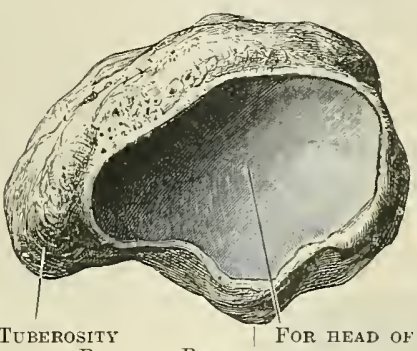

Plantar Process talus

A

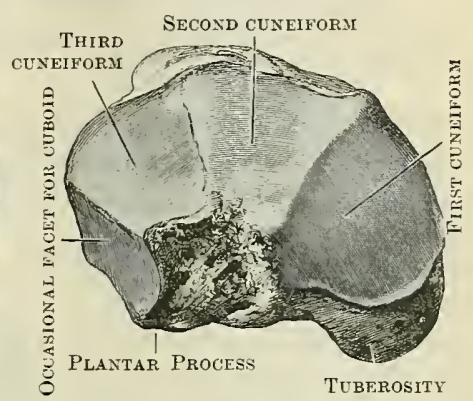

B

Fig. 261. - The Right Navicular Bone.

A. Seen from behind. B. Seen from the front.

plantar calcaneo-navicular ligament. The lateral surface is narrow from before backwards, and rounded from above downwards. In 70 per cent of cases (Manners Smith) it is provided with a facet which rests upon a corresponding area on the cuboid. Behind this in rare instances there is a facet for the calcaneus. The medial surface of the bone projects beyond the general line of the medial border of the foot, so as to form a thick rounded tuberosity (tuberositas oss. navicularis), the position of which can be easily determined in the living. To the medial and under surface of this process an extensive portion of the tendon of the tibialis posterior muscle is inserted.

\section{The Cuneiform Bones.}

The cuneiform bones, three in number, are placed between the navicular proximally and the bases of the first, second, and third metatarsal bones distally, for which reason they are now named the first, second, and third cuneiforms (O.T. internal, middle, and external). More or less wedge-shaped, as their name implies, the first is the largest, whilst the second is the smallest of the group. Combined, they form a compact mass, the proximal surface of which, fairly regular in outline, rests on the distal surface of the navicular; whilst distally they form a base of support for the three medial metatarsals, the outline of which is irregular, owing to the base of the second metatarsal bone being recessed between the first and third cuneiforms, as it articulates with the distal extremity of the shorter second cuneiform.

The first cuneiform bone, the largest of the three, lies on the medial border of the foot between the base of the metatarsal bone of the great toe distally, and the medial part of the distal surface of the navicular proximally. In form the bone is less characteristically wedge-shaped than its fellows of the same name and differs from them in this respect, that whilst the second and third cuneiforms are so disposed that the bases of their wedges are directed upwards towards the dorsum of the foot, the first cuneiform is so placed that its base is 
directed towards the plantar aspect; further, the vertical diameter of the bone is not the same throughout, but is much increased at its anterior or distal end. The

II. Metatarsal

I. MetataRsal

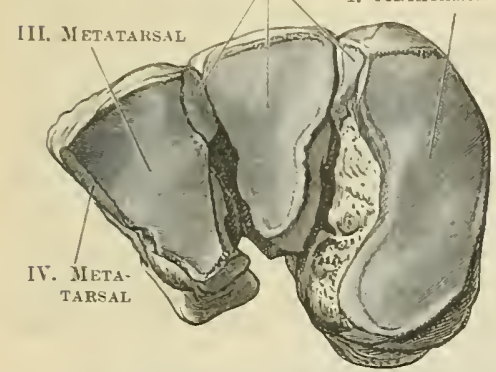

Fig. 262.-Distal SURFACES OF THE THREE Coneifora Bones of the Right Foot. dorsal and medial surfaces are confluent, and form a convexity from above downwards, which is most pronounced inferiorly, where it is turned to become continuous with the plantar or inferior aspect, which is rough and irregular round the plantar side of the foot. On the distal part of the medial aspect of the bone there is usually a distinct oval impression, which indicates the surface of insertion of a portion of the tendon of the tibialis anterior muscle. Elsewhere this surface is rough for ligamentous attachments. The Iateral surface of the bone, quadrilateral in shape, is directed towards the second cuneiform; but as it exceeds it in length, it also comes in contact with the medial side of the base of the second metatarsal bone. Running along the proximal and dorsal edges of this area is an $\Gamma$-shaped articular surface, the distal and dorsal part of which is for the base of the second metatarsal bone, the remainder articulating with the medial side of the second cuneiform. The non-articular part of this aspect of the bone is rough for the attachment of thestrong interosseous ligaments which bind it to the second cuneiform and second metatarsal bones, respectively. The proximal end of the

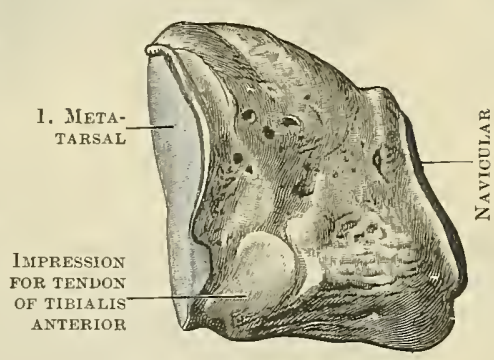

Fig. 263.-The Right First Cunerform (Medial Side).

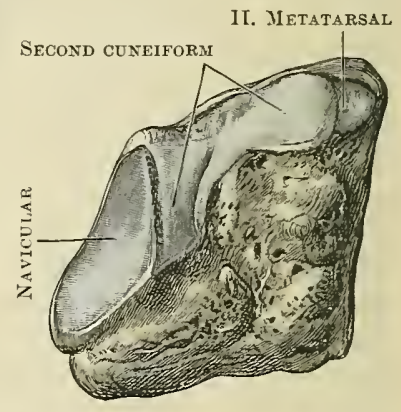

Fig. 264.-THE Right FiRst Coneiform (Lateral Side). bone is provided with a piriform facet which fits on the medial articular area of the navicular. Here the wedge-shaped form of the bone is best displayed. Distally the vertical diameter of the bone is much increased, and the facet for the

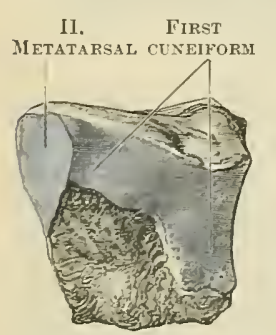

FIG. 265.-THE RighT SECOND CUNEIFORM (Medial Sille).

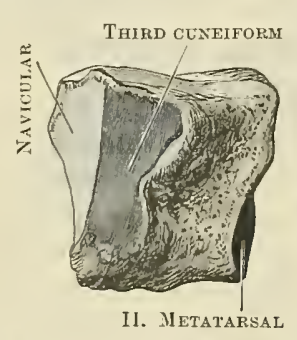

FIG, 266. - Тне Right SECOND CUNEIFORM (Lateral Side). base of the metatarsal bone of the great toe is consequently much larger than that for the navicular. This metatarsal facet is usually of semilunar form, but not infrequently is more reniform in shape, and may in some cases display complete separation into two oval portions.

The second cuneiform is of a typical wedge shape, the base of the wedge being directed towards the dorsum of the foot; shorter than the others, it lies between them, articulating with the base of the second metatarsal in front, and the middle facet on the distal surface of the navicular behind. Its dorsal surface, which corresponds to the base of the wedge, conforms to the roundness of the instep, and is slightly convex from side to side, affording attachments for the dorsal ligaments. Its plantar aspect.is narrow and rough, forming the edge of the wedge; with this the plantar ligaments are connected. The medial surface, quadrilateral in outline, is furnished with an $r$-shaped articular area along its proximal and dorsal borders in correspondence with the similar area on the lateral side of the first cuneiform. The rest of this aspect is rough for ligaments. 
The lateral side displays a facet arranged along its proximal border, and usually somewhat constricted in the middle; this is for the third cuneiform. Distal to this the bone is rough for the interosseous ligaments, which bind the two bones together. The proximal end is provided with a triangular facet slightly concave from above downwards; this rests on the central articular surface on the anterior aspect of the navicular. In front the bone articulates by means of a wedgeshaped facet with the base of the metatarsal bone of the second toe.

The third cuneiform, intermediate in size between the first and second, is also of a fairly typical wedge shape; though its anteroposterior axis is not straight but bent, so that the distal end of the bone turns slightly medially. Its dorsal

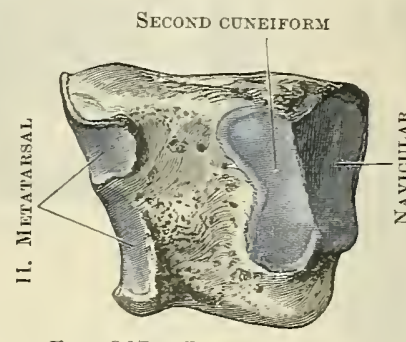

FIG. 267.-Right ThIRD Cunerform (Medial Side).

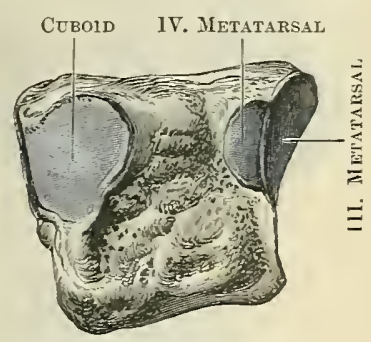

FIG. 268.-Right ThIRD CuNeIform (Lateral Side).

surface, which corresponds to the base of the wedge, is slightly convex from side to side, and provides attachments for the dorsal ligaments. Its inferior or plantar aspect forms a rough blunt edge, and serves for the attachment of the plantar ligaments. Its medial side, of quadrilateral form, displays two narrow articular strips, placed along its distal and proximal borders respectively, each somewhat constricted in the middle. The distal articulates with the lateral side of the base of the second metatarsal bone, the proximal with the lateral side of the second cuneiform. The rough non-articular surface, which separates the two elongated facets, serves for the attachment of ligaments. The lateraI aspect of the bone is characterised by a large circular or oval facet, placed near its proximal border, for articulation with the cuboid; in front of this the distal border is lipped above by a small semi-oval facet for articulation with the medial side of the base of the fourth metatarsal. The rest of the bone around and between these facets is rough for ligaments. Proximally the bone is furnished with a blunt, wedge-shaped facet for articulation with the corresponding area on the distal surface of the navicular. Below this the surface is narrow and rough for the attachment of ligaments. The distal end of the bone articulates with the base of the third metatarsal by a surface of triangular shape.

\section{Os Cuboideum.}

The cuboid lies on the lateral side of the foot, about its middle, articulating with the calcaneus proximally and the fourth and fifth metatarsal bones distally. Its dorsal surface, plane in an antero-posterior direction, is slightly rounded from side to side, and provides attachment for ligaments. Its plantar aspect is traversed obliquely from the lateral side medially and forwards by a thick and prominent ridge, the lateral extremity of which, at the point where it is confluent with the lateral surface, forms a prominent tubercle (tuberositas oss. cuboidei), the anterior and lateral surface of which is smooth and facetted to allow of the play of a sesamoid bone which is frequently developed in the tendon of the peronæus longus muscle. Distal to this ridge there is a groove (sulcus peronæi) in which the tendon of the peronæus longus muscle is lodged as it passes across the under surface of the bone. Proximal to the ridge the bone is rough, and serves for the attachment of the plantar calcaneo-cuboid ligament, the superficial fibres of which pass forwards and are attached to the summit of the ridge. The lateral aspect of the bone is short and rounded, and is formed by the confluence of the dorsal and plantar surfaces : it is more or less notched by the peroneal groove which turns round its plantar edge. The medial surface of the bone is the most extensive; it is easily recognisable on account of the presence of a rounded or oval facet situated near 
its middle and close to its dorsal border. This is for articulation with the lateral side of the third cuneiform; proximal and distal to this the surface is rough for ligaments. Not iufrequently, proximal to the facet for the third cuneiform, there is

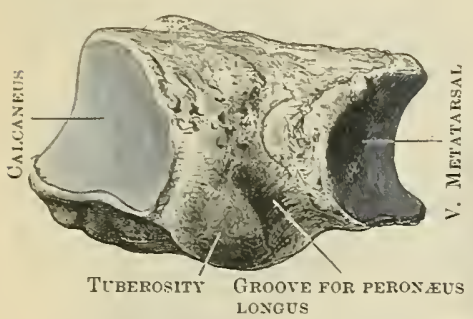

A

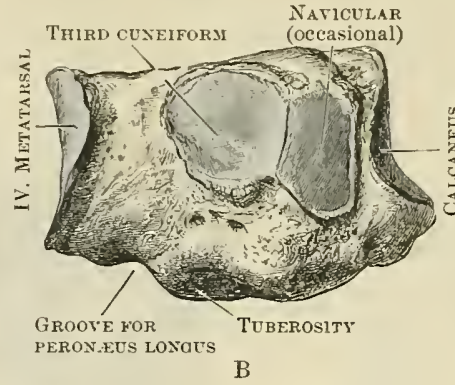

Fig. 269.-The Right Cobold Bone.

A. Lateral Side.

B. Nedial Side.

a small articular surface for the navicular, as is the case normally in the gorilla, whilst proximally and on the plantar aspect the projecting inferior angle is sometimes provided with a facet on which the head of the talus rests. (Sutton, "Proc.

Anat. Soc.," Journ. Anat. and Physiol. vol. xxvi. p. 18.) The distal surface is oval or conical in outline; sloping obliquely from the medial side laterally and backwards, it is divided about its middle by a slight vertical ridge into two parts, the medial of which articulates with the base of the fourth metatarsal bone, the lateral with that of the fifth. The proximal surface, also articular, has a semilunar outline, the convex margin of which corresponds to the dorsal roundness of the bone. The inferior lateral angle corresponds to the tubercle on the lateral border of the bone, whilst the inferior medial angle forms a pointed projection which is sometimes called the calcanean process. This surface articulates with the calcaneus by means of a saddle-shaped facet, which is convex from side to side, and concave from dorsal to plantar margins.

The tarsus as a whole may be conveniently described as arranged in two

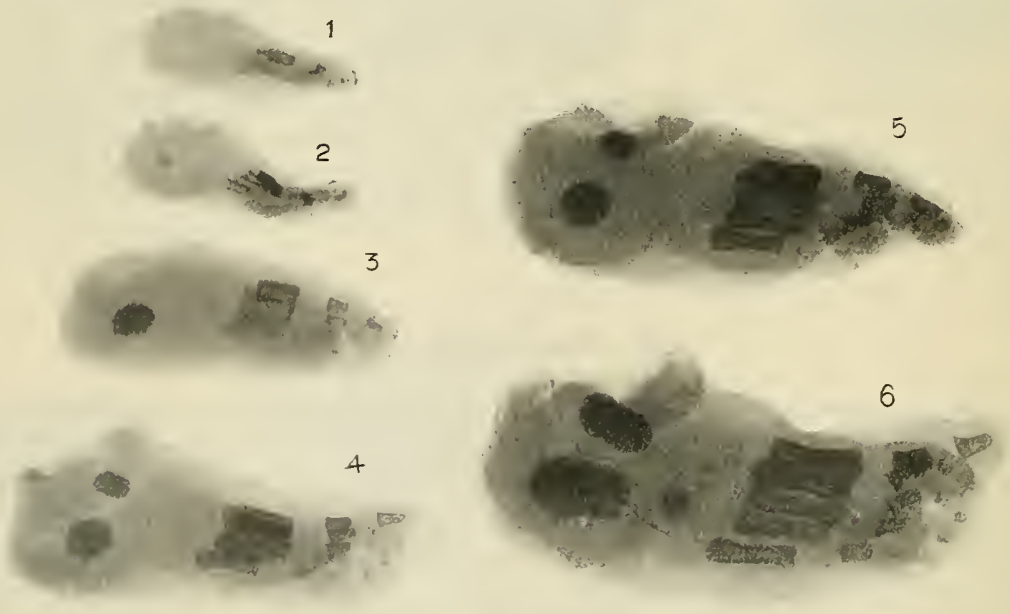

Frg. 270.-Radiographs of the Fettal Foot.

1. About fifth month. No ossification in the tarsus visible.

2. About sixth month. Appearance of a nucleus for the calcaneus.

3. A bout seventh month. Nucleus for calcaneus well developed.

4 and 5. About eighth month. Centres for talus and calcaneus now seen.

6. About birth. Centres for the talus and calcaneus are well developed, there is also a considerable centre for the cuboid, and the appearance of a centre for the third cuneiform is now displayed.

columns; the medial, corresponding to the medial border of the foot, comprising the talus, navicular, and three cuneiforms, and forming a base for the support of the three medial metatarsal bones and their phalanges. The lateral column, formed by the calcaneus and cuboid, supports the fourth and fifth metatarsal bones together with their phalanges. The dorsal surface of the anterior portion of the 
tarsus determines the side-to-side roundness of the instep, whilst its plantar surface forms arches in both a transverse and longitudinal direction, in which the softer tissues of the sole are lodged, and so protected from injury.

Ossification.-Unlike the carpus, the tarsus is at birth partially ossified. At this period there is a well-marked osseous nucleus within the body and neck of the talus, and the calcaneus is extensively ossified. In the latter the deposition of earthy matter appears as early as the sixth month of fotal life, whilst in the talus the ossific centre makes its appearance in the later weeks of gestation. Shortly before or after birth the

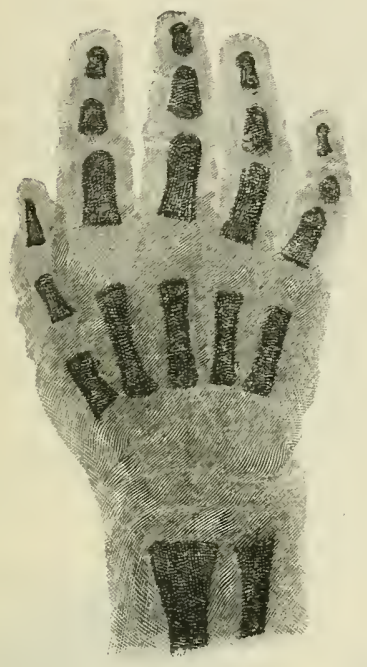

FIG, 271.-RADIOGRAPH OF THE HAND AT BIRTH.

It will be noticed that whilst the primary centres for the metacarpus and phalanges are well ossified, the carpus is still entirely cartilaginous.

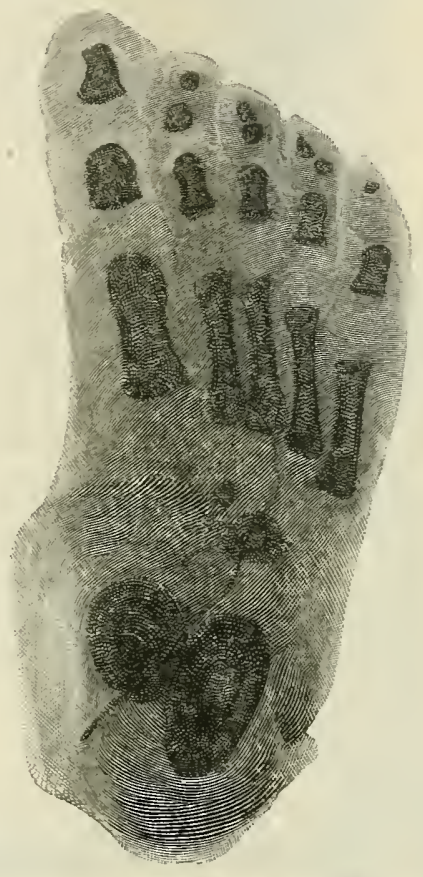

Fig. 272.-Radiograph OF the Foot AT BIRTH.

The centres of ossification for the calcaneus and talus are well developed, the nucleus for the cuboid is quite distinct, and in this instance the third cuneiform is already commencing to ossify.

cuboid begins to ossify, succeeded early in the first year by the third cuneiform, followed in order by the second cuneiform, first cuneiform, and navicular. The ossific centre of the latter appears at the third year or somewhat later. An epiphysis, which forms a cap over the extremity of the tuberosity of the calcaneus, appears from the seventh to the ninth year, and fusion is completed between the ages of sixteen and twenty.

To emphasize the different conditions which obtain in the wrist and ankle, at, and for some time after birth, drawings of radiographs of both are given.

\section{The Metatarsus.}

The metatarsal bones, five in number, in their general configuration resemble the metacarpal bones. They are, however, slightly longer, their bases are proportionately larger, their shafts more slender and laterally compressed, and their heads proportionately smaller. They are named numerically the first, second, third, fourth, and fifth metatarsal bones, in order from the tibial to the fibular side. The first can be readily recognised on account of its stoutness; it is also the shortest of the series. The second is the longest of the five, and the fifth can easily be distinguished by the projecting tubercle at its base. 
The first metatarsal or metatarsal bone of the great toe, the shortest of the series, is remarkable for its stoutness. Its proximal end or base, where the bone

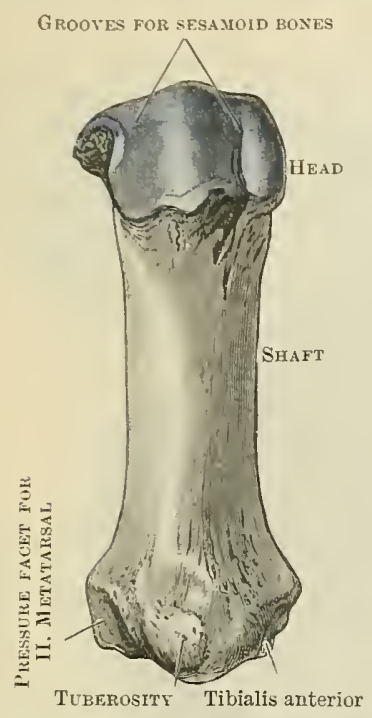

Fig. 273. - The First Metatarsal Bone of THE Right Foot (Plantar Aspect).

bone is pitted for the strong collateral ligaments of the joint.

The second metatarsal, the longest of the series, has a base of wedge-shaped

II. METATARSAL
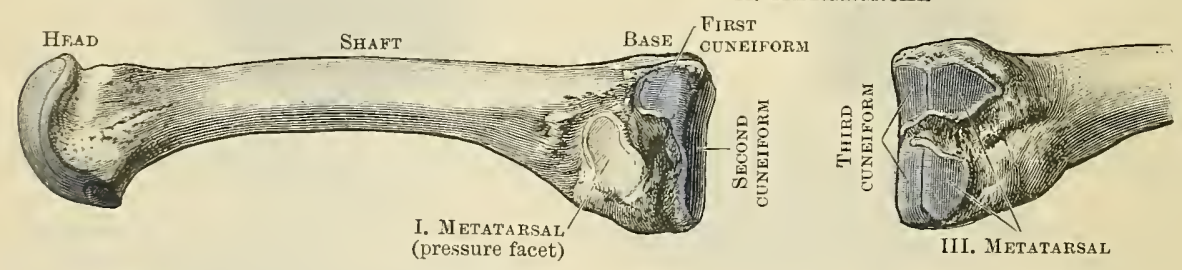

III. METATARSAI
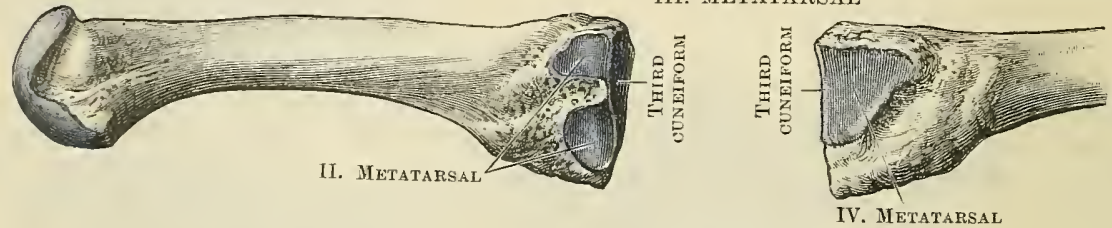

IV. METATARSAL

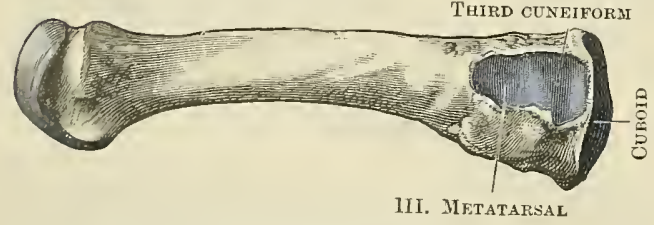

A. Medial sides.

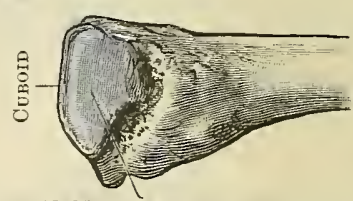

V. Metatarasal

B. Lateral sides.

Fig. 274. - Vien of the Bases and Shafts of the Second, Third, and Fodrth Metatarsal Bones OF THE RIGHT FOOT.

form, the proximal aspect of which articulates with the second cuneiform. On its tibial aspect, near its dorsal edge there is a small circular facet for the first 
cuneiform; distal to this and near the plantar surface there is sometimes a tubercle with a "pressure" facet on it, where the bone comes in contact with the base of the first metatarsal. On the fibular side of the base there is one, more usually two small facets, each divided into two parts, a proximal for articulation with the third cuneiform, and a distal for the base of the third metatarsal. The shafts of this and the three succeeding bones are slender and laterally compressed. The heads are small and narrow, and display a pronounced side-to-side and vertical convexity.

The third metatarsal bone also possesses a base of wedge-shaped form, the proximal surface of which articulates with the third cuneiform. On its tibial side it is provided with one, more usually two, small facets, for articulation with the base of the second metatarsal. Laterally the base has a larger facet for articulation with the base of the fourth metatarsal, more or less conical in outline, and having its plantar edge sharply defined by a narrow groove which underlies it.

The fourth metatarsal has a base more cubical in shape. articulates with the cuboid, whilst medially an elongated oval facet, divided by a slight vertical ridge, provides surfaces for articulation with the third metatarsal distally and the lateral side of the first cuneiform proximally. On the lateral side there is a demi-oral facet, bearing a slightly saddleshaped surface, for articulation with the tibial side of the base of the fifth metatarsal.

The fifth metatarsal can be readily recognised by the peculiar shape of its base, from the lateral side of which there projects proximally and laterally a prominent tuberosity (tuberositas oss. metacarpi quinti). To the proximal extremity of this is attached the tendon of the peronæus brevis muscle. Into its dorsal surface the tendon of the peronæus tertius is inserted, whilst its plantar surface provides an origin for the flexor digiti quinti brevis muscle. The tibial surface of the base is provided with a demi-oval, slightly concave facet, for the lateral side of the base of the fourth metatarsal, whilst proximally it articulates with the cuboid by means of a semicircular facet.

Vascular Foramina.--The canals for the nutrient vessels open, as a rule, on the plantar aspects of the middle of the shafts. Those of the lateral metatarsals are directed towards the bases of the bones, whilst that for the metatarsal of the great toe passes towards its head.

Its proximal aspect

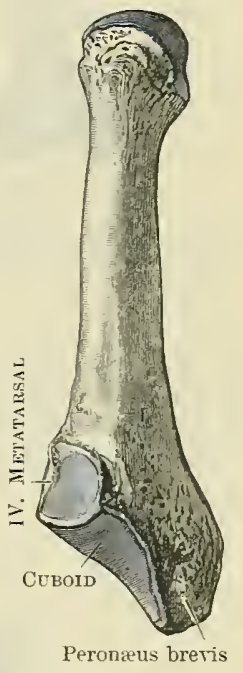

Fig. 275.-FifTH Right METATARSAL BONE (Dorsal Aspect).

Ossification.-In correspondence with the mode of ossification which obtains in the metacarpus, the primary centres for the metatarsus appear as early as the third month of fotal life. In the case of the second, third, fourth, and fifth, these centres furnish the bases and shafts of the bones, the heads being developed from secondary centres which appear from two to four years after birth, fusion with the shaft being usually completed about the eighteenth year. In striking contrast to this is the mode of ossification of the first metatarsal. From its primary centre the head and shaft is developed; the secondary centre appears at its base about the second or third year, and fuses with the shaft about eighteen. In this respect, therefore, the metatarsal bone of the great toe resembles in its mode of development the phalanges. Mayet, however (Bull. Soc. Anat. Paris, 1895), describes the occurrence of two ossific centres in the proximal epiphysis. These fuse early, and he considers that the one represents the metatarsal element, whilst the other may be regarded as phalangeal in its origin.

\section{Phalanges Digitorum Pedis.}

The phalanges of the toes differ from those of the fingers in the striking reduction of their size, and in the case of the bones of the first row, in the lateral compression of their shafts. Each toe is provided normally with three phalanges, except the great toe, which has only two. In their general 
configuration and in the arrangement of their articular facets they resemble the phalanges of the fingers, though owing to the reduction in their size, the shafts, particularly those of the second row, are often so compressed longitudin-

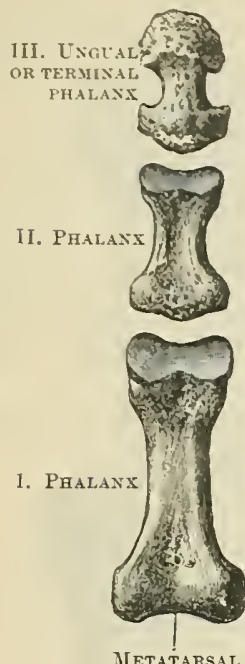

Fig. 276. - The Phalanges of THE TOES (Plantar Aspect). ally as to reduce the bone to a mere nodule. The proximal end of each of the bones of the first row is proportionately large, and is provided with a simple hollow in which the head of the metatarsal bone rests; the distal ends are furnished with condyloid surfaces. The proximal extremities of the second row are each provided with two small concavities, separated by a slight ridge for articulation with the condyles of the first row. The joint between the second and third row displays the same arrangement- the third, or ungual phalanx, being easily distinguished by the spatula-shaped surface at its extremity, on which the bed of the nail is supported.

The phalanges of the great toe, two in number, differ from the others in their size and length. Into the base of the first phalanx are inserted the short muscles of the great toe, whilst the second phalanx receives on its plantar aspect the insertion of the flexor hallucis longus muscle, the teudon of the extensor hallucis longus being inserted into the dorsal aspect.

Ossification.-Each phalanx is developed from two centres -one primary for the shaft and distal extremity, the other for the epiphysis on the proximal end. The primary centres for the ungual phalanges are the first to appear, commencing to ossify from the eleventh to the twelfth week of fœtal life. The centre for the ungual phalanx of the great toe makes its appearance before that of its corresponding metatarsal bone. The primary centres for the phalanges of the first row appear from the fourteenth to the sixteenth week. The primary centres for the middle phalanges of the second and

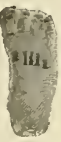

A

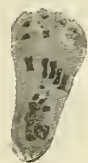

B

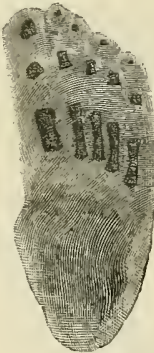

$\mathrm{D}$

FIG. 277.

A. About the end of the third month. The primary centres of all the metatarsals are shown as well as the centres for the phalanges of the great toe and the terminal phalanx of the third toe.

B. ${ }^{1}$ A little later. The centres for the terminal phalanges of the four medial toes are seen, as well as the centres for the first phalanges of the great and second toe.

C. About the fourth month. The centres for all the terminal phalanges as well as those of the first row are well ossified.

D. About the fifth month. In this the centre for the second phalanx of the second toe has already made its appearance.

1 This specimen displays the occurrence of anomalous centres within the tarsus the significance of which is not apparent. The appearance is not due to any defect in the plate, but rccurred in repeated radiographs.

third toes begin to ossify about the sixth month, those for the fourth and fifth toes not till later - the shaft of the middle phalanx of the fourth toe being frequently cartilaginous at birth, the normal condition in the case of the fifth toe (Lambertz). The proximal epiphyses do not begin to ossify until about the fourth year, and are usually fused with the diaphyses about the age of sixteen or eighteen. Union between the shafts and epiphyses of the first row precedes that of the second and third rows. 


\section{Ossa Sesamoidea.}

As in the hand, small independent nodules of bone, called sesamoid bones, are met with in the ligaments and tendons of the foot. The most constant of these are found in connexion with the metatarso-phalangeal articulation of the great toe, where they lie in grooves on the plantar surface of the head of the metatarsal bone in connexion with the tendons of the short muscles of the great toe. Small osseous nodules occupying a corresponding position are occasionally met with in the other toes, and instances have been recorded of like ossicles occurring on the plantar aspect of the interphalangeal joint of the great toe.

An osseous nodule is not infrequently met with in the tendon of the peronæus longus as it turns round the lateral border of the foot to lie in the groove on the under surface of the cuboid. 


\title{
APPENDICES TO THE SECTION ON OSTEOLOGY.
}

\author{
A. Architecture of the Bones of the Skeleton. \\ B. Variations in the Skeleton. \\ C. Serial Homologies of the Vertebræ. \\ D. Measurements and Indices employed in Physical Anthropology. \\ E. Development of the Chondro-Cranium and Morphology of the Skull. \\ F. Morphology of the Limbs.
}

\section{APPENDIX A.}

\section{ARCHITECTURE OF THE BONES OF THE SKELETON.}

The Vertebræ.-The vertebræ are formed of spongy bone confined within a thin and dense envelope. In the bodies the arrangement of the spongy tissue, which is traversed by venous channels, is such as to display a vertical striation with lamellæ arranged horizontally. The lateral, superior, and inferior walls are very thin - that directed to the vertebral canal being usually thicker and denser than the others. In the roots of the vertebral arches and roots of the transverse processes the spongy tissue is much more open. The outer envelope is much thicker where it bounds the vertebral canal, and where it forms the bottom of the superior and inferior intervertebral notches. In the laminæ the spongy tissue is confined between two compact layers, of which that directed to the vertebral canal is the thicker. In the spinons processes the upper edge is always the more compact.

The Sternum consists of large-celled spongy bone, which is highly vascular, and is contained between two layers of thin compact tissue.

The Ribs.-Each rib consists of a curved and compressed bar of bone, the interior of which consists of highly vascular spongy tissue with an external envelope of compact bone. The inner table is much the stronger, attaining its maximum thickness opposite the angle-in front and behind which it becomes gradually reduced. The outer table, much thinner, is stoutest opposite the angle; on the posterior surface of the tubercle and neck it forms but a thin layer. The compact layers forming the upper and lower borders are not so thick as those forming the inner and outer surfaces. The spongy tissue, loose and open in the shaft, is most compact in the region of the head and towards the anterior extremity.

The Frontal Bone.-The frontal bone is composed, like the other bones of the cranial vault, of two layers of compact tissue, enclosing between then a layer of spongy cancellous texture-the diploë. In certain definite situations, owing to the absorption of this intermediate layer, the bone is hollow, forming the frontal air-sinuses. The position and extent of these is to some extent indicated by the degree of projection of the superciliary ridges, though this must not be taken as an absolutely reliable guide, for cases are recorded where the ridges were low and the sinuses large, and vice versa. Of much surgical importance, these air-spaces only attain their full development after the age of puberty, being of larger size in the male than in the female, a circumstance which accounts for the more vertical appearance of the forehead in woman as contrasted with man. Usually two in number, they are placed one on either side of the median plane, and communicate by means of the infundibulum with the nasal cavity of the same side. It is exceptional to find the sinuses of opposite sides in communication with each other, as they are generally separated by a complete partition which, however, is occasionally much deflected to one or other side. Logan Turner "On the Illumination of the Air Sinuses of the Skull, with some Observations upon the Surgical Anatomy of the Frontal Sinus," Edin. Med. Journ., May 1898) gives the average dimensions of these sinuses as follows:- Height, $31 \mathrm{~mm}$., i.e. from the frontonasal aperture upwards ; breadth, $30 \mathrm{~mm}$., i.e. from the septum horizontally in a lateral direction; depth, $17 \mathrm{~mm}$., from the anterior wall at the level of fronto-nasal suture backwards along the orbital roof. Exceptionally large sinuses are sometimes met with extending hackwards over the orluit so as to form a double roof to that space. There is a specimen in the Oxford collection in which the sinus is so large, and extends so far back, that the optic nerve is transmitted through it in a bony tube. Another point of some practical importance is that the sinuses are hardly ever symmetrical. It is rare to meet with cases of their complete absence, although sometimes the sinus on one or other side may be wanting.

The zygomatic process, from the arrangement of its surfaces and the density of its structure, is particnlarly well adapted to resist the pressure to which it is subjected when the jaws are firmly closed.

The Parietal Bone.-Thin towards its lower part, where it enters into the formation of the temporal fossa, it is thickest along the superior border and in the neighbourhood of the posterior superior angle.

The Occipital Bone.-The squamous part displays thickenings in the position of the various ridge and crests, the stoutest part corresponding to the internal and external occipital protuberances, 
though it should be noted that the two protuberances do not necessarily coincide, the internal being, as a rule, placed at a higher level than the external. If the bone be held up to the light it will be at once apparent that it is much thinner where it forms the floor of the inferior fossæ than in the upper part. The basilar portion consists of a spongy core surrounded by a more compact outer envelope, thickest on its lower surface. In the condyles the spongy tissue is arranged radially to their convex articular surfaces, the hypoglossal canal being surrounded by jarticularly dense and compact bone, which assists in strengthening this naturally weak part of the bone.

The Temporal Bone.-The temporal bone is remarkable for the hardness and density of its petrous part, wherein is lodged the osseous labyrinth, which contains the delicate organs associated with the senses of hearing and equilibration. The middle ear or tympanum is a cavity which contains the small auditory ossicles, and is separated from the external acoustic meatus by the membrana tympani. In front it communicates with the pharynx by the auditory tube; behind, it opens into the tympanic antrum and mastoid air-cells by the aditus ad antrum. Superiorly, it is separated from the middle cranial fossa by a thin plate of bone called the tegmen tympani. Inferiorly, its floor is formed in part by the roof of the jugular fossa and the carotid canal. Medially, it is related to the structures which form the inner ear, notably the cochlea and vestibule, in front of which it is separated by a thin plate of bone from the carotid canal. Owing to the disposition of the internal and external acoustic meatus the weakest part of the bone corresponds to a liue connecting these two channels, the only parts intervening being the cochlea and tympanum. It is usually in this position that fracture of the bone occurs. Curving over the cavity of the tympanum is the canalis facialis, the thin walls of which are occasionally deficient. These details, together with an account of the tympanic ossicles, will be further dealt with in the section devoted to the Organs of Sense.

The Sphenoid Bone.--In the adult the body of the bone is hollow and encloses the sphenoidal air-sinuses, usually two in number, separated by a septum. The arrangement and extent of these air-sinuses vary; sometimes they are multilocular, at other times simple, while occasionally they extend backwards into the basi-occipital and laterally and downwards into the roots of the great wings and pterygoid processes. Cases are on record in which in the adult the body of the bone was not pneumatic.

The Lacrimal Bone.-The bone consists of a thin papery translucent lamina, somewhat strengthened by the addition of the vertical crest.

The Vomer. - The bone is composed of two compact layers fused below, but separated above by the groove for the lodgment of the rostrum of the sphenoid behind, and the septal cartilage in front. The lamellæ are also separated from each other by a canal which runs horizontally from behind forwards in the substance of the bone, and which transmits the nutrient vessel of the bone.

The Nasal Bone.-Formed of dense and compact bone; the strength of the nasal bones is increased by their mode of union and the formation of a median crest posteriorly.

The Maxilla. - The disposition of the maxillary sinus within the body of the bone has been already referred to. In union with its fellow, the vaulted arrangement of the hard palate is well displayed, and the arched outline of the alveolar processes is obvious. It is in these latter processes around the sockets for the reception of the teeth that the spongy tissue of the bone is seen; elsewhere its walls are formed by thin and dense bone.

The Zygomatic Bone. - In structure the bone is compact, with little spongy tissue. Together with the zygomatic process of the temporal bone it forms the buttress which supports the maxilla and the lateral wall of the orbit. Additional streugth is imparted to the bone by the angular mode of union of its orbital and facial parts.

The Mandible. - The mandible is remarkable for the density and thickness of its medial and lateral walls. Where these coalesce below at the base of the body, the bone is particularly stout. Superiorly, where they form the walls of the alveoli, they gradually thin, being thicker, however, on the medial than the lateral side, except in the region of the last molar tooth, where the medial wall is the thinner. The spongy substance is open-meshed below, finer and more condensed where it surrounds the alveoli. The mandibular canal is large and has no very definite wall; it is prolonged beyond the mental foramen to reach the incisor teeth. From it numerous channels pass upwards to the sockets of the teeth, and it communicates freely with the surrounding spongy tissue. Above the canal the substance of the bone is broken up by the alveoli for the reception of the roots of the teeth. In the substance of the condyle the spongy tissue is more compact, with a general striation vertical to the articular surface.

The mental protuberance is an essentially human characteristic ; by some it is associated with the development of speech in man, others regard it as due to the reduction in the size of the teeth.

The Clavicle. - The shaft consists of an outer layer of compact bone, thickest towards the centre, but gradually thinning towards the extremities, the investing envelope of which consists merely of a thin shell. Within the shaft the spongy tissue displays a longitudinal striation, which internally assumes a more cellular appearance. At the acromial end the general arrangement of the fibres resembles the appearance of the sides of a Gothic arch. The curres of the bone impart an elasticity to it, which is of much service in reducing the effects of the shocks to which it is so frequently subjected.

The Scapula. - For so light and thin a bone, the scapula possesses a remarkable rigidity. This is owing to the arrangenent of its parts. Stout and thick where it supports the glenoid cavity 
and coracoid process, the rest of the bone is thin, except along the axillary margin ; but strength is imparted to the body by the mamner in which the spine is fused at right angles to its dorsal surface.

The Humerus.-The shaft consists of a layer of compact bone surrounding a long medullary canal. The onter shell, thickest in the distal third of the bone, gradually thins until it reaches the proximal epiphysial line, where it forms a layer no thicker than stout paper. Distally the external shell is thicker and stouter than it is proximally, until it reaches the epicondyles, distal to which the articular surfaces are formed of a layer of compact spongy bone. The proximal end of the medullary canal is surrounded by loose spongy tissue, the fibres of which arch inwards from the inner surface of the compact onter layer, whilst at the distal end the spongy tissue which springs from the onter shell sweeps distally in a radiating fashion on either side of the olecranon fossa towards the epicondyles. Proximal to the olecranon fossa there is a number of laminæ of dense bone which arch across from one side to the other, the convexity of the arches being directed distally. The proximal epiphysis, formed of spongy bone, is mited to the shatt by a wavy line, concave laterally and convex medially, leading fron the base of the greater tuberosity on the lateral side to the distal articular edge on the medial side. The mass above this includes the head and two tuberosities. The spongy tissue of the head is fine, and is arranged generally in lines radial to its surface; that of the greater tuberosity is more open, and often displays large spaces towards its interior, which in old bones communicate freely with the medullary cavity of the shaft. The general direction of the fibres is parallel to the lateral surface of the tuberosity. The distal articular end is formed of fine spongy tissile, more compact towards the surface, and arranged in lines more or less at right angles to its articular planes. In the adult the principal nutrient canal, viz, that which opens on the surface near the insertion of the coraco-brachialis, traverses the outer compact wall of the shaft obliquely distally for a distance of two and a quarter inches before it opens into the medullary cavity.

The Ulna.-The weakest parts of the bone are the constricted portion of the semilunar notch, and the shaft in its distal third, the bone being most liable to fracture at these points. On section the medullary cavity is seen to extend proximally as high as the base of the coronoid process; distally it reaches the proximal end of the distal fifth of the bone. The walls of the shaft, which are formed of dense bone, are much thicker on the dorsal surface than on the volar. Proximally they are continuous with the volar surface of the coronoid process and the dorsal surface of the olecranon, where they are composed of layers of looser texture, which, however, gradually become thinner as the points of these processes are reached. Distally they gradually taper until the head and styloid process are reached, round which they form a thin shell, considerably thickened, however, in the region of the groove for the extensor carpi ulnaris muscle. The bulk of the proximal extremity is formed of loose spongy bone, arranged in a series of arcades, stretching from the interior to the dorsal wall over the proximal end of the medullary canal. Proximal to the constricted part of the semilunar notch the bone displays a different structure; here it is formed of spongy bone, of closer texture, arranged generally in lines radiating from the articular surface. At the point of constriction of the semilunar notch the layer immediately subjacent is much denser and more compact.

The distal fifth of the bone is formed of loose spongy bone, the fibres of which have a general longitudinal arrangement; towards its extremity the meshes become smaller.

The Radius.-The neck is the narrowest part of the bone; here fracture may occur, though not commonly. The point at which the bone is usually broken is about one inch proximal to the distal extremity. This is accounted for by the fact that the radius supports the hand at the radio-carpal articulation, and the shocks to which the latter is subjected, as in endeavouring to save oneself from falling, are naturally transmitted to the radius. On section, the medullary canal is seen to extend to the neck; distally, it reaches to the level of the distal fifth of the bone. Its walls are thick as compared with the diameters of the bone, particularly along the interosseous border, thus imparting rigidity to the curve of the shaft; these walls thin out proximally and distally. Proximally, the surface of the tuberosity is formed of a thin shell of bone, which, however, thickens again where it passes on to the neck. The proximal extremity is formed of spongy bone arranged in the form of arcades, reaching distal to the level of the tuberosity medially, but not extending distal to the level of the neck laterally. Beneath the capitular articular surface there is a dense layer, thickest in the centre, and thinning towards the circumference; this is overlain by a very thin layer of less compact bone.

The distal fifth of the shaft and distal extremity are formed of loose spongy bone arranged more or less longitudinally. Immediately subjacent to the carpal articular surface the tissne is more compact, and displays a striation parallel to the articular plane. The nutrient canal of the shaft pierces the volar wall of the proximal part of the medullary cavity obliquely running proximally for the space of half an inch.

The Carpus.-The bones are formed of fairly compact spongy tissue, surrounded by a thin shell of denser bone. They are very vascular, and their non-articular surfaces are pierced by many foramina.

The Metacarpus.-Similar in arrangement to that of long bones generally, though it may be noted that the compact walls of the shaft are thicker in proportion to the length of the bone than in the other long bones of the upper extremity.

The Phalanges. - Each phalanx has a medullary cavity, the walls of the shaft being formed of dense compact bone, especially thick along the dorsal aspect. The extremities are made up of spongy bone within a thin dense shell. 
The Hip Bone.-As a flat bone the os coxae consists of spongy tissue between two compact external layers. These latter vary much in thickness, being exceptionally stout along the ilio-pectineal line and the floor of the iliac fossa immediately above it. The gluteal aspect of the ilium is also formed by a layer of considerable thickness. The spongy tissue is loose and cellular in the thick part of the ilium and in the body of the ischinm ; absent where the floor of the iliac fossa is formed by the coalescence of the thin dense confining layers; fine grained and more compact in the tuberosity of the ischinm, the iliac crest, and the floor of the acetabulum, in which latter situation it, is striated by fibres which are directed radially to the surface of that hollow, these again being crossed at right angles by others which are arranged circnmferentially. This spongy tissue forms a more compact layer over the surface of the upper and posterior portion of the acetabular articular area. The bottom of the floor of the acetabulum varies in thickness; in most cases it is thin, and in exceptional instances the bone is here deficient. The same condition has been met with in the iliac

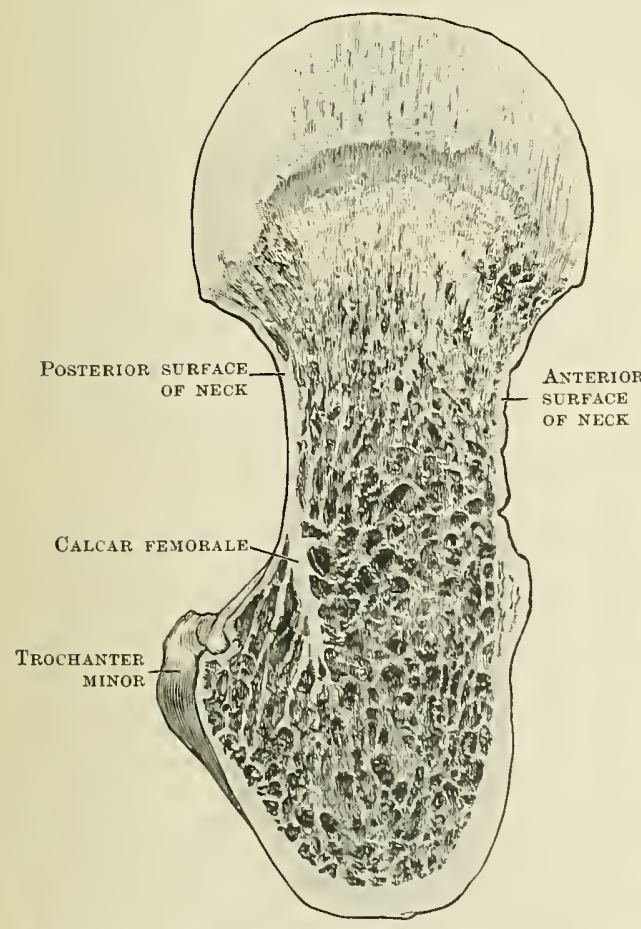

Fig, 279.-Section throvgh Head and Neck of Femur to show Calcar Femorale.
Fig. 278.-Dissection showing the Calcar Femorale.

A slice of bone has been removed from the posterior aspect of the proximal part of the shaft of the femur, passing through the trochanter major superiorly and the trochanter minor inferiorly and to the medial side. The loose spongy tissue has been scraped away, leaving the more compact tissue with the dense core forming the calcar femorale. By a similar dissection from the front the anterior surface of the calcar may be exposed.

fossa, where absorption of the thin bony plate has taken place.

The Femur.- The shaft has a mednllary cavity which reaches the root of the lesser trochanter proximally. Distally it extends to within $3 \frac{1}{2}$ inches of the distal articular surface. In the proximal half the outer compact wall is very thick, but distal to the middle of the shaft it gradually thins until it reaches the condyles, over which it passes as a thin, hardly definable external layer. Proximally, it is especially thick along the line of the linea aspera, and here the large nutrient canal may be seen passing obliquely towards the proximal end in the substance of the dense bone for the space of two inches. In the proximal end of the shaft the osseous lamellæ springing from the sides of the medullary cavity arch inwards towards the centre, intersecting each other in a manner comparable to the tracery of a Gothic window. The lower wall of the neck is thick distally, near the trochanter minor, but thins rapidly before it reaches the head. From this aspect of the neck there spring a series of oblique lamellæ which pass proximally and upwards, spreading in fan-shaped manner into the under surface of the head. These are intersected above by lamelli which arch medially from the lateral side of the 
shaft distal to the greater trochanter, as well as from the under surface of the thin but compact outer shell of the upper surface of the neck, the whole forming a bracket-like arrangement which assists materially in adding to the strength of the neck. Further support is afforded by the addition of a rertical layer of more compact bone within the spongy tissne of the neck. Distally, as may be seen in Fig. 278 , this is continuous with the dense posterior wall of the shaft below; whilst proximally it sweeps up beneath the lesser trochanter, from which it is separated by a quantity of loose spongy tissue, to fuse proximally with the posterior dense wall of the reck above and medial to the intertrochanteric crest. It may be regarded as a continuation proximally of the posterior wall of the shaft beneath the trochanteric epiphysis. When studied in section (see Fig. 279), the central dense core of this partition exhibits a spur-like appearance : hence the name calcar femorale applied to it. It is of surgical importance in cases of fracture of the neck of the femur. (R. Thompson, Journ. Anat. and Physiol., vol. xlii. p. 60.) From it, stout lamellie having a vertical direction arise. The spongy tissue of the head and greater trochanter is finely reticulated, that of the distal part of the neck and proximal part of the shaft being more open in its texture. Passing vertically through this tissue there is a rascular canal, the orifice of which opens externally on the floor of the trochanteric fossa.

The spongy tissue of the distal part of the shaft is more delicate and uniform in its arrangement, displaying a more or less parallel striation in a longitudinal direction. Subjacent to the articular surface the tissue is rendered more compact by the addition of lamellæ disposed in curves in harmony with the external aspect of the bone.

The Patella.-The bone consists of a thick dense layer anteriorly, which thins towards the edges on either side and distally; above, it corresponds to the area of insertion of the quadriceps. The femoral articnlar surface is composed of a layer of compact bone, thickest in correspondence with the vertical elevation. Sandwiched between these two layers is a varying thickness of spongy tissue of fairly close grain, the striation of which on cross section runs in parallel lines from back to front; on vertical section the tissue appears to be arranged in lines passing radially from the deep surface of the femoral area to the more extensive anterior dense plate.

The Tibia.-The shaft of the bone is remarkable for the thickness and density of the osseous tissue which underlies the anterior crest. The posterior wall is stout, but the medial and lateral walls are thinner. The several walls are thickest opposite the middle of the shaft, and thin out proximally and distally where the shaft unites with the epiphyses. The medullary canal, nalrow and circular in the middle of the bone, increases in all its diameters proximally and distally, and reaches to within $2 \frac{1}{2}$ to 3 inches of either extremity. Proximally the arrangement of the lamellæ of the spongy tissue resembles a series of arches springing from the dense outer walls. These form a platform on which the proximal epiphysis rests, the spongy tissue of which displays a more or less vertical striation. This is much more compact under the condylic surfaces, the superficial aspect of which is formed by a thin layer of dense bone. The intercondyloid eminence and the tuberosity are also formed of compact tissue, whilst the circumference of the condyles is covered by a thinner and less dense wall. In the distal end of the shaft the spongy tissue, of a loose and cellular character, is arranged in vertical fibres, blending with the closer tissue of the distal epiphysis, the articular surface of which is covered by a thin but dense layer.

In the adult bone the nutrient canal for the shaft is embedded in the dense posterior wall for the space of two inches.

The Fibula.-A medullary canal runs throughout the length of the shaft, reaching the neck proximally, and extending to a point about $2 \frac{1}{2}$ inches from the distal extremity of the lateral malleolus. The lateral wall of the shaft is usually considerably thicker than the medial. The head is formed of loose spongy bone, enclosed within a very thin dense envelope. The spongy tissue of the distal extremity is more compact, and acquires considerable density on the surfaces underlying the articular area and the pit behind it. The canal for the nutrient artery of the shaft opens into the medullary cavity about an inch distal to its external aperture.

The Bones of the Foot.-A longitudinal section through the articulated bones of the foot reveals the fact that the spongy structure of each individual bone is determined by the stress to which it is habitually subjected. In this connexion it is necessary to refer to the arched arrangement of the bones of the foot, a subject which is also treated in the section which deals with the Joints. The summit of the arch is formed by the talus, on which rests the tibia. Subjected as the talus is to a crushing strain, it is obvious that this load must be distributed throughout the arch, of which the calcanens is the posterior pillar, whilst the heads of the metatarsal bones constitute the anterior pillar. It is found, consequently, that the lamellæ of the spongy tissue of the talus are arranged in two directions, which intercross and terminate below the proximal articular surface. Of these fibres, some sweep backwards and downwards towards the posterior calcanean facet, beyond which they are carried in the substance of the calcaneus in a curved and wary manner in the direction of the heel, where they terninate; whilst others, curving downwards and forwards from the trochlea of the talus, pass through the neck to reach the articular surface of the head, through which in like manner they may be regarded as passing onwards through the several bones which constitute the anterior part of the arch, thus accounting for the longitudinal striation as displayed in the structure of the navicular, cuneiform, and metatarsal bones. In the calcaneus, in addition to the foregoing arrangement, another set of curving fibres sweep from back to front of the bone beneath the more compact tissue which forms its inder shell. These are obviously of advantage to prevent the spread of the bone when subjected to the crushing strain. In the sustentacnlum tali a bracket-like 
arrangement of fibres is evident, and the plantar surface of the neck of the talns is further strengthened by lamellæ arranged vertically.

In the separate bones the iuvesting envelope is thin, though under the articular surfaces there is a greater density, due to the accession of lamellæ lying parallel to the articular planes. The stoutest bony tissue in the talus is met with in the region of the plantar surface of the neck, whilst in the calcaneus the greatest density occurs along the floor of the sinus tarsi.

The Metatarsus.-In structure and the arrangement of their lamellæ the metatarsal bones agree with the metacarpus.

The Phalanges. - In their general structure they resemble the bones of the fingers.

\section{APPENDIX B.}

\section{VARIATIONS IN THE SKELETON.}

Cervical Vertebræ.-Szawlowski records the presence of an independent rib element in the transverse process of the fourth cervical vertebra. (Anat. Anz. Jena, vol. xx. p. 306.)

Atlas. - The foramen transversarium is often deficient in front. Imperfect ossification occasionally leads to the anterior arch, and more frequently the posterior arch, being incomplete. The superior articular surfaces are occasionally partially or completely divided into anterior and posterior portions. In some instances the extremity of the transverse process has two tubercles. The transverse process may, in rare cases, articulate with a projecting process (paroccipital) from the under surface of the jugular process of the occipital bone (see p. 278). An upward extension from the medial part of the anterior arch, due probably to an ossification of the anterior occipito-atlantal ligament, may articulate with the anterior surface of the sunmit of the dens of the epistropheus. Allen has noticed the articulation of the superior border of the posterior arch with the posterior border of the foramen magnum. Cases of partial or complete fusion of the atlas with the occipital bone are not uncommon (see p. 278).

Epistropheus.-In some instances the summit of the dens articulates with a prominent tubercle on the anterior border of the foramen magnum (third occipital condyle, see p. 278). Bennett (Trans. Path. Soc. Dublin, vol. vii.) records a case in which the dens was double, due to the persistence of the primitive condition in which it is developed from two centres. Occasionally the dens fails to be united with the body of the epistropheus, forming an os odontoideum comparable to that met with in the crocodilia. (Giacomini, Romiti, and Turner.) The foramen transversarium is not infrequently incomplete, owing to the imperfect ossification of the posterior root of the transverse process. Elliot Smith has recorded a case in which there was fusion between the atlas and epistropheus without any evidence of disease. side,

Seventh Cervical Vertebra.--The foramen transversarium may be absent on one or other

Thoracic Vertebræ.-Barclay Smith (Journ. Anat. and Physiol. Lond. 1902, p. 372) records five cases in which the superior articular processes of the twelfth thoracic vertebra displayed thoracic and lumbar characteristics on opposite sides. Duckworth (Journ. of Anat. and Physiol. vol. xlv. p. 65) has described a first thoracic vertebra, in which a bony process, arising from the front of the root of the transverse process, curves forwards and medially so as almost to enclose a foramen like that of the cervical vertebræ. The ventral surface of this process articulates with the neck of the first rib.

Lumbar Vertebræ.-The mamillary and accessory processes are sometimes unduly developed. The rertebral arch of the fifth lumbar vertebra is occasionally interrupted on either side by a synchondrosis which runs between the upper and lower articular processes. In macerated specimens the two parts of the bone are thus separate and independent. The anterior includes the body, together with the roots of the vertebral arches and the transverse and superior articular processes; the posterior comprises the inferior articular processes, the laminæ, and the spine. (Turner, Challenger Reports, vol. xvi.) Fawcett has seen the same condition in the fourth lumbar vertebra. Szawlowski and Dwight record instances of the occurrence of a foramen in the transverse process of the Vth lumbar vertebra (Anat. Anz. Jena, vol. xx.), and Ramsay Smith describes a case in which the right transverse process of the IVth lumbar vertebra of an Australian sprang from the side of the body in front of the root of the vertebral arch, being unconnected either with the arch or articular process.

Sacrum.-The number of sacral segments may be increased to six or rednced to four (see p. 276). Transition forms are occasionally met with in which the first sacral segment displays on one side purely sacral characters, i.e. it articulates with the hip bone, whilst on the opposite side it may present all the features of a lumbar vertebra. Through deficiency in the development of the laminæ, the sacral canal may be exposed throughout its entire length, or to a greater extent than is normally the case. (Paterson, Roy. Dublin Soc. Scientific Trans. vol. v. Series II.) Szawlowski and Barclay Smith record the occurrence of a foramen in the lateral part of the Ist sacral vertebra. (Journ. of Anat. and Physiol. Lond. vol. xxxri. p. 372.)

Vertebral Column as a Whole.-Increase in the number of vertebral segments is usually 
due to differences in the number of the coccygeal vertebræ; these may vary from fourwhich may be regarded as the normal number-to six. The number of presacral or movable vertebræ is normally 24 (7 C, $12 \mathrm{Th}$, and $5 \mathrm{~L})$; in which case the 25th vertebra forms the first sacral segment (vertebra fulcralis of Welcker). The number of presacral vertebræ may be increased by the intercalation of a segment either in the thoracic or lumbar region without any alteration in the number of the sacral or coccygeal elements: thus we may have $7 \mathrm{C}, 13 \mathrm{Th}$, and $5 \mathrm{~L}$, or $7 \mathrm{C}, 12 \mathrm{Th}$, and $6 \mathrm{~L}$, or it may be reduced by the disappearance of a vertebral segment - thus, $7 \mathrm{C}, 12 \mathrm{Th}$, and $4 \mathrm{~L}$. Such an arrangenent presupposes developmental errors either of excess or default in the segmentation of the column. On the other hand, the total number of vertebral segments remaining the same (24 or 25), we may have variations in the number of those assigned to different regions due to the addition of a vertebral segment to one, and its consequent subtraction from another region. Thus, in the 24 presacral vertebræ, in cases of the occurrence of cervical ribs the formula is rearranged thus $-6 \mathrm{C}, 13 \mathrm{Th}$, and $5 \mathrm{~L}$, or, in the case of a thirteenth rib being present, the formula would be $7 \mathrm{C}, 13 \mathrm{Th}, 4 \mathrm{~L}$, as happens normally in the gorilla and chimpanzee. Similarly, the number of the presacral vertebræ (24) may be increased by the withdrawal of a segment from the sacral region- $-7 \mathrm{C}, 12 \mathrm{Th}, 6 \mathrm{~L}$, and $4 \mathrm{~S}-$ or diminished by an increase in the number of the sacral vertebræ, as in the formula $7 \mathrm{C}, 12 \mathrm{Th}, 4 \mathrm{~L}$, and $6 \mathrm{~S}$. Increase in the number of sacral segments may be due to fusion with a lumbar vertebra, or by the addition of a coccygeal element: the latter is more frequently the case. This variability in the constitution of the sacrum is necessarily correlated with a shifting backwards and forwards of the pelvic girdle along the vertebral column. Rosenburg considers that the $26 \mathrm{th}, 27 \mathrm{th}$, and $28 \mathrm{th}$ vertebræ are the primitive sacral segments, and that the sacral characters of the 25 th vertebræ (the first sacral segment in the normal adult column) are only secondarily acquired. He thus supposes that during development there is a forward shifting of the sacrum and pelvic girdle, with a consequent reduction in the length of the presacral portion of the column. This view is opposed by Paterson (Roy. Dublin Soc. Scientific Trans. vol. v. Ser. II.), who found that ossification took place in the alæ of the 25 th vertebra (first adult sacral segment) before it made its appearance in the alæ of the 26th vertebra. He thus assumes that the alæ of the 25th vertebra may be regarded as the main and primary attachment with the ilium. His conclusions, based on a large number of observations, are at variance with Rosenburg's views, for, according to his opinion, liberation of the first sacral segment is more common than assimilation with the fifth lumbar vertebra, and assimilation of the first coccygeal vertebra with the sacrum is more common than liberation of the fifth sacral, thus leading to the inference that the sacrum tends to shift backwards more often than forwards. Dwight (Anat. Anz. Jena, vol. xxviii. p. 33), after a study of this question, whilst admitting that some of these variations may be reversive, denies that there is any evidence that they are progressive, and further states that after the occurrence of the original error in development, there is a tendency for the vertebral column to assume as nearly as possible its normal disposition and proportions.

Sternum.-The sternum is liable to considerable individual variations affecting its length and direction. The majority of bones are asymmetrical, displaying irregularities in the levels of the clavicular facets. The higher costal facets may be closer together on one, usually the right side, than the other, whilst the synchondrosis sternalis is often oblique, sloping somewhat to the right. According to Birmingham, these are the result of the strain thrown on the shoulder by pressure either directly applied or through the pull of a weight carried in the hand.

Sometimes the sternum articulates with eight rib cartilages. This may happen on one or both sides, but when unilateral, much more frequently on the right side-a condition by some associated with right-handedness. It is, however, more probably a persistence of the primitive condition of the cartilaginous sternum, in which each half is connected with the anterior extremities of the first eight costal arches. In some rare cases only six pairs of ribs articulate by means of their costal cartilages with the sternum. Recently Lickley has brought forward evidence to show that the seventh rib is undergoing regressive changes. (Anat. Anz. vol. xxiv. p. 326.)

Occasionally the presternum supports the first three ribs; in other words, the manubrium has absorbed the highest segment of the body. Keith has pointed out that this is the condition most commonly met with in the gibbon, and regards its occurrence in man as a reversion to the simian type. As far as is at present known, its occurrence seems more common in the lower races. Through errors of development the sternum may be fissured throughout, due to failure of fusion of the cartilaginous hemisterna. The two ossified halves are usually widely separated above, but united together below by an arthrodial joint. The heart and pericardium are thus uncovered by the bone. Occasionally this condition is associated with ectopia cordis, under which circumstances life is rendered impossible. Through defects in ossification the body of the sternum may be pierced by a hole, nsually in its lower part, or through failure of fusion of the lateral centres one or more of the segments of the body may be divided longitudinally.

Sometimes small ossicles are found in the ligaments of the sterno-clavicular articulation. These are the so-called episternal bones, the morphological significance of which, however, has not yet been satisfactorily determined. They are by some regarded as the homologues of the interclavicle or episternal bone of monotremata, whilst by others they are considered to represent persistent and detached portions of the pre-coracoids.

Ribs. - The number of ribs may be increased or diminished. Increase may occur by the addition of a cervical rib due to the independent development of the costal element in the transverse process of the seventh cervical vertebra. This may happen on one or both sides. The range of development of these cervical ribs varies; they may unite in front with the sternum, or they may 
be fused anteriorly with the cartilage of the first rib, or the cerrical rib may be free. It may in some instances be represented mainly by a ligamentous band, or its rertebral and stemal ends mas be alone developed, the intermediate part being fibrous. At times the rertebral end only may be formed, and may be fused with the first rib, thus leading to the formation of a bicipital rib such as occurs in mant cetaceans. (For a detailed account of this anomaly see Wingate Tod's paper in the Journ. of Anat. and Physiol. vol. xlvi. pp. 211-258.) Increase in the number of ribs may also be due to the ossification of the costal element which is normally present in the embryo in connexion with the first lumbar rertebra. (Posenberg, Morph. Jahrb. $\dot{\mathrm{i}}_{\text {.) }}$ Reduction in the number of ribs is less common. The twelfth rib rarely aborts; in some cases the first rib is rudimentary. Cases of congenital absence of some of the ribs hare been recorded by Hutchinson, Murray, and Ludeke. Fusion of adjacent ribs may occur. (Lane, Guys Hosp. Pieports, 1£s3.) In this war, too, the occurrence of a bicipital rib is explained. This anomaly occurs most usually in connexion with the first rib, which either fuses with a cerrical rib abore or with the second rib below.

Variations in form may be in great part due to the occupation of the indiridual and the constricting influence of corsets. Independentlr of these influences, the rentral part of the shaft is sometimes cleft so as to appear double; at other times the cleft mar be incomplete so as to form a perforation. Occasionaliy adjacent ribs are united towards their posterior part by processes having an intermediate ossicle between (Areckel), thus recalling the condition normall met with in birds; more usually, however, the bony projections are not in contact.

The number of true or vertebro-sternal ribs mat be reduced to six, or increased to eight (vide ante, p. 276). Dwight (Journ. of Anat. and Physiol. rol. rlr. p. 435) describes a series of cases in which the interval between the transverse process of the first thoracic vertebra and the neck of the first rib is bridged across or converted into a linear cieft by a dorsal extension from the neck of the rib.

Costal Cartilages.-Occasionally a costal cartilage is unduly broad, and mas be pierced by a foramen. The number of costal cartilages connected with the sternum mar be reduced to six or increased to eight (see p. 276). In adranced life there is a tendency towards ossification in the layers underlying the perichondrium, more particularly in the case of the first rib cartilage, in which it may be regarded as a more or less normal occurrence.

Frontal Bone.-The variation most frequently met with is a persistence of the suture which unites the two halres of the bone in the infantile condition: skulls displaring this peculiarity are termed metopic. The researches of rarious observers-Broca, Ranke, Gruber, Manourier, Anoutchine, and Papillault (Rer. mens. de l'école d'Anthropol. de Paris, année 6, n. 3-point to the more frequent occurrence of this metopic suture in the higher than in the lower races of man; and Calmette asserts its greater frequence in the brachrcephalic than the dolichocephalic trpe. Separate ossicles (ossa suturarum) may occur in the region of the anterior fontanelle. The fusion of these with one or other half of the frontal explains how the metopic suture is not always in line with the sagittal suture (Stieda, Anat. Anz.1897, p. 227); they occasionally persist, howerer, and form by their coalescence a bregmatic bone. (G. Zoja, Bull. Scientifico, xvii. p. 76, Pavia.) Turner (Challenger Reports, part xxix.) records an instance of direct articulation of the frontal with the fronta] process of the maxilla in a Bush skull, and other examples of the same anomaly, which obtains normally in the skulls of the chimpanzee and gorilla, have been observed. (Journ. Anat. and Physiol. vol. xxir. p. 349.)

There is sometimes a small arterial groove just medial to the supra-orbital notch or foramen, and occasionally the latter is double, the lateral aperture piercing the orbital margin wide of its middle point. Frequently the bone corresponding to the floor of the lacrimal fossa displays a cribriform appearance.

Schwalbe (1901) records the presence of small independent ossicles (supra-nasal bones) in the anterior part of the metopic suture. The same anatoraist has also directed attention (Zeit. $f$. Morph. und Anthr. vol. iii. p. 93) to the existence of the metopic fontanelle, first described by Gerdy, and the occurrence of metopic ossicles (ossa interfrontalia) and canals.

Parietal. - A number of cases have been recorded in which the parietal is divided into an upper and lower part by an antero-posterior suture parallel to the sagittal suture. Coraini (Atti d. XI. Congr. Med. Internaz. Roma, 1894, rol. v.) records a case in which the parietal was incompletely divided into an anterior and posterior part by a rertical suture. A tripartite condition of the bone has also been observed (Frasetto). The parietal foramina vary greatly in size, and to some extent in position. They are sometimes absent on one or other sidè, or both. They correspond in position to the sagittal fontanelle. Sometimes the ossification of this fontanelle is incomplete and a small transverse fissure remains. The parietal foramen represents the patent lateral extremity of this fissure after its edges hare coalesced. Occasionally in the region of the anterior fontanelle an ossicle of rariable size may be met with. This is the so-called pre-interparietal bone. According to its fusion with adjacent bones it may disturb the direction of the sagittal suture.

Occipital. - The torus occipitalis transwersus is the term applied to an occasional eleration of the bone which includes the external occipital protuberance and extends laterally alung the superior curved line. Occasionally an emissary rein pierces the boue opposite the occipital protuberance. In about 15 per cent of cases the hypoglossal canal is double. Juch rarer three or eren four foramina may be met with. The most striking of the many variations to which this bone is subject is the separation of the upper part of the squanous part of the occipital to form an independent bone-the interparietal bone, called also, from the frequency 
of its occurrence in Peruvian skulls, the os Ince. By a reference to the account of the ossification of the bone, the occurrence of this anomialy is explained developmentally. In place of forming a single bone the interparietal is occasionally met with in two symmetrical halves, and instances have been recorded of its occurrence in three or even four pieces. In the latter cases the two anterior parts form the pre-interparietals. Not uncommonly the internal occipital crest is split and furrowed close to the foramen magnum for the lodgment of the rermiform lobe of the cerebellum, and is hence called the vermiform fossa. Instances are recorded of the presence of a separate epiphysis between the basi-occipital and the sphenoid, the os basioticum (Albrecht) or the os mre-basi-occipitale. An oval pit, the fovea bursæ or pharrngeal fossa, is sometimes seen in front of the tuberculum pharyngeum. This marks the site of the bursa pharyngea. Occasionally the basilar part is pierced by a small venous canal. The articular surface of the condyles is sometimes divided into an anterior and posterior part. The so-called third occipital condyle is an outstanding process rising from the anterior border of the foramen magnum, the extrenity of which articulates with the dens of the epistropheus. Guerri has recorded a case, in which in a fœtal skull, there were two projecting tubercles in the position of the third occipital condyle, independent of the basi-occipital portions of the condyles. (Anat. Anz. rol. xix. p. 42.) This appears to confirm the view of Macalister that there are two different structures included under this name-one a medial ossification in the sheath of the notochord, and the second, a lateral, usually paired process, caused by the deficiency of the medial part of the hypochordal element of the hindmost occipital vertebra, with thickenings of the lateral parts of the arch. Springing from the under surface of the extremity of the jugular process, a rough or smooth elerated surface, or else a projecting process, the extremity of which may articulate with the transverse process of the atlas, is sometimes met with. This is the paroccipital or paramastoid process. The size and shape of the foramen magnum raries much in different indiriduals and races, as also the disposition of its plane. Elliot Smith has called attention to the asymmetry of the cerebral fossæ, which is correlated with asymmetry of the caudal poles of the cerebral hemispheres. Numerous instances of fusion of the atlas with the occipital bone have been recorded. Many are, no doubt, pathological in their origin; others are associated with errors in development. Interesting anomalies are those in which there is evidence of the intercalation of a new vertebral element between the atlas and occipital, constituting what is termed a pro-atlas.

Temporal Bone.-The occurrence of a deficiency in the floor of the external acoustic meatus is not uncommon in the adult. It is met with commonly in the child till about the age of fire, and is due to incomplete ossification of the tympanic plate. The line of the petro-squamosal suture is occasionally grooved for the lodgment of a sinus (petro-squamosal); sometimes the posterior end of this is continuous with a canal which pierces the superior border of the bone and opens into the transverse sinus. Anteriorly the groove may pass into a canal which pierces the rout of the zygoma and appears externally above the lateral extremity of the petro-tympanic fissure. These are the remains of channels through which the blood passed in the foetal condition (see ante). Kazzander has recorded a case in which the squamons part of the temporal was pneumatic, the sinus reaching as high as the parietal and the squamoso-sphenoidal suture. Symington has described a case in which the squamous part was distinct and separate from the rest of the temporal bone in an adult; whilst Hyrtl has observed the division of the squamous part of the temporal into two by a transverse suture. The zygomatic process has been observed separated from the rest of the bone by a sutme close to its root (Adacni). P. P. Laidlaw (Journ. Anat. and Physiol. vol. xxxvii. p. 364) describes a temporal bone in which there was absence of the internal acoustic meatus and of the stylo-mastoid foramen. The jugular fossa also was absent, and there was partial absence of the groove for the transverse sinus associated with the presence of a large mastoid foramen. An instance of a rudimentary condition of the carotid canal is also referred to in the same volume by G. H. K. Macalister.

G. Caribbe (Anat. Anz. rol. xx. p. 81) notes the occurrence in idiots and imbeciles of a more pronounced form of post-glenoid tubercle, and associates it with regressive changes in the development of the temporal bone.

Sphenoid.-Through imperfect ossification the foramen spinosum and foramen ovale are sometimes incomplete posteriorly. Le Double (Bull. et mém. de la Soc. d'Anth. de Paris, $5^{\mathrm{e}}$ sér. rol. iii. p. 550) records a case in which the foramen rotundum and the superior orbital fissure were united so as to form a single cleft.

Through deficiency of its lateral wall, the optic foramen, in rare instances, communicates with the superior orbital fissure. Duplication of the optic foramen is also recorded as a rare occurrence, the artery passing through one canal, the nerve through the other. Persistence of the cranio-pharyngeal canal is also occasionally met with. Owing to the ossification of fibrous bands which frequently connect the several bony points, anomalous foramina are frequently met with. Of such are the carotico-clinoid formed by the union of the anterior and middle clinoid processes, the pterygo-spinous foramen enclosed by the ossification of the ligament connecting the angular spine with the lateral pterygoid lamina, and the porus crotaphiticobuccinatorius similarly developed by the ossification of ligament immediately below and lateral to the inferior aperture of the foramen ovale.

Ethmoid. - The size of the lamina papyracea is liable to considerable variations. In the lower races it tends to be narrower from above downwards than in the higher, in this respect resembling the condition met with in the anthropoids. The lamina papyracea may fail to articulate with the lacrimal owing to the union of the frontal with the frontal process of the maxilla 
in front of it. (Orbito-maxillary-frontal suture. A Thomson, Journ. Anat. and Physiol. vol. xxiv. p. 349.) Division of the lamina papyracea by a vertical suture into an anterior and posterior part has been frequently recorded. The number of the conchæ may be increased from two to four, or may be reduced to one. (Report of Committee of Collect. Invest., Journ. Anat. and Physiol. vol. xxviii. p. 74.)

Maxillæ.-Not infrequently there is a suture running vertically through the bar of bone which separates the infra-orbital foramen from the infra-orbital margin. Through imperfections in ossification, the infra-orbital canal may form an open groove along the floor of the orbit.

Duckworth records four instances of a spinous process projecting inwards into the apertura piriformis from the lower part of the nasal notch. A case has been described (Fischel) in which there was complete absence of the premaxillæ, together with the incisor teeth.

A not uncommon anomaly is the occurrence of a rounded elongated ridge extending along the interpalatal or intermaxillary sutures on the under surface of the hard palate. This is called the torus palatinus, and is of interest because its presence has given rise to the assumption that it was due to a pathological growth. (See Stieda, Virchow's Festschrift, vol. i. p. 147.)

The sulcus lacrimalis may be constricted towards its centre.

A part of the antrum may be constricted off anteriorly and, owing to its relation to the nasolacrimal duct, is for this reason called the recessus lacrimalis.

Underwood (Journ. Anat. and Physiol. vol. xliv. p. 359) records the occurrence of all but complete septa dividing the antral cavity.

Zygomatic Bone.-Cases of division of the zygomatic bone by a horizontal suture have been recorded, as well as instances of its separation into two parts by a vertical suture. Owing to the supposed more frequent occurrence of this divided condition in Asiatics the zygomatic has been named the os Japonicum. Barclay Smith ("Proc. Anat. Soc." Journ. Anat. and Physiol., April 1898, p. 40) describes a case in which the zygomatic bone was divided into two parts, an upper and lower, by a backward extension of the maxilla, which articulated with the zygomatic process of the temporal, thus forming a temporo-maxillary arch. Varieties of a like kind have also been described by Gruber and others. Cases have been noted where, owing to deficiency in the development of the zygomatic, the continuity of the zygomatic arch has been incomplete.

Nasal Bones.-The size and configuration of the nasal bones vary greatly in different races, being, as a rule, large and prominent in the white races, and flat and reduced in size, as well as depressed, in the Mongolian and Negro stock. Complete absence of the nasal bones has been recorded, and their division into two or more parts has also been noted. Obliteration of the internasal suture is unusual; it is stated to occur more frequently in negroes, and is the recognised condition in adult apes.

Duckworth has recorded a case (Journ. Anat. and Physiol. vol. xxxvi. p. 257) of undue extension downwards of the nasal bone, which may be perhaps accounted for on the supposition that the lower part is a persistent portion of the premaxilla.

Lacrimal.-The lacrimal is occasionally absent. In some cases it is divided into two parts; in others replaced by a number of smaller ossicles. In rare instances the hamulus may extend forwards to reach the orbital margin, and so bear a share in the formation of the face, as in lemurs (Gegenbauer). In other instances the hamulus is much reduced in size. Occasionally the lacrimal is separated from the lamina papyracea of the ethmoid by a down-growth from the frontal, which articulates with the frontal process of the maxilla, as is the normal disposition in the gorilla and chimpanzee. (Turner, Challenger Reports, "Zoology," vol. x. Part IV. Plate I. ; and A. Thomson, Journ. Anat. and Physiol., London, vol. xxiv. p. 349.)

Inferior Concha.-A case in which the inferior conchæ were: absent has been recorded by Hyrtl.

Vomer--Owing to imperfect ossification there may be a deficiency in the bone, filled up during life by cartilage. The separation of the two lamellæ along the anterior border varies considerably, and instances are recorded where they were separated by a considerable cavity within the substance of the bone. Instances of an extension forwards of the sphenoidal air sinus into and separating the laminæ of the bone have also been described. The spheno-vomerine canal is a minute opening behind the rostrum of the sphenoid, and between it and the alæ of the vomer, by which the nutrient artery enters the bone.

Palate Bones.-The occurrence of a torus palatinus may be noted (see Variations of MIaxilla).

Mandible.-Considerable differences are met with in the height of the coronoid process: usually its summit reaches the same level as the condyle, or slightly above it; occasionally, however, it rises to a much higher level; in other cases it is much reduced. These differences naturally react on the form of the mandibular notch. The projection of the mental protuberance is also liable to vary. Occasionally the mental foramen is double, and sometimes the mylo-hyoid groove is for a short distance converted into a canal. There is often a marked eversion of the angle of the mandible, which Dieulafe homologises with the angular apophysis met with in lemurs and carnivora.

Clavicle.-The clavicles of women are more slender, less curved, and shorter than those of men. In the latter the bone is so inclined that its acromial end lies slightly highel or on the same level with the sternal end. In women the bone usually slopes a little downward and laterally. The more pronounced curves of some bones are probably associated with a more powerful development of the pectoral and deltoid muscles, a circumstance which also affords an explanation of the differences usually seen between the right and left bones, the habitual use of the right 
upper limb reacting on the form of the bone of that side. The influence of muscular action, however, does not wholly accomint for the production of the curves of the bone, since the bone has been shown to display its characteristic features in cases where there has been defective development or absence of the upper limb (Reymanlt). Partial or complete absence of the clavicle nas been recorded. IV. S. Trylor exhibited an interesting case of this lind at the Clinical Society of London, October 25, 1901. Sometimes there is a small canal through the anterior border of the bone near its middle for the transmission of one of the supra-clavicular nerves.

Scapula.-The most common variation met with is a separated acromion. In these cases there has been failure in the ossific union between the spine and acromion, the junction between the two being effected by a layer of cartilage or by an articulation possessing a joint carity. The condition is usually symmetrical on both sides, though instances are recorded where this arrangement is milateral. Tery much rarer is the condition in which the coracoid process is separable from the rest of the bone. The size and form of the scapular notch differs. In certain cases the superior border of the bone describes a miform curve reaching the base of the coracoid without any indication of a notch. In some scapulæ, more particularly in those of very old people, the floor of the subscapular fossa is deficient owing to the absorption of the thin bone, the periosteal layers alone filling up the gap.

At birth the vertical length of the bone is less in proportion to its width than in the adult.

Humerus.-As has been stated in the description of the bone, the olecranon and coronoid fossa may communicate with each other in the macerated bone. The resulting supratrochlear foramen is most commonly met with in the lower races of man, as well as in the anthropoid apes, and in some other mammals. The occurrence of a hook-like spine, called the epicondylic process, which projects in front of the medial epicondylic ridge, is not uncommon. Its extremity is connected with the medial epicondyle by means of a fibrous band, underneath which the median nerve, accompanied by the brachial artery, or one of its large branches, may pass, or in some instances, the nerve alone, or the artery unaccompanied by the nerve. This arrangement is the homologue in a rudimentary form of a canal present in many animals, notably in the carnivora and marsupials. In addition to the broad radial groove already described, and which is no doubt produced by the twisting or torsion of the shaft, there is occasionally a distinct narrow groove posterior to it, which marks precisely the course of the radial nerve as it turns round the lateral side of the shaft of the bone.

Ulna.-Cases of partial or complete absence of the ulna through congenital defect have been recorded. Rosenmiiller has described a case in which the olecranon was separated from the proximal end of the bone, resembling thus in some respects the patella. In powerfully developed bones there is a tendency to the formation of a sharp projecting crest corresponding to the insertion of the triceps.

Radius.-Cases of congenital absence of the radius are recorded; in these the thumb is not infrequently wanting as well.

Carpus.-Increase in the number of the carpal elements is occasionally met with, and these have been ascribed to division of the navicular, os lunatum, os triquetrum, capitate, lesser multangular, and os hamatum. Of these the most interesting is the os centrale, first described by Rosenberg, and subsequently investigated by Henke, Leboucq, and others. This is met with almost invariably as an independent cartilaginous element during the earlier months of fœtal life, and occasionally becomes developed into a distinct ossicle placed on the back of the carpus between the navicular and capitate bones and the lesser multangular. Its significance depends on the fact that it is an important component of the carpus in most mammals, and is met with normally in the orang and most monkeys. Ordinarily in man, as was pointed out by Leboncq, it becomes fused with the navicular, where its presence is often indicated by a small tubercle, a condition which obtains in the chimpanzee, the gorilla, and the gibbons. Dwight has described a case in which there was an os subcapitulum in both hands. The ossicle lay between the base of the middle metacarpal bone and the capitate bone, with the lesser multangular to its radial side. (Anat. Anz. vol.xxiv.) Further addition to the number of the carpal elements may be due to the separation of the styloid process of the third metacarpal bone and its persistence as a separate ossicle.

Reduction in the number of the carpus has been met with, but this is probably due to pathological causes. Morestin (Bull. Soc. Anat. de Paris, tome 71, p. 651), who has investigated the subject, finds that ankylosis occurs most frequently between the bases of the second and third metacarpal bones and the carpus, seldom or never between the carpus and the first metacarpal, or between the pisiforu and os triquetrum. Instances of complete fusion of the os lunatum and triquetral bones, without any apparent pathological change, have been recorded in Europeans, Negroes, and an Australian.

Metacarpal Bones. - As previously stated above, the styloid apophysis of the third metacarpal bone appears as a separate ossicle in about 1.8 per cent of cases examined. ("Fourth Annual Report of the Committee of Collect. Invest. Anat. Soc. Gt. Brit. and Ireland," Journ. Anat. and Physiol. vol. xxviii. p. 64.) In place of being united to the third metacarpal, the styloid apophysis may be fused with either the capitate bone or the lesser multangular, under which conditions the base of the third metacarpal bone is without this characteristic process.

Phalanges.- Several instances have been recorded of cases in which there were three phalanges in the thumb. Bifurcation of the terminal phalanges has occasionally been met with, and examples of suppression of a phalangeal segment or its absorption by another phalanx have also been described. (Hasselwander, Zeits. fiir Morph. u. Anthr. vol. vi. 1903.) 
Hip Bone.-Some of the anomalies met with in the hip bone are due to ossification of the ligaments connected with it; in other cases they depend on errors of development. Failure of union between the pubic and ischial rami has also been recorded. Cases have occurred where the obturator groove has been bridged across by bone, and one case is noted of absence of the acetabular notch on the acetabular margin. In rare cases the os acetabuli (see Ossification) remains as a separate bone. Derry (Journ. Anat. and Physiol. vol. xlv. p. 202) has drawn attention to the occurrence of a small accessory articular facet, situated on the rough non-articular area immediately behind the auricular surface of the ilium, which articulates with a depressed facet on the posterior surface of the sacrum to the lateral side of the first posterior sacral foramen, in the neighbourhood of the transverse process of the second sacral segment. This he homologises with the normal articulation between the ilium and sacral transverse processes found in many lower animals.

Femur.-Absence of the forea on the head of the femur for the attachment of the ligamentum teres has been recorded. This corresponds with the condition met with in the orang. Not infrequently there is an extension of the articular surface of the head on to the fore and upper aspect of the neck; this is a "pressure facet" caused by the contact of the iliac portion of the acetabular margin with the neck of the bone, when the limb is maintained for long periods in the flexed position, as in tailors, and also in those races who habitually squat (Lane, Journ. Anat. and Physiol. vol. xxii. p. 606).

The occurrence of a trochanter tertius has been already referred to. Its presence is not confined to individuals of powerful physique, but may occur in those of slender build, so far suggesting that it is not to be regarded merely as an indication of excessive muscular development. The observations of Dixon (Journ. Anat. and Physiol. vol. xxx. p. 502), who noted the occurrence of a separate epiphysis in three cases in connexion with it, seem to point to its possessing some morphological significance. Occasionally the gluteal tuberosity may be replaced by a hollow, the fossa hypotrochanterica, or in some cases the two may co-exist.

The angle of the neck is more open in the child than in the adult, and tends to be less when the femoral length is short and the pelvic width great-conditions which particularly appertain to the female. There is no evidence to show that after growth is completed any alteration takes place in the angle with advancing years (Humphry).

The curvature of the shaft may undergo considerable variations, and the appearance of the posterior surface of the bone may be modified by an absence of the linea aspera, a condition resembling that seen in apes; or by an unusual elevation of the bone which supports the ridge (fémur à pilastre), produced, as Manouvrier has suggested, by the excessive development of the muscles here attached.

Under the term "platymerie," Manouvrier describes an antero-posterior compression of the proximal part of the shaft, frequently met with in the femora of prehistoric races.

Patella.-Cases of congenital absence of the patella have been recorded.

F. C. Kempson (Journ. Anat. and Physiol. vol. xxxvi.) has recently drawn attention to the condition described as emargination of the patella. In specimens displaying this appearance the margin of the bones is concave from a point about half an inch to the lateral side of the middle line, to a point half-way down the lateral margin of the bone; here there is usually a pointed spine directed proximally and laterally. The condition appears to be associated with the insertion of the tendon of the vastus lateralis. G. Joachimstal (Archiv u. Atlas der normalen und pathologischen Anatomie in typischen Röntgenbildern, Bd. 8) figures a case in which on both sides the patella was double in an adult, the distal and much the smaller portion was embedded in the ligamentum patellæ.

Tibia.-The tibia is often unduly laterally compressed, leading to an increase in its antero-posterior diameter as compared with its transverse width. This condition is more commonly met with in the bones of prehistoric and savage races than in modern Europeans. Attention was first directed to this particular form by Busk, who named the condition platyknemia. The general appearance of such tibiæ resembles that seen in the apes, and depends on an exceptional development of the tibialis posterior muscle, though, as Manouvrier has pointed out, in apes this is associated with the direct action of the muscle on the foot, as in climbing, whereas in man, as a consequence of the bipedal mode of progression, the muscle is employed in an inverse sense, viz., by steadying the tibia on the foot, and thus providing a fixed base on which the femur can move. This explanation, however, is disputed by Derry (Journ. Anat. and Phys. vol. xli. p. 123). Such platyknemic tibire are occasionally met with in the more highly civilised races, and are, according to Manourrier, associated with habits of great activity among the inhabitants of rough and mountainous districts.

Another interesting condition is one in which the proximal extremity is more strongly recurved than is usual. This retroversion of the head of the tibia was at one time supposed to represent an intermediate condition in which the knee could not be fully extended so as to bring the axis of the leg in line with the thigh; but such opinion has now been upset by the researches of Manouvrier, who claims that it is the outcome of a habit not uncommon amongst peasants and countrymen, viz., that of walking habitually with the knees slightly bent.

Habitual posture also leaves its impress on the form of the tibia, and in races in which the use of the chair is unknown, the extreme degree of flexion of the knee and ankle necessitated by the adoption of the squatting position as an attitude of habitual rest is associated with an increase in the convexity of the lateral condylic surface, and the appearance, not infrequently, of a pressure facet on the anterior border of the distal extremity, which rests in that position on the neck of the talus. Cases of congenital absence of the tibia have been frequently described, amongst the most recent being those recorded by Clutton, Joachimsthal, Bland-Sutton, and Waitz. 
Fibula. - The fibula may be ridged and grooved in a remarkable manner, as is the case in many bones of prehistoric races. This is probably associated with a greater or perhaps more active development of the muscles attached to it.

The proximal articular facet varies much in size. Bennett (Dublin Journ. Med. Sc., Aug. 1891) records a case in which it was double, and also notes the occurrence of specimens in which it was absent and in which the head of the bone did not reach the lateral condyle of the tibia.

Many instances of partial or complete absence of the bone have been published. (Lefèbre, Contribution à l'étude de l'abscnce congénitale du péroné, Lille, 1895.)

Talus.-The anterior is sometimes separated from the middle calcanean facet by a nonarticular furrow. The posterior process, often largely developed, is occasionally $(2.6$ per cent) a separate ossicle forming what is known as the os trigonum (Bardeleben); or it may be united to the body of the talus by a distinct synchondrosis. A smooth articular surface may occasionally be found on the medial side of the proximal surface of the neck. This is a pressure facet dependent on the frequent use of the ankle-joint in a condition of extreme flexion, and is caused by the opposition of the bone against the anterior edge of the distal end of the tibia.

The form of the bone at birth differs from that of the adult in that the medial splay of the neck on the body is more pronounced, forming on an average an angle of $35^{\circ}$ as compared with a mean of $12^{\circ}$ in the adult; moleover, the articular surface for the medial malleolus extends forwards along the medial side of the neck, and to some extent overruns its superior surface. This is doubtless a consequence of the inverted position of the foot maintained by the fœtus during intra-uterine life. In these respects the fotal bone conforms to the anthropoid type.

For a detailed study of the varieties of this bone, see R. B. S. Sewell. (Journ. Anat. and Physiol. vol. xxxviii.)

Calcaneus.-The trochlear process is occasionally unduly prominent, constituting the submalleolar apophysis of Hyrtl, and cases are recorded of the calcaneus articulating with the navicular. (Morestin, H., Bull. de la Soc. Anat. de Paris, 1894, 5e sér. t. 8, n. 24, p. 798; and Petrini, Atti del XI. Congr. Med. Internaz. Roma, 1894, vol. ii., "Anat." p. 71.) Pfitzner (Morphologische Arbeiten, vol. vi. p. 245) also records the separation of the sustentaculum tali to form an os sustentaculi. (See also P. P. Laidlaw, Journ. Anat. and Physiol. vol. xxxviii. p. 133.)

Navicular.-According to Manners Smith this bone displays more variety of form than any other of the tarsal bones. He accounts for this both on morphological and mechanical grounds. He regards the tuberosity as probably of threefold origin, an apophysial, an epiphysial, and a sesamoid element, the latter being the so-called sesamoid bone in the tendon of the tibialis posterior. Cases are recorded where the tuberosity has formed an independent ossicle.

Cuneiform Bones.-Numerons cases of division of the first cuneiform bone into dorsal and plantar parts have been recorded; the frequent division of its metatarsal articular facet is no doubt correlated with this anomalous condition. T. Dwight has described (Anat. An\%. vol. xx. p. 465) in two instances the occurrence of an os intercuneiforme. The ossicle so named lies on the dorsum of the foot at the proximal end of the line of articulation between the first and second cuneiform bones.

Cuboid.-Blandin has recorded a case of division of the cuboid. Occasionally there is a facet on the lateral surface of the bone for articulation with the tuberosity of the fifth metatarsal (Manners Smith).

Tarsus as a Whole.--Increase in the number of the tarsal elements may be due to the occurrence of division of either the first cuneiform or the cuboid bone, or to the occasional presence of an os trigonum. Cases of separation of the tuberosity of the navicular bone have been recorded, and instances of supernumerary ossicles between the first cuneiform and second metatarsal bone have been noted. Stieda mentions the occurrence of a small ossicle in connexion with the articular surface on the anterior and upper part of the calcaneus, and Pfitzner notes the occurrence of an os sustentacnli. For further information on the variations of the skeleton of the foot, see Pfitzner. (Morphologische Arbeiten, vol. vi. p. 245.)

The possibility of an injury having been the cause of the occurrence of some of these so-called supernumerary ossicles must not be overlooked. The use of the Röntgen rays has proved that accidents of this kind are much more frequent than was at first supposed.

The reduction in the number of the tarsus is due to the osseous union of adjacent bones. In many instances this is undoubtedly pathological, but cases have been noticed (Leboucq) of fusion of the cartilaginous elements of the calcaneus and talus, and the calcaneus and navicular in fotuses of the third month.

Metatarsal Bones.-Several instances of separation of the tuberosity of the fifth metatarsal (os Vesaleanum) have been recorded, whilst numerous examples of an os intermetatarsum between the bases of the first and second metatarsal bones have been recorded by Gruber and others. The tubercle on the base of the first metatarsal for the attachment of the peronæus longus tendon is occasionally met with as a separate ossicle. An epiphysis over the spot where the tuberosity of the fifth metatarsal rests on the ground has been described. (Kirchner, Archiv lin. Chir. B 80.)

Phalanges.-It is not uncommon to meet with fusion of the second and third phalanges, particularly in the fifth, less frequently in the fourth, and occasionally in the second and third toes. The union of the phalangeal elements has been observed in the foetus as well as the adult (Pfitzner). The proportionate length of the phalanges varies much; in some cases the ungual phalanges are of fair size, the bones of the second row being mere nodules, whilst in other instances the reduction in size of the terminal phalanges is most marked. 


\section{APPENDIX C.}

\section{SERIAL HOMOLOGIES OF THE VERTEBR $\Psi$.}

It is a self-evident fact that the vertebral column consists of a number of segments or vertebræ all possessing some characters in common. These vertebræ or segments undergo modifications

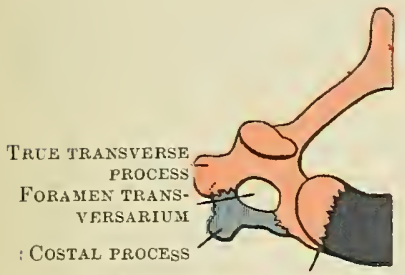

Neuro-central suture

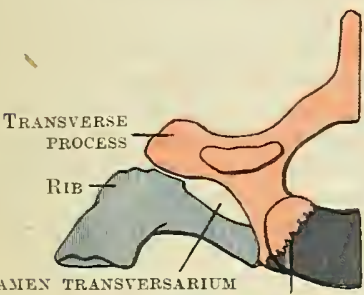

NeUro-central suture
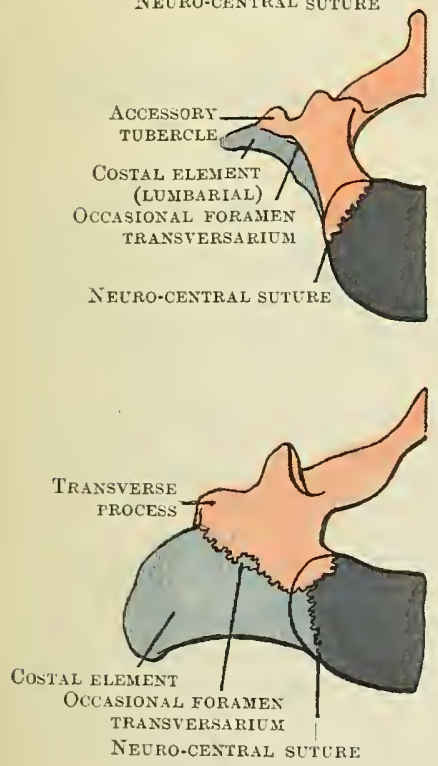

Costal futenters
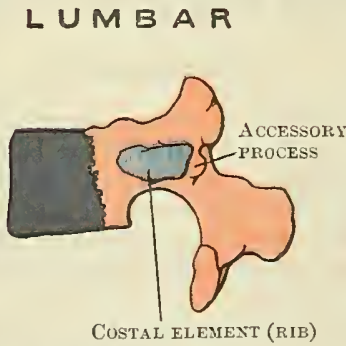

SACRAL

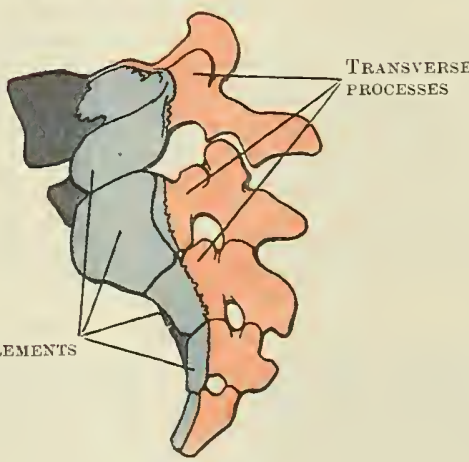

B ments. according to the region they occupy and the functions they are called upon to serve, so that their correspondence and identity is thereby obscured. There is no difficulty in recognising the homology of the bodies and vertebral arches throughout the column. According to some anatomists the vertebral arch is the more primitive element in the formation of a vertebra, whilst others hold that the bodies are the foundation of the column. Be that as it may we find that in the higher vertebrates, at least, the bodies are the parts which most persist. They are, however, subject to modifications dependent on their fusion with one another. This occurs in the cervical part of the column where the body of the first cervical or atlas has for functional reasons become fused with the body of the second or epistropheus to form the dens of that segment. For similar reasons, and in association with the union of the girdle of the hind-limb with the column, the bodies of the vertebræ which correspond to the sacral segment become fused together to form a solid mass. In the terminal portion of the candal region the bodies alone represent the vertebral seg-

As regards the vertebral arch, this in man becomes deficient in the lower sacral region, and absent altogether in the lower coccygeal segments. The spinous processes are absent in the case of the first cervical, lower sacral, and all the coccygeal vertebræ, and display characteristic differences in the cervical, thoracic, and lumbar regions, which have been already described. The articular processes (zygapophyses) are secondary developments, and display great diversity of form, deter. mined by their functional requirements. It is noteworthy that, in the case of the upper

Fig. 280.-Diagram to lleustiate the Homologous Parts of the Vertebre.

The bodies are coloured purple; the vertebral arch and its processes, red ; the costal elements, blue. A, from above. B, from the sille.

two cervical vertebræ, they are so disposed as to lie in front of the foramina of exit of the upper two spinal nerves, and by this arrangement the weight of the head is transmitted to the solid column formed by the vertebral bodies, and not on to the series of vertebral arches. It is in regard to the homology of the transterse processes, so called, that most difficulty arises. In the 
thoracic region they can best be studied in their simplest form ; here the ribs-which Gegenbauer regarls as a differentiation from the inferior or hæmal arches, in opposition to the view advanced by others that they are a secondary derelopment from the fibrous intermuscular septa-articulate with the transverse processes and bodies of the thoracic vertebrx through the agency of the tubercular (diapophrses) and capitular (parapophyses) processes respectively, the latter being placed, strictly speaking, on the vertebral arch behind the line of the neuro-central synchondrosis.

An interval is thus left between the neck of the rib and the front of the transverse process; this forms an arterial passage which corresponds to the foramen transversarim in the transverse processes of the cervical vertebre, the anterior bar of which is homologous with the head and tubercle of the thoracic rib, whilst the posterior part lies in series with the thoracic transverse process. These homologies are further emphasised by the fact that in the case of the seventh cervical vertebra the anterior limb of the so-called transverse process is developed from an independent ossific centre, which occasionally persists in au independent form as a cervical rib.

In the lumbar region the lateral or transverse process is serially homologous with the thoracic ribs, though here, owing to the coalescence of the contiguous parts, there is no arterial channel between the rib element and the true transverse process, which is represented by the accessory processes (anapophyses), placed posteriorly at the root of the so-called transverse process of human anatomy. Support is given to this view by the presence of a distinct costal element in connexion with the transverse process of the first lumbar vertebra, which accounts for the occasional formation of a supernumerary rib in this region. The cases of foramina in the transverse processes of the lumbar vertebræ (see p. 275) are also noteworthy as supporting this view.

In the sacrum the lateral part of the bone is made up of combined transverse and costal elements, with only rery exceptionally an intervening arterial channel. In the case of the upper three sacral segments the costal elements are largely developed and assist in supporting the ilia, and they are called the true sacral vertebræ; whilst the lower sacral segments, which are not in contact with the ilia, are referred to as the pseudo-sacral vertebræ.

The anterior arch of the atlas vertebra is, according to Froriep, developed from a hypochordal strip of cartilage (hypochordal spange).

\section{APPENDIX D.}

\section{MEASUREMENTS AND INDICES EMPLOYED IN PHYSICAL ANTHROPOLOGY.}

\section{(1) Craniometry.}

The various groups of mankind display in their physical attributes certain features which are more or less characteristic of the stock to which they belong. Craniology deals with these differences so far as they affect the skull. The method whereby these differences are recorded involves the accurate measurement of the skull in most of its details. Such procedure is included under the term craniometry. Here only the outlines of the subject are briefly referred to; for such as desire fuller information on the subject, the works of Broca, Topinard, Flower, and Turner may be consulted.

The races of man display great variations in regard to the size of the skull. Apart altogether from individual differences and the proportion of head-size to body-height, it may be generally assumed that the size of the skull in the more highly civilised races is much in excess of that displayed in lower types. The size of the head is intimately correlated with the development of the brain. By measuring the capacity of that part of the skull occupied by the encephalon, we are enabled to form some estimate of the size of the brain. The cranial capacity is determined by filling the cranial cavity with some suitable material and then taking the cubage of its contents. Various methods are employed, each of which has its advantage. The use of fluids, which of course would be the most accurate, is rendered impracticable, without special precautions, owing to the fact that the macerated skull is pierced by so many foramina. As a matter of practice, it is found that leaden shot, glass beads, or seeds of various sorts are the most serviceable. The results obtained display a considerable range of variation. For purposes of classification and comparison, skulls are grouped according to their cranial capacity into the following varieties :-

Microcephalic skulls are those with a capacity below 1350 c.c., and iuclude such well-known races as Andamanese, Veddahs, Australians, Bushmen, Tasmanians, etc.

Mesocephalic skulls range from 1350 c.c. to 1450 c.c., and embrace examples of the following varieties: American Indians, Chinese, some African Negroes.

Megacephalic skulls are those with a capacity over 1450 c.c., and are most commonly met with in the more highly civilised races: Mixed Europeans, Japanese, etc.

Apart from its size, the form of the cranium has been regarded as an important factor in the classification of skulls; though whether these differences in shape have not been unduly emphasised in the past is open to question.

The relation of the breadth to the length of the skull is expressed by means of the cephalic index which records the proportion of the maximum breadth to the maximum length of the
skull, assuming the latter equal 100, or-

Max. breadth $\times 100$

Max. length

Cephalic index. 
The results are classified into three groups:-

1. Dolichocephalic, with an index below 75 : Australians, Kaffirs, Zulus, Eskimo, Fijians.

2. Mesaticephalic, ranging from 75 to 80 : Europeans (mixed), Chinese, Polynesians (mixed).

3. Brachycephalic, with an index over 80 : Malays, Burmese, American Indians, Andamanese.

In order to provide for uniformity in the results of different observers, some system is necessary by which the various points from which the measurements are taken must correspond. Whilst there is much difference in the value of the measurements insisted on by individual anatomists, all agree in endeavouring to select such points on the skull as may be readily determined, and which have a fairly fixed anatomical position. The more important of these "fixed points" are included in the subjoined table:-

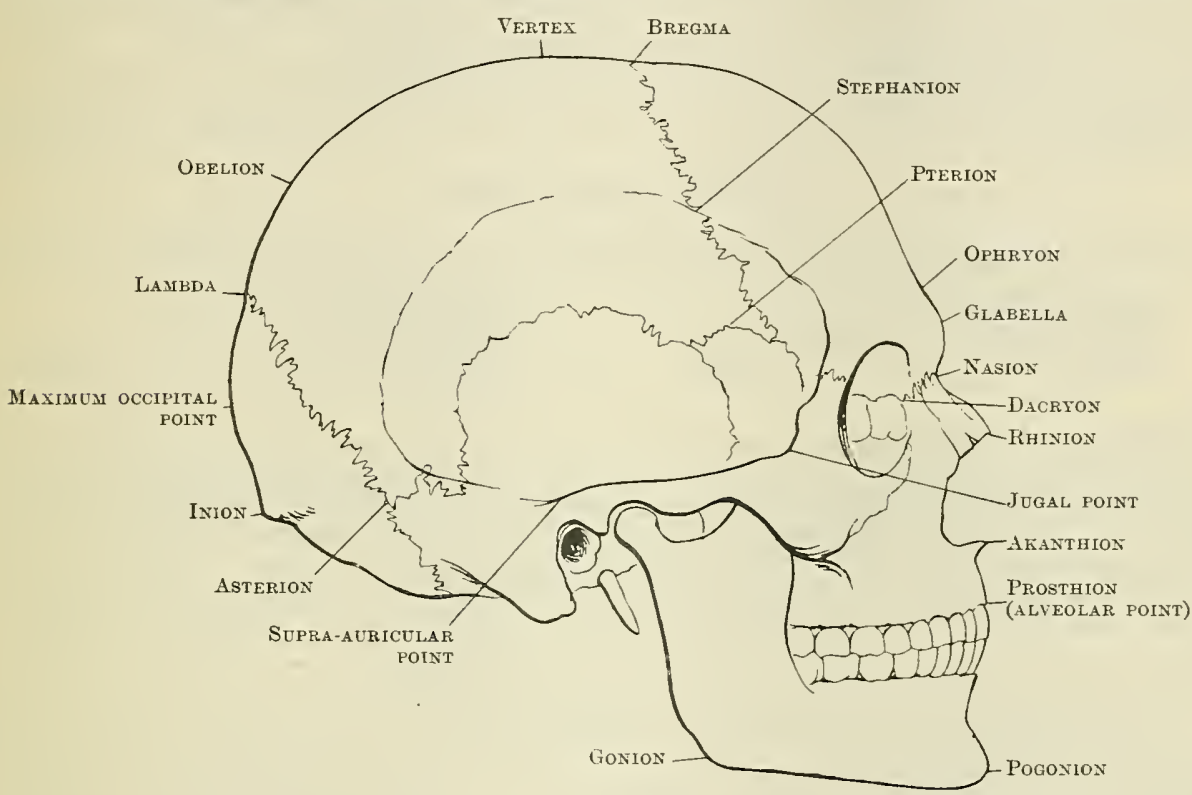

F1G. 281.

Nasion.-The middle of the naso-frontal suture.

Glabella.-A point midway between the two superciliary ridges.

Ophryon.-The central point of the narrowest transverse diameter of the forehead, measured from one temporal line to the other.

Inion.-The external occipital protuberance.

Maximum Occipital Point.-The point on the squamous part of the occipital in the sagittal plane most distant from the glabella.

Opisthion.-The middle of the posterior margin of the foramen magnum.

Basion.-The middle of the anterior margin of the foramen magnum.

Bregma.-The point of junction of the coronal and sagittal sutures.

Rhinion.- The most proninent point at which the nasal bones tonch one another.

Alveolar Point or Prosthion.-The centre of the anterior margin of the upper alveolar margin.

Subnasal Point.-The middle of the inferior border of the piriform (anterior nasal) aperture at the centre of the anterior nasal spine.

Akanthion.- The most prominent point on the nasal spine.

Vertex.-The sumnit of the cranial vault.

Obelion.-A point over the sagittal suture, on a line with the parietal foramina.

Lambda.- The meeting-point of the sagittal and lambdoid sutures.

Pterion.-The region of the antero-lateral fontanelle where the angles of the frontal, parietal, squamous part of the temporal, and great wing of sphenoid lie in relation to one another. As a rule, the sutures are arranged like the letter $H$, the parietal and great wing of sphenoid separating the frontal from the squamous temporal. In other cases the form of the suture is like an $X$; whilst in a third variety the frontal and squamous part of the temporal articulate with each other, thus separating the great wing from the parietal.

Asterion is the region of the postero-lateral fontanelle where the lambdoid, parieto-mastoid, and occipito-mastoid sutures meet.

Stephanion. - The point where the coronal suture crosses the temporal line.

Dacryon. - The point where the vertical lacrimo-maxillary suture meets the fronto-nasal suture at the inner angle of the orbit. 
Jugal Point.-Corresponds to the angle between the vertical border and the margin of the temporal process of the zygonatic bone.

Supra-auricular Point.-A point immediately above the middle of the orifice of the external acoustic meatus close to the edge of the posterior root of the zygoma.

Gonion. - The onter side of the angle of the mandible.

Pogonion.-The most prominent point of the chin as represented on the mandible.

The measurements of the length of the skull may be taken between a variety of points-the nasion, glabella, or ophryon in front, and the inion or maximum occipital point behind. Or the maximum length alone may be taken without reference to any fixed points. In all cases it is better to state precisely where the measurement is taken. The maximum breadth of the head is very variable as regards its position; it is advisable to note whether it occurs above or below the parieto-squamosal suture. The inter-relation of these measurements as expressed by the cephalic index has been already referred to. The width of the head may also be measured from one asterion to the other, biasterionic width, or by taking the bistephanic diameter.

The height of the cranium is usually ascertained by measuring the distance from the basion to the bregma. The relation of the height to the length may be expressed by the height or vertical index, thus-

$$
\frac{\text { Height } \times 100}{\text { Length }}=\text { Vertical index. }
$$

Skulls are classified in accordance with the relations of length and height as follows :-

Tapeinocephalic index below 72 .

Metriocephalic index between 72 and 77 . Akrocephalic index above $7 \tau$ (Turner).
Chamæcephalic index up to 70.

Orthocephalic index from $70 \cdot 1$ to 75 .

Hypsicephalic index $75 \cdot 1$ and upwards (Kollmann, Ranke, and Virchow).

The horizontal circumference of the cranitum, which ranges from $450 \mathrm{~mm}$. to $550 \mathrm{~mm}$., is measured around a plane cutting the glabella or ophryon anteriorly, and the maximum occipital point posteriorly. The longitudinal arc is measured from the nasion in front to the opisthion behind; if to this be added the basi-nasal length and the distance between the basion and the opisthion, we have a record of the vertico-median circumference of the cranium. This may further be divided by measuring the lengths of the frontal, parietal, and occipital portions of the superior longitudinal arc. In this way the relative proportions of these bones may be expressed.

The measurements of the skeleton of the face are more complex, but, on the whole, of greater value than the measurements of the cranium. It is in the face that the characteristic features of race are best observed, and it is here that osseous structure most accurately records the form and proportions of the living.

The form of the face varies, like that of the cranium, in the relative proportions of its length and breadth. Generally speaking, a dolichocephalic cranium is associated with a long face, whilst the brachycephalic type of head is correlated with a rounder and shorter face. This rule, however, is not universal, and there are many exceptions to it.

The determination of the facial index varies according to whether the measurements are made with or without the mandible in position. In the former case the length is measured from the ophryon or nasion above to the mental tubercle below, and compared with the maximum bizygomatic width. This is referred to as the total facial index, and is obtained by the formula-

\section{$\frac{\text { Ophryo-mental length } \times 100}{\text { Bizygomatic width }}=$ Total facial index}

More usually, however, owing to the loss of the mandible, the proportions of the face are expressed by the superior facial index. This is determined by comparing the ophryo-alveolar or naso-alveolar length with the bizygomatic width, thus-

\section{$\frac{\text { Ophryo-alveolar length } \times 100}{\text { Bizygomatic width }}=$ Superior facial index.}

The terms dolichofacial or leptoprosope and brachyfacial or chamœprosope have been employed to express the differences thus recorded.

Uniformity in these measurements, however, is far from complete since many anthropologists compare the width with the length $=100$.

The proportion of the face-width to the width of the calvaria is roughly expressed by the use of the terms cryptozygous and phænozygous as applied to the skull. In the former case the zygomatic arches are concealed, when the skull is viewed from above, by the overhanging and projection of the sides of the cranial box; in the latter instance, owing to the narrowness of the calvaria, the zygomatic arches are clearly visible.

The projection of the face, so characteristic of certain races (Negroes for example), may be estimated on the living by meastring the angle formed by two straight lines, the one passing from the middle of the external acoustic meatus to the lower margin of the septum of the nose; the other drawn from the most prominent part of the forehead above to tonch the incisor teeth below. The angle formed by the intersection of these two lines is called the facial angle Camper), and ranges from $62^{\circ}$ to $85^{\circ}$. The smaller angle is characteristic of a muzzle-like 
projection of the lower part of the face. The larger angle is the concomitant of a more vertical profile. The degree of projection of the maxilla in the macerated cranium is most commonly expressed by employing the gnathic or alveolar index of Flower. This records the relative proportions of the basi-alveolar and basi-nasal lengths, the latter being regarded as $=100$, thus-

$$
\frac{\text { Basi-alveolar length } \times 100}{\text { Basi-nasal length }}=\text { Gnathic index. }
$$

The results are conveniently grouped into three classes:-

Orthognathous, index below 98 : including mixed Europeans, ancient Egyptians, etc. Mesognathous, index from 98 to 103 : Chinese, Japanese, Eskimo, Polynesians (mixed).

Prognathous, index above 103: Tasmanians, Australians, Melanesians, varions African Negroes.

Unfortunately, however, little reliance can be placed on the results obtained by this method, since it takes no account of the proportion of the third or facial side of the gnathic triangle. For a further discussion of this matter see Thomson and MacIver, Races of the Thebaid (Oxford: Clarendon Press, 1905).

The form of the piriform aperture in the macerated skull is of much value from an ethnic standpoint, as it is so intimately associated with the shape of the nose in the living. The greatest width of the aperture is compared with the nasal height (measured from the nasion to the lower border of the aperture) and the nasal index is thus determined :-

\section{Skulls are-}

$$
\frac{\text { Nasal width } \times 100}{\text { Nasal height }}=\text { Nasal index. }
$$

Leptorhine, with a nasal index below 48: as in mixed Europeans, ancient Egyptians, American Indians, etc.

Mesorhine, with an index ranging from 48 to 53 : as in Chinese, Japanese, Malays, etc.

Platyrhine, with an index above 53: as in Australians, Negroes, Kaffirs, Zulus, ete.

The form of the orbit varies considerably in different races, but is of much less value from the standpoint of classification. The orbital index expresses the proportion of the orbital height to the orbital width, and is obtained by the following formula :-

$$
\frac{\text { Orbital height } \times 100}{\text { Orbital width }}=\text { Orbital index. }
$$

The orbital height is the distance between the upper and lower margins of the orbit at the middle; whilst the orbital width is meastured from a point where the ridge which forms the posterior boundary of the lacrimal groove meets the fronto-lacrimal suture (Flower), or from the dacryon (Broca) to the most distant point from these on the anterior edge of the lateral border of the orbit.

The form of the orbital aperture is referred to as-

Megaseme, if the index be over 89 ;

Mesoseme, if the index be between 89 and 84 ;

Microseme, if the index be below 84 .

The variations met with in the form of the palate and dentary arcade may be expressed by the palato-maxillary index of Flower. The length is measured from the alveolar point to a line drawn across the posterior borders of the maxillæ, whilst the width is taken between the outer borders of the alveolar arch immediately above the middle of the second molar tooth. To obtain the index, the following formula is employed:-

$$
\frac{\text { Palato-maxillary width } \times 100}{\text { Palato-maxillary length }}=\text { Palato-maxillary index. }
$$

For purposes of classification Turner has introduced the following terms :-

Dolichuranic, index below 110.

Mesuranic, index between 110 and 115 .

Brachyuranic, index above 115 .

As is elsewhere stated the size of the teeth has an important influence on the architecture of the skull. Considered from a racial standpoint, the relative size of the teeth to the length of the cranio-facial axis has been found by Flower to be a character of much value. The dental length is taken by measuring the distance between the anterior surface of the first premolar and the posterior surface of the third molar of the upper jaw.

To obtain the dental index the following formula is used :-

$$
\frac{\text { Dental length } \times 100}{\text { Basi-nasal length }}=\text { Dental index. }
$$


Following the convenient method of division adopted with other indices, the dental indices may be divided into three series, called respectively-

Microdont, index below 42 : including the so-called Caucasian or white races.

Mesodont, iudex between 42 and 44 : including the Mongolian or yellow races.

Megadont, index abore 44 : comprising the black races, including the Australians.

Many complicated instruments have been devised to take the various measurements required, but for all practical purposes the calipers designed by Flower or the compas glissière of Broca are sinfficient.

As an aid to ealculating the indices, the tables published in the Osteological Catalogue of the Royal College of Surgeons of England, Part I., Man; Index-Tabellen zum anthropometrischen Gebrauche, C. M. Furst, Jena, 1902; or the index calculator invented by Waterston will be found of much service in saving time.

\section{(2) Indices and Measurements of other Parts of the Skeleton.}

In addition to the indices employed to express the proportions of the cranial measurements, there are others similarly made use of to convey an idea of the proportions of different parts of the skeleton. Of these the following may be mentioned as those in most common use :-

Scapula.-At birth the form of the human scapula more closely resembles the mammalian type in that its breadth, measured from the glenoid cavity to the vertebral border, is greater in comparison with its length than in the adult. This proportion is expressed as follows:-

\section{$\frac{\text { Breadth from glenoid eavity to vertebral border } \times 100}{\text { Length from medial to inferior angle }}=$ Scapular index.}

The index ranges from 87 in African pygmies, which therefore have proportionately broader scapulæ, to 61 in Eskimos. The average European index is about 65.

Hip Bone. The relation of the breadth of this bone to its height is computed as follows :-

\section{$\frac{\text { Iliac breadth } \times 100}{\text { Ischio-iliac height }}=$ Innominate index.}

Man as compared with the apes is distinguished by possessing proportionately broader and shorter hip bones. The index in man ranges from 74 to 90 .

Pelvis.-The form of the human pelvis is characterised by an increased proportionate width and a reduced proportionate height or length. The relation of these diameters is expressed by the formula :-

Ischio-iliac height $\times 100$

Greatest breadth between the outer lips of the iliac crests $=$ Pelvic breadth-height index.

The average index for white races is 73 .

Pelvic Cavity.- The measurements usually taken are those of the superior aperture. In man there is a proportionate increase in the transverse diameter as compared with lower forms :Antero-posterior diameter (conjugate) from mid-point of sacral promontory to the posterior margin of pubic symphysis $\times 100$ Greatest transverse width between ilio-pectineal lines $=$ Pelvic or brim index

Turner has classified the indices into three groups:-

Dolichopellic, index above 95 : Australians, Bushmen, Kaffirs.

Mesatipellic, index between 90-95: Negroes, Tasmanians, New Caledonians.

Platypellic, index below 90 : Europeans and Mongolians generally.

Vertebral Column.-A characteristic feature of man's vertebral column is the pronounced lumbar curve associated with the erect posture in the living. Apart from the consideration of the interposition of the intervertebral fibro-cartilage between the segments, the bodies of the lumbar vertebræ influence and react on the curve by exhibiting differences in their anterior and posterior vertical diameters. Advantage has been taken of this to endeavour to reconstruct the lumbar curve from the dried and macerated bones, but it must be borne in mind that habitual posture or increased range of movements may yield results which are possibly misleading. Thus there is reason for believing that the squatting position, when habitually adopted, may give rise to a compression of the anterior parts of the bodies of the vertebræ which it might be assumed was associated with an absence of or flattening of the lumbar curve, which in fact did not exist during life.

The quality of the curve is estimated from the macerated bones by an index which is computed as follows:-

Sum of posterior vertical diameters of the bodies of five lumbar vertebræ $\times 100$

Sum of anterior vertical diameters of the bodies of five lumbar $=$ General lumbar index. vertebræ 
The results are classified as follows :-

Kurtorachic, index below 98, displaying a forward convexity: includes Europeans generally, Chinese.

Orthorachic, index between 98 and 102, column practically straight: includes examples of Eskimo and Maori.

Koilorachic, index above 102, displaying a backward convexity: includes Australians, Negroes, Bushmen, and Andarnanese.

Sacrum.-Man's sacrum is characterised by its great breadth in proportion to its length. These relations are expressed as follows:-

Greatest breadth of base of sacrum $\times 100$

Length from middle of promontory to middle of anterior inferior border of $=$ Sacral index.

fifth sacral vertebræ

The diverse forms are grouped as follows :-

Dolichohieric, index below 100, sacra longer than broad : includes Australians, Tasmanians, Bushmen, Hottentots, Kaffirs, and Andamanese.

Platyhieric, index above 100, sacra broader than long: includes Europeans, Negroes, Hindoos, North and South American Indians.

Limb Bones.-The proportionate length of the limb bones to each other and to the body height is of practical interest. It is a matter of common knowledge that the forearms of Negroes are proportionately longer than those of Europeans. Great differences, too, are met with in the absolute and proportionate length of the lower limbs, nor must the relation of these to body height be overlooked. An enumeration of the more important of these indices, and the manner of their computation, will suffice. The proportion of the length of the radius to the length of the humerus is expressed as follows:-

\section{$\frac{\text { Length of radius } \times 100}{\text { Length of humerus }}=$ Radio-humeral index.}

Sub-divided into three groups :-

Brachykerkic, index less than 75 : includes Europeans, Lapps, Eskimo.

Mesatikerkic, index between 75-80: Chinese, Australians, Polynesians, Negroes.

Dolichokerkic, index above 80: Andamanese, Negritoes and Fuegians, Bonindae in general.

The proportion of the length of the tibia to the femur is computed by the formula-

Length of tibia from surface of condyle to articular surface for talus $\times 100$ Oblique length of femur

Sub-divided into two groups :-

Brachyknemic, index 82 and under: includes Europeans and Mongolians generally.

Dolichoknemic, index 83 and over: includes Australians, Negroes, Negritoes, AmericanIndians.

The proportion of the length of the upper limb to that of the lower limb is obtained thus :-

$$
\frac{\text { Lengths of humerus }+ \text { radius } \times 100}{\text { Lengths of femur }+ \text { tibia }}=\text { Intermembral index. }
$$

A comparison between the relative lengths of the upper segments of the limbs is obtained by the following formula:-

$$
\frac{\text { Length of humerus } \times 100}{\text { Length of femur }}=\text { Humero-femoral index. }
$$

Platymeria (see p. 281).-The amount of compression of the femur is estimated as follows :-

Sagittal diameter of shaft immediately distal to lesser trochanter $\times 100$

Transverse diameter of shaft immediately distal to lesser trochanter $=$ Platymeric index

Platyknemia (see p. 281)-The degree of compression of the tibia is estimated by the formula-

Transverse diameter of shaft at level of nutrient foramen $\times 100$

Antero-posterior diameter of shaft at level of nutrient foramen $=$ Platyknemic index.

The index ranges from 60 in a Maori tibia to 80 to 108 in modern French tibiæ.

For further and more detailed information relating to the rarious measurements and indices employed by the physical anthropologist, the reader is referred to Topinard's Élements d'Anthropologie; Sir W. Turner's Challenger Memoirs, Part 47, vol. xvi.; and Duckworth's Morphology and Anthropology. 


\section{APPENDIX E.}

\section{DEVELOPMENT OF THE CHONDRO-CRANIUM AND MORPHOLOGY OF THE SKULL.}

As has been already stated, the chorda dorsalis or notochord extends forwards to a point inmediately beneath the anterior end of the mid-brain. In front of this the head takes a bend so that the large fore-brain overlaps the anterior extremity of the notochord. At this stage of derelopment the cerebral vesicles are enclosed in a membranous covering derived from the mesen-

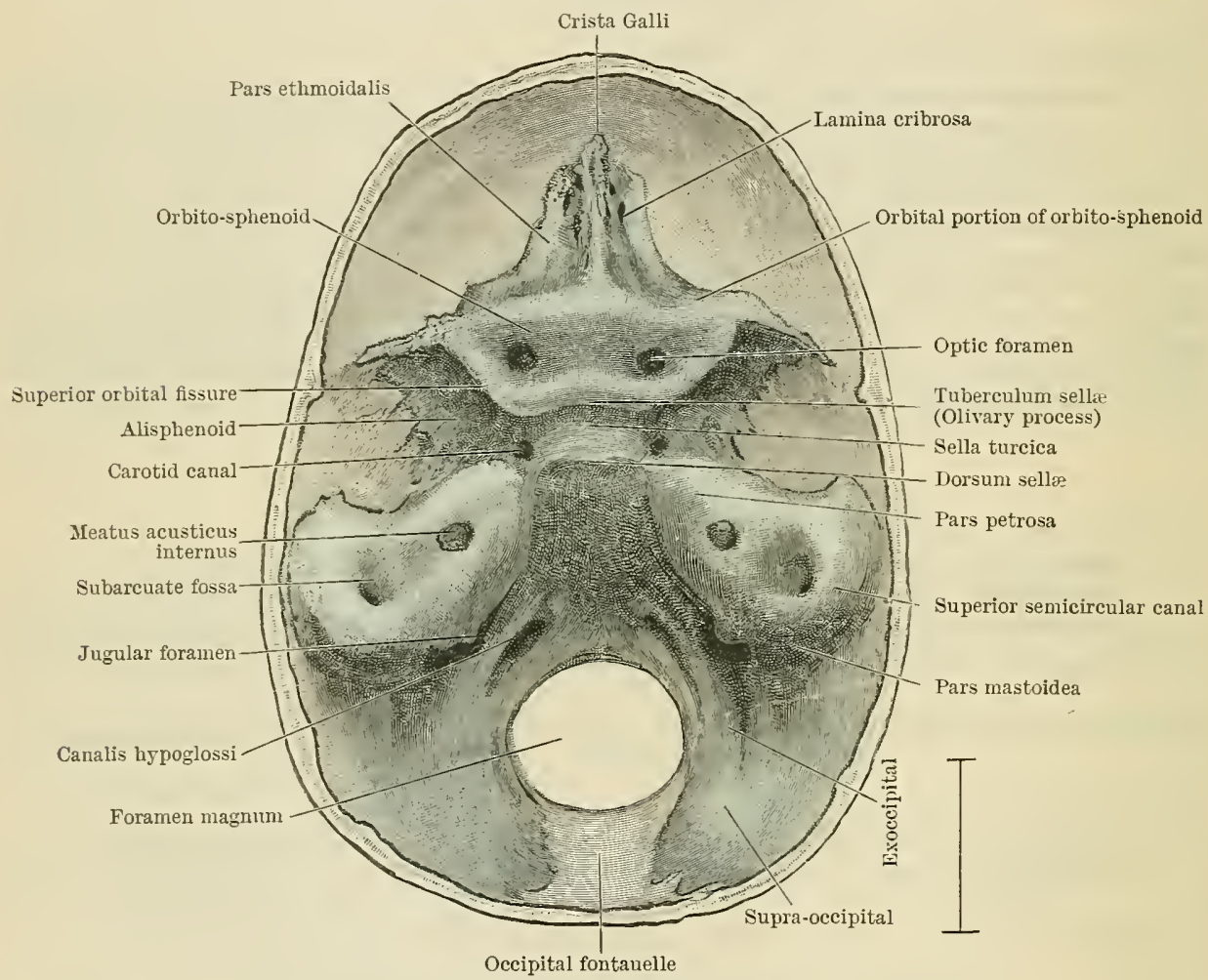

Fig. 282. - View of the Chondro-Cranium of a Human Fetus 5 CM. in length from Vertex to Coccrx (about the middle of the third month); the cartilage is coloured blue. The line to the right of the drawing shows the actual size.

chyme surrounding the notochord; this differentiated mesodermal layer is called the primordial membranous cranium. From it the meninges which invest the brain are derived. In Iower vertebrates this membranous capsule becomes converted into a thick-walled cartilaginous envelope, the primordial cartilaginous cranium. In mammals, however, only the basal part of this capsule becomes chondrified, the roof and part of the sides remaining membranous. In considering the chondrification of the skull in mammals, it must be noted that part only of the base is traversed by the notochord, viz., that portion which extends from the foramen magnum to the dorsum sellæ of the sphenoid. It is, therefore, conveniently divided into two parts-one posterior, surrounding the notochord, and hence called chordal, and one in front, into which the notochord does not extend, and hence termed prechordal. These correspond respectively to the vertebral and evertebral regions of Gegenbauer. In the generalised type, a pair of elongated cartilages called the parachordal cartilages appear on either side of the chorda in the chordal region, similarly in the prechordal region two curved strips of cartilage named the prechordal cartilages, or the trabeculæ cranii of Rathke, develop on either side of the cranio-pharyngeal canal. In the human embryo, however, this symmetrical arrangement has not hitherto been observed. In man, chondrification of the cranial base commences early in the second month and attains its maximum development about the end of the third month, at which time the chordal part of the chondrocranium consists of a ring of cartilage, the ventral part of which is formed by the fusion of tro parachordal cartilages, so forming around the chorda dorsalis, a central axial part, 
which comprises the basilar portion of the occipital bone. From this there pass extensions which form the lateral parts of the occipital bone, and serve to unite the occipital plate, as this part of the cartilaginous base is sometimes called, to the cartilaginous auditory capsules on either side. These latter are formed by the chondrification of the cochlear and canalicular parts of the labyrinth, which do not derelop at the same rate, so that the part around the semicircular canals is completed much sooner than the cochlear portion; in consequence, at the end of the second month, the facial nerve and the genicular ganglion lie in a groove, to be subsequently converted into a canal, on the vestibular part of the capsule.

The dorsal part of the ring consists of a thin cartilaginous plate, the tectum posterius, from which is developed the only part (i.e. the inferior part of the occipital squama) of the cranial vault preformed in cartilage. In the membranous tissue from which this plate is developed chondrification at first begins, on either side, by an extension from the posterior aspect of the pars lateralis of the occipital; growing rapidly forwards this ultimately mites with the posterior and dorsal borders of the cartilaginous auditory capsule, from which it is for some time separated by a narrow membranous interval. At a later stage the cartilages of either side unite, dorsal to the foramen magnum, to form the tectum posterius or the tectum synoticum (Keibel and Mall).

To the axial part of this portion of the chondrified base the chorda dorsalis has the following

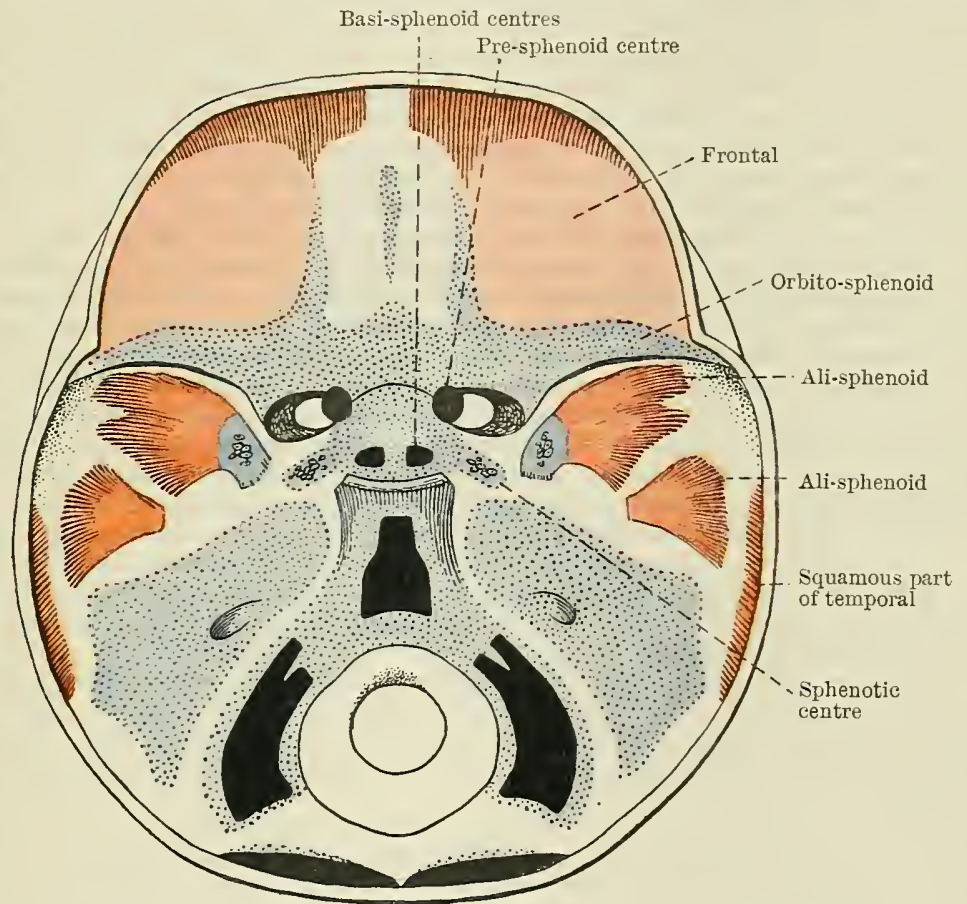

Fig. 283.-Ossification on Base and Lateral Walls of Skdll of fodr and a half Months' FETUs (Schultze's method). Cartilage, blue; cartilage-bone, black; membrane-bone, red.

relations: in front of the foramen magnum it runs for a short distance in a groore on the dorsa surface of the occipital plate, then pierces the cartilage so as to lie ventral to it in the retropharyngeal tissue, again enters the chondro-cranium by passing dorsalwards in the suture between the occipital plate and sphenoidal cartilage and endo-dorsal to the latter cartilage.

The prechordal portion of the cartilaginous basis cranii in man displays the following features : at the thirl month it is irregularly diamond-shaped in outline, its posterior angle is redged in between the two auditory capsules and is related to the fore part of the axial portion of the occipital plate. The anterior angle forms the rentral end of the nasal capsule, whilst the lateral angles extend over the orbital cavities and correspond to the tips of the alæ orbitales of the sphenoid.

Within this area chondrification takes place as follows (Bardeen). In the region of the posterior angle above referred to a cartilaginous nodule appears anterior and rentral to the end of the chorda dorsalis; from this arises the cartilaginous body of the sphenoid, the further derelopment of which is associated with its union with the anterior end of the median portion of the occipital plate and the formation there, by the appearance of an independent transverse strip of cartilage, of the dorsum selle of the sphenoid; whilst from its anterior and superior surface on either side there extend forwards strips of cartilage which surround the liypophyseal pocket, and unite in front of it to form the anterior part of the body of the sphenoid, thereby enclosing the hypophyseal canal, which, at first wide, is gradually closed by the chondrification of its walls. It may, howerer, remain open. 
The region occupied by the ala temporalis is slow to chondrify. According to Fawcett, the only part of it which is preformed in cartilage is that which corresponds to the root of the two ptergoid laminx in the adult: this is, perforated by the maxillary division of the trigeminal nerve. According to the same authority, the whole of the lateral pterygoid lamina and that part of the ala temporalis projected into the orbital and temporal fossa are ossified in membrane. So, too, are the foramen ovale and foramen spinosum.

The ala orbitalis, at first much larger than the ala temporalis, is described as chondrifying in the following way. The process begins by the appearance of cartilage posterior to the position of the optic foramen; medially this fuses with the lateral aspect of the anterior part of the body of the sphenoid, laterally it extends into the orbital plate, with the independent cartilaginous centre of which it unites. The foramen opticum is completed by the extension of the cartilage from the side of the anterior extremity of the body of the sphenoid, in front of the nerve, to reach the orbital plate. These three centres fuse to form a single piece of cartilage during the third month.

Anterior to the orbito-sphenoids, the base of the skull is intimately associated with the nasal capsule, and is the last part of the chondro-cranium to become cartilaginous, this change not being effected till the third month. The roof of the capsule is formed by the coalescence of cartilaginous elements appearing, first in the nasal septum by an extension of the cartilage from the ventral surface of the body of the sphenoid and secondly by an independent centre in each lateral wall of the capsule. At first the nasal capsule is open dorsally on either side of the nasal septum in correspondence with the olfactory bulbs, but during the third month the wall of the capsule corresponding to the cribriform plate commences to chondrify around the perforating nerve-fibres, and so the lamina cribrosa is preformed in cartilage. Laterally strips of cartilage (cartilago ethmosphenoidalis) pass backwards from the lateral edges of the cribriform plate to unite it with the anterior edges of the alæ orbitales of the sphenoid.

By the third montl the nasal capsule has become cartilaginous. As has been stated above, the nasal septum chondrifies by an extension forwards of the ventral part of the body of the cartilaginous sphenoid. On either side of the ventral margin of this septum anteriorly are developed the paraseptal cartilages, which in man persist till after birth. These are connected posteriorly by means of a connective tissue bridge with small pieces of cartilage-the posterior paraseptal cartilages, which are in turn associated with the paranasal cartilages posteriorly, and there in part form the floor of the recessus terminalis or cupola of the cartilaginous nasal capsule (Fawcett). In man, owing to the deficiency of the lamina transversalis anterior, the fenestra narina and the fenestra basalis which pierce the floor of the nasal capsule, on either side of the septum, become confluent and form the fissura rostroventralis of Gaupp. Meanwhile the lateral walls of the nasal capsule are chondrifying independently, forming the paranasal cartilages. These become subsequently united anteriorly with the nasal septum to form the tectum nasi or roof of the nose. At first this is open posteriorly where it is in relation with the olfactory bulb, but later, as has been already described, the tissue around the nerve filaments chondrifies to form the cartilaginous lamina cribrosa. The inferior concha is derived from the cartilage of the lower and lateral part of the nasal capsule, from which, however, it becomes isolated about the seventh month. Above and behind this the middle and superior conchæ, the ethmoidal turbinals, become chondrified, as well as the cartilaginous rudiments which subsequently form the agger nasi, the bulla ethmoidalis, and the concha sphenoidale or ossiculum Bertini.

Throughout life certain parts of the cartilaginous nasal capsule persist as the cartilaginous nasal septum and the cartilages of the alæ of the nose, whilst other parts are absorbed and are replaced by surrounding bones of membranous origin.

The various foramina met with in the cranial base are formed either as clefts in the line of union of the several cartilaginous elements, or through inclusion by means of bridging processes derived from these same elements.

From the ventral surface of this cartilaginous platform-formed, as described, by the union of the trabeculæ, parachordal cartilages, and cartilaginous auditory capsules-is suspended the cartilaginous framework of the visceral arches, which play so important a part in the development of the face, an account of which is elsewhere given.

A consideration of the facts of comparative anatomy and embryology appears to justify the assumption that the mammalian skull is of twofold origin-that, in fact, it is composed of two envelopes, an outer and an inner, primarily distinct, but which in the process of evolution have become intimately fused together. The inner, called the primordial skull, is that which has just been described, and consists of the chondro-cranium and the branchial skeleton. The outer, which is of dermic origin, includes the bones of the cranial vanlt and face which are developed in membrane. This secondary skull, which first appears in higher fishes as ossified dermal plates overlying the primary skull, acquires a great importance in the mammalia, as owing to the expansion of the brain and the progressive reduction of the chondro-cranium, these dermal bones become engrafted on and incorporated with the primordial skmll, and act as covering bones to the cavities of the cranimm and face; for it may be well to point out that these dermal or membrane bones are not necessarily external in position, as over the cranial vault, but also develop in the tissues underlying the mucous membrane of the cavities of the face.

Advantage is taken of this difference in the mode of development of the bones of the skull to classify them according to their origin into cartilage or primordial bones, and membrane or secondary bones. These differences in the growth of the bone must not be too much insisted on in determining the homologies of the bones of the skull, as it is now generally recognised that 
all bone is of membranons origin, and that whilst in some cases cartilage may become calcified, it never undergoes conversion into true bone, but is replaced by ossific deposit derived from a membranous solurce. In the subsequent growth of the sknll, parts of the cartilaginous cranium persist as the septal and alar cartilages of the nose, whilst for a considerable period the basisphenoid and basi-occipital are still mnited by cartilage. The cartilage also which blocks the foramen lacerum may be regarded as a remnant of the chondro-cranium.

Whilst in many instances the primordial and secondary bones remain distinct in the fullydeveloped condition, they sometimes fuse to form complex bones, such as the temporal and sphenoid.

Various theories have been advanced to account for the mode of formation of the skull. The earliest of these was ealled the vertebrate theory, which assumed that the cranium was built 11 p of a series of modified vertebræ, the bodies of which corresponded to the basi-cranial axis, whilst the vertebral arches were represented by the covering bones of the cranium. In view of the more recent researches regarding the composite origin of the skull above referred to, this theory was necessarily abandoned. It gave way to the suggestion of Gegenbauer that the primordial cranium has arisen by the fusion of several segments equivalent to vertebræ, the number of which he determined by noting the metameric arrangement of the cerebral nerves, of which he concluded there were nine pairs, arranged much like spinal nerves, both as to their origin and distribution. The olfactory and optic nerves, though frequently referred to as cerebral nerves, are excluded, since from the nature of their development they are to be regarded as metamorphosed parts of the brain itself. Gegenbauer therefore assumed that that portion of the cranial base which is traversed by the nine pairs of segmentally arranged cerebral nerves mist be formed by the fusion of nine vertebral segments; and as the region where the nerves escape corresponds to the part of the chondro-cranium traversed by the notochord, he calls it the vertebral portion of the cranial base, in contradistinction to the trabecular or non-vertebral part which lies in front. This latter he regards as a new formation adapted to receive the greatlydeveloped brain and afford protection to the organs of sight and smell.

As has been pointed ont by Hertwig, there is an essential difference between the development of the axial cartilaginous skeleton of the trunk and head. The former becomes segmented into distinct vertebræ alternating with intervertebral ligaments; whilst the latter, in order to attain the rigidity necessary in this part of the skeleton, is never so divided. It follows from this that the original segmentation of the head is only expressed in three ways, viz., in the appearance of several primitive segments (myotomes), in the arrangement of the cerebral nerves, and in the fundament of the visceral skeleton (visceral arches). According to Froriep, the mammalian occipital corresponds to the fusion of four vertebræ, and there is some reason for supposing that in some classes of vertebrates the occipital region of the primordial craninm is increased by fusion with the higher cervical segments.

The form of skull characteristic of man is dependent on the large proportionate development of the cranial part, which contains the brain, and the reduction in size of the visceral part (face), which protects the organs of special sense. This leads to a decrease in the mass and projection of the jaws, as well as a reduction in the size of the teeth. Associated with the smaller mandible there is a feebler musculature, with a reduced area of attachment to the sides of the sknll. In this way the disappearance of the muscular crests and fossæ, so characteristic of lower forms, is accounted for. At the same time the fact that the skull is poised on the snmmit of a vertical column, leads to important modifications in its structure. The disposition of parts is such that the occipito-vertebral articulation is so placed that the fore and hind parts of the head nearly balance each other, thus obviating the necessity for a powerful muscular and ligamentous mechanism to hold the head erect.

Another noticeable feature in connexion with man's skeleton is the prolonged period during which growth may occur before maturity is reached; this is associated with a more complete consolidation of the skull, since bones, which in lower forms remain thronghout life distinct, are in man fused with each other, as exemplified in the case of the presphenoid and postsphenoid, the occipital and the interparietal, to mention one or two instances among many. It is noteworthy, however, that during ontogeny the morphological significance of these bones is clearly demonstrated by their independent ossification.

The points of exit of the various cerebral nerves remain remarkably constant, and in their primitive condition serve to suggest the segmental arrangement of the cartilaginous chondroeranium already referred to. Owing to the rery great modifications which the mammalian skull has undergone in the process of its evolution, it may be pointed out that the passage of the nerves through the dura mater-a derivative, the readers nay be reminded, of the primordial membranons cranium (see ante) - alone represents the primitive disposition of the nerves. Their subsequent escape through the bony base is a later and secondary development. In some cases the two, membranous or primary and the osseous or secondary foramina, correspond. In other instances the exit of the nerves throngh the dura mater does not coincide with the passage through the bone.

Of interest in this connexion it may be pointed out that the foramina and canals which traverse the skull are either siturated in the line of suture between adjacent bones or in the line of fusion of the constituent parts of which the bone pierced is made up. For example, the superior orbital fissure is situated between the orbito and alisphenoids; the hypoglossal canal between the basi and exoccipitals; the jugular between the petrons, basi, and exoccipital; the optic between the orbito-sphenoid and the presphenoid ; the pterygoid between the alisphenoid, medial pterygoid lamina, and the lingula. 
APPENDIX F.

\section{MORPHOLOGY OF THE LIMBS.}

\section{Development and Morphology of the Appendicular Skeleton.}

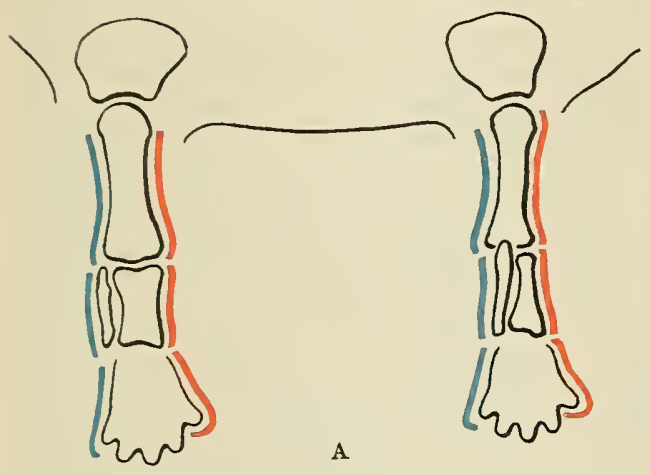

The paired limbs first appear in the human embryo about the third week as snuall buds on either side of the cephalic and caudal ends of the trunk. That these outgrowths are derived from a large number of trunk segments is assumed on the ground that they are supplied by a corresponding number of segmental nerves, and the circumstance that they are more particularly associated with the ventral offsets of these nerves would point to the conclusion that they belong rather to the ventral than the dorsal surface of the body.

At first the surfaces of these limb buds are so disposed as to be directed ventrally and dorsally, the ventral aspect corresponding to the future flexor surface of the limb, the dorsal to the extensor side. At the
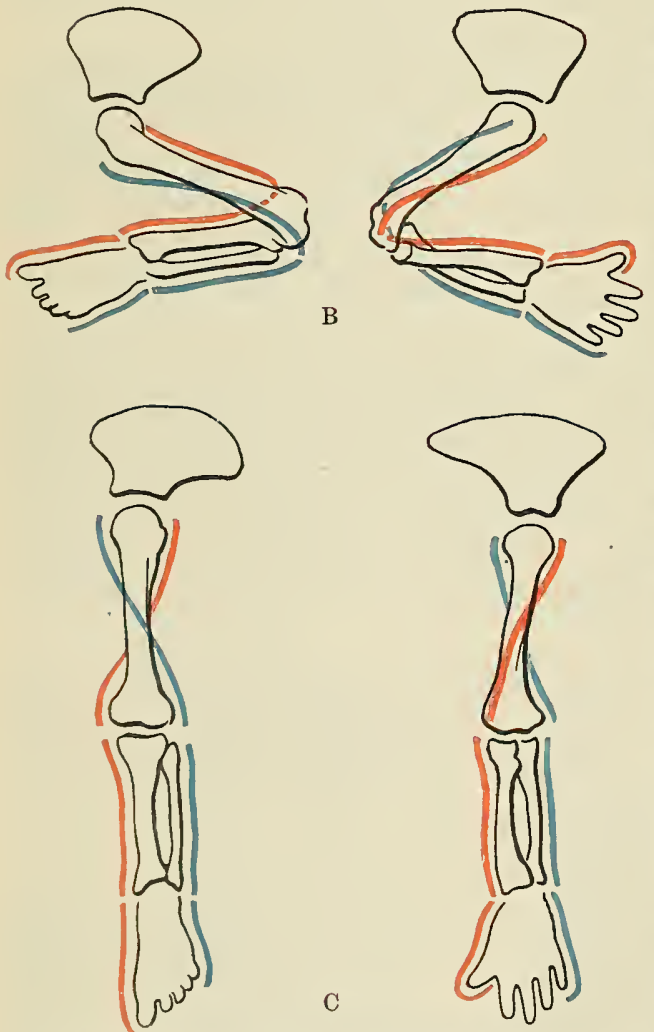

Fig. 284.-Diagram to illustrate the Homologies of THE BONES OF THE LIMBS.

The two limb buds of an embryo prior to flexion and rotation. The anterior or pre-axial border is coloured red; the posterior or post-axial border, blue. B. After the assumption of the foetal position. Flexion and rotation have now taken place. The red and blue lines indicate the altered position of the pre-axial and post-axial borders. C. The fully developed limbs with the flexor aspects directed towards the reader. The coloured lines indicate the effect of the torsion of the upper segment of the limb through quarters of a circle. same time, the borders are directed headwards (pre-axial), and tailwards (post-axial). As the limbs grow, they soon display evidence of division into segments corresponding to the hand and foot, forearm and leg, upper arm and thigh. Coincident with this (about the second month) the cartilaginous framework of the limb is being differentiated. The disposition of these cartilages furnishes a clue to their homologies. In the fore-limb the radius and thumb lie along the pre-axial borders, and correspond to the tibia and great toe, which are similarly disposed in the hind-limb; whilst the ulna and fifth finger are homo. logous with the fibula and fifth toe, which are in like manner arranged in relation to the posterior (post-axial) border of their respective limbs. Up to this time the limbs are directed obliquely ventralwards. During the third month a change in the position of the limbs takes place, associated with the assumption of the fotal position. Owing to the elongation of the limbs, they become necessarily bent at the elbow and knee, the upper arm inclining downward along the thoracic wall, whilst the thigh is directed upwards in contact with the abdominal parietes. At the same time a rotation of each of these segments of the limb takes place in an inverse direction, so that the pre-axial border of the humerus is turned laterally, whilst the pre-axial border of the femur is turned medially. Assuming that these borders are homologous, it results from this, that the lateral condyle of the humerus corresponds to the medial condyle of the femur. This torsion of the limb is in part effected at the shoulder and hip joints, and to some extent also in the shafts of the bones. Some anatomists hold that this rotation is not confined to the $\operatorname{limb}$, but involves the dorsal part of the limb girdles. Others maintain that there is no evidence that such takes place. In the upper limb, owing to a certain amount of pronation, the 
pre-axial (radial) side of the forearm is now directed forwards and somewhat laterally, whilst in the hind limb the pre-axial (tibial) side of the leg is turned backwards and laterally, the pre-axial borders of the hand with thumb, and foot with great toe being in correspondence. In consequence of these changes in the position of the limbs, amounting in all in the upper segments to a rotation through an angle of $90^{\circ}$, the extensor surface of the fore limb is directed backwards, whilst that of the hind limb is directed forwards. In order to homologise the arrangement of the bones in the extended limb, it is necessary to place them so that their flexor or extensor surfaces are similarly disposed. It will then be observed (see diagram) that the medial or tibial side of the leg and foot (primitively pre-axial) corresponds to the lateral or radial side of the forearm and hand (primitively pre-axial), whilst the fibula and lateral border of the foot homologise with the ulnar or medial border of the forearm and hand (primitively post-axial), the result, as previously explained, of the torsion or twisting in opposite directions throngh an angle of $90^{\circ}$ of the upper segment of the limb. In accordance with this view, it will be evident that in the fore limb there is nothing homologous with the patella, whilst in the hind limb there is no part to represent the olecranon.

In the axial mesoderm of each member, differentiation into cartilaginous segments begins about the second month; each of these cartilages becomes invested by a perichondrial layer which stretches from segment to segment, and ultimately forms the ligaments surrounding the joints, which are subsequently developed between the segments. Chondrification first begins in the basal part of the limb, and extends towards the digits.

The homodynamy of the carpal and tarsal elements may be tabularly expressed, and compared with the more generalised types from which they are evolved.

Type.

$\begin{array}{ll}\text { Radiale (Tibiale) } & =\text { Navicular (body) } \\ \text { Intermedium } & =\text { Os lunatum } \\ \text { Ulnare (Fibulare) } & =\text { Os triquetrum } \\ \text { Centrale } & =\text { Absent, or fused with Navicular } \\ \text { Carpale (Tarsale), i. } & =\text { Greater multangular } \\ \text { Carpale (Tarsale), ii. } & =\text { Lesser multangular } \\ \text { Carpale (Tarsale), iii. } & =\text { Capitate } \\ \text { Carpale (Tarsale), iv. } & =\text { Os hamatum } \\ \text { Carpale (Tarsale), v. }\end{array}$

Foot.

$=$ Talus.

$=$ Absent, or Os trigonum (?). $=$ Calcaneus.

= Navicular, less its tuberosity. $=$ First Cuneiform. $=$ Second Cuneiform. $=$ Third Cuneiform.

$=$ Cuboid, plus the peroneal sesamoid.

The pisiform is omitted from the above table, since it is now generally regarded as being a vestige of an additional digit placed post-axial to the little finger (digitus post-minimus). Its homologue in the foot is by some considered as fused with the calcaneus. The tuberosity of the navicular, formed, as has been stated, of three elements, of which the sesamoid bone in the tendon of the tibialis posterior may be one, is to be regarded as the homologue of the pre-axial sesamoid in the hand, which probably fuses with the navicular to form its tuberosity. The peroneal sesamoid probably corresponds to the hamulus (sometimes an independent ossicle) of the os hamatum. Similarly, on the pre-axial border of the hand and foot, vestiges of a suppressed digit (prepollex and prehallux) may occasionally be met with. The frequent occurrence of an increase in the number of digits seems to indicate that phylogenetically the number of digits was greater than at present, and included a prepollex or prehallux, and a digitus postminimus. The correspondence of the metacarpus with the metatarsus and the phalanges of the fingers with those of the toes is so obvious that it is sufficient merely to mention it.

The differences in size, form, and disposition of the skeletal elements of the hand and foot is easily accounted for by a reference to the functions they subserve.

In the hand strength is sacrificed to mobility, thus leading to a reduction in the size of the carpal elements, and a marked increase in the length of the digital phalanges. The freedom of movement of the thumb, and its opposability to the other digits, greatly enhances the value of the hand as a grasping organ. In the foot, where stability is the main requirement, the tarsus is of much greater proportionate size, whilst the phalanges are correspondingly reduced. Since the foot no longer serves as a grasping organ, the great toe is not free and opposable like the thumb.

Limb Girdles.-The free limbs are linked to the axial skeleton by a chain of bones which constitute their girdles. The fundamental form of these limb girdles consists each of a pair of curved cartilages placed at right angles to the axis of the trunk on either side, and embedded within its musculature. Each cartilage has an articular surface laterally, about the middle, for the reception of the cartilage of the first segment of the free limb. In this way each pectoral and pelvic cartilage is divided into an upper or dorsal half and a lower or ventral half. The dorsal halves constitute the scapula and ilium of the pectoral and pelvic girdles respectively. With regard to the ventral halves there is more difficulty in establishing their homologies. The original condition is best displayed in the pelvic girdle; here the ventral segment divides into two branches-one anterior, which represents the pubis, the other posterior, which ultimately forms the ischium. Ventrally, the extremities of these cartilages unite to enclose the obturator foramen. In the pectoral girdle the disposition of the ventral cartilages is not so clear, consisting primitively of an anterior branch or precoracoid, and a posterior portion or coracoid; these, in higher forms, have undergone great modifications in adaptation to the requirements of the fore limbs. The posterior or coracoid element, the homologue of the ischial cartilage in the pelvic girdle, is but feebly represented in man by the coracoid process and the coraco-clavicular ligament. 
With regard to the homologue of the pubic element in the pectoral girdle, there is much difference of opinion; in reptiles and amphibia it corresponds most closely to the precoracoid, but it is doubtful what represents it in mammals. According to Goette and Hoffman, the clavicle is a primordial bone, and not, as suggested by Gegenbaur, of secondary or dermic origin. If this be so, it corresponds to the rentral anterior segment of the pectoral girdle, and is therefore homologous with the rentral anterior (pubic) segment of the pelvic girdle. On the other hand, if Gegenbaur's view be accepted, the clavicle has no representative in the pelvic girdle. It must, howerer, be borne in mind that during its ossification it is intimately associated with cartilage, and that that cartilage may represent the precoracoid bar; nor must too great stress be laid upon the fact that the clavicle begins to ossify before it is preformed in cartilage, since that may be merely a modification in its histogenetic development.

According to another view (Sabatier), the subcoracoid centre (see Ossification of Scapula) is derived from the posterior ventral segment, and corresponds to the ischium, whilst the coracoid process is the remains of the anterior ventral segment (precoracoid), and is homodynamous with the pubis.

In no part of the skeleton does function react so much on structure as in the arrangement of the constituent parts of the pectoral or pelvic girdles. In man, owing to the assumption of the erect position and the bipedal mode of progression, the pelvic girdle acquires those characteristics which are essentially human, viz., its great relative breadtl and the expansion of its iliac portions, which serve as a support to the abdominal viscera, and also furmish an extensive origin for the powerful muscles which control the movements of the hip-joint. The stability of the

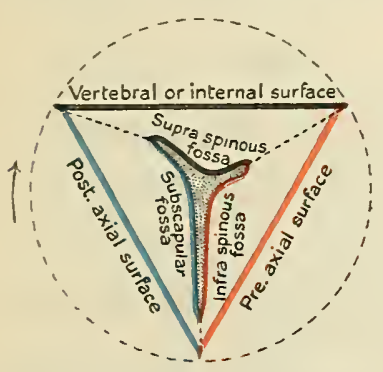

$\mathrm{B}$

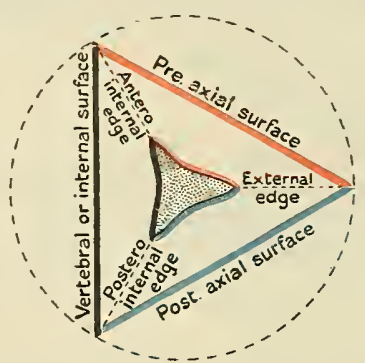

A

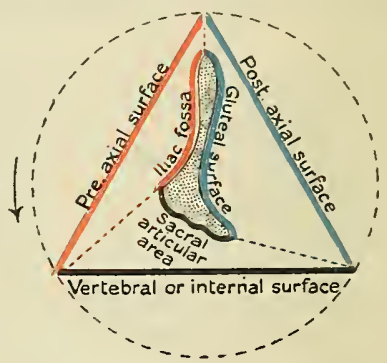

C

Fig. 285.-Diagair to illestrate the Homologots Parts of the Scapela and Ilium ACCORDING TO Flower.

A, ideal type; three-sided rod. B, scupula rotated forward through quarter of a circle $\left(90^{\circ}\right)$, so that the primitive medial or vertebral surface is now directed anteriorly. C, ilium rotated backwards through quarter of a circle so that the primitive medial surface is now turned posteriorly. In the diagram the primitive medial or vertebral surface of each figure is coloured black, the pre-axial surfaces red, and the post-axial surfaces blue.

pelvic girdle is insured by the nature of its union with the axial skeleton, as well as by the osseous fusion of its several parts, and their union in front at the symphysis pubis.

Various attempts have been made to homologise the several parts of the ilium and scapula. All are open to objection; that by Flower is perhaps the most generally accepted. Assuming that the primitive type is represented by a prismatic rod, of which the dorsal end represents either the epiphysial border of the vertebral edge of the scapula or the iliac crest, whilst the ventral end corresponds to the glenoid or acetabular articular areas respectively, the surfaces of the three-sided rod are disposed so that one is vertebral or medial, another pre-axial, and the third post-axial. These surfaces are separated by borders, of which one is lateral, separating the pre-axial and post-axial surfaces, whilst the antero-medial and postero-medial margins separate the pre-axial and post-axial surfaces respectively from the vertebral or medial aspect. It is a necessity of Flower's theory that this part of the girdle undergoes a rotation along with the rest of the limb. Thus in the fore limb the surfaces of the primitive type are turned so that the vertebral surface looks forward, whilst in the case of the hind limb the vertebral surface is turned backward. A study of the accompanying diagram will enable the reader to realise how the ventral surface of the scapula is thus rendered homologous with the gluteal surface of the ilium, for by reference to the type, both these surfaces will be seen to correspond to the postaxial areas of the primitive condition. In accordance with this view the surfaces and borders of the scapula are homologised by Flower, as shewn in the subjoined table:-

SURFACES

Scapula.

Ideal.

Supra-spinous fossa

1. Vertebral

Infra-spinous fossa

Subscapular fossa
2. Pre-axial

3. Post-axial

\section{Pelvis.}

Inner surface of iliunı behind linea arcuata interna, including the articular surface for the sacrum and the portion of the bone above and below this

Internal iliac fossa

Gluteal surface of ilium 
Borders

Axillary border, posterior on most animals (attachment of triceps muscle)

Spine continued into acromion

Superior border, anterior in most animals, with scapulocoracoid notch

\section{Lateral}

\section{Antero-medial}

3. Postero-medial
Anterior border (attachment of rectus muscle)

Linea arcuata interna continued into pubis

Posterior border with greater sciatic notch

Flower's views of this matter were strenuously opposed by Humphry, who maintained that there is strong presumptive evidence against any rotation of the superior parts of the girdles, since it is difficult to suppose that the scapula and ilium can undergo a rotation which is not participated in by the coracoid and ischium. According to this anatomist the homologous parts of the two bones are as stated below :-

\section{Scapula.}

Pre-spinal ridge forming the floor of the prespinal tossa

Spine and acromion

Post-spinal part of scapula forming the floor of the post-spinal fossa

Posterior angle

Posterior border

Medial or ventral surface
Ilium.

Linea ilio-pectinea

Fore part of the blade and crest of the ilium, with its anterior spine or angle

Hinder part of blade and crest of ilium

\section{Posterior spine or angle}

Posterior or sciatic border of ilium

Inner or true pelvic surface of ilium, including the surface for the articulation of the sacrum

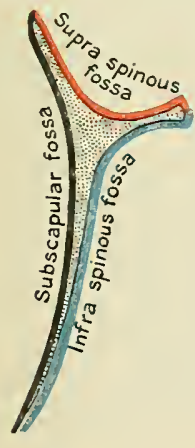

$\mathrm{B}$

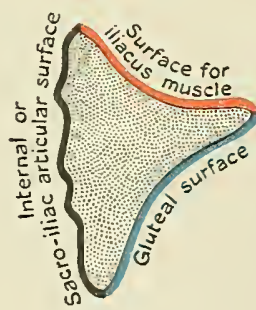

A

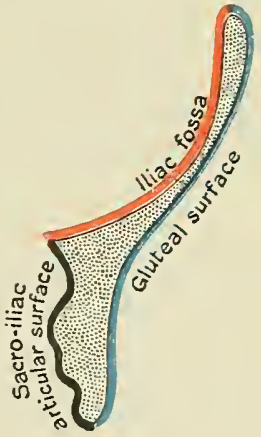

C

Fig. 286.-Diagran to illestrate the Hohologots Parts of ine Scaptla and Ilfum, ACCORDIYG TO HU.MPHRY.

A, primitive rod-like ilium of kangaroo, prismatic on section. B, scapula, C, ilium. The corresponding surfaces are similarly coloured.

The difficulty arising in this scheme of attempting to homologise the attachments of the triceps and rectus femoris, Humphry explains by pointing out that the former muscle also arises from the lateral surface of the scapula, whilst the rectus overruns the lateral surface of the ilium above the acetabulum, so that there is a correspondence in the origins of both these muscles from the lateral surface of their respective bones; but in consequence of the rotation of the extensor surfaces of the limbs in opposite directions the triceps has been turned backwards on to the posterior border of the scapula, whilst the rectus has been turned forwards on to the anterior border of the ilium. Sufficient has been said to enable the reader to recognise that all attempts to determine in detail the homologies of these parts are beset with difficulty. It is wiser, therefore, in our present state of knowledge to be content with establishing a general correspondence, and so avoid the error of endeavouring to establish a closer homological relationship than actually exists.

In man, since the erection of the figure no longer necessitates the use of the fore limb as a means of support, the shoulder girdle has become modified along lines which enhance its mobility and determine its utility in association with a prehensile limb. Some of its parts remain independent (clavicle and scapula), and are united by diarthrodial joints, whilst others have 
become much rednced in size or suppressed (coracoid-precoracoid, see ante). The dorsal part of the girdle (scapula) is not directly united with the axial skeleton as is the ilium, but is only indirectly joined to it through the medium of the clavicle, which is linked in front with the presteruun. The same underlying principles determine the differences in mobility and strength between the shoulder, elbow, and wrist, and the hip, knee, and ankle joints of the fore and hind limbs respectively, whilst the utility of the hand is further enhanced by the movements of pronation and supination which occur between the bones of the forearm. In the leg such movements are absent, as they would interfere with the stability of the limb. 


\title{
THE ARTICULATIONS OR JOINTS.
}

\section{SYNDESMOLOGY.}

\author{
By David Hepburn.
}

Syndesmology is that branch of human anatomy which treats of the articulations or joints.

A junctura ossium (articulation or joint) constitutes a mode of union or connexion subsisting between any two separate segments or parts of the skeleton, whether osseous or cartilaginous, and having for its primary object either the preservation of a more or less rigid continuity of the parts joined together, or else to permit of a variable degree of mobility, subject to the restraints of the uniting media.

Classification of Joints.-In attempting to frame a classification of the numerous joints in the body, several considerations must be taken into account, viz., the manner and sequence of their appearance in the embryo; the nature of the uniting media in the adult, and also the degree and kind of movement permitted in those joints where movement is possible.

In this way we obtain two main subdivisions of joints:-

(1) Those in which the uniting medium is co-extensive with the opposed surfaces of the bones entering into the articulation, and in which a direct union of these surfaces is thereby effected.

(2) Those in which the uniting medium has undergone more or less of interruption in its structural continuity, and in which a cavity of greater or less extent is thus formed in the interior of the joint.

To the first group belong all the immovable joints, many of which are only of temporary duration; to the second group belong all joints which possess, as their outstanding features, mobility and permanence.

\section{SYNARTHROSES.}

The general characteristics of this group are partly positive and partly negative. Thus, there is uninterrupted union between the opposed surfaces of the bones joined together at the plane of the articulation, i.e. there is no trace of a joint cavity, and further, there is an entire absence of movement. Developmentally, these joints result from the approximation of ossific processes which have commenced from separate centres of ossification, and therefore the nature of the uniting medium varies according as the bones thus joined together have originally ossified in membrane or in cartilage. In the former case mnion is effected by an interposed fibrous membrane continuous with, and corresponding to, the periosteum. To such articulations the term sutura (Fig. 287) is applied. In the latter case the uniting medium is a plate of hyaline cartilage. Such

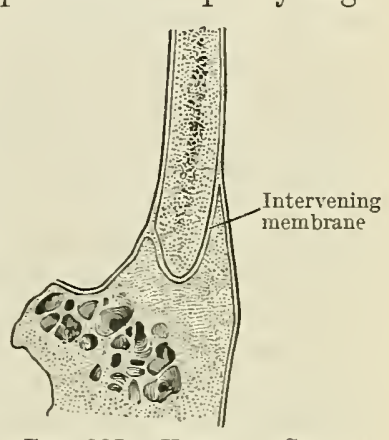

Fig: 287.-VERTical Section THROUGH A SUTURE.

articulations are called synchondroses (Fig. 288). In all the synchondroses, and in many of the sutures, the uniting medium tends to disappear in the progress of 
ossification, and thus the plane of articulation becomes obliterated, so that direct structural continuity between the osseous segments takes place. The primary

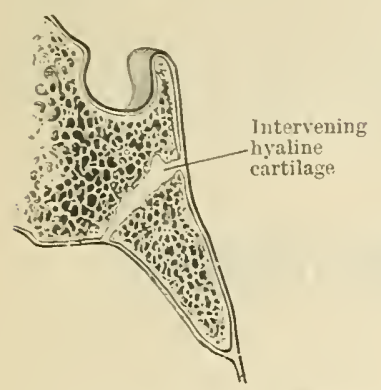

Fig. 28S. - SEctioN THROUGH THE OCCIPITO-SPHEXOID SYNCHOXDROSIS. features common to all synarthroses are- $(a)$ continuous and direct union of the opposing surfaces; $(b)$ no joint cavity; (c) no movement.

Sutura.-This form of synarthrosis is found only in connexion with the bones of the skull. In a large number of cases the bones which articulate by suture present irregular interlocking margins, between which there is the interposed fibrous membrane to which reference has already been made. When these interlocking margins present well-defined projections they are said to form a sutura vera (true suture); on the other hand, when the opposed surfaces present ill-defined projections, or even flat areas, they are described as sutura notha (false suture). In each of these subdivisions the particular characters of the articulating margins are utilised in framing additional descriptive terms. Thus true sutures may possess interlocking margins whose projections are tooth-like (sutura dentata), e.g. in the interparietal suture; saw-like (sutura serrata) (Fig. 289), e.g. in the interfrontal suture; ridge-like, or comparable to the parallel ridges on the welt of a boot (sutura limbosa). Similarly false sutures may articulate by margins which are scalelike (sutura squamosa), e.g. in the squamoso-parietal suture; or by rough opposed surfaces, sutura harmonia, e.g. in the suture between the palatine processes of the maxillary bones. There is one variety of synarthrosis which, in the adult, can scarcely be called a suture, although the differences are of minor importance, viz., schindylesis, which is an articulation between the edge of a platelike bone, such as the rostrum of the sphenoid, and the cleft in another, such as the vomer.

Synchondrosis. - Illustrations of this group can be found only FIG. 289.-Sutura in the young growing individual, because as age advances and growth ceases, the process of ossification affects the hyaline cartilage which constitutes the uniting medium, and the plane of articulation disappears. Under this heading we may include the planes of junction between all epiphyses and the diaphyses to which they severally belong. The occipito-sphenoid (Fig. 288) and the petro-jugular articulations in the base of the skull provide other well-marked examples.

\section{AMPHIARTHROSES-DIARTHROSES (MOVABLE JOINTS).}

The leading features of this group are capability of movement and permanence. In very few instances do such joints ever become obliterated under normal conditions. Determining their permanence, and regulating the amount of possible movement, there is always more or less of interruption in the continuity of the structures which bind the osseous elements together. That is, there is always some evidence of a cavum articulare (joint cavity), although as a matter of course such interruption can never be so extensive as to entirely disassociate the articulating elements. Therefore in all movable joints a new class of structures is found, viz., ligamenta (the ligaments), by means of which continuity is maintained even when all the other uniting media have given place to an articular cavity. The further subdivision of this group is founded upon the amount of movement permissible, and the extent to which the articular cavity takes the place of the original continuous uniting medium. Thus we obtain the amphiarthroses, or partly movable, and the diarthroses, or freely movable.

An amphiarthrosis (Fig. 292) presents the following characteristies: (a) partial movement; $(b)$ union by ligaments and by an interposed plate or disc of fibro-cartilage, in the interior of which there is $(c)$ an incomplete or partial joint eavity, which may be lined by a rudimentary stratum synoviale (synovial membrane) 
whose function it is to secrete a lubricating fluid, the synovia or joint-oil; $(d)$ a plate of hyaline eartilage coating each of the opposing surfaces of the bones concerned. All the joints belonging to this group occur in the median plane of the body. It includes the symphysis pubis, the joints between the bodies of the vertebræ, and the joint between the manubrium sterni and the body of the sternum.

A diarthrosis (Fig. 291) is the most elaborate as well as the most complete form of articulation. It is characterised by (a) capability of movement which is more or less free in its range; $(b)$ a reduction of the uniting structures to a series of retaining ligaments; (c) an articular cavity which is limited only by the surrounding ligaments; $(d)$ the constant presence of synovial membrane; (e) cartilago articularis (hyaline encrusting cartilage) which clothes the opposed surfaces of the articulating bones. The majority of the joints in the adult belongs to this group. This series of joints has been subdivided into a number of minor sections, in order to emphasise the occurrence of certain wellmarked structural features, or because of the particular nature of the movement by which they are characterised. Although in all diarthroses there is a certain amount of

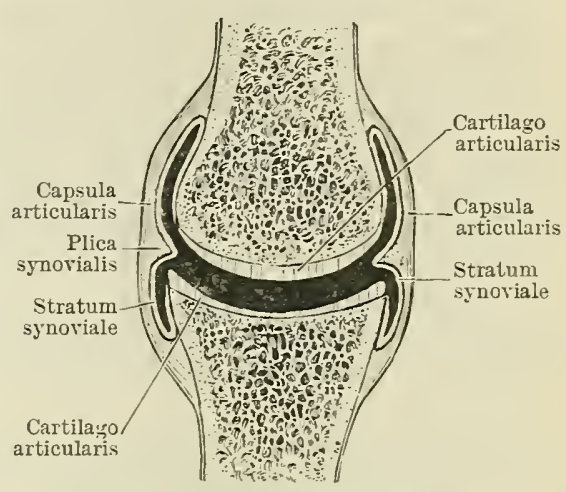

Fig. 290.-Diagram of a Diarthrodial JorNT. gliding movement between the opposed surfaces of the bones which enter into their formation, yet, when this gliding movement becomes their prominent feature, as in most of the joints of the carpus and tarsus, they are termed arthrodia. But bones may be articulated together so as to permit of movement in one, two, or more fixed axes of movement, or in modifications of these axes. Thus in uniaxial joints the axis of movement may lie in the longitudinal axis of the joint, in which case the trochoid rotatory form of joint results, as in the proximal and distal radio-ulnar articulations; or it may correspond with the transverse axis of the articulation, as in the elbow-joint and knee-joint, when the ginglymus or hinge variety results. If movement takes place about two principal axes situated at right angles to each other, as in the radio-carpal joint, the terms ellipsoid (biaxial or condyloid) are applied. Movements occurring about three principal axes placed at right angles to each other, or in modifications of these positions, constitute multiaxial joints, in which the associated structural peculiarities provide the alternative terms of enarthrosis or ball-and-socket joints.

\section{STRUCTURES WHICH ENTER INTO THE FORMATION OF JOINTS.}

The structures which enter into the formation of joints vary with the nature of the articulation. In every instance there are two or more skeletal elements, whether bones or cartilages, and in addition there are the uniting media, which are either simple or elaborate according to the provision made for rendering the joint more or less rigid, or capable of movement. We have already seen that the uniting medium in synarthrodial joints is a remnant of the common matrix, whether fibrovascular membrane or hyaline cartilage, in which ossification has extended from separate centres. Among the amphiarthroses there is still extensive union between the opposing surfaces of the articulating bones, but the character of the uniting medium has advanced from the primitive embryonic tissue to fibrous and fibrocartilaginous material, as well as hyaline cartilage. These, with very few exceptions, are permanent non-ossifying substances, such as may be seen between the opposing osseous surfaces of two vertebral bodies. The joint cavity, more or less rudimentary, is confined to the centre of the fibro-cartilaginous plate, and may result from the softening or imperfect cleavage of the central tissue. It may also present rudiments of a synovial membrane.

In the diarthrodial group the extensive carity has produced great interruption in the continuity of the uniting structures which originally existed between the 
bones forming such a joint. Ligaments have therefore additional importance in this group, for not only do they constitute the uniting media which bind the articulatiug bones together, but, to a large extent, they form the peripheral boundary of the joint cavity, although not equally developed in all positions. Thus, every diarthrodial joint possesses a fibrous or ligamentous envelope constituting the fibrous stratum of the articular capsule, which is attached to the adjacent ends of the articulating bones. For special purposes, particular parts of the fibrous stratum may undergo enlargement and thickening, and so constitute strong ligamentous bands, although still forming continuous constituents of the envelope.

The fibrous stratum is lined by a stratum synoviale (O.T. synovial membrane), the two strata constituting the capsula articularis. The synovial stratum is continued from the inner surface of the fibrous stratum to the surface of the intraarticular portion of each articulating bone. The part of the bone included within the joint consists of a "non-articular" portion covered by the synovial layer and an "articular" portion covered by encrusting hyaline cartilage. The latter provides the surface which comes into apposition with the corresponding area of another bone. In its general disposition the synovial layer may be likened to a cylindrical tube open at each end. This layer is richly supplied by a close network of vessels and nerves.

Certain diarthroses present intracapsular structures which may be distinguished as interarticular ligaments and articular dises and menisci (O.T. interarticular fibro-cartilages).

Ligamenta Interarticularia.-Interarticular ligaments extend between, and are attached to, non-articular areas of the intracapsular portions of the articulating bones. They usually occupy the long axis of the joint, and occasionally they widen sufficiently to form partitions which divide the joint-cavity into two compartments, e.g. the articulation of the heads of the ribs with the vertebral column, and certain of the costo-sternal joints.

Articular discs and menisci (O.T. interarticular fibro-cartilages) (Fig. 291) are more or less complete partitions situated between and separating opposing articular surfaces, and when complete they divide the joint cavity into two distinct

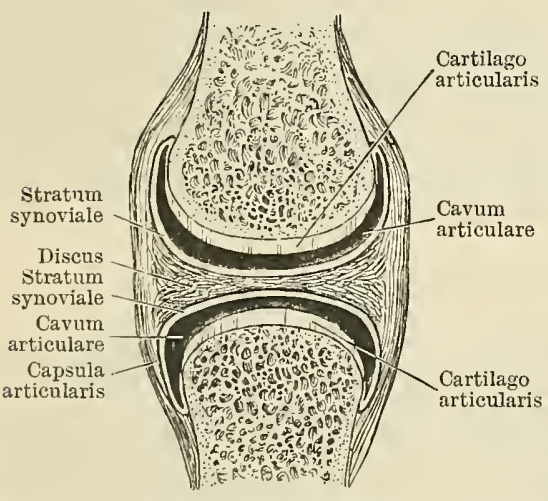

Fig. 291.-Diagram of a Diarthrodial Jotnt with Articdlar Disc Dividing the JolntCavity into two Compartments.

the changing conditions of the articulation.

compartments. By its periphery, a disc is rather to be associated with the articular capsule than with the articulating bones, although its attachments may extend to non-articular areas on the latter. Those found in the knee-joint are called menisci; those found in other joints are called articular discs.

Both interarticular ligaments and articular discs and menisci have their free surfaces covered by the synovial stratum.

Adipose tissue, forming pads of varying size, is usually found in certain localities within the joint, between the synovial stratum and the surfaces which it covers. These pads are soft and pliable, and act as packing material, filling up gaps or intervals in the joint. During movement they adapt themselves to

In addition to merely binding together two or more articulating bones, ligaments perform very important functions in connexion with the different movements taking place at a joint. They do not appreciably lengthen under strains, and thus ligaments may act as inhibitory structures, and by becoming tense may restrain or check movement in certain directions.

Synovial strata, in the form of closed sacs termed mucous or synovial bursæ, are frequently found in other situations besides the interior of joints. Such bursæ are developed for the purpose of reducing the friction, $(\alpha)$ between the integument and certain prominent subcutaneous bony projections, as, for instance, the point of the elbow, or the anterior surface of the patella 
(subcutaneous mucous bursæ); (b) between a tendon and some surface, bony or cartilaginous, over which it plays (subtendinous mucous bursæ); (c) between a tendon or a group of tendons and the walls of osteo-fascial tunnels, in which they play (vaginæ mucosæ tendinum or mucous sheaths of tendons). Subtendinous mucous bursæ are often placed in the neighbourhood of joints, and in such cases it not infrequently happens that there is a direct continuity between the bursa and the synovial stratum which lines the cavity of the joint through an aperture in the articular capsule.

\section{THE DIFFERENT KINDS OF MOTEMENT AT JOINTS.}

Reference has already been made to the existence of fixed axes of movement as a basis for the classification of certain forms of diarthrodial joints. Hence it is evident that the movements which are possible at any particular joint depend to a large extent upon the shape of its articular surfaces as well as upon the nature of its various ligaments. Therefore the technical terms descriptive of movements either indicate the directions in which they occur, or else the character of the completed movement.

In the great majority of articulations between short bones, the amount of movement is so restricted, and the displacement of the opposing articular surfaces so slight, that the term gliding sufficiently expresses its character.

A gliding movement of an extensive kind, for example that of the patella upon the femur, in which the movement largely resembles that of the tyre of a wheel revolving in contact with the ground so that different parts are successively adapted to each other, is called co-aptation.

Articulations between long bones, on the other hand, are usually associated with a much freer range of movement, with a corresponding variety in its character. Rotation is a movement around an axis which is longitudinal. Sometimes it is the only form of movement which a joint possesses; at other times it is merely one of a series of movements capable of execution at the same joint. Flexion or bending is a movement in which the formation of an angle between two parts of the body is an essential feature. As it is possible to perform this movement in relation to two axes, viz., a transverse and an antero-posterior axis, it is necessary to introduce qualifying terms. Thus, when two anterior or ventral surfaces are approximated, as at the hip-, elbow-, or wrist-joints, the movement is called ventral, anterior, or palmar flexion; but if posterior or dorsal surfaces are approximated by the process of bending, then the flexion becomes posterior or dorsi-flexion, as at the knee- or wristjoints. Further, at the wrist-joint, the formation of an angle between the ulnar border of the hand and the corresponding aspect of the forearm, produces ulnar flexion, and similarly the bending of the hand towards the radial border of the forearm is radial flexion.

Extension or straightening consists in obliterating the angle which resulted from flexion. In the case of certain joints, therefore, such as the elbow, wrist, and knee, the segments of the limb occupy a straight line as regards each other when extended.

At the ankle-joint the natural attitude of the foot to the leg is flexion at a right angle. The diminution of this angle by approximating the dorsum of the foot towards the anterior aspect of the leg constitutes flexion; whilea ny effort at placing the foot and leg in a straight line, i.e. obliteration of the angle, as in pointing the toes towards the ground and raising the heel, constitutes extension.

Abduction is a term which either expresses movement of an entire limb, in a direction away from the median plane of the body, or of a digit, away from the plane of the middle finger in the hand, or the plane of the second toe in the case of the foot.

Adduction is the reverse of abduction, and signifies movement towards the median plane of the body, or towards the planes indicated for the digits of the hand and foot.

Circumduction is a movement peculiarly characteristic of multiaxial or balland-socket joints. It consists in combining such angular movements as flexion, extension, abduction, and adduction, so as to continue the one into the other, whereby the joint forms the apex of a cone of movement, and the free end of the limb travels through a circle which describes the base of this cone. 


\section{THE DEVELOPMENT OF JOINTS.}

Just as the question of structure determines to a large extent the presence or absence of movement in joints, so in tracing their development it will be found that the mamner of their appearance forecasts their ultimate destination as immovable or movable articulations.

All joints arise in mesodermic tissue which has undergone more or less differentiation.

When this differentiation has produced a continuous membranous layer, in which ossific centres representing separate skeletal segments make their appearance, we get the primitive form of suture. The plane of the articulation merely indicates the limit of the ossific process extending from different directions. If, again, the differentiation of the mesoblast has resulted in the formation of a continuous cartilaginous layer, in which ossification commences at separate centres, the plane of the articulation is marked out by the unossified cartilage -in other words, the articulation is a synchondrosis. Ultimately this disappears through the extension of the process of ossification.

To some extent sutures also disappear, although their complete obliteration is not usual even in aged people. Developmentally, therefore, synarthroses or immovable joints do not present any special structural element, and, speaking generally, they have only a temporary existence.

The development of all movable joints is in marked contrast to that of synarthroses. Not only are they permanent arrangements so far as concerns normal conditions, but they never arise merely as planes which indicate the temporary phase of an ossific process. From the outset they present distinct skeletal units, from which the special structures of the joint are derived.

The primitive movable joint is first recognised as a mass of undifferentiated mesodermic cells situated between two masses, which have differentiated into primitive cartilage.

The cell-mass which constitutes the joint-unit presents the appearance of a thick cellular disc, the proximal and distal surfaces of which are in accurate apposition with the primitive cartilages, while its circumference is defined from the surrounding mesoderm by a somewhat closer aggregation of the cells of which the disc is composed. From this cellular disc or joint-unit all the structures characteristic of amphiarthrodial and diarthrodial joints are ultimately developed.

Thus, by the transformation of the circumferential cells into fibrous tissue the investing ligaments are produced. Within the substance of the disc itself a transverse cleft, more or less well-defined and complete, makes its appearance. In this manner the disc is divided into proximal and distal segments, separated from each other by an interval which is the primitive articular cavity. This cleft, however, never extends so far as to interrupt the continuity of the circumferential part of the disc which develops into the fibrous tissue of the investing ligaments. From the proximal and distal segments of the articular disc the various structures, distinctive of movable joints, are developed.

Thus, in amphiarthrodial joints the cellular articular disc or primitive joint-unit gives origin to the following structures:-From its circumference, investing ligaments; from its interior, the fibro cartilaginous plate in which an imperfect articular cavity with corresponding imperfect synovial stratum may be found.

In the case of a diarthrodial joint the changes take place on a more extended scale. The articular cavity becomes a prominent feature, in relation to which the surrounding fibrous structures form an investing capsule, lined with a synovial stratum.

When a single cleft arises, but does not extend completely across the longitudinal axis of the articular disc, the undivided portion develops into fibrous interarticular ligaments. On the other hand, when two transverse clefts are formed, that portion of the cellular disc which remains between them becomes transformed into a fibro-cartilaginous disc (or in the case of the knee-joint, menisci), which in its turn may either be complete or incomplete, and thus we may obtain two distinct synovial joint cavities belonging to one articulation. ${ }^{1}$

In considering the development of the synovial layer, and the surfaces on which it is found in the interior of a joint, it is necessary to keep clearly in mind that a synovial layer is a special structure, whose function it is to produce a lubricating fluid or synovia, and that, therefore, its position is determined by the essential necessity of proximity to a direct blood-supply. In other words, this condition is provided by all parts of

I From a series of observations upon the development of diarthrodial joints, the writer considers that there is evidence to show that the "cellular articular disc" is directly responsible for the production of the epiphyses which adjoin the completed articular cavity, and that, among such amphiarthroses as exist between the bodies of vertebræ, not only the intervertebral fibro-cartilage, but the proximal and distal epiphyses which ultimately unite with the vertebral bodies have a common origin in the joint-unit. 
the interior of an articular cavity except the articular encrusting cartilage. Consequently the synovial stratum is absent only from the free surface of articular cartilage, although it forms a thicker layer upon the inner surface of the articular capsule than upon the free surfaces of interarticular ligaments, discs, and menisci.

It is not necessary to simppose that the synovial stratum has disappeared from these articular cartilages as the result of friction, because, notwithstanding constant friction, such parts as the interior of articular capsules or the menisci of the knee-joint have not been denuded of their synovial covering.

As the epiphyses adjoining articular cavities are produced in the joint-units, the attachments of the capsule should be found upon, and restricted to, the non-articular surfaces of the articular epiphyses. While this is the case in their earliest stages, yet, as development advances, considerable variations arise, until, in the adult condition, the capsule of the larger articulations, more particularly of the extremities, is not always restricted to the epiphyses for its attachments. The student will readily perceive and appreciate these variations by comparing the accounts and illustrations of the epiphyses with those of the articulations, and he should note that in some cases the epiphysial line is extra-capsular, i.e. the capsular attachment is restricted to the epiphysis; in some the line is intra-capsular; and in some the epiphysial line is partly intra-capsular and partly extra-capsular.

\section{MORPHOLOGY OF LIGAMENTS.}

From what has been said in connexion with the development of joints, it will be evident that ligaments are essentially products derived from the cellular articular disc.

Nevertheless, in relation to the fully formed joint, many structures are described as ligaments which do not take origin in the manner just indicated. Some of these ligamentons structures remain fairly distinct from the articular capsules with which they are immediately associated; others become thoroughly incorporated with the articular capsules and cannot be separated therefrom, while yet others may be found situated within the capsule of a joint, and thus play the part of interarticular ligaments.

Instances of each of these forms of adventitious ligaments may be readily given. For example, we may instance the expansion of the tendon of the semimembranosus muscle to the oblique ligament of the knee-joint, and the offshoots from the tendon of the tibialis posterior muscle to the plantar aspects of various tarsal bones, as illustrations of structures which play an important part as ligaments, but are not indelibly incorporated with the joint capsule.

Of structures which have become indelibly incorporated with the primitive capstule, we may instance the broad tendinous expansions of the quadriceps extensor muscle around the knee-joint.

The tibial collateral ligament of the same joint is regarded as a detached portion of the tendon belonging to that part of the adductor magnus muscle which takes origin from the ischium, while the fibular collateral ligament of the knee is considered by some to be the primitive femoral origin of the peronieus longus muscle. Another illustration of the same condition is found in the coraco-humeral ligament, which is regarded by some as representing a detached portion of the pectoralis minor muscle.

Two illustrations may be given of structures playing the part of ligaments within the capsule of a joint, although in the first instance they are not developed as ligaments. It is questionable if the ligamentum teres of the hip-joint is an interarticular ligament in the true sense of the term; it has been regarded as the isolated and displaced tendon of the ambiens muscle found in birds. In the shoulder-joint, many observers look npon the superior gleno-humeral ligament as representative of the ligamentum teres.

Such structures as the stylo-hyoid ligament and the spheno-mandibular ligament, although described as ligaments, are in reality skeletal parts which have not attained their complete ossific development.

Again, certain portions of the deep or muscular fascia of the body which become specialised into restraining and supporting bands (e.g. the ilio-tibial tract of the fascia lata; the stylo-mandibular ligament; the transverse carpal and dorsal carpal ligaments of the wrist-joint; the transverse crural ligament, and lig. laciniatum of the ankle-joint), although called ligaments, have no direct developmental association with articular ligaments.

Lastly, the inguinal ligament of Poupart and the lacumar liganent of Gimbernat, being special developments in connexion with an expanded tendon or aponeurosis, are still further removed from association with an articulation.

\section{LIGAMENTA COLUMNAE VERTEBRALIS ET CRANII.}

Ligaments of the Vertebral Column and Skull.-All vertebre, with the exception of those which deviate from the common rertebral type, present two sets of articulations whose various parts are arranged upon a uniform pattern. Thus, every pair of typical vertebræ presents an articulation between the bodies, and a pair of articulations between the rertebral arches. With the latter there 
are associated various important accessory ligaments which bind together laminæ, spinous processes, and transverse processes.

Articulations between Bodies of Vertebræ.-These are amphiarthrodial joints. Singly, they present only a slight degree of mobility, but when this amount of movement is added to that of the whole series, the range of movement of the vertebral

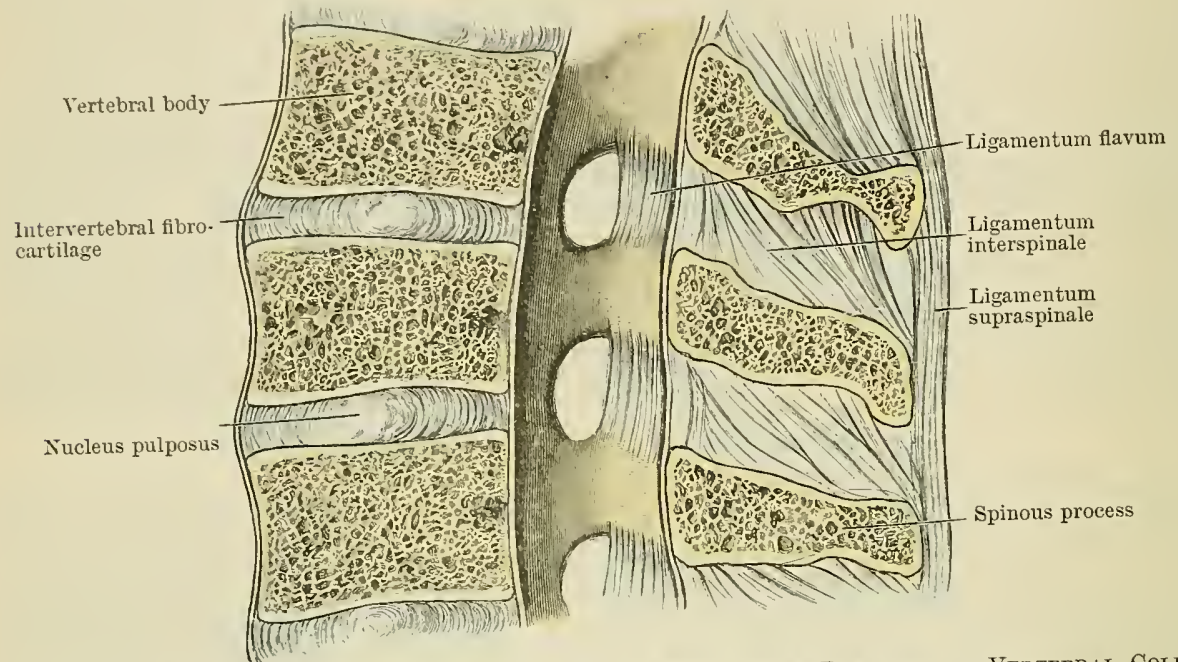

Fig. 292. - Median Section through a Portion of the lumbar Part of the Vertebral Columin. column becomes considerable. The articular surfaces are the flattened surfaces of adjacent vertebral bodies. They are bound together by the following structures:-

Fibrocartilagines Intervertebrales (Fig. 292).-Each intervertebral fibrocartilage accommodates itself to the space it occupies between the two vertebral bodies, to both of which it is firmly adherent. The fibro-cartilages, from different

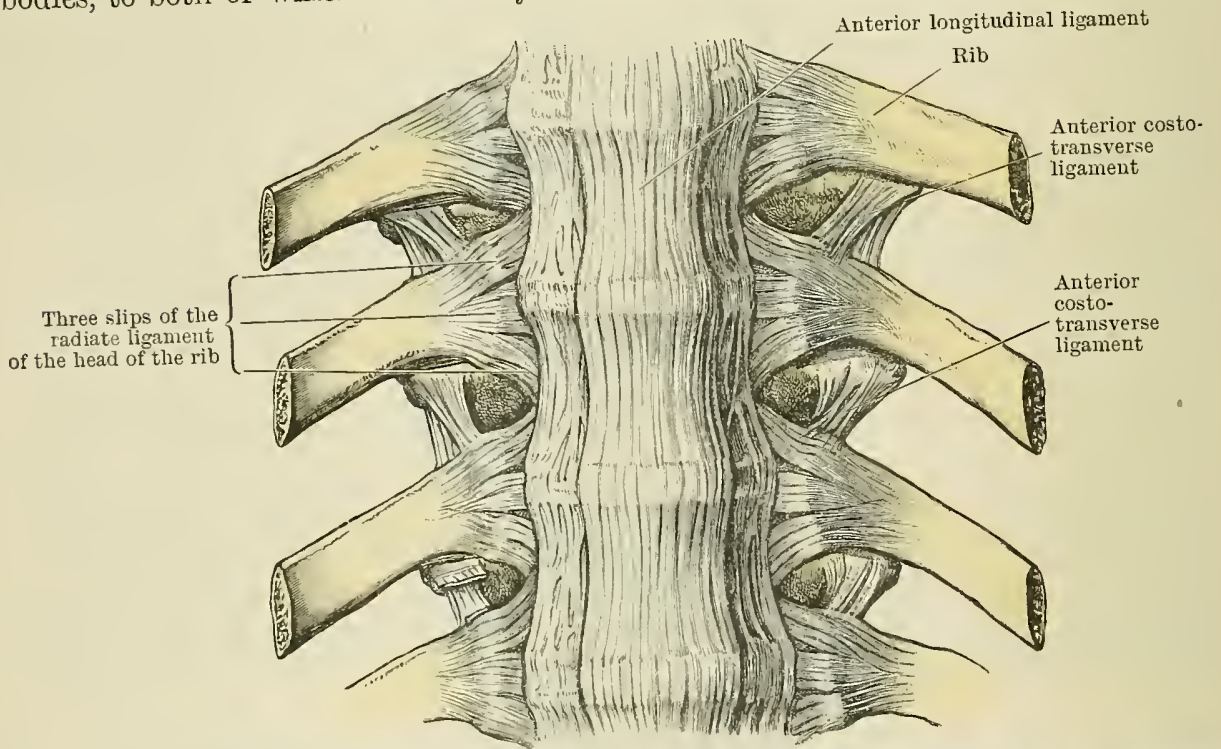

Fig, 293.-Anterior Longitudinal Ligament of the Vertebral Coldme, and the Costo-vertebral JOINTS AS SEEN FROM THE FRONT.

parts of the vertebral column, vary in vertical thickness, being thinnest from the third to the seventh thoracic vertebra, and thickest in the lumbar region. In the cervical and lumbar regions each fibro-cartilage is thicker anteriorly than posteriorly, thereby assisting in the production of the anterior convexity which characterises the vertebral column in these two regions. In the thoracic region 
the fibro-cartilages are thinnest on their anterior aspects in correspondence with the anterior concavity of this section of the rertebral column.

Each fibro-cartilage consists of a circumferential portions, annulus fibrosus, formed for the most part of oblique parallel fibres running from one vertebra to the other; horizontal fibres are also found. The axial or central part of the fibrocartilage, the nucleus pulposus, is elastic, soft, and pulpy.

The superior and inferior surfaces of the fibro-cartilage are closely adherent to the adjoining epiphyseal plates of the vertebral bodies, and as ossification advances, the distinction between epiphyseal plates and vertebral body disappears.

As a rule the transverse diameter of the fibro-cartilage corresponds to that of the vertebral bodies which it joins together; but in the cervical region, where the inferior margin of the super-imposed vertebra is overlapped on each side by the one which bears it, the fibro-cartilage does not extend to the extreme lateral margin, and in this position a small diarthrosis may be seen at each lateral margin of the fibro-cartilage.

Lig. Longitudinale Anterius. - The anterior longitudinal ligament (O.T. anterior common ligament) (Fig. 293) consists of a wide stratum of longitudinal fibres which extends from the front of the epistropheus vertebra to the front of the superior segment of the sacrum, and becomes gradually wider from above downwards. It lies on the anterior surfaces of the intervertebral fibro-cartilages, to which it is firmly attached as it passes from one vertebra to the other. Its fibres vary in length. Some are attached to contiguous margins of two adjoining vertebre; others pass in front of one vertebra to be attached to the next below, and yet others find their lower attachment three or four vertebræ below the one from which they started. None of the fibres are attached to the transverse depression on the anterior surface of a vertebral body.

Lig. Longitudinale Posterius. - The posterior longitudinal ligament (O.T. posterior common ligament) (Fig. 294) is found within the vertebral canal upon the posterior aspect of the vertebral bodies. It consists of longitudinal fibres, and it extends from the sacrum to the epistropheus vertebra, superior to which it is continued to the skull as the membrana tectoria. Opposite each intervertebral fibro-cartilage it is attached to the entire width of the adjacent margins of the two vertebral bodies, its fibres being continued over the posterior surface of the fibro-cartilage. In the lumbar and thoracic regions the width of the ligament is considerably reduced opposite the back of each vertebral body, and thus it forms a series of dentate projections along both of its margins; but in the cervical region the width of the ligament is more uniform. One or two large thin-walled reins escape from the body of each vertebra under cover of this ligament.

\section{Articulations between Vertebral Arches.-}

The vertebral arch of each typical vertebra carries two pairs of articular processes, by means of which it articulates with adjacent vertebral arches. The articulations between these processes are true diarthroses of the arthrodial variety.

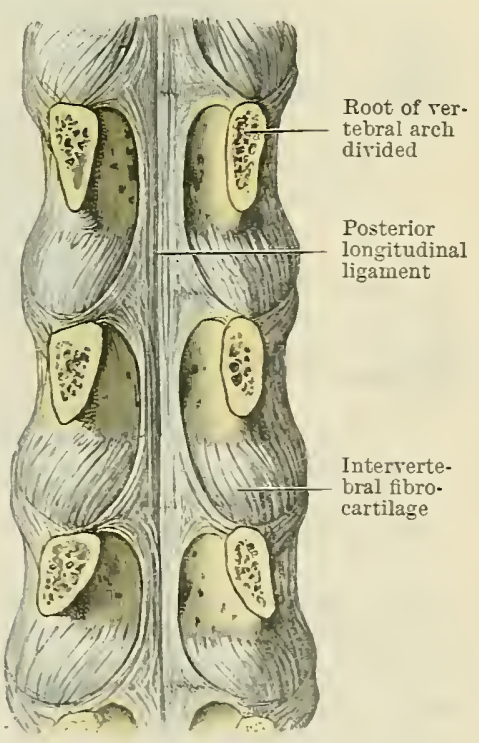

Fig. 294.-Posterior LoygitcdinaL Ligaiest of the Tertebral Colcar.

The distinctive characters of these articular surfaces, as regards their shape and direction in the different groups of vertebræ, have been referred to in the section on osteology.

All these articulations are provided with complete but very thin-walled capsulæ articulares, which are thinnest and loosest in the cervical region, where also the movements are freest. Each capsule is lined with a stratum synoviale.

Associated with these joints between rertebral arches are certain ligaments which are accessory to the articulations, although they are quite distinct from the capsule. 
The laminie of adjoining vertebre are bound together by the ligamenta flava (O.T. subflava) (Fig. 295), which consist of yellow elastic fibres. The ligamenta Hava cluse the rertebral canal in the intervals between the laminæ. Each ligament is attached superiorly to the anterior aspect of one lamina at a short distance above its inferior border, and inferiorly it is attached to the posterior aspect of the subjacent lamina.

In the thoracic region, where the imbrication of adjoining laminæ is a prominent feature, these ligiments are not so distinctly visible from behind as they are in the regions where imbrication of the laminie is not so marlied.

Laterally they extend as far as the articular capsules, while medially the margins of the ligaments of opposite sides meet under cover of the root of the spinous process.

Contiguous spinous processes are also attached to each other by ligamenta interspinalia (interspinous ligaments) (Fig. 292). These are strongest in the lumbar, and weakest in the thoracic region. Each consists of layers of obliquely interlacing fibres which spring from near the tips of the two adjacent spinous process

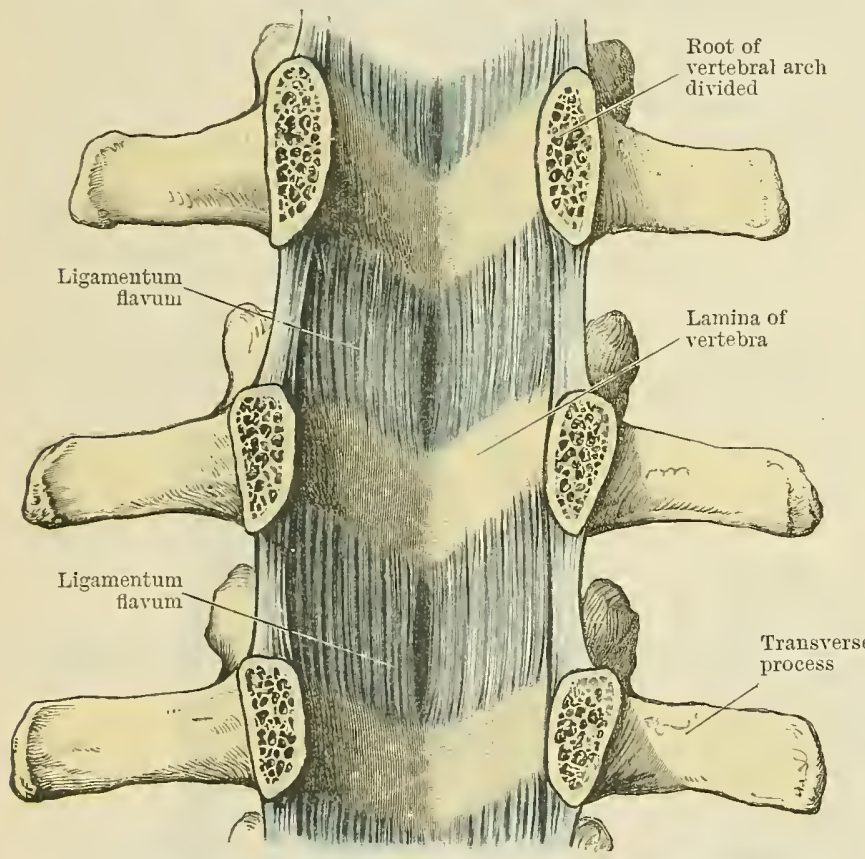

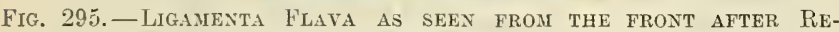
Motal of THE Bodies OF THE VERTEBRE BY SAWING THROUgh THE Roots of the Tertebral Arches. posing margins. In the antero - posterior direction they extend from the base to the tip of the spinous process.

The ligamenta supraspinalia (supra-spinous ligaments) (Fig. 292) consist of longitudinal bands of fibres of varying lengths. They extend from spine to spine, being attached to their tips, and are situated superficial to, although in continuity with, the ligamenta interspinalia.

In the cervical region this series of ligaments is extensively developed, where they project backwards from the spinous processes between the muscles of the two sides of the neck in the form of an elastic partition called the ligamentum nuchæ.

The antero-posterior extent of the ligamentum nuchæ increases as it approaches the occiput, where it is attached to the external occipital crest from the external occipital protuberance to the posterior border of the foramen magnum. Its posterior margin is free, and extends from the extemal occipital protuberance to the spine of the vertebra prominens.

Between the transverse processes there are ligamenta intertransversaria, which consist of vertical fibres extending from the postero-inferior aspect of one transverse process to the superior margin of that next below. These ligaments are generally absent from the cervical and upper thoracic regions.

Sacro-coccygeal Symphysis.-The last piece of the sacrum is joined to the first piece of the coccyx by an intervertebral fibro-cartilage, and the junction is rendered more secure by the presence of certain strong ligaments. A lig. sacrococcygeum anterius, continuous with the lig. longitudinale anterius, is placer in front. A lig. sacrococcygeum posterius, which stretches downwards from the sharp border of the lower opening of the sacral canal, strengthens the joint behind. A 
lig. sacrococcygeum laterale supports the joint on each side, whilst strong bands pass between the cornua of the two bones and constitute the interarticular ligaments.

Intercoccygeal Joints.-So long as they remain separate, the different pieces of the coccyx are joined by intervertebral fibro-cartilages and by anterior and posterior ligaments.

Movements of the Vertebral Column.-Although the amount of movement permissible between any two vertebre is extremely limited, yet the total range of movement capable of being attained by the entire vertebral column is very considerable.

Flexion may occur both forwards and backwards at the articulations of rertebral bodies, but more freely in the lumbar and cervical regions than in the thoracic region, where the limited amount of intervertebral fibro-cartilage and the imbrication of the laminæ and spines restrict the movement. Backward flexion is most pronounced in the cervical region, and forward flexion in the lumbar region. Between the articular surfaces of the articulations between vertebral arches a variety of movements are permitted, dependent upon the directions of these surfaces. Thus lateral flexion is permitted in the lumbar, but not in the cervical or dorsal regions. Again, in the lumbar region rotation does not occur, owing to the shape of the articular processes, while it is possible in the thoracic region. In the cervical region the shape and position of the articular surfaces prevent the occurrence both of lateral flexion and of rotation as isolated movements, but a combination of these two movements may take place, whereby rotatory movement in an oblique median axis results. Finally, in the lumbar region, by combining the four forms of flexion, viz., forward, backward, and lateral, a certain amount of circumduction is possible.

\section{Articulatio Atlantoepistrophica.}

Between the atlas and epistropheus vertebræ three diarthroses occur. Two of them are situated laterally, in relation to the articular processes, and are called

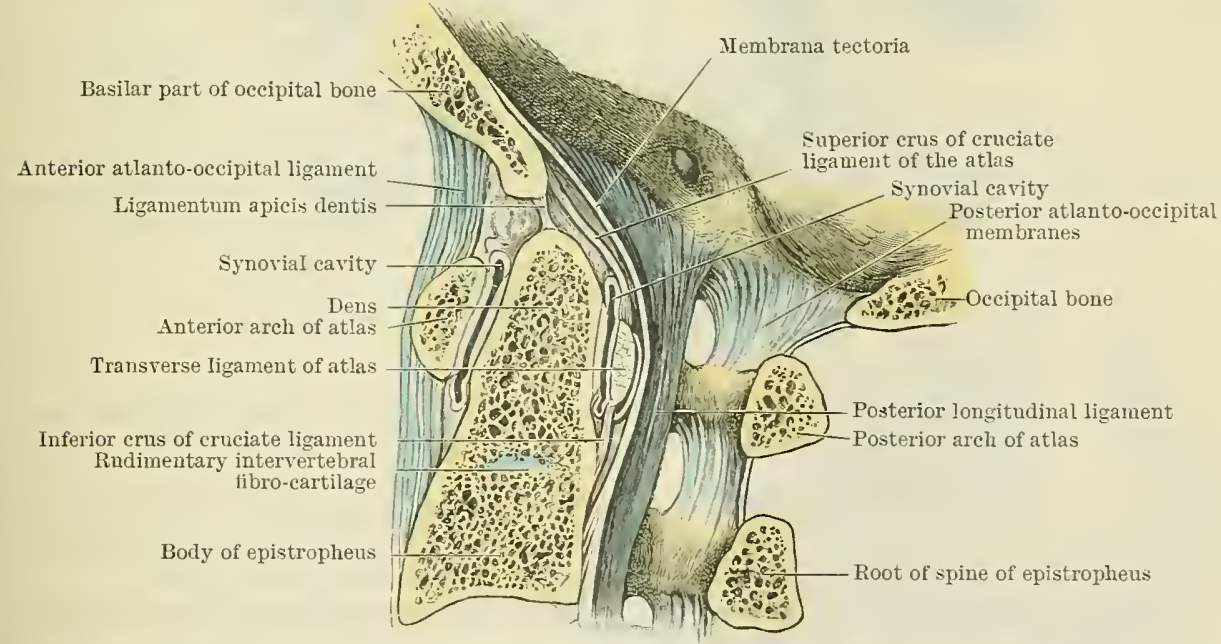

Fig. 296.-Median Section throdgh the Atlanto-uccipital ayd Atlanto-epistropheal Jolits.

arthrodial diarthroses, because of the flattened nature of the articulating surfaces. The third articulation is median in position. It is found between the smooth anterior surface of the dens of the epistropheus and the articular facet on the posterior aspect of the anterior arch of the atlas. This joint is a rotatory diarthrosis.

Ligamenta.-Each of the joints is furnished with a capsula articularis, whereby the articular cavity is circumscribed. In the case of the lateral articulations, each articular capsule presents a distinct band, named the accessory ligament, which is situated within the vertebral canal ( Fig. 297), and passes downwards and inwards from the lateral mass of the atlas to the superior aspect of the body of the epistropheus.

The following additional ligaments constitute the leading bonds of union :-

Lig. Obturatorium Atlantoepistrophica Anterior.-The anterior covering atlanto-epistropheal ligament (O.T. anterior atlo-axoid ligament) (Fig. 296) is a membranous structure which is thin laterally, but strong in the median plane, where it is thickened by a prolongation of the lig. longitudinale anterius. It extends from the anterior arch of the atlas to the front of the body of the epistropheus. 
Lig. Obturatorium Atlantoepistrophica Posterior.-The posterior covering atlanto-epistropheal ligament (O.T. posterior atlo-axoid ligament) (Fig. 296) occupies the position which is elsewhere taken by the ligamenta flava. It extends from the posterior arch of the atlas to the upper border of the vertebral arch of the epistropheus.

Lig. Transversum Atlantis.-The transverse ligament of the atlas (Figs. 296 and 297 ) is a strong band, placed transversely, which arches backwards behind the neck of the dens of the epistropheus. By its extremities it is attached to the tubercle on the medial aspect of each lateral mass of the atlas. A thin plate of fibro-cartilage is developed in its central part.

A stratum synoviale (synovial membrane) lines each of the three articular capsules, and in addition a synovial sac is developed between the dens and the lig. transversum atlantis. This is more extensive than the synovial cavity between the dens and the atlas.

\section{Articulatio Atlanto-occipitalis.}

There are two articulations between the atlas and the occipital bone. Each is a diarthrosis in which morement takes place in relation to two axes, viz., the

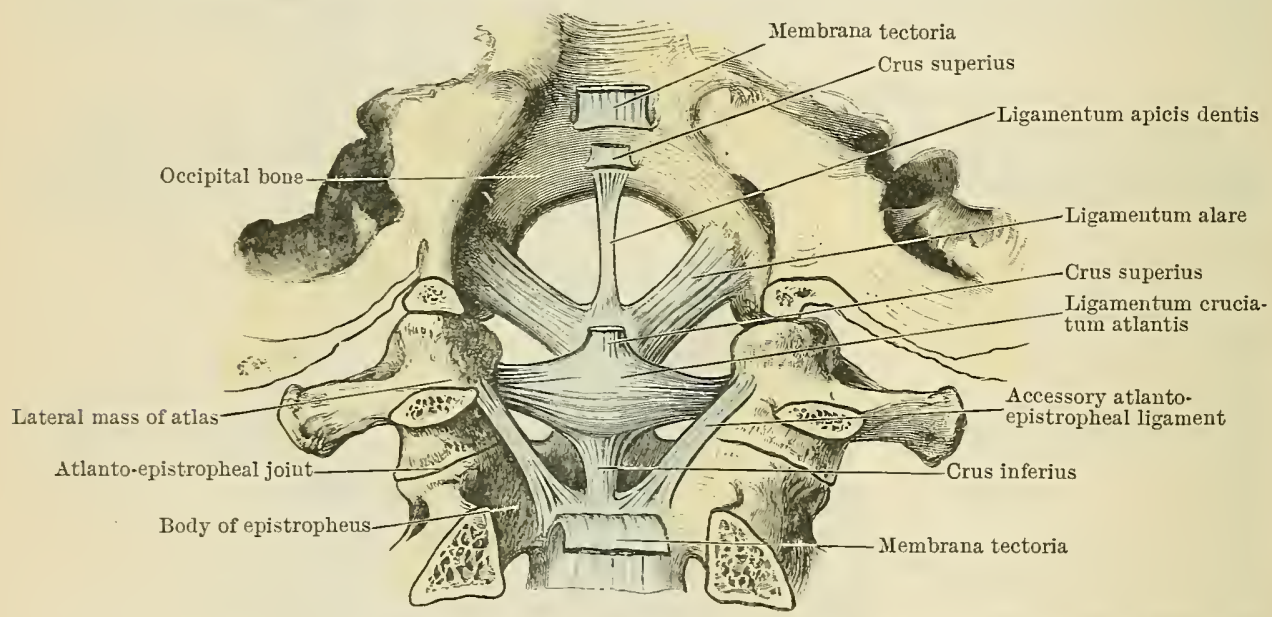

Fig. 297.-Dissection from behind of the Ligaments connecting the Occipital Bone, the AtLas, A.T THE EPISTROPHEUS WITH EACH OTHER.

transverse and the antero-posterior. The condyle of the occipital bone is biconvex, and fits into the bi-concave superior articular surface of the atlas, while the long axes of the two joints are directed horizontally forwards and medially.

Ligamenta.-Each articulation is provided with a capsula articularis which is thin but complete. It is attached to the rough non-articular surfaces surrounding the articular areas on the atlas and occipital bone.

The following supplementary ligaments are the chief structures which bind the atlas to the occipital bone:-

The membrana atlanto-occipitalis anterior (anterior occipito-atloid membrane) (Fig. 296) is a strong although thin membrane, attached inferiorly to the anterior arch of the atlas, and superiorly to the anterior half of the circumference of the foramen magnum. Laterally it is in continuity with the articular capsules, while in the median plane, where it extends from the anterior tubercle of the atlas to the basilar part of the occipital bone, it presents a specially well-defined thickened band which might be regarded as a separate accessory ligament or as the beginning of the anterior longitudinal ligament of the vertebræ.

The membrana atlanto-occipitalis posterior (posterior occipito-atloid membrane) (Fig. 296) is another distinct but still thin membrane which is attached superiorly to the posterior half of the circumference of the foramen magnum, and inferiorly to the upper border of the posterior arch of the atlas. Laterally it also is continuous with the articular capsules. On each side of the median plane its inferior border 
is arched in relation to the vertebral groove, and is therefore to some extent free, in order to permit the passage of the posterior ramus of the first cervical nerve and the vertebral artery. Not infrequently this arched border becomes ossified, thus converting the groove on the bone into a foramen.

A synovial stratum lines each of the articular capsules.

There is no direct articulation between the epistropheus and the occipital bone, but union between them is effected by means of the following accessory ligaments :-

The membrana tectoria (Fig. 296) is situated within the rertebral canal, and is usually regarded as the upward continuation of the posterior longitudinal ligament of the vertebral bodies. It extends from the posterior surface of the body of the epistropheus to the basilar groove on the superior surface of the basilar part of the occipital bone, spreading laterally on the circumference of the foramen magnum. Some of its deepest fibres are attached to the atlas immediately above the atlantoepistropheal articulation.

Subjacent to the membrana tectoria there is the ligamentum cruciatum atlantis (Fig. 297), a structure which is very closely associated with the lig. transversum atlantis. It consists of a crus transversum, formed by the superficial fibres of the transverse ligament of the atlas; a crus inferius, consisting of median longitudinal fibres which are attached below to the posterior surface of the body of the epistropheus, and above to the crus transrersum; and a crus superius, also median and longitudinal, whose fibres extend from the crus transversum upwards to the posterior surface of the basilar part of occipital bone, immediately subjacent to the membrana tectoria.

Ligamenta Alaria.-The alar ligaments (O.T. check ligaments) (Fig. 297) are two very powerful, short, and somewhat rounded bands. They are attached medially to the sides of the summit of the dens, and laterally to the tubercle on the medial aspect of the condylar portions of the occipital bone.

Ligamentum Apicis Dentis. - The ligament of the apex of the dens (O.T. middle odontoid) (Fig. 297) consists of fibres running vertically upwards from the apex of the dens to the median part of the anterior margin of the foramen magnum. This ligament to some extent represents an intervertebral fibro-cartilage, in the centre of which remains of the notochord may be regarded as present.

Even in advanced life a small lenticular mass of cartilage, completely surrounded by bone, persists in the plane of fusion between the dens and the body of the epistropheus.

Movements at these Joints. At the joints between occipital bone and atlas the movements are very simple, and consist essentially of movements whereby the head is elerated and depressed upon the vertebral column (nodding movements). In addition a certain amount of oblique movement is possible, during which great stability is attained by resting the anterior and posterior parts of opposite condrles upon corresponding parts of the atlas.

The head and the atlas rotate together upon the epistropheus, the pivot of rotation being the dens, and the amount of rotation is limited by the ligamenta alaria. No rotation can occur between the occiput

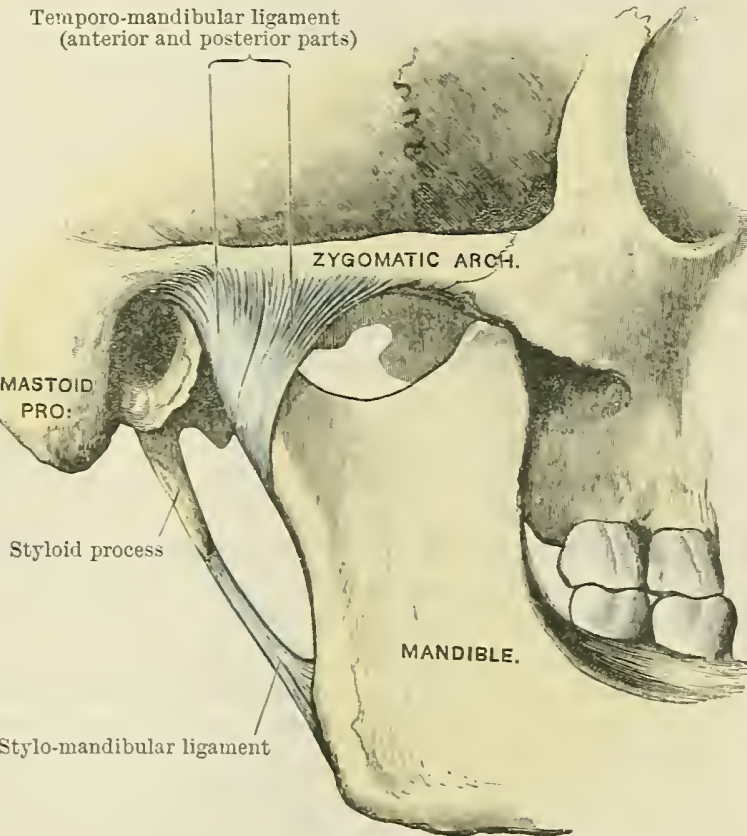

Fig. 298. - MaNdibUtaR Jorvt. and atlas, and stability between atlas and epistropheus is best attained after a slight amount of rotation, similar to the oblique movement between occipital bone and atlas. 


\section{ARTICULATIO MANDIBULARIS.}

The mandibular joint (O.T. temporo-mandibular) is an arthrodial diarthrosis. It occurs between the mandibular fossa of the temporal bone and the condyle of the mandible. These two articular surfaces are markedly dissimilar both in size and shape. In its general outline the articular surface of the head of the

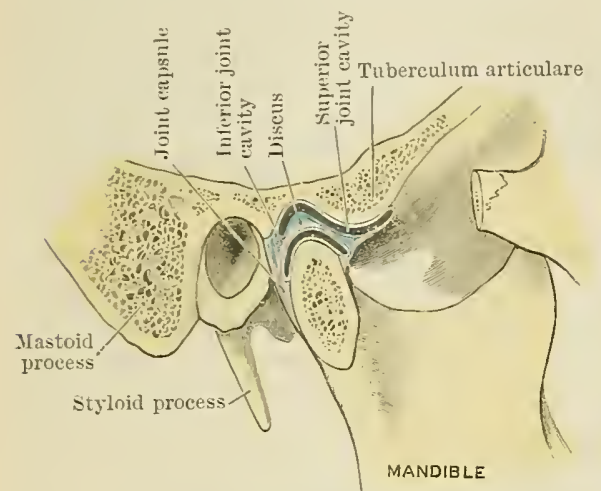

Fig. 299.-Section throdgh the MaNdrbdLaR JoINT. mandible is eylindrical, having its long axis directed from the medial side laterally and forwards. On the other hand, the mandibular fossa is concavo-conrex from behind forwards. Its articular surface includes the tuberculum articulare-the eminence at the base of the anterior root of the zygoma. The articular surfaces of the bones are clothed with hyaline encrusting cartilage, whilst the articular cavity is divided into a superior and inferior part by a disc of fibro-cartilage.

Ligaments. - The joint is invested by an articular capsule which is quite complete, but is very thin on the medial side. The lateral part of the fibrous stratum of the capsule - the temporo-mandibular liga-

ment (O.T. external lateral) (Fig. 298)-is divisible into anterior and posterior portions which are attached superiorly to the root tubercle and inferior border of the zygomatic process of the temporal bone, and inferiorly to the lateral side and posterior border of the neck of the mandible. The direction of its fibres is downwards and backwards.

Within the capsule there is a disc of fibro-cartilage, the discus articularis (Fig. 299), which is moulded upon the condyle of the mandible below, and on the articular surface of the temporal bone above. It thus compensates for the incongruity between the articular surfaces of the two bones. The disc is attached circumferentially to the capsule. It is widest in the transverse direction, thicker posteriorly than anteriorly, and thinnest towards the centre, where it may be perforated. Its anterior margin is intimately associated with the insertion of the external pterygoid muscle.

A synovial stratum lines each of the compartments into which the joint cavity is divided by the disc. As a rule these membranes are separate from each other, but they become continuous when the disc is perforated. The superior synovial stratum is larger and more loosely disposed than the lower.

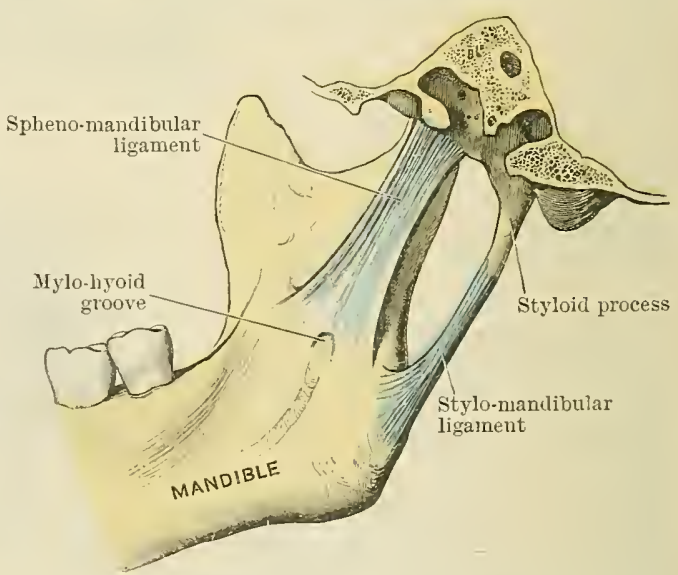

Fig. 300.--Sphexo-Mandibular Ligament of the Maxdibular Joint.

Situated on the medial aspect of the joint, but at a short distance from it, and quite distinct from the capsule, there is an accessory band called the lig. sphenomandibulare (Fig. 300). Superiorly the spheno-mandibular ligament (O.T. internal lateral) is attached to the angular spine of the sphenoid bone, and inferiorly to the inferior as well as the posterior border or lingula of the inferior alveolar foramen. It is not an articular ligament in the true sense; for, instead of being connected with the joint, it is developed in the tissue surrounding part of Meckel's cartilage. 
Portions of the following structures are found in the interval between the spheno-mandibular ligament and the ramus of the mandible - viz., the external pterygoid muscle; internal maxillary ressels; inferior alveolar vessels and nerve; middle meningeal vessels; auriculotemporal nerve ; and sometimes a deep portion of the parotid gland.

Movements of the Mandible.-The nature of the movements which the mandible can perform is determined partly by the character of the articular surfaces of the mandibular joint, and partly by the fact that, while the two joints always act simultaneonsly, they may also, to some extent, perform the same movement alternately.

When movement takes place throngh the long or transverse horizontal axis of each joint, the mandible may be elevated, as in clenching the teeth, or it may be depressed, as in gaping. In the latter movement the condyle leaves the mandibular fossa, and, along with the disc, it moves forwards until they rest upon the tuberenlum articulare. Meantime the chin describes the arc of a circle, of which the centre or point of least movement corresponds to the position of the inferior alveolar foramen, and thus the structures which enter at that foramen are protected against stretching. Coincidently with the forward movement of the condyle, it glicles in a revolving manner upon the inferior aspect of the disc.

At any stage in the movement of depressing the chin the mandible may be protruded, so that the inferior incisor teeth are projected in front of the upper set, a movement which results from the condyles of the mandible being drawn forwards upon the articular tubercles. A similar relation of the condyle to the articular tubercle occurs during the exaggerated depression of the mandible which results from yawning, in which position the articulation is liable to be dislocated. When the two joints perform the same morement alternately, a certain amount of lateral motion results, from the fact that the long axis of each joint presents a slight obliquity to the transverse axis of the skull, and consequently a grinding or oblique movement in the horizontal plane is produced. Excessive depression, with the risk of dislocation, is resisted by the fibres of the temporo-mandibular ligament, which becomes tense.

In all morements of the mandible the disc conforms closely to the position of the condyle, and they move forwards and backwards together, but at the same time the disc does not restrict the movements of the condyle. Thus while the disc, along with the condyle, is gliding upon the temporal aspect of the joint, the condyle itself revolves upon the inferior surface of the disc.

\section{Cranial Ligaments not directly associated with Articulations.}

Lig. Stylomandibulare.-The stylo-mandibular ligament (Figs. 298 and 300) is a specialised portion of the deep cervical fascia which extends from the anterior aspect of the tip of the styloid process of the temporal bone to the posterior border of the angle of the mandible, between the insertions of the masseter and internal pterygoid muscles.

Lig. Pterygospinosum.-The pterygo-spinous ligament is a membrane extending from the upper part of the posterior free margin of the lateral pterygoid lamina, posteriorly and slightly laterally, to the angular spine of the sphenoid. An interval is left between its upper border and the floor of the skull for the outward passage of those branches of the inferior maxillary nerve which supply the external pterygoid, temporal, and masseter muscles. This ligament has a tendency to ossify either wholly or partially.

Lig. Stylohyoideum.-The stylo-hyoid ligament may be regarded as the downward continuation of the styloid process of the temporal bone. Inferiorly it is attached to the lesser cornu of the hyoid bone. It is not infrequently ossified, in which case it constitutes the epihyal bone found in many animals.

\section{THE JOINTS OF THE THORAX.}

\section{Articulationes Costovertebrales (Costo-vertebral Articulations). - The} typical rib articulates with the vertebral column both by its head and by its tubercle. Thus, two sets of articulations, with their associated ligaments, exist between the ribs and the vertebræ, but each set is constructed upon a common plan, with the exception of certain joints situated at the upper and lower ends of the series, where the ribs themselves deviate from the typical form.

\section{Articulationes Capitulorum.}

The articulations of the heads of the ribs with the bodies of the vertebræ (Fig. 293) are all diarthroses, which, from their somewhat hinge-like action, may be classed as ginglymoid. 
The head of every typical rib is wedge-shaped, and presents two articular facets, an upper and a lower, separated from each other by an antero-posterior ridge which abuts against an intervertebral fibro-cartilage, while the articular facets articulate with similar surfaces on the contiguous margins of the two vertebræ adjoining the fibro-cartilage. These surfaces form a wedge-shaped depression or cup, the bottom of which is more elastic than the sides, and thus an arrangement is provided which tends to reduce the shock of blows upon the walls of the chest.

Each of these articulations is provided with an articular capsule which surrounds and encloses the joint, and is attached to contiguous non-articular margius on the head of the rib and the two vertebral bodies. On its anterior or rentral aspect the capsule presents three radiating fasciculi which collectively form the lig. capituli costæ radiatum (radiate ligament of the head of the rib (O.T. stellate)) (Fig. 293). These fasciculi radiate from a centre on the anterior surface of the head of the rib, so that the middle fasciculus becomes attached to the intervertebral fibro-cartilage while the upper and lower fasciculi proceed to the adjacent margins of the two vertebræ between which the fibro-cartilage is situated, and with which the rib articulates. To a slight extent these radiating fasciculi pass under cover of the lateral margin of the anterior longitudinal ligament of the vertebral bodies. In those joints in which the head of the rib does not articulate with an intervertebral fibro-cartilage the central fasciculus of the radiate ligament is wanting, but the other two retain the same general arrangement.

Lig. Capituli Costæ Interarticulare.-The interarticular ligament of the head of the rib consists of short transverse fibres within the capsule. These are attached, on the one hand, to the ridge which intervenes between the two facets on the head of the rib, and on the other to the lateral aspect of the intervertebral fibro-cartilage. This ligament is not a disc or meniscus, but merely an interarticular ligament, of width sufficient to divide the joint cavity into an upper and a lower compartment. It is absent from those joints which do not articulate with an intervertebral fibrocartilage, i.e. from those ribs which articulate with the body of only one vertebra.

The interarticular ligament is supposed to represent the lateral end of a ligament which, under the name of the lig. conjugale costarum, connects the heads of the ribs of certain mammals across the posterior aspect of the intervertebral fibro-cartilage, and, in the human subject, until the seventh month of fotal life, connects the posterior aspects of the necks of a pair of ribs with each other across the median plane.

A stratum synoviale lines each joint cavity, and therefore, in all cases where the joint is divided into two compartments, each one has its own synovial lining.

\section{Articulationes Costotransversarie.}

In the costo-transverse joints the tubercle of each typical rib articulates with the transverse process of the lower of the two thoracic vertebræ with which the head of the rib is associated. Near the tip of the transverse process there is an articular facet, on its anterior aspect, for articulation with the corresponding facet on the medial articular part of the rib tubercle. The joint so formed is an arthrodial diarthrosis.

The joint cavity is surrounded by a comparatively feeble capsula articularis, which is attached immediately beyond the margins of the articular facets, and in which no special bands can be distinguished.

A simple stratum synoviale lines the capsule in all cases where the latter is present.

The following accessory ligaments, in connexion with this joint, strengthen and support the articulation:-

Ligamentum Costotransversarium Anterius.-The anterior costo-transverse ligament (O.T. superior) (Fig. 293) consists of strong bands of fibres which are attached to the superior border of the neck of the rib, extending from the head laterally to the non-articular part of the tubercle. All these fibres may be traced upwards. Those situated nearest to the head of the rib proceed obliquely upwards and laterally, to be attached to the transverse process immediately above, but with 
extensions to the adjoining rib and its costo-transverse articular capsule. Others proceed almost vertically upwards to the adjoining transverse process, while those which ascend from the upper surface of the tubercle pass obliquely upwards and inwards to reach the postero-inferior aspect of the adjoining transverse process. Some posterior fibres connected with the transverse process at its junction with the lamina are called the posterior costo-transverse ligament.

Lig. Tuberculi Costæ. - The ligament of the tubercle of the rib is a band of transverse fibres applied to the postero-lateral aspect of the capsule. By one end these fibres are attached to the tip of the transverse process behind its articular facet, and by the other to the external rough surface of the tubercle of the rib.

Lig. Colli Costæ. - The ligament of the neck of the rib (O.T. middle costotransverse ligament) consists of short fibres which stretch from the posterior aspect of the neck of the rib, backwards and medially, to the anterior aspect of the transverse process, but, in addition, a proportion of the fibres passes to the posterior aspect of the inferior articular process of the upper of the two vertebræ with which the head of the rib articulates.

The following exceptions to the general plan of rib-articulation indicated above must be noted :-

1. There is no articulation between the eleventh and twelfth ribs and the transverse processes of the corresponding vertebræ.

2. The anterior costo-transverse ligament is wanting from the first rib, and is either rudimentary or wanting in the case of the twelfth rib.

3. The lig. colli costæ is rudimentary in the eleventh and twelfth ribs.

The ligamentum lumbocostale extends from the inferior surface of the base of the transverse process of the first lumbar vertebra to the inferior surface of the neck of the twelfth rib, as well as to the inferior surface of the transverse process of the twelfth thoracic vertebra.

\section{Articulationes Costochondrales.}

Each rib possesses an, unossified portion, termed its costal cartilage. As age advances, this cartilage may undergo a certain amount of superficial ossification, but it never becomes entirely transformed. The line of demarcation between bone and cartilage is clear and abrupt, and usually the bone forms an oval cup, in which the end of the cartilage is retained by means of the continuity which exists between the periosteum and the perichondrium. There is no articulation in the proper sense between the rib and its cartilage, although a synovial cavity has occasionally been found between the first rib and its cartilage.

\section{Articulationes Interchondrales.}

Interchondral joints are arthrodial diarthroses, and they are found between adjoining margins of certain of the costal cartilages, viz., from the fifth to the eighth or ninth. The cartilages which thus articulate develop flattened, somewhat conical, prolongations of their substance, and thereby the intercostal spaces are interrupted where these flat articular facets abut against each other. Each joint is closed by a surrounding articular capsule, the superficial and thoracic aspects of which are specially strengthened by external and internal interchondral ligaments. Thesc bands extend obliquely between adjacent cartilages.

A stratum synoviale lines each joint capsule.

\section{Articulationes Steriocostales.}

The upper seven pairs of costal cartilages, as a rule, extend to the lateral margins of the sternum to form sterno-costal joints. Of these, the first pair is implanted directly upon the manubrium sterni. The ossific process ends abruptly in connexion with the rib, and also ceases as suddenly in connexion with the sternum, and hence the cartilage does not normally present an articulation at either end. From the second to the serenth pairs of ribs inclusive, the sterno-costal joints are constructed upon the type of arthrodial diarthroses, although, in the case 
of the sixth and seventh cartilages, the joint cavity is always small, and is frequently obliterated.

The sternal end of each of these costal cartilages presents a slight antero-posterior ridge which fits into a shallow $V$-shaped depression upon the lateral margin of the sternum. With the exception of the sixth cartilage, they articulate opposite the lines of union between the primary segments of the sternum; the sixth articulates upon the side of the lowest segment of the body of the sternum.

Each joint is enclosed by a capsula articularis, the fibrous stratum of which is attached to the adjacent borders of the articulating elements. Specially strong fibres distinguish the superficial and deep aspects of the capsule.

The lig. sternocostale radiatum (O.T. anterior costo-sternal ligament) (Fig. 301) is composed of strong fibres "which radiate from the anterior surface of the costal cartilage, near its sternal end, to the front of the sternum. The ligaments of opposite sides interlace with each other, and so cover the front of the sternum with a felted membrane-the membrana sterni.

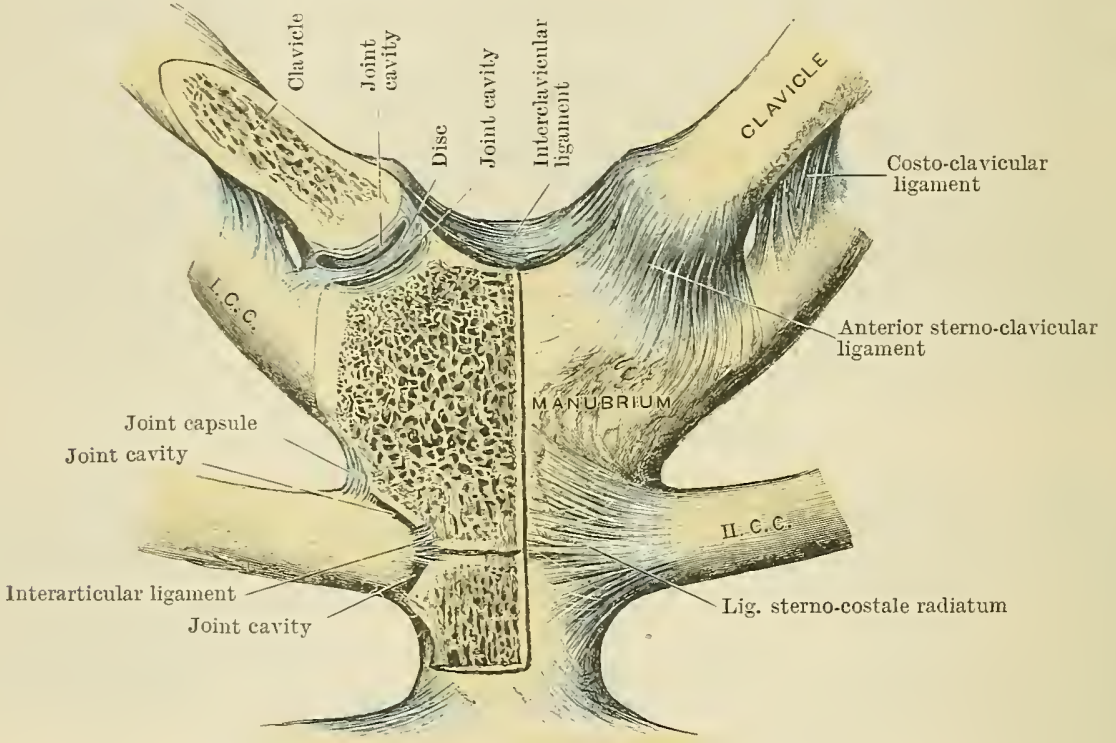

Fig. 301.-Sterno-chaticular and Sterno-costal Joints.

The lig. sternocostale posterius (posterior costo-sternal ligament)-also a part of the capsule-has attachments similar to the foregoing, but the arrangement of its fibres is not so powerful.

The ligamentum costoxiphoideum passes from the front of the upper part of the xiphoid process, obliquely upwards and laterally to the front of the seventh, and sometimes to the front of the sixth costal cartilage.

Writhin the capsules of these joints ligamenta sternocostalia interarticularia (interarticular ligaments) (Fig. 301) may be found. Their disposition is somewhat uncertain, for whereas, in the case of the second pair of cartilages, they invariably divide the joint cavity into two distinct compartments - an upper and a lower-such an arrangement is rery uncertain in the other joints, and they occasionally, especially in the cases of the sixth and seventh cartilages, entirely obliterate the joint cavity. These ligaments extend horizontally between the ends of the costal cartilages and the side of the sternum.

The stratum synoviale is found wherever a joint cavity is developed, and therefore there may be one or two synovial strata, according to the presence or absence of a proper interarticular ligament. When the joint cavity is obliterated by the fibrous structure which represents the interarticular ligament, a synovial stratum is also absent. 


\section{Articulationes Sterni.}

Primarily the sternum consists of an elongated plate of hyaline cartilage, which becomes subdivided into segments by the process of ossification.

The four segments of which the body of the sternum is originally composed unite with each other after the manner of typical synchondroses.

Similarly the xiphoid process and the body ultimately become united. It is not usual to find the joint between the manubrium and the body obliterated by the ossification of the two bony segments. Even in advanced life it remains open, and the joint, which is named the synchondrosis sternalis, partakes of the nature of an amphiarthrosis (Fig. 301), although a joint cavity is not found under any circumstances in the plate of fibro-cartilage which intervenes between the manubrium and the body of the sternum.

The membrana sterni, to which reference has already been made, assists in strengthening the union between the different segments of the sternum.

Movements of the Ribs and Sternum.-These morements mar be considered either independently of, or as associated with, respiration.

In the former condition the ribs move in comnexion with flexion and extension of the vertebral column, being more or less depressed and approximated in the former, and elerated or pulled apart in the latter case. Considered in connexion with respiration, it is necessary to observe that, to all intents and purposes, the rertebral column and the sternum are rigid structures. Next, we must remember that the heads of all the ribs occupy fixed positions, and similarly the anterior ends of seren pairs of cartilages are fixed to the lateral margins of the sternum. The ribs thus form arches, presenting a large amount of obliquity from behind forwards. Therefore, during inspiration, when the rib is elevated, the arch becomes more horizontal, and the transrerse diameter of the chest is increased. At the same time, the anterior ends of the sternal ribs tend to thrust the sternum forwards and upwards; but the nature of the attachment of the first pair of ribs to the sternum, as well as the attachment of the diaphragm to the xiphoid process, prerents this morement from becoming excessive, and hence the sternum becomes a line of resistance to the forward thrust of the ribs. As a consequence, the ribs rotate upon themselves about an oblique axis which passes downwards, laterally, and posteriorly through the capitular joint and the neck of the rib anterior to the costo-transrerse joint.

In this way increase, both of the antero-posterior and transverse diameters of the thorax, is prorided for, although the amount of increase is not equally pronounced in all planes. Thus at the level of the first rib very little eversion is possible, because the axis of rotation is nearly transrerse, and therefore any increase in the transrerse or antero-posterior thoracic diameters at this lerel may be disregarded, although a certain amount of elevation of the manubrium sterni and anterior end of the first rib is evident.

Below the level of the sixth rib elevation and rotation of the rib during inspiration are usually said to be complicated by a certain amount of backward morement, due to the character of the costo-transverse joint, until, in the case of the last two ribs, which are destitute of costotransverse joints, a movement backwards is almost entirely substituted for elevation. It is probable, however, that the morements of the asternal ribs exactly correspond to those of the sternal series, and that by the contraction of the costal digitations of the diaphragm the anterior ends of the false ribs are prorided with fixed positions comparable to those supplied by the sternum to the ribs of the sternal series.

We may therefore say that during inspiration the ribs more upwards and laterally between their fixed ends, while as a whole the rib rotates, and its anterior end is thrust slightly forwards.

During expiration these morements are simply rerersed.

\section{THE ARTICULATIONS OF THE SUPERIOR EXTREIITY.}

The bony arch formed by the claricle and scapula articulates directly with the axial skeleton only at one point, viz., the sterno-clavicular joint.

\section{ARTICULATIONS OF THE CLAVICLE.}

\section{Articulatio Sterioclayicularis.}

The sterno-clavicular joint is an example of an arthrodial diarthrosis. The articular surfaces concerued in its formation present the following appearances :-

1. The sternal end of the clavicle is somewhat triangular in outline, haring its most prominent angle directed inferiorly and posteriorly. The anterior and 
posterior sides of the triangle are slightly roughened for the attachment of ligaments, while the base or inferior side is smooth and rounded, owing to the prolongation of the articular surface to the inferior aspect of the bone. In the antero-posterior direction the articular surface tends to be concave, while vertically it is slightly convex.

2. An articular facet, situated on the superior lateral angle of the manubrium sterni, but in a plane slightly behind the supra-sternal notch, articulates with the clavicle. This facet is considerably smaller than the clavicular facet with which it articulates.

3. The superior surface of the first costal cartilage close to the sternum also participates to a small extent in the articulation.

It should be noted that the articular surfaces of the clavicle and sternum are covered mainly by fibro-cartilage.

A capsula articularis is well marked on all sides except inferiorly, where it is very thin. The epiphyseal line of the clavicle is intra-capsular.

Lig. Sternoclaviculare Anterius. - The anterior sterno-clavicular ligament (Fig. 301) forms part of the fibrous stratum of the articular capsule, and consists of short fibres which extend obliquely inferiorly and medially from the anterior aspect of the sternal end of the clavicle to the adjoining anterior surface of the sternum and the anterior border of the first costal cartilage.

Lig. Sternoclaviculare Posterius. - The posterior sterno-clavicular ligament also forms part of the fibrous stratum of the capsule, and consists of similarly disposed, but not so strong as the anterior ligament, oblique fibres situated on the posterior aspect of the articulation.

Discus Articularis.--A fibro-cartilaginous articular disc (Fig. 301) divides the joint cavity into two compartments. It is nearly circular in shape, and adapts itself to the articular surfaces between which it lies. It is thickest at the circumference and thinnest at the centre, where it occasionally presents a perforation, thereby permitting the two synovial cavities to inter-communicate. By its circumference it is in contact with, and adherent to, the surrounding capsule, but its superior margin is attached to the apex of the articular surface of the clavicle, while by its inferior margin it is fixed to the sternal end of the first costal cartilage.

Two accessory ligaments are associated with this joint, viz., the interclavicular and the costo-clavicular.

Lig. Interclaviculare.-The interclavicular ligament (Fig. 301) is a structure of considerable strength, forming a broad band of fibrous tissue which is attached to the superior rounded angle or apex of the sternal end of the clavicle as well as to the adjacent margins of the articular surface. Its fibres pass across the interclavicular notch to become attached to corresponding parts of the opposite clavicle, but in their course they dip down into the supra-sternal notch, in which many of them are fixed to the sternum. In this way their presence neither bridges nor obliterates the notch between the two clavicles, and the ligament really becomes a superior sternoclavicular ligament for each joint.

Lig. Costoclaviculare.-The costo-clavicular ligament (Fig. 301) consists of short, strong fibres which are attached inferiorly to the superior surface of the first costal cartilage. They pass obliquely upwards, laterally and posteriorly, to a rough impression situated on the inferior aspect of the sternal end of the clavicle, and are distinct from the articular capsule. Occasionally a bursa is found in the interior of this ligament.

As a rule there is a synovial stratum lining each of the two joint cavities (Fig. 301), separated from each other by the articular disc. Sometimes, however, the two membranes establish continuity through a perforation in the disc.

\section{Articulatio Acromioclavicularis.}

The acromio-clavicular joint is another instance of an arthrodial diarthrosis. It is situated between the acromial end of the clavicle and the medial aspect of the acromion. Each articular surface is an oval, flattened facet, covered with fibro-cartilage. 
The ligaments which surround this small joint form a complete articular capsule, of which the superior and inferior parts are specially strong, and are therefore named the superior and inferior acromio-clavicular ligaments (Fig. 303). These consist of short fibres passing between the adjacent rough margins of the two bones in the positions indicated by their names.

An articular disc, which is nearly always incomplete, and may occasionally be wanting, is usually found within the joint cavity, where it lies obliquely, with its superior margin farther from the median plane than its inferior margin, and having its borders attached to the surrounding capsule. Frequently the disc is wedgeshaped, with its base directed upwards and its apex free.

A synovial stratum is found forming either a single or a double sac, according to the condition of the disc. Complete division of the joint cavity, however, is rare.

Ligamentum Coracoclaviculare.-Accessory to this articulation there is the strong coraco-clavicular ligament which binds the acromial end of the clavicle to the coracoid process of the scapula. It is readily divisible into two parts, viz., lig. conoideum and the lig. trapezoideum.

The conoid ligament (Fig. 303) is situated medial to and slightly posterior to the trapezoid. It is narrow and pointed at its inferior end, by which it is attached to the superior aspect of the coracoid process, in close proximity to the scapular notch. Its superior end widens out in the manner expressed by its name, and is attached to the coracoid tuberosity of the clavicle.

The trapezoid ligament (Fig. 303) is attached inferiorly to the superior surface of the posterior half of the coracoid process, lateral and anterior to the attachment of the conoid ligament. Superiorly it is attached to the ridge on the inferior surface of the acromial end of the clavicle. Its lateral and medial borders are free. Its anterior surface is principally directed upwards, and its posterior surface, to a similar extent, looks downwards.

A mucous or synovial bursa usually occupies the re-entrant angle between these two ligaments.

Movements at the Clavicular Joints.-The movements of the medial end of the clavicle at the sterno-clavicular joint are limited in their range, owing to the tension of the ligaments. When the shoulder is raised or depressed the acromial end of the clavicle moves upwards and downwards, whilst its sternal end glides upon the surface of the articular disc; when, on the other hand, the shoulder is carried forwards or backwards, the sternal end of the clavicle along with the articular disc moves upon the sternal facet. In addition to these movements of elevation, depression, forward movement and backward movement of the clavicle, there is also allowed at the sterno-clavicular joint a certain amount of circumduction of the clavicle.

The part which is played by certain of the ligaments in restraining movement requires careful consideration. The costo-clavicular ligament checks excessive elevation of the shoulder, and restrains within certain limits both backward and forward movement of the clavicle. When the clavicle is depressed, as in cases where a heavy weight, such as a bucket of water, is carried in the hand, it receives support by resting upon the first rib, and the tendency for the medial end of the bone to start up out of its sternal socket is obviated by the tension of the articular disc, the interclavicular ligament, and the anterior and posterior sterno-clavicular ligaments.

The articular disc not only acts as a cushion which lessens the shock of blows received upon the shoulder, but it also acts as a most important bond of union, and prevents the medial end of the clavicle from being driven upwards upon the top of the sternum when force is applied to its lateral end.

The movements at the acromio-clavicular joint are of such a kind as to allow the inferior angle, and to some extent the rertebral border of the scapula, to remain more or less closely applied to the chest-wall during the various morements of the shoulder. The strong connexion between the coracoid process and the acromial end of the clavicle, by means of the conoid and trapezoid ligaments, reuders it necessary that the scapula should follow the clavicle in its varions excursions. The presence of the acromio-clavicular joint, however, enables the scapula to change its position somewhat with reference to the clavicle as the shoulder is moved. Thus, when the shoulder is raised and depressed, a marked difference takes place in the angle between the two bones; again, when the shoulder is thrown forwards or backwards, these movements can be performed without altering in a material degree the direction of the glenoid cavity of the scapula, or in other words, the socket of the shoulder-joint.

The conoid and trapezoid ligaments set a limit upon the movements of the scapula at the acromio-clavicular joint. They both, but more particularly the trapezoid ligament, prevent the acromion from being carried medially below the lateral end of the clavicle when blows fall upon the lateral aspect of the shoulder. 


\section{Ligaments OF the SCAPUla.}

These ligaments are not directly comnected with any articulation.

Lig. Coracoacromiale.-The coraco-acromial ligament (Fig. 302) completes the arch between the coracoid process and the acromion, and thus provides a secondary socket for the greater protection and security of the shoulder-joint. It is a flat triangular structure stretched tightly between its lines of attachment. By its base it is fired to a varying amount of the postero-lateral border of the coracoid process, and by its narrower apical end to the tip of the acromion, immediately lateral to the acromio-claricular joint. Its surfaces look upwards and downwards, and its free borders laterally and medially. It is thinnest in the centre, where it is sometimes perforated by a prolongation of the tendon of the pectoralis minor muscle.

Lig. Transversum Scapulæ Superius. - The superior transverse scapular ligament (O.T. suprascapular ligament) is a distinct but short flat band which bridges the scapular notch. It may be continuous with the conoid ligament, and it is frequently ossified. As a rule the foramen completed by this ligament transmits the suprascapular nerve, while the transverse scapular vessels pass superior to the ligament to reach the supraspinous fossa.

A small duplicate of this ligament may often be found bridging the foramen on its costal aspect, subjacent to which small branches of the transverse scapular artery return from the supraspinous to the subscapular fossa.

Lig. Transversum Scapulæ Inferius.-The inferior transverse scapular ligament (O.T. spino-glenoid ligament) consists of another set of bridging fibres which are situated on the posterior aspect of the neck of the scapula. By one end they are attached to the lateral border of the scapular spine, and by the other to the adjacent part of the pasterior aspect of the head of the scaptila. The suprascapular nerve and the transverse scapular vessels pass subjacent to this ligament.

\section{ARTICULATIO HUMEPI.}

The shoulder-joint is one of the largest as well as the most important of the joints of the upper limb. It is an example of the enarthrodial, i.e. ball-and-socket, variety of a diarthrosis, and, at the cost of a certain amount of security, it has obtained an extended range of movement.

The bones which enter into its formation are the glenoid cavity of the scapula and the head of the humerus.

The glenoid cavity is a shallow piriform articular surface, having its narrow end directed upwards and slightly forwards. The superior half of the anterior margin of the fossa is characterised by a shallow notch which accommodates the narrow part of the subscapularis muscle as it runs laterally to its insertion. At the apex of the cavity there is a flat area for the attachment of the long tendon of the biceps brachii muscle. The head of the humerus is hemispherical and articular, while, lateral to its articular margin, there is a slight constriction (the anatomical or true neck of the humerus), which is most strongly marked in relation to the greater and lesser tubercles of the humerus.

Under ordinary conditions the two articular surfaces are maintained in apposition by muscular action, aided by atmospheric pressure, and thus, when the muscles are removed, the bones fall asunder to the full extent of the restraining ligaments. Only a small part of the head of the humerus is in contact with the glenoid cavity at any particular moment, because the humeral head is much larger than the cavity, but, by reason of the shallow character of the cavity, all parts of the two articular surfaces may successively be brought into contact with each other.

In the position of rest, as the limb hangs parallel to the vertical axis of the trunk, the inferior aspect of the neck of the humerus is brought into close relation with the inferior part of the glenoid cavity.

Labrum Glenoidale.-The labrum glenoidale (O.T. glenoid ligament) (Fig. 303) deepens the glenoid cavity, and thus extends the articular surface. It is situated within the fibrous stratum of the articular capsule, and to some slight extent increases the security of the articulation. It consists of a strong ring of dense fibrous 
tissue attached to the free margin of the glenoid cavity. Many of its fibres are short, and pass obliquely from the inner to the outer aspect of the ridge, so that its attached base is broader than its free edge, and therefore in cross section it appears somewhat triangular. The long tendon of the biceps, which arises from the apex of the glenoid cavity, becomes to a considerable extent incorporated with the labrum glenoidale.

Capsula Articularis.- The fibrous stratum (O.T. capsular ligament) (Fig. 302) of the articular capsule presents the general shape which is characteristic of the corresponding part in other ball-and-socket joints, viz., a hollow eylinder. By its proximal end the fibrous stratum is attached to the circumference of the glenoid cavity, external to the labrum glenoidale, and also, to a considerable extent, to the labrum glenoidale itself.

By its distal end it is attached to the neck of the humerus, and therefore beyond the articular area of the head. The fibrous stratum is strongest on its superior aspect, while inferiorly, where the neck of the bone is least defined, it

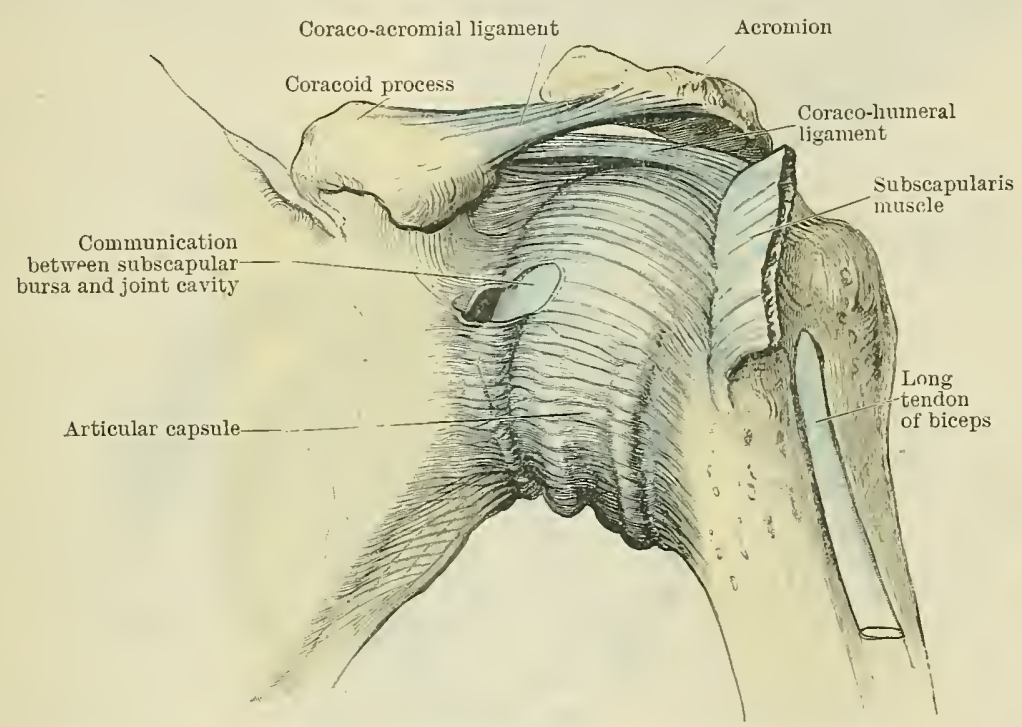

Fig. 302.-Capsulé of the Shoulder-Jornt and Coraco-acromial Ligament.

extends distally for a short distance upon the humeral shaft. Its fibres for the most part run longitudinally, but a certain number of them pursue a circular direction:

The greater part of the epiphyseal line of the proximal end of the humerus is extra-capsular, but it is intra-capsular on the medial side of the bone.

A prolongation of the fibrous stratum, the transverse humeral ligament presenting both longitudinal and transverse fibres, bridges that part of the intertubercular groove which is situated between the tubercles of the humerus. At this point an interruption in the fibrous stratum, beneath the transverse humeral ligament, permits the long tendon of the biceps to escape from its interior. In addition to the opening just referred to, there is another very constant deficiency in the superior and anterior part of the fibrous stratum, where the narrowing tendon of the subscapularis muscle is brought into contact with a bursa formed by a protrusion of the synovial stratum. This defect in the fibrous stratum has its long axis in the direction of the longitudinal fibres. Occasionally there is a similar but smaller opening under cover of the tendon of the infraspinatus muscle. Through the two latter openings the joint cavity communicates with bursæ situated between the capsule and the muscles referred to.

The tendons of the subscapularis, supraspinatus, and infraspinatus muscles fuse with, and so strengthen, the articular capsule as they approach their respective insertions.

On the superior aspect of the articulation the capsule is augmented by an 
accessory structure, the ligamentum coracohumerale (Fig. 302). By its proximal end, which is situated immediately above the glenoid cavity, but subjacent to the coraco-acromial ligament, it is attached to the lateral border of the root of the coracoid process, while its distal end is attached to the humeral neck close to the greater tubercle. This ligament forms a flattened band, having its posterior and inferior border fused with the articular capsule, but its anterior and superior margin presents a free edge, slightly raised above the level of the capsule. This structure is believed to represent that portion of the pectoralis minor to which reference has already been made in connexion with the coraco-acromial ligament (p. 320).

The coraco-glenoid ligament is another accessory structure, which is not always present. It springs from the coracoid process along with the former ligament, and extends to the superior and posterior margin of the head of the scapula.

Gleno-humeral Ligaments (Fig. 303).-If the articular capsule is opened from behind, and the head of the humerus removed, it will be seen that the longitudinal fibres of the anterior part of the fibrous stratum are specially developed in the form of thick flattened bands which extend from the anterior border of the glenoid cavity to the anterior aspect of the neck of the humerns. These gleno-humeral ligaments are three in number, and occupy the following positions: the

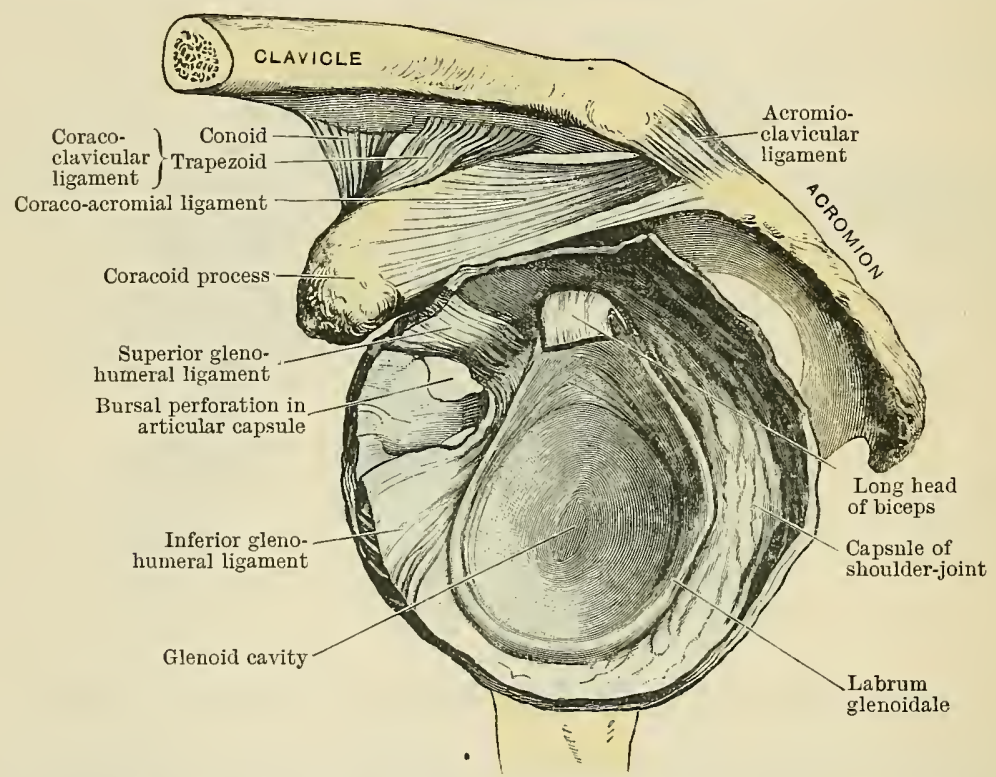

Fig. 303.-Capsdlar Ligadent of Shodlder-Joint cut across and Humerus removed.

superior is placed above the aperture in the front of the capsule; the middle and inferior on the antero-inferior aspect of the capsule, and below the aperture mentioned.

The superior gleno-humeral ligament, which some believe to represent the ligamentum teres of the hip-joint, springs, along with the middle gleno-humeral band, from the superior part of the cavity. The inferior ligament is the strongest of the three, and springs from the inferior part of the anterior margin of the glenoid.

Intra-capsular Structures.-1. The labrum glenoidale, already described. 2. The long tendon of the biceps passes laterally from its attachment to the apex of the glenoid cavity and the adjoining part of the labrum glenoidale, above the head and neck of the humerus, to escape from the interior of the capsule by the opening between the tubercles of the humerus, subjacent to the transverse humeral ligament.

A synovial stratum (Fig. 304) lines the fibrous stratum of the capsule, and extends from the margin of the glenoid cavity to the humeral attachments of the fibrous stratum, where it is reflected towards the margin of the articular cartilage. It is therefore important to note that the inferior aspect of the humeral neck has the most extensive clothing of the synovial stratum. Further, the synovial stratum envelops the intra-capsular part of the tendon of the biceps, and although this tubular sheath is prolonged upon the tendon into the proximal part of the 
intertubercular sulcus, yet the closed character of the synovial cavity is maintained. Thus, while the tendon is within the capsule, it is not within the synovial cavity. The synovial stratum is continuous with those bursæ which communicate with the joint cavity through openings in the fibrous stratum of the capsule.

Bursæ (a) Communicating with the Joint Cavity.-Practically there is only one bursa which is constant in its position, viz., the subscapular, between the capsule and the tendon of the subscapularis muscle. It varies considerably in its dimensions, but its lining membrane is always continuous with the synovial stratum of the capsule (Figs. 301 and 302), and therefore it may be regarded merely as a prolongation of the articular synovial stratum. Occasionally a similar but smaller bursa occurs between the capsule and the tendon of the infraspinatus muscle.

(b) Not communicating with the Joint Cavity. - The subdeltoid or sub-acromial bursa is situated between the muscles on the superior aspect of the shoulder-joint on the one hand and the deltoid muscle on the other. It is an extensive bursa, and is prolonged subjacent to the acromion and the coracoacromial ligament. It does not communicate with the

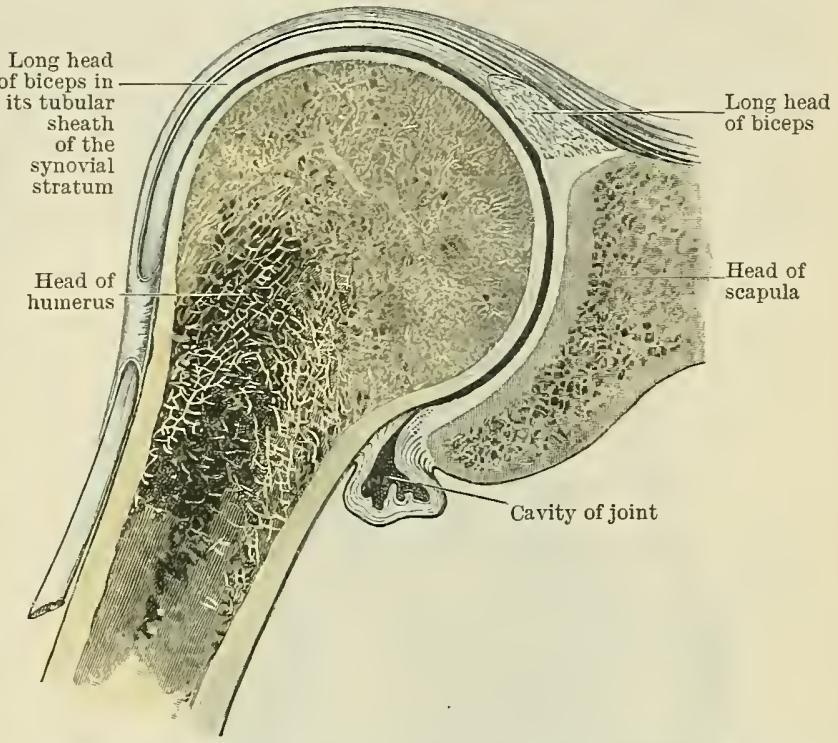

Fig. 304.-Vertical Section throdgh the Shodlder-Joint. shoulder-joint, but it greatly facilitates the movements of the proximal end of the humerus against the inferior surface of the coraco-acromial arch.

Movements at the Shoulder-Joint.-A ball-and-socket joint permits of a great variety of movements, practically in all directions ; but if these movements are analysed, it will be seen that they resolve themselves into movements around three primary axes at right angles to each other, or around axes which are the possible combinations of the primary ones.

Thus, around a transverse axis, the limb may move forwards (flexion) or backwards (extension). Around an antero-posterior axis it may move laterally, i.e. away from the median plane of the trunk (abduction), or medially, i.e. towards, and to some extent up to, the median plane (adduction).

Around a vertical axis, the humerus may rotate upon its axis in a medial or lateral direction to the extent of a quarter of a circle.

Since these axes all pass through the shoulder-joint, and since each may present varying degrees of obliquity, it follows that very elaborate combinations are possible until the movement of circumduction is evolved. In this movement the head of the humerus acts as the apex of a cone of movement with the distal end of the humerus, describing the base of the cone.

The range of the shoulder-joint movements is still further increased owing to the mobility of the scapula as a whole, and owing to its association with the movements of the clavicle already described.

\section{ARTICULATIO CUBITI.}

The elbow-joint ${ }^{I}$ provides an instance of a diarthrosis capable of performing the movements of flexion and extension around a single axis placed transversely, i.e. a typical ginglymus diarthrosis or hinge-joint.

The bones which enter into its formation are the humerus, ulna, and radius. The trochlea of the humerus articulates with the semilunar notch of the ulna (articulatio humeroulnaris); the capitulum of the humerus articulates with the shallow depression or cup on the proximal aspect of the head of the radius (articulatio humeroradialis). The articular cartilage clothing the trochlea of the humerus terminates in a sinuous or concave margin both anteriorly and posteriorly, so that it does not line either the coronoid or the olecranon fossa. Medially, it merely rounds off the medial margin of the trochlea, but laterally it is continuous with the encrust-

1 The articulatio eubiti or elbow-joint includes the humero-radial, limmero-ulnar, and the proximal radio-ulnar joints ; but, for convenience, the description given here is limited to the humero-radial and humero-nlnar joints. 
ing cartilage covering the capitulum, to the margin of which the cartilage extends in all directions, aud thus it presents a convex edge in relation to the radial fossa. The cartilage which lines the semilunar notch of the ulna presents a transverse interruption, considerably wider on its medial as compared with its lateral aspect. Thereby the coronoid and olecranon segments of the notch are separated from each other. The cartilage which clothes the coronoid segment is continuous with that which elothes the radial notch of the ulna. The shallow cup-shaped depression on the head of the radius is corered with cartilage which rounds off the margin, and is prolonged without interuption upon the vertical aspect of the head, extending to its most distal level on that part opposed to the radial notch of the ulna.

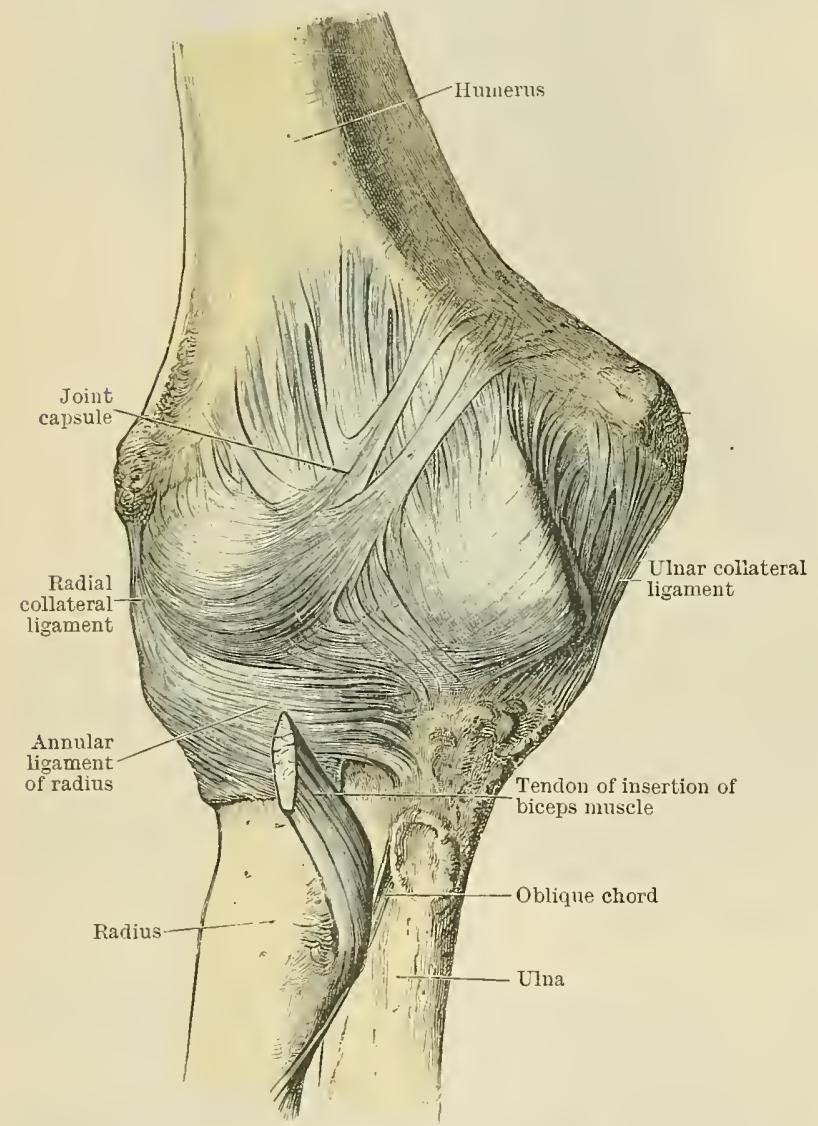

Fig. 305.-ANTEliror View of Elbow-Joint.

Capsula Articularis.Taken as a whole, the ligaments form a complete fibrous stratum of the articular capsule, which is not defective at any point, although it is not of equal thickness throughout, and certain bands of fibres stand out distinctly because of their greater strength.

The common epiphyseal line for the trochlea, capitulum, and the lateral epicondyle of the humerus, is partly intra-capsular and partly extra-capsular; that for the medial epicondyle is extra-capsular. The epiphyseal line of the olecranon is intra-capsular only anteriorly, and it may be altogether extra-capsular.

Lig. Anterius. - The anterior ligament (Fig. 305) consists of a layer whose fibres run in several directions - obliquely, transversely, and longitudinally -and of these the vertical fibres are of most importance. It is attached proximally to the proximal margins of the coronoid and radial fossæ; distally, to the margins of the coronoid process and to the annular ligament of the proximal radio-ulnar joint, but some loosely arranged fibres reach as far as the neck of the radius. The marginal portions of this ligament, which are situated in front of the capitulum and the medial margin of the trochlea respectively, are much thinner and weaker than the central part. Fibres of origin of the brachialis muscle are attached to the front of this ligament.

Lig. Posterius. - The posterior ligament is an extremely thin, almost redundant layer. Proximally it is attached, in relation to the margin of the olecranon fossa, at a varying distance from the trochlear articular surface, and distally to the summit and sides of the lip of the olecranon. Laterally some of its fibres pass from the posterior aspect of the capitulum to the posterior border of the radial notch of the ulna. This ligament derives material support from, and participates in the movements of, the triceps brachii muscle, since they are closely adherent to each other in the region of the olecranon.

Lig. Collaterale Ulnare.-The ulnar collateral ligament (O.T. internal lateral) 
(Figs. 305 and 306) is a fan-shaped structure of unequal thickness, but its margins, which are its strongest bands, are continuous with the adjoining parts of the anterior and posterior ligaments. By its proximal end it is attached to the anterior, distal, and posterior aspects of the medial epicondyle of the humerus. By its broad distal end it is attached to the medial margin of the semilunar notch, so that the anterior band is associated principally with the medial margin of the coronoid process, and the posterior band with the medial margin of the olecranon, while the intermediate weaker portion sends its fibres downwards to join a transverse band, sometimes very strong, which bridges the notch between the adjoining medial margins of the coronoid process and the olecranon.

Lig. Collaterale Radiale. - The radial collateral ligament (O.T. external lateral) (Fig. 305) is a strong flattened band attached proximally to the distal and

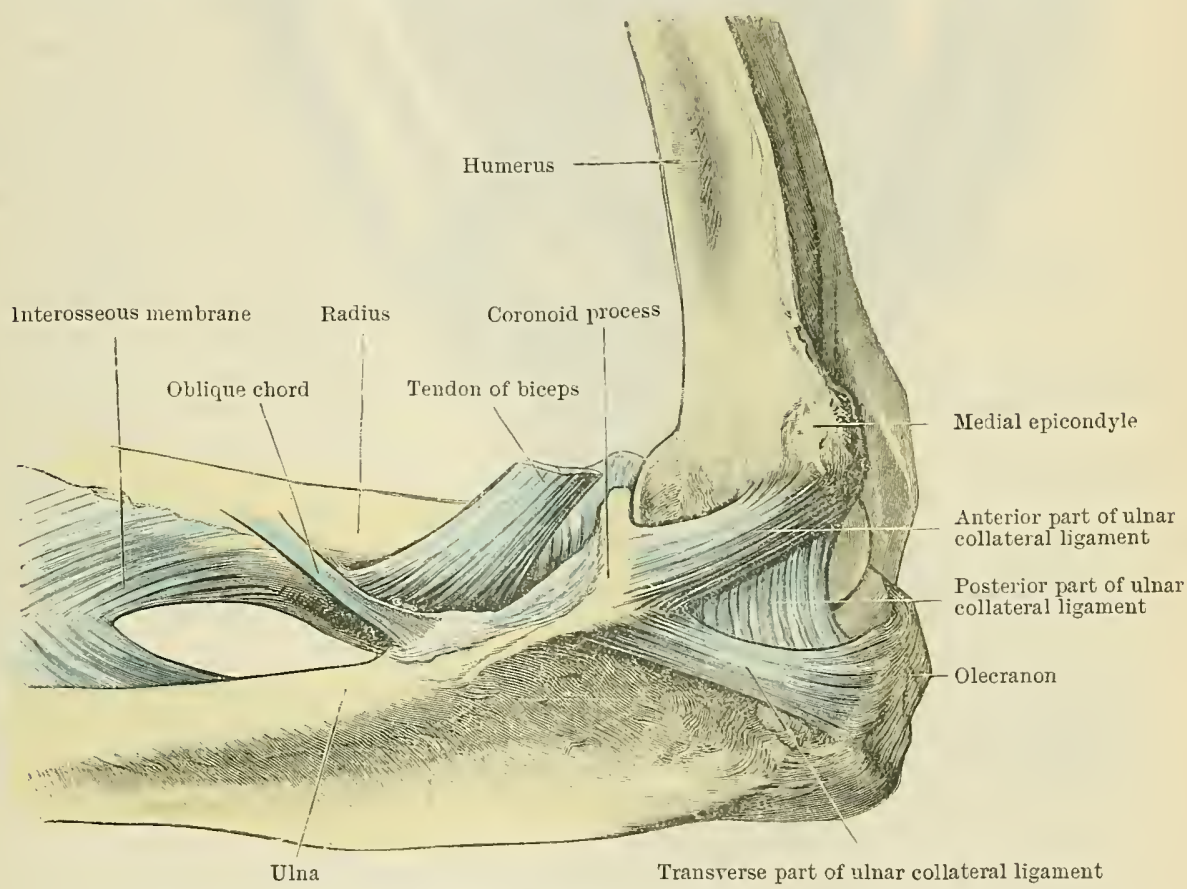

Fig. 306.-ELbow-Jorvт (Medial Aspect).

posterior aspects of the lateral epicondyle of the humerus. It completes the continuity of the articular capsule on the lateral side, and blends distally with the lig. annulare radii, on the surface of which its fibres may be traced both to the anterior and posterior ends of the radial notch of the ulna. Both of the collateral ligaments are intimately associated with the muscles which take origin from the medial and lateral epicondyles of the humerus.

Synovial Pads of Fat (Fig. 307).- Internal to the fibrous stratum of the articular capsule, there are several pads of fat situated hetween it and the symovial stratum. Small pads are so placed as to lie immediately in front of the coronoid and radial fossæ, but a larger one projects towards the olecranon fossa.

A stratum synoviale (Fig. 307) lines the entire fibrous stratum and clothes the pads of fat referred to above, as well as those portions of bone enclosed within the capsule which are not covered by articular cartilage. By its disposition the elbow and the proximal radio-ulnar joints possess a common joint carity. It should be specially noted that the proximal part of the neck of the radius is surrounded by this synovial layer.

Movements at the Elbow-Joint.-The movements of the radius and ulna upon the hmmerus have already been referred to as those characterising a miaxial joint constructed on the plan of a hinge. In this case the axis of the joint is obliquely transverse, so that in the extended position the humerus and ulna form an obtuse angle open towards the radius, whereas in the 
flexed position the hand is carried medially in the direction of the mouth. Extreme flexion is checked by the soft parts in front of the arm and of the forearm coming into contact, and extreme extension by the restraining effect of the ligaments and muscles. In each case the morement is checked before either the coronoid process or the olecranon come into contact

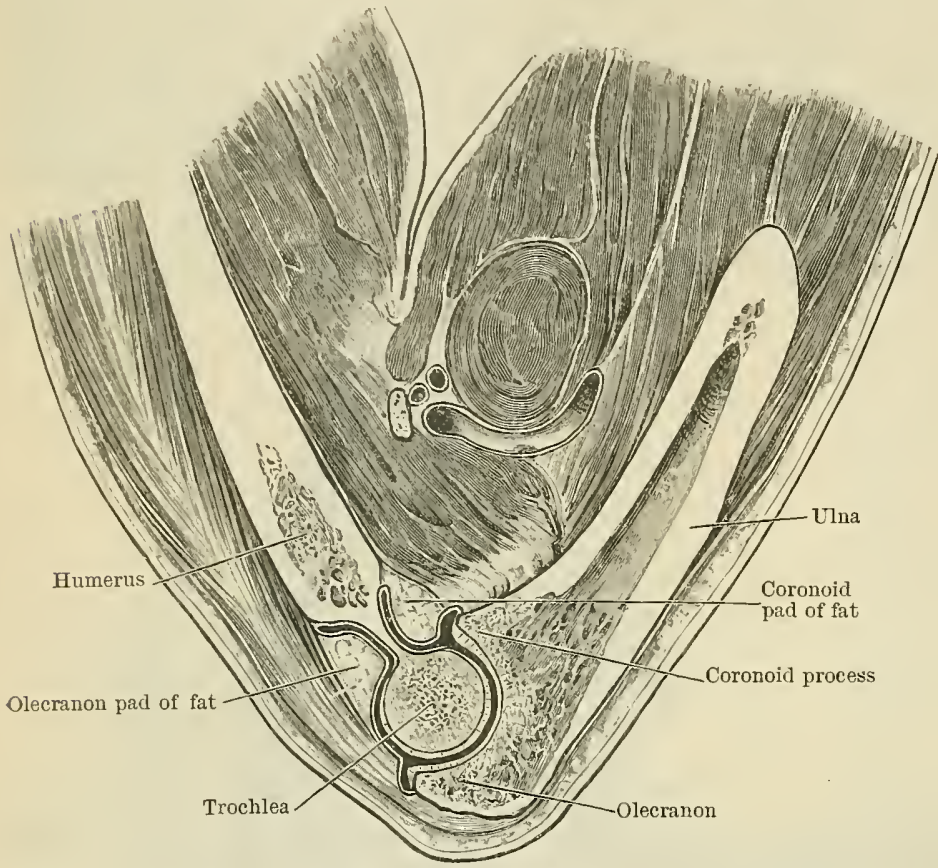

Fig. 307.-Vertical Section throdgh the Hunero-ulnar Part of the ELBOW-JOINT. with the humerus. The anterior and posterior bands of the ulnar collateral ligament are important factors in these results. Lateral movement of the ulna is not a characteristic movement, although it may occur to a slight extent, owing to a want of complete adaptation between the trochlear surface of the humerus and the semilunar notch of the ulna. This incongruence is noteworthy since the medial lip of the trochlea is prominent in front, and the lateral lip is prominent behind. Consequently, this latter part is associated with a surface on the lateral side of the olecranon which is only utilised in complete extension.

The capitulum and the opposing surface upon the head of the radius are always in varying degrees of contact. The head of the radius participates in the movements of flexion and extension, and is most closely and completely in contact with the humerus during the position of semi-flexion and semi-pronation. In complete extension a very considerable part of the capitulum is uncovered by the radius.

\section{THE RADIO-ULNAR JOINTS.}

These articulations, which are two in number, are situated at the proximal and distal ends of the radius and ulna. They provide an adaptation whereby the radius rotates around a longitudinal axis in the movements of pronation and supination, and hence this form of uniaxial diarthrosis is termed lateral ginglymus.

Articulatio Radioulnaris Proximalis.-The proximal radio-ulnar joint forms a part of the articulatio cubiti or elbow-joint. The articular surfaces which enter into its formation are the radial notch of the ulna and the lateral aspect of the head of the radius. In each case the articular cartilage is continuous with an articular surface entering into the formation of the humero-radial and humeroulnar joints, consequently the joint cavity is continuous with the cavities of these joints, and therefore, in a sense, it lies within the cover of the articular capsule of the elbow-joint; but its special feature is the annular ligament of the radius.

Lig. Annulare Radii.-The annular ligament of the radius (O.T. orbicular ligament) (Figs. 305 and 308) has been mentioned above as the distal line of attachment of the radial collateral ligament and the ligaments on the front and back of the elbow-joint.

It is a strong, well-defined structure, attached by its extremities to the volar and dorsal margins of the radial notch of the ulna, and thus it forms nearly four-fifths of an osseo-tendinous circle or ring. This circle is somewhat wider at the proximal than at the distal margin of the annular ligament of the radius, which, by encircling the proximal part of the neck of the radius, tends to prevent 
displacement of the head of that bone in a distal direction. The distal margin of this ligament is not directly attached to the radius.

The synovial stratum is continuous with that which lines the elbow-joint. It closes the joint cavity at the distal unattached margin of the annular ligament, where it is somewhat loosely arranged in its reflexion from the ligament to the neck of the radius. The epiphyseal line at the proximal end of the radius is intra-capsular.

Articulatio Radioulnaris Distalis. - The distal radio-ulnar joint is situated between the lateral aspect of the head of the ulna and the ulnar notch on the medial side of the distal end of the radius. In addition, it includes the distal surface of the head of the ulna, which articulates with the proximal surface of a triangular articular disc by means of which the joint is excluded from the radio-carpal articulation.

Discus Articularis.-The triangular articular disc (Figs. 309 and 311), besides presenting articular surfaces to two separate joints, is an important ligament concerned in binding together the distal ends of the radius and ulna. It is attached by its apex to the depression at the lateral side of the root of the

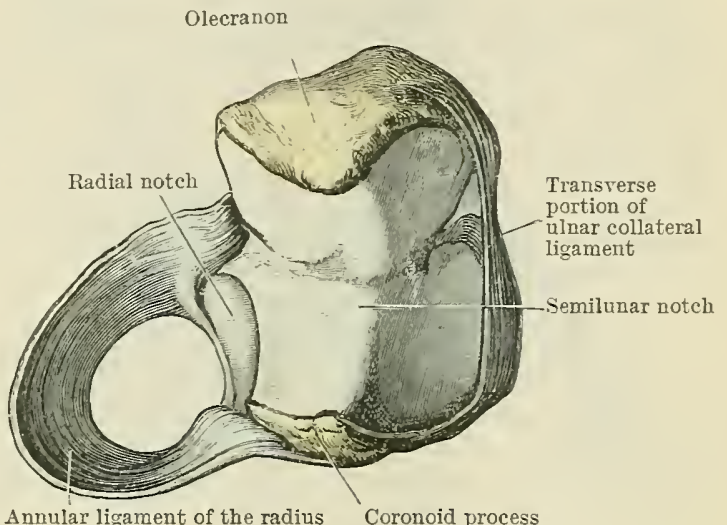

Annular ligament of the radius Coronoid process

Fig. 308.-Axvolar Liganext of the Radius. styloid process of the ulna, and by its base to the sharp line of demarcation between the ulnar notch and the carpal articular surface of the radius.

Capsula Articularis.-The fibrous stratum is very imperfect, and consists of scattered fibres, termed the anterior and posterior radio-ulnar ligaments (Fig. 310). These ligaments pass transversely between adjoining non-articular surfaces on the radius and ulna, and are of sufficient length to permit of the movements of the radius in pronation and supination.

The synovial stratum completes the closure of the joint cavity. It forms a loose bulging projection (recessus sacciformis), passing proximally between the distal ends of the shafts of the radius and ulna, and it also clothes the proximal surface of the articular disc (Fig. 311). The cavity of this joint is quite distinct from that of the radio-carpal articulation, except when the articular disc presents a perforation.

Between the proximal and distal radio-ulnar articulations there are two accessory ligaments, viz., the interosseous membrane and the chorda obliqua, which connect together the shafts of the radius and ulna.

Membrana Interossea Antibrachii.-The interosseous membrane of the fore-

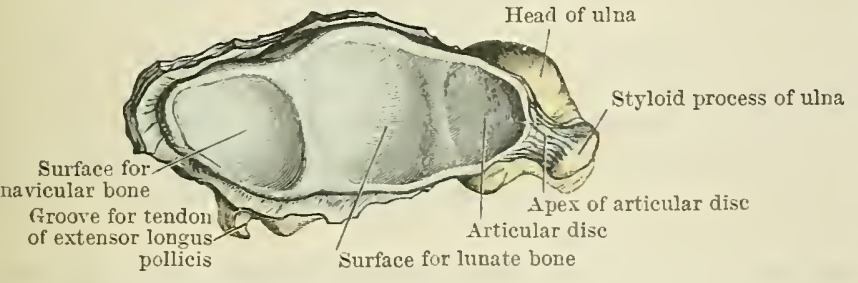

Fig. 309.-Carpal Articular Surface of the Radius, and Articular Disc of the Wrist. $\operatorname{arm}($ Fig. 306)is a strong fibrousmembrane which stretches across the interval between the radius and ulna, and is firmly attached to the interosseous crest of each. Distally it extends to the distal limit of the space between the bones, whilst proximally it only reaches a point about one inch distal to the tuberosity of the radius. A gap, called the hiatus interosseus, is thus left between its proximal margin and the chorda obliqua, and through this the dorsal interosseous vessels pass backwards between the bones to reach the dorsal aspect of the forearm. The fibres which compose the interosseous membrane run for the most part distally and medially from the radius to the ulna, although on its dorsal aspect several bands may be observed stretching in an opposite direction. The interosseous membrane 
augments the surface available for the origin of the muscles of the forearm; it braces the radius and ulna together; and when shocks are communicated from the hand to the radius, owing to the direction of its fibres, the interosseous membrane transmits these, to some slight extent, to the nlna.

Chorda Obliqua.-The oblique chord (Fig. 306) is a slender fibrous band of very varying strength which springs from the lateral part of the coronoid process of the ulna, and stretches obliquely distally and laterally to the radius where it is attached immediately distal to the tuberosity of the radius.

Movements of the Radius on the Ulna.-The axis around which the radius mores is a longitudinal one, haring one end passing through the centre of the head of the radius and the other through the styloid process of the ulna and the line of the ring-finger. In this axis the head of the radius is so secured that it can only rotate upon the radial notch of the ulna within the anuular ligament of the radins, and consequently the radial head remains upon the same plane as the unna; but the distal end of the radius being merely restrained by the articular disc, is able to describe nearly a half-circle, of which the apex of this ligament is the centre. In this morement the radius carries the hand from a position in which the palm is directed forwards, and in which the radius and ulna lie parallel to each other (supination), to one in which the palm is directed backwards, and the radius lies diagonally across the front of the unlna (pronation).

The ulna is unable to rotate upon a long axis, but while the radius is travelling through the arc of a circle from lateral to medial side in front of the ulna, it will usually be seen that the ulna appears to move through the arc of a smaller circle in the reverse direction, viz., from medial to lateral side. If the humerus is prevented from moving at the shoulder-joint, a very large proportion, if not the entire amount, of this apparent movement of the ulna will disappear. At the same time some observers maintain that it really occurs at the ellow-joint, associated with lateral movement during slight degrees of flexion and extension at that joint.

\section{ARTICULATIO RADIOCARPEA.}

The radio-carpal joint is a bi-axial diarthrosis, frequently called a condyloid joint.

The articular elements which enter into its formation are: on its proximal side, the carpal surface of the distal end of the radius, together with the distal surface of the discus articularis; on its distal side, the proximal articular surfaces of the navicular, lunate, and triquetral bones. The articular surface of the radius is concave both in its antero-posterior and transverse diameters, in order to adapt itself to the opposing surfaces of the navicular and lunate, which are convex in the two axes named. In the ordinary straight position of the hand the articular disc is in contact with the lunate bone, and the proximal articular surface of the triquetral bone is in contact with the capsule of the joint. When, however, the hand is bent towards the ulna the triquetral bone is carried laterally as well as the lunate and navicular and the articular disc comes into contact with the triquetral. The articular surface of the radius is subdivided by an antero-posterior, slightly elevated ridge, into a lateral triangular facet which usually articulates with the navicular, and a medial quadrilateral facet for articulation with a portion of the lunate bone.

In the intervals between the navicular, lunate, and triquetral bones, the continuity of the articular surfaces is usually maintained by the presence of interosseous ligaments which are situated upon the same level as the articular cartilage.

Capsula Articularis.-An articular capsule completely surrounds the joint. It is somewhat loosely arranged, and its fibrous stratum permits of subdivision into the following four portions:-

Lig. Radiocarpeum Laterale.-The lateral radio-carpal ligament (O.T. external lateral) (Fig. 310) is a well-defined band which is attached by one end to the tip of the styloid process of the radius, and by the other to a rough area at the base of the tuberosity of the navicular bone, i.e. lateral to its radial articular surface.

Lig. Ulnocarpeum IMediale.-The medial ulno-carpal ligament (O.T. internal lateral) (Fig. 310) is also a distinct rounded structure, having one end attached to the tip of the styloid process of the ulna, and the other to the rough non-articular border of the triquetral bone, some of its fibres being prolonged to the pisiform bone

Lig. Radiocarpeum Volare.-The volar radio-carpal ligament (O.T. anterior ligament) (Fig. 310) is attached proximally to the volar margin of the distal end 
of the radius, as well as slightly to the base of the styloid process of the ulna.

Some transverse fibres may be seen, but the greater number pass obliquely distally and medially to the volar non-articular surfaces of the navicular, lunate, and triquetral bones, while some of them may even be continued as far as the capitate bone. Those fibres from the ulna run obliquely laterally. On its deeper aspect this ligamentis closely adherent to the volar border of the articular disc of the distal radioulnar articulation.

Lig. Radiocarpeum Dorsale. - The dorsal radio-carpal ligament (O.T. posterior ligament) extends from the dorsalmargin

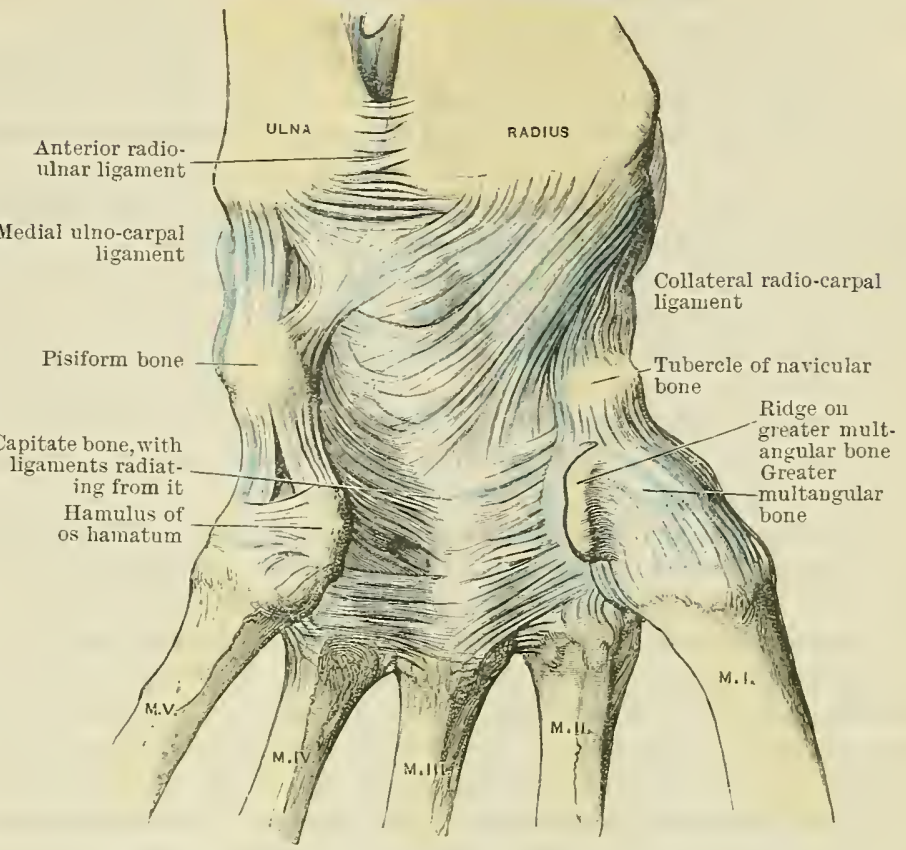

Fig. 310.--Ligaments on Volar Aspect of Radio-Carpal, CARPAL, AND CARPO-NETACARPAL JOINTS.

of the distal end of the radius, in an oblique direction distally and medially, to the dorsal non-articular areas on the proximal row of the carpal bones. The slip to the latter assists in forming the fibrous sheath through which the tendon of the extensor carpi ulnaris muscle travels to its insertion. The principal bundle of fibres is connected with the triquetral bone.

The stratum synoviale (Fig. 311) is simple, and is confined to the articulation, except in those cases in which the articular disc is perforated, or in which one of the interosseous ligaments between the carpal bones of the first row is absent. The epiphyseal lines at the distal ends of radius and ulna are extra-capsular.

Movements at the Radio-carpal Joint.-The radio-carpal joint affords an excellent example of a bi-axial articulation, in which a long transverse axis of movement is situated more or less at right angles to a short axis placed in the antero-posterior direction. The nature of the movements which are possible around these two axes is essentially the same in both cases, viz., flexion and extension. The movements around the longer transverse axis are anterior or volar flesion, extension, and its continuation into dorsi-flexion. Around the shorter antero-posterior axis we get movements which result from combined action by certain flexor and extensor muscles, whereby the radial or uhnar borders of the hand may be approximated towards the corresponding border's of the forearm. Lateral movement also may be possible to a slight extent. The range of morement in connexion with either of the principal axes is largely a matter of individual peculiarity, for, with the exception of the lateral ligaments, there is no serious obstacle to the cultivation of greater mobility at the radio-carpal joint.

\section{ARTICULATIONES INTERCARPEA.}

Carpal Joints.-The articulations subsisting between the individual carpal bones are all diarthroses, and although the total amount of morement throughout the series is considerable, yet the extent of movement which is possible between the two rows or between any two carpal bones is extremely limited. For this reason, as well as because of the nature of the morement, these articulations are called gliding joints (arthrodia).

It is advisable to consider, first, the articulations between individual bones of the proximal row; second, the articulations between the separate bones of the distal row ; third, the articulation of the proximal and distal rows with each other; fourth, the pisiform articulation. 
The proximal row of carpal articulations (Fig. 311) comprises the joints between the naricular, lunate, and triquetral bones. On their adjacent aspects these bones are partly articular and partly non-articular.

Three sets of simple but strong, although short, ligamentous bands bind these three carpal bones together, and form an investment for three sides of their intercarpal joints. These are-(1) the ligamenta intercarpea volaria (anterior or volar ligaments), two in number, which consist of transverse fibres passing between the adjacent rough volar surfaces of the bones; (2) the ligamenta intercarpea dorsalia (posterior or dorsal ligaments), also two in number, and composed of similar short transverse fibres passing between the adjacent dorsal surfaces; (3) the ligamenta intercarpea interossea (interosseous ligaments) (Fig. 310), again two in number, and transverse in direction, situated on a level with the proximal articular surfaces, and extending from the volar to the dorsal aspect of the bones while attached to non-articular areas of the opposing surfaces. The radio-carpal joint is entirely shut off from the intercarpal joints, and also from the joint between the two rows of carpal bones, except in rare cases, when an interosseous ligament is wanting.

The distal row of carpal articulations (Fig. 311) includes the joints between the greater multangular, lesser multangular, capitate, and hamate bones. Articular facets occur on the opposing faces of the individual bones.

Associated with this row there are again simple bands of considerable strength, and presenting an arrangement similar to that seen in the proximal row. As in the former case, they invest the intercarpal articulations, except on the proximal aspect, where they communicate with the transverse carpal joint, and on the distal aspect, where they communicate with the carpo-metacarpal joint cavity.

The ligamenta intercarpea volaria (anterior or volar ligaments) are three in number. They extend in a transverse direction between contiguous portions of the rough volar surfaces of the bones. The ligamenta intercarpea dorsalia (posterior or dorsal ligaments), also three in number, are similarly disposed on the dorsal aspect. The ligamenta intercarpea interossea (interosseous ligaments) (Fig. 311) are two or three in number. That which joins the capitate to the os hamatum is the strongest; that between the lesser multangular and the capitate bone is situated towards the dorsal parts of their opposing surfaces; the third, situated between contiguous non-articular surfaces of the greater and lesser multangular bones, is always the feeblest, and is frequently absent.

The transverse carpal articulation (Fig. 311) is situated between the proximal and distal rows of the carpus. The bones of the proximal row present the following characters on their distal aspect. The lateral part of the articular surface is deeply concave, both in the antero-posterior and in the transverse directions, but the medial part of the same surface is concavo-convex, more especially in the transverse direction.

Proximally, the articular surfaces of the distal row of carpal bones present an irregular outline. That part pertaining to the greater and lesser multangular bones is concave in the antero-posterior and transverse directions, and lies at a considerably more distal level than the portion belonging to the capitate aud os hamatum, which is, moreover, markedly convex in the antero-posterior and transverse directions, with the exception of the most medial part of the os hamatum, where it is concavoconvex in both of these directions.

This articulation is invested by a complete short articular capsule (Fig. 310) which binds the two rows of the carpus together, and sends prolongations to the investing capsules of the proximal and distal articulations. The ligament, as a whole, is very strong, and individual bands are not readily defined, although certain special bands may be described. The lig. carpi radiatum (radiate carpal ligament (volar ligament)) radiates from the capitate bone to the navicular, triquetral, and pisiform bones. The interval between the capitate and lunate is occupied by oblique fibres, some of which pass from navicular to triquetral, while these are joined by others, prolonged obliquely distally and medially, from the radial end of the anterior radio-carpal ligament. By these different bands the volar aspect of the joint is completely closed.

The ligamenta intercarpea dorsalia (dorsal ligaments) are more feeble than the 
volar. They form a thin, loosely arranged stratum, in which the only noteworthy bands are one which joins the navicular to the capitate, and another which joins the triquetral to the os hamatum.

Lig. Collaterale Carpi Radiale.-The radial collateral carpal ligament (O.T. external lateral) (Fig. 310) extends between contiguous rough areas on the lateral aspects of the navicular and greater multangular bone. By its margins it is continuous both with the volar and dorsal ligaments.

Lig. Collaterale Carpi Ulnare.--The ulnar collateral carpal ligament (O.T. internal lateral) (Fig. 310) is arranged like the former in regard to its margins, and by its ends it is attached to the contiguous rough ulnar surfaces of the triquetral and the os hamatum.

Both of these collateral ligaments are directly continuous with the corresponding collateral ligaments of the radio-carpal joint.

A lig. interosseum (interosseous ligament) (Fig. 311) is occasionally found within the capsule, extending across the joint cavity between the capitate and the navicular.

Articulatio Ossis Pisiformis.-The pisi-triquetral articulation is an arthrodial diarthrosis. The mutual articular surfaces of the two bones are flattened and circular, and permit of only a small amount of gliding movement.

The joint is provided with a thin but complete articular capsule, the fibrous stratum of which is specially strengthened distally by two strong bands, viz., lig. pisohamatum and lig. pisometacarpeum (Fig. 310). Both of these bands extend from the distal and medial aspect of the pisiform to adjoining parts of the hook of the os hamatum and base of the fifth metacarpal bone respectively. To a great extent these ligamentous bands may be regarded as extensions of the insertion of the tendon of the flexor carpi ulnaris muscle, which is attached to the proximal part of the pisiform bone. Looked at as ligaments, however, they are specially strong to prevent the displacement of the pisiform bone during contraction of the muscle inserted into it.

The synovial strata (synovial membranes) (Fig. 311) of the carpal joints are two in number. Of these, one is restricted to the pisi-triquetral articulation, and is correspondingly simple, although occasionally the joint cavity may communicate with that of the radio-carpal joint.

The other synovial stratum is associated with the transverse carpal joint which extends transversely between the two rows of carpal bones, with prolongations into the intervals between the adjoining bones of each row, i.e. the intercarpal articulations. It is, therefore, an elaborate cavity, which may be still further extended, by the absence of interosseous ligaments, so as to reach the radio-carpal and carpo-metacarpal series of

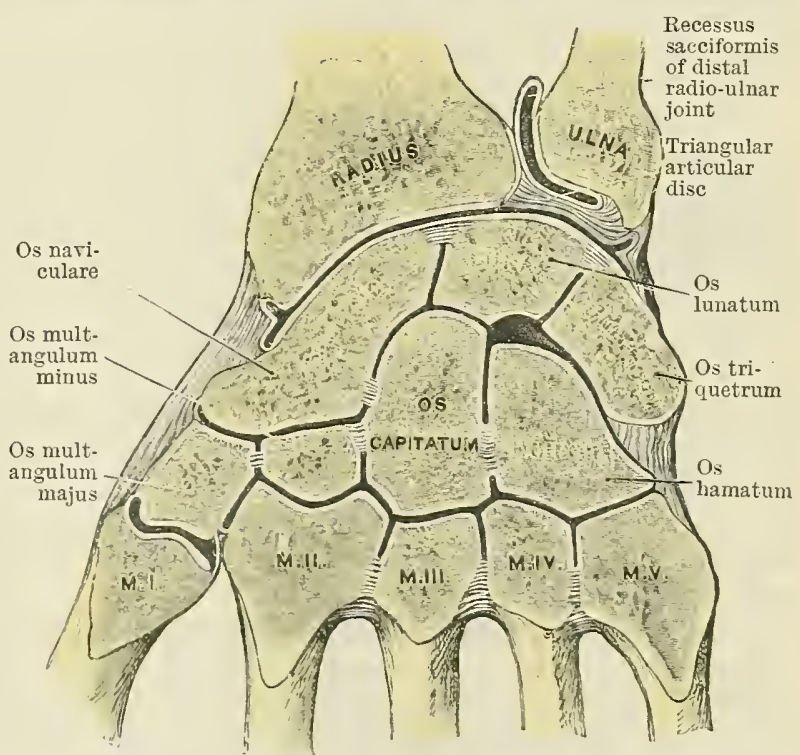

Fig. 311.-FRONTAL SECTION through the radio-carpal, carpal, carpometacarpal, and intermetacarpal joints, to show joint cavities and interosseous ligaments (diagrammatic).

joints. The first condition is rare, but the second is not uncommon, and results from the absence of the interosseous ligament between the greater and lesser multangular bones, or of that between the lesser multangular and the capitate bone. 


\section{ARTICULATIONES INTERMETACARPE.}

Intermetacarpal Joints. - The four medial metacarpal bones articulate with each other at their proximal ends or bases, between the opposing surfaces of which joint cavities are found-arthrodial diarthroses. These cavities are continuous with the carpo-metacarpal joint (not yet described), and hence the ligamentous arrangements only enclose three aspects of each joint.

Three strong transverse ligaments (Figs. 310 and 311) bind adjacent volar, dorsal, and interosseous areas of the bases of the metacarpal bones, and hence they are called ligamenta basium (oss. metacarp.) volaria, dorsalia et interossea. A synovial stratum is associated with each of these joints, but it may be regarded as a prolongation from the carpo-metacarpal articulation.

\section{ARTICULATIONES CARPOIETACARPEA.}

Carpo-metacarpal Joints. - The articulation of the metacarpal bone of the thumb with the greater multangular differs in so many respects from the articulation between the other metacarpal bones and the carpus, that it must be considered separately.

(A) The articulatio carpometacarpea pollicis (Figs. 310 and 311 ) is the joint between the disto-lateral surface of the greater multangular and the proximal surface of the base of the first metacarpal bone. Both of these surfaces are saddleshaped, and they articulate by mutual co-aptation.

The joint cavity is surrounded by an articular capsule, in the fibrous stratum of which we may recognise volar, dorsal, lateral, and medial bands, the last being the strongest and most important.

A synovial stratum lines the fibrous stratum, and the joint cavity is isolated and quite separate from the other carpal and carpo-metacarpal articulations.

At this joint movements occur around at least three axes. Thus, around a more or less transverse axis, flexion and extension take place; in an antero-posterior ax is abduction and adduction (movements which have reference to the middle line of the hand) are found ; while a certain amount of rotation is possible in the longitudinal axis of the digit. The very characteristic movement of opposition, in which the tip of the thumb may be applied to the tips of all the fingers, results from a combination of flexion, adduction, and rotation, and by combining all the movements possible at the various axes a considerable degree of circumduction may be produced.

$(B)$ The articulationes carpometacarpeæ digitorum are the joints between the bases of the four medial metacarpal bones and the four bones of the distal row of the carpus. They are all arthrodial diarthroses, and the opposed articular surfaces present alternate elevations and depressions which form a series of interlocking joints. The joint cavities between the carpal bones of the distal row, and also the more extensive intermetacarpal joint cavities, open into this articulation.

This series of joints is invested by a common articular capsule which is weakest on its radial side, but is otherwise well defined. Its fibres arrange themselves in small slips, which pass obliquely in different directions, and vary in number for each metacarpal bone. Thus the ligamenta carpometacarpea volaria (volar carpometacarpal ligaments (O.T. oblique palmar)) (Fig. 310) usually consist of one slip for each metacarpal bone, but there may be two slips, and the third metacarpal bone frequently has three, of which one lies obliquely in front of the tendon of the flexor carpi radialis muscle.

The ligamenta carpometacarpea dorsalia (dorsal carpo-metacarpal ligaments (O.T. oblique dorsal)) are similar short bands, of greater strength and clearer definition, by which the index metacarpal is bound to the greater and lesser multangular bones: the middle metacarpal to the capitate, and frequently to the lesser multangular; the ring metacarpal to the capitate and os hamatum, and the metacarpal of the 5th finger to the os hamatum.

Ligamenta interossea (interosseous ligaments), one or sometimes two in number, occur within the capsule. They are usually situated in relation to one or both of the contiguous margins of the bases of the third and fourth metacarpal bones, from which they extend proximally to adjacent margins of the capitate and os hamatum. Occasionally they are sufficiently developed to divide the joint cavity into radial and ulnar sections. 
The synovial stratum (Fig. 311) is usually single and lines the fibrous stratum, but, as already explained, it has prolongations into the intermetacarpal and intercarpal series of joints. In connexion with the intercarpal series, the frequent absence of the interosseous ligament between the greater and lesser multangular bones permits the free communication of this joint cavity with that of the transverse carpal joint.

\section{ARTICULATIONES METACARPOPHALANGEF.}

Metacarpo-phalangeal Joints.-In the case of the pollex this joint is constructed on the plan of a ginglymus diarthrosis; the four corresponding joints of the fingers are also diarthroses of a slightly modified ball-and-socket variety. With the exception of the metacarpal bone of the pollex, each metacarpal bone has a somewhat spherical head articulating with a shallow oval cup upon the base of the first phalanx. It is important to note that the articular surface upon the head of each of these metacarpal bones is wider on the volar aspect and narrower on the dorsal aspect. The articulation in the thumb presents features similar to those of an interphalangeal joint.

Each joint possesses a capsula articularis (Fig. 312) which presents very different degrees of strength in different aspects of the articulation. Thus, on the dorsal aspect, it cannot be demonstrated as an independent structure, but the necessity for dorsal ligaments is to a large extent obviated by the presence of the strong flattened expansions of the extensor tendons.

The epiphyseal lines are extra-capsular.

Ligamenta Collateralia.-The collateral ligaments (O.T. internal and external lateral) (Fig. 312) are strong cord-like bands which pass from the tubercles and adjacent depressions on the sides of the heads of the metacarpal bones to the contiguous non-articular areas on the bases of the proximal phalanges. They are intimately connected on their volar aspects with the volar ligaments.

Ligamenta Accessoria Volaria.-The volar accessory ligaments (O.T. palmar ligaments) consist of thick plates of fibro-cartilage loosely connected to the metacarpal bones, but firmly adherent to the phalanges. They are placed between the collateral ligaments, to both of which they are in each case connected. Each plate is grooved on the volar surface for the long flexor tendons, whilst on its dorsal or joint surface it supports and glides upon the head of the metacarpal bone during flexion and extension of the joint. In the case of the thumb this plate of fibro-cartilage is usually replaced by sesamoid bones, and in the case of the index finger one such sesamoid nodule

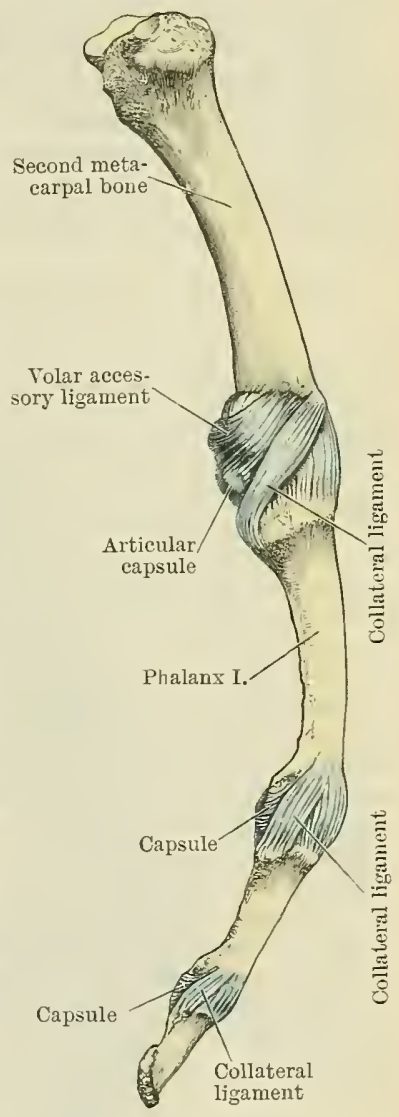
is frequently found at the radial side of the plate.

An important accessory ligament is found in connexion with the four medial metacarpo-phalangeal articulations, viz. :-

Ligamenta Capitulorum (Oss. Metacarpalium) Transversa.-The transverse ligament of the heads of the metacarpal bones (or transverse metacarpal ligament) binds together the distal extremities of the four medial metacarpal bones. The name is applied to three sets of transverse fibres of great strength which are situated in front of the three medial interosseous spaces. These fibres are continuous with the ligamen ta accessoria volaria (volar metacarpo-phalangeal ligaments) at their lateral margins.

A stratum synoviale lines the capsula articularis of each joint. 


\section{ARTICULATIONES DIGITORUM MANUS.}

Interphalangeal Joints._Of these joints there are two for each finger and one for the thumb. They all correspond, in being ginglymus diarthroses in which the trochlear character of their articular surfaces is associated with one axis of movement directed transversely.

In their general arrangement they correspond with each other, and to a large extent with the metacarpo-phalangeal series already described. Each is provided with a definite articular capsule (Fig. 312), of which the volar and cord-like lateral portions are well marked, while on the dorsal aspect the extensor tendons act as the chief support. The volar portions contain fibrous plates of considerable thickness, and are attached to the two collateral ligaments and to the intervening rough surface on the distal phalanges, while their proximal margins are not attached to bone. Each ligament has its lateral margins prolonged proximally to the adjacent sharply defined lateral ridges on the phalangeal shafts.

The collateral ligaments (Fig. 312) are strong, rounded, short bands, continuous with the preceding, and attached to the non-articular sides of adjacent heads and bases of the phalanges.

Each joint possesses a synovial stratum which lines its fibrous stratum, but its arrangement presents no special peculiarity. The epiphyseal lines of the bases of the phalanges are extra-capsular.

\section{Movements of the Carpal, Intermetacarpal, Metacarpo-Phalangeal AND INTERPHALANGEAL JOINTS.}

The amount of movement which is possible at individual joints of the intercarpal, intermetacarpal, and carpo-metacarpal series is extremely limited, both on account of the interlocking nature of the articular surfaces and the restraining character of the ligamentous bands. Taken as a whole, however, the movements of the carpus and metacarpus enable the hand to perform many varied and important functions. This is largely due to the greater mobility of those joints on the radial and ulnar borders of the hand, as well as to the general elasticity of the arches formed by the carpus and metacarpus. These conditions particularly favour the movements of opposition and prehension. In the opposite direction, i.e. when pressure is applied from the volar aspect, the metacarpal and carpal arches tend to become flattened, but great elasticity is imparted by the tension of the various ligaments.

The four medial metacarpo-phalangeal joints are ball-and-socket joints, and movements of volar-flexion and extension are freely performed about a transverse axis. In exceptional cases a certain amount of dorsi-flexion is possible. About an antero-posterior axis movements occur which are usually referred to the middle line of the hand, and hence called abduction and adduction, but in consequence of the difference in the width of the articular surface on the dorsal and volar aspects of the heads of the four medial metacarpal bones it is only possible to obtain abduction when the joints are extended, while in the flexed position the joints become locked and abduction is impossible.

The movements of the index finger are less hampered than in the case of the others, but each of them can perform a modified kind of circumduction.

The metacarpo-phalangeal joint of the thumb and all the interphalangeal joints are uniaxial or hinge-joints acting about a transverse axis, which permits of volar-flexion and extension being freely performed, but dorsi-flexion is, as a rule, entirely prevented by the volar and lateral ligaments.

\section{ARTICULATIONES ET LIGAMENTA CINGULI EXTREMITATIS INFERIORIS.}

Articulations and Ligaments of the Pelvis.-Although we may consider the pelvis as a separate part of the skeleton, yet it is essential to remember that the bones which enter into its composition belong to the vertebral column (sacrum, coccyx) and the lower limb (hip bone). Accordingly, the articulations, with their corresponding ligaments, may be arranged as follows:-

(a) Those by which the segments of the coccyx are joined together (already described, v. p. 310 );

(b) That by which the sacrum articulates with the coccyx (already described, v. p. 309); 
(c) Those by which the sacrum articulates with the last lumbar vertebra (Lumbo-sacral joints);

(d) Those by which the hip bones are attached to the vertebral column (Sacro-iliac joints);

(e) That by which the hip bones are attached to each other (Symphysis pubis).

\section{ARTICULATIONES SACROLUMBALES.}

Lumbo-sacral Joints. - The articulation of the sacrum with the fifth lumbar vertebra is constructed precisely on the principle of the articulations between two typical vertebræ, and the usual ligaments associated with such joints are repeated. There is, however, an additional accessory ligament, termed the lateral lumbo-sacral ligament. This extends from the anterior aspect of the inferior border of the transverse process of the last lumbar vertebra, downwards and slightly laterally, to the front of the lateral aspect of the ala of the sacrum, close to the sacroiliac joint. Further, a variable membranous band extends between the lateral aspect of the inferior part of the body of the last lumbar vertebra and the front of the ala of the sacrum. This band lies in front of the anterior ramus of the fifth lumbar nerve.

\section{ARTICULATIO SACROILIACA.}

Each hip bone articulates with the sacral section of the vertebral column on each side through the intervention of a cliarthrosis, termed the sacro-iliac joint.

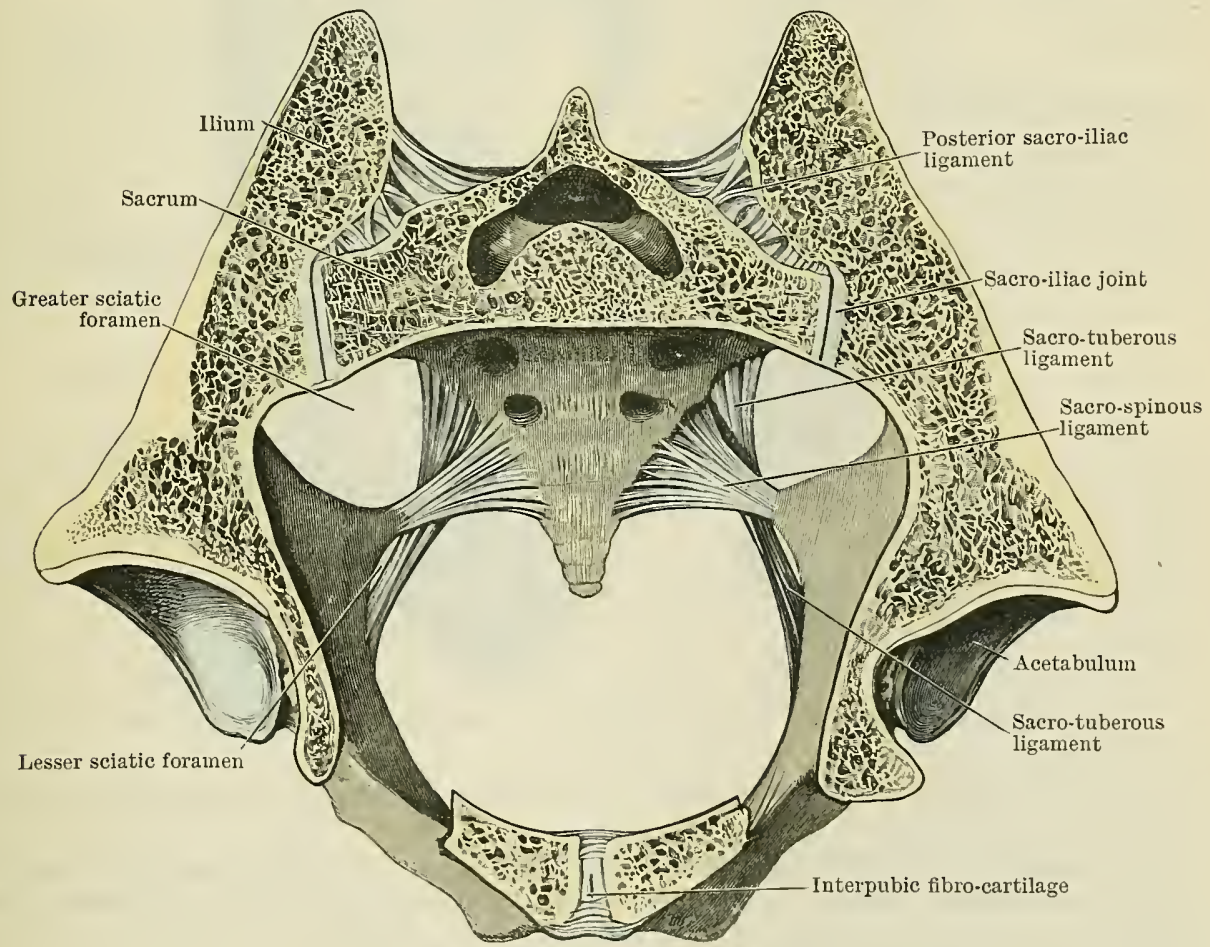

Fig. 313.-Frontal Section of Pelvis.

This joint is formed between the contiguous auricular surfaces of the sacrum and ilium. Each of these surfaces is more or less completely clothed with hyaline articular cartilage. The joint cavity, which is little more than a capillary interval, may be crossed by fibrous bands. 
The carmm articulare (joint cavity) is surronnded by ligaments of varying thickness and strength, which constitute the fibrous stratum of its articular capsule. Thus, its anterior part is thin, and consists of short but strong fibres which pass between adjoining surfaces on the ala of the sacrum and the iliac fossa of the hip bone; they form the anterior sacro-iliac ligament. On the posterior aspect there are three ligaments. The interosseous sacro-iliac ligament (Fig. 313) consists of numerous strong fasciculi, which pass from the rough area on the medial aspect of the ilium, above and behind its auricular surface, downwards and medially to the transverse tubercles and the depressions behind the first and second segments of the sacrum. This ligament is of great strength, and with its fellow

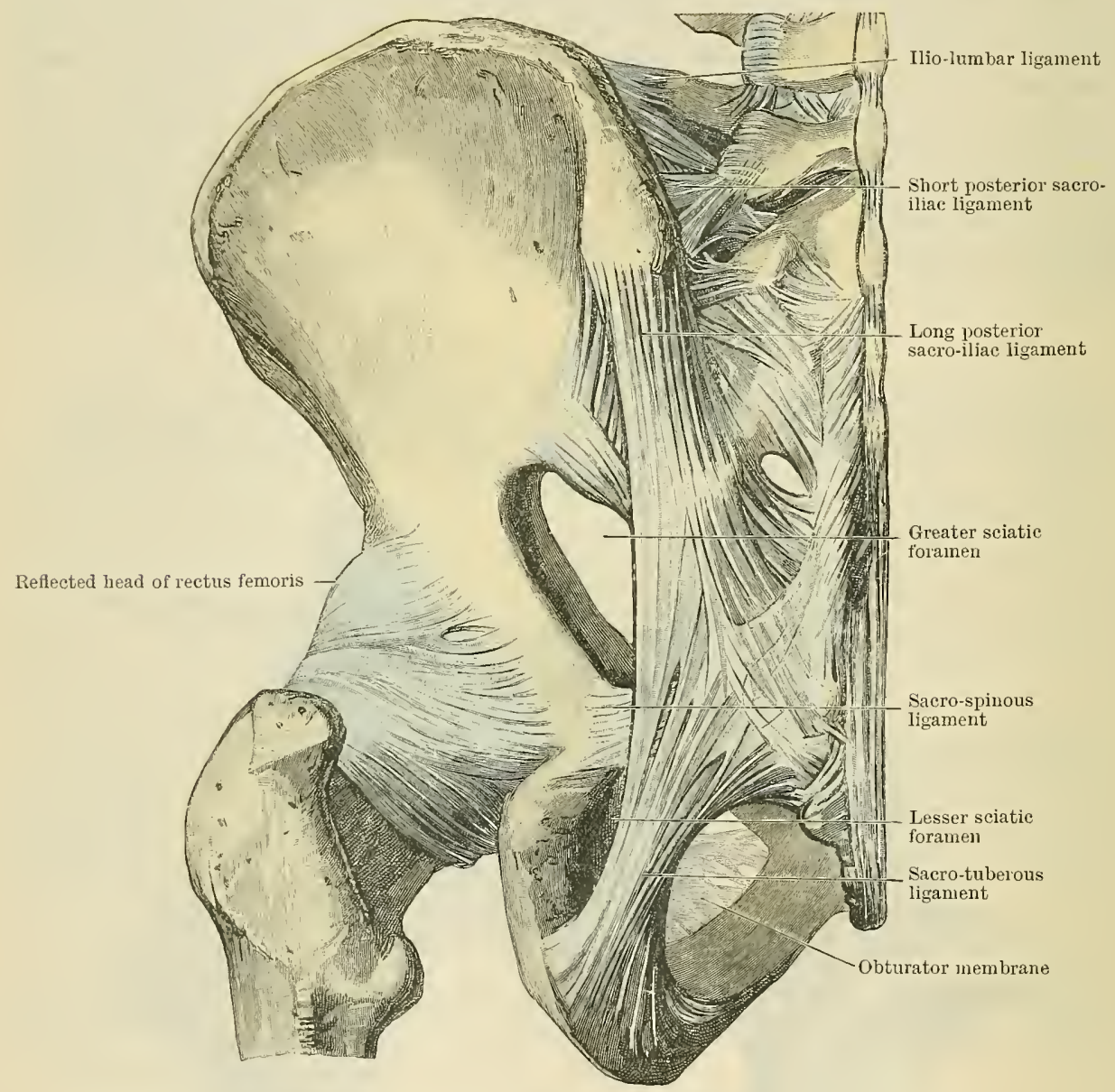

Fig. 314.-Posterior View of the Pelvic Ligaments and of the Hip-Joint.

it is responsible for suspending the sacrum and the weight of the superimposed trunk from the hip bones.

The long posterior sacro-iliac ligament (Fig. 314) is a superficial thickened portion of the interosseous ligament. It consists of a definite band of fibres passing from the posterior superior iliac spine to the transverse tubercles of the third and fourth segments of the sacrum.

The short posterior sacro-iliac ligament consists of superficial fibres of the interosseous ligament passing from the posterior superior iliac spine to the first and second transverse tubercles of the sacrum.

The articular cavity of this joint is very imperfect and rudimentary.

Several accessory ligaments are associated with the articulation of the hip bone to the sacral section of the vertebral column. 
Lig. Iliolumbale.-The ilio-lumbar ligament (Fig. 314), which is merely the thickened anterior lamina of the lumbo-dorsal fascia, extends from the tip of the transverse process of the last lumbar vertebra, almost horizontally laterally, to the inner lip of the iliac crest at a point a short distance behind its highest level. A proportion of these fibres is attached to the medial rough surface of the ilium between the iliac crest and the auricular impression. To these the name of the lig. iliolumbale inferius is applied.

Lig. Sacrotuberosum.- The sacro-tuberous ligament (O.T. great sacro-sciatic lig.) (Fig. 314) is somewhat triangular in outline. It occupies the interval between the sacrum and the hip bone, and is attached medially to the posterior inferior spine of the ilium; to the posterior aspect of the transverse tubercles and lateral margins of the third, fourth, and fifth segments of the sacrum, as well as to the side of the first segment of the coccyx. It passes downwards and laterally, becoming narrower as it approaches the ischium, near to which, however, it again expands, to be attached to the medial side of the tuber ischiadicum, immediately below the groove for the tendon of the obturator internus muscle, i.e. the lesser sciatic notch. A continuation of the medial border of the ligament-the processus falciformis (Fig. 314) - runs upwards and forwards on the medial aspect of the ramus of the ischium.

The ligamentum sacrotuberosum is believed by many to represent the original or proximal end of the long or ischial head of the biceps femoris muscle.

Ligamentum Sacrospinosum.-The sacro-spinous ligament (O.T. small sacrosciatic lig.) (Figs. 314 and 313) is situated in front, and in a measure under cover of the sacro-tuberous ligament. Triangular in form, it is attached by its base to the last two segments of the sacrum and the first segment of the coccyx, and by its pointed apex to the tip and superior aspect of the spina ischiadica. This ligament is intimately associated with the coccygeus muscle, and by some it is regarded as being derived from it by fibrous transformation of the muscle fasciculi.

By the sacro-tuberous and sacro-spinous ligaments the two sciatic notches of the hip bone are converted into foramina. Thus the sacro-spinous ligament (lig. sacrospinosum) completes the boundaries of the greater sciatic foramen (foramen ischiadicum majus); while the sacro-tuberous ligament (lig. sacrotuberosum), assisted by the sacro-spinous ligament (lig. sacrospinosum), closes the lesser sciatic foramen (foramen ischiadicum minus).

\section{SYMPHYSIS OSSIUM PUBIS.}

The anterior wall of the osseous pelvis is completed by the articulation of the bodies of the two pubic bones, which constitutes the symphysis pubis. This joint conforms in its construction to the general plan of an amphiarthrosis. Thus it is median in position; each pubic bone is covered by a layer of hyaline cartilage, which closely adapts itself to the rough tuberculated surface of the pubic bone; while between these two hyaline plates there is an interposed fibro-cartilage called the lamina fibrocartilaginea interpubica, in the interior of which there is usually a vertical antero-posterior cleft. This cavity, which is placed nearer the posterior than the anterior aspect of the joint, does not appear until between the seventh and tenth years, and as it is not lined by a synovial stratum, it is supposed to result from the breaking down of the interpubic lamina.

Lig. Pubicum Anterius.-The anterior pubic ligament (Fig. 313) is a structure of considerable thickness and strength. Its superficial fibres, which are derived very largely from the tendons and aponeuroses of adjoining muscles, are oblique, and form an interlaced decussation. The deeper fibres are short, and extend transversely from one pubic bone to the other.

Lig. Pubicum Posterius.-The posterior pubic ligament (Fig. 313) is very weak and consists of scattered fibres which extend transversely between contiguous pubic surfaces posterior to the articulation.

Lig. Pubicum Superius.-The superior pubic ligament also is weak; it consists of transverse fibres passing between the two pubic crests. 
Lig. Arcuatum Pubis.-The arcuate ligament of the pubis (O.T. inferior or subpubic ligament) occupies the arch of the pubis, and is of considerable strength. It gives roundness to the pubic arch and forms part of the inferior aperture of the pelvis. It has considerable vertical thickness immediately below the interpubic fibro-eartilage, to which it is attached. Laterally it is attached to adjacent sides of the descending rami of the pubis. Its inferior border is free, and separated from the fascia inferior of the urogenital diaphragm by a transverse oval interval, through which the dorsal rein of the penis passes backwards to the interior of the pelvis.

\section{Fascia Diaphragmatis Urogenitalis Inferior.}

The inferior fascia of the urogenital diaphragm (O.T. superficial layer of the triangular ligament) is a membranous structure which occupies the pubic arch below and distinct from the arcuate ligament of the pubis. It assists in completing the pelvic walls anteriorly in the same manner that the obturator membrane does laterally. Indeed, these two structures oceupy the same morphological plane. The fascia presents two surfaces-one superficial or perineal, the other deep or pelvicand both of these surfaces are associated with muscles. Its lateral borders are attached to the sides of the pubic arch, while its base is somewhat ill-defined, by reason of its fusion with the fascia of Colles in the urethral region of the perineum.

The apex of the fascia is truncated, free, and well defined, constituting the transverse perineal ligament, above which there is the interval for the dorsal vein of the penis. It is pierced by a number of vessels and nerves, but the principal opening is situated in the median plane one inch below the pubic arch, and transmits the urethra.

\section{Membrana Obturatoria.}

The obturator membrane (Fig. 316) occupies the obturator foramen. It is attached to the pelvic aspect of the circumference of this foramen. It consists of fibres irregularly arranged and of varying strength, so that sometimes it almost appears fenestrated. At the highest part of the foramen it is incomplete and forms a U-shaped border, between which and the bony circumference of the foramen the obturator canal is formed. In this position the membrane is continuous with the parietal pelvic fascia which clothes the medial side of the obturator internus muscle, above the superior free margin of the muscle. From the lateral or femoral aspect of the membrane some of its fibres are prolonged to the antero-inferior aspect of the capsule of the hip-joint.

Mechanism and Movements of the Pelvis.-The human pelvis presents a mechanism the principal requirement of which is stability and not movement, for, through the pelvis, the weight of the trunk, superimposed upon the sacrum, is transmitted to the lower limbs. Moreover, its stability is largely concerned in the maintenance of the erect attitude. The movements of its various parts are therefore merely such as are consistent with stability, without producing absolute rigidity.

The two hip bones, being bound together by powerful ligaments at the pubic articulation, constitute an inverted arch, of which the convexity is directed downwards and forwards, while its piers are turned upwards and backwards, and considerably expanded in relation to the posterior parts of the iliac bones. Between the piers of this inverted arch the sacrum is situated. This bone is in no sense a key-stone to an arch, because, as may readily be seen in antero-posterior transverse section, the sacrum is wider in front than behind, and the superposed weight naturally tends to make the sacrum fall towards the pelvic cavity, and so fit less closely between the hip bones. The sacrum is in reality an oblique platform, in contact with each hip bone through its articular auricular surfaces, and in this position it is suspended by the interosseous and posterior sacro-iliac ligaments, and kept securely in place by the "grip" due to the irregularity of the opposed surfaces of the two sacro-iliac articulations. Since the weight of the trunk is transmitted to the anterior and superior end of this sacral platform, there is a natural tendency for the sacrum to revolve upon the transverse axis which passes through its sacro-iliac joints. If this were permitted, the promontory of the sacrum would rotate downwards and forwards towards the pelvic cavity, as really does occur in certain deformities. This revolution or tilting downwards of the anterior part of the sacrum is prevented by the action of the sacrotuberous and sacro-spinous ligaments, extending from the ischial tuberosity to the posterior and inferior end of the suspended platform of the sacrum. Not only so, but these ligaments, acting on a rigid sacrun, tend to hold up the weight upon the sacral promontory. 
The various ligaments passing between the last lumbar vertebra and the sacrum and ilium retain the weight of the trunk in position upon the anterior end of the sacrum, and resist its tendency to slip forwards and downwards towards the pelvic cavity. The entire weight of the trunk and pelvis is transmitted to the heads of the thigh bones in the most advantageous position, both for effectiveness and the strengthening of the inverted back of the hip bones, for it will be evident that the heads of the femora thrust inwards upon the convex side of the arch, very much at the place where the arches are weakest, viz., at the springing of the arch from its piers. The forces which tend to cause movement of the pelvic bones during parturition act from within the pelvis, and have for their object the increase of the various pelvic diameters, in order that the foetal head may more readily be transmitted. For this purpose the wedge-like dorsal surface of the sacrum is driven backwards, and a certain amount of extra space may thereby be obtained. An important factor, however, in the increase of the pelvic capacity at this period is found in the relaxation of its various ligaments.

\section{ARTICULATIONES EXTREMITATIS INFERIORIS.}

\section{ARTICULATIO COXE.}

The Hip-Joint. - The human body provides no more perfect example of an enarthrodial diarthrosis than the hip-joint. Combined with all that variety of movement which characterises a multi-axial joint, it nevertheless presents great stability, which has been obtained by simple arrangements, for restricting the range of its natural movements. This stability is of paramount importance for the maintenance of the erect attitude, and the mechanical adaptations whereby this result is obtained are such that the erect attitude may be preserved without any great degree of sustained muscular effort.

Articular Surfaces.-The head of the femur is globular in shape, and considerably exceeds a hemisphere. It is clothed with hyaline articular cartilage on those parts which come into direct contact with the acetabulum. There is frequently more or less of extension of the articular cartilage from the head to theadjoining anterior part of the neck, an extension which is accounted for by the close and constant apposition of this portion of the neck with the posterior aspect of the ilio-femoral ligament. The limit of the articular cartilage covering the head is indicated by a sinuous border. Further, there is an absence of articular cartilage from the fovea or pit on the head of the femur.

The acetabulum is a deep cup-shaped cavity which presents a notch on its anteroinferiormargin. Theinterior of the cup is lined with a ribbon-like band of articular cartilage which extends to the brim of the cavity, but

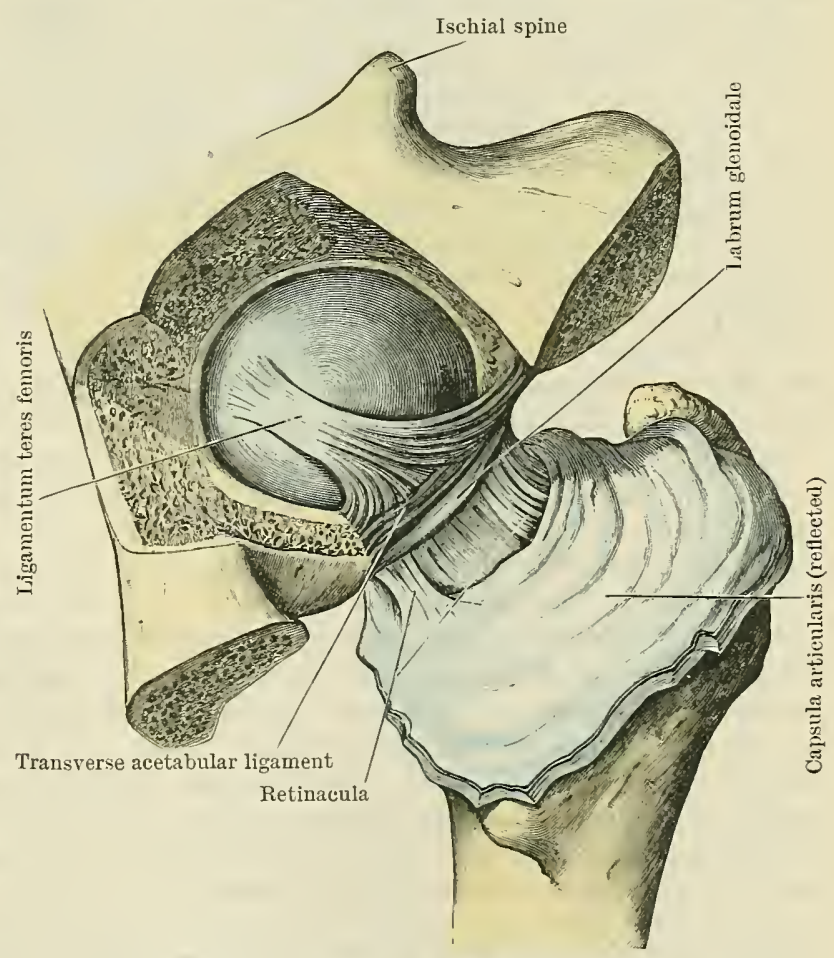

Fig. 315.-Dissection of the Hip-Joint.

Bottom of the acetabulum removed, and capsule of the joint thrown laterally towards the trochanters. does not cover its floor. This articular ribbon-shaped band is widest on its superoposterior aspect, and narrowest at the anterior margin of the acetabular notch.

Lig. Transversum Acetabuli.-The transverse ligament (Fig. 315) bridges the acetabular notch, and consists of strong transverse fibres which are attached to 
both of its margins, but more extensively to the postero-inferior. This ligament does not entirely fill the notch, but leaves an open interval between its inferior border and the bottom of the notch through which vessels and nerves enter the cup. The acetabular aspect of this ligament constitutes an articular surface.

The acetabulum is deepened by the labrum glenoidale (O.T. cotyloid ligament) (Figs. 315 and 316), which consists of a strong ring of fibro-cartilaginous tissue attached to the entire rim of the cup. The attached surface of the ring is broader than its free edge, and, moreover, the latter is somewhat contracted, so that the ligament grasps the head of the femur which it encircles. Its fibres are partly oblique and partly circular in their direction. By the former it is firmly implanted on the rim of the acetabulum and the lig. transversum acetabuli; by the latter the depth of the cup is increased through the elevation of its edge, and its mouth slightly narrowed. By one surface this ligament is also articular.

Capsula Articularis.-An articular capsule (Figs. 315 and 316) completely invests the joint cavity. Its fibrous stratum is of great strength, although it is not of equal thickness throughout, being considerably thicker on the supero-anterior aspect than at any other part. Unlike the corresponding structure of the shoulderjoint, it does not permit of the withdrawal of the head of the femur from contact with the acetabular articular surfaces, except to a very limited extent. Its fibres are arranged both in the circular and in the longitudinal direction, the former, known as the zona orbicularis, being best marked posteriorly, while the longitudinal fibres stand out more distinctly in front, where they constitute special ligaments. Looked at as a whole, the fibrous stratum of the capsule has the following attachments: proximally it surrounds the acetabulum, on the superior and posterior aspects of which it is attached directly to the hip bone, while on the anterior and inferior aspects it is attached to the non-articular surfaces of the labrum glenoidale and transverse ligaments of the acetabulum; distally it encircles the neck of the femur, where it is attached in front to the intertrochanteric line; above, to the medial aspect of the root of the greater trochanter; below, to the lower part of the neck of the femur, in close proximity to the lesser trochanter; behind, to the line of junction of the lateral and middle thirds of the neck of the femur. It is a matter of some importance to note that only part of the posterior surface of the neck of the femur is enclosed within the articular capsule. The femoral attachments of the fibrous stratum of the capsule vary considerably in their strength, being particularly firm above and in front, but much weaker below and posteriorly, where the orbicular fibres are well seen. Many fibres of the fibrous stratum, are reflected from its deep aspect proximally upon the neck of the femur, where they form ridges, and to these the term retinacula (Fig. 315) is applied.

The epiphyseal line of the head of the femur is intra-capsular; the epiphyseal lines of the two trochanters are extra-capsular.

The longitudinal fibres of the fibrous stratum of the capsule are arranged so as to form certain definite bands, viz. :-

(1) Lig. Iliofemorale.-The ilio-femoral ligament (Fig. 316) consists of a triangular set of fibres attached proximally, by their apex, to the inferior part of the auterior inferior iliac spine and the immediately adjoining part of the rim of the acetabulum, and distally, by their base, to the intertrochanteric line of the femur. This ligament is the thickest part of the fibrous stratum, but its sides are more pronounced than its centre, especially towards its base. Consequently the ilio-femoral ligament presents some resemblance to an inverted $Y(\lambda)$; and therefore was formerly named the Y-shaped ligament of Bigelow.

The lateral or upper limb of the ilio-femoral ligament may be somewhat extended by the inclusion of additional longitudinal fibres, and described as the ilio-trochanteric ligament. This. band arises from the anterior part of the dorsum of the acetabulum, and extends to the femoral neck, close to the anterior end of the medial surface of the greater trochanter.

(2) Lig. Pubocapsulare.-The pubo-capsular ligament (Fig. 316) is composed of some bands of fibres of no great strength, which extend from the lateral end of the superior ramus of the pubis, the ilio-pectineal eminence, the obturator crest and the obturator membrane, to lose themselves for the most part in the capsule, although 
a certain proportion of them may be traced to the inferior aspect of the femoral neck, where they adjoin the distal attachment of the ilio-femoral ligament.

(3) Lig. Ischiocapsulare.-The ischio-capsular ligament consists of a broad band of short, fairly strong longitudinal fibres, which, by their proximal ends, are attached to the ischium between the lesser sciatic notch and the obturator foramen, while their distal ends become merged in the zona orbicularis of the general capsule.

Within the capsule, and quite distinct from it, there are the ligamentum teres and the Haversian gland.

Lig. Teres Femoris.-The round ligament (Fig. 315) is a strong, somewhat flattened band of fibrous tissue, attached by one end to the superior half of the pit or depression on the head of the femur. By its medial end it is attached to the lower edge of the articular surface of the transverse ligament, with extensions to the opposite borders of the acetabular notch, but chiefly to the posterior or ischial border. This ligament varies very greatly in its strength and development in different subjects, and in certain rare cases it is absent.

The so-called Haversian gland occupies the bottom or non-articular area of the acetabulum. It consists of a mass of fat covered by the synovial stratum of

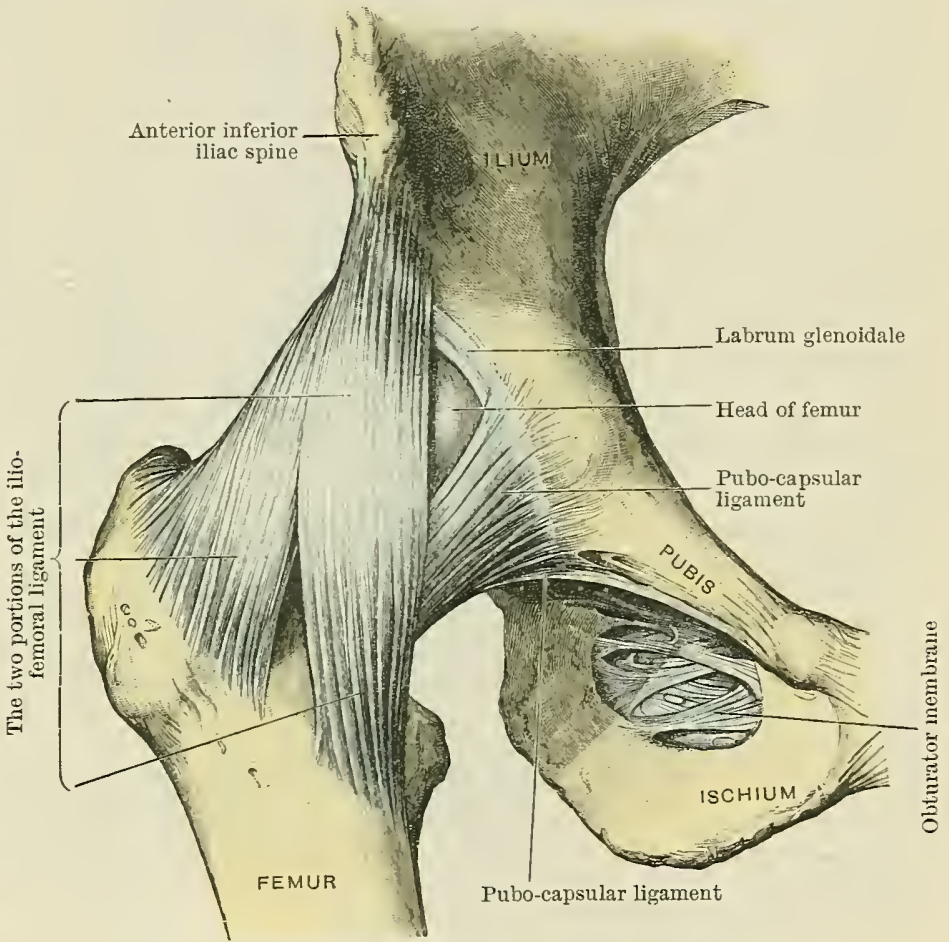

Fig. 316. -Dissection of the Hip-Jolnt frov the front. the joint. This pad of fat is continuous with the extra-capsular fat through the passage subjacent to the transverse ligament of the acetabulum.

A synovial stratum lines the fibrous stratum of the capsule from which it is reflected to the neck of the femur along a line which corresponds to the femoral attachments of the fibrous stratum. Thus the synovial stratum clothes more of the femoral neck anteriorly than in any other position. Posteriorly, where the fibrous stratum is feebly attached to the neck of the femur, the synovial stratum may be seen from the ontside of the capsule. The synovial stratum extends close up to the articular margin of the head of the femur, and on the superior and inferior aspects of the neck it is gathered into loose folds upon the retinacula. These folds or plice synoviales are best marked along the line of synovial reflection, and do not reach as far as the femoral head. At its acetabular end the synovial stratum is prolonged from the inside of the capsule to the outer non-articular surface of the labrum glenoidale and transverse ligament, upon which it is continued as a lining for their acetabular or articular surfaces, and further, it provides a covering for the fat at the bottom of the acetabular fossa, as well as a complete tubular investment for the ligamentum teres femoris.

Occasionally the synovial bursa, which is subjacent to the tendon of the iliopsoas muscle, communicates with the interior of the hip-joint through an opening 
in the anterior wall of the capsule (Fig. 316), situated between the pubo-capsular ligament and the medial or lower limb of the ilio-femoral ligament.

Movements at the Hip-Joint.-The movements which occur at the hip-joint are those of a multiaxial joint. These are flexion, extension, abduction, adduction, rotation, and circumduction. The range of each of these movements is less extensive than in the case of the shonlder-joint, because, at the hip, the freedom of movement is subordinated to that stability which is essential alike for the maintenance of the erect attitnde and for locomotion. When standing at rest in the erect attitude the hip-joint occupies the position of extension, and as the weight of the trunk is transmitted in a perpendicular which falls behind the centres of the hip-joints, both the erect attitude and the extended position are maintained to a large extent mechanically, by means of the tension of the ilio-femoral ligament, without sustained muscular action. Moreover, the tension of this ligament is sustained by the pressure of the front of the head and neck of the femur against its synovial surface. In this association of parts it is important to note that the articular cartilage of the femoral head may be, and in certain races is, prolonged to the front of the femoral neck; and further, that the constant friction does not destroy the synovial stratum of the capsule. Again, the same mechanism which preserves the erect attitude prevents an excessive degree of extension or dorsiflexion. In movement forwards, i.e. ventral flexion, the front of the thigh is approximated to the anterior abdominal wall. The amount of this movement depends upon the position of the knee-joint, because when the latter is flexed the thigh may be brought into contact with the abdominal wall, whereas wheu the knee-joint is straightened (i.e. extended) the tension of the hamstring muscles greatly restricts the amount of flexion at the hip-joint. Abduction and adduction are likewise much more restricted than at the shoulder-joint. Abduction is brought to a close by the tension of the pubo-capsular band and the lower part of the capsule, and, in addition, the upper aspect of the neck of the femur locks against the margin of the acetabulum. Excessive adduction is prevented by the tension of the upper band of the ilio-femoral ligament and the upper part of the capsule. Rotation or movement in a longitudinal axis may be either medially, i.e. towards the front, or laterally, i.e. toward the back. In the former the movement is brought to a close by the tension of the ischio-capsular ligament and posterior part of the capsule, aided by the muscles on the back of the joint; in the latterrotation laterally-the chief restraining factor is the lateral or upper limb of the ilio-femoral ligament. The total amount of rotation is probably less than $60^{\circ}$.

Circumduction is only slightly less free than at the shoulder, but it is complicated by the preservation of the balance upon one foot.

The valne and influence of the ligamentum teres femoris are not easily estimated, because it may be absent without causing any known interference with the usefulness of the joint. In the erect attitude this ligament lies lax between the lower part of the femoral head and the acetabular fat. In the act of walking it is rendered tense at the moment when the pelvis is balanced on the summit of the supporting femur. Analysis of this position shows the femur to be adducted, with probably, in addition, a small amount of flexion (i.e. bending forwards) and medial rotation. Again, this ligament is said to be tense when the thigh is rotated laterally. The equivalent of this movement is doubtless found in the rotation of the pelvis, which occurs in the act of walking at the moment of transition from the toe of the supporting foot to the heel of the advancing foot. The interest connected with this ligament is perhaps rather morphological than physiological. It is believed by some to represent the tendon of a muscle which in birds occupies a position external to the joint capsule.

\section{ARTICULATIO GENU.}

The knee-joint is the largest articulation in the body, and its structure is of a very elaborate nature. The part it plays in maintaining the erect attitude materially influences its construction, and special arrangements are provided for the mechanical retention of the joint in the extended position in view of the fact that the line of gravity falls in front of the centre of the articulation. Its principal axis of movement is in the transverse direction, consequently it belongs to the ginglymus or hinge variety of the diarthroses. At the same time a slight amount of rotation of the tibia in its long axis is permitted during flexion; but while this fact is of considerable importance in the study of certain accidents to which the joint is liable, as well as in the study of its comparative morphology, it is not sufficiently pronounced to interfere with its classification as a hinge-joint.

Articular surfaces pertaining to the femur, tibia, and patella enter into the formation of the knee-joint. The articular surface of the femur extends over a large part of both condyles, and may be divided into patellar and tibial portions by faintly-marked, almost transverse grooves, which pass across the articular surface immediately in front of the intercondylar notch. As a rule marginal indentations of the articular surface render the positions of these transverse grooves more distinct. 
The patellar portion (Fig. 317) is situated anteriorly, and is common to both condyles, although developed to a larger extent in association with the lateral condyle, on which it ascends to a more proximal level than on the medial condyle. This surface is trochlear, and forms a vertical groove bordered by prominent borders.

The tibial portion of the articular surface of the femur is divided into two articular areas, in relation to the distal aspects of the two condyles, by the wide non-articular intercondyloid notch. These two surfaces are for the most part parallel, but in front the medial tibial surface turns obliquely laterally as it passes into continuity with the patellar trochlea, while posteriorly, under certain circumstances, e.g. the squatting posture, the articular surface of the medial condyle may extend to the adjoining portion of the popliteal area of the bone.

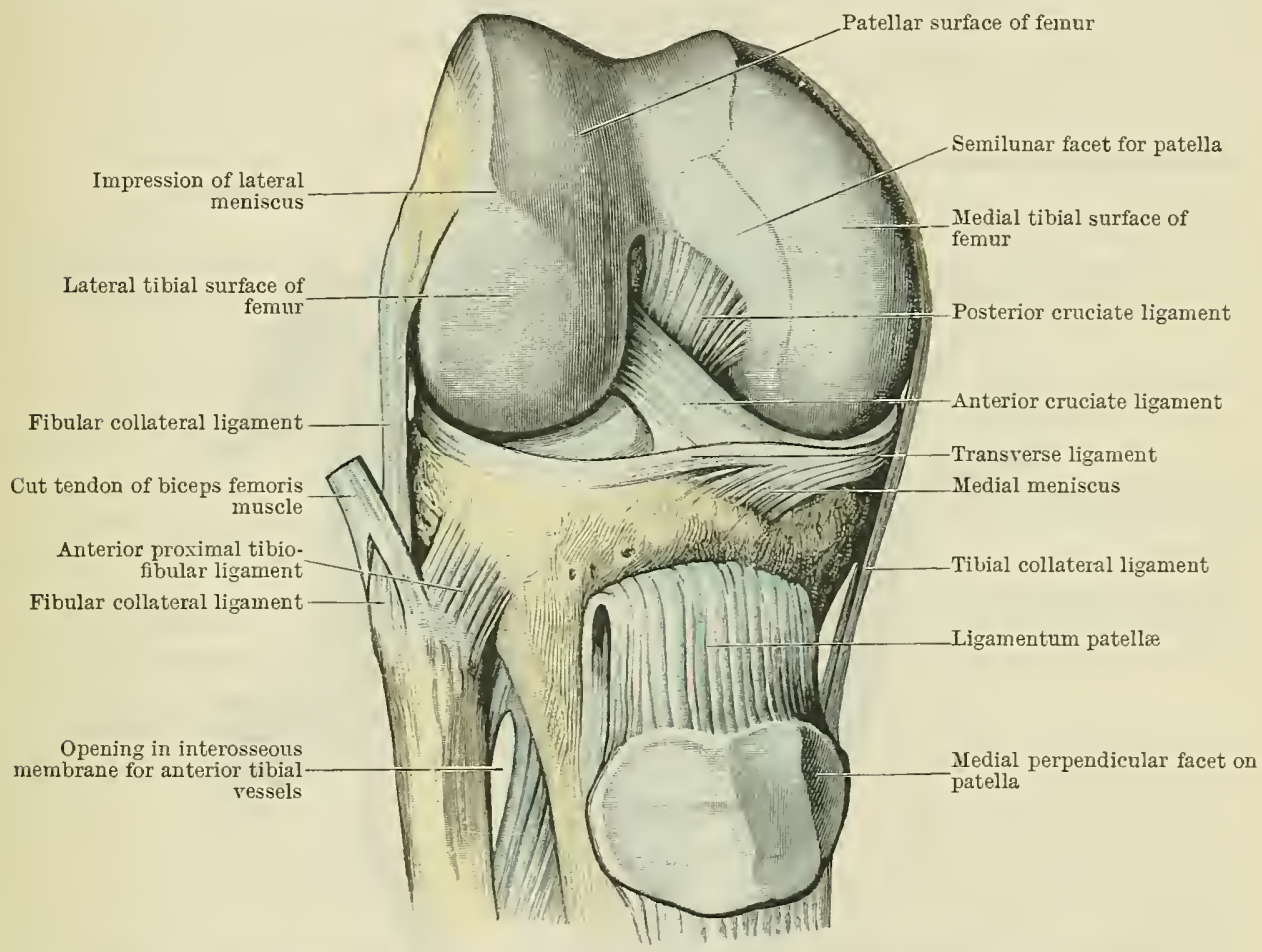

Fig. 317.-Dissection of the Knee-Joint from the front : Patella thrown distally.

When the joint is in the position of extreme flexion, the patella is brought into direct contact with that part of the articular surface on the medial condyle which bounds the intercondyloid notch mpon its medial and anterior aspects. This relationship is indicated by the presence of a distinct semilunar facet on the cartilage in that situation (Fig. 317). The articular surface of the femur may therefore be regarded as presenting femoro-patellar and femoro-tibial areas.

The patella presents on its posterior aspect a transversely elongated oval articular facet and a distal rough, triangular, non-articular area. The articular facet is divided into two principal portions by a prominent rounded vertical ridge. Of these the lateral is the wider. A less pronounced and nearly vertical ridge marks off an additional facet called the medial perpendicular facet, close to the medial margin of the articular surface. Two faint transverse ridges cut off narrow proximal and distal facets from the general articular surface without encroaching on the narrow, most medial vertical facet (Goodsir) (Fig. 317).

The head of the tibia presents on its superior aspect two condylar articular surfaces, separated from each other by a non-articular antero-posterior area, which is wider anteriorly and posteriorly than in the middle, where it is elevated to form a bifid eminentia intercondyloidea.

The lateral condylar facet is slightly concavo-convex from before backwards 
and slightly concave transversely. This surface is almost circular, and extends to the free lateral border of the tibial condyle, where it is somewhat flattened. Posteriorly the articular surface is prolonged downwards on the condyle in relation to the position occupied by the tendon of the popliteus muscle. The medial condylar facet is oval in outline, and distinctly concave both in its anteroposterior and transverse diameters.

Ligaments.-Like all diarthroses, this joint is invested by an envelope or capsula articularis, which does not, however, entirely surround the articular cavity, for it is absent as a fibrous stratum proximal to the articular cavity, subjacent to the tendon of the quadriceps extensor muscle. Its specially named bands are not

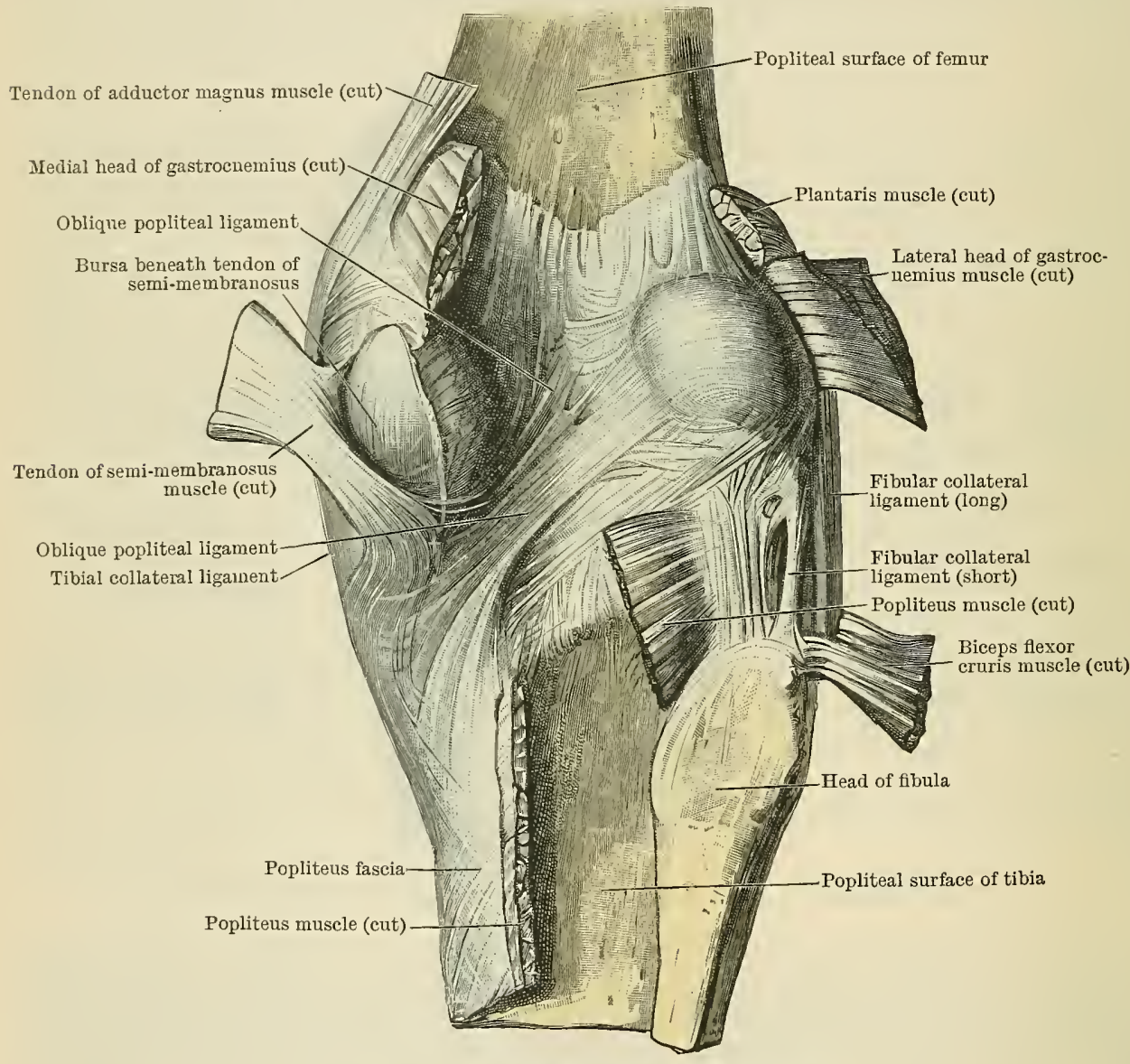

Fig. 318.-The KneE-Joint. Posterion View.

of themselves sufficient to form a complete investment, and the fibrous stratum, which largely consists of augmentations from the fascia lata and the tendons of surrounding muscles, supplies the defective areas. Thus, anteriorly, on each side of the patella and the ligamentum patellæ, expansions of the vasti tendons and fascia lata, constituting the collateral patellar ligaments, are evident. On the lateral side of the joint the fibular collateral ligament is hidden within a covering derived from the ilio-tibial tract of the fascia lata. On the medial side expansions from the tendons of the sartorius and semi-membranosus muscles augment the articular capsule, which here becomes continuous with the ligamentum collaterale tibiale. Posteriorly the articular capsule also receives angmentation from the tendon of the semi-membranosus muscle, but it is very thin subjacent to the origins of the gastrocnemius muscle, where it covers the posterior parts of the condyles. Not unfrequently the articular capsule presents an opening of communication between 
the interior of the articular cavity and a bursa which lies under cover of the medial head of the gastrocnemius muscle.

The epiphyseal line of the distal end of the femur is partly intra-capsular and partly extra-capsular; that of the proximal end of the tibia is extra-capsular.

Ligamentum Patellæ.-The ligamentum patellæ or anterior ligament (Fig. 318 ) is a powerful flattened band, attached proximally to the apex and adjoining margins of the patella, and distally to the rough anterior tuberosity at the proximal end of the shaft of the tibia. This ligament also serves as a tendon of insertion for the quadriceps extensor muscle, and a certain number of the fibres of the tendon may be observed to run distally as a thin fibrous covering for the anterior surface of the patella. The deep surface of the tendon is separated from the front of the head of the tibia by a synovial bursa, and proximal to this it rests upon the infra-patellar pad of fat, which is placed between the tendon and the synovial stratum of the joint.

The ligamentum posterius posterior (ligament) (Fig. 318) is a compound structure of unequal strength, and those portions by which it establishes continuity with the lateral parts of the articular capsule are remarkably thin. It is attached proximally to the popliteal surface of the femur, close to the intercondyloid notch, with lateral extensions to the non-articular areas immediately proximal to the posterior articular margins of the two condyles, where it is closely associated with the origins of the gastrocnemius muscle.

Distally it is attached to the rough non-articular posterior border of the head of the tibia, where, to its fibular side, it presents an opening of exit for the tendon of the popliteus muscle (Fig. 318).

The tendon of insertion of the semi-membranosus muscle contributes an important expansion which augments the posterior ligament on its superficial aspect. This expansion-lig. popliteum obliquum-passes obliquely proximally and laterally to lose itself in the general ligament, but it is most distinct in the region between the femoral condyles, where it may present proximal and distal areuate borders (lig. popliteum arcuatum). A number of vessels and nerves perforate this ligament, and hence it presents a number of apertures.

Lig. Collaterale Tibiale.-The tibial collateral ligament (O.T. internal lateral) (Figs. 317 and 318) is a well-defined, strong, flat band which is applied to the medial side of the knee-joint, and is rather wider in the middle than at either end. It is frequently regarded as consisting of two portions-an anterior or long portion, and a posterior or short one. The two parts arise close together from the medial epicondyle, immediately distal to the adductor tubercle. The short or posterior portion passes distally and slightly backwards, to be attached to the postero-medial aspect of the medial part of the tibia proximal to the groove for the semimembranosus tendon. The long or anterior portion inclines somewhat forwards, and extending distally superficial to the tendon of the semi-membranosus, it is attached to the proximal part of the medial surface of the shaft of the tibia distal to the level of the tuberosity.

On its superficial aspect the tibial collateral ligament is augmented by prolongations from the tendons of the semi-membranosus and sartorius muscles, but is separated by a bursa from the tendons of the gracilis, semi-tendinosus, and sartorius. Its deep surface is adherent to the convex edge of the meniscus medialis, but more distally the distal and medial articular vessels intervene between the ligament and the shaft of the tibia.

Lig. Collaterale Fibulare.-The fibular collateral ligament (O.T. external lateral) (Figs. 317 and 318) is a distinct rounded band which is under cover of the ordinary capsule, and yet well separated from the articular cavity by intervening objects. It is attached proximally to the lateral epicondyle, immediately proximal to the groove occupied by the tendon of the popliteus muscle, superficial to which the ligament extends distally to be attached to the lateral side of the head of the fibula, in front of the styloid process. In its course it splits the tendon of insertion of the biceps femoris (Fig. 317), the portions of which are fixed to the head of the fibula on either side of the ligament, and a bursa may intervene between the tendon and the ligament. The distal lateral articular vessels pass 
forwirds subjacent to this ligament and proximal to the head of the fibula. Unlike the tibial collateral ligament, it is not attached to the corresponding meniscus.

The ligamentum laterale externum breve seu posterius (Fig. 317) is an inconstant structure which is attached by its proximal end immediately behind the preceding, and subjacent to the lateral head of the gastrocnemins muscle. It likewise passes superficial to the popliteal tendon, and is affixed distally to the apex capituli of the fibula.

The intra-articular structures of the knee-joint are more important and more numerous than in any other joint of the body.

Ligamenta Cruciata Genu.-The cruciate ligaments (O.T. crucial ligaments) are two strong, rounded, tendinous bands, which extend from the non-articular area

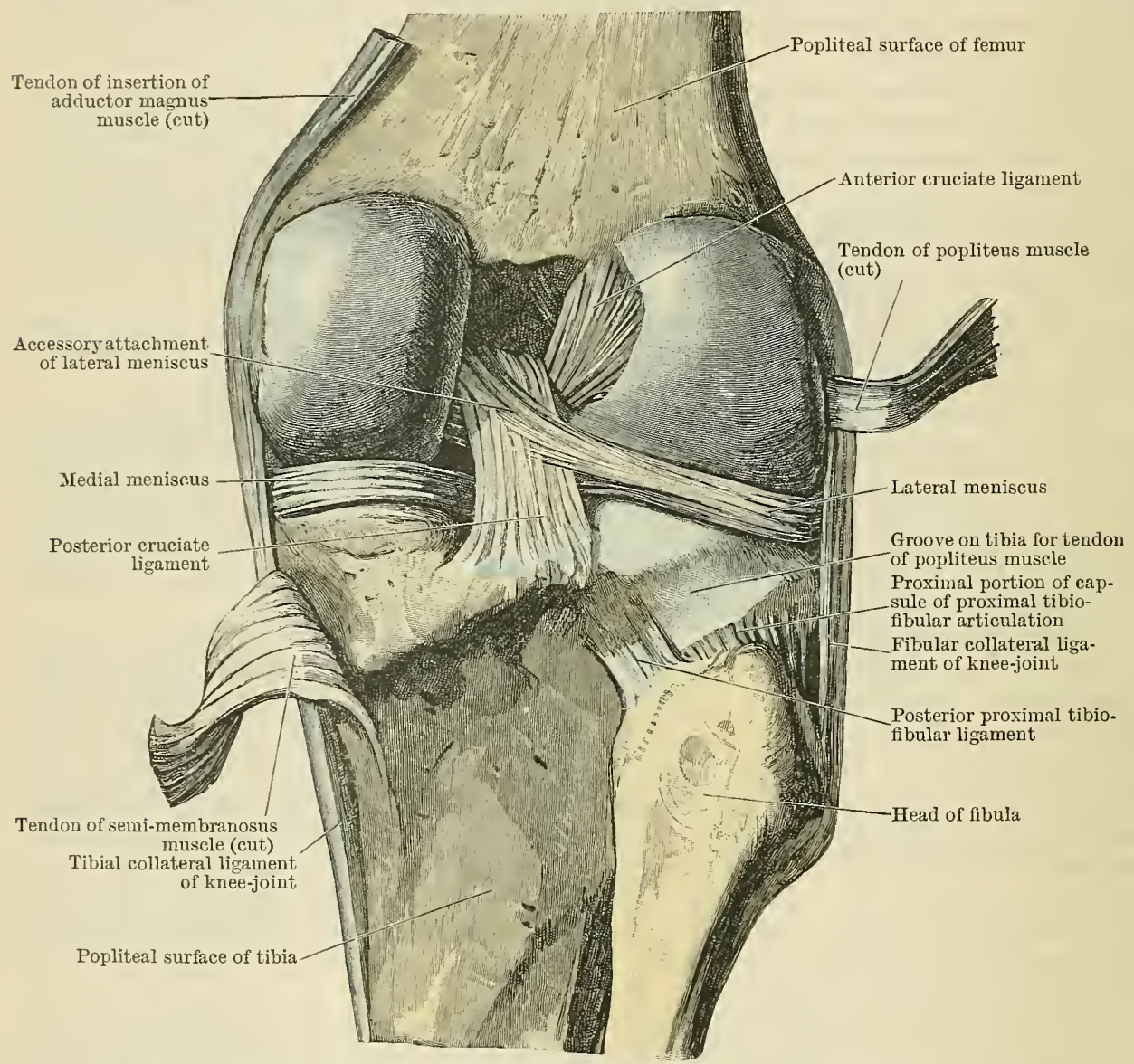

F1G. 319.-The KneE-Joint opened From Behind by the Removal of the Posterior Ligament.

on the proximal surface of the head of the tibia to the non-articular sides of the intercondyloid notch of the femur. These interarticular ligaments are distinguished from each other as the anterior or lateral and the posterior or medial. They cross each other like the limbs of an $X$, yet they remain distinct throughout, and each has its own partial synovial covering. They lie within the articular capsule, and extend between non-articular surfaces in relation to the longitudinal axis of the limb.

The ligamentum cruciatum anterius (Figs. 317, 319, and 320) is attached distally to the medial part of the rough, depressed area in front of and close to the intercondyloid eminence of the tibia. It passes obliquely proximally, laterally, and backwards to the medial non-articular surface of the lateral condyle, where it finds attachment far back in the posterior part of the intercondyloid notch. This 
ligament is tense in the position of extension, and therefore it assists in maintaining the erect attitude.

The ligamentum cruciatum posterius (Figs. 317,319 , and 320) is somewhat shorter than the preceding. It is attached distally to the posterior part of the depressed surface behind the intercondyloid eminence of the tibia and close to the popliteal notch. Its fibres pass obliquely proximally, forwards, and medially, to be inserted into the lateral non-articular surface of the medial condyle, far forwards towards the anterior margin of the intercondyloid notch. It is rendered tense in the position of flexion.

The semilunar menisci are two in number-a medial and a lateral-placed horizontally between the articular surfaces of the femur and tibia. In general outline they correspond to the circumferential portions of the tibial facets upon which they rest. Each has a thick, convex, fixed border in relation to the periphery of the joint, and a thin, concave, free border directed towards the interior of the joint. Neither of them is sufficiently large to cover the whole of the tibial articular surface upon which it rests. The proximal and distal surfaces of each meniscus are smooth and free, and each terminates in an anterior and a posterior fibrous horn or cornu.

Meniscus Medialis.The medial meniscus (O.T. internal semilunar fibro-cartilage) (Figs. 319 and 320) forms

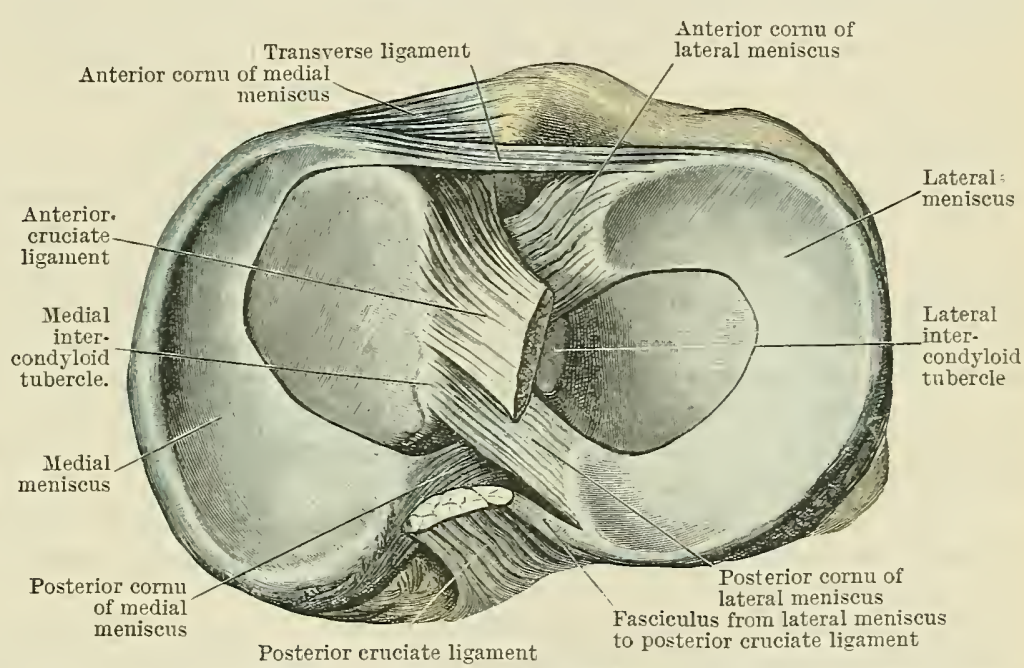

Fig. 320.-Proximal Exd of Tibia with Menisci and attached Portioxs of Cruciate Liganents.

very nearly a semicircle. It is attached by its anterior horn to the non-articular surface on the head of the tibia, in front of the tibial attachment of the anterior cruciate ligament, and by its posterior horn to the non-articular surface immediately in front of the tibial attachment of the posterior cruciate ligament. The deep or posterior part of the tibial collateral ligament is attached to its periphery.

Meniscus Lateralis.-The lateral meniscus (O.T. external semilunar fibrocartilage) (Figs. 319 and 320 ) is attached by its anterior horn to the non-articular surface of the tibia in front of the intercondyloid eminence, where it is placed to the lateral side, and partly under cover of the tibial end of the anterior cruciate ligament. By its posterior horn it is attached to the interval between the two tubercles which surmount the intercondyloid eminence, i.e. in front of the attachment of the posterior horn of the meniscus medialis. This fibro-cartilage, with its two horns, therefore forms almost a complete circle. Posteriorly it is attached by its periphery to the posterior ligament, but on the lateral side it is separated from the fibular collateral ligament by the tendon of the popliteus muscle, and on this aspect its periphery is free.

The two horns of the lateral meniscus are embraced by the two horns of the medial meniscus, and, while the anterior cruciate ligament has its tibial attachment almost between the anterior horns of the two menisci, the tibial attachment of the posterior cruciate ligament is situated behind the posterior horns of the two menisci.

Both menisci possess certain accessory attachments. Thus the lateral meniscus sends a large bundle of fibres from its convex posterior border to augment the posterior aspect of the posterior cruciate ligament by which these fibres are 
conducted to the femur. Again, the convex or peripheral margins of each meniscus possess certain attachments to the deep surface of the fibrous stratum of the capsule on its medial and posterior aspects, as has already been explained, but, in addition, they are attached to the non-articular circumference of the tibial head by short fibrous bands known as the ligamenta coronaria. Lastly, a rounded band which varies in strength, the lig. transversum genu (transverse ligament) (Figs. 317 and 320), stretches between the anterior convex margins of the two menisci, crossing the front part of the non-articular area on the tibial head in its course.

The stratum synoviale of the knee-joint is not only the largest, but the most elaborately arranged of its kind in the body. It not only lines the fibrous stratum of the capsule articularis, but it forms a more or less extensive covering for the intracapsular ligaments and the free surface of the infra-patellar pad of fat. This pad acts as a wedge which fits into the interval between the patella, tibia, and femoral condyles, and the symovial stratum upon its surface forms a band or fold which extends from the region distal to the level of the patellar articular surface to the anterior part of the intercondyloid notch. It is named the plica synovialis patellaris. At its femoral end it is narrow and attenuated, but at its patellar end it expands on each side to form wing-like fringes or membranes-the plicæ alares-medial and lateral. These folds are more or less loaded with fat.

Apart from these special foldings, the synovial stratum lines the deep surface of the common extensor tendon, and extends for a variable distance proximal to the patella. This extension of the articular cavity almost always communicates with a large bursa situated still more proximally on the front of the femur. Tracing the synovial stratum distally, it will be found to cover both surfaces of the two menisci. The peripheral or convex margins of these menisci are only covered by this membrane where they are unattached to the capsule. A prolongation invests the intracapsular portion of the tendon of the popliteus muscle, and separates this tendon from the posterior part of the tibial head, besides intervening between the lateral meniscus and the head of the tibia.

From the posterior part of the articular cavity the synovial stratum extends forwards, and provides a partial covering for the cruciate ligaments between which a bursa may be found.

This somewhat complicated arrangement of the synovial stratum may be readily comprehended if it is borne in mind that it really represents the fusion of three separate synovial cavities, which in some animals are permanently distinct. These are indicated in the two femoro-tibial and the single femoro-patellar parts of the articulation.

The articular cavity may communicate with bursæ situated in relation to the medial head of the gastrocnemius muscle and the tendon of the semi-membranosus muscle, besides the large supra-patellar bursa already described. Lastly, there may be intercommunication between this articular cavity and that of the proximal tibio-fibular articulation.

Movements at the Knee-Joint.-In studying the movements which may occur at the human knee-joint, it is necessary to bear in mind that the lower limb of man is primarily required for purposes of support and locomotion. The principal requirement of the former function is stability accompanied by rigidity, whereas in the latter function the special desideratum is regulated and controlled mobility. Thus, in the same joint, two entirely opposite conditions have to be provided. The stable conditions of support are chiefly concerned in the maintenance of the erect attitude, and the mechanism associated therewith does not call for the exertion of a large degree of sustained muscular effort.

In standing erect the attitude of the limb is that of extension, which mainly concerns the femoro-tibial parts of the joint. In this position the force of gravity acts along a vertical line which falls in front of the transverse axis of the joint, and therefore any tendency to flexion, i.e. bending backwards, is mechanically counteracted by the application of a force which tends to produce bending forwards (so-called over-extension). This, however, is absolutely prohibited in normal states of the joint, by the tension of the posterior and collateral ligaments aided by the anterior cruciate ligament. The value of this fact may be seen by observing the effect produced by giving the joint a sudden push from behind, which causes an immediate reversal of the positions of the transverse and vertical axes, whereby the body weight at once produces flexion of the joint.

The menisci and the infra-patellar pad of fat also assist in maintaining extension, by reason of their close adaptation to, and packing round the condyles as these rest upon the tibia. 
The anterior margin of the intercondyloid fossa is also brought into contact with the front of the anterior cruciate ligament.

In the position of extension the patella is retained at such a proximal level in relation to the trochlear surface of the femur, that the distal articular facets of the patella are in contact with the trochlea.

During locomotion the movements of the knee-joint are somewhat intricate, for both the femoro-tibial and the femoro-patellar sections of the joint are brought into action. The principal movement which results is flexion, with which there is associated, both at its beginning and ending, a certain amount of screw movement or rotation. Flexion and rotation occur at the femoro-tibial sections of the joint, whereas the movement at the femoro-patellar portion produces a regulating and controlling influence upon flexion.

Taking these factors separately, we observe that each femoral condyle adapts itself to a shallow cup formed by the corresponding tibial condyle and meniscus, and as the two femoral condyles move simultaneously and parallel to each other, there is more than the characteristic hinge-joint action, for each femoral condyle glides and rolls in its cup "like a wheel restrained by a drag" (Goodsir) when the movement of bending occurs. Thus the different parts of the condyles are successively brought into relation with the transverse axis of the joint while it passes from extension to flexion and vice versa. From the fact that the medial femoral condyle is longer than the lateral, it is believed that extension is completed by a movement of rotation whereby the joint becomes locked, and the anterior cruciate, the posterior and the collateral ligaments, become tense. A similar rotation initiates the movement of flexion, and unlocks the joint by relaxing the ligaments just mentioned.

Since the tibia and foot are fixed in the act of walking, it is the femur which rotates upon the tibia in passing from extension to flexion and vice versa; and as relaxation of the ilio-femoral ligament is essential for this rotation, some observers are of opinion that the body weight falls behind the transverse axis of the knee-joint, as in the case of the hip-joint, and consequently that extension of the knee-joint is maintained by the ilio-femoral ligament, as it is not possible to bend the knee without first having bent the hip-joint.

During flexion and extension the menisci glide along with the condyles, so as to maintain their close adaptation and preserve their value as packing agents. When the movement of flexion is completed, the condyles are retained upon the tibia, and prevented from slipping off by the tension of the posterior cruciate ligament. In this position a small degree of rotation of the tibia, both medially and laterally, is also permissible.

The regulating and controlling influence of the femoro-patellar portion of the articulation is brought into play during the movements of flexion and extension. In the latter position the distal pair of patellar facets is in apposition with the proximal part of the femoral trochlea. As flexion advances, the middle pair of facets adapt themselves to a deeper area of the trochlea, into which the patellar keel fits. When flexion is still further advanced, the proximal pair of patellar facets will be found fitting into that part of the trochlea adjoining the intercondyloid notch; and fiually, when flexion is complete, the patella lies opposite the intercondyloid notch, while the forward thrust of the longer medial femoral condyle brings its semilunar facet (Goodsir) into apposition with the somewhat vertical facet at the medial border of the patella. The wedge-like influence of the patella is most marked, for it is only in the position of extension that it can be moved from side to side. The movements of the patella may be described as gliding and co-aptation, as it slips or rocks from one pair of facets to another in its progress along the trough of the femoral trochlea.

\section{ARTICULATIONES TIBIOFIBULARES.}

The Tibio-Fibular Joints.-The proximal and distal ends of the fibula articulate with the tibia. Primarily, the fibula is required to form a strong lateral support for the ankle-joint, and therefore its articulations are so arranged as to provide a certain amount of elasticity without any sacrifice of the rigidity necessary for security. Hence the amount of movement is very small, but what there is enables these joints to be classified as arthrodial diarthroses.

Articulatio Tibiofibularis.-The proximal tibio-fibular joint is formed, on the one hand, by a flat oval or circular facet which is situated upon the postero-lateral aspect of the lateral condyle of the tibia, and is directed distally and posteriorly; on the other hand, by a similar facet on the proximal surface of the head of the fibula in front of the apex capituli.

An articular capsule (Fig. 317) invests the joint, and it may be regarded as holding the articular surfaces in apposition, although certain special bands receive separate designations. Occasionally there is an opening in the stratum fibrosum by which communication is established between the articular cavity and the knee-joint through the intermediation of the synovial prolongation, subjacent to the tendon of the popliteus muscle.

The proximal epiphyseal line of the fibula is extra-capsular. 
Lig. Capituli Fibulæ Anterius.-The anterior ligament of the head of the fibula (Fig. 317) is a strong flat band whose fibres extend from the anterior aspect of the fibular head, proximally and medially, to the adjoining part of the condyle of the tibia.

Lig. Capituli Fibulæ Posterius.-The posterior ligament of the head of the fibula (Fig. 319) is a similar, but weaker band, passing proximally and medially from the posterior aspect of the fibular head to the posterior aspect of the lateral condyle of the tibia, where they are attached immediately distal to the opening in the capsule of the kuee-joint, from which the tendon of the popliteus muscle escapes.

Equally strong but much shorter bands are found on the proximal and distal aspects of the joint. The former is intimately associated with the tendon of the

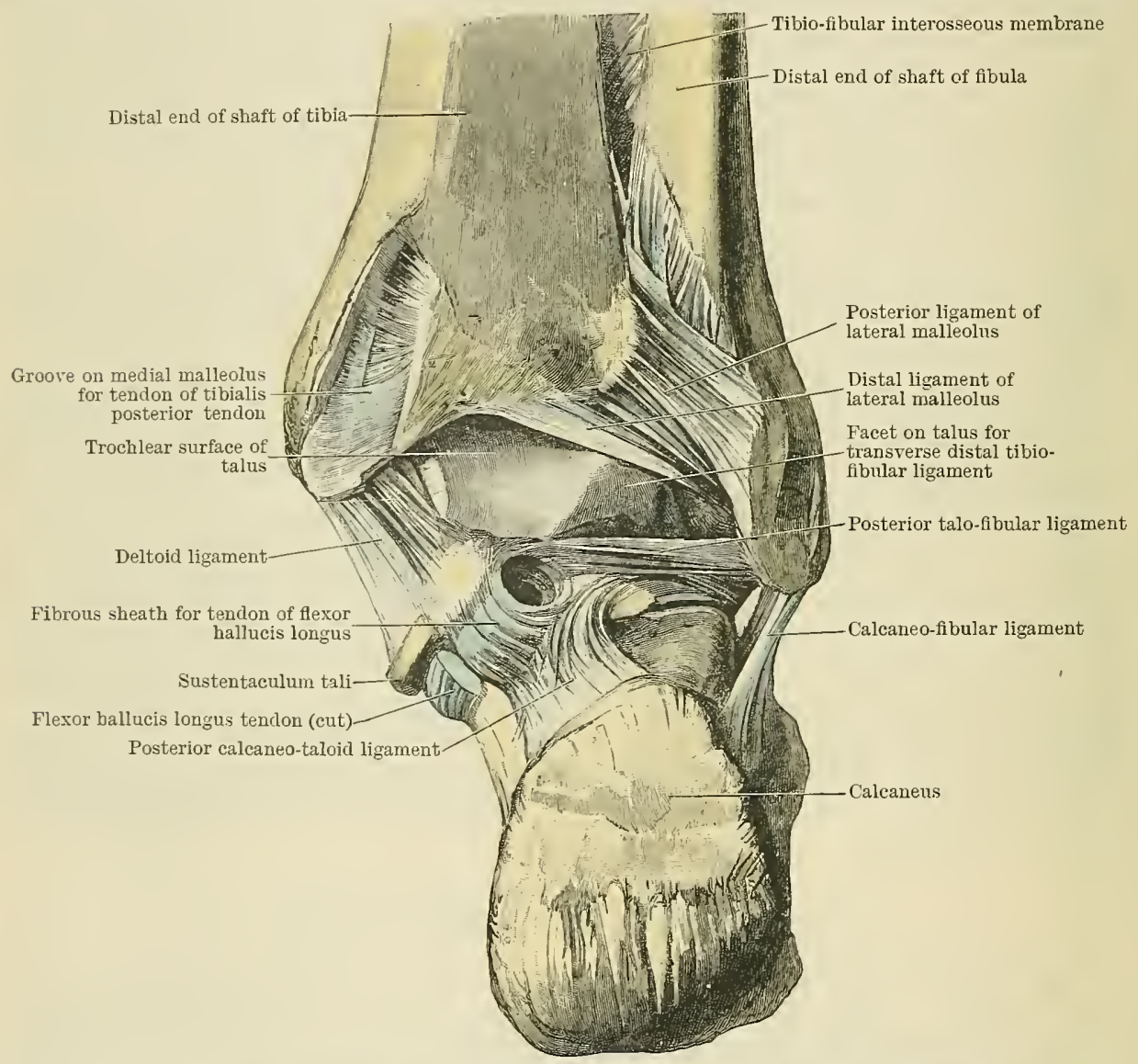

Fig. 321.-Ankle-Joint dissected from behind with Part of the Articular Capsule removed.

biceps flexor cruris muscle which strengthens the proximal aspect of the joint, and here also is found the occasional opening by which it communicates with the kneejoint.

The synovial stratum is in certain cases continuous with that of the kneejoint in the manner already described.

Membrana Interossea Cruris.-The interosseous membrane (Figs. 317 and 321) plays the part of an accessory ligament both for the proximal and the distal tibiofibular joint. It is attached to the interosseous borders on the shafts of the tibia and fibula, and binds them together. The general direction of its fibres is from the tibia distally and laterally to the fibula, but many fibres pass in the opposite direction. The membrane may extend upwards until it comes into contact with the ligaments of the proximal tibio-fibular joint, but there is always a vertical oval aperture in its proximal part for the forward passage of the anterior tibial vessels. 
This aperture (Fig. 317), which is about one inch long, adjoins the shaft of the fibula at a point rather less than one inch distal to its head. Towards the distal end of the leg the distance between the tibia and the fibula rapidly diminishes, and consequently the width of the interosseous membrane is correspondingly reduced, so that it is tense throughout its entire length. In the distal part of the membrane there is a small opening for the passage of the perforating peroneal vessels. There is no sharply marked demarcation between the interosseous membrane and the interosseous ligament which connects the distal ends of the tibia and fibula-the one, indeed, may be said to run into the other.

Syndesmosis Tibiofibularis. - The distal tibio-fibular joint is not on all occasions provided with articular cartilage, so that it may either be a separate articulation, or it may merely present a series of ligaments which are accessory to the (ankle-joint), because it is clear that, under any circumstances, the object aimed at in this articulation is to obtain additional security for the ankle-joint. The articular surface on the tibia, when present, constitutes a narrow articular strip on the lateral side of the distal end of the bone, and the joint-cavity is practically an upward extension of the ankle-joint. The corresponding fibular facet is continuous with the extensive articular area, by means of which the fibula articulates with the talus. By far the greater part of the opposing surfaces of tibia and fibula are, however, non-articular and rough.

The supporting ligaments are of great strength.

Lig. Malleoli Lateralis Anterius.-The anterior ligament of the lateral malleolus (O.T. anterior inferior tibio-fibular ligament) (Fig. 322) consists of strong fibres which pass obliquely distally and laterally from the front of the distal end of the tibia to the front of the lateral malleolus.

Lig. Malleoli Lateralis Posterius. - The posterior ligament of the lateral malleolus (O.T. posterior inferior tibio-fibular ligament) (Figs. 321 and 322) is equally strong, and passes in a similar direction between corresponding posterior surfaces.

Lig. Malleoli Lateralis Distale. - The distal ligament of the lateral malleolus (O.T. transverse inferior tibio-fibular ligament) (Figs. 321 and 322) stretches between the posterior border of the distal end of the tibia and the proximal end of the pit on the medial and posterior aspect of the lateral malleolus.

Ligamentum Interosseum.-An interosseous ligament, powerful and somewhat extensive, connects the contignous rough non-articular surfaces. Proximally, as already mentioned, it is continuous with the interosseous membrane. Anteriorly and posteriorly it comes into contact with the more superficial ligaments. Distally it descends until it comes into intimate association with the articular cavity.

A synovial stratum is found lining the small articular cavity, but it is always a direct prolongation from that which lines the ankle-joint.

\section{ARTICULATIONES PEDIS.}

\section{ARTICULATIO TALOCRURALIS.}

The ankle-joint is a ginglymus variety of a diarthrosis. The bones which enter into its formation are the distal ends of the tibia and fibula, with the articular areas on the superior, lateral, and medial surfaces of the talus. The tibia and fibula, aided by the distal ligament of the lateral malleolus, form a three-sided socket within which the talus is accommodated. The roof or most proximal part of the socket, which is wider in front than behind, is formed chiefly by the quadrilateral articular surface which characterises the distal end of the tibia, but towards its postero-lateral margin the distal ligament of the lateral malleolus assists in its formation. Here also the tibial articular surface is continuous with the narrow articular facet already described as forming part of the tibio-fibular syndesmosis. The medial wall of the socket is formed by the articular facet on the lateral side of the medial malleolus, and there is no interruption of the articular cartilage between the roof and.medial wall. The lateral wall of the socket is quite separate from the foregoing parts, and consists of a large triangular facet upon the medial side 
of the lateral malleolus. This facet is situated immediately in front of the deep pit which characterises the posterior part of this surface of the fibula.

A small lumated facet is frequently found upon the anterior surface of the distal end of the tibia, particularly among those races characterised by the adoption of the "squatting" postnre. When this facet exists it is continuons with the anterior margin of the roof of the socket, and it articulates with a similar facet upon the superior surface of the neck of the talus in the extreme flexion of the ankle-joint which "squatting" entails.

The articular surface upon the body of the talus adapts itself to the tibiofibular socket, and presents articular facets corresponding to the roof and sides of the socket. Thus the superior surface of the talus possesses a quadrilateral articular area, wider in front than behind, distinctly convex in the antero-posterior direction, and slightly concave transversely. In addition, towards its posterolateral margin, there is also a narrow antero-posterior facet corresponding to the distal ligament of the lateral malleolus. The articular cartilage of this superior surface is continned without interruption to the tibial and fibular sides of the bone, although the margins of the superior area are sharply defined from the facets on

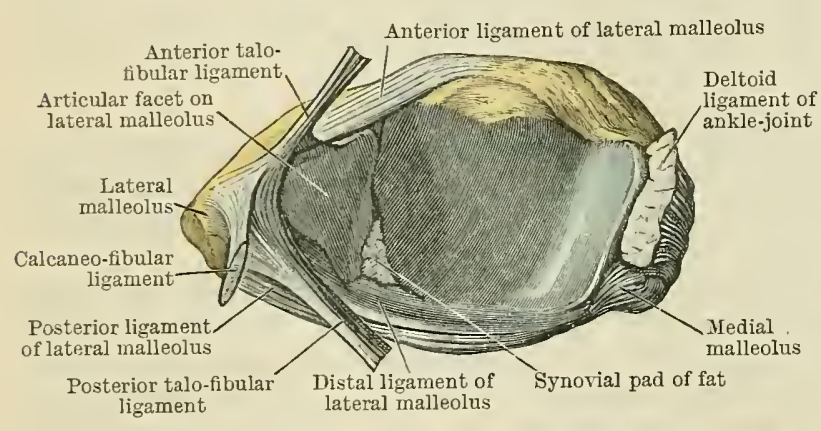

Fig. 322.-Articular Surfaces of Tibia axd Fibula which ARE OPPOSED TO THE TALUS. restricted to the epiphyses of the distal ends of the tibia and fibula, and the epiphyseal lines are therefore extra-capsular.

The anterior ligament is an extremely thin membrane, containing very few longitudinal fibres. It extends from the distal border of the tibia to the proximal border of the head of the talus, passing in front of a pad of fat which fills up the hollow above the neck of that bone.

The posterior ligament is attached to contiguous non-articular borders of the tibia and talus. Many of its fibres radiate medially from the lateral malleolus. This aspect of the joint is strengthened by the strong, well-defined, distal ligament of the lateral malleolus already described in connexion with the tibio-fibular syndesmosis.

The lateral ligament (Figs. 321, 322, and 324) is very powerful, and is divisible into three fasciculi, which are distinguished from each other by names, descriptive of their chief points of attachment.

Lig. Talofibulare Anterius.-The anterior fasciculus is the shortest. It extends from the anterior border of the lateral malleolus to the talus immediately in front of its lateral articular surface.

Lig. Calcaneofibulare.-The middle fasciculus is a strong and rounded cord. It is attached by one end to the front of the tip of the lateral malleolus, and by the other to the lateral side of the calcaneus immediately proximal to the groove for the peroneal tendons.

Lig. Talofibulare Posterius.-WThe posterior fasciculus is the strongest. It runs transversely between the distal part of the fibular fossa on the medial aspect of the malleolus and the posterior surface of the talus, where it is attached to the posterior process and the adjoining rough surface. Sometimes this process is detached from the talus, and represents a separate bone-the os trigonum.

Lig. Deltoideum.-The deltoid ligament is the medial ligament of the ankle-joint (Figs. 322 and 323). It has the general shape of a delta, and is even stronger 
than the lateral ligament. It is attached proximally to a marked impression on the distal part of the medial malleolus, and below, in a continuous layer, to the navicular, talus or calcaneus. In it we may recognise the following special bands-(a) the lig. talotibiale anterius, which extends from the front of the medial malleolus to the neck of the talus; (b) the lig. talotibiale posterius, stretching between the back of the medial malleolus and the postero-medial rough surface of the talus; (c) the lig. tibionaviculare, which extends from the tip of the medial malleolus to the medial side of the navicular body; $(d)$ the lig. calcaneotibiale, which extends between the tip of the medial malleolus and the medial side of the sustentaculum tali; (e) lig. talotibiale profundum, which consists of deeper fibres extending from the tip of the medial malleolus to the medial side of the talus.

A synovial stratum lines the fibrous stratum of the articular capsule and, as

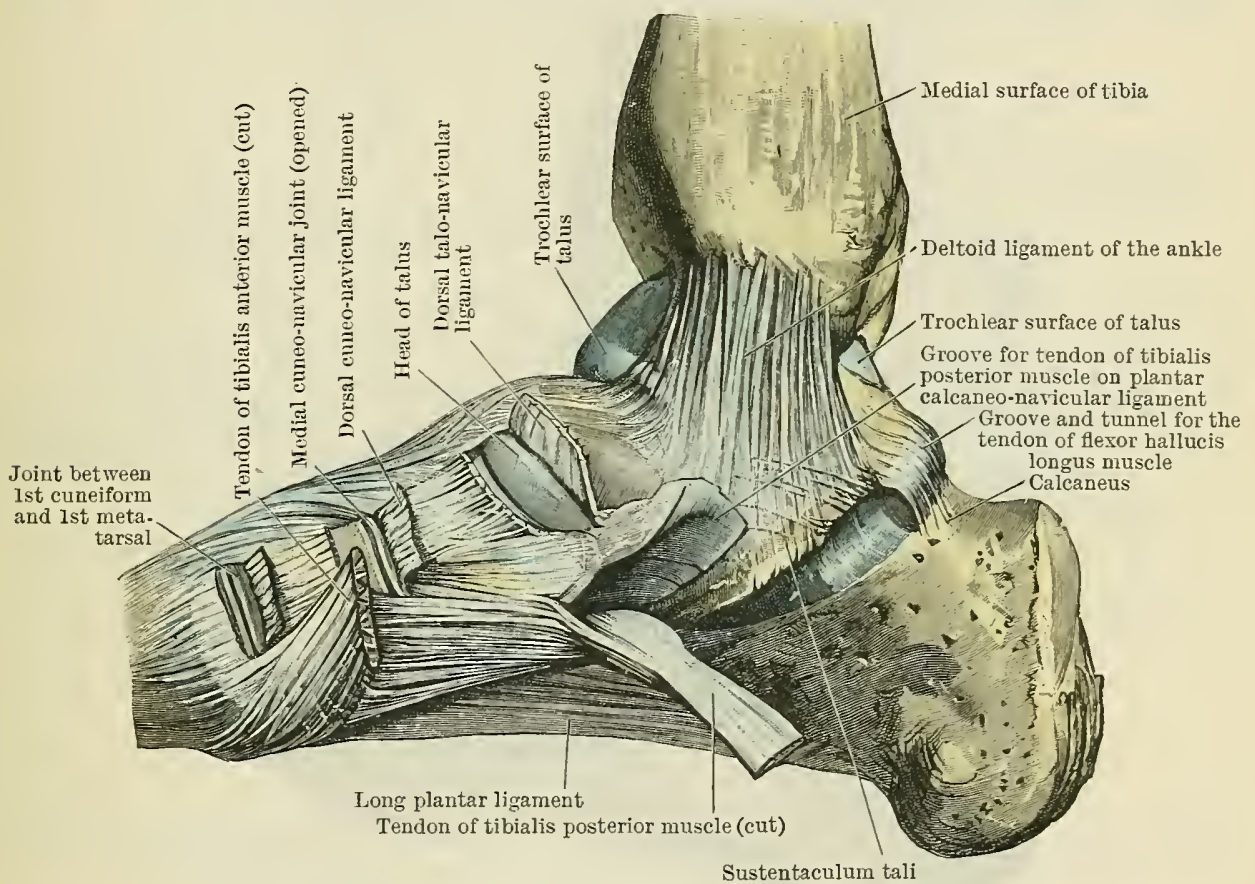

Fig. 323.-Ankle and Tarsal-Jonts froy the Tibial Aspect.

already described, the articular cavity extends into the interval between the tibia and fibula distal to the tibio-fibular interosseous ligament. Both at the front and back of the ankle-joint, as well as proximally in the angle formed by the three bones, the synovial membrane covers pads of fat.

Movements at the Ankle-Joint.-In the erect attitude the foot is placed at right angles to the leg; in other words, the normal position of the ankle-joint is flexion. Those movements which tend to diminish the angle so formed by the dorsum of the foot and the front of the leg are called dorsiflexion, while those which tend to increase the angle, i.e. to straighten the foot upon the leg, are called extension. As a matter of fact neither dorsiflexion nor extension is ever completely carried out, and the range of movement of which the foot is capable is limited to about $90^{\circ}$. These movements occur about an obliquely transverse axis, as is indicated by the natural lateral pointing of the toes. The weight of the body falls slightly anterior to the anklejoint, so that a certain amount of muscular action is necessitated in order to maintain the foot at right angles to the leg; but additional stability is obtained from the obliquity above mentioned.

When the foot is raised from the ground, muscular action tends naturally to produce a certain amount of extension. When the foot is extended, as in standing on the toes, the posterior narrow part of the talus moves forwards into the wider part of the interval between the tibia and fibnla, whereas in dorsiflexion, as in raising the anterior part of the foot from the ground, the widest part of the talus is forced back between the tibia and fibula; but notwithstanding the difference between these two morements, the fibula remains in close contact with the talus by reason of the action of the ligamentum malleoli lateralis distale and the posterior talo-fibular ligament, so that lateral movement is prevented. 
It is doubtful whether lateral morement at the ankle-joint can be obtained by any natural morement of the foot, although it is generally believed that in the position of partial extension a small amount of side-to-side morement may be produced by the application of external force. "This apparent play" of the ankle-joint during extension "is really due to oscillation of the small bones of the foot on each other, largely of the navicular on the talus, but also of the cuboid on the calcaners. Excessive mobility of these latter is restrained by an important function of the posterior tubercle of the cuboid which locks into a notch in the calcaneus" (Blake).

\section{ARTICULATIONES INTERTARSEE.}

The intertarsal joints are all diarthroses in which the gliding movement is characteristic, as in the carpus. With the view of obtaining a proper conception of the many beautiful mechanical principles involved in the construction of the foot, it is necessary to study these articulations with considerable attention to detail.

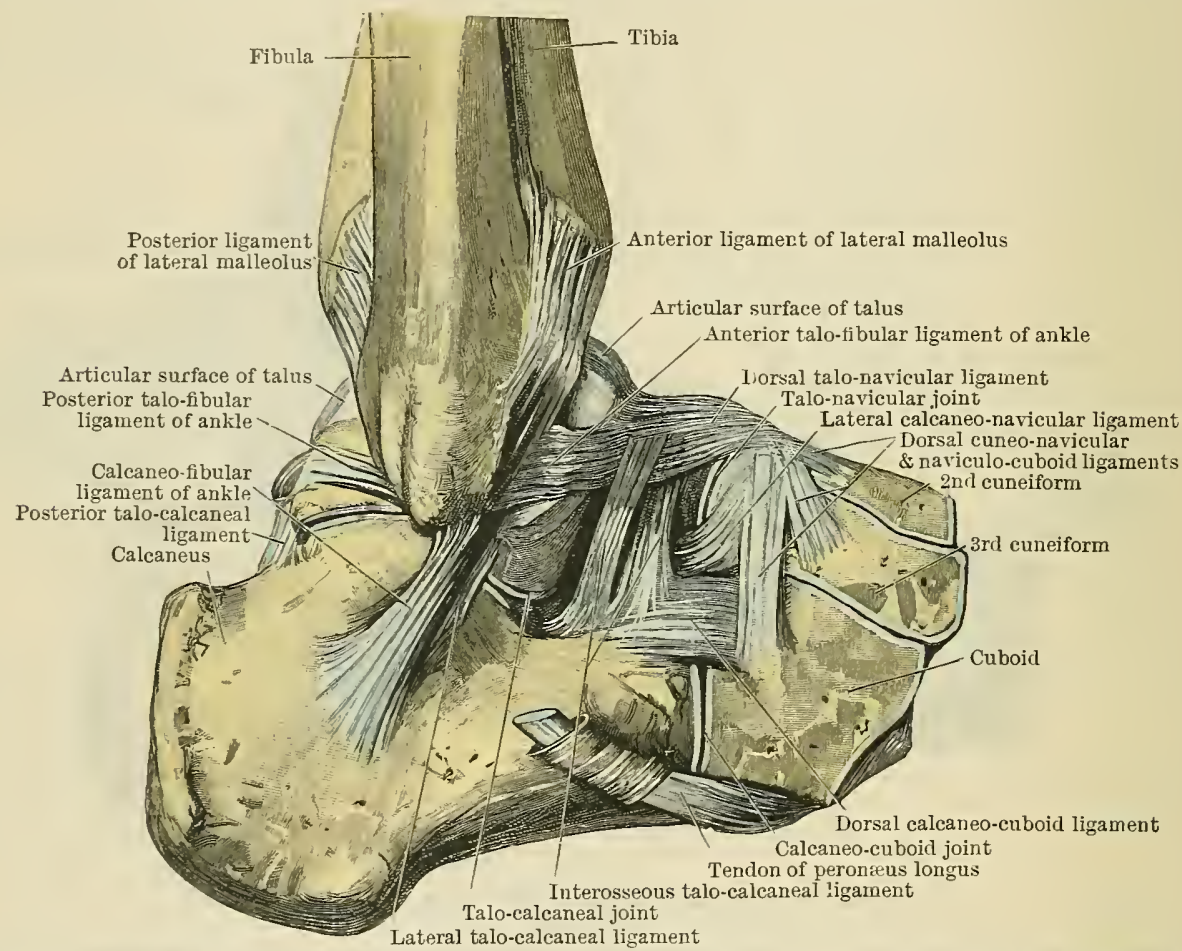

Fig. 324. - Ligaments on the Lateral Aspect of the Ankle-Jontt and on the Dorsum of the Tarsus.

Articulatio Talocalcanea.-The talus and calcaneus articulate with each other in the talo-calcaneal joint.

This joint is situated between the inferior facet on the body of the talus and a corresponding facet on the superior aspect of the posterior part of the calcaneus. On each bone the articulation is limited in front by a wide, deep groove which runs obliquely across each bone from the medial to the lateral side and forwards.

The supporting and investing ligaments form the fibrous stratum of an articular capsule, consisting for the most part of short fibres, but the joint derives additional strength from the calcaneo-fibular ligaments of the ankle-joint. The fibrous stratum of the capsule is subdivided into the following talo-calcaneal bands:-

The ligamentum talocalcaneum anterius consists of a band of short fibres placed immediately in relation to the anterior end of the deep groove which bounds the articular facets. They are attached to the antero-lateral aspect of the neck of the talus, from which they extend downwards to the adjacent superior surface of the calcaneus.

The ligamentum talocalcaneum laterale (Fig. 324) is in continuity with the posterior border of the preceding ligament, and it is placed parallel to, but on 
a deeper plane than, the calcaneo-fibular ligament of the ankle-joint. It consists of short fibres passing between the adjacent rough lateral margins of the two bones.

The ligamentum talocalcaneum posterius (Fig. 324) closes the joint-cavity on its posterior aspect. It consists of fibres which radiate from the posterior aspect of the posterior process of the talus to the superior surface of the calcaneus, immediately behind the articular facet.

The ligamentum talocalcaneum mediale lies obliquely on the medial side of the joint, and consists of fibres which extend from the medial posterior tubercle of the talus to the posterior roughened border of the sustentaculum tali. Some of its fibres become continuous with the plantar calcaneo-navicular ligament.

The ligamentum talocalcaneum interosseum (Fig. 325) closes the antero-medial aspect of the joint. It is the strongest of the series of ligaments entering into the capsule. Compared with it the other bands are, comparatively speaking, insignificant. Its attachments are to the bottom of each groove, so that it occupies the tarsal canal formed by these opposing grooves.

A synovial stratum lines the fibrous stratum, and it is distinct from other tarsal synovial membranes.

\section{Articulatio Talocal- caneonavicularis. - This} is one of the most important of the joints of the foot, not only because the talus is here situated in relation to the summit of the antero-posterior arch of the foot, but because the head of the talus is received into a composite socket made up of the sustentaculum tali, the navicular, and the plantar calcaneonavicular ligament.

The articular surface

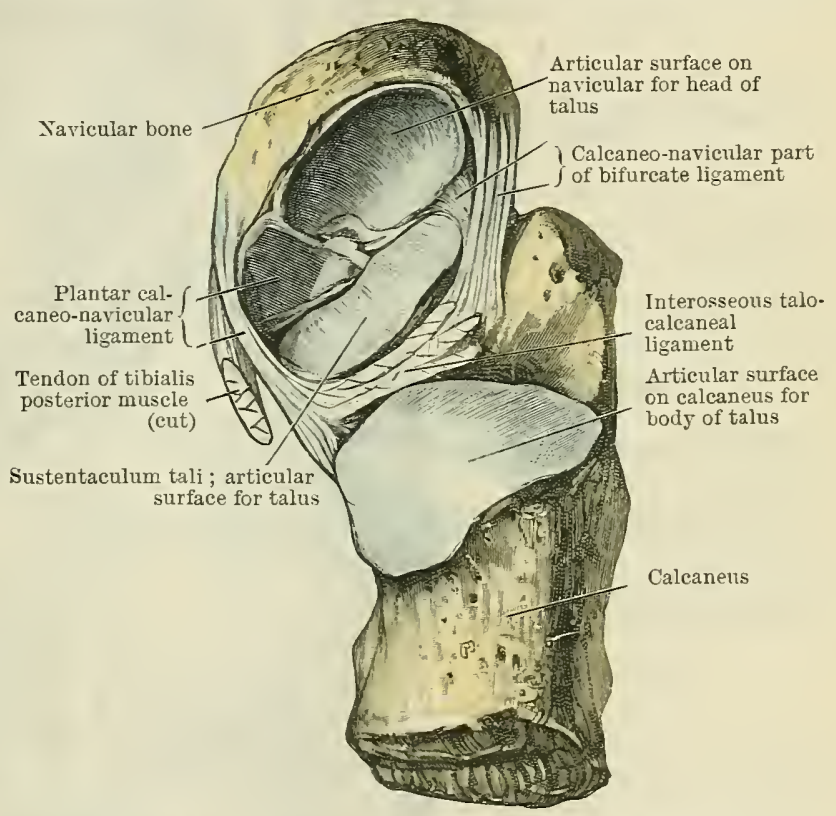

Fig. 325.-The Composite Articular Socket for the Head of THE TaLCS.

on the head of the talus presents anteriorly a convex rounded facet for articulation with the navicular, inferiorly a convex facet which rests upon the sustentaculum tali, and intermediate between these two there is a triangular facet which articulates with the plantar calcaneo-navicular ligament. All these facets are in continuity with each other, and are in front of the tarsal groove on the inferior surface of the talus. Occasionally a fourth narrow facet is found along the lateral and posterior part of the articular surface of the head of the talus, whereby it articulates with the calcaneo-navicular part of the bifurcate ligament.

The navicular bone presents a shallow, cup-shaped, articular cavity towards the head of the talus.

The articular surface of the sustentaculum tali is concave, and is usually marked off into two facets.

Two ligaments play an important part in binding together the calcaneus and the navicular, although these bones do not directly articulate; and further, these ligaments provide additional articular surfaces for the head of the talus. These are the two following:-

(a) The ligamentum calcaneonaviculare plantare (Figs. 325 and 326) is an extremely powerful fibro-cartilaginous band. It extends between the anterior margin of the sustentaculum tali and the plantar surface of the navicular. Certain of its upper fibres radiate upwards on the medial surface of the navicular, and 
become continuous with the tibio-navicular portion of the deltoid ligament of the ankle-joint. The plantar aspect of this ligament is in contact with the tendon of the tibialis posterior muscle, through which the head of the talus receives great support. Superiorly it contributes an articular surface which forms a triangular portion of the floor of the composite socket in which the head of the talus is received.

(b) The calcaneo-navicular part of the bifurcate ligament (Fig. 325) lies deeply in the front part of the sinus tarsi, i.e. the interval between the talus and calcaneus. Its fibres are short, and extend from the dorsal surface of the front part of the

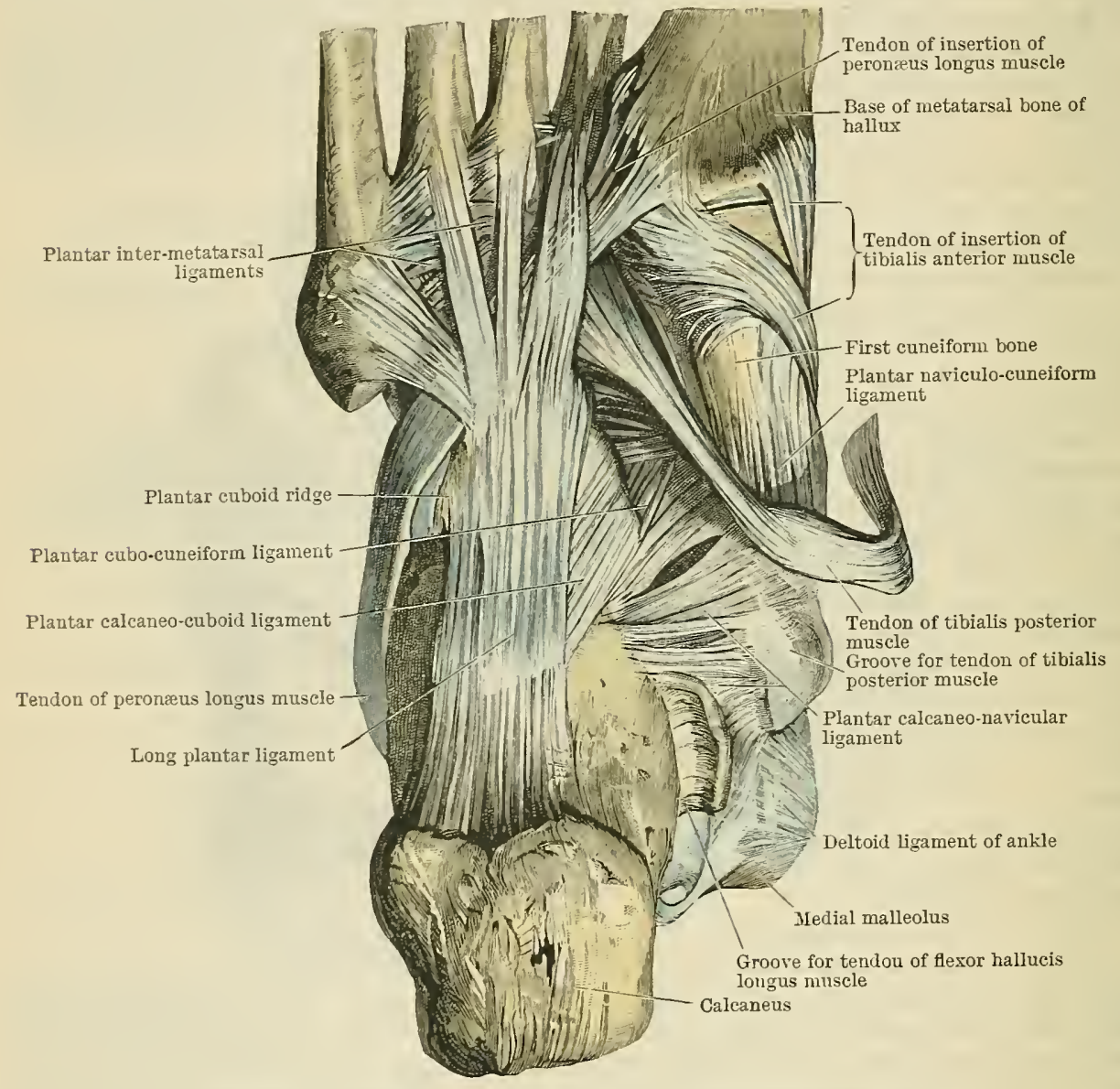

Fig. 326.-Plaxtar aspect of Tarsal axd Tarso-metatarsal Joints.

calcaneus, immediately to the lateral side of the sustentacular facet, forwards to the lateral side of the navicular bone. Frequently the ligament presents a surface which articulates with the head of the talus, and in these cases it forms a part of the composite socket.

The cavity of the talo-calcaneo-navicular joint is closed posteriorly by the interosseous talo-calcaneal ligament already described. On its medial and lateral inferior aspects it is closed by the calcaneo-navicular ligaments.

The superior and lateral aspects are covered by the ligamentum talonaviculare dorsale. This ligament is thin, and extends from the proximal non-articular area on the head of the talus to the dorsal surface of the navicular bone. It may be subdivided into dorsal, lateral, and medial talo-navicular bands (Fig. 324), which, with the calcaneo-navicular and interosseous talo-calcaneal ligaments, cornplete the capsular investment of the joint. 
A distinct synovial stratum lines all parts of the capsule of the joint.

Articulatio Calcaneocuboidea.-This is situated between the anterior concavo-convex surface of the calcaneus and the posterior similar surface of the cuboid.

The ligaments which invest this joint constitute a calcaneo-cuboid capsule, whose parts are arranged in relation to the four non-articular sides of the cuboid bone, and are especially strong upon the plantar aspect, in relation to their great importance in resisting strains.

The medial calcaneo-cuboid ligament occupies part of the interval between the talus and calcaneus-the sinus tarsi. It is the calcaneo-cuboid part of the lig. bifurcatum, and is a V-shaped structure, of which the single end is attached to the calcaneus, and the double ends separate to reach contiguous areas on the navicular and cuboid respectively.

The dorsal calcaneo-cuboid ligament (Fig. 324) is a broad portion of the fibrous stratum of the capsule extending from the dorsal and lateral surfaces of the calcaneus to the dorsal surface of cuboid.

The lateral calcaneo-cuboid ligament is another but narrower part of the capsule which extends from the lateral aspect of the calcaneus to the lateral side of the cuboid, immediately behind the facet on the tuberosity.

The inferior calcaneo-cuboid ligament consists of two parts-a superficial and a deep. The superficial series of fibres, the long plantar ligament (Fig. 326), is attached to the plantar surface of the calcaneus in front of the processes of the tuber calcanei. It forms a long powerful structure which runs forwards to be fixed to the plantar surface of the cuboid ridge, but many of its fibres pass superficial to the tendon of the peronæus longus, and extend to the bases of the third, fourth, and fifth metatarsal bones.

The deep series of fibres, the plantar calcaneo-cuboid ligament (O.T. short plantar ligament) (Fig. 326), is distinctly separated from the long plantar ligament by a layer of areolar tissue. It forms a broad but short band of great strength, which is attached to the plantar surface of the distal end of the calcaneus, and extends to the plantar surface of the cuboid just behind the ridge. Both of these ligaments are of great importance in maintaining the longitudinal arch of the foot, and in this respect are only second to the plantar calcaneo-navicular ligament.

A synovial stratum lines the capsule.

Articulatio Tarsi Transversa (Choparti).-This is a term sometimes applied to the talo-navicular and calcaneo-cuboid joints. These articulations do not communicate with each other; and althongh there is an occasional direct articulation between the navicular and cuboid, it does not constitute an extension of the transverse tarsal joint, but is a prolongation from the series of cuneo-navicular and cuneo-cuboid articulations.

Nevertheless there is always a set of ligaments which bind the navicular and cuboid bones together, and these may be regarded as accessory to the various transverse tarsal joints.

The dorsal cuboideo - navicular ligament (Fig. 324) consists of short oblique fibres which attach the contiguous dorsal surfaces of the cuboid and navicular bones.

The plantar cuboideo-navicular ligament is transverse in direction, and extends between adjacent plantar areas of the cuboid and navicular bones.

The interosseous cuboideo-navicular ligament intervenes between contiguous surfaces of the same bones. When there is an extension of the cuneo-navicular joint backwards between the navicular and cuboid, it is situated in front of the lastmentioned ligament, and is called the articulatio cuboideonavicularis. Around this joint the preceding ligaments are grouped. Since, however, the joint is inconstant while the ligaments are always present, it is preferable to consider them as above indicated.

Articulatio Cuneonavicularis. - The cuneo-navicular articulation joint is situated between the navicular and the three cuneiform bones. The anterior surface of the navicular presents facets for each of the cuneiform bones, but its articular surface is not interrupted. These facets form a somewhat convex anterior surface 
which fits into the shallow articular concavity presented by the proximal ends of the three cuneiform bones. This joint may be extended by the occasional cuboideo-navicular articulation already referred to.

The fibrous stratum of the articular capsule is composed of short strong bauds which are distinctly visible on all sides except towards the cuboid bone, where the joint may communicate with the cuneo-cuboid and cuboideo-navicular joints. Anteriorly the joint communicates with the intercuneiform articulations. The dorsal parts of the capsule are short longitudinal bands termed dorsal cuneo-navicular ligaments (Figs. 323 and 324). These extend without interruption to the medial aspect of the joint. Inferiorly there are similar bands, known as plantar cuneo-navicular ligaments, also longitudinal in direction, but intimately associated with offsets from the tendon of the tibialis posterior muscle.

The synovial stratum which lines the fibrous stratum sends prolongations forwards on each side of the second cuneiform bone, and in addition it often communicates with the cuneo-cuboid joint cavity, and it always communicates with the cuboideo-navicular cavity when that joint exists.

Articulationes Intercuneiformeæ.-These are two in number, and exist between adjacent contiguous surfaces of the three cuneiform bones. These surfaces are partly articular and partly non-articular. The small size of the second cuneiform bone allows the first cuneiform as well as the third cuneiform to project forwards beyond it on both sides, and therefore the articular surfaces turned towards the second cuneiform are not entirely occupied by that bone. They form a recess towards the metatarsus, into which the base of the second metatarsal bone is thrust.

Ligamenta intercuneiformea dorsalia constitute fairly strong transverse bands which extend between adjacent dorsal surfaces and invest the joint cavities in this direction.

The ligamenta intercuneiformea plantaria are two stroug bands which pass from the rough non-articular areas on opposite sides of the second cuneiform to the opposing surfaces of the first and third cuneiform bones. These ligaments shut in the joint cavities inferiorly, and also anteriorly in the case of the lateral of the two joints.

The synovial stratum is an extension of that which lines the cuneo-navicular joint; but while it is restricted to the lateral of the two joints, in the case of the medial one it is prolonged still farther forward to the tarso-metatarsal series of joints.

Articulatio Cuneocuboidea.-This occurs between the rounded or oval facets on the opposing surfaces of the cuboid and third cuneiform.

The ligamentum cuneocuboideum dorsale is a flat, somewhat transverse band which closes the joint on its dorsal aspect, and extends between the dorsal surfaces of the two bones.

The ligamentum cuneocuboideum plantare is difficult to determine. It is situated deep to the long plantar ligament, and extends between adjacent rough surfaces of the two bones.

The ligamentum cuneocuboideum interosseum is the strongest. It closes the joint cavity anteriorly, and is attached to the contiguous non-articular surfaces of the two bones.

The synovial stratum is frequently distinct, but at other times the joint cavity communicates with those of the cuneo-navicular and cuboideo-navicular articulations.

Synovial Strata of the Intertarsal Joints.-Four and sometimes five distinct and separate synovial strata may thus be enumerated in connexion with the tarsal articulations, viz.: (1) talo-calcaneal; (2) talo-calcaneo-navicular; (3) calcaneo-cuboid; (4) cuneo-navicular and its extensions; (5) occasionally cuneocuboid. 


\section{ARTICULATIONES TARSOMETATARSEE.}

The tarso-metatarsal joints are found between certain articular facets on the cuboid and three cuneiform bones on the one hand, and others on the bases of the five metatarsal bones. These articulations are associated with three distinct synovial cavities-namely, a medial, lateral, and intermediate.

(1) The medial tarso-metatarsal articulation occurs between the distal convex reniform surface of the first cuneiform bone and the concavo-reniform surface on the proximal aspect of the base of the first metatarsal bone.

Ligaments which form the fibrous stratum of the articular capsule surround the articulation. In the capsule the ligamenta tarsometatarsea dorsalia et plantaria are its strongest parts, but it is not deficient either on the medial or on the lateral aspects.

A separate synovial stratum lines the fibrous stratum.

(2) The intermediate tarso-metatarsal articulation is an elaborate joint. It involves the three cuneiform bones and the bases of the second, third, and part of the fourth metatarsal bones.

The articulation presents the outline of an indented parapet both on its tarsal and its metatarsal aspects. Thus, on its tarsal side, the first and the third cuneiform bones project in front of the second cuneiform, so that the latter only presents a distal surface to the articulation; while the first cuneiform presents a portion of its lateral surface, and the third cuneiform presents both its distal and portions of its lateral and medial surfaces, since it projects in front of the cuboid bone. On its metatarsal side the base of the second metatarsal bone fits into the indentation between the third and first cuneiforms, to which it presents lateral and medial articular facets, but its proximal facet rests upon the distal facet of the second cuneiform. The base of the third metatarsal bone rests its proximal facet upon the third cuneiform. The fourth metatarsal base presents part of its medial facet to the lateral side of the third cuneiform. In this way the indentations alternate on the two sides of the articulation, and an extremely powerful interlocking of parts is provided, which places any marked independent movement of these metatarsal bones entirely out of the question.

The ligamenta tarsometatarsea dorsalia are broad, flat bands which represent the most distinct part of the fibrous stratum of an investing articular capsule. They pass from behind forwards, and while the second metatarsal bone receives three, i.e. one from each cuneiform, the third metatarsal only receives one-from the third cuneiform.

The ligamenta tarsometatarsea plantaria correspond with the foregoing in their general arrangement, but they are weaker. That for the second metatarsal is the strongest. Oblique bands extend from the first cuneiform bone to the second and third metatarsals.

The ligamenta cuneometatarsea interossea are three in number. The medial connects the lateral side of the first cuneiform with the medial side of the base of the second metatarsal bone. The middle connects the medial side of the third cuneiform with the lateral side of the base of the second metatarsal. The lateral connects the adjacent lateral sides of the third cuneiform and third metatarsal.

The stratum synoviale, which lines this articulation, sends a prolongation backwards between the first and second cuneiform bones, where it opens into the cuneonavicular joint. It is likewise prolonged forwards upon both sides of each of the bases of the second and third metatarsal bones.

(3) The lateral tarso-metatarsal articulation is found between the proximal surfaces of the bases of the fourth and fifth metatarsal bones and the distal surface of the cuboid.

The fibrous stratum of the investing articular capsule may be resolved into the following ligaments :-

The ligamenta tarsometatarsea dorsalia resemble those already described. The base of the fourth metatarsal receives one from the third cuneiform and one from the cuboid. The base of the fifth metatarsal receives one from the cuboid. 
The ligamenta tarsometatarsea plantaria are the weakest bands of the series, and consist of scattered fibres passing from the cuboid to the bases of the two metatarsals. Some fibres, which are almost transverse, extend from the third cuneiform to the fifth metatarsal, and additional fibres reach the fifth metatarsals from the long plantar ligament.

Occasionally the tarsal end of the ligamentum cuneometatarseum interosseum laterale is attached to the medial margin of the cuboid.

The synovial stratum is restricted to this articulation, and merely sends a prolongation forwards between the opposing articular surfaces of the fourth and fifth metatarsal bases.

\section{ARTICULATIONES INTERMETATARSEA.}

The intermetatarsal articulations are found between adjacent lateral aspects of the bases of the four lateral metatarsal bones. The articular facets are small, oval, or rounded surfaces which occupy only a limited portion of the flattened contiguous surfaces of the bones. Each joint is provided with an articular capsule, which, however, is not a complete investment, because the three joint cavities are in free communication on their proximal aspects with the tarso-metatarsal joint cavities -one with the lateral and two with the intermediate. The definite fibres of each fibrous stratum are situated chiefly in the transverse direction

The ligamenta basium dorsalia are short bands which extend from one base to the other.

The ligamenta basium plantaria and the ligamenta basium interossea are similarly arranged, but the interosseous ligaments are the strongest and most important members of this series.

The synovial stratum of each capsule is an extension from the lateral and intermediate tarso-metatarsal joints.

Frequently a bursa is found between the bases of the first and second metatarsal bones. It produces an appearance of indistinct facetting upon these bones, and it may communicate with the first cuneo-metatarsal joint.

The ligamentum metatarsale transversum (transverse metatarsal ligament) lies upon, and is attached to, the non-articular plantar aspects of the heads of all the metatarsal bones. It differs from the corresponding ligament in the palm in the fact that it binds all the metatarsal bones together, whereas in the palm the thumb is left free. It is closely associated with the plantar fibrous plates of the metatarsophalangeal joints, to the plantar surfaces of which it contributes prolongations.

\section{ARTICULATIONES METATARSOPHALANGE}

Metatarso-phalangeal Joints.-Each of these joints is a modified ball-andsocket in which a shallow cup upon the bases of the first phalanges receives the somewhat globular head of a metatarsal bone.

Each joint retains a modified articular capsule which invests the joint. Its only distinct bands of the fibrous stratum are the ligamenta collateralia. These are strong cord-like bands which are situated on the medial and lateral sides of each joint, where they extend between adjacent rough surfaces.

On the dorsal aspect, ligaments distinct from the dorsal expansion of the extensor tendons can hardly be said to exist. The plantar aspect of the capsule consists of a thick fibrous plate strengthened by transverse fibres to form the plantar accessory ligament, which in the case of the great toe presents developed within it two large sesamoid bones. In the other toes this plate remains fibrous throughout, and is grooved on its plantar aspect for the accommodation of the long flexor tendons. It will thus be seen that the metatarso-phalangeal joints are constructed upon a plan very similar to that of the corresponding joints in the hand.

A synovial stratum lines the capsule of each articulation; and the epiphyseal lines of the metatarsals and phalanges are extra-capsular. 


\section{ARTICULATIONES DIGITORUM PEDIS.}

Interphalangeal Joints. - Each toe possesses two interphalangeal joints except the great toe, which has only one. Not infrequently in the little toe the distal joint is obliterated through ankylosis. All the joints of this series are uniaxial or hinge joints. The nature of the articular surfaces closely resembles the corresponding joints in the fingers.

Each joint possesses an articular capsule which is either very thin or limited to the synovial stratum on the dorsal aspect. The plantar surface of the capsule is strengthened by a fibrous plate. The ligamenta collateralia are well-defined bands similar to those already described in connexion with the metatarso-phalangeal joints.

A synovial stratum lines each capsule in the series. The epiphyseal lines are extra-capsular.

Mechanism of the Foot.-The bones of the foot are arranged in the form of a longitudinal and a transverse arch. The longitudinal arch is built on a very remarkable plan. Posteriorly the mass of the calcaneus constitutes a rigid and stable pier of support, while anteriorly, by increasing the number of component parts, the anterior pier acquires great flexibility and elasticity without sacrificing strength or stability. The summit of the arch is formed by the talus, which receives the weight of the body from the tibia, and the resilience of the arch is assured by the calcaneo-navicular, calcaneo-cuboid, and long plantar ligaments, together with the plantar aponeurosis, which act as powerful braces or tie-hands, preventing undue separation of the piers of the arch, and consequent flattening of the foot. The weight of the body is distributed over all the five digits, owing to the arrangement of the bones of the foot in two parallel columns, a medial and a lateral. The former, consisting of the talus, navicular, and the three cuneiforms, with the three medial metatarsal bones, distributes weight through the talo-navicular joint, while the latter (i.e. the lateral column), comprising the calcaneus, cuboid, and the two lateral metatarsal bones, acts in a similar manner through the talo-calcanean joint. The main line of immobility of this arch passes from the heel forwards through the middle toe, but its anterior section, which is slender, is supported on either side by two metatarsal bones, with their proximal tarsal associations, in all of which greater freedom of movement is found. The transverse arch is most marked at the level of tarso-metatarsal articulations. The intersection of these two arches at right angles to each other introduces an architectural feature of great importance in connexion with the support of heavy weights. These longitudinal and transverse arches of the foot are in effect "vaults" intersecting each other at right angles, and in relation to the area which is common to both "vaults" the body weight is superposed exactly as the dome of a cathedral is carried upon two intersecting raults.

Movements at the Joints of the Tarsus, Metatarsus, and Phalanges.-Considered in detail, the amount of movement which takes place between any two of these bones is extremely small, and, so far as the tarsus and metatarsus are concerned, it is mostly of the nature of a gliding motion.

At the metatarso-phalangeal and interphalangeal joints movement is much more free, and is of the nature of flexion (bending of the toes towards the sole of the foot, i.e. plantar flexion) and extension. The latter movement when continued so as to raise the toes from the ground, and bend or approximate them towards the front of the leg, is termed dorsifiexion. Coincident with dorsiflexion there is always associated a certain amount of spreading of the toes, which is called abduction, and similarly with prolonged flexion there follows a diminution or narrowing of the transverse diameter of the anterior part of the foot by drawing the toes together-a movement termed adduction. In the foot the movements of abduction and adduction take place in regard to a plane which bisects the foot antero-posteriorly through the second toe, for this toe carries the first and second dorsal interosseous muscles.

Notwithstanding the small amount of possible movement in connexion with individual tarsal and metatarsal joints, yet the sum total of these movements is considerable as regards the entire foot. In this way the movements of inversion and eversion of the foot result. By inversion we mean the raising of the medial border of the foot so that the sole looks medially, while the toes are depressed towards the ground, and the lateral border of the foot remains downwards. This takes place chiefly at the talo-calcanean joint, but the transverse tarsal joints also participate.

Eversion is chiefly the opposite of inversion, and the return of the foot to the normal position of the erect attitude; but under certain conditions it may be carried further, so that the lateral border of the foot is raised from the ground, while the medial border is depressed. In both of these movements there is rotation between the talus and calcanens about an oblique axis which passes from the medial side of the neck of the talus to the lateral and inferior part of the calcaneus.

Of course, all the movements of the foot are subordinated to its primary functions as an organ of support and progression. For these purposes its longitudinal and transverse arches are of extreme importance. The longitudinal arch resting on the calcaneus behind and the heads of 
the metatarsal bones in front receires the weight of the body, as already explained, on the sumnit of the talus in the line of the third toe. Hence it is that the medial malleolus appears to be unduly prom inent on the medial side of the ankle. The transverse arch buttresses the longitudinal one, and therefore, whether the body weight fall to the lateral or the medial side of the longitudinal arch, it is supported by a mechanism at once stable, flexible, and elastic, or resilient, and capable of reducing to a minimum all jars that may be received by the fore part of the foot. As the heel is raised in the act of walking, the weight is gradually transferred from the lateral to the medial

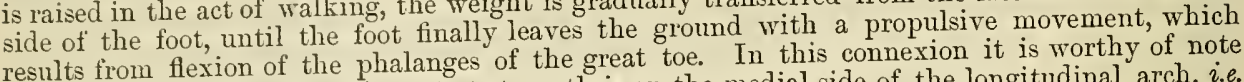
that the longitudinal line of greatest strength is on the medial side of the longitudinal arch, i.e. in relation to the great toe. 


\title{
THE MUSCULAR SYSTEM.
}

\section{MYOLOGY.}

\author{
By A. M. Paterson.
}

THE movements of the various parts and organs of the body are brought about by the agency of muscle-cells, which are characterised by a special histological structure and by the special function of contracting in length under the influence of a proper stimulus.

There are three classes of muscle-cells: (1) the striated, and usually voluntary muscle-cells, out of which the skeletal muscular system is constructed; (2) the nonstriated, involuntary muscle-cells, occurring in the walls of vessels and hollow viscera, etc. ; and (3) the cardiac muscle-cells, striated but involuntary, of which the substance of the heart is composed.

The following section deals solely with the skeletal muscles, the structure, arrangement, and mechanical action of which are based upon a common plan.

The cells of which the skeletal muscles are composed are long, narrow, and characterised by a peculiar striation, which is different from the striation of the muscle-cells of the heart; they also differ both in structure and function from the non-striated muscle-cells which occur in viscera and vessels.

A typical skeletal muscle consists of a fleshy mass enveloped in a membranous aponeurosis or fascia, and provided at its extremities or borders with membranous or tendinous attachments to bone, cartilage, or fascia.

Each muscle is made up of a number of fasciculi or bundles, arranged together in different muscles in different ways, so as to give rise to the particular form of the muscle in question. These fasciculi are clothed and connected together by a delicate connective tissue, the perimysium externum, continuous externally with the fascia enclosing the muscle.

Each muscular bundle or fasciculus is composed of a number of narrow, elongated muscle-cells or fibres, held together by a still more delicate connective tissue, the perimysium internum. This tissue is connected on the one hand with the sarcolemma or cell-wall of the muscle-cell, and on the other hand with the coarser tissue of the perimysium externum enclosing the muscular bundles.

By means of these connective tissue envelopes the muscle-cells, the essential agents of motor activity, are brought into firm and intimate relation with the osseous or other attachments of the muscle. Through the agency of sarcolemma, perimysium internum, perimysium externum, fascia, and tendon, the musclecell when it contracts can produce a precise and definite effect upon the weight to be moved.

Each muscle is supplied by one or more nerves, which, in their course through the muscle, separate into smaller and smaller branches, ultimately, by their terminal filaments (axons), forming special end-organs in relation to each muscle-cell.

While a muscle may thus be looked upon as an organ endowed with particular properties, and executing a definite movement in response to a stimulus by the simultaneous contraction of its constituent cells, the various muscles may further be considered in groups, associated together by mode of development, nerve-supply, and co-ordination of action. For example, we speak of the hamstring muscles of 
the thigh, the muscles of the back, and the prevertebral muscles,-groups in which separate muscles are associated together by development, nerre-supply, and action. In their development the separate muscles arise from the subdivision of a larger stratum, as in the limbs, or from the fusion of segmental elements (myotomes), as in the case of the axial muscles. The peripheral nerves supplying skeletal muscles are distributed, through the plexuses or directly, so as to associate particular muscles morphologically and physiologically, and to secure a co-ordinated movement by the simultaneous contraction of several muscles.

\section{FASCIÆE.}

Beneath the skin there are two (or in some regions three) layers of tissue which require consideration in relation to the muscular system: the superficial fascia (panniculus adiposus), the deep fascia, and, in animals, the panniculus carnosus (rudimentary in man, and represented chiefly by the platysma in the neck).

Fascia Superficialis (Superficial Fascia). - The superficial fascia is a continuous sheet of areolar tissue which underlies the skin of the whole body. It is closely adherent to the cutis vera, and is sometimes termed panniculus adiposus, from the fact that, except beneath the skin of the eyelids, penis, and scrotum it is usually more or less impregnated with fat. The cutaneous vessels and nerves ramify in this fascia; and its deep surface, membranous in character, is in loose connexion with the subjacent deep fascia. It is in this layer that dropsical effusions chiefly occur.

Fascia Profunda (Deep Fascia).-Underneath the skin and superficial fascia is a fibrous membrane, bluish white in colour, devoid of fat, and in closest relation to skeleton, ligaments, and muscles. This is the deep fascia. It covers, invests, and in some cases forms the means of attachment of the various muscles. It has a special tendency to become attached to all subcutaneous bony prominences, and to be continuous with the connecting ligaments. It forms septal laminæ, which separate groups of muscles and individual muscles; enclose glands and viscera; and form sheaths for vessels and nerves. Around joints it gives rise to bands which strengthen the capsule or limit the mobility of the joint, or, as in the region of the wrist and ankle, bind down the tendons passing over the joint. It not only ensheathes vessels and nerves, but is perforated by those which pass between superficial and deeper parts.

The term aponeurosis is used in relation to muscles. It is synonymous with deep fascia, either as an investing fascia, or as a membranous layer which (e.g. vertebral aponeurosis) performs at one and the same time the purpose of a deep fascia and the expanded membranous attachment of a muscle.

The panniculus carnosus is a thin muscular layer enveloping the trunk of animals with a hairy or furry coat. It is strongly developed in the hedgehog. In man it is represented mainly by the (rudimentary) platysma. It is placed between the superficial and the deep fascia.

Bursæ.-Where a tendon passes over a bony surface, or where the superficial fascia and skin cover a bony prominence, there is generally formed a mucous (synovial) sac, or bursa, containing fluid, for the purpose of lubricating the surface over which the tendon or fascia glides. Allied to these are the mucous or synovial sheaths which envelop the tendons passing over the wrist and the ankle joints.

Description of Muscles.-In studying the muscular system it is necessary to note the following characters in reference to each individual muscle: (1) The shape of the muscle-flat, cylindrical, triangular, rhomboidal, etc. ; and the character of its extremities-membranous, tendinous, or fleshy. (2). The attachments of the muscle. The origin is the more fixed or central attachment: the insertion is the more movable or peripheral attachment. (3) The relations of the surfaces and borders of the muscle to bones, joints, muscles, and other important structures. (4) Its vascular and nervous supply; and (5) its action. It must be borne in mind that hardly any single muscle acts alone. Each muscle, as a rule, forms one 
of a group acting more or less in harmony with, and antagonised by, other and opposite groups.

\section{DESCRIPTION OF THE MUSCLES.}

The skeletal muscles may be divided into two series: axial and appendicular. The axial muscles comprise the muscles of the trunk, head, and face, including the panniculus carnosus (platysma). These muscles are more or less segmental in arrangement, grouped around the axial skeleton. The appendicular muscles, the muscles of the limbs, are grouped around the appendicular skeleton. They are not segmental in arrangement, they are morphologically separate from the axial muscles, and they are arranged in definite strata in relation to the bones of the limbs.

\section{APPENDICULAR MUSCLES.}

\section{THE UPPER LIMB.}

\section{FASCIÆ AND SUPERFICIAL MUSCLES OF THE BACK.}

\section{Fasciæ.}

The superficial fascia of the back presents no peculiarity. It is usually of considerable thickness, and contains a quantity of fat.

The deep fascia closely invests the muscles. It is attached in the median plane of the back to the ligamentum nuchæ, supraspinous ligaments, and vertebral spines; laterally it is attached to the spine of the scapula and to the clavicle, and is continued over the deltoid region to the arm. In the neck it is attached above to the superior nuchal line of the occipital bone, and is continuous laterally with the deep cervical fascia. Below the level of the shoulder it is continuous, round the border of the latissimus dorsi muscle, with the fascia of the axilla and of the abdominal wall. In the back and loin it constitutes the fascia lumbodorsalis or aponeurosis of the latissimus dorsi. This layer conceals the sacrospinalis muscle, and is attached medially to the vertebral spines, and laterally to the angles of the ribs, and to the iliac crest.

\section{The Superficial Muscles of the Back.}

The muscles of the back are arranged in four series according to their attachments: (1) vertebro-scapular and vertebro-humeral; (2) vertebro-costal; (3) vertebrocranial; and (4) vertebral. The first of this series consists of the posterior muscles connecting the superior extremity to the trunk, and comprises the first two layers of the muscles of the back-(1) trapezius and latissimus dorsi, and (2) levator scapulæ and rhomboidei (major and minor). The deeper (axial) muscles of the back are dealt with later (p. 437).

M. Trapezius.-The trapezius is a large triangular muscle occupying the upper part of the back. It arises from the superior nuchal line of the occipital bone in its medial third, from the external occipital protuberance (Fig. 396, p. 444), from the ligamentum nuchæ, from the spines of the seventh cervical and all the thoracic vertebræ, and the intervening supraspinous ligaments. The origin is by direct fleshy attachment, except in relation to the occipital bone, the lower part of the neck, and the lower thoracic vertebræ, in which places the origins are tendinous.

From their origin the muscular fibres converge towards the bones of the shoulder, to be inserted continuously from before backwards as follows: (1) The occipital and upper cervical fibres-into the posterior surface of the clavicle in its lateral third (Figs. 327, p. 366, and 329, p. 368); (2) the lower cervical and upper thoracic fibres - into the medial border of the acromion, and the upper border of the spine of the scapula; and (3) the lower thoracic fibres, by a 
triangular flat tendou, beneath which a bursa is placed-into a rough tuberosity at the base of the spine of the scapula (Fig. 328, p. 367). The fibres inserted into the clavicle, acromion, and the upper border of the spine of the scapula spread over the adjacent subcutaneous surfaces of these bones for a variable distance. The occipital portion of the muscle may be in the form of a separate slip, or may be entirely absent.

The trapezius is superficial in its whole extent. Its upper lateral border forms the posterior limit of the posterior triangle of the neck. The inferior lateral border, passing over the upper edge of the latissimus dorsi and the vertebral margin of the scapula, forms a boundary of the so-called triangle of auscultation, completed below by the latissimus dorsi, and laterally by the vertebral margin of the scapula. This space is partly filled up by the rhomboideus major. The muscle overlaps the latissimus dorsi, and covers the levator scapulæ, rhomboidei, and the deeper axial muscles of the back, along with the ascending and the descending branch of the transverse artery of the neck, the accessory nerve, and muscular branches from the cervical plexus.

Nerve-Supply.--The trapezitus has a double nerve-supply: (1) from the terminal fibres of the accessory nerve, and (2) from the cervical plexus (C. 3. and 4.). These nerves communicate with the accessory nerve both in the posterior triangle of the neck and beneath the trapezius.

Action. - The main action of the trapezius is to draw the scapula backwards and upwards. The upper fibres of the muscle elevate the shoulder-girdle, while the lower fibres, pulling on the base of the spine of the scapula, depress the vertebral margin; the two movements result in a rotation of the scapula, by which the glenoid cavity is tilted upwards, as in the movement of raising the arm above the head in a forward direction.

M. Latissimus Dorsi.-The latissimus dorsi is a large triangular muscle occupying the lower part of the back. It has a triple origin. The greater part

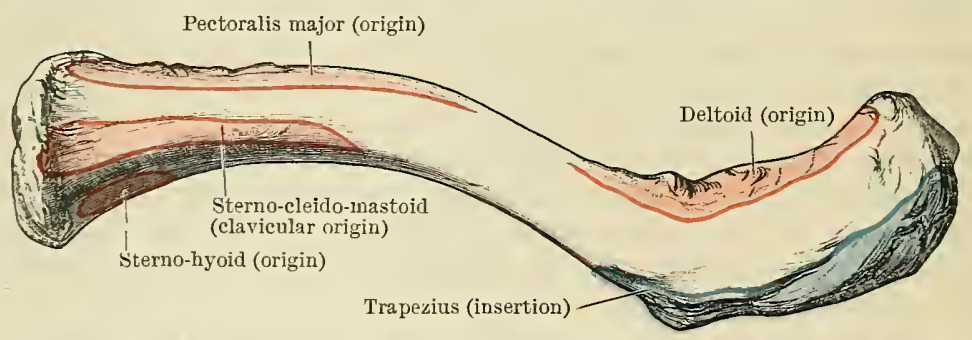

Fig. 327.-Muscle-Attachiments to the Right Clavicle (Upper Surface).

of the muscle arises-(1) from the posterior layer of the lumbo-dorsal fascia. This is a thick membrane which conceals the sacrospinalis muscle in the lower part of the back. Through it the latissimus dorsi gains attachment to the spines of the lower six thoracic vertebræ, the spines of the lumbar vertebræ, and the teudon of the sacrospinalis, with which the fascia blends below. It also arises laterally from the posterior part of the iliac crest.

From this origin the muscle is directed upwards and laterally, its fibres converging to the inferior angle of the scapula. In relation to its lateral and upper borders additional fibres arise. (2). Along the lateral border muscular slips arise from the lower three or four ribs, interdigitating with the slips of origin of the obliquus aldominis externus. (3) As the superior border of the muscle passes horizontally over the inferior angle of the scapula, an additional fleshy slip usually takes origin from this part of the bone to join the muscle on its deep surface (Fig. 329, p. 368).

Beyond the inferior angle of the scapula the latissimus dorsi, greatly narrowed, curves spirally round the teres major muscle, and forms the prominence of the posterior axillary fold. It ends in a ribbon-like tendon, which is closely adherent at first to the teres major, and is inserted into the floor of the intertubercular sulcus of the humerus, extending for about three inches distal to the distal and lateral part of the lesser tubercle (Fig. 336, p. 376). It is placed behind the axillary vessels and nerves, and in front of the insertion of the teres major, from which it is separateo by a bursa. 
In the back the latissimus dorsi is superficial, except in its upper part, which is concealed by the trapezius. It covers the lumbo-dorsal fascia, serratus

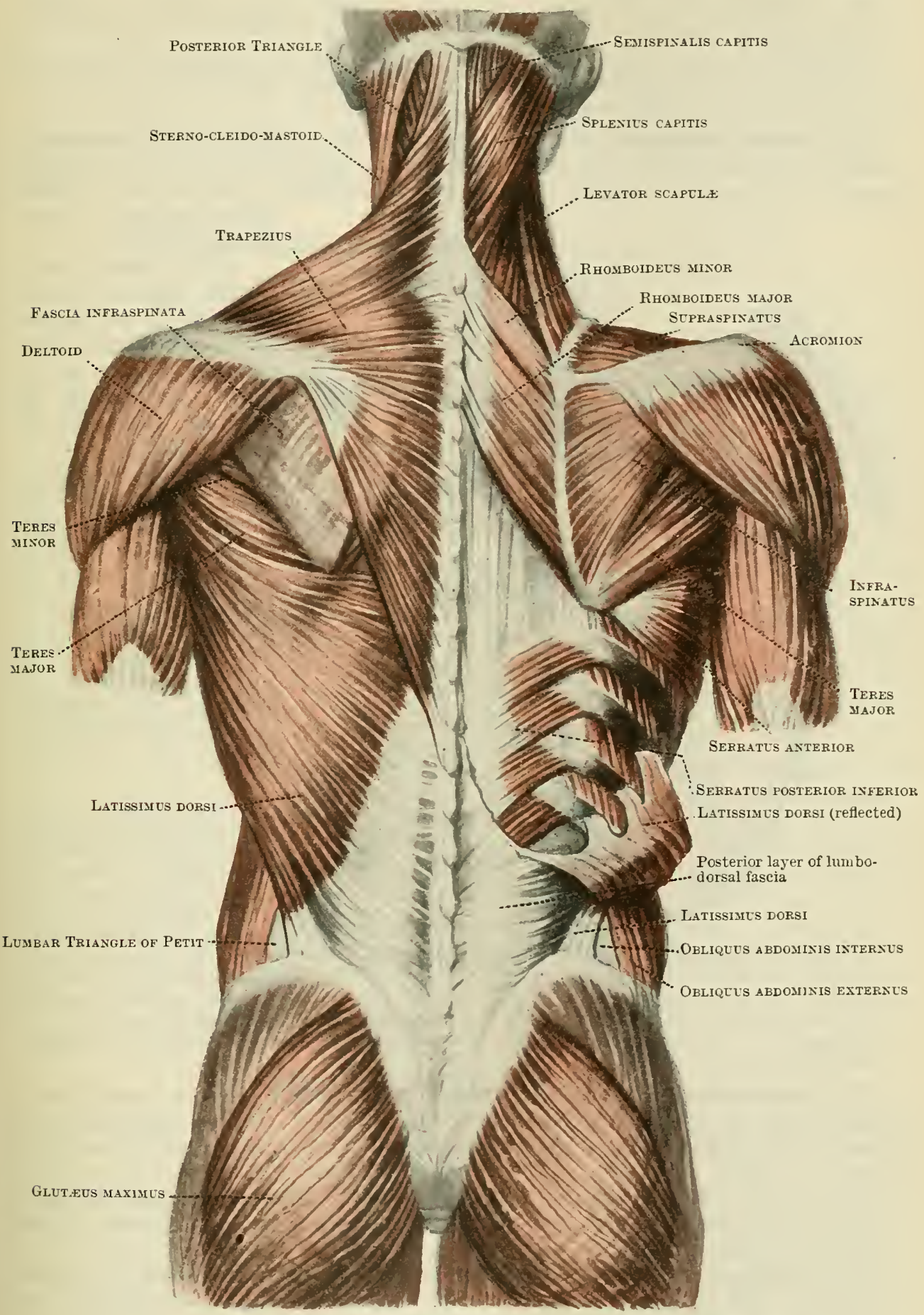

Fig. 328,--Superficlal Muscles of the Back, axd Vertebro-scapdlar Micscles.

posterior inferior, the ribs, and inferior angle of the scapula, and at its borders two triangular spaces are formed; at the upper border is the so-called triangle of auscultation; at the lateral border is the lumbar triangle of Petit, a small space 
bounded by the iliac erest, the latissimus dorsi, and the obliquus abdominis externus. This is sometimes the site of a lumbar hernia.

Nerve-Supply. - The muscle has a single nerve-the thoraco-dorsal nerve-which supplies it in its deep (axillary) surface. It is a branch from the posterior cord of the brachial plexus (C. (6.) 7. 8.).

Action. - The main action of the latissimus dorsi muscle is to depress and rotate the humerus medially, so lowering the arm as in swimming. Acting from the humertus it elevates the lower ribs, and is an extraordinary muscle of inspiration.

M. Levator Scapulæ.-The levator scapulæ is a strap-like muscle, arising by tendinous slips from the posterior tubercles of the transverse processes of the first three or four cervical vertebræ, between the attachments of the scalenus medius

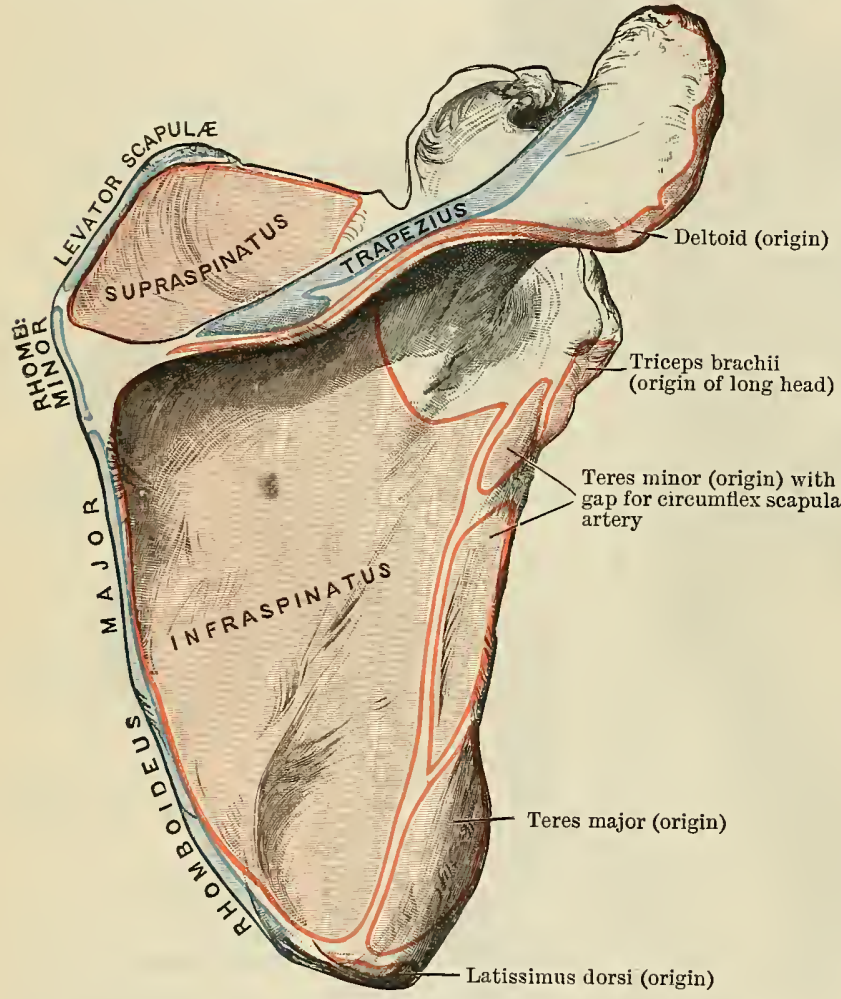

Fig. 329.--Muscle-Attachments to the Right Scapula (Dorsal Surface). in front and the splenius cervicis behind.

It is directed downwards along the side of the neck, to be inserted into the vertebral margin of the scapula in its upper fourth, from the superior angle to the spine (Fig. 329).

It is concealed in its upper third by the sterno-mastoid muscle. In its middle third it occupies the floor of the posterior triangle. In its lower third it is again hidden from view by the trapezius. It conceals the splenius cervicis and iliocostalis cervicis.

Nerve - Supply. - The levator scapulæ has a double nerve-supply:--(1) from the dorsal scapular nerve from the brachial plexus (C. 5.), which either pierces or goes beneath the muscle, and (2) from the cervical plexus. Small branches from the anterior trunks of the third and fourth cervical nerves enter the muscle on its superficial surface near its origin.

Action.--The levator scapulæ raises the superior angle and vertebral margin of the scapula, as in shrngging the shoulders.

M. Rhomboideus Minor. - The rhomboideus minor may be regarded as a separated slip of the rhomboideus major, with which it is often continuous. It arises from the ligamentum nuchoe and the spines of the seventh cervical and first thoracic vertebræ.

Passing obliquely downwards and laterally it is inserted into the vertebral margin of the scapula below the levator scapulæ muscle, and opposite to the base of the spine (Fig. 329).

M. Rhomboideus Major.-The rhomboideus major arises from the spinous processes of the thoracic vertebræ from the second to the fifth inclusive, and from the corresponding supraspinous ligaments.

Passing downwards and laterally it is inserted below the rhomboideus minor into the vertebral margin of the scapula, between the spine and the inferior angle (Fig. 329). The muscle is only inserted directly into the scapula by means of its inferior fibres. Its superior part is attached to a membranous band, which, 
connected for the most part by loose areolar tissue to the vertebral margin of the scapula, is fixed to the bone at its extremities, above near the base of the spine, and below at the inferior angle.

The rhomboid muscles are concealed for the most part by the trapezius. The lower part of the rhomboideus major is superficial in the triangle of auscultation. The muscles cover the serratus posterior superior and vertebral aponeurosis.

Nerve-Supply. - The rhomboid muscles are supplied by the dorsal scapular nerve from the brachial plexus (C. 5.), which supplies branches in the deep surface of the muscles.

Action. - The rhomboid muscles elevate and draw backwards the vertebral margin of the seapula.

\section{THE FASCIE AND MUSCLES OF THE PECTORAL REGION.}

\section{FASCI㞋.}

The superficial fascia of the chest usually contains a quantity of fat, in which the mamma is embedded. The origin of the platysma muscle lies beneath its superior part.

The deep fascia is attached above to the clavicle, and in the median plane to the sternum. Below it is continuous with the fascia of the abdominal wall. It gives origin to the platysma and iuvests the pectoralis major. At the lateral border of the great pectoral muscle it is thickened, and forms the floor of the axillary space (axillary fascia), continued posteriorly on to the posterior fold of the axilla and laterally into connexion with the deep fascia of the arm.

Costo-Coracoid Membrane.-Beneath the pectoralis major a deeper stratum of fascia invests the pectoralis minor muscle. At the superior border of this muscle it forms the costo-coracoid membrane, which passes upwards to the inferior border of the subclavius muscle, where it splits into two layers, attached in front of and behind that muscle to the borders of the inferior surface of the clavicle. The membrane traced medially along the subclavius muscle is attached to the first costal cartilage; passing laterally along the upper border of the pectoralis minor it reaches the coracoid process. The part of the membrane extending directly between the first costal cartilage and the coracoid process is thickened and forms the costo-coracoid ligament. The costo-coracoid membrane is otherwise thin and of comparatively small importance. It is pierced by the cephalic rein, thoraco-acromial artery and vein, and branches of the lateral anterior thoracic nerve. By its deep surface it is connected to the sheath of the axillary vessels.

At the inferior border of the pectoralis minor there is a further extension of the deep fascia beneath the pectoralis major. It passes downwards to join the fascia forming the floor of the axilla, and is continued laterally into the fascia covering the biceps and coracobrachialis muscles.

\section{MUSCLES OF THE PECTORAL REGION.}

The anterior muscles connecting the upper limb to the axial skeleton comprise the pectoralis major, pectoralis minor, subclavius, serratus anterior, and sternocleido-mastoid. The last is described in a later section (p. 458).

M. Pectoralis Major.-The pectoralis major is a large fan-shaped muscle arising in three parts: (1) a pars clavicularis arising from the anterior surface of the clavicle in its medial half or two-thirds (Figs. 327, p. 366, and 331, p. 371); (2) a pars sternocostalis, the largest part of the muscle, arising from the anterior surface of the manubrium and body of the sternum by tendinous fibres decussating with those of the opposite muscle (Fig. 330, p. 370), and, more deeply, from the cartilages of the first six ribs; (3) a pars abdominalis, a small and separate slip, arising from the aponeurosis of the obliquus abdominis externus muscle. The abdominal slip, at first separate, soon merges with the sterno-costal portion, but a distinct interval usually remains between the two first-named parts of the muscle. 
The fibres converge towards the proximal part of the arm, and are inseparably blended at a point half an inch from their insertion into the humerus. The muscle is inserted into (1) the lateral border of the sulcus intertubercularis of the humerus, extending proximally to the greater tubercle and blending laterally with the insertion of the deltoid, medially with the insertion of the latissimus dorsi (Fig. 336, p. 376); (2) from the proximal border of the insertion a membranous band extends proximally to the capsule of the shoulder-joint, enveloping at the same time the tendon of the biceps; and (3) from the distal border a band of fascia passes distally to join the fascia of the arm.

The arrangement of the fibres of the muscle at its insertion is peculiar. The muscle is twisted on itself, so that the lower (sterno-costal) fibres are directed

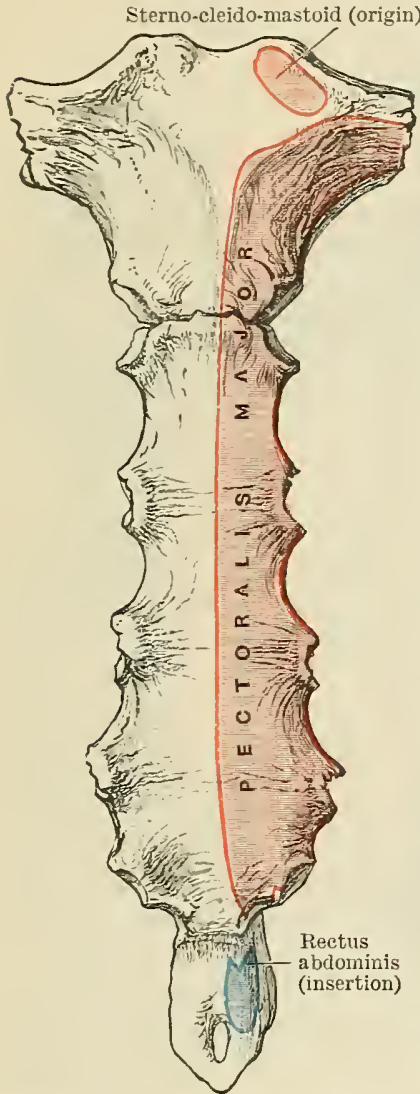

Fig. 330.- Muscle-Attachients to the FroNt of the SterndM. upwards and laterally behind the upper (clavicular) part of the muscle ; in consequence the clavicular part is attached to the humerus more distally than the sterno-costal portion, and is inserted also into the fascia of the arm. The twisting of the fibres is specially found in the inferior sterno-costal fibres of the muscle and the abdominal fibres. These curve upwards behind the superior sterno-costal fibres, and have the highest attachment to the shaft of the humerus, helping to form the fascial expansion which extends upwards over the biceps tendon to the capsule of the shoulder-joint. In this way a bilaminar tendon is produced united along its inferior border; consisting of a superficial lamina formed by the superior sternocostal fibres, blending for the most part with the tendon of the clavicular portion; and a deep lamina, composed of the twisted lower sterno-costal and abdominal fibres. The disposition of the muscular fibres at their insertions is the reason for the application of the terms "portio attollens" to the clavicular portion, and "portio deprimens" to the sterno-costal and abdominal portions of the muscle.

Placed superficially, the pectoralis major forms the anterior wall and anterior fold of the axilla. Its superior border is separated from the edge of the deltoid muscle by an interval in which lie the cephalic vein and deltoid branches of the a. thoracoacromialis. Its deep surface is in relation with the ribs and intercostal muscles, the costo-coracoid membrane and the structures piercing it, the pectoralis minor, the axillary vessels, and the nerves of the brachial plexus.

Nerve-Supply.-The pectoralis major has a double nervesupply, from both anterior thoracic nerves. The lateral anterior thoracic nerve, derived from the lateral cord of the brachial plexus (C. 5. 6. T.), divides into two trunks. One pierces the costo-coracoid membrane, and supplies the clavicular part, and superior portion of the sterno-costal part of the muscle. The other branch communicates over the axillary artery with the medial anterior thoracic nerve, a derivative of the medial cord of the brachial plexus (C. 8. T. 1.). They then supply the pectoralis minor and, piercing that muscle, terminate in the lower part of the pectoralis major.

Action.-The pectoralis major draws the arm to the side. The clavicular fibres flex the shoulder-joint and raise the arm besides drawing it forwards. The, sterno-costal and abdominal portions, on the other hand, depress the arm, while drawing it forwards.

Sternalis Muscle.-The sternalis is an occasional muscle placed, when present, parallel to the sternum upon the sterno-costal origin of the pectoralis major. It has attachments which are very variable both above and below, to the costal cartilages, sternum, rectus sheath, sternomastoid, and pectoralis major. Its nerve-supply is from one or both of the anterior thoracic nerves. In certain rare cases it has been said to be innervated by intercostal nerves. It is present in 4.4 cases out of 100, and it is slightly more frequent in the male than in the female. It has been regarded by different observers as (1) a vestige of the panniculus carnosus, (2) a homologue of the sterno-mastoid, or (3) a displaced slip of the pectoralis major.

Chondroepitrochlearis, Dorsoepitrochlearis, Axillary Arches, Costocoracoideus.-One 
or other of the above-named slips is occasionally present, crossing the floor of the axilla in the interval between the latissimus dorsi and the pectoralis major. They take origin from the costal cartilages, ribs, or borders of the pectoralis major (chondroepitrochlearis, axillary arches, costocoracoideus), or from the border of the latissimus dorsi (dorsoepitrochlearis, axillary arches, costocoracoideus). Their insertion is variable. The chondroepitrochlearis and dorsoepitrochlearis are inserted into the fascia of the arm, the medial intermuscular septum, or the medial epicondyle of the humerus. The axillary arches are inserted into the border of the pectoralis major, the fascia of the arm, or the coracobrachialis or biceps muscle. The costocoracoideus, arising from the ribs or the aponeurosis of the obliquus externus, or detaching itself from the border of the pectoralis major or latissimns dorsi, is attached to the coracoid process, alone or along with one of the muscles attached to that bone. These rariable slips of muscle are supplied by the medial anterior thoracic nerve, the medial cutaneous nerre of the arm, or the intercostobrachial.

II. Pectoralis Minor.-The pectoralis minor is a narrow, flat, triangular muscle. It arises, under cover of the pectoralis major, from (1) the surfaces and superior borders of the third, fourth, and fifth ribs near their anterior ends, and (2) from the fascia covering the third and fourth intercostal spaces between these ribs. It may have an additional origin from the second rib (Fig. 414, p. 468); and that from the fifth rib is often absent.

Directed obliquely upwards and laterally, it is inserted by a short, flat tendon into the lateral half of the anterior border and upper surface of the coracoid process (Fig. 333, p. 372), and usually also into the conjoint origin of the biceps brachii and coracobrachialis.

It enters into the formation of the anterior wall of the axilla, and gives attachment along its superior border to the costo-coracoid membrane. It crosses the axillary vessels and the cords of the brachial plexus, and is pierced by branches of the anterior thoracic nerves.

Either in part or wholly the pectoralis minor may pass over the coracoid process of the scapula, separated from it by a bursa, to be inserted into the coraco-acromial ligament, or the acromion process; or piercing the coraco-acromial ligament, it may be attached to the capsule of the shoulder-joint (coraco-humeral ligament).

Pectoralis Minimus. - This is a slender slip, rarely present, which extends between the first costal cartilage and the coracoid process.

Nerve-Supply. - The pectoralis minor is innervated like the pectoralis major by both anterior thoracic nerves. The lower division of the lateral nerve (C. 5. 6. 7.) communicates with the medial anterior thoracic nerve (C. 8. T. 1.) over the axillary artery. Both nerves pierce and supply the pectoralis minor, and end in the pectoralis major.

Action. - The main use of the pectorals minor is to draw the shoulder forwards. It is thus a. chief assistant of the serratus anterior muscle.

M. Subclavius.-The subclavius muscle arises from the superior surface of the

Coraco-clavic-

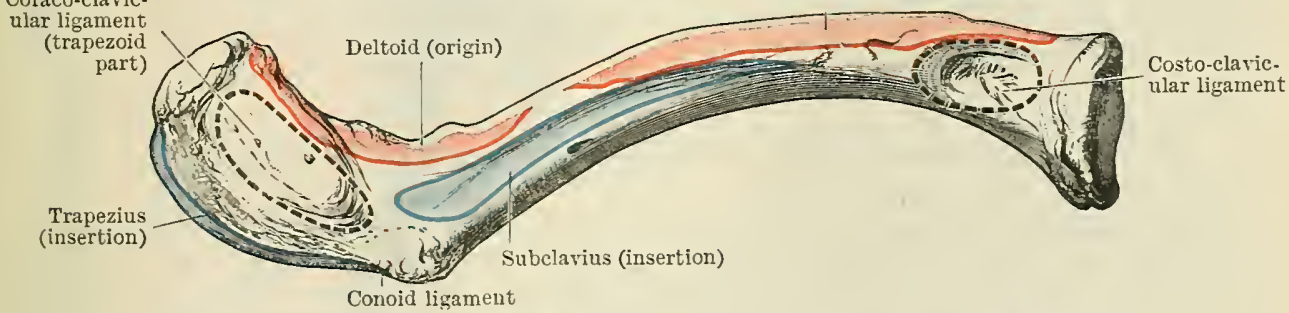

Fig. 331.-Midscle-Attachamests to the Right Cinicle (Inferior Surface).

first costal cartilage in front of the costo-clavicular ligament, and from the upper surface of the sternal end of the first rib (Fig. 414, p. 468).

It is inserted in to a groove in the middle third of the inferior surface of the clavicle (Fig. 331).

The muscle is invested by the fascia which forms the costo-coracoid membrane, and is concealed by the clavicle and the clavicular origin of the pectoralis major.

Nerve-Supply.-The nerve to the subclavius is a fine branch of the brachial plexus (C. 5. 6.), which arises above the clavicle, and passes over the subclavian artery to reach the muscle.

Action.-It acts as a depressor of the clavicle; or, the shoulder girdle being fixed, it is capable of raising and fixing the first rib, in inspiration. 


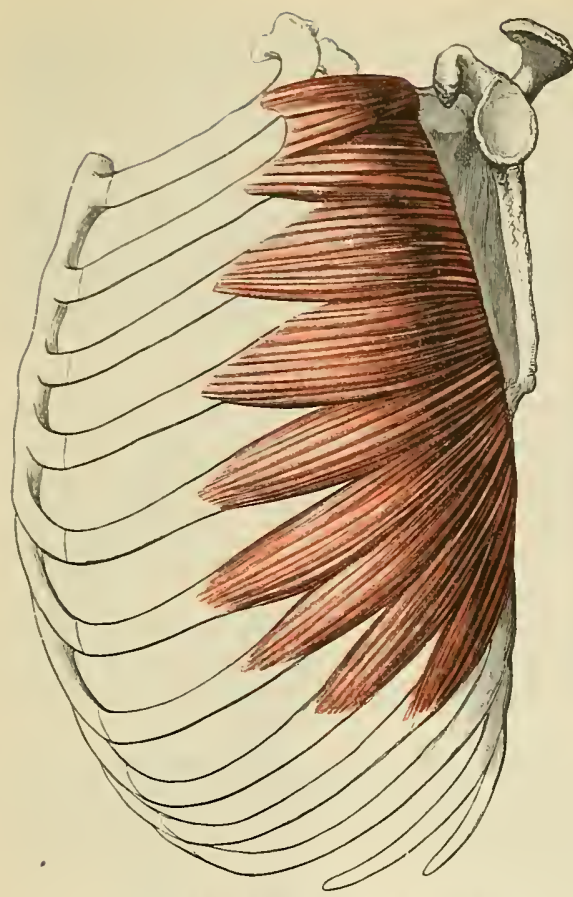

Frg. 332.-The Left SERratus ANterior Muscle.

The sternoclavicularis is a small separate slip, rarely present, extending beneath the pectoralis naajor from the upper part of the sternum to the clavicle.

M. Serratus Anterior.-The serratus anterior (O.T. serratus magnus) is a large curved quadrilateral muscle occupying the side of the chest and medial wall of the axilla. It arises by fleshy slips from the lateral aspect of the upper eight and occasionally (as in the figure) from nine ribs. The first slip is a double one, arising from the first two ribs and the fascia covering the intervening space (Fig. 332).

The insertion of the muscle is threefold. (1) The first portion of the muscle (from the first and second ribs) is directed posteriorly to be inserted into the costal aspect of the superior angle of the scapula. (2) The next three slips of the muscle (from the second, third, and fourth ribs) are inserted into the vertebral margin of the scapula. (3) The last four slips (from the fifth, sixth, seventh, and eighth ribs) are directed obliquely upwards and posteriorly, to be inserted on the costal aspect of the inferior angle of the scapula (Fig. 333).

The lateral surface of the muscle is partly superficial below the axillary space, on the side wall of the chest, where its slips of origin are seen inter-digitating with those of the obliquus externus abdominis. Higher up it forms the medial wall of the axilla, and is in contact with the pectoral muscles anteriorly and the subscapularis posteriorly. Its superior border appears in the floor of the posterior triangle, and over it the axillary artery and the cords of the brachial plexus pass in their course through the axilla. The inferior border is oblique, and is in contact with the latissimus dorsi muscle. The muscle may extend higher than usual, so as to be continuous in the neck with the levator scapulæ.

Nerve-Supply. - The serratus anterior muscle receives its nerve from the long thoracic nerve, a branch from the anterior trunks of the fifth, sixth, and seventh cervical nerves. After piercing the scalenus medins, the nerve enters the axilla, and supplies branches to the several digitations of the muscle on their superficial surface. The highest fibres of the muscle are supplied by the fifth, the lowest fibres by the seventh, and the intermediate part of the muscle by the sixth cervical nerve.

Action.-The primary action of the muscle is to draw the base of the scapula forwards. This causes

Deltoid (origin) Biceps and coracobrachialis (origin) I Pectoralis minor (insertion)

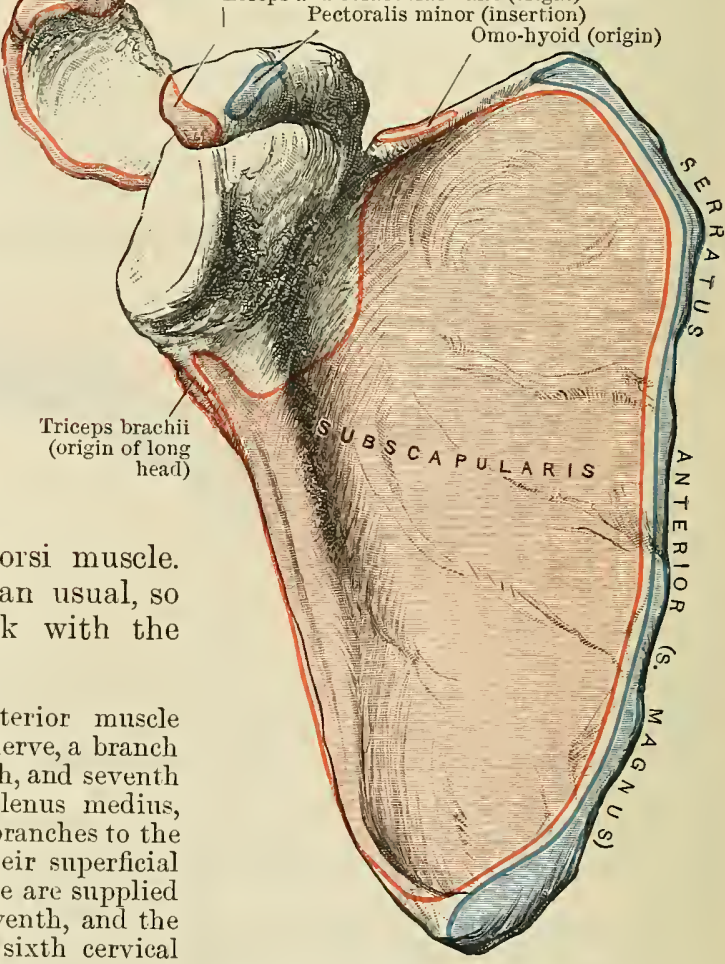

FIG. 333.-MIUSCLE-A TTACHMENTS TO THE Right Scapula (Anterior Aspect). 
the whole shoulder to be brought forward by a movement at the sterno-clavicular joint. The movement of stretching forward the arm as in fencing is due to this action of the muscle. Further, by its relation to the inferior angle of the scapula, the serratus anterior causes (along with the trapezius) a rotation of the scapula, resulting in a tilting upwards of the glenoid cavity, and so facilitating the upward movement of the arm above the head. Acting from the shoulder on the ribs the serratus is a powerful muscle of inspiration.

Action of Muscles on the Sterno-Clavicular and Acromio-Clavicular Joints.-The muscles just considered (along with the sterno-cleido-mastoid and omo-hyoid muscles) act for the most part in the sterno-clavicular and acromio-clavicular joints.

A. Sterno-Clavicular Joint.-The movements at this articulation are vertical, horizontal and rotatory, and the muscles concerned may be tabulated as follows:-

\section{Sterno-Clavicular Joint.}

\begin{tabular}{|c|c|c|c|}
\hline a. Movement in & Vertical Plane. & b. Movement $\mathrm{j}$ & Horizontal Plane. \\
\hline Elevation. & Depression. & Forwards. & Backwards. \\
\hline Trapezius (superior & Trapezius (inferior & Serratus anterio & Trapezi \\
\hline fibres) & fibres) & Pectoralis major & Rhomboidei \\
\hline Levator scapulæ & Subclavius & Pectoralis minor & Latissimus dorsi \\
\hline Rhomboidei & Pectoralis minor & & \\
\hline Sterno-mastoid & Latissimus dorsi & \multirow{2}{*}{\multicolumn{2}{|c|}{$\begin{array}{c}\text { c. Rotation-a combination of these } \\
\text { muscles. }\end{array}$}} \\
\hline Omo-hyoid & $\begin{array}{l}\text { Pectoralis major } \\
\text { (lower fibres) }\end{array}$ & & \\
\hline
\end{tabular}

B. Acromio-Clavicular Joint.-Movements at this joint are associated with rotation of the scapula. By the combined action of such muscles or the trapezius and serratus anterior (inferior fibres), the inferior angle of the scapula is drawn or thrust forwards, the body of the scapula is rotated, and the glenoid cavity is tilted upwards, so facilitating the upward movement of the arm above the horizontal level.

In forced inspiration, the sterno-mastoid, trapezius, levator scapulæ, rhomboidei, subclavius, omo-hyoid, serratus anterior, pectoral muscles, and latissimus dorsi, acting together, raise and fix the shoulder girdle; while those of them which have costal attachments-subclavius, pectoral muscles, serratus anterior, and latissimus dorsi-simultaneously elevate the ribs and expand the thorax.

Lateral flexion and rotation of the vertebral column in the neck is effected partly by the action of the trapezius, levator scapulæ, and rhomboid muscles (with the shoulder fixed). The latissimus dorsi and pectoralis major act in climbing in a similar way, raising up the trunk towards the shoulder.

Action on the Upper Limb.-By reason of their insertion into the humerus the pectoralis major and latissimus dorsi muscles assist the movements of the upper limb. Acting together, the two muscles depress the shoulder, and draw the arm to the side of the body, at the same time rotating the humerus medially. The two parts of the pectoralis major have slightly different actions on the humerus. The clavicular part of the muscle (portio attollens) draws the arm medially and upwards; the sterno-costal part of the muscle (portio deprimens) draws it medially and downwards. The latissimus dorsi acting alone, besides rotating the limb, draws it medially and backwards, as in the act of swimming.

\section{FASCIAE AND IMUSCLES OF THE SHOULDER.}

The deep fascia covering the scapular muscles presents no feature of special importance. Attached to the clavicle, acromion, and scapular spine, it is thin over the deltoid muscle. Below the deltoid it is thicker; it encases and gives origin to the infraspinatus muscle, and is continuous with the fasciæ of the axilla and the back.

\section{Muscles.}

The muscles proper to the shoulder comprise the deltoid, supraspinatus, infraspinatus, teres minor, teres major, and subscapularis.

M. Deltoideus.-The deltoid, a coarsely fasciculated multipennate muscle, has an extensive origin from (1) the front of the clavicle in its lateral third (Figs. 327, p. 366, and 331, p. 371); (2) the lateral border of the acromion; (3) the inferior edge of the free border of the spine of the scapula (Figs. 329, p. 368, and 333, p. 372); and (4) from the deep fascia covering the infraspinatus muscle. Its origin embraces the insertion of the trapezius.

The fibres of the muscle converge to the lateral aspect of the shaft of the 
humerus, to be inserted into a well-marked $V$-shaped impression above the radial groove (Fig. 336, p. 376). The insertion is partly united with the tendon of the pectoralis major.

The most anterior part of the deltoid muscle is formed of parallel fibres, not

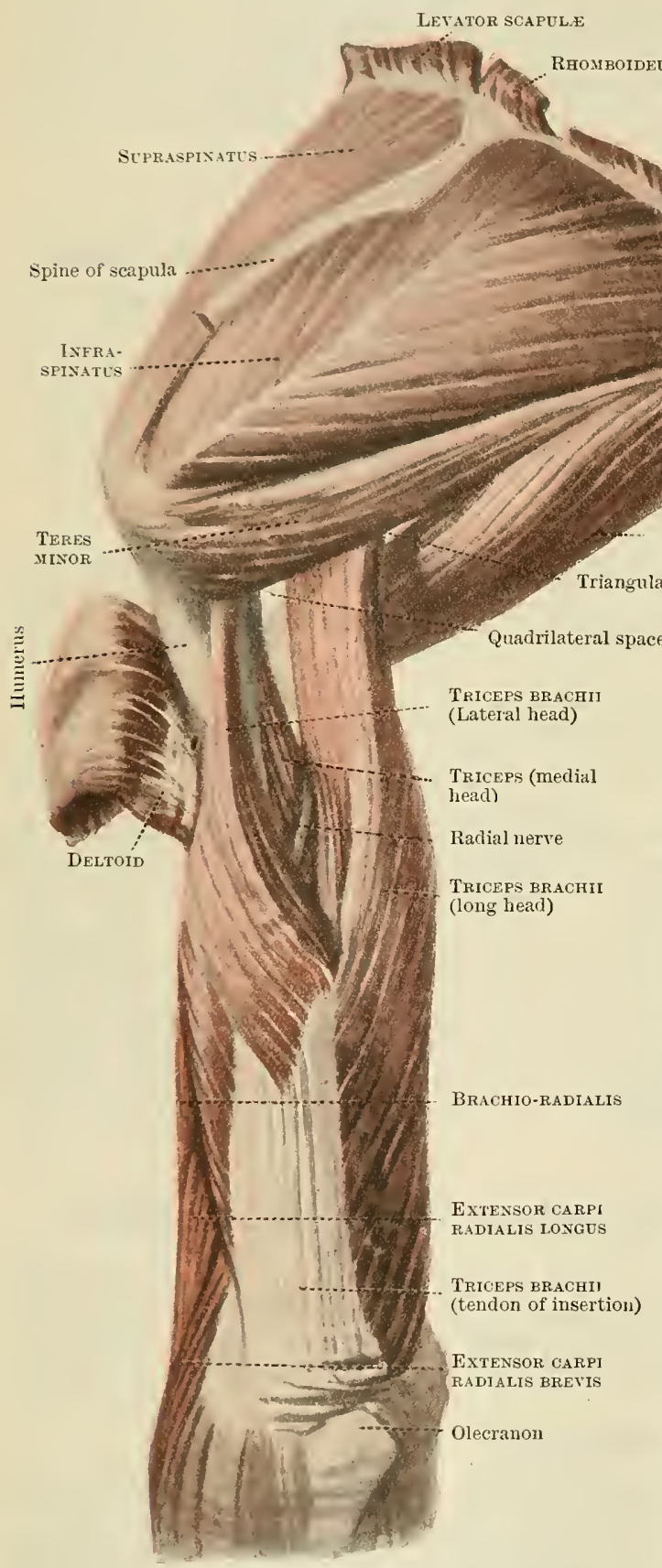
uncommonly separate from the rest of the muscle at their origin from the clavicle. These fibres may be continuous with the trapezius over the clavicle. The most posterior part arises by a tascial origin from the spine of the scapula and the fascia over the infraspinatus muscle. These portions are attached respectively to the front and back of the main tendon of insertion. The intermediate fibres are multi-pennate, attached above and below to three or four septal tendons, which extend for a variable distance downwards and upwards from the origin and insertion of the muscle.

The deltoid is superficial in its whole extent, and forms the prominence of the shoulder. Its anterior border is separated from the pectoralis major by a narrow interval, in which the cephalic vein and deltoid branch of the thoracoacromial artery are placed. Thedeep surface of the muscle, separated from the capsule of the shoulder-joint by a large bursa, is related to (1) the coracoid process, associated with which are the coraco-acromial ligament, and the attachments of the pectoralis minor, the coracobrachialis, and the short head of the biceps brachii; (2) the capsule of the shoulder-joint covering the head of the humerus, associated with which are the long head of the biceps, and the attachments of the subscapularis, supraspinatus, infraspinatus, and teres minor; and (3)

Fig. 334.- Left Scapular Mescles and Triceps. the proximal yart of the lateral surface of the shaft of the humerus, associated with
which are the posterior circumflex vessels of the humerus and the axillary nerve.

Nerve-Supply. - The deltoid muscle is supplied by the terminal branches of the axillary (O.T. circumflex) nerve from the fifth and sixth cervical nerves.

Action. - The main action of the deltoid, is to abduct the arm, and bring the humerus into 
the horizontal position. In this movement it is aided by the supraspinatus and infraspinatus. The anterior (clavicular) portion of the muscle assists the pectoralis major in drawing the arm forwards, while the posterior portion draws it backwards.

MI. Supraspinatus.- The supraspinatus arises by fleshy fibres from the supraspinous fossa (except near the neck of the bone) and from the deep fascia over it (Fig. 329, p. 368).

It is directed laterally under the trapezius muscle, the acromion and coracoacromial ligament, to be inserted by a broad thick tendon into the most proximal facet on the larger tubercle of the humerus, and into the capsule of the shoulderjoint (Fig. 336, p. 376).

Nerve-Supply. - The muscle is supplied by the supra-scapular nerve (C. 5. 6.).

Action.-The supraspinatus assists the deltoid in abducting the arm from the side.

M. Infraspinatus.-The infraspinatus arises from the infra-spinous fossa of the scapula (excepting near the neck of the bone and the flat surface along the axillary margin) and from the thick fascia over it (Fig. 337, p. 376).

The fibres of the muscle converge to the neck of the scapula; and are inserted by tendon into the middle facet on the larger tubercle of the humerus, and into the capsule of the shoulder-joint (Fig. 336 , p. 376). A bursa separates the muscle from the neck of the scapula, and in a minority of cases communicates with the synovial cavity of the shoulder-joint.

The supraspinatus and the upper part of the infraspinatus muscles are concealed by the trapezius, acromion, and deltoid. They cover the neck of the scapula, the transverse scapular artery, and suprascapular nerve, and the capsule of the shoulder-joint.

Nerve-Supply. - Supra-scapular nerve.

Action.- The muscle assists the deltoid in abducting and drawing back the arm at the shoulder-joint.

\section{Teres Minor.-The teres minor} is a small muscle, arising by fleshy fibres from the proximal two-thirds of the flat surface on the dorsal aspect of the axillary margin of the scapula, and from fascial septa separating it from the infraspinatus and teres major muscles (Fig. 337, p. 376).

Lying alongside the lateral border of the infraspinatus, it is inserted under cover of the deltoid by a thick flat tendon into the most distal of the three facets on the 
larger tubercle of the humerus and into the capsule of the shoulder-joint, and by Heshy fibres into the posterior aspect of the surgical neck and shaft of the humerus distal to the tubercle for about an inch (Fig. 341, p. 380).

It is separated from the teres major by the long or scapular head of the triceps brachii, and by the posterior circumflex vessels of the humerus and the axillary

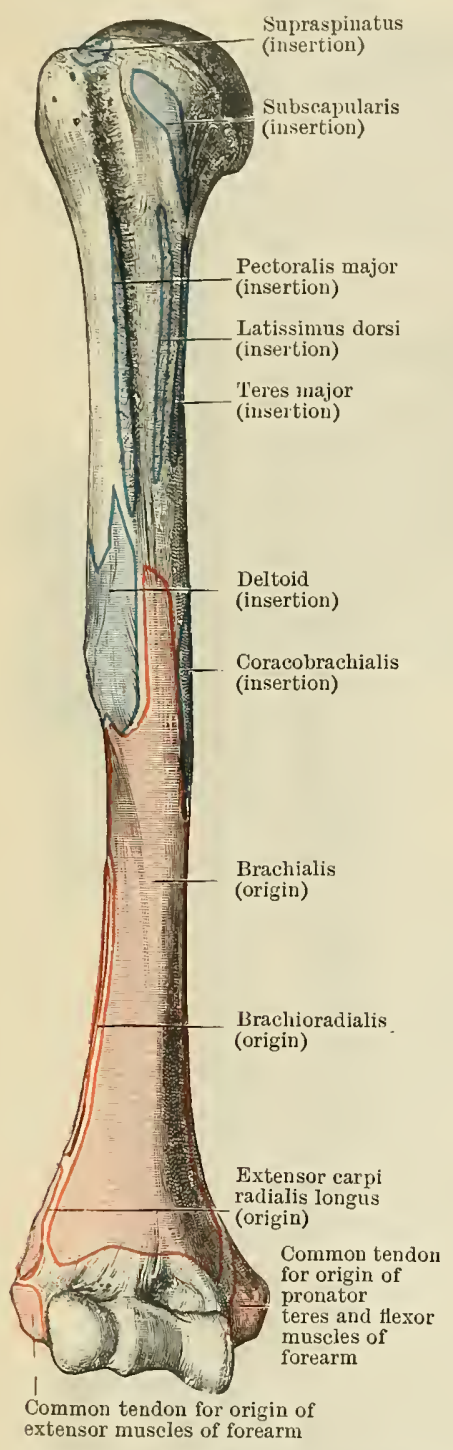

Fig. 336. - MUSCle - ATtTachments to THE ANTERIOR ASPeCt OF THE RIGHT HUMERUS. nerve. Its origin is pierced by the circumflex scapular artery. The muscle is invested by the deep fascia enclosing the infraspinatus, and is sometimes inseparable from that muscle.

Nerve-Supply. - The teres ninor is supplied by a branch of the axillary nerve (C. 5. 6.). The nerve has a pseudoganglion, a fibrous swelling on it in its course to the muscle.

Action. - The muscle is a lateral rotator of the humerus.

M. Teres Major.--The teres major is much larger than the preceding muscle. It arises by fleshy fibres from the lower third of the flat surface on the dorsum of the scapula along its axillary

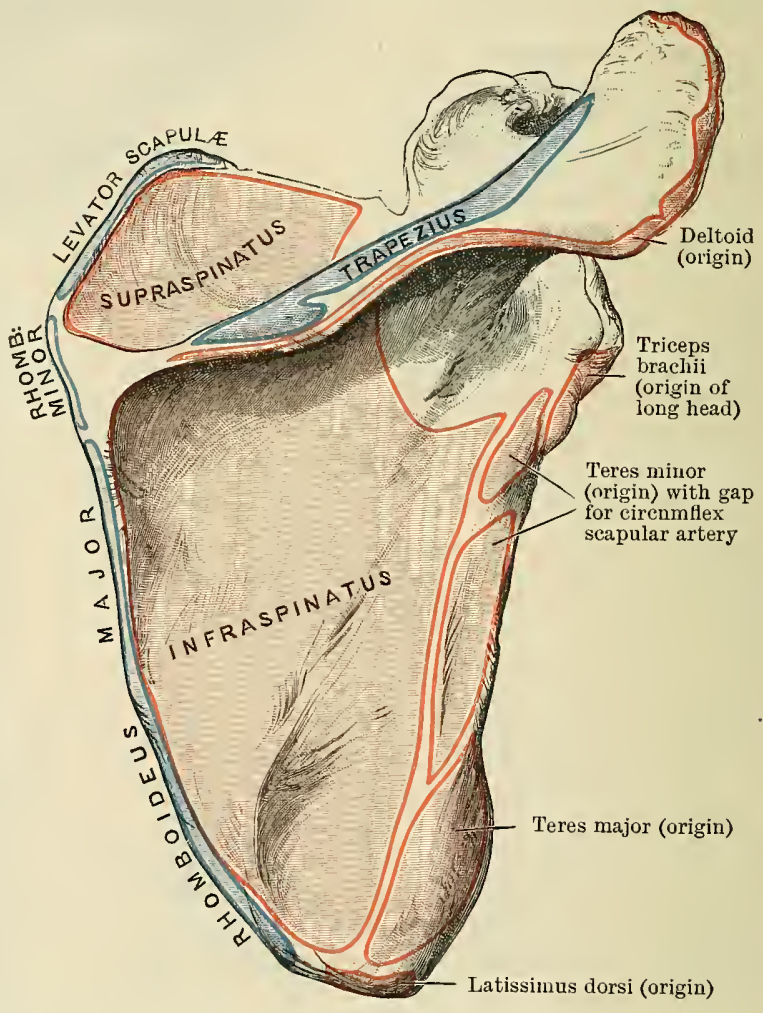

F1G. 337.-Muscle-Attachuents to the Right Scapula (Dorsal Surface).

margin (except for a small area at the inferior angle), and from fascial septa, which separate it on the one side from the subscapularis, and on the other from the infraspinatus and teres minor (Fig. 337).

The muscle is directed along the axillary margin of the scapula to the front of the shaft of the humerus, where it is inserted by a broad flat tendon into the medial border of the sulcus intertubercularis medial to the latissimus dorsi muscle (Fig. 337). Just before its insertion it is closely adherent to the tendon of the latissimus dorsi.

The teres major lies below the subscapularis muscle in the posterior wall of 
the axilla. The latissimus dorsi muscle, sweeping round from the back, covers its axillary surface on its way to its insertion. The muscle forms the inferior boundary of a triangular space in the posterior wall of the axilla, of which the other boundaries are, above, the borders of the subscapularis and teres minor muscles, and laterally the surgical neck of the humerus. This space is subdivided by the long head of the triceps brachii, which passes behind the teres major muscle, into (a) a quadrilateral space above, for the passage of the axillary nerve and posterior circumflex artery of the humerus; and $(b)$ a smaller triangular space below, for the circumflex scapulæ artery.

Nerve-Supply.--The teres major is supplied, along with part of the subscapularis muscle, by the lower subscapular nerve (C. 5. 6.).

Action. - A medial rotator of the humerus.

M. Subscapularis.-The subscapularis is a large triangular muscle occupying the costal surface of the scapula. It arises by fleshy fibres from the whole of the subscapular fossa and the groove along the axillary margin, excepting the surfaces at the angles of the bone (Fig. 333, p. 372). Springing from several ridges in the fossa are septa projecting into the substance of the muscle, which increase the extent of its attachment.

Converging to the head of the humerus, the muscular fibres are inserted by a broad, thick tendon into the smaller tubercle of the humerus and into the capsule of the shoulder-joint, and by fleshy fibres into the surgical neck and the shaft of the humerus distal to the tubercle for about an inch, under cover of the coracobrachialis and short head of the biceps (Fig. 336, p. 376).

This muscle forms the greater part of the posterior wall of the axilla. Its medial or anterior surface is in contact with the serratus anterior and the axillary vessels and nerves. It is separated from the neck of the scapula by a bursa, which is in direct communication with the synovial cavity of the shoulder-joint.

The subscapularis minor is an occasional muscle situated below the capsule of the shoulderjoint. It arises from the axillary border of the scapula below the subscapularis, and is inserted into the capsule of the joint or the proximal part of the shaft of the humerus.

Nerve-Supply.- There are two and often three nerves supplying the subscapularis, viz., the short subscapular (C. 5. 6.), which is often double; and the lower subscapular (C. 5. 6.), which, after supplying its lateral (lower) portion, ends in the teres major.

Actions.-The muscle aids in drawing the arm forward and medially rotating the humerus.

The principal action of the above group of muscles is on the shoulder-joint. They have also secondary actions in relation to movements of the trunk and limbs.

\section{Movements at the Shoulder-Joint.}

\begin{tabular}{|c|c|c|c|}
\hline a. Abduction. & Adduction. & b. Flexion (Forwards). & Extension (Backwards). \\
\hline $\begin{array}{l}\text { Deltoid } \\
\text { Supraspinatus }\end{array}$ & $\begin{array}{l}\text { Teres major } \\
\text { Teres minor } \\
\text { Pectoralis major } \\
\text { Latissimus dorsi } \\
\text { Coracobrachialis } \\
\text { Biceps (short head) } \\
\text { Triceps brachii (long } \\
\text { head) } \\
\text { Weight of limb }\end{array}$ & $\begin{array}{l}\text { Deltoid (anterior fibres) } \\
\text { Subscapularis } \\
\text { Pectoralis major } \\
\text { Coracobrachialis } \\
\text { Biceps brachii }\end{array}$ & $\begin{array}{l}\text { Deltoid (posterior fibres) } \\
\text { Teres major } \\
\text { Infraspinatus } \\
\text { Latissimus dorsi } \\
\text { Triceps brachii }\end{array}$ \\
\hline
\end{tabular}

c. Rotation Laterally.

Deltoid (posterior fibres)

Infraspinatus

Teres minor
Rotation Medially.

Deltoid (anterior fibres)

Teres major

Pectoralis major

Latissimus dor'si

d. Circumduction-combination of previous muscles.

The various movements at the shoulder-joint are greatly aided by the muscles acting on the shoulder girdle. In raising the arm above the head, for instance, the humerus is brought to the horizontal position by the deltoid and supraspinatus, and the movement is continued by the 
elevators of the shoulder girdle. Again, in forward and backward movements at the shoulderjoint, great assistance is derived from muscles acting directly on the shoulder girdle-pectoralis minor and serratus anterior; trapezius and rhomboidei.

2. In relation to the trunk and limbs, the shonlder muscles, by fixing the humerus, have anxiliary power on the one hand in movements of the trunk, such as forced inspiration; on the other hand, acting along with muscles fixing the elbow-joint, they stiffen the limb so as to permit of the more refined movements of the wrist and fingers.

\section{FASCIFE AND IMUSCLES.OF THE ARIM.}

\section{FASCI无.}

The superficial fascia presents no features of importance. There is a bursa beneath it over the olecranon, and occasionally another over the medial epicondyle of the humerus.

The deep fascia forms a strong tubular investment for the muscles on the anterior and posterior aspects of the humerus. It is continuous above with the deep fascia of the shoulder and axilla, and is further strengthened by fibres derived from the insertions of the pectoralis major, latissimus dorsi, and deltoid muscles. At the elbow it becomes continuous with the deep fascia of the forearm, and gains attachment to the epicondyles of the humerus and the olecranon of the ulna; it is strengthened also by important bands associated with the insertions of the biceps anteriorly and the triceps posteriorly, to which reference will be made in the account of these muscles.

About the middle of the arm on the medial side, the deep fascia is perforated for the passage of the basilic vein and the medial cutaneous nerve of the forearm.

The intermuscular septa are processes of the deep fascia attached to the epicondylic ridges of the humerus. The medial and stronger septum is placed between the brachialis muscle anteriorly and the medial head of the triceps posteriorly, and gives origin to both. It extends proximally to the insertion of the coracobrachialis (which is often continued into it), and the ulnar nerve and superior ulnar collateral vessels pass distally over its medial edge. The lateral septum is thinner. It separates the brachialis muscle and brachioradialis in front from the medial and lateral heads of the triceps behind, and gives origin to these muscles. It extends proximally to the insertion of the deltoid, and is pierced by the radial nerve and profunda brachii vessels.

\section{MUSCLES OF THE ARM.}

The muscles of the arm comprise the biceps, coracobrachialis, and brachialis on the anterior aspect, and the triceps brachii on the posterior aspect of the humerus. Except at its extremities, the biceps brachii is superficial, and forms a rounded fleshy mass on the anterior aspect of the arm. The coracobrachialis is visible on its medial side in the proximal half of the arm, particularly when the arm is raised. The brachialis is concealed by the biceps. The triceps brachii forms the thick mass of muscle covering the posterior surface of the humerus.

II. Coracobrachialis.-The coracobrachialis is a rudimentary muscle. It arises under cover of the deltoid from the tip of the coracoid process by fleshy fibres in common with the short head of the biceps, and also frequently from the tendon of insertion of the pectoralis minor muscle.

The fleshy belly is pierced by the musculo-cutaneous nerve, and ends in a flat tendon inserted into a faint linear impression about an inch in length on the middle of the medial border of the shaft of the humerus (Fig. 336, p. 376). It is often continued into the medial intermuscular septum.

The coracobrachialis is the remains of a threefold muscle, of which only two elements are usually present in man, but of which in anomalous cases all the parts may be more or less fully developed. The passage of the musculo-cutaneous nerve through the muscle is an indication of its natural separation into two parts, which represent the persistent middle and distal elements. 
The commonest variety is one in which the more superficial (distal) part of the muscle extends more distally than usual, so as to be inserted into the medial intermusenlar septum, or eren into the medial epicondyle of the humerts. A third slip (coracobrachialis superior or brevis,

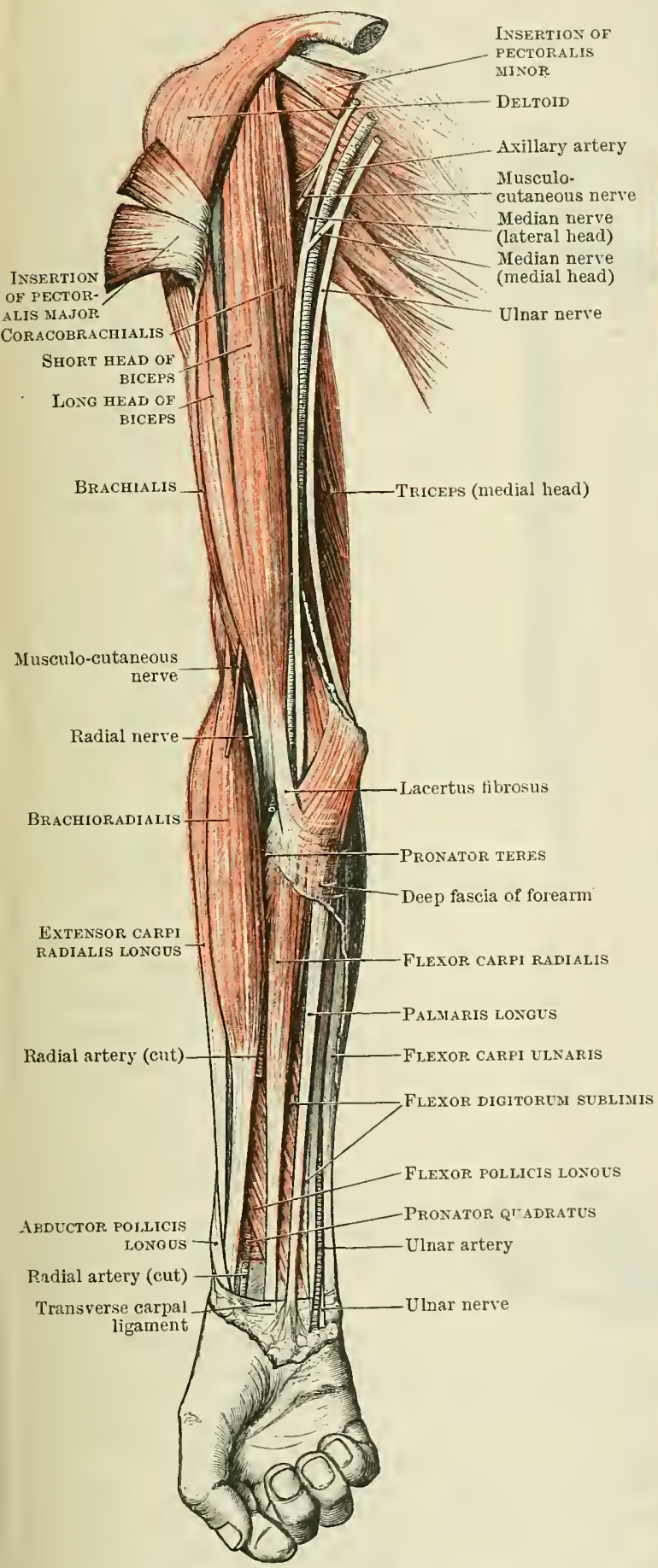

ig. 338. - Superficial Muscles on the ANterior Aspect ow the Right ARM and Forearm.

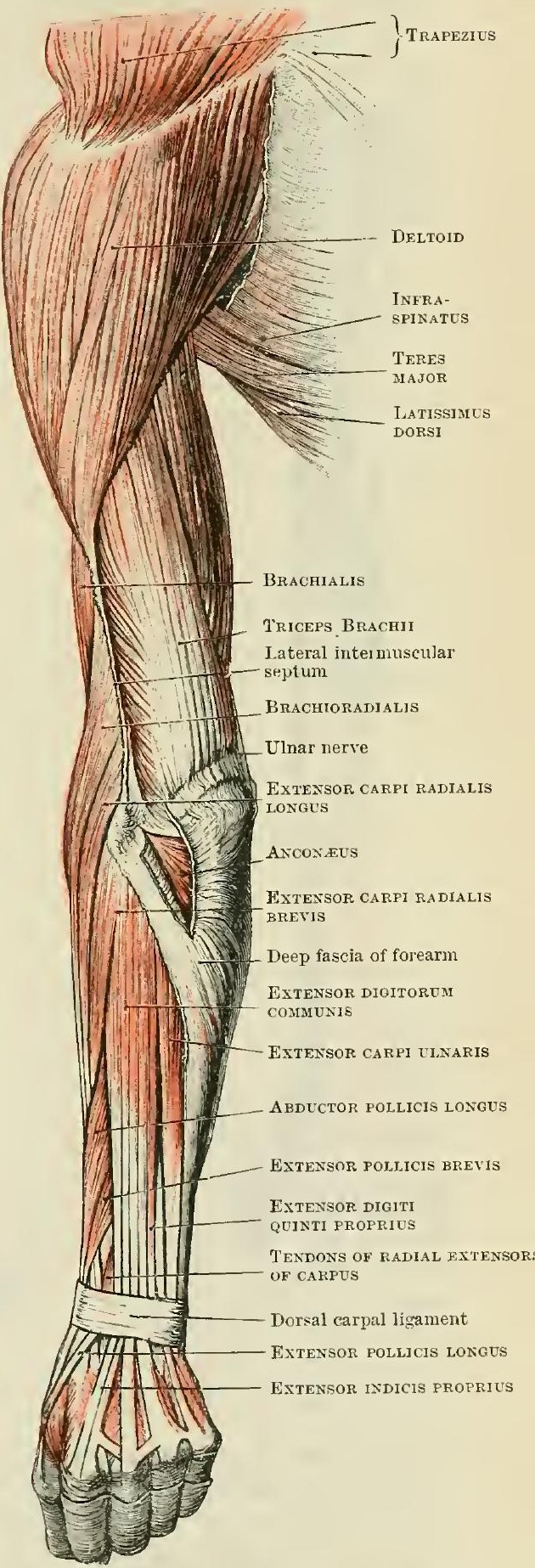

Fig, 339 - The Mígcles on the Posterior Sid OF THE LEFT ARM, FOREARM, AND HAND.

rotator humeri) may more rarely be present, forming a shor't muscle arising from the root of the coracoid process, and inserted into the medial side of the humerus just distal to the capsule of the shoulder-joint. 
Nerve-Supply. - The nerve to the coracobrachialis comes from the 7 th or 6 th and 7 th cervical nerves. Incorporated with the musculo-cutaneous, the nerve separates to supply the muscle before the latter nerre pieres it.

Action. - The muscle assists the biceps to raise the arm and draw it medially.

M. Biceps Brachii.-The biceps brachii arises by two tendinous heads.

The short head (caput breve) is attached in common with the coracobrachialis to

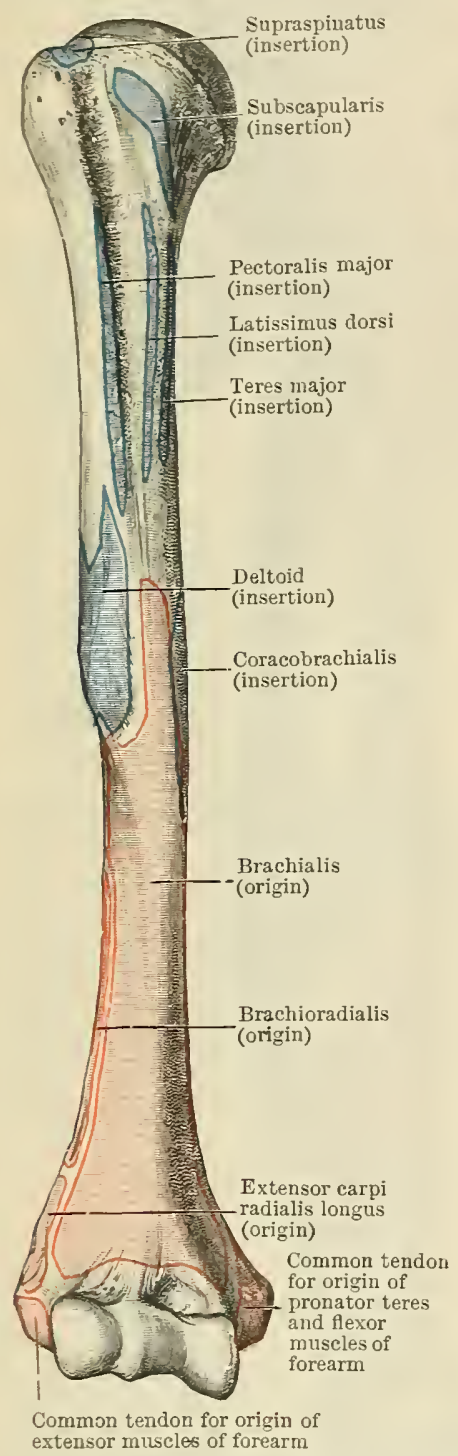

Fig. 340.-MICscle - AtTachiests TO THE A.TTERIOR ASPECT OF THE Right HUMERUS.

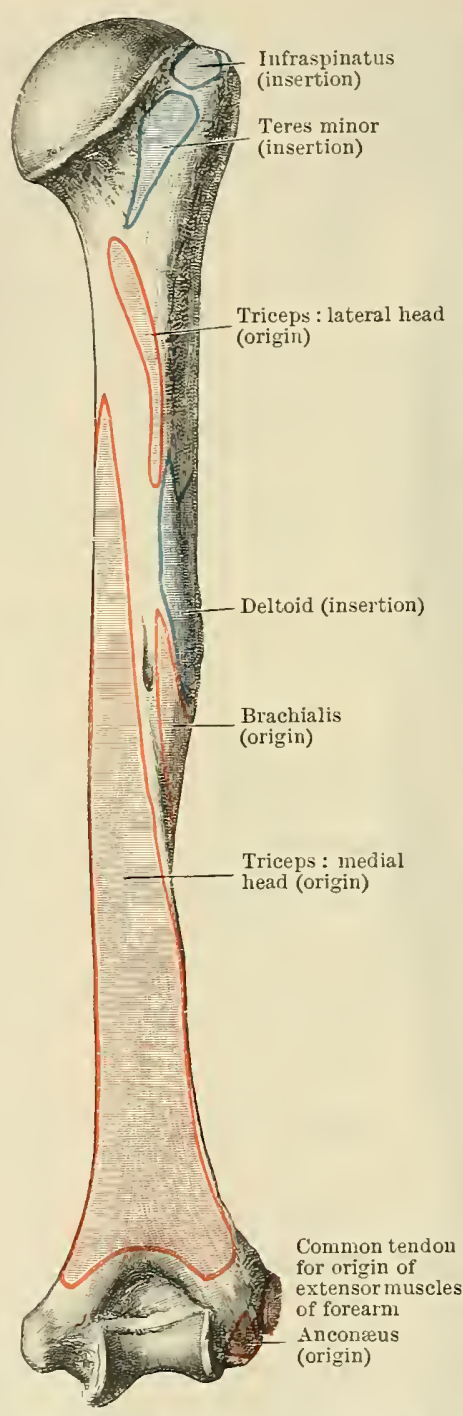

Fig. 341.-MUSCLE - ATTACHMExts To the Posterior Surface of the Pight HuMerds. the tip of the coracoid process of the scapula (Fig. 333, p. 372). Concealed by the deltoid and tendinous at first, this head forms a separate fleshy belly, which is united to the long head by an investment of the deep fascia. (2) The long head (caput longum) arises by a round tendon from the supraglenoidal tuberosity at the root of the coracoid process and from the labrum glenoidale on either side. Its tendon passes through the cavity of the shoulderjoint, and emerging from the capsule beneath the transverse humeral ligament (invested by a prolongation of the synovial membrane), it occupies the intertubercular groove of the humerus covered by a fascial prolongation of the tendon of the pectoralis major. In the arm it forms a fleshy belly united to that derived from

the short head by an envelope of deep fascia (intertubular mucous sheath).

The insertion of the muscle is likewise twofold. (1) The two bellies become connected to a strong tendon, attached deeply in the hollow of the elbow to the rough dorsal portion of the tubercle of the radius (Figs. 335, p. 375, and 348 , p. 389). A bursa separates the tendon from the volar portion of the tuberosity. (2) From the medial and anterior part of the tendon, and partly in continuity with the fleshy fibres of the muscle, a strong membranous band (the lacertus fibrosus) extends distally and medially over the hollow of the elbow to join the deep fascia covering the origins of the flexor and pronator muscles 
of the forearm. Its proximal part is thickened and can be felt subcutaneously as a crescentic border.

In the arm the biceps conceals the brachialis muscle and the musculo-cutaneous nerve. Its medial border is the guide to the position of the brachial artery and median nerve.

The biceps is an extremely variable muscle. Its chief anomalies are due to an increase or diminution in the number of origins. A third head of origin is common (10 per cent), and usually arises from the humerus, between the insertions of the deltoid and coracobrachialis. Two or even three additional heads may be present at the same time. The long head of the musele may be absent, or may take origin from the intertubercular groove. The muscle may have an additional insertion into the medial epicondyle of the humerus, or into the fascia of the forearm.

Nerve-Supply. - The biceps is supplied by the musculo-cutaneous nerve (C. 5. 6.).

Actions. - The actions of the biceps are complex, in that they affect three articulationsthe shonlder, humero-radial, and radio-ulnar joint. The musele raises and draws forward the humerns at the shoulder-joint, it flexes the elbow-joint, and it supinates the forearm. The combination of these actious results in a simple morement like that of raising the hand to the mouth.

MI. Brachialis.-The brachialis (O.T. brachialis anticus) is a large muscle arising from the distal two-thirds of the anterior aspect of the shaft of the humerus and from the intermuscular septum on each side (Figs. 340 and 341 , p. 380).

Clasping the insertion of the deltoid proximally, it ends distally in a strong tendon inserted deep in the hollow of the elbow into the anterior ligament of the elbow - joint, the distal surface of the coronoid process, and slightly into the volar surface of the shaft of the ulna immediately distal to this (Fig. 348, p. 389). The lateral part of the muscie arising from the lateral epicondylic ridge and lateral intermuscular septum forms a slip more or less separate, which may be partially fused with the brachioradialis muscle.

It is concealed for the most part by the biceps muscle in the arm. It forms the floor of the cubital fossa, and covers the anterior aspect of the elbow-joint.

Nerve-Supply.--It is supplied by the musenlo-cutaneous nerve (C. 5. 6.); and also (in most instances) at its lateral border by a fine branch of the radial nerve (C. (5.) 6.).

Action. - This muscle is a flexor of the elbow-joint.

M. Triceps Brachii.-The triceps brachii is the only muscle on the posterior aspect of the arm. It arises by three heads: a lateral and a medial head, from the humerus, and a long or middle head, from the scapula. (1) The Iong head (caput longum) begins as a strong tendon attached to a rough triangular surface on the axillary border of the scapula just below the cavity (infra-glenoidal tuberosity) (Figs. 333 , p. 372 , and 337, p. 376). This gives rise to a fleshy belly which, after passing between the teres major and teres minor muscles, occupies the middle of the back of the arm. (2) The lateral head is attached by fibres, partly tendinous and partly fleshy, to the curved lateral border of the humerus from the insertion of the teres minor proximally to the radial groove distally, and receives additional fibres from the posterior surface of the lateral intermuscular septum (Fig. 341, p. 380). Its fibres are directed distally and medially over the radial groove, concealing the radial (musculo-spiral) nerve, the profunda brachii artery, and the medial head of the muscle, to the tendon of insertion. (3) The medial head arises by fleshy fibres from an elongated triangular area on the posterior surface of the humerus, extending proximally to the level of the insertion of the teres major, and distally nearly to the margin of the olecranon fossa (Fig. 341, p. 380). It also arises on each side from the intermuscular septum,-from the whole length of the medial septum, and from the part of the lateral septum which is below the passage of the radial nerve.

The three heads of origin are inserted by a common tendon, broad and membranous, into an impression occupying the posterior part of the proximal end of the olecranon of the ulna (Fig. 355, p. 397), and into the deep fascia of the forearm on either side of it. The long aud lateral heads join the borders of the tendon of insertion, and the medial head is attached to its deep surface. A small 
thick-walled bursa separates the tendon of the triceps from the posterior ligament of the elbow-joint and the proximal end of the olecranon.

The subanconæus is a small muscle occasionally present, which consists of scattered fibres arising from the distal end of the humerus beneath the triceps, and inserted into the posterior ligament of the elbow-joint.

The muscle is superficial in almost its whole extent. The long (scapnlar) head is concealed at its origin by its relation to the teres muscles, between which it passes.

Nerve-Supply.- The sereral heads of the muscle are supplied separately by branches of the radial nerve. The lateral head receives fibres from C. (6.) 7. 8.; the long and medial head from C. 7. 8. The medial head has a double supply. One nerve enters its proximal part, another (ulnar collateral nerve of Krause) enters the distal part of the muscle.

Actions. - The triceps is the extensor muscle of the elbow-joint. The long head also acts as an adductor of the humerus at the shoulder-joint.

The chief action of these muscles (excepting the coracobrachialis) is on the elbow-joint, producing along with other muscles flexion and extension. The flexor muscles are much more powerful than the extensors.

Table of Muscles acting on the Elbow-Joint.

\begin{tabular}{|l|l|}
\multicolumn{1}{c|}{ Flexors. } & \multicolumn{1}{|c|}{ Extensors. } \\
\hline $\begin{array}{l}\text { Biceps brachii } \\
\text { Brachialis } \\
\text { Brachioradialis }\end{array}$ & Triceps brachii \\
$\begin{array}{l}\text { Pronator teres } \\
\text { Flexors of wrist and fingers } \\
\text { Extensors of wrist (in pronation) }\end{array}$ & Anconæus \\
\hline
\end{tabular}

\section{FASCIAE AND MUSCLES OF THE FOREARM AND HAND.}

\section{Fasciae.}

The superficial fascia in the forearm presents no exceptional features. On the dorsum of the hand it is loose and thin; in the palm it is generally well furnished with fat, forming pads for the protection of the vessels and nerves. It is closely adherent to the palmar aponeurosis and to the skin, especially along the lines of flexure.

M. Palmaris Brevis.-The palmaris brevis is a quadrilateral subcutaneous muscle occupying the medial side of the hand under the superficial fascia. It arises from the medial border of the thick central portion of the palmar aponeurosis and from the volar surface of the transverse carpal ligament of the wrist, and is inserted into the skin of the medial border of the hand for a variable distance. It covers the ulnar artery and nerve, branches of which supply it. Its action is to wrinkle the skin of the medial border of the hand, and by raising up the skin and superficial fascia, to deepen the hollow of the hand.

The deep fascia of the forearm and hand is continuous above with the deep fascia of the arm. In the proximal part of the forearm it is strengthened by additional fibres around the elbow; in front by fibres from the lacertus fibrosus (semilunar fascia) of the biceps, behind by the fascial insertions of the triceps, and laterally by fibres derived from the humeral epicondyles in relation to the common tendons of origin of the flexor and extensor muscles of the forearm which in part take their origin from them. It is attached to the dorsal margin of the ulna, and affords increased attachment to the flexor and extensor carpi ulnaris and the flexor digitorum profundus muscles. Above the wrist the fascia is pierced anteriorly by the tendon of the palmaris longus, and by the ulnar artery and nerve. At the wrist it gains attachment to the bones of the forearm and carpus, is greatly strengthened by addition of transverse fibres, and constitutes the transverse carpal and dorsal carpal ligaments.

Ligamentum Carpi Transversum.-The transverse carpal ligament (O.T. anterior annular ligament) is a band about an inch and a half in depth, continuous proximally and distally with the deep fascia of the forearm and the palm of the 
hand. It is attached laterally to the navicular and large multangular; medially to the pisiform and os hamatum; and it forms a membranous arch binding down in the hollow of the carpus the flexor tendons of the fingers, and the median nerve. It is divided into two compartments, the larger accommodating the tendons of the flexors of the digits and the median nerve, the smaller (placed laterally) containing the tendon of the flexor carpi radialis. There are three synovial membranes in these compartments: one for the flexor carpi radialis tendon, and two others, which often communicate together, enveloping the tendon of the flexor pollicis longus and the flexor tendons of the fingers respectively. The surface of the ligament is crossed by the palmar branches of the median and ulnar nerves; by the tendon of the palmaris longus muscle, which is attached to its surface; and by the ulnar artery and nerve, which are again bridged over and protected by a band of fibrous tissue, called the volar carpal ligament, which passes from the pisiform bone and the superficial fascia to the surface of the transverse carpal ligament. To the distal border of the ligament are attached the palmar aponeurosis in the centre, and the superficial muscles of the thumb and the muscles of the little finger on each side.

Ligam ent u m Carpi Dorsale.-The dorsal carpal ligament (O.T. posterior annular liga-

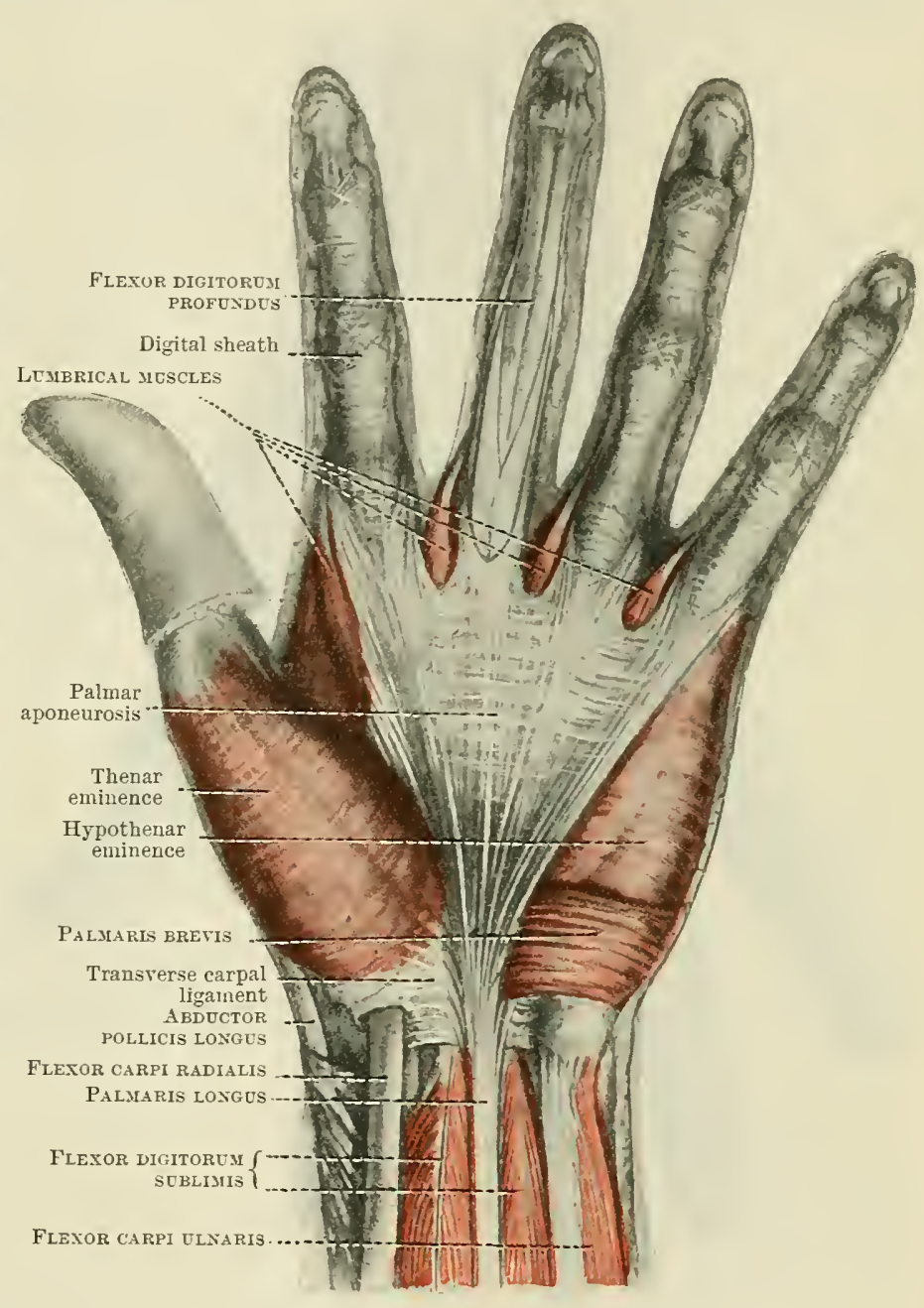

Fig. 342.-The Paliar Aponecrosis. ment) is placed at a more proximal level than the transverse carpal ligament. It consists of an oblique band of fibres about an inch broad, continuous proximally and distally with the deep fascia of the forearm and hand. It is attached laterally to the lateral side of the distal end of the radius, and medially to the distal end of the ulna (styloid process), the carpus, and the ulnar collateral ligament of the wrist. It is crossed by veins, by the superficial ramus of the radial nerve, and by the dorsal branch of the ulnar nerve. Six compartments are formed beneath it by the attachment of septal bands to the distal ends of the radius and ulna. Each compartment is provided with a synovial membrane, and they serve to transmit the extensor tendons of the wrist and fingers in the following order from lateral to medial side :-

(1) Abductor pollicis longus and extensor pollicis brevis, (2) Extensores carpi 
radiales, longus and brevis, (3) Extensor pollicis longus, (4) Extensor digitorum communis and extensor indicis proprius, (5) Extensor digiti quinti proprius, (6) Extensor carpi ulnaris.

The thin deep fascia of the dorsum of the hand is lost over the expansions of the extensor tendons on the fingers. Between the metacarpal bones a strong layer of fascia covers and gives attachment to the interossei muscles.

Aponeurosis Palmaris. - The palmar aponeurosis is of considerable importance. In the centre of the palm it forms a thick triangular membrane, the apex

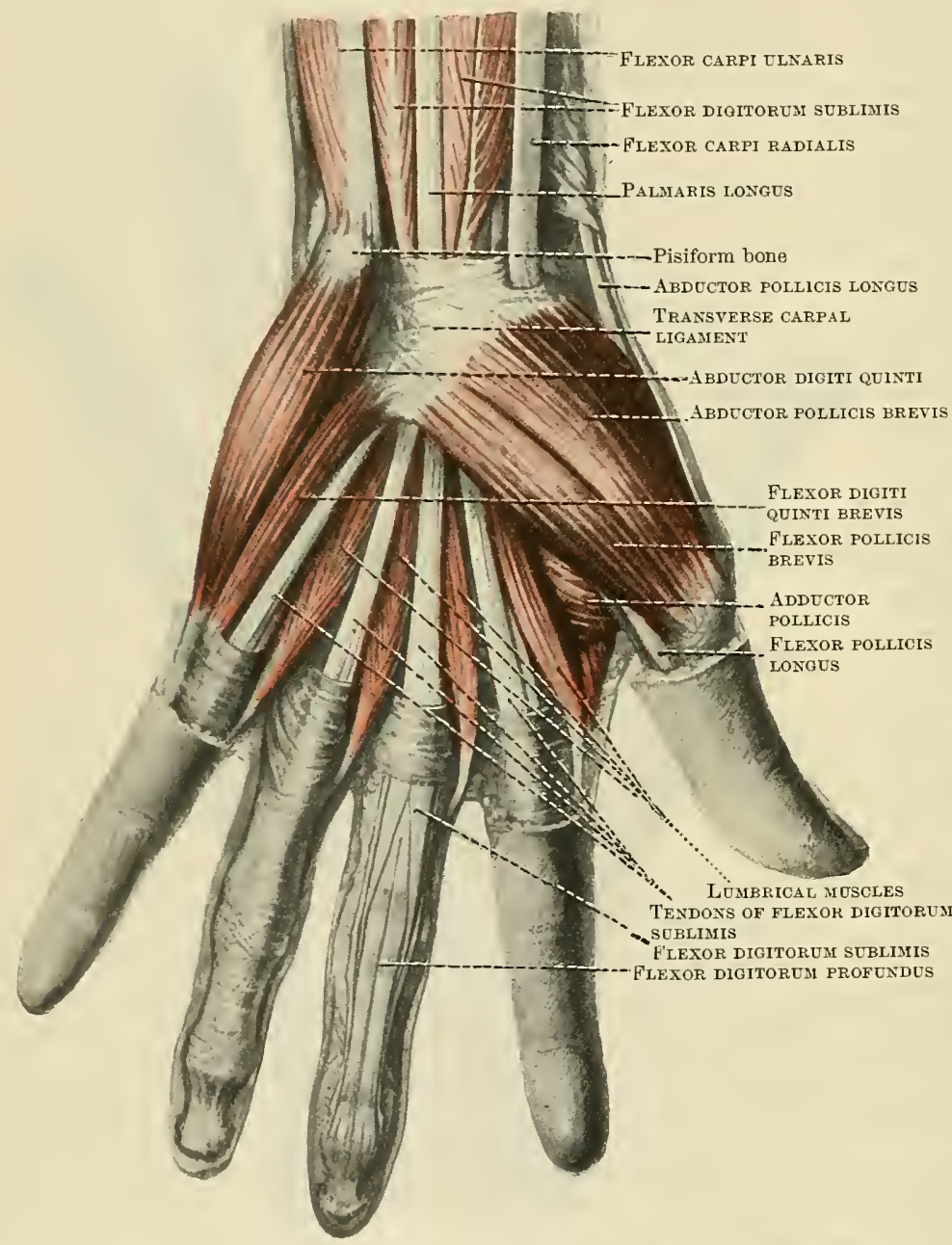
of which joins the distal edge of the transverse carpal ligament, and more superficially receives the insertion of the tendon of the palmaris longus muscle. The fascia separates below into four slips, one for each finger, connected together by transverse fibres, and forming beneath the webs of the fingers the superficial transverse metacarpal ligament (fasciculi transversi). Beyond this each slip separates into two parts, to be connected to the sides of the metacar po$\mathrm{ph}$ a la nge a l joints and the first phalanx of the medial four digits. In the cleft between the two halves of each slip the digital sheath is attached and extends distally on to the finger. The lateral borders of this triangular central portion of the palmar aponeurosis are continuous with thin layers of deep fascia, which cover and envelop the muscles of the thenar and hypothenar eminences. The medial border gives origin to the palmaris brevis muscle (p. 382).

The digital sheaths (vaginæ mucosæ) are tubular envelopes extending along the palmar aspect of the digits and enclosing the flexor tendons. Each consists of a fibrous sheath attached to the lateral borders of the phalanges and inter-phalangeal joints, and continuous proximally with the palmar aponeurosis. Opposite each inter-phalangeal articulation the digital sheath is loose and thin ; opposite the first two phalanges (the first only in the case of the thumb) it becomes extremely thick, and gives rise to the ligamenta vaginalia, which serve to keep the tendons closely 
applied to the bones during flexion of the fingers. Within each digital sheath are the flexor tendons, enveloped in a synovial membrane which envelops the tendon and lines the interior of the sheath. The synovial membranes of the digital sheaths extend a short distance proximally in the palm, and in some cases communicate with the large synovial membranes lining the flexor tendons beneath the transverse carpal ligament. There may be a separate distinct synovial membrane for each digit; but most commonly only the sheaths for the three middle digits have separate synovial membranes; those for the flexor pollicis longus and the flexor tendons of the little finger usually communicate with the synovial membranes placed beneath the transverse carpal ligament.

\section{THE MUSCLES ON THE ANTERIOR AND MEDIAL ASPECTS OF THE FOREARM.}

The muscles on the anterior and medial aspects of the forearm comprise the pronators and the flexors of the wrist and fingers. In the forearm they are arranged in three strata: (1) a superficial layer consisting of four muscles which radiate from the medial epicondyle of the humerus, from which they take origin by a common tendon. They are named, from radial to ulnar side, pronator teres, flexor carpi radialis, palmaris longus, and flexor carpi ulnaris. These muscles conceal the muscle which by itself constitutes (2) the intermediate stratum-the flexor digitorum sublimis, and this again conceals for the most part (3) the deep layer of muscles, including the flexor digitorum profundus covering the ulna, the flexor pollicis longus on the radius, and the pronator quadratus, which is more deeply placed than the previous muscles, and stretches across the forearm between the distal ends of the radius and ulna.

\section{Superficial Muscles.}

M. Pronator Teres.-The pronator teres is the shortest muscle of this group. It has a double origin: (1) a superficial head (caput humerale), the main origin, partly fleshy, partly tendinous, from the most distal part of the medial epicondylic ridge of the humerus and from the medial intermuscular septum, from the medial epicondyle of the humerus, from the fascia over it, and from an intermuscular septum between it and the flexor carpi radialis (Fig. 346, p. 387); (2) a deep head (caput ulnare), a slender tendinous slip from the medial side of the coronoid process of the ulna, which joins the superficial origin of the muscle on its deep surface (Fig. 348, p. 389). The median nerve separates the two heads from one another.

The muscle is directed distally and laterally to be inserted by tendon into an oval impression on the middle of the lateral surface of the shaft of the radius (Figs. 346, p. 387, and 348, p. 389). The fibres of the muscle are twisted on themselves, so that the most proximal humeral fibres form the most distal fibres of the tendon of insertion, and the most distal humeral fibres and those arising from the coronoid process are most proximal at the insertion.

The muscle forms the medial boundary of the hollow of the elbow. It is superficially placed, except near its insertion, where it is covered by the brachioradialis muscle and by the radial vessels and superficial branch of the radial nerve.

Nerve-Supply.-Median nervie (C. 6.).

Action.-The muscle is a flexor of the elbow-joint and a pronator of the forearm.

M. Flexor Carpi Radialis.-The flexor carpi radialis muscle takes its origin from the common tendon from the medial epicondyle of the humerus, from the fascia over it, and from the intermuscular septa on either side.

Its fleshy belly gives place to a strong round tendon in the distal half of the forearm, which, at the wrist, enters the hand in a special compartment beneath the transverse carpal ligament, and after occupying the groove on the large multangular bone, is inserted into the proximal ends of the second and third metacarpal 
bones on their anterior surfaces (Fig. 351, p. 392). The chief tendon is that to the second metacarpal bone.

The muscle is superficial except near its insertion. Its tendon in the distal half of the forearm is an important guide to the radial vessels, which are placed to its radial side. After passing beneath the transverse carpal ligament the tendon is concealed by the origins of the short muscles of the thumb, and is crossed from medial to lateral side by the tendon of the flexor pollicis longus. Besides the synovial bursa enveloping the tendon beneath the ligament, another is placed beneath the tendons at their insertion.

Nerve-Supply.-Median nerve (C. 6.).

Actions. - This muscle has a threefold action. It is mainly a flexor of the elbow and wrist, but it also acts as an accessory pronator of the forearm.

IM. Palmaris Longus.-The palmaris longus arises also from the common flexor tendon from the medial epicondyle of the humerus, from the fascia over it,

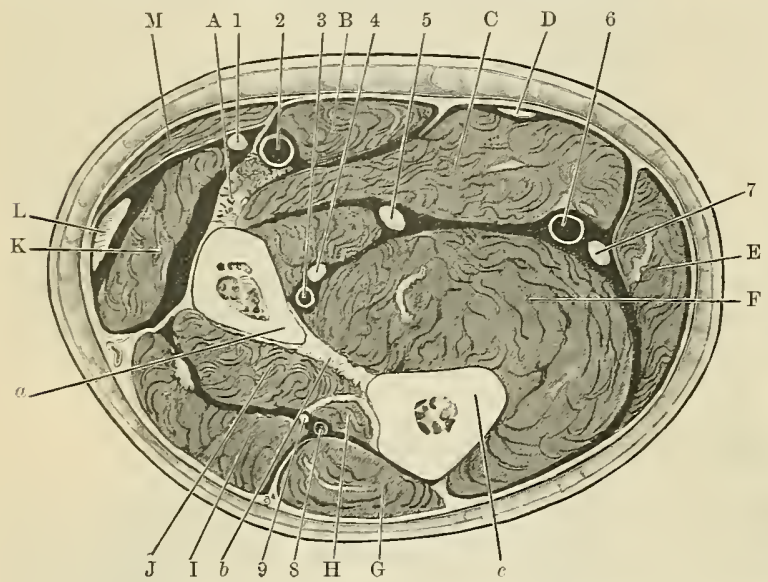

Fig. 344. - Distal Surface of a Section across the Right Forearm in the Middle Third.

A, Pronator teres (insertion); B, Flexor carpi radialis; C, Flexor digitorum slblimis; D, Palmaris longds; E, Flexor carpi ulnaris ; F, Flexor digitorti profundUS; G, Extensor CARPI ULNARIS; H, Extexsor pollicis lonaus; I, Extexsor Digitorum COMMUNIS AND EXTENSOR DIGITI QUINTI PROPRIUS; J, ABDUCTOR POLLICIS LONGUS; $\mathrm{K}$, EXTENSOR CARPI RADIALIS BREVIS ; $I_{i}$, ExTENSOR CARPI RADIALIS LONGUS ; M, Brachioradialis. $a$, Radius; $b$, Interosseous membrane; $c$, Uina. 1, Superficial ramus of radial nerve; 2, Radial artery; 3, Volar inter osseous artery; 4, Volar interosseous nerve (underneath flexor pollicis longus); 5 , Jedian nerve; 6 , Ulnar artery; 7 , Ulnar nerve; 8 , Dorsal interosseous artery ; 9, Dorsal interosseous nerve.

most variable muscle in the body, and is often absent (10 per cent). and from intermuscular septa on either side.

It forms a short fusiform muscle, which ends in the middle of the forearm in a long flat tendon. This pierces the deep fascia near the wrist, and passing over the transverse carpal ligament, is inserted (1) into the surface of the transverse carpal ligament, and (2) into the apex of the thick central portion of the palmar aponeurosis. A tendinous slip is frequently sent to the short muscles of the thumb and the fascia covering them.

The palmaris longus is the smallest muscle of the forearm. In the distal third of the forearm its tendon is placed directly over the median nerve, along the radial border of the tendons of the flexor digitorum sublimis.

The palmaris longus is the

Nerve-Supply.-Median nerve (C. 6.)

Actions. - The muscle assists in flexion of the elbow and wrist. It also by tightening the palmar aponeurosis deepens the hollow of the hand and helps to flex the fingers.

M. Flexor Carpi Ulnaris.-The flexor carpi ulnaris muscle has a double origin, from the humerus and from the ulna. (1) It arises from the common tendon attached to the medial epicondyle of the humerus, from the fascia over it, and from a lateral intermuscular septum. (2) By means of the deep fascia of the forearm it obtains an attachment to the medial border of the olecranon and the dorsal margin of the ulna in its proximal three-fifths.

The fleshy fibres join a tendon which lies on the anterior border of the muscle and is inserted into the pisiform bone, and in the form of two ligamentous bands (piso-hamate and piso-metacarpal) into the hamulus of the os hamatum, and the proximal end of the fifth metacarpal bone (Fig. 351, p. 392).

The muscle is superficially placed along the medial border of the forearm. It conceals the flexor digitorum profundus muscle, the ulnar nerve (which enters 


\section{Intermediate Layer.}

M. Flexor Digitorum Sublimis.-The flexor digitorum sublimis occupies a deeper plane than the four previous muscles. It has a threefold origin, from the humerus, radius, and uIna. (1) The chief or humeral head of origin is from the medial epicondyle of the humerus by the common tendon, from the ulnar collateral ligament of the elbow, and from adjacent intermuscular septa. (2) The ulnar head of origin is by a slender fasciculus from the medial border of the coronoid process of the ulna, proximal and medial to the origin of the pronator teres (Fig. 348, p. 389).

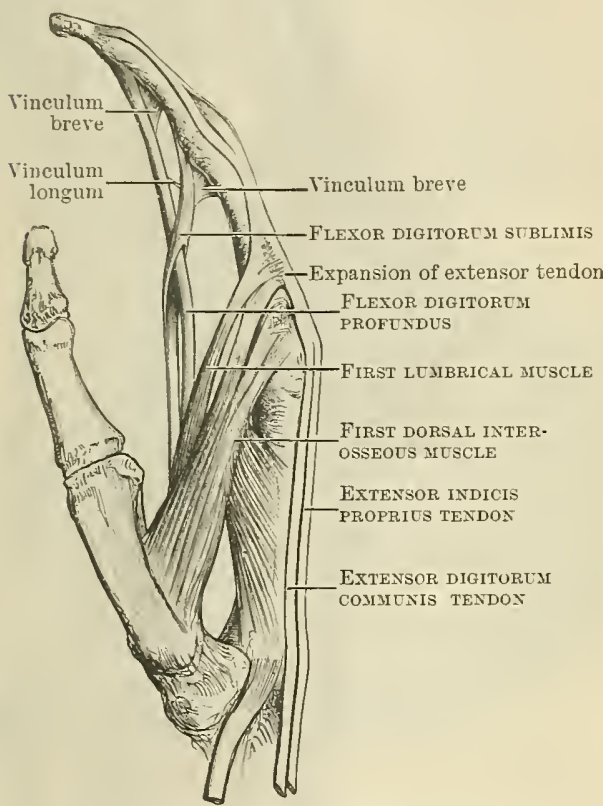

Fig. 347.-.The Tendons atTached to THE INDEX FINGER.

(3) The radial head of origin is from the proximal two-thirds of the volar margin of the radius by a thin fibromuscular attachment (Fig. 348, p. 389).

The muscle divides in the distal third of the forearm into four parts, each provided with a separate tendon which goes beneath the transverse carpal ligament, passes through the palm of the hand, and enters the corresponding digital sheath of the finger. At the wrist the four tendons are arranged in pairs, those for the middle and ring fingers in front, and those for the fore and little fingers behind, and are surrounded by a synovial sheath, along with the tendons of the flexor digitorum profundus, beneath the transverse carpal ligament. In the palm of the hand the tendons separate, and conceal the deep flexor tendons and lumbrical muscles.

Within the digital sheath each tendon is split into two parts by the tendon of the flexor digitorum profundus; after surrounding that tendon the two parts are partially re-united on its deep surface, and are inserted, after partial decussation, in two portions into the sides of the second phalanx.

The vincula tendinum form additional insertions of the muscle. They consist of delicate bands of connective tissue enveloped in synovial membrane, and are known as the vincula longa and brevia. The vinculum breve is a triangular band of fibres containing yellow elastic tissue (ligamentum subflavum), occupying the interval between the tendon and the digit for a short distance close to the insertion. It is attached to the front of the inter-phalangeal articulation and the head of the first phalanx. The ligamentum longum is a long narrow band extending from the back of the tendon to the proximal part of the palmar surface of the first phalanx.

Nerve-Supply.-Median nerve (C. 6.).

Actions. - The muscle is a flexor of the elbow, wrist, metacarpo-phalangeal and first (proximal) interphalangeal joints.

\section{Deep Layer.}

II. Flexor Digitorum Profundus.-The flexor digitorum profundus is a large muscle arising from the ulna, the interosseous membrane, and the deep fascia of the forearm, under cover of the flexor digitorum sublimis and the flexor carpi ulnaris. Its ulnar origin is from the volar and medial surfaces of the bone in its proximal two-thirds, extending proximally so as to include the medial side of the olecranon, and to embrace the insertion of the brachialis muscle into the coronoid 
process. It arises laterally from the medial half of the interosseous membrane in its middle third (Figs. 348, p. 389, and 349, p. 390), and medially from the deep fascia of the forearm dorsal to the origin of the flexor carpi ulnaris.

The muscle forms a broad thick tendon which passes beneath the transverse carpal ligament, covered by the tendons of the flexor digitorum sublimis, and enveloped in the same synovial sac, and divides in the palm into four tendons for insertion into the terminal phalanges of the fingers. The tendon associated with the forefinger is usually separate from the rest of the tendons in its whole length.

Each tendon enters the digital sheath of the finger beneath the tendon of the flexor digitorum sublimis, which it pierces opposite the first phalanx, and is finally inserted into the base of the terminal phalanx. Like the tendons of the flexor sublimis, those of the deep flexor are provided with vincula, viz., vincula brevia attached to the capsule of the second interphalangeal articulation, and vincula longa, which are in this case connected to the tendons of the subjacent flexor digitorum sublimis.

Mm. Lumbricales. - The lumbricales are four small cylindrical muscles associated with the tendons of the flexor digitorum profundus in the palm of the hand. The two lateral muscles arise each by a single head from the radial sides of the tendons of the flexor digitorum profundus destined respectively for the fore and middle fingers. The two medial muscles arise, each by two heads, from the adjacent sides of the second and third, and third and fourth tendons.

From these origins the muscles are directed distally to the lateral side of each of the metacarpo-phalangeal joints, to be inserted into the capsules of these articulations, the lateral border of the first phalanx, and chiefly in to the lateral side of the

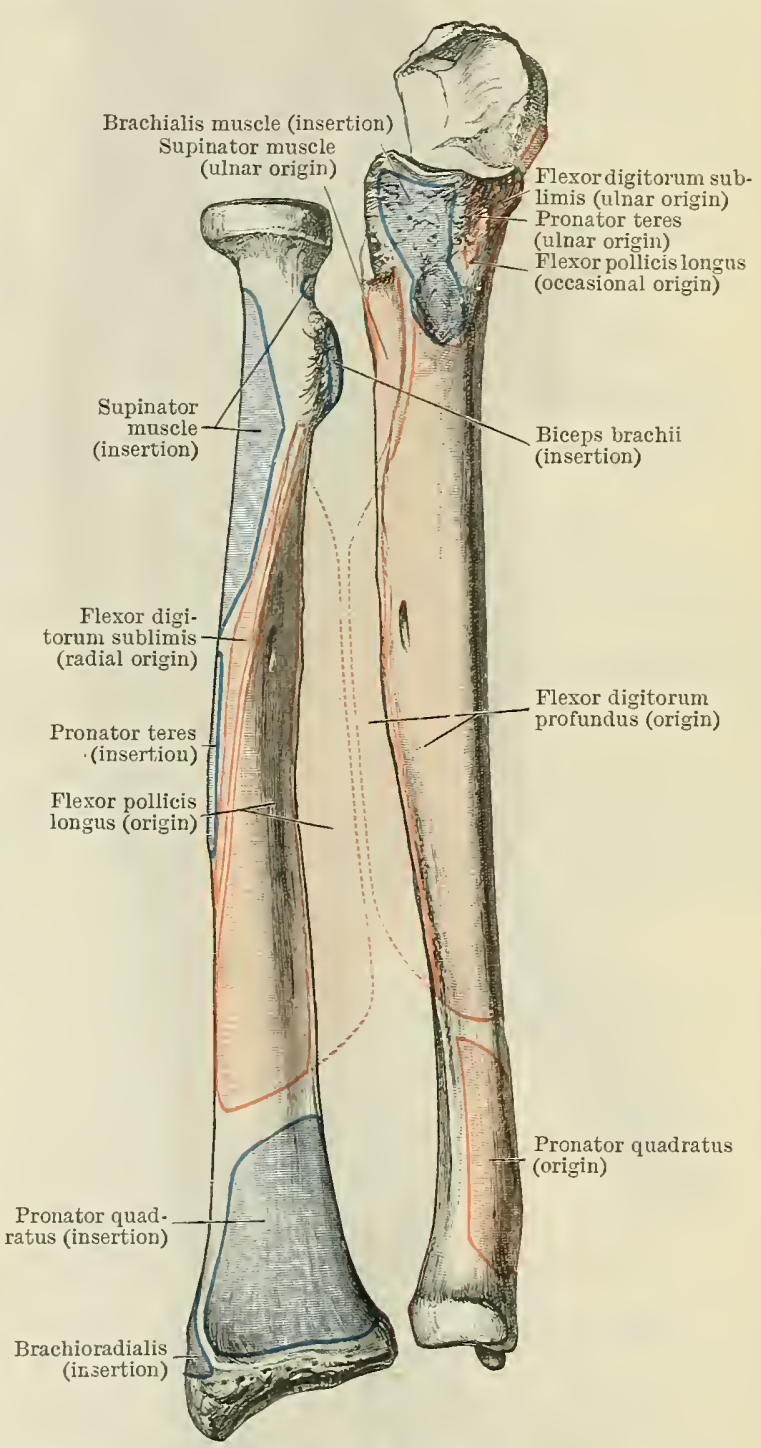

F1G. 348.-MUSCLE-AtTACHMexts To THE Right RadiUs AND ULNA (Volar Aspects).

extensor tendon on the dorsum of the phalanx. The lumbricales vary considerably in number, and may be increased to six or diminished to two.

Nerve-Supply. - The flexor digitorum profundus is supplied in its lateral part by the volar interosseous branch of the median nerve (C. 7. 8. T. 1.); and in its medial part by the ulnar nerve (C. 8. T. 1.). The lateral two lumbricales are supplied by the median nerve (C. 6. 7.), and the medial two muscles by the ulnar nerve (C. 8. (T. 1.)).

Actions. - The flexor digitorum profundus is a powerful flexor of the wrist. It also flexes the fingers at the metacarpo-phalangeal joint, and acts in a similar way at both the interphalangeal joints.

The lumbrical muscles act as flexors of the fingers at the metacarpo-phalangeal joints, and 
(by their attachment to the extensor tendons) as extensor's of the fingers, acting on both interphalangeal joints.

M. Flexor Pollicis Longus.-The flexor pollicis longus arises beneath the Hexor digitorum sublimis by fleshy fibres from the volar surface of the shaft of

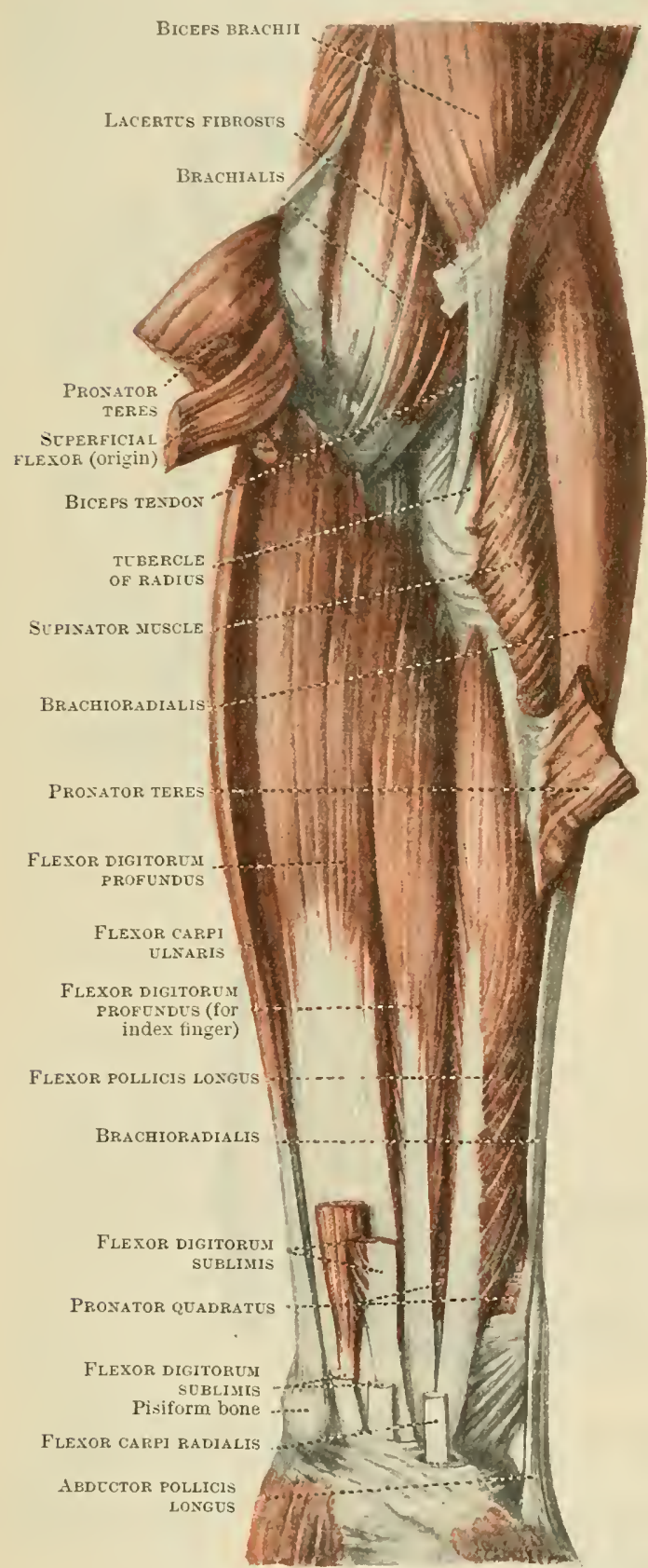

Fig. 349. - The Deepest Muscles on the Volar Aspect OF THE LEFT FOREARM.

front of the attachment of the interosseous membrane (Fig. 348, p. 389).

The pronator quadratus is subject to considerable variations. It may even be absent; or it may have an origin from radius or ulna, or from both bones, and an insertion into the carpus. fourths, and from a corresponding portion of the interosseous membrane. It has an additional origin occasionally from the medial border of the coronoid process of the ulna (Fig. 348, p. 389). Its radial origin is limited proximally by the oblique proximal part of the volar margin of the radius and the origin of the flexor digitorum sublimis, and distally by the insertion of the pronator quadratus muscle.

The muscle ends proximal to the wrist in a tendon, which passes over the pronator quadratus into the hand beneath the transverse carpal ligament, enveloped in a special synovial sheath.

In the palm the tendon is directed distally along the medial side of the thenar eminence, between the flexor brevis and adductor muscles of the thumb, to be inserted into the base of the terminal phalanx of the thumb on its palmar surface.

The muscle is placed deeply in the forearm, being concealed by the superficial layer of muscles and by the flexor digitorum sublimis.

Nerve-Supply.-Tolar interosseous branch of the median (C. 7. 8. T. 1.).

Actions.-The muscle is a flexor of the wrist and thumb, acting in the latter movement on the metacarpal bone and both phalanges.

M. Pronator Quadratus.-The pronator quadratus is a quadrilateral fleshy muscle, occupying the distal fourth of the forearm. It is placed beneath the deep flexor tendons, and arises from the distal fourth of the volar margin and surface of the ulna (Fig. 348, p. 389).

It is directed transversely laterally to be inserted into the distal fourth of the volar surface of the radius, and into the narrow triangular area on its medial side in the radius in its middle two- 
thumb constituting the thenar eminence, the three muscles of the little finger constituting the hypothenar eminence, and the interossei muscles, which are deeply placed between the metacarpal bones.

\section{Muscles of the Thumb.}

The short muscles of the thumb are the abductor, opponens, and flexor brevis (with its deep portion, interosseus primus volaris), and the adductor muscle, subdirided into two heads-oblique and transverse.

M. Abductor Pollicis Brevis.-The abductor pollicis brevis (O.T. abductor pollicis) arises by fleshy fibres from the tubercle of the navicular, the ridge of the greater multangular, the rolar surface of the transverse carpal ligament, and from

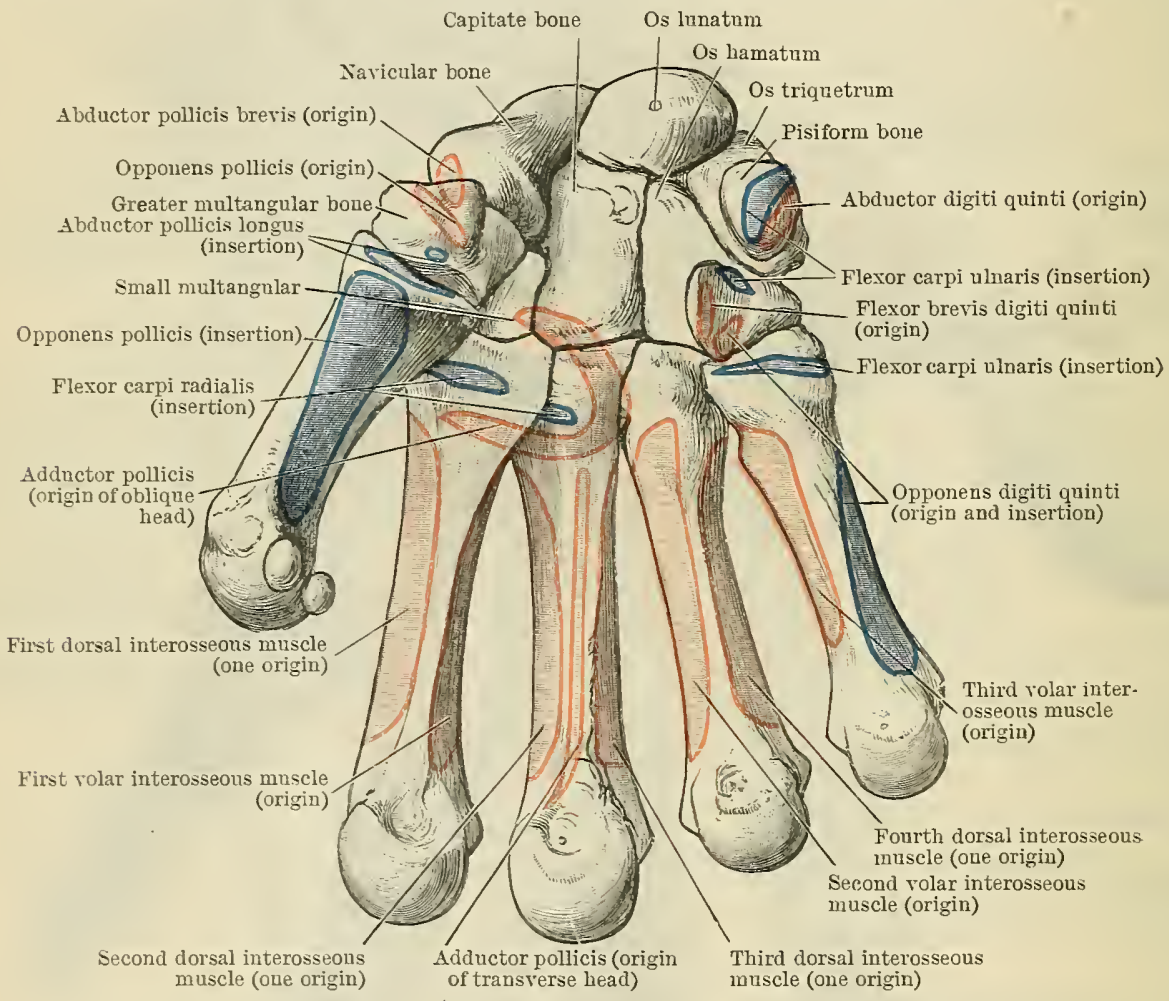

Fig. 351.-Midscle-Attachuests to the Tolar aspect of the Carpus and Metacarpus.

tendinous slips derived from the insertions of the palmaris longus and abductor pollicis longus muscles (Fig. 350, p. 391). Strap-like in form, and superficial in position, it is inserted by a short tendon into the radial side of the first phalanx of the thumb at its proximal end, and into the capsule of the metacarpo-phalangeal joint.

Nerve-Supply.-Wedian nerve (C. 6. 7.).

Actions. - The muscle acts on the thumb at both the carpo-metacarpal and metacarpophalangeal joints. It abducts and draws forward the thumb.

M. Opponens Pollicis.-The opponens pollicis, partially concealed by the preceding muscle, arises by fleshy and tendinous fibres from the volar surface of the transierse carpal ligament and from the ridge on the greater multangular bone.

Extending distally and laterally it is inserted into the whole length of the lateral border and the radial half of the volar surface of the first metacarpal bone (Fig. 351, p. 392 ). 
Nerve-Supply.-Median nerve (C. 6. 7.). thumb.

Action. - It acts solely on the first metacarpal bone, in the movement of opposition of the

M. Flexor Pollicis Brevis.-The flexor pollicis brevis consists of two parts. a. The superficial part of the muscle, partly concealed by the abductor pollicis brevis, arises by fleshy and tendinous fibres from the distal border of the transverse carpal ligament, and sometimes from the ridge of the greater multangular.

It is inserted into the radial side of the base of the first phalanx of the thumb, a sesamoid bone being present in the tendon of insertion.

b. The deep part of the muscle (interosseus primus volaris) arises from the medial side of the base of the first metacarpal bone.

It is inserted into the medial side of the base of the first phalanx of the thumb along with the adductor pollicis.

This little muscle is deeply situated in the first interosseous space, in the interval between the adductor pollicis obliquus and the first dorsal interosseous muscle. It may be regarded as homologous with the volar interossei muscles, with which it is in series.

Nerve-Supply.-Wedian nerre (C. 6. 7.).

Actions. - It is a flexor of the thrmb and assists also in the morement of opposition of the thumb to the fingers.

M. Adductor Pollicis.-The adductor pollicis is separated into two parts by the radial artery.

(1) The oblique head lies deeply in the palm, corered by the tendons of the long: flexors of the thumb and fingers. It arises by fleshy fibres from the volar surfaces of the greater and lesser multangular and capitate bones, from the sheath of the tendon of the flexor carpi radialis, from the bases of the second, third, and fourth metacarpal bones, and from the volar ligaments connecting these bones together (Fig. 351, p. 392).

It is inserted by a tendon, in which a sesamoid bone is dereloped, into the medial side of the base of the first phalanx of the thumb. At its lateral border a slender slip separates from the rest of the muscle, and passing obliquely beneath the tendon of the flexor pollicis longus, is inserted into the lateral side of the base of the first phalanx along with the superficial part of the flexor pollicis brevis.

(2) The transverse head, lying deeply in the palm beneath the flexor tendons, arises by fleshy fibres from the medial ridge on the volar aspect of the shaft of the third metacarpal bone, in its distal two-thirds (Fig. 351, p. 392), and from the fascia covering the interosseous muscles in the second and third spaces.

Triangular in form, it is directed laterally, orer the interossei muscles of the first two spaces, to be inserted by tendon into the medial side of the base of the first phalanx of the thumb along with the oblique head.

Nerve-Supply. - Deep branch of the ulnar nerre (C. 8. (T. I.)).

Actions. - Adduction and opposition of the thumb.

\section{Muscles of the Little Finger.}

The short muscles of the little finger are the adductor, opponens, and flexor brevis digiti quinti.

M. Abductor Digiti Quinti.--The abductor digiti quinti is most superficial. It arises from the pisiform bone and from the tendon of the Hexor carpi ulnaris and its ligamentous continuations (Fig. 351, p. 392).

It is inserted by tendon into the medial side of the base of the first phalanx of the little finger.

Nerve-Supply.-Deep branch of the ulnar nerre (C. 8. (T. 1.)).

Actions. - The muscle separates the little finger fron the ring finger, and assists in flexion of the finger at the metacarpo-phalangeal joint.

M. Opponens Digiti Quinti.-The opponens digiti quinti arises beneath the 
preceding muscle by tendinous fibres from the transverse carpal ligament and from the hamulus of the os hamatum.

It is inserted into the medial margin and medial half of the volar surface of the

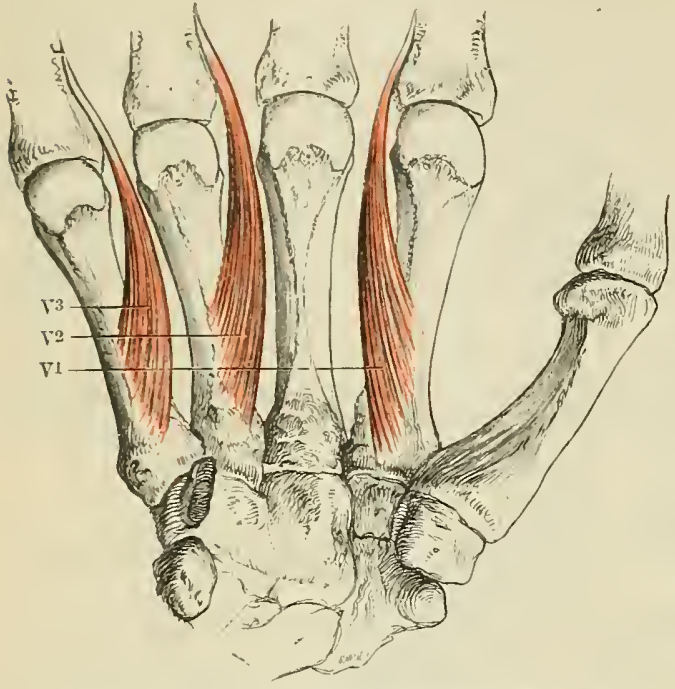

Fig. 352.-The Volar INTerosseous MUscles (Right Side).

$\mathrm{V}^{1}$, first ; $\mathrm{V}^{2}$, second ; and $\mathrm{V}^{3}$, third volar interosseous muscles. fifth metacarpal bone in its distal three-fourths (Fig. 351, p. 392).

Nerve-Supply.--Deep branch of the ulnar nerve (C. 8. (T. 1.)).

Action.-The muscle acts only on the metacarpal bone, drawing it forward, so as to deepen the hollow of the hand.

\section{Flexor Digiti Quinti Brevis.} -The flexor digiti quinti brevis may be absent or incorporated with either the opponens or abductor digiti quinti. It arises by tendinous fibres from the transverse carpal ligament and from the hamulus of the os hamatum (Fig. 351, p. 392).

It is inserted along with the abductor into the medial side of the first phalanx of the little finger.

Nerve-Supply.-The deep branch of the uInar nerve (C. 8. (T. 1.)).

Actions.-Flexion of the little finger at the carpo-metacarpal and metacarpophalangeal joints.

\section{The Interosseous Muscles.}

The interosseous muscles of the hand occupy the spaces between the metacarpal bones. They are arranged in two sets, volar and dorsal.

Mm. Interossei Volares.-The volar (O.T. palmar) interossei are three in

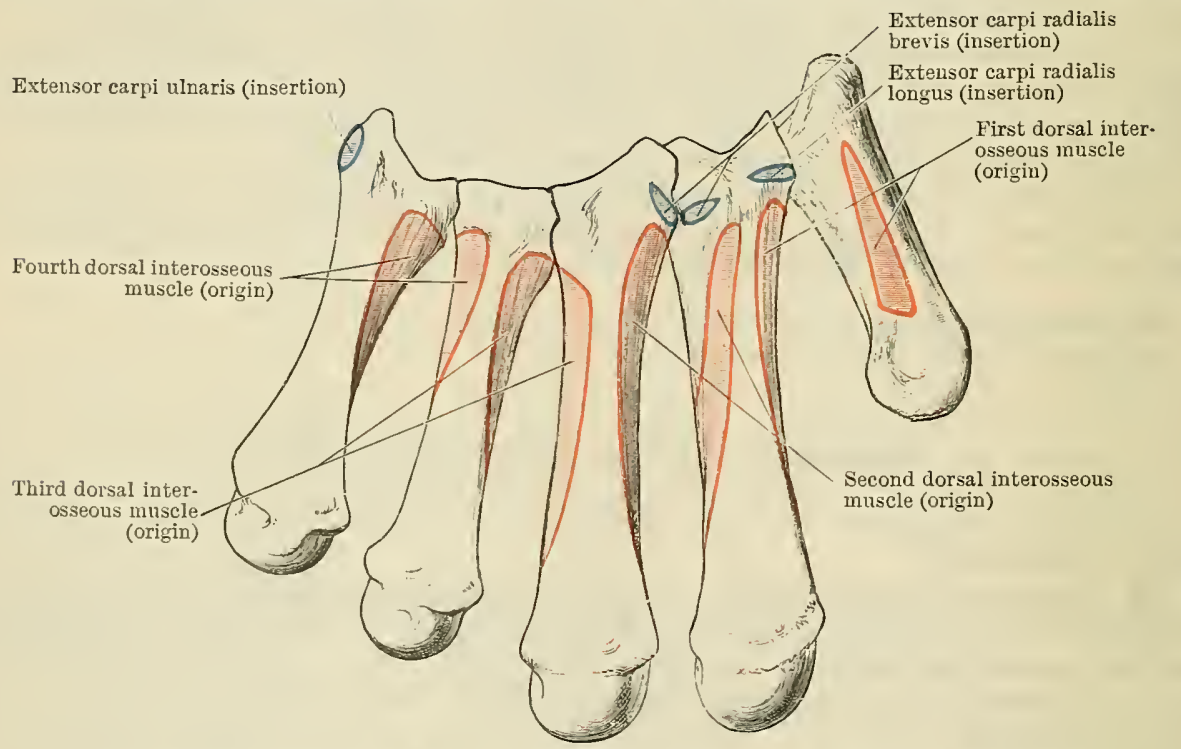

Fig. 353.-Micscle-Attachiests to the Dorsal Aspect of the Right Metacarpos.

number, occupying the three medial interosseous spaces. Each arises by a single head; the first from the medial side of the shaft of the second metacarpal bone; the second and third from the lateral sides of the shafts of the fourth and fifth metacarpal 
bones respectively (Fig. 352, p. 394). Each ends in a tendon which is directed distally behind the deep transverse metacarpal ligament, to be inserted into the dorsal expansion of the extensor tendon, the capsule of the metacarpo-phalangeal articulation, and the side of the first phalanx of the finger; the first is inserted into the medial side of the second finger; the second and third into the lateral sides of the fourth and fifth fingers. The deep part of the flexor pollicis brevis (interosseus primus volaris) is to be regarded as the homologous muscle of the first interosseous space.

Mm. Interossei Dorsales.-The dorsal interossei are four in number. Each arises by two heads from the sides of the metacarpal bones bounding each interosseous space (Figs. 353, p. 394, and 354, p. 395).

Each forms a fleshy mass, ending in a membranous tendon which, passing distally behind the deep transverse metacarpal ligament, is inserted exactly like the volar muscles into the dorsal aspect of each of the four fingers. The insertion of the first dorsal interosseous muscle is into the lateral side of the index finger; the second muscle is attached to the lateral side of the middle finger; the third

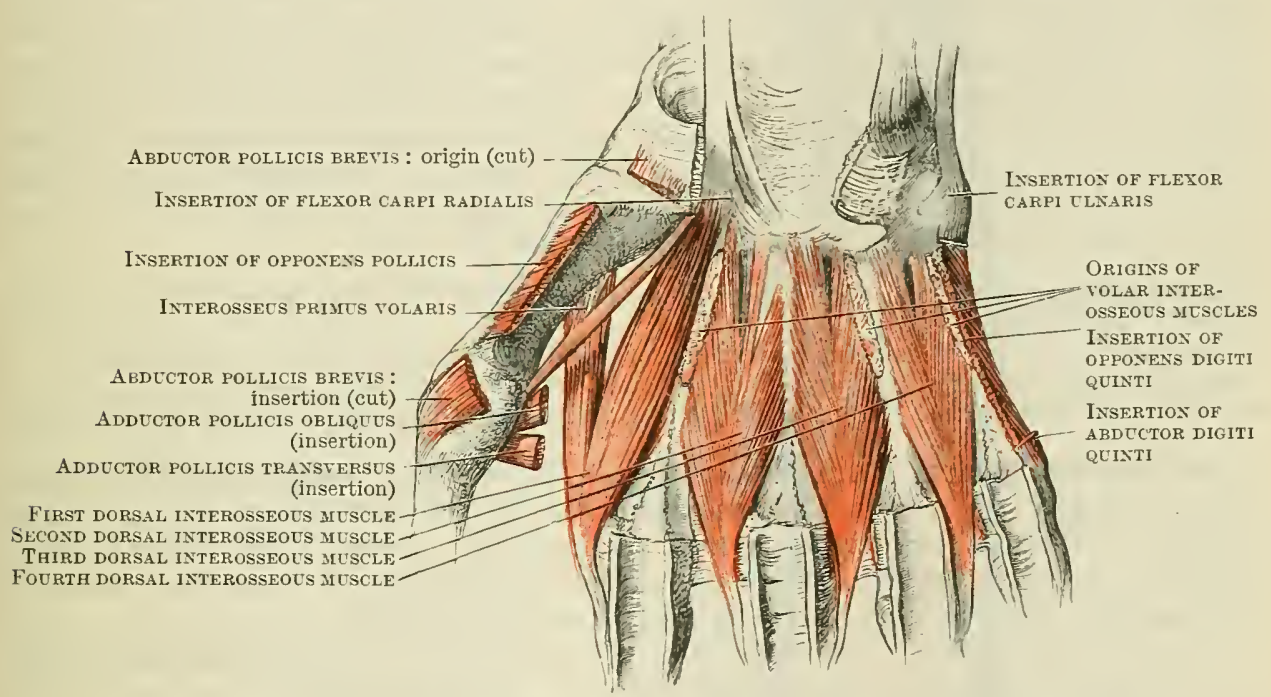

Fig. 354.-Dorsal Interosseods Muscles of the Haxd (seen from the Volar Aspect).

muscle to the medial side of the same finger; and the fourth muscle to the medial side of the ring finger.

The interosseous muscles of the hand in some cases have a disposition similar to that of the corresponding muscles of the foot (p. 435).

Nerve-Supply.-The deep branch of the ulnar nerve (C. 8. (T. 1.)).

Actions. - The interossei muscles act in a similar way to, and along with, the lumbricales, flexing the fingers at the metacarpo-phalangeal joints, and extending them at the interphalangeal joints. In addition, the dorsal interossei serve to abduct the fingers into which they are inserted (fore, middle, and ring fingers) from the middle line of the middle finger; the volar muscles on the other hand are adductors of the fingers into which they are inserted (fore, ring, and little finger) towards the middle line of the middle finger.

\section{THE MUSCLES ON THE DORSAL SURFACE OF THE FOREARM.}

The group of muscles occupying the lateral side of the elbow and the dorsal surface of the forearm and hand include the supinator muscles of the forearm and the extensors of the wrist and digits. They are divisible into a superficial and a deep layer.

The superficial layer comprises seven muscles, which are in order, from the radial to the ulnar side of the forearm, the brachioradialis, the two radial extensors of the carpus, the extensor digitorum communis and extensor digiti quinti proprius, the extensor carpi ulnaris, and the anconieus. 
The deep muscles are five in number: one, the supinator, extends between the proximal parts of the ulna and radius; the others are the special extensors of the thumb and forefinger, viz., the abductor pollicis longus, extensor pollicis longus and extensor pollicis brevis, and extensor indicis proprius. They cover the dorsal surface of the bones of the forearm and the interosseous membrane, and are almost wholly concealed by the superficial muscles. Only the abductor pollicis longus and the extensor pollicis brevis become superficial in the distal part of the forearm, emerging between the radial extensors of the carpus and the extensor digitorum communis.

\section{Superficial Muscles.}

M. Brachioradialis.-The brachioradialis arises by fleshy fibres from the anterior aspect of the proximal two-thirds of the lateral epicondylic ridge of the humerus, and from the anterior surface of the lateral intermuscular septum (Fig. 340, p. 380).

Occupying the lateral side of the hollow of the elbow, the muscle passes distally along the lateral border of the forearm, and ends about the middle in a narrow flat tendon which is inserted under cover of the tendons of the abductor pollicis longus and extensor pollicis brevis, by a transverse linear attachment, into the proximal limit of the groove for the above-named muscles on the lateral side of the distal extremity of the radius. Some of its fibres gain an attachment to the ridge on the volar margin of the groove, and others spread over the surface of the groove for a variable distance (Figs. 355, p. 397, and 348, p. 389).

Nerve-Supply. - The muscle is supplied by a branch of the radial nerve (C. 5. 6.) in the hollow of the elbow.

Actions. - The muscle is primarily a flexor of the elbow-joint. It is also a semi-pronator and semi-supinator of the forearm, bringing the limb from the supine or prone position, into a positiou in which the radius is uppermost. It thus assists both the pronator and supinator muscles.

\section{Extensor Carpi Radialis Longus.--The extensor carpi radialis longus} arises by fleshy fibres from the anterior aspect of the distal third of the lateral epicondylic ridge of the humerus, from the anterior surface of the lateral intermuscular septum, and from the common tendon of origin of succeeding muscles, attached to the lateral epicondyle (Figs. 356 and 357, p. 399).

It ends in a tendon in the distal half of the forearm, which passes beneath the dorsal carpal ligament, to be inserted into the dorsal surface of the base of the second metacarpal bone on its radial side (Fig. 353, p. 394).

The muscle is concealed in its proximal part by the brachioradialis, and its tendon in the distal half of the forearm is crossed obliquely by the abductor pollicis and by the extensor pollicis brevis.

Nerve-Supply. - The muscle is supplied by a branch of the radial nerve in the hollow of the elbow (C. (5.) 6. 7. 8.). joint.

Actions.-The muscle is an extensor of the wrist, and also an accessory flexor of the elbow-

II. Extensor Carpi Radialis Brevis.-The extensor carpi radialis brevis arises from the common tendon, from the radial collateral ligament of the elbow, from the fascia over it, and from intermuscular septa on either side.

It passes distally in the dorsal surface of the forearm and under the dorsal carpal ligament in close relation to the previous muscle, to be inserted by a tendon into the bases of the second and third metacarpal bones (Fig. 353, p. 394). A bursa is placed beneath the two radial extensor tendons close to their insertion.

It is practically concealed in the forearm by the extensor carpi radialis longus, and in the distal half is crossed obliquely by the abductor pollicis longus and the extensor pollicis brevis. The tendons of the two muscles are crossed on the dorsum of the wrist by the tendon of the extensor pollicis longus.

Nerve-Supply.--The muscle is supplied by the deep branch of the radial nerve.

Actions.-Like the long extensor, this muscle extends the hand at the wrist; and is a subsidiary flexor of the elbow-joint. 
IM. Extensor Digitorum Communis.-The extensor digitorum communis arises from the common tendon, from the lateral epicondyle of the humerus, from the fascia over it, and from intermuscular septa on either side. Extending along the dorsum of the forearm it ends proximal to the wrist in four tendons, of which the most lateral often has a separate fleshy belly. After passing beneath the dorsal carpal ligament in a compartment along with the extensor indicis proprius, the tendons separate ou the dorsum of the hand, where the three most medial tendons are joined together by two obliquely placed bands. One passes distally and laterally, and connects together the third and second tendons; the other is a broader and shorter band, which passes also distally and laterally, and joins the fourth to the third tendon. In some cases a third band is present which passes distally and medially from the first to the second tendon; and frequently the tendon for the little finger is joined to the tendon for the ring finger, and separates from it only a short distance above the distal end of the metacarpal bone.

The tendons are inserted in the following manner:- On the finger each tendon spreads out so as to form a membranous expansion over the knuckle and on the dorsum of the first phalanx. The border of the tendon is indefinite over the metacarpo-phalangeal articulation, of which it forms the dorsal ligament. On the dorsum of the first phalanx the tendon receives at its sides the insertions of the interosseous and lumbrical muscles. At the distal end of the first phalanx it splits' into ill-defined median and collateral slips, proceeding over the dorsum of the first inter-phalangeal articulation, of which they form the dorsal ligament. The median slip is inserted into the dorsum of the base of the second phalanx, while the two lateral pieces become united to form a membranous tendon on the dorsum of the

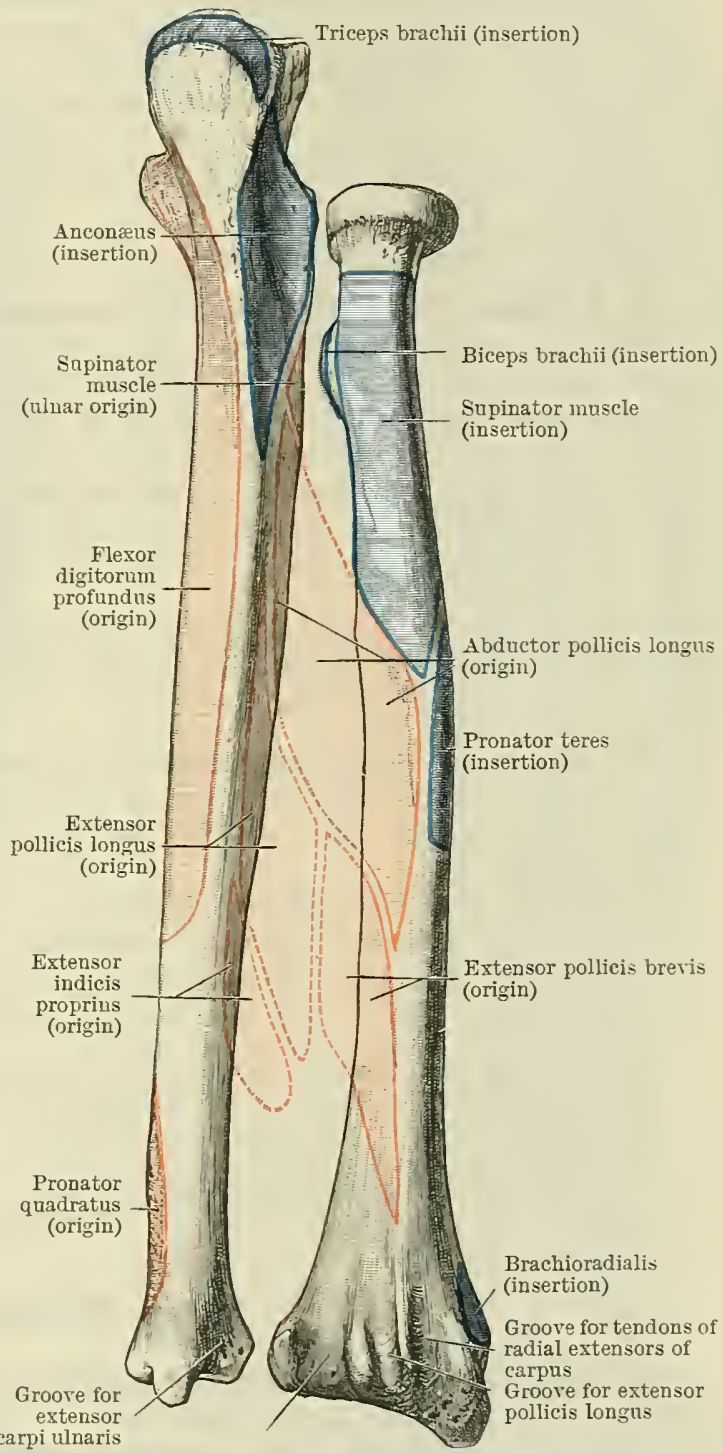

Groove for extensor digitorum communis and extensor indicis proprius

Fig. 355.-NCscle-Attachuents to the Right Radies AND ULNA (Dorsal Aspect). second phalanx, which, after passing over the second inter-phalangeal articulation, is inserted into the base of the terminal phalanx.

The muscle is placed superficially in the forearm between the extensors of the carpus and the proper extensor of the little finger.

Nerve-Supply.-.-The dorsal interosseous nerve (C. (5.) 6. 7. 8.).

Actions. - The muscle extends the elbow, wrist, and fingers. On account of the attachment together of the tendons to the third, fourth, and fifth fingers by accessory bands in the dorsum of the hand, these three fingers can only be fully extended together, while extension of the first finger 
can take place separately. In extension of the inter-phalangeal joints, the muscle is aided by the interossei and lumbrical muscles.

M. Extensor Digiti Quinti Proprius.-The extensor digiti quinti proprius has an origin similar to and closely connected with that of the preceding muscle, from the common tendon, the fascia over it, and from intermuscular septa.

Passing along the dorsum of the forearm as a narrow fleshy slip, between the extensor digitorum communis and the extensor carpi ulnaris, it ends in a tendon which occupies a groove between the radius and ulna in a special compartment of the dorsal carpal ligament of the wrist. On the dorsum of the hand the tendon, usually split into two parts, lies on the medial side of the tendons of the extensor digitorum communis, and is finally inserted into the expansion of the extensor tendon on the dorsum of the first phalanx of the little finger.

Nerve-Supply.-The dorsal interosseons nerve (C. (5.) 6. 7. 8.).

Actions.- The muscle extends the elbow, wrist, and little finger.

M. Extensor Carpi Ulnaris.-The extensor carpi ulnaris has a double origin: (1) from the common tendon from the lateral epicondyle of the humerus, from the fascia over it, and from the intermuscular septa; and (2) through the medium of the deep fascia, from the dorsal margin of the ulna in its middle two-fourths.

Lying in the forearm upon the dorsal surface of the ulna, it ends in a tendon which occupies a groove on the dorsal surface of the ulna in a special compartment of the dorsal ligament of the wrist, and is inserted into the medial side of the base of the fifth metacarpal bone (Fig. 353, p. 394).

Nerve-Supply.-The dorsal interosseons nerve (C. (5.) 6. 7. 8.).

Actions. - The muscle is an extensor of the wrist, and at the same time, acting with the flexor carpi ulnaris it is a powerful adductor of the wrist. Its humeral attachment makes it also a subordinate extensor of the elbow-joint.

M. Anconæus. - The anconæus is a small triangular muscle arising by a separate tendon from the distal part of the dorsal surface of the lateral epicondyle of the humerus (Fig. 341, p. 380), and from the dorsal part of the capsule of the elbow-joint.

Spreading out over the dorsal surface of the elbow-joint and proximal part of the ulna, it is inserted by fleshy fibres into a triangular surface on the lateral aspect of the olecranon and dorsal surface of the ulna, as far distally as the oblique line (Fig. 355, p. 397). It is also inserted into the fascia which covers it.

The epitrochleoanconæus is an occasional small muscle arising from the dorsal surface of the medial epicondyle of the humerus, and inserted into the medial side of the olecranon. It covers the ulnar nerve in its passage to the forearm.

Nerve-Supply. - The muscle is supplied by the terminal branch of the nerve to the medial head of the triceps muscle from the radial (C. 7. 8.).

Actions.- The anconæus is an extensor of the elbow.

\section{Deep Muscles.}

M. Supinator.-The supinator muscle (O.T. supinator radii brevis) is the most proximal of the deeper muscles. It is almost wholly concealed by the superficial muscles, and has a complex origin,-(1) from the lateral epicondyle of the humerus ; (2) from the radial collateral, and annular ligaments of the elbow-joint; (3) from the triangular surface on the shaft of the ulna just distal to the radial notch; and (4) from the fascia over it.

From this origin the muscle spreads laterally and distally, enveloping the proximal part of the radius, and is inserted into the volar and lateral surfaces of the bone, as far forwards as the tubercle of the radius, as far proximally as the neck, and as far distally as the oblique line and the insertion of the pronator teres (Figs. 348, p. 389, and 355 , p. 397).

The muscle is divisible into superficial and deep parts with humeral and ulnar origins, between which the deep branch of the radial nerve passes in its course to the dorsal part of the forearm. 
Nerve-Supply. - The supinator is supplied by a branch from the deep branch of the radial nerve, which arises from the nerve before the main trunk enters the muscle.

Action.-The muscle is an extensor of the elbow, and the main supinator of the forearm. In the latter action it is assisted by the biceps.

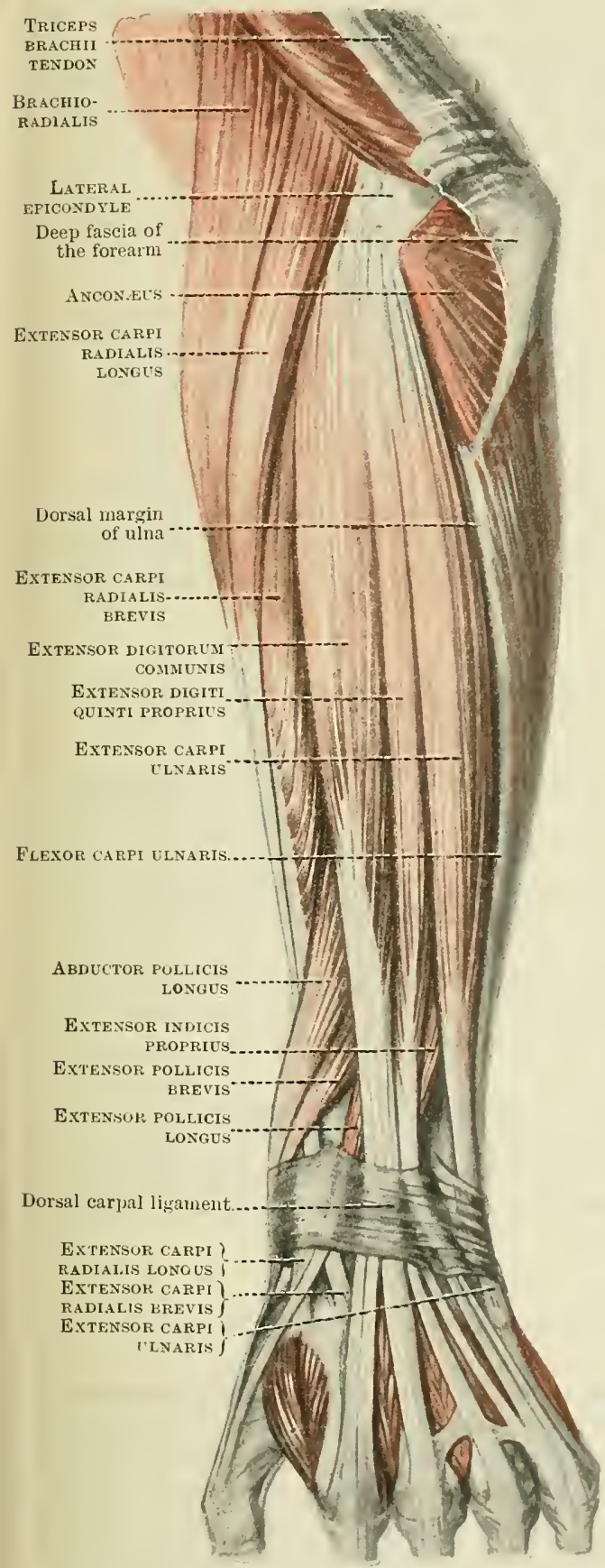

Fig. 356.- Superficial Muscles on the Dorsun OF THE LEFT FOREARM.

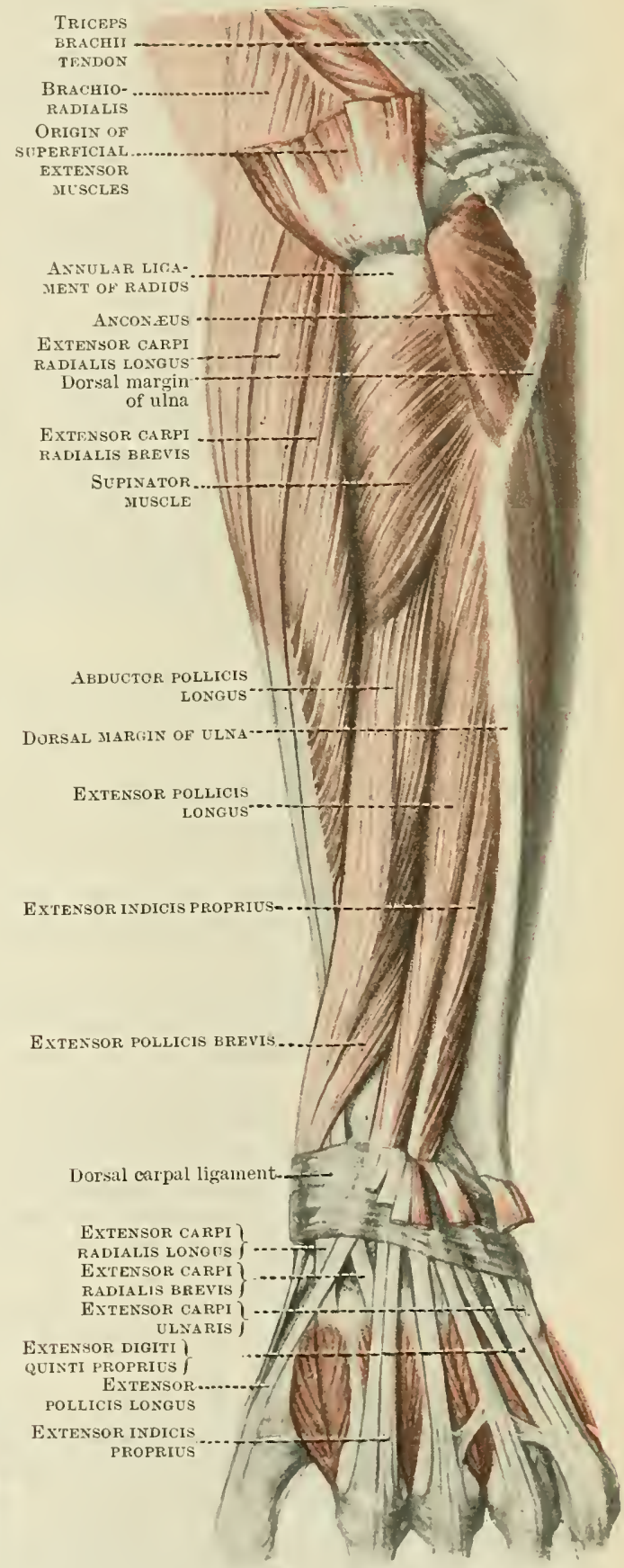

Fig. 357.-DEep MUscles ON THE DORSUM OF THE LEET FOREARM.

M. Abductor Pollicis Longus. - The abductor pollicis longus (O.T. extensor ossis metacarpi pollicis) arises by fleshy fibres distal to the supinator muscle from the most proximal of the narrow impressions on the lateral half of the dorsal surface of the ulna; from the middle third of the dorsal surface of 
the radius; and from the intervening portion of the interosseous membrane (Fig. 355, p. 397).

Becoming superficial in the distal part of the forearm along with the extensor pollicis brevis, between the extensors of the wrist and the common extensor of the fingers, its tendon passes with the latter muscle beneath the dorsal ligament of the wrist, to be inserted into the lateral side of the base of the first metacarpal bone (Fig. 356, p. 399). From the tendon close to its insertion a tendinous slip passes to the abductor pollicis brevis and the fascia over the thenar eminence, and another is frequently attached to the greater multangular bone.

Nerve-Supply.-The dorsal interosseous nerve (C. (5.) 6. 7. 8.).

Actions. - The muscle abducts the metacarpal bone of the thumb, and assists in abduction and extension of the wrist.

\section{Extensor Pollicis Brevis.-The extensor pollicis brevis (O.T. extensor} primi internodii pollicis), an essentially human muscle, is a specialised portion of the previous muscle. It arises from a rhomboid impression on the dorsal surface of the radius, and from the interosseous membrane, distal to the abductor pollicis longus (Fig. 355 , p. 397). It is closely adherent to that muscle, and accompanies it beneath the dorsal ligament of the wrist and over the radial artery to the thumb.

Its tendon is then continued along the dorsal surface of the first metacarpal bone, to be inserted into the dorsal surface of the base of the first phalanx of the thumb. Before reaching its insertion the tendon helps to form the capsule of the metacarpo-phalangeal joint.

Nerve-Supply.-The dorsal interosseous nerve (C. (5.) 6. 7. 8.).

Actions. - The muscle extends the wrist and thumb (or the metacarpo-phalangeal joint), and assists in abduction of the wrist and thumb.

M. Extensor Pollicis Longus.-The extensor pollicis longus (O.T. extensor secundi internodii pollicis) arises from the lateral part of the dorsal surface of the ulna in its middle third, and from the interosseous membrane, distal to the abductor pollicis longus (Fig. 355, p. 397). Its tendon grooves the dorsal surface of the radius, and occupies a special compartment beneath the dorsal ligament of the wrist.

Extending obliquely across the dorsal surface of the hand, the tendon crosses the radial artery, and helps to form the capsule of the first metacarpo-phalangeal articulation, and is inserted into the dorsal surface of the base of the second phalanx of the thumb.

At the wrist the tendons of the muscles of the thumb, the abductor pollicis longus and extensor pollicis brevis laterally, and the extensor pollicis longus medially, bound a hollow (the "anatomical snuff-box") best seen in extension and abduction of the thumb, which corresponds to the position of the radial artery as it winds round the wrist to reach the palm of the hand.

Nerve-Supply.-The dorsal interosseous nerve (C. (5.) 6. 7. 8.).

Actions. - This muscle is an extensor and an abductor of the thumb, and of the wrist.

M. Extensor Indicis Proprius.-The extensor indicis proprius (O.T. extensor indicis) arises distal to the extensor pollicis longus from the most distal impression on the dorsal surface of the ulna, extending distally from the middle of the shaft to within two inches of its distal end, and sometimes also from the interosseous membrane (Fig. 355, p. 397). Its tendon passes through a compartment of the dorsal carpal ligament along with the tendons of the extensor digitorum communis.

On the dorsum of the hand the tendon lies on the medial side of the tendon of the common extensor destined for the forefinger, and is inserted into the forefinger, joining the membranous expansion of the tendon of the extensor digitorum communis on the dorsum of the first phalanx.

Nerve-Supply.-The dorsal interosseous nerve (C. (5.) 6. 7. 8.).

Actions. - The muscle is an extensor of the wrist and forefinger. 


\section{Actions of the Muscles of the Forearm and Hand.}

These muscles are concerned in the movements of the elbow, wrist, and digits.

In the majority of cases the muscles act upon more than one joint.

1. Action on the Flbow-Joint.-It has been shown already that flexion and extension of the elbow are assisted by certain of these muscles. The flexor muscles are the pronator teres, and the flexor muscles of the wrist and fingers. In the position of pronation, the movement of flexion is aided by the brachioradialis and extensor muscles of the wrist and fingers. The extensors are the supinator muscle and anconæus, and the extensor muscles of the wrist and fingers.

2. Pronation and supination of the hand are performed by special museles, aided by muscles which act also upon other joints. The brachioradialis assists in flexion and pronation on the one hand, and in extension and supination on the other hand. In the supine position it assists pronation, and in the prone position it assists supination, in each case bringing the hand into the position intermediate between pronation and supination.

\begin{tabular}{l|l}
\multicolumn{1}{c|}{ Pronation. } & \multicolumn{1}{c}{ Supination. } \\
\hline Pronator teres & Supinator \\
Pronator quadratus & Biceps brachii \\
Brachioradialis & Brachioradialis \\
Flexor carpi radialis & Extensors of thumb and fingers \\
Weight of the limb & Weight of the limb \\
\hline
\end{tabular}

3. Action on the Wrist-Joint.-The movements at the wrist-joint are flexion and extension, abduction and adduction. Flexion and adduction are much more extensire movements than extension and abduction, on account of the form of the wrist-joint. The following muscles produce these movements :-

\begin{tabular}{|c|c|c|c|}
\hline Flexion. & Extension. & Adduction. & Abduction. \\
\hline $\begin{array}{l}\text { Flexor carpi radialis } \\
\text { Palmaris longus } \\
\text { Flexor carpi ulnaris } \\
\text { L ong flex ors of } \\
\text { thumb and fingers }\end{array}$ & $\begin{array}{l}\text { Extensors of the wrist } \\
\text { Extensors of thumb } \\
\text { and fingers }\end{array}$ & $\begin{array}{l}\text { Flexor carpi ulnaris } \\
\text { Extensor carpi ulnaris }\end{array}$ & $\begin{array}{l}\text { Flexor carpi radialis } \\
\text { Extensors of wrist } \\
\text { Extensors of thumb. }\end{array}$ \\
\hline
\end{tabular}

4. Movements of the Fingers.-Two separate series of movements occur in relation to the articulations of the fingers: flexion and extension (at the metacarpo-phalangeal and interphalangeal joints), and abduction and adduction (only at the metacarpo-phalangeal joints). The movements and the muscles concerned are given in the following tables:-

\section{Flexion.}

Flexor digitorum sublimis Flexor digitorum profundus Lumbricales ) (acting on the metacarpoInterossei $f$ phalangeal articulations) Flexor digiti quinti brevis

\section{Extension.}

Extensor digitorum communis

Extensor indicis proprius

Extensor digiti quinti proprius

Lumbricales $)$ (acting on the inter-pha-

Interossei $\int$ langeal articulations)

\begin{tabular}{|c|c|}
\hline Abduction. & Adduction. \\
\hline $\begin{array}{l}\text { Lumbricales } \\
\text { Flexor brevis and } \\
\text { Opponens, digiti (from the medial side }\end{array}$ & \\
\hline Dorsal interossei $\left\{\begin{array}{c}\text { (from the middle } \\
\text { line of the middle } \\
\text { finger) }\end{array}\right.$ & Palnar interossei $\left\{\begin{array}{l}\text { (to the middle line } \\
\text { of the middle } \\
\text { finger })\end{array}\right.$ \\
\hline
\end{tabular}

Flexion is more powerful and complete than extension of the fingers. The flexor digitorum profundus alone acts on the terminal phalanges; the flexor sublimis and flexor profundus together Hlex the proximal inter-phalangeal joint; and flexion of the metacarpo-phalangeal articulation is effected by these muscles, assisted by the interossei, lumbricales, and flexor digiti quinti breris. Extension of the phalanges is effected by the mited action of the extensors of the digits, the interossei and lumbricales; extension of the finger's at the metacarpo-phalangeal joints is produced solely by the long extensor muscles. Separate extension of the index finger only is possible; the three inner fingers can only be flexed and extended together, on account of the connecting bands joining the extensor tendons together on the back of the hand.

5. Movements of the Thumb. - The morements of which the thumb is capable are flexion 
and extension (occurring at the carpo-metacarpal, metacarpo-phalangeal, and inter-phalangeal joints); abduction and adduction, together with circumduction (occurring at the carpo-metacarpal joint).

The muscles and their respective actions are given in the following table :-

\begin{tabular}{|c|c|}
\hline Flexion. & Extension. \\
\hline 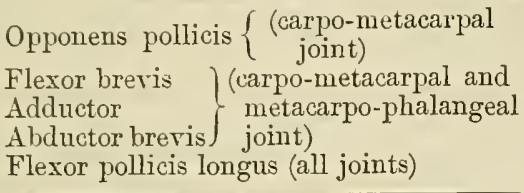 & $\begin{array}{l}\text { Abductor pollicis }\left\{\begin{array}{c}\text { (carpo-metacarpal } \\
\text { joint) }\end{array}\right. \\
\text { longus } \\
\text { Extensor pollicis }\left\{\begin{array}{c}\text { (carpo-metacarpal and } \\
\text { metacarpo-phalan- } \\
\text { geal joint) }\end{array}\right. \\
\text { brevis }\end{array}$ \\
\hline Adduction. & Abduction. \\
\hline $\begin{array}{l}\text { Adductor of the thumb } \\
\text { Flexor pollicis brevis } \\
\text { Opponens pollicis } \\
\text { First dorsal interosseous }\end{array}$ & $\begin{array}{l}\text { Abductor pollicis brevis } \\
\text { Extensors of the thumb }\end{array}$ \\
\hline
\end{tabular}

The characteristic features of the movements of the upper limb are their range and refinement. The hand, in addition to its intrinsic powers, can be moved through a wide range and in several planes by the muscles acting on the wrist and radio-ulnar joints ; this range is increased by the fore and aft movements at the elbow-joint, and the extensive morements of which the shoulder and clavicular joints are capable. The result is that the hand can be brought into a position to cover and guard any portion of the body. The precision and refinement of movement is made possible by the coordinate movements of the various muscles acting upon the several joints, so that actions can be performed (as raising the food to the mouth) in which all the articulations of the limb are brought into play; while others (such as writing) are possible by movements at the joints of the wrist and fingers along with fixation of the elbow-joint.

\section{THE LOWER LIMB.}

\section{FASCIE AND MUSCLES OF THE THIGH AND BUTTOCK.}

FASCI死.

The superficial fascia of the thigh and buttock is continuous above with the fascia of the abdomen and back, medially with that of the perineum, and distally with that of the leg. It presents noticeable features in the buttock and groin.

In the buttock the superficial fascia is of considerable thickness, and is usually loaded with fat, whereby it assists in forming the contour of the buttock and the fold of the nates.

In the groin it is divisible into two layers: a superficial fatty layer, continuous with a similar layer on the anterior surface of the abdominal wall above, and over the perineum medially, and a deeper membranous layer, which is attached above to the medial half of the inguinal ligament, and to the deep fascia of the thigh just distal to the lateral half of that ligament. Medially it is attached to the pubic arch, and below the level of the femoral triangle it blends inseparably with the superficial fatty layer. The separation of these two layers of the superficial fascia is occasioned by the presence between them of the inguinal and superficial subinguinal lymph glands, the great saphenous vein and its tributaries, and some small arteries. The attachment of the deeper layer of the fascia to the pubic arch and the inguinal ligament euts off the superficial tissues of the thigh from the perineum and the abdominal wall, and prevents the passage into the thigh of fluid collected in the perineum or beneath the fascia of the abdominal wall. 
The deep fascia or fascia lata forms a tubular investment for the muscles and vessels of the thigh and buttock. It is firmly attached above to the iliac crest, the sacro-tuberous ligament, the ischium, the pubic arch, the pubic symphysis and crest, and the inguinal ligament. In the distal part of the thigh it forms the intermuscular septa; and in relation to the knee, it is continuous with the deep fascia of the leg, gains attachment to the patella, the condyles of the tibia and the head of the fibula, and forms the collateral ligaments of the patella.

On the front of the thigh the deep fascia is thick and strong. It is pierced by numerous openings for vessels and nerves, the most important of which is the fossa ovalis (O.T. saphenous opening) for the passage of the great saphenous vein. A femoral

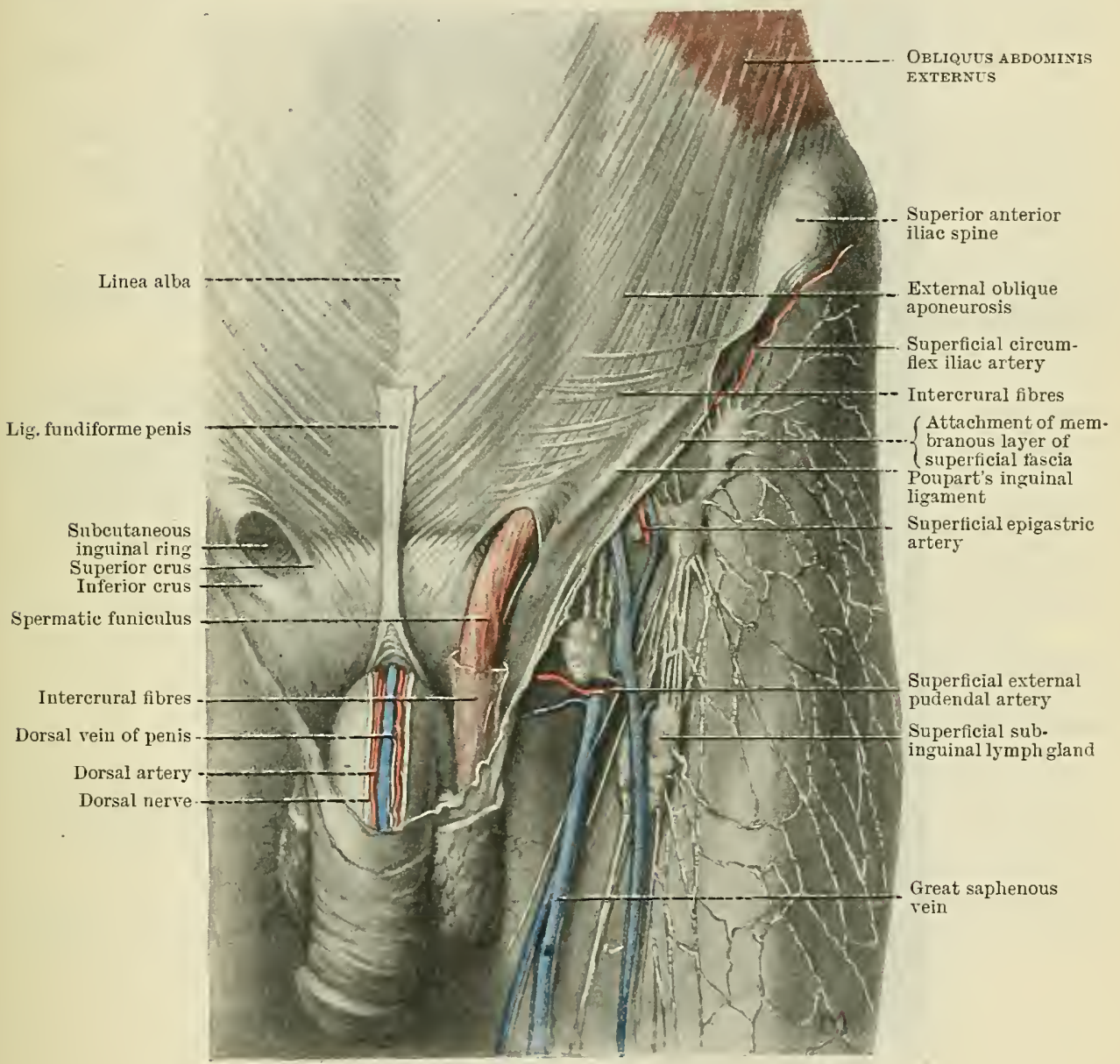

Fig. 358.-Superficlal ANatomi of the Left Groin.

hernia passes through this opening to reach the groin and anterior abdominal wall. It is an oval opening of variable size situated just distal to the medial half of the inguinal ligament, and immediately anterior to the femoral vessels. It is covered by the superficial fascia, and by a special layer of fascia, the fascia cribrosa, a thin perforated lamina attached to the margins of the opening. The lateral edge of the opening (margo falciformis) is formed by the margin of the iliac portion of the fascia lata, which is attached above to the iliac crest and the inguinal ligament; the medial edge is formed by the fascia pectinea which is continued proximally behind the femoral sheath, over the adductor longus and pectineus muscles to the ilio-pectineal line and the capsule of the hip-joint. These two layers of the fascia lata are continuous at the distal concave margin of the fossa ovalis, forming its inferior cornu. As they pass proximally towards the pelvis they occupy different 
planes, the iliac portion being in front of the sheath of the femoral vessels, while the pectineal fascia is behind it. The superior cornu of the fossa ovalis, placed in front of the sheath, is derived solely from the iliac portion of the fascia lata. It forms a strong triangular band of fascia known as the falciform margin, attached above to the medial half of the inguinal ligament. It has an important share in directing the course of a femoral hernia upwards on to the abdominal wall.

On the medial side of the thigh the fascia lata is thin where it covers the adductor muscles. At the knee it is associated with the tendons of the vasti muscles, and forms the collateral ligaments of the patella, attached to the borders of the patella and to the condyles of the tibia. On the lateral side of the thigh it

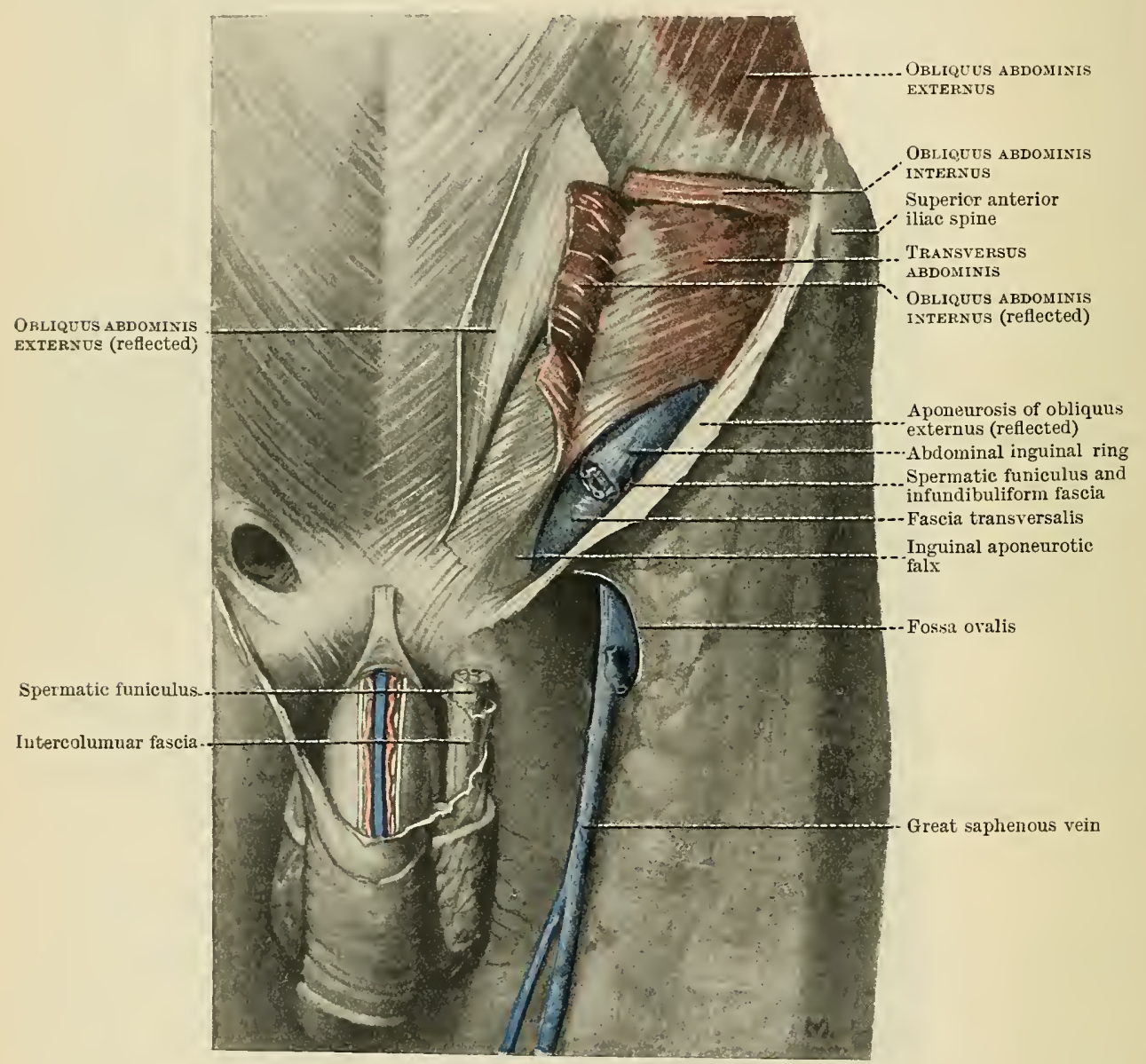

Fig. 359.-The Dissection of the Left Ingdival Cayal.

forms the tractus iliotibialis - a broad thick layer of fascia which is attached above to the iliac crest, and receives the insertions of the tensor fasciæ latæ, and part of the glutæus maximus muscles; its distal attachment is to the capsule of the kneejoint and the lateral condyle of the tibia. A strong band of fascia continued proximally from the ilio-tibial tract beneath the tensor fasciæ latæ muscle joins the tendon of origin of the rectus femoris and the capsule of the hip-joint.

On either side of the thigh above the knee an intermuscular septum is formed. The lateral intermuscular septum extends medially from the ilio-tibial tract to the lateral epicondylic line and linea aspera of the femur, and gives attachment to the vastus lateralis and vastus intermedius anteriorly, and the short head of the biceps posteriorly. The medial intermuscular septum in the distal third of the thigh is associated with, and to a large extent represented by, the tendon of insertion of the adductor magnus muscle. It is also related to the fascia which envelops the 
adductor muscles, and forms the sheaths for the sartorius and gracilis muscles. In the middle third of the thigh the fascia under the sartorius is greatly thickened by transverse fibres and binds together the vastus medialis and adductor longus and adductor magnus muscles. This layer of fascia roofs over the femoral vessels in their course through Hunter's adductor canal.

The fascia lata of the buttock is thick anteriorly where it covers and gives origin to the glutæus medius, thinner posteriorly over the glutæus maximus, at the upper border of which it splits to enclose the muscle. It is thickened over the greater trochanter, where it forms the insertion of the greater part of the latter muscle.

On the posterior surface of the thigh and over the popliteal fossa the fascia is strengthened by transverse fibres derived from the hamstring muscles. The popliteal fascia forming the roof of the popliteal fossa is specially thick, and is usually pierced by the small saphenous vein.

Femoral Sheath.-This is a conical membranous investment, derived from the fascial lining of the abdominal cavity, the fascia transversalis in front and the fascia iliaca behind, prolonged along the femoral vessels in their passage behind the inguinal ligament into the femoral triangle. The sheath is about an inch and a half in length, and is divided into three compartments-a lateral space for the artery, an intermediate space for the vein, and a medial channel containing lymph vessels and fat, and named the femoral canal. This canal is the passage through which a femoral hernia enters the thigh. Its proximal limit is the femoral ring bounded anteriorly by the inguinal ligament, posteriorly by the origin of the pectineus muscle from the pubis, medially by the ligamentum lacunare (Gimbernati), and laterally by the femoral vein. In front of it the fascia transversalis forming the sheath is thickened to form the deep femoral arch. The part of the inguinal ligament in front of the ring is called the superficial femoral arch. The inferior epigastric artery separates the ring from the abdominal inguinal ring. The canal ordinarily contains fat which is continuous above with the extra-peritoneal tissue. The ring is filled by a plug of fat or a lymph gland, constituting the femoral septum.

The femoral canal ends behind the fossa ovalis, covered by the fascia cribrosa, while the falciform margin crosses over it and conceals its proximal portion. The course of a femoral hernia is determined by this band. The hernia descends through the femoral ring, pushing the femoral septum before it; after passing through the femoral canal, it is directed forwards through the fossa ovalis. The anterior part of the hernia being pressed upon and retarded by the femoral arches, and by the falciform margin, the posterior part pushes onwards, hooks round the falciform margin, and is directed upwards over the inguinal ligament. The coverings of a femoral hernia, in addition to peritoneum and extra-peritoneal tissue (femoral septum), are femoral sheath, fascia cribrosa, superficial fascia, and skin.

\section{MUSCLES OF THE THIGH AND BUTTOCK.}

The muscles of the thigh and buttock are divisible into four main groups by their situation, action, and nerve-supply. On the anterior surface of the thigh are the quadriceps femoris, the sartorius, ilio-psoas, and pectineus muscles; on the medial side of the thigh are the adductor muscles; in the region of the buttock are the glutæi and rotators of the hip-joint; and on the posterior aspect of the thigh are the hamstring muscles.

\section{THE MUSCLES ON THE ANTERIOR ASPECT OF THE THIGH.}

The chief muscle on the anterior aspect of the thigh is the quadriceps femoris, which occupies the space between the tensor fasciæ latæ and ilio-tibial tract laterally, and the sartorius medially. The sartorius crosses the thigh obliquely; it separates the quadriceps femoris from the adductor muscles; it forms in the proximal third of the thigh the lateral boundary of the femoral triangle, and in 


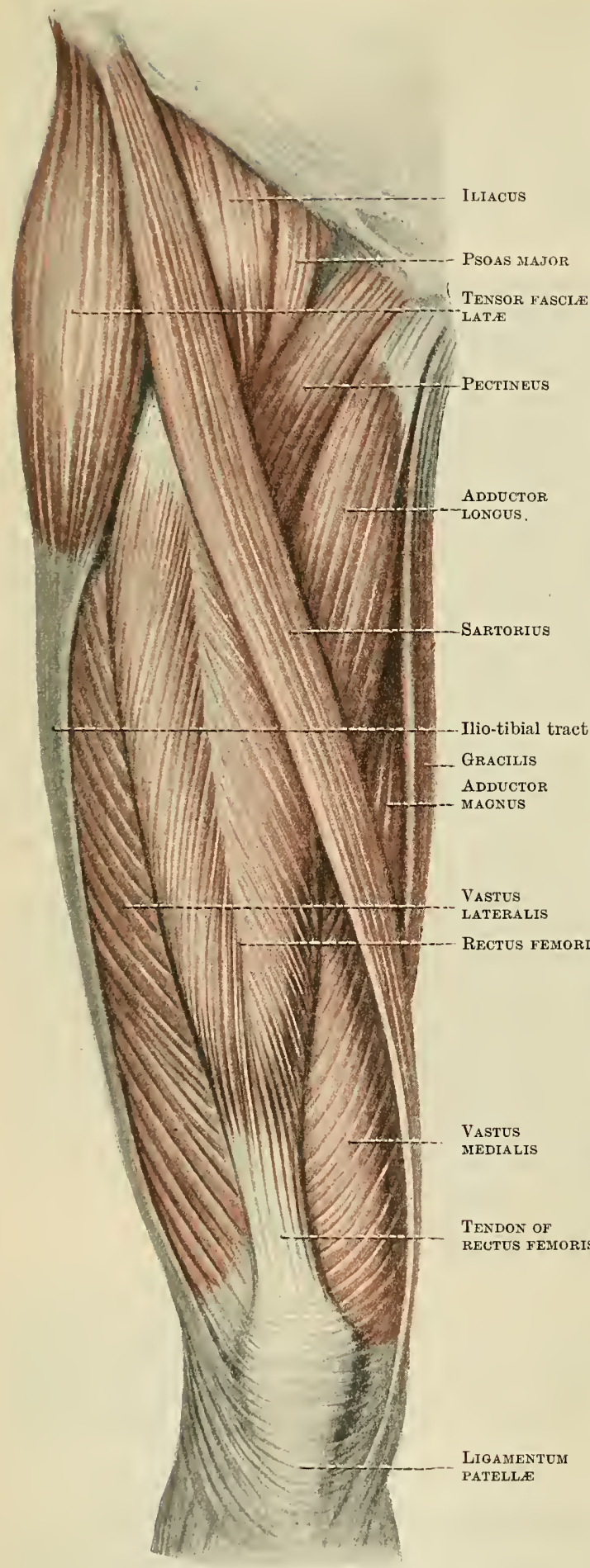

Fig. 360.-The Muscles of the Anterior Aspect of THE RIGHT THIGH. the middle third of the thigh, the roof of Hunter's adductor canal. The ilio-psoas, passing into the thigh beneath the inguinal ligament, assists along with the pectineus and adductor muscles in forming the floor of the femoral triangle.

II. Sartorius.-The sartorius, a long strap-like muscle, arises from the superior anterior spine of the ilium and half of the notch below it (Fig. 360).

It passes distally in the thigh to the medial side of the knee, where it is inserted by aponeurotic fibres into the medial surface of the shaft of the tibia just distal to the medial condyle, and by its borders into fascial expansions which join the capsule and the tibial collateral ligament of the knee-joint, and the fascia lata of the leg (Fig. 363, p. 408).

The sartorius is superficial in its whole extent. Its proximal third forms the lateral boundary of the femoral triangle; its middle third forms the roof of the adductor canal; and its distal third, in contact with the medial side of the knee, is separated from the tendon of the gracilis muscle by the saphenous nerve and the saphenous branch of the arteria genu suprema. A bursa lies beneath the tendon at its insertion.

Nerve-Supply. - The sartorius is supplied by two sets of nerves associated with the two intermediate cutaneous branches of the femoral nerve (L. 2. 3.).

Actions. - The sartorius, "the tailor's muscle," is a flexor of the hip and knee. It also everts the thigh and assists in medial rotation of the kneejoint.

II. Quadriceps Femoris.The quadriceps femoris is composed of four muscles-the rectus femoris, vastus lateralis, vastus intermedius, and vastus medialis.

The rectus femoris is superficial except at its origin, which is covered by the glutæi, sartorius, and tensor fasciæ latæ muscles. The vasti lie on either side of the rectus muscle, the vastus lateralis being partially concealed

by the tensor fasciæ latæ and ilio-tibial tract, the vastus medialis by the sartorius 
muscle. The vastus intermedius envelops the femur, and is concealed by the other muscles.

M. Rectus Femoris. - The rectus femoris has a double tendinous origin.

The straight head arises from the inferior anterior spine of the ilium (Fig. 366, p. 412); (2) the reflected head springs from a rough groove on the dorsum ilii just above the highest part of the acetabulum (Fig. 366, p. 412). A bursa lies beneath this head of origin. The two heads, bound together and connected to the capsule of the hip-joint by a band of fascia derived from the deep surface of the tensor fasciæ latæ (ilio-tibial tract), give rise to a single tendon which extends for some distance on the anterior surface of the muscle, and from which the muscular fibres arise. The muscular fibres springing from this tendon, and also from a median septal tendon, present a bipennate arrangement, and end below in a broad tendon which passes proximally for some distance along the posterior surface of the muscle. This tendon gradually narrows towards the knee, and spreading out again, is inserted into the proximal border of the patella. It receives laterally parts of the insertions of the lateral and medial rasti muscles, and on its deep surface is joined by the insertion of the vastus intermedius.

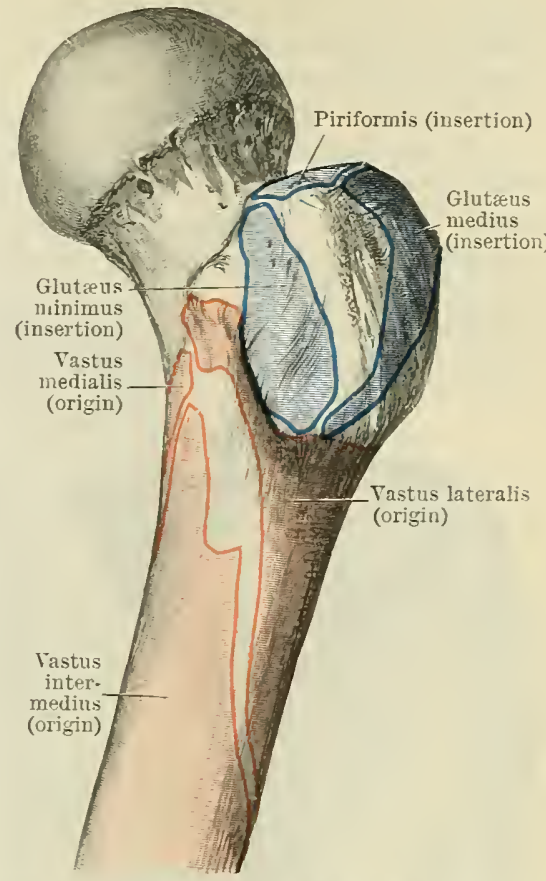

Fig. 361.-HeScle-ATtachuENTS TO THE Ax. TERIOR SURFACE OF THE PROYMAL PART OF THE LEFT FEMOR. distal end of the shaft of the femur.

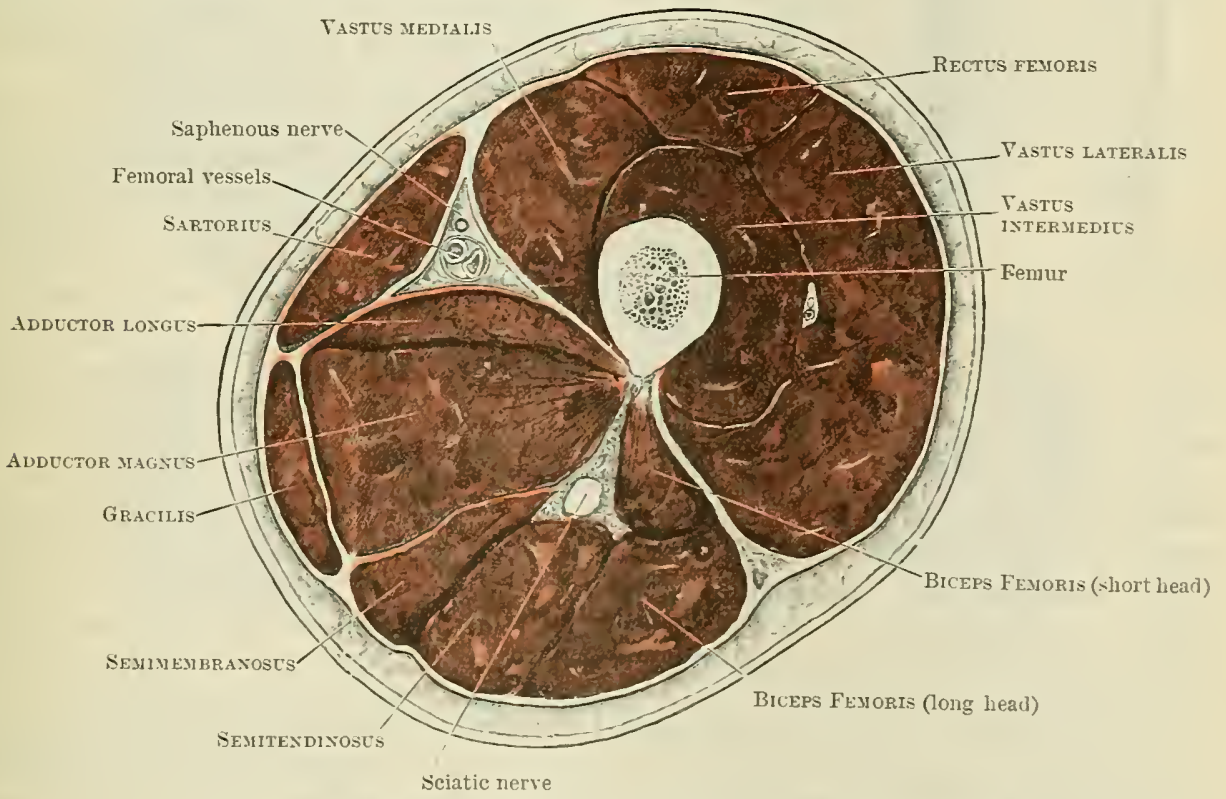

Fig. 362.-Traxsterse Section of the 'Thigh (Huxter's Addector Cayal).

M. Vastus Lateralis.-The vastus lateralis has an origin, partly fleshy, partly membranous, from (1) the capsule of the hip-joint, (2) the tubercle of the femur, (3) a concave surface on the anterior surface of the shaft of the bone medial to the 
greater trochanter, (4) the distal border of the greater trochanter, (5) the lateral margin of the gluteal tuberosity of the femur and the tendon of the glutæus maximus, (6) the proximal half of the linea aspera, and (7) the fascia lata and lateral intermuscular septum (Fig. 360, p. 406).

It forms a thick, broad muscle directed distally and forwards, and is inserted by a broad membranous tendon into (1) the lateral border of the tendon of the rectus femoris, (2) the proximal and lateral border of the patella, and (3) the capsule of the knee-joint and the fibular collateral ligament of the patella. A bursa intervenes between it and the membranous insertion of the glutæus maximus.

M. Vastus Medialis.-The vastus medialis is larger than the vastus lateralis and has a more extensive origin, from (1) the distal two-thirds or more of the spiral

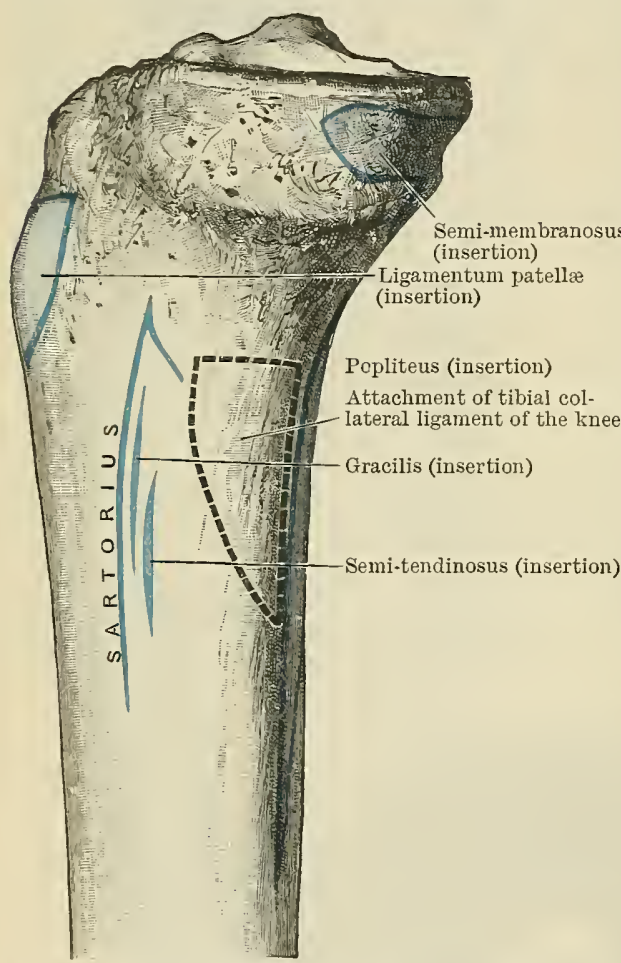

Fig. 363. - Muscle-Attachuents to the Medial Side of the PROJIMAL PART OF THE Right Tibia.

line, the linea aspera, and the proximal two-thirds of the line leading from the linea aspera to the medial condyle of the femur; (2) the membranous expansion of the fascia lata which lies beneath the sartorius and forms the roof of the adductor canal; and (3) the medial intermuscular septum and the tendon of the adductor magnus (Figs. 359 , p. 404 , and 365 , p. 410 ).

From its origin the muscle 'is directed distally and laterally towards the knee; it is inserted by a strong aponeurotic tendon into (1) the medial border of the rectus tendon; (2) into the proximal and medial border of the patella; and (3) the capsule of the knee-joint and the collateral ligament of the patella. The muscle conceals the medial side of the shaft of the femur and the vastus intermedius, with which it is closely incorporated in its distal two-thirds.

II. Vastus Intermedius. - The vastus intermedius muscle (O.T. crureus) arises by fleshy fibres from (1) the proximal two-thirds of the shaft of the femur on the anterior and lateral surfaces-but not the medial surface; (2) the distal half of the lateral lip of the linea aspera and the proximal part of the line leading therefrom to the lateral condyle; and (3) a corresponding portion of the lateral intermuscular septum (Fig. 35̆9, p. 404).

For the most part deeply placed, the muscle is directed distally to an insertion into the deep surface of the tendons of the rectus and vasti muscles by means of fibres which join a membranous expansion on its surface. It is closely adherent to the vastus lateralis muscle in the middle third of the thigh; it is inseparable from the vastus medialis below the proximal third. In the distal third of the thigh it conceals the articularis genu muscle, a bursa, and the proximal prolongation of the synovial membrane of the knee-joint.

M. Articularis Genu.-The articularis genu (O.T. subcrureus) muscle consists of a number of separate bundles of muscular fibres arising beneath the vastus intermedius from the distal fourth of the anterior surface of the femur, and inserted into the synovial membrane of the knee-joint.

The four elements composing the quadriceps femoris muscle have been traced in their convergence to the patella. Their ultimate insertion is into the tubercle of the tibia (Fig. 363), by means of the ligamentum patellæ, and the vasti 
muscles are in addition connected with the collateral ligaments of the patella. The patella, indeed, is in one sense a sesamoid bone formed in the tendon of the muscle, the ligamentum patellæ being the real tendon of insertion, and the collateral ligaments fascial expansions from its borders. The insertion of the muscle forms the anterior part of the capsule of the knee-joint.

lntermediate lumbo-costal arch

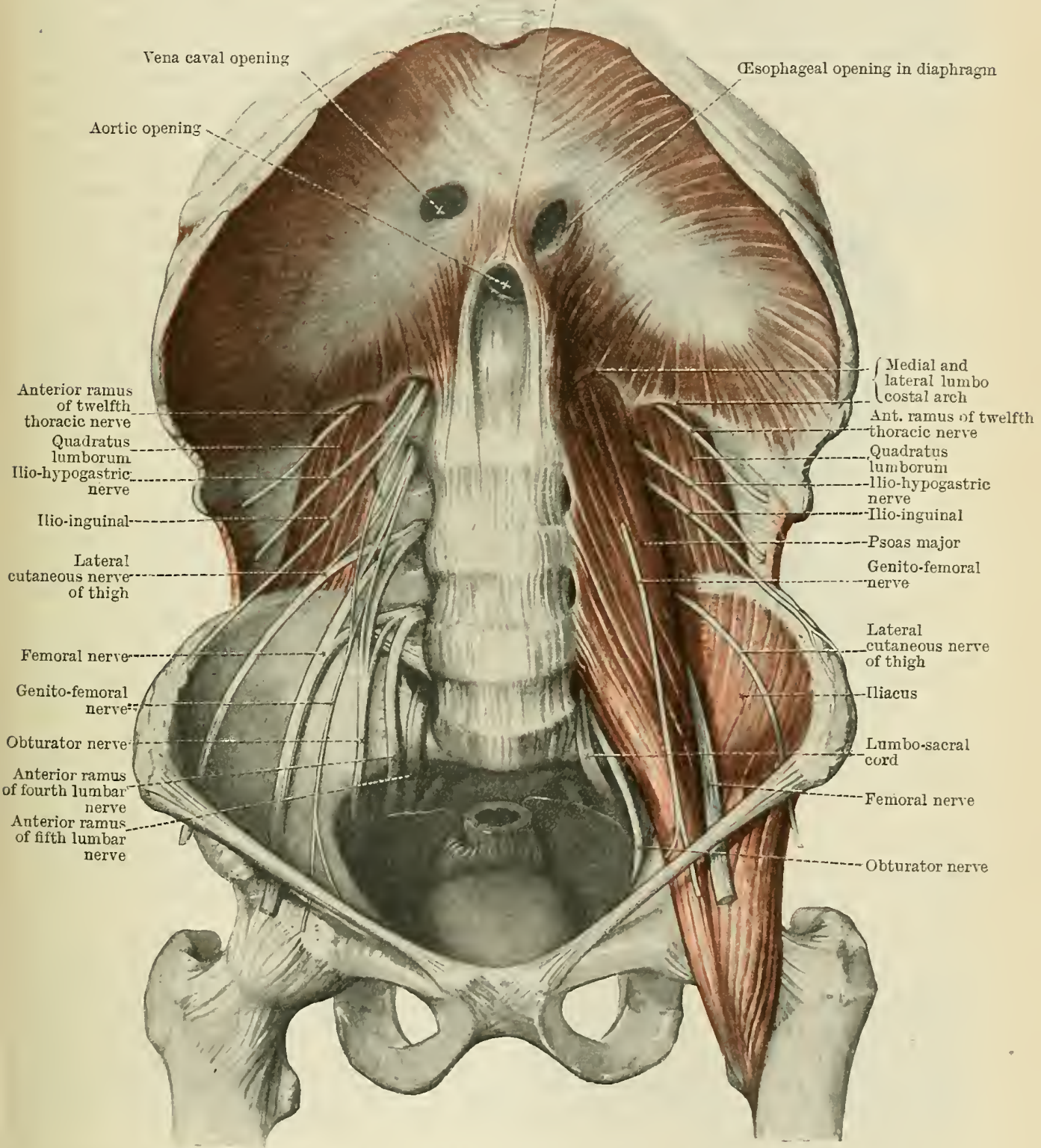

Fig. 364.-The Vessels and Nerves os the Posterior Abdomital Wall.

Nerve-Supply.-The parts of the quadriceps extensor are supplied by separate branches of the femoral nerve (L. 3. 4.).

Actions. - The quadriceps muscle is the great extensor of the leg at the knee-joint. The articularis genu draws proximally the synovial sheath of the joint during this morement.

The rectus femoris is in addition a flexor of the hip-joint. The straight head acts when the movement begins; the reflected head is tightened when the thigh becomes bent.

The ilio-psoas muscle is a compound muscle, consisting of two elements, psoas (major and minor), connecting the femur and pelvic girdle to the axial 
skeleton: and another element, the iliacus, extending between the lip bone and the femur. The muscles chiefly occupy the posterior wall of the abdomen and pelvis major, their insertions only appearing in the thigh below the inguinal ligament, in the lateral part of the genuoral triangle.

M. Psoas Major.-The psoas major is a large piriform muscle, which has an extensive origin by fleshy fibres from the vertebral column in the lumbar region. It arises from (1) the intervertebral fibro-cartilages above each lumbar vertebra, and the adjacent margins of the vertebræ-from the inferior border of the 12 th thoracic to the superior border of the 5th lumbar vertebra; (2) it arises also from four aponeurotic arches which pass over the sides of the bodies of the first four lumbar vertebræ; and (3) it has an additional origin posteriorly from the

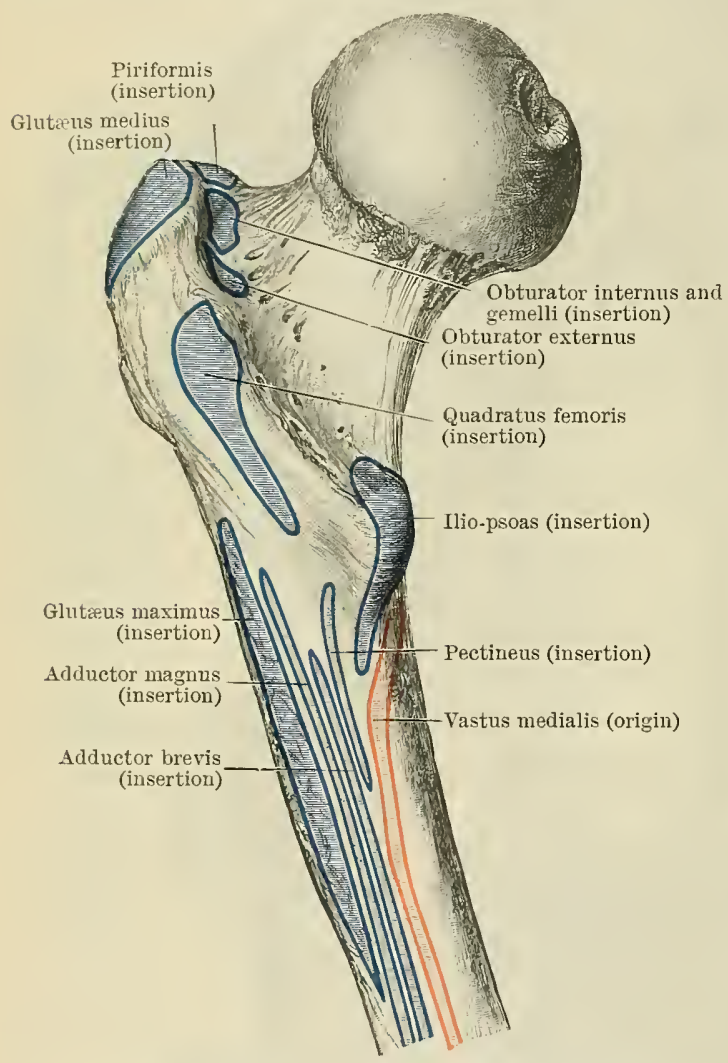

Fig. 365.-Muscle-Attachments to the Posterior Aspect OF' THE PROXIMAL PART OF THE LEFT FEMUR. transverse processes of all the lumbar vertebræ. The fibres form a fusiform muscle directed inwards over the superior aperture of the pelvis and beneath the inguinal ligament, ending in a tendon which is inserted into the apex of the lesser trochanter of the femur (Fig. 365). A bursa, which may be continuous with the synovial cavity of the hipjoint, separates the tendon from the pubis and the capsule of the hip-joint.

M. Psoas Minor.-The psoas minor (O.T. parvus) is often absent (40 per cent). It arises from the intervertebral fibro-cartilage between the last thoracic and first lumbar vertebræ, and from the contiguous margins of these vertebræ. The muscle is closely apposed to the anterior surface. of the psoas major.

It forms a slender fleshy belly, and is inserted by a narrow tendon into the middle of the linea terminalis and the ilio-pectineal eminence, its margins blending with the fascia covering the psoas major.

M. Iliacus. - The iliacus muscle arises in the pelvis major by fleshy fibres, mainly from a horseshoe-shaped origin around the margin of the iliac fossa; it has additional origins also from the ala of the sacrum, the anterior sacro-iliac, lumbo-sacral, and ilio-lumbar ligaments, and outside the pelvis, from the proximal part of the capsule of the hip-joint (ilio-femoral ligament). It is a fan-shaped muscle, its fibres passing distally over the hip-joint towards the lesser trochanter of the femur.

Lying lateral to the psoas muscle, it passes through the femoral triangle, and is inserted by fleshy fibres (1) into the lateral side of the tendon of the psoas major; (2) into the concave anterior and upper surfaces of the lesser trochanter; and (3) into the shaft of the femur distal to the lesser trochanter for about an inch (Fig. 365); and (4) by its most lateral fibres into the capsule of the hip-joint. These fibres are often separate, forming the iliacus minor, or iliocapsularis.

Nerve-Supply. - The psoas major is supplied directly by branches from the anterior rami of the second and third lumbar nerves with additional branches in some cases from the first and fourth. 
The psoas minor receives a nerve from the first or second lumbar nerve. The iliacus is supplied by branches from the femoral nerve (L. 2. 3. 4.) within the abdomen.

Actions. - The psoas minor assists the psoas major in flexing forwards and laterally the vertebral column.

Besides this action the psoas major acts with the iliacus muscle as a flexor of the hip. With the thighs fixed the two muscles can draw the trunk downwards.

II. Pectineus.-The pectineus muscle arises by fleshy fibres from (1) the sharp anterior portion of the linea terminalis of the pubis, and the triangular surface of the pubic bone in front of this (Fig. 366, p. 412), (2) the femoral surface of the ligamentum lacunare, and (3) the pectineal portion of the fascia lata which covers it.

Forming a broad muscular band, occupying the floor of the femoral triangle, medial to the ilio-psoas, it is inserted by a thin flat tendon about two inches in length into the proximal half of the pectineal line, leading from the back of the lesser trochanter of the femur towards the linea aspera; its distal attachment being placed in front of the insertion of the adductor brevis muscle (Fig. 365, p. 410). The muscle may be occasionally divided into medial and lateral parts, the former innervated by the obturator, the latter by the femorai nerve.

Nerve-Supply.-The pectineus is always supplied by a branch of the femoral nerve (L. 2. 3.) which passes medially behind the femoral ressels to enter its lateral border. It receives in some instances an additional nerve from the obturator, or when that is present, the accessory obturator nerve.

Actions.- The muscle is mainly an adductor of the hip-joint. It is also a flexor of the hip.

\section{THE MUSCLES ON THE MEDIAL SIDE OF THE THIGH.}

The muscles on the medial side of the thigh include the adductors of the femur - the adductor longus, adductor brevis, and adductor magnus; the gracilis, and the obturator externus.

The gracilis is superficially placed along the medial side of the thigh. The adductor muscles, occupying the space between the hip bone and the femur, are placed on different planes, the adductor longus being in the same plane as the pectineus and lying superficially in the femoral triangle; the adductor brevis, on a deeper level, is in contact with the obturator externus, and along with it is largely concealed by the pectineus and adductor longus; the adductor magnus, the largest and deepest of these muscles, is in contact with the other adductors and the sartorius anteriorly, while its posterior surface is in relation to the hamstring muscles on the back of the thigh.

M. Gracilis.-The gracilis muscle is a long flat band placed on the medial side of the thigh and knee. It arises by a tendon from the lower half of the edge of the symphysis pubis, and for a similar distance along the border of the pubic arch (Fig. 366, p. 412).

Its flattened belly passes distally on the medial side of the thigh to the knee, to end in a tendon, placed between the sartorius and semitendinosus, which expands to be inserted into the medial surface of the shaft of the tibia just distal to the medial condyle, behind the sartorius, and proximal to and in front of the semitendinosus (Fig. 376, p. 420). It is separated from the sartorius tendon by a bursa, and beneath its tendon is another bursa common to it and the semitendinosus. It is superficial in its whole extent.

Nerve-Supply.-Obturator nerve (L. 2. 3.).

Actions. - The gracilis has a threefold action. It adducts the hips, and it flexes and rotates medially the knee.

M. Adductor Longus. - The adductor longus is a triangular muscle occupying the femoral triangle and the floor of Hunter's adductor canal. It arises from the anterior surface of the body of the pubis in the angle between the crest and symphysis (Fig. 366, p. 412).

Extending distally and laterally, it is inserted into the middle two-fourths of the medial lip of the linea aspera in front of the adductor magnus. 
Nerve-Supply.-Obturator nerve (L. 2. 3.).

Actions.- The muscle adducts and assists in flexing the thigh.

M. Adductor Brevis.-The adductor brevis is a large muscle which arises from an elongated oval surface on the front of the body and upper part of the inferior ramus of the pubic bone, surrounded by the other muscles of this group (Fig. 366).

Directed distally and laterally the muscle expands, to be inserted by a short aponeurotic tendon, behind the insertion of the pectineus, into the distal twothirds of the line leading from the lesser trochanter of the femur to the linea aspera, and to the proximal fourth of the linea aspera itself (Fig. 365, p. 410).

Nerve-Supply.-Obturator nerve (L. 2. 3. 4.).

Actions. - The muscle adducts and flexes the thigh.

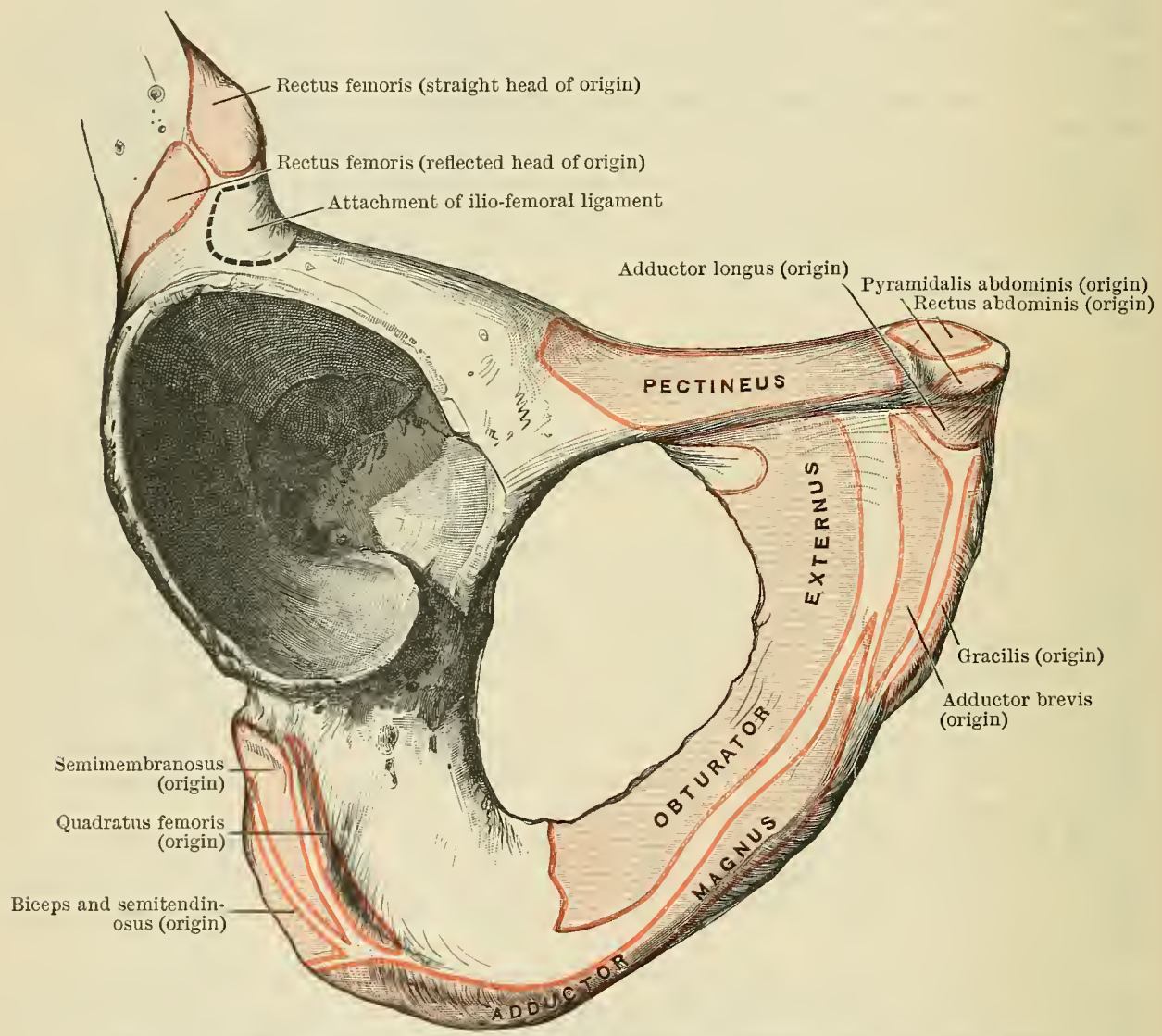

Fig. 366.-Muscle-Attachments to the Odter SUrface of the Right Pubis and Ischium.

M. Adductor Magnus.-The adductor magnus, the largest of the adductor group, is a roughly triangular muscle arising mainly by fleshy fibres by a curved origin from the lower part of the lateral border and a large portion of the adjoining inferior surface of the sciatic tuberosity, from the edge of the inferior ramus of the ischium, and from the anterior surface of the inferior ramus of the pubic bone, its most anterior fibres arising between the obturator externus and adductor brevis (Fig. 366). Its upper fibres are directed horizontally and laterally from the pubic bone towards the proximal part of the femur; the lowest fibres are directed distally from the sciatic tuberosity to the medial condyle of the femur; while the intermediate fibres radiate obliquely laterally and downwards.

The muscle is inserted by tendinous fibres (1) into the space distal to the insertion of the quadratus femoris, proximal to the linea aspera; (2) into the 
whole length of the linea aspera; (3) into the medial epicondylic line of the femur; (4) into the adductor tubercle on the medial condyle of the femur; and (5) into the medial intermuscular septum (Fig. 365, p. 410). The part of the muscle attached to the space proximal to the linea aspera is often separated from the rest as the adductor minimus. The attachment of the muscle to the epicondylic ridge is interrupted for the passage of the femoral vessels into the popliteal fossa. The attachment to the medial condyle is by means of a strong tendon which receives the fibres arising from the ischium (the part of the muscle associated with the hamstring group). This tendon is closely connected with the tibial collateral ligament of the knee-joint.

The muscle is covered anteriorly by the other adductors and by the sartorius muscle. The profunda femoris artery separates it from the adductor longus muscle

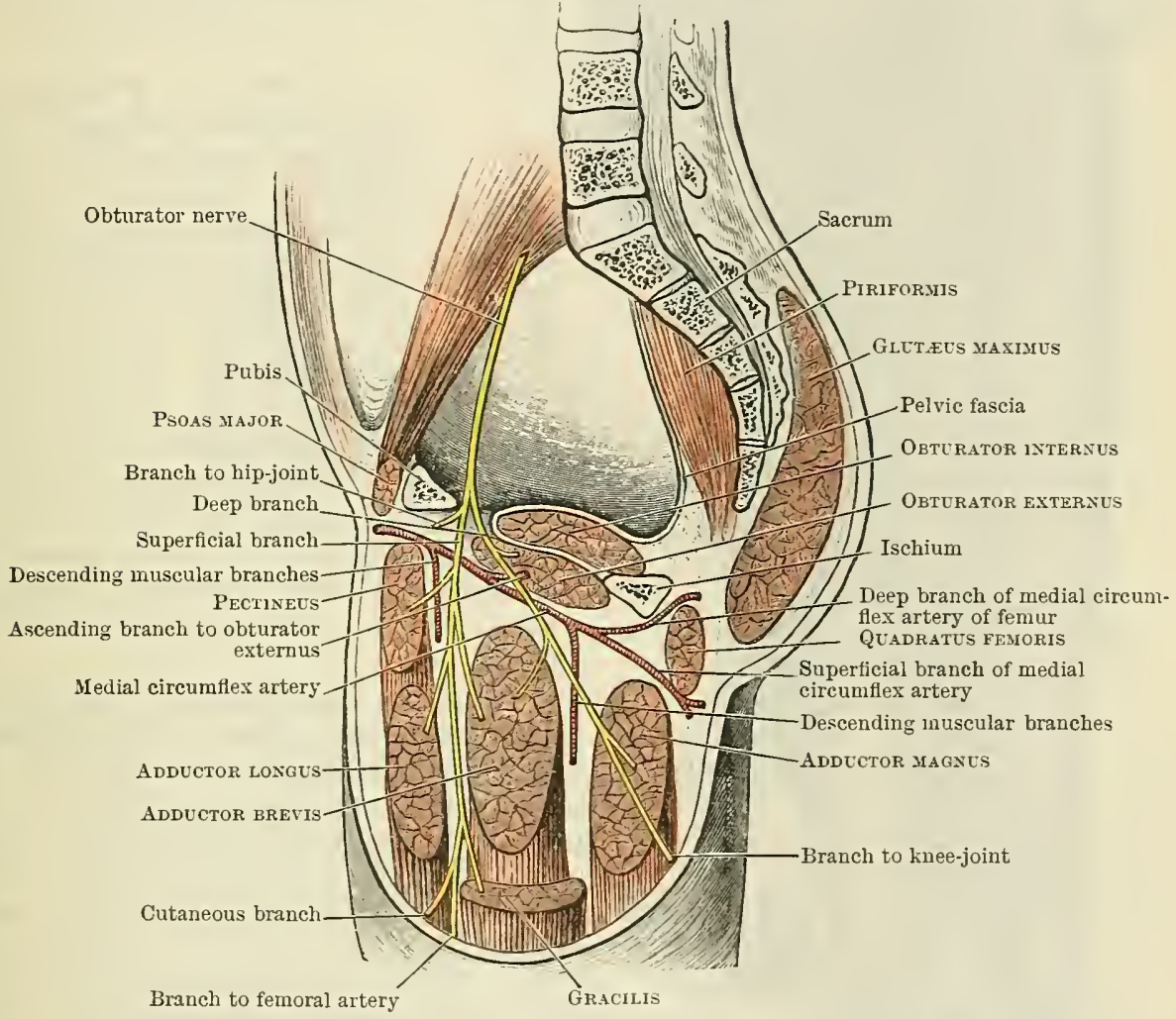

Fig. 367.-Scheme of the Course axd Distribution of the Right Obturator Nerie.

while the femoral artery is in contact with the muscle as it pursues its course through the adductor canal. The posterior surface of the muscle is in relation with the hamstring muscles.

Nerve-Supply. - The adductor magnus is a double muscle, and has a double nerre-supply. The medial part of the muscle extending between the tuber ischiadicum and the medial condyle of the femur, associated with the hamstring group of muscles, derives its nerve from the nerve to the hamstring muscles, from the tibial nerve (L. 4. 5. S. 1.). This enters the muscle on its posterior surface.

The adductor portion of the muscle is supplied on its anterior surface by the deep branch of the obturator nerve (L. 3. 4.).

Actions. - The adductor magnus is an adductor and extensor of the thigh.

M. Obturator Externus.-The obturator externus is placed deeply under cover of the previous muscles. It is a fan-shaped muscle lying horizontally in the angle between the hip bone and the neck of the femur.

It arises from the surfaces of the pubic bone and ischium, which form the inferior half of the margin of the obturator foramen, and from the corresponding 
portion of the superficial surface of the obturator membrane (Figs. 366, p. 412, and 367, p. 413 ).

Its fibres converge towards the greater trochanter, and end in a stout tendon

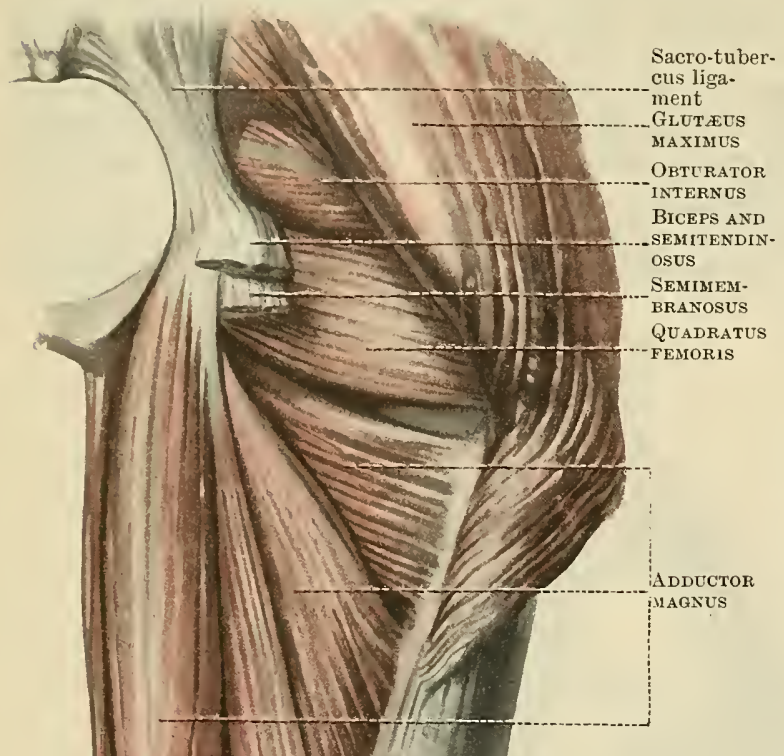
which, after passing distal to and posterior to the hip-joint, is inserted into the trochanteric fossa of the greater trochanter of the femur (Figs. 365 , p. 410 , and 373, p. 417 ).

Nerve-Supply.-The deep part of the obturator nerve ( $L_{\text {. }}$ 3. 4.).

Actions. - This muscle is mainly a lateral rotator of the thigh; it also flexes and adducts it.

Trigonum Femorale.The femoral triangle (O.T. Scarpa's triangle) is a large triangular space on the front of the thigh in its proximal third, which contains the femoral vessels in the proximal part of their course and the femoral nerve. It is bounded above by the inguinal ligament, laterally by the sartorius, and medially by the medial border of the adductor longus muscle. Its floor is iormed laterally by the ilio-psoas, and medially by the pectineus, adductor longus, and a small part of the adductor brevis.

Canalis Adductorius Hunteri.The adductor canal (O.T. Hunter's canal) occupies the middle third of the medial side of the thigh, and contains the femoral vessels in the distal part of their course. It is bounded superficially by the sartorius, under which is a dense fascia derived from the fascia lata, binding together the vastus medialis, which forms the lateral wall of the canal, and the adductors, longus and magnus, which form the medial wall or floor of the canal. Besides the femoral vessels and their sheath, the canal contains the saphenous nerve.

\section{THE MIUSCLES OF THE BUTTOCK.}

This group includes the three glutæi muscles, the tensor fasciæ latæ, piriformis, obturator internus and gemelli, and quadratus femoris.

The glutæus maximus and tensor fasciæ

Frg 368.-Deep Muscles oy the Posteriok Aspect of the Right Thigh. lat: muscles are in the same plane, invested by envelopes of the fascia lata. The glutæus medius, partially covered by the glutæus maximus, conceals the glutæus minimus; while the piriformis, obturator internus, gemelli, and quadratus femoris intervene between the glutæus maximus and the posterior surface of the hip-joint. 
M. Glutæus Maximus.-The glutæus maximus is a large quadrilateral muscle, with a crescentic origin arising from (1) a portion of the area on the dorsum ilii above the posterior gluteal line (Fig. 369); (2) the tendon of the sacrospinalis muscle; (3) the dorsal surface of the sacrum and coccyx (Fig. 395, p. 443); and (4) the posterior surface of the sacro-tuberous ligament. The fibres which form its superior and lateral border take origin directly from the fascia lata which envelops the muscle.

The muscle forms a large fleshy mass, whose fibres are directed obliquely over the buttock, invested by the fascia lata, and are inserted by short tendinous fibres, partly into the fascia lata over the greater trochanter of the femur (joining the ilio-tibial tract), and partly into the gluteal tuberosity (Fig. 370, p. 416). The fascia lata receives the insertion of the whole of the superficial fibres of the muscle and the superior half of the deep fibres. The inferior half of the deep portion of

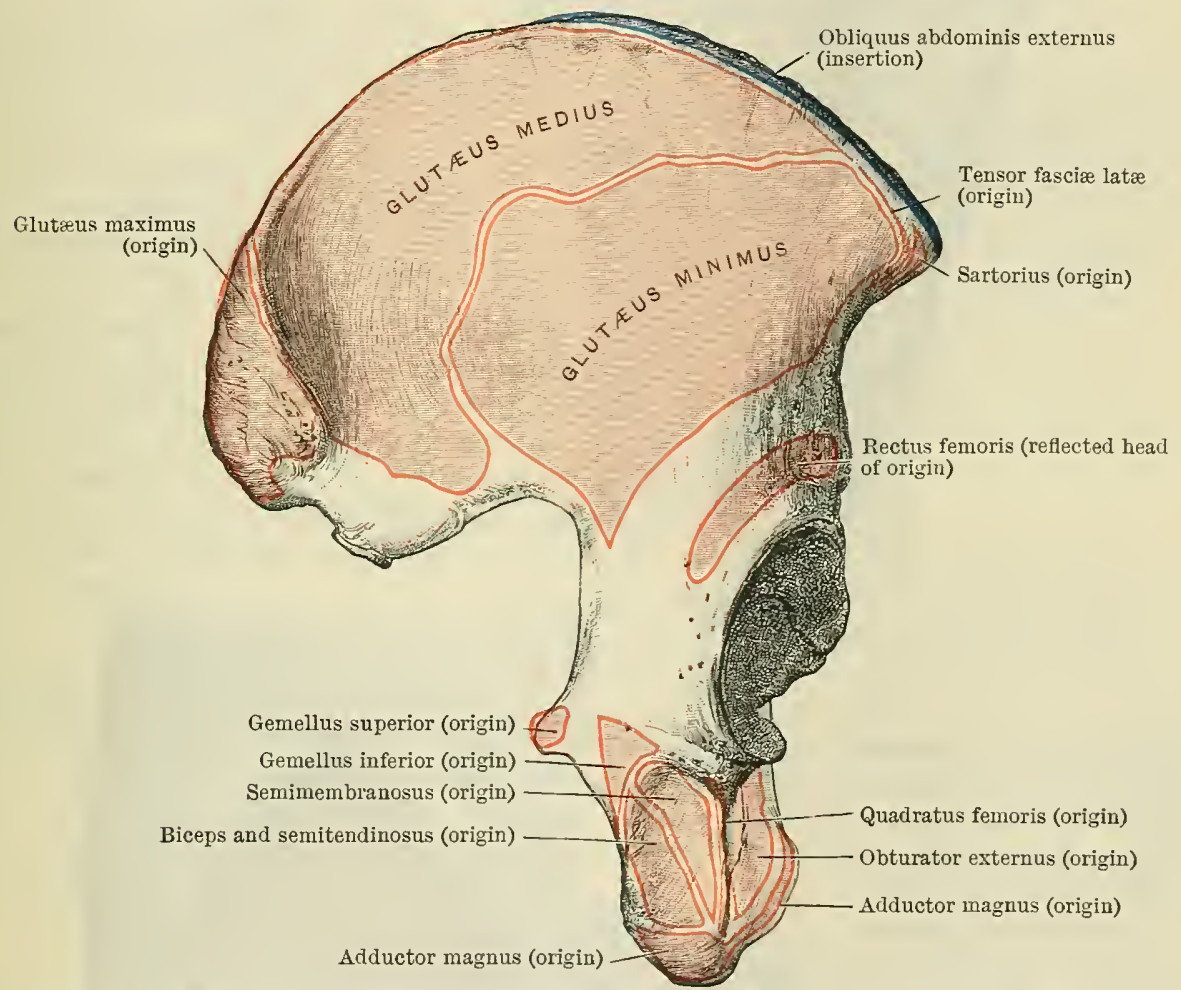

Fig. 369. - Muscle-Attachuents to the Right Dorsum Ilit and Tuber Ischiadicom.

the muscle is inserted for the most part into the gluteal tuberosity; but the most inferior fibres of all are inserted into fascia lata, and are thereby connected with the lateral intermuscular septum and the origin of the short head of the biceps.

The glutæus maximus is the coarsest and heaviest muscle in the body. By its weight it helps to form the fold of the nates. It is superficial in its whole extent. The glutæus medius is visible at its superior border, covered by the fascia lata; at its lower border the hamstring muscles and sciatic nerve appear on their way to the thigh. Three bursæ are beneath it: one (not always present) over the sciatic tuberosity, a second over the lateral side of the greater trochanter, and a third over the vastus lateralis. The fibres of the glutæus maximus arising from the coccyx may form a separate muscle (agitator caudæ).

Nerve-Supply.-Inferior gluteal nerve, from the sacral plexus (L. 5. S. 1. 2.).

Actions. - The glutæus maximus is mainly an extensor of the thigh, and has a powerful action in straightening the lower limb, as in climbing or running. Its lower fibres also adduct the thigh and rotate it laterally.

M. Tensor Fasciæ Latæ.-The tensor fasciæ latæ arises from the iliac crest 


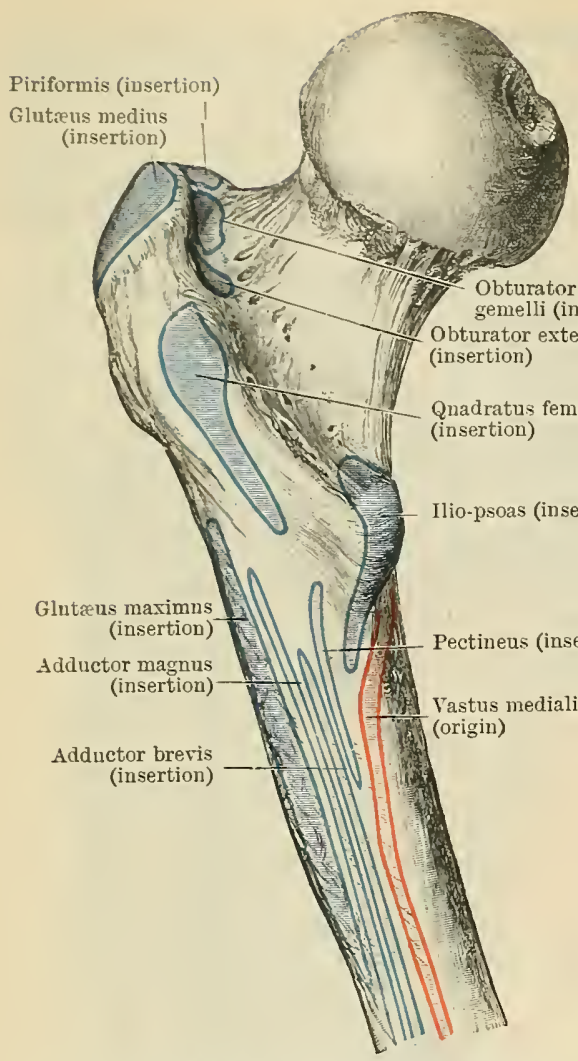

Fig. 370.-MUSCle-ATtachments TO THE Posterior ASPECT OF THE PROIIMAL PART OF THE LEFT FEMUR.

verging to the greater trochanter, to be inserted by a dorsal fascia strong, short tendon into the postero-superior angle of the greater trochanter, and into a well-marked diagonal line on its lateral surface (Fig. 370 , and Fig. 372, p. 417). A bursa is placed beneath the tendon at its insertion.

The muscle is partly superficial, partly concealed by the glutæus maximus. It covers the glutrus minimus, and the superior gluteal nerve and the deep branches of the superior gluteal artery.

Nerve-Supply.-The superior gluteal nerve from the sacral plexus (L. 4. 5. S. 1.).

Actions. - This muscle is a powerful abductor and medial rotator of the thigh.

I. Glutæus Iinimus.The glutæus minimus arises, under cover of the glutæus and the dorsum ilii just lateral to the superior anterior spine, and from the fascia covering its lateral surface (Fig. 369, p. 415).

Invested like the glutæus maximus by the fascia lata, it is inserted distal to the level of the greater trochanter of the femur into the fascia, which forms the ilio-tibial tract (p. 404). The muscle is placed along the anterior borders of the glutæus medius and glutæus minimus.

Nerve-Supply. - The superior gluteal nerve from the sacral plexus (L. 4. 5. S. 1.) ends in this muscle after passing between the glntæus medins and glutæus minimus.

Actions. - It assists in the abduction and rotation of the thigh; and along with the glutæus maximus, by its insertion into the ilio-tibial tract, it helps to support the knee-joint in the extended position.

M. Glutæus Medius. - The glutæus medius arises from (1) the dorsum ilii, between the iliac crest and posterior gluteal line above and the anterior gluteal line below (Fig. 369, p. 415), and (2) the strong fascia lata covering its surface anteriorly.

It is a fan-shaped muscle, its fibres con-

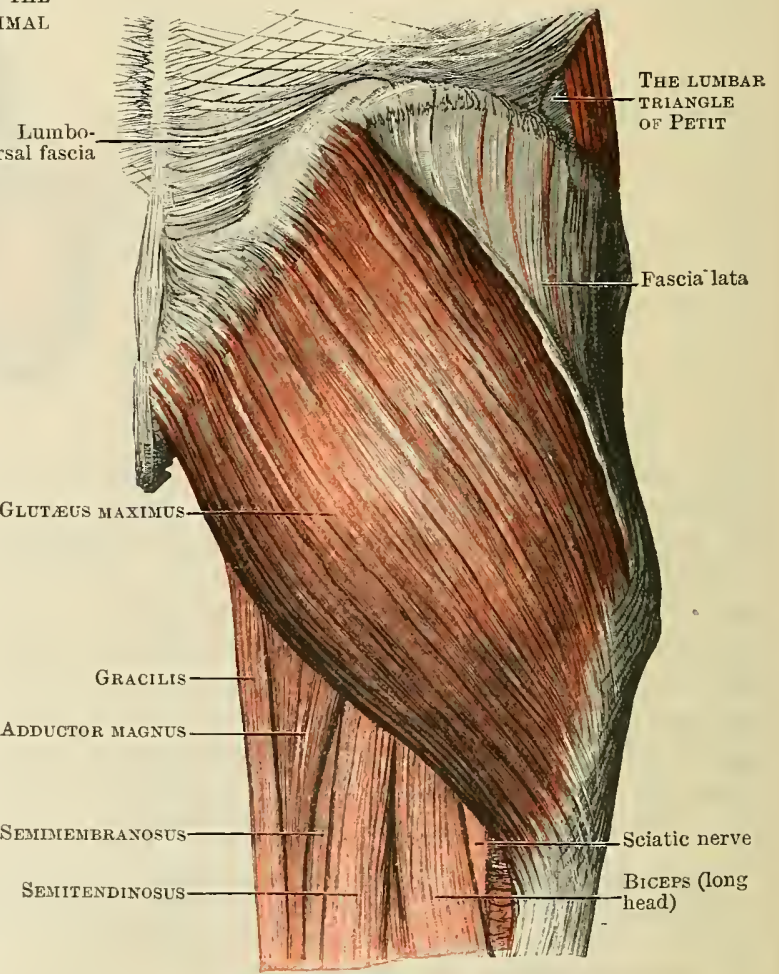

Fig. 371.-The Right Gletels Maximus Muscle. 
medius, by fleshy fibres from the dorsum ilii between the anterior and inferior gluteal lines (Fig. 369, p. 415).

This muscle is fan-shaped and its fibres converge to the antero-superior angle of the greater trochanter, to be inserted into the anterior surface of the trochanter, and sometimes also into the front part of the superior border (Figs. 361, p. 407, and 373 ). It is also inserted into the capsule of the hip-joint. A bursa is placed beneath the tendon in front of the greater trochanter.

Nerve-Supply.The superior gluteal nerve from the sacral plexus (L. 4. 5. S. 1.).

Actions.-The muscle is primarily an abductor of the thigh. Its anterior fibresin addition produce medial rotation and its posterior fibres lateral rotation of the limb.

\section{Piriformis.-} The piriformis is one of the few muscles connecting the lower limb to the

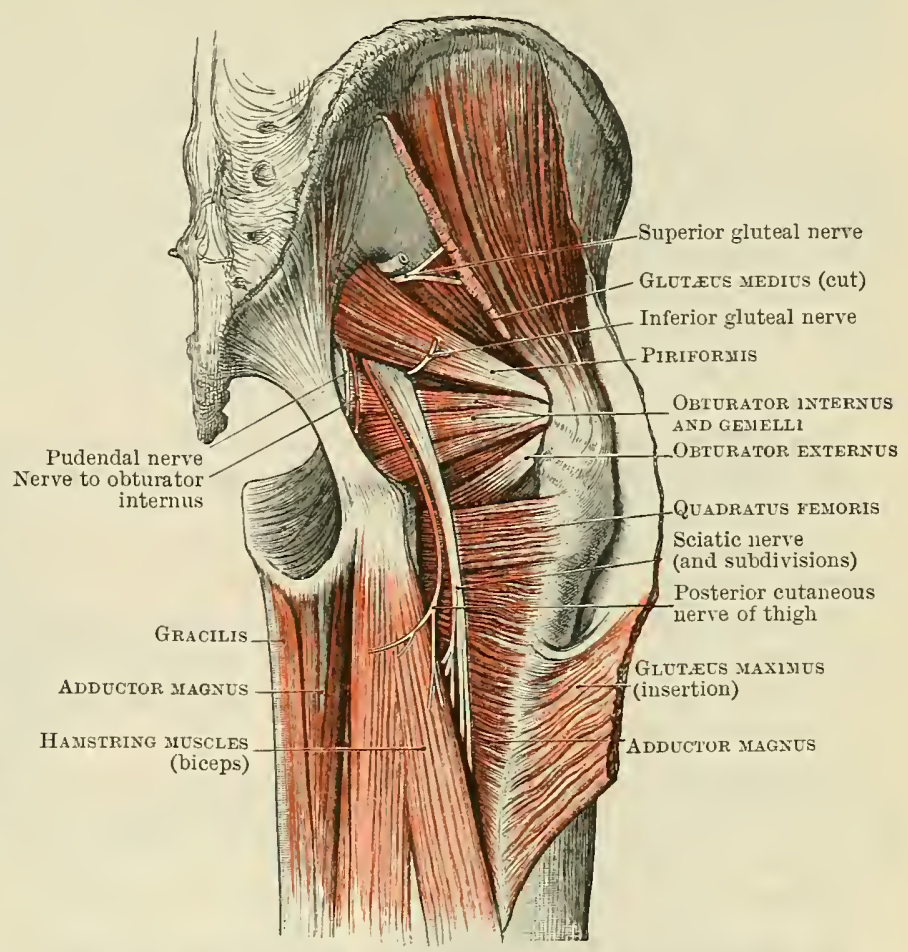

Fig. 372.-The Muscles and Nerves of the Right Buttock.

The glutæus maximus is reflected; and the glutæus medius is cut in part to show the glutæus minimus.

axial skeleton. It arises (1) within the pelvis from the roots of the vertebral arches of the second, third, and fourth sacral vertebræ, and from the adjacent part of the bone lateral to the anterior sacral foramina. Passing out through the greater sciatic foramen, it receives an origin from (2) the upper margin of the

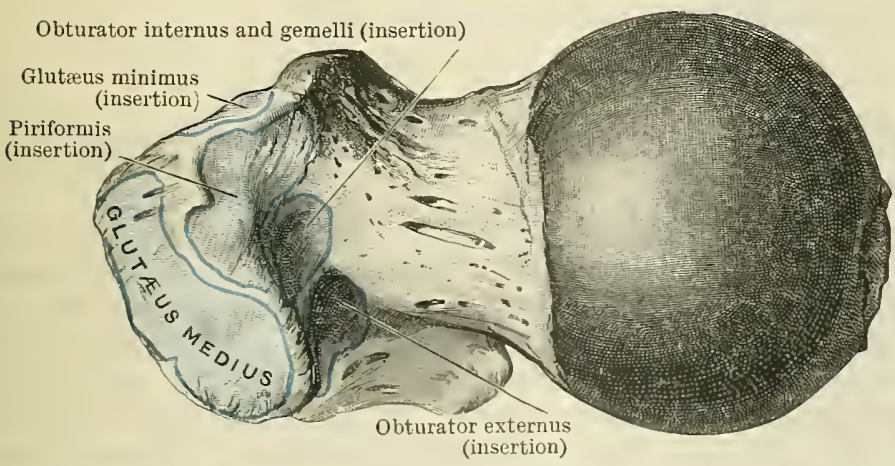

Fig. 373.-Muscle-Attachments to the Proxiatal Aspect of the Greater Trochanter of the Left FeMtr. greater sciatic notch of the ilium, and (3) the pelvic surface of the sacro-tuberous ligament.

In the buttock it forms a rounded tendon, which is inserted into a facet on the superior border and medial aspect of the greater trochanter of the femur (Figs. 370, p. 416, and 373 ).

The piriformis, at its origin, lines the posterior wall of the pelvis. In the buttock it is covered by the glutæus maximus, and lies behind the capsule of the hip-joint, between the glutæus medius and superior gemellus.

Nerve-Supply.-Branches direct from the anterior rami of the first and second sacral nerves. 
Actions. - The muscle is an abductor and lateral rotator of the hip.

M. Obturator Internus.-The obturator internus arises on the pelvic aspect of the hip bone, from (1) the whole of the margin of the obturator foramen (except the obturator notch); (2) the surface of the obturator membrane; (3) the whole of the pelvic surface of the hip bone behind and above the obturator foramen; and (4) the parietal pelvic fascia covering it medially.

It is a fan-shaped muscle, and its fibres converging to the lesser sciatic foramen, give rise to several tendons united together, which hook round the margin of the foramen (a bursa intervening), and after passing over the posterior surface of the hip-joint, are inserted into a facet on the medial surface of the greater trochanter of the femur above the trochanteric fossa (Figs. 370, p. 416, and 373, p. 417).

In the pelvis the muscle occupies the lateral wall, covered by the parietal pelvic fascia, which separates it from the pelvic cavity above and the ischio-rectal fossa below. In the buttock the tendon is embraced by the gemelli muscles which are attached to its superior and inferior margins.

The gemelli muscles form accessory portions of the obturator internus.

II. Gemellus Superior.-The superior gemellus arises from the gluteal surface of the ischial spine (Fig. 369, p. 415).

It is inserted into the upper margin and superficial surface of the tendon of the obturator internus muscle.

M. Gemellus Inferior.-The gemellus inferior arises from the superior part of the gluteal surface of the ischial tuberosity (Fig. 369, p. 415).

It is inserted into the inferior margin and superficial aspect of the tendon of the obturator internus.

Nerve-Supply. - The obturator internus and superior gemellus receive branches from a special nerve, the nerve to the obturator internus from the anterior aspect of the sacral plexus (S. 1. 2. 3.). The inferior gemellus is supplied by the nerve to the quadratus femoris, a branch derived also from the anterior aspect of the sacril plexus (L. 4. 5. S. 1.).

Actions. - The obturator internus and gemelii are abductors and lateral rotators of the hip.

II. Quadratus Femoris.-The quadratus femoris arises from the lateral margin of the tuber ischiadicum (Figs. 366, p. 412, and 369, p. 415). It is inserted into the quadrate tubercle and quadrate line of the femur (Fig. 370, p. 416).

The muscle is concealed by the glutæus maximus and the hamstring muscles. Its deep surface is in contact with the obturator externus muscle and the lesser trochanter of the femur, a bursa intervening. The muscle is not infrequently fused with the adductor magnus.

Nerve-Supply.-A special nerve from the sacral plexus (L. 4. 5. S. 1.) which enters its deep (anterior) surface.

Actions.-The muscle is an adductor and lateral rotator of the thigh.

\section{THE MUSCLES ON THE POSTERIOR ASPECT OF THE THIGH.}

\section{The Hamstring Muscles.}

The muscles comprised in this series include the biceps, semitendinosus, and semimembranosus. A part of the adductor magnus, already described, also belongs morphologically to this group. They occupy the buttock and posterior aspect of the thigh, and diverge at the knee to bound the popliteal fossa. The origins of the muscles are concealed by the glutæus maximus. In the back of the thigh, enveloped by the fascia lata, they are placed behind the adductor magnus-the semitendinosus and semimembranosus medially, the biceps laterally. The former two muscles help to form the medial boundary of the popliteal fossa, of which the biceps is a lateral boundary.

IM. Biceps Femoris.-The biceps femoris has a double origin. (1) Its long head arises by means of a tendon, in common with the semitendinosus, from the inferior and medial facet upon the sciatic tuberosity (Figs. 366, p. 412, and 369, p. 415) and from the sacro-tuberous ligament. This head, united for a 
distance of two or three inches with the semitendinosus, forms a separate fleshy mass, which extends to the distal third of the thigh, to end in a tendon joined by the short head of the muscle. (2) The short head arises separately from (1) the whole length of the lateral lip of the linea aspera and the proximal two-thirds of the lateral epicondylic line of the femur, and (2) the lateral intermuscular septum. The proximal limit of its origin is sometimes blended with the insertion of the lowest fibres of the glutæus maximus.

The fibres of the short head, directed distally, join the tendon of the long head, and the muscle is inserted (1) into the head of the fibula by a strong tendon, which is split into two parts by the fibular collateral ligament of the knee-joint; (2) by a slip attached to the lateral condyle of the tibia; and (3) along its posterior border by a fascial expansion which connects the tendon with the popliteal fascia.

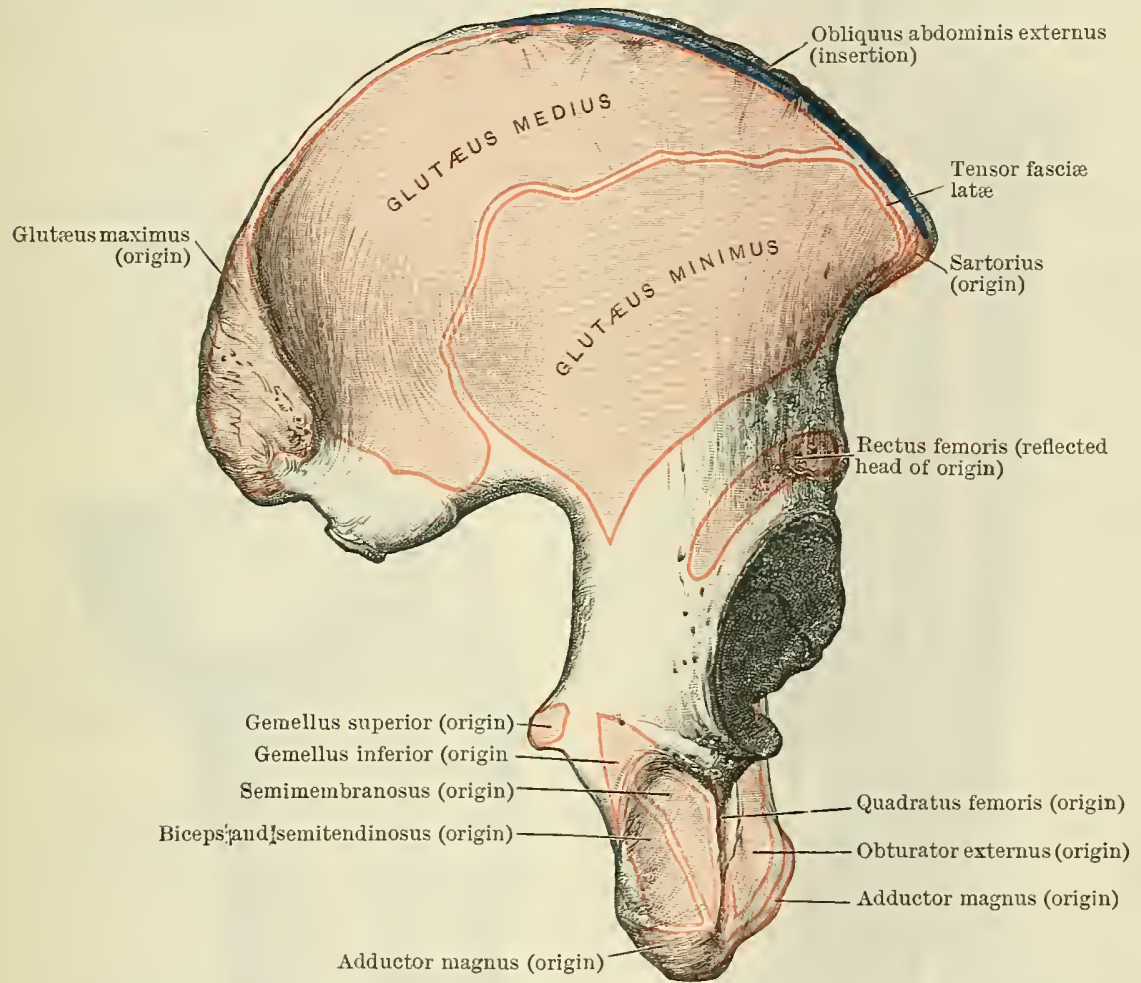

Fig. 37.-Muscle-Attachments to the Right Dorsem Ilit and Tuber Ischiadictu.

There is a bursa between the tendon and the fibular collateral ligament of the knee-joint.

The short head may be absent: there may be an additional origin from the ischium or femur; and the long head may send a slip to the gastrocnemius or tendo calcaneus (Achillis) (tensor fasciæ suralis).

M. Semitendinosus.-The semitendinosus arises, in common with the long head of the biceps, from the inferior and medial facet upon the ischial tuberosity (Fig. 374, p. 419). Separating from the common tendon two or three inches from its origin, the muscle forms a long, narrow band which becomes tendinous in the middle third of the thigh.

Passing over the medial side of the knee it spreads out and becomes membranous and is inserted (1) into the medial side of the shaft of the tibia just distal to the medial condyle, distal to the gracilis and behind the sartorius (Fig. 376, p. 420), and (2) into the deep fascia of the leg. A bursa separates it from the sartorius superficially, and another, common to it and the gracilis, lies deep to its insertion. The belly of the muscle is marked by an oblique septal tendinous intersection about its middle. 
Nerve-Supply. - The semitendinosus is supplied by two branches from the nerve to the hamstring muscles (T. 5. S. 1. 2.)

Actions.-A flexor and medial rotator of the knee, and an extensor of the hip.

IM. Semimembranosus.-The semimembranosus arises by a tendon from the

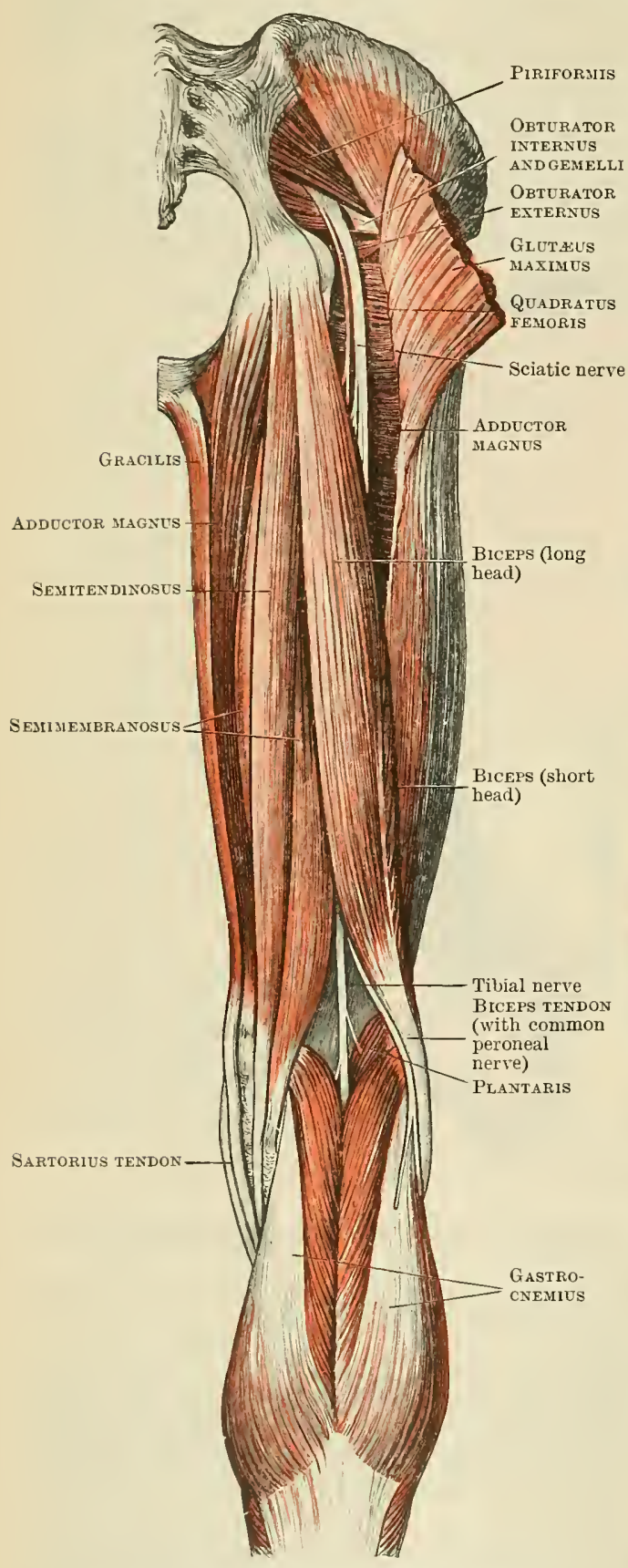

Fig. 375.-The Muscles on the Posterior Aspect of the Right Thigh. superior and lateral facet on the ischial tuberosity (Figs. 366, p. 412 , and 374 , p. 419). In the proximal third of the thigh the tendon gives place to a rounded fleshy belly, which lies beneath the ischial origin of the biceps and semitendinosus muscles.

Becoming tendinous at the back of the knee, it is inserted into the horizontal groove on the posteromedial aspect of the medial condyle of the tibia (Figs. 376, below, and 384 , p. 428). A buisa lies deep to the tendon at its insertion. It has three additional membranous insertions: (1) a fascial band extends distally and medially to join the posterior border of the tibial collateral ligament of the knee-joint; (2) another fascial band extends distally

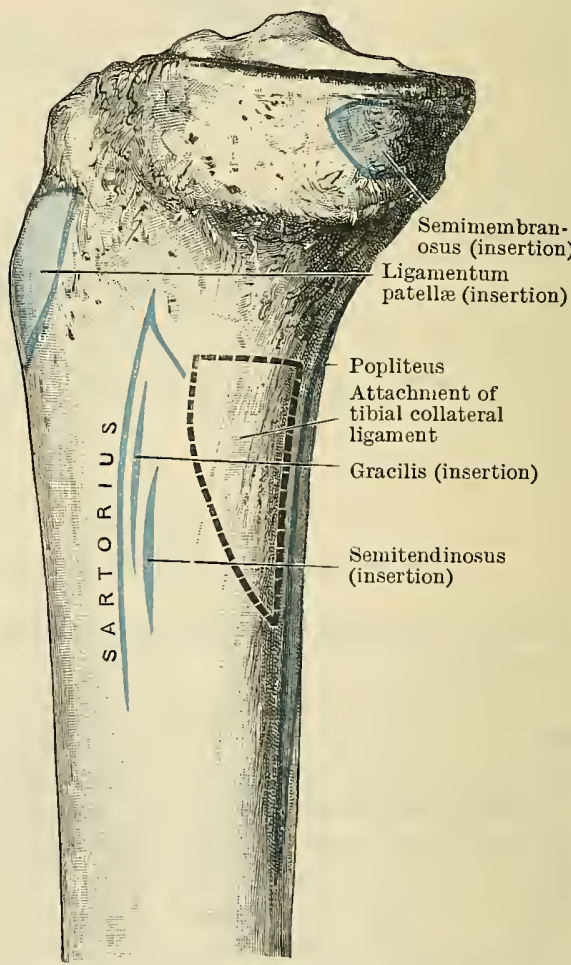

Fig. 376.-Muscle-AtTachments to the Medial Surface of the Proximal Part of the Right Tibia.

and laterally, forms the fascia covering the popliteus muscle (popliteus fascia), and is attached to the oblique line of the tibia; and (3) a third strong band extends proximally and laterally to the back of the lateral condyle of the femur, forming the oblique popliteal ligament of the knee-joint. 
The membranous origin of the muscle is concealed by the orifices of the semitendinosus and long head of the biceps. The insertion covers the origin of the inner head of the gastrocnemius.

Nerve-Supply.- It is innervated by the nerve to the hamstring muscles (L. 5. S. 1. 2.).

Actions.-A flexor and medial rotator of the knee, as well as an extensor of the hip.

\section{Actions of the Muscles of the Thigh and Buttock.}

Most of the above muscles act on the pelvis and on the hip- and knee-joints. The psoas major muscle in addition assists in the movements of the vertebral colnmn (p. 411).

1. Movements at the Hip-Joint. - The movements of the thigh at the hip-joint are flexion and extension, adduction and abduction, medial and lateral rotation. The following table gives the muscles producing these movements :-

\begin{tabular}{|c|c|c|}
\hline & a. Flexion and & Extension. \\
\hline $\begin{array}{l}\text { Sartorius } \\
\text { Iliacus } \\
\text { Psoas major } \\
\text { Rectus femoris } \\
\text { Pectineus } \\
\text { Adductor longus } \\
\text { Gracilis } \\
\text { Obturator externus }\end{array}$ & & $\begin{array}{l}\text { Glutæus maximus } \\
\quad " \quad \text { medius } \\
\text { Biceps femoris } \\
\text { Semitendinosus } \\
\text { Semimembranosus } \\
\text { Adductor magnus }\end{array}$ \\
\hline
\end{tabular}

\begin{tabular}{|c|c|c|c|}
\hline & b. Adduction and & Abduction. & \\
\hline $\begin{array}{l}\text { Pectineus } \\
\text { Adductor longus } \\
\qquad, \quad \text { brevis } \\
\text { Gracilis magnus } \\
\text { Quadratus femoris } \\
\text { Glutæus maximus } \\
\text { (lower fibres) }\end{array}$ & & $\begin{array}{l}\text { Tensor fasciæ latæ } \\
\text { Glutæus medius } \\
\quad, \quad \text { minimus } \\
\text { Obturator externus } \\
\text { Piriformis } \\
\text { Obturator internus } \\
\text { Gemelli } \\
\text { Sartorius } \\
\text { Glutæus maximus } \\
\text { (upper fibres) }\end{array}$ & $\begin{array}{l}\text { during } \\
\text { fllexion }\end{array}$ \\
\hline
\end{tabular}

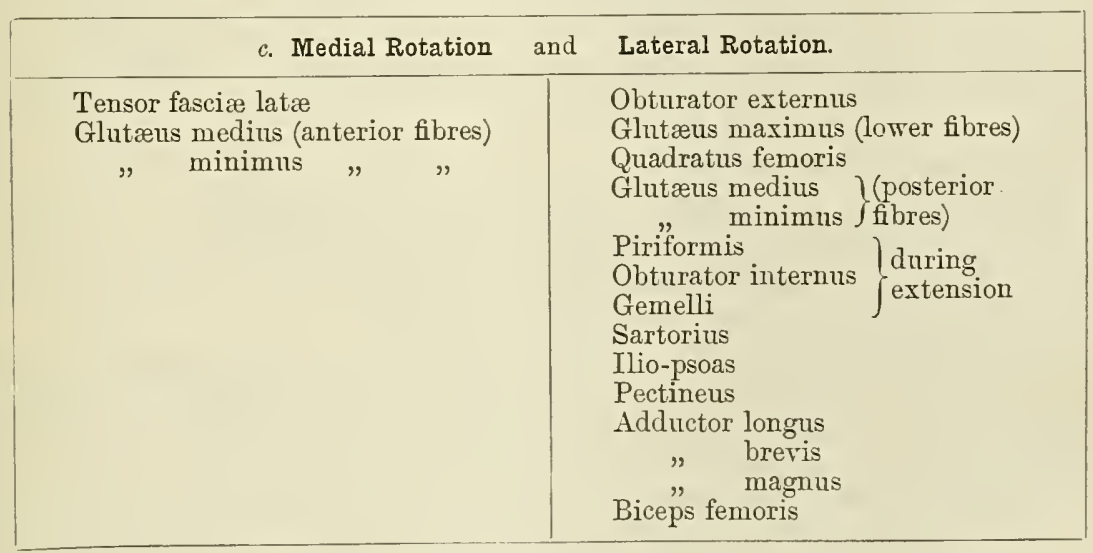

2. Movements of the Peivis on the Thigh. - It is to be noted that the several movements tabulated above refer to the movements of the femur at the hip-joint. The contraction of the same groups of muscles produces similar movements of the pelvis on the femur, exemplified in the various changes in the attitude of the pelvis in relation to the thigh and the rertebral column, which occur in locomotion.

3. Movements at the Knee-Joint. - The movements at the knee-joint are mainly flexion and extension. Flexion is much more powerful than extension. There is also a limited amount of rotation of the tibia. The movements are produced by certain of the muscles described above, associated with certain of the muscles of the leg. 


\begin{tabular}{|l||l|l|l|}
\multicolumn{1}{|c|}{$\alpha$. Flexion } & and Extension. & \multicolumn{3}{|c|}{ Rotation medially and Rotation laterally. } \\
\hline Sartorius & Quadriceps femoris & Sartorius & Biceps femoris \\
Gracilis & Gracilis & \\
Semitendinosus & & Semitendinosus & \\
Semimembranosus & & Semimembranosus & \\
Biceps femoris & & Popliteus & \\
Gastrocnemius & & & \\
Plantaris & & & \\
Popliteus & & & \\
\hline
\end{tabular}

\section{THE FASCIAE AND MIUSCLES OF THE LEG AND FOOT.}

\section{FASCI床。}

The superficial fascia of the leg and foot presents no special features except in the sole, where it is greatly thickened by pads of fat, particularly under the tubercles of the calcaneus, and under the balls of the toes.

The deep fascia has numerous important attachments about the knee. Posteriorly it forms the popliteal fascia, and is joined by expansions from the tendons of the sartorius, gracilis, semitendinosus, and biceps femoris muscles. In front of the knee it is attached to the patella, the ligamentum patellæ, and the tubercle of the tibia; laterally it is connected to the condyles of the tibia and the head of the fibula, and forms the collateral patellar ligaments-broad fascial bands which pass obliquely from the sides of the patella to the condyles of the tibia, and are joined by fibres of the vasti muscles. Passing into the leg, the fascia blends over the medial surface of the tibia with the periosteum of the bone. It extends round the lateral side of the leg from the anterior crest to the medial border of the tibia, binding together and giving origin to the muscles, and gaining an attachment to the distal part of the shaft of the fibula. Two septa pass from its deep surface; one septum (anterior peroneal septum), attached to the anterior crest of the fibula, encloses the (superficial peroneal) nerve, and separates the extensor from the peronæi muscles. The other septum (posterior peroneal septum) is attached to the lateral crest of the fibula, and separates the peronæi from the flexor muscles. From the last-named septum another extends across the back of the leg, forms a partition between the superficial and deep flexor muscles, and encloses the posterior tibial vessels and the tibial nerve. It gives rise to subordinate septa attached to the vertical line of the tibia and the medial crest of the fibula, which separate the tibialis posterior from the flexors of the toes on either side.

At the ankle the deep fascia is strengthened by additional transverse fibres, which give rise to thickened bands named the ligamentum laciniatum, lig. transversurn cruris, lig. cruciatum cruris and the retinaculum of the peroneal muscles. They were formerly known as the annular ligaments.

The ligamentum laciniatum (O.T. internal annular ligament) stretches between the medial malleolus and the tuberosity of the calcaneus. While it is continuous at its proximal border with the general investment of the deep fascia, it is chiefly formed by the septal layer covering the deep muscles on the back of the leg. It sometimes gives insertion to the plantaris muscle. It is continuous distally with the plantar aponeurosis, and gives origin to the abductor hallucis muscle. It is pierced by the calcanean vessels and nerve. Along with the posterior tibial vessels and the tibial nerve, the tendons of the tibialis posterior, flexor digitorum longus, and flexor hallucis longus, pass beneath it, each enclosed in a separate synovial sheath.

The superior peroneal retinaculum (O.T. lateral annular ligament) is a thickened band of the deep fascia stretching between the lateral malleolus and the calcaneus. It binds down the tendons of the peronæi, which occupy a space beneath the ligament, lined by a single synovial membrane; while the inferior 
peroneal retinaculum binds them down separately on the lateral surfaces of the calcaneus.

The ligamentum transversum cruris (O.T. anterior annular ligament, upper band), broad and undefined at its proximal and distal borders, stretches across the front of the ankle between the two malleoli. This band binds down to the distal end of the tibia the tendons of the tibialis anterior and extensor muscles of the toes. One synovial sheath is found beneath it, surrounding the tendon of the tibialis anterior.

Ligamentum Cruciatum Cruris.-On the dorsum of the foot, where the general covering of deep fascia is much thinner, a special well-defined band, named the ligamentum cruciatum cruris (O.T. anterior annular ligament, lower band), stretches over the extensor tendons. It has an attachment laterally to the lateral border of the dorsal surface of the calcaneus. It divides into two bands as it passes medially over the dorsum of the foot-a proximal part, which joins the lig. transversum cruris and is attached to the medial malleolus, and a distal part, which passes across the dorsum of the foot, and joins the fascia of the sole at its medial border. Beneath this ligament are three special compartments with separate synovial sacs, one for the tibialis anterior tendon, a second for that of the extensor halIucis longus, and a third for the extensor digitorum longus and peronæus tertius tendons. There are occasionally other additional bands of the deep fascia passing like the straps of a sandal across the dorsum of the foot.

The plantar

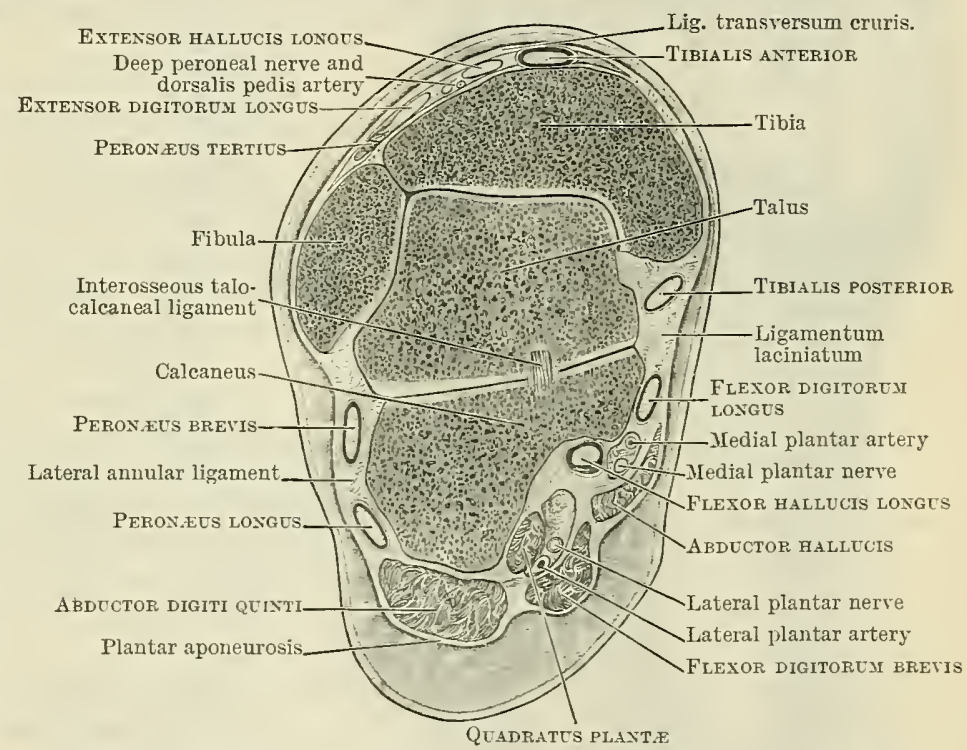

Fig. 37 $7 .-$ Frontal Section throdgh the Left ANkle-Joint, Talus, and Calcaneus.

aponeurosis is of great importance. In the centre of the sole it forms a thick triangular band, attached posteriorly to the tuberosity of the calcaneus. It spreads out anteriorly and separates into five slips, which are directed forwards to the bases of the toes. These slips as they separate are joined together by ill-defined bands of transverse fibres, which constitute the superficial transverse metatarsal ligament (fasciculi transversi aponeurosis plantæ). The slip for each toe joins the tissue of the web of the toe and is continuous with the digital sheath. It splits to form a band of fibres directed forwards on each side of the toe to be attached to the sides of the metatarso-phalangeal articulation and the base of the first phalanx.

This central portion of the plantar aponeurosis assists in preserving the arch of the foot, by drawing the toes and the calcaneus together.

On each side it is continuous with a much thinner layer which corers the lateral and medial muscles of the sole, and joins the fascia of the dorsum of the foot at each border. It also gives rise to intermuscular septa, which pass deeply on each side of the flexor digitorum brevis, enclosing that muscle in a separate sheath, and giving investments on either side to the abductor muscles of the great and little toes. At the lateral border of the foot the calcaneo-metatarsal ligament, a thickened band of the fascia, connects the tuberosity of the calcaneus with the base of the fifth metatarsal bone. 
The digital sheaths, though smaller, are the same in arrangement as those of the fingers (p. 389). Vaginal ligaments are present in relation to the first and second phalanges.

\section{THE MUSCLES OF THE LEG AND FOOT.}

The muscles of the leg and foot are divisible into three series: (1) the extensor

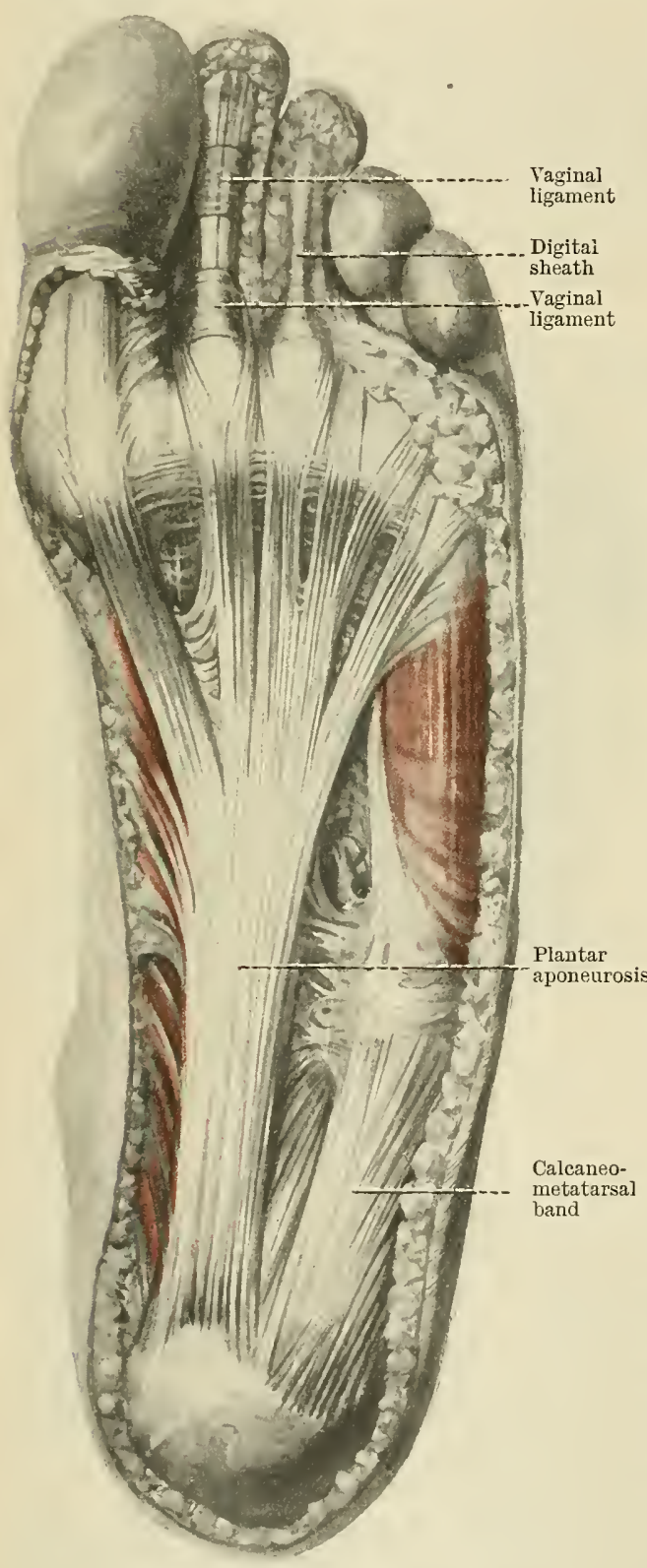

Fig. 378.-The Left Plantar Fascia. muscles on the front of the leg and dorsum of the foot; (2) the peronæi on the lateral aspect of the leg; and (3) the flexor muscles on the back of the leg and in the sole of the foot.

\section{The Muscles on the Front of the Leg and Dorsum of the Foot.}

The muscles on the front of the leg and dorsum of the foot include two groups: (1) on the front of the leg, the tibialis anterior, long extensors of the toes and peronæus tertius; and (2) on the dorsum of the foot, the extensor digitorum brevis, and extensor hallucis brevis.

On the front of the leg the tibialis anterior and the extensor digitorum longus and peronæus tertius are superficially placed, and conceal the extensor hallucis longus muscle. On the dorsum of the foot the extensor digitorum brevis muscle lies beneath the tendons of the long extensor of the toes.

M. Tibialis Anterior. - The tibialis anterior arises from the lateral condyle and the proximal two-thirds of the lateral surface of the shaft of the tibia, from the interosseous membrane from the fascia over it, and from an intermuscular septum laterally. The muscle ends in a strong tendon which passes over the dorsum of the foot, to be inserted into a facet on the medial surface of the first cuneiform and the medial side of the base of the first metatarsal bone (Fig. 379, p. 425). Its tendon ocçupies special compartments beneath both ligamentum transversum and lig. cruciatum cruris, enclosed in a separate, single, synovial sac.

The tibio-fascialis anterior is a separated portion of the muscle occasionally present, inserted into the fascia on the dorsum of the foot.

Nerve-Supply.-Deep peroneal nerve (L. 4. 5. S. 1.).

Actions.-The muscle is a dorsi-flexor of the ankle, and (in combination with the tibialis posterior) it invests the foot. 
M. Extensor Digitorum Longus.-The extensor digitorum longus arises by fleshy fibres from the lateral side of the lateral condyle of the tibia, from the proximal two-thirds or more of the anterior part of the medial surface of the shaft of the fibula, from the fascia over it, and from intermuscular septa on either side.

It gives rise to a tendon which passes beneath the ligamentum transversum and cruciatum, and in front of the ankle subdivides into four tendons, inserted into the four lateral toes, exactly in the same way as the corresponding tendons in the hand (see p. 397). They form membranous expansions on the dorsum of the first phalanx, joined by the tendons of the extensor digitorum brevis, lumbricales,

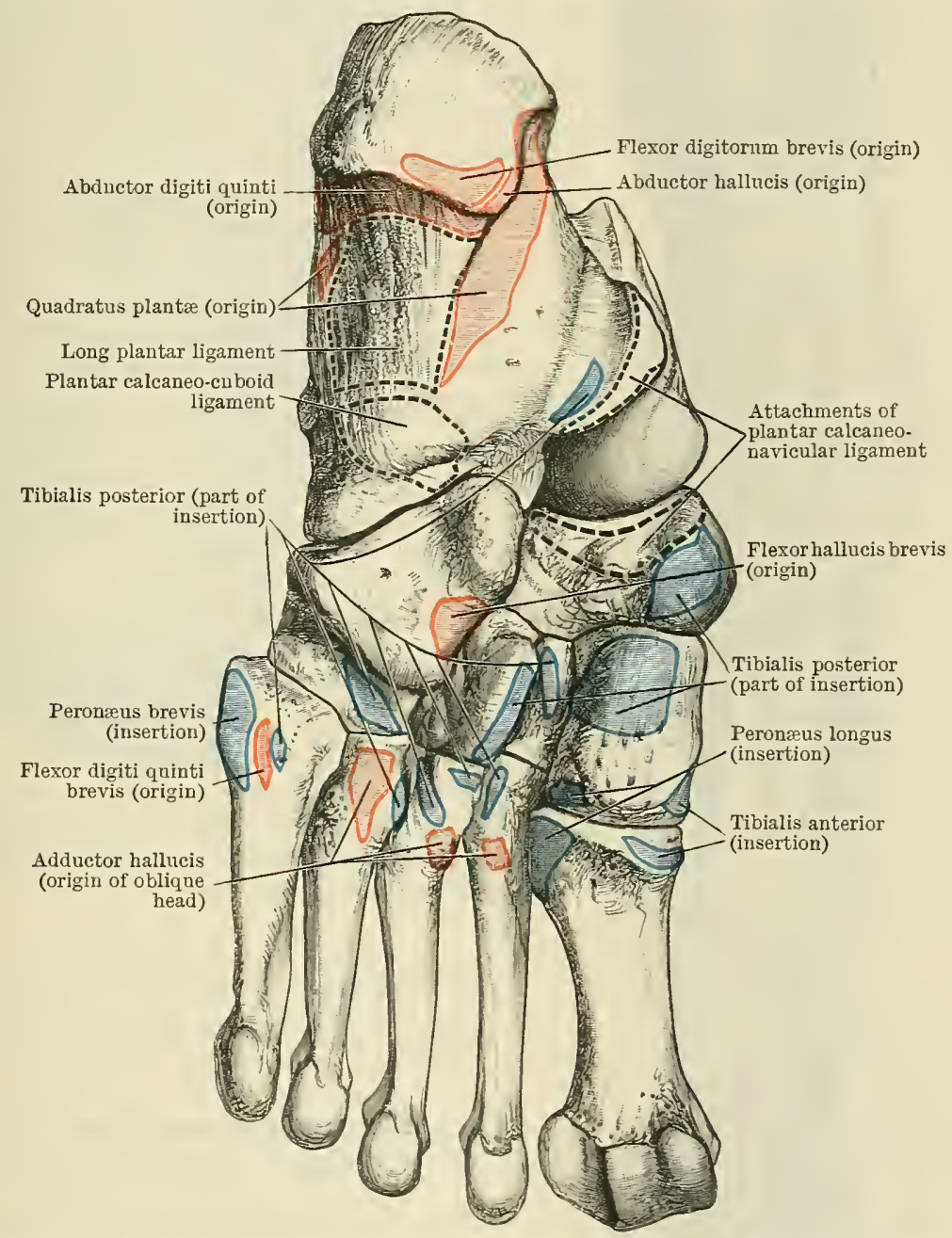

Fig. 379.-Muscle-Attachments to Left Tarsus and Metatarses (Plantar Aspect).

and interossei, each of which separates into one central and two collateral slips, attached respectively to the middle and terminal phalanges. The tendon occupies a separate compartment along with the peronæus tertius beneath the ligamentum cruciatum cruris, invested by a special synovial membrane.

Nerve-Supply.-Deep peroneal nerve (L. 4. 5. S. 1.).

Actions.-A dorsi-flexor of the ankle and an extensor of the four lateral toes.

M. Peronæus Tertius.-The peronæus tertius is a separated portion of the extensor digitorum longus. It is an essentially human muscle. It arises (inseparably from the extensor digitorum longus) from the anterior part of the medial surface of the fibula, and from the inter-muscular septum lateral to it. 
The tendon of the muscle is inserted into the dorsal aspect of the base of the fifth metatarsal bone.

Nerve-Supply.-Deep peroneal nerve (L. 4. 5. S. 1.).

Actions. - The muscle dorsi-flexes the ankle and raises the lateral border of the foot (as in skating or dancing).

M. Extensor Hallucis Longus.-The extensor hallucis longus arises from

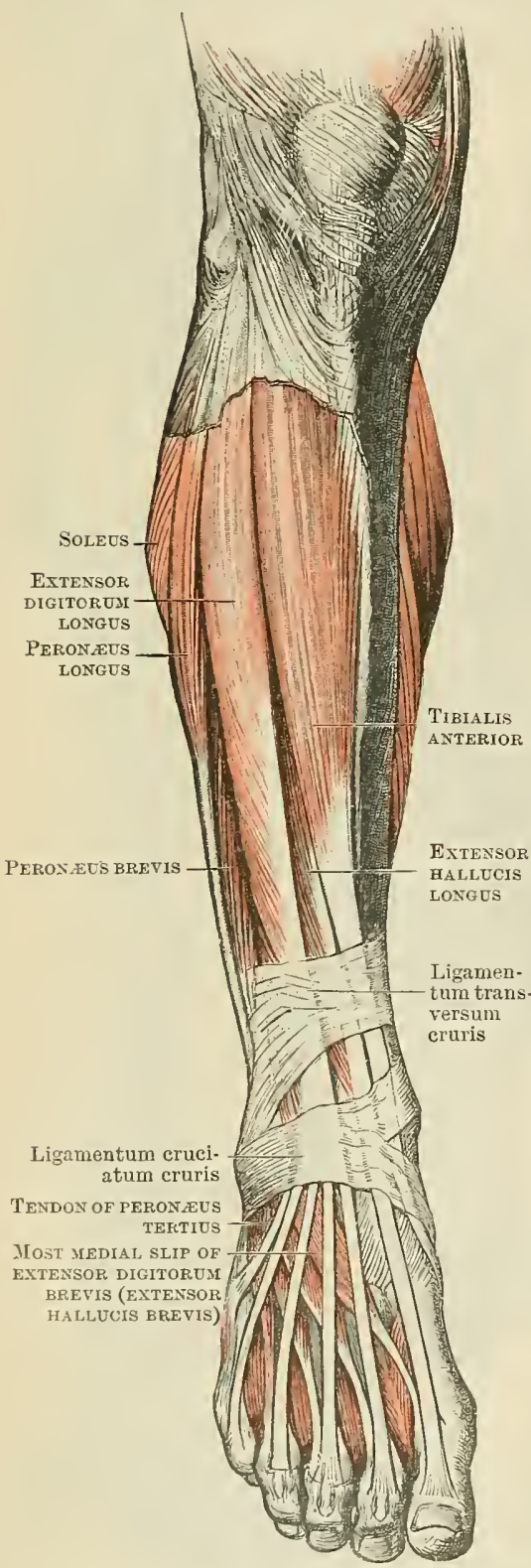

Fig. 380.-MUSCLES OF THE Front OF THE Right Leg and Dorsum of the Right Foot. the anterior part of the medial surface of the fibula in its middle three-fifths, medial to the origin of the extensor digitorum longus, and for a corresponding extent from the interosseous membrane. Its tendon passes over the dorsum of the foot, to be inserted into the base of the terminal phalanx of the great toe.

The extensor primi internodii longus and extensor ossis metatarsi hallucis are occasional separate slips of this muscle inserted into the proximal phalanx and the metatarsal bone.

Nerve-Supply.-Deep peroneal nerve (L.4. 5. S. 1.).

Actions.-This muscle dorsi-flexes the ankle, and extends the great toe.

IM. Extensor Digitorum Brevis. - The extensor digitorum brevis arises on the dorsum of the foot from a special impression on the dorsal surface of the calcaneus, and from the deep surface of the ligamentum cruciatum cruris.

It usually gives rise to four fleshy bellies, from which narrow tendons are directed forwards and medially, to be inserted into the four medial toes. The three lateral tendons join those of the long extensor muscle to form the membranous expansions on the dorsum of the toes. The most medial tendon (extensor hallucis brevis) is inserted separately into the base of the first phalanx of the great toe. S. 1.)

Nerve-Supply. - Deep peroneal nerve (L. 4. 5.

Actions. --Extension of the four inner toes.

\section{The IMuscles on the Lateral Side of the Leg.}

These muscles comprise the peronæi,longus and brevis. They are placed on the lateral side of the leg between the extensor digitorum longus in front, and the soleus and flexor hallucis longus behind, enclosed in a special compartment of the deep fascia.

II. Peronæus Longus.-The peronæus longus arises from the head and the proximal two-thirds of the lateral surface of the shaft of the fibula, from intermuscular septa on either side, and from the fascia over it.

It forms a stout tendon, which, lying superficial to the peronæus brevis, hooks round the lateral malleolus beneath the peroneal retinaculum, crosses the lateral side of the calcaneus, and passing through a groove on the cuboid bone, is directed across the sole of the foot to be inserted in to the lateral sides of the first emneiform and the 


\section{The Muscles on the Posterior Aspect of the Leg.}

The muscles on the back of the leg are divisible into two groups, superficial and deep.

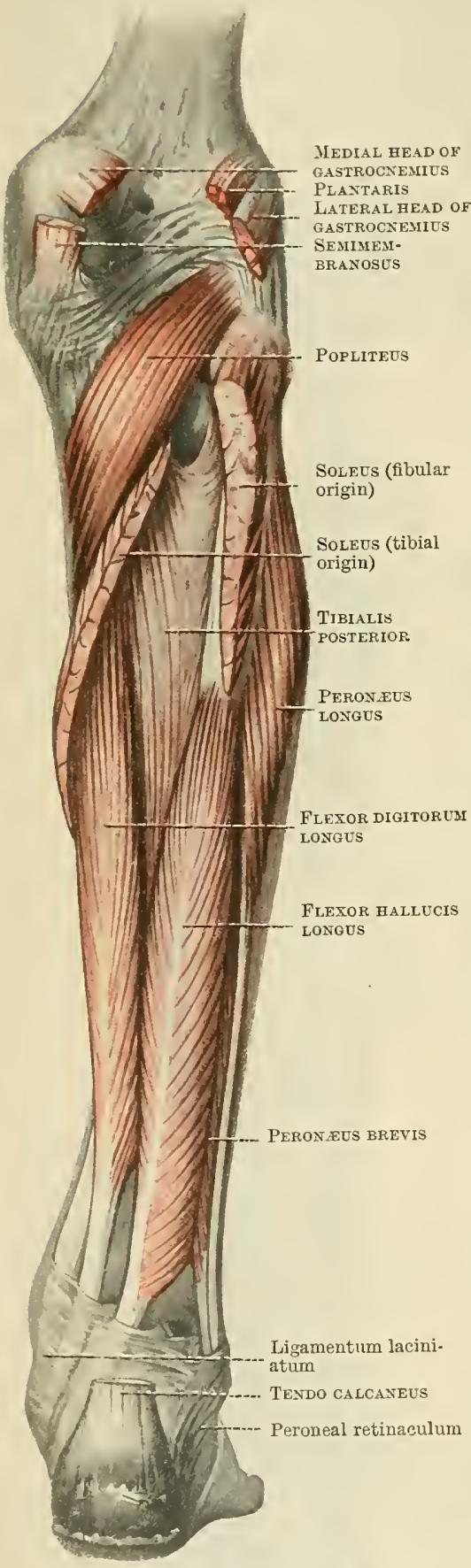

Fig. 383.-THE DeEP MUSCLES ON THE BACK OF THE RIgHT LEG.

The superficial group comprises the gastrocnemius and soleus (constituting together the triceps suræ) and the plantaris. They form the prominence of the calf of the leg. The gastrocnemius is superficial except at its origin, where the two bellies forming the boundaries of the popliteal fossa are overlapped by the tendons of the hamstring muscles. The soleus muscle is partially concealed by the gastrocnemius and plantaris, and becomes superficial in the distal part of the leg on each side of the common tendon (tendo calcaneus).

M. Gastrocnemius. -The gastrocnemius arises by two heads, medial and lateral, by means of strong tendons which are prolonged over the surface of the muscle. The lateral head arises from an impression on the proximal and posterior part of the lateral surface of the lateral condyle of the femur, and from the distal end of the lateral epicondylic line; while the medial head arises from a prominent rough mark on the popliteal surface of the femur proximal to the medialepicondyle and posterior to the adductor tubercle. Each head has an additional origin from the back of the capsule of the knee-joint. A bursa lies beneath each tendon of origin.

Each fleshy belly

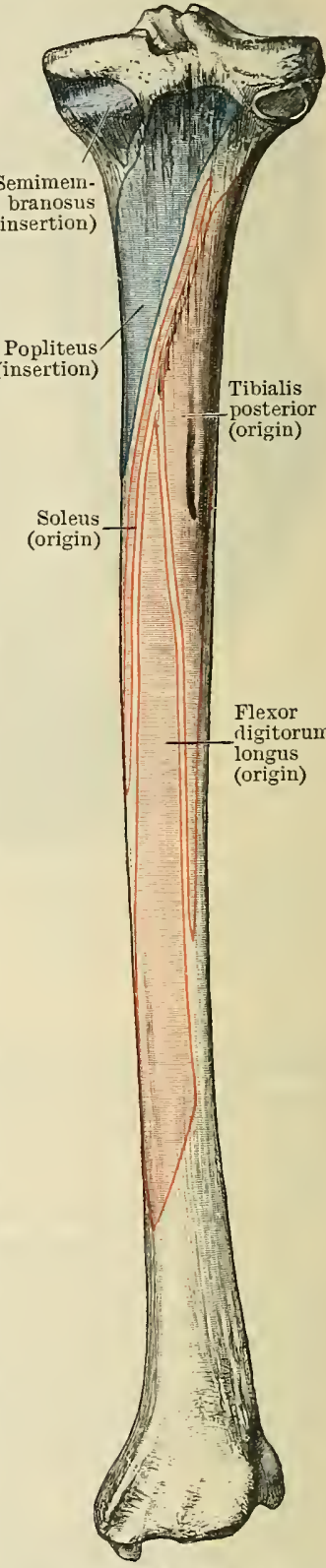

Fig. 384.-Muscle - AttachIIENTS TO THE POSTERIOR Surface of the Right Tibia.

of the muscle is inserted separately into a broad membranous tendon, prolonged proximally on its deep surface for some distance. 'The medial head is the larger.

The tendo calcaneus is formed by the union of the two membranous insertions 
of the bellies of the gastrocnemius. Prolonged upwards beneath the separate bellies, the tendon forms a broad membranous band connecting together the distal parts of the two bellies.

Narrowing gradually, and becoming thicker in the distal half of the leg, the tendon is finally inserted into the posterior aspect of the calcaneus. A bursa lies beneath the tendon at its insertion. The tendo calcaneus also affords insertion to the soleus and (sometimes) the plantaris muscles.

Nerve-Supply. - Each head of the muscle is innervated by a branch from the tibial nerve (S. 1. 2.).

Actions. - The muscle is a powerful flexor of the knee and extensor of the ankle.

IM. Plantaris.-The plantaris arises by fleshy fibres from the lateral epicondylic line of the femur for about an inch at its distal end, from the adjacent part of the popliteal surface of the femur, and from the oblique ligament of the knee-joint.

It forms a narrow fleshy slip which ends in a tendon extending distally in the back of the leg, to be inserted into the medial side of the tuberosity of the calcaneus, or the tendo calcaneus, or the ligamentum laciniatum. The tendon of the muscle is capable of considerable lateral extension.

The plantaris lies between the lateral head of the gastrocnemius and the soleus. In the distal half of the leg its tendon lies along the medial border of the tendo calcaneus. The muscle is not always present.

Nerve-Supply.-Tibial nerve (L. 4. 5. S. 1.).

Actions.--The muscle is an accessory flexor of the knee and extensor of the ankle.

M. Soleus.-The soleus has a triple origin from (1) the posterior surface of the head and the shaft of the fibula in its proximal third; (2) a fibrous arch (arcus tendineus m. solei) stretching over the popliteal vessels and tibial nerve between the tibia and fibula; and (3) the oblique line and middle third of the medial border of the tibia (Fig. 384, p. 428).

From this origin the proximal muscular fibres are directed distally to join a tendon placed on the superficial aspect of the muscle, which is inserted into the tendo calcaneus; the most distal fibres are inserted directly into the tendo calcaneus to within one or two inches of the calcaneus.

Nerve-Supply.-Two nerves supply this muscle. One from the tibial nerve in the popliteal space enters its superficial surface (S. 1. 2.); the other from the tibial nerve in the back of the leg supplies the deep surface of the muscle (L. 5. S. 1. 2.).

Actions.- The soleus is a powerful extensor of the ankle.

The deep muscles of the back of the leg comprise the popliteus, flexor digitorum longus, flexor hallucis longus, and tibialis posterior.

The popliteus muscle is deeply placed behind the knee-joint in the floor of the popliteal fossa, and is covered by the popliteal vessels and tibial nerve. The flexor digitorum longus lies behind the tibia, the flexor hallucis longus behind the fibula, and the tibialis posterior lying between them is related to the interosseous membrane and both bones of the leg. All these muscles are concealed by the superficial group, and are bound down to the bones of the leg by layers of the deep fascia.

M. Popliteus. - The popliteus arises by a stout tendon from a rough impression in front of a groove on the lateral aspect of the lateral epicondyle of the femur. The tendon passes between the lateral meniscus and the capsule of the knee-joint, and pierces the oblique ligament, from which it takes an additional fleshy origin. A bursa is placed beneath the tendon, which usually communicates with the synovial cavity of the knee-joint.

The muscle is inserted by fleshy fibres (1) into a triangular surface on the back of the tibia above the oblique line (Fig. 384, p. 428), and (2) into the fascia orer it (the popliteus fascia, derived from the tendon of the semimembranosus muscle).

The popliteus minor is a small occasional muscle attached to the popliteal surface of the femur and the posterior ligament of the knee-joint.

Nerve-Supply. - The poplitens is supplied by a branch of the tibial nerve (L. 4. 5. S. I.), which winds round the distal border of the muscle and enters it in its deep surface.

Actions.-A medial rotator and flexor of the knee. 
M. Flexor Digitorum Longus.-The flexor digitorum longus occupies both the back of the leg and the sole of the foot. Its origin is by fleshy fibres from the posterior surface of the shaft of the tibia in its middle three-fifths, distal to the oblique line, medial to the vertical line and the origin of the tibialis posterior, from the fascia over it, and from an intermuscular septum on each side

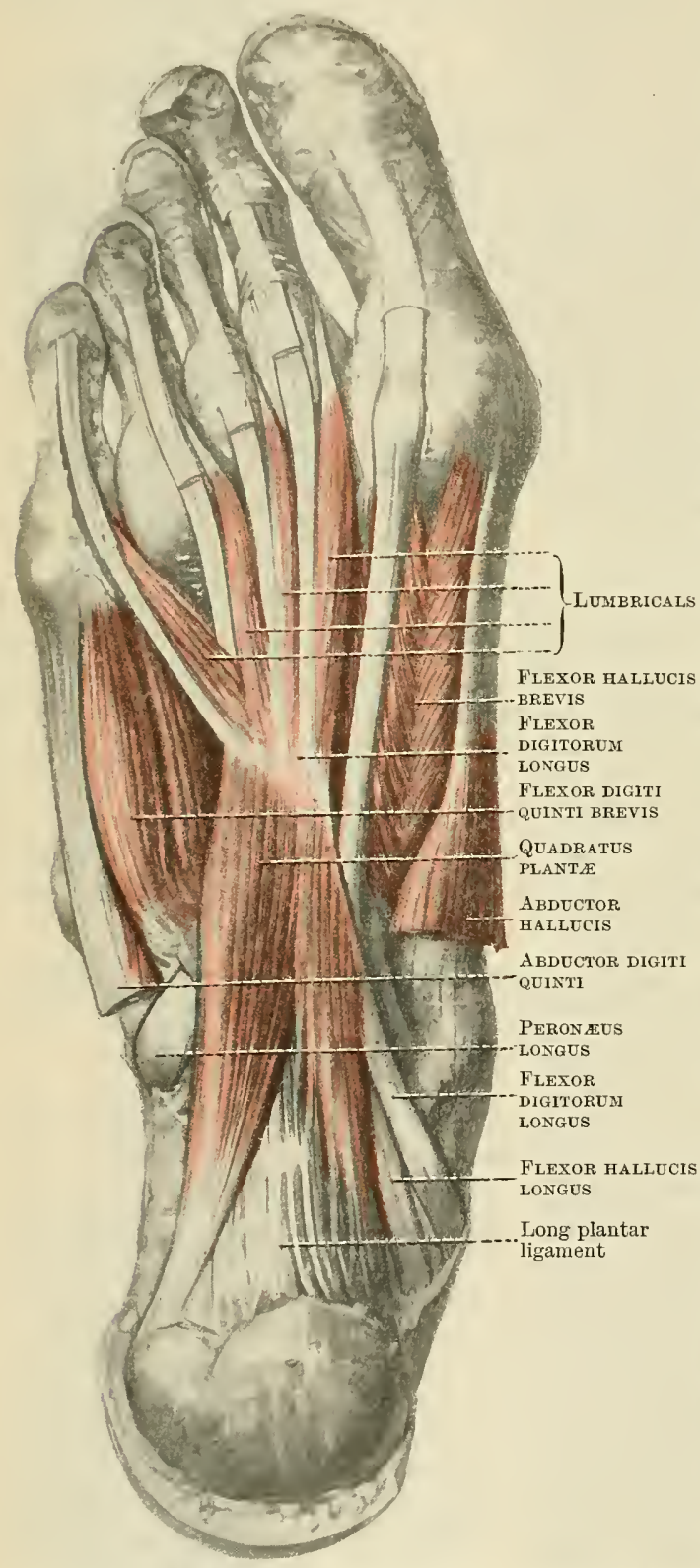

Fig. 385.-The Muscles of the Right Foot (Second Layer). (Fig. 384, p. 428).

Its tendon, after crossing obliquely over the tendon of the tibialis posterior, passes beneath the ligamentum laciniatum, invested in a special synovial sheath, and enters the sole of the foot. There it crosses superficially the tendon of the flexor hallucis longus, and finally divides into four subordinate tendons, which are inserted into the four lateral toes in precisely the same manner as the flexor digitorum profundus is inserted in the hand (p. 389). Each tendon enters the digital sheath of the toe, perforates the tendon of the flexor digitorum brevis, and is inserted into the base of the terminal phalanx. Vincula accessoria (longa and brevia) are present as in the hand.

The tendon of the flexor hallucis longus sends a fibrous band to the tendon of the flexor digitorum longus as it crosses it in the sole of the foot, which usually passes to the tendons destined for the second and third toes. Associated with this muscle in the sole of the foot are the lumbricales and quadratus plante muscles.

Mm. Lumbricales.-The lumbricales are four small muscles arising in association with the tendons of the flexor digitorum longus in the sole. The first muscle arises by a single origin from the tibial side of the tendon of the flexor digitorum longus for the second toe; the other three arise by two heads from the adjacent sides of all four tendons.

Each muscle is inserted into the dorsal expansion of the extensor tendon, the metatarso-phalangeal capsule, and the base of the first phalanx, precisely as in the case of the lumbrical muscles of the hand. Each muscle passes forwards on the tibial side of the corresponding toe, superficial to the transverse metatarsal ligament.

Nerve-Supply.-The flexor digitorum longus is supplied by the tibial nerve (L. 5. S. 1.). The first lumbrical is supplied by the medial plantar nerve (L. 4. 5. S. 1.); the other three, by the lateral plantar nerve (S. 1. 2.).

Actions. - The flexor digitorum longus extends the ankles and flexes the four outer toes. 
The lumbrical muscles have a similar action to those of the hand; they flex the metatarsophalangeal, and extend the interphalangeal joints of the four lateral toes.

M. Quadratus Plantæ.-The quadratus plantæ (O.T.accessorius) arises by two heads: (1) the lateral tendinous head springs from the lateral border of the plantar surface of the calcaneus and from the lateral border of the long plantar ligament; (2) the medial head, which is fleshy, arises from the concave medial surface of the calcaneus in its whole extent, and from the medial border of the long plantar ligament (Fig. 379, p. 425). The long plantar ligament separates the two origins.

The two heads unite to form a flattened band, which is inserted into the dorsal aspect of the tendons of the flexor digitorum longus, and usually into those destined for the second, third, and fourth toes.

In the sole of the foot the tendons of the flexor digitorum longus, along with the lumbricales and quadratus plantæ, and the flexor hallucis longus muscles, constitute the second layer of muscles, lying between the abductors of the great and little toes and the flexor digitorum brevis superficially, and the flexor brevis and adductor of the great toe more deeply.

Nerve-Supply.-Lateral plantar nerve (S. 1. 2.).

Actions. - The muscle is an accessory flexor of the toes, assisting the long flexor of the toes. It tends to draw the tendons into which it is inserted into the middle of the sole of the foot.

M. Flexor Hallucis Longus.-The flexor hallucis longus arises on the back of the leg, between the tibialis posterior and the peronæi muscles, from the distal two-thirds of the posterior surface of the shaft of the fibula, from the fascia over it, and from intermuscular septa on either side.

Its tendon passes beneath the ligamentum laciniatum enclosed in a special synovial sheath, and after grooving the posterior surface of the distal end of the tibia, the talus, and the plantar surface of the sustentaculum tali of the calcaneus, it is directed forwards in the sole of the foot, to be inserted into the base of the terminal phalanx of the great toe.

In the foot it crosses over the deep aspect of the tendon of the flexor digitorum longus, and gives to it a strong fibrous slip, which is prolonged into the tendons for the second and third toes.

Nerve-Supply.-Tibial nerve (L. 5. S. 1. 2.).

Actions. -The muscle is one of the most important in the leg and foot. It is an extensor of the ankle and a flexor of the great toe. By its position in relation to the tarsus and inferior calcaneo-navicular ligament, it has an important share in maintaining and supporting the arch of the foot.

M. Tibialis Posterior.-The tibialis posterior has a fourfold fleshy origin in the leg. It arises (1) from the proximal four-fifths of the medial surface of the shaft of the fibula between the medial crest and the interosseous crest; (2) from the distal part of the lateral condyle, and from the proximal two-thirds of the shaft of the tibia distal to the oblique line and between the vertical line and the interosseous border (Fig. 384, p. 428); (3) from the interosseous membrane; and (4) from the fascia over it and the septa on either side. The muscle gives rise to a strong tendon which passes beneath the ligamentum laciniatum, invested by a special synovial sheath, and grooves the back of the medial malleolus, on its way to the medial border of the foot.

After crossing over the plantar calcaneo-navicular ligament between the sustentaculum tali and the navicular bone, the tendon spreads out and is inserted by three bands into (1) the tubercle of the navicular bone and the plantar surfaces of the first and second cuneiform bones, (2) the plantar aspects of the bases of the second, third, fourth, and sometimes the fifth metatarsal bones, the second and third cuneiform bones, and the groove on the cuboid, and (3) into the medial border of the sustentaculum tali of the calcaneus (Fig. 379, p. 425).

The peronæo-calcaneus muscle, when present, arises from the fibula, and is inserted into the calcaneus.

Nerve-Supply. - Tibial nerve (L. 5. S. 1.).

Actions.-The muscle extends the ankle and inverts the foot. 


\section{The Muscles in the Sole of the Foot.}

The muscles in the sole of the foot are divisible into four layers placed beneath the plantar aponeurosis.

The first layer includes the abductor hallucis, flexor digitorum brevis, and abductor digiti quinti. The second layer consists of the lumbricales and quadratus plantæ, together with the tendons of the flexor hallucis longus and flexor digitorum longus. The third layer comprises the flexor hallucis brevis, adductor hallucis, and

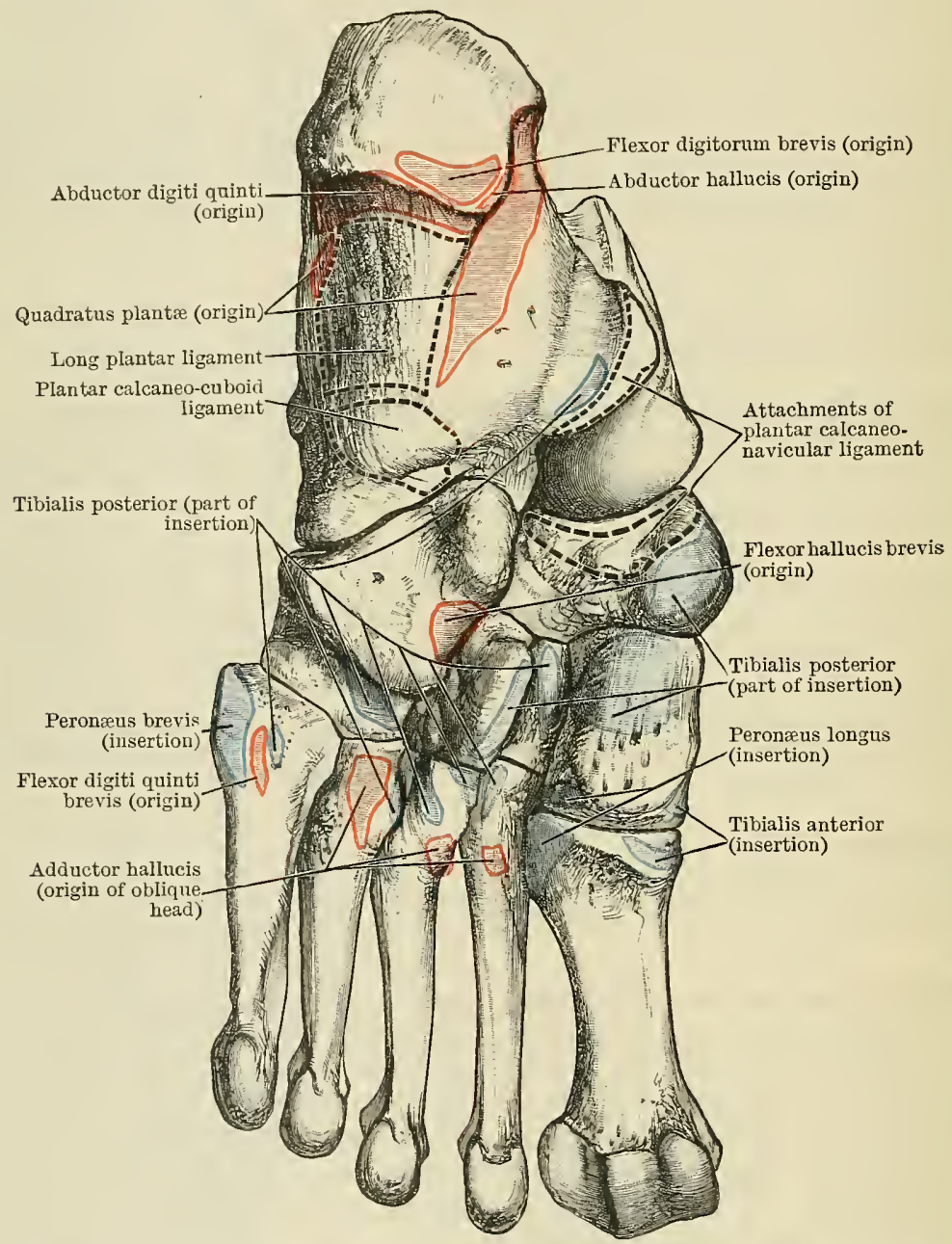

Fig. 386. - Muscle-Attachments to Left Tarsos and Metatarsus (Plantar Aspect).

flexor digiti quinti brevis. The fourth layer consists of the interossei (plantar and dorsal), placed between the metatarsal bones: and the tendons of insertion of the tibialis posterior and peronæus longus.

\section{FIRST LAYER.}

M. Abductor Hallucis.-The abductor hallucis has a double origin: (1) by a short tendon from the medial side of the medial process of the tuberosity of the calcaneus (Fig. 386), and (2) by fleshy fibres from the ligamentum laciniatum, the plantar aponeurosis which covers it, and the intermuscular septurn between it and the flexor digitorum brevis.

Lying superficially along the medial border of the sole, its tendon is inserted, 
along with part of the flexor hallucis brevis, into the medial side of the base of the first phalanx of the great toe.

Nerve-Supply.-Medial plantar nerve (L. 4. 5. S. 1.).

Actions. - A flexor and abductor of the great toe.

M. Flexor Digitorum Brevis.-The flexor digitorum brevis has likewise a double origin: (1) from the anterior part of the medial process of the tuberosity of the calcaneus (Fig. 386, p. 432), and (2) from the thick central part of the plantar aponeurosis which covers it, and from the intermuscular septa on either side.

Passing forwards, it gives rise to four slender tendons, which are inserted into the second phalanges of the four lateral toes, after having been perforated by the long flexor tendons, just as in the case of the tendons of the flexor digitorum sublimis of the hand (p. 389).

Nerve-Supply. - Medial plantar nerve (L. 4. 5. S. 1.).

Actions. - The muscle is a flexor of the toes, acting on the metatarsophalangeal and first inter-phalangeal articulations of the four lateral toes.

IM. Abductor Digiti Quinti. -The abductor digiti quinti also has a double origin: (1) by fleshy and tendinous fibres from the anterior part of both processes of the tuberosity of the calcaneus, partly concealed by the flexor digitorum brevis (Fig. 386, p. 432), and (2) by fleshy fibres from the lateral portion of the plantar aponeurosis and the calcaneo-metatarsal ligament, and from the intermuscular septum between it and the flexor digitorum brevis.

Its tendon lies along the fifth metatarsal bone, and is inserted into the lateral side of the posterior end of the first phalanx of the little toe. The most lateral fibres usually obtain an additional insertion into the lateral side of the plantar surface of the fifth metatarsal bone.

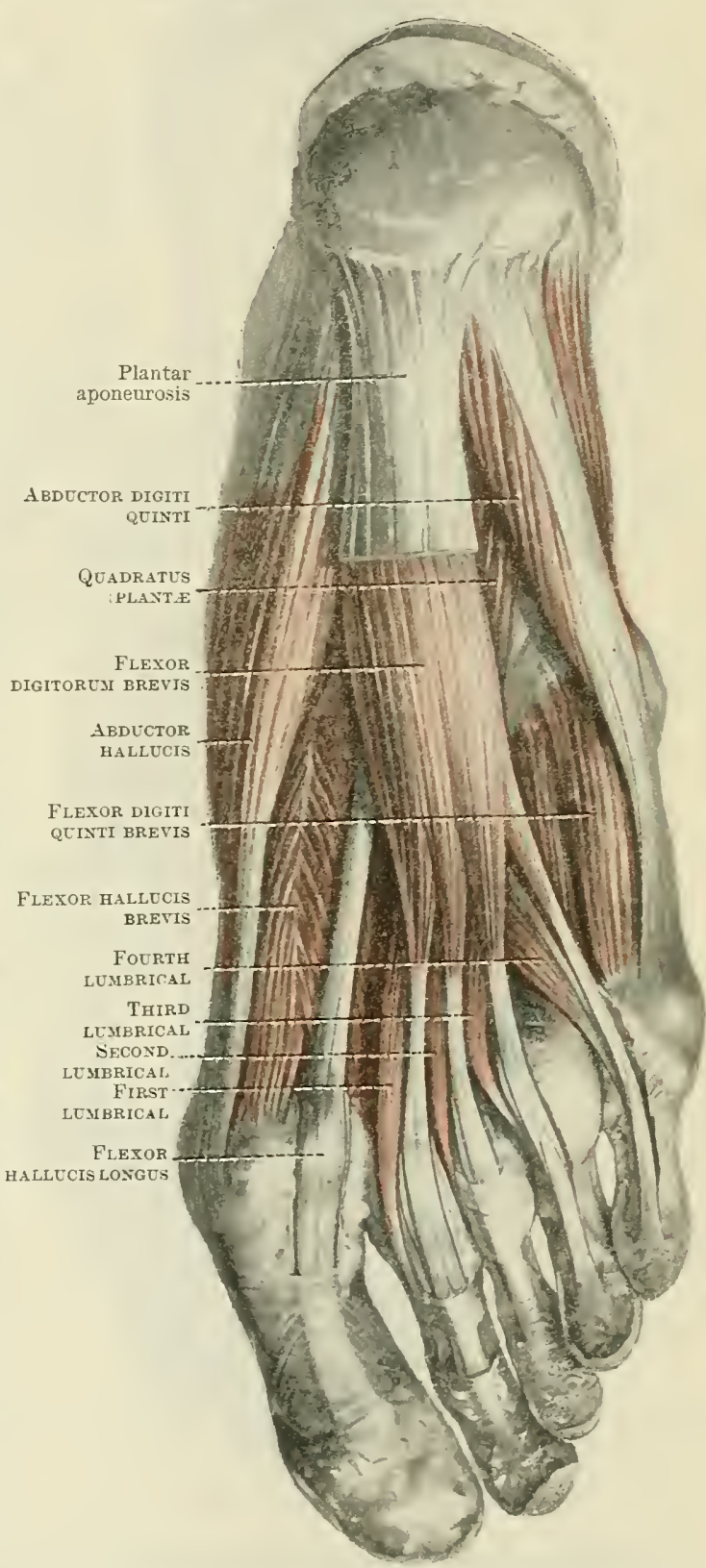

Fig. 357.-Stoperficial Midscles of the Right Foot.

Nerve-Supply.-Lateral plantar nerre (S. 1. 2.).

Actions.-Flexion and abduction of the little toe.

\section{SECOND LAYER.}

The tendons of the long flexors of the toes, the lumbricales and quadratus plantæ muscles, constituting the second layer of muscles, have already been described 
(p. 430). Lying deep to the abductor hallucis and the flexor digitorum brevis, they occupy the hollow of the tarsus and the space between the first and fifth metatarsal bones; their deep surfaces are in contact with the adductor of the

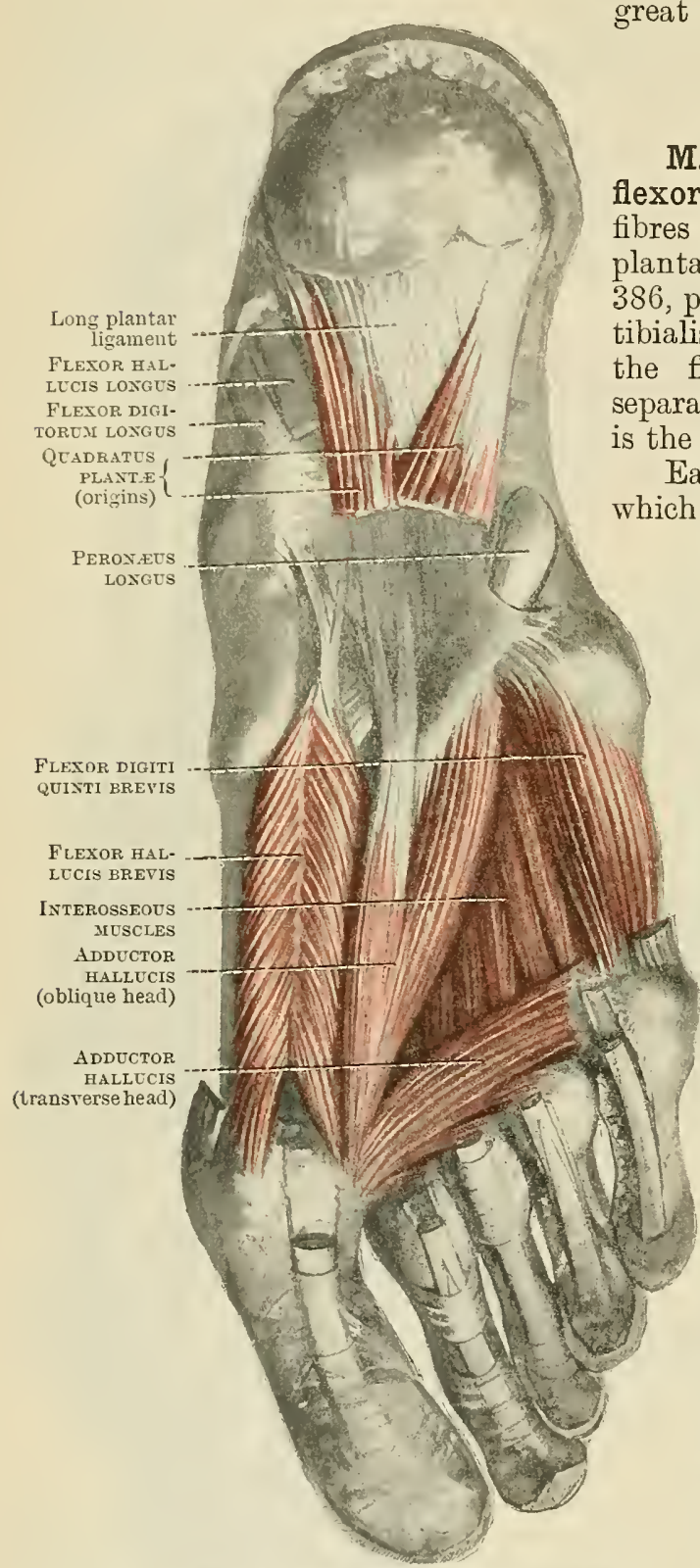

Fig. 388.-Deep Muscles of the SOLE of the Foot.

\section{THIRD LAYER.}

M. Flexor Hallucis Brevis. - The flexor hallucis brevis arises by tendinous fibres from (1) the medial part of the plantar surface of the cuboid bone (Fig. 386, p. 432), and (2) the tendon of the ibialis posterior. Directed forwards over the first metatarsal bone, the muscle separates into two parts, between which

Each portion gives rise to a tendon which is inserted into the corresponding side of the base of the first phalanx of the great toe; in each tendon, under the metatarso-phalangeal articulation, a sesamoid bone is developed. The medial tendon is united with the insertion of the abductor, the lateral tendon with the insertions of the adductor muscle of the great toe.

Nerve - Supply. - Medial plantar nerve (L. 4. 5. S. 1.).

Actions.-A flexor of the metatarsophalangeal joint of the great toe.

M. Adductor Hallucis.-The adductor hallucis consists of two parts. The oblique head of the muscle arises (1) from the sheath of the peronæus longus, and (2) from the plantar surfaces of the bases of the second, third, and fourth metatarsal bones (Fig. 386, p. 432). Occupying the hollow of the foot, on a deeper plane than the long flexor tendons and lumbricales, and on the lateral side of the flexor hallucis brevis, it is directed obliquely medially and forwards, to be inserted on the lateral side of the base of the first phalanx of the great toe between and along with the flexor brevis

and the transverse head of the adductor hallucis.

The transverse head arises from (1) the capsules of the lateral four metatarsophalangeal articulations and (2) the transverse metatarsal ligament.

Directed transversely medially under cover of the flexor tendons and lumbricales, the muscle is inserted, along with the oblique head, into the lateral side of the base of the first phalanx of the great toe.

Nerve-Supply.--Lateral plantar nerve (S. 1. 2.).

Actions. - Flexion and adduction of the great toe towards the middle line of the foot. 
M. Flexor Digiti Quinti Brevis.-The flexor digiti quinti brevis arises from (1) the sheath of the peronæus longus and (2) the base of the fifth metatarsal bone (Fig. 386, p. 432).

Partially concealed by the abductor digiti quinti, the muscle passes along the fifth metatarsal bone, to be inserted, in common with that muscle, into the lateral side of the base of the first phalanx of the little toe.

Nerve-Supply.-Lateral plantar nerve (S. 1. 2.).

Actions.-Flexion of the little toe.

\section{FOURTH LAYER.}

Mm. Interossei.-The interossei muscles of the foot resemble those of the hand except in one respect. In the hand the line of action of the muscles is the middle line of the middle finger. In the foot the second toe is the digit round which the museles are grouped, and their attachinents and their actions differ accordingly.

There are four dorsal and three plantar muscles, which occupy together the four interosseous spaces, and project into the hollow of the foot.

The four
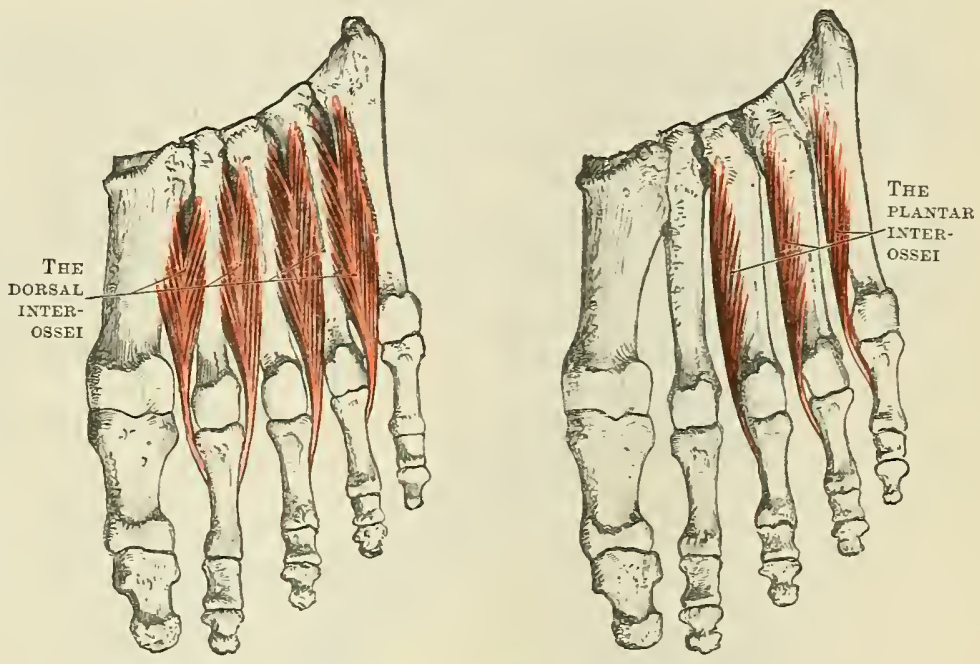

dorsal muscles,

Fig. 389.-Interosseous Muscles of the Right Foot.

one in each interosseous space, arise by two heads each from the shafts of the metatarsal bones.

Each gives rise to a tendon, which, after passing dorsal to the transverse metatarsal ligament, is inserted on the dorsum of the foot, into the side of the first phalanx, the metatarso-phalangeal capsule, and the dorsal expansion of the extensor tendon. The first and second muscles are inserted respectively into the medial and lateral sides of the proximal end of the first phalanx of the second toe. The third and fourth muscles are inserted into the lateral sides of the third and fourth toes.

The three plantar muscles occupy the three lateral interosseous spaces. Each arises by a single head from the medial side of the third, fourth, and fifth metatarsal bones respectively.

Each ends in a tendon which passes dorsal to the transverse metatarsal ligament, and is inserted, in the same manner as the dorsal muscles, into the medial sides of the third, fourth, and fifth toes.

Nerve-Supply.--Lateral plantar nerve (S. 1. 2.).

Actions. - The muscles are flexors of the metatarso-phalangeal joints, and extensors of the inter-phalangeal joints of the four lateral toes. The dorsal interossei abduct the toes into which they are inserted from the middle line of the second toe. The plantar interossei adduct the three lateral toes towards the second toe.

\section{Actions of the Muscles of the Leg and Foot.}

The muscles of the leg and foot act chiefly in the morements of the ankle-joint (assisted by movements of the intertarsal joints) ; of the metatarso-phalangeal joints (assisted by morements of the tarso-metatarsal and inter-metatarsal joints); and of the inter-phalangeal joints.

I. Tibio-Fibular Articulations. - The proximal tibio-fibular articulation is only capable of 
slight glicling morement, occasioned by the action of the biceps and poplitens and the muscles arising from the fibula.

II. Movements at the Ankle-Joint.-The movements at the ankle-joint are movements of flexion and extension of the foot on the leg, along with inversion and eversion (only during extension). These morements are produced at the ankle, aided by movements in the intertarsal joints, and are occasioned by the following muscles:-

\section{$\alpha$. Flexion.}

Tibialis anterior

Extelssor digitorum longus

Extensor hallucis longus

Peronæus tertius

\begin{tabular}{|l|}
\multicolumn{1}{|c|}{ Extension. } \\
\hline Gastrocnemius \\
Plantaris \\
Soleus \\
Tibialis posterior \\
Peronæus longus \\
Peronæus brevis \\
Flexor digitorum longus \\
Flexor hallucis longus
\end{tabular}

III. Movements of the Toes.-A. At the Metatarso-Phalangeal Joints (assisted by movements at the tarso-metatarsal and inter-metatarsal joints).-These movements are flexion and extension, abduction and adduction (in a line corresponding to the axis of the second toe).

\begin{tabular}{|c|c|}
\hline a. Flexion. & Extension. \\
\hline $\begin{array}{l}\text { Flexor digitorum longus } \\
\text { Quadratus plantæe } \\
\text { Lumbricales } \\
\text { Flexor hallucis longus } \\
\text { Flexor hallucis brevis } \\
\text { Flexor digitorum brevis } \\
\text { Flexor digiti quinti brevis } \\
\text { Interossei }\end{array}$ & $\begin{array}{l}\text { Extensor digitorum longus } \\
\text { Extensor digitorum brevis } \\
\text { Extensor hallucis longus } \\
\text { Extensor hallucis brevis }\end{array}$ \\
\hline b. Abduction. & Adduction. \\
\hline \multicolumn{2}{|c|}{ (From and to the middle line of the second toe.) } \\
\hline $\begin{array}{l}\text { Abductor hallucis } \\
\text { Dorsal interossei } \\
\text { Abductor digiti quinti }\end{array}$ & $\begin{array}{l}\text { Adductor hallucis } \\
\text { Plantar interossei }\end{array}$ \\
\hline
\end{tabular}

$B$. At the inter-phalangeal joints the movements are limited to flexion and extension.

\begin{tabular}{|c|c|c|}
\hline Flexion. & Extension. & \\
\hline $\begin{array}{l}\text { Flexor digitorum brevis (acting on the first } \\
\text { joint) } \\
\text { Flexor digitorum longus (acting on both } \\
\text { joints) } \\
\text { Flexor hallucis longus (acting on the hallux) }\end{array}$ & $\begin{array}{l}\text { Extensor digitorum longus } \\
\text { Extensor digitorum brevis } \\
\text { Interossei } \\
\text { Lumbricales } \\
\text { Extensor hallucis longus }\end{array}$ & $\begin{array}{l}\text { (acting on both } \\
\text { joints) }\end{array}$ \\
\hline
\end{tabular}

\section{Movements of the Lower Limb generally.}

The characteristic features of the lower limb are stability and strength, and its muscles and joints are both subservient to the functions of transmission of weight and of locomotion. In the standing position the centre of gravity of the trunk falls between the heads of the femora, and is located about the middle of the body of the last lumbar vertebra. It is transmitted from the sacrum through the posterior sacro-iliac ligaments to the hip bone, and through the bones of the lower limb to the arch of the foot, where the talus distributes it backwards through the calcaneus to the heel, and forwards through the tarsus and metatarsus to the balls of the toes.

Locomotion.-The three chief means of progression are walking, running, and leaping. In walking, the body and its centre of gravity are inclined forwards, the trunk oscillates from side to side as it is supported alternately by each foot, the arms swing alternately with the corresponding leg, and one foot is aiways on the ground. The act of progression is performed by the leg, aided in two ways by gravity. The movements of the leg occur in the following way. At the beginning of a step, one leg, so to speak, "shoves off"; the heel is raised and the limb is extended. By the action of the muscles flexing the hip and knee-joints, and extending the ankle-joint and toes, this limb is raised from the ground sufficiently to clear it, and passes forwards by the action of gravity, aided by the force given to the movement by the extensor muscles. After passing the 
line of the centre of gravity the flexion of the joints ceases, the muscles relax, and the limb gradually returns to the ground. The other limb then passes through the same cycle, the weight of the body now resting on the limb which is in contact with the ground. As the foot reaches the ground it, as it were, rolls over it; the heel touches it first, then the sole, and lastly, as the foot leaves the ground again, only the toes. In running, the previous events are all exaggerated. The time of the event is diminished, while the force and distance are increased. Both feet are off the ground at one time; the action of flexors and extensors alternately is much more powerful, so that on the one hand the knees are drawn upwards to a greater extent in the forward movement, and not the whole foot, but only the toes reach the ground in the extension of the limb. The attempt is made to bring the foot to the ground in front of the line of the centre of gravity. At the same time the trunk is sloped forwards much more than in walking. In leaping, the actions of the limbs are still more exaggerated. The movements of flexion of the limb are still more marked, and the foot reaches the ground still farther in front of the line of the centre of gravity

\section{AXIAL MUSCLES.}

\section{THE FASCIAE AND IMUSCLES OF THE BACK.}

\section{THE FASCI磨 OF THE BACK.}

The general fascial investments of the back have been described along with the superficial muscles associated with the shoulder-girdle (p. 365). The latissimus dorsi muscle has been described as arising in large part from the posterior layer of the lumbo-dorsal fascia. This is a strong fibrous lamina which conceals the sacrospinalis muscle. In the loin it extends from the spines of the lumbar vertebræ outwards to the interval between the last rib and the iliac crest, where it joins the middle layer. Below the loin the posterior layer of the lumbodorsal fascia is attached to the iliac crest, and more medially blends with the subjacent tendinous origin of the sacrospinalis. The layer can be followed upwards over the sacrospinalis in the region of the thorax, where it

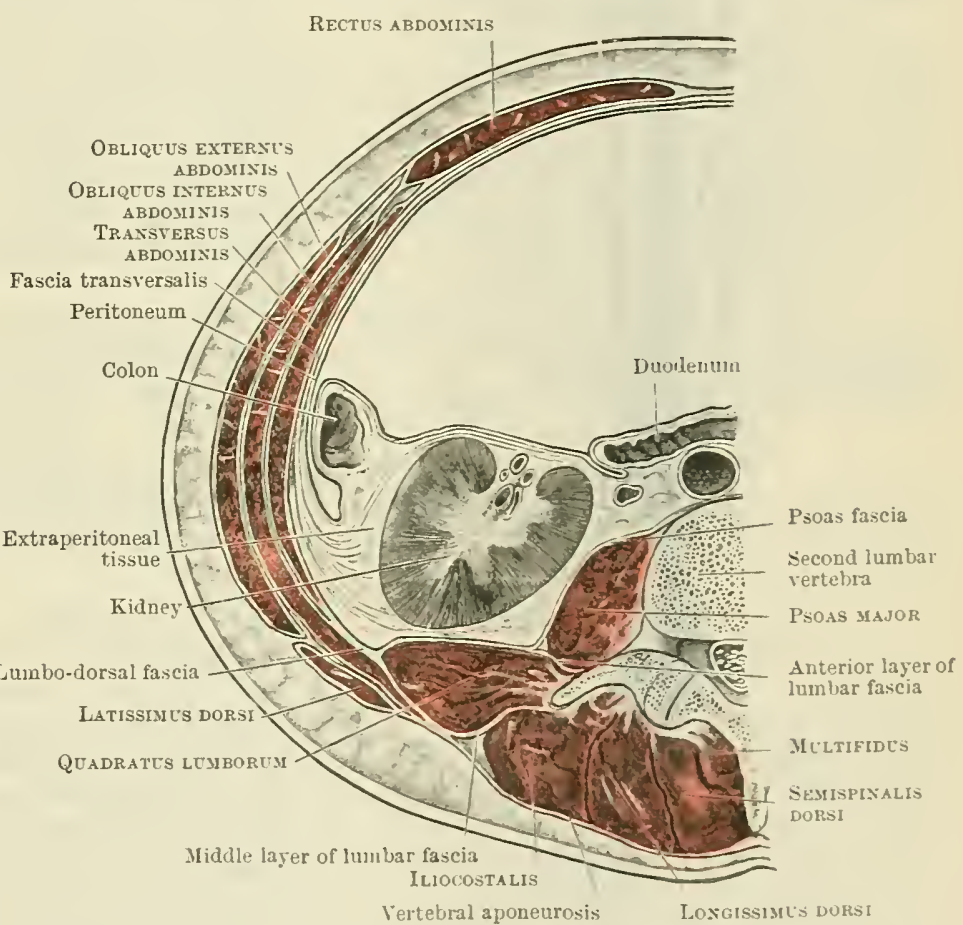

Fig. 390.-Transverse Section throdgh the Abdonex, oppusite the Secoyd Levbar Vertebra.

ally to the ribs and is continuous with the intercostal aponeuroses. In the lower part of the thorax it is replaced by the muscular slips of the serratus posterior inferior; in the upper part of the thorax it passes beneath the serratus posterior superior and blends with the deep cervical fascia.

Fascia Lumbodorsalis. - The lumbo-dorsal fascia consists of three fascial strata, called respectirely the posterior layer, just described; the middle, and the anterior layers. They unite at the lateral margin of the sacrospinalis muscle to 
form a narrow ligamentous band which connects the last rib to the iliac crest between the muscles of the back on the one haud and those of the abdominal wall on the other. The middle layer is a fascia which stretches laterally from the ends of the transverse processes of the lumbar vertebræ, between the sacrospinalis behind and the quadratus lumborum muscle in front. The anterior layer is attached to the

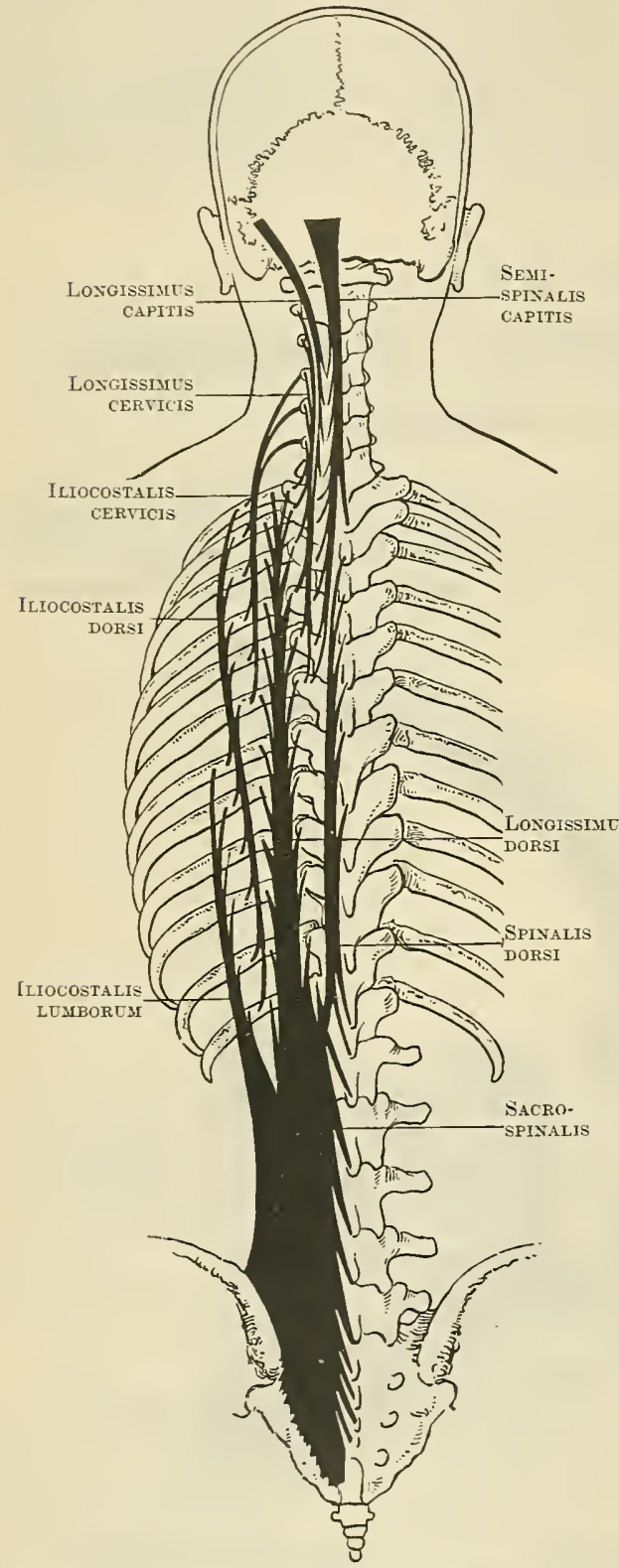

Fig. 391. - Schematic Representation of the Parts of the Left Sacrospinalis Muscle. vertebral groove in the thorax, and giving rise to the muscular mass at the back of the neck.

\section{First Group.}

II. Serratus Posterior Superior.-The serratus posterior superior has a membranous origin from the ligamentum nuchæ and the spines of the last cervical 
and upper three or four thoracic vertebræ. It is directed obliquely downwards and laterally, to be inserted by separate slips into the second, third, fourth, and fifth ribs. The muscle is concealed by the vertebro-scapular muscles, and crosses obliquely over the splenius, sacrospinalis and semispinalis capitis. It lies superficial to the lumbo-dorsal fascia.

Nerve-Supply. - Posterior rami of upper thoracic nerres.

Actions. - It is an accessory muscle of inspiration and an extensor of the vertebral column. Acting on the vertebral column, from the costal attachment, it assists in lateral movement of the column.

M. Serratus Posterior Inferior.-The serratus posterior inferior has a membranous origin through the medium of the lumbo-dorsal fascia from the last two thoracic and first two lumbar spinous processes.

It forms four muscular bands which pass almost horizontally to an insertion into the last four ribs. The muscular slips overlap one another from below upwards. The muscle is on the same plane as the posterior layer of the lumbodorsal fascia, and is concealed by the latissimus dorsi.

Nerve-Supply.-Posterior rami of the lower thoracic nerves.

Actions. - The muscle is an extensor of the rertebral column and an accessory muscle of inspiration, raising, everting, and fixing the lower four ribs.

IM. Splenius.-The splenius muscle is a broad, flattened band which occupies the back of the neck and the upper part of the thoracic region. It arises from the ligamentum nuchæ (from the level of the fourth cervical vertebra downwards) and from the spinous processes of the last cervical and higher (four to six) thoracic vertebræ.

Its fibres extend upwards and laterally into the neck, separating in their course into an upper and a lower part. The upper part forms the splenius capitis, which is inserted into the mastoid process and the lateral part of the superior nuchal line of the occipital bone (Fig. 396, p. 444). The lower part forms the splenius cervicis, which is inserted into the posterior tubercles of the transverse processes of the upper three or four cervical vertebræ, behind the origin of the levator scapulæ.

The muscle is partially concealed by the trapezius and sterno-mastoid, and appears between them in the floor of the posterior triangle of the neck (splenius capitis). It is covered by the rhomboid muscles, levator scapulæ, and serratus posterior superior.

Nerve-Supply. - Posterior rami of cervical and upper thoracic nerves.

Actions. - The splenius cervicis extends the spine, and assists in lateral movement and rotation. The splenius capitis helps in the movements of raising the head, and also of lateral flexion and rotation.

\section{Second Group.}

II. Sacrospinalis. - The sacrospinalis (O.T. erector spinæ) possesses rertebral, vertebro-cranial, and vertebro-costal attachments. It consists of an elongated mass coinposed of separated slips extending from the sacrum to the skull. Simple at its origin, it becomes more and more complex as it is traced upwards towards the head.

It arises (1) by fleshy fibres from the iliac crest; (2) from the posterior sacroiliac ligament; and (3) by tendinous fibres continuous with the former from the iliac crest, the dorsum of the sacrum, and the spines of the upper sacral and all the lumbar vertebræ. Its fibres extend upwards through the loin, enclosed between the posterior and middle layers of the lumbo-dorsal fascia, and separate into two columns - a lateral portion derived from the lateral fleshy origin, the iliocostalis, and a medial portion comprising the remaining larger part of the muscle, the longissimus.

M. Iliocostalis. - The iliocostalis lumborum is inserted by six slender slips into the lower six ribs.

Medial to the insertion of each of these slips is the origin of the iliocostalis dorsi (O.T. accessorius), which, arising from the lower six ribs medial to the 
iliocostalis lumborum, is inserted in line with it by similar slips into the upper six ribs.

The iliocostalis cervicis (O.T. cervicalis ascendens) arises in the same way by six slips from the upper six ribs, medial to the insertions of the previous muscle. It forms a narrow band, which, extending into the neck, is inserted into the posterior tubercles of the transverse processes of the fourth, fifth, and sixth cervical vertebræ, behind the scalenus posterior. The iliocostales, lumborum, dorsi, and cervicis form together a continuous muscular column, and constitute the most lateral group of the component elements of the sacrospinalis.

M. Longissimus.-The longissimus is the largest element in the sacrospinalis muscle. The longissimus dorsi forms the middle column of the muscle. It is continued up into the neck as the longissimus cervicis and longissimus capitis. Mostly tendinous on the surface at its origin, it becomes fleshy in the upper part of the loin. It is thickest in the loin, and becomes thinner as it passes upwards in

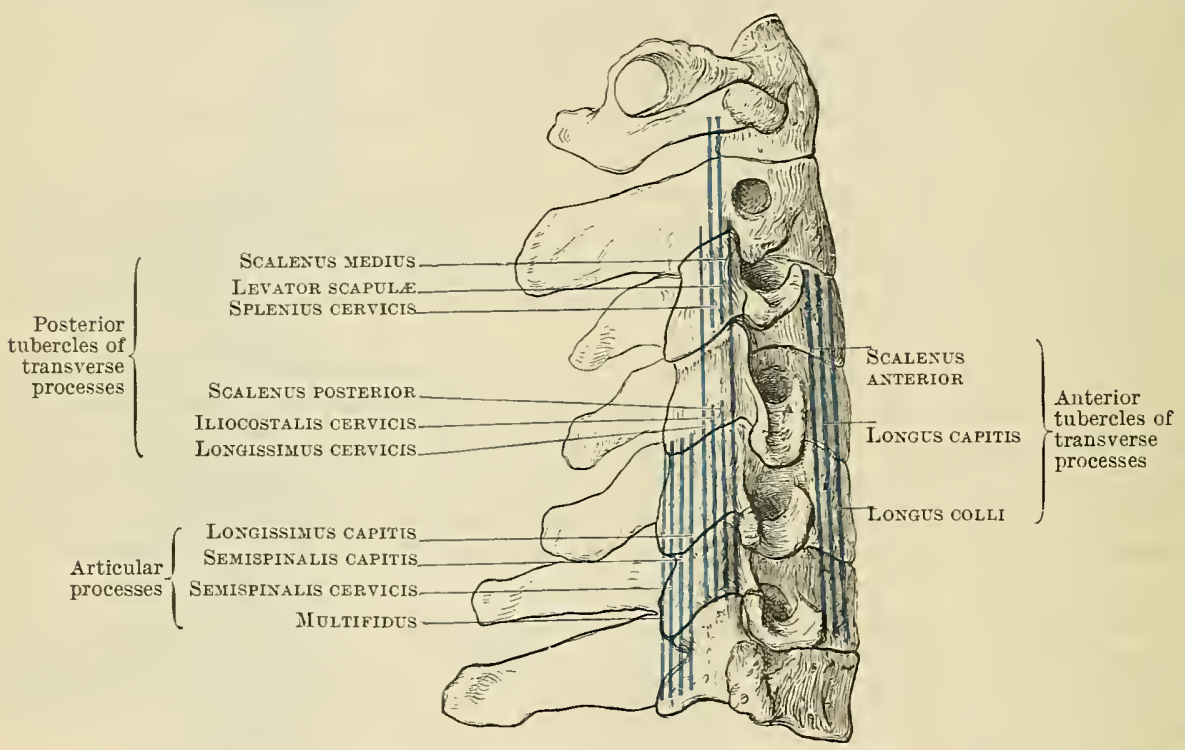

Fig. 392.-Schene of Muscular-Attachments to the Transverse axd Articllar Processes of the Cervical Vertebre.

the back between the column formed by the iliocostalis and its upward continuations laterally, and the spinalis dorsi medially.

It is inserted by two series of slips, medial and lateral, laterally into nearly all the ribs, and medially into the transverse processes of the thoracic and the accessory processes of the upper lumbar vertebræ. It is prolonged upwards into the neck by its association with the common origin of the longissimus cervicis and the longissimus capitis.

The longissimus cervicis (transversalis cervicis) has an origin from the transverse processes of the upper six thoracic vertebræ, medial to the insertions of the longissimus dorsi.

Extending upwards into the neck, it is inserted into the posterior tubercles of the transverse processes of the second, third, fourth, fifth, and sixth cervical vertebræ. It is concealed in the neck by the iliocostalis cervicis and splenius cervicis muscles.

The longissimus capitis (trachelo-mastoid) arises, partly by an origin common to it and the previous muscle, from the transverse processes of the upper six thoracic vertebræ, and partly by an additional origin from the articular processes of the lower four cervical vertebræ.

Separating from the longissimus cervicis, the muscle ascends through the neck as a narrow band which is inserted into the mastoid process beneath the splenius 


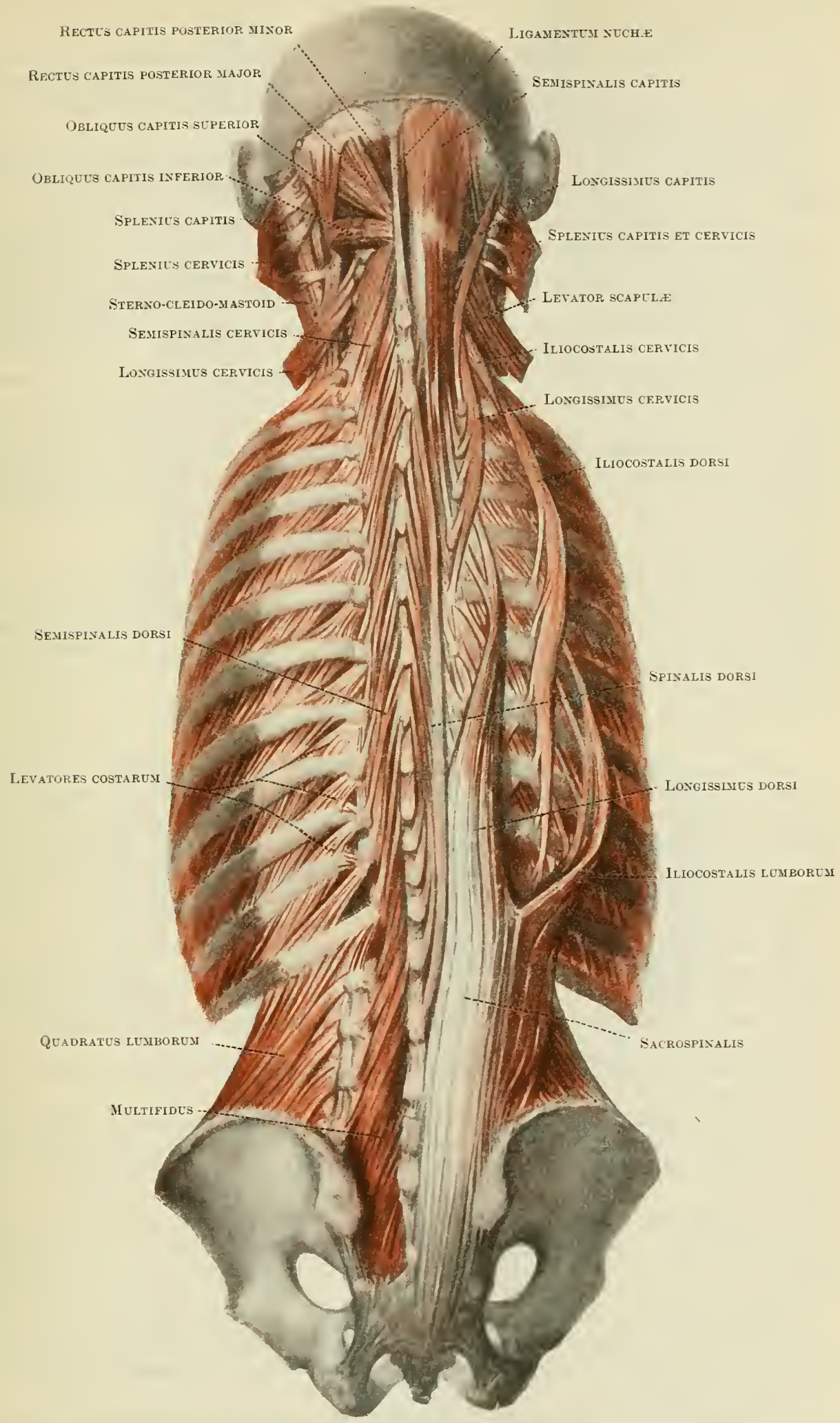

Fig. 393.-The Deep Juscles of the Back. 
capitis muscle. In the neck the muscle is placed between the splenius capitis and semispinalis capitis.

M. Spinalis Dorsi.-The spinalis dorsi forms the medial column of the sacrospinalis. It occupies the thoracic region, and arises by tendinous fibres from the lower two thoracic and upper two lumbar spinous processes, and also directly from the tendon of the longissimus dorsi.

It is a narrow muscle which, lying close to the thoracic spinous processes medial to the longissimus dorsi, is inserted into the upper (four to eight) thoracic spines. It is not prolonged into the neck.

The semispinalis capitis (O.T. complexus) closely resembles in position and attachments the longissimus capitis.

It takes origin from the transverse processes of the upper six thoracic and the articular processes of the lower four cervical vertebræ, medial to the longissimus cervicis and longissimus capitis. It has an additional origin also from the spinous process of the last cervical vertebra.

It forms a broad muscular sheet which extends upwards in the neck, to be inserted into the medial impression between the superior and inferior nuchal lines of the occipital bone (Fig. 396, p. 444). The medial portion of the muscle is separate, and forms the biventer cervicis, consisting of two fleshy bellies with an intervening tendon, placed vertically in contact with the ligamentum nuchæ. The muscle is covered mainly by the splenius and longissimus capitis muscles. It conceals the semispinalis cervicis and the muscles of the suboccipital triangle.

Nerve-Supply.-Posterior rami of spinal nerves.

Actions.-The several parts of the sacrospinalis muscle have a complex action, on the vertebral column, head, ribs, and pelvis. The muscle serves as an extensor of the vertebral column, and assists in lateral movement and rotation. The longissimus capitis and semispinalis capitis assist in extension, lateral movement and rotation of the head. The iliocostales and longissimus are accessory mnscles of inspiration. The whole muscle helps in extension and lateral movement of the pelvis in the act of walking.

\section{Third Group.}

This group comprises the semispinales (dorsi and cervicis) and multifidus. They occupy the vertebral furrow under cover of the sacrospinalis and semispinalis capitis muscles. They are only incompletely separate from one another. The semispinales, dorsi and cervicis, form a superficial stratum, the multifidus being more deeply placed. The more superficial muscles have the longer fibres; the fibres of the multifidus pass over fewer vertebræ. Both muscles extend obliquely upwards from transverse to spinous processes.

M. Semispinalis.-The semispinalis muscle extends from the loin to the second cervical vertebra. Its fibres are artificially separated into an inferior part, the semispinalis dorsi, and a superior part, the semispinalis cervicis.

The semispinalis dorsi arises from the transverse processes of the lower six thoracic vertebræ.

It is inserted into the spinous processes of the last two cervical and first four thoracic vertebræ.

The semispinalis cervicis arises from the transverse processes of the upper six thoracic, and the articular processes of the lower four cervical vertebræ.

It is inserted into the spines of the cervical vertebræ from the second to the fifth.

M. Multifidus.-The multifidus (O.T. multifidus spinæ) differs from the previous muscle in extending from the sacrum to the second cervical vertebra, and in the shortness of its fasciculi, which pass over fewer vertebræ to reach their insertion.

It arises from the sacrum, from the posterior sacro-iliac ligament (Fig. 395, p. 443), from the mamillary processes of the lumbar vertebræ, from the transverse processes of the thoracic vertebræ, and from the articular processes of the lower four cervical vertebræ.

It is inserted into the spines of the vertebræ up to and including the second cervical. 


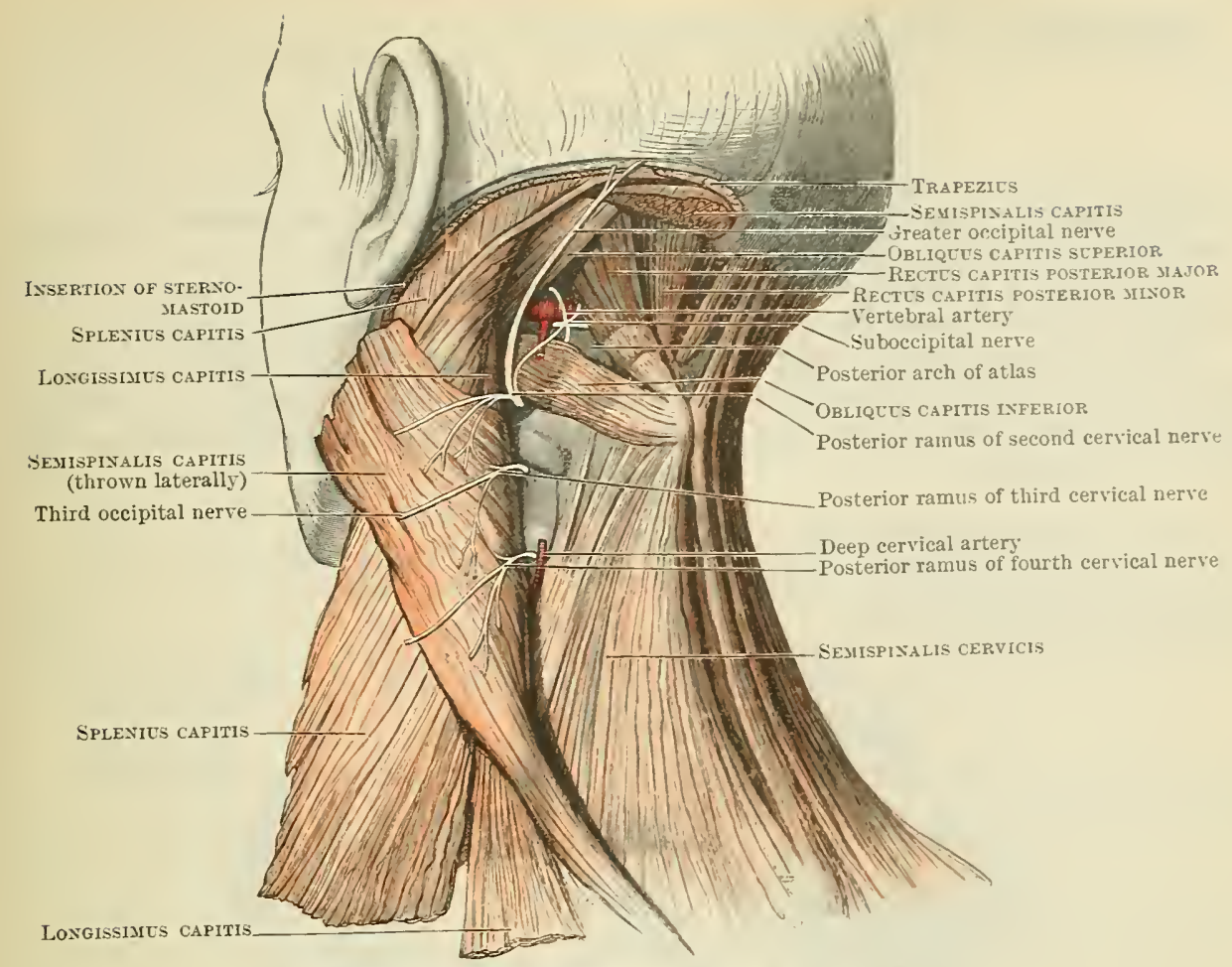

Fig. 394.-The Suboccipital Triangle of the Left Side.

Lying in contact with the vertebral laminæ, the muscle is covered in the neck and back by the semispinalis, and in the loin by the sacrospinalis muscle.

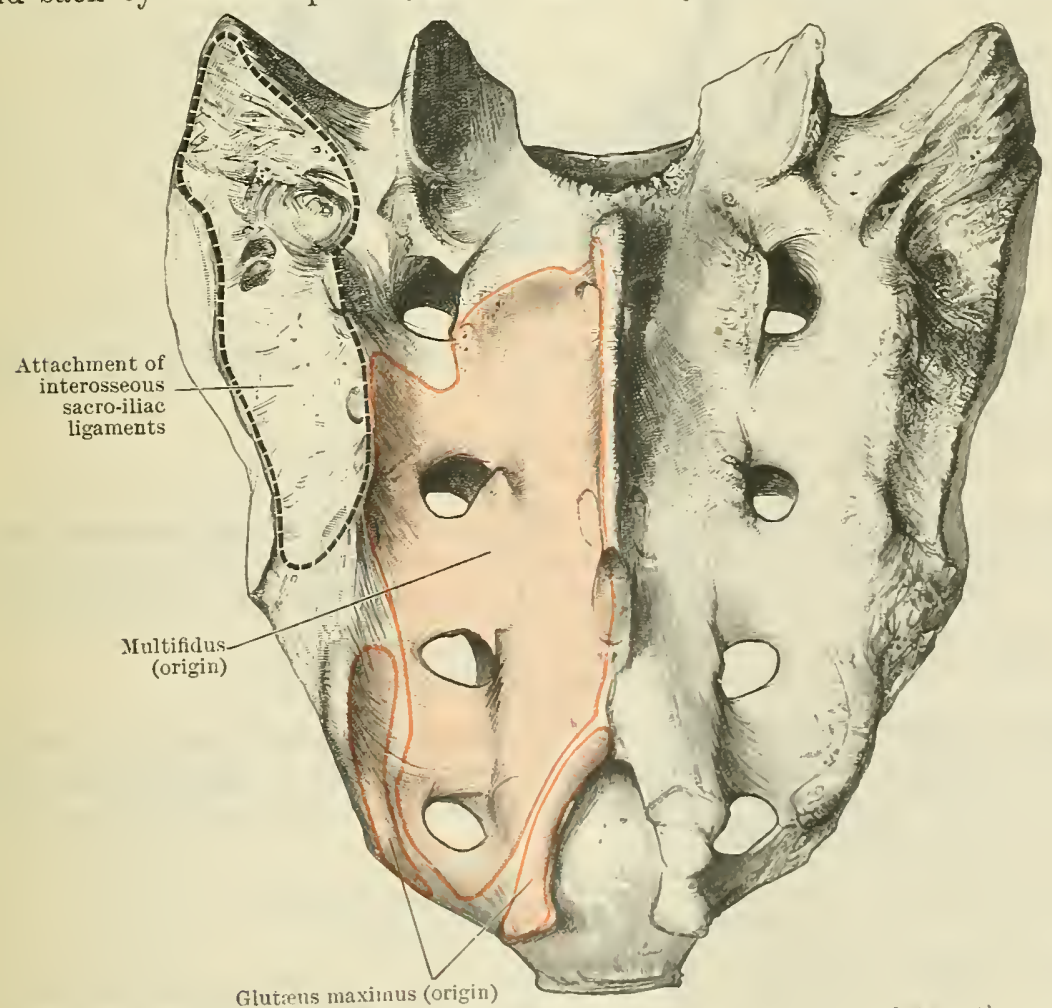

Fig. 395.-MUScle-Attacharexts to THE SAcrum (Dorsal Aipect). 
Nerve-Supply.--Posterior rami of the spinal nerves.

Actions. - These muscles are concerned in extension, lateral movement and rotation of the spine.

\section{Fourth Group.}

This group includes several sets of small muscles, which are vertebro-cranial or intervertebral in their attachments.

The muscles bounding the suboccipital triangle are four in number-obliqui capitis, inferior and superior, and recti capitis posteriores, major and minor.

These muscles are concealed by the semispinalis capitis and splenius capitis; they enclose a triangular space (the suboccipital triangle) in which the vertebral artery, the posterior ramus of the suboccipital nerve, and the posterior arch of the atlas are contained.

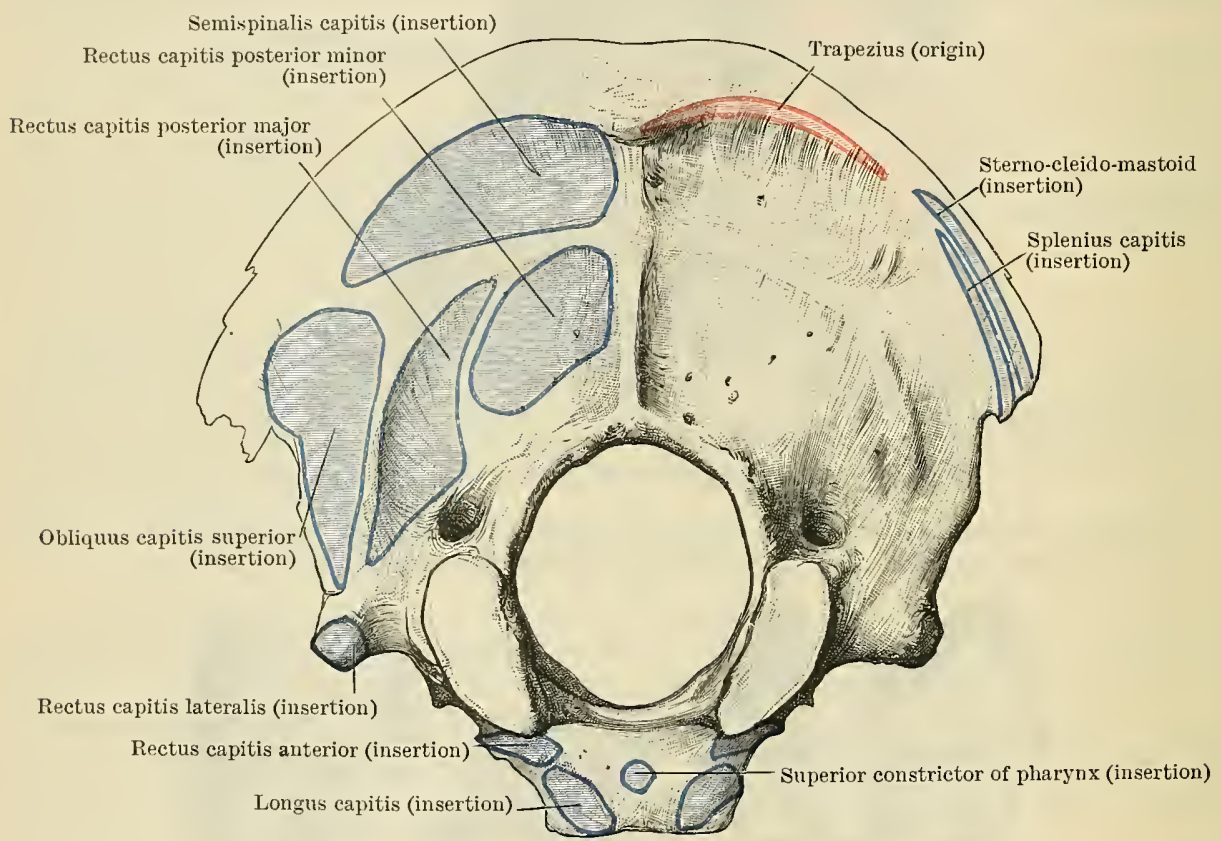

Fig. 396.-Muscle-Attachments to the Occipital Bone.

The obliquus capitis inferior arises from the spine of the epistropheus, and is inserted into the transverse process of the atlas.

Nerve-Supply.-Posterior ramus of the first cervical (suboccipital) nerve.

Actions. - Extension, lateral flexion and rotation of the atlas in the axis.

II. Obliquus Capitis Superior.-The obliquus capitis superior arises from the transverse process of the atlas, and is inserted into the occipital bone beneath and lateral to the semispinalis capitis and above the inferior nuchal line (Fig. 396).

Nerve-Supply.-Posterior ramus of the first cervical (suboccipital) nerve.

Actions.--Elevation, lateral movement and rotation of the head on the atlas.

M. Rectus Capitis Posterior Major.-The rectus capitis posterior major arises from the spine of the second cervical vertebra, and is inserted into the occipital bone beneath the obliquus capitis superior and semispinalis capitis and below the inferior nuchal line (Fig. 396).

Nerve-Supply.-Posterior ramus of the first cervical (subocipital) nerve.

Actions. - Elevation, lateral movement and rotation of the head.

M. Rectus Capitis Posterior Minor.-The rectus capitis posterior minor arises beneath the previous muscle from the posterior tubercle of the atlas, and is 
inserted into the occipital bone below the inferior nuchal line medial to and beneath the rectus capitis posterior major (Fig. 396, p. 444).

Nerve-Supply.-Posterior ramus of the first cervical (suboccipital) nerve.

Actions.-Elevation, lateral movement and rotation of the head.

IMm. Rotatores. - The rotatores are eleven pairs of small muscles occupying the vertebral groove in the thoracic region, beneath the semispinalis dorsi, of which they form the deepest fibres. Each consists of a small slip arising from the transverse process and inserted into the lamina of the vertebra directly above.

Nerve-Supply.-Posterior rami of the thoracic nerves.

Actions.-Extension and rotation of the rertebral column.

Mm. Interspinales.-The interspinales are bands of muscular fibres connecting together the spinous processes of the vertebræ.

Nerve-Supply.--Posterior rami of the spinal nerves.

Action.-Extension of the vertebral colnmn.

Mm. Intertransversarii.--The intertransversarii are slender slips extending between the transverse processes. They are double in the neck, the anterior branches of the spinal nerves passing between them. In the loin the inter-transverse muscles are usually double, but they are often absent, or are replaced by membrane.

Nerve-Supply.-Anterior rami of the spinal nerves.

Actions. - Lateral movement and rotation of the vertebral column.

Mm. Rectus Capitis Lateralis.-The rectus capitis lateralis, extending from the transverse process of the atlas to the jugular process of the occipital bone (Fig. 396, p. 444), is homologous with the posterior of the two inter-transverse muscles.

Nerve-Supply.-Anterior ramus of the first cervical (suboccipital) nerve.

Action.-Lateral movement and rotation of the head. The action of these muscles is extremely complex. Not only do they act on the vertebral column, ribs, head, and pelvis, in conjunction with other muscles, but some of them act also in relation to the movements of the limbs as well. In this section will be given an analysis of their movements in relation to the vertebral column, head, and pelvis. The movements of the limbs and of the ribs (respiration) are dealt with in other sections. The chief muscles are engaged in preserving the erect position, and in the movements of the trunk they are assisted in large measure by muscles whose chief actions are referred to elsewhere.

1. Movements of the Vertebral Column.-The movements of the vertebral column are flexion, extension, and lateral movement or rotation. These movements occur in all regionsneck, thorax, and loin; flexion and extension and lateral movement are most limited in the region of the thorax; while rotation is most limited in the region of the loin.

\section{a. Flexion}

Longus colli

Longus capitis

Scaleni anteriores (together)

Psoas major and minor

Levator ani

Coccygens

Sphincter ani externus

Rectus abdominis

Pyramidalis

Obliquus abdominis externus

Obliquus " internus

Transversus "
Extension.

Serrati posteriores

Splenius capitis

Splenius cervicis

Sacrospinalis

Semispinalis dorsi

Semispinalis cervicis

Semispinalis capitis

Multifidus

Interspinales

Intercostal muscles

Diaphragm

Transversus thoracis

b. Lateral Movement (Rotation).

Levator scapulæ

Serrati posteriores

Splenius cervicis

Sacrospinalis

Semispinalis capitis

Semispinalis (dorsi and cervicis)

Multifidus

Rotatores

Intertransversarii

Longus colli
Longus capitis

Scaleni, anterior, medius, posterior

Psoas (major and minor)

Quadratus lumbortum

Obliquus abdominis extermus

Obliquus ,

Transversus ",

Rectus ",

Pyramidalis , 
2. Movements of the Head.-The movements of the head are flexion and extension, at the occipito-atlantoid articulation; lateral movement and rotation at the atlanto-epistropheal joint.

\begin{tabular}{|l|l|}
\hline \multicolumn{1}{|c|}{ a. Flexion. } & \multicolumn{1}{c|}{ Extension. } \\
\hline Digastric & Sterno-mastoid \\
Stylo-hyoid & Splenius capitis \\
Stylo-pharyngeus & Longissimus capitis \\
Mylo-hyoid & Semispinalis capitis \\
Hyo-glossus & Obliquus capitis inferior \\
Sterno-hyoid & Recti capitis posteriores (major and minor) \\
Sterno-thyreoid & \\
Omo-hyoid & \\
Longus capitis & \\
Rectus capitis anterior & \\
\multicolumn{2}{|}{} \\
\end{tabular}

\begin{tabular}{|c|c|}
\hline b. Lateral Movement. & c. Rotation. \\
\hline $\begin{array}{l}\text { Sterno-mastoid } \\
\text { Splenius capitis } \\
\text { Longissimus capitis } \\
\text { Semispinalis capitis } \\
\text { Obliquus capitis superior } \\
\text { Rectus capitis lateralis }\end{array}$ & $\begin{array}{l}\text { Sterno-mastoid } \\
\text { Splenius capitis } \\
\text { Longissimus capitis } \\
\text { Semispinalis capitis } \\
\text { Obliquus capitis inferior } \\
\text { Recti capitis" posteriorior (major and minor) }\end{array}$ \\
\hline
\end{tabular}

Movements of the Pelvis.-The movements of the pelvis (as in locomotion) are partly caused by certain of the muscles of the back. Those muscles, which are attached to the vertebral column or the ribs on the one hand, and to the hip bone on the other, prodnce the movements (flexion, extension, and lateral movement) of the whole pelvis. In addition, the muscles passing between the hip bone and femur, in certain positions of the lower limb, assist in these movements.

\begin{tabular}{|c|c|}
\hline a. Extension. & Flexion. \\
\hline $\begin{array}{l}\text { Latissimus dorsi } \\
\text { Sacrospinalis } \\
\text { Multifidus (acting on both sides) }\end{array}$ & $\begin{array}{l}\text { Psoas major and minor } \\
\text { Rectus abdominis } \\
\text { Pyramidalis abdominis } \\
\text { Obliquus abdominis externus } \\
\text { Obliquus internus } \\
\text { Transversus abdominis (acting on both } \\
\text { sides) } \\
\text { Piriformis } \\
\text { Glutæi } \\
\text { Obturator (externus and internus) } \\
\text { Sartorius } \\
\text { Tensor fasciæ latæ } \\
\text { Iliacus } \\
\text { Rectus femoris } \\
\text { Adductors (in the erect position) }\end{array}$ \\
\hline \multicolumn{2}{|c|}{ b. Lateral Movement. } \\
\hline Flexors and extensors of one side only & Quadratus lumborum \\
\hline
\end{tabular}

\section{THE FASCIAE AND MUSCLES OF THE HEAD AND NECK.}

\section{FASCIF.}

The superficial fascia of the head and neck possesses certain features of special interest. Over the scalp it is closely adherent to the skin and subjacent galea aponeurotica and contains the superficial vessels and nerves. Beneath the skin of the eyelids it is loose and thin and contains no fat. Over the face and at the side of the neck it is separated from the deep fascia by the facial muscles and the platysma. Between the buccinator and the masseter it is continuous with a pad of fat (corpus adiposum buccce) occupying the interval between these muscles. 
The deep fascia of the head and neck presents many remarkable characters. Over the scalp it is represented by the galea aponeurotica (O.T. epicranial aponeurosis), the tendon of the epicraneus muscle. This is a tough membrane, tightly stretched over the calvaria, from which it is separated by loose areolar tissue. It is attached posteriorly, partly through the agency of the occipitalis muscle, to the superior nuchal line of the occipital bone; anteriorly it joins the frontalis muscle and the orbicularis oculi, and has no bony attachment; laterally it is attached to the temporal line and the mastoid process. Below the temporal line it is continuous with the temporal fascia, a stout layer of fascia attached to the temporal line and zygomatic arch, which covers and gives origin to the temporal muscle. This fascia separates into two layers above the zygomatic arch, to enclose a quantity of fat along with branches of the temporal and zygomatico-orbital arteries. On the face the fascia is practically non-existent anteriorly in relation to the facial muscles. Posteriorly it forms the thin parotideo - masseteric fascia, and is much thicker in relation to the parotid gland, for which it forms a capsule.

In the neck the deep fascia invests the muscles, and forms fascial coverings for the pharynx, trachea, œesophagus, glands, and large vessels. It encloses the sterno-mastoid muscle, and can be traced backwards over the posterior triangle to the trapezius and deeper muscles, which it surrounds; it

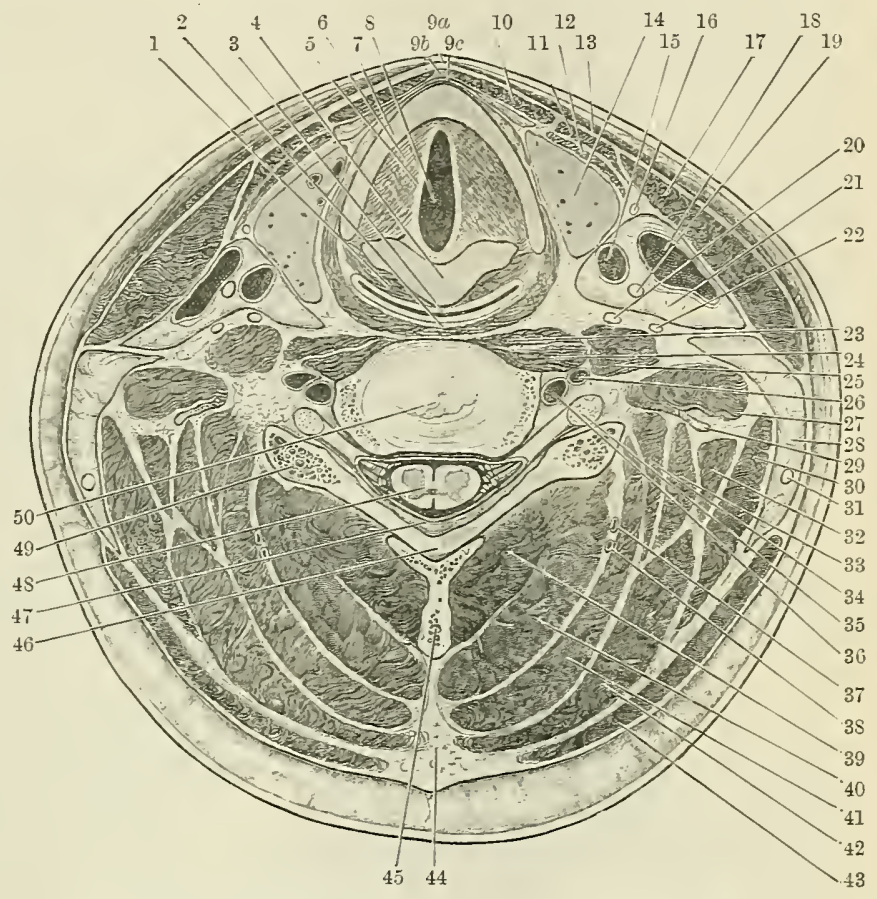

Fig. 397.-Traxsverse Section in the Cervical Region (between the fourth and fifth cervical vertebræ).

1. CRICO-ARYTENOIDEUS POSTERIOR MITSCLE.

2. ITFERIOR CONSTRICTOR MUSCLE.

3. Pharynx.

4. Cricoid cartilage.

$\begin{array}{ll}\text { 5. Vocal fold. } & \text { 31. Accessory nerve. } \\ \text { 6. Vocalis axd Thyreoarytexoiders } & 32 \text {. Splexius cervicis }\end{array}$

26. Vertebral vein.

27. SCALENUS HeDics.

28. Posterior triangle.

29. SCALENUS POSTERIOR.

30. LEVATOR SCAPULE.

7. Thyreoid cartilage.

S. Rima Glottidis.

9. Layers of deep cervical fascia.

10. STERXO-HYOID MESCLE.

11. OMO-HYOID MOSCLE.

12. STERNO-THYREOID MUSCLE.

13. Cervical fascia.

14. Thyreoid gland.

15. Common carotid arters.

16. Descendens hypoglossi nerve.

17. STERTO-MIASTOID MESCLE.

1S. Internal jugular vein.

19. Vagus nerve.

20. Sympathetic trunk.

21. Carotid sheath.

22. Phrenic nerve.

23. LONGUS COLLI MLSCLE.

24. Loxgus capitis.

25. SCALENUS ANTERIOR.
3.. SPLENILS CETVICIS.

34. Loxgissimes capitis.

35. Fifth cervical nerve.

36. Tertebral artery.

37. Profunda cervicis rein.

38. Profunda cervicis artery.

39. Multifidus.

40. Sedispisalis CER Vicis.

41. Semispisalis Capitis.

42. SPLExit' CAPITIS.

43. Trapezics.

44. Ligamentuin nuchæ.

45. Spine of fourth cervical vertebra.

46. Lamina of fifth cervical rertebra.

4i. Dura mater.

4S. Spinal medulla.

49. Transverse process.

50. Fibro-cartilage between fourth and fifth cervical rertebra. can be traced forwards over the anterior triangle to the median plane of the neck, where it forms a continuous membrane. Above the sternum the fascia, after enclosing the sterno-mastoid muscles, is attached in the form of two layers to the front and back of the jugular notch. The layer enclosing the infra-hyoid muscles passes across the median plane of the neck anterior to the trachea, and is attached above to the hyoid bone, below to the sternum, clavicle, and first rib. A third layer of fascia passes medially anterior to the trachea, enclosing the thyreoid gland. Beneath the sterno-mastoid the fascia helps to form the carotid sheath, which is completed by septal processes stretching medially across the neck in relation to the infra-hyoid muscles, trachea, 
œsophagus, and pharyux, and the prævertebral muscles. The trachea, œsophagus, and pharynx are likewise encapsuled in cervical fascia, a septal layer passing across the median plane of the neck between the trachea and cesophagus. Lastly, a strong prævertebral fascia passes across the neck anterior to the prævertebral muscles, and posterior to the cesophagus and pharynx.

The cervical fascia is attached above to the bones of the skull: superficially to the superior nuchal line of the occipital bone, the mastoid process, the zygoma (over the parotid gland), and the inferior border of the mandible; more deeply to the styloid and vaginal processes of the temporal bone, the great wing of the sphenoid and the basilar part of the occipital bone. This deeper attachment (prcevertebral fascia) is posterior to the parotid gland and pharynx, and is associated with the formation of three ligaments: stylo-mandibular ligament, sphenomandibular ligament, and pterygo-spinous ligament. The fascia is attached below, through its muscular connexions, to the sternum, first rib, clavicle, and scapula. By means of its connexion with the trachea and the common carotid artery it is carried down behind the first rib into the superior mediastinum, and so becomes continuous with the pericardium. By means of its connexion with the subclavian vessels and brachial nerves it is carried down to the axilla, as the axillary sheath, which becomes connected with the costo-coracoid membrane.

\section{THE MUSCLES OF THE HEAD.}

The muscles of the head are divisible into three separate groups: the superficial muscles, muscles of the orbit, and muscles of mastication.

\section{Superficial Muscles.}

The superficial muscles comprise a large gromp, including the muscles of the scalp and face, and the platysma in the neck.

The platysma is a thin quadrilateral sheet extending from chest to face over the side of the neck, between the superficial and deep fasciæ. It arises from the deep fascia of the pectoral region and the clavicle.

It is directed upwards and forwards, and is partly inserted (by its intermediate fibres) into the inferior border of the mandible, becoming connected with the quadratus labii inferioris and triangularis muscles (Fig. 398, p. 449). The more anterior fibres pass across the median plane of the neck and decussate for a variable distance below the chin with those of the opposite side. The posterior fibres sweep over the angle of the jaw and become continuous with the risorius muscle. The platysma is the rudiment of the cervical portion of the panniculus carnosus of lower animals, in which it has a much more intimate connexion with the muscles of the face than is usually the case in man.

Nerve-Supply. - Cervical branch of the facial nerve.

Actions. - It depresses the mandible and laterally flexes the head. It also throws into folds the skin of the side of the neck.

\section{The Muscles of the Scalp.}

The muscles of the scalp comprise the epicranius muscle and the muscles of the auricle.

M. Epicranius.-The epicranius (O.T. occipitofrontalis) is a muscle with two bellies and an intervening tendon (the galea aponeurotica) which stretches uninterruptedly across the median plane of the cranium. The posterior belly (occipitalis) arises as a broad flat band from the lateral two-thirds of the superior nuchal line of the occipital bone. The anterior belly (frontalis) has no bony attachments; arising from the galea aponeurotica about the level of the coronal suture, it passes downwards to the supra-orbital arch, where it blends with the orbicularis oculi and corrugator supercilii muscles. It extends across the full width of the forehead, and blends in the median plane with the muscle of the opposite side. 
The galea aponeurotica (O.T. epicranial aponeurosis), extending between the two fleshy bellies, is a continuous membrane which glides over the calvaria, and has attachments laterally to the temporal ridge, and behind, between the posterior bellies, to the superior nuchal lines of the occipital bone. It has no osseous attachment anteriorly.

Nerve-Supply.-The occipitalis is supplied by the posterior auricular branch of the facial nerve. The frontalis is supplied by the temporal branches of the same nerve.

Actions. - The epicraneus is usually rudimentary. By the contraction of the fibres of the frontalis muscle the skin of the forehead is thrown into horizontal parallel folds.

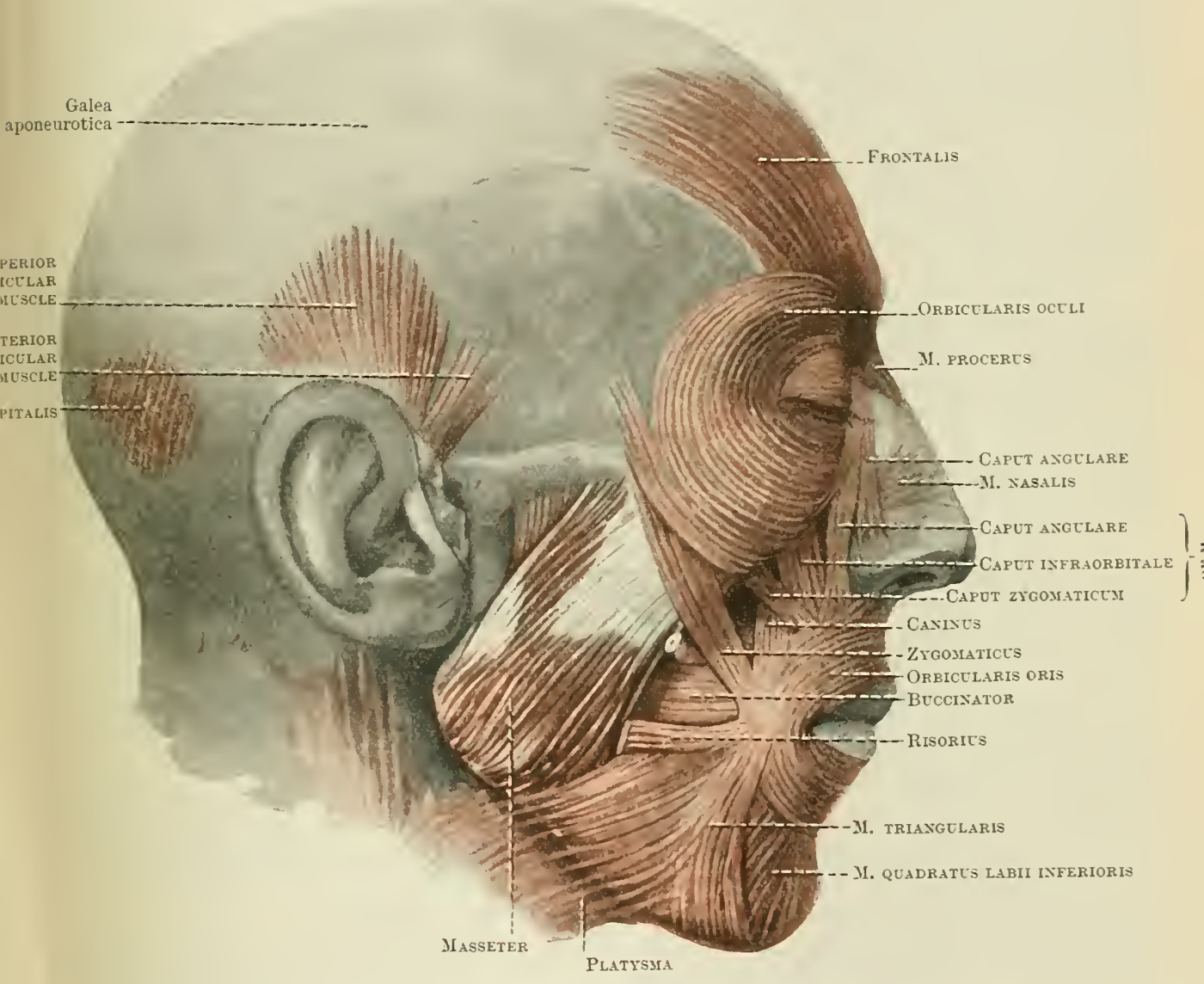

Fig, 398. - The Muscles of the Face and Scalp (Muscles of Expression).

The extrinsic muscles of the ear are three in number: posterior, superior, and anterior. They are rudimentary and usually functionless.

The $\mathrm{m}$. auricularis posterior (O.T. retrahens aurem) is a narrow fleshy slip which arises from the surface of the mastoid process and is inserted into the cranial surface of the auricle. It bridges across the groore between the mastoid process and the auricle, and conceals the posterior auricular vessels and nerve.

The m. auricularis superior (O.T. attollens aurem) is a small fan-shaped muscle which arises from the temporal fascia, and descends to be inserted into the top of the root of the auricle.

The m. auricularis anterior (O.T. attrahens aurem) is a similar small muscle, llaced in front of the auricularis superior, and stretching obliquely between the temporal fascia and the top of the root of the auricle. 


\section{The Muscles of the Face.}

The facial muscles are divided into three groups, associated with the several apertures of the eye, nose, and mouth.

1. The muscles of the eyelids include four muscles: the levator palpebræ superioris (described with the orbital muscles (p. 452)), orbicularis oculi, lacrimal part of the orbicularis, and corrugator supercilii.

M. Orbicularis Oculi.-The orbicularis oculi is a transversely oval sphincter muscle surrounding and occupying the eyelids. It is divisible into an orbital portion (par's orbitalis) composed of coarse fibres, spreading on to the forehead, temple, and cheek, and a palpebral portion (pars palpebralis), composed of finer fibres, situated beneath the skin of the eyelids. At the medial commissure of the eye the muscle (by its palpebral fibres) gains an attachment to the medial palpebral ligament and the borders of the naso-lacrimal groove. Its fibres enclose the lacrimal sac and the canaliculi. The posterior fibres, extending between the posterior edge of the naso-lacrimal groove and the tarsal ligaments behind the lacrimal sac, constitute the pars lacrimalis (O.T. tensor tarsi muscle). The fibres of the muscle which extend along the margins of the lids constitute a separate ciliary bundle.

Laterally the orbicularis oculi has no bony attachment; so that when it contracts and closes the eyelids, both lids at the same time tend to be drawn towards the medial commissure of the eye.

M. Corrugator Supercilii.-The corrugator supercilii arises from the medial part of the superciliary arch, and passing horizontally laterally, blends with the upper fibres of the orbicularis oculi on its deep surface. The contraction of this muscle throws the skin of the forehead into vertical folds, while at the same time drawing the medial half of the eyebrow upwards, it produces concentric curved folds on each side of the median plane of the forehead.

2. The muscles of the nose comprise five small muscles proper to the nose, and one common to the nose and upper lip: the $\mathrm{m}$. procerus, nasalis, dilatores naris (anterior and posterior), depressor alæ nasi, and angular head of the quadratus labii superioris. They are all small and feeble muscles.

The $\mathrm{m}$. procerus (O.T. pyramidalis nasi) arises from the epicranius muscle and the skin over the glabella; it is inserted into a membrane stretching over the nose, which gives attachment to the compressor naris also.

The m. nasalis (O.T. compressor naris) arises by a narrow origin from the maxilla, under cover of the quadratus. It passes forwards over the bridge of the nose, and ends in a membranous insertion common to it and the preceding muscle.

The mm. dilatores naris are feeble muscular slips placed on the lateral surface of the margin of the nostril, one anteriorly, the other posteriorly.

The $\mathrm{m}$. depressor alæ nasi is a small muscle arising from the upper part of the incisor fossa of the maxilla; it divides into two parts as it passes upwards and medially, and is inserted into the ala and the septum of the nose (depressor septi).

The caput angulare (O.T. levator labii superioris alreque nasi) is a portion of the quadrate muscle of the upper lip, and is a narrow band arising from the root of the frontal process of the maxilla. It descends alongside the nose, and is inserted, partly into the ala of the nose and partly into the orbicularis oris muscle.

3. The muscles of the mouth comprise a number of muscles, of which all but one, the orbicularis oris, are bilaterally placed. The muscles are: (1) quadratus labii superioris, which includes the angular head just described, the infra-orbital head, and the zygomatic head; (2) the canine muscle; (3) zygomaticus; (4) risorius; (5) orbicularis oris; (6) triangularis; (7) quadratus labii inferioris; (8) mentalis; and (9) buccinator.

IM. Orbicularis Oris.-The orbicularis oris is the sphincter muscle surrounding the lips. It is continuous with the other muscles converging to the mouth. It lies between the skin and mucous membrane of the mouth, and is limited superiorly by the nose, inferiorly by the junction of the lower lip and chin. Its medial fibres are attached above to the septum of the nose (naso-labial band) and 
to the incisor fossa (superior incisive bundle); below they are attached to the mandible on each side of the symphysis (inferior incisive bundle). These bundles radiate laterally to join the rest of the muscle, which is joined at its margin by the elevators and depressors of the lower lip and angle of the mouth, and by the buccinator muscle. The lower fibres of the muscle are continued laterally into the buccinator and canine muscles; its upper fibres are continued into the buccinator and triangularis muscles.

M. Quadratus Labii Superioris.-The quadratus labii superioris comprises three muscles.

(1) The caput angulare (O.T. levator labii superioris alæque nasi) has already been described.

(2) The caput infra-orbitale (O.T. levator labii superioris) arises from the maxilla just above the infra-orbital foramen. It passes almost vertically downwards to join the orbicularis oris and the skin of the upper lip between the attachments of the caput angulare and the caninus. It conceals the infra-orbital vessels and nerve.

(3) The caput zygomaticum (O.T. zygomaticus minor) arises from the zygomatic bone, and is often continuous with the most peripheral fibres of the orbicularis oculi. It is directed obliquely downwards and forwards over the caninus, to be inserted along with the caput infra-orbitale into the margin of the orbicularis oris.

M. Caninus.-The caninus (O.T. levator anguli oris) arises from the canine fossa of the maxilla below the infra-orbital foramen and under cover of the caput zygomaticum. It is directed laterally and downwards, to be inserted into the orbicularis oris and the skin at the angle of the mouth.

M. Zygomaticus.-The zygomaticus (O.T. zygomaticus major) is a narrow muscular band which arises from the zygomatic portion of the zygomatic arch. It passes to the angle of the mouth, to be inserted partly into the skin, partly into the orbicularis oris.

M. Risorius.-The risorius is a thin flat muscle which forms in part a continuation of the platysma on the face, in part a separate muscle, with an origin from the parotideo-masseteric fascia. It passes transversely forwards, to be inserted at the angle of the mouth into the orbicularis oris and skin.

M. Triangularis.-The triangularis (O.T. depressor anguli oris) arises from the oblique line of the mandible and is continuons with the platysma (Fig. 398, p. 449). It is triangular in form, its fibres converging to the angle of the mouth, where they are inserted into the orbicularis oris and the skin. Some of the fibres reach the upper lip through the orbicularis muscle.

M. Quadratus Labii Inferioris.-The quadratus labii inferioris (O.T. depressor labii inferioris) arises from the lateral surface of the mandible deep and medial to the preceding muscle (Fig. 398, p. 449). It is quadrilateral in form, and is directed upwards, to be inserted into the orbicularis oris and the skin of the lower lip. Its lateral fibres are overlapped by the triangularis. Its medial fibres join with those of the opposite muscle.

M. Mentalis.-The mentalis (O.T. levator menti) is a small muscle which arises from the incisor fossa of the mandible and is inserted into the skin of the chin.

M. Buccinator.-The buccinator muscle forms the lateral wall of the mouth, and is in series posteriorly with the constrictor muscles of the pharynx. It arises (1) from the alveolar arches of the maxillæ and mandible (Fig. 407, p. 457), and between these attachments; (2) from the pterygo-mandibular raphe. Its fibres are directed forwards to the angle of the mouth, where they blend with the corresponding (upper and lower) portions of the orbicularis oris muscle. The middle fibres of the muscle decussate at the angle of the mouth, so as to pass, the lower set to the upper lip, the upper set to the lower lip. The buccinator is covered on its deep surface by the mucous membrane of the mouth. Superficially it is concealed by the muscles above mentioned, which converge to the angle of the mouth; it is separated from the masseter by the corpus adiposum bucce; it is pierced by the duct of the parotid gland, and by branches of the buccinator nerve. 
Nerve-Supply.-The facial and scalp muscles are all innervated by the facial nerve. The posterior auricular branch supplies the posterior auricular muscle and occipitalis; the branches into which it breaks up in the parotid gland supply the frontalis, superior and anterior auricular muscles, the several muscles associated with the apertures of the eye, nose, and mouth (inciuding the buccinator), and the platysma.

Actions.-The almost infinite variety of facial expression is produced partly by the action of these muscles, partly by their inactivity, or by the action of antagonising muscles (antithesis). On the one hand joy, for example, is betrayed by the action of one set of muscles, while grief is accompanied by the contraction of another (opposing) set. Determination or eagerness is accompanied by a fixed expression due to a combination of muscles acting together; despair, on the other hand, is expressed by a relaxation of muscular action. For a philosophical account of the action of the facial muscles, the student should consult Darwin's Expression of the Emotions in Man and Animals, and Duchenne's Mécanisme de la Physiologie humaine.

The platysma retracts and depresses the angle of the mouth, and depresses the mandible. The epicranius, by its anterior belly, raises the eyebrows; both bellies acting together tighten the skin of the scalp; acting along with the orbicularis oculi, it shifts the scalp backwards and forwards. The corrugator supercilii draws the eyebrow medially and wrinkles the skin of the forehead vertically. The procerus draws downwards the skin between the eyebrows, as in frowning. The upper eyelid is raised by the levator palpebræ superioris. The closure of the lids is effected by the orbicularis oculi, whose fibres also assist in the lowering of the eyebrows, in the protection of the eyeball, and, by pressure on the lacrimal gland, in the secretion of tears. The tarsal part, acting along with the orbicularis oculi, compresses the lacrimal sac and aids in the passage of its contents into the naso-lacrimal duct. The muscles of the ear and nose have quite rudimentary actions. Of the muscles of the mouth, the orbicularis oris has a complex action, depending on the degree of contraction of its component parts. It causes compression and closure of the lips in various ways, tightening the lips over the teeth, contracting them as in osculation, or causing pouting or protrusion of one or the other. The accessory muscles of the lips draw them upwards (zygomaticus, quadratus labii superioris), laterally (zygomaticus, risorius, platysma, triangularis, buccinator), and downwards (triangularis, quadratus labii inferioris, platysma). The mentalis muscle elevates the skin of the chin and protrudes the lower lip. The buccinator retracts the angles of the mouth, flattens the cheeks, and brings them in contact with the teeth.

\section{The Fascize and Muscles of the Orbit.}

The eyeball, with its muscles, vessels, and nerves, is lodged in a mass of soft and yielding fat which entirely fills up the cavity of the orbit. Surrounding the

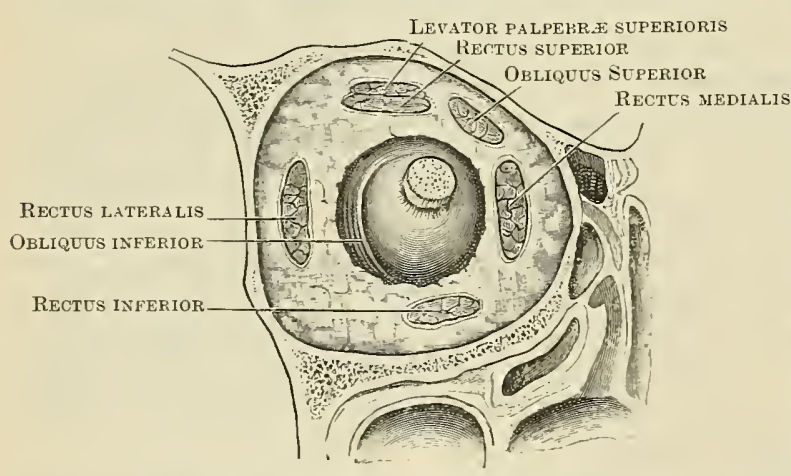

Fig. 399.-Transterse Vertical SeCtion throdgh the Left Orbit BEHIND THE EYeBall TO SHOW THE ARRANGEMENT OF MUSCLES. posterior part of the eyeball is the fascia bulbi (O.T. capsule of Tenon), which constitutes a large lymph space or synovial bursa in relation to the posterior part of the eyeball. Anteriorly the capsule is in contact with the conjunctiva, and intervenes between the latter and the eyeball; posteriorly it is pierced by and prolonged along the optic nerve. It is a smooth membrane connected to the globe of the eye by loose areolar tissue. It is pierced by the tendons of the ocular muscles, along which it sends prolongations continuous with the muscular sheaths.

The muscles of the orbit are seven in number: one, the levator palpebræ superioris, belongs to the upper eyelid; the other six are muscles of the eyeball.

IM. Levator Palpebræ Superioris.--The levator palpebræ superioris lies immediately beneath the orbital periosteum and covers the superior rectus muscle. It has a narrow origin above that muscle from the margin of the optic foramen.

It expands as it passes forwards, to end, in relation to the upper lid, in a membranous expansion which is inserted in a fourfold manner: (1) into the orbicularis oculi and skin of the upper lid, (2) mainly into the superior border of the superior tarsus, (3) into the conjunctiva, and (4) by its edges into the upper border of the margin of the orbital opening. 
Nerve-Supply. - The muscle is supplied by the superior division of the oculo-motor nerve.

Actions. - It elevates the upper eyelid and antagonises the action of the orbicularis oculi muscle.

Mm. Recti.-The recti muscles are four in number-superior, inferior, medial, and lateral. They all arise from a membranous ring surrounding the optic foramen, which is separable into two parts-a superior common tendon, giving origin to the superior and medial recti and the superior head of the lateral rectus; and an inferior common tendon, giving origin to the medial and inferior recti and the inferior head of the lateral rectus. The two origins of the lateral rectus muscle are separated by the passage into the orbit of the oculo-motor, naso-ciliary, and abducent nerves. Forming flattened bands which lie in the fat of the orbit around the optic nerve and eyeball, the four muscles end in tenclons which pierce the fascia bulbi, and are inserted into the sclera about eight millimetres (three to four lines) behind the margin of the cornea.

The superior and inferior recti are inserted in the vertical plane slightly medial to the axis of the eyeball; the lateral and medial recti in the trans-

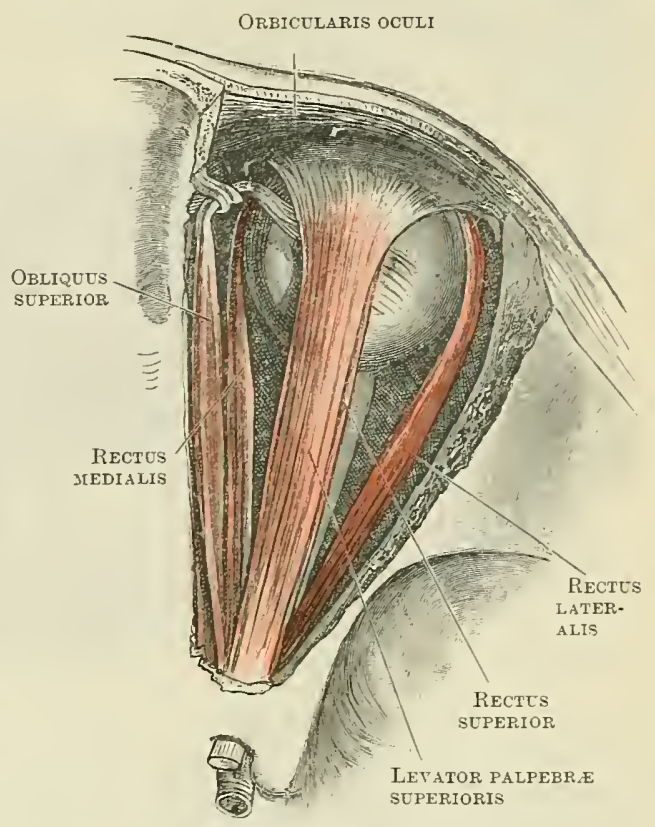

Fig.400.-MIUscles of the Right ORBIt (from above). verse plane of the eyeball; and all are attached in front of the equator of the eyeball.

M. Obliquus Superior.-The obliquus superior arises from the margin of the optic foramen between the rectus superior and rectus medialis. It passes forwards as a narrow muscular band medial to the rectus superior, and at the anterior

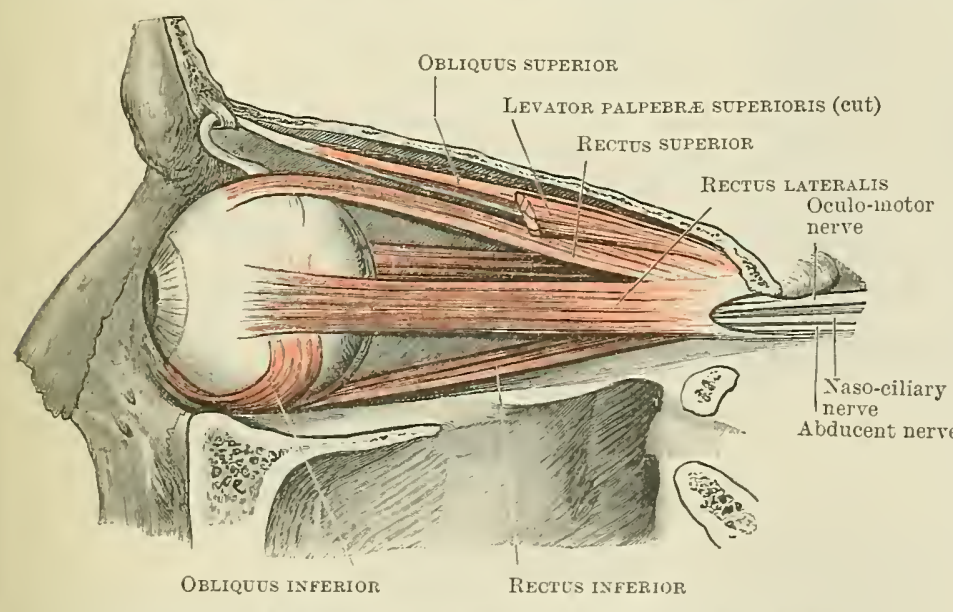

Fig. 401.-Muscles of THE Left ORBIT (from lateral aspect). margin of the orbit forms a narrow tendon which passes through a special fibrous pulley (trochlea) attached to the roof of the orbit.

Its direction is then altered, and passing laterally between the tendon of the superior rectus and the eyeball, it is inserted into the sclera between the superior and lateral recti, midway between the margin of the cornea and the entrance of the optic nerve.

M. Obliquus Inferior.-The obliquus inferior arises from the medial side of the floor of the orbit just behind its anterior margin, and lateral to the nasolacrimal groove.

It forms a slender rounded slip, which curls round the inferior rectus tendon, 
and passes between the lateral rectus and the eyeball, to be inserted into the sclera between the superior and lateral recti, and farther back than the superior oblique muscle.

M. Orbitalis (O.T. Müller's muscle) is a rudimentary bundle of non-striated muscular fibres bridging across the inferior orbital fissure and infra-orbital groove. It is supplied by fibres from the sympathetic, and may have a slight influence in the protrusion of the eyeball.

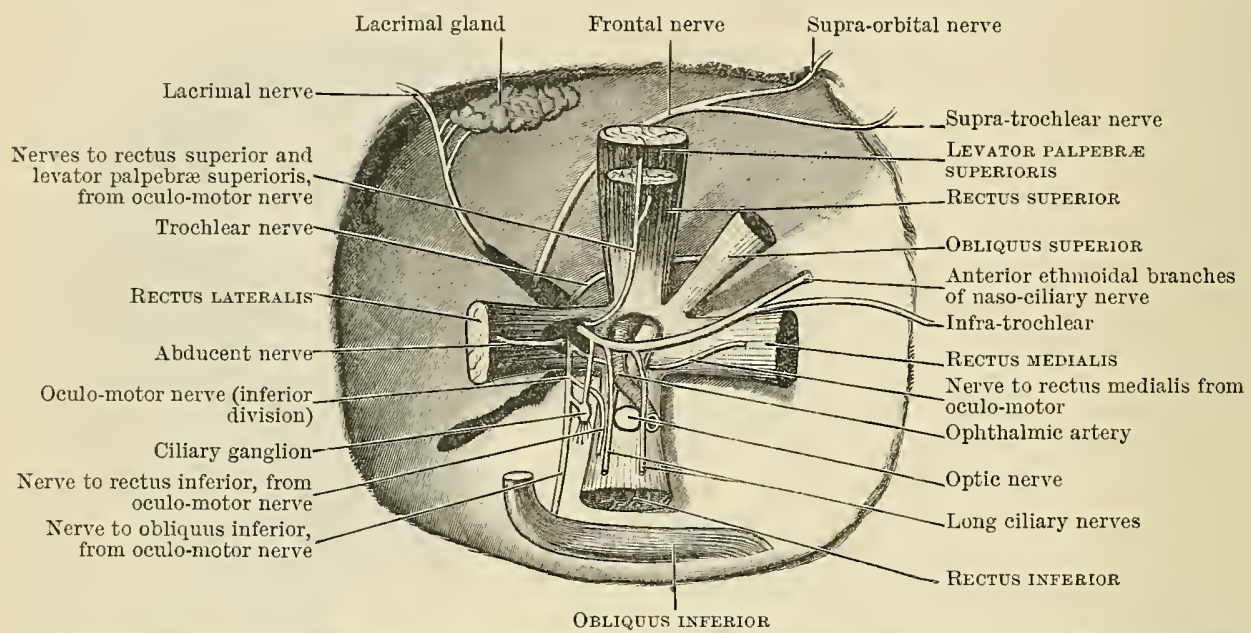

Fig. 402.-Schematic Representation of the Nerves which traverse the Cavity of the Right Orbit.

Nerve-Supply.-The muscles of the eyeball are supplied by the third, fourth, and sixth cerebral nerves. The trochlear (fourth nerve) supplies the obliquus superior; the abducent (sixth) supplies the rectus lateralis; the oculo-motor (third nerve) supplies the others-recti, superior, inferior, and medialis, and obliquus inferior.

Actions. - The six muscles inserted into the eyeball serve to move the longitudinal axis of the eyeball upwards, downwards, medially, and laterally, besides causing a rotation of the eyeball on its own axis. The following table expresses the action of individual muscles. It must be remembered that, while similar movements occur simultaneously in the two eyeballs, the horizontal movements may, by adduction of the muscles of both sides, cause convergence of the axes of the two eyeballs for the purposes of near vision.

\begin{tabular}{|c|c|}
\hline a. Adduction. & Abduction. \\
\hline $\begin{array}{l}\text { Rectus medialis } \\
\text { Rectus superior } \\
\text { Rectus inferior }\end{array}$ & $\begin{array}{l}\text { Rectus lateralis } \\
\text { Obliquus superior } \\
\text { Obliquus inferior }\}_{\text {adductors) }}^{\text {(correcting }}\end{array}$ \\
\hline b. Elevation. & Depression. \\
\hline $\begin{array}{l}\text { Rectus superior } \\
\text { Obliquus inferior }\end{array}$ & $\begin{array}{l}\text { Rectus inferior } \\
\text { Obliquus superior }\end{array}$ \\
\hline c. Rotation laterally. & Rotation medially. \\
\hline Obliquus inferior & $\left.\begin{array}{l}\text { Obliquus superior } \\
\text { Rectus superior } \\
\text { Rectus inferior }\end{array}\right\}$ (in adduction) \\
\hline
\end{tabular}

\section{Muscles of Mastication.}

The muscles of mastication comprise the masseter, temporal, external and internal pterygoids, and buccinator (described above).

IM. Masseter.-The masseter is the most superficial. Covered by the parotid gland on the side of the face, it has an origin which is partly tendinous and partly fleshy. It arises in two parts: (1) superficially from the inferior border of the zygomatic arch in its anterior two-thirds, and (2) more deeply from the deep surface of the zygomatic arch in its whole length. The superficial fibres are 
directed downwards and backwards towards the angle of the mandible; the deeper fibres are directed vertically downwards.

The muscle is inserted by fleshy and tendinous fibres into the lateral surface of the ramus and angle of the mandible and the coronoid process (Fig. 403). The deepest fibres blend with the fibres of the subjacent temporal muscle.

The muscle is partially concealed on the face by the parotid gland, accessory parotid gland, and parotid duct; by the external maxillary artery; the branches of the facial nerve; and by the zygomatic and platysma muscles. It conceals the ramus of the jaw, and, at its anterior border, is

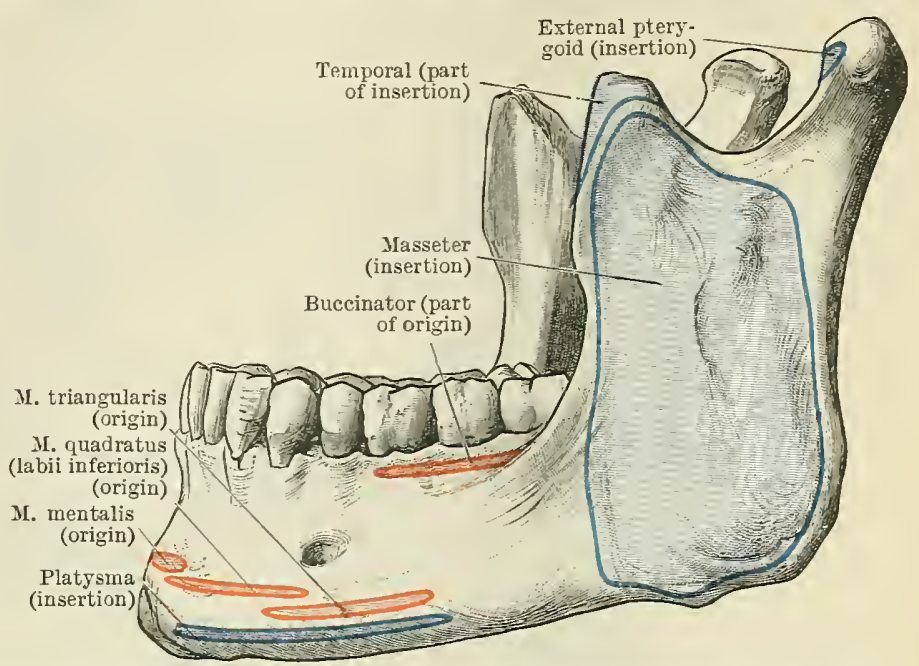

Fig. 403.-Muscle-Attachments to the Lateral Aspect of the Maxdible. separated from the buccinator muscle by the corpus adiposum buccce.

M. Temporalis.-The temporal muscle is a fan-shaped muscle arising from the whole area of the temporal fossa, as well as from the temporal fascia which covers it. Its converging fibres pass beneath the zygomatic arch.

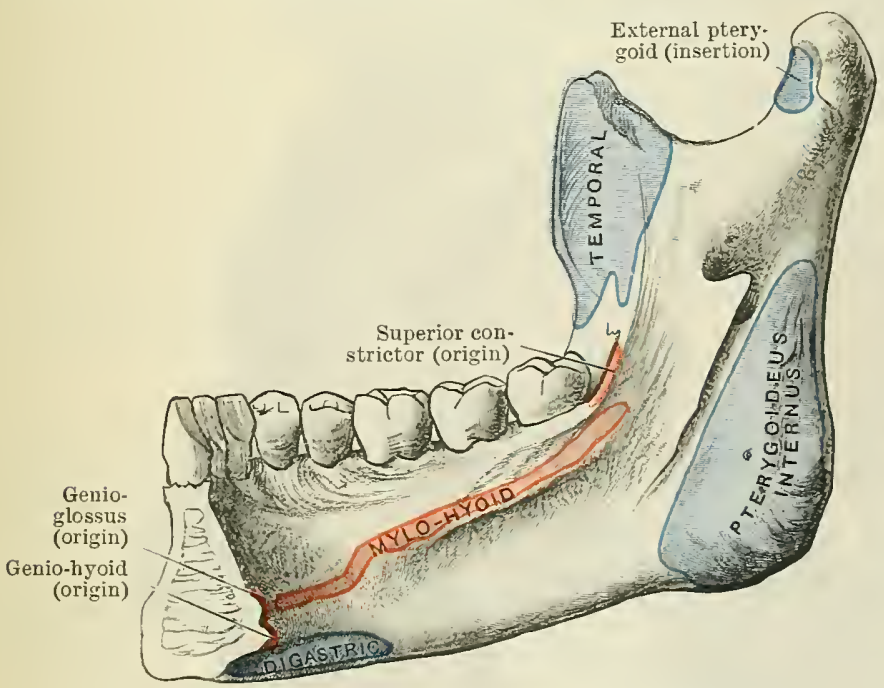

Fia. 401.-Muscle-Attachaexts on the Medial Side of the MIAXDIBLE.

The muscle is inserted into the deep surface and apex of the coronoid process, and in to the anterior border of the ramus of the mandible (Figs. 403 and 404).

The origin of the muscle is concealed by the temporal fascia. As it passes to its insertion the muscle is concealed by the zygomatic arch, the masseter muscle, and the coronoid process of the mandible. It is separated from the external pterygoid in a majority of cases by the internal maxillary artery. The masseteric nerve and vessels appear at its posterior border; the buccinator nerve and vessels at its anterior border.

M. Pterygoideus Externus.-The external pterygoid muscle is deeply placed under cover of the temporal muscle, in the infra-temporal fossa. It arises by two heads, superior and inferior. The superior head is attached to the infra-temporal surface of the great wing of the sphenoid; the inferior head takes origin from the lateral surface of the lateral pterygoid lamina of the pterygoid process.

The muscle is directer laterally and backwards, to be inserted into (1) the 


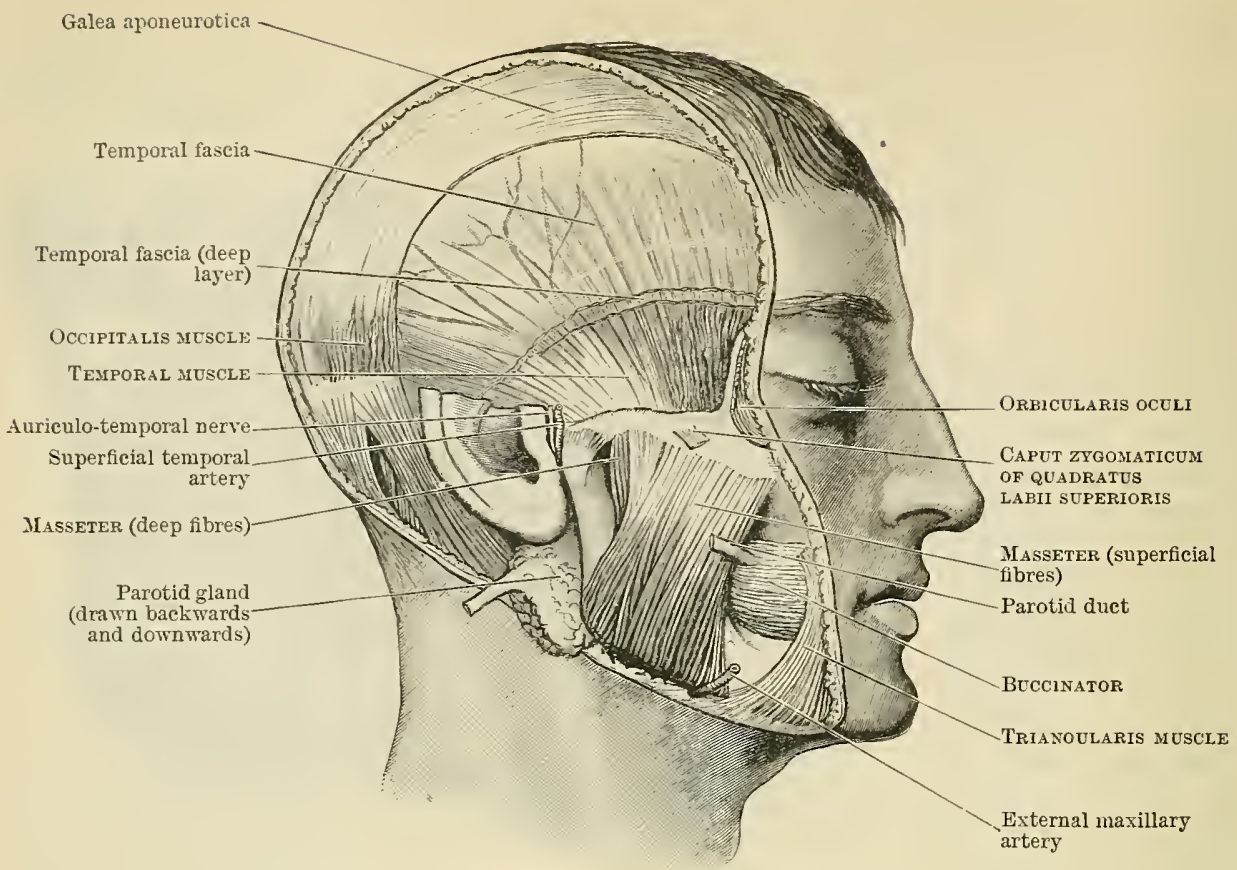

Fig. 405.-Muscles of Miastication (superficial riew).

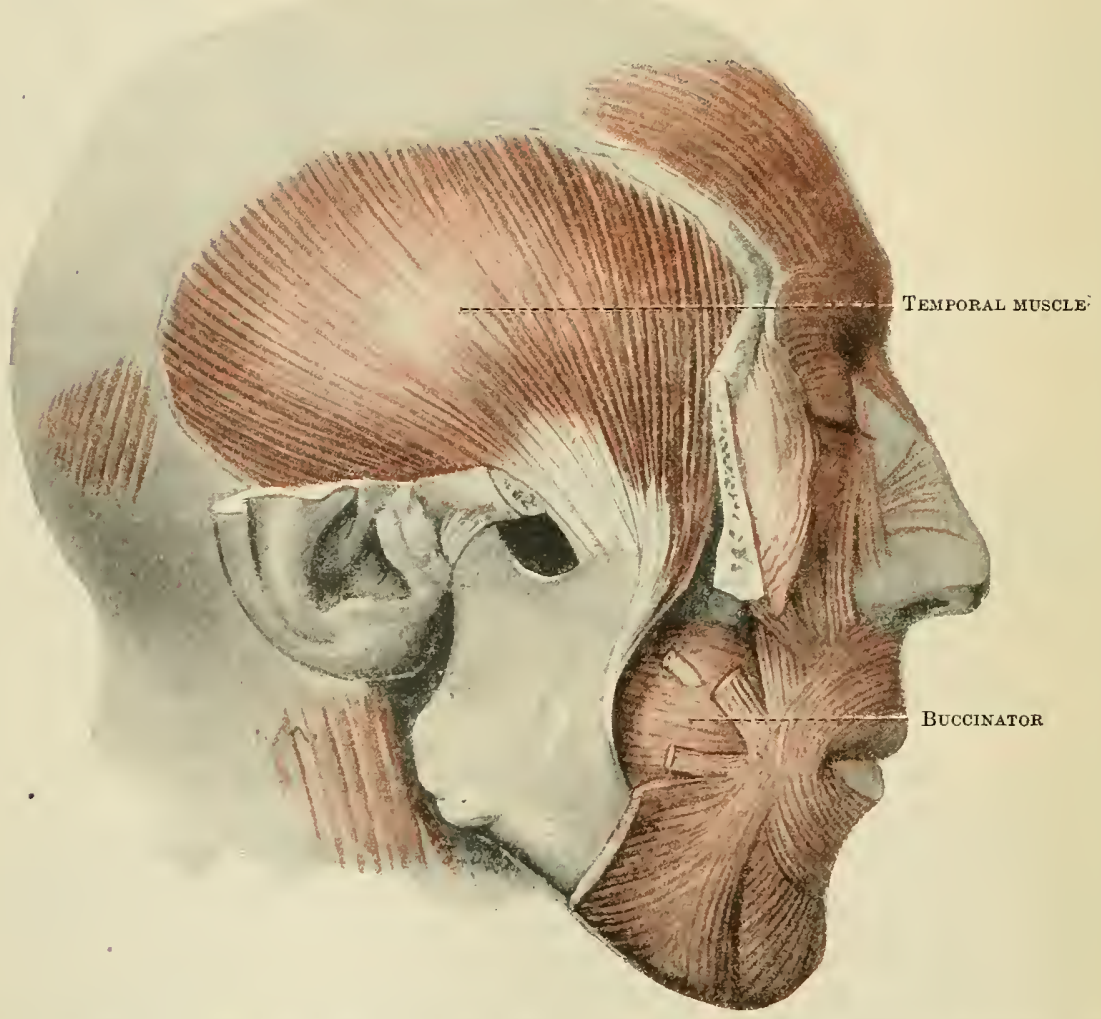

Fig. 406.-The Right Temporal Muscle. (The Zygomatic Arch and the Masseter Miscle have been removed.) 
fovea pterygoidea on the anterior aspect of the neck of the mandible (Figs. 403 and 404, p. 455), and (2) the articular disc and capsule of the mandibular articulation.

This muscle is covered by the insertion of the temporal muscle and the coronoid process of the mandible, and is usually crossed by the internal maxillary artery. It conceals the mandibular branch of the trigeminal nerve, and the pterygoid origin. of the internal pterygoid muscle.

IM. Pterygoideus Internus.-The internal pterygoid muscle, placed beneath the external pterygoid muscle and the ramus of the mandible, has likewise a double origin-(1) from the deep surface of the lateral pterygoid lamina and the pyramidal process of the palate bone, and (2) by a stout tendon from the tuberosity

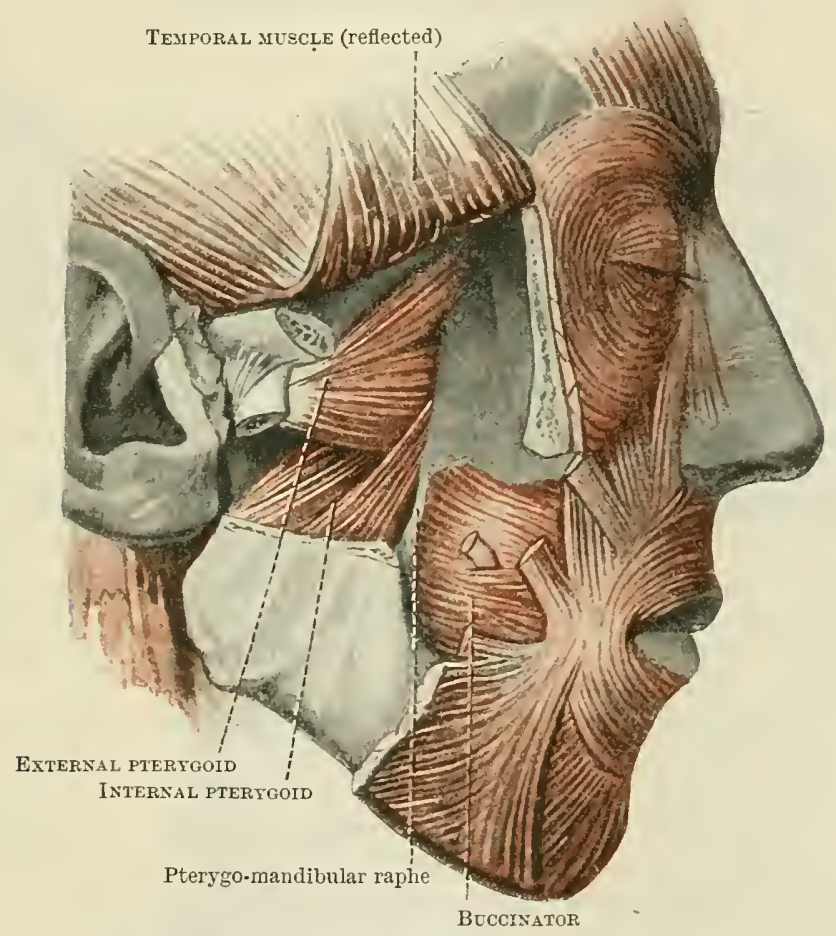

Fig. 407.-The Ptertgoid Midscles of the Right Side.

of the maxilla. Its two heads of origin embrace the inferior fibres of the external pterygoid muscle.

It is quadrilateral in form, and is directed downwards, laterally, and backwards over the auditory tube and the tensor and levator muscles of the palate, to be inserted into a triangular impression on the medial surface of the mandible, between the mylo-hyoid groove and the angle of the bone (Fig. 404, p. 455).

This muscle is covered by the ramus of the mandible and temporal muscle, and partially by the external pterygoid muscle. In contact with its superficial surface are the spheno-mandibular ligament, and the inferior alveolar and lingual nerves and their accompanying vessels. The muscle conceals the tensor reli palatini and the wall of the pharynx (superior constrictor).

Nerve-Supply. - The mandibular division of the trigeminal nerve supplies all the muscles of mastication except the buccinator, which is supplied by the facial nerve. The internal pterygoid muscle is supplied by the nerve before its division into anterior and posterior parts; the other muscles are innervated by the anterior trunk.

Actions-The above muscles, assisted by others in the neck, prodnce the varions movements of the mandible as follows:- 


\begin{tabular}{|c|c|}
\hline a. Opening of the Mouth. & Closure of the Mouth. \\
\hline $\begin{array}{l}\text { Weight of the mandible } \\
\text { Digastric } \\
\text { Mylo-hyoid } \\
\text { Genio-hyoid } \\
\text { Genioglossus } \\
\text { Infra-hyoid muscles }\end{array}$ & $\begin{array}{l}\text { Masseter } \\
\text { Temporal } \\
\text { Internal pterygoid }\end{array}$ \\
\hline b. Protrusion of the Mandible. & Retraction of the Mandible. \\
\hline $\begin{array}{l}\text { External pterygoid } \\
\text { Internal pterygoid } \\
\text { Temporal (anterior fibres) }\end{array}$ & Temporal (posterior fibres) \\
\hline \multicolumn{2}{|c|}{ c. Lateral Movement of the Mandible. } \\
\hline \multicolumn{2}{|c|}{$\begin{array}{l}\text { External pterygoid } \\
\text { Internal }\end{array}$} \\
\hline
\end{tabular}

\section{THE MUSCLES OF THE NECK.}

In addition to those included among the muscles of the back (p. 438), the following series of muscles occur in the neck: (1) sterno-cleido-mastoid; (2) the muscles of the hyoid bone (supra-hyoid and infra-hyoid); (3) the muscles of the tongue (extrinsic and intrinsic); (4) the muscles of the pharynx and soft palate; and (5) the prævertebral muscles.

M. Sternocleidomastoideus. - The sterno-mastoid muscle is the prominent muscle projecting on the side of the neck, and separating the anterior from the posterior triangle. It arises by two heads-(1) a narrow tendinous sternal head, from the anterior surface of the manubrium sterni (Fig. 330, p. 370), and (2) a broader clavicular origin, partly tendinous, partly fleshy, from the superior surface of the clavicle in its medial third (Fig. 327, p. 366). The muscle is inserted into the lateral surface of the mastoid process and into the superior nuchal line of the occipital bone (Fig. 396, p. 444).

The muscle passes obliquely over the side of the neck separating the anterior from the posterior triangle. It is almost superficial in its whole extent, but is overlapped superiorly by the parotid gland and is covered in its inferior part by the platysma. It is crossed by the external jugular vein, and by superficial branches of the cervical plexus. Its deep surface is in contact with: $(a)$ in its lower third, the infra-hyoid muscles, which separate it from the common carotid artery, and the subclavian artery and the internal jugular vein; $(b)$ in its middle third, with the cervical nerves which emerge between the transverse processes of the cervical vertebræ to form the cervical plexus; and $(c)$ in its superior third, with the splenius capitis muscle, and the accessory nerve which here pierces the deep surface of the muscle. Near its insertion the muscle is related to the splenius capitis, longissimus capitis, the posterior belly of the digastric, and the occipital artery.

The sterno-cleido-mastoid muscle is properly divisible into three parts: (1) sterno-mastoid, placed superficially, and passing obliquely from the sternum to the mastoid process; (2) cleidomastoid, placed more deeply, and directed vertically upwards from the clavicle to the mastoid process; and (3) cleido-occipitalis, passing obliquely upwards and backwards behind the cleidomastoid to the superior nuchal line of the occipital bone.

Nerve-Supply.- The sterno-mastoid muscle is innervated by the accessory nerve, joined by a branch from the cervical plexus (C. 2.).

Actions. - When one muscle acts alone, it flexes the head laterally, and rotates it to the opposite side. The two muscles acting together (1) flex the head in a forward direction, and (2) act as extraordinary muscles of inspiration, by raising the sternum and clavicles.

\section{The Muscles of the Hyoid Bone.}

The muscles attached to the hyoid bone are in three series: (1) infra-hyoid muscles, connecting the hyoid bone to the scapula, thorax, and thyreoid cartilage; 
(2) supra-hyoid muscles, connecting it to the mandible, cranium, and tongue; and (3) the middle constrictor muscle of the pharynx (p. 461).

The infra-hyoid muscles comprise the omo-hyoid, sterno-hyoid, sterno-thyreoid, and thyreo-hyoid muscles.

M. Omohyoideus.-The omo-hyoid is a muscle with two bellies, anterior and posterior. The posterior belly arises from the superior margin of the scapula and the superior transverse scapular ligament (Fig. 333, p. 372). It forms a narrow muscular band, which is directed obliquely forwards and upwards, to end in an intermediate tendon beneath the sterno-mastoid muscle.

From this tendon the anterior belly proceeds upwards to be inserted into the lateral part of the inferior border of the body of the hyoid bone.

The posterior belly of the muscle separates the posterior triangle into occipital and subclavian parts; the anterior belly crosses the common carotid artery at the

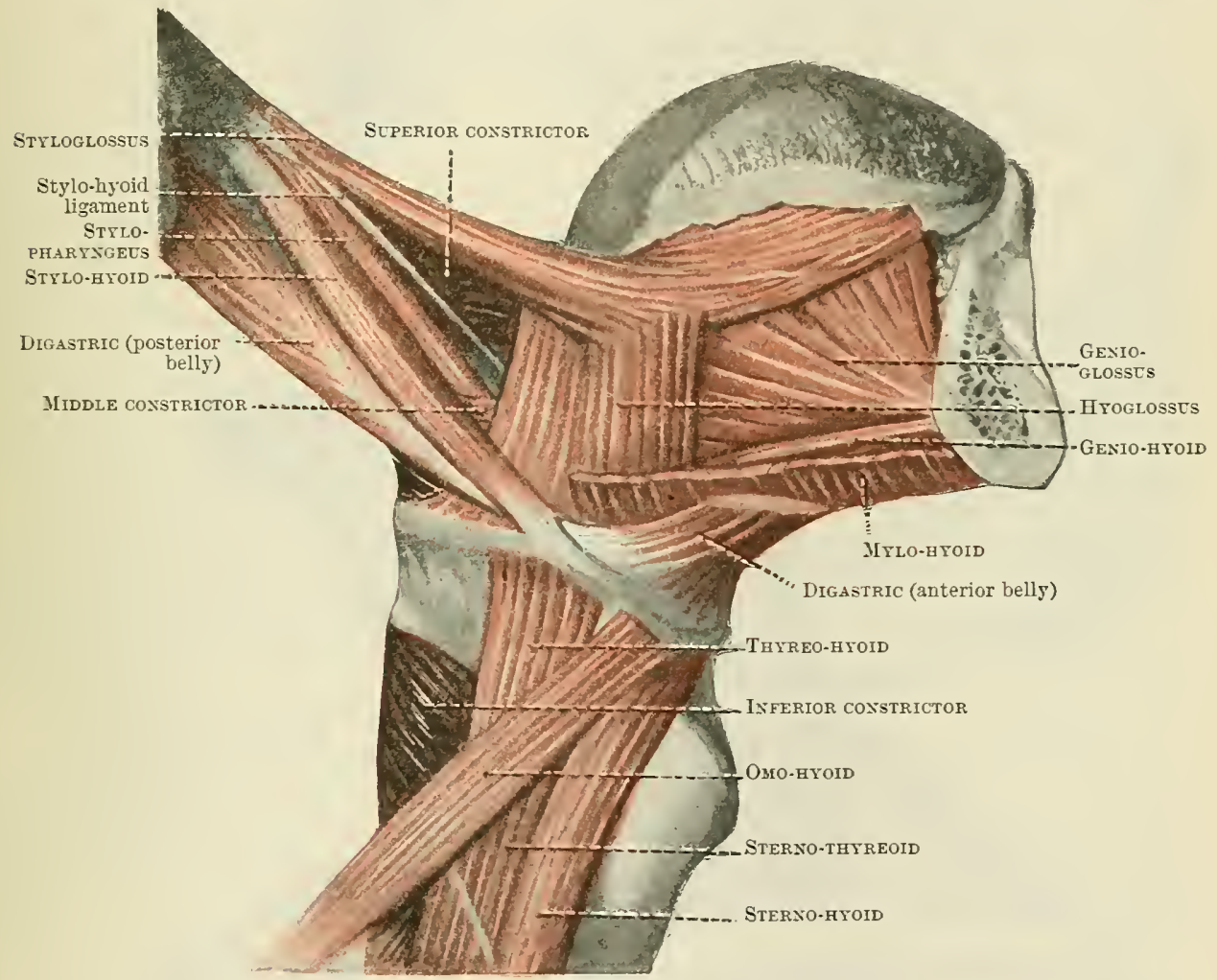

Fig. 408. - The Miescles of the Tosgee axd Hroid Bose (right side).

level of the cricoid cartilage, and in the anterior triangle forms the boundary between the muscular and carotid triangles. A process of the deep cervical fascia binds down the tendon and the posterior belly to the scapula and the first rib.

M. Sternohyoideus.-The sterno-hyoid muscle arises from the posterior surface of the manubrium, from the back of the first costal cartilage, and from the clavicle (Fig. 327, p. 366).

It passes vertically upwards in the neck, medial to the omo-hyoid and anterior to the sterno-thyreoid muscle, to be inserted into the medial part of the body of the hyoid bone. Except near its origin, which is covered by the sternum, clavicle, and sternal head of the sterno-mastoid, the muscle is superficially placed.

M. Sternothyreoideus. - The sterno-thyreoid muscle arises beneath the sterno-hyoid from the back of the manubrium and first costal cartilage.

Broader than the preceding muscle, it passes upwards and slightly in a lateral direction in the neck in front of the trachea and thyreoid gland, and beneath the sterno-mastoid, omo-hyoid, and sterno-hyoid muscles, to be inserted into the oblique 
line of the thyreoid cartilage. The muscle is marked by an oblique tendinous intersection in the middle of its length.

M. Thyreohyoideus. - The thyreo-hyoid muscle continues the line of the preceding muscle to the hyoid bone. Short and quadrilateral, it arises from the oblique line of the thyreoid cartilage.

Passing over the thyreo-hyoid membrane beneath the omo-hyoid and sternohyoid, it is inserted into the body and great cornu of the hyoid bone.

The levator glandulæ thyreoideæ is an occasional slip stretching between the lhyoid bone and the isthmus or pyramid of the thyreoid gland.

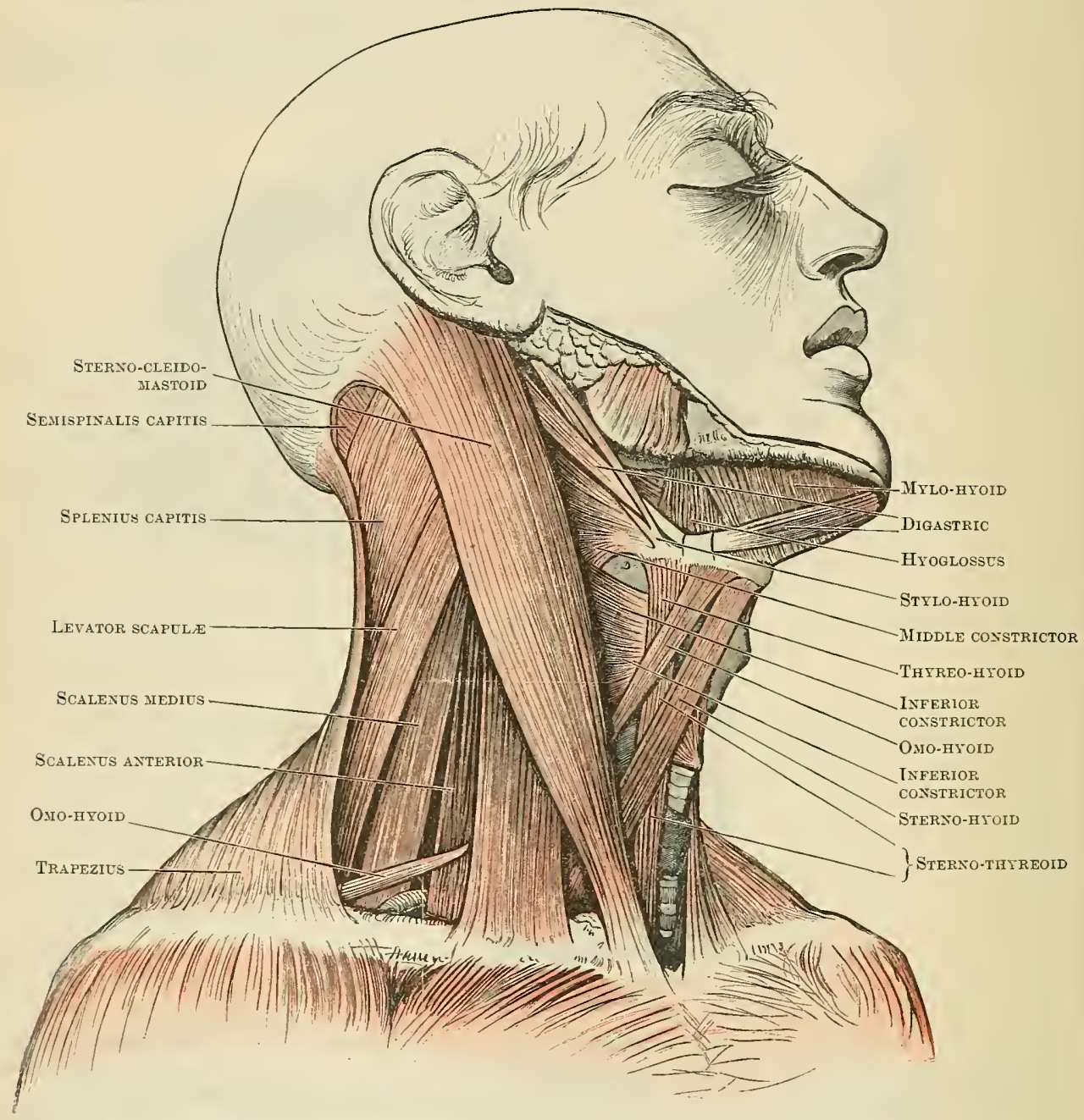

Fig. 409.-The MCscles OF THE Side of THE NeCK (anterior and posterior triangles).

Nerve-Supply. - The sterno-hyoid, sterno-thyreoid, and omo-hyoid are supplied by the ansa hypoglossi; the thyreo-hyoid, by a special branch from the hypoglossal nerve. Through the ansa hypoglossi the muscles are inmervated by nerves which are ultimately derived from the first three cervical nerves. The descendens hypoglossi is derived from the first two cervical nerves, the descendens cervicis by the second and third; and these two trunks combine to form the ansa. The thyreo-hyoid inuscle is innervated (through the hypoglossal) from the loop between the first and second cervical nerves.

Actions.-The sterno-hyoid, sterno-thyreoid, and omo-hyoid are depressors of the hyoid bone The two former muscles are also accessory muscles of inspiration. The omo-hyoid is a feeble elevator of the scapula. The thyreo-hyoid is, on the one hand, an elevator of the thyreoid cartilage, and acting with the previous muscles, on the other hand, it is a depressor of the hyoid bone.

The supra-hyoid muscles comprise the digastric, stylo-hyoid, mylo-hyoid, and 
genio-hyoid muscles; and also two muscles, the genioglossus and hyoglossus, which will be described along with the extrinsic muscles of the tongue.

M. Digastricus.-The digastric muscle, as its name implies, possesses two bellies-anterior and posterior.

The posterior belly arises under cover of the sterno-mastoid muscle from the mastoid notch medial to the mastoid process. It is directed forwards and downwards, in company with the stylo-hyoid muscle, to end in an intermediate tendon, which is connected by a pulley-like band of cervical fascia to the body of the hyoid bone.

The anterior belly of the muscle is directed forwards and upwards over the mylo-hyoid muscle to the chin, and is inserted into the oval digastric fossa on the inferior border of the mandible close to the symphysis (Fig. 410).

The muscle forms the inferior boundary of the submaxillary dirision of the anterior triangle, containing the submaxillary gland. The posterior belly in company with the stylo-hjoid crosses the carotid arteries and internal jugular vein. The occipital artery extends posteriorly along its inferior margin, and the parotid gland covers its superior border. The hypoglossal nerve emerges from under cover of the muscle. The anterior belly lies upon the mylo-hyoid muscle on its way to its insertion.

Nerve - Supply. - The posterior belly is supplied by the facial nerve; the anterior belly by the nerve to the mylo-hyoid, a branch of the inferior alveolar nerve.

\section{Stylohyoideus.} -The stylo-hyoid muscle arises from the inferior border of the styloid process of the temporal bone.

Crossing the anterior triangle obliquely along with the posterior belly of the digastric muscle, it is inserted into the body of the hyoid bone by two slips which enclose the tendon of the digastric muscle.

Nerve-Supply.-Facial nerve.

M. Mylohyoideus. - The mylo-hyoid muscle forms with its fellow a diapbragm in the floor of the mouth. It arises from the inferior three-fourths of the mylo-hyoid ridge of the mandible (Fig. 410).

It is directed downwards and medially, to be inserted into (1) the superior border of the body of the hyoid bone, and more anteriorly (along with the opposite muscle) into (2) a median raphe extending from the hyoid bone nearly to the chin.

The muscle has in contact with its superficial or lateral surface the digastric muscle and the submaxillary gland. Its deep or medial surface is partially covered by the mucous membrane of the floor of the mouth, and is separated from the muscles of the tongue by the deep part of the submaxillary gland, the sublingual gland, the submaxillary duct, and the lingual and hypoglossal nerres.

Nerve-Supply. - The muscle is supplied by the nerve to the mylo-hyoid, a branch of the inferior alveolar nerve.

M. Geniohyoideus.-The genio-hyoid muscle arises from the inferior of the two mental spines on the posterior surface of the symphysis of the mandible (Fig. 410). 
It is directed downwards and somewhat posteriorly, along the inferior border of the genioglossus, to be inserted into the anterior surface of the body of the hyoid bone. The muscles of opposite sides are often fused together.

The muscle is placed deeper than the anterior belly of the digastric muscle and the mylo-hyoid, and is in contact with the inferior border of the genioglossus muscle.

Nerve-Supply.-It is supplied by the hypoglossal nerve, but its nerve can be traced back to an origin from the communication between that nerve and the first and second cervical nerves.

Actions.--The digastric, stylo-hyoid, mylo-hyoid, and genio-hyoid muscles are all elevators of the hyoid bone. The posterior belly of the digastric and stylo-hyoid also retract, while the anterior belly of the digastric and the genio-hyoid protract it. The anterior belly of the digastric, mylo-hyoid, and genio-hyoid also assist in opening the mouth.

\section{The Muscles of the Tongue.}

The muscular substance of the tongue consists of two symmetrical series of muscles placed on either side of a membranous raphe in the median plane. The

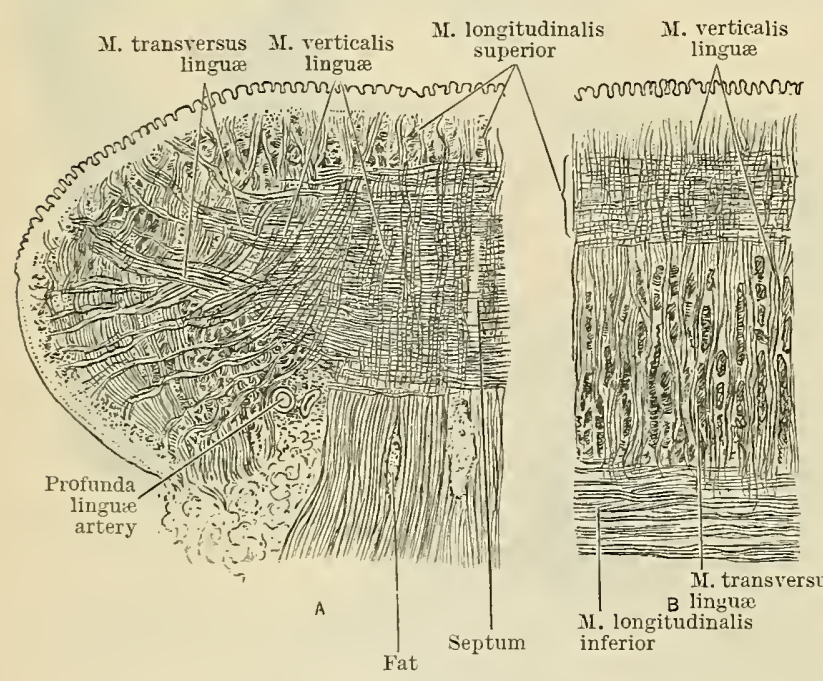

Fig. 411.-A, Trajsverse, and B, Longitudinal Vertical SECTIONS THROVGH THE TONGUE (Krause). series comprise (1) extrinsic muscles arising from the soft palate, styloid process, hyoid bone and mandible, and (2) intrinsic muscles proper to the tongue itself. Each set consists of four series of muscles.

A. The extrinsic muscles are four in number: (1) genioglossus, (2) hyoglossus, (3) styloglossus, and (4) glossopalatinus.

M. Genioglossus.The genioglossus muscle (O.T. geniohyoglossus) (Fig. 408, p. 459) is an extrinsic muscle of the tongue as well as a supra-hyoid muscle.

It is a fan-shaped muscle arising by its apex from the superior of the two mental spines, behind the symphysis of the mandible (Fig. 410, p. 461).

From this origin the muscular fibres diverge; the lowest fibres are directed downwards and backwards, to be inserted into the body of the hyoid bone; the highest fibres curve forwards, to be attached to the tip of the tongue; the intermediate fibres are attached to the substance of the tongue in its whole length between the base and tip.

The muscles of opposite sides are separated by the median raphe of the tongue. On the lateral aspect of each are the hyoglossus and mylo-hyoid muscles.

M. Hyoglossus.-The hyogiossus muscle is also an extrinsic muscle of the tongue as well as a supra-hyoid muscle.

It arises from the body and great cornu of the hyoid bone.

It is directed upwards and forwards, to be inserted into the side of the tongue, its fibres interlacing with the fibres of the styloglossus.

The muscle is quadrilateral, and lies between the genioglossus and mylo-hyoid muscles, separated from the latter by the mucous membrane of the floor of the mouth, the sublingual and part of the submaxillary glands, the lingual and hypoglossal nerves, and the submaxillary duct.

The chondroglossus is a small separated slip of the hyoglossus, not always present. 
M. Styloglossus.-The styloglossus muscle arises from the superior border of the styloid process near its tip, and from the stylo-hyoid ligament.

It sweeps forwards and medially, and is inserted into the side and inferior surface of the tongue, its fibres spreading out to decussate with those of the glossopalatinus and hyoglossus muscles beneath the submaxillary gland and the mucous membrane of the tongue.

M. Glossopalatinus.-The glossopalatinus (O.T. palatoglossus) is a thin sheet of muscular fibres arising from the inferior surface of the soft palate, where it is continuous with fibres of the opposite muscle.

It passes downwards in the glosso-palatine arch, and spreads out, to be inserted into the sides of the tongue, blending with the styloglossus and the deep transverse fibres of the tongue.

The muscle is placed directly beneath the mucous membrane of the soft palate and tongue.

B. Intrinsic Muscles of the Tongue.-Besides receiving the fibres of insertion of the extrinsic muscles, the substance of the tongue is composed of four intrinsic muscles on either side-two in the sagittal plane, the superior and inferior longitudinal muscles; two in the frontal plane, the transverse and vertical muscles.

M. Longitudinalis Superior.-The superior longitudinal muscle extends from base to tip of the tongue. It is placed on its dorsum immediately under the mucous membrane, into which many of its fibres are inserted.

M. Longitudinalis Inferior.-The inferior longitudinal muscle is a cylindrical band of muscular fibres occupying the inferior part of the organ on each side, in the interval between the genioglossus and the hyoglossus muscles. Posteriorly some of its fibres extend to the hyoid bone.

M. Transversus Linguæ.-The transversus linguæ (O.T. transverse fibres) arises from the median raphe, and radiates outwards to the dorsum and sides of the tongue, intermingling with the extrinsic muscles and the fibres of the vertical muscle. It occupies the substance of the tongue between the superior and inferior longitudinal muscles.

M. Verticalis Linguæ.-The verticalis linguæ (O.T. vertical fibres) arises from the dorsal surface of the tongue, and sweeps downwards and laterally to its sides, intermingled with the fibres of the preceding muscle and the insertions of the extrinsic muscles. The transverse and vertical muscles form a very considerable part of the total muscular substance of the organ.

Nerve-Supply. - All these muscles except the glossopalatinus are supplied by the hypoglossal nerve. The glossopalatinus is supplied by the accessory nerve through the pharyngeal plexus.

Actions.-The genioglossus and the hyoglossus are both elevators of the hroid bone besides having actions in relation to the tongue. The tongue is protruded by the action of the posterior fibres of the genioglossus, retracted by the anterior fibres aided by the styloglossus. The styloglossus and glossopalatinus are elevators, while the genioglossus and hypglossus are depressors of the tongue.

Actions of the Infra-hyoid and Supra-hyoid Muscles, and the Muscles of the Tongue.-These muscles have a complexity of action, owing to their numerous attachments to more or less movable points. The movements for which thes are responsible in whole or part are : (1) movements of the hyoid bone in mastication and deglutition, (2) movements of the thyreoid cartilage, (3) movements of the tongue, (4) morements of the head, (5) movements of the shoulder, and $(6)$ respiration.

(1) Movements of the Hyoid Bone.-The hyoid bone is elevated or depressed, and moved forwards or backwards along with the mandible and tongue, in speech, mastication, and swallowing.

a. Elevation.

Digastric

Stylo-hyoid

Mylo-hyoid

Genio-hyoid

Genioglossus

Hyoglossus

Muscles closing the mouth
Depression.

Thyreo-hyoid Sterno-hyoid

Omo-hyoid

Sterno-thyreoid

\section{Retraction.}

Genio-hyoid

Genioglossus

Stylo-hyoid

I Iiddle constrictor 
(2) Movements of the Thyreoid Cartilage.-The thyreoid cartilage is raised and lowered during speech and deglutition.

\begin{tabular}{|l|l|}
\hline \multicolumn{1}{|c|}{ Elevation. } & \multicolumn{1}{c|}{ Depression. } \\
\hline Thyreo-hyoid & $\begin{array}{l}\text { Sterno-thyreoid } \\
\text { Stylopharyngeus }\end{array}$ \\
$\begin{array}{l}\text { Pharyngopalatinus } \\
\text { Elerators of hyoid bone }\end{array}$ & $\begin{array}{l}\text { Depressors of hyoid bone } \\
\text { Iuscles closing mouth }\end{array}$ \\
\hline
\end{tabular}

(3) Movements of the Tongue.-The chief movements of the tongue in speech and deglutition are elevation and depression, protrusion and retraction, and lateral movements.

\begin{tabular}{|c|c|}
\hline \multicolumn{1}{|c|}{$a$. Elevation. } & \multicolumn{1}{c|}{ Depression. } \\
\hline $\begin{array}{l}\text { Styloglossus (base) } \\
\text { Glossopalatinus } \\
\text { Muscles elevating hyoid bone } \\
\text { Muscles closing Inouth }\end{array}$ & $\begin{array}{l}\text { Genioglossus } \\
\text { Hyoglossus } \\
\text { Chondroglossus } \\
\text { Muscles depressing the hyoid bone }\end{array}$ \\
\hline b. Protrusion. & \begin{tabular}{l} 
Retraction. \\
\hline Genioglossus (posterior fibres) \\
Styloglossus (anterior fibres)
\end{tabular} \\
\hline c. Lateral Movements. -The muscles of one side only. \\
\hline
\end{tabular}

(4) Movements of the Head.-The sterno-mastoid muscles, acting together, flex the head on the vertebral column, assisted by the supra-hyoid and infra-hyoid muscles. The sterno-mastoid muscle of one side, acting alone, bends the head to the same side, and simultaneously rotates it to the opposite side, as seen in torticollis (wryneck).

(5) Movements of the Shoulder Girdle.-The omo-hyoid and sterno-mastoid muscles have a.ready been included among the elevators of the shoulder girdle.

(6) Respiration.-The muscles in the front of the neck are auxiliary muscles in extraordinary or difficult inspiration. The masseter and temporal muscles fix the mandible; the hyoid bone is raised and fixed by the supra-hyoid muscles; and the sternum is raised by the sterno-mastoid and infra-hyoid muscles.

\section{The Muscles of the Pharynx.}

The muscular envelope of the pharynx is composed of two strata. The external or circular layer consists of the three fan-shaped constrictor muscles; the internal or longitudinal layer consists of the fibres of the stylopharyngeus and pharyngopalatinus muscles.

II. Constrictor Pharyngis Superior. - The superior constrictor muscle arises successively from the inferior half of the posterior border of the medial lamina of the pterygoid process (pterygopharyngeus), from the pterygomandibular raphe (buccopharyngeus), from the mylo-hyoid line of the mandible (mylopharyngeus) (Fig. 410, p. 461), and from the mucous membrane of the floor of the mouth (glossopharyngeus).

The muscular fibres radiate backwards, and are inserted for the most part into a raphe extending down the posterior wall of the pharynx in the median plane. The highest fibres are attached to the pharyngeal tubercle of the occipital bone (Fig. 396, p. 444), and the lowest fibres are overlapped by the middle constrictor. A crescentic interval occurs above the muscle, below the base of the skull, in which the auditory tube and the levator and tensor veli palatini muscles appear. Its lower border is separated from the middle constrictor by the stylopharyngeus muscle.

II. Constrictor Pharyngis IMedius.-The middle constrictor muscle arises from the stylo-hyoid ligament and from both cornua of the hyoid bone (chondropharyngeus, ceratopharyngeus).

From its origin the muscular fibres radiate backwards, to be inserted into the median raphe on the posterior aspect of the pharynx. 
The superior fibres overlap the inferior part of the superior constrictor; the inferior fibres are concealed from view by the inferior constrictor muscle. In the interval between the middle and inferior constrictors are found the superior laryngeal artery and internal laryngeal nerve.

M. Constrictor Pharyngis Inferior.-The inferior constrictor muscle arises from the oblique line of the thyreoid cartilage (thyreopharyngeus), and from the side of the cricoid cartilage (cricopharyngeus).

Its fibres radiate backwards, to be inserted into the median raphe on the posterior wall of the pharynx, the superior fibres overlapping the inferior part of the middle constrictor, the inferior fibres blending with the muscular fibres of the cesophagus. Below the inferior border of the muscle the inferior laryngeal artery and nerve enter into relation with the larynx.

Nerve-Supply. - The constrictors of the pharynx receive their nerve-supply throngh the pharyngeal plexus from the accessory nerve. The inferior constrictor is supplied also by the external laryngeal and recurrent branches of the ragus nerve.

The deeper longitudinal stratum of muscles in the pharyngeal wall is composed of the insertions of the stylopharyngeus and pharyngopalatinus muscles.

M. Stylopharyngeus.-The stylopharyngeus arises from the root of the styloid process on its medial side, and passes downwards between the external and internal carotid arteries. It enters the wall of the pharynx in the interval between the superior and middle constrictor muscles.

Spreading out beneath the middle constrictor muscle, it is inserted into the superior and posterior borders of the thyreoid cartilage and into the wall of the pharynx itself, becoming continuous posteriorly with the palatopharyngeus. In the neck the glossopharyngeal nerve winds round it on its way to the tongue.

N erve-S u p p I y.-Glossopharyngeal nerve.

M. Pharyngopalatinus. - The pharyngopalatinus (O.T. palatopharyngeus) occupies the soft palate and the pharyngeal wall. In the

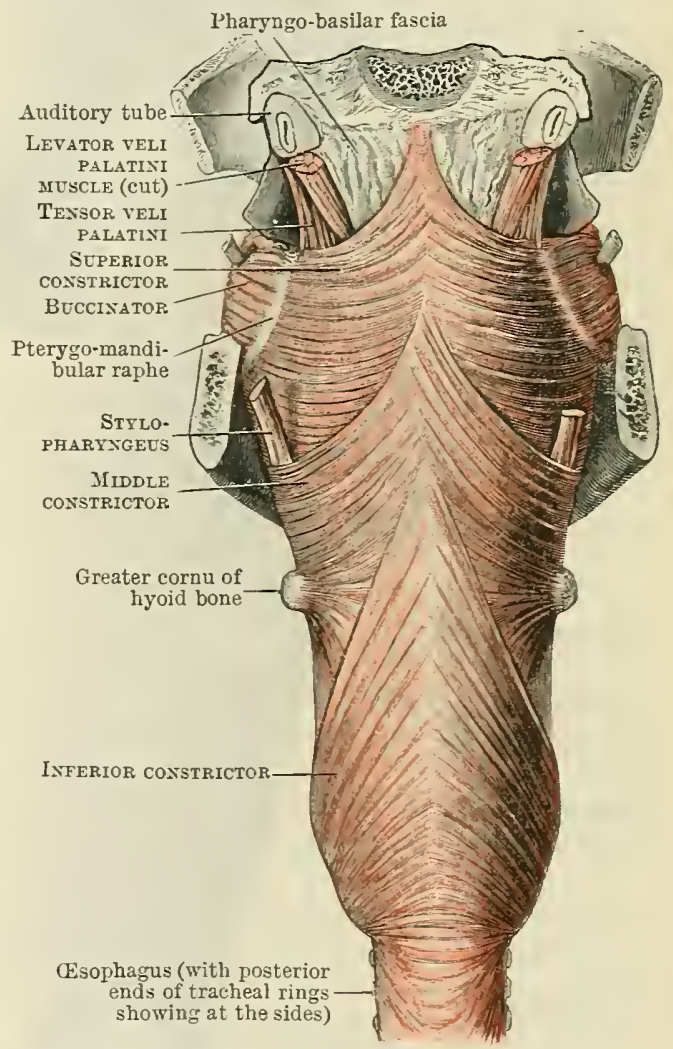

Fig. 412.-Posterior View of the Pharyxi axd Cosstrictor Muscles. substance of the soft palate it consists of two layers, a postero-superior laser, thin, and continuous across the median plane with the corresponding layer on the opposite side, and an antero-inferior layer, which is thicker, and is attached to the posterior border of the hard palate. The levator veli palatini and the musculus uvulæ are enclosed between the two layers, which unite at the posterior edge of the palate, receiving at the same time additional fibres arising from the auditory tube (salpingopharyngeus). The muscle descends to the pharynx in the pharyngo-palatime arch.

Its fibres spread out in the form of a thin sheet in the wall of the pharynx, in continuity anteriorly with the stylopharyngeus, and are inserted into the posterior border of the thyreoid cartilage, and behind that into the aponeurosis of the pharynx, reaching down as far as the inferior border of the inferior constrictor. The muscle is placed beneath the middle and inferior constrictors, and the fibres 
of the muscles of opposite sides decussate in the median plane, in the inferior part of the pharyngeal wall.

Nerve-Supply. - The muscle is innervated through the pharyngeal plexus, by the accessory nerve.

\section{The Muscles of the Soft Palate.}

The soft palate and uvula form a muscular fold, covered on each surface by mucous membrane, projecting backwards into the pharynx, and forming the posterior

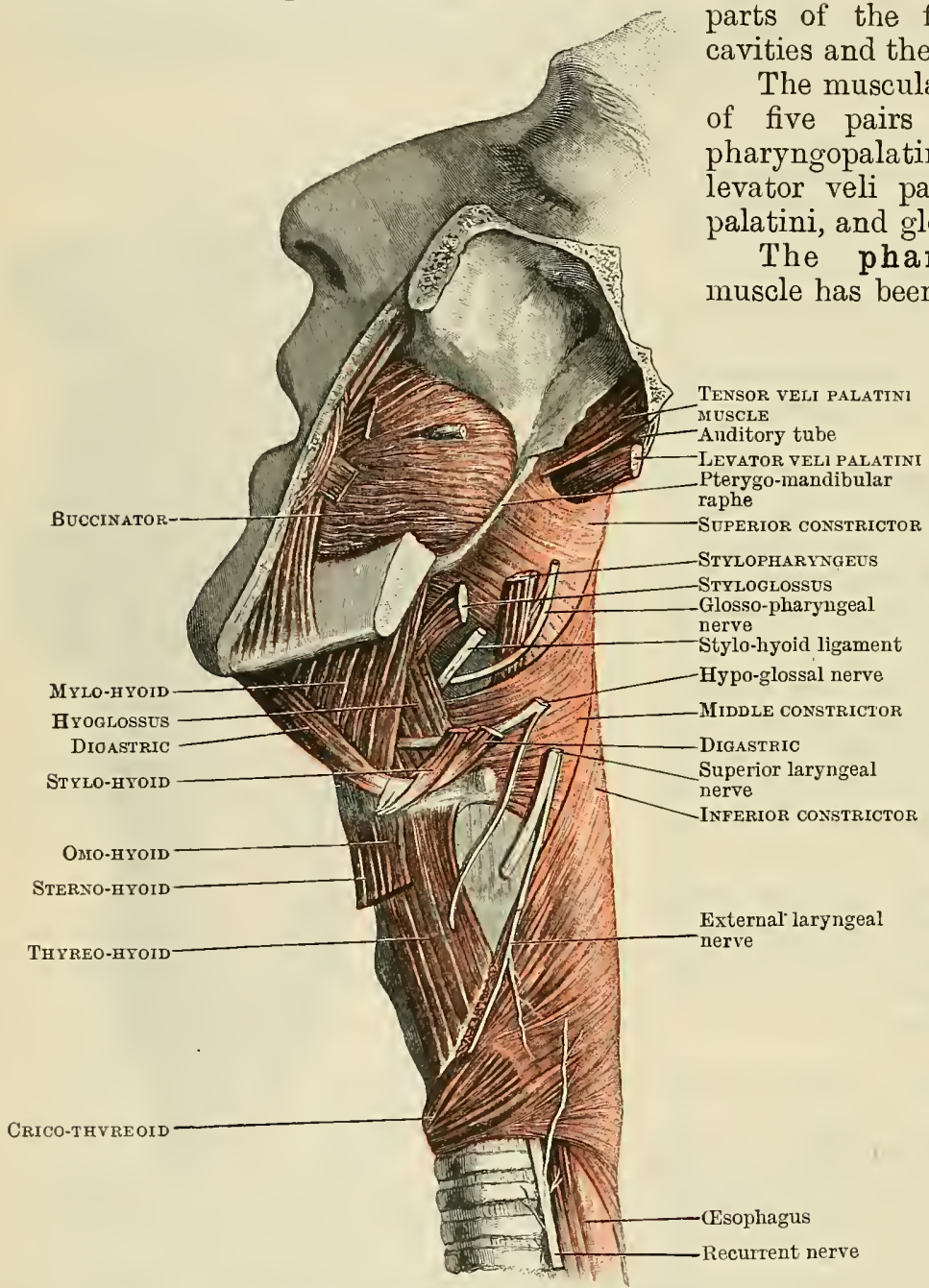

Fig. 413.-Lateral View of the Wall of the Pharyex. (p. 465).

The m. uvulæ (O. T. azygos uvulæ) consists of two narrow bundles enclosed, along with the insertion of the levator veli palatini, between the layers of the pharyngopalatinus. The slips arise from the posterior nasal spine and the aponeurosis of the soft palate, and unite as they proceed backwards to end in the uvula.

II. Levator Veli Palatini.The levator veli palatini has a double origin: (1) from the inferior surface of the apex of the petrous portion of the tem-

poral bone, and (2) from the inferior part of the cartilaginous part of the auditory tube. It passes obliquely downwards and medially, across the superior border of the superior constrictor muscle, and enters the soft palate between the two layers of the pharyngopalatinus muscle.

It is inserted into the aponeurosis of the soft palate, and some of its fibres become continuous with those of the opposite muscle.

It is separated from the tensor veli palatini muscle by the auditory tube and the deeper layer of the pharyngopalatinus muscle.

M. Tensor Veli Palatini.-The tensor veli palatini arises (1) from the scaphoid fossa and the angular spine of the sphenoid bone, and (2) from the lateral side of the cartilaginous part of the auditory tube. 
It descends between the internal pterygoid muscle and the medial pterygoid lamina and ends in a tendon which hooks round the pterygoid hamulus, and is inserted beneath the levator veli palatini into the posterior border of the hard palate, and into the aponeurosis of the soft palate.

M. Glossopalatinus.-The glossopalatinus (O.T. palatoglossus), occupying the inferior surface of the soft palate and the glosso-palatine arch, has already been described with the muscles of the tongue (p. 463).

Nerve-Supply. - The muscles of the soft palate (except the tensor veli palatini, which is innervated through the otic ganglion by the trigeminal nerve) are supplied through the pharyngeal plexus by the accessory nerve.

Actions of the Muscles of the Pharynx and Soft Palate.-The muscles of the pharynx and soft palate are chiefly brought into action in the act of swallowing. This act is divided into a voluntary stage, in which the bolus lies anterior to the arches of the fauces, and an involuntary stage, during which the food passes from the mouth through the pharynx. The movements occurring during the passage of tood through the mouth are as follows: the cheeks are compressed by the action of the buccinator muscles; the tongue, hyoid bone, and thyreoid cartilage are successively raised upwards by the action of the muscles which close the mouth and elevate the hyoid bone. By these means the food is pushed backwards between the palatine arches.

At the same time, by the contraction of the glosso-palatinus and pharyngo-palatinus, the palatine arches of the fauces are narrowed, while the muscles of the soft palate, contracting, tighten the soft palate, and by bringing it in contact with the posterior wall of the pharynx, shut off the nasal portion of the cavity. The elevation of the tongue, hyoid bone, and larynx simultaneonsly causes the elevation of the epiglottis and the superior aperture of the larynx, which is closed by the approximation of the arytænoid cartilages and the combined action of laryngeal muscles (arytænoideus, thyreoarytænoideus, and thyreoepiglotticus). The food thus slips over the posterior surface of the epiglottis and the closed superior aperture of the larynx, and between the palatine arches on either side, into the pharynx. It is now clasped by the constrictor muscles, which, by their contractions, force it down into the œsophagus. The contraction of the constrictor muscles results in a flattening of the pharynx and elevation of its anterior attachments.

During the act of swallowing, it is generally thought that the auditory tube is opened by the contraction of the tensor veli palatini muscle, which arises from it. It has been held, on the other hand, that the auditory tube is closed during swallowing by the compression of its wall by the contraction of the levator veli palatini.

\section{Deep Lateral and Præevertebral Muscles of the Neck.}

Three series of muscles are comprised in this group: (1) vertebro-costal (scaleni, anterior, medius, and posterior), (2) vertebro-cranial (longus capitis and rectus capitis anterior, and lateralis), and (3) vertebral (longus colli). They clothe the anterior surface of the cervical portion of the vertebral column for the most part, and are in relation anteriorly with the pharynx and cesophagus, and the large vessels and nerves of the neck.

M. Scalenus Anterior.-The scalenus anterior (O.T. anticus) arises from the anterior tubercles of the transverse processes of the third, fourth, fifth, and sixth cervical vertebræ.

It descends posterior to the carotid sheath and subclavian vein, to be inserted into the scalene tubercle and ridge on the first rib (Fig. 414, p. 468).

It is separated posteriorly from the scalenus medius by the roots of the brachial plexus, the subclavian artery, and the pleura, and it is concealed by the sternomastoid muscle.

M. Scalenus Medius.-The scalenus medius arises from the posterior tubercles of the transverse processes of the cervical vertebræ, from the second to the sixth inclusive.

It descends in the posterior triangle behind the subclarian artery and the roots of the brachial plexus, to be inserted into the rough impression on the first rib behind the subclavian groove (Fig. 414, p. 468). The muscle is pierced by the dorsal scapular and long thoracic nerves.

It is separated from the scalenus anterior by the subclavian artery and the roots of the brachial plexus.

IM. Scalenus Posterior.-The scalenus posterior arises behind the scalenus medius from the posterior tubercles of the fourth, fifth, and sixth cervical transverse processes. It is inserted into an impression on the lateral side of the second rib. 


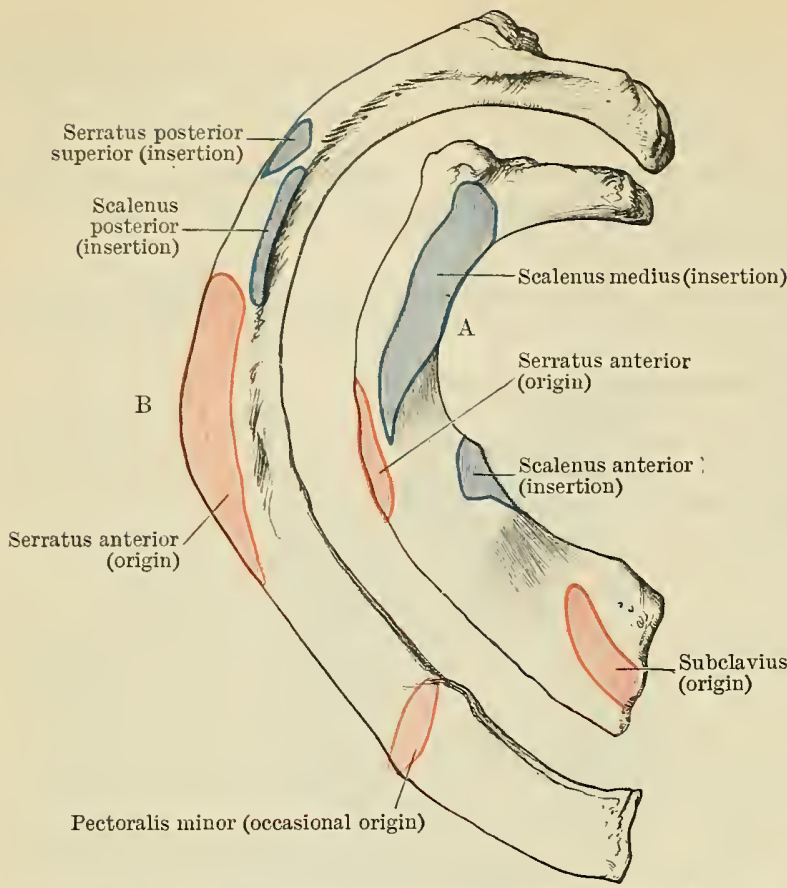

Fig. 414.-Muscle-Attachments to the Superior Surface of the First Rib, and the External Surface of the Second Rib (RIGHT SIDE).

$$
\text { A, First rib ; B, Second rib. }
$$

Nerve-Supply. - The scalene muscles are supplied by branches which arise directly from the anterior rami of the lowest four or five cervical nerves.

Actions. - The actions of those muscles are twofold. They are lateral flexors of the vertebral column, and are also important muscles of respiration, as elevators of the first and second ribs.

\section{Longus Capitis.-} The longus capitis (O.T. rectus capitis anticus major) arises from the anterior tubercles of the transverse processes of the third, fourth, fifth, and sixth cervical vertebræ.

It forms a flat triangular muscle, which is directed upwards alongside the longus colli muscle and behind the carotid sheath, to be inserted into an impression on the inferior surface of the basilar part of the occipital bone, anterior and lateral to the pharyngeal tubercle (Fig. 417, p. 469).
Nerve-Supply. - The muscle receives nerves directly from the anterior rami of the first four cervical nerves.

Action. - Flexion of the head and cervical vertebræ.

II. Rectus Capitis Anterior.-The rectus capitis anterior (O.T. rectus capitis anticus minor) arises, under cover of the preceding muscle, from the lateral mass of the atlas. It is inserted into the basilar part of occipital bone between the preceding muscle and the occipital condyle (Fig. 417, p. 469).

Nerve-Supply.-The muscle is innervated by the loop between the first two cervical nerves (anterior rami).

Action. - Flexion of the head on the vertebral column.

M. Longus Colli.-The longus colli is a flattened muscular band extending from the third thoracic vertebra to the atlas. It

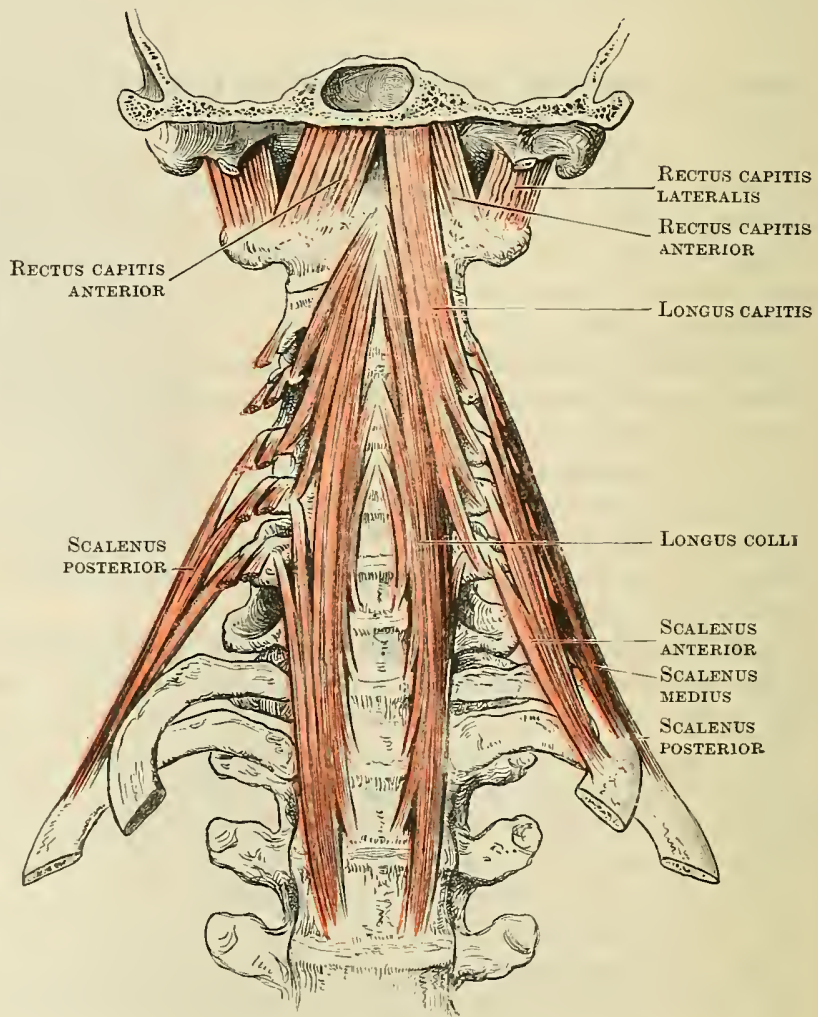

Fig. 415.-The Prevertebral Muscles of the Neck. 
LATERAL AND PR EVERTEBRAL MUSCLES OF THE NECK. 469

is divisible into three portions-a vertical, an inferior oblique, and a superior oblique portion.

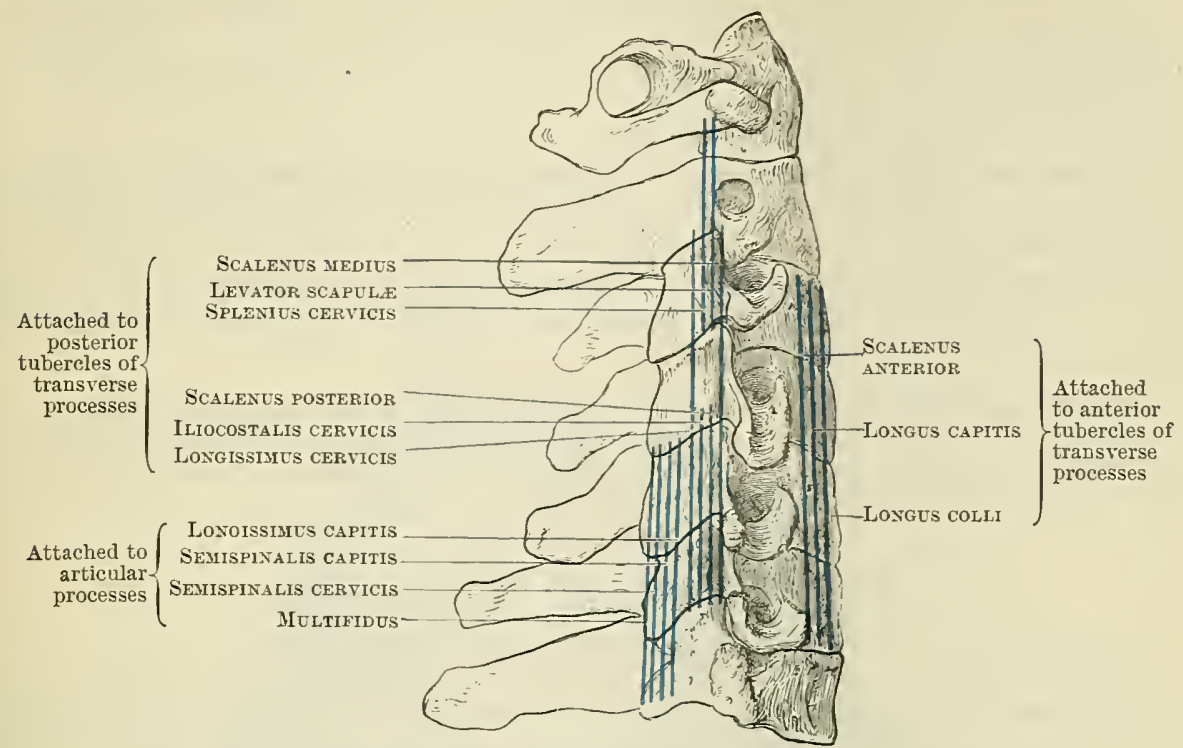

Fig. 116.-Scheme of Muscular Attachments to Cervical Vertebre.

The vertical portion of the muscle arises from the bodies of the first three thoracic and the last three cervical vertebræ.

Passing vertically upwards, it is inserted into the bodies of the second, third, and fourth cervical vertebræ.

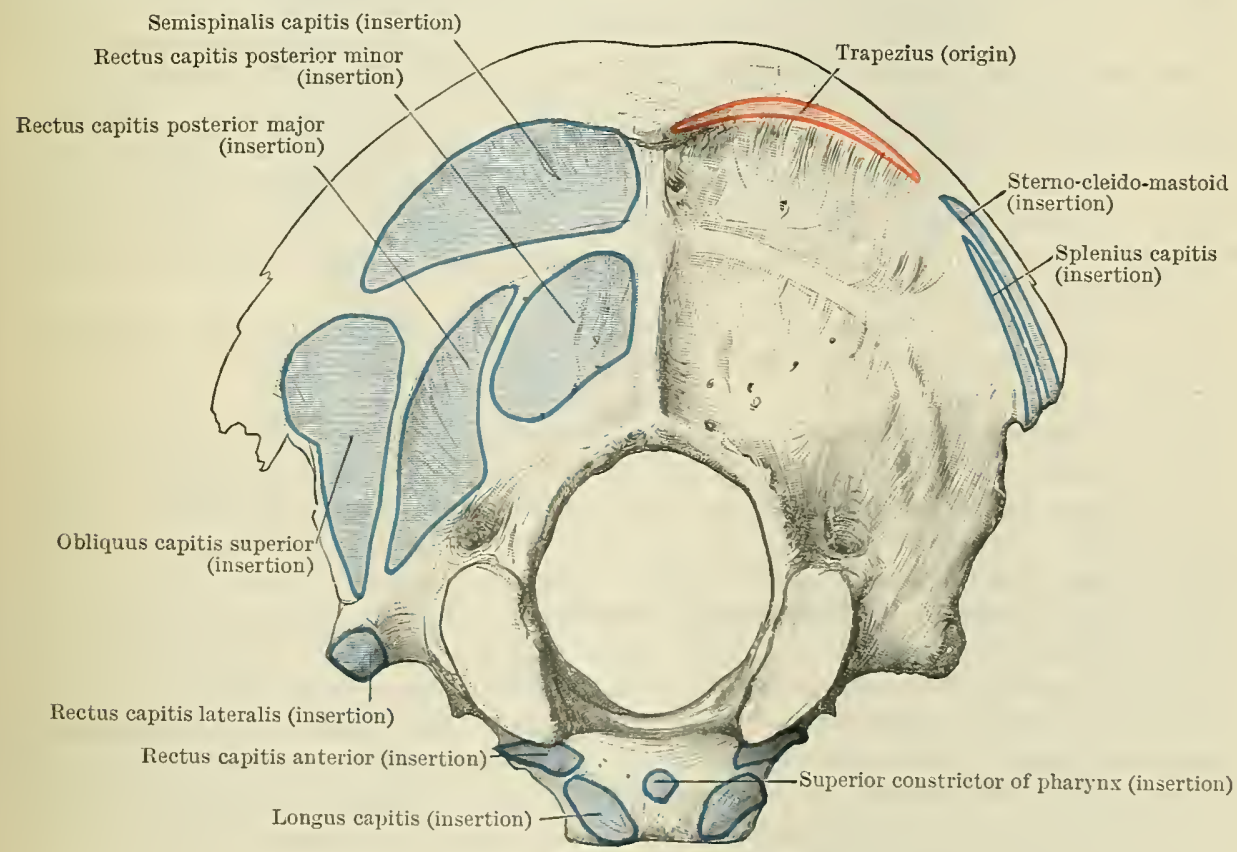

Fig. 417.-Muscle-Attachyexts to the Occipital Bone.

The inferior oblique portion arises from the bodies of the first three thoracic vertebræ.

It is inserted into the anterior tubercles of the fifth and sixth cervical vertebræ. 
The superior oblique portion arises from the anterior tubercles of the transverse processes of the third, fourth, and fifth cervical vertebræ.

It is directed upwards, to be inserted into the anterior tubercle of the atlas.

Nerve-Supply.-It is supplied by nerves from the anterior rami of the second, third, and fourth cerrical nerves.

Action. - A flexor of the rertebral column.

M. Rectus Capitis Lateralis.-The rectus capitis lateralis, in series with the posterior inter-transverse muscles in the neck, arises from the transverse process of the atlas.

It is inserted into the inferior surface of the jugular process of the occipital bone. It is placed alongside the rectus capitis anterior, separated from it by the anterior ramus of the first cervical nerve.

Nerve-Supply. - The loop between the anterior rami of the first two cervical nerves.

Actions. - A lateral flexor of the head and vertebral column. The movements produced by these muscles are considered along with those of other muscles acting on the head, vertebral column, and thorax (pp. 445, 446).

\section{THE MUSCLES OF THE THORAX. Muscles of Respiration.}

The muscles which complete the boundaries of the thorax are the diaphragm and intercostal muscles (external and internal), along with three series of smaller muscles-the transversus thoracis, the levatores costarum, and the subcostal muscles.

IMm. Intercostales.-The intercostal muscles are arranged in eleven pairs, which occupy the intercostal spaces.

Each external muscle arises from the sharp lower border of a rib, and is directed inferiorly and anteriorly, to be inserted into the external edge of the superior border of the rib below. It extends from the tubercle of the rib posteriorly nearly to the costal cartilage anteriorly. The anterior intercostal aponeurosis is continuous with it anteriorly, and extends forwards to the side of the sternum.

Each internal muscle arises from the costal cartilage and the internal or superior edge of the costal groove, and is directed inferiorly and posteriorly, to be inserted into the internal edge of the superior border of the rib and costal cartilage below. It extends from the side of the sternum anteriorly to the angle of the rib posteriorly, where it is replaced by the posterior intercostal aponeurosis extending to the tubercle of the rib.

The superficial surface of the external muscle is covered by the muscles of the chest, axilla, abdomen, and back. The deep surface of the internal muscle is in contact with the pleura.

Mm. Levatores Costarum.-The levatores costarum are in series with the external intercostal muscles. They are twelve small slips arising from the transverse processes of the seventh cervical and upper eleven thoracic vertebræ. They spread out in a fan-like manner as they descend, to be inserted into the lateral surface of each of the ribs, posterior to the angles.

$\mathrm{Mm}$. Subcostales.-The subcostal muscles are slips of muscles found on the internal surface of the lower ribs near their angles. They are in series with the internal intercostal muscles, but pass over the deep surface of several ribs.

M. Transversus Thoracis. - The transversus thoracis (O.T. triangularis sterni) occupies the posterior aspect of the anterior thoracic wall, and is separated from the costal cartilages by the internal mammary vessels. It arises from the posterior surface of the xiphoid process and body of the sternum as high as the level of the third costal cartilage.

From this origin its fibres radiate laterally, the lower horizontally, the upper fibres obliquely upwards, to be inserted into the second, third, fourth, fifth, and sixth costal cartilages. The muscle is continuous below with the transversus abdominis. 
Diaphragma.-The diaphragm is the great membranous and muscular partition separating the cavities of the thorax and abdomen. It forms a thin lamella arching over the abdominal cavity, and clothed on this surface for the most part by peritoneum. It is related on its inferior concave surface to the liver, stomach, and spleen, the kidneys and suprarenal glands, and the duodenum and pancreas. Its superior convex surface projects into the thoracic cavity, rising higher on the right than on the left side, and is related to the pericardium and pleuræ, and along its margin to the chest wall. The cesophagus and thoracic aorta are in contact with it posteriorly.

It possesses a peripheral origin from the sternum, ribs, and vertebral column,

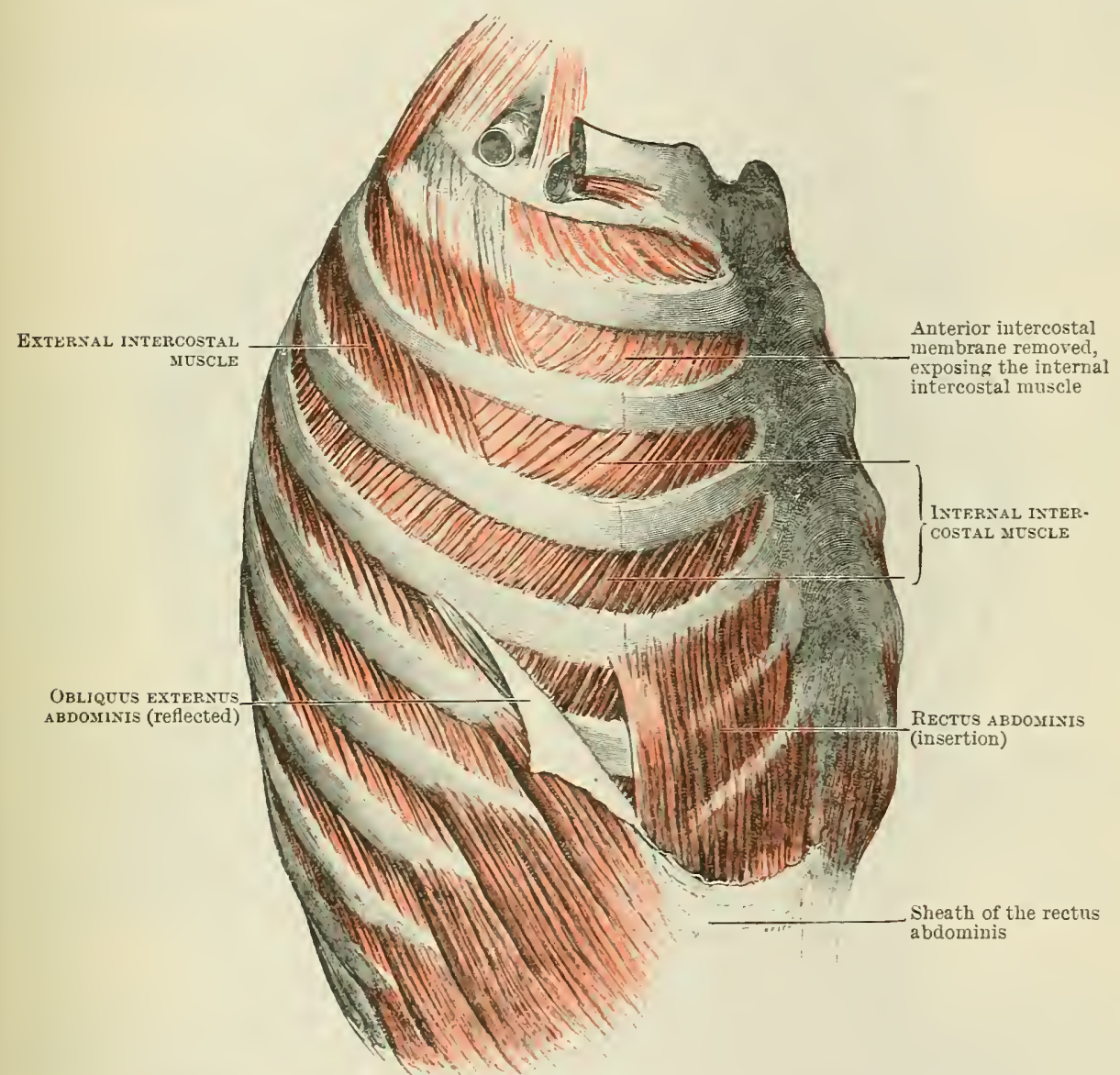

Fig. 418.-The Muscles of the Right Side of the Thoracic Wall.

and an insertion into a central tendon. It arises (1) anteriorly (pars sternalis) from the posterior surface of the xiphoid process by two slender fleshy slips, directed backwards; (2) laterally (pars costalis), from the deep surface of the lower six costal cartilages on each side by fleshy bands which interdigitate with those of the transversus abdominis; (3) posteriorly (pars lumbalis), from the lumbar vertebra, by the crura, and the medial and lateral lumbo-costal arches. The crura are two elongated fibro-muscular bundles which arise on each side of the aorta from the anterior surface of the bodies of the lumbar vertebræ, on the right side from the first three, on the left side from the first two lumbar vertebræ. They are directed upwards and decussate across the median plane in front of the aorta, the fibres of the right crus passing anterior to those of the left crus. The fibres then encircle the œsophagus, forming an elliptical opening for its passage, and finally join the central tendon, after a second decussation anterior to the gullet. 
The medial part of each crus is wholly tendinous and is sometimes called the crus mediale; it is connected with its fellow of the opposite side by a tendinous band called the middle arcuate ligament, which arches between them, in front of the aorta, and gives origin to fibres which join the crura as they decussate to encircle the gullet. The most outlying part of the crus is sometimes called the crus laterale; its infero-lateral margin is continuous with the medial lumbo-costal arch. The intermediate part of the crus is the crus intermedium; the splanchnic nerves pierce the diaphragm between it and the medial crus. The sympathetic trunk sometimes pierces the diaphragm between the intermediate and lateral crura.

The arcus lumbocostalis medialis (O.T. internal arcuate ligament) is a thickening formed by the attachment of the psoas fascia to the body of the first lumbar vertebra medially and its transverse process laterally. Stretching across the superior end of the psoas muscle, the ligament gives origin to muscular fibres which join the fibres of the crus.

The arcus lumbocostalis lateralis (O.T. external arcuate ligament) is the thickened superior border of the fascia over the quadratus lumborum muscle

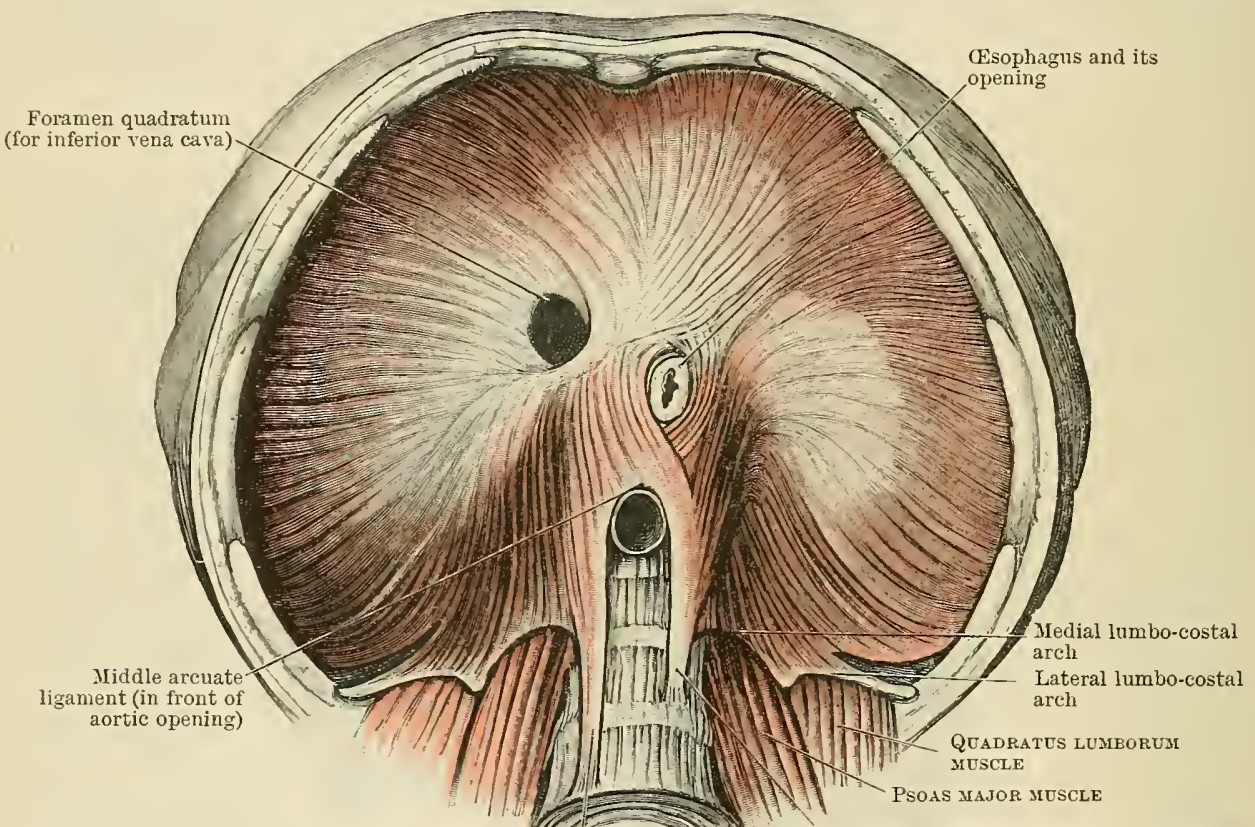

Right crus of diaphragm

Left crura (medial and lateral) of diaphragm

FIg. 419. - The Diaphragm (from below).

and is attached medially to the transverse process of the first lumbar vertebra, and laterally to the last rib. It gives origin to a broad band of muscular fibres, separated by an interval from the fibres arising from the medial lumbocostal arch which sweep upwards to the central tendon.

From this extensive origin the muscular fibres of the diaphragm converge to an insertion into a large trilobed central tendon called the centrum tendineum. Of its lobes the right one is the largest, the middle or anterior is intermediate in size, and the left is the smallest. It does not occupy the centre of the muscle, being placed nearer the front than the back. The fibres of the crura are consequently the longest; those from the xiphoid process are the shortest.

The diaphragm is pierced by numerous structures. The superior epigastric artery enters the sheath of the rectus abdominis between its sternal and costal origins; the musculo-phrenic artery passes between its attachments to the seventh and eighth ribs. The sympathetic trunk and the splanchnic nerves pierce, or pass posterior to the diaphragm; the last thoracic nerve passes beneath the lateral lumbo-costal arch; and the aorta, the azygos vein, and thoracic duct pass between the crura, underneath the middle arcuate ligament (hiatus aorticus or aortic opening). The special foramina are two in number. The foramen vence cavce (O.T. foramen 
quadratum) in the right lobe of the central tendon transmits the inferior vena cava, and small branches of the right phrenic nerve. The hiatus cesophageus (cesophageal opening) is in the muscular substance of the diaphragm, posterior to the central tendon, and is surrounded by a sphincter-like arrangement of the crural fibres. Besides the cesophagus, this opening transmits the two vagi nerves.

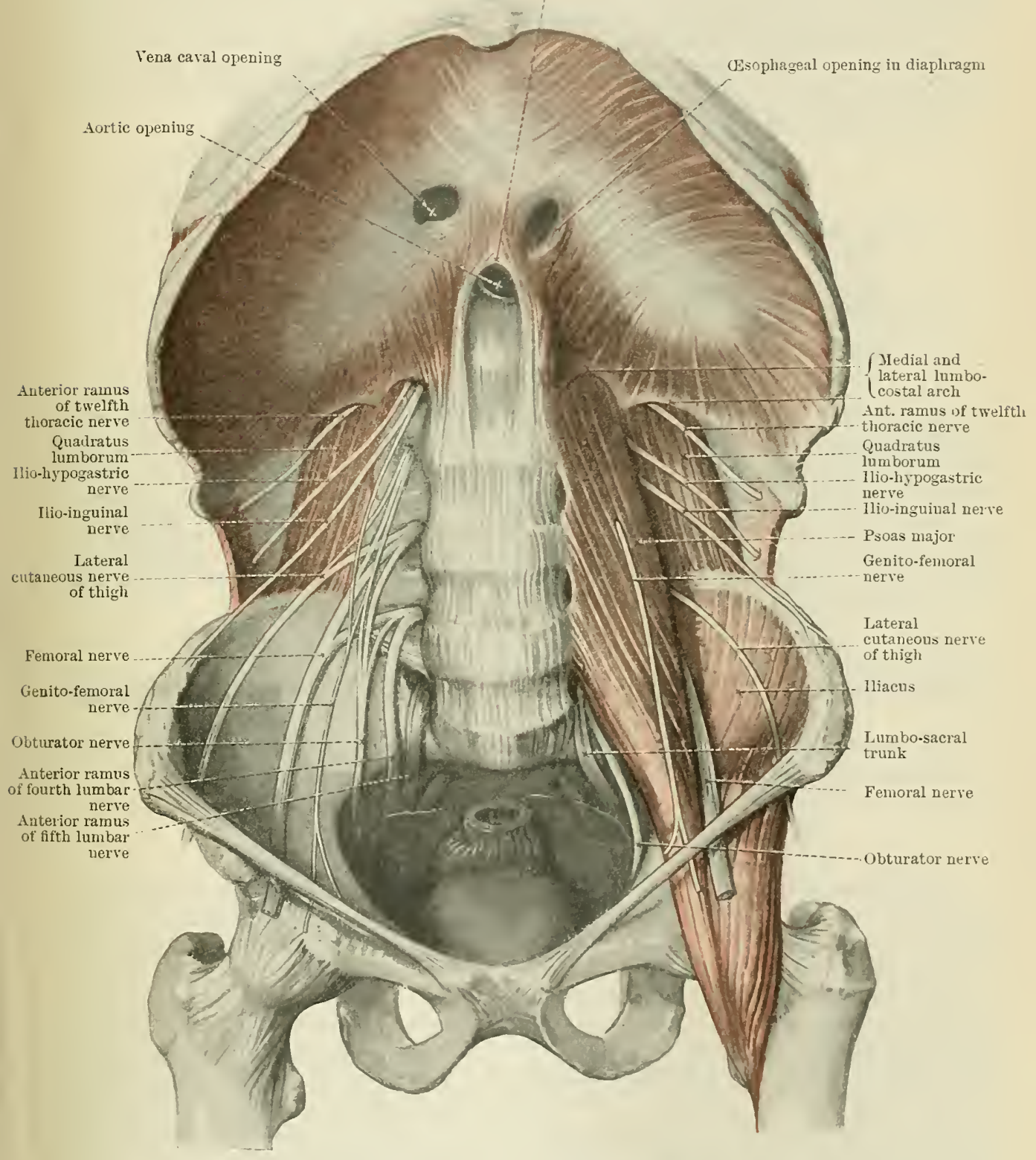

Fig. 420.-The Diaphraga asid Posterior abdominal Wall.

The diaphragm is found as a complete septum between the thorax and abdomen only in mammals. It is occasionally deficient in the human subject, producing hernia of the diaphragm, either into the pericardial cavity through the central tendon, or into the pleural carity through the lateral portions of the muscle. A rare condition is congenital deficiency of a part of the lateral half of the muscle, generally placed posteriorly, and ou the left side. This produces, by continuity of the pleural and peritoneal carities behind the diaphragm, a congenital diaphragmatic hernia. 
Nerve-Supply.--The intercostal muscles, levatores costarum, subcostal muscles, and transversus thoracis, are all supplied by the anterior rami of the thoracic nerves. The diaphragm receives its chief, if not its entire, motor supply from the phrenic nerves (C. 3. 4.5.). It is innervated also by the diaphragmatic plexus of the sympathetic, and is sometimes said to receive fibres from the lower thoracic nerves.

Actions. - The act of respiration consists of two opposite movements-inspiration and expiration.

1. The movement of expiration is performed by (1) the elasticity of the lungs, (2) the weight of the chest walls, (3) the elevation of the diaphragm, (4) the action of muscles-transversus thoracis and muscles of the abdominal wall. It is sometimes stated that the interosseous fibres of the internal intercostal muscles are depressors of the ribs.

2. The movement of inspiration results in the enlargement of the thoracic cavity in all its diameters. Its antero-posterior and transverse diameters are increased by the elevation and forward movement of the sternum, and by the elevation and eversion of the ribs, while its vertical diameter is increased by the descent of the diaphragm.

The muscles of inspiration are divided into two series-ordinary and accessory.

\begin{tabular}{|l|l|}
\hline \multicolumn{1}{|c|}{$a$. Ordinary Muscles. } & b. Extraordinary and Accessory Muscles. \\
\cline { 2 - 3 } Diaphragm & Quadratus lumborum \\
Intercostals & Pectorales \\
Scaleni & Serratus anterior \\
Serrati posteriores & Sterno-mastoid \\
Levatores costarum & Latissimus dorsi \\
Subcostales & Infra-hyoid muscles \\
& Extensors of the vertebral column \\
\hline
\end{tabular}

Of the ordinary muscles the diaphragm is the most important. Its action is twofoldcentrifugal, elevating the ribs and increasing the transverse and antero-posterior diameters of the thorax, and centripetal, drawing downwards the central tendon and increasing the vertical diameter of the thorax. Of the two movements the former is the more important. There has been considerable diversity of opinion regarding the action of the intercostal muscles. It is generally agreed that the external muscles elevate the ribs; it is probable that the whole of each internal muscle acts in the same way, althongh it has been stated by different observers that the whole internal muscle is a depressor; or that the interosseous part is a depressor, the interchondral portion of the muscle an elevator of the ribs.

\section{FASCI AE AND MUSCLES OF THE ABDOMINAL WALL.}

The space between the base of the bony thorax and the pelvis is filled up by a series of muscular sheets, covered externally and internally by fasciæ.

\section{FASCI尼.}

The fasciæ of the abdominal wall are-externally, the superficial and deep fasciæ ; internally, the fascia transversalis, which clothes the interior of the abdominal cavity, and is continuous with the diaphragmatic, lumbo-dorsal, psoas, iliac, and pelvic fasciæ, and is lined within by the subserous coat of extra-peritoneal tissue.

The superficial fascia of the abdomen is liable to contain a large quantity of fat. In the groin it is separated into two layers: a superficial fatty layer continuous over the inguinal ligament with the fascia of the anterior surface of the thigh (p. 402), and a deeper membranous layer attached to the medial half of the inguinal ligament, and more laterally to the fascia lata of the thigh distal to the inguinal ligament. The two layers are separated by the lymph glands and the superficial vessels of the groin. Higher up in the abdominal wall the two layers blend together. Passing downwards over the spermatic funiculus, they unite to form the fascia and dartos muscle of the scrotum. The attachment of the fascia to the groin prevents the passage into the thigh of fluid extravasated in the abdominal wall.

The deep fascia of the abdominal wall resembles similar fasciæ in other situations. It forms an investment for the obliquus externus muscle, and becomes thin and almost imperceptible in relation to the aponeurosis of that muscle. 
Fascia Transversalis.-The fascial lining of the abdominal carity (fascia transversalis) consists of a continuous layer of membrane which receives different names in different parts of its extent. It covers the deep surface of the transversus muscle, and is continuous medially with the fasciæ of the quadratus lumborum and the psoas muscles. It is continuous above with the diaphragmatic fascia, and below the iliac crest and the inguinal ligament with the fascia iliaca. Along with the last-named fascia it forms the femoral sheath, enclosing the femoral vessels and the femoral canal in their passage to the thigh behind the medial part of the inguinal ligament (p. 405). It is pierced by the spermatic funiculus or

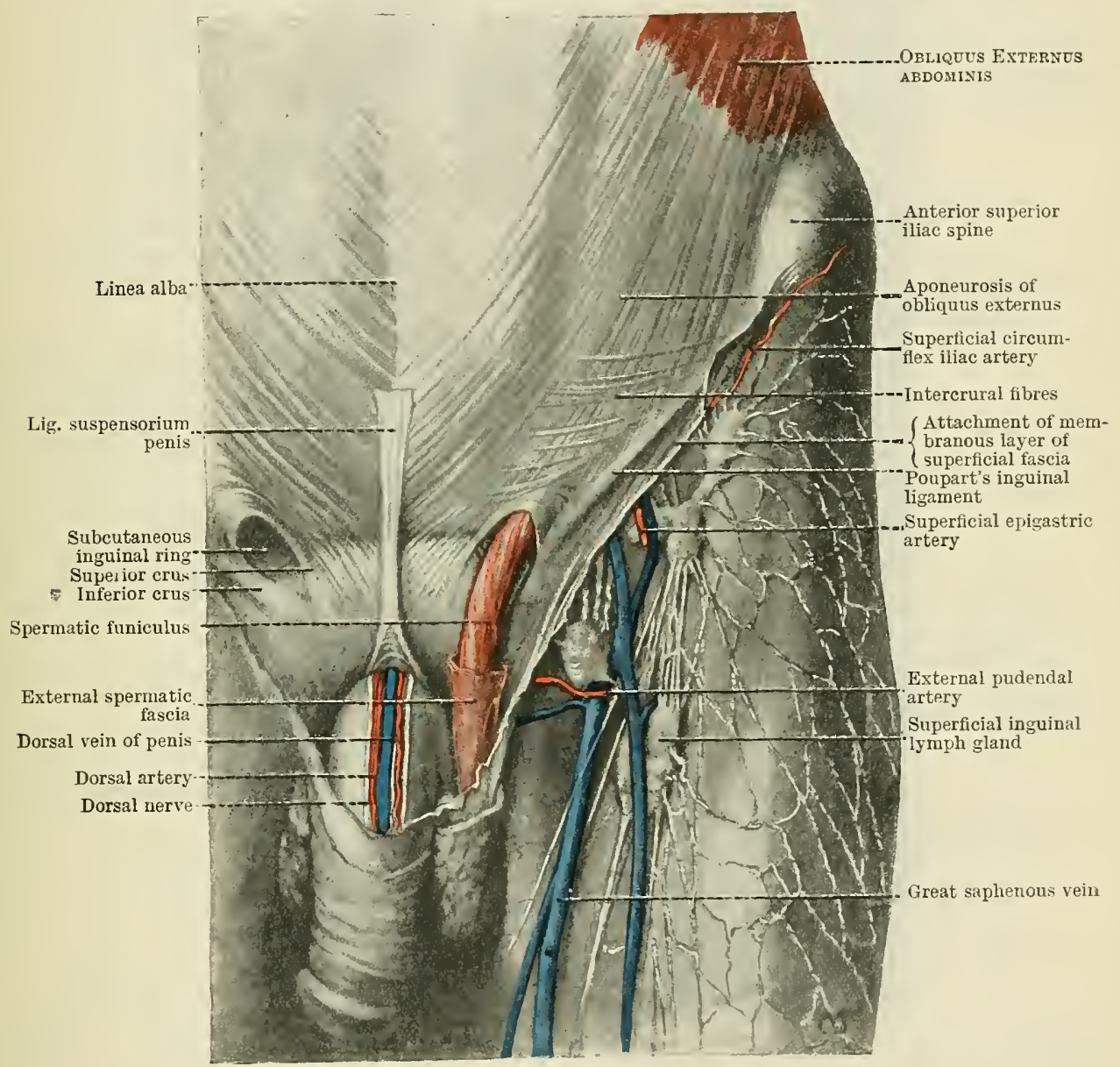

Fig. 421.-Superficial Anatomy of the Groin.

round ligament of the uterus at the abdominal inguinal ring, and its prolongation into the inguinal canal around the funiculus forms the internal spermatic or infundibuliform fascia. It is lined internally by the peritoneum, from which it is separated by a layer of extraperitoneal tissue.

The subserous coat or extraperitoneal tissue is usually loaded with fat; it envelops the kidneys, ureters, suprarenal glands, abdominal aorta and inferior vena cava and their branches, and forms sheaths for the vessels and ducts (ureter, ductus deferens, etc.). It is continued upwards into the posterior mediastinum of the thorax through the aortic opening in the diaphragm, and below is in continuity with the extraperitoneal tissue in the pelvis. It not only completely invests the kidneys and suprarenal glands, but it also becomes interpolated between the layers of peritoneum upholding and enveloping the intestines. This tissue is absent in relation to the diaphragm, on the under surface of which there is no fat. 


\section{THE MUSCLES OF THE ABDOMINAL WALL.}

The muscles of theabdominal wall are in threeseries-lateral, anterior, and posterior.

The lateral muscles of the abdominal wall comprise the obliquus externus abdominis, obliquus internus abdominis, and transversus abdominis.

M. Obliquus Externus Abdominis.-The obliquus externus abdominis is a broad thin sheet of muscle, with an origin from the lateral surfaces of the lower eight ribs, by slips which interdigitate with the serratus anterior and latissimus

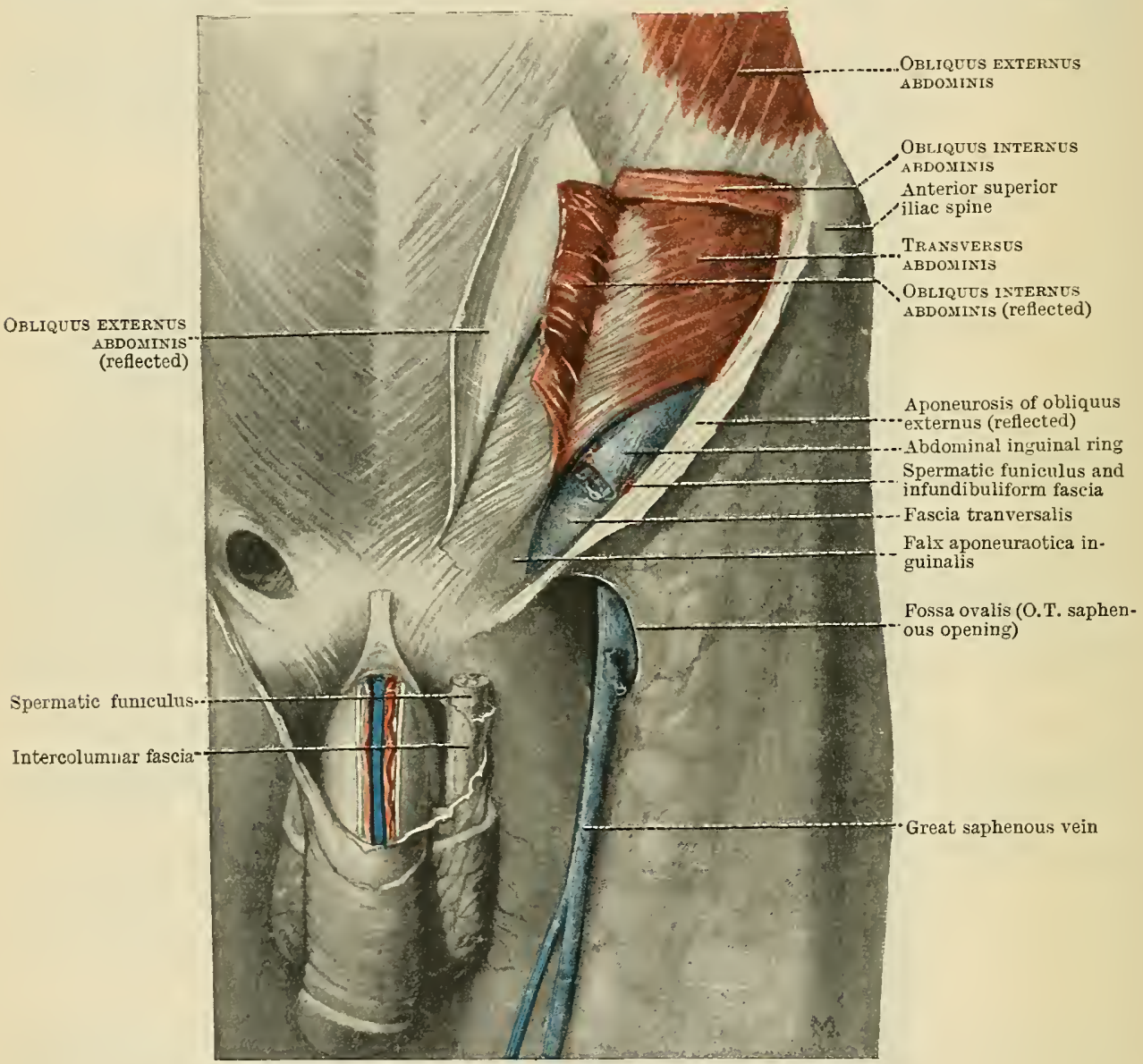

Fig. 422.-The Dissection of the Ingunal CanaL.

dorsi muscles. The muscular fibres radiate downwards and forwards, the lowest fibres passing vertically downwards.

The lower and posterior part of the muscle is inserted directly by fleshy fibres into the external lip of the iliac crest in its anterior half or two-thirds (Fig. 369, p. 415). The rest of the muscle is inserted into an extensive triangular aponeurosis covering the anterior abdominal wall. This aponeurosis is broader below than above; it is united with part of the aponeurosis of the obliquus internus in the superior three-fourths of its extent, to form the anterior layer of the sheath of the rectus muscle. It thus gains an attachment, above to the xiphoid process, below to the symphysis pubis, and by its intermediate fibres to the linea alba, a broad interlacing band of fibres about half an inch in width which occupies the median plane of the anterior abdominal wall in its whole extent, is pierced by the umbilicus (annulus umbilicalis), and forms the greater part of the ultimate insertion of all the lateral abdominal muscles. 
The superior part of the aponeurosis covers the insertion of the rectus abdominis muscle on the chest wall, and gives origin to fibres of the pectoralis major. Inferiorly, in the groin, it gives rise to the inguinal ligament, the ligamentum lacunare, the subcutaneous inguinal ring with its two crura, the intercolumnar fascia and the intercrural fibres, and the ligamentum inguinale reflexum of Colles.

Lig. Inguinale [Pouparti].-The inguinal ligamentum (O.T. Poupart's ligament) is an aponeurotic band which extends from the anterior superior iliac spine to the tubercle of the pubis, arching over the iliacus, psoas, and pectineus muscles. It represents the inferior limit of the aponeurosis of the obliquus externus abdominis, and it gives attachment below to the iliac portion of the fascia lata of the thigh. Its lateral part affords partial origin to the obliquus internus and transversus muscles, and receives the attachment of the fascia transversalis and fascia iliaca; the medial part forms the gutter-like floor of the inguinal canal. At its medial end a triangular band of fibres is reflected horizontally backwards to the ilio-pectineal line, forming the lig. lacunare [Gimbernati] (O.T.Gimbernat's ligament), the lateral edge of which forms the medial boundary of the femoral ring. The femoral vessels enclosed in the femoralsheath enter the thigh posterior to the inguinal ligament (on the anterior surface of the psoas major muscle, and the term superficial femoral arch is given to the part of the ligamentwhich covers the vessels.

Annulus Inguinalis Subcut-

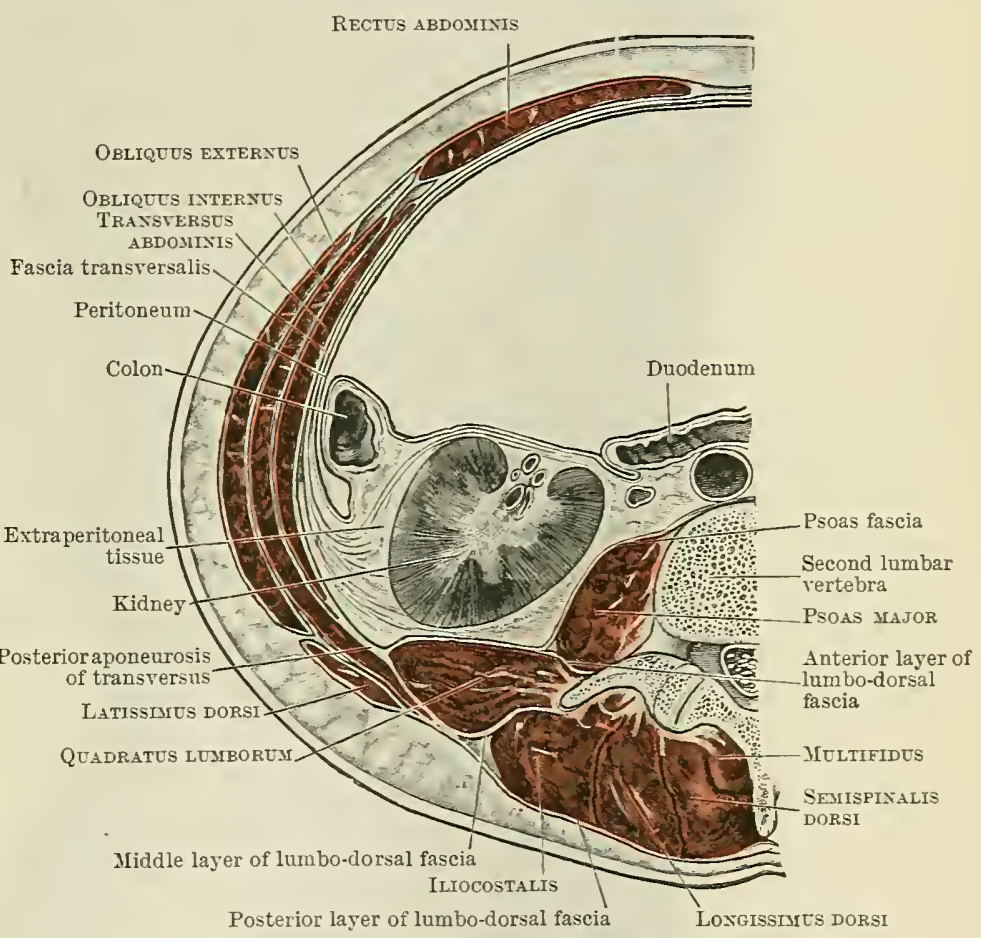

Fig. 423.-Trassverse Section throdgh the AbDomex, opposite the Second LUMBar Vertebra.

aneus.-The subcutaneus inguinal ring (O.T. external abdominal ring), the place of exit of an inguinal hernia, is a split in the aponeurosis of the obliquus externus, just above the tubercle of the pubis. It transmits the spermatic funiculus, or (in the female) the round ligament of the uterus, covered by the cremaster muscle or cremasteric fascia. The opening is of considerable extent, and its edges are drawn together by a thin fascia, strengthened superficially by a number of arched and horizontal fibres, called the intercrural fibres, which arise from the inguinal ligament and sweep medially across the cleft in the aponeurosis.

The margins of the ring constitute its crura. The inferior crus is narrow, and is formed from that part of the aponeurosis which joins the pubic tubercle, and is continnous with the medial end of the inguinal ligament. The superior crus is the part of the aponeurosis medial to the ring which is attached to the crest and symphysis of the pubis. It is flat and broad.

The intercrural fibres and the crura of the subcutaneous inguinal ring are continuous with a thin tubular sheath, the intercolumnar or external spermatic fascia, which is attached to the margins of the "ring," and forms an envelope for the 
spermatic funiculus or round ligament in their further passage beyond the abdominal wall.

Lig. Inguinale Reflexum Collesi.-The reflexed inguinal ligament of Colles (O.T. triangular fascia), lastly, is a triangular band of fibres placed behind the medial superior crus of the subcutaneous inguinal ring. It consists of fibres from the

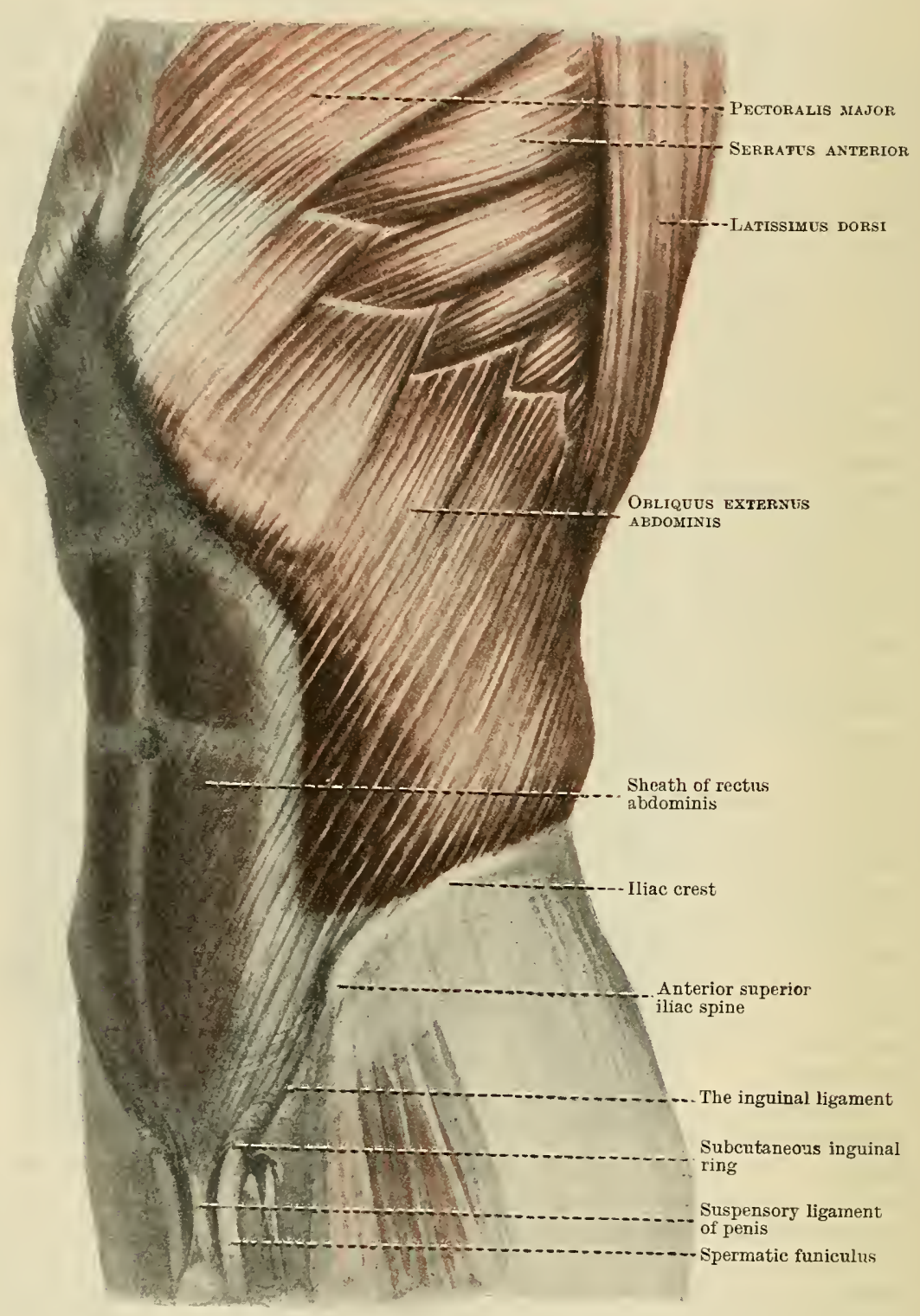

Fig. 424.-The Left Obliques Externds Abdominis.

opposite external oblique aponeurosis, which, having traversed the linea alba, gain an insertion into the crest and tubercle of the pubis.

The obliquus externus muscle is superficial in almost its whole extent. It is overlapped posteriorly by the latissimus dorsi muscle, but may be separated from it just above the iliac crest by an angular interval (trigonum lumbale or triangle of Petit).

M. Obliquus Internus Abdominis.-The obliquus internus abdominis, a broad thin sheet lying between the obliquus externus and the transversus, arises from 
(1) the lumbo-dorsal fascia, (2) the anterior two-thirds of the iliac crest, and (3) the lateral half of the inguinal ligament.

Directed for the most part upwards and forwards, its highest fibres are inserted directly into the last three ribs. The rest of the fibres form an extensire aponeurosis, broader above than below, which splits along the linea semilunaris, to form, along with the aponeuroses of the obliquus externus and transversus muscles, the

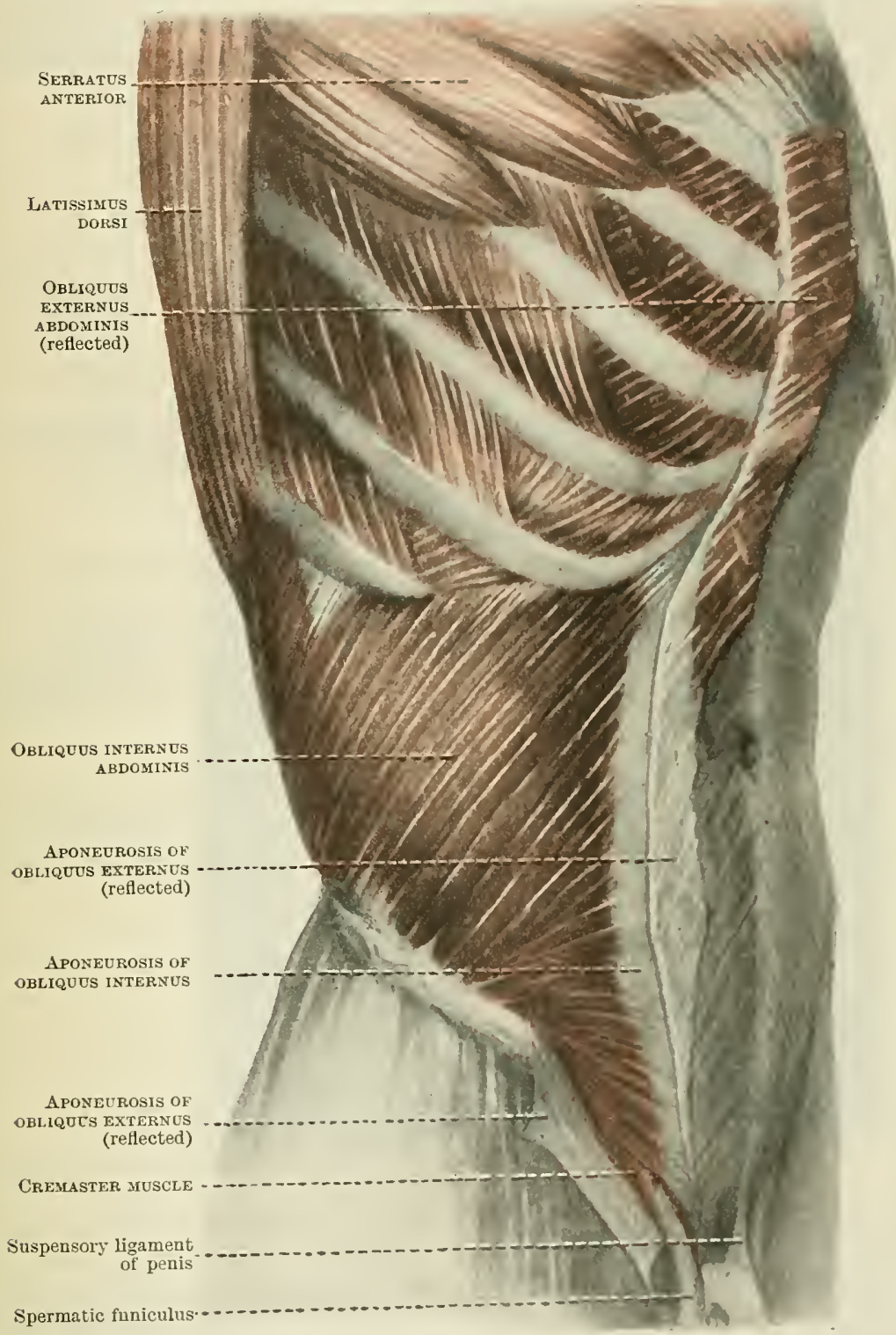

Fig. 425.-The Right Orliquos interne's Abdomisis.

sheath of the rectus abdominis, and is inserted into the serenth, eighth, and ninth costal cartilages, and into the linea alba from the xiphoid process to the symphysis pubis. The fibres arising from the inguinal ligament join with those of the transversus muscle having a similar origin to form the falx aponeurotica inguinalis (O.T. conjoined tendon), which passes altogether anterior to the rectus muscle, to be attached to the pubic crest and tuhercle, and to the ilio-pectineal line.

The obliquus internus is limited above by the inferior marerin of the thoma. 
Its lower fibres, arching over the spermatic cord, assist in forming, laterally, the anterior wall of the inguinal canal; medially, by means of the falx inguinalis, it helps to form the posterior wall of the canal.

Its lowest fibres are continued into the cremaster muscle, which is prolonged along the spermatic cord through the inguinal canal.

M. Cremaster. - The cremaster muscle forms an investment for the testis and spermatic funiculus beneath the intercolumnar fascia. In the female it is more largely represented by fascia than muscular fibres, and constitutes the cremasteric fascia. It may be said to have an origin from the inferior edge of the obliquus internus and the adjacent

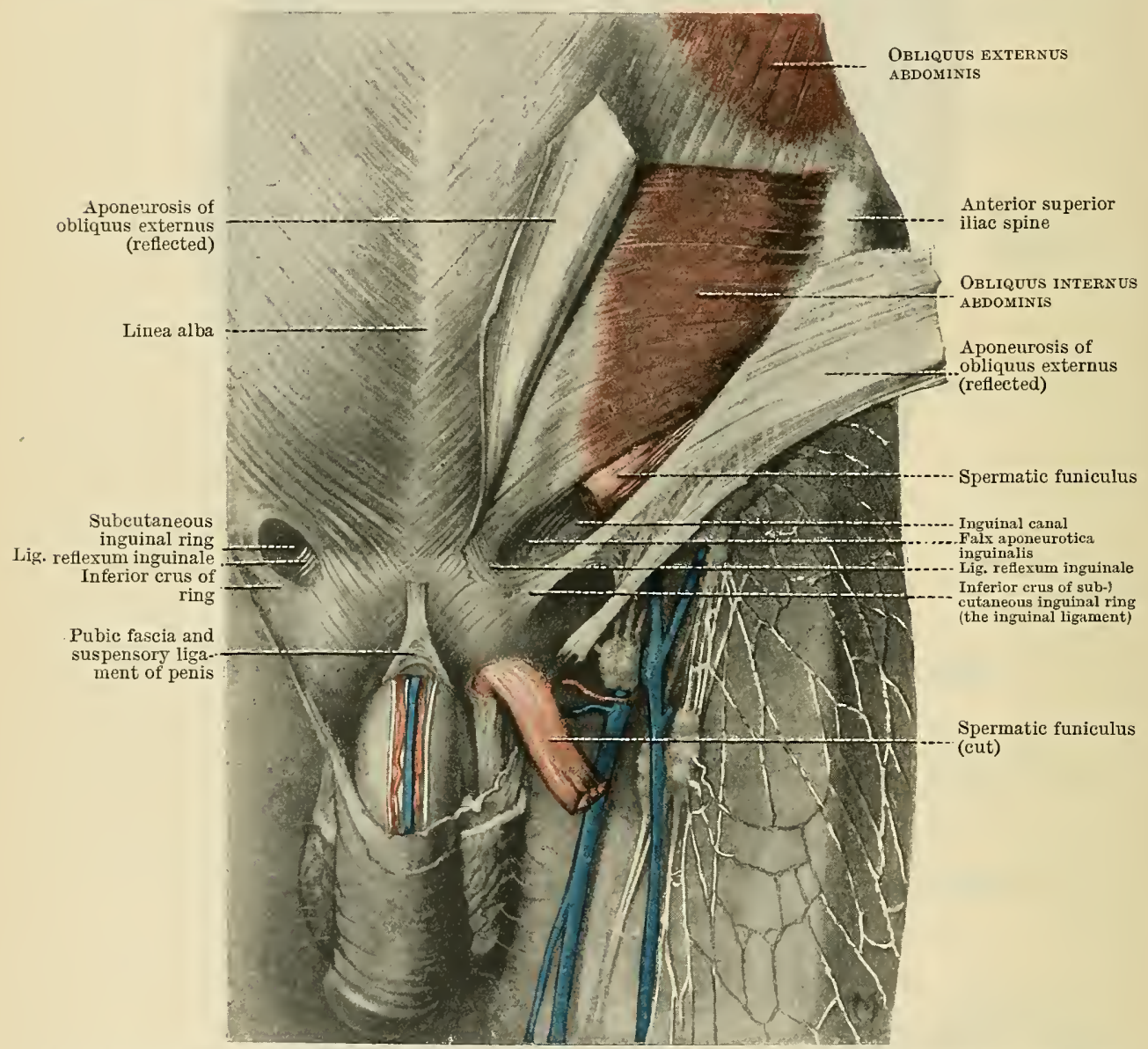

Fig. 426.-The Left Inguinal Canal. Strdctures seen on reflection of the Obliquds Externus.

part of the inguinal ligament. Its fibres form loops over the spermatic funiculus and testis, the highest fibres getting an insertion into the pubic tubercle.

M. Transversus Abdominis.-The transversus abdominis muscle arises (1) from the deep surface of the costal cartilages of the lower six ribs, interdigitating with the origins of the diaphragm; (2) from the lumbo-dorsal fascia; (3) from the anterior half of the medial lip of the iliac crest; and (4) from the lateral third of the inguinal ligament.

The muscular fibres are directed for the most part horizontally forwards, and end in an aponeurosis which has a twofold insertion. (1) After forming (along with the aponeurosis of the obliquus internus) the posterior layer of the sheath of the rectus, the aponeurosis is attached to the xiphoid process and linea alba. (2) The inferior fibres of the muscle arising from the inguinal ligament are joined by the inferior part of the obliquus internus to form the larger part of the falx 
aponeurotica inguinalis (O.T. conjoined tendon), which passes anterior to the inferior part of the rectus muscle, to be inserted into the crest and tubercle of the pubis and the ilio-pectineal line.

The transversus muscle is separated by the lower intercostal nerves from the obliquus internus muscle, and is lined on its deep surface by the fascia transversalis. Its inferior border forms a concave edge, separated from the inguinal ligament by a lunular interval in which the fascia transversalis appears, and through which the spermatic funiculus emerges at the abdominal inguinal ring, under cover of the obliquus internus muscle and the aponeurosis of the obliquus externus.

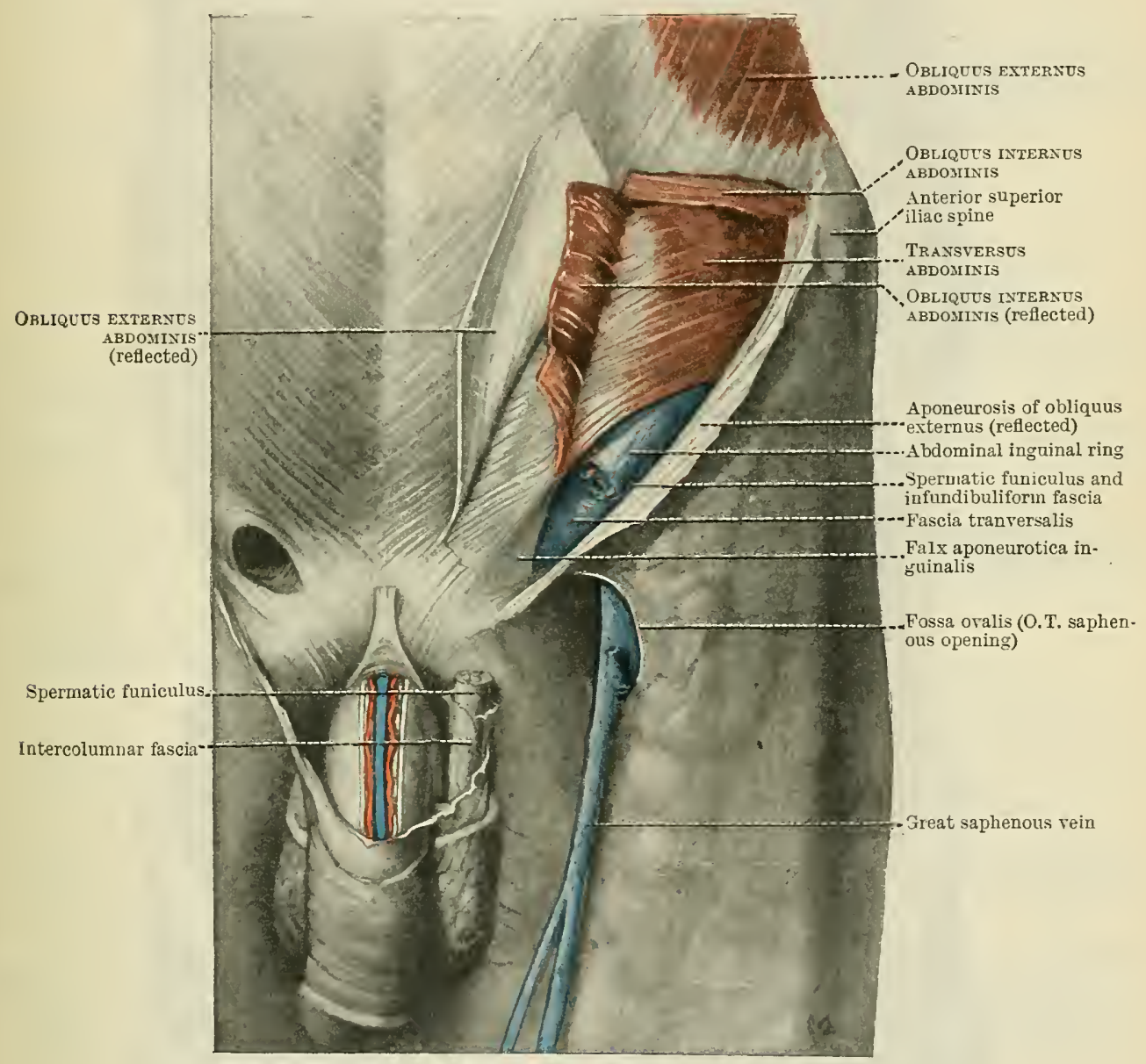

Fig. 427.-The Dissection of the Inguinal Canal.

The anterior muscles of the abdominal wall include the pyramidalis and rectus abdominis, enveloped by the sheath of the rectus, on either side of the linea alba.

M. Pyramidalis Abdominis. - The pyramidalis abdominis is a small triangular muscle arising from the pubic crest, anterior to the rectus muscle (Fig. 428, p. 482).

It is directed obliquely upwards, to be inserted for a variable distance into the linea alba. The muscle is often absent.

M. Rectus Abdominis.-The rectus abdominis muscle is broad and straplike, and arises, by a medial and a lateral head, from the symphysis and crest of the pubis (Fig. 428, p. 482).

Expanding as it passes upwards, the muscle is inserted, from medial to lateral side into the anterior surface of the xiphoid process (Fig. 428, p. 482), and into the superficial surface of the serenth, sixth, and fifth costal cartilages. On its anterior 
surface, but not extending through the entire substance of the muscle, are three or more transverse tendinous intersections (inscriptiones tendinex), adherent to the sheath of the muscle; the lowest opposite the umbilicus, and the highest about the level of the xiphoid process. The medial border of the muscle lies alongside the linea alba; its lateral border is convex, and corresponds to the linea semilunaris. The muscle is pierced by the terminal branches of the lower thoracic nerves.

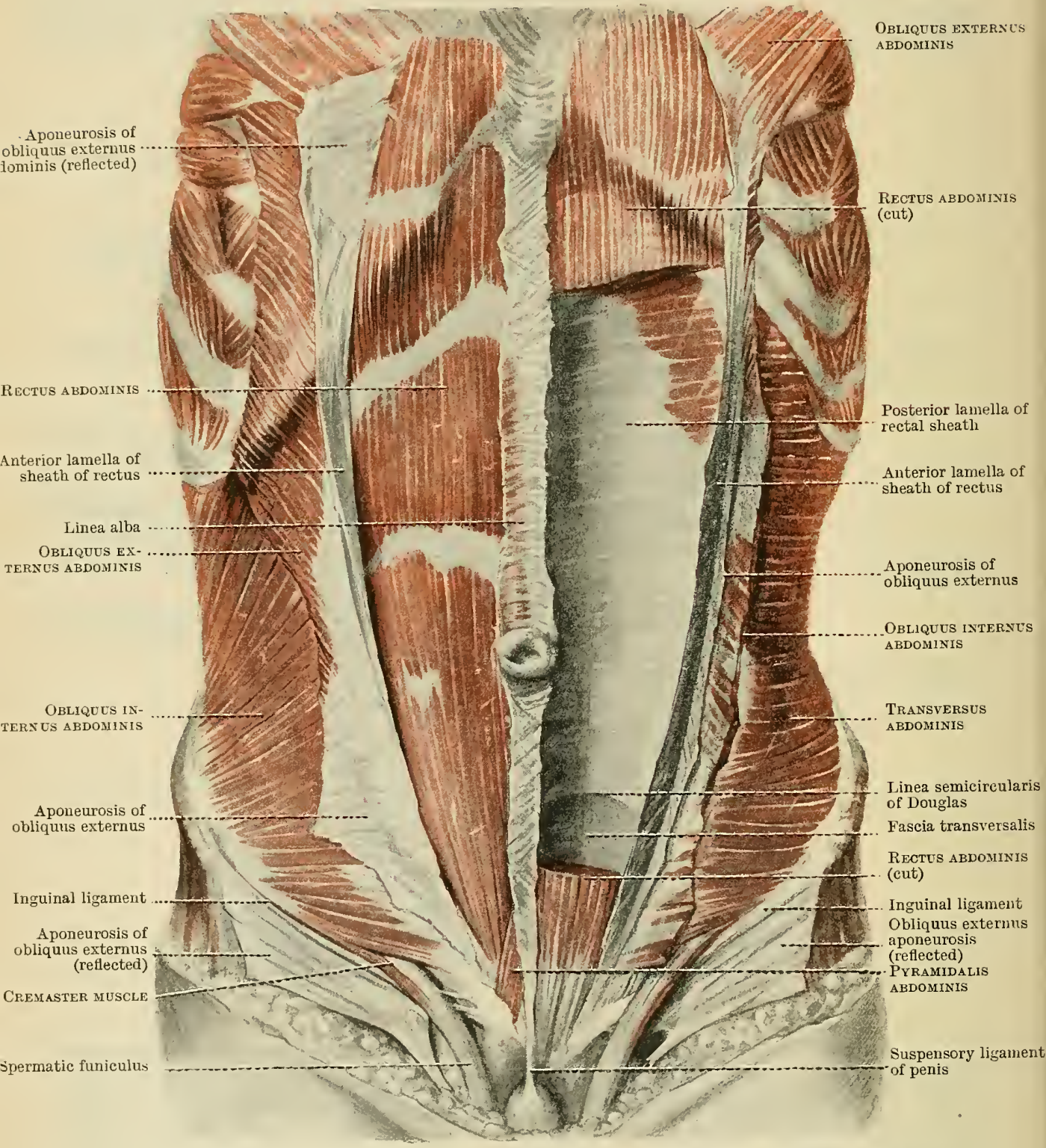

Fig. 428.-Deep Dissection of the Abdominal Wall. The Rectus Muscle and its Sheath.

Vagina IM. Recti Abdominis.-The sheath of the rectus muscle is derived from the aponeuroses of the lateral muscles of the abdominal wall, which, after enclosing the muscle, give rise, in the median plane, to the linea alba. At the linea semilunaris along the lateral border of the rectus muscle, the aponeurosis of the obliquus internus splits into anterior and posterior layers. The anterior layer, joined by the aponeurosis of the obliquus externus, passes in front of the rectus, and constitutes the anterior lamina of the sheath. The posterior layer, joined by 
the aponeurosis of the transversus muscle, passes behind the rectus, and constitutes the posterior lamina of its sheath. This arrangement obtains in the superior threefourths of the abdominal wall. Below the level of the iliac crest the sheath of the muscle is deficient posteriorly, and a crescentic border, the linea semicircularis (semilunar fold of Douglas), marks the inferior limit of the posterior lamina. In consequence, the rectus in the lower fourth of the abdominal wall rests directly upon the fascia transversalis. Close examination, however, usually reveals a thin layer behind the muscle in continuity with the fold of Douglas, and merging below with the fascia transversalis. In this region the rectus is covered anteriorly by the falx aponeurotica inguinalis of the obliquus internus and transversus, and by the aponeurosis of the obliquus externus, which gradually separates from the subjacent aponeurosis. The superior part of the rectus, lying on the chest wall, is only covered anteriorly by a single layer of aponeurosis derived from the obliquus externus, which in this situation is giving origin to the pectoralis major muscle.

Canalis Inguinalis. --Inguinal canal. The spermatic funiculus in the male, and the round ligament in the female, in their passage through the inferior part of the abdominal wall, pass through the inguinal canal, which is bounded by these abdominal muscles. The canal begins at the abdominal inguinal ring, placed half an inch above the inguinal ligament, and midway between the anterior superior iliac spine and the symphysis pubis. It ends at the subcutaneous inguinal ring, placed above the tubercle and crest of the pubis. The anterior wall of the canal is formed by the aponeurosis of the obliquus externus, and in its lateral part by the muscular fibres of the obliquus internus; the posterior wall of the canal is formed by the fascia transversalis, and in its medial part by the falx aponeurotica inguinalis; while the floor of the canal is formed by the inguinal ligament, and in its medial part by the lacunar ligament. The spermatic funiculus, piercing the transversalis fascia, enters the inguinal canal

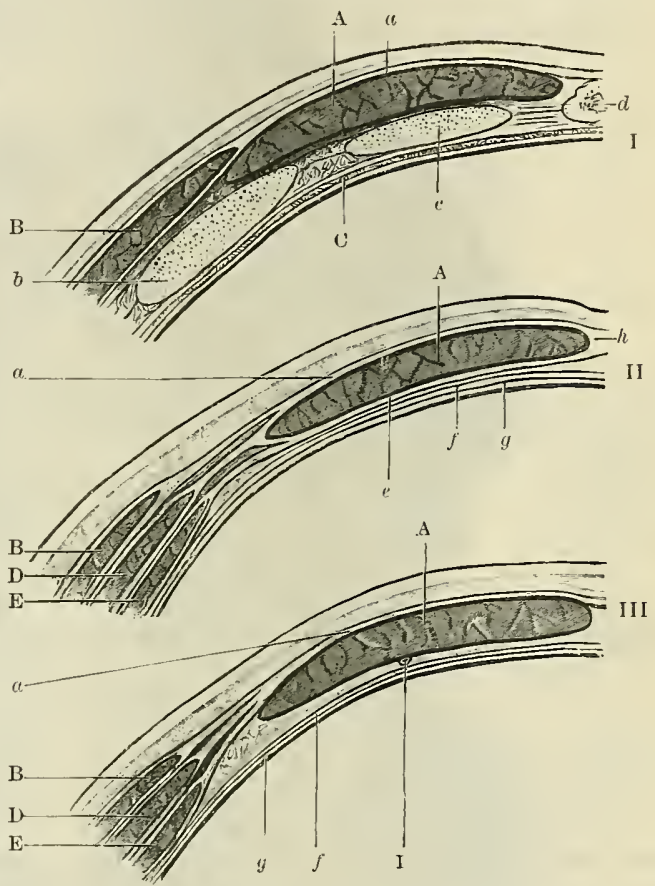

Fig. 429.-The Sheath of the Rectus Abdoninis MUSCLE.

(I.) In the thoracic wall; (II.) In the superior threequarters of the abdominal wall; (III.) In the inferior fourth of the abdominal wall.

A, Rectus huscle; B, Obliques externos; C, Dia Phragar; D, ObliquUs internus ; E, TransverSUS $\triangle B D O M I N I S . \quad a$, Anterior layer of rectus sheatl ; $b$, Fifth costal cartilage ; $c$, Sixth costal cartilage; $d$, Xiphoid process; e, Posterior layer of rectus sheath ; $f$, Fascia transversalis ; $g$, Peritoneum ; $h$, Linea alba. 1, Inferior epigastric artery. at the abdominal inguinal ring, and is there invested by its first envelope, the infundibuliform or internal spermatic fascia, a sheath of fascia derived from the margins of the ring and continuous with the fascia transversalis. It then passes obliquely medially, downwards, and forwards, and escapes below the inferior border of the obliquus internus muscle, from which it carries off a second investment, partly fascial, partly muscular, - the cremaster muscle or cremasteric fascia. Continuing its course in front of the falx inguinalis, it emerges through the subcutaneous inguinal ring, from the edges of which the intercolumnar fascia is derived, the third or external investment for the funiculus.

Hesselbach's triangle, bounded below by the line of the inguinal ligament, medially by the rectus abdominis muscle, and laterally by the inferior epigastric artery coursing upwards and medially beneath the fascia transversalis on the medial side of the abdominal inguinal ring, is the site of one form of inguinal hernia. 
The spermatic funiculus passes over the base of the triangle, covered over by the aponeurosis of the obliquus externus. Behind the funiculus, and forming the floor of the triangle, is the fascia transversalis partially covered in the medial portion of the triangle by the falx inguinalis of the obliquus internus and transversus muscles.

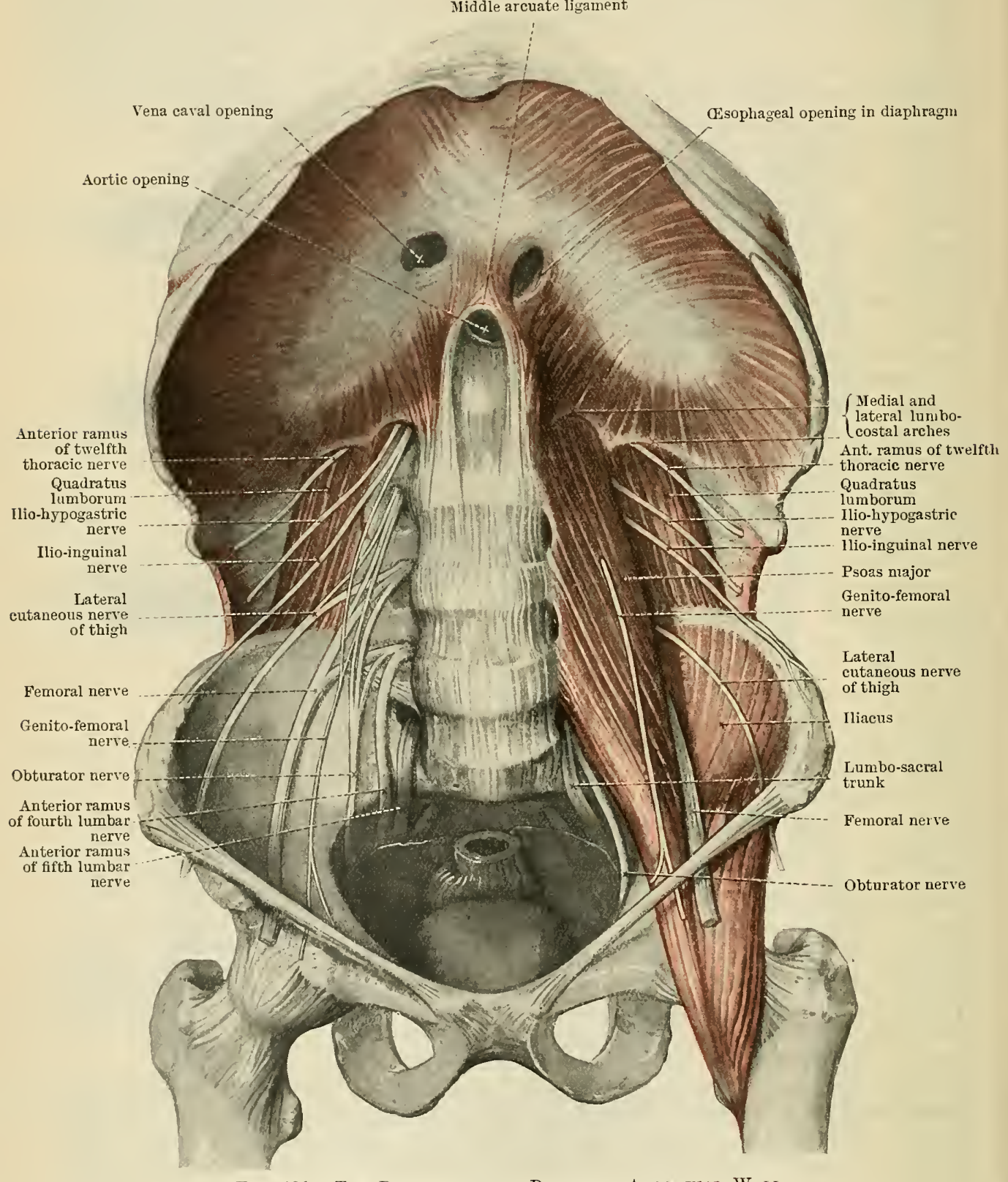

Fig. 430.-The Diaphragm and Posterior abdomixal Wall.

Inguinal Hernia.-For an account of the anatomical relations of the inguinal canal to the various forms of inguinal hernia, see the section on "Applied Anatomy."

Nerve-Supply.-The nerve-supply of the majority of the foregoing muscles is derived from the anterior rami of the lower six thoracic nerves. The pyramidalis muscle is innervated by the last thoracic nerve. The cremaster muscle receives its supply from the genito-femoral nerve (L. 1. 2.).

Actions.-(1) The chief action of these muscles is to retract the abdominal walls. By compressing the contents of the abdomen, they are powerful agents in vomiting, defæcation, 
micturition, parturition, and laboured expiration. (2) They are also flexors of the vertebral column and pelvis-the muscles of both sides acting together; the vertebral column and pelvis are laterally flexed, when one set of muscles acts alone.

The posterior muscles of the abdominal wall and pelvis major include the psoas (major and minor) and iliacus, described already (p. 410), and the quadratus lumborum.

IM. Quadratus Lumborum.-The quadratus lumborum lies on the posterior wall of the abdomen, lateral to the psoas, and extends between the iliac crest and the last rib. It arises from the posterior part of the iliac crest, from the iliolumbar ligament, and from the transverse processes of the lower lumbar vertebræ.

It is inserted above into the medial part of the inferior border of the last rib and the transverse processes of the lumbar vertebræ. Its lateral border is directed obliquely upwards and medially.

It is enclosed between the anterior and middle lajers of the lumbo-dorsal aponeurosis (p. 437), between the psoas major muscle, in front, and the sacrospinalis behind.

Nerve-Supply.-The quadratus lumborum is supplied directly by branches from the anterior, rami of the first three or four lumbar nerves.

Actions. - The muscle is a lateral flexor of the vertebral column, an extensor of the column and a muscle of inspiration.

\section{FASCI AE AND MUSCLES OF THE PERINEUIM AND PELVIS.}

\section{FASCI瓜 OF THE PERINEUM.}

The superficial fascia of the perineum possesses certain special features. It is continuous with the superficial fascia of the abdominal wall, thigh, and buttock, and is prolonged on to the penis and scrotum. In relation to the penis, it is devoid of fat and consists only of areolar tissue. In relation to the scrotum, it is intermingled with involuntary muscular fibres, and constitutes the dartos muscle, which assists in suspending the testes and corrugating the skin of the scrotum. This fascia also forms the septum of the scrotum, which, extending upwards, incompletely separates the two testes and their coverings. In the female the superficial fascia, in which there is a considerable quantity of fat, takes a large share in the formation of the mons Veneris and labia majora pudendi.

The fascia over the posterior part of the perineum fills up the ischio-rectal fossæ, in the form of two pads of adipose tissue, on either side of the rectum and anus, Over the tuberosities of the ischitm the fat is intermingled with bands of fibrous tissue closely adherent to the subjacent deep fascia.

The fascia in the anterior part of the perineum closely resembles the same fascia in the groin. It is divisible into a superficial fatty and a deeper membranous layer; the former continuous with the same layer in the thigh, and with the fat of the ischio-rectal fossa posteriorly. The deeper membranous layer is attached laterally to the pubic arch, posteriorly to the base of the fascia inferior of the urogenital diaphragm and in the median plane to the root of the penis (bulb and corpus cavernosum urethra) by a median raphe continuous, farther forwards, with the septum of the scrotum mentioned above. Anteriorly the fascia is continued over the spermatic funiculi to the anterior abdominal wall. The importance of this fascia lies in relation to the extravasation of urine from a rupture of the urethra in the perineum. By the fascial attachments the fluid is prevented from passing posteriorly into the ischio-rectal fossa, or laterally into the thigh. It is directed forwards into relation with the scrotum and penis, and along the spermatic funiculus to the anterior abdominal wall. The septum of the scrotum being incomplete, fluid extravasated on one side can pass across the median plane to the opposite half of the perineum and scrotum.

The deep fascia of the perineum exists only in the form of the delicate fasciæ of the muscles. 


\section{THE MUSCLES OF THE PERINEUM.}

The perineal muscles are naturally separated into a superficial and a deep set by the fascia inferior of the urogenital diaphragm. Superficial to it are the sphincter ani externus, transversus perinei superficialis, bulbocavernosus, and ischiocavernosus; deep to it are the sphincter muscle of the membranous urethra and the transversus perinei profundus.

M. Sphincter Ani Externus.-This muscle is fusiform in outline, flattened, and obliquely placed around the anus and anal canal. It can be separated into three layers,- - subcutaneous, superficial, and deep. (1) The most superficial lamina

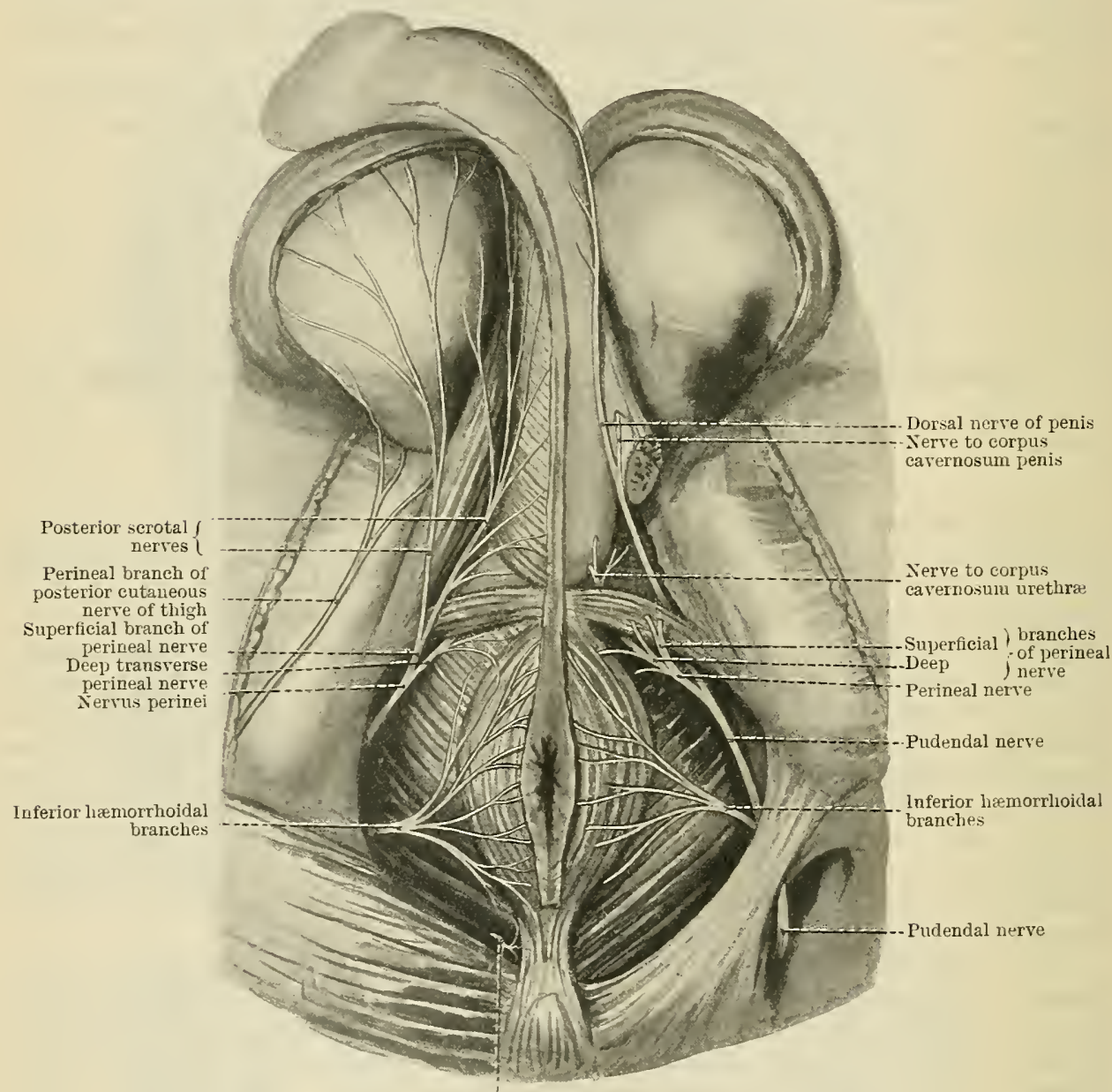

Fig. 431.-The Muscles and Nertes of the Male Perineud.

consists of subcutaneous fibres decussating posterior and anterior to the anus, but without bony attachments. (2) The sphincter ani superficialis constitutes the main portion of the muscle. It is attached posteriorly to the coccyx, and, anterior to the anus, it reaches the central point of the perineum. (3) The deep fibres of the muscle form for the most part a complete sphincter for the anal canal. They are continuous with the fibres of the levator ani: they encircle the anal canal, and blend anteriorly with the central point of the perineum and the transversus perinei superficialis muscle.

M. Corrugator Cutis Ani.-The corrugator cutis ani consists of bundles of unstriped muscular fibres which radiate from the margin of the anal opening superficial to the external sphincter. 
Nerve-Supply.-The external sphincter is supplied by the inferior hæmorrhoidal branch of the pudendal nerve (S. 3. 4.), by the perineal branch of the fourth sacral nerve, and by the deep perineal branch of the pudendal nerve (S. 3. 4.).

Actions. - The muscle closes the anal aperture. It is a voluntary muscle.

II. Transversus Perinei Superficialis.-The transversus perinei superficialis is not always present. It consists of a more or less feeble bundle of fibres, arising from the inferior ramus of the ischium and the fascia over it, and from the base of the fascia inferior of the urogenital diaphragm.

It passes obliquely over the base of the fascia inferior to be inserted into the central point of the perineum.

Nerve-Supply. - Deep perineal branch of pudendal nerve (S. 3. 4.).

Action.-The two muscles acting togetler draw backwards and fix the central point of the perineum.

M. Bulbocavernosus. - The bulbocavernosus (O.T. ejaculator urinæ), in the male, surrounds the bulb, corpus cavernosum urethræ, and root of the penis. It is sometimes separated into two partsposterior (compressor bulbi), and anterior (compressor radicis penis). It arises from the central point of the perineum, and from a median raphe on the under surface of the bulb and corpus cavernosum urethræ.

The muscular fibres are directed laterally and forwards and have a triple insertion : from behind forwards, (1) into the inferior surface of the fascia inferior of the urogenital diaphragm; (2) into the dorsal aspect of the corpus cavernosun urethræ; and (3), after encircling the corpora cavernosa penis, into the fascia covering the dorsum of the penis.

The ischiobulbosus, not always present, arises from the ischium,

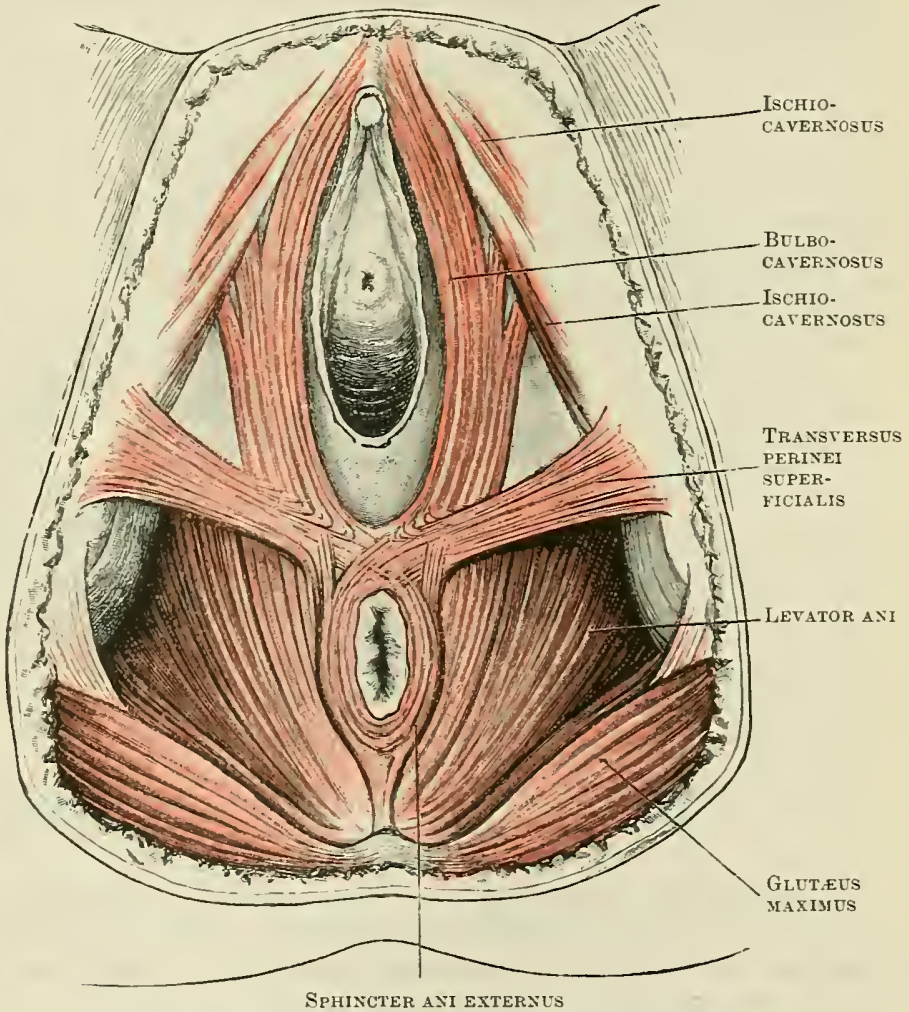

Fig. 432.-The Muscles of the Frarale Periveum (after Peter Thompson). and passes obliquely medially and forwards over the bulbocavernosus, to be inserted into the raphe superficial to that muscle. It belongs to the same stratum as the transversus perinei superficialis and ischiocavernosus.

The compressor hemispheriorum bulbi is frequently absent. It consists of a thin cap-like layer of muscular fibres surrounding the extremity of the bulb under corer of the bulbocavernosus.

M. Bulbocavernosus. - The bulbocavernosus, in the female (O.T. sphincter vaginæ), is separated into lateral halves by the raginal and urethral openings. It forms two thin lateral layers covering the bulb of the restibule, and arises behind the vaginal orifice from the central point of the perineum.

Anteriorly it is inserted into the root of the clitoris, some of its fibres embracing the corpora cavernosa clitoridis so as to reach the dorsum of the clitoris. 
Nerve-Supply. - Deep branch of the perineal nerve (pudendal, S. 3. 4.).

Actions. - In the male.-The bulbocavernosus contracts the urethra in the emission of urime and semen, and is an accessory muscle in erection of the penis.

In the Female. - The muscle contracts the vaginal orifice, and compresses the bulb of the restibule of the ragina.

M. Ischiocavernosus. - The ischiocavernosus (O.T. erector penis), in the male, covers the crus penis. It arises from the ischial tuberosity and the sacrotuberous ligament.

Passing forwards, it is inserted by a fascial attachment into the inferior surface of the crus penis, and into the lateral and dorsal aspects of the corpus cavernosum penis.

The ischiocavernosus (O.T. erector clitoridis), in the female, has a similar disposition, but is of much smaller size than in the male.

The pubocavernosus is an occasional slip arising from the pubic ramus, and inserted into the dorsum of the penis. It corresponds to the levator penis of lower animals.

Nerve-Supply.-Deep branch of the perineal nerve (pudendal, S. 3. 4.).

Action. - The muscle assists in erection of the penis (or clitoris).

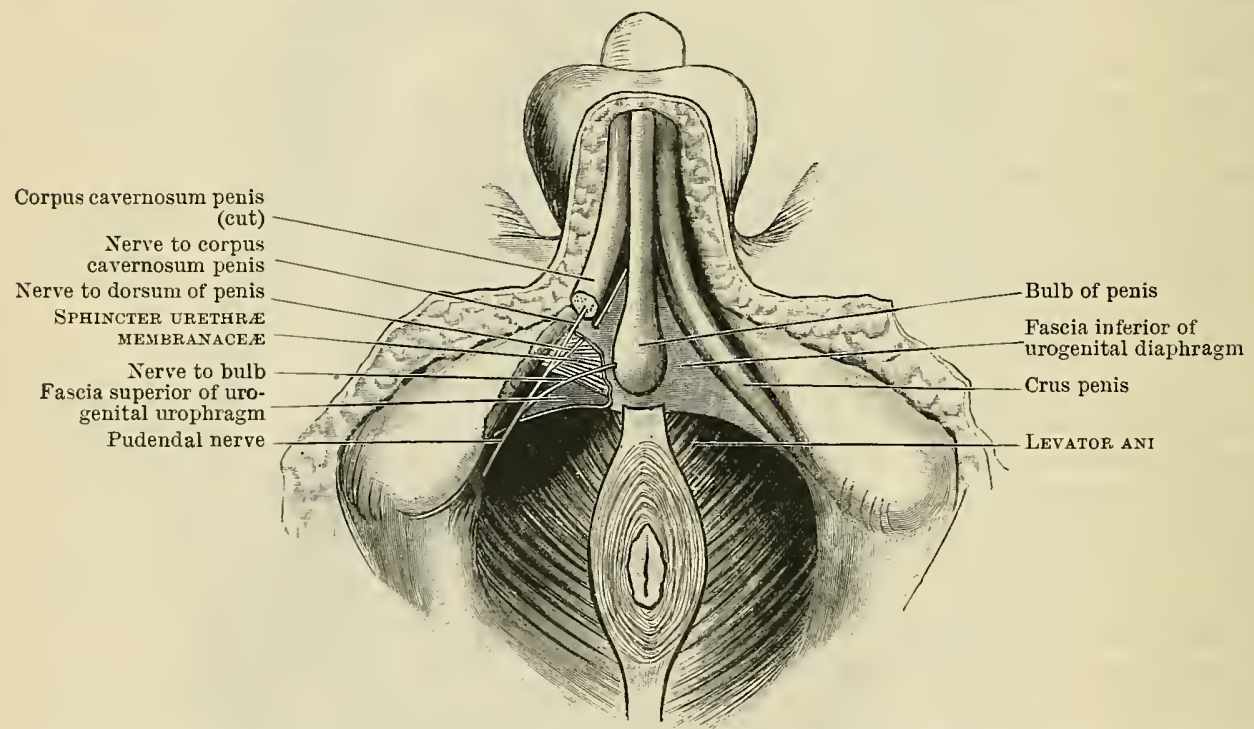

Fig, 433.-The Fascie of the Urogenital Diaphragm of the Perinedu, and the Termination of the Pudendal Nerve.

Diaphragma Urogenitale.-The sphincter urethræ membranaceæ and the transversus perinei profundus constitute the deeper muscular stratum of the perineum and form the urogenital diaphragm. They lie between two layers of fascia called the fascia inferior, and fascia superior of the urogenital diaphragm (O.T. superficial and deep layers of the triangilar ligament).

IM. Sphincter Urethræ Membranaceæ.-The sphincter of the membranous urethræ (O.T. compressor urethræ) arises from the inferior part of the pubic ramus, and is directed medially, its fibres radiating so as to enclose the membranous urethra.

It is inserted into a median raphe, partly anterior to the urethra, but for the most part posterior to it. The fibres most intimately related to the urethra form a muscular sheath for the canal, and have no bony attachments.

IM. Transversus Perinei Profundus.-The transversus perinei profundus consists of a bundle of fibres on each side, arising from the inferior ramus of the ischium just below the sphincter urethræ membranaceæ. It is inserted into a median raphe continuous with that of the sphincter urethræ membranaceæ. The muscle, in fact, constitutes a separate bundle below and behind the sphincter.

The ischiopubicus is a term applied to a feeble bundle of fibres which, when present, lies above and in front of the sphincter urethræ membranaceæ. It arises from 
the pubic ramus, and is inserted into a median raphe on the dorsum of the membranous urethra. This muscle is homologous with the compressor venæ dorsalis penis of lower animals.

The sphincter urethræ in the female is smaller than in the male. Its insertion is modified by the relations of the urethra to the vagina. The anterior fibres are continuous with those of the opposite side above the urethra; the intermediate fibres pass between the urethra and vagina, and the posterior fibres are attached, along with the transversus perinei profundus (transversus vaginæ), into the side of the vagina.

Nerve-Supply.-Deep branch of the perineal nerve (pudendal, S. 3. 4.).

Action. - It is a feeble compressor of the membranous urethra, and by no means a sphincter. In the female it has an accessory influence in constricting the vagina.

\section{THE FASCIF OF THE PELVIS.}

The extra-peritoneal tissue in the pelvic cavity is of great importance. The hypogastric vessels and their branches, the visceral nerves and plexuses, the ureters, and ductus deferentes, take their course in this tissue beneath the peritoneum. It forms in relation to the rectum a thick sheath, for the most part devoid of fat, which encloses the lower part of the rectum completely, down to its termination in the anal canal. It forms a kind of packing for the parts of the bladder uncovered by peritoneum, and is present under the organ in relation to the symphysis pubis and pubo-prostatic ligaments. In the female it forms, in addition, the basis or matrix of the broad ligament, and also occurs as a layer devoid of fat, which loosely connects the anterior surface of the cervix uteri with the base of the bladder.

\section{FASCIA PELVINA.}

The cavity of the pelvis minor in the erect position resembles a basin tilted forward, with its margin formed by the superior aperture of the pelvis, with a cylindrical wall, and a concave floor, formed by bones, ligaments, and muscles. The deficiencies in the bony walls of the cavity are filled up laterally by the obturator membrane and the sacro-tuberous and sacro-spinous ligaments. Inferiorly and anteriorly, behind the symphysis pubis, the fascia diaphragmatis urogenitalis inferior fills up the pubic arch, and separates the anterior part of the pelvic cavity from the perineum. Within this osseo-ligamentous chamber a series of muscles clothe its interior; the piriformis and coccygeus posteriorly, the obturator internus on each side, and the sphincter urethræ membranacer and transversus perinei profundus, inferiorly and anteriorly, on the pelvic surface of the inferior fascia of the urogenital diaphragm.

The pelvic fascia, continuous above with the fascial lining of the abdominal cavity, forms a continuous cylindrical investment for these muscles. On the pelvic surface of the pubis, where muscles are absent, it is merged with the periosteum. It gains an attachment to the spine of the ischium as that projects between the piriformis and obturator internus muscles. Perforations occur in relation to it for the transmission of the obturator nerve and the parietal branches of the hypogastric artery. Reaching the inferior aperture of the pelvis, it is attached to the posterior border or base of the fascia inferior of the urogenital diaphragm, to the ischial ramus and tuberosity, and to the lower edge of the sacro-tuberous ligament. Different names are applied to the fascia in relation to the several muscles which it covers. Posteriorly it constitutes the piriformis fascia: laterally it is the obturator fascia, while that part of the sheet of fascia which covers the pelvic surface of the sphincter urethræ membranaceæ and transversus perinei profundus is known as the fascia diaphragmatis urogenitalis superior.

The disposition of the pelvic fascia is complicated by its relations to (1) the structures which constitute the pelvic floor, and (2) the genito-urinary passages and the rectum. 
The peivic floor, tense in its anterior part and flexible posteriorly, is formed behind the symphysis pubis by, successively, (1) the fasciæ of the urogenital diaphragm and the transversus perinei profundus and sphincter muscle of the membranous urethra between them, the latter enclosing the urethra; and the vagina in the female. (2) The perineal body. (3) The levator ani and external sphincter of the anus on each side of the anal canal; (4) the ano-coccygeal body, between the anal canal and the coccyx, containing the main insertions of the levatores ani and external sphincter.

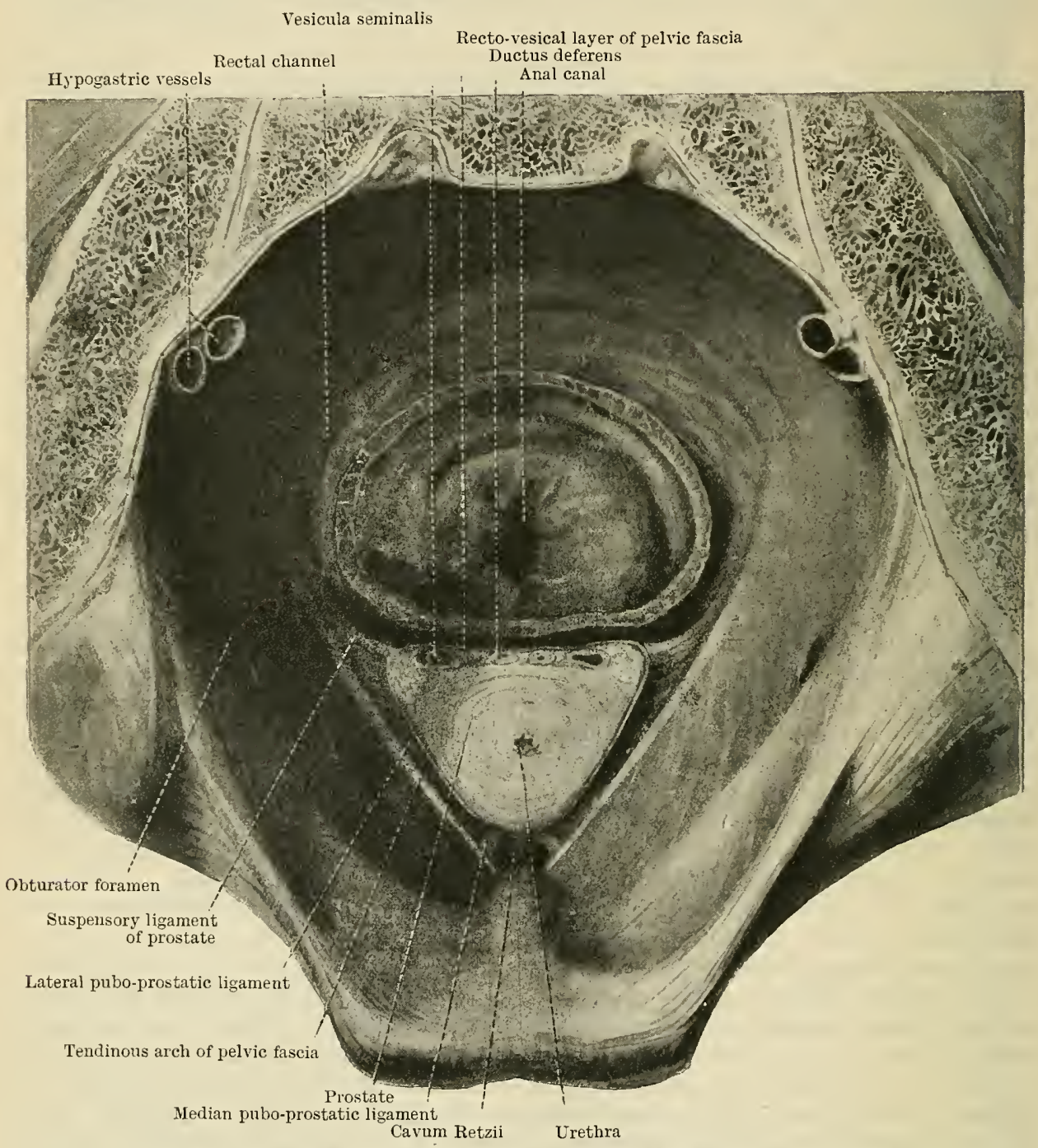

Fig. 434.- Relations of the Pelvic Fascia to the Rectum and Prostate.

The levator ani muscle completes the concave floor of the pelvic cavity, sweeping downwards and backwards from its lateral wall, so as to form a muscular diaphragm, with an intra-pelvic and a perineal surface. Its superior concave pelvic surface occupies the lateral part of the pelvic floor. Its inferior convex surface forms the oblique medial wall of the ischio-rectal fossa, the lateral wall of which is formed by the obturator fascia covering the pelvic surface of the obturator internus. In this wall is a fascial sheath containing the pudendal vessels and nerve. The levator ani is covered on both surfaces by pelvic fascia. The anal fascia clothing its perineal surface is thin and unimportant. The fascia covering its intra-pelvic surface is thick and strong. At the origin 
of the muscle it is continuous with the general fascial lining of the pelvic cavity, and gives rise to a conspicuous thickening, the tendinous arch (arcus tendineus) of the pelvic fascia, which stretches like a bow-string from the back of the symphysis pubis to the ischial spine. This band is related not so much to the origin of the levator ani muscle, which often extends higher up beneath the pelvic fascia, as to the attachments of the fascial investments of the genito-urinary passages, to be described below. There are sometimes additional thickenings of the fascia, branching upwards from the tendinous arch towards the superior aperture of the pelvis. At the insertion of the levator ani, the fascia clothing its pelvic surface is attached to the perincal body, the margin of the anal canal, and the ano-coccygeal body, over which it passes to be continuous, above the raphe of insertion of the levatores ani, with the layer of the opposite side. At the antero-

Posterior (recto-vesical) layer

Superior layer : lateral true ligament of the bladder
Suspensory ligament of the prostate gland Rectal channel

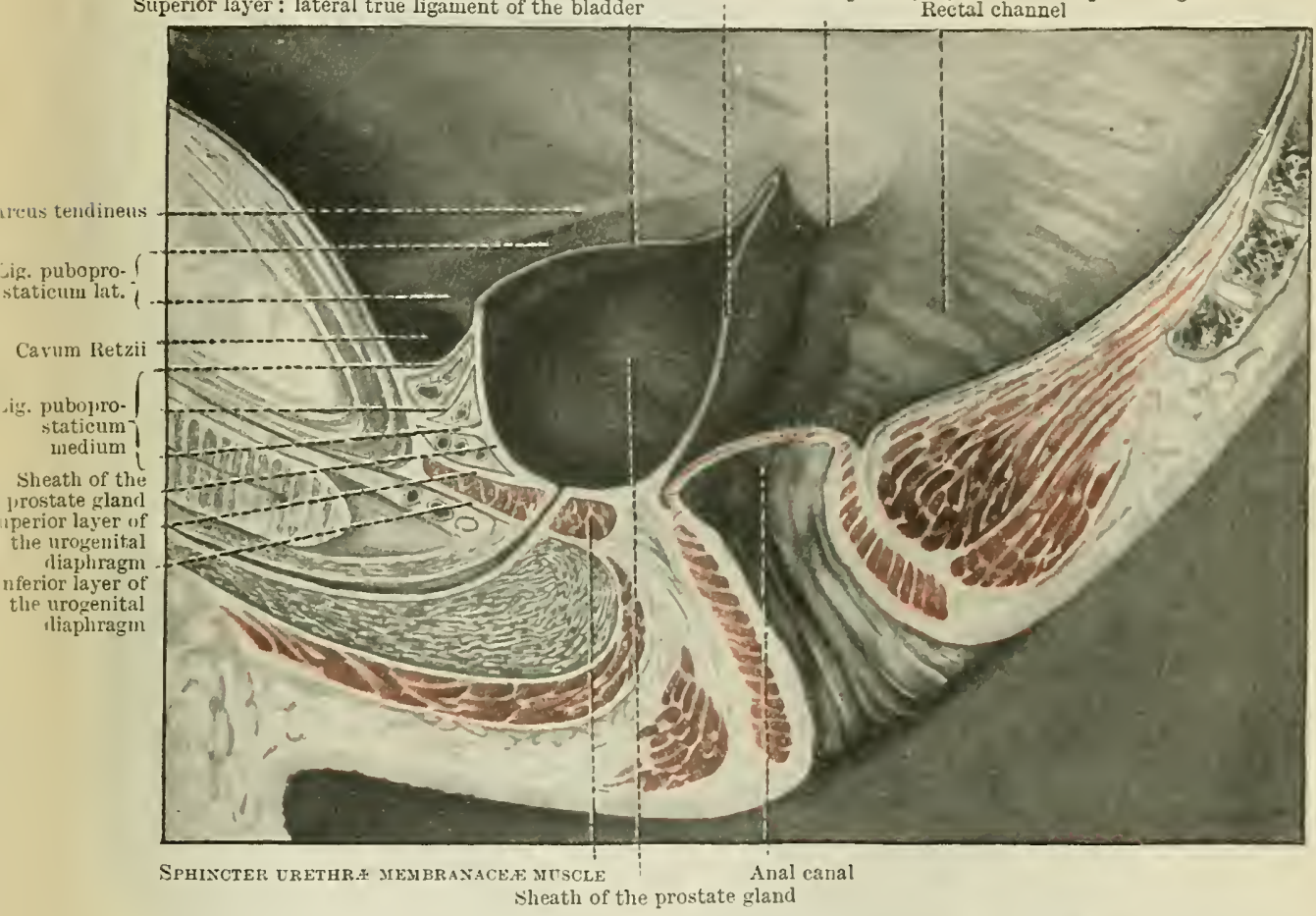

Fig. 435.--Relations of Pelvic Fascia to the Rected and Prostate (Median Section of the Pelvis).

inferior border of the muscle the fascixe enclosing it become continuous with the superior fascia of the urogenital diaphragm; at its postero-superior border they join the fascia enclosing the coccygeus muscle.

Within the pelvic basin, the walls and floor of which are thus continuously invested by the pelvic fascia, are contained the rectum and bladder, and in the female the uterus, suspended and maintained in position by the peritoneum, extra-peritoneal tissue, and the pelvic vessels and nerves. They are essentially free to distend or collapse, and are not bound down by the pelvic fascia. The rectum in both sexes extends down to the floor of the pelvis, where the anal canal takes its origin. It is invested by the peritoneum and extra-peritoneal tissue, and occupies a special rectal channel; this is lined by pelvic fascia, which gains an attachment to the floor of the pelvis at the margin of the anal canal.

The arrangement of the fascia in relation to the genito-urinary passages is essentially difierent.

$J u s t$ as from the perineal aspect the inferior aperture of the pelvis is divisible into two different parts, - a posterior or dorsal part, comprising the ischio-rectal 
fossæ for the passage of the anal canal, and characterised by looseness and distensibility; and an anterior or ventral part,- the urethral triangle for the genitourinary passages, and characterised by firm fixation to the pubic bones; so also from the abdominal aspect it is found that, while in the posterior part of the pelvis a rectal channel exists, in which the rectum is free to collapse and distend, in the ventral part of the basin the genito-urinary passages are firmly fixed by means of

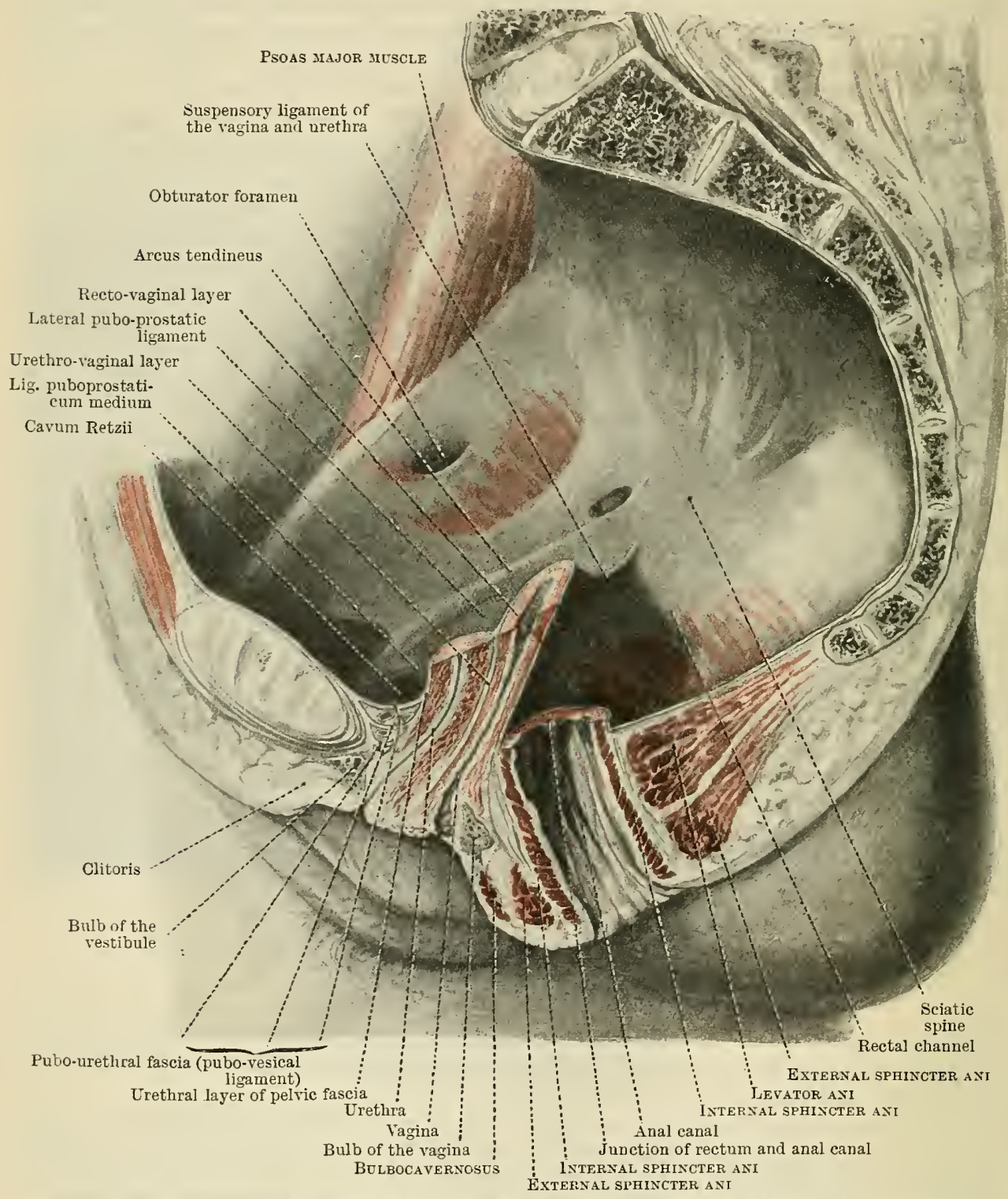

Fig. 436.-Relations of the Pelvic Fascia to the Rectum, Urethra, and Vagina (Median Section).

the pelvic fascia, which gives rise to a special suspensory ligament for the prostate gland and the prostatic urethra in the male, and for the urethra and vagina in the female.

A crescentic fold of pelvic fascia (suspensory ligament) arises in the neighbourhood of the sciatic spine from the general fascia covering the pelvic wall. It has a posterior free edge, through which the ductus deferens, vesical vessels, and nerves pass. Sweeping across the median plane, this border is continuous with the fold of the opposite side, the two together constituting the anterior limit of the rectal 
channel. The fascial fold is composed of two layers, posterior and superior, between which is a large plexus of veins. They have separate attachments laterally to the general pelvic fascia. The posterior (recto-vesical) layer passes across the pelvis between the prostate gland and the rectum. Its inferior edge is attached to the perineal body between the base of the fascia of the urogenital diaphragm and the beginning of the anal canal. It forms a sheath for the vesiculæ seminales and ductus deferentes. This is rather in the form of a septum than a complete sheath; it effectually separates the vesiculæ seminales and the bladder from the rectum, forming the anterior wall of the rectal channel, but it allows the vesiculæ seminales to rest directly against the bladder. The superior layer extends forwards to the symphysis pubis. It has a lateral origin from the arcus tendineus in its whole length, and sweeping over the prostate gland, it is inserted along its line of junction with the bladder, and constitutes the so-called lig. puboprostaticum laterale (lateral true ligament of the bladder). It contains numerous bundles of muscular fibres in its anterior part, and forms a sheath for the passage of the inferior vesical vein along the lateral surface of the prostate gland. In front the fascia stretches from the back of the symphysis pubis, the arcuate ligament of the pelvis, and the superior fascia of the urogenital diaphragm to the neck of the bladder and the prostate gland, forming the lig. puboprostaticum medium. It is continuous across the median plane with the ligament of the opposite side. In the median line, where the two ligaments unite, a hollow occurs behind the symphysis pubis, known as the cavum Retzii. This ligament is composed of several layers separated by large veins (the pudendal plexus), which connect the inferior vesical vein with the dorsal vein of the penis and the hypogastric vein.

The sheath of the prostate gland (fascia prostatæ) is formed by (1) the superior fascia of the urogenital diaphragm on which it lies, (2) by the general pelvic fascia covering the intra-pelvic surfaces of the levatores ani on each side, and (3) it is completed above and behind by the two special layers of pelvic fascia just described. By these means the prostate gland and prostatic urethra are given a firm attachment to the anterior part of the pelvic walls and floor.

In the female an essentially similar arrangement of the pelvic fascia occurs in relation to the vagina and urethra. A crescentic fold of the fascia springs from the pelvic wall in the neighbourhood of the spina ischiadica, and sweeping medially to the lateral fornix of the vagina and in front of the rectum, separates into two layers, posterior and superior. Between the layers are numerous vessels, which, along with the visceral nerves, pierce its free edge. The posterior (recto-vaginal) layer passes medially behind the vagina, and gaining the median plane between the vagina and rectum, gives rise to the anterior wall of the rectal channel, and is attached below to the perineal body in the floor of the pelvis. The superior layer, taking origin from the arcus tendineus, is attached medially to the neck of the bladder, and constitutes the lateral pubo-vesical ligament. It is continuous in front with the anterior pubo-vesical ligament, which, as in the male, is divisible into several layers separated by veins. An intermediate (urethro-vaginal) layer of the fascia passes between and separates the urethra and vagina.

The urethra and vagina are by means of these layers of fascia firmly bound to the pelvic walls and floor, while the uterus and bladder are free to distend in the pelvic cavity.

\section{MUSCLES OF THE PELVIS.}

Diaphragma Pelvis.-The pelvic diaphragm is formed by the levator ani and coccygeus muscles, which serve to uphold the pelvic floor, and are related to the rectum and the prostate gland or vagina.

M. Levator Ani.-The levator ani arises from (1) the inferior part of the posterior surface of the body of the pubis, (2) the general pelvic fascia above or along the arcus tendineus, and (3) the pelvic surface of the spine of the ischium.

Its fibres are directed downwards and backwards, to be inserted into (1) the central point of the perineum (perineal body), (2) the external sphincter around 
the origin of the anal canal, (3) the ano-coccygeal raphe behind the anus, and ( 4 ) into the sides of the lower coccygeal vertebræ.

The levator ani muscle fills up and completes the pelvic floor on each side of the median plane. Enclosed in a sheath derived from the general pelvic fascia along the arcus tendineus, the muscle presents an upper concave surface in relation to the pelvic cavity, prostate gland (or vagina), and rectum, and an

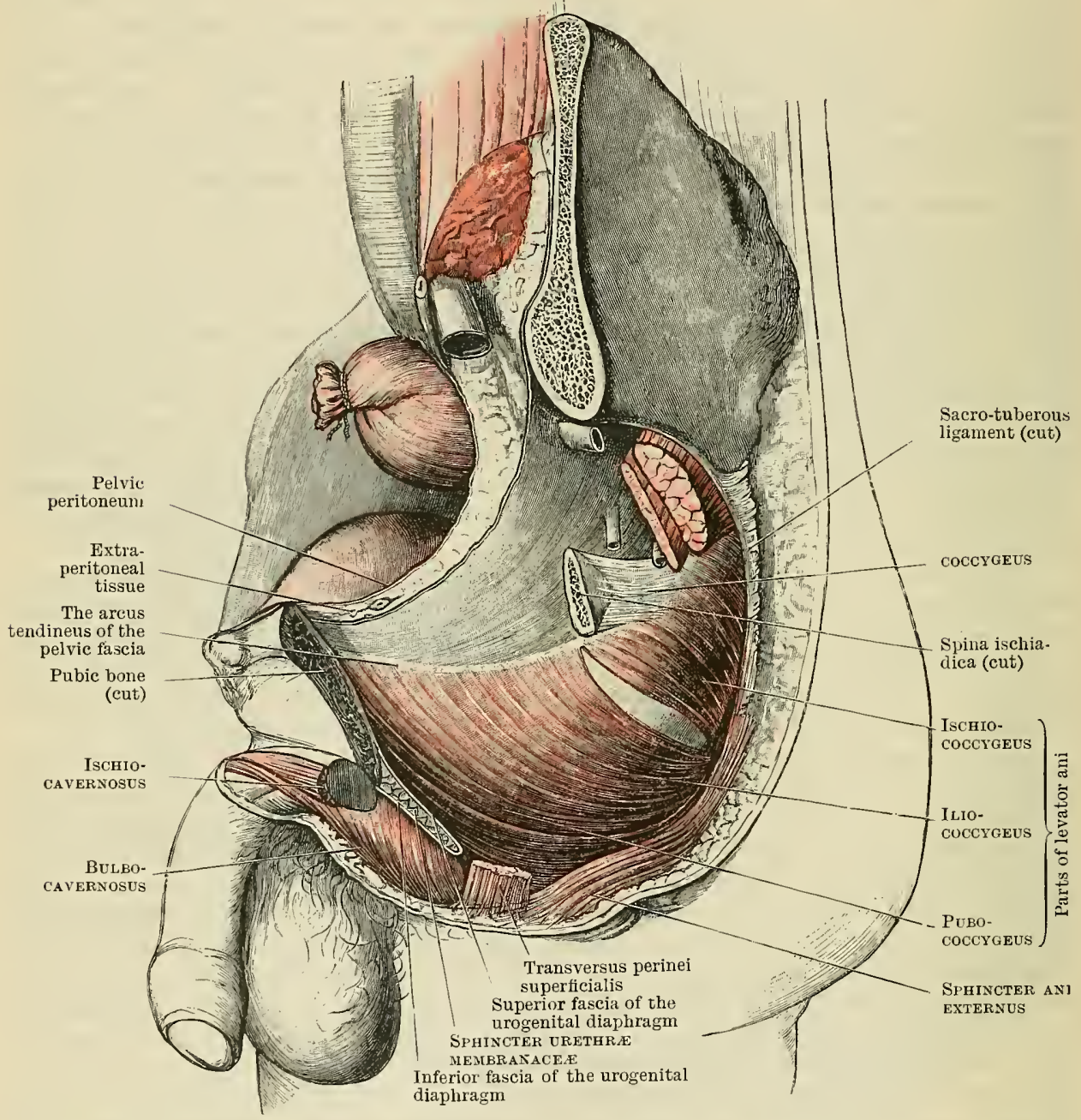

Fig. 437.-The Fascial and Muscular Wall of the Pelvis after Removal of Part of the LEFT HIP BONE.

inferior convex surface which appears in the perineum and forms the medial wall of the ischio-rectal fossa.

The levator ani is divisible into fuur parts-puborectalis, pubococcygeus, iliococcygeus, and iliosacralis. The puborectalis (levator prostatæ) is the part inserted into the central point of the perineum. The pubococcygeus is the part inserted into the anus and the ano-coccygeal raphe, and the iliococcygeus and ischiococcygeus are represented by the fibres attached to the sacrum and coccyx. The first two are best developed; the last two series of fibres are the most rudimentary. These several parts of the muscle represent the remains of the flexor caudæ of tailed animals.

Nerve-Supply.-The levator ani is supplied from two sources: by the perineal (muscular) branch of the pudendal nerve, and, on its pelvic surface, by special branches from the third and fourth sacral nerves. 
Actions.-(1) The levator ani muscle serves to uphold and slightly raise the pelvic floor. (2) It is likewise capable of producing slight flexion of the coccyx. (3) The anterior fibres of the levator ani, in the female, sweeping round the vagina, compress its walls laterally, and along with the sphincter vaginæ, help to voluntarily diminish the lumen of the tube. (4) The same part of the muscle in the male elevates the prostate gland (levator prostatæ). (5) The chief action of the levator ani is in defocation. Along with the external sphincter it acts as a sphincter of the rectum, closing the anal canal. During defæcation the muscle draws upwards the anus orer the fæcal mass, and so assists in its expulsion. (6) In parturition, in the same way, the muscle, contracting below the descending fœtal head, retards delivery. Contracting on the fœtal head, it draws upwards the pelvic floor over the fœtus, and so assists delivery.

M. Coccygeus.-The coccygeus is a rudimentary muscle overlapping the posterior border of the levator ani. It arises from the ischial spine and the sacrospinous ligament.

It is inserted into the sides of the lower two sacral and upper two coccygeal vertebræ. The muscle is in contact by its anterior border with the levator ani. It is enclosed in pelvic fascia, assists in forming the pelvic floor, and is in contact laterally with the sacro-tuberous and sacro-spinous ligaments.

Nerve-Supply.-The coccygeus is supplied on its pelvic surface by the third and fourth sacral nerves.

Actions.-The muscle is a feeble lateral flexor of the coccyx, and assists the lerator ani to uphold the pelvic floor.

\section{THE DEVELOPMENT AND MORPHOLOGY OF THE SKELETAL MUSCLES.}

The mesoderm on either side of the embryonic medullary tube separates into three main parts-the myotome, nephrotome, and sclerotome or lateral plates (somatopleure and splanchnopleure).

The myotomes are probably directly or indirectly the source of the striated muscles of the whole body. Each consists at first of a quadrilateral bilaminar mass, resting against the medullary tube and notochord on either side. The cleft between its two layers represents the remains of the cœlomic cavity. In the early stages of embryonic life the growth of the myotome is rapid. On its medial side masses of cells arise, which grow medially and surround the medullary tube and notochord to form the foundation of the vertebral column. On its lateral side cells appear to be given off which participate in the formation of the cutis vera. At the same time the dorsal and rentral borders of the myotome continue to extend, and present extremities (growing points) with an epithelial structure for a considerable period. On the dorsal side it overlies the medullary tube, and gives rise to the muscles of the back; while by its ventral extension, which traverses the somato-pleuric mesoderm in the body wall, it produces the lateral and ventral muscles of the trunk. By a medial extension it probably gives rise also to the hypaxial muscles of the neck and loin. The cells of the medial layer of the myotome are responsible for the formation of the muscle fibres. The cells elongate in a direction parallel to the long axis of the embryo, and give rise, by fusion with the cells of neighbouring myotomes, to the columns and sheets of muscles of the back and trunk. For the most part (e.g. back and abdomen) the originally segmental character of the muscular elements is lost by the more or less complete fusion of adjacent myotomes. The intercostal muscles, however, are the direct derivatives of individual myotomes.

Muscles of the Limbs.-In fishes and (doubtfully) reptiles there is evidence that the myotomes are concerned in the formation of the limb-muscles by their extension into the limb-bud in a manner similar to that described for the trunk. In birds and mammals, however, in which the limb-bud arises as an undifferentiated, unsegmented mass of mesodermic tissue, partly from the mesoderm surrounding the notochord, and partly from the somato-pleuric mesoblast, the myotomes stop short at the root of each limb, and do not penetrate into its substance. Instead, the muscular elements of the limb take origin independently as double dorsal and ventral strata of fusiform cells on the dorsal and ventral surfaces of the limb-bud. These strata are unsegmented; they are grouped around the skeletal elements of the limb, and they gradually become differentiated into the muscle masses and individual muscles of the limb.

Muscles of the Head.-Notwithstanding the obscurity and complexity of this 
subject, it appears certain that at least two series of elementary structures are concerued in the formation of the muscles of the head and face-the cephalic myotomes and the muscular structure of the branchial arches.

The number of myotomes originally existing in the region of the head is not known, although it is stated with some authority that nine is the complete number. The first three are described as persisting in the form of the ocular muscles, the last three in relation to the muscles of the tongue, while the three intervening myotomes disappear.

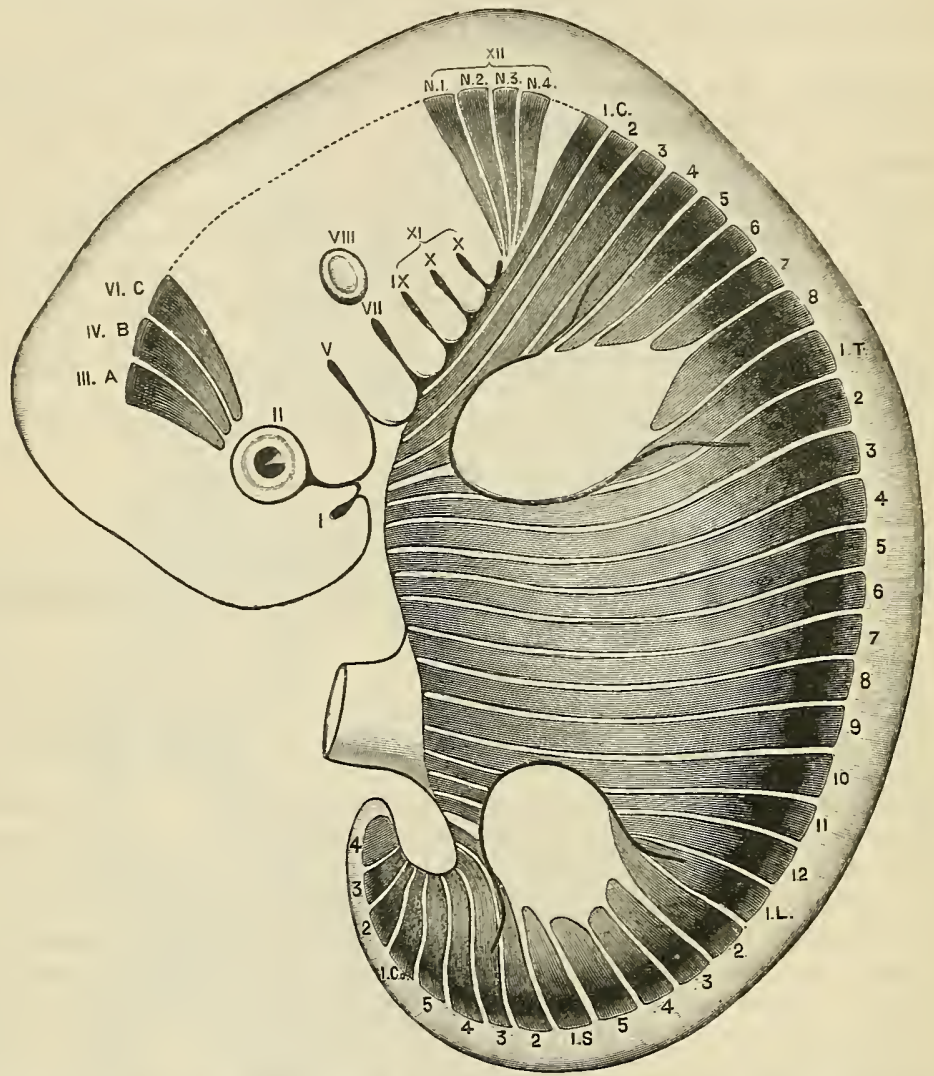

Fig. 438.-Scheme to illustrate the Disposition of the Mirotomes in the Embryo in relation to THE Head, Trunk, and Limbs.

A, B, C, First three cephalic myotomes ; N, 1, 2, 3, 4, Last persisting cephalic myotomes ; C., T., L., S., Co., The myotomes of the cervical, thoracic, Iumbar, sacral, aud caudaI regions; I., II., III., IV., V., VI., VII., VIII., IX., X., XI., XII., refer to the cerebral nerves and the structures with which they may be embryologically associated.

The following table shows the possible fate of the cephalic myotomes:-

First, Superior, medial and inferior recti, obliquus inferior, levator palpebræ superioris.

Second, Obliquus superior.

Third, Rectus lateralis.

Fourth, Fifth and Sixth, Absent.

Seventh,

Eighth,

Ninth,

Tenth (first cervical)

Muscles of the tongue.

The mesoblastic tissue of the branchial arches is probably concerned in the production of the following muscles of the face and neck :First (mandibular) arch Muscles of mastication.

\section{Second (hyoid) arch}

Platysma and facial muscles.

Muscles of the soft palate.

Stapedius, stylo-hyoid, and digastric.

\section{Third (thyreo-hyoid) arch}

Stylopharyngeus.

Fourth and Fifth (branchial) arches isuperior constrictor. 


\title{
THE NERVOUS SYSTEM.
}

\section{I.-THE CENTRAL NERVOUS SYSTEMI.}

\author{
ORIGLitally WRitTEN BY D. J. CUNniNghaM, F.R.S., \\ Late Professor of Anatomy, University of Edinburgh; \\ Revised axd PaRtly Rewrittex by G. Elliot Suith, F.R.S., \\ Professor of Anatomy, University of Manchester
}

[In its original form this chapter represented perhaps the most characteristic work of the late Editor of this Text-book, which continues to bear his name, and is a lasting memorial of his personality and scientific attainments. By his lamented death the difficult task has fallen upon the reviser of making such considerable alterations as the rapid changes in the state of our knowledge of the nervous systern have rendered unavoidable, while endeavouring at the same time to preserve unaltered the general character of his friend's work.]

\section{ELEMENTS OF THE CENTRAL NERVOUS SYSTEM.}

EvERY type of nervous system with which we are acquainted, from the simplest and most primitive, such as that of Hydra, to the most complex and highly elaborated mechanism found in man, is composed essentially of three categories of elements. These are (1) sensory cells, so situated and so specialised in structure as to be capable of being affected by changes in the animal's environment, and of transmitting the effects of such stimulation, directly or indirectly, to (2) efferent nerve-cells, which influence the muscles or other active tissues, so that it may find expression in some appropriate action; and (3) intercalated nervecells, which regulate such responsive behaviour by bringing it

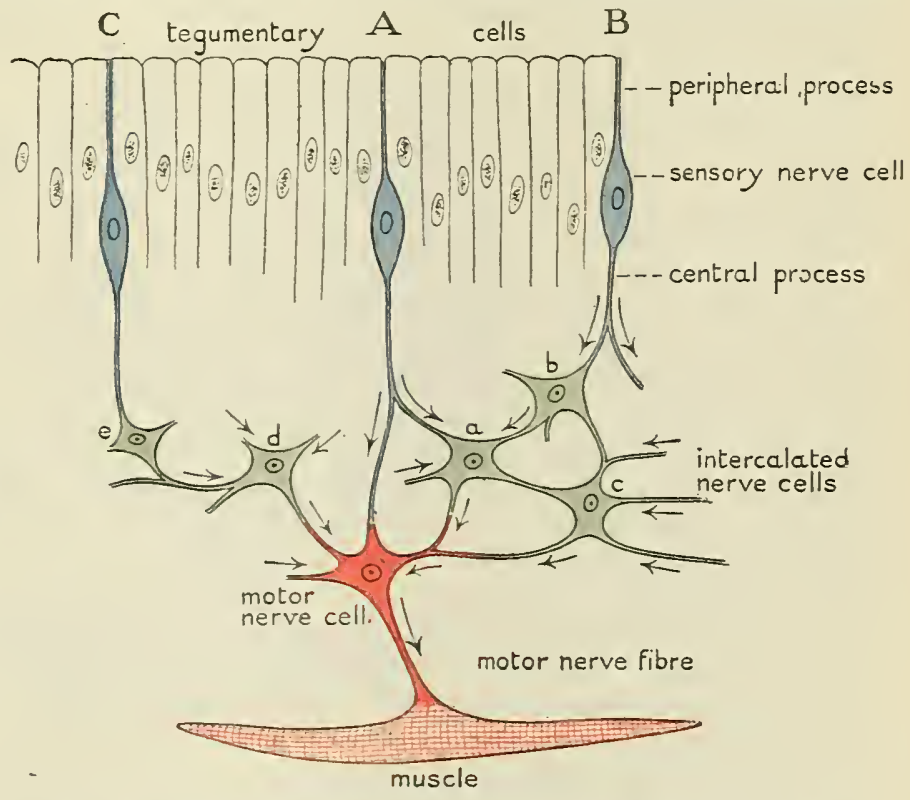

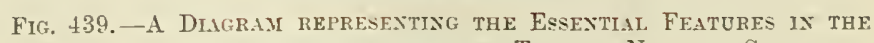
ArRaygenest of the Most primitre Type of Nertot's Sister. under the influence of other sensory impressious and of the state and activities of the body as a whole. 
The study of a simple scheme representing the relationship that obtains between these three classes of elements in the extremely primitive animal, Hydra (Fig. 439), will make these fundamental facts plain. Changes in the animal's environment / affect the extremities of the peripheral processes of the sensory cells $(A, B$, and $C)$, which in Hydra are situated amongst the ordinary tegumentary cells: the Zeffect is transmitted by the central processes of such cells ( $A$, for example), either directly to the efferent cell, represented in the diagram by a motor nerve-cell, or 3 more usually to an intercalated nerve-cell $(a, b$, or $e$ ). Into this $(a)$ impulses 4 stream from other intercalated cells ( $b$ and $c$ ), bringing the impulse from the sensory cell $A$ under the influence of those coming from $B$ and from more distant parts of the body through the intermediation of the intercalated cell $c$. The cells

$5 a, c$, and $d$ are connected with the motor nerve-cell. Thus, there is provided a mechanism whereby the conditions affecting other regions of the body, $B$ and $C$, may influence the nature of the response which the stimulation of $A$ evokeseither increasing or diminishing its effect or perhaps altering its character.

In this way the intercalated nerve-cells form a great co-ordinating mechanism, linking together all parts of the body in such a way that the activity of any part of the organism may be influenced by the rest, and thus be enabled to act in the interest of the whole.

Hence the nervous system becomes the chief means whereby the various parts of the body are brought into functional relationship one with the other, and coordinated into one harmonious whole.

Throughout the whole course of its subsequent evolution the nervous system is formed of these three kinds of elements; and the essential feature in its elaboration and increasing complexity is the multiplication of the intercalated cells, and their concentration, together with the motor nerre-cells, to form a definite organ, which we call the central nervous system.

During this process of development of the more complex forms of nervous system, most of the sensory cells migrate from their primitive positions in the skin (Fig. 439); and, as the free extremity of the peripheral process retains its primitive relationship to the skin, such migration of the cell bodies necessitates a great elongation of their peripheral processes. Although these sensory cells thus move inwards into the deeper tissues of the body, the great majority of them do not become incorporated in the central nervous system, but become collected into groups, which form the ganglia of the sensory nerves.

In addition to its primary functions of (a) providing the means whereby the organism can be brought under the influence of its surroundings, and $(b)$ coordinating the activities of the whole body, the nervous system also comes to perform other functions of wider significance.

In the course of its evolution the co-ordinating mechanism formed by the intercalated cells becomes so disposed in each animal that an appropriate stimulus applied to the sensory nerves can evoke a definite response, often of great complexity and apparent purposiveness. In other words, the nervous system becomes the repository of those inherited dispositions of its constituent parts which determine the instincts: and in the course of time it eventually provides also the apparatus by which individual experience and the effects of education can be brought to bear upon and modify such instinctive behaviour. In other words, from the nervous system is formed the instrument of intelligence; and the relatively great bulk and extreme complexity of that instrument-the brain-in man are in a sense the physical expression of human intellectual pre-eminence.

In conformity with its primary function of affording a means of communication with the outside world, almost the whole nervous system in the human embryo, as in other animals, is developed from the ectoderm, as has already been explained in the chapter dealing with General Embryology (p. 30 et seq.). In the most primitive Metazoa the sensory cells remain in the ectoderm (Fig. 439), but other ectodermal cells become converted into motor nerve-cells and intercalated nerve-cells, which wander into the underlying tissues (Fig. 439). In the human embryo there is an analogous process of development, but with the important difference that the various nervous elements do not wander into the mesoderm individually. A 
definite patch of ectoderm is set apart to produce the greater part of the nervous tissues for the whole body; and all except the margins of this area sinks into the body, en masse.

In one area of ectoderm all the motor nerve-cells develop (Fig. 440, $d$ ), in another $(c)$ only intercalated nerve-cells, in yet another $(b)$ the sensory cells originate; and the rest forms the skin $(a)$. With our knowledge of the fact that the sensory cells were originally distributed throughout the skin (Fig. 439), the idea naturally suggests itself that in man also the units of the sensory ganglia might be formed in situ in the ectoderm, and that the collection of sensory cells in the ganglia might possibly be brought about by the migration of such sensory cells inwards, while their peripheral processes elongate to permit such migration of the cell bodies without disturbing their original endings in the skin. But there is no evidence

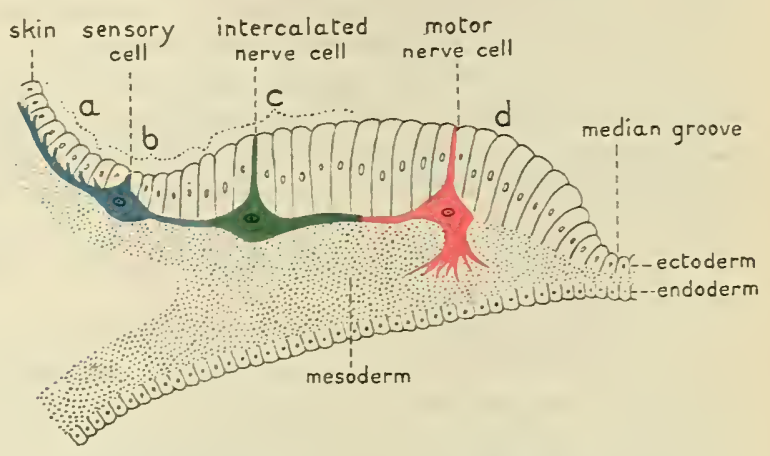

Fig. 440. -Diagray Represextiag (in BLack) The LeFT HalF of a Transterse Section of a 2 mor. HUMax Enbryo. Superimposed upon it there is shown (in colours) the hypothetical primitive arrangement of the nervous elements derived from each part of the ectoderm.

to show, or eren to suggest, that such a process takes place in the human embryo. The facts at our disposal seem to indicate that the sensory cells are derived from sharply circumscribed patches of ectoderm, and that the peripheral processes of these cells are distributed to the outlying area of ectoderm beyond them, from which the epidermis is eventually formed (Fig. 440).

At the beginning of the second week the nervous system of the human embryo is represented by two thickened plates of ectoderm lying parallel the one to the

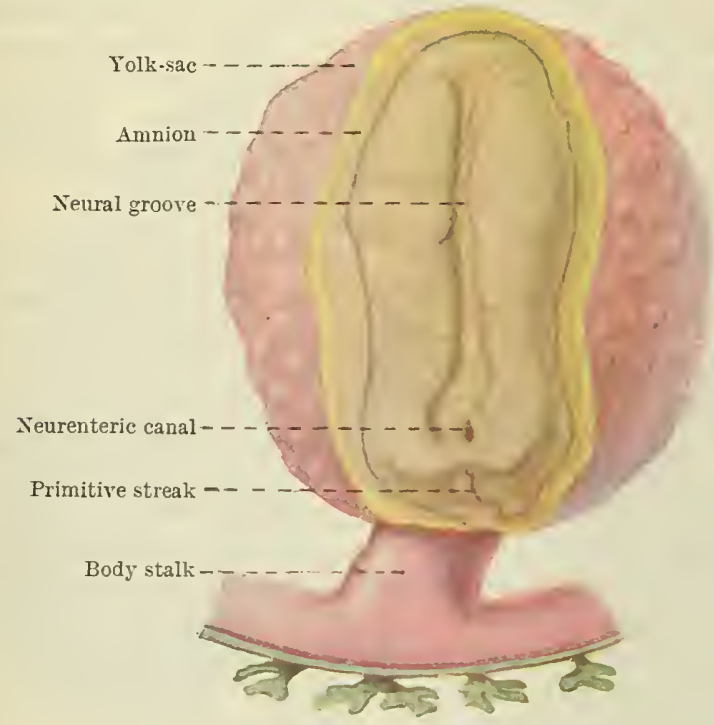

Fig. 441. - The Dorsal aspect of a Tery Early Human Embrio (after von Spee).

other, alongside the median axis of the embryo (Fig. 441), which is occupied by a shallow furrow.

Upon a diagram (Fig. 4t0), representing a transverse section througl one-half of such an embryo (the uncoloured part), colours (corresponding to those employed in 
Fig. 439) have been placed to inclicate the nature of the elemeuts that are known to develop in relation with each area of the ectoderm at a later period in the history of the embryo: $b$ represents an area which later will form the crista neuralis, from which the sensory cells will be developed. The peripheral processes of these cells will pass into the skin (a) and their central processes into the area $c d$, which will become part of the neural tube. In the area $c$ intercalated cells will develop to receive the incoming sensory nerves; and in the area $d$ the motor nerve-cells (as well as other intercalated cells) will be formed.

When it is recalled that all the elements of the primitive nervous system of Hydra are modified ectodermal cells, and, moreover, that when the intercalated and motor nerve-cells wauder into the deeper tissues the protoplasm of the whole nervous network remains in uninterrupted continuity (Fig. 439), it is instructive to note that in the primitive human nervous system the rudiment of the skin is linked to the medullary plate by the patch of ectoderm from which the sensory ganglia will be formed.

In the discussion of the inter-relationships of the various constituent elements of the nervous system, there will be occasion to refer to this matter again. But while we are studying Fig. 440 it is important to emphasise the fact that in accordance with the commonly accepted ideas it is taught that the area $b$ becomes completely severed from $a$ and $c$, and shortly afterwards fibres are budded off from the cells in the area $b$ to form the sensory nerves linking $a$ to $c$, thus re-establishing a connexion which existed a few days earlier. This suggests the possibility that the connexions between these three series of elements may not have been completely sundered during the intermediate phase of development. Early in the second week in the human embryo the axial groove separating the two bands of thickened ectoderm (Fig. 441) that form the medullary plate becomes deepened by the tilting-up of the lateral margins of the two bands. This process becomes accentuated during the next day or two until a deep cleft is formed, the walls of which consist of the thickened ectoderm and the floor of the thinner ectoderm (floor-plate) joining them together. Before the end of the week the dorsal edges of these thickened plates become joined in the region which will develop into the neck; and during the third week the sealing of the lips of the neural groove extends upwards (headwards) and downwards (caudally), so that the neural tube becomes completely closed by the end of that week. The extreme anterior (head-) end and the dorsal aspect of the caudal extremity of the tube are the last parts to close, the latter being, as a rule, a little later than the former. When the tube is in the stage of being patent only at its two ends, the openings are known as the neuroporus anterior and neuroporus posterior, respectively.

In the process of closing, the extreme dorsal edge of the medullary plate becomes excluded, in the greater part of its extent, from participation in the constitution either of the neural tube or of the skin, and forms a column of cells lying between the two. This is the neural crest (Fig. 442, A, B, and C; $x$ and $y$ represent the places where the apparent sundering occurs).

It is commonly supposed that the neural crests do not extend the whole length of the neural tube. Nevertheless, peculiar ectodermal areas, which ultimately give origin to sensory nerves, are found at the junction of the medullary plate with the skin in those regions where the neural crest is supposed to be lacking. At the extreme anterior end of the neural tube the margins of the anterior neuropore become thickened to form crest-like patches; but when the tube closes these areas do not separate from the skin (at $x$, Fig. 442, D), as the rest of the neural crest does. They remain part of the skin and become the olfactory areas, in which sensory cells, precisely like those found in Hydra (Fig. 439), develop.

A little farther on the caudal side of the olfactory region a very large crestlike mass of ectoderm fails to separate from the medullary plate as it closes, and becomes a constituent part of the neural tube (Fig. 442, E). It develops into the optic diverticulum from which the cells of origin of the optic nerve are formed.

In several other regions sensory nerves originate from cells of ectodermal, and possibly even entodermal, areas which do not form parts of the neural crest, as that term is usually understood. The nerves of hearing and taste are developed 
in a way that seems at first sight utterly abnormal, until it is remembered that they afford examples of very primitive methods of nerveformation.

The essential part of the organ of hearing is an ectodermal sac (otic vesicle) that develops as a diverticulum on the side of the head, from a thickened patch of ectoderm, which in the lower vertebrates forms part of a more extensive area, known as the dorsolateral placode. Some of the cells of this area seem to become transformed into nervecells, which migrate into the space between the otic vesicle and the neural tube (Fig. 443) and form the acoustic ganglion.

At the upper margins of the branchial clefts a series of ectodermal (and possibly also entodermal) thickenings develop, which are known as the epibranchial placodes. Comparison with the process of development in fish embryos, which has been elucidated by Landacre (Journal of Comparative Neurology and Psychology, 1910-1912), suggests that the
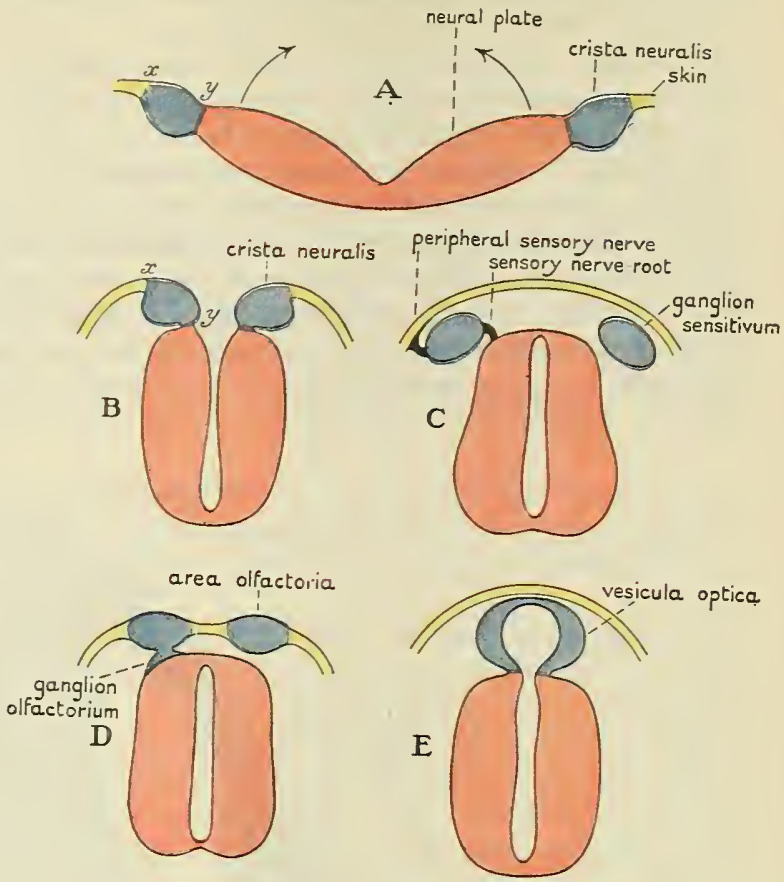

Fig. 442.-Diagrajis of Traxsterse Sections RePREsentixg Three Stages (A, B, AND C) in the DetelopMest OF A Sexsory Gaxglion from the Netral Crest; and Two Diagrams (D axd E) suggestisg a Possible Homology of the Olfactory (D) axd Visdal (E) EPITHELICM WITH the NeURal Crest.

nerve-cells may arise from these placodes, from which the nerves of taste originate.

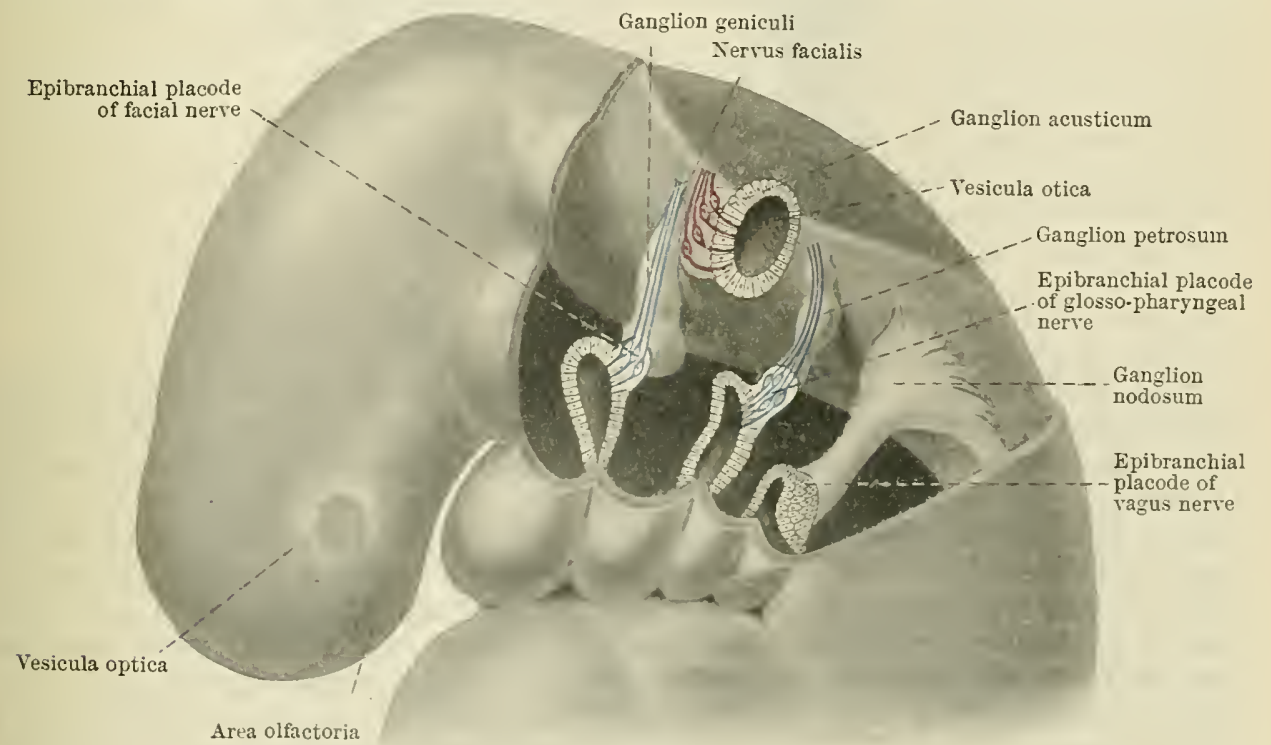

Fig. 443.-Reconstruction of the Gangla of the facial, Acoustic, Glosso-pharyigeal, and Vagrs Nerves of a Hudan Eabryo 5 Minlimetres loyg (abudt three weeks old).

The epithelium of three branchial clefts and the otic vesicle is represented diagrammatically; and the supposed mode of origin of the gustatory nerve-cells (and their fibres) from the epibranchial placodes is indicated in blue, and of the acoustic nerve-cells from the otic vesicle in purple. 
Such fibres are constituent elements of the facial, glosso-pharyngeal, and in some animals also the vagus cerebral nerves (Fig. 443), in connexion with the ganglia of which these epibranchial placodes are formed (Froriep and Streeter). The observations of Professor J. P. Hill upon embryos of Echidna seem to suggest that in mammals these gustatory neuroblasts are derived from the entoderm.

When first formed, the neural tube is compressed from side to side and presents an elliptical outline in transverse section (Fig. 444). The two lateral walls are very thick, whilst the narrow dorsal and ventral portions of the wall are thin, and are termed the roof-plate and floor-plate respectively (Fig. 444). The cavity of the tube in transverse section appears as a narrow slit. The wall of the neural tube consists at first of low columnar epithelium arranged in a fairly regular series, but with a certain number of large spherical so-called germinal cells scattered between the columns. But this regular disposition as a single layer

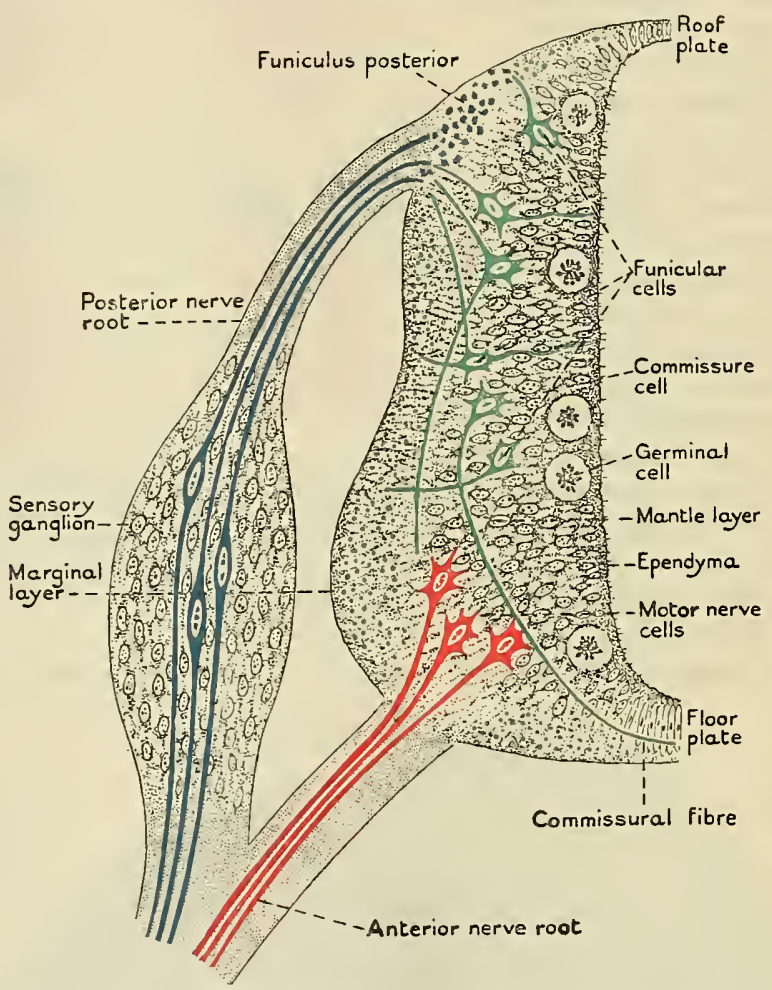

Fig. 444.-Diagram of Transvetse Section of Early Netral Tube.

of cells does not last long. For even by the second week the rapid proliferation of the cells has led to a marked increase in the thickness of the lateral wall and a scattering of the more numerous nuclei, apparently irregularly, throughout its substance (Fig. 444). The latter consists of a network of protoplasm in which definite outlines of cells cannot be detected. As growth proceeds the innermost part of this nucleated protoplasmic syncytium becomes condensed to form a delicate membrane termed the internal limiting membrane, which lines the lumen of the tube, whilst its outermost part presents a similar relation to an external limiting membrane, which invests the outer surface of the tube. Toward the end of the first month the lateral walls of the tube show signs of a differentiation into three layers. Next to the central canal there is an epitheliallike arrangement of the innermost cells of the syncytium, forming the ependyma. Then there is an intermediate layer crowded with nuclei, hence known as the nuclear or mantle layer. On the surface is a layer singularly free from nuclei, which is called the non-nuclear or marginal layer. The germinal cells are 
placed in the ependymal layer between its radially arranged cells as they pass in towards the internal limiting membrane; and the protoplasm of the germinal cells forms part of the syncytium.

At one time it was imagined that the germinal cells were embryonic nerve-cells, the parent-cells of the real neuroblasts, and that the whole of the rest of the syncytium represented the supporting tissues, which in the adult form the neuroglia. But it is now known that from the proliferation of the germinal cells, in which mitotic figures can usually be seen, some cells are formed which become ependymal epithelium, and others which migrate peripherally into the mantle layer. There, while forming part of the mantle syncytium, they undergo further proliferation and some of the resulting cells develop into spongioblasts, which constitute the supporting framework, the embryonic neuroglia; others become rudimentary nervecells or neuroblasts, and others again are known as indifferent cells. The latter are destined to undergo further subdivision and become the parents of more spongioblasts and neuroblasts.

From this it is clear that the greater part-all except the germinal cellsof the syncytium, which is known as the myelospongium, is not merely supporting neuroglial tissue, as was once supposed, but is the rudiment of both neuroglia and true nervous tissues.

The details of the process by which the neuroblasts become dissociated from the neuroglial network are quite unknown. It is commonly supposed that a spherical cell in the mantle layer that is to be transformed into a neuroblast frees itself from the syncytium, and remains for a time independent and wholly unattached amidst the meshes of the neuroglial network: it is supposed further that its true nature as a neuroblast becomes revealed when it takes on a pearshape, and a protoplasmic process, the stalk of the pear, pushes its way into some other part of the nervous system, or out of it into the mesoderm to reach some muscular or glandular tissue, and becomes the axis cylinder process or axon of the nerve-cell.

Such an interpretation of the appearances exhibited in the walls of the neural tube at the end of the first month is adduced in support of a view concerning the constitution of the nervous system known as the neurone theory. "Neurone" is the term applied to a nerve-cell and all its processes; and the neurone doctrine assumes that there is no continuity whatever between the sulstance of one neurone and that of another, such as occurs in Hydra (Fig. 439), and that the functional connexions between them are brought about merely by the contact of the processes of one element with the processes, or the cell-body itself, of another element. In accordance with this conception the facts of embryology are supposed (by His) to demonstrate that when the axon grows out from a previously spherical and unattached cell it is able to push into the surrounding tissues, and, as it were guided by some instinct, eventually finds its way to that particular area of skin, muscle, gland, or other part of the body where nature intends it to go.

This is the current teaching in regard to the neurone-theory; and it is supposed to have been conclusively demionstrated by the facts revealed not only by embryology and the study of the minute structure of the nervous system, but also by the phenomena of degeneration and regeneration. Harrison has shown that the outgrowth of processes can be witnessed in the living nerve-cells of the frog. There are certain facts, however, which have always led some anatomists to refuse to believe in the validity of the neurone doctrine as a true expression of the real constitution of the nervous system. It has been clearly demonstrated by Graham Kerr that at a very early stage of development the neural syncytium of the spinal medulla (of the mud-fish Lepidosiren) is in free and uninterrupted continuity with the protoplasm of the muscle-plate, which lies in contact with the neural tube; and no stage is known in which these connexions do not exist. When, in the course of the subsequent growth of the embryo, the muscle-plate becomes removed further and further away from the central nervous system the protoplasmic strand, which links them the one to the other, gradually becomes stretched and elongated. As the neuroblast matures its chemical constitution becomes modified; it becomes specialised in structure to fit it for the peculiar functions it has to perform. These 
changes manifest themselves first in the body of the neurone itself and thence spread along its processes. With the knowledge that protoplasmic bridges exist long before the time His supposed the axon of his neuroblast to push its way outward, it seems not unreasonable to suppose that it is the chemical modification of these existing bridges which has been revealed in stained specimens, as it spreads from the cell body outwards into its processes.

It is now a well-recognised fact that soon after the neural tube becomes closed the outlines of its constituent cells become blurred and then disappear, and a continuous protoplasmic network or syncytium is formed. No one has ever been able to detect the process of detachment of embryonic nerve-cells (neuroblasts) from this syncytium; and it is at least a possibility that the free anastomosis of the protoplasmic processes of many of the cells is not destroyed in the way demanded by the neurone doctrine. The known facts might be interpreted, at least as reasonably, by supposing that when nerve currents begin to traverse the syncytium (Fig. 444) structural modifications occur around the nuclei of the cells affected, and gradually spread along their processes, so as to give the appearance (in sections stained by special methods) of processes growing out from each neurone.

Impulses brought from the skin by the sensory nerves, the nutrition of which is controlled by the cells in the sensory ganglion (Fig. 443), are carried into the wall of the neural tube, where they are received by processes of intercalated cells, which in turn transmit their effects directly or indirectly to $(a)$ motor nerve-cells (or other kind of efferent nerve-cells), which stimulate a muscle, a viscus, or other active tissue to perform some work, or $(b)$ to intercalated cells, the axons of which proceed to some other part of the nervous system, perhaps above or below the place where the sensory nerve enters (Fig. 444, funicular cells). As the walls of the neural tube increase in size the various neurones gradually become drawn apart, and the protoplasmic links uniting them become stretched and extended to form processes of varying length.

It is right to explain that most writers give an explanation of the process of development which is at variance with that just sketched. The neuroblast is supposed to originate as a free-lying spherical cell, which is stimulated by some unknown force, sometimes assumed to be of the nature of a chemical attraction (chemotaxis), to protrude a process, which gradually elongates and pushes its way through the tissues, perhaps to some particular patch of skin, muscle, gland, or some other nerve-cell. The difficulty involved in such a conception is not only that it is opposed to all that is known of the early stages in the evolution of the nervous system, but also that it is difficult to conceive that every one of the millions of nerve-cells, muscle-cells, visceral and cutaneous elements can each have some specific attractive power which leads every individual nerve fibril to its appropriate and predestined place in the body.

The Efferent Nerves.-The efferent cells of the neural tube are distinguished by the fact that their axons leave the central nervous system and traverse the mesoderm for a longer or shorter distance to end in relation to some muscle, gland, or other tissue outside the nervous axis. At an early stage of development (Fig. 445) such efferent fibres pass not only to muscles but also to viscera and other kinds of tissues. In the course of the growth of the body these various structures supplied by efferent fibres become removed progressively further and further from the central nervous system; and in this process a distinction can be detected in the behaviour of the efferent fibres proceeding (a) to the striped or voluntary muscles, $(c)$ and the viscera and unstriped muscle, respectively. The efferent cells $(\alpha)$ which innervate voluntary muscles retain their positions in the central nervous system, their axiscylinder processes (motor nerves) becoming elongated in proportion to the migration of the muscle from its original situation. But the cells (c) innervating non-striped muscles and viscera behave in a different manner. As the viscus or muscle migrates (Fig. 445, B), the nerve-cell (c) follows it more or less closely, being as it were dragged out of the wall of the neural tube by its axon into a peripheral position, where it becomes a constituent element of one of the so-called sympathetic or autonomic ganglia. As these sympathetic cells migrate from the central nervous system, each of them appears to draw out with it the axon of an inter- 
calated cell $(d)$; and it is customary to distinguish these latter elements (within the central nervous system) as splanchnic efferent cells. It is, however, a matter of fundamental importance to recognise clearly that the real splanchnic efferent cells, the homologues of the somatic efferent cells, are found in the sympathetic ganglia, and that the elements to which this term is usually applied are in reality intercalated cells.

This account is at variance with the customary description of the development of the sympathetic system, according to which the cells of the sympathetic ganglia are said to be wholly derived from the sensory ganglia ; but it offers a reasonable explanation of the facts (i.) that the cells in the sympathetic ganglia are of the efferent, and not of
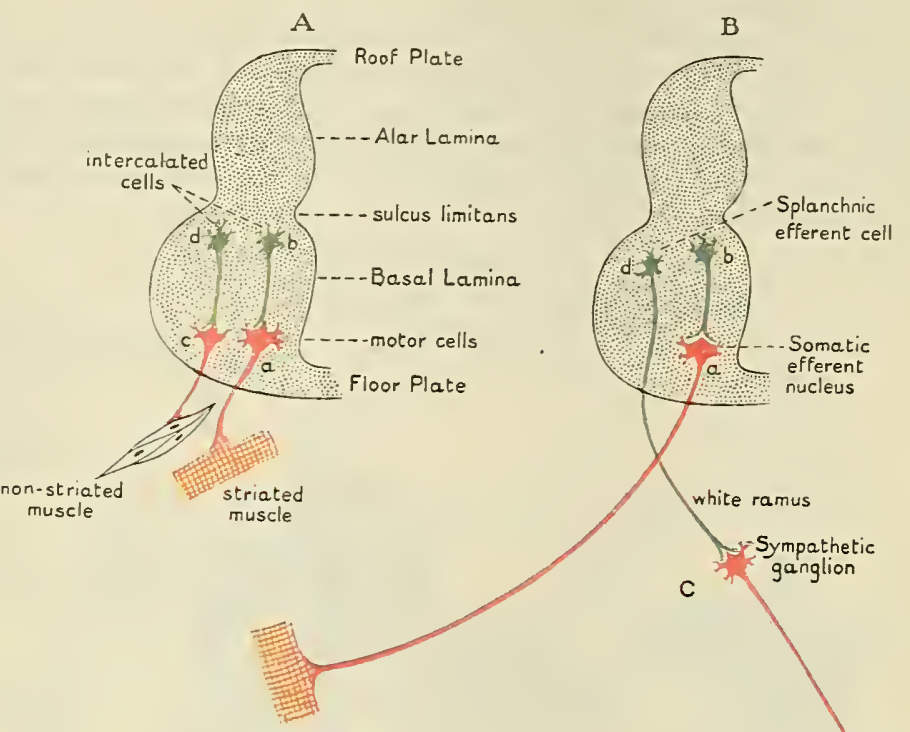
the sensory, type, and (ii.) that the fibres from the central nervous system establishing relations with them emerge along the motor nerves. Moreover, the information brought to light by recent research in embryology (Froriep, Kuntz, and others) affords positive evidence in support of this view. Elliott, however, opposes this interpretation (Journal of Physiology, 1907, p. 438).

Many, if not all, of the sympathetic cells are derived from the walls of the neural tube, and they migrate along the pathways formed by the motor, rather than the sensory, nerves. In the case of the spinal medulla they pass out chiefly along the anterior roots, and from the brain along the motor nerves-the oculomotor, and the motor divisions of the facial and vagus nerves.

Nerve Components.-From the statements in the preceding paragraphs it must be evident that there are several varieties of afferent and efferent nerves respectively entering and leaving the central nervous system. The cells of origin of the efferent nerves are all placed in the ventral part of the lateral wall of the neural tube; and for this reason this part of the wall becomes swollen at an early stage of development (Figs. 445 and 446). It is called the basal lamina. Most of the cells that emit afferent fibres are situated in the sensory ganglia outside the central nervous system, so that their growth can have no direct influence upon the form of the neural tube; but their central processes become inserted into the dorsal part of the lateral wall of the tube, which is called the alar lamina; and groups of intercalated cells collect around the entering fibres to form receptive or terminal nuclei. The growth of these terminal nuclei leads to an expansion of the alar lamina which is analogous to, but much less extensive than, that seen in the basal lamina. This unequal swelling of the dorsal and ventral parts of each lateral wall of the neural tube leads to the development of a longitudinal groove, sulcus limitans, as a demarcation between the alar and basal laminæe.

The nuclei of origin of the efferent fibres, which are found in the basal laminæ, may be divided into two (and, in some regions of the nervous axis, three) main groups. There is first the group of large multipolar nerve-cells which emit fibres to innervate the ordinary striped voluntary muscles. This is commonly called 
the somatic efferent nucleus. Then there is a group of small multipolar cells, the axons of which pass out into sympathetic ganglia, and indirectly control the involuntary unstriped muscles and other active parts of viscera. These cells form the splanchnic efferent nucleus.

In the upper cervical and lower cranial region a portion of the somatic efferent nucleus is set apart to innervate the striped muscles developed in the branchial arches. This is the lateral somatic or intermediate efferent nucleus. Many recent writers are of the opinion that this nucleus is splanchnic; but its fibres directly innervate striped voluntary muscles, which are developed from the same material

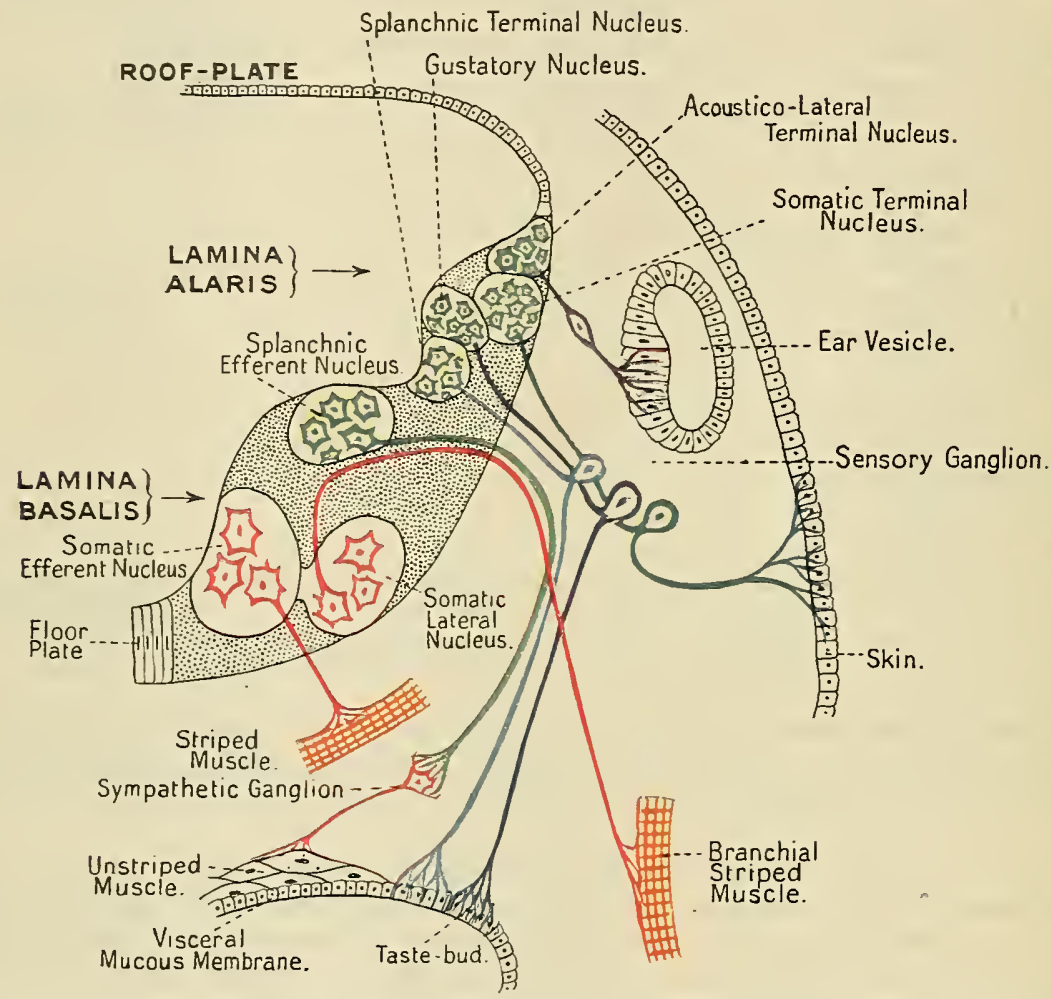

Fig. 446.-Dlagray of a Tratsverse Section throdgh the Right Half of the Fetal Rhombencephalon ajd Epithelial Areas associated with it to illostrate the Different Categories of Nerve Components atd their Central Nuclei.

(myotomes) from which the other striped muscles are formed (Agar and Graham Kerr).

The alar lamina also can be subdivided into a series of functional areas (Fig. 446).

At the dorsal edge is the somatic afferent terminal nucleus, which receives impulses coming from the skin. In one region a part of this nuclens is specialised for the reception of impulses coming from the internal ear (acoustico-lateral terminal nucleus). Then there is a group of cells collected around the incoming visceral sensory nerves-the splanchnic afferent terminal nucleus. A part of this is specialised to receive taste impressions - the gustatory nucleus-but this has not yet been clearly demarcated from the rest of the nucleus.

This analysis of the various functional elements that may enter into the constitution of the various cerebral and spinal nerves is made use of in elaborating the theory of nerve components, which will help us to understand many features of the structure of the nervous system that otherwise would be unintelligible.

Nerve-cells.-We have already noticed that there is a broad distinction between the nerve-cells which are found in the ganglia of sensory nerves and those 
found in the rest of the nervous system. They differ not only in their mode of origin and in their subsequent development, but also in the connexions of their nerve-fibre processes.

Nerve-cells of the Brain and Spinal Medulla.-The cells in the cerebrospinal axis are variable both in size and form. Some are relatively large, as, for example, certain of the pyramidal cells of the cerebral cortex and the motor cells in the spinal medulla, which almost come within the range of unaided vision; others are exceedingly minute, and require a high power of the microscope to bring them into view. The cell consists of a protoplasmic nucleated body, from which the axon proceeds, and the protoplasmic processes of Deiters, or the dendrites (Fig. 447).

The axon presents a uniform diameter and a smooth and even outline. It gives off in its course fine collateral branches, but does not suffer thereby any marked diminution in its girth. The most important point to note in connexion with the axon, however, is the fact that it becomes continuous with the axiscylinder of a nervefibre. The axon then is simply a nerve-fibre, and in certain circumstances it assumes one or two investing sheaths, of which more will be said later. The axon may run its entire course within the substance of the brain or spinal medulla, either for a. short or a long distance (intercalated cells), or it may emerge from the brain or spinal medulla in one of the cerebral or spinal

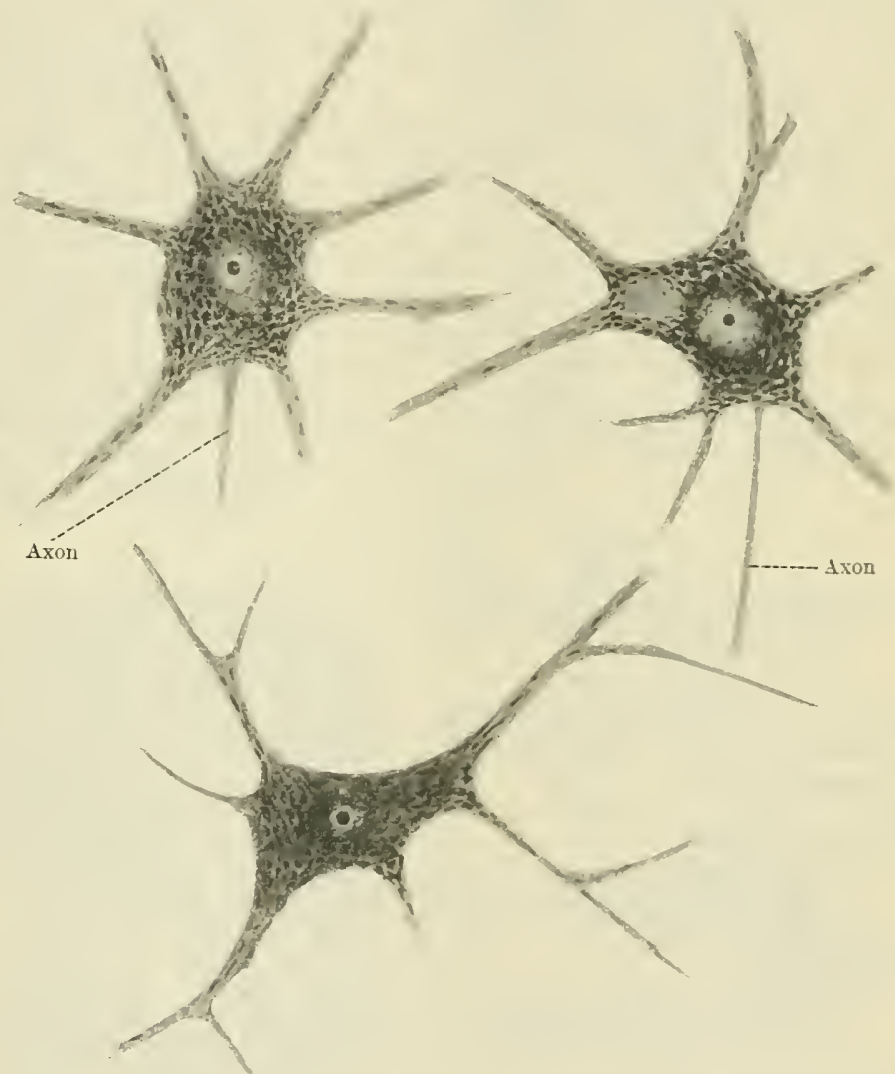

Fig, 147.-Thlee Nerve-cells from the Axterior Coltmn of Gray Matter of the HuMay Spixal Medella.

nerves as the essential part of an efferent nerve-fibre, and run a variable distance before it finally reaches the peripheral structure in relation to which it ends (efferent nerve-cells). The axon and the collaterals which spring from it appear to terminate either in small button-like swellings or knobs, or more frequently in terminal arborisations, the extremities of which seem to be furnished with exceedingly small terminal varicosities. In those cases where the axon or its collaterals end within the brain or spinal medulla, some of the terminal arborisations interlace with the dendrites of nerve-cells, whilst others are twined around the bodies of other cells. In the latter case the interlacement may be so close and complete that it almost presents the appearance of an enclosing basket-rrork. In cases where the axon emerges from the cercbro-spinal axis its terminal arborisation ends in relation to a muscle-fibre or some other tissue in the manner described. below. 
Nerve - fibres. - Nerve - fibres, arranged in bundles of greater or less bulk, form the nerves which pervade every part of the body. They also constitute the greater part of the brain and spinal medulla. Nerve-fibres are the conducting elements of the nervous system; they serve to bring the nerve-cells into relation both with each other and with the various tissues of the body.

There are different varieties of nervefibres, but in all the leading and essential constituent is a delicate thread-like axon. The most obvious difference between individual fibres depends upon the nature of the covering of the axon. When it is coated on the outside by a more or less thick sheath of a fatty substance, termed myelin, it is said to be a myelinated or medullated fibre. When the coating of myelin is absent, the fibre is termed a non-myelinated or a non-medullated fibre. A second sheath - thin, delicate, and membranous, and placed externally - may also be present in both cases. It is termed the primitive sheath or the neurolemma. From a structural point of

Fig. 448.-Two Moltipolar NerveCELLS (from a specimen prepared by the Golgi method).

view, therefore, four different forms of nerve-fibre may be recognised:-

Non-medullated-_

1. Naked axis-cylinders.

2. Axis-cylinders with primitive sheaths.

\section{Medullated-}

3. Primitive sheath absent.

4. Primitive sheath present.

Every nerve-fibre near its origin and as it approaches its termination is unprovided with sheaths of any kind, and is simply represented by a nonmedullated naked axiscylinder. The fibres of the olfactory nerves afford us an example of non-medullated fibres furnished with a primitive sheath.

Medullated fibres are present in greater quantity in the cerebro-spinal system than non-medullated fibres. Thus, all the nerves attached to the

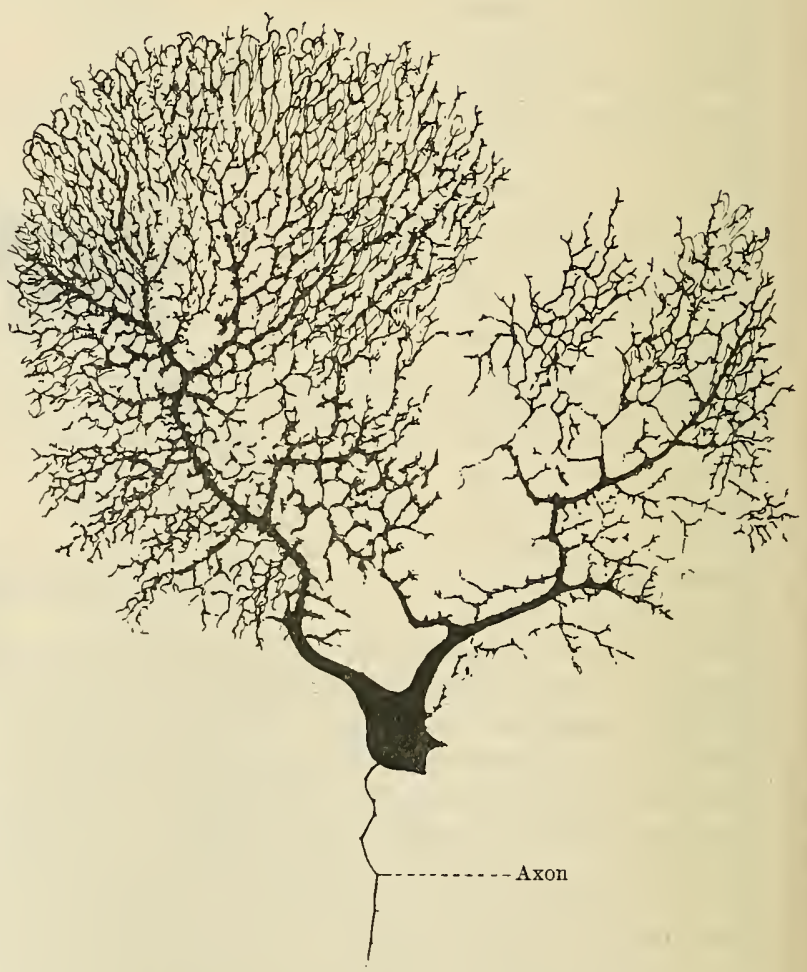

Fig. 449. - Nerve-cell From Cerebellum (Cell of Purkinje) showing the Branching of the Dendritic Processes (from a photograph by Professor Symington). 
brain and spinai medulla, with the exception of the olfactory and optic, are formed of medullated fibres provided with a primitive sheath; whilst the entire mass of the white substance of the brain and spinal medulla, and also the optic nerves,

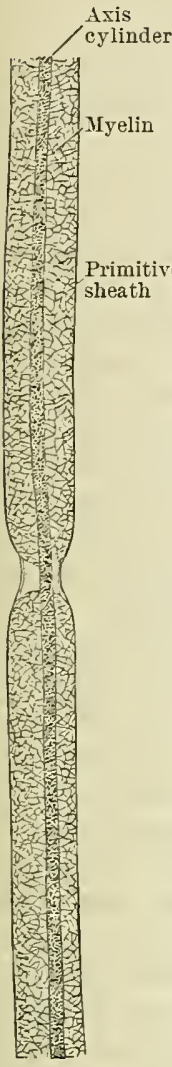

FIG. 450 .

NERTE-FIBRE FROM A FROG (after v. Kölliker). are formed of medullated fibres devoid of a primitive sheath.

It is important to note that the distinction between the medullated and non-medullated fibres is not one which exists throughout all stages of development. As will be presently pointed out, every fibre is the prolongation of a cell, and in the first instance it is not provided with a medullary sheath. Indeed, it is not until about the fifth month of fotal life that those fibres which are to form the white substance of the cerebro-spinal axis begin to acquire their coating of myelin. Further, this coating appears in the fibres of different fasciculi or tracts at different periods, and a knowledge of this fact has enabled anatomists to follow out the connexions of the tracts of fibres which compose the white matter of the brain and spinal medulla.

Every nerve-fibre is directly continuous by one extremity with a nerve-cell, whilst its opposite extremity breaks up into a number of ramifications, all of which end in relation to another nerve-cell, or in relation to certain tissues of the body, as, for example, musclefibres or the epithelial cells of the epidermis. The length of nervefibres, therefore, varies very greatly. Some fibres are short and merely bring two neighbouring nerve-cells into relation with each other; others travel long distances. Thus, a fibre arising from one of the motor cells of the lower end of the spinal medulla may, after leaving the spinal medulla, extend to the most outlying muscle in the sole of the foot, before it reaches its destination. But even when a fibre does not leave the central axis, a great length may be attained, and cells situated in the uppermost part of the brain give origin to fibres which pass down to the lower end of the spinal medulla.

It has already been explained that fibres which form the nerves may be classified into two sets, afferent and efferent. Afferent nerve-fibres conduct impressions from the peripheral organs into the central nervous system; and as a change of consciousness, or, in other words, a sensation is a frequent result, these fibres are often called sensory. Efferent nerve-fibres carry impulses out from the brain and spinal medulla to peripheral organs. The majority of these fibres go to muscles and are termed motor; others, however, go to glands and are called secretory; whilst some are inhibitory and serve to carry impulses which restrain or check movement or secretion.

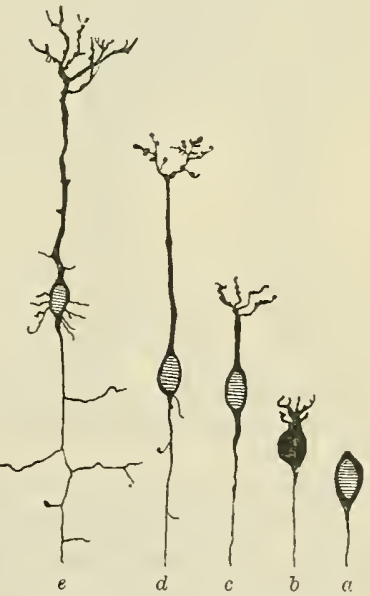

Fig. 151. - RaMón Y CaJaL's IxTERPRETATION OF THE DEVELOPMeNTal Stages EXHIBITED BI a PYRAMIDAL CELL OF the BRAIN.

, Neuroblast. with rudimentary axon, but no dendrites ; $b$ and $c$, The dendrites beginning to sprout ont ; $d$ and $e$, Further development of the dendrites and appearance of collateral branches on the axon. cell, are thicker than the axon, and present a roughedged irregular contour. They divide into numerous branches, and these gradually, as they pass from the cell-body, become more and more attenuated until finally they appear to end in free extremities. The branching of the dendritic processes sometimes attains a marvellous degree of complexity (Fig. 449), but it is commonly supposed that there is no anastomosis between the dendrites of neighbouring cells, or between the dendrites of the same cell.

It is commonly believed that the neuroblast passes through stages analogous to those shown in the diagram (Fig. 45̃1); that just as a seed gives off a root which strikes downward, and leaves which grow upward, so the neuroblast sprouts out an 
axon (a) and subsequently develops a bunch of dendritic processes $(b)$. In the case of the axon reasons have already been given for not accepting this view as the whole explanation; and in the case of the dendrites, although the appearance of microscopic sections seems to favour the view expressed in the diagrams, the fact that the neuroblasts are united into a continuous network or syncytium at an early stage of development (see p. 503) raises the possibility that the dendrites may be formed by the gradually drawing out of the existing bridges as the linked cell-bodies become moved apart.

The Ganglia of the Sensory Nerves.-The cells found in the ganglia of the cerebral nerves and on the posterior or dorsal roots of the spinal nerves have a different origin, and present many points of contrast with neurones in the gray matter of the brain and spinal medulla. As already indicated, the ganglia in question are derived from the neural crest. The cells forming these ganglionic masses are somewhat oval in form, and each extremity or pole becomes drawn out into a process, so that the neurones become bipolar. These processes are distinguished as central and peripheral, according to the direction which they take. The central processes

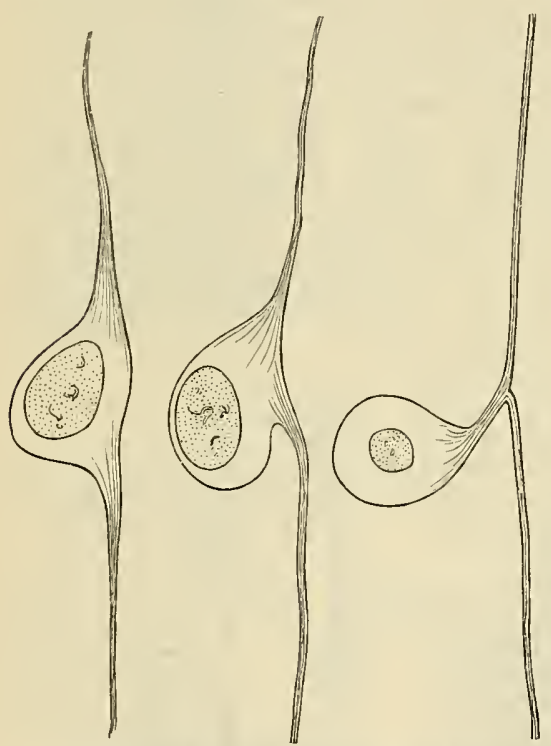

Fig. 452.-Three Stages in the Development of a Cell in a Spinal Ganglion. penetrate the wall of the neural tube. In the region of the spinal medulla they form almost the whole of the fibres which enter into the composition of the posterior roots of the spinal nerves. In the substance of the cerebro-spinal axis they give off numerous collaterals, and after a course of varying extent they end, after the manner of an axon, in terminal arborisations, which enter into relationships with certain nerve-cells in the cerebro-spinal axis. The peripheral processes proceed along the path of the particular nerve with which they are associated, and they finally reach the skin or other sensory surface. Thus, to take one example: the majority of the fibres which go to the skin break up into fine terminal filaments, which end freely between the epithelial cells of the epidermis. The two processes of a ganglion cell, therefore, form the afferent fibres of the cerebro-spinal nerves, and constitute the path along which the influence of peripheral impressions is conducted towards the brain and spinal medulla. The body of the cell is, as it were, interposed in the path of such impulses.

But the original bipolar character of these cells, with very few exceptions (ganglia in connexion with the acoustic nerve and the bipolar nerve-cells in the olfactory mucous membrane), gradually undergoes a change which ultimately leads to their transformation into unipolar cells. This is brought about by the tendency which the cell-body has to grow to one side, viz., the side towards the surface of the ganglion ( $\vee$. Lenhossek). This unilateral growth leads to a gradual approximation of the attached ends of the processes, and finally to a condition in which they appear to arise from the extremity of a short common stalk in a T-shaped manner (Fig. 452). It is interesting to note that in fishes the original bipolar condition of these cells is retained throughout life, without change.

Both the central and peripheral processes of these ganglionic cells become the axis-cylinders of nerve-fibres, which, acquiring a medullary sheath, belong therefore to the medullated variety. From this it might very naturally be thought that the ganglionic neurone, with its two axons and no typical dendrites, is a nervous unit very different from a neurone in the gray matter of the cerebro-spinal axis. It is believed by some, however (van Gehuchten and Cajal), that the peripheral process, in spite of its enclosure within a medullary sheath, and though presenting all the characters of a true axon, is in reality a dendrite. If this is the case, the 
morphological difference between a dendrite and an axon disappears, and van Gehuchten's functional distinction alone remains characteristic, viz., that the axon is cellulifugal and conducts impulses away from the cell, whilst the dendrites are cellulipetal and conduct impulses towards the cell.

It is, however, more in accordance with the facts to regard the sensory neurones as genetically quite distinct from the rest of the nervous system (see p. 498).

Neuroglia.-The neuroglia is the supporting tissue of the cerebro-spinal axis. It may be considered to include two different forms of tissue, viz., the lining ependymal cells and the neuroglia proper. We place these under the one heading, seeing that they have a common developmental origin.

The ependymal cells are the columnar epithelial cells which line the central canal of the spinal medulla and the rentricles of the brain. In the embryonic condition a process from the deep extremity of each cell, traverses the entire thickness of the neural wall, and reaches the surface. It is not known whether this process exists in the adult.

The neurogiia proper is present in both the white and the gray matter of the cerebro-spinal axis. It constitutes an allpervading basis substance, in which the various nerve elements are embedded in such a way that they are all bound together into a consistent mass, and are yet all severally isolated from each other. Neuroglia consists of cells and fine filaments. The fibrils are present in enormous numbers, and by their interlacements they constitute what appears to be a fine feltwork. At the points where the fibrils intercross may be seen the flattened glial cells. Whilst the neuroglia is for the most part intimately intermixed with the nerve elements, there are, in both brain and spinal medulla, certain localities where it is spread out in more or less pure layers. Thus, upon the surface of the brain and of the spinal medulla there is such a layer; likewise beneath the epithelial lining of the central canal and of the cavities of the brain there is a thin stratum of neuroglia.

The ependymal cells are derived from the original neuro-epithelial cells of the early neural tube, and in all probability the neur-

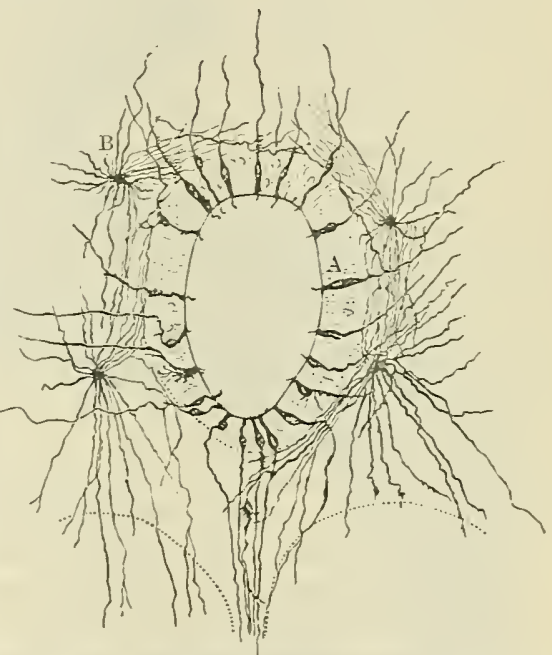

Fig. 453. - Section Throdgh the CextraI Canal of the Spryal Medtlla of a HuMax Embrio, SHowng Ependyal ayd NedrOGLIAL CELLS (after v. Lenhossek).

A, Ependymal cell. B, Neuroglial cell.

[Note that the dorsal (posterior) aspect is belou.] oglia proper has a similar origin. They both, therefore, are products of the ectoderm.

Summary.-1. The cerebro-spinal nervous system is composed of two parts, viz., (a) a central part, consisting of the brain and spinal medulla, with the efferent nervefibres which pass out from them; $(b)$ the ganglionic part, with the afferent nerve-fibres.

2. Each of these parts has a different origin, and is composed of neurones which possess characteristic features.

3. The ganglionic neurones are derived from the primitive cells of the neural crest, and have each one process, which divides into two. Of these the central division enters the cerebro-spinal axis, whilst the peripheral division becomes connected with a peripheral part. The central fibres from the ganglionic cells in the region of the spinal medulla form the dorsal or posterior roots of the spinal nerves. The cells of origin of these posterior roots are outside the spinal medulla, and carry impulses into its substance.

4. The cerebro-spinal neurones are derived from the neuroblasts in the wall of the early neural tube. Certain of these furnish efferent nerve-fibres, which issue from the spinal medulla in separate bundles termed the anterior or ventral roots of the spinal nerves. In the case of the cerebral nerves, however, with the exception of the trigeminal and facial nerves, the efferent fibres are not thus separated from the afferent fibres at their attachment to the brain. 
5. The brain and spinal medulla, when studied by the naked eye, are seen to be composed of white matter and gray matter. The white matter forms very nearly twothirds of the entire cerebro-spinal axis. It is composed of medullated nerve-fibres embedded in neuroglial tissue. The gray matter is composed of nerve-cells with their dendrites and axons. Some of the axons are in the form of naked axis cylinders, whilst others have a coating of myelin. Intimately intermixed with these parts is the neuroglia, which isolates them more or less completely from each other.

\section{THE NATURE OF THE BRAIN}

In the foregoing account it has been explained that the nervous system is composed of a series of afferent nerves bringing information from every part of the body into the central nervous system, from which efferent nerves pass out to the muscular and other active parts of the body, providing the means for translating such information into appropriate action. But it has been seen that the essential part of the central nervous system is the intercalated cells, which provide the means whereby the information brought in by any sensory nerve may be placed at the service of the whole body, and the response which it excites may be controlled and regulated by the condition of the rest of the body. The system of intercalated cells links together into one co-ordinated mechanism the whole nervous system, and, through it, every part of the body itself.

In some very primitive and remote ancestor of man (and in fact of the vast majority of animals) the front end of the nervous system became enhanced in importance to form a brain, which assumed a dominant influence over the rest. This was brought about in the first place by the fact that in an elongated prone animal moving forwards, the front end would naturally come first into relationship with any change in environment; and this earlier acquisition of information concerning the outside world would necessarily give the head end of the nervous system exceptional opportunities for influencing the rest of the nerrous system. This predominance is further accentuated by the development in the head region of the organs of special sense, which provide mechanisms specially adapted to be influenced by light, sound, and such delicate chemical forms of stimulation as excite in ourselves sensations of smell and taste. As the information conveyed by these special senses, such as the scent of food or the visual impression of some enemy, must be able immediately to influence the movements of the whole body, it follows that a specially abundant system of intercalated elements link the central ends of these nerves of the special senses with the rest of the central nervous system. Moreover the predominant influence of the head end of the central nervous system implies that it must be provided with a specially large series of nerve-fibres, not only for the purpose of bringing this influence to bear upon the rest of the nervous system, but also of being itself brought into intimate relationship with the nervous system as a whole, seeing that sensory impulses are constantly pouring into every part of it.

Thus the head end of the central nervous system becomes the brain, which is characterised by a series of large irregular swellings, due to $(a)$ the development around the insertion of each special sensory nerve of a mass, or group of masses, of intercalated cells which will enable the effects of the visual, acoustic, olfactory, gustatory or other sensations to influence the whole nervous system, and $(b)$ the evolution of complicated systems of intercalated cells, which receive, and in a sense blend, impressions coming from all parts of the nervous system, and emit fibres which pass, directly or indirectly, to the various groups of motor nerve-cells and control their activities and, through them, the behaviour of the animal.

In the development of the human embryo this distinction between the head end and the rest of the central nervous system is indicated even before the medullary plate is completely folded up to form the neural tube. The widened 
Even at a time, during the second week, when the anterior (oral) end of the neural tube is still open (neuroporus anterior), a right-angled bend has already developed in the rudiment of the brain (cerebral vesicle). Slightly less than half of the length of the vesicle had projected beyond the upper (anterior) end of the

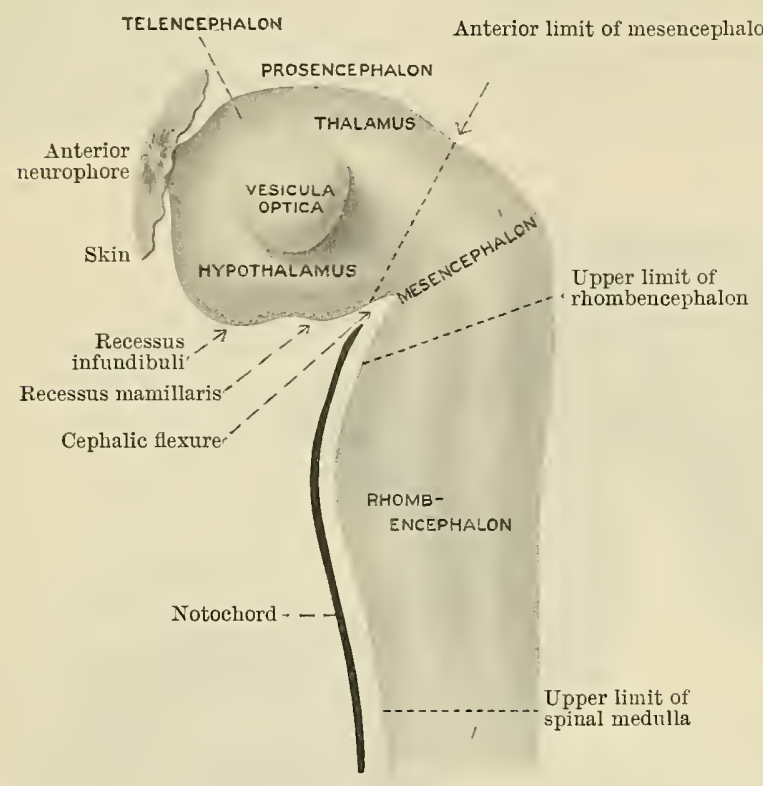

Fig. 455.-Left Lateral Aspect of an Early Human Embryo (after His's model, reversed). notochord and becameflexed ventrally round it (Fig. 455).

This bend is known as the cephalic flexure. The region of the brain vesicle in which it develops will later on become the mesencephalon or mid-brain; and even at the early stage of development now under consideration (Fig. 455) there is a slight narrowing of the tube (isthmus) that marks the boundary between the mid-brain and the rhombencephalon or hind-brain. Just beyond the end of the notochord there is an even fainter trace of a constriction indicating the line of demarcation between the mid-brain and the prosencephalon or fore-brain.

Shortly after the appearance of the cephalic flexure a similar bending occurs in the region where the encephalon becomes continuous with the medulla spinalis (Fig. 456, A). This is the cervical flexure.

But at this stage, or even earlier (Fig. 456), there has been developing a third bend which produces effects differing from those just mentioned. At the end of the second week a slight bulging can be detected on the ventral side of the hind-

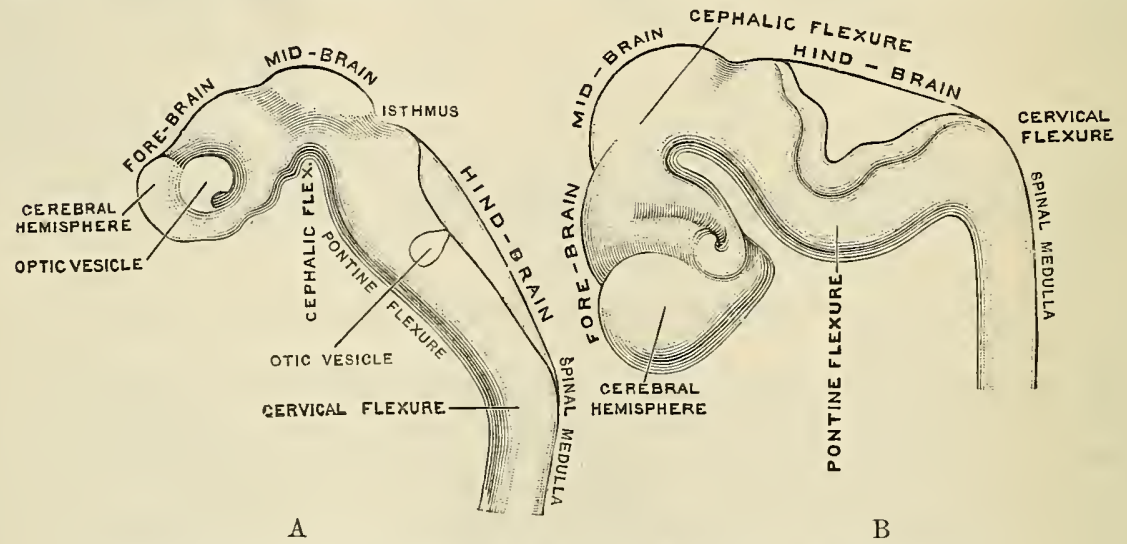

Fig. 456.-Two Stages in the Development of the Human Brain (after His).

A, Brain of an embryo of the third week. B, Brain of an embryo of five weeks.

brain (Fig. 455): during the next four weeks this steadily becomes accentuated and forms the pontine flexure. The convexity of the bend is directed ventrally, differing in this respect from both of the other flexures. This difference in direction has a profound influence upon the form which the hind-brain assumes. If a plastic tube is bent a strain is thrown upon the wall in the concavity 
of the flexure. If this wall is strong and resisting, like the floor-plate of the neural tube (in the cases of the cephalic and cervical flexures) the bending does not affect the outline of the tube (in section) very materially. But when the strain is thrown upon the thin roof-plate during the development of the pontine flexure it is not strong enough to resist; it becomes stretched and allows the lateral walls of the neural tube to splay laterally in precisely the same manner as occurs when a rubber tube is bent towards a side which has been split (or weakened) longitudinally (Fig. 457). This mechanical factor determines the curious form assumed by the hind-brain at the end of the first month; and gives its cavity, the fourth ventricle, a lozenge or rhomboid form, when seen from its dorsal aspect through the thin translucent roof. For this reason the hind-brain is known as the rhombencephalon.

The rhombencephalon forms at first more than half of the encephalon, and as it expands it appears to become marked off from the rest by a constriction (the isthmus rhombencephali).

The development of the pontine flexure subdivides the rhombencephalon into two parts, one joined to the spinal medulla, the myelencephalon, and the other, joined to the rest of the brain, the metencephalon.

In the myelencephalon develop the nuclei of the nerves that regulate the activities of the heart, lungs, and a considerable part of the alimentary canal, and also the receptive nuclei of the nerves of taste. It is known as the medulla oblongata.

The insertion of the nervus acusticus in the neighbourhood of the outsplayed lateral angle of the rhombencephalon leads to the profound transformation of the metencephalon. The nervus acusticus conveys into the hind-brain impulses which are stimulated by movements of fluid in the closed sac developed from the otic vesicle (Fig. 443, p. 501). The truly acoustic function of this apparatus is called into activity when the movements of this fluid

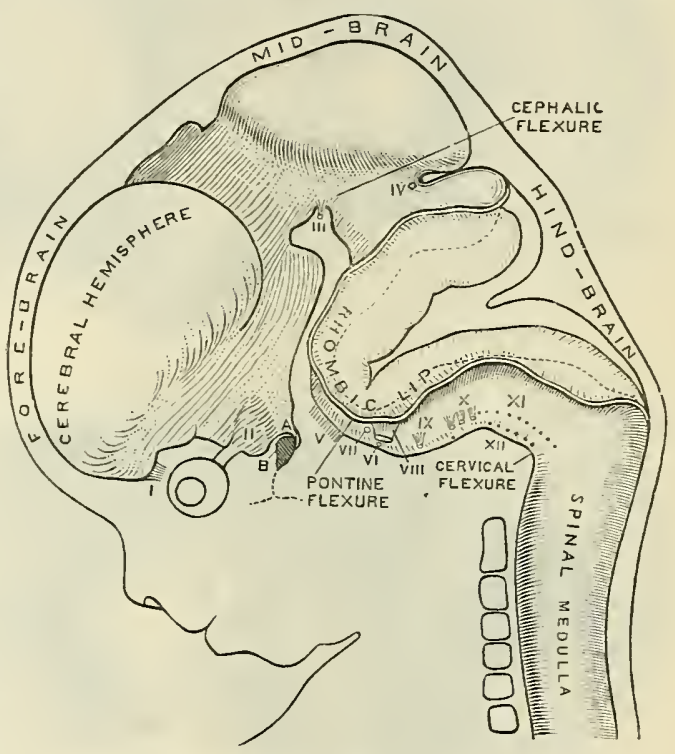

Fig. 457.-Profile View of the Brain of a Humas EMBRYo of TeN WEEKS (His).

The various cerebral nerves are indicated by numerals.

A, Cerebral diverticulum of hypophysis cerebri.

$\mathrm{B}$, Buccal diverticulum of hypopbysis cerebri. are caused by waves of sound transmitted to it from the outside world. But it is obvious that motion may also be set up in this fluid by changes in position of the body itself; in other words, movements in the fluid of the otic vesicle may stimulate nerves to convey to the brain information concerning the position and movements of the body itself. A great mass of nerve-cells develops around the insertion of the nervus acusticus (that part of it, however, which is called vestibular and is not concerned with the function of hearing) to make use of this information for the regulation of the movements of the body in balancing or equilibration. To enable this terminal vestibular nucleus the better to perform this function of equilibration, depending as it does upon the co-operation and adjustment of the movements of vast numbers of widely separated muscles, nerve tracts coming from muscles and skin areas of all parts of the body make their way into this vestibular nucleus; and it expands and forms a great excrescence which is known as the cerebellum. And as this cerebellum has to adjust the activities of all the muscles of the body it necessarily becomes the great organ of muscular co-ordination, and as such it is made use of by those parts of the brain which have to initiate and control complex actions such as skilled movements. It will be shown in the subsequent account how the 
cerebellum becomes linked to the mesencephalon to co-ordinate the movements of the body which are excited by this part of the encephalon; and later how it becomes associated with the prosencephalon, when the latter becomes responsible for the acquisition and control of the most highly skilled actions. For the latter purpose a great pathway of nerve-fibres is laid down to connect the fore-brain with the cerebellum: the terminal stage of this connexion is situated upon the ventral (anterior) aspect of the metencephalon in the form of a great mass of transverse fibres. At one time these strands of nerve-fibres were looked upon as a bridge between the two lateral parts of the cerebellum: hence the name pons was applied to them. This term is now applied not only

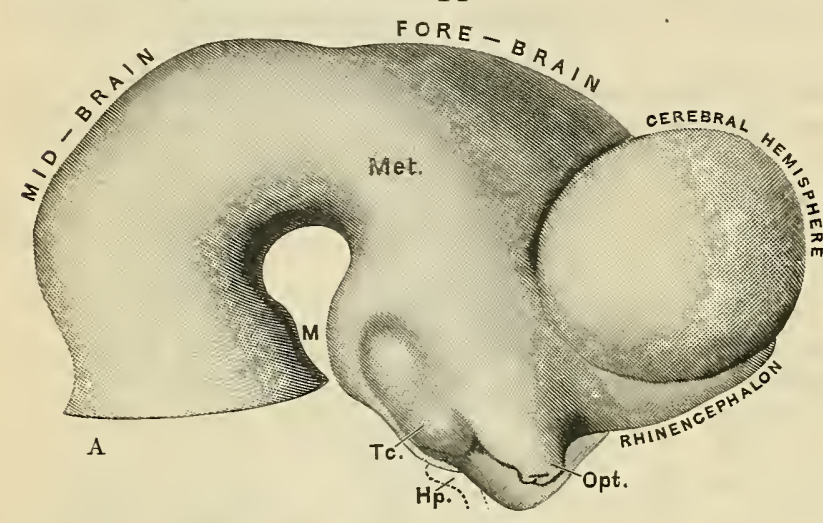

to the fibres themselves, but also to the upward prolongation of the medulla oblongata, to the surface of which they are applied.

The subdivision of the rest of the encephalon into mesencephalon and prosencephalon develops later and is less fundamental than the primary demarcation between them and the rhombencephalon.

The visual apparatus is connected both with the mid-brain and the fore-

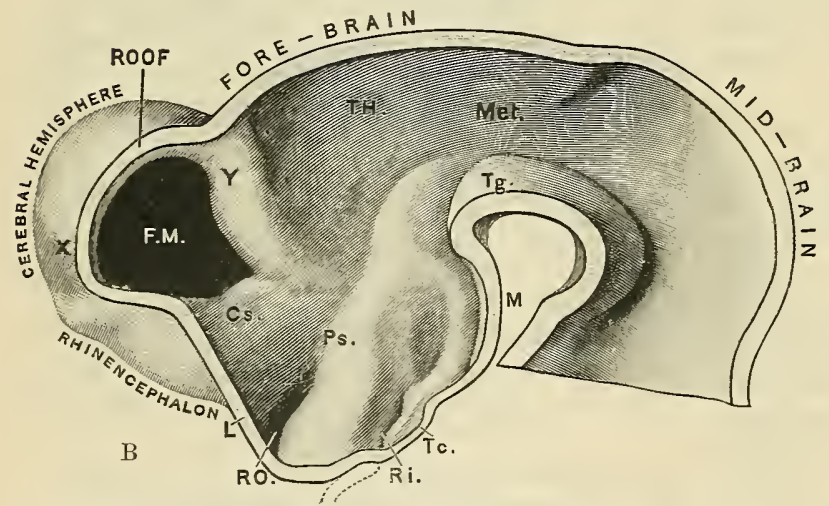

Fig. 458.-The Brain of a Human Embryo in the Fifte Week (from His).

A, Brain as seen in profile. B, Mediau section through the same brain. I, Mamillary eminence; Tc, Tuber cinereum; Hp, Hypophysis (hypophyseal diverticulum from buccal cavity); Opt, Optic stalk ; TH, Thalamus; Tg, Tegmental part of mesencephalon; Ps, Hypothalamus ; Cs, Corpus striatum; FM, Foramen interventriculare; L, Lamina terninalis ; RO, Recessus opticus; Ri,
Recessus infundibuli.

control the motor nuclei of the muscles of the trunk to enable the mid-brain to the fasciculi tectospinales (tectume are called the fasciculi tectospinales (tectum being a synonym for corpora quadrigemina). A group of intercalated cells known as the nucleus ruber develops upon each side of the mesencephalon for the purpose of establishing connexions between the cerebellum and the mid-brain. When an impulse passes out of the mid-brain by the tectospinal bundle to excite some movement of the body, the red nucleus provides the link by which the cerebellum can co-ordinate the actions of the muscles involved. By means of a fasciculus rubrospinalis it can bring its influence to bear directly upon the nuclei of motor nerves in the brain and spinal medulla (Fig. 45t).

The prosencephalon is at first, and in some of the lower fishes remains, the most insignificant of the three brain vesicles, but in the human brain (as also in that of most other vertebrates, though in varying degrees) a pair of enormous 
excrescences-the cerebral hemispheres-are budded off from it; and they become the dominant part of the nervous system (Fig. 458).

Each hemisphere is formed, however, from a relatively small part of the lateral wall of the prosencephalon, the rest of which goes to form the optic diverticula, the thalamus, and the hypothalamus, among other structures. The cerebral hemisphere is at first pre-eminently olfactory in function, the nerves of smell being inserted directly into it. But impressions of the associated sense of taste make their way into the cerebral hemisphere in the most primitive vertebrates: the gustatory nerves are inserted into the medulla oblongata, but fibre-paths are laid down to establish connexions with the hypothalamus, which in turn emits fibres to the cerebral hemisphere (Fig. 454). The thalamus is a greatly swollen part of the prosencephalic wall adjoining the mesencephalon. Its main part receives sensory impressions brought up from the spinal medulla and the terminal nuclei of the sensory cerebral nerves and transmits them to the cerebral hemisphere. Its caudal portion becomes specialised as a special receptive nucleus for visual and acoustic impressions for transmission to the cerebral hemisphere. It is called the metathalamus or corpora geniculata. Thus the cerebral hemisphere from being essentially a receptive organ for smell impressions ultimately becomes the terminus of all the sensory paths, and the structure that is concerned with the consciousness of all kinds of sensations. It also controls the voluntary movements of one-half of the body and emits a great strand of fibres-pedunculus cerebri-to establish relations with the cerebellum and all the motor nuclei on the other side of the encephalon and spinal medulla (Fig. 454, p. ó13).

\section{MEDULLA SPINALIS.}

The spinal medulla is that part of the central nervous system which occupies the upper two-thirds of the vertebral canal. It is an elongated cylindrical structure, slightly flattened in front and behind, which extends from the margin of the foramen magnum to the level of the inferior border of the body of the first lumbar vertebra or to the superior border of the body of the second lumbar vertebra. Its average length in the male is $45 \mathrm{~cm}$. and in the female $43 \mathrm{~cm}$.

A considerable amount of variation within certain limits (viz., the mid-point of the body of the last thoracic vertebra and the superior border of the body of the third lumbar vertebra) is observed in different individuals as to the precise level at which the spinal medulla ends inferiorly, and in the female there would appear to be a tendency for the medulla to reach a slightly lower point in the canal than in the male. Further, the relation presented by the spinal medulla to the vertebral column differs in a marked degree in the foetus and infant at different periods of development. Up to the third month of intra-uterine life the spinal medulla occupies the entire length of the vertebral canal; it extends downwards to the lowest limit of the vertebral canal. But from this time onwards, as growth proceeds, the vertebral column lengthens at a more rapid rate than the medulla. The spinal medulla, therefore, has the appearance of shriuking in an upward direction within its canal, and at birth its inferior end is usually found to be opposite the body of the third lumbar vertebra.

The attitude assumed by the individual affects to a small degree the position of the inferior end of the

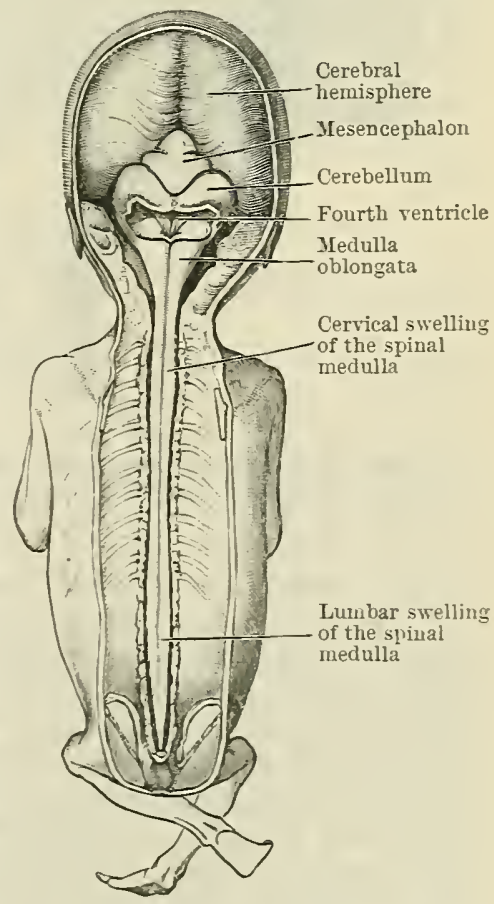

Fig. 459.-HuMax Fotus ix the THird MOSTH OF DETELOPMENT, WITH THE Brais aNd SPINAL MEDULLA EXPOSED FROM BEHIXD. spinal medulla. Thus, when the trunk is bent well forwards, it is neticed that the terminal part of the spinal medulla rises slightly within its bony canal. 
At the margin of the foramen magnum the spinal medulla becomes continuous with the medulla oblongata of the brain, whilst below, it tapers rapidly to a point and forms a conical extremity termed the conus medullaris. From the end of the conus medullaris a slender glistening thread is prolonged downwards within the vertebral canal, and finally anchors the spinal medulla to the back of the coccyx. This prolongation receives the name of the filum terminale. The diameter of the spinal medulla is very much shorter than that of the vertebral canal within which it lies. A wide interval is left between its surface and the walls of its canal, and this excess of space is clearly a provision for allowing free movement of the vertebral column without producing any jarring contact between the delicate spinal medulla and the surrounding bones.

Three protective membranes are wrapped around the spinal medulla. From within outwards these are termed (1) the pia mater, (2) the arachnoid, and (3) the

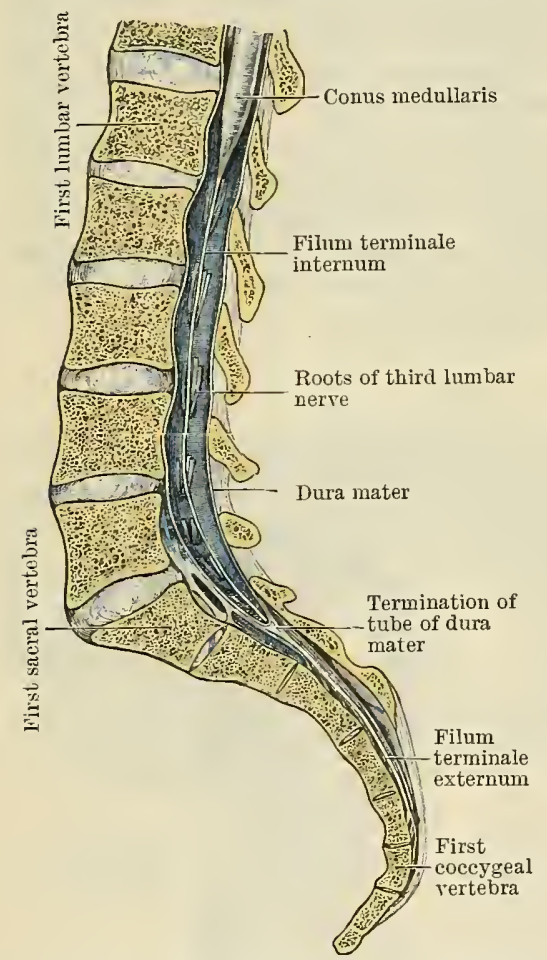

Fig. 460.-The Condo Medullaris and the Filum Terminale exposed withis the Tertebral Canal. dura mater. The pia mater is a fibrous membrane which forms the immediate investment. It is closely applied to the spinal medulla, and from its deep

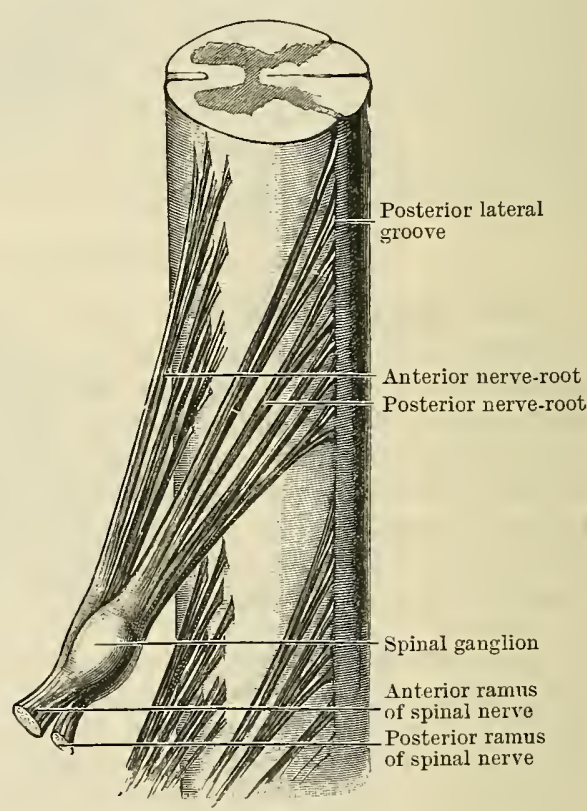

Fig. 461. - The Roots OF ORIGIN OF THE Seventh Thoracic Nerve (semi-diagrammatic).

surface numerous fine septa penetrate into the substance of the spinal medulla. The arachnoid is an exceedingly delicate transparent membrane which is loosely wrapped around the spinal medulla so as to leave a considerable interval, termed the subarachnoid space, between itself and the pia mater, in which there is always a varying amount of cerebro-spinal fluid. Outside the arachnoid, the dura mater forms a wide, dense, fibrous, tubular sheath, which extends downwards within the vertebral canal for a considerable distance beyond the conical extremity of the spinal medulla. The spinal medulla is suspended within its sheath or theca of dura mater by two lateral wing-like ligaments, termed the ligamenta denticulata. These extend laterally from the sides of the spinal medulla and are attached by a series of pointed or tooth-like processes to the inner surface of the theca of dura mater. Between the wall of the vertebral canal and the dura mater there is a narrow interval, which is filled up by soft areolo-fatty tissue and numerous thin-walled veins arranged in a plexiform manner.

Thirty-one pairs of spinal nerves arise from the sides of the spinal medulla. 
These are classified into eight cervical, twelve thoracic, five lumbar, five sacral, and one coccygeal; and according to the attachments of these groups of nerves the spinal medulla is arbitrarily subdivided into cervical, thoracic, lumbar, and sacral regions. In employing these terms, therefore, for different districts of the spinal medulla, it must be understood that the regions are determined by the nerve attachments and not by any direct relationship between these parts of the spinal medulla and the sections of the vertebral column which bear the same names.

Each spinal nerve is attached to the spinal medulla by an anterior or ventral and a posterior or dorsal root, and as these are traced to their central attachments they are seen to break up into a number of separate nerve fascicles or bundles, which spread out, in some cases very widely from each other, as they approach the side of the spinal medulla (Fig. 461). Each pair of nerves is therefore attached to a portion of spinal medulla of some length, and such a portion, with its pair of nerves, receives the name of a "segment of the spinal medulla." It must be clearly understood, however, that, in so far as the surface of the spinal medulla is concerued, there is no means of marking off one segment from another except by the nerve attachments.

In the cervical and lumbar regions of the spinal medulla the nerve-roots are somewhat crowded together, so that little or no interval is left between the adjoining root fila or fascicles of neighbouring nerves. In the thoracic region, however, distinct intervals may be observed, and the root fila are more loosely arranged. From this, it will be evident that the segments in different parts of the spinal medulla are not of equal length. In the cervical region the segments measure about $12 \mathrm{~mm}$. in length, in the thoracic region from 20 to $24 \mathrm{~mm}$., and in the lumbar region about $10 \mathrm{~mm}$. The number of fila which attach the different nerve-roots to the spinal medulla is very different in different nerves, and is not necessarily the same in the same nerve-root in different individuals.

Owing to the great difference which exists between the length of the spiual medulla and the length of the vertebral column, the farther we pass down the greater the distance becomes between the attachment of the various nerve-roots to

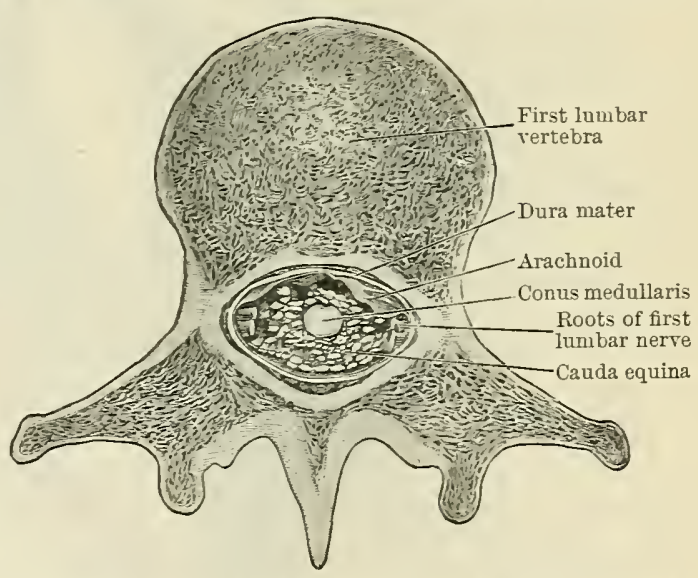

Fig. 162.-SEctiox through the CoNCs Medullaris ATD the CaUda EqUixa as they lie 11 the Tertebral Caxal. the spinal medulla and the intervertebral foramina through which the corresponding nerves leave the vertebral canal. The lower nerve-roots, therefore, have to traverse the vertebral canal for a considerable distance before they reach their apertures of emergence. It thus happens that the nerve-roots which spring from the lumbar and sacral regions of the spinal medulla attain a very great length and descend vertically in the lower part of the vertebral canal in a bunch or leash, in the midst of which lie the conus medullaris and the filum terminale. This great bundle of nerve-roots receives the appropriate name of the cauda equina.

Enlargements of the Spinal Medulla.-Throughout the greater part of the thoracic region, the spinal medulla presents a uniform girth and a very nearly sircular outline when seen in transverse section. In the cervical and lumbar regions, however, it shows marked swellings. The intumescentia cervicalis or cervical enlargement is the more evident of the two. It begins rery gradually at the upper end of the spinal medulla, attains its greatest breadth (12 to $14 \mathrm{~mm}$.) opposite the fifth or sixth cervical vertebra, and finally subsides opposite the second thoracic vertebra. To this portion of the spinal medulla are attached the great nerves which supply the upper limbs. The intumescentia lumbalis or lumbar enlargement begins at the level of the tenth thoracic vertebra, and acquires its maximum transverse diameter (11 to $13 \mathrm{~mm}$.) opposite the last thoracic vertebra. Below, it rapidly tapers away into the conus medullaris. To the lumbar enlargement are attached the great nerves of the lower limbs. 
These enlargements of the spinal medulla are associated with the outgrowth of the limbs. In the earlier developmental stages of the spinal medulla they are not present, and they take form only as the limbs become developed. In different animals their size corresponds with the degree of development of the limbs. Thus, in the long-armed orang and gibbon the cervical swelling stands out with a remarkable degree of prominence.

Development of the Spinal Medulla.-The early stages of the process by which the originally simple epithelial neural tube becomes converted into the central nervous system have already been considered. It remains to be explained how the features specially distinctive of the spinal medulla are produced.

In the early stages of the development of the spinal medulla (Fig. 463), the neuroblasts are found to be scattered in the intermediate of the three bands of

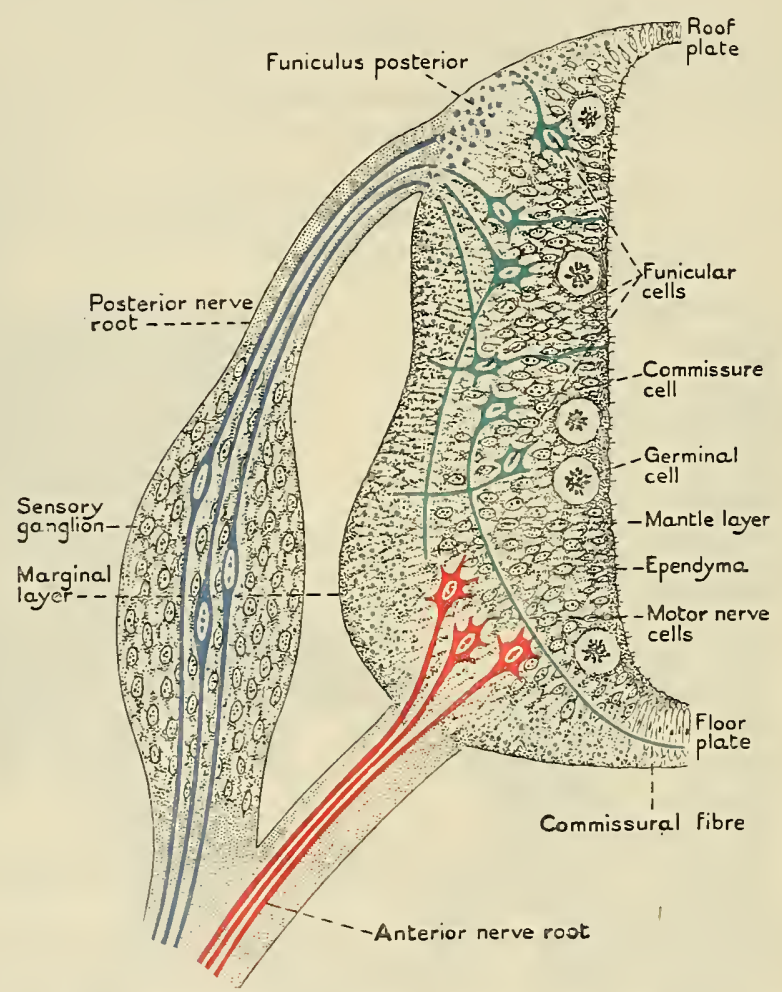

Fig. 463.-Diagram of Transverse Section of the left half of Early Neural Tube.

which the thick lateral wall of the neural tube is composed-the mantle layer. These primitive nerve-cells soon congregate in much larger numbers in the ventral part of the basal lamina (Fig. 464), so that the mantle layer expands there into a broad excrescence, which is the rudiment of the columna anterior or anterior cornu of gray matter. This anterior column contains the efferent or motor nervecells, the axons of which emerge as the radix anterior of a spinal nerve. At this stage the rest of the mantle layer consists of a thin stratum of neuroblasts (Fig. 463), mainly intercalated cells, which receive the sensory impressions entering the spinal medulla through the radix posterior, and transmit impulses into axons passing $(a)$ to the motor nuclei, $(b)$ to the other side of the spinal medulla through the floor-plate (Fig. 463), or (c) into the superficial stratum (peripheral layer) of the spinal medulla where they bend upwards or downwards as constituent elements of the funiculi (or white columns). As development proceeds (Fig. 463) the substantia grisea formed of these intercalated cells becomes much more abundant and forms a broad blunt boss (Figs. 464, B and C), which is the rudiment of the columna posterior (O.T. posterior cornu).

The surfaces of these gray columns become coated with a layer of white sub- 
stance, composed at first mainly of the axons of cells in the root ganglia and intercalated cells in the spinal medulla; and as these funiculi increase in size they help to mould the form of the columnæ griseæ. This is displayed best in the case of the posterior column (O.T. posterior cornu). The major portion of the white substance, funiculus posterior, which accumulates behind (and afterwards lies on the medial side of ) the posterior column, does not consist of fibres springing from intercalated cells, either of the spinal medulla or any other part of the central nervous system, but of the direct continuations of the central processes of the cells in the spinal ganglion on the posterior root (Figs. 463 and 464). A large proportion of the fibres of the posterior root do not enter the gray columns immediately after their insertion into the alar lamina, but bifurcate to form two vertical nerve-fibres, one passing upwards, and the other downwards, in the funiculus posterior before they end in the columna grisea, some distance above or below the place where they gained admission to the medulla spinalis. As the spinal medulla grows, the originally blunt columna posterior becomes drawn backwards into an increasingly attenuated process, and the funiculus posterior, which was placed originally upon its lateral surface (Fig. 464, A), and then upon its posterior surface (Fig.464, B), gradually assumes a wedge-shaped form (Figs. 464, C, and 466), upon the medial side of the gray matter.

Development of the Anterior Median Fissure, Posterior Median Septum, and of the Central Canal.-As the anterior columns of gray matter and the anterior funiculi of white matter increase in size, the anterior surface of the spinal medulla, on either side of the median plane, bulges forwards, and the fissura mediana anterior (Fig. $464, \mathrm{~A}, \mathrm{~B}$, and C) is produced as the natural result.

There has been considerable discussion as to the mode of formation of the posterior median septum; but there is now no doubt as to the essential facts. Early in the third month the walls of the posterior three-fourths (of the sagittal extent) of the central canal of the spinal medulla become approximated (Fig. 464), and later they fuse to obliterate that part of the canal. But the part of the septum thus formed is only an insignificant portion of the whole. For most of the septum is produced by the gradual elongation of the epithelial cells lining the remnant of the central canal as the fibremasses of the posterior funiculi expand and separate the posterior surface of the spinal medulla further and further from the situation of the canal (see Fig. 453, p. 511).

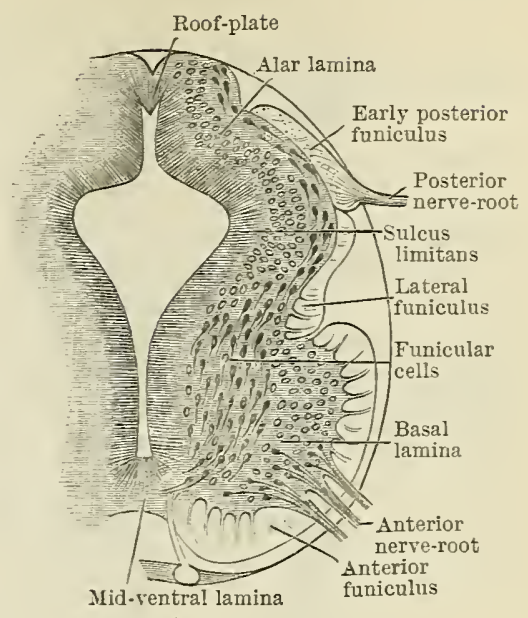

A.

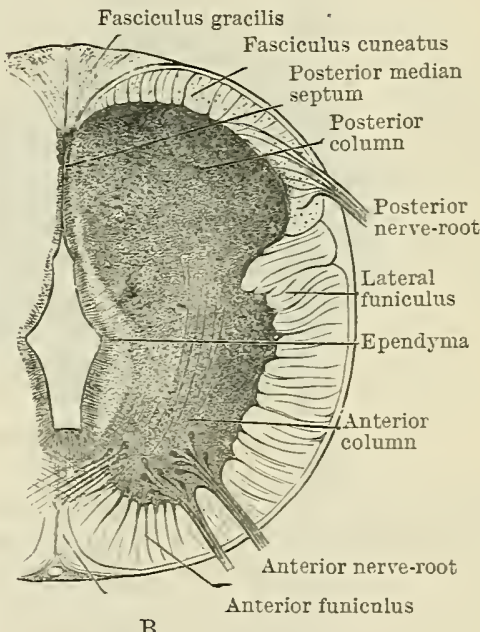

B

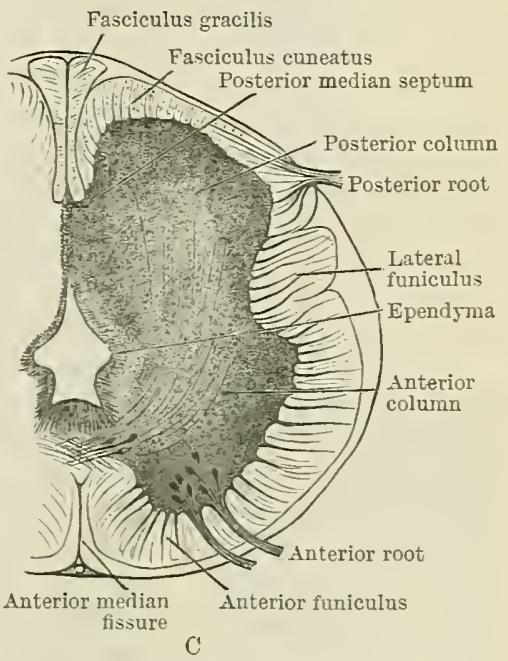

Fig. 464.-Three Stages in the Detelop. yest of the Spixal Medulla (His).

Furrows of the Spinal Medulla.-When cross-sections of the adult spinal 
medulla are made, it is seen to be a bilateral structure which is partially subdivided

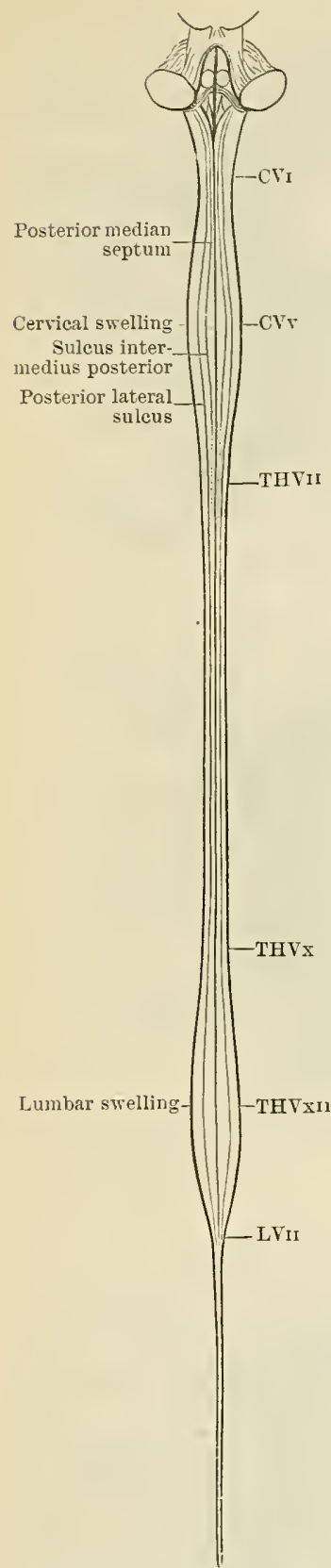

Fig. 465.-DiAgRaM OF THE SPINAL MIEDULLA AS SEEN FROM BEHIND.

$\mathrm{CV}_{1}$ shows the level of the 1st cervical vertebra; CVv of the 5th cervical vertebra; THVII of the 2nd thoracic vertebra; THVx of the 10th thoracic vertebra; THVxil of the 12th thoracic vertebra; LVII of the and lumbar vertebra. into a right and left half by a median cleft (fissura mediana anterior)in frontand a septum(septum medianum posterius) behind. The fissura mediana anterior penetrates only for a distance corresponding to somewhat less than a third of the antero-posterior diameter of the spinal medulla. The pia mater dips down into it and forms a fold or reduplication within it. The septum in the cervical and thoracic regions penetrates into the spinal medulla until it reaches a point somewhat beyond its centre. It is extremely narrow, and consists of ependymal and neuroglial elements, and is intimately connected with the adjacent sides of the two halves of the spinal medulla, between which it intervenes. The pia mater, which invests the surface of the spinal medulla, passes continuously over the posterior median septum and sends no prolongation of any kind into it. In the lumbar region of the spinal medulla the septum becomes shallower, whilst the anterior median fissure deepens, and ultimately in the inferior part of the spinal medulla the fissure and septum present a very nearly equal depth.

The two halves of the spinal medulla may show trifling differences in the arrangement of the parts which compose them; but to all intents and purposes they are symmetrical. They are joined together by a more or less broad band or commissure, which intervenes between the median fissure and the septum.

An inspection of the surface of each lateral half of the spinal medulla brings into view a longitudinal groove or furrow, at some little distance from the posterior median septum, which extends along the whole length of the spinal medulla. Along the bottom of this groove the fascicles of the posterior nerve-roots enter the spinal medulla in accurate linear order. It is called the sulcus lateralis posterior. There is no corresponding furrow on the anterior part of each lateral half of the spinal medulla in connexion with the emergence of the fascicles of the anterior nerve-roots. These fascicles emerge irregularly over a broad strip of the surface of the spinal medulla, which corresponds in its width to the thickness of the subjacent extremity of the anterior column of gray matter.

The sulcus lateralis posterior subdivides each lateral half of the spinal medulia into a small funiculus posterior and a much larger antero-lateral funiculus, and it is customary to map arbitrarily off the latter into a funiculus lateralis and a funiculus anterior by a line corresponding to the emergence of the most lateral of the fascicles of the anterior nerve-roots.

In the cervical region a distinct longitudinal groove may be observed on the surface of the posterior funiculus. It is placed rather nearer to the posterior median septum than to the posterior lateral furrow, and as it is traced down into the thoracic region it gradually becomes indistinct and finally disappears. This is called the sulcus intermedius posterior, and it marks on the surface the position of a septum of pia mater which dips into the spinal medulla and subdivides the posterior funiculus into a lateral part, termed the fasciculus cuneatus or the column of Burdach, and a medial portion, which receives the name of the fasciculus gracilis or the column of Goll. 


\section{Internal Structure of the Spinal Medulla.}

The spinal medulla is composed of a central core of gray matter thickly coated on the outside by white matter. At only one spot does the gray matter come close to the surface, viz., at the bottom of the sulcus lateralis posterior.

Gray Matter of the Spinal Medulla.-The gray matter in the interior of the spinal medulla has the form of a fluted column, but it is customary to describe it as it appears in transverse sections. It then presents the appearance of the capital letter $H$. In each lateral half of the spinal medulla there is a semilunar or crescentic mass, shaped somewhat like a comma, the concavity of which is directed laterally and the convexity medially. The two crescents of opposite sides are connected across the median plane by a transverse band, which receives the name of the commissura grisea (gray commissure). The posterior median septum cuts through the spinal medulla until it reaches the gray commissure. The bottom of the anterior median fissure, however, is separated from it by an intervening strip of " hite matter, which is termed the commissura anterior alba, or anterior white commissure. In the gray commissure may be seen the central canal of the spinal medulla (canalis centralis), which tunnels the entire length of the spinal medulla and is just visible to the naked eye as a minute speck. The portion of the gray commissure which lies behind the central canal is called the commissura posterior; whilst the portion in front receives the name of the commissura anterior grisea.

Each crescentic mass of gray matter presents certain well-defined parts. The projecting portions which extend behind and in front of the connecting transverse graycommissure are termed respectively the

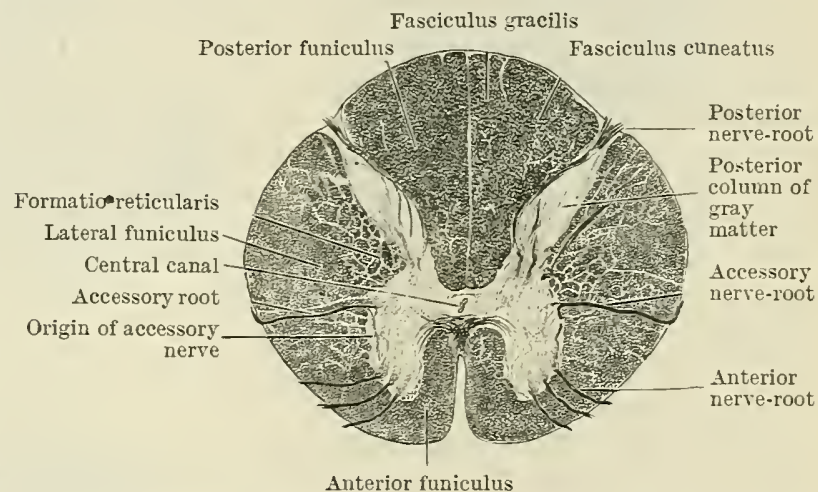

Fig. 466. -Transverse Section throtgh the SUPErior Part of the Cervical Region of the Spiñal Medulla of ax Orayg. (From a specinen prepared by the Weigert-Pal method, by which the white matter is rendered dark whilst the gray matter is bleached.)

posterior and the anterior columns of gray matter (columnæ griseæ). These stand out in marked contrast to each other. The columna anterior (O.T. anterior cornu) is short, thick, and very blunt at its extremity. Further, its extremity falls considerably short of the surface of the spinal medulla and is separated from it by a tolerably thick coating of white matter. Through this the fascicles of the anterior nerve-roots, as they emerge from the gray matter of the anterior column, pass on their way to the surface. Throughout the greater part of the spinal medulla the columna posterior (O.T. posterior cornu) is elongated and narrow, and is drawn out to a fine point, which almost reaches the bottom of the posterior lateral sulcus. This pointed extremity receives the name of the apex columnæ posterioris; the slightly swollen part which succeeds it is the caput columnæ; whilst the slightly constricted part adjoining the gray commissure goes under the name of the cervix columnæ posterioris.

The apex or tip of the posterior column differs considerably in appearance from the general mass of the gray matter. It is composed of a material which presents a lighter hue and has a somewhat translucent look. It is called the substantia gelatinosa [Rolandi], and, when seen in transverse section, it exhibits a V-shaped outline and fits on the posterior column like a cap.

A pointed and prominent triangular projection juts out from the lateral aspect of the gray matter nearly opposite the gray commissure. This is the columna lateralis (O.T. lateral cornu), and it is best marked in the upper thoracic region (Fig. 467, B). Traced upwards it becomes absorbed in the greatly expanded anterior column of the cervical swelling, but it reappears again in the upper part of the spinal medulla, and is particularly noticeable in the second and third cervical 
segments; followed in a downward direction it blends with the anterior column in the lumbar swelling and contributes to the thickening of that column.

The gray matter is for the most part mapped off from the surrounding white matter with a considerable degree of sharpness; but in the cervical region, on the lateral aspect of the crescentic mass and in the angle between the anterior and posterior columns, fine bands of gray matter penetrate the white matter, and, joining with each other, form a network, the meshes of which enclose small islands of white matter. This constitutes what is called the formatio reticularis. Although best marked in the cervical region, traces of the same reticular formation may be detected in lower segments of the spinal medulla.

Characters presented by the Gray Matter in Different Regions of the Spinal Medulla.- The gray matter is not present in equal quantity nor does it exhibit the same form in all regions of the spinal medulla. Indeed, each segment presents its own special characters in both of these respects. It is not necessary, however, in the present instance, to enter into this matter with any degree of minute detail. It will be sufficient if the broad distinctions which are evident in the different regions are pointed out.

It may be regarded as a general law that, wherever there is an increase in the size of the nerves attached to a particular part of the spinal medulla, a corresponding increase in the amount of gray matter will be observed. It follows from this that the regions where the gray matter bulks most largely are the lumbar and the cervical swellings. The great nerve-roots which go to form the nerves of the large limb-plexuses enter and pass out from those portions of the spinal medulla. In the thoracic region there is a reduction in the quantity of gray matter in correspondence with the smaller size of the thoracic nerves.

In the thoracic region (Fig. $467, \mathrm{~B}$ ) both columns of gray matter are narrow, although the distinction between the anterior column and the still more attenuated posterior column is sufficiently manifest. In this region the lateral column of gray matter is likewise characteristic, and the substantia gelatinosa in transverse section is pointed and spear-shaped.

In the upper three segments of the cervical region the anterior columns of gray matter are not large and resemble the corresponding columns in the thoracic region. A lateral column also is present. But in these segments (and more especially in the first and second) there is a marked attenuation of the neck of the posterior column, and the posterior commissure is very broad.

In the cervical swelling the contrast between the two columns is most striking; the anterior column is of great size and presents a very broad surface towards the anterior aspect of the spinal medulla, whilst the posterior column remains narrow. This great increase in the bulk of the anterior column is due to a marked addition of gray matter on the lateral side of the column, and seeing that this additional matter is traversed by a greater number of fibres, it stands out, in well-prepared specimens, more or less distinctly from the part of the column which lies to the medial side, and which may be considered to represent the entire anterior column in the thoracic and upper cervical segments. Within this lateral addition to the anterior column are placed those collections of cells which constitute the nuclei of origin of the motor nerves of the muscles of the upper limb. The characteristic thickening of the anterior column of gray matter is evident, therefore, in those segments of the spinal medulla to which the nerves which enter tiue brachial plexus are attached, viz., the lower five cervical segments and the first thoracic segment.

In the lumbar swelling the anterior columns again broaden out, and for the same reason as in the case of the corresponding columns in the cervical swelling. The nuclear masses which contain the cells from which the motor fibres which supply the muscles of the lower limbs take origin are added to the lateral aspect of the columns and give them a very characteristic appearance. In this region of the spinal medulla, however, the posterior columns are also broad and are capped by substantia gelatinosa which in transverse section presents a semilunar outline. There is consequently no difficulty in distinguishing, from an inspection of the gray matter alone, between transverse sections of the spinal medulla taken from the cervical and lumbar swellings of the spinal medulla. 
matter which separates the broad extremity of the anterior column from the surface of the spinal medulla. This latter portion of the anterior funiculus is traversed by the emerging fascicles of the anterior nerve-roots.

In cross-sections of the spiual medulla the partition of pia mater, which dips in at the sulcus intermedius posterior and divides the posterior funiculus into the medial fasciculus gracilis and the lateral fasciculus cuneatus, is very strongly marked in the cervical regions, but as it is traced downwards into the thoracic region it becomes shorter and fainter, and finally disappears altogether at the level of the eighth thoracic nerve. Below this point there is no visible demarcation of the posterior funiculus into two parts.

The white matter is not present in equal quantity throughout the entire length of the spinal medulla. It increases steadily from below upwards, and this increase is most noticeable in the lateral and posterior funiculi. In the lower part of the conus medullaris the amount of gray matter is actually greater than that of the white matter: but very soon this state of affairs is changed, and in the lumbar region the proportion of gray to white matter is approximately as $1: 2 \cdot 1$; in the thoracic region as $1: 5$; and in the cervical region as $1: 5 \cdot 1$. When it is remembered how the gray matter expands in the lumbar and cervical regions, and how greatly it becomes reduced in the thoracic region, the significance of these figures will become more apparent.

Canalis Centralis.-As previously stated, the central canal is found in the gray commissure. It is a very minute tunnel, barely visible to the naked eye when seen in transverse section, and it traverses the entire length of the spinal medulla. Above, it passes into the medulla oblongata, and finally opens into the fourth ventricle of the brain; below, it is continued for a variable distance into the filum terminale, and in this it ends blindly. Only in the lumbar region does the centra] canal occupy the centre of the spinal medulla. Above this level, in the thoracic and cervical regions, it lies very much nearer the anterior than the posterior aspect of the spinal medulla; whilst below the lumbar region, as it is traced down into the conus medullaris, it inclines backwards and approaches the posterior aspect of the spinal medulla. The calibre of the canal also varies somewhat in different parts of the spinal medulla. It is narrowest in the thoracic region; and in the lower part of the conus medullaris it expands into a distinct fusiform dilatation (very nearly $1 \mathrm{~mm}$. in transverse diameter), which is termed the ventriculus terminalis (Krause).

The central canal is lined with a layer of ciliated columnar cells, the deep tapering ends of which are prolonged into slender processes which penetrate into the substance of the spinal medulla. These cells constitute the lining ependymal cells of the canal. The cilia of the epithelial cells are very early lost, and it is not uncommon to find the canal blocked up by epithelial debris.

The central canal is of interest because it represents in the adult the relatively wide lumen of the early ectodermal neural tube from which the spinal medulla is developed.

Filum Terminale.-The delicate thread to which this name is applied is continuous with the inferior tapered end of the conus medullaris. It is easily distinguished by its silvery and glistening appearance from the numerous long nerve-roots (cauda equina) amidst which it lies. It is about six inches long, and down to the level of the second sacral vertebra it is enclosed with the surrounding nerve-roots within the dura mater. Below this point the dura mater is applied directly to the surface of the filum terminale and is called filum duræ matris spinalis. The filum terminale proceeds downwards in the sacral canal, and finally receives attachment to the periosteum on the posterior aspect of the coccyx (Fig. 460, p. 518). It is customary to speak of the filum as consisting of two parts, viz., the filum terminale internum and the filum terminale externum, or the part inside and the part outside the tube of dura mater.

The filum terminale externum is simply a fibrous thread, strengthened by the prolongation it receives from the dura mater. The filum terminale internum is composed largely of pia mater; but in its superior half it encloses the terminal part of the central canal, and around this a variable amount of the gray substance of the cord is prolonged downwards into the filum. When transverse sections are made through 
the superior part of the filum terminale internum some bundles of medullated nerve-tibres are observed clinging to its sides, and with these are associated some nerve-cells identical with those in the spinal ganglia. These represent rudimentary or aborted caudal nerves (Rauber).

\section{Summary of the Chief Characters presented by the Spinal Medulla} in its Different Regions.

\begin{tabular}{|c|c|c|c|}
\hline Cervical Region. & Thoracic Region. & Lumbar Region. & Sacral Region. \\
\hline $\begin{array}{l}\text { In transverse section, out- } \\
\text { line of spinal medulla } \\
\text { transversely oval; in } \\
\text { the middle of the } \\
\text { cervical swelling the } \\
\text { transverse diameter } \\
\text { being nearly one-third } \\
\text { longer than the antero- } \\
\text { posterior diameter. }\end{array}$ & $\begin{array}{l}\text { In transverse section, } \\
\text { outline of spinal } \\
\text { medulla more nearly } \\
\text { circular; but still the } \\
\text { transverse diameter is } \\
\text { greater than the } \\
\text { antero-posterior dia- } \\
\text { meter. }\end{array}$ & $\begin{array}{l}\text { In trausverse section, } \\
\text { outline of spinal } \\
\text { medulla more nearly } \\
\text { circular than in } \\
\text { tholacic region. }\end{array}$ & $\begin{array}{l}\text { In transverse section, } \\
\text { outline of spinal } \\
\text { medulla, nearly circu- } \\
\text { lar, but still some- } \\
\text { what compressed from } \\
\text { before backwards. }\end{array}$ \\
\hline $\begin{array}{l}\text { Postero - median sep- } \\
\text { tum verydeep, extend- } \\
\text { ing beyond the centre } \\
\text { of the spinal medulla; } \\
\text { antero-median fis- } \\
\text { sure shallow. }\end{array}$ & $\begin{array}{l}\text { Postero-median sep- } \\
\text { tum verydeep, extend- } \\
\text { ing beyond centre of } \\
\text { the spinal medulla: } \\
\text { antero-median fis- } \\
\text { sure shallow. }\end{array}$ & $\begin{array}{l}\text { Postero-median sep- } \\
\text { tum not nearly so deep } \\
\text { as in regions above: } \\
\text { antero-median fis- } \\
\text { sure, on the other } \\
\text { hand, much deeper. }\end{array}$ & $\begin{array}{l}\text { Postero - median sep- } \\
\text { tum and antero- } \\
\text { median fissure of } \\
\text { equal depth. }\end{array}$ \\
\hline $\begin{array}{l}\text { Gray matter greatly in- } \\
\text { creased in quantity in } \\
\text { the cervical swelling: } \\
\text { anterior column thick } \\
\text { and massive; posterior } \\
\text { column slender in } \\
\text { comparison. Lateral } \\
\text { column evident only } \\
\text { above the level of the } \\
\text { fourth cervical nerve. } \\
\text { Processus reticularis } \\
\text { strongly marked. }\end{array}$ & $\begin{array}{l}\text { Gray matter greatly } \\
\text { reduced in quantity. } \\
\text { Both columns slender. } \\
\text { Lateral column well } \\
\text { marked. Processus } \\
\text { reticularis scarcely ap- } \\
\text { parent. }\end{array}$ & $\begin{array}{l}\text { Gray matter greatly in- } \\
\text { creased in the lumbar } \\
\text { swelling. Both } \\
\text { columns very thick } \\
\text { and massive. Lateral } \\
\text { column absorbed in } \\
\text { anterior column. Pro- } \\
\text { cessus reticularis ab- } \\
\text { sent. }\end{array}$ & $\begin{array}{l}\text { Both columns of gray } \\
\text { matter very thick and } \\
\text { massive. Lateral } \\
\text { column apparent. No } \\
\text { processus reticularis. }\end{array}$ \\
\hline $\begin{array}{l}\text { White matter in great } \\
\text { quantity, and especi- } \\
\text { ally massed in the } \\
\text { lateral and posterior } \\
\text { funiculi. }\end{array}$ & $\begin{array}{l}\text { White matter less } \\
\text { in quantity than in } \\
\text { cervical region, but } \\
\text { bulking largely in } \\
\text { comparison with the } \\
\text { quantity of gray } \\
\text { matter. }\end{array}$ & $\begin{array}{l}\text { White matter small in } \\
\text { quantity compared } \\
\text { with higher regions, } \\
\text { and very small in } \\
\text { amount in relation to } \\
\text { increased quantity of } \\
\text { gray matter. }\end{array}$ & $\begin{array}{l}\text { White matter very } \\
\text { small in quantity in } \\
\text { comparison with the } \\
\text { gray matter. }\end{array}$ \\
\hline $\begin{array}{l}\text { Sulcus intermedius } \\
\text { posterior and corre- } \\
\text { sponding septum well } \\
\text { marked. }\end{array}$ & $\begin{array}{l}\text { Sulcus intermedius } \\
\text { posterior absent; but } \\
\text { the corresponding sep- } \\
\text { tum can be traced as } \\
\text { low down as the eighth } \\
\text { thoracic nerve. }\end{array}$ & $\begin{array}{l}\text { No sulcus intermedius } \\
\text { posterior or corre- } \\
\text { sponding septum. }\end{array}$ & $\begin{array}{l}\text { No sulcus intermedius } \\
\text { posterior and no } \\
\text { corresponding septum. }\end{array}$ \\
\hline $\begin{array}{l}\text { Central canal consider- } \\
\text { ably nearertheanterior } \\
\text { surface than the pos- } \\
\text { terior surface of the } \\
\text { spinal medulla. }\end{array}$ & $\begin{array}{l}\text { Central canal consider- } \\
\text { ablynearertheanterior } \\
\text { surface than the pos- } \\
\text { terior surface of the } \\
\text { spinal medulla. }\end{array}$ & $\begin{array}{l}\text { Central canal in the } \\
\text { centre of the spinal } \\
\text { medulla. }\end{array}$ & $\begin{array}{l}\text { Central canal in the } \\
\text { centre of the spinal } \\
\text { melulla. }\end{array}$ \\
\hline
\end{tabular}

\section{Component Parts of the Gray Matter of the Spinal Medulla.}

Neuroglia enters largely into the constitution of the gray matter of the spinal medulla. It forms a bed within which the nervous elements are distributed. These nervous elements consist of (1) nerve-cells and (2) nerve-fibres-both medullated and non-medullated. The nerve-cells lie in small spaces in the 
neuroglia, whilst the nerve-fibres traverse fine passages the walls of which are formed of the same substance. The neuroglia is thus an all-pervading basis substance, which isolates more or less completely the nervous elements one from the other, and at the same time binds them together into a consistent solid mass. In two situations the gray matter presents peculiar features, viz., the apex of the posterior column and the tissue surrounding the central canal. In both situations the gray matter stains more deeply with carmine and presents a more translucent appearance; in other respects the substantia grisea centralis and the substantia gelatinosa are very different.

The substantia grisea centralis forms a thick ring around the central canal. It is traversed by the fine processes which proceed from the deep ends of the ependymal cells which liue the canal. It is composed almost entirely of neuroglia.

In transverse sections of the spinal medulla the substantia gelatinosa, in the cervical and thoracic regions, presents the appearance of a V-shaped mass, embracing the extremity of the posterior column of gray matter; in the lumbar region this cap assumes a semilunar outline.

In the substantia gelatinosa the neuroglia is present in small quantity, and small nerve-cells are developed within it in considerable numbers.

Nerve-Cells. - The nerve-cells are scattered plentifully throughout the gray matter, but perhaps not in such great numbers as might be expected when we note the enormous number of nerve-fibres with which they stand in relation. They are all, without exception, multipolar, and send off from their various aspects several branching protoplasmic processes or dendrites, and one axon, which becomes the axis-cylinder of a nerve-fibre. In size they vary considerably, and as a rule (to which, however, there are many exceptions) the bulk of a nerve-cell has a more or less definite relation to the length of the axis-cylinder which proceeds from it.

When the nerve-cells are studied in a series of transverse sections of the spinal medulla, it will be noticed that a large proportion of them are grouped in clusters in certain districts of the gray matter; and as these groups are seen in very much the same position in successive sections, it is clear that these cells are arranged in longitudinal columns of greater or less length. Thus we recognise (1) a ventral group or column of cells in the anterior column of gray matter; $(2)$ an intermedio-lateral group or column in the lateral column of gray matter, where this exists; and (3) a posterior vesicular column of cells (nucleus dorsalis), forming a most conspicuous group in the medial part of the neck of the posterior column in the thoracic region of the spinal medulla.

Other cells, besides those forming these columns, are scattered somewhat irregularly throughout the gray matter of the posterior column and the part of the gray crescent which lies between the two columns; and although these also in some measure may be classified into groups, the arrangement thus effected is not of so definite a character as to justify us in dwelling upon it in the present instance.

Ventral Cell-Column and the Origin of the Fibres of the Anterior Nerveroots.-The ventral cell-group occupies the anterior column of gray matter, and in it are found the largest and most conspicuous cells in the spinal medulla. It extends from one end of the medulla to the other. These ventral nerve-cells have numerous wide-spreading dendritic processes, and it is to be noticed that certain of these dendrites do not confine their ramifications to the gray matter. Thus, some of the cells along the medial border of the anterior column of gray matter send dendrites across the median plane in the anterior commissure to end in the anterior gray column of the opposite side; whilst others, lying along the lateral margin of the anterior column of gray matter, send dendrites in amongst the nervefibres of the adjoining white matter.

The axons or axis-cylinder processes of a large proportion of the ventral cells converge together; and, becoming medullated, they form bundles which pass out from the gray matter, and through the white matter which separates the thick end of the anterior column from the surface of the spinal medulla, to emerge finally as the fila of the anterior nerve-roots. These cells, then, are the sources from which the nerve-fibres of the anterior nerve-roots proceed, and in consequence they are frequently spoken of as the "motor cells" of the spinal medulla. Whilst this is 
the arrangement of the axons of the great majority of the motor cells, it should be noted that a few cross the median plane in the anterior white commissure and emerge in the fila of origin of the opposite anterior nerve-root.

The ventral cells are not scattered uniformly throughout the anterior column of gray matter. They are aggregated more closely together in certain parts of the anterior column, and thus form sub-groups or columns more or less perfectly marked off from each other.

Thus, one sub-group or column of ventral cells occupies the medial part of the anterior column of gray matter throughout almost its whole length. In only two segments of the medulla is it absent, viz., the fifth lumbar and the first sacral; at this level in the spinal medulla alone is its continuity broken (Bruce). It is termed the antero-median column or group of ventral cells. Behind this cell-column there is another classed with it to which the name of postero-median column or group is given, but this column of cells is not continuous throughout the entire length of the medulla. It is present in the thoracic region of the spinal medulla, where the motor nuclei for the muscles of the limbs are absent; and it is seen also in two or three of the segments of the cervical region and in the first lumbar segment (Bruce); elsewhere it is not represented.

In the cervical and lumbar swellings of the medulla, where the marked lateral ont-

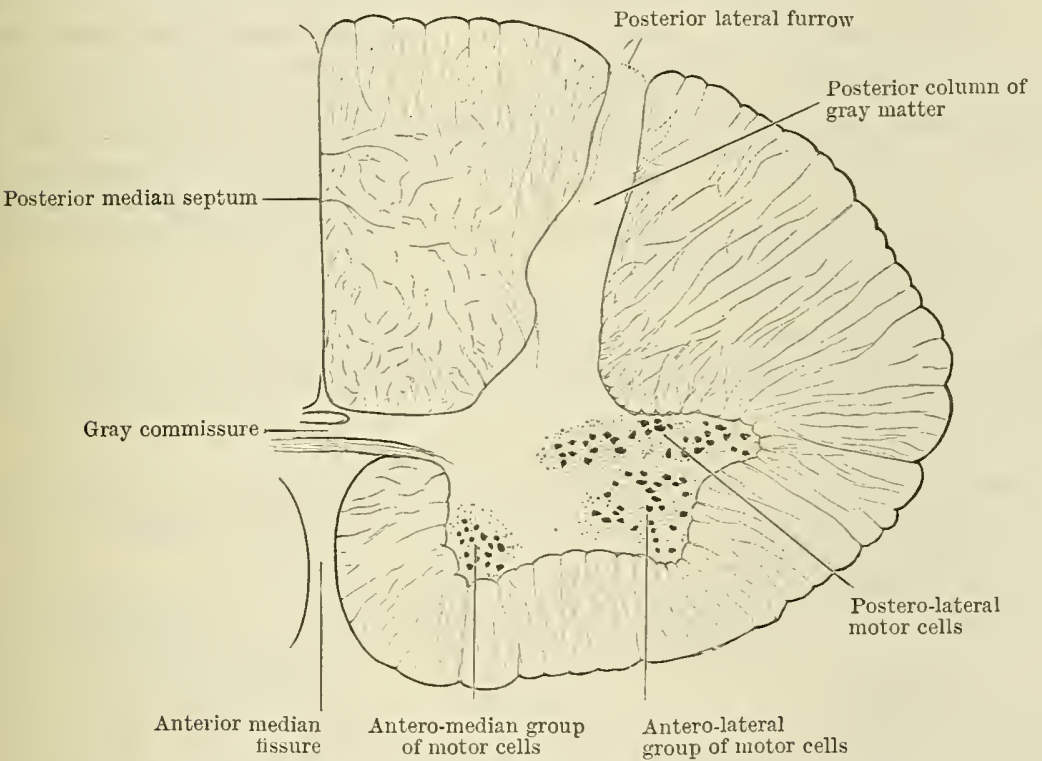

Fig, 468. - Section throdgh the Fifth Certical Segrenst of the Sptyal Medulla.

(To a large extent founded on Plates in Dr. Bruce's Atlas.)

growth is added to the lateral side of the anterior column of gray matter, certain groups of large multipolar cells are visible. These are the nuclei of origin of the motor-fibres which supply the muscles of the limbs, and consequently they are not represented in the upper three cervical segments of the spinal medulla; nor in any of the thoracic segments, with the exception of the first thoracic segment; nor in the lowest two sacral segments.

These lateral cells are arranged in several columns, which extend for varying distances in the superadded lateral parts of the anterior column of gray matter. The two main columns are an antero-lateral and a postero-lateral column; in certain segments there is likewise a retro-postero-lateral column, and in a number of segments in the lumbar and sacral regions a central column of cells (Bruce).

There cannot be a doubt that the grouping of the motor cells in the anterior horn of gray matter of the medulla stands in relation to the muscle groups to which their axis-crlinder processes are distributed; but from what has been said it will be apparent that sharply defined cell-clusters associated with particular muscles do not exist. Still, much can be learned regarding the localisation of the motor nuclei in the anterior column of gray matter of the medulla from the study of the changes which occur in the cell-columns after atrophy of isolated muscles or groups of muscles, and after complete or partial amputations of limbs. It has been pointed ont that the long muscles of the trunk (as, for example, the different parts of the sacro-spinalis muscle) receive nerve-fibres from all the 
segments of the medulla. Now, we have noted that there is only one cell-column, the ventro-median column, which pursues an almost uninterrupted course throughout the

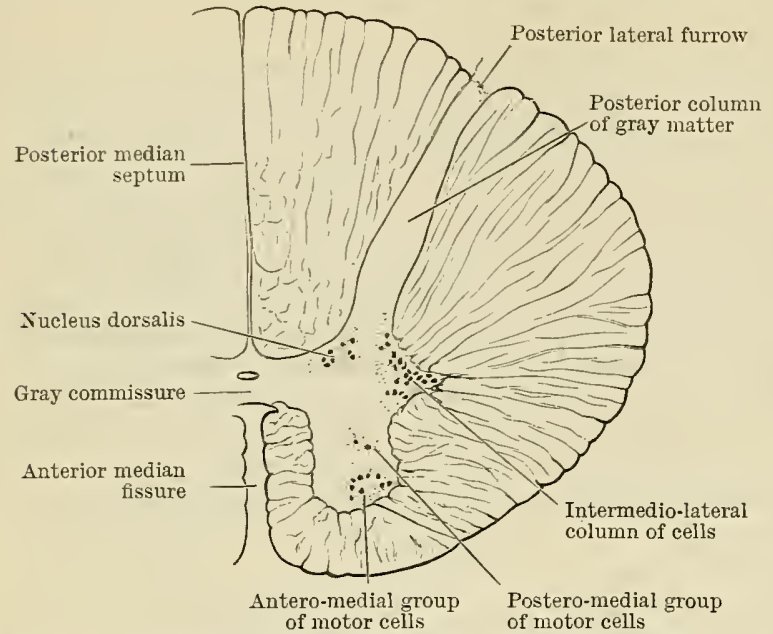

Fig. 469.--Section throdgh the Eighth Thoracic Segment of the Spinal Medulla. (To a large extent founded on Plates in Dr. Bruce's Atlas.) entire length of the medulla. It may be assumed, therefore, that the nerve-fibres which go to these long trunk-muscles take origin in these medial cells.

Edinger states that in the anterior column of gray matter the nuclei of origin of the nerves which supply the proximal muscles are medially placed; that those for the distal muscles are in general situated laterally. If this were the case, the cells connected with the shoulder muscles would lie nearer the middle of the anterior column of gray matter than those which are connected with the handmuscles. In cases where the forearm and hand, or the leg and the foot, are amputated, it would appear that it is the postero-lateral column of cells that shows changes in consequence of its separation from the muscles to which its fibres are distributed. ${ }^{1}$

Intermedio-lateral Cell-column.-The intermedio-lateral cells form a long slender column which extends throughout the entire thoracic region of the medulla in the lateral column of gray matter. It is also prolonged downwards into the first and second lumbar segments, where it disappears. In transverse sections through the medulla this cell-group presents a very characteristic appearance, because the cells which compose it are small and are closely packed together. Although these cells, as a continuous column, are restricted to the region indicated, it should be noted that the same group of cells reappears above, in certain of the cervical segments, and also in the third and fourth sacral segments. From these cells very fine fibres arise and leave the medulla spinal, intermingled with the motor fibres of the

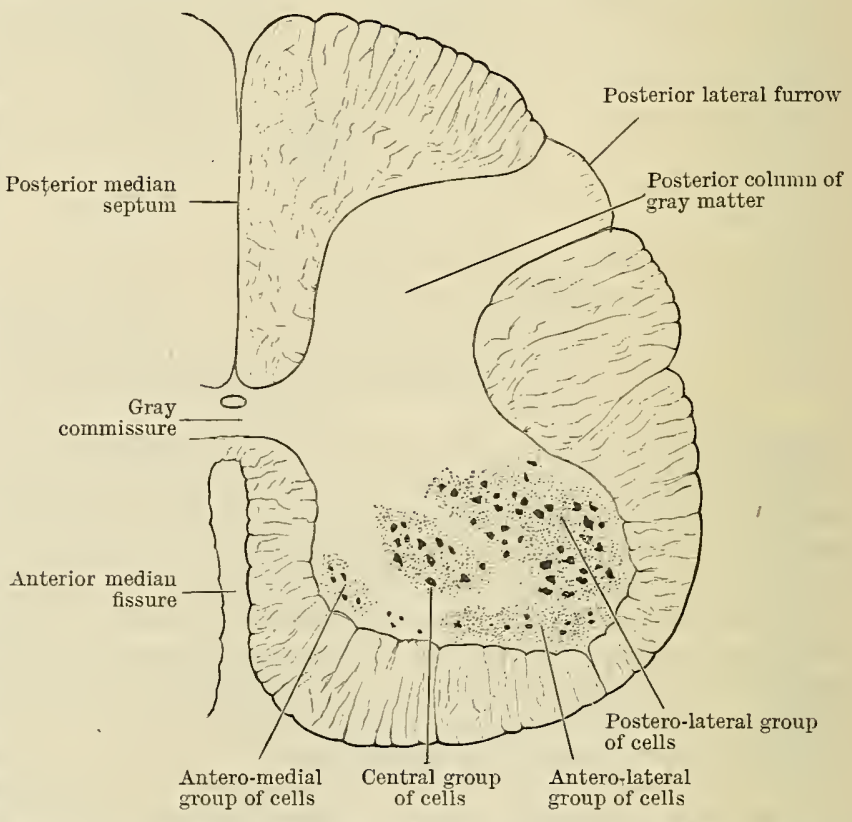

Fig. 470.- Section throdgh the Third Lumbar Segment of the Spinal Medulla to show the grodping of the Motor Cells. (To a large extent founded on Plates in Dr. Bruce's Atlas.) anterior nerve-roots; they pass into the sympathetic ganglia, of which they con-

1 Those who seek further information regarding the grouping of the ventral cells of the medulla may with advantage study Dr. Alexander Bruce's Atlas of the Spinal Cord. 
stitute the white rami communicantes. They represent the splanchnic efferent fibres of the medulla spinalis.

Nucleus Dorsalis (O.T. Clarke's Column). -This occupies the posterior column of gray matter and is the most conspicuous of all the cell-groups in the medulla. It does not, however, extend along the whole length of the medulla; indeed it is almost entirely confined to the "dorsal" region, which is the reason for the designation "nucleus dorsalis." (When, in the recent revision of nomenclature, the term "thoracic" was substituted for "dorsal" the revisers omitted to change the name of this structure to "thoracic"). Above, it begins opposite the seventh or eighth cervical nerve, whilst below, it may be traced to the level of the second lumbar nerve, where it disappears. In transverse section of the medulla it presents an oval outline, and is seen in the median part of the cervix of the posterior column of gray matter, immediately behind the gray commissure (Fig. 469, p. 530). On the lateral side it is circumscribed by numerous curved fibres from the entering posterior nerve-root, and in the lower thoracic region of the spinal medulla (opposite the eleventh and. twelfth thoracic nerves) it becomes so marked that it forms a bulging on the median aspect of the posterior gray column.

The cells of the nucleus dorsalis are large, and possess several dendritic processes. The axons enter the lateral funiculus of white matter and there form a strand of fibres, which will later on be described under the name of the fasciculus spinocerebellaris (wrongly called "cerebellospinalis" in the B.N.A.).

Nerve-fibres in the
Gray Matter of the
Medulla Spinalis.Nerve-fibres both of the medullated and nonmedullated variety pervade every part of the

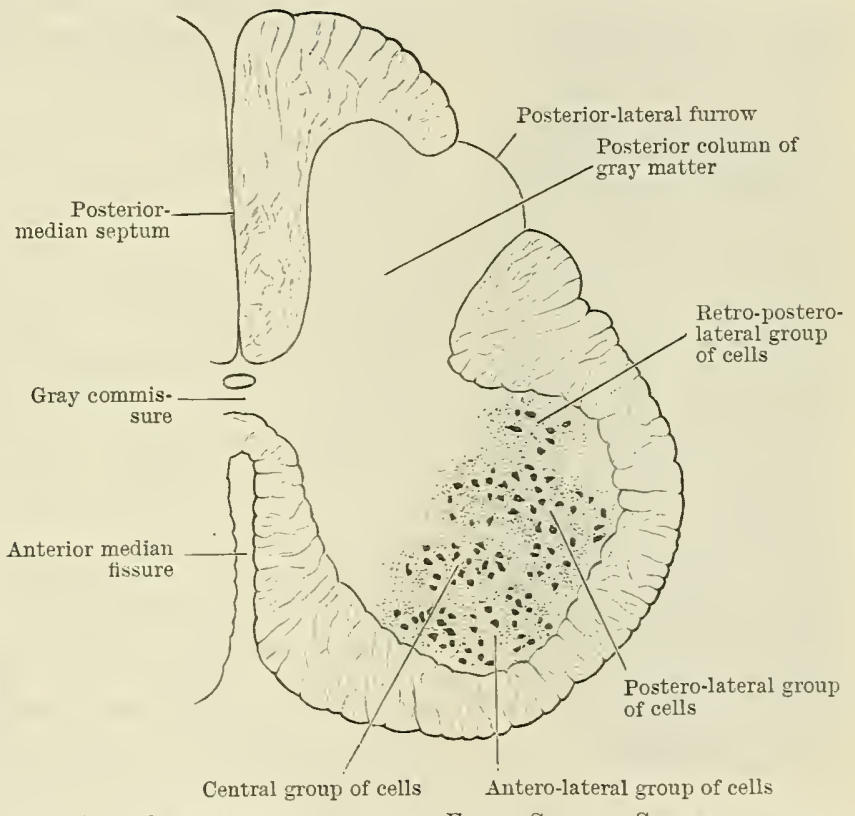

Fig. 471.-Section throdgh the First Sacral Segmext of the SPIsid Medella to show the grotping of the Motor NerieCELLS. (To a large extent founder on Plates in Dr. Bruce's Atlas.) gray matter. They are of three kinds, viz., (1) collaterals, (2) terminations of nervefibres, (3) axons given off by the cells. Many of the nerve-fibres which compose the funiculi of the medulla give off numerous fine collateral branches, which pass into the gray matter from all sides and finally end in relation with the nervecells. The majority of the nerve-fibres themselves, which thus give off collaterals, finally enter the gray matter, and end similarly. The axons of the majority of the cells leave the gray matter and emerge either for the purpose of entering a peripheral nerve or for the purpose of entering a strand of fibres in the white matter of the spinal medulla.

The nerve-fibres thus derived are interwoven together in the gray matter in a dense inextricable interlacement.

\section{Component Parts of the White Matter of the Spixal Medulla.}

The white matter of the spinal medulla is composed of medullated nerve-fibres, embedded in neuroglia. The fibres, for the most part, pursue a longitudinal course ; and, from the deep surface of the pia mater which surrounds the medulla, fibrous septa or partitions are carried in along vertical planes between the fibres so as 
to form an irregular and very imperfect fibrous framework of support. The neuroglia is disposed in a layer of varying thickness around the medulla, subjacent to the pia mater, and is carried into the medulla so as to give a coating to both sides of the various pial septa. The neuroglia is disposed also around the various nerve-fibres, so that each of these may be said to lie in a canal or tunnel of this substance. The nerve-fibres are all medullated, but they are not provided with primitive sheaths. It is the medullary substance of the nerve-fibres which gives to the white matter its opaque, milky-white appearance. When a thin transverse section of the medulla is stained in carmine and examined under the microscope the white matter presents the appearance of a series of closely applied circles, each with a dot in the centre. The dot is the transversely divided axis-cylinder of a nerve-fibre, and the dark ring which forms the circumference of the circle represents the wall of the neuroglial canal which is occupied by the fibre. The medullary substance is very faintly seen. It presents a filmy or cloudy appearance

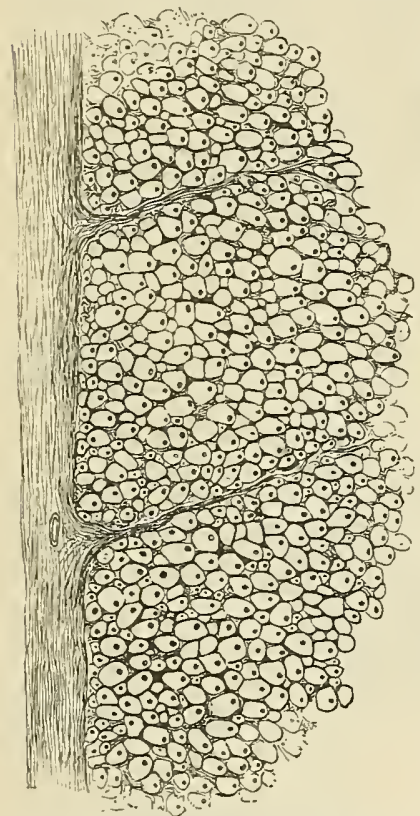

Fig. 472.-Transterse Section THROUGH THE WHITE MATter OF THE Medulla Spinalis, as seen through the microscope. between the axis-cylinder and the neuroglial ring.

Arrangement of the Nerve-fibres of the White Matter in Fasciculi or Tracts.-When the white matter of a healthy adult spinal medulla is examined, the fibres which compose it are seen to vary considerably in point of size; and although there are special places where large fibres-or it may be small fibres -are present in greater numbers than elsewhere, yet, as a rule, both great and small fibres are mixed up together. No conclusive evidence can be obtained in such a medulla, by any means at our disposal, of the fact that the longitudinally arranged fibres are grouped together in more or less definite tracts or fasciculi, the fibres of which run a definite course and present definite connexions. Yet this is known to be the case, and the existence of these separate tracts has been proved both by embryological investigation as well as by the examination of the effects of injuries produced experimentally or accidentally on the nervous system in living beings.

By the experimental method it has been shown that when a nerve-fibre is severed the part which is detached from the nerve-cell from which it is an offshoot degenerates, whilst the part which remains connected with the nerve-cell undergoes little or no change. This is called the law of "Wallerian" degeneration. Thus, if in a living animal one-half of the spinal medulla is cut across, and after a few weeks the animal is killed and the medulla examined, it will be seen that there are degenerated tracts of fibres in the white matter, both above and below the plane of division; but, still further, it will also be manifest that the tracts which are degenerated above the plane of division are not the same as those which are degenerated in the part of the medulla which lies below this level. The interpretation of this is obvious. The nerve-tracts which have degenerated above the plane of section are the offshoots of nerve-cells which lie in lower segments of the medulla or in spinal ganglia below the plane of section. Severed from these nerve-cells, they undergo what is called ascending degeneration. The nervetracts, on the other hand, which have degenerated in the portion of the medulla below the plane of division are the axons of cells which lie at a higher level than the plane of section, either in higher segments of the spinal medulla or in the brain itself. Cut off from the nerve-cells from which they proceed, they present an example of descending degeneration.

The embryological method was first employed by Flechsig, and it is often referred to as Flechsig's method. It is based upon the fact that nerve-fibres in the earliest stages of their development consist of naked axis-cylinders, and are not provided with medullary sheaths. Further, the nerve-fibres of different strands assume the medullary sheaths at different periods. By examining the fotal central nervous system at different stages of its development, it is a comparatively easy matter to locate the different tracts of fibres by evidence of this kind. Speaking broadly, the tracts which myelinate first are those which bring the central nervous system into relation with the peripheral parts (skin, muscles, etc.); then those fibres which bind the various segments of the central nervous system together; next, those which connect the spinal medulla with the cerebellum; and, lastly, the tracts which connect the spinal medulla with the cerebral hemispheres. The nervous apparatus for the perforniance of antomatic movements is fully 
provided, therefore, before this is put under the control and direction of the higher centres. It by no means follows that in all the higher animals corresponding strands myelinate at relatively corresponding periods. Take the case of a young animal which from the time of its birth is able to move about and perform voluntary movements of various kinds in a more or less perfect manner, and compare it with the helpless new-born infant which is only capable of exhibiting automatic movements. In the former the cerebro-spinal tracts, or motor tracts, which descend from the cerebrum into the spinal medulla, and which are the paths along which the mandates of the will travel, myelinate at an early period; whilst in the infant the corresponding fibres do not obtain their medullary sheaths until after birth. The study of the dates, therefore, at which the various strands of nerve-fibres myelinate not only gives the anatomist a means of locating their position in the white matter of the central nervous system, but it also affords the physiologist most important information regarding their functions, and also the periods at which these functions are called into play.

It is a matter of interest to note that influences which either accelerate or retard the periods at which nerve-fibres are brought into functional activity have also an effect in determining the dates at which these fibres assume their sheaths of myelin. Thus, when a child is prematurely born the whole process of myelinisation is, as it were, hurried up; and further, when in newborn animals light is freely admitted to one eye whilst it is carefully excluded from the other, the fibres of the optic nerve of the former myelinate more rapidly than those of the opposite nerve.

Study of the minute structure (Anatomical method) of the central nervous system, especially of material that has been stained by the methods of Golgi and Ramon y Cajal or by the use of methylene blue, completes the results attained by these other methods, by demonstrating the precise mode of origin and termination of the various fasciculi.

Posterior Funiculus and the Posterior Roots of the Spinal Nerves.-In the cervical and upper thoracic regions of the spinal medulla the posterior funiculus is divided by the posterior intermediate sulcus and septum into the fasciculus cuneatus, which lies lateral and next to the posterior column of gray matter, and the fasciculus gracilis, which lies medially and next to the posteriormedian septum. The fasciculus cuneatus is composed of nerve-fibres, which are for the most part larger than those entering into the formation of the fasciculus gracilis, and both tracts have a most intimate relation to the posterior nerve-roots; indeed. they are both composed almost entirely of fibres which enter the medulla by these roots, and then pursue a longitudinal course.

The nerve-fibres which form the posterior nerve-roots, on entering the medulla along the sulcus lateralis posterior, divide within the fasciculus cuneatus into ascending and descending branches. These branches diverge abruptly from each other; and the former take an upward course, whilst the latter proceed downwards. The descending fibres are, as a rule, short, and soon end in the gray matter of the spinal medulla. These descending fibres occupy an area in the posterior funiculus along the line of separation of the fasciculus gracilis and the fasciculus cuneatus, and, hence, may be called the fasciculus interfascicularis (comma tract of Schultze). This area, when the spinal medulla is divided, undergoes descending degeneration and then presents a comma-shaped outline. (Fig. 473).

The ascending fibres vary greatly in length, and at differing distances from the point where the parent fibres enter the medulla they end in the gray matter. A small contribution, however, of ascending fibres, from each posterior nerve-root, extends upwards to the upper end of the spinal medulla, to end in the medulla oblongata (Figs. 474 and 475 ).

As each posterior nerve-root enters, its fibres range themselves in the lateral part of the fasciculus cuneatus close up against the posterior column of gray matter. The nervefibres of the nerve-root next above take the same position, and consequently those which entered from the nerve immediately below are displaced medially, and come to lie in the fasciculus cuneatus nearer to the median plane. This process goes on as each nerveroot enters, and the result is that the fibres of the lower nerves are gradually pushed nearer and nearer to the posterior median septum in a successive series of lamellar tracts. Of course, the greater proportion of the fibres which are thus carried upwards from the posterior nerve-roots sooner or later leave the posterior funiculus and enter the gray matter, to end there in relation to some of its cells; but, as we have said, every posterior nerve-root sends a few fibres up the whole length of that portion of the spinal medulla which lies above, and thus the posterior funiculus gradually increases in bulk as it is traced upwards, and in all except the lowest part of the spinal medulla a fasciculus gracilis is present. The fasciculus gracilis is composed of the long ascending fibres of the posterior nerve-roots, which have entered the lower segments of the spinal medulla. To put the matter differently, the fibres of the sacral roots are displaced medially by the entering lumbar fibres, while the fibres of the lumbar roots are in their turn pushed medially 
by the entering thoracic fibres, and, lastly, the fibres of the cervical roots displace the thoracic fibres. The difference between the fasciculus gracilis and the fasciculus cuneatus consists simply in this, that the former is composed of the fibres of posterior nerve-roots which have entered the medulla at a lower level than those which enter into the formation of the fasciculus cuneatus. The fibres of the fasciculus gracilis, taking them as a whole, must therefore necessarily run a very much longer course.

Our knowledge of the constitution of the posterior columns of the spinal medulla is largely derived from studying the course of degeneration in monkeys, after the medulla has been cut across - either partially or completely. But we also have a direct knowledge of the lamination of the posterior columns of the human spinal medulla (Fig. 473), that has been acquired from the examination of cases in which the medulla or its nerve-roots had been injured during life.

Numerous collateral fibrils stream into the gray matter of the posterior column both from the ascending and descending branches of the entering fibres of the posterior nerve-roots. These are classified into long and short collaterals. The long

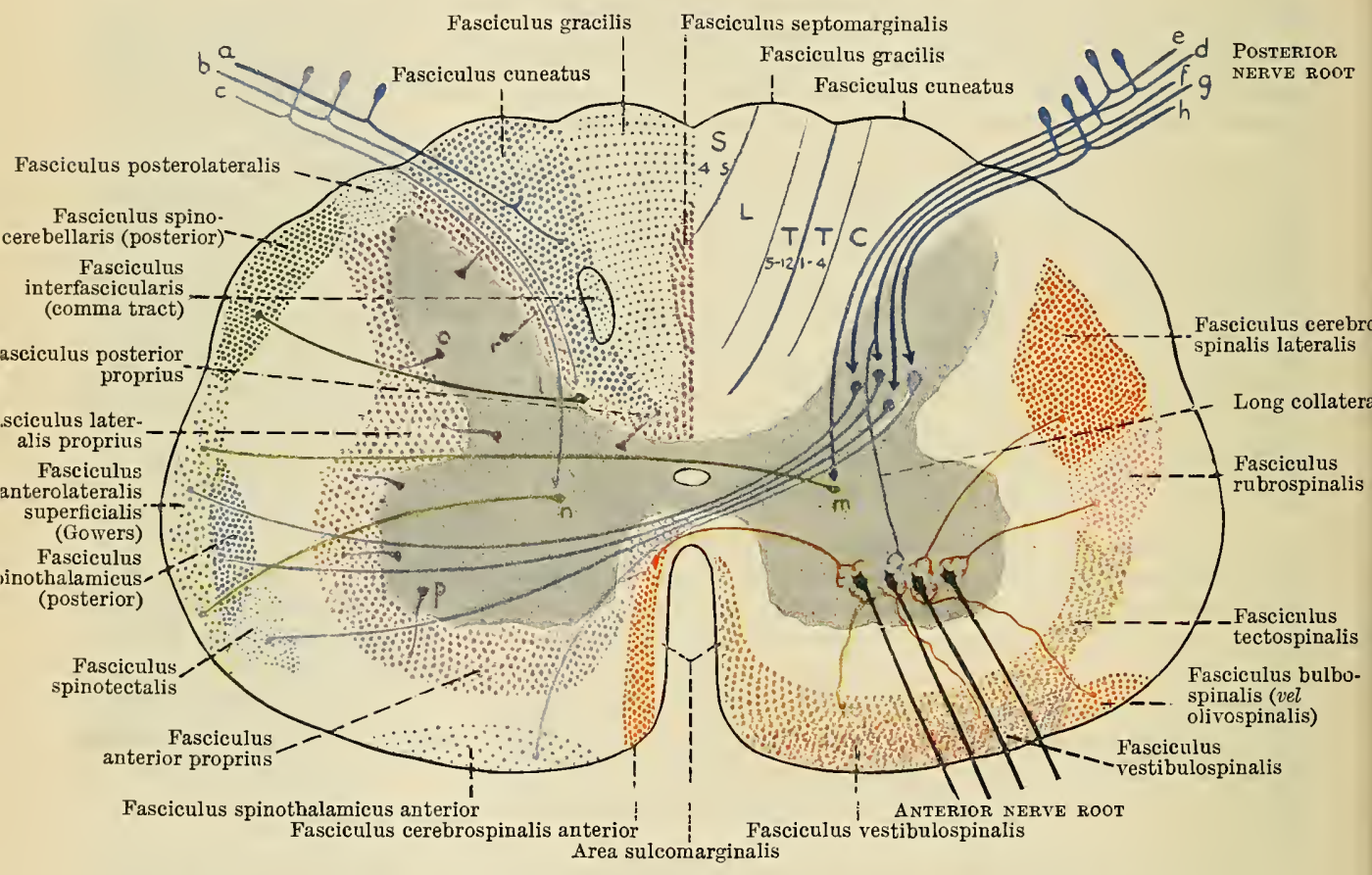

Fig. 473.-A Diagram to illustrate the Grodping of the various Fasciculi in the Spinal MEDUlLa (in transverse section).

collaterals extend forwards into the anterior column of gray matter and end in relation to the ventral nerve-cells. The short collaterals end in relation to the nerve-cells in the substantia gelatinosa, and other nerve-cells of the posterior column of gray matter.

The majority of the fibres of the posterior nerve-root enter the spiual medulla on the medial side of the apex of the posterior column of gray matter. The manner in which these are related to the fasciculus cuneatus and the fasciculus gracilis has been noticed; but a certain number of those fibres which lie most laterally take a curved course forwards on the medial side of the posterior column of gray matter and then pass into it. In the thoracic region these curved fibres end in connexion with the cells of the nucleus dorsalis (Fig. 467, B, p. 525, and Fig. 473).

Fasciculus Posterolateralis (O.T. Tract of Lissauer).-This is a small tract of nerve-fibres of minute calibre which assume their medullary sheaths at a comparatively late period. It is placed at the surface of the medulla close to the sulcus lateralis posterior. It is formed by some of the lateral fibres of the posterior nerve-roots which do not enter the fasciculus cuneatus, but pass upwards in the medulla close to the substantia gelatinosa, in which they ultimately end.

It must now be evident that the fibres which enter the medulla spinalis through each 
posterior nerve-root have three main modes of distribution: (1) the majority take part in the formation of the fasciculus cuneatus, and pass upwards or downwards to end in the gray matter at some other level in the central nervous system; (2) some fibres, and many collaterals of fibres in the fasciculus cuneatus, lie close to the posterior column and describe a series of graceful ${ }^{-}$curres as they pass forwards, prior to turning laterally into all regions of the gray matter to end at the same level as they enter the medulla spinalis; (3) a third series form the postero-lateral fasciculus and end in connexion with the cells of the substantia gelatinosa and other cells in the posterior and anterior columns of gray matter (Fig. 473).

The fibres derived from the posterior nerve-roots which ascend in the posterior funiculi of the medulla spinalis to the medulla oblongata of the brain constitute a direct sensory tract; other fibres are described which give rise to a crossed semsory tract termed the fasciculus spinothalamicus. These latter fibres arise as the axons of certain of the cells in the posterior column in connexion with which fibres from the posterior nerveroots have ended, and crossing to the opposite side of the medulla spinalis through the anterior commissure they ascend in the antero-lateral funiculus to the brain, where they ultimately reach the thalamus. As the spino-thalamic tract ascends in the spinal medulla its fibres are not gathered into a compact strand, but are more or less loosely scattered in the lateral funiculus (Fig. 473).

Association Fibres in the Posterior Funiculus.-But the whole of the fibres of the posterior funiculus are not derived from the posterior nerve-roots. A few fibres exist in this funiculus which have a different origin. They are derived from certain of the cells of the gray matter, and, entering the posterior funiculus, they divide into ascending and descending branches which pass upwards and downwards in the funiculus for a varying distance, before they finally turn in to end in the gray matter at a higher and a lower level. These fibres, therefore, constitute links of connexion between different segments of the spinal medulla, and they constitute the fasciculus posterior proprius. Our information regarding these fibres at present is somewhat defective; but it is believed that the deepest part of the funiculus, i.e. the part next the posterior gray commissure, and the fasciculus septomarginalis of Bruce, placed in apposition with the posterior-median septum and in the adjoining part of the surface, belong mainly to this category.

Funiculus Lateralis and Funiculus Anterior. - It is convenient to consider the anterior along with the lateral funiculus and to call the whole mass

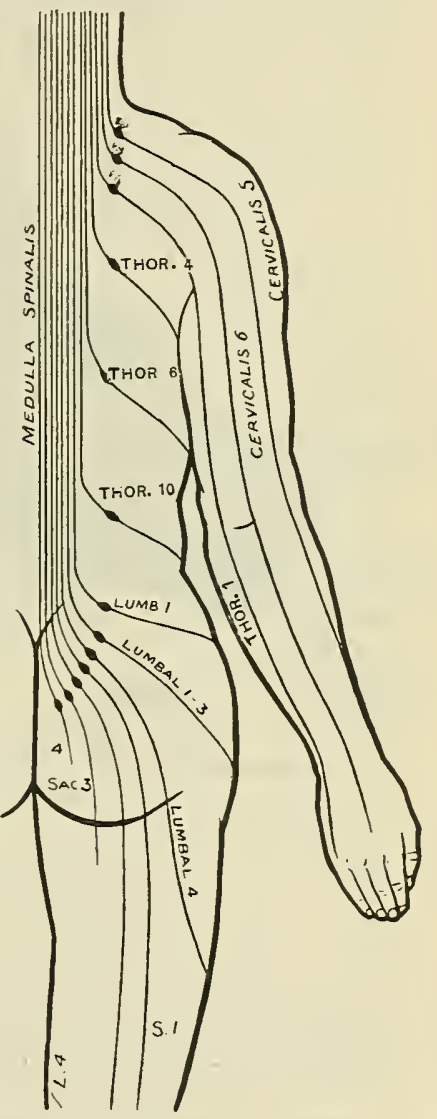

FIG. 474.-DIAGRAM TO SHOW THE MANNER IN WHICH THE Fibres OF THE POSTERIOR NERVE-RoOTS ENTER AND ASCEND IN THE POSTERIOR FUNICULUS OF THE SPINAL MEdulla. (From Edinger.) of white substance that is left, after eliminating the posterior funiculus, the anterolateral funiculus. In contact with the surface of the gray columns there is a broad band of white matter the parts of which are known respectively as the fasciculus proprius anterior and lateralis (O.T. the ground bundles of the antero-lateral funiculus). It is composed wholly of fibres which spring from nerve-cells in the gray columns, and, after passing for varying distances upwards or downwards, end in the gray matter of the spinal medulla. Thus they constitute an intrinsic system of fibres linking together different levels of the spinal medulla. They become medullated before any other fibres, except the root-fibres and their continuations in the posterior funiculus. When cut across some of the fibres degenerate above, others below, the injury, and the degeneration extends for varying distances upwards and downwards respectively. 
The best-known long or extrinsic systems of fibres in the antero-lateral funiculus are those known as the fasciculus cerebrospinalis lateralis (O.T. crossed pyramidal tract), the fasciculus cerebrospinalis anterior (O.T. direct pyramidal tract), the fasciculus cerebellospinalis (O.T. direct cerebellar tract) (which goes from the spinal medulla to the cerebellum, and ought therefore to be called spinocerebellaris, as it will be subsequently named in this account), and the fasciculus anterolateralis superficialis (O.T. Gowers' tract).

There are, however, many other fasciculi at least as important as these, but there is as yet no close agreement as to their precise limits or connexions. One reason for this is that some of the elements of one tract may become intermingled with those of another; moreover, the position and relations of certain of them

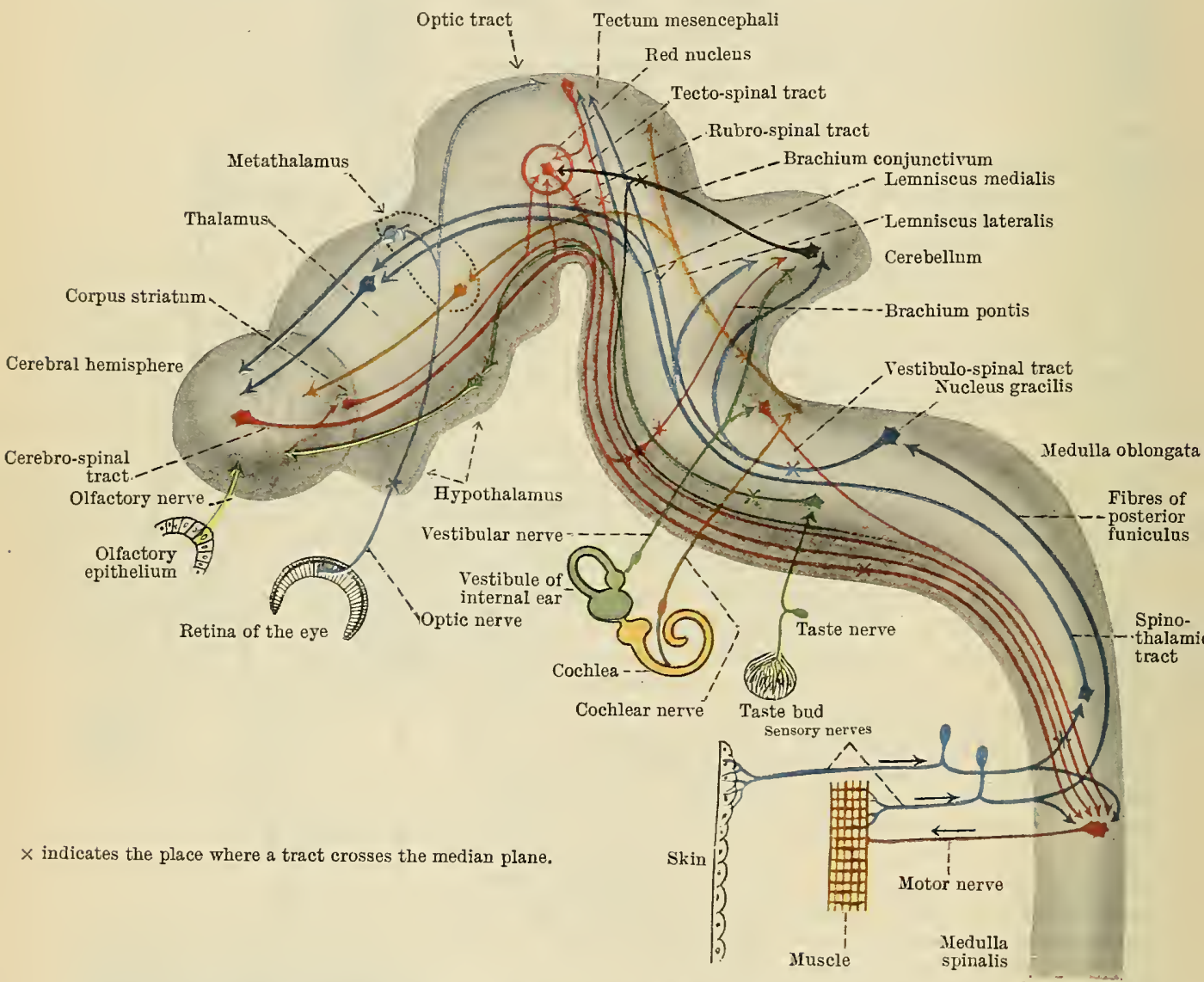

Fig. 475.-Diagram represexting the Connexions of some mportant Sensory and Motor Tracts IN THE BRATY.

vary considerably at different levels of the spinal medulla. In Fig. 473 an attempt has been made to present the present state of our knowledge of these great strands of white fibres. This diagram is not intended to represent any definite level of the spinal medulla, though certain features are shown which occur only in the cervical region; and in respect of other features, the arrangement found in lower regions of the spinal medulla has been introduced to render the diagram more serviceable.

Much of the apparent complexity of this chart will disappear if the reader recalls some general statements (p. 512) made with regard to the outstanding features of the brain. It was then explained that when sensory nerves, coming from the skin and muscles, enter the spinal medulla, they not only establish relations with the motor nuclei and other spinal structures in the neighbourhood of their insertion, but also give rise, directly or indirectly (see Fig. 475) to many 
fasciculi, which pass upwards in the spinal medulla to reach the medulla oblongata, the pons and cerebellum, the mesencephalon (corpora quadrigemina), the thalamus, and the cerebral hemisphere. In the neighbourhood of each level where these ascending sensory tracts end, such as for example the region of the vestibular nucleus and cerebellum, the tectum mesencephali, the corpus striatum, and the cerebral hemisphere, great descending tracts originate and pass downwards in the spinal medulla (Fig. 475-the red lines). Thus we have cerebro-spinal, rubro-spinal, tecto-spinal, vestibulo-spinal, and bulbo-spinal fasciculi passing down the spinal medulla; and each system eventually ends around the series of motor nuclei (Fig. 475), many of them in the spinal medulla.

In the anterolateral funiculus the various fasciculi will be found to be grouped roughly into three bands:- Next to the gray columns is the fasciculus proprius, then comes a band of descending (motor) fasciculi, and then upon the surface a series of ascending (sensory) fasciculi. This arrangement, however, is not maintained with any degree of exactitude in the anterior funiculus, where the sharp demarcation between ascending and descending fasciculi is in great part destroyed by the intermingling of fibres passing in opposite directions.

The fibres of the posterior nerve-root have already been studied so far as their relation to the posterior funiculus is concerned. No clear conception of the nature and significance of the ascending fasciculi in the anterolateral funiculus can be obtained unless they also are studied in relationship with the fibres of the posterior root.

It has already been explained that of the fibres which enter the spinal medulla in the posterior root the great majority enter the fasciculus cuneatus, most of which (Fig. 473, a) bifurcate, one branch passing upward as a constituent of the fasciculus cuneatus and perhaps, if it ascends far enough, passing into the fasciculus gracilis, the other descending in the fasciculus interfascicularis (O.T. comma tract). Other fibres perhaps enter the posterolateral fasciculus (O.T. Lissauer's bundle). But all the other fibres of the posterior root, together with the majority of the fibres of the fasciculus cuneatus, sooner or later enter the gray matter (Fig. $473, b$ to $h$ ) of the spinal medulla.

Some of them $(b)$ pass directly to end in the nucleus dorsalis of their own side, and from its cells fresh fibres arise, which pass laterally through the posterior column and lateral funiculus to reach the surface, where they bend upwards as constituent tibres of the spino-cerebellar fasciculus. These pass upwards throughout the whole length of the spinal medulla (above their place of origin), into the medulla oblongata, thence into the cerebellum through the restiform body.

Other fibres on the same (c), and perhaps also on the other side $(d)$, end amidst cells of the gray matter, the axis-cylinder processes of which pass into the anterolateral superficial fasciculus (O.T. Gowers' tract). In this they ascend throughout the spinal medulla, medulla oblongata, and pons, to enter the cerebellum alongside the brachium conjunctivum (superior peduncle). This element in the anterolateral fasciculus is sometimes designated the fasciculus spinocerebellaris anterior, to distinguish it both from the non-cerebellar fibres of the parent fasciculus and from the fasciculus spinocerebellaris [posterior] (O.T. the direct cerebellar tract). These two spino-cerebellar tracts convey to the cerebellum information from the muscles and overlying skin which assists it to co-ordinate the muscles for carrying on precisely adjusted movements.

Other fibres of the posterior nerve-root $(e, f, g$, and $h)$ terminate in relationship with cells in the gray columns of their own side of the spinal medulla, the axons of which cross the median plane in the anterior commissure to pass respectively (e) into the anterolateral superficial fasciculus [not to be confused with the cerebellar constituents of this bundle]; $(f)$ into the real fasciculus spinothalamicus, of which the last-mentioned fibres are merely outlying members; $(g)$ into the fasciculus spinotectalis, to ascend to the mesencephalon; and $(h)$ into the marginal area of the anterior funiculus to form a group which may be called the fasciculus spinothalamicus anterior.

The careful investigations of the late Dr. Page May led him to attach a definite physiological significance to this grouping of the ascending paths. The fasciculus spinothalamicus [posterior] is supposed to convey upwards to the thalamus (for 
transmission to the cerebral cortex, which is concerned with the conscious appreciation of sensations) all impulses of pain, heat, and cold coming from the skin upon the opposite side of the body. The fasciculus spinothalamicus anterior conveys impulses of touch and pressure from the opposite side.

The spino-cerebellar fasciculi [anterior and posterior] convey to the cerebellum respectively homolateral and bilateral unconscious afferent impulses underlying muscular co-ordination and reflex tone.

Among the descending tracts that establish connexions between various parts of the brain (see Fig. 475) and the motor nerve-cells in the anterior column may be mentioned the cerebrospinal, the rubro-spinal (from the red nucleus), the tectospinal (from the corpora quadrigemina), the vestibulo-spinal (from the terminal nucleus of the vestibular nerve), and the bulbo-spinal tracts. The last-mentioned forms a peculiar triangular area upon the surface immediately to the lateral side of the anterior nerve-roots (Fig. 473), but there is great uncertainty as to its mode of origin: it is often called the fasciculus olivospinalis, from the fact that its discoverer, Helweg, believed it to originate from the olivary nucleus in the bulb or medulla oblongata. It may be regarded as an outlying part of the vestibular (or cerebellar) tract to the motor nuclei of the spinal medulla.

The fasciculus cerebrospinalis lateralis (O.T. crossed pyramidal tract) is a large well-defined descending tract which lies immediately in front of the posterior column of gray matter, and subjacent to the spinocerebellar fasciculus, which shuts it out from the surface. Below the point where the spino-cerebellar fasciculus begins the cerebrospinal fasciculus becomes superficial, and in this position it can be traced as low as the fourth sacral nerve, at which level it ceases to exist as a distinct strand. The cerebro-spinal fasciculus is composed of an admixture of both large and small fibres. These arise in the brain from the large pyramidal cells of the motor or precentral area of the cerebral cortex, and pass downwards through various subdivisions of the brain to gain the spinal medulla. As they enter the spinal medulla they cross the median plane from one side to the other, and it thus happens that the cerebro-spinal tract in the right lateral column of the spinal medulla has its origin in the cortex of the left cerebral hemisphere, and vice versa. As the tract descends in the spinal medulla it gradually diminishes in size; and this is due to the fact that, as it traverses each spinal segment, numerous fibres leave it to enter the anterior column of gray matter, and end in connexion with the anterior motor cells from which the fibres of the anterior nerve-roots arise. The entire strand is ultimately exhausted in this way. Numerous collateral fibrils spring from the cerebro-spinal fibres, and, entering the gray matter, end in a similar manner. In this way a single cerebro-spinal fibre may be connected with several spinal segments before it finally ends. The lateral cerebro-spinal fasciculus must be regarded as a great motor strand which brings the spinal motor apparatus under the control of the will.

Schäfer believes that many of the fibres of the cerebro-spinal fasciculus end in connexion with the cells of the uucleus dorsalis.

In many marsupials, rodents, and ungulates the lateral cerebro-spinal fasciculus lies in the posterior funiculus of the spinal medulla.

The fasciculus lateralis proprius represents the remainder of the lateral funiculus. Its fibres are largely derived from the cells situated in all parts of the gray matter, and also from the nerve-cells of the opposite side of the spinal medulla. After a course of very varying length in the fasciculus lateralis, these fibres turn medially and re-enter the gray matter. Such fibres may thus be regarded as inter-segmental association fibres binding two or more segments of the spinal medulla together. It may be mentioned that the association fibres which link together segments of the spinal medulla which are near to each other lie close to the gray matter, whilst those which connect the more distant segments are situated further out in the lateral funiculus.

Funiculus Anterior.-One well-defined tract is situated in the funiculus anterior. This is termed the fasciculus cerebrospinalis anterior. The remainder of the funiculus receives the name of the fasciculus anterior proprius. 
The fasciculus cerebrospinalis anterior (O.T. direct pyramidal tract) is usually a nerve-strand of small size which lies near the anterior median fissure. As a rule it cannot be traced lower than the middle of the thoracic region of the spinal medulla. It is a descending tract and must be associated with the lateral cerebro-spinal fasciculus of the opposite side, seeing that both of these strands arise from the motor area of the cortex of the same cerebral hemisphere. From this it must be clear that the anterior cerebro-spinal fasciculus does not cross the median plane as it enters the spinal medulla, but descends on the side of the spinal medulla corresponding to the cerebral hemisphere in which it arises. Nevertheless, its fibres do not end in the same side of the spinal medulla, but at every step along the path of the strand they make use of the anterior commissure, and cross to the opposite side of the spinal medulla, to terminate in relation to the opposite ventral motor cells in the same manner as the lateral cerebro-spinal fibres.

From this crossing of the cerebro-spinal fasciculi, it follows that the destruction of the fibres which compose them as they descend in one side of the brain must result in paralysis of the muscles supplied by the efferent nerves of the opposite side of the spinal medulla.

In cases of old brain lesion it is sometimes possible to detect some degenerated fibres in the lateral cerebro-spinal fasciculus of the sound side of the spinal medulla, and from this it is supposed that this tract contains a few uncrossed fibres. If this is the case, each side of the spinal medulla stands in connexion with the motor area of both cerebral hemispheres.

It is well to note that the fibres of both lateral cerebro-spinal fasciculi are not medullated until the time of birth. They are the latest of all the fasciculi of the spinal medulla to myelinate.

Commissura Anterior Alba.-The anterior white commissure is composed of medullated nerve-fibres passing from one side of the spinal medulla to the other and entering the anterior column of gray matter, and also the anterior funiculus of white matter. It is to be regarded more as a decussation than as a commissure, and its width, which varies somewhat in different regions, fluctuates in correspondence with the diameter of the spinal medulla.

Amongst the fibres which cross in the anterior commissure may be mentioned: (1) The fibres of the fasciculus cerebrospinalis anterior; (2) collaterals from both the anterior and lateral funiculi ; (3) axons of many of the cells of the gray matter; (4) the dendritic processes of some of the medial anterior cells.

Commissura Grisea.-Although this is composed of gray matter with a large admixture of neuroglia, numerous nerve-fibres pass transversely through it, so as to establish relations between the cells in the gray matter on the two sides of the spinal medulla.

\section{THE ENCEPHALON OR BRAIN.}

The brain is the enlarged and greatly modified upper part of the cerebro-spinal nervous axis. It is surrounded by the same membranes that envelop the medulla spinalis (viz., the dura mater, the arachnoid, and the pia mater), and it almost completely fills up the cavity of the cranium. So closely, indeed, is the skull capsule moulded upon the brain that the impress of the latter is almost everywhere evident upon the inner surface of the cranial wall. The relations, therefore, of cranium to brain are totally different from those presented by the vertebral canal to the spinal medulla. As we have noted, the medulla spinalis occupies only a part of its bony case; and there is not only a wide and roomy space between the arachnoid and the pia mater, but also an interval of some width between the dura mater and the walls of the vertebral canal.

General Appearance of the Brain.-When viewed from above the brain presents an ovoid figure, the broad end of which is directed backwards. Its greatest transverse diameter is usually found in the neighbourhood of that part which lies between the two parietal tuberosities of the cranium. The only parts which are visible when the brain is inspected from this point of view are the two convoluted cerebral hemispheres. These present an extensive convex surface, which 
is closely applied to the internal aspect of the cranial vault, and are separated from each other by a deep median cleft, termed the fissura longitudinalis cerebri, which extends from the front to the back of the brain.

The inferior aspect of the brain is usually termed the basis cerebri. It presents an uneven and irregular surface, which is more or less accurately adapted to the inequalities on the floor of the cranial cavity. Upon this aspect of the brain some of its main subdivisions may be recognised. Thus, posteriorly, is seen the short cylindrical portion, called the medulla oblongata, through which, at the foramen magnum, the brain becomes continuous with the medulla spinalis. The medulla oblongata lies on the ventral aspect of the cerebellum, and occupies the vallecula or hollow which intervenes between the two cerebellar hemispheres. The cerebellum

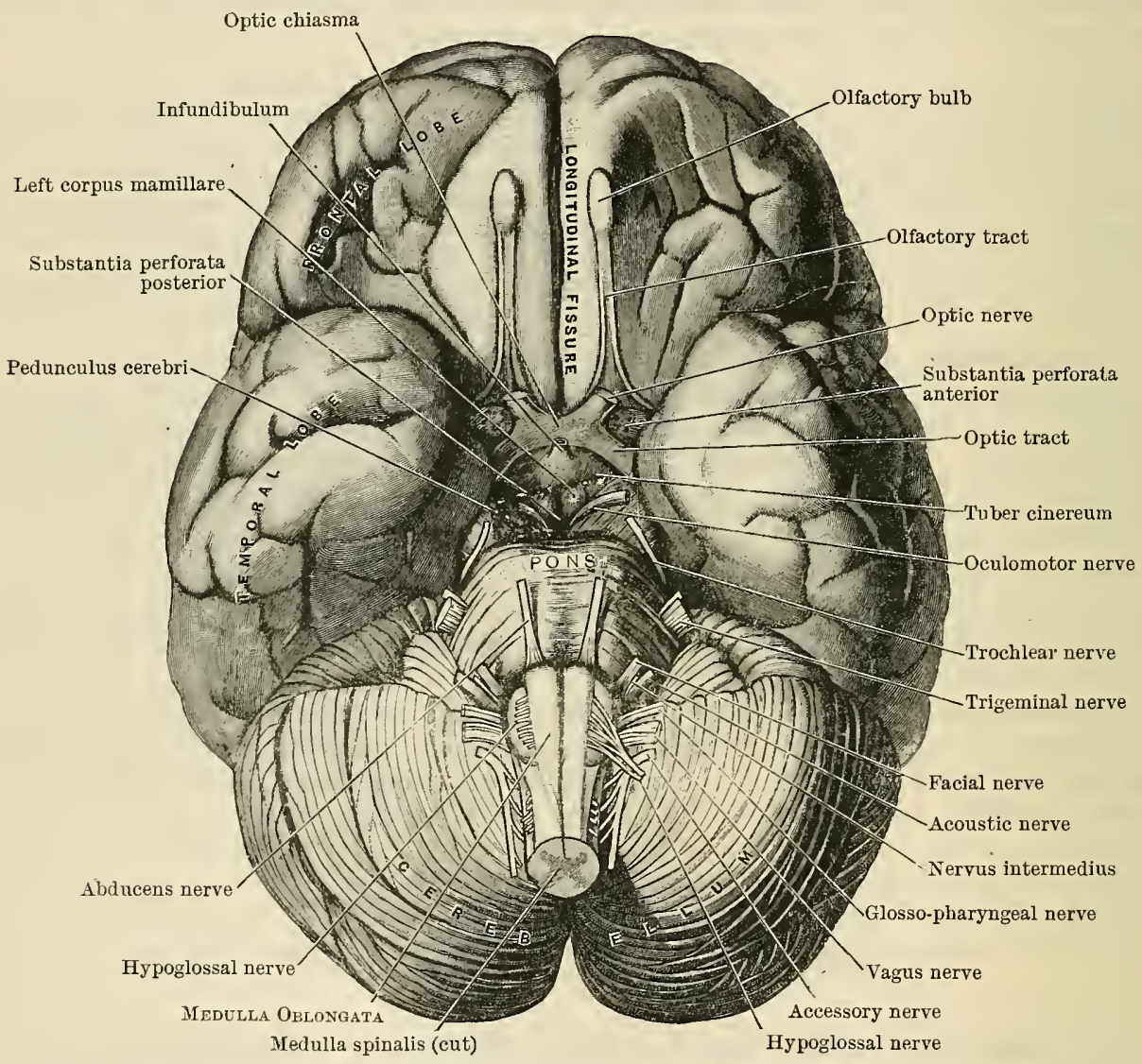

Fig. 476.-The Base of the Brain with the Cerebral Nerves attached.

is a mass of considerable size which is placed below the posterior portions of the two cerebral hemispheres. It is easily recognised on account of the closely set, curved, and parallel fissures which traverse its surface and give it a foliated appearance. Above the medulla oblongata, and in close connexion with it, is a prominent white elevation called the pons. Immediately in front of the pons there is a deep hollow or recess. This is bounded behind by the pons, on each side by the projecting temporal lobe of the cerebral hemisphere, and in front by the orbital portions of the frontal lobes of the cerebral hemispheres. Passing out from each side of the anterior part of this recess is the deep lateral fissure of the brain which intervenes between the pointed and projecting extremity of the temporal lobe and the frontal lobe of the cerebrum, whilst, in the median plane in front, the longitudinal fissure, which separates the frontal portions of the cerebral hemispheres, opens into it.

Within the limits of this deep hollow, on the base of the brain, two large rope- 
like strands, the pedunculi cerebri, may be seen issuing from the under surface of the cerebral hemispheres. As they pass downwards these peduncles are inclined obliquely towards the median plane, so that when they plunge into the pons they are situated in close apposition the one to the other (Fig. 478). Turning round the lateral side of each peduncle, where it emerges from the cerebrum, a flattened band termed the optic tract may be observed. These bands come from the anterior part of the hollow, where they are joined together by a short connecting piece termed the optic chiasma. The optic nerve is inserted, on each side, into the chiasma.

The pedunculi cerebri, the optic tracts, and the optic chiasma enclose a deep rhomboidal or lozenge-shaped interval on the base of the brain, which is termed the fossa interpeduncularis. Within the limits of this area the following parts may be seen as we pass from behind forwards: (1) the substantia perforata posterior; (2) the corpora mamillaria: (3) the tuber cinereum and the stalk of the hypophysis cerebri (O.T. pituitary body).

At its posterior angle, immediately in front of the pons, the interpeduncular fossa is very deep and is floored by a layer of gray matter, which is perforated by numerous small apertures. This is the substantia perforata posterior. Through the apertures which are dotted over its surface the small postero-medial basal branches of the posterior cerebral artery enter the brain.

The corpora mamillaria are two small white pea-like eminences placed side by side in front of the substantia perforata posterior.

The tuber cinereum is a slightly-raised field of gray matter, which occupies the interval between the anterior portions of the optic tracts in front of the corpora mamillaria. Springing from the anterior part of the tuber cinereum, immediately behind the optic chiasma, is the infundibulum, or the stalk which connects the hypophysis cerebri with the base of the brain (Fig. 478).

Lateral to the limits of the anterior part of the interpeduncular space there is, on each side, a small depressed triangular field of gray matter, which leads laterally into the lateral cerebral fissure. It is perforated by the antero-medial and the antero-lateral groups of basal arteries, and receives the name of the substantia perforata anterior.

General Connexions of the Several Parts of the Brain.-The medulla oblongata, the pons, and the cerebellum occupy the posterior cranial fossa, and they are separated from the cerebral hemispheres, which lie above them, by a partition of dura mater, termed the tentorium cerebelli. Further, they surround a cavity, a portion of the primitive cavity of the early neural tube, which is termed the fourth ventricle of the brain, and they all stand in intimate connexion, one with the other. The medulla oblongata is for the most part carried upwards into the pons; but at the same time two large strands from its dorsal aspect, termed the restiform bodies, are prolonged into the cerebellum, and constitute its inferior peduncles, or the chief bonds of union between the medulla (oblongata and spinalis) and the cerebellum. The pons has large numbers of transverse fibres entering into its composition, and the great majority of these are gathered together on each side in the form of a large rope-like strand. This plunges into the corresponding hemisphere of the cerebellum, and constitutes its middle peduncle, which is known as the brachium pontis.

The cerebrum, which forms the great mass of the brain, occupies the anterior and middle cranial fossæ, and extends backwards into the occipital region above the tentorium and the cerebellum. The greater part of the cerebrum is formed by the cerebral hemispheres, which are separated from each other in the median plane by the longitudinal tissure. At the bottom of this fissure is the corpus callosum, a broad commissural band which connects the two hemispheres with each other. Each hemisphere is hollow, the cavity in its interior being termed the lateral ventricle of the brain. Between and below the cerebral hemispheres, and almost completely concealed by them, is the inter-brain or diencephalon. The principal parts forming this portion of the brain are two large masses of gray matter, termed the thalami. Between these is the third ventricle of the brain-a deep narrow cavity occupying the mediau plane. The third ventricle communicates 
with the lateral ventricles by two small apertures, called the foramina interventricularia.

The cerebrum is connected with the parts in the posterior cranial fossa (pons, cerebellum, and medulla oblongata) byı narrow stalk called the mesencephalon. The mid-brain is built up of the pedunculi cerebri, passing from the pons to the cerebrum ; the corpora quadrigemina, forming its dorsal part; and the brachia conjunctiva (O.T. superior cerebellar peduncles), proceeding from the cerebellum to the cerebrum. It is tunnelled by a narrow passage, the aquæductus cerebri, which extends between the fourth and third ventricles.

In a view of the intact brain the greater part of the mesencephalon and diencephalon is hidden by the cerebral hemispheres; but a precise idea will be obtained of the inter-relationships of the various parts of the brain, if we study

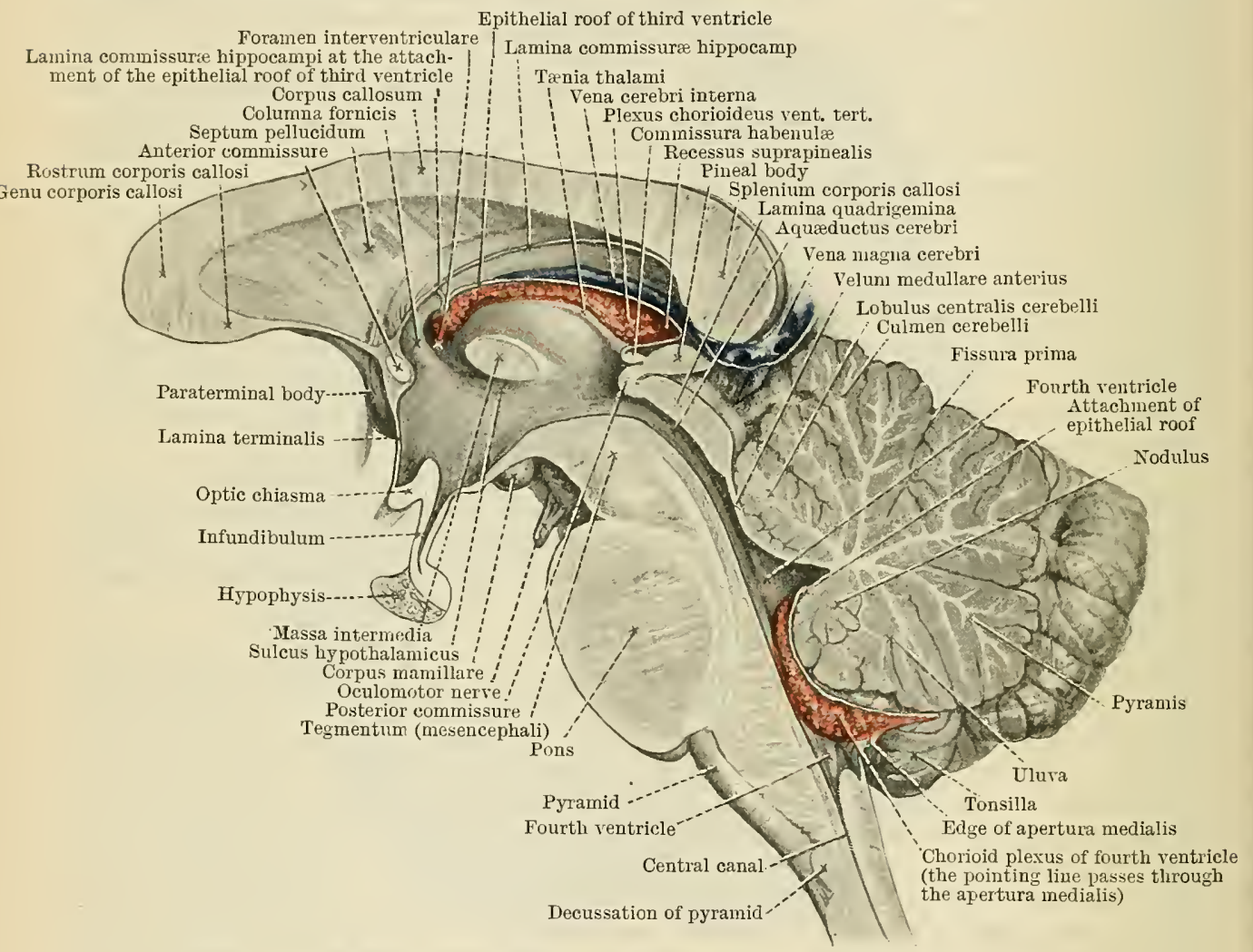

Fig. 477. - The parts of the Brain cot throdgh in a Median sagitTal sectiox.

The lateral walls of the ventricular cavities are also shown.

the relationship of these structures to the series of cavities in the interior of the brain as they are displayed in a median sagittal section (Fig. 477).

The central canal which tunnels the spinal medulla is seen to extend into the medulla oblongata for a short distance; then it expands into the irregular cavity of the fourth ventricle, the floor (anterior wall) of which is formed partly by the medulla oblongata and partly by its continuation upwards, the pars dorsalis pontis. Behind the fourth ventricle lies the cerebellum, but it forms only a small part of the roof (tegmen). This consists mainly of the velum medullare anterius above and the thin epithelial lamina (lamina chorioidea epithelialis) below.

The fourth ventricle is continued upwards into the aquæductus cerebri, which tunnels the mesencephalon, of which the thick mass of the tegmentum is placed in front of it and the lamina quadrigemina behind.

The aqueduct opens in front into the third ventricle, the major portion of each lateral wall of which is formed by the thalamus. Near the antero-superior 
corner of each lateral wall of the third ventricle the small foramen interventriculare (O.T. foramen of Monro) leads into the cavity of the corresponding cerebral hemisphere, which is known as the lateral ventricle.

\section{MEDULLA OBLONGATA.}

The medulla oblongata is the continuation upwards of the medulla spinalis. It is not more than $25 \mathrm{~mm}$. (one inch) in length, and it may be regarded as beginning immediately above the uppermost root of the first cervical nerve, or, roughly,

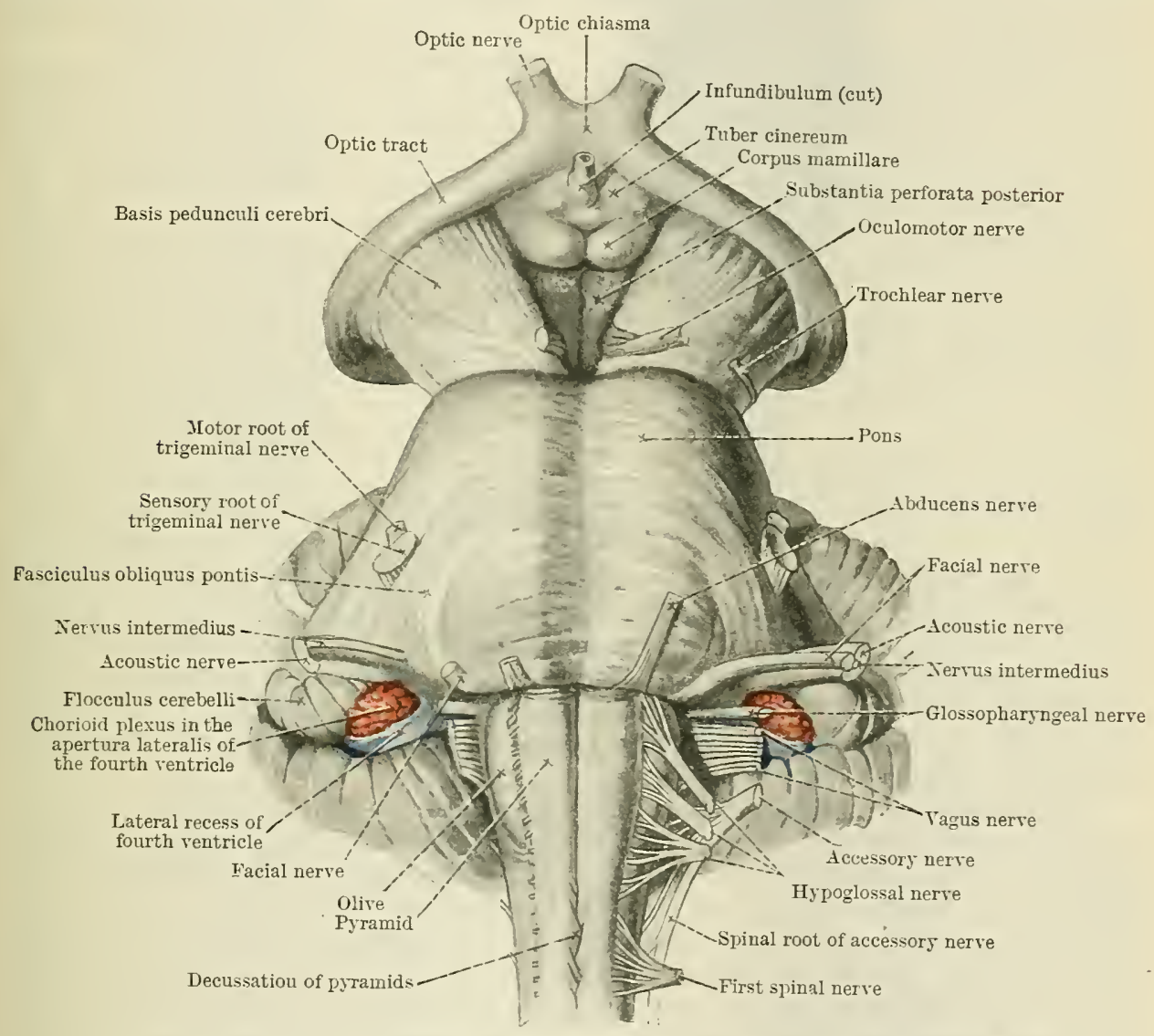

Fig. 478.-Froxt View of the Medulla Oblongata, Poxs, and Mesexcephalox of a FULL-TIME HUMAX FETUS.

about the level of the foramen magnum. From this it proceeds upwards in a very nearly vertical direction, and ends at the lower border of the pons. At first its girth is similar to that of the spinal medulla, but it rapidly expands as it approaches the pons, and consequently it presents a more or less conical form. Its anterior surface lies behind the grooved surface of the basilar portion of the occipital bone, whilst its posterior surface is sunk into the vallecula of the cerebellum. The medulla oblongata is a bilateral structure, and this is indicated on the surface by the presence of anterior and posterior median fissures, on the ventral and dorsal surfaces respectively.

The fissura mediana anterior, as it passes from the spinal medulla on to the medulla oblongata, is interrupted at the level of the foramen magnum by several strands of fibres which cross the median plane from one side to the other. This intercrossing is termed the decussation of the pyramids. Above this level the fissure 
is carried upwards to the lower border of the pons, but is often rendered very shallow by numerous external arcuate fibres which emerge upon the surface

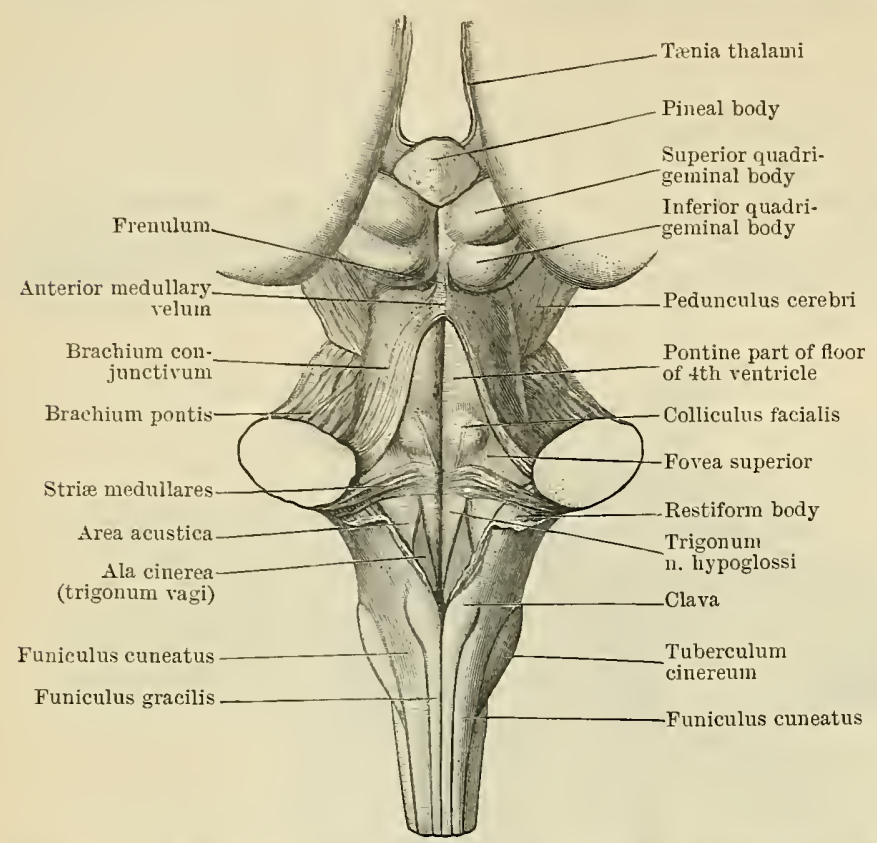

Fig. 479.-Posterior View of the Medulla, Pons, and Mesencbphalon OF A FULL-TIME HUMAN FoETUS. between its lips and then curve laterally to reach the posterior part of the medulla oblongata. At the lower margin of the pons it expands slightly and ends in a blind pit, which receives the name of the foramen cæcum of Vicq d'Azyr.

The fissura mediana posterior is present only on the lower half of the medulla oblongata. As it ascends it rapidly becomes shallower. Half-way up, the central canal opens on the dorsal surface of the medulla oblongata, and at this point the lips of the posterior median fissure are thrust apart from each other and constitute the boundaries of a triangular field, which is thus opened up on the dorsal surface. This triangular field is the lower part of the fossa rhomboidea, or the floor of the fourth ventricle of the brain. The lower half of the medulla oblongata, containing as it does the continuation of the central canal of the spinal medulla, is frequently termed the closed part of the medulla oblongata; the upper half, above the opening of the canal, which by its dorsal surface forms the lower part of the floor of the fourth ventricle, is then called the open part.

Deferring for the present the examination of the floor of the fourth ventricle, the appearance presented by the real surface of the medulla oblongata may now engage our attention. In the spinal medulla the corresponding surface area is divided into three districts or funiculi by the emerging motor roots and the entering sensory roots of the spinal nerves. Of these the sensory enter along the bottom of the sulcus lateralis posterior, whilst the motor fila are spread over a relatively broad surface area and have no groove in connexion with their emergence from the spinal medulla. In the case of the medulla oblongata corresponding rows of fila enter and emerge from the surface of each side. The fila of the hypoglossal nerve carry up the line of the anterior nerve-roots of the spinal medulla. In one respect, however, they differ: they emerge in linear order and along the bottom of a distinct furrow, termed the sulcus lateralis anterior, which proceeds upwards on the surface of the medulla oblongata. The fila which carry up the line of the posterior nerve-roots on the surface of the medulla oblongata are the root-bundles of the accessory, the glosso-pharyngeal, and the vagus nerves. These are attached along the bottom of a furrow which is the direct continuation upwards of the sulcus lateralis posterior of the spinal medulla, and therefore receives the name of the sulcus lateralis posterior of the medulla oblongata. The root-bundles of these nerves differ, however, in so far that they are not all composed of afferent fibres which spring from ganglionic cells placed without and enter the medulla. Certain of them are purely efferent (roots of accessory), whilst others contain a considerable number of efferent fibres also, and are therefore to be regarded as mixed roots.

By the sulci laterales, and also by the two rows of fila attached along the 
bottom of these furrows, the surface of the medulla oblongata on each side is divided into three districts, viz., an anterior, a lateral, and a posterior, similar to the surface areas of the three funiculi on the side of the spinal medulla. Indeed, at first sight, they appear to be direct continuations upwards of these three portions of the spinal medulla; this, however, is not the case, because the fibres of the three funiculi of the spinal medulla undergo a rearrangement as they proceed upwards into the medulla oblongata.

Anterior Area of the Medulla Oblongata-Pyramis.-The district between the anterior median fissure, and the sulcus lateralis anterior, along the bottom of which the root-fascicles of the hypoglossal nerve issue from the medulla oblongata, receives the name of the pyramid. An inspection of the surface is sufficient to show that the pyramid is composed of a compact strand of longitudinally directed nerve-fibres. It represents, in fact, the portion of the great cerebro-spinal fasciculus which is destined to carry fibres from the cerebral hemisphere to all the motor nuclei on the other side of the medulla oblongata and medulla spinalis. Somewhat constricted at the place where it emerges from the pons (Fig. 478) it swells immediately to form a prominent rounded column, which passes vertically downward, separated from the pyramid of the other side by the fissura mediana anterior. Towards the lower part of the medulla oblongata it gradually tapers.

Although the pyramid at first sight appears to be continuous with the anterior funiculus of the medulla spinalis, only a very small proportion of the fibres contained in the latter are derived from the pyramid. This at once becomes manifest when the lips of the anterior median fissure are thrust apart at the place of junction between the medulla oblongata and spinal medulla. The pyramid is then seen to divide at this level into two parts, viz., a small portion composed of a. variable number of the most lateral fibres of the pyramid, termed the fasciculus cerebrospinalis anterior (O.T. direct pyramidal tract), and a much larger portion situated next the median fissure, called the fasciculus cerebrospinalis lateralis (O.T. crossed pyramidal tract). The anterior cerebro-spinal fasciculus is continued down into the anterior funiculus of the medulla spinalis, and in this it takes up a medial position next the median fissure. The lateral cerebro-spinal fasciculus is broken up into three or more coarse bundles, which sink backwards and at the same time cross the median plane, to take up a position in the posterior part of the opposite lateral funiculus of the spinal medulla. The term decussatio pyramidum (decussation of the pyramids) is applied to the intercrossing of the corresponding bundles of the lateral cerebrospinal fasciculi of opposite sides.

The anterior cerebro-spinal fasciculus is, therefore, the only part of the pyramid which has a place in the anterior funiculus of the spinal medulla. The much larger part of this funiculus, termed the fasciculus anterior proprius, as it is traced up into the medulla oblongata, is seen to be thrust aside by the decussating bundles of the lateral cerebrospinal fasciculus. It thus comes to occupy a deep position in the substance of the medulla oblongata, behind and to the lateral side of the pyramid.

Lateral Area of the Medulla Oblongata. - This is the district on the surface of the

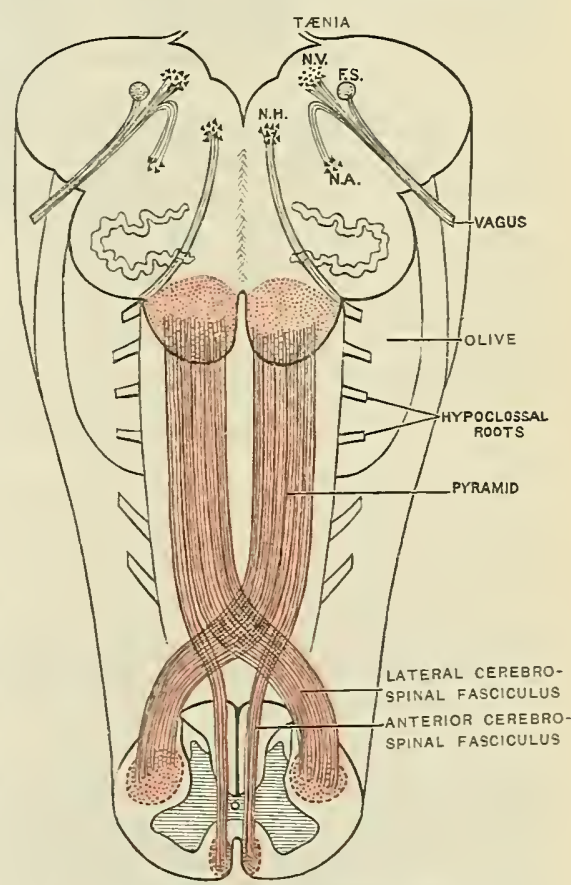

Fig. 480.-Diagrall of the Dectssation of THE PYRAMIDS (modified from van Gehuchten).

NH, Nucleus bypoglossi ; NV, Tago-glossopharyngeal nucleus; FS, Tractus solitarius ; NA, Tucleus ambiguus. medulla oblongata which is included between the two rows of nerve-roots, viz., the hypoglossal roots in front, and the root-bundles of the accessory, the vagus, and the 
glossopharyngeal nerves behind. It presents a very different appearance in its upper and lower parts. In its lower portion it simply appears to be a continuation upwards of the lateral area of the spinal medulla; in its upper part a striking oval prominence bulges out on the surface of the medulla, and receives the name of oliva (O.T. olivary eminence).

The lower part of this district, however, is very far from being an exact counterpart of the lateral funiculus of the spinal medulla. The large lateral cerebrospinal tract is no longer present, seeing that it forms, in the medulla oblongata,

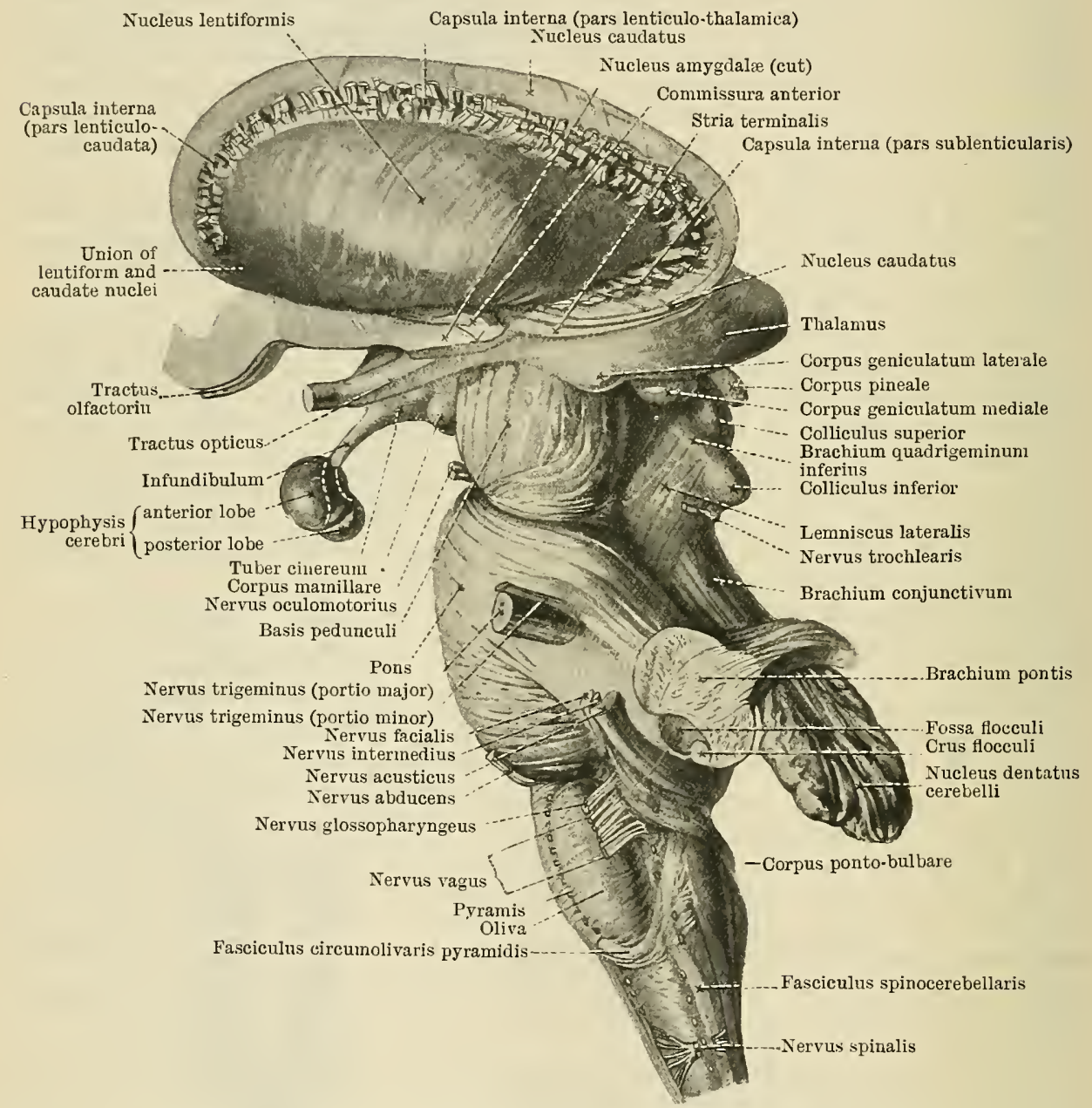

Fig. 481. - Left Lateral Aspect of a Brain from which the Cerebral Hemisphere (with the exception of the Corpus Striatum) and the Cerebelitu (exceptisg tTs Nucleus Dentatus) hate BEEN REMOVED.

the greater part of the pyramid of the opposite side. Another strand of fibres, viz., the fasciculus spinocerebellaris, prolonged upwards in the lateral funiculus of the medulla spinalis, gradually leaves this portion of the medulla oblongata. This tract lies on the surface, and is frequently visible to the naked eye as a white band (Fig. 481), which inclines obliquely backwards into the posterior district of the medulla oblongata to join its upper part, or, in other words, the restiform body. The remainder of the fibres of the lateral funiculus, comprising the fasciculus lateralis proprius and the fasciculus anterolateralis superficialis, is continued upwards in the lateral area of the medulla oblongata, and at the inferior border of the olive the majority of these fibres disappear from the surface by dipping into 
the substance of the medulla oblongata under cover of that projection. A small proportion of the fibres, however, are retained on the surface and travel upwards towards the pons in the interval, which exists between the posterior border of the olive and the roots of the vagus and glossopharyngeal nerves.

The olive is a smooth oval projection which bulges out from the upper part of the lateral area of the medulla oblongata. Its long axis is vertical and is about half an inch long. It marks the position of the subjacent nucleus olivaris inferior, a crumpled thin-walled sac of gray matter, which is separated from the surface only by a very thin layer of superficial white matter.

Posterior Area of the Medulla Oblongata.-In its inferior half, this district is bounded behind by the posterior median fissure, and in its superior half by the lateral margin of the medullary part of the floor of the fourth ventricle of the brain. In front it is separated from the lateral area by the row of root-fascicles belonging to the accessory, glossopharyngeal and vagus nerves. As in the lateral area, we recognise an inferior portion and a superior portion, which appear continuous but in reality are almost quite distinct the one from the other.

The inferior part of the posterior area corresponds more or less closely with the posterior funiculus of the spinal medulla. In the cervical region the posterior funiculus is divided by a septum of pia mater into a medial fasciculus gracilis and a lateral fasciculus cuneatus. These are prolonged upwards into the medulla oblongata, and in the lower part of the posterior area they stand out distinctly, and are separated one from the other by a continuation upwards from the spinal medulla of the sulcus intermedius posterior. In the medulla oblongata the medial of these strands is called the funiculus gracilis, whilst the lateral one is designated the funiculus cuneatus. When they reach the level of the inferior part of the floor of the fourth ventricle, each ends in a slightly expanded bulbous prominence. The swollen extremity of the funiculus gracilis is called the clava. This is thrust aside from its fellow of the opposite side by the opening up of the medulla oblongata to form the floor of the fourth ventricle, and the central canal opens on the surface in the angle between the two clavæ.

The elongated prominences formed on the surface of the medulla oblongata by these two strands and their enlarged extremities are due to the presence of two elongated nuclei or collections of gray matter which make their appearance subjacent to the strands, and represent the termini of these uppermost extensions of the spinal posterior root-fibres. These are termed respectively the nucleus gracilis and nucleus cuneatus. [As it is the slenderness of the one nucleus and the wedge-shape of the other in transverse section which gave rise to the terms gracilis and cuneatus respectively, it is clecurly wrong to introduce the word funiculi into the terminology. The funiculi were named from the nuclei and not the nuclei from the funiculi.]

But a third longitudinal elevation is also apparent on the surface of the inferior part of the posterior area of the medulla oblongata. This is placed on the lateral side of the funiculus euneatus - between it and the posterior row of nerve-rootsand it has no counterpart in the posterior funiculus of the medulla spinalis. It is called the tuberculum cinereum. It is produced by a mass of substantia gelatinosa coming close to the surface and forming a bulging in this situation. Extremely narrow below, it widens as it is traced upwards, and finally ends in an expanded extremity. A thin layer of white matter, composed of longitudinally arranged fibres, is spread over this district, and separates the substantia gelatinosa from the surface. These fibres constitute the tractus spinalis of the trigeminal nerve, which here assumes a superficial position as it descends in the medulla oblongata.

The corpus restiforme (restiform body) forms the upper part of the posterior area of the medulla oblongata. It lies between the fioor of the fourth ventricle and the roots of the vagus and glossopharyngeal nerves. It is a large and prominent rope-like strand, which inclines upwards and laterally, and then finally takes a turn backwards and enters the cerebellum. It forms the great link of connexion between the cerebellum on the one hand and the medulla oblongata and spinal medulla on the other, and consequently it is also called the inferior cerebellar peduncle. A study of the surface of the medulla oblongata yields some important 
information regarding the constitution of the restiform body. Thus the spinocerebellar tract (Fig. 481) from the lateral column of the spinal medulla can be traced into it, and large numbers of fibres which take a curved course on the surface of the medulla oblongata may likewise be followed into it. These are the external arcuate fibres. Numerous other fibres enter the restiform body on its deep aspect, but these will be studied at a later stage.

Fibræ Arcuatæ Externæ.--The external arcuate fibres enter into the constitution of the restiform body, after pursuing a longer or shorter course on the surface of the medulla (Fig. 481).

They are more particularly seen in the neighbourhood of the olive, over the surface of which they may be observed coursing in the form of a number of fine curved bundles or as a continuous sheet of fibres. They vary greatly in number and in distinctness, and they are sometimes so numerous that they cover the olive almost entirely. An attentive examination will show that the majority of them come to the surface in the median fissure between the pyramids, and also not infrequently in the groove between the pyramid and olive, or through the substance of the pyramid itself. The anterior median fissure in its upper part is often almost completely blocked up by these emerging fibres. The arcuate fibres, reaching the surface of the medulla in this manner, turn backwards, and the great majority enter the restiform body and form a considerable part of its outer portion.

Other arcuate fibres arise in the cuneate and gracile nuclei, and enter the restiform body of the same side. Van Gehuchten, however, denies this.

There is frequently present, especially upon the left side, a bundle of fibres that is usually mistaken for a group of arcuate fibres. It is the fasciculus circumolivaris pyramidis (Fig. 481). It consists of a bundle of varying size which emerges from the pyramid, bends backwards, curving round the inferior border of the olive, and then passes obliquely upward and backwards to end in a fusiform ridge of gray matter, the corpus ponto-bulbare (Essick), which crosses the restiform body very obliquely (Fig. 481, the ridge immediately posterior to the fila of the vagus nerve).

These structures are of great morphological interest, and will be referred to again in the succeeding pages (see Fig. 499, p. 566).

\section{PONS.}

The pons (O.T. pons Varolii) is a marked white prominence on the basal aspect of the brain which is interposed between the medulla oblongata and the pelunculi cerebri, and lies in front of the cerebellum. It is convex from side to side, and from above downwards, and transverse streaks on its surface show that, superficially at least, it is composed of bundles of nerve-fibres, most of which course transversely. On each side these transverse fibres are collected together in the form of a large compact strand, which sinks in a backward and lateral direction into the white matter of the corresponding hemisphere of the cerebellum. This strand is termed the brachium pontis, and the term "pons," applied to the entire structure, expresses in an admirable way the arch-like manner in which this portion of the brain bridges across the interval between the two cerebellar hemispheres.

The ventral surface of the pons is in relation to the basilar part of the occipital bone and the dorsum sellæ of the sphenoid bone. It presents a median groove (sulcus basilaris), which gradually widens as it is traced upwards: it lodges the basilar artery. This median depression is produced by the prominence which is caused on each side by the passage of the cerebro-spinal fasciculus downwards through the pons. The trigeminal nerve, with its large entering sensory root and its small emerging motor root, is attached to the side of the anterior aspect of the pons, nearer its superior than its inferior border (Fig. 481). It is usual to restrict the term "pons" to that portion of the structure which lies between the two trigeminal nerves, and to apply the designation of brachium pontis to the part which extends beyond the nerve into the hemisphere of the cerebellum. The abducens nerve, the facial nerve, and acoustic nerve are attached to the brain at the inferior border of the pons. The abducens nerve emerges at the inferior border of the pons 
opposite the lateral border of the pyramid; the facial and acoustic are also attached to the inferior edge of the pons, but far away from the median plane. The acoustic nerve is in contact with the cerebellum and the facial is on its medial side, with its sensory root (the nervus intermedius) between them (Figs. 478, 481). A large bundle of fibres upon the front of the pons departs from the transverse course pursued by most of the pontine fibres, and starting at the medial side of the trigeminal nerve, passes almost vertically downwards between the facial and acoustic nerves (Fig. 526, p. 593) and reaches the lateral aspect of the medulla oblongata, where it passes into the corpus ponto-bulbare (Fig. 481). This bundle is known as the fasciculus obliquus [pontis]. It is curious to observe that while the facial nerve lies upon the medial side of this oblique bundle, its sensory root (the nervus intermedius) is placed on its lateral aspect alongside the acoustic nerve (Fig. 527, p. 594).

Immediately below the insertion of the acoustic nerve at the inferior margin of the pons a little calyx-like appendage of the epithelial roof of the fourth ventricle (recessus lateralis) projects laterally partly behind the glossopharyngeal nerve. Through an elliptical aperture in this epithelial process (apertura lateralis ventriculi quarti) a little cauliflower-like mass of chorioid plexus becomes extruded. between the acoustic and the glossopharyngeal nerves (Fig. 527, p. 594).

The posterior surface of the pons looks backwards towards the cerebellum, and presents a triangular area covered with gray matter, which forms the superior part of the anterior wall or floor of the fourth rentricle. This area is directly continuous inferiorly with the medullary part of the floor of the fourth ventricle, and is bounded on each side by a band of white matter termed the brachium conjunctivum (Fig. 482).

Brachia Conjunctiva (O.T. Superior Peduncles of the Cerebellum).-These are hidden from view by the superior part of the cerebellum, under cover of which they lie. They emerge from the lateral hemispheres of the cerebellum, and, as they proceed upwards on the dorsal aspect of the pons, they converge towards each other until, at the inferior level of the corpora quadrigemina, the medial margins of the two brachia become almost contiguous (Fig. 482, p. 550). At first they form the lateral boundaries of the superior part of the fourth ventricle; but, as they ascend and approach closer to each other, they gradually come to overhang that cavity, and thus enter into the formation of its roof. They disappear from the surface by dipping under cover of the quadrigeminal bodies and entering the substance of the mesencephalon.

Velum IMedullare Anterius.-Filling up the triangular interval between the two brachia conjunctiva, and stretching across from the medial and free margin of the one to the corresponding margin of the other, is a thin layer of white matter which completes the roof or dorsal wall of the upper part of the fourth ventricle, and receives the name of the anterior medullary velum. When traced downwards, the velum is seen to be carried, with the brachia conjunctiva, into the white matter of the cerebellum. Spread out on its posterior surface is a small, thin, tongue-shaped prolongation of gray matter from the cortex of the cerebellum, which is termed the lingula, whilst issuing from its substance close to the inferior quadrigeminal bodies are the two trochlear nerves.

\section{VENTRICULUS QUARTUS.}

Fourth Ventricle.-The fourth ventricle of the brain is somewhat rhomboidal in form. Below, it tapers to a point and becomes continuous with the central canal of the lower half of the medulla oblongata; above, it narrows in a similar manner and is continued into the aquæductus cerebri, which tumnels the mesencephalon. The posterior wall is termed the tegmen or roof and is concealed by the cerebellum. The anterior wall is called the floor and is formed by the dorsal surfaces of the medulla oblongata and pons. On each side a long, curved and narrow prolongation of the ventricular cavity is carried laterally from its widest part and curves round the upper part of the corresponding restiform body. This is termed the recessus lateralis. The roof of the cavity is rery thin and is intimately connected with the cerebellum. It is better, therefore, to defer its description until that part of the brain has been studied. 
Fossa Rhomboidea (floor of the fourth ventricle). - In its inferior part the floor of the fourth ventricle is formed by the dorsal surface of the open part of the medulla oblongata, whilst in its superior part it is formed by the dorsal surface of the pons (Fig. 482). The area thus constituted is lozenge-shaped, its widest part being opposite the superior ends of the restiform bodies or inferior peduncles of the cerebellum. A thick layer of gray matter, continuous with that which surrounds the central canal, is spread out like a carpet over the ventricular floor, and covering this is the usual ependymal layer, which lines all the ventricles of the brain. The area is circumscribed by definite lateral boundaries. Thus, below, it is bounded on each side by the clava, the cuneate tubercle, and the restiform body; whilst above, the lateral limits are formed by the brachia conjunctiva.

The fossa rhomboidea is divided into two lateral and symmetrical portions by a median groove. Its lower narrow pointed portion between the two clavæ receives the name of the pars inferior, or, from its fancied resemblance to the point of a pen,

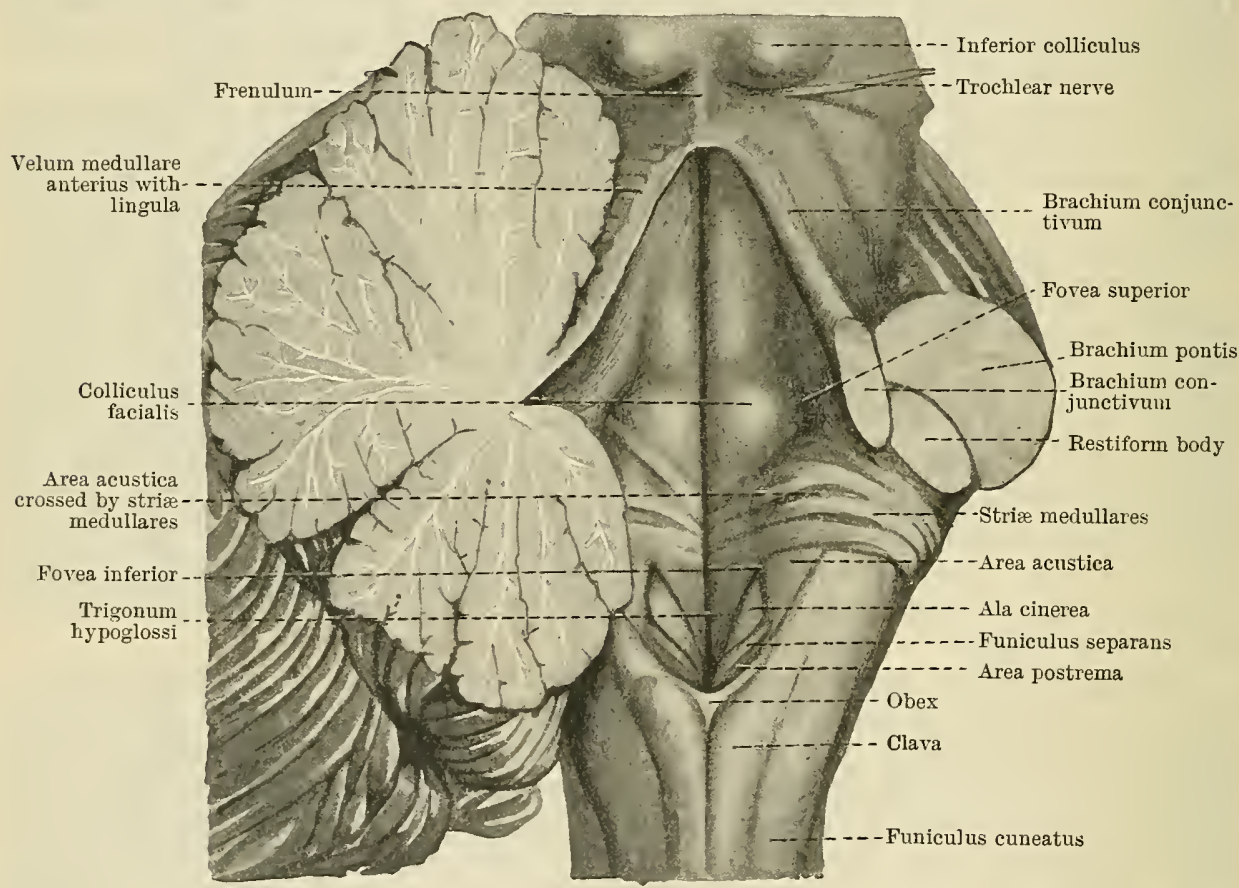

Fig. 482.-Floor of the Fourth Ventricle. On the right side the right half of the cerebellum has been removed by cutting through its three peduncles and dividing it in the median plane. On the left side the left half of the cerebellum is drawn over to the left so as to expose the floor of the ventricle fully.

the calamus scriptorius. Crossing each half of the floor, at its widest part, are several more or less conspicuous bundles of fibres termed the striæ medullares. They begin upon the lateral and posterior aspects of the restiform body, where they spring from the cochlear nuclei, pass transversely medially, and disappear from view in the median furrow. The strix medullares exhibit a large amount of variation in different specimens, both in their degree of prominence and also in the direction which they pursue. It is not uncommon to find that no trace of them is visible upon the surface.

On the inferior (bulbar) district of the ventricular floor a small triangular depression, placed immediately below the strix medullares, catches the eye. This is termed the fovea inferior. It is shaped somewhat like an arrow-head. The apex or point looks towards the striæ, whilst the lateral angles of the base are prolonged downwards in the form of diverging grooves (Fig. 482). Of these, the medial groove runs towards the opening of the central canal at the calamus scriptorius, whilst the lateral groove runs towards the lateral boundary of the floor. In this 
manner the portion of the floor which lies below the striæ medullares is mapped out into three triangular areas. The medial subdivision is slightly elevated and is telmed the trigonum nervi hypoglossi, because subjacent to the medial part of this area is the nucleus of origin of the hypoglossal nerve. The intermediate area between the two diverging grooves which proceed from the base of the fovea inferior is the ala cinerea. It is sometimes called the trigonum $\mathrm{n}$. vagi because the nucleus of the vagus and the glossopharyngeal nerves lies subjacent to it. Near the lateral angle is the area acustica. The base of this area is directed upwards and runs continuously into an eminence over which the strix medullares pass. Subjacent to this district of the floor of the ventricle lies the large terminal chief nucleus of the vestibular division of the acoustic nerve. A more accurate name for the area acustica would be area vestibularis.

A close inspection of the pars inferior fossæ rhomboidex will show that the base of the trigonum vagi is separated from the medial margin of the clava by a narrow lanceolate strip of the ventricular floor, to which Retzius has given the name of area postrema. Beneath this area is some vascular tissue (Streeter), and marking it off on its superior and medial aspect from the base of the trigonum vagi there is a translucent cord-like ridge called the funiculus separans.

When the floor of the ventricle is examined under water with a magnifying glass, the trigonum hypoglossi is seen to consist of a narrow medial strip which corresponds to the hypoglossal nucleus, and a wider lateral part which has been shown to be the surface representation of another nucleus termed the nucleus intercalatus (Streeter).

On the part of the floor of the ventricle which lies above the strix medullares, and corresponds to the dorsal surface of the pons, there is also a slight depression, termed the fovea superior. Between it and the median groove is a marked prominence called the eminentia medialis. Inferiorly this elevation passes downwards and becomes continuous with the trigonum hypoglossi, whilst superiorly it is carried upwards towards the opening of the aquæductus cerebri. In both directions it gradually becomes less prominent, but still it forms a distinct elongated elevation, which stretches alongside the whole length of the median groove. As already stated, the area acustica extends upwards into the pontine part of the ventricular floor and forms an elevated region in the most lateral part of its widest portion, below and to the lateral side of the fovea superior. Proceeding upwards from the fovea superior to the opening of the aquæductus cerebri there is a shallow depression termed the locus cœruleus, seeing that it usually presents a faint slate-blue colour. When the ependyma is scraped away from the surface of this part of the floor, the colour is seen to be due to the substantia ferruginea, - a name applied to a linear group of strongly pigmented cells, which lies in the lateral part of the gray matter covering this portion of the ventricular floor. When transverse sections are made through the superior part of the pons, the substantia ferruginea appears on the cut surface as a small black spot or dot.

\section{INTERNAL STRUCTURE OF MEDULLA OBLONGATA AND PONS.}

The structure of the medulla oblongata and pons differs in a marked degree from that of the spinal medulla: indeed in its superior part it presents very little in common with the latter. Some of the largest fasciculi which come up from the spinal medulla (such as the funiculus posterior) end in the lower part of the medulla oblongata; others leave the medulla oblongata and pass into the cerebellum; and of the bundles of fibres which pass upwards or downwards, from or to the spinal medulla respectively, most of them come to occupy very different positions in the medulla oblongata and pons.

The gray matter instead of being moulded into one compact column, as is the case in the spinal medulla, becomes broken up into a series of discrete nuclei. Thus, there are developed from the basal lamina of the rhombencephalon not one compact mass like the spinal anterior column, but three distinct broken columns of efferent nuclei (Fig. 526, p. 593):-(1) a medial somatic column, which in turn is broken up into two parts, a bulbar nucleus (the hypoglossal) which supplies the motor fibres to the tongue muscles, and a pontine nucleus (the abducens) which supplies the lateral rectus of the eye; (2) a lateral somatic column broken up into separate nuclei, viz., accessorius, ambiguus, facial, and trigeminal supplying the 
sterno-mastoid and trapezius muscles and the striated muscles of the larynx, pharynx and face and those concerned with mastication; and (3) a splanchnic column of nuclei giving efferent fibres, which pass out in the vagus, glossopharyngeal and facial nerves to be widely distributed to unstriped muscle, glands and other tissues in the head, neck, thorax and abdomen.

The terminal nuclei of the sensory nerves which are developed in the alar lamina of the rhombencephalon again do not unite to form a definite posterior column, as happens in the spinal medulla, but form discrete masses; and as these act as receptive organs for a much greater variety of sensory nerves than are represented in the spinal nerves there is a much greater number of nuclei than would be formed if the various components of the posterior column in the spinal medulla were dissociated. Thus, there are terminal nuclei in the medulla oblongata not only for the ordinary cutaneous nerves, but also for nerves coming from the mucous membranes of the alimentary and respiratory organs, as well as from other visceral structures; and there are also special nerves of taste (nervus intermedius and glossopharyngeal), hearing (cochlear part of the acoustic) and equilibration (vestibular part of the acoustic). But this does not exhaust the peculiar features of the terminal sensory nuclei of the rhombencephalon. In the description of the spinal medulla attention was called to the fact that certain of the fibres of the posterior nerve-root did not end in the gray matter of the spinal medulla, but passed upwards throughout the whole length (above their points of entry) of the funiculus posterior to reach the medulla oblongata. Special terminal nuclei are developed from the alar lamina to receive these fibres. They are the nucleus gracilis and nucleus cuneatus.

Then again, part of the terminal vestibular nucleus receives accessions of fibres from these (gracile and cuneate) nuclei as well as from other sensory terminal nuclei in the spinal medulla and develops into that great mass of tissue, the cerebellum, to which vast numbers of other fibres come and go, adding considerably to the complexity of the region of the pons and medulla oblongata. Moreover, there is developed from the alar lamina a whole series of other masses of gray matter-the nucleus olivaris inferior, nuclei arcuati, nucleus pontobulbaris and nuclei pontis-as links in the complex chains that bind all parts of the central nervous system to the great co-ordinating mechanism of the cerebellum.

Thus it comes about that, instead of having, as in the spinal medulla, a definite column of gray matter ensheathed in a thick mass of white substance, the rhombencephalon is composed of many scattered masses of gray matter; and its white substance is represented partly by great longitudinal strands, but also by many great systems of fibres passing transversely through its substance or, as in the pons and many of the arcuate fibres, upon its surface.

From what has already been said concerning the external form of the medulla oblongata and pons it will be apparent that the curious distortion of the neural tube which occurred as the result of the pontine flexure has also been largely responsible for the distinctive features of this region of the brain.

As the pontine flexure develops, a strain is thrown upon the thin roof-plate, which yields and becomes stretched so as to permit the thick lateral walls of the neural tube to fall laterally (Figs. 483 and 484). One result of this process is the great lateral expansion of the cavity of the hind-brain, which assumes the characteristic rhomboid form. If the thin and greatly attenuated epithelial roof is torn away from the rhombencephalon of an embryo of the third month the fourth ventricle will present the appearance (viewed from behind) shown in Fig. 483. The ventricle is seen to be prolonged laterally, on each side, to form a little recess upon the lateral aspect of the rhombencephalon. This is called the recessus lateralis.

This thin epithelial roof becomes invaginated towards the cavity of the fourth ventricle, on each side of the median plane, in the whole length of the epithelial roof, i.e. from the cerebellar attachment above almost as far as the closed part of the medulla oblongata below (Fig. 519). The upper end of this invaginated fold becomes prolonged laterally as far as the extremity of the recessus lateralis (Fig. 527). Pia mater and blood-vessels extend into these folds, which are then known as the chorioid plexuses of the fourth ventricle. At the extremities of these two 
plexuses, which are situated at the three corners of the epithelial roof of the ventricle, oval or elliptical perforations develop in the roof at about the fifth month of fotal life. These are known as the apertura medialis ventriculi quarti (O.T. foramen of Magendie), which opens between the clavæ on the posterior surface and the aperturæ laterales upon the anterior (Fig. 527), behind the insertion of the glossopharyngeal nerve on each side. Through each of these lateral openings the great swollen cauliflower-like extremity of the chorioid plexus becomes extruded from the ventricle. The inferior extremities of the two plexuses lying side by side present an analogous relationship to the apertura. medialis, but they are exceedingly attenuated and the epithelial lamella from which they spring becomes dragged backwards into contact with the cerebellum (Fig. 477), so that, when seen from below, the apertura medialis is a great funnel-shaped tube leading into the fourth ventricle and the chorioid plexuses look like two delicate vascular fringes on the cerebellum.

These three apertures are the only means provided for the escape of the fluid contained in the ventricles of the central nervous system. The fluid is poured into a space, enclosed by the arachnoid, which is called the subarachnoid space.

As a result of the pontine flexure the lateral walls of the neural tube in the neighbourhood of the bend fall away the one from the other and eventually come to be placed in the same transverse plane,

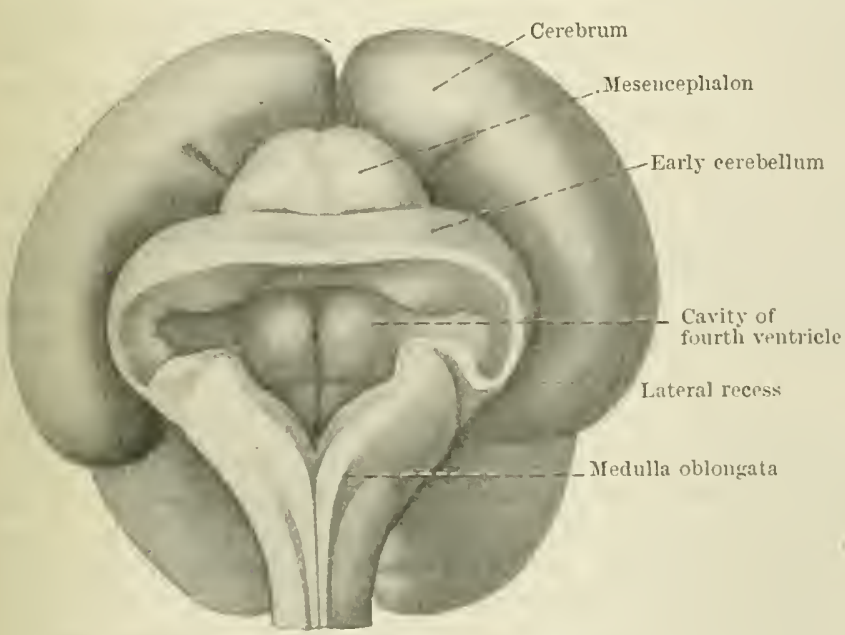

Fig. 484.-THE BRAIX OF AN EMBRYo OF ELEvex WrEks, viewed from behind. The epithelial roof of the fourth ventriale has heen removed. At this stage the cerebellum is in the form of a simple band or plate which arches over the posterior aspect of the anterior part of the cavity of the hind-brain. (From His.)

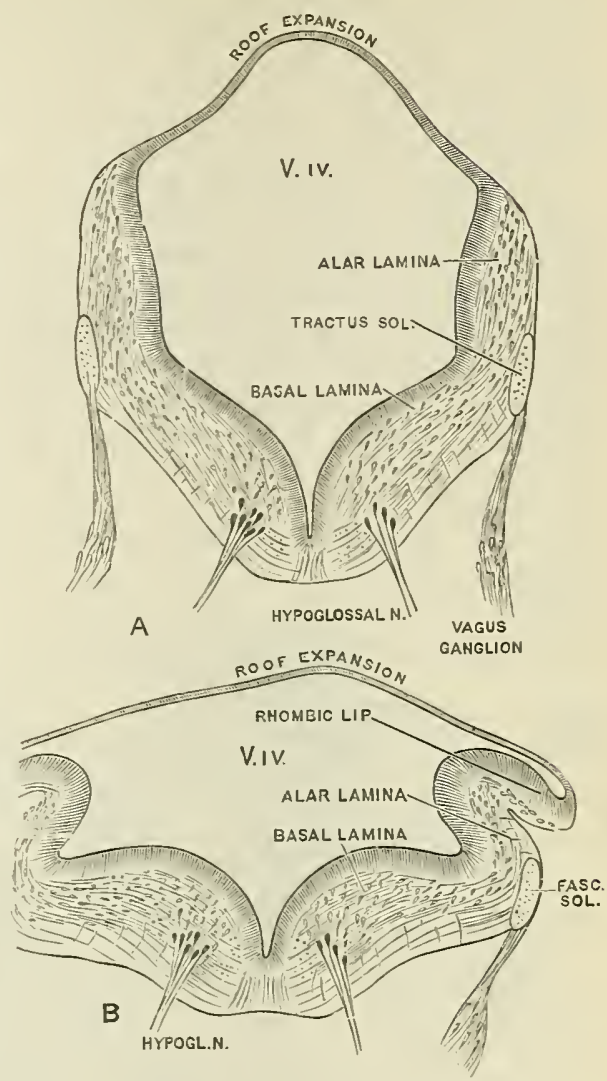

Fig. 4S3. - TraNSVERSE SECTIONS ACROSS THE Medudal Oblontiata in two Hodrax EMbryos, REPRESENTING Differext Stages iN THE ExPATSION OF THE ROOF AND THE FALLING LATERALLY OF THE LATERAL WALLS. (From His, slightly modified.)

one with the other and also with the floor-plate. At the time this process is in operation (see Fig. 483) the alar and basal laminæ are particularly well defined, and the limiting sulci are accentuated by the bending of the lateral wall; but this sharp distinction is soon lost as the result of the great expansion of the basal lamina (Fig. 485). This is due not only to growth of its intrinsic elements, but eren more to its inrasion ly large numbers of neviroblasts which migrate from the alar into the basal lamina. 
Later still the development of the great sensory and motor tracts contributes largely to the dimensions of the basal lamina.

As the two basal laminx (one on each side of the median plane) increase in thickness the epithelial cells in the intervening floor-plate become stretched and lengthened (Fig. 483), so that a definite septum or raphe is formed between the two halves of the rhombencephalon.

The fate of the extreme posterior edge of the alar lamina is a very curious one. The nervus acusticus is inserted into this edge in the region of the recessus lateralis, and from it masses of neuroblasts develop to form receptive nuclei for the two parts of this nerve, these being the cochlear and vestibular. These are the nucleus cochlearis and nucleus vestibularis respectively. Sensory fasciculi, bringing impulses from muscles, skin and related structures in all parts of the body, make their way into the superior part of the vestibular nucleus, and it grows and forms a large thickening of the posterior edge above the recessus lateralis. Eventually as it extends medially (Fig. 484) it reaches and invades the roof-plate and fuses with the corresponding rudiment of the other side. Thus a semilunar band, the primitive cerebellum, is formed, arching across the posterior aspect of the metencephalon. The part of the dorsal edge which lies below the vestibular nucleus becomes bent over (forwards) to form what is known as the rhombic lip (Fig. 483). It is destined to be transformed into a series of masses of gray matter, the chief

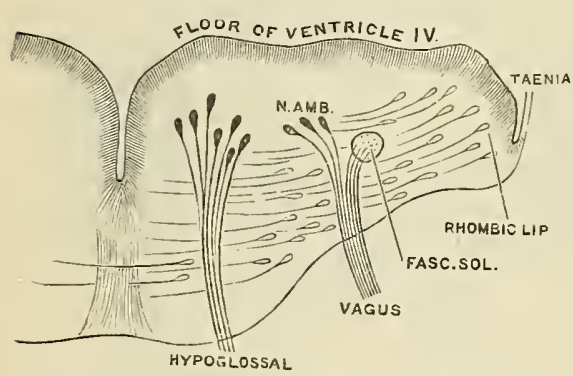

Fic. 485.-Transverse Section of the Huxir Embryo at a Later Stage than those SHown in Fig. 483. (After His.) function of which is to emit fibres to carry impulses into the cerebellum. But most of these fibres pass not so much to the part of the cerebellum derived from their own side but to that of the opposite side. Thus, from above downwards, the thickened margin of the fossa rhomboidea on each side develops into the following structures:-cerebellum, the rest of the vestibular nucleus, the cochlear nucleus, the nuclei pontis (and arcuate nuclei), the olivary nucleus, the nucleus gracilis and nucleus cuneatus. At an early stage of development most of the neuroblasts that form the rudiments of the nuclei pontis, nuclei arcuati, and nucleus olivaris inferior begin a curious process of migration, the course of which is determined by the source and direction of the afferent tracts passing into each nucleus. Such migrations are of common occurrence throughout the brain, and attempts to explain them have given rise to much discussion. The attractive force which appears to lead certain nerve-cells away from the place where they originally developed has been called neurobiotaxis by Ariens-Kappers. But the solution of the problems of these migrations is quite a simple one. If we take the case of a nerve-cell $(A)$ at an early stage of development, which collects afferent impulses through its dendrites from the cell $B$, and emits an efferent impulse through its axon to the cell $C$, as the whole nervous system is very small at the stage under consideration, the three cells necessarily will be comparatively close the one to the other-a fact which may be represented by the positions of the letters thus:-

$$
B-A-C \text {. }
$$

In the course of subsequent growth it must inevitably happen that the points $B$ and $C$ will become removed further and further apart. If we suppose that the cell $B$ remains constant the cell $A$ will be faced with two alternatives if it is to continue to link together the elements $B$ and $C$ : either its dendrites or its axon must elongate. Now the axon is specially modified in structure for conducting impulses for long distances, and the dendrites are not so specialised. Therefore it invariably happens that it is the axon that becomes lengthened. In other words the cell-body $A$, considered in its relations to $C$, appears to migrate towards the direction $B$ from which its chief supply of afferent impulses comes. This may be represented thus:- 
In the specific case we are considering the vestibular nucleus and the cerebellum receive their chief supply of afferent fibres from the incoming vestibular nerve: hence there is no reason for migration. Similarly the nucleus gracilis and nucleus cuneatus receive the fibres which come up through the funiculus posterior and remain where they are. But the nuclei pontis, the olivary nucleus, and the arcuate nuclei are "fed" with impulses passing downwards (and some perhaps upwards) in the basal lamina, close to the median plane, and they "migrate" towards the direction from which their afferent paths are approaching; the nuclei pontis towards the peduncles of the cerebrum bringing cerebro-pontine fibres from the cerebral cortex, and the olivary nucleus to the neighbourhood of certain descending tegmental tracts and ascending spinal sensory tracts that seem to supply the attractive force, which leads them to forsake the rhombic lip of the alar lamina and migrate in to the basal lamina.

The majority of the cells destined to form the nuclei pontis wander obliquely upwards and forwards between the facial and acoustic nerves to reach the basal

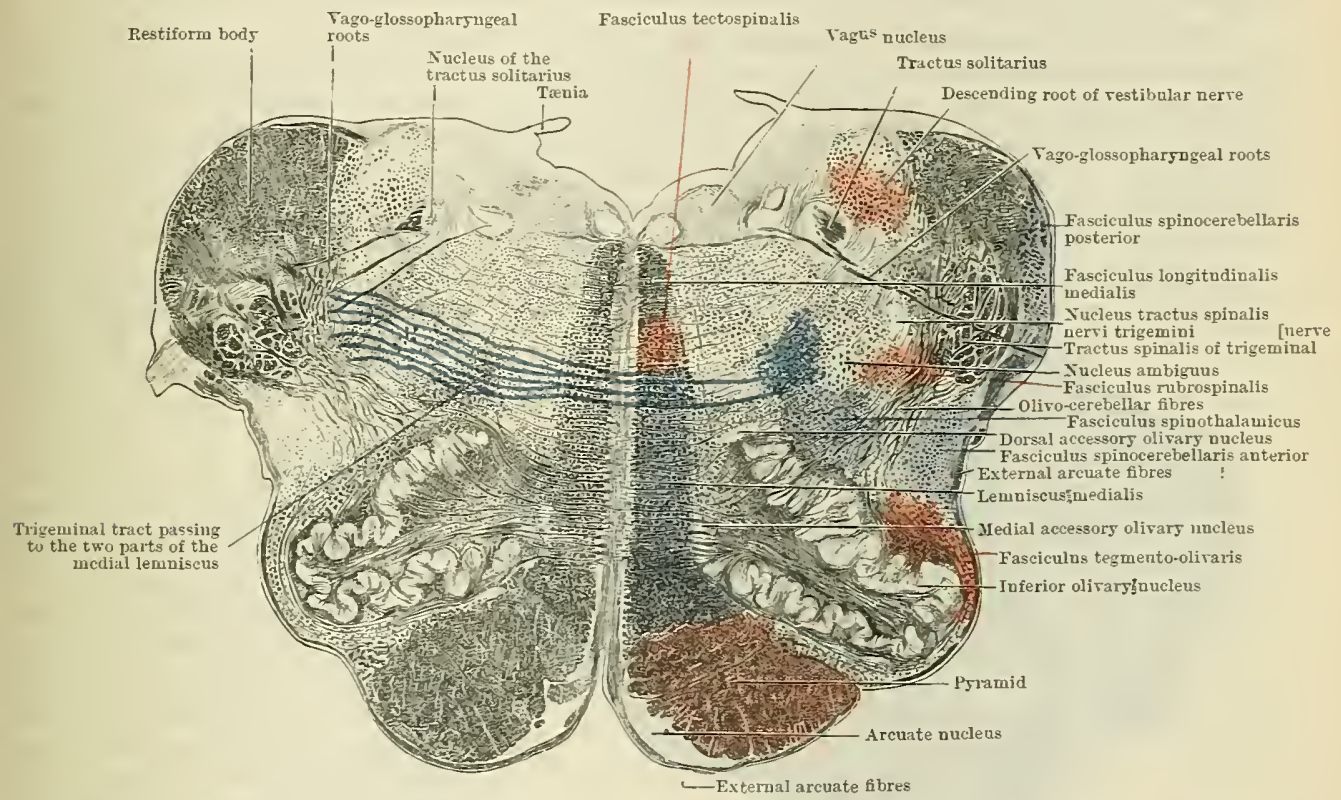

Fig. 486. - Transverse Sectiox throdgh the Middle of the Olifary Region of the Homax Medulla OBLONGATA.

The floor of the fourth ventricle is seen, and it will be noticed that the restiform body, on each side, has now taken definite shape. Some of the descending tracts in red; ascending tracts in blue.

lamina of the metencephalon. But strewn along this pathway from the edge of the fossa rhomboidea to the front of the pons are scattered nerve-cells which have, so to speak, fallen by the way, and remain to indicate in the adult brain the path taken by the majority of their sister cells. This remnant forms the corpus pontobulbare: the pontine fibres that spring from its cells and are making their way upwards to fall in line (Fig. 499, p. 566) with the other transverse fibres of the pons form the fasciculus obliquus [pontis], and the cerebro-pontine fibres that pass below the pons in order to reach this outlying part (corpus ponto-bulbare) of the nuclei pontis constitute the fasciculus circumolivaris pyramidis (Fig. 517, p. 583).

But not all of the elements of the nuclei pontis that migrate pass into the metencephalon; a certain proportion of them invariably pass into the myelencephalon. These collect upon the anterior surface of the pyramids to form small irregular patches of gray matter which have receired the name nuclei arcuati. Their afferent fibres (probably cerebro-pontine) come from the pyramids; and their efferent fibres (which proceed to the cerebellum) form some of the fibræ arcuatæ externæ, which are visible upou the surface of the medulla oblongata (Fig. 486).

Olivary Nuclei.-The most conspicuous of the isolated clumps of gray matter 
in the medulla are the inferior olivary nucleus and the two accessory olivary nuclei. The nucleus olivaris inferior is the mass of gray substance which produces the swelling known as the olive, and constitutes a very striking object in transverse sections through this region. It presents the appearance of a thick wavy or undulating line of gray matter, folded on itself, so as to enclose a space filled with white matter. It is in reality a crumpled lamina arranged in a purse-like manner, with an open mouth or slit, which is called the hilus (hilus nuclei olivaris), directed towards the median plane. The hilus does not reach either extremity, so that in transverse sections through either end of the nucleus the gray lamina is seen in the form of a completely closed capsule. Into and out of the open mouth of the olivary capsule streams a dense crowd of fibres. These constitute what is called the olivary peduncle.

The accessory olivary nuclei are two band-like laminæ of gray matter, which are respectively placed on the dorsal and medial aspects of the main nucleus. In transverse section each of these nuclei presents a rod-like appearance (Fig. 486).

The medial accessory olivary nucleus (medialis) extends lower down in the medulla oblongata than the main nucleus, and it is much larger in its lower than its upper part. It begins immediately above the decussation of the pyramids, where it is seen lying on the lateral side of the cerebro-spinal fasciculus and the lemniscus medialis (Fig. 486). Higher up it lies across the mouth of the main nucleus and on the lateral side of the medial lemniscus. The dorsal accessory olivary nucleus is placed close to the dorsal aspect of the main nucleus. The two accessory nuclei fuse together before they finally disappear.

The nerve-cells of the inferior olivary nucleus are small and round, and emit a large series of short radiating, complexly branched dendrites, so that the cell-body seems to lie

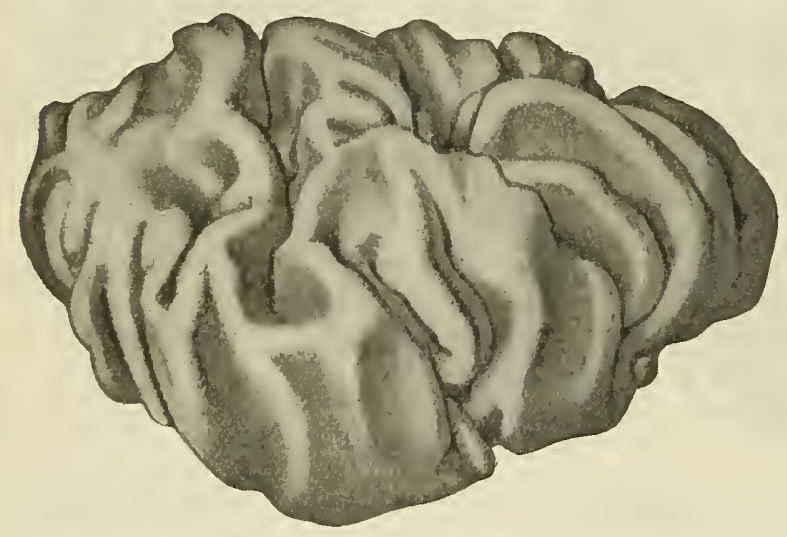

Fig. 487.-The Inferior Olivary Nucleus, as reconstructed and figured by Florence R. Sabin.

View of the dorso-lateral and lateral surfaces. in the centre of a spherical mass formed by its own dendrites and an almost equally complex mass of intertwined end branches of the axons, which bring impulses into these cells. There is no definite information as to the place of origin of these afferent fibres. Flechsig and Bechterew, using different methods of investigation, have demonstrated the presence of a large descending tract in the mesencephalon and rhombencephalon, which ends amidst the cells of the lateral pole of the olivary nucleus. This has been called the fasciculus thalamo-olivaris, but it is not quite certain that it arises
re in the neighbourhood of it. in the thalamus, although its origin must be somewhere in the neighbourhood of it.
Flechsig denies that any fibres reach the olivary nucleus from the spinal medulla, but the proximity of the spino-thalamic and bulbo-thalamic (lemniscus medialis) fibres and the demonstration of Ramon y Cajal that fibres enter the nucleus olivaris from adjoining fasciculi in these regions suggest that there may be a spinal afferent path.

There seems to be a direct relationship between the size of the inferior olivary nucleus and the extent of the cortical area that presides over highly skilled movements.

The axons emitted by the cells of the olivary nucleus cross the median raphe and pass through the opposite side of the medulla oblongata as internal arcuate fibres, which enter the restiform body and pass into the cerebellum. ${ }^{1}$

These fibres are seen only in the superior part of the medulla oblongata. They form the deep part of the restiform body and constitute its chief bulk. Streaming out from the hilus of the inferior olivary nucleus, they cross the median plane, and in the opposite side of the medulla oblongata they either pass through the inferior

1 These fibres should be called the fasciculus olivocerebellaris, by which designation they will be referred to in this account, but iu the recognised nomenclature (which most writers do not follow in this instance) the tract is called "cerebello-olivaris." 
olivary nucleus of that side or sweep round it. Ultimately, on the dorsal aspect of the olivary nucleus, they are gathered together in the form of a conspicuous group of arcuate fibres, which curve backwards to take up a position in the deep part of the restiform body. In passing back, they traverse the tractus spinalis of the trigeminal nerve and break it up into several separate bundles. The cerebello-olivary fibres thus connect the inferior olivary nucleus of one side with the opposite side of the cerebellum. Each part of the inferior olivary nucleus is connected with a definite part of the cerebellum.

Decussation of the Pyramids and the Changes produced thereby.-As we examine, under the microscope, a series of successive transverse sections through the inferior end of the medulla oblongata and the upper end of the spinal medulla, the most striking change which meets the eye is the decussation of the lateral cerebrospinal tracts. From their position alongside the anterior median fissure of the medulla oblongata most of the fibres of the pyramid cross the median plane and,

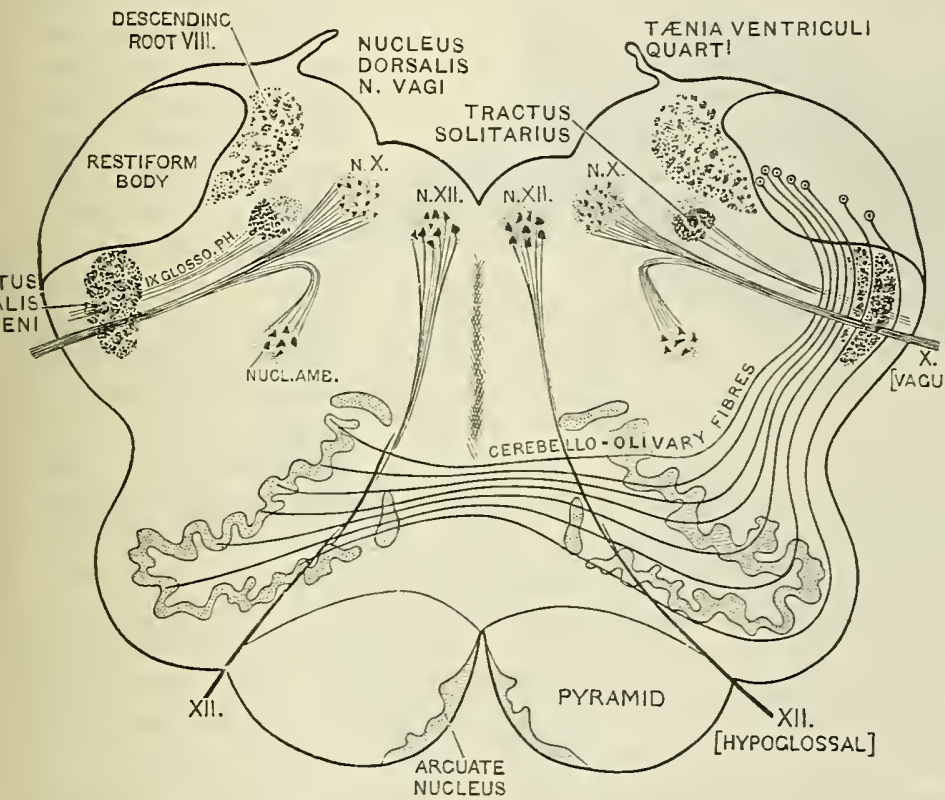

Fig. 488.-Diagram of the Fascicults Oltrocerebellaris (CerebelloOLIVARY FIBRES).

(This diagram has been constructed from the specimen figured on p. 555.) N.X., Vago-glossopharyngeal nucleus.

N.XII., Hypoglossal nucleus. after passing right through the anterior column of gray matter, bend downwards in the laterul funiculus of the opposite side of the spinal medulla. Strands from the right lateral cerebro-spinal tract alternate with corresponding strands from the left side, and the interval between the bottom of the anterior median furrow and the gray matter surrounding the central canal becomes filled up with a great mass of intercrossing bundles of fibres.

As a rule the medial three-fourths of the pyramid are composed of fibres which, lower down in the opposite lateral funiculus of the spinal medulla, form the fasciculus cerebrospinalis, whilst the lateral fourth of the pyramid proceeds downwards in the anterior funiculus of the spinal medulla of the same side, as the fasciculus cerebrospinalis anterior. A considerable amount of variation, however, occurs in the proportion of fibres which is allotted to the formation of these two tracts. Sometimes the lateral cerebrospinal tract is much larger than usual, and then the anterior cerebro-spinal tract suffers a corresponding diminution in size. Cases, indeed, occur in which the entire pyramid enters into the decussation, and in these there is no anterior cerebro-spinal tract. Further, it is not uncommon to meet with rariations of an opposite kind which lead to an increase of the anterior cerebro-spinal tract at the expense of the lateral cerebrospinal tract. Sometimes the decussation is asymmetrical, and the corresponding cerebrospinal tracts on opposite sides of the spinal medulla are then unequal in size. One factor that often comes into play and causes asymmetry is the prolongation downwards into the pyramid on one side (usually the left) of some of the cerebro-pontine fibres. In such cases these fibres soon leave the pyramid and form the fasciculus circumolivaris.

The variations indicated above receive an additional interest when viewed in the light of comparative anatomy. It would appear that only in man and the anthropoid apes is the decussation of the pyramids in the inferior part of the medulla oblongata incomplete. 
According to Sherrington, an anterior cerebro-spinal tract in the spinal medulla of the anthropoid apes stands in connexion with the arm-centre in the cerebral cortex. If this is the case in man it must have other comnexions as well, seeing that it is carried down the spinal medulla for a considerable distance beyond the level of the spinal segments which give motor fibres to the upper limb. In the lower apes an anterior cerebro-spinal tract

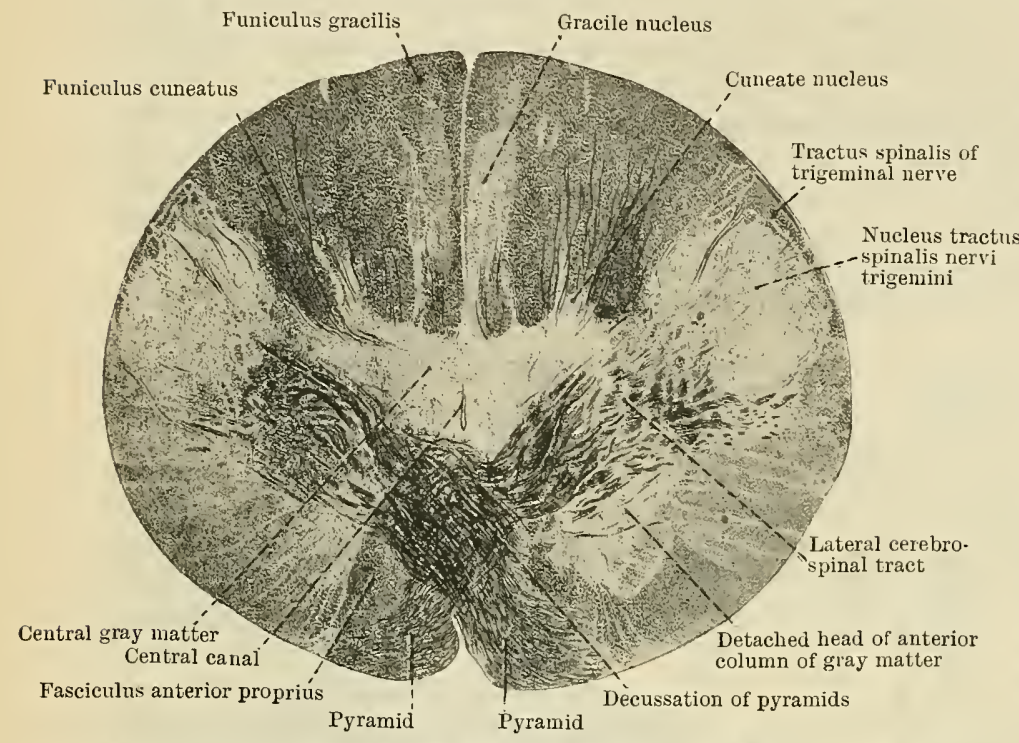

Fig. 489.-Section throdgh the Inferior End of the Medulla Oblongata oF A ChimpanzeE. does not seem to exist: the whole pyramid crosses over to the opposite side of the spinal medulla in the shape of the lateral cerebrospinal tract.

As we have noted, the decussating pyramidal bundles pass through the anterior column of gray matter, and cut it into two portions (Figs. 489 and 490). The basal part remains in position on the anterior and lateral aspect of the central canal, and forms part of the thick layer of gray matter which surrounds it. The detached head of the anterior column is set free; and from the large multipolar cells which lie in its midst some of the fibres of the anterior root of the first cervicabnerve, and also some of the root fibres of the accessory nerve, take origin.

As we proceed into the medulla oblongata another effect of the decussation of the pyramids is seen in the submergence from the surface of the strand of fibres which, in the anterior funiculus of the spinal medulla, lies to the lateral side of the anterior cerebro-spinal tract, and which receives the name of the fasciculus anterior proprius. While the decussation is going on the fasciculus proprius is thrust aside, and in the medulla oblongata, it takes up its position as a flattened band-like strand on the lateral side of the pyramid (Fig. 489). When the decussation is completed, this strand is seen to lie close to the median plane on the dorsal aspect of the pyramid, where it is separated from its fellow of the opposite side by the median raphe alone (Fig. 491). In the upper part of the medulla oblongata it approaches still nearer to the dorsal surface and appears to form

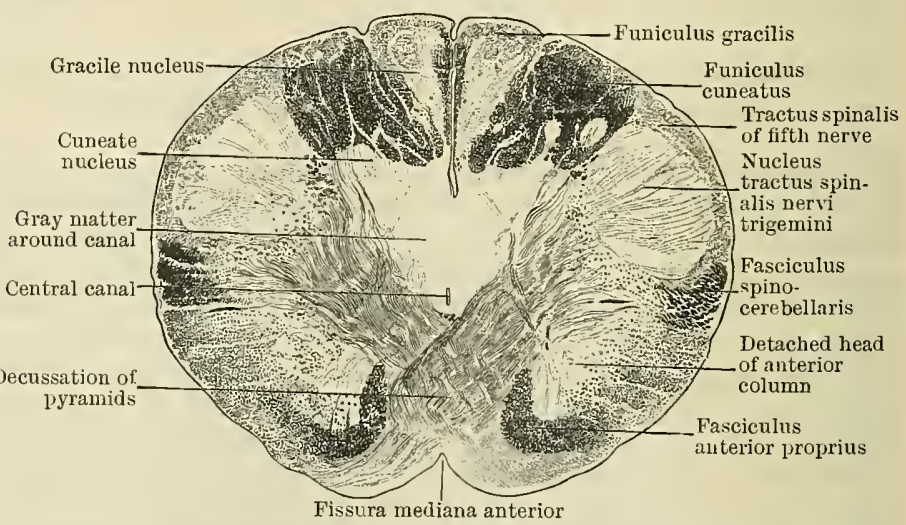

Fig. 490.- Transverse Section through the Inferior End of the Medulla Oblongata of a full-time Feetus,

Treated by the Weigert-Pal method. The gray matter is bleached white, and the medullated tracts of fibres are black. the greater part of a strand, which is termed the medial longitudinal bundle (Figs. 494 and 495). The detached head of the anterior column of gray matter of the spinal medulla, 
as it is traced upwards, is observed to cling closely to its original relationship with the fasciculus anterior proprius. It is applied to the lateral side of this strand, and, gradually becoming smaller, finally disappears at the level of the inferior part of the inferior olivary nucleus.

Cuneate and Gracile Fasciculi, with their Nuclei.--As the fasciculus gracilis and the fasciculus cuneatus of the posterior funiculus of the spinal medulla are traced up into the medulla oblongata they seem to increase in bulk, and in transverse sections they assume the form of massive wedge-shaped strands, quite distinct from each other. They increase in width and lose considerably in depth, and consequently the transverse diameter of the area which they occupy becomes greater. As a result of this, and also owing to the removal of the lateral cerebro-spinal tract from the lateral funiculus of the spinal medulla immediately in front, the posterior column of gray matter is gradually rotated forwards and comes to lie transversely and in the same straight line with its fellow of the

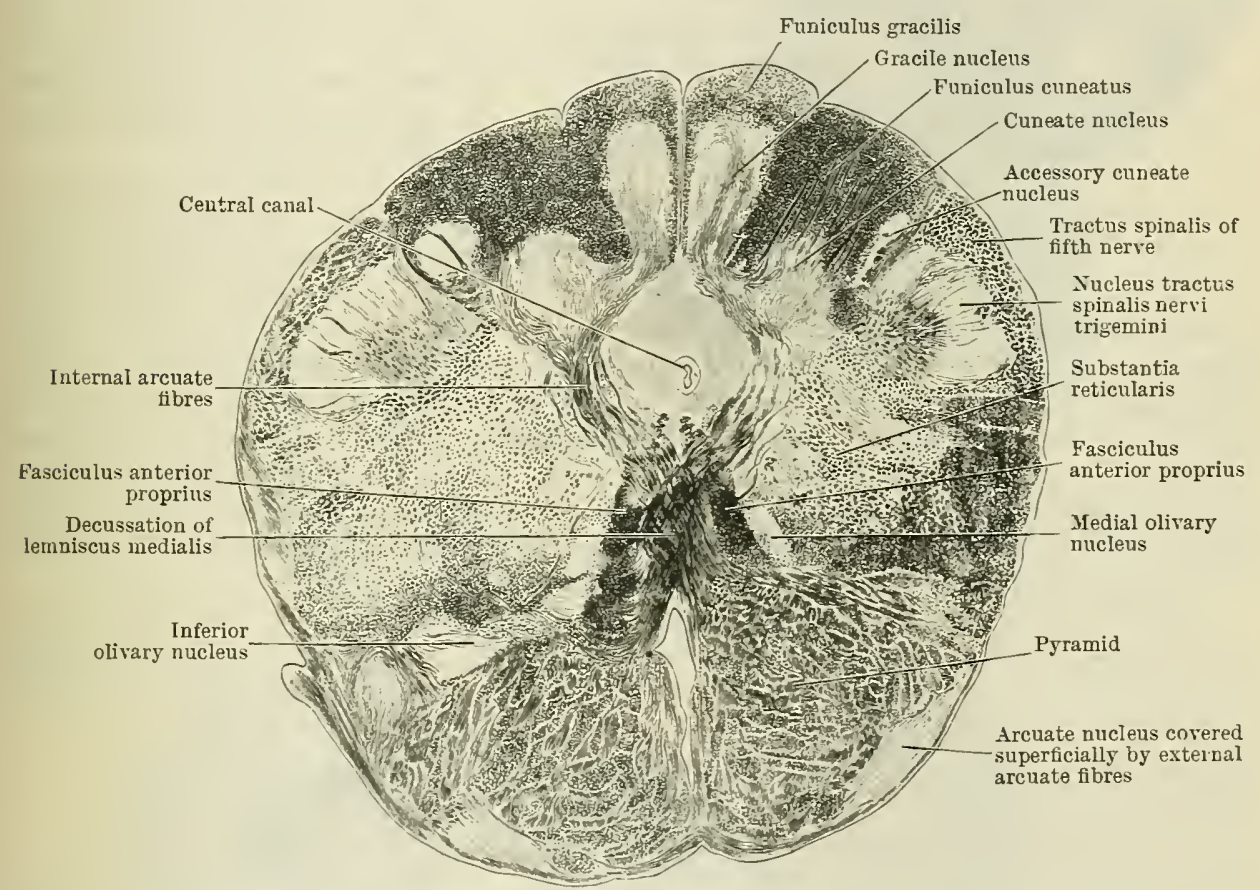

Fig. 491. - Section throdgh the Closed Part of the Homan Medulla Oblongata immediately above the Decussation of the Prramids (Weigert-Pal specimeil).

opposite side (Figs. 490 and 491). The substantia gelatinosa, at the same time, becomes increased in quantity and presents a horseshoe-shaped outline in transverse section. It clasps within its concavity the somewhat reduced head of the posterior column, and forms with it a conspicuous circular mass of gray matter which lies close to the surface, and produces upon it the bulging termed the tuberculum cinereum. The basal portion of the posterior column of gray matter remains upon the dorsal and lateral aspect of the central canal, and forms a portion of the central gray mass of the closed part of the medulla oblongata; but very soon the neck of the column, which at this level is greatly reduced owing to the alsence of entering posterior nerve-roots, is invaded by bundles of fibres which traverse it in different directions and convert it in to a formatio reticularis. By this means the rounded head of the posterior column becomes cut off from the central gray matter, and from this point upwards it remains as an isolated gray column intimately associated with the spinal root of the trigeminal nerve. It has, in fact, become the nucleus tractus spinalis nervi trigemini.

The gracile and cuneate nuclei are seen in their most typical form in sections at the level of the decussation of the pyramids (Figs. 489 and 490). The gracile 
nucleus appears in the form of a relatively slender mass of gray matter in the interior of the funiculus gracilis.

The cuneate nucleus is a direct offshoot from that part of the base of the posterior column of gray matter which is preserved as a portion of the central gray mass. In transverse section it is seen to invade the funiculus cuneatus upon its deep aspect, and it gradually grows backwards into its substance. It presents

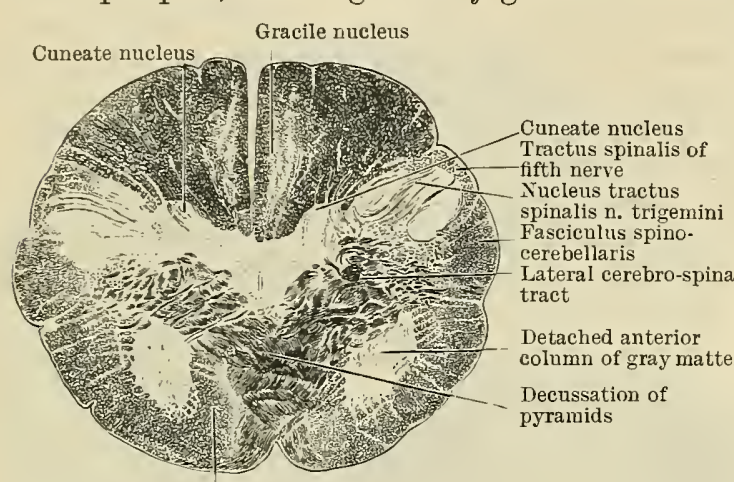

Anterior basis-bundle

Fig. 492.-Section throdgh the INferior Part of THE Medulla Oblongata of the ORang. a very different appearance from the gracile nucleus, because throughout its whole length the gray nucleus and the fibres of the strand are separated from each other by a sharp line of demarcation. A little higher up a second and much smaller mass of gray matter appears in the funiculus cuneatus, superficial to the main nucleus. This is termed the accessory or the lateral cuneate nucleus (Fig. 491).

As a series of sections is studied from below upwards, it will be noticed that the number of fibres in the gracile and cuneate funiculi rapidly decreases, until, at the level of the clava and cuneate tubercles, it is seen that these eminences are composed almost entirely of the gray nuclei, covered by a thin layer of the few remaining fibres of the two fasciculi involved. It would appear that no fibres belonging to the funiculus gracilis and funiculus cuneatus get beyond these nuclei. They all end in fine terminal ramifications around the cells of the nuclei. In the case of the funiculus cuneatus the bundles of fibres, as they pass from the surface into the subjacent gray nucleus, are very distinctly seen in transverse sections through the bulb.

When the medulla oblongata opens up into the fourth ventricle the gracile and cuneate nuclei are pushed laterally by the expanding ventricular floor, and the gracile nucleus soon comes to an end; but the cuneate nucleus extends upwards for a short distance farther, and terminates only when the restiform body begins to take definite shape on its lateral aspect.

Decussatio Lemniscorum.Immediately above the level of the decussation of the pyramids another decussation of fibres takes place in the substance of the medulla oblongata in the median plane, and upon the dorsal aspect of the pyra-

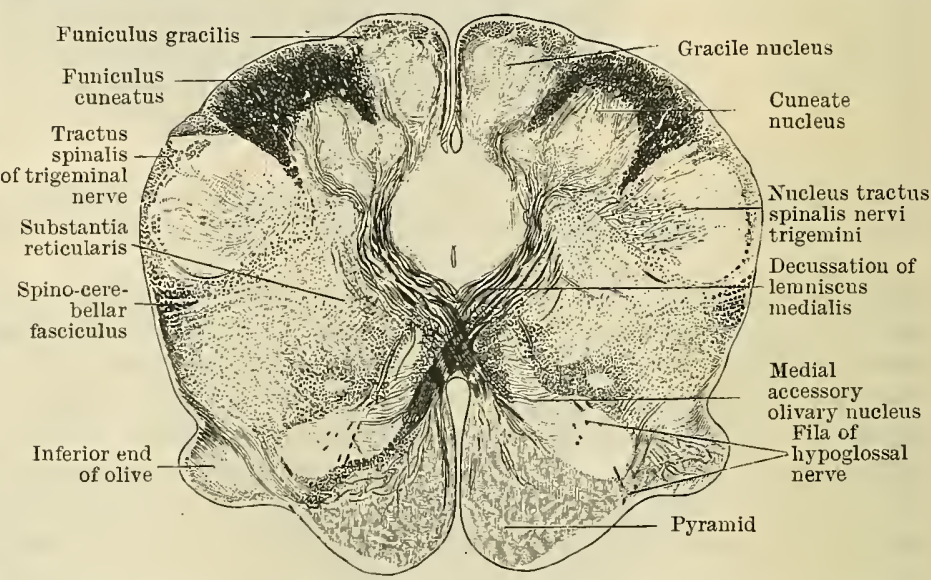

F'ig. 493.-Transverse Section throdgh the Closed Part of a Fatid Medolla, immedately above the Decussation of the Prrairids. Treated by Weigert-Pal method.

mids. This is the decussation of the lemniscus medialis, or the sensory decussation, so-called in contradistinction to the term "motor decussation," which is sometimes applied to the decussation of the pyramids. The fibres which take part in this decussation are called internal arcuate fibres, and they are derived from the cells of the gracile and cuneate nuclei. From the deep aspects of these nuclei these fibres 
until a rery large part of each lateral half of the medulla is seen to be traversed by these arcuate fasciculi (Fig. 495). The internal arcuate fibres decussate in the median plane with the internal arcutate fibres of the opposite side. They then change their direction and turn upwards, and the lemniscus, as already stated, takes form and gradually increases in volume as it ascends. This great and important tract is thus laid down between the pyramid and the fasciculus longitudinalis medialis ; and the consequence of this is that the latter tract is pushed still farther backwards, and, when the lemuiscus is fully established, it comes to lie immediately beneath the gray matter of the floor of the fourth ventricle (Fig. 495). But the lemniscus is not in direct contact with the fasciculus longitudinalis, for a bundle of fibres, the continuation of which has been seen in the anterior funiculus of the medulla spinalis, the fasciculus tectospinalis, separates them as well as fibres coming from sensory nuclei of the cerebral nerves which are crossing the raphe to join the medial lemniscus (Fig. 495).

It is important that we should realise at this stage the full significance of the decussation of the lemniscus and have a clear conception of the connexions of the fibres which take part in it. The funiculus posterior, which ends in the cuneate and gracile nuclei, is derived from the posterior roots of the spinal nerves. The lemniscus fibres therefore carry on the continuity of part of the posterior funiculus, the gracile and cuneate nuclei, which are thrown across its path in the lower part of the medulla oblongata, merely constituting a nodal interruption. At this point the lemniscus is transferred to the opposite side of the medulla oblongata. But it will be remembered that a large proportion of the fibres of the entering posterior nerveroots of the spinal nerves end in connexion with the cells of the posterior column of gray matter of the spinal medulla. It must not be supposed that the path represented by these latter fibres comes to a termination thereby; from these posterior column cells other fibres arise which cross, in the anterior white commissure, to the opposite side of the spinal medulla and proceed up the spinal medulla to the lateral part of the medulla oblongata. These fibres constitute the spino-thalamic tract already referred to. The practical bearing of this is that, owing to the crossing of the lemniscus medialis and lower down of the spino-thalamic tract, unilateral lesions of the medulla oblongata are apt to produce complete hemi-ancesthesia; whilst unilateral lesions of the spinal medulla produce only partial hemi-ancesthesia.

The pyramid forms a massive tract in front of and quite distinct from the lemniscus medialis. The lemniscus medialis, the tecto-spinal bundle, and the medial longitudinal bundle are, in the first instance, not marked off from each other. They appear as a broad flattened band applied to the raphe. One edge of this band is directed backwards and reaches the gray matter on the floor of the fourth ventricle, while the other edge looks forwards, and is in contact with the pyramid. In the upper part of the medulla oblongata the lemniscus and the medial longitudinal fasciculus begin to draw asunder from each other. The intermediate longitudinal fibres becorne reduced in number and the two strands grow denserthe one on the dorsal aspect of the pyramid, and the other immediately beneath the gray matter of the floor of the fourth ventricle (Fig. 495).

The fasciculus longitudinalis medialis is largely formed of fibres homologous with those which in the spinal medulla constitute the fasciculus anterior proprius. As they are followed upwards these fibres are thrust back by the two decussations: the lower decussation pushing them behind the pyramids, and the upper decussation displacing them still farther backwards to a position behind the lemniscus medialis.

Corpus Restiforme.-The gracile and cuneate nuclei gradually give place to the restiform body in the superior part of the posterior district of the medulla oblongata. Fibres from various quarters converge to form this great strand. It first takes shape as a thin superficial layer of longitudinal fibres, which are gathered together on the lateral aspect of the cuneate nucleus; but after that nucleus has come to an end, and as the superior part of the medulla oblongata is reached, the restiform body is seen to have grown into a massive strand, which presents a kidneyshaped or oval outline on transverse section (Fig. 495); and it ultimately enters the white central core of the cerebellum as its inferior peduncle. The fibres which build up the restiform body are the following: (1) the fasciculus spinocerebellaris; (2) arcuate fibres coming from the nucleus gracilis and nucleus cuneatus of both 
sides of the medulla oblongata; (3) external arcuate fibres coming from the arcuate nuclei; and (4) olivo-cerebellar fibres.

The fasciculus spinocerebellaris extends upwards from the lateral funiculus of the medulla spinalis. In the lateral district of the medulla oblongata it occupies a similar position; but before the olive is reached it inclines backwards, crosses the posterior lateral furrow and passes obliquely upwards into the restiform body. As its fibres diverge backwards, they pass over and cover up the tractus spinalis of the trigeminal nerve and its nucleus, thus shutting them out from the surface. The fibres of the fasciculus spinocerebellaris, in the first instance, enter into the lateral or superficial part of the restiform body.

Bruce has shown that the fibres of the spino-cerebellar tract ultimately lie in the centre of the restiform body, forming as it were its central core, and that, in the cerebellum, they can be traced to the superior vermis.

The posterior external arcuate fibres

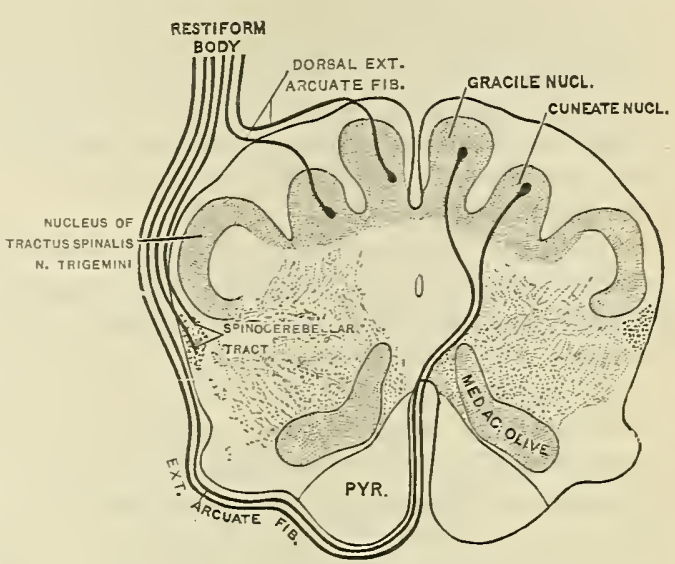

FIG. 496.-Diagrai,

Which shows in part the fibres which enter into the constitution of the restiform body. take origin from the gracile and cuneate nuclei, and enter the superficial part of the restiform body of the same side.

The anterior external arcuate fibres proceed from the inferior portions of the gracile and cuneate nuclei of the opposite side. It can easily be determined that, after decussating in the median plane, all the internal arcuate fibres which arise from these nuclei do not enter the lemniscus medialis. A large proportion of them gain the surface by sweeping round the medial aspect of the pyramid in the anterior median fissure. Many of them gain the surface by piercing the pyramid or by passing out between it and the olive. These fibres constitute the anterior external arcuate group, and on the surface of the medulla oblongata they sweep

Fasciculus gracilis Gracile nucleus

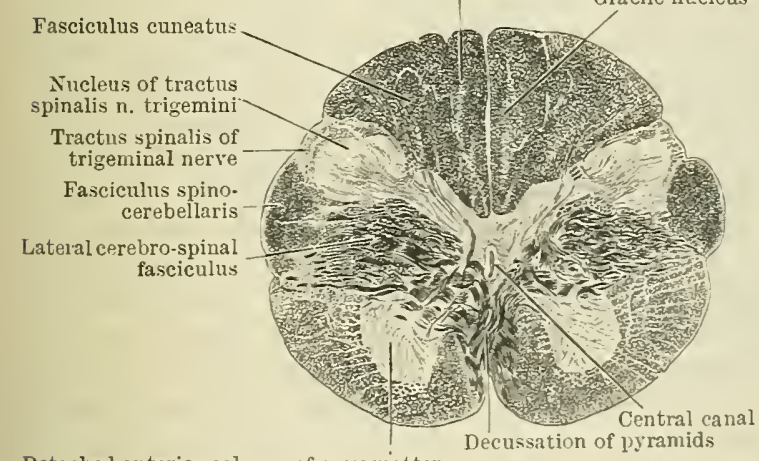

Detached anterior colmmn of gray matter

Fig. 497.-SECTION THROUGH THE JUXCTION BETWEEN THE Spinal Medulla and Medulla Oblongata of the Orang. The spino-cerebellar tract is well seen, especially on the right side. backwards around it, forming a thin layer over the olive and ultimately reaching the restiform body. The anterior external arcuate fibres, as well as the spino - cerebellar tract-fibres, cover over the tractus spinalis of the trigeminal nerve, which thus comes to take up a deeper position in the substance of the medulla oblongata (Figs. 495 and 496).

The other elements in the restiform body, viz., those derived from the nucleus olivaris inferior and the nuclei arcuati, have already been described.

Thus, the restiform body conveys to the cerebellum (1) fibres conveying impulses from the posterior spinal roots of the same and also from the opposite side of the medulla spinalis, the former after being interrupted in the nucleus dorsalis and the nucleus gracilis and nucleus cuneatus of the same side, the latter in the nucleus gracilis and nucleus cuneatus of the other side; and (2) fibres from the olivary and arcuate nuclei, which convey impulses from the higher regions of the brain, directly or indirectly (probably the latter) from the motor area of the cerebral cortex. 
Formatio Reticularis. - Behind the olive and the pyramid is the formatio reticularis. In the medulla oblongata it occupies a position which, to a large extent, corresponds with that of the lateral funiculus in the spinal medulla. In trausverse section it appears as an extensive area, which is divided into a lateral and a medial field by the fila of the hypoglossal nerve as they traverse the substance of the medulla oblongata to reach the surface. In the lateral portion, which lies behind the olive, a considerable quantity of gray matter, continuous with that in the spinal medulla, is present in the reticular formation; it is, therefore, called the formatio reticularis grisea. In the medial part, which lies behind the pyramid, the gray matter is extremely scanty, and the reticular matter here is termed the formatio reticularis alba.

The nerve-fibres which traverse the formatio reticularis run both in a transverse and in a longitudinal direction. The transverse fibres are the internal arcuate fibres. The longitudinal fibres are derived from different sources in the two fields. In the formatio grisea they represent to a large extent the fibres of the lateral funiculus of the spinal medulla, after the removal of the spino-cerebellar and the lateral cerebro-spinal tracts. They consist, therefore, of the fibres of the fasciculi rubrospinalis, thalamo-olivaris, spinothalamicus, and spinocerebellaris anterior (anterolateralis superficialis) of the spinal medulla. In the formatio alba the longitudinal fibres are the tract of the lemniscus medialis, fasciculus tectospinalis, and the medial longitudinal bundle, all of which have already been described.

Central Canal and the Gray Matter which surrounds it.-The central canal, as it proceeds upwards through the closed part of the medulla, is gradually forced to assume a more dorsal position, owing to the accumulation of fibres on its ventral aspect. (Moreover, the posterior cleft-like part of the cavity of the fotal neural tube, which becomes obliterated in the spinal medulla by the fusion of its walls, remains patent in the medulla oblongata. Hence the central canal in the closed part of the medulla oblongata extends backwards to the roof-plate.) First the decussation of the pyramids, and then the decussation of the medial lemniscus, both of which take place in front of the canal, tend to push it backwards; and the formation of the longitudinal strands in which these intercrossings result (viz., the pyramid and the medial lemniscus), together with the continuation upwards of the funiculus anterior proprius, leads to a great increase in the amount of tissue which separates it from the anterior surface of the medulla oblongata. In the closed part of the medulla oblongata the canal is surrounded by a thick layer of gray matter, which is continuous with the basal portions of the anterior and posterior columns of gray matter of the spinal medulla. This central gray matter is sharply defined on each side by the internal arcuate fibres, which curve forwards and medially around it. Finally, the central canal opens on the dorsal aspect of the medulla oblongata into the cavity of the fourth ventricle. The central mass of gray matter which surrounds the canal in the closed part of the medulla oblongata is now spread out in a thick layer on the floor of the fourth ventricle, and in such a manner that the portion which corresponds to the basal part of the anterior column of the spinal medulla is situated close to the median plane, whilst the part which represents the base of the posterior column occupies a more lateral position. This is important, because the nucleus of origin of the hypoglossal nerve is placed in the medial part of the floor, whilst the nuclei of termination of the afferent fibres of the vagus, glossopharyngeal, and acoustic nerves lie in the lateral part of the floor. The gray matter of the ventricular floor is covered with ependyma.

Three Areas of Flechsig.-In transverse sections, throngh the upper, open part of the medulla oblongata, the fila of the hypoglossal and vagus nerves are seen traversing the substance of the medulla oblongata. The nuclens of origin of the hypoglossal is placed in the gray matter of the floor of the fourth ventricle close to the median plane; the nncleus of the vagus is situated in the gray matter of the ventricular floor immediately to the lateral side of the hypoglossal nucleus. From these nuclei the root-bundles of the two nerves diverge from each other as they are traced to the surface and subdivide the substance of the medulla, as seen in transverse section, into the three areas of Flechsig, viz., an anterior, a lateral, and a posterior.

The anterior area, which is bounded medially by the median raphe and laterally by the hypoglossal roots, presents within its limits: (a) the substantia alba; $(b)$ the pyramid; $(c)$ the lemniscus medialis; $(d)$ the medial longitudinal fasciculus; $(e)$ the medial accessory olivary nucleus; $(f)$ the arcmate nuclens. 
The lateral area lies between the root fibres of the hypoglossal and those of the vagus. It contains: $(a)$ the inferior olivary nucleus; $(b)$ the dorsal accessory olivary nucleus; $(c)$ the nucleus lateralis; $(d)$ the nucleus ambiguus; $(e)$ the splanchnic efferent nucleus of the ragus and glossopharyngeal nerves; $(f)$ the formatio reticularis grisea.

The posterior area is situated behind the vagus roots, and within its limits are seen : (1) the restiform body ; (2) the superior part of the cuneate nucleus; $(3)$ to the medial side of this a crowd of transversely cut bundles of fibres, loosely arranged and forming the descending root of the restibular part of the acoustic nerve; (4) close to these, but placed more deeply, a round, compact, and very conspicuous bundle of transversely cut fibres, viz., the tractus solitarius, or descending root of the vagus and glossopharyngeal nerves; (5) the large tractus spinalis of the trigeminal nerve close to the lateral side of its nucleus composed of substantia gelatinosa.

\section{INTERNAL STRUCTURE OF THE PONS.}

When transverse sections are made through the pons, it is seen to be composed of a basilar part and a dorsal or tegmental part. The latter may be regarded as

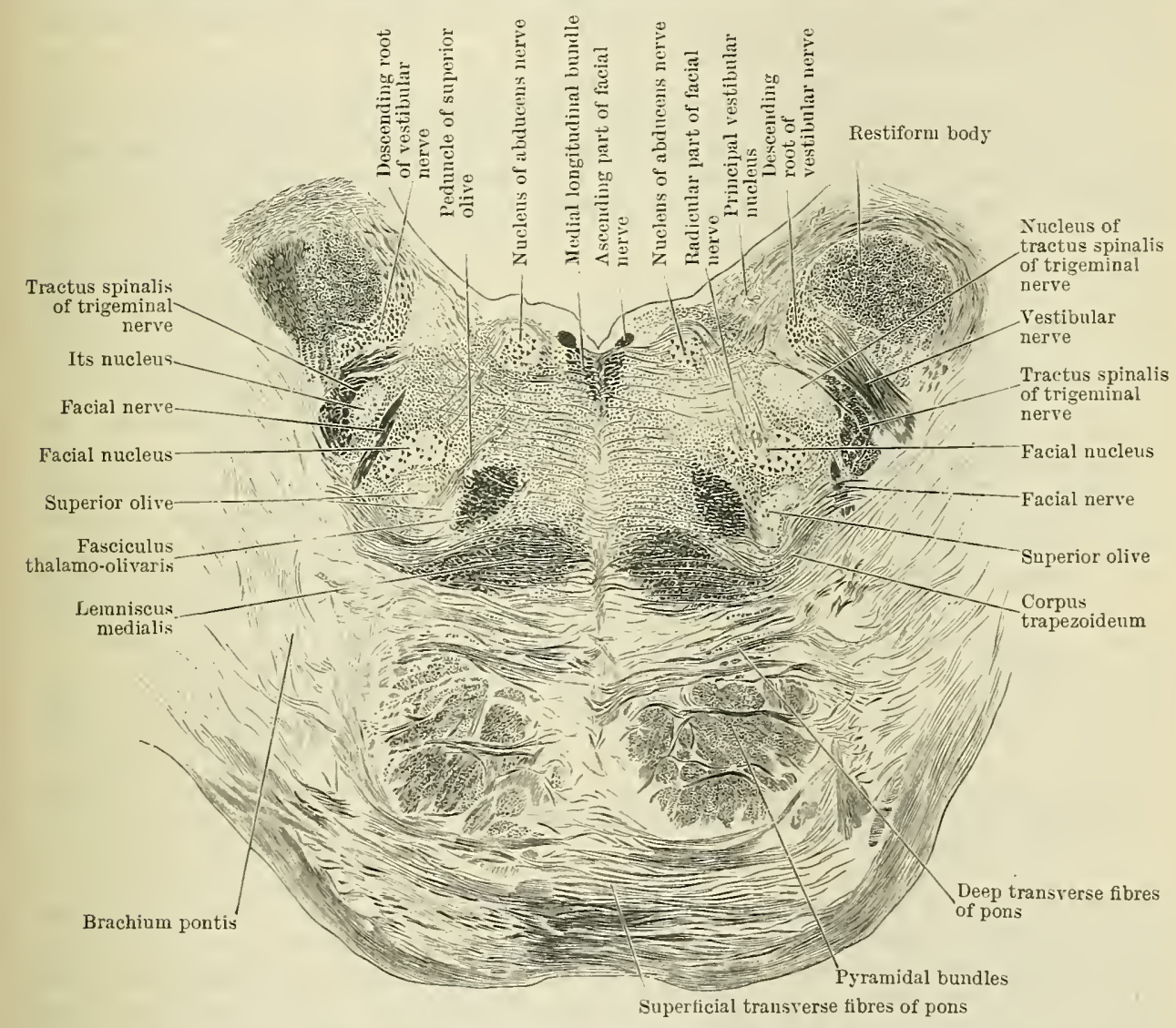

Fif, 498.-Section throdgh the Lower Part of the Homax Poxs mumedately above the MEDULIAA OBLONgata.

the upward prolongation of the medulla oblongata, exclusive of the pyramids which are drawn forward into the basilar part.

Pars Basilaris Pontis.-This constitutes the chief bulk of the pons. It is composed of: (1) transverse fibres arranged in coarse bundles, fibræ pontis; (2) longitudinal fibres, gathered together in massive bundles; and (3) a large amount of gray matter, termed the nuclei pontis, which fills up the interstices between the intersecting bundles of fibres.

The fasciculi longitudinales, to a large extent, consist of the same fibres which, lower down, are gathered together in the two solid pyramidal tracts of the medulla oblongata. When the pyramids are traced upwards into the pons they are seen to 
present the form of two compact bundles. Superiorly, however, they are broken up into smaller bundles by the transverse fibres of the pons, and are spread out over a wider area. At the upper border of the pons they again come together and form two solid strands, each of which is continuous with the central part of the corresponding basis of the cerebral peduncle. Added to these there are twice as many other fibres entering the pons from the basis pedunculi to terminate in the nuclei pontis.

The fibræ pontis at the inferior border of the pons are placed on the superficial or ventral aspect of the pyramidal bundles. As we proceed upwards they increase in number, and many are seen breaking through the pyramids and even passing across upon their dorsalaspect. Laterally, these transverse fibres are collected together into one compact mass, which enters the white central core of the cerebellum and constitutes the brachium pontis (O.T. middle cerebellar peduncle). At the median plane the transverse fibres of the two sides of the basilar portion of the pons intercross and form a coarse decussation.

The nuclei pontis form a considerable part of the bulk of the basilar portion of the pons. The gray matter is packed into the intervals between the intersecting transverse and longitudinal bundles.

There is some analogy between the pyramidal portions of the medulla oblongata and the ventral part of the pons. In the medulla oblongata fine arcuate fibres, on their way to the surface, pass through the pyramids. Other external arcuate fibres sweep over the surface of the pyramids. These present a strong resemblance to the transverse fibres of

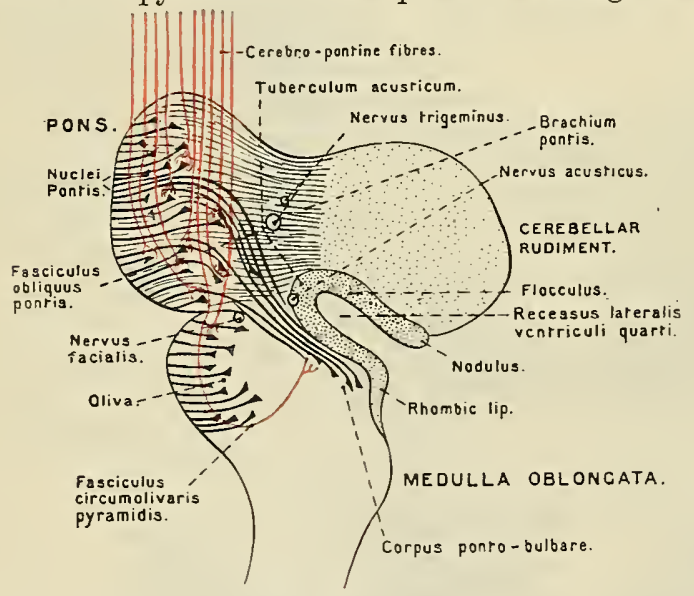

Fig. 499.-Diagram of the Left Lateral aspect of the Fotal RHOMBEXCEPHALON REPRESENTING SOME OF tHE CELL GrovpS aNd Fibre Tracts. the pons. They likewise reach the cerebellum, although by a different route, viz., the restiform body. The nuclei pontis are represented also in the pyramidal part of the medulla oblongata by the arcuate nuclei, which are covered over by the external arcuate fibres, and even tend to penetrate, to a slight extent, into the pyramidal tracts. These arcuate nuclei, as already pointed out, are continuous with the nuclei pontis.

\section{Connexions of the} Longitudinal and Transverse Fibres. - When a transverse section through the superior part of the pons is compared with one close to its inferior border, it becomes at once apparent that the numerous scattered bundles of longitudinal fibres which enter the ventral part of the pons from above, if brought together into one tract, would form a strand very much larger than the two pyramids which leave its lower aspect and enter the medulla oblongata. It is clear, therefore, that many of the longitudinal fibres which pass into the pons from above do not pass out from it below into the medulla oblongata. What becomes of these fibres that are thus absorbed in the pons? It is known that the pyramidal bundles suffer a small loss by the fibres which they send to the nuclei of origin of the efferent nerves which arise within the pons (viz., the motor root of the trigeminal, abducens, and facial nerve nuclei) ; but this loss is, comparatively speaking, trifling. It is clear, therefore, that other longitudinal bundles enter the pons from above apart from those which form the pyramidal tracts. These bundles occupy a lateral and dorsal position in the ventral part of the pons, and may be termed the cerebro-pontine fibres, seeing that they come from the cerebral cortex and end in fine ramifications around the cells of the nuclei pontis (Fig. 498).

The transverse fibres take origin as axons of the cells of the nuclei pontis. Crossing the median plane, they enter the brachium pontis of the opposite side, and thus reach the cerebellar cortex, where they end in ramifications round certain of the cortical cells. Some authorities believe that there are also fibres passing in the opposite direction, i.e. 
from the cerebellum to the nuclei pontis; but there is some doubt concerning the existence of any such fibres. The brachium pontis thus may contain both efferent and afferent cerebellar fibres; but no fibres pass continuously through the pons from one brachium pontis into the other.

Certain of the transverse fibres of the pons turn backwards and enter the dorsal or tegmental part of the pons, but the precise connexions of these are doubtful.

Corpus Trapezoideum.-This name is applied to a group of transverse fibres which traverse the lower part of the pons (Fig. 498). They are quite distinct from those which have been just described as entering the brachium pontis, and they lie in the boundary between the dorsal and basilar parts of the pons, but encroaching considerably into the ground of the former. They arise from the cells of the terminal nucleus of the cochlear division of the acoustic nerve, and constitute a tract which establishes certain central connexions for that nerve. They will be more fully described when we treat of the cerebral connexions of the acoustic nerve.

Pars Dorsalis Pontis (Dorsal or Tegmental Part of the Pons).--On the dorsal surface of the tegmental part of the pons there is spread a thick layer of gray matter, covered with ependyma, which forms the floor of the upper or pontine part of the fourth ventricle. Beneath this the median raphe of the medulla oblongata is continued up into the pons, so as to divide its tegmental part into two symmetrical halves.

In the inferior part of the pons, immediately beyond the medulla oblongata, the restiform body is placed on the outer side of the dorsal part (Fig. 498). In transverse sections through the pons it appears as a large, massive oval strand of fibres which gradually inclines backwards into the cerebellum, and thus leaves the pons. Between the restiform body and the median raphe the tegmental part of the pons is composed of substantia reticularis, continuous with the same material in the medulla oblongata. Thus arcuate or transverse fibres, curving in towards the raphe, and also longitudinal fibres, are seen breaking through a mass of gray matter which occupies the interstices of the intersecting fibres. To the naked eye the formatio reticularis presents a uniform gray appearance, but its constituent parts are revealed by low powers of the microscope in properly stained and prepared specimens. Embedded in this substantia reticularis are various clumps of compact gray matter and certain definite strands of fibres. These we shall describe as we pass from the restiform body medially towards the median raphe.

(1) Spinal Root of the Trigeminal Nerve and its Nucleus. - Close to the medial side of the restiform body, but separated from it by the vestibular root of the acoustic nerve as it proceeds backwards through the pons, is seen a large crescentic group of coarse transversely divided bundles of fibres. This is the tractus spinalis (O.T. spinal root) of the trigeminal nerve, and applied to its medial concave side is a small mass of gray matter, which is the direct continuation upwards of the substantia gelatinosa.

(2) The nucleus of the facial nerve comes next. It is sunk deeply in the dorsal part of the pons and lies close to the transverse fibres of the corpus trapezoideum. It is a conspicuous, obliquely placed, ovoid clump of gray matter. From its lateral and dorsal aspect the root-fibres of the facial nerve stream backwards and medially towards the gray matter on the floor of the fourth ventricle. Passing forwards between this nucleus and the trigeminal sensory nucleus a solid nerve-bundle may be observed. This is the facial nerve, traversing the pons towards its place of emergence from the brain.

(3) Immediately medial to the facial nucleus, but placed more deeply in the tegmental part of the pons, is the superior olivary nucleus. It lies in a bay formed for it by the transverse fibres of the corpus trapezoideum. These fibres curve round its ventral aspect, and many of them may be observed penetrating into its substance. In man, it is a very small mass of gray matter, and presents little resemblance to the inferior olivary nucleus, except in the size and shape of its constituent cells. In sections through the part of the pons where it attains its greatest size, it appears in the form of two, or it may be three, small isolated masses of gray matter. It is intimately connected with the acoustic fibres, and establishes manifold connexions between them and the nuclei of other nerves. 
Upon the medial and dorsal aspect of the superior olive there is a dense group of longitudinal fibres. These constitute the fasciculus thalamo-olivaris or central tegmental tract, to which we have already referred in discussing the inferior olivary nucleus (Fig. 498). It is uncertain whether this tract arises in the thalamus.

(4) The medial longitudinal bundle and the lemniscus medialis come next. As they proceed upwards through the tegmental part of the pons, these longitudinal tracts occupy the same relative position as in the medulla oblongata. They are placed close to the median raphe; but they have drawn further apart from each other, and their fibres are more distinctly concentrated into separate strands, with an interval of some little width between them, which is occupied by the tecto-spinal tract. The medial longitudinal bundle lies immediately under cover of the gray

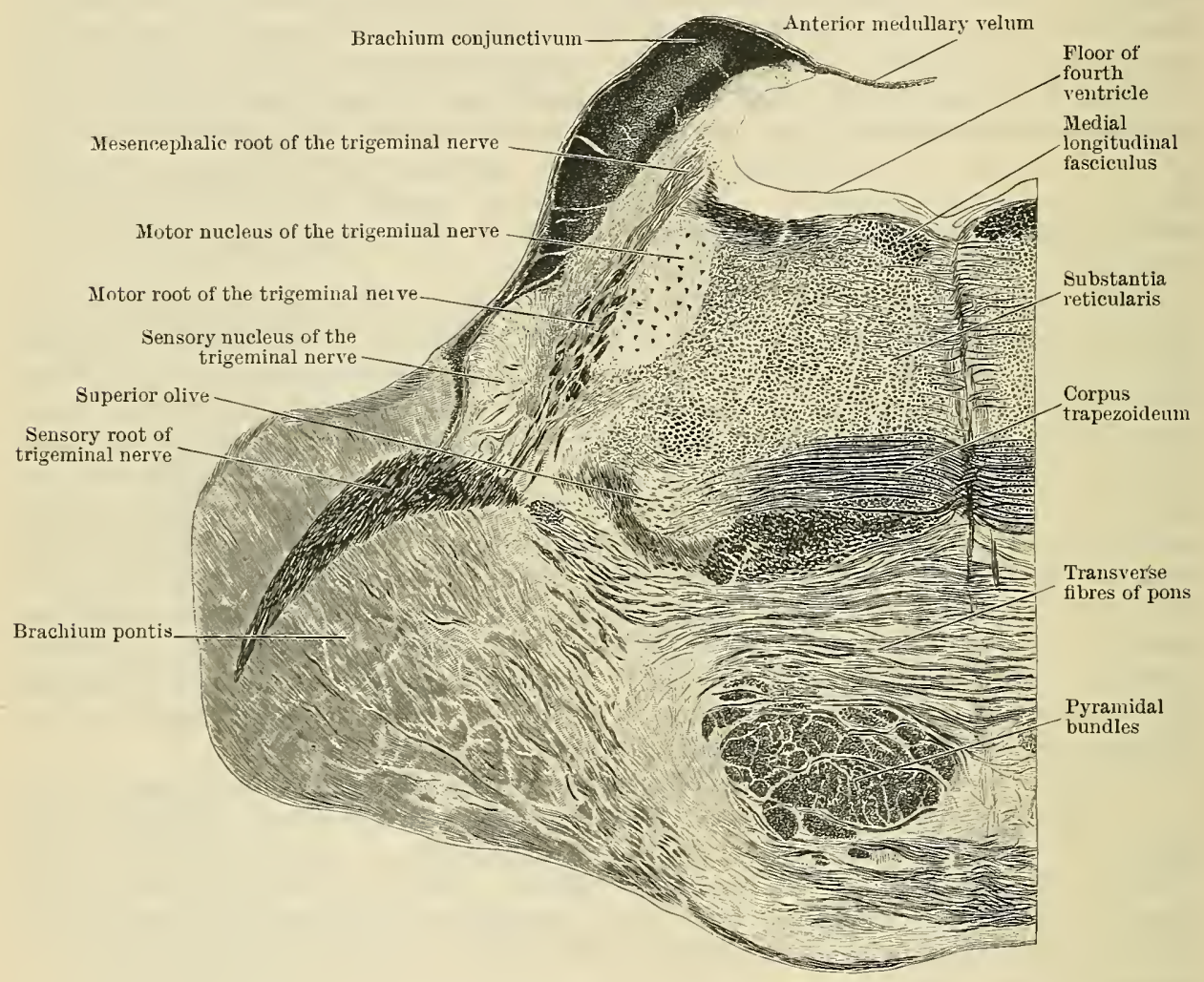

Fig. 500. - Transverse Section throdgh the Pons at the level of the Nuclei of the Trigeminal Nerve (Orang).

matter of the floor of the fourth ventricle. The lemniscus medialis is placed close to the trapezial fibres, many of which traverse it as they pass towards the median plane.

(5) The nucleus of the abducens nerve also forms a conspicuous object in sections through the lower part of the pons. It is a round mass of gray matter, which is situated close to the lateral side of the medial longitudinal bundle, and immediately under cover of the gray matter of the floor of the fourth ventricle. From its medial side numerous root-bundles of the abducens nerve pass out and proceed forwards between the lemniscus medialis and the superior olivary nucleus. They occupy in the pons, therefore, a position similar to that occupied by the hypoglossal rootfibres in the medulla oblongata.

$\mathrm{Up}$ to the present only the inferior part of the dorsal portion of the pons has been described, i.e. the portion immediately adjoining the medulla oblongata. As we proceed upwards and gain a point above the level of the trapezial fibres, many of the structures which have attracted attention lower down gradually disappear from the formatio reticularis. The lemniscus medialis becomes markedly 
increased in size by the addition of the fibres of the spino-thalamic tract. Further, the floor of the fourth ventricle becomes narrower, and other objects appear in the tegmental substance.

The brachium conjunctivum (O.T. superior cerebellar peduncle) is a very conspicuous object, in sections, through - the middle and upper parts of the pons. In transverse section it presents a semilunar outline, and as it emerges from the cerebellum it lies immediately on the lateral side of the fourth ventricle, towards which its concave aspect is turned (Fig. 500). Its dorsal border is joined with the corresponding brachium of the opposite side by the thin lamina of white matter, termed the anterior medullary velum, whilst its ventral border is sunk to a small extent in the dorsal part of the pons. As it is traced upwards it sinks deeper and deeper into the pons until it becomes completely submerged, with the exception of the dorsal border to which the anterior medullary velum is attached. It now lies on the lateral side of the tegmental or reticular substance of the pons, and this position it maintains until the mesencephalon is reached (Fig. 501).

About half-way up the pons the nuclei of the trigeminal nerve mark a very

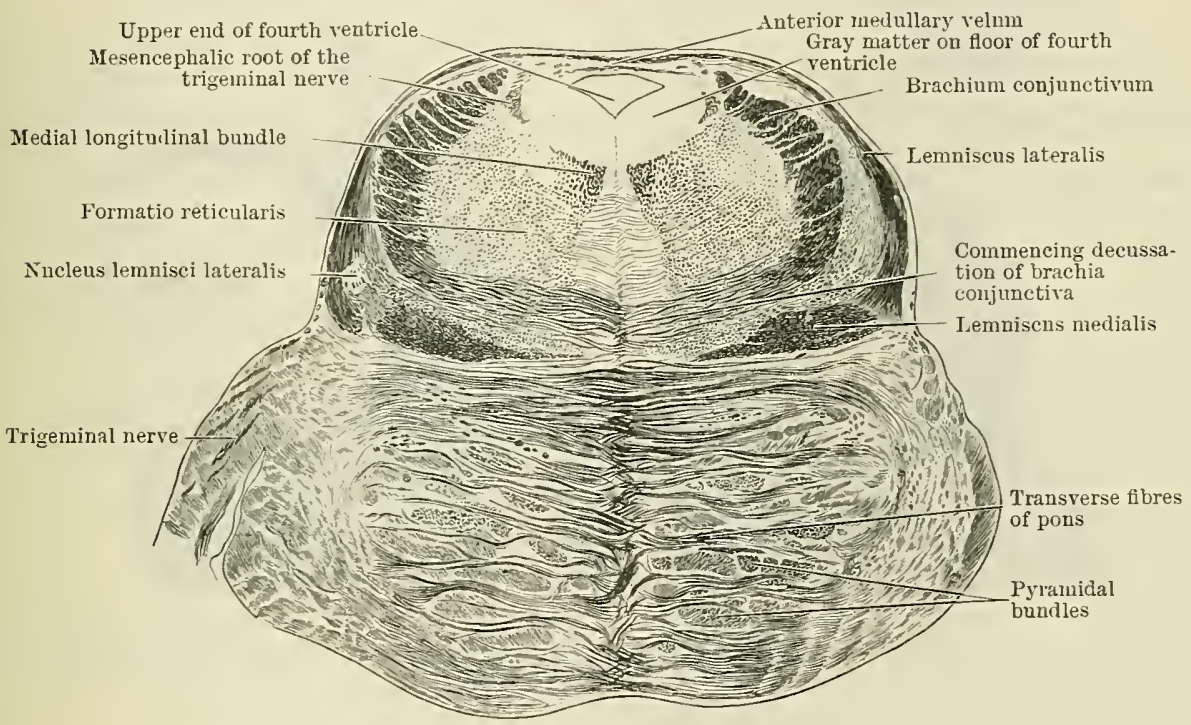

Fig. 501.-Section throdgh the Superior Part of the Pons of the Orang, abote the Letel of the Trigeminal Nuclei.

important stage in its tegmental portion. These nuclei are two in number on each side, viz., a large oval terminal nucleus for certain of the sensory fibres of the nerve and a nucleus of origin, equally conspicuous, for certain of the motor fibres (Fig. 500). The sensory nucleus lies close to the lateral surface of the pons, deeply sunk in its tegmental part, and in the interval between the submerged anterior border of the brachium conjunctivum and the ventral part of the pons. The motor nucleus is placed on the medial side of the sensory nucleus, but somewhat nearer the dorsal surface of the pons. At this level the tractus spinalis of the trigeminal nerve begins by the bending downward of the fibres of the sensory portion. The sensory and motor roots of the fifth nerve traverse the ventral part of the pons on their way to and from the region of the nuclei.

Above the level of the nuclei of the trigeminal nerve a new tract of fibres comes into view. This is the mesencephalic root of the trigeminal nerve, as it descends towards the rest of the nerve. It is a small bundle of nerve-fibres, semilunar in cross section, which lies close to the medial side of the brachium conjunctivum and on the lateral and deep aspect of the gray matter on the floor of the fourth ventricle (Figs. 500 and 501).

On a slightly deeper plane than the mesencephalic root of the fifth nerve, between it and the medial longitudinal bundle, and in close relation to the gray 
matter of the Hoor of the ventricle, is the collection of pigmented cells which constitutes the substantia ferruginea.

The medial longitudinal bundle, as it is traced upwards through the tegmental part of the pons, maintains the same position throughout, and as it ascends it becomes more clearly mapped out as a definite and distinct tract. It lies close to the median raphe, and immediately subjacent to the gray matter of the floor of the fourth ventricle.

The lemniscus medialis, as it ascends through the tegmental part of the pons, undergoes striking changes in shape. In the lower portion of the pons its fibres, which in the medulla oblongata are spread out along the side of the median raphe, are collected together in the form of a loose bundle, which occupies a wide field, somewhat triangular in shape, on either side of the median raphe and immediately behind the basilar portion of the pons. As it proceeds up, the fibres spread out laterally until a compact ribbon-like layer is formed in the interval between the tegmental and basilar portions of the pons (Figs. 501 and 502).

Above the level of the trigeminal nuclei another flattened layer of fibres comes

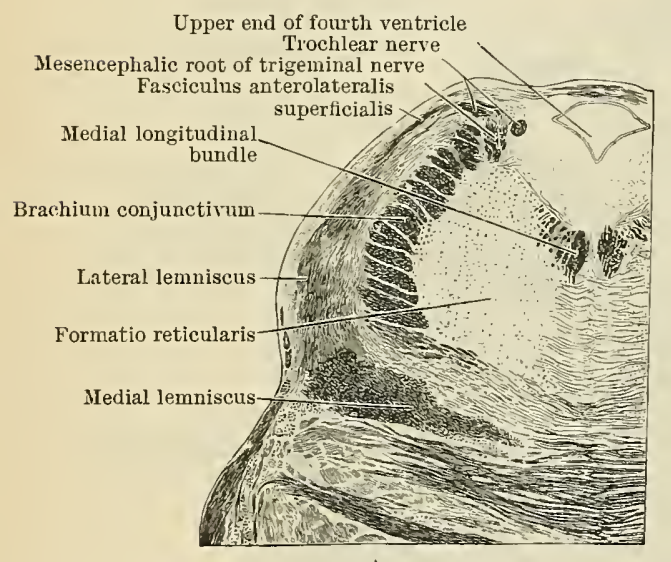

A

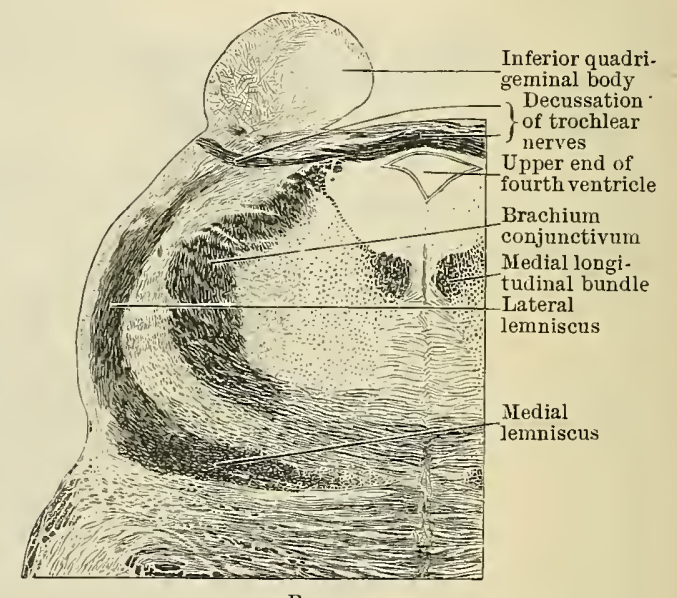

B

Fig. 502.--Two Sections throdgh the Dorsal Portion of the Pons at its Superior Part, close to the Mesencephalon.

$A$ is at a slightly lower level than B.

into view to the lateral side of the lemniscus medialis. To this the name of lemniscus lateralis is given. These fibres spread laterally and backwards, and finally take up a position on the lateral surface of the brachium conjunctivum. In the angle between the medial and lateral lemnisci a little knot of compact gray matter, termed the nucleus lemnisci lateralis, comes into view (Fig. 501). This appears to be in more or less direct continuity with the superior olivary nucleus. Many of the fibres of the lemniscus lateralis take origin in this nucleus. Bruce called attention to the continuity between the superior olive and the nucleus of the lateral lemniscus in man, and Cunningham confirmed the observation in so far as the orang brain is concerned. In many other mammals the nuclei are quite distinct.

\section{THE CEREBELLUM.}

In the foregoing account it has been seen that the cerebellum is formed from two distinct rudiments, each derived from the posterior edge of the alar lamina immediately above the pontine flexure and the insertion of the vestibular nerve. As development proceeds during the second month there is a rapid proliferation of cells in the mantle layer of the cerebellar rudiments, and they become considerably thickened. But at first this thickening manifests itself not so much as a swelling of the superficial aspect of the cerebellum but as a bulging inwards into the cavity of the fourth ventricle (Fig. 503). 
The accentuation of the pontine flexure at this stage brings the two cerebellar rudiments into the transverse direction and in line one with the other and the roof-plate, which is now being thickened by immigrant neuroblasts from the medial extremities of the two cerebellar rudiments. When one organ is thus formed by the union in the roof-plate of the originally separate rudiments, it presents the form of a dumb-bell shaped mass (Fig. 503). Upon the inferior aspect of this mass there is a slight ridge, to which the tela chorioidea ventriculi quarti is attached. Opposite the lateral cerebellar rudiments (but not in the median plane) the attachment of the tela becomes thickened to form the posterior medullary vela.

Early in the third month the growth of the cerebellar rudiment begins to manifest itself by lateral bulgings of its surface.

The rhombic lip, the inferior part of which has been seen to play an important part in the development of the nuclei pontis and nucleus olivaris inferior, is also continued upwards beyond the pontine flexure on to the cerebellar rudiment, where it forms a marginal fringe. Thus even

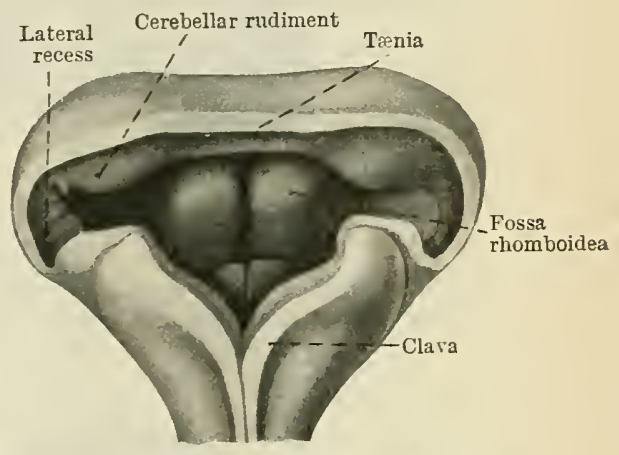

Fig. 503.-Dorsal ASPECT of THE RHOMb. ENCEPHALON IN A HUMAN EMBRYO. in the second month a groove can be detected upon the cerebellum separating off a band which is continuous with the tuberculum acusticum. The part nearest to the latter represents the rudiment of the flocculus and the medial extremity the nodulus (Fig. 503). During the third month the cerebellum appears as a rounded bar transversely placed across the upper part of the roof of the fourth ventricle, and as the lateral extremities of this bar expand (Fig. 504), it assumes a dumb-bell shape not unlike that presented a few weeks earlier (Fig. 503) on its ventricular aspect. As these lateral bosses (lobi laterales) develop, a mass of transverse fibres in connexion with them also becomes apparent. It represents the fibræ transversæ of the pons. They arise from the cells (nuclei pontis) which have wandered into the basal lamina of the metencephalon from the rhombic lip of the myelencephalon (Fig. 499); and the fibres which enter each cerebellar boss come mainly from the nuclei pontis of the other side. Towards the end of the fourth month, or even a month earlier in some cases, a little bud grows out from the cerebellum on each side immediately above the flocculus. It is the paraflocculus or flocculus

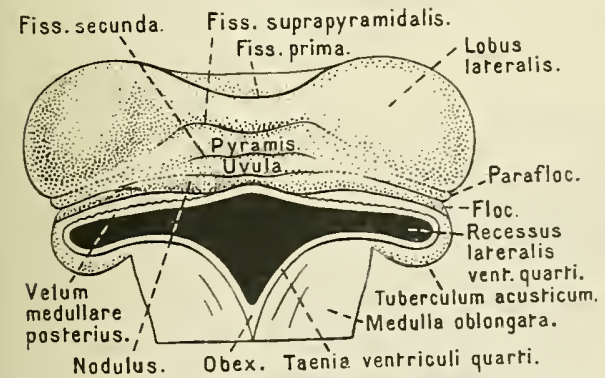

Fig. 504. - The Posterior Aspect of a Fotal (Fotrth Month) Cerebellum, Medulla OBLONGATA AND Fossa RhoNBoIdeA. secundarius. In man it never attains a large size, but in most mammals it develops into a large lobe, even as big as one-third the size of a cerebellar hemisphere (in the manatee), and in many animals a deep fossa is formed in the temporal bone to lodge this part of the cerebellum.

As the cerebellum grows the lateral hemispheres expand much more rapidly than the medial part-the handle of the dumb-bell. But the superficial area of the latter becomes increased by means of transverse folds which begin to make their appearance at the close of the third month. Earlier in that month the median part of the cerebellum presents near its inferior margin (fissura postnodularis) demarcating the nodulus. As development proceeds during the third month the nodular region becomes bent. forwards upon the rest of the cerebellum (Fig. 507, B), thus starting the posterior diverticulum of the fourth ventricle, which ultimately assumes a tent-like outline (Fig. 519).

At the close of the third month the irregular growth of the surface of the 
median bridge, which can now be called the vermis, leads to the appearance of

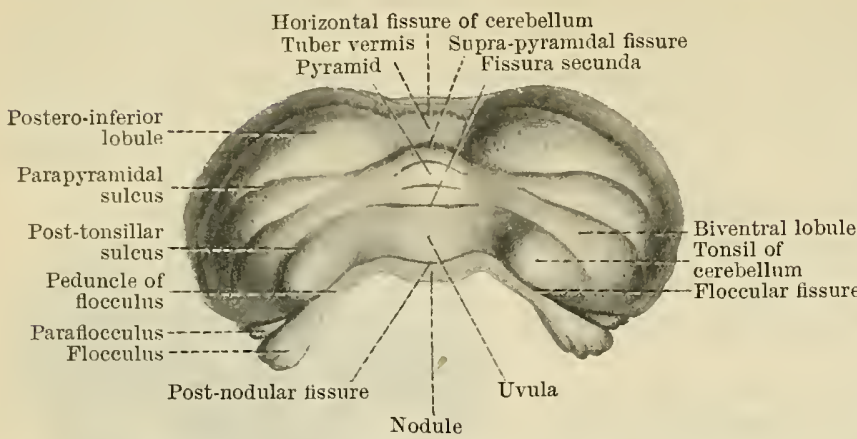

Fig. 505.-INferior Surface of the Cerebellum of a Human Fotus which has reached the End of the Fifth Month of Development.

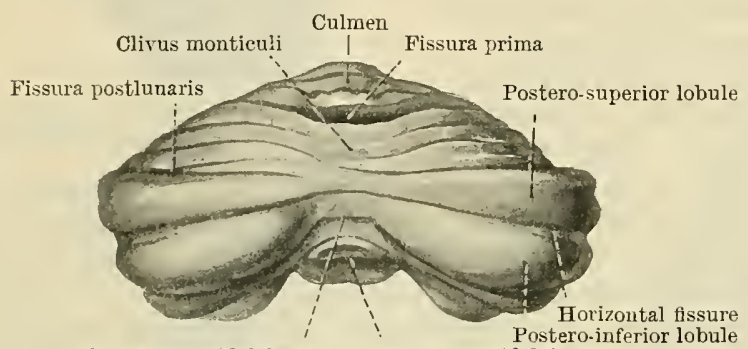

Supra-pyramidal fissure Infra-pyramidal fissure

a transverse depression upon the superior surface. This is the fissura prima (Fig. 507, B, C, and D), which becomes the deepest and most complex of all the multitude of fissures that ultimately cut into the cerebellum (Fig. 519). Soon afterwards the fissura secunda makes its appearance (Fig. 507, C) and with the fissura prima subdivides the vermis into anterior, medial, and posterior lobes. ${ }^{1}$

Other transverse fissures appear in rapid succession until the vermis becomes cut up into the following parts, named from above (at the velum medullare anterius) downwards: lingula, lobulus centralis, culmen, declive, pyramid, uvula, and nodule.

Fig. 506.-Cerebellem of a Hedan Fotus which has reached the Exd OF the Fifth Month of Development. Viewed from above and behind.

Quite unnecessary importance is usually attached to the subdivisions of the part here called
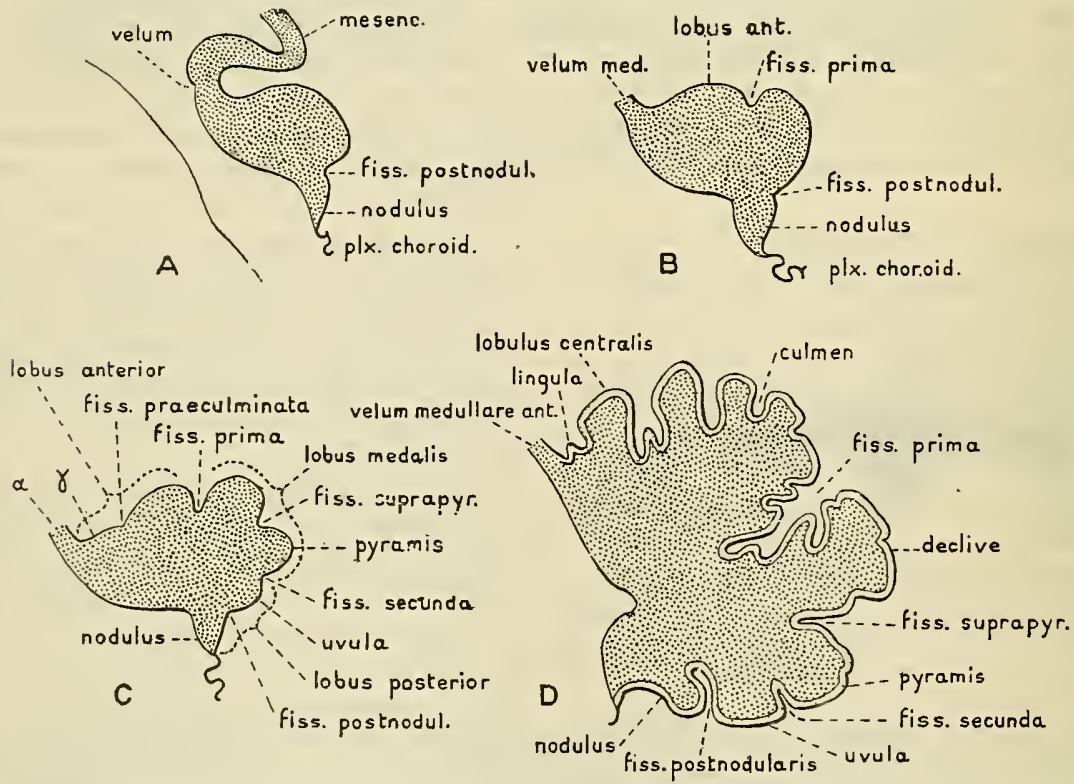

Fig. 507. - Median Sagittal Sections of Fetal Cerebella in Four Stages of Development. $\mathrm{A}$ and $\mathrm{B}$, third month; $\mathrm{C}$, fourtl month ; D, fifth month.

declive which is described as consisting of three parts (declive, folium vermis, and tuber vermis).

1 The term merlial is used advisedly because, the anterior and posterior lobes having quite insignificant lateral comexions, the rest of the vermis is virtually the medial continuation of (or bridge between) the lateral lobes. 
There is no justification for such a subdivision, nor is any useful purpose served by linking together two parts so distinct, morphologically and physiologically, as the culmen and declive and calling the complex monticulus.

Only some of the fissures of the vermis become prolonged laterally beyond the limits of the vermis, but as the boss-like lateral lobes begin to expand their surface becomes folded and a series of independent lateral fissures are formed. [The anterior lobe, however, is prolonged laterally upon each side into tapering wings and all the fissures in them are merely prolongations of the fissures of the vermis.]

After the limiting fissures of the flocculus and paraflocculus, the first independent fissure to make its appearance is one which develops behind and almost parallel to the lateral prolongations of the fissura prima. Kölliker called the intervening strip of cerebellum lobulus lunatus posterior and the fissure may be called fissura postlunaris. These postlunar fissures begin far out on the lateral swelling in the fourth monthand gradually approach themedian plane, where they may meet and become confluent on the vermis. But it often happens that they do not meet, in which case no folium vermis is cut off the declive.

At the end of the fourth or beginning of the fifth month an oval swelling makes its appearance upon each side of the uvula upon the inferior surface of each lateral lobe (Fig. 505). This is called the tonsilla cerebelli or tonsil, and the fissure which develops behind it and delimits it is called posttonsillar. As a rule the

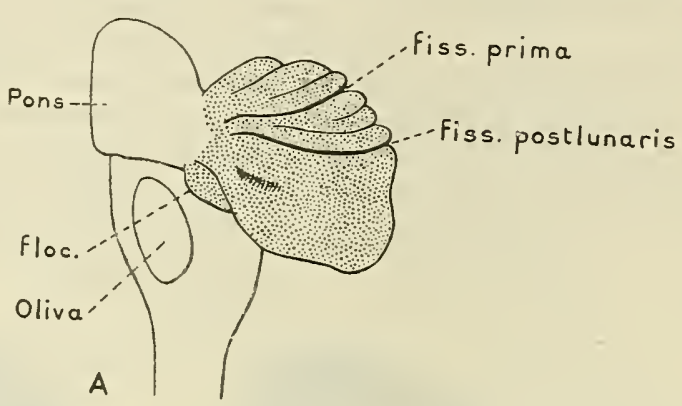

two post-tonsillar fissures become confluent with the fissura secunda upon the vermis and the whole furrow in the adult may be called fissura secunda. At the middle of the fifth month a lateral fissure called parapyramidal makes its appearance some distance behind the post-tonsillar, from which it is separated by an area called the lobulus biventer. As a rule these parapyramidal fissures become confluent with the suprapyramidal fissure. The whole furrow is known in the adult by the latter name. The fissure to which most importance is usually attached develops quite late in the human cerebellum, and not at all in that of the great majority of other animals. It is called the fissura horizontalis cerebelli. In the adult it begins upon the front, where the brachium pontis plunges into the cerebellum, and the furrow is formed in a more or less mechanical way by the bulging forwards (above and below the cerebellar peduncles) of the exuberant mass of the cerebellar hemispheres. The actual infolding is preceded by the appearance of several irregular depressions (Fig. 508) in the place where the horizontal fissure will develop. This fissure begins in front and 
passes continuously round the circumference of the organ, cutting deeply into its lateral and posterior margins. In front, its lips diverge to enclose the three cerebellar peduncles as they pass into the interior of the cerebellum. The horizontal fissure divides the organ into a superior and an inferior part, which may be studied separately.

In some cases it meets the corresponding fissure of the other side upon the vermis, but very often such a confluence does not occur. The folium vermis in such cases is not distinguished from the tuber vermis.

The cerebellum is subdivided somewhat arbitrarily into a median portion termed the vermis, and two much larger lateral portions, called the lateral hemispheres. The demarcation between these main subdivisions of the organ is not very evident from every point of view. In front, and also behind, there is a marked deficiency or notch. The incisura cerebelli posterior (O.T. marsupial notch) is smaller and narrower than the anterior notch. It is bounded laterally by the lateral hemispheres, whilst its bottom is formed by the axial lobe or vermis. It is occupied by a fold of dura mater, called the falx cerebelli. The incisura cerebelli anterior (O.T. semilunar notch) is wide, and, when viewed from above, it is seen to be occupied by the inferior quadrigeminal bodies and by the brachia

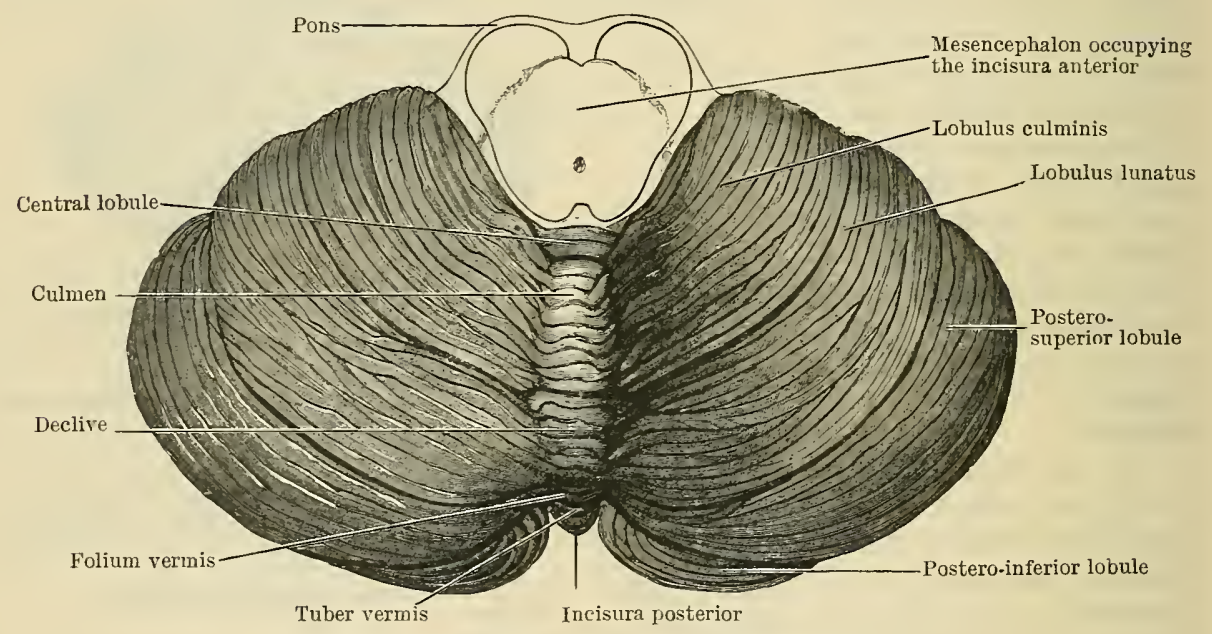

Fig. 509.-Superior Surface of the Cerebellum.

conjunctiva. As in the case of the posterior notch, its sides are formed by the lateral hemispheres and the bottom by the vermis.

On the superior surface of the cerebellum there is little distinction to be noted between the median lobe and the superior surface of each lateral hemisphere. On this aspect the median lobe receives the name of superior vermis, and it forms a high median elevation, from which the surface slopes gradually downwards on each side to the margin of the hemisphere. The superior vermis is highest in front, immediately behind the anterior notch, and from this it shows a somewhat sharp descent towards the posterior notch. This elevation of the superior vermis is frequently called the monticulus. The folia on the surface of the superior vermis are thicker and fewer in number than those on the upper surface of the lateral hemisphere. It is this which gives it the worm-like appearance from which it derives its name.

On the inferior surface of the cerebellum the distinction between the three main constituent parts of the organ is much better marked (Fig. 510). On this aspect the lateral hemispheres are full, prominent, and convex, and occupy the cerebellar fossæ in the floor of the cranium. They are separated by a deep median hollow, which is continued forwards from the posterior notch. This hollow is termed the vallecula cerebelli, and in its fore part is lodged the medulla oblongata. When the medulla oblongata is raised and the lateral hemispheres are pulled apart, so as to expose the bottom of the vallecula, it will be seen that this is formed by the vermis 
inferior, or inferior aspect of the median lobe, and, further, that the latter is separated on each side from the corresponding lateral hemisphere by a distinct furrow, termed the sulcus valleculæ.

Lobes on the Superior Surface of the Cerebellum.- When examined from before backwards, the superior vermis presents the following subdivisions: (1) the lingula cerebelli; (2) the lobulus centralis; (3) the culmen; (4) and the declive. With the exception of the lingula, each of these is continuous on either side, with a corresponding district on the upper surface of the hemisphere. Thus the central lobule is prolonged laterally on either side in the form of a small, flattened, winglike expansion called the ala lobuli centralis. The culmen together with its lateral prolongations can be called the lobulus culminis of the hemispheres; the declive stands in the same relation to the lobulus lunatus; and the postero-superior lobules of the hemispheres may be linked by a folium rermis.

The lingula can be seen only when the part of the cerebellum which forms the bottom of the anterior notch is pushed backwards. It consists of four or fire small flat folia continuous with the gray matter of the vermis superior, which are prolonged forwards on the superior surface of the anterior medullary velum in the interval between the two brachia conjunctiva.

The lobulus centralis lies at the bottom of the anterior cerebellar notch, and is only seen to a very small extent on the superior surface of the organ. It is a little median mass which is prolonged laterally for a short distance round the anterior notch in the form of two expansions, termed the alæ lobuli centralis.

The culmen constitutes the highest part or summit of the monticulus of the vermis superior. It is bounded behind by a deep and strongly marked fissura prima, and is prolonged laterally on either side into the lateral hemisphere. This is the most anterior subdivision on the superior surface of the hemisphere.

The declive lies behind the culmen, from which it is separated by the fissura prima, and it forms the sloping part or descent of the monticulus of the vermis superior. On each side it is continuous with the lateral hemisphere, and the three parts are included under the one name of lobulus lunatus (Fig. 509).

Lobes on the Inferior Surface of the Cerebellum.-The connexion between the several parts of the inferior vermis and the corresponding districts on the inferior surface of the two hemispheres is not so distinct as in the case of the vermis superior and the lobules on the superior surface of the hemispheres. A groove, the sulcus valleculæ, intervenes between the vermis inferior and the hemisphere on each side.

From behind forwards the following subdivisions of the rermis inferior may be recognised: (1) the tuber vermis; (2) the pyramis; (3) the uvula; (4) the nodulus.

On the inferior surface of the hemisphere there are four main lobules mapped out by intervening fissures. From behind forwards these are: (1) the postero-inferior lobule, a large subdivision which bounds the horizontal fissure on its inferior aspect; (2) the biventral lobule, which lies in front of the postero-inferior lobule, and is partially divided into two parts by a curved fissure which traverses its surface; (3) the tonsil, a small rounded lobule which bounds the fore part of the vallecula, and is lodged in a deep concavity on the medial aspect of the biventral lobule; (4) the flocculus, a minute lobule situated on the brachium pontis of the cerebellum in front of, and partially overlapped by, the anterior border of che biventral lobule.

These lobules, with the corresponding portions of the vermis inferior, constitute the lobes on the inferior surface of the cerebellum. Still, it should be noted that, just as in the case of the superior surface of the organ, this subdivision is to some extent artificial, and is not in every particular provided with a sound morphological basis.

The tuber vermis (usually not definitely marked off from the declive) forms the most posterior part of the vermis inferior, and is composed of several transversely arranged folia which, on either side, run directly into the postero-inferior lobule.

The postero-inferior lobule, which is wider towards the vallecula than it is more 
laterally, is traversed by two or it may be three curved fissures. The most anterior of these cuts off a narrow, curved strip of cerebellar surface, which presents a more or less uniform width throughout its whole length. This is the so-called lobulus gracilis.

The pyramid is connected with the biventral lobule on each side by an elevated ridge which crosses the sulcus valleculæ. The term lobus pyramidis is applied to the three lobules, which are thus associated with each other.

The uvula is a triangular elevation of the vermis inferior. It lies between the two tonsils, and is connected with each of these by a low-lying band-like ridge of gray matter scored by a few shallow furrows, and in consequence termed the furrowed band. The two tonsils and the uvula form the lobus uvulæ.

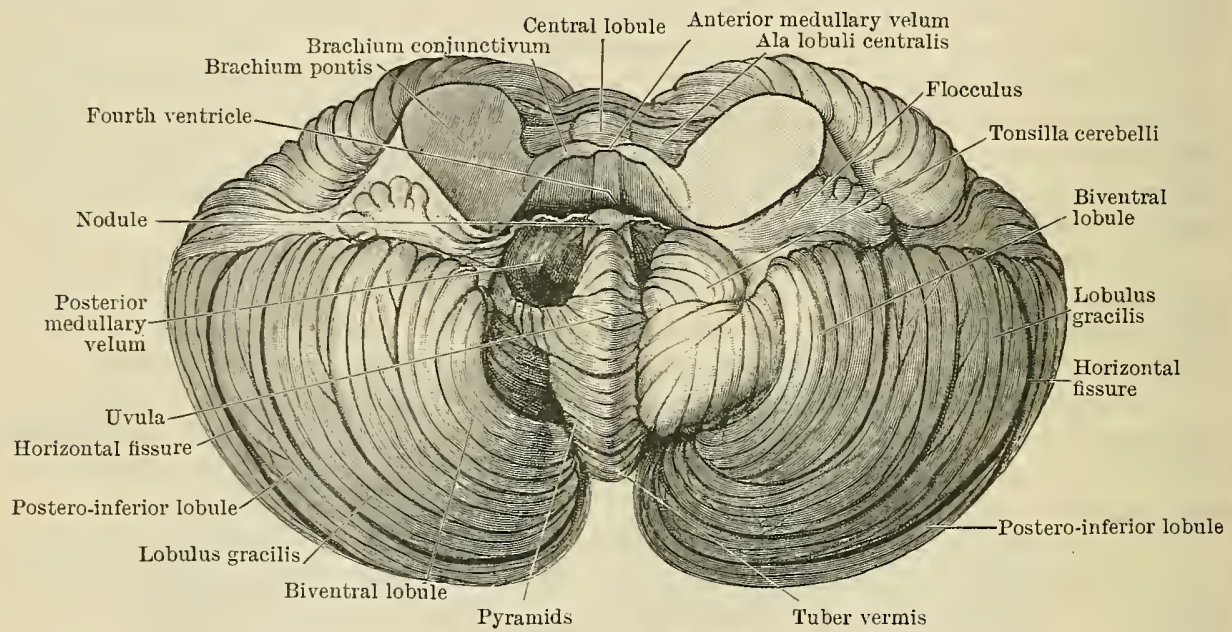

Fig. 510. - Inferior Surface of the Cerebellum.

The tonsil on the right side has been removed so as to display more fully the posterior medullary velum and the furrowed band.

The nodule and the flocculus of each side are linked by a delicate connecting lamina which is formed by the posterior medullary velum.

\section{The Structure and Connexions of the Cerebellum.}

Arrangement of the Gray and White Matter of the Cerebellum.-The white matter of the cerebellum forms a solid compact mass in the interior, and over this is spread a continuous and uniform layer of gray matter. In each lateral hemisphere the white central core is more bulky than in the vermis, in which the central white matter is reduced to a relatively thin bridge thrown across between the two lateral hemispheres. When sagittal sections are made through the cerebellum, the gray matter on the surface stands out clearly from the white matter in the interior. Further, from all parts of the surface of the central core stout stems of white matter are seen projecting into the lobes of the cerebellum. From the sides of these white stems secondary branches proceed at various angles, and from these again tertiary branches are given off. Over the various lamellæ of white matter thus formed the gray cortex is spread, and the fissures on the surface show a corresponding arrangement, dividing up the organ into lobes, lobules, and folia. When the cerebellum is divided at right angles to the general direction of its fissures and folia, a highly arborescent appearance is thus presented by the cut surface. To this the term arbor vitæ is applied.

Nucleus Dentatus and other Gray Nuclei in the White Matter of the Cerebellum.-Embedded in the midst of the mass of white matter which forms the central core of each lateral hemisphere there is an isolated nucleus of gray matter, which presents a strong resemblance to the inferior olivary nucleus of the medulla. It is called the nucleus dentatus, and it consists of a corrugated or plicated lamina 
of gray matter, which is folded on itself so as to enclose, in a flask-like manner, a portion of the central white matter (Figs. 511 and 512). This gray capsule is not completely closed. It presents an open mouth, termed the hilus, which is directed medially and upwards, and out of this stream the fibres of the brachium conjunctivum.

Three small additional masses of gray matter are also present on each side of the median plane in the central white matter of the cerebellum. These are termed the nucleus emboliformis, the nucleus globosus, and the nucleus fastigii. The nucleus emboliformis or embolus is a small lamina of gray matter which lies just medial to the hilus of the nucleus dentatus, being thus

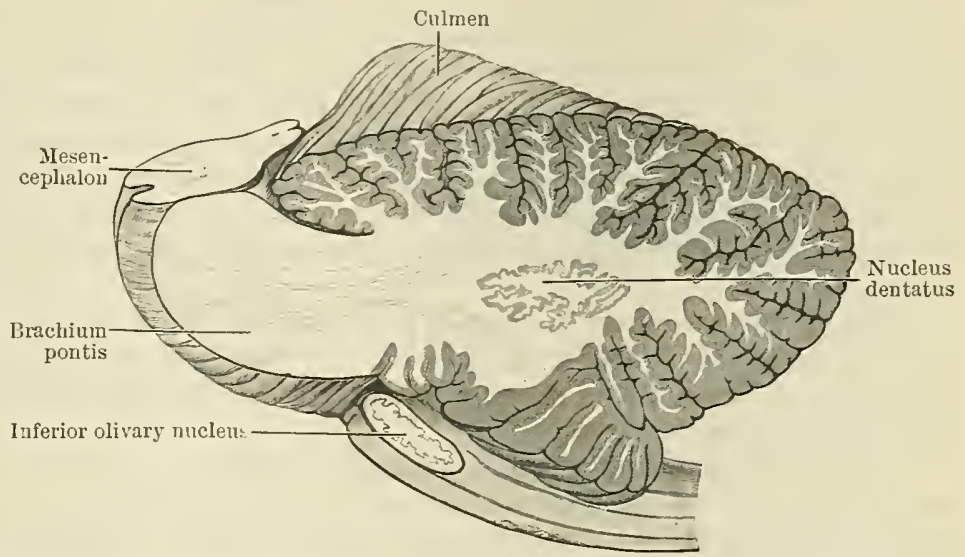

Fig. 511. - Sagittal Section throdgh the Left Lateral Hemisphere OF THE CEREBellom.

Showing the "arbor vitæ" and the nucleus dentatus.

what in the same manner that the medial accessory olivary nucleus is related to the main inferior olivary nuclens. The nucleus globosus lies medial to the unclens emboliformis and on a scmewhat deeper horizontal plane. The nucleus fastigii or roof nucleus is placed in the white substance of the vermis close to the median plane and its fellow of the opposite side. It is, therefore, situated on the medial aspect of the nucleus globosus.

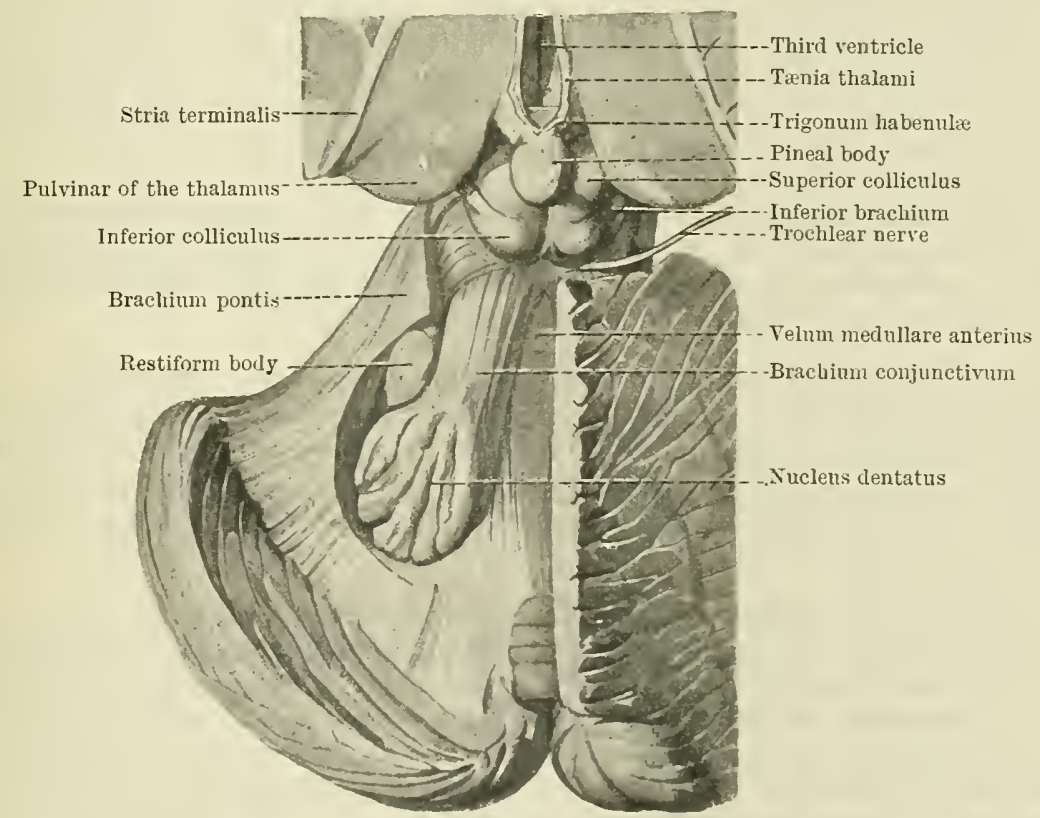

FIG. 512.-From a dissection by Dr. Edward B. Jamieson in the Anatomical Department of the University of Edinburgh. The nucleus dentatus is displayed from above and the brachinm conjunetivum has been traced from it to the mesencephalon.

The nucleus dentatus and the emboliform nucleus present a structure very similar to that of the inferior olivary nucleus. In the nucleus globosus and the nucleus fastigii the cells are somewhat larger in size.

Cerebellar Peduncles.-These are three in number on each side, viz., the 
middle, the inferior, and the superior (Fig. 519, p. 585). The fibres of which they are composed all enter or emerge from the white medullary centre of the cerebellum.

The middle peduncle or brachium pontis is much the largest of the three, and has already been described on pp. 565 and 566 . It is formed by the transverse fibres of the pons, and it enters the cerebellar hemisphere on the lateral aspect of the other two peduncles. The lips of the anterior part of the horizontal fissure are separated widely from each other to give it admission (Fig. 510). Within the cerebellar hemisphere its fibres are distributed in two great bundles. Of these, one, composed of the superior transverse fibres of the pons, radiates out in the inferior part of the hemisphere; whilst the other, consisting of the inferior transverse fibres of the pons, spreads out in the superior part of the hemisphere.

The inferior peduncle is simply the restiform body of the medulla oblongata. After leaving the bulb it ascends for a short distance on the dorsal surface of the pons and then turns sharply backwards, to enter the cerebellum between the other two peduncles.

The superior peduncle or brachium conjunctivum, as it issues from the cerebellum, lies close to the medial side of the middle peduncle (Fig. 512). Its further course upwards on the dorsum of the pons to the inferior quadrigeminal body has been previously described (pp. 548 and 569).

Connexions established by the Peduncular Fibres. - The fibres of the brachium pontis represent the second stage of the connexion between the cerebral hemisphere of one side and the opposite cerebellar hemisphere. The connexions which they establish in the pons are described on p. 566.

The restiform body is also composed of afferent fibres (see p. 563); only the more important connexions which these establish in the cerebellum can be touched on here. The principal afferent strand is the fasciculus spinocerebellaris. The fibres of this strand end in the cortex of the superior vermis on both sides of the median plane, but chiefly on the opposite side. The olivo-cerebellar tract (fasciculus olivocerebellaris) are also afferent. It appears that they end in connexion with cells in the cortex of both the vermis and hemisphere, and also cells in the nucleus dentatus. The numerous arcuate fibres which enter the restiform body establish connexions with cells in the cortex of the lateral hemisphere and of the vermis.

The brachium conjunctivum is an efferent tract: its fibres come from the cells of the nucleus dentatus, and pass to the red nucleus and thalamus of the opposite side. According to Ramon y Cajal collateral branches springing from these fibres descend to the motor nuclei in the medulla oblongata and spinal medulla.

There is, however, a bundle of fibres passing downwards alongside the brachium conjunctivum from the tegmentum of the mesencephalon and possibly from the thalamus: these fibres cross in the mid-brain and pass inferiorly to the cerebellum in contact with the lateral margin of (or intermingled with) the fibres of the brachium. They probably convey to the cerebellum fibres from the visual centres of the opposite side.

The fasciculus anterolateralis superficialis of the spinal medulla (O.T. Gowers' tract), for which the better name fasciculus spinocerebellaris anterior is now in common use, also enters the cerebellum alongside the emerging brachium conjunctivum. It has been noticed in connexion with the lateral funiculus of the spinal medulla (p. 537). The fibres which compose it are carried upwards through the formatio reticularis grisea of the medulla oblongata and the corresponding part of the tegmental portion of the pons. In this part of its course the fibres are scattered and do not form a conipact strand. Reaching the superior end of the pons the tract turns backwards across the brachium conjunctivum, enters the anterior medullary velum, and proceeds downwards in it into the cerebellum.

Roof of the Fourth Ventricle.-In its superior part the roof of the fourth ventricle is formed by the anterior medullary velum as it stretches across between the two brachia conjunctiva, and also, to some extent, by the approximation of these brachia themselves as they approach the mesencephalon. 
In its inferior part the roof of the ventricle is exceedingly thin and is not all formed of nervous matter. The posterior medullary velum is a mere ridge which can hardly be said to enter into its formation: the epithelial lining of the cavity, supported by pia mater, is carried downwards towards the inferior boundaries of the floor of the ventricle. At the lowest part of the calamus scriptorius, and also along each lateral boundary of the floor, the epithelial roof becomes thickened at its attachment to the parts of the medulla oblongata. The small semilunar lamina which stretches across between the inferior parts of the two clavæ at the calamus scriptorius and overhangs the opening of the central canal is termed the obex (Fig. 482, p. 550). A downwardly directed protrusion of the epithelial roof is often found behind the obex.

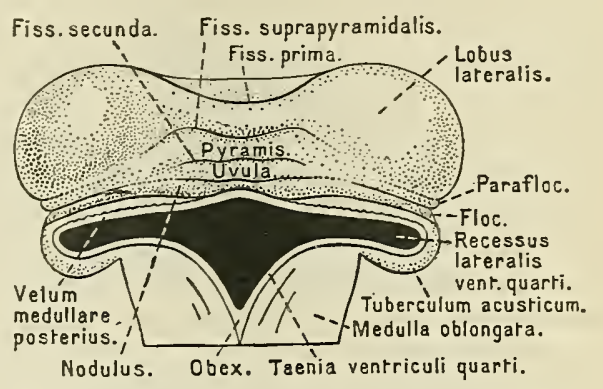

Fig. 513. - The Posterior Aspect of a Fetal Cerebellum and Medella Oblongata.

\section{The Histogenesis and Minute Structure of the Cerebellum.}

The developmental history of the cerebellum presents certain peculiar features which seem quite enigmatic unless considered from the point of view of the evolution of the connexions and functions of the organ. The cerebellum is derived from part of the alar lamina of the rhombencephalon, and at an early stage of its development the rudiment shows the regular lamination into ependyma, mantle layer, and

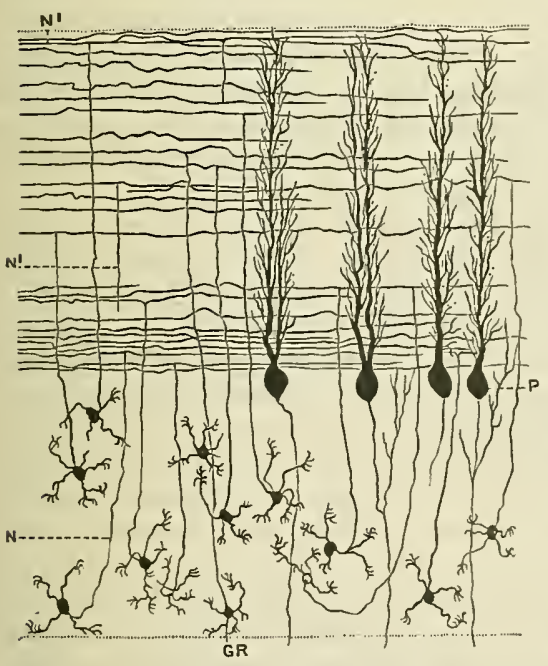

Fig. 514. - Section throdgh the Molecular and Granular Layers in the Long Axis of a Cerebellar Folium (after Kölliker). Treated by the Golgi method.

P. Cell of Purkinje.

GR. Granule cells.

N. Axon of a granule cell.

$\mathrm{N}^{1}$. Axons of granule cells in molecular layer. marginal layer, which has already been described as distinctive of the corresponding place of development in the whole nervous system. The cells of this mantle layer are to be looked upon as an outlying (superior) part of the receptive nucleus of the vestibular nerve, the cells to which information concerning the position and movements of the body as a whole or of the head will be transmitted from the semicircular ducts of the internal ear. But, if such information is to be put to any use in influencing behaviour, it is obvious that the activity of these cerebellar cells must, firstly, be correlated with visual impressions, which also supply information concerning the position and movements of the body, and with all those nerves which are bringing into the encephalon or spinal medulla impressions of touch, pressure, or any other information concerning the state of the muscles, tendons, joints, or other structures which are concerned in movements; and, secondly, be brought to bear upon the various motor nuclei and other motor regulating parts of the brain (such as the red nucleus, tectum mesencephali, basal ganglia, and cerebral cortex) to which the co-ordinating influence of the cerebellum is essential for the properly adjusted performance of complex actions.

The neuroblasts which receive all these extrinsic sensory impulses, visual, tactile, musculo-sensory, et cetera, collect at the threshold of what was originally the vestibular cerebellar rudiment; and they can be seen during the latter part of the second month migrating from the rhombic lip into the marginal lajer of the cerebellum, until eventually its whole surface has been invaded by these alien neuroblasts, so 
that the originally non-nucleated marginal layer becomes a densely packed granular layer (stratum marginale embryonale). When this stage is reached the cerebellum consists of an inner ependymal layer, a mantle layer crowded with locally developed neuroblasts, a clear layer (the inner part of the original marginal layer), and the superficial layer of neuroblasts which have invaded the outer part of the marginal layer. As development proceeds in the mantle layer the axons of its neuroblasts are directed mainly towards the ventricular surface-the reverse of what happens in the spinal medulla; and as these fibre-masses increase in quantity the main part of the mantle layer lecomes pushed farther and farther away from the ependyma by the accumulation of their own (and other) axons. Some of the neuroblasts, however, do not become pushed out into the line of the embryonic cerebellar cortex, but remain behind amidst the fibre-mass and receive the axons that come from the cortical cells. These neuroblasts left amidst the fibres gradually assume the form of the dentate, fastigial, globose, and emboliform nuclei already described; and their axons pass out (as the brachia conjunctiva) to the thalamus, mesencephalon, and pons. In the meantime many of the neuroblasts of the mantle layer have been converted into the large pear-shaped Purkinje-cells.

While these events have been occurring in the true mantle layer a peculiar process has been taking place in the superficial layer of immigrant cells. One by one they begin to leave their places upon the surface and dip into the mantle layer; many of them pass between the Purkinje-cells to a deeper plane, where they cease their wanderings and form a densely packed layer of granule cells (Fig. 514), the axons of which indicate the course of these migrations.

\section{Minute Structure of a Cerebellar Folium.}

A cerebellar folium is composed of a central core of white matter, covered with a layer of gray matter. The gray cortex is arranged in two very evident layers, viz., a superficial molecular layer and a subjacent rust-coloured granular layer. Between these strata a single layer of large cells, termed the cells of Purkinje, are disposed in the form of a very nearly continuous sheet. The cells of Purkinje constitute the most characteristic, and probably the most essential, constituents of the cerebellar cortex.

The cells of Purkinje are most numerous on the summit of the folium. At the bottom of the sulci which intervene between the folia they become fewer in number, and, therefore, looser in their arrangement. Each consists of a large flask-shaped or piriform cell body, the narrow end of which projects into the molecular layer, whilst the thicker, deeper end rests on the granular layer. From the latter arises a single axon, which passes into the granular layer and presents the peculiarity of almost immediately assuming its medullary sheath. From this axon a few collateral branches soon arise, which, taking a recurrent course, enter the molecular layer, to end in connexion with certain of the adjoining cells of Purkinje. They would seem to have the function of binding together adjacent cells, and thus enabling them to carry on their operations in harmony with each other.

The dendritic processes spring from the narrow end of the cell in the form of either one or perhaps two stout stalks. These ascend into the molecular layer, branching and rebranching until an aborescent arrangement of extraordinary richness and extent results. The dendritic branches extend throughout the entire thickness of the molecular layer, and the branching takes place in one plane only, viz., in a plane which is transverse to the long axis of the folium. Consequently, it is only when transverse sections through a folium are made that the full dendritic effect is obtained (Fig. 515); in sections made parallel to the long axis of the folium the cells are seen in profile, and are observed to occupy quite a narrow area (Fig. 514). The branching of the dendrites of a cell of Purkinje may, therefore, be compared to that which takes place in the case of a fruit-tree which is trained against a wall.

In the molecular layer the cells are not very numerous, and of these the most characteristic are the basket-cells which lie in the deeper part of the layer. In addition to numerous dendrites the basket-cell gives off an axon which runs transversely, as regards the long axis of the folium, between the planes of adjacent dendritic arborisations of the cells of Purkinje. At first very fine, these axons gradually become coarse and thick, and at intervals they give off collaterals which run towards the bodies of the cells of Purkinje. Reaching these, they break up into an enormous number of fine terminal 
branches, which enclose the cells of Purkinje, as well as the short non-medullated portions of their axons, in a close basket-work of fine filameuts.

The granular layer is, for the most part, composed of large numbers of small granule-like bodies closely packed together. Each of these possesses a somewhat large nucleus, with a very small amount of surrounding protoplasm. From the cell body three or four, or perhaps five, dendrites and one axon proceed. The dendrites are short and radiate out from different aspects of the cell body. They end in tufts of clawlike twigs, which either embrace or are otherwise in contact with neighbouring granule cells. The whole multitude of granule cells, therefore, are brought into intimate connexion with each other. The axon passes into the molecular layer, in which it ends, at a varying distance from the surface, by dividing into two branches. These diverge so sharply from each other that they form almost a rightangle with the parent stem, and they run parallel to the long axis of the folium, threading their way $\mathrm{F}$. among the branches of the $\mathrm{K}$ and $\mathrm{K}^{1}$. Fibres from white core of folium ending in molecular layer in various dendritic planes of the cells of Purkinje and $\mathrm{G}$

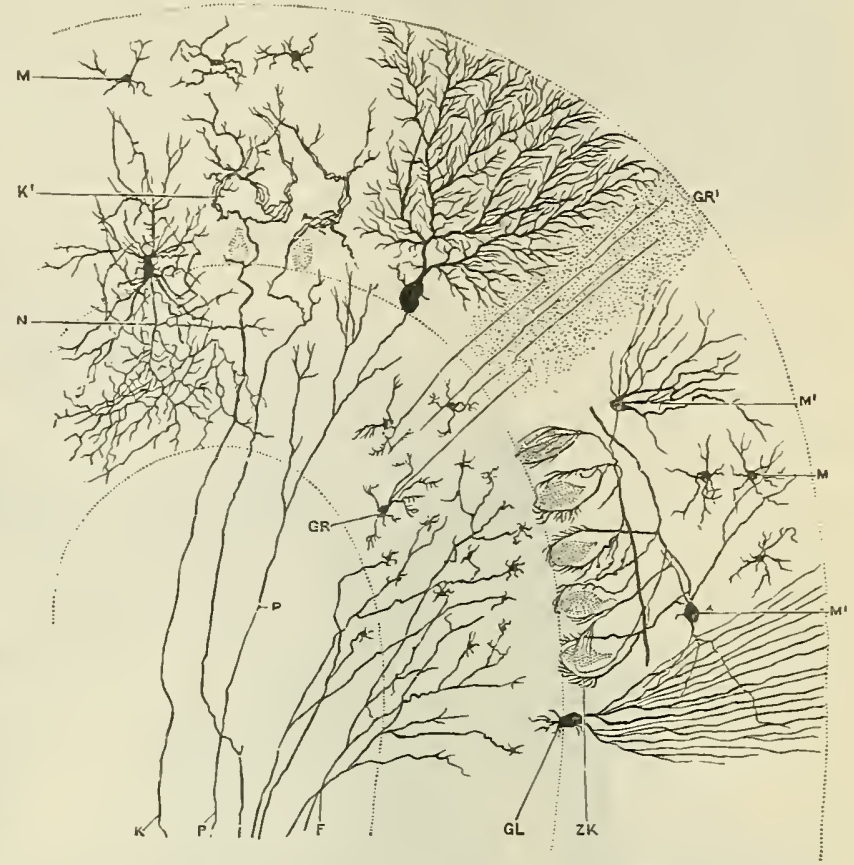

Fig. 515.-Trdysterse Section through a Cerebellar Folium (after Kölliker).

Treated by Golgi's method.

entering into contact associ- $\mathrm{GR}^{1}$. Axons of granule cells in molecular layer cut transversely.

ation with them. When it $\mathrm{MI}^{1}$. Basket-cells.

is borne in mind that the $\mathrm{ZK}$. Basket-work around the cells of Purkinje.

number of granule cells N. Axon of an association cell.

is very great, and that

each sends an axon into the molecular layer, the important part which these fibres, with their longitudinal branches, take in building up the molecular layer will be understood. They are found pervading its entire thickness-from the surface down to the bodies of the cells of Purkinje.

\section{THE MESENCEPHALON.}

The mesencephalon or mid-brain is the short, narrow part of the brain-stem which occupies the aperture of the tentorium cerebelli (incisura tentorii), and connects the cerebrum, which lies above, with the parts which occupy the posterior cranial fossa. It is about three-quarters of an inch in length, and it consists of a dorsal part, composed of the corpora quadrigemina, and a much larger ventral part, which is formed by the two pedunculi cerebri.

The pedunculi cerebri can be seen to some extent on the base of the brain, where they bound the posterior part of the interpeduncular fossa. Encircling the upper end of each cerebral peduncle, where it emerges from the cerebrum, is the optic tract (Fig. 527, p. 594).

The mesencephalon is tunnelled from below upwards by a narrow passage, called the aquæductus cerebri, which connects the fourth ventricle with the third 
ventricle (Fig. 519, p. 585). This channel lies much nearer the dorsal aspect than the ventral aspect of the mesencephalon.

Corpora Quadrigemina.- This name is applied to four rounded eminences or colliculi on the dorsal aspect of the mesencephalon (Figs. 516 and 517). The superior pair are larger and broader than the inferior pair, but they are not so well defined nor are they so prominent. A longitudinal and a transverse groove separate the colliculi from each other. The longitudinal groove occupies the median plane and extends upwards to the posterior commissure of the brain. The superior end of this groove widens out into a shallow depression, in which the pineal body, a small conical structure which belongs to the diencephalon, rests. From the lower end of the same groove a short but well-defined and projecting band, the frenulum

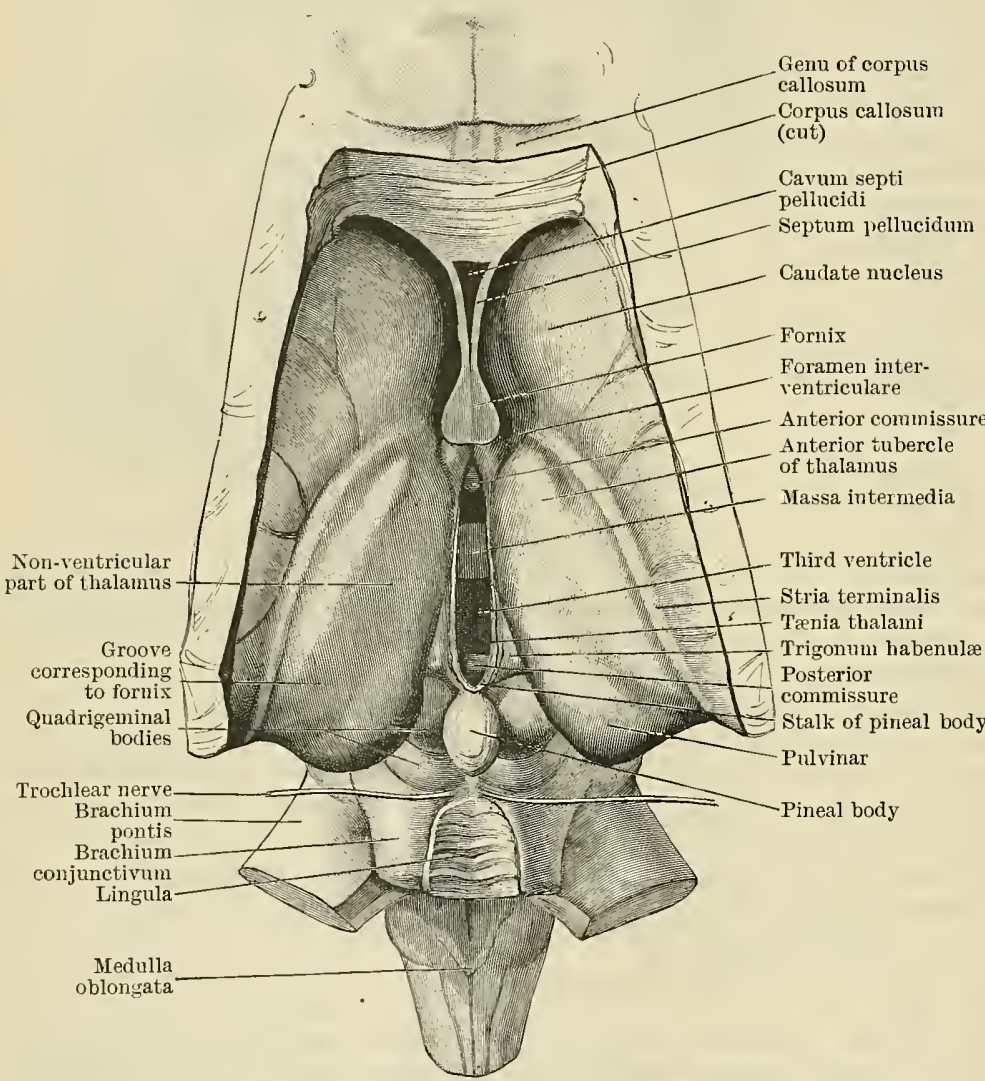

Fig. 516.-The Corpora Quadrigemina and the Neighbodring Parts. veli, passes to the anterior medullary velum, which lies immediately below the inferior colliculi. The transverse groove curves round below each of the superior pair of colliculi and separates them from the inferior pair. It is also continued in an upward and ventral direction on the lateral aspect of the mesencephalon.

The quadrigeminal bodies are not marked off laterally from the sides of the mesencephalon, but each has in connexion with it, on this aspect, a prominent strand, which is prolonged superiorly and ventrally towards the thalamic region. These strands are called the brachia of the corpora quadrigemina, and they are separated from each other by a continuation, on the side of the mesencephalon, of the transverse groove which intervenes between the two pairs of bodies.

The corpus geniculatum mediale is closely associated with the brachia, although it does not form part of the mesencephalon, but belongs to the prosencephalon. It is a small, sharply defined oval eminence, which lies on the lateral side of the superior part of the mesencephalon under shelter of the posterior end of the thalamus.

The brachium quadrigeminum inferius, proceeding upwards from the colliculus inferior, advances towards the corpus geniculatum mediale and disappears from view under cover of this prominence.

The brachium quadrigeminum superius is carried superiorly and ventrally between the overhanging thalamus and the corpus geniculatum mediale. A superficial examination of the mesencephalon is sufficient to show that, while a large part of this strand enters the corpus geniculatum laterale, a considerable portion is a continuation of the lateral root of the optic tract. 
Pedunculi Cerebri.-The cerebral peduncles (Figs. 517 and 527) appear upon the ventral or basal aspect of the mesencephalon as two large rope-like strands which emerge from the cerebral hemispheres and disappear below by plunging into the pars basilaris of the pons. At the place where each peduncle emerges from the corresponding side of the cerebrum it is encircled by the optic tract.

Each pedunculus cerebri is composed of two parts, viz., a dorsal tegmental part (tegmentum), which is prolonged upwards into the region below the thalamus (hypothalamus), and a ventral portion (basis pedunculi), which, when traced upwards into the cerebrum, is seen to take up a position on the lateral side of

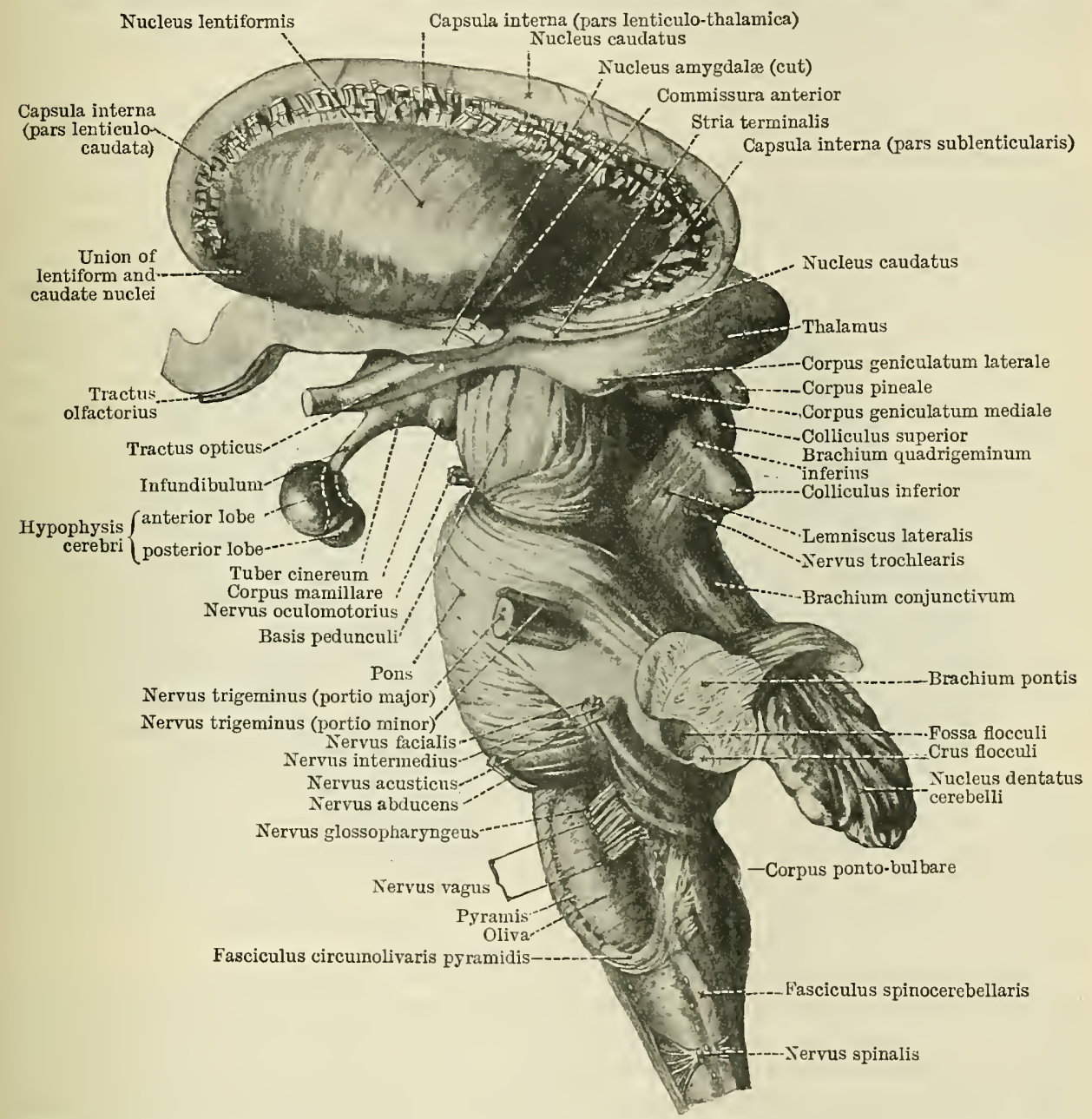

Fig. 517. - The left Lateral Aspect of the Braix-stem after the Cerebral Henisphere (except the Corpus Striatum) and the Cerebellum (except the Nucleus Dentatus) have been reuoved.

the thalamus and to be continuous with the internal capsule of the brain. When the base of the brain is examined, it is the basis pedunculi which is seen, and it is observed to be white in colour and streaked in the longitudinal direction. In the tegmentum the longitudinally-arranged fibres are, in large part, corticipetal, or, in other words, fibres which are ascending towards the cortex of the cerebrum; the basis pedunculi, on the other hand,is entirely composed of longitudinal strands of fibres which are corticifugal, or fibres which descend from the cerebral hemisphere.

On the surface of the mesencephalon the separation between the tegmental and basal portions of the pedunculus cerebri is clearly indicated by a medial and a lateral groove. The medial furrow is the more distinct of the two. It looks into the interpeduncular fossa, and from it emerge the fila of the oculo-motor 
nerve. It is termed, therefore, the sulcus n. oculomotorii. The lateral groove, which is placed on the lateral aspect of the mesencephalon, receives the name of the sulcus lateralis [mesencephali]. When traced downwards, it is observed to become continuous with the furrow which intervenes between the brachium pontis and brachinm conjunctivum of the cerebellum.

A close inspection of the lateral surface of the tegmental part of the pedunculi cerebri, below the level of the brachia, will reveal some faintly-marked bundles of fibres curving obliquely upwards and backwards to reach the inferior colliculus (Fig. 517, p. 583). These are fibres of the lateral lemniscus, coming to the surface at the sulcus lateralis and sweeping over the subjacent brachium conjunctivum to gain the inferior colliculus, inferior brachium, and medial geniculate body.

\section{INTERNAL STRUCTURE OF THE MESENCEPHALON.}

When transverse sections are made through the mesencephalon the aquæductus cerebri is seen to be surrounded by a thick layer of gray matter, which receives the name of the stratum griseum centrale or the central gray matter of the aqueduct. On the dorsal aspect of this gray matter the corpora quadrigemina form a layer which

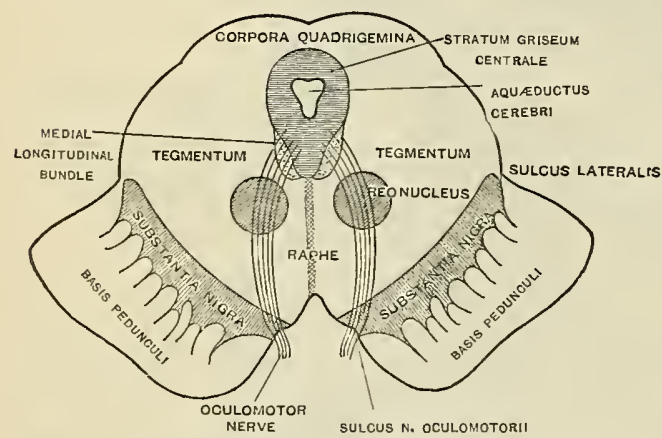

Fig. 518.-Diagramatic View of the Cut Surface of a Transverse Section throdgh the SUperior Part OF THE MESENCEPHALON.

to the third ventricle above. It is not quite three-quarters of an inch in length, and it lies much nearer the dorsal than the ventral surface of the mesencephalon. When examined in transverse section, it presents a triangular outline as it passes into the fourth ventricle and a $\mathrm{T}$-shaped outline close to the third ventricle. In the intermediate part of its course it assumes different outlines, and not always the same form at the same level in different specimens.

The aqueduct is lined with ciliated epithelium, and outside this is the thick layer of central gray matter, which is directly continuous below with the gray matter spread out on the floor of the fourth ventricle, and above with gray matter on the floor and sides of the third ventricle. Scattered more or less irregularly throughout the central gray matter are numerous nerve-cells of varying forms and sizes, whilst in addition to these there are three definite collections or clusters of cells, which constitute the nuclei of origin of the trochlear nerve, the oculomotor nerve, and the mesencephalic root of the trigeminal nerve. The position and relations of these will be given at a later stage.

Substantia Nigra. - When seen in transverse section, the substantia nigra presents a semilunar outline. It consists of a mass of gray matter, in the midst of which are large numbers of deeply pigmented nerve-cells. It is only when this substance is examined in bulk that it appears dark; in thin sections it does not differ much in colour from ordinary gray matter, although, under the microscope, the brown-coloured cells stand out very conspicuously, even under low powers. The substantia nigra is disposed in the form of a thick layer, interposed between the tegmental and basal portions of the cerebral peduncle. It begins below at the superior border of the pons and extends upwards into the hypothalamus. The margins of this layer of dark-coloured substance come to the surface at the 
oculomotor and the lateral sulci of the mesencephalon, and its medial part is traversed by the emerging fila of the oculomotor nerve. It is not equally thick throughout. Towards the lateral sulcus it becomes thin, whilst it thickens considerably near the medial aspect of the pedunculus cerebri. The surface of the substantia nigra, which is turned towards the tegmentum, is concave and uniform; the opposite surface is convex and rendered irregular by the presence of numerous slender prolongations of the substance into the basis pedunculi.

The morphological and physiological significance of the substantia nigra is not fully understood, and the connexions established by its cells are imperfectly known.

Bechterew, however, is of the opinion that fibres arising in the motor area of the cerebral cortex end in relationship with the cells of the substantia nigra, the axons of which proceed to the motor trigeminal nucleus for the purpose of coordinating the muscles of mastication.

Colliculi Inferiores (orinferior quadrigeminal bodies)._Each inferior colliculus

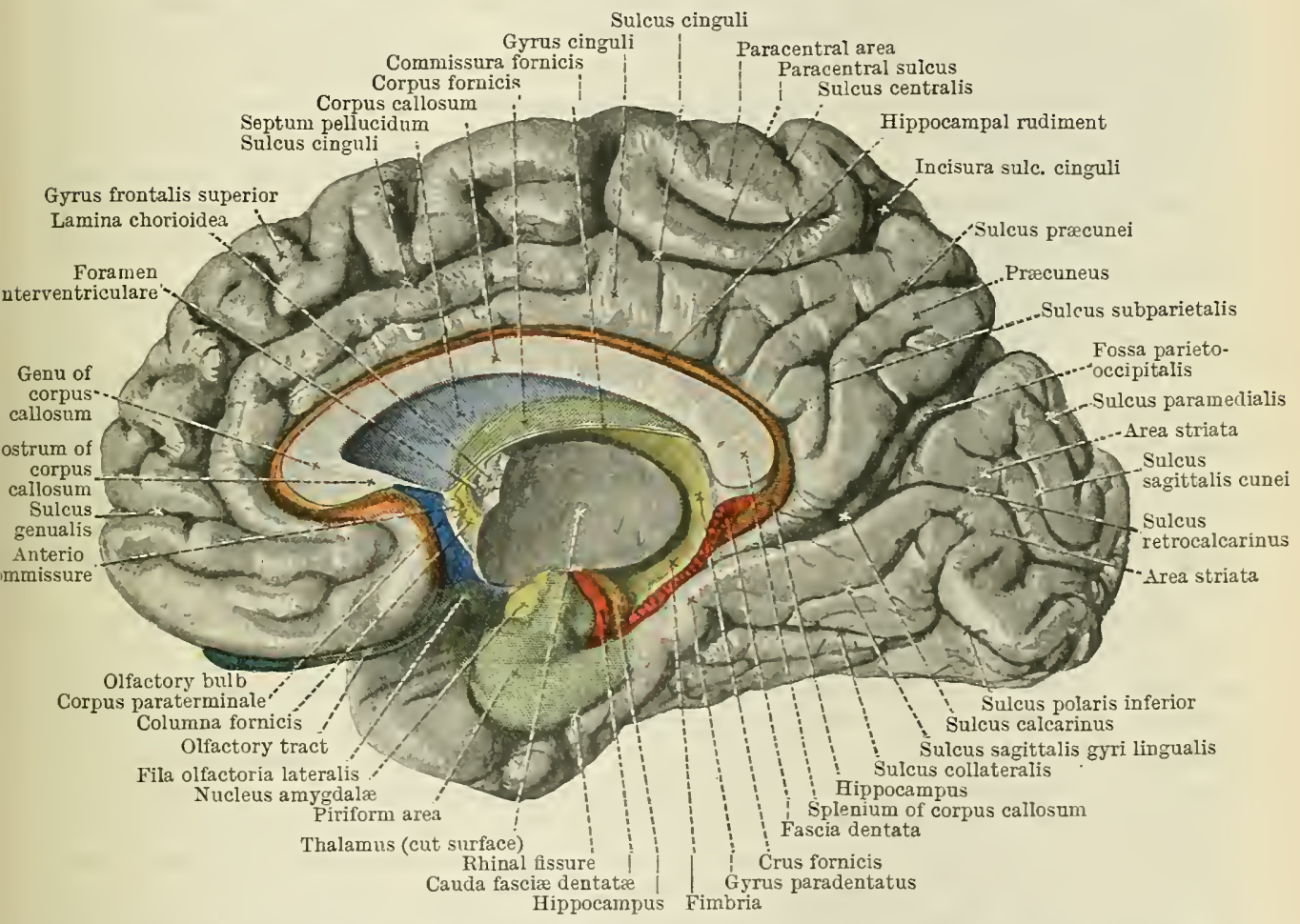

Fig. 519. -The Medial aspect of the Right Half of the Brain exposed by a Mediax Sagixtal Section.

is composed largely of a mass of gray matter which, in transverse section, presents an oval outline (Fig. 520, p. 587). This central nucleus is, to a large extent, encapsulated by white matter. Numerous cells of various sizes are scattered throughout it, and the whole mass is pervaded by an intricate interlacement of fine fibres, which are derived, to a large extent, from the lateral lemniscus.

In transverse sections through this region, the lateral lemniscus is seen to abut against the lateral margin of the central nucleus. Many of the fibres of this tract enter it at once and become dispersed amongst its cells; others sweep orer its dorsal surface, so as to give it a superficial covering; whilst a third gromp is carried medially, in the form of a thin layer, on its ventral aspect, so as to mark it off from the subjacent central gray matter of the aqueduct (Fig. 520, p. 587). In this manner, therefore, the inferior colliculus becomes partially circumscribed by the fibres of the lateral lemniscus. Several of the lateral lemniscus fibres, which proceed over the superficial or dorsal aspect of the nucleus, reach the median plane and form a loose decussation with the corresponding fibres of the opposite side.

The intimate connexion which is thus exhibited between the fibres of the lateral lemniscus 
and the nucleus of the inferior colliculus is very significant. The lateral lemniscus, to a large extent, comes from the nuclei of termination of the cochlear nerve of the opposite side. We must associate, therefore, the inferior colliculus, and also the corpus geniculatum mediale, which likewise receives fibres from the lateral lemniscus, with the organ of hearing.

This view regarding the inferior colliculi is supported both by experimental and by morphological evidence. Speaking broadly, it may be stated that the inferior colliculi becomes prominent only in mammals, and then they are invariably correlated with a spirally wound and welldeveloped cochlea. That they have nothing to do with sight is shown by the fact that, when the eye-balls are extirpated in a young animal, the inferior colliculi remain unaffected, whilst the superior colliculi after a time atrophy (Gudden). When, on the other hand, the cochlear terminal nuclei are destroyed, fibres which have undergone atrophy may be followed to the inferior colliculi of both sides, but particularly to that of the opposite side (Baginski, Bumm, and Ferrier and Turner). A very considerable tract of ascending fibres takes origin within the inferior colliculus and passes upwards, in the inferior brachium, into the tegmentum subjacent to the medial geniculate body. Within the tegmentum they proceed up to the thalamus (Ferrier and Turner).

Colliculi Superiores (or superior quadrigeminal bodies). -The superior colliculus presents a more complicated structure (Fig. 521). Superficially, it is coated with a very thin layer of white matter, which is termed the stratum zonale. Underneath this there is a gray nucleus, called the stratum griseum, which, in transverse section, exhibits a crescentic outline and rests in a cap-like manner upon the subjacent part of the eminence. The succeeding two strata, which respectively receive the names of stratum opticum and the stratum lemnisci, present this feature in common, that they are composed of gray matter, traversed by numerous fibres. The source from which the fibres are derived is different, however, in each case.

Nerve-fibres reach the superior colliculus through-(1) the lemnisci and (2) the superior brachium.

The fibres of the lemnisci constitute the stratum lemnisci. The superior brachium contains fibres of two different kinds, viz., fibres from the optic tract and fibres from the cortex of the occipital lobe of the cerebrum. By the former it is connected with both retinæ, and by the latter with the visual centre in the occipital region of the cerebral cortex. The great majority of these fibres pass into the margin of the colliculus superior and form a layer-stratum opticum-underneath the stratum griseum, in which they ultimately terminate.

Tegmentum.-The tegmentum of the pedunculus cerebri may be regarded as the continuation upwards of the formatio reticularis of the medulla oblongata and the dorsal or tegmental portion of the pons into the mesencephalon. It consists, therefore, of fine bundles of longitudinal fibres intersected by arching fibres, which take a transverse and curved course. The interstices between these nervebundles is occupied by gray matter containing irregularly scattered nerve-cells. On its dorsal aspect the tegmentum is continuous, at the side of the central gray matter, with the bases of the corpora quadrigemina, whilst, ventrally, it is separated from the basis pedunculi by the substantia nigra. The tegmenta of opposite sides are, to some extent, marked off from each other in the median plane by a prolongation upwards of the median raphe of the pons and medulla oblongata, although, in the inferior part of the mesencephalon, this is much obscured by the decussation of the brachia conjunctiva. The two longitudinal strands, termed the medial longitudinal bundle and the medial lemniscus, are prolonged upwards throughout the entire length of the mesencephalon; and they present the same relations to the tegmentum as in the inferior parts of the brain. The medial longitudinal fasciculus is placed in relation to its dorsal aspect, whilst the lemniscus is carried up in its ventral part.

The tegmentum of the mesencephalon may be considered as presenting two parts: viz., (1) an inferior part, which is placed subjacent to the inferior colliculi and is largely occupied by the decussation of the brachia conjunctiva (Fig. 520); and (2) a superior part, subjacent to the superior colliculi which is traversed by the emerging bundles of the oculomotor nerve. The superior part contains a large and striking nuclear mass, termed the nucleus ruber or the red tegmental nucleus (Fig. 521). In the inferior part of the central gray matter of the mesencephalon is the nucleus of the trochlear nerve; in the superior part, the nucleus of the oculomotor nerve. 
Brachia Conjunctiva.-As the brachia conjunctiva leave the pons and sink into the tegmentum of the mesencephalon, they undergo a complete decussation, subjacent to the inferior colliculi and the central gray matter (Figs. 520, 521, p. 587; and 522, p. 588). In this manner each brachium is transferred from one side, across the median plane, to the opposite side. The decussation is completed at the level of the superior borders of the inferior colliculi, and then each brachium proceeds upwards into the superior part of the tegmentum, where it encounters the red nucleus. Into this a large proportion of its fibres plunge, and come to an end in connexion with the nuclear cells. Many of the fibres, however, are carried around the nucleus so as to form for it a

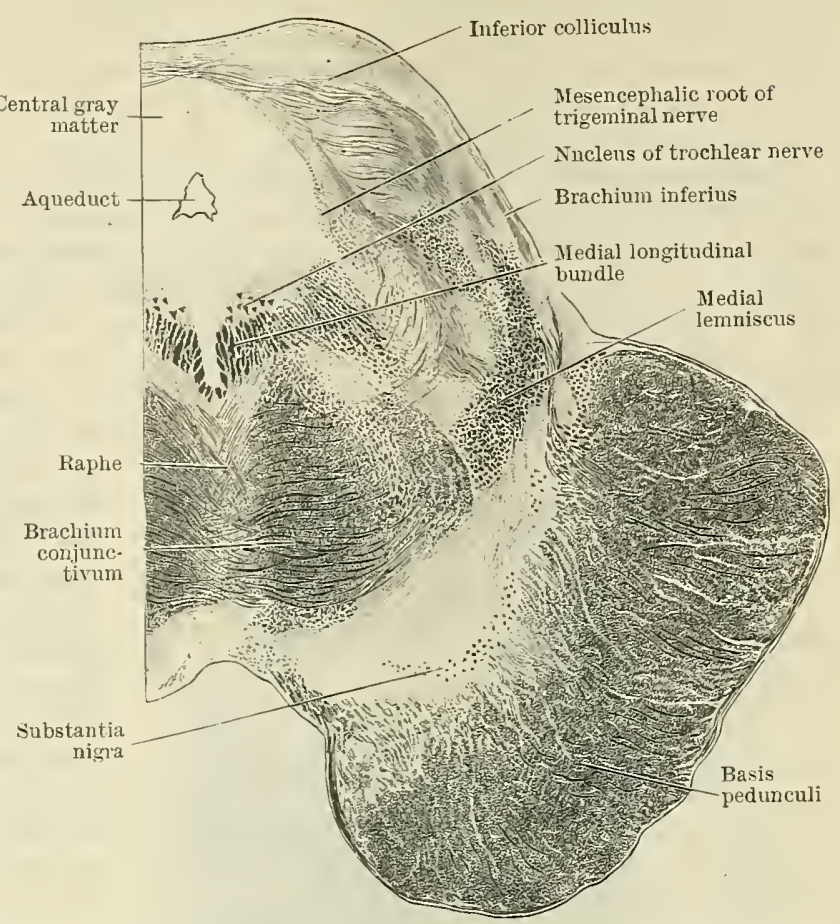

Fig. 520.-Transierse Section throdgh the Human Mesexcephalon AT THE LEVEL OF THE INFERIOR COLLICUlus.

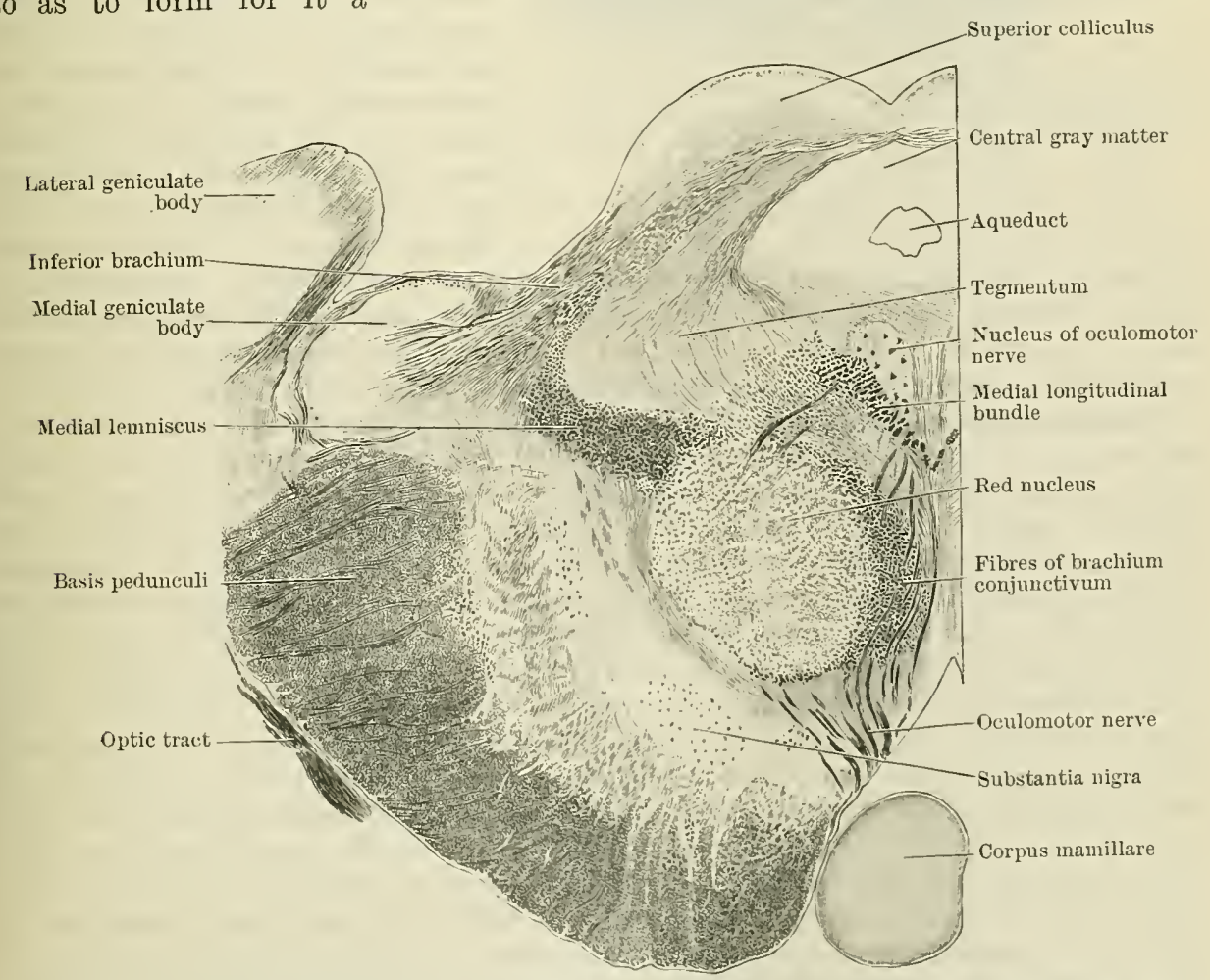

Fig. 521.-Transverse Section through the Humas Nesencephalon at the level of the 
capsule, which is thicker on the medial than on the lateral side (Fig. 521). These are prolonged into the thalamus, and end ultimately in connexion with the ventral thalamic cells. The brachium conjunctivum is, therefore, a great efferent tract which issues from the nucleus dentatus of the cerebellum, crosses the median plane in the inferior part of the mesencephalon, and ends in the red nucleus and the ventral part of the thalamus.

Nucleus Ruber. - The red nucleus is a rounded nuclear mass, of a reddish tint in the fresh brain, which lies in the superior part of the tegmentum, and in the path of the brachium conjunctivum. In transverse section it presents a circular outline. It begins at the level of the inferior border of the superior colliculus and it extends upwards into the hypothalamus. At first it is small and is placed at a little distance from the median plane; but, as it proceeds upwards, it increases in bulk and approaches more nearly to the median raphe, and to its

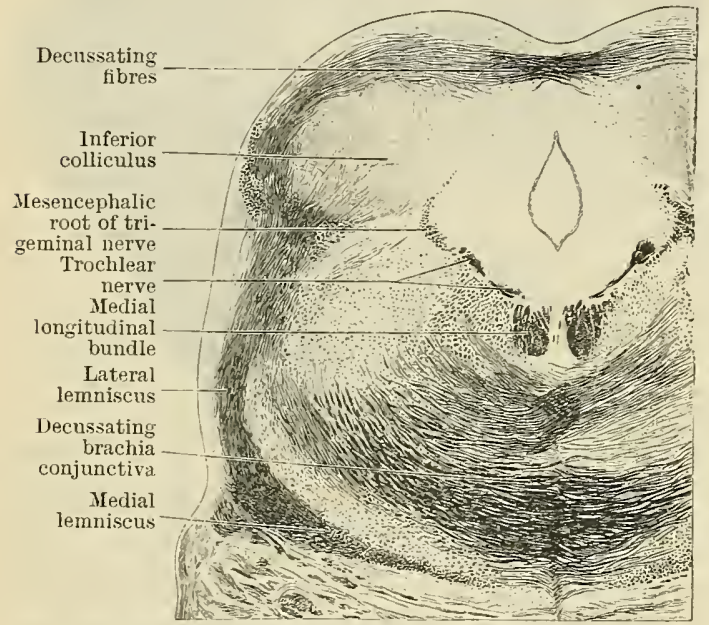

Fig. 522.- SECtioN THROUGH THE INFERIOR COLliodlus AND THE Tegmentum OF the Mesencephalon BeLOW the Level OF the Necleus of the Trochlear Nerve in the Orang. (The decussation of the brachia conjunctiva and the course of the trochlear nerve in the central gray matter are seen.) fellow of the opposite side. The curved emerging bundles of the oculomotor nerve pass through it on their way to the surface. The relation which the fibres of the opposite brachium conjunctivum present to it has been described. These fibres traverse its inferior part in such numbers that in Weigert-Pal specimens it presents a very dark colour; but higher up, as the fibres gradually end in nuclear mass, they become less numerous in its midst, and the nucleus assumes a paler tint.

Numerous fibres which descend from the cerebral cortex, and others from the corpus striatum, enter the red nucleus. It also sends out fibres which proceed in two directions: (1) upwards into the thalamus; (2) downwards to the spinal medulla. The thalamic fibres may be regarded as carrying on the

continuity of the path of the brachium conjunctivum after its nodal interruption in the red nucleus. The fibres to the spinal medulla, called the rubro-spinal tract and first described by Monakow, cross to the opposite side and then descend in the tegmentum to reach the lateral funiculus of the spinal medulla (Fig. 473, p. 534).

Fasciculus Longitudinalis Medialis. - The medial longitudinal fasciculus is a very conspicuous tract of longitudinal fibres which extends throughout the whole length of the medulla oblongata, pons, and mesencephalon, in the formatio reticularis or tegmental part of each. Below, at the level of the decussation of the pyramids, it becomes continuous with the fasciculus anterior proprius of the spinal medulla (p. 562), whilst, by its opposite or superior end, it establishes intricate connexions in the region immediately above the mesencephalon. Throughout its whole length it lies close to the median plane and its fellow of the opposite side. In the mesencephalon it is applied to the ventral aspect of the central gray matter, whilst in the pons and medulla oblongata it is situated immediately subjacent to the gray matter of the floor of the fourth ventricle. One of its most salient features is the intimate association which it presents with the three motor nuclei from which the nerves for the supply of the muscles of the eyeball take origin, viz., the oculomotor nucleus, the trochlear nucleus, and the abducent nucleus. The first two of these are closely applied to its medial and dorsal aspect, whilst the abducent nucleus is placed on its lateral side. Into each of these nuclei it sends many collaterals, and probably also some of its constituent fibres, and these end around the nuclear cells. It would appear, therefore, that one of the most 
important functions of this strand is to bind together these nuclei, and thus enable them to act in harmony one with the other. Fibres also enter the medial longitudinal fasciculus from the vestibular nucleus of the acoustic nerve system. The results obtained by degeneration would seem to indicate that, to a large extent, it is formed of fibres which run a short course within it.

That it is a brain tract of high importance, is evident from the fact that it is present in all vertebrates, and, further, that its fibres assume their medullary sheaths at an extremely early period. In fishes, amphibians, and reptiles, it is one of the largest bundles of the medulla oblongata. In man, its fibres medullate between the sixth and serenth months of fotal life, and at the same time as the fibres of the fasciculus anterior proprius of the spinal medulla, with which it stands in connexion.

According to van Gehuchten and Edinger, it extends upwards beyond the level of the oculomotor nucleus, and in the thalamic region its tibres take origin from a special nucleus of its own in the gray matter of the third ventricle, immediately behind the level of the corpora mamillaria. Fibres also enter the medial longitudinal bundle from a nucleus common to it and the posterior commissure of the brain. This nucleus is placed in the fore part of the central gray matter of the mid-brain. Held asserts that numerous fibres, arising from cells in the superior colliculus, curve in an arcuate manner in the tegmentum outside the central gray matter, to take part on the ventral aspect of this in what is called the fountain decussation. Reaching the opposite side, these fibres turn downwards and join the

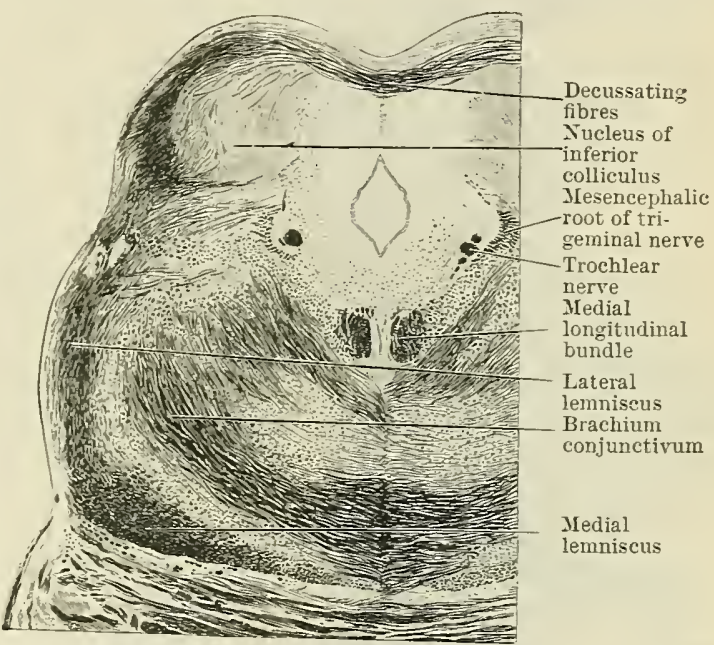

Fig. 523.- Section through The Isferior Colliculus AND THE TEGMExTUM OF THE MESExCEPHALON, AT A SLIGHTLY LOWER LEVEL THAN Fig. 522.

medial longitudinal bundle. The same authority considers that fibres from the ventral part of the posterior commissure can also be traced downwards into the medial longitudinal bundle. Edinger, on the other hand, places these fibres as a distinct tract on the ventral and lateral aspect of the medial longitudinal bundle, although in apposition with it.

Mendel believed that fibres from the oculomotor nucleus are carried down in the medial longitudinal bundle, and, from this, into the facial nerve for the supply of the orbicularis oculi and the corrugator supercilii, bringing these muscles, therefore, under the control of the same nucleus as the levator palpebræ superioris muscle. This view was adopted by many clinicians because this upper group of facial muscles is often spared in cases of facial paralysis; but Harman has adduced reasons in support of the view that there is a superior prolongation of the facial nucleus which innervates these muscles. It has been suggested further that fibres from the hypoglossal nucleus may, by the medial longitudinal bundle, reach the facial nerve, and through it the orbicularis oris. In this manner the same nucleus would hold sway over the tongue and the sphincter muscle of the lips. The close relation which exists between the ascending part of the intrapontine portion of the facial nerve and the medial longitudinal bundle would render the passage of fibres from one to the other a circumstance which could easily be understood. But the balance of evidence now available inclines us to regard the facial nucleus as the origin of the fibres innervating all the facial muscles. Another interchange of fibres through the medial longitudinal bundle has been described by Duval and Laborde. According to these authorities, fibres from the abducens nucleus ascend in the medial longitudinal bundle into the mesencephalon, and establish connexions 
with that part of the oculomotor nucleus from which the nerve for the medial rectus of the opposite side derives its fibres. If this view is correct, it affords a ready and simple anatomical explanation of the harmonious action of the lateral and medial recti muscles in producing movements of the two eyeballs simultaneously to the right and to the left. From the investigations of $\mathrm{E}$. $\mathrm{H}$. Fraser it would appear that no fibres from the abducens nucleus go directly into the oculomotor nerve. The same observer has shown that many fibres from Deiters' nucleus, a part of the vestibular nucleus of the acoustic nerve to be described later in this account, enter the oculomotor and the trochlear nuclei through the path afforded by the medial longitudinal bundle.

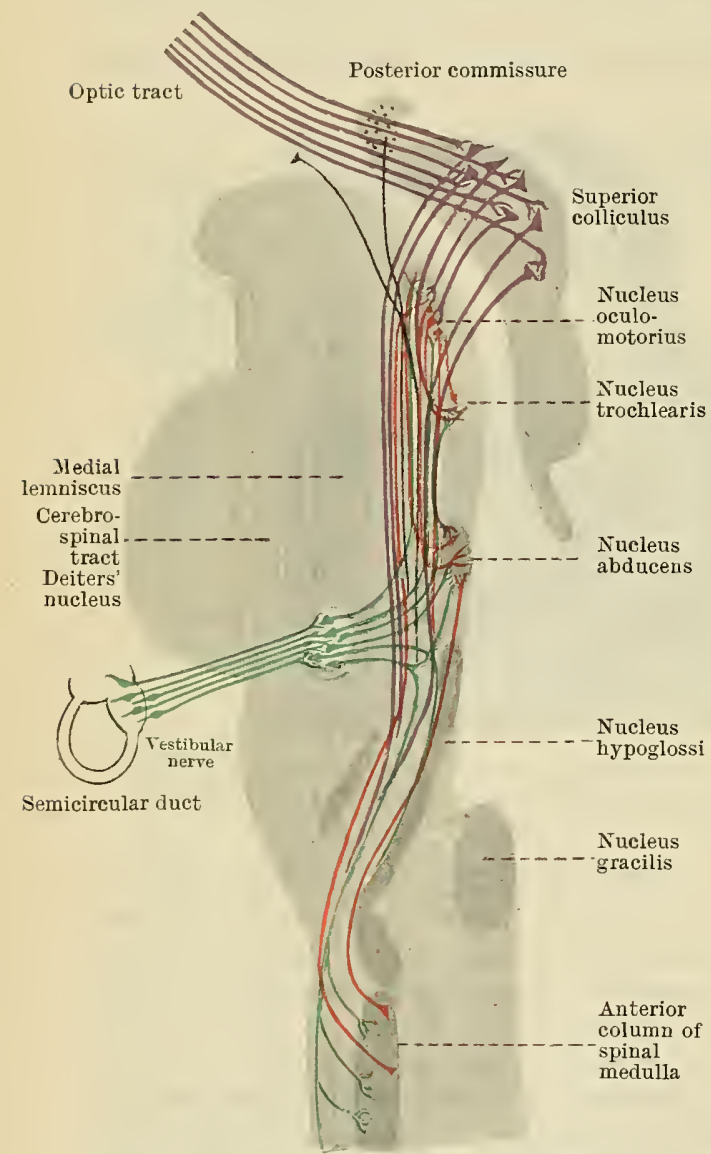

Fig. 524.-DiagraM REPRESENTING SOME OF the Constituent Elements of the Fasciculdo Longitudinalis Medialis.

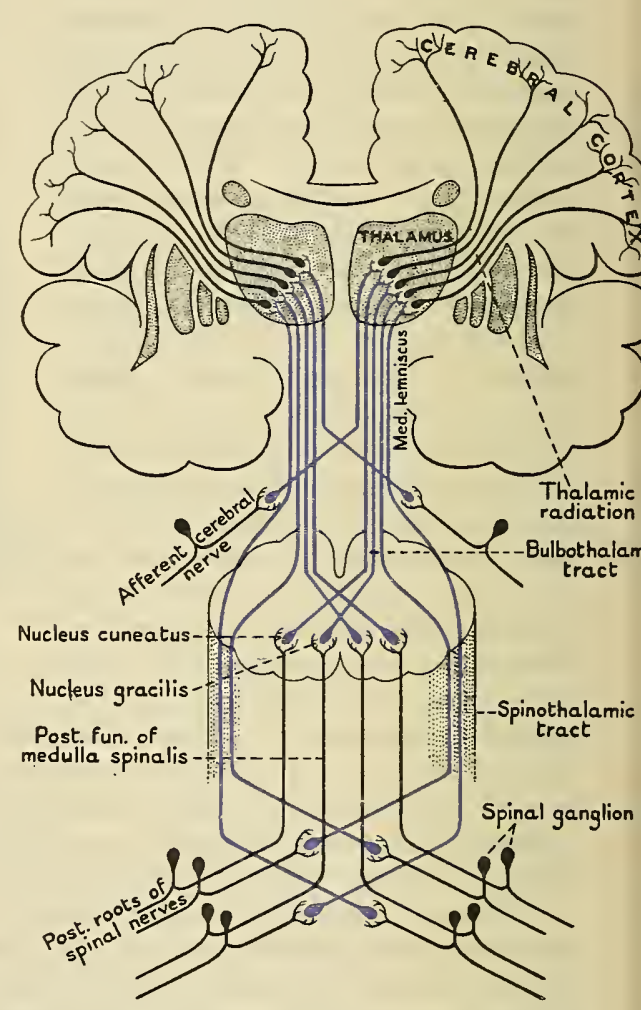

Fig. 525.-Diagram of the ConNexions of the Medial Lemniscus and also OF CERtain of the Thalamo-cortical Fibres.

Lemniscus Lateralis.-The Iateral lemniscus is a definite tract of longitudinal fibres, which extends upwards through the lateral part of the tegmental substance of the superior portion of the pons and the mesencephalon. It is formed by the fibres of the corpus trapezoideum and striæ medullares in the inferior part of the pons, turning abruptly upwards and taking a course towards the quadrigeminal region. But the details of the arrangement and connexions of this important fasciculus must be left for fuller consideration when we are discussing the central connexions of the acoustic nerve.

Lemniscus Medialis.-The medial lemniscus has already been followed through the medulla oblongata and pons, and its position in each of these portions of the brain-stem has been defined (pp. 561 and 562). In the tegmentum of the inferior part of the mesencephalon it is carried up in the form of a more or less flattened 
band on the ventral aspect of the decussating brachia conjunctiva. To its lateral side, and forming an angle with it (as seen in transverse section), is the lateral lemniscus (Figs. 522 and 523), and at this level there is no clear demarcation between these two tracts. In the superior part of the mesencephalon the appearance of the red nucleus in the tegmentum causes the medial lemniscus to take up a more lateral and dorsal position, so that it now comes to lie subjacent to the corpus geniculatum mediale (Fig. 521, p. 587). At this level it exhibits a crescentic outline in transverse section, and the lateral lemniscus has to a large extent disappeared from its lateral side.

A part of the medial lemniscus, which is called the fasciculus bulbothalamicus, takes origin in the inferior part of the medulla oblongata from the gracile and cuneate nuclei of the opposite side (p. 560). Seeing that the posterior funiculus of the spinal medulla ends in these nuclei, the medial lemniscus may be considered to continue that funiculus upwards into the brain. Other fibres arise from the terminal nuclei of the various sensory cerebral nerves of the opposite side. The rest of the tract consists of the superior part of the fasciculus spinothalamicus from the spinal medulla. In the mesencephalon a considerable contribution of fibres is given by the medial lemniscus to the superior colliculus, and then the remainder of the tract proceeds into the lateral (ventro-lateral) nucleus of the thalamus. Here its fibres end amidst the thalamic cells.

Ganglion Interpedunculare and Fasciculus Retroflexus.-Immediately above the pons a small collection of nerve-cells is found in the median plane, wedged in between the two cerebral peduncles. It is all that is found in the human brain to represent a large nucleus projecting into the interpeduncular fossa in most other animals, especially those with a highly developed sense of smell. In this interpeduncular ganglion ends the fasciculus retroflexus, a tract of fibres which comes from the nucleus habenulæ of the epithalamus. We shall return to the consideration of this tract later.

Fountain Decussation. - If the region ventral to the medial longitudinal bundles is examined in the superior part of the mesencephalon a very close decussation of fibres in the median plane will be observed in the interval between the two red nuclei. This is the "fountain decussation." According to Held, the fibres which take part in the dorsal portion of the fountain decussation (decussation of Meynert) come from the superior colliculi, and, after they have gained the opposite side, they turn downwards in the medial longitudinal fasciculus.

Many of the fibres that cross in this decussation enter a descending tract (fasciculus tecto-bulbaris et spinalis) which connects the corpora quadrigemina with the motor nuclei on the other side of the medulla oblongata and spinal medulla.

Basis Pedunculi. - The basis pedunculi presents a somewhat crescentic outline when seen in transverse section, and it stands quite apart from its fellow of the opposite side. It is composed of a compact mass of longitudinally directed fibres, all of which, as Déjerine has shown, arise in the cortex of the cerebrum and pursue an unbroken corticifugal course into and through the pedunculus cerebri. These fibres may be classified into two distinct sets, viz., cerebro-pontine and pyramidal or cerebro-spinal.

The cerebro-pontine fibres possess this leading character: in their course downwards they are all arrested in the ventral part of the pons, and end amidst the cells of the nuclei pontis. These tracts would appear to hold a very definite position within the crus. Thus, it has been satisfactorily established that the fibres coming from the temporal area of the cerebral cortex (temporo-pontine strand) form the lateral fifth of the basis pedunculi, whilst those coming from the frontal area (fronto-pontine strand) hold a similar position in the medial part of the basis pedunculi.

The pyramidal fibres constitute the great motor tract from the cerebral cortex. They occupy a position corresponding to the middle three-fifths of the basis. The pyramidal tract differs from the cerebro-pontine strands in being carried downwards through the ventral part of the pons and on the ventral aspect of the medulla oblongata into the spinal medulla, which it enters in the form of the fasciculi cerebrospinales lateralis and anterior. On its way through the pons and 
medulla oblougata it sends fibres across the median plane to the various motor nuclei on the opposite side of those sections of the brain-stem.

\section{Development of the Mesencephalon.}

Even in the early embryo the mesencephalon constitutes the smallest section of the brain-tube, although the disproportion in size between it and the other primitive subdivisions of the brain is not nearly so marked as in the adult. Owing to the cephalic flexure, the mid-brain for a time occupies the summit of the head. Later it becomes completely covered over by the expanding cerebral hemispheres.

The corpora quadrigemina are derived from the alar laminæ of the lateral walls of the brain-tube, whilst the basal laminæ thicken and ultimately form the tegmenta. The original cavity of the mid-brain is retained as the aqueduct.

For a considerable time the cavity of the mesencephalon remains relatively large, and the lower part of its dorsal wall is carried downwards in the form of a diverticulum or recess, which overlaps the cerebellar plate. About this time, also, the dorsal wall shows a median fold or ridge. Both of these conditions are transitory. As the corpora quadrigemina take shape, the median ridge disappears and is replaced by the median longitudinal groove, which separates the quadrigeminal bodies. Only its inferior part is retained, and this is represented by the frenulum veli of the adult brain. The diverticulum of the cavity gradually becomes reduced, and finally disappears as the aqueduct assumes form.

The precise mode of origin of the red nucleus is not known.

Later in this account reasons will be given for the belief that the representatives of the neural crests in the region of the mesencephalon become absorbed and assimilated in the walls of the neural tube as it closes in.

\section{THE DEEP CONNEXIONS OF THE CEREBRAL NERVES ATTACHED TO} THE MEDULLA OBLONGATA, PONS, AND MESENCEPHALON.

There are twelve pairs of cerebral nerves, of which the inferior eight are attached to the medulla oblongata and pons. From above downwards these are named the trigeminal (fifth), the abducens (sixth), the facial (seventh), the acoustic (eighth), the glossopharyngeal (ninth), the vagus (tenth), the accessory (eleventh), and the hypoglossal (tweltth). Two others, the trochlear (fourth) and oculomotor (third) spring from the mesencephalon. The hypoglossal, the accessory, the greater part of the facial, the abducens, the motor root of the trigeminal, the trochlear and the oculomotor are efferent nerves; the acoustic, the nervus intermedius (sensory root of the facial) and the sensory root of the trigeminal are purely afferent nerves; whilst the vagus and the glossopharyngeal are composed of both efferent and afferent fibres. In all these cases (with a possible reservation in the case of part of the trigeminal) afferent fibres arise from ganglionic cells placed outside the brain and penetrate the brain-stem, to end in connexion with the cells of certain nuclei of termination. Efferent fibres, on the other hand, take origin within the brain as the axons of cells which are grouped together in certain places in the form of nuclei of origin.

Nuclei of Origin, or Motor Nuclei. - In the spinal medulla the nuclei of origin are represented by elongated columns of cells which run more or less continuously in the anterior column of gray matter of successive spinal segments, and from these the series of efferent anterior nerve-roots take origin. In the medulla oblongata, pons, and inesencephalon the nuclei of origin, or, in other words, the motor nuclei of the individual nerves, become, for the most part, discontinuous, and are represented by certain isolated clumps of compact gray matter, in which are placed the clusters of cells from which the fibres of the efferent nerves arise. The nucleus ambiguus, however, which consists of a column of cells from which root-fibres of the bulbar part of the accessory, of the vagus, and also of the glossopharyngeal are derived, is an exception to this rule. At the decussation of the pyramids, the anterior column of gray matter of the spinal medulla is broken up by the in tercrossing bundles into a detached head and a basal part which remaims in relation with the ventrolateral aspect of the central canal. Certain of the efferent nuclei of the medulla oblongata, pons, and mesencephalon lie in the line of the basal portion of the anterior column of gray matter of the spinal medulla, and, thus, close to the median plane. These are termed medial somatic nuclei, and are met with at different levels in the 
brain-stem. This group comprises the hypoglossal nucleus, the abducens nucleus and, in the mesencephalon, the trochlear nucleus and part of the oculomotor nucleus. Other motor nuclei of origin are present in the form of isolated clumps or columns of gray matter, which lie at different levels in the medulla oblongata and pons in a more lateral and deeper situation. They are the nucleus ambiguus of the accessory, vagus and glossopharyngeal, the facial nucleus, and the nucleus of the motor root of the trigeminal nerve. From their position in the substantia reticularis of the medulla oblongata and pons they constitute a group to which the name of lateral somatic nuclei is applied.

In addition to these two columns of motor nuclei there is a third efferent column of splanchnic nuclei represented by the dorsal nucleus of the vagus and glossopharyngeal nerves, and similar nuclei emitting sympathetic fibres into the

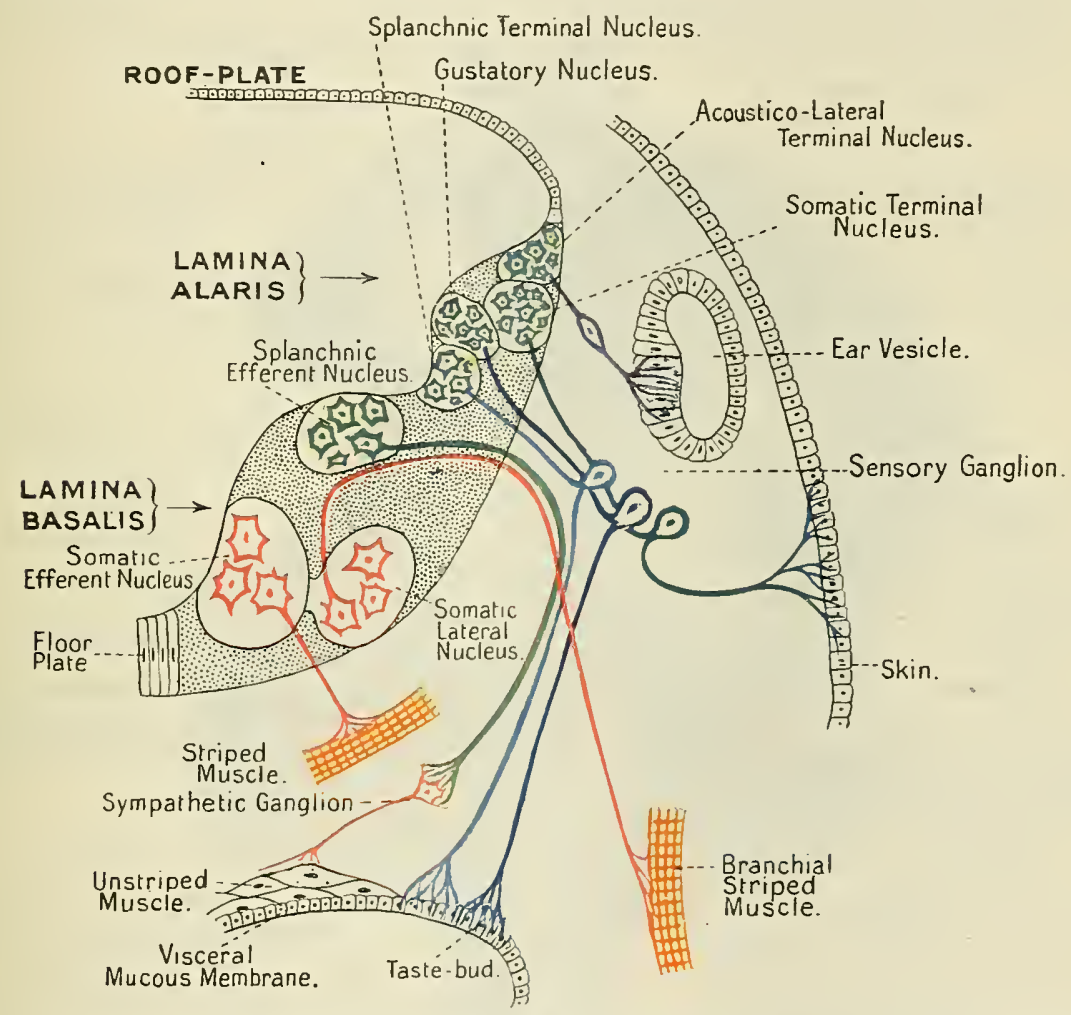

Fig. 526.-Diagram representing the Different Kinds of Components foond in the Cerebral Nerves axd of their Nuclei of Origin or Termination.

facial and oculomotor nerves. It is possible some splanchnic efferent fibres may pass into the trigeminal nerve.

The different nuclei of origin of the efferent fibres which belong to the various cerebral nerves, both medial and lateral, are connected with the motor area of the cerebral cortex by fibres of the cerebro-spinal tract of the other side, which enter the nuclei and end in association with their cells.

Nuclei Terminales.-The general scheme of arrangement of the terminal nuclei has already been explained (Fig. 526); its details will be further elucidated as the various nerves are considered seriatim.

The axons of many of the cells of the nuclei of termination enter the substantia reticularis as arcuate fibres, and, crossing the median plane, are carried upwards in the substantia reticularis of the opposite side, to establish direct connexions with the thalamus and indirectly through it with the cerebral cortex (Fig. 525).

Others pass to the nuclei of motor nerves, to the cerebellum or other groups of nerve-cells, to form connexions necessary for the performance of reflex actions. 
Nervus Hypoglossus.-The nucleus of origin of the hypoglossal nerve, the motor nerve of the tongue, lies in the substance of the medulla oblongata. It is composed of several groups of large multipolar cells, which closely resemble the cells in the anterior column of gray matter in the spinal medulla, and is pervaded by an intricate network of fine fibrils. In form it is elongated and rod-like, and in length it is about $18 \mathrm{~mm}$. It extends from a point immediately above the decussation of the pyramids up to the level of the striæ medullares. The inferior portion of the nucleus is thus placed in the closed part of the medulla oblongata (Fig. 494, p. 561), whilst its superior part is situated in the open part (Fig 495, p. 561). The former lies in that part of the central gray matter which is continuous with the basal part of the anterior column of gray matter of the

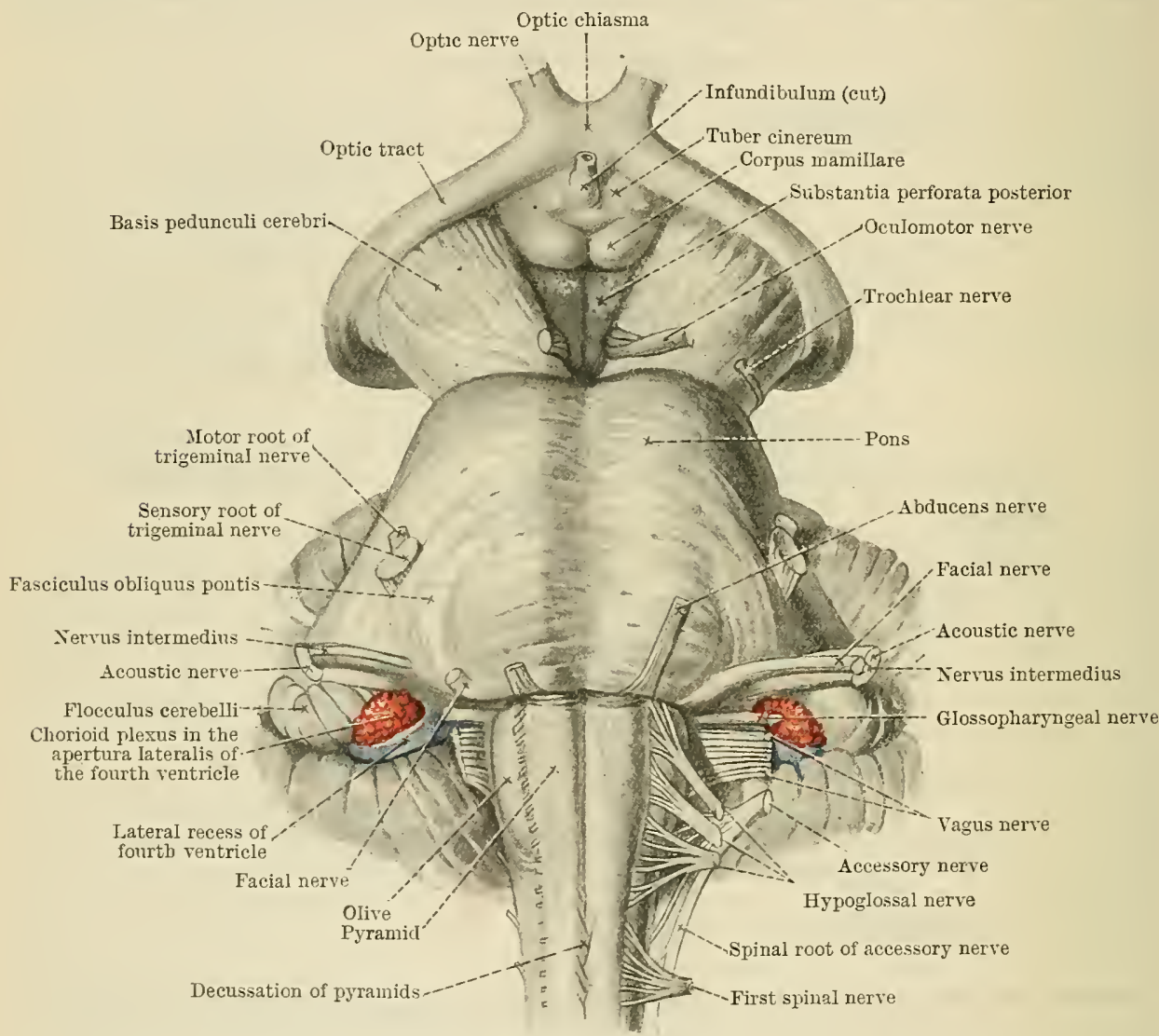

Fig. 527.-The Ventral Aspect of the Medulla Oblongata, Pons, and Miesencephalox, showing the nerve roots.

spinal medulla. It is thus placed on the anterior and lateral aspect of the central canal, close to the median plane and the corresponding nucleus of the opposite side. The superior part of the nucleus occupies a position in the gray matter on the floor of the fourth ventricle, subjacent to the medial part of the surface area, which has been described under the name of the trigonum hypoglossi. Within the nucleus the axons of the cells arrange themselves in converging bundles of fine fibres, which come together and leave the ventral aspect of the nucleus as the fila radicularia of the nerve. The nerve bundles thus formed traverse the entire antero-posterior thickness of the medulla oblongata, between the substantia reticularis grisea and the substantia reticularis alba, and emerge on the surface, in linear order, at the bottom of the furrow between the olive and the pyramid. After they emerge these fibres collect to form three definite bundles like the anterior nerve-roots of three spinal nerves (Fig. 527). In the substance of the medulla oblongata the fila radicularia of the 
hypoglossal pass between the main inferior olivary nucleus and the medial accessory olivary nucleus, and many of them on their way to the surface pierce the ventral lamina of the main olivary nucleus.

No decussation between the nerves of opposite sides takes place in the medulla oblongata, but commissural fibres pass between the two nuclei (Kölliker). Further, numerous fibres from the opposite pyramidal tract enter the nucleus and end in connexion with its cells. The nucleus is thus brought into connexion with the motor area of the opposite side of the cerebral cortex.

Nervus Accessorius.-The accessory nerve also is a motor nerve, and it is generally described as consisting of a spinal and a cerebral or accessory part.

The spinal part of the nerve emerges by a series of roots which issue from the surface of the lateral column of the superior part of the spinal medulla as low down as the fifth cervical nerve. These take origin in a column of cells situated in the anterior column of gray matter of the spinal medulla, close to its lateral margin, and

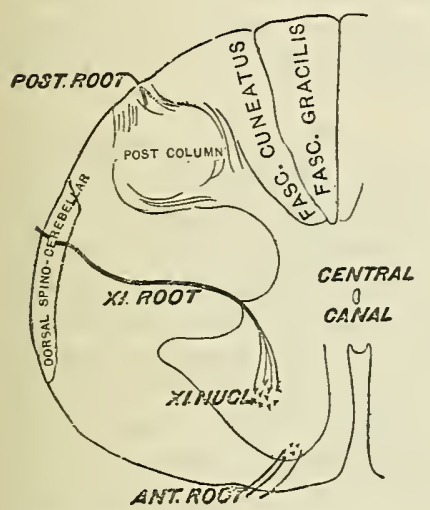

Fig. 528.-Diagram of the SPINAL ORIGIN OF THE ACCESSORT NERVE (after Bruce).

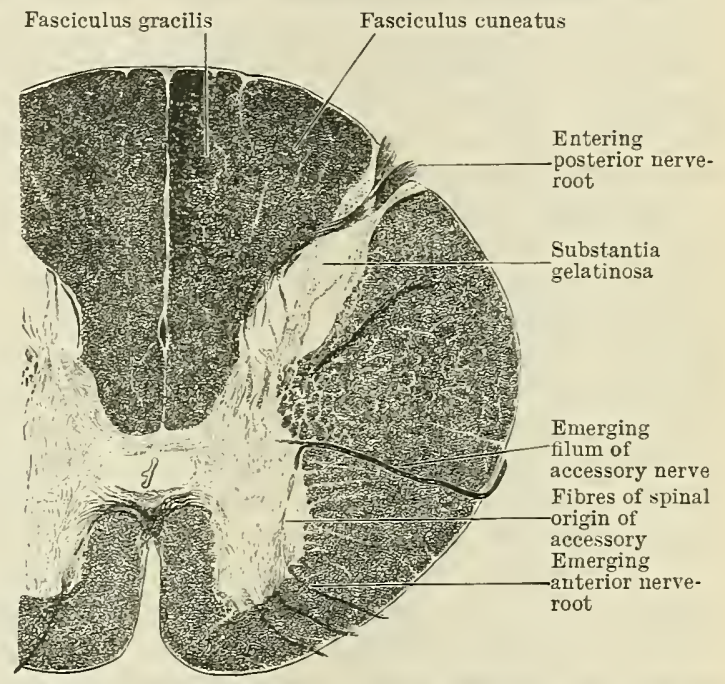

Fig. 529.-Section through the Superior Part of the

Cervical Region of the Spinal Medulla (Orang).

Showing the origin of the spinal part of the accessory nerve.

immediately behind the nerve-cells which give rise to the fibres of the anterior roots of the upper five cervical nerves. The cells of the accessory nucleus are large, multipolar, and in every respect similar to the motor cells of the spinal nerves. The axons from these cells leave the dorsal aspect of the nucleus in converging groups to form the fila radicularia or root-bundles of the nerve. These, in the first place, proceed straight backwards in the anterior column of gray matter. Reaching the bay between the two columns of gray matter, they turn sharply laterally into the white matter and traverse the lateral funiculus to gain their points of exit from the spinal medulla. At the decussation of the pyramids, fila, which join the accessory nerve, are seen to proceed from the detached head of the anterior column of gray matter.

The cerebral part of the accessory nerve has its nucleus of origin in the medulla oblongata; and its fila, as they proceed laterally from this, can be distinguished by the fact that they pursue a course on the ventral side of the tractus spinalis of the trigeminal nerve, whereas the vagus roots, with which they are apt to be confused, pass through or lie on the dorsal aspect of the trigeminal root (Kölliker). The nucleus of origin of the cerebral part of the accessory nerve is formed by the same column of cells which constitutes the nucleus ambiguus, and which, at a higher level, gives motor fibres to the vagns and glossopharyngeal nerves.

The part of the accessory nerve which takes origin in the spinal medulla supplies the sterno-mastoid and trapezius muscles. The cerebral portion joins the vagus, and through the external laryngeal and recurrent nerves it supplies the muscles of the larynx. The portion of 
the nuclens ambiguus from which it arises has thus been termed the laryngeal nucleus (Edinger) but it is not certain whether it is vagal or accessory.

Collaterals and fibres of the opposite lateral cerebro-spinal tract end in connexion with the cells of origin of the accessory nerve, and thus bring its nucleus into connexion with the motor area of the cerebral cortex. Fibres also from the posterior roots of the spinal nerves (afferent or sensory fibres) end in the nucleus.

Nervus Vagus, Nervus Glossopharyngeus.-The vagus and glossopharyngeal nerves present similar counexions with the brain, and they may therefore be studied together. The greater part of both nerves is composed of afferent fibres, which arise outside the brain-stem from ganglionic cells placed in relation to the nerve-trunks. Both nerves possess efferent fibres also, which spring from two special nuclei of origin situated within the medulla oblongata and termed respectively the dorsal or splanchnic nucleus and the nucleus ambiguus, which is the somatic nucleus. The afferent ganglionic fibres of the vagus and glossopharyngeal enter the brain by a series of roots which penetrate the medulla oblongata along the ventral side of the restiform body. Within the medulla oblongata they separate into two sets, viz., a series of bundles (composed chiefly of vagus fibres, i.e. afferent splanchnic), which end in the dorsal nucleus of termination of the vagus and glossopharyngeal nerves, and another series of bundles (composed chiefly of glossopharyngeal fibres, i.e. taste fibres), which join a conspicuous longitudinal tract of fibres called the tractus solitarius.

The dorsal nucleus (Figs. 488, p. 557 , and 526, p. 593) of the vagus and glossopharyngeal nerves is mixed, and contains both motor cells which give origin to efferent fibres, and cells around which afferent fibres of the vagus, and possibly also of the glossopharyngeal nerve, break up into terminal arborisations. It very nearly equals in length the nucleus of the hypoglossal nerve, with which it is closely related. Above, it reaches as high as the striæ medullares, whilst, below, its inferior end falls slightly short of that of the hypoglossal nucleus. In specimens stained by the Weigert-Pal method the two nuclei offer a marked contrast. The hypoglossal nucleus presents a dark hue, owing to the enormous numbers of fine fibres which twine in and out amidst its cells; the vago-glossopharyngeal dorsal nucleus is pale from the scarcity of such fibres within it. Its cells, like those of all splanchnic efferent nuclei, are much smaller than the somatic cells of the nucleus ambiguus. In the closed part of the medulla oblongata the dorsal vago-glossopharyngeal nucleus lies in the central gray matter immediately behind the hypoglossal nucleus, and upon the lateral aspect of the central canal; in the open part of the medulla oblongata it lies in the gray matter of the floor of the fourth ventricle, immediately to the lateral side of the hypoglossal nucleus and subjacent to the surface area termed the trigonum vagi or ala cinerea.

All the fibres which arise from this dorsal or splanchnic efferent nucleus are very fine, and in sections of the vagus nerve can readily be distinguished from the much coarser somatic fibres, which come from the nucleus ambiguus, and also from the medium-sized sensory fibres, which spring from the ganglia placed upon the nerves. The fine fibres from the dorsal nucleus are distributed (probably indirectly, i.e. after being interrupted in a peripheral ganglion), to the involuntary striped muscle of the osophagus and heart, and the unstriped muscle of the osophagus, stomach and respiratory system (van Gehuchten and Molhant, La Névraxe, June 15, 1912, p. 55).

The nucleus ambiguus (Figs. 488, 530, 526) gives origin to the somatic motor fibres of the glossopharyngeal and vagus nerves. All the fibres from this nucleus which pass into the glossopharyngeal nerve end in the stylo-pharyngeus muscle; the vagal branches are distributed to the striated muscles of the pharynx and larynx. The cells of the nucleus ambiguus are large, multipolar, and similar in every respect to the large cells in the anterior column of the spinal medulla. These cells are arranged in a slender column which is best developed in the open part of the medulla oblongata. Here the nucleus can easily be detected, in transverse sections, as a small area of compact gray matter which lies in the substantia reticularis grisea, midway between the dorsal accessory olive and the nucleus tractus spinalis nervi trigemini. It therefore lies more deeply in the substance of the medulla oblongata than the dorsal vago-glossopharyngeal nucleus. Kölliker states that it can be traced downwards as low as the level of the decussation of 
the medial lemniscus, and upwards as high as the place of entrance of the cochlear root of the acoustic nerve. From its dorsal aspect the axons of the cells proceed, and in the first instance they pass backwards towards the floor of the fourth ventricle; then, bending suddenly laterally and forwards, they join the afferent roots of the vagus and the glossopharyngeal nerves, and emerge from the brain in company with these.

Sensory or Terminal Nuclei of the Glossopharyngeal and Vagus. Splanchnic and Gustatory Components.-The cells in the portion of the dorsal nucleus which acts as a nucleus of termination are spindle-shaped in form and

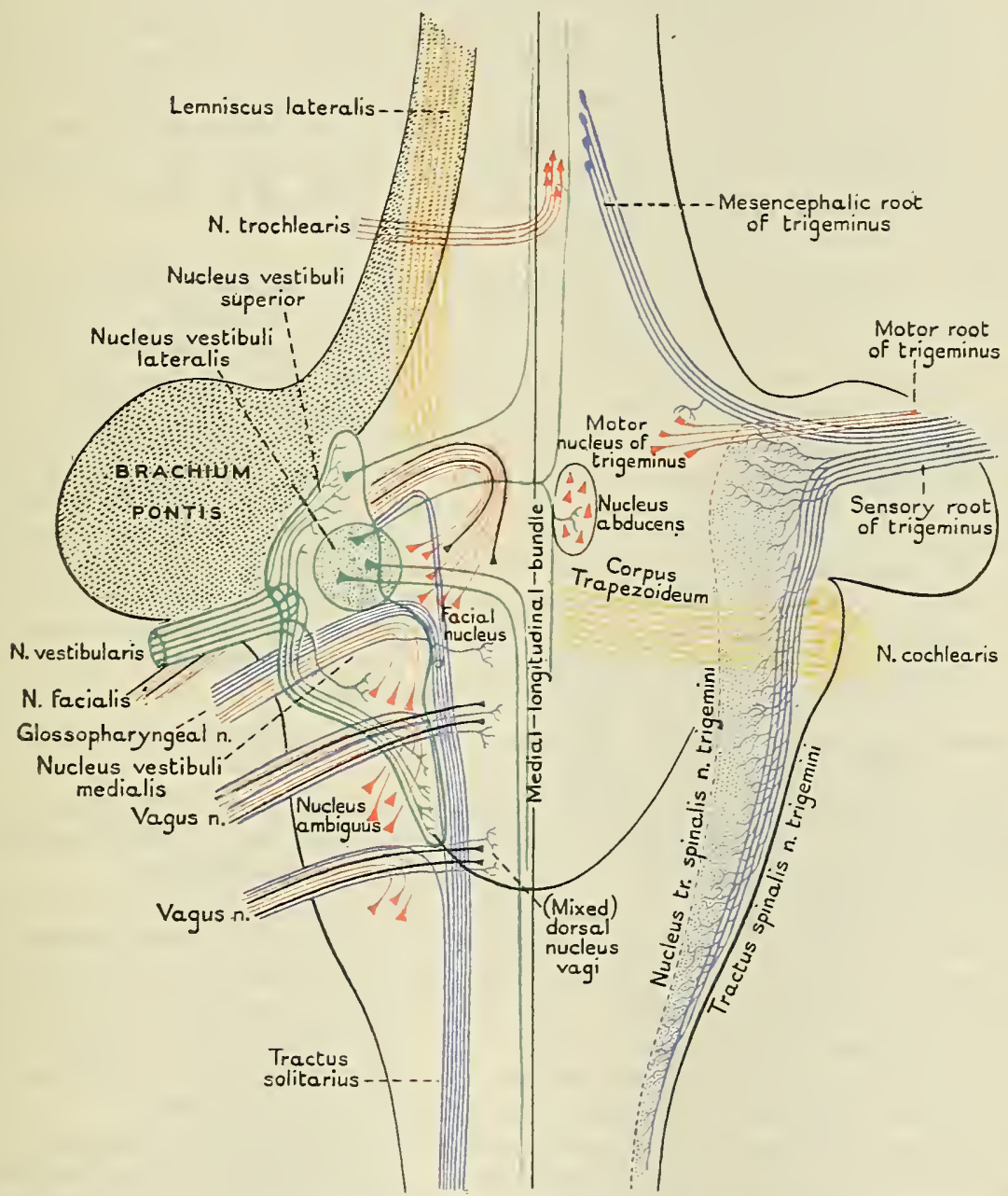

FIG. 530.-DIAGRAsI, showing the brain connexions of the vagus, glossopharyngeal, acoustic, facial, abducens, and trigeminal nerves.

similar to those found in the posterior column of gray matter in the spinal medulla. In connexion with these cells, the greater number of the afferent fibres of the vagus nerve, and a small proportion of the afferent fibres of the glossopharyngeal nerve, end in fine terminal arborisations. A small part of the superior portion of the nucleus may be said to belong to the glossopharyngeal nerve and the remainder of the nucleus to the vagus nerve.

The tractus solitarius (Figs. 494, p. 561; 495, p. 561; and 530) is a round bundle of longitudinal fibres which forms a very conspicuous object in transverse sections through the medulla oblongata. It begins at the superior limit of the medulla oblongata, and can be traced downwards through its whole length. Its precise point of termination is not known, but some authorities believe 
that it is carried for some distance downwards into the superior part of the spinal medulla, and, according to Kölliker, to the level of the fourth cervical nerve. Most modern writers, however, limit it to the medulla oblongata. The relations of the tractus solitarius are not the same in all parts of its course. It lies immediately to the lateral side of the dorsal vago-glossopharyngeal nucleus; but, whereas. in the superior part of the medulla oblongata it is situated somewhat on the ventral side of that nucleus, in the inferior, closed part of the medulla oblongata it is placed on its dorsal aspect. Throughout its entire length it is intimately associated with a column of gelatinous gray substance called the nucleus tractus solitarii, which constitutes the nucleus of termination in which its fibres end. When traced from above downwards, the tractus solitarius is observed to become gradually smaller owing to the loss of fibres which it thus sustains. The great bulk of the tractus solitarius is formed of fibres derived from the glossopharyngeal nerve; only a few of the afferent fibres of the vagus enter it, but fibres of the sensory root (nervus intermedius) of the facial also enter it. As the fibres of the three nerves join the fasciculus they immediately turn downwards, and at different levels come to an end in the associated nucleus tractus solitarii.

As the afferent root-bundles of the vagus and the glossopharyngeal nerves traverse the substance of the medulla oblongata in a backward and medial direction to reach the tractus solitarius and the dorsal nucleus of termination, they pass through the tractus spinalis of the trigeminal nerve and the nucleus of that tract. As the afferent root of the vagus passes through the trigeminal tractus spinalis and its nucleus, which is somatic sensory in nature, it gives off to this nucleus its own somatic sensory branches, the peripheral ends of which constitute the auricular branch, distributed to the skin on the back of the auricle. The other afferent fibres in the glossopharyngeal and vagus nerves include taste fibres, sensory fibres from the pharynx, larynx, and other parts of the respiratory and alimentary systems, and other splanchnic afferent fibres. Although there is no sharp demarcation between the terminal nuclei of these various components, it is probable that the taste fibres proceed to the nucleus tractus solitarii, the splanchnic afferent fibres to the dorsal nucleus, and the somatic afferent fibres to the nucleus of the spinal trigeminal tract.

Nervus Acusticus.-As this is a nerve of special sense it will be left for consideration after the rest of this series.

Nervus Facialis (Figs. 530 and 531).-The facial nerve is composed of two distinct parts, viz., a large efferent (mainly motor) portion, the facial nerve proper, and a small afferent sensory portion termed the nervus intermedius.

The facial nerve proper emerges from the brain at the inferior border of the pons, to the medial side of the acoustic nerve, whilst the nervus intermedius sinks into the superior part of the medulla oblongata between the facial and acoustic nerves, but alongside the latter, rather than the former, from which it is separated by the fasciculus obliquus pontis (Fig. 527). The three nerves, therefore, lie in intimate relation with each other, where they are attached to the surface of the brain, and they pass in company into the internal acoustic meatus.

The fibres of the nervus intermedius arise from the cells of the ganglion geniculi of the facial nerve. These, like the cells of a spinal ganglion, are unipolar, the single process in each case dividing into a peripheral and a central branch. The group of peripheral fibres represent parts of the greater superficial petrosal nerve and chorda tympani branch of the facial nerve, whilst the central fibres form the nervus intermedius. The central fibres penetrate the brain, and, passing either through or on the dorsal side of the tractus spinalis of the trigeminal nerve, they finally reach the superior part of the column of gray matter in connexion with the tractus solitarius, and in this they end. The nervus intermedius presents, therefore, the same terminal connexions within the brain as the glossopharyngeal nerve.

The motor nucleus of the facial nerve contains elements serially homologous with both the somatic (nucleus ambiguus) and splanchnic (nucleus dorsalis) efferent nuclei of the glossopharyngeal and vagus. It is composed partly of the larger cells characteristic of the former and the smaller cells distinctive of the latter. The axons of the somatic cells innervate the striated muscles of the face, whereas the splanchnic efferent fibres pass to the spheno-palatine, otic 
and submaxillary ganglia (as their white rami communicantes), and are largely concerned with the regulation of the secretory activity of the large salivary glands and other glands around the mouth.

The facial nucleus is situated close to the place where the nerve emerges from the brain, but the nerve does not at once pass to this point of exit. It pursues a long and devious path within the pons before it finally reaches the surface. This intrapontine part of the nerve may be divided into three parts, viz. : (1) a radicular part, (2) an ascending portion, and (3) an emergent part.

The radicular part of the facial nerve (Fig. 531) is composed of a large number of fine loosely arranged bundles of fibres, which issue from the lateral and dorsal aspect of the nucleus and proceed backwards and slightly medially through the pons. Reaching the floor of the fourth ventricle they curve medially, and the bundles which lie highest up sweep over the lateral and dorsal aspect of the inferior part of the nucleus of the sixth nerve. Close to the median plane they turn sharply upwards and are collected into a single solid nerve-bundle, which constitutes the ascending part of the facial nerve (Figs. 530 and 531). This proceeds upwards immediately beneath the ependyma of the rentricular floor on the dorsal aspect of the medial longitudinal bundle, and along the medial side of the abducent nucleus for a distance of about five millimetres. Then the nerve bends laterally at a right angle, and curves a second time over the dorsal aspect of the abducent nucleus. This gives rise to a prominent hemispheral projection in the floor of the fourth ventricle, the colliculus facialis (Fig. 531 and Fig. 482, p. 550). The nerve now passes straight to the place of exit from the brain, and this part of the intrapontine trunk may be termed the emergent portion (Figs. 498 and 531). The facial nerve thus forms a curved loop over the dorsal aspect of the abducent nucleus. The emergent part of the nerve takes an oblique course through the pons to reach the surface. It inclines laterally and downwards as it proceeds towards the ventral aspect of the pons, and on its way it passes between its own nucleus and the tractus spinalis of the trigeminal nerve.

Entering the facial nucleus, and ending in fineterminal arborisations around its cells, are many fibres from the opposite pyramidal tract; fibres from the spinal tract of the fifth nerve; fibres from the

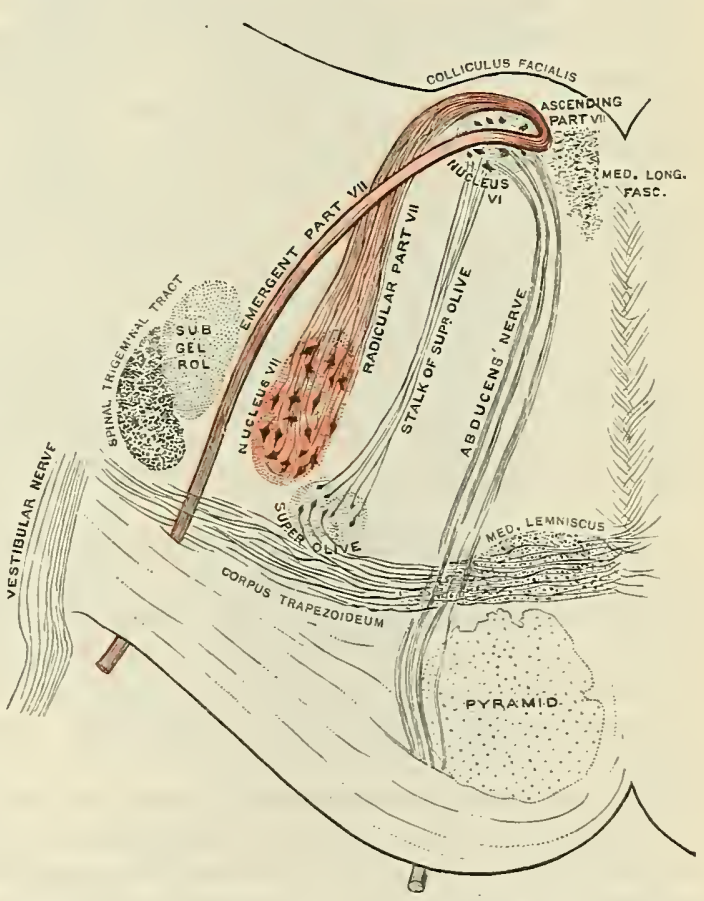

FIg. 531.-DIAGRAM OF THE INTRAPONTINe CoURSE of the Facial Nerve.

Sub. gel. rol. refers to the nucleus of the spinal trigeminal tract. corpus trapezoideum, etc. The nucleus is thus brought into connexion with the motor area of the cerebral cortex, with the trigeminal nerve or sensory nerve of the face, and with the acoustic nerve.

The peculiar course of the efferent fibres of the facial nerve within the pons is to be explained in accordance with the general principle regulating migrations of nerve-cells, to which reference has already been made (p. 554). In the embryo the nucleus facialis develops alongside the nucleus abducens. The latter, controlling one of the eye-muscles, receives most of its afferent impulses from the medial longitudinal bundle (descending from the optic centres in the superior colliculus), and therefore it remains alongside the medial longitudinal bundle 
and perhaps moves slightly upwards, i.e. towards the mesencephalon. The facial nuclens, however, receives most of its stimuli from the nucleus tractus spinalis nervi trigemini, and therefore, as the walls of the metencephalon thicken during their growth, this nucleus retains its proximity to the trigeminal nucleus (Fig. 531), and so migrates along a course which remains mapped out by its emerging fibres. Streeter, working with human embryos, and Arïens-Kappers, on comparative and therefore broader lines, have elucidated the meaning of this peculiar intracentral course of the facial nerve.

Nervus Abducens (Figs. 498 and 531). - The abducens nerve is a small motor nerve which emerges from the brain at the inferior border of the pons above the lateral side of the pyramid of the medulla oblongata. It is the nerve of supply to the lateral rectus muscle of the eyeball. Its nucleus of origin is a small spherical mass of gray matter, containing large multipolar cells, which lies in the dorsal part of the tegmental portion of the pons, close to the median plane and immediately subjacent to the gray matter of the floor of the fourth ventricle. Its position can be easily indicated on the ventricular floor, seeing that it is placed subjacent to the colliculus facialis and immediately above the level of the striæ medullares. Its peculiar and intimate relation to the intrapontine portion of the facial nerve has already been indicated. It lies on the ventral aspect of, and within the concavity formed by, the two limbs of the loop of that nerve.

The axons of the multipolar cells of this nucleus emerge from the medial aspect of the nucleus in the form of several bundles, which proceed through the whole dorso-ventral thickness of the pons towards the place of exit. As they pass forwards they incline downwards and slightly laterally. In the dorsal part of the pons they proceed forwards on the medial side of the nucleus olivaris superior, whilst in the basilar part of the pons they keep for the most part to the lateral side of the pyramidal bundles, although several of the nerve fila pierce these on their way to the surface.

It would appear probable that certain of the axons of the cells of the abducens nucleus enter the medial longitudinal fasciculus and proceed upwards in it to end in the ocnlomotor nucleus of the opposite side. Fibres and collaterals from the basis pedunculi of the opposite side enter the nucleus, and, ending around the cells, bring the nucleus into connexion with the motor area of the cerebral cortex. The pedicle of the nnclens olivaris superior ends partly within the nucleus of the abducent nerve (Fig. 530).

Nervus Trigeminus.-The trigeminal nerve strikes its roots deeply into the brain and establishes a connexion with it which extends from the upper part of the mesencephalon above to the level of the second cervical nerve below. No other cerebral nerve presents so extensive a connexion (Fig. 530, p. 597). It is composed of two roots - a large afferent or sensory root and a small efferent or motor root. Both roots appear close together on the surface of the pons, rather nearer its superior than its inferior border, and in the same line as the facial, and glossopharyngeal and vagus nerves (Fig. 527, p. 594).

The sensory root of the trigeminal nerve is composed of fibres which arise outside the brain from the cells of the semilunar ganglion. They end within the brain in a somewhat tadpole-shaped terminal nucleus, the swollen body of which is situated in the pons and is termed the main sensory nucleus of the trigeminal nerve: the tail is a long column of gray matter which is directly continuous below with the substantia gelatinosa of the spinal medulla.

The main sensory nucleus (Fig. 532) is an oval mass of gray matter placed half-way up the pons in the lateral part of its dorsal or tegmental portion. It lies close to the lateral surface of the pons and immediately subjacent to the ventral submerged margin of the brachium conjunctivum. It is directly continuous with the substantia gelatinosa, and may be regarded as being merely the enlarged superior end of that column of gray matter.

The fibres of the sensory root of the trigeminal nerve, on reaching the sensory nucleus, divide, in the same way as the fibres of the entering posterior roots of the spinal nerves, into a system of ascending and descending branches (Fig. 530, p. 597). The ascending fibres are short, and almost immediately enter the sensory nucleus and end within it; the descending fibres turn sharply downwards and form the 
tractus spinalis. This tract descends on the lateral side of the column of gray matter formed by the substantia gelatinosa, which constitutes its terminal nucleus, nucleus tractus spinalis nervi trigemini. Fibres constantly leave it to enter the nucleus, so that the lower it gets the smaller does the spinal tract become until, in the upper part of the spinal medulla, about the level of the first or second spinal nerve, it disappears altogether.

The large spinal tract of the trigeminal nerve is a conspicuous object in sections through the pons and medulla oblongata. In the pons it traverses the dorsal or tegmental part, first, between the emergent part of the facial nerve and the vestibular nerve; and then lower down, between the restiform body and the nucleus of the facial nerve (Fig. 498, p. 565). In cross sections it presents a well-defined semilunar or curved piriform ontline. In the superior part of the medulla oblongata it lies on the ventral aspect of the restiform body, and therefore nearer the surface than in

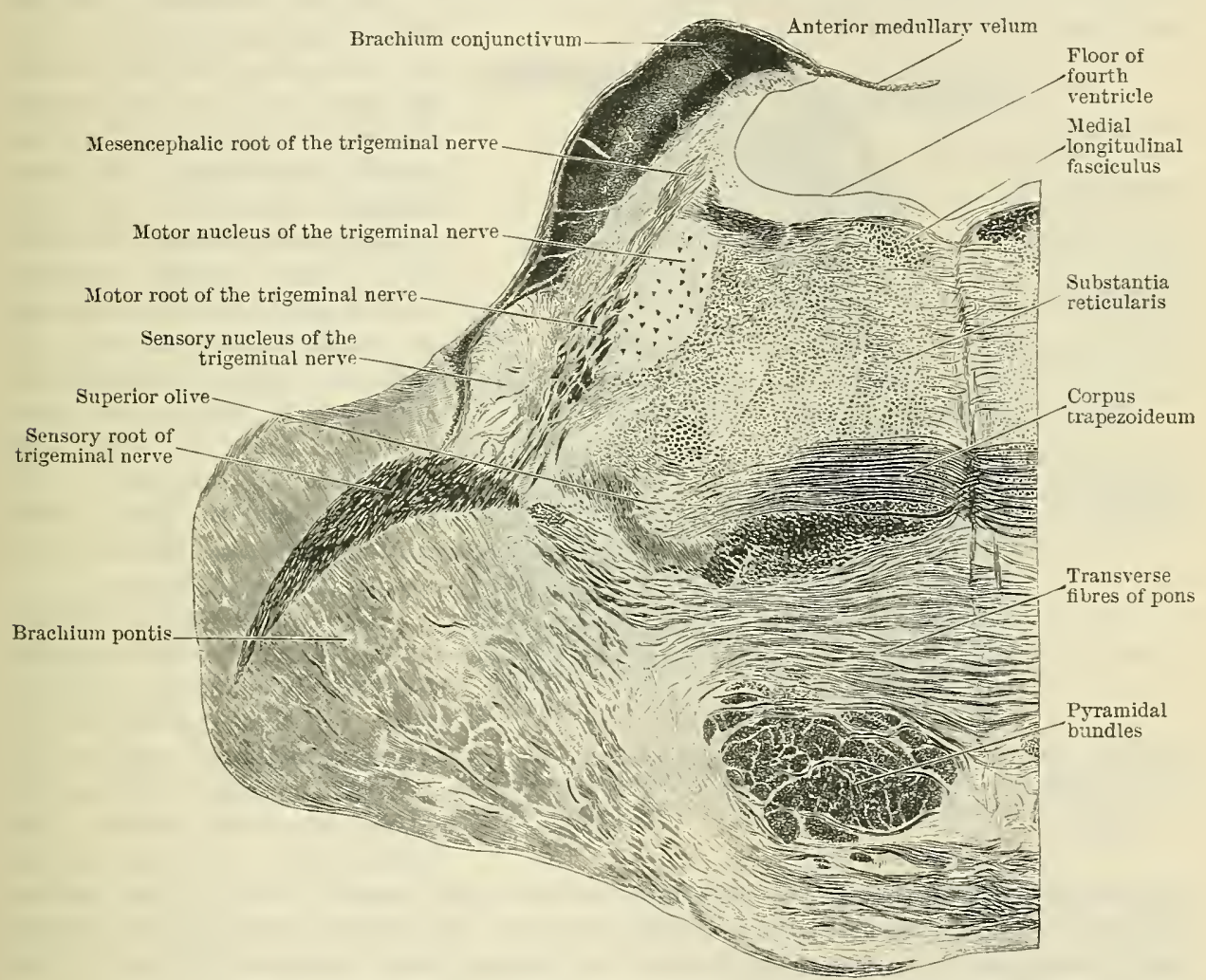

Fig. 532.- Section through the Poxs of the Orang, at the Level of the Nuclei of the Trigeminal Nerve.

the pons (Fig. 495, p. 561 ). Here it is traversed and broken up into separate bundles by the olivo-cerebellar fibres and the roots of the glossopharyngeal and vagus nerves. Finally, it comes to the surface and its fibres are spread over the area on the side of the medulla oblongata known as the tuberculum cinereum of Rolando (Fig. 49t, p. 261 ).

The small motor part of the trigeminal nerve is distributed chiefly to the muscles of mastication, and derives its fibres from the motor nucleus.

The motor nucleus (Fig. 532) lies in the lateral part of the tegmental portion of the pons, close to the medial side of the main sensory terminal nucleus, but somewhat nearer the floor of the fourth ventricle. It is serially homologous with the motor nuclei of the lateral somatic group, namely, the facial and nucleus ambiguus. It does not become displaced so far forwards as these nuclei, because its chief source of sensory impulses-the terminal nucleus of the trigeminal afferent fibres-is placed alongside it, and there is no need for any definite migration (Fig. 532).

The mesencephalic root or radix descendens nervi trigemini takes origin from 
a column of loosely arranged pear-shaped unipolar cells which are placed in the extreme lateral part of the gray matter surrounding the aquæductus cerebri. As this root is traced downwards it gradually increases in size by the accession of new fibres, and it assumes a crescentic form in transverse section (Figs. 501, p. 569; 532 , p. 601 ; 533 ; and 534, p. 603). In the inferior part of the mesencephalou it lies on the medial side of the brachium conjunctivum; and the trochlear nerve, on its way to the surface, runs downwards in its concavity and on its medial aspect. In the superior part of the pons it continues its course downwards on the lateral and deep aspect of the gray matter in the floor of the fourth ventricle. Finally, reaching the level of the nuclei of the trigeminal nerve, the fibres of the mesencephalic root turn forwards and are said to join the sensory part (Johnston) of the trigeminal nerve. Otto May and Horsley, however, confirm the usual description, viz., that it passes into the motor root; but, according to them, it cannot be traced beyond the semilunar ganglion.

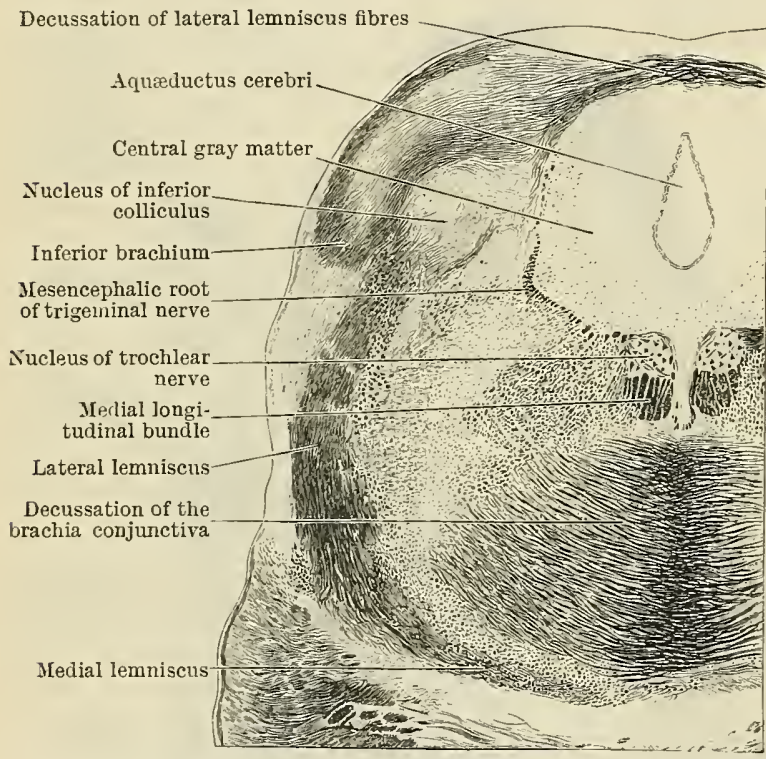

Fig. 533.--Section throdgh the INFERIOR Colliculds AND the Tegaentum of the Mesencephalon at the Level of the Middle Part of the Nucleus of the Trochlear Nerte (Orang).

mesencephali. If Johnston's view is correct, the neural crest in the mesencephalic region must have been drawn into the neural tube during development and given rise to this sensory nucleus of origin (not a terminal nucleus) within the central nervous system.

Otto May and Sir Victor Horsley have shown that the mesencephalic root is a mixture of ascending and descending fibres, but there is no evidence to show that the latter may not be sensory like the former. Nothing is known of their peripheral distribution.

Nervus Trochlearis.-The trochlear nerve supplies the superior oblique muscle of the eyeball. It emerges from the brain, on its dorsal aspect, at the superior part of the anterior medullary velum, immediately below the lower border of the inferior colliculus (Fig. 517, p. 583). The nucleus from which it arises is a small oval mass of gray matter, placed in the ventral part of the central gray matter, at the level of the superior part of the inferior colliculus. The close association of this nucleus with the medial longitudinal bundle has already been referred to. ' It is sunk deeply in a bay which is hollowed out on the dorsal and medial aspect of that tract. The nerve has a course of some length within the mesencephalon. The axons of the cells leave the lateral aspect of the nuclear mass, and curve backwards and laterally in the central gray matter until they reach the concave medial surface of the mesencephalic root of the trigeminal nerve. Here they are gathered together 
into one or two round bundles, which, bending sharply, turn downwards at a right angle and descend on the medial side of the trigeminal root. When the region below the inferior colliculus is reached, the nerve makes another sharp bend. This time it turns medially, enters the superior end of the anterior medullary velum, in which it decussates with its fellow of the opposite side. Having thus crossed the median plane, the trochlear nerve emerges at the medial border of the brachium conjunctivum. The course pursued by the trochlear nerve within the central gray matter may be traced by examining in succession Fig. 533; Fig. 534; Fig. 502, p. 570; and Fig. 512, p. 577.

Nervus Oculomotorius.-The oculomotor nerve supplies the levator palpebræ superioris, all the ocular muscles, with the exception of the superior oblique and the lateral rectus, and also two muscles within the eyeball, viz., the sphincter iridis and the musculus ciliaris. The nucleus of origin is placed in the ventral part of the central gray matter subjacent to the superior colliculus (Fig. 521, p. 587). In length it measures from 5 to 6 $\mathrm{mm}$. Its inferior end is partially continuous with the nucleus of the trochlear nerve, whilst its superior end extends upwards for a short distance beyond the mesencephalon into the gray matter on the lateral wall of the third ventricle. Its relation to the medial longitudinal bundle is even more intimate than that of the trochlear nucleus. It is closely applied to the dorsal and medial aspect of this strand; many of its cells occupy a position in the intervals between the nervebundles of the tract, and some even are seen on its ventral or tegmental aspect. The axons of the nuclear cells leave the nucleus in numerous bundles, which describe a series of curves as they proceed for-

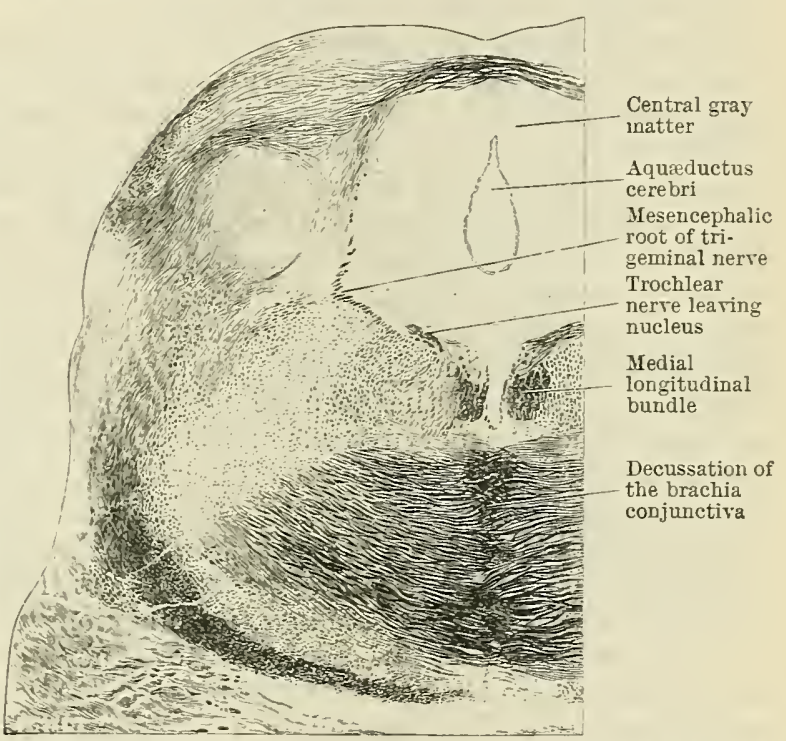

Fig. 534.-SECtioN THROUgh THE INFerior Collicdlds AND THE Tegmentu of the Mesencephaloy at the Level of the Ixferior Part of the Nucleus of the Trochlear Nerte (Orang).

wards through the medial longitudinal bundle, the tegmentum, red nucleus, and medial margin of the substantia nigra, to emerge finally from the brain-stem along the bottom of the sulcus oculo-motorius on the medial aspect of the basis pedunculi.

The cells of the oculomotor nucleus are not uniformly distributed throughout it. They are grouped into several more or less distinct collections or clumps, some of which possess cells which differ in size and appearance from the others. These cell-clusters are very generally believed to possess a definite relation to the several branches of the nerve and the muscles which they supply. Perlia recognises no less than seven such cell-clusters in each nucleus, with a small medial nucleus placed accurately on the median plane, and from which fibres for both nerves spring. Whilst the majority of the fibres in the oculomotor nerve arise from the cell-groups which lie on its own side of the median plane, it has been satisfactorily established that a certain proportion of its fibres are derived from the nucleus of the opposite side, thus forming a crossed connexion and giving rise to a median decussation. These crossed fibres are supposed by some to supply the medial rectus muscle; and we have seen that there is reason to believe that the part of the nucleus from which these fibres are derived stands in connexion through the medial longitudinal fasciculus with the abducens nucleus from which proceeds the nerve of supply for the lateral rectus muscle. The harmonious action of the medial and lateral recti in producing the conjugate movements of the eyeballs is thus explained. 
The oculomotor nucleus is connected-(1) with the occipital part of the cerebral cortex by fibres which reach it through the optic radiation; (2) with the vestibular, trochlear and abducent nuclei (and probably with other nuclei) by fibres which come to it through the medial longitudinal bundle; (3) possibly with the facial nerve by fibres which pass out from it into the medial longitudinal bundle (p. 589); (4) with the visual system by fibres which enter it from the cells of the superior colliculus.

It is important to recognise that although the main part of the oculomotor nucleus belongs to the medial somatic group, which also includes the trochlear, abducent and hypoglossal nuclei, it also includes a representative (the EdingerWestphal group of small cells) of the column of splanchnic efferent nuclei in series with those of the facial, glossopharyngeal, and vagus nerves. Its axons pass out along with the other fibres of the oculomotor nerve and enter the ciliary ganglion, where they end in relationship with the cells that innervate the ciliary muscle and the circular muscle of the iris.

Nervus Acusticus. - This is a large nerve which enters the brain at the inferior border of the pons. Its fibres spring from bipolar ganglionic cells in the immediate neighbourhood of the labyrinth or internal ear (see section dealing with the Organs of Sense). One group of these forms the spiral ganglion, the peripheral branches of which are distributed to the organ of Corti in the cochlea: another group constitutes the vestibular ganglion (often called Scarpa's), which distributes tibres to the ampullæ of the semicircular ducts and the utricle. Although the central processes of the cells in these two ganglia accompany one another and are known collectively as the acoustic nerve they really remain distinct throughout, in their mode of termination in the brain as well as in their peripheral distribution. Reaching the brain the acoustic nerve divides into two parts, viz., the nervus cochlearis and the nervus vestibularis, which present totally different connexions, corresponding to their distinct functions. In their further course these two divisions deviate from each other so as to embrace the restiform body - the vestibular part entering the pons on the medial aspect of the restiform body, whilst the cochlear part sweeps round its lateral surface. Special nuclei of termination require to be studied in connexion with each part of the nerve.

The cochlear nerve is composed of finer fibres than the vestibular nerve, and these acquire their medullary sheaths at a later period. It is the true nerve of hearing, and its fibres end in a nucleus which lies in intimate relation to the restiform body. It may be described as consisting of two parts. Of these one, called the dorsal cochlear nucleus, is a piriform mass which is placed on the dorsal aspect of the restiform body-between it and the flocculus of the cerebellum. The second part, termed the ventral cochlear nucleus, is placed on the ventral aspect of the restiform body in the interval between the cochlear and vestibular divisions of the acoustic nerve, after they have separated from each other. The fibres of the cochlear nerve enter these two ganglia and end around the cells in arborisations, which are finer, closer, and more intricate than those met with in any other nerve-ending in the brain.

The vestibular nerve enters the brain at a slightly higher level than the cochlear nerve and on the medial aspect of the ventral cochlear nucleus. It proceeds backwards through the pons between the restiform body, which lies on its lateral side, and the spinal tract of the trigeminal nerve, which is placed on its medial side. Its fibres end in a series of terminal nuclei (Fig. 530, p. 597), viz.: (1) the nucleus vestibularis dorsalis, often known as the principal nucleus, (2) its inferior prolongation, nucleus tractus descendentis, (3) the nucleus vestibularis lateralis (Deiters'), (4) the nucleus vestibularis superior (Bechterew's), and (5) the cerebellar cortex.

The principal nucleus (Figs. 498, p. 565, and 535, p. 605) is a large diffuse nuclear mass, which lies in the floor of the fourth ventricle subjacent to the surface district known as the area acustica (Fig. 482, p. 550). It is situated, therefore, in both the pons and the medulla oblongata to the lateral side of the fovea superior and the fovea inferior. In transverse section it is prismatic in outline, and crossing the surface of its upper or pontine part immediately under the ependyma of the ventricle are the striæ medullares. 
When the nervus vestibularis, as it traverses the brain, reaches the medial aspect of the dorsal portion of the restiform body, its fibres bifurcate to form ascending and descending tracts. The latter pass vertically downwards in separate bundles and form the descending tract of the vestibular nerve (Figs. 498, p. 565; 495, p. 561; and 530, p. 597). This proceeds through the inferior part of the pons into the medulla oblongata, in which it may be traced as far as the level of the decussation of the medial lemniscus. Associated with the descending tract there is a column of gray matter, with nerve-cells strewn sparsely throughout it. This is the nucleus of the descending tract, and the fibres end in fine arborisations around these nerve-cells.

Some of the ascending fibres of the vestibular nerve end in the nucleus lateralis. This nucleus is composed of a number of large and conspicuous multipolar nerve-cells, which are scattered amidst the bundles of the vesti bu la r nerve. As it is traced upwards into the pons the nucleus gradually inclines backwards, and finalIy it occupies a place in the lateral wall of the fourth ventricle. It attains its greatest development at the level of the emerging part of the facial nerve and this upper part is sometimes termed the nucleus

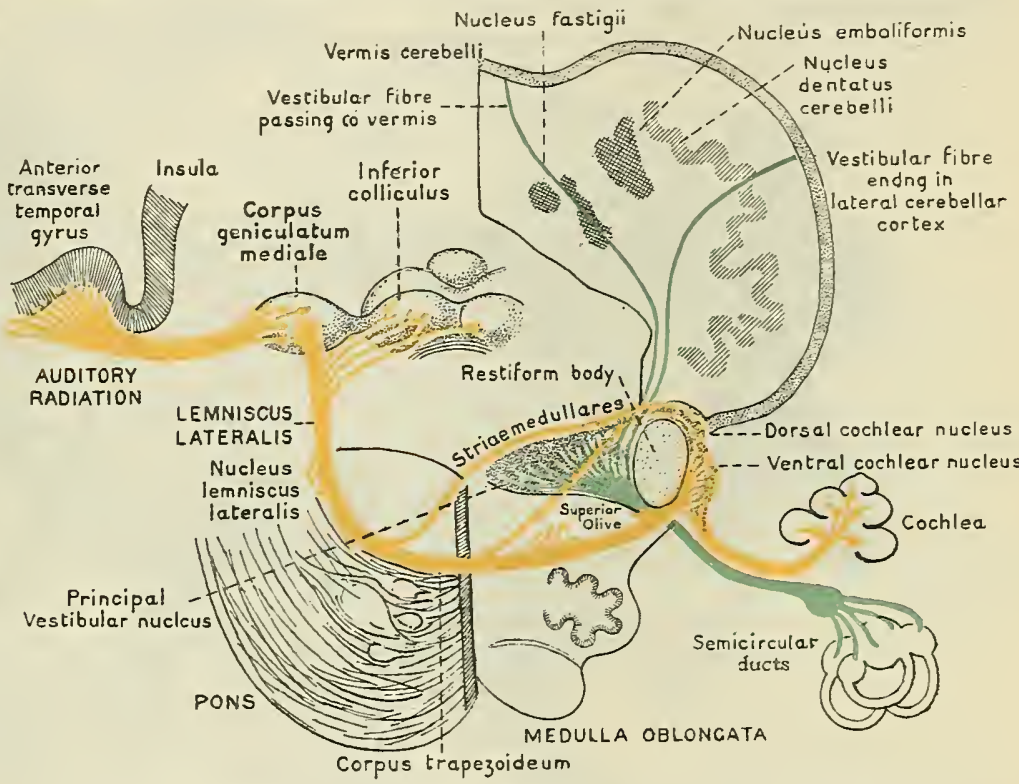

Fig. 535.-Central Convexions of the Cochlear and Vestibular Ditisions of the Acodstic Nerve.

Vestibular fibres green. Cochlear fibres yellow. superior.

Other ascending fibres pass without interruption into the cerebellum to terminate in the cortex of the vermis and lateral lobe. In their course many of these fibres pass through the nucleus fastigii, and many writers describe them as terminating in this nucleus; but according to Ramon y Cajal they merely traverse it on their way to the cerebellar cortex.

From the large-celled nucleus lateralis-best known as Deiters' nucleus-a strand of fibres passes medially to reach the medial longitudinal fasciculus, of which it forms one of the most important constituent elements. Some of these fibres pass upwards to the nuclei of the oculomotor, trochlear, and abducens nerves; others downwards, probably to the nucleus of the accessory nerve, which are concerned in regulating the movements of the eyes and the head respectively, because they need to be thus closely linked to the receptive nucleus of the nerve (vestibular), which is concerned with the appreciation of movements of the head and the position of the body in space. Other fibres arise from the lateral nucleus and pass directly to the spinal medulla without passing through the medial longitudinal bundle; they form the fasciculus vestibulospinalis, which passes downwards in the funiculus anterior and distributes fibres to the various motor nuclei in the anterior column of the spinal medulla (Fig. 524, p. 590, and Fig. 473, p. 534).

The nucleus superior (Bechterew's nucleus) likewise emits a group of fibres 
which pass directly to the mid-brain (fasciculus vestibulomesencephalicus), chiefly to the oculomotor and trochlear nuclei (Fig. 524, p. 590).

Central Connexions of the Cochlear Nerve.-The cochlear nuclei are brought into connexion with the inferior colliculus and the medial geniculate body of the opposite side by the fibres of the corpus trapezoideum and the lateral lemniscus.

The fibres of the cochlear nerve end in the ventral cochlear nucleus and in the dorsal cochlear nucleus (tuberculum acusticum). From the cells of these nuclei two tracts arise, viz., a ventral tract, composed of the fibres of the corpus trapezoideum, and a dorsal tract, which is represented by the strix medullares.

The corpus trapezoideum (Figs. 531 and 532) is formed of the axons of the cells of the ventral cochlear nucleus, as well as certain of the axons of the cells of the dorsal nucleus. In the midst of the corpus trapezoideum are lodged large cells which are known as the nucleus trapezoideus, and these give off axons which join the strand with which they are associated. Many of the fibres of the corpus trapezoideum end in a large mass of gray matter called the nucleus olivaris superior, which is placed immediately behind the

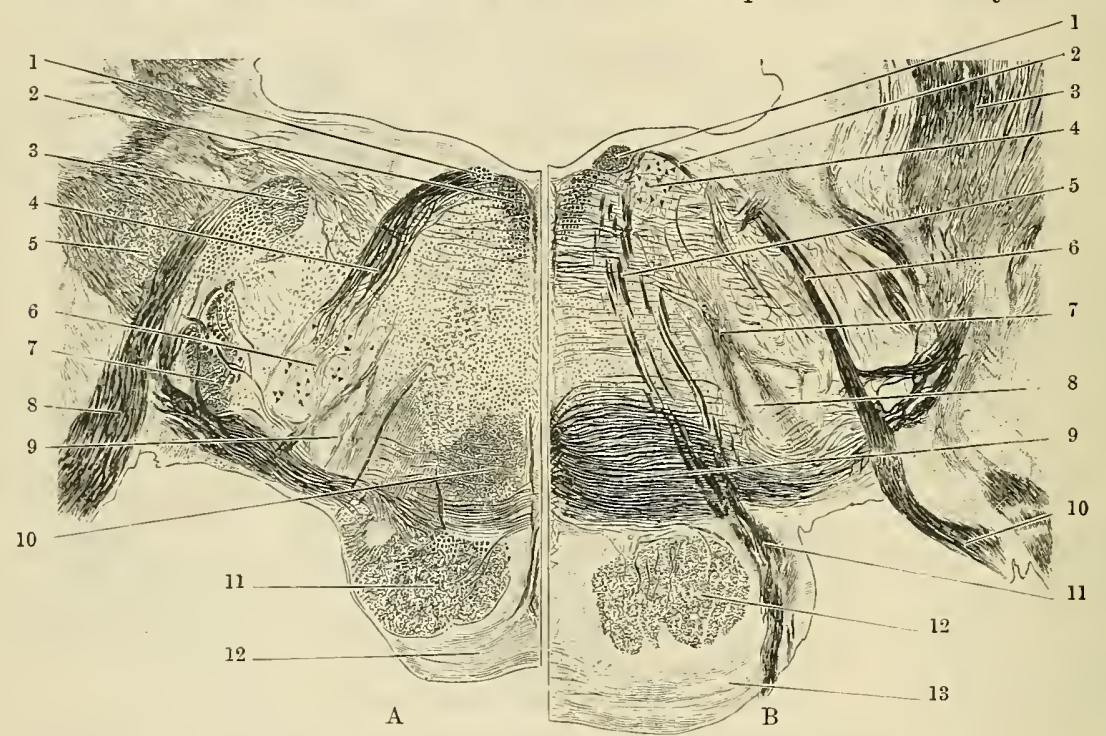

Fig. 536. - Section throdgh the Pons of the Orang.

The left side of the drawing is taken from a section at a level slightly inferior to the section from which the right side is taken.

A

1. Ascending part of facial nerve.

1. Ascending part of facial ner

3. Descending root of vestibular nerve.

4. Radicular fibres of facial nerve.

5. Restiform body

6. Facial nucleus.

7. Spinal tract of trigeminal nerve

8. Vestibular nerve.

9. Superior olive.

10. Lemniscus medialis.

11. Pyramidal tract.

12. Transverse fibres of pons.
B

1. Ascending part of facial nerve.

2. Emergent portion of facial nerve.

3. Restiform body.

4. Nucleus of abducens nerve.

5. Abducens nerve.

6. Emergent part of facial nerve.

7. Peduncle of superior olive.

8. Superior olive.

9. Corpus trapezoideum.

10. Facial nerve.

11. Abducens nerve.

12. Pyramidal tract.

13. Transverse fibres of pons.

trapezoid body. The trapezial fibres cross the median plane and decussate with the corresponding fibres of the opposite side. Reaching the opposite superior olivary nucleus, more fibres leave the trapezoid body, and almost immediately after this the strand bends upwards and forms the lemniscus lateralis (Figs. 535, p. 605; 537, p. 607). But still another nucleus is interposed in its path, viz., the nucleus lemnisci lateralis. Here some fibres are dropped, whilst from the nuclear cells others are acquired, and the lateral lemniscus then proceeds upwards until it reaches the inferior colliculus and the medial geniculate body, in which its fibres end.

Other fibres arise from the cells of the dorsal cochlear nucleus, and arrange themselves in the conspicuous bundles which sweep round the dorsal aspect of the restiform body and proceed inwards across the floor of the fourth ventricle, often immediately beneath the ependyma (Fig. 482, p. 550). Reaching the median plane they dip forwards into the substance of the pons, and, crossing the median plane, they join the lateral 
lemniscus. It is important to remember that the striæ medullares are not always risible in the floor of the fourth ventricle (Fig. 535), but are often buried more or less deeply.

The connexion between the terminal cochlear nuclei and the inferior colliculus is not altogether with that of the opposite side, as the foregoing description and the diagram (Fig. 534) might lead one to infer. A few fibres pass directly to the inferior colliculus of the same side, but none to the corresponding medial geniculate body: the connexion with the latter is entirely crossed (Ferrier and Turner).

From the medial geniculate body there proceeds a tract to the cerebral cortex of the transverse temporal gyri (Heschl's). The whole nervous apparatus is thus linked on to the cerebral cortex, and the succession of neurones which build up the entire chain are therefore: (1) in the cochlea of the internal ear, the bipolar cells of the spiral

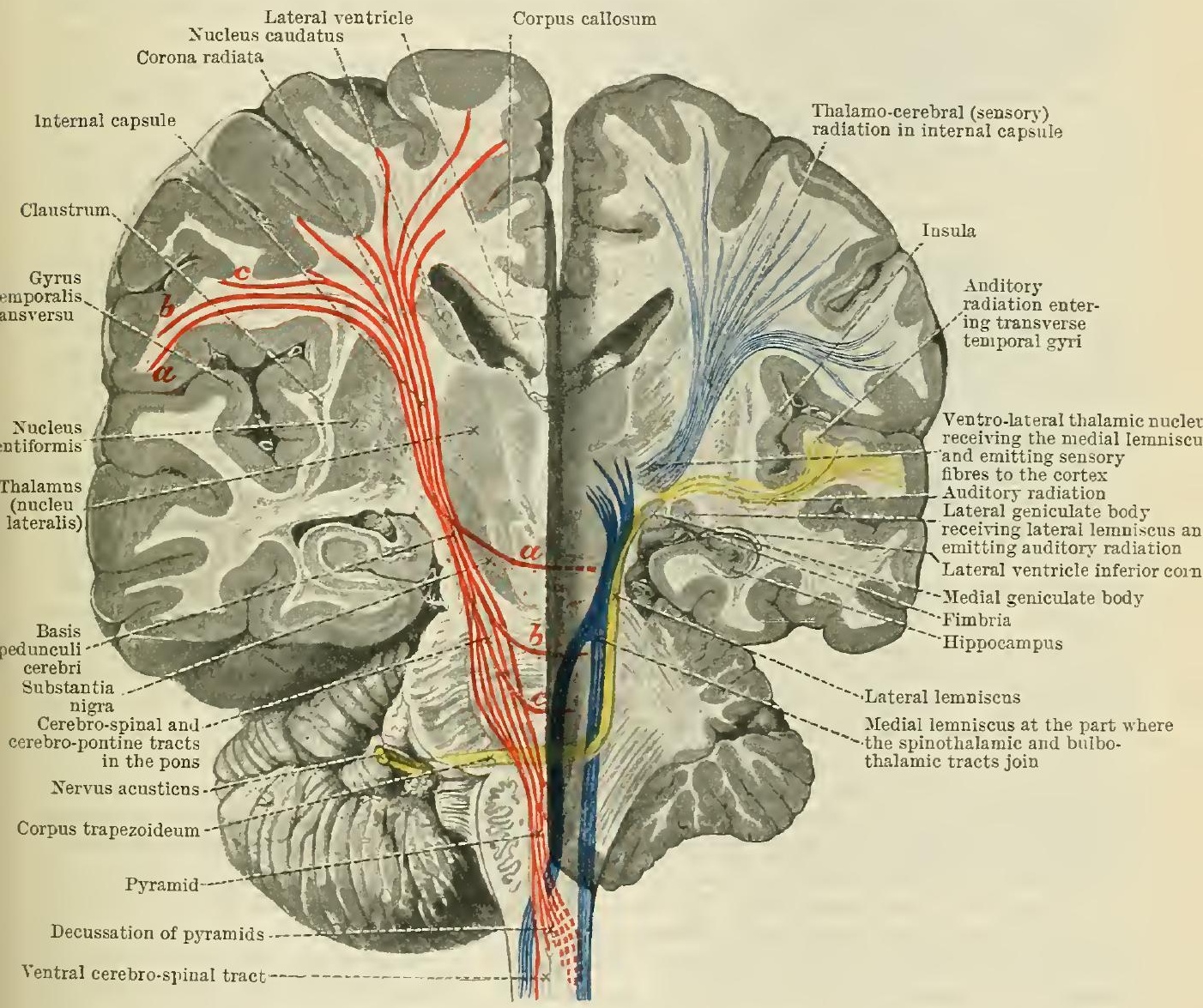

F1G. 537.-A Vertical Trassverse Sectiox of the Braix to show the Whole of the Cextral Acoustic Path. The left hemisphere (right side of the figure) is cut on a plane posterior to that of the right. Hotor fibres red. Sensory fibres blue. Acoustic fibres yellow.

ganglion emit axons that terminate in the brain; in (2) the cochlear nuclei, from the nerve-cells of which fibres arise and cross to the lateral lemniscus of the opposite side, proceeding to (3) the medial geniculate hody, from which fibres pass to the cerebral cortex.

It must be borme in mind that all the axons of the cells of the superior olive do not join the trapezoid strand. Many leave its dorsal aspect and pass backwards in a group called the pedicle of the superior olive, to end in the nucleus of the abducens nerre, and, through the medial longitudinal bundle, in the nnclei of the trochlear and oculomotor nerres. In this way the organ of hearing is brought into connexion with the nuclei which preside orer the movements of the eyeballs (Figs. 531, p. 599, and 536, p. $606)$.

\section{PROSENCEPHALON OR FORE-PRAIN.}

The fore-brain vesicle in the embryo has been subdivided, somewhat arbitrarily, 
into two parts - an anterior, termed the telencephalon, and a posterior, called the diencephalon, which forms the greater part of the walls of the third ventricle. The extreme anterior part of the third ventricle belongs to the telencephalon, and this includes the anterior wall of the neural tube, which is known as the lamina terminalis.

\section{Develophent of Parts derived from Fore-Brain.}

The alar part of each lateral wall of the telencephalon is pushed out to form a diverticulum, which ultimately constitutes the cerebral hemisphere, and thus from a very early period the primitive position of this part of the lateral wall is indicated by the wide foramen interventriculare, or aperture of communication between the cavity of the cerebral hemisphere and the third ventricle (Fig. 538).

The alar part of the lateral wall of the diencephalon is utilised for the development of the thalamus, the epithalamus, and the metathalamus. Of these the thalanus is derived from the anterior and by far the greatest part of the alar wall. It arises as a large oral swelling, which gradually approaches its fellow of the opposite side, and thus diminishes the width of the third ventricle. Finally, the two bodies sometimes come into contact in the median plane and cohere over an area corresponding to the massa intermedia. This may occur about the end of the second month.

From that section of the lateral wall to which the name of metathalamus is given the two geniculate bodies arise. Each of these shows, in the first place, as a depression on the iuside, and a slight elevation on the outside, of the wall of the diencephalon. As the thalamus grows backwards, it encroaches greatly upon the territory occupied by the geniculate bodies. It thus comes abont that in the adult brain the medial geniculate body seems to hold a position on the lateral aspect of the mesencephalon, whilst the lateral geniculate body, viewed from the surface, appears to be a part of the thalamus.

From the epithalamic region of the wall of the diencephalon are developed the pineal body, its peduncle, and the habenular region. These parts are relatively much more evident in the embryonic than in the adult brain. The pineal body appears to be developed as a diverticulum of the posterior part of the roof of the diencephalon, but in reality it is a derivative of the alar lamina. Viewed from the dorsal aspect of the braintube, this diverticulum shows in the first instance, as a rounded elevation, from either side of which a broad ridge runs forwards. This ridge becomes the tænia thalami, whilst in the region of its junction with the pineal elevation the trigonum habenulæ takes shape. The pineal diverticulum ultimately becomes solid, but a small portion of the original cavity is retained as the recessus pinealis of the third ventricle.

The part of the diencephalon and telencephalon which represents the basal lamina (i.e. lies below the lerel of the sulcus hypothalamicus) retains its primitive form, and undergoes only slight change. Consequently, when this region in the adult brain is compared with the corresponding region in the embryonic brain, the resemblance between the two is very striking.

In the fore-brain, therefore, it is the alar lamina which plays the predominant part in the formation of the cerebrum. The value, also, of the basal part of the wall of this portion of the neural tube is still further reduced by the fact that it no longer contains the nuclei of origin of efferent nerves. The highest of these nuclei (the oculomotor) is placed in the mesencephalon. [Johnston has recently announced the discovery of a sensory nerve (nervus terminalis) attached to the fore-brain in human embryos; and of course the optic and olfactory nerves enter the fore-brain.]

The region of the fore-brain which lies below the sulcus hypothalamicus is termed the hypothalamus. The part of this which corresponds to the diencephalon is called the pars mamillaris hypothalami, whilst the part in front, which belongs to the telencephalon, receives the name of pars optica hypothalami. From the pars mamillaris hypothalami are derived the corpus mamillare and a portion of the tuber cinereum. With the pars optica hypothalami are associated the following parts, viz., the tuber cinereum, with the infundibulum and the cerebral part of the hypophysis, the optic chiasma, the optic recess, and the lamina terminalis. The corpora mamillaria form, in the first instance, a relatively large ventral bulging of the floor of the brain-tube. As development goes on this bulging becomes relatively small, and about the fourth month the single projection becomes divided into the two tubercles. The infundibulum and posterior or cerebral lobe of the hypophysis are developed as a hollow downward diverticulum of the floor of the telencephalon (Fig. 538). A portion of the original cavity is retained in the upper part of the infundibulum, and constitutes the infundibular recess in the floor of the third ventricle. 
The optic nerve is chiefly formed by the passage of fibres backwards from the retina in the wall of the original optic stalk, whilst the chiasma takes form by the transit of fibres across the median plane in front of the infundibulum and behind the optic recess. To a large extent these fibres are derived from the optic nerve. The optic recess of the third ventricle marks the spot where the hollow optic vesicle was originally attached to the inferior and lateral part of the fore-brain, and in the adult it therefore represents a portion of the primitive cavity of the tubular stalk of the optic vesicle. In the course of development the optic nerve fibres, which appear in the stalk of the optic vesicle to form the optic nerve, seek an attachment much further back, and through the optic tract they are even carried as far as the mesencephalon.

The roof of the forebrain remains thin, and does not proceed to the development of nervous elements, although its posterior part becomes invaded by nervous tissue to form the pineal body and the posterior commissure. In front of these structures the roof of the fore-brain is epithelial, and remains so during life. It constitutes the epithelial roof of the third ventricle, and it becomes involutedalong the median plane into the cavity to form the chorioid plexuses of the ven-
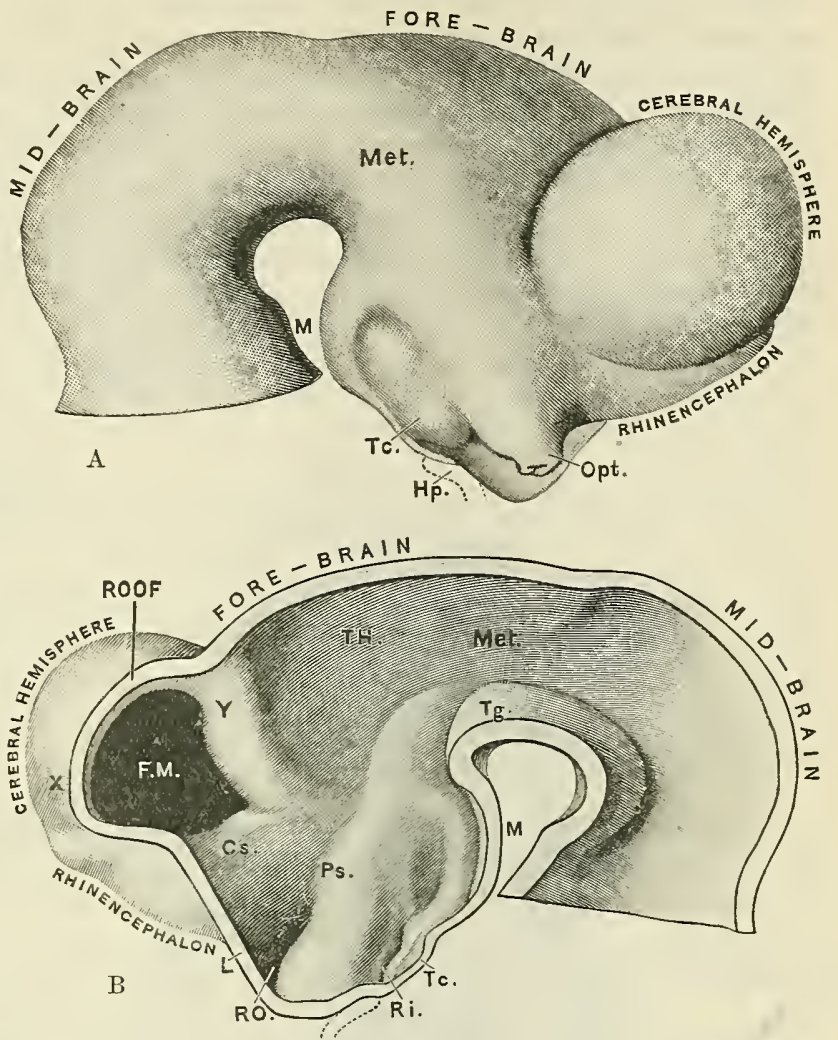

Fig. 538.-Two Drawings of the Embryonic Brain (by His).

A, Reconstruction of the fore-brain and mid-brain of His's embryo $\mathrm{KO}$; profile view. B, Same brain as A, divided along the median plane and viewed upon its inner aspect.

I, Mamillary eminence; Tc, Tuber cinereum; Hp, Hypophysis (hypophyseal diverticulum from buccal cavity); Opt, Optic stalk; TH, Thalanus; Tg, Tegmental part of mesencephalon; Ps, Pars hypothalamica ; Cs, Corpus striatum ; FM, Foramen interventriculare; L, Lamina terminalis ; RO, Recessus opticus ; Ri, Recessus infundibuli.

tricle (Fig. 549, p. 622). The posterior commissure appears as a transverse thickening at the bottom of a transverse groove which appears in the roof of the early brain-tube, behind the pineal diverticulum.

\section{Parts Derived from the Diencephalon.}

Under this heading we have to consider: (1) the thalamus; (2) the epithalamus, which comprises the pineal body and the habenular region; (3) the metathalamus, or the corpora geniculata; and (4) the hypothalamus.

The hypothalamus consists of two portions, viz., the pars mamillaris hypothalami, which comprises the corpus mamillare and the portion of the central gray matter which forms the floor of the third ventricle in its immediate vicinity; and the pars optica hypothalami, which embraces the tuber cinereum, the infundibulum, the hypophysis (O.T. pituitary body), and the lamina terminalis. Strictly speaking, the optic part of the hypothalamus does not belong to the diencephalon, but it is convenient to study the parts which it represents at this stage.

The original cavity of that part of the brain-tube which forms the diencephalon is represented by the greater part of the third ventricle of the brain.

Thalamus.-The thalamus is the principal object in this section of the brain 
(Fig. 538). It is a large ovoid mass of gray matter, which lies obliquely across the path of the cerebral peduncle as it descends from the cerebral hemisphere. The smaller auterior end of the thalamus lies close to the median plane, and is separated from the corresponding part of the opposite side only by a very narrow interval. The enlarged posterior ends of the two thalami are placed more widely apart, and in the interval between them the corpora quadrigemina are situated.

The two thalami, in their anterior two-thirds, lie close together on either side of a deep median cleft, which receives the name of the third ventricle of the brain. The inferior and lateral aspects are in apposition, and, indeed, directly connected with adjacent parts of the brain, and on this account it is customary to study them by means of sections through the brain. The superior and medial surfaces are free.

The lateral surface of the thalamus is applied to a thick layer of white matter

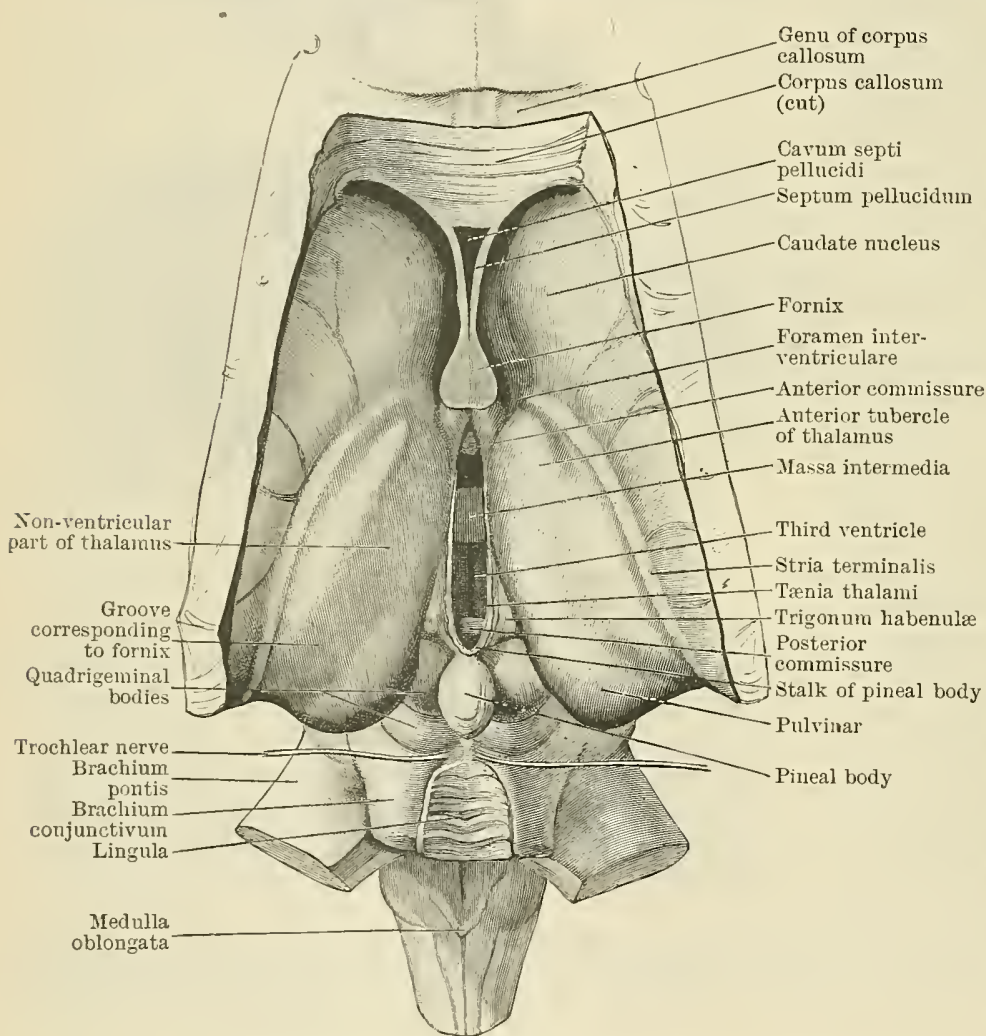

Fig. 539. - The Thalami and the Parts of the Brain surrounding them. Superior aspect. interposed between it and the lentiform nucleus, called the internal capsule, and composed of fibres passing both upwards towards and downwards from the cerebral cortex. A large proportion of these fibres descend to form the basis pedunculi. From the entire extent of the lateral surface of the thalamus large numbers of fibres stream out and enter the internal capsule, to reach the cerebral cortex. They constitute what is termed the thalamic radiation. As the fibres leave the thalamus, over the whole of the lateral surface of the ganglionic mass they form a very distinct reticulated zone or stratum, which is termed the external medullary lamina.

The inferior surface of the thalamus rests on the hypothalamus. From the latter region many fibres enter the thalamus on its inferior aspect, whilst other fibres leave this surface of the thalamus to take part in the thalamic radiation.

The superior surface of the thalamus is free. Laterally it is bounded by a groove, which traverses the floor of the lateral ventricle of the brain and intervenes between the thalamus and the caudate nucleus. In this groove are placed a slender band of longitudinal fibres, termed the stria terminalis, and in its forepart the vena terminalis. Medially, the superior surface of the thalamus is separated from the medial surface in its anterior half by a sharp edge or prominent ledge of the ependyma of the third ventricle. This is termed the tænia thalami, and the ridge which it forms is accentuated by the fact 
that, subjacent to it, there lies a longitudinal strand of fibres called the stria medullaris. When these two structures, viz., the ependymal ridge and the subjacent stria, are traced backwards, they are seen to turn medially and become continuous with the stalk or peduncle of the pineal body. Behind the portion of the tænia thalami which turns medially towards the pineal body a small depressed triangular area, the trigonum habenulæ, situated in front of the superior colliculus, forms a very definite medial boundary for the posterior part of the superior surface of the thalamus.

The superior surface of the thalamus is slightly bulging or convex, and is of a whitish colour, owing to the presence of a thin superficial covering of nerve-fibres, termed the stratum zonale. It is divided into two areas by a faint oblique groove, which begins in front at the medial border, a short distance behind the anterior extremity of the thalamus, and extends laterally and backwards to the lateral part of the posterior extremity. This groove corresponds to the lateral edge of the fornix. The two areas which are thus mapped out are very differently related to the ventricles of the brain, and also to the parts which lie above the thalamus. The lateral area, which includes the anterior extremity of the thalamus, forms a part of the floor of the lateral ventricle. It is covered with ependyma, overlapped by the chorioid plexus of this ventricle, and lies immediately subjacent to the corpus callosum. Along the line of the groove the epithelial lining of the lateral ventricle is reflected over the chorioid plexus of this cavity. The medial area, which includes the posterior end of the thalamus, intervenes between the lateral and third ventricles of the brain, and takes no part in the formation of the walls of either. It is covered by a fold of pia mater, termed the tela chorioidea of the third ventricle, above which is the fornix, and these two structures intervene between the thalamus and the corpus callosum.

The anterior extremity of the thalamus, called the tuberculum anterius thalami, forms a marked bulging. It projects into the lateral ventricle, behind and to the lateral side of the free portion of the column of the fornix. The foramen interventriculare, a narrow aperture of communication between the lateral and third ventricles of the brain, is bounded in front by the column of the fornix and behind by the anterior tubercle of the thalamus.

The posterior extremity of the thalamus is very prominent and forms a cushionlike projection, which overhangs the brachia of the corpora quadrigemina. This prominence is called the pulvinar. Another oval bulging on the posterior part of the thalamus receives the name of the corpus geniculatum laterale. It is situated below, and to the lateral side of, the pulvinar, and presents a very intimate connexion with the optic tract.

The medial surfaces of the two thalami are placed close together, and are covered not only by the lining ependyma of the third ventricle, but also by a tolerably thick layer of gray matter, continuous below with the central gray substance which surrounds the aquæductus cerebri in the mesencephalon. A band of gray matter, termed the massa intermedia, crosses the third ventricle and joins the medial surfaces of the two thalami together.

Intimate Structure and Connexions of the Thalamus.-The upper surface of the thalamus is covered by the stratum zonale, a thin coating of white fibres derived to some extent from the optic tract, and probably also from the optic radiation. The inner surface has a thick coating of central gray matter, whilst intervening between the internal capsule and the outer surface is the lamina medullaris externa. The lower surface merges into the hypothalamus.

The gray matter of the thalamus is marked off into three very apparent parts -termed the anterior, the medial, and the lateral thalamic nuclei-by a thin vertical sheet of white matter, continnous with the stratum zonale, termed the lamina medullaris interna. The lateral nucleus (nucleus lateralis thalami) is by far the largest of the three. It is placed between the medial and the lateral medullary laminæ, and it stretches backwards beyond the medial nucleus, and thus includes the whole of the pulvinar (Fig. 541). The medial nucleus (nucleus medialis thalami) reaches only as far back as the habeuular region. It is placed between the central gray matter of the third ventricle and the internal medullary lamina. The lateral nucleus is more extensively pervaded by fibres than the medial nucleus. 
From the lateral nucleus by far the greatest number of the fibres which form the radiatio thalami pass, and these are seen crossing it in various directions towards the lamina medullaris externa. The anterior nucleus (nucleus anterior thalami) is the smallest of the three thalamic nuclei. It forms the prominent anterior tubercle, and is prolonged in a wedge-shaped manner, for a short distance, downwards and backwards between the anterior parts of the medial and lateral nuclei. The internal medullary lamina splits into two parts and partially encloses the anterior nucleus. In connexion with its large cells a very conspicuous bundle of fibres, the fasciculus thalamomamillaris, comes to an end. As this bundle arises in the corpus mamillare, it ought to be called "fasciculus mamillo-thalamicus."

A diffuse gray mass imperfectly marked off from the inferior surface of the lateral nucleus receives the name of the ventral nucleus. Its inferior part is composed of the central nucleus of Luys and the nucleus arcuatus. In section the former appears as a circular mass of gray matter, which comes into view immediately behind the point where the internal medullary lamina disappears. It would seem to be intimately connected with fibres which reach it from the red nucleus and from the posterior commissure. These fibres pass round it so as to mark it off from the rest of the thalamus, and in front of the nucleus many of them enter the internal medullary lamina. The nucleus arcuatus is a small semilunar mass of gray matter placed below and to the lateral side of the central nucleus of Luys.

The connexions of the thalamus are of an extremely intricate kind. It would appear to be a ganglionic mass interposed between the tegmental corticipetal tracts and the cerebral cortex. In its posterior part, and through its stratum zonale, it also has important connexions with the optic tract. The corticipetal tegmental tracts, which enter it from below, will be noticed in connexion with the hypothalamic

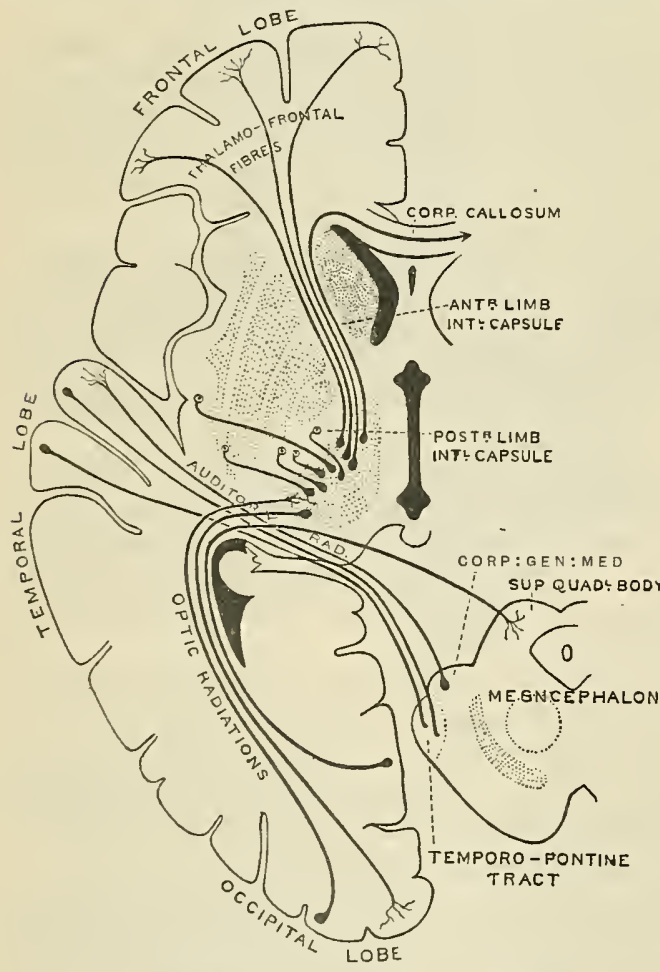

Frg. 540.- SCHEMA. Founded on the observations of Flechsig, and Ferrier and Turner. region. Suffice it to say, for the present, that these fibres end in the midst of the thalamus in connexion with the thalamic cells. In addition to these, enormous numbers of fibres, arising within the thalamus as the axons of its cells, stream out from its lateral and inferior surfaces to form the thalamic radiation. These thalamo-cortical fibres pass to every part of the cortex; and although there is no separation of them into distinct groups as they leave the thalamus, it is customary to regard them as constituting a frontal stalk, a parietal stalk, an occipital stalk, and a ventral stalk. But fibres from the cortex, cortico-thalamic fibres, likewise stream into the thalamus in large numbers, and end in fine arborisations around its cells. A double connexion with the cerebral cortex is thus established by the thalamus.

The frontal stalk of the thalamic radiation emerges from the anterior part of the lateral surface of the thalamus and passes through the anterior limb of the internal capsule, to reach the cortex of the frontal lobe. Many of these fibres end in the caudate and lentiform nuclei, between which they proceed. The parietal stalk issues from the lateral surface of the thalamus, and, passing throngh the internal capsule (and to some extent, also, through the lentiform nucleus and the external capsule), gains the cortex of the posterior part of the frontal lobe and of the parietal lobe. The occipital stalk emerges from the lateral aspect of the pulvinar and constitutes the so-called optic radiation. These fibres sweep laterally and backwards round the lateral side of the posterior horn of the lateral ventricle to gain the cortex of the occipital lobe. The 
ventral stalk streams out from the under aspect of the anterior part of the thalamus, in front of the hypothalamic tegmental region and the corpus mamillare. Its fibres arise in both the medial and lateral nuclei, and sweep downwards and laterally to reach the region below the lentiform nucleus. One very distinct band which lies dorsal to the other fibres (ansa lenticularis) comes from the lentiform nucleus to the thalamus, whilst the remainder (ansa peduncularis) proceed in a lateral direction from the thalamus below the lentiform nucleus and gain the cortex of the temporal lobe and of the insula.

Flechsig divides the thalamo-cortical fibres of ordinary sensation into three sensory systems. These he has been able to distinguish by studying the order in which they assume their sheaths of myelin in the fotus and infant.

Ferrier and Turner, by the degenerative method of investigation, corroborate Flechsig's results. They confirm the observation of Flechsig that, while thalamic fibres are distributed to the several regions of the cerebral cortex to an almost equal extent, there is one district, viz., the frontal pole, to which the supply is scanty. Another very important result has been obtained by these authors. They have established the fact that many of the thalamic fibres cross the median plane in the corpus callosum, and thus gain the cortex of the opposite cerebral hemisphere. Hamilton's crossed callosal tract thus receives confirmation.

Intimate Structure of the Corpus Geniculatum Laterale.-Sections through the lateral geniculate body reveal the fact that it is composed of a series of alternately placed gray and white curved laminæ. This gives it a very characteristic appearance. The white laminæ are composed of fibres which enter the body from the optic tract. The connexions of the geniculate bodies will be studied with the optic tract.

\section{Hypothala- mic Region. -} The tegmental part of the pedunculus cerebri is prolonged upwardsand assumes a position below the posterior part of the thalamus. The red nucleus is a conspicuous object in sections through the lower part of this region

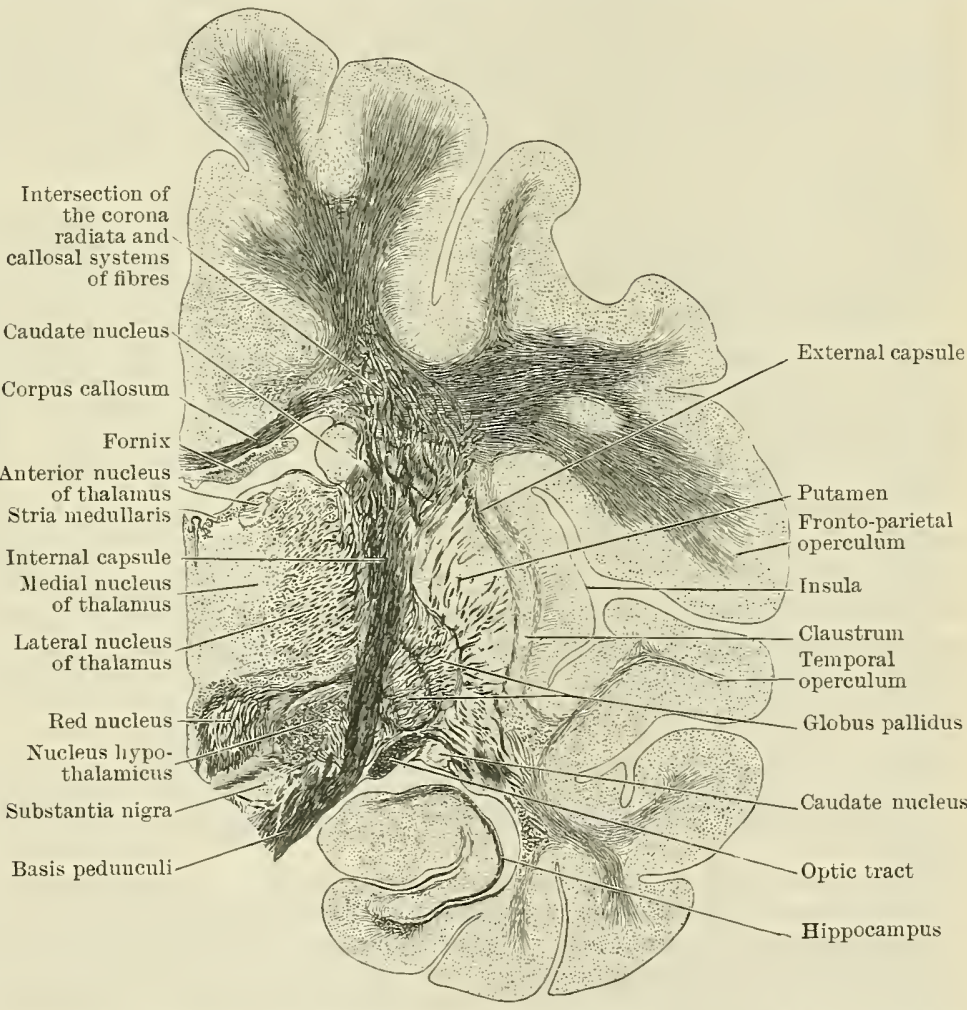

Fig. 541.-Frontal Section throdgh the Cerebrum of an Orang passing throdgh the Hipothalamic Tegantal Region.

(Fig. 541). It presents the same appearance as lower down in the mesencephalon, and, gradually diminishing, it disappears before the level of the corpus mamillare is reached. Carried up around it are the same longitudinal tracts of fibres which have been studied in relation to it in the tegmental part of the mesencephalon. Certain of these fibres, placed in immediate relation to the red mucleus, form a coating or capsule for it. This coating is partly derived from those fibres of the brachium conjunctivum which pass directly up into the thalamus and also partly from fibres which issue from the nucleus itself. The medial lemniscus, also, which in the superior part of the mesencephalon is observed to take up a position on the lateral and dorsal aspect of the red nucleus, maintains a similar position in the hypothalamic region. When the red nucleus comes to an end these various fibres are continued onwards and form, in the position previously occupied 
by the nucleus, a very evident and dense mass of fibres. The fibres of the medial lemniscus, of the brachimm conjunctivum, and of the red nucleus are prolonged upwards into the ventral part of the thalamus, where they end in connexion with the thalamic cells (ventro-lateral nucleus).

The substantia nigra is likewise carried into the hypothalamic region, where it maintains its original position on the dorsal aspect of the basis pedunculi. As it is traced upwards, it is seen gradually to diminish in amount. It shrinks from the medial to the lateral side, and finally disappears when the posterior part of the corpus mamillare is reached.

In frontal sections through the hypothalamic region, the most conspicuous object which comes into view is the nucleus hypothalamicus or the nucleus of Luys (Fig. 541). It is a small mass of gray matter, shaped like a biconvex lens, which makes its appearance on the dorsal aspect of the basis pedunculi immediately to the lateral side of the substantia nigra. At first it lies in an angle which is formed by the meeting of the cerebral peduncle and the internal capsule; but, rapidly enlarging in a medial direction, it takes the place of the diminishing substantia nigra on the dorsal surface of the basis pedunculi at the level of the inferior part of the corpus mamillare. The nucleus hypothalamicus is rendered all the more evident by the fact that it is sharply defined by a thin capsule of white fibres. On its medial aspect these fibres proceed medially and form a very evident decussation across the median plane in the floor of the third ventricle, immediately above the posterior ends of the corpora mamillaria.

The nucleus hypothalamicus, in the fresh condition, presents a brownish colour, partly from the fact that its cells are pigmented, and partly also on account of the numerous capillary blood-vessels which pervade its substance.

Corpus Pineale. - This is a small, dark, reddish body, about the size of a cherrystone and shaped after the fashion of a fir-cone. Placed between the posterior ends of the two thalami, it occupies the depression on the dorsal aspect of the mesencephalon, which intervenes between the two superior colliculi. Its base, which is directed upwards, is attached by a hollow stalk or peduncle. This stalk is separated into a dorsal and a ventral part by the prolongation backwards into it of a small pointed recess of the cavity of the third ventricle. The dorsal part of the stalk curves laterally and forwards, and on each thalamus becomes continuous with the tænia thalami; the ventral part is folded round a narrow but conspicuous cord-like band of white matter, which crosses the median plane immediately below the base of the pineal body and receives the name of the posterior commissure of the cerebrum (Fig. 519, p. 585).

The pineal body is not composed of nervous elements. The only nerves in its midst are the sympathetic filaments which enter it, with its blood-vessels. It is composed of spherical and tubular follicles, filled with epithelial cells, and containing a variable amount of gritty, calcareous matter.

The pineal body is a rudimentary structure, but in certain vertebrates it attains a much higher degree of development than in man. In the lamprey, lizard, etc., it is present in the form of the so-called pineal eye. In structure it resembles, in these animals, an invertebrate eye, and it possesses a long stalk, in which nerve-fibres are developed. Further, it is carried throngh an aperture in the cranial wall, and consequently lies close to the surface on the dorsum of the head between the parietal bones.

Trigonum Habenulæ. -The small, triangular, depressed area which receives this name is placed immediately in front of the superior colliculus in the interval between the peduncle of the pineal body and the posterior end of the thalamus (Fig. 539, p. 610). It marks the position of an important collection of nerve-cells, which constitute the ganglion habenulæ. The axons of these cells are collected on the ventral aspect of the ganglion into a bindle, called the fasciculus retroflexus, which takes a curved course downwards and forwards in the tegmentum of the mesencephalon. The fasciculus retroflexus lies close to the medial side of the red nucleus, and finally comes to an end in a group of cells termed the ganglion interpedunculare, situated in the inferior part of the substantia perforata posterior (see p. 591).

The ganglion habenulæ is likewise intimately connected with the stria medullares (tænia thalami) and the dorsal part of the stalk of the pineal body. 
As previously stated, the stria medullaris-a very evident band of white matter-lies on the thalamus, subjacent to the ependymal ridge termed the tænia thalami. When traced backwards, many of the fibres of the stria medullaris are observed to end amongst the cells of the ganglion habenulæ, whilst others are continued past the ganglion to enter the peduncle of the pineal body, and, through it, to reach the ganglion habenulæ of the opposite side, in connexion with the cells of which they terminate. The stria medullaris, therefore, ends partly in the ganglion habenulæ of their own side and partly in the corresponding ganglion of the opposite side. The decussation of fibres across the median plane forms the dorsal part of the pineal stalk or peduncle, and is termed the commissura habenularum.

When the stria medullaris is traced in the opposite direction, it is noticed to split into dorsal and ventral parts near the column of the fornix. The dorsal part arises from cells in the hippocampus: these fibres pass into the fornix and when they reach its column they turn abruptly backwards to enter the stria medullaris. The ventral part springs from a collection of cells in the gray matter on the base of the brain close to the optic chiasma. The striæ medullares are believed to form a part of the olfactory apparatus.

Commissura Posterior.-The posterior commissure is a slender band of white matter, which crosses the median plane under cover of the stalk of the pineal body and overlies the entrance of the aqueduct of the brain into the third ventricle. The fibres which enter into the formation of the posterior commissure are believed to arise in a special nucleus, which is placed in the central gray matter immediately above the oculo-motor nucleus. They decussate with each other across the median plane and thus the commissure is formed. The other connexions of this little band are not satisfactorily established, but Held believes that some of its ventral fibres pass downwards into the medial longitudinal bundle.

Substantia Perforata Posterior.-This has already been described on p. 542 . Some delicate bands of white matter, termed the tænia pontis, may frequently be seen emerging from the gray matter of this region; they then curve round the pedunculus cerebri in close relation to the superior border of the pons, with which they enter the cerebellum to end in the nucleus dentatus (Horsley).

Corpora Mamillaria.-The corpora mamillaria are two round white bodies, each about the size of a pea, which lie side by side in the interpeduncular fossa on the base of the brain, immediately in front of the substantia perforata posterior.

Each corpus mamillare is coated on the outside by white matter derived from the column of the fornix, and contains, in its interior, a composite gray nucleus with numerous nerve-cells. Several important strands of fibres are connected with the corpus mamillare: (1) The column of the fornix curves downwards in the lateral wall of the third ventricle to reach the corpus mamillare, and their fibres end amidst the cells of that body. (2) A bundle of fibres, the fasciculus mamillo-thalamicus, takes origin in the midst of each corpus mamillare and extends upwards into the thalamus, to end in fine arborisations around the large cells in the anterior thalamic nucleus. (3) Another bundle of fibres, the pedunculus corporis mamillaris, takes form within the corpus mamillare and extends downwards in the gray matter of the floor of the third rentricle, to reach the tegmentum of the mesencephalon. These tracts together with the striæ medullares (thalami) and the fasciculi retroflexi are amongst the most ancient fibre-systems in the brain. They represent the paths by which olfactory impulses may reach the brain-stem, and perhaps the spinal medulla also, and so influence the muscles of the body.

Tuber Cinereum and Infundibulum.-The tuber cinereum is a small, slightly prominent field of gray matter, which occupies the anterior part of the interpeduncular fossa between the corpora mamillaria behind and the optic chiasma in front. From its anterior part the infundibulum, or stalk of the hypophysis, projects downwards and connects that body with the base of the brain. In its upper part the infundibulum is hollow, a small, fumnel-shaped direrticnlum of the cavity of the third rentricle being prolonged downwards into it.

Hypophysis (O.T. Pituitary Body).-This is a small oval structure, flattened from above downwards, and with its long axis directed transversely, which 
occupies the fossa hypophyseos in the floor of the cranium. It is composed of two lobes-a large anterior lobe and a smaller posterior lobe, which are closely applied

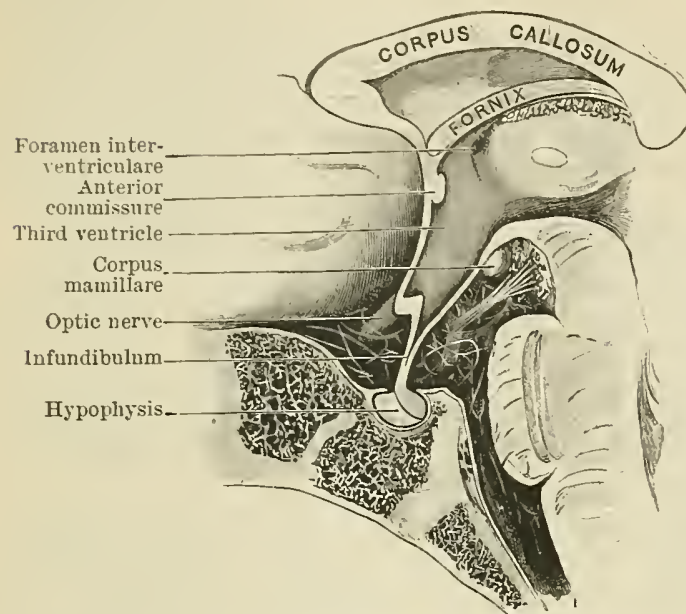

Fig. 542.- Median Section throdgh the Hypophyseal Regios in a Child Twelve Months OLd.

(From a photograph by Professor Symington.) the one to the other. The infundibulum, which extends downwards from the tuber cinereum, is attached to the posterior lobe.

The infundibulum and posterior lobe of the hypophysis are developed in the form of a hollow diverticulum, which grows downwards from the floor of that part of the embryonic brain which afterwards forms the third ventricle. The original cavity of this diverticulum becomes obliterated, except in the superior part of the infundibulum. In structure, the posterior lobe of the hypophysis shows little trace of its origin from the wall of the brain-tube. It is chiefly composed of connective tissue and blood-vessels, with branched cells scattered throughout it.

The anterior lobe has quite a different origin, and may be regarded as the functional part of the hypophysis. It is derived from a tubular diverticulum, which grows upwards from the primitive buccal cavity or stomodæum. Its connexion with the latter (canalis craniopharyngeus) is in the course of time cut off, and the diverticulum becomes encased within the cranial cavity in intimate association with the cerebral portion of the organ. Structurally, it consists of tubules or alveoli, lined with epithelial cells and surrounded by capillary vessels. Its structure is in some respects not unlike that of the parathyreoid bodies. In the disease known as acromegaly, the hypophysis is usually greatly enlarged.

Lamina Terminalis.-This is a thin, delicate lamina which may be seen on the basal aspect of the brain, stretching from the upper aspect of the optic chiasma in an upward direction to become connected with the anterior end of the corpus callosum.

Anterior Commissure of the Cerebrum.-In the anterior part of the cleft between the two thalami, and immediately in front of the columns of the fornix, a round bundle of fibres crosses the median plane. This is the anterior commissure.

Ventriculus Tertius. - The third ventricle is the narrow cleft which separates the two thalami. Its depth rapidly increases from

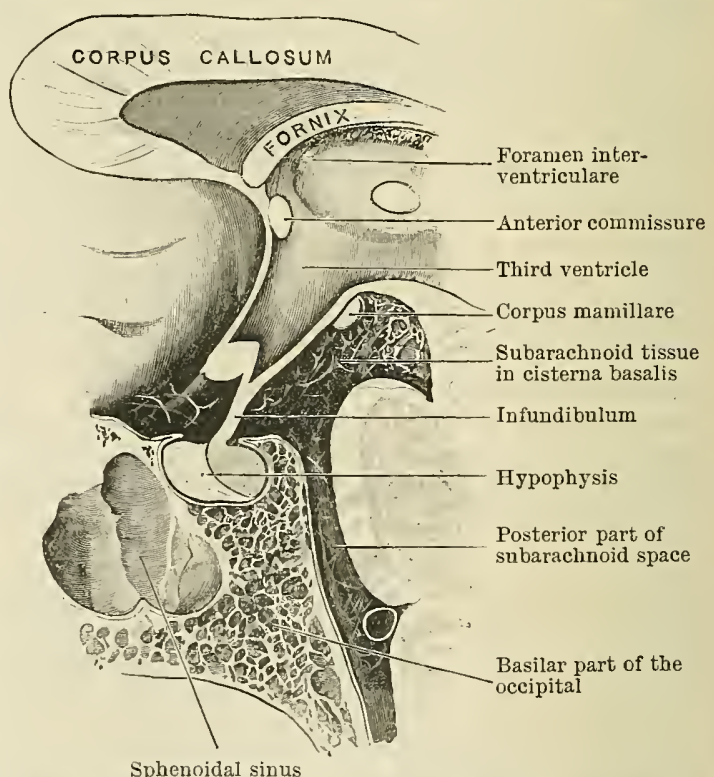

Fig. 543.- Miedian Section throdgh the HypophrseaL Region in the Adult. behind forwards, and it may be said to extend from the pineal body behind to the lamina terminalis in front. Its floor is formed by the tuber cinereum and the corpora mamillaria: the gray matter of the substantia perforata posterior, and the tegmenta of the cerebral peduncles may also be looked upon as forming part of the floor (Figs. 542 and 543). It is interesting to note that the central gray 
matter which surrounds the aqueduct is directly continuous with the gray matter of the substantia perforata posterior and tuber cinereum, and in this way it comes to the surface in the base of the brain. The optic chiasma crosses the floor in front and marks the place where the latter becomes contiuuous with the anterior wall of the cavity. The front wall of the third ventricle is formed by the lamina terminalis, which extends upwards from the optic chiasma. The anterior commissure, as it crosses from one side to the other, projects into the rentricle, but of course it is excluded from the cavity by the ventricular epithelial lining. It may be taken as indicating the place where the roof joins the anterior wall. The roof of the third ventricle is formed by a thin epithelial layer, which is part of the thin epithelial lining of the cavity, which stretches across the median plane from one tænia thalami to the other. Applied to the superior surface of the epithelial roof

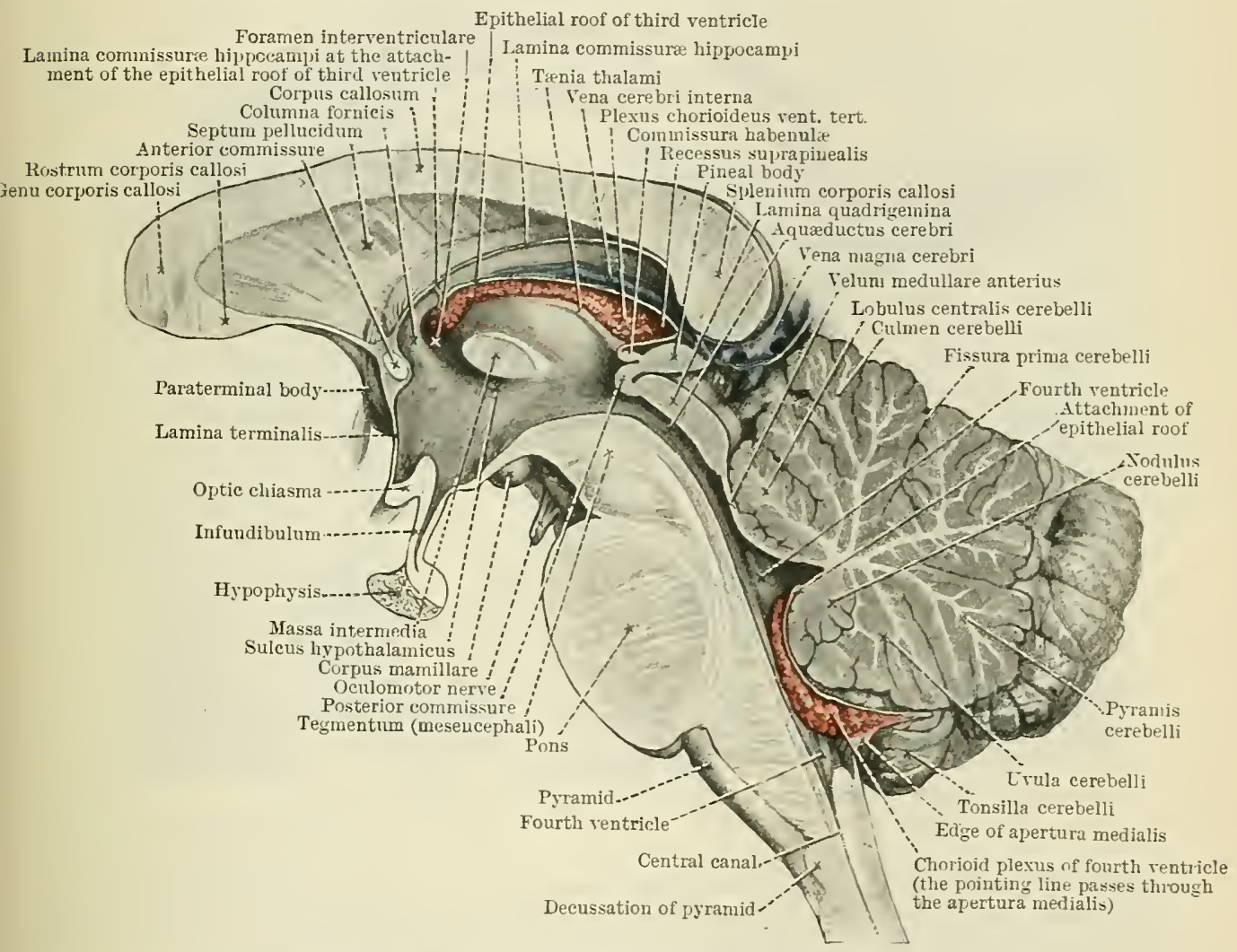

Fig. 544.-The Parts of the Braix cut through in a Mediax Sagittal Sectiox.

The lateral walls of the rentricular carities are also shown.

is the fold of pia mater, termed the tela chorioidea, and the roof is invaginated into the cavity along its whole length by two delicate chorioid plexuses, which hang down from the under surface of this fold. When the pia mater is removed the thin epithelial roof is torn away with it, leaving only the lines of attachment in the shape of the tænia thalani (Fig. 549).

The lateral wall of the third ventricle is formed for the greater part of its extent by the medial surface of the thalamus, covered by a thick layer.of central gray matter continuous with the central gray matter of the mesencephalon. A little in front of the middle of the ventricle the carity is often crossed by the massa intermedia, which connects the thalami one with the other, and in front of this the columna fornicis is seen curving downwards and backwards in the lateral wall. At first the bulging which it forms is distinctly prominent, but it gradually subsides as the strand, on its way to end in the corpus mamillare, becomes more and more sunk in the gray matter on the side of the ventricle. 
The third rentricle communicates with both of the lateral ventricles, and also with the fourth rentricle. The aquæductus cerebri, the narrow channel which tunnels the mesencephalon, brings it into communication with the fourth ventricle. The opening of this aqueduct is placed at the posterior part of the floor of the third ventricle, immediately below the posterior commissure. The foramina interventricularia bring it into communication with the lateral ventricles. These apertures are placed at the upper and anterior parts of the lateral walls, and lead laterally and slightly upwards between the most prominent parts of the columns of the fornix and the anterior tubercles of the thalami. They are just large enough to admit a crow-quill, and through these passages the epithelial lining of the three ventricles becomes continuous. From the foramen a distinct groove on

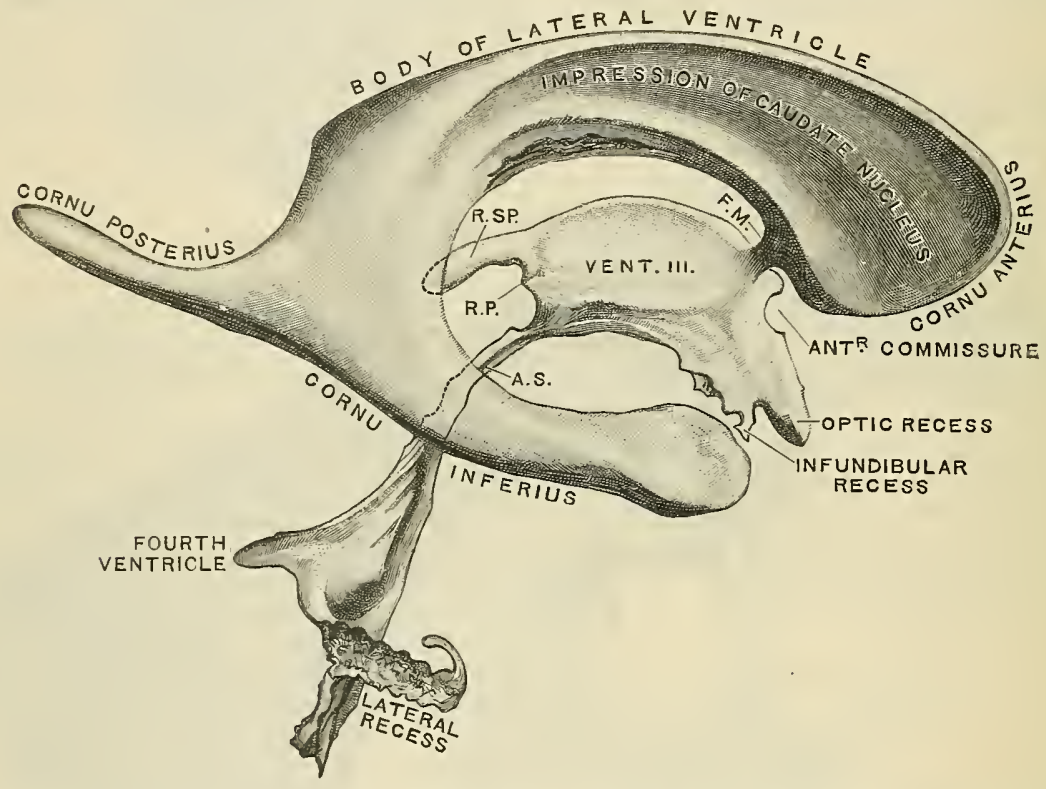

Fig. 545.-Profile View of a Cast of the Ventricles of the Brain (from Retzius),

This figure faces in the direction opposite to that of Fig. 544.

R.SP. Recessus suprapinealis.

R.P. Recessus pinealis.
A.S. Aquæductus cerebri.

F.II. Foramen interventriculare.

the lateral wall of the ventricle leads posteriorly towards the mouth of the aqueduct. It is termed the sulcus hypothalamicus, and is of interest, inasmuch as it is considered by His to represent in the adult brain the furrow which divides the lateral wall of the embryonic brain-tube into an alar and a basal lamina.

The outline of the third ventricle, when viewed from the side in a median section through the brain (Fig. 544), or as it is exhibited in a plaster cast of the ventricular system of the brain (Fig. 545 ), is seen to be very irregular. It presents several diverticula or recesses. 'Thus, in the anterior part of the floor there is a funnel-shaped pit or recess, leading down through the tuber cinereum into the infundibulum of the hypophysis. Another recess, the recessus opticus, leads forwards immediately in front of this, above the optic chiasma. Posteriorly two diverticula are present. One, the recessus pinealis, passes backwards above the posterior commissure and the mouth of the aquæductns cerebri for a short distance into the stalk of the pineal body. The second is placed above this and is carried backwards for a greater distance. It is a diverticulum of the epithelial roof, and, therefore, is difficult to demonstrate. It is termed the recessus suprapinealis. 


\section{Cerebral Connexions of the Optic Tract.}

The optic nerve is connected with the hypothalamus. At the optic chiasma the optic nerves of the two sides are joined together and a partial decussation of fibres takes place. The fibres which arise in the medial half of each retina cross the median plane and join the optic tract of the opposite side. The optic tract proceeds backwards round the cerebral peduncle, and in the neighbourhood of the geniculate bodies appears to divide into two roots, viz., a lateral and a medial (Fig. 546), but only the former is really part of the tract.

Commissure of Gudden.-The so-called medial root disappears under cover of

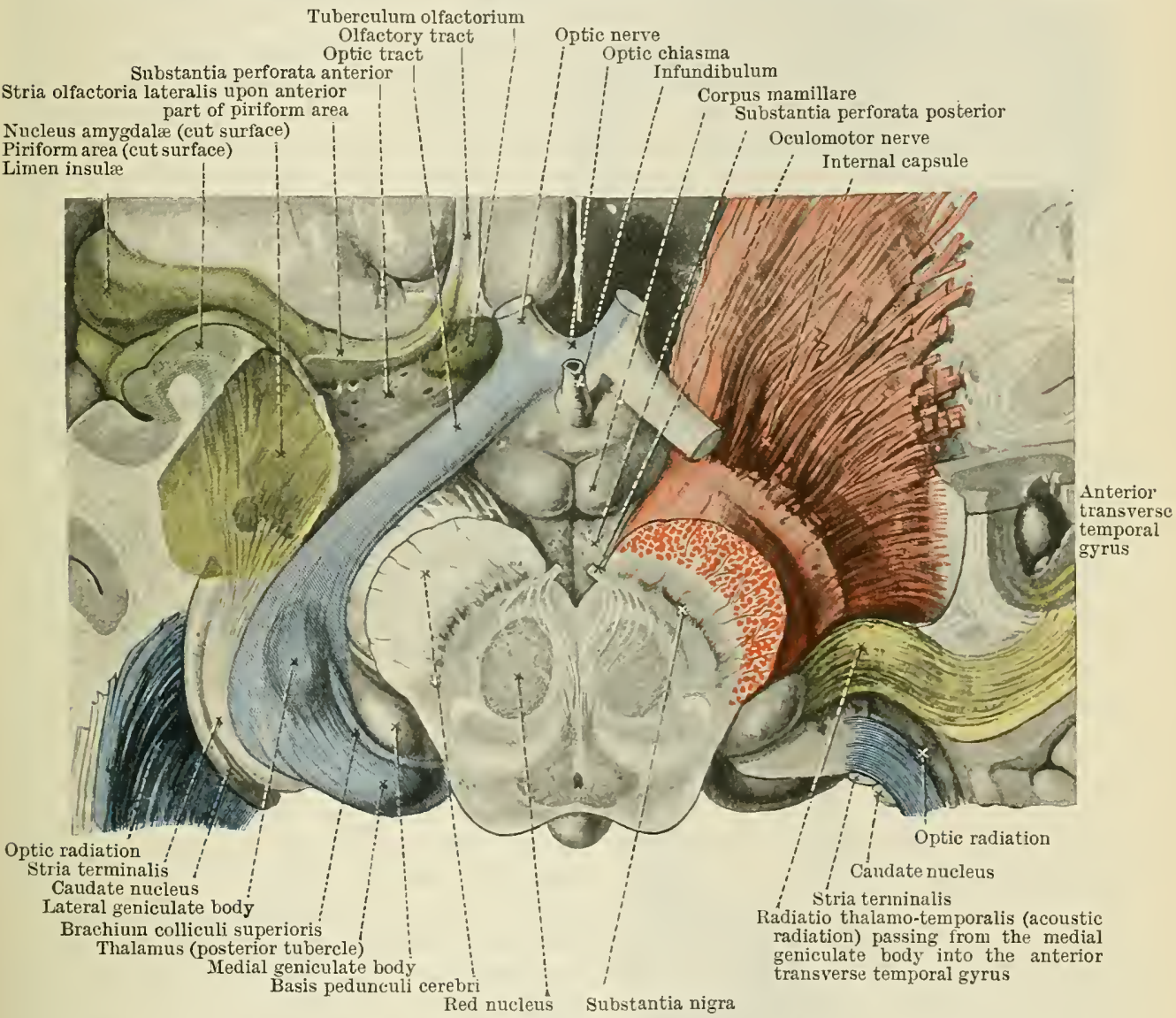

Fig. 546.-The Ventral aspect of Part of the Prosencephalon, showing the Right Optic Tract. The mesencephalon has been cut across. Olfactory area, dull yellow; optic fibres, blue; motor fibres, red; acoustic fibres, bright yellow.

the medial geniculate body and a large proportion of its fibres arise or end in this nuclear body. The medial root, although it is composed of fibres which are intermingled with those of the optic tract, has nothing to do with the optic nerve. These fibres, when traced forwards, cross the median plane in the posterior angle of the optic chiasina and are carried backwards alongside the opposite optic tract. The fibres constitute a bond of union, called the commissure of Gudden, between the medial geniculate body of one side and the colliculus inferior of the other (Fig. 547).

The Optic Tract.-The optic tract is composed of fibres which come-(1) from the lateral half of the retina of its own side; and (2) from the medial half of the retina of the opposite side, which have crossed the median plane in the optic chiasma. But in addition to the afferent retinal fibres there are a certain number 
of efferent fibres in the optic tract, fibres which take their origin in the brain and end in the retina. These are distinguished from the afferent retinal fibres by their exceeding fineness.

The fibres of the optic tract end in the superior colliculus, in the lateral greniculate body, and in the pulvinar of the thalamus (Fig. 546). The fibres to the superior colliculus reach it through the superior brachium (p. 586), and for the most part sink into its substance to end in terminal arborisations around its cells. The corpus geniculatum laterale receives the largest contribution of fibres from the optic tract. These partly sink into its interior and partly spread out over its surface. The former enter into the construction of the curved lamellæ of white matter which traverse this nuclear mass, and to a large extent end in the gray matter which intervenes between these lamellæ. The deep fibres which are not exhausted in this way proceed onwards through the lateral geniculate body and enter the pulvinar. Of the superficial fibres which spread over the surface of the lateral geniculate body some dip into its substance and end there, but the majority are carried over it and enter the stratum zonale of the pulvinar. Most of the fibres

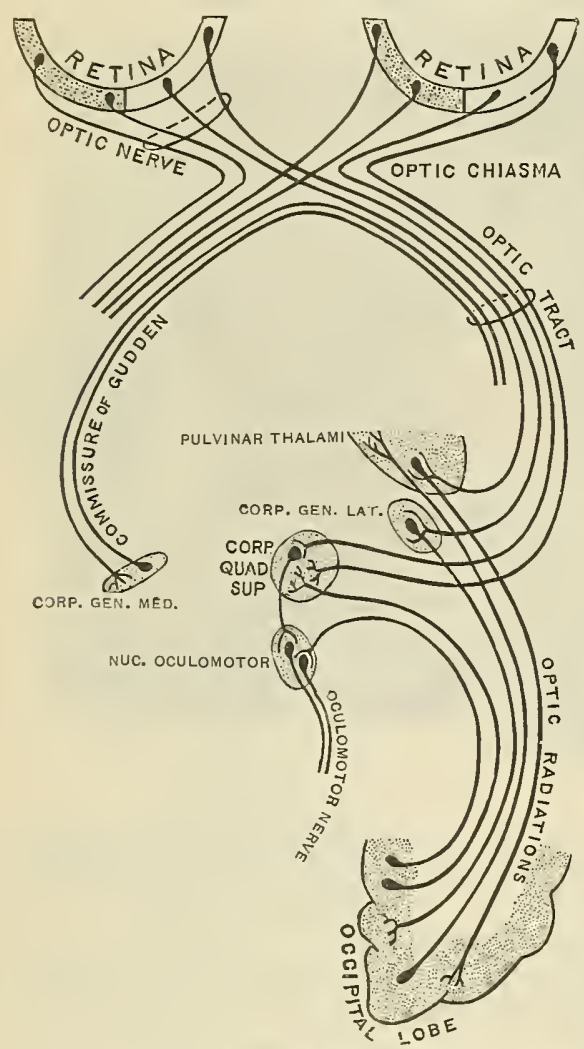

Fig. 517. - Diagram of the Central Connexions of the Optic Nerve and Optic Tract. of the optic tract, which end in the pulvinar, therefore reach their destination by passing either over or through the lateral geniculate body.

Cortical Connexions of the Optic Path.-The superior colliculus, the lateral geniculate body, and the pulvinar constitute the lower visual centres or terminal nuclei of the optic tract. The higher visual centre is placed in the cortex of the occipital region of the cerebral hemisphere, and the connexions between this and the lower centres are established by a large strand of fibres which runs in the central white matter of the posterior part of the cerebral hemisphere, and which constitutes the optic radiation. The optic radiation is composed both of corticipetal and corticifugal fibres. The former arise as the axons of the cells in the lateral geniculate body and the pulvinar, around which the retinal fibres end, and they terminate in the cortex of the occipital lobe. The corticifugal fibres take origin in the cortex of the occipital lobe and end in the pulvinar and superior quadrigeminal body (Ferrier and Turner). Thus constituted, the optic radiation forms a conspicuous strand (Figs. 546, p. 619; 552, p. $624 ; 567$, p. 638 ), which, reaching the retrolenticular part of the internal capsule, sweeps backwards into the occipital lobe of the cerebral hemisphere on the lateral side of the posterior horn of the lateral ventricle. Its connexions will be studied more fully at a later stage.

\section{THE PARTS DERIVED FROM THE TELENCEPHALON.}

\section{Cerebral Hemispheres.}

The cerebral hemispheres form the largest part of the fully developed brain. When viewed from above they form an ovoid mass, the broadest end of which is directed backwards, and the longest transverse diameter of which will be found in 
the vicinity of the parts which lie subjacent to the parietal tuberosities of the cranium. The massive rounded character of the anterior or frontal end of each cerebral hemisphere constitutes a leading human characteristic; but the posterior or occipital end is narrow and pointed, and is directed somewhat downwards. The two cerebral hemispheres are separated from each other by a deep median cleft, termed the longitudinal fissure.

The cerebral hemisphere is formed from a small area of the extreme anterior end of the alar lamina in the angle between the foremost part of the roof and the upper end of the lamina terminalis (Fig. 548, L), which becomes continuous with the roof (at the point marked $\mathrm{X}$ ).

The rapid expansion of this area leads to the development of a lateral bulging containing a diverticulum of the third ventricle, which is known as the ventriculus lateralis. This at first communicates with the third ventricle by means of a wide opening (F.M.), the foramen interventriculare [Monroi], corresponding in size to the extent of the area of the lateral wall that was bulged outwards to form the hemisphere vesicle. The thin epithelial roof of the telencephalon takes no share in the formation of the two cerebral hemispheres, but serves with the lamina terminalis (L) as a bond of union between them. At a somewhat later stage in development two folds become invaginated from this epithelial roof in the whole extent of the prosencephalon, both its telen-
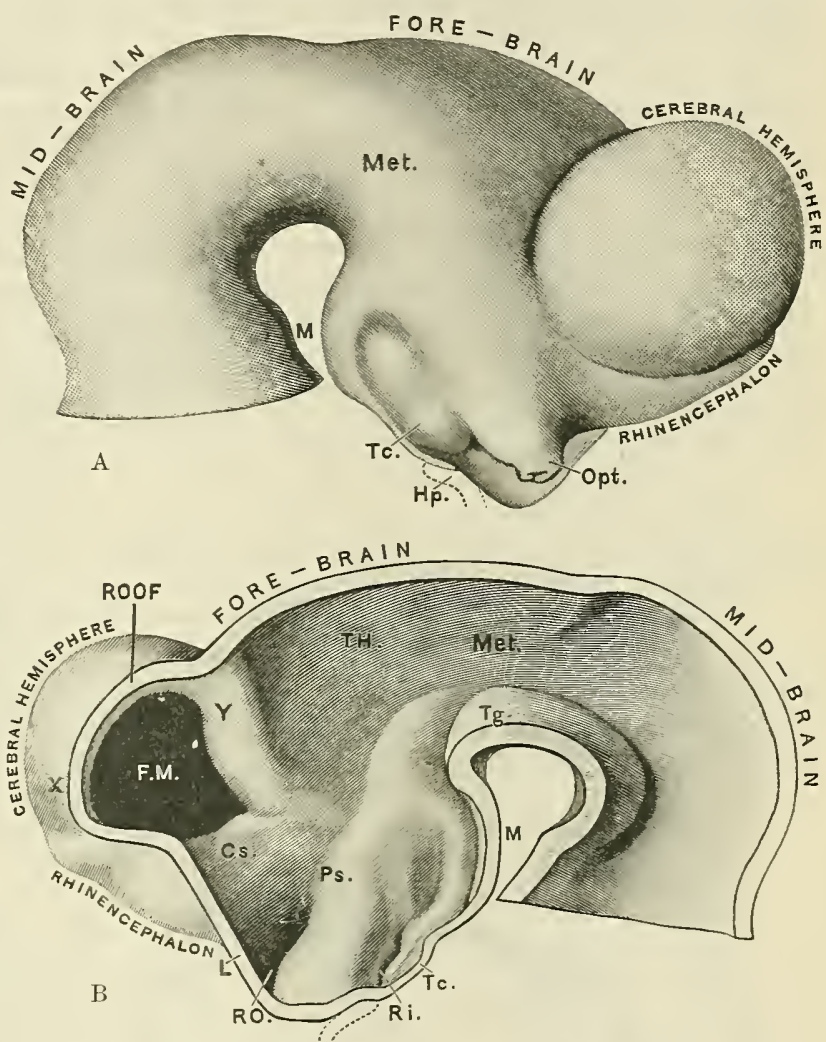

Fig. 548.-Two Dratings of the EMbryonic Brain (by His).

A, Reconstruction of the fore-brain and mid-brain of His's embryo KO ; profile view. B, Same brain as A, divided along the median plane and viewed upon its inner aspect.

II, Namillary eminence; T'c, Tuber cinereum; Hp, Hypophysis (hypophyseal diverticulım from buccal cavity); Opt, Optic stalk; TH. Thalamus; Tg, Tegmental part of mesencephalon; Ps, Pars hypothalamica; Cs, Corpus striatum ; FM, Foramen iuterventriculare ; L, Lamina terminalis ; RO, Recessus opticns ; Ri, Recessus infundibuli, Met, Metathalamus.

cephalic and diencephalic parts. In the greater part of their length these folds project into the third ventricle, and form its chorioid plexus (Kig. 549); but the anterior parts of the two chorioidal folds, namely, those parts formed from the roof of the interventricular foramind (F.M.), become greatly enlarged and project each into the corresponding lateral ventricle. The furrow corresponding to this invagination of the roof is called the fissura chorioidea. When the hemisphere vesicle first begins to expand, the thinner part of the hemisphere wall, which is called the pallium, is freely continuous around the vertical caudal margin of the foramen interventriculare (Fig. 548, Y) with the thalamus (TH).

But as development proceeds the wall of the prosencephalon becomes attenuated along the line of this pallio-thalamic junction, and eventually the edge of the pallium fringing this attachment to the thalamus becomes reduced to a thin lajer of epithelium which is continuous at its superior end with the lamina chorioidea of 
the roof. Into this secondarily formed caudal extension of the chorioid lamina the invacrination that commenced in the roof of the foramen interventriculare extends until it reaches the inferior extremity of the deep cleft separating the cerebral hemisphere from the thalamus (Fig. 548, A). Below this point the thalamus remains in uninterrupted continuity with the floor of the cerebral hemisphere (Cs), which is becoming thickened to form the corpus striatum.

At a very early stage in the development of the embryo, long before there is any sign of the hemisphere vesicles, the ectoderm upon each side of the anterior neuro-

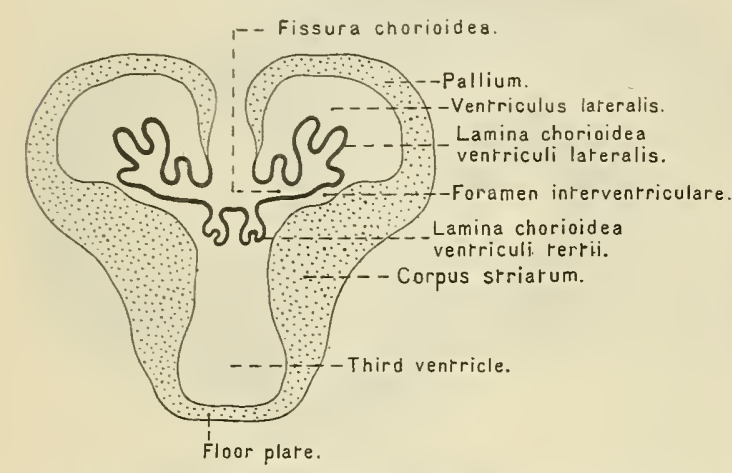

Fig. 549.-Diagran of a Transterse Section throcgh a Fotal Brain to show the Invagination of the Roof THROUGH EACH INTERVENTRICULAR FORAMEN. but become attached to the adjoining part of the neural tube. These cells form the olfactory ganglion, which acts as the receptive organ for the impressions brought into it by the processes of the sensory cells in the olfactory epithelium; and the
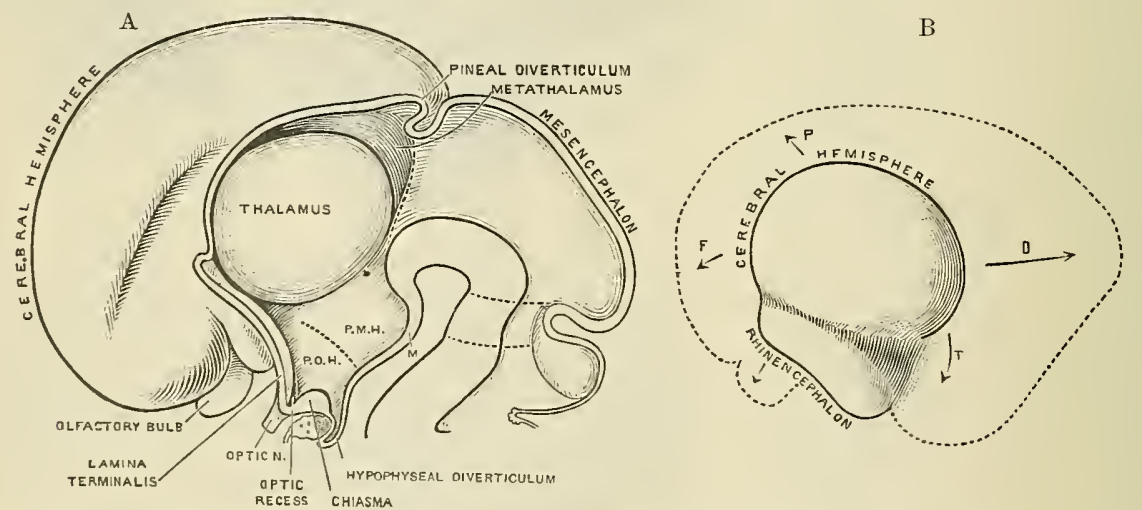

Fig. 550.-Two Drawings by His, illustrating the Development of the Human Brain.

A, Iedian section through a fotal human brain in the third month of development.

$B$, Schema showing the directions in which the cerebral hemisphere expands during its growth.

P. M.H. Pars mamillaris hypothalami.

P.O.H. Pars optica hypothalami.
M. Mamillary region.
F. Frontal lobe.

P. Parietal lobe. o. Occipital lobe.

T. Temporal lobe.

area of the neural tube to which it becomes attached is destined to become part of the cerebral hemisphere. At the end of the first month this portion of the hemisphere becomes drawn out as a hollow protrusion, the distal end of which is coated with a layer of olfactory ganglion and is known as the bulbus olfactorius; the rest forms a peduncle. In the course of its subsequent development in the human brain (though not in those of most mammals) the cavity in the bulb and peduncle becomes completely obliterated. The peduncle becomes so greatly elongated and attenuated that, to the unaided eye, it appears to be wholly formed 
of white nerve-fibres passing to and fro between the olfactory bulb and the hemisphere; hence it is called the tractus olfactorius.

The cerebral hemisphere first appears in the form of a slight bulging upon each side of the fore-brain, but it soon assumes large dimensions. At first it grows forwards and upwards (Fig. 550), and a distinct cleft, the floor of which is the roof-plate and lamina terminalis, appears between the two hemispheres: this is known as the fissura longitudinalis cerebri. The separation of the two cerebral vesicles by the longitudinal fissure begins at the end of the first month. This fissure becomes occupied by mesodermic tissue, which later on forms the falx cerebri. The cerebral hemisphere, in its further growth, is carried progressively backwards over the posterior parts of the developing brain. At the end of the third month it has covered the thalamus. A month later it reaches the corpora quadrigemina, and by the seventh month it has not only covered these, but also the entire upper surface of the cerebellum.

In the earlier stages of its development the cerebral hemisphere is a thin-walled vesicle with a relatively large cavity, which represents the primitive condition of the lateral ventricle. At first the vesicle is bean-shaped and the cavity is curved. As development proceeds the posterior portion of the hemisphere grows backwards over the cerebellum in the shape of a hollow protrusion, and a distinct occipital lobe enclosing the posterior horn of the lateral ventricle is the result. This developmental stage begins about the fourth month.

\section{The Connexions of the Olfactory Nerves.}

The olfactory nerves are the axons of the spindle-shaped bipolar cells situated in the olfactory mucous membrane (Fig. 551). These axons collect in the submucous layer to form small bundles, which enter the cranial cavity through the foramina in the lamina cribrosa of the ethmoid bone. They at once enter the inferior surface of the bulbus olfactorius, and each fibre breaks up into a tuft of terminal filaments. Towards these tufts dendrites proceed from large mitral cells placed in a deeper plane within the bulb, and each dendrite also breaks up into numerous terminal branches intertwined with those of the olfactory nerves. In this way are formed a large number of globular bodies, each consisting of the arborescent terminations of a mitral dendrite and of certain olfactory nervefibres. These are the olfactory glomeruli of the bulb. Each mitral cell gives off several dendrites and one axon. Only one dendrite enters into the formation of a glomerulus, but several nerve-fibres may be connected with such a body. It thus happens that, through its dendrite, a mitral cell may stand in connexion with several olfactory nerve-fibres. The axon of the mitral cell passes upwards to the white matter of the bulb, enters this, and, bending backwards, is conducted through the tract towards the cerebral cortex.

The olfactory bulb is a small, flattened, elliptical mass of gray substance placed upon the upper surface of the lamina cribrosa of the ethmoid. Its posterior extremity is attached to the rest of the cerebral hemisphere by the long tractus olfactorius (Fig. 476), a prismatic band of white substance placed in a furrow (sulcus olfactorius) on the under surface of the frontal region of the cerebral hemisphere. A short distance in front of the optic chiasma each olfactory tract becomes inserted into the hemisphere (Fig. 552). The swollen pyramidal-shaped 
attached end of the peduncle is called the trigonum olfactorium. Immediately behind the trigone a small obliquely placed ovoid area of gray matter, the tuberculum olfactorium, can sometimes be detected in the human brain; but in the brains of most mammals with a greater development of the organs of smell this swollen area is much more prominent and constant. In most human brains, however, it is difficult to distinguish it from a much more extensive area, which extends behind and to its lateral side, the substantia perforata anterior (Fig. 552). Along the anterior margin of this perforated substance there can sometimes be detected a small, rounded, rope-like strand of gray matter, the medial end of which passes into the trigonum olfactorium. This is the anterior part of the area piri-

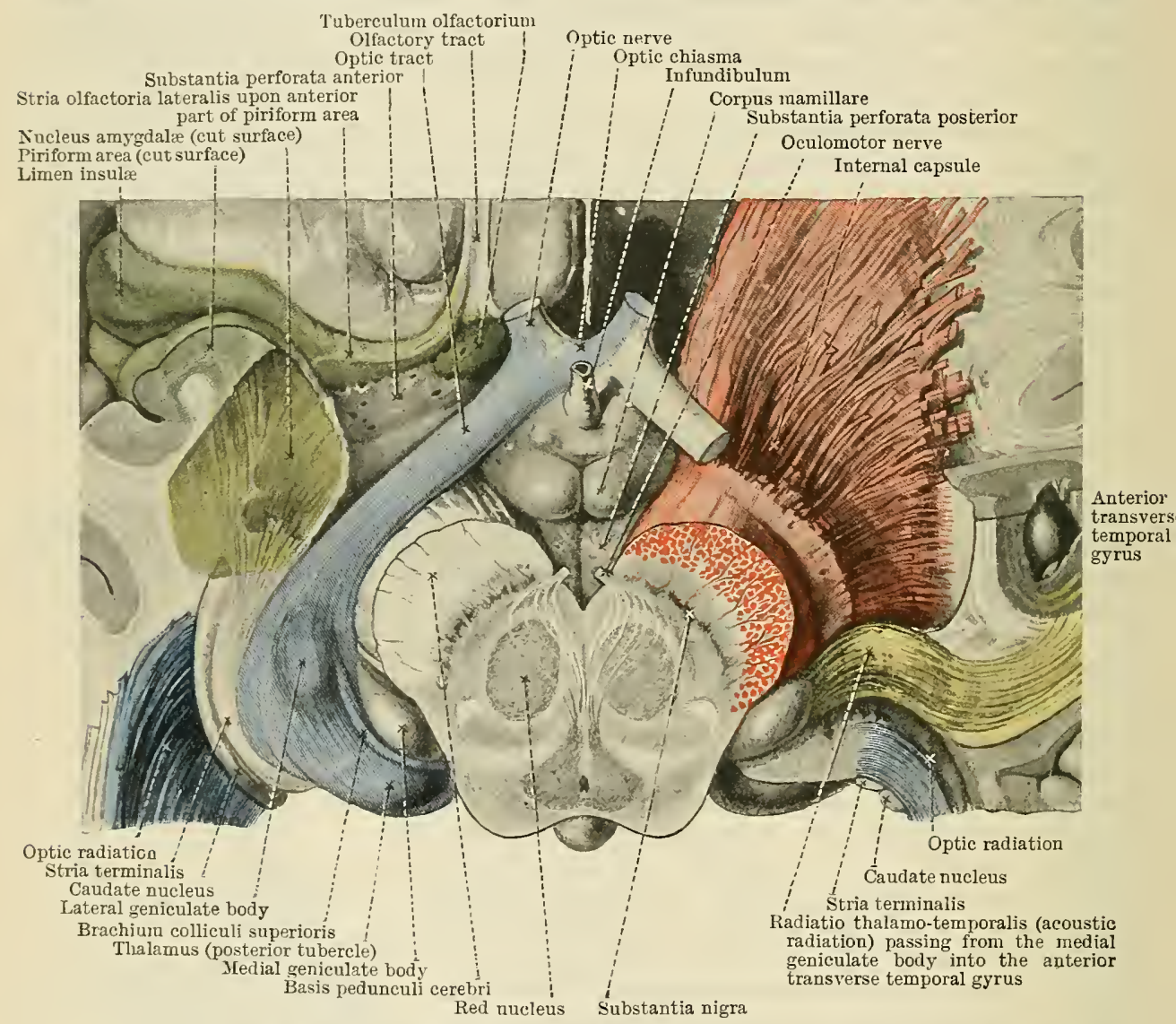

Fig. 552.-Part of the Ventral Surface of the Prosencephalon, showing the AttachMent of the OlFactory TRact.

Olfactory area, dull yellow ; optic, blue ; motor fibres, red ; acoustic fibres, bright yellow.

formis-the stalk of the pear-shaped lobe-and upon its surface is placed a very well-defined narrow band of nerve-fibres, the stria olfactoria lateralis, which is composed of axons of mitral cells (in the olfactory bulb) proceeding to the piriform area. Even when the anterior part of the piriform area is not distinguishable, the stria lateralis is always a prominent feature.

The piriform area extends transversely laterally in the deep valley between the orbital and temporal regions of the hemisphere (fossa cerebri lateralis); becoming slightly broader, and reaching what is known as the insula (of which it forms the limen insulæ), it becomes sharply bent upon itself (Figs. 552, and 553, C). It then passes medially and backwards, and emerges from the fossa as a broad area upon the under surface of the temporal region (Fig. 553, C). This greatly expanded caudal extremity of the pear is the area piriformis in the strict sense of the term. 
If the brain of almost any other mammal is examined (take the rabbit's as an example), the area piriformis will be found to constitute relatively an enormously larger proportion of the cerebral hemisphere than it does in the human brain; and it is separated from the part of the hemisphere (neopallium) that lies above it by a longitudinal furrow called the fissura rhinalis. The enormous expansion of the neopallium in the human brain accentuates the flexure of the piriform area at the point $x$ (Fig. 553), and at the point $y$ the exuberant growth of neopallium relegates the swollen posterior part of the piriform area on to the medial surface (Fig. 554), where the posterior part of the rhinal fissure persists to separate it from the neopallium.

The surface of the piriform area often presents numerous small wart-like
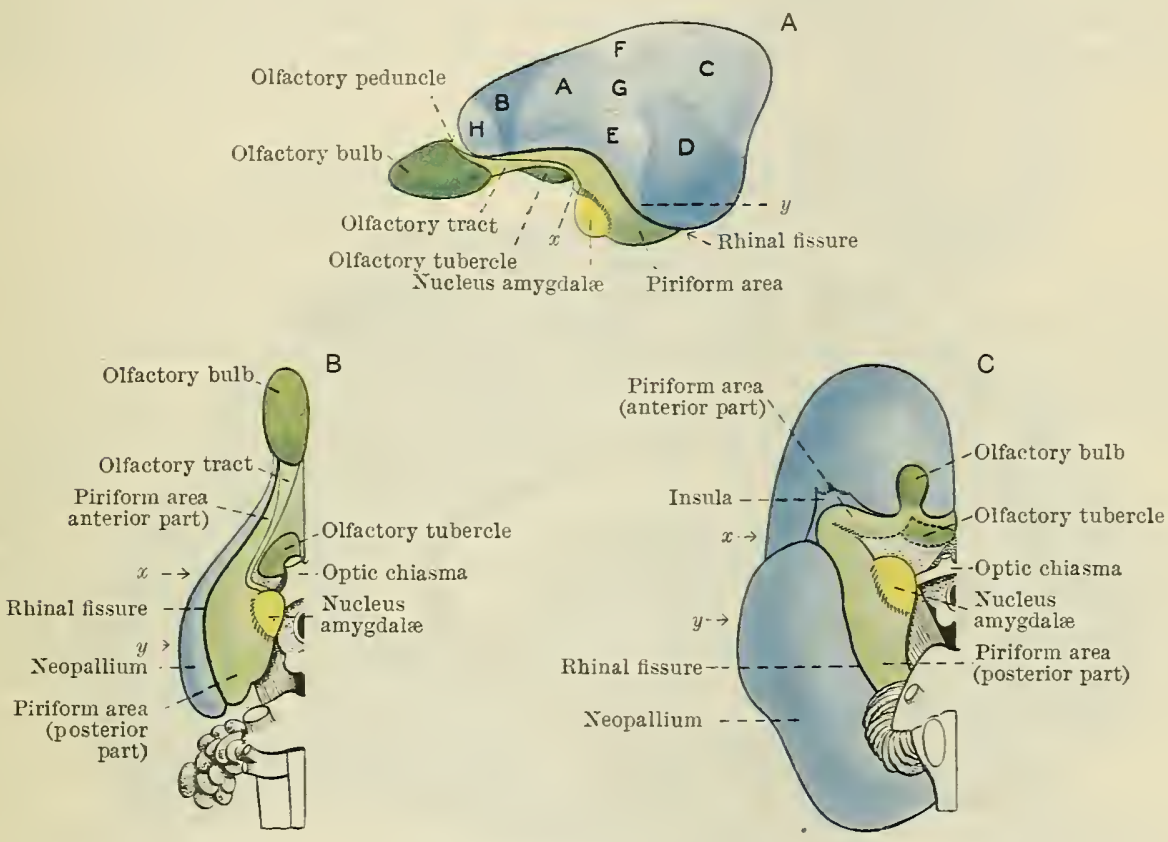

FIG. 553 .

A, The lateral aspect of the left cerebral hemisphere of a rabbit. $B$, The inferior aspect of the right half of a rabbit's brain. C, The corresponding view of a human foetal brain at the fifth month.

Olfactory areas, green; neopallium, blue.

excrescences; and it is whitened by a thin layer of fibres (substantia reticularis alba) prolonged backwards from the stria olfactoria lateralis. By these fibres olfactory impulses are poured directly from the mitral cells of the bulb into the piriform area. If we call the olfactory nerves the primary olfactory neurones, the fibres which pass from the bulb to the piriform area would then be secondary olfactory neurones.

Formatio Hippocampalis.-From all parts of the area piriformis, as well as the trigonum and tuberculum olfactorium, fibres arise (tertiary olfactory neurones), and proceed on to the medial aspect of the hemisphere, where they terminate in the edge of the pallium, alongside the lamina chorioidea. In the human brain the vast majority of these tertiary neurones proceed from the posterior extremity of the piriform area, but a certain number arise in the neighbourhood of the substantia perforata anterior and proceed at once on to the medial surface of the hemisphere. The large number of small nerve-cells that collect in the medial edge of the pallium become specially modified in structure to form a receptive organ for impressions of smell, known as the fascia dentata; and the axons of these cells pass into the pallium immediately surrounding the peripheral edge of the fascia dentata, which is known as the hippocampus (Fig. 556). In the latter area 
impressions of smell are brought into relation with those of other senses (probably taste); and from the hippocampal cells fibres are emitted to form a system known as the fornix, which establishes connexions with the hippocampus of the other hemisphere and with the hypothalamus, thalamus, and more distant parts of the brain.

The rudiment of the hippocampal formation that develops on the medial surface begins in front, alongside the place where the stalk of the olfactory peduncle (which becomes the trigonum olfactorium) is inserted; it passes upwards to the superior end of the lamina terminalis, from the rest of which it is separated by a triangular mass of gray matter, the corpus paraterminale (Fig. 555); and then it proceeds backwards, fringing the fissura chorioidea in the whole of its extent, ending below in the temporal region alongside the posterior part of the area piriformis. The anterior part of this great hippocampal fringe of the pallium does not attain its full development in the human brain and remains as a more or less vestigial aborted

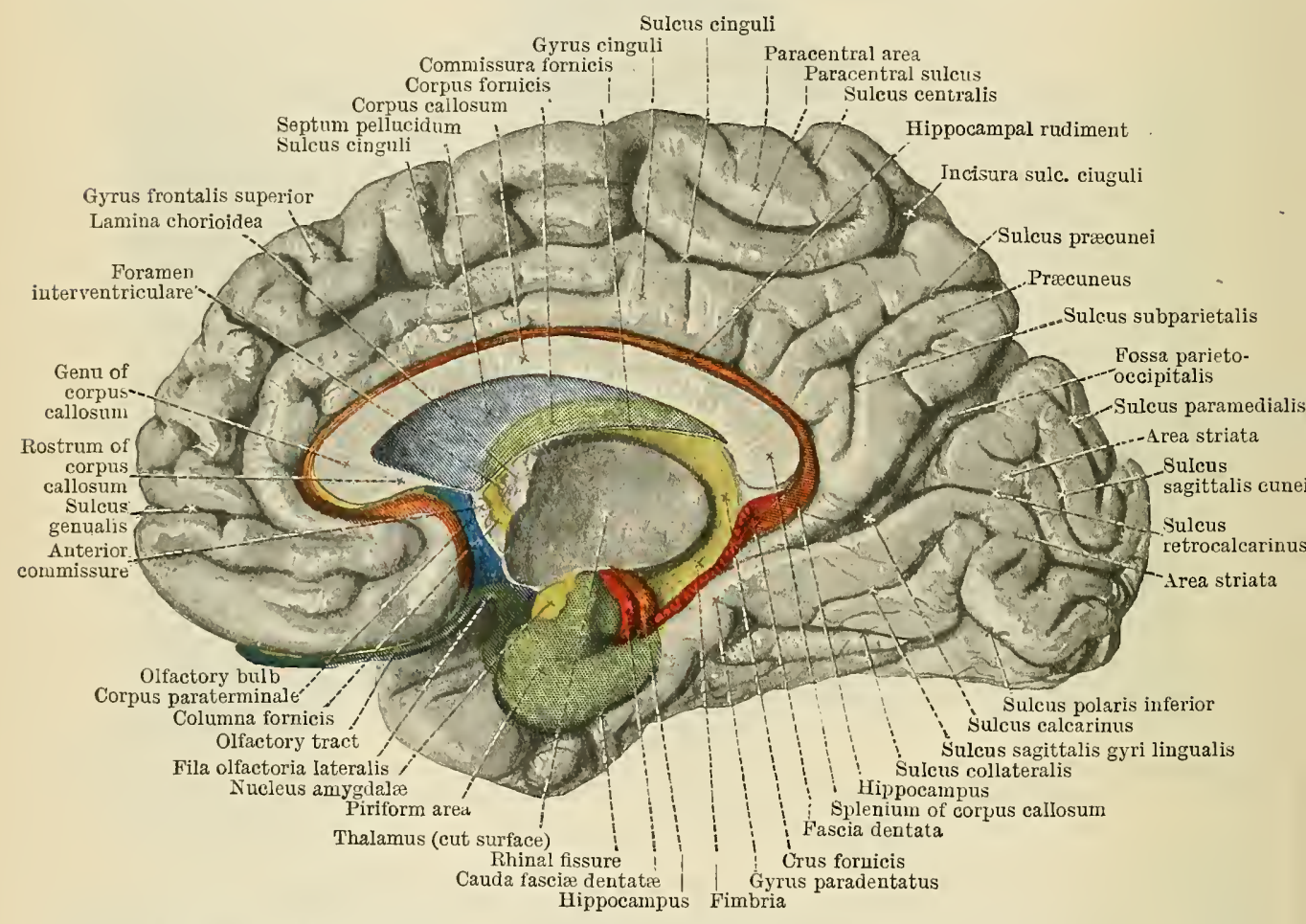

Fig. 554.-Medial Aspect of the Pight Cerebral Hemisphere, with the Olfactory Parts colodred

structure; but the posterior part undergoes a curious transformation. The tertiary olfactory neurones, coming mainly from the posterior part of the area piriformis, enter the margin of the hippocampal formation, and the small cells which receive these incoming fibres multiply rapidly during the third month, and arrange themselves in a densely packed row of granules, which represent the distinctive feature of the fascia dentata (Fig. 556). At first this cell-column is continuous at its peripheral margin with a much more loosely packed column of larger and less numerous cells, which represent the hippocampus; and these in turn give place to the more diffusely arranged and laminated cells of the typical cortex cerebri, which we call the neopallium. As development proceeds both the dentate and hippocampal columns of cells rapidly increase in length, and both appear to push their way towards the ventricle (Fig. $556, \mathrm{~B}$ ) into the substance of the wall, which becomes correspondingly thickened. The ventricular swelling thus formed is the hippocampus; and it is important to recognise that this swelling is not produced by any invagination of the surface, such as is usually described under the name of the 
fissura hippocampi. There is no fissura hippocampi in the human brain. What is usually described under this name is an artificial cleft made by pushing the handle of a scalpel into the hippocampal formation at the edge of the exposed part of the fascia dentata (Fig. $556, \mathrm{~B}$ and $\mathrm{C}$, at $x$ ) and separating the morphological surface of the hippocampus from that of the buried part of the fascia dentata. Cleavage readily occurs along this line because there are numerous nerve-fibres, hippocampal and dentate respectively, upon each side of it.

As development proceeds a break occurs in the cell-column at the junction of its hippocampal and dentate parts, and the two columns (Fig. 556, C) become partially interlocked.

The axons of the hippocampal cells collect upon its ventricular surface to form the alveus, the fibres of which converge towards the margin of the fascia dentata, where they bend into the longitudinal direction (i.e. parallel to the edge of the pallium and the lamina chorioidea) to form a prominent white marginal fringe, the fimbria.

The fibres of the fimbria pass upwards and forwards (Fig. 555), and ultimately

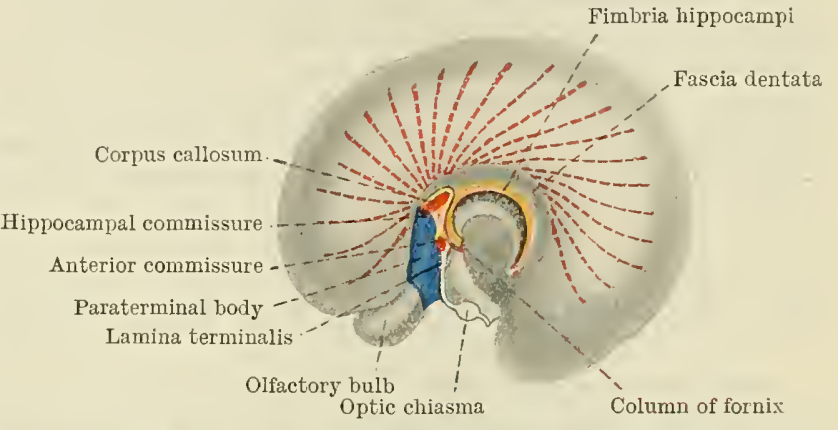

Fig. 555.- Medial Aspect of the Right Cerebral Hemisphere of a Hrman Fetos of the Fodrth Month.

The broken red lines indicate the paths taken by callosal fibres in the neopallium to reach the upper end of the lamina terminalis. reach the upper end of the lamina terminalis, which provides a bridge to conduct a certain number of them across the median plane into the fornix or

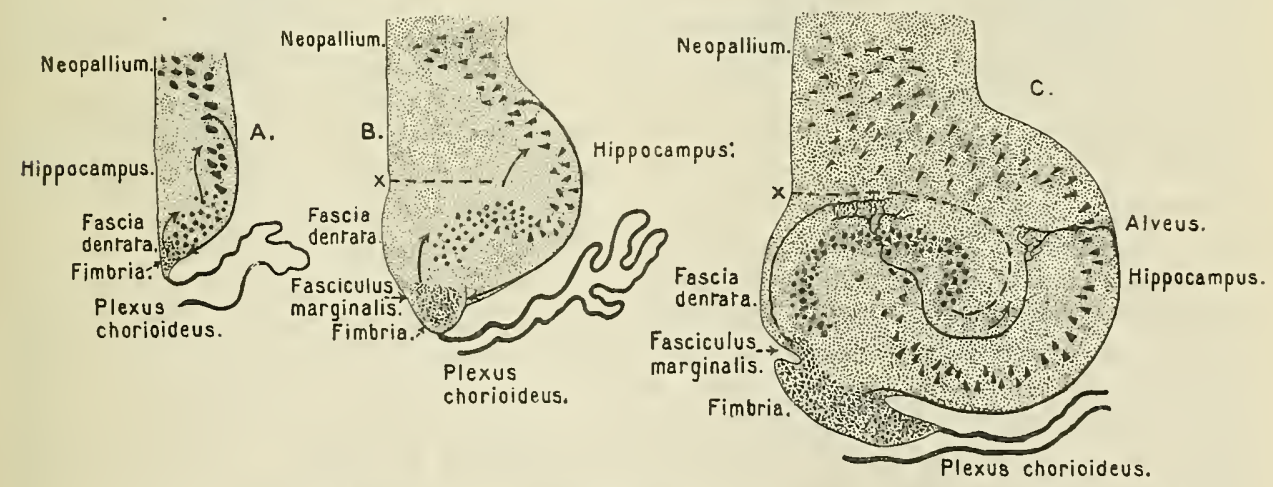

Fig. 556.-Diagranis representing three Stages in the Development of the Hippocampal Formation.

fimbria of the other hemisphere, so as to link together in functional association the two hippocampi. These crossing fibres are known as the commissura hippocampi.

Most of the fibres that go up in the fimbria from the hippocampus do not pass into the hippocampal commissure, but bend downwards in the anterior lip of the foramen interventriculare to enter the thalamic region. They are collected into a vertical rounded column, which is called the columna fornicis; when it reaches the hypothalamus it bends backward to end in the corpus mamillare.

The olfactory bulb and tract, the area piriformis, tuberculum olfactorium, corpus paraterminale, and the formatio hippocampalis together form a part of the hemisphere, which is concerned mainly with the function of smell. Hence they may be grouped together as the rhinencephalon; but this term has been used in so many different ways that it is of doubtful utility. 
In the lowest rertebrates the whole hemisphere is practically rhinencephalon. Nevertheless, fibres coming from other parts of the nervous system and conveying impressions from other sense organs than those of smell make their way into the cerebral hemisphere and influence the state of its activities. In other words, the hemisphere is primarily an olfactory receptive nucleus, but is also the place where impressions of smell are brought under the modifying influences of other sensory impressions before they make their effects manifest in behaviour.

But it is only in the most highly organised types of brain, more especially those of mammals and birds, that the non-olfactory senses acquire a representation in the hemisphere which is relatively independent of, or at any rate not wholly subservient to, the influence of the sense of smell. In the mammalian brain a definite area of pallium is set apart to receive impressions of the tactile, visual, acoustic, and other senses. This area is the neopallium. In the human brain it has grown to such an extent that it forms almost the whole of the hemispheresa mass far greater than the whole of the rest of the central nervous system.

\section{THE CEREBRAL COMMISSURES AND THE SEPTUM PELLUCIDUM.}

We have seen that certain fibres from the hippocampi cross from one hemisphere to the other, using the upper part of the lamina terminalis as a bridge across the median plane. But at an earlier stage of development other fibres can be detected at a slightly lower level in the lamina terminalis forming a bundle, of oval outline in sagittal section, called the commissura anterior. Its fibres come from the olfactory bulb, area piriformis, tuberculum olfactorium, and a small temporal area of neopallium. If the composition of the hippocampal commissure is analysed in a foetus of the third month, it will be found that there are intermingled with the truly hippocampal fibres some which come from the neopallium. During the fourth month the bulk of the neopallial element in this dorsal commissure outgrows the hippocampal element. The latter fibres become crowded into the postero-inferior corner of the commissure and the neopallial fibres come to form a flattened transverse bridge - the corpus callosum - above them. These fibres are enclosed in a neuroglial matrix derived from the lamina terminalis and the adjoining paraterminal bodies. Some nerve-cells also may make their way into this matrix. As it elongates, the corpus callosum pushes its way forwards in the upper part of the paraterminal body of each hemisphere, and as development proceeds a small area of this body becomes almost completely circumscribed by the corpus callosum and commissura hippocampi. As these commissural bands inerease in size this small circumscribed patch of paraterminal body becomes greatly stretched and expanded to form a thin translucent leaf. The two leaves thus formed in the medial walls of the two hemispheres are known as the septum pellucidum; and the narrow cleft that separates them the one from the other in the median plane is called the cavum septi pellucidi.

There is still an element of uncertainty concerning the precise manner in which these changes are brought about, and especially as to the precise mode of closure of the cavum septi. As the cerebral hemisphere expands, some parts of it grow forwards, others upwards, and others again backwards. Such growth in each part will naturally tend to exert traction upon its commissural fibres that pass throngh the corpus callosum. Hence the anterior part of this great commissure becomes drawn forward, its posterior part backwards, and the greater intermediate part upwards, so that it comes to assume the form shown in Fig. 557, C. As the posterior part of the corpus callosum pushes its way backwards, it exerts traction upon the fibres of the hippocampal commissure and their matrix, which becomes enormously stretched so as to form a thin lamella (the floor of the cavum septi) stretching from a point just above the anterior commissure to the under surface of the swollen posterior end of the corpus callosum, which is called the splenium (Fig. 558). The hippocampal commissural fibres are scattered throughout this lamella. The backward growth of the splenium also thrusts back the 
upper end of the hippocampal formation so that it becomes removed far from the lamina terminalis. The fibres of the fimbria which are prolonged forwards under the corpus callosum and septum pellucidum to bridge this great gap form the crus fornicis on each side. As a rule in the human adult brain the crura fornicis of the two hemispheres become crowded together at the median plane so as to obscure the connecting lamella which serves as a matrix for the commissura hippocampi (Fig. 557, C); but the true arrangement can be seen in the brains of fotuses of the sixth, seventh, and eighth months, and is at once revealed in the adult if the corpus callosum is raised up by an accumulation of fluid in the lateral ventricles (hydrocephalus), so as to put a strain upon the septum pellucidum. The mass formed by the crura fornicis and their commissure is called the corpus fornicis.

The fascia dentata appears as a curious notched band behind and below the fimbria; its upper end passes on to the under surface of the splenium of the corpus callosum, where it tapers and ends (fasciola cinerea); but as it dwindles the upper end of the hippocampus emerges upon the surface below and behind it and passes into a thin film of gray matter-indusium griseum-which is prolonged on to the upper surface of the corpus callosum. It proceeds forward, becoming as a rule still

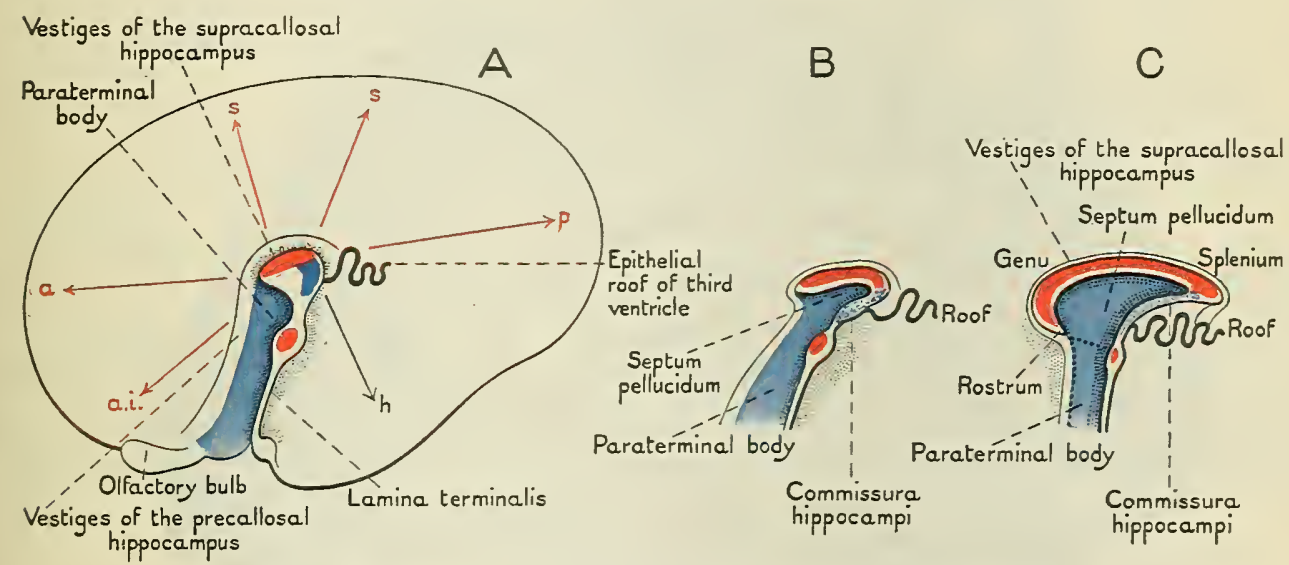

Fig. 557.-Three Stages ia the Detelopmext of the Corpes Callostr.

more attenuated, and after surrounding the anterior end (genu) of the corpus callosum it passes downwards towards the trigonum olfactorium along the line that separates the corpus paraterminale from the neopallium. The indusium represents the atrophied remains of the anterior part of the hippocampal arc of the fotal brain (Fig. 555), from which the fascia dentata has entirely disappeared. It is accompanied by longitudinal fibres homologous to the fornix system, in other words the fornix fibres of the atrophied supracallosal hippocampus; they form the striæ longitudinales of the corpus callosum (Fig. 558; Fig. 564, p. 635; Fig. 559, p. 631).

The inferior (or anterior) extremity of the fascia dentata dips into a deep furrow, around which the area piriformis is bent in a hook-like manner (uncus); in this it becomes considerably reduced in diameter and then emerges (at right angles to its previous direction) to form Giacomini's "banderella," which we may call the cauda fasciæ dentatæ. Behind this the inferior end of the hippocampus comes to the surface, but is turned inside out, hippocampus inversus. Just in front of the upper ending of the cauda fasciæ a little knob of solid gray matter appears upon the surface, surrounded by area piriformis. It is the nucleus amygdalæ (Fig. 558).

Corpus Callosum. - The corpus callosum is the great transverse commissure which passes between the two cerebral hemispheres. It is placed nearer the anterior than the posterior aspect of the brain, and it unites the medial surfaces of the hemispheres throughout very nearly a half of their antero-posterior 
length. The corpus callosum is highly arched from before backwards, and presents a convex superior surface and a concave inferior surface when viewed from the side (Fig. 558).

The superior surface of the corpus callosum forms the bottom of the longitudinal fissure, and on each side of this it is covered by the gyrus cinguli. Only in its posterior part is it approached by the falx cerebri; in front, this process of dura mater falls considerably short of it. The superior surface of the corpus callosum is covered by a thin layer of induseum continuous at the bottom of the sulcus corporis callosi with the gray cortex on the surface of the hemisphere. In this there are embedded on either side of the median plane two delicate longitudinal bands of fibres, called respectively the stria longitudinalis medialis and lateralis. The stria longitudinalis medialis is the more strongly marked of the two, and it is separated from its fellow of the opposite side by a faint median furrow. The stria longitudinalis lateralis is placed farther out, under cover of the callosal

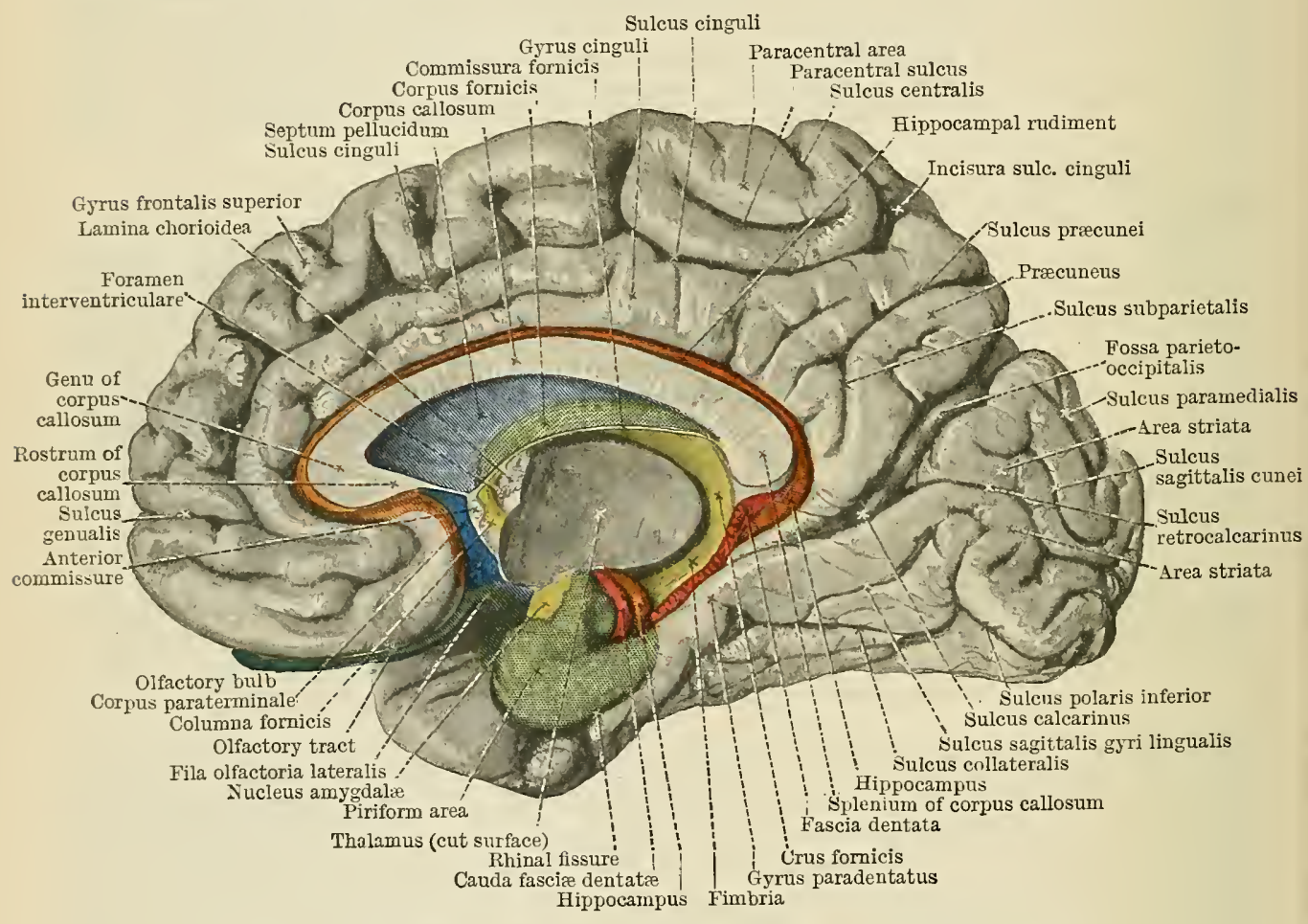

Fig. 558.- The medial Aspect of the Right Cerebral Hemisphere.

gyrus. The thin coating of gray matter, with the two striæ, represents the aborted remains of the hippocampus (see p. 627). So thin is this gray coating that the transverse direction pursued by the callosal fibres proper can be easily perceived through it.

The two extremities of the corpus callosum are much thickened, whilst the intermediate part or body is considerably thinner. The massive posterior end, which is full and rounded, lies over the mesencephalon and extends backwards as far as the highest point of the cerebellum. It is called the splenium, and it consists of a superior and inferior part. The latter is bent forwards under the upper part, to the inferior surface of which it is closely applied. The anterior end of the corpus callosum is not quite so massive, and it is folded downwards and backwards on itself. It is termed the genu. The recurved inferior part of the genu is separated from the part of the corpus callosum which lies above, by an interval. It rapidly thins as it passes backwards and receives the name of the rostrum. The fine terminal edge of the rostrum becomes connected by means of a band of neuroglial 
tissue with the lamina terminalis on the antero-superior aspect of the anterior commissure (Fig. 558).

The inferior surface of the corpus callosum on each side of the median plane is coated with ependyma (Fig. 564, p. 635), and forms the roof of the anterior horn and body of the lateral ventricle. In the median plane, however, it is attached to subjacent parts, viz., to the septum pellucidum in front and directly or indirectly (Fig. 564) to the body of the fornix behind (Fig. 558, p. 630).

The transverse fibres of the corpus callosum, as they enter the white medullary centre of the cerebral hemisphere, separate from each other so as to reach most parts of the cerebral cortex. These diverging fibres are termed the radiatio corporis

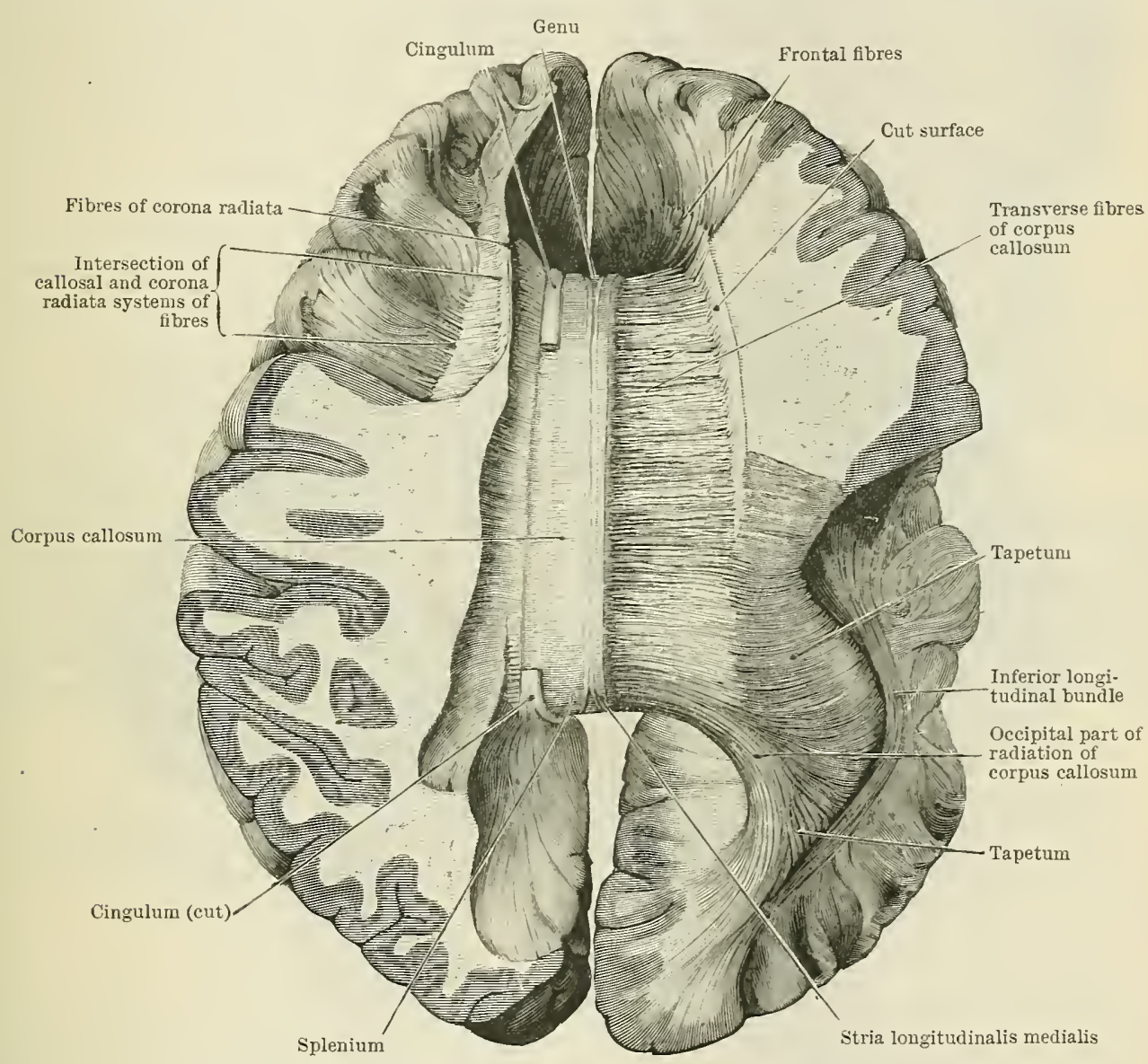

Fig. 559.-The Corpus Callosum, exposed from above and the right half dissected, to show the course taken by its fibres.

The lateral longitudinal stria (which lies near the cingulum) is not shown.

callosi and they intersect those which form the corona radiata, or, in other words, the fibres which extend between the internal capsule and the cerebral cortex (Figs. 570, p. 640, and 576, p. 649). The more anterior of the fibres which compose the genu of the corpus callosum sweep forwards in a series of curres into the anterior frontal region of the hemisphere. A large part of the splenium, forming a solid bundle termed the occipital part of the radiation of the corpus callosum (O.T. forceps major), bends suddenly and abruptly backwards into the occipital lobe (Fig. 559). Fibres from the body and superior part of the splenium, curving round the lateral ventricle, form a very definite stratum, called the tapetum. This is a thin layer in the medullary centre of the hemisphere, which constitutes the immediate roof and lateral wall of the posterior horn and the lateral wall of the posterior part of the inferior horn of the lateral ventricle. 
In frontal sections through the occipital and posterior temporal regions the tapetum stands out very distinctly (Fig. 559, p. 631; see also Figs. 565, p. 636, and 567, p. 638 ).

Septum Pellucidum. - The septum pellucidum is a thin vertical partition which intervenes between the two lateral ventricles. It is triangular in shape, and posteriorly it is prolonged backwards for a variable distance between the body of the corpus callosum and the fornix, to both of which it is attached. In front it occupies the gap behind the genu of the corpus callosum, whilst below, in the narrow interval between the posterior edge of the rostrum of the corpus callosum and the fornix, it is prolonged downwards in the paraterminal body towards the base of the brain. The septum pellucidum is composed of two thin laminæ in apposition with each other in the median plane (Fig. 562; Fig. 564 , p. 635).

Cavum Septi Pellucidi.-This name is applied to the median cleft between the

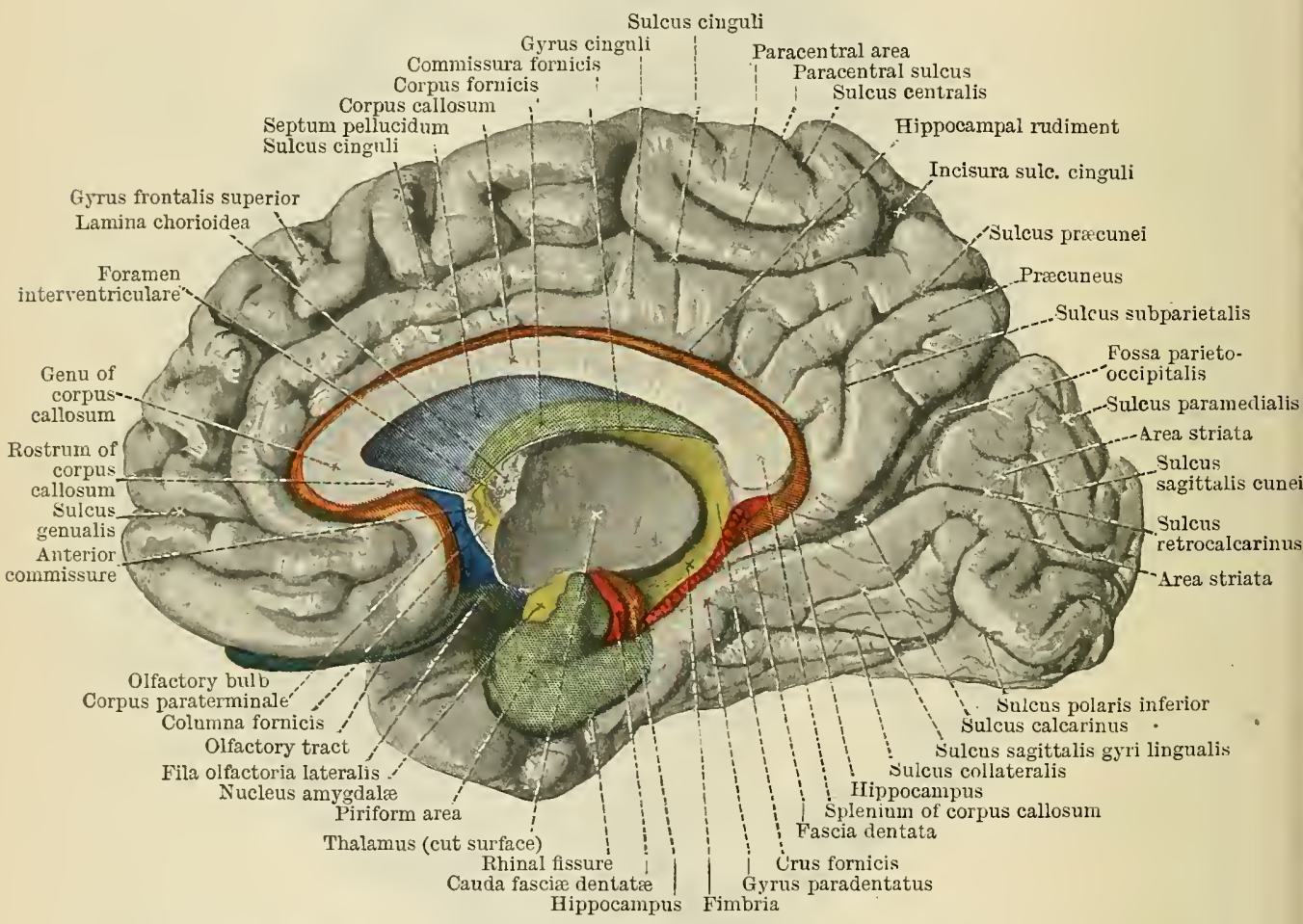

Fig. 560. -The Miedial Aspect of the Right Half of the Bratn exposed by a Mediax Sagtttal Section.

two laminæ of the septum pellucidum. It varies greatly in size in different brains.

\section{Ventriculus Lateralis.}

The cavity in the interior of the cerebral hemisphere is called the lateral ventricle. It is lined throughont by ependyma continuous with the ependymal lining of the third ventricle. In some places the walls of the cavity are in apposition, whilst in other localities spaces of varying capacity, and containing cerebro-spinal fluid, are left between the bounding walls.

The lateral ventricle communicates with the third ventricle of the brain by means of a small foramen, just large enough to admit a crow-quill, which is termed the foramen interventriculare. This aperture is placed in front of the anterior end of the thalamus and behind the column of the fornix.

The highly-irregular shape of the lateral ventricle can be best understood by the 
study of a cast of its interior (Figs. 561 and 545 , p. 618). It is usual to describe it as being composed of a body and three horns, viz. an anterior, a posterior, and an inferior horn. The cornu anterius is that part of the cavity which lies in front of the interventricular foramen. The body or pars centralis is the portion of the ventricle which extends from the interventricular foramen to the splenium of the corpus callosum. At this point the posterior and inferior horns diverge from the posterior part of the body. The cornu posterius curves backwards and medially into the occipital lobe. It is very variable in its length and capacity: the chief reason for this variability is that adhesions between the walls of this part of the ventricle are of common occurrence. The cornu inferius proceeds with a bold sweep round the posterior end of the thalamus, and then tunnels in a forward and medial direction through the temporal lobe

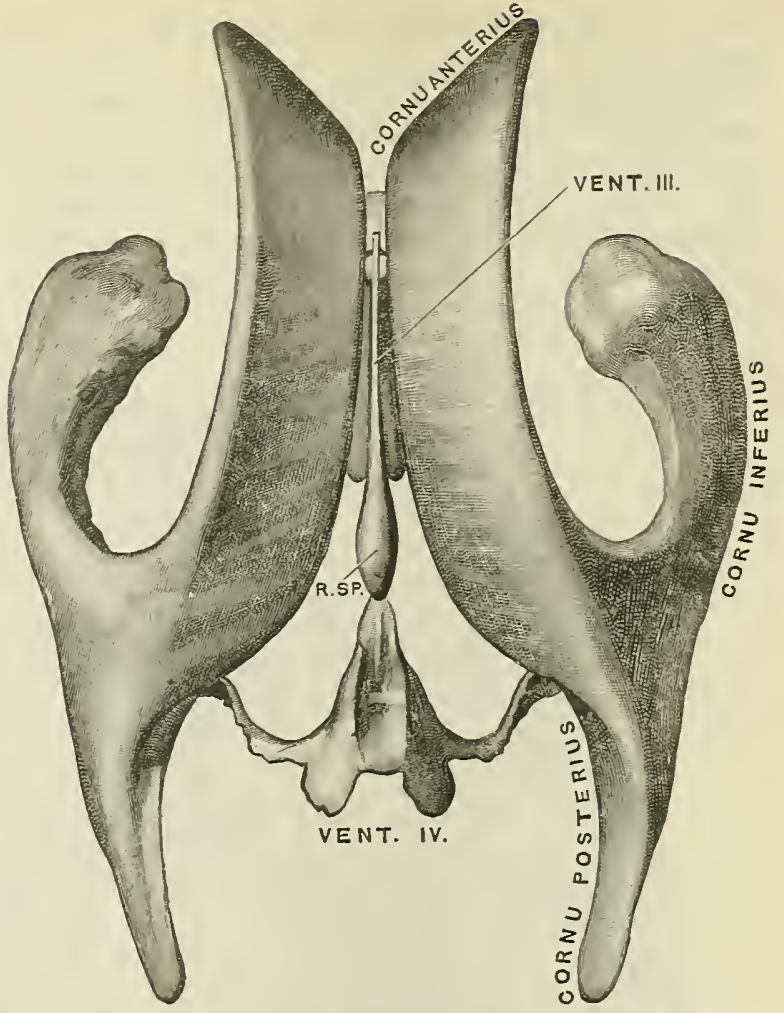

Fig, 561.-Drawing takes from a Cast of the Textricelar SYSTEM of THE BRAIs, as seeu from above. (After Retzius.)

Vent. III. Third rentricle. Tent. IV. Fourth rentricle. R.SP, Recessus suprapinealis.

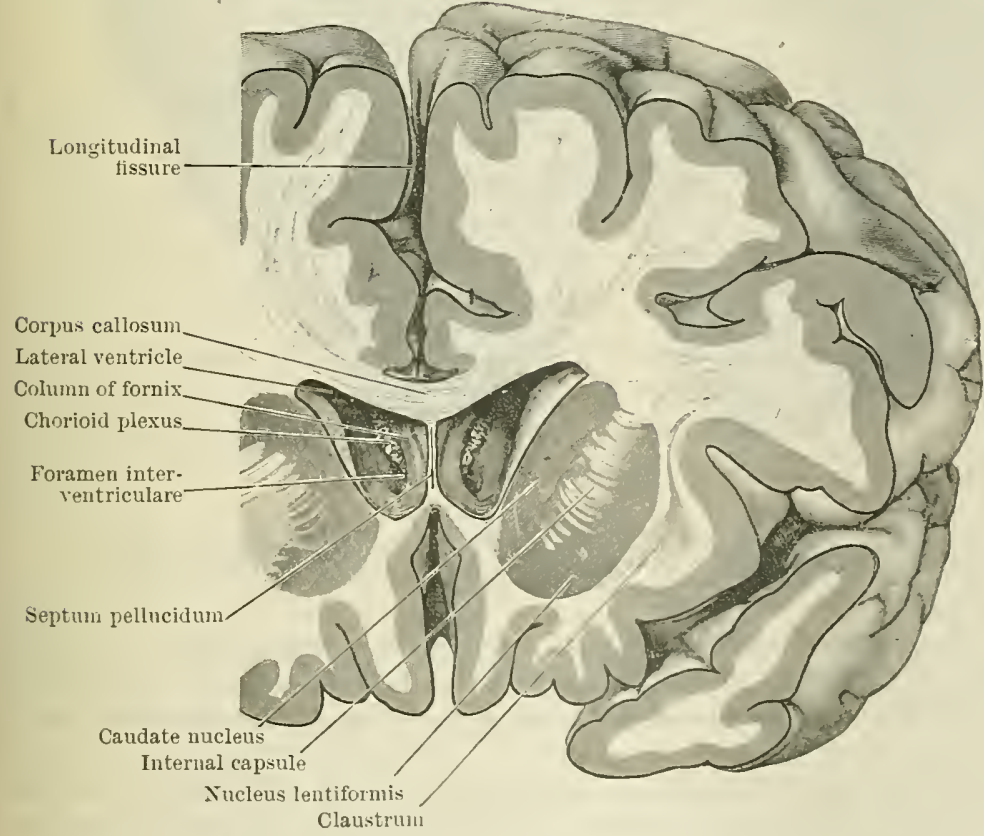

Fig. 562. - Frostal Section throvgh the Cerebral Hemispheres so as to cut through the anterior horus of the lateral ventricles, through which the central part of the rentricles, the columus of the fornix, and the interventricular foramina can be seen. towards the tem. poral pole.

The early fotal lateral ventricle is very capacious and presents an arched or semilunar form. It is composed of parts which correspond to the anterior horn, the central part and the inferior horn, and there is little or no demarcation between them. The posterior horn is a later production. It comes into existence as a diverticulum or elongated pouch, which grows 
backwards from the superior and posterior part (i.e. the convexity) of the primitive cavity.

Cornu Anterius.-The anterior horn forms the foremost part of the cavity, and extends in a forward and lateral direction in the frontal lobe. When seen in frontal section (Fig. 562) it presents a triangular outline, the floor sloping upwards and laterally to meet the roof at an acute angle. It is bounded in front by the posterior surface of the genu of the corpus callosum; the roof also is formed by the

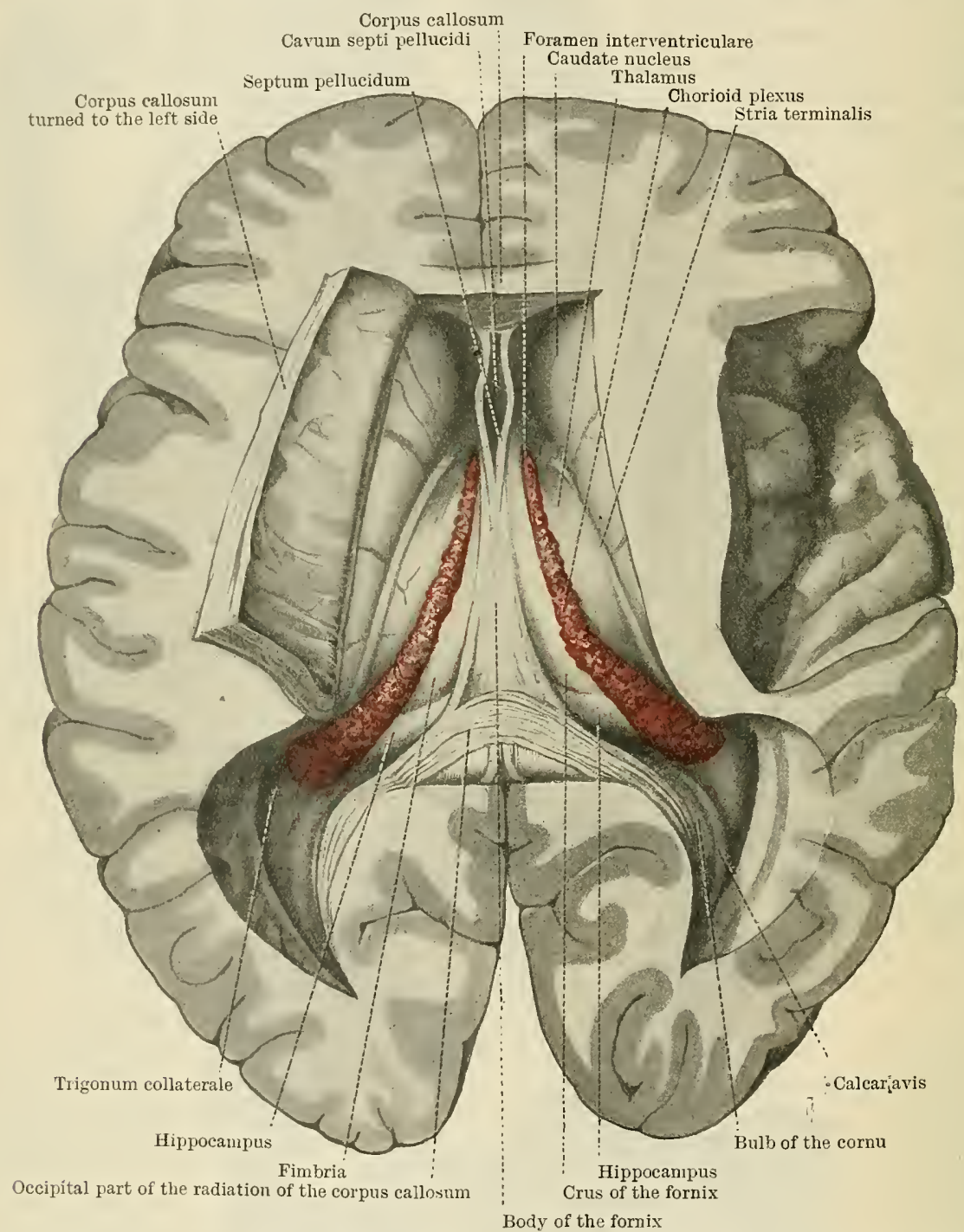

Fig. 563.-Dissection, to show the formix and lateral ventricles; the body of the corpus callosum has been turned over to the left.

corpus callosum. The medial wall, which is vertical, is formed by the septum pellucidum; whilst the sloping floor presents a marked elevation or bulging, viz. the smooth, rounded, and prominent extremity of the pear-shaped caudate nucleus.

Pars Centralis. - The pars centralis of the cavity is likewise roofed by the corpus callosum. On the medial side it is bounded by the posterior part of the septum pellucidum which attaches the fornix to the inferior surface of the corpus callosum. On the lateral side it is closed, as in the case of the anterior horn, by the meeting of the floor and the roof of the cavity. On the floor a number of important 
objects may be recognised. From the lateral to the medial side these are met in the following order: (1) the caudate nucleus; (2) a groove which extends obliquely from before backwards and laterally between the caudate nucleus and the thalamus, in which are placed the vena terminalis and a white band called the stria terminalis; (3) a portion of the superior surface of the thalamus; (4) the chorioid plexus; (5) the thin, sharp edge of the fornix (Fig. 564).

The caudate nucleus narrows rapidly as it proceeds backwards on the lateral part of the floor of the lateral ventricle. The vena terminalis (vein of the corpus striatum) is covered over by ependyma. It joins the vena cerebri interna close to the foramen interventriculare. The connexions of the stria terminalis will be dealt with later. The portion of the superior surface of the thalamus which appears in the floor of the ventricle is in great part hidden by the chorioid plexus, which lies upon it. The lamina chorioidea is an epithelial fringe which is attached to the sharp lateral edge of the fornix superiorly and after surrounding a rich vascular fold of pia mater becomes fixed to the superior surface of the thalamus. The vascular fold is the chorioid plexus. In front it is continuous, in the interventricular foramen, with the corresponding chorioid plexus of the third ventricle (Fig. 560), whilst behind, it is carried into the inferior horn of the ventricle. Although the chorioid plexus has all the appearance of lying free within the ventricle, it must be borne in mind that it is invested by the epithelial

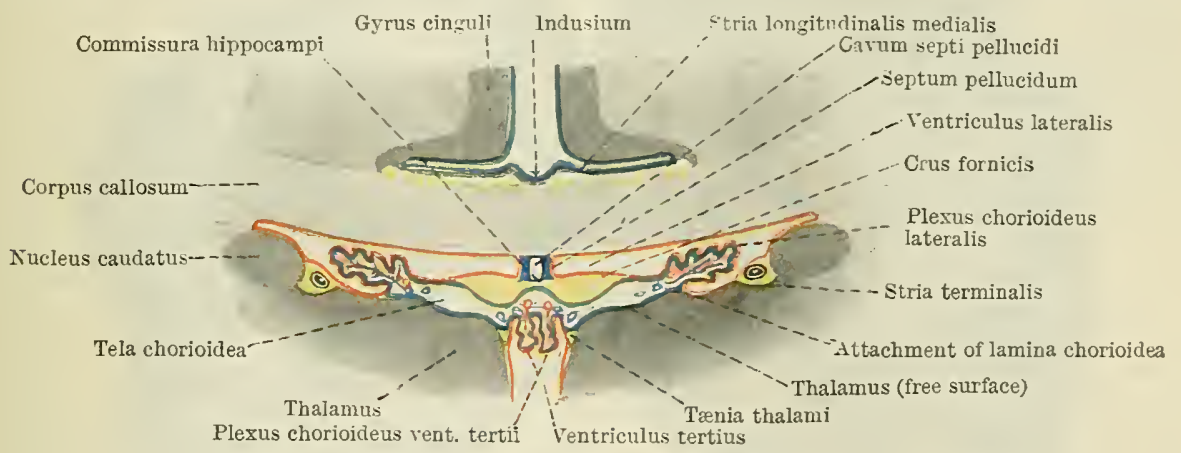

Fig. 56t.-Diagray of Traxsyerse Section across the Cextral Parts of the Lateral Vextricles.

chorioidal lamina which represents a portion of the hemisphere wall and excludes it from the cavity.

Cornu Posterius.-The posterior horn is an elongated diverticulum carried backwards into the occipital lobe from the posterior end of the ventricle. It tapers to a point and describes a gentle curve, the convexity of which is directed laterally. The roof and lateral wall of this portion of the ventricular cavity are formed by the tapetum of the corpus callosum. In frontal sections through the occipital lobe this is seen as a thin but distinct layer of white fibres, which lies immediately lateral to the ependyma and to the medial side of a much larger strand of fibres in the medullary substance of the occipital lobe, viz., the optic radiation.

On. the medial wall two elongated curved elevations may be observed. The uppermost of these is termed the bulb of the cornu (bulbus cornu posterioris), and is produced by the fibres of the radiation of the corpus callosum as they curve abruptly backwards from the lower part of the splenium of the corpus callosum into the occipital lobe. Below this is the elevation known as the calcar. It varies greatly in size in different brains, and is cansed by an infolding of the rentricular wall in correspondence with the anterior part of the calcarine sulcus on the exterior of the hemisphere. It may come into contact with and adhere to the lateral wall of the ventricle in a part or even the whole of its extent.

Cornu Inferius.-The inferior horn is the continuation of the cavity into the temporal region. At first directed posteriorly and laterally, the inferior horn suddenly sinks downwards behind the thalamus into the temporal region, in the 
centre of which it takes a curved course forwards and medially to a point about an inch behind the extremity of the temporal pole.

In the angle between the diverging posterior and descending horns the cavity of the rentricle presents an expansion of a somewhat triangular shape. To this the name of trigonum collaterale is sometimes given.

The roof of the inferior horn is formed for the most part by the tapetum of the corpus callosum. At the extremity of the horn the roof presents a bulging into the cavity. This is produced by a collection of gray matter termed the amygdaloid nucleus. The stria terminalis and the attenuated tail of the caudate nucleus are both prolonged into the inferior hom and are carried forwards, in its roof, to the amygdaloid nuclens.

On the floor of the inferior horn the following structures are seen: (1) hippocampus; (2) the chorioid plexus; (3) the fimbria; and (4) the eminentia collateralis.

The hippocampus is for the most part covered by the chorioid plexus of the lateral ventricle. If this is detached a fissure appears between the fimbria and the roof of the ventricular horn. This is the chorioid fissure. It appears at a very

Splenium of corpus callosum

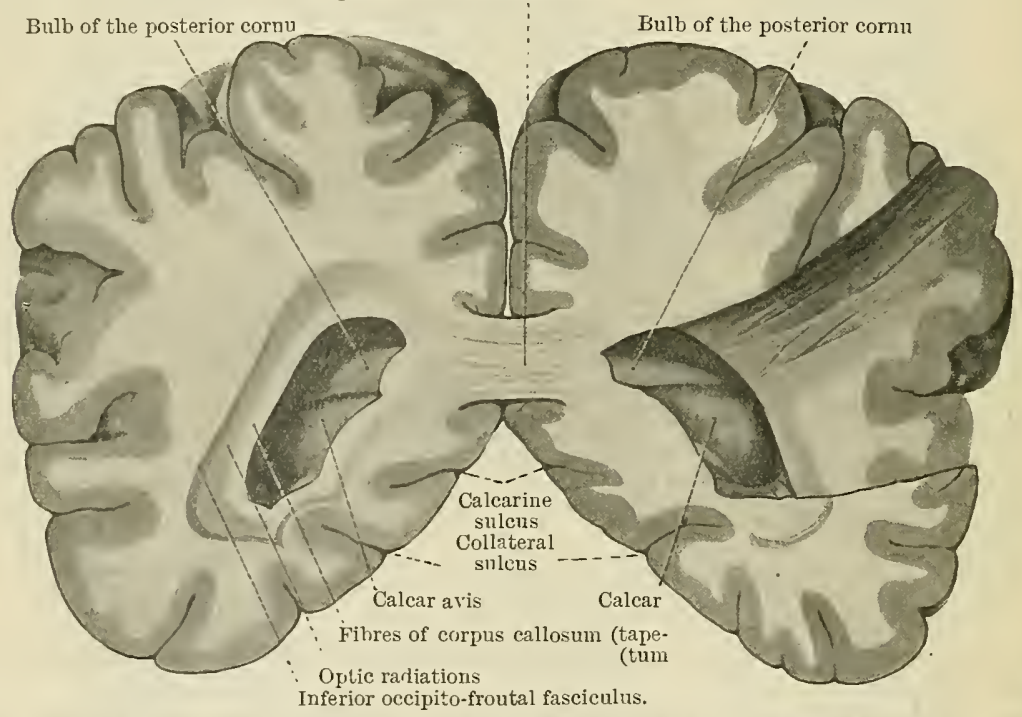

Fig. 565.-Frojtal Section throdgh the Posterior Horns of the Lateral Ventricles, TIEWED FROM THE FRONT.

early date in the development of the cerebral hemisphere, and takes an arcuate course round the posterior end of the thalamus. In the region of the pars centralis of the lateral ventricle it extends as far forwards as the foramen interventriculare and is formed by the involution of an epithelial part of the wall of the ventricle over the chorioid plexus (p. 622). In the region of the inferior horn, when the chorioid plexus with the involuted epithelial layer which covers it is withdrawn, the chorioid fissure is converted into an artificial gap which leads directly into this part of the ventricular cavity.

The chorioid plexus is a convoluted system of blood-vessels in connexion with a fold of pia mater, which is prolonged into the inferior horn of the lateral ventricle. It lies on the surface of the hippocampus and is continuous, behind the posterior part of the thalamus, with the chorioid plexus in the pars centralis of the lateral ventricle. But it must not be supposed that the chorioid plexus lies free in the ventricular cavity. It is clothed in the most intimate manner by an epithelial layer, which represents the medial wall of the inferior horn involuted into the cavity over the chorioid plexus. The ventricle, therefore, opens on the surface only through the chorioid fissure when this thin epithelial layer is torm away by the withdrawal of the chorioid plexus. From the above, it will be under- 
stood that the arcuate chorioid fissure, throughout its whole length (viz., from the interventricular foramen to the extremity of the inferior horn of the lateral ventricle), is formed by the involution of the roof and a portion of the wall of the hemisphere which remains epithelial. In the central part of the ventricle this layer is attached, on the one hand, to the sharp lateral margin of the fornix, and on the other to the superior surface of the thalamus; in the inferior horn it is attached, in like manner, to the edge of the fimbria hippocampi or crus of the fornix, whilst above it joins the roof of this portion of the ventricle along the line of the stria terminalis (Fig. 564).

The eminentia collateralis shows very great differences in its degree of development.

The trigonum collaterale is a smooth elevation in the floor of the ventricle, in the interval which is left between the calcar avis and the hippocampus as they diverge one from the other.

\section{Basal Ganglia of the}

Cerebral Hemisphere.

Under this heading are included certain masses of gray matter more or less com-

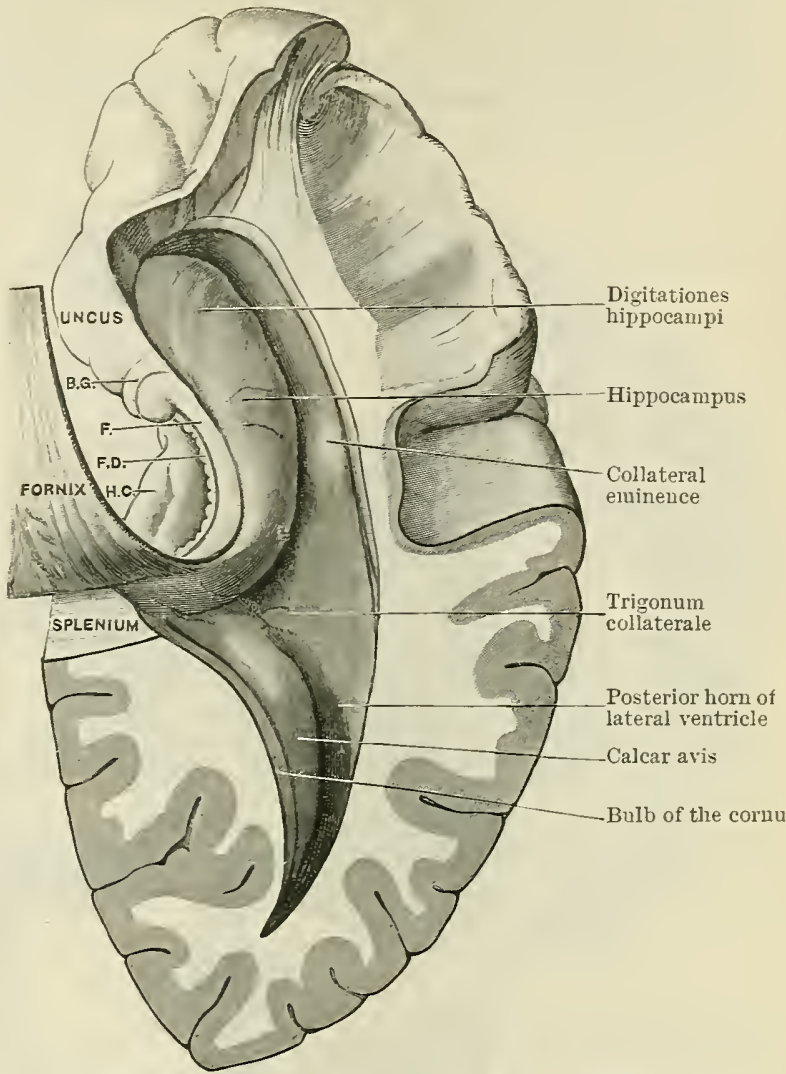

Fig. 566.-Dissection from above, to show the posterior and inferior cornua of the lateral ventricle.

B.G. Cauda fasciæ dentatæ. F.D. Fascia dentata hippocanpi. F. Fimbria hippocampi. H.C. Gyrus hippocampi. pletely embedded in the white medullary substance of the hemisphere, and which are developed in its wall. They compose the caudate and lentiform nuclei, which together form the corpus striatum, and the anygdaloid nucleus.

The nucleus caudatus bulges into the lateral ventricle. It is a piriform, highly arched mass of gray matter, which presents a thick, swollen head, or anterior extremity, and a long, attenuated tail. The head projects into the anterior horn of the lateral ventricle, whilst its narrower part is prolonged laterally and posteriorly in the floor of the ventricle, where it is separated from the thalamus by the stria terminalis. Finally, its tail curves downwards with a bold sweep and enters the inferior horn of the lateral ventricle. In the roof of this horn it is prolonged forwards to the amygdaloid nucleus, the lower part of which it joins. The caudate nucleus thus presents a free ventricular surface, covered with ependyma, and a deep surface embedded in the white substance of the cerebral hemisphere, and for the most part related to the internal capsule.

Owing to its arched form it follows that, in horizontal sections through the cerebral hemisphere below a particular level, it is cut at two points, and both the head and the tail appear on the field of the section (Fig. 567). In frontal sections behind the amygdaloid nucleus, it is also divided at two places (Fig. 580, p. 652).

The anterior extremity of the head of the caudate nucleus coincides very nearly with that of the anterior horn of the lateral ventricle. In the region of the substantia perforata anterior, the head of the caudate nucleus gains the surface and its gray matter becomes continuous with that of the cerebral cortex. 
The nucleus lentiformis lies on the lateral side of the caudate nucleus and thalamus, and is for the most part embedded within the white medullary substance of the cerebral hemisphere. It does not extend either so far forwards or so far backwards as the caudate nucleus. Indeed, it presents a very close correspondence in point of extent with the insula on the surface. When seen in horizontal section, it presents a shape similar to that of a biconvex lens. Its medial

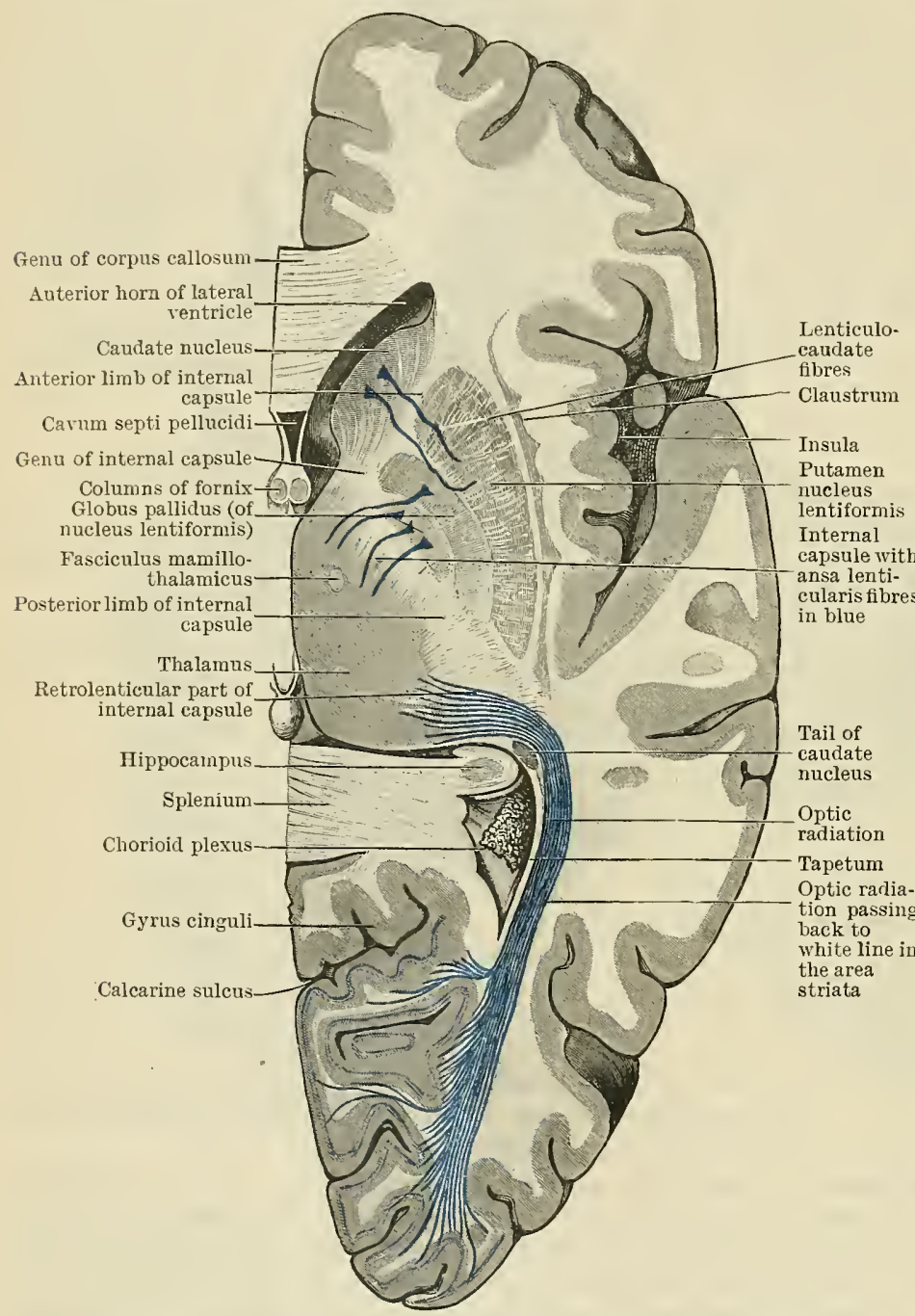

Fig. 567.-Horizontal Seotion throdgh the Right Cerebral Hemisphere at the Level of the Widest Part of the Lentiform Nucleus. surface bulges more than the lateral surface, and its point of highest convexity is placed opposite the stria terminalis or the interval between the caudate nucleus and the thalamus. In frontal section the appearance presented by the lentiform nucleus differs very much in different planes of section. Fig. 568 represents a section through its anterior portion. Here it is semilunar or crescentic in outline and is directly continuous below with the head of the caudate nucleus; above, also, it is intimately connected with the caudate nucleus by bands of gray matter, which pass between the two nuclei and break up the white matter of the fore part of the intervening internal capsule. It is due to the ribbed or barred appearance, which is presented by such a section as this, that the term corpus striatum is applied to the two nuclei. In the region of the substantia perforata anterior both nuclei reach the surface and become continuous with the cortex.

When a section is made in a plane further back (e.g. immediately posterior to the anterior commissure, as in Fig. 569) the divided lentiform nucleus assumes an altogether different shape, and is seen to be completely cut off from the candate nucleus by the internal capsule. It is now triangular or wedge-shaped. Its base is turned towards the insula and is in direct relation to a thin lamina of white matter, termed the external capsule. Its medial surface is oblique and is applied to the internal capsule, whilst its inferior surface is horizontal and is directed downwards towards the base of the brain. But, further, two white laminæ, the 
external and internal medullary laminæ, are now evident, which trarerse its substance in a vertical direction and divide it into three masses. The lateral, basal, and larger mass is termed the putamen; the two medial portions together constitute the globus pallidus.

The putamen forms much the largest part of the lentiform nucleus. It is darker in colour than the globus pallidus, and in this respect resembles the caudate nucleus. It is traversed by fine radiating bundles of fibres, which enter it from the external medullary lamina. Both in point of structure and in mode of development it is closely associated with the caudate nucleus, and it is the only part of the lentiform nucleus which is connected by intervening bands of gray matter with the caudate nucleus. The anteroposterior length, as well as the vertical depth of the putamen, is much greater than in the case of the globus pallidus; consequently, in both frontal and horizontal sections

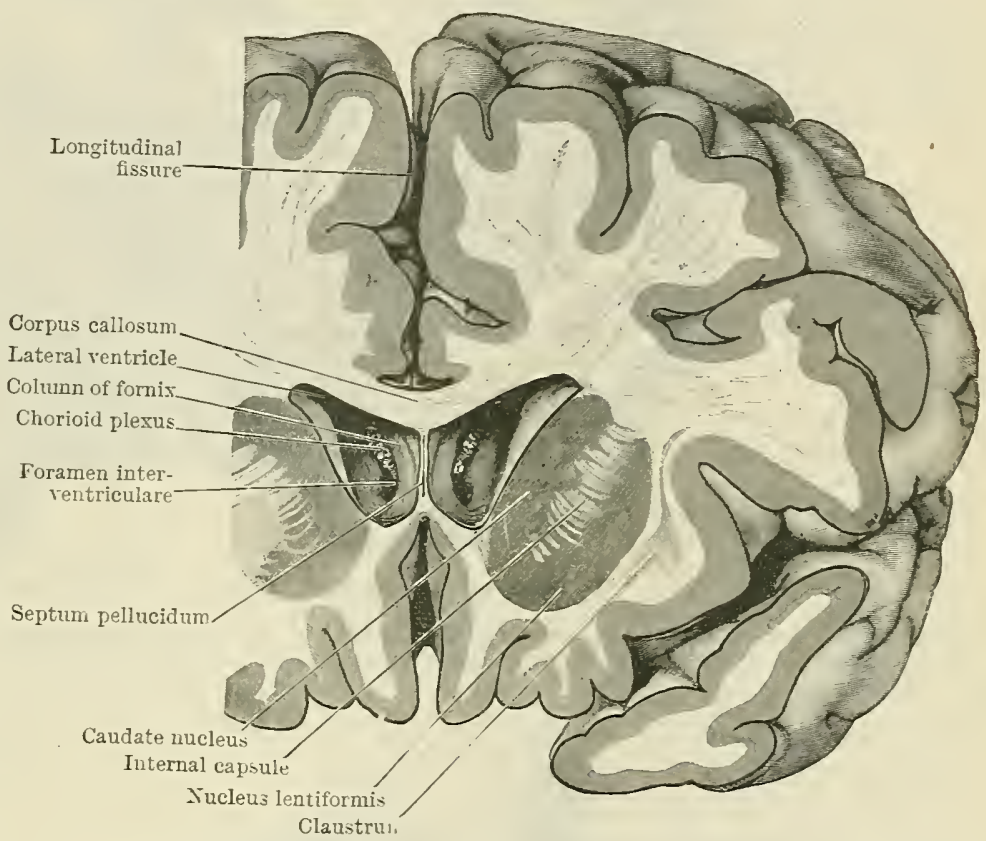

Fig. 568.-Frontal Section throdgh the Cerebral Hejispheres so as to cut through the anterior part (putamen) of the lentiform nucleus in front of the globus pallidus. Tiewed from in front; looking through the anterior horn into the central part of the ventricle.

through the cerebrum it is encountered before the plane of the globus pallidus is reached.

The external capsule is loosely connected with the lateral surface of the putamen, and it can be readily stripped off. This accounts for the tendency, exhibited in hæmorrhages in this locality, for the effused blood to spread out in the interval between these structures.

The globus pallidus is composed of the two smaller and medial masses of the lentiform nucleus. They present a faint yellowish tint, and are paler and more abundantly traversed by fibres than the putamen. The mass next the putamen (i.e. the intermediate part) is much larger than the medial subdivision. It extends forwards to a point a little in front of the plane of the anterior commissure. When the lentiform nucleus is cut in a frontal direction, and in its widest part, the medial mass shows an indication of a separation into two parts, so that here the globus pallidus appears to consist of three subdivisions.

Connexions of the Corpus Striatum.-Recent clinical investigation has demonstrated the importance of the functions of the corpus striatum, which seems to exercise a "steadying influence" (Kinnier Wilson) upon the muscles which perform roluntary movements that call for delicate co-ordination. Hence it is desirable to study the connexions of these large masses of gray matter. Fibres of the internal capsule coming: from the motor cortex (as well as from all other cortical areas) end in the corpus striatum (Fig. 571), so that when a voluntary morement is initiated this structure is called into activity. Fibres coming from the nucleus caudatus break through the anterior limb of the internal capsule (Fig. 572), some of them to reach the putamen, others to pass through the exterual medullary lamina to the globus pallidus. Other tracts pass from 


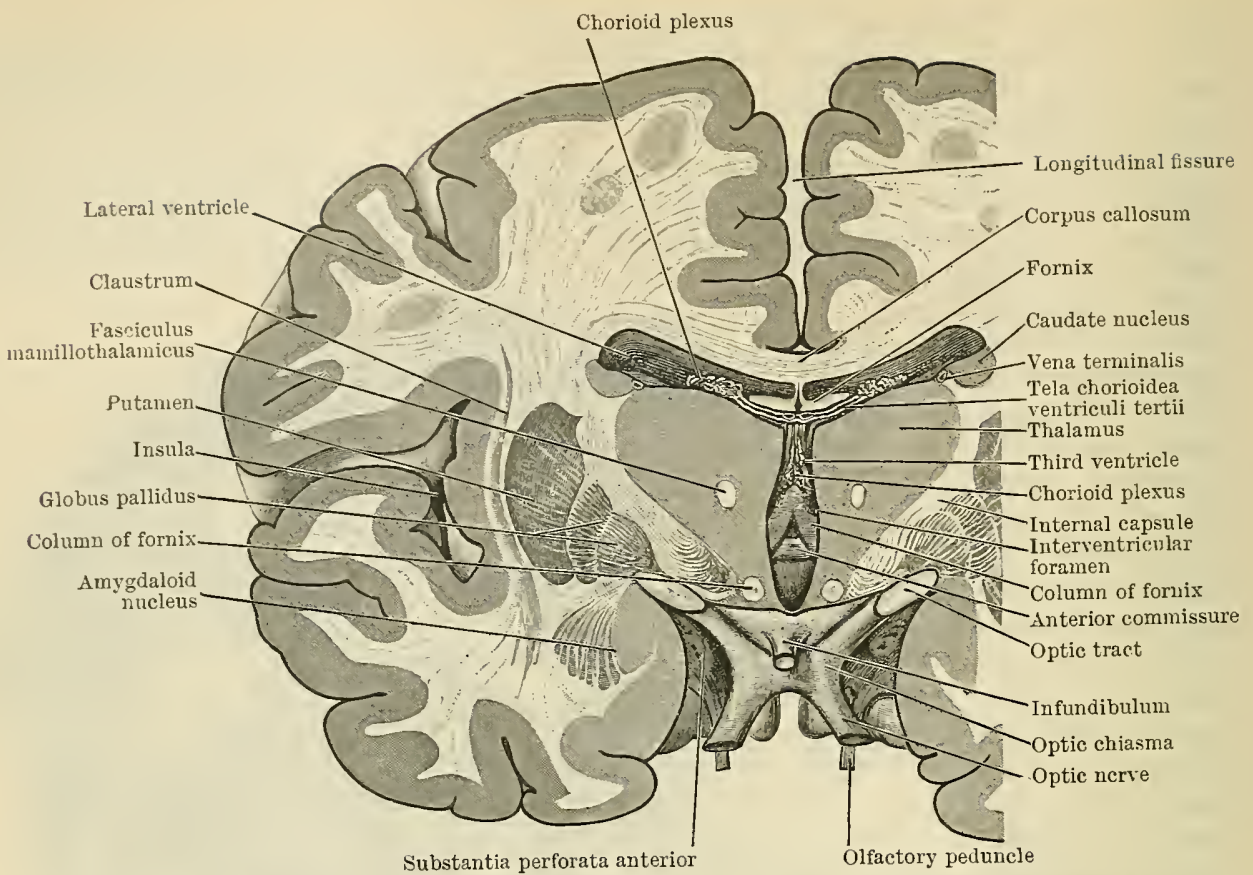

Fig, 569.-Frontal Section throdgh the Cerebrum so as to cut through the three divisions of the lentiform nucleus; posterior surface of the section shown here.

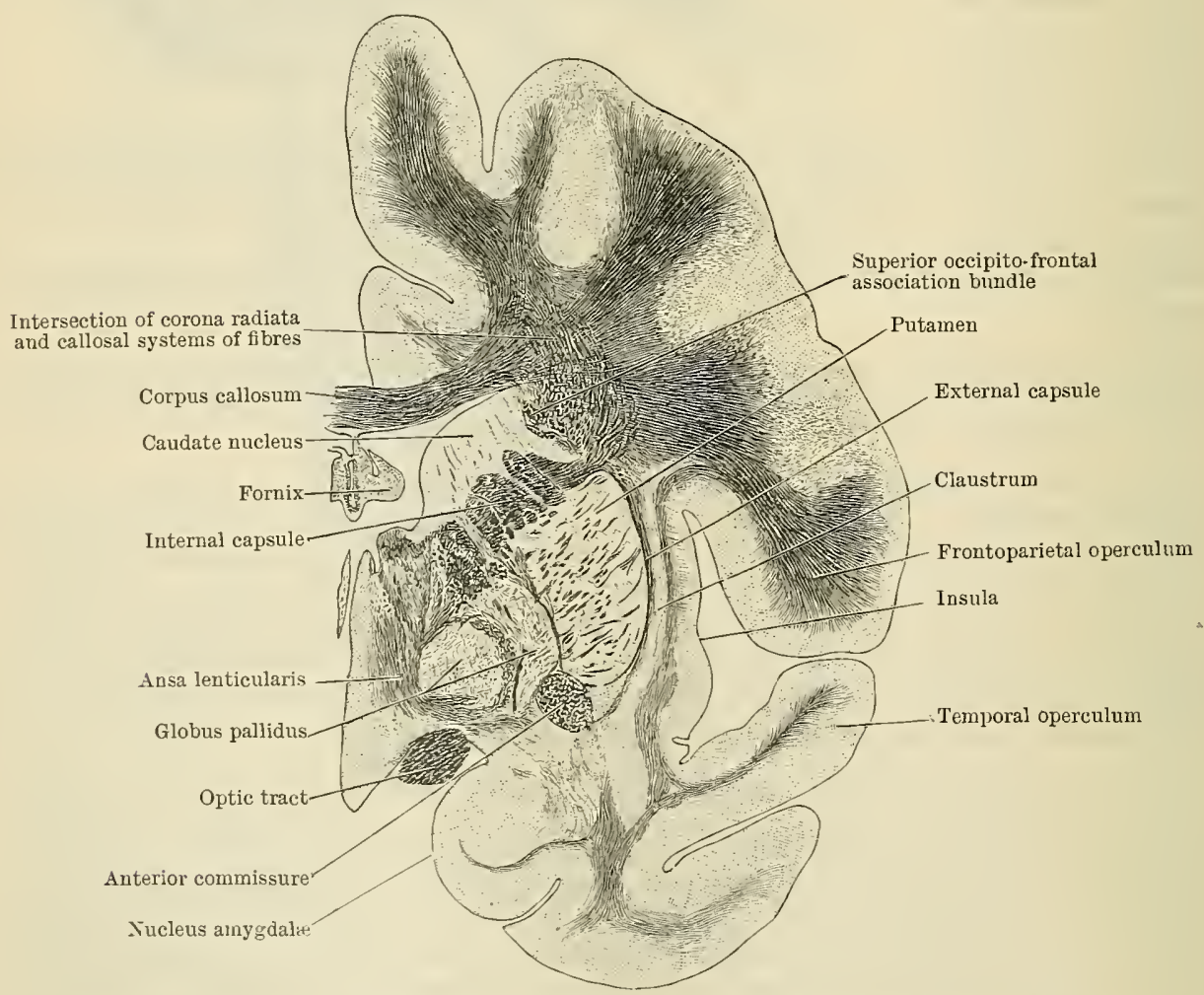

Fig. 570.-Frontal Section throdgh the Left Side of the Cerebrum of an Oratg (Weigert-Pal specimen).

The section passes through the middle of the lentiform nucleus. 
the lentiform nucleus into the caudate nucleus (fibræ lenticulocaudatæ). From the globus pallidus fibres arise which proceed into the internal capsule in the region of the genu and the neighbouring part of the posterior limb (Fig. 572). Many of these fibres become collected on the inferior aspect of the lentiform nucleus, where they form a transversely directed bundle (Fig. 570), known as the ansa lenticularis, which is distributed to the thalamus (Fig. 571 , fasciculus striothalamicus) and hypothalamus, the red nucleus (fasciculus striorubricus) and substantia niger (fasciculus strionigricus). These connexions afford some explanation of the difficulties of articulation and swallowing and in the performance of delicate voluntary movements that result from damage to the corpus striatum or to this system of fibres.

This system of fibres is phylogenetically very old, being the

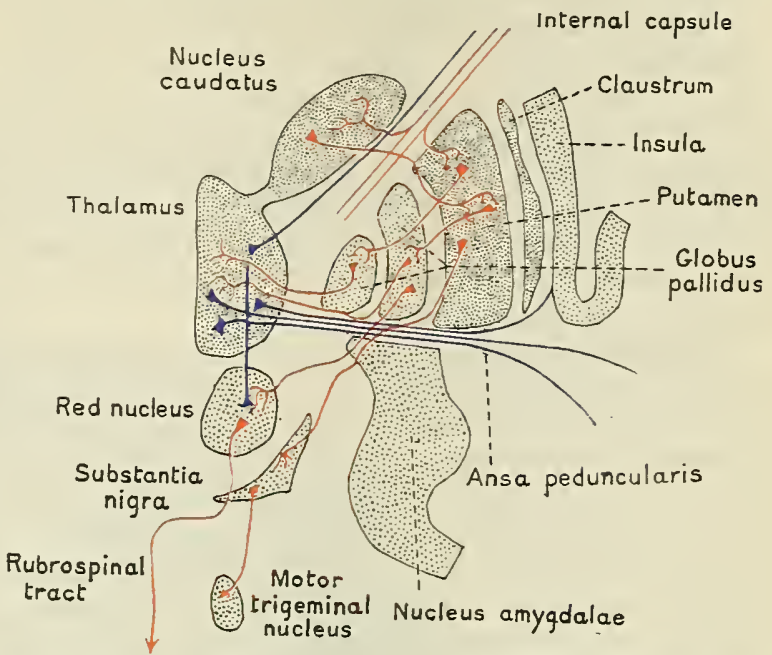

Fig. 571.-Diagram of a Frontal Section to illustrate the Fibre ConNexions of the Corpus Striatum. most primitive efferent tract from the cerebral hemisphere.

Claustrum. - This is a thin plate of gray substance embedded in the white matter, which intervenes between the lentiform nucleus and the gray cortex of the insula. Followed in an upward direction, it becomes gradually thinner and ultimately disappears. As it is traced downwards, however, it thickens consider-

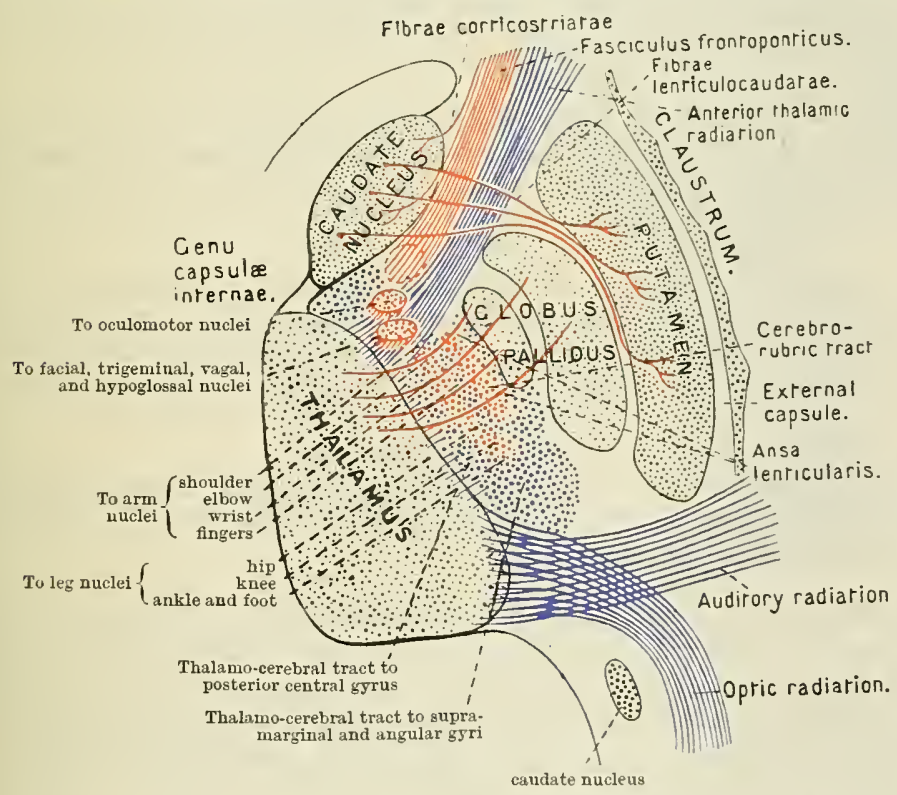

Fig. 572.-Diagramatic Representation of the Internal Capsole (as seen in Horizontal Section). ably, and at the base of the brain it comes to the surface at the anterior perforated substance and becomes continuous with the gray matter of the cortex. Its extent corresponds very closely with the area occupied by the insula, and its surface towards this portion of the cerebral cortex shows ridges and depressions corresponding to the insular gyri and sulci.

Nucleus Amygdalæ. - In the fore part of the temporal region, above the piriform area a fusiform mass of gray matter appears upon the surface (Fig. 55s, p. 630), at the lateral extremity of the substantia perforata anterior (Fig. 584, p. 657). It is part of a large rounded mass, called the amygdaloid nucleus, which occupies a position in front of, and to some extent above the extremity of the inferior horn of the lateral ventricle. The tail of the caudate nucleus joins its inferior part (Fig. 573, p. 643), whilst above it is carried up into the putamen (Fig. 570). 
Inferiorly it is continuous with the gray cortex of the piriform area, to which it is functionally related, probably in the same way that the major part of the corpus striatum is associated with the neopallium.

Stria Terminalis. - This is a band of fibres which, for the most part, arise in the amygdaloid nucleus. From this it runs backwards in the roof of the inferior horn of the lateral ventricle (Fig. 584, p. 657, and Fig. 573, p. 643), and then arches upwards and forwards, so as to gain the floor of the pars centralis of the lateral ventricle. In both situations it lies close to the medial side of the nucleus caudatus, and finally, at the interventricular foramen, it bends downwards towards the anterior commissure. Some of its fibres pass in front and others behind the commissure, and ultimately they end in the neighbourhood of the substantia perforata anterior (Kölliker).

Internal Capsule.-This term is applied to the broad band of white matter which intervenes between the lentiform nucleus, on the lateral, and the thalamus and caudate nucleus on the medial side. It presents many different appearances, according to the plane in which the brain is cut. A frontal section through the brain which passes through the cerebral peduncles shows that, in great part, the internal capsule is directly continuous with the basal part of the cerebral peduncle (Fig. 580, p. 652). Viewed from the lateral aspect after removing all else of the cerebral hemisphere excepting the corpus striatum (Fig. 573), the cut ends of the fasciculi of the internal capsule form three-fourths of an ellipse, the other fourth of which is occupied by the bridge of union between the lentiform and caudate nuclei, the substantia perforata anterior, the amygdaloid nucleus and the anterior commissure. It may be divided into an anterior (lenticulo-caudate) part, a superior (lenticulo-thalamic) part, a retrolenticular part (not labelled in the figure), and a postero-inferior (sublenticular) part. The last three parts are usually grouped together as the posterior limb. In horizontal section the internal capsule is observed to be bent upon itself opposite the stria terminalis, or the interval between the caudate nucleus and the thalamus. This bend, which points medially, is called the genu. About one-third of the internal capsule lies in front of the genu, and is termed the anterior limb; the remaining two-thirds, which lie behind the genu, constitute the posterior limb (Fig. 572).

The anterior limb of the internal capsule intervenes between the lentiform nucleus and the caudate nucleus. In its inferior and anterior part it is much broken up by the connecting bands of gray matter which pass between the anterior part of the putamen and the caudate nucleus.

The anterior limb of the internal capsule is composed largely of corticipetal fibres belonging to the anterior thalamic radiation. It contains corticifugal fibres also. The corticipetal fibres arise in the median and anterior part of the lateral nucleus of the thalamus, and go through the anterior limb of the internal capsule to reach the cortex of the frontal lobe.

The corticifugal filres are represented by the fronto-pontine tract.

The fronto-pontine tract arises in the cortex of the frontal region, traverses the anterior limb of the internal capsule, forms the medial fifth of the basis of the cerebral peduncle, and finally ends in the nuclei pontis.

The posterior limb of the internal capsule is placed between the thalamus and the lentiform nucleus, and it extends posteriorly for a short distance beyond the posterior end of the putamen on the lateral side of the posterior part of the thalamus and of the tail of the caudate nucleus. The posterior limb, therefore, is spoken of as consisting of a lenticular, a retrolenticular, and a sublenticular part.

The lenticular or more properly lenticulo-thalamic part of the posterior limb is composed of both corticipetal and corticifugal fibres. The corticipetal fibres enter the internal capsule from the lateral aspect of the thalamus, and are composed of fibres which arise within the thalamus from the ventral (ventro-lateral) nucleus, and proceed upwards to the cerebral cortex.

The corticifugal fibres consist of the cerebro-spinal tract and the cortico-thalamic fibres.

The great motor or cerebro-spinal tract, descending from the cerebral cortex, occupies the anterior half of the lenticular part of the internal capsule. The fibres, that go 
to the nuclei of the oculomotor, trigeminal, and facial nerves, lie close to the genu, and behind these are the fibres which go to the hypoglossal nuclens; still further back are cerebro-spinal fibres which enter the spinal medulla and end around the motor cells of the anterior colnmn of gray matter. This cerebro-spinal tract has been observed occupying the middle part of the pedunculus cerebri, into which it passes directly from the internal capsule.

According to Monakow the posterior limb contains also an important tract of fibres passing from the motor cortex to the red nucleus (fasciculus cerebrorubricus).

The retrolenticular part of the posterior limb contains: (1) the fibres of the optic radiation as they pass from the lateral geniculate body to establish their connexions with

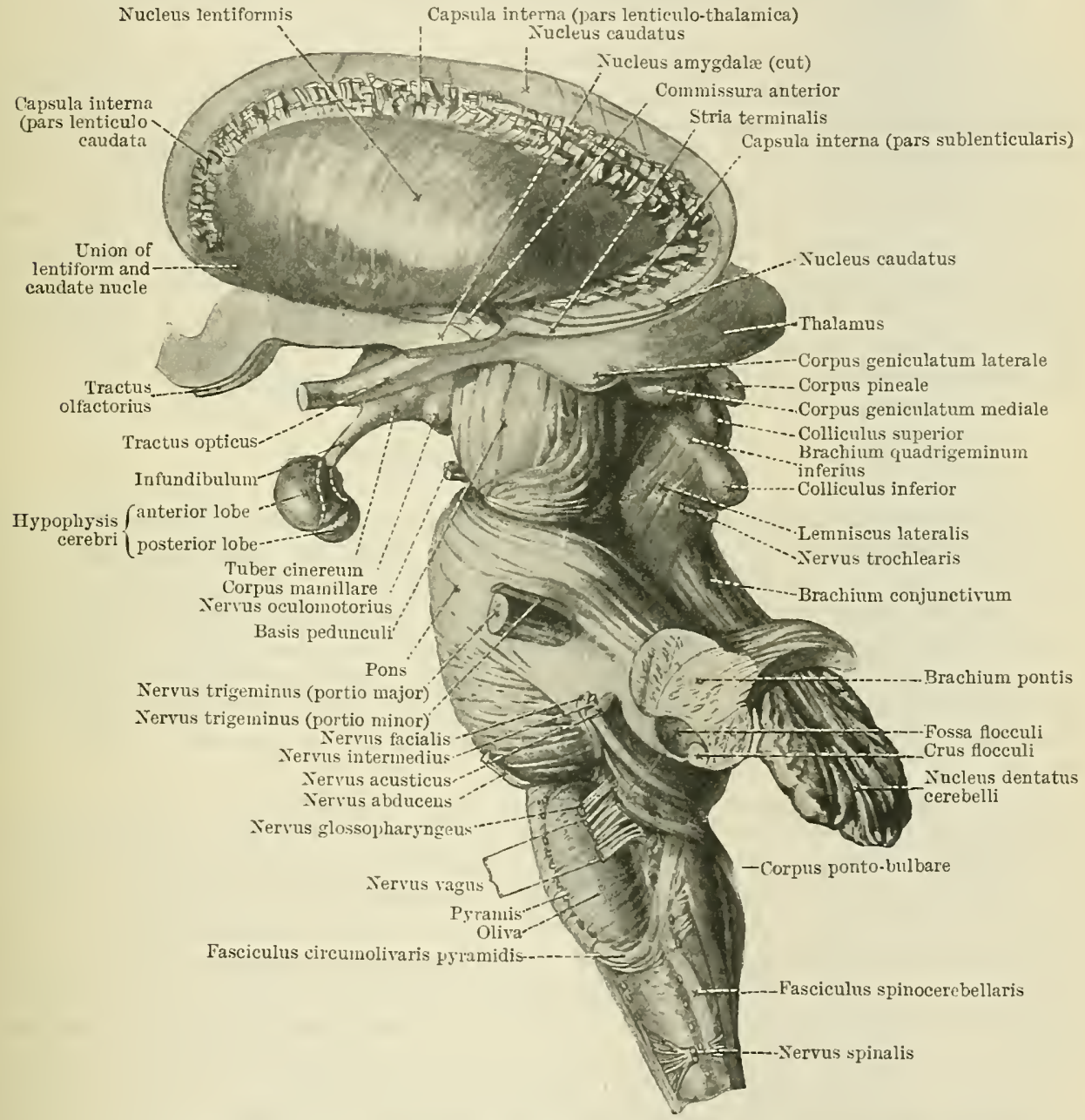

Fig. 573.-Dissection exposing the Lateral Aspect of the Lentiform Nuclets of the LEFT HeMisphere.

the occipital cerebral cortex; (2) the fibres of the aconstic radiation, or those which connect the medial geniculate body with the acoustic cortical field in the temporal lobe (Fig. 572, p. 641, and Fig. 578, p. 650); (3) the temporo-pontine tract, which is composed of fibres which take origin in the middle and inferior gyri of the temporal lobe and pass through the sublenticular section of the internal capsule to reach the lateral part of the pedunculus cerebri. Through this they reach the basilar part of the pons, in the gray matter of which they end. This tract is accompanied by the fasciculus temporothalamicus, which has a widespread origin from the temporal and occipital regions and passes through the sublenticular part of the internal capsule.

If the fibres of the internal capsule are traced upwards they are found to spread out widely from each other in a radiating or fan-shaped manner, as they 
are followed to the various gyri of the cerebral hemisphere. This arrangement is termed the corona radiata. The callosal system of fibres, as they proceed into the hemisphere, also radiate, and they intersect the fibres of the corona radiata (Fig. 576, p. 649).

External Capsule.-The thin lamina of white matter between the lateral aspect of the putamen and the claustrum is called the external capsule. This joins with the internal capsule in front of and behind the putamen, and in this manner the nucleus lentiformis is encapsuled by white matter.

\section{INTIMATE STRUCTURE OF THE CEREBRAL HEMISPHERE.}

The cerebral hemisphere is composed of an external coating of gray matter, termed the cortex, spread over an internal mass of white matter, which is called the medullary centre. The cortex is of peculiar interest, seeing that there is good reason for believing that in it the higher functions of the brain, or those which may be classed under the general designation of the intellectual functions, take place. It is within the same layer of gray matter that the influence of those external impressions, which gain access to the cerebro-spinal axis through the senses, finally take shape as consciousness; and in it are placed also the centres which carry on the psycho-motor functions. The white medullary centre is composed of nerve-fibres which constitute the paths along which the influence of impressions is carried to and from the cortex, and from one part of the cortex to another.

\section{THE CEREBRAL CORTEX.}

The gray cortex is spread over the entire surface of the cerebral hemisphere, but it does not form a layer of equal thickness in all localities. At the summit of a gyrus it is apt to be thicker than at the bottom of a furrow. The maximum thickness of cortex (about $4 \mathrm{~mm}$.) is attained in the superior parts of the motor area, whilst the minimum (about $1.25 \mathrm{~mm}$.) may be observed in the region of the occipital pole. The amount of gray cortex differs considerably in different individuals, and appreciably diminishes in old age. It is also stated, but upon imperfect evidence, that it is relatively more abundant in the male than in the female.

In structure, likewise, marked differences may be noted in the gray cortex of different regions, and much has been recently done in the direction of pointing out the connexion of these structural peculiarities with the functional characteristics of particular areas and applying them to the determination of the significance of the furrows that subdivide the cerebral cortex into a series of ridges or gyri. This structural difference is quite apparent to the naked eye when sections are made through the cortex in a fresh brain, and sharp transitions in structure occur at the place where one area joins another. It is only to those general structural features which more or less characterise the entire cortical layer that we shall be able to refer.

When sections are made through the fresh brain, and the cut surface is closely inspected, it will usually be apparent that the cortex is distinctly stratified. On the outside there is a thin, whitish layer, and beneath this the gray matter presents two strata of very nearly equal thickness, viz., a middle, gray-coloured stratum and an inner, yellowish-red stratum. Between the two latter layers a narrow white band is, in many places, visible. This is termed the outer band of Baillarger. When the layers indicated above are present, four strata, superimposed one upon the other, are recognised; but in certain regions a second white streak traverses the deep or inner gray layer and divides it into further stratifications. This is termed the inner white band of Baillarger, and, when it is present, the gray cortex becomes divided obscurely into six alternating white and gray layers.

The outer band of Baillarger is strongly marked in the region behind the calcarine sulcus and gives a characteristic appearance to this portion of the cortex. In this locality it receives the name of the stria of Gennari (Fig. 567, p. 638).

White Medullary Centre of the Cerebral Hemisphere.-The white matter of the 
hemisphere which lies subjacent to the gray cortex is composed of medullated nervefibres, arranged in a very intricate manner. But the arrangement of these fibres cannot be properly understood until the configuration of the surface of the hemisphere has been considered.
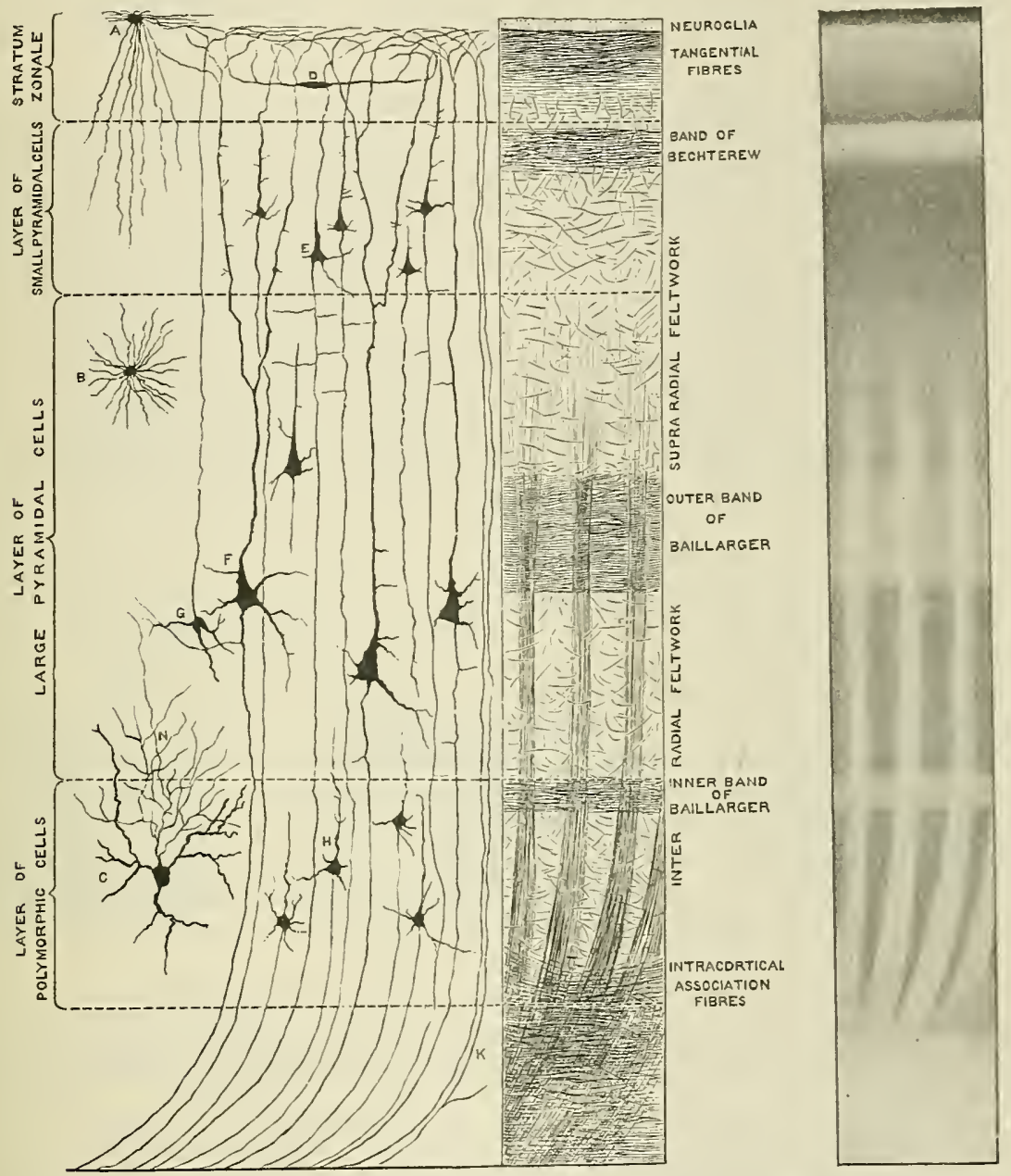

Fig. 574.-Diagram to illustrate the Mivete Strccture of the Cerebral Cortex ajd explaiN how it iNfluexces the Macroscopic APPEARANCE.
A. JNeuroglia cells.
E. Small pyramidal cell.
C. Cell with short axon (N) which breaks
F. Large pyramidal cell.
G. Cell of Martinotti. up in a free arborisation.
H. Polymorphic cell.
D. Spindle-shaped cell in stratum zonale.
K. Corticipetal fibres.

\section{THE NEOPALLIUM.}

Fibre-tracts proceed into different districts of the neopallium from the rarious nuclei of the thalamus to serve as the channels through which tactile, visual, acoustic, and other kinds of sensory impressions are poured into it. These districts may be regarded as the receptive sensory areas, tactile, visual, acoustic, etc.; but around each sensory area there is differentiated a series of more or less concentric bands of neopallium, which are related to an incoming sensory path only through the intermediation of the sensory area which it fringes. Finally, there are interposed between the sensory area and its fringing bands of one sense and those of another, certain association areas, which cannot be regarded as the territory of 
any one sense, but as the place of meeting (and the physical counterpart of the blending in conscionsness) of the impressions of different senses. In the human brain the neopallium becomes mapped out into a large series (more than forty) of areas, which differ one from the other in structure and in their connexions, and presumably therefore in their functions; and many of these areas may be further subdivided into a series of less obtrusively differentiated territories (Figs. 553 and 581).

The gray matter of the neopallium is spread over the surface of the white matter as a thin film (cortex cerebri), which is nowhere more than 4 millimetres, and may be only 1.25 millimetres thick. In different regions it presents every gradation of thickness between these two extremes. As the cortex increases in volume it does so not by any addition to its depth, but solely by an expansion of its superficial area. Thus it happens that in all larger mammalian brains, as the cerebral hemisphere expands and there is an increasing disproportion between the bulk of the hemisphere and the area of its surface, the cortex must become folded to accommodate itself to the limited area of surface upon which it has to be packed. But this process of folding does not take place in any haphazard or purely mechanical way. The situations of the furrows or sulci which make their appearance are determined, for the most part, by the arrangement and the relative rates of expansion of the various areas into which the neopallium becomes differentiated.

The great majority of the furrows belong to a group, which we may call (1) sulci terminales, i.e. they make their appearance along the boundary lines between areas of different structure. The fissura rhinalis and sulcus centralis are examples of this group. Another group, which may be called (2) sulci axiales, develop by the folding of areas of uniform structure, i.e. along the axis of certain territories. The retro-calcarine sulcus and the sulcus occipitalis lateralis belong to this group. There is a third group of (3) sulci operculati, where the edge of one area becomes pushed over an adjoining territory, so that a trough is formed (Fig. 575, C), which is neither a limiting nor an axial sulcus. The sulcus lunatus is an example. And finally there is a fourth group, in which some more definitely mechanical factor comes into play to complicate the operation of these other factors, or even to determine the development of a furrow. The sulcus parieto-occipitalis and the fissura lateralis are examples of the fourth group.

[It is the custom to call certain furrows sulci and others fissures, and to call some of them complete, because they indent the whole thickness of the wall of the ventricle, and to call the rest incomplete. There is no justification whatever for any such distinctions.

It is usual also to subdivide the surface of the hemisphere in a purely arbitrary manner into "lobes" and to speak of interlobar fissures, but this is an artificial and misleading terminology which we shall avoid as far as possible.]

Fissura Longitudinalis Cerebri.-The longitudinal fissure is not a fissure of the cortex but is the great cleft between the two cerebral hemispheres. In front and behind it separates the cerebral hemispheres completely the one from the other. In its middle part, however, the fissure is interrupted and floored by the corpus callosum, a white commissural band, which passes between the hemispheres and connects them together. The superior surface of the corpus callosum can be displayed by gently drawing asunder the contiguous medial surfaces of the cerebral hemispheres. The longitudinal fissure is occupied by a median fold of dura mater, termed the falx cerebri, which partially subdivides the part of the cranial cavity allotted to the cerebrum into a right and left chamber.

External Configuration of each Cerebral Hemisphere.-Each cerebral hemisphere presents a lateral, a medial, and an inferior surface. The lateral surface is convex and is adapted accurately to the internal surface of the cranial vault. The medial surface is flat and perpendicular, and bounds the longitudinal fissure. In great part it is separated from the corresponding surface of the opposite hemisphere by the falx cerebri. The inferior surface is irregular and is adapted to the anterior and middle cranial fossæ of the cranial floor and, behind these, to the superior surface of the tentorium cerebelli. Traversing this surface in a transverse 
direction, nearer the anterior end of the hemisphere than the posterior end, is the stem of the lateral fissure. This deep cleft divides the inferior surface into an anterior or orbital area, which rests on the orbital part of the frontal bone and is consequently concave from side to side, and a more extensive posterior or tentorial area, which lies on the floor of the lateral part of the middle cranial fossa and upon the superior surface of the tentorium cerebelli. This surface is arched from before backwards, and looks medially as well as downwards. In its posterior two-thirds it lies above the cerebellum, from which it is separated by the tentorium cerebelli.

The borders which intervene between these surfaces are the supero-medial, the superciliary, the infero-lateral, the medial occipital and medial orbital. The superomedial border, convex from before backwards, intervenes between the convex lateral surface and the flat medial surface of the hemisphere. The superciliary border is highly arched and separates the orbital surface from the lateral surface. The infero-lateral border marks off the tentorial surface from the lateral surface. The medial occipital border can be seen only in cases where the brain has been hardened in situ and faithfully retains the natural form. It extends from the posterior end of the hemisphere towards the posterior extremity of the corpus callosum, and intervenes between the medial and tentorial surfaces. It is the border which lies along the straight blood sinus, and it therefore occupies the angle which is formed by the attachment of the posterior part of the falx cerebri to the superior surface of the tentorium cerebelli. The medial orbital border separates the medial from the orbital surface.

The most projecting part of the anterior end of the cerebral hemisphere is called
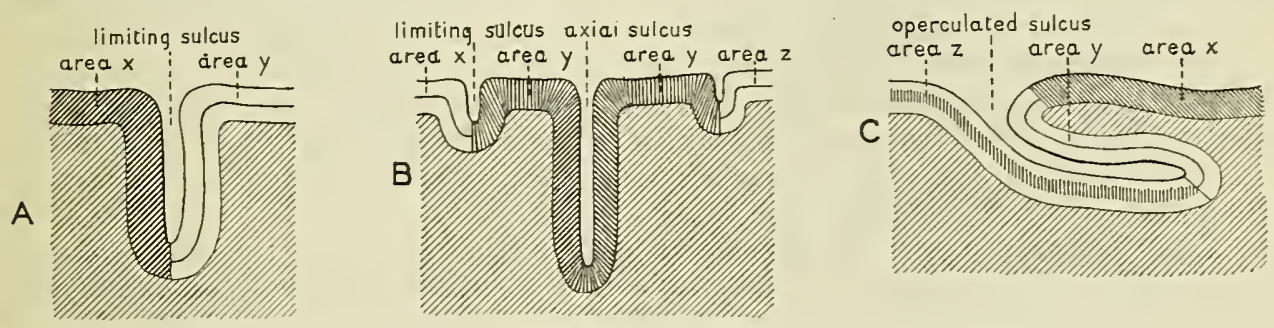

Fig. 575.-Diagrajs to explain Three Types of Cerebral Furrows.

the frontal pole, whilst the most projecting part of the posterior end is termed the occipital pole. On the inferior surface of the hemisphere the prominent point of cerebral substance which extends forwards below the lateral fissure receives the name of the temporal pole. In a well-hardened brain a broad groove is usually present on the medial and inferior aspect of the occipital pole of the right hemisphere. This corresponds to the commencement of the right transverse venous sinus. A less distinct groove on the occipital pole of the left hemisphere frequently indicates the commencement of the left transverse sinus. On the tentorial surface, a short distance behind the temporal pole, a well-marked depression, impressio petrosa, is always visible. This corresponds to the elevation on the anterior surface of the petrous portion of the temporal bone orer the superior semicircular canal.

\section{The White Matter of the Cerebral Hemispheres.}

According to the connexious which they establish the fibres forming the white medullary matter of the hemispheres may be classified into three distinct groups, viz., (1) commissural fibres; (2) association fibres; and (3) projection fibres.

Commissural Fibres.-These are fibres which link together portions of the gray cortex of opposite cerebral hemispheres. They are arranged in three groups forming three definite structures, viz., the corpus callosum, the anterior commissure, and the hippocampal commissure.

The corpus callosum has in a great measure been already studied (p. 628). As it enters each hemisphere, its fibres spread out in an extensive radiation (the radia- 
tion of the corpus callosum). It thus comes about that every part of the cerebral cortex, with the exception of the bulbi olfactorii, the olfactory parts of the hemisphere, and the inferior and anterior part of the temporal lobe, is reached by the callosal fibres. But it should be clearly understood that all the regions of the cortex do not receive an equal proportion of fibres; in other words, some cortical areas would appear to be more plentifully supplied than others. Another point of some importance consists in the fact that the callosal fibres do not, as a rule, connect together symmetrical portions of the gray cortex. As the fibres cross the median plane they become greatly scattered, so that dissimilar parts of the cortex of opposite hemispheres come to be associated with each other.

The commissura anterior is a structure supplemental to the corpus callosum, although originally it was the principal cerebral commissure long before the corpus callosum was evolved. It connects together the two olfactory bulbs, and also portions of the opposite temporal lobes. It presents a cord-like appearance and in median section appears as a small oval bundle in the lamina terminalis (Fig. 544, p. 617). The middle free portion is placed immediately in front of the columns of the fornix as they curve downwards, and also in intimate relation to the anterior end of the third ventricle. Posteriorly, the small portion of the anterior commissure which appears in the ventricle between the two columns of the fornix is clothed with the ventricular ependyma; anteriorly, the commissure is connected with the lamina terminalis as it stretches from the optic chiasma upwards towards the inferior (anterior) end of the hippocampal commissure.

The lateral part of the anterior commissure penetrates the cerebral hemisphere, and, gaining the inferior part of the anterior end of the internal capsule, divides into two portions, viz., a small inferior olfactory part and a much larger temporal part.

The olfactory portion of the anterior commissure is an exceedingly small fasciculus. It passes downwards and forwards, and finally enters the olfactory tract. It is composed (1) of true commissural fibres, which bind one olfactory bulb to the other; and (2) of other fibres, which connect the olfactory bulb of one side with the piriform area of the other side.

The temporal portion is formed of almost the whole of the fibres of the commissure. It is carried laterally under the lentiform nucleus, until it gains the interval between the globus pallidus and the putamen. At this point it changes its direction and sweeps backwards. In frontal sections through the brain, posterior to this bend, the temporal portion of the anterior commissure appears as an oval bundle of fibres cut transversely and placed in close contact with the inferior surface of the lentiform nucleus (Fig. 576). Finally, it turns sharply downwards on the lateral aspect of the amygdaloid nucleus, and its fibres are lost in the white medullary centre of the temporal lobe. When the lateral part of the anterior commissure is displayed by dissection, it is seen to be twisted like a rope.

The hippocampal commissure is composed of fibres which connect the hippocampus of one side with the corresponding structure of the opposite side. It is described on p. 629.

Association Fibres.-The association fibres bind together different portions of the cortex of the same hemisphere. They are grouped into long and short association bundles.

The greater number of the short association fibres pass between adjacent gyri. They curve round the bottoms of the sulci in U-shaped loops. Some of these occupy the deepest part of the gray cortex itself, and are termed intracortical association fibres (Figs. 577 and 578); others lie immediately subjacent to the gray matter-between it and the general mass of the white matter-and receive the name of subcortical fibres. Many groups of short association fibres, instead of linking together contiguous gyri, pass between gyri more or less remote. It is only after birth, when intellectual effort and education have stimulated different portions of the cortex to act in harmony and in conjunction with each other, that these association fibres assume their sheaths of myelin and become functional.

The long association fibres are arranged in bundles which run for considerable distances within the white medullary centre of the cerebral hemisphere, and unite 
districts of gray cortex which may be far removed from each other. The better known of these fasciculi are the following: (1) the uncinate bundle; (2) the cingulum; (3) the superior longitudinal bundle; (4) the inferior longitudinal; and (5) the occipito-frontal.

The fasciculus uncinatus is composed of fibres which arch over the stem of the
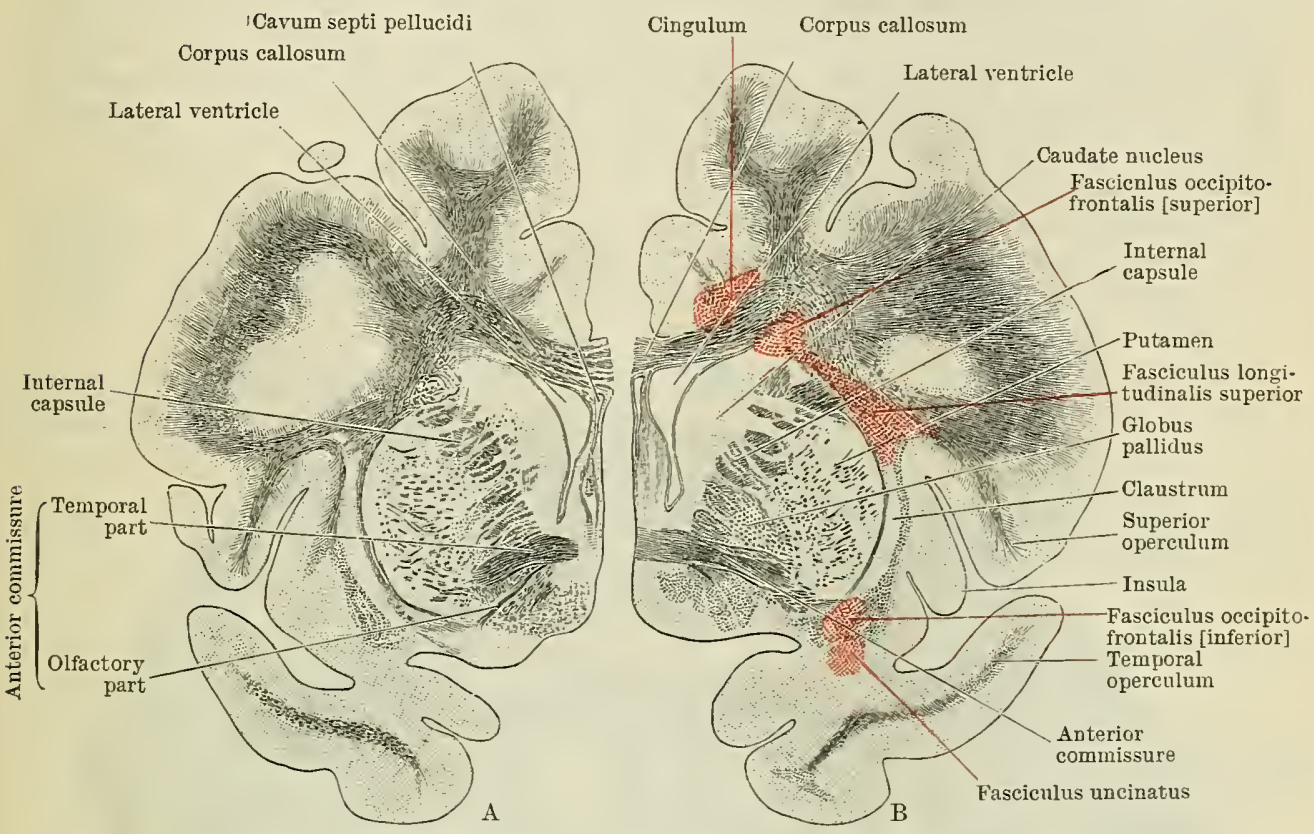

Fig. 576.-Two Frontal Secions throdgh the Cerebral Hemispheres of an Orang, in the Plane of the ANterior Commissure.

A, Section through the left hemisphere in a plane a short distance behind $B$, which is a section through the right hemisphere. The positions of the great longitudinal association tracts are indicated in red.

lateral cerebral fissure and connect the frontal pole, and the orbital gyri of the frontal lobe, with the anterior portion of the temporal lobe.

The cingulum is a very well-marked and distinct band, which is closely associated with the medial edge of the neopallium. Beginning in front, in the region of the anterior perforated substance, it arches round the genu of the corpus callosum and

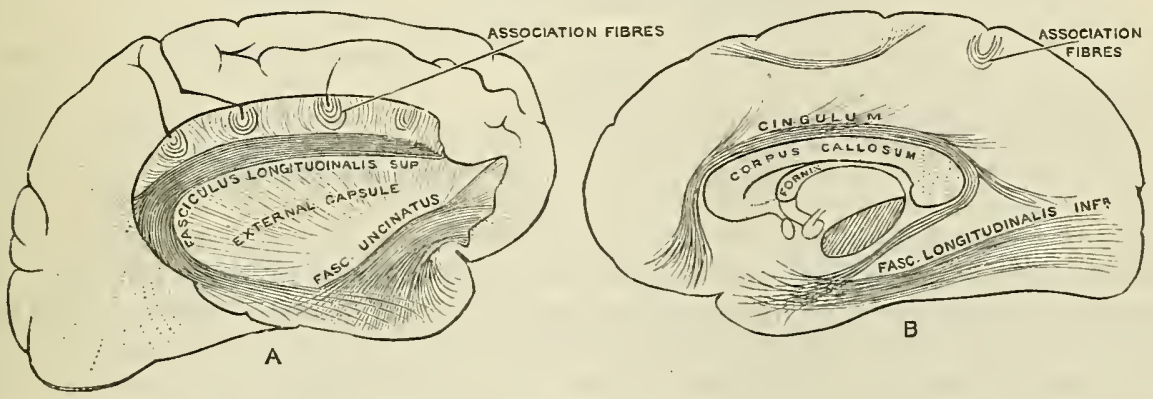

Fig. 577.-Diagrays of the Leadixg Association Bundegs of tae Cerebral Heyisphere. (Founded on the drawings of Déjerine).

As Lateral aspect of hemisphere.

$B$, Metial aspect of hemisphere.

is carried posteriorly on the superior surface of this structure at the place where its fibres pass into the callosal radiation. The cingulum, therefore, lies under cover of the gyrus cinguli and stands in intimate relation to the white centre of this gyrus (Fig. 559, p. 631). At the posterior end of the corpus callosum the cingulum turns round the splenium and is carried forwards, in relation to 
the hippocampal gyrus, to the uncus and the temporal pole. The cingulum is composed of several systems of fibres which run only for short distances within it.

The fasciculus longitudinalis superior is an arcuate bundle which is placed on the lateral aspect of the foot or basal part of the corona radiata and connects the frontal, occipital, and temporal regions of the hemisphere. It lies in the base of the superior operculum and sweeps backwards over the insular region to the posterior end of the lateral cerebral fissure. Here it bends downwards round the posterior eud of the putamen and proceeds forwards in the temporal lobe, to reach its anterior extremity. As it turns downwards to reach the temporal lobe numerous fibres radiate from it into the occipital lobe.

The fasciculus longitudinalis inferior is a very conspicuous bundle which extends along the whole length of the occipital and temporal regions (Fig. 577, B). Curran has recently demonstrated that the fasciculus uncinatus and the inferior longi-

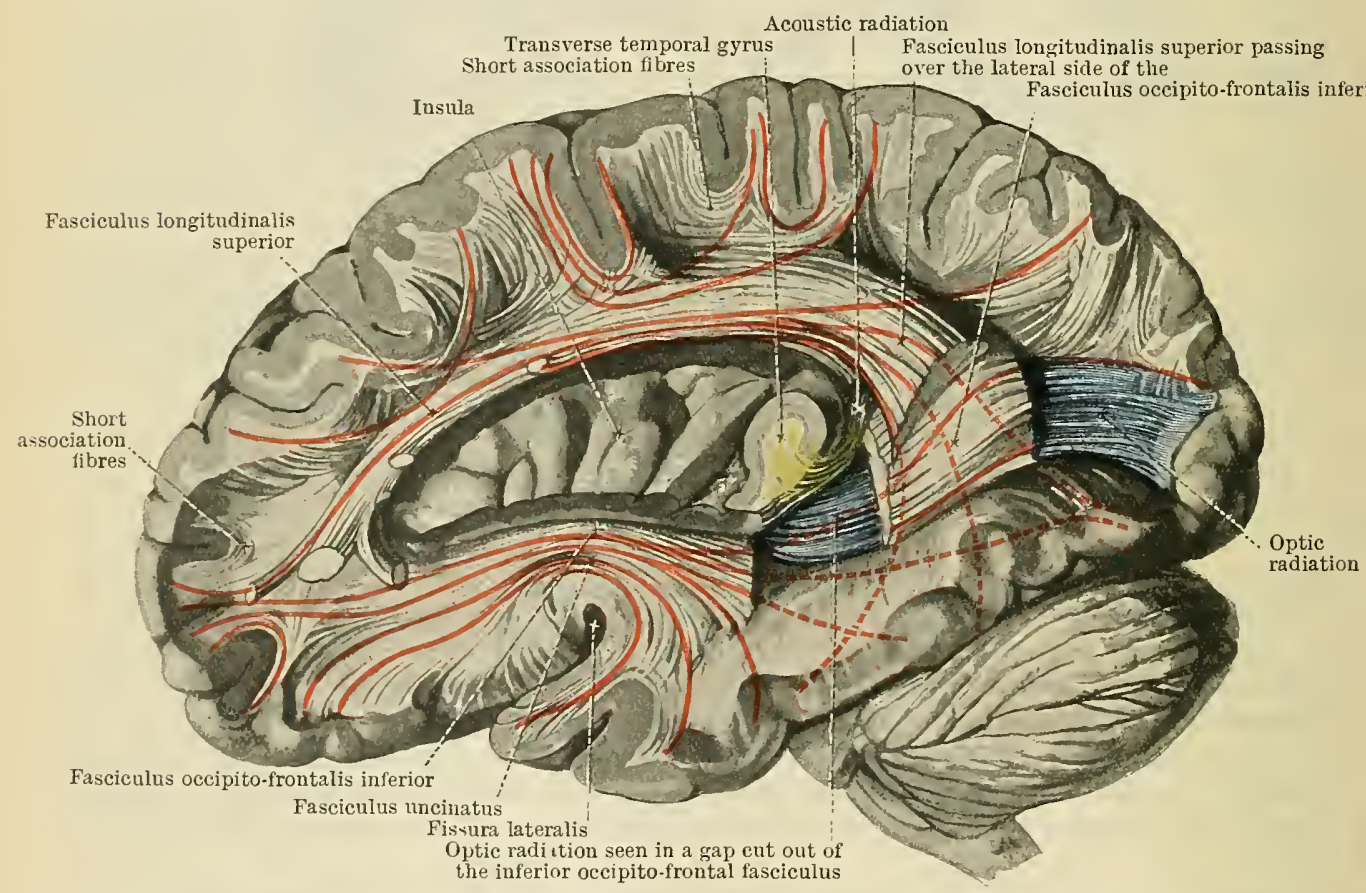

Fig. 578.-Dissection to display sone of the Principal Association Bundles of the Cerebral HEMISPHERE.

The occipito-temporal extremity of the superior Iongitudinal bundle has been cut away in order to expose the subjacent inferior occipito-frontal bundle, parts of which in turn have been removed to expose the origin and termination of the still deeper optic radiation (coloured blue); (acoustic fibres, yellow).

tudinal bundle are merely the shorter inferior fibres of a much bigger and longer tract (Fig. 578), to which he has applied the name occipito-frontalis inferior. The arrangement of these longitudinal tracts may be put concisely by saying that fibre connexions of differing lengths link together the various cortical areas in the longitudinal direction, the deeper fibres (i.e. those furthest removed from the cortex, medial, lateral, superior or inferior) being progressively longer than the superficial. The deepest fibres extend the whole length of the hemisphere and are pushed aside by the insula (Fig. 578) and collected into two great bundles, a superior longitudinal and an inferior occipito-frontal bundle. In the occipital lobe the inferior occipito-frontal bundle is placed on the lateral aspect of the optic radiation, which takes a similar direction and from which it is distinguished by the greater coarseness of its fibres (Figs. 576, p. 649;578;559, p. 631). It is not present in the macaque monkey (Ferrier and Turner), but is well developed in the orang and the chimpanzee. 
The fascicuius occipito-frontalis superior is a bundle of fibres which runs in a sagittal direction in intimate relation to the lateral ventricle (Fig. 576, p. 649). It may be regarded as the medial edge of the superior longitudinal bundle. It has been pointed out (Forel, Onufrowicz, and others) that, in cases where the corpus callosum fails to develop, the tapetum remains apparently unaffected, and Déjerine has endeavoured to prove that the fibres of this layer really belong to the fasciculus occipito-frontalis. The fasciculus occipito-frontalis lies on the medial aspect of the corona radiata in intimate relation to the caudate nucleus, and posteriorly it spreads out over the superior and lateral aspect of the lateral ventricle, immediately outside the ependyma, where, according to Déjerine, it constitutes the tapetum (see p. 632).

Projection Fibres.-We have already seen that every part of the cerebral cortex is linked to other cortical areas, not only in its own neighbourhood (short association fibres) (Fig. 578), but also in the most distant parts of the hemisphere (long association fibres), as well as to the cortex of the other hemisphere (commissural fibres). In addition there are two large series of fibres: (i.) an ascending group which conveys to the cerebral cortex impulses coming from the thalamus and metathalamus, the corpora quadrigemina and the red nucleus, and the various other sensory nuclei scattered throughout the brain stem and spinal medulla; and (ii.) a descending group connecting the cerebral hemisphere with the corpus striatum, various parts of the diencephalon, mesencephaion and cerebellum, as well as with all the motor nuclei scattered throughout the central nervous system. These two groups of tracts, respectively passing to and from the cerebral cortex, are known collectively as its projection fibres.

While examining the general arrangement of these projection fibres of the cerebral hemisphere it is convenient to refer incidentally to certain other fibre-tracts which do not fall strictly within this group.

The Sensory Tracts.-A certain

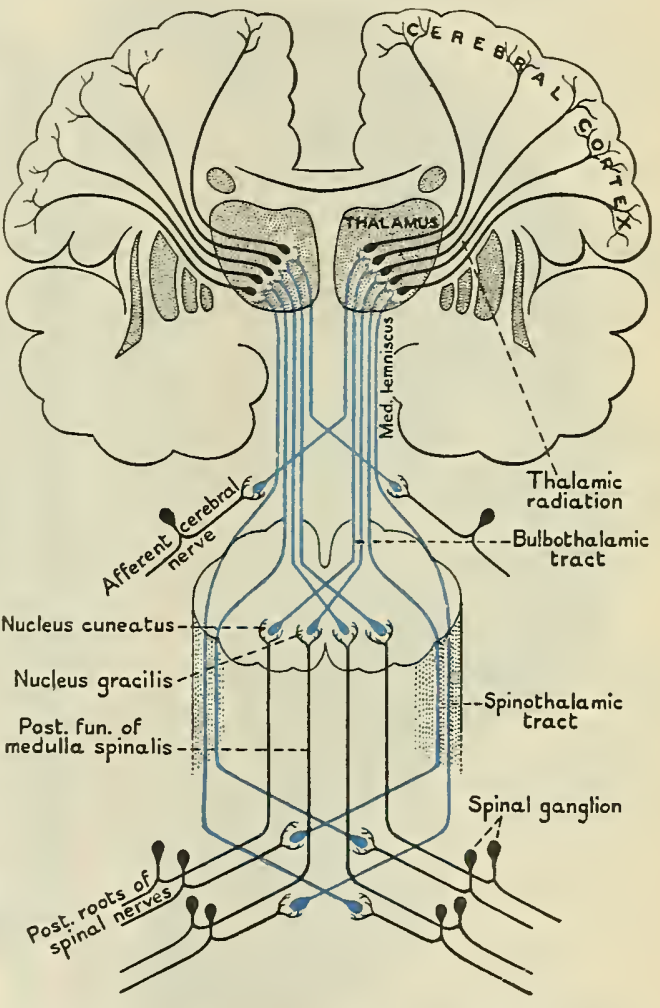

Fig. 579.-Diagram of the Sensort Tracts from the Spinal Medulia to the Cerebral Cortex. proportion of the fibres that enter the spinal medulla by its posterior root, which are supposed to be the sensory nerves of muscles, tendons, and joints, pass upwards without interruption in the posterior funiculi throughout the whole length of the spinal medulla until they reach the medulla oblongata, where they end in the nucleus gracilis and nucleus cuneatus. From these nuclei, arcuate fibres (fasciculus bulbothalamicus) arise and, after crossing the median plane, proceed upwards in the medial lemniscus of the other side to end in the ventro-lateral nucleus of the thalamus, from which a third group of nemrones arises and proceeds upwards through the interual capsule to the cerebral cortex, where the impulses conveyed by it excite a consciousness of position and movement. But other sensory fibres end in the spinal medulla near their place of entry into it, and from the cells related to the endings of these fibres a new tract (fasciculus spinothalamicus) arises, crosses the median plane to reach the antero-lateral funiculus of the opposite side, in which it proceeds upwards throughout the whole length of the spinal medulla (that lies above its origin), the rhombencephalon and mesencephalon to the thalamus, where it ends alongside the bulbo-thalamic tract in 
relationship with cells of the ventro-lateral nucleus. The fibres arising from this nucleus proceed to the gyrus centralis posterior, and convey impulses to it, which may excite a consciousness of touch, pressure, pain, heat, or cold. Some of these spino-thalamic fibres enter the medial lemniscus in the medulla oblongata, but others remain separate from it (Fig. 580) until they reach the level of the pons, where they become added to the lateral margin of the bulbo-thalamic tract.

[In Fig. 580 the line from the label "lemniscus medialis" points to the place of junction of the spino- and bulbo-thalamic tracts.]

Other groups of fibres, serially homologous to both the spino-thalamic and the bulbo-thalamic tracts, come from the various sensory cerebral nerves-trigeminal,

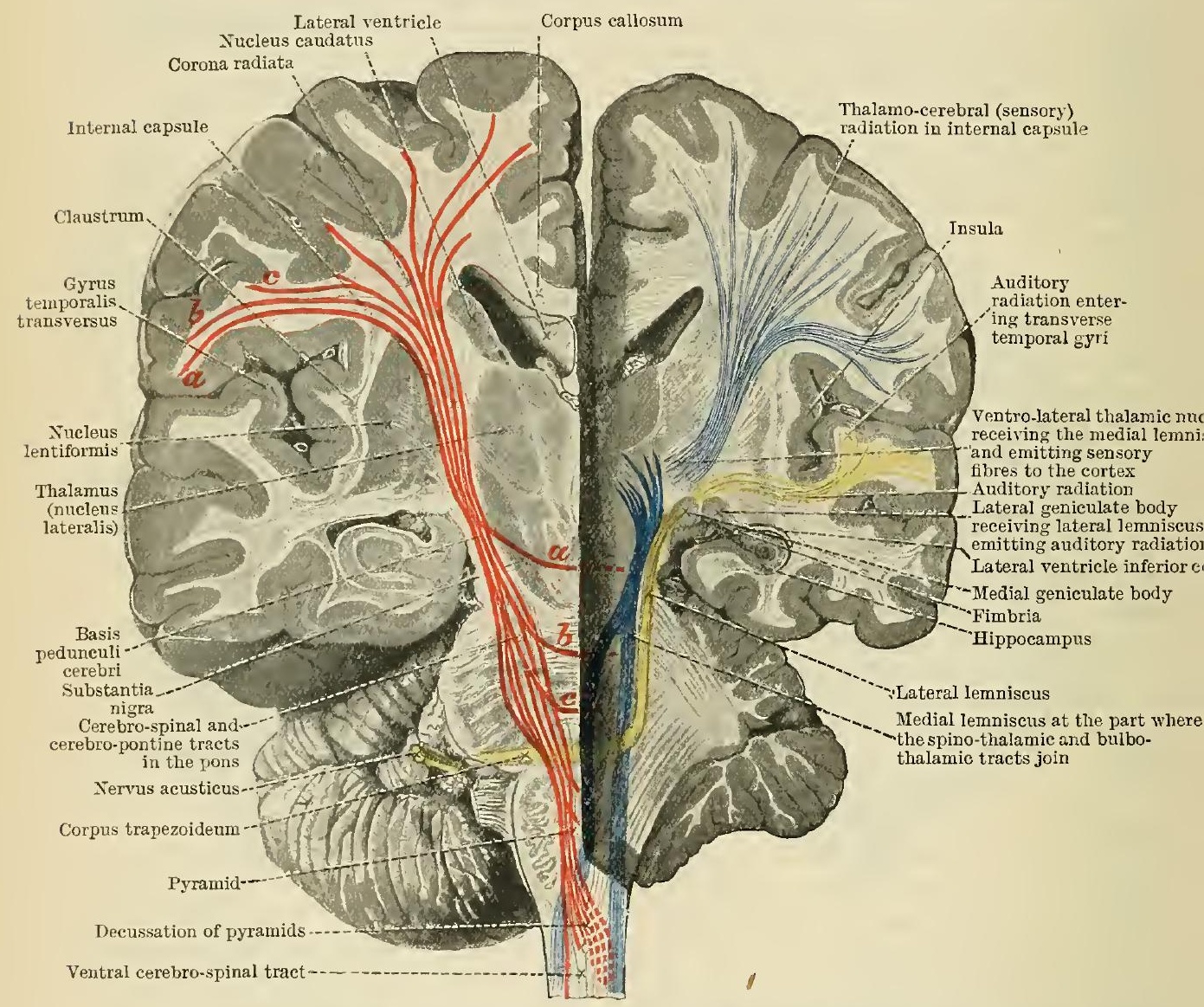

Fig. 580.-Frontal Section of Brain, passing in the Line of the Cerebro-Spinal Tract (marked in red) IN THE Right Hemisphere (left side of Fig.), and on a more posterior plane in the left hemisphere, where the sensory paths (tactile in blue, and acoustic in yellow) have been represented.

facial, glossopharyngeal, and vagus-and become added to the great strands that are proceeding upwards to the thalamus (Figs. 579 and 494, p. 561).

Of the other great ascending tracts in the spinal medulla, such as the two pairs of fasciculi spinocerebellares, nothing further need be said; nor is it necessary to do more than remind the reader that from the nucleus dentatus of the cerebellum a great tract (brachium conjunctivum) ascends to the opposite red nucleus and thalamus, and through them establishes an indirect connexion with the cerebral cortex in the precentral and frontal regions.

The other sensory pathways to the cerebrum, auditory, vestibular, visual, gustatory, and olfactory, are described elsewhere.

The Corticifugal Projection Strands.-The fasciculus cerebrospinalis, the great motor or pyramidal tract, is composed of fibres which arise from giant pyramidal 
cells of Betz in the posterior part of the precentral cortex (p. 663) in the district immediately in front of the sulcus centralis. The fibres descend through the corona radiata into the posterior limb of the internal capsule. From this point the further course of the pyramidal tract has been traced, viz., through the central part of the basal region of the cerebral peduncle and pons, and the pyramid of the medulla oblongata. At the level of the foramen magnum it decussates in the manner already described, and enters the spinal medulla as the lateral cerebrospinal and anterior cerebro-spinal tracts. The fibres composing these end in connexion with the ventral or motor column of cells, from which the fibres of the anterior roots of the spinal nerves arise.

Similar fibres arise from the inferior part of the precentral area and proceed through the internal capsule and cerebral peduncle to all the motor nuclei upon the opposite side of the brain stem (fasciculi cerebronucleares). Hence the cerebral cortex of one hemisphere can control all the muscles of the opposite side of the body.

The fronto-pontine strand is composed of fibres which arise as the axons of the cells in the cortex which covers the frontal region that lies in front of the precentral furrows. It descends in the anterior limb of the internal capsule, enters the medial part of the base of the cerebral peduncle, through which it gains the basilar part of the pons. In this its fibres end amongst the cells of the nuclei pontis, from which axons arise and establish relations with the cortex of the opposite cerebellar hemisphere.

The temporo-pontine tract consists of fibres which spring from the cells of that part of the cortex which covers the middle portions of the lower two temporal gyri. The temporo-pontine tract passes medially under the nucleus lentiformis, enters the retrolenticular part of the posterior limb of the internal capsule, and thus gains the lateral part of the cerebral peduncle. From this it descends into the basilar part of the pons, in which it ends in the nuclei pontis.

Cortico-striate and other Descending Fibres. - From the fibres of the internal capsule numerous collateral branches are given off to the nucleus caudatus and nucleus lentiformis and from these basal ganglia fibres arise which enter the cerebral peduncle as constituent elements of the great cerebro-spinal tract.

Some of the fibres from the corpus striatum, especially the nucleus lentiformis, as well as others descending from the frontal cortex, pass into the red nucleus (Fig. 571), which also receives afferent tracts from the tectum mesencephali and from the cerebellum : it emits an important efferent tract (fasciculus rubrospinalis), which crosses the median plane and descends in the brain stem and spinal medulla to the various motor nuclei (see Figs. 454 and 475 ).

\section{THE SULCI AND GYRI OF THE CEREBRAL HEMISPHERES.}

Fissura Cerebri Lateralis (O.T. Fissure of Sylvius).-This is the most conspicuous furrow on the surface of the cerebral hemisphere. In reality it is formed, not as a furrow upon the surface of the hemisphere, but as a great fossa, the margins of which develop into large lip-like folds that bulge over the fossa and meet to form the superficial pattern of the lateral fissure. It is composed of a short main stem, from the lateral extremity of which two or three branches or limbs radiate. The stem of the lateral fissure is placed on the inferior surface of the hemisphere. It begins at the substantia perforata anterior and passes laterally, forming a deep cleft between the temporal pole and the orbital surface of the frontal region. Appearing on the lateral surface of the hemisphere, the fissure immediately divides into two or three radiating rami. These are: (1) the ramus posterior; (2) the ramus anterior horizontalis; (3) the ramus anterior ascendens, of which the last is inconstant.

The posterior ramus is the longest and most constant of the three limbs. It extends backwards, with a slight inclination upwards, on the lateral surface of the hemisphere for a distance which may vary from about two to three inches. It intervenes between the frontal and parietal regions, which lie above it, and the temporal region which lies below it; and it finally ends in the region subjacent to 
the parietal tuberosity of the cranial wall by turning upwards into the parietal region in the form of an ascending terminal piece.

The anterior horizontal ramus extends horizontally forwards in the frontal region for a distance of not more, as a rule, than three-quarters of an inch, immediately above and parallel to the posterior part of the superciliary margin of the hemisphere.

The ascending ramus proceeds upwards, with a slight inclination forwards, into the inferior part of the lateral surface of the frontal region for a variable distance (an inch or less). In many cases the two anterior limbs spring from a common stem of greater or less length, and not infrequently there is only a single anterior limb.

Sulcus Circularis.-If the lips of the posterior ramus of the lateral fissure are pulled widely asunder from each other, the insula (island of Reil) will be seen at the

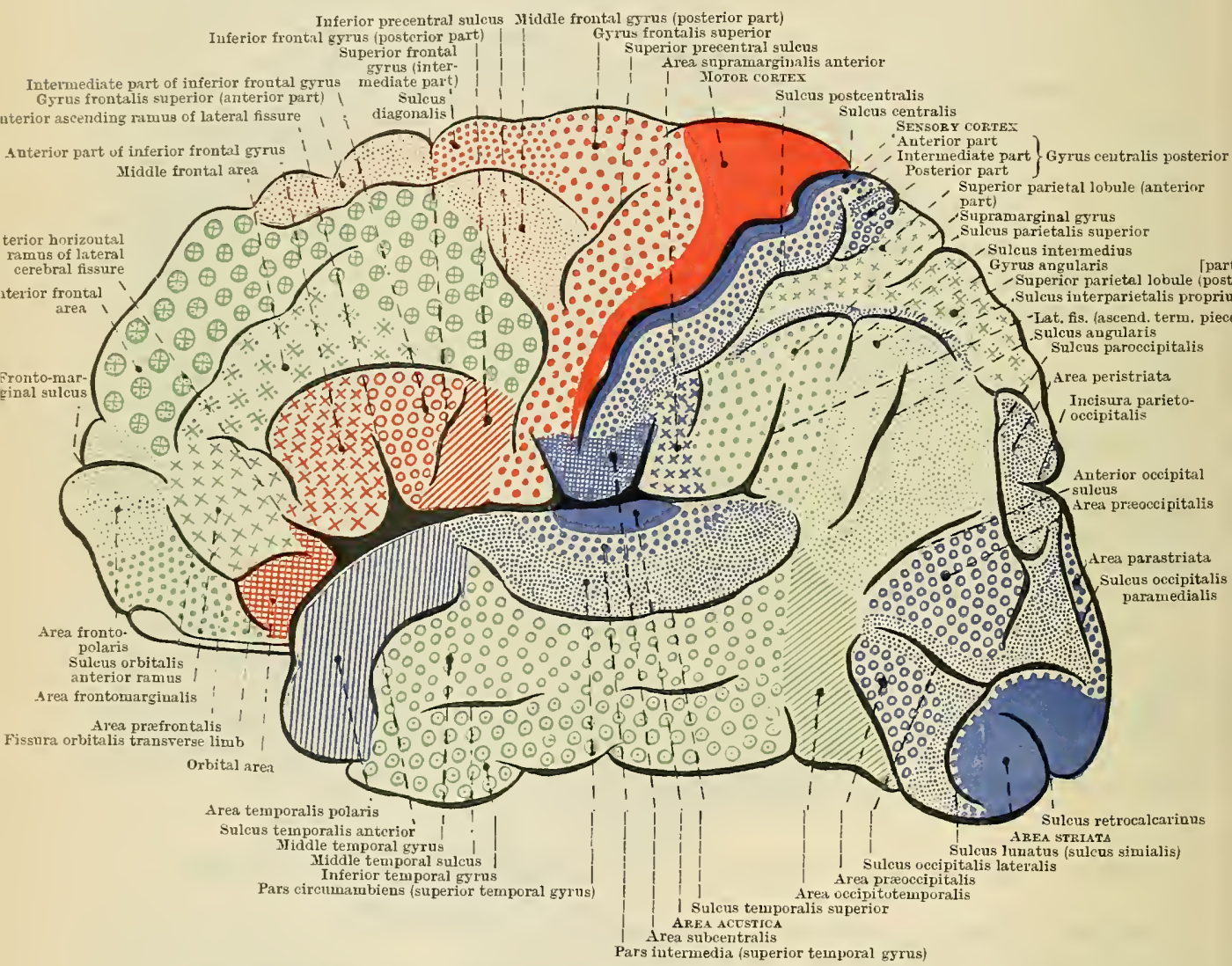

Fig. 581.-A Diagrair of the Lateral aspect of the Left Cerebral Hemisphere.

The inferior frontal sulcus (the superior boundary of the inferior frontal gyrus), the midille frontal sulcus (separating the anterior and middle frontal areas), and the superior frontal sulcus (bounding the superior frontal gyrus) are not labelled.

bottom. The insular district of the cortex is completely hidden from view, when the lateral fissure is closed, by overlapping portions of the cerebral hemisphere, and, when brought into view in the manner indicated, it is observed to present a triangular outline and to be surrounded by a limiting sulcus, of which three parts may be recognised, viz., a superior part, bounding it above and separating it from the parietal and frontal regions; an inferior part, marking it off below from the temporal region; and an anterior part, separating it in front from the frontal region.

The insula consists of three areas of different structure. At the antero-inferior corner (where the sulcus circularis is deficient) the knee-like bend of the area piriformis (see Figs. 582 and 584) appears at the limen insulæ. The rest is subdivided by an oblique furrow (sulcus centralis insulæ) into a posterior part divided into gyri longi and an anterior part divided into gyri breves. 
Opercula Insulæ.-The overlapping portions of the cerebral substance which cover over the insula are termed the insular opercula, and they form, by the apposition of their margins, the three rami of the lateral fissure. The rami of the fissure extend from the exposed surface of the hemisphere to the submerged surface of the insula, and, in this manner, separate the opercula from each other.

The temporal operculum (pars temporalis) extends upwards over the insula from the temporal region, and its superior margin forms the inferior lip of the posterior ramus of the lateral fissure.

The superior operculum is carried downwards from the parietal (pars parietalis) and frontal (pars frontalis) regions over the insula, and its inferior margin, meeting the temporal operculum, forms the superior lip of the posterior ramus of the lateral fissure.

The small triangular piece of cerebral substance which sometimes intervenes between the ascending and horizontal anterior rami of the lateral fissure is formed by the bending downwards of the front part of the upper operculum. It

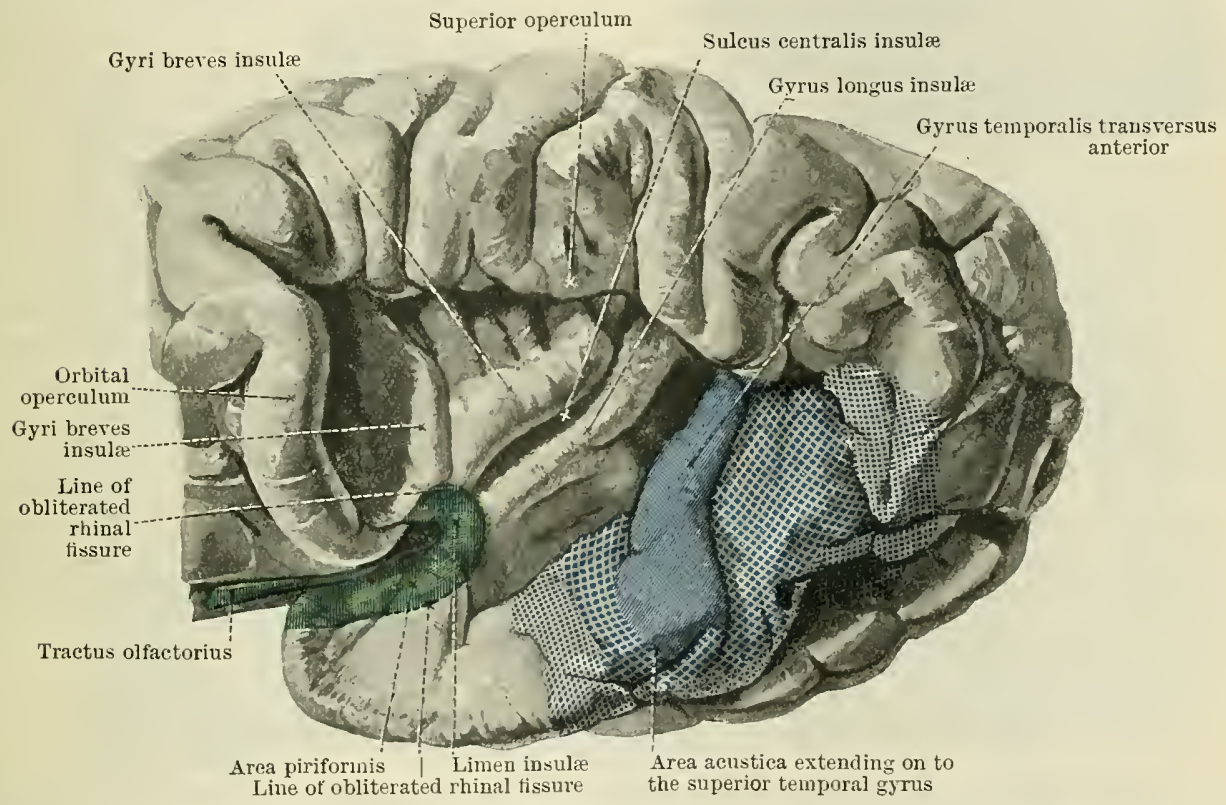

Fig. 582.-Part of a Left Cerebral Hemisphere with the Opercula of the Insula widely separated to expose the Instla and the Superior Sorface of the Temporal Operceldy.

The area acustica is coloured a uniform blue, the area intermedia with large blue spots and the area circumambiens with fine blue dots.

covers over a small part of the anterior portion of the insula, and is sometimes termed the pars triangularis.

The orbital operculum is, for the most part, on the inferior surface of the hemisphere. It lies below and to the medial side of the horizontal anterior ramus of the lateral fissure, and proceeds backwards from the orbital aspect of the frontal lobe over the fore-part of the insula.

Development of the Lateral Fissure and of the Insular District of the Cerebral Hemisphere.-It is only during the latter half of the intra-uterine period of development that the opercula take shape and grow over the insula, so as to shut it out from the surface. In its early condition the insula presents the form of a depressed area on the side of the cerebral hemisphere, surrounded by a distinct boundary wall formed by the surrounding more elevated surface of the hemisphere (Fig. 583, A). After a time this depressed area, which is called the fossa lateralis, assumes a triangular ontline, and then the bounding wall is observed to be composed of three distinct parts, viz., a superior or frento-parietal, an inferior or temporal, and an anterior or orbital part (Fig. 583, B). The angle formed by the meeting of the superior and anterior portions of the boundary may become flattened, and a short oblique part of the limiting wall develop into a small triangular frontal operculum (Fig. 583, F). Each of these portions of the bounding wall of the fossa becomes a line of growth, from which an operculum 
takes origin, and by the approximation of these opercula, as they grow over the surface of the fossa, the insula becomes closed in and the rami of the lateral fissure are formed (Fig. 583, C).

The lateral fissure is an example of the fourth category of furrows enumerated above. It is largely the result of the operation of the mechanical factors incidental to the bending downwards of the pallium in front of and behind the place where the hemisphere-wall is supported and held in position by the corpus striatum. The cortical area roughly corresponding to the surface of the corpus striatum is the insula; the temporal region extends downwards behind it, and to a less extent

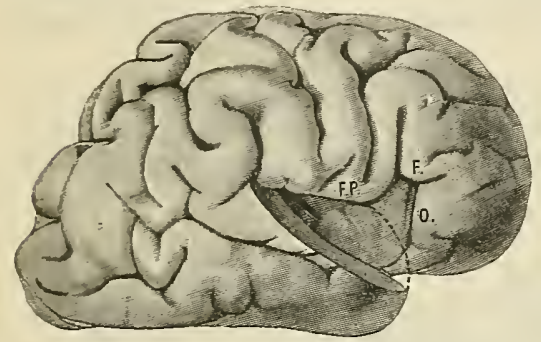

C

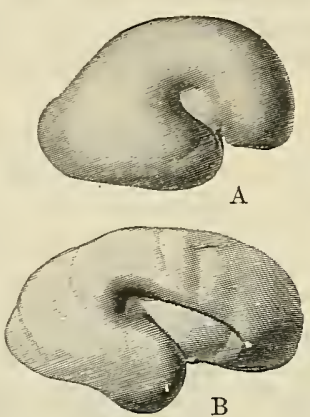

$\mathrm{B}$

Fig. 583.-Right Hemispheres of Hoyay Fetuses showing Three Stages in the DENElopdent of THE INSUla aNd THE INSUlar Opercula.

A, Right cerebral hemisphere from a fotus in the latter part of the fourth month of development; B, Right cerebral hemisphere from a foetus in the fifth
month of development; C, Right cerebral hemisphere from a foetus in the latter part of the eighth month of development. the temporal operculum has been removed, and thus a large part of the cula-which graduinsula is exposed. The outline of the temporal operculum is indicated by a dotted line.

F.P, Superior operculım. F, Frontal operculum. O, Orbital operculum. the frontal region in front of it (Fig. 583, A). Then towards the end of the fifth month of fœtal life the exuberant growth of the free frontoparietal pallium above the insula (Fig. 583, B) and the temporal pallium below and behind it leads to the development of lip-like folds of neopallium-the operally approach one another(Fig. 583,C) and eventually cover up the insula. Other factors come into play in determining the form and topographical relations of the fissura lateralis. For example, the posterior part of the fissure is the morphological boundary between the acoustic and tactile territories of the neopallium.

\section{THE ACOUSTIC AREA AND FIBRE-TRACTS.}

In the embryo of the fifth month (Fig. 583, B), as well as in every later stage, even up to the adult condition (Fig. 582), an area upon the superior surface of the temporal operculum can be seen to slope medially towards the upper limb of the sulcus circularis, behind the insula. This area constitutes the receptive centre for acoustic impressions-the gyrus temporalis transversus or Heschl's convolution -although the extent of this acoustico-sensory area does not coincide exactly with that of the transverse temporal gyrus. The area formed by the upper surface of the temporal operculum immediately behind this prominent transverse gyrus is also called by the same name, so that there are anterior and posterior transverse temporal gyri (Fig. 582 ; the posterior transverse temporal gyrus is not labelled in the figure).

In studying the brain-stem we have seen that a tract of fibres originating in the cochlear terminal nuclei (in the medulla oblongata) crosses the median plane (corpus trapezoideum) and bends upwards in the lateral lemniscus of the other side (Fig. 580) to end in the medial geniculate body of the metathalamus. From the medial geniculate body a new tract arises (composed of tertiary acoustic neurones), which passes laterally (Figs. 580 and 584) to end in the transverse temporal gyri. This tract may be called the radiatio thalamotemporalis.

The area into which this acoustic radiation is inserted occupies not only the region of the anterior transverse temporal gyrus (Fig. 582) hidden within the lateral fissure, but also extends over its inferior lip, on to the exposed surface of the superior temporal gyrus (Fig. 581). Surrounding this area there are two concentric bands, 
which are also concerned with acoustic functions, but are related to the acoustic radiation only through the intermediation of the area acustica of the transverse gyrus (Figs. 581 and 582).

These areas may be distinguished as the pars intermedia and pars circumambiens, respectively, of the gyrus temporalis superior. During the sixth month of foetal life a furrow makes its appearance along the line of the inferinr boundary of the superior temporal area (Fig. 590). It is called the sulcus temporalis superior.

At a much later stage of development another furrow (sulcus temporalis anterior) makes its appearance further forwards in the temporal region, as the posterior boundary of the area temporalis polaris; it often becomes confluent with

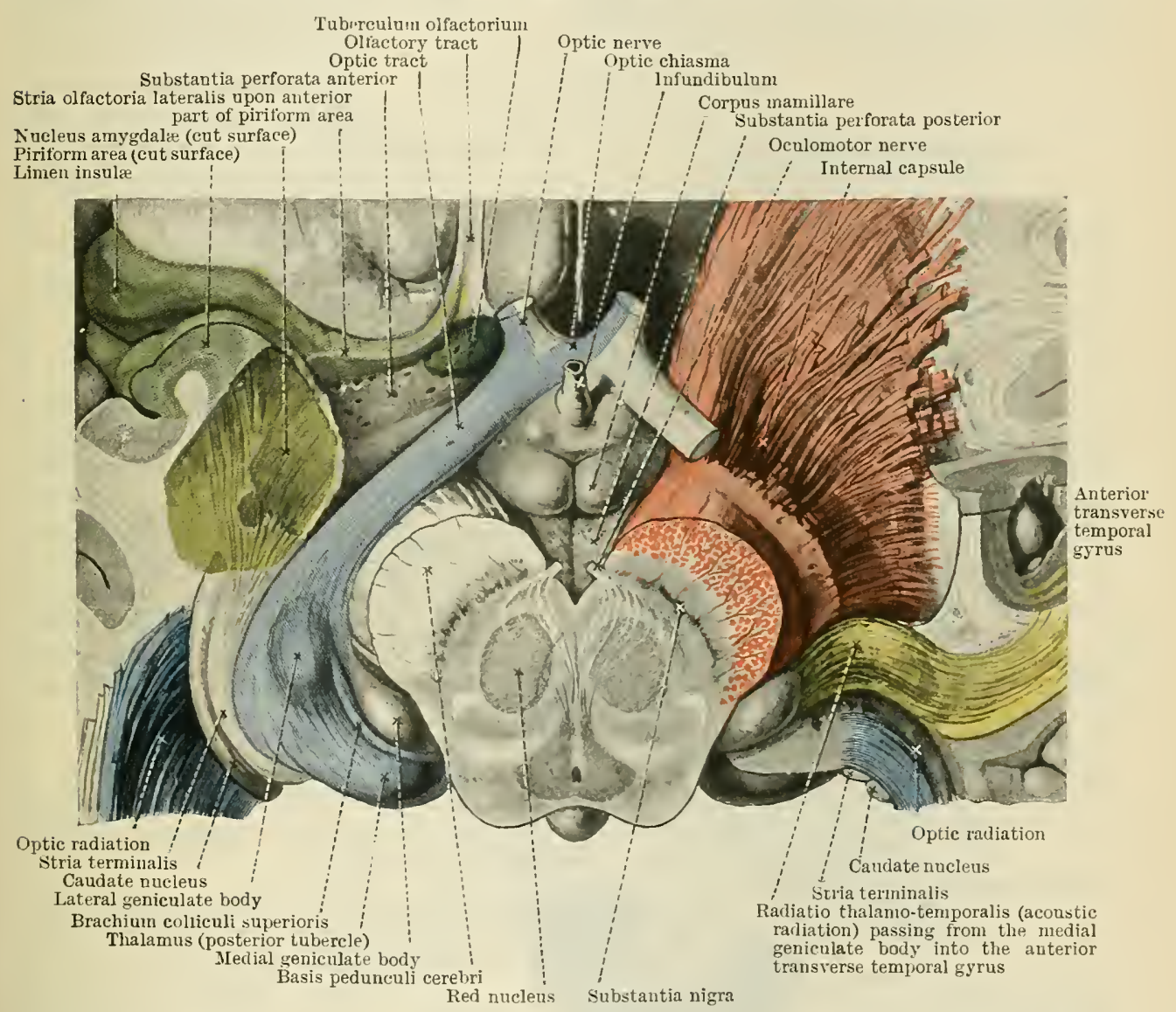

Fig. 584.-INFERior Aspect of PART OF the BRAIx. The mesencephalon has been cut across and a great part of the cerebral hemisphere dissected away to expose the acoustic radiation (right side of figure in yellow) passing laterally from the medial geniculate body to the deep surface of the transverse temporal gyri, of which a small part is shown in section. Notor fibres in red; optic fibres, blue; olfactory, dull yellow.

the real sulcus temporalis superior, and is usually described as part of it. But it is genetically quite distinct from it (Fig. 581).

If the area acustica is cut across in a perfectly fresh brain it will be found to be composed of a thin layer $(1.75 \mathrm{~mm}$.) of cortical gray matter, in which two very dense and fairly broad bands of white matter are visible (Fig. 584). These bands are composed largely of fibres of the acoustic radiation, which have entered the cortex to terminate in it. The superior temporal area is composed of somewhat thicker cortex with two bands which are not so densely white as those of the area acustica. The cortex of the temporal polar area is composed of moderately thick, clear, gray matter in which there is a single, narrow, sharply defined white line. 
The remainder of the true temporal region is composed of an extensive district below the superior temporal sulcus. It is composed of thicker cortex than the superior temporal area, ranging from $3 \mathrm{~mm}$. just below the superior temporal sulcus to $2.5 \mathrm{~mm}$. at the inferior border of the hemisphere. It is composed of three bands of different texture, the middle temporal gyrus, the inferior temporal gyrus, and the pararhinal gyrus, which fringes the area piriformis on the tentorial surface. Upon the lateral aspect of the temporal region a series of irregular furrows are situated along the line of demarcation between the gyrus temporalis medius and the gyrus temporalis inferior; they are considered to represent a sulcus

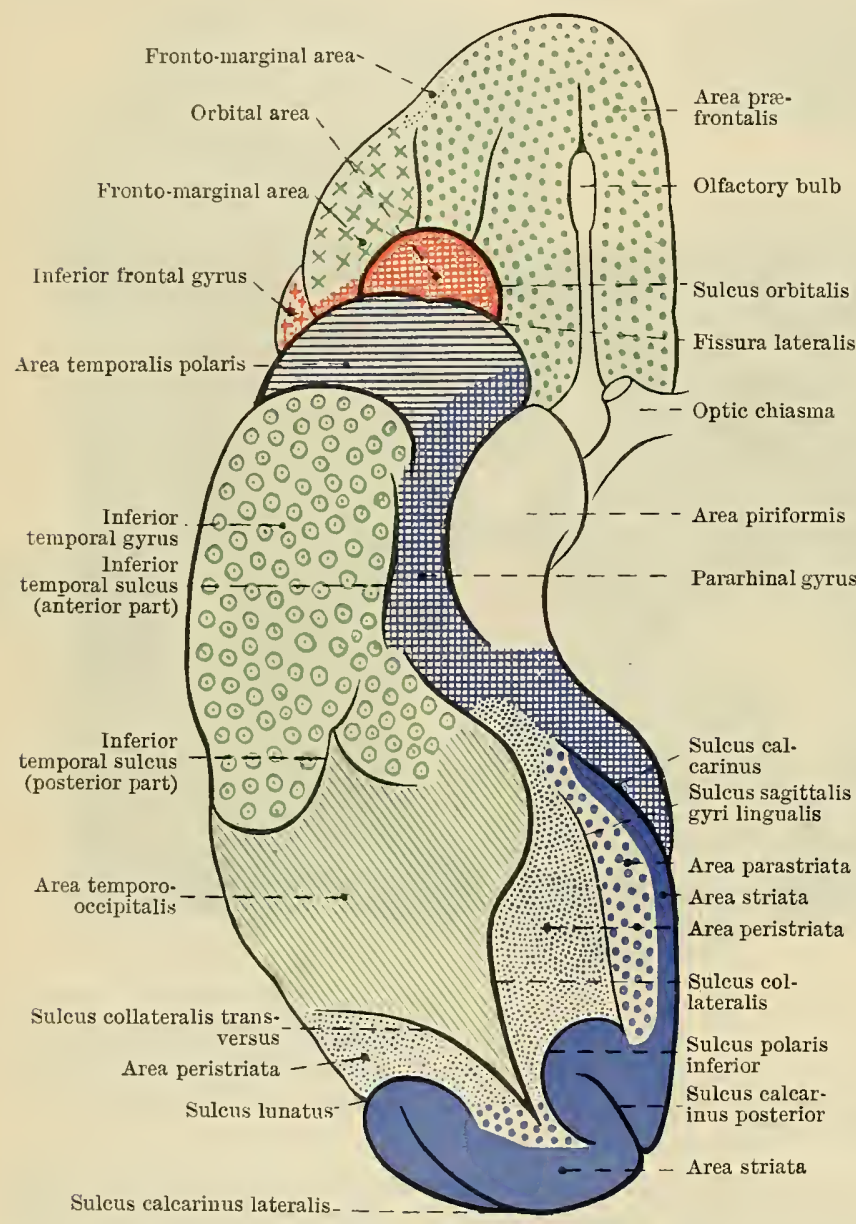

FIG. 585.-CORTICAL AREas on the tentorial and orbital aspects of the cerebral hemispheres.

temporalis medius, but they are subject to much irregularity, especially in highly developed brains. The sulcus temporalis inferior, which forms the line of demarcation between the gyrus temporalis inferior and the gyrus fusiformis, is placed upon the inferior aspect of the temporal region.

The great extent of the middle and inferior temporal gyri constitutes one of the outstanding features distinctive of the human brain. Flechsig has shown that the fibres passing to and from these two gyri are the last to become medullated, later even than the important parietal and frontal areas.

\section{THE VISUAL AREAS AND FIBRE-TRACTS.}

We have already seen (Figs. 578 and 584) that each optic tract ends in the lateral geniculate body, the posterior tubercle of the thalamus, and the superior colliculus. From the lateral geniculate body (and according to most writers the thalamus also, though this is not admitted by all) a tract arises which conveys visual impulses back to the occipital pole of the hemisphere. This radiatio thalamo-occipitalis (Gratiolet's optic radiation) is seen from various points of view in the figures mentioned, but it is possible (see Fig. 587) to expose it in a section which will display it in its relationship to the rest of the visual path (Fig. 586).

From this it will be seen that the fibres of the optic radiation, after emerging from the lateral geniculate body, bend backwards in the lateral wall of the ventricle and proceed to an extensive district of thin cortex $(1.5 \mathrm{~mm}$. or less in thickness), occupying an area of about 3000 sq. mm. of the medial surface and pole of the occipital area. The cortex in this area is distinguished by the presence of 
a very distinct white line or stria, which was first noticed by Gennari in the year 1776.

If this visual receptive area striata of the occipital cortex is excised and spread out in one.plane, it will be found to present an elongated ovoid form and a superficial extent of about $3000 \mathrm{sq}$. mm. (varying in different brains from about 2700 to 4000). The narrow extremity of the oval is placed a short distance behind and below the splenium of the corpus callosum; and from this point the area extends horizontally backwards to the occipital pole, or even beyond it on to the lateral aspect of the hemisphere. In the course of development this area striata becomes folded along its axis during the sixth month, and the furrow thus formed is called the sulcus calcarinus. This name was applied to the furrow by Huxley because its deep anterior part indents the whole thickness of the medial

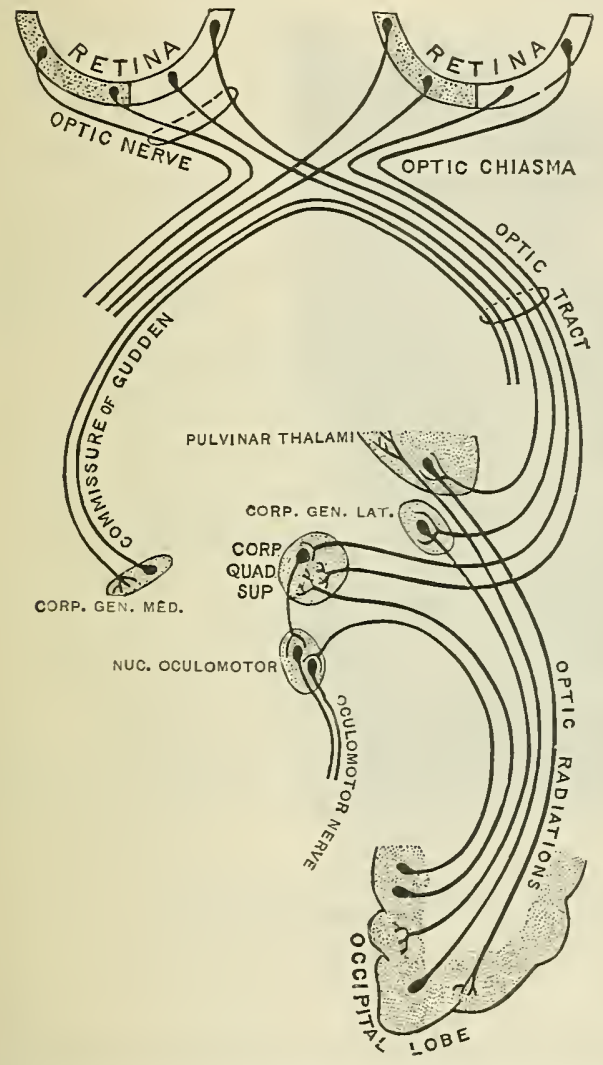

Fig. 586.- Diagram of the Cextral Connexions of the Optic Nerve and Optic Tract.

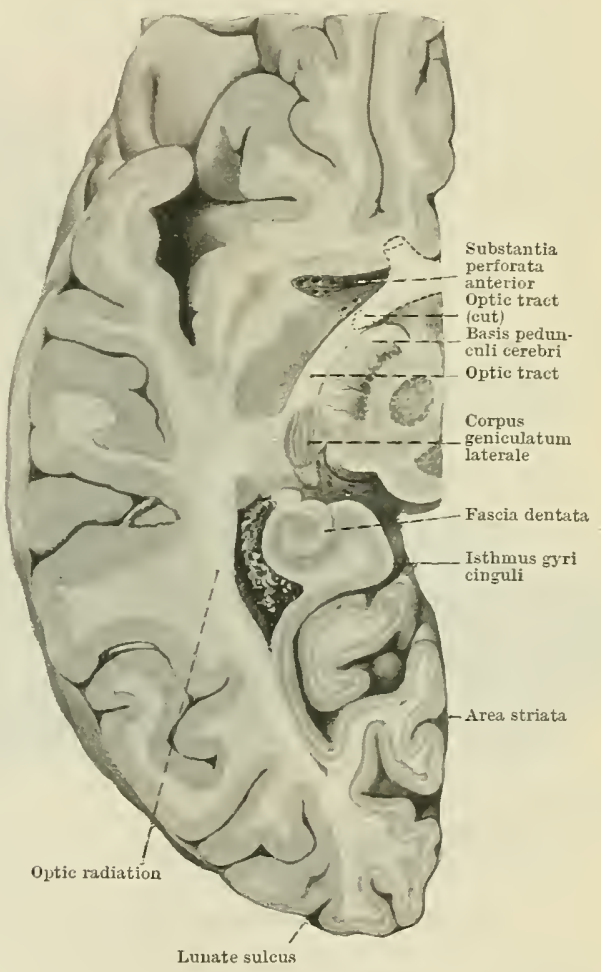

Fig. 587.-A Slightey Obliqde (almost Horizontal) Section throdgh a Cerebral HemiSPhere IN THE Plaxe of the Optic Tract AND RaDIATION.

wall of the hemisphere, and the swelling so produced in the posterior cornu of the lateral ventricle was supposed by the older anatomists to resemble a cock's spur, and was hence called calcar avis (see Fig. 566, p. 637).

The anterior part of this furrow is much deeper, more constant in form and position, more precocious in development, and phylogenetically much older than the posterior part. As it is the part of the sulcus which gives rise to the calcar avis, it is the true calcarine; while the newer, shallower posterior part is wholly on the caudal side of the calcar avis, and is called sulcus calcarinus posterior. If the area striata is prolonged on to the lateral surface, it also may become folded in the line of its axis, and so give rise to a sulcus calcarinus lateralis.

There is a fundamental distinction between the calcarıne sulcus and the posterior calcarine in their relations to the area striata. For the stria of Gennari is found only in the inferior wall of the sulcus calcarinus, which is therefore a sulcus 
limitans; whereas the stria extends throughout both walls of the posterior calcarine sulcus, and in most cases beyond its lips on to the surface of the cuneus and the gyrus lingualis (Figs. 588 and 589), the exposed cortical areas placed upon the superior and inferior aspects respectively of the sulcus calcarinus posterior.

Along the superior and inferior boundary lines of this area shallow limiting sulci usually develop (Fig. 589), and these furrows often pass posteriorly into little arched sulci polares, which are furrows of the operculated variety (see p. 646), called into existence by the broadening out of the area striata (not an actual broadening, but an unfolding) as it passes round the edge of the hemisphere.

At the point of transition from the deep sulcus calcarinus into the shallower sulcus calcarinus posterior (Fig. 588) a submerged ridge is usually found-the gyrus cuneolingualis anterior; and other similar ridges, which may be exposed on the

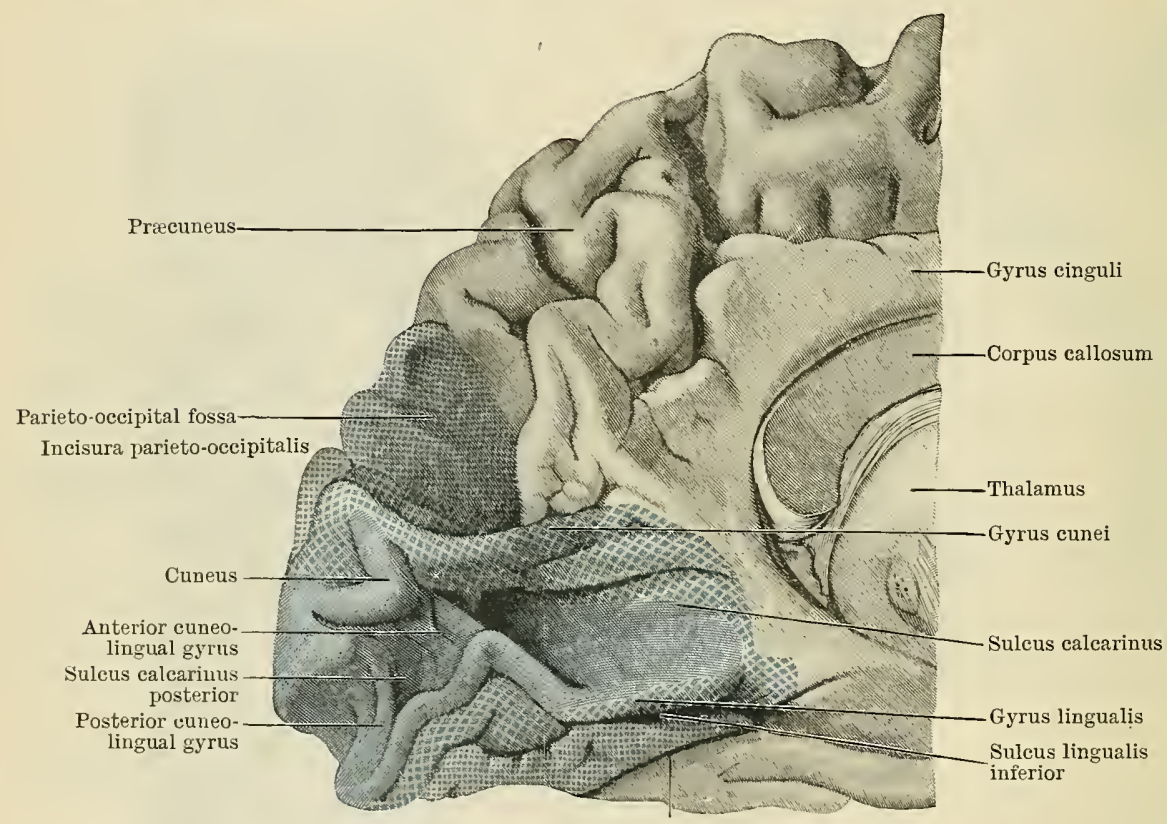

Fig. 588. - The Parieto-occipital and the Calcarine Sulci fully opened up, so as to show the deep transitional gyri marking off the several elements of the $\prec$-shaped system.

Area striata, uniform blue ; area parastriata, large blue spots ; area peristriata, fine blue dots.

surface or may be submerged, are often found interrupting the posterior and lateral calcarine sulci themselves (Fig. 588).

The posterior and lateral calcarine sulci are subject to a very wide range of variation in form, but they are always axial foldings of the area striata.

When the area striata crosses on to the lateral surface of the hemisphere a small semilunar furrow develops a short distance in front of its anterior edge. This is the sulcus lunatus. The larger the lateral extension the closer does the edge of the area striata approximate to the caudal lip of the sulcus, which under such circumstances assumes a definitely operculated form. Such cases occur most often in the left hemisphere and in the brains of primitive people; and they represent a perfect realisation of a furrow once supposed not to occur in the human brain, but to be distinctive of the ape. Hence it used to be called the "Affenspalte" or sulcus simialis.

The area striata is surrounded by two peripheral concentric bands-an inner, which may be called area parastriata, and an outer, the area peristriata. Sulci develop along the boundary lines of each of these areas; and those which indicate the superior and inferior limits of the peripheral band (i.e. peristriate area) 
make their appearance relatively early in development and become very deep furrows.

The inferior of these is placed upon the tentorial surface, and is known as the sulcus collateralis ; the superior limiting furrow of the visual territory (its peristriate part) is upon the superior surface of the hemisphere, and is usually regarded as the ramus occipitalis of the sulcus interparietalis. But it is genetically independent of the latter furrow, and may be distinguished as the sulcus paroccipitalis.

Near the supero-medial margin of the hemisphere there is a furrow, which indicates the line of demareation between the para- and the peristriate areas-the sulcus occipitalis paramedialis. It may be situated upon either the medial or the superior surface of the hemisphere. In some cases it belongs to the category of limiting sulci, in others to the group of operculated sulci (see p. 646).

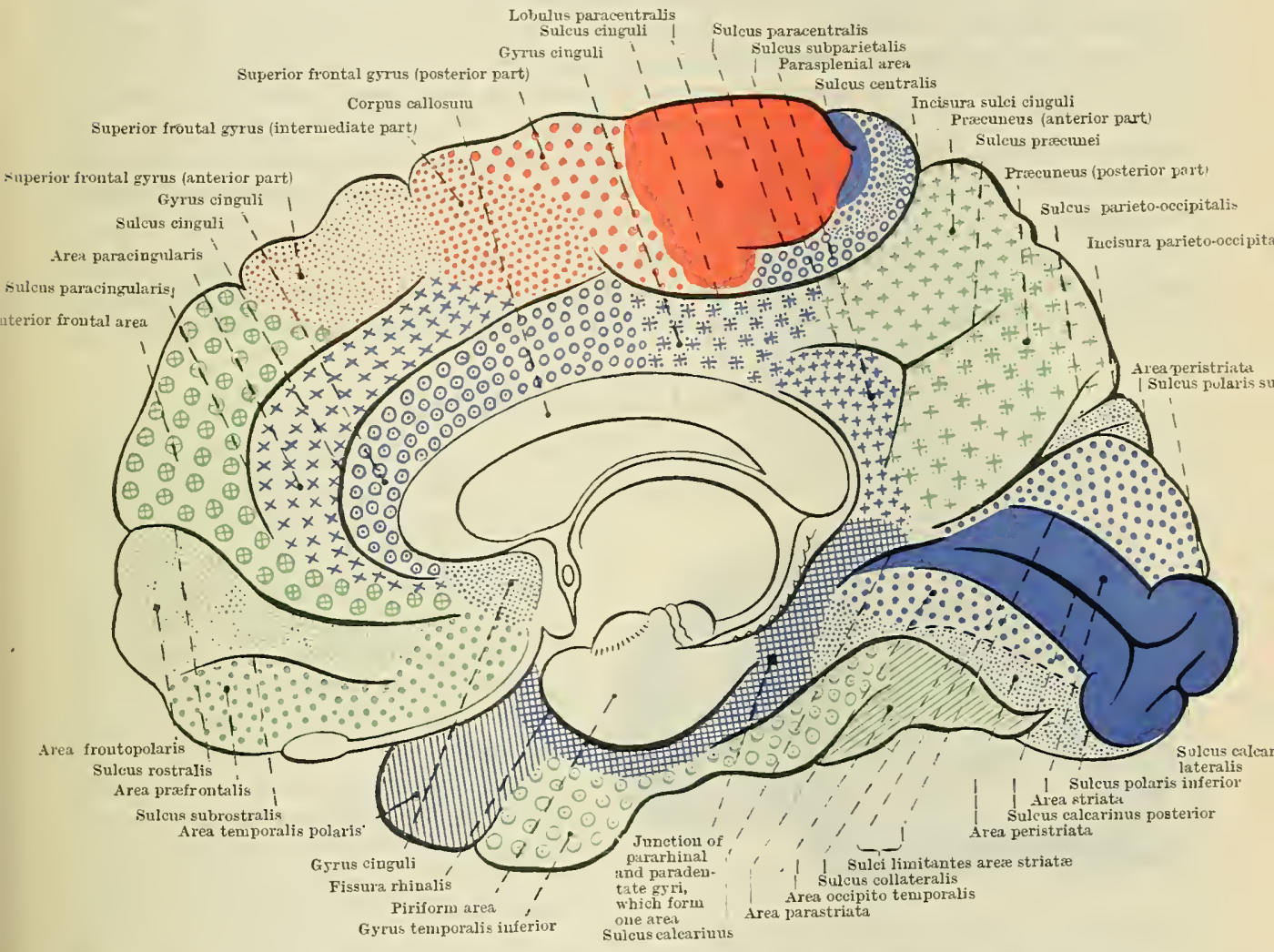

Fig. 589. - The Cortical Areas on the Medial Aspect of the Cerebral Hemisphere.

Passing horizontally forwards upon the lateral surface of the hemisphere there is a constant furrow formed by the axial folding of part of the peristriate area, approximately in line with the axial folding of the striate area (sulcus calcarinus lateralis); it is the sulcus occipitalis lateralis. When there is a fully developed sulcus lunatus the lateral occipital sulcus joins it near its midpoint (Fig. 581, p. 654).

The sulcus (or fossa) parieto-occipitalis (Fig. 554) is usually a deep furrow upon the medial aspect of the hemisphere which passes vertically downwards from the supero-medial border and appears to join the calcarine sulcus near its union with the posterior calcarine, forming upon the surface a $Y$-shaped pattern, the stem of which is calcarine, the limbs posterior calcarine and parieto-occipital respectively, and the wedge-shaped area between the limbs the cuneus (Fig. 588 ; compare with the pattern shown in Fig. 589, where the parieto-occipital sulcus is not labelled).

If, however, the lips of these three furrows are divaricated (Fig. 588), the parietooccipital depression will be found to be separated from the calcarine by a prominent 
submerged cortical ridge, the gyrus cunei; and the parieto-occipital will be found to be something more than a mere sulcus. It is, in fact, a great fossa in which are submerged the anterior parts of the area parastriata and area peristriata, and the posterior part of the parietal area known as the præcuneus, as well as the sulci which separate these territories one from the other. It is a great trough formed by the splenium of the corpus callosum as in the course of its development it thrusts itself backwards and crumples up the cortex. When the corpus callosum fails to develop, no parieto-occipital fossa makes its appearance. The part of the sulcus that notches the supero-medial border (Figs. 589 and 593) forms a distinct element, which Retzius has called the incisura parieto-occipitalis.

Sulcus Collateralis.-The collateral sulcus is a strongly marked furrow on the tentorial face of the cerebral hemisphere. It begins near the occipital pole and extends forwards towards the posterior end of the rhinal fissure, with which it sometimes becomes confluent. In its posterior part it is placed below, and parallel to, the calcarine fissure, from which it is separated by the lingual gyrus. From the posterior extremity a sulcus proceeds forwards and then laterally across the inferior surface of the occipital region, forming a $V$-shaped pattern with the collateral sulcus (Fig. 585). As it is serially homologous with the latter, being like it an inferior boundary of the area peristriata, it may be called the sulcus collateralis transversus. The lingual gyrus is sometimes subdivided by a furrow (sulcus sagittalis gyri lingualis) midway between the collateral sulcus and the inferior margin of the area striata. It is the line of demarcation between the parastriate and peristriate areas, and when deep is often mistaken for the collateral sulcus.

\section{THE PARIETAL REGION.}

We have seen that the acoustic pathway leads into the temporal region and the visual pathway into the occipital region. The facts of clinical medicine show

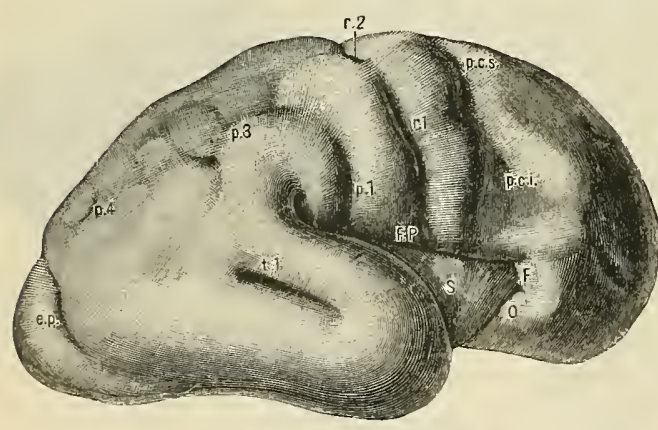

Fig. 590.-Left Cerebral Hemisphere, from a fœtus in the early part of the seventh month of development.

p.c.s. Sulcus præcentralis superior.

p.e.i. Sulcus præeentralis inferior.

$r^{2}$. Inferior part of central sulcus.

$\mathrm{r}^{2}$. Superior part of central sulcus.

$p^{1}$. Inferior postcentral sulcus.

$\mathrm{p}^{3}$. Sulcus interparietalis proprins.

$\mathrm{p}^{ \pm}$. Sulcus paroceipitalis.

$t^{1}$. Superior temporal suleus.

S. Lateral fossa.

F.P. Fronto-parietal wall.

F. Frontal wall.

o. Orbital wall. that large areas in these two regions beyond the limits of the cortex in which the acoustic and optic radiations end are concerned with the functions of hearing and vision. A large part of the parietal area is interposed between these temporal and occipital territories, and its integrity and normal functioning is a necessary condition for the proper performance of many acts, such as reading written or printed documents, in the acquisition of which both hearing and vision have played some part. But the parietal region also includes the cortical area in which a part, at least, of the chief thalamo-cerebral tract ends-the bundle of fibres that represents the third stage of the great sensory pathway, the first stage of which is formed by the spinal and cerebral sensory nerves and their central prolongations, and the second stage by the spino-thalamic, bulbo-

thalamic, and ponto-thalamic fasciculi, which pass upwards in the medial lemniscus and end in the ventral nucleus of the thalamus (Figs. 579 and 580).

The sensory area in question forms part of the gyrus centralis posterior, which intervenes between two oblique furrows, the sulcus centralis and the sulcus postcentralis, which extend across the whole breadth of the hemisphere above the sulcus lateralis (Fig. 581).

Sulcus Centralis.-During the sixth and seventh months of foetal life the expand- 
ing posterior central area becomes raised up into a prominent ridge, and a similar ridge is formed immediately in front of it (Fig. 590) from the area which emits the great efferent or motor tract to control all the motor nuclei upon the other side of the brain and spinal medulla. As these ridges become raised up a depression is left between them: this is the sulcus centralis. At first it consists of two parts, a superior and an inferior (Fig. 590, $\mathrm{r}^{2}$ and $\mathrm{r}^{1}$ ); but as a rule these become confluent later.

The sulcus centralis in the adult takes an oblique course across the lateral convex surface of the cerebral hemisphere, and intervening between the frontal and parietal regions it forms the immediate posterior boundary of the motor area of the cortex. Its upper end cuts the supero-medial border of the hemisphere a short distance behind the mid-point between the frontal and occipital poles, whilst its inferior end terminates above the middle of the posterior ramus of the lateral fissure. Its superior extremity, as a rule, turns round the supero-medial border of the hemisphere, and is then continued backwards for a short distance on the medial surface. Although, in its general direction, the sulcus is oblique, it is very far from being straight. It takes a sinuous course across the hemisphere. This is largely due to the varying breadth of the motor areas representing the leg, trunk, arm, and head respectively, which are placed immediately in front of it.

When the sulcus centralis is widely opened up, so that its bottom and its opposed sides may be fully inspected, it will be seen that the two bounding gyri are dovetailed into each other by a number of interlocking gyri, which do not appear on the surface (Fig. 591). Further, two of these, placed on opposite sides of the fissure, are frequently joined across the bottom of the sulcus in the form of a sunken bridge of connexion, which constitutes what is termed a deep transitional gyrus. The continuity of the sulcus is thus, to some extent, interrupted. This condition is rendered interesting when considered in connexion with the development of the sulcus. The deep interlocking gyri indicate a great exuberance of cortical growth in this situation in the early stages of the develop-

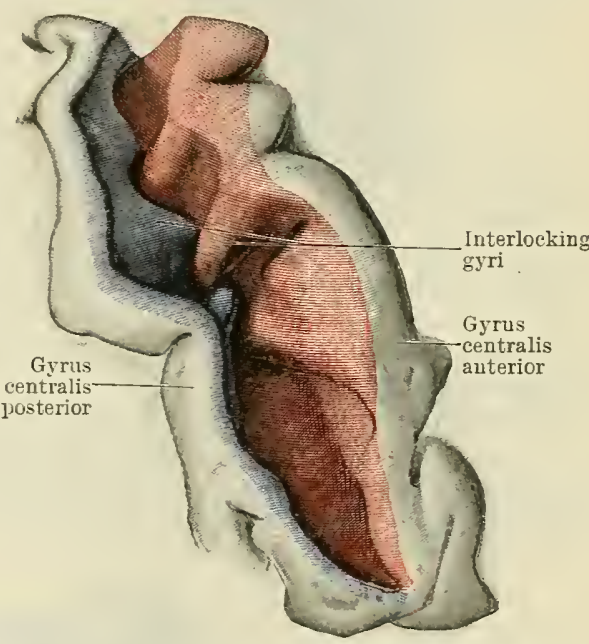

Fig. 591.-Sulcus Cextralis fully opexed UP, so as to exhibit the interlocking gyri and deep transitional gyrus within it.

Motor cortex coloured red, sensory cortex blue. ment of the sulcus; and the presence of the deep transitional gyrus is explained by the fact that the sulcus generally develops in two pieces, which run into each other to form the continuous sulcus of the adult, viz., a part corresponding to the inferior two-thirds, and a superior part, which represents the superior third and which appears at a slightly later date. In certain very rare cases the sulcus centralis is found to remain double throughout life, throngh a failure of its two pieces to unite. In such cases the deep transitional gyrus, which is frequently seen at the bottom of the furrow, remains on the surface. Heschl, who examined 2174 cerebral hemispheres, found this anomaly only six times; Eberstaller met with it twice in 200 brains.

If a section is made at right angles to this sulcus in a fresh brain (Fig. 592), it will be seen that its anterior (gyrus centralis anterior) and posterior (gyrus centralis posterior) walls present a marked contrast the one to the other, and that the transition from the one type of cortex to the other takes place precisely at, or near to, the bottom of the sulcus. The anterior wall is composed of thick ( 3.5 to $4 \mathrm{~mm}$.) motor cortex thickly laden with medullary matter arranged in the form of three or four pale bands with blurred edges and multitudes of fine pencils of fibres passing to and fro between it and the white matter of the hemisphere. The posterior wall is composed of thin $(1.5 \mathrm{~mm}$.) cortex containing two narrow and sharply defined white lines.

This sensory area forms little more than the posterior wall of the sulcus centralis, and barely emerges upou the surface to form the posterior lip of the sulcus (Fig. 581). Here it becomes continuous with a slightly thicker cortex with 
doubled lines which are less dense than those of the sensory cortex; this area forms the crest of the gyrus centralis posterior, and then gives place to another slightly modified type of cortex which forms the anterior wall of the sulcus postcentralis. Thus the sensory cortex has two fringing bands analogous to those already noticed alongside the visual and acoustic areas.

The motor and sensory areas cross on to the medial aspect of the hemisphere,

Sulcus centralis

Sulcus centralis
Gyrus centralis anterior $\mid$ Gyrus centralis posterior

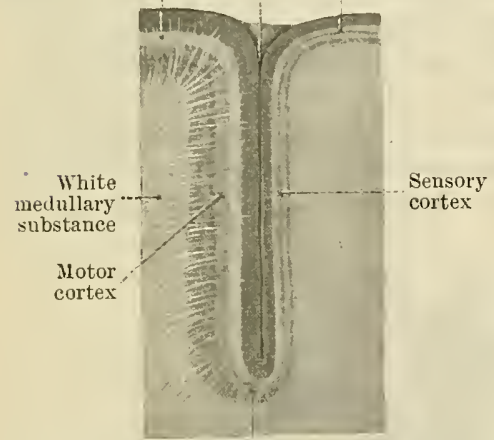

Boundary line between motor and sensory cortex

Fig. 592.-Section across the Superior Part of the Sulcus Centralis in a Fresh Brain.

and the sulcus paroccipitalis (ramus occipitalis transversus.

These four furrows develop quite independently one of the other, the postcentral sulci as the posterior boundary of the sensory territory, the paroccipital sulcus as the supero-lateral boundary of the visual territory, and the more variable horizontal ramus (the sulcus interparietalis, in the strict sense of the term) as a demarcation

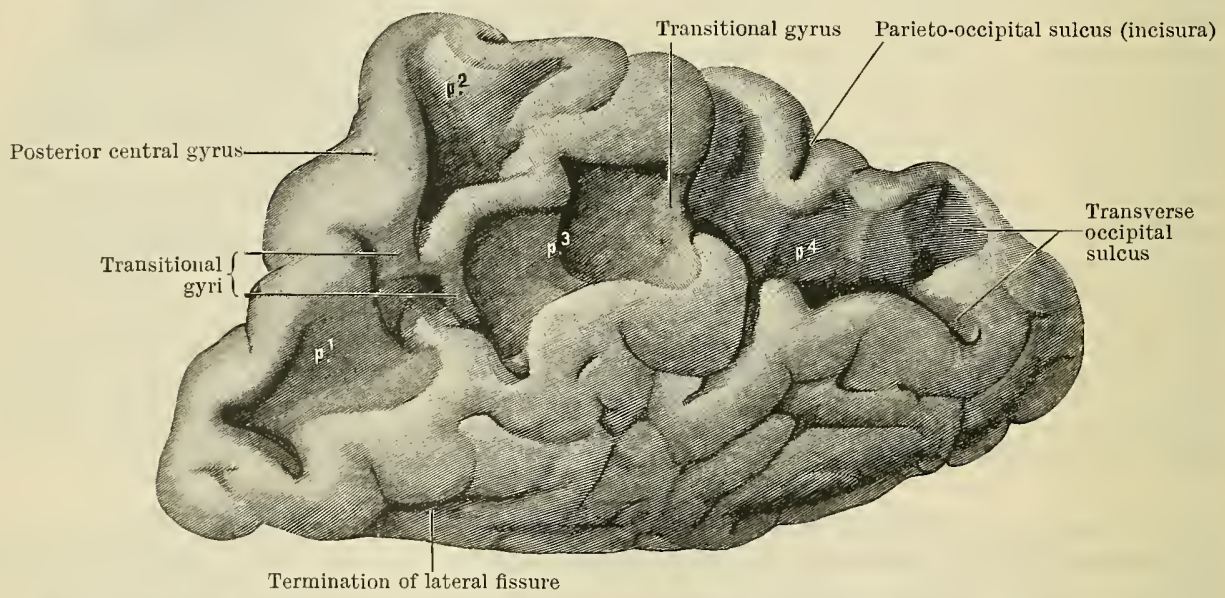

Fig. 593.-The Four SUlci of the Interparietal Complex opened up, so as to show the deep transitional gyri intervening between them.

$\mathrm{p}^{1}$. Sulcus postcentralis inferior.

$\mathrm{p}^{2}$. Sulcus postcentralis superior.

$\mathrm{p}^{3}$. Ramus horizontalis (sulcus interparietalis proprins). $\mathrm{p}^{4}$. Ramus oceipitalis (suleus paroccipitalis).

between the two parietal lobules. The four furrows may unite to form any possible combination.

The superior parietal lobule is composed of moderately thick cortex ( 2.5 to $3 \mathrm{~mm}$.) placed between the interparietal sulcus (ramus horizontalis) and the superior border of the hemisphere, where it becomes continuous on the medial surface with the precuneus. Each of these parts is subdivided by a transverse sulcus, the 
superior lobule by the sulcus parietalis superior and the precuneus by the sulcus præcunei (Fig. 589).

The latter sulcus usually joins a small inverted U-shaped furrow (sulcus subparietalis), which encloses a cortical territory of distinctive structure-the area parasplenalis [præcunei].

The inferior parietal lobule, which from its position is the natural meeting-place for impressions coming from the visual, acoustic, and tactile territories, is naturally a region of great functional significance. It is composed of a series of areas differing in thickness and texture. The anterior region forms a convolution (gyrus supramarginalis) surrounding the upturned extremity of the lateral fissure; behind it there is a second convolution called the gyrus angularis, which surrounds a vertical sulcus angularis, often described as the extremity of the sulcus temporalis superior; but in reality it is quite independent of the latter furrow, but it often becomes confluent with it. Behind the gyrus angularis and separated from it by a transverse furrow (sulcus occipitalis anterior) there is a cortical territory (area parietooccipitalis) which may perhaps be looked upon as a specialised and outlying part of the peristriate area of the visual cortex.

\section{THE FRONTAL REGION.}

The frontal region is the biggest of the main cortical areas-the so-called "lobes." On the lateral surface of the hemisphere, it is bounded behind by the sulcus centralis and below in part by the lateral fissure. It presents a lateral surface, a medial surface, and an inferior or orbital surface.

On its lateral aspect the surface is broken up by a large series of furrows, which exhibit considerable variability.

The inferior precentral sulcus consists of a vertical and an oblique part. The vertical portion lies in front of the inferior part of the sulcus centralis, whilst the oblique part extends forwards and upwards (Fig. 594).

The superior precentral sulcus is a short vertical sulcus which lies at a higher level than the inferior precentral sulcus, in front of the upper part of the sulcus centralis. It is almost invariably connected with the posterior end of the superior frontal sulcus.

The anterior central gyrus is a long continuous gyrus, which is limited in front by the two precentral furrows and behind by the sulcus centralis. Inferiorly it is continuous with the area subcentralis which links it to the posterior central gyrus, which is limited in front and behind by the anterior and posterior subcentral sulci (not labelled in Fig. 594).

The superior frontal sulcus extends forwards in a more or less horizontal direction from the sulcus præcentralis superior.

The gyrus frontalis superior is the narrow convolution between the supero-medial border of the hemisphere and the superior frontal sulcus and the continuation of this convolution into a broad area upon the medial surface.

The inferior frontal sulcus occupies a lower level than the superior frontal sulcus. Its posterior end is placed in the angle between the vertical and horizontal parts of the inferior precentral sulcus, and is not infrequently confluent with one or other of these. It proceeds forwards towards the superciliary margin of the hemisphere and ends a short distance from this in a terminal bifurcation (Fig. 594).

The gyrus frontalis medius is the name given to the broad convolution which lies between the superior and inferior frontal sulci.

The gyrus frontalis inferior is that portion of the lateral surface of the frontal region which is placed in front of the inferior precentral sulcus and below the inferior frontal sulcus. The inferior frontal convolution includes three cortical areas (Fig. 594) differing in structure the one from the other. The sulcus diagonalis separates the intermediate of these from the posterior.

The sulcus frontalis medius begins midway between the anterior ends of the superior and inferior frontal sulci and proceeds obliquely forwards towards the frontal pole. When the furrow reaches the superciliary margin of the hemisphere it ends near a transverse furrow, called the fronto-marginal sulcus. 
On the medial aspect of the frontal lobe there are two convolutions, the larger peripheral area which forms part of the gyrus frontalis superior and a smaller inner part encircling the corpus callosum, which is called the gyrus cinguli. These gyri are separated by the sulcus cinguli (Fig. 589).

The posterior part of the sulcus cinguli is genetically distinct from the anterior part-and it circumscribes a broader area, the lobulus paracentralis, which is continuous with the gyri centrales.

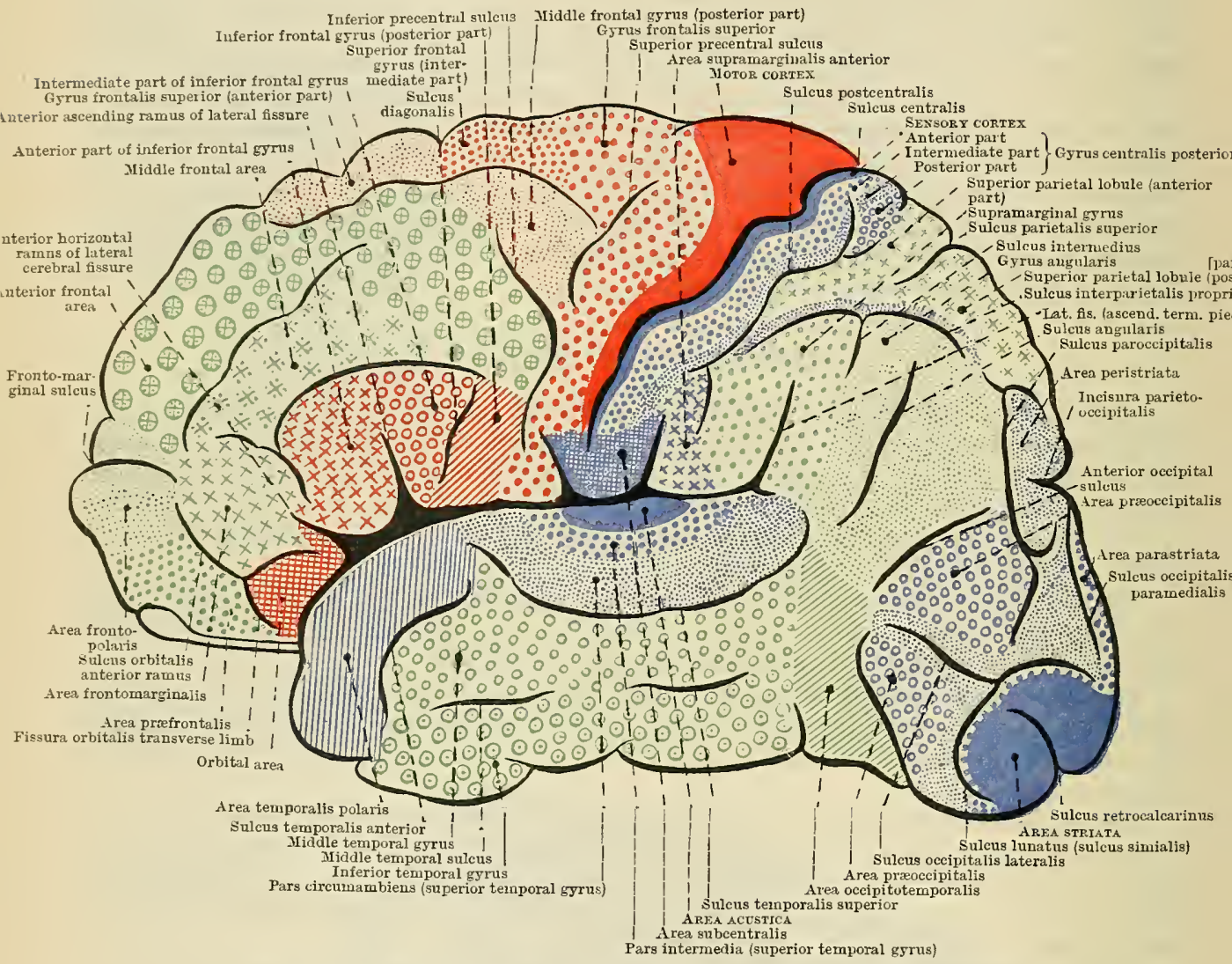

Fig. 594.-Areas on lateral Aspect of Left Cerebral Hemisphere.

The superior, middle, and inferior frontal sulci are not labelled. The middle is in the midst of the green area, the superior and inferior respectively at its superior and inferior boundaries.

On the orbital aspect of the frontal region there are two sulci, viz., the olfactory and the orbital.

The olfactory sulcus is a straight furrow which runs parallel to the medial border of the hemisphere. It is occupied by the olfactory tract and bulb, and it cuts off a narrow strip of the orbital surface close to the medial border, which receives the name of gyrus rectus.

The orbital sulcus is a composite furrow which assumes many different forms. It consists essentially of a $U$-shaped furrow, the convexity of which is directed anteriorly (Fig. 585), and one or two variable branches passing forwards from it.

The conventional manner of subdividing the cortical territory anterior to the sulcus centralis into gyri, which has just been sketched, is apt to convey a misleading idea of the distribution of the anatomical areas of differentiated cortex.

The gyrus centralis anterior together with the major portion of the paracentral lobule and the posterior part of the middle and superior frontal gyri form a natural subdivision of the cortex, which Brodmann calls the regio præcentralis. It is composed of a series of areas of different structure, which may be grouped as the area præcentralis posterior (the true motor area), the area præcentralis intermedius, and 
the area præcentralis anterior (Fig. 594). Most of the motor area is hidden in the sulcus centralis, but towards the supero-medial margin of the hemisphere a considerable area emerges upon the surface of both the gyrus centralis anterior and the paracentral lobule.

Brodmann calls the rest of the frontal territory the regio frontalis; but in the colour scheme adopted in Figs. 585, 589, and 594 the inferior frontal gyrus and the orbital area posterior to the orbital sulcus have been associated with the "precentral" rather than the "frontal" regions.

\section{WeIGHT OF the BraiN.}

The average weight of the adult male brain may be said to be about 1360 grammes. The female brain weighs rather less, but this is to be expected from the smaller bulk of the female body. Probably the relative weight of the brain in the two sexes is very much the same. The variations met with in brain-weight are very great, but it is doubtful if normal intellectual functions could be carried on in a brain which weighs less than 960 grammes. In microcephalic idiots brains of extremely small size are met with.

\section{THE MENINGES OF THE ENCEPHALON AND MEDULLA SPINALIS.}

The brain and spinal medulla are enclosed within three membranes, which are termed the meninges or meningeal membranes. From without inwards these are: (1) the dura mater, (2) the arachnoid, and (3) the pia mater. The space between the dura mater and the arachnoid receives the name of subdural space, while the much more roomy interval between the arachnoid and the pia mater is called the subarachnoid space.

\section{DURa Mater.}

The dura mater is a dense and thick fibrous membrane which possesses a very considerable degree of strength. Its arrangement within the cranial cavity is so different from that within the vertebral canal that it is customary to speak of it as consisting of two parts, viz., a cranial and a vertebral, although in adopting this subdivision it must be clearly understood that both portions are continuous with each other at the foramen magnum.

Dura Mater Encephali.-The cranial dura mater is adherent to the inner surface of the cranial wall, and performs a double office. It serves as an internal periosteum for the bones which it lines and constitutes an envelope for the brain. Its inner surface, which bounds the subdural space, is smooth and glistening, and is covered with a layer of endothelial cells. The outer surface when separated from the cranial wall, is rough, this being due to numerous fine fibrous processes and blood-vessels which pass between it and the bones. Its degree of adhesion to the cranial wall differs considerably in different regions. To the vault of the cranium, except along the lines of the sutures, the connexion is by no means strong, and in the intervals between the fibrous processes which pass into the bone there are small lymph spaces (epidural spaces) where the outer surface of the membrane is covered by endothelial cells. So long as the sutures are open the dura mater is connected with the periostem on the exterior of the skull, along the sutural lines, by a thin layer of fibrous tissue which intervenes between the bony margins. Around the foramen magnum, and to the floor of the cranium, the dura mater is very firmly adherent. This is more particularly marked in the case of the projecting parts of the cranial floor, as, for example, the petrous portions of the temporal bones, the clinoid processes, and so on. This firm adhesion in these regions is still further strengthened by the fact that the nerves, as they leave the cranium through the various foramina, are followed by sheaths of the fibrous dura 
mater. Outside the cranium these prolongations of the membrane blend with the fibrous sheaths of the nerves, and likewise become connected with the periosteum on the exterior of the skitl. In the child, during the growth of the cranial bones, and also in old age, the dura mater is more adherent to the cranial wall than during the intermediate portion of life.

The cranial dura mater is composed of two layers intimately connected with each other, but yet capable of being demonstrated in most regions of the cranium. Along certain lines these two layers separate from each other so as to form channels lined with endothelium. These channels are the venous blood-sinuses which receive the blood from veins which come from various parts of the brain. They are described in the section dealing with the Vascular System.

Strong fibrous partitions or septa are given off along certain lines from the deep

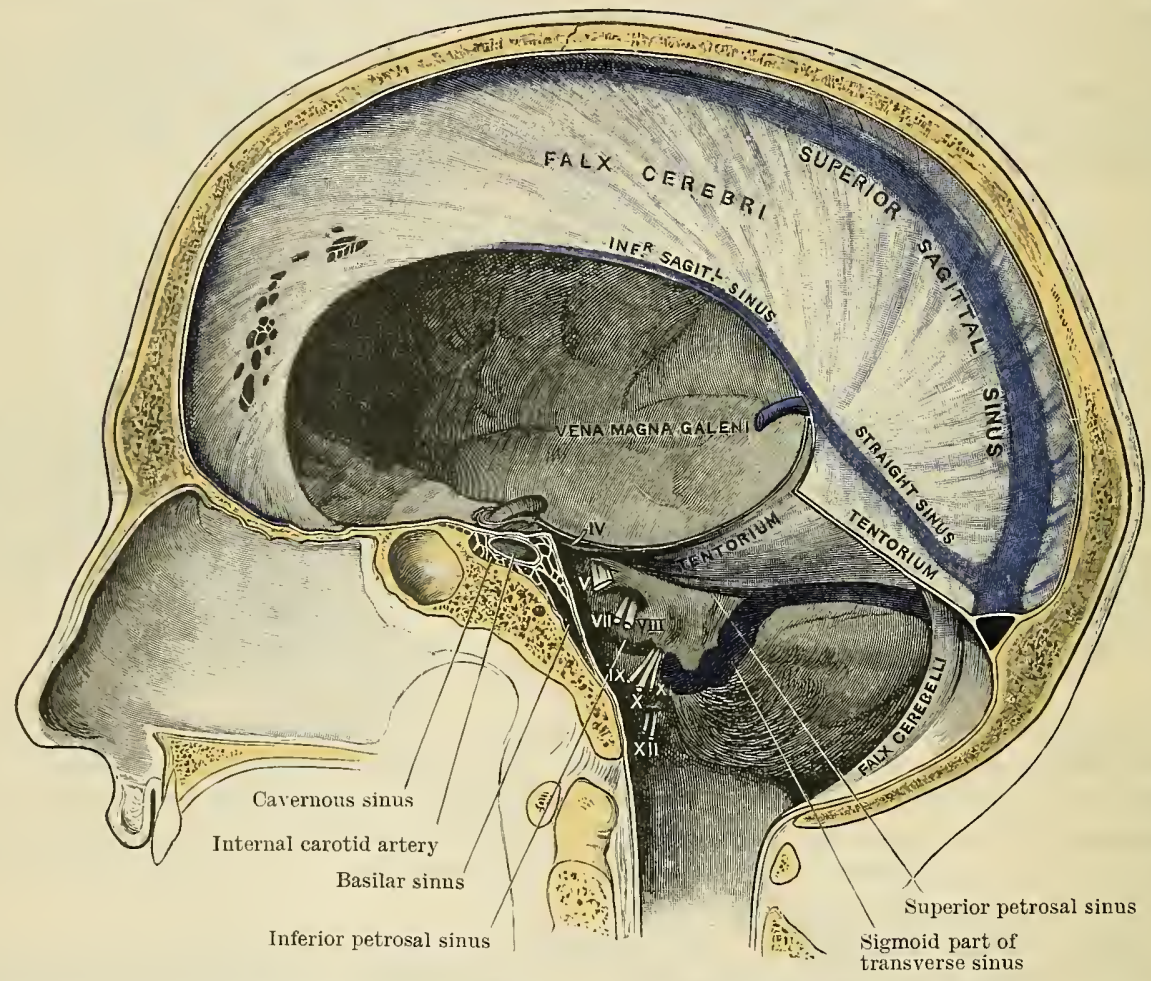

Fig. 595. - Sagittal Section throdgh the Skull, a little to the Left of the Median Plane to show the arrangement of the dura mater.

The cerebral nerves are indicated by nunerals.

surface of the dura mater. These project into the cranial cavity, and subdivide it partially into compartments which all freely communicate with each other, and each of which contains a definite subdivision of the brain. These septa are: (1) the falx cerebri; (2) the tentorium cerebelli; (3) the falx cerebelli; and (4) the diaphragma sellæ.

The falx cerebri is a sickle-shaped partition which descends in the great longiludinal fissure between the two hemispheres of the cerebrum. In front it is narrow, and attached to the crista galli of the ethmoid bone. As it is followed backwards it increases in breadth, and behind it is attached along the median plane to the upper surface of the tentorium. The anterior narrow part of the falx is frequently cribriform, and is sometimes perforated by apertures to such an extent that it almost resembles lace-work. Along each border it splits into two layers, so as to enclose a blood-sinus. Along its superior convex attached border runs the superior sagittal sinus; along its concave free border sometimes courses the much smaller inferior 
sagittal sinus; whilst along its attachment to the tentorium is enclosed the straight sinus.

The tentorium cerebelli is a large crescentic partition of dura mater, which forms a membranous tent-like roof for the posterior cranial fossa, and thus intervenes between the posterior portions of the cerebral hemispheres and the cerebellum. It is accurately applied to the superior surface of the cerebellum. Thus its highest point is in front and in the median plane, and from this it slopes downwards towards its attached border. It is kept at a high degree of tension, and this depends on the integrity of the falx cerebri, which is attached to its superior aspect in the median plane.

The posterior border of the tentorium is convex, and is attached to the horizontal ridge which marks the deep surface of the occipital bone. Beyond this, on each side, it is fixed to the postero-inferior angle of the parietal bone, and then forwards along the superior border of the petrous portion of the temporal bone. From the internal occipital protuberance to the postero-inferior angle of the parietal bone this border encloses the sinus transversus, whilst along the superior border of the petrous bone it encloses the superior petrosal sinus. The anterior border of the tentorium is sharp, free, and concave, and forms with the dorsum sellæ an oval opening shaped posteriorly like a pointed arch. This opening receives the name of the incisura tentorii, and within it is placed the mesencephalon, or the stalk of connexion between the parts which lie in the posterior cranial fossa and the cerebrum. Beyond the apex of the petrous part of the temporal bone the two margins of the tentorium cross each other like the limbs of the letter $X$; the free margin is continued forwards, to be attached to the anterior clinoid process, whilst the attached border proceeds medially, to be fixed to the posterior clinoid process.

The falx cerebelli is a small, sickle-shaped process of dura mater placed below the tentorium, which projects forwards in the median plane from the internal occipital crest. It occupies the notch which separates the two hemispheres of the cerebellum posteriorly. Inferiorly it bifurcates into two small diverging ridges which gradually fade away as they are traced forwards on each side of the foramen magnum.

The diaphragma sellæ is a small circular fold of dura mater which forms a roof for the fossa hypophyseos. A small opening is left in its centre for the transmission of the infundibulum.

Dura Mater Spinalis.-In the vertebral canal the dura mater forms a tube which encloses the spinal medulla, and which extends from the foramen magnum above to the level of the secund or third piece of the sacrum below. It is very loosely applied to the spinal medulla and the nerve-roots which form the cauda equina; in other words, it is very capacious in comparison with the volume of its contents. Moreover, its calibre is not uniform. In the cervical and lumbar regions it is considerably wider than in the thoracic region, whilst in the sacral canal it rapidly contracts, and finally ends by blending with the filum terminale externum, the chief bulk of which it forms. At the superior end of the vertebral canal the spinal dura mater is firmly fixed to the third cervical vertebra, to the epistropheus vertebra, and around the margin of the foramen magnum. In the sacral canal the filum terminale externum, with which it blends, extends downwards to the back of the coccyx, to the periostem of which it is fixed. The inferior end of the tube is thus securely anchored and held in its place.

Within the cranial cavity the dura mater is closely adherent to the bones, and forms for them an internal periosteum. As it is followed into the vertebral canal its two constituent layers separate. The inner layer is carried downwards as the long cylindrical tube which encloses the spinal medulla. The outer layer, which is much thinner, becomes continuous behind and on each side of the foramen magnum with the periosteum on the exterior of the cranium, whilst in front it is prolonged downwards into the vertebral canal in connexion with the periosteum and ligaments on the anterior wall of the canal. The spinal dura mater, therefore, corresponds to the inner layer of the cranial dura mater, and to it alone. It is separated from the walls of the vertebral canal by an interval, the cavum epidurale, which is occupied by 
soft fat and a plexus of thin-walled veins. In connexion with the spinal dura mater there are no blood-sinuses such as are present in the cranial cavity, but it should be noted that the veins in the epidural space, placed as they are between the periosteum of the rertebral canal and tube of dura mater, occupy the same morphological plane as the cranial blood-simuses. Another feature which serves to distinguish the spinal dura mater from the cranial dura mater consists in the fact that it gives off from its deep surface no partitions or septa.

The cylindrical tube of spinal dura mater does not lie absolutely free within the vertebral canal. Its attachments, however, are of such a character that they in no way interfere with the free movement of the vertebral column. On each side the spinal nerve-roots, as they pierce the dura mater, carry with them into the intervertebral foramina tubular sheaths of the membrane, whilst in front loose fibrous prolongations - more numerous above and below than in the thoracic regionconnect the tube of dura mater to the posterior longitudinal ligament of the vertebral column. No connexion of any kind exists between the dura mater and the posterior wall of the vertebral canal.

When the interior of the tube of spinal dura mater is inspected, the series of apertures of exit for the roots of the spinal nerves is seen. These are ranged in pairs opposite each intervertebral foramen.

Viewed from the inside of the tube of dura mater, each of the two roots of a spinal nerve is seen to carry with it a special and distinct sheath. When examined on the outside, however, the appearance is such that one might be led to conclude that both roots are enveloped in one sheath of dura mater. This is due to the fact that the two sheaths are firmly held together by intervening connective tissue. The two tubular sheaths remain distinct as far as the ganglion on the posterior root, and then blend with each other.

Cavum Subdurale.-The dura mater and the arachnoid are closely applied to each other, and the capillary interval between them is termed the subdural space. It contains a minute quantity of fluid, which is just sufficient in amount to moisten the opposed surfaces of the two bounding membranes.

The subdural space in no way communicates with the subarachnoid space. The fluid which it contains is led into the venous blood-sinuses around the arachnoideal granulations (O.T. Pacchionian bodies), and thus gains exit. The subdural space is carried outwards for a very short distance on the various nerves which are connected with the brain and the spinal medulla, and it has a free communication with the lymph-paths present in these nerves. In the case of the optic nerve the sheath of dura mater is carried along its whole length, and with it the subdural space is likewise prolonged to the back of the eyeball.

\section{ARACHNOIDEA.}

The arachnoid is a very thin membrane, remarkable for its delicacy and transparency, which envelopes both the brain and the spinal medulla between the dura mater and the pia mater. The cranial part of the arachnoid or the arachnoidea encephali, except in the case of the longitudinal and the lateral fissures, does not dip into the sulci on the surface of the brain. In this respect it differs from the pia mater. It bridges over the inequalities on the surface of the brain. Consequently, on the basal aspect of the encephalon it is spread out in the form of a very distinct sheet over the medulla oblongata, the pons, and the hollow which lies in front of the pons, and in certain of these regions it is separated from the brainsurface by wide intervals.

The spinal part of the arachnoid or arachnoidea spinalis, which is directly continuous with the cranial arachuoidea, forms a loose wide investment for the spinal medulla. This arachnoideal sac is most capacious towards its inferior part, where it envelopes the inferior end of the spinal medulla and the collection of long nerve-roots which constitute the cauda equina.

As the nerves, both from the brain and the spinal medulla, pass outwards they receive an investment from the arachnoid, which runs for a short distance upon them and then comes to an end. 
Cavum Subarachnoideale.-The interval between the arachnoidea and the pia mater receives the name of the subarachnoid space. It contains the cerebro-spinal fluid, and communicates freely through certain well-defined apertures with the ventricular cavities in the interior of the brain (aperturæ ventriculi quarti).

Within the cranium the subarachnoid space is broken up by a meshwork of fine filaments and trabeculæ, which connects the two bounding membranes (viz., the arachnoidea and the pia mater) in the most intimate manner, and forms a delicate sponge-like interlacement between them. Where the arachnoidea passes over the summit of a cerebral convolution, and is consequently closely applied to the subjacent pia mater, the meshwork is so dense and the trabeculæ so short that it is hardly possible to discriminate between the two membranes. To all intents and purposes they form in these localities one lamina. In the intervals between the rounded margins of adjoining convolutions, however, distinct angular spaces exist, where the subarachnoid trabecular tissue can be studied to great advantage. These

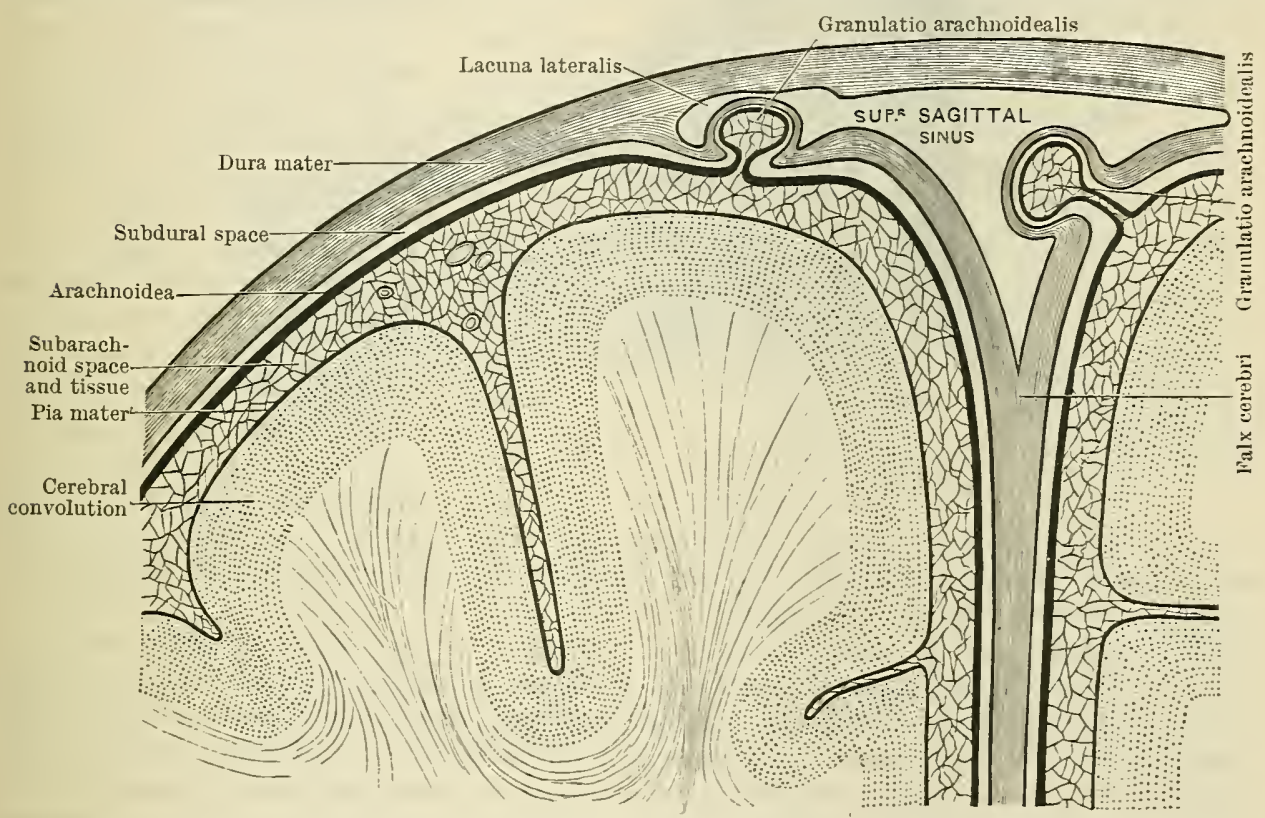

Fig. 596.-Diagray to show the relations of the membranes of the brain to the cranial wall and the cerebral convolutions, and also of the arachnoideal granulations to the superior sagittal sinus and the lateral lacunæ.

intervals on the surface of the cerebrum constitute numerous communicating channels which serve for the free passage of the subarachnoid fluid from one part of the brain to another. The larger branches of the arteries and veins of the brain traverse the subarachnoid space; their walls are directly connected with the subarachnoid trabeculæ, and are bathed by subarachnoid fluid.

In certain situations within the cranium the arachnoidea is separated from the pia mater by intervals of considerable width and extent. These expanded portions of the subarachnoid space are termed cisternæ subarachnoideales. In these the subarachnoid tissue is much reduced. There is no longer a close meshwork; the trabeculæ connecting the two bounding membranes take the form of long filamentous intersecting threads which traverse the spaces. All the subarachnoid cisterns communicate in the freest manner with each other and also with the narrow channels on the surface of the cerebrum.

Certain of these cisterns require special mention. The largest and most conspicuous is the cisterna cerebellomedullaris. It is formed by the arachnoid membrane bridging over the wide interval between the posterior part of the inferior surface of the cerebellum and the medulla oblongata. It is continuous 
through the foramen magnum with the posterior part of the wide subarachnoid space of the spinal medulla.

The cisterna pontis is the continuation upwards on the floor of the cranium of the anterior part of the subarachnoid space of the spinal medulla. In the region of the medulla oblongata it is continuous behind with the cisterna cerebellomedullaris, so that this subdivision of the brain, like the spinal medulla, is

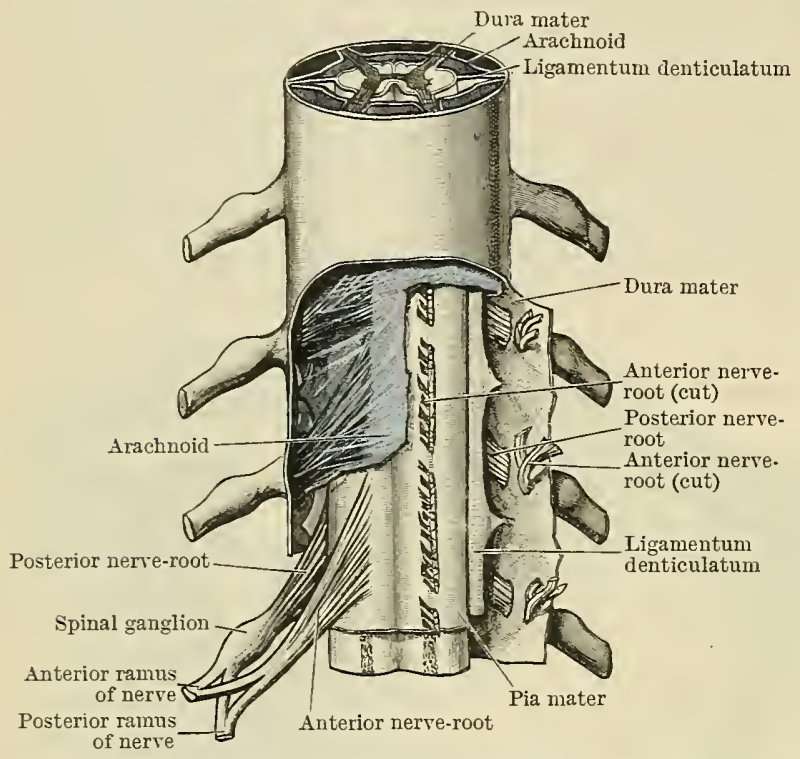

Fig. 597.-Membraves of the Spinal Medolla, aNd the mode of ORIGIN OF tHE SPINAL NeRTES. surrounded by a wide subarachnoid space.

In front of the pons the arachnoidea bridges across between the projecting temporal lobes, and covers in the deep hollow in this region of the brain. This space is called the cisterna interpeduncularis, and within it are placed the large arteries which take part in the formation of the arterial circle (of Willis). Leading out from the interpeduncular cistern there are certain wide subarachnoid channels. Two of these are prolonged into the lateral fissures, and in these are accommodated the middle cerebralarteries. Anteriorly the interpeduncular cistern passes into a space in front of the optic chiasma.(cisterna chiasmatis), and from this it is continued into the longitudinal fissure above the corpus callosum. In this subarachnoid passage the anterior cerebral arteries are lodged.

The spinal part of the subarachnoid space is a very wide interval which is partially subdivided into compartments by three incomplete septa. One of these is a medial partition called the septum posterius, which connects the pia mater covering the posterior aspect of the spinal medulla with the arachnoid. In the upper part of the cervical region the septum posterius is imperfect, and is merely represented by some strands passing between the two membranes; in the inferior part of the cervical region and in the thoracic region it becomes tolerably complete. The other two septa are formed by the ligamenta denticulata which spread laterally one from each side of the spinal medulla. These will be described with the pia mater.

Granulationes Arachnoideales.-When the surface of the dura mater is inspected after the removal of the calvaria, a number of small fleshy-looking excrescences, purplish-red in colour, are seen ranged in clusters on each side of the superior sagittal sinus, and when this sinus is opened they are also observed protruding in considerable numbers into its interior. These are the arachnoideal granulations (O.T. Pacchionian bodies), and they are also found in smaller numbers and distinctly smaller size in connexion with other blood-sinuses, such as the transverse sinus, the straight sinus, and the cavernous sinus. At first sight they appear to belong to the dura mater, but in reality they are projections from the arachnoid. In the child they are exceedingly small and rudimentary, and it is only as life advances that they become large and conspicuous.

Each granulation is a bulbous protrusion of the arachnoid. It is attached to the arachnoid by a narrow pedicle, and into its interior is prolonged through this a continuation of the subarachnoid space and its characteristic meshwork. The granulations do not pierce the dura mater. As they push their way into a blood-sinus they carry before them a thin covering continuous with the 
sinus wall. On each side of the superior sagittal sinus there is a number of irregular spaces in the dura mater which communicate with the sinus either by a small aperture or a narrow channel. These spaces are called the lacunæ laterales, and certain of the meningeal veins and some of the diploic veins open into them. Granulations push themselves into the lateral lacunæ from below in such a manner that they receive a complete covering from the layer of dura mater which forms the sinus floor. Nor does the bone escape. As the granulations enlarge they cause absorption of the cranial wall, and small pits are hollowed out on its internal surface for their reception. It must be clearly understood, however, that in such cases the granulation is separated from the bone by the following:-(1) A continuation round the granulation of the subdural space; (2) the thinned floor of the lateral lacuna; (3) the lumen of the sinus; and (4) the greatly thinned upper wall of the sinus.

The granulations have a special function to perform. Through them fiuid can pass from the subarachnoid space into the venous sinuses with which they stand in connexion. Whenever the pressure of blood in the sinuses is lower than that of the fluid in the subarachnoid space and the ventricles of the brain, the cerebro-

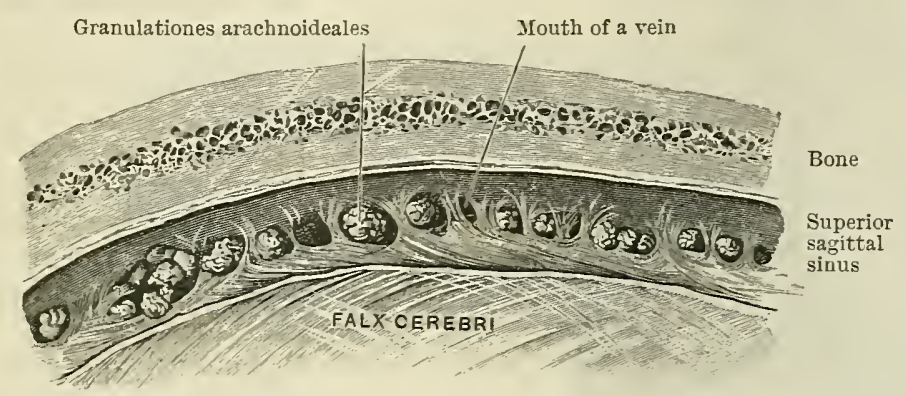

Fig. 598.- Mediax Section throdgh the Cranial Vault in the Frontal Regiox. Displays a portion of the superior sagittal sinus and the arachnoideal granulations protruding into it (enlarged).

spinal fluid filtrates through the granulations into the blood-sinuses. This is not the only way that subarachnoid fluid may obtain exit. The subarachnoid space is carried outwards for a short distance on the nerves in connexion with their arachnoideal sheaths, and communicates with the lymph channels of the nerves. This connexion is more complete in the case of the olfactory, the optic, and the acoustic nerves than in other nerves. A very free communication between the subarachnoid space and the lymph-vessels of the nasal mucous membrane is said to exist.

\section{The Pia Mater.}

The pia mater forms the immediate investment of the brain and spinal medulla. It is a delicate and very vascular membrane.

Pia Mater Encephali.-The pia mater which covers the brain is finer and more delicate than that which clothes the spinal medulla. It follows closely all the inequalities on the surface of the brain, and in the case of the hemisphere it dips into each sulcus in the form of a fold which lines it completely. On the cerebellum the relation is not so intimate; it is only into the larger fissures that it penetrates in the form of folds.

The larger blood-ressels of the brain lie in the subarachnoid space. The finer twigs ramify in the pia mater before they proceed into the substance of the brain. As they enter they carry with them sheaths derived from the pia mater. When a portion of the membrane is raised from the surface of the encephalon, numerous fine processes are withdrawn from the cerebral surface. These are the blood-ressels with their sheaths, and they give the deep surface of the pia mater a rough and flocculent appearance.

As the pia mater is carried orer the inferior part of the roof or posterior wall of the fourth ventricle of the brain it receires the name of the tela chorioidea 
ventriculi quarti, and it is in connexion with this portion of the pia mater that the chorioid plexuses of that cavity are developed. The tela chorioidea ventriculi tertii (O.T. velum interpositum),is a fold of pia mater which is invaginated into the brain, so that it comes to lie over the third ventricle and to project in the shape of chorioid plexuses into the lateral ventricles. This invagination requires special notice.

The tela chorioidea ventriculi tertii (O.T. velum interpositum) is a double layer or fold of pia mater which intervenes between the body of the fornix, which lies above it, and the epithelial roof of the third ventricle and the two thalami, which lie below it. Between its two layers are blood-vessels, and some subarachnoid

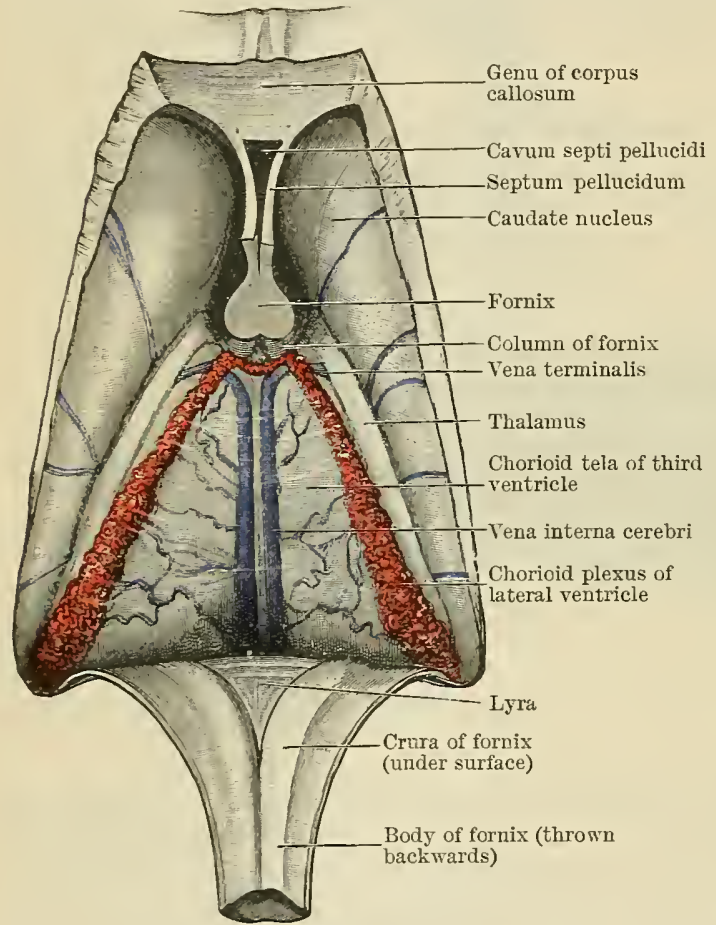

Fig. 599.-Dissection to show the Chorioid Tela of the Third Ventricle, and the Parts in mimfidate RelaTION TO IT.

trabecular tissue. In shape the chorioid tela of the third ventricle is triangular, and the narrow anterior end or apex reaches forwards as far as the interventricular foramina. The base lies under the splenium of the corpus callosum, and here the two layers of the tela separate and become continuous with the investing pia mater on the surface of the brain by passing out through a cleft called the transverse fissure.

Along each lateral margin the tela chorioidea of the third ventricle is bordered by the chorioid plexus of the body of the lateral ventricle, which projects into the ventricular cavity from under cover of the free lateral margin of the fornix. It should be borne in mind that the epithelial lining of the ventricle gives a complete covering to the chorioid plexus. Posteriorly the chorioid plexus is continuous with the similar structure in the inferior horn of the ventricle, whilst in front it narrows greatly, and becomes continuous across the median plane with the corresponding plexus of the opposite side, behind the epithelial layer which lines the interventricular foramen. From this median junction two much smaller chorioid plexuses run backwards on the under surface of the tela chorioidea, and project downwards into the third ventricle. These are the chorioid plexuses of the third ventricle

The most conspicuous blood-vessels in the tela chorioidea are the two internal cerebral veins, which run backwards, one on each side of the median plane. In front, each is formed at the apex of the fold by the union of the vena terminalis and a large vein issuing from the chorioid plexus; behind, they unite to form the vena cerebri magna [Galeni], and this pours its blood into the anterior end of the straight sinus (Fig. 599, p. 674).

The continuous cleft in the brain through which the chorioid tela of the third ventricle and the chorioid plexuses of the two inferior horns of the lateral ventricles are introduced into the interior of the brain is sometimes called the transverse fissure. It consists of a superior intermediate part and two lateral parts. The former passes forwards between the corpus callosum and the fornix above and the roof of the third ventricle and the thalami below. It is limited on each side by the epithelial covering of the chorioid plexuses, which shuts out these structures from the cavity of the lateral ventricles. The 
lateral part is the chorioidal fissure. This is continuous with the intermediate part, and has already been described in connexion with the inferior horn of the lateral ventricle (p. 636).

Pia Mater Spinalis.-The pia mater of the spinal medulla is thicker and denser than that of the brain. This is largely due to the addition of an outside fibrous layer, in which the fibres run chiefly in the longitudinal direction. The pia mater is very firmly adherent to the surface of the spinal medulla, and in front it sends a fold into the anterior-median fissure of the spinal medulla. The posterior median septum is likewise firmly attached to its deep surface. In front of the anterior-median fissure of the spinal medulla the pia mater is thickened in the form of a longitudinal glistening band, termed the linea splendens, which runs along the whole length of the spinal medulla, and blends with the filum terminale below. The blood-ressels of the spinal medulla lie between the two layers of the pia mater.

The nerves which leave both the brain and spinal medulla receive closely

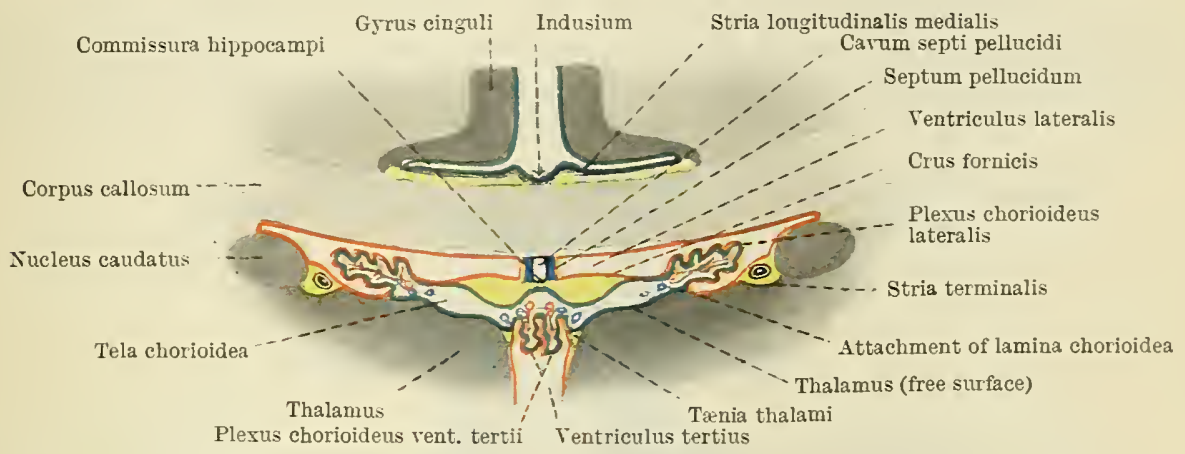

Fig. 600.-Diagram of a Frontal Sectiox across the Choriord Tela of the Third Textricle.

applied sheaths from the pia mater. These blend with the connective-tissue sheaths of the nerves.

The ligamentum denticulatum is a strong fibrous band which stretches out like a wing from the pia mater on each side of the spinal medulla, so as to connect the pia mater with the dura mater. The pial or medial attachment of the ligament extends in a continuous line between the anterior and posterior nerve-roots, from the level of the foramen magnum above to the level of the first lumbar vertebra below. Its lateral margin is serrated or denticulated, and for the most part free. From twenty to twenty-two denticulations may be recognised. They occur in the intervals between the spinal nerres, and pushing the arachnoid before them, they are attached by their pointed ends to the inner surface of the dura mater. The ligamenta denticulata partially subdivide the wide subarachnoid space in the vertebral canal into an anterior and a posterior compartment. The anterior nerve-roots traverse the anterior compartment, whilst the posterior nerveroots traverse the posterior compartment. Further, the posterior compartment is imperfectly subdivided into a right and a left lateral part by the septum posterius.

By means of the ligamenta denticulata the spinal medulla is suspended in the middle of the tube of dura mater. 



\title{
THE PERIPHERAL NERVES AND THE SYMPATHETIC SYSTEM.
}

\author{
By A. Melville Paterson, M.D., F.R.C.S. \\ Professor of Anatomy in the University of Liverpool.
}

THE nervous mechanism comprised under this title is responsible for the transmission of peripheral impulses to the brain and spinal medulla, through afferent nerves, and for the distribution of central impulses to peripheral structures through efferent nerves. The peripheral nerves are at the outset divisible into two series :-

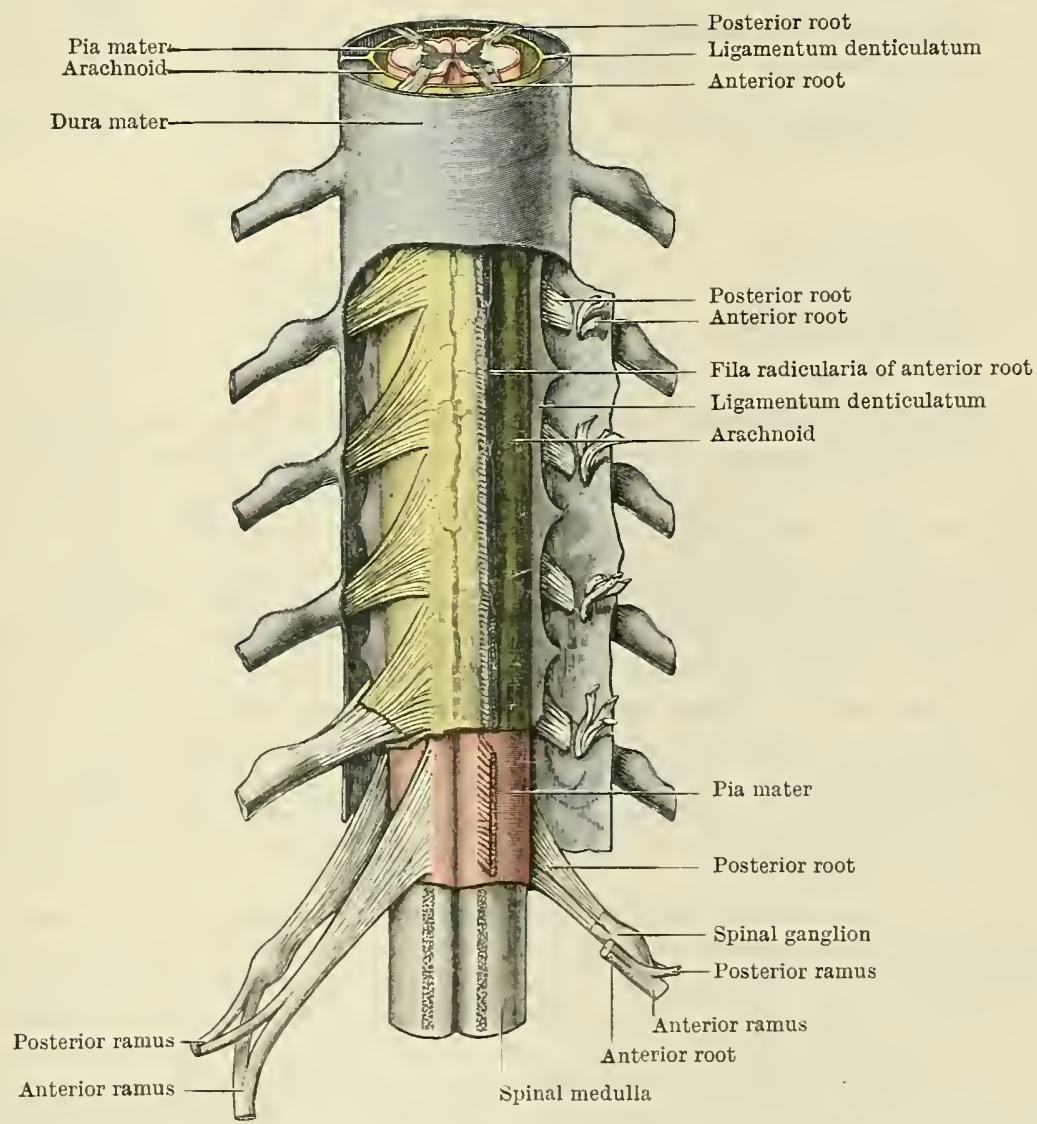

Fig. 601.-Scheme of the Arrangement of the Membranes of the Spinal Medella axd the Roots of the SpiNal Nerves.

cerebral nerves, derived from or associated with the brain, and spinal nerves, arranged in pairs in relation to the spinal medulla. Associated with the spinal nerves is the sympathetic system. The animal body is naturally divided into two different areas or regions, the somatic area, forming the trunk and body wall, and innervated by the larger (somatic) parts of the spinal nerves, and the splanchnic 
area, comprising the chief viscera contained within the body-cavity. This area is governed by the sympathetic system, subordinate to and controlled by its connexions with the splanchnic or visceral branches of the spinal nerves.

The cerebral nerves are twelve in number, arranged in pairs; they present striking differences in origin, in distribution, and in functions.

\begin{tabular}{|c|c|c|c|}
\hline Number. & Name. & Function. & $\begin{array}{l}\text { Superficial Attachment } \\
\text { to Brain. }\end{array}$ \\
\hline l. & & ell & Olfactory bulb. \\
\hline II. & & & \\
\hline III. & Ocul & $\begin{array}{l}\text { Motor to the muscles of eyeball and } \\
\text { orbit }\end{array}$ & Cerebral peduncle. \\
\hline IV. & Trochlear & $\begin{array}{l}\text { Motor to superior oblique muscle of } \\
\text { eyeball }\end{array}$ & $\begin{array}{l}\text { Anterior medullary } \\
\text { velum. }\end{array}$ \\
\hline V. & Trigeminal . & $\begin{array}{l}\text { Sensory to face, tongue, and teeth; } \\
\text { motor to muscles of mastication }\end{array}$ & Pons. \\
\hline VI. & Abducent & $\begin{array}{l}\text { Motor to lateral rectus muscle of } \\
\text { eyeball }\end{array}$ & $\begin{array}{l}\text { Junction of pons and } \\
\text { medulla oblongata. }\end{array}$ \\
\hline VII. & Facial . & $\begin{array}{l}\text { Motor to muscles of scalp and face, } \\
\text { sensory to tongue }\end{array}$ & $\begin{array}{l}\text { Posterior border of } \\
\text { pons. }\end{array}$ \\
\hline VIII. & Acoustic & Hearing and equilibrium & $\begin{array}{l}\text { Posterior border of } \\
\text { pons. }\end{array}$ \\
\hline IX. & Glossopharyngeal & Sensory to tong & Medulla oblongata. \\
\hline $\mathrm{x}$ & Vagus. & $\begin{array}{l}\text { Sensory to pharynx, esophagus and } \\
\text { stomach, and respiratory organs }\end{array}$ & Medulla oblongata. \\
\hline XI. & Accessory & $\begin{array}{l}\text { (a) Accessory to vagus.-Motor to } \\
\text { muscles of palate, pharynx, œso- } \\
\text { phagus, stomach and intestines, } \\
\text { and respiratory organs; inhibitory } \\
\text { for heart }\end{array}$ & Medulla oblongata. \\
\hline & & $\begin{array}{l}\text { (b) Spinal part : motor to trapezius } \\
\text { and sterno-mastoid muscles }\end{array}$ & Spinal medulla. \\
\hline XII. & Hypoglossal & Motor to muscles of the tongue & Medulla oblongata. \\
\hline
\end{tabular}

The spinal nerves are usually thirty-one in number, also arranged in pairs. Each nerve arises by two roots from the spinal medulla, one posterior and ganglionic, the other anterior and not gangliated. After each root has pierced separately the dura mater, the two roots become enclosed in a common sheath, and unite to form the spinal nerve in the intervertebral foramen; emerging from this, the nerve is distributed to the trunk and limbs in a manner to be described later.

The nerves are designated cervical, thoracic, lumbar, sacral, and coccygeal, in relation to the vertebræ between which they emerge from the vertebral canal. Each nerve appears below the corresponding vertebra, except the first of the cervical series, which passes out of the vertebral canal between the occipital bone and the atlas. There are thus eight cervical nerves (the last appearing between the seventh cervical and first thoracic vertebræ); there are twelve thoracic, five lumbar, five sacral, and one coccygeal nerve, all appearing below the corresponding vertebræ.

The thirty-first nerve is occasionally absent; and there are sometimes one or two additional pairs of minute filaments below the thirty-first, which, however, do not emerge from the vertebral canal. These are rudimentary caudal nerves.

The size of the spinal nerves varies extremely. The largest are those which take part in the formation of the great nerve-trunks for the supply of the limbs (lower cervical and first thoracic, and lower lumbar and upper sacral nerves); and of these the nerves destined for the lower limbs are the larger. The coccygeal nerve is the smallest of the spinal nerves; the thoracic nerves (except the first) are much more slender than the limb nerves; and the cervical nerves diminish in size from below upwards.

Systema Sympathicum.-The sympathetic system consists of a gangliated trunk, connected on the one hand in certain regions to the spinal nervous system by a series of white rami communicantes-splanchnic or visceral branches of the spinal nerves; and on the other hand distributing branches $(a)$ to the spinal nerves (gray rami communicantes), and $(b)$ to the viscera and vessels occupying the splanchnic area. It 
serves to collect and transmit to the spinal medulla impulses from the viscera, and to distribute efferent fibres to vessels in the splanchnic area, and to glands and involuntary muscle-fibres.

\section{DEVELOPMENT OF THE PERIPHERAL NERVES AND SYMPATHETIC SYSTEM.}

\section{Development of the Spinal Nerves.}

I. Origin of the Spinal Nerve Roots. - The process of development of the spinal nerves commences by means of the outgrowth of posterior and anterior roots from the medullary tube. The two roots take origin in pairs in quite different ways.
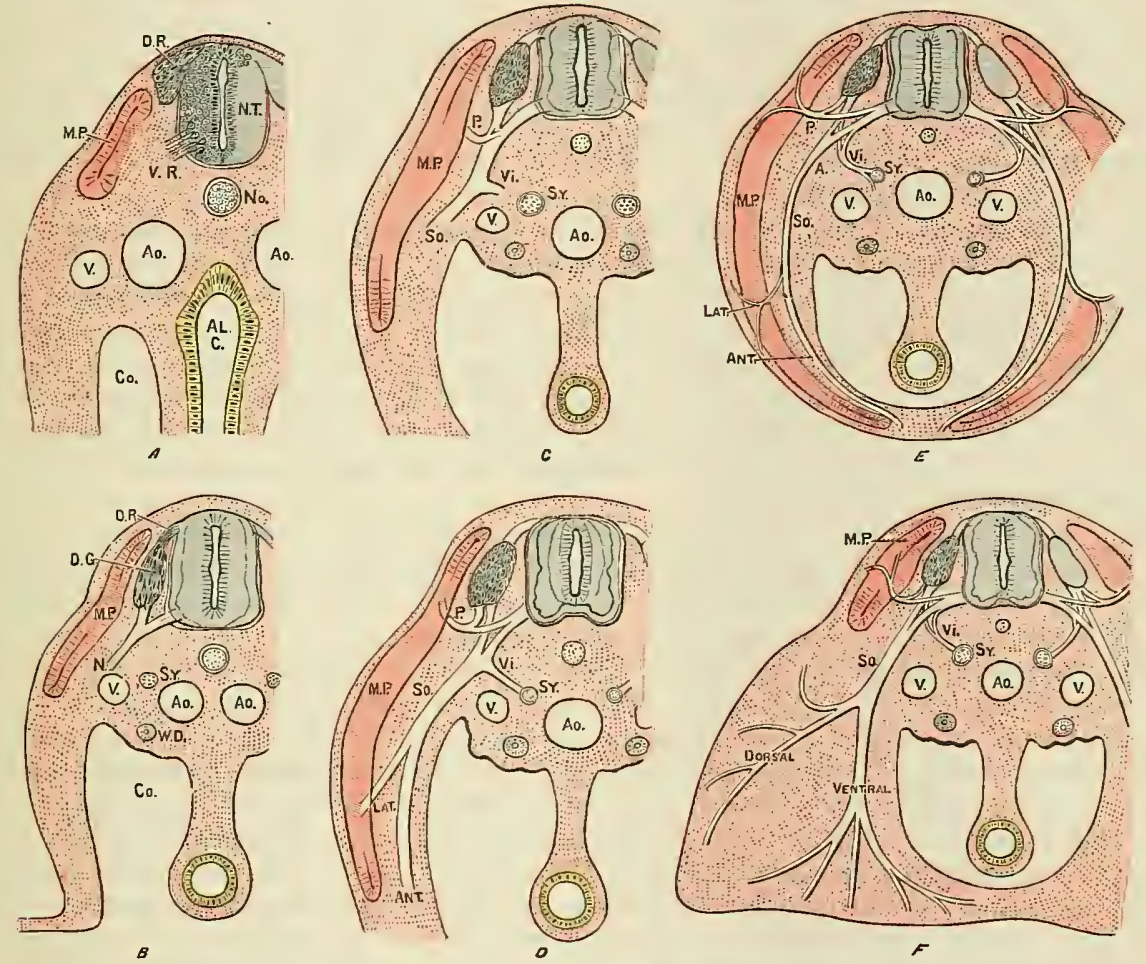

Fig. 602.-Development of the Spinal Nerves.

A, Formation of nerve roots.

D.R, Posterior root.

V.R, Anterior root.

N.T, Neural tube.

No, Notochord.

C, Formation of nerves.

So, Somatic division.

Vi, Visceral branch.

$\mathrm{P}$, Posterior ramus.
Al.C, Alimentary canal.

Ao, Aorta.

$V$, Cardinal vein.

II.P, Muscle plate.

D, E, Formation of subordinate branches.

Lat, Lateral, and

Ant, Anterior, branches.
$B$, Formation of nerve trunk (N).

D.G, Spinal ganglion.

Sy, Sympathetic trunk.

W.D, Wolffian ciuct.

Co, Cœlom.

F, Fornation of nerve trunks in relation to the limb: dorsal and rentral trunks corresponding to lateral and anterior trunks in $\mathrm{D}$ and $\mathrm{E}$.

The posterior root is the first to appear,- - before, during, or after the union of the medullary plates and the formation of the neural tube.

It takes origin as a ganglionic crest, forming a continuous lateral unsegmented band, on the dorsal surface of the medullary tube. It may arise in one of three ways: (1) from the junction of the medullary plate and surface epiblast, before the closure of the medullary groove; (2) from a neural crest, a median ridge on the dorsum of the completed tube; or (3) as a direct outgrowth from the dorsal surface of the medullary tube. The ganglionic crest becomes completely scparated from the medullary tube, and secondarily its cells (neuroblasts) become rapidly spindle-shaped, and br the end of the fourth week give rise to two sets of processes: (1) a central series, which grow centrally 
and are secondarily connected with the dorso-lateral aspect of the medullary tube as the fibres of the posterior root; and (2) a peripheral series, which constitute the posterior root-fibres of the spinal nerve and join the anterior root, to form the spinal nerve proper. It is only after the appearance of these nerve-fibres that the ganglionic crest becomes notched along its peripheral border, and it is gradually divided up to form the individual segmental spinal ganglia.

The anterior root of a spinal nerre arises in quite a different way, from cells (neuroblasts) in the substance of the medullary tube. In the account of the development of the spinal medulla it has been shown how the cellular. constituents of the medullary tube are converted into two classes of cells: (1) spongioblasts, which produce the matrix (neuroglia) of the spinal medulla; and (2) neuroblasts, which produce the nerve-cells of the gray matter of the spinal medulla. The neuroblasts give rise to the axiscylinder processes or axons, which, penetrating the spongy tissue of the medullary tube and the outer limiting membrane, find their way into the mesodermic tissue on the ventro-lateral surface of the tube. Fibrous from their earliest origin and derived from nerve-cells which remain within the medullary tube, the axons of the anterior root become surrounded by mesodermic cells immediately on their emergence, which give rise to the sheaths of the nerve. The anterior root is a little later in its date of appearance than the posterior root. It begins to be evident at the twenty-fourth day and is completely formed by the twenty-eighth day.

II. Formation of the Spinal Nerve.-The fibres of the posterior root ganglion and the anterior root grow by extension from the cells with which they are respectively connected, and meet in the space between the myotome and the side of the medullary tube to form the spinal nerve. In the adult there is a fundamental division of the spinal nerve into posterior and anterior rami. In the process of development this separation is eren more obvious. As the fibres of the posterior and anterior roots approximate, they separate at the same time each into two unequal portions: the smaller parts of the two roots unite together to form the posterior, and the larger parts unite to form the anterior ramus of the spinal nerve.

The posterior ramus, curving laterally and dorsally, passes through the myotome and is connected with it. In the substance of the myotome it separates into branches as it proceeds towards the dorsal wall of the embryo. At a later stage, the branches are definitely arranged into a lateral and a medial series.

The anterior ramus grows gradually in a ventral direction to reach the somatosplanchnopleuric angle, under cover of the growing myotome. It spreads out at its distal end and eventually separates into two portions : a smaller, splanchnic, or visceral ; and a larger, somatic, or parietal portion. (1) The smaller, splanchnic, or visceral portion grows inwards, dorsal to the Wolffian ridge, to be connected through the sympathetic trunk with the innervation of organs in the splanchnic area. This branch of the spinal nerve becomes the white ramus communicans of the sympathetic. It is not present in the case of all the spinal nerves, but only in relation to the thoracic and upper lumbar and the third and second or fourth sacral nerves. It will be referred to again in connexion with the sympathetic system. (2) The larger, somatic, or parietal portion becomes the main part of the anterior ramus of the nerve. It continues the original ventral course of the nerve, and, reaching the body wall, subdivides into two terminal branchesa lateral branch, which grows laterally and downwards and reaches the lateral aspect of the trunk, after piercing the myotome; and a ventral or anterior branch, which grows onwards in the body wall to reach the ventral axis. This arrangement is met with in the trunk between the limbs and in the neck.

III. Formation of Limb-plexuses.-The method of growth of the spinal nerves, just described, is modified in the regions where the limbs are developed. In relation to the limbs, which exist in the form of buds of undifferentiated cellular mesoblast before the spinal nerves have any connexion with them, the development of the anterior ramus of the nerve proceeds exactly in the way described up to the point of formation of somatic and splanchnic branches. The somatic branches then stream out into the limb bud, passing into it below the ends of the myotomes and spreading out into a bundle of fibres at the basal attachment of the limb. Later, the nerves separate each into a pair of definite trunks, which are named posterior or dorsal and anterior or ventral, and which, dividing round a central core of mesoderm, proceed to the dorsal and ventral surfaces respectively of the limb bud. While this process is going on, a secondary union takes place between parts of adjacent dorsal and ventral trunks. Dorsal trunks unite with dorsal trunks, ventral trunks unite with ventral trunks, to form the nerves distributed ultimately to the surfaces and periphery of the limb. These dorsal and ventral 
trunks are homologous with the lateral and ventral branches of the somatic nerves in other regions.

\section{DEVELOPMENT OF THE SYMPATHETIC SYSTEM.}

There are two diametrically opposite views of the mode of development of the sympathetic system.

In birds and mammals the first rudiment of the sympathetic trunk occurs in the formation of a longitudinal unsegmented column of mesodermic cells (which stain more deeply than the mesoderm in which they lie) on either side of the aorta, and coterminous with it. This column of cells becomes joined at an early stage by the visceral branches of the spinal nerves which grow inwards from the main nerve trunks into the splanchnic area, and result from the division of the nerve into somatic and visceral parts. These visceral branches constitute the white rami communicantes. They receive contributions usually from both posterior and anterior roots, and gradually approaching the above-mentioned column of mesodermic cells, they become intimately associated with the cells. In some cases fibres of the visceral nerves pass over the cellular column into the splanchnic area without connexion with it (Fig. 603). By the junction of these visceral nerves with the cells of the column, certain cells persist and produce the ganglia. The intervening portions of the column, by changes in the cells, and by the addition of fibres belonging to the visceral nerves, give rise to the commissural cords. The cellular column, besides producing the gangliated trunk, by the further growth of its cells and their extension centrally and peripherally, produces the gray rami communicantes, parts of the peripheral branches, and the peripheral (collateral and terminal) ganglia, as well as the medullary portion of the suprarenal gland. The cervical, lower lumbar, and sacral portions of the sympathetic gangliated trunk are secondary extensions from the primitive trunk, gradually growing upwards and downwards along the main vessels. These portions of the system are not provided with white rami communicantes. The ganglia of the sympathetic assume their segmented appearance (1) from the persistence of the primitive cells and their connexion with the spinal nerves by means of the white and gray rami communicantes, and (2) from the way in which the primitive column is moulded by the surrounding structures (bones, segmental arteries, etc.).

In another account of the development of

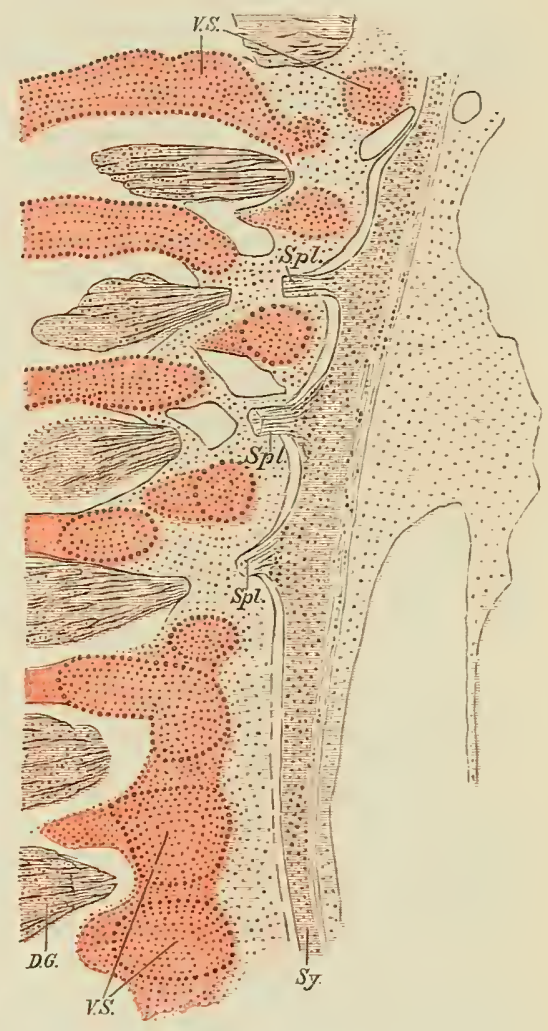

Fig. 603.-The Detelopment of the Sympathetic Gaxglated Trunk.

Sy, Sympathetic trunk; Spl, Splanchnic branches of spinal nerves (white rami communicantes) ; V.S, Vertebral segments ; D.G, Spinal ganglia. the sympathetic system (Onodi), the gangliated trunk is described as an outgrowth of the thoracic spinal ganglia of the spinal nerves. It is said that each ganglion gives off a bud at its inferior end, which, growing inwards into the splanchnic area, becomes attached to the trunk of the spinal nerve just beyond the union of the posterior and anterior roots. The bud still extending inwards into the splanchnic area, remains associated with the nerve by an attenuated stalk. These buds, it is said, become the ganglia, which, after reaching their permanent place in the splanchnic area, are supposed to grow upwards and downwards so as to coalesce and form a beaded chain of ganglia. The stalks connecting the ganglia with the spinal nerves become the white rami communicantes. This mode of development does not satisfactorily account for several important features of the sympathetic system-the development of those parts of the gangliated trunk which possess no white rami, the absence of a truly segmental character in the trunk, and the constancy of its continuity. No instance is recorded 
of a hiatus between two ganglia. It is, on the other hand, an attractive view, as it ascribes to one germiual layer (ectoderm) the formation of all the elements of the nervous system, and it brings the sympathetic ganglia into serial homology with the isolated ganglia-ciliary, spheno-palatiue, and otic-associated with the trunks of the trigeminal cerebral nerve.

\section{THE DEVELOPMENT OF THE CEREBRAL NERVES.}

The cerebral nerves are divisible morphologically into three series:-(1) those associated with seuse organs - the first or olfactory, second or optic, and eighth or acoustic; (2) those connected with the embryonic branchial arches-the fifth or trigeminal, seventh or facial, ninth, tenth, and eleventh, glossopharyngeal, vagus, and accessory; and (3) motor nerves distributed to muscles derived from cephalic myotomes-the third or oculomotor, fourth or trochlear, sixth or abducent, and twelfth or hypoglossal.

Omitting the olfactory and optic nerves, which are special vesicular outgrowths of the brain itself, it is possible to trace a distinct homology in the process of development of the other cerebral and the spinal nerves. In the primitive brain the gray matter is arranged into Alar and Basal Laminæ (His), comparable to the postero-lateral and anterior areas of gray matter (columns) of the spinal medulla. The basal lamina again may be split up into lateral and medial areas.

The origin of the third, fourth, sixth, and twelfth cerebral nerves-all motor efferent nerves-is from the medial part of the basal lamina of the primitive brain, in serial homology with the anterior efferent roots of the spinal nerves.

The efferent motor roots of the fifth, seventh, ninth, tenth, and eleventh nerves arise from the lateral part of the basal lamina, and so may be differentiated from the previous series.

The afferent sensory roots of the fifth, seventh (intermediate nerve), eighth, ninth, and tenth nerves are homologous with the posterior roots of the spinal nerves. They are all gangliated, and are connected with the alar lamina of the brain.

I. The olfactory nerves are associated in their development with the formation of the olfactory pit and the olfactory bulb.

The olfactory pits appear on each side of the front of the head at a little later period than the formation of the lens and the auditory vesicle. They become converted into the nasal cavities by the formation of the pre-oral visceral clefts and arches,-fronto-nasal and ethmo-vomerine in the median plane, and lateral ethnoid and maxillary processes at the sides (p. 49).

The Rhinencephalon or olfactory bulb is a hollow outgrowth from each telencephalon or cerebral hemisphere, and appears in the first month. It grows forwards into relation with the deep surface of the nasal pit. In many animals (as in the horse) the olfactory bulb remains hollow; bnt in the human subject it loses its lumen and becomes a solid bulb (olfactory bulb) connected to the brain by a narrow stalk, the olfactory tract.

The epithelium of the olfactory pit is responsible for the formation of theolfactory nerves. There are two views as to the mode of their development from the epithelial cells. Both views admit the proliferation of the epithelium of the nasal pit so as to produce neuroblasts. According to the one view these neuroblasts detach themselves from the epithelial surface, and constitute an olfactory ganglion which becomes applied to and incorporated with the olfactory bulb. The cells of the ganglion become bi-polar, and the peripheral axons constitute the olfactory nerves, while the central axons (in the second month) proceed backwards to the brain along the olfactory tract. According to the other view (based on Disse's investigations), the proliferating cells of the nasal epithelium remain in the wall of the nasal pit, and become the olfactory cells of the nasal cavity, with peripheral processes projecting to the surface of the epithelium. Their central axons become the olfactory nerve fibres which end in the olfactory bulb, forming dendrites associated with the dendritic processes of the nerve-cells of the bulb. The central axons of these latter cells develop into the fibres of the olfactory tract.

II. The optic nerve is developed wholly from the brain. Its formation begins with the outgrowth of the optic vesicle, a paired hollow outgrowth from the ventral surface of the diencephalon. The ectodermic invagination of the lens, growing inwards from the surface of the head, causes the collapse of the vesicle and its conversion into the optic 
cup, the narrow tube connecting the vesicle to the brain becoming the optic stalk. This stalk becomes solid, and forms the basis of the optic tract, optic chiasma, and optic nerve. The optic cup, bilaminar in form, and by its edge clasping the lens, is imbedded in mesodermic tissne, which gives rise to the envelopes of the eyeball, etc. The outer layer of the optic cup prodnces the layer of hexagonal pigment cells of the retina. The cells of the inner layer produce the tissues of the retina proper. They form nenroblasts with peripheral and central processes. The peripheral processes are converted into retinal nerve tissues; the central processes extend backwards along the optic stalk, and give rise to the optic nerve, optic chiasma, and optic tract. Spongioblasts in the inner lamina of the optic cup produce the sustentacular tissue of the retina (Mïller's fibres). The mesodermic tissue surrounding the optic cup and lens gives rise to the rest of the structure of the eyeball, the formation of which is described in the section which deals with the organs of sense.

III. The oculomotor nerve arises, like the ventral root of a spinal nerve, from a group of neuroblasts in the medial part of the basal lamina of the mid-brain. The peripheral fibres cxtend forwards, to end around the optic cup in the mesodermic tissue, from which the eye muscles are derived. Numerous cells are carried along with the cell processes in their course, and these have been described as being concerned in the formation of the ciliary ganglion.

IV. The trochlear nerve also arises from a group of neuroblasts occupying the medial part of the basal lamina of the mid-brain, close to its junction with the hind-brain. The peripheral processes do not emerge directly from the brain, but extend dorsally from their origin along the side of the brain to its dorsal aspect, where they appear, after decussating with the fibres of the opposite nerve, just behind the quadrigeminal lamina.

$\mathrm{V}$. The trigeminal nerve is developed by means of a large posterior and a small anterior root. Their origin to a large extent resembles the mode of formation of the roots of a spinal nerve.

The large posterior (afferent) root is formed by means of a cellular bud from the alar lamina of the hind-brain. This bud separates from the brain, and forms the semilunar ganglion. Its cells becoming bipolar, like the cells of a spinal ganglion, are secondarily connected with the brain by means of their central processes; while the peripheral processes, separating into three groups, proceed along the fronto-nasal and maxillary processes, and along the mandibular arch, to form the three main divisions of the nerve. Numerous cells accompany each main division in its course from the ganglion, and form eventually the subordinate ganglia-the ciliary on the ophthalmic nerve, the spheno-palatine on the maxillary nerve, and the otic ganglion on the mandibular nerve.

The small anterior (efferent) root of the trigeminal nerve, like the motor anterior root of a spinal nerve, is later in its appearance than the sensory root. It arises as the peripheral fibres of a group of neuroblasts occupying the lateral part of the basal lamina of the hind-brain, which proceed directly to the surface to join the mandibular division of the nerve.

VI. The abducens nerve resembles in its mode of development the oculomotor and trochlear nerves with which in its origin it is in series. It is formed by the peripheral processes of a group of neuroblasts in the medial part of the basal lamina in the upper part of the hind-brain. These processes pierce the part of the brain in which, at a later stage, the fibres of the pyramid are developed. They then proceed to the mesodermic tissue round the optic cup, which is destined to form the eye muscles.

VII. The facial nerve has developmentally a double origin. (I) In connexion with the formation of the acoustic nerve a group of cells becomes separated from the alar lamina of the hind-brain opposite the auditory vesicle. This group becomes separated into three parts, of which the middle portion is the rudiment of the genicular ganglion which becomes incorporated with the efferent part of the facial nerve, and is connected to the brain by a slender root, known as the intermediate nerve (O.T. pars intermedia). (2) The efferent root of the nerve arises from a group of neuroblasts in the lateral part of the basal lamina of the hind-brain, in series with efferent fibres of the rago-glossopharyngeal nerves; after a tortuous course within the brain its fibres emerge beneath the above-mentioned cellular mass, opposite the auditory vesicle. They are joined by the ganglionic root, and in their conrse round the auditory vesicle become imbedded in the auditory capsule (canalis facialis). The chorda tympani nerve appears early as a branch of the facial nerve. It is probable that the intermediate nerve, the genicular ganglion, and the chorda tympani nerve together represent the posterior afferent element in the constitution of this nerve.

VIII. The acoustic nerve arises as a cellular bud from the alar lamina of the hind. 
brain, dorsal to the efferent portion of the facial nerve, opposite to the auditory vesicle, and in close association with it.

Becoming separated from the brain, the cellular mass separates into three portions, of which the intermediate part is associated with the facial nerve and intermediate nerve (as the genicular ganglion), while the medial and lateral parts are converted into the medial (vestibular) and, lateral (cochlear) ganglia and the roots of the acoustic nerve. The cells becoming bipolar, their central processes are secondarily connected with the brain on the dorsal (lateral) aspect of the facial nerve; the peripheral processes proceed to the auditory vesicle, to which they are distributed as the vestibular and cochlear nerves. Numerous cells are carried along with the nerve trunks into relation with the auditory capsule, and constitute the vestibular and cochlear ganglia.

IX. and X. The glossopharyngeal and vagus nerves are developed from the side of the hind-brain, both in the same way, and each by two roots. A collection of cells separates itself from the alar lamina of the hind-brain behind the auditory vesicle to form the ganglionic afferent root. The ganglion of the vagus is much larger than that of the glossopharyngeal. Each ganglion becomes divided into two parts, a proximal and a distal portion, connected together by a commissural band of fibres. The proximal ganglion (superior ganglion of the glossopharyngeal; jugular ganglion of the vagus) is secondarily connected by centripetal fibres to the hind-brain. From the distal ganglion (petrous

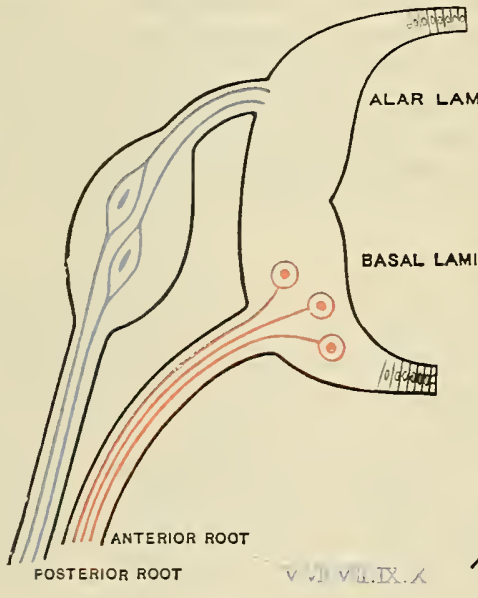

A

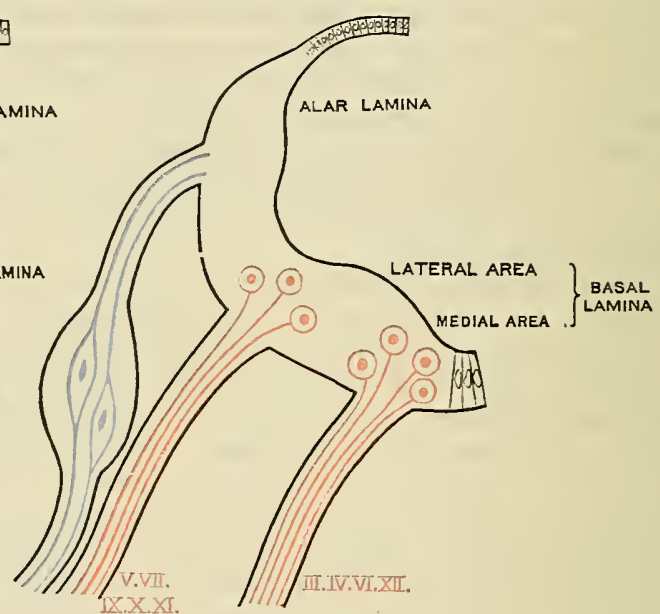

$\mathrm{B}$

Fig. 604.-Comparison of Origixs of Nerve Roots from Spinal Medella and Hind-Brain (after His).

A. Spinal medulla; B. Hind-brain.

ganglion of the glossopharyngeal; ganglion nodosum of the vagus) peripheral fibres grow outwards to form the nerve trunk.

Each nerve is also provided with a small efferent root, consisting of nerve fibres, arising from a collection of neuroblasts in the lateral part of the basal lamina of the hindbrain, and emerging beneath the ganglionic root at the junction of the alar and basal laminæ (in series with the fibres of the efferent root of the facial nerve above and of the accessory nerve below).

XI. The accessory nerve arises in two parts-one medullary, the other spinal. The medullary (accessory) portion develops as the processes of a series of neuroblasts in the lateral portion oi the basal lamina of the hind-brain, which emerge in series with the efferent roots of the glossopharyngeal and vagus nerves. The spinal portion arises as the processes of a group of neuroblasts in the anterior part of the medullary tube (anterior column), which, turning outwards, emerge as a series of roots on the lateral aspect of the spinal medulla.

XII. The hypoglossal nerve is developed, not in series with the nerves above mentioned, but like the third, fourth, and sixth nerves, from the medial part of the basal lamina of the hind-brain, in the space between the glossopharyngeal and other nerves above, and the first cervical nerve below. It is formed as a series of peripheral processes from a collection of neuroblasts occupying the hind-brain. Froriep's ganglion is a transitory collection of nerve cells developed from the alar lamina of the hind-brain on the dorsal aspect of the nerve, and represents in a rudimentary condition its posterior ganglionic root. The ganglion gives off no branches and soon disappears. 


\section{DESCRIPTION OF THE PERIPHERAL NERVES AND SYMPATHETIC SYSTEM.}

\section{The Spinal Nertes.}

Origin of the Spinal Nerves.-Each spinal nerve is attached to the spinal medulla by two roots, called respectively posterior (dorsal, afferent) and anterior (ventral, efferent).

The posterior root is larger than the anterior root; it contains a larger number of radicular fibres, and the individual fibres are of larger size than in the anterior root. It has a vertical linear attachment to the postero-lateral sulcus of the spinal medulla. The fibres of contiguous posterior roots are in close relation, and, in some instances, overlap. The posterior root separates as it passes away from the spinal medulla into two bundles, both of which become connected with the proximal end of a spinal ganglion. From the distal end of this ganglion the posterior root proceeds to its junction with the anterior root in the intervertebral foramen.

The spinal ganglia are found on the posterior roots of all the spinal nerves. (In the case of the first cervical or sub-occipital nerve, the spinal ganglion may be rudimentary or absent; and the posterior root itself may be wanting, or derived from the accessory nerve.) They occupy the intervertebral foramina, except in the case of the sacral and coccygeal nerves, the ganglia of which lie within the vertebral canal; and the first and second cervical nerves, the ganglia of which lie upon the vertebral arches of the atlas and epistropheus respectively. With the exception of the coccygeal ganglia they are outside the cavity of the dura mater, but are invested by the membrane. The ganglia are of ovoid form, bifurcated in some cases at their proximal ends. They consist of unipolar nerve-cells, whose axons, after a rery short course, divide into central (root) and peripheral (trunk) fibres. The central fibres form the portion of the root entering the spinal medulla; the peripheral fibres are continued in a lateral direction from the ganglion into the spinal nerve.

Ganglia Aberrantia (aberrant spinal ganglia).-Between the spinal ganglion and the spinal medulla small collections of cells are occasionally found on the posterior roots, either as scattered cells or distinct ganglia. They are most frequently met with on the posterior roots of the lumbar and sacral nerves.

The anterior root is smaller than the posterior root. It arises from the anterior surface of the spinal medulla (anterior root zone) by means of scattered bundles of nerve-fibres, which occupy a greater horizontal area and are more irregular in their arrangement than the radicular fibres of the posterior root. It possesses no ganglion in its course. The rootlets sometimes overlap, and are not infrequently connected with neighbouring radicular fibres above and below.

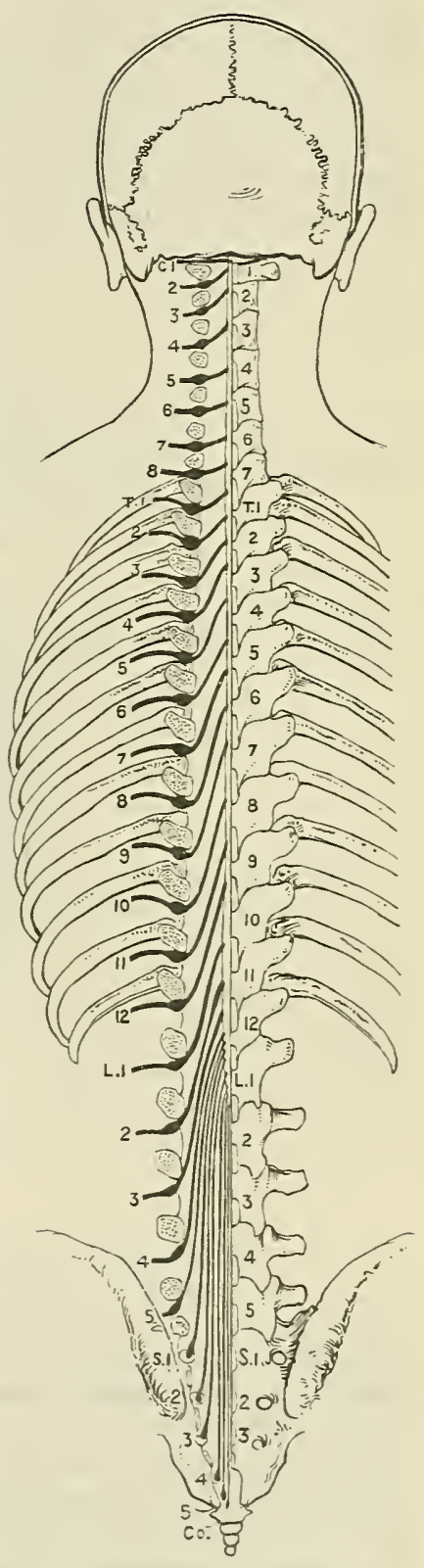

Fig. 605.-Diagramuatic RepreSENTATION OF THE ORIGLF OF THE SPINAL NerFes, showing the position of their roats and ganglia respectively in relation to the rertebral column. The nerves are shown as thick black lines on the left side. 
laterally in the rertebral canal towards the intervertebral foramina, where they unite to form the spinal nerve. The direction of the roots of the first two nerves is upwards and laterally; the roots of the remaining nerves course obliquely downwards and laterally, the obliquity gradually increasing until, in the case of the lower lumbar, the sacral and coccygeal nerve-roots, their course is vertically downwards in the vertebral canal. The collection of nerve-roots which occupies the lower part of the canal below the first lumbar vertebra, and comprises all the nerve-roots below those of the first lumbar nerve, is designated the cauda equina. They arise from the lumbar enlargement and conus medullaris, and surround the filum terminale of the spinal medulla.

Within the vertebral canal the nerve-roots are in relation with the meninges of the spinal medulla, and are separated from one another by the ligamentum denticulatum, and, in the neck, by the spinal part of the accessory nerve. Each receives a covering of pia mater, continuous with the neurilemma; the arachnoid invests

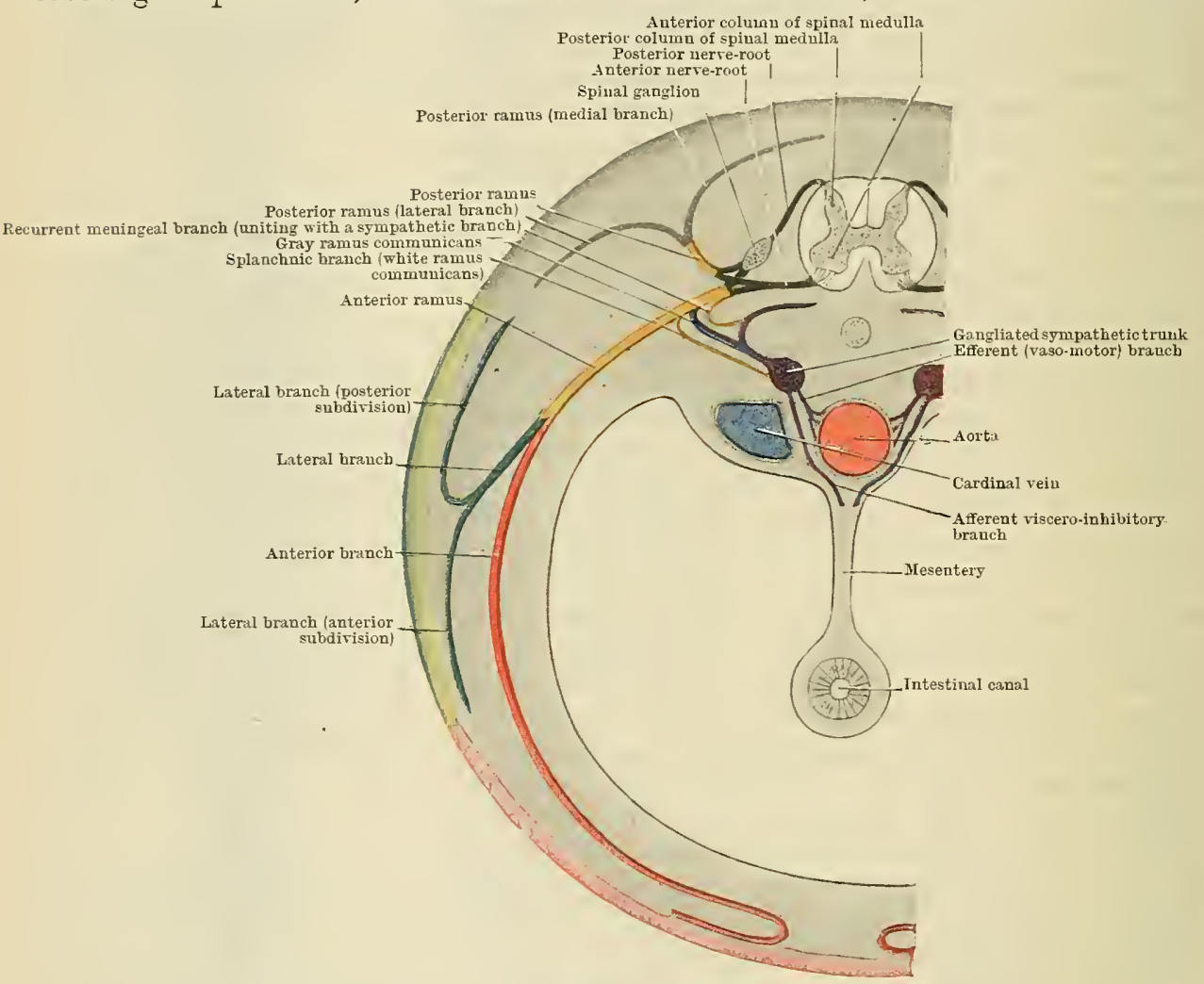

Fig. 606.-The Origin axd Distribution of a Trpical Spinal Nerve.

each root as far as the point where it meets with the dura mater; and each root pierces the dura mater separately. The two roots are thereafter enclosed in a single tubular sheath of dura mater, in which is included the spinal ganglion of the posterior root. The spinal nerve thus ensheathed occupies the intervertebral foramen (except the first two cervical and the sacral and coccygeal nerves).

Divisions of a Spinal Nerve. - After emerging from the intervertebral foramen the nerve immediately divides into two primary divisions, named respectively the posterior and anterior rami (O.T. posterior and anterior primary divisions). Just before its division each nerve gives off a minute meningeal (recurrent) branch, which re-enters the vertebral canal after effecting a junction with a branch from the sympathetic trunk, and is distributed to the spinal medulla and its membranes.

The posterior and anterior rami of the spinal nerves are mainly somatic in their distribution, and are responsible for the innervation of the skeletal muscles and of the skin covering the trunk and limbs. 
White Rami Communicantes.-From the anterior rami of certain nerves (second thoracic to second lumbar inclusive) a series of fine nerres arises, which serves to connect the spinal with the sympathetic system. These visceral or splanchnic branches, or white rami communicantes, through the medium of the gaugliated trunk of the sympathetic, serve to innervate the vessels and viscera in the splanchnic area. A second stream of pelvic splanchnic nerves, associated with the second and third, or third and fourth sacral nerves, connects these spinal nerves with the pelvic sympathetic plexuses (p. 766).

The posterior and anterior rami of the nerves contain fibres from both posterior and anterior roots. Indeed, each root can be seen, on removal of its sheath, to divide into two portions, of which one portion enters into the formation of the posterior, the other into the formation of the anterior ramus. The posterior rami, with the exception of the first two, are smaller than the anterior rami. They are responsible for the innervation of the skin and axial muscles of the back. They do not supply the muscles of the limbs; although in their cutaneous distribution they are prolonged on to the back of the head, the shoulder, and the buttock. They form two small plexuses-the posterior cervical and the posterior sacral plexuses. The anterior rami are, with the exception of the first two cervical nerves, much larger than the posterior rami. They supply the sides and anterior parts of the body, the limbs, and the perineum. For the most part they have a complicated arrangement. The thoracic or intercostal nerves alone have a simple mode of distribution; the other nerves give rise to the three great plexusescervical, brachial, and lumbo-sacral.

Distribution of the Spinal Nerves.-Although the distribution, like the origin of the spinal nerves, presents primarily and essentially a segmental arrangement, this is masked, and in some instances obliterated by developmental changes in the parts supplied. In no region can an isolated nerve be traced to a complete segment. The nearest approach to a complete girdle of innervation is found in the thoracic region, in such a nerve as the sixth thoracic nerve. Yet even such a nerve is not distributed to any part entirely alone. In its cutaneous distribution it supplies a complete belt of skin, a distinctly segmental area from the median plane posteriorly to the median plane anteriorly; yet at the same time the adjacent nerves orerstep, so to speak, the boundaries of the area and assist in the cutaneous nerve supply. Its muscular distribution, also, is segmental; the anterior ramus supplies the intercostal muscles of the space in which it lies; but in this it forms communications with adjacent nerves. The posterior ramus supplies axial muscles of the back, not, however, in an obviously segmental manner, ou account of the fusion of the segmental myotomes in the formation of complex longitudinal muscles, which are together supplied by the series of muscular branches derived from the posterior rami of contiguous nerves. In other regions still greater changes of structure are accompanied by deviations from a segmental type of distribution, causing the fonndation of the nerve-plexuses by which the truuk and limbs are innervated.

\section{POSTERIOR RAMI OF THE SPINAL NERVES.}

The posterior rami (O.T. posterior primary divisions) of the spinal nerves innervate both skin and muscles; the skin of the trumk posteriorly, the back of the head, the shoulder and the buttock, and the longitudinal muscles of the back, but not the muscles of the limbs.

Each posterior ramus divides as a rule into two parts, a medial and a lateral trunk (Fig. 606, p. 686). In the upper half of the body the medial trunks generally supply the cutaneous branches, while the lateral trunks are purely muscular nerves. In the lower part of the body the opposite is the case: the lateral trunks provide the cutaneous nerves and the medial trunks are distributed entirely to muscles. The cutaneous branches have a different course in the two cases. In the upper half of the back they course backwards beneath and among the muscles to within a short distance of the spinous processes of the vertebre, close to which they become superficial. They then extend laterally in the superficial fascia. In the lower half of the back the cutaneous nerres are directed downwards 
and laterally among the muscles, and become superficial at a greater distance from the median plane. In both regions the nerves pursue a sinuous course to the surface, and the lower series emerge and become superficial a considerable distance below the level of their spinal origin. There are considerable individual differences in the origin, course, and distribution of the several nerves.

\section{CERVICAL NERVES.}

First Cervical Nerve (N. sub-occipitalis).-It has already been pointed out that the posterior root of this nerve may berudimentary, or even absent altogether. Its posterior ramus is larger than the anterior ramus; it does not divide into medial or lateral branches, and it does not directly supply any cutaneous branch.

$\mathrm{P}$ assin $\mathrm{g}$ backwards, in the space between the occipital boneand the posterior arch of the atlas, the nerve occupies the sub-occipitai triangle, and is placed below and behind the vertebral artery, and under cover of the semispinalis capitis muscle. It supplies the following branches:-

(a) Muscular branches to the semispinalis

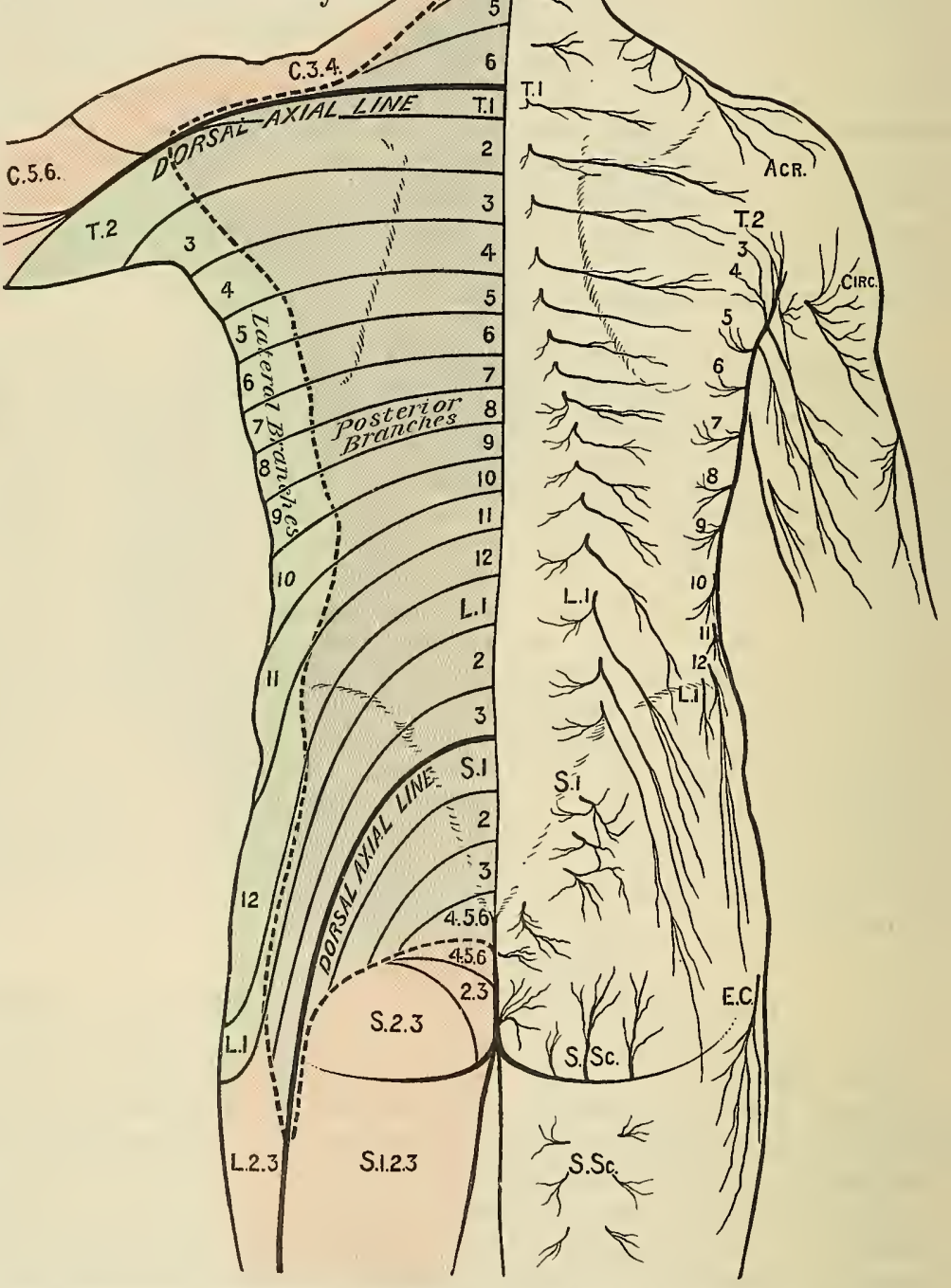

Fig. 607.-The Distribution of Cutaneous Nerves on the Back of the Trunk.

On one side the distribution of the several nerves is represented, the letters indicating their nomenclature.

G.O (C.2), Greater occipital ; C.3, Third occipital; T.1 et seq., Posterior rami of thoracic nerves ; L.1 et seq., Posterior rami of first three lumbar nerves; S.1 et seq., Posterior rami of sacral nerves ; Acr, Posterior Cutaneous branches of axilary cervical plexus; T.2-12, Lateral branches of thoracic nerves; Circ, Cutaneous branches of axillary nerve ; L.1, Iliac branch of ilio-hypogastric nerve ; E.C, Lateral cutaneous On the nerve thigh.

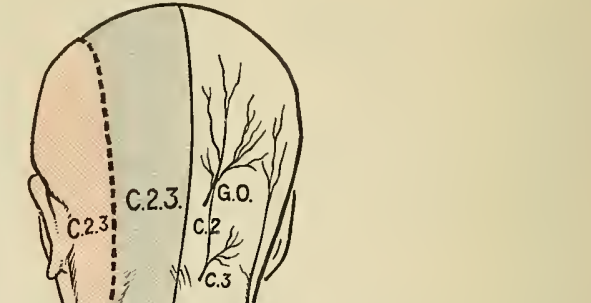


capitis, rectus capitis posterior major and minor, and obliqui capitis, superior and inferior.

(b) A communicating branch descends to join the second cervical nerve.

The communicating branch may arise in common with the nerve to the obliquus inferior, and reach the second cervical nerve by piercing or passing over or beneath that muscle; or it may accompany the nerve to the semispinalis capitis and communicate with the greater occipital nerve, under or over that muscle.

Second Cervical Nerve.-The posterior ramus of this nerve is larger than the corresponding anterior ramus. It passes backwards between the atlas and epistropheus, and in the interval between the obliquus inferior and the semispinalis cervicis muscles, under cover of the semispinalis capitis muscle. In this situa-

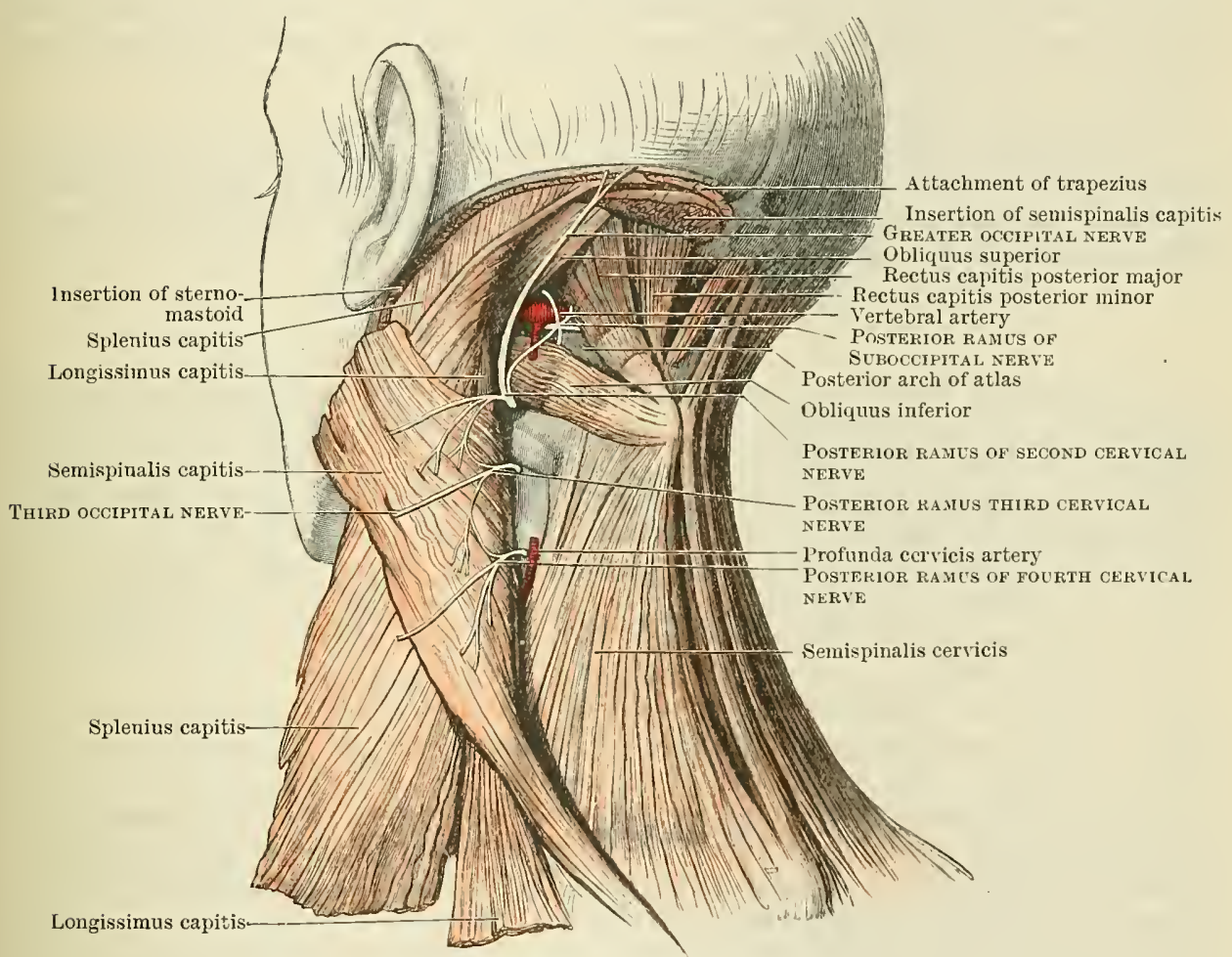

Fig. 608.-Posterior Cervical Plexus.

tion the nerve gives off several small muscular and communicating branches The main trunk, after piercing the semispinalis capitis and trapezius muscles, accompanies the occipital artery to the scalp as the greater occipital nerve. This is the chief cutaneous nerve for the back part of the scalp. It enters the superficial fascia at the level of the superior nuchal line of the occipital bone and about an inch from the external occipital protuberance. Ramifying over the surface, it supplies the skin of the scalp as far as the vertex. It communicates on the scalp with the following nerves: great auricular, lesser occipital, posterior auricular, and third occipital.

The muscular branches of the second cervical nerve are destined for the semispinalis capitis, obliquus inferior, semispinalis cervicis, and multifidus.

Its communicating branches form the posterior cervical plexus. Descending over the posterior arch of the atlas is a branch from the sub-occipital nerve which forms a loop or network with a corresponding branch of the second nerve. From this loop twigs are supplied to the surronnding muscles. A similar loop is formed by a communication between branches of the second and third nerves, from which muscles are also supplied. Occasionally an additional loop is formed between branches of the third and fourth nerves. 
Third Cervical Nerve.-This is much smaller than the second nerve. Near its origin it forms a loop of communication with the second, and it may give off a similar communicating branch to the fourth nerve. The main trunk divides into medial cutaneous and lateral muscular branches. The lateral muscular branch enters contiguous muscles; the medial cutaneous branch passes backwards and medially, and becomes superficial as the third occipital nerve (n. occipitalis minimus), close to the median plane of the neck. It supplies fine branches to the neck and scalp, and communicates with the greater occipital nerve.

The fourth, fifth, and sixth cervical nerves are still smaller. Beneath the semispinalis capitis each divides into lateral muscular and medial cutaneous branches. The muscular branches supply neighbouring muscles; the cutaneous branches are small nerves, which, passing backwards, become superficial close to the median plane. They supply the skin of the back of the neck. The sixth is the smallest, and the cutaneous branches of the fifth and sixth nerves may be absent altogether. In certain cases the fourth nerve forms, with the third, a loop of communication from which muscles are supplied.

Seventh and Eighth Cervical Nerves.-These are the smallest of the posterior rami of the cervical nerves. They give off ordinarily no cutaneous branches, and end in the deep muscles of the back. There is occasionally a small cutaneous offset from the eighth nerve.

\section{THORACIC NERVES.}

The posterior ramus of each thoracic nerve divides into medial and lateral branches. In the case of the upper six or seven thoracic nerves the medial branches are chiefly distributed as cutaneous nerves,- - only giving off small muscular branches-while the lateral branches are wholly muscular in their distribution; in the case of the lower five or six thoracic nerves the opposite is the case. In all cases the muscular branches serve to innervate the longitudinal muscles of the back. The distribution of the cutaneous branches is different in the upper and lower part of the back. The upper six or seven thoracic nerves innervate the skin of the scapular region. The medial cutaneous branches, after a sinuous backward course from their origin, among the dorsal muscles, reach the surface near the spines of the vertebræ and are directed almost horizontally laterally over the trapezius muscle. The first is small; the second is very large and reaches to the acromion. The rest diminish in size, from above downwards, and become more and more oblique in direction. The lateral cutaneous branches of the lower five or six thoracic nerves are directed from their origin obliquely downwards and laterally among the parts of the sacro-spinalis muscle. Becoming cutaneous by piercing the latissimus dorsi at some distance from the median plane, they supply the skin of the back in the lower part of the chest and loin, the lowest nerves (eleventh and twelfth) reaching over the iliac crest on to the buttock. The lower nerves often subdivide into two branches before or after their emergence from the latissimus dorsi muscle.

\section{LUMBAR NERVES.}

First three Lumbar Nerves.-The posterior rami of the first three lumbar nerves subdivide into medial and lateral branches, in the same way. as the lower thoracic nerves. The medial branches are muscular and innervate the deep muscles of the back. The lateral branches are chiefly cutaneous. They are directed obliquely downwards and outwards among the fibres of the sacro-spinalis and become superficial by piercing the lumbo-dorsal fascia, just above the iliac crest and a short distance in front of the posterior iliac spine. They are then directed downwards in the superficial fascia of the buttock, and supply a lengthy strip of skin, extending from the median plane above the iliac crest to a point distal to and behind the greater trochanter of the femur. There may be only two cutaneous branches, derived from the first two lumbar nerves; in other cases the three nerves are the branches of the twelfth thoracic and first two lumbar nerves. 
The fourth and fifth lumbar nerves (like the last two cervical nerves) usually supply only muscular branches to the longitudinal muscles of the back. The fifth nerve in many cases sends a branch to form a loop of connexion with the posterior ramus of the first sacral nerve (posterior sacral plexus).

\section{SACRAL AND COCCYGEAL NERVES.}

The posterior rami of the sacral nerves issue from the posterior sacral foramina. As in the case of the thoracic and lumbar nerves, the upper sacral nerves differ from the lower in their distribution.

The first three sacral nerves supply medial muscular branches for the multifidus, and lateral cutaneous branches which pierce the fibres of the sacrotuberous ligament and the glutæus maximus muscle, and supply the skin over the back of the sacrum and contiguous part of the buttock, giving rise to the posterior sacral plexus.

The posterior sacral plexus consists, like the posterior cervical plexus, of loops or plexiform communications over the back of the sacrum between the posterior rami of the first three sacral nerves, to which are frequently joined branches of the last lumbar nerve and fourth and even the fifth sacral nerve. From these loops branches proceed to supply the multifidus muscle; others, piercing the sacro-tuberons ligament, form secondary loops beneath the glutæus maximus muscle. From the secondary loops, two or more cutaneous branches arise, which, after traversing the muscle, supply the skin over the sacrum and medial part of the buttock.

Posterior Ano-coccygeal Nerve.-The posterior rami of the fourth and fifth sacral nerves do not divide into medial and lateral branches. They unite together to form a loop which is joined by the minute posterior ramus of the coccygeal nerve. The union of the three nerves constitutes the posterior ano-coccygeal nerve, which, after perforating the sacro-tuberous ligament, is distributed to the skin in the neighbourhood of the coccyx. It supplies no muscles. This nerve is the representative of the superior caudal trunk of tailed animals.

\section{Morphology of the Posterior Ram.}

There are several points of morphological interest in relation to the posterior rami of the spinal nerves.

1. Muscular Distribution.-In their muscular distribution they are strictly limited to the longitudinal muscles of the back: namely, those associated with the axial skeleton alone.

2. Cutaneous Distribution.-Their cutaneous distribution represents two points of interest.

A. In the first place, while the skin of the back is supplied in a regularly segmental manner by the several nerves, certain of them fail to reach the surface at all. The absence of a cutaneons branch from the sub-occipital nerve may be due either to the absence of a perfect posterior root, or to its communication with the second nerve. The other nerves which do not usually supply the skin are the last two, three, or four cervical, and the fourth and fifth lumbar nerves. These nerres are placed in the centre of regions in which the upper and lower limbs are developed. They are minute nerves, while the corresponding anterior rami are among the largest of the spinal nerves. Thus, opposite the centre of each limb, posteriorly, there is a hiatus in the segmental distribution of the posterior rami of the spinal nerves to the skin of the shoulder and buttock, attributable to the formation of the limbs, and the extension into them of the greater part of the nerves of the region. This gap, in the case of the upper limb, commences at the level of the vertebra prominens; in the case of the lower limb it commences opposite the level of the posterior superior iliac spine. It can be continned on to each limb as a hypotletical area (the dorsal axial line), which indicates the area of contact (and overlapping) of cutaneous nerves not in strictly numerical sequence. Thus, in the region of the shoulder, the sixth (or fifth) cervical nerve innervates an area of skin adjoining that supplied by the eighth cervical or first thoracic nerve; in the region of the buttock the third lumbar nerve supplies an area contiguous with that supplied by the fifth lumbar or first sacral nerve.

B. The cutaneous branches of the posterior rami of the spinal nerves differ from the muscular branches in respect of their penetration into regions beyond those supplied by their motor roots. The cutaneous branches, in regions where outgrowths or extensions from the trmnk have occurred, follow these extensions; and, in consequence, supply skin corering parts which do not belong to segments represented by the nerves in question. Tlius the second and third cervical nerves (greater and third occipital) are drawn upwards so as to supply the posterior part of the scalp; the upper thoracic nerves are drawn laterally over the scapular region; the upper lumbar and sacral nerves supply the skin of the buttock; and the ano-coccygeal nerve forms a rudimentary caudal nerve. 
3. Plexuses.-The plexuses formed by the posterior rami of the upper cervical and upper sacral nerves are the simplest met with in the human body. The posterior cervical plexus is one from which muscular branches are supplied; the posterior sacral plexus is mainly concerned in prodncing cutaneons offsets. In the case of the posterior cervical plexus the loops of communication between the first three or four cervical nerves result in the formation of a series of nerves for the supply of the semispinales and other muscles, which bring into contact with these muscles, simultaneonsly, a considerable area of the spinal medulla, and provide a combined and simultaneons inmervation for the several parts of each muscle. In the case of the posterior sacral plexus, the formation of loops between the nerves results in the innervation of any given spot in the cutaneous area supplied from these loops by more than one spinal nerve. As has been said already, the cutaneous nerves, even without the formation of plexuses, overlap in their cutaneous distribution. The formation of a plexus causes a more intimate union of neighbouring spinal nerves, so that stimulation of the surface affects a wider area in the spinal medulla than if the nerves passed separately to it from the surface. While segmentation becomes less obvious, increased co-ordination is effected both of movement and sensation.

\section{ANTERIOR RAMI OF THE SPINAL NERVES.}

The anterior rami (O.T. anterior primary divisions) of the spinal nerves, are, with the exception of the first two cervical nerves, much larger than the corresponding posterior rami. Composed of elements of both posterior and anterior roots, each nerve separates from the posterior ramus on emerging from the intervertebral foramen, and, proceeding laterally, is distributed to structures on the lateral and anterior aspects of the body,-including the limbs.

Each nerve is joined near its origin by a gray ramus communicans from the sympathetic gangliated trunk; and in the case of certain thoracic, lumbar, and sacral nerves, the anterior ramus gives off a delicate bundle of fibres, which forms the white ramus communicans of the sympathetic trunk. That part of the spinal nerve which is distributed to the body wall and limbs may be termed somatic; the small white ramus communicans, innervating structures in the splanchnic area, may be termed the visceral or splanchnic part of the spinal nerve.

The anterior rami of the spinal nerves are distributed in a regular segmental manner only in certain cases. Except in the case of the thoracic nerves, the anterior rami combine to form the three great plexuses-cervical, brachial, and lumbo-sacral-and their arrangement and distribution is rendered exceedingly complex.

A thoracic nerve, such as the fifth or sixth, may be regarded as a type to illustrate the mode of distribution of the anterior rami of the spinal nerves (Fig. 606, p. 686). It occupies an intercostal space; near its origin it possesses gray and white rami communicantes; it courses through the interval between the intercostal muscles; it supplies branches to these muscles and gives off, when it reaches the side of the chest, a lateral branch, which, after supplying small muscular branches, pierces the external intercostal muscle, and is distributed to an area of skin over the lateral part of the trunk, contiguous dorsally with a similar area, innervated by the cutaneous branches of the posterior ramus of the same nerve. The lateral branch generally subdivides into a smaller posterior and a larger anterior ramus, as it pierces the muscles clothing the wall of the chest. The anterior ramus of the nerve then pursues its course obliquely forwards to the side of the sternum, where, after piercing the pectoral muscles, it appears superficially as the terminal anterior cutaneous branch. .This supplies an area of skin continuous with that supplied by the anterior part of the lateral branch of the same nerve. Such a nerve thus supplies, by means of its lateral and anterior branches, an area of skin which (with the area supplied by the cutaneous branch of its posterior ramus) forms a continuous and uninterrupted belt, extending from the median plane behind to the median plane in front. The lateral and anterior branches of the nerve innervate in their course the intercostal and other muscles, to be afterwards mentioned in detail.

\section{NERVI CERVICALES.}

The anterior rami of the cervical nerves, together with parts of the first and second thoracic nerves, are distributed to the head, neck, and upper extremity. 
The first four cervical nerves, by means of the cervical plexus, innervate the neck;

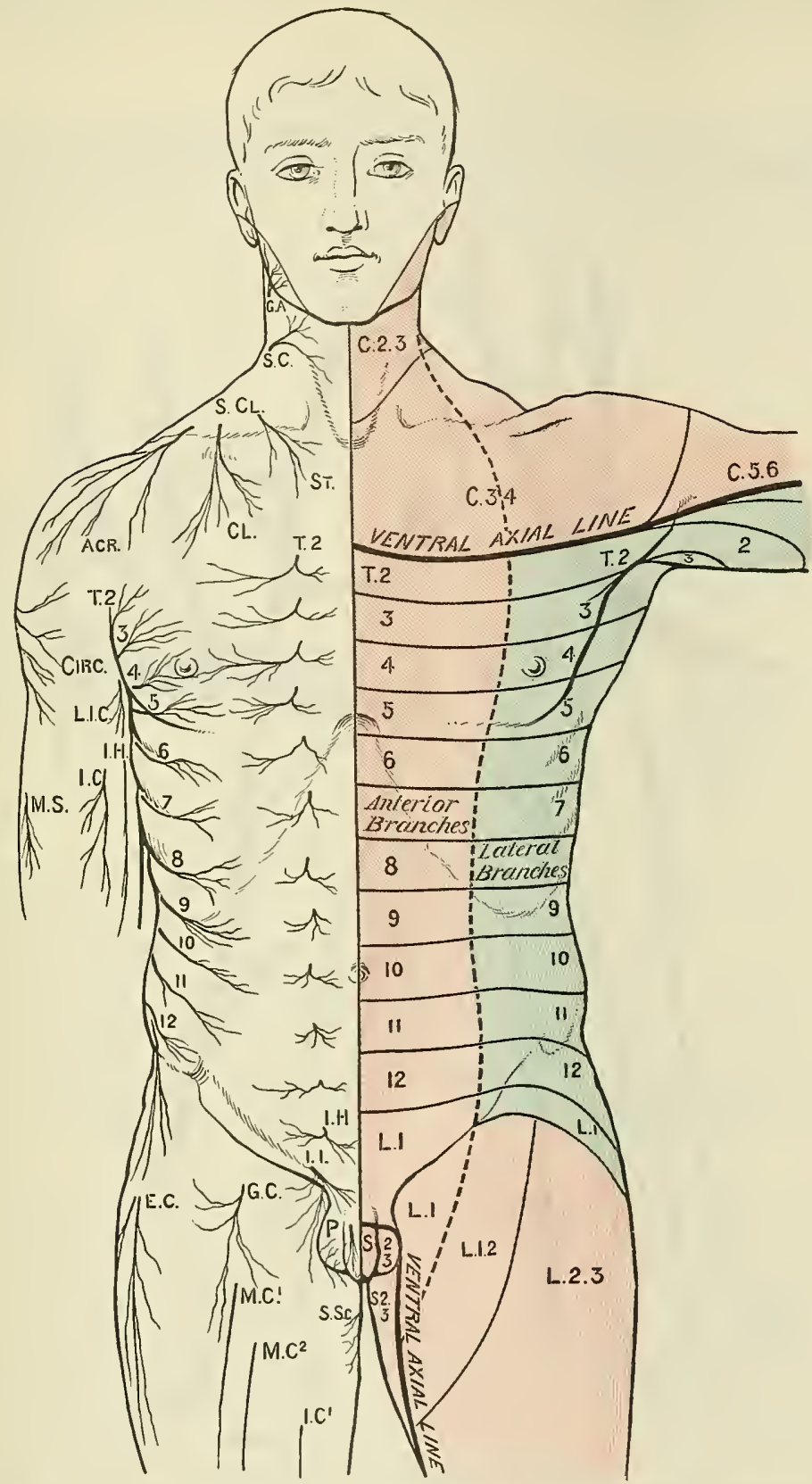

Fig. 609.-The Distribution of Cutaneods Nerves on the Front of the Tronk.

On one side the distribution of the several nerves is represented, the letters indicating their nomenclature.

G.A, Great auricular nerve ; S.C, N. cutanens colli ; S.CL, Supra-clavicular nerves ; Acr, Posterior* ; CL, Middle ; ST, Anterior; T.2-12, Lateral and anterior branches of thoracic nerves; I.H, llio-hypogastric nerve ; I.I, Nlio-inguinal nerve; Circ, Cutaneous branch of axillary nerve; L. I. C, Medial cutaneous nerve of the arm (lesser internal cutaneous nerve); I.H, Intercosto-brachial: I.C, Medial cutaueous nerve of the forearin (internal cutaneous) ; I.S, Cutaneous branch of radial nerve; E.C, Lateral cutaneous nerves; G.C, Lumbo-inguinal nerve; M.C. ${ }^{2}$, Intermediate cutaneous nerves ; I.C ${ }^{1}$, Branch of medial cutaneous nerve ; $\mathrm{P}$, Branches of pudendal merve; S.Sc, Branches of posterior cutaneous nerve of the thigh.

On the other side a schenatic representation is given of the areas supplied by the above nerves, the numerals indicating the spinal origin of the branches of distribution to each area.

the last four cervical nerves, together with a large part of the first thoracic nerve, 
through the brachial plexus, supply the upper limb. The second thoracic nerve may contribute a trunk to this plexus, and always assists in the innervation of the arm.

\section{PLEXUS CERVICALIS.}

The anterior rami of the first four cervical nerves are concerned in forming the cervical plexus. Each nerve emerges from the vertebral canal posterior to the

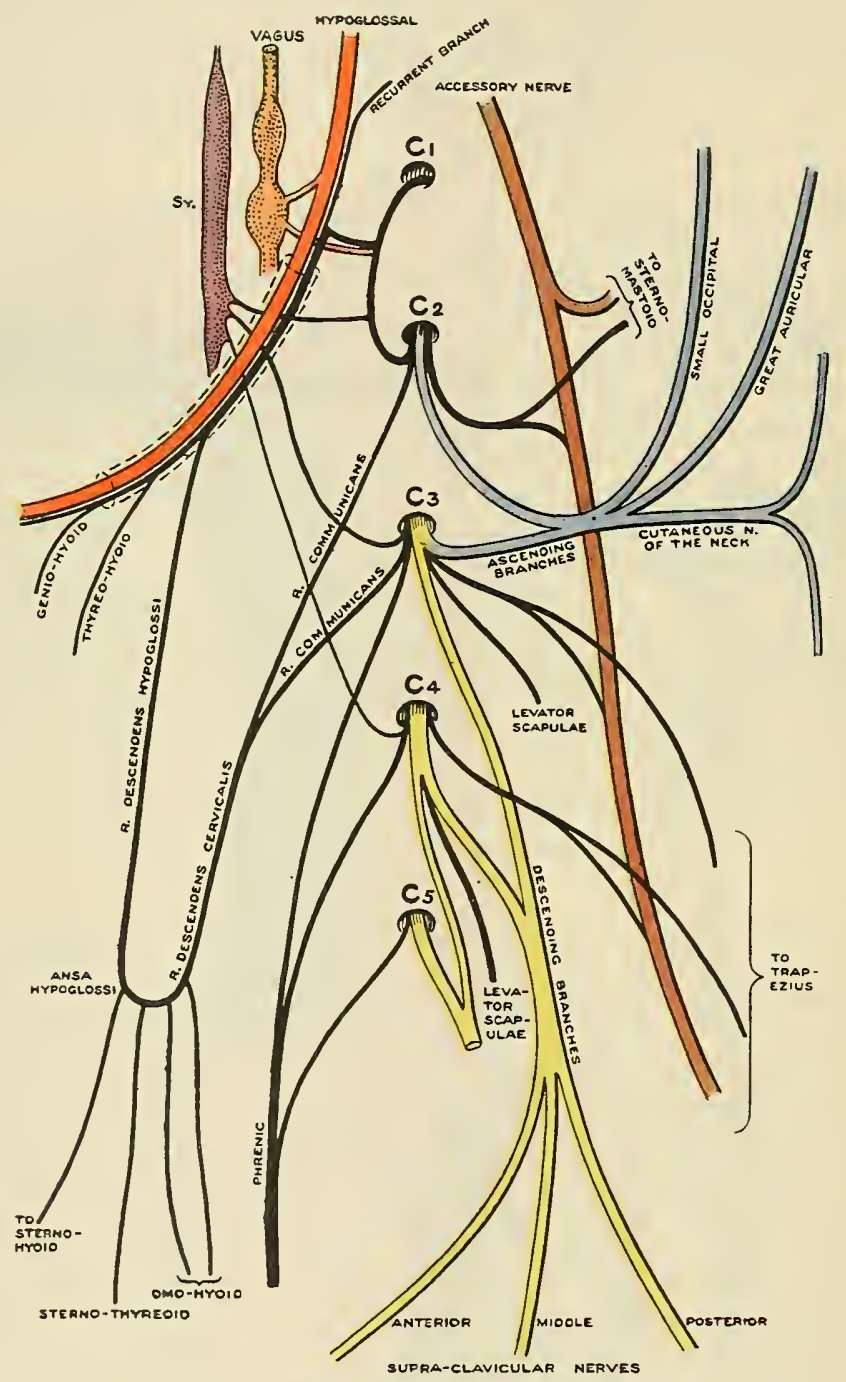

Fig. 610.--The Cervical Plexds.

vertebral artery. Each is joined on its emergence from the intervertebral foramen, at the side of the vertebral column, by a gray ramus communicans from the superior cervical ganglion of the sympathetic. In the neck the cervical nerves are concealed by the sterno-mastoid muscle; in front lies the longus capitis muscle, and behind are the scalenus medius, and (behind the first or sub-occipital nerve) the rectus capitis lateralis. The cervical plexus is constituted by the combination of these nerves in an irregular series of loops under cover of the sterno-mastoid muscle.

From these loops the branches of distribution arise, as (a) cutaneous branches to the head, neck, and shoulder; $(b)$ muscular branches to muscles of the neck and to 
the diaphragm; and (c) communicating branches to the vagus, accessory, hypoglossal, and sympathetic nerves.

For convenience of description, the nerves derived from the plexus may be classified as follows:-

\section{Superficial (cutaneous) Branches-}

A. Ascending Branches (C. 2, 3).

$\mathrm{N}$. occipitalis minor (smalier occipital),

N. auricularis magnus (great auricular),

N. cutaneus colli (O.T. superficial cervical).
B. Descending (supra-clavicular) Branches (C. 3, 4).

$\mathrm{Nn}$. supraclaviculares anteriores (O.T. suprasternal),

Nin. supraclaviculares medii (O.T. supra-clavicular),

Nin. supraclaviculares posteriores (O.T. supraacromial).

\section{Deep (muscular and communicating) Branches-}

\section{A. Lateral Branches.}

1. Muscular branches to Sterno-mastoid (C. 2),

Trapezius (C. 3, 4),

Levator scapulæ (C. 3, 4),

Scaleni (medius and posterior) (C. 3, 4).

2. Communicating branches to

Accessory nerve (C. 2, 3, 4).

\section{B. Medial Branches.}

1. Muscular to

Prevertebral muscles (C. 1, 2, 3, 4),

Infra-hyoid muscles (C. 1, 2, 3) (ansa hypoglossi),

Diaphragm (C. 3, 4) (phrenic nerve).

2. Communicating branches to

Vagus nerve (C. 1, 2),

Hypoglossal nerve (C. 1, 2),

Comm. hypoglossi (C. 2, 3),

Sympathetic (C. 1, 2, 3, 4).

The second, third, and fourth cervical nerves are the chief nerves engaged in forming the plexus. The first cervical nerve only enters into the formation of a small part-the medial portion of the deep part of the plexus.

Superficial Cutaneous Branches.--These nerves, six in number, are entirely cutaneous. They radiate from the plexus, and appear in the posterior triangle of the neck at the posterior border of the sterno-mastoid muscle. They are divisible into two series, the one ascending : smaller occipital, great auricular, and cutaneous nerve of the neck; the other descending (supra-clavicular): posterior, middle, and anterior.

Ascending Branches.-The smaller occipital nerve is variable in size and is sometimes double. Its origin is from the second and third cervical nerves (more rarely from the second only). It extends backwards beneath the sterno-mastoid, and then upwards along its posterior border. Piercing the deep fascia near the apex of the posterior triangle, it divides into auricular, mastoid, and occipital branches, and supplies small cervical branches to the upper part of the neck. The auricular branch supplies the skin of the cranial surface of the auricle; the mastoid and occipital branches supply the scalp. The nerve communicates on the scalp with the greater occipital and great auricular nerves, and with the posterior auricular branch of the facial nerve.

The great auricular nerve is the largest of the cutaneous branches. It arises from the second and third cervical nerves (or, more rarely, from the third alone). Winding round the posterior border of the sterno-mastoid muscle, it courses vertically upwards towards the ear. In this course it crosses the sterno-mastoid muscle obliquely and is covered by the platysma muscle. Before arriving at the ear it subdivides into mastoid, auricular, and facial branches. The mastoid branches ascend over the mastoid process and supply the skin of the scalp behind the ear, communicating with the smaller occipital and posterior auricular nerves. The auricular branches ascend to the ear and supply the lower part of the auricle on both aspects; they communicate with the same nerves. The facial branches, passing over the angle of the jaw and through the substance of the parotid gland, 
supply the skin of the cheek over the inferior part of the masseter muscle and the parotid gland. They communicate with branches of the facial nerve in the parotid gland.

The nervus cutaneus colli arises from the second and third cervical nerves. It winds round the posterior border of the sterno-mastoid muscle, and crosses the muscle to reach the anterior triangle, under cover of the platysma muscle and the external jugular vein. It divides near the anterior edge of the sterno-mastoid muscle into superior and inferior branches, which are distributed through the platysma to the skin covering the anterior triangle of the neck. The upper branches communicate freely beneath the platysma with the ramus colli of the facial nerve.

Descending (supra-clavicular) Branches.-By the union of two roots derived

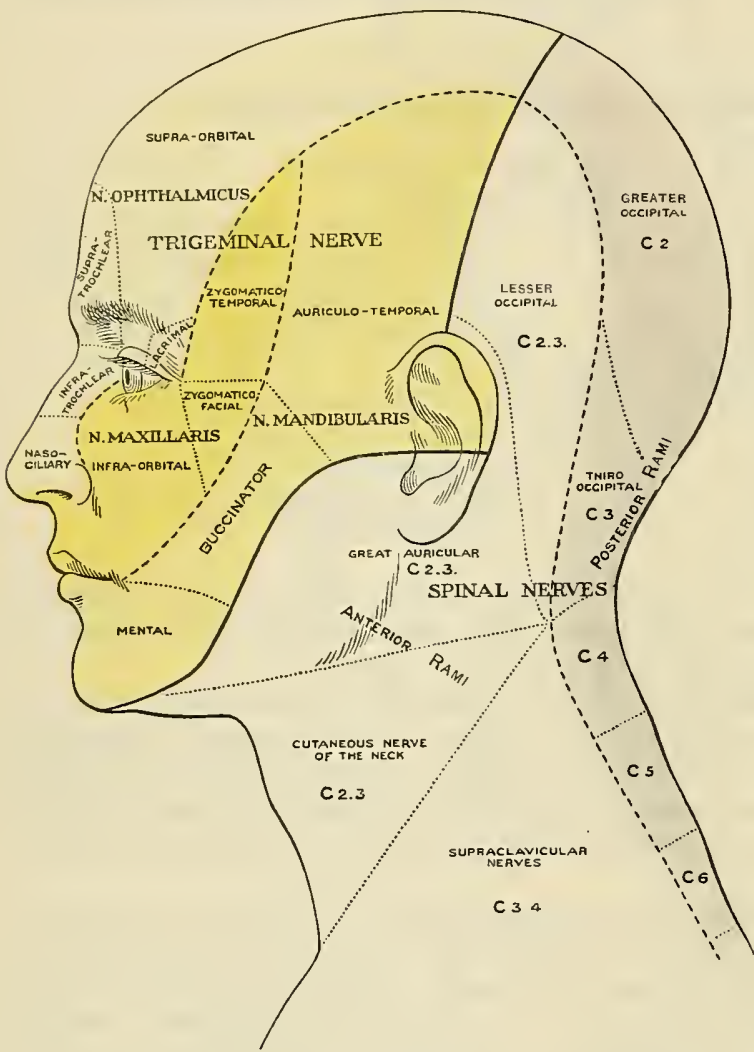

Fig. 611.-Distribution of Cutaneous Nerves to the Head AND NECK. from the third and fourth cervical nerves a considerable trunk is formed, which emerges from under cover of the sternomastoid muscle and extends obliquely downwards through theinferior part of the posterior triangle of the neck. It subdivides into radiating branches -anterior, middle, and posterior - which pierce the deep fascia of the neck above the clavicle, and are distributed to the skin of the inferior part of the side of the neck, to the front of the chest, and the shoulder. The anterior (O.T. supra-sternal) branches are the smallest. Passing over the medial end of the clavicle, they supply the skin of the neck and chest as far down as the synchondrosis sternalis. The middle (O.T. supra-clavicular) branches pass over the intermediate third of the clavicle, beneath the platysma, and can be traced as low as the nipple. The posterior (O.'T. supra-acromial) branches pass over or through the insertion of the trapezius muscle, and over the lateral third of the clavicle, to the shoulder, where they supply the skin as far down as the distal third of the deltoid muscle.

Deep Branches.--The deep branches of the cervical plexus are naturally separated into a lateral and a medial set by their relation to the sterno-mastoid muscle. Beneath the muscle, the lateral branches are directed laterally towards the posterior triangle, the medial branches medially towards the anterior triangle.

The lateral branches consist of muscular and communicating nerves, which for the most part occupy the posterior triangle.

The muscular branches are the following: (1) To the sterno-mastoid, from the second cervical nerve. This enters the muscle on its deep surface and communicates with the accessory nerve. (2) To the trapezius, from the third and fourth cervical nerves. These nerves cross the posterior triangle and end in the trapezius, after having communicated with the accessory nerve, both in the posterior triangle, and beneath the muscle. (3) To the levator scapulo, from the third and fourth cervical 
nerves. Two independent branches enter the lateral surface of the muscle in the posterior triangle. (4) To the scaleni (medius and posterior), from the third and fourth cervical nerves.

The communicating branches are three in number. They join the accessory nerve in three situations:-(a) A branch from the second cervical nerve to the sterno-mastoid joins the accessory nerve beneath that muscle. (b) Branches to the trapezius from the third and fourth nerves are connected with the accessory nerve in the posterior triangle. (c) Branches from the same nerves join the nerve beneath the trapezius muscle.

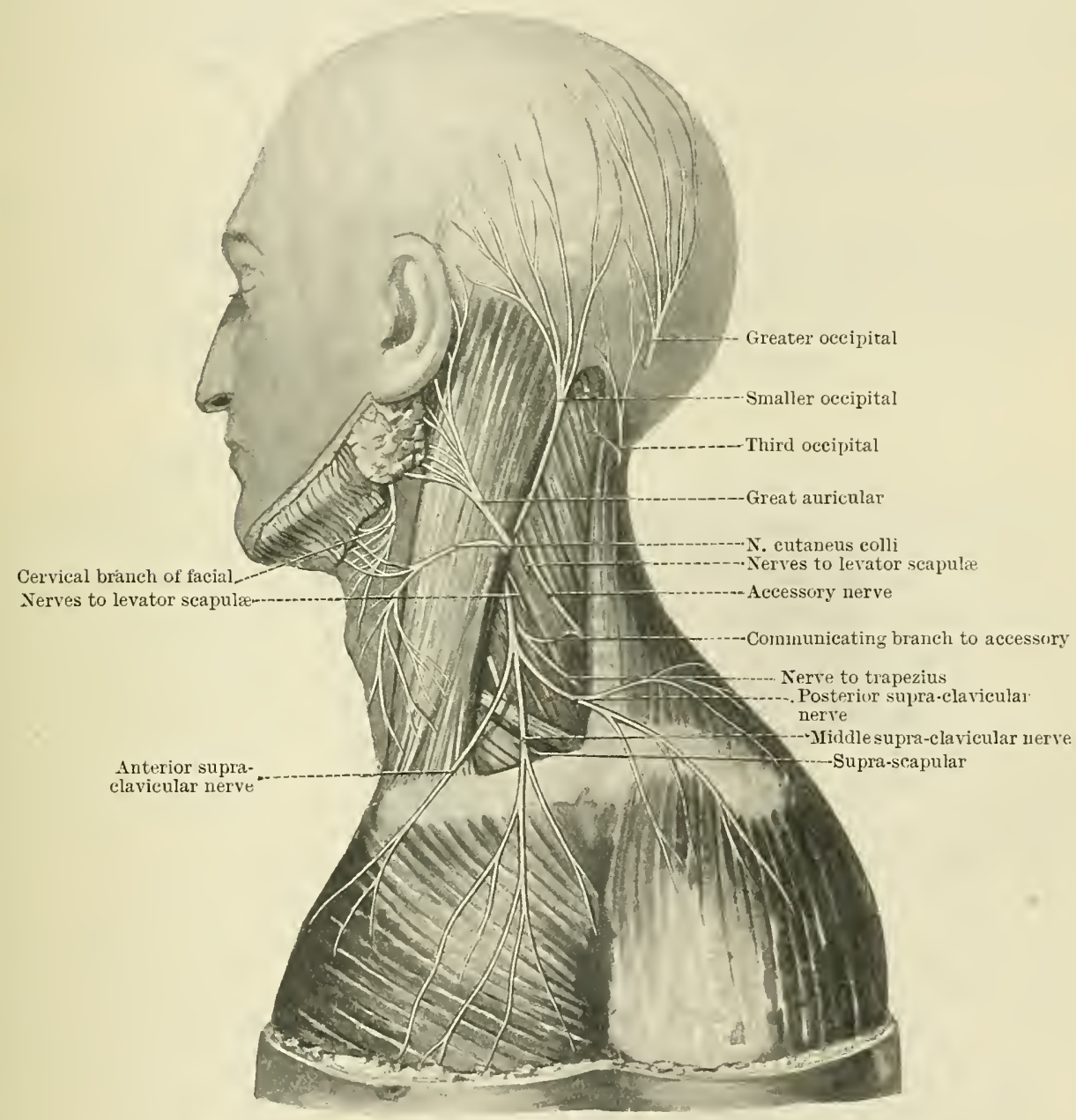

Fig. 612.-The Nerves of the Side of the Neck.

The medial branches of the plexus also comprise muscular and communicating branches. The first cervical nerve assists in the formation of this series of nerves, forming a slender loop with part of the second nerve in front of the transverse process of the atlas.

Communicating Branches.-(a) $W^{\top}$ ith the sympathetic-Gray rami communicantes pass to each of the first four cervical nerves, near their origins, from the superior cervical ganglion or from the trunk below the ganglion. (b) With the vagus nerve.-The ganglion nodosum of the vagus nerve may be connected by a slender nerve with the loop between the first two cervical nerves. This communication is not constant. (c) With the hypoglossal.-An important communication occurs between the hypoglossal nerve and the loop between the first and second 
cervical nerves (Fig. 613). A trunk from the loop joins the hypoglossal just beyond its exit from the skull. One fine branch from this trunk passes upwards along the hypoglossal nerve to the cranium (meningeal branch). The main part of the trunk accompanies the hypoglossal and separates from it to form successively three nerves-the descendens hypoglossi, and the nerves to the thyreo-hyoid and genio-hyoid muscles. The portion of the nerve which remains accompanies the hypoglossal to the muscles of the tongue. It is probable that no part of the hypoglossal nerve itself is concerned in the formation of these three branches. The descending branch of the hypoglossal descends in front of the internal and common carotid

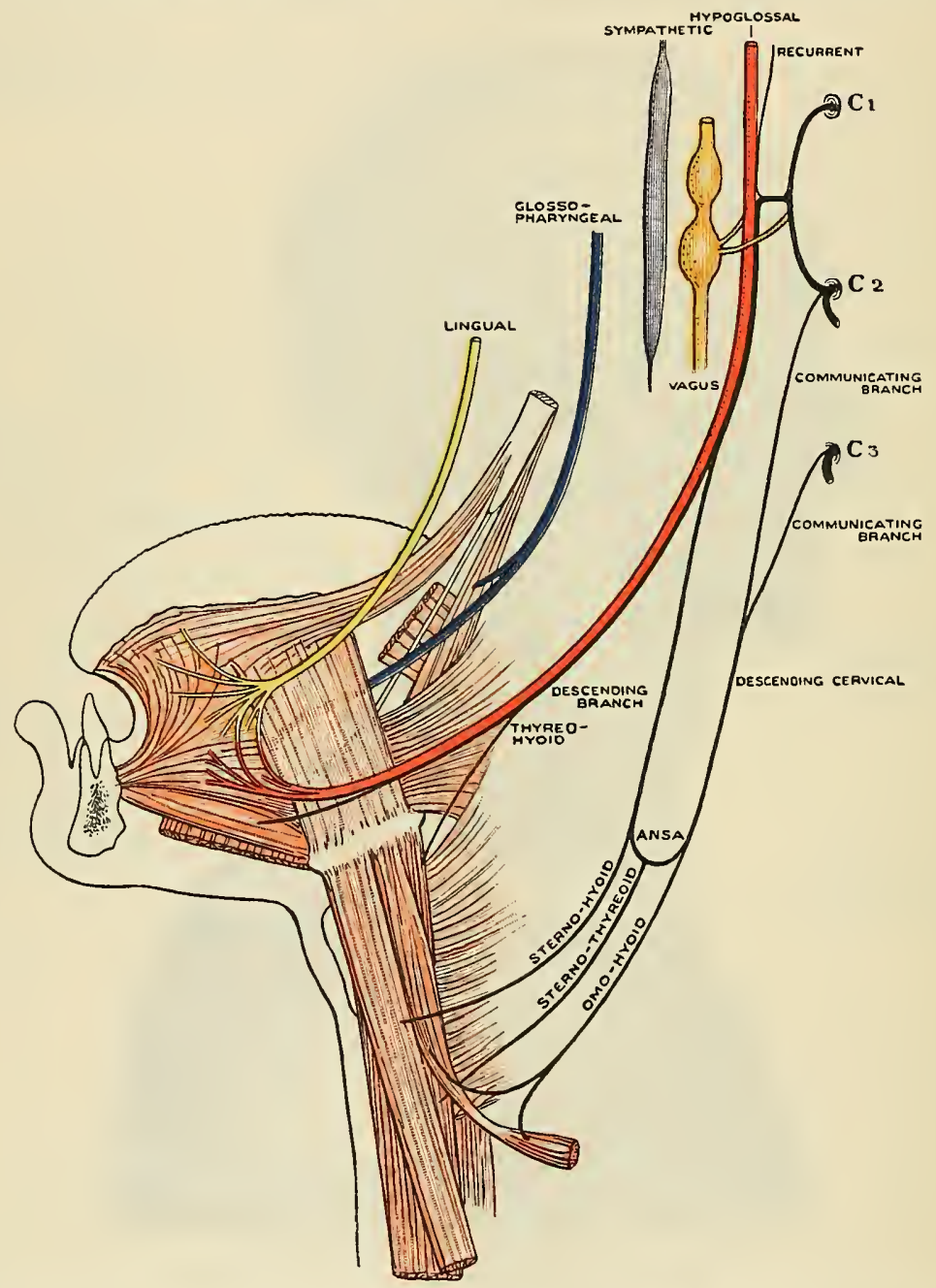

Fig. 613.--The Muscles of the Hyoid Bone and Strloid Process, and the Extrinsic Moscles of THE TONGUe, With THEIr Nerves.

arteries, and is joined in the anterior triangle of the neck by the descending cervical nerve, to form the ansa hypoglossi, from which the infra-hyoid muscles are innervated. (The descending branch of the hypoglossal, in some cases, arises from the vagus nerve.)

Muscular Branches. - The muscles supplied by the medial branches of the plexus are the prevertebral muscles, the genio-hyoid and the infra-hyoid muscles, and the diaphragm.

(a) Prevertebral Muscles.-1. From the loop between the first and second cervical nerves a small branch arises, for the supply of the rectus capitis lateralis, 
longus capitis, and the rectus capitis anterior. 2. From the second, third, and fourth nerves small branches supply the inter-transverse, longus colli, and longus capitis muscles. 3. From the fourth nerve a branch arises for the upper part of the scalenus anterior.

(b) Genio-hyoid and Infra-hyoid Muscles.-The descending cervical nerve is formed in front of the internal jugular vein by the union of two slender trunks from the second and third cervical nerves (conmunicantes hypoglossi). It forms a loop of communication in front of the carotid sheath with the descending branch of the hypoglossal nerve (derived ultimately from the first two cervical nerves). This loop of communication is called the ansa hypoglossi. It is often plexiform; and from it branches are given to the sterno-hyoid, sterno-thyreoid, and each belly of the omo-hyoid muscles. The nerve to the sterno-hyoid muscle is often continued behind the sternum, to join, in the thorax, with the phrenic nerve or the cardiac plexus.

The thyreo-hyoid and genio-hyoid muscles are supplied by branches of the hypoglossal nerve, which are also traceable back to the communication between the hypoglossal and the first two cervical nerves.

The anterior muscles in immediate relation to the median plane of the neck, between the chin and the sternum, are thus continuously supplied by the first three cervical nerves. The hy: oglossal is the nerve of the muscles of the tongue, and it is not certain that it contributes any fibres to the above-named muscles.

(c) Diaphragm.-The phrenic nerve supplies the diaphragm.

\section{Nervus Phrenicus.}

The phrenic nerve is derived mainly from the fourth cervical nerve, reinforced by roots from the third (either directly or through the nerve to the sterno-hyoid) and fifth (either directly or through the nerve to the subclavius muscle). It passes downwards in the neck upon the scalenus anterior muscle; at the root of the neck it enters the thorax between the subclavian artery and vein, and traverses the mediastinum to reach the diaphragm, lying in the middle mediastinum between the pericardium and pleura, and anterior to the root of the lung. In its course it presents certain differences on the two sides. In the neck, on the left side, it crosses the first part of the subclavian artery; on the right side it crosses the second part. In the superior mediastinum, on the left side, it lies between the left subclavian and carotid arteries, and crosses the vagus nerve and the aortic arch. On the right side it accompanies the innominate vein and superior vena cava, and is entirely separate from the vagus nerve. The left nerve is longer than the right, owing to the position of the heart and the left half of the diaphragm. The right nerve sends fibres along the inferior vena cava through the foramen venæ cavæ. Reaching the diaphragm the nerve separates into numerous branches for the supply of the muscle; some enter its thoracic surface (sub-pleural branches), but most of the fibres supply it after piercing the muscle (sub-peritoneal branches).

The branches of the phrenic nerve are-1. Muscular (to the diaphragm); 2 . pleural ; 3. pericardiac; 4 . inferior vena-caval ; 5 . suprarenal; and 6 . hepatic.

The branches to the pleura and pericardium arise as the phrenic nerve traverses the mediastinum. The branches to the inferior vena cava, suprarenal gland, and liver arise after communication of the phrenic nerve with the diaphragmatic plexus of the sympathetic on the abdominal surface of the diaphragm.

Communications of the Phrenic Nerve.- 1 . The phrenic nerve may communicate with the nerve to the subclavius muscle. 2. It may communicate with the ansa hypoglossi, or a branch from it (the nerve to the sterno-hyoid). 3. It frequently communicates with the cervical part of the sympathetic. 4. It communicates with the cœliac plexus by a junction upon the abdominal surface of the diaphragm with the diaphragmatic plexus on the inferior phrenic artery, in which a small diaphragmatic ganglion is found on the right side. From this junction brauches are given off to the inferior vena cava, suprarenal gland, and hepatic plexus. 


\section{Morphology of the Cervical Plexus.}

The characteristic feature of the cervical plexus is the combination of parts of adjacent nerves into compound nerve-trunks by the formation of series of loops. 'The result of the formation of these loops is that parts (particularly cutaneons areas) are supplied by branches of more than one spinal nerve.

A. Cutaneous Distribution.-By the combinations of the nerves into loops the discrimination of the elements in the upper cervical nerves, corresponding to the lateral and anterior rami of a typical thoracic nerve, is made a matter of some difficulty. The second, third, and fourth nerves, through the cervical plexus, supply an area of skin extending, laterally, from the side of the head to the shoulder; anteriorly, from the face to the level of the nipple. The higher nerres supply the upper region (second and third); the lower nerves supply the lower region (third and fourth). It is not possible to strictly compare the individual nerves with the lateral and anterior rami of a thoracic nerve. A line drawn from the ear to the middle of the clavicle separates, however, a lateral from an anterior cutaneous area; and certain of the cutaneous nerves fall naturally into one of these two categories. The nerves homologous with anterior rami of intercostal nerves are the $n$. cutaneus colli and the anterior branches of the supra-clavicular series; those homologous with lateral branches are the smaller occipital and posterior supra-clavicular brañches. The great auricular and middle supra-clavicular branches are mixed nerves, comprising elements belonging to both sets.

B. Muscular Distribution. - The nerves from the cervical plexus, supplying muscles, are simpler in their arrangement. They are not generally in the form of loops, and they are easily separated into lateral and anterior series. The lateral nerves comprise the branches to the rectus capitis lateralis, sterno-mastoid, trapezius, levator scapulæ. 'The nerves in the anterior series are those to the longus capitis, rectus capitis anterior, the hyoid muscles, and the diaphragm.

It is noteworthy that the last-named muscles-genio-hyoid, thyreo-hyoid, sterno-hyoid, omohyoid, sterno-thyreoid, and diaphragm-are continuously supplied by branches from the first five cervical nerres: the higher muscles by the higher nerves; the lower muscles by the lower nerves.

\section{PLEXUS BRACHIALIS.}

The Brachial Plexus is formed by the anterior rami of the fifth, sixth, seventh, and eighth cervical nerves, along with the greater part of the first thoracic nerve. In some cases a slender branch of the fourth cervical nerve is also engaged; and the second thoracic nerve, in all cases, also contributes to the innervation of the arm, through the intercosto-brachial (O.T. intercosto-humeral) nerve. In many cases it contributes also directly to the plexus, by an intra-thoracic communication with the first thoracic nerve.

Position of the Plexus. - The nerves forming the brachial plexus appear in the posterior triangle of the neck between the scalenus anterior and scalenus medius muscles; the plexus is formed in close relation to the subclavian and axillary arteries; the nerves emanating from it accompany the artery to the axilla, where they are distributed to the shoulder and upper limb.

Communications with the Sympathetic.-The lower four cervical nerves communicate with the cervical portion of the sympathetic by means of gray rami communicantes. Two branches arise from the middle cervical ganglion, and join the anterior rami of the fifth and sixth nerves. Two arising from the inferior cervical ganglion join the seventh and eighth nerves. They reach the nerves either by piercing the prevertebral muscles or by passing round the border of the scalenus anterior muscle.

Composition of the Brachial Plexus.-In an analysis of the brachial plexus four stages may be always seen :-

(1) The undivided nerves.

(2) The separation of the nerves into anterior and posterior trunks; and the formation of three primary cords.

(3) The formation of three secondary cords-lateral, medial, and posterior.

(4) The origin of the nerves of distribution.

(1) The undivided nerves have only a very short independent course at the side of the neck, after passing between the scalene muscles.

(2) Almost immediately after entering the posterior triangle there are formed three primary cords: the first cord is formed by the union of the fifth and sixth nerves together; the second, by the seventh nerve alone; and the third, by the union of the eighth cervical and first thoracic nerves together. While these cords are being formed, a division occurs in each of the nerves, into anterior and posterior trunks. The anterior and posterior trunks of the fifth, sixth, and seventh 
nerves are nearly equal in size. The posterior trunk of the eighth cervical nerve is much smaller. The posterior trunk of the first thoracic nerve is very minute, and may not be present at all.

(3) The secondary cords of the plexus are formed by combinations of these anterior and posterior trunks in relation to the axillary artery. They are three in number. The lateral cord is formed by a combination of the anterior trunks of the fifth, sixth, and seventh nerves, and lies on the lateral side of the axillary artery. The medial cord is formed by a combination of the anterior trunk of the eighth cervical with the part of the first thoracic nerve engaged in the formation of the plexus; it lies on the medial side of the axillary artery. The posterior cord is made up of all the dorsal trunks from the fifth, sixth, seventh, and eighth cervical and first thoracic nerves, and lies behind the axillary artery.

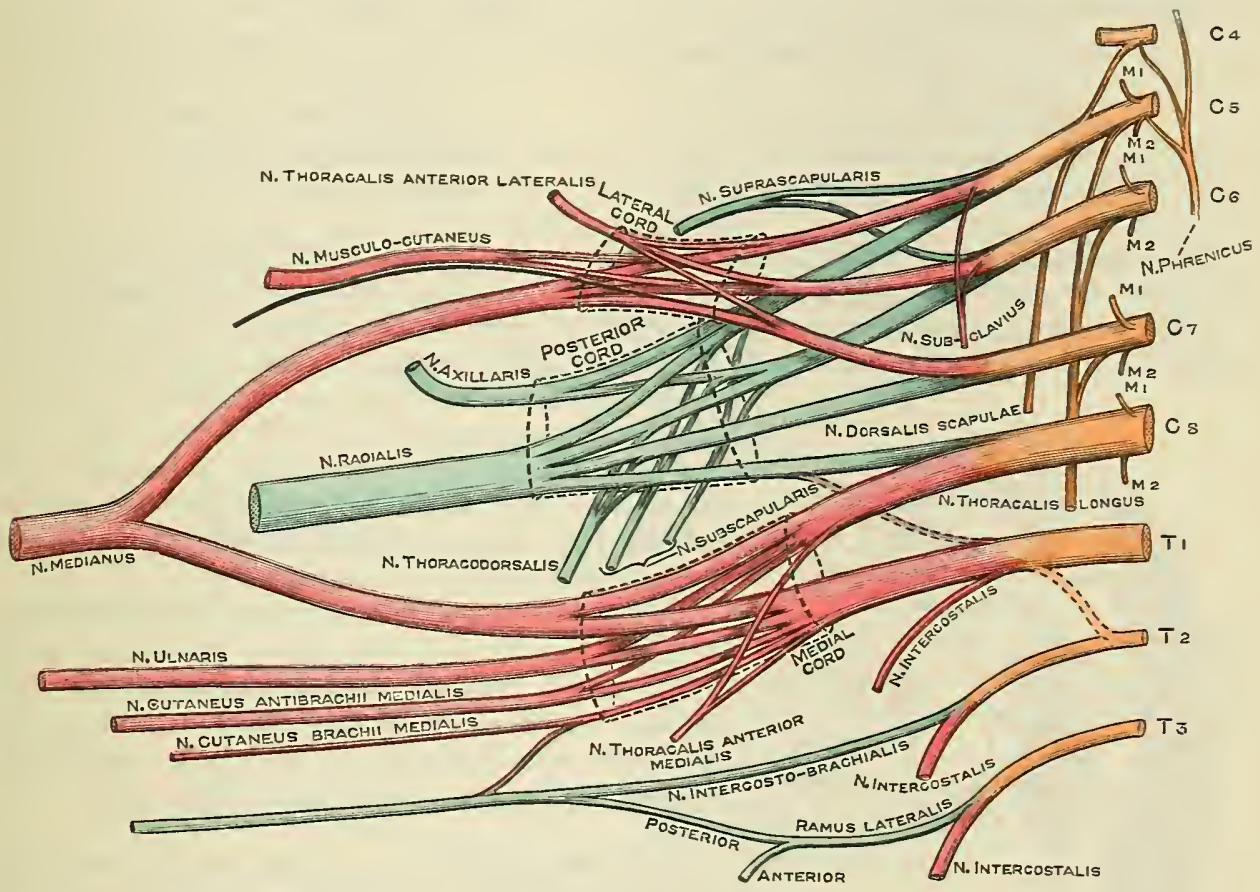

Fig. 614.-The Neries of the Brachial Plexus.

The first thoracic nerve may not contribute to the posterior cord, and the branch when present is a very small nerve.

(4) The nerves of distribution for the shoulder and arm are derived from these secondary cords, and receive in this way various contributions from the constituent spinal nerves. From the lateral cord arise the lateral anterior thoracic and musculocutaneous nerves, and the lateral head of the median nerve. From the medial cord arise the medial head of the median nerve, the ulnar nerve, medial cutaneous nerve of the forearm, medial cutaneous nerve of the arm, and the medial anterior thoracic nerve. From the posterior cord arise the axillary, the two subscapular, the thoraco-dorsal, and the radial nerves.

It is to be remembered that, although derived from a secondary cord formed by a certain set of spinal nerves, any given nerve does not necessarily contain fibres from all the constituent nerves; e.g. both the musculo-cutaneous and axillary nerves, from the lateral and posterior cords respectively, are ultimately derived only from the fifth and sixth cervical nerves. In other words, the secondary cords are merely collections of nerres of distribution bound together in a common sheath in their passage throigh the axilla.

\section{The Braxches of the Brachial Plexus.}

It is customary to separate artificially the nerves of distribution of the brachial plexus into two sets: (1) supra-clavicular and (2) infra-clavicular. Clinically it is 
important to realise the position of origin of certain nerves. The nerves to the prevertebral muscles, the communication with the phrenic, the dorsal scapular, and long thoracic nerves, arise from the anterior rami of the nerves involved in the plexus. The supra-scapular and the nerve to the subclavius arise at the level of formation of the secondary cords; and the anterior thoracic, subscapular, and thoraco-dorsal nerves arise from the secondary cords, prior to their ultimate subdivision into the nerves of distribution for the upper limb.

Pars Supraclavicularis.-The nerves derived from the plexus above the level of the clavicle are, like the main trunks, divisible into two series; anterior branches arising from the front, and posterior branches arising from the back of the plexus (Fig. 614, p. 701).

\section{Anterior Branches.}

1. Nerves to scalenus anterior and longus colli.

2. Communicating nerve to join the phrenic nerve.

3. Nerve to the subclavius muscle.

\section{Posterior Branches.}

1. Nerves to scaleni, medius and posterior.

2. Dorsal (posterior) scapular nerve.

3. Long thoracic nerve.

4. Supra-scapular nerve.

The muscular twigs to the anterior scalene and longus colli muscles arise from the lower four cervical nerves, as they emerge from the intervertebral foramina.

The communicating branch to the phrenic nerve arises usually from the fifth cervical nerve at the lateral border of the anterior scalene muscle. It is sometimes

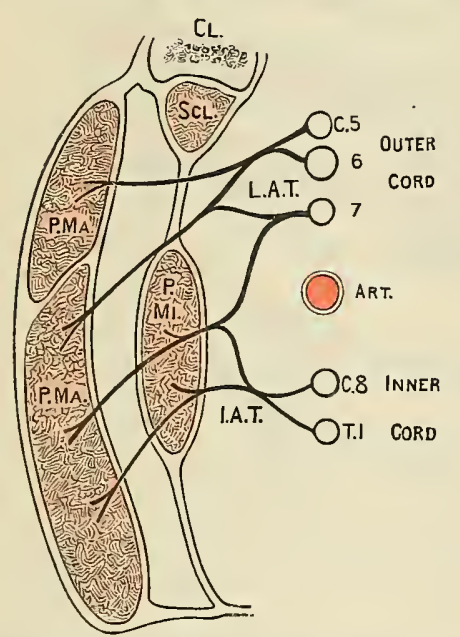

Fig. 615.-Diagram OF THE ORIGIN AND Distribution OF THE NeRves to THE Pectoral Muscles.

L.A.T, Lateral anterior thoracic nerve; I.A.T, Medial anterior thoracic nerve; C. $5,6,7$, C.8, T.1, Nerves of the brachial plexus; ART, Axillary artery; CL, Clavicle; ScL, Subclavius muscle; P.Mr, Pectoralis minor, joined to subclavius by costo-coracoid membrane P.MA, Pectoralis major.

muscles. It occasionally pierces the levator scapulæ. absent, and occasionally an additional root is present from the sixth cervical nerve. In some instances the nerve is replaced by a branch from the nerve to the subclavius, which passes medially behind the sterno-mastoid muscle to join the phrenic at the inlet of the thorax.

N. Subclavius. - The nerve to the subclavius is a slender nerve, which arises from the front of the cord formed by the fifth and sixth cervical nerves. It descends in the posterior triangle of the neck over the third part of the subclavian artery. It often communicates with the phrenic nerve.

The branches to the scaleni, medius and posterior, are small trunks which arise from the lower four cervical nerves as they emerge from the in tervertebral foramina.

N. Dorsalis Scapulæ. - The dorsal scapular nerve (O.T. posterior scapular or nerve to the rhomboids) arises from the back of the fifth cervical nerve, as it emerges from the intervertebral foramen. It appears in the posterior triangle of the neck, after piercing the scalenus medius muscle. It is directed downwards, under cover of the levator scapulæ and rhomboid muscles, and along the vertebral margin of the scapula, to be distributed to the levator scapulæ, rhomboideus minor, and rhomboideus major

N. Thoracalis Longus. - The long thoracic nerve (O.T. posterior thoracic or external respiratory nerve of Bell) arises by three roots, of which the middle one is usually the largest, from the back of the fifth, sixth, and seventh nerves, as they emerge from the intervertebral foramina. The nerve pierces the scalenus medius as two trunks, of which the lower represents the contribution from the seventh cervical nerve, and, descending along the side of the neck behind the cords of the brachial plexus, it enters the axilla between the superior edge of the serratus 
anterior muscle and the axillary artery. It continues its downward course over the outer surface of the serratus, to the slips of which it is distributed.

There is a more or less definite relation between the roots of this nerve and the parts of the serratus muscle. The first part of the muscle is innervated by the fifth nerve alone; the second part by the fifth and sixth, or the sixth alone; the third part by the sixth and seventh, or the seventh nerve alone.

N. Suprascapularis.-The supra-scapular nerve arises from the back of the cord formed by the fifth and sixth cervical nerves in the posterior triangle of the neck. It occupies a position above the main cords of the brachial plexus, and courses downwards and laterally parallel to them towards the superior margin of the scapula. It passes through the scapular notch to reach the dorsum of the scapula. After supplying the supra-spinatus muscle it winds round the great scapular notch in company with the transverse scapular artery and terminates in the infra-spinatus muscle. It also supplies articular branches to the back of the shoulder-joint.

Pars Infraclavicularis. - The so-called infra-clavicular branches of the brachial plexus are distributed to the chest, shoulder, and arm. According to their origin they are divisible into two sets-an anterior set, derived from the lateral and medial cords, and a posterior set, derived from the posterior cord. In their distribution the same arrangement is maintained. The anterior nerves of distribution, springing from the lateral and medial cords, supply the chest and the front of the limb; the posterior nerves, springing from the posterior cord, supply the shoulder and the back of the limb.

\section{Anterior Branches.}

From the Lateral Cord.

Lateral anterior thoracic.

Median (lateral head).

Musculo-cutaneous.

\section{From the Medial Cord.}

Medial anterior thoracic.

Median (medial head).

Ulnar.

Medial cutaneous nerve of forearm (O.T. interual cutaneous).

Medial cutaneous nerve of arm (O.T. lesser internal cutaneous).

\section{Posterior Branches.}

Axillary nerve.

Radial nerve.

Two subscapular nerves.

Thoraco-dorsal nerve.

\section{Nervi Thoracales ANteriores.}

The anterior thoracic nerves are two in number, lateral and medial. The lateral anterior thoracic nerve arises from the lateral cord of the brachial plexus by three roots-from the fifth, sixth, and seventh cervical nerves. The medial anterior thoracic nerve arises from the medial cord of the plexus, from the eighth cervical and first thoracic nerves. Each courses downwards and forwards on either side of the axillary artery. A loop of communication is formed between them in front of the artery. They are finally distributed to the pectoralis major and minor muscles (Fig. 615).

The nerves are distributed to the pectoral muscles in the following way. Two sets of branches from the lateral anterior thoracic nerve pierce the costo-coracoid membrane. The superior branches supply the clavicular part of the pectoralis major; the inferior branches are distributed to the superior fibres of the sternal portion of the muscle. The superior branches come from the fifth and sixth cervical nerves; the inferior branches, from the fifth, sixth, and seventh nerves. The pectoralis minor is pierced by two sets of nerves-the superior set is derived from the loop of communication between the two anterior thoracic nerves over the axillary artery; the inferior set is derived from the medial anterior 
thoracic nerve alone. These nerves supply the pectoralis minor muscle, and, after piercing it, supply the sternal part of the pectoralis major. The inferior nerve, in many cases, sends its branches to the pectoralis major round the inferior border of the

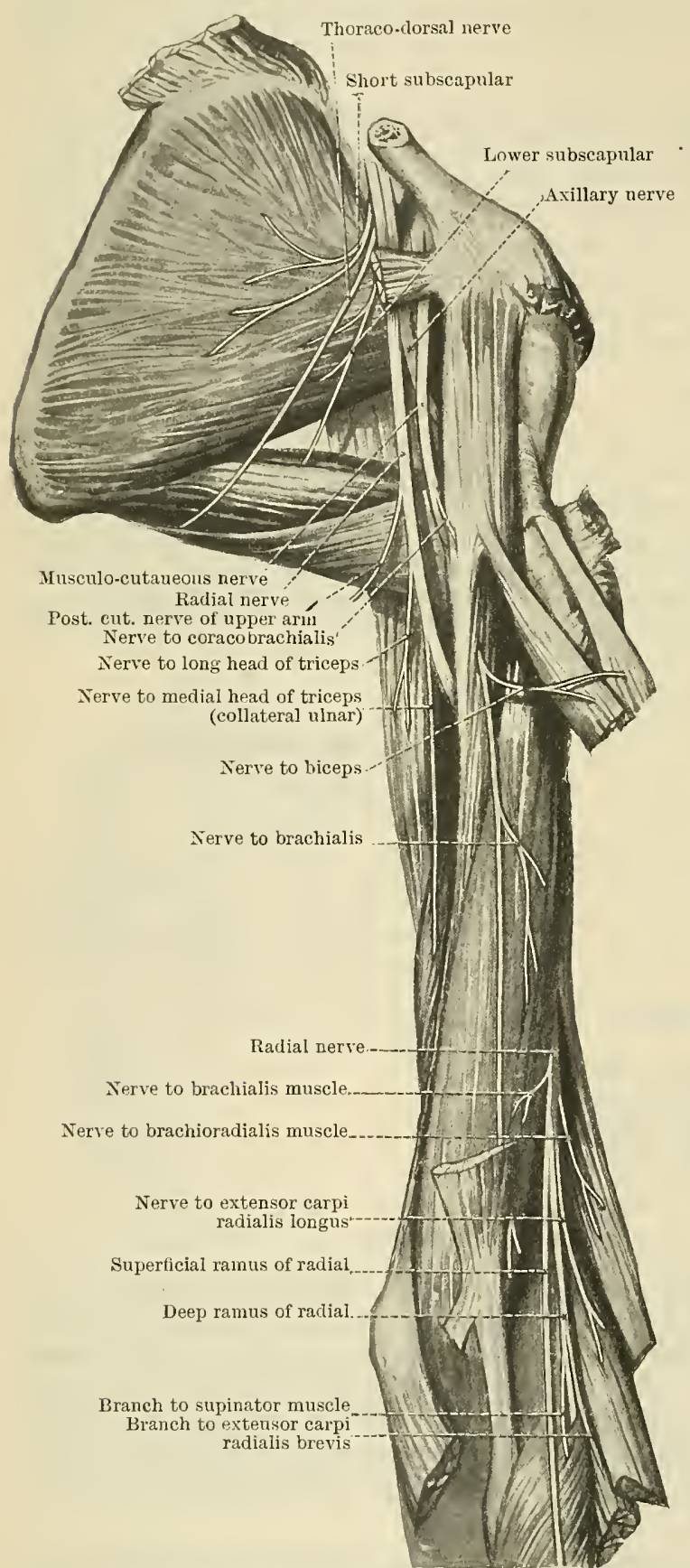

Fig. 616.-The Deeper Nerves of the Arm. pectoralis minor, and it may supply on its way the axillary arches, if present. These two branches are derived-the superior from the seventh and eighth cervical, and first thoracic nerves; the inferior from the eighth cervical and first thoracic nerves. The pectoral muscles are thus both supplied by the two anterior thoracic nerves. The clavicular fibres of the pectoralis major are innervated by the fifth and sixth nerves; the sternal fibres, from above downwards, by the fifth, sixth, seventh, and eighth cervical, and first thoracic nerves; and the pectoralis minor is supplied by the seventh and eighth cervical, and first thoracic nerves.

\section{Nervus Musculocutaneus.}

The musculo-cutaneous nerve takes origin from the lateral cord of the plexus, from the fifth and sixth cervical nerves (Fig. 614). The nerve to the coracobrachialis muscle, arising from the seventh or sixth and seventh nerves, is usually associated with it. Separating from the lateral head of the median nerve, the musculo-cutaneous nerve lies at first between the coracobrachialis muscle and the axillary artery. It is then directed distally between the two parts of the coracobrachialis, and passes between the biceps and brachialis muscles, to the bend of the elbow. It pierces the deep fascia over the front of the elbow, between the biceps and brachioradialis, and terminates as the lateral cutaneous nerve for the supply of the lateral aspect of the forearm. In its course it may send a branch under the biceps to join the median nerve.

The branches of the nerve are muscular and cutaneous. The muscular branches are supplied to the two heads of the biceps and the brachialis, as the nerve lies between the muscles. The nerve to the coracobrachialis (usually incorporated with the trunk of the musculo-cutaneous nerve) has an independent origin from 
the seventh or sixth and seventh nerves. It is usually double, one branch entering each portion of the muscle. The lateral cutaneous nerve of the forearm divides into volar and dorsal branches (Fig. 616, p. 704). The volar branch runs distally along the front of the lateral aspect of the forearm to the wrist, and supplies an area extending medially to the middle line of the forearm anteriorly, and distally so as to include the ball of the thumb. It communicates, proximal to the wrist with the superficial ramus of the radial nerve, and supplies branches to the radial artery. The dorsal branch passes posteriorly and distally over the extensor muscles and supplies the skin on the lateral aspect of the forearm posteriorly in its proximal three-fourths, communicating with the cutaneous branches of the radial nerve.

In addition to the above branches, the musculo-cutaneous nerve supplies in many cases the following small twigs in the arm: (1) a medullary branch to the humerus ; (2) a periosteal branch to the distal end of the humerus on its anterior surface; and (3) a branch to the brachial artery.

\section{Nervus Medianus.}

The median nerve arises by two heads-one from the lateral cord, the other from the medial cord of the brachial plexus. The lateral head, from the (fifth), sixth, and seventh nerves, descends along the lateral side of the axillary artery; the medial head, from the eighth cervical and first thoracic nerves, crosses the end of the axillary artery or the beginning of the brachial artery, to join the other head in the proximal part of the arm. Descending along the lateral aspect of the brachial artery, the nerve crosses over it obliquely in the distal half of the arm. In the hollow of the elbow, it lies on the medial side of the brachial artery, beneath the lacertus fibrosus and the median basilic vein. It passes into the forearm between the two heads of the pronator teres muscle, separated from the ulnar artery by the deep origin of that muscle. Extending distally along the middle of the forearm, between the superficial and deep muscles, to the wrist, it enters the palm of the hand on the lateral side of the flexor tendons of the fingers, and beneath the transverse carpal ligament. In the hand it spreads out at the distal border of the transverse carpal ligament beneath the palmar aponeurosis and superficial palmar arch, and separates into its six terminal branches. In the forearm a small artery accompanies it,- the median branch of the volar interosseous artery. Proximal to the wrist it is comparatively superficial, lying on the lateral side of the superficial flexor tendons and directly beneath the tendon of the palmaris longus.

Branches.-The median nerve usually gives off no branches in the (upper) arm.

Branches in the Forearm.-(1) Articular Branches.-Minute articular filaments are distributed to the front of the elbow-joint.

(2) Muscular Branches. - Just below the elbow a bundle of nerves arises to be distributed to the following muscles: pronator teres, flexor carpi radialis, palmaris longus, flexor digitorum sublimis. Nerves are also generally traceable from this bundle to the upper fibres of the flexor pollicis longus and flexor digitorum profundus. The nerve to the pronator teres often arises independently in the hollow of the elbow.

(3) The volar interosseous nerve of the forearm (O.T. anterior interosseous) arises from the posterior surface of the median nerve in the forearm, passes distally on the volar aspect of the interosseous membrane along with the volar interosseous artery, passes dorsal to the pronator quadratus muscle, and terminates by supplying articular filaments to the radio-carpal articulation. In its course the nerve supplies muscular branches to the flexor pollicis longus, the lateral half of the flexor digitorum profundus, and the pronator quadratus, minute medullary branches to the radius and ulna, and twigs to the periosteum and interosseous membrane.

(4) Palmar Ramus.--In the distal third of the forearm a small cutaneous branch arises, which pierces the deep fascia and crosses the transverse carpal ligament to reach the palm of the hand. It supplies the skin of the palm and com- 
municates with a similar branch of the ulnar nerve. This branch is not always present.

Branches in the Hand.-In the hand the median nerve gives off its terminal branches. These are muscular and cutaneous.

The main muscular branch arises just distal to the transverse carpal ligament and passes to the base of the thenar eminence; entering the ball of the thumb superficially on the medial side, it supplies branches to the abductor pollicis brevis, opponens pollicis, and the flexor pollicis brevis.

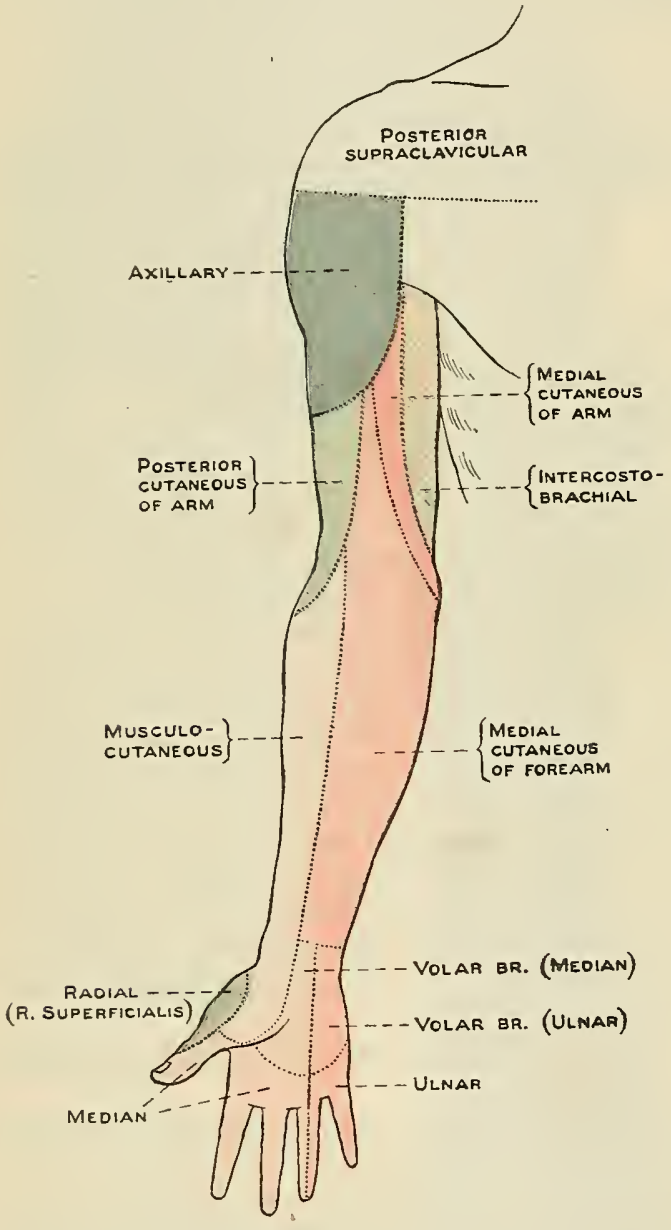

A

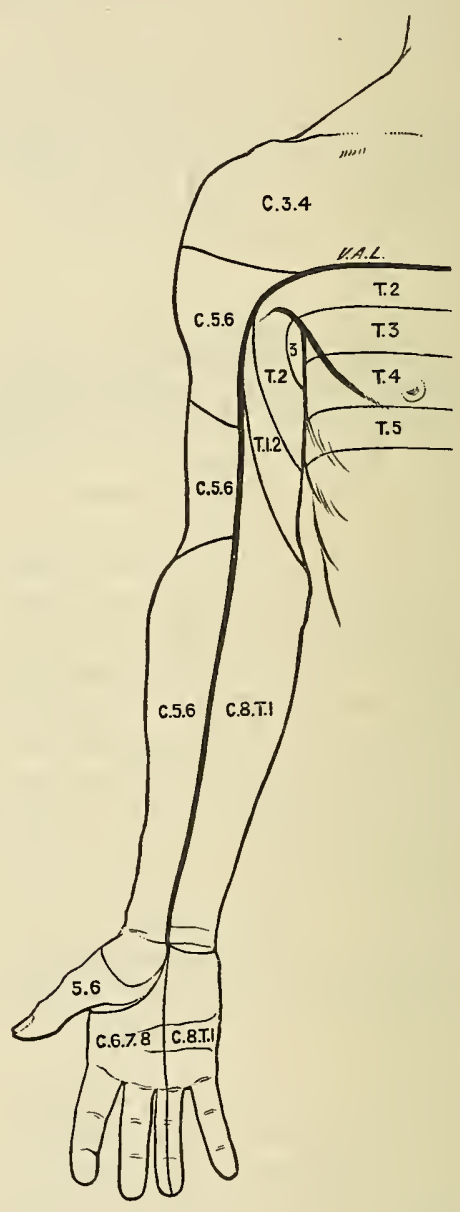

B

Frg. 617.-The Distribution of Cutaneous Nerves on the front of the Arm and Hand.

(B) is a schematic representation of the areas supplied by the above nerves, the lettering indicating the spinal origin of the branches of distribution to each area. V.A.L., Ventral axial line.

The cutaneous branches are five in number. Three separate branches supply each side of the thumb and the lateral side of the index finger. The two remaining branches ( $n n$. digitales volares communes) subdivide at the cleft between the second and third, and the third and fourth fingers respectively, into branches (nn. digitales volares proprii) which supply the adjacent sides of the second and third, and the third and fourth fingers. From the nerves which supply respectively the lateral side of the index finger, and the contiguous sides of the index and third fingers, fine muscular branches arise for the first two lumbrical muscles. The cutaneous branches of the median nerve are placed in the palm between the superficial palmar arch and the flexor tendons. They become super- 
ficial at the roots of the fingers between the slips of the palmar aponeurosis, or, in the case of the nerves to the thumb and lateral side of the index finger, at the lateral edge of the central portion of the palmar aponeurosis. In the fingers they are placed superficial to the digital arteries, and are distributed to the sides and volar aspects of the fingers. Each nerve supplies one or more dorsal branches, distributed to the skin on the dorsal aspect of the terminal phalanx of the thumb and the distal two

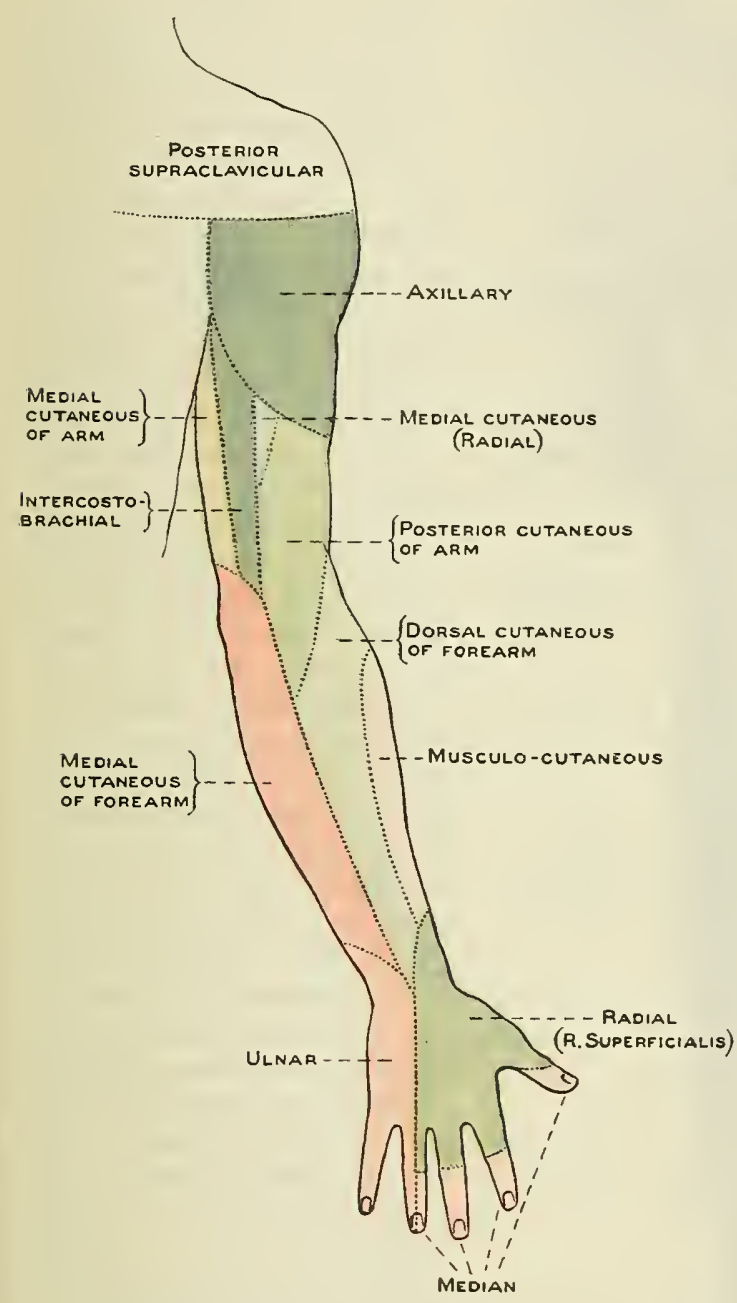

A

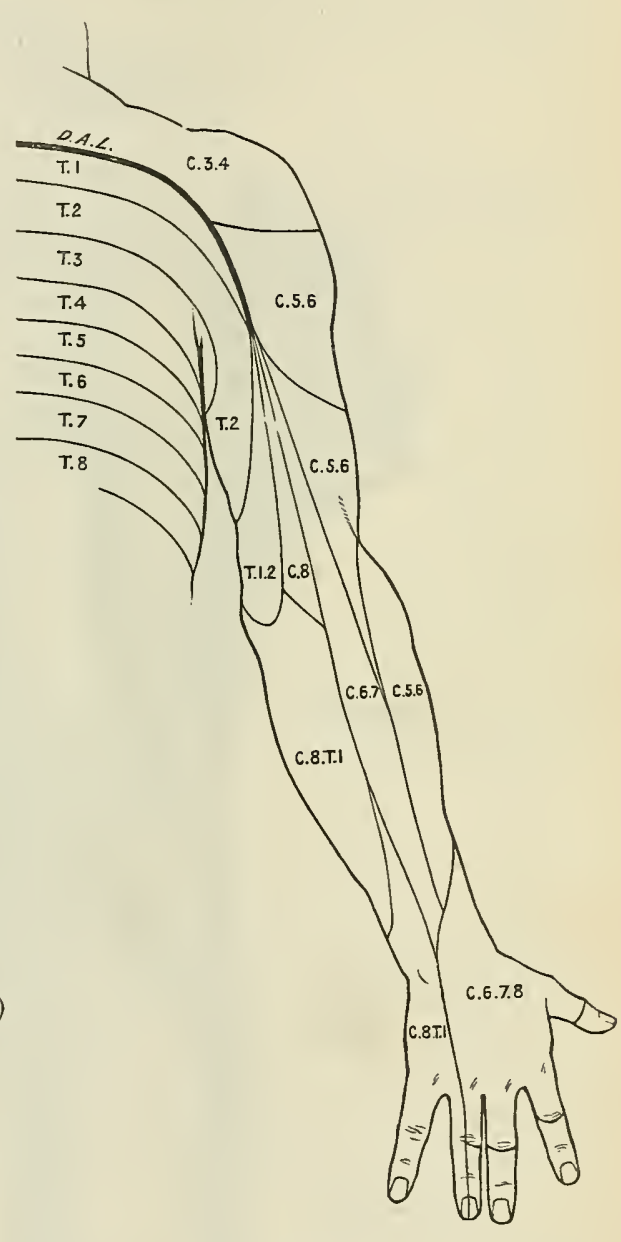

B

Fig. 618.-The Distribution of Cutaneous Nerves on the back of the Arji axd Haid.

(B) is a schematic representation of the areas supplied by the above nerves, the lettering indicating the spinal origin of the branches of distribution to each area. D.A.L., Dorsal axial line.

phalanges of the first two and a half fingers, thus making up for the deficiency of the superficial branch of the radial nerve in these situations.

Communications.-(1) The median nerve, in some cases, receives a communicating branch from the musculo-cutaneous nerve in the arm. (2) It communicates in some cases, in the proximal part of the forearm, with the ulnar nerve beneath the flexor muscles. (3) It communicates by means of its cutaneous branches with the ulnar nerve in the palm of the hand (ramus anastomoticus cum nervo ulnari). 


\section{Nervos UlNaris.}

The ulnar nerve arises from the medial cord of the brachial plexus, from the eighth cerrical and first thoracic nerves. It also occasionally has a root from
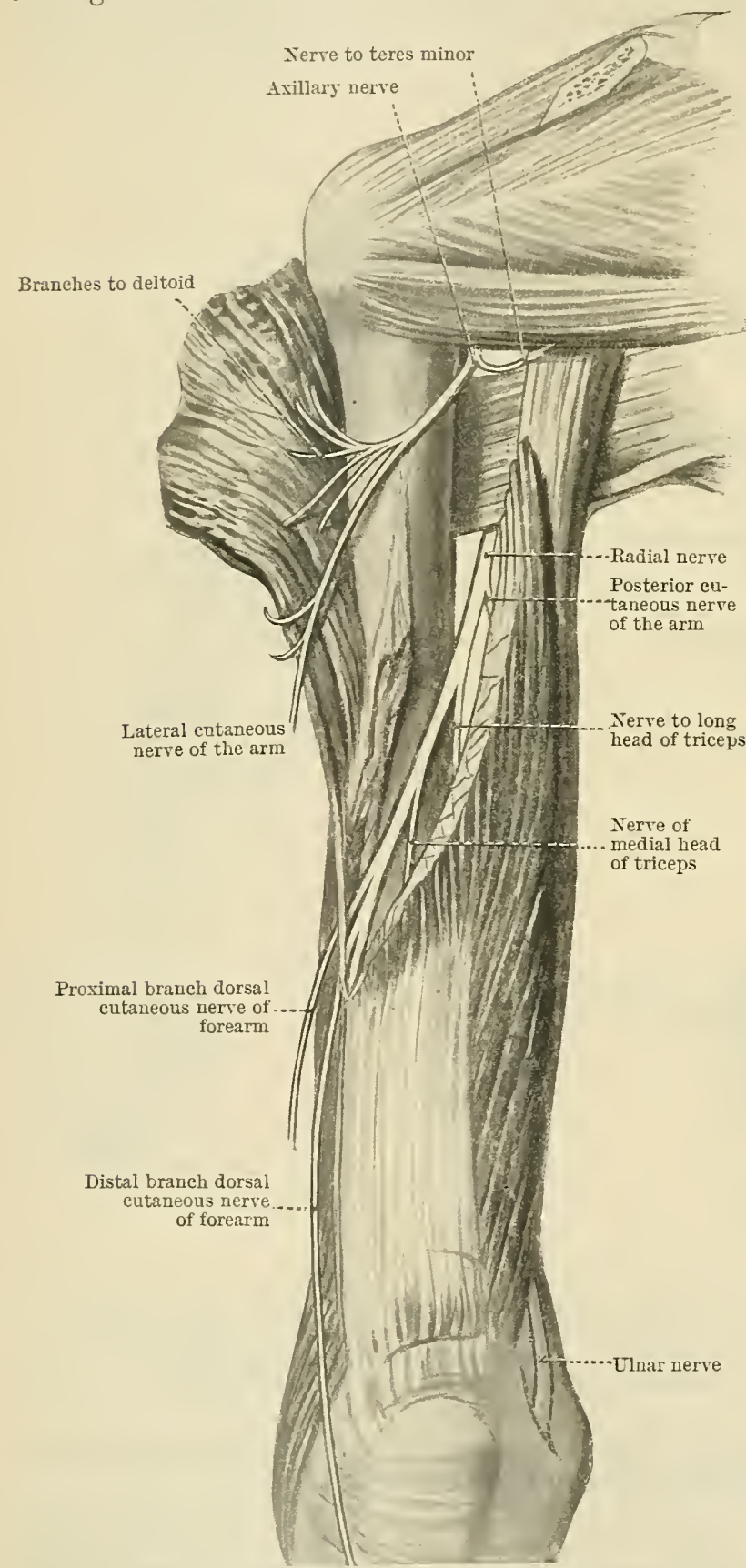

Fig. 619.-The Axillary and Radial Nerves. the lateral cord of the plexus (seventh cervical nerve). In the axilla it lies between the axillary artery and rein, and behind the medial cutaneous nerve of the forearm (O.T. intermal cutaneous); in the proximal half of the arm it lies on the medial side of the brachial artery anterior to the triceps muscle. In the distal half of the arm it is separated from the brachial artery; and passing behind the intermuscular septum, and in front of the medial head of the triceps in company with the superior ulnar collateral (O.T. inferior profunda) artery, it reaches the interval between the medial epicondyle of the humerus and the olecranon. It is here protected by an arch of deep fascia stretching between the epicondyle and the olecranon. It enters the forearm between the humeral and ulnar origins of the flexor carpi ulnaris, and courses distally between the flexor carpi ulnaris and flexor digitorum profundus. In the distal half of the forearm it becomes comparatively superficial, lying on the medial side of the ulnar artery beneath the tendon of the flexor carpi ulnaris. Just proximal to the transverse carpal ligament, and lateral to the pisiform bone, it pierces the deep fascia in company with the artery and passes into the hand over the transverse carpal ligament. Reaching the palm it divides beneath the palmaris brevis muscle into its two terminal branches, superficial and deep.

Branches.--The ulnar nerve gives off no branches till it reaches the forearm.

In the forearm it gives off articular, muscular, and cutaneous branches. 
The articular branch is distributed to the elbow-joint and arises as the nerve passes behind the medial epicondyle of the humerus.

The muscular branches arise as soon as the nerve enters the forearm. They are distributed to the muscles between which the ulnar nerve lies-the flexor carpi ulnaris and the medial half of the flexor digitorum profundus.

The cutaneous branches are two in number, palmar and dorsal.

The palmar cutaneous ramus is variable in size and position. It pierces the deep fascia in the distal third of the forearm and passes to the hypothenar eminence and palm of the hand, to the skin over which it is distributed. It gives branches to the ulnar artery, and communicates often with the medial cutaneous nerve of the forearm and the palmar branch of the median nerve.

The dorsal ramus of the hand is much larger (Fig. 618). It arises from the ulnar nerve in the middle third of the forearm; and, directed obliquely distally and posteriorly beneath the tendon of the flexor carpi ulnaris, it becomes cutaneous on the medial side of the forearm in its distal fourth. It passes on to the back of the hand, and after giving off branches to the skin of the wrist and hand, which communicate with the superficial ramus of the radial nerve, it terminates in two dorsal digital nerves, to supply the little finger and half the ring-finger in the following way:- the medial branch courses along the medial side of the dorsum of the hand and little finger: the lateral branch subdivides at the cleft between the ring and little fingers to supply the adjacent sides of these fingers; this branch communicates with the superficial ramus of the radial nerve. The nerve may supply two and a half fingers on the dorsum of the hand.

Ramus Volaris Manus.-In the palm the ulnar nerve supplies a small muscular branch to the palmaris brevis, and then subdivides into its terminal branches, which are named superficial and deep.

Ramus Superficialis.-The superficial branch is purely cutaneous; it passes distally beneath the palmar aponeurosis, and subdivides into a medial and a lateral branch. The medial branch courses along the medial border of the little finger, which it supplies on its palmar aspect. The lateral branch (common volar digital nerve) becomes superficial at the cleft between the fourth and fifth fingers, between the slips of the palmar aponeurosis, and subdivides into two branches (proper volar digital nerves) which supply the adjacent sides of these fingers on their palmar aspect. It communicates with the adjacent digital branch of the median nerve.

Ramus Profundus.- The deep branch is purely muscular. It separates from the superficial branch, and passes deeply between the flexor brevis and abductor digiti quinti muscles; it supplies these nuuscles and the opponens digiti quinti, and, turning laterally along the line of the deep palmar arch and under cover of the deep flexor tendons, it supplies branches to the following muscles: interossei, third and fourth lumbricales (on their deep surfaces), the adductor pollicis (oblique and transverse parts), and the interosseus primus volaris (deep part of the flexor pollicis brevis).

Communications.-(1) The ulnar nerre communicates in some cases with the median nerve in the forearm; (2) with the medial cutaneous nerve of the forearm and sometimes the median nerve by its palmar branch; (3) with the eutaneous part of the median nerve in the palm by means of its terminal cutaneous branches; (4) with the superficial ramus of the radial nerve on the dorsum of the hand by means of its dorsal branch.

\section{Nervus Cutaneus Antibrachi Medialis.}

The medial cutaneous nerve of the forearm (O.T. internal cutaneous nerve) arises from the medial cord of the brachial plexus, from the eighth cervical and first thoracic nerves (Figs. 614 and 617). In the axilla and proximal half of the arm it lies superficial to the main artery. It becomes cutaneous by piercing the deep fascia about the middle of the arm on its medial side, and accompanying the basilic vein through the distal half of the arm, it divides at the front of the elbor into its two terminal branches.

Branches.-In the arm, as soon as it becomes superficial, the nerve gives off a branch which supplies the skin of the distal half of the anterior surface of the 
arm on its medial side. At the elbow it divides into two terminal branchesvolar and ulnar, which, crossing over or under the median basilic vein, are distributed to the medial side of the forearm.

The volar branch can be followed to the wrist and supplies the whole of the volar surface of the forearm in the medial half; the ulnar branch is not so large, and, passing obliquely backwards and distally over the origins of the pronator and flexor muscles, it is distributed to the proximal two-thirds or three-fourths of the dorsal aspect of the forearm on the medial side.

Communication. - The medial nerve of the forearm communicates with the volar branch of the ulnar nerve in the distal part of the forearm.

\section{Nerves Cutaneus Brachil Medialis.}

The medial cutaneous nerve of the arm (O.T. lesser internal cutaneous nerve) arises from the medial cord of the brachial plexus, and ultimately from the first thoracic nerve (Fig. 614, p. 701). It lies at first between the axillary artery and vein : and after descending over, under, or even, in some cases, through the axillary vein, it perforates the deep fascia and is distributed to the skin of the arm for the proximal half or more on its medial side.

The nerve varies considerably in size. It may be absent, its place being taken by branches of the intercosto-brachial or by branches from the posterior cutaneous branch of the radial nerve. It generally bears a distinct relation in size to the intercosto-brachial, due to the fact that the size of the latter depends upon the size of the part of the second thoracic nerre connected with the first in the thorax. If an intra-thoracic connexion occurs between the first and second thoracic nerres, the intercosto-brachial may be deprived of a certain number of its fibres, which in that case reach the upper limb through the medial cutaneous nerve of the arm. When traced up to the plexus the medial cutaneous nerve of the arm is found to have an origin from the posterior part of the cord formed by the eighth cerrical and first thoracic nerves, and usually receires fibres from the first thoracic nerve only. In cases where "axillary arches" are present they may be supplied by this nerve.

\section{Nertus Axillaris.}

The axillary nerve (O.T. circumflex) at its origin is just below the suprascapular and comes from the same spinal nerves-the fifth and sixth cervical nerves (Fig. 614, p. 701). Extending distally and laterally behind the axillary artery, it leaves the axilla by passing round the lateral border of the subscapularis muscle, in company with the posterior circumflex artery of the humerus, in a quadrilateral space bounded by the humerus, subscapularis, triceps (long head), and teres major. Winding round the surgical neck of the humerus from medial to lateral side, it terminates by supplying the deltoid muscle (Fig. 619, p. 708).

Branches.-Muscular branches are supplied to the teres minor and deltoid muscles. The nerve to the teres minor enters the lateral aspect of the muscle. It possesses a pseudo-ganglion, a thickening of fibrous tissue, on its trunk.

Articular branches enter the posterior part of the capsule of the shoulder-joint.

A cutaneous branch of considerable size-the lateral cutaneous nerve of the armpasses obliquely distally and forwards from beneath the deltoid muscle, becoming superficial at its posterior border. Sometimes branches pierce the muscle. It supplies the skin orer the insertion of the deltoid and the proximal half of the arm on its lateral aspect (Figs. 617, p. 706, and 618, p. 707).

\section{Nervus Radialis.}

The radial nerve (O.T. musculo-spiral) appears to be the continuation into the upper limb of the posterior cord of the brachial plexus. It usually takes origin from all the nerres which form the posterior cord-the fifth, sixth, seventh, and eighth cervical and first thoracic nerres (Fig. 614, p. 701). In some cases the first thoracic contributes no fibres, and often the fifth cervical nerve is excluded from it. It extends from the axilla round the back of the humerus to the bend of the elbow, where it ends by dividing into its superficial and deep terminal branches. 
In the axilla it lies behind the axillary artery, and in front of the subscapularis, teres major, and latissimus dorsi muscles.

In the arm, in the proximal third, it lies to the medial side of the humerus, behind the brachial artery, and upon the long head of the triceps. In the middle third of the arm it courses obliquely laterally and distally in the radial groove of the humerus, along with the profunda brachii artery, separating the long, lateral, and medial heads of the triceps muscle (Fig. 619, p. 708). In the distal third of the arm, piercing the proximal part of the intermuscular septum at the lateral border of the triceps muscle, it passes to the bend of the elbow in front of the lateral epicondyle of the humerus, in the interval between the brachio-radialis and brachialis muscles. Under cover of the former muscle, in the hollow of the elbow, it divides into its two terminal branches, the superficial and deep rami.

The collateral branches are in three sets, arising $(a)$ on the medial side, $(b)$ on the back, and $(c)$ on the lateral side of the humerus (Fig. 620).

\section{Branches arising medial to the Humerus.-} 1. $\mathrm{N}$. cutaneus brachii posterior (O.T. upper internal cutaneous branch of musculo-spiral). - This branch, arising in common with one of the following, or independently, pierces the fascia on the medial side of the arm near the axilla. It supplies the skin of the medial side of the arm in the proximal third, proximal and posterior to the area supplied by the medial nerve of the arm (O.T. lesser internal cutaneous) (Fig. 618, p. 707). This nerve varies in size, according to the bulk of the last-named and the intercosto-brachial nerves.

2. Rami Musculares (Muscular Branches).-These are in two sets. One series supplies the long head of the triceps muscle near its origin; the other series enters the medial head of the muscle. One of the latter, separating itself from the rest, accompanies the ulnar nerve in the middle third of the arm, and supplies the distal part of the muscle. This is sometimes called the collateral ulnar nerve.

II. Branches arising on the Posterior Surface of the Humerus.-Muscular branches arise from the nerve in the radial groove for the supply of all three heads of the triceps muscle. The branch which enters the medial head of the muscle, besides supplying it, passes through the muscle and behind the lateral epicondyle of the humerus, to terminate in the anconæus.

III. Branches arising at the Lateral Side of the Humerus.-1. The dorsal cutaneous nerve of the forearm consists of two branches, proximal and distal. Arising

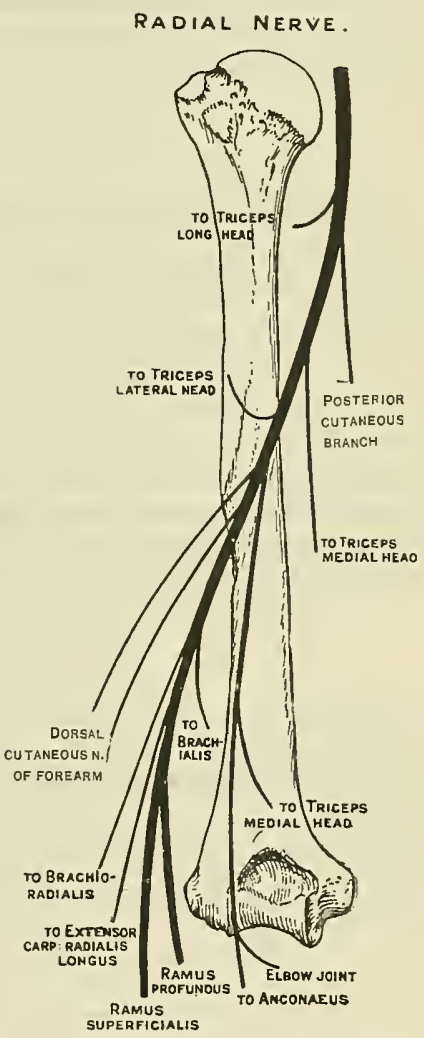

Fig. 620.-Diagrammatic RepreSENTATION OF THE BRANCHES OF the Radial Nerve. from the radial nerve before it pierces the lateral intermuscular septum, these branches pierce the deep fascia close together on the lateral side of the arm in its distal half. Passing distally over the back of the lateral epicondyle, the proximal branch supplies the skin of the lateral side and posterior surface of the arm in its distal third, and the dorsal surface of the forearm in its proximal half. The distal branch supplies an area of skin on the dorsal surface of the forearm in the proximal two-thirds, medial to the area innervated by the:musculo-cutaneous nerve (Fig. 618, p. 707).

2. Muscular Branches.-The radial nerve, as it lies in the interval between the brachialis and brachio-radialis muscles, supplies a small branch to the brachialis (which in some cases is not present) and nerves to the brachio-radialis and extensor carpi radialis longus. It may also provide the nerve to the extensor carpi radialis brevis. 


\section{Ramus Superficialis Nervi Radialis.}

The superficial ramus (O.T. radial nerve) is entirely cutaneous in its distribution. Arising in the hollow of the elbow beneath the brachio-radialis, it

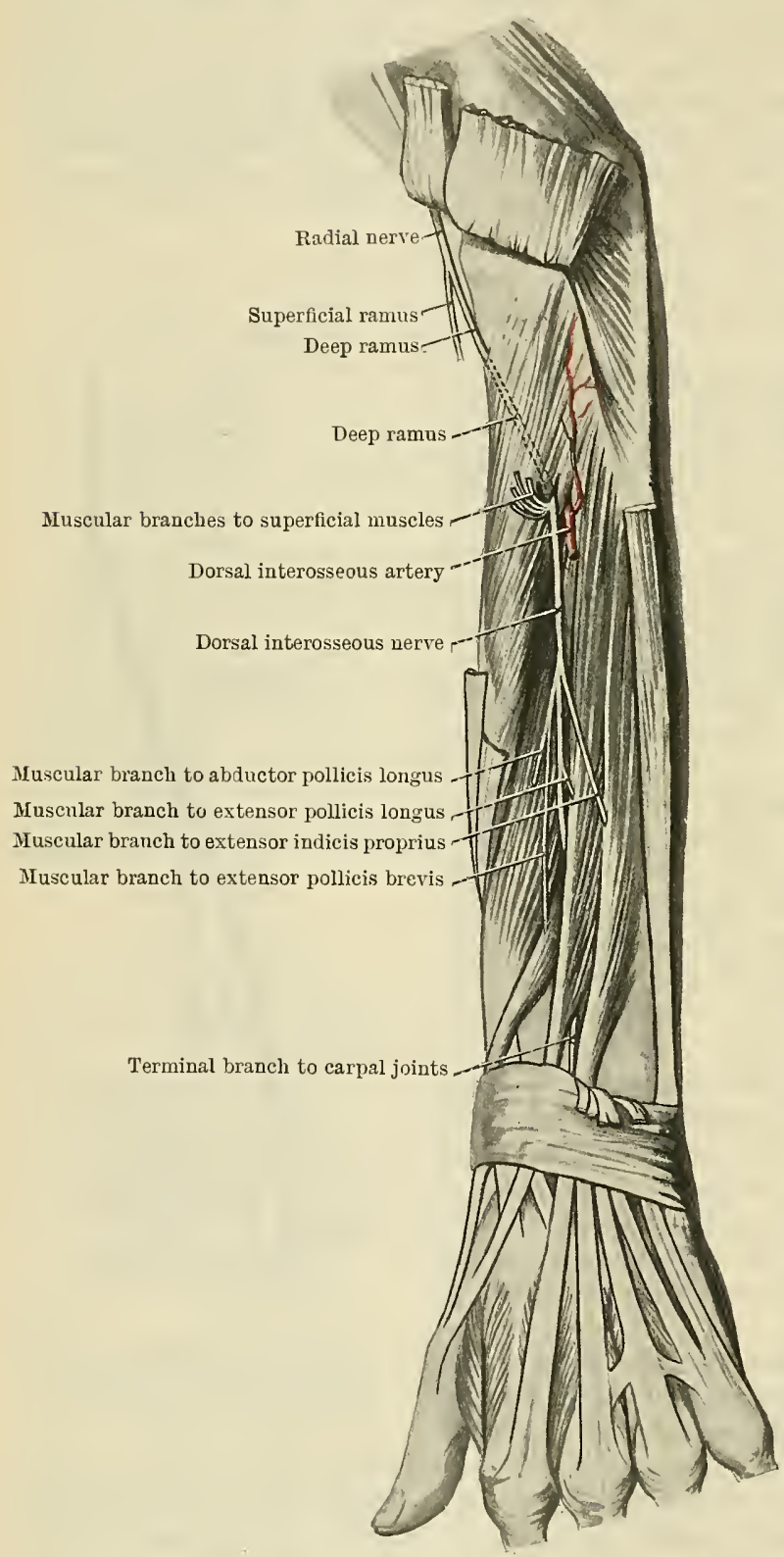

Fig. 621.-Distribution of the Deep Branch of the Radial Nerve. courses distally under cover of that muscle through the proximal two-thirds of the forearm, and accompanies the radial artery in the middle third of the forearm. It then passes posteriorly beneath the tendon of the brachio-radialis and pierces the deep fascia on the lateral aspect of the forearm in the distal third. It is distributed to the skin of the dorsum of the wrist, the lateral side and the dorsum of the hand, and the dorsum of the thumb and lateral two and a half fingers (Fig. 618, p. 707). Its branches communicate on the ball of the thumb with the musculo-cutaneous nerve, and on the dorsum of the hand with the dorsal branch of the ulnar nerve (ramus anastomoticus ulnaris). The digital nerves are small, and are five in number. Two pass to the back of the thumb and reach the level of the inter-phalangeal articulation. One supplies the lateral side of the index finger as far as the second phalanx. The remaining two branches divide at the clefts between the second and third, and third and fourth fingers respectively, and innervate the adjacent sides of these fingers as far as the second phalanx. The rest of the skin of these digits to the tips is supplied by digital branches of the median nerve. The nerve may only supply the thumb and one and a half fingers, being replaced by branches from the ulnar nerve.

\section{Ramus Profundus Nervi Radialis.}

The deep ramus (O.T. posterior interosseous nerve) is entirely muscular and articular in its distribution. It arises like the superficial ramus beneath the brachio-radialis muscle. Directed obliquely distally and posteriorly, it reaches the back of the forearm, after passing round the lateral aspect of the radius, by piercing the fibres of the supinator muscle (Fig. 621). On the dorsal surface of the 
forearm it is called the dorsal interosseous nerve, and is placed in the proximal part of its course beneath the superficial extensor muscles, and upon the supinator and abductor pollicis longus, along with the dorsal interosseous artery. In the distal half of the forearm it passes beneath the extensor pollicis longus, and lies upon the interosseous membrane. At the wrist it passes beneath the extensor tendons on to the back of the carpus, where it terminates in a gangliform enlargement of small size, from which branches pass to the inter-carpal articulations. The nerve supplies the following branches:-

(1) Terminal articular branches to the carpal joints.

(2) Muscular branches, in its course through the forearm. Thus on the lateral side of the radius it supplies the extensor carpi radialis brevis and the supinator muscles before it enters the fibres of the last-named muscle. After emerging from the supinator it supplies a large bundle of nerves which enter the extensor digitorum communis, extensor digiti quinti proprius, and extensor carpi ulnaris near their origins. At a more distal level the nerve gives off branches to the abductor pollicis longus, extensor pollicis longus and extensor pollicis brevis, and extensor indicis proprius.

\section{Nervi Subscapulares.}

There are two subscapular nerves (Figs. 614 and 616).

The first or short subscapular nerve is generally double, and there may be three trunks present. It arises from the posterior cord of the plexus behind the axillary nerve, and comes from the fifth and sixth cervical nerves. It passes distally behind the axillary artery and enters the subscapularis muscle.

The second or lower subscapular nerve also arises behind the axillary nerve from the posterior cord of the plexus (from the fifth and sixth cervical nerves). Its origin is distal and lateral to that of the first nerve. It courses distally behind the axillary artery and the axillary and radial nerves, to the teres major muscle. It supplies branches to the lateral part of the subscapularis muscle and ends in the teres major.

\section{Nervus Thoracodorsalis.}

The thoraco-dorsal nerve (O.T. long subscapular) arises from the back of the posterior cord of the plexus, behind the radial nerve, and from the sixth, seventh, and eighth cervical nerves, or from the seventh and eighth nerves only. It is directed distally and laterally between the two previous nerves, behind the axillary artery and over the posterior wall of the axilla, in company with the subscapular artery, to the latissimus dorsi muscle, which it supplies on its anterior (deep) surface.

\section{NERVI THORACALES.}

The anterior rami of the thoracic nerves are twelve in number, each nerve emerging below the corresponding vertebra and rib. Eleven of the series are intercostal, the twelfth lying below the last rib. The first, second, third, and twelfth nerves present peculiarities in their course and distribution. The other thoracic nerves, as already stated, are simple, and may be regarded as types both in course and distribution.

The anterior ramus of the first thoracic nerve is the largest of the series. It emerges from the vertebral canal below the neck of the first rib, and divides in the first intercostal space into two very unequal, superior and iuferior, parts. The superior and larger part ascends obliquely over the neck of the first rib, lying lateral to the arteria intercostalis suprema, and enters the neck behind the subclavian artery and the pleura. It proceeds laterally upon the scalenus medius muscle and enters into the formation of the brachial plexus, as already described.

The inferior, intercostal part of the nerve is much smaller in size. It courses 
forwards in the first intercostal space and supplies the intercostal muscles. It usually gives off no anterior branch to the skin of the chest and no lateral cutaneous branch.

In some cases a lateral cutaneous branch emerges from the side of the first intercostal space. This may be derived from the first nerve, or it may be the intercosto-brachial nerve, the lateral branch of the second thoracic nerve. In many cases an anterior cutaneous branch perforates the first intercostal space and supplies the skin on the front of the chest. This branch, similarly, is sometimes traceable to the second thoracic nerve.

Communications.-Besides its junction with the eighth cervical to form the brachial plexus, the first thoracic nerve effects the following communications:- $(a)$ The last cervical or first thoracic ganglion of the sympathetic sends a gray ramus communicans to join the nerve on its appearance in the thorax. (b) The second thoracic nerve in a majority of cases communicates with the first. This communication varies considerably in size and distribution. It may reinforce the intercostal branch of the nerve, it may send one branch to the intercostal portion and another to the part of the nerve joining the

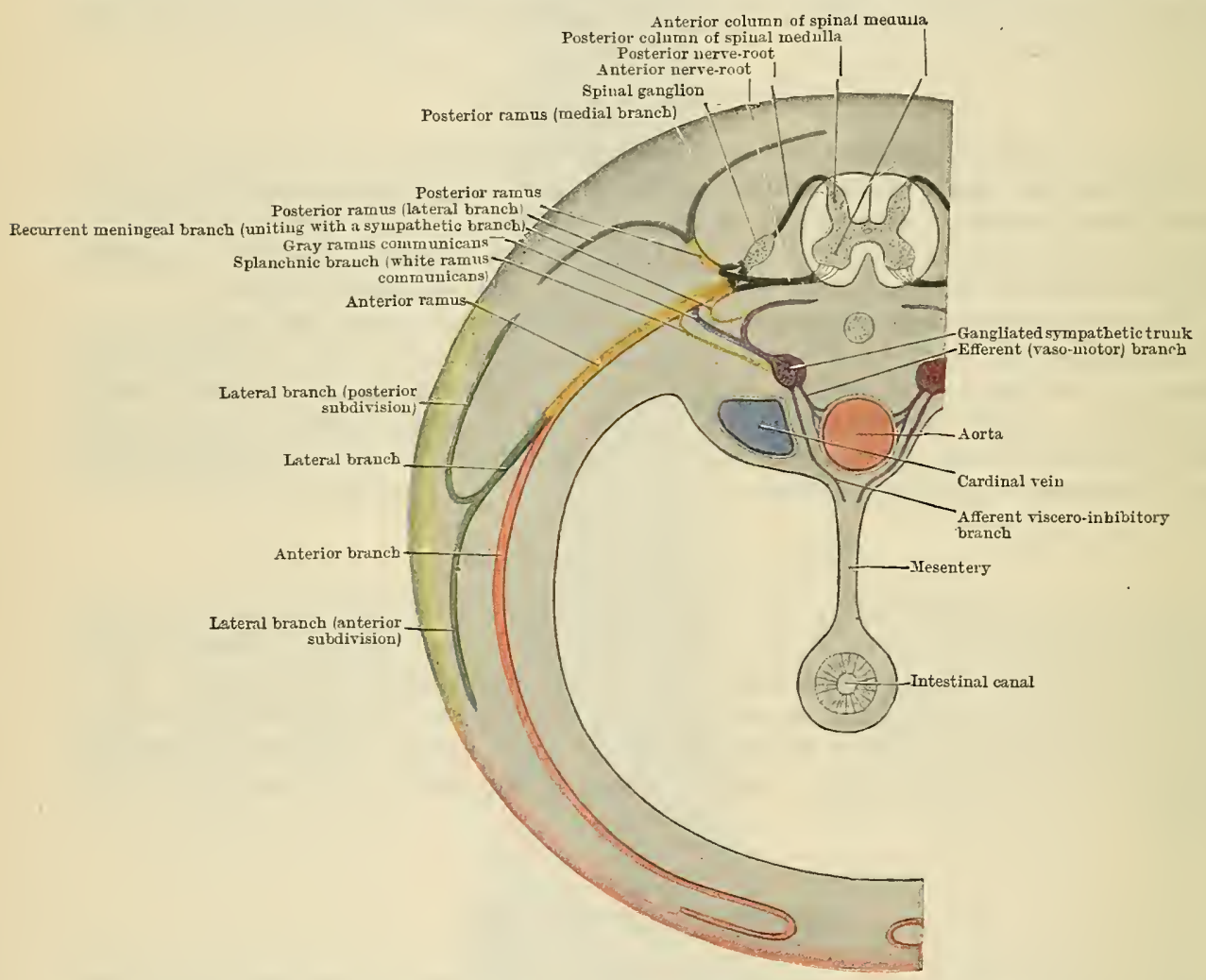

Fig. 622.- Scheme of the Distribution of a Typical Spinal Nerve.

brachial plexus, or it may consist of a nerve proceeding solely to join the brachial plexus by a junction in the first intercostal space with the part of the first thoracic nerve, which is engaged in forming the plexus. (c) It is possible that the first white ramus communicans in the thoracic region connects the first thoracic nerve with the sympathetic trunk, but this is not known with certainty.

The anterior ramus of the second thoracic nerve is of large size, though much smaller than the first. It passes forwards in the second intercostal space, lying at first in the costal groove, between the external and internal intercostal muscles. At the level of the mid-axillary line it gives off a large lateral branch; continuing its course it pierces the internal intercostal muscle and lies upon the pleura; finally, at the lateral border of the sternum, it passes forwards in front of the internal mammary artery and through the internal intercostal muscle, and 


\section{THORACIC NERVES.}

the aponeurosis of the external intercostal muscle and pectoralis major, and ends

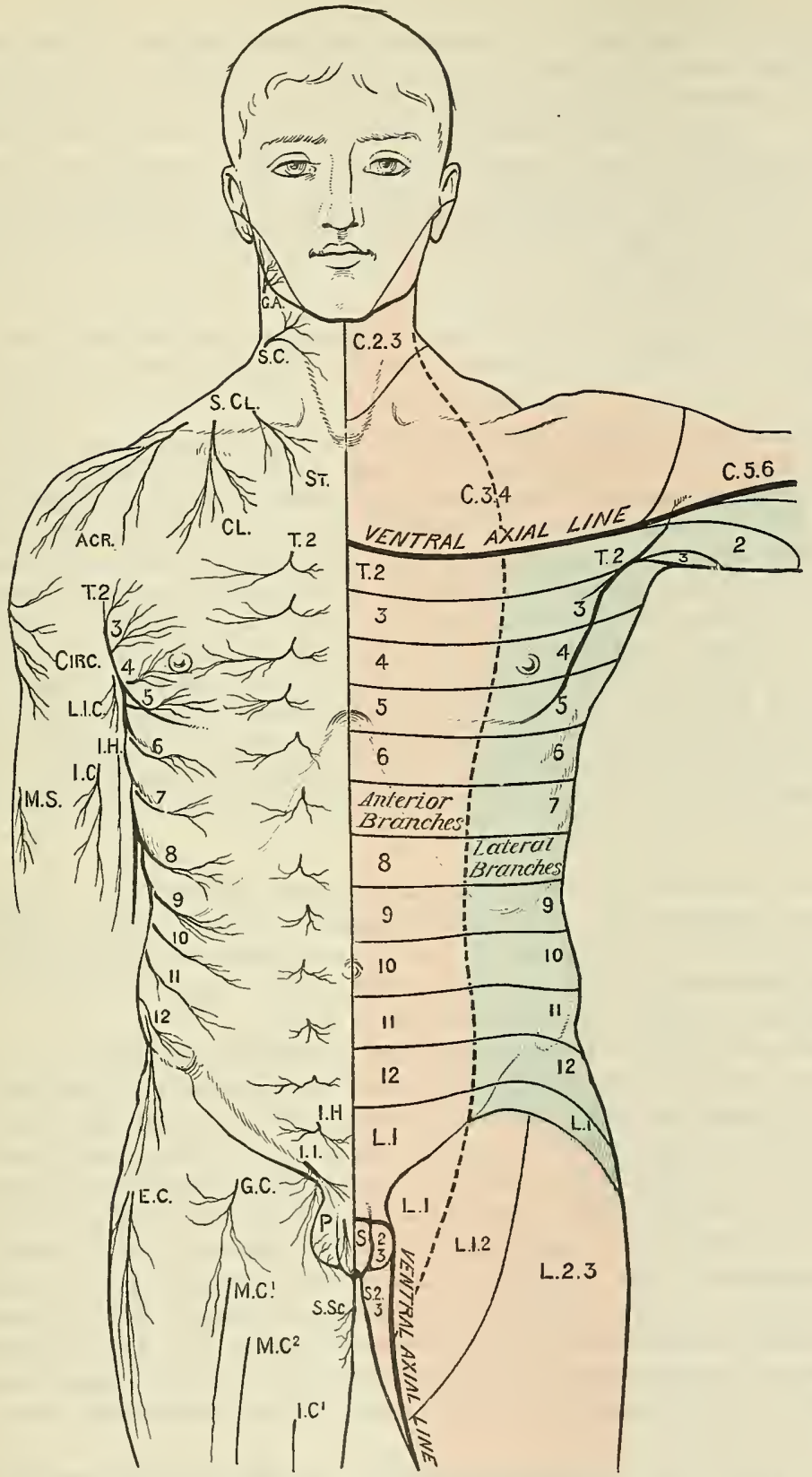

Fig. 623. - The Distribution of Cutaneous Nerves on the froxt of the Trunk.

On one side the distribution of the several nerves is represented, the letters indieating their nomenclature.

G.A, Great auricular nerve ; S.C, N. cutaneus colli ; S.CL, Supra-clavicular nerves ; Acr, Posterior ; CL, Middle ; ST, Anterior ; T.2-12, Lateral and anterior branches of thoracic nerves; I.H, Ilio-hypogastric nerve ; I.I, Ilio-inguinal nerve ; Crac, Cutaneous branch of axillary nerve; L.I.C, Medial cutaneous nerve of the arm (O.T. lesser internal cutaneous nerve); I.H, Intercosto-brachial ; I.C, Medial cutaneous nerve of the forearm (O.T. internal cutaneous) ; M.S, Cutaneous branch of radial nerve; E.C, Lateral cutaneous nerres ; G.C, Lumbo-inguinal nerve ; M. ( $^{2}$, Intermediate cutaneous nerves; I.C , Branch of medial cutaneous nerve; P, Branches of pudendal nerve; S.Sc, Branches of posterior cutaneous nerve of the thigh.

On the other side a schematic representation is given of the areas supplied by the above nerves, the numerals indicating the spinal origin of the branches of distribution to each area.

by supplying the skin of the front of the chest over the second intercostal space. 
The nerve supplies the following branches:-

1. Muscular branches to the muscles of the second intercostal space.

2. Cutaneous branches. (a) Anterior terminal branches to the skin over the second intercostal space (Fig. 623). (b) A large lateral cutaneous branch, the intercostobrachial (0.T. intercosto-humeral) nerve (Fig. 614, p. 701). This nerve pierces the intercostal and serratus anterior muscles, and, crossing the axilla, extends to the arm. It pierces the deep fascia just beyond the posterior fold of the axilla, and can be traced as far as the interval between the medial epicondyle of the humerus and the olecranon. It supplies an area of skin stretching across the axilla and along the posterior surface of the arm on the medial side as far as the elbow (Fig. 617, p. 706). It may supply the axillary arches, when present.

The intercosto-brachial nerve varies in size. It may pierce the first intercostal space, and it is often divisible into anterior and posterior branches, like the lateral branch of an ordinary intercostal nerve.

Communications.--(1) The intercosto-brachial nerve communicates with two adjacent nerves. Either before or after piercing the fascia of the axilla it is joined by the medial cutaneous nerve of the arm. It also communicates with the posterior part of the lateral branch of the third intercostal nerve by means of the branches distributed to the floor and boundaries of the axilla. (2) Besides the branches referred to, the second thoracic nerve in many cases transmits a nerve to the brachial plexus, which becomes incorporated with the first thoracic nerve after passing over the neck of the second rib. This branch is inconstant. As already mentioned, it may join only the intercostal part of the first thoracic nerve, it may join the brachial plexus only, or it may send branches to both parts of the first thoracic nerve. (3) Besides the communications effected by branches of the second thoracic nerve in its course, it also receives a gray ramus communicans from the second thoracic ganglion of the sympathetic trunk in the thorax. It also sends to the sympathetic a white ramus communicans, probably the first, though this is not known with certainty.

The anterior ramus of the third thoracic nerve differs from a typical thoracic nerve only in one respect. Its lateral branch divides in the usual way into anterior and posterior parts, of which the latter is carried to the arm and supplies an area of skin on the medial side near the root of the limb. It effects a junction with the intercosto-brachial nerve (Fig. 614, p. 701).

The anterior rami of the fourth, fifth, and sixth thoracic nerves have a course and distribution which is simple and typical. Except for the peculiarities above mentioned, the second and third thoracic nerves have a similar distribution.

The nerves lie on the posterior wall of the thorax, in the costal groove of the corresponding rib. They extend forwards between the intercostal muscles as far as the middle of the chest wall, lying at a lower level than the intercostal vessels. At the side of the chest each nerve passes obliquely through the internal intercostal muscle, and comes to lie upon the pleura, transversus thoracis muscle, and internal mammary artery. Thereafter, piercing the fibres of the internal intercostal muscle, the aponeurosis of the external muscle, and the pectoralis major, each nerve ends by supplying the skin of the front of the chest, over an area corresponding to the medial or anterior part of the intercostal space to which it belongs.

Branches.-Each intercostal nerve supplies, in addition to the anterior terminal cutaneous branches, muscular branches to the intercostal muscles and a lateral cutaneous ramus, which, piercing the intercostal and serratus anterior muscles, divides into anterior and posterior branches for the innervation of the skin over the side of the chest. Each area of skin thus innervated is continuous anteriorly with the area innervated by the anterior rami of the same nerves, and posteriorly with the areas supplied by their posterior rami.

The upper six intercostal nerves supply the muscles of the first six intercostal spaces and the transversus thoracis $(3,4,5,6)$. The second, third, fourth, fifth, and sixth nerves supply the skin of the front of the chest: the second, opposite the sternal synchondrosis; the sixth, opposite the base of the xiphoid process. Their lateral branches supply branches to the intercostal muscles and the skin of 
the side of the chest, the second (intercosto-brachial) and the third, in part, being drawn out to the arm. The fourth supplies the nipple (Fig. 623).

Communications.-Each of these intercostal nerves communicates with the sympathetic trunk and ganglia by two branches-a white ramus communicans to the corresponding sympathetic ganglion or the adjacent part of the sympathetic trunk; and a gray ramus communicans, which passes to each nerve from the corresponding ganglion.

The anterior rami of the seventh, eighth, ninth, tenth, and eleventh thoracic nerves differ from the preceding nerves only in regard to a part of their course and distribution. Each has the same course and communications as the preceding nerves in the thoracic wall. In addition, these nerves have a further course and distribution in the abdominal wall. Each nerve traverses an intereostal space in the way described. At the anterior end of the space, the nerve pierces the attachment of the diaphragm and the transversus abdominis muscle to the costal cartilages, and courses forwards in the abdominal wall between the transversus and obliquus internus muscles. The nerve then passes between the rectus abdominis muscle and the posterior layer of its sheath, and eventually reaches the anterior abdominal wall and becomes cutaneous by piercing the rectus abdominis itself and the anterior layer of its sheath.

Muscular Branches.-The lower intercostal nerves supply the intercostal muscles of the spaces in which they lie; and in the abdominal wall they innervate the transversus, obliquus externus and internus, and rectus abdominis. The branches arise from the main trunk as well as from its lateral and anterior branches. (The ninth, tenth, and eleventh nerves are described as assisting in the innervation of the diaphragm by communications with the phrenic nerve.)

Cutaneous Branches.-These are lateral and anterior. The lateral branches divide into anterior and posterior parts, and, becoming superficial along the line of inter-digitation of the obliquus externus muscle with the serratus anterior and latissimus dorsi, they are directed more obliquely downwards than the lateral branches of the higher intercostal nerves, and are distributed to the skin of the loin as low down as the buttock. The lateral branch of the eleventh nerve can be traced over the iliac crest (Fig. 625).

The anterior branches are small. That of the seventh nerve innervates the skin at the level of the xiphoid process. The eighth and ninth appear between the xiphoid process and the umbilicus; the tenth nerve supplies the region of the umbilicus; and the eleventh, the area immediately below the umbilicus.

The cutaneous branches of these nerves, inclnding those of the posterior rami, thus stupply continuous belts of skin, which can be mapped out on the body from the vertebral column behind to the median plane in front. These areas are not placed horizontally, but tend to be drawn downwards as the series is followed from the upper to the lower nerves.

The anterior ramus of the twelfth thoracic nerve is peculiar in its course and distribution. It emerges below the last rib (Fig. 625), and passes laterally and downwards in the posterior abdominal wall under cover of the psoas muscle, and between the lateral lumbo-costal arch and the quadratus lumborum muscle; it pierces the transversus abdominis muscle, and courses forwards in the interval between it and the obliquus internus as far as the sheath of the rectus muscle. After piercing the posterior layer of the sheath, the rectus muscle, and the anterior layer of the sheath, it terminates by supplying the skin of the anterior abdominal wall midway between the umbilicus and the os pubis. The branches of the nerve are muscular to the transversus, obliqui, rectus, and pyramidalis muscles of the abdominal wall; and cutaneous branches, two in number-an anterior terminal branch, which supplies the skin of the anterior abdominal wall midway between the umbilicus and the pubis, aud a large lateral cutaneous branch, which, passing obliquely downwards through the lateral muscles of the abdominal wall, becomes superficial above the iliac crest, a couple of inches behind the anterior superior spine. It supplies the skin of the buttock as far down as a point below and anterior to the greater trochanter of the femur (Fig. 623, p. 715).

The twelfth thoracic nerve, in many cases, receives a communicating branch from the eleventh, near its origin, and still more frequently sends a fine branch to join the origin of the first 
lumbar nerve in the psoas muscle. It may communicate also with the ilio-hypogastric nerve, as they lie together in the abdominal wall.

Inter-communications of the Thoracic Nerves. - It has been already noted that the belts or areas of skin supplied by the branches of the thoracic nerves are also innervated by adjacent nerves on either side which invade the area supplied by a given nerve. Communications also take place between the branches of the nerves supplying the intercostal muscles, whereby the muscles of a given space derive their innervation from more than one intercostal nerve.

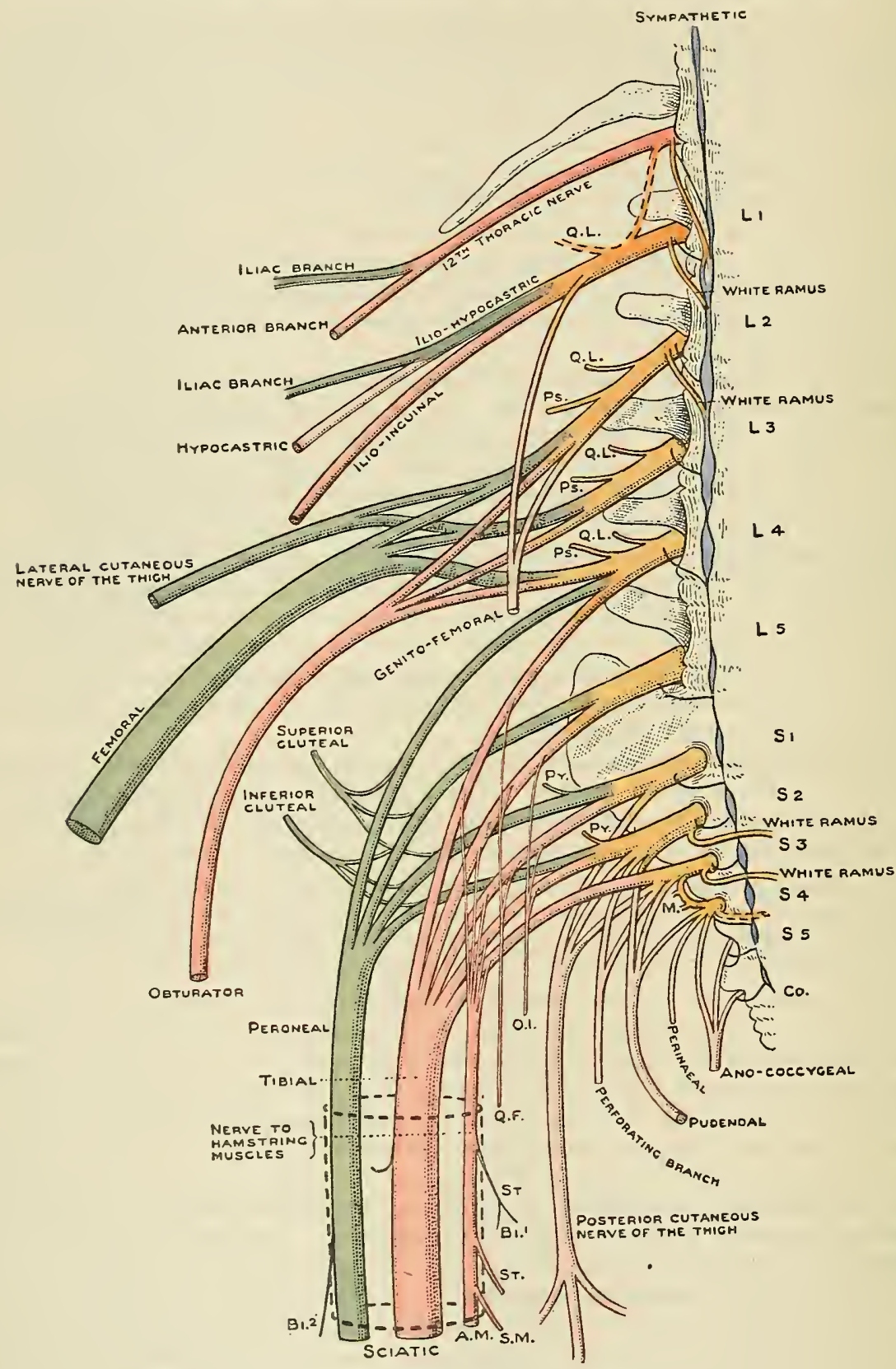

Fig. 624.-Nertes of the Lumbo-Sacral Plexus.

\section{PLEXUS LUMBOSACRALIS.}

The lumbo-sacral plexus is formed by the union of the anterior rami of the remaining spinal nerves-five lumbar, five sacral, and one coccygeal. Frequently 
a fine communicating branch of the twelfth thoracic nerve joins the first lumbar nerve near its origin.

Of the nerves in question the first sacral is generally the largest in size, the nerves diminishing gradually above and rapidly below this nerve. The plexus, for the most part, forms the nerves destined for the supply of the lower limb. In addition, however, nerves arise at its superior limit which are distributed to the trunk above the level of the limb, and at the inferior end of the plexus nerves arise for the supply of the perineum.

Partly for convenience of description, and partly on account of the differences in position and course of some of the nerves emanating from it, the plexus is subdivided into three subordinate parts - lumbar, sacral, and pudendal plexuses. There is, however, no strict line of demarcation between the three parts.

Plexus Lumbalis.-The lumbar plexus is formed by the first four lumbar nerves, and is often joined by a branch from the twelfth thoracic nerve as well. It is limited below by the fourth lumbar nerve ( $n$. furcalis), which enters also into the composition of the sacral plexus. The nerves of the Iumbar plexus are formed in the loin, and supply that region as well as part of the lower limb. They are separated from the nerves of the sacral portion of the plexus by the articulation of the hip bone with the sacrum.

Plexus Sacralis.-The sacral plexus is formed by the fourth and fifth lumbar, and the first two or three sacral nerves. It is generally limited below by the third sacral nerve ( $n$. bigeminus), which assists also in forming the pudendal plexus. The nerves of the sacral plexus are placed on the posterior wall of the pelvis, and are destined almost entirely for the lower limb.

Plexus Pudendus. - The pudendal plexus is formed by the second, third, fourth, and fifth sacral nerves, and the minute coccygeal nerve. It is placed on the posterior wall of the pelvis and supplies branches mainly to the perineum.

Communications with the Sympathetic.-Each of these nerves has communications with the gangliated trunk of the sympathetic in the abdomen and pelvis.

Gray Rami Communicantes.-From the lumbar and sacral ganglia long slender gray rami communicantes are directed posteriorly and laterally over the bodies of the rertebræ, and (in the lumbar region) beneath the origins of the psoas muscle, to reach the spinal nerves. These branches are irregular in their arrangement. A given nerve may receive branches from two ganglia, or one ganglion may send branches to two nerves. The rami are longer in the loin than in the pelvis, owing to the projection of the lumbar portion of the vertebral column.

White Rami Communicantes.-Certain lumbar and sacral nerves are also connected with the abdominal and pelvic sympathetic by means of white rami communicuntes. From the first two, and possibly in some cases also the third and fourth lumbar nerves, white rami communicantes are directed forwards, either independently or incorporated with the corresponding gray rami, to join the upper part of the lumbar sympathetic trunk. The fifth lumbar nerve and the first sacral nerves are unprovided with white rami communicantes. From the anterior rami of the second and third, or third and fourth sacral nerves, white rami (visceral or splanchnic branches) pass medially, and, crossing over (without joining) the sympathetic trunk, enter the pelvic plexus of the sympathetic. The fifth sacral and coccygeal nerves possess no white rami communicantes.

\section{PLEXUS LUMBALIS.}

The lumbar plexus is formed by the anterior rami of the first three and a part of the fourth lumbar nerves, with the addition, in some cases, of a sinall branch from the twelfth thoracic nerve. The nerves increase in size from above downwards (Fig. 624).

Position and Constitution.-The plexus is formed in the substance of the psoas muscle, in front of the transverse processes of the lumbar vertebri. The nerres, on emerging from the intervertebral foramina, are connected as above described with the sympathetic system, and then divide in the following manner in the substance of the psoas major muscle. The first and second nerves divide into superior 
and inferior branches. The superior branch of the first nerve (which may be joined by the branch from the twelfth thoracic nerve) forms two nerves, the ilio-hypogastric and ilio-inguinal. The inferior branch of the first joins the superior branch of the second nerve, to produce the genito-femoral nerve (O.T. genito-crural). The inferior branch of the second nerve, the whole of the third, and that part of the fourth nerve engaged in the constitution of the plexus divide each into two unequal parts - smaller anterior and larger posterior parts. The smaller anterior portions combine together to form the obturator nerve, which is thus formed by the second, third, and fourth lumbar nerves. The root from the second nerve is not always present. The larger posterior portions of the same nerves combine together to form the femoral nerve (O.T. anterior crural). From the posterior aspect of the posterior parts of the second and third nerves the lateral cutaneous nerve of the thigh (O.T. external cutaneous) arises. The nerves also provide, near their origins, irregular muscular branches for the psoas and quadratus lumborum muscles. The following is a list of the nerves which spring from the lumbar plexus (Figs. 624 and 625):-
(1) Muscular branches to the quadratus lumborum and psoas muscles.
(2) Ilio-hypogastric.
(3) Ilio-inguinal.

(4) Genito-femoral.

(5) Lateral cutaneous.

(6) Obturator.

(7) Femoral.

Muscular Branches.-The nerves to the quadratus lumborum muscle arise independently from the first three or four lumbar nerves (and sometimes also from the twelf th thoracic nerve). The nerves to the psoas muscles arise from the second and third lumbar nerves, with additions, in some cases, from the first or fourth. They are often associated in their origin with the nerve to the iliacus from the femoral nerve. The psoas minor, when present, is innervated by the first or second lumbar nerve.

The ilio-hypogastric and ilio-inguinal nerves closely resemble, in their course and distribution, the lower thoracic nerves, with which they are in series.

N. Iliohypogastricus.-The ilio-hypogastric nerve is the highest branch of the first lumbar nerve. It receives fibres also from the twelfth thoracic, when that nerve communicates with the first lumbar nerve. After traversing the psoas muscle obliquely, it appears at its lateral border on the surface of the quadratus lumborum and behind the kidney. It courses through the loin, lying between the transversus and obliquus abdominis internus muscles, above the crest of the ilium. About an inch in front of the anterior superior spine it pierces the obliquus internus, and continues its course in the groin beneath the aponeurosis of the obliquus externus. It finally becomes cutaneous in the anterior abdominal wall, by piercing the aponeurosis of the obliquus externus about an inch and a half above the subcutaneous inguinal ring (Fig. 623, p. 715).

Its branches are-(1) muscular to the muscles of the abdominal wall; and (2) cutaneous branches, two in number. The lateral cutaneous branch corresponds with the lateral branch of an intercostal nerve, and, after piercing the obliquus internus and obliquus externus, becomes cutaneous just above the iliac crest, below and behind the iliac branch of the last thoracic nerve. It is small, and may be absent. It is distributed to the skin over the superior part of the lateral side of the buttock, in continuity with the cutaneous branch of the posterior ramus of the first lumbar nerve. The anterior cutaneous branch is the anterior terminal branch of the nerve. It supplies the skin of the anterior abdominal wall below the level of the last thoracic nerve and above the os pubis.

$\mathrm{N}$. Ilioinguinalis.-The ilio-inguinal nerve is the second branch given off from the first lumbar nerve. It also may receive fibres from the last thoracic nerve. Not infrequently the ilio-hypogastric and ilio-inguinal nerves are represented for a longer or shorter part of their course by a single trunk. When separate the nerve takes a course similar to that of the ilio-hypogastric nerve, but at a lower level, as far as the anterior abdominal wall. It then pierces the obliquus internus farther forward and lower down than the ilio-hypogastric; and conrsing forwards beneath the aponeurosis of the obliquus externus, just 
above the inguinal ligament, it becomes superficial after passing through the subcutaneous inguinal ring and external spermatic fascia (Fig. 623, p. 715).

Its branches are muscular to the muscles of the abdominal wall, among which it passes, and cutaneous branches (anterior scrotal, or labial nerves), which innervate

Median lumbo-costal arch

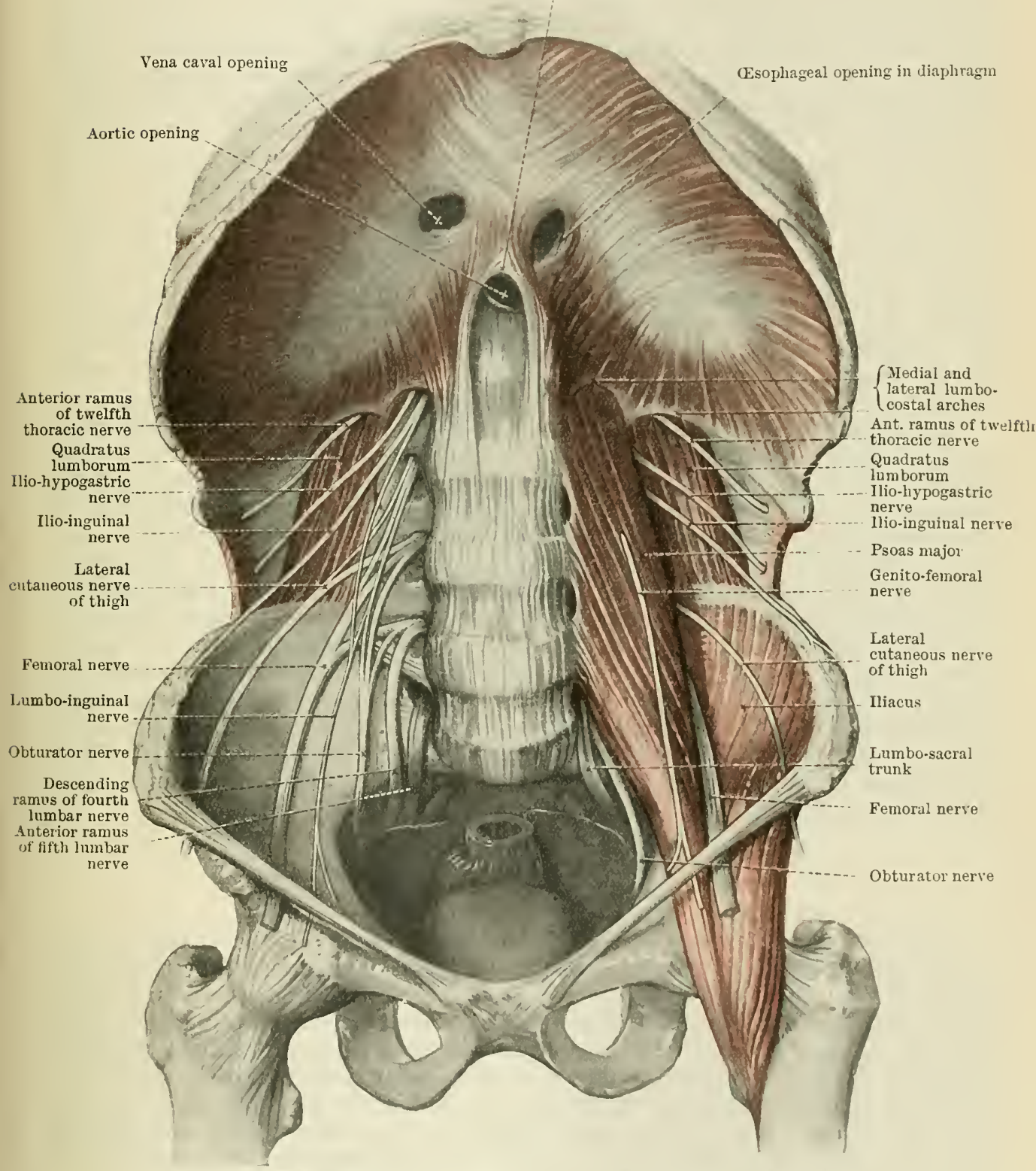

Fig. 625.-The Muscles and Nerves un the Postemior abdominal Wall.

the skin (1) of the anterior abdominal wall over the symphysis pubis, (2) of the thigh over the superior and medial part of the femoral triangle, and (3) of the superior part of the scrotum, and root and dorsum of the penis (of the mons Veneris and labium majus in the female). These last-named branches are contiguous to branches of the perineal and pudendal uerves. No lateral cutaneous branch arises from the ilio-inguinal nerve. It thus corresponds, like the anterior cutaneous part of the ilio-hypogastric nerve, to the anterior trunk of a typical thoracic nerve. 
N. Genitofemoralis.-The genito-femoral nerve (O.T. genito-crural) usually arises by two independent roots from the front of the first and second lumbar nerves, which unite in the substance of the psoas major to form a slender trunk. It appears on the posterior abdominal wall, lying on the psoas major, medial to the psoas minor, and, piercing the psoas fascia, it extends downwards on the lateral aspect of the common and external iliac vessels and behind the ureter to the iuguinal ligament (Fig. 625, p. 721). At a variable point above that ligament it divides into two branches. 1. The external spermatic branch is a minute nerve. It crosses the terminations of the external iliac vessels, and, along with the ductus deferens and testicular and external spermatic vessels, enters the inguinal canal through the abdominal inguinal ring. It terminates by supplying small branches to the skin of the scrotum and adjacent part of the thigh. In the female it accompanies the round ligament to the labium majus. This nerve gives off in its course the following small branches: (1) to the external iliac artery; (2) to the cremaster muscle; (3) to communicate with the spermatic plexus of the sympathetic. 2. The lumbo-inguinal branch continues the course of the parent nerve into the thigh, lying on the lateral aspect of the femoral artery. It becomes cutaneous by passing through the fossa ovalis or through the iliac portion of the fascia lata, and supplies an area of skin over the femoral triangle, lateral to that supplied by the ilio-inguinal nerve (Fig. 623, p. 715). It communicates in the thigh with the intermediate cutaneous branch of the femoral nerve. Before piercing the deep fascia it gives a minute branch to the femoral artery.

N. Cutaneus Femoris Lateralis.-The lateral cutaneous nerve of the thigh is only distributed to the skin (Fig. 625). It arises from the back of the lumbar plexus, and usually from the second and third lumbar nerves. Emerging from the lateral border of the psoas major muscle, the nerve crosses the iliacus muscle, beneath the fascia iliaca, to reach the anterior superior iliac spine. It enters the thigh beneath the lateral end of the inguinal ligament, and either over, under, or through the origin of the sartorius muscle. It extends distally along the front of the thigh for a few inches, lying at first beneath the fascia lata, and afterwards in a tubular investment of the fascia. It gives off small branches in this part of its course, and finally, piercing the fascia about four inches distal to the anterior superior iliac spine, it separates into anterior and posterior terminal branches. The anterior branch is the larger, and is distributed on the lateral aspect of the front of the thigh almost to the knee. The smaller posterior branch supplies the skin of the lateral side of the buttock distal to the greater trochanter and of the proximal two-thirds of the lateral aspect of the thigh (Fig. 625, p. 721).

\section{Nervus Obturatorius.}

The obturator nerve supplies the muscles and skin on the medial side of the thigh. It arises in the substance of the psoas major muscle by three roots placed in front of those of the femoral nerve, and derived from the second, third, and fourth lumbar nerves (Fig. 624, p. 718). Sometimes the root from the second nerve is absent. Passing vertically downwards, the nerve emerges from the psoas major at its medial border, behind the common iliac, and on the lateral side of the hypogastric vessels. It passes forwards below the pelvic brim in company with the obturator artery to the obturator groove of the obturator foramen, through which it reaches the thigh. While in the obturator groove it separates into its two main branches, named anterior and posterior (Fig. 626, p. 723).

The anterior (O.T. superficial) branch enters the thigh in front of the obturator externus and adductor brevis muscles, and beneath the pectineus and adductor longus. In the middle third of the thigh it is found coursing along the medial border of the adductor longus, anterior to the gracilis; and it finally divides into two slender terminal filaments, of which one enters the adductor canal and ends on the femoral artery, while the other supplies the skin for a variable distance on the medial side of the thigh and joins in the obturator plexus.

The branches of the anterior part of the nerve are:- 
1. An articular branch to the hip-joint which arises from the nerve as soon as it enters the thigh, and supplies the joint through the acetabular notch.

2. Muscular branches to the adductor longus, gracilis, adductor brevis (usually), pectineus (occasionally). The last-named muscle is not usually supplied from the obturator nerve.

3. A cutaneous branch of very variable size forms one of the terminal branches (Fig. 626). It becomes superficial between the gracilis and adductor longus, in the middle third of the thigh, and may stipply the skin of the distal two-thirds of the thigh in its medial side. It is generally of small size, and is connected with branches of the medial cutaneous aud saphenous nerves behind the sartorius muscle to form the obturator (O.T. sub-sartorial) plexus. The branch from the saphenous nerve to the plexus passes medially behind the sartorius after piercing the

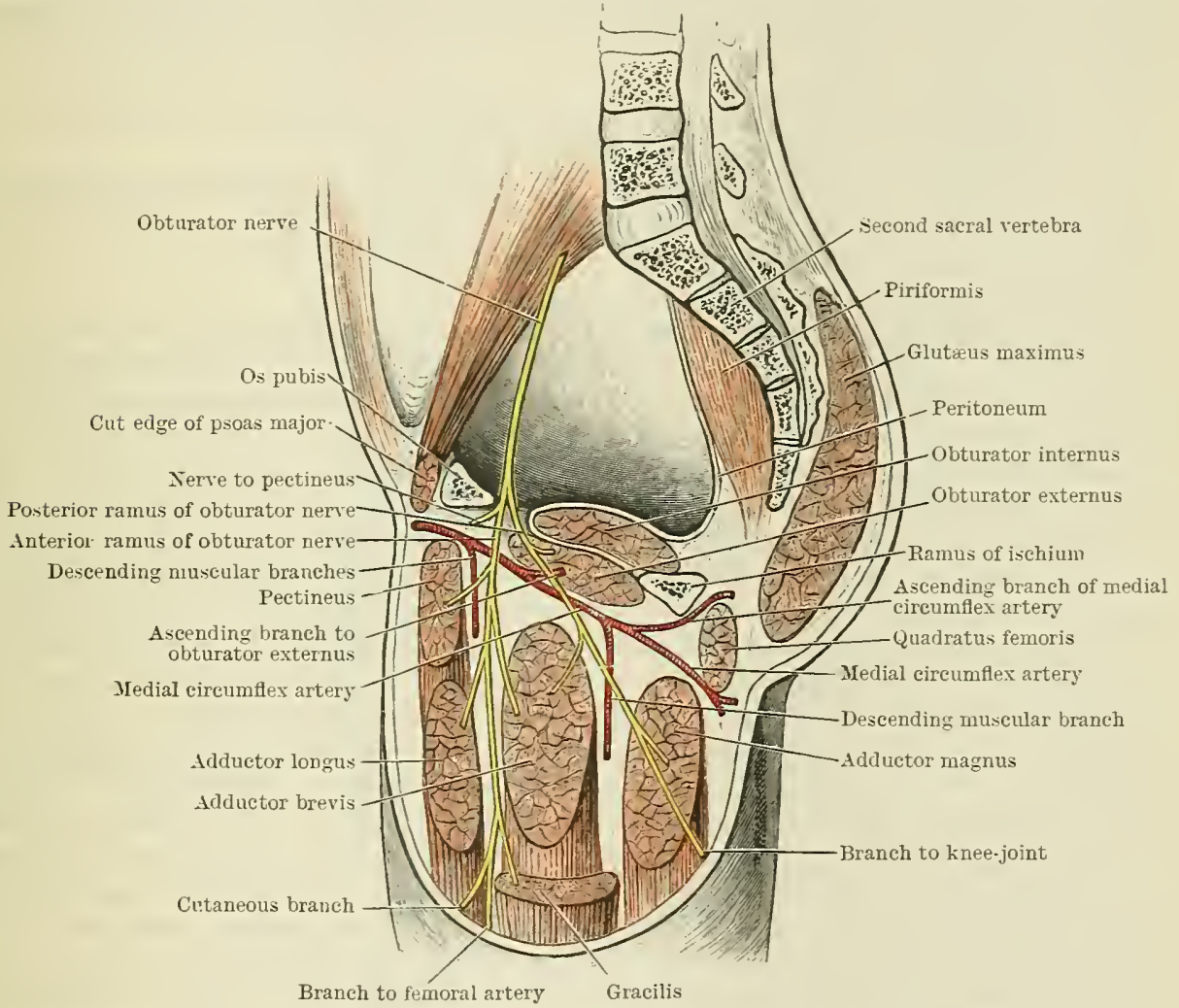

Fig. 626.-Scheme of the Course axid Distributiox of the Obturator Nerte.

aponeurotic covering of the adductor canal. The branch from the medial cutaneous nerve is generally superficial at the point of formation of the plexus.

4. The branch to the femoral artery is the other terminal branch of the nerve. It enters the adductor canal along the medial border of the adductor longus, and ramifies over the distal part of the artery.

5. A fine communicating branch sometimes joins the femoral nerve in front of the hip-joint.

The posterior (O.T. deep) branch of the obturator nerve reaches the thigh by piercing the obturator externus muscle. It passes distally between the adductor brevis and adductor magnus muscles. After passing obliquely through the adductor magnus, it appears in the popliteal fossa on the popliteal ressels, and terminates by piercing the oblique ligament of the knee and supplying the kneejoint.

Its branches are:-(1) muscular branches to the obturator externus, adductor magnus, and (when the muscle is not supplied by the superficial part of the nerve) 
the adductor brevis. The branch to the obturator externus arises before the nerve enters the muscle, in the obturator groove. The nerve to the adductor magnus is given off as the obturator nerve passes through the substance of the muscle. (2) An articular terminal branch is supplied to the posterior aspect of the knee-joint.

\section{Nerves Femoralis.}

The femoral nerve (O.T. anterior crural) is the great nerve for the muscles and skin of the front of the thigh. It arises in the substance of the psoas major muscle, from the back of the second, third, and fourth lumbar nerves, posterior to the obturator nerve. Passing obliquely through the psoas major muscle, it emerges from its lateral border in the large pelvis (Fig. 625, p. 721). Passing downwards in the groove between the psoas and iliacus, it enters the thigh beneath the inguinal ligament, lateral to the femoral sheath and femoral vessels. In the femoral triangle it breaks up into a large number of branches, among which the lateral circumflex artery of the thigh passes.

The branches of the femoral nerve, which are (1) muscular, (2) articular, and (3) cutaneous, arise in the following way:-

In the abdomen a muscular branch arises from the lateral aspect of the nerve and enters the iliacus muscle.

In the femoral triangle the terminal muscular, articular, and cutaneous branches arise in the form of a large bundle of nerves.

1. Rami IMusculares.-The muscular branches supply the pectineus, sartorius, and quadriceps. The nerve to the pectineus arises close to the inguinal ligament, and, coursing obliquely distally and medially behind the femoral vessels, enters the muscle at its lateral border. It is not infrequently double. It sometimes gives off a fine communicating branch to the anterior part of the obturator nerve. The nerves to the sartorius are in two sets : a lateral short set of nerves associated with the lateral part of the intermediate cutaneous nerve, which supply the proximal part of the muscle; and a medial longer set which are associated with the medial part of the intermediate cutaneous nerve, and enter the middle of the muscle. The parts of the quadriceps are supplied by several branches. The vastus lateralis and rectus femoris are supplied on their deep surface by separate nerves which are accompanied by branches of the lateral circumflex artery of the thigh. The vastus intermedius muscle is supplied superficially by a nerve which passes through the muscle, and innervates also the muscle of the knee-joint (subcrureus). It also receives fibres from one of the nerves to the vastus medialis. The vastus medialis muscle is supplied by two nerves: a proximal trunk, which supplies the proximal part of the muscle, and sends fibres to the vastus intermedius as well; and a distal trunk, which descends on the lateral side of the femoral artery along with the saphenous nerve, and passing beneath the sartorius, over or under the aponeurotic covering of the adductor canal, enters the medial side of the muscle. This nerve gives off a small branch which enters the medullary canal of the femur.

2. The articular branches supply the hip and knee-joints. The articular branch to the hip-joint arises from the nerve to the rectus femoris, and is accompanied by branches from the lateral circumflex artery of the thigh. The articular branches to the knee-joint are four in number. Three of them arise from the nerves to the vastus lateralis, vastus intermedius, and vastus medialis, which, after the muscular nerves are given off, are continued downwards to the knee-joint along the front of the femur. A fourth articular branch arises (sometimes) from the saphenous nerve.

3. Rami Cutanei Anteriores.-The cutaneous branches are the intermediate and medial cutaneous, and the saphenous nerves (Fig. 627).

The intermediate cutaneous nerve arises in two parts, a lateral and a medial branch, in the proximal part of the femoral triangle. The two branches descend vertically and become cutaneous by piercing the fascia lata over the proximal third of the sartorius muscle. They carry muscular branches to the sartorius, and the lateral branch in many cases pierces the muscle. These two nerves supply the skin of the distal three-fourths of the front of the thigh, between the lateral cutaneous nerve of the thigh laterally and the medial cutaneous on the medial side. They 
reach to the front of the patella, and there assist in the formation of the patellar plexus. The lateral branch communicates in the proximal third of the thigh with twigs from the lumbo-inguinal branch of the genito-femoral nerve.

The medial cutaneous nerve lies at first in the femoral triangle on the lateral side of the femoral vessels. At the apex of the triangle it crosses over the femoral vessels, and is directed distally over or through the sartorius muscle, and beneath

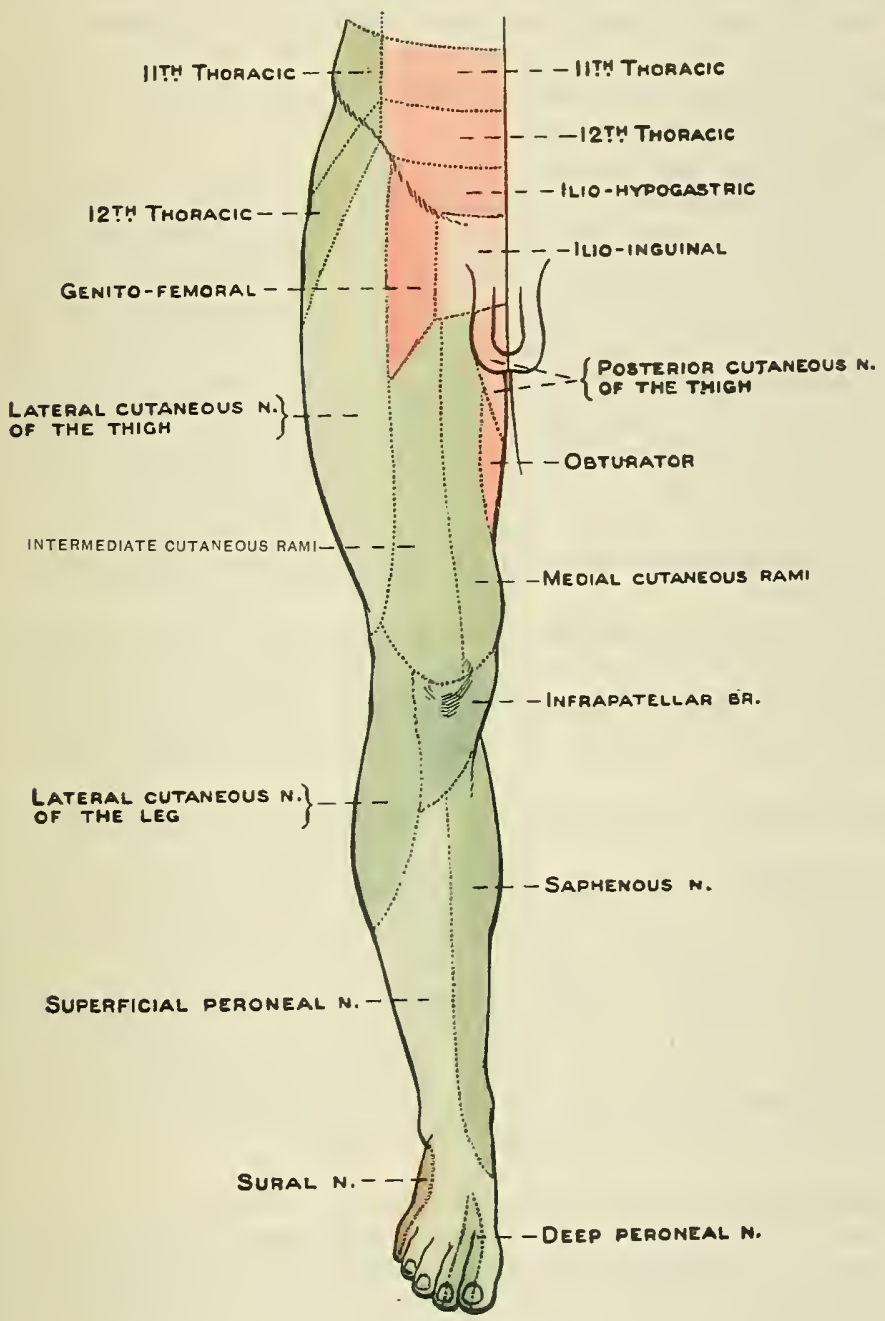

A

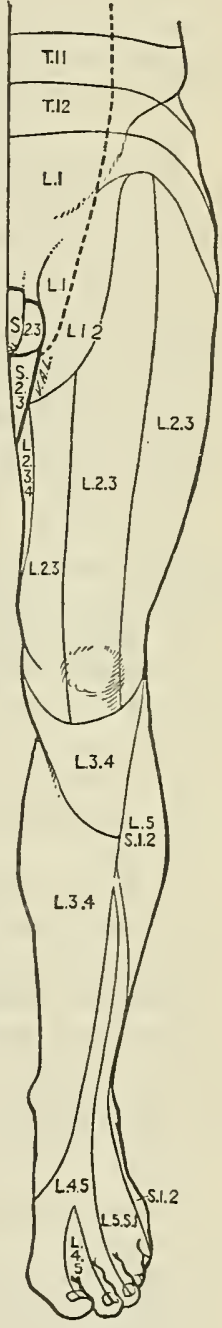

$\mathrm{B}$

Fig. 627.-Distribution of Cutaneous Nerves on the front of the Lower Limb.

On the left side the distribution of the several nerves is represented in colour.

On the right side a schematic representation is given of the areas supplied by the above nerres, the figures indicating the spinal origin of the branches of distribution to each area.

the fascia lata, to the distal third of the thigh. It is distributed to the skin of the distal two-thirds of the thigh on the medial side by means of three branches - proximal, middle, and distal.

The proximal branch may be represented by two or more twigs. It arises from the main nerve near its origin, and pierces the fascia lata near the apex of the femoral triangle. It is distributed to the skin of the proximal part of the thigh, along the line of the great saphenous vein. The middle or anterior branch is a larger nerve. It separates from the distal branch at the apex of the femoral triangle, and passing over the sartorius muscle becomes cutaneous in the middle 
third of the thigh on the medial side. It supplies the skin of the distal half of the thigh, extendiug as far as the knee, where it joins in the formation of the patellar plexus.

The distal branch represents the termination of the nerve. It passes along the medial side of the thigh over the sartorius muscle, and communicates in the middle third of the thigh with the saphenous and obturator nerves to form the obturator plexus. Piercing the fascia lata on the medial side of the thigh in the distal third, it ramifies over the side of the knee, and assists in the formation of the patellar plexus.

The size of the medial cutaneous nerve varies with the size of the cutaneous part of the obturator, and of the saphenous nerve.

N. Saphenus.-The saphenous nerve may be regarded as the terminal branch of the femoral nerve. It is destined for the skin of the leg and foot. From its origin in the femoral triangle it extends distally alongside the femoral vessels to the adductor canal. In the canal it crosses obliquely over the fernoral sheath from lateral to medial side. At the distal end of the canal, accompanied by the saphenous branch of the arteria genu suprema, it passes over the tendon of the adductor magnus, and opposite the medial side of the knee-joint becomes cutaneous by passing between the sartorius and gracilis muscles. The nerve then extends distally in the leg along with the great saphenous vein, and coursing over the front of the ankle it terminates at the middle of the medial border of the foot.

Branches.-1. A communicating branch arises in the adductor canal, and passing medially beneath the sartorius joins with branches of the obturator nerve in forming the obturator plexus.

2. Ramus Infrapatellaris. - The infra-patellar branch arises at the distal end of the adductor canal, and piercing the sartorius muscle is directed distally and forwards below the patella, and over the medial condyle of the tibia to the front of the knee and proximal part of the leg. It enters into the formation of the patellar plexus.

3. An articular branch sometimes arises from the nerve at the medial side of the knee.

4. Rami Cutanei Cruris Mediales.-The terminal branches of the saphenous nerve are distributed to the skin of the front and medial side of the leg and the posterior half of the dorsum and medial side of the foot.

Plexus Patellaris. - The patellar plexus consists of fine communications beneath the skin in front of the knee, between the branches of the cutaneous nerves supplying that region. The nerves which enter into its formation are the infra-patellar branch of the saphenous, medial and intermediate cutaneous nerves, and sometimes the lateral cutaneous nerve of the thigh.

The accessory obturator nerve (n. obturatorius accessorius) is only occasionally present (29 per cent, Eisler). It arises from the third, or third and fourth lumbar nerves, between the roots of the obturator and femoral nerves. Associating itself with the obturator, from which, however, it is quite separable, it appears in the abdomen at the medial side of the psoas muscle, and coursing over the pelvic brim behind the external iliac vessels, it leaves the obturator nerve, and enters the thigh in front of the os pubis.

In the thigh, behind the femoral vessels, it usually ends in three branches: a nerve which replaces the branch from the femoral nerve to the pectineus, a nerve to the hip-joint, and a nerve which communicates with the superficial part of the obturator nerve. In some cases it only supplies the nerve to the pectineus; more rarely it is of considerable size, and reinforces the obturator nerve in the innervation of the adductor muscles.

The accessory obturator nerve was first described by Winslow as the n. accessorius anterioris cruralis. Schmidt later described it in great detail, and gave it the name it now bears. It is more closely associated with the femoral than with the obturator. Its origin is behind the roots of the obturator: it is separated, like the femoral, from the obturator by the pubic bone, and its chief branch, to the pectineus mnscle, replaces the normal branch from the femoral nerve. On the other hand, for a part of its course it accompanies the obturator, and in rare cases it may replace branches of that nerve. 


\section{PLEXUS SACRALIS.}

The sacral portion of the lumbo-sacral plexus is destined almost entirely for the lower limb. It is usually formed by the anterior rami of a part of the fourth lumbar nerve ( $n$. furcalis), the fifth lumbar, the first, and parts of the second, and third sacral nerves (n. bigeminus).

Communications with the Sympathetic.-Each of the nerves named is connected to the lumbar or pelvic sympathetic by gray rami communicantes, as already described; and white rami communicantes pass usually from the third and usually also from the second or fourth sacral nerves to join the pelvic plexus of the sympathetic.

Position and Constitution.-The plexus is placed on the posterior wall of the pelvis between the parietal pelvic fascia and the piriformis muscle. In front of it are the pelvic colon, the hypogastric vessels, and the ureter.

The plexus is constituted by the convergence of the nerves concerned towards the inferior part of the greater sciatic foramen, and their union to form a broad triangular band, the apex of which is continued through the greater sciatic foramen below the piriformis muscle into the buttock, as the sciatic nerve. From the anterior and posterior surfaces of this triangular band numerous small branches arise, which are distributed to the parts in the neighbourhood of the origin of the nerve.

The sciatic nerve ends in the thigh by dividing into two large nerves, the tibial (O.T. internal popliteal), and common peroneal (O.T. external popliteal). In many cases these two nerves are distinct at their origin, and are separated sometimes by fibres of the piriformis muscle. In all cases on removal of the sheath investing the sciatic nerve the tibial and peroneal nerves can be traced up to the plexus, from which they invariably take origin by distinct and separate roots.

Formation.-The descending branch of the fourth lumbar nerve (n. furcalis) after emerging from the border of the psoas major muscle, medial to the obturator nerve, divides behind the iliac vessels into anterior and posterior (ventral and dorsal) parts, each of which joins a corresponding part of the fifth lumbar nerve. The anterior ramus of the fifth lumbar nerve descends over the ala of the sacrum, and divides into anterior and posterior parts, which are joined by the corresponding parts of the fourth lumbar nerve. The two resulting trunks are sometimes called the truncus lumbosacralis or lumbo-sacral trunk. The first and second sacral nerves pass almost horizontally laterally from the anterior sacral foramina, and divide in front of the piriformis into similar anterior and posterior parts. The third sacral nerve (n. bigeminus) divides into superior and inferior parts. The inferior part is concerned in forming the pudendal plexus. The superior part is directed laterally, and slightly upwards, towards the second nerve, and does not separate into two parts, but remains undivided.

These trunks combine to form the sacral plexus, and its main subdivisions, in the following way. Lying in apposition, and converging to the lower part of the greater sciatic foramen, the posterior (dorsal) trunks of the fourth and fifth lumbar nerves (lumbo-sacral trunks), and of the first and second sacral nerves, combine to form the common peroneal nerve and the subordinate nerves which arise from the posterior aspect of the plexus. The anterior (ventral) trunks of the fourth and fifth lumbar nerves (lumbo-sacral trunk), and of the first and second sacral nerves, together with that part of the third sacral nerve which is contributed to the plexus, unite to form the tibial nerve and the subordinate nerves arising from the front of the plexus.

Of these nerves the fifth lumbar and first sacral are the largest; the others diminishing in size as they are traced uptrards and downwards. There is no distinct demarcation between the sacral and pudendal plexuses. The second and third sacral nerves (and in some cases the first sacral also) are concerned in the formation of both plexuses.

Branches. - The nerves of distribution derived from the sacral plexus are divided according to their origin into an anterior (ventral) and a posterior (dorsal) 
series. Each set comprises one of the two essential terminal parts of the sciaticperoneal and tibial nerves-and numerous smaller collateral branches.

Anterior (Ventral) Branches.

Tibial nerre

Muscular branches-

Nerves to hamstring muscles quadratus femoris gemelli obturator internus

Articular" branches (to hip-joint)
Posterior (Dorsal) Branches.

Common peroneal nerve Muscular branches-

Nerves to short head of biceps " piriformis

Superior gluteal nerve

Inferior gluteal nerve

Articular branches (to knee-joint)

\section{Nervus Ischiadicus.}

It has already been shown how the sciatic nerve is formed. It comprises the two main nerves of the sacral plexus, bound together by an investing sheath, which contains, in addition to the common peroneal and tibial nerves, a subordinate branch of each, the nerve to the hamstring muscles, from the tibial, and the nerve to the short head of the biceps femoris, from the peroneal nerve. A thick band about half an inch in breadth is formed, consisting, from medial to lateral side, of (1) nerves to the hamstring muscles, (2) tibial, (3) common peroneal, (4) nerve to the short head of the biceps muscle. The sciatic nerve extends through the buttock into the back of the thigh. Forming a continuation of the sacral plexus, it enters the buttock by passing through the greater sciatic foramen, in the interval between the piriformis and superior gemellus. Concealed by the glutæus maximus muscle, it passes distally to the thigh, accompanied by the inferior gluteal artery, and the arteria comitans nervi ischiadici. It lies in the hollow between the greater trochanter of the femur and the tuberosity of the ischium, and en ers the thigh beneath the fold of the nates at the lower border of the glutæus maximus. At this spot it is comparatively superficial, lying in the angle between the edge of the glutæus maximus above and laterally, and the origins of the hamstring muscles medially. In the thigh it is placed upon the adductor magnus, beneath the hamstring muscles, and it terminates at a variable point by dividing into the tibial and common peroneal nerves. As already stated, these two nerves may be separate from their origins, and their separation may occur at any point between the greater sciatic foramen and the proximal part of the popliteal fossa.

\section{The Nerves of Distribution from the Sacral Plexus.}

These are divisible into two series-collateral and terminal branches. Each subdivision consists of a series of anterior and posterior trunks.

1. Collateral Branches.-The anterior branches are (a) muscular branches (to the quadratus femoris, gemelli, obturator internus, and hamstring muscles); and (b) articular branches (to the hip-joint). These nerves all arise from the anterior aspect of the sacral plexus.

The nerve to the quadratus femoris (and inferior gemellus) arises from the front of the fourth and fifth lumbar and first sacral nerves. It passes downwards over the back of the capsule of the hip-joint (to which it sends a fine branch) beneath the sacral plexus, gemelli, and obturator internus muscles. It supplies a nerve to the inferior gemellus, and terminates in the deep surface of the quadratus femoris.

The nerve to the obturator internus (and superior gemellus) arises from the anterior aspect of the fifth lumbar and first two sacral nerves. In the buttock it lies medial to the sciatic nerve on the lateral side of the pudendal vessels; crossing the ischial spine, it enters the ischio-rectal fossa through the lesser sciatic foramen. The nerve supplies in the buttock a branch to the superior gemellus, and terminates by entering the pelvic surface of the obturator internus.

The nerve to the hamstring muscles forms the most inedial part of the sciatic trunk in the lower part of the buttock. It arises from all the roots of the tibial nerve on their anterior aspect, viz., from the fourth and fifth lumbar and 
the first three sacral nerves. These roots unite to form a cord which is closely associated with the tibial nerve and is placed in front of it and afterwards on its medial side. Extending into the thigh, the trunk is distributed to the hamstring muscles by means of two sets of branches. Just distal to the ischial tuberosity a proximal set of nerves enters the proximal part of the semitendinosus and the ischial head of the biceps. More distally in the thigh the remaining portion of the nerve separates off from the tibial part of the sciatic trunk and supplies branches to the semimembranosus, the distal part of the semitendinosus, and the adductor magnus.

Articular branches for the hip-joint arise from the nerve to the quadratus femoris, and often directly from the anterior surface of the tibial part of the sciatic nerve near its origin. They enter the back of the capsule of the joint in the region of the buttock.

The posterior branches are: (a) muscular branches-a nerve to the piriformis, the superior gluteal nerve, the inferior gluteal nerve, and a nerve to the short head of the biceps; $(b)$ articular branches (to the knee-joint).

These nerves all arise from the posterior aspect of those roots of the sacral plexus, which are associated with the origin of the common peroneal nerve.

The nerve to the piriformis muscle may be double. It arises from the back of the second, or first and second sacral nerves, and at once enters the anterior surface of the muscle.

N. Glutæus Superior.-The superior gluteal nerve arises from the posterior surface of the fourth and fifth lumbar and first sacral nerves, and is directed backwards and laterally into the buttock, above the piriformis muscle, along with the superior gluteal artery. Under cover of the glutæus maximus and glutæus medius, it passes over the glutæus minimus, along with the inferior branch of the deep division of the superior gluteal artery, to the deep surface of the tensor fasciæ latæ, in which it ends. On its way it supplies branches to the glutæus medius and glutæus minimus muscles.

N. Glutæus Inferior.-The inferior gluteal nerve arises from the posterior surface of the fifth lumbar and first two sacral nerves. It appears in the buttock at the lower border of the piriformis muscle, superficial to the sciatic nerve, and at once breaks up into a number of branches for the supply of the glutæus maximus. In its course in the buttock it is closely associated with the posterior cutaneous nerve of the thigh. Its origin is sometimes combined with that of the following nerve.

The nerve to the short head of the biceps springs from the lateral side of the common peroneal trunk in the proximal part of the thigh. When traced to its origin, it is found to arise (sometimes in combination with the inferior gluteal nerve) from the fifth lumbar and first two sacral nerves. In its course it is closely applied to the common peroneal nerve, from which it separates in the middle third of the thigh, usually in combination with the articular branches of that nerve for the knee-joint. In some cases it has an independent course in the thigh, and it may be associated in the buttock with the inferior gluteal nerve.

An articular branch for the lateral and anterior aspects of the knee-joint generally arises from the common peroneal nerre in common with the nerve to the short head of the biceps. When traced up to the plexus, it is found to arise from the posterior surface of the fourth and fifth lumbar and first sacral nerres. It passes through the proximal part of the popliteal fossa concealed by the biceps muscle, and separates into proximal and distal branches, which accompany the superior and inferior lateral articular arteries to the knee-joint.

Terminal Branches.-The common peroneal (O.T. external popliteal) and tibial (O.T. internal popliteal) nerves are the two main trunls resulting from the combination of the posterior and anterior cords of the sacral plexus respectively. The common peroneal nerve is homologous with the radial nerve of the upper limb; the tibial nerve represents a medio-ulnar trunk; and, as already stated, the two nerves, constituting the sciatic nerve, are enveloped in a common sheath for a variable distance before pursuing an independent course in the leg. 


\section{Nervus Peron æus Communis.}

The common peroneal (O.T. external popliteal) nerve arises from the posterior part of the sacral plexus from the fourth and fifth lumbar and first two sacral nerves. Incorporated with the sciatic nerve in the buttock and proximal part of the thigh, it passes distally from the bifurcation of that nerve through the popliteal fossa, to its termination at a point about an inch distal to the head of the fibula. It is concealed at first by the biceps muscle. Following the tendon of that muscle, it passes obliquely through the proximal and lateral part of the popliteal fossa and over the lateral head of the gastrocnemius muscle to the posterior aspect of the head of the fibula. In the distal part of its course and at its termination it is uncovered by muscle.

Collateral Branches.-These are divided into two sets: (a) Nerves arising from the roots or trunk of the nerve while it is in combination with the tibial nerve in the sciatic trunk. These have been already described, as a muscular branch to the short head of the biceps, and an articular branch to the knee-joint. (b) Nerves arising in the popliteal fossa. These are cutaneous branches, viz., the lateral sural nerve or lateral cutaneous nerve of the calf and the peroneal anastomotic ramus.

N. Cutaneus Suræ Lateralis. - The lateral sural branch is irregular in size and distribution, and may be represented by two or more branches (Fig. 628, p. 731). Arising from the common peroneal nerve in the popliteal fossa, often in common with the succeeding nerve, it pierces the deep fascia over the lateral head of the gastrocnemius, and is distributed to the skin on the lateral aspect of the back of the leg in the proximal two-thirds. The extent of its distribution varies with that of the posterior cutaneous nerve of the thigh and the nervus suralis.

Ramus Anastomoticus Peronæus.-The peroneal anastomotic nerve (O.'T. communicans fibularis), arising in the popliteal fossa, passes over the lateral head of the gastrocnemius beneath the deep fascia to the middle third of the leg, where it assists in forming the nervus suralis by its union with an anastomotic (communicating) branch of the tibial nerve called the medial sural nerve or medial cutaneous nerve of the calf. In many cases the two branches do not unite. In such cases the peroneal anastomotic nerve may be limited in its distribution to the skin of the lateral side of the leg, heel, and ankle, or it may be distributed to the area usually supplied by the nervus suralis.

Terminal Branches.- The terminal branches of the common peroneal nerve are three in number:-recurrent tibial, deep peroneal (O.T. anterior tibial), and superficial peroneal (O.T. musculo-cutaneous). They arise just distal to the head of the fibula, and are directed forwards, diverging in their course, beneath the peroneus longus muscle.

The recurrent tibial nerve is the smallest branch. Passing forwards beneath the origin of the peronæus longus and the extensor digitorum longus muscles, it divides distal to the lateral condyle of the tibia into branches which supply the proximal fibres of the tibialis anterior muscle, the proximal tibio-fibular articulation, and the knee-joint.

\section{Nervus Peroneus Profundus.}

The deep peroneal nerve (O.T. anterior tibial) passes obliquely distally, beneath the peronæus longus, extensor digitorum longus, and extensor hallucis longus muscles, to the front of the leg. In its course it is deeply placed upon the interosseous membrane and the distal part of the tibia, in company with the anterior tibial artery. At the ankle it lies beneath the transverse ligament of the leg and the tendon of the extensor hallucis longus, and crossing over the ankle-joint, it divides on the dorsum of the foot into its terminal branches.

1. Collateral Branches (in the leg).--These are given off to the muscles between which the deep peroneal nerve passes, namely: tibialis anterior, extensor hallucis longus, extensor digitorum longus, and peronæus tertius. A fine articular branch supplies the ankle-joint. 
2. Terminal Branches (on the foot).-The terminal branches are medial and lateral. The medial branch passes along the dorsum of the foot on the lateral side of the dorsalis pedis artery to the first interosseous space, where it divides into two dorsal digital branches for the supply of the skin of the lateral side of the great toe and the medial side of the second toe (nervi digitales dorsales hallucis lateralis et digiti secundi medialis). Each of these branches communicates with branches of the superficial peroneal (O.T. musculo-cutaneous) nerve. It gives off one or two dorsal interosseous branches, which supply the medial tarsometatarsal and metatarso-phalangeal articulations, and enter the first dorsal interosseous muscle.

The lateral branch passes obliquely over the tarsus beneath the extensor digitorum brevis, and ends in a gangliform enlargement (similar to the gangliform enlargement on the dorsal interosseous nerve of the forearm at the back of the wrist). From this enlargement muscular branches arise for the supply of the extensor digitorum brevis, along with branches for the tarsal, tarso-metatarsal, and metatarso-phalangeal articulations. Its dorsal interosseous branches may be as many as four in number. Of these the lateral two, extremely small, may only reach the tarso-metatarsal articulations. The medial two are fine branches, which, besides supplying the articulations, may give branches to the second and third dorsal interosseous muscles.

The branches from the nerve to the interosseous muscles are probably sensory, the motor supply of these muscles being certainly derived from the lateral plantar nerve.

\section{Nervus Peroneus Superficialis.}

The superficial peroneal nerve (O.T. musculocutaneous), the last of the branches of the common peroneal nerve, passes distal to the head of the fibula and beneath the proximal fibres of the peronæus longus muscle. Lying in a sheath in the intermuscular septum, between the peronæi and the extensor digitorum longus, it proceeds distally in front of the fibula to the distal third of the leg, where it pierces the deep fascia in two branches, medial and lateral.

Its branches are: (1) collateral muscular branches distributed to the peronæus longus and peronæus brevis, as the nerve lies in relation to these muscles; (2) terminal cutaneous branches, medial and lateral.

Nn. Cutanei Dorsales Medialis et Intermedius.The medial terminal branch (n. cutaneus dorsalis medialis) courses distally over the transverse ligament of the leg, and after supplying offsets to the distal third of the leg and dorsum of the foot, divides into three branches. (1) The most medial branch supplies the skin of the dorsum of the foot and the medial side of the great toe, and communicates with the saphenous nerve. (2) The intermediate branch passes to the interval between the great toe and the second, and divides into two branches which communicate with the medial branch of the deep peroneal nerve. (3) The lateral branch passes to the interval betreen the second and third toes, and divides into dorsal digital branches to supply the adjacent sides of these toes.

The lateral terminal branch (n. cutaneus dorsalis intermedius) of the nerve passes over the transverse ligament of the leg, and after supplying branches to the distal part of the leg and the dorsum of the foot, divides into two parts, which, passing to the intervals between the third and fourth, and fourth and fifth toes respectively, divide into dorsal digital branches for the adjacent sides of these toes. These branches communicate with offsets of the nervus suralis (nerve of the calf). 
The arrangement of the cutaneous branches of the superficial peroneal nerve is liable to considerable variation. The lateral division of the nerve may be increased in size, and may supply the nerve to the adjacent sides of the second and third toes; or it may be reduced in size, in which case the nervus suralis takes its place on the dorsum of the foot, often supplying as many as two and a half toes on the lateral side.

The cutaneous nerves on the dorsum of the toes are much smaller than the corresponding plantar digital nerves. They are reinforced on the dorsum of the terminal phalanges by twigs from the plantar nerves, which supply the tips of the toes and the nails.

\section{Nervus Tibialis.}

The tibial nerve (O.T. internal popliteal) arises from the anterior surface of the sacral plexus, usually from the fourth and fifth lumbar and first three sacral nerves (Fig. 631, p. 736). It is incorporated in the sciatic trunk in the buttock and proximal part of the thigh. At the bifurcation of the sciatic nerve it passes onwards through the popliteal fossa and the back of the leg. The part of the nerve from its origin from the plexus or the bifurcation of the sciatic nerve to the distal border of the popliteus muscle, was formerly called internal popliteal; the part of the nerve in the back of the leg being then designated posterior tibial. The course of the nerve through the buttock and thigh has already been described (p. 728). In the popliteal fossa it is concealed at first by the semimembranosus and other hamstring muscles. It passes to the medial side of the popliteal vessels, and is thereafter found upon the popliteus muscle, under cover of the gastrocnemius and plantaris. In the back of the leg, from the distal border of the popliteus muscle to the ankle, the tibial (O.T. posterior tibial) nerve lies on the tibialis posterior muscle and the tibia, and, along with the posterior tibial vessels, occupies a sheath in the intermuscular septum separating the superficial and deep muscles of the back of the leg. In the proximal part of the leg the nerve is medial to the vessels, but, crossing over them, it lies on their lateral side in the distal portion of its course. It terminates beneath the ligamentum laciniatum by dividing into the lateral and medial plantar nerves.

The collateral branches may be divided into three series arising respectively in the region of the thigh, the popliteal fossa, and the back of the leg:-

(a) Branches arising from the Roots or Trunk of the Nerve while it is incorporated with the Sciatic Nerve.-These have been already described as muscular branches to the quadratus femoris, gemelli, obturator internus, and the hamstring muscles, and an articular branch to the hip-joint (Fig. 631, p. 736).

(b) Branches arising in the Popliteal Fossa proximal to the Knee-Joint.These are in three sets-articular, muscular, eutaneous.

1. The articular branches are slender nerves, variable in number. There are usually two, an azygos branch which pierces the oblique ligament of the kneejoint, and a medial branch, a long fine nerve which, crossing the popliteal vessels, runs distally on the medial side of the fossa to accompany the distal medial articular artery to the knee-joint. In its course it gives off a branch, often absent, which accompanies the proximal medial articular artery.

2. The muscular branches are five in number. Nerves for the two heads of the gastrocnemius, and the plantaris enter these muscles at the borders of the popliteal fossa. A nerve for the soleus enters the superficial surface of the muscle. A nerve for the popliteus muscle passes over the surface of that muscle, and after winding round its distal border, supplies it on its deep (anterior) surface. As this nerve passes beneath the popliteus it supplies branches to the tibialis posterior, an interosseous branch for the interosseous membrane, which can be traced as far as the tibio-fibular syndesmosis, an articular branch for the proximal tibio-fibular joint, and a medullary braneh for the shaft of the tibia.

3. N. Cutaneous Suræ Medialis (O.T. N. Communicans Tibialis). - The cutaneous branch is the medial cutaneous nerve of the leg. This nerve passes from the popliteal fossa in the groove between the two heads of the gastrocnemius muscle, and afterwards lies upon the tendo calcaneus. It pierces the deep fascia in the middle third of the back of the leg, and is joined immediately afterwards by the peroneal anastomotic ramus from the common peroneal nerve. From 
their union the nerve of the calf (n. suralis) results, which reaches the foot, winding round the back of the malleolus along with the small saphenous vein. The nervus suralis supplies cutaneous branches to the lateral side and back of the distal third of the leg, the ankle and heel, and the side of the foot and little toe, as well as articular branches to the ankle and tarsal joints.
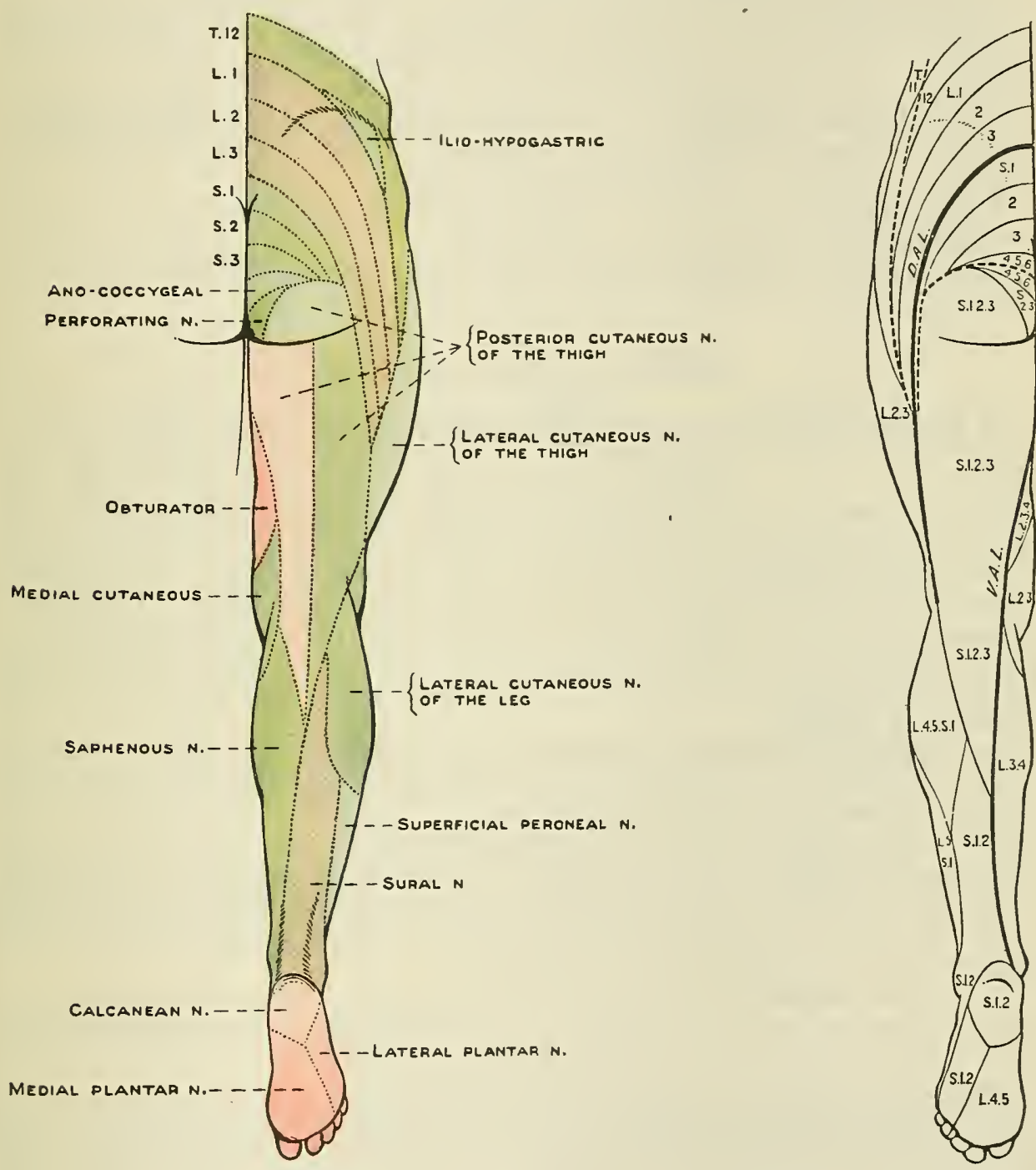

A

B

Fig. 629.-Distribution of Cutaneods Nerves on the back of the Lower Limb.

In $\mathrm{A}$ the distribution of the several nerves is represented, their names being given.

In $B$ a scliematic representation is given of the areas supplied by the above nerves, the figures indicating the spinal origin of the branches of distribution to each centre.

The $\mathrm{n}$. suralis communicates on the foot with the superficial peroneal nerve, and its size varies with the size of that nerve. It may extend on to the dorsum of the foot for a considerable distance, and may either reinforce or replace the branches of the abovenamed nerve to the intervals between the fourth and fifth and the third and fourth toes. The mode of formation of the nervus suralis is very variable. The usual arrangement is that described. Frequently the peroneal anastomotic nerve and the medial sural nerve (medial cutaneous nerve of the leg) do not unite, and in such cases the more usual arrangement is for the tibial trunk to form alone the nervus suralis (nerve of the calf), 
the peroneal anastomotic ramus extending only to the ankle and heel. It is less usual for the peroneal anastomotic ramus to form alone the nervus suralis, the medial sural nerve in these cases ending at the heel.

(c) Branches arising in the Back of the Leg distal to the Knee-Joint.-These brauches are mainly muscular and cutaneous.

The muscular branches are four in number, comprising nerves to the soleus (entering its deep surface) and tibialis posterior, often arising by a common trunk, and nerves to the flexor digitorum longus and flexor hallucis longus, the latter generally accompanying the peroneal artery for some distance.

Rami Calcanei Mediales. - The cutaneous branches are the medial calcanean rami, which pierce the ligamentum laciniatum, and is distributed to the skin of the heel and posterior part of the sole of the foot.

In addition, a medullary nerve to the fibula, and a small articular branch to the ankle-joint, are supplied by the tibial nerve.

The terminal branches of the tibial nerve are the medial and lateral plantar nerves.

\section{Nervus Plantaris Medialis.}

N. Plantaris Medialis.-The medial plantar nerve is homologous with the median nerve in the hand (Fig. 629, p. 733). It is rather larger than the lateral plantar. It courses forwards in the sole of the foot beneath the ligamentum lanciniatum and abductor hallucis to the interval between that muscle and the flexor digitorum brevis, in company with the medial plantar artery.

The collateral branches are muscular, cutaneous, and articular. The muscular branches supply the abductor hallucis and the flexor digitorum brevis. The plantar cutaneous branches are small twigs which pierce the plantar aponeurosis in the interval between these muscles to supply the medial part of the sole of the foot. The articular branches are minute twigs which supply the tarsal and tarsometatarsal articulations.

Nn. Digitales Plantares Communes.-The terminal branches are four in number, the common plantar digital nerves, and may be designated first, second, third, and fourth, from medial to lateral side.

The first (most medial) branch separates from the nerve before the others, and pierces the plantar aponeurosis behind the ball of the great toe. It supplies a muscular branch to the flexor hallucis brevis, and cutaneous branches to the medial side of the foot and ball of the great toe. It terminates as the plantar digital nerve for the medial side of the great toe.

The second branch arises along with the third and fourth; after supplying a branch to the first lumbrical muscle, it becomes superficial in the interval between the first and second toes, and terminates by dividing into two proper digital nerves for the supply of the adjacent sides of these toes.

The third and fourth branches are entirely cutaneous in their distribution. They become superficial in the intervals between the second and third and the third and fourth toes, respectively, and there divide into proper digital branches for the supply of the adjacent sides of these toes.

Nn. Digitales Plantares Proprii. - The plantar proper digital nerves supply the whole length of the toes on the plantar aspect, and, in relation to the terminal phalanges, furnish minute dorsal offsets for the supply of the nails and tips of the toes on their dorsal surface. The medial plantar nerve thus supplies the skin of the three and a half medial toes in the sole of the foot; and four muscles:the abductor hallucis and flexor digitorum brevis, the flexor hallucis brevis, and the first lumbrical muscle.

\section{Nervus Plantaris Lateralis.}

The lateral plantar nerve is homologous with the ulnar nerve in the hand. From its origin beneath the ligamentum laciniatum it extends forwards 
and laterally in the sole, in company with the lateral plantar artery, between the flexor digitorum brevis and quadratus plantæ, towards the base of the fifth metatarsal bone. Here it terminates by dividing into superficial and deep branches.

Collateral Branches.-IIuscular branches are given off from the undivided nerve to the quadratus plante and abductor digiti quinti muscles. Cutaneous branches pierce the plantar fascia at intervals along the line of the intermuscular septum, between the flexor digitorum brevis and abductor digiti quinti.

Terminal Branches-Ramus Superficialis.-The superficial branch is mainly cutaneous. Passing forwards between the flexor digitorum brevis and abductor digiti quinti, it divides into lateral and medial parts.

The lateral branch, after supplying the flexor quinti digiti brevis muscle, and sometimes one or both interossei of the fourth space, becomes superficial behind the ball of the little toe, and supplies cutaneous twigs to the sole of the foot and ball of the toe. It terminates as the proper digital branch for the lateral side of the little toe.

The medial branch passes forwards to the interval between the fourth and fifth toes, where it becomes cutaneous, and divides into two proper digital branches for the supply of the adjacent sides of these toes. It communicates with the fourth terminal branch of the medial plantar nerve.

Ramus Profundus. - The deep branch of the lateral plantar nerve, passing deeply along with the lateral plantar artery, extends medially towards the great toe, bemeath the quadratus plantæe and oblique head of the adductor hallucis. It gives off articular branches to the tarsal and tarso-metatarsal articulations, and muscular branches to the interossei of each space (except in some cases the muscles of the fourth space): to the adductor hallucis, and the lateral three lumbrical muscles. These nerves enter the deep surface of the muscles, that to the second lumbrical reaching its muscle after passing

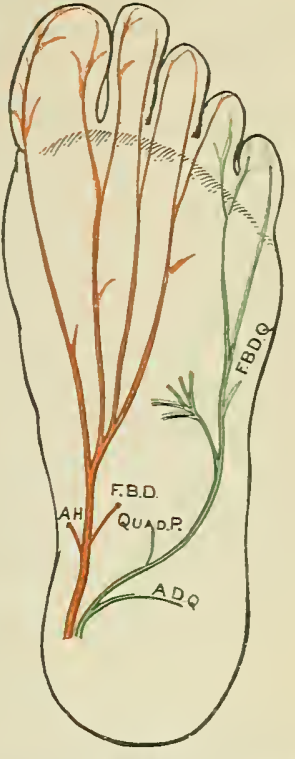

Fig. 630.-ScheMe of DistriBUTION OF THE PLAITAR Nerves.

In brown, meclial plantar nerve, and its cutaneous and muscular branches ; F.B.D, Flexor digitorum breris ; A.H, Abductor hallucis ; F.B.H, Flexor hallncis brevis; L.I, First lumbrical. In green. lateral plantar nerre, and its cutaneous and muscular branches; Quad. P, Quadratus plantæ; A.D.Q. Abductor digiti quinti; F.B.D.Q, Flexor breris digiti quinti. forwards beneath the transverse head of the adductor hallucis.

\section{PLEXUS PUDENDUS.}

The pudendal plexus constitutes the third and last subdivision of the lumbosacral plexus. It is composed for the most part of the spinal nerves below those which form the sacral plexus; but, as already stated, there is no distinct point of separation between the two plexuses. On the contrary, there is considerable overlapping, so that two and sometimes three of the principal nerves derived from the pudendal plexus have their origin in common with nerres of the sacral plexus.

The plexus is formed by fibres from the anterior rami of the first three sacral nerves, and by the whole of the anterior rami of the fourth and fifth sacral and coccygeal nerres. The size of the nerres diminishes rapidly from the first sacral to the coccygeal, which is extremely slender.

Position and Constitution.-The plexus is formed on the posterior wall of the pelvis. Of the nerves forming it, the upper ones emerge from the anterior sacral foramina; the fifth sacral nerve appears between the last sacral and first coccygeal vertebra; and the coccygeal nerve appears below the transverse process of that vertebra. The nerves of distribution derived from the plexus are the following :- 
1. Visceral branches.

2. Posterior cutaneous nerve of the thigh.

3. Perforating cutaneous nerve.
4. Pudendal nerve.

5. Muscular branches.

6. Ano-coccygeal nerve.

Omitting the visceral branches, all the nerves are distributed to the perineum.

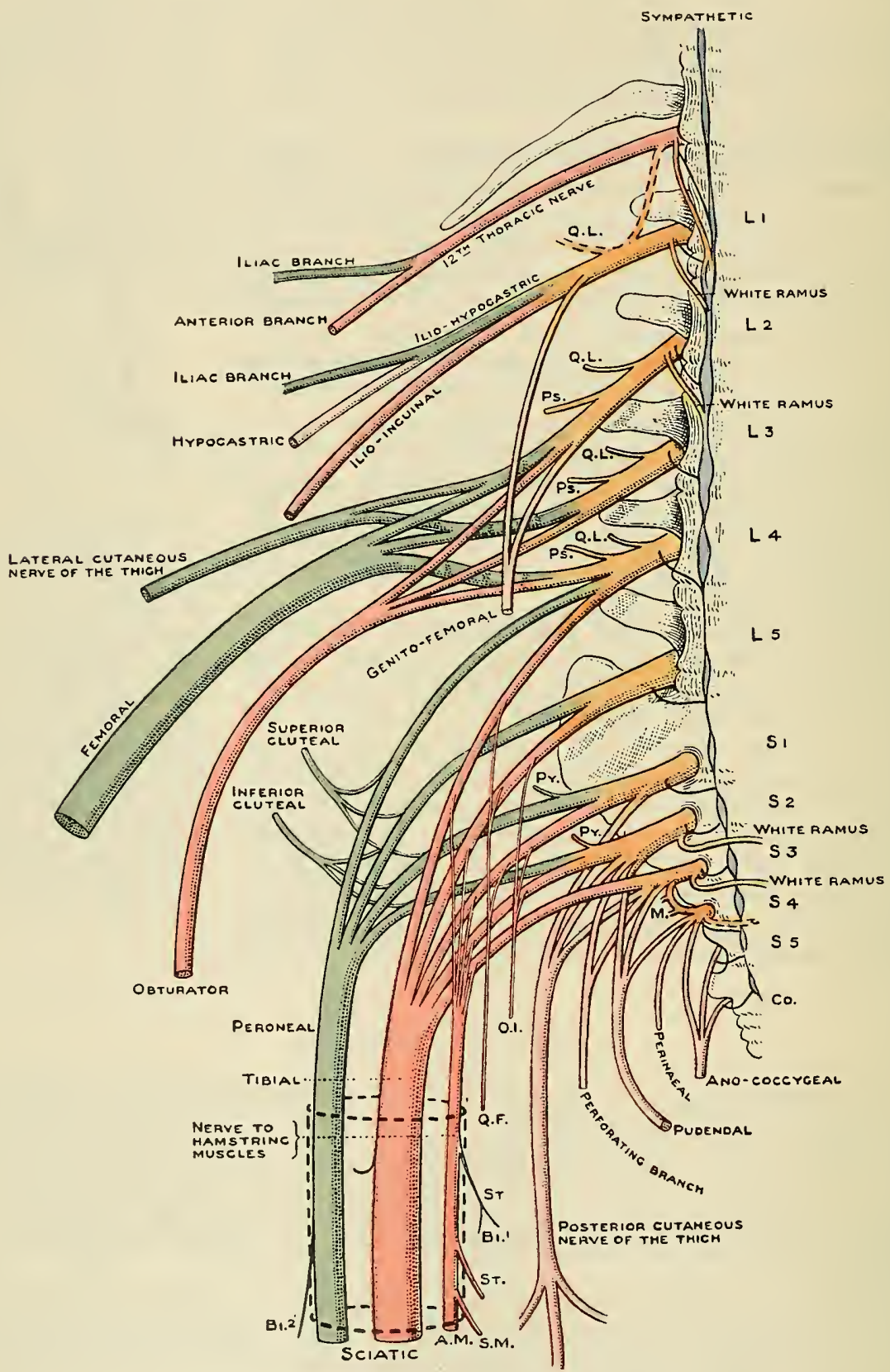

Fig. 631.-Nerves of the Lumbo-Sacral Plexus.

Only two, the posterior cutaneous nerve of the thigh and the perforating cutaneous nerve, send branches to the lower limb.

Visceral Branches.-Like the other spinal nerves, the fourth and fifth sacral and coccygeal nerves are provided with fine gray rami communicantes from the sacral sympathetic trumk, which join them after a short course on the front of 
the sacrum. The third (along with the second or fourth) sacral nerve, in addition, sends a considerable white ramus communicans or visceral branch direct to the pelvic plexus and viscera.

N. Cutaneus Femoris Posterior-Posterior Cutaneous Nerve of the Thigh (O.T. Small Sciatic). - This nerve is complex both in origin and distribution (Fig. 631, p. 736). Springing from the junction of the sacral and pudendal plexuses, it is derived from the first three or second and third sacral nerves. It is distributed to the lower limb and perineum, and is associated with other nerves belonging to both regions. It arises from the back of the roots of the sacral plexus in the pelvis. Its higher roots from the first and second sacral nerves are intimately associated with the origin of the inferior glnteal nerve; its lowest root from the third sacral nerve is associated with the origins of the perforating critaneous or of the pudendal nerve. It enters the buttock through the greater sciatic notch below the piriformis, along with the inferior gluteal artery and nerve. Proceeding distally posterior to the sciatic nerve, it enters the thigh at the lower border of the glutæus maximus muscle, where it gives off considerable branches. Becoming gradually smaller as it courses distally over the hamstring muscles to the popliteal fossa, it finally pierces the popliteal fascia in one or more cutaneous branches, which supply the skin over the calf of the leg for a variable distance (Fig. 629, p. 733 ).

Branches.-The nerve is purely cutaneous. It supplies branches to the perineum, buttock, thigh, and leg.

Rami Perineales. - The perineal branch arises at the lower border of the glutæus maximus muscle (Fig. 631, p. 736). It sweeps in a medial direction to the perineum, lying on the origin of the hamstring muscles distal to the ischial tuberosity; and becoming subcutaneous after passing over the pubic arch, its terminal branches supply the skin of the scrotum and root of the penis, or in the female the labium majus and clitoris, some of them being directed backwards towards the anus and central point of the perineum. They communicate with the inferior hæmorrhoidal and perineal branches of the pudendal nerve, and with the ilio-inguinal nerve. In its course to the perineum the nerve gives off collateral branches to the skin of the proximal and medial part of the thigh.

Nn. Clunium Inferiores.-The inferior gluteal branches are large and numerous (Fig. 631, p. 736). They arise from the nerve beneath the glutrus maximus, and become subcutaneous by piercing the fascia lata at different points along its lower border. They supply the skin of the lower half of the buttock. The most lateral branches, reaching to the back of the greater trochanter, overlap the terminal filaments of the gluteal branches of the lateral cutaneous nerve of the thigh, and the posterior rami of the first three lumbar nerves. The most medial branches, which may pierce the sacro-tuberous ligament, reach nearly to the coccyx, and are co-extensive in their distribution with the branches of the perforating cutaneous nerve, which they reinforce and not infrequently replace.

The femoral branches are divisible into two sets-medial and lateral. They pierce the fascia lata of the thigh at intervals, and supply the skin of the back of the thigis.

The sural branches are two or more slender nerves which pierce the fascia over the popliteal fossa, and are distributed for a variable extent to the skin of the back of the leg. They may stop short over the popliteal fossa, or may extend as far as the ankle. Usually they innervate the skin as far as the middle of the calf. They communicate with the nervus suralis.

In cases where the sciatic nerve is naturally divided at its origin into tilial and common peroneal nerves (e.g. by the piriformis muscle), this nerve is also separated into two parts: a posterior part, associated with the common peroneal nerve and arising in common with the lower roots of the inferior gluteal nerve (usually from the first and secund sacral nerves), and comprising the gluteal and lateral femoral branches; and an anterior part, associated with the tibial nerve and arising nsually from the second and third sacral nerves, along with the perforating cutaueous and pudendal nerves, and comprising the perineal and medial femoral branches.

Perforating Cutaneous Nerve (n. perforans ligamenti tuberoso-sacri (Schwalbe), n. cutanens clunium inferior medialis (Eisler)).-This nerve arises 
from the back of the second and third sacral nerves (Fig. 631, p. 736). At its origin it is associated with the lower roots of the posterior cutaneous nerve of the thigh. Passing distally it pierces the sacro-tuberous ligament, along with the coccygeal branch of the inferior gluteal artery; and after winding round the lower border of the gluteus maximus muscle, or in some cases piercing its lower fibres, it becomes cutaneous a little distance from the coccyx, and supplies the skin over the lower part of the buttock and the medial part of the fold of the nates.

The perforating cntaneous nerve is not always present. In a minority of cases it is associated at its origin with the pudendal nerve. When absent as a separate nerve, its place is taken by (1) gluteal branches of the posterior cntaneous nerve of the thigh, or (2) a branch from the pudendal nerve, or (3) a small nerve (n. perforans coccygeus major, Eisler), arising separately from the posterior part of the third and fourth sacral nerves.

Muscular Branches.-Between the third and fourth sacral nerves (occasionally reinforced by the second, Eisler) a plexiform loop is formed, from which muscular nerves are given off to the levator ani (supplying the muscle on its pelvic surface), coccygeus, and external sphincter. The nerve to the external sphincter (perineal branch of fourth sacral) pierces the sacro-tuberous ligament and the coccygeus muscle, to which it gives offsets, and appears in the ischio-rectal fossa between the glutæus maximus and the external sphincter. Besides supplying the posterior fibres of the external sphincter, it distributes cutaneous offsets to the skin of the ischio-rectal fossa and the fold of the nates behind the anus. This nerve replaces in some instances the perforating cutaneous nerve.

$\mathrm{Nn}$. Anococcygei (Ano-coccygeal Nerve).-By the union of the remaining part of the fourth with the fifth sacral and coccygeal nerves, the so-called plexus coccygeus (coccygeal plexus) is formed. A fine descending branch of the fourth sacral nerve passes over or through the sacro-tuberous ligament, to join the fifth sacral nerve. This fifth sacral nerve, joined by the descending branch of the fourth, descends alongside the coccyx and is again joined by the coccygeal nerve, so that a plexiform cord, the ano-coccygeal nerve results, homologous with the inferior caudal trunk of tailed animals. Fine twigs arise from it, which pierce the sacrotuberous ligament and supply the skin in the neighbourhood of the coccyx, medial to the branches of the perforating cutaneous nerve and behind the anus.

\section{Nervus Pudendus.}

The pudendal nerve (O.T. pudic) is the principal nerve for the supply of the perineum. It arises in the pelvis usually by three roots from the second, third, and fourth sacral nerves (Fig. 631, p. 736). (Frequently one of its branches, the inferior hæmorrhoidal nerve, arises independently from the third and fourth sacral nerves.) The nerve passes to the buttock through the greater sciatic foramen below the sciatic nerve, and lies on the sacro-spinous ligament, or the spine of the ischium, medial to the internal pudendal artery. It enters the perineum along with the artery through the lesser sciatic foramen. In the perineum it is deeply placed in the lateral wall of the ischio-rectal fossa, enclosed in a special sheath derived from the parietal pelvic fascia covering the medial surface of the obturator internus muscle. At the anterior limit of the ischio-rectal fossa, the nerve approaches the surface and divides at the base of the urogenital diaphragm into its terminal branches, the perineal nerve and the dorsal nerve of the penis.

The branches of the nerve are essentially the same in the two sexes. As a rule no branches are given off till it enters the perineum, but sometimes the inferior hæmorrhoidal nerve has an independent origin from the plexus, merely accompanying the pudendal nerve in the first part of its course; and in exceptional cases the perforating cutaneous nerve of the buttock is a branch of the pudendal nerve.

Nn. Hæmorrhoidales Inferiores.-The inferior hæmorrhoidal nerve arises from the nerve under cover of the glutæus maximus, at the posterior part of the ischio-rectal fossa. In cases in which it has an independent origin from the plexus, it arises from the third and fourth sacral nerves. It crosses the ischio-rectal fossa 
in company with the inferior hæmorrhoidal vessels, and separates into numerous branches-muscular, cutaneous, and communicating.

The muscular branches end in the external sphincter ani muscle. The cutaneous branches supply the skin around the anus. The communicating branches connect the inferior hæmorrhoidal with three other nerves-the perineal branches of the posterior cutaneous nerve of the thigh, pudendal, and fourth sacral nerves.

Nervus Perinei.-The perineal nerve, one of the two terminal branches of the pudendal nerve, arises near the base of the urogenital diaphragm. It almost immediately divides into two parts, superficial and deep.

The superficial part is purely cutaneous and consists of two nerves, the posterior

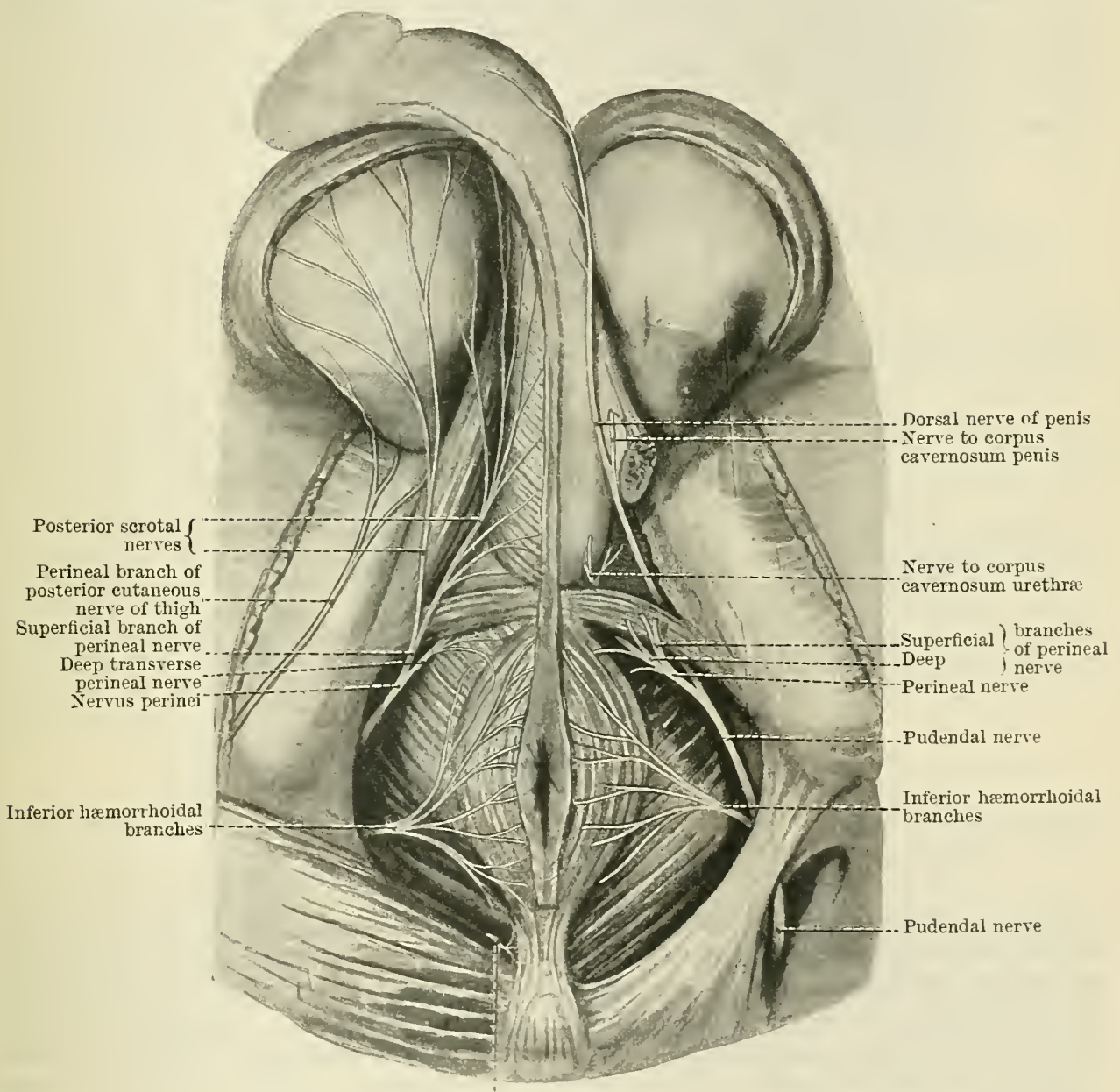

Fig. 632.-Distribution of the Pedendal Nerve.

or lateral and the anterior or medial superficial perineal nerves (nn. scrotales posteriores or nn. laterales posteriores), which pass, along with the superficial perineal vessels, to the anterior part of the perineum. The posterior or lateral superficial perineal nerve, at the anterior limit of the ischio-rectal fossa, usually passes over the base of the urogenital diaphragm and over the (superficial) transversus perinei muscle. The anterior or medial superficial perineal nerve, lying more deeply, pierces the base of the fascia inferior of the urogenital diaphragm and goes underneath or through the transversus perinei muscle. Becoming superficial in the anterior (urethral) triangle of the perinem, they are distributed to the skin of the scrotum (or labium majus), and communicate with the perineal rami of the posterior cutaneous nerve of the thigh and with the inferior hremorrhoidal nerve.

The deep part of the perineal nerve is mainly but not entirely muscular 
Coursing forwards through the anterior part of the ischio-rectal fossa, it passes between the two layers of fascia of the urogenital diaphragm towards the urethra. It supplies muscular branches to the anterior parts of the levator ani and external sphincter, to the transversus perinei, superficialis and profundus, ischio-cavernosus, bulbo-cavernosus (or sphincter vaginæ), and sphincter urethræ membranaceæ. It terminates as the nerve to the bulb, which, piercing the urogenital diaphragm, enters the bulb of the urethra and supplies the erectile tissue of the bulb and corpus cavernosum urethræ, as well as the mucous membrane of the urethra as far as the glans penis (or clitoridis).

N. Dorsalis Penis vel Clitoridis.-The dorsal nerve of the penis or clitoris, the other terminal branch of the pudendal nerve accompanies the internal pudendal artery beneath the fascia inferior of the urogenital diaphragm. It passes forward close to the pubic arch, lying beneath the crus and ischio-cavernosus, and fascia inferior of the urogenital diaphragm, and upon the sphincter urethræ membranaceæ muscle; piercing the fascia inferior of the urogenital diaphragm near

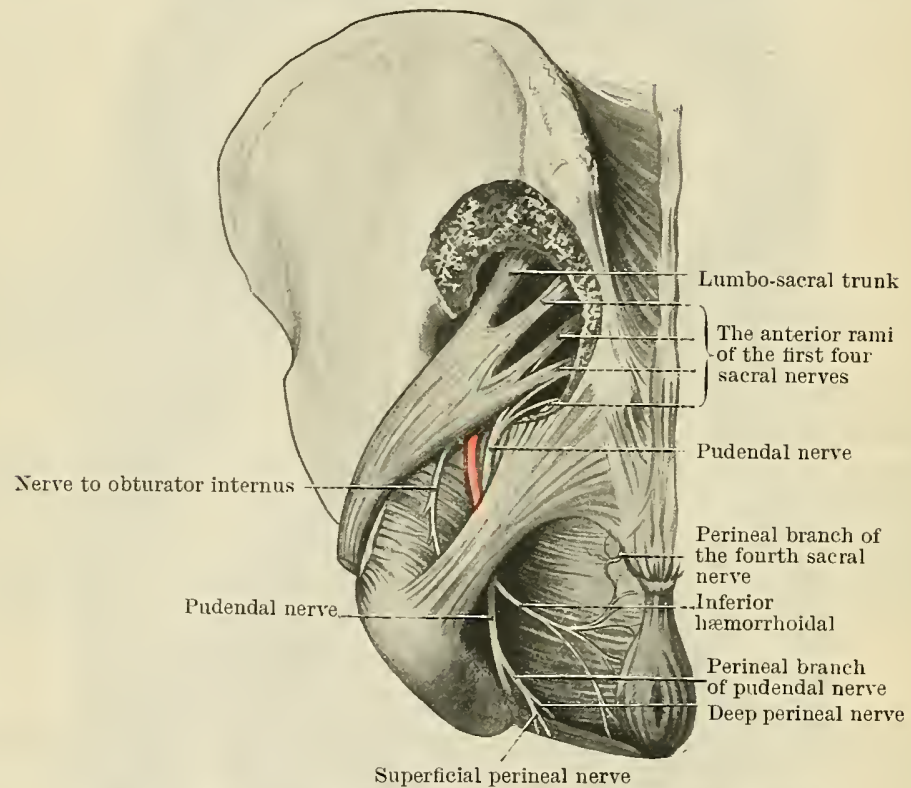

Fig. 633.-The Origin and Course of the Pudendal Nerve.

its apex, at the lateral side of the dorsal artery of the penis (or clitoris), it passes on to the dorsum of the penis or clitoris, to which it is distributed in its distal two-thirds, sending branches round the sides of the organ to reach its under surface. In the female the nerve is much smaller than in the male. The dorsal nerve of the penis supplies one branch, the nerve to the corpus cavernosum penis, as it lies beneath the inferior fascia of the urogenital diaphragm. This is a slender nerve, which, piercing the fascia inferior, supplies the erectile tissue of the crus and corpus cavernosum penis.

Morphology of the Pudendal Plexus. - The structures occupying the perineum are placed in the ventral axis of the body, and comprise from before backwards, the penis and scrotum, or mons Veneris and vulva, the central point of the perineum, the anus and ischio-rectal fossa, and the coccyx. They are placed on the medial side of the attachment of the lower limbs-the penis or mons Veneris in relation to the preaxial border; the coccyx in relation to the postaxial border
of the limb.

The nerves of the perineum, thus reaching the ventral axis of the trunk, are homologous with the anterior (ventral) terminatious of other nerves. They are separable into two series. Mrainly supplied through the pudendal plexus by the last four sacral and the coccygeal nerves, the perineum is also innervated to a minor extent by the first lumbar nerve through the ilioinguinal nerve, which reaches the root of the penis and the scrotum. The region is thus supplied by two series of widely separated nerves, which have their meeting-place on the dorsum and side of the penis and scrotum. This junction of the ilio-inguinal and pudendal nerves constitutes the beginning of the ventral axial line, which extends peripherally along 
the medial side of the lower limb. Apart from this break in their distribution, a definite numerical order may be followed in the arrangement of the perineal nerves. The higher parts of the perineum are innervated by the higher spinal nerves; the lower parts, by the lower nerves. This is best exemplified in the distribution of the cutaneous nerves. The base of the penis and scrotum (or mons Veneris) is supplied by the first lumbar nerve (ilio-inguinal). The dorsal nerve of the penis (or clitoris), when traced back to the pudendal plexus, is found to come from the second, and to a less extent from the third sacral nerves; the scrotal nerves (perineal branches of the pudendal and posterior cutaneous nerve of the thigh) similarly arise from the third, and to a less extent from the second sacral nerves; the skin of the ischio-rectal fossa and anus is innervated by the inferior hæmorrhoidal (third and fourth sacral nerves), and the perineal branch of the fourth sacral nerve. The ano-coccygeal nerve (coccygeal plexus), lastly, supplies the skin round the coccyx (fourth and fifth sacral and coccygeal nerves). Judged from its nerve supply the perineum is to be regarded as occupying, for the most part, a position behind or more caudal than that of the lower limb in relation to the trunk. There is here

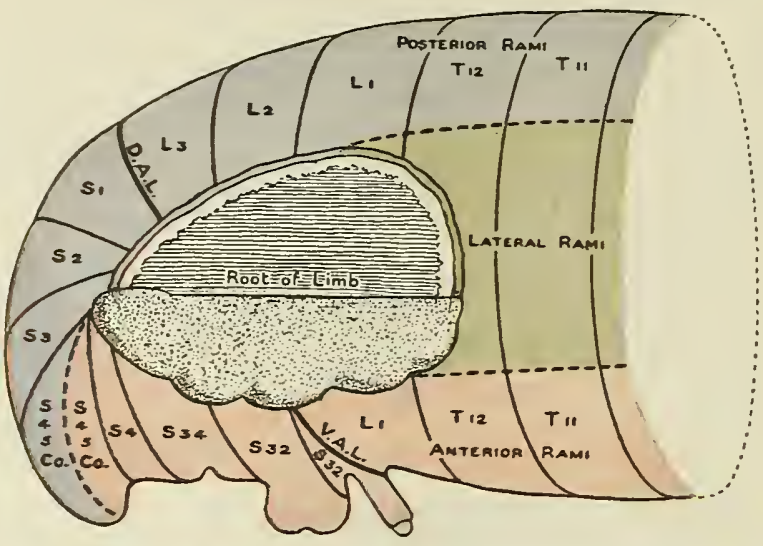

FIG. 634. - SCHENE of the innervation of the hinder portion of the trunk and of the perineum, and the interruption of the segmental arrangement of the nerres associated with the formation of the limb. a remarkable gap in the numerical sequence of the nerves supplying the ventral axis of the body. All the nerves between the first lumbar and the second sacral fail to reach the mid ventral line of the trunk and are wholly concerned in the innervation of the lower limb.

At the preaxial border of the limb (groin) the first lumbar nerve, the highest nerve supplying the perineum, is concerned also in innervating the skin of the limb. At the postaxial border of the limb (fold of the nates and back of the thigh), the nerves which are the highest of those constituting the pudendal plexus (the second and third sacral nerves) are also implicated in innervating that border of the limb. The fourth sacral nerre is only concerned to a very slight extent in the innervation of the limb by means of the perineal branch, which reaches the beginning of its postaxial border; the last two spinal nerves are wholly unrepresented in the limb proper and end entirely in the trunk behind the limb.

\section{Morphology of the Limb-Plexuses.}

The arrangement of the limb nerves is rendered complex and the significance of the plexuses is obscured by the changes through which, coincidently, the nerves on the one hand and the parts supplied by them on the other hand have passed in the course of derelopment.

Nature of the Limbs.-As already described, the mammalian limbs arise as flattened buds from the extremities of the Wolffian ridge. Each bud possesses a preaxial and a postaxial border, and a dorsal and a ventral surface, continuous with the dorsal and ventral aspects of the trunk and homologous with its lateral and ventral surfaces. Each bud consists at first of a mass of undifferentiated, unsegmented mesoderm, covered with epithelium. Around the central core of mesoderm,which produces the skeletal axis, the vessels and muscles of the limb are formed in situ, the muscles as double dorsal and ventral strata, beneath the corresponding surfaces of the bud.

Each limb bud is connected to the lateral and ventral aspects of the trunk, and is associated with a number of body segments, varying in the two extremities and in different animals. Although the mesodermal material of which the limb bud is composed exhibits in itself no segmental divisions at any period of its development, a clear indication of the segmental relations of the limbs is obtained from the arrangement of the limb nerves. Taking the nerves which supply the limbs in man as a guide, the segments engaged in the formation of the upper extremity are the last five cervical and first two thoracic. The lower extremity is related by its nerves to all the lumbar and the first three sacral segments. In each limb, the segments at the preaxial and postaxial borders are only partially concerned in limb formation.

It has been already sliown that the somatic branches of the nerves enter the substance of the embryonic limb and divide in their course into dorsal and ventral trunks, which supply the dorsal and ventral surfaces of the limb bud. The higher nerves supply the preaxial border, the lower nerves supply the postaxial border, while the nerves most centrally situated extend furthest towards the periphery of the limb.

In order to understand properly the constitution of the limb-plexuses, it is wecessary further to make a comparison of the surfaces and borders of the embryonic and adult limbs.

Upper Limb.-(A) Borders,-The preaxial border of the upper extremity extends from the 
middle of the clavicle, in the line of the cephalic vein, distally along the frout of the shoulder, the lateral border of the arm, forearm and hand, to the lateral border of the thumb. The postaxial border extends from the middle of the axilla along the medial side of the arm (in the line of the basilic rein), the medial side of the forearm and hand, to the medial border of the little finger.

$(B)$ Surfaces.-The areas of the limb between these lines, anteriorly and posteriorly, correspond to the rentral and dorsal surfaces of the embryonic limb bud. The ventral surface is represented by the front of the chest, arm, and forearm, and the palm of the hand. The dorsal surface is represented by the scapular and deltoid regions, the back of the arm, forearm, and hand.

Lower Limb. - $(A)$ Borders. - The preaxial border of the lower limb extends from the middle of the ingninal ligament distally along the medial side of the thigh and leg in the line of the great saphenons vein, to the medial side of the great toe. The postaxial border, beginning at the coccyx, extends along the fold of the nates and the lateral border and back of the thigh and leg (in the line of the small saphenous vein) to the lateral border of the foot and little toe.

$(B)$ Surfaces. - The areas between these lines correspond to the primitive dorsal and ventral surfaces of the embryonic limb bud. The unequal amount of rotation in the parts of the lower limb obscures the relation of fœtal and adult surfaces, which are most easily made out in the infantile position of the limbs, with the thighs and knees flexed and the soles of the feet inverted. The ventral surface of the embryonic limb is represented by the medial side and posterior part of the thigh, the back of the leg, and the sole of the foot. The dorsal surface is represented by the front of the thigh and buttock, the front of the leg, and the dorsum of the foot.

Composition of the Limb-plexuses.-In all mammals the same definite plan underlies the constitution of the limb-plexuses. The nerves concerned are the anterior rami of certain segmental spinal nerves, which (with certain exceptions at the preaxial and postaxial borders) are destined wholly and solely for the innervation of the limb. Each of the anterior rami engaged divides into a pair of secondary trunks, named dorsal or posterior, ventral or anterior. The dorsal and ventral trunks again subdivide into tertiary trunks, which combine with the corresponding subdivisions of neighbouring dorsal and ventral trunks to form the nerves of distribution. The combinations of dorsal trunks provide a series of nerves for the supply of that part of the limb which is derived from the dorsal surface of the embryonic limb bud ; the combinations of ventral trunks give rise to nerves of distribution to the regions corresponding to its ventral surface. The relation of the nerves derived from the limb-plexuses to the areas of the limbs is given in the accompanying tables :-

\section{Upper Limb.}

\begin{tabular}{|c|c|c|c|c|}
\hline \multicolumn{2}{|c|}{ Origin. } & Nerves. & \multicolumn{2}{|l|}{ Distribution. } \\
\hline \multirow{2}{*}{$\begin{array}{c}\text { Brachial } \\
\text { Plexus }\end{array}$} & $\begin{array}{l}\text { Dorsal trunks } \\
\text { (Posterior cord) }\end{array}$ & 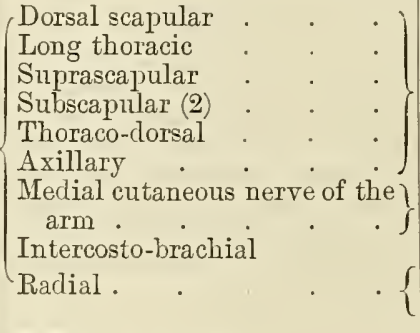 & $\begin{array}{l}\text { Scapular region and } \\
\text { shoulder } \\
\text { Arm, medial side } \\
\text { Back of arm, fore- } \\
\text { arm, and hand }\end{array}$ & $\begin{array}{r}\text { Dorsal } \\
\text { surface }\end{array}$ \\
\hline & $\begin{array}{l}\text { Ventral trunks } \\
\text { (Lateral and } \\
\text { medial cords) }\end{array}$ & 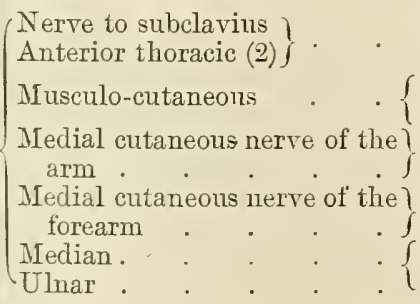 & $\begin{array}{l}\text { Front of chest } \\
\text { Front of arm and } \\
\text { forearm } \\
\text { Medial side of arm } \\
\text { Front of arm and } \\
\text { forearm } \\
\text { Front of forearm and } \\
\text { hand }\end{array}$ & $\begin{array}{l}\text { Ventral } \\
\text { surface }\end{array}$ \\
\hline
\end{tabular}


II. Lower Limb.

\begin{tabular}{|c|c|c|c|c|}
\hline \multicolumn{2}{|c|}{ Origin. } & Nerves. & \multicolumn{2}{|l|}{ Distribution. } \\
\hline $\begin{array}{l}\text { Lumbo- } \\
\text { sacral } \\
\text { Plexus }\end{array}$ & $\begin{array}{l}\text { Ventral } \\
\text { trunks }\end{array}$ & 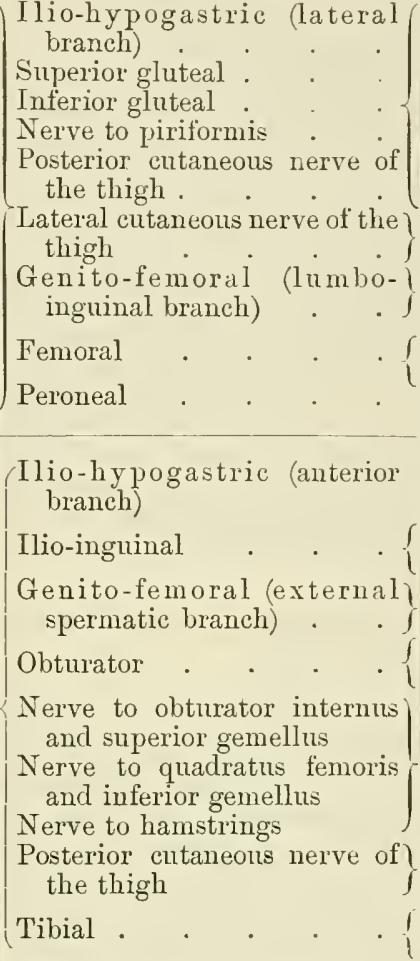 & $\begin{array}{l}\text { Buttock } \\
\text { Buttock and thigh, lateral side } \\
\text { and front } \\
\text { Front of thigh } \\
\text { Front and medial side of thigh, } \\
\text { leg, and foot } \\
\text { Front of leg and foot } \\
\text { Abdominal wall (ventral sur- } \\
\text { face) } \\
\text { Abdoninal wall, thigh, and } \\
\text { perineum } \\
\text { Groin } \\
\text { Thigh (inedial side) and knee } \\
\text { (back) } \\
\text { Buttock and back of thigh } \\
\text { Back of thigh and perineum } \\
\text { Back of knee, leg, and sole of } \\
\text { foot }\end{array}$ & $\begin{array}{c}\text { Dorsal } \\
\text { surface }\end{array}$ \\
\hline
\end{tabular}

In the regions of the limbs no anterior cutaneous branches, derived from the limb nerves, supply the trunk. The whole of the nerve is carried into the limb and is absorbed in its innervation, and the dorsal and ventral trunks forming the limb-plexuses are to be looked upon as homalogous with the lateral and anterior trunks of an intercostal nerve. Two series of anomalies in relation to the formation and distribution of the nerves to the limbs must, however, be considered, becanse it has been suggested (Goodsir) that the nerves of the limbs are serially homologous not with the whole, but only with the lateral branches of the anterior rami of the intercostal nerves.

(1) Nerves in connexion with the primitive borders of the Limbs.-At the preaxial border of the upper limb, at its root, the fourth cervical nerve, which supplies the anterior and lateral surfaces of the neck, is also distributed through the supraclavicular nerves to the skin of both ventral and dorsal surfaces of the limb. The nerves and surfaces are liere not merely homologous, but in actual continuity.

At the preaxial border of the lower limb, similarly, the first lumbar nerve, by means of the ilio-hypogastric and ilio-inguinal branches, supplies on the one hand the buttock, in series with the lateral branches of the lower thoracic nerves, and, on the other hand, the lower part of the abdominal wall and the adjacent medial side of the thigh, in series with the anterior terminal branches of the lower thoracie nerves.

At the postaxial border of the upper limb the first and second thoracic nerves are concerned in supplying trunk segments as well as parts of the limb. The first thoracic nerve, besides supplying the limb through the medial cord of the plexus, also innervates at least the muscles of the first intercostal space ; the second thoracic nerve is concerned in the innervation of the limb, principally by means of its lateral branch only, which, as the intercosto-brachial nerve, supplies the skin along the postaxial border of the limb and on its dorsal side. At the postaxial border of the lower limb, in the same way, the third and fourth sacral nerves, partially implicated in the innervation of the limb (through the tibial, posterior cutaneous nerve of the thigh, perforating cutaneous nerve, and perineal branch of the fourth sacral nerve), are also engaged in supplying the trunk (perineum) through the pudendal nerve. These peculiarities of arrangement of the nerves at the borders of the limbs may be explained on the supposition that the segment corresponding to the nerve named is only partially concerned in limb formation, and is, at the same time, implicated to a greater or less extent in the formation of structures belonging to the trunk.

(2) The origin and distribution of the nerves at the postaxial border of the limbs present 
a special difficulty. In the composition of the brachial plexus the first thoracic nerve is almost wholly engaged in forming the rentral series of nerves. It only gives a minute nerve to join the posterior cord, and this is not always present. In the case of the lumbo-sacral plexus the third sacral nerve does not as a rule divide into ventral and dorsal trunks, but contributes only to the formation of the ventral series of nerves. A solution of this difficulty may be found in the examination of the areas of distribution of the nerves derived from the first thoracic and third sacral nerves respectively. In the case of the brachial plexus (the medial cord of which receives normally the whole contribution of the first thoracic nerve) the medial cutaneous nerve of the arm, the nlnar branch of the medial cutaneous nerve of the forearm, and the dorsal branch of the ulnar nerve supply the dorsal aspect of the limb on its postaxial border. These nerves are in serial lomology with the intercosto-brachial and lateral trunks of intercostal nerves. In the case of the limbo-sacral plexus similarly, in which the third sacral nerve does not divide into ventral and dorsal trunks, the posterior cutaneous nerve of the thigh and tibial nerves containing the contribution from the third sacral nerves innervate, by means of the gluteal and lateral femoral branches of the former and the medial sural nerve (medial cutaneons nerve of the calf) of the latter, the dorsal surface of the limb along the postaxial border, in series with the perforating cutaneous nerve and the perineal branch of the fourth sacral.

These apparent anomalies appear to indicate that, instead of dividing into its proper dorsal and ventral trunks, the entire contribution of the spinal nerve concerned, is in these instances carried undivided along the postaxial border of the limb in association with the ventral trunks, and that the dorsal subdivisions are thrown off successively as the plexus cords approach the periphery. Indeed, in the case of the posterior cutaneous nerve of the thigh, Eisler has shown that, when the common peroneal and tibial nerves are separated at their origin, its gluteal and lateral femoral branches arise from and are connected with the dorsal, and the perineal and medial femoral branches with the ventral trunk.

\section{The Distribution of the Spinal Nerves to the Muscles and Skin OF THE LIMBS.}

By dissection, experiment, and clinical observation, it is conclusively proved that as a rule each nerve of distribution in the limb, whether to muscle or skin, is made up of fibres derived from more than one spinal nerve; and, further, that in cutaneous distribution a considerable overlapping occurs in the course of the several peripheral nerves. Moreover, the arrangement of the distribution of the nerves to skin and to muscles is not identical. In the case of the skin of the limbs, by the covering of the limb being drawn on to it from adjacent parts in the process of growth, cutaneous nerves are engaged, which are derived from sources not represented in the muscular innervation of the limbs. Again, among the muscles, some have undergone fusion, others have become rudimentary, and others again have altered their position in the limb. Bearing these qualifications in mind, it is possible to formulate a definite plan for the innervation of the skin and muscles of the upper and lower limb. The accompanying tables give an analysis of the distribution of the spinal nerves to the skin and muscles of the upper and lower limb respectively :-

\section{Upper Limb. A. Cutaneous Nerves.}

\section{Dorsal (Posterior) Surface.}

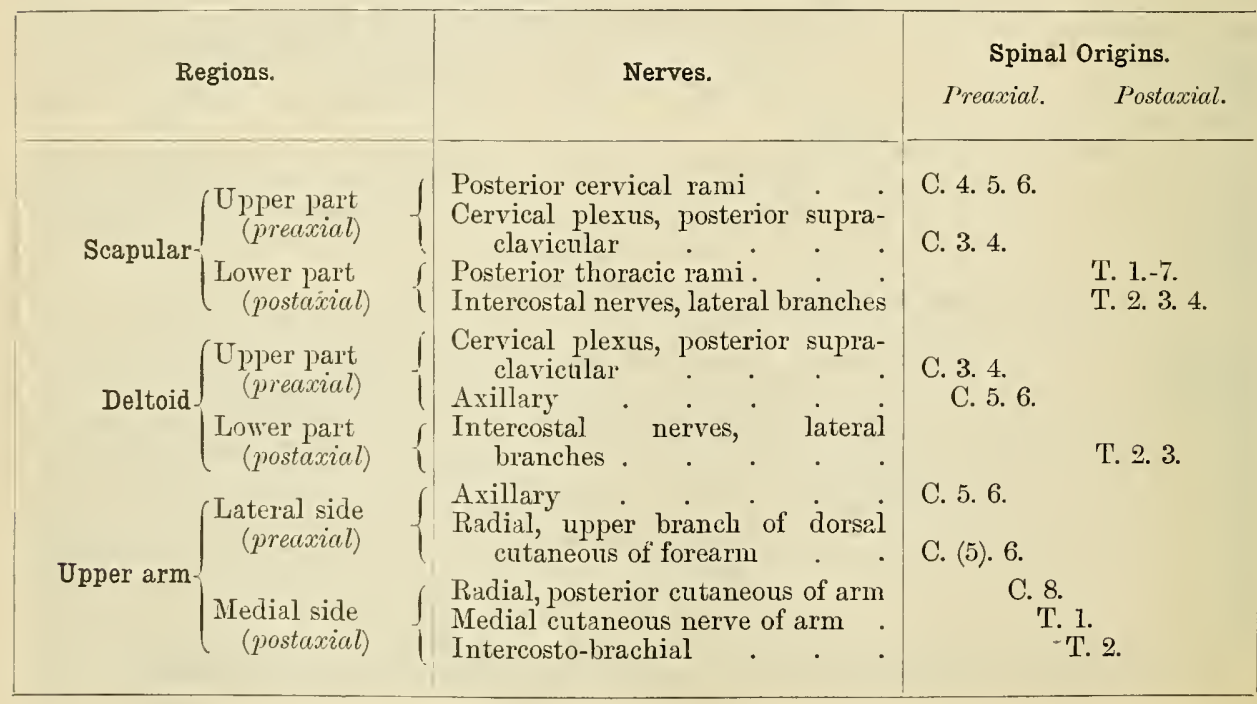


1. Dorsal (Posterior) Surface-continued.

\begin{tabular}{|c|c|c|c|c|}
\hline \multirow{2}{*}{\multicolumn{2}{|c|}{ Regions. }} & \multirow{2}{*}{ Nerves. } & \multicolumn{2}{|c|}{ Spinal Origins. } \\
\hline & & & Preaxial. & Postaxial. \\
\hline $\begin{array}{l}\text { Forearm } \\
\text { Hand }\end{array}$ & $\begin{array}{l}\left\{\begin{array}{r}\text { Lateral side } \\
\text { (preaxial) }\end{array}\right. \\
\begin{array}{r}\text { Medial side } \\
\text { (postaxial) }\end{array} \\
\left\{\begin{array}{r}\text { Lateral side } \\
\text { (preaxial) } \\
\text { Medial side } \\
\text { (postaxial) }\end{array}\right.\end{array}$ & $\begin{array}{l}\text { Radial, upper branch of dorsal } \\
\text { cutaneous nerve of forearm } \\
\text { Radial, lower branch of dorsal } \\
\text { cutaneous nerve of forearm } \\
\text { Musculo-cutaneous, posterior } \\
\text { branch . } \\
\text { Superficial branch of radial . } \\
\text { Mredial cutaneons nerve of fore- } \\
\text { arm (ulnar branch). } \\
\text { Ulnar, dorsal branch } \\
\text { Superficial branch of radial. } \\
\text { Ulnar. }\end{array}$ & $\begin{array}{l}\text { C. }(5) .6 . \\
\text { C. } 6.7 .8 . \\
\text { C. } 5.6 . \\
\text { C. } 6.7 .\end{array}$ & $\begin{array}{l}\text { C. } 8 . \text { T. } 1 . \\
\text { C. } 8 . \\
\text { C. } 8 .\end{array}$ \\
\hline
\end{tabular}

\section{Ventral (Anterior) Surface.}

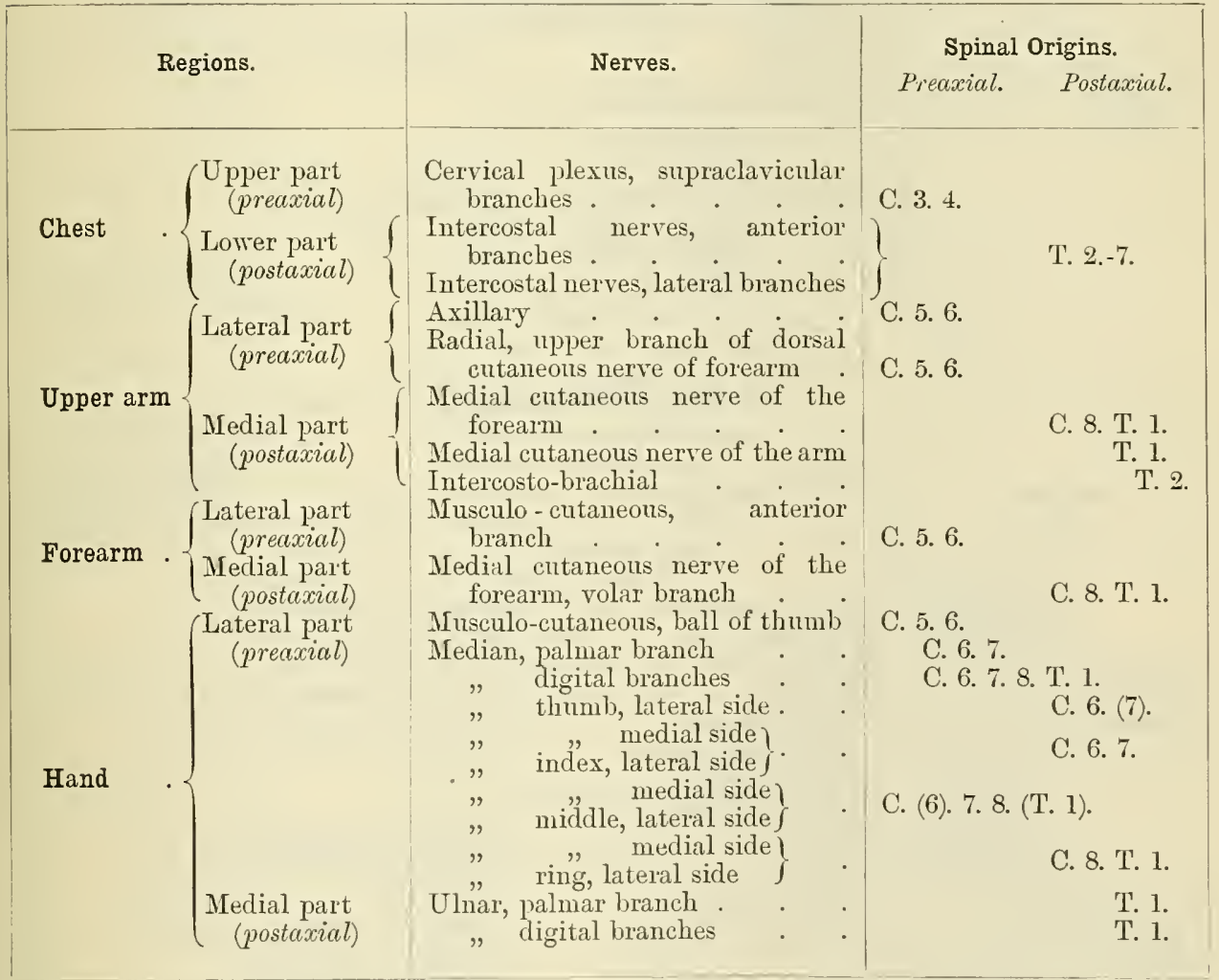

\section{B. Muscular Nerves.}

1. Dorsal (Posterior) Surface.

Regions.

Muscles.

Shoulder $\left\{\begin{array}{c}\text { Upper part } \\ \text { (preaxial } \\ \text { muscles) }\end{array}\right.$

Trapezius

Levator seapulix

Rliomboidei
Nerves.

Cervical plexus

fCervical plexus

UDorsal scapular

Dorsal seapular
Spinal Origins.

Preaxicel. Postaxial.

C. 3.4 .

C. 5 .

C. 5 . 
1. Dorsal (Posterior) Surface-continued.

\begin{tabular}{|c|c|c|c|c|}
\hline Reg & gions. & Muscles. & Nerves. & $\begin{array}{l}\text { Spinal Origins. } \\
\text { Prearial Postaxial }\end{array}$ \\
\hline Upper arm & $\begin{array}{l}\text { Lower part } \\
\text { (postaxial } \\
\text { muscles) }\end{array}$ & 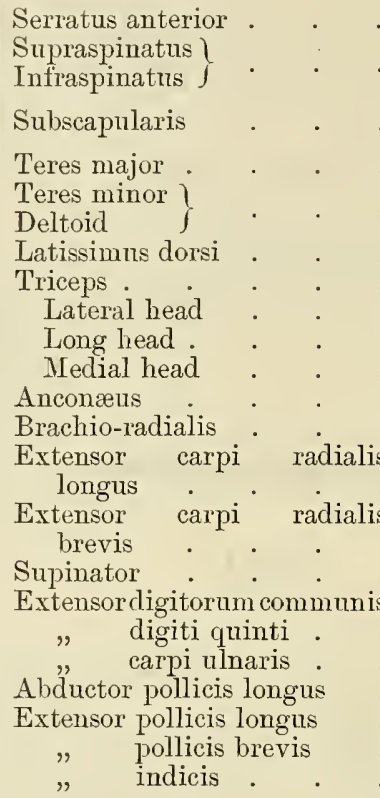 & 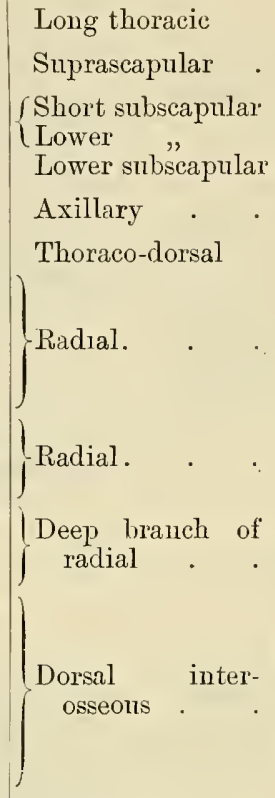 & $\begin{array}{l}\text { C. } 5.6 . \\
\text { C. } 6.7 .8 . \\
\text { C. }(6) .7 .8 . \\
\text { C. } 7.8 . \\
\text { C. } 5.6 . \\
\text { C. }(5) .6 .7 .8 . \\
\text { C. }(5) .6 .7 .(8) . \\
\text { C. }(5) .6 .\end{array}$ \\
\hline
\end{tabular}

2. Ventral (Anterior) Surface.

\begin{tabular}{|c|c|c|c|c|}
\hline \multicolumn{2}{|c|}{ Regions. } & Muscles. & Nerves. & $\begin{array}{c}\text { Spinal Origins. } \\
\text { Preaxial. Postaxial. }\end{array}$ \\
\hline $\begin{array}{l}\text { Pectoral } \\
\text { Region }\end{array}$ & $\begin{array}{l}\text { Upper part } \\
\text { (preaxial } \\
\text { muscles) } \\
\\
\text { Lower part } \\
\text { (postaxial } \\
\text { muscles) } \\
\left(\begin{array}{c}\text { Lateral part } \\
\text { (preaxial) }\end{array}\right.\end{array}$ & 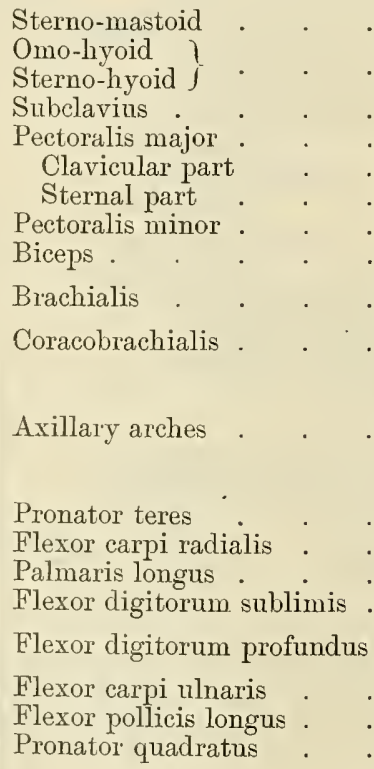 & 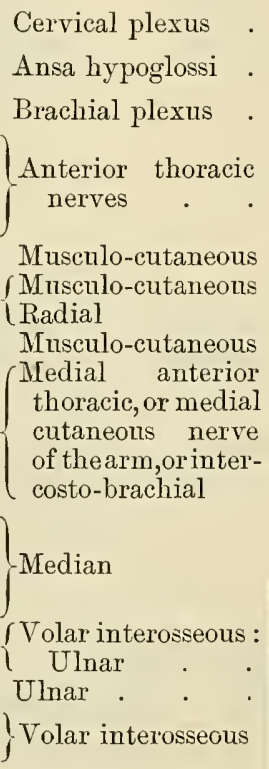 & $\begin{array}{l}\text { C. } 2 . \\
\text { C. } 1.2 .3 . \\
\text { C. } 5.6 . \\
\text { C. } 5.6 .7 .7 .1 . \\
\text { C. } 5.6 . \\
\text { C. } 5.6 .7 .7 . \text { T. } 1 . \\
\text { C. } 7.8 . \text { T. } 1 . \\
\text { C. } 5.6 . \\
\text { C. }(5) .6 . \\
\text { C. } 7 . \\
\text { C. } 8 . \text { T. } 1 .(2) . \\
\text { C. } 6 . \\
\text { C. } 6 . \\
\text { C. } 7.8 . \text { T. } 1 . \\
\text { C. } 8 . \text { T. } 1 . \\
\text { C. } 8 . \text { T. } 1 . \\
\text { J. } 7.8 . \text { T. } 1 .\end{array}$ \\
\hline
\end{tabular}


2. Ventral (Anterior) Surface-continued.

\begin{tabular}{|c|c|c|c|c|}
\hline \multicolumn{2}{|c|}{ Regions. } & Muscles. & Nerves. & Spinal Origins. \\
\hline Hand & $\left\{\begin{array}{l}\text { Lateral part } \\
\quad \text { (preaxial) } \\
\\
\\
\text { Medial part } \\
\text { (postaxial) }\end{array}\right.$ & $\begin{array}{l}\text { Abductor pollicis brevis } \\
\text { Opponens pollicis } \\
\text { Flexor pollicis brevis } \\
\text { Lateral two lumbricales } \\
\text { Medial two lumbricales } \\
\text { Interossei } \\
\text { Adductor pollicis (transverse } \\
\text { and oblique parts) } \\
\text { Abductor digiti quinti. } \\
\text { Opponens digiti quinti } \\
\text { Flexor digiti quinti brevis }\end{array}$ & $\left\{\begin{array}{l}\text { Median. } \\
\text { Ulnar. }\end{array}\right.$ & C. 6.7. \\
\hline
\end{tabular}

II. Lower Limb. $A$. Cutaneous Nerves.

1. Dorsal Surface.

(Front and lateral part of thigh, buttock, front of leg, dorsum of foot.)

\begin{tabular}{|c|c|c|c|}
\hline \multicolumn{2}{|l|}{ Regions. } & Nerves. & $\begin{array}{c}\text { Spinal Origins. } \\
\text { Preaxial. } \\
\text { Postaxial. }\end{array}$ \\
\hline 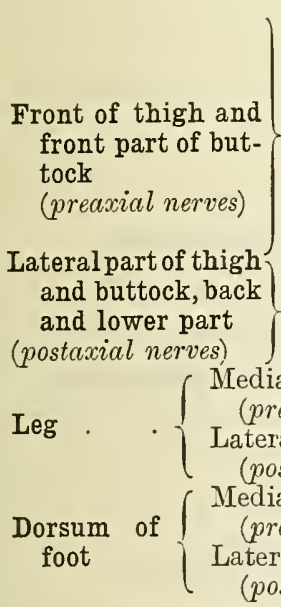 & $\begin{array}{l}\text { Buttock } \\
\text { al side } \\
\text { eaxial) } \\
\text { al side } \\
\text { staxial) } \\
\text { al side } \\
\text { eaxial) } \\
\text { al side } \\
\text { staxial }\end{array}$ & $\begin{array}{l}\text { Genito-femoral (lumbo-inguinal } \\
\text { branch) } \\
\text { Femoral, medial branch } \\
\text { Femoral, intermediate cutaneous } \\
\text { Lateral cutaneous. } \\
\text { Twelfth thoracic, lateral branch } \\
\text { Ilio-hypogastric, lateral branch } \\
\text { Posterior lumbar rami . } \\
\text { Posterior sacral rami } . \\
\text { Posterior coccygeal ramus } \\
\text { Posterior cutaneons of thigh : } \\
\text { gluteal, and femoral branches } \\
\text { Saphenous } \\
\text { Infrapatellar branch } \\
\text { Superficial peroneal } \\
\text { Peroneal, sural branches } \\
\text { Saphenous } \\
\text { Deep peroneal } \\
\text { Superficial peroneal } \\
\text { N. suralis }\end{array}$ & 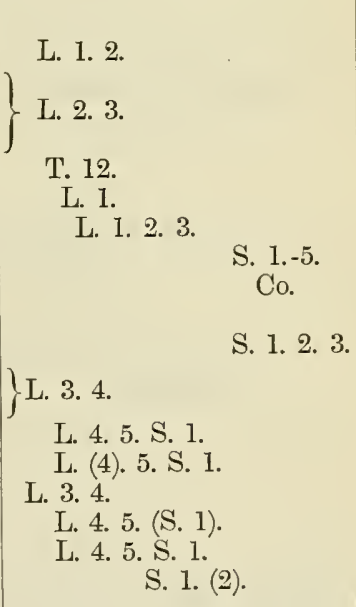 \\
\hline
\end{tabular}

2. Ventral Surface.

(Medial side and back of thigh, back of leg, and sole of foot.)

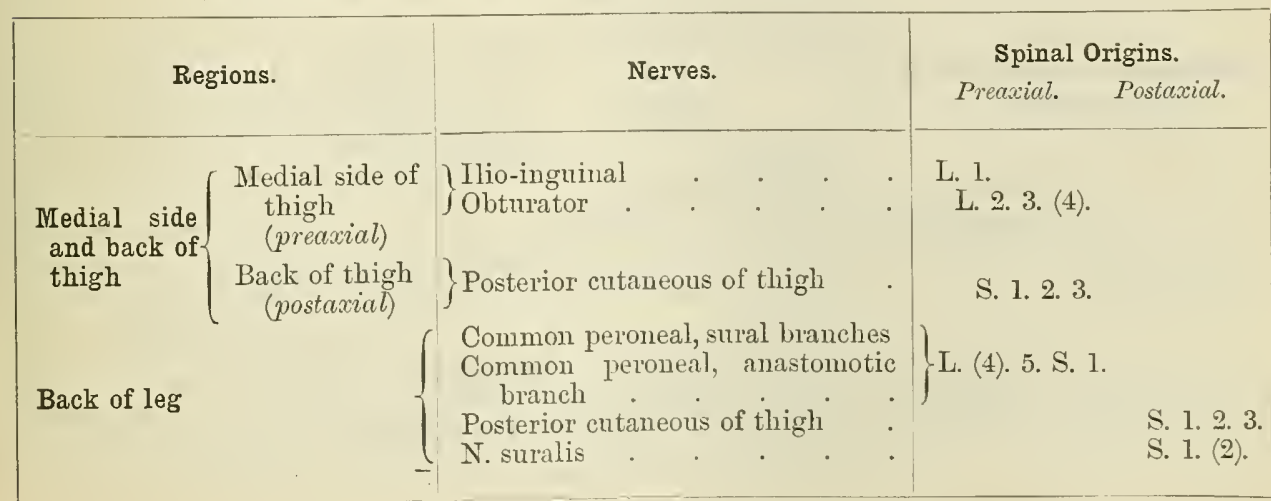


2. Ventral Surface-continued.

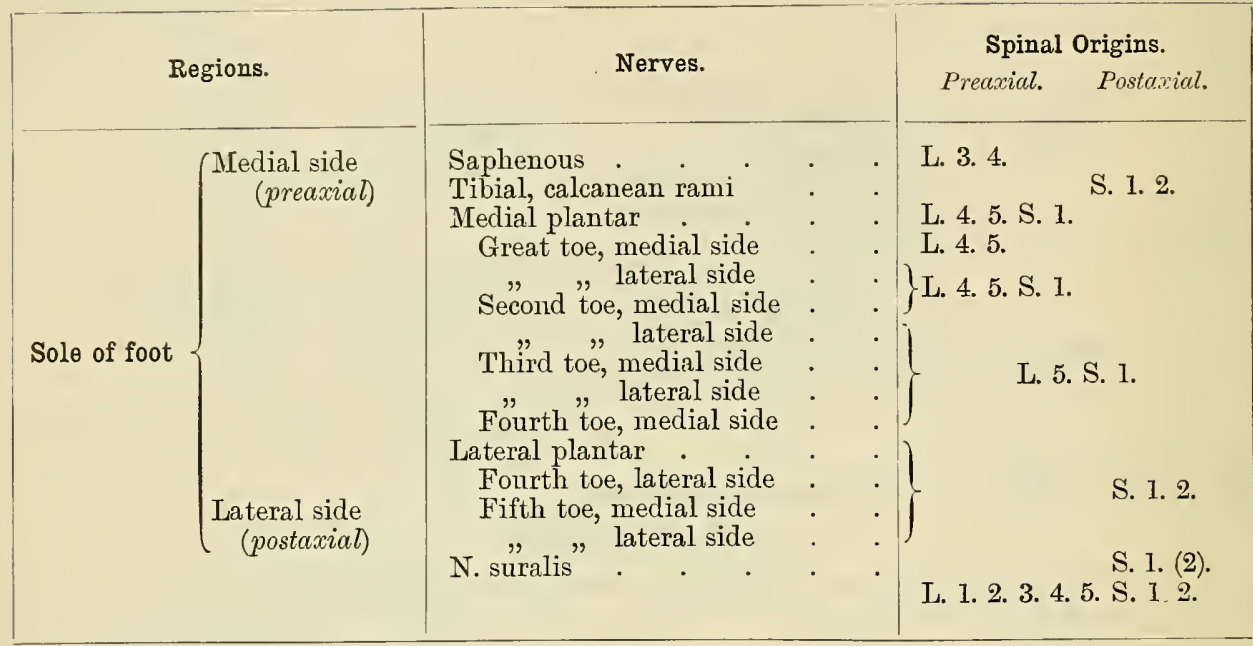

B. Muscular Nerves.

1. Dorsal Surface.

(Front and lateral part of thigh, buttock, front and lateral part of leg, dorsum of foot.)

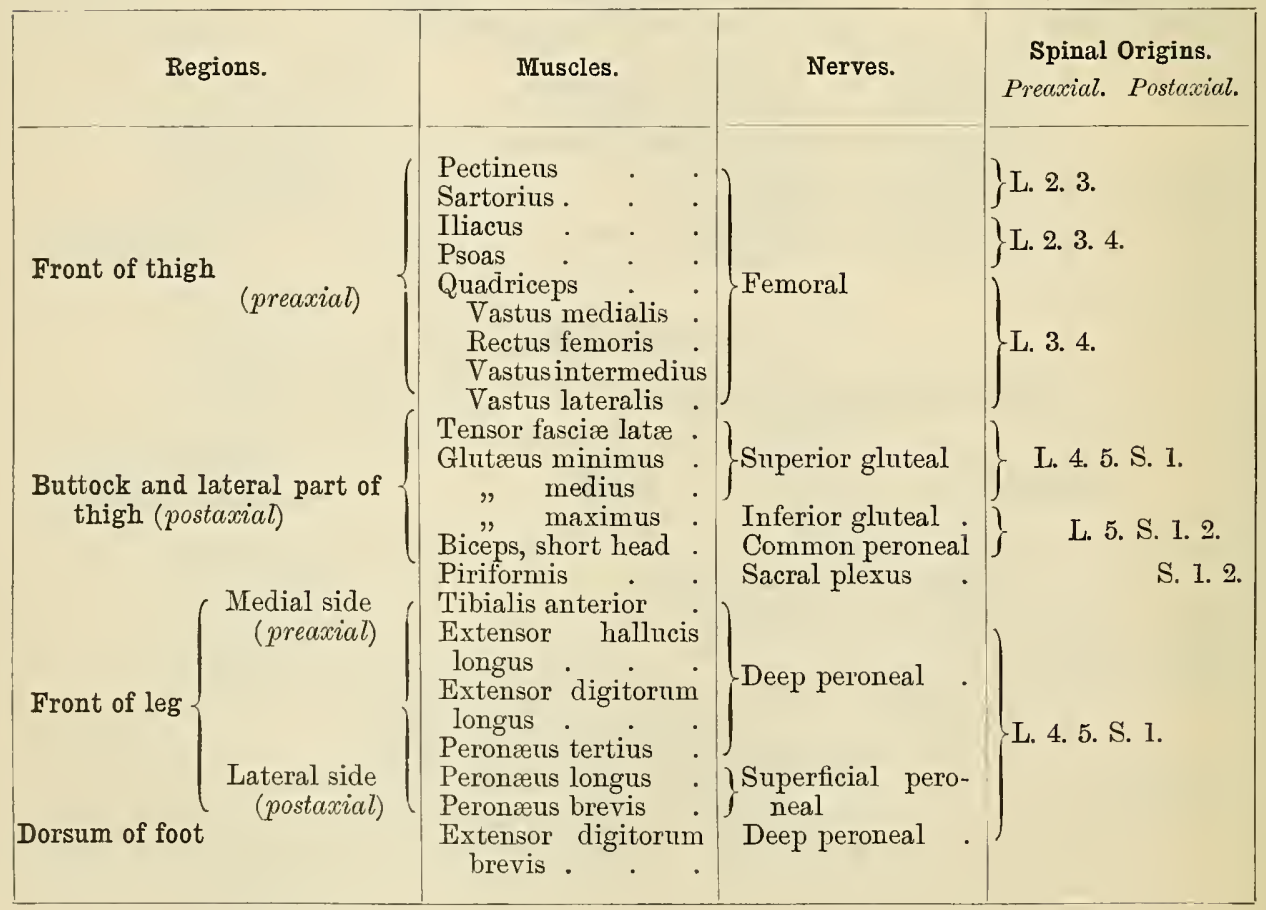




\section{Ventral Surface.}

(Medial side and back of thigh, back of leg, and sole of foot.)

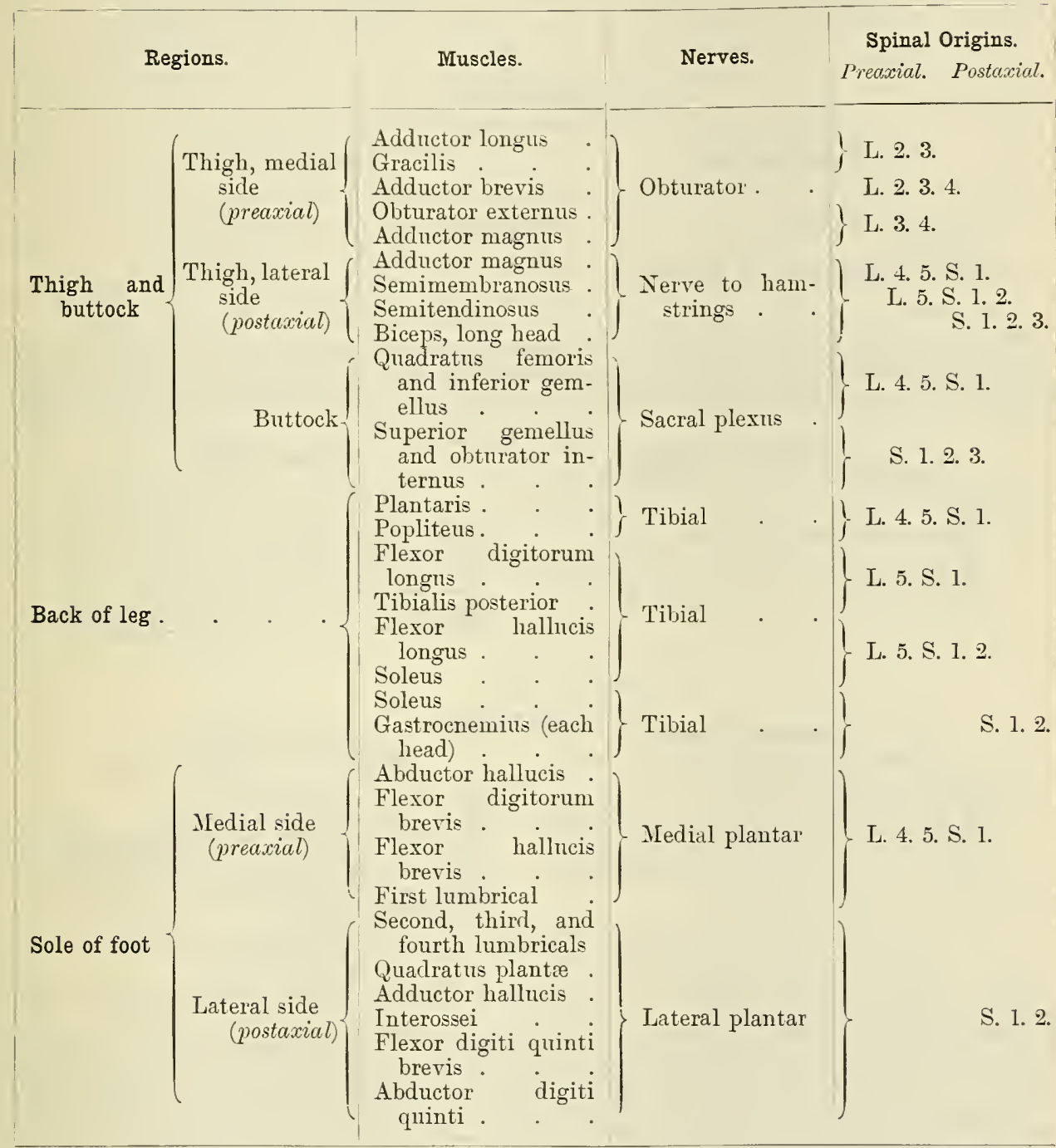

A. Innervation of the Muscles of the Limbs.-The following laws appear to be applicable to the upper and lower limbs alike :-

1. No limb-muscle receives its nerve-supply from posterior rami.

2. The dorsal and ventral strata of muscles are always supplied by the corresponding dorsal and ventral branches of the nerves concerned. The ventral muscular stratum is more extensive than the dorsal; the ventral nerves are the more numerous, and the additional nerves are postaxially placed. The spinal nerves stupplying muscles of the upper limb are C. 5, 6, 7, 8 (dorsal), and C. 5, 6, 7, 8, T. 1 (ventral); the nerves for the muscles of the lower limb are L. $2,3,4,5, \mathrm{~S} .1,2$ (dorsal), and L. $2,3,4,5$, S. $1,2,3$ (ventral).

3. The dorsal and ventral trunts of the nerves are distributed in the limb in a continuous, segmental manner; so that, "of two muscles, that nearer the head end of the body tends to be supplied by the higher nerve, and that nearer the tail end by the lower nerve" (Herringham).

4. The nerves placed most centrally in the plexus extend furthest into the limb, and the more preaxial nerves terminate sooner in the limb than the more postaxial nerves. 
Upper Limb.

\begin{tabular}{|c|c|c|c|}
\hline \multicolumn{2}{|c|}{ Dorsal Surface. } & \multicolumn{2}{|c|}{ Ventral Surface. } \\
\hline $\begin{array}{c}\text { Muscles of shoulder } \\
\quad, \quad \text { arm } \\
, \quad \text { forearm }\end{array}$ & $\begin{array}{l}\text { C. } 3,4,5,6,7,8 \text {. } \\
\text { C. } 6,7,8 \text {. } \\
\text { C. } 6,7 \text {. }\end{array}$ & $\begin{array}{cl}\text { Muscles of chest } \\
\quad, \quad \text { arm } \\
" \quad \text { forearm } \\
", \quad \text { hand }\end{array}$ & $\begin{array}{l}\text { C. } 5,6,7,8, \text { T. } 1 \text {. } \\
\text { C. } 5,6,7 . \\
\text { C. } 6,7,8, \text { T. } 1 . \\
\text { C. } 6,7,8 \text { (T. 1). }\end{array}$ \\
\hline
\end{tabular}

\section{Lower Limb.}

\begin{tabular}{|c|c|c|}
\hline Dorsal Surface. & Ven & ral Surface. \\
\hline $\begin{array}{l}\text { Muscles of thigh and } \\
\text { buttock } \\
\text { Mruscles of leg and foot L. } 2,3,5,4,5, \text { S. } 1,2 \text {. }\end{array}$ & $\begin{array}{c}\text { Muscles of thigh } \\
\quad, \quad \text { leg } \\
" \quad \text { foot }\end{array}$ & $\begin{array}{l}\text { L. } 2,34,5, \text { S. } 1,2,3 . \\
\text { L. } 4,5, \text { S. } 1.2 . \\
\text { L. } 5, \text { S. } 1,2 .\end{array}$ \\
\hline
\end{tabular}

The only exception to this rule is on the ventral (anterior) surface of the arm, where a suppression of the muscle elements leads to an absence of the regular series of segmental nerves (C. 8, T. I) on its postaxial border. These nerves reappear in the forearm, and the occasional
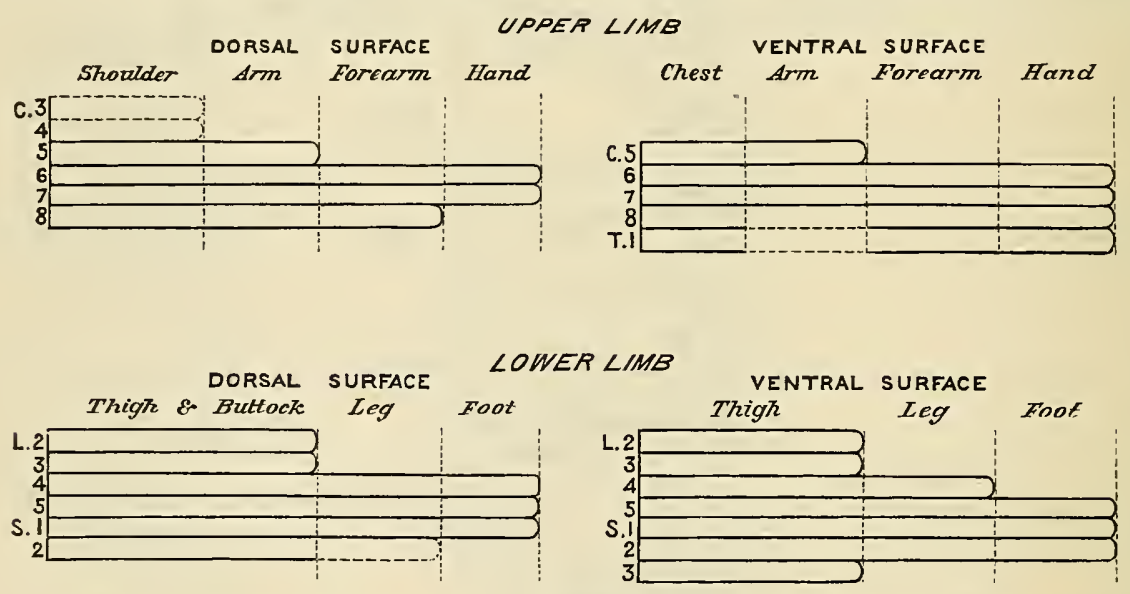

DiAGRAM of the segmental distribution of the muscular nerves of the upper and lower limbs.

"axillary arches" may be regarded as the muscular elements usually suppressed, and, when present, supplied by these nerves.

Muscles with a Double Nerve-supply.-The existence of more than one nerve to a muscle indicates usually that the muscle is composite and is the representative of originally separate elements, belonging to more than one segment or to both surfaces of the limb. In the case of the pectoralis major, subscapularis and flexor digitorum profundus, adductor magnus, and soleus, parts of the same (ventral or dorsal) stratum have fused, to form muscles innervated from the corresponding ventral or dorsal nerves. The other muscles having a double nerve-supplybrachialis, biceps femoris, and (sometimes) pectineus-are examples of fusion at the preaxial or postaxial border of muscular elements derived from the dorsal and ventral surfaces of the limb, which are correspondingly innervated by branches from both dorsal and ventral series: e.g. the brachialis is innervated by the musculo-cutaneous and radial nerves; the biceps femoris by the peroneal (short head) and tibial nerves (long head); and the pectineus, by the femoral and (sometimes) obturator nerves.

B. Innervation of the Skin of the Limbs.-While the scheme of cutaneous innervation of the limbs is fundamentally segmental, yet the arrangement is confused and complicated by various causes. The growth of the limb from the trunk has caused the skin to be drawn out over it like a stretched sheet of india-rubber (Herringham), and at the same time the extent of the dorsal area of the limb is increased at the expense of the ventral area. The central nerves of the plexus remain buried deeply in the substance of the limb, only coming to the surface towards the periphery. The proximal parts of both surfaces of the limb thus become innervated by cutaneous nerves otherwise not necessarily concerned in the innervation of the limbs. Herringham has shown that-(A) Of two spots on the skin, that nearer the preaxial border tends to be supplied by the higher nerve. (B) Of two spots in the preaxial area, the lower tends to be supplied by 
the lower nerve; and of two spots in the postaxial area, the lower tends to be supplied by the higher nerve. In other words, from the root of the $\operatorname{limb}$ along the preaxial border to its distal extremity, and along the postaxial border to the root of the limb again, there is a definite numerical sequence of spinal nerves supplying skin areas through nerves of the limb-plexuses. A similar numerical sequence in the arrangement of the nerves is also found extending over the dorsal and ventral surfaces of the limbs from preaxial to postaxial border, except in certain situations.

On the dorsal and ventral surfaces of both upper and lower limbs there is a hiatus, for a certain distance, in the numerical sequence of the spinal nerves in their cutaneous distribution, explicable on the gromnd that the central nerves of the plexus, which fail to reach the surface in these situations, are replaced by cutaneous branches from neighbouring nerves. This hiatus has been named the axial area or line.

In the upper limb, the dorsal axial area or line extends from the median line of the back, opposite the vertebra prominens, to the insertion of the deltoid.

The ventral axial area or line extends anteriorly from the median plane of the trunk, at the sternal synchondrosis, across the chest, distally along the front of the arm and forearm to the wiist.

In the lower limb, the dorsal axial area or line may be traced from the median plane of the back over the posterior superior iliac spine, across the buttock and thigh, to the head of the fibula.

A ventral axial area or line can also be traced from the root of the penis along the medial side of the thigh and knee, and along the back of the leg to the heel.

These areas or lines represent the meeting-place and overlapping of nerves, which are not in numerical sequence; and it is only at the peripheral parts of the limbs, on the dorsal and ventral surfaces, that the nerves appear in numerical sequence from the preaxial to the postaxial border. In the case of the upper limb the hiatus is caused, in both surfaces of the limb, by the absence of cutaneous branches of the seventh cervical nerve; in the case of the lower limb the hiatus is due to the absence of branches from the fifth lumbar nerve on both surfaces of the limb, and the absence of branches from the fourth lumbar nerve, in addition, on the dorsal surface.

Understanding the significance of these dorsal and ventral axial areas or lines, and at the same time bearing in mind the overlapping which occurs in the cutaneous distribution of each spinal nerve, the areas of skin supplied through the limb-plexuses can be mapped out with considerable precision, as indicated in the following tables :-

\section{A. Cutaneous Distribution. Upper Limb.}

\begin{tabular}{|c|c|c|c|}
\hline & res. & Spinal Origin. & Distribution. \\
\hline $\begin{array}{c}\text { Preaxial border } \\
\text { from neck to } \\
\text { hand } \\
\downarrow\end{array}$ & $\begin{array}{l}\text { Supraclavicular nerves } \\
\text { Axillary . } \\
\text { Radial (upper branch } \\
\text { of dorsal cutaneous } \\
\text { of forearm) } \\
\text { Radial (lower branch } \\
\text { of dorsal cutaneous } \\
\text { of forearm) } \\
\text { Munsculo-cutaneous } \\
\text { Superficial branch of } \\
\text { radial } \\
\text { Ulnar. } \\
\text { Musculo-cutaneous } \\
\text { Median . } \\
\text { Ulnar. } \\
\text { Median . } \\
\text { Ulnar . } \\
\text { Medial cutaneous of } \\
\text { forearm } \\
\text { Radial (posterior cu- } \\
\text { taneous of arm) } \\
\text { Medial cutaneous of } \\
\text { arm } \\
\text { Intercosto-brachial } \\
\text { Intercosto-brachial } \\
\text { Third intercostal } \\
\text { Fourth }\end{array}$ & $\begin{array}{l}\text { C. 6. 7. } 8 . \text { T. } 1 . \\
\text { C. } 8 . \text { T. } 1 . \\
\text { C. } 8 . \text { T. } 1 . \\
\text { C. } 8 . \\
\text { T. } 1 . \\
\text { T. 2. } \\
\text { T. } 2 . \\
\text { T. } 3 . \\
\text { T. } 4 .\end{array}$ & 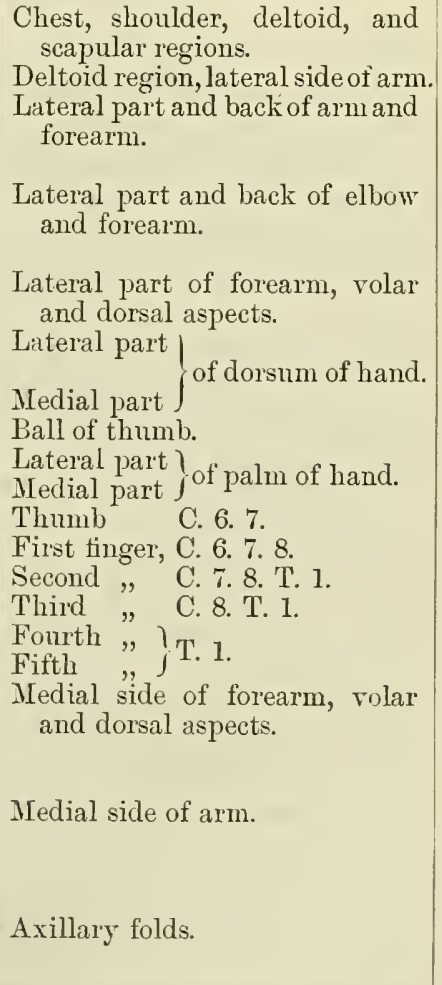 \\
\hline
\end{tabular}




\section{B. Cutaneous Distribution. Lower Limb.}

\begin{tabular}{|c|c|c|c|}
\hline & & Spina & Distribution. \\
\hline $\begin{array}{c}\text { Postaxial border } \\
\text { from foot to } \\
\text { coccyx } \\
\uparrow\end{array}$ & 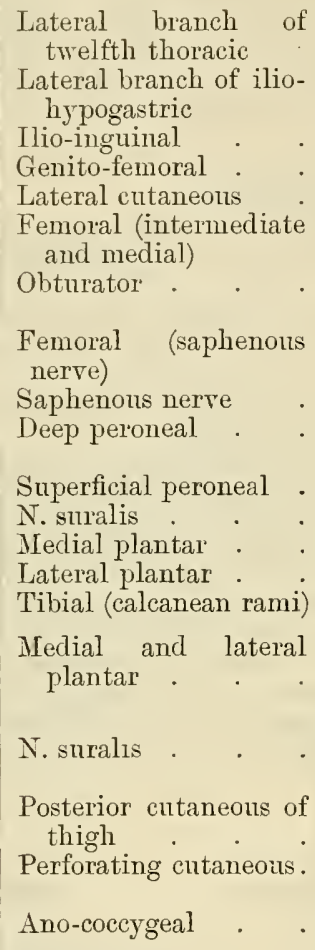 & $\begin{array}{l}\text { T. } 12 . \\
\text { L. } 1 . \\
\text { L. 1. } \\
\text { L. 1. } 2 . \\
\text { L. 2. } 3 . \\
\text { L. 2. } 3 . \\
\text { L. 2. 3. (4). } \\
\text { L. 3. 4. } \\
\text { L. 3. 4. } \\
\text { L. 4. 5. S. (1). } \\
\text { L. 4. 5. S. } 1 . \\
\text { S. 1. (2). } \\
\text { L. 4. 5. S. } 1 . \\
\text { S. 1. 2. } \\
\text { S. 1. 2. } \\
\text { L. 4. 5. S. } 1 . \\
\text { S. 1. 2. } \\
\text { S. 1. (2). }\end{array}$ & $\begin{array}{l}\text { Lateral part of buttock. } \\
\text { Lateral part of buttock. } \\
\text { Groin and over femoral triangle. } \\
\text { Front of thigh, proximal third. } \\
\text { Front and lateral part of thigh. } \\
\text { Front and medial part of thigh, } \\
\text { distal two-thirds. } \\
\text { Medial part of thigh, middle } \\
\text { third. } \\
\text { Knee and leg, medial part and } \\
\text { front. } \\
\text { Medial side of foot. } \\
\text { Interval between first and } \\
\text { second toes. } \\
\text { Dorsum of foot and toes. } \\
\text { Lateral side of foot. } \\
\text { Medial part } \\
\text { Lateral part } \\
\text { Heel and back part }\} \text { of sole. } \\
\text { Great toe, L. 4. } 5 \text {. S. 1. } \\
\text { Second toe, L. 4. 5. S. } 1 \text {. } \\
\text { Third " L. 5. S. 1. } \\
\text { Fourth " L. 5. S. } 1.2 \text {. } \\
\text { Fifth "S. 1. } 2 \text {. } \\
\text { Lateral part of foot and leg, } \\
\text { distal third. } \\
\text { Back of leg, thigh, and buttock. } \\
\text { Buttock (fold of nates, medial } \\
\text { half). } \\
\text { Anal fold. }\end{array}$ \\
\hline
\end{tabular}

\section{Variations in the Position of the Limb-Plexuses.}

Two different kinds of variations occur in relation to the limb-nerves.

(1) Individual variations, both in the extent of origin and in the area of distribution of a given nerve, are not uncommon; these variations are usually concomitant with compensatory variations in adjacent nerves, and are due to the fibres of a given spinal nerve taking an abnormal course in the trunk of another nerve of distribution and effecting a communication with the proper nerve peripherally. In this way the variations in the origin and distribution of the intercosto-brachial nerve may be explained; and, similarly, the ulnar nerve may have some of its fibres carried as far as the forearm, incorporated with the median and transferred to it by a communication between the two nerves in that region.

(2) Variations in the limb-plexus, in relation to the vertebral colımn, are the chief cause of variations in the constitution of the limb-nerves. These variations affect more or less the whole series of nerves in the plexus.

The brachial plexus is subject only to very slight variation in position and arrangement. It may be reinforced at the upper end by a slender trunk from the fourth cervical nerve, and, more frequently, by an intra-thoracic communication between the second and first thoracic nerves. The presence of one or other of these nerves is an indication of a slight tendency towards a cephalic or candal shifting of the whole plexus in relation to the spinal medulla. It is, however, never sufficient to cause the exclusion to any extent of the nerves normally implicated. The presence of a cervical rib may coincide with little or no change in the relation of the nerves. Indeed, the inclusion of the second thoracic nerve in the plexus may be, as already stated, merely an individual variation, a change in the path to the limb of the intercosto-brachial nerve. Concomitant variations occur among groups of nerves, however, which indicate a certain tendency to variation in the position of the whole plexus. At one end, the suprascapular and musculo-cutaneous nerves may arise from the fourth and fifth, fifth alone, or fifth and sixth cervical nerves. At the other end of the plexus, the radial may or may not receive a root from the first thoracic nerve, and this addition is rather more likely to occur when the second thoracic nerve is implicated in the plexus.

The lumbo-sacral plexus shows a very considerable variability in position and constitution. Eisler records concomitant variations in the plexus in 18 per cent of the cases examined by him. The variations occur within wide limits. The plexus may begin at the eleventh or twelfth 
thoracic or first lumbar nerve. The last nerve in the sciatic cord may be the second, third, or fourth sacral nerve. The position of the $\mathrm{n}$. furcalis is a guide to the arrangement of the plexus. It may be formed by the third, third and fourth, fourth, fourth and fifth, or fifth lumbar nerves. The resulting variations are illustrated by the following extreme cases:-

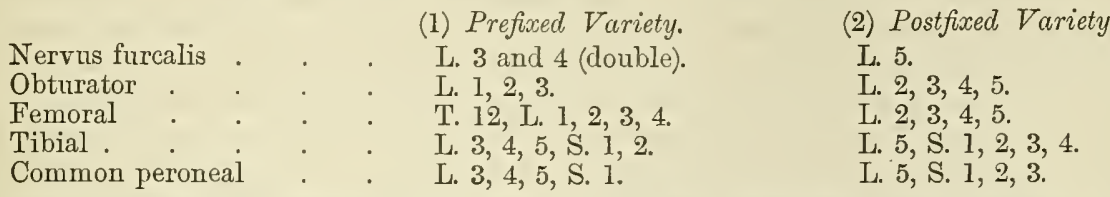

Those variations in the constitution of the lumbo-sacral plexus are most numerous which are due to the inclusion of nerves more candally placed. Thus, out of twenty-two variations in the position of the $n$. furcalis, in nineteen Eisler found it formed by the fifth lumbar nerve; in two cases only, by the third lumbar nerve. There is further evidence that variations in the position of the plexus are accompanied by variations in the vertebral column itself. Out of the twenty-two abnormal plexuses examined by Eisler, sixteen were coincident with abnormal arrangement of the associated vertebræ.

\section{SigNifICANCE OF THE LIMB-PLEXUSES.}

From the above considerations, it is obvious that something more than convenience of transit for the spinal nerves to skin and muscles is secured by the formation of the limb-plexuses. It has been shown that by their combinations in the plexuses, every spot or area of skin in the limbs is innervated by more than one spinal nerve; and generally, also, each limb-muscle is supplied by more than one spinal nerve. Each cutaneons area and each limb-muscle is thus brought into relationship with a wider area of the spinal medulla than would occur if the plexuses were non-existent. A simultaneous record of sensation is thus transmitted from any given point on the surface of the limb through more than one posterior roct; and a more ready co-ordination of muscular movement is brought about by the transmission of motor impulses from the anterior root of a given spinal nerve to more than one muscle at the same time. In a word, a plexus exists to supply the whole limb and the limb as a whole, as an organ which has its different active parts connected with the central nervous system by means of the limb-plexus.

\section{SYSTEMA NERVORUM SYMPATHICUM.}

The sympathetic nervous system comprises a pair of elongated gangliated trunks, extending through the whole length of the body from the base of the skull to the coccyx, connected to the peripheral spinal nerves by one series of nerves, and to the viscera by another series. At its cephalic end each sympathetic trunk passes into the cranial cavity along with the internal carotid artery, on which it forms plexuses, and thereby forms complex relations with certain cerebral nerves. At their caudal ends the two sympathetic trunks are joined together by fine filaments and unite with the coccygeal ganglion (g. impar).

The sympathetic system is essentially dependent on and subservient to the spinal nervous system. It distributes efferent fibres from the peripheral spinal nerves to (a) the viscera and vessels of the splanchnic area, and (b) through recurrent (gray) rami to vessels, glands, and involuntary muscles in the course of the somatic divisions of the spinal nerves. It further collects and transmits to the cerebrospinal system afferent fibres from the viscera (Fig. 635).

General Structure of the Sympathetic System.-The sympathetic system is composed of two elements-ganglia and nerve fibres.

Ganglia Trunci Sympathici.-The ganglia are variable in number, form, size, and position. They are not definitely segmental in position, but they are always connected together by a system of narrow commissural cords of nerve fibres. A ganglion (Fig. 635) consists of a larger or smaller number of multipolar nerve cells, enclosed in a capsule of connective tissue. Each cell is provided with one axon and a number of dendrites. The axon may enter into the composition of $(a)$ the commissural cord; $(b)$ a central branch (gray ramus communicans); or $(c)$ a peripheral branch from the sympathetic trunk. These axons are commonly medullated at their origin, but become non-medullated in their course from the parent cell. Besides these ganglia, two other series of ganglia are present in connexion with the peripheral branches of the sympathetic: ganglia plexuorum sympathicorum, 
intermediate or collateral ganglia, on the branches or in the sympathetic plexuses; and terminal ganglia, in close relation to the endings of the nerves in the viscera.

The nerve-fibres in the sympathetic system are of two classes, medullated and non-medullated. The distinction is not absolute. The medullated fibres may lose their medullary sheaths before reaching their terminations; and the non-medullated fibres may at their origin possess a medullary sheath. The medullated fibres form the series of white rami communicantes (the visceral branches of the spinal nerves). They take origin from the anterior rami of certain spinal nerves in two streams: thoracico-Iumbar from the second thoracic to the second lumbar nerve inclusive, and pelvic, or sacral, from the second and third, or third and fourth sacral nerves. The roots of these rami arise from both posterior and anterior roots of the spinal nerves,

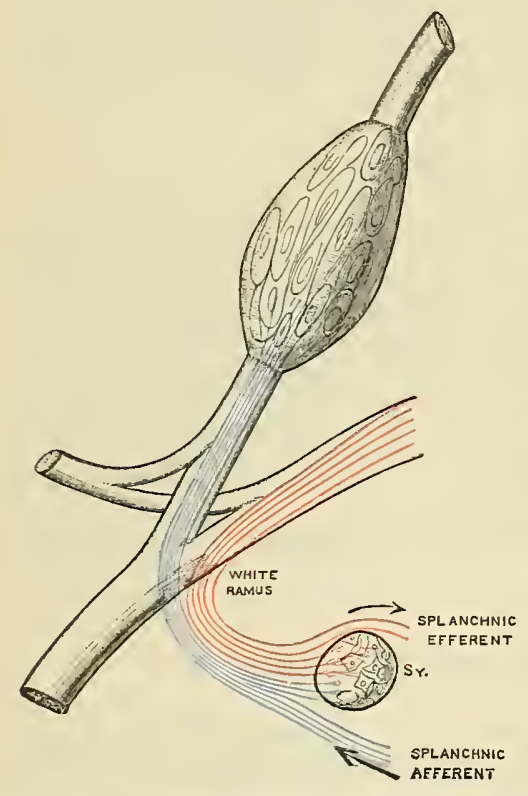

Fig. 635.-SCheMe OF THE Constitution of the White Ramus Communicans of the SYMPATHETIC.

The roots and trunks of a spinal nerve are shown, with the white ramus passing between the spinal nerve and a sympathetic ganglion (Sy). The splanchnic efferent fibres (in red) are shown, partly ending in the ganglion, and partly passing beyond the ganglion into a peripheral branch. The splanchnic afferent fibres (in blue) are shown, partly entering the ganglion, and passing upwards or downwards in the gangliated cord; partly passing over the cord into peripheral branches.

The non-medullated fibres in the sympathetic system are derived from the axons of the sympathetic ganglion cells. They have different destinations. (a) Some fibres appear to contribute to the formation of the commissural cord connecting the ganglia together, and to end in arborisations round the cells of a neighbouring ganglion. (b) Non-medullated fibres form a large part of the system of peripheral (splanchnic efferent) branches, streaming into the splanchnic area in an irregular manner, both from the ganglia and the connecting commissures. (c) The gray rami communicantes form a series of non-medullated fibres (with a small number of medullated fibres intermingled) proceeding centrally from the ganglia to the spinal nerves. These gray rami are found in connexion with each and all of the spinal nerves. Their origin from the gangliated trunk is quite irregular: they may come from the ganglia or the commissure; they may divide after their origin, so 
that two spinal nerves are supplied from one ganglion; or two ganglia may supply branches to a single spinal nerve. The gray ramus is distributed along the somatic divisions of the spinal nerves, supplying branches to unstriped muscular fibres (vaso-motor, pilo-motor) and glands (secretory). They also provide small recurrent branches, ending in the membranes enveloping the spinal nerve-roots. Mingled with the non-medullated fibres of the gray rami are a small number of medullated fibres, regarded as a fferent fibresaxons passing to the spinal ganglia which are incorporated with the gray rami.

The commis sural cords of the sympathetic system are composed of white and gray fibres. The white fibres are: (1) splanchnic efferent fibres, passing to a ganglion above or below the point of entrance into the sympathetic system; (2) splanchnic afferent fibres, guided along the commissure and over or through the ganglia. The gray fibres are the axons of sympathetic ganglion cells: (1) true commissural fibres passing into connexion with the cells of a neighbouring ganglion; (2) fibres passing along the commissure for a certain distance upwards or downwards before entering the splanchnic area as peripheral branches.

The peripheral branches of the sympathetic trunk consist of-(1) white
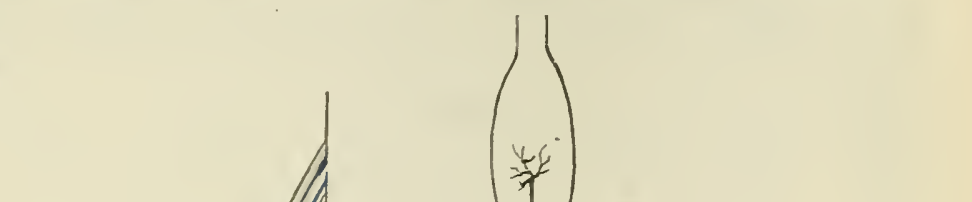
fibres, which may be either splanchnic afferent fibres on their way from the viscera through the gangliated trunk to the spinal ganglia, or splanchnic efferent fibres which, after traversing the gangliated trunk, proceed to join and end in collateral or terminal ganglia in relation to viscera; (2) gray fibres, efferent branches, the axons of the ganglion cells, distributed on the one hand peripherall $\Gamma$ to the vessels and viscera of the splanchnic area, and on the other hand centrally through the gray rami communicantes and the somatic divisions of the spinal nerres, to the glands and involuntary muscles in the somatic area, as secretory, and vaso-motor and pilo-motor fibres.

Although forming always one continuous cord, the sympathetic sjstem may 
for convenience of description be dealt with in four parts - cephalic and cervical, thoracic, lumbar, and pelvic.

\section{PARS CEPHALICA ET CERVICALIS SYMTEMATIS SYMPATHICI.}

The cephalic and cervical part of the sympathetic trunk is to be regarded as an upward prolongation of the primitive sympathetic system along the great vessels of the neck. It is characterised by the absence of segmental ganglia and by the absence of white rami communicantes joining it to the spinal nerves. Its connexion with the spinal nervous system is through the white rami communicantes of the upper thoracic nerves, which join the gangliated trunk in the thorax, and stream upwards into the cervical portion of the trunk. The trunk possesses two or three ganglia, from which branches are distributed to structures belonging to head, neck, and thorax: (1) motor fibres to involuntary muscles (e.g. dilator of the pupil); (2) vaso-motor fibres for arteries of the head, neck, and upper limbs; (3) pilo-motor fibres (along the cervical spinal nerves) to the skin of the head and neck; (4) cardio-motor fibres; and (5) secretory fibres (e.g. submaxillary gland).

The gangliated trunk in the neck is placed upon the prevertebral muscles and behind the carotid vessels. It extends from the root of the neck, where it is continuous behind the subclavian artery with the thoracic portion of the trunk, to the base of the skull, where it ends in the formation of plexiform branches upon the internal carotid artery. It consists of a narrow commissure composed of medullated and non-medullated fibres, with two or three ganglia-a superior ganglion at the upper end, an inferior ganglion at the point of junction with the thoracic portion of the trunk, and a middle ganglion varying in position and often absent.

Ganglion Cervicale Superius.-The superior cervical ganglion situated at the base of the skull, lies between the internal jugular vein and the internal carotid artery. It is the largest of the sympathetic ganglia, measuring an inch or more in length. The commissural cord connects it with the ganglion cervicale medius (middle ganglion), which is of small size, is frequently absent, and may be divided into two parts. It is usually placed over the inferior thyreoid artery as it passes behind the carotid sheath.

Ganglion Cervicale Inferius.-The inferior ganglion is joined by the commissural cord to the middle (or superior) ganglion above, and is only imperfectly separated from the first thoracic ganglion below. It is of considerable size, irregular in shape, and is placed behind the first part of the subclavian artery in the interval between the last cervical transverse process and the neck of the first rib.

The branches from the cervical sympathetic ganglia and commissural cords are divisible into two sets- $(A)$ Central communicating branches for other nerves; $(B)$ Peripheral branches of distribution, which alone, or along with other nerves, form plexuses, accompanying and supplying vessels and viscera of the head, neck, and thorax. Although this distinction is made, it is to be borne in mind that the branches of communication are as much nerves of distribution as the others.

\section{Ganglion Cervicale Superius.}

Central Communicating Branches.-1. Gray rami communicantes pass from the ganglion to the anterior rami of the first four cervical nerves.

2. Communications with Cranial Nerves.-Just outside the skull, in the deep part of the neck, communicating branches pass to the following cerebral nerves: $(a)$ to the petrous ganglion of the glossopharyngeal and the jugular ganglion of the vagus; $(b)$ to the ganglion nodosum of the vagus; $(c)$ to the hypoglossal nerve.

Peripheral Branches of Distribution.-1. Pharynx.-Plexus Pharyngeus Ascendens.-A pharyngeal branch passes behind the carotid sheath to reach the wall of the pharynx, where it joins (along with the pharyngeal branches of the glossopharyngeal and vagus nerves) in the formation of the ascending pharyngeal plexus, and assists in supplying the muscles and mucous membrane of the pharynx. 
2. Heart.-N. Cardiacus Superior.-The superior cardiac branch is a slender nerve which, on the right side, descends behind the large vessels into the thorax to join the deep cardiac plexus. On the left sicle the course of the nerve is similar in the neck, but in the superior mediastinum it passes between the left carotid and subclavian arteries, and over the aortic arch, to join with the inferior cervical cardiac branch of the ragus in the formation of the superficial cardiac plexus. In their course both nerres form connexions with the other cardiac nerves of the sympathetic, and with cardiac and other branches of the vagus (recurrent and external laryngeal).

3. Vessels.-(a) The nn. carotici externi (external carotid branches) pass

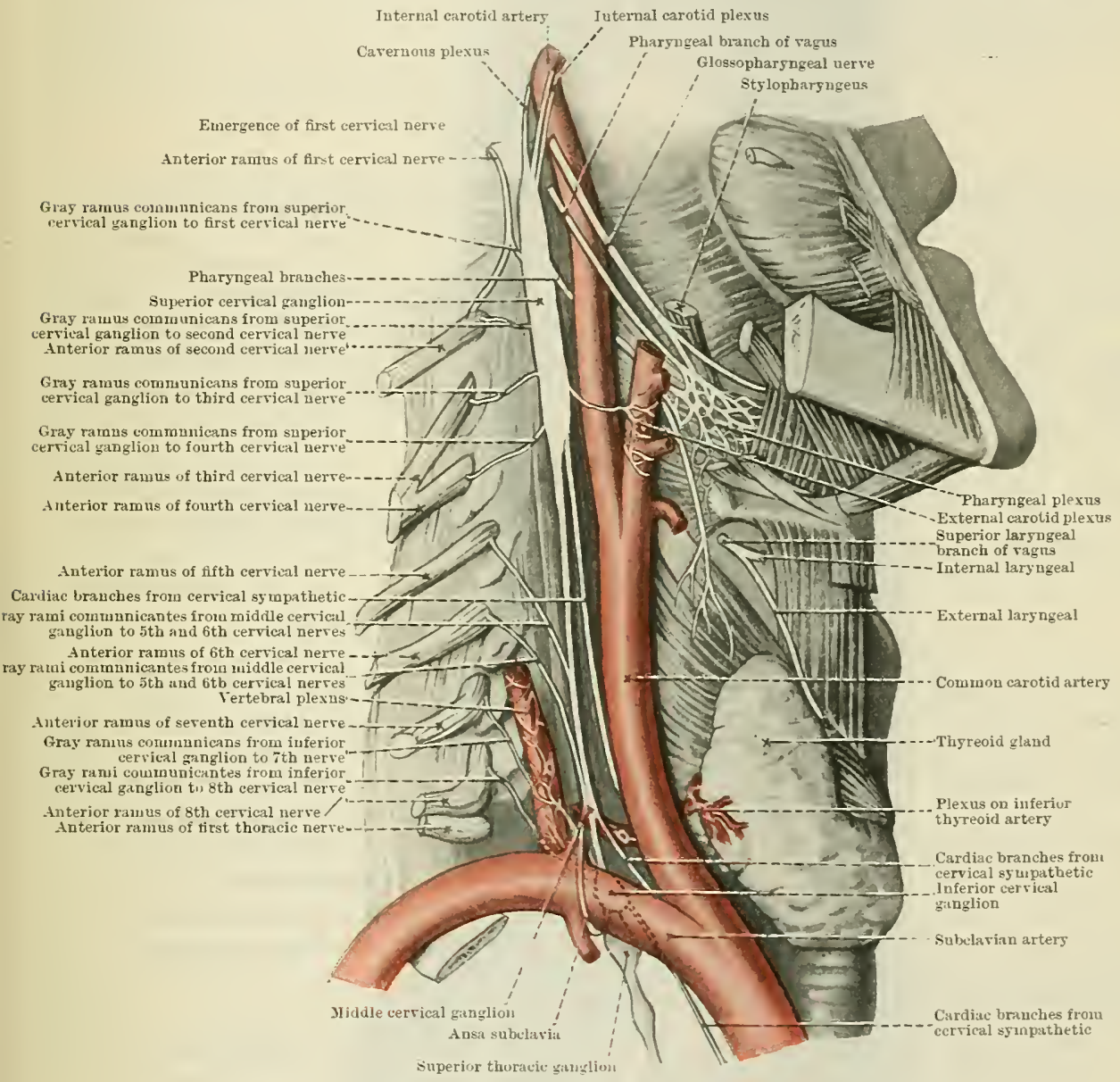

Fig. 637.-Distribetiox of the Srapathetic in the Neck.

forwards to the external carotid artery, and form the plexus caroticus externus (external carotid plexus), which supplies offsets to that artery and its branches, as well as to the glomus caroticum (inter-carotid body). From the subordinate plexuses on the external maxillary and middle meningeal branches of the artery sympathetic fibres are supplied to the submaxillary and otic ganglia, respectively

(b) N. Caroticus Internus. - The internal carotid branches form an upward prolongation of the ganglion, which applies itself in the form of bundles of nerve-fibres to the internal carotid artery as it enters the carotid canal in the temporal bone. The branches separate into lateral and medial parts, which form plexuses investing the artery in the cranium. The lateral division forms the inferior or internal carotid plexus (pl. caroticus internus); the medial division gives rise to the superior 
or cavernous plexus (pl. cavernosus). Both plexuses supply offsets to the artery and its branches, and form communications with certain cerebral nerves.

Pl. Caroticis Internus. - The internal carotid plexus communicates by fine

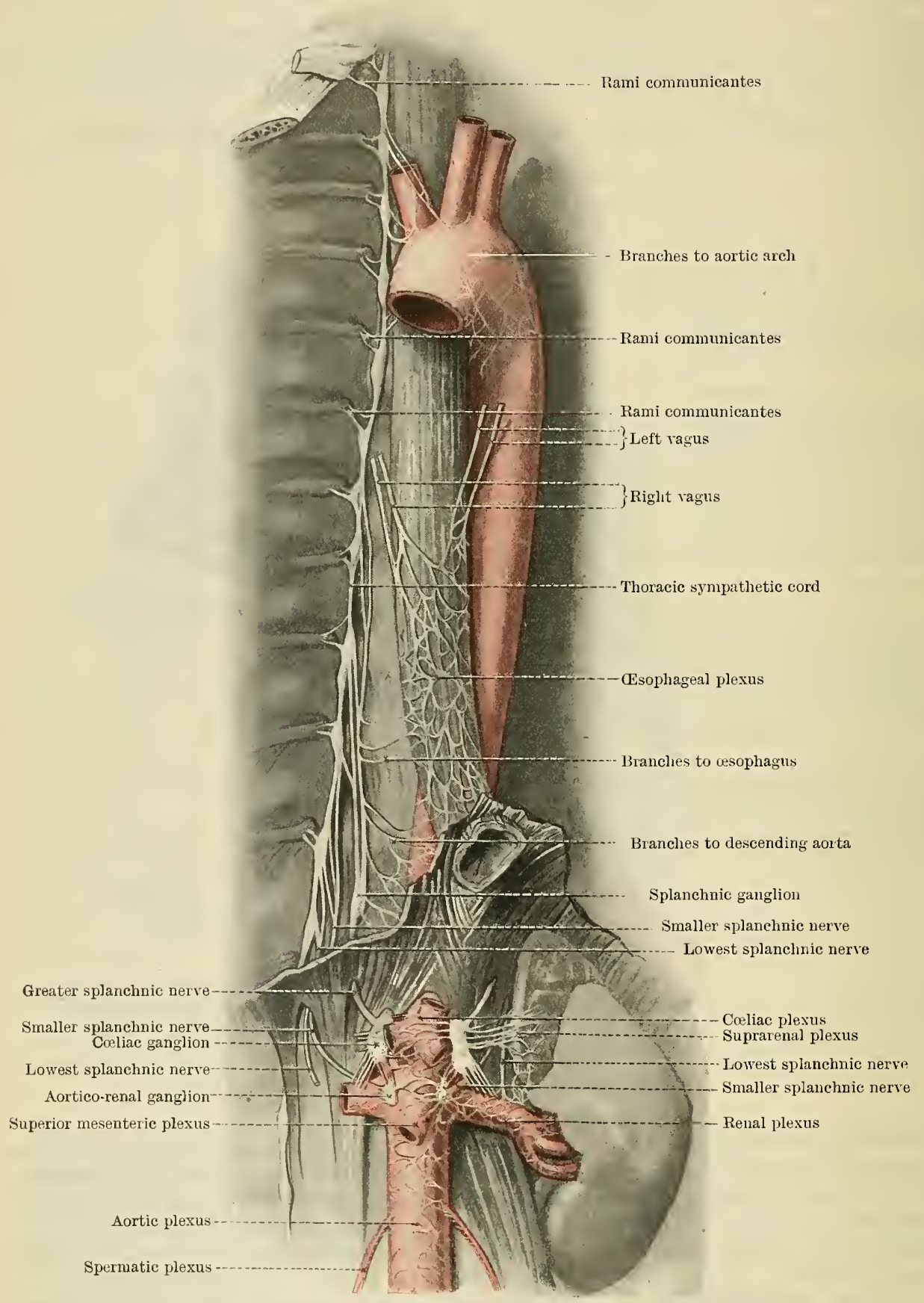

Fig. 638.-The Sympathetio Trunk in the Thorax.

branches with $(a)$ the abducens nerve, and $(b)$ the semilunar ganglion, and gives off $(c)$ the great deep petrosal and $(d)$ the carotico-tympanic nerves. The deep petrosal nerve joins the larger superficial petrosal nerve from the genicular ganglion 
of the facial, over the foramen lacerum. By their union the pterygoid nerve is formed, which, after traversing the pterygoid canal, ends in the spheno-palatine ganglion. The carotico-tympanic nerves pass to the tympanic plexus. This plexus, formed by the carotico-tympanic nerves, the tympanic branch of the glossopharyngeal, and a twig from the genicular ganglion of the facial nerve, is placed on the labyrinthic wall of the tympanum. It supplies the mucous lining of the tympanum and auditory tube; and the smaller superficial petrosal nerve passes from it to the otic ganglion.

Plexus Cavernosus. - The cavernous plexus communicates with $(a)$ the oculo-motor, (b) the trochlear nerve, and (c) the ophthalmic division of the trigeminal nerve; it also (d) supplies twigs to the hypophysis (pituitary body), and (e) forms the sympathetic root of the ciliary ganglion. This may pass to the ganglion independently, or it may be incorporated in the long root of the ganglion from the naso-ciliary branch of the ophthalmic nerve.

\section{Ganglion Cervicale Medius.}

Central Communicating Branches.-1. Gray rami communicantes arise from the ganglion or from the commissural cord for the anterior rami of the fifth and sixth cervical nerves. 2. The ansa subclavia (ansa Vieussenii) is a loop of communication from this ganglion, which, after passing over and supplying offsets to the subclavian artery and its branches, joins the inferior cervical ganglion.

Peripheral Branches of Distribution.-1. Heart.-A slender middle cardiac branch descends, either separately or in company with other cardiac nerves, behind the large vessels into the thorax, where it ends in the deep part of the cardiac plexus on each side.

2. Thyreoid Gland.-Branches extend inwards along the inferior thyreoid artery to supply the thyreoid gland.

When the middle ganglion is absent the branches described arise from the commissural cord.

\section{Ganglion Cervicale Inferius.}

Central Communicating Branches. - 1. Gray rami communicantes arise from this ganglion for the anterior rami of the seventh and eighth cervical nerves. 2. The ansa subclavia already mentioned connects the middle and inferior ganglia over the front of the subclavian artery. 3. A communication frequently occurs with the recurrent nerve.

Peripheral Branches of Distribution.-1. Heart.-An inferior cardiac branch is given off on each side to enter the deep cardiac plexus.

2. Vessels.-(a) The vertebral plexus is a dense plexus of fibres surrounding the vertebral artery and accompanying its branches in the neck and the cranial cavity. (b) The subclavian plexus is derived from the ansa subclavia (subclavian loop), and supplies small offsets to the subclavian artery. It gives branches to the internal mammary artery, and communicates with the phrenic nerve.

\section{PARS THORACALIS SYSTEMATIS SYMPATHICI.}

The thoracic part of the sympathetic trunk lies behind the pleura, in front of the necks of the ribs, and the intercostal vessels and nerves. It consists of a number of ganglia of an irregularly angular or fusiform shape, joined together by commissural bands of considerable thickness. The number of ganglia is usually ten or eleven; but the first and sometimes others may be so fused with the neighbouring ganglia as to still further reduce the number.

This part of the sympathetic trunk is characterised by its union with the thoracic spinal nerves. Each thoracic nerve, with the probable exception of the first, sends a visceral branch (white ramus communicans) to join the gangliated trunk in the thorax. These white rami separate into two main streams in relation to the sympathetic trunk. Those of the upper five nerves are for the most part directed upwards to be distributed through the cervical part of the sympathetic trunk 
in the manner already described. The white rami of the lower thoracic nerves are for the most part directed downwards in the inferior part of the sympathetic trunk and its branches, to be distributed in the abdomen; at the same time some of their fibres are directly supplied to certain thoracic viscera,-lungs, aorta, œesophagus.

These white rami are composed of (1) splanchnic afferent fibres passing from its peripheral branches through the sympathetic trunk into the ganglia of the

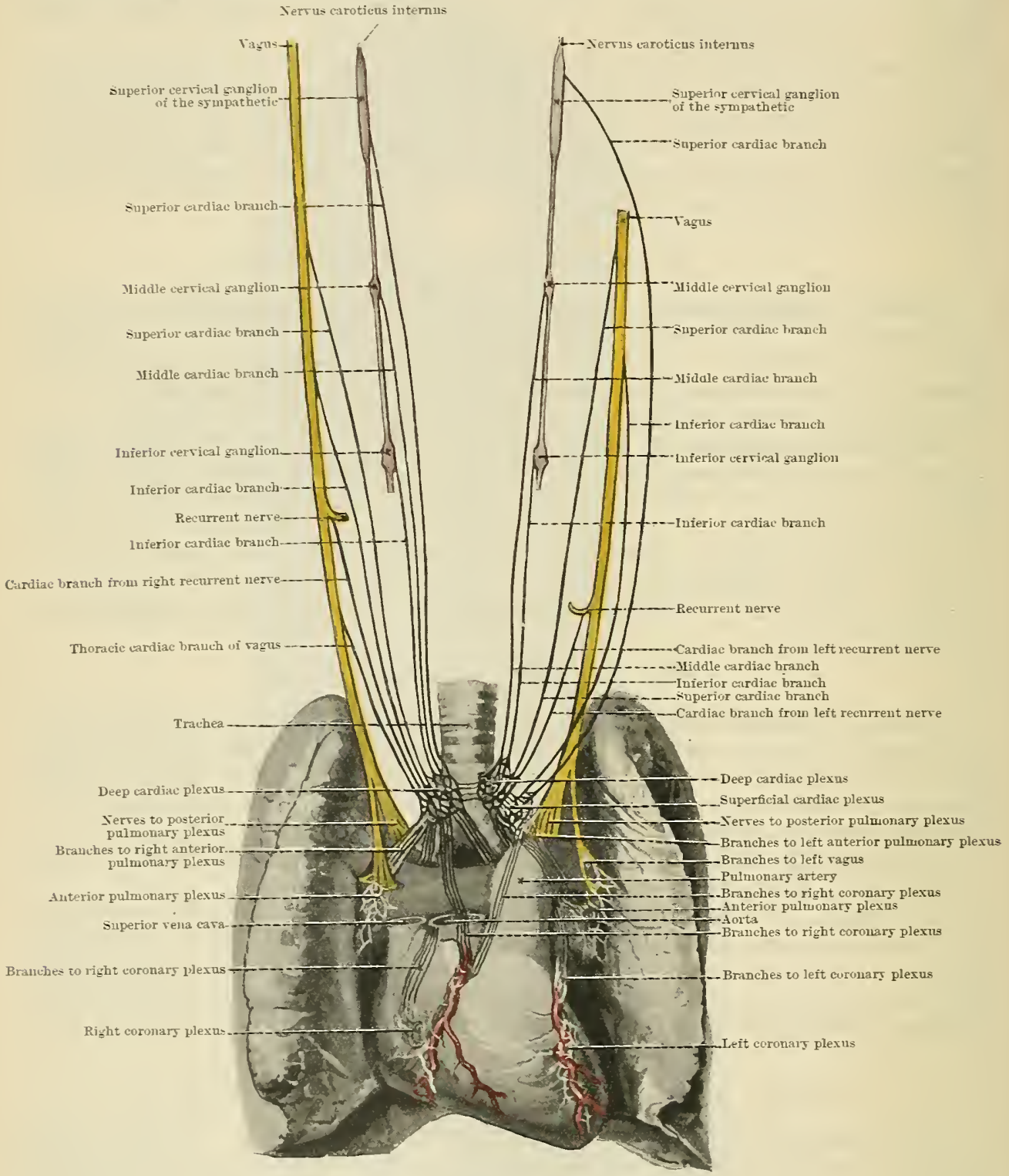

Fig. 639.-The Cardic Plexuses.

spinal nerres-medullated nerve-fibres unconnected with sympathetic ganglion cells; and (2) somatic and splanchnic efferent fibres, small medullated nerves which, after a longer or shorter course in the gangliated trunk or its peripheral branches, become connected with the sympathetic ganglion cells, or with the cells of peripheral (collateral or terminal) ganglia, from which again (non-medullated) axons proceed to supply branches to riscera and ressels. The ultimate destination of the upper stream of white rami from the thoracic nerves has been mentioned in the description of the cervical sympathetic. 
The peripheral branches supplying thoracic organs contain vaso-motor fibres for the lungs and aorta. The peripheral branches from the lower part of the sympathetic trunk in the thorax, receiving white rami from the lower thoracic nerves, are mainly distributed to structures below the diaphragm. They comprise $(a)$ viscero-inhibitory fibres for the stomach and intestines; (b) motor fibres for part of the rectum; (c) pilo-motor fibres for the lower part of the body; $(d)$ vasomotor fibres for the abdominal aorta and its branches, and for the lower limbs; $(e)$ secretory, and $(f)$ sensory fibres for the abdominal viscera.

The branches from the gangliated trunk are, as in the neck, divisible into two sets- $(A)$ Central branches, communicating with other nerves, and $(B)$ peripheral branches, distributed in a plexiform manner to the thoracic and abdominal viscera.

(A) Central Communicating Branches.-The white rami communicantes from the thoracic nerves have already been described. Passing forwards from the anterior rami of the nerves, they become connected with the ganglia or the commissural cord of the sympathetic.

The gray rami communicantes are branches arising irregularly from each thoracic ganglion; passing backwards along with the white rami, they join the anterior rami of the thoracic nerves, and are distributed in a manner already described (p. 754).

$(B)$ Peripheral Branches of Distribution.-These branches arise irregularly from the ganglia and the commissural cord. They are composed of non-medullated (splanchnic efferent) fibres derived from the ganglion cells, and medullated fibres (splanchnic efferent and afferent) derived directly from the white rami, without the intervention of the cells of the ganglia.

1. Rami Pulmonales.-Pulmonary Branches.-From the gangliated trunk opposite the second, third, and fourth ganglia fine filaments arise which join the posterior pulmonary plexus.

2. Rami Aortici--Aortic Branches.-The upper part of the thoracic aorta receives five branches from the upper five thoracic ganglia.

3. Nn. Splanchnici.-Splanchnic Nerves. - Three nerves arise from the inferior part of the gangliated trunk, partly from the ganglia themselves, and partly from the commissural cord between the ganglia. Passing downwards over the bodies of the thoracic vertebræ they pierce the diaphragm, to end in the abdomen.

(a) N. Splanchnicus Major.-The greater splanchnic nerve arises from the gangliated trunk between the fifth and ninth ganglia. By the union of several irregular strands a nerve of considerable size is formed, which descends in the posterior mediastinum, and piercing the crus of the diaphragm, joins at once the anterior end of the coliac ganglion. In its course in the thorax the splanchnic ganglion is formed upon the nerve. It is more prominent in the foetus than in the adult. From both nerve and ganglion branches arise in the thorax, for the supply of the œsophagus and descending thoracic aorta (Fig. 638).

(b) N. Splanchnicus Minor.-The smaller splanchnic nerve arises from the gangliated trunk opposite to the ninth and tenth ganglia. It passes over the bodies of the lower thoracic vertebræ, pierces the diaphragm near or along with the greater splanchnic nerve, and ends in the coliac plexus (aortico-renal ganglion).

(c) N. Splanchnicus Imus. - The lowermost splanchnic nerve arises from the last thoracic ganglion of the sympathetic, or it may be a branch of the smaller splanchnic nerve. It pierces the diaphragm, and ends in the renal plexus.

\section{PARS ABDOMINALIS SYSTEMATIS SYMPATHICI.}

The abdominal part of the sympathetic trunk is placed upon the bodies of the lumbar vertebræ, medial to the origins of the psoas major muscle, and in front of the lumbar vessels. It is connected with the thoracic portion of the trunk by an attenuated commissure, which either pierces or passes behind the diaphragm. It is continuous below with the pelvic portion of the trunk by a commissure, which passes behind the common iliac artery.

It is joined by medullated fibres (white rami communicantes) from the first two 
lumbar spinal nerves, and it contains as well medullated fibres continued down from the lower part of the thoracic sympathetic trunk, and derived from the visceral branches (white rami communicantes) of the lower thoracic nerves.

This part of the trunk is characterised by great irregularity in the number of the ganglia. They are usually four in number, but there are frequently more (up to eight); and in extreme cases fusion may occur to such an extent that the

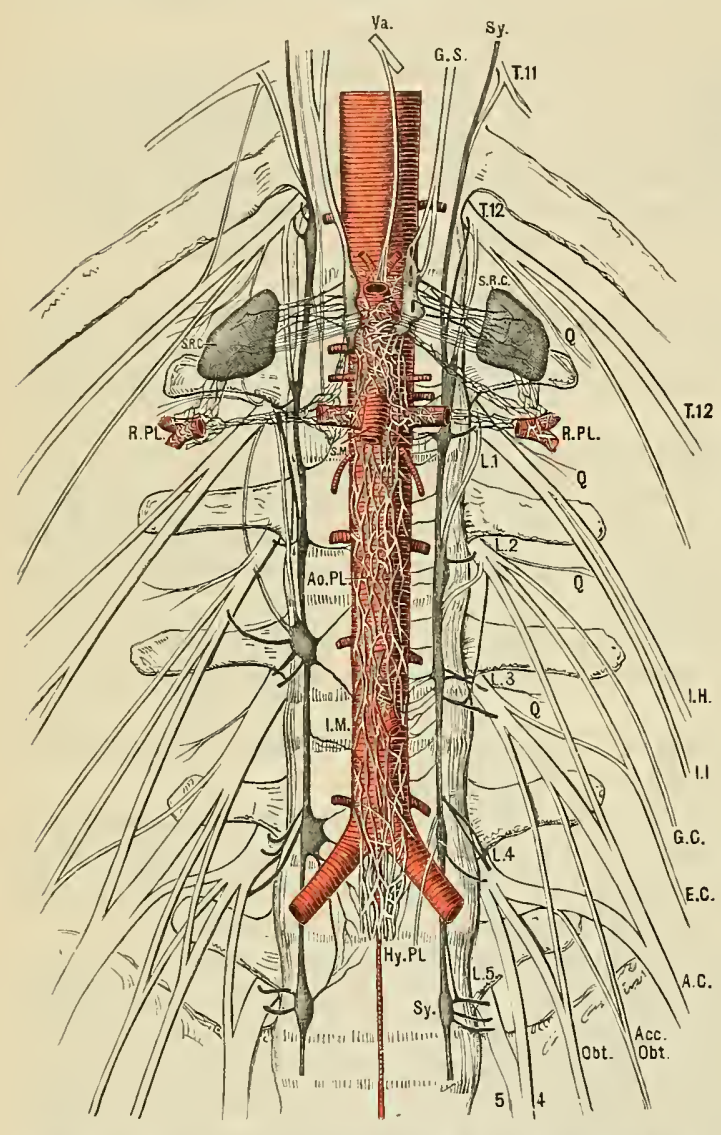

Fig. 640.-The Lumbar Portion of the Sympathetic Gaigliated Cord and lumbar Plexus. (From a dissection.)

T.11, T.12, L.1, L.2, L.3, L.4, L.5, Anterior rami of spinal nerves, with white and gray rami communicantes.

Sy, Sympathetic trunk; Va, Vagus nerve; G.S, Greater splanchnic nerve, joining celiac ganglion ; S.R.C, Suprarenal gland and plexus; R.PI, Renal plexus; Ao.Pl, Aortic plexus; S.M, Superior mesenteric plexus; I.M, Inferior mesenteric plexus; $\mathrm{Hy} . \mathrm{Pl}$, Hypogastric plexus; Q, Nerves to quadratus lumborum ; I.H, Ilio-hypogastric nerve; I.I, Ilio-inguinal nerve; G.C, Genito-felnoral nerve; E.C, Lateral cutaneous nerve; A.C, Femoral nerve; Acc. Obt, Accessory obturator nerve; Obt, Obturator nerve; 4, 5, Lumbo-sacral trunk. separation of individual ganglia becomes impossible.

\section{Central Communicating} Branches.-White rami communicantes. - Only the first two (or three) lumbar spinal nerves send visceral branches (white rami communicantes) to the upper lumbar ganglia or to the sympathetic trunk. These nerves form the lower limit of the thoraciclumbar visceral branches of the spinal nerves. They comprise vasomotor fibres(for the genital organs), and motor fibres for the bladder and uterus.

Gray rami communicantes pass from the gangliated trunk to the anterior rami of the lumbar nerves in an irregular manner. One ramus may divide so as to supply branches to two adjacent spinal nerves; or one spinal nerve may be joined by several (two to five) gray rami from the sympathetic trunk.

The rami course beneath the origin of the psoas major muscle and over the bodies of the vertebræ. Gray rami sometimes pierce the fibres of the psoas muscle.

2. Peripheral Branches of Distribution.-From the lumbar sympathetic trunk numbers of small branches arise irregularly, and supply the abdominal aorta, reinforcing the aortic plexus (derived from the coliac plexus).

\section{PARS PELVINA SYS- TEMATIS SYMPATHICI.}

The pelvic part of the sympathetic trunk, like the cervical and lower abdominal portions of this system, receives no white rami communicantes from the spinal nerves. The
visceral branches (pelvic splanchnic) of the third, and usually, also, the second or fourth sacral nerves, enter the plevic plexus without being directly connected with the sympathetic trunk. These nerves, however, are to be regarded as homologous with the white rami communicantes of the thoracico-lumbar nerves (abdominal splanchnic). They convey to the pelvic viscera-(1) motor and inhibitory fibres for rectum, uterus, and bladder, (2) vaso-dilator fibres for the genital organs, and (3) secretory fibres for the prostate gland. 
This portion of the sympathetic trunk is placed on the pelvic surface of the sacrum, medial to the anterior sacral foramina. It is connected above by a commissural cord with the abdominal portion of the sympathetic, and below it ends in a plexiform union over the coccyx with the trunk of the other side, the two being frequently connected by the ganglion impar or coccygeal ganglion. The number of ganglia is variable; there are commonly four. They are of small size, gradually diminishing from above downwards.

Central communicating branches arise irregularly in the form of gray rami communicantes from the sacral ganglia, which join the anterior rami of the sacral and coccygeal nerves.

Peripheral Branches of Distribution.-(1) Visceral branches of small size arise from the upper part of the pelvic sympathetic trunk, and join the pelvic plexus (see below).

(2) Parietal branches, also of small size, ramify over the front of the sacrum, and form, in relation to the middle sacral artery, a plexiform union with branches from the sympathetic trunk of the other side.

\section{PLEXUS SYMPATHICI.}

Sympathetic Plexuses.-It has already been seen that the peripheral branches of the sympathetic trunk throughout its length are characterised by forming or joining plexuses in their neighbourhood.

The cervical sympathetic ganglia and nerves give rise to the carotid and cavernous plexuses; the external carotid, pharyngeal, thyrecid, vertebral, and subclavian plexuses; and they send important branches to the cardiac plexuses (described with the vagus nerve).

The thoracic ganglia send branches to join the pulmonary and asophageal plexuses (described with the vagus nerve). They form plexuses on the thoracic aorta, and by means of the splanchnic nerves they form the chief source of the cœliac plexus.

\section{The Caliac and Pelvic Plexuses.}

These great plexuses serve to distribute nerves to the viscera and vessels of the abdominal and pelvic cavities. Taken together they include three plexuses-the cœliac plexus, the hypogastric plexus, and the pelvic plexus. They are constituted by peripheral branches of the lower thoracic, abdominal, and upper pelvic parts of the sympathetic trunk; and they are related to the central nervous system by means of the visceral branches (white rami communicantes) of the lower thoracic and upper lumbar nerves on the one hand, and by the visceral branches of the second and third, or third and fourth sacral nerves, on the other liand. The thoracico-lumbar series join the sympathetic trunk, and reach the cœliac plexus mainly through the splanchnic nerves, and to a lesser extent through the abdominal part of the sympathetic trunk. The sacral series enter the pelvic plexus without connexion with the sympathetic trunk. The hypogastric plexus serves as a connecting link between the cœliac and pelvic plexuses.

\section{Plexus Ceiliacus.}

The cœliac plexus lies on the posterior abdominal wall in relation to the abdominal aorta and behind the stomach. It is composed of three elements: the cœliac plexus surrounding the origin of the coliac artery, between the crura of the diaphragm; and two coliac ganglia, each lying on the corresponding crus of the diaphragm, and overlapped by the suprarenal gland, and on the right side by the inferior vena cava. The plexus is continuous with subordinate plexuses, diaphragmatic, suprarenal, renal, superior mesenteric and aortic; and by means of the hypogastric nerves the aortic plexus is continued into the hypogastric plexus, which again forms the chief origin of the pelvic plexuses.

The cœliac ganglia constitute the chief ganglionic centres in the solar plexus. They are irregular in form. They are often partially subdivided, and one 
detached portion at the lower end is named the aortico-renal ganglion. Other small scattered masses of cells are present in the coliac plexus. At the upper end the cœliac ganglion receires the greater splanchnic nerve. The aortico-renal ganglion

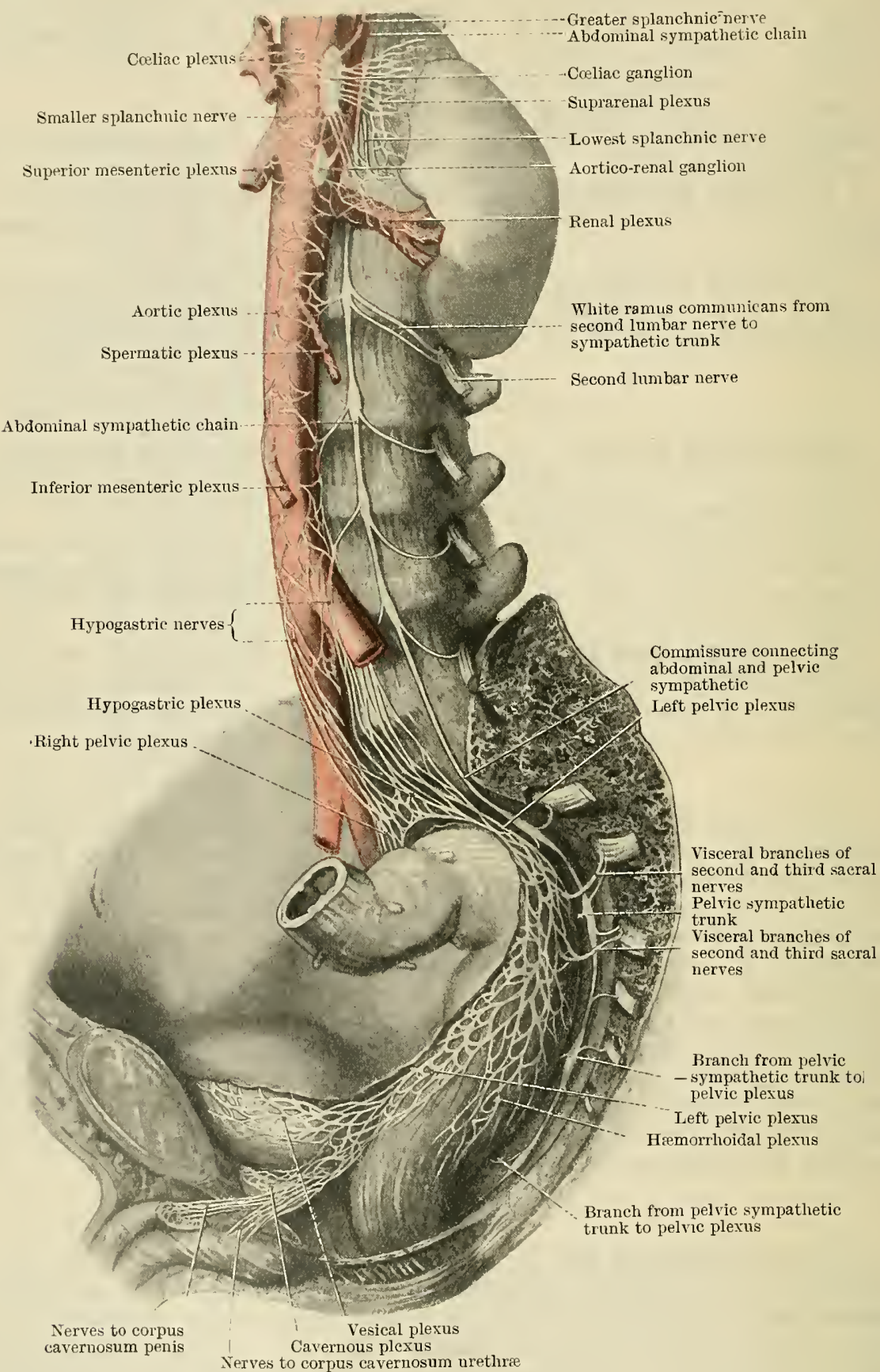

Fig. 641.-The Sympathetic in the Abdomen and Pelvis.

at its lower end receives the smaller splanchnic nerve. Branches from the ganglion radiate in all directions-medially to join the coliac plexus, upwards to form the diaphragmatic plexus, laterally to the suprarenal plexus, downward to the renal, superior mesenteric, and aortic plexuses. 
The cœliac plexus forms a considerable plexiform mass surrounding the cœliac artery. It consists of a dense meshwork of fibres with ganglia intermingled, joined by numerous branches from the coliac ganglion on each side, and by branches from the right vagus nerve. It is continuous below with the superior mesenteric and aortic plexuses. Investing the coeliac artery, it forms subsidiary plexuses which are distributed along the branches of the artery. The coronary plexus supplies branches to the esophagus and stomach; the hepatic plexus supplies branches to the liver and gall-bladder, stomach, dnodenum, and pancreas; and the splenic plexus sends offsets to the spleen, pancreas, and stomach.

Subordinate plexuses are formed on the aorta and its branches by nerves derived from the cœliac ganglia and cœliac plexus.

a. Plexus Phrenicus. - The phrenic plexus consists of fibres arising from the cœliac ganglion, and accompanies the inferior phrenic artery. Besides supplying the diaphragm, it gives branches to the suprarenal plexus, and-on the right side to the inferior vena cava - on the left side to the oesophagus. It communicates on each side with the phrenic nerve. At the junction of the plexus and the phrenic nerve of the right side a ganglion is formed (phrenic ganglion).

b. Plexus Suprarenalis. - The suprarenal plexus is of considerable size. It is mainly derived from branches of the coliac ganglion, reinforced by nerves from the inferior part of the coliac plexus which stream laterally on the suprarenal arteries. It is joined by branches from the phrenic plexus above and from the renal plexus below. The nerves enter the substance of the suprarenal gland.

c. Plexus Renalis. - The renal plexus is derived from (1) branches of the coeliac ganglion, and (2) fibres from the aortic plexus, extending laterally along the renal artery to the hilus of the kidney. It receives also the lowermost splanchnic nerve, and is connected by numerous branches to the suprarenal plexus.

d. Plexus Mesentericus Superior.-The superior mesenteric plexus is inseparable above from the coliac plexus, and is joined on either side by fibres from the coliac and aortico-renal ganglia. It is continuous below with the aortic plexus. A separate detached ganglionic mass (superior mesenteric ganglion) is present in the plexus. Accompanying the superior mesenteric artery it forms subordinate plexuses around the branches of the vessel. The plexuses at first surround the intestinal arteries, but near the intestine they form fine plexuses between the layers of the mesentery, from which branches pass to the wall of the gut. This plexus supplies the small intestine, cæcum, vermiform process, ascending and transverse portions of the colon.

e. Plexus Aorticus Abdominalis.-The aortic plexus is the continuation downwards of the coliac plexus around the abdominal aorta. It is continuous above with the coliac and superior mesenteric plexuses; it is reinforced by the peripheral branches of the lumbar sympathetic trunk; and it is connected with the hypogastric plexus below by the hypogastric nerves. Besides investing and supplying the aorta, the plexus is connected with various subordinate plexuses on the branches of the artery. It contributes to the suprarenal and renal plexuses, and it gives rise to the spermatic or ovarian, and the inferior mesenteric plexuses.

Plexus Spermaticus.-The spermatic plexus invests and accompanies the spermatic artery. It is derived from the aortic plexus, and receives a contribution from the renal plexus. It supplies the spermatic cord and testis.

Plexus Arteriæ Ovaricæ.-The plexus of the ovarian artery in the female arises like the spermatic plexus. It accompanies the ovarian artery to the pelvis, and supplies the ovary, broad ligament, and uterine tube. It forms communications in the broad ligament with the uterine plexus (from the pelvic plexus), and sends fibres to the uterus.

Plexus Mesentericus Inferior.-The inferior mesenteric plexus is a derivative from the aortic plexus, prolonged along the inferior mesenteric artery. It forms subordinate plexuses on the branches of the artery (colic, sigmoid, and superior hæmorrhoidal), and is distributed to the descending colon, iliac colon, pelvic colon, and upper part of the rectum. 


\section{Plexus Pelvini.}

The hypogastric nerves form the continuation of the aortic plexus into the pelvic cavity. They consist of numerous plexiform bundles of nerve-fibres which descend along the front and back of the bifurcation of the aorta and the origin of the common iliac arteries, and over the sacral promontory, where, becoming inextricably mingled, they constitute the hypogastric plexus.

The hypogastric plexus is continued downwards in front of the sacrum on either side of the rectum, and ends in the pelvic plexuses.

The pelvic plexuses are formed by the separation of the hypogastric plexus into two halves on either side of the rectum. Each is joined by fibres from the upper portion of the pelvic part of the sympathetic trunk, and by the visceral branches (white rami communicantes) from the second and third or third and fourth sacral nerves. Accompanying the hypogastric artery and its branches, each pelvic plexus gives off subordinate plexuses for the pelvic viscera.

a. Plexus Hæmorrhoidalis.-The hæmorrhoidal plexus supplies the rectum, and joins the superior hæmorrhoidal plexus from the inferior mesenteric plexus.

b. Plexus Vesicalis. - The vesical plexus accompanies the vesical arteries to the bladder-wall. Besides supplying the muscular wall and mucous membrane of the bladder, it forms subordinate plexuses for the lower part of the ureter, the vesicula seminalis, and the ductus deferens.

c. Plexus Prostaticus. - The prostatic plexus is of considerable size. It is placed on either side of the gland, and in addition to supplying its substance and the prostatic urethra, it sends offsets to the neck of the bladder and the vesicula seminalis. It is continued forwards on each side to form the plexus cavernosus penis (cavernous plexus of the penis). Bundles of nerves pierce the layers of the fascia of the urogenital diaphragm, and after supplying the membranous urethra, give off branches which enter and supply the corpus cavernosum penis. The cavernous nerves communicate with branches of the pudendal nerve and give offsets to the corpus cavernosum urethræ and the penile portion of the urethra.

d. Plexus Uterovaginalis. - The uterine plexus passes upwardsı with the uterine

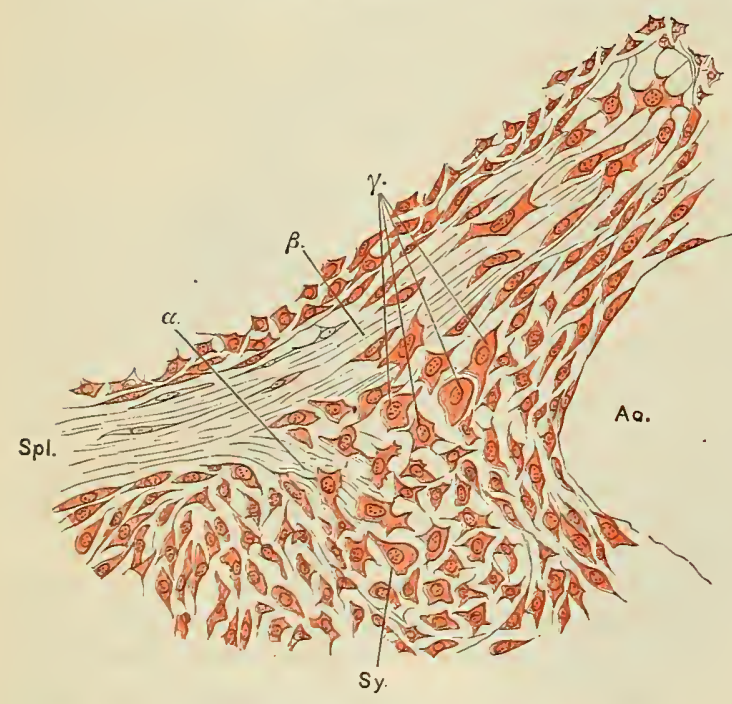

Fig. 642.-Section throdgh the SyMpathetic Trdik of AN EMBRYo.

Showing the connexion with the ganglion $(\mathrm{Sy})$ of the white ramus communicans (Spl); $(\alpha)$ a portiou of the ramus joining the ganglion; $(\beta)$ fibres passing over the trunk, accompanied by a stream of cells; $(\gamma)$ continuous with those of the ganglion ; (Ao) Aorta.

distinct elements-fibres of cerebro-spinal origin and "sympathetic" cells and fibres. While the function of the sympathetic trunk and its branches seems to be absolutely dependent upon the artery between the layers of the broad ligament, and is distributed to the surfaces and substance of the organ. It communicates between the layers of the broad ligament with the plexus of the ovarian artery.

The vaginal plexus is formed mainly by the visceral brauches of the sacral nerves entering the pelvic plexus. It supplies the wall and mucous membrane of the vagina and urethra, and provides a cavernous plexus for the clitoris. The uterine and vaginal plexuses of the female correspond to the prostatic plexus of the male.

\section{The Morphology of the Sympathetic System}

From a consideration of its structure, functions, and development, there appear to be two separate structures represented in the sym patheticnervous system - the spinal and the sympathetic elements. The structure of the system 
cerebro-spinal nerrous system, it is certain that the cells and fibres of the sympathetic system possess a vital activity apart from their connexion with the central nervous system. In the development of the sympathetic it is at least highly probable that a mesoblastic rudiment or precursor forms the basis of the sympathetic system, which is secondarily joined by nervefibres from the roots of the spinal nerves.

Morphologically this part of the nervous system is essentially a longitudinal cord or column, associated with involuntary muscles and glandular tissues, and particularly related to the organs in the splanchnic area. Like other longitudinal structures in the body, and especially like the organs of the splanchnic area, the sympathetic system is not truly segmental. The sympathetic trunk is only quasi-segmental, the segmentation being attributable to its junction with the visceral branches of the spinal nerves. The peripheral branches from the sympathetic trunk are by no means segmental; even the gray rami are not properly metameric, but, like the ganglia, assume a segmental character in consequence of their connexions with the spinal nerves.

The phylogenetic relation of the sympathetic and the cerebro-spinal elements in the system it is impossible to determine. It may be that the sympathetic system is the representative of an ancient architecture independent of the cerebro-spinal nervous system, the materials of which are utilised for a more modern nervous system; or it may be that the correlation of spinal nerves and sympathetic are both the consequences of the formation of new organs and structures in the splanchnic area. Examined in every light, it possesses features which effectulally differentiate it from the cerebro-spinal system, although it has become inextricably united with it and subservient to it.

\section{THE CEREBRAL NERVES.}

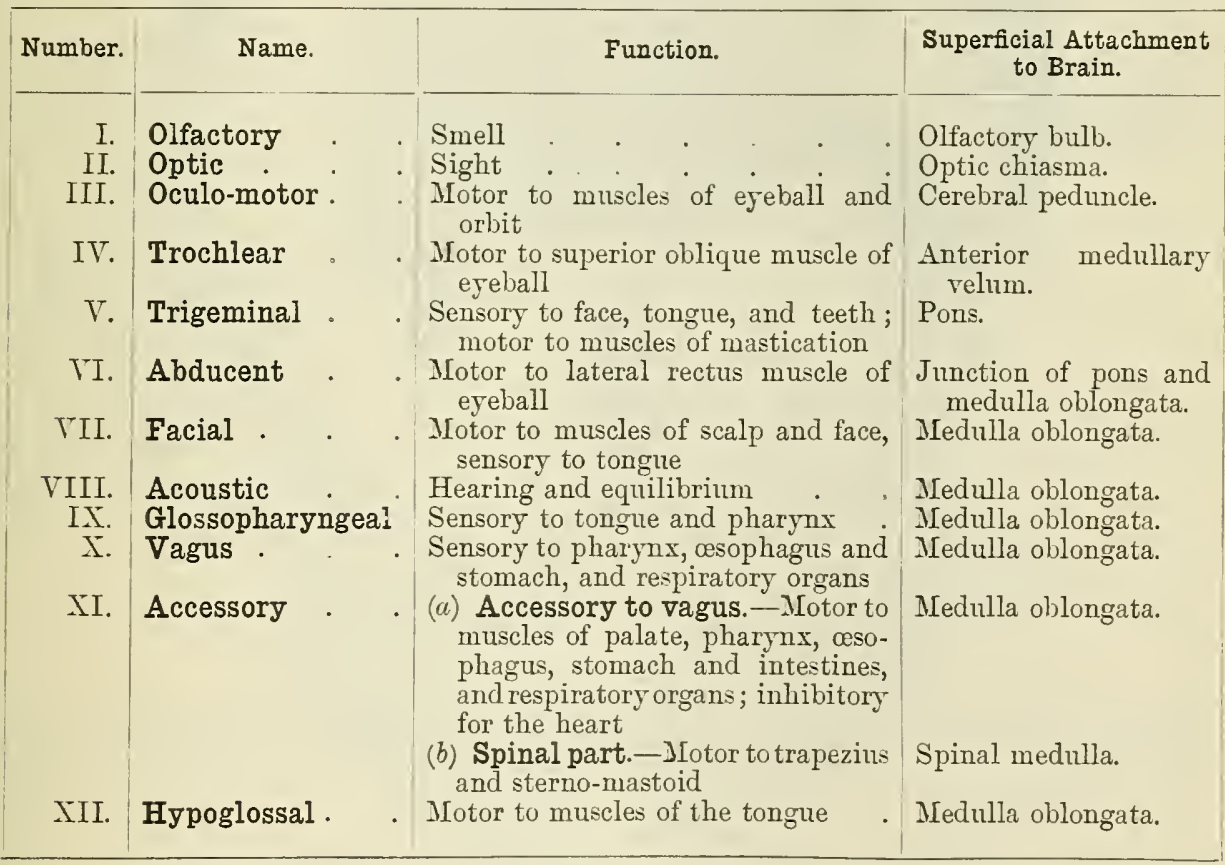

The deep connexions of the cerebral nerves are dealt with in the section which treats of the Brain (pp. 592 to 607). Certain general points in connexion with these nerves are also touched upon in the chapter introductory to the Nervous System (p. 500). Their development is given on p. 501 et seq.

\section{Nervi OlfactoriI.}

The first or olfactory nerves consist of several parts: (1) a series of fine nerves, which arise from (2) the olfactory bulb. This again is connected by (3) the olfactory tract with the brain, to which it is attached by (4) two striæ or roots (Fig. 643).

The anatomy of the roots, tract, and bulb of the olfactory nerve are described elsewhere (pp. 623 to 628). 
The olfactory nerves, about twenty in number, arise from the under surface of the olfactory bulb. The fibres are non-medullated. Piercing the cribriform plate of the ethmoid bone, enveloped in sheaths of dura mater, they are distributed in the nasal cavity as the nerves of smell. The fibres form fine plexuses over a limited area on the superior portion of the nasal septum, and to a less extent over the lateral wall of the nose.

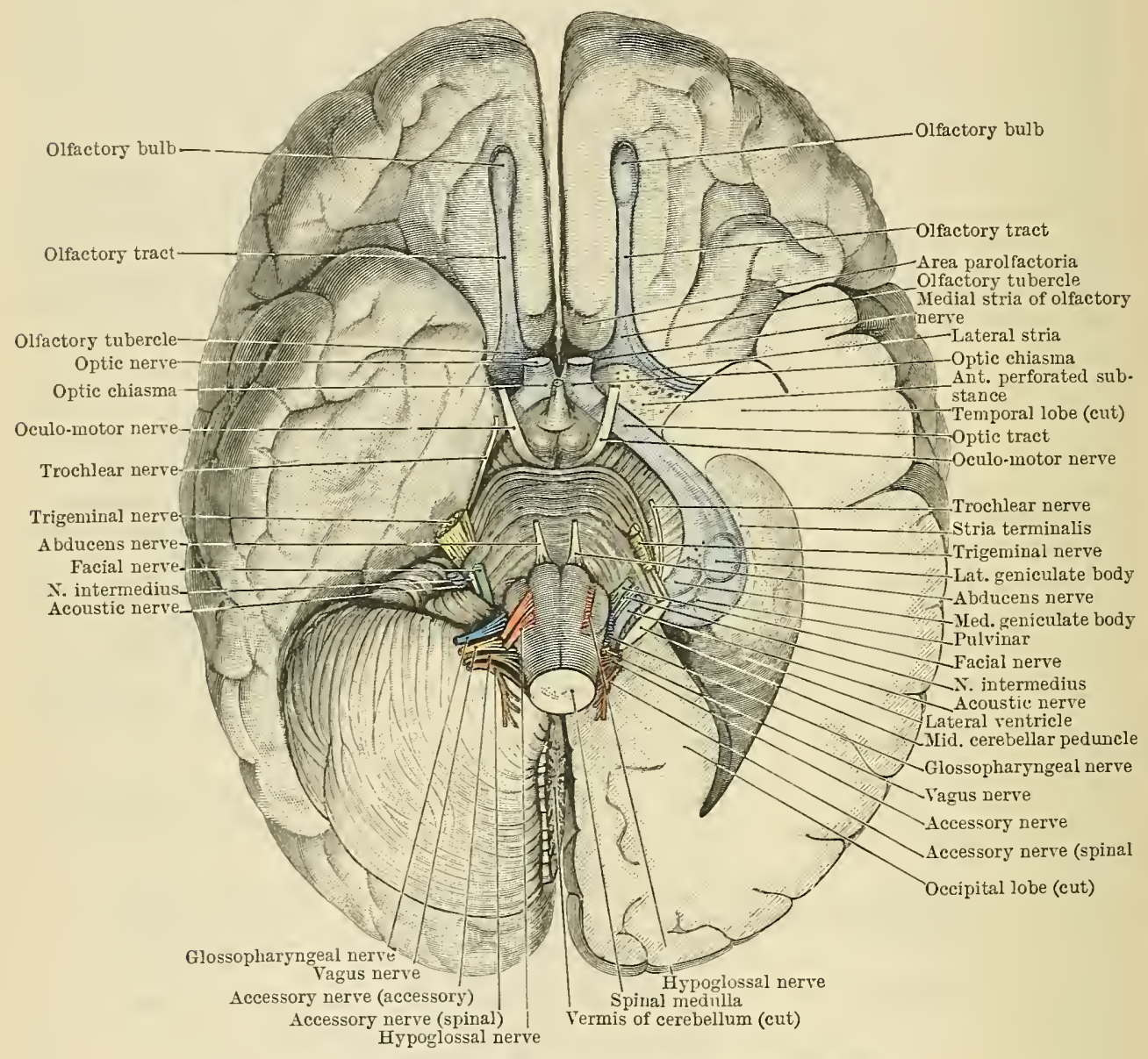

Fig. 643.--View OF the INfERior SURFace of the Brain,

With the lower portion of the temporal and occipital lobes, and the cerebellum on the left side removed, to show the origins of the cerebral nerves.

\section{Nervus Opticus.}

The second or optic nerve arises from the brain by means of the optic tract (Fig. 643). This takes origin from the pulvinar of the thalamus, from the lateral and medial geniculate bodies, and from the brachium of the upper of the two corpora quadrigemina (vide pp. 619 and 620). The optic tract reaches the base of the brain after sweeping round between the cerebral peduncle and the gyrus hippocampi. The two optic tracts converge in front of the inter-peduncular fossa, medial to the anterior perforated substance and the termination of the internal carotid artery, and unite to form the optic chiasma. This adheres to the inferior surface of the floor of the third ventricle in front of the tuber cinereum, and gives rise at each end to the optic nerve. The optic nerve, directed laterally and forward, pierces the dura mater, and passes from the cranial cavity into the orbit through the optic foramen in company with the ophthalmic artery. In the orbit the nerve is embedded in the fat behind the eyeball, and is 
surrounded by the ocular muscles. It is connected with the globe of the eye at a point one-eighth of an inch on the medial side of the axis of the eyeball. After piercing the fibrous and vascular coats, the nerve spreads out at the optic papilla to form the innermost layer of the retina. In the orbit the nerve is crossed by the ophthalmic artery and the naso-ciliary nerve, and nearer to its termination it is surrounded by the ciliary vessels and nerres, and by the fascia bulbi. It is pierced obliquely on its inferior surface by the arteria centralis retinæ.

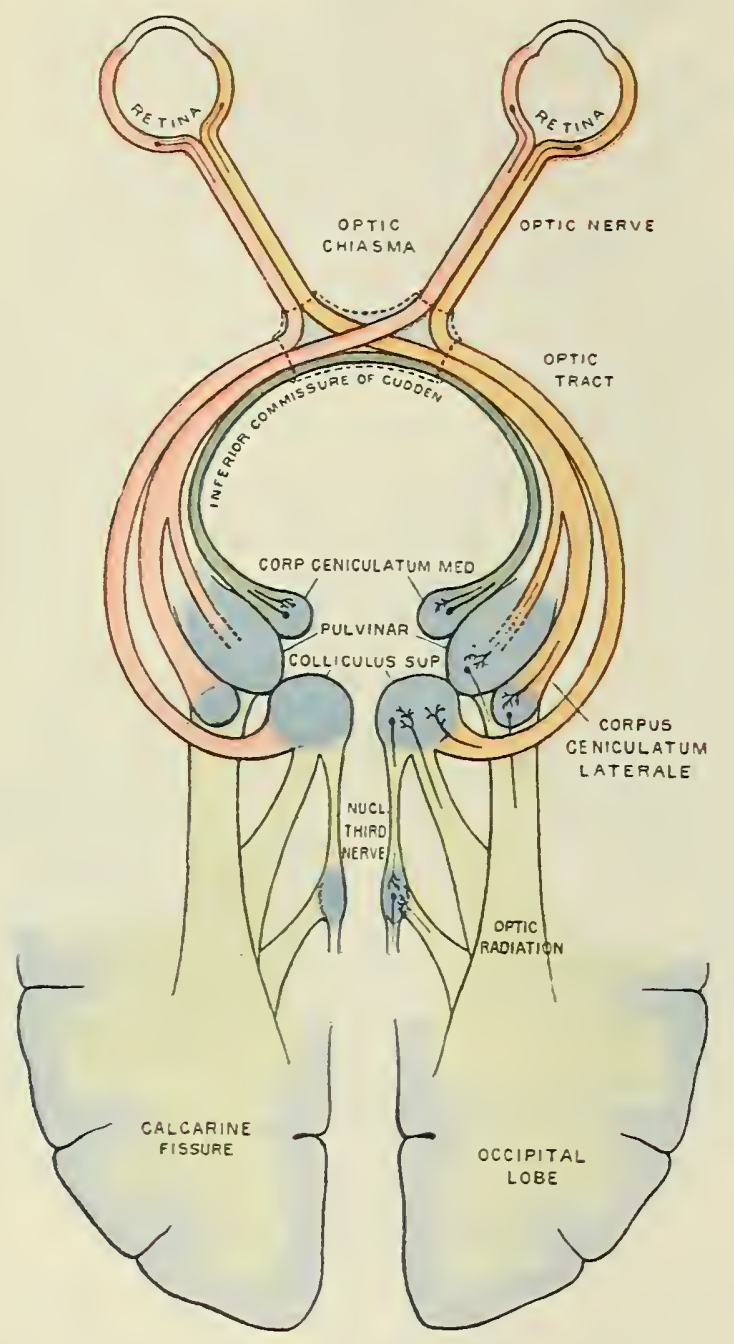

Fig. 644.-Cextral Consexions of the Optic Nerve and Optic Tracts.

Decussation in the Optic Chiasma.-In the optic chiasma the fibres of the two optic tracts separate, the medial part of each tract decusaating to form the medial half of the opposite optic nerve. The other, lateral, part of each tract, continues its course to form the lateral half of the optic nerve on the same side. At the back of the chiasma another bundle of fibres is found passing from tract to tract behind the decussating fibres, and known as Gudden's commissure (see p. 619).

\section{Nerves Oculomotorius.}

The third or oculo-motor nerve arises from the brain, in the region of the posterior perforated substance, by several fila radicularia (radicles) emerging from the oculo-motor sulcus, on the medial side of the cerebral peduncle, just in front of the pons (Fig. 643). Passing forwards between the posterior cerebral and 
superior cerebellar arteries, the nerve pierces the dura mater beside the posterior clinoid process, in a small triangular space between the free and attached borders of the tentorium cerebelli. Beneath the dura mater the nerve courses through the

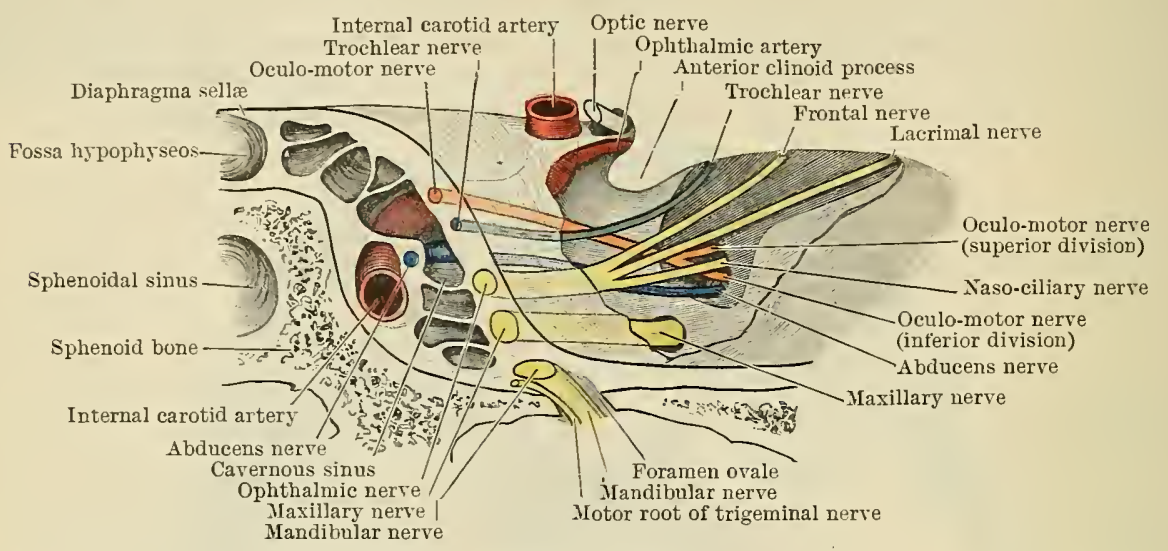

Fig. 645.-Relations of Structures in the Cavernous Sinus and Superior Orbital Fissure.

lateral wall of the cavernous sinus, and enters the orbit through the superior orbital fissure and between the two heads of the lateral rectus muscle. As it enters the orbit it divides into upper and lower branches, separated by the nasociliary nerve.

Branches. - The superior branch of the nerve supplies two muscles of the orbit-the superior rectus and the levator palpebræ superioris.

The inferior branch passes forwards, and after giving branches to the medial and inferior recti, ends in the inferior oblique muscle. The short root of the ciliary ganglion arises from the terminal branch which goes to the inferior oblique muscle.

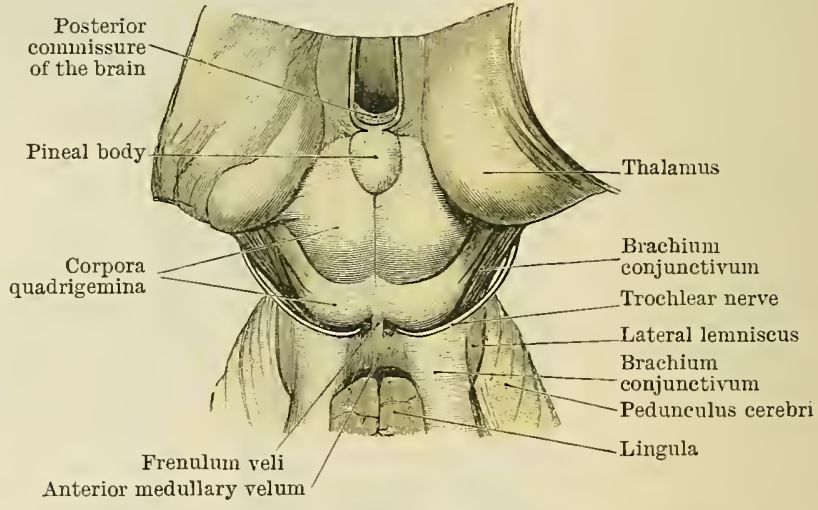

Fig. 646.-DORSAL SURFACE OF THE MID-BRAIN, to show the origin of the trochlear (fourth) nerve.

Communications.-1. In the cavernous sinus the oculo-motor nerve communicates with the cavernous plexus on the internal carotid artery. 2. In the cavernous sinus it also receives a slender communication from the ophthalmic division of the trigeminal nerve. 3. The short root of the ciliary ganglion passes upwards from the branch of the nerve which supplies the inferior oblique muscle.

\section{Nervus Trochlearis.}

The fourth or trochlear nerve emerges from the dorsal surface of the midbrain. It arises at the side of the frenulum veli from the anterior end of the anterior medullary velum, just behind the corpora quadrigemina. It is extremely slender, and of considerable length. Passing round the cerebral peduncle, the nerve appears in the base of the brain behind the optic tract, in the interval between the cerebral peduncle and the temporal lobe of the brain. Continued forwards to the base of the skull, it pierces the free border of the tentorium cerebelli, lateral to the oculo-motor nerve, and proceeds forwards in the lateral wall of the cavernous sinus, to the superior orbital fissure, lying between the oculo- 
motor nerve and the ophthalmic division of the trigeminal nerve. It enters the orbit above the muscles of the eyeball, and terminates in the orbital (superior) surface of the superior oblique muscle.

Communications. - In the cavernous sinus the nerve receives (1) a communicating

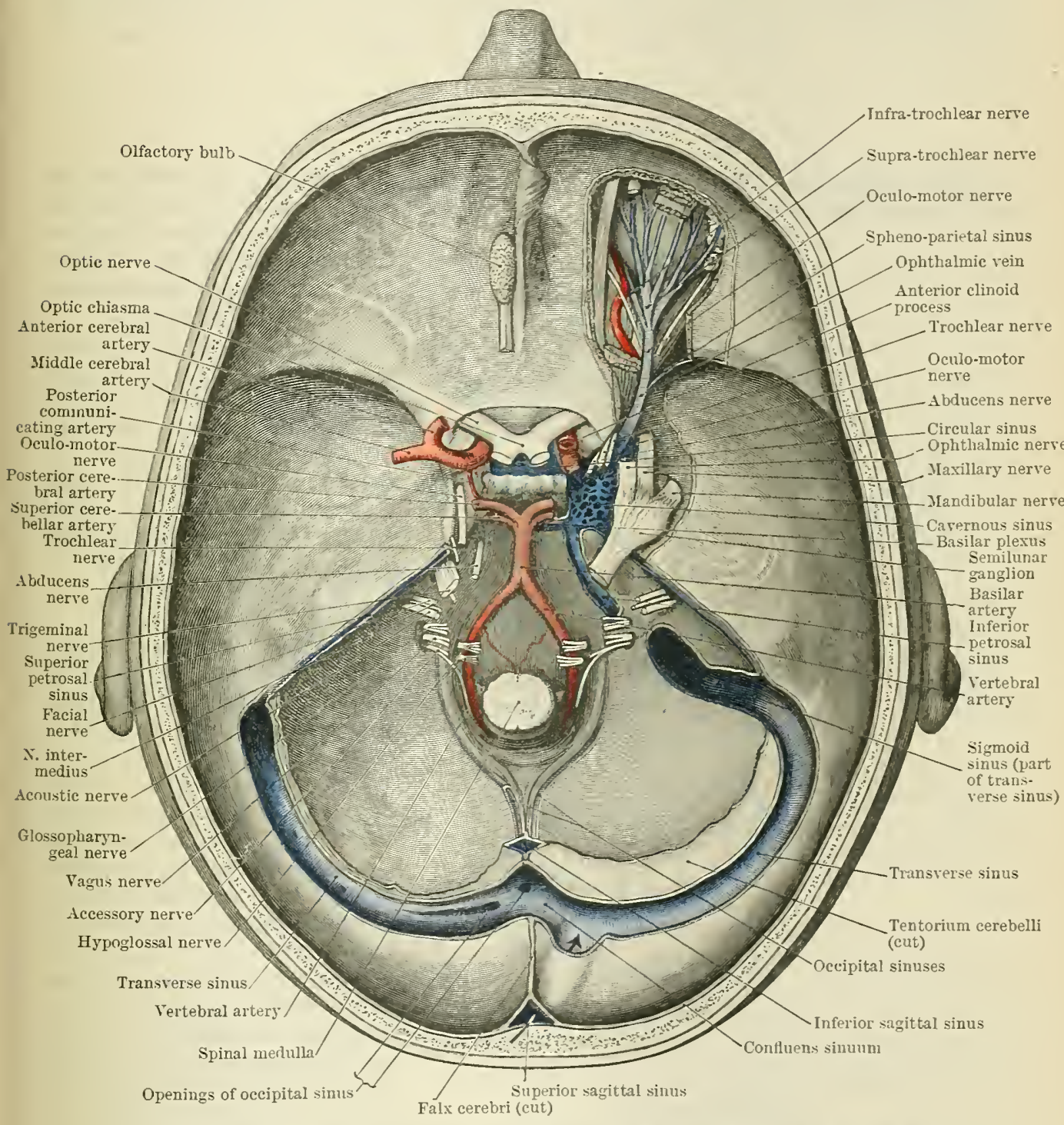

Fig. 647. - The BASE OF THE SkULL, to show the dura mater, sinuses, arteries, and nerves.

branch from the cavernous or carotid plexus on the internal carotid artery, and (2) a slender filament from the ophthalmic division of the trigeminal nerve.

\section{Nerves Trigeminus.}

The fifth or trigeminal nerve arises from the inferior surface of the pons in its lateral part by two roots, a large sensory root and a small motor root (Fig. 643, p. 768). The two roots proceed forwards in the posterior fossa of the skull, and piercing the dura mater beneath the attachment of the tentorium cerebelli to the superior angle of the petrous part of the temporal bone, enter a cavity in the dura mater (cavum Neclielii) over the apex of the petrous bone. 
The large sensory root gradually conceals the small motor root in its course forwards, and expands beneath the dura mater into a large flattened ganglionthe semilunar ganglion. This ganglion occupies an impression on the apex of the petrous portion of the temporal bone, and from it three large trunks arise-the ophthalmic or first, the maxillary or second, and the mandibular or third divisions of the nerve. The small motor root of the nerve passes forward beneath the ganglion, and is incorporated wholly with the mandibular division of the nerve.

\section{Nervus Ophthalmicus.}

The ophthalmic nerve passes forwards to the orbit through the middle fossa of the skull, beneath the dura mater. It lies in the lateral wall of the cavernous

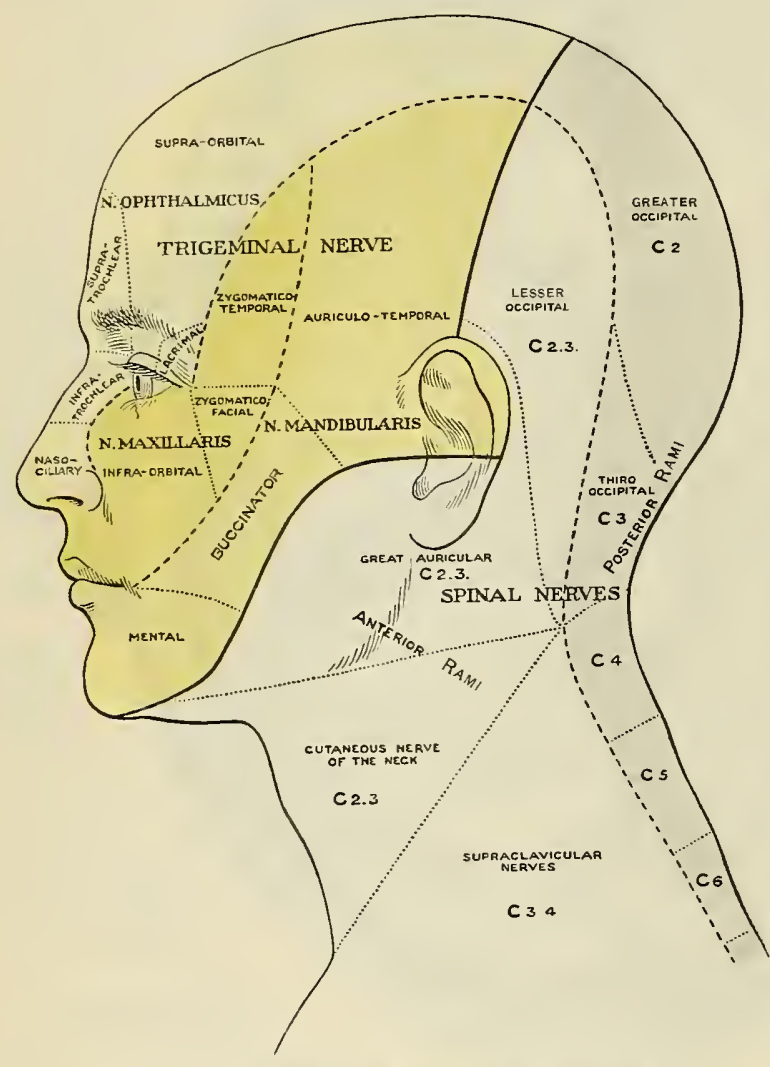

Fig. 648.-Distribution of Sensort Nerves to THE Head AND NeCK. sinus, at a lower level than the trochlear nerve, and reaches the orbit through the superior orbital fissure (Fig. 645).

In the wall of the cavernous sinus the ophthalmic nerve gives off (1) a small recurrent branch to the dura mater ( $n$. tentorii), (2) communicating branches to the cavernous plexus of the sympathetic on the internal carotid artery, and (3) small communicating twigs to the trunks of the oculo-motor, trochlear, and abducent nerves.

In the superior orbital fissure the nerve divides into three main branches-lacrimal, frontal, and naso-ciliary (Fig. $645)$.

N. Lacrimalis. - The lacrimal nerve enters the orbit through the lateral angle of the superior orbital fissure, above the orbital muscles. Passing forwards between the periosteum and the orbital contents to the anterior part of the orbit, the nerve ends by supplying branches $(a)$ to the lacrimal gland, $(b)$ to the conjunctiva, and (c) to the skin of the lateral commissure of the eye.

The lacrimal nerve communicates in the orbit with the zygomatic branch of the maxillary nerve, and on the face, by its terminal branches, with the temporal branches of the facial nerve (Fig. 653).

N. Frontalis.--The frontal nerve, entering the orbital cavity through the superior orbital fissure, courses forwards above the ocular muscles, and divides at a variable point into two branches-a larger supra-orbital and a smaller supratrochlear nerve.

N. Supraorbitalis. - The supra-orbital nerve passes directly forwards, and leaves the orbit through the supra-orbital groove or foramen to reach the forehead. It gives off the following secondary branches: (1) the principal (frontal) branches (rami frontales) are distributed to the forehead and scalp, reaching backwards as far as the vertex; (2) small branches supply the upper eyelid; and (3) twigs are 
distributed to the frontal sinus. On the forehead the supra-orbital nerve communicates with the temporal branches of the facial nerve.

N. Supratrochlearis.-The supra-trochlear nerve courses obliquely forwards and medially over the tendon of the superior oblique muscle to reach the medial side of the supra-orbital arch. Leaving the cavity of the orbit, the nerve is distributed to the skin of the medial part of the forehead, the root of the nose, and the medial commissure of the eye.

It communicates with the infra-trochlear branch of the naso-ciliary nerve, either before or after leaving the orbital cavity.

N. Nasociliaris.-The naso-ciliary nerve (O.T. nasal) enters the orbit through the superior orbital fissure, between the heads of the lateral rectus muscle, and between the two divisions of the oculo-motor nerve (Fig. 652, p. 776). It crosses the orbital cavity obliquely to reach the anterior ethmoidal foramen, lying in its course below the superior rectus and superior oblique muscles, and above the optic nerve and medial rectus muscle. The nerve is transmitted, under the name of anterior ethmoidal, through the anterior ethmoidal foramen into the cranial cavity, where it lies embedded in dura mater on the lamina cribrosa of the ethmoid bone. It enters the nasal cavity through the nasal fissure, and terminates by dividing into medial and lateral branches. The medial division supplies the mucous membrane over the upper and anterior part of the nasal septum. The lateral branch, after supplying collateral offsets to the lateral wall of the nasal cavity, finally appears on the face as the external nasal nerve between the nasal bone and lateral cartilage, and supplies branches to the skin of the lower part and tip of the nose.

The branches of the naso-ciliary nerve may be divided into three sets, arising (a) in the orbit, $(b)$ in the nose, and (c) on the face.

In the orbit the branches are given off in three situations-lateral to, above, and medial to the optic nerve. (a) As the nerve lies on the lateral aspect of the optic nerve, it gives off the radix longa ganglii ciliaris (long root of the ciliary ganglion). (b) As it crosses the optic nerve, nn. ciliares longi (two long ciliary branches) arise, and pass forwards alongside the optic nerve to the eyeball. (c) On the medial side of the optic nerve the $n$. infratrochlearis (infra-trochlear nerve) arises, a slender branch which courses forward beneath the pulley of the superior oblique muscle to the front of the orbit. It ends on the face by supplying the skin of the root of the nose and the eyelids, and communicates either in the orbit or on the face with the supra-trochlear nerve. On the face it also communicates with zygomatic branches of the facial nerve.

In the nose the rami nasales mediales (medial nasal branches) supply the mucous membrane of the anterior part of the nasal septum; the rami nasales laterales (lateral nasal branches) supply the anterior part of the lateral wall of the nasal cavity.

On the face the terminal filaments of the nerve are distributed, as the ramus nasalis externus (external nasal branch), to the skin of the lower half and tip of the nose. The terminal branch communicates with the zygomatic branches of the facial nerve (Fig. 653).

Ganglion Ciliare.-The ciliary ganglion is associated with the naso-ciliary branch of the ophthalmic nerve and with the inferior division of the oculo-motor nerve. It is a small reddish ganglion, placed between the lateral rectus muscle and the optic nerve, and in front of the ophthalmic artery. Its roots are three in number: (1) sensory or long, derived from the naso-ciliary branch of the ophthalmic nerve; (2) motor or short, derived from the inferior division of the oculo-motor nerve; and (3) sympathetic, a slender filament from the cavernous plexus on the internal carotid artery, which may exist as an independent root or may be incorporated with the long root from the naso-ciliary nerve. The branches from the ganglion are twelve to fifteen $\mathrm{nn}$. ciliares breves (short ciliary nerves), which pass to the eyeball in two groups above and below the optic nerve. They supply the coats of the eyeball, including the iris and ciliary muscles. The circular fibres of the iris and the ciliary muscle are innervated by the third nerve; the radial fibres of the iris by the sympathetic. 


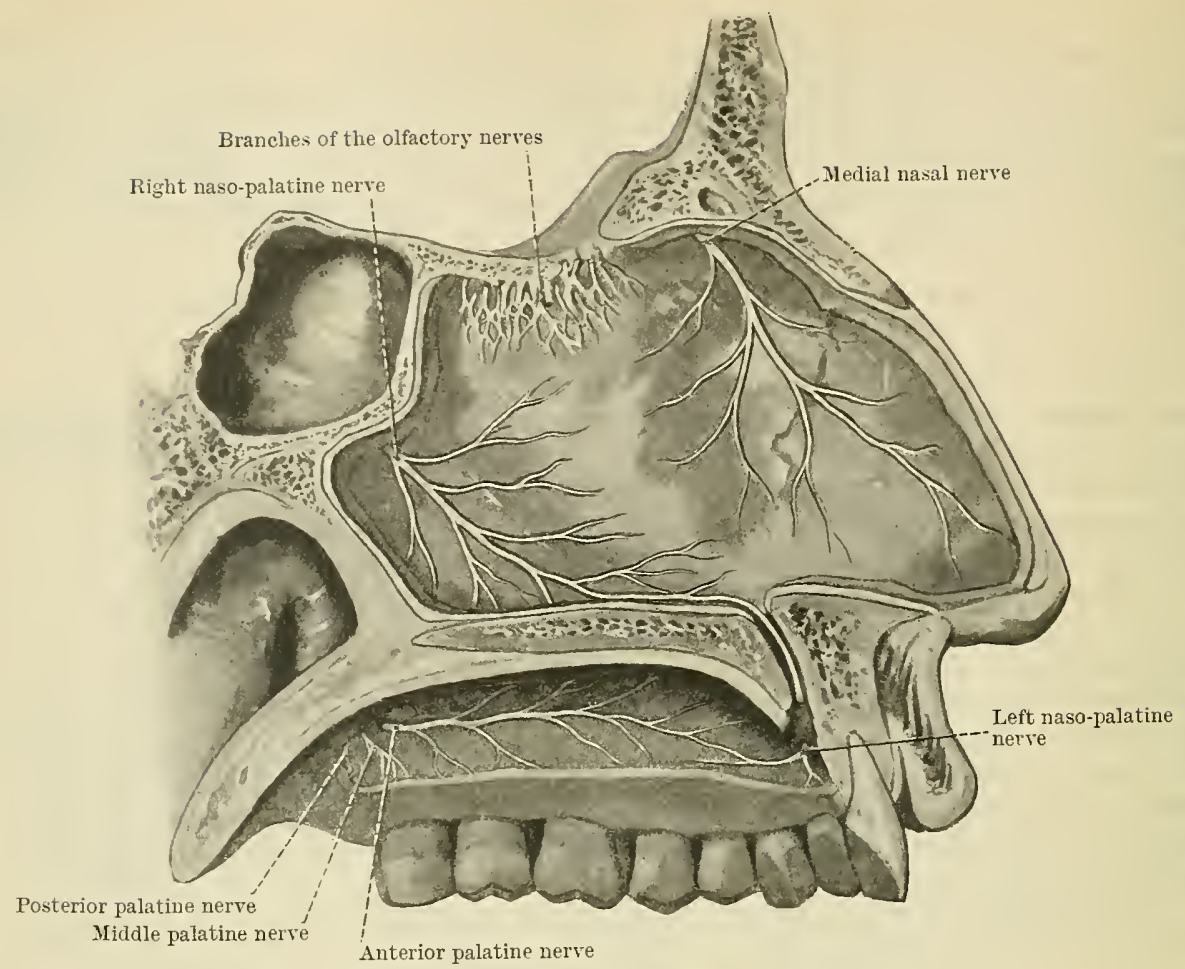

Fig. 649.-Injertition of Nasai Septum and Palate.

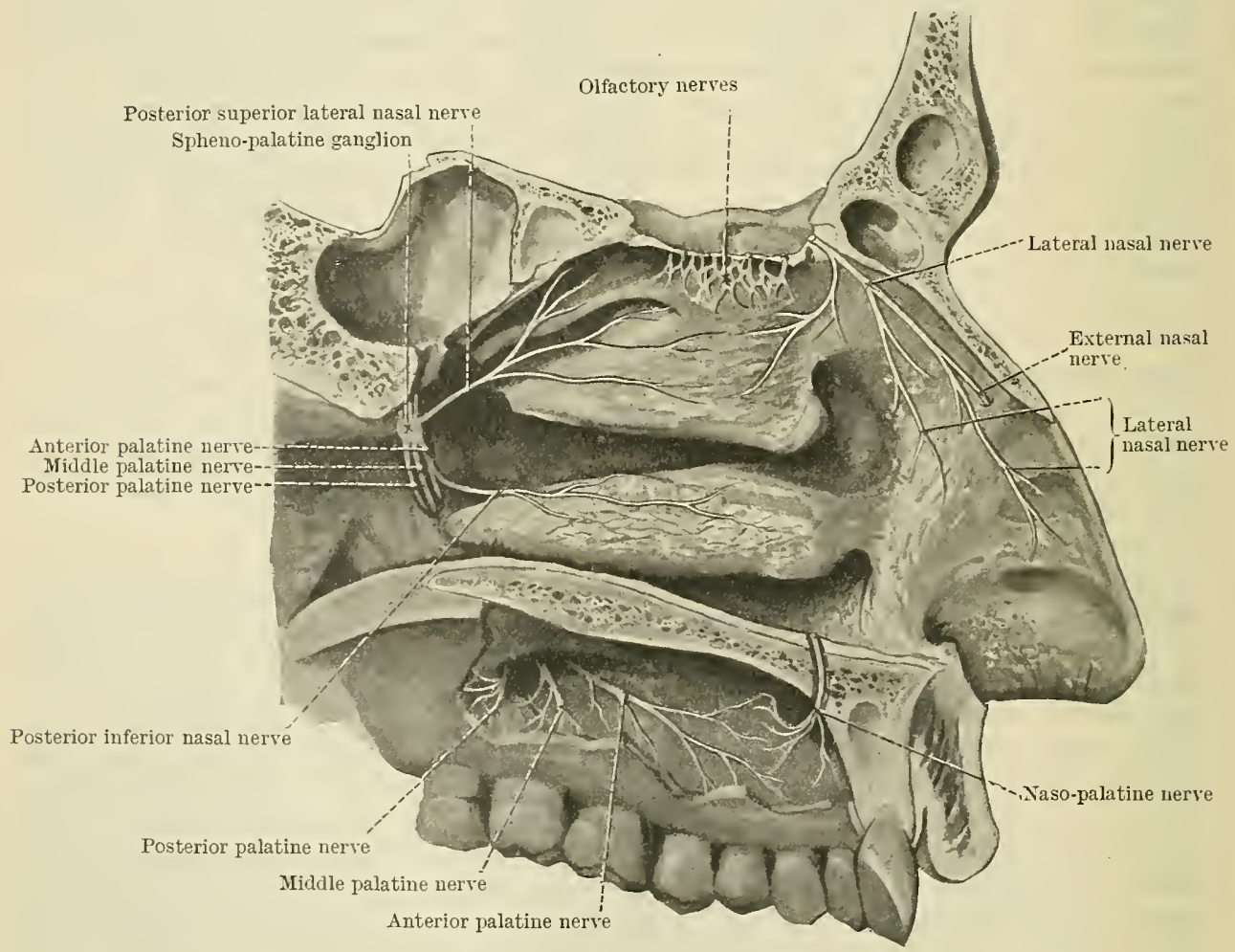

Fig. 650.-Innergyation of Lateral Wall of Nasal Catity and Palate. 


\section{Nervus Maxillaris.}

The Maxillary Nerve.-This large nerve courses forwards from its origin in the semilunar ganglion through the middle fossa of the skull, beneath the dura mater, and in relation to the lower part of the cavernous sinus (Fig. 647, p. 771). Passing through the foramen rotundum, it traverses the pterygo-palatine fossa. It enters the orbit as the infra-orbital nerve, through the inferior orbital fissure, and occupying successively the infra-orbital groove and canal, it finally appears on the face through the infra-orbital foramen (Fig. 653).

The branches and communications of this nerve occur $(a)$ in the cavity of the cranium, $(b)$ in the pterygo-palatine fossa, $(c)$ in the infra-orbital canal, and $(d)$ on the face.

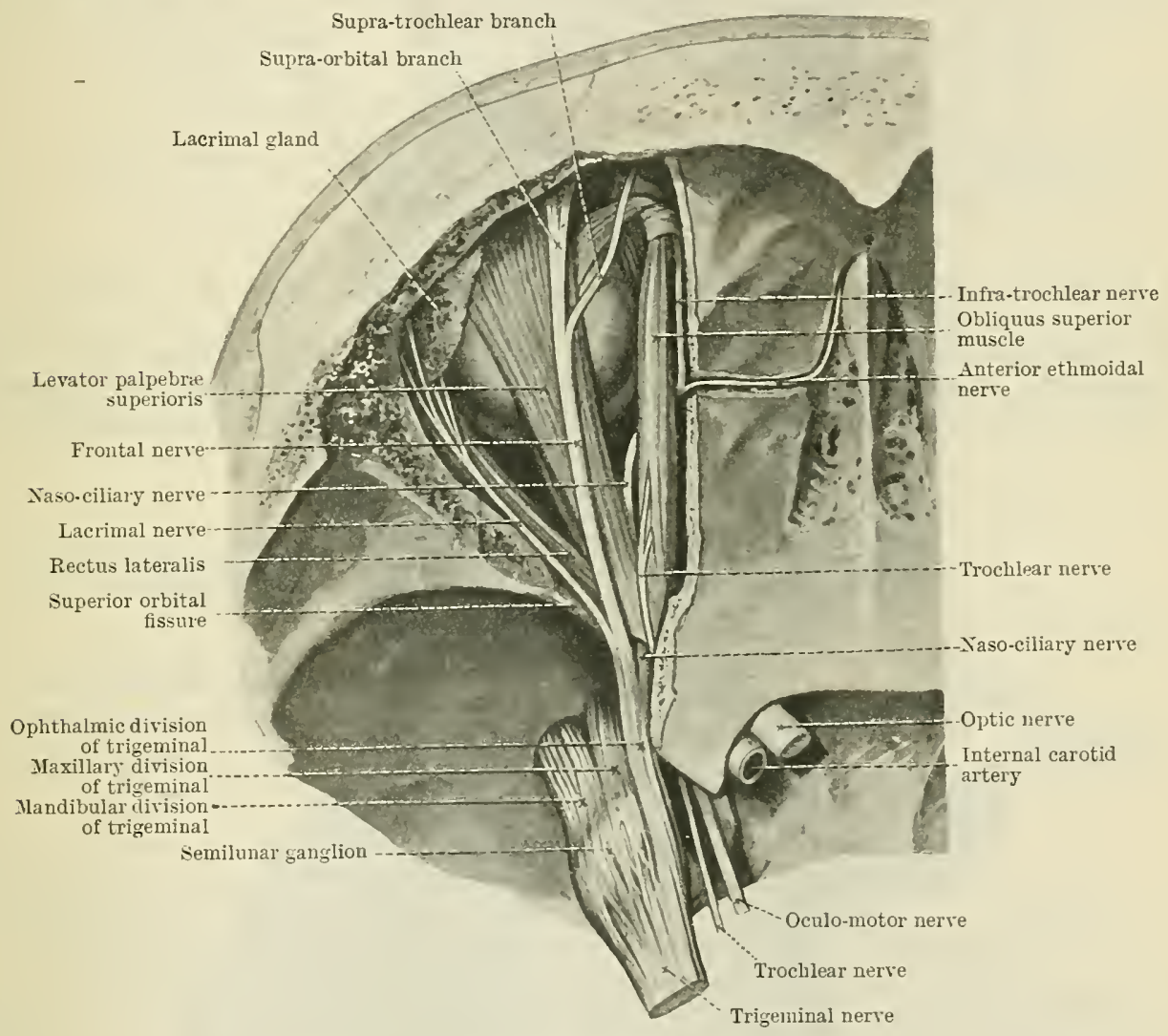

Fig. 651.-The Nerves of the Orbit from ABote.

In the cavity of the cranium the nerve gives off a minute (n. meningeus medius) middle meningeal (O.T. recurrent nerve) to the dura mater of the middle fossa of the skull.

In the pterygo-palatine fossa the nerve gives off-(1) two short thick nn. sphenopalatine (spheno-palatine nerves), the sensory roots of the spheno-palatine ganglion. (2) Rami alveolares superiores posteriores (posterior superior alveolar nerves, which may be double), descend through the pterygo-maxillary fissure to the lateral side of the maxilla, and proceed forwards along the alveolar arch, in company with the posterior superior alveolar artery. They supply the gum and the upper molar teeth by branches which perforate the bone to reach the alveoli. The nerves form a fine plexus joined by the middle alveolar nerve before finally reaching the teeth. (3) A small zygomatic (O.T. orbital) branch enters the orbital cavity through the inferior orbital fissure, and proceeding along the lateral wall, communicates 
with the lacrimal nerve, and passes through the zygomatico-orbital foramen in the zygomatic bone, where it divides into two branches. The zygomatico-facial (O.'T. malar) branch appears on the face, after traversing the zygomatic bone, and supplies

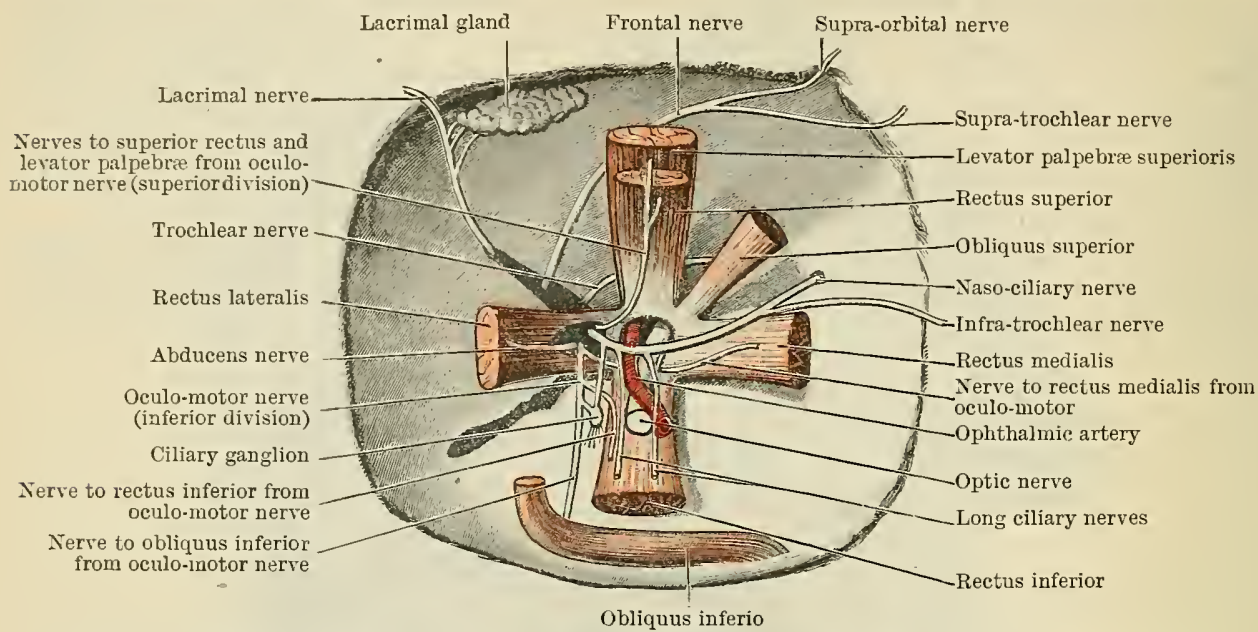

Fig. 652.-Schematic Representation of the Nerves which traverse the Cavity of the ORBit.

the skin over that bone. It communicates with the zygomatic branches of the facial nerve. The zygomatico-temporal (O.T. temporal) branch perforates the temporal surface of the zygomatic bone, and is distributed, after piercing the temporal fascia

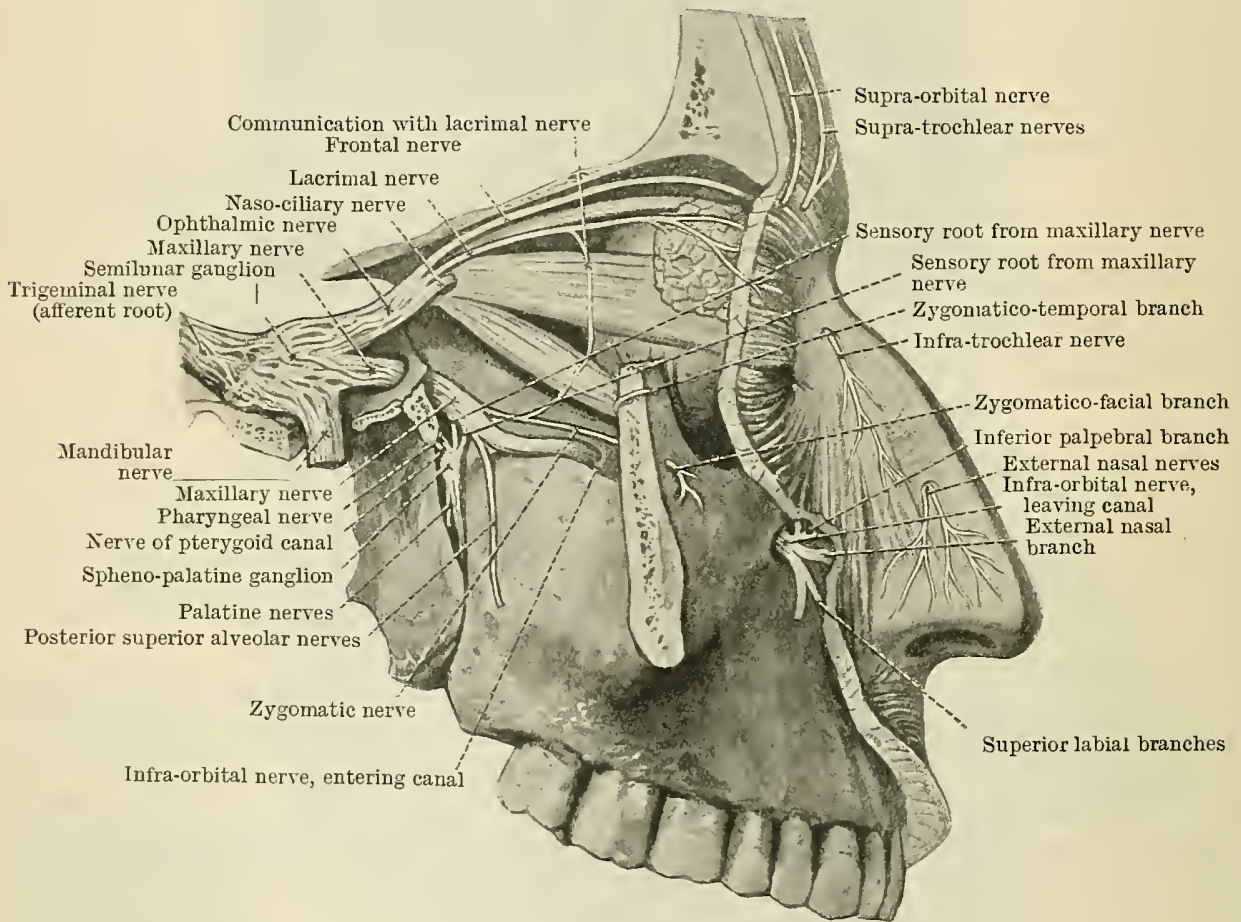

Fig. 653. - The Course of the Ophthalmic and Maxillary Nerves.

to the skin over the anterior part of the temple. It communicates with the temporal branches of the facial nerve. It may be very minute, and not pass further than the temporal fascia, between the two layers of which it may form a communication with the facial nerve. (4) The infra-orbital nerve (n. infraorbitalis) 
is the terminal branch of the maxillary nerre, which enters the orbit through the inferior orbital fissure and traverses the infra-orbital canal to reach the face.

In the infra-orbital canal the infra-orbital nerve supplies one and sometimes two branches to the teeth-the middle and anterior superior alveolar nerves (ramus alveolaris superior medius et rami alveolares superiores anteriores). The former may be only a secondary branch of the latter nerres, or they may arise independently from the infra-orbital nerve. However formed, the nerves descend in bony canals in the wall of the maxillary sinus (to the lining of which branches are given), and reach the alveolar arch, where they form minute plexuses and supply the teeth (joining posteriorly with the branches of the posterior superior alveolar nerve). The anterior superior alveolar nerve supplies the incisor and canine teeth; the middle superior alveolar nerve supplies the premolar teeth.

After emerging on the face from the infra-orbital foramen, the infra-orbital nerve divides into a number of radiating branches arranged in three sets- $(a)$

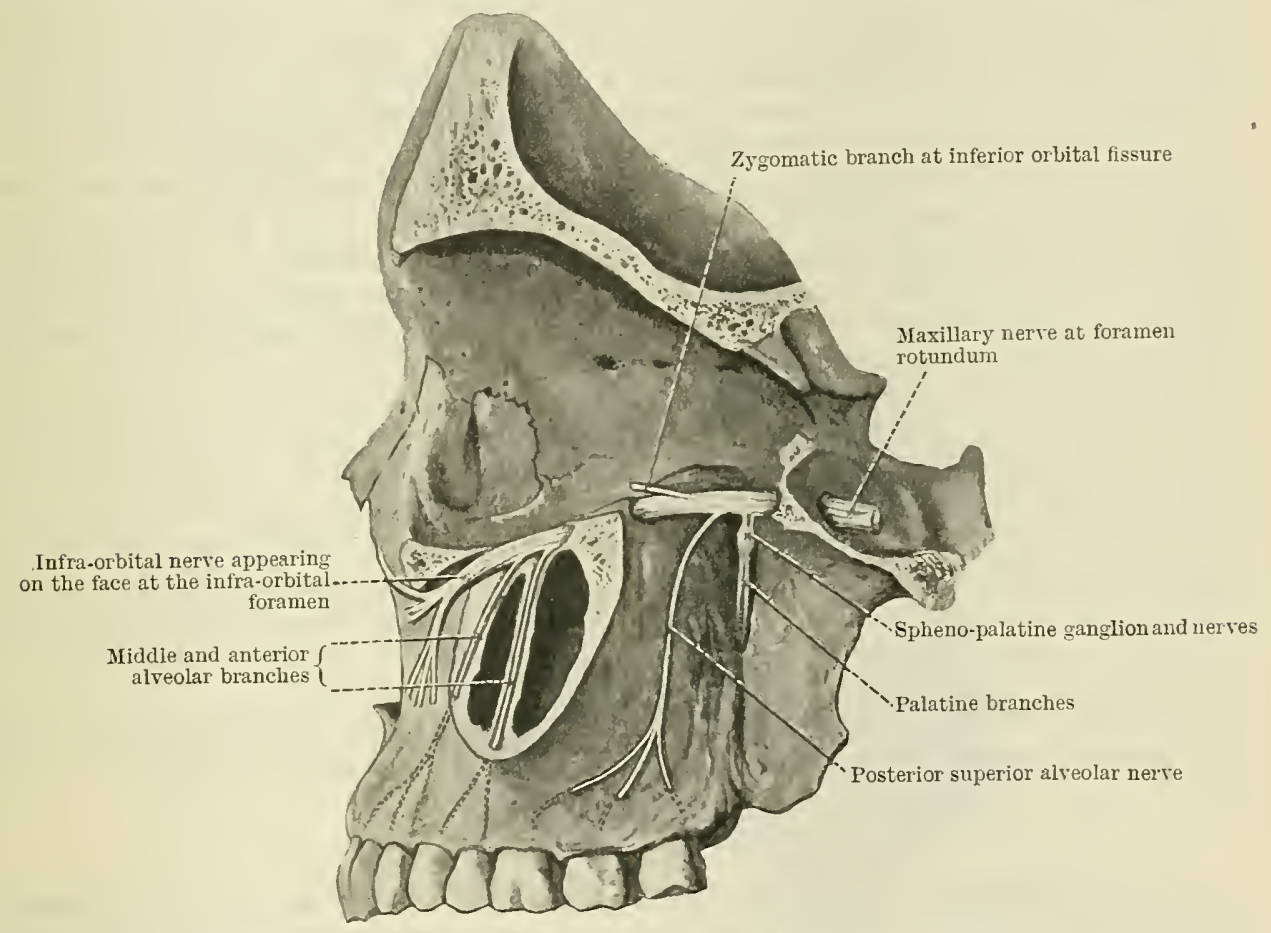

Fig. 654.-Cocrse and Brayches of the Maxillary Nerve.

inferior palpebral (rami palpebrales inferiores), for the lower eyelid; $(b)$ external nasal (rami nasales externi), for the skin of the side of the nose; and (c) superior labial (rami labiales superiores), for the cheek and upper lip. These branches form communications with the zygomatic branches of the facial nerve, and give rise to the infra-orbital plexus (Fig. 657, p. 783).

Ganglion Spheno-palatinum. - The spheno-palatine ganglion occupies the upper part of the pterygo-palatine fossa. It is a small reddish-gray ganglion, suspended from the maxillary nerre by the two spheno-palatine branches which constitute its sensory roots. The motor and sympathetic roots of the ganglion are derived from the nerve of the pterygoid canal. This nerve is formed in the cavity of the skull upon the cartilage filling up the foramen lacerum, by the union of the greater superficial petrosal nerve from the genicular ganglion of the facial nerve (emerging from the temporal bone through the hiatus canalis facialis) with the deep petrosal nerve, a branch of the carotid plexus of the sympathetic on the internal carotid artery. The nerve of the pterygoid canal passes through the pterygoid canal to the pterygo-palatine fossa, where it joins the spheno-palatine ganglion. 
The branches from the ganglion are seven in number.

(a) The pharyngeal branch passes backwards through the pharyngeal canal to supply the mucous membrane of the roof of the pharynx.

(b) Nervi Palatini.-The palatine nerves, three in number, are directed downwards to the palate through the palatine canals. The large n. palatinus anterior (anterior palatine nerve) emerges on the under surface of the palate through the greater palatine foramen, and at once separates into numerous branches for the supply of the mucous membrane of the soft and the hard palate. Its anterior filaments communicate with branches of the naso-palatine nerve. The main nerve gives off, as it lies in the palatine canal, a small posterior inferior lateral nasal nerve (rami nasales posteriores inferiores laterales), which enters the nasal cavity and supplies the mucous membrane of the lower part of its lateral wall. The n. palatinus medius (middle palatine nerve) descends through a small palatine canal, and, piercing the pyramidal process of the palate bone, is distributed to the mucous membrane of the soft palate, uvula, and palatine tonsil. It possibly conveys motor fibres to the levator veli palatini and uvular muscles. The n. palatinus posterior (posterior palatine nerve) consists of one or more small twigs which pass through lesser palatine canals, and supply branches to the mucous membrane of the tonsil, soft palate, and uvula.

(c) The branches directed medially from the spheno-palatine ganglion enter the nasal cavity through the spheno-palatine foramen. They are two in number-the posterior superior lateral nasal and the naso-palatine. The posterior superior lateral nasal branch (rami nasales posteriores superiores laterales) is a small nerve destined for the mucous membrane of the superior and posterior part of the lateral wall of the nasal cavity. The $n$. nasopalatinus (naso-palatine nerve), after passing through the spheno-palatine foramen, crosses the roof of the nasal cavity, and extends obliquely downwards and forwards along the nasal septum, grooving the vomer in its course, to reach the incisive foramen near the front of the hard palate. The nerves pass through the subordinate median foramina (of Scarpa), the left nerve in front of the right. In the incisive foramen the two nerves communicate together. They then turn backwards and supply the mucous membrane of the hard palate. They communicate posteriorly with terminal filaments of the anterior palatine nerves. In its course through the nasal cavity the naso-palatine nerve furnishes collateral branches to the mucous membrane of the roof and septum of the nose (posterior superior medial branches) (Fig. 649, p. 774).

(d) Rami Orbitales. - The orbital branches, one or more minute branches, pass upwards to the periosteum of the orbit from the spheno-palatine ganglion.

\section{Nervus Mandibularis.}

The mandibular nerve is formed by the union of two roots; a large sensory root, from the semilunar ganglion, and the small motor root of the trigeminal nerve, which is wholly incorporated with this trunk. The two roots pass together beneath the dura mater of the middle fossa of the base of the skull to the foramen ovale, through which they emerge into the infra-temporal fossa. Outside the skull they combine to form a single trunk, which soon separates into anterior and posterior divisions.

At its emergence from the skull the nerve is deeply placed beneath the middle of the zygomatic arch, and is concealed by the ramus of the mandible, and by the masseter, temporal, and external pterygoid muscles.

The branches of the nerve may be divided into two series-(1) those derived from the undivided nerve, and (2) those derived from its terminal divisions.

The branches of the undivided nerve are two in number. (a) A small nervus spinosus (O.T. recurrent nerve) arises just outside the skull, and accompanying the middle meningeal artery through the foramen spinosum, supplies the dura mater. (b) In the infra-temporal region a small branch arises for the supply of the internal pterygoid muscle. This nerve forms a connexion with the otic ganglion.

The terminal divisions of the nerve are a small anterior and a large posterior trunk.

The small anterior trunk (nervus masticatorius or masticator nerve) passes 
downwards and forwards beneath the external pterygoid muscle, and separates into the following branches:-(1) A branch for the external pterygoid muscle, which supplies it on its deep surface; (2) a branch to the masseter muscle (n. massetericus), which passes over the superior border of the external pterygoid and through the mandibular notch of the mandible; (3) and (4) two deep temporal branches (nn. temporales profundi) anterior and posterior to the temporal muscle, which also ascend above the external pterygoid muscle; and (5) the n. buccinatorius (buccinator (O.T. buccal) nerve), which passes obliquely forwards between the two heads of the external pterygoid to reach the buccinator muscle. This nerve is sensory, and its fibres are in part distributed to the skiu of the cheek (communieating with buccal branches of the facial nerve); they are also in part distributed to the mucous membrane of the inside of the mouth, to reach which they pierce

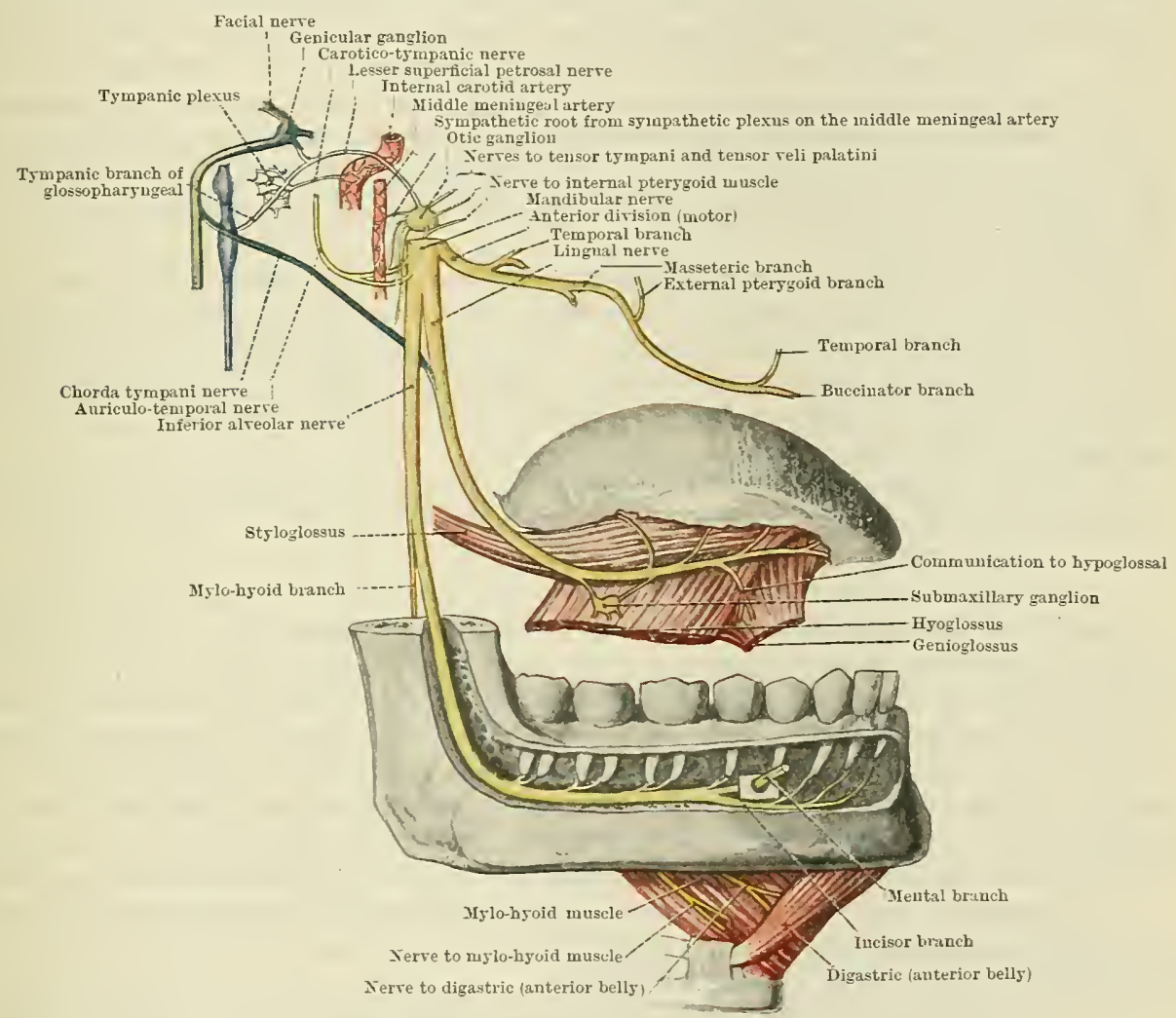

Fig. 655.-The Mindibular Nerte.

the fibres of the buccinator muscle. The buccinator nerve usually supplies a third branch to the temporal muscle, after emerging between the two heads of the external pterygoid muscle (Fig. 655).

The large posterior trunk extends downwards a short way beneath the external pterygoid muscle. After giving off by two roots the auriculo-temporal nerve, it ends by dividing into two, the lingual and the inferior alveolar nerres.

N. Auriculotemporalis. - The auriculo-temporal nerve is formed by the union of two roots which embrace the middle meningeal artery. The nerve passes backwards beneath the external pterygoid muscle and between the spheno-mandibular ligament and the neck of the mandible. After passing through the parotid gland, it is directed upwards to the temple over the zygoma, in company with the superficial temporal artery. It is finally distributed as a cutaneous nerve of the temple and scalp, and reaches almost to the vertex of the skull.

The auriculo-temporal nerve gives off the following branches:-(1) A small branch to the mandibular articulation. (2) Branches to the parotid gland (rami 
parotidei). (3) A twig for the supply of the skin of the external acoustic meatus and membrana tympani (n. meatus auditorii externi et ramus membranæ tympani). (4) Branches to the superior half of the auricle on its lateral aspect. (5) Terminal branches to the skin of the temple and scalp (rami temporales superficiales).

It has the following communications with other nerves:-(1) Important communications are effected by the roots of the nerve, which are separately joined by small branches from the otic ganglion. (2) The parotid branches of the nerve are connected with branches of the facial nerve in the substance of the gland (rami anastomotici c. nervo faciali). (3) The temporal branch of the nerve is in communication superficially with the temporal branches of the facial nerve.

N. Lingualis.-The lingual nerve is the smaller of the two terminal branches of the posterior division of the mandibular trunk. It proceeds downwards in front of the inferior alveolar nerve, beneath the external pterygoid muscle, to its inferior border. After passing between the internal pterygoid muscle and the ramus of the mandible, it crosses beneath the mucous membrane of the floor of the mouth in the interval between the mylo-hyoid and hyoglossus muscles and beneath the duct of the submaxillary gland. It sweeps forwards and medially to the side of the tongue, to the mucous membrane over the anterior two-thirds of which it is distributed.

Two nerves communicate with the lingual nerve in its course to the tongue :(1) The chorda tympani branch of the facial nerve joins it beneath the external pterygoid muscle, and is incorporated with it in its distribution to the tongue. (2) The hypoglossal nerve forms larger or smaller loops of communication with the lingual nerve as they course forwards together over the hyoglossus muscle (rami anastomotici cum nervo hypoglosso).

Besides supplying the aforesaid branches to the mucous membrane over the sides and dorsum of the tongue in its anterior two-thirds, the lingual nerve supplies the mucous membrane of the lateral wall and floor of the mouth. It also assists, along with the chorda tympani nerve, in forming the roots of the submaxillary ganglion.

Ganglion Submaxillare. - The submaxillary ganglion is a minute reddish ganglion placed on the hyoglossus muscle, between the lingual nerve and the duct of the submaxillary gland. It is suspended from the former by two trunks, consisting for the most part of fibres of the lingual and chorda tympani nerves, which at this point become separated from the lingual nerve and incorporated with the ganglion. The roots of the ganglion are-(1) an afferent root, derived from the lingual nerve; (2) an efferent root, derived from the chorda tympani; and (3) a sympathetic root, from the sympathetic plexus upon the external maxillary artery.

The branches from the ganglion are distributed to the submaxillary gland and duct (rami submaxillares), and by fibres which become reunited with the trunk of the lingual nerve, to the sublingual gland.

N. Alveolaris Inferior. - The inferior alveolar nerve (O.T. inferior dental) is larger than the lingual nerve. It passes from beneath the inferior border of the external pterygoid muscle to reach the interval between the ramus of the mandible and the spheno-mandibular ligament. Entering the mandibular canal through the mandibular foramen, it traverses the substance of the ramus and body of the mandible, distributing branches in its course to the teeth. A fine plexus is formed by the dental branches before they finally supply the teeth.

Branches and Communications.-(1) N. Mylohyoideus. - The mylo-hyoid nerve is a small branch arising just before the inferior alveolar nerve passes through the mandibular foramen. Grooving the ramus in its course, it descends into the submaxillary triangle on the superficial aspect of the mylo-hyoid muscle. Concealed in this situation by the submaxillary gland and the external maxillary artery, it is distributed to the mylo-hyoid and anterior belly of the digastric muscles. (2) N. Mentalis. - The mental branch of the inferior alveolar nerve is a trunk of considerable size arising from the main nerve in the mandibular canal. It emerges from the mandible through the mental foramen, and is distributed by many branches to the chin and lower lip. It communicates beneath the facial muscles with the ramus marginalis mandibulæ of the facial nerve (Fig. 657, p. 783). (3) The incisor 
branch is the terminal part of the inferior alveolar nerve remaining after the origin of the mental branch. It supplies the incisor and canine teeth.

Ganglion Oticum. - The otic ganglion is situated deep to the mandibular nerve just below the foramen ovale. Like the other ganglia described above, it possesses three roots:-(1) A motor root, derived from the nerve to the internal pterygoid muscle; (2) a sensory root, formed by the smaller superficial petrosal nerve from the tympanic plexus (through which communications are effected with the tympanic branch of the glossopharyngeal nerve, and a branch from the genicular ganglion of the facial nerve); (3) a sympathetic root, from the plexus on the middle meningeal artery (Fig. 656).

Five branches arise from the ganglion-three communicating and two motor branches. The three communicating nerves are fine branches which join respectively the nerve of the pterygoid canal, the roots of the auriculo-temporal, and the chorda tympani nerve. The two motor nerves supply the tensor tympani and tensor reli palatini muscles.

Summary.-The trigeminal, the largest and most complex of the cerebral nerves, is (1) the chief sensory nerve for the face, the anterior half of the scalp, the orbit and eyeball, the nose and nasal cavity, the lips, teeth, mouth, and anterior two-thirds of the tongue; (2) the motor fibres of the nerve supply the muscles of mastication, the mylo-hyoid and anterior belly of the digastric, possibly the levator veli palatini and uvular muscle (through the spheno-palatine ganglion), and the tensor tympani and tensor veli palatini muscles (through the otic ganglion); (3) through the ganglia placed on the three divisions of the nerve, not only are important organs, areas, and muscles innervated, but communications are also effected with the sympathetic system, with the oculo-motor nerve (ciliary ganglion), facial nerve (spheno-palatine and otic ganglia), and glossopharyngeal nerve (otic ganglion).

In its distribution to the skin of the face the branches of the fifth nerve present two striking peculiarities:-(1) While the branches to the skin reach the surface at many points and in diverse ways, the three main divisions are severally, by their branches, responsible for the supply of three clearly demarcated cutaneous areas (Fig. 648, p. 772). (2) By numerous communications with the facial nerve, sensory fibres are given to the muscles of expression supplied by the facial nerve.

\section{Nervus ABDUCENS.}

The sixth or abducens nerve issues from the brain at the inferior border of the pons, just above the pyramid of the medulla oblongata (for the deep origin, see p. 600). It is directed forwards, and pierces the dura mater in the posterior fossa of the base of the skull alongside the dorsum sellæ (Fig. 647, p. 771). It then occupies the medial wall of the cavernous sinus and is placed on the lateral side of the internal carotid artery. It passes through the superior orbital fissure below the oculo-motor and naso-ciliary nerves and between the two heads of the lateral rectus muscle (Fig. 652, p. 776). In the cavity of the orbit it supplies the lateral rectus muscle on its deep (ocular) surface.

Communications. - In the wall of the cavernous sinus the sixth nerve receives two communicating filaments :-(1) From the carotid plexus of the sympathetic, and (2) from the ophthalmic division of the trigeminal nerve.

\section{Nervus Factalis.}

The seventh or facial nerve emerges from the brain at the inferior border of the pons, below the trigeminal nerve and medial to the acoustic nerve (for the deep origin, see p. 598). Between it and the latter nerve is the minute nervus intermedius (Fig. 656, p. 782). The facial nerve passes through the internal acoustic meatus, and through the canalis facialis in the petrous portion of the temporal bone, emerges at the base of the skull by the stylo-mastoid foramen, and passes forwards through the parotid gland to supply the muscles of the face. In the internal acoustic meatus the nerve is placed upon the acoustic nerve, the nervus intermectius intervening. In the canalis facialis the nerve first passes backwards on the medial side of the tympanum, and then downwards behind the tympanum, in the medial wall of the tympanic antrum. In the parotid gland the nerve crosses the external carotid artery and the posterior facial vein superficially. On the face its branches radiate from the anterior border of the parotid gland and enter the deep surface of the facial muscles. 
Branches and Communications.-(i.) In the internal acoustic meatus the nervus intermedius, lying between the facial and acoustic, sends communicating branches to both nerves. The branch to the acoustic nerve probably separates from it again to join the genicular ganglion of the facial nerve.

(ii.) In the canalis facialis the ganglion geniculi is formed at the point where the facial nerve bends backwards. It is an oval swelling on the nerve, and is joined by a branch from the upper (vestibular) trunk of the acoustic nerve, by which it probably receives fibres of the mervus intermedius. From the ganglion three small nerves arise:-(1) The greater superficial petrosal nerve passes forwards through the hiatus canalis facialis to the middle fossa of the skull. On the upper surface of the foramen lacerum it is joined by the deep petrosal nerve from the sympathetic plexus on the internal carotid artery to form the nerve of the pterygoid canal, which, after traversing the pterygoid canal, ends in the spheno-palatine ganglion. (2) A minute nerve (ramus ancstomoticus cum plexu tympanico) pierces the temporal bone and joins the tympanic branch of the glosso-

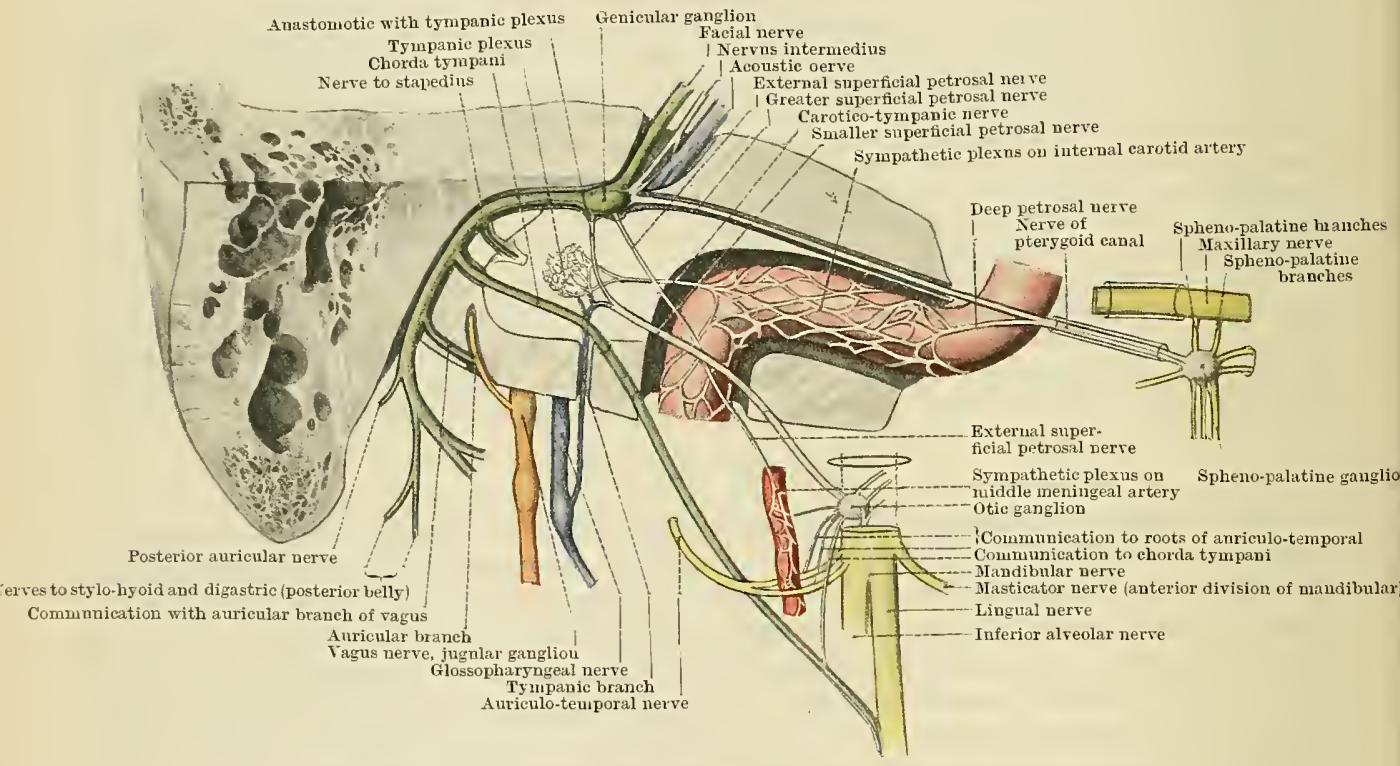

Fig. 656.-The Connexions of the Facial Nerve in the Temporal Bone.

pharyngeal in the substance of the bone. By their union the lesser superficial petrosal nerve is formed, which pierces the temporal bone and ends in the otic ganglion. (3) The external superficial petrosal nerve is a minute inconstant branch which joins the sympathetic plexus on the middle meningeal artery.

In the course of the facial nerve in the lower part of the canalis facialis, behind the tympanum, three branches arise-(1) $\mathbf{N}$. Stapedius.-The small nerve to the stapedius muscle, which passes forwards to the tympanum. (2) Chorda Tympani.-The chorda tympani nerve (probably associated with the nervus intermedius), which enters the tympanic cavity through the tympanic aperture of the canaliculus chordce, passes over the membrana tympani and the handle of the malleus, and leaves the cavity through the medial end of the petro-tympanic fissure to reach the infra-temporal fossa. Beneath the external pterygoid muscle it becomes incorporated with the lingual branch of the mandibular nerve, and in its further course is inseparable from that nerve. It supplies a root to the submaxillary ganglion, and is finally distributed to the side and dorsum of the tongue in its anterior two-thirds. The chorda tympani nerve receives, beneath the external pterygoid muscle, a fine communication from the otic ganglion. (3) Before it leaves the canalis facialis a fine communicating branch arises from the facial nerve to join the auricular branch of the vagus nerve. 
(iii.) In the neck the facial nerve gives off three muscular branches: (1) and (2) Ramus Stylohyoideus, Ramus Digastricus.-Small branches supply the stylo-hyoid and the posterior belly of the digastric, the latter nerve sometimes communicating with the glossopharyngeal. (3) N. Auricularis Posterior.-The posterior auricular nerve bends backwards and upwards over the anterior border of the mastoid process along with the posterior auricular artery. It divides into two branches-an auricular branch for the posterior auricular muscle and the intrinsic muscles of the auricle, and an occipital branch for the occipital belly of the epicranius muscle.

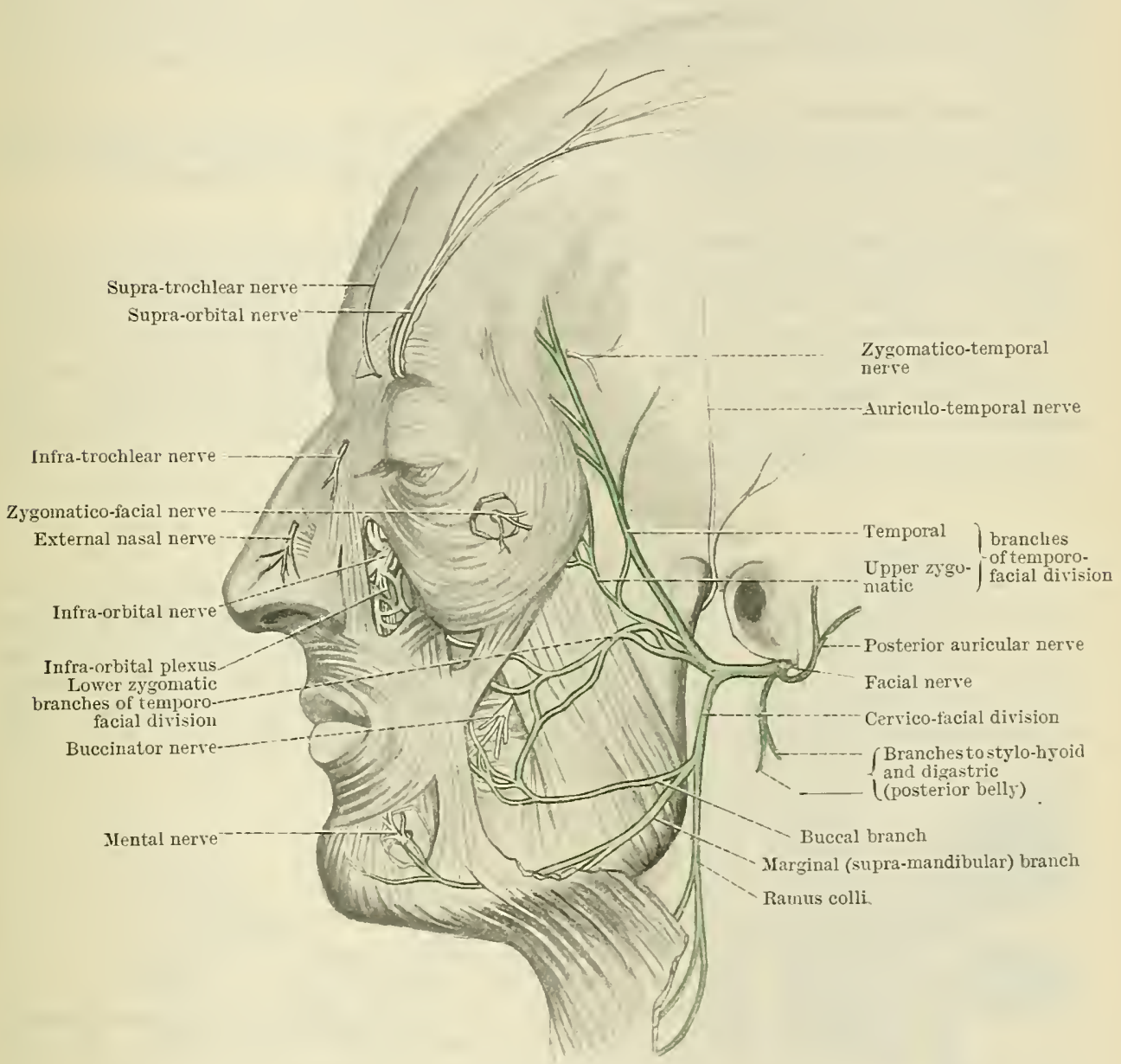

Fig. 657. The Distribution of the Trigemixal and Factal Nertes on the Face.

The posterior auricular nerve communicates with the great auricular, lesser occipital, and auricular branch of the vagus nerves in its course.

(iv.) In the parotid gland the facial nerve spreads out in an irregular series of branches (plexus parotideus), indefinitely divided into a temporo-facial and a cervicofacial division. Communications occur in the substance of the gland between the main trunks and the great auricular and auriculo-temporal nerves.

The temporo-facial division gives off two series of subordinate branches which radiate forwards and upwards from the parotid gland.

1. Rami Temporales.-The temporal branches are of large size, and, sweeping out of the parotid gland over the zygomatic arch, are distributed to the orbicularis oculi, frontalis, corrugator supercilii, auricularis anterior and superior. The temporal branches communicate in their course with the auriculo-temporal, zygomaticotemporal, lacrimal, and supra-orbital branches of the trigeminal nerve. 
2. Rami Zygomatici.-The upper zygomatic branches are small, and sometimes are inseparable from the temporal or lower zygomatic nerves. Extending forwards across the zygomatic bone, they supply the orbicularis oculi and zygomatic muscle, and communicate with the zygomatico-facial branch of the maxillary nerve.

The lower zygomatic branches are of considerable size. Passing forwards over the masseter muscle in company with the parotid duct, they supply the orbicularis oculi, the zygomaticus, buccinator, and the muscles of the nose and upper lip. The infra-orbital plexus is formed by the union of these nerves with the infra-orbital branch of the maxillary nerve below the lower eyelid. Smaller communications occur with the infra-trochlear and nasal nerves on the side of the nose.

The cervico-facial division of the facial nerve supplies three series of secondary branches.

1. Rami Buccales.-The buccal branch (or branches) extends forwards to the angle of the mouth to supply the muscles converging to the month, including the buccinator. It communicates with the buccinator branch of the mandibular nerve in front of the anterior border of the masseter muscle.

2. Ramus Marginalis Mandibulæ. - The marginal branch of the mandible (O.T. supramandibular) passes along the mandible to the interval between the lower lip and chin, and supplies the triangularis oris, quadratus labii inferioris, and orbicularis oris. It communicates with the mental branch of the inferior alveolar nerve.

3. Ramus Colli. - The cervical branch (O.T. infra-mandibular) emerges from the parotid gland near its lower end, and sweeps forwards below the angle of the mandible to the front of the neck. It supplies the platysma, and forms loops of communication with the nervus cutaneus colli.

\section{Nervus Acusticus.}

The eighth or acoustic nerve (O.T. auditory) arises from the brain by two roots, medial and lateral. The medial, vestibular root emerges between the olive and the restiform body. The lateral, cochlear root, continuous through the cochlear nucleus with the striæ medullares of the fourth ventricle, winds round the lateral side of the restiform body (for the deep connexions, see p. 604). The two roots unite with one another to form the trunk of the nerve, which is attached to the

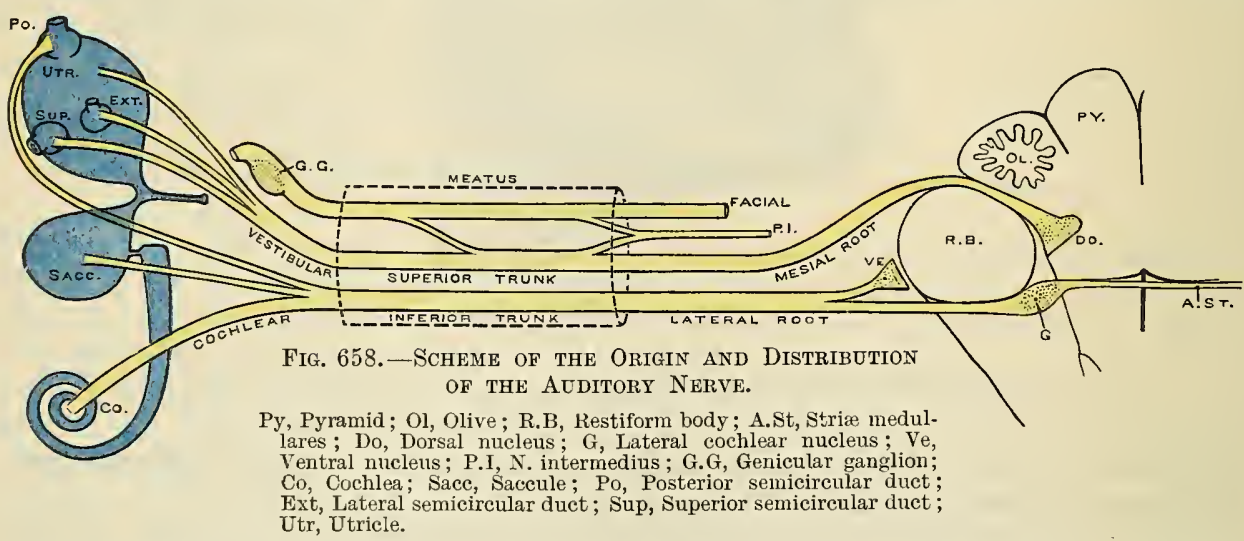

brain on the lateral side of the facial nerve and nervus intermedius at the posterior border of the pons (Fig. 643, p. 768).

The nerve passes laterally through the internal acoustic meatus, lying beneath the facial nerve and nervus intermedius (Fig. 647, p. 771). In the meatus its two component parts separate from one another, forming a superior or vestibular trunk continnous with the medial root, and an inferior or cochlear trunk continuous with the lateral root. These trunks again subdivide, and piercing the lamina cribrosa, supply the several parts of the labyrinth.

N. Vestibuli. - The superior or vestibular nerve in the internal acoustic meatus usually receives fibres from the nervus intermedius, and gives off a communicating 
branch to the genicular ganglion of the facial nerve. It then separates into three terminal branches which pierce the lamina cribrosa. (1) N. Utricularis. - The utricular nerve supplies the macula acustica of the utricle. (2) and (3) N. Ampullaris Superior et Lateralis.-The superior and lateral ampullary nerves supply the ampullæ of the superior and lateral semicircular ducts.

N. Cochleæ.-The inferior or cochlear nerve gives off (1) n. saccularis, a saccular nerve to the macula acustica of the saccule, (2) n. ampullaris inferior, an inferior ampullary nerve to the ampulla of the posterior semicircular duct, and (3) is continued through the lamina cribrosa to the labyrinth as the cochlear nerve, which is distributed through the modiolus and osseous spiral lamina to the organ of Corti in the cochlea.

Both the vestibular and cochlear nerves contain among their fibres collections of nerve cells, forming in each nerve a distinct ganglion-the vestibular ganglion on the vestibular trunk, and the ganglion spirale or spiral ganglion of the cochlea on the cochlear trunk.

\section{Nervus Glossopharyngeus.}

The ninth or glossopharyngeal nerve (Fig. 643, p. 768) arises from the brain by five or six fine fila radicularia (radicles) which emerge from the medulla oblongata between the olive and the restiform body, close to the facial nerve above, and in series with the fila of the vagus nerve below (for the deep connexions, see p. 596). The fila combine to form a nerve which passes through the jugular foramen, along with the vagus and accessory nerves, but enveloped in a separate sheath of dura mater (Fig. 647, p. 771). Reaching the neck, the nerve arches downwards and forwards to the interval between the hyoid bone and the mandible. It lies at first between the internal carotid artery and the internal jugular vein, and then between the internal and external carotid arteries, in its course to the side of the pharynx. It sweeps round the stylopharyngeus muscle and the stylo-hyoid ligament, and disappears beneath the hyoglossus muscle, to reach its termination in the tongue.

The branches of the nerve may be classified in three series according to their origin-(i.) in the jugular foramen; (ii.) in the neck; (iii.) in relation to the tongue.

In the jugular foramen there are two enlargements upon the trunk of the nerve-the superior and petrous ganglia. The superior ganglion (O.T. jugular) is small, does not implicate the whole width of the nerve, and may be fused with the petrous ganglion, or even absent altogether. No branches arise from it.

Ganglion Petrosum.-The petrous ganglion is distinct and constant. It is placed upon the nerve at the lower part of its course through the jugular foramen. 
Branches and Communications of the Petrous Ganglion.-N. Tympanicus.-The tympanic branch is the most important offset from this ganglion. It passes through a small canal in the bridge of bone between the jugular foramen and the carotid canal to reach the cavity of the tympanum, where it breaks up into branches, to form, along with branches from the carotid plexus of the sympathetic on the internal carotid artery (nn. caroticotympanici superior et inferior, O.T. small deep petrosal), the plexus tympanicus Jacobsoni (tympanic plexus), for the supply of the mucous lining of the tympanum, mastoid cells, and auditory tube (Fig. 656, p. 782). The fibres of the tympanic branch of the glossopharyngeal nerve become reunited to form, by their union with a small nerve from the genicular ganglion of the facial nerve (anastomotic with the tympanic plexus), the lesser superficial petrosal nerve in the substance of the temporal bone. This passes forwards through the temporal bone, and eventually joins the otic ganglion.

Besides forming the tympanic branch, the petrous ganglion of the glossopharyngeal nerve communicates with three other nerves-(1) with the superior cervical ganglion of the sympathetic; (2) with the auricular branch of the vagus; and (3) sometimes with the jugular ganglion of the vag'us.

In the neck the glossopharyngeal nerve gives off two branches. (1) As it crosses over the stylopharyngeus muscle it supplies the nerve to that muscle (ramus stylopharyngeus), fibres of which pierce the muscle to reach the mucous membrane of the pharynx. (2) Rami Pharyngei.-The pharyngeal branches of the nerve supply the mucous membrane of the pharynx directly after piercing the superior constrictor muscle, and indirectly after joining, along with the pharyngeal offsets from the vagus and the superior cervical ganglion of the sympathetic, in the formation of the pharyngeal plexus.

The terminal branches of the nerve supply the mucous membrane of the tongue and adjacent parts. Rami Tonsillares. - A tonsillar branch forms a plexus to supply the mucous membrane covering the tonsil, the adjacent part of the soft palate, and the palatine arches. Rami Linguales.-Lingual branches supply the mucous membrane of the dorsal third and lateral half of the tongue, extending backwards to the glosso-epiglottic folds and the front of the epiglottis.

\section{Nervus Vagus.}

The tenth or vagus nerve (O.T. pneumogastric) arises from the brain by numerous fila radicularia attached to the anterior margin of the restiform body of the medulla oblongata, in series with the glossopharyngeal nerve above and the accessory nerve below it (for the deep connexions, see p. 656). The fila of the nerve unite to form a single trunk which emerges in the neck through the jugular foramen.

In the jugular foramen the nerve occupies the same sheath of dura mater as the accessory nerve, and is placed behind the glossopharyngeal nerve. Two ganglia are present on the trunk in this situation. The higher and smaller is the jugular ganglion; the lower and larger is the ganglion nodosum.

In the neck the vagus nerve pursues a vertical course in front of the vertebral column. It occupies the carotid sheath, lying between and behind the internal and common carotid arteries and the internal jugular vein. It enters the thorax behind the large veins : on the right side, after crossing over the subclavian artery; on the left side, in the interval between the left common carotid and subclavian arteries.

In the thorax the nerves occupy the superior and posterior mediastinal spaces, and their relations are different on the two sides. (a) In the superior mediastinum the right nerve continues its course alongside the innominate artery and the trachea, and behind the right innominate vein and superior vena cava, to the posterior surface of the root of the lung. The left nerve courses downwards between the left common carotid and subclavian arteries, and behind the left innominate vein and the phrenic nerve. It passes over the aortic arch, and then proceeds to the posterior surface of the root of the left lung. (b) In the posterior mediastinum the vagi nerves are concerned in the formation of two great plexuses-the pulmonary and the osophageal. Behind the root of each lung the nerve breaks up to form 


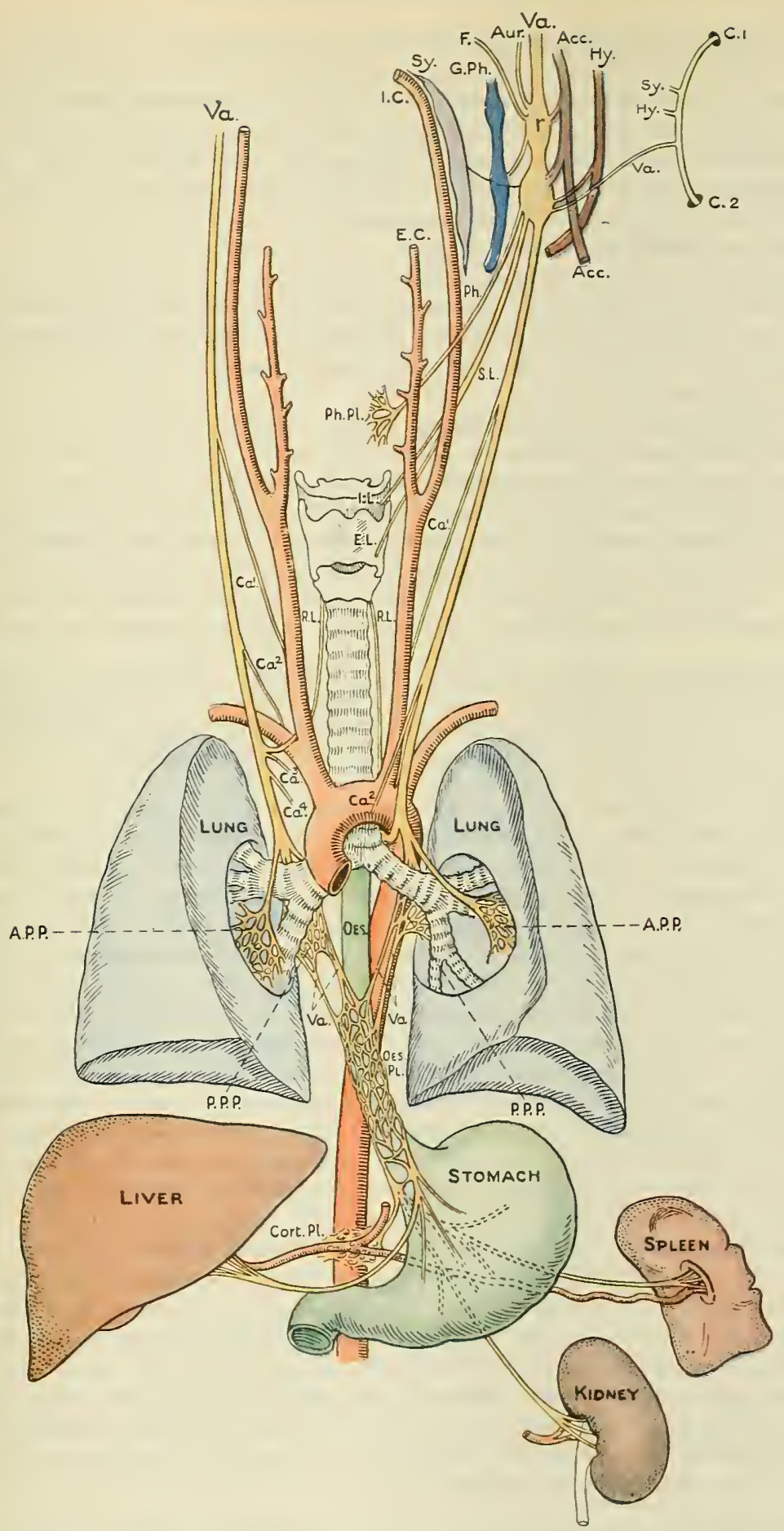

Fig. 660.-The Distribetiox of the Vilil's Nerve.

Va, Right and left vagi; r, Ganglion jugulare and connexions with Sy, Sympathetic, superior cerrical ganglion ; G.Ph, Glossopharyngeal; Acc, Accessory nerve; F, Meningeal branch; Anr, Auricular branch; Va, Connexion with ganglion nodosum of vagus; Sy, Nerve to stylo-byoid; $\mathrm{Hy}$, Nerve to hyoglossus; $\mathrm{Cl}$, C2, Loop between the first two cervical nerves; Sy. Sympathetic, superior cervical ganglion; Acc, Accessory nerve; Ph. Pharyngeal branch; Ph.Pl, Pharyngeal plexus ; S.L, Superior laryngeal nerve ; I.L, Internal laryngeal branch; E.L, External laryngeal branch; I.C, Internal, and E.C, External carotid arteries: Cal, Superior cervical cardiac branch; Ca2, Inferior cervical cardiac branch: P.L, Recurrent nerve; Ca3, Cardiac branches from recurrent werves; Cat, Thoracic cardiac branch (right vagus); A.P.P, Anterior, and P.P.P, Posterior pulmonary plexuses; Oes.Pl, Esoplageal plexus; Cort.Pl, Coeliac plexus. 
the large posterior pulmonary plexus, from the lower end of which two nerves emerge on each side. These nerves on the right side pass obliquely over the vena azygos; on the left side they cross the descending thoracic aorta. Both series reach the cesophagus, and divide into small anastomosing branches which form the œsophageal plexus. At the cesophageal opening of the diaphragm the two nerves become separated from the plexus, and entering the abdomen-the left nerve in front of the esophagus, the right nerve behind it-they terminate by supplying the stomach and other abdominal organs.

The communications and branches of the vagus nerve may be described as (i.) ganglionic, (ii.) cervical, (iii.) thoracic, and (iv.) abdominal (Fig. 660).

Ganglion Jugulare.--The jugular ganglion (O.T. ganglion of the root) is small and spherical. It occupies the jugular foramen, and gives off two branchesmeningeal and auricular.

Ramus Meningeus. - The meningeal branch passes backwards to supply the dura mater of the posterior fossa of the skull.

Ramus Auricularis. - The auricular branch ascends to the ear in a fissure between the jugular and stylo-mastoid foramina. It receives near its origin a twig from the tympanic branch of the glossopharyngeal nerve, and usually communicates with the facial nerve by a branch arising from the latter in the canalis facialis. The nerve is distributed to the back of the auricle and the external acoustic meatus, and communicates superficially with the posterior auricular nerve.

Communications.--Besides supplying the meningeal and auricular branches, this ganglion receives communications from (1) the superior cervical ganglion of the sympathetic; (2) the accessory nerve; and (3) (sometimes) the petrous ganglion of the glossopharyngeal nerve (ramus anastomoticus cum nervo glossopharyngeo).

Ganglion Nodosum. - The ganglion nodosum (O.T. ganglion of the trunk), placed immediately below the preceding, is large and fusiform. Like the jugular ganglion, it supplies two branches-the pharyngeal and superior laryngeal nerves.

Rami Pharyngei. - The pharyngeal branch receives its fibres (through the ganglion) from the accessory nerve. It passes obliquely downwards and medially to the pharynx between the internal and external carotid arteries, and combines with the pharyngeal branches from the glossopharyngeal and superior cervical ganglion of the sympathetic to form the pharyngeal plexus. From this plexus the muscles of the pharynx and soft palate (except the stylopharyngeus and tensor veli palatini) are supplied. The lingual branch is a small nerve which separates itself from the plexus and joins the hypoglossal nerve in the anterior triangle of the neck.

N. Laryngeus Superior.-The superior laryngeal nerve passes obliquely downwards and medially, behind the external and internal carotid arteries, towards the thyreoid cartilage. It divides in its course into two unequal parts-a larger internal and a smaller external laryngeal branch.

Ramus Internus. - The internal laryngeal branch passes medially into the larynx between the middle and inferior constrictor muscles of the pharynx and through the thyreo-hyoid membrane. It supplies the mucous membrane of the larynx, reaching upwards to the epiglottis and base of the tongue, and forms communications beneath the lamina of the thyreoid cartilage with the branches of the inferior laryngeal nerve (ramus anastomoticus cum nervo laryngeo inferiore).

Ramus Externus. - The external laryngeal branch passes downwards upon the inferior constrictor muscle of the pharynx. It supplies branches to that muscle, and ends in the crico-thyreoid muscle.

Communications.--Besides supplying these pharyngeal and laryngeal nerves, this ganglion has the following communications with other nerves: (1) with the superior cervical ganglion of the sympathetic; (2) with the hypoglossal; (3) with the loop between the first and second cervical nerves; and (4) with the accessory nerve. This nerve applies itself to the ganglion, and thereby supplies to the vagus nerve the inhibitory fibres for the heart, as well as the motor fibres for the pharynx, œsophagus, stomach and intestines, larynx and respiratory organs.

Branches of the Vagus in the Neck. - In the neck the vagus nerve 
supplies cardiac branches and (on the right side) the recurrent (laryngeal) nerve (Fig. 661).

Rami Cardiaci Superiores. - The cardiac branches are superior and inferior. On the right side both cardiac branches pass downwards into the thorax behind the subclavian artery, and proceed alongside the trachea to join the deep cardiac plexus. On the left side the two nerves separate on reaching the thorax. The superior nerve passes deeply alongside the trachea to join the deep cardiac plexus. The inferior nerve accompanies the vagus nerve over the aortic arch, along with the superior cervical cardiac branch of the sympathetic, to end in the superficial cardiac plexus.

N. Recurrens. - The right recurrent (laryngeal) nerve arises at the root of the neck, as the vagus crosses over the first part of the subclavian artery. It hooks round the artery, and passes obliquely upwards and medially behind the subclavian, the common carotid, and the inferior thyreoid artery and the thyreoid gland. It finally disappears beneath the inferior border of the inferior constrictor muscle, and, receiving the name of inferior laryngeal nerve, it ends in supplying the muscles of the larynx. In its course it gives off the following branches:-

(1) Cardiac branches (rami cardiaci inferiores) arise as the nerve winds round the subclavian artery, and course downwards alongside the trachea to end in the deep cardiac plexus.

(2) Communicating branches to the inferior cervical ganglion of the sympathetic arise from the nerve behind the subclavian artery.

(3) Muscular branches supply the trachea, œsophagus (rami tracheales et œsophagei), and the inferior constrictor of the pharynx.

(4) Terminal branches supply the muscles of the larynx (except the crico-thyreoid) and communicate beneath the lamina of the thyreoid cartilage with branches of the internal laryngeal nerve.

Branches of the Vagus in the Thoraz. - In the thorax the vagi form the great pulmonary and cesophageal plexuses. The right nerve, in addition, furnishes cardiac branches; and the left nerve gives off the recurrent (laryngeal) nerve.

N. Recurrens. - The left recurrent (laryngeal) nerve differs from the nerve of the right side mainly in its point of origin and in the early part of its course. It springs from the vagus as it crosses the aortic arch, and, after hooking round the arch, lateral to the ligamentum arteriosum, it passes upwards in the superior mediastinum, in the interval between the trachea and oesophagus, to the neck. In the neck its course and relations are similar to those of the nerve of the right side. The branches of the nerve are the same as those of the right nerve. The cardiac branches are larger, and, arising below the aortic arch, proceed to the deep cardiac plexus.

Cardiac branches from the right vagus nerve arise in the superior mediastinum, and pass downwards alongside the trachea to join the deep cardiac plexus. On the right side thoracic cardiac branches are thus supplied from both the trunk of the nerve and its recurrent branch; on the left side the cardiac branches in the thorax arise solely from the recurrent branch.

Abdominal Branches.-After the formation of the cesophageal plexus the two vagi nerves resume their course, and passing along with the gullet through the diaphragm, terminate by supplying the stomach. The right nerve enters the abdominal cavity behind the gullet, and is distributed to the posterior surface of the stomach. It sends communicating offsets to the cœliac, splenic, and renal plexuses. The left nerve applies itself to the anterior surface and small curvature of the stomach, to which it is distributed. It sends communicating offsets along the small curvature of the stomach to the right vagus, and between the layers of the gastro-hepatic ligament to the hepatic plexus.

\section{Plexus Thoracales.}

Plexus Cardiaci.-The cardiac branches of the vagus nerve (both cervical and thoracic) combine with the cardiac branches of the sympathetic to form the superficial and deep cardiac plexuses. 
The superficial cardiac plexus is placed in the hollow of the aortic arch, superficial to the pericardium. It contains a small ganglion (cardiac ganglion of Wrisberg), and is joined by two small nerves-(1) the cardiac branch from the superior cervical ganglion of the sympathetic, and (2) the inferior cervical cardiac branch of the vagus-both of the left side-which reach it after passing over the arch of the arta.

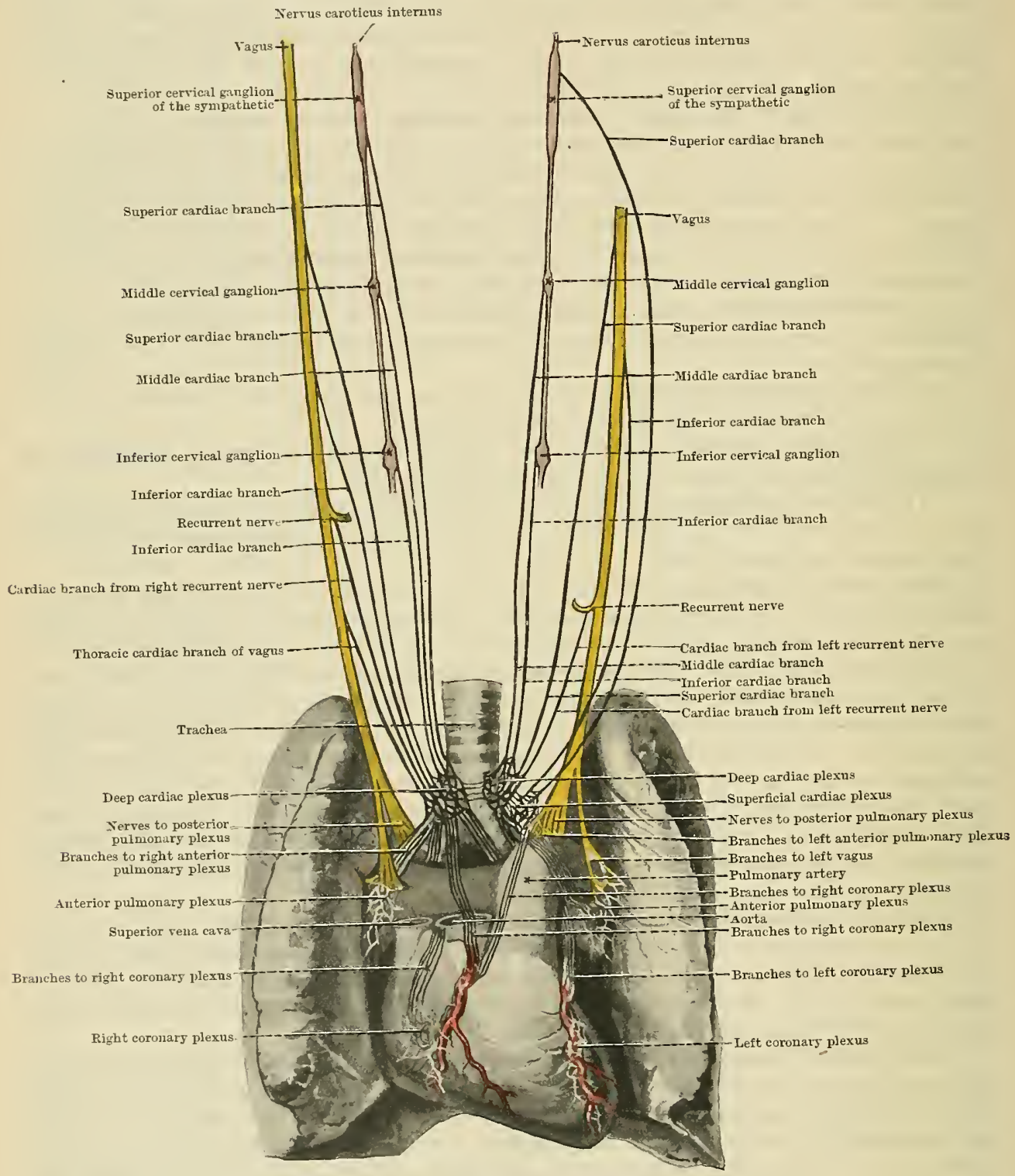

Fig. 661.-The InNervation of the Heart.

Branches and Communications.-From the plexus branches of communication pass (1) to the left half of the deep cardiac plexus, between the aortic arch and the bifurcation of the pulmonary artery; (2) to the left anterior pulmonary plexus along the left branch of the pulmonary artery; (3) the branches of distribution to the heart extend along the pulmonary artery to join the anterior (right) coronary plexus, which supplies the substance of the heart in the course of the right coronary artery.

Plexus Cardiacus Profundus.-The deep cardiac plexus is much larger. It 
is placed behind the arch of the aorta, on the sides of the trachea, just above its bifurcation. It consists of two lateral parts, joined together by numerous communications around the termination of the trachea. The two portions of the plexus are different in their constitution and distribution. The right half of the plexus is joined by both the cervical and thoracic branches of the right vagus and by the branches of the right recurrent nerve, as well as by branches from the superior, middle, and inferior cervical ganglia of the sympathetic. The left half of the plexus is joined by the superior cervical cardiac branch of the left vagus, by branches from the left recurrent nerve, and by branches from the middle and inferior cervical ganglia of the left sympathetic; it also receives a contribution from the superficial cardiac plexus.

The deep cardiac plexus is distributed to the heart and lungs. The right half of the plexus for the most part constitutes the anterior coronary plexus, reaching the heart alongside the ascending aorta, and is distributed to the heart substance in the course of the right coronary artery. It is reinforced by fibres from the superficial cardiac plexus, which reach the heart along the pulmonary artery. Fibres from the right half of the deep cardiac plexus pass also to join the posterior coronary plexus, and others extend laterally to join the anterior pulmonary plexus of the right side.

The left half of the deep cardiac plexus, reinforced by fibres from the superficial cardiac plexus, is distributed to the heart in the form of the posterior coronary plexus, which is joined by a few fibres behind the pulmonary artery from the right half of the plexus, and supplies the heart substance in the course of the left coronary artery. The left half of the plexus contributes also to the left anterior pulmonary plexus by fibres which extend laterally to the root of the lung along the left branch of the pulmonary artery.

Plexus Pulmonales (Pulmonary Plexuses).-As already stated, the vagus nerve on each side, on reaching the back of the root of the lung, breaks up into numerous plexiform branches for the formation of the posterior pulmonary plexus. From each nerve a few fibres pass to the front of the root of the lung; above its upper border, to form the much smaller anterior pulmonary plexus.

Plexus Pulmonalis Anterior.-The anterior pulmonary plexus on each side is joined by a few fibres from the corresponding part of the deep cardiac plexus, and on the left side from the superficial cardiac plexus as well. It surrounds and supplies the constituents of the root of the lung anteriorly.

Plexus Pulmonalis Posterior. - The posterior pulmonary plexus, placed behind the root of the lung, is formed by the greater part of the vagus nerve, reinforced by fine branches from the second, third, and fourth thoracic ganglia of the sympathetic. Numerous branches proceed from it in a plexiform manner along the bronchi and vessels into the substance of the lung.

Plexus Esophageus Anterior et Posterior (Esophageal Plexus). - The oesophagus in the thorax is supplied by the vagus nerve both in the superior and posterior mediastina. In the superior mediastinum it receives branches from the vagus nerve on the right side, and from its recurrent branch on the left side.

In the posterior mediastinum the gullet is surrounded by the oesophageal plexus, formed from the trunks of the vagi nerves emerging from the posterior pulmonary plexuses, which form a large plexus surrounding the gullet. This part of the oesophagus also receives fibres from the greater splanchnic nerve and ganglion. From the cesophageal plexus branches supply the muscular wall and mucous membrane of the cesophagus.

Pericardiac branches are also supplied from the plexus to the posterior surface of the pericardium.

\section{Nervus Accessorius.}

The eleventh or accessory nerve (O.T. spinal accessory) consists of tro essentially separate parts, different both in origin and in distribution. One portion is accessory to the vagus nerve, and arises, in series with the fila of that nerve, from the side of the medulla oblongata. The other, spinal portion, arises from 


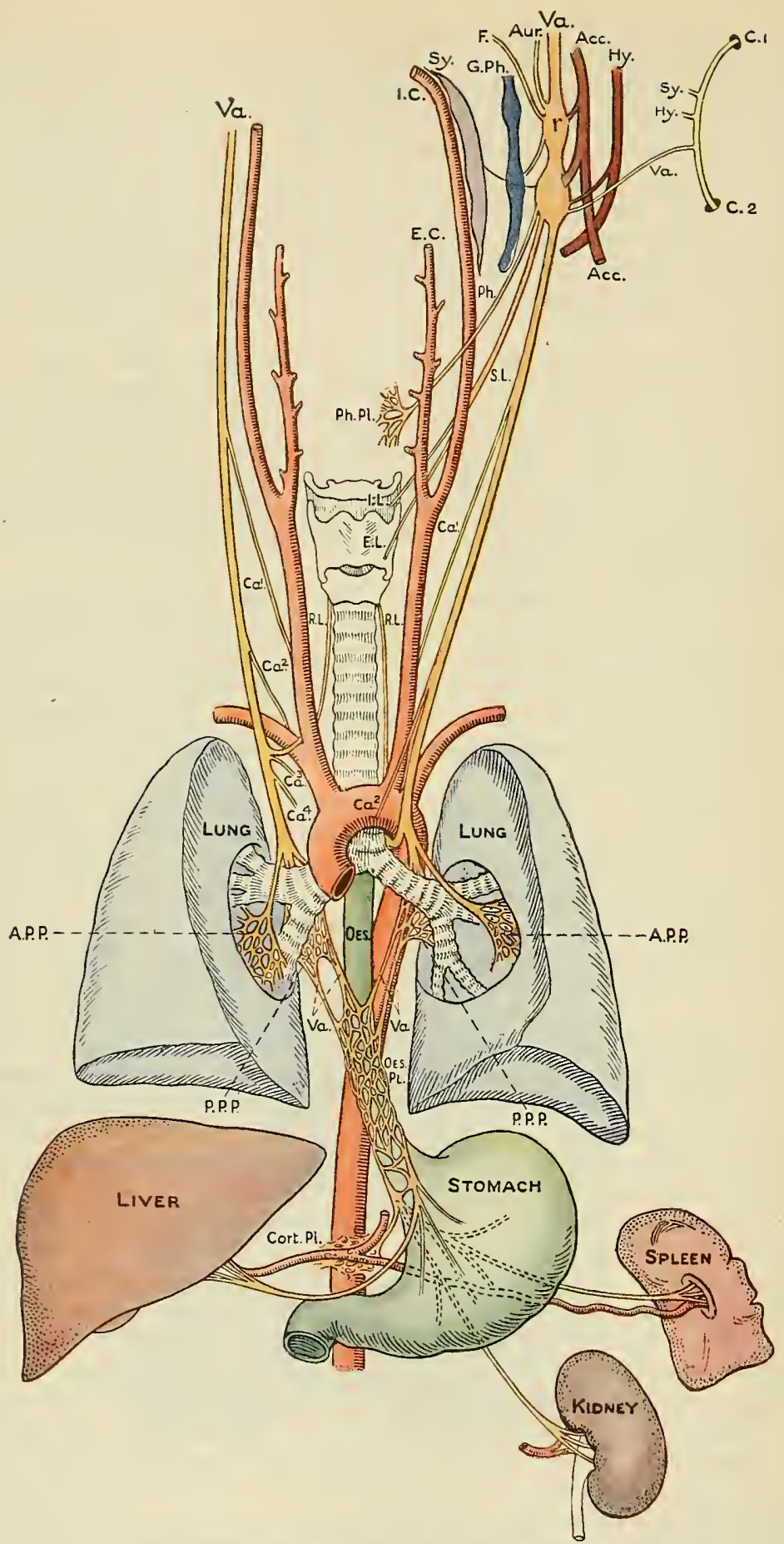

Fig. 662.-The Distribution of the Pnedmogastric Nerve.

Ta, Right and left vagi: $r$, Ganglion jugulare and connexions with Sy, Sympathetic, superior cervical ganglion; G.Ph, Glossopharyngeal; Acc, Accessory nerve; F, Meningeal branch ; Aur, Auricular branch; Va, Connexion with ganglion nodosum of vagus; Sy, Nerve to stylo-hyoid; Hy, Nerve to hyoglossus; C1, C2, Loop between the first two cervical nerves; Sy, Sympathetic, superior cervical ganglion; Acc, Accessory nerve; Ph. Pharyngeal branch; Ph.Pl, Pharyngeal plexus; S.L, Superior laryngeal nerve; I.L, Internal laryngeal branch; E.L, External laryngeal branch; I.C, Internal, and E.C, External carotid arteries; Cal, Superior cervical eardiac branch; Ca2, Inferior cervical cardiac branch; P.L, Recurrent nerve; Ca3, Cardiac branches from recurrent nerves; Ca4, Thoracic cardiac branch (right vagus); A.P.P, Anterior, and P.P.P, Posterior pulnonary plexuses ; Oes.Pl, CEsophageal plexus ; Cort. Pl, Cœliac plexus. 
the lateral aspect of the spinal medulla, between the anterior and posterior roots of the spinal nerves, its origin extending from the level of the accessory portion as low as the origin of the sixth cervical nerve (for the deep origin, see p. 596). Successively joining together, the fila radicularia (rootlets) form a trunk which ascends in the subdural space of the spinal medulla, posterior to the ligamentum denticulatum, to the foramen magnum. There the two portions unite into a single trunk, which leaves the cranial cavity through the jugular foramen in the same compartment of dura mater as the vagus nerve (Fig. 647, p. 771).

Ramus Internus.-In the jugular foramen the accessory portion of the nerve or internal ramus (after furnishing a small branch to the jugular ganglion of the vagus) applies itself to the ganglion nodosum, and in part joins the ganglion, in part the trunk of the nerve beyond the ganglion. By means of these connexions the vagus receives viscero-motor and cardioinhibitory fibres.

Ramus Externus.--The spinal portion of the nerve, or external ramus, extends into the neck, where at first it lies along with other nerves, in the interval between the internal carotid artery and the internal jugular vein. Passing obliquely dowuwards and laterally over the vein, it descends close beneath the sterno-mastoid muscle, which it supplies as it pierces it on its deep surface. After crossing the posterior triangle the nerve ends by supplying the trapezius muscle on its deep surface. This portion of the nerve communicates in three situations with nerves from the cervical plexus-(1) in or beneath the sterno-mastoid, with the branch for the muscle derived from the second cervical nerve; (2) in the posterior triangle, with branches from the third and fourth cervical nerves; (3) beneath the trapezius, with the branches for the muscle derived from the third and fourth cervical nerves.

\section{Nervus Hypoglossus.}

The twelfth or hypoglossal nerve arises by numerous fila radicularia from the front of the

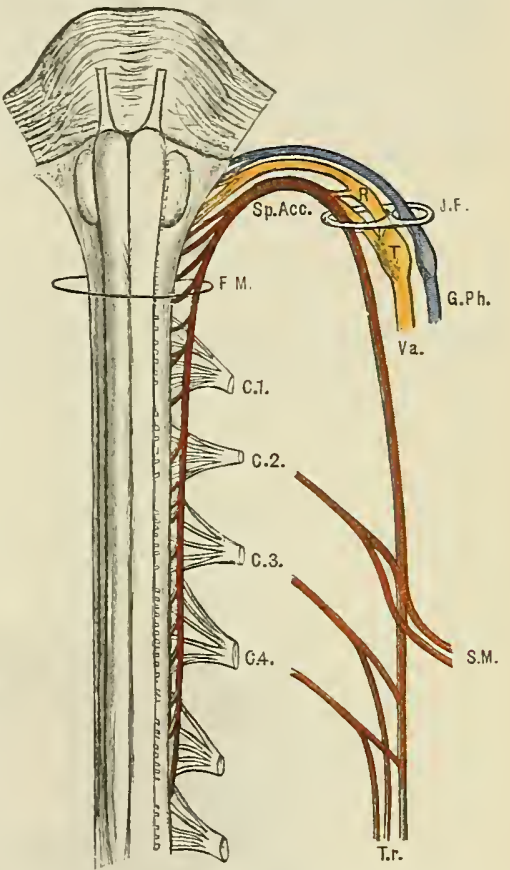

Fig. 663.-SCHEME OF THE ORIGIN, CONNexioNs, AND DISTRIBUTION OF THE Accessory Nerve.

Sp.Acc, Accessory nerve; C.1.4, First four cervical nerves (posterior roots); Va, Vagus nerve; R, Ganglion jugulare ; T, Ganglion nodosum ; G.Ph, Glossopharyngeal nerve; S.M, Nerves to sternocleido-mastoid ; Tr, Nerves to trapezius : F.M, Foramen magnum; J.F, Jugular foramen. medulla oblongata between the pyramid and the olive (Fig. 643, p. 768) (for the deep origin, see p. 594). The fila arrange themselves in two bundles which separately pierce the dura mater, and unite in the hypoglossal canal, or after emerging from the skull. In the neck the nerve arches downwards and forwards towards the hyoid bone, and then turns medially among the supra-hyoid muscles to the tongue. At first it is placed deeply, along with other cerebral nerves, on the lateral side of the internal carotid artery; it then curves forwards and downwards over the two carotid arteries, lying beneath the digastric and stylo-hyoid muscles. As it crosses the external carotid artery it hooks round the occipital artery. Above the greater cornu of the hyoid bone the nerve conceals the lingual artery; and it then disappears between the mylo-hyoid and hyoglossus muscles to reach the tongue, in the muscular substance of which it terminates.

Communications. - In its course the hypoglossal nerve has the following communications with other nerves:- Near the base of the skull it is connected by small branches with (1) the superior cerrical ganglion of the sympathetic; $(2)$ the garglion nodosum of the vagus; (3) by a larger branch, with the loop between the first tiro cervical nerves; (4) as it crosses the external carotid artery it receives a communication from the 
pharrngeal plexus (lingual branch of the vagus); and (5) beneath the mylo-hyoid muscle, at the anterior border of the hyoglossus, it forms loops of communication with the lingual branch of the mandibnlar nerve.

The branches of the nerve are:-(1) Recurrent; (2) Descending; (3) Thyreohyoid; and (4) Lingual.

Ramus Recurrens. - The recurrent branch passes from the nerve near its origin to supply the dura mater of the posterior fossa of the base of the skull. It probably derives its fibres from the communication with the first and second cervical nerves.

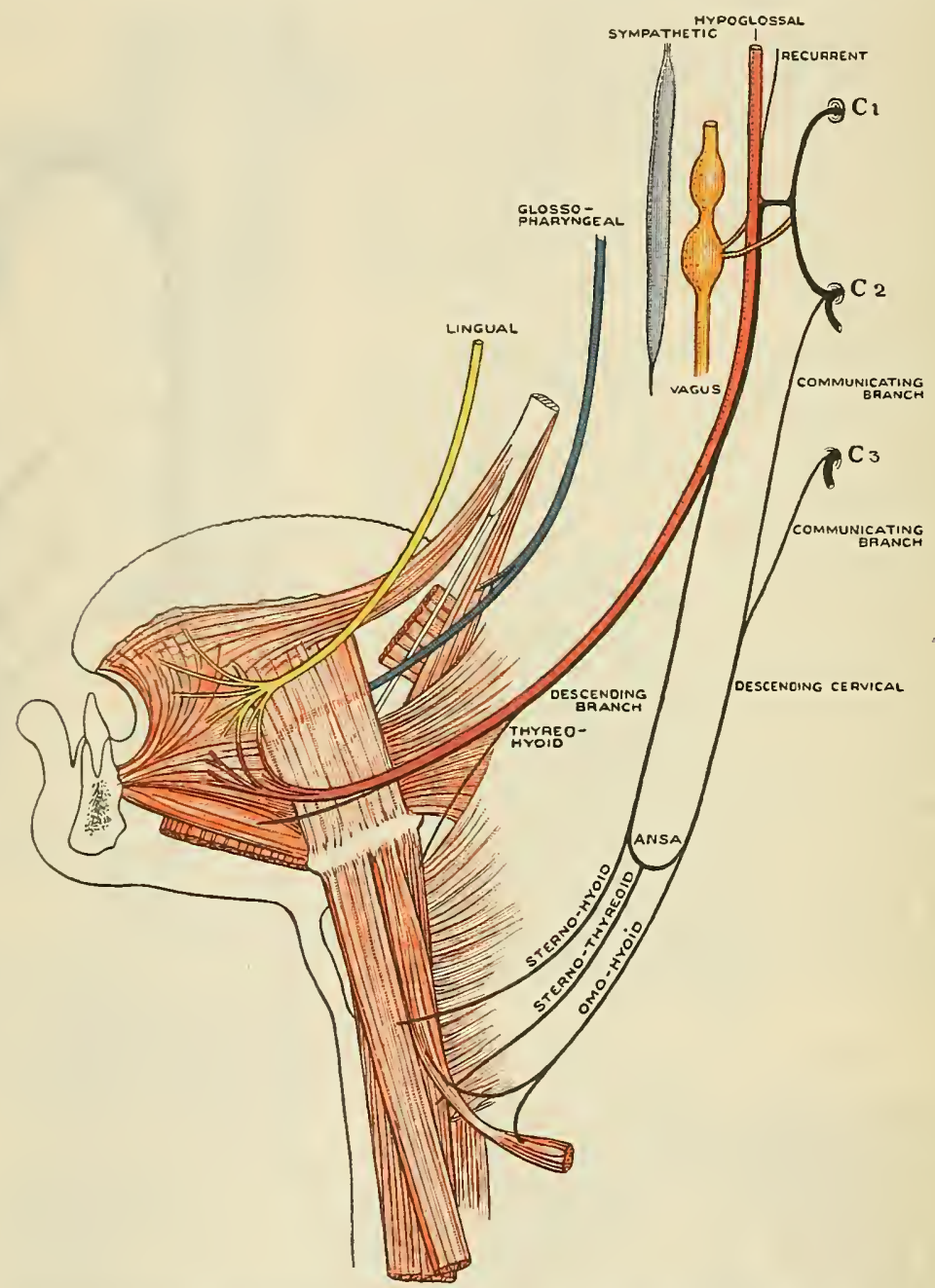

Fig. 661.-The Muscles of the Hroid Bone and Stylom Process, ANd the Extrinsic Muscles of the Tongue, with their Nerves.

Ramus Descendens. - The descending branch of the hypoglossal nerve is the chief branch given off in the neck. It arises from the hypoglossal nerve as it crosses the internal carotid artery, and descends in the anterior triangle in front of the carotid sheath. It is joined about the middle of the neck by the descending cervical nerve (from the second and third cervical nerves). By their union the ansa hypoglossi (hypoglossal loop) is formed, from which branches are distributed to the majority of the infra-hyoid muscles-both bellies of the omo-hyoid, the sternohyoid, and the sterno-thyreoid. The descending branch of the hypoglossal nerve derives its fibres from the communication to the hypoglossal nerve from the loop between the first and second cervical nerves; so that the ansa hypoglossi is made up of fibres of the first three cervical nerves. 
Ramus Thyreohyoideus.-The nerve to the thyreo-hyoid muscle is a small branch which arises from the hypoglossal nerve before it passes beneath the mylohyoid muscle. It descends behind the greater cornu of the hyoid bone to reach the muscle. When traced backwards this nerve is found associated with the loop between the first and second cervical nerves.

Rami Linguales.- The lingual branches of the hypoglossal nerve are distributed to the hyoglossus, genio-hyoid, and genioglossus, and to all the intrinsic muscles of the tongue. The nerve to the genio-hyoid is said to be derived from the loop between the first and second cervical nerves. It is not known if these two cervical nerves are implicated in the innervation of the proper muscles of the tongue, but it appears certain that the muscles named-the genio-hyoid, thyreo-hyoid, sternohyoid, omo-hyoid, and sterno-thyreoid-are not supplied by the hypoglossal, but only by cervical nerves, the genio-hyoid and thyreo-hyoid by the first two, the other muscles by the first three cervical nerves.

\section{THE MORPHOLOGY OF THE CEREBRAL NERVES.}

The head and face, possibly the oldest, and from every point of view the most fundamental and important portion of the body fabric, present in some respects a more conserrative type of

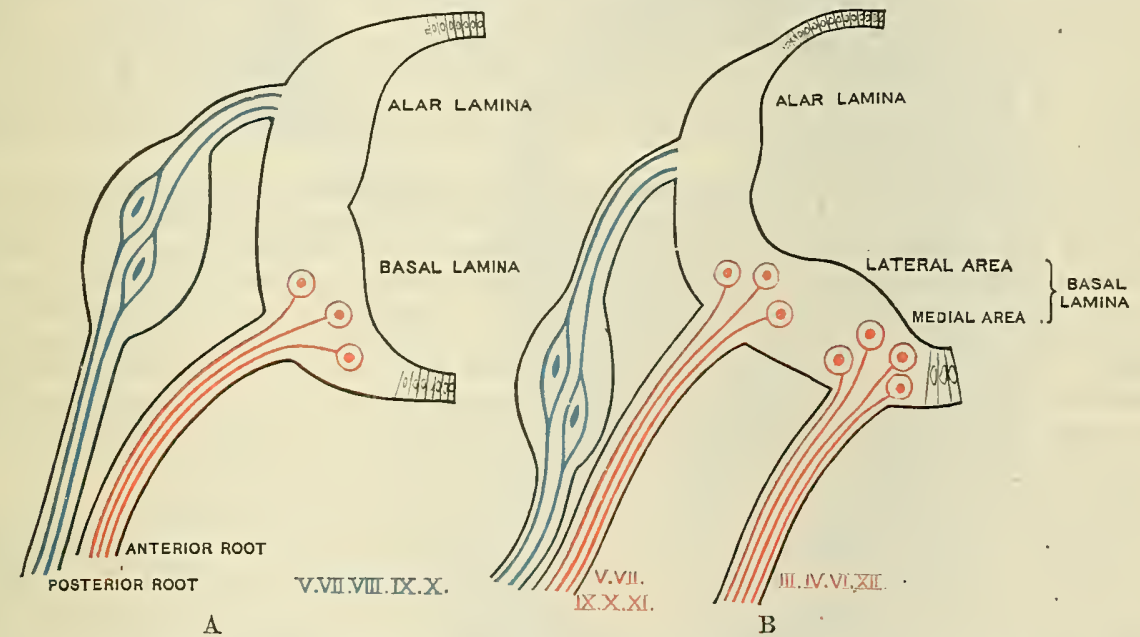

Fig. 665. - Comparisox of Origins of Nerte Roots from Sptnal Medulla avd Hind-Braix (after His). A. Spinal medulla; B. Hind-brain.

structure, and in other aspects have been subject to more profound alterations than other parts of the body. Segmentation is characteristic of the trunk, pervading bones, muscles, vessels, and nerves. An absence of true segmentation is characteristic of the head region-omitting for the moment the cerebral nerves. The head is characterised by the possession of an unsegmented tubular nervous system, enclosed in a bony capsule not obviously segmental, with which the capsules of the sense-organs become united. The pre-oral and post-oral visceral arches and clefts are not truly segmental like the costal arches of the trunk. The branchial clefts are said to be inter-segmental; and their muscles (associated with the myoblast surrounding the developing heart) are described as visceral, and not myotomic, so that the branchial vessels and nerves (similarly) are not to be regarded as comparable to the segmental vessels and nerves of the trunk. The truly segmental structures present are certain persistent myotomes or muscle plates, which give rise to muscles innervated by the third, fourth, sixth, and twelfth cerebral nerves.

Another difficulty in the morphology of the head arises from the absence of body carity, and the consequent difficulty of differentiating the somatic and splanchuic mesoderm, and the somatic and splanchnic distribution of a given nerve.

Under these circumstances there is little help to be derived from head structures other than the nerves themselves in seeking a solution of the question of the morphological relations of the cerebral nerves. The spinal nerves are, generally speaking, all alike. The cerebral nerves, on the other liand, are all different. Scarcely any two nerves are alike; and no single cerebral nerve possesses in itself all the characteristic features of a spinal nerve. As seen in the account of its development (p.504), the cranial nervous system possesses a series of dorsal ganglia, comparable in position and development to the spinal ganglia with which afferent nerves are associated; and the efferent roots are developed in the same way, and occupy somewhat the same position 
as the anterior roots of the spinal nerves. But there is no single complete segmental nerve in the head. The rery essence of the architecture of the head is a want of segmentation; and this character is shared by the cerebral nerves. In addition it must be borne in mind that, in relation to the mammalian head, there are organs which have no homologues in the trunk, and on whose existence the essential arrangement of the cerebral nerves depends-e.g. sense-organs and gill-arches.

Among the cerebral nerves there are several which possess a resemblance to one or other of the elements of a typical spinal nerve. In the neck the origin of the fibres of the accessory nerve is from the side of the spinal medulla, and it is in series with the motor roots of the vagoglossopharyngeal, facial, and fifth nerves. His (as shown in the account of the development of the nerves) has described the neuroblastic origin of the motor roots of these nerves from the lateral part of the basal lamina of the primitive brain. They thus form a series apart-lateral motor roots-separable from the series of motor roots originating from the medial part of the basal lamina, comprising those of the third, fourth, sixth, and twelfth nerves; the latter nerve roots being comparable to and in series with the anterior roots of the spinal nerves. The lateral motor roots are not represented in the spinal series except in the neck. It is questionable if there is any fundamental distinction between the lateral and anterior motor roots of the cerebral nerves. The accessory fibres, for example, when traced into the spinal medulla, have an origin from the anterior column of the spinal medulla, and only differ from the motor or anterior root fibres of a spinal nerve in their different comrse to the surface. The ganglia in association with the cerebral nerves are comparable to the spinal ganglia. The trigeminal nerve, with the semilunar ganglion, the ganglion of the facial, the ganglia of the acoustic, of the glossopharyngeal and the vagus, and the transitory (Froriep's) ganglion of the hypoglossal nerves, arise from the brain in a comparable position, and in the same way as the spinal ganglia. But another series of structures-the sense organs of the lateral line, and the so-called "epibranchial" organs which are highly developed in lower vertebrates (e.g. elasmobranchs), and which appear transitorily only, or are absent altogether in mammalian development, may possibly have a share in the formation of certain of these ganglia or parts of them (e.g. ciliary ganglion, genicular ganglion, ganglia of the acoustic nerve, petrous ganglion of the glossopharyngeal, and the ganglion nodosum of the vagus).

Certain of the cerebral nerves are apparently distinctly segmental, supplying muscles derived from the persisting myotomes of the head. The first three myotomes are said to give rise to the muscles of the eyeball. The first produces the superior rectus, inferior rectus, medial rectus, and inferior oblique muscles, and its segmental nerve is the oculo-motor. The second myotome is said to produce the superior oblique muscle, and its segmental nerve is the trochlear. The third myotome is said to produce the lateral rectus muscle, and its segmental nerve is the abducent. It has been asserted that the tongue muscles are derived from the last three or four cephalic and first cervical myotomes, and that the hypoglossal nerve is the segmental nerve for these myotomes, comprising the motor elements of several (four or five) segmental nerves. The intervening myotomes between the first three and this occipital series disappearing, the corresponding elements of segmental nerves are supposed to be absent also (Fig. 666).

Certain of the cerebral nerves are essentially related to the structures derived from and associated with the pre-oral and post-oral visceral clefts and arches (Fig. 667). The trigeminal nerve is essentially the nerve of the mandibular arch. By its efferent root it supplies the muscles of that arch. By its afferent root and branches it is related to (1) the fronto-nasal process (ophthalmic division and ciliary ganglion); (2) the maxillary arch (maxillary nerve); and (3) the mandibular arch (mandibular nerve). The mandibular is at first the main nerve; and the maxillary division is sometimes regarded as a subordinate branch (præ-branchial, præ-trematic) for the supply of the anterior margin of the cleft (month), with which the nerve is in relation. The ophthalmic nerve is sometimes regarded as a morphologically separate nerve. The nerves to these arches have been compared to the anterior rami of spinal nerves, the branches which they supply to the forehead and temple (frontal, zygomatic, and auriculo-temporal) representing the posterior rami. The ganglia on each division of the nerve are formed as extensions from the semilunar ganglion.

The facial nerve is essentially the nerve of the second (hyoid) arch and the cleft in front of that arch (spiracular cleft, auditory tube). Its motor root supplies the muscles of that arch (stapedius, stylo-hyoid, and digastric), and the epicranial and facial muscles and platysma, which are developments from the hyoid arch (Rabl). The chorda tympani nerve is regarded as the subordinate (præ-branchial, præ-trematic) branch to supply the anterior margin of the first post-oral cleft. It is possible that the genicular ganglion, with the nervus intermedius and the chorda tympani, may, in part at least, represent the ganglionic and afferent element of the nerve. Or the genicular ganglion, and the nerves in relation to it, may be associated with an "epibranchial" sense-organ.

The acoustic nerve, on the other hand, may be either the sensory element of the branchial nerve, associated with the hyoid arch and first post-oral cleft, or it may represent the nerve or nerves belonging to ancestral sense-organs of the lateral line.

The glossopharyngeal is the branchial nerve of the third post-oral (thyreo-hyoid) arch and the cleft in front. Its efferent fibres supply the muscle of this arch, - the stylopharyngeus. The superior constrictor of the pharynx is also assigned to this arch; the middle and inferior muscles to the fourth (first branchial) arch. The afferent portion of the nerve is possibly composed of two separate parts; the petrous ganglion being associated with an epibranchial or lateral line sense-organ, and the rest of the nerve forming the afferent fibres for the gill-cleft 
and arch. The lingual branches are regarded as the main stem (post-trematic), the pharyngeal branches as subordinate branches; the tympanic branch being the præ-branchial or præ-trematic branch for the anterior margin of the third gill-cleft.

The vagus nerve is generally regarded as representing the fusion of all the branchial nerves behind the glossopharyngeal. Its efferent fibres are in series with those of the glossopharyngeal above and the accessory nerve below, and belong to the lateral series of His. Its afferent fibres, like those of the glossopharyngeal, represent two elements. The ganglion nodosum has possible connexions with epibranchial sense-organs-the rest of the nerve representing the fused branchial nerves of fishes. The superior laryngeal nerve is looked upon as the branchial nerve of the fourth, and the recurrent nerve as the branchial nerve of the fifth arch. While the relation of the nerve to the hinder gill-arches and clefts makes it possible to understand the innervation by the vagus of the heart and lungs, no satisfactory explanation is forthcoming of the passage of the nerve into the abdomen, and its distribution to the stomach and other organs below the diaphragm.

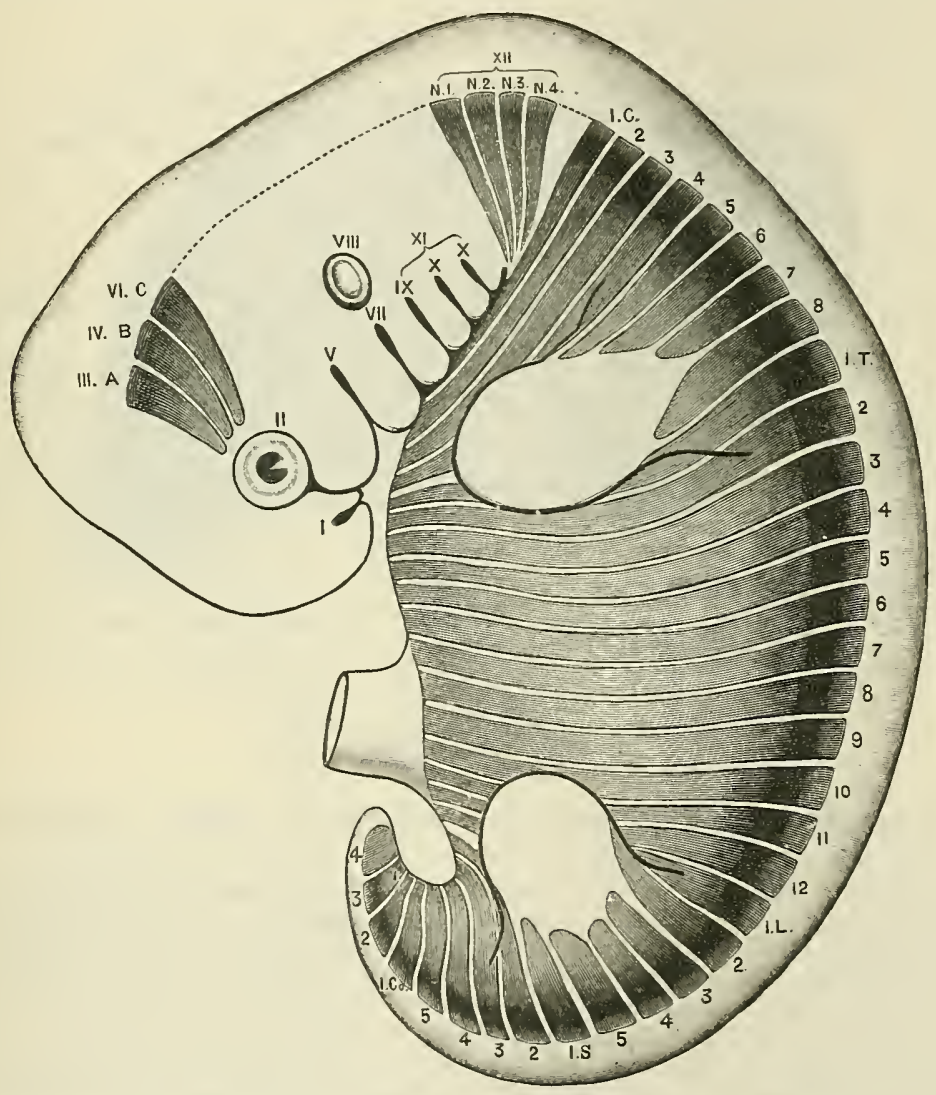

Fig. 666.-Scheme to illustrate the Disposition of the Mrotomes in the EMbryo in relation to the Head, Trunk, and Limbs.

A, B, C, First three cephalic myotomes; N, 1, 2, 3, 4, Last persisting cephalic myotomes; C, T, L, S, $\mathrm{Co}$, The myotomes of the cervical, thoracic, lumbar, sacral, and caudal regions ; I., II., III., IV., V., VI., VII., VIII., IX., X., XI., XII., refer to the cerebral nerves, and the structures with which they may be embryologicaliy associated.

The accessory nerve consists of two parts. The internal ramus (accessory portion) of the nerve consists of efferent fibres for the branchial region, in series with the lateral motor roots of the glossopharyngeal and vagus nerves. The external ramus (spinal portion) of the nerve is also composed of efferent fibres, and represents the only lateral motor elements arising from the spinal medulla.

Olfactory Nerve.-There is complete uncertainty regarding the morphology of this nerre. It consists of three elements: (1) the olfactory bulb, derived from the cerebral hemisphere, solid in man, but a hollow cerebral diverticulum in certain animals, and forming the rhinencephalon; (2) the olfactory ganglion, with its central and peripheral processes, derived from the ectoderin; (3) the nasal pit. Attention has been specially fixed on the olfactory ganglion, which has been compared to (1) a spinal ganglion, derived from the anterior end of the medullary groove; and to (2) a lateral line sense-organ.

The optic nerve also presents an insoluble problem in regard to its morphological position 
in the series of cerebral merves. The optic stalk and optic eup have been regarded as a highly modified spinal ganglion; but there is insuperable difficulty in accepting this view. The peripheral processes do not become commected with either ectodermal or mesodermal structures, but become the tissue of the retina; while the central processes, growing backwards, envelop the optic stalk, and obtain connexions with the brain. The retina must be regarded as a highly modified nerve-larer, morphologically in series with the wall of the fore-brain ; and the ectodermal structure of superficial origin comparable to the olfactory ganglion or the auditory vesicle is the lens (which may possibly be homologous with a lateral line sense-organ). The optic nerve, optic clifasma, and optic tract are then to be looked upon as cerebral commissures, and not as nerves in the ordinary sense.

The simplest and most primitive condition of the head, in relation to the morphology of the cerebral nerves, is found before the formation of the gill-clefts, when the salient features are

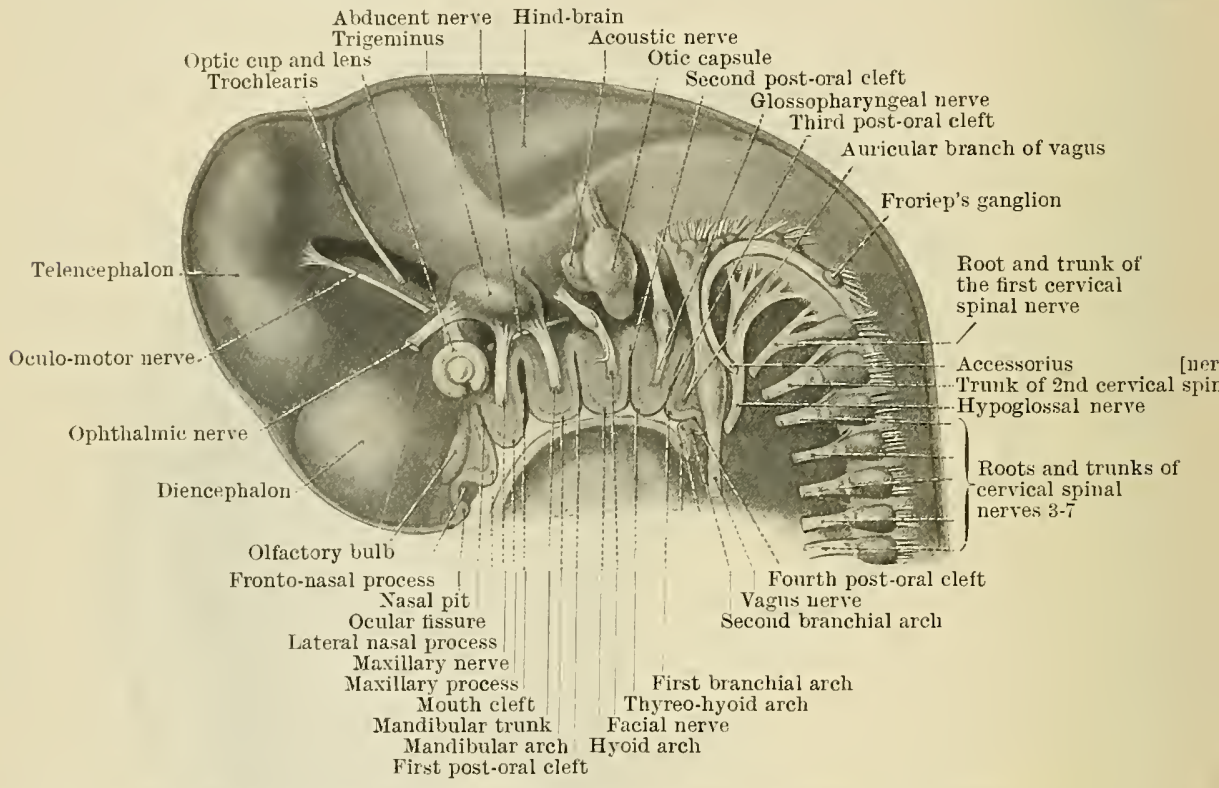

Fig. 667.-The Embryological Arrangement of the Cerebral Nerves. (Modified from Mall.)

a tubular and simple brain, and a series of superficial invaginations which pass from the surface inwards to become connected with outgrowths corresponding to them from the primitive brain. On each side of the head three hollow invaginations occur:-(1) The nasal pit bearing the olfactory epithelium becomes connected by the olfactory ganglion with the rhinencephalon, an outgrow th from the fore-brain, and so forms the basis of an olfactory organ and nerve; (2) a similar invagination produces the lens, connected with a protrusion of the optic vesicle from the forebrain, by which the basis of the eye and the optic nerve is formed; (3) behind the oral cavity a third invagination forms the auditory vesicle, which is connected with the solid extension from the hind-brain of the acoustic ganglia, to form the essentials of the organ of hearing and acoustic nerve.

The trigeminal nerve is essentially the nerve of the buccal cavity and the subordinate cavities, nasal and oral, derived from it. The branchial arches and clefts are secondary structures, and their nerves are (1) the trigeminal for the first (mandibular) arch and the cleft in front of it; (2) the facial for the second (hyoid) arch and cleft ; (3) the glossopharyngeal for the third (thyreo-hyoid) arch and cleft; and (4) the vagus for the succeeding arches and clefts. The cerebral part of the accessory nerve is inseparable from the motor portion of the vago-glossopharyngeal nerves; the spinal part is beyond the series of the cerebral nerves.

Lastly, there are certain truly segmental nerve elements, motor fibres which, remaining associated with certain persistent cephalic myotomes, give rise to the oculo-motor, trochlear, abducent, and hypoglossal nerves. 


\title{
ORGANA SENSUUM ET INTEGU- MENTUM COMMUNE.
}

\author{
By Robert Howden, M.D., F.R.S.E. \\ Professor of Anatomy in the University of Durham.
}

\section{ORGANA SENSUUM.}

THE organs of the senses are derived from cells of the ectoderm and constitute the apparatus by which man is made acquainted with his surroundings.

Every sense organ consists of three parts:-(a) a peripheral or receptive, capable of responding to external stimuli, $(b)$ an intermediate or conductive, along which the impulses are conveyed, and (c) a central or perceptive, where the impulses are collected and transformed into sensations. The intermediate and central parts have been described in the section on the Nervous System; the peripheral parts form the subject matter of this chapter, and may be grouped under two headings :(a) those connected with the special senses of smell, sight, hearing, and taste, and located in the nose, eye, ear, and mouth, respectively; and (b) those of general sensations (pressure, heat, cold, pain, etc.), which are widely distributed throughout the body.

\section{ORGANON OLFACTUS.}

The nose is the peripheral olfactory organ and consists of the nasus externus, which projects from the face, and the cavum nasi, which is divided by a vertical septum into right and left cavities.

Nasus Externus. - The external nose forms a more or less triangular pyramid, of which the upper angle is termed the root, and is usually separated from the forehead by a depression, while its base, directed downwards, is perforated by the nares or nostrils. Its free angle is named the apex; and the anterior border, joining root and apex, is termed the dorsum; the upper part of the dorsum is supported by the nasal bones, and is named the bridge. Each side of the nose forms an open angle (naso-facial angle) with the cheek, and ends below in a mobile expanded portion, the ala nasi, which forms the lateral boundary of the naris, and is limited above by a furrow, the alar sulcus. The skin of the nose is thin and morable over the root, but thick and adherent over the apex and alæ, where it contains numerous large sebaceous glands.

The arterial supply of the external nose is derived from the external maxillary and ophthalmic arteries, and its veins open into the anterior facial vein and communicate with the ophthalmic vein. Its principal lymph vessels follow the course of the anterior facial vein and open into the submaxillary lymph glands. From the root of the nose one or two vessels run laterally in the upper eyelid and end in the upper anterior anricular lymph glands, while a third group runs below the orbit to the lower anterior auricular lymph glands. Its muscles are supplied by the facial nerre, and the skin covering it is supplied by the infra-trochlear and naso-ciliary branches of the ophthalmic nerve and the infra-orbital branch of the maxillary nerve.

The external nose presents great varuety as to its size and shape, and certain well-defined types, such as aquiline, Grecian, etc., are described. The relation which its breadth, measured across the alæ, bears to its length, measured from root to apex, is termed the nasal index, and is expressed thus : 
In white races this index is below 70 (leptorhines); in yellow races, between 70 and 85 mesorhines); and in black races, above 85 (platyrhines).

\section{CARTILAGINES NASI.}

Fire chief cartilages are concerned in the formation of the nose; they are the lateral and greater alar cartilages on each side and the cartilage of the septum.

Cartilago Nasi Lateralis. - The lateral cartilage (Figs. 669, 670) is triangular in shape and is situated immediately below the nasal bone. Its posterior edge is thin and is attached to the maxilla and the nasal bone; its anterior edge is thick and its superior part is directly continuous with the cartilage of the septum; its inferior margin is joined by fibrous tissue to the upper edge of the greater alar cartilage.

Cartilago Alaris Major.-The greater alar cartilage (Figs. 668, 669, 670) encircles the anterior part of the nostril and assists in keeping it open. It consists

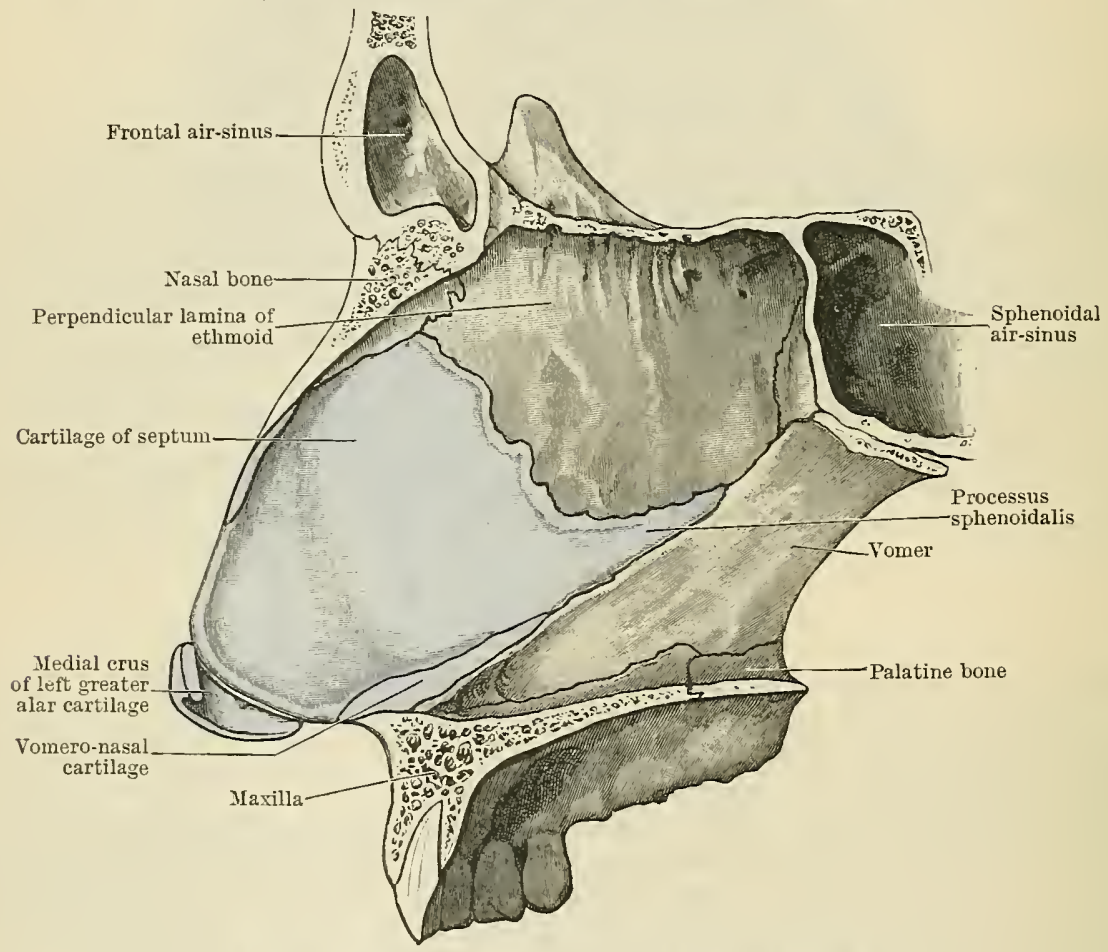

Fig. 668.-View of Nasal Septum fron the Left Side.

of a lateral and a medial crus, which are continuous with each other in a rounded angle at the apex of the nose. The lateral crus is oval in shape and is attached to the lateral cartilage and the maxilla by fibrous tissue. Above and behind it are two or three lesser alar cartilages, while sometimes a horizontal furrow cuts off a narrow linear part from its superior margin. The inferior edge of the lateral crus does not descend as far as the opening of the nostril, the ala being here devoid of cartilage and composed of fatty and connective tissue covered with skin. The medial crus (Fig. 668) bounds the medial wall of the nostril and lies in the septum mobile, below the anterior part of the cartilage of the septum. The medial crura of the two cartilages are separated, in front, by a notch which corresponds with the apex of the nose, and the posterior end of each curves slightly lateralwards and ends in a rounded extremity.

Cartilago Septi Nasi.-The cartilage of the septum (Fig. 668) is of an irregularly quadrilateral form. Its postero-superior edge is attached to the perpendicular lamina of the ethmoid; its postero-inferior margin to the vomer and the maxillæ. Its antero-superior border is thick, and is fixed above to the back of the internasal 
suture; immediately below the level of the nasal bones it is continued, on each side, into the lateral cartilages, which may be looked upon as its wing-like expansions. The inferior part of this border is separated by a fissure from the lateral cartilage, and extends downwards between the greater alar cartilages, to which it is attached by fibrous tissue; in this fibrous tissue a small accessory cartilage is usually seen on either side of the median plane. Its anteroinferior border is short, and is attached by fibrcus tissue to the medial crura of the greater alar cartilages, while its anterior angle is rounded and does not reach as far as the apex of the nose. The lowest part of the nasal septum is not formed by the septal cartilage, but by the medial crura of the greater alar cartilages and by the integument, and, being freely movable, is termed the septum mobile nasi. The cartilage of the septum may be prolonged backwards (especially in children) as a narrow process, the processus sphenoidalis, into the angle between the vomer and ethmoid; this process varies from 4 to $6 \mathrm{~mm}$. in width, and sometimes reaches as far as the body of the sphenoid.

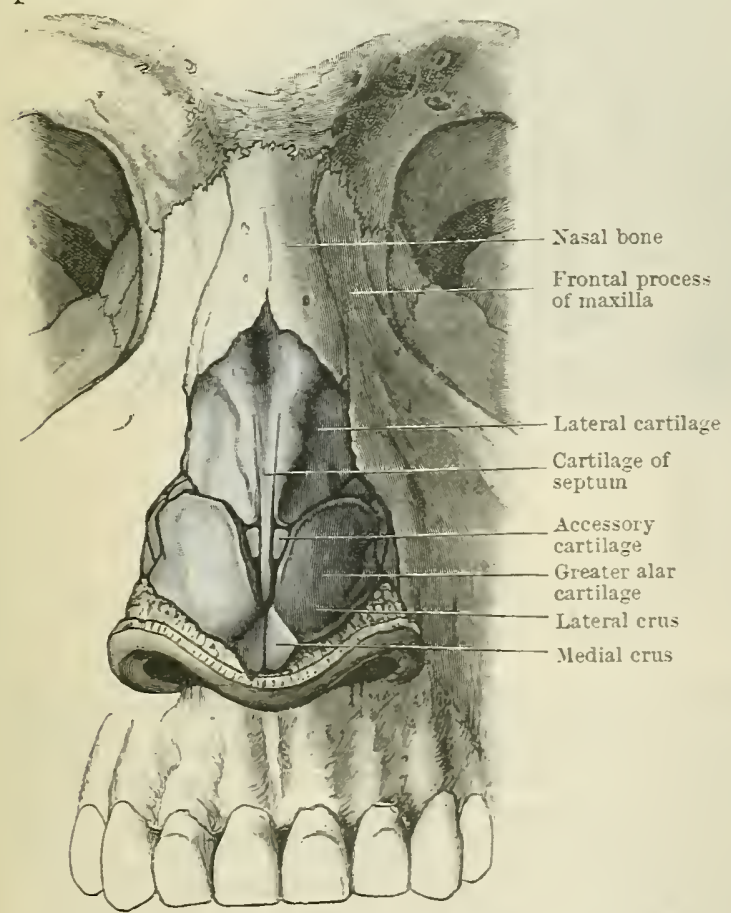

Fig. 670.-Front VieT of the Boyt asd Cartilaginots Skeletor of the EtTersal Nose.

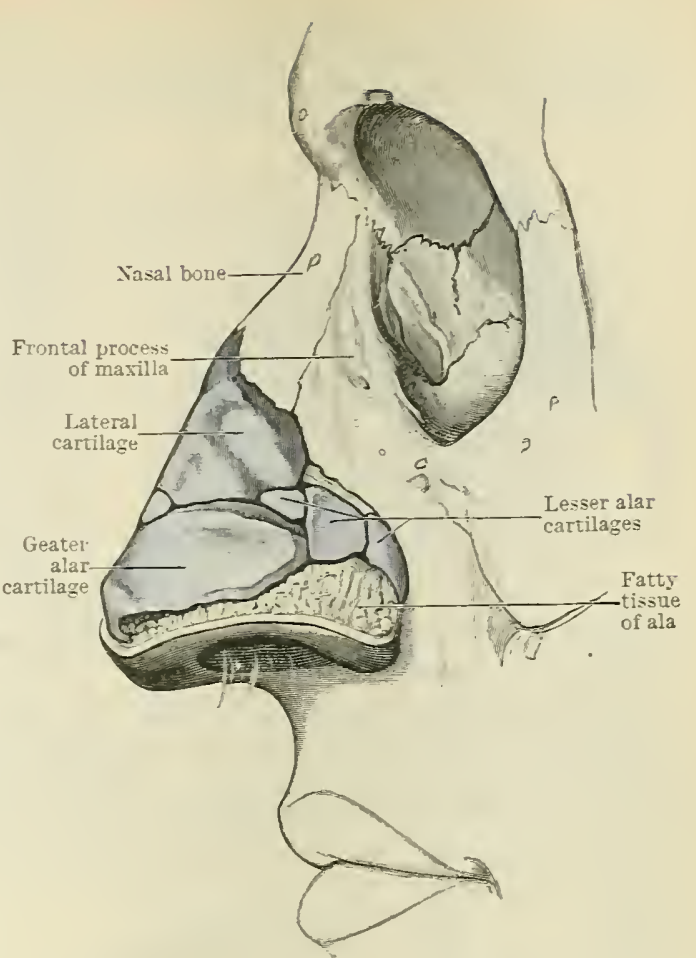

Fig. 669.-Profile Tiew of the Bort axd Carti. lagisods Skeletor of the Exterial Nose.

On either side of the inferior edge of the cartilage of the septum, and seen best in a frontal section of the nose, is a narrow band of cartilage, the vomero-nasal cartilage ; it measures from 6 to $12 \mathrm{~mm}$. in length, and is attached to the vomer.

\section{CAVUM NASI.}

The nasal cavity (Fig. 672) is divided by the nasal septum into a right and a left nasal cavity, which extend from the nostrils in front to the choanæ behind, and open, through the choanæ, into the nasal part of the pharnyx. Their bony boundaries are described in the section on Osteology (p. 183). On the lateral wall of each are found the orifices of the frontal, ethmoidal, sphenoidal, and maxillary sinuses, together with that of the naso-lacrimal duct.

Immediately abore the aperture of the nostril is a slighlty 
expanded area, the vestibule; this is bounded laterally by the lateral crus of the greater alar cartilage, and medially by the lower part of the septum; it is prolonged as a small recess towards the apex of the nose. Partly subdivided by a curved

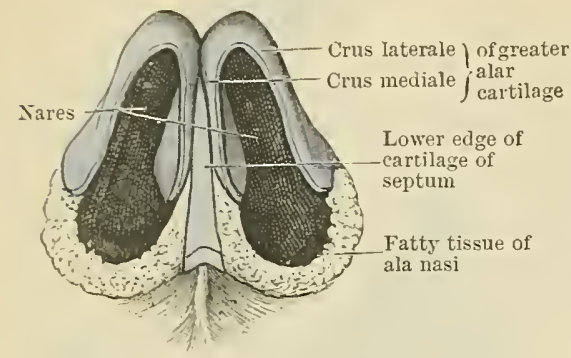

Fig. 671.-CARTIL.ages OF Nose Fron BeLOW. ridge, the vestibule is lined with skin and, in its lower half, there are hairs and sebaceous glands; the hairs are curved downwards to guard the entrance to the nostril. The superior part of the vestibule is smooth, and is limited above and posteriorly by a slightly marked arched prominence, the limen nasi, beyond which the nasal cavity is lined with mucous membrane.

Each nasal cavity, above and behind the vestibule, is divided into a superior or olfactory, and an inferior or respiratory region. The olfactory region is a narrow slit-like space, and comprises the middle of the superior nasal concha and the corresponding portion of the septum. The respiratory region includes the remaining part of the cavity.

Septum Nasi (Fig. 668).-Where the bony septum of the nose is deficieut, below and in front, the gap is filled by the septal cartilage. Until the seventh year the nasal septum lies, as a rule, in the median plane, but after this age it is very often bent to one or other side-more frequently to the right-the deflection being greatest usually along the line of junction of the vomer with the perpendicular lamina of the ethmoid. Deflectiou of the septum is more common in European than in nonEuropean skulls - occurring in about 53 per cent of the former and in about 28 per cent of the latter (Zuckerkandl). Associated with, or apart from, this deviation, crests or spurs of bone are found, projecting from the septum into one or other nasalcavity, in about 20 per cent of skulls. In the septum, a little above and in front of the naso-palatine recess, is a minute orifice, not

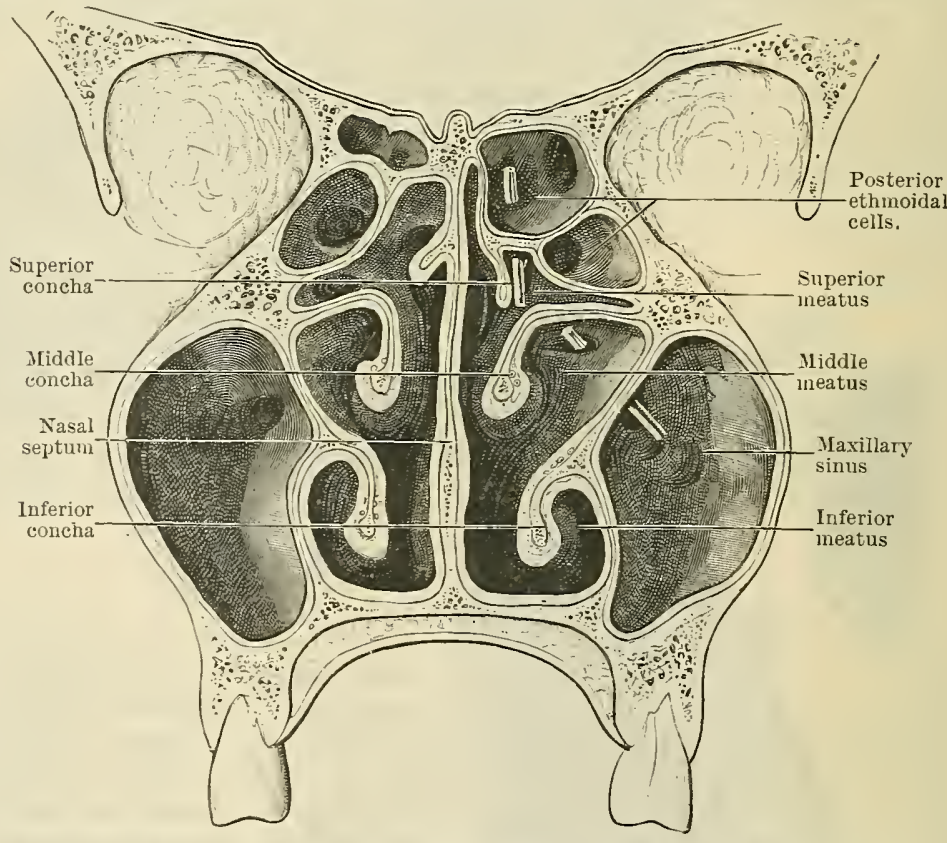

Fig. 672. -Froxtal Section throdgh Nasal Cayities; Axterior Half of SECTION VIETED FROM BEHIND.

always recognisable, from which a blind pouch extends upwards and backwards for a distance of from 2 to $9 \mathrm{~mm}$. This is the vomero-nasal organ of Jacobson, and is supported by the vomero-nasal cartilage. In man this organ is rudimentary, but in many of the lower animals it is well developed (Fig. 673), and probably plays a part in the sense of smell, since it is lined with epithelium similar to that covering the olfactory region, and is supplied by branches of the olfactory nerve.

Lateral Wall(Fig. 674).- In the lateral wall of the nasal cavity, above the superior nasal concha, is a narrow recess, the recessus sphenoethmoidalis, into the posterior 
part of which the sphenoidal air-sinus opens. The superior meatus of the nose is a short oblique fissure, directed downwards and backwards under cover of the superior nasal concha; into it the posterior ethmoidal cells open by one or more orifices. A small meatus, bounded superiorly by a concha suprema, frequently exists above the superior meatus. The narrow slit-like interval between the nasal septum and the medial surface of the middle nasal concha is named the olfactory cleft or sulcus.

The middle meatus, situated below and lateral to the middle nasal concha, is a roomy passage, and is continued forwards into a slightly depressed area, termed the atrium meatus nasi, which lies immediately above the vestibule. The atrium is limited superiorly and anteriorly by a low ridge, the agger nasi, the representative of the noso-turbinal found in many animals. When the middle nasal concha has been removed the lateral wall of the meatus is exposed. On it is seen a narrow semilunar cleft, the hiatus semilunaris, bounded above by a rounded eleration, the bulla ethmoidalis, and below by the sharp edge of the processus uncinatus of the

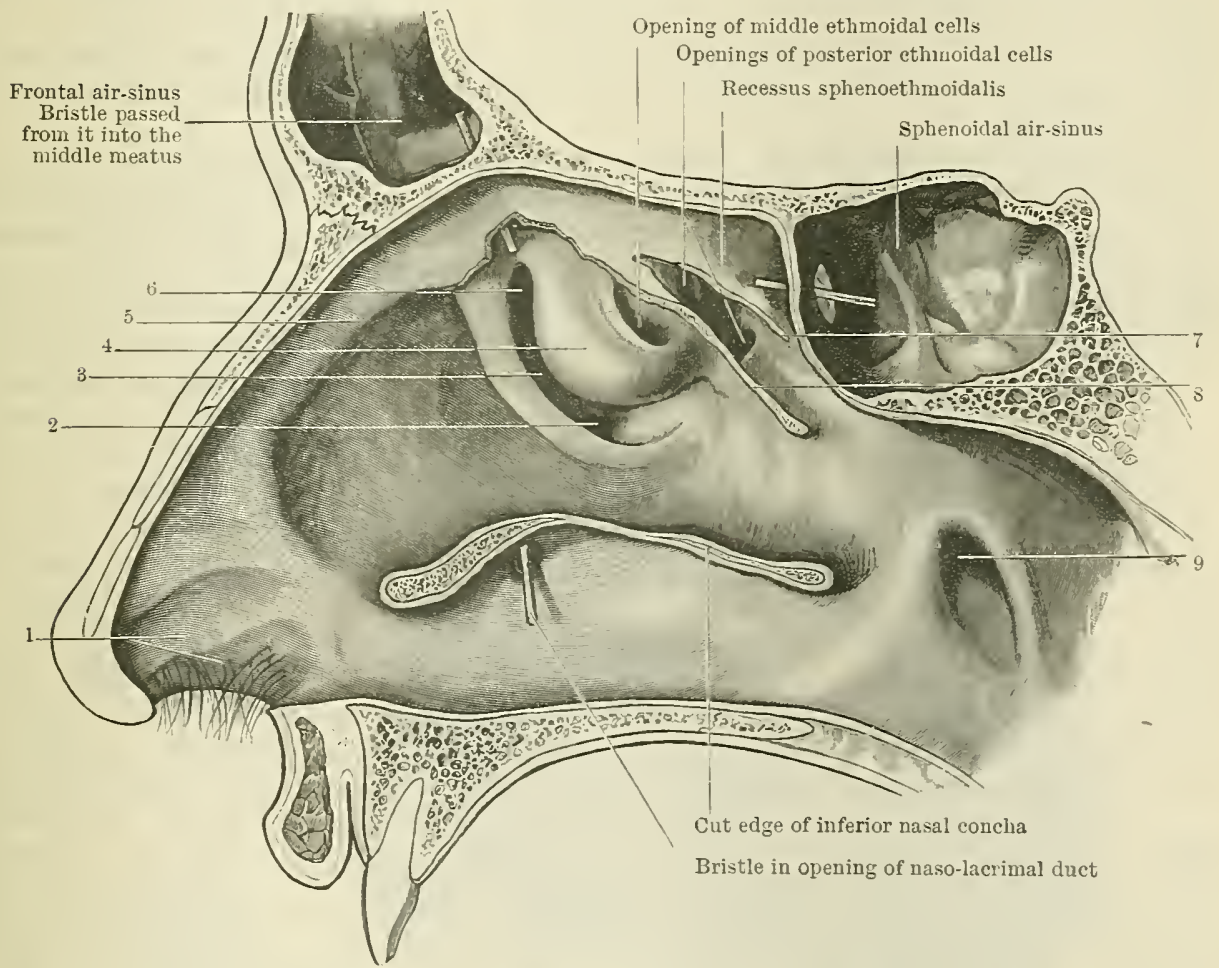

Fig. 674.-View of the Lateral Wall of the Nose-the Nasal Conche hating beex ReMored.

1. Vestibule.

2. Opening of maxillary sinus.

3. Hiatus semilunaris.

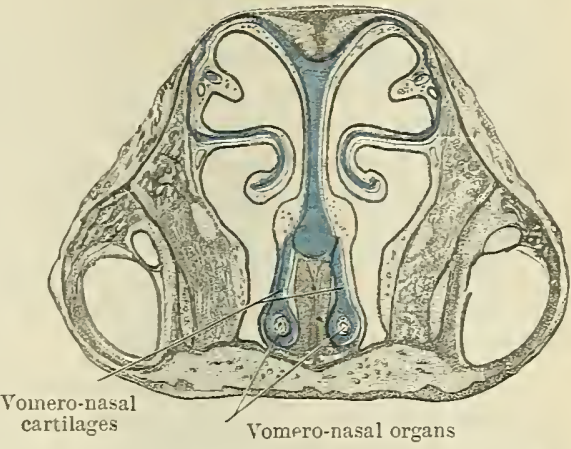

Fig. 673.-SECTIOX THROUGH Nose OF A KITTEx, showing position of the vomero-nasal organs.

On it is seen a narrow semilunar
by a rounded eleration, the bulla
of the processus uncinatus of the (1)

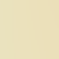


the openings of the anterior ethmoidal cells, and, in rather more than fifty per cent of skulls, is continued upwards as the fronto-nasal duct into the frontal air-sinus; in the remainder it is shut off from the lower end of the fronto-nasal duct by the union of the anterior part of the bulla ethmoidalis with the upper end of the processus uncinatus, and the fronto-nasal duct then opens into the anterior part of the middle meatus. The ostium maxillare or opening of the maxillary sinus is placed below the bulla ethmoidalis, and is hidden by the lower end of the processus uncinatus; an accessory ostium is frequently seen in the middle meatus, above the posterior part of the inferior nasal concha.

The inferior meatus lies below the inferior nasal concha, under cover of the anterior part of which is the slit-like orifice of the naso-lacrimal duct (see p. 825).

The roof is very narrow, except at its posterior part, and is divisible into three portions, fronto-nasal, ethmoidal, and sphenoidal, in accordance with the bones which enter into its formation.

The floor is nearly horizontal from before backwards, and is formed by the palatine process of the maxilla and the horizontal part of the palatine bone. In it, close to the inferior margin of the septum and immediately over the incisive foramen, a slight depression, the naso-palatine recess, is sometimes seen; it is directed downwards and forwards for a short distance, and indicates the position of a communication which existed between the nasal and buccal cavities in early fotal life.

Membrana Mucosa Nasi. - The nasal mucous membrane is thick, highly vascular, and firmly bound to the subjacent periosteum and perichondrium. It is continuous, through the choanæ, with the mucous lining of the nasal part of the pharynx; through the naso-lacrimal and lacrimal ducts, with the conjunctiva; and, through the apertures leading into the air-sinuses, with the delicate lining of these cavities.

Throughout the respiratory region it is covered with columnar, ciliated epithelium, interspersed amongst which are goblet or mucin cells, whilst between the bases of the columnar cells smaller pyramidal cells are interpolated. It contains a freely anastomosing venous plexus, which in some parts, e.g. over the inferior nasal conchæ, forms a cavernous plexus. Many acinous glands, secreting a watery fluid, are embedded in it, and are especially large and numerous in the posterior halves of

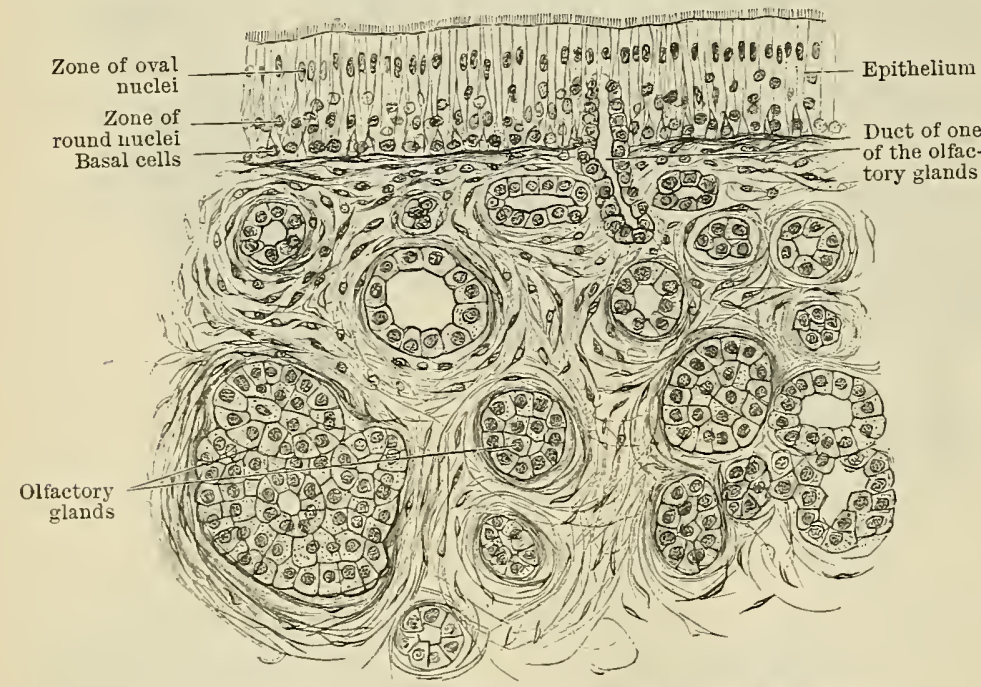

Fig. 67j.--Section through the Olfactory Mucous Membrane. the nasalcavities, while in children the mucous membrane contains a considerable amount of adenoid tissue.

In the olfactory region the mucous membrane is yellowish in colour, more delicate, and is covered with non-ciliated columnar epithelium (Figs. $675,676)$. Embedded in it are numerous tubular and branched glands, the olfactory glands, which are lined with polygonal cells and open by fine ducts on its free surface. The epithelium of the olfactory region consists of: (1) supporting cells, (2) olfactory cells, and (3) basal cells.

1. Supporting Cells.-The superficial parts of these cells are columnar in shape and contain fine granules of yellow pigment, whilst the deeper portions are continued 
for some distance as attenuated or branched processes. These cells contain elliptical or oval nuclei, which are situated at the deep ends of the columnar parts of the cells, and form what is termed the zone of oral nuclei. In many
animals the free surface of this columnar epithelium is covered by a thin limiting membrane.

\section{Olfactory Cells.} - These are bipolar nerve-cells, the central processes of which are continued as the axons of the olfactory nervefibres. They are homologous with the cells of the spinal ganglia, but differ from them in that they retain their primitive position in the surface epithelium. The cell bodies are spindleshaped and are arranged in several rows between the deeper, attenuated parts of the supporting cells. Each consists of a large, spherical nucleus with a small amount of enveloping protoplasm;

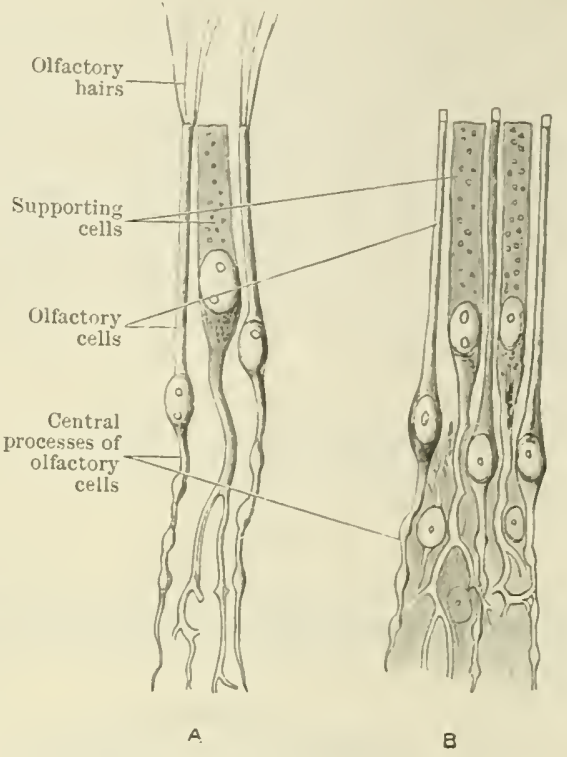

Fig. 676.-Olfactory axd Supporting Cells.

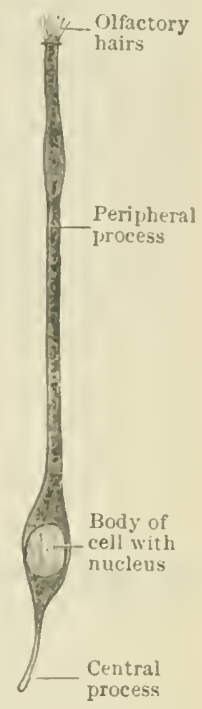

C

$\left.\begin{array}{l}\text { A. Frog } \\ \text { B. Human }\end{array}\right\}$ M. Schultze. C. Human (v. Brunn).

the nuclei form a layer of some thickness, termed the zone of round nuclei. The peripheral process of each cell is rod-like, and extends between the columnar portions of the supporting cells as far as their free surfaces, where it pierces the external limiting membrane and divides into a number of fine hair-like processes, termed olfactory hairs. The central process is a delicate, beaded filament, and is continued upwards as the axon of an olfactory nerve-fibre.

3. Basal Cells.-These cells are branched, and lie on a basement membrane between the deep extremities of the supporting and olfactory cells.

Olfactory Nerves.- The fibres of the olfactory nerves are devoid of medullary sheaths, and arise, as stated, from the olfactory cells. They are collected into fasciculi which form a plexiform network under the mucous membrane and ascend on the medial and lateral walls of the olfactory region of the nasal cavity. They are lodged, near the base of the skull, in grooves or canals in the ethmoid bone and pass into the cranial cavity through the foramina in the lamina cribrosa of the ethmoid. Immediately above this lamina they enter the olfactory bulb, in the glomerular layer of which they subdiride and form synapses with the dendrites of the mitral cells of the bulb.

The trigeminal nerve supplies branches of ordinary sensation to the nasal mucous menlume as follows:-The septum is chiefly supplied by the naso-palatine nerve, but its posterior part receives some filaments from the spheno-palatine ganglion and from the nerve of the pterygoid canal, and its anterior portion from the naso-ciliary branch of the ophthalnic. The lateral wall is supplied-(1) by the upper nasal branches of the nerve of the pterygoid cant and from the spheno-palatine ganglion; (2) by the lower nasal branches lerived from the anterior palatine; and in front by (3) the naso-ciliary branch of the oplithalmic. The floor and anterior part of the inferior meatus are supplied by a nasal branch of the anterior superior alveolar nerre.

Blood-vessels. - Arteries. - The chief artery of the nose is the spheno-palatine branch of the internal maxillary artery. This reaches the nasal cavit $y$ throngh the spheno-palatine foramen, and divides into- $(a)$ posterior nasal, which ramifies over the meatuses and conchre and scud. branches to the maxillary and frontal sinuses and the ethmoidal cells; and $(b)$ naso-palatine, the artery of the septum. Twigs are given to the upper portion of the eavity by the anterior and posterior ethmoidal arteries, while its posterior part receives sume small branches from the descending palatine. The nostrils are supplied by the lateral nasal branch of the external maxiliary, and by 
the septal artery from the superior labial. The maxillary sinus is partly supplied by the infraorbital artery, whilst the sphenoidal sinus gets its chief supply from the spheno-palatine artery. The veins form a dense cavernous plexus; this condition is well seen in the respiratory region, and especially so over the middle and inferior nasal conchæ and on the lower part of the septrm. The renous blood is carried in three chief directions, viz., anteriorly into the anterior facial vein, posteriorly into the spheno-palatine rein, and superiorly into the ethmoidal veins. The ethmoidal reins communicate with the ophthalmic veins and the veins of the dura mater ; further, an ethmoidal vein passes up throngh the lamina cribrosa of the ethmoid, and opens either into the renous plexus of the olfactory bulb or directly into one of the veins on the orbital surface of the frontal lobe of the brain. The lymph vessels form an irregular network in the superficial part of the mucons membrane, and can be injected from the subdural or subarachnoid cavities. The larger ressels are directed posteriorly towards the choanz, and are collected into two trunks, of which the larger passes to a lymph gland in front of the epistropheus, and the smaller to one or two lymph glands situated near the greater cornu of the hyoid bone.

The development of the nose is described in the section which deals with "General Embryology" (p. 50).

\section{ORGANON VISUS.}

\section{OCULUS.}

The bulb of the eye (O.T. eyeball) constitutes the peripheral part of the organ of sight; associated with it are certain accessory structures, such as the eyelids and the lacrimal apparatus.

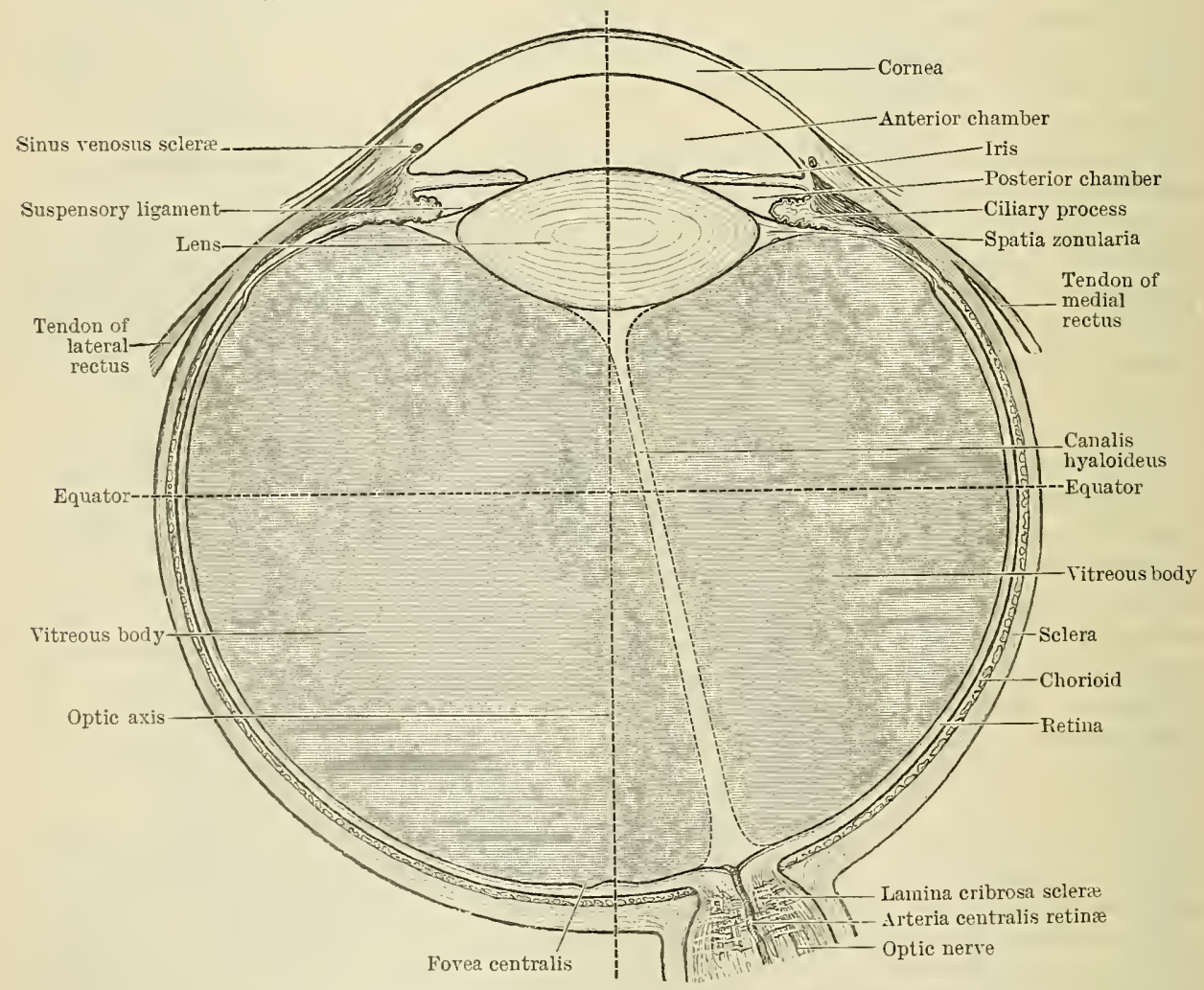

Fig. 67\%.-Diagray of a Horizontal Section through Left Bulbus Oculi and Optic Nerve $(\times 4)$.

Bulbus Oculi.-Situated in the anterior part of the orbital cavity, the bulb of the eye is protected in front by the eyelids, and is pierced behind by the optic nerve, which ramifies in its innermost tunic, the retina. The tendons of the ocular muscles are attached to the outer surface of the bulb, a short distance in front of 
its equator, while its posterior two-thirds are enveloped by a loose membrane termed the fascia bulbi (O.T. capsule of Tenon).

The bulb of the eye is not quite spherical, being composed of the segments of two spheres, viz., an anterior, transparent, corneal segment, possessing a radius of 7 or $8 \mathrm{~mm}$, and a posterior, opaque, scleral segment, with a radius of about $12 \mathrm{~mm}$. (Fig. 677). The anterior or corneal segment, in consequence of its shorter radius, projects as a dome in front of the scleral portion, the union of the two parts being indicated externally by a slight groove, the sulcus scleræ. The central points of the anterior and posterior curved surfaces of the bulb constitute, respectively, its anterior and posterior poles, and a straight line joining the two poles is termed the optic axis; an imaginary line encircling the bulb, midway between the poles, is named the equator. The axes of the two bulbs are almost parallel, diverging only slightly in front; but the axes of the optic nerves converge behind, and, if prolonged backwards, would meet in the region of the dorsum sellæ of the sphenoid. The sagittal and transverse diameters of the bulb are nearly equal-about $24 \mathrm{~mm}$; its vertical diameter is about $23.5 \mathrm{~mm}$. All three diameters are rather less in the female than in the male, but the size of the bulb is fairly constant in the same sex. What are popularly described as large eyes owe their apparent size to a greater prominence of the bulb and to a wider fissure between the eyelids.

At birth the bulb of the eye is nearly spherical and has a diameter of about $17.5 \mathrm{~mm}$. By the age of puberty this has increased to 20 or $21 \mathrm{~mm}$, after which it rapidly reaches its adult size.

Fascia Bulbi.-The fascia bulbi (O.T. capsule of Tenon) is a fibrous tunic enveloping the posterior two-thirds of the bulb of the eye, and separating the posterior part of the bulb from the surrounding orbital. fat. It blends posteriorly with the sheath of the optic nerve and with the sclera around the lamina cribrosa; anteriorly it is continued into the ocular conjunctiva, and is also attached to the ciliary region of the bulb. It is pierced by the tendons of the ocular muscles, and is reflected on each as a tubular sheath. The sheath on the tendon of the obliquus superior surrounds the tendon as far as its pulley, to which it is attached; that on the obliquus inferior is prolonged as far as the floor of the orbit. The sheaths on the recti muscles are continuous posteriorly with the perimysium of these muscles, and each gives off an expansion. The expansion from the sheath of the rectus superior blends with the sheath of the levator palpebræ superioris, and that from the sheath of the rectus inferior is attached to the tarsus of the inferior eyelid. The expansions from the sheaths of the medial and lateral recti are strong, especially that from the latter muscle, and are attached to the lacrimal and zygomatic bones respectively; they are named the medial and lateral check ligaments, because they probably limit the action of the corresponding muscles. The portion of the fascia bulbi which lies inferior to the bulb of the eye has been named the suspensory ligument (Lockwood); it is expanded in the centre, and is slung like a hammock from side to side, its narrow ends being fixed to the lacrimal and zygomatic bones.

The bulb of the eye (Fig. 677) consists of three concentric tunics or coats, and contains three transparent refracting media. The three tunics are: (1) an outer fibrous tunic, consisting of an opaque posterior part, the sclera, and a transparent anterior portion, the cornea; (2) an intermediate vascular, pigmented, and partly muscular tunic, the tunica vecsculose oculi, comprising, from behind forwards, the chorioid, the ciliary body, and the iris; (3) an internal nerrous tunic, the retina. The three refracting media are named, from before backwards, the aqueous humour, the crystalline lens, and the vitreous body.

\section{TUNICA FIBROSA OCULI.}

Sclera.-The sclera is a firm, opaque membrane, forming approximately the posterior five-sixths of the onter tunic. Thickest posteriorly (about $1 \mathrm{~mm}$.), it thins at the equator to 0.4 or $0.5 \mathrm{~mm}$., and again increases to $0.6 \mathrm{~mm}$. near the sulcus 
sclera. In the child it is thinner than in the adult, and presents a bluish appearance caused by the pigment of the chorioid shining through it; in old age it assumes a yellowish tinge. In front of the equator it gives attachment to the tendons of the ocular muscles, while its anterior part is covered by the conjunctiva. Its deep surface presents a brownish colour, and is loosely attached to the chorioid, except at the entrance of the optic nerve and in the neighbourhood of the sulcus scleræ. It is pierced behind by the optic nerve, the entrance for which is funnel-shaped, wide behind and narrow in front, and is situated $3 \mathrm{~mm}$. to the nasal side and slightly below the level of the posterior pole. The fibrous sheath of the nerve blends with the outer part of the sclera, while the nerve bundles pass through a series of orifices; this perforated portion is named the lamina cribrosa scleræ. Around the entrance of the optic nerve are some fifteen to twenty small apertures for the passage of the ciliary nerves and short ciliary arteries. The two long posterior ciliary arteries pierce it, one on each side, some little distance from the entrance of the optic nerve; while a little behind the equator are four openings, two above and two below, for the exit of veins, called venæ vorticosæ; near the sulcus scleræ it is perforated by the anterior ciliary arteries. The deep surface of the sclera is lined

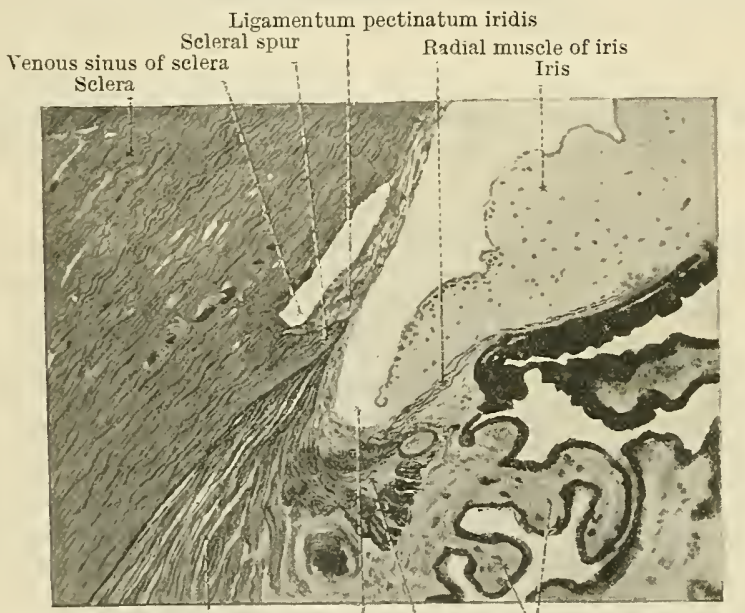

Meridional fibres of ciliary muscle

Iridial angle
Parts of ciliary processes Cireular fibres of eiliary muscle with flattened endothelial cells; and between it and the chorioid is an extensive lymph space, the spatium perichorioideale, which is traversed by the ciliary nerves and arteries just mentioned, and by an irregular meshwork of fine, pigmented, counective tissue, the lamina fusca, which loosely attaches the sclera to the chorioid. At the sclero-corneal junction the fibrous tissue of the sclera passes continuously into that of the cormea, and in the deeper part of this junction there is a circular canal, the sinus venosus

Fig. 678.-Section of Iridial Axgle. (Prof. Arthur Thomson.) scleræ (O.T. canal of

Schlemm) (Fig. 678).

When seen in a meridional section of the sclero-corneal junction, the sinus venosus scleræ appears as a narrow cleft; its outer wall is formed by the compact tissue of the sclera, while its inner consists of a triangular mass of trabecular tissue; the apex of the triangle is directed forwards and is continuous with the posterior elastic lamina of the cornea. The sinus is lined with endothelium, and occasionally contains a few red blood corpuscles. It communicates, on the one hand, with the anterior ciliary veins, and on the other, through the spatia anguli iridisin the trabecular tissue, with the anterior chamber of the eye.

Structure.-The sclera consists of bundles of white fibrous tissue, together with some fine elastic fibres, the bundles forming eqnatorial and meridional layers, which interlace with each other. Numerous spaces containing connective tissue cells and migratory cells exist between the fibres. Pigmented cells are plentiful in the lamina fusca, and a few are found also in the tissue of the sclera, near the entrance of the optic nerve, and in the region of the sclero-corneal junction.

Vascular and Nervous Supply.-The sclera receives its blood-supply from the short posterior ciliary and the anterior ciliary arteries, while its veins open into the venæ vorticosæ and anterior ciliary veins. The cell spaces play the part of lymph vessels and communicate with the perichorioidal and suprascleral lymph spaces. Its nerves are derived from the ciliary nerves, which, after losing their medullary sheaths, pass between the fibrous bundles; their exact mode of ending is not known.

Cornea.-The cornea is transparent and forms the anterior sixth of the outer tunic; its index of refraction is from 1.33 to $1: 35$; the thickness of its central part 
is about $95 \mathrm{~mm}$., of its peripheral part, about $1.19 \mathrm{~mm}$. Its anterior surface is covered with a stratified epithelium, continuous with that which lines the conjunctiva; its posterior surface is directed towards the anterior chamber of the eye and is in contact with the aqueous humour. Its degree of curvature varies in different individuals; it is greater in youth than in old age, and is, as a rule, slightly greater in the vertical than in the horizontal plane; it diminishes from its centre to its circumference, and is less on the nasal than on the temporal side of the anterior pole. The outline of the anterior surface of the cornea is almost circular, measuring $11 \mathrm{~mm}$. vertically and $11.9 \mathrm{~mm}$. transversely;

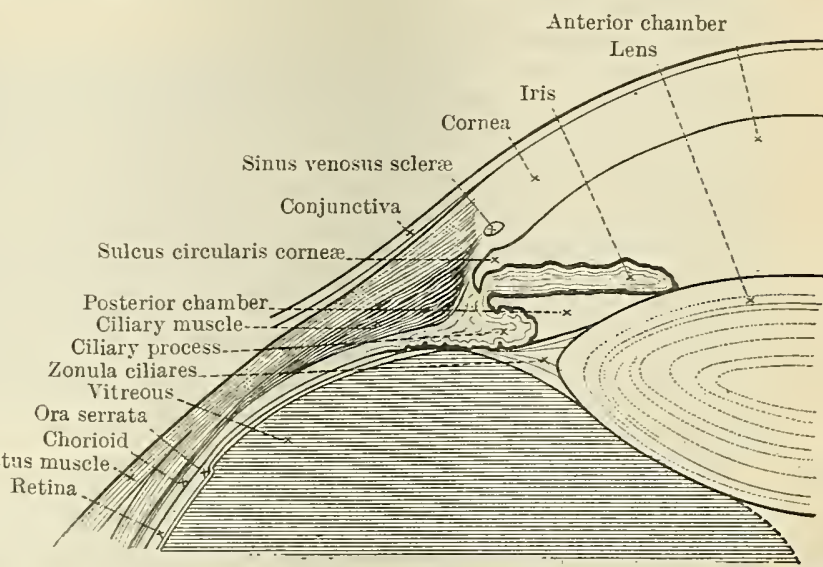

Fig. 679.-Section of a Portion of the Bulb of the Eye showing the Sulcos Circularis Corne..

that of the posterior surface is circular and has a diameter of $13 \mathrm{~mm}$.

The tissue of the cornea is continuous posteriorly with that of the sclera, the line of union being known as the sclero-corneal junction. Directly in front of this junction the inner surface of the cornea projects in the form of a rounded rim; behind this rim, in the interval between the sclero-cormeal junction and the attachment of the iris, is a groove, the sulcus circularis cornex (Arthur Thomson) ${ }^{1}$ (Fig. 679). The outer wall of this sulcus is composed of a thin stratum of trabecular tissue placed on the inner side of the sinus venosus scleræ. Between this trabecular tissue

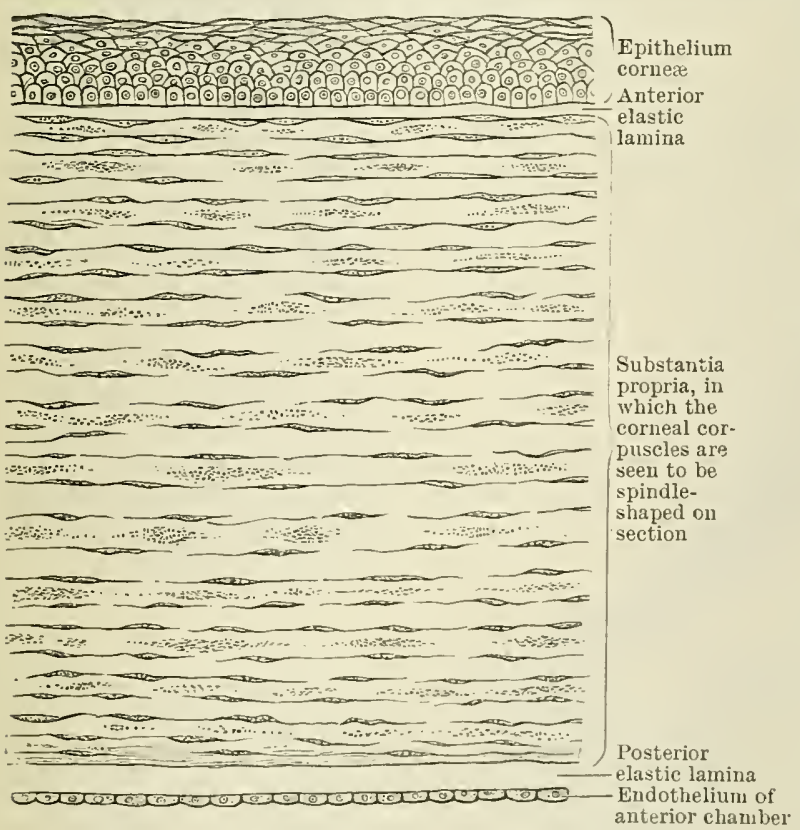

Fig. 6S0.-Tertical Section of Cornea (magnified). and the front of the circumference of the iris is a narrow recess which on section appears as an acute angle; it is named the filtration angle or angle of the iris.

Structure.-The cornea consists, from before backwards, of the following strata, viz., (Fig. 680) :-
1. Epithelium corneæ.
2. Anterior elastic lamina.
3. Substantia propria.
4. Posterior elastic lamina.
5. Endothelium of anterior chamber.

1. The epithelium corneæ is continuous with that covering the free surface of the conjunctiva and consists of six or eight strata of nucleated cells. Deepest of all is a single layer of perpendicularly arranged columnar cells, the flattened bases of which rest on the anterior elastic lamina, while their opposite euds are rounded and contain the nuclei. Superficial to this layer are three or four strata of polygonal cells, the majority of which exhibit finger-like processes joining with the corresponding processes of neighbouring cells; the more superficial layers consist of squamous cells. The thickness of this stratified epithelium is about $45 \mu$ at the centre, and about $80 \mu$ at the periphery of the cornea. 
2. The anterior elastic lamina is from 19-20 $\mu$ thick, and is regarded merely as a differentiation of the anterior part of the substantia propria, from which it is with difficulty separated ; it is not stained yellow by picrocarmine, thus differing from true elastic tissue. Its degree of development varies in different animals.

3. The substantia propria presents, in a fresh condition, a homogeneous appearance; but, with the assistance of reagents, it is seen to consist of modified connective tissue, with a few elastic fibres. An amorphous interstitial substance binds the fibres into bundles, and, in turn, cements the bundles into lamellæ which are flattened from before backwards. The fibres of any one lamella cross those of adjacent lamellæ almost at right angles, while the superimposed lamellæx are joined by sutural fibres and by amorphous substance. Between the lamellæ are found the cell spaces or lacunæ of the cornea-irregularly stellate in shape, and communicating freely with each other by means of fine canaliculi. The corneal cells or corpuscles are contained in these lacme, without, however, completely filling them, the remainder of the cavities being occupied by lymph. The cells are nucleated, flattened, and star-like, and their branched processes join those of neighbouring cells in the canaliculi. Migratory or lymph cells are also found in cell spaces.

After middle age a grayish opaque ring, 1.5 to $2 \mathrm{~mm}$. in breadth, is frequently seen near the perjphery of the cornea; it is termed the arcus senilis, and results from a deposit of fat granules in the lamellæ and corneal corpuscles.

4. The posterior elastic lamina is a clear homogeneous membrane, covering the posterior surface of the substantia propria and possessing a thickness of 6-8 $\mu$ at the centre and 10-12 $\mu$ at the periphery of the cornea. Less firmly attached than the anterior elastic lamina, it may be stripped off, when it will be found to roll up with its attached surface inwards. Between the ages of twenty and thirty years small wart-like projections appear on its deep surface, near its periphery, and these increase in size and number as years advance, so that in old age the membrane may attain a thickness of $20 \mu$. At the sclero-corneal junction the posterior elastic lamina splits into bundles of fine fibres which interlace and form the triangular area of trabecular tissue already referred to (p. 808), and which is ustally spoken of under the name of the ligamentum pectinatum iridis. The meshes or spaces between the trabeculix are termed the spatia anguli iridis (O.T. spaces of Fontana), and are lined with endothelium prolonged from the endothelium of the anterior chamber. They communicate internally with the filtration angle and extelnally with the sinus venosus sclere, and form important channels through which fluid may filter from the anterior chamber into the sinus and thence into the anterior ciliary veins. When the trabecular tissue of the ligamentum pectinatum iridis is followed backwards most of its fibres are seen to be attached to the anterior surface of an inwardly directed rim of scleral tissue ; in a meridional section this rim appears as a triangular projection, and is named the scleral spur. A few fibres of the trabecular tissue are carried past the apex of the scleral spur on to the inner surface of the origin of the meridional fibres of the ciliary muscle, and, passing behind the filtration angle, are prolonged into the iris (Fig. 678), where they are directly continuous with the fibres of the dilatator pupillæ muscle (Arthur Thomson). ${ }^{1}$

5. The endothelium of the anterior chamber consists of a single stratum of nucleated, flattened, polygonal cells, which present a fibrillar structure and are continued as a lining to the spatia anguli iridis; this layer of endothelium is also reflected on to the anterior surface of the iris.

Vascular and Nervous Supply of the Cornea.-In the fotus the cornea is traversed, almost as far as its centre, by capillaries; but in the adult it is devoid of blood-vessels, except near its margin. The capillaries of the conjunctiva and sclera pass into this marginal area for a distance of about $1 \mathrm{~mm}$., where they terminate in loops. All the remainder of the cornea is nourished by the lymph which circulates in its cell spaces and canaliculi.

The nerves of the cornea are derived from the ciliary nerves. Around its periphery they form an annular plexus, from which fibles pass into the cornea, where, after a distance of 1 or $2 \mathrm{~mm}$., they lose their medullary sheaths and ramify in the substantia propria, forming what is termed the fundamental or stroma plexus. Fibres extend from this plexus through the anterior elastic lamina and form a subepithelial plexus, from which fine filaments ramify between the epithelial cells as far as the superficial layers. From the annular and stroma plexuses fibrils pass to the substantia propria and come into close relation with the corneal corpuscles.

\section{TUNICA VASCULOSA OCULI.}

The middle, vascular, and pigmented tunic of the bulb of the eye comprises, from behind forwards, the chorioid, the ciliary body, and the iris (Fig. 681).

Chorioidea.-The chorioid intervenes between the sclera and the retina, reaching as far forwards as the ora serrata of the retina (p. 815). It is dark brown or black in colour, and is thicker behind than in front; posteriorly it is pierced by the optic nerve, and is here firmly attached to the sclera. Its outer surface is flocculent and is connected to the sclera by the loose lamina fusca; its inner surface is smooth and is adherent to the outermost or pigmented layer of the retina.

The chorioid consists of a loose connective tissue, embedded in which are bloodvessels and branched pigment cells; from without inwards it consists of three 
layers, viz.: $(a)$ the lamina suprachorioidea; $(b)$ the proper tissue of the chorioid; and (c) the lamina basalis (Fig. 681).

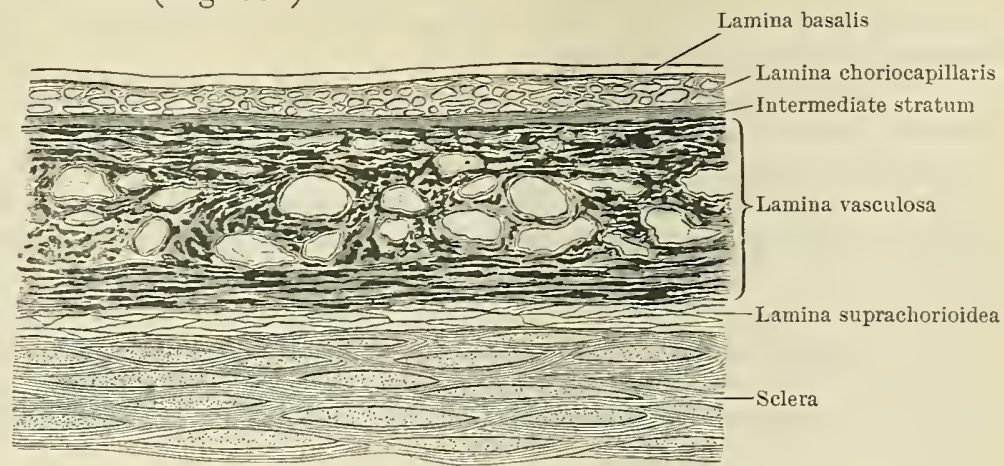

Fig. 681.-Vertical Section of Chorioid and Inner Part of Sclera.

The lamina suprachorioidea resembles the lamina fusca of the sclera, and consists of a series of fine non-vascular lamellæ, each containing a delicate network of elastic fibres, amongst which are stellate, pigmented cells and amœboid cells. The spaces between the laminæ are lined with endothelium, and together form the spatium perichorioideale, already referred to (p. 808).

The proper tissue of the chorioid consists of blood-vessels and numerous pigmented cells, supported by connective tissue, elastic fibres, and some nonstriped muscular fibres. Its outer part contains the larger blood-vessels, and is named the lamina vasculosa, while its inner portion is composed of a network of fine capillaries, and is termed the lamina choriocapillaris ; these two laminæ are joined by a thin intermediate stratum. The arteries of the chorioid are derived from the short posterior ciliary vessels which pierce the sclera around the entrance of the optic nerve, and form a wide-meshed plexus in the lamina

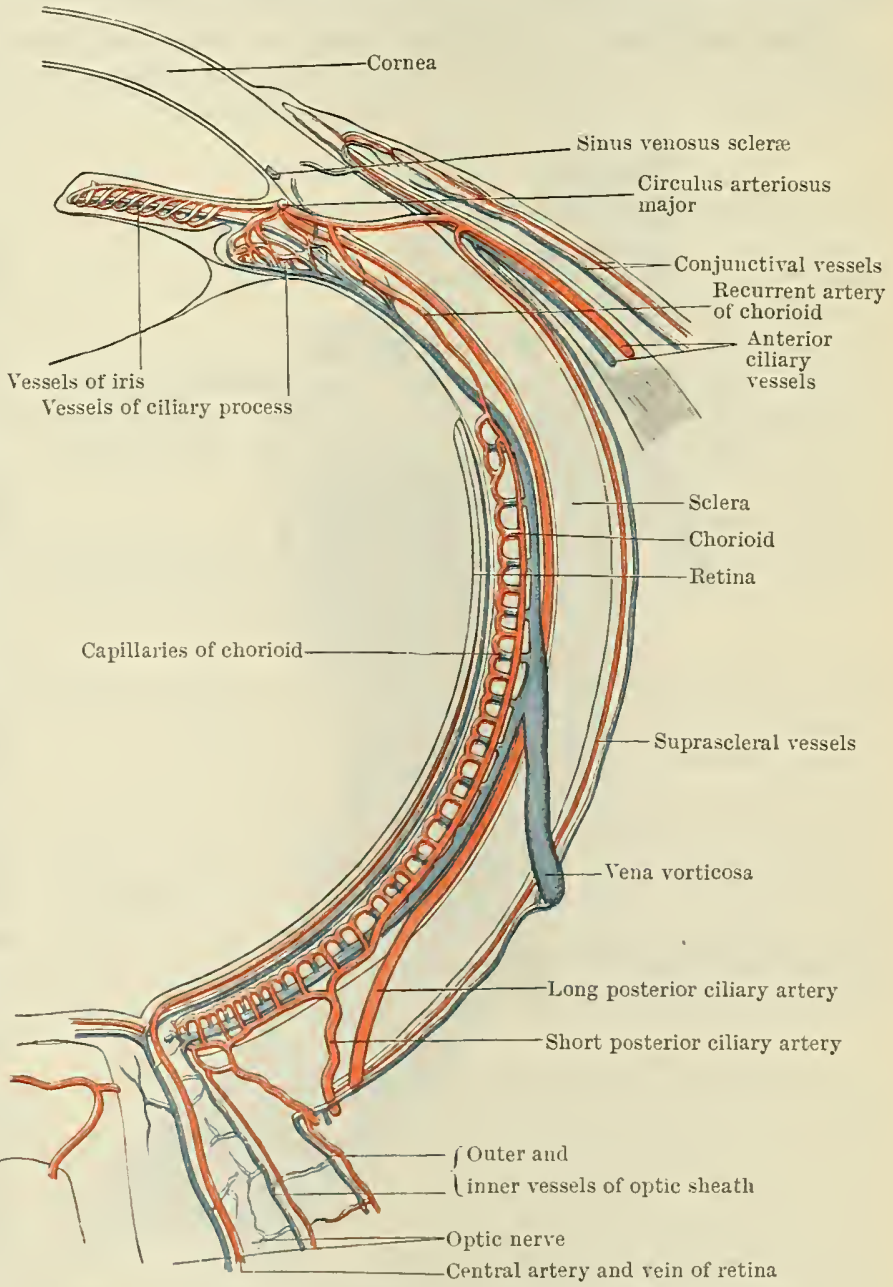

Fig. 6S2.-Diagram of the Circulation ix the Eye (Leber). vasculosa. The circular muscular coats of the arteries are well dereloped, and longitudinal muscular fibres also are present in the larger branches. The veins, 
destitute of muscular tissue, are superficial to the arteries; they are surrounded by perivascular lymph sheaths and converge to form whorls, which open into the venæ vorticosæ. In the tissue between the blood-vessels are numerous stellate, flattened, and pigmented cells.

The lamina choriocapillaris is composed essentially of small capillaries, which form an exceedingly close network, embedded in a finely granular or almost homogeneous tissue.

The intermediate stratum between the lamina vasculosa and lamina choriocapillaris consists of a network of delicate elastic fibres and contains almost no pigment cells; it is lined, next the lamina choriocapillaris, with a layer of endothelium.

The lamina basalis is transparent and nearly structureless. Its outer surface exhibits a trellis-like network of fibres which unite it to the lamina choriocapillaris, while its inner surface is smooth and is in contact with the pigmented layer of the retina.

Tapetum.-In many animals a brilliant iridescence is seen on the postero-lateral part of the chorioid; to this the name tapetum is applied. Absent in man, it may be due, as in the horse, to a markedly fibrous condition of the stratum intermedium (tapetum fibrosum), or as in the seal, to the presence of some five or six layers of flattened iridescent cells lying immediately outside the lamina choriocapillaris (tapetum cellulosum).

Corpus Ciliare.-The ciliary body connects the chorioid to the circumference of the iris (Fig. 683), and comprises three zones, viz.: (a) the orbiculus ciliaris,

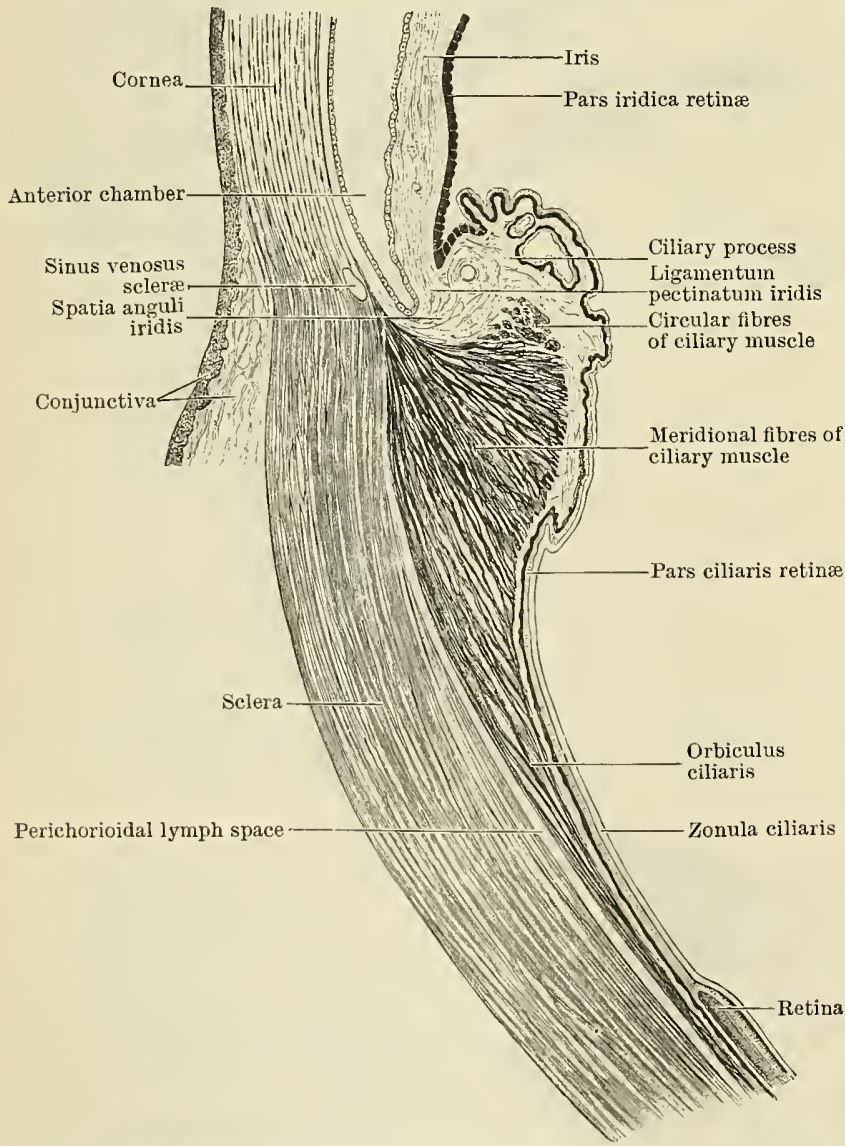

(b) the ciliary processes, and $(c)$ the ciliary muscle.

The orbiculus ciliaris is a zone of about $4 \mathrm{~mm}$. in width immediately adjoining the chorioid; it exhibits numerous radially arranged ridges.

Processus Ciliares. - The ciliary processes, about seventy in number, form a circle of radial thickenings, each of a somewhat triangular shape; the base of the triangle is directed forwards, towards the equator of the lens, while the apex is continuous behind with some three or four ridges of the orbiculus ciliaris. They vary in size, the largest having a length of $2-5$ $\mathrm{mm}$.

The structure of the orbiculus ciliaris and ciliary processes is similar to that of the chorioid, but the capillaries are larger and more tortuous, and there is no lamina choriocapillaris. The Fig. 683.-Section throdgh Ciliary Region of the Bulb of the Ete. deep surface of the ciliary processes is covered by two strata of columnar epithelium, the anterior layer of which is pigmented; these two strata form a direct continuation forwards of the retina and constitute the 
pars ciliaris retinæ; this epithelium is invaginated to form more or less tubular glands.

M. Ciliaris.-The ciliary muscle is triangular on horizontal or vertical section, and consists of two sets of fibres-meridional and circular (Fig. 683). The meridional fibres arise from the scleral spur, already described, and radiate backwards, to be attached to the ciliary processes and orbiculus ciliaris. When they contract the chorioid is drawn forwards and the lens becomes more convex, owing to the relaxation of its suspensory ligament (see p. 810). The circular fibres form a triangular zone behind the filtration angle, close to the periphery of the iris. Considerable individual differences are found as to the degree of development of these two portions of the ciliary muscle; the meridional fibres are always more numerous than the circular fibres, the latter being absent or rudimentary in myopic eyes, but well developed, as a rule, in hypermetropic eyes.

Iris.-The iris forms a contractile diaphragm in front of the lens, and is pierced, a little to the nasal side of its centre, by an almost circular aperture, the pupil, which, during life, is continually varying in size in order to regulate the amount of light admitted into the interior of the eye. It partially divides the space between the cornea and lens into two portions, which are filled by the aqueous humour, and named respectively the anterior and posterior chambers of the eye. It is thinnest at its peripheral or ciliary margin which is directly continuous with the ciliary body, and, through the medium of the ligamentum pectinatum iridis, with the posterior elastic lamina of the cornea. Its pupillary or free margin forms the circumference of the pupil, and rests upon the anterior surface of the capsule of the lens.

The distinctive colour of the eye, in different individuals, depends on the arrangement of the pigment in the iris; in the blue eye the pigment is limited to the posterior surface of the iris, but in the brown or black eye it is also scattered throughout its stroma; in the albino the pigment is absent.

The pupil is closed, during the greater part of fœtal life, by a thin transparent vascular membrane, the membrana pupillaris, continuous with the pupillary margin of the iris. Its vessels are derived partly from the vessels of the iris and partly from those of the capsule of the lens; they converge towards the middle of the membrane, near which they form loops so as to leave the central part non-vascular. About the seventh month the vessels begin to be obliterated, from the centre towards the circumference; and this is followed by a thinning and absorption of the membrane, which becomes perforated by the aperture of the pupil. This perforation gradually enlarges, and at birth the membrane has entirely disappeared ; in exceptional cases it persists.

On the anterior surface of the iris is a layer of flattened endothelium, placed on a basement membrane, and continuous with the endothelium of the anterior chamber. Depressions or crypts are here and there seen in which the endothelium and basement membrane are absent, and are, by some, regarded as stomata, through which the lymph vessels of the iris communicate with the cavity of the anterior chamber. The posterior surface of the iris is covered with a basement membrane, on which are placed two layers of columnar, pigmented epithelium, continuous with the pars ciliaris retinæ, and termed the pars iridica retinæ. The stroma iridis, or proper tissue of the iris, consists of delicate connective tissue and elastic fibres, with pigmented cells, blood-vessels, nerves, and non-striped muscle.

The blood-vessels of the iris (Fig. 682) are derived from the long ciliary and the anterior ciliary arteries. The long ciliary arteries, two in number, pierce the sclera on the medial and lateral sides of the optic nerve respectively, and extend forwards, between the sclera and chorioid, towards the ciliary margin of the iris. Here each divides into a superior and an inferior branch, and the resulting four branches anastomose in the form of a circle, termed the circulus arteriosus major. This circle is joined by a varying number of anterior ciliary arteries derived from the lacrimal and muscular branches of the ophthalmic artery, and, after supplying the ciliary muscle, sends converging branches towards the aperture of the pupil, where a second circle, the circulus arteriosus minor, is formed. The veins proceed 
towards the ciliary margin of the iris, and communicate with the veins of the ciliary processes and with the sinus venosus scleræ. The convergence of the blood-

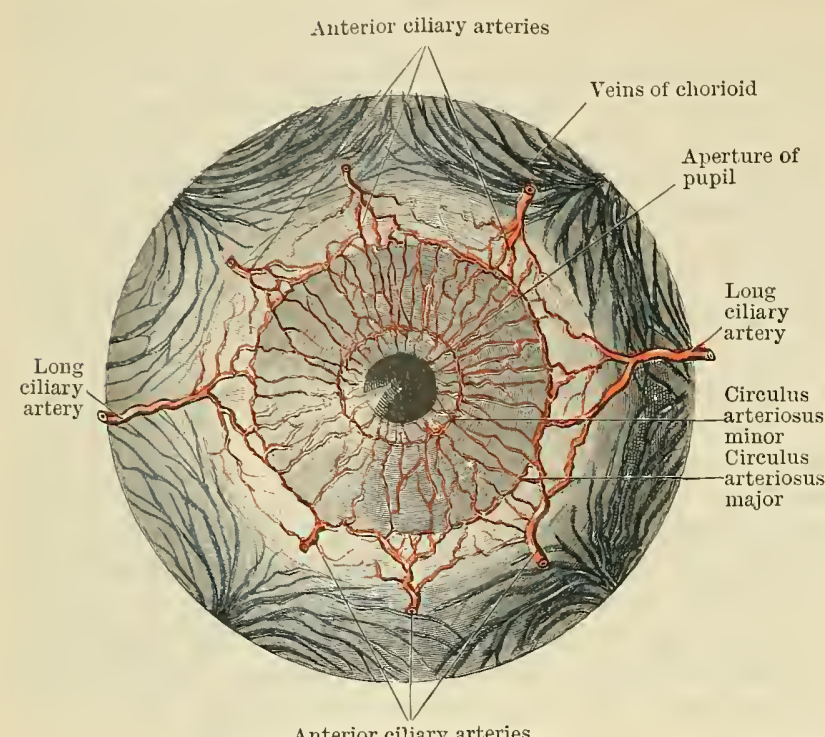

Anterior ciliary arteries vessels towards the aperture of the pupil gives to the anterior surface of the iris a striated appearance.

The non-striped muscular fibres of the iris are arranged in two sets: (a) circular, (b) radial. The circular fibres form a band, the $\mathrm{m}$. sphincter pupillæ, around the pupillary aperture; by the contraction of these fibres the size of the pupil is lessened. The radial fibres constitute the $\mathrm{m}$. dilatator pupillæ and extend outwards from the sphincter to the ciliary margin. Many anatomists regard the radial fibres, in man and most mammals, as being elastic and not muscular. In Fig. 684. - Blood-vessels of Iris aND ANTERIor PART of Choriord, animals in which the radial
viewed from the front (Arnold). fibres are muscular, the degree of their development varies considerably; they are feebly marked in the rabbit, but are well developed in the bird, and still more so in the otter.

The nerves of the chorioid and iris (Fig. 685) are derived from the long and short ciliary nerves. The former, two or three in number, are branches of the nasociliary nerve; the latter, varying from eight to fourteen, are derived from the ciliary ganglion. Piercing the sclera around the entrance of the optic nerve, the ciliary nerves traverse the perichorioidal lymph space, where they form a plexus, rich in nerve-cells, from which filaments are supplied to the blood-vessels of the chorioid. In front of the ciliary muscle a second plexus, also rich in nerve-cells, is formed; this supplies the ciliary muscle and sends filaments into the iris, as far as its pupillary margin, for the

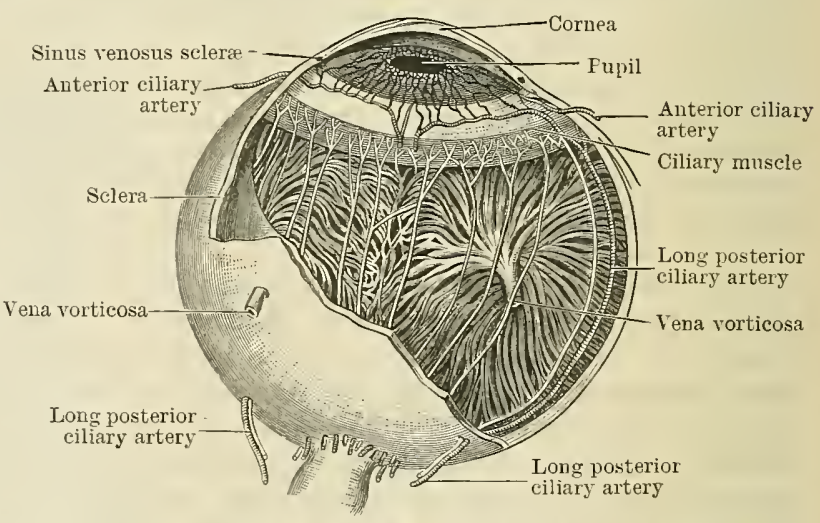

Fig. 685.-Dissection of the Ereball showrig the Tascular Tuxic and the Arrangement of the Crliary Nerves and VESSELS.

supply of its muscular fibres and blood-vessels. The sphincter pupillæ is supplied by the oculo-motor nerve, the dilatator pupillæ by the sympathetic.

\section{RETINA.}

The retina, or nervous tunic of the eyeball, is a soft, delicate membrane, in which the fibres of the optic nerve are spread out. It consists of two strata, viz.: (a) an outer, pigmented layer, attached to the chorioid; and (b) an inner nervous lamina, the retina proper, in contact with the hyaloid membrane of the vitreous body, but attached to it only around the entrance of the optic nerve and in the region of the ciliary processes. Expanding from the entrance of the optic nerve, 
the retina appears to end, a short distance behind the ciliary body, in a wavy border, the ora serrata (Fig. 686). Here its nervous elements cease and the membrane becomes suddenly thinned, but a delicate continuation of it is prolonged over the posterior aspect of the ciliary body and iris. This continuation consists of the pigmented layer, together with a layer of columar epithelium, and constitutes the pars ciliaris retinæ and pars iridica retinæ, already referred to (p. 813). The portion behind the ora serrata is termed the pars optica retinæ, and its thickness gradually diminishes from $0.4 \mathrm{~mm}$. near the

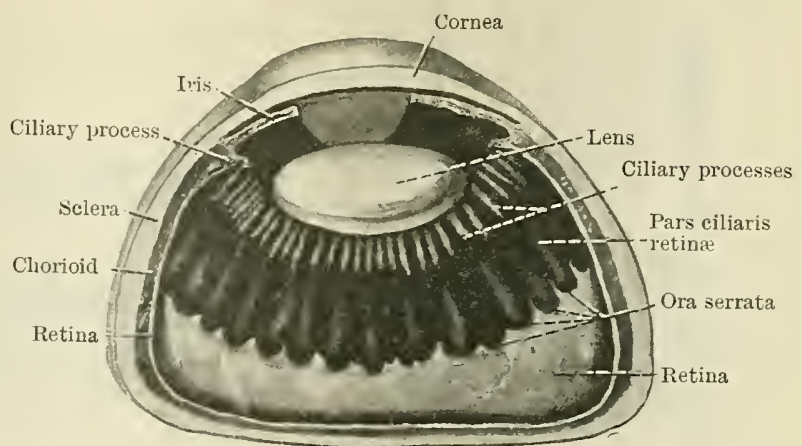

Fig. 686.-A Segment of the Bulbus Ocdli showing the Ora SERrata.

entrance of the optic nerve, to $0.1 \mathrm{~mm}$. at the ora serrata. It presents, at the posterior pole of the eye, and therefore directly in the optic axis, a small, oval yellowish spot, the macula lutea. The greatest or transverse diameter of the macula measures from 2-3 mm.; its central part is depressed and is named the forea centralis. About $3 \mathrm{~mm}$. to the nasal side and slightly below the level of the posterior pole is a whitish, circular disc, the optic disc, which corresponds with the entrance of the optic nerve, and has a diameter of about $1.5 \mathrm{~mm}$. The circumference of the optic disc is slightly raised and is named the papilla nervi optici, while its depressed central portion is termed the excavatio papillæ nervi optici (O.T. optic cup). The optic disc consists merely of nerve-fibres, the other layers

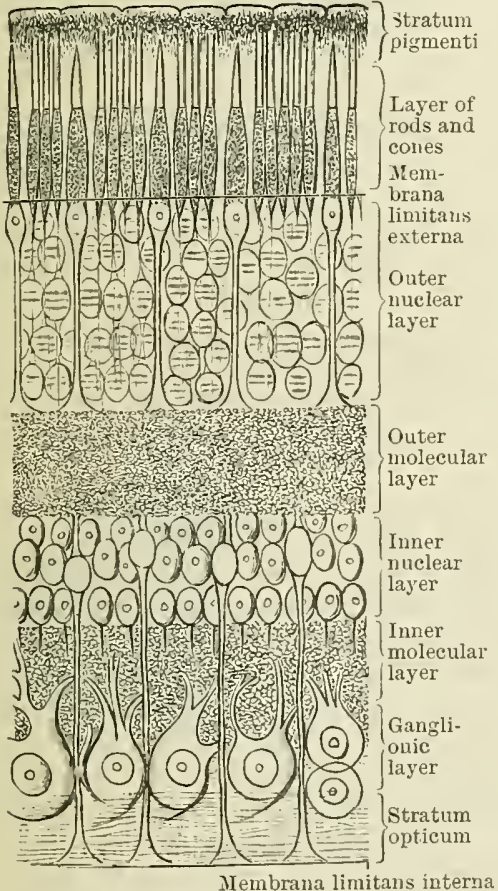

Fig. 687.-Diagramatic Section of the Human Retina (modified from Schultze). of the retina being absent, and it constitutes the "blind spot."

The nervous layer of the retina is transparent during life, but becomes opaque and of a grayish colour soon after death. If an animal is kept in the dark before the removal of its eyeball, the retina presents a purple tinge, due to the presence of a colouring matter named rhodopsin or visual purple, which is rapidly bleached on exposure to sunlight. This colouring matter is absent from the macula lutea, and absent also over a narrow zone, 3-4 mm. in width, near the ora serrata.

Structure of the Retina (Figs. 687, 688, $689)$. - The nervous elements of the retina are supported by non-nervous or sustentacular fibres, and are arranged in seven layers, to which must be added the stratum jigmenti.

The layer's from within outwards, i.e. from vitreous body to chorioid, are:

1. Stratum opticum or layer of nerve-fibres.

2. Ganglionic or nerve-cell layer.

3. Inner molecular or imner plexiform lajer.

4. Inner nuclear layer or layer of inner granules.

5. Outer molecular or outer plexiform layer.

6. Outer nuclear layer or layer of outer granules.

7. Layer of rods and cones.

8. Stratum pigmenti.

1. Stratum opticum or layer of nerve-fibres.-Most of the fibres of this stratum are centripetal, and are direct continnations of the axons of the cells in the 
ganglionic layer; a few are centrifugal and end in branched clubbed extremities in the inner molecular or inner nuclear layers of the retina.
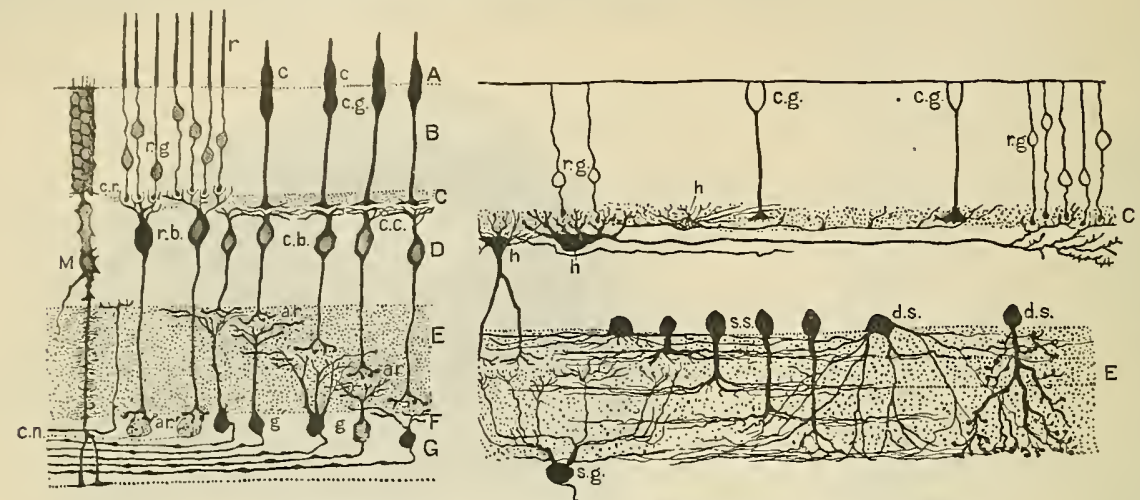

Fig. 688.-Perpendicular Sections of Mammalian Retina (Cajal).

A, Layer of rods and cones; B, Onter nuclear layer ; C, Onter molecular layer ; D, Inmer nuclear layer ; E, Inner molecular layer ; F, Ganglionic layer ; G, Stratum opticum ; $r$, rods ; $c$, cones, r.g, rod granules ; $c . g$, cone granules; r.b, rod bipolars; c.b, cone bipolars; c.r, contact of rod bipolars with the spherules of the rod fibres; $c . c$, contact of cone bipolars with the branches of the cone fibres; ar, internal arborisation of cone bipolars ; $a r^{\prime}$, internal arborisation of rod bipolars ; $c . n$, centrifugal nerve fibre; $h$, horizontal cells; $s . s$, stratified spongioblasts; $d . s$, diffuse spongioblasts; $s . g$, stratified gauglion cell ; M, Sustentacular fibre.

2. Ganglionic or nerve-cell layer.-The cells of this stratum vary in size, are oval or piriform in shape, and form a single layer, except at the macula lutea, where several

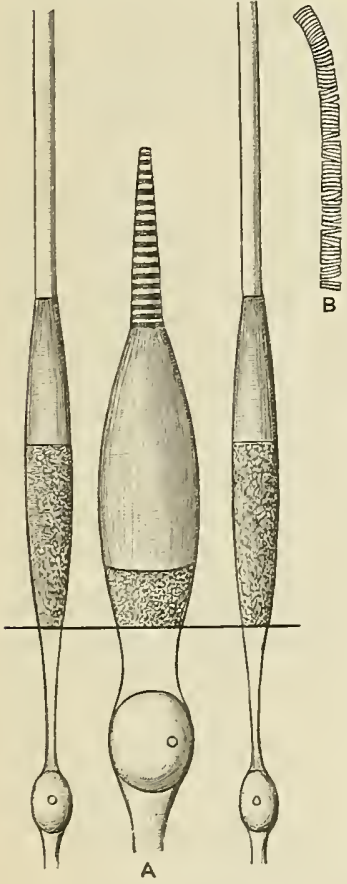

F1G. 689. strata are present. Each cell contains a large nuclens, and gives off, from its inner surface, an axon which is continued as a fibre of the stratum opticum. From the onter surface of each cell numerous dendrites arise, which form arborisations in the inner molecular layer. The cells may be divided into unistratified, multi-stratified, and diffinse, according as their dendrites ramify in one or in several strata of the inner molecular layer, or extend throughout nearly its whole thickness.

3. Inner molecular or inner plexiform layer.-This is constituted chiefly by the interlacement of the dendritic arborisations of the cells of the ganglionic layer with those of the inner nuclear layer, and has been divided by Ramon y Cajal into five strata. It sometimes contains horizontal cells (spongioblasts), whose branched processes ramify in it.

4. Inner nuclear layer or layer of inner granules.This is the most complicated of the retinal strata, and consists of numerous cells which may be divided into three groups, viz. : (a) bipolar cells, (b) horizontal cells, and (c) spongioblasts, or amacrine cells.

(a) The bipolar cells, by far the most numerous, are fusiform and nucleated, and each gives off an external and an internal process. The internal processes terminate in flattened tufts, at different levels, in the inner molecular layer, while the external produce an abundant ramification in the external zone of the outer molecular layer. These bipolar cells are divided into rod bipolars, cone bipolars, and giant bipolars. The rod bipolars end peripherally in vertical arborisations around the button-like ends or spherules of the rod fibres, and, centrally, in branched extremities which mostly become applied to the cells of the ganglionic layer. The cone bipolars end peripherally in flattened arborisations in the outer molecular layer, in contact with the ramifications of the foot-plates of the cone fibres, and, centrally, ramify in some one of the five strata of

the inner molecular layer. The giant bipolars form, peripher-
ally arranged arborisation in the onter molecular layer ; centrally, A cone and two rods from the
human retina (modifiel from Max Schultze); B, Outer part of rod separated into dises. ally, an extensive liorizontally arranged arborisation in the onter molecula
they ramify in one or other of the strata of the inner molecular layer. 
(b) The horizontal cells are of two varieties: (1) small, flattened, star-like cells, lying immediately internal to the outer molecular layer, and sending a tuft of dendrites outwards, towards the bases of the cone fibres, while their axons are directed horizontally, for a variable distance; (2) large, irregular cells, lying internal to the above and ending in finger-like ramifications in the outer molecular layer. Their axons run horizontally for some distance, and end, in extensive varicose arborisations, under the spherules of the rod fibres.

(c) The spongioblasts are situated in the innermost part of the inner nuclear layer; their processes ramify in the inner molecular layer, it may be in one stratum (stratified spongioblasts) or in several strata (diffuse spongioblasts).

5. Outer molecular or outer plexiform layer.-This is constituted by the interlacement of the dendrites of the bipolar and horizontal cells, just described, with the spherules of the rod fibres and the ramifications of the foot-plates of the cone fibres. It is divided into two strata: $(a)$ external, indicating the contact of the rod bipolars with the spherules of the rod fibres; $(b)$ internal, the line of contact between the cone bipolars and the branches of the cone fibres.

6. Outer nuclear layer or layer of outer granules.-This is made up of clear granules which somewhat resemble those of the inner nuclear layer, and are divisible into two kinds: $(a)$ cone granules, $(b)$ rod granules. The cone granules are the larger, and each contains an oval nucleus; they lie immediately inside the outer limiting membrane, through which they are continuous with the cones of the next layer. Each is prolonged internally as a straight fibre, which, on reaching the outer molecular layer, expands to form a footplate, from which several horizontal fibrils are given off. The rod granules are far more numerous than the cone granules, and each contains a small oval nucleus, which is transversely striated. Their onter processes are continuous, through the outer limiting membrane, with the rods of the next layer, while their inner processes pass into the outer molecular layer and end in free, unbranched spherules amougst the arborisations of the rod bipolars.

7. Layer of rods and cones.-This consists of two sets of structures, viz., rods and cones. Except at the macula lutea the rods are far more numerous than the cones, and assume the form of elongated cylinders, while the cones are shorter than the rods, and taper externally to fine points. Each rod and cone consists of two segments-inner and outer. The inner segment of the rod only slightly exceeds in diameter its onter segment, whereas the inner segment of the cone greatly exceeds its outer part. The inner segments of both rods and cones have an affinity for staining reagents, and consist of a basal homogeneous portion and an outer longitudinally striated part, the proportion of the latter to the former being greater in the cones than in the rods. The outer segments have not the same affinity for reagents, but tend to break transversely into numerous discs (Fig. 689, B). The colouring matter, rhodopsin, already referred to, is found only in the outer segments of the rods, the terminal parts of which extend into the layer of pigmented epithelium.

8. Stratum pigmenti.- This consists of a single stratum of cells which, on surface view, are hexagonal (Fig. 690), their outer flattened surfaces being firmly attached to

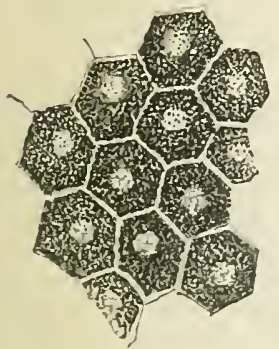

Fig. 690. - Stratua Pigmenti of HuMaN Rerrina (viewed from the surface). in single or forked which a bases, by the apposition of which a delicate membrane, the membrana limitans interna, is formed. In the ganglionic layer they give off' a few side branches, and, on passing through the inner nuclear layer, supply ramifications amongst the inner granules a large oval nucleys and is devoid of pigment, while the inner portion is filled with pigment and extends as a series of thread-like processes amongst the outer segments of the rods and cones. When the eye is kept in the dark the pigment accumulates near the outer part of the cell, but when exposed to light it streams in between the rods and cones (Fig. 691).

Sustentacular fibres of the retina.-These form a framework for the support of the nervous structures (Fig. 688, II). They begin at the inner surface of the nerve-fibre layer

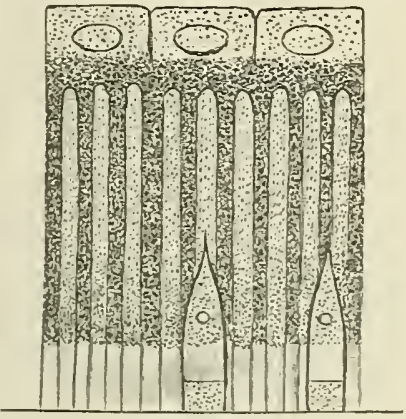

Fig. 691.-SECTION THROUGH OUTER Laters of Retixa (semi-diagram. matic). the chorioid. When seen in profile the outer part of each cell contains 
for their support; in this part of each fibre there is an oval uucleus. In the outer nuclear layer they break up into a network of fibrils which surround the rod and cone granules and fibres, and end externally at the bases of the rods and cones in a delicate membraue, the membrana limitans externa.

Structure of the macula lutea and fovea centralis. - The yellow colour of the macula is clue to the presence of pigment in the immer layers of the retina. At the circumference of the macula the nerve-fibre layer is greatly thinned and the rods are few in number; the ganglionic layer, on the other hand, is thickened and may contain from seven to nine strata of cells, while the onter grannlar layer also is thicker and its granules hare an oblique direction. At the fovea centralis the retina is much thinned, since here its nerve-fibre and ganglionic layers are absent and its other strata greatly attenuated. The stratum pigmenti, on the other hand, is thicker and its pigmentation more pronounced. The cone nuclei are situated some distance internal to the outer limiting membrane, aud thus the thin inner and outer granular layers are in apposition. There are no rods, and the cones, closely crowded together, are narrower and their outer segments more elongated than elsewhere, so that the line of their bases, indicated by the membrana limitans externa, presents a convexity directed forwards. The fovea centralis and macula lutea are spoken of by physiologists as the "region of distinct vision."

Structure of the ora serrata.-Here the nervous layers of the retina suddenly cease ; the layer of rods and cones ends a little behind the margin of the ora serrata; the ather nervous strata persist as far as its margin. In front of the ora serrata the retina is prolonged over the ciliary processes in the form of two layers of cells: $(a)$ an inner layer of columnar epithelium, and $(b)$ an outer, consisting of the stratum pigmenti, the two forming the pars ciliaris retinæ. The same two layers are prolonged over the back of the iris, where botb are pigmented and form the pars iridica retinæ.

Vessels of the retina (Fig. 692).-The retina is supplied by the arteria centralis retinæ, a branch of the ophthalmic artery, which pierces the sheath of the optic nerre about $2 \mathrm{c.m}$. behind the bulb of the eye, and makes its appearance in the centre of the optic papilla. Here it divides into an upper and a lower branch, and each of these again bifnrcates into a medial or nasal, and a lateral or temporal, branch. The resulting four branches ramify towards the periphery of the retina, and are named the superior and inferior temporal

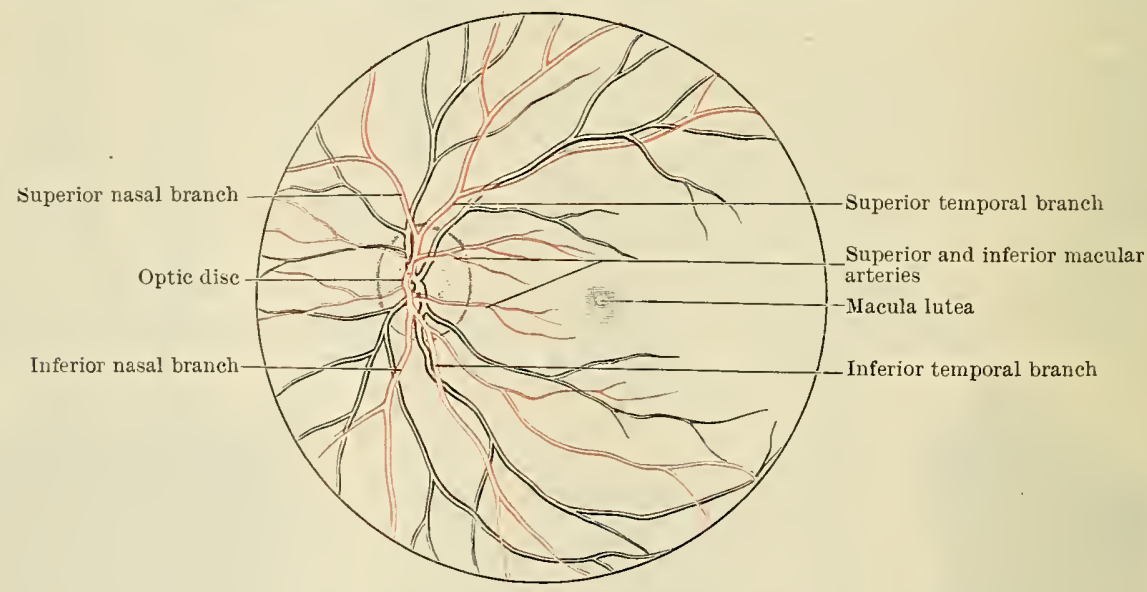

F1G. 692.-Blood-vessels of the Retina.

and the superior and inferior nasal arteries. The temporal arteries pass laterally above and below the macnla lutea, to which they give snuall branches; these do not, however, extend as far as the fovea centralis, which is devoid of blood-vessels. The macula also receives two small arteries (superior and inferior macular) directly from the stem of the arteria centralis. The larger vessels run in the nerve-fibre layer near the membrana limitans interna and form two capillary networks - an inner, in the nerve-fibre layer, and an outer, in the inner nuclear layer. The inner network arises directly from the arteries and sends numerous small branches to form the outer network, from which the veins take origin. The vessels do not penetrate deeper than the inner granular layer, nor do the arteries anastomose, except through the capillary plexuses. The veins follow the course of the arteries; they have no muscular coats, but consist merely of a layer of endothelial cells, outside which is a perivascular lymph sheath, surrounded by delicate retiform tissue. 


\section{PEFRACTING MEDIA.}

Corpus Vitreum.-The vitreous body is a transparent, jelly-like substance situated between the crystalline lens and the retina, and occupying the posterior four-fifths of the bulb of the eye (Fig. 67T). In front it presents a deep concavity, the hyaloid fossa (O.T. fossa patellaris), for the reception of the posterior convexity of the lens. It is enclosed within a thin transparent membrane, the membrana hyaloidea, which is in contact with the membrana limitans interna of the retina, and is adherent to it at the entrance of the optic nerve. The portion of the membrana hyaloidea in front of the ora serrata is thickened and strengthened by radial fibres, and is termed the zonula ciliaris. Situated behind the ciliary body, the zonula is radially folded and presents a series of alternating furrows and elevations. The ciliary processes are received into, and are firmly adherent to, the furrows, with the result that, if removed, some of their pigment remains attached to the zonula. The elevations of the zonula are not attached to the interciliary depressions, but are separated by a series of lymph spaces named the recessus cameræ posteriores; these may be regarded as diverticula of the posterior chamber with which they communicate. As the zonula approaches the equator of the lens it splits into two chief layers, viz.: (a) a thin posterior lamina, which lines the hyaloid fossa; and (b) a thicker anterior layer, termed the suspensory ligament of the lens (Fig. 677), which blends with the front of the lens capsule a short distance from the equator of the lens. Scattered fibres of this ligament are also attached to the equator itself and to the regions immediately anterior and posterior to it. By this suspensory ligament the lens is retained in position, and its convexity varies inversely with the degree of tension of the ligament. The radial fibres of the ciliary muscle, by pulling forward the ciliary processes and the attached zonula ciliaris, relax the ligament, and thus allow the lens to become more convex. Behind the suspensory ligament, a sacculated lymph space surrounds the equator of the lens; it is named the spatia zonularia (O.T. canal of Petit), and may be easily inflated on introducing a fine blow-pipe through the suspensory ligament (Fig. 677). In the fotus a blood-vessel, termed the arteria hyaloidea, is continued from the arteria centralis retinæ forwards through the vitreous body, for the supply of the capsule of the lens. Its position, in the adult, is represented by a lymph channel, termed the canalis hyaloideus of Stilling (Fig. 677), the

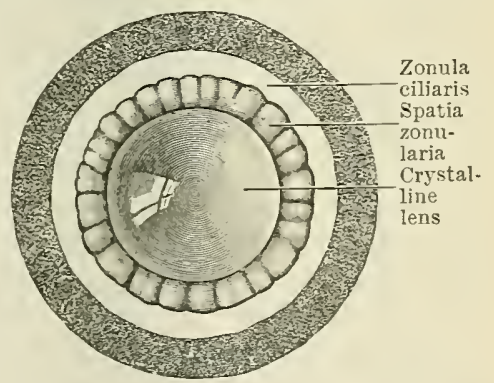

Fig. 693.-The Spatia Zoxularia disTENDED AND VIETED FRON THE Frost (enlarged). presence of which may be demonstrated by shaking up the vitreous body in a solution of picrocarmine, when some of the pigment may be seen to extend along

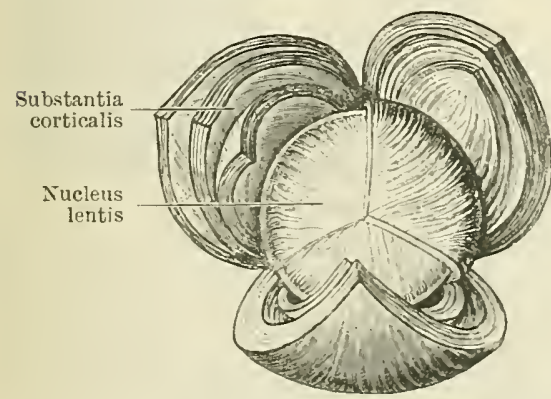

Fig. 694.-Lens hardened is Formalin and DISSECTED TO SHOW ITS CONCENTRIC LAMINA (enlarged). (Fig. 67\%). It is enclosed in a thin, transparent, homogeneous capsule, the capsule of the lens. The central points of its anterior and posterior surfaces are termed

When the vitreous body is treated by a weak solution of chromic acid it presents a series of concentric, peripherally arranged striæ, together with numerons radial striæ converging towards its centre. Between these the more fluid part lies, and it frequently contains vacuolated amcboid cells scattered through it. The vitreous body consists of 98.4 per cent of water, having in solution about 1.4 per cent of sodium chloride and traces of extractives and albumen.

Lens Crystallina.-The crystalline lens lies in front of the vitreous body and behind the iris, and is a biconvex, transparent body 
respectively its anterior and posterior poles, a line joining which is known as its axis; its peripheral circumference is named the equator. Its axial measurement is $4 \mathrm{~mm}$., and its transverse diameter from 9 to $10 \mathrm{~mm}$. Its anterior surface is less
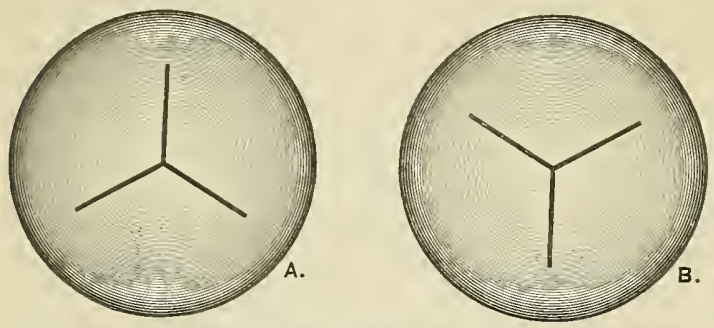

Fig. 695.-Diagramatic Reprisentation of the Radial LiNes OF THE FETAL LENS.

A, Seen from the front; B, From behind. curved than the posterior and on it rests the pupillary margin of the iris; the central part of the surface corresponds with the aperture of the pupil and is directed towards the anterior chamber; the peripheral part is separated from the iris by the aqueous humour of the posterior chamber. Its posterior surface, more convex than the anterior, occupies the hyaloid fossa of the vitreous body. The curvatures of its surfaces, especially that of the anterior, are constantly varying during life for the purpose of focussing near or distant objects on the retina.

The substantia lentis consists of a soft outer part, the substantia corticalis, easily crushed between the finger and thumb, and of a dense central part, the nucleus lentis. The refractive index of the substantia corticalis is about 14 ; that of the nucleus lentis about $1 \cdot 45$. Faint radial lines run from the anterior and posterior poles of the lens towards its equator. In the fotms they are three in number, and form angles of $120^{\circ}$ with each other (Fig. 696). From the anterior pole one ray ascends vertically and the other two diverge downwards, while from the posterior pole one ray descends vertically and the other two diverge upwards. In the adult the rays may be increased to six or more. They represent the free edges of a corresponding number of septa which dip into the substance of the lens, and along which the extremities of the different groups of lens fibres come into contact, and are attached by a clear, amorphous substance. The lens, when hardened, exhibits a series of concentrically arranged laminæ (Fig. 694), superimposed like the scales of an onion and attached to each other by a clear, amorphous substance. Each lamina is split along the radiating lines, and consists of a series of hexagonal, riband-like fibres, the fibræ lentis, which are adherent to each other by their margins; those of the deeper laminæ are small and serrated, but nonnucleated; while those of the superficial coats are large and nucleated, but non-serrated. The fibres extend in a curved manner from the rays on the anterior surface to the rays on the posterior surface, but no fibre extends from pole to pole. Fibres which start at or near one pole end at or near the equator on the opposite surface, and vice versa, while the intervening fibres take up intermediate positions. Between the substantia lentis and the anterior part of the capsule there is a layer of nucleated columnar epithelial cells, the epithelium lentis. On being traced towards the equator its cells become gradually elongated and transformed into lens fibres, which, when fully formed, lose all trace of their nuclei, except in the more superficial laminæ. Each lens fibre represents, therefore, a greatly elongated columnar cell (Fig. 696).

In the foetus the leus is soft, of a pinkish colour, and

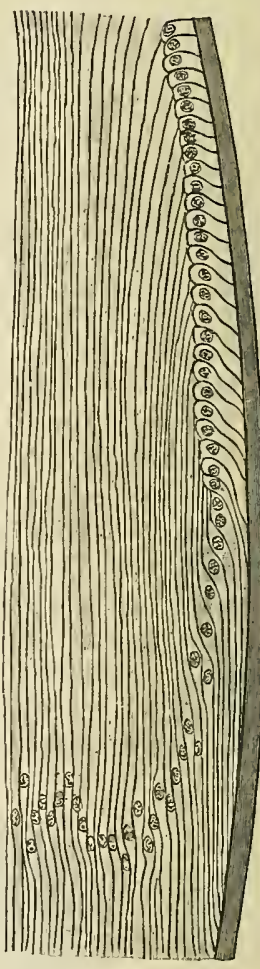

FIG. 696.

SECTION THROUGH THE EQUATOR OF THE LENS.

Showing the gradual transition of the epithelium into lens fibres (after Babuchin). nearly spherical; while in old age it becomes somewhat flattened, and assumes a yellowish tint.

Cameræ Oculi (Fig. 677).-As ahready stated (p. 813), the space between the cornea and the lens is divided by the iris into two unequal parts, viz., the camera 
oculi anterior in front and the camera oculi posterior behind. These are filled with the aqueous humour, and, in the adult, communicate freely through the aperture of the pupil, but in the foetus are separated from each other by the membrana pupillaris. The camera oculi anterior or anterior chamber is bounded in front by the cornea, behind by the iris and lens, whilst peripherally it communicates with the spatia anguli iridis. The camera oculi posterior or posterior chamber is triangular on section, and is bounded in front by the iris, behind by the circumferential part of the lens and its suspensory ligament; the base of the triangle corresponds with the thick, anterior extremities of the ciliary processes. It communicates with the recessus cameræ posteriores and spatia zonularia. The aqueous humour has a refractive index of about 1.336, and consists of about 98 per cent of water, with 1.4 per cent of sodium chloride, and traces of albumen.

\section{PALPEBRA.}

The eyelids are two movable curtains situated in front of the bulb of the eye, and named, from their positions, superior and inferior. The superior is the larger and more movable, being provided with a special elevator muscle, the $m$ : levator palpebro superioris. The interval between the eyelids is termed the palpebral fissure, and measures transversely about 30 mm., but varies considerably in different individuals and in different races. When the eye is open the fissure is elliptical in shape, but when closed it assumes the form of a transverse slit, which lies on a level with the lower margin of the cornea. The two lids meet at the extremities of the fissure, and form the lateral and medial commissures. Their free margins are flat-

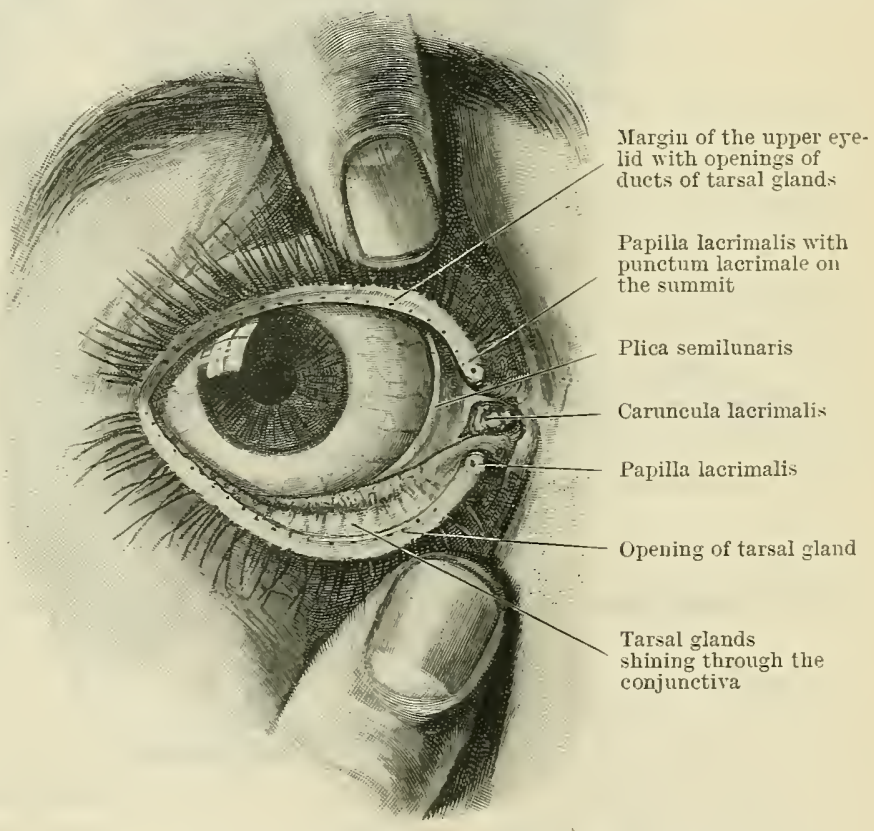

FIG. 697. EYELID SLIGHTLY EVERTED TO SHOW THE CONJLNCTIVA (enlarged). tened and are surmounted by eyelashes, from the lateral commissure to a point about $5 \mathrm{~mm}$. from the medial commissure-a point indicated by a small papilla, the papilla lacrimalis. Medial to this papilla the margins are rounded and destitute of eyelashes, and form the upper and lower boundaries of a triangular space, termed the lacus lacrimalis, which is occupied by a small pale red body, the caruncula lacrimalis. The caruncula consists of a small island of modified skin, and contains sudoriferous and sebaceous glands, and fine hairs. Posteriorly the lids are lined with mucous membrane, the conjunctiva, and are in contact with the bulb of the eye, except near the medial commissure, where, between the bulb of the eye and the caruncula lacrimalis, there intervenes a vertical fold of conjunctiva, the plica semilunaris conjunctivæ, which in many animals contains a plate of cartilage.

In each eyelid there exists a framework of condensed fibrous tissue, which gives consistence and shape to the lid, and is termed the tarsus. In front of the tarsus are the fibres of the orbicularis oculi muscle and the integument, while embedded in its posterior surface, and covered by the conjunctiva, are numerous modified 
sebaceous glands, named the tarsal glands. The superior tarsus is larger than the inferior, and of a half oval shape, with its greatest vertical diameter measuring about 10 or $11 \mathrm{~mm}$. Its upper margin is thin and convex, and is continuous with the tendon of the levator palpebræ superioris muscle, while its lower edge is thick and straight. The inferior tarsus is a thin, narrow strip, with a nearly uniform vertical diameter of about $5 \mathrm{~mm}$. The extremities of the two plates are continuous with the lateral palpebral raphe and the medial palpebral ligament. The lateral palpebral raphe is a narrow band attached to the zygomatic bone; it divides, at the lateral commissure, into superior and inferior pieces which are fixed to the margins of the respective tarsi. The medial palpebral ligament is a strong band attached to the frontal process of the maxilla, directly in front of the lacrimal

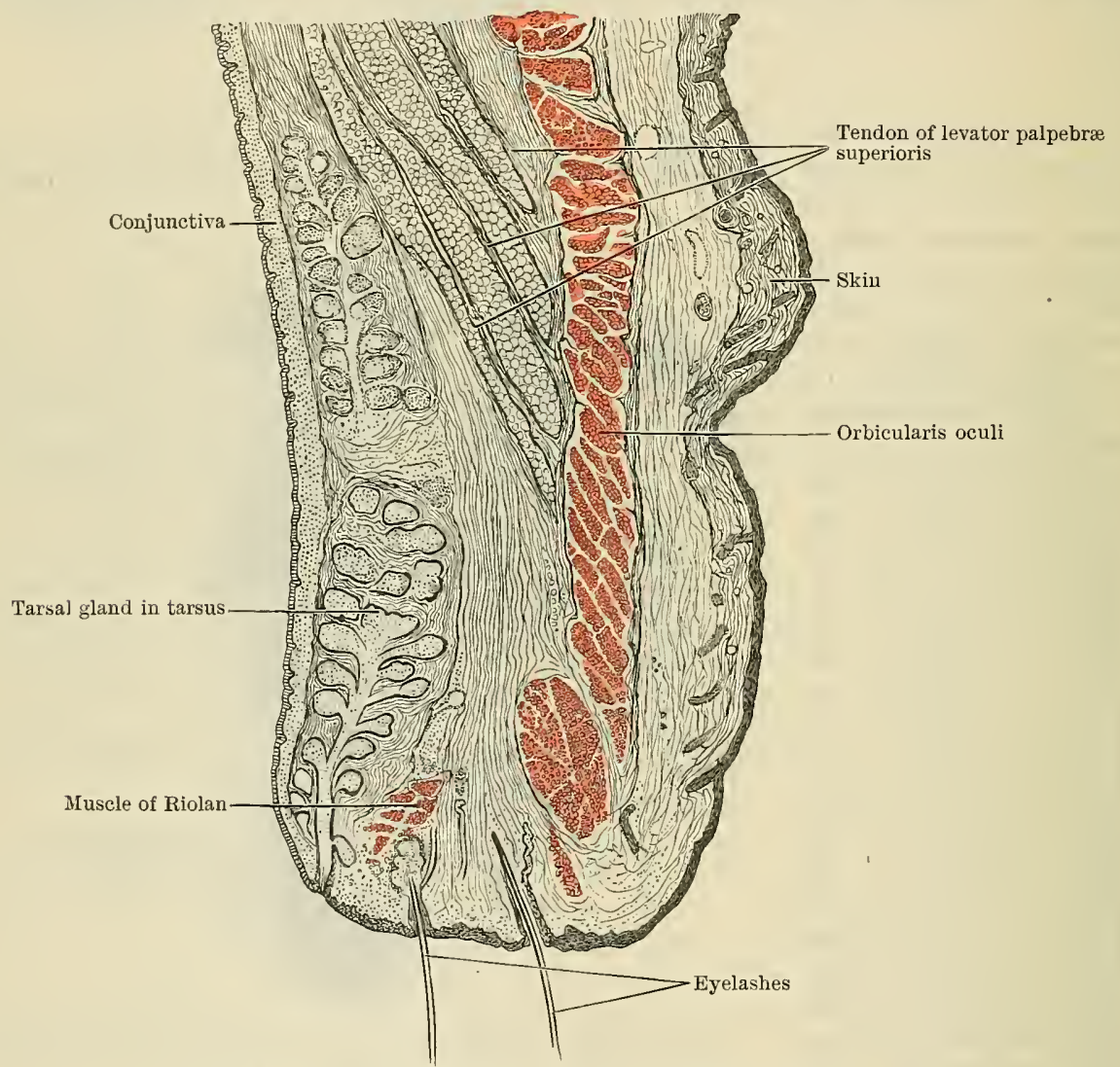

Fig. 698.-Sagittal Section through Superior Eyelid.

groove; it divides at the medial commissure into two slips, one for each tarsus (Fig. 699).

The eyelids are further strengthened by membranous expansions, termed the superior and inferior palpebral ligaments, which extend into them from the margin of the orbit. The superior palpebral ligament is continuous, along the superior margin of the orbit, with the pericranium and with the periosteal lining of the orbit, and blends below with the tendon of the levator palpebræ superioris. The inferior palpebral ligament is prolonged from the lower edge of the inferior tarsus to the inferior margin of the orbit, where it is continuous with the periosteum of the face and orbital floor. Laterally the two palpebral ligaments fuse to form the lateral palpebral raphe, while medially they become thinned, and, separating from the medial palpebral ligament, are attached to the lacrimal bone, behind the lacrimal sac. The superior and inferior palpebral ligaments form the septum orbitale, between the superficial and deep structures of the eyelids; this septum is perforated by the vessels and nerves, which extend from the orbital cavity to the face or scalp. 
The skin covering the eyelids is thin and delicate, and is continuous, at their margins, with their conjunctival lining. It contains numerous small sudoriferous glands and fine hairs, the latter being provided with sebaceous follicles. Branched pigment cells are present in the cutis, and pigment exists also in the deep layers of the epidermis. The subcutaneous tissue is loose and devoid of fat, and in it are found the fibres of the orbicularis oculi muscle-a small separate bundle of which, termed the muscle of Riolan, occupies the margin of the lids behind the eyelashes.

The glandulæ tarsales (O.T.Meibomian glands) are

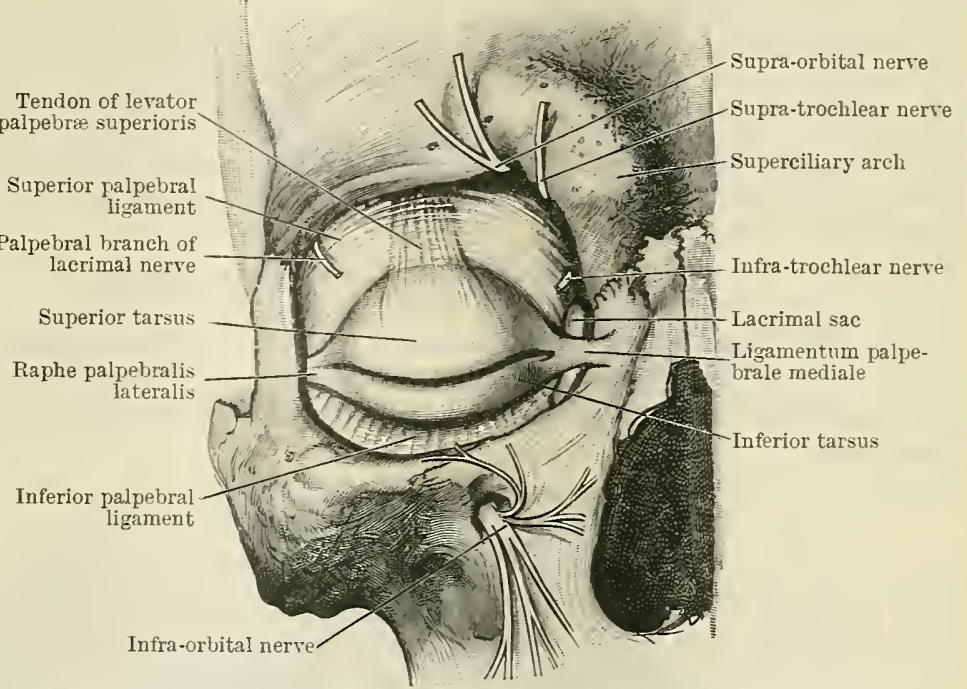

Fig. 699.-Dissectiox of the Right Eyelid. The orbicularis oculi has been completely removed.

elongated sebaceous glands with numerous lateral offshoots; they are embedded in the tarsi and are filled with cubical epithelium. There are from twenty-five to thirty in the superior eyelid, and from twenty to twenty-five in the inferior; they open by small ducts, about $1 \mathrm{~mm}$. in length, along the lid margins, behind the eyelashes; the ducts are lined with stratified epithelium, placed on a basement membrane. Between the eyelashes and the muscle of Riolan are two or three rows of modified sudoriferous glands, termed the glands of Moll.

H. Müller described a layer of non-striped muscle in each lid : in the superior extending from the tendon of the levator palpebræ superioris to the upper tarsus, and in the inferior connecting the inferior tarsus with the inferior oblique muscle.

The eyelashes are curved, silky hairs which project from the free margins of the lids; in the upper lid they are longer and more numerous than in the lower, and are curved upwards, while those of the lower lid are bent downwards.

Conjunctiva.-The conjunctiva is the mucous membrane which lines the eyelids, and is continued from them on to the front of the bulb of the eye. The part on the eyelids is termed the tunica conjunctiva palpebrarum, that on the bulb of the eye the tunica conjunctiva bulbi; the lines of reflection of the membrane from the eyelids to the bulb are known as the superior and inferior conjunctival formices. The conjunctiva palpebrarum is intimately adherent to the tarsi and presents numerous papillæ. It is covered with a layer of columnar epithelial cells, beneath the bases of which are small flattened cells; near the fornices a number of acino-tubular glands, much more plentiful in the upper than in the lower eyelid, open on its free surface. The conjunctiva bulbi is thinner than the conjunctiva palpebrarum, and is loosely attached to the sclera by submucous tissue. The plica semilunaris conjunctivæ has already been referred to (p. 821). On the cornea the conjunctiva is represented merely by the epithelium corneæ (p. 809).

Vessels and Nerves.-The chief arteries of the eyelids are the superior and inferior palpebral branches of the ophthalmic, which pierce the septum orbitale above and below the medial palpebral ligament, and run laterally in the corresponding lid near its free margin. On reaching the region of the lateral palpebral commissure they anastomose with each other and with twigs from the lacrimal, superficial temporal, and transverse facial arteries, and in this way an arch is formed in each lid. Secondary smaller arches are found, one above the primary arch in the upper lid, and another below that of the lower lid, while the upper lid receives branches also 
from the supra-orbital and frontal arteries. The veins are arranged in two sets: (a) subconjunctival or retrotarsal, opening into the muscular tributaries of the ophthalmic veins, and (b) pretarsal, into the angular and superficial temporal veins. The lymph vessels, like the veins, form pre- and retrotarsal networks, which communicate with each other through the tarsal plates. The lymph is drained chiefiy into the anterior auricular and parotid lymph glands, but partly, by ressels which accompany the anterior facial vein, into the submaxillary lymph glands. The sensory nerves of the eyelids are supplied by the trigeminal nerve-the upper lid chiefly by the supra-orbital and supra-trochlear branches of the ophthalmic; the lower, by the infraorbital branch of the maxillary. The region of the lateral commissure receives some filaments from the lacrimal nerve, that of the medial from the infra-trochlear. These sensory nerves form a marginal plexus behind the orbicularis oculi muscle. The levator palpebræ superioris muscle is supplied by the oculomotor nerve.and the non-striped fibres of the eyelids by the sympathetic.

\section{APPARATUS LACRIMALIS.}

The lacrimal apparatus consists of: (1) the lacrimal gland, which secretes the tears: (2) the lacrimal ducts, by which the tears are drained from the front of the eye; and (3) the lacrimal sac and naso-lacrimal duct, which convey them into the nasal cavity.

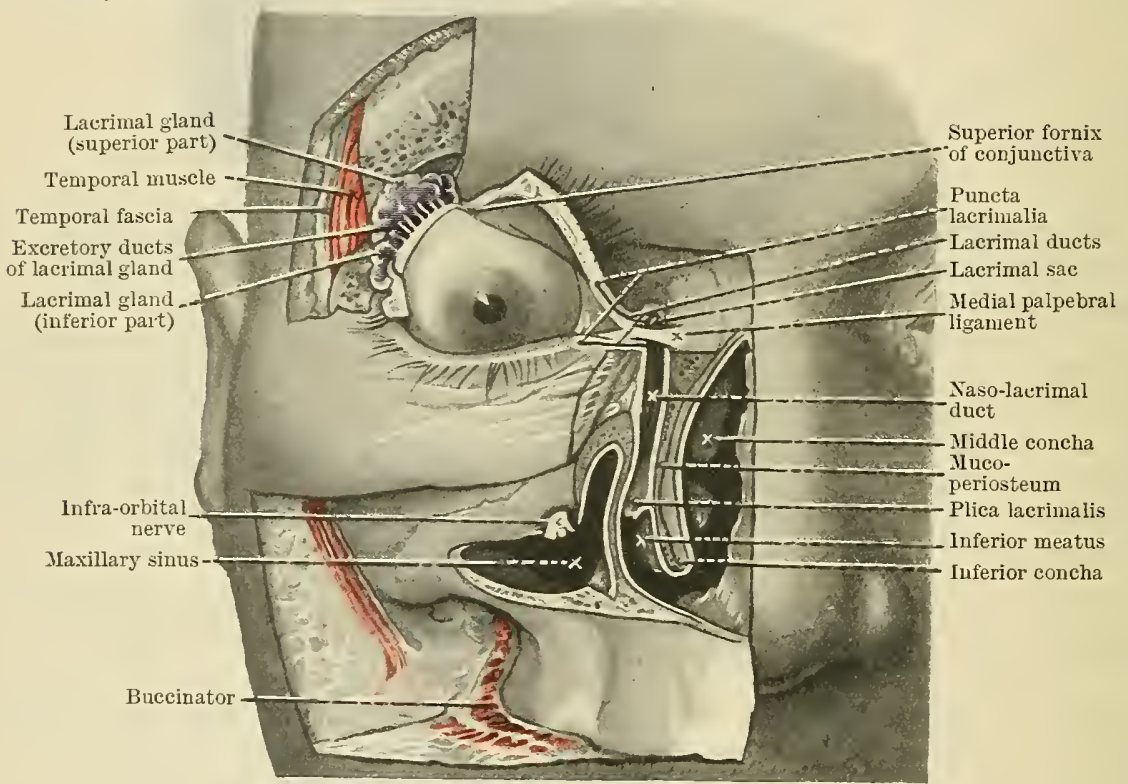

Fig. 700.-Dissection to show the Lacrimal Apparatus.

Glandula Lacrimalis.-The lacrimal gland is a flattened, oval body situated in the superior and lateral part of the orbital cavity; it consists of two portions - superior and inferior-imperfectly separated from each other by the expansion of the tendon of the levator palpebræ superioris muscle. The glandula lacrimalis superior is firm and much larger than the inferior; it measures transversely about $20 \mathrm{~mm}$, and sagittally from 12 to $14 \mathrm{~mm}$. It occupies the fossa lacrimalis on the medial surface of the zygomatic process of the frontal bone, and is fixed by fibrous bands to its periosteum, while its inferior surface is in contact with the levator palpebræ superioris and rectus lateralis muscles, which intervene between it and the bulb of the eye. The glandula lacrimalis inferior consists of small, loosely aggregated lobules; it lies below and in front of the orbital portion, and projects into the posterior part of the upper eyelid, where its deep surface is in contact with the conjunctiva. The ducts draining the glandula superior are from three to five in number; they pass between the lobules of the glandula inferior, and open at the upper and lateral part of the fornix conjunctivæ superior. The ducts of the glandula inferior number from three to nine; some of them join those from the glandula superior, while others open separately at the fornix conjunctivæ superior. The lacrimal gland has a structure resembling that of the parotid, and 
is supplied by the sympathetic and lacrimal nerves and by the lacrimal artery, while its veins are drained into the ophthalmic vein.

Ductus Lacrimales. - The lacrimal ducts, two in number, commence in minute orifices, termed the puncta lacrimalia, at the apices of the papillæ lacrimales (p. 821), and are directed medialwards along the medial parts of the margins of the eyelids, above and below the lacus lacrimalis. The superior duct at first ascends for a short distance and then inclines downwards; the inferior duct descends for a short distance and then runs horizontally; at the angles where they change direction each is dilated into an ampulla. The two ducts open close together into the lateral and front part of the lacrimal sac, a little below its middle; sometimes they open separately into a pouch-like dilatation of the sac, termed the sinus of Maier. The ducts are lined with stratified epithelium placed on a tunica propria, outside which is a layer of striped muscular fibres derived from the lacrimal part of the orbicularis oculi. These muscular fibres are arranged somewhat spirally around the ducts, but at the base of each papilla lacrimalis they are circular in direction and form a species of sphincter. On contraction they serve to empty the contents of the lacrimal ducts into the lacrimal sac.

The saccus lacrimalis and ductus nasolacrimalis together form the passage by which the tears are conveyed from the lacrimal ducts to the nasal cavity.

The lacrimal sac is the upper expanded part of the passage, and measures from 12 to $15 \mathrm{~mm}$. in length, about $7 \mathrm{~mm}$. antero-posteriorly, and from 4 to $5 \mathrm{~mm}$. transversely. It lies in the groove formed by the lacrimal bone and frontal process of the maxilla, and ends above in a rounded, blind extremity or fundus, while it narrows below into the naso-lacrimal duct. Here a fold of mucous membrane, named the valve of Beraud, together with a laterally directed pouch, the sinus of Arlt, are sometimes present. Near its superior extremity it is crossed, in front, by the medial palpebral ligament (O.T. tendo oculi), from the upper and lower edges of which the orbicularis oculi takes origin; the lacrimal part of the orbicularis oculi muscle is behind it.

The naso-lacrimal duct averages about $18 \mathrm{~mm}$. in length, and has a diameter of from 3 to $4 \mathrm{~mm}$. Rather narrower in the middle than at its extremities, it is directed downwards and slightly backwards, and opens into the inferior meatus of the nose at the junction of its anterior fourth with its posterior three-fourths, i.e. a distance of 30 to $35 \mathrm{~mm}$. from the posterior boundary of the nostril. Its lower orifice is somewhat variable in form and position, and is occasionally duplicated. It is frequently guarded by a fold of mucous membrane, termed the plica lacrimalis (Hasneri). Through this orifice the mucous lining of the duct is continuous with that of the nasal cavity. The mucous membrane of the duct is thrown into inconstant folds, several of which have been described as valves. Its epithelium is columnar and in part ciliated; opening into the lower part of the duct are numerous glands, similar to those in the nasal mucous membrane.

The nerves of the lacrimal ducts and sac are derived from the infra-trochlear branch of the naso-ciliary ; their arteries from the inferior palpebral and nasal. The veins of the naso-lacrimal duct are large and numerous, forming a sort of erectile tissue similar to that in the nasal cavity.

\section{DeVELOPJENT OF THE Eye.}

The retina and optic nerve are developed from a hollow outgrowth of the fore-brain, termed the optic vesicle (see pp. 54 and 33). This extends towards the side of the head, and its connexion with the brain is gradually elongated to form the optic stalk. The ectoderm overlying the optic resicle beeomes thickened, invaginated, and finally cut off as a hollow island of cells, which is named the lens vesicle. This vesicle indents the outer and lower part of the optic resicle, converting it into a cup (optic cup), lined by two layers of cells continuous with each other at the margin of the cup. The inner of these strata, thicker than the outer, is named the retinal layer, and becomes differentiated into the nerrous and supporting elements of the retina; while the outer, named the pigmentary layer, forms the stratum pigmenti. The edge of the optic cup extends in front of the equator of the lens, and bounds the future aperture of the pupil. In front of the lens, and also opposite its equator, the retinal layer is thin, and represented only by a stratum of columnar cells which becomes closely applied to the pigmentary layer, the two forming the 
pars ciliaris and pars iridica retine. The indentation of the optic cup extends as a groove for some distance along the postero-inferior aspect of the optic stalk, forming what is termed the chorioidal fissure (Fig. 701). Throngh this fissure mesoderm passes inwards between the lens and the retina to form a part of the vitreous body, while the arteria centralis retinæ also becomes enclosed in it and so gains its future position in the centre of the optic
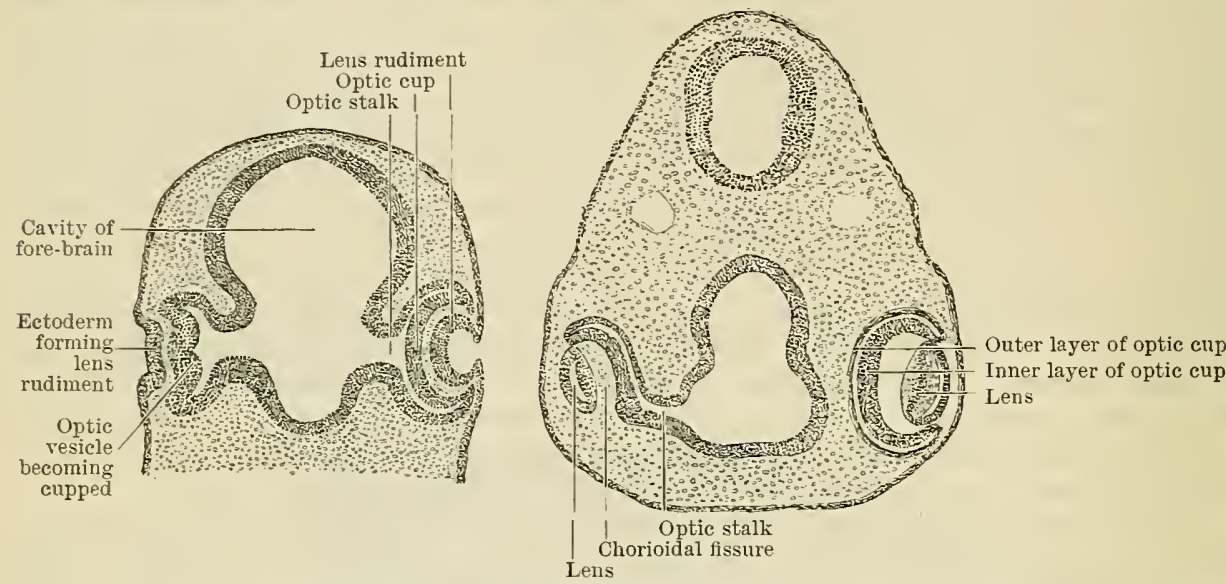

Fig. 701.--Sections throdgh Portions of the Heads of Fettal Rabits, to illustrate the connexion of the optic cup with the fore-brain, and the invagination of the ectoderm to form the lens.

nerve. The arteria centralis is prolonged forwards from the porus opticus through the vitreous body, as a cone of branches, as far as the back of the lens. By the fifth or sixth month all these branches have disappeared except one, the arteria hyaloidea, which persists until the last month of fotal life, when it also atrophies, leaving only the canalis hyaloideus to indicate its position.

The vitreous body is developed between the optic cup and the lens, and is derived partly from ectoderm and partly from mesoderm. It consists primarily of a series of

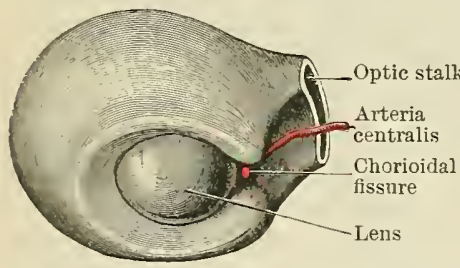

Fig. 702.-OPTIC CUP AND LENS VIEWED FROM BEHIND AND BELOW, to show formation of chorioidal fissure and enclosure of the arteria centralis retinæ (from inodel by Ziegler). fine protoplasmic fibres which project from the cells of the retinal layer of the cup and form a delicate reticular tissue. At first these fibres are seen in relation to the whole of the optic cup, but later they are limited to the ciliary region, where by a process of condensation they appear to form the zonula ciliaris. When the mesoderm reaches the cup through the chorioidal fissure it unites with this reticular tissue to form the ritreons body.

The lens, at first in contact with the ectoderm from which it is derived, is soon separated from it by mesoderm, and then consists of a rounded vesicle with epithelial walls. The anterior wall remains as a single layer of cells-the anterior lens epithelium of the adult; the cells of the posterior wall become elongated into lens fibres, and by the forward growth of these the cavity of the vesicle is obliterated. This elongation into lens fibres is greatest at the centre of the lens, while near the equator the fibres are shorter, and here the gradual transition between the anterior epithelium and the lens fibres is seen (Fig. 696). The lens becomes enveloped in a vascular tunic, which receives its vessels from the arteria centralis retinæ and from the vessels of the iris. The front part of this tunic forms the membrana pupillaris, and this, like the rest of the tunic, disappears before birth.

The hollow optic stalk becomes solid by the thickening of its walls and, acquiring nerve-fibres, is transformed into the optic nerve. These nerve-fibres are mostly centripetal, and are derived from the nerve-cells of the retina; but a few are centrifugal and have their origin in the brain. The further derelopment of the retina resembles, in certain respects, that of the spinal medulla.

Cameron states (Jiurn. Anat. and Physiol., vol. xxxix.) that in the early stages of the development of the inner or retinal layer of the optic cup all the structures, described by His as being present in the spinal medulla of the human embryo, are to be formd, viz., $(a)$ spongioblasts, (b) germinal cells, and $(c)$ neuroblasts. 
The spongioblasts undergo ramification and form a network or myelospongium, and also give rise to the inner and outer limiting membranes; the latter is next the original cavity of the optic vesicle, and therefore corresponds to the inner limiting membrane of the spinal medulla. The spongioblasts also form the groundwork of the inner and outer molecular layers into which the processes of the neuroblasts grow and arborise.

The germinal cells are always situated beneath the external limiting membrane, and by their division give rise to the neuroblasts. The first-formed neuroblasts are larger than those of succeeding generations, and are found in the site of the future ganglionic layer. The germinal cells in the middle of the convexity of the retinal cup cease to divide at an early stage of development, and become directly transformed into the rod and cone cells from which the rods and cones develop as processes; hence these structures appear first over the middle of the convexity of the retina, and gradually extend towards the margin of the retinal cup.

The molecular layers make their appearance as plexuses of myelospongium. The internal molecular layer is first developed at the centre of the retinal cup, and gradually extends torrards the cup margin, and into it the processes from the nuclei on either side grow and ramify. The rod and cone fibres, and the outer processes of the internal nuclear layer, grow into and arborise within the external molecular layer.

The condensed mesoderm surrounding the optic cup becomes the sclera and chorioid. In the portion of the mesoderm which lies in front of the lens a cleft-like fissure appears, and divides it into a thick anterior and a thin posterior layer. The former becomes the substantia propria of the cornea ; the latter, the stroma of the iris and anterior part of the vascular tunic of the lens. The fissure represents the future camera oculi anterior, and its lining cells form the endothelium of this chamber.

The eyelids arise as two integumentary folds above and below the cornea, each being covered on both its surfaces by the ectoderm. By the third month the folds meet and unite with each other at their edges, the eyelids being only permanently opened shortly before birth; in many animals they are not opened until after birth. The ectoderm forms the epithelium of the conjunctiva and the epithelium corver. It is also invaginated at the lid margins to form the hair follicles and the lining cells of the tarsal glands and glands of Moll, and, at the fornix conjunctiræ superior, to form the lining of the alveoli and ducts of the lacrimal gland.

The naso-lacrimal duct, lacrimal sac, and ducts represent the remains of the furrow between the maxillary and lateral nasal processes (p. 49). It is at first filled with a solid rod of cells, which becomes hollowed out to form the sac and ducts.

\section{ORGANON AUDITUS.}

The ear or auditory organ (Fig. 703) consists of three portions-external, middle, and internal - the last constituting its essential part, since the peripheral terminations of the acoustic nerve are distributed within it.

\section{EXTERNAL EAR.}

The external ear ${ }^{1}$ includes-- $(\alpha)$ the auricula, attached to and projecting from the side of the head; and $(b)$ the external acoustic meatus leading inwards from the most depressed part of the auricula to the tympanic membrane.

\section{Auricula.}

The auricle (O.T. pinna) (Fig. 70t) presents two surfaces, lateral and medial, the latter forming an angle (cephalo-auricular angle) of about $30^{\circ}$ with the side of the head. The lateral surface is irregularly concave, but presents sereral wellmarked elevations and depressions. The deepest of the depressions is situated near its middle, and is named the concha auriculæ. It is divided by an almost transverse ridge, the crus helicis, into an upper, smaller, and a lower, larger portion: the former is termed the cymba conchæ; the latter, which leads into the meatus, the cavum conchæ. Anteriorly, the crus helicis is continuous with the margin of the auricula or helix, which is incurved in the greater part of its extent, and is directed at first upwards, and then backwards and downwards, to become gradually

1 Although it is usual to speak of the exterual, nilldle, and internal ear, it would be more correct to uso the terms external, middle, and internal portions of the ear. 
lost in the upper part of the lobule. Near the point where the helix begins to descend a small tubercle, the tuberculum auriculæ (Darwini), is often seen.

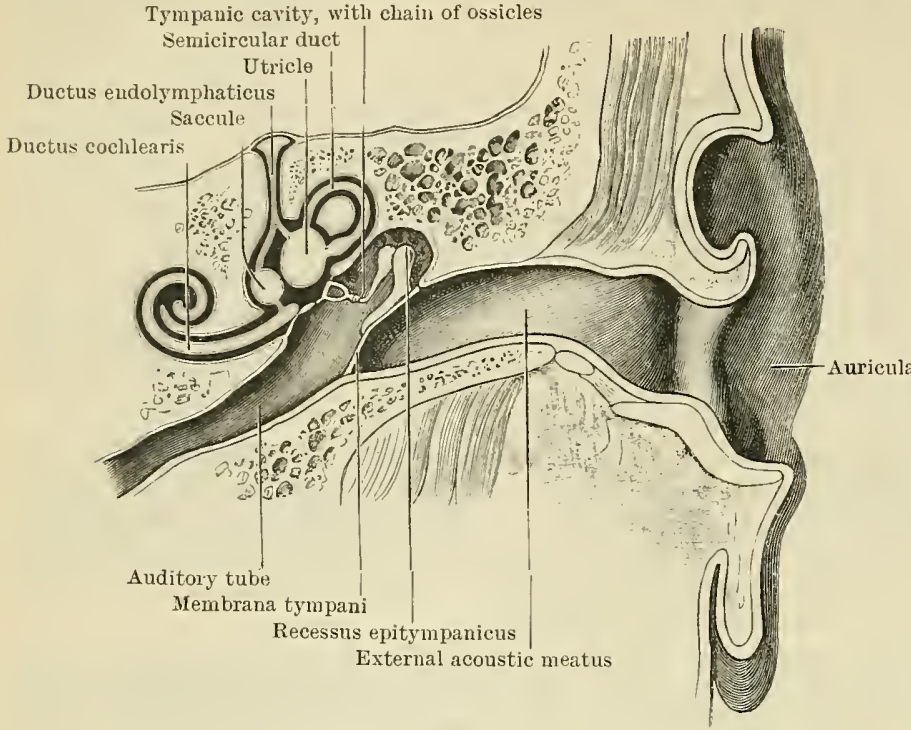

Fig. 703.-Diagramuatic View of the Organ of Heatixg.
In front of the descending part of the helix is a second elevation, the antihelix. Single below, it divides superiorly into two limbs, termed the crura antihelicis, between which is a triangular depression, the fossa triangularis. The elongated furrow between the helix and antihelix is named the scapha. The concavity of the concha is overlapped in front by a tongue-like process, the tragus, and behind by a triangular projection, the antitragus; the

notch, directed downwards and forwards between these two processes, is named the incisura intertragica. The tragus consists really of two tubercles, the upper of which constitutes the tuberculum supratragicum of His, and is separated from the helix by a groove, the sulcus auris anterior. The lobule is situated below the incisura intertragica, and is the most dependent part of the auricle.

The medial or cranial surface also is irregular, and presents elevations corresponding to the depressions on its lateral surface, e.g. eminentia conchæ, eminentia triangularis, etc.

The auricula is usually smaller and more finely modelled in the female than in the male, but presents great variations in size and shape in different individuals. In the newly born child its length is abont one-third of that of the adult, while it increases slightly in length and breadth in old age.

The relation of the width to the

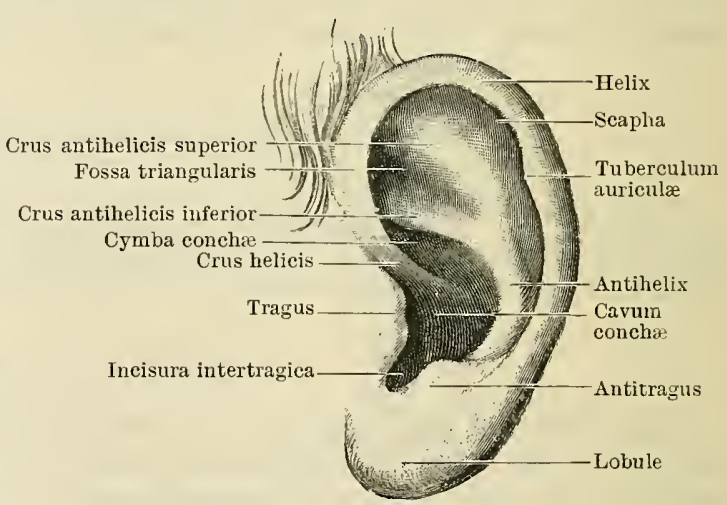

Fig. 704.-View of Lateral Surface of Left AdRicdlat (half natural size). height is termed the auricular index, and is expressed as follows :-

$$
\frac{\text { width of auricula } \times 100}{\text { length of auricula }}=\text { Auricular index. }
$$

This index is less in white than in dark races.

The cephalo-auricular angle may be practically absent, as in those cases where the skin of the head passes directly on to the lateral surface of the auricula, or it may be increased to nearly a right angle, so that the lateral surface of the auricula looks directly forwards. The tuberculum auriculæ, the significance of which was recognised by Darwin, is a somewhat triangular prominence which projects forwards in cases where the helix is well rolled over, but backwards and upwards when the incurving of the helix has been arrested. More frequently present in men than in women, it is of developmental interest since it has been shown to be well marked at the sixth month of fotal life, the entire auricula, at this stage, resembling in appearance that of the adult macaque monkey.

The lobule may be small and sessile or considerably elongated; it may adhere to the skin of the cheek (i.e. webbed), or may tend to bifurcate at its lower extremity. 
Structure of the Auricula.-The greater part of the auricula consists of a lamella of yellow fibro-cartilage, the cartilago auriculæ; the cartilage is, however, absent from the lobule, which is composed of fat and connective tissue. When laid bare, the cartilage (Figs. 705 , 706) presents, in an exaggerated condition, all the inequalities of the auricula, and is prolonged medially to form a considerable portion of the external acoustic meatus. The cartilage of the helix projects anteriorly as a conical eminence, the spina helicis, and its inferior extremity extends downwards as a tail-like process, the cauda helicis, which is separated from the lower part of the antitragus by the fissura antitragohelicina. The cartilage of the auricula is continuous with that of the meatus by a narrow isthmus, the

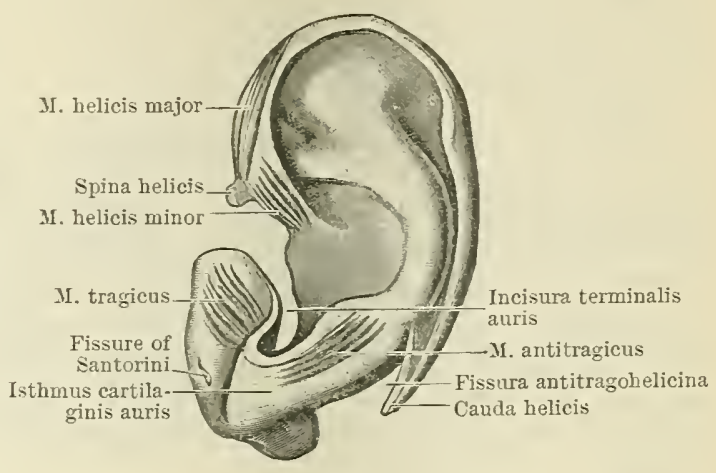

Fig. 705.-Lateral Surface of Cartilage of the AURICDLA (one-half natural size).

isthmus cartilaginis auris, measuring from 8 to $9 \mathrm{~mm}$. in breadth. This isthmus corresponds laterally with the deepest part of the incisura intertragica, and medially it forms the outer boundary of a deep fissure, the incisura terminalis auris, which separates the cartilage of the meatus from that of the concha. The upper edge of the tragus fits into an angle below the crus helicis. Two fissures, in addition to those already described, are usually present, one in the tragus and another immediately behind the spina helicis.

On the cranial surface of the cartilage (Fig. 706) the eminences produced by the concha and fossa triangularis are separated by a transverse furrow, the sulcus

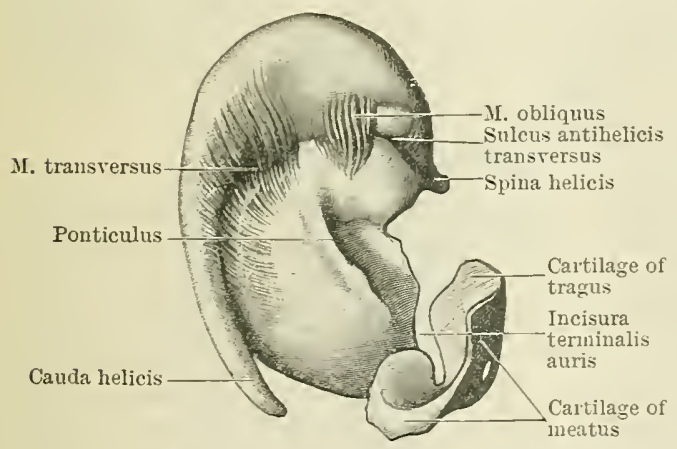

Fig. 706.-MEdial SURface of the CaRtilage of THE AURICLla (one-half natural size). antihelicis transversus, corresponding with the crus antihelicis inferior; further, the eminentia conchr is crossed horizontally by a groove, the sulcus cruris helicis, and almost vertically by a slight ridge, the ponticulus: the latter indicates the attachment of the $\mathrm{m}$. auricularis posterior.

Ligaments of the Auricula.-The cartilage of the auricle is attached to the temporal bone by two fibrous bands which form its extrinsic ligaments, viz.: an anterior, stretching from the zygomatic process to the spina helicis and tragus; and a posterior, passing from the eminentia conchæ and upper wall of the meatus to the mastoid process. Small ligamentous bands pass between individual parts of the auricle, and form what are termed its intrinsic ligaments.

Muscles of the Auricula (Figs. 705, 706). - The muscles of the auricle are divided into two groups, extrinsic and intrinsic. The extrinsic muscles pass to the auricula from the skull or the scalp, and are described in the section on Myology. The intrinsic muscles, on the other hand, are confined to the auricula and are six in number, four on its lateral and two on its cranial or medial surface.

(a) On the lateral surface (Fig. 705) -

1. M. helicis major passes upwards from the spina helicis along the ascending part of the helix. 2. M. helicis minor covers the crus helicis. 3. M. tragicus, quadrangular in shape, consists of fibres running vertically over the greater part of the tragus. Some of its fibres are prolonged upwards to the spina helicis and constitute the m. pyramidalis. 4. M. antitragicus covers the antitragus and runs obliquely upwards and backwards as far as the antihelix and cauda helicis. 
(b) On the medial surface (Fig. 706)-

1. M. transversus auriculæ consists of scattered fibres, which stretch from the eminentia conchre to the convexity of the helix. 2. M. obliquus auriculæ (Tod) comprises a few fasciculi, which run obliquely or vertically across the furrow corresponding with the crus antihelicis inferior. A small muscle, the $\mathrm{m}$. stylo-auricnlaris, sometimes extends from the root of the styloid process to the cartilage of the meatus.

Skin of the Auricula.-The skin covering the auricle is thin and smooth, and is prolonged, in the form of a tube, as a lining to the external acoustic meatus. On the lateral surface of the auricula, it adheres firmly to the subjacent perichondrium. Strong hairs are present on the tragus and antitragus, and also in the incisura intertragica, forming the barbula hirci, which guard the entrance to the concha; soft downy hairs are found over the greater part of the auricula and point towards the tuberculum auriculæ. Sebaceous glands, present on both surfaces of the auricle, are most numerous in the concha and fossa triangularis. Sudoriferous glands are found on the medial surface; few or none on the lateral surface.

Vessels of the Auricula.-The arteries of the auricle are derived-(a) from the superficial temporal, which sends two or three branches to the lateral surface; and $(b)$ from the posterior auricular, which gives three or four branches to the medial surface. From the posterior auricular artery two sets of twigs are prolonged to the lateral surface, one turning round the free margin of the helix, and the other passing throngh small fissures in the cartilage. The veins from the lateral surface open into the superficial temporal vein ; those from the medial surface chiefly join the posterior auricular vein, but some communicate with the mastoid emissary rein. The lymph vessels take three directions, viz.: (a) forwards to the parotid lymph glands, and especially to the anterior auricular gland in front of the tragus; $(b)$ downwards to the lymph glands which accompany the external jugular vein, and to the lymph glands under the sternocleidomastoidens; and (c) backwards to the posterior auricular lymph glands.

Nerves of the Auricula. - The muscles of the auricle are supplied by the facial nerre. The skin receires its sensory nerves from- $(a)$ the great auricular, which supplies nearly the whole of the medial surface, and sends filaments in company with the branches of the posterior auricular artery to the lateral surface; (b) the auriculo-temporal, which supplies the tragus and ascending part of the helix; $(c)$ the lesser occipital, which sends a branch to the upper part of the medial surface.

\section{Meatus Acusticus Externus.}

The external acoustic meatus (Figs. 707, 708) is the passage leading from the concha to the membrana tympani. Its average length, measured from the bottom of the concha, is about $24 \mathrm{~mm}$., but, if measured from the level of the tragus, about $35 \mathrm{~mm}$. On account of the obliquity of the membrana tympani the anterior and inferior walls of the meatus are longer than the posterior and superior. The meatus consists of two parts, viz.: (a) an external portion, the pars cartilaginea, about $8 \mathrm{~mm}$. in length; and $(b)$ an internal portion, the pars ossea, about $16 \mathrm{~mm}$. in length. The entire meatus forms a somewhat $\mathrm{S}$-shaped bend) Fig. 708), and may be divided into three portions-external, intermediate, and internal; each is directed medialwards, but, in addition, the external part is inclined forwards and slightly upwards; the intermediate, backwards; and the internal, the longest, forwards and slightly downwards. On transverse section the canal is seen to be elliptical, its greatest diameter having an inclination downwards and backwards. Widest at its lateral extremity, it becomes somewhat narrower at the medial end of the pars cartilaginea; once more expanding in the lateral portion of the pars ossea, it is again constricted near the medial end of the latter, where its narrowest part, or isthmus, is found at a distance of about $19 \mathrm{~mm}$. from the bottom of the concha. The medial extremity of the meatus is nearly circular and is closed by the membrana tympani.

Bezold gives the diameters of the meatus as follows :-

At the commencement of the pars cartilaginea 
The lumen of the pars cartilaginea is influenced by the movements of the mandible, being increased when that bone is depressed. This can be easily verified by inserting a finger into the meatus, and then alternately opening and shutting the mouth.

The condyle of the mandible lies in front of the pars ossea, while between the condyle and the pars cartilaginea a portion of the parotid gland is sometimes present. Behind the pars ossea, and separated from it by a thin plate of bone, are the

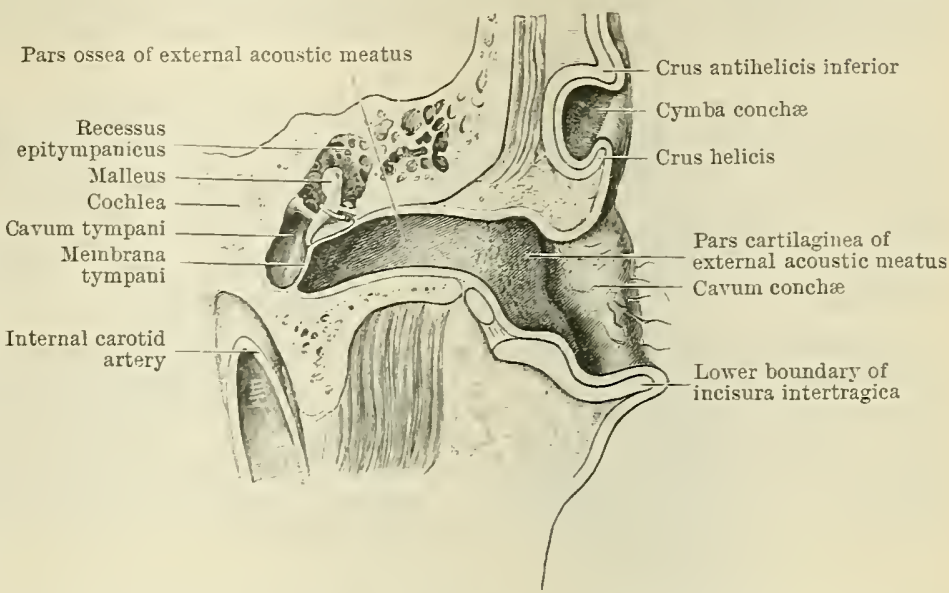

Fig. 707.-Froytal Section of Right Ear ; Axterior Half of Sectiox; viewed from behind (natural size). mastoid air-cells.

Structure of the Meatus.-The cartilage of the meatus, directly continuous with that of the auricula, is folded on itself to form a groove, opening upwards and backwards, the margins of which are connected by fibrous tissue. The medial end of the cartilaginous tube is firmly fixed to the lateral margin of the bony meatus, whilst its lateral extremity is continuous with the cartilage of the tragus

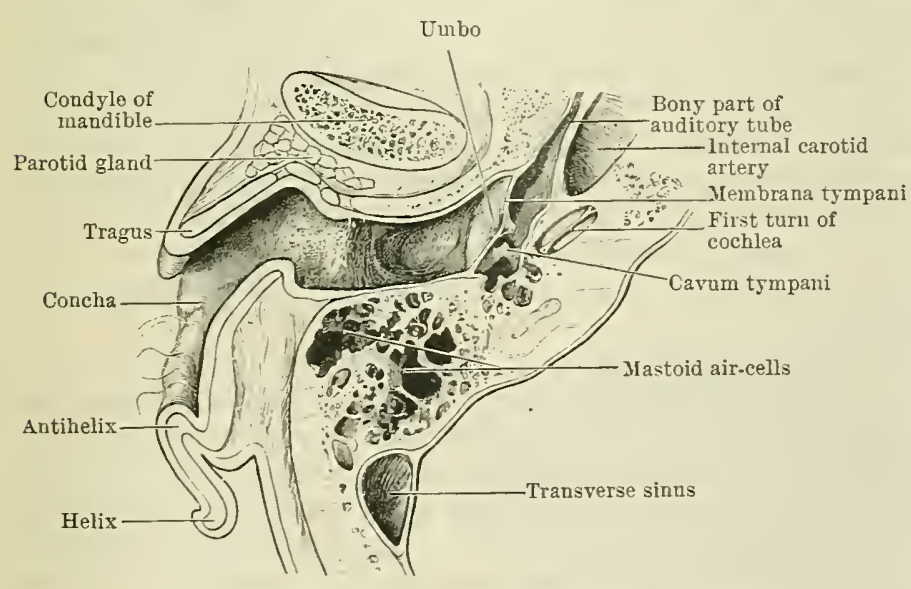

Fig. 708. - Horizontal Section throdgh Right Ear; Upper Half of SECrION, seen from below (natural size).

(p. 829). Two fissures exist in the anterior portion of the pars cartilaginea, and are filled by fibrous tissue. In the lateral part of the meatus the cartilage forms about threefourths of the circumference of the tube; but, near the medial end of the pars cartilaginea the cartilage forms merely a part of the anterior and lower boundaries of the canal.

The pars ossea of the meatus is described on $p$. 127 ; but it may be well to state here that in the new-born child it is represented ouly by an mcomplete ring of bone, the annulus tympanicus, together with a small portion of the squama temporalis, which articulates with, and bridges over the interval between, the extremities of the ring superiorly. In the concavity of the annulus is a groove, the sulcus tympanicus, in which the circunference of the membrana tympani is fixed. On the medial surface of the anterior part of the annulus, a little below its free extremity, a groove, the sulcus malleolaris, is directed downwards and forwards. It transmits the anterior process and the anterior ligament of the mallens, the tympanic artery, and the chorda tympani nerve. It is limited above by a ridge, the crista spinarum (Henle), which ends in front and behind in a spinous process (spina tympanica major and minor). Below the sulcus malleolaris there is a second, less prominent ridge, the crista tympanica (Gruber), which subsequently unites with a process of the tegmen tympani, and so shuts off the canalis musculotubarius from the petrotympanic fissure. A fibrous tympanic plate (Symington) intervenes between the annulus tympanicus and the cartilage of the meatus, and into this plate the bony ring extends. The bony outgrowth does not, however, proceed uniformly from the whole of circunference of the annulus, but occurs most rapidly in its anterior and posterior parts. These outgrowths fuse about the end of the second 
year of life, so as to surround a foramen (foramen of Huschke) in the floor of the meatus; this foramen is usually closed by the fifth year, but persists until adult life in some 19 per cent of skulls (Bürkner).

The lumen of the meatus in the new-born child is extremely small : its outer part is funnelshaped; its inner a mere slit, bounded below by the fibrous tympanic plate and above by the obliquely placed meiubrana tympani.

The skin which envelops the auricula lines the entire meatus, and covers also the outer surface of the membrana tympani. It is thick in the pars cartilaginea, and contains fine hairs and sebaceous glands, the latter extending for some distance along the postero-superior wall of the pars ossea. The sudoriferous glands are enlarged and of a brownish colour; they constitute the glandulæ ceruminosæ and secrete the ear wax or cermmen.

Vascular and Nervous Supply of the Meatus.-The external acoustic meatus receives its blood-supply from the posterior auricular and superficial temporal arteries, and also from the deep auricular branch of the internal maxillary artery, the last distributing some minute twigs to the membrana tympani. The veins open into the external jugular and internal maxillary reins, and also into the pterygoid plexus, while the lymph vessels have a similar mode of termination to those of the auricle. Sensory nerves are supplied to the meatus by the auriculo-temporal branch of the trigeminal and by the auricular branch of the vagus.

\section{CAVUM TYMPANI OR MIDDLE EAR.}

The tympanic cavity is a small air chamber in the temporal bone, between the membrana tympani and the lateral wall of the internal ear or labyrinth (Figs. 707, 708). Lined with mucous membrane, it contains a chain of ossicles,-malleus, incus, and stapes,--which reaches from its lateral to its medial wall, and transmits the vibrations of the membrana tympani across the cavity to the internal ear. Attached to the ossicles are several ligaments and two small muscles.

The tympanic cavity consists of two portions: (1) The tympanum proper, or atrium, lying medial to the membrana tympani; and (2) the recessus epitympanicus, or attic, lying above the level of the membrane and containing the greater part of the incus and the upper half of the malleus. Including this recess, the vertical and antero-posterior diameters of the tympanic cavity each measure about $15 \mathrm{~mm}$. The distance between its lateral and medial walls is about 6 $\mathrm{mm}$. above and $4 \mathrm{~mm}$. below, while at its central part, owing to the bulging of the two walls towards the cavity, it measures only from 1.5 to $2 \mathrm{~mm}$.

The tympanic cavity is enclosed by six walls, tegmental, jugular, labyrinthic, mastoid, carotid, and membranous.

Paries Tegmentalis.-The tegmental wall or roof (Fig. 709) is formed by a thin plate of bone, the tegmen tympani, constituting a portion of the anterior surface of the petrous part of the temporal. It extends backwards so as to cover in the tympanic antrum, and forwards, to roof in the semicanal for the tensor tympani muscle. It separates the tympanic cavity and antrum from the cranial cavity, and may contain a few air-cells, whilst occasionally it is partly deficient. In the child its lateral edge corresponds with the petro-squamous suture, traces of which can generally be seen in the adult bone.

Paries Jugularis.-The jugular wall or floor is narrower than the tegmental wall, and consists of a thin plate of bone which separates the tympanic cavity from the fossa jugularis; anteriorly, it extends upwards and is continuous with the posterior wall of the carotid canal. The inner orifice of the foramen for the transmission of the tympanic nerve is seen near the junction of the jugular and labyrinthic walls.

Paries Labyrinthica. - The labyrinthic or medial wall of the tympanic cavity is formed by the lateral surface of the internal ear (Fig. 709). It presents-(1) a rounded eminence, the promontory, which is caused by the first coil of the cochlea, and is grooved for the tympanic plexus of nerves. (2) An oval or somewhat reniform opening, the fenestra vestibuli, which is situated above and behind the promontory, with its long axis directed antero-posteriorly. It measures $3 \mathrm{~mm}$. in length and $1.5 \mathrm{~mm}$. in width and, in the macerated bone, leads into the vestibule of the osseous labyrinth, but is closed in the recent state by the base or foot-plate 
of the stapes, surrounded by its ligamentum annulare. (3) An elevation, the prominentia canalis facialis, which is situated above the fenestra restibuli, in the recessus epitympanicus; this elevation indicates the position of the upper part of the canalis facialis (O.T. aqueduct of Fallopius), which contains the facial nerve, and

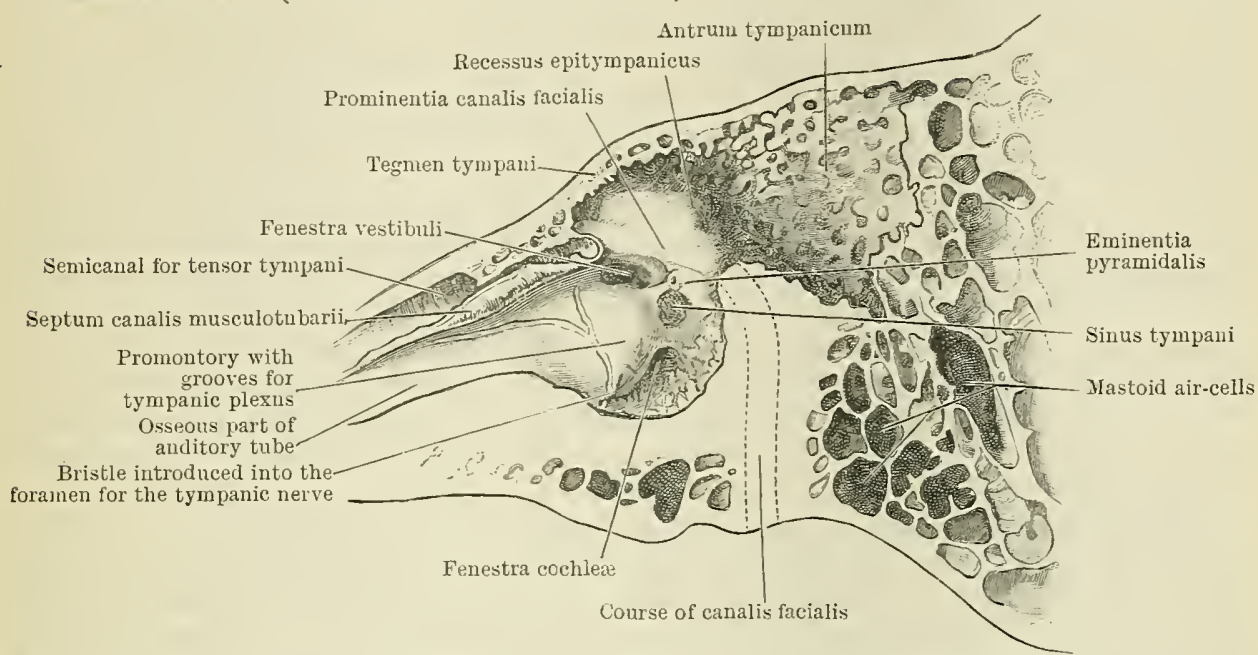

Fig. 709. - Section throdgh Left Temporal Bone, showing labyrinthic wall of tympanic eavity, etc.

is continued backwards and downwards behind the tympanic cavity, to end at the stylo-mastoid foramen. (4) The septum canalis musculotubarii (O.T. processus cochleariformis), which extends backwards, above the anterior end of the fenestra vestibuli, where it makes a sharp lateral eurve, and forms a pulley over which the tendon of the tensor tympani muscle plays. (5) A funnel-shaped recess, situated behind and below the promontory, and almost hidden by its overhanging edge, leads to an irregularly oval opening, termed the fenestra cochleæ; in the macerated bone this fenestra communicates with the cochlea, but in the recent state is closed by the membrana tympani secundaria; this nembrane is bent angularly along a line joining its antero-inferior two-thirds with the postero-superior third; and consists of three layers : (a)

lateral, continnous with the mucous lining of the tympanum, and containing a network of capillaries; (b) intermediate, or membrana propria, the fibres of which radiate chiefly towards the periphery of the membrane-some branched, dendritic fibres are also present; (c) medial, continuous with the epithelial lining of the labyrinth. (6) Be-

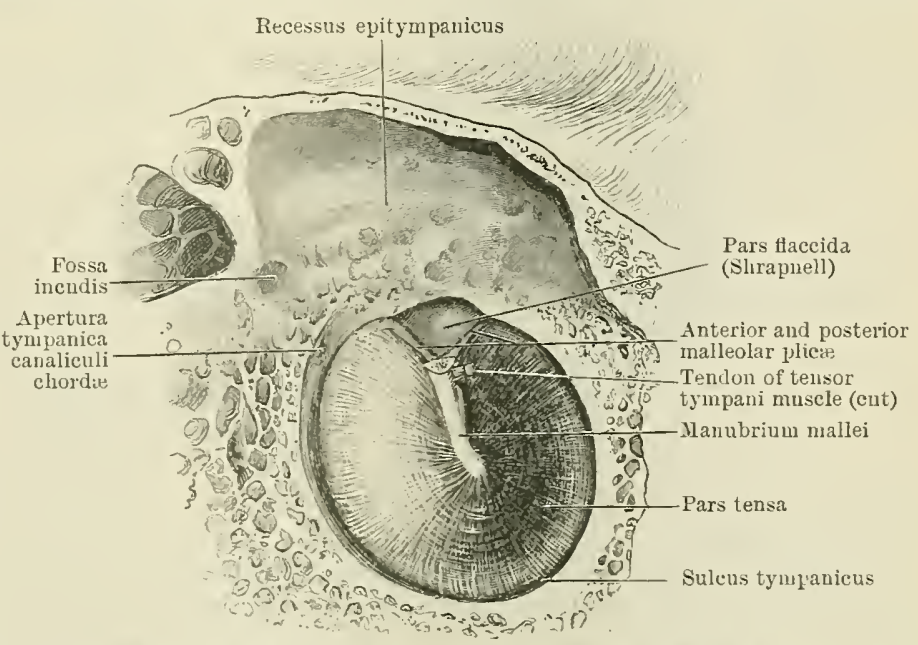

Fig. 710.-Left Membrana Tyupayi and Recessus Epitrupasicus, riewed from within. The head aud neck of the malleus have been removed to show the pars flaccida and the malleolar plicas. $\times 3$.

tween the fenestra vestibuli above and the fenestra cochlere below is a small circular depression, the sinus tympani, which is perforated by one or two minute foramina for blood-vessels, and indicates the position of the ampullated end of the posterior semicircular canal. 
Paries Mastoidea.-The mastoid or posterior wall presents, from above downwards: (1) a rounded or triangular opening, extending backwards from the recessus epitympanicus and leading into the tympanic antrum (Fig. 709); (2) a depression, the fossa incudis, situated in the postero-inferior part of the recessus epitympanicus (Fig. 710), for the reception of the end of the short crus of the incus; (3) a minute conical bony projection, the eminentia pyramidalis (Fig. 709), the summit of which is perforated by a round aperture for the passage of the tendon of the stapedius muscle. This aperture is continued downwards and backwards as a canal in front of the facial canal, and frequently opens, by a minute orifice, on the base of the skull in front of the stylo-mastoid foramen; it communicates with the facial canal by one or two small foramina, which transmit the vessels and nerve to the stapedius muscle; a minute spicule of bone often extends from the eminentia pyramidalis to the promontory on the labyrinthic wall of the tympanum; (4) a small aperture, the apertura tympanica canaliculi chordæ (Fig. 710), which is situated close to the posterior edge of the membrana tympani, nearly on a level with the upper end of the manubrium mallei; (5) a rounded eminence, the prominentia styloidea, is sometimes seen below the last, and is caused by the upward and forward prolongation of the styloid process.

Paries Carotica.-The carotid or anterior wall is narrowed in its transverse diameter by the approximation of the lateral and medial boundaries of the tympanic cavity, and in its vertical diameter by the descent of the roof and the ascent of the carotid canal. It presents (Fig. 709) two parallel semicanals, one above the other, separated by a thin lamella of bone, the septum canalis musculotubarii (O.T. processus cochleariformis). These run forwards on the lateral wall of the carotid canal and open in the angle between the squama and the petrous part of the temporal bone. The higher and smaller of the two is termed the semicanalis $\mathrm{m}$. tensoris tympani, and lies immediately below the tegmen tympani. It has a diameter of about $2 \mathrm{~mm}$., and extends on to the medial wall of the tympanic cavity above the anterior part of the fenestra vestibuli. The lower and larger semicanal gradually increases in size from before backwards, and is named the semicanalis tubæ auditivæ. It forms the bony part of the auditory tube and opens on the carotid wall of the tympanic cavity opposite the orifice leading into the tympanic antrum. Below the orifice of the auditory tube the anterior part of the tympanic cavity is separated from the ascending portion of the carotid canal by a thin plate of bone in which there are sometimes gaps or deficiencies. It is perforated by the carotico-tympanic canal, which transmits the carotico-tympanic nerve from the sympathetic plexus of the carotid artery to the tympanic plexus. The auditory tube is described on p. 837.

Paries Membranacea.-The membranous or lateral wall is formed almost entirely by the membrana tympani (Fig. 710), which closes the medial end of the exterual acoustic meatus, and is fixed throughout the greater part of its circumference in a groove, the sulcus tympanicus. The bony ring containing this sulcus is deficient superiorly, where it exhibits a distinct notch, the notch of Rivinus. On a level with the upper edge of the membrane, and in front of the ring of bone in which it is fixed, is the medial end of the petrotympanic fissure. This transmits the tympanic branch of the internal maxillary artery, and lodges the anterior process and anterior ligament of the malleus. Close to the medial end of the fissure is the iter chordæ anterius through which the chorda tympani nerve leaves the tympanic cavity.

IMembrana Tympani.- The tympanic membrane is an elliptical disc, its greatest diameter, 9 to $10 \mathrm{~mm}$., being directed from above, downwards and forwards, whilst its least diameter is from 8 to $9 \mathrm{~mm}$. It is placed very obliquely, forming an angle of about $55^{\circ}$ with the lower and anterior walls of the external acoustic meatus; it is said to be more oblique in cretins and deaf mutes, and more perpendicular in musicians.

The circumference of that portion of the membrane which is fixed in the sulcus tympanicus is considerably thickened, and is named the annulus fibrocartilagineus. It is prolonged from the anterior and posterior extremities of the notch of Rivinus to the processus lateralis of the malleus, in the form of two ligamentous bands, the 
anterior and posterior malleolar plicæ. The small triangular portion of the membrane (Fig. 710) situated above these folds is thin and lax, and constitutes the pars flaccida (O.T. membrane of ShrapnelI); the main portion of the membrane is, on the other hand, tightly stretched and termed the pars tensa. A small orifice, sometimes seen in the pars flaccida, is probably either a pathological condition or has been produced artificially during manipulation. The manubrium mallei is firmly fixed to the medial surface of the membrana tympani, the central portion of which is drawn towards the tympanic cavity so that its lateral surface is concave. The deepest part of this concavity corresponds with the lower end of the manubrium of the malleus, and is named the umbo membranæ tympani.

The membrana tympani consists of three layers: (1) a lateral, the stratum cutaneum; (2) an intermediate, the membrana propria; (3) a medial, the stratum mucosum.

The stratum cutaneum is continuous with the skin of the meatus, and consists of a thin layer of cutis covered with epidermis. The cutis is thickest near the circumference; the epidermis, on the other hand, is thickest near the centre of the membrane.

The membrana propria consists of two sets of fibres: (a) a lateral, the stratum radiatum, situated immediately under the stratum cutaneum, and radiating from the manubrium of the malleus to the annulus fibrocartilagineus; (b) a medial, the stratum circulare, the fibres of which are numerous near the circumference, but scattered and few in number near the centre of the membrane (Fig. 710). Both radial and circular fibres are absent from the pars flaccida, which consists only of the cutaneous and mucous strata. Gruber pointed out that, in addition to the radial and circular fibres, there exists, next the stratum mucosum, a series of dendritic or branched fibres, which are best developed in the posterior part of the membrane.

The stratum mucosum is continuous with the mucous lining of the tympanic cavity. It is thicker over the upper part of the membrane than near its centre, and is covered with pavement epithelium.

Otoscopic Examination of the Membrana Tympani (Fig. 711).-The membrana tympani, in the living, is of a "pearl-gray" colour, but may present a reddish or yellowish tinge, depending upon the condition of its mucous lining and on the condition of the cutaneous lining of the meatus; the posterior segment is usually clearer than the anterior. At the antero-superior part, close to its periphery, a whitish point appears as if projecting towards the meatus; this is the processus lateralis of the malleus. Passing downwards and backwards from this point to the umbo is a ridge caused by the manubrium mallei, the lower extremity of which appears rounded. Two ridges, corresponding with the malleolar plicx, extend from the processus lateralis of the mallens, one forwards and upwards, the other backwards and upwards. Behind, and near the lower extremity of the

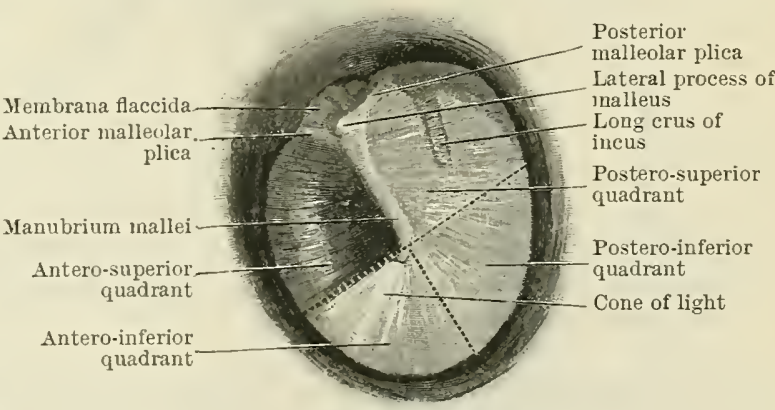

Fig. 711.-Left Trmpanic Membrane (as viewed from the external aconstic meatus). $\times 3$. manubrium mallei, is a reddish or yellowish spot, due to the promontory of the medial wall of the tympanic cavity shining through. If the membrane is very transparent, the long crus of the incus may be visible behind the upper part of the manubrium mallei, and reaching downwards as far as its middle. From the lower end of the manubrium mallei, the "cone of light" or "luminous triangle" extends downwards and forwards, its apex being directed towards the handle; this triangle varies in size in different people. A line prolonging the manubrium downwards divides the membrane into two parts, while another, drawn at right angles to this through the umbo, will subdivide it into quadrants, viz., postero-superior, postero-inferior, antero-superior, and antero-inferior; this subdivision is useful in enabling the otologist to localise and describe accurately the seat of lesions in the membrane.

Vascular and Nervous Supply of the Membrana Tympani.-The arteries are arranged in two sets, one on the cutaneous and another on the mucous surface; they anastomose by means of small branches which pierce the membrane, especially near its periphery. The first set is derived chiefly from the deep auricular branch of the internal maxillary, whilst those on the 
mucous surface are small and proceed from the anterior tympanic branch of the internal maxillary, and from the stylo-mastoid branch of the posterior auricular. 'The veins from the cutaneous surface open into the external jingular; those from the mucous surface partly into the venous plexus on the auditory tube, and partly into the transverse sinus and veins of the dura mater. The lymph vessels, like the blood-ressels, are arranged in two sets, cutaneous and mucous, which, however, communicate freely with each other. Kessel has described as lymphatics the spaces between the branches of Gruber's dendritic fibres. The lateral surface of the membrane receives its nerves from the auriculo-temporal branch of the trigeminal and from the auricular branch of the vagus ; the medial surface, from the tympanic branch of the glossopharyngeal.

\section{Antrum Tympanicum et Cellule Mastoidea.}

Antrum Tympanicum.- The tympanic antrum (O.T. mastoid antrum) is an airspace situated above and behind the tympanic cavity. It is nearly as large in the new-born child as in the adult. In the adult its measurements are-length from

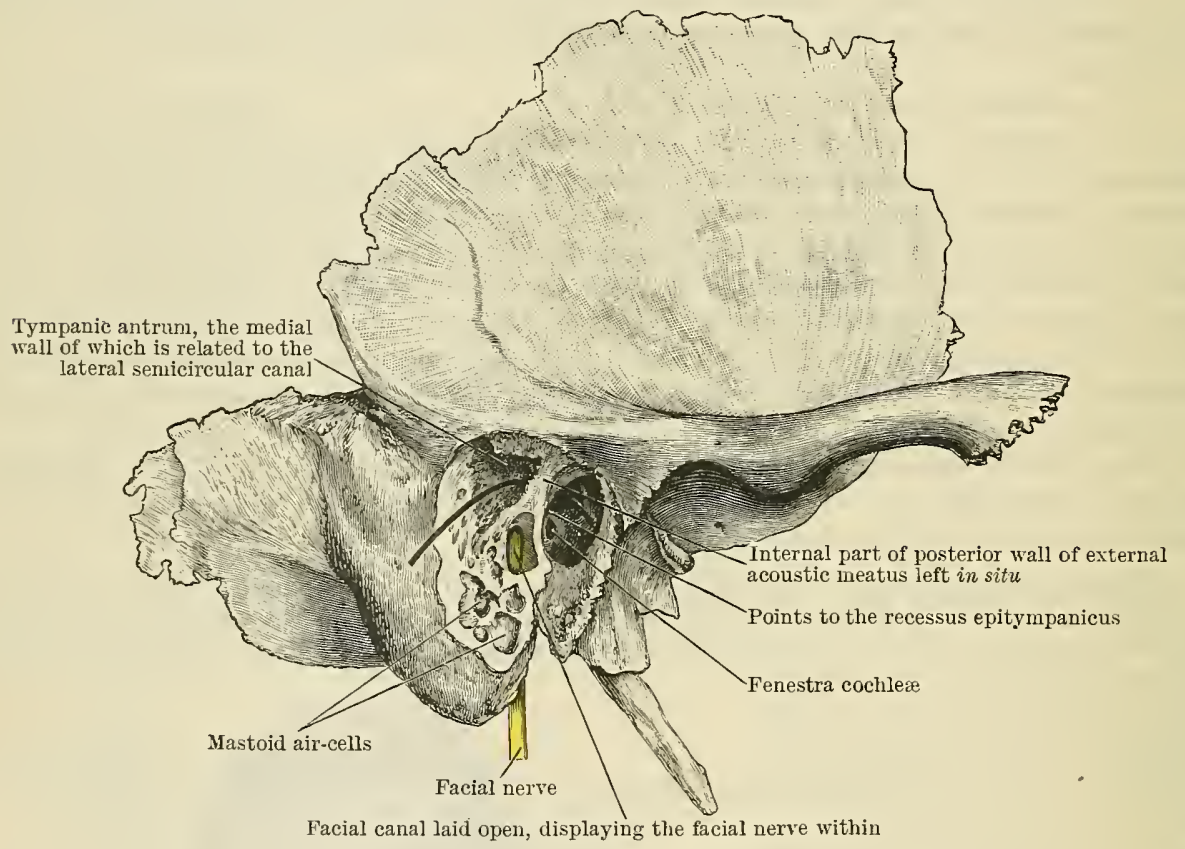

Fig. 712 .

Preparation to display the position and relations of the tympanic antrum. The greater part of the posterior wall of the external acoustic meatus has been removed, leaving only a bridge of bone at its inner extremity; under this a bristle is displayed, passing from the tympanic antrum through the iter to the cavity of the tympanum.

12 to $15 \mathrm{~mm}$., height from 8 to $10 \mathrm{~mm}$., and width from 6 to $8 \mathrm{~mm}$. It is roofed in by the tegmen tympani, and its floor and medial wall are formed by the pars petrosa and pars mastoidea of the temporal bone, while laterally it is closed by the junction of the thin outer part of the squama with the pars mastoidea. It communicates with the epitympanic recess by a triangular or rounded opening, on the medial wall of which, immediately above and behind the canalis facialis, is a smooth, convex area of bone indicating the position of the ampullated extremities of the superior and lateral semicircular canals. At birth the lateral wall of the antrum has a thickness of only 1-2 $\mathrm{mm}$., but by the ninth year this has increased to about $10 \mathrm{~mm}$. Coincident with the growth of the mastoid process the mastoid air-cells are developed downwards and backwards as diverticula from the antrum, and present the greatest possible variation in different skulls.

Cellulæ Mastoideæ. - The mastoid air-cells may be large, comparatively few in number, and involve the whole mastoid process, in which case the compact bone surrounding them is extremely thin, and the innermost cells are separated 
from the transverse sinus by a transparent lamella which, in some instances, is partly deficient. In other cases the cells may be small and numerous, invading only a portion of the process, the remainder consisting of diploëtic tissue; occasionally a solid mastoid is met with. No definite conclusion can be formed as to their condition by external percussion or examination. The air-cells are not limited to the mastoid process, but extend forwards over the roof of the meatus, upwards towards the squama temporalis, and medially towards the temporo-occipital suture; occasionally they invade the pars jugularis of the occipital bone. The tympanic antrum and the mastoid air-cells are lined with thin mucous membrane, continuous with that of the tympanic cavity; the deep surface of the mucous membrane is fixed to the periosteum; its free surface is covered with a layer of flattened, non-ciliated epithelium.

\section{Tuba Auditiva.}

The auditory tube (O.T. Eustachian tube) leads from the tympanic cavity to the nasal part of the pharynx, and transmits air to the former, in order that the pressures on the medial and lateral surfaces of the membrana tympani may be equalised; it may also serve to convey mucous secretion from the tympanic cavity. Its tympanic orifice (Fig. 709) opens into the anterior part of the tympanic cavity below the semicanal for the tensor tympani muscle. Directed downwards and medialwards, the tube ends on the upper part of the nasal part of the pharynx by a wide pharyngeal orifice (Fig. 674 , p. 803 ). It measures about $35 \mathrm{~mm}$. in length, and forms with the horizontal plane an angle of $30^{\circ}$ to $40^{\circ}$, with the sagittal plane an angle of about $45^{\circ}$, and with the bony part of the external acoustic meatus an angle of $135^{\circ}$ to $140^{\circ}$. It consists of two portions: $(a)$ an antero-medial, the pars cartilaginea tubæ auditivæ, having a length of about $25 \mathrm{~mm}$; and $(b)$ a postero-lateral, the pars ossea tubæ auditivæ, measuring about $10 \mathrm{~mm}$. in length. The two portions are not in the same plane, the cartilaginous part inclining downwards a little more than the osseous portion, and forming with it a wide angle. The lumen of the tube is widest at the pharyngeal orifice, narrowest at the junction of the bony and cartilaginous portions, forming here the isthmus, and again expanding towards the tympanic cavity; hence it presents, on longitudinal section, somewhat the appearance of an hour-glass. The pars ossea occupies the angle between the tympanic part and the petrous part of the temporal bone, and is separated by the septum canalis musculotubarii from the semicanal containing the tensor tympani muscle; medial to it is the carotid canal. The pars cartilaginea consists partly of cartilage and partly of fibrous membrane. The cartilage of the auditory tube is an elongated triangular plate, of which the apex is firmly attached to the medial end of the pars ossea, while the base is free, and forms a projection on the upper and posterior aspects of the pharyngeal orifice. The upper edge of this cartilaginous plate is bent laterally in the form of a hook, and so produces a furrow

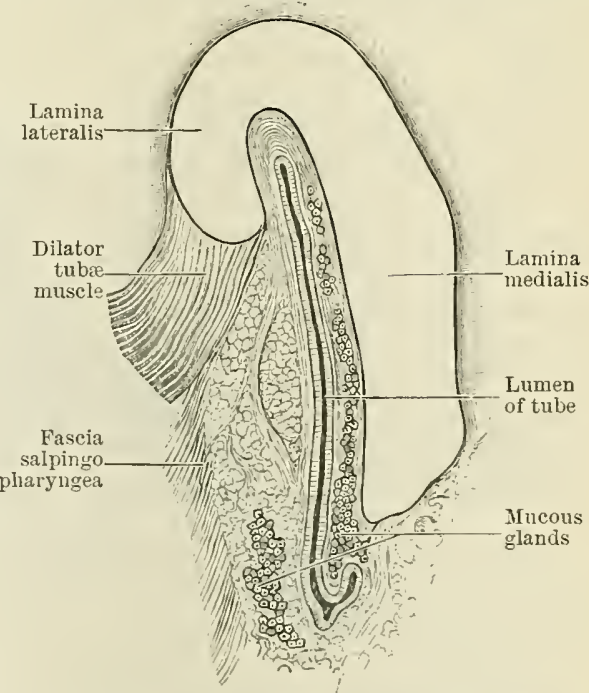

Fig. 713.-Transverse Section of the Cartilaginous Part of the Auditory Tube. open below, the furrow being converted into a complete canal by the membranous lamina of the tube. On transverse section (Fig. 713) the cartilage presents two lamina continuous with each other superiorly: (a) lamina medialis, broad and thick; and (b) lamina lateralis, thin and hook-shaped. At the pharyngeal orifice the lamina medialis forms the entire medial wall of the tube, but it gradually diminishes in breadth on approaching the isthmus tubre. Fissures are often seen 
in the cartilage; sometimes it is completely separated into several pieces, or accessory islands may be observed in the roof, floor, or membranous lamina.

The upper and medial surfaces of the medial lamina are firmly fixed to the base of the skull, where it lies in a groove, the sulcus tubæ auditivæ, between the great wing of the sphenoid and the petrous part of the temporal. Extending forwards on to the root of the pterygoid process this sulcus ends at a projection, the processus tubarius, on the medial pterygoid lamina. The tensor veli palatini muscle lies on the lateral side of the tube and receives some fibres of origin from its lamina lateralis; these fibres constitute the dilatator tubæ muscle (Riidinger). On the medial side of the cartilage are the levator veli palatini and the mucous membrane of the pharynx. The membranous lamina consists of a strong fibrous membrane, stretching between the two edges of the cartilage, and so completing the lower and lateral walls of the tube. Thin above, it becomes thickened below and forms the fascia salpingopharyngea of Tröltsch, which gives origin to some of the fibres of the tensor veli palatini muscle. Between this fascia and the mucous lining of the tube is a layer of adipose tissue.

The pharyngeal orifice of the auditory tube, triangular or oval in shape, is situated on the lateral wall of the nasal part of the pharynx, the centre of the opening being on a level with the posterior end of the inferior nasal concha. It is bounded above and behind by a pad, the torus tubarius, produced by the base of the cartilage, which here abuts against the mucous membrane; the posterior part of the torus is very prominent and forms the anterior boundary of the pharyngeal recess. Prolonged downwards from it is an elevation of the mucous membrane, termed the plica salpingopharyngea, which covers the small salpingopharyngeus muscle. From the upper part of the torus an indistinct fold, the plica salpingopalatina, extends to the palate.

The mucous lining of the tube is continuous behind with that of the tympanic cavity, and in front with that of the nasal part of the pharynx. It is thin in the pars ossea, contains few, if any, mucuus glands, and is firmly fixed to the bony wall; in the pars cartilaginea it is loose and thrown into longitudinal folds. Numerous mucous glands open into the tube near its pharyngeal orifice, and here also exists a considerable amount of adenoid tissue, which constitutes the "tube-tonsil" of Gerlach. This adenoid tissue is continuous with that of the nasal part of the pharynx, and, like it, is especially well developed in children. The lumen of the tube is lined with ciliated columnar epithelium.

The tube is opened, during deglutition, by the dilatator tubæ and salpingopharyngeus muscles. The former springs superiorly from the cartilaginous hook of the tube, and blends inferiorly with the tensor veli palatini. When the dilatator tubæ contracts, the cartilaginous hook and the membranous lamina of the tube are drawn lateralwards and forwards. Some anatomists believe that the entire tensor veli palatini acts chiefly as a dilator of the tube, and Rüdinger named it the abductor tubæ. The salpingopharyngeus muscle draws downwards and backwards the medial lamina, increasing the angle between it and the lateral lamina. Some difference of opinion exists as to the precise action of the levator veli palatini; probably it assists in opening the tube.

The auditory tube receives its blood-supply from the ascending pharyngeal artery, and from the middle meningeal artery and the artery of the pterygoid canal, both of which are branches of the internal maxillary artery. Its veins form a network which drains into the pterygoid venous plexus. The sensory nerves of the tube are derived from the tympanic plexus and from the pharyngeal branch of the spheno-palatine ganglion.

The auditory tube of the child differs considerably from that of the adnlt; its lumen is relatively wider, its direction more horizontal, and its pars ossea relatively shorter. Kunkel states that its pharyngeal orifice is below the level of the hard palate in the fœtus; at birth it is on the same level as the palate, whilst at the fourth year it is 3 to $4 \mathrm{~mm}$., and in the adult $10 \mathrm{~mm}$., above it. In the child the pharyngeal orifice forms a narrow fissure, and its cartilage projects less towards the middle line.

\section{Ossicula Auditus.}

The auditory ossicles form an articulated column connecting the lateral with the medial wall of the tympanic cavity; they are named, from without 
inwards, the malleus, incus, and stapes. The first is attached to the medial surface of the membrana tympani; the last is fixed within the circumference of the fenestra vestibuli.

The malleus (Fig. 714, B, D), the largest of the three ossicles, has a length of 8 to $9 \mathrm{~mm}$, and consists of a head, a neck, a manubrium, and two processes, viz. :

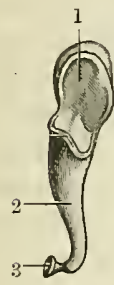

A

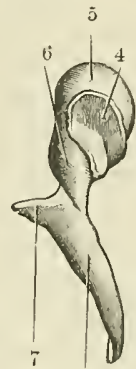

S B

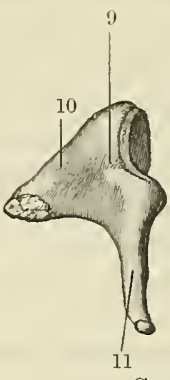

C

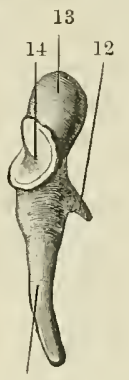

$15 \mathrm{D}$

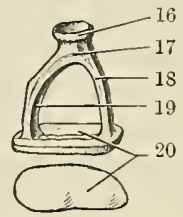

E

Fig. 714.-ADDitori Ossicles OF LEFT EAR (enlarged about three times).

A, Incus, seen from the front; B, Malleus, viewed from behind; C, Incus, and D, Malleus, seen from medial aspect; E, Stapes.
1. Body of incus, with articular surface for head of malleus.
2. Crus longum.
3. Processus lenticularis.
4. Articular surface for incus.
5. Head of Mallens.
i. Neck of Malleus.

7. Processus lateralis.
8. Manubrium.
9. Body of incus.
10. Crus breve.
11. Crus longum.
12. Processus anterior.
13. Head of malleus.

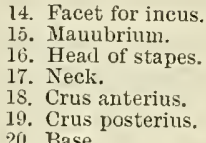

19. Crus posterius 20. Base.

(a) processus anterior, (b) processus lateralis. The head and neck are situated in the epitympanic recess; the processus lateralis and manubrium are fixed to the medial surface of the membrana tympani; while the processus anterior is directed forwards towards the petro-tympanic fissure, to which, in the adult, it is connected by ligamentous fibres. The head, somewhat rounded, is smooth and convex above and in front, and presents, on its posterior surface, a facet for articulation with the body

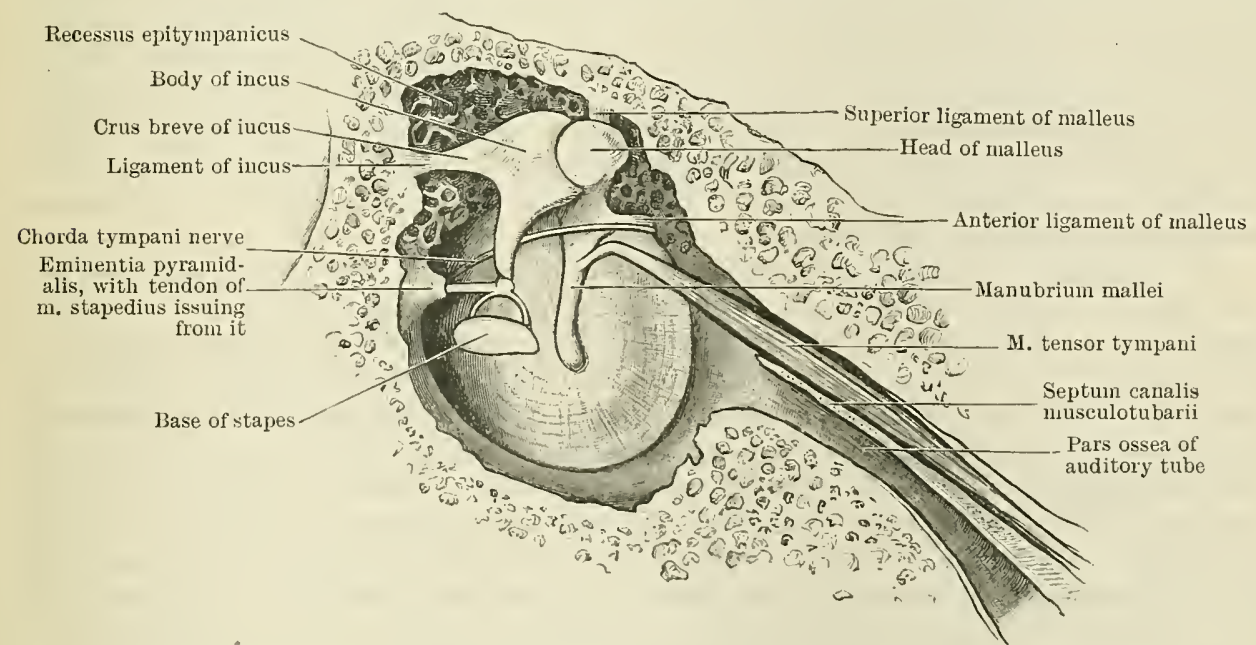

Fig. 715. - Lefi Membrana Trmpani and Chain of Auditory Ossicles (seen from the inedial aspect). $\times 3$.

of the incus. This facet is directed obliquely downwards and medialwards, and is more or less elliptical in form. It is constricted near the middle so as to resemble, somewhat, the figure 8 ; an oblique ridge, corresponding with the constriction, divides the facet into two parts-an upper and larger, directed backwards, and a lower and lesser, directed medialwards. Opposite the lower part of the constriction the inferior edge of the facet is very prominent, and is continued upwards into the oblique ridge just referred to; it forms a tooth-like process, the spur or cog-tooth of 
the malleus. On the back of the head, below this spur, is an oblique crest, the crista mallei, to which is attached the lateral ligament of the malleus. The neck is the slightly constricted portion immediately below the head. Flattened from before backwards, its lateral surface is directed towards the membrana flaccida, whilst its medial surface is crossed by the chorda tympani nerve. The manubrium or handle is directed downwards, backwards, and medialwards from the neck, forming with the long axis of the head an angle of $126^{\circ}$ to $150^{\circ}$. Its upper part is flattened from before backwards, but towards the lower end it is twisted on itself, so that its surfaces look laterally and medially; moreover, the lower end is slightly curved, the concavity being directed forwards and laterally. It is fixed, along its entire length, to the membrana propria of the tympanic membrane by its periosteum and by a layer of cartilage (Gruber). The cartilage intervenes between the manubrium and the membrane, and must be regarded as a residue of that stage of development when the entire malleus was cartilaginous. On the medial surface of the manubrium, near its upper extremity, is a slight projection for the attachment of the tendon of the tensor tympani muscle. The processus anterior, a slender spicule, springs from the front of the neck and is directed forwards towards the petro-tympanic fissure. In the foetus it is the longest process of the malleus, but in the adult it usually assumes the form of a small projection, since its anterior part is replaced by ligamentous tissue. The processus lateralis may be looked upon as the upper extremity of the manubrium projected laterally; it is fixed to the upper part of the membrana tympani by the cartilaginous layer already referred to, and to the extremities of the notch of Rivinus by the anterior and posterior malleolar plicx.

The incus (Fig. 714, A, C) may be likened to a præmolar tooth with widely divergent roots. It consists of a body, a crus longum, and a crus breve; the crura form with each other an angle of $90^{\circ}$ to $100^{\circ}$. The body and crus breve are situated in the recessus epitympanicus. The body presents a more or less saddle-shaped surface for articulation with the head of the malleus. This surface is directed forwards, and its lower part is hollowed out for the accommodation of the cog-tooth of the malleus; in front of this hollow it is prominent and spur-like. The crus breve is thick, triangular in shape, and projects horizontally backwards; its conical extremity, covered with cartilage, is received into the fossa incudis in the posteroinferior part of the epitympanic recess. The crus longum projects, almost perpendicularly, downwards from the body into the tympanic cavity, where it lies parallel with, but $1.25 \mathrm{~mm}$. behind and medial to, the manubrium mallei. Its lower end is bent medialwards and narrowed to form a short neck, on the end of which is a small knob of bone, the processus lenticularis, for articulation with the head of the stapes. Until the sixth month of fotal life this process exists as a separate ossicle, termed the os orbiculare.

The stapes (Fig. 714, E) consists of a head, a neck, two crura, and a base. The head, directed lateralwards, is concave for articulation with the processus lenticularis of the incus. The neck is slightly constricted, and from it the two crura spring; the tendon of the stapedius is inserted into the posterior aspect of the neck. The crus anterius is shorter and less curved than the crus posterius. Diverging from each other, the crura are directed medialwards and are attached-one near the anterior, the other near the posterior end of the base. The base almost completely fills the fenestra vestibule, and, like it, is somewhat oval or reniform, its anterior end being the more pointed. In the recent condition a membrane fills the arch formed by the crura and the base, the crura being grooved for its reception. In the child the crura of the stapes are less curved than in the adult, and the opening bounded by them and the base is nearly triangular.

Articulations of the Auditory Ossicles.-The incudo-malleolar joint between the head of the malleus and the body of the incus is diarthrodial, and may be described as one of reciprocal reception. It is surrounded by an articular capsule, and from the inner surface of the fibrous stratum a wedge-shaped meniscus projects into the joint carity and incompletely divides it. The incudo-stapedial articulation between the processus lenticularis and the head of the stapes is of the nature of an enarthrosis and is surrounded by an articular capsule. An interarticular cartilage has been described as occurring in this joint, while some observers deny 
the presence of a synovial cavity and regard the articulation as a syndesmosis, the articular surfaces being held together by fibrous tissue.

Ligamenta Ossiculorum Auditus. - The malleus is attached to the walls of the tympanic cavity by three ligaments (Fig. 715), viz. : anterior, superior, and lateral. The anterior ligament consists of two portions: (a) the band of Meckel, which is attached to the base of the processus anterior, and passes forwards through the petrotympanic fissure to reach the spine of the sphenoid; it represents the remnant of a portion of Meckel's cartilage, and was formerly described as the laxator tympani muscle; (b) a firm bundle of fibres, the anterior ligament of Helmholtz, which extends from the spina tympanica posterior at the anterior boundary of the notch of Rivinus to the anterior surface of the malleus, above the base of the processus anterior. The superior ligament stretches, almost vertically, from the head of the malleus to the roof of the epitympanic recess. The lateral ligament is short and fan-shaped; its fibres converge from the posterior half of the notch of Rivinus to the crista mallei. The posterior part of this ligament is strong and constitutes the posterior ligament of Helmholtz; it forms, together with the anterior ligament of the malleus, the axis around which the malleus rotates, and the two constitute what Helmholtz termed the "axis-ligament" of the malleus.

The posterior extremity of the crus breve of the incus is tipped with cartilage and fixed by means of a ligament to the fossa incudis (Fig. 715). Some observers describe this as a diarthrodial joint. The vestibular surface and the circumference of the base of the stapes are covered with hyaline cartilage, and a similar layer lines the opening of the fenestra vestibuli; that encircling the base of the stapes is joined to that lining the fenestra by a dense ring of elastic fibres, named the ligamentum annulare baseos stapedis. The posterior fibres of this ligament are thicker and shorter than the anterior, and thus during the movements of the stapes, the anterior end of its base is free to make greater excursions than the posterior.

Development of the Auditory Ossicles.-It is generally maintained that the malleus and incus are developed from the upper end of Meckel's cartilage, and that the stapes arises from the mesoderm in the region of the fenestra vestibuli, where it is developed around a small artery, the stapedial artery, which atrophies in man, but persists in many mammals. On the other hand, Gadow (Phil. Trans., London, vol. clxxix.) says "the whole system of the one to four elements of the middle ear, which have all the same function, is to be looked upon as one organ, of one common origin, viz., a modification of the hyomandibular, the proximal paramere of the second visceral arch." Ossification commences in all three bones about the third month of fœtal life. The malleus is ossified from two centres, one for the head and manubrium, and one for the processus anterior; the incus from two centres, one for the body including the crura, and a second for the processus lenticularis; the stapes from one centre which appears in the base.

Muscles of the Tympanic Cavity.-These are two in number, viz., m. tensor tympani and $m$. stapedius.

The $\mathrm{m}$. tensor tympani is the larger, and takes origin from the roof of the cartilaginous part of the auditory tube, from the adjacent part of the great wing of the sphenoid, and from the bony canal in which the muscle lies. The muscle ends in a tendon which bends laterally, nearly at a right angle to the belly of the muscle, round the pulley-like posterior extremity of the septum canalis musculotubarii. Passing across the tympanic carity this tendon is inserted into the medial edge and anterior surface of the manubrium mallei, near its upper end. When the muscle contracts it draws the manubrium of the malleus towards the tympanic cavity, and so renders tense the membrana tympani; it probably also slightly rotates the malleus around its long axis. It receires its nerve from the motor division of the trigeminal nerve, through the otic ganglion.

The $\mathrm{m}$. stapedius arises within the eminentia pyramidalis, and from the canal which prolongs the hollow of the pyramidal eminence downwards. Its tendon emerges from the apex of the eminence and is inserted into the posterior surface of the neck of the stapes. On contraction it draws back the head of the stapes, and so tilts the anterior end of the base towards the tympanic cavity and the 
posterior end towards the labyrinth, thus rendering tense the ligamentum annulare - the lateral movement of the anterior end of the base being greater than the medial movement of its posterior end. The muscle is supplied by the facial nerve.

Movements of the Auditory Ossicles. - The manubrium mallei follows all the novements of the membrana tympani, while the malleus and incus move together around an axis extending forwards through the crus breve of the incus and the anterior ligament of the malleus. When the membrana tympani moves medialwards it carries with it the manubrium mallei, while the incus, moving medialwards at the same time, forces the base of the stapes towards the labyrinth. This movement is communicated to the fluid (perilymph) in the labyrinth, and causes a lateral bulging of the secondary tympanic membrane, which closes the fenestra cochleæ. These movements are reversed when the membrana tympani is relaxed, unless the lateral movement of the membrane is excessive. In such a condition the incus does not follow the full movement of the malleus, but merely glides on this bone at the incudo-malleolar joint, and thus the forcible dragging of the base of the stapes out of the fenestra vestibuli is prevented. The cog-tooth arrangement, already described, on the head of the malleus and body of the incus, causes the incudo-malleolar joint to become locked during the medial movement of manubrium mallei, the joint becoming unlocked during its lateral movement.

Tunica Mucosa Tympanica. - The mucous lining of the tympanic cavity is continuous, through the auditory tube, with that of the nasal part of the pharynx; it extends backwards also and lines the tympanic antrum and the mastoid air-cells. Thin, transparent, and closely united with the subjacent periosteum, it covers the medial surface of the membrana tympani and is reflected over the auditory ossicles and their ligaments. It also supplies sheaths for the tendons of the tensor tympani and stapedius muscles, and forms the following folds, viz.: (a) one from the roof of the recessus epitympanicus to the head of the malleus and body of the incus; (b) one enveloping the chorda tympani nerve and crus longum of the incus; (c) two extending from the processus lateralis mallei-one to the anterior, the other to the posterior margin of the notch of Rivinus. A recess, the pouch of Prussak, is situated between the membrana flaccida and the neck of the malleus. Communicating behind with the tympanic cavity, this pouch may serve as a reservoir to confine pus or other fluid, since its opening into the tympanic cavity is above the level of its floor, a condition analogous to the opening from the maxillary sinus into the nasal cavity. The fold of mucous membrane which extends downwards to envelop the chorda tympani nerve gives rise to two pouches, one in front of, and the other behind, the manubrium mallei; these are named the anterior and posterior recesses of Trölsch. The epithelium which lines the mucous membrane is flattened over the membrana tympani, promontory, and auditory ossicles, but ciliated and columnar over the greater portion of the rest of the cavity.

Vessels and Nerves of the Tympanic Cavity.-The arteries supplying the tympanic cavity are: (1) The anterior tympanic artery, a branch of internal maxillary, which reaches the cavity by way of the petro-tympanic fissure. (2) The stylo-mastoid branch of posterior auricular, which passes through the stylo-mastoid foramen and the facial canal; it supplies branches to the tympanic antrum and mastoid air-cells, to the stapedius muscle, to the floor and medial wall of the tympanic cavity, and forms an anastomotic circle, around the membrana tympani, with the anterior tympanic artery. (3) The middle meningeal artery sends a branch to the tensor tympani muscle, and, after entering the skull, gives off its petrosal artery, which is conducted to the tympanic cavity along the hiatus canalis facialis; some twigs from the posterior division of the middle meningeal reach the tympanic antrum and epitympanic recess through the petrosquamous fissure. (4) The internal carotid artery, in its passage through the canal in the temporal bone, gives off one or two tympanic twigs, while (5) a branch from the ascending pharyngeal accompanies the tympanic nerve. The veins drain into the pterygoid plexus, and the superior petrosal sinus. The lymph vessels form a network in the mucous membrane and end mainly in the retro-pharyngeal and parotid lymph glands. The nerves supplying the muscles of the tympanic cavity have already been referred to (pp. 832, 834). The mucous membrane receives its nerves from the tympanic plexus, which is described on p.786. The chorda tympani branch of the facial nerve passes from behind, upwards, and forwards through the tympanic eavity. Its course is described on p. 782.

Early Condition of Tympanic Cavity.--During the greater part of intra-uterine existence the tympanic cavity is almost completely filled by a soft, reddish, jelly-like embryonic tissue in which there is a slit-like space lined with epithelium. Towards the end of foetal life this tissue disappears and at birth the cavity is filled with fluid which becomes absorbed, after the entrance of air from the nasal part of the pharynx through the auditory tube. 


\section{AURIS INTERNA.}

The internal ear or essential part of the organ of hearing is situated in the substance of the petrous part of the temporal bone, and consists of two sets of structures, viz.: (1) a series of passages hollowed out of the bone and constituting the osseous labyrinth; these are continuous with each other, and are named

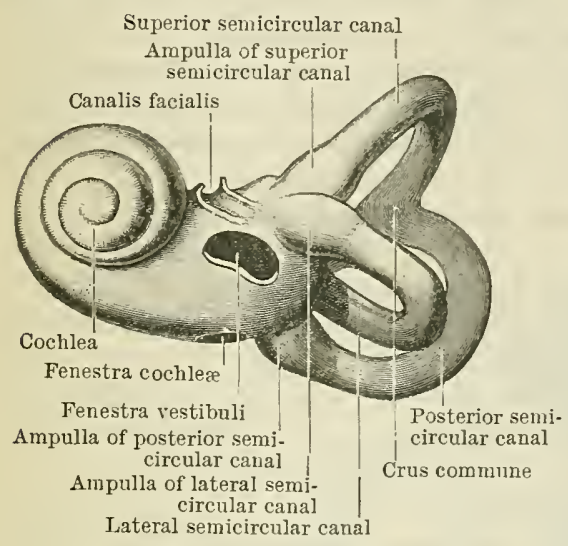

Fig. 716.-LeFT BoNy LABYinTH (viewed from the lateral aspect).

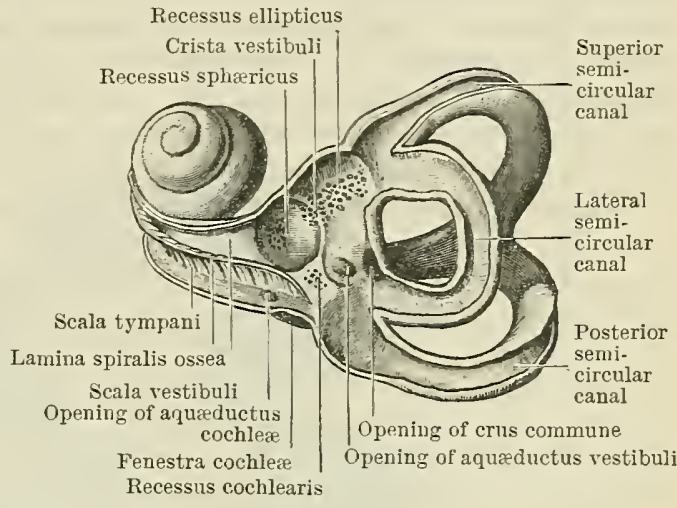

Fig. 717 .- INTERior of Left Bony Labyrinte (viewed from lateral aspect).

from before backwards the cochlea, vestibule, and semicircular canals (Figs. 716, 717); (2) a complex arrangement of membranous channels (Fig. 720), situated within, but not nearly filling, the bony labyrinth and forming the membranous labyrinth. These channels are named the ductus cochlearis, the utricle, the saccule, and the semicircular ducts; the utricle and saccule are lodged within the vestibule.

\section{LABYRINTHUS OSSEUS.}

Vestibulum.-The vestibule is the central portion of the osseous labyrinth, and communicates behind with the semicircular canals and in front with the cochlea. It is somewhat ovoid in shape, its long axis being directed forwards and lateralwards; it measures about $6 \mathrm{~mm}$. antero-posteriorly, $4-5 \mathrm{~mm}$. vertically, and about $3 \mathrm{~mm}$. transversely. Its lateral wall is directed towards the tympanic cavity, and in it is the fenestra vestibuli, which is closed by the base of the stapes. Its medial wall corresponds with the bottom of the internal acoustic meatus, and presents, at its antero-inferior part, a rounded depression, the recessus sphæricus, which lodges the saccule. This recess is perforated by twelve or fifteen small foramina (macula cribrosa media), which transmit the filaments of the acoustic nerve to the saccule. The recessus sphæricus is linited above and behind by an oblique ridge, the crista vestibuli, the anterior extremity of which is triangular in shape and named the pyramis vestibuli. Posteriorly this crista divides into two limbs, between which is a small depression, the recessus cochlearis, perforated by about eight small foramina, which give passage to the nerrous filaments supplying the vestibular end of the ductus cochlearis. Above and hehind the crista vestibuli, in the roof and medial wall of the vestibule, is an oval depression, the recessus ellipticus, which lodges the utricle. The pyramis vestibuli and adjacent part of the recessus ellipticus are perforated by twenty-five or thirty small apertures (macula cribrosa superior). The foramina in the pyramis vestibuli transmit the nerves to the utricle; those in the recessus ellipticus, the nerves to the ampullæ of the superior and lateral semicircular ducts. Behind and below the recessus ellipticus is a furrow, gradually deepening to form a canal, the aquæductus vestibuli, which passes backwards through the petrous part of the temporal bone, and opens, as a slit-like fissure, about midway between the internal acoustic meatus and the groove for the transverse sinus. This aqueduct measures $8-10 \mathrm{~mm}$. in length, and gives passage to the 
ductus endolymphaticus and a small vein. The posterior part of the vestibule receives the five rounded apertures of the semicircular canals; its anterior part leads, by an elliptical opening, into the scala vestibuli of the cochlea. This opening is bounded inferiorly by a thin osseous plate, the lamina spiralis ossea, which springs from the floor of the vestibule immediately lateral to the recessus sphæricus, and forms, in the cochlea, the bony part of the septum between the scala tympani below and the scala vestibuli above. From the anterior part of the floor of the vestibule a narrow cleft, the fissura vestibuli, extends forwards into the bony canal of the cochlea. It is bounded internally by the lamina spiralis ossea, and externally by a second, smaller lamina, the lamina spiralis secundaria, which. projects from the outer wall of the cochlea. These two lamina are continuous with each other round the posterior extremity of the fissura vestibuli.

Canales Semicirculares Ossei.-The osseous semicircular canals (Figs. 716, 717), three in number, are situated above and behind the vestibule. They are distinguished from each other by their position, and are named superior, posterior, and lateral. They open into the vestibule by five apertures, since the medial end of the superior and the upper end of the posterior join to form a common canal or crus commune. Differing slightly in length, each forms about two-thirds of a circle, one extremity of which is dilated and termed the osseous ampulla. They are somewhat compressed from side to side, and their diameter is from 1 to $1.5 \mathrm{~mm}$., whilst that of the ampullæ is about $2 \mathrm{~mm}$.

The superior semicircular canal, 15 to $20 \mathrm{~mm}$. in length, is vertical and placed transversely to the long axis of the petrous part of the temporal bone. Its convexity is directed upwards, and its position is indicated on the anterior surface of the petrous part of the temporal bone by the arcuate eminence. Its ampulla is anterior and lateral, and opens into the vestibule immediately above that of the lateral canal. Its opposite extremity joins the non-ampullated end of the posterior canal to form the crus commune, which is about $4 \mathrm{~mm}$. in length, and opens into the upper and medial part of the vestibule. The posterior semicircular canal is the longest and measures from 18 to $22 \mathrm{~mm}$. Its ampulla is placed inferiorly, and opens into the lower and back part of the vestibule, where may be seen about six or eight small apertures (macula cribrosa inferior), for the transmission of the nerves to this ampulla. Its upper extremity ends in the crus commune. The lateral canal is the shortest; it measures from 12 to $15 \mathrm{~mm}$., and arches nearly horizontally. Of its two extremities the lateral is ampullated, and opens into the vestibule immediately above the fenestra vestibuli and in close relationship to the ampullary end of the superior canal.

Crum Brown (Journ. Anat. and Physiol., London, vol. viii.) pointed out that the lateral canal of one ear is very nearly in the same plane as that of the other; while the superior canal of one ear is nearly parallel to the posterior canal of the other.

Cochlea. ${ }^{1}$ - When freed from its surroundings the cochlea assumes the form of a short cone (Fig. 720); the central part of its base corresponds with the bottom of the internal acoustic meatus, whilst its apex or cupula is directed forwards and laterally, and comes into close relation with the semicanal for the tensor tympani muscle. It measures about $9 \mathrm{~mm}$. across the base and about $5 \mathrm{~mm}$. from base to apex, and consists of a spirally arranged tube, which forms from $2 \frac{1}{2}$ to $2 \frac{3}{4}$ coils around a central pillar, termed the modiolus. The length of the tube is from 28 to $30 \mathrm{~mm}$., and its diameter, near the base of the cochlea, $2 \mathrm{~mm}$. Its coils are distinguished by the terms basal, central, and apical; the first, or basal coil, gives rise to the promontory on the labyrinthic wall of the tympanic cavity.

The modiolus is about $3 \mathrm{~mm}$. in height, and diminishes rapidly in diameter from base to apex, while its tapered extremity fails to reach the cupula by a distance of $1 \mathrm{~mm}$. Its base corresponds with the area cochleæ on the fundus of the internal acoustic meatus, and exhibits the tractus spiralis foraminosus, which transmits the nerves for the basal and central coils of the cochlea and the foramen centrale, which gives passage to the nerves for the apical coil. The foramina of the tractus spiralis foraminosus traverse the modiolus, at first parallel to its long axis, but, after a

\footnotetext{
1 In the following description the cochlea is supposed to be placed on its base.
} 
varying distance, they bend outwards to reach the attached edge of the lamina spiralis ossea, where they expand and form by their apposition a spiral canal, the canalis spiralis cochleæ, which lodges the ganglion spirale cochleæ. From this spiral canal numerous small foramina, for the transmission of vessels and nerves, pass outwards to the free edge of the lamina spiralis ossea. The lamina spiralis ossea, a thin, flat shelf of bone, winds round the modiolus like the thread of a screw, and, projecting about half-way into the cochlear tube, incompletely divides it into two passages - an upper is named the scala vestibuli; a lower, the scala tympani. The lamina spiralis ossea begins at the floor of the vestibule, near the fenestra cochleæ, and ends close to the apex of the cochlea in a sickle-shaped process, the hamulus laminæ spiralis, which assists to bound an aperture named the helicotrema. In the

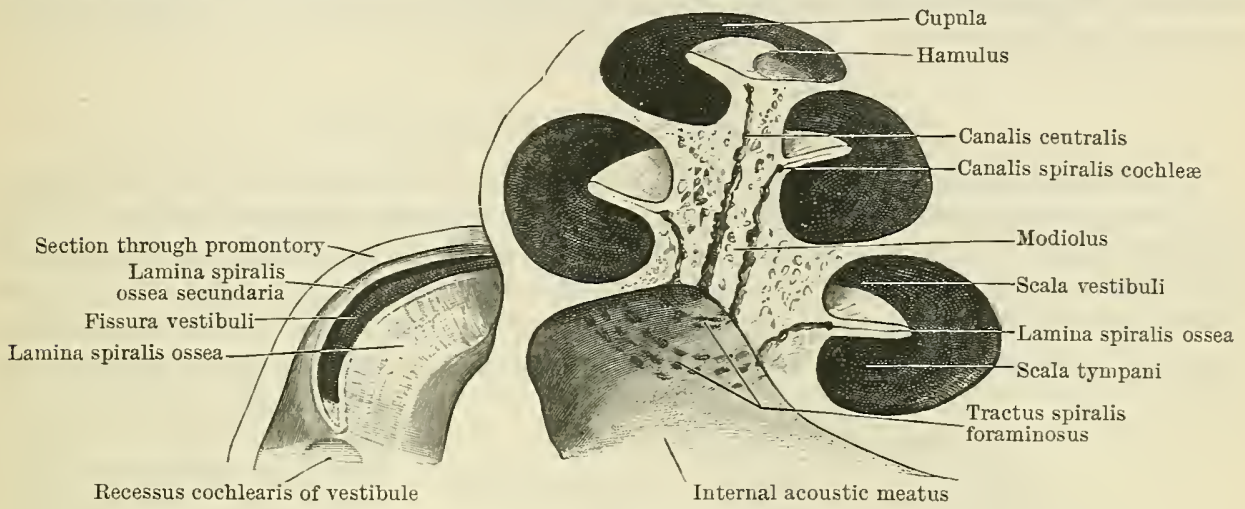

Fig. 718.-Section of Bory Cochlea.

basal coil the upper surface of the lamina spiralis ossea forms almost a right angle with the modiolus, but the angle becomes more and more acute on ascending the tube. In the lower half of the basal coil a second smaller bony plate, the lamina spiralis secundaria, projects from the outer wall of the cochlea towards the lamina spiralis ossea, without, however, reaching it. If viewed from the vestibule the slit-like fissura vestibuli, already referred to (p. 844), is seen between the two laminæ. A membrane, the membrana basilaris, stretches from the free edge of the lamina spiralis ossea to the onter wall of the cochlea, and completes the septum between the scala vestibuli and scala tympani, but the two scalæ communicate with each other through the opening of the helicotrema at the apex of the cochlea. The scala tympani begins at the fenestra cochleæ, which is closed by the secondary tympanic membrane (vide p. 833). At the commencement of the scala tympani a crest, termed the crista semilunaris, stretches from the attached margin of the lamina spiralis ossea towards the orifice of the fenestra cochleæ. Close to this crest is seen the inner orifice of the aquæductus cochleæ, a canal measuring from 10 to $12 \mathrm{~mm}$. in length, and opening on the under surface of the petrous part of the temporal bone medial to the fossa jugularis. Through it a communication is established between the scala tympani and the subarachnoid cavity, and through it, also, a small vein passes to join the inferior petrosal sinus. The scala vestibuli, the higher of the two passages, begins in the vestibule; its diameter in the basal coil is less than that of the scala tympani, but in the upper coils it exceeds that of the scala tympani.

Meatus Acusticus Internus. - It is

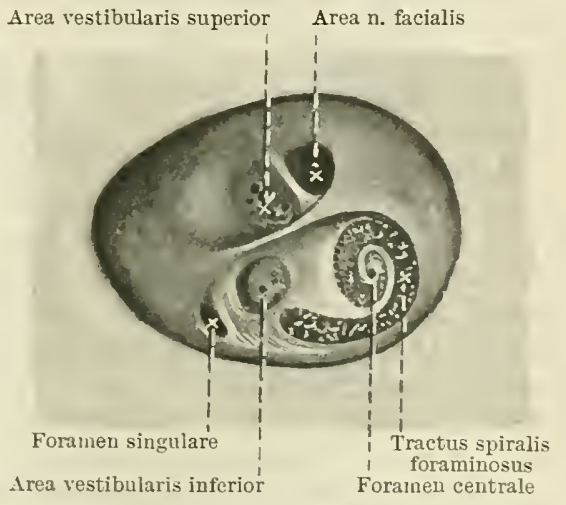

Fig. 719. - Botton of Internal ACodstic MEATES DIVIDED INTO UPPER AND LOWER AREAS by the Crista Transtersa.

convenient, at this stage, to study the fundus of the internal acoustic meatus, which has been referred to as forming the medial wall of the vestibule and the 
base of the modiolus. It is divided by a transverse ridge, the crista transversa, into two parts - an upper or fossula superior and a lower or fossula inferior. The anterior part of the fossula superior is termed the area n. facialis and exhibits a single large opening, the commencement of the facial canal, for the transmission of the facial nerve. Its posterior part is named the area vestibularis superior, and is perforated by the nerves for the utricle and the ampullæ of the superior and lateral semicircular ducts. The anterior part of the fossula inferior is termed the area cochlex, and consists of the canalis centralis and the surrounding tractus spiralis foraminosus, for the passage of the nerves to the cochlea. Behind the area cochleæ, and separated from it by a ridge, is the area vestibularis inferior, which is pierced by the nerves to the saccule; at the posterior part of the fossula inferior is the foramen singulare, which gives passage to the nerves for the ampulla of the posterior semicircular duct.

\section{LABYRINTHUS MEMBRANACEUS.}

The membranous labyrinth (Fig. 720) is contained within the bony labyrinth, but does not nearly fill it. It contains a fluid termed endolymph, while the interval between it and the bony labyrinth is named the perilymphatic space, and is occupied by a fluid termed perilymph. The perilymphatic space in the vestibule is continuous behind with the perilymphatic space of the semicircular canals, and opens in front into the scala vestibuli. At the apex of the cochlea it is continuous, through the

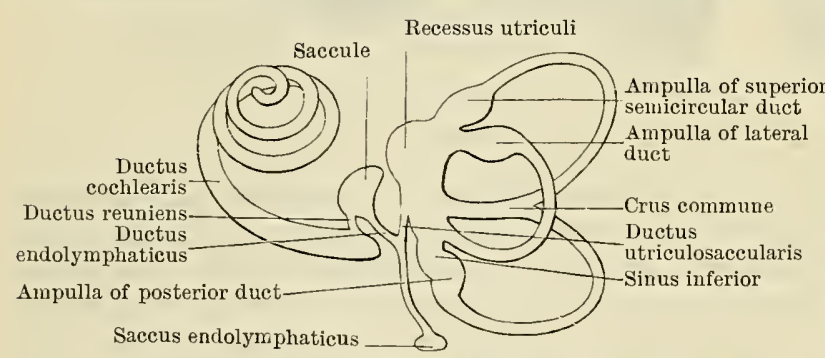

Fig. 720.-Diagrammatic Representation of the Different Parts of the Membranous Labyrinth. helicotrema, with the scala tympani, which is shut off from the tympanic eavity by the secondary tympanic membrane. The perilymphatic space is prolonged into the aquæductus cochleæ, at the extremity of which it communicates with the subarachnoid cavity. The ductus semicirculares and the ductus cochlearis follow the course and lie along the inner surface of the outer walls of the corresponding bony tubes. The bony vestibule, on the other hand, contains two chief membranous structures, the utricle and saccule. The former receives the extremities of the ductus semicirculares, whilst the latter communicates with the ductus cochlearis. Moreover, the cavities of the utricle and saccule are indirectly connected, and thus all parts of the membranous labyrinth communicate with each other, and the endolymph is free to move from one portion to another. The vestibule contains also the ductus endolymphaticus and the commencement of the ductus cochlearis.

Utriculus.-The utricle, the larger of the two sacs (Fig. 720), occupies the postero-superior portion of the vestibule. Its highest part, or recessus utriculi, lies in the recessus ellipticus and receives the ampullæ of the superior and lateral semicircular ducts. Its central part receives on its lateral aspect the nonampullated end of the lateral semicircular duct, and is prolonged upwards and backwards as the sinus superior, into which the crus commune of the superior and posterior semicircular ducts open. 'The ampulla of the posterior semicircular duct opens into the lower and medial part, or sinus inferior. The floor and anterior wall of the recessus utriculi are thickened to form the macula acustica utriculi, to which the utricular fibres of the acoustic nerve are distributed. Whitish in colour, and of an oval or nearly rhombic shape, this macula measures $3 \mathrm{~mm}$. in length and $2.3 \mathrm{~mm}$. in its greatest breadth.

Sacculus.-The saccule occupies the recessus sphæricus, in the lower and anterior part of the vestibule (Fig. 717). Smaller than the utricle, it is of an oval shape and measures $3 \mathrm{~mm}$. in its longest, and about $2 \mathrm{~mm}$. in its shortest diameter. It presents 
anteriorly an oval, whitish thickening, the macula acustica sacculi. This has a breadth of about $1.5 \mathrm{~mm}$, and to it the saccular fibres of the acoustic nerve are distributed. The superior extremity of the saccule is directed upwards and backwards, and forms the sinus utricularis sacculi, which abuts against, but does not fuse with, the wall of the utricle. From the lower part of the saccule a short canal, the ductus reuniens (Henseni), opens into the ductus cochlearis, a short distance in front of its vestibular extremity. A second small channel, the ductus endolymphaticus, is continued from the posterior part of the saccule, and, passing between the utricle and the medial wall of the vestibule, is joined by a small canal, the ductus utriculosaccularis, which arises from the medial side of the utricle. It then enters and traverses the aquæductus vestibuli and ends, under the dura mater on the posterior surface of the petrous part of the temporal bone, in a dilated blind extremity, termed the saccus endolymphaticus; this, according to Riudinger, is perforated by minute foramina, through which the endolymph may pass into the meningeal lymphatics.

The vestibule also contains the vestibular extremity of the ductus cochlearis, which lies immediately below the saccule in the recessus cochlearis.

The walls of the utricle and saccule are composed of connective tissue which blends with the periosteal lining of the vestibule. It is modified medially to form a homogeneous membrana propria, which is covered with a layer of pavement epithelium and is thickened at the maculæ acusticæ. Towards the periphery of the maculæ the epithelium is cubical, while on them it is columnar.

The structure of the maculæ in the utricle and saccule is practically the same; two kinds of cells are found, viz., (a) supporting cells, and (b) hair cells. The supporting cells are somewhat fusiform, each containing, near its middle, a nucleus. Their branched, deep extremities are attached to the membrana propria; their free ends lie between the hair cells and form a thin inner limiting cuticle. The hair cells are flask-shaped and do not reach the membrana propria, but end in rounded extremities which lie between the supporting cells. Each contains, at its deepest part, a large nucleus, the rest of the cell being granular and pigmented. From the free end of each there projects a stiff, hair-like process, which, on the application of reagents,

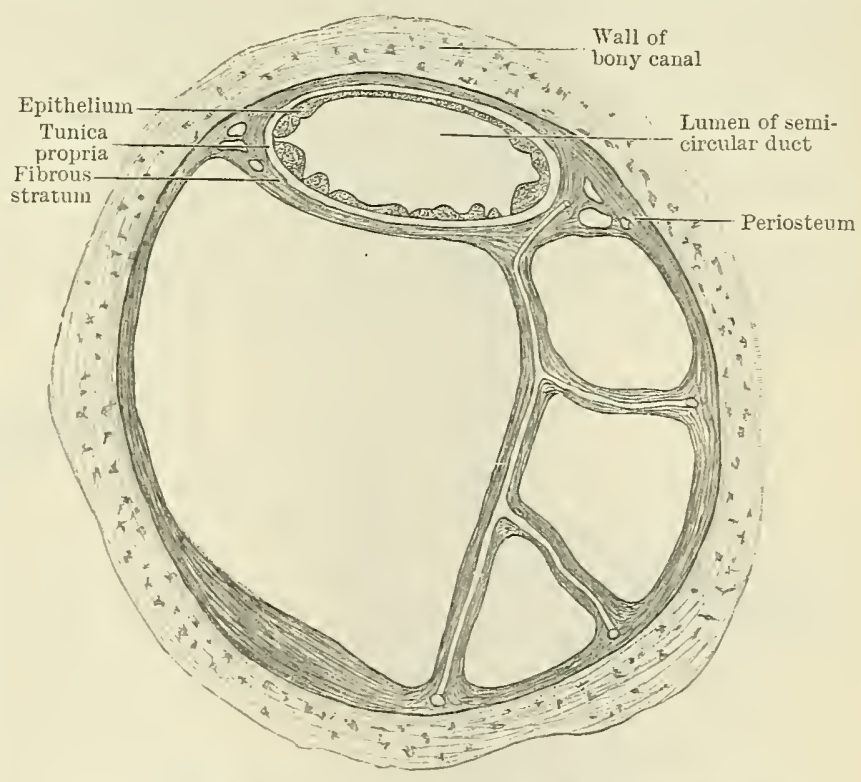

Fig. 721.-TRatsverse Section of HuMAy Semicircolar Caxal axd Semicircolar Dtct (Rudinger).

splits into several finer filaments. The nerve-fibres pierce the membrana propria, and ramify around the deep extremities of the hair cells (Fig. 722). A collection of small, rhombic crystals of carbonate of lime, termed otoconia, adheres to each of the maculæ.

Ductus Semicirculares.-The semicircular ducts are elliptical on transverse section (Fig. 721), and are attached to the walls of the bony canals. The convex wall of each duct is fixed to the periosteal lining of the canal, whilst the opposite part is free, except that it is connected by irregular ligamentous bands, which pass through the perilymphatic space to the bony wall. Like the bony canals, each of the semicircular ducts is dilated at one extremity into a membranous ampulla, 
which is especially developed towards the concavity of the tube. The membranous ampullie nearly fill the corresponding portions of the bony tubes, but the diameter of the semicireular ducts is only about one-fourth of that of the osseous canals.

Each semicircular duct consists of three layers, viz.: (a) an outer vascular and partly pigmented fibrous stratum which fixes the duct to the bony wall;

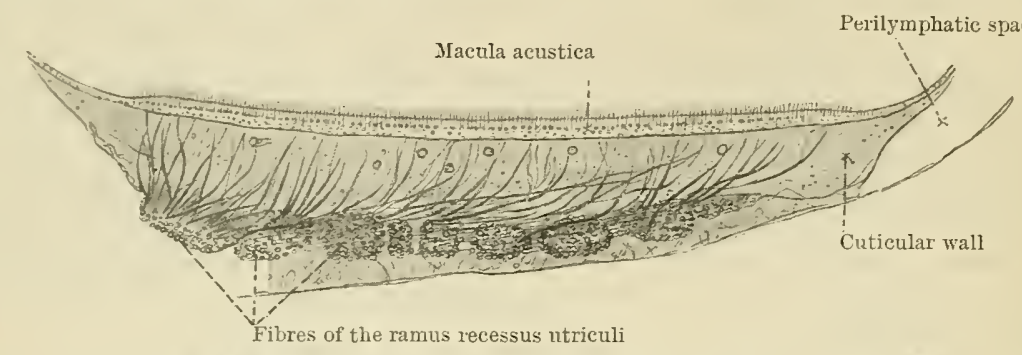

Fig. 722. - Vertical Section of the Wall of the Recessus Utricoli hith the Macula Acustica AND the bejdles of Nerve Fibres.

(b) an intermediate, transparent tunica propria, presenting a number of papilliform elevations which project towards the lumen. The fibrous layer and tunica propria are thinnest along the attached surface of the duct, and in this region also the papilliform elevations are absent; (c) an internal epithelial layer, composed of pavement cells. In the ampullæ the tunica propria is much thickened, and projects into the cavity as a transverse elevation, termed the septum transversum, which, when seen from above, is somewhat fiddle-shaped; its most prominent part is covered by acoustic epithelium forming the crista ampullaris, at each end of which is a half-moon-shaped border of small columnar cells, the planum semilunatum. The cells covering the crista ampullaris consist of supporting cells and hair cells, and are similar in their arrangement to those in the maculæ of the utricle and saccule; the hairs of the hair cells are, however, considerably longer, and project as far as the middle of the ampullary lumen. In fresh specimens they appear to end free, but in hardened preparations are seen to terminate in a soft, clear, dome-like structure, the cupula terminalis, which is striated, the striæ converging towards its concavity. The nerves form arborisations around the bases of the hair cells.

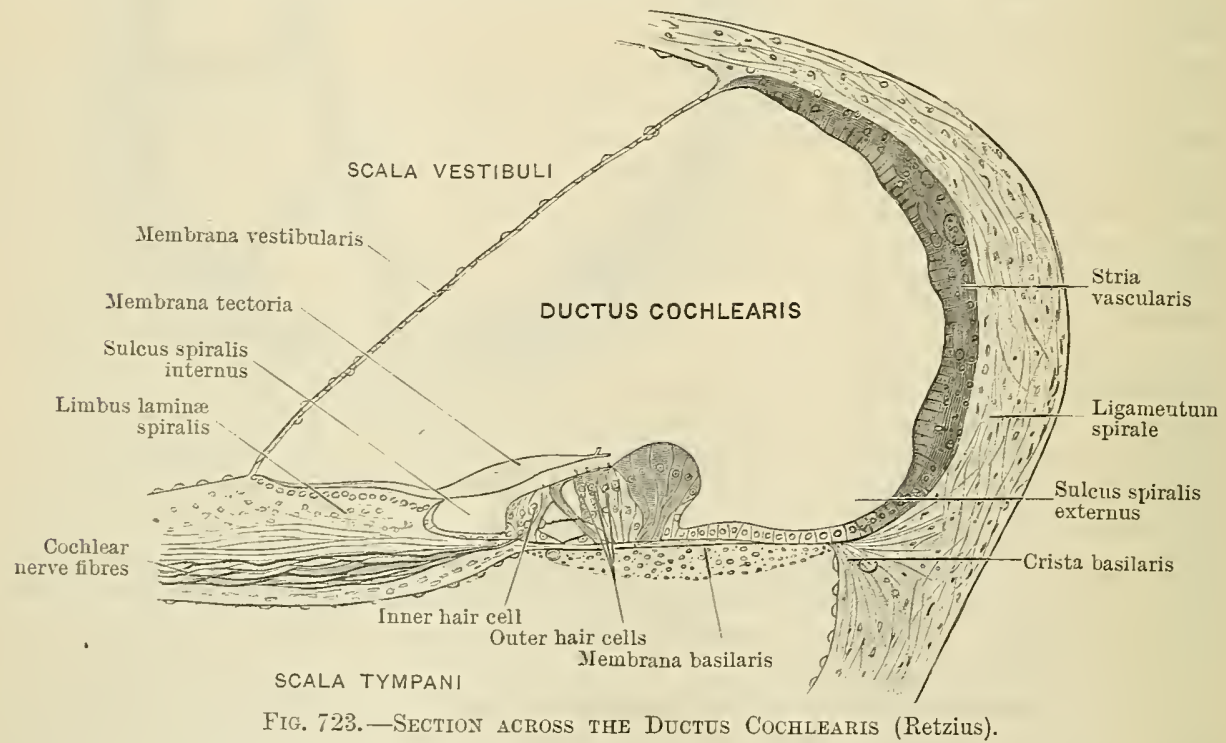

Ductus Cochlearis.-The ductus cochlearis (O.T. membranous cochlea or scala media) is closed at both of its extremities; the lower extremity occupies the recessus cochlearis of the vestibule and communicates with the saccule through the ductus reuniens. It forms a spirally arranged canal inside the cochlea, and at 
the apex of the latter its upper extremity, the lagena, or cæcum capulare, is fixed to the cupula and partly bounds the helicotrema. As already stated, the membrana basilaris extends from the free edge of the lamina spiralis ossea to the outer wall of the cochlea. A second, more delicate membrane, the membrana vestibularis (O.T. membrane of Reissner), stretches from the thickened periosteum covering the upper surface of the lamina spiralis ossea to the outer cochlear wall, some little distance above the external attachment of the membrana basilaris. A canal is thus enclosed between the underlying scala tympani and the overlying scala vestibuli, and constitutes the ductus cochlearis. Triangular on transverse section, the duct possesses a roof, an outer wall, and a floor, and is lined throughout with epithelium and filled with endolymph. On its floor the epithelium is greatly modified, and here are found the endings of the cochlear nerve.

The roof or vestibular wall of the ductus cochlearis is formed by the membrana vestibularis, a delicate, nearly homogeneous membrane, covered on each surface by a layer of epithelium. Its entire thickness is about $3 \mu$.

The outer wall of the ductus cochlearis (Fig. 724) consists of the periosteal lining of the bony cochlea, which, however, is thickened and greatly modified to form the ligamentum spirale cochlex. Occupying the whole outer wall, this ligament projects inwards inferiorly as a triangular prominence, the crista basilaris, to which the outer edge of the membrana basilaris is attached. In the upper part of the ligamentum spirale the periosteum is of a reddish-yellow colour, and contains, immediately under its epithelial lining, numerous small blood-vessels and capillary loops, forming the stria vascularis. The lower limit of this stria is bounded by a prominence, the prominentia spiralis, in which is seen a vessel, the vas prominens, and between this prominence and the crista basilaris is a concavity, the sulcus spiralis externus. The height of the outer wall diminishes towards the apex of the cochlea.

The floor or tympanal wall of the ductus cochlearis is formed by the periosteum covering that portion of the lamina spiralis ossea which is situated to the outer side of the membrana vestibularis, and by the membrana basilaris, which stretches from the free edge of the lamina spiralis ossea to the crista basilaris. On the inner part of the membrana basilaris the complicated structure termed the organon spirale (O.T. organ of Corti) is situated. The lamina spiralis ossea consists of two plates of bone, between which are placed the canals for the branches of the cochlear nerve. On the upper plate the periosteum is thickened and modified to form the limbus laminæ spiralis, the outer extremity of which forms a C-shaped con.cavity, the sulcus spiralis internus. The portions of the limbus which project above and below this concavity are

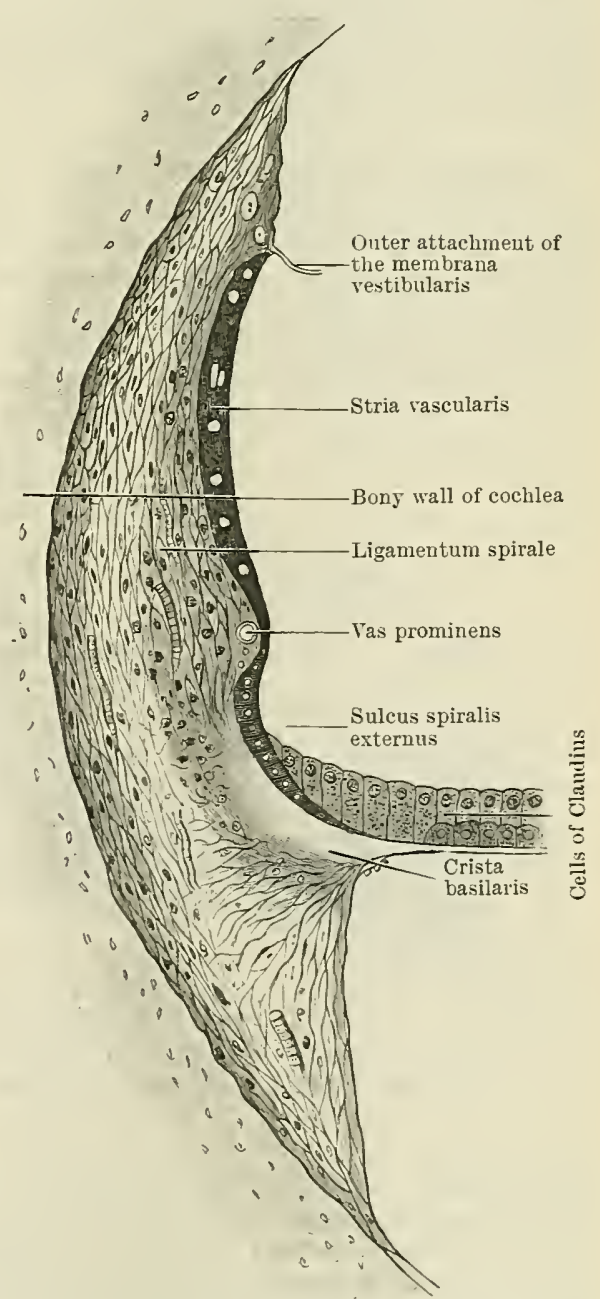

Fig. 724.-Traxsyelrse Section through Odter Wall of Dectos Cochlearis (Schwalbe). 
of the cochlear nerres, and is continuous with the membrana basilaris. The upper surface of the labium vestibulare presents a number of furrows crossing each other nearly at right angles, and intersecting a series of elevations which, at the free margin of the labium, form a row of tooth-like structures, about 7000 in number, the auditory teeth of Huschke. Covering the limbus is a layer of apparently squamous epithelium; the deeper protoplasmic portions of the cells, however, with their contained nuclei, lie in the intervals between the elevations and auditory teeth. This layer of epithelium is continuous above with that covering the under surface of the membrana vestibularis and below with that which lines the sulcus spiralis internus.

Membrana Basilaris.-The inner part of this membrane is thin, and supports the organon spirale; it is named the zona arcuata, and reaches as far as the footplate of the outer rod of Corti. Its outer part, extending from the foot-plate of the outer rod of Corti to the crista basilaris, is thicker and distinctly striated, and is termed the zona pectinata. The substantia propria of the membrane is almost homogeneous, but exhibits, in its deeper part, numerous fibres. These fibres are most distinct in the zona pectinata, and number, according to Retzius, about 24,000 . Covering the under surface of the membrana basilaris is a layer of connective tissue, containing, in its inner part, small blood-vessels; one of these is larger than the others and lies below the tunnel of Corti, and is named the vas spirale. The width of the membrana basilaris increases from $210 \mu$ in the basal coil to $360 \mu$ in the apical coil.

Organon Spirale (0.T. Organ of Corti) (Fig. 725).-Placed upon the inner portion of the membrana basilaris, the organon spirale consists of an epithelial eminence which extends along the entire length of the ductus cochlearis, and comprises the following structures, viz.: (1) Corti's rods or pillars, (2) hair cells (inner and outer), (3) supporting cells of Deiters, (4) the cells of Hensen and Claudius, (5) the lamina reticularis, and (6) the membrana tectoria.

The rods of Corti form two rows, inner and outer, of stiff, pillar-like strnctures, and each rod presents a base or foot-plate, an intermediate elongated portion, and an upper

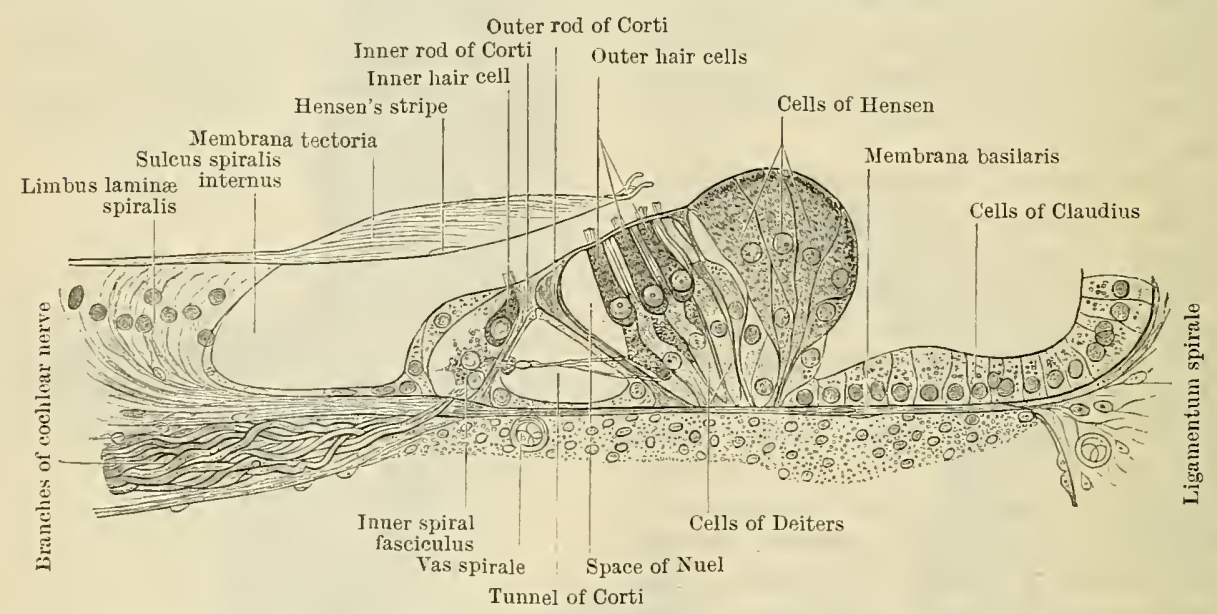

Fig. 725.-Transterse Section of the Orgaxion Spirale from the Central CoIL of the DUCTUS Cochlearis (Retzius).

end or head. The bases of the two rows are planted on the membrana basilaris some little distance apart. The intermediate portions of the rods incline towards each other and the heads come into contact, so that, between the two rows above and the membrana basilaris below, a triangular tunnel, the tunnel of Corti, is enclosed; this tunnel increases both in height and width on passing towards the apex of the cochlea. The inner rods number nearly 6000 , and the head of each resembles somewhat the proximal end of the ulua, presenting externally a deep concavity for the reception of a corresponding convexity on the head of the outer rod. The part of the head which overhangs this concavity is prolonged outwards, under the name of the head-plate, and overlaps the head of the 
outer rod. The expanded bases of the inner rods are situated on the innermost portion of the membrana basilaris, immediately to the outer side of the foramina nervosa of the labium tympanicum. The intermediate parts of the inner rods are sinuously curved, and form with the membrana basilaris, an angle of about $60^{\circ}$. The outer rods number about 4000 , and are longer than the inner, especially in the upper part of the cochlea. They are more inclined towards the membrana basilaris, and form with it an angle of about $40^{\circ}$. The head of each is convex internally, to fit the concavity on the head of the inner rod, and is prolonged outwards as a plate, the phalangeal process, which becomes connected with the lamina reticularis; in the head is an oval body which has an affinity for certain reagents. The main part of each rod consists of a nearly homogeneous material, which is finely striated. At the bases of the rods, on the side next Corti's tunnel, is a nucleated mass of protoplasm which reaches as far as the heads of the rods, and covers also the greater part of the tunnel floor; this protoplasm may be regarded as the undifferentiated part of the cell from which the rod was developed. Slit-like intervals, for the transmission of nerves, exist between the intermediate portions of adjacent rods.

Hair Cells. - These, like Corti's rods, form two sets, inner and outer. The former consists of a single row lying immediately internal to the inner rods-the latter of three, or, it may be, four rows placed to the outer side of the external rods. The inner hair cells are about 3500 in number; the diameter of each is greater than that of an inner rod, and so each inner hair cell is supported by more than one rod. Somewhat oval in shape, their free extremities are surmounted by about twenty fine hair-like processes, arranged in the form of a crescent, with its concavity directed inwards. The deep end of the cell contains a large nucleus and is rounded; it reaches only about half-way down the rod, and is in contact with the arborisatious of the nerve terminations. To the inner side of this row of hair cells are two or three rows of elongated columnar cells, which act as supporting cells, and are continuous with the low columnar cells lining the sulcus spiralis internus. The outer hair cells number about 12,000, and form three rows in the basal coil and four rows in the upper two coils, although in the higher coils the rows are not so regularly arranged. The rounded free ends of the hair cells support some twenty hairlets arranged in the form of a crescent, opening inwards. Their deep extremities reach about half-way to the membrana basilaris, and are in contact with the nerve arborisations.

Alternating with the rows of the outer hair cells are the rows of Deiters' supporting cells, the lower extremities of which are expanded on the membrana basilaris, whilst their upper ends are tapered ; the nucleus is placed near the middle of each cell, and, in addition, each cell contains a bright, thread-like structure called the supporting fibre. This fibre is attached by a club-shaped base to the membrana basilaris, and expands, at the free end of the cell, to form a phalangeal process of the membrana reticularis.

The cells of Hensen, or outer supporting cells, consist of about half a dozen rows, immediately ontside Deiters' cells, and form a well-marked elevation on the floor of the ductus cochlearis. Their deep extremities are narrow and attached to the membrana basilaris, while their free ends are expanded; each cell contains a distinct nucleus and some pigment granules. The columnar cells, situated externally to the cells of Hensen, cover the outer part of the zona pectinata, and are named the cells of Claudius. A space, the space of Nuel, exists between the outer rods of Corti and the neighbouring row of hair cells; it communicates internally with Corti's tunnel, and extends outwards between the outer hair cells as far as Hensen's cells.

The lamina reticularis is a thin cuticular structure which lies over the organon spirale, and extends from the heads of the outer rods as far as Hensen's cells, where it ends in a row of quadrilateral areas which form its outer border. It consists of two or three rows of structures, named phalanges, which are elongated cuticular plates resembling in shape the digital phalanges. The innermost row is formed by the phalangeal processes of the heads of the outer row of Corti's rods; the succeeding row, or rows, represent the expanded upper ends of Deiters' supporting cells. The number of rows of phalanges, therefore, varies with the number of rows of outer hair cells and the alternating cells of Deiters. The free ends of the hair cells occupy the somewhat circular apertures between the constricted middle portions of the phalanges.

The membrana tectoria (Fig. 725) is an elastic membrane overlying the sulcus spiralis internus and the organon spirale. Attached, by its inner end, to the limbus laminæe spiralis, near the lower edge of the membrana vestibularis, it reaches outwards as far as the outer row of hair cells. Its inner portion is thin and overlies the auditory teeth of Huschke. Its outer part is thickened, but becomes attenuated near its external border, which, according to Retzius, is attached to the outer row of Deiters' cells. Its lower edge 
presents a firm, homogeneous border, and opposite the inner row of hair cells contains a clear, spirally arranged band, named Hensen's stripe.

Nervus Acusticus (Fig. 726). - The acoustic nerve divides within the internal acoustic meatus into an anterior or cochlear and a posterior or vestibular nerve.

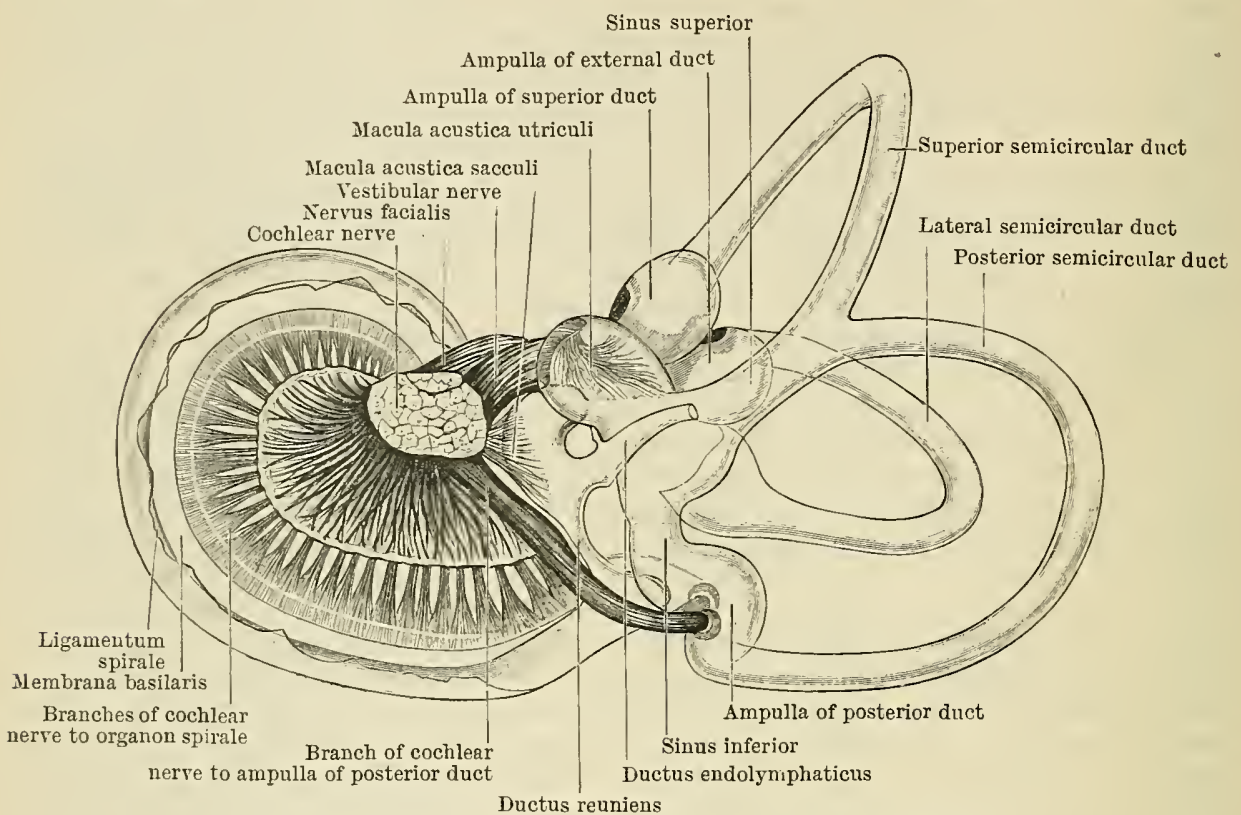

Fig. 726.-Membranous Labyrinth of a Five Months' Fetus, viewed from its postero-medial aspect (Retzius).

N. Cochleæ.-The cochlear nerve is distributed to the hair cells of the organon spirale, the branches for the basal and middle coils entering the foramina in the tractus spiralis foraminosus, those for the apical coil running in the canalis centralis of the modiolus. Extending upwards, in the bony canals of the modiolus, the nervefibres radiate outwards between the lamellæ of the lamina spiralis ossea. Contained

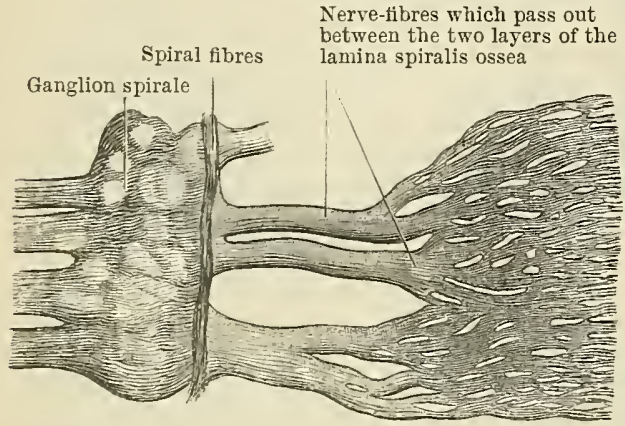

Fig. 727.-PART of Cochlear Nerve, highly magnified (Henle). in the spiral canal of the modiolus, near the attached margin of the lamina, is a ganglion of bipolar nerve-cells which winds spirally round the modiolus, and is named the ganglion spirale (O.T. ganglion of Corti) (Fig. 727); the fibres of the nerve arise from the cells of this ganglion. Beyond the ganglion spirale the nerve-fibres extend outwards, at first in bundles, and then in a more or less continuous sheet, from the outer edge of which they are again collected into bundles, which pass through the foramina nervosa of the labium tympanicum. Beyond this they appear as naked axis-cylinders, and, turning in a spiral manner (inner or first spiral fasciculus), send fibrillæ towards the inner row of hair cells. Other fibrils run between the inner rods and form a second spiral fasciculus in Corti's tunnel, from which fibrils extend outwards across the tunnel, and, passing between the onter rods, enter Nuel's space. They form a spiral fasciculus on the inner aspect of each row of Deiters' cells, and fibrillæ pass from these fasciculi towards the bases of the outer hair cells.

The cochlear nerve gives off a vestibular branch, the terminal filaments of 
which go through the foramina in the recessus cochlearis and are distributed to the hair cells of the vestibular part of the ductus cochlearis. On this vestibular branch, close to its origin from the cochlear nerve, is a minute ganglion (Bœttcher).

N. Vestibuli. - The vestibular nerve is distributed to the utricle, the saccule, and the ampullæ of the semicircular ducts. It divides into three branches, superior, inferior, and posterior, and each of these splits into filaments which pass through foramina in the fundus of the internal acoustic meatus. The filaments from the superior branch go through the foramina in the area vestibularis superior and supply the macula of the utricle and the cristæ ampullares of the superior and lateral semicircular ducts; those from the inferior branch run through the foramina in the area vestibularis inferior to the macula of the saccule. The posterior branch passes through the foramen singulare, and its filaments, six to eight in number, are distributed to the crista ampullaris of the posterior semicircular duct.

Ganglion Vestibulare.-On the trunk of the vestibular nerve, within the internal acoustic meatus, is a ganglion, the vestibular ganglion, of bipolar nerve cells ; the fibres of the nerve arise from the cells of this ganglion. Sometimes the vestibular nerve divides on the proximal side of the ganglion and the latter is then split into three parts, one on each of the three branches of the nerve.

Vessels of the Internal Ear.-The internal auditory artery, a branch of the basilar, enters the internal acoustic meatus and divides into vestibular and cochlear branches. The vestibular branch supplies the soft tissues in the vestibule and semicircular canals, each canal receiving two arteries, which, starting from opposite extremities of the canal, anastomose on the summit of the arch. The cochlear branch divides into numerous twigs, which enter the foramina in the tractus spiralis foraminosus, and run outwards in the lamina spiralis ossea to reach the soft structures; the largest of these arteries runs in the canalis centralis. The stylo-mastoid artery also supplies some minute branches to the cochlea. Siebenmann describes the internal auditory artery as dividing into three branches, viz. : (1) anterior vestibular, (2) cochlear proper, and (3) restibulocochlear. The veins from the cochlea and vestibule unite, at the bottom of the meatus, with the veins from the semicircular canals to form the internal auditory vein, which may open either into the posterior part of the inferior petrosal sinus or into the transverse sinus. Small veins also pass through the aquæductus cochleæ and aquæductus vestibuli, the former opening into the inferior petrosal sinus or into the internal jugular vein, the latter into the superior petrosal sinus.

\section{DEVELOPMENT OF LABYRINTH.}

The epithelial lining of the labyrinth is derived from an invagination of the cephalic ectoderm, termed the auditory pit, which appears opposite the hind brain immediately above the first visceral cleft. The mouth of the pit is closed by the growing together of its margins, and it then assumes the form of a hollow vesicle, the otic vesicle, which severs its connexion with the ectoderm and sinks into the subjacent mesoderm. The vesicle soon becomes pear-shaped; and its dorsal tapering part rapidly

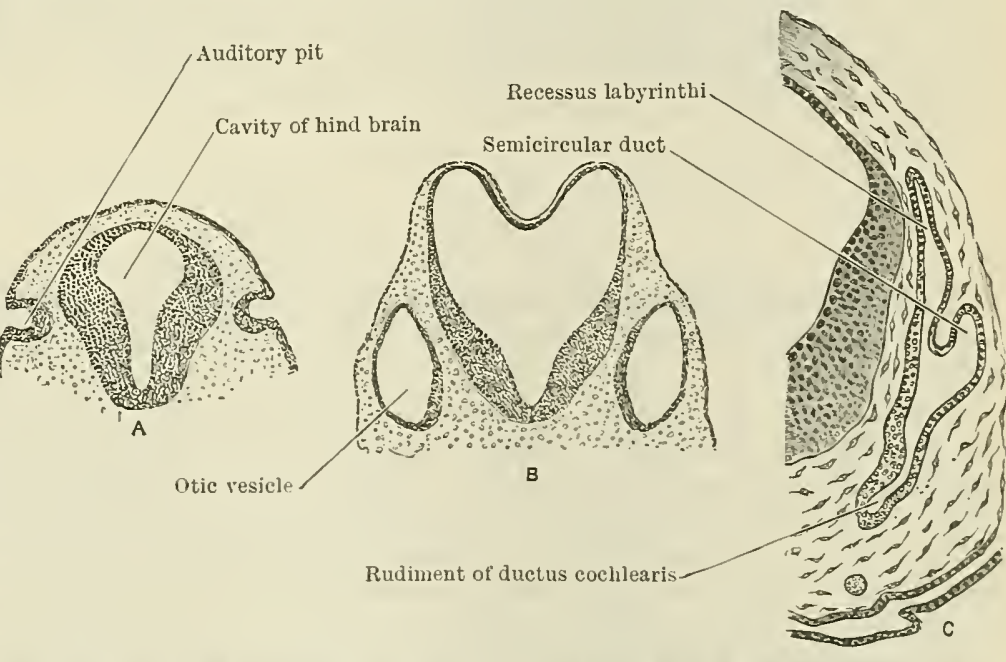

Fig. 728.-Sections through the Region of the Hixd Brain of Fgetal fabbits (to illustrate the development of the labyrinthine epithelium).

In $\mathbf{A}$ the ectoderm is invaginated to form the auditory pit; in $\mathrm{B}$ the auditory pit is closed and detached from the ectoderm, forming the otic vesicle; while $\mathrm{C}$ shows a further stage in the development of the resicle.

lengthens into a recess, the recessus labyrinthi, which later forms the ductus and saccus 
endolymphaticus. About the fifth week, the lower part of the vesicle is prolonged forwards as a diverticulum, the future ductus cochlearis. This is at first straight, but

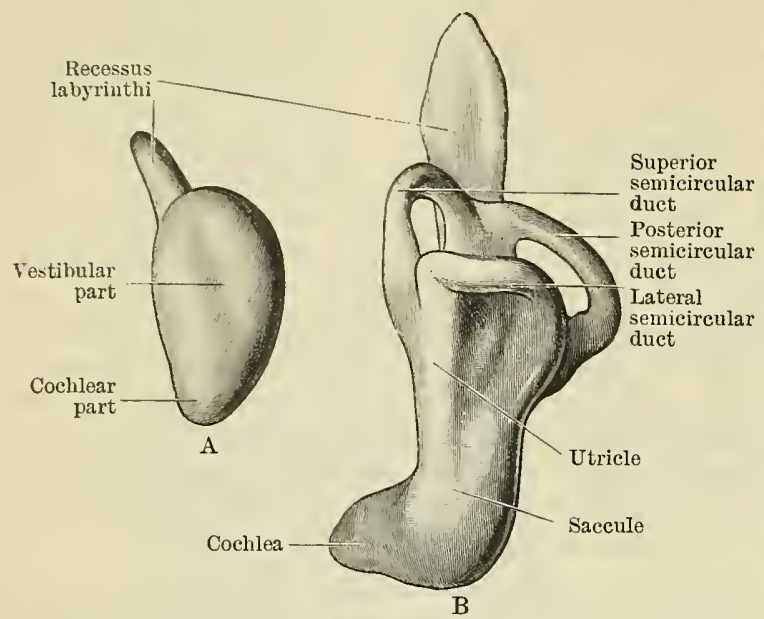

FIG. 729 . as it elongates it curves on itself, so that at the twelfth week all three coils are differentiated. From the upper part of the vesicle the semicircular ducts are developed, and appear as three hollow, disc-like evaginations; the central parts of the walls of each disc coalesce and disappear, leaving only the peripheral ring or canal. The three ducts are free about the beginning of the second month, and are developed in the following order, viz. : superior, posterior, and lateral. The intermediate part of the otic vesicle represents the vestibule, and is divided by a constriction into an anterior part, the saccule, communicating with the ductus cochlearis, and a posterior portion, the utricle, receiving the extremities of the semicircular ducts. The constriction extends for some distance into the ductus endolymphaticus, and

A, Left labyrinth of a human embryo of about four weeks ; B, Left labyrinth of a human embryo of about five weeks (from W. His, jun.).

thus the utricle and saccule are connected by a Y-shaped tube. Another constriction makes its appearance between the saccule and the vestibular end of the ductus cochlearis and forms the canalis reuniens. The epithelial lining is at first columnar, but becomes cubical throughout the whole labyrinth, except opposite the terminations of the acoustic nerve, where it forms the columnar epithelium of the maculæ of the utricle and saccule, of the cristæ ampullæ, and of the organon spirale. On the floor of the ductus cochlearis two ridges appear, of which the inner forms the limbus laminæ spiralis, whilst the cells of the outer become modified to form the rods of Corti, the hair cells, and the supporting cells of Deiters and Hensen.

The mesoderm surrounding the otic vesicle is differentiated into: (1) a fibrous layer, the wall of the membranous labyrinth; (2) a cartilaginous capsule, the future petrous bone; and (3) an intervening layer of gelatinous tissue, which is ultimately absorbed, leaving the perilymphatic space between the bony and membranous labyrinths.

The development of the external and middle parts of the ear are described on pp. 50-53.

\section{ORGANON GUSTUS.}

The peripheral gustatory organ consists of groups of modified epithelial cells, termed calyculi gustatorii or taste buds, found on the tongue and in its immediate neighbourhood.

Taste buds are present in large numbers around the circumference of the papillæ vallatæ, while some are found also on their opposing walls (Fig. 730). They are very numerous over the foliate papillæ, which correspond with the papillæ foliatæ of the tongue of the rabbit, and are found also over the posterior part and sides of the tongue, either on the papillæ fungiformes or throughout the stratified epithelium. They exist, also, on the oral surface of the velum palatinum and on the posterior surface of the epiglottis.

Structure of Taste Buds (Fig. 731).-The taste buds are oval or flask-shaped, and occupy nests in the stratified epithelium of the regions mentioned. The deep extremity of each is expanded and rests upon the corium; the free end is perforated by a minute pore, termed the gustatory pore. They consist of two kinds of epithelial cells_- $(a)$ supporting cells, and $(b)$ gustatory cells (Fig. 732). The supporting cells are elongated, nucleated spindles, and are mostly arranged like the staves of a cask to form the outer envelope of the bud; but some are found in the 
in terior of the bud, amongst the gustatory cells. The gustatory cells occupy the centre

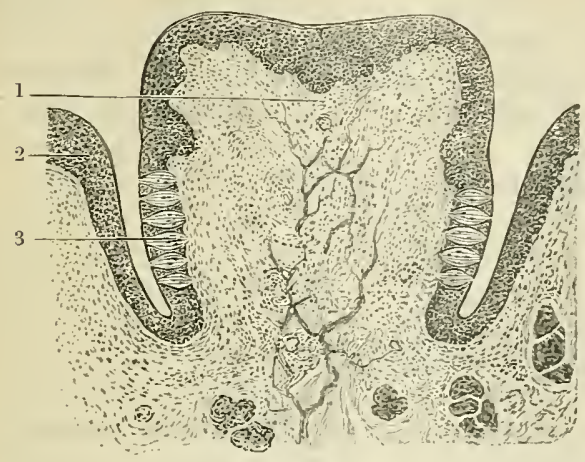

A

FIG. 730.

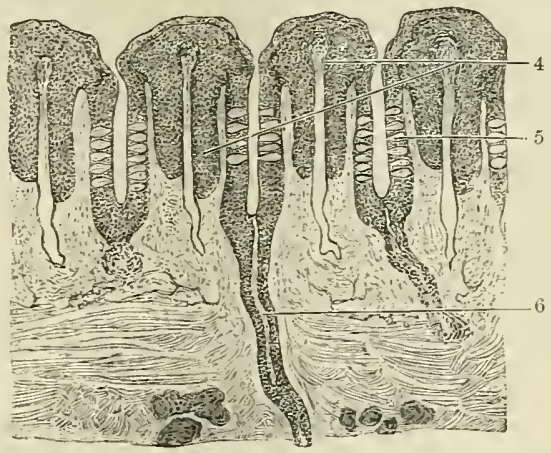

B

A, Section through a papilla vallata of human tongue.

B, Section through a part of the papilla foliata of a rabbit.
1. Papilla.
2. Vallum.
3. Taste buds.
4. Papillæ.
5. Taste buds.
6. Duct of serous gland.

of the bud, and each consists of a nucleated cell-body, prolonged into a peripheral

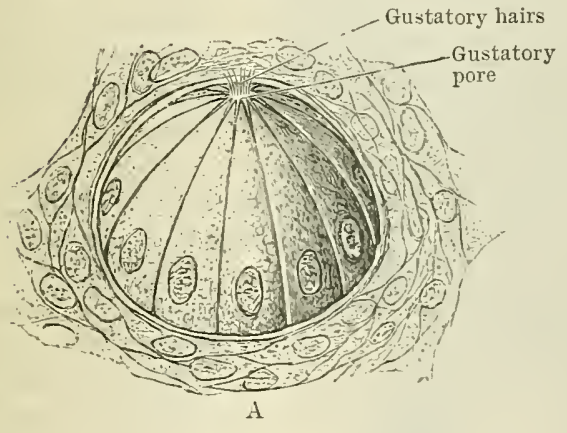

FIG. 731 .

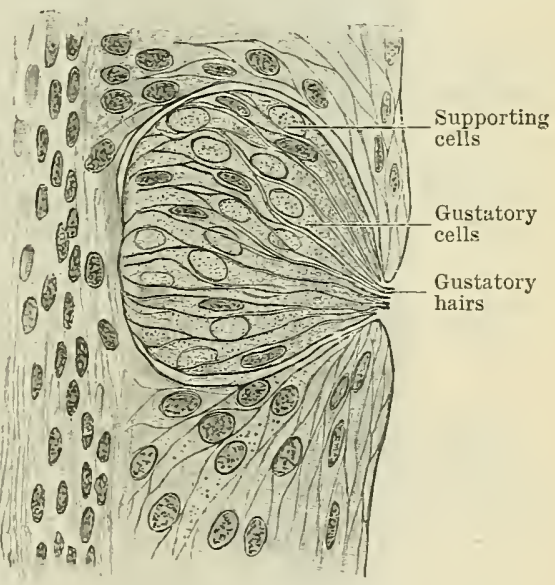

B

A, Three-quarter surface view of taste bud from the papilla foliata of a rabbit (highly magnified).
B, Vertical section of taste bud from the papilla foliata of a rabbit (highly magnified).

and a central process. The peripheral process is rod-like and almost hyaline, and terminates at the gustatory pore in a slender filament, the gustatory hair. The central process passes towards the deep extremity of the bud, where it ends free, as a single or branched varicose filament.

Nerves of Taste.-The nerve supplying the taste buds over the anterior part of the tongue is the chorda tympani, which is derived from the sensory root of the facial nerve; that for the posterior part is the glossopharyngeal. The nerve fibrils, having lost their medullary sheaths, ramify partly between the gustatory cells and partly amongst the supporting cells of the taste buds.

The ducts of Ebner's glands open into the bottom of the valleys surrounding the papillæ
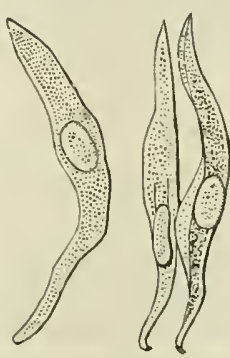

$\alpha$

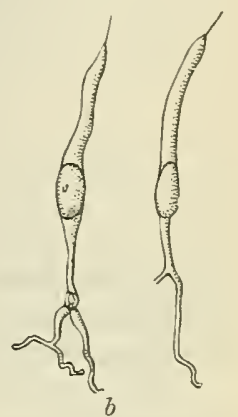

Fig, 732.-Isolated Cells from Taste Bud of RabBit (Eugelmann).

(, Supporting cells. $\quad b$, Gustatory cells. vallatæ, and the serous-like secretion of these glands probably washes the free 
hair-like extremities of the gustatory cells, and so renders them ready to be stimulated by successive substances. It should be added that there is a close association between the senses of smell and taste. This can be best appreciated by considering the defective taste perceptions resulting from inflammatory conditions of the nasal mucous membrane, or the common practice of holding the nose in order to minimise the taste of nauseous drugs.

The derelopment of the tongue is described on pp. 45-46.

\section{INTEGUMENTUM COMMUNE.}

The integument or skin covers the body, and is continuous, at the orifices on its surface, with the mucous lining of its alimentary and other canals. It contains the peripheral terminations of many of the sensory nerves, and serves as an organ of protection to the deeper tissues. It is the chief factor in the regulation of the body temperature, and by means of the sudoriferous and sebaceous glands, which

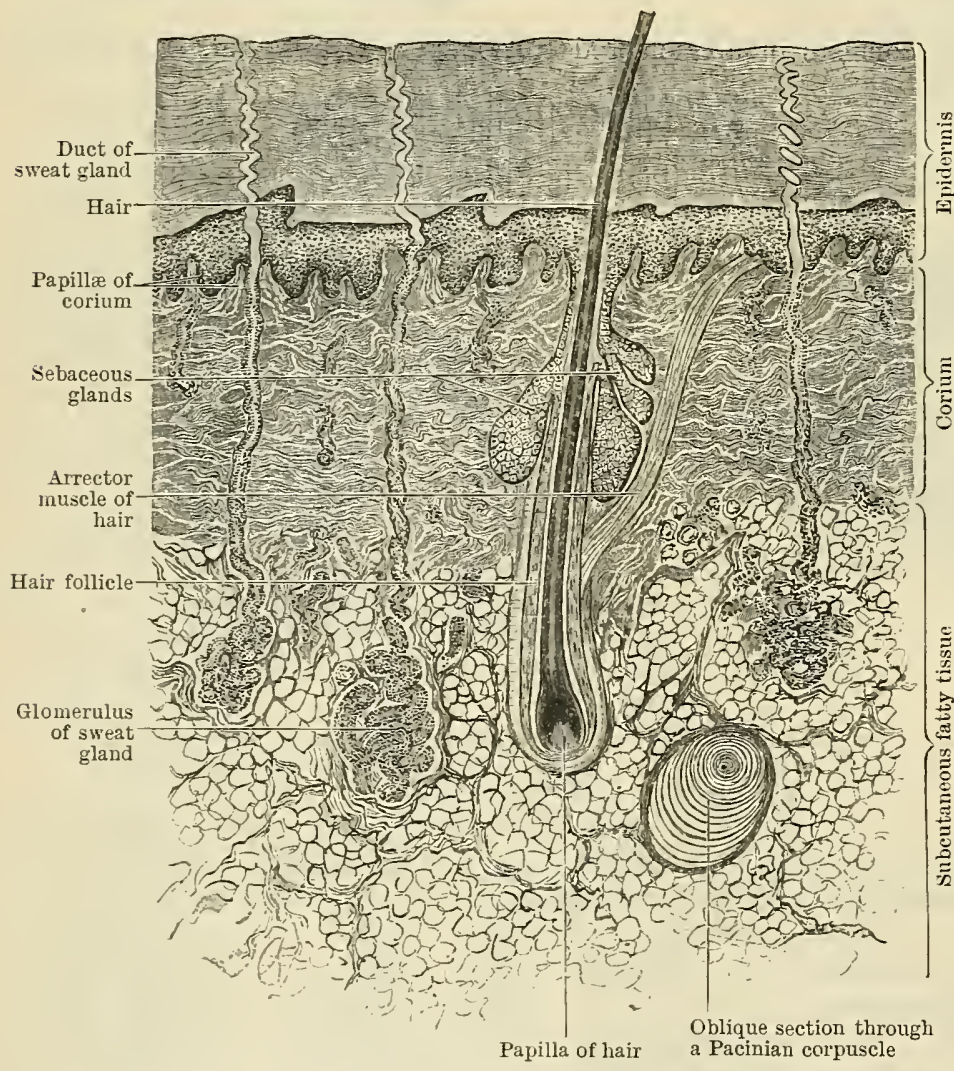

Fig. 733.-Vertical Section of the Skin (schematic). open on its free surface, constitutes animportant excretory structure. Its superficial layers are modified to form appendages in the shape of hairs and nails.

The skin is very elastic and resistant, and its colour, determined partly by its own pigment and partly by that of the blood, is deeper on exposed parts and in the regions of the genitals, axillæ, and mammary areolæ, than elsewhere. The colour varies also with race and age, the different races of the world being roughly classified, according to the colour of their skin, into the three groups of white, yellow, and black. Pinkish in colour in childhood, the skin assumes a yellowish tinge in old age, while in certain diseases (e.g. icterus and melasma Addisonii) the colour undergoes marked alteration.

The surface of the skin is perforated by the hair follicles and by the ducts of the sudoriferous and sebaceous glands, and on the palms, soles, and flexor aspect of the digits it presents numerous permanent ridges, the cristæ cutis, which correspond with rows of underlying papillæ. Over the terminal phalanges these ridges form distinctive patterns, which are retained from youth to old age, and are utilised for purposes of identification. Retinacula of the skin are seen in the neighbourhood 
of the joints, and it can be thrown into wrinkles by the contraction of the subcutaneous muscles, where these exist. Over the greater part of the body it is freely movable; but on the scalp and lateral surfaces of the auriculæ, as well as on the palms and soles, it is bound down to the subjacent tissues.

The skin consists of two strata, viz. : a deep, termed the corium, and a superficial, the epidermis (Fig. 734).

The corium or cutis vera is derived from the embryonic mesoderm, and consists essentially of a felted interlacement of connective tissue and elastic fibres. In its deeper part, or stratum reticulare, the fibrous bundles are coarse and form an open network, in the meshes of which are vessels, nerves, pellets of fat, hair follicles, and glands. This reticular stratum passes, as a rule, without any line of demarcation, into the panniculus adiposus or subcutaneous fatty tissue, but in some parts it rests upon a layer of striped or unstriped muscular fibres - the latter in the case of the scrotum. In the superficial layer, or stratum papillare, of the corium, the connective tissuebundles are finer and form a close network. Projecting from its superficial surface are numerous finger-like, single, or branched elevations, termed papillæ (Fig. 734), which are received into corresponding depressions on the under surface of the epidermis. These papillæ vary in size, being small on the eyelids, but large on the palms and soles, where they may attain a length of $225 \mu$, and where they produce the permanent curved

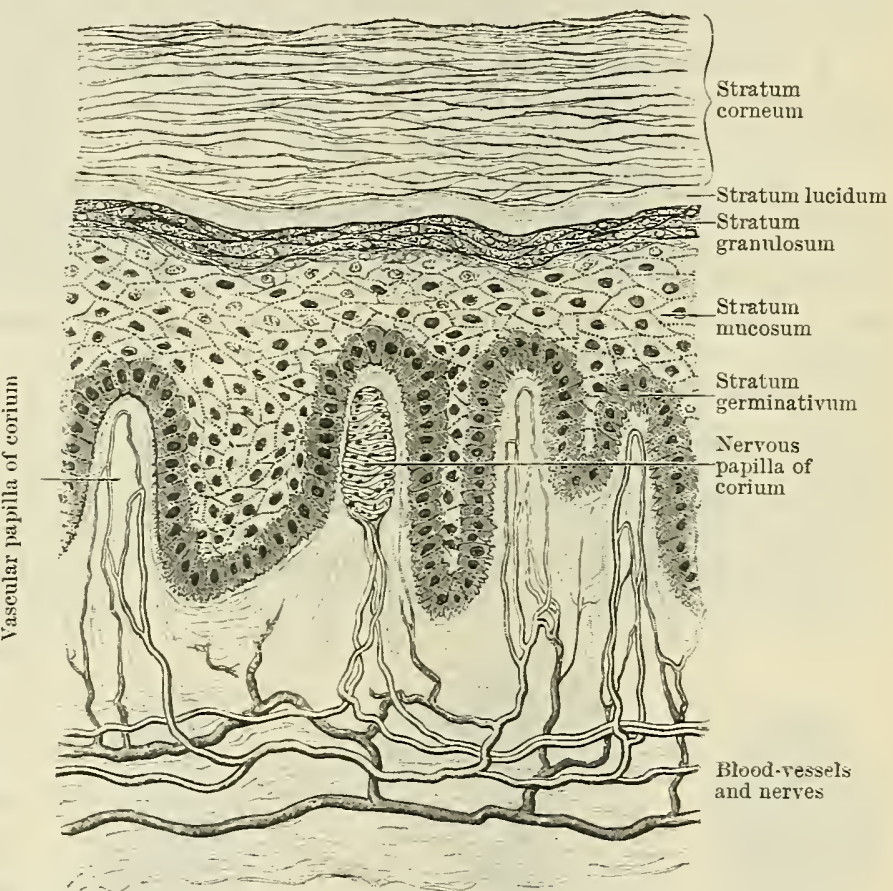

Fig. 734.- Vertical Section of Epideris and Papillex of Corium (highly magnified).

ridges already referred to. Each ridge usually contains two rows of papillæ, between which the ducts of the sudoriferous glands pass to reach the surface. The papillæ consist of fine connective tissue and elastic fibres, mostly arranged parallel to the long axis of the papillæ; the majority contain capillary loops, but some contain the terminations of nerves. The superficial surface of the corium is covered with a thin, homogeneous basement membrane.

The epidermis or cuticle is derived from the embryonic ectoderm and covers the corium. Its thickness varies in different parts of the body and ranges from $0.3 \mathrm{~mm}$. to $1 \mathrm{~mm}$. or more; it is thickest on the palms of the hands and soles of the feet, and thinnest on the eyelids and penis. It is non-vascular and consists of stratified epithelium; its superficial layers are modified to form the stratum corneum, which may be separated by maceration or blistering from the deeper, softer portion, or stratum mucosum (Malpighi). The epidermis consists from within outwards of the following five strata (Fig. 734):-

1. The stratum germinativum is a single stratum of nucleated columnar cells planted by denticulated extremities on the basement membrane of the corium.

2. The stratum mucosum consists of six or eight layers of polygonal, nucleated "prickle" or "finger" cells, the processes of which join those of adjacent cells. Between the cells of this layer are minute channels, in which leucocytes or pigment 
granules may be seen. The cells of the stratum mucosum are characterised by the presence of numerous epidermic fibrils, which are coloured violet by hæmatoxylin and red by carmine. These fibrils are unaffected by boiling, but swell up under the action of acids and alkalies, and form the filaments of union between adjacent cells. On account of their presence, L. Ranvier has named this layer the stratum filamentosum. The dark colour of the negro's skin is caused by the presence of numerous pigment granules in the deeper layers of the stratum mucosum; the pigment-of which melanin forms an important constituent-is absent from the more superficial layers of the epidermis.

3. The stratum granulosum comprises two or three layers of horizontally arranged, flattened cells, scattered around the nuclei of which are elliptical or spherical granules of eleidin, a substance staining deeply with carmine and hæmatoxylin, and probably representing an intermediate stage between the protoplasm of the deeper cells and the keratin of the superficial layers.

4. The stratum lucidum, an apparently homogeneous layer, is in reality made up of several strata of flattened or irregular squames, which contain granules or droplets of keratohyalin, a hyaline substance, staining less deeply than eleidin.

5. The stratum corneum comprises several layers of flattened non-nucleated squames, the more superficial of which assume the form of horny scales and are from time to time removed by friction. The deeper cells contain granules of a fatty material having the consistency and plasticity of beeswax, and staining with osmic acid. The peripheral parts of the cells consist of keratin, a highly resistant substance which is unaffected by mineral acids, and is indigestible in pepsinhydrochloric acid.

L. Ranvier has pointed out that the stratum lucidum is really double, and has named the deeper of its two layers the stratum intermedium; this he describes as consisting of two or three layers of clear cells with atrophied nuclei, while in the cell-walls the epidermic fibrils "are rolled up like the threads of a cocoon."

Regeneration of the epidermis is generally regarded as taking place by cell proliferation in the stratum germinativum, the young cells gradually passing through the polyhedral and

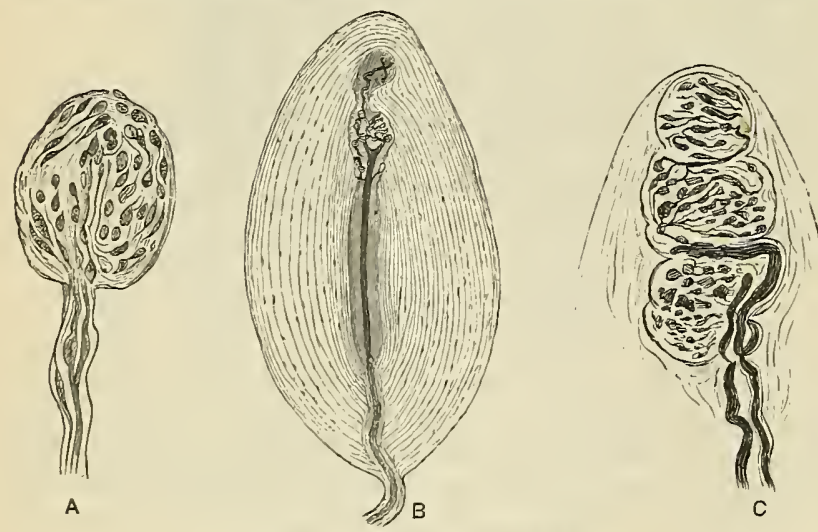

Fig. 735.-Tactile Corpuscles.

A, Eud bulk (Krause).

B, Corpuscle of Pacini $\}$ (after Ranvier).

granular stages, and ultimately becoming the flattened squames of the stratum corneum, while the eleidin granules of the stratum granulosum are converted into the keratin of the stratum corneum.

Vessels and Nerves of the Skin. - In the subcutaneous tissue the arteries form a plexus from which branches extend into the corium, where they supply the hair follicles and glands, and form a second plexus under the papille, to which small loops are given. The veins and the lymphatic vessels commence in the papillæ, and, after forming subpapillary plexuses, open into their respective subcutaneous vessels.

The nerves of the skin vary in number in different parts
of the body; they are extremely numerous where the sense of touch is acute, e.g. on the palmar surfaces of the terminal phalanges, while in the skin of the back, where the sensibility is less, they are fewer in number. Their different modes of ending are described on pp. 863-866.

\section{APPENDAges OF THE SKIN.}

The appendages of the skin are the nails, the hairs, the sebaceous glands, and the sudoriferous or sweat glands.

Ungues.-The nails (Figs. 736, 737) are epidermal structures, and represent the hoofs and claws of the lower animals. The root of the nail is hidden 
from view and embedded in a fold of skin; the body, or uncovered part, rests on the corium and ends in a free margin. The greater part of the lateral margin is overlapped by a duplicature of skin, termed the vallum unguis or nail-wall. The nails are pink in colour, with the exception of a small semilunar area near the root, which is more opaque than the rest, and is named the lunula. The lunulæ diminish in size from the thumb towards the little finger, while the thickness of the nail diminishes towards its root and lateral margins. The corium under the nail is highly vascular and sensitive, and presents, especially under

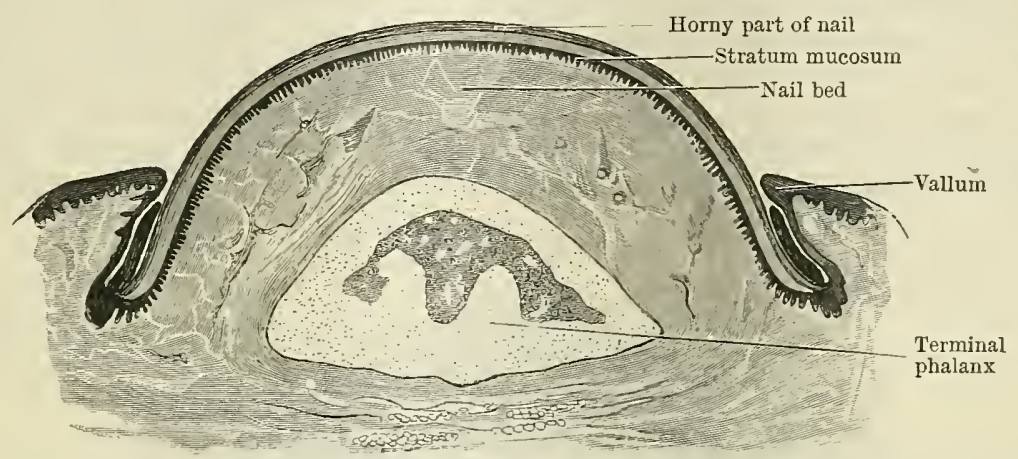

Fig. 736.-Transverse Section of a Nail.

the anterior part of the body, numerous longitudinally arranged ridges. The part of the corium under the body is termed the nail bed; that under the root, the nail matrix. The deep part of the nail consists of the stratum germinativum and stratum mucosum, while its superficial horny portion is constituted by a greatly thickened stratum lucidum, and consists of nucleated, keratinised squames. The stratum corneum is represented by the thin cuticular fold overlapping the lunula, and termed the eponychium, while the stratum granulosum can be traced only as far forwards as the nail root.

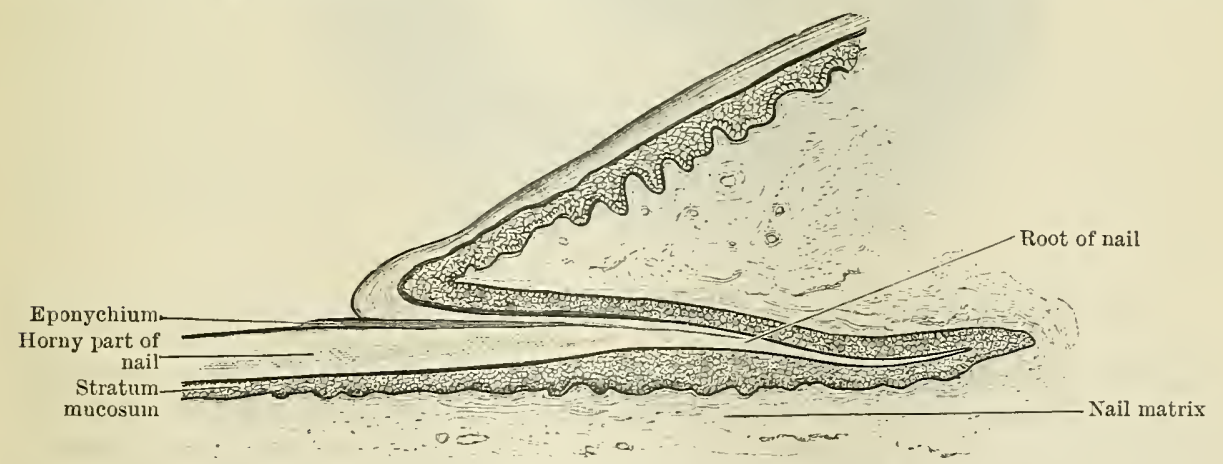

Fig. 737.-Longitudinal Section through Root of Nail.

Pili.-Hairs are well developed on the external genitals, scalp, and margins of the eyelids, in the axilla, the vestibule of the nose, and at the entrance to the concha, and also on the face of the male. Those on the genitals and face appear about puberty. Rudimentary over the greater part of the body, they are entirely absent from the flexor surfaces of the hands and feet, the dorsal surfaces of the terminal phalanges, the glans penis, the inner surface of the prepuce, and medial surfaces of the labia. Marked variations, individual and racial, exist as to the colour of the hair, and also as to the manner of its growth; hence the terms straight, curly, woolly, etc. are used to designate it. Straight hairs are coarser than curly ones, and have, moreover, a circular or oval ontline on transverse section, curly hairs being flat and riband-like.

The root of the hair is embedded in a depression of the skin, termed the hair follicle (Fig. 738); the free portion is named the scapus or shaft, and consists 
from without inwards of three parts, viz., cuticle, cortex, and medulla. The cuticle is formed by a layer of imbricated scales which overlap one another from below upwards. The cortex consists of longitudinally arranged fibres made up of elongated, closely applied, fusiform cells, which contain pigment and sometimes air spaces, the latter especially in white hairs. The medulla, absent from the fine hairs of the body generally and from the hairs of young children, forms a central core, which appears black by transmitted, and white by reflected light, and is composed of polyhedral nucleated cells containing pigment, fat granules, and air spaces.

The hair follicle consists of an oblique or curved-the latter in curly hairs-invagination of the epidermis and corium, and in the case of large hairs extends into the subcutaneous tissue (Fig. 733); some little distance below its orifice the ducts of the sebaceous glands open into it. The dermic coat or portion of the follicle derived from the corium consists of a fibrous sheath of external longitudinal and internal circular connective tissue fibres, the latter being lined by a hyaline layer directly

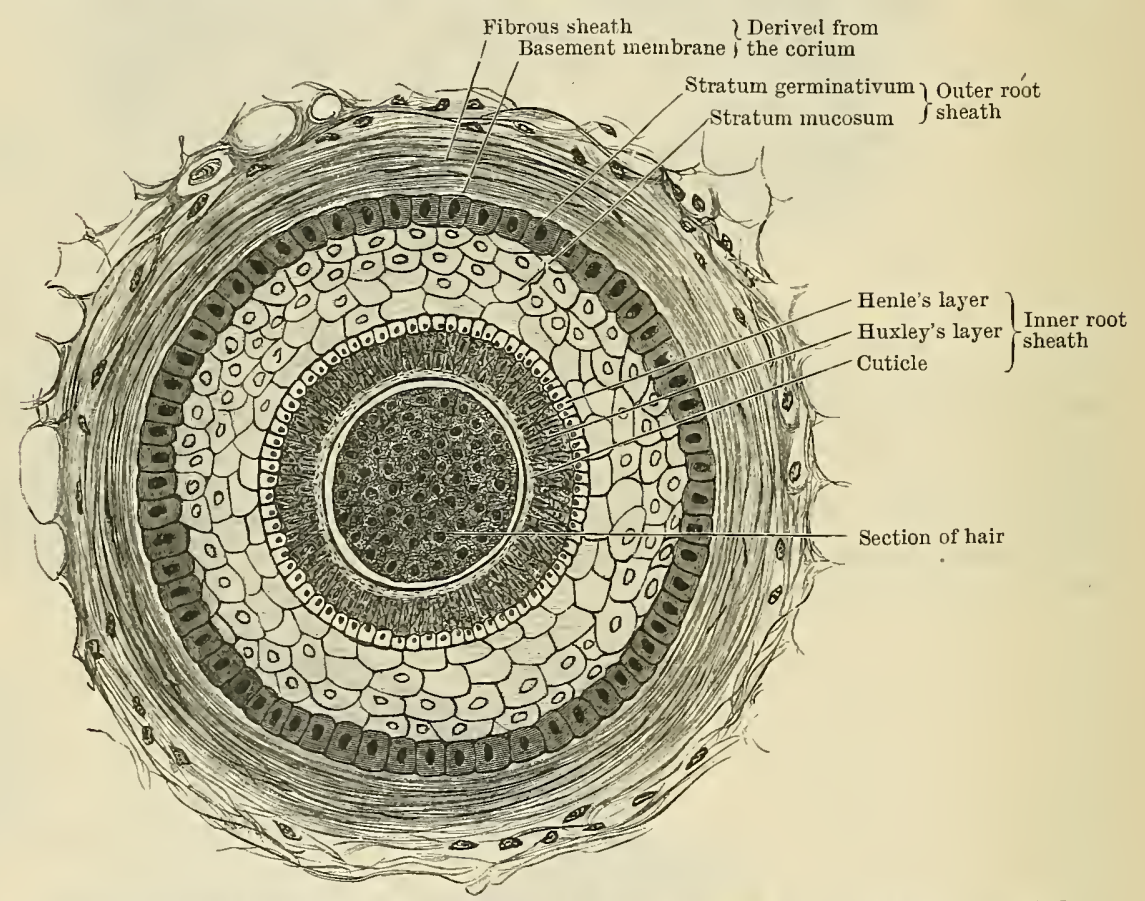

Fig. 738.-Transverse Section of Hair Follicle with contained Hair (highly magnified).

continuous with the basement membrane of the corium. The parts of the follicle derived from the epidermis are named the inner and outer root sheaths. Below the orifices of the sebaceous gland ducts the outer root sheath is formed by the stratum germinativum and stratum mucosum, while above them all the epidermal strata contribute to it. The inner root sheath surrounds the cuticle of the hair, and comprises from without inwards-(a) Henle's layer, a single stratum of nucleated cubical cells; (b) Huxley's layer, a single or double layer of polyhedral nucleated cells; and (c) a delicate cuticle, composed of a single layer of flattened imbricated cells, with atrophied nuclei. The bottom of the hair follicle is moulded on a vascular papilla, derived from the corium and capped by the bulb of the hair or expanded part of the hair root. The cells of the bulb are continuous with those of the outer root sheath, and form the different parts of the hair, as well as its inner root sheath. The vessels form capillary loops in the papilla of the hair, and send twigs into the outer layer of its fibrous sheath; the inner and outer root sheaths and the different parts of the hair are non-vascular. The nerves end in longitudinal and annular fibrils below the level of the sebaceous glands and outside the hyaline layer of the follicle.

Glandulæ Sebaceæ.-Sebaceous glands exist wherever there are hairs, and their 
ducts open into the superficial parts of the hair follicles (Fig. 733); the number of glands associated with each follicle varies from one to four. On the labia minora and mammary areolæ they open on the surface of the skin independently of hair follicles, and in the latter situations undergo great enlargement during pregnancy. The deep extremity of each gland expands into a cluster of oval or flask-shaped alveoli, which are surrounded by a basement membrane, and filled with polyhedral cells containing oil droplets. By the breaking down of the superficial cells, their oily contents are liberated as the sebum cutaneum and discharged into the hair follicle, whilst the deeper cells undergo proliferation. The size of the gland bears no proportion to that of the hairs, since they are very large in the minute hair follicles of the fotus and newly born child, and also in the follicles of the rudimentary hairs of the nose and certain parts of the face.

Bundles of non-striped muscular fibre are associated with the hair follicles, and are named the $\mathrm{mm}$. arrectores pilorum. Attached to the deep part of the hair follicle, and forming with it an acute angle, they pass outwards close to the sebaceous glands, and end in the papillary layer of the corium. They are situated on the side towards which the hair slopes, so that, on contraction, they diminish the obliquity of the hair follicle and render the hair more erect, and, at the same time, compress the sebaceous glands and expel their contents. The condition of "goose-skin" is caused by the contraction of these slender muscles.

Arthur Thomson suggests that the condition of curly hair is produced by the contraction of the $\mathrm{mm}$. arrectores pilorum. Straight hair is thick and cylindrical; curly hair is flat and ribbonlike. When the arrector muscle contracts, the thick rounded hair resists the tendency of the muscle to bend it, while the flat hair, not sufficiently strong to resist the strain of the muscle, becomes bent, and this is probably the explanation why the follicle assumes the curved form characteristic of the scalp of a bushman. The sebaceous gland lies in the concavity of the bend between the follicle and the muscle, and forms a mass of greater resistance, around which the follicle may be curved by the contraction of the muscle. The cells at the root of the hair accommodate themselves to the curved follicle, and, becoming more horny as they advance to the surface, retain the form of the follicle in which they are moulded.

Glandulæ Sudoriferæ.-Sudoriferous or sweat glands are found in the skin of nearly every part of the body; they are relatively few in number on the back of the trunk, but are very plentiful on the palms and soles, where they open on the summits of the curved ridges. Each consists of an elongated tube, the deeper portion of which forms its secretory part, and is coiled in the subcutaneous tissue or deep part of the corium in the form of an ovoid or spherical ball, termed the corpus glandulæ sudoriferæ (O.T. glomerulus) (Fig. 733). The superficial part of the tube, or ductus sudoriferus, extends through the corium and epidermis, and opens on the surface by a funnel-shaped orifice, the porus sudoriferus; where the epidermis is thick the duct is spirally coiled. The bodies of the glands, as a rule, vary in diameter from 0.1 to $0.5 \mathrm{~mm}$., but in the axillæ they are much larger, and may measure from 1 to $4 \mathrm{~mm}$. Each is surrounded by a capillary network and by a capsule of connective tissue, inside which is a homogeneous basement membrane. The lumen of the tube is lined with a layer of nucleated, granular, and striated, columnar, or prismatic epithelial cells, between the deep extremities of which and the basement membrane is a layer of non-striped muscular fibres, the long axis of which is more or less parallel with that of the tube. The excretory ducts are devoid of muscular fibres, and consist of a basement membrane lined by two or three layers of polyhedral cells, which are covered, next the lumen of the duct, with a thin cuticle.

The glandulæ ciliares, at the margins of the eyelids, and the glandulæ ceruminosæ of the external acoustic meatus, are modified sudoriferous glands; the former are, however, not coiled, while the cell protoplasm of the latter contains yellowish pigment, and their gland ducts, in the fotus, open into hair follicles.

\section{Developifent of the Skin and its Appendages.}

Skin.-The vascular and sensitive corium is developed from the mesoderm, the cells of which, immediately underlying the ectoderm, have, by the second month of fœtal life, become aggregated together and flattened parallel to the surface of the embryo. By the third month they are seen to form two layers, the superficial of which becomes the 
corium, and the deeper the subcutaneous tissue; the papille of the corium make their appearance in the fourth month. The epidermis, nails, hairs, sudoriferous and sebaceous glands are of ectodermal origin.

The epidermis at first consists of a single layer of cells, but by the end of the second month it is duplicated, and then exhibits a superficial layer of irregular cells and a deeper layer of more or less cubical cells. By the third month three strata are seen : $(a)$ a deep layer, consisting of a single layer of cubical cells-the future stratum germinativum; (b) a middle layer, comprising two or three strata of irregular cells-the future stratum mucosum; and $(c)$ an outer layer, a double stratum of large cells. This outer layer appears to be homologous with a thin membrane, termed the epitrichium, first described as covering the embryo of the sloth and overlying its hairs, but since shown to be present also in birds and mammals. Over the hairy parts of the body it disappears about the sixth month; but over the free edge and root of the nails, and on the palms and soles, it develops into several layers of cells, which, in these parts, probably persist to form the thick stratum corneum. The part which persists over the root of the nail is termed the eponychium, and covers the proximal part of the lunula (vide p. 859, Fig. 737).

Nails. - The first rudiment of the nails is seen about the beginning of the third month of embryonic life, and consists of a thickening of the epitrichium over the ends of the digits. Owing to the greater growth of the volar surfaces of the digits, the nail rudiment comes to be placed dorsally, and, at its proximal edge, an ingrowth of the stratum mucosum occurs to form its root, while the future nail is limited behind and at the sides by a groove. The superficial cells of the stratum mucosum become keratinised to form a thick stratum lucidum, the future nail proper, over the greater part of which the epitrichium disappears. The latter persists in the adult as the eponychium across the root of the nail, and, until fifth month, also forms a thick mass over the extremity of the nail, and is continued into the stratum corneum over the end of the digit. The future distal edge of the nail, at this stage, is continuous with the stratum lucidum in front of it; but this continuity is lost, and by the seventh month the nail presents a free border. The nails grow in length, and are renewed, in case of removal, by a proliferation of the cells of the stratum mucosum at the root of the nail, while an increase in their thickness takes place from the part of the same stratum which underlies the lunula.

Hairs.-The hair rudiments appear about the third month of embryonic life as solid downgrowths of the stratum mucosum, which pass obliquely into the subjacent corium. The deep end of this column of cells expands to form the hair bulb, and is moulded on a papilla derived from the corium; the epidermis immediately overlying the papilla becomes differentiated into the hair and its inner root sheath, while the peripheral cells form its outer root sheath. The surrounding corium is condensed to form the fibrous sheath of the hair follicle, the hyaline layer of which is continuous with the basement membrane covering the corium. The hair gradually elongates, and, reaching the neck of the follicle, its extremity lies at first under the epitrichium, but becomes free on the disappearance of the latter. This takes place about the fifth month of fotal life, and the first crop of hairs constitutes the lanugo, and is well developed by the seventh month. The lanugo consists of very delicate hairs, some of which are shed before, the remainder shortly after birth-the last to drop out being those of the eyelashes and scalp-and are replaced by stronger hairs. Shedding and renewal of the hairs take place during life ; prior to the shedding of a hair active growth and proliferation of the cells of the hair bulb cease, and the papilla becomes atrophied, while the hair root, gradually approaching the surface, at last drops out. New hairs arise from epidermic buds, which extend downwards from the follicle, and their development is identical with that of the original hairs.

Sebaceous Glands. - These appear about the fifth month as solid outgrowths from the sides of the hair follicles, and consist of epidermal offshoots continued from the cells of the outer root sheath. Their deep ends become enlarged and lobulated, to form the secreting part of the gland, while the narrow neck connecting this with the follicle forms its duct. The sebaceous secretion, together with the cast-off epidermal cells, is collected on the surface of the body during the last months of intra-nterine life, and forms a layer of varying thickuess, termed the vernix caseosa or smegma embryonum.

Sudoriferous Glands.--These, like the hairs, arise as solid downgrowths of the stratum mucosum. They descend, however, perpendicularly, instead of obliquely, and are of a yellowish colour; they appear on the palms and soles early in the fifth month, but much later over the hairy parts of the body. The downgrowths extend through the corium, and, on reaching the subcutaneous tissue, become coiled up to form the body or secreting part of the gland. The ducts of the glands do not open on the surface until the seventh month. 


\section{ENDINGS OF NERVES OF GENERAL SENSATIONS.}

The peripheral endings of the nerves associated with the special senses have been described in the preceding pages. Under this heading will be considered the terminations of those sensory nerves which are widely distributed throughout the body and are associated with the muscular sense and the senses of pressure, heat, cold, and pain. These nerves may end as fine ramifications of the axis cylinders lying free amongst the tissues, or in special end organs where the terminations of the axis cylinders are surrounded by connective tissue capsules.

\section{FREE NERVE-ENDINGS.}

Free nerve-endings are found chiefly in the epithelium covering the skin or the mucous membranes. The nerve-fibres, after subdividing in the sub-epithelial connective tissue, lose successively their medullary and primitive sheaths and are continued as naked axis cylinders, which, if stained with gold chloride, are seen to consist of fine varicose filaments. The axis cylinders subdivide and form primary and secondary plexuses, and from the latter numerous fibrillæ pierce the sub-epithelial basement membrane and ramify between the overlying epithelial cells where they end in minute knobs of flattened discs. In the epidermis the nerve fibrillæ are limited to the stratum mucosum, but in the cornea they reach the surface layers of epithelium

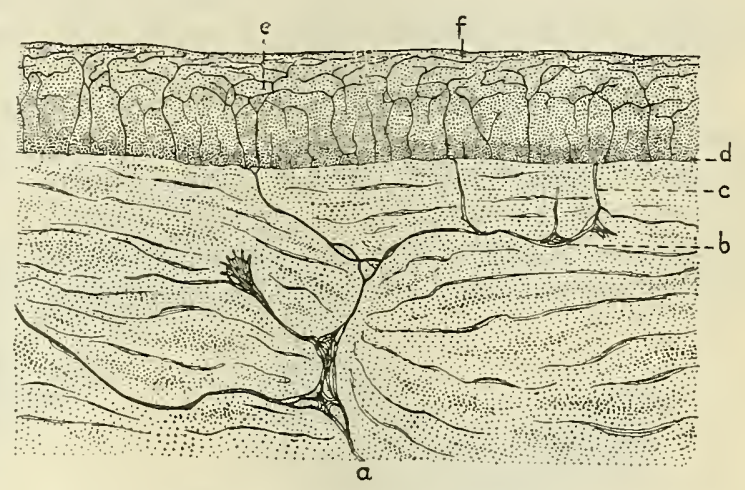

Fig. 739.-Vertical Section of Cornea Stained With Chloride of Gold (Ranvier).

$a, b$, primary plexus in connective tissue of cornea; $c$, branch passing to sub-epithelial plexus $e ; f$, intra-epithelial plexus ; $d$, terminations of fibrils. (Fig. 739). Free nerve-endings also occur around the sudoriferous glands, in the papillæ and root sheaths of the hair follicles, in the sub-epithelial and intermuscular connective tissues, and in serous membranes.

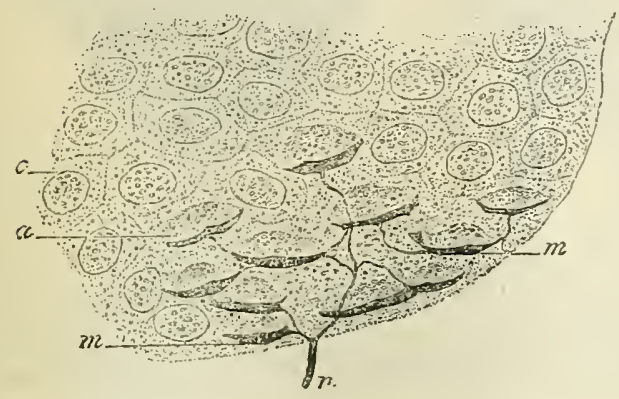

Fig. 740. - Exding of Nerve in TaCtile Discs of THE PIG's Svout (Ranvier). (From Quain's Anatomy.) $n$, mednllated fibre; $m$, terminal dises in muscle; $e$ cells from the stratun mucosum of the epidermis $a$, somewhat modified cell to which a tactile disc is applied.

(1) End Bulbs of Krause (Fig. 742). - These are minute cylindrical or oval bodies which are found in the conjunctiva, in the mucous membrane of the lips, and in 
the skin of the glans penis and glans clitoridis. Each consists of a thin connective tissue capsule enclosing a core of homogeneous or nucleated semifluid substance.
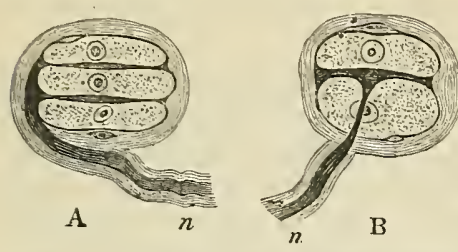

Fig. 741.-Grandry's Corpusches Fron THE DUCK's TONGUE (Izquiardo). (From Quain's A natomy.)

A, composed of three cells with two interposed discs, into which the axis cylinder of the nerve-cell is observed to pass. In $B$ there is but one tactile disc enclosed between two tactile cells.

epithelial cells enclosed within a capsule, and the axis.cylinder ends in flattened "tactile discs" which lie between the cells.

(3) Corpuscles of Pacini (Fig. 742). - These are widely distributed and consist of small oval bodies which measure from 2 to $3 \mathrm{~mm}$. in length and about $1 \mathrm{~mm}$. in width. They are found on the cutaneous nerves of the hand and foot, on the infraorbital and intercostal nerves, on the cutaneous nerves of the neck, nipple, and mamma, and on the nerves of the solar plexus. They are present in the parietal peritoneum and on the nerves of the joints, and are very plentiful in the mesentery

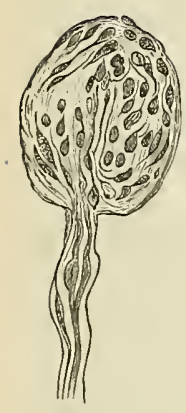

A

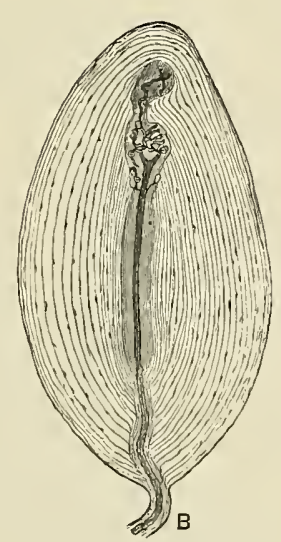

FIG. 742.

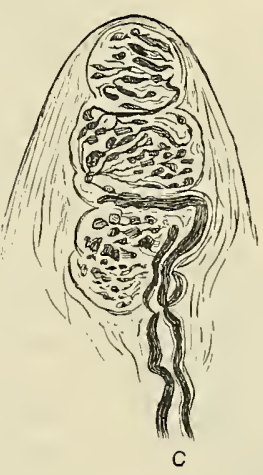

C

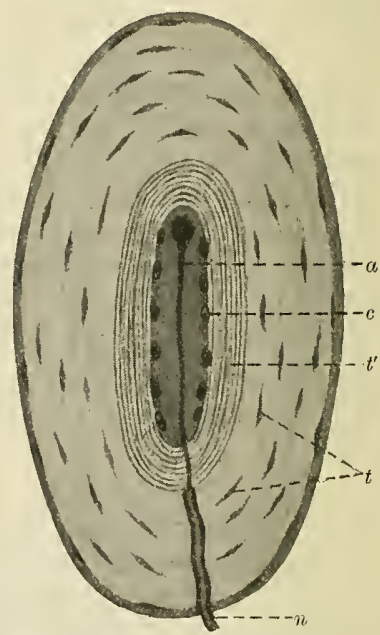

Fig. 743.- -Herbst CoRpuscle OF DUCK (Sobotta). $n$, medullated nerve-fibre ; $a$, its axis cylinder ending in an enlargement ; $c$, nuclei of cells of core ; $t$, nuclei of cells of outer tunies : $t^{\prime}$, inner tunics.

of the cat. The capsule of the corpuscle consists of a number of connective tissue tunics arranged concentrically around a central core of more or less clear protoplasm; the deeper tunics are closely applied to each other, but those towards the circumference of the corpuscle are here and there separated by narrow lymphatic spaces. Each corpuscle is attached to a nerve trunk by a narrow pedicle composed of a single medullated nerve-fibre which pierces the capsule and, on reaching the core, loses its medullary sheath. The axis cylinder is continued into the core as 
far as its distal end and there terminates in one or more enlargements in which the neuro-fibrillæ form a dense plexus. The corpuscles of Herbst (Fig. 743), which are found in the skin of birds, differ from the Pacinian corpuscles in that their cores consist of nucleated cells, between which the axis cylinder extends as a single or branched process.

(4) Corpuscles of Golgi and Mazzoni.-These are present in the subcutaneous tissue of the pulp of the fingers and also in other parts of the skin. Their capsules are thinner and their cores thicker than those of the Pacinian corpuscles, while their axis cylinders undergo a greater degree of ramification and their terminal filaments end in somewhat flattened expansions.

(5) Tactile Corpuscles of Wagner and Meissner (Fig. 742).-These are plentifully distributed in the papillæ of the corium of the hand, foot, and front of the forearm. They are found also in the skin of the lips, in the mucous membrane of the tip of the tongue, in the palpebral conjunctiva and the skin of the nipple. They are oval in shape, and their length varies from $04 \mathrm{~mm}$. to $15 \mathrm{~mm}$., and their thickness from $03 \mathrm{~mm}$. to $06 \mathrm{~mm}$. One or more nerve-fibres pierce the capsule of the corpuscle, losing, at the same time, their medullary sheaths. The axis cylinders, which are frequently varicose, assume a spiral or convoluted course and end in terminal enlargements. From the deep surface of the capsule imperfect membranous septa are continued inwards between the nerve ramifications.

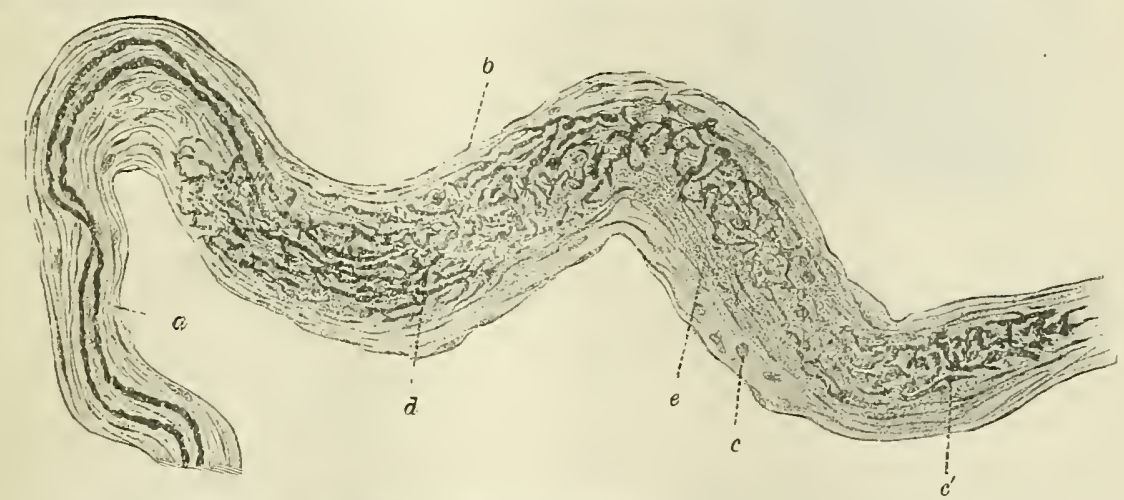

Fig. 744.-An Organ of Ruffini from the Subcutaneods Tissee (Rufini). (From Quain's Anatomy.) $a$, Entering nerve-fibres ; $b, d$, endings of their axons ; $e, c$, capsule of organ ; $c^{\prime}$, core.

(6) Organs of Ruffini (Fig. 744).- These were fornd by Ruffini in the subcutaneous connective tissue of the fingers. They are of considerable size, and their shape is oval or fusiform. One or more nerve-fibres penetrate the side of the capsule, within which they pursue a curved course and then lose their medullary sheaths.

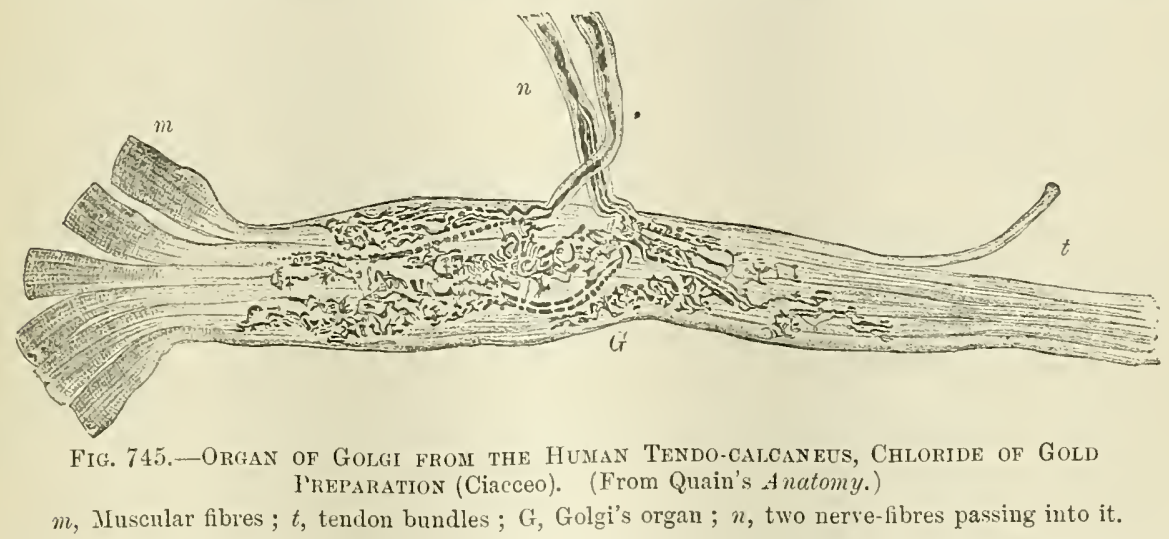

The axis cylinders break up into a close-meshed network which lies between, or partly encircles, the smaller fasciculi of connective tissue.

(7) Neuro-tendinous Spindles (Fig. 745).-These were first described by Golgi in 
187S. They consist of long spindle-shaped bodies, and are usually found near the junctions of the tendons with their muscles. Each is surrounded by a capsule

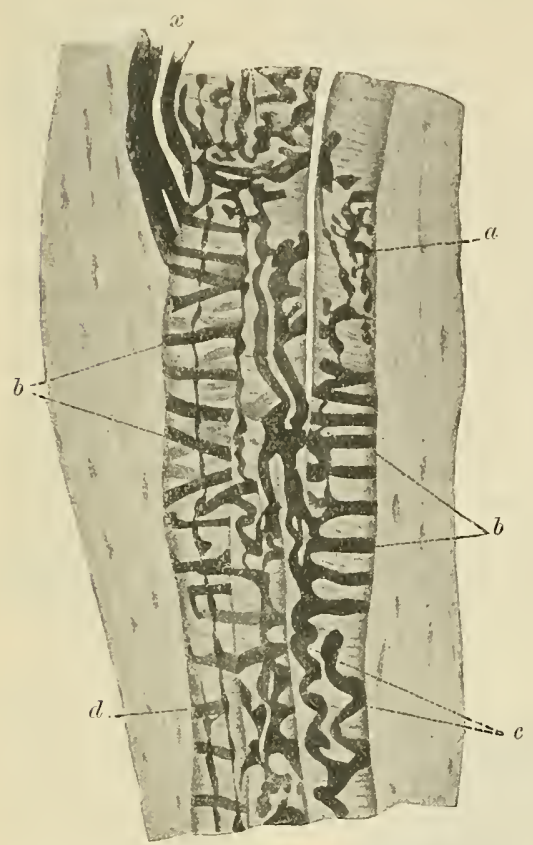

Fig. 746.-Ending of Nerve-Fibres in Muscle SPINDLE (Ruffini). (From Quain's Anatomy.)

'Three intrafusal muscle fibres are shown: $x$, nerve-fibres entering spindle ; $a$, axis cylinders terminating around and between the intrafusal fibres in $b$, ring-like; $c$, spiral ; and $d$, irregularly ramified endings. which encloses a number of intrafusal tendon fasciculi. The nervefibres pierce the side of the capsule and then lose their medullary sheaths; the axis cylinders subdivide, and their terminal branches ramify between, or partly encircle, the smaller tendon bundles and end in plate-like expansions.

(8) Neuro-muscular Spindles (Fig. 746).These are widely distributed throughout the voluntary muscles but are more numerous in the muscles of the limbs than in those of the trunk, and are plentifully found in the muscles of the hand and foot. They have not yet been seen in the intrinsic muscles of the tongue, and only a few are present in the ocular muscles. They lie in the connective tissue between the muscular bundles, and each consists of a lamellated capsule enclosing a fasciculus of striped muscular fibres (intrafusal fibres), together with minute blood-vessels and three or four medullated nerve-fibres. These intrafusal muscular fibres display many of the characteristics of embryonic muscle; they are smaller both in length and diameter than ordinary muscular fibres; they contain numerous nuclei near the centre of the spindle where their cross striation is less distinct; they also possess more protoplasm than ordinary muscular fibres. The nerve-fibres pierce the side of the capsule, inside which they lose their medullary sheaths and undergo subdivision; they are then prolonged in a spiral or annular manner around the individual muscular fibres and end in flattened or ovoid enlargements. 


\title{
THE VASCULAR SYSTEM.
}

\author{
By the late Alfred H. Young, \\ Professor of Anatomy, Victoria University, Manchester, \\ AND \\ Arthur Robinsor, \\ Professor of Anatomy, University of Birmingham.
}

Revised by Arthur Robinson, F.R.S.E., Professor of Anatomy in the University of Edinburgh.

THE vascular system consists of a series of tubular vessels, with more or less distinct walls, which run through all parts of the body. Some contain blood, others are filled with a colourless fluid called lymph; hence the distinction between the blood-vascular system and the lymph-vascular system. The two systems differ, not only as regards their contents, but also in their relations to the tissues amongst which they lie; for whilst the vessels of the former system, with the possible exception of the splenic vessels, are closed, those of the latter communicate freely with intercellular spaces and serous sacs.

The blood-vascular system is tubular throughout; the tubes or vessels possess distinct walls; they vary in size and in the structure of their walls, but all contain blood, which is conveyed, through them, to and from the tissue elements of the body. The blood is propelled along the vessels chiefly by a central propulsive organ-the heart. The outgoing vessels from the heart, along which blood is transmitted to the tissues, are termed arteries; the vessels which return blood from the tissues to the heart are known as veins; whilst the smallest tubes-those which connect the arteries and veins together, constituting at once the terminations of the arteries and the commencements of the veins-are called capillaries.

Blood capillaries are very small (hair-like) vessels, with exceedingly thin walls which permit of the easy passage of the nutritive plasma outwards from the blood to the tissues, and, of the passage in the opposite direction, of some of the products of tissue changes and of modified food material from the alimentary canal.

Arteries and veins are simply conducting passages; structurally they differ from capillaries in the greater complexity of their walls. They vary greatly in size, but are always larger than capillaries. The calibre of each artery and vein increases progressively from the periphery up to the heart, where the vessels reach their greatest size. With the increase in calibre there is a corresponding increase in the thickness and complexity of the walls.

Structure of Blood Capillaries.-Capillaries measure from $8 \mu$ to $12.5 \mu$ in diameter, and about $\cdot 75 \mathrm{~mm}$. in length. Their walls are simple, and, in the smallest capillaries, consist principally of elongated elastic endothelial cells, with sinuous edges, pointed extremities, and oval nuclei. The cells are cemented to one another, along their margins, by intercellular cement, which readily stains with nitrate of silver. Here and there the cement substance appears to accumulate, forming minute spots indicative of the less perfect apposition of the edges of the cells. These spots, when small, form the so-called stigmata; when larger they are known as stomata.

The larger capillaries are invested by a connective tissue sheath consisting of branched cells which are united together and to the endothelial cells of the capillary wall. This sheath is termed the tunica externa capillaris.

Capillaries are arranged in networks, the nature and character of which differ 
in different tissues. The small arteries which end in them are known as capillary arterioles, and the venous radicles which commence from them are appropriately termed capillary veins.

Structure of Arteries and Veins. - The delicate elastic endothelial membrane which forms the wall of the simplest capillaries extends also, as a continuous lining, throughout the whole of the blood-vascular system. In the arteries the constituent cells are fusiform, narrow, and pointed, whilst in the veins they are somewhat shorter and broader.

The most essential structural difference between capillaries on the one hand and the arteries and veins which they unite together on the other, is the presence, in

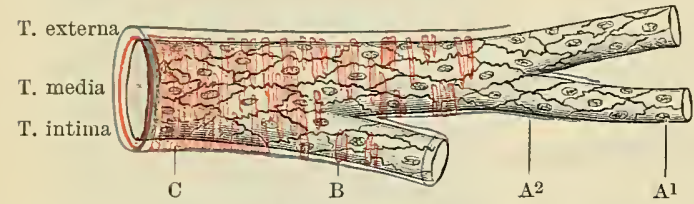

Fict. 747.-STruCture of Blood-vessels (diagrammatic).

$A^{1}$, Capillary - with simple endothelial walls. A2, Larger capillary -with connective tissue sheath, "adventitia capillaris." B, and scattered. C, Artery-museular elements of the tunica media forming a continuous layer. white connective tissue are added in varying proportions. The walls of the vessels thus become rnore complex, and numerous strata may be distinguished; which, for convenience, are regarded as forming three layers, known as the tunica intima and the middle and outer tunics. Superadded to the tunics is the investing fibrous sheath or vagina basis.

Structure of Arteries.-The walls of arteries are stronger and thicker than those of veins of corresponding size, the tunica intima and middle tunic being particularly rich in elastic and muscular elements.

Tunica Intima.- In the tunica intima the endothelial lining is strengthened by the addition of yellow elastic tissue, the fibres of which are arranged in such a manner as to simulate a fenestrated membrane. In arteries of medium size the elastic lamina is separated from the endothelium by a layer of connective tissue consisting of branched cells and numerous fibrils. In the larger arteries the subendothelial connective tissue is considerably increased, and delicate elastic fibres appear which connect it with the more extermally situated fenestrated elastic layer.

Tunica Media.-In the capillary arterioles the tunica media consists solely of scattered unstriped muscle fibres; the individual fibres are circularly disposed, but do not entirely surround the vessel. In small arteries the muscle cells are so far increased in amount that they form a continuous though thin layer. As the arteries increase in size additional layers of muscle cells are added, and the greater thickness of the arterial wall is mainly due to this increase of the muscular elements of the middle coat. In the larger vessels delicate laminæ of elastic tissue alternate with the layers of muscular fibres, and in the aorta and the carotid arteries, as well as in some of the branches of the latter, the elastic elements largely preponderate. In the first part of the aorta, in the pulmonary artery, and in

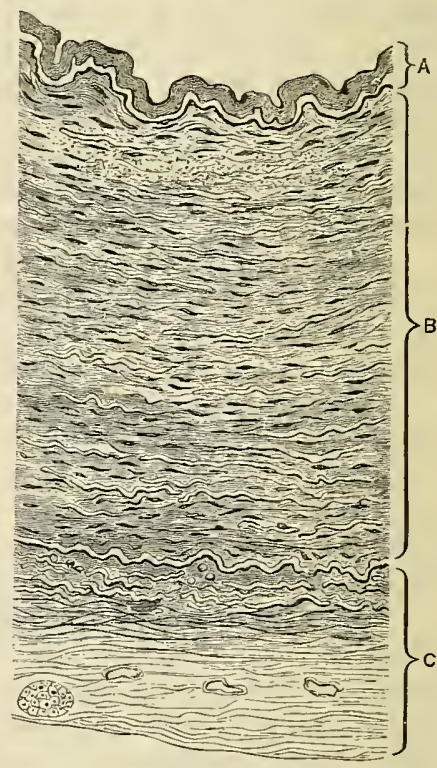

Fig. 748.-Transverse Section THROUGH THE WALL OF a LARGE ARTERY.

A, Tunica intima. B, Tunica media. C, Tunica externa.

the arteries of the retina, the muscular fibres are entirely replaced by elastic tissue.

Tunica Externa.-The outer tunic of an artery consists almost entirely of fibrillated connective tissue, with connective tissue corpuscles lying in corre- 
sponding spaces. In all but the smallest arteries numerous elastic fibres are also present. The elastic element is specially strong near the middle coat in small and medium sized vessels, and is sometimes described as the external elastic membrane. In some arteries longitudinally arranged unstriped muscular fibres are also found in the external coat.

Vagina Vasis.-In addition to the three tunics above described, arteries are enclosed in a sheath of the surrounding connective tissue, and are more or less connected with it by fine strands of fibrillated connective tissue.

Structure of Veins.-The walls of veins are similar in structure to those of arteries; they are, however, thinner, so much so, that, although veins are cylindrical tubes when full of blood, they collapse when empty and their lumina almost disappear. The structural details of the three tunics vary somewhat in different veins; in most the innermost tunic is marked by folds which constitute valves. Like the arteries, the veins are enclosed in connective tissue sheaths.

Tunica Intima.-In the majority of the veins the tunica intima includes an internal endothelial layer, a middle layer of subendothelial connective tissue, and an outer layer of elastic tissue. The innermost tunic of a vein is less brittle than the inner coat of an artery, and is more easily peeled off from the middle coat. The subendothelial tissue is a fine fibrillated connective tissue, less abundant than in the arteries, and in many cases it is absent. The elastic layer consists of lamellæ of elastic fibres which are arranged longitudinally; it rarely has the appearance of a fenestrated membrane.

One of the chief peculiarities of the tunica

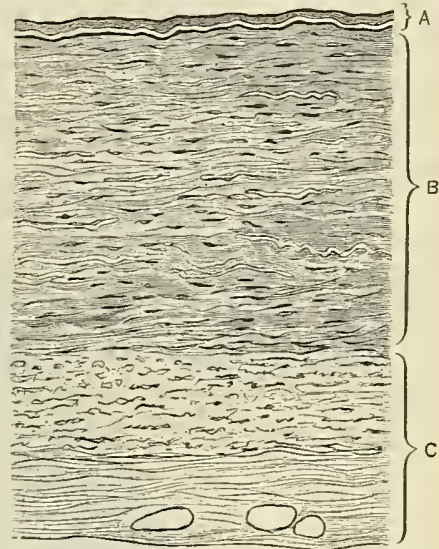

Fig. 749.-Transterse Section of THE WALL OF A VEIN.

A, Tunica intima. B, Tunica media. C, Tunica externa. intima is the presence of folds of its substance which constitute valves. The valves are of semilunar shape, and they are usually arranged in pairs. Their convex borders are continuous with the vessel wall, and their free borders are turned towards the heart; whilst, therefore, they do not interfere with the free flow of blood from the periphery, they prevent any backward flow towards it, and they help to sustain the column of blood in all vessels in which there is an upward flow. Each valve consists of a fold of the endothelial layer, strengthened by a little connective tissue. As a general rule, the wall of the vein is dilated on the central side of each valve into a shallow pouch or sinus; consequently, when the veins are distended they assume a nodulated appearance. The valves are more numerous in the deep than in the superficial veins, and in the veins of children than in the veins of adults.

Tunica Media.-The middle tunic is much thinner than the corresponding tunic of an artery, and it contains a smaller amount of muscular and a larger amount of ordinary connective tissue; indeed, so much does the latter preponderate that it separates the muscular fibres into a number of bands isolated from each other by strands of connective tissue; therefore the muscle fibres do not form a continuous layer. In some of the veins the more internal muscular fibres do not retain the transverse direction which is usually met with both in arteries and veins; on the contrary, they run longitudinally. This condition is met with in the branches of the mesenteric veins, in the femoral and iliac veins, and in the umbilical veins. The middle tunic is absent in the thoracic part of the inferior vena cava; it is but slightly developed in many of the larger veins, whilst in the jugular veins its muscular tissue is very small in amount.

Tunica Externa.-This tunic consists of white fibrous and elastic tissue. In many of the larger veins a considerable amount of muscular tissue is also present; this is the case in the iliac and axillary veins, the abdominal part of the inferior vena cava, the azygos and hemiazygos veins, and in the renal, spermatic, splenic, superior mesenteric, portal, and hepatic reins. The striped muscle fibres of 
the heart are prolonged into it at the terminations of the venæ cavæ. The external tunic is frequently thicker than the middle tunic, and the two are not easily separable from one another.

Vascular and Nervous Supply of Arteries and Veins.-Blood-vessels.-The walls of the blood-vessels are supplied by numerous small arteries, called vasa vasorum, which are distributed to the outer and middle tunics. They arise either from the vessels they supply or from adjacent arteries, and after a short course enter the walls of the vessels in which they end. The blood is returned by small venæe vasorum.

Lymphatics.-Although the cell spaces in the middle and inner tunics may be regarded as the commencement of lymphatics, definite lymphatic vessels are limited to the outer tunic.

Nerves.-Arteries and veins are well supplied with both medullated and nonmedullated nerve-fibres. The fibres form dense plexuses on the outer surfaces of the vessels, from which filaments pass to the middle tunic to be distributed almost entirely to its muscular fibres.

Divisions of the Blood-Vascular System.-Blood-vessels convey blood to or from the tissues of the body generally, or to and from the lungs. The former constitute the systemic vesseis or general system; the latter form the pulmonary system. These two systems are connected together by the heart.

The venous trunks passing to the liver, and their tributaries, form a subsidiary part of the general systemic group of vessels, which is known as the portal system.

\section{COR.}

The heart is a hollow muscular organ, which is enclosed in a fibro-serous sac known as the pericardium. It receives blood from the veins, and propels it into and along the arteries. The cavity of the fully developed heart is completely separated into right and left halves by an obliquely placed longitudinal septum, and each half is divided into an upper receiving chamber, the atrium, and a lower ejecting chamber, the ventricle. The separation of the atrium from the ventricle, however, is not complete. Externally a comparatively shallow constriction, running transversely to the long axis of the organ, indicates the distinction between the atria and ventricles; internally a wide aperture is left between the atrium and ventricle of each side. Each atrio-ventricular aperture is provided with a valve which allows the free passage of blood from the atrium to the ventricle, but effectually prevents its return.

It has already been pointed out that the delicate walls of the blood capillaries allow of the free passage outwards of nutritive plasma from the blood. The plasma passes into spaces, or intercellular channels, in which the tissue elements lie; thus the latter are directly bathed in blood plasma. The intercellular spaces may be looked upon as the commencement of the lymph-vascular system. They communicate together, and lymph passes from them into lymph vessels which carry the plasma back to the blood-vascular system, but in addition lymph vessels also convey new nutritive material, the product of digestive processes, from the alimentary canal.

Lymph vessels, in other words, convey material from the tissues. Blood-vessels convey material both to and from the tissues.

The removal of waste products from the blood is provided for by special organs, some of which are simply interposed in the course of the general circulation-e.g. the liver, the kidneys, and the skin. The lungs, however, where the impure or venous blood receives its main supply of oxygen and gives up most of its carbon dioxide, etc., do not lie in the course of the general or systemic circulation; for them a secondary or pulmonary circulation is established, by which venous blood is conveyed from the heart to the lungs by the pulmonary artery and its branches, and, after passing through the pulmonary capillaries, is returned again to the heart, as oxygenated or arterial blood, by the pulmonary veins.

The heart, anatomically a single organ, is correspondingly modified, and, as described above, it is divided by a septum into a right and a left part. The right side receives the blood from the systemic veins, and ejects it into the pulmonary artery; whilst the left side receives blood from the pulmonary veins, and ejects it into the main systemic artery-the aorta.

The shape of the heart is that of an irregular and somewhat flattened cone; and a base, an apex, two surfaces (inferior or diaphragmatic and antero-superior or sterno-costal), and three borders (right, left, and inferior) are distinguishable. 
An oblique groove, the sulcus coronarius, runs transversely to the long axis of the organ, and separates the postero-superior or atrial portion from the anteroinferior or ventricular part. The separation of the atrial portion into right and left chambers is marked, externally, at the base of the heart only, where an indistinct interatrial groove exists. The division of the ventricular part into right and left ventricles is more definitely marked on the surface by anterior and an inferior longitudinal sulcus.

The heart lies in the middle mediastinum. It rests below on the diaphragm, and is enclosed in the pericardium, which intervenes between it and the neighbouring structures. Its long axis, from base to apex, runs obliquely from behind anteriorly, downwards, and to the left.

Basis Cordis. - The base which is formed by the atria, and almost entirely by

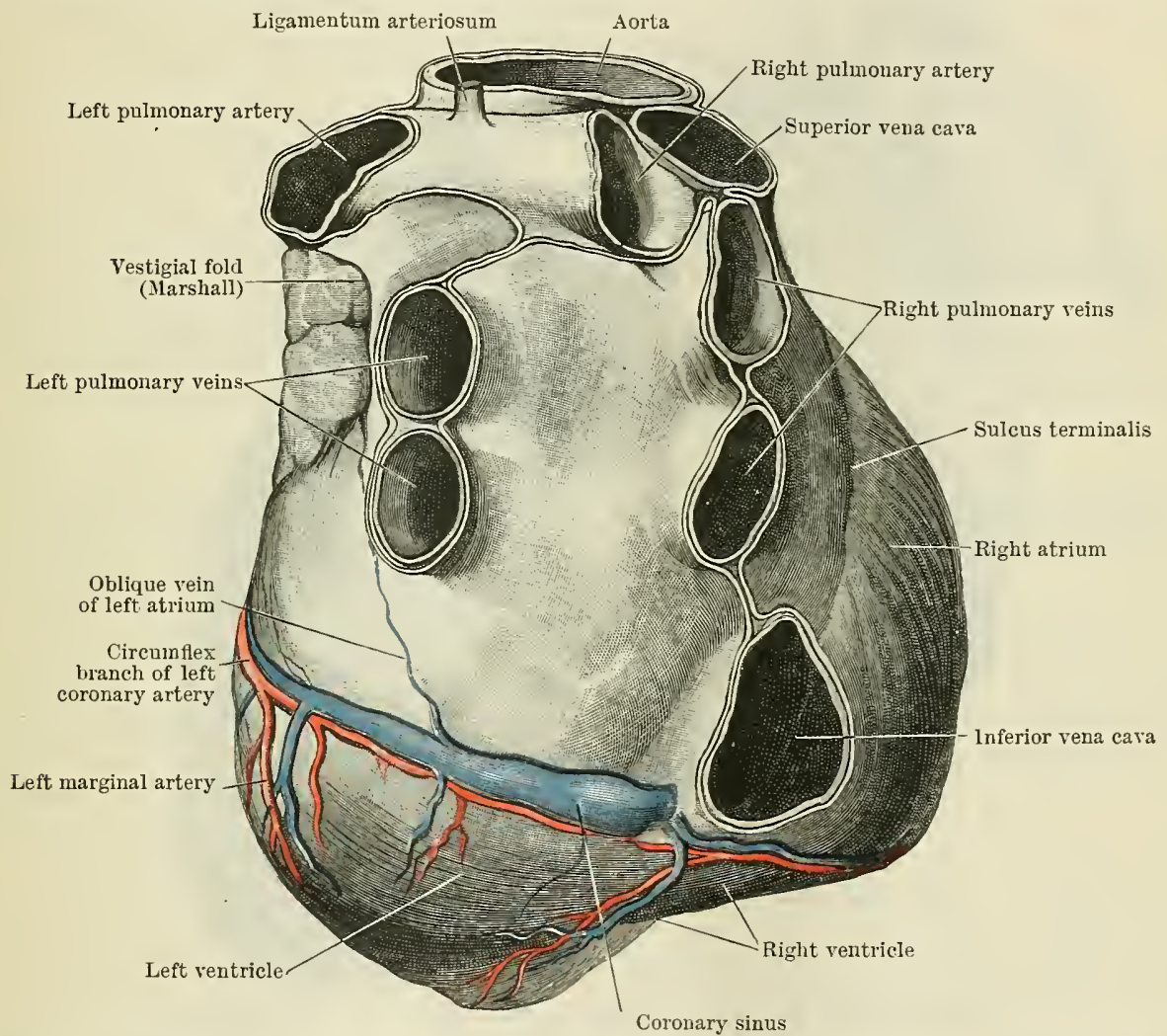

Fig. 750.-The Base and Diaphragmatic Surface of the Heart, showing the openings of the great vessels and the line of reflection of the serous pericardiun in a formalin hardened preparation.

the left atrium, is directed upwards, posteriorly, and to the right. It lies anterior to the descending thoracic aorta, the csophagus, and the lower right pulmonary vein, which separate it from the bodies of the sixth, seventh, and eighth thoracic vertebræ.

On the whole the base is somewhat flattened. It is irregularly quadrilateral in form, and the terminations of the superior and inferior venæ cavæ and the four pulmonary veins pass through it. The opening of the superior vena cava is situated at the upper right angle, that of the inferior cava occupies the lower angle on the right side; between and a little to the left of these openings are the orifices of the two right pulmonary veins, and immediately to the right of the latter is the indistinct posterior interatrial sulcus, which descends to the left of the orifice of the inferior vena cava. The openings of the two left pulmonary veins are situated near the left border of the base; and the portion of the surface which lies between the right and left pulmonary veins forms the anterior boundary of the great oblique sinus of the pericardium. 
The base is limited below by the inferior part of the coronary sulcus, in which the coronary sinus lies; its upper border is in relation with the pulmonary arteries. A fold of pericardium, the vestigial fold, descends, near the left border of the base, from the left branch of the pulmonary artery above to the left superior pulmowary vein below. It contains the ligamentum v. cavæ sinistræ, and from its lower end a small vein, the oblique vein of the left atrium, passes below the oritice of the lower left pulmonary vein, and descends to the coronary sinus. Further, it is from the base that the visceral layer of the pericardium, which elsewhere completely invests the heart, is reflected, the lines of reflection corresponding with the orifices of the great vessels. ${ }^{1}$

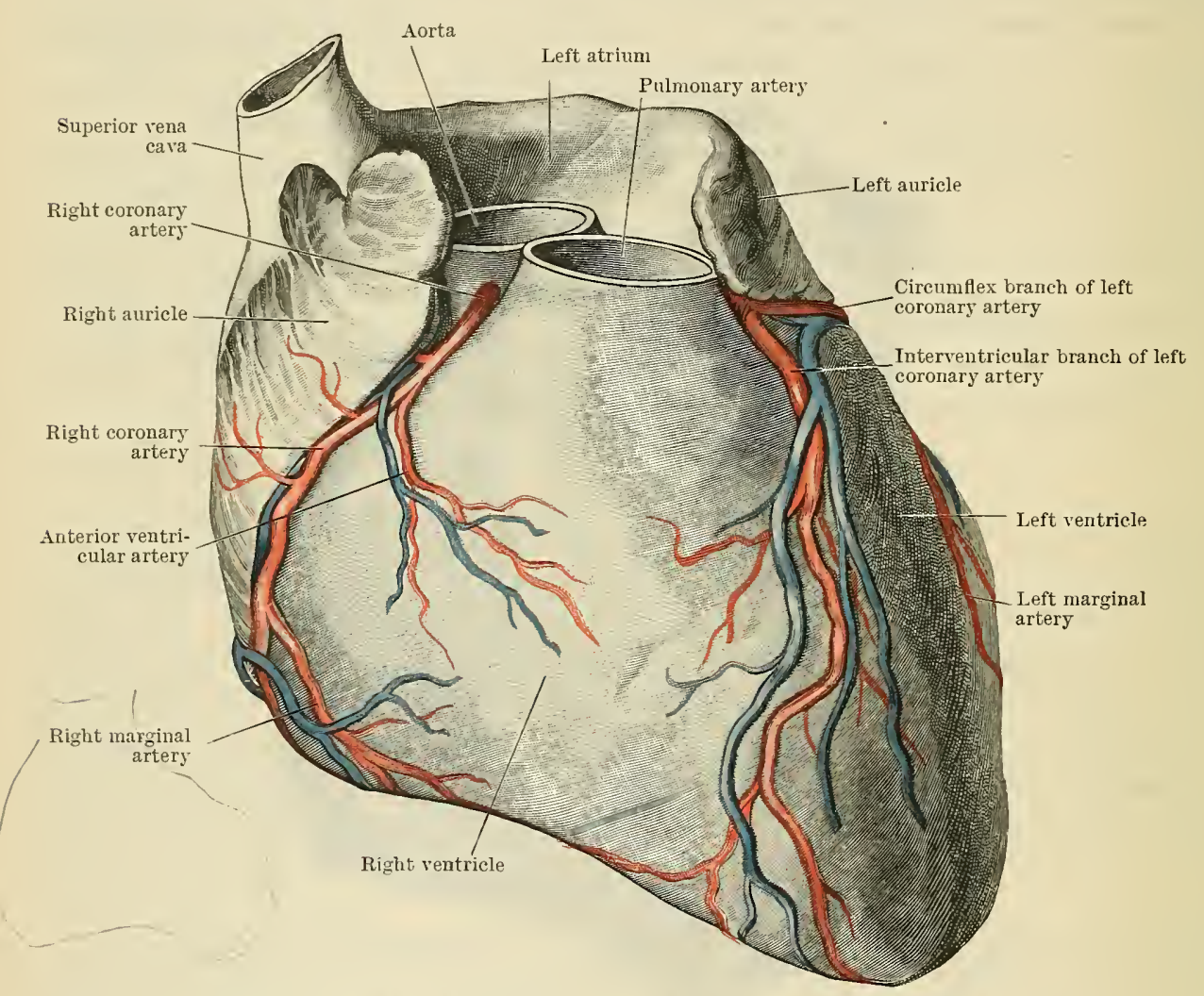

Fig. 751.-The Sterio-costal Surface of Formalin Fided Heart.

The apex, bluntly rounded, is formed entirely by the left ventricle. It is directed downwards, anteriorly, and to the left, and is situated, under cover of the anterior borders of the left lung and pleura, behind the fifth left intercostal space, three and a half inches from the anterior median line.

The diaphragmatic surface is formed by the ventricular part of the heart. It rests upon the diaphragm, chiefly on the central tendon, but, upon the left side, on a small portion of the muscular substance also, and it is divided into two areas -a smaller to the right side and a larger to the left side-by an oblique anteroposterior groove, the inferior interventricular sulcus. It is separated from the base by the posterior or inferior portion of the coronary sulcus.

The sterno-costal surface is directed upwards, anteriorly, and to the left. It lies posterior to the body of the sternum and the medial extremities of the cartilages of the third, fourth, fifth, and sixth ribs on the right side, and a greater extent of the corresponding cartilages on the left side. This surface is separated into upper and lower sections by the anterior portion of the

1 In the foetus and young child the atrial portion of the heart forms not only the base, but also the posterior part of the inferior or diaphragmatic surface. 
coronary sulcus, which runs obliquely from above downwards, and from left to right, from the level of the third left to that of the sixth right costal cartilage. The upper section of the surface, which is concave anteriorly, is formed by the atria; it is separated from the sternum by the ascending aorta and the pulmonary artery, and is continuous laterally with the auricles of the atria which, projecting forwards, embrace the great vessels. The lower section of the sterno-costal surface is convex; it is formed by the ventricular part of the heart, and is divided, by an anterior interventricular sulcus, into a smaller left and a larger right part. At the junction of the atrial and ventricular parts of this surface are the orifices of the pulmonary artery and the aorta, the former lying anterior to the latter.

The right margin of the heart is formed by the right atrium. It lies posterior to the cartilages of the third, fourth, fifth, and sixth ribs on the right side, about half an inch from the margin of the sternum; it is in relation with the right pleura and lung, the phrenic nerve with its accompanying vessels intervening, and it is marked by a shallow groove-the sulcus terminalis - which passes from the front of the superior vena cava to the front of the inferior vena cava.

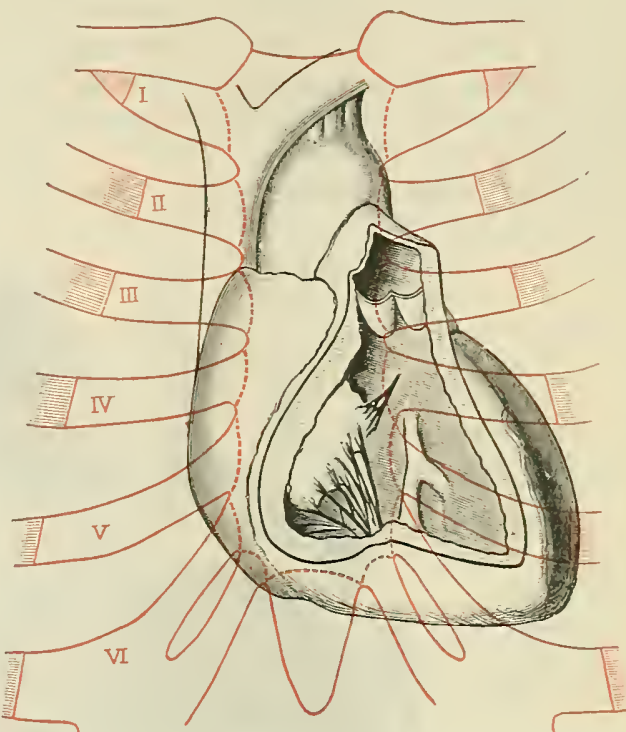

Fig. 752.-THE Relation of the Heart to the ANTERIOR WALL OF THE THORAT.

I, II, III, IV, $\mathrm{F}, \mathrm{FI}$, the upper six costal cartilages.

The inferior margin of the sterno-costal surface is sharp, thin, and usually concave corresponding with the curvature of the anterior part of the diaphragm; it is formed by the right ventricle, and it lies, almost horizontally, in the angle between the diaphragm and the anterior wall of the thorax, passing from the sixth right costal cartilage, posterior to the lower part of the body of the sternum, or the xiphoid process, and the cartilages of the sixth and seventh ribs on the left side, to the apex of the heart.

The left margin is formed mainly by the left ventricle, and only to a small extent by the left atrium, and is thick and rounded. It lies in relation with the left pleura and lung, the phrenic nerve and its accompanying vessels intervening, and it passes from just above the third left costal cartilage, about an inch from the sternum, to the apex of the heart, descending obliquely and with a convexity to the left.

\section{THE CHAMBEPS OF THE HEART.}

Atria.-The atrial or basal portion of the heart is cuboidal in form. Its long axis, which lies transversely, is curved, with the concavity of the curve forwards. It is divided into two chambers-the right and left atria-by a septum which runs from the anterior wall backwards and to the right, so obliquely that the right atrium lies anterior and to the right, and the left atrium posterior and to the left.

Each atrium is also somewhat cuboidal in form, the long axes of both being vertical, and each chamber possesses a well-marked ear-shaped, forward prolongation, which projects from its anterior and upper angle, and is known as the auricle.

Atrium Dextrum.-The right atrium receives, posteriorly, the superior rena cava above and the inferior vena cava below. Between these, and a little above its middle, it is crossed posteriorly by the lower right pulmonary vein. It is continuous below and anteriorly with the right ventricle at the atrio-ventricular 
aperture. Above and anteriorly it is in relation with the ascending aorta, and from the junction of this aspect with the right lateral boundary the right auricle is prolonged anteriorly and to the left. Its right side forms the right margin of the heart, and is in relation with the right phrenic nerve and its accompanying ressels, and with the right pleura and lung, the pericardium intervening. On the left this atrium is limited by the oblique septum which separates it from the left atrium. The sulcus terminalis is a shallow groove on the surface of the right atrium, which passes from the front of the superior vena cava to the front of the inferior vena cava. It indicates the junction of the primitive sinus venosus with the atrium proper.

The interior of the right atrium is lined with a glistening membrane, the endo-

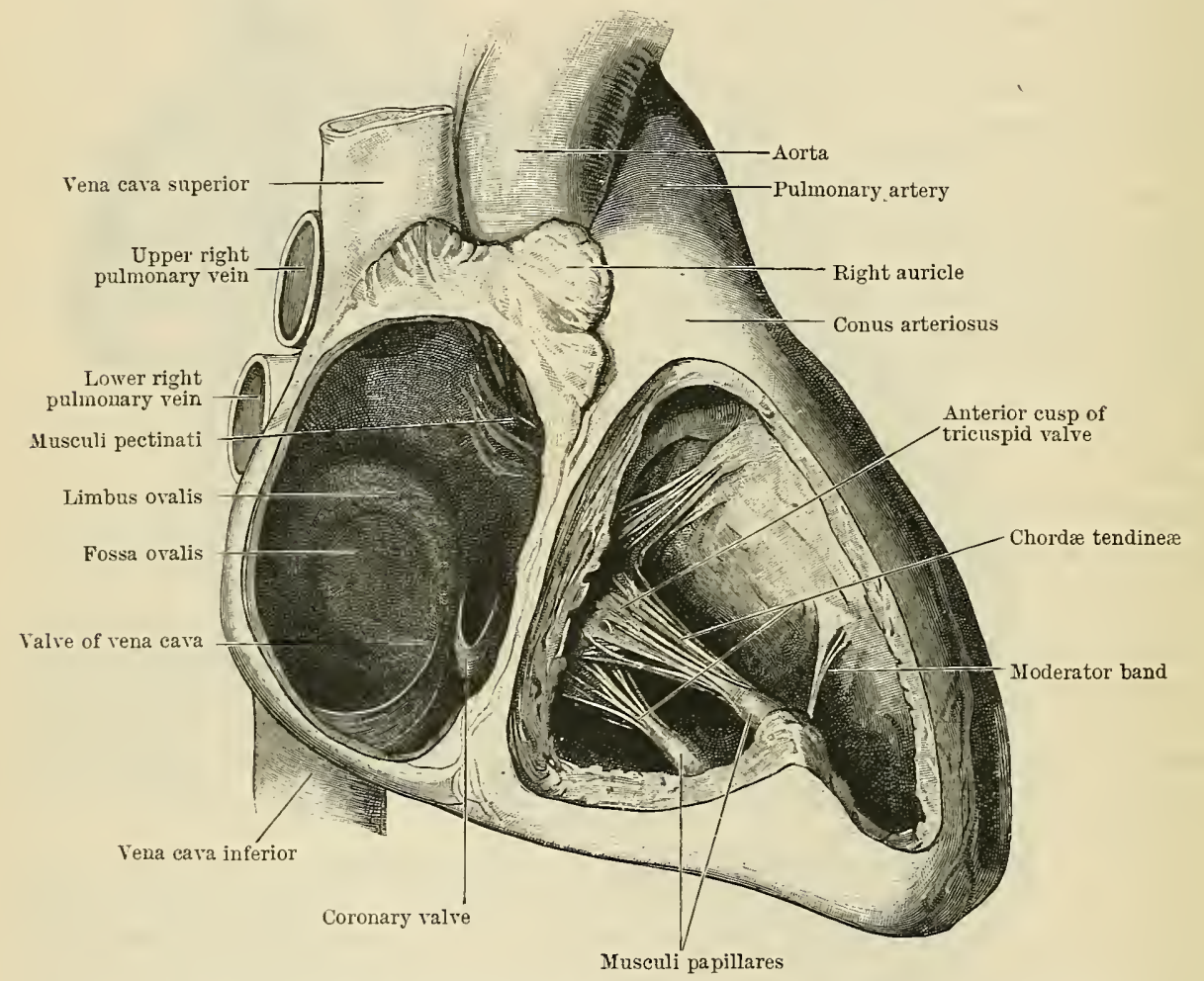

Fig. 753.-The Canities of the Pight Atrium and Right Ventricle of the Heart.

From a formalin fixed heart.

cardium; its walls are smooth, except anteriorly and in the auricle where muscular bundles, the musculi pectinati, form a series of small vertical columns. These terminate above in a crest, the crista terminalis, which corresponds in position with the sulcus terminalis externally.

At the upper and posterior part of the cavity is the opening of the superior vena cava, devoid of a valve. At the lower and posterior part is the orifice of the inferior vena cava, bounded, anteriorly, by the rudimentary valve of the vena cava (O.T. Eustachian); and immediately anterior and to the left of this valve, between it and the atrio-ventricular orifice, is the opening of the coronary sinus, guarded by the coronary valve. The atrio-ventricular aperture, guarded by a tricuspid valve, is known as the tricuspid orifice. It is situated in the inferior part of the anterior boundary, and admits three fingers. A number of small fossæ, foramina venarum minimarum, are scattered over the walls, and into some of these the venæ cordis minimæ open. In the septal wall is an oval depression, the fossa ovalis, bounded above and anteriorly by a raised margin, the limbus fossæ ovalis, which is continuous inferiorly with the valve of the vena cava; this fossa 
is the remains of an aperture, the foramen ovale, through which the two atria communicated with each other before birth. Even in the adult a portion of the aperture persists at the upper part of the fossa in about one in five cases. Between the apertures of the superior and inferior venæ cavæ, and posterior to the upper part of the fossa ovalis, a small eminence may be distinguished, which is called the tuberculum intervenosum; it probably directs the blood from the superior vena cava to the tricuspid orifice during fotal life.

The valvula venæ cavæ inferioris is a thin and sometimes fenestrated fold of endocardium and subendocardial tissue, which extends from the anterior and lower margin of the orifice of the inferior vena cava to the anterior part of the limbus ovalis. It varies very much in size; is usually of falciform shape; its apex is attached to the limbus and its base to the margin of the inferior caval orifice. It is an important structure in the fotus, directing the blood from the inferior vena cava through the foramen ovale into the left atrium.

The valvula sinus coronarii is usually a single fold of endocardium which is

Right anterior cusp of pulmonary valve

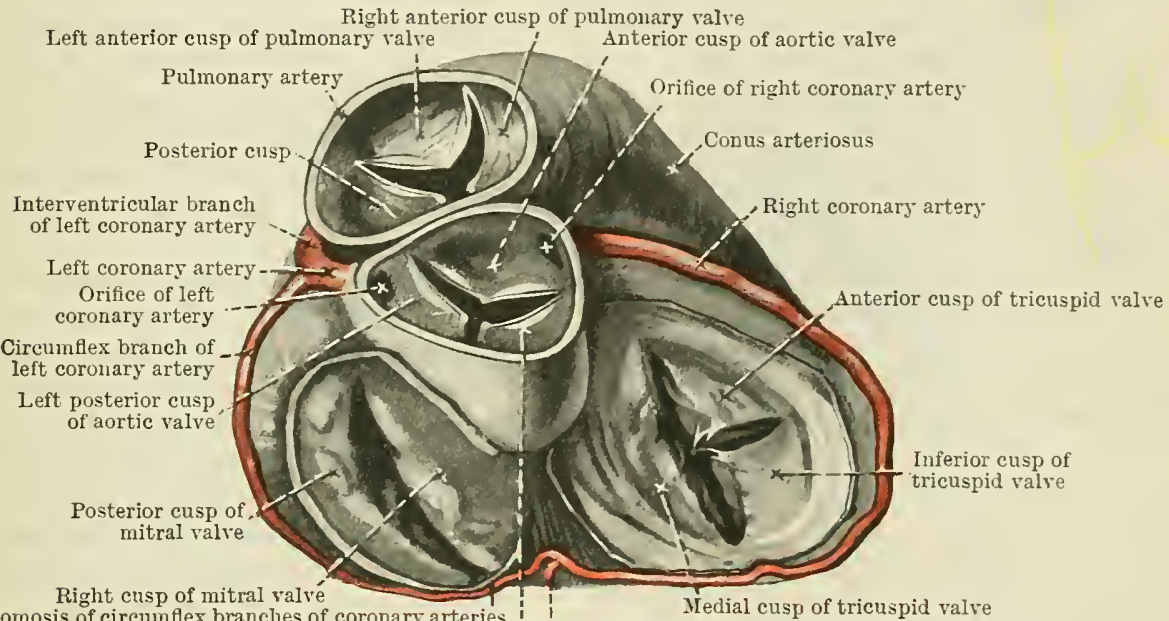

Anastomosis of circunflex branclies of coronary arteries

Right posterior cusp of aortic valve Interventricular branch of right coronary artery

Fig. 754.-The BaSes of THE Vextricles of the Heart, showing the auriculo-ventricular, aortic, and pulmonary orifices and their valves.

placed at the right margin of the orifice of the coronary sinus. It is almost invariably incompetent.

Atrium Sinistrum. - The left atrium is in relation posteriorly with the descending thoracic aorta and the cesophagus, but is separated from them by the pericardium. Below and anteriorly it is continuous with the left rentricle. Its sterno-costal surface is concave, and lies in close relation to the ascending aorta, the pulmonary artery, and the left coronary artery. Its right side, formed by the interatrial septum, is directed anteriorly and to the right. Its left side forms a very small portion of the left margin of the heart, and from it, at its junction with the antero-superior surface, the long and narrow auricle is prolonged forwards round the left side of the ascending portion of the aorta and the trunk of the pulmonary artery.

The four pulmonary veins enter the upper part of the posterior surface, two on each side.

The interior of the left atrium is lined with endocardium, and its walls are smooth, except in the auricle, where musculi pectinati are present, and on the septum, in a position corresponding with the upper part of the fossa oralis on the right side, where there are several musculo-fibrous bundles radiating anteriorly and upwards. These septal bundles are separated at their bases by small semilunar depressions, in the largest of which remains of the foramen ovale may be found. Foramina venarum minimarum, and the apertures of venæ cordis minimæ, are scattered irregularly over the inner aspect, whilst in the inferior 
part of the anterior boundary is the atrio-ventricular aperture. The latter is oval in form; its long axis is placed obliquely antero-posteriorly, and from left to right, and is capable of admitting two fingers. It is guarded by a valve formed of two large cusps, and is known as the mitral orifice.

Ventriculi.-The ventricular portion of the heart is conical and somewhat flattened. The base, directed upwards, and posteriorly, is partly continuous with the atrial portion and partly free. It is perforated by four orifices, the two atrio-ventricular, the aortic, and the pulmonary. The atrio-ventricular orifices are placed, one on each side, inferiorly and posteriorly; anteriorly and between

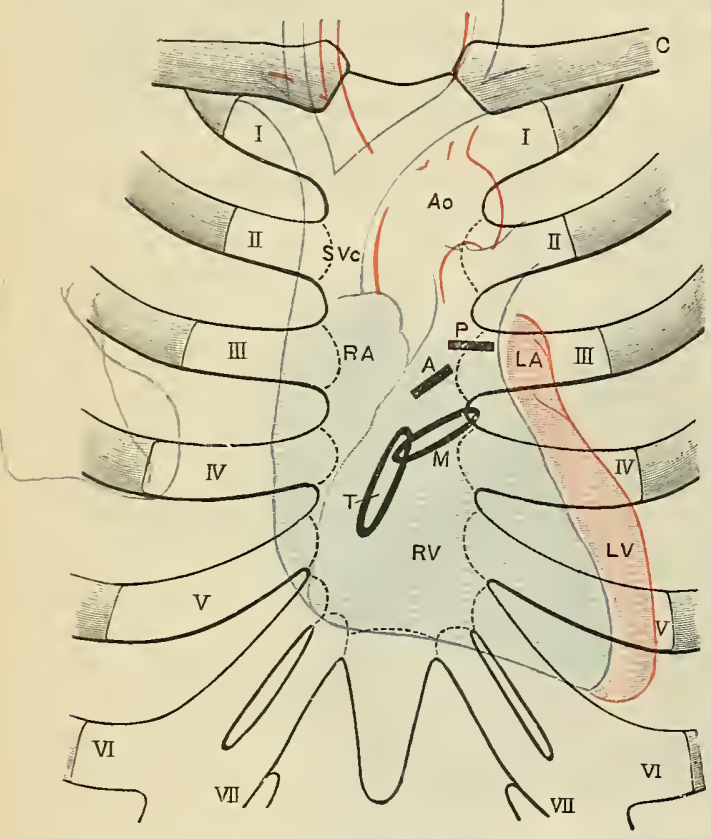

Fig. 755.-The Relations of the HeART AND THE Atrio - VeNTriCdLAR, AORTIC, AND PULMONARY Orifices to the ANTERIOR Thoracic WaLL.

I to VII, Costal cartilages. $A$, Aortic orifice.

Ao, Aorta.

C, Clavicle.

LA, Left atrium.

LV, Left ventricle. $\mathrm{P}$, Pulmonary orifice. RA, Right atrium. $R V$, Right ventriele. SVe, Superior vena cava. T, Tricuspid oritice.
M, Mitral orifice. them is the aortic orifice, whilst the orifice of the pulmonary artery is still more anterior, and slightly to the left of the aortic orifice.

In the triangle between the atrioventricular and the aortic orifices is embedded a mass of dense fibrous tissue which is the representative of the os cordis of the ox. It is continuous with the upper part of the interventricular septum, and with fibrous rings which surround the apertures at the bases of the ventricles.

The diaphragmatic surfaces and the sterno-costal surfaces of the two ventricles constitute respectively the greater portions of the corresponding surfaces of the heart; the former rest upon the diaphragm, whilst the latter are directed upwards and anteriorly towards the sternum and the costal cartilages of the left side. The apex of the left ventricle forms the apex of the heart.

The inferior margin, which is thin, forms the inferior margin of the heart; and the left margin, which is thick and rounded, forms the greater part of the left margin of the heart.

The ventricular portion of the heart is divided into right and left chambers by the ventricular septum, which is placed obliquely, with one surface directed anteriorly and to the right, and the other posteriorly and to the left; it bulges into the right ventricle, and its lower margin lies to the right of the apex of the heart, which is, therefore, formed entirely by the left ventricle. The margins of the septum are indicated on the two surfaces of the ventricular part of the heart by anterior and inferior interventricular sulci.

Ventriculus Dexter.-The right ventricle is triangular in form. Its base is directed upwards and to the right, and, in the greater part of its extent, it is continuous with the right atrium, with which it communicates by the atrioventricular orifice; but its left and anterior angle is free from the atrium, and gives origin to the pulmonary artery. Its inferior wall rests upon the diaphragm. The sterno-costal wall lies posterior to the lower part of the left half of the sternum and the cartilages of the fourth, fifth, and sixth ribs of the left side. The left or septal wall, which is directed posteriorly and to the left, bulges into its interior, and on this account the transverse section of the cavity has a semilunar outline. The cavity itself is a bent tube consisting of an inferior portion or body into which the atrio-ventricular orifice opens, and of an antero-superior part, the infundibulum or conus arteriosus, which terminates in the pulmonary artery. 
The angle between the two limbs is formed by a thick ledge of muscle, the supraventricular crest.

The right atrio-ventricular orifice is guarded by a tricuspid valve. The three cusps of this valve are an anterior, which intervenes between the atrio-ventricular orifice and the infundibulum, a medial or septal, and an inferior. Each cusp consists of a fold of endocardium, strengthened by a little intermediate fibrous tissue. The bases of the cusps are generally continuous with each other at the atrio-ventricular orifice, where they are attached to a fibrous ring, but they may be separated by small intermediate cusps which fill the angles between the main segments. The apices of the cusps project into the ventricle. The margins, which are thinner than the central portions, are notched and irregular. The atrial surfaces are smooth. The ventricular surfaces are roughened, and, like the margins and apices, they give attachment to fine tendinous cords, the chordæ tendineæ. The opposite extremities of the chordæ tendineæ are attached to muscular bundles, the musculi papillares, which project from the wall into the cavity of the ventricle.

The pulmonary orifice, which lies anterior and to the left of the tricuspid orifice, is guarded by a pulmonary valve composed of three semilunar segments, two of which are placed anteriorly and one posteriorly. The convexity or outer border of each semilunar segment is attached to the wall of the pulmonary artery. The inner border is free, and it presents at its centre a small nodule, the nodulus valvulæ semilunaris, and on each side of this body a small, thin marginal segment of semilunar form, the lunule. Each segment of the valve is formed by a layer of endocardium on its ventricular surface, an endothelial layer of the inner coat of the artery on its arterial surface, and an intermediate stratum of fibrous tissue. Both the attached and the free margins of the cusps are strengthened by fibrous bands, and strands of condensed fibrous tissue radiate from the outer borders to the noduli, but they do not enter the lunulæ. When the valve closes the noduli are closely apposed, the lunulæe of the adjacent segments of the valve are pressed together, and both noduli and lunulæ project vertically upwards into the interior of the artery.

The cavity of the right ventricle is lined with endocardium; the walls are smooth in the conus arteriosus, but are rendered rugose and sponge-like in the body by the inward projection of numerous muscular bundles, the trabeculæ carneæ. These bundles are of two kinds: the simpler are merely columns raised in relief on the wall of the ventricle; the other class are rounded bundles, free in the middle, but attached at each end to the wall of the ventricle. One special bundle of the second group, called the moderator band, is attached by one extremity to the septum, and by the other to the sterno-costal wall, at the base of the anterior papillary muscle; it tends to prevent over-distension of the cavity. In addition to the trabeculæ carneæ conical muscular eminences, the musculi papillares, project into the cavity of the ventricle. The bases of the papillary muscles are continuous with the wall of the ventricle, and their apices terminate in numerous chordæ tendineæ which are attached to the apices, the borders, and ventricular surfaces of the cusps of the tricuspid valve.

The musculi papillares of the right ventricle are-(1) a large anterior muscle, from which the chordre pass to the anterior and inferior segments of the valve; (2) a smaller and more irregular inferior muscle, sometimes represented by two or more segments, from which chordæe pass to the inferior and medial cusps; and (3) a group of muscular bundles, varying in size and number, which spring from the septum and are united by chordre to the anterior and medial cusps.

The walls of the right ventricle, the septal excepted, are much thinner than those of the left, but the trabeculie carneæ are coarser and less numerous in the right than in the left ventricle.

Ventriculus Sinister. - The left ventricle is a conical chamber, and its carity is oval in transverse section. The base is directed upwards and posteriorly, and in the greater part of its extent it is continuous with the corresponding atrium, with which it communicates through the mitral orifice; but anteriorly and to the 
right of its communication with the atrium it is continued into the ascending aorta.

The mitral orifice is oval; its long axis runs obliquely from above downwards and to the right, and it is guarded by a valve consisting of two cusps, which is known as the bicuspid or mitral valve. The two cusps of the valve are triangular and of unequal size. The smaller of the two is placed to the left and inferiorly; and the larger, placed to the right and anteriorly, between the mitral and aortic orifices, is known as the aortic cusp. The bases of the cusps are either continuous with each other at their attachments to the fibrous ring around the mitral orifice, or they are separated by small intermediate cusps of irregular form and size. The apices of the cusps project into the cavity of the ventricle. The atrial surfaces are smooth; the ventricular surfaces are roughened by the attachments of the chordæ tendineæ, which are connected also with the irregular and notched margins and with the apices. The structure is the same as that of the cusps of the tricuspid valve, but the ventricular surface of the anterior cusp is relatively smooth; therefore the blood flow into the aorta is not impeded.

The aortic orifice is circular; it lies immediately anterior and to the right of the mitral orifice, from which it is separated by the anterior cusp of the mitral valve, and it is guarded by the aortic valve, formed of three semilunar segments, one of which is placed anteriorly and the other two posteriorly. The structure of these cusps and their attachments are similar to those of the cusps of the pulmonary valve.

The cavity of the left ventricle is separable, like that of the right, into two portions, the body and the aortic vestibule; the latter is a small section placed immediately below the aortic orifice; its walls are non-contractile, consisting of fibrous and fibro-cartilaginous tissue. The wall of the cavity is lined by endocardium. ' The inferior wall and the apex are rendered sponge-like by numerous fine trabeculæ carneæ, whilst the upper part of the sterno-costal wall and the septum are relatively smooth.

There are two papillary muscles of much larger size than those met with in the right ventricle-an anterior and an inferior; each is connected by chordæ tendineæ with both cusps of the mitral valve.

The walls of the left ventricle are three times as thick as those of the right ventricle, and they are thickest in the region of the widest portion of the cavity, which is situated about a fourth of its length from the base. The muscular portion of the wall is thinnest at the apex, but the thinnest portion of the boundary is at the upper part of the septum, which consists entirely of fibrous tissue; this part is occasionally deficient, and an aperture is left through which the cavities of the two ventricles communicate.

The ventricular septum is a musculo-membranous partition. It is placed obliquely, one surface looking anteriorly and to the right, and bulging into the right ventricle, and the other looking posteriorly and to the left towards the left ventricle. Its sterno-costal and inferior margins correspond respectively with the anterior and the inferior portions of the interventricular sulcus, and it extends from the right of the apex to the interval between the pulmonary, the aortic, and the atrio-ventricular orifices. In the main part of its extent it is muscular, and this portion is developed from the wall of the ventricular part of the heart; but its upper and posterior portion, the pars membranacea, which is developed from the septum of the tunicus arteriosus, is entirely fibrous, and constitutes the thinnest portion of the ventricular walls. The pars membranacea lies between the aortic vestibule of the left ventricle, on the left, and the upper part of the right ventricle, and the lower and left part of the right atrium, on the right.

\section{Structure of the Heart.}

The walls of the heart consist mainly of peculiar striped muscle, the myocardium, which is enclosed between the visceral layer of the pericardium, or epicardium, externally, and the endocardium internally. The muscular fibres differ from those of ordinary voluntary striped 
muscle in several ways: they are shorter, many of them being oblong cells with forked extremities which are closely cemented to similar processes of adjacent cells; they form a reticulum, and the nuclei lie in the centres of the cells. Moreover, still more peculiar fibres, the fibres of Purkinje, are found immediately beneath the subendocardial tissue. These are large cells which unite with each other at their extremities; their central portions consist of granular protoplasm, in which sometimes one but more frequently two nuclei are embedded, and the peripheral portion of each cell is transversely striated. These cells, in short, present in a permanent form a condition which is transitory in all other striped muscle cells.

The reticulating cardiac muscle cells are grouped in sheets and strands which have a more or less characteristic and definite arrangement in different parts of the heart; by careful dis. section, and after special methods of preparation, it is possible to recognise many layers and bundles, some of which are, however, probably artificially produced.

In the atria the muscular fasciculi fall naturally into two groups: (a) superficial fibres common to both atria; $(b)$ deep fibres special to each atrium.

The superficial fibres are most numerous on the sterno-costal aspect and in the neighbourhood of the coronary sulcus. They run transversely across the atria and a few of them dip into the interatrial septum.

The deep fibres are-(1) looped fibres. The extremities of the looped fibres are attached to the fibrous rings around the atrio-ventricular orifices and the fibres pass antero-posteriorly over the atria. (2) Annular fibres which surround $(a)$ the extremities of the large vessels which open into the atria; $(b)$ the auricles; $(c)$ the fossa ovalis.

In the ventricles the muscular fasciculi form more or less definite $V$-shaped loops which commence from and end at the fibrous rings which surround the large orifices at the bases of the ventricles. In their courses the loops embrace the cavities of either one or both ventricles, one stem of each loop lying on the outer surface of the heart and the other in the interior, and some of the loops possessing very acute whilst others have very open bends.

The superficial fibres on the sterno-costal surface pass towards the left, those on the inferior surface towards the right. At the apex all are coiled into a whorl or vortex through which they pass into the interior of the ventricular walls and ascend towards the base, some in the septum and others in the papillary muscles. The various bundles which have been described can, according to Mall, be resolved into two main systems. One system arises from the conus arteriosus and the root of the aorta, that is from the remains of the primitive aortic trunk: it is called the "bulbo-spiral" system. The other springs from the region of the primitive venous sinus and is termed the "sino-spiral." Both systems are separable into superficial and deep portions, and the general plan of more or less spirally curved $V$-shaped loops is retained in each, but the details of the arrangement are too complicated for consideration within the limits of an ordinary text-book (see Amer. Journ. of Anat. vol. ii. 1910-1911).

The Atrio-Ventricular Bundle.-It would appear from the preceding description that the muscle-fibres of the atria and the ventricles are entirely separated from each other by the fibrous rings which surround the atrio-ventricular orifices; that, however, is not the case, for the two groups are connected together by a bundle of muscle fibres of pale colour and rudimentary structure, which lies immediately adjacent to the endocardium and constitutes the atrio-ventricular bundle.

The bundle commences in a nodular enlargement which lies in the lower part of the wall of the right atrium, close to the base of the medial cusp of the tricuspid valve. From this point the bundle runs along the posterior and lower borders of the membranous part of the ventricular septum to the upper and posterior part of the muscular portion of the septum, where it divides into right and left branches. The right branch runs along the right side of the ventricular septum to the moderator band, along which it passes into the anterior papillary muscle of the right ventricle. The left branch runs along the left side of the septum and both branches give off numerous ramifications, by means of which the main bundle is associated with all parts of the walls of the two ventricles.

Both the function and the origin of the atrio-ventricular bundle are uncertain. After the discovery of the bundle it was asserted that impulses were conveyed from the atria to the ventricles by the muscle fibres of the atrio-ventricular bundle and by then alone; more recently it has been shown that minute nerve fibrils are intimately interningled with the muscle fibres of the bundle, and it has yet to be decided whether the impulses which pass from the atria to the ventricles, for the purpose of maintaining the proper sequence of the movements of the chambers, travel by the nerve fibrils or the muscle fibres or by both.

The atrio-ventricular bundle is probably a remnant of the muscular continuity which existed in the early stages of development between the atrial and ventricular chambers of the heart, but it may be, wholly or in part, a new formation.

The epicardium, or visceral portion of the pericardium, consists of white connective and of elastic tissue, the latter forming a distinct retieulum in the deeper part. The surface which looks towards the pericardial cavity is covered with flat polygonal endothelial plates, which are partially separated, here and there, by stomata, through which the pericardial cavity communicates with the lynphatics of the ejicardium.

The endocardium lines the cardiac cavities and is contimuous with the inner coats of the vessels which enter and leave the heart. It consists, like the epicardimm, of white connective tissue and elastic fibres, but it is much thimner than the epicarlium, and its elastic fibres are in some places blended into a fenestrated membrane. Its inner surface is covered with endothelial cells, and it rests externally upon the subendocardial tissue, in which there are blood-ressels and nerves ; the endocardium itself is entirely devoid of vessels. 
Size of the Heart. -The heart is about $125 \mathrm{~mm}$. (fire inches) long, $87 \mathrm{~mm}$. (three and a half inches) broad; its greatest depth from its sterno-costal to its diaphragmatic surface is $62 \mathrm{~mm}$. (two and a half inches), and it is ronghly estimated as being about the same size as the closed fist. The size, however, is variable, the volume increasing at first rapidly, and then gradually, with increasing age, from $22 \mathrm{cc}$. at birth to $155 \mathrm{cc}$. at the fifteenth year, and to $250 \mathrm{cc}$. by the twentieth year. From this period to the fiftieth year, when the maximum volume $(280 \mathrm{cc}$.) is attained, the increase is much more gradual, and after fifty a slight decrease sets in. The volume is the same in both sexes up to the period of puberty, but thereafter it preponderates in the male.

Weight. - The average weight of the heart in the male adult is 310 grms. (11 ounces), and in the female adult 255 grms. (9 ounces); but the weight varies greatly, always, howerer, in definite relation to the weight of the body, the relative proportions changing at different periods of life.

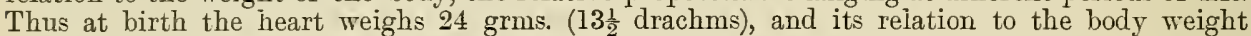
is as $I$ to 130 , whilst in the adult the relative proportion is as 1 to 205 . The heart is said to increase rapidly in weight up to the seventh year, then more slowly up to the age of puberty, when a second acceleration sets in ; but after the attainment of adult life the increase, which continues till the seventieth year, is very gradual.

The above changes affect the whole heart, but the several parts also vary in their relation to each other at different periods of life. During fœetal life the right atrium is heavier than the left ; in the first month after birth the two become equal, and at the second year the right again begins to preponderate, and it is heavier than the left during the remainder of life. In the latter part of fœtal life the two rentricles are equal; after birth the left grows more rapidly than the right, until, at the end of the second year, a position of stability is gained, when the right is to the left as 1 to 2 , and this proportion is maintained until death.

Capacity.-During life the capacity of the ventricles is probably the same, and each is capable of containing about four ounces of blood, whilst the atria are a little less capacious. After death the cavity of the right ventricle appears larger than that of the left.

Vascular Supply of the Heart.-The walls of the heart are supplied by the coronary arteries (p. 887), the branches of which pass through the interstitial tissue to all parts of the muscular substance and to the subendocardial and subepicardial tissues; the endocardium and the valves are devoid of vessels. The capillaries, which are numerous, form a close-meshed network around the muscular fibres. Sometimes the valves contain a few muscular fibres, and in these cases they also receive some minute vessels. The majority of the veins of the heart end in the coronary sinus, which opens into the lower part of the right atrium; some few very small veins, however, open directly into the right atrium, and others are said to end in the left atrium, and in the cavities of the ventricles.

Lymphatics of the Heart.-Iymphatic vessels are freely distributed throughout the whole substance of the heart. They all communicate with the superficial network which lies beneath the epicardium. The efferent vessels from this network accompany the coronary arteries to the atrio-ventricular suIcus and pass thence to the arterior mediastinal glands.

Nerves of the Heart. - The heart receives its nerves from the superficial and deep cardiac plexuses. The former lies beneath the aortic arch and the latter between the arch and the bifurcation of the trachea, and through the plexuses it is connected with the vagus, the accessory (through the vagus), and the sympathetic nerves. After leaving the cardiac plexuses many of the nerve-fibres enter the walls of the atria and anastomose together in the subepicardial tissue, forming a plexus in which many ganglion cells are embedded, especially near the terminations of the inferior vena cava and the pulmonary veins. From the subepicardial atrial plexus, nerve filaments, on which nerve ganglion cells have been found, pass into the substance of the atrial walls.

Other fibres from the cardiac plexuses accompany the coronary arteries to the ventricles, and upon these also ganglion cells are found in the region immediately below the coronary sulcus.

The nerve-fibres which issue from the ganglionated plexuses of the heart are non-medullated. They form fine plexuses round the muscle fibres, and they terminate either in fine fibrils on the surfaces of the muscle fibres, or in nodulated ends which lie in contact with the muscle cells.

\section{PERICARDIUM.}

The pericardium is a fibro-serous sac which surrounds the heart. It lies in the middle mediastinum, and is attached below to the diaphragm, and above and posteriorly to the roots of the great vessels. Anteriorly and posteriorly it is in relation with the structures in the corresponding mediastina and laterally it is in close apposition with the pleural sacs.

The fibrous pericardium is a strong fibrous sac of conical form; its base is attached to the central tendon and to the adjacent part of the muscular substance of the diaphragm, and it is pierced by the inferior vena cava. At its apex and posteriorly it is gradually lost upon the great vessels which enter and emerge from the heart, giving sheaths to the aorta, the two branches of the pulmonary artery, the superior vena cava, the four pulmonary veins, and the ligamentum arteriosum. Its anterior surface forms the posterior boundary of the anterior 
mediastinum, and it gives attachment, above and below, to the superior and inferior sterno-pericardial ligaments. In the greater part of its extent it is separated from the anterior wall of the thorax by the anterior margins of the lungs and pleural sacs, but it is in direct relation with the left half of the lower portion of the body of the sternum and, in many cases, with the medial ends of the cartilages of the fourth, fifth, and sixth ribs of the left side and the left transversus thoracis muscle. Its posterior surface forms the anterior boundary of the posterior mediastinum; it

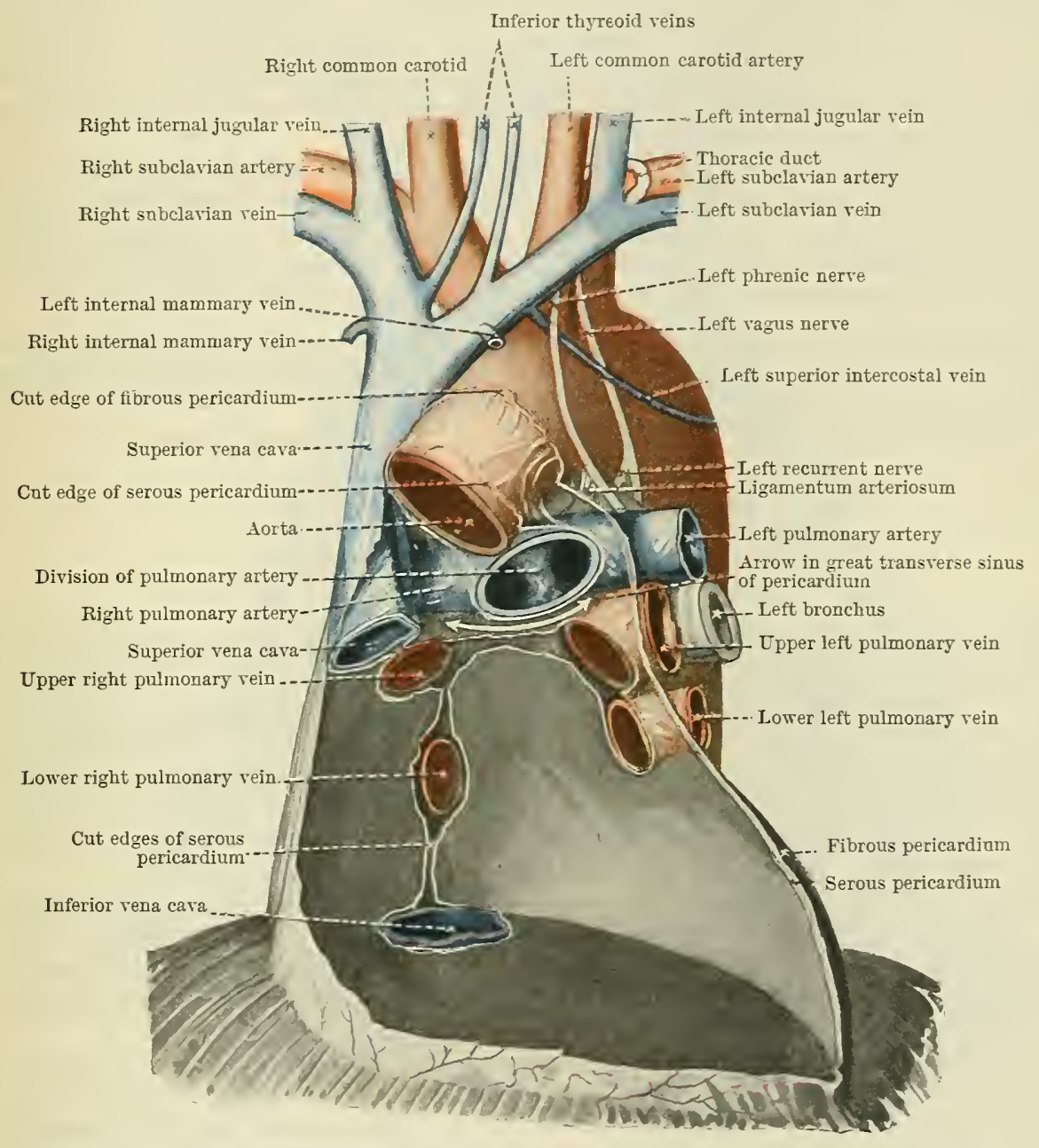

Fig. 756.-Posterior Wall of the Pericardium after the Remotal of the Heart. Showing the relation of the serous pericardium to the great ressels.

is in relation with the cesophagus and the descending aorta, both of which it separates from the back of the left atrium. Each lateral aspect is in close contact with the mediastinal portion of the parietal pleura, the phrenic nerve and its accompanying vessels intervening. The inner surface of the fibrous sac is lined by the serous pericardium, which is closely attached to it.

The serous pericardium is a closed sac containing a little fluid (liquor pericardii). It is surrounded by the fibrous pericardium and invaginated by the heart. It is, therefore, separable into two portions - the parietal, which lines the inner surface of the fibrous sac, and the risceral, which ensheaths, or partially ensheaths, the heart and the great vessels; but the two portions are, of course, continuous with each other where the serous layer is reflected on to the great vessels as they pierce the fibrous layer. The majority of the great vessels receire only partial corerings from the visceral layer: thus, the superior vena cava is covered anteriorly and on 
each side; the pulmonary veins anteriorly, above, and below; and the inferior vena cava anteriorly and on each side. The aorta and the pulmonary artery are enclosed together in a complete sheath of the visceral layer. Therefore, when the pericardial sac is opened from the front, it is possible to pass the fingers behind them and in front of the atria, from the right to the left side, through a passage called the great transverse sinus of the pericardium (Fig. 756). The spaces or pouches which intervene between the vessels which receive partial coverings from the serous pericardium are also called sinuses; and the largest of them, which is bounded below and on the right by the inferior vena cava, and above and on the left by the left inferior pulmonary vein, is known as the great oblique sinus. It passes upwards and to the right behind the left atrium, and lies anterior to the osophagus and the descending thoracic aorta.

A small fold of the serous pericardium, the vestigial fold, passes from the left pulmonary artery to the left superior pulmonary vein, posterior to the left extremity of the transverse sinus. It merits special attention because it encloses a fibrous strand, the ligamentum venæ cavæ sinistræ. This is a remnant of the left superior vena cava or duct of Cuvier, which atrophied at an early period of fœtal life.

Structure.-The fibrous pericardium consists of ordinary connective tissue fibres felted together into a dense, unyielding membrane. The serous pericardium is covered on its inner aspect by a layer of flat endothelial cells. These rest npon a basis of mixed white and elastic fibres in which run numerous blood-vessels, lymphatics, and nerves.

\section{ARTERIÆ.}

\section{ARTERIA PULMONALIS.}

The pulmonary artery springs from the anterior and left angle of the base of the right ventricle, at the termination of the conus arteriosus. It is slightly larger at its commencement than the aorta, and is dilated, immediately above the valves, into three pouches, the sinuses of the pulmonary artery. It runs upwards and posteriorly, towards the concavity of the aortic arch, curving from the front round the left side of the ascending aorta to reach a plane posterior to the latter; and it terminates, by dividing into right and left branches, opposite the sixth thoracic vertebræ. Its length is a little more than two inches.

Relations.-The pulmonary artery is enclosed within the fibrous pericardium, and is enveloped, along with the ascending aorta, in a common sheath of the visceral layer of the serous pericardium. It lies behind the anterior extremity of the second left intercostal space, from which it is separated by the anterior margins of the left lung and pleural sac.

Its posterior relations are the bulb of the aorta, the anterior wall of the left atrium, and the first part of the left coronary artery. To the right it is in relation with the right coronary artery, the auricle of the right atrium, and the ascending aorta, and to the left with the left coronary artery and the auricle of the left atrium. Immediately above its bifurcation, between it and the aortic arch, is the superficial cardiac plexus.

The right branch of the pulmonary artery is longer and larger than the left. It passes to the hilus of the right lung, forming one of the constituents of its root, and, entering the lung, descends, with the main bronchus, to the lower extremity of the organ.

Relations.-Before it enters the lung the right pulmonary artery passes posterior to the ascending aorta, the superior vena cava, and the upper right pulmonary vein. At first it lies below the arch of the aorta and the right bronchus, anterior to the osophagus, and above the left atrium and the lower right pulmonary vein; then it crosses anterior to the right bronchus, immediately below the eparterial branch, and reaches the hilus of the lung. After entering the lung the artery descends, posterior and lateral to the main bronchus and between its ventral and dorsal branches.

Branches.-Before entering the hilus it gives off a large branch to the upper lobe of the right lung which accompanies the eparterial bronchus, and in the substance of 
the lung it gives off numerous branches which correspond with and accompany the dorsal, ventral, and accessory branches of the right bronchus.

The left branch of the pulmonary artery, shorter, smaller, and somewhat higher in position than the right, passes laterally and posteriorly from the bifurca-

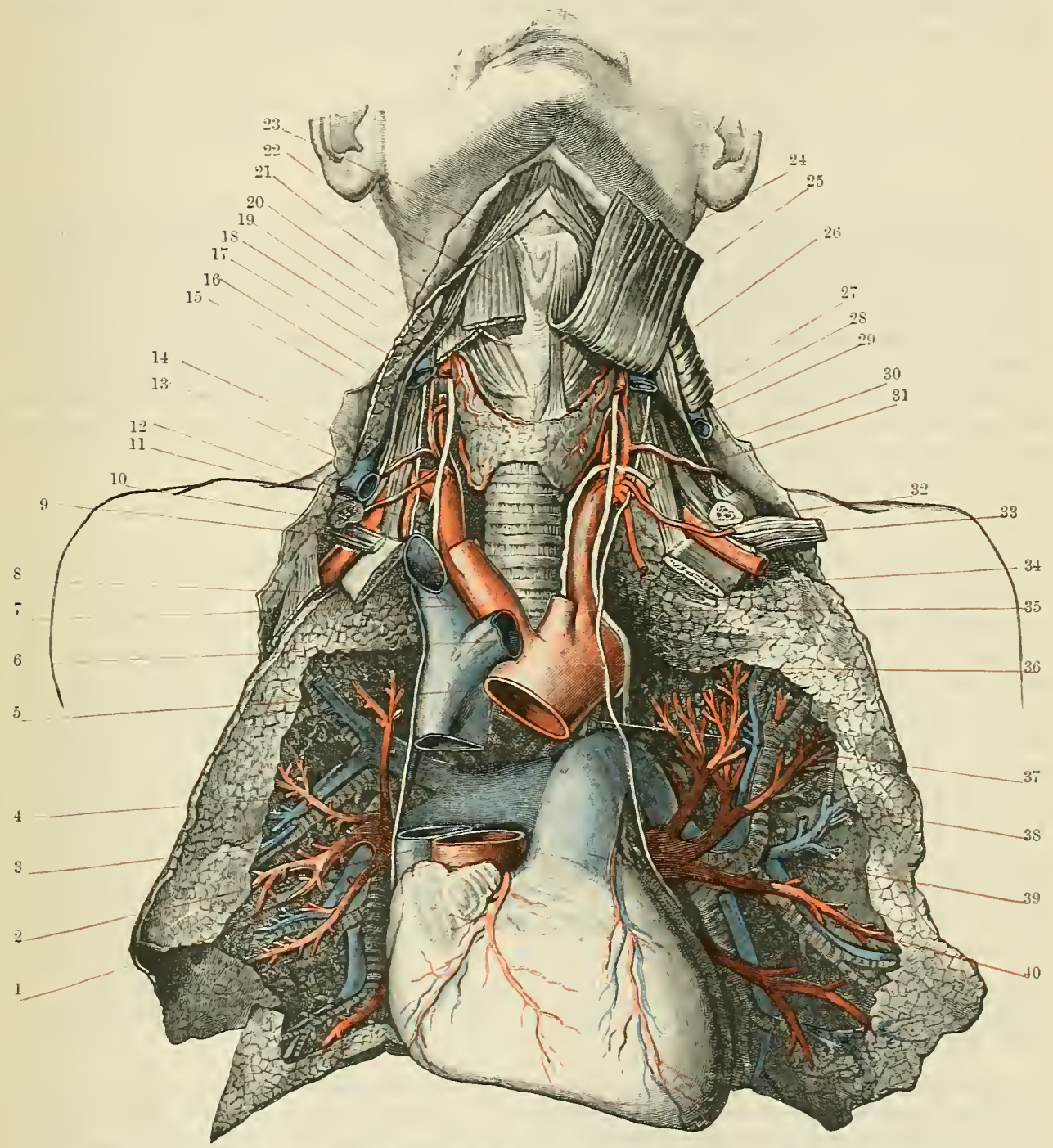

Fig. 757. - The PUlmonart Arteries axd Teiss axd their Relations in a Formalishardexed Preparatiox.

The ascending aorta and part of the superior rena cava have been removed.

1. Aorta.

2. Superior rena cara.

3. Upper right puluonary vein.

4. Right pulmonary artery.

5. Superior vena cava.

6. Left innominate rein

7. Innominate artery.

s. Right innonimate vein

9. Subclarius muscle.

10. Clavicle.

\begin{abstract}
11. Internal mamnary artery. 12. Subclavian vein.

13. Transverse scapular artery. 14. Transverse cervical artery. 15. Vertebral artery:

16. Inferior thyreoid artery.

17. Internal jugnlar vein.

18. Common carotid artery.

19. Superior thyreoid artery.

20. Sterno-thyreoid muscle.

21. Omo-hyoid muscle.
\end{abstract}

22. Sterno-hyoid muscle. 23. Platysms.

24. Sterno-hyoid nuscle. 25. Sterno-thyreoid muscle. 26. Sterno-mastoid muscle. 27. Phrenic nerve.

28. Vagts nerve.

29. Vertebral artery.

30. Inferior thyreoid artery. 31. Thoracic duct.

32. Left subclavian artery.
33. Subclavius muscle.

34. 1st rib.

35. Left conimon carotid artery:

37. Lorta. 38. Left pulmonary artery.

39. Upper left pulmonary 40. Pulmonary artery.

tion of the pulmomary stem, and runs, in the root, to the hilus of the left lung; it then descends, in company with the main bronchus, to the lower end of the lung.

Relations.-Before it enters the lung it is crossed, anteriorly, by the upper left pulmonary vein; posterior to it, are the left bronchus and the descending aorta ; above, are 
the aortic arch, to which it is connected by the ligamentum arteriosum, and the left recurrent nerve; below, it is in relation with the lower left pulmonary vein. After entering the lung it descends, like the right pulmonary artery, posterior and lateral to the stem bronchus, and between its ventral and dorsal branches.

Branches.-Just before passing through the hilus it gives off a branch to the upper lobe of the left lung, and in the substance of the lung its branches correspond with the rentral, dorsal, and accessory branches of the bronchial tube.

\section{THE SYSTEMIC ARTERIES.}

\section{AORTA.}

The aorta is the main trunk of the general arterial system. It commences at the base of the left ventricle and ascends, with an inclination to the right, to the level of the second right costal cartilage; then, curving backwards and to the left, it reaches the left side of the lower border of the fourth thoracic vertebra; finally it descends, through the thorax into the abdomen, and terminates, on the left of the median plane, at the level of the fourth lumbar vertebra, by bifurcating in to the two common iliac arteries. 'The portion of the aorta which is situated in the thorax is, for convenience, termed the thoracic aorta, and the rest of the vessel is known as the abdominal aorta.

\section{AORTA THORACALIS.}

The thoracic aorta is subdivided into aorta ascendens, arcus aortæ, and aorta descendens.

Aorta Ascendens.-The ascending aorta lies in the middle mediastinum. It springs from the base of the left ventricle, posterior to the left margin of the sternum, opposite the lower border of the third left costal cartilage and the body of the sixth thoracic vertebra. From its origin it passes upwards, anteriorly, and to the right, and it terminates in the arch of the aorta, posterior to the right margin of the sternum, at the level of the second costal cartilage. Its length is from 50 to $56 \mathrm{~mm}$. (2 to $2 \frac{1}{4}$ inches), and its breadth is $28 \mathrm{~mm}$. ( $1 \frac{1}{8}$ inches). In the adult it is a little narrower at its commencement than the pulmonary artery is, but in old age it enlarges and exceeds the latter vessel in size. The diameter, however, is not uniform throughout the whole length of the ascending aorta. Its dilated commencement, the bulbus aortæ, has three secondary dilatations, the sinus aortæ (Valsalva) in its wall, immediately above the semilunar cusps of the aortic valve; one is anterior in position, and two are situated posteriorly. At a higher level there is a diffuse bulging of the right wall, which is known as the grecit sinus of the aorta.

Relations.-The ascending aorta is completely enclosed within the fibrous pericardium which blends above with the sheath of the vessel, and it is enveloped, together with the stem of the pulmonary artery, in a tubular prolongation of the serous pericardium. At its origin it has the pulmonary artery in front, the anterior wall of the left atrium behind, and the auricle of the right atrium on its right side. In the upper part of its course the ascending aorta is overlapped by the anterior margins of the right lung and right pleural sac, whilst posterior to it are the right atrium, the right branch of the pulmonary artery, the right bronchus, and the left margin of the superior vena cava. The superior vena cava lies on the right side, and partly posterior to the upper part of the ascending aorta, whilst the pulmonary artery is at first anterior to it and then, at a higher level, on its left side.

Branches.- Two branches arise from the ascending aorta, viz., the right and the left coronary arteries. The right coronary artery springs from the anterior, and the left from the left posterior sinus of the aorta (Valsalva) (Fig. 751).

Arcus Aortæ.-The arch of the aorta lies in the superior mediastinum, posterior to the lower part of the manubrium sterni, and connects the ascending with the descending aorta. It commences posterior to the right margin of the sternum, on a level with the second costal cartilage, and extends to the left side of the lower 
border of the fourth thoracic vertebra. As its name implies, it forms an arch; and the arch makes two curves, one with the convexity upwards, and the other with the convexity forwards and to the left. From its origin it runs for a short distance upwards, posteriorly, and to the left, anterior to the trachea; then it passes posteriorly, round the left side of the trachea to the left side of the body of the fourth thoracic vertebra. Finally it turns downwards to become continuous with the descending aorta.

At its commencement it has the same diameter as the ascending aorta, $28 \mathrm{~mm}$. $\left(1 \frac{1}{8}\right.$ inches), but after giving off three large branches, the diameter is reduced to $23 \mathrm{~mm}$. (a little less than one inch).

Relations.-It is overlapped anteriorly and on the left side by the right and left lungs and pleural sacs, but much more by the left than the right, and in the interval between and posterior to the anterior borders of the pleural sacs it is corered by the remains of the thymus. As it turns backwards it is crossed vertically, on the left side, by four nerves in the following order from before backwards:-the left phrenic, the inferior cervical cardiac branch of the left vagus, the superior cardiac branch of the left sympathetic, and the trunk of the left vagus. The left superior intercostal vein passes obliquely upwards and to the right, across it, between the left vagus and left phrenic nerves.

Posterior to, and to the right side of the arch, are the trachea, the deep cardiac plexus, the left recurrent nerve, the left border of the œsophagus, and the thoracic duct. Above are its three large branches--the innominate, the left common carotid, and the left subclavian arteries; and crossing anterior to the roots of these is the left innominate vein. Below is the bifurcation of the pulmonary artery and the root of the left lung; the ligamentum arteriosum, which is also below, attaches it to the commencement of the left pulmonary artery, whilst to the right of the ligament is the superficial cardiac plexus, and to its left is the left recurrent nerve.

Branches.-The three great vessels which supply the head and neck, part of the thoracic wall, and the upper extremities-viz. the innominate, the left common carotid, and the left subclavian arteries-arise from the aortic arch.

Aorta descendens.-The thoracic portion of the descending aorta lies in the posterior mediastinum; it extends from the termination of the arch, at the lower border of the left side of the fourth thoracic vertebra, to the aortic opening in the diaphragm, where, opposite the twelfth thoracic vertebra, it becomes continuous with the abdominal portion. Its length is from 17.5 to $20 \mathrm{~cm}$. (seven to eight inches), and its diameter diminishes from $23 \mathrm{~mm}$. at its commencement to 21 $\mathrm{mm}$. at its termination.

Relations.-Immediately posterior to it are the vertebral column and the anterior longitudinal ligament. It rests also on the accessory hemiazygos and the hemiazygos veins, whilst from its posterior aspect the aortic intercostal branches are given off.

Anteriorly it is in relation, from above downwards, with the root of the left lung, the pericardium, which separates it from the back of the left atrium, the oesophagus with the cesophageal plexus of nerves, and the crura of the diaphragm which separate it from the caudate lobe of the liver. On the left side are the left lung and pleura. On the right side the thoracic duct and the vena azygos form immediate relations along its whole length. The cesophagus also lies to the right of the upper part of the descending aorta, whilst the right lung and pleura are in relation below.

Branches.-Nine pairs of aortic intercostal arteries, two left bronchial arteries, four or five osophageal, some small pericardial, and a few posterior mediastinal and superior phrenic branches, usually arise from the descending aorta.

\section{AORTA ABDOMINALIS.}

The abdominal portion of the descending aorta lies in the epigastric and umbilical regions of the abdomen. It extends from the middle of the lower border of the last thoracic vertebra to the body of the fourth lumbar vertiebra, where, to the left of the median plane, it bifurcates into the right and left common iliac arteries. The point of division is a little below and to the left of the umbilicus, opposite 
a line drawn transversely across the abdomen on a level with the highest points of the iliac crests.

At its commencement it is $21 \mathrm{~mm}$. in diameter, but after the origin of two large branches, the coliac and the superior mesenteric arteries, it diminishes considerably, and then retains a fairly uniform diameter to its termination.

Relations.-Posteriorly, it is in contact with the upper four lumbar rertebre and intervening fibro-cartilages, the anterior longitudinal ligament, and the left lumbar veins;

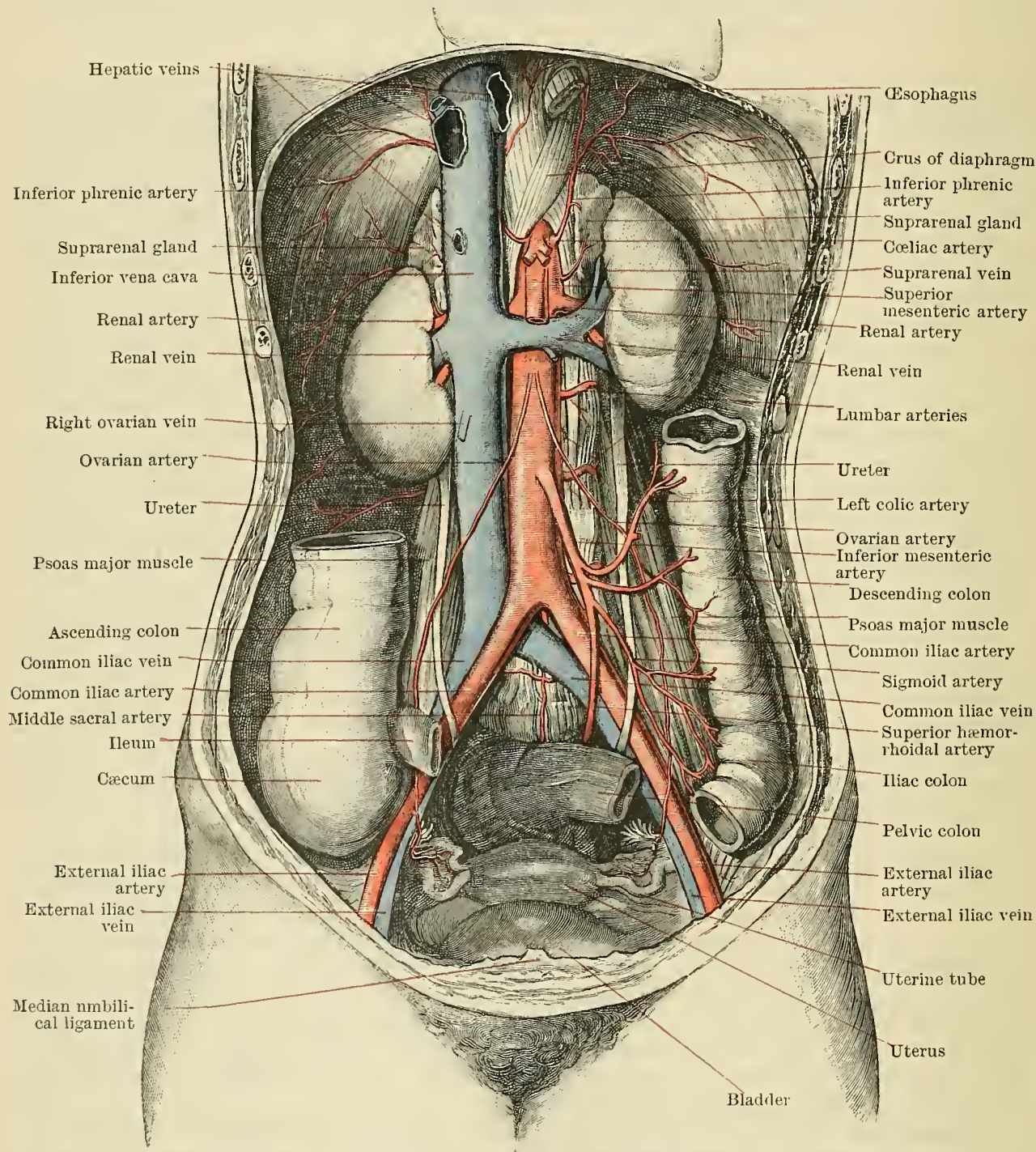

Fig. 758.-The Abdoninal Aorta and its Branches in a Formalin-hardened Preparation.

the lumbar and the middle sacral arteries spring from the posterior surface of the vessel. Anteriorly, and in close relation with it, there are from above downwards the following structures: the cœliac axis and cœliac plexus, the pancreas and splenic vein, the superior mesenteric artery, the left renal vein, the third part of the duodenum, the root of the mesentery, the aortic plexus, the inferior mesenteric artery, the peritoneum and coils of small intestine. More superficially the stomach, the transverse colon, and the greater and lesser omenta are in front. On the right side, in the upper part of its extent, are the thoracic duct and cisterna chyli, the vena azygos, and the right crus of the diaphragm, the latter separating it from the right coliac ganglion and from the upper part of the 
inferior vena cava. In its lower part it is in direct relation with the inferior vena cava. On the left side, the left crus of the diaphragm with the left cœliac ganglion, and the terminal portion of the duodenum, are in close relation with its upper part, whilst in the lower portion of its extent the peritoneum and some coils of the small intestine are in contact with it. Lumbar lymph glands lie around it on all sides.

Branches.-The branches form two groups, visceral and parietal, and each group consists of paired and unpaired vessels, as follows :-

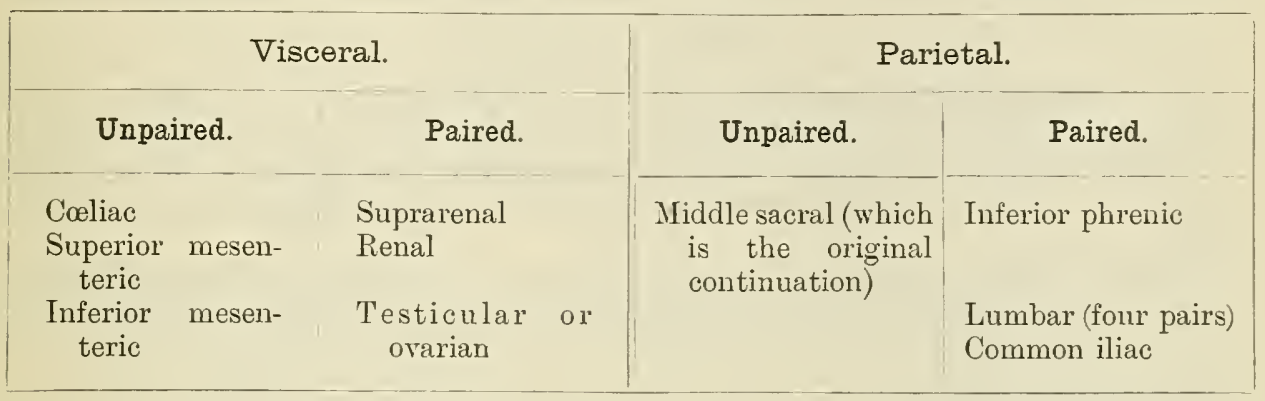

\section{BRANCHES OF THE ASCENDING AORTA.}

\section{Arterie CoRonarie.}

The coronary arteries are two in number, a right and a left; they are distributed almost entirely to the heart, but give also some small branches to the roots of the great vessels, and to the pericardium (Figs. 750, 751, and 754).

The right coronary artery springs from the anterior aortic sinus. It runs forwards, between the root of the pulmonary artery and the auricle of the right atrium, to the coronary sulcus, in which it passes to the right, and then, turning round the right margin of the heart, is continued to the left as far as the posterior end of the inferior interventricular sulcus, where it gives off its interventricular branch and then ends by anastomosing with the circumflex branch of the left coronary artery. It is accompanied by branches from the cardiac plexus, and is in relation with the right coronary vein.

Branches.-The interventricular branch runs forwards in the inferior interventricular sulcus, supplies both ventricles, and anastomoses, at the apex of the heart, with the interventricular branch of the left coronary artery.

Aortic and pulmonary twigs are distributed to the roots of the aorta and pulmonary artery respectively. A right atrial branch passes upwards on the anterior surface of the right atrium, between it and the ascending aorta; one or more anterior ventricular branches, of small size, descend on the anterior surface of the right ventricle; a branch of larger size, the right marginal artery, runs along the inferior margin and gives branches to both surfaces of the right ventricle.

The left coronary artery arises from the left posterior aortic sinus. Its trunk is short, and it runs forwards, between the root of the pulmonary artery and the left auricle, to the coronary sulcus at the upper end of the anterior interventricular groove, where it divides into a circumflex and an interventricular branch.

Branches.-The circumflex branch l'uns to the left margin of the heart, and there turns to the inferior surface where it comes into relation with the coronary sinus; it ends by anastomosing with the right coronary artery. It supplies branches to the left atrimm, the left margin of the heart, and the posterior part of the inferior surface of the left ventricle. The interventricular terminal branch passes down the anterior interventricular suleus to the apex of the heart, where it anastomoses with the interventricular branch from the right coronary; it supplies both ventricles, and is accompanied by cardiac nerves and by the great cardiac vein.

A left atrial branch or branches of small size pass to the wall of the left atrium, and small aortic and pulmonary branches are also given to the roots of the aorta and pulmonary artery.

\section{BRANCHES OF THE ARCH OF THE AORTA.}

The branches which arise from the arch of the aorta supply the head and neck, the upper extremities, and part of the body wall. 
They are three in number, viz., the innominate, the left common carotid, and the left subclavian arteries. The innominate is a short trunk, from the termination of which the right common carotid and the right subclavian arteries spring (Figs. 756 and 757 ); thus there is, at first, a difference between the stem vessels of opposite sides, but beyond this the subsequent course and the ultimate distribution of these vessels closely correspond.

\section{ARTERIA ANONYMA.}

The innominate artery (Fig. 757) arises, posterior to the middle of the manubrium sterni, from the convexity of the arch of the aorta near its right or anterior extremity, and it terminates opposite the right sterno-clavicular articulation, where it divides into the right subclavian and right common carotid arteries.

Course.-The trunk, which measures from 37 to $50 \mathrm{~mm}$. ( $1 \frac{1}{2}$ to 2 inches) in length, runs upwards, posteriorly, and laterally in the superior mediastinum and the root of the neck.

Relations.-Posterior.--It is in contact behind, with the trachea below and with the right pleural sac above.

Anterior.-The left innominate vein crosses in front of the lower part of the artery, and above this the sterno-thyreoid muscle separates it from the sterno-hyoid and the right sterno-clavicular joint. The remains of the thymus, which separate it from the manubrium sterni, are also in front.

Right Lateral.-The right innominate vein and the upper part of the superior vena cara are on the right side of the artery.

Left Lateral.-On its left side is the origin of the left common carotid artery, whilst at a higher level the trachea is in contact with it.

Branches.- Is a rule the innominate artery does not give off any branches except its two terminals, but occasionally it furnishes an additional branch, the thyreoidea ima.

The thyreoidea ima is an inconstant and slender vessel. When present it sometimes arises from the arch of the aorta, but it springs usually from the lower part of the innominate. It passes upwards, anterior to the trachea, through the anterior part of the superior mediastinum and the lower part of the neck, and gives off branches to the lateral lobes and isthmus of the thyreoid body and to the trachea.

\section{THE ARTERIES OF THE HEAD AND NECK.}

The vessels distributed to the head and neck are chiefly derived from the carotid trunks; there are, however, in addition, other vessels which arise from the main arterial stems of the upper extremities, and it will be advantageous to describe the most important of these, viz., the rertebral arteries, with the carotid system. The smaller additional branches will be considered along with the remaining branches of the subclavian arteries.

The carotid system of arteries consists, on each side, of a common carotid trunk, which divides into internal and external carotid arteries, from which numerous branches are given off.

The internal carotid arteries are distributed, almost entirely, to the contents of the cranial cavity, internal to the dura mater, and to the structures in the cavity of the orbit. The external carotid arteries, on the other hand, supply structures of the head and neck more externally situated.

It is to be observed, however, that the vascular supply of the brain is not wholly derived from the internal carotid vessels, but that the vertebral arteries also contribute largely to it.

\section{ARTERIE CAROTIDES COMMUNES.}

The right and the left common carotid arteries are of unequal length. The right common carotid commences at the bifurcation of the innominate artery 
posterior to the right sterno-clavicular articulation; the left arises in the superior mediastinum, from the arch of the aorta; but each terminates at the level of the upper border of the thyreoid cartilage; the left artery has thus a short intrathoracic course, and, so far, its relations call for separate consideration; whilst in the rest of its course it passes upwards in the neck, like the right common carotid, and has almost similar relations.

Thoracic Portion of the Left Common Carotid.-The thoracic or mediastinal portion of the left common carotid artery extends from the upper aspect of the aortic arch, immediately posterior and to the left of the origin of the innominate artery, to the left sterno-clavicular articulation, where the cervical portion commences. It is from 25 to $37 \mathrm{~mm}$. ( 1 or $1 \frac{1}{2}$ inches) in length, and it runs upwards and slightly laterally through the upper part of the superior mediastinum, lying on a more posterior plane than the innominate artery.

Relations.-Posterior.-The ressel is in contact posteriorly, and from below upwards, with the trachea, the left recurrent nerve, the œesophagus, and the thoracic duct; and the thoracic part of the left subclavian artery is a postero-lateral relation.

Anterior:-The left innominate rein runs obliquely across the anterior aspect of the artery, upon which cardiac branches from the left vagus and sympathetic descend rertically. These structures, together with the remains of the thymus and the anterior margins of the left lung and pleura, separate the artery from the manubrium sterni, and from the origins of the sterno-hyoid and sterno-thyreoid muscles.

Medial.-The innominate artery below, and the trachea above, are on the right side.

Lateral.-The left pleura, and, on a posterior plane, the left phrenic and ragus nerres and the left subclavian artery are on its left side.

Cervical Portion of the Left Common Carotid Artery.-The cervical part of the left common carotid artery is about $85 \mathrm{~mm}$. (three and a half inches) long; it extends from the left sterno-clavicular articulation to the level of the upper border of the thyreoid cartilage and the lower border of the third cervical vertebra, where it ends by dividing into the external and internal carotid arteries.

Course.-It runs upwards, laterally, and backwards, through the muscular and the lower portion of the carotid divisions of the anterior triangle of the neck. In the lower part of its extent it is separated from its fellow of the opposite side by the trachea and the csophagus, and in the upper part by the relatively wide pharynx.

Relations.-It is enclosed, together with the internal jugular vein and the vagus nerve, in a sheath of deep cervical fascia-the carotid sheath.

Posterior.-The longus colli and scalenus anterior below, and the longus capitis above, are separated from the posterior surface of the artery and its sheath by the prevertebral fascia and the sympathetic trunk. The vertebral artery and the thoracic duct are posterior to it at the level of the seventh cervical vertebra; the inferior thyreoid artery crosses behind it, either between it and the vertebral or between it and the transverse process of the sixth cervical vertebra, and the ragus nerve lies postero-lateral to it.

Superficial.-The descendens branch of the hypoglossal nerve lies superficial to the artery, usually outside the sheath, but sometimes enclosed in it. Opposite the sixth cervical vertebra the omo-hyoid muscle and the sterno-mastoid branch of the superior thyreoid artery cross superficial to the carotid artery, which is overlapped, above the omohyoid muscle, by the anterior border of the sterno-mastoid and by cervical lymph glands. It is frequently crossed, in this part of its extent, by the superior thyreoid rein. Below the omo-hyoid the artery is covered by the sterno-thyreoid, the sterno-hyoid, and the sterno-mastoid muscles, and it may be overlapped by the lateral lobe of the thyreoid gland; it is also crossed, deep to the muscles, by the middle thyreoid rein, whilst occasionally it communication between the common facial and anterior jugular veins descends anterior to the artery along the anterior border of the sterno-mastoid. Just above the sternum the anterior jugular vein is in front of the artery, but separated from it by the sternohyoid and sterno-thyreoid muscles.

Medial.-The trachea and œesophagus, with the recurrent nerve in the angle between them, are medial to the lower part of the artery; the pharynx and larynx are medial to its upper part. The carotid gland or glomus caroticum lies on the medial side of the termination of the artery. 
Lateral. - The internal jugular vein occupies the lateral part of the carotid sheath, and lies not only to the lateral side of the artery, but also overlaps it, especially in the lower part of its extent.

Branches.-As a rule no branches are given off from either of the common carotid arteries, except the terminal branches and some minute twigs from each to the corresponding carotid sheath and carotid gland.

The right common carotid artery, as already stated, differs as regards origin

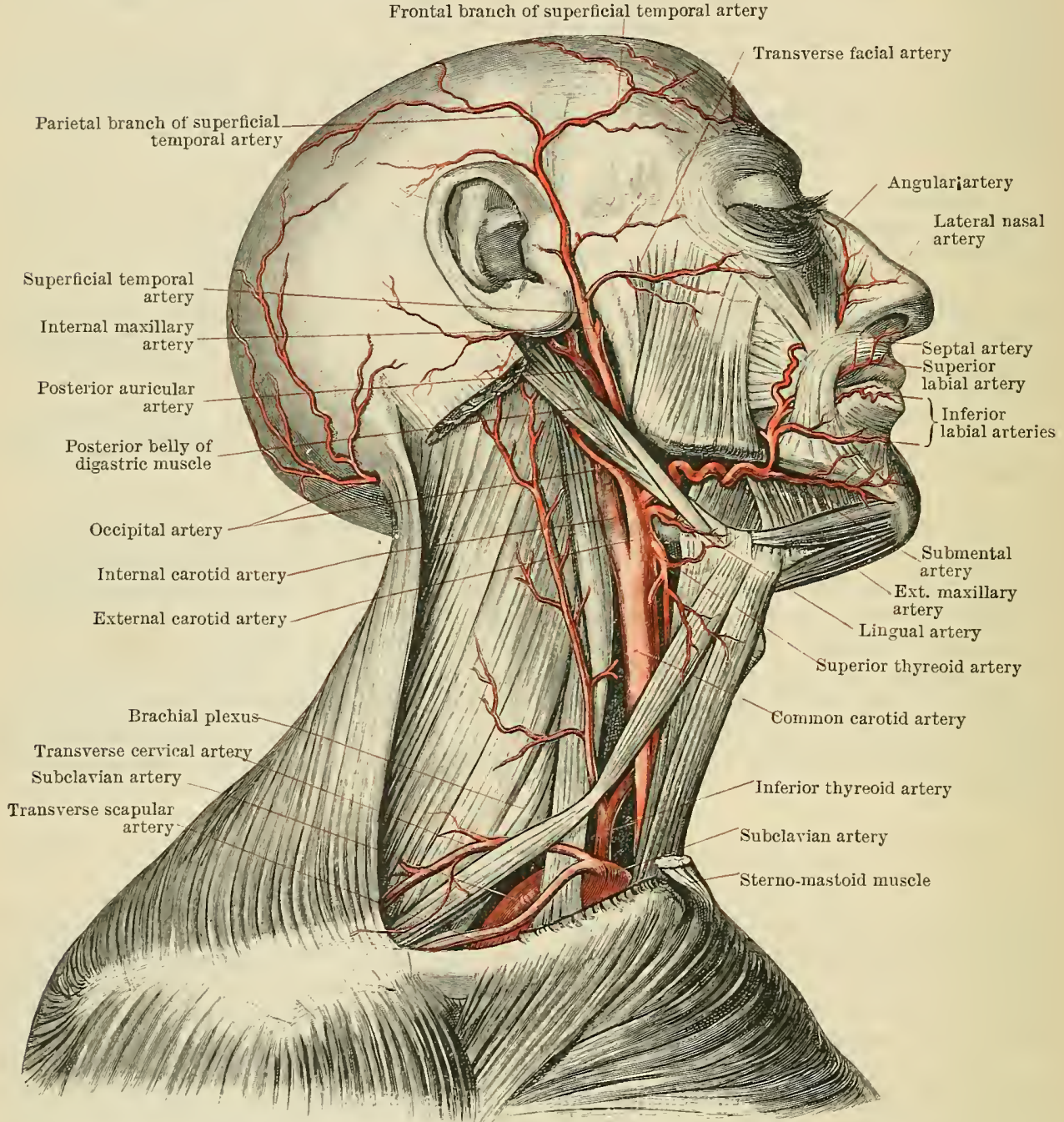

Fig. 759.-Dissection of the Carotid and Subclavian Arteries axd their Braxches.

from the left common carotid. In length and general position it corresponds with the cervical portion of the left common carotid, and its relations also are very similar. Such differences as exist may be briefly summarised as follows:-The internal jugular vein on both sides lies lateral to the artery; on the left side in the lower part of the neck it is anterior to the artery, whilst on the right side the vein is separated from the lateral surface of the artery, at its lower end, by a wellmarked interval in which the vagus nerve appears. The thoracic duct does not come into relation with the right common carotid, and there is also a difference in the relations of the recurrent nerves to the arteries on the two sides. On the left side the nerve crosses posterior to the mediastinal part of the left artery, and lies medial to its cervical part, whilst the corresponding nerve on the right side 
passes posterior to the lower part of the carotid artery in the neck to reach its medial side, and the œsophagus has a less intimate relation with the right than with the left common carotid artery.

\section{ARTERIA CAROTIS ENTERNA.}

The external carotid artery (Fig. 759) is the smaller of the two terminal branches of the common carotid; its length is about $62 \mathrm{~mm}$. ( $2 \frac{1}{2}$ inches). It extends from the upper border of the thyreoid cartilage to the back of the neck of the mandible, where it terminates by dividing into the superficial temporal and the internal maxillary arteries.

Course.-It commences in the carotid triangle, passes upwards, medial to the posterior belly of the digastric and the stylo-hyoid muscles and the lower part of the postero-medial surface of the parotid gland, then it enters a groove in the medial border of the gland, through which it passes to the upper part of the antero-medial surface, posterior to the neck of the mandible, where it terminates.

At its commencement it lies somewhat anterior and medial to the internal carotid artery, but, inclining posteriorly as it ascends, it becomes superficial to the latter vessel. Its course is indicated by a line drawn from the lobule of the ear to the posterior extremity of the greater cornu of the hyoid bone.

Relations.-Posterior:--In the lower part of its extent it is in close relation with the internal carotid; and in the upper part of its course with the antero-medial surface of the parotid gland.

Medial.-At its commencement the fibres of the inferior constrictor muscle are in contact with its medial side, but at a higher level the structures which intervene between it and the internal carotid-viz., the stylo-pharyngeus muscle, the tip of the styloid process, the stylo-glossus muscle, the glosso-pharyngeal nerve, and the pharyngeal branch of the vagus-separate it from the wall of the pharynx; whilst medial both to it and to the internal carotid artery are the external and internal laryngeal branches of the superior laryngeal nerve.

Superficial.-In the carotid triangle the lingual, common facial, and sometimes the superior thyreoid veins are superficial to it, and the hypoglossal nerve crosses the artery immediately below the origin of its occipital branch. At a higher lerel it is crossed superficially by the posterior belly of the digastric and the stylo-hyoid muscles, and from the tip of the mastoid process downwards it is overlapped by the anterior border of the sterno-mastoid muscle. Above the posterior belly of the digastric the parotid gland is superficial to the artery, while still more superficially are the superficial fascia and the skin. In the substance of the parotid gland the posterior facial vein (O.T. temporomaxillary) descends on the lateral side of the artery, and the facial nerve crosses on the lateral side of the vein, at right angles to it.

Branches.-Eight branches arise from the external carotid artery; of these, three-the superior thyreoid, the lingual, and the external maxillary-spring from its anterior aspect in the carotid triangle; two arise from its posterior aspect, viz., the occipital and the posterior auricular, the former commencing below the posterior belly of the digastric and the latter above it; one from its medial side, viz., the ascending pharyngeal, which arises in the carotid triangle; and two from its termination, viz., the superficial temporal and the internal maxillary.

\section{Branches of the External Carotid Artery.}

(1) Arteria Thyreoidea Superior. - The superior thyreoid artery (Figs. 759 and 761) springs from the anterior aspect of the lower part of the external carotid artery, just below the tip of the greater cornu of the hyoid bone, and terminates at the upper extremity of the lateral lobe of the thyreoid gland by dividing into its terminal branches.

Course.-From its commencement, in the carotid triangle, the artery runs downwards and forwards to its termination.

Relations.-Medially it is in relation with the inferior constrictor muscle and the external laryugeal branch of the superior laryngeal nerve.

Superficially it is covered at its origin by the anterior border of the sterno-mastoid; 
afterwards, for a short distance, by fascia, platysma, and skin, and in the lower part of its extent by the omo-hyoid, the sterno-hyoid, and the sterno-thyreoid muscles, and it is overlapped by an accompanying vein.

Branches.-(1) In the carotid triangle-(a) A hyoid branch runs along the lower border of the greater cornu of the hyoid bone, under cover of the thyreo-hyoid muscle, to anastomose with its fellow of the opposite side and with the hyoid branch of the lingual artery. It supplies the thyreo-hyoid muscle and membrane.

(b) The superior laryngeal branch runs forwards, deep to the thyreo-hyoid muscle. It pierces the thyreoid hyo-membrane, in company with the internal laryngeal nerve, supplies the muscles, ligaments, and mucous membrane of the larynx, and anastomoses with its fellow of the opposite side, with branches of the crico-thyreoid artery, and with the terminal branches of the inferior thyreoid artery.

(c) The sterno-cleido-mastoid branch passes downwards and posteriorly, along the upper border of the anterior belly of the omo-hyoid muscle and across the common carotid artery, to the deep surface of the sterno-mastoid muscle. It anastomoses, in the sternomastoid, with branches of the occipital and transverse scapular arteries.

(2) In the muscular triangle-(d) A crico-thyreoid branch passes anteriorly, either superficial or deep to the sterno-thyreoid, and crosses the crico-thyreoid muscle to anastomose in front of the crico-thyreoid ligament with its fellow of the opposite side, and, by branches which perforate the crico-thyreoid ligament, with laryngeal branches of the superior and inferior thyreoid arteries. It supplies the adjacent muscles and membrane.

(e) The terminal branches are anterior and posterior.

The anterior terminal branch descends along the anterior border of the lateral lobe of the thyreoid gland, and, extending on to the upper border of the thyreoid isthmus, anastomoses with its fellow of the opposite side. The posterior branch, larger than the anterior, descends along the posterior border of the lateral lobe. It is not uncommonly represented by a medial and a lateral branch. Both terminal branches supply glandular branches to the thyreoid gland. They anastomose with each other and with branches from the inferior thyreoid artery.

(2) Arteria Lingualis.-The lingual artery (Figs. 759 and 761) springs from the anterior aspect of the external carotid, opposite the tip of the greater cornu of the hyoid bone, and terminates, as the arteria profunda linguæ (O.T. ranine artery), which ends beneath the tip of the tongue, where it anastomoses with its fellow of the opposite side.

Course.-Whilst in the carotid triangle, the first part of the artery forms a loop with the convexity upwards. The second part passes forwards, medial to the hyoglossus muscle, immediately above the greater cornu of the hyoid bone, to the anterior border of the muscle, where it gives off a sublingual branch and becomes the arteria profunda linguæ. The profunda linguæ artery passes obliquely forwards and upwards, under cover of the anterior border of the hyo-glossus, and then turns directly forwards on the under surface of the tongue to the tip, lying between the inferior lingualis laterally and the genio-glossus medially.

Relations. - The first part of the lingual artery is crossed superficially by the hypoglossal nerve, and is covered by skin, fascia, and the platysma; it rests medially against the middle constrictor of the pharynx. The second part is deeper. It lies between the middle constrictor medially and the hyo-glossus laterally, and is separated by the latter from the hypoglossal nerve, the vena comitans hypoglossi, and the lower part of the submaxillary gland. The profunda artery of the tongue ascends almost vertically, parallel with and medial to the anterior fibres of the hyo-glossus, which is here covered by the mylohyoid, and between the hyoglossus and the genio-glossus; then it runs forwards between the inferior lingualis and the genio-glossus muscles, and is covered, on its lower surface, by the mucous membrane of the tongue. Thus, at its termination, near the frenulum linguæ, it is comparatively superficial.

Branches.- (a) The ramus hyoideus, a small branch which arises in the carotid triangle and runs along the upper border of the great cornu of the hyoid bone. It anastomoses with its fellow of the opposite side and with the hyoid branch of the superior thyreoid artery.

(b) The dorsalis linguæ is a branch of moderate size which arises from the second part of the artery and is not uncommonly double. It ascends between the hyo-glossus and the genio-glossus to the dorsum of the tongue, where it branches and anastomoses with its fellow of the opposite side around the foramen cæcum. It supplies the posterior part of 
the tongue as far back as the epiglottis, and sends branches, posteriorly, to the palatine tonsil which anastomose with the tonsillar twigs of the ascending palatine branch of the external maxillary and with the ascending pharyngeal artery.

(c) A sublingual branch arises at the lower part of the anterior border of the hyoglossus muscle and runs anteriorly and upwards, between the mylo-hyoid and the genioglossus, to the sublingual gland, which it supplies; it also supplies the mylo-hyoid, the genio-glossus, and the genio-hyoid muscles. It anastomoses with its fellow of the opposite side, with the arteria profunda by a branch which it sends along the frenulum linguæ, and through the mylo-hyoid muscle with the submental branch of the external maxillary.

(3) Arteria Maxillaris Externa (O.T. Facial). - The external maxillary artery (Fig. 759) springs from the front of the external carotid, immediately above the lingual, and terminates at the angle of the mouth, where it becomes the angular artery.

Course. - It commences in the carotid triangle immediately above the lingual, and passes upwards to the angle of the mandible, on the lateral surface of the middle constrictor muscle. Still ascending, it lies between the posterior belly of the digastric and the stylo-hyoid muscles laterally, and the superior constrictor medially, and it is separated from the palatine tonsil by the superior constrictor. When it reaches the upper border of the stylo-hyoid it enters a groove in the posterior end of the submaxillary gland through which it ascends. Then it turns downwards and anteriorly, between the lateral surface of the gland and the internal pterygoid muscle, and reaches the lower border of the masseter. There it pierces the deep cervical fascia, and, turning round the inferior border of the mandible, enters the face and continues upwards and medially to its termination.

Relations.-In the carotid triangle the artery is comparatively superficial, except just at its origin, which is overlapped by the anterior fibres of the sterno-mastoid muscle. As it ascends it is in relation, on the medial side, with the middle and superior constrictor muscles, and, as already stated, the superior constrictor separates it from the palatine tonsil. Its relations between its entrance into the groove in the posterior end of the submaxillary gland and the lower border of the mandible have been given in the description of its course.

After turning round the lower border of the body of the mandible, which it grooves slightly, the artery becomes more superficial than in any other part of its course, being corered only by platysma, fascia, and skin. At this point the anterior facial vein is immediately posterior to the artery, lying on the surface of the masseter. In the face the artery lies between the platysma, the risorius, the zygomaticus major, and the infraorbital section of the quadratus labii superioris (O.T. levator labii superioris), which, with skin and fascia, are superficial to it, and the buccinator and the musculus caninus (O.T. levator anguli oris), which are deeper. The termination of the artery is in the substance of the quadratus labii superioris.

The anterior facial vein, though still posterior to the artery in the face, runs a somewhat straighter course, and is situated at some little distance from it.

Branches.-Four named branches are given off in the neck, and several in the face.

In the Neck.-(a) The ascending palatine branch (Fig. 761) is a small artery which arises from the external maxillary under cover of the posterior belly of the digastric. It ascends, and, passing between the stylo-glossus and the stylo-pharyngeus muscles, reaches the apex of the petrous portion of the temporal bone, where it turns downwards, accompanying the levator veli palatini muscle, pierces the pharyngeal aponeurosis, and enters the soft palate.

It supplies the lateral wall of the upper part of the pharynx, the soft palate, the palatine tonsil, and the auditory (O.T. Eustachian) tube, and it anastomoses with the tonsillar branch of the external maxillary, the dorsalis lingure, the descending palatine branch of the internal maxillary, and with the ascending pharyngeal artery, which sometimes replaces it.

(b) The tonsillar branch, a small artery which arises close to the ascending palatine. It passes upwards between the internal pterygoid and the stylo-glossus, pierces the superior constrictor, and terminates in the palatine tonsil. It supplies the middle and superior constrictor museles, and it anastomoses with the dorsalis lingnæ, with the ascending palatine branch, and with the ascending pharyngeal artery.

(c) The submaxillary or glandular branch is frequently represented by two or three small twigs which pass directly into the submaxillary gland. 
(d) The submental branch arises from the external maxillary just as the latter vessel turns round the inferior border of the mandible. It is the largest branch given off in the neck, and it runs forwards, on the lateral surface of the mylo-hyoid muscle, and medial to the upper part of the submaxillary gland, to the symphysis menti, where it turns upwards, round the margin of the mandible, and terminates by anastomosing with branches of the mental and inferior labial arteries. In the neck the submental artery supplies the mylohyoid muscle, and the submaxillary and sublingual glands, the latter by a branch which perforates the mylo-hyoid muscle. It anastomoses with the mylo-hyoid branch of the inferior dental and with the sublingual artery. In the face it supplies the structures of the lower lip, and anastomoses with the mental branch of the inferior dental, and with the inferior labial branches of the external maxillary artery.

In the Face.-(e) The inferior labial branch (O.T. inferior coronary) arises from the front of the external maxillary artery below the level of the angle of the mouth. It runs medially, deep to the triangularis, the quadratus labii inferioris, and the orbicularis oris. In the substance of the lower lip it lies close to the mucous membrane and anastomoses, in the median plane, with its fellow of the opposite side. It supplies the structures in its immediate neighbourhood.

(f) The superior labial (0.T. superior coronary) springs from the front of the external maxillary about the level of the angle of the mouth. It runs medially, between the orbicularis oris and the mucous membrane of the upper lip, to the median plane, supplying the skin, muscles, and mucous membrane of the upper lip, and, by a septal branch, the lower and anterior part of the septum of the nose. It anastomoses with its fellow of the opposite side, with the lateral nasal, and, on the septum nasi, with the septal branch of the spheno-palatine artery.

(g) The masseteric branch, sometimes represented by several twigs, arises from the posterior aspect of the facial trunk a short distance above the lower margin of the mandible. It passes upwards and posteriorly, across the masseter, and anastomoses with the transverse facial artery.

(h) The buccal is an inconstant branch which, when present, arises from the posterior aspect of the external maxillary artery above the masseteric branch. It runs upwards and posteriorly, across the buccinator muscle, to anastomose with the buccinator branch of the internal maxillary artery.

(i) The lateral nasal springs from the external maxillary at the point where it becomes the angular. It ramifies on the ala of the nose, supplying the skin, muscles, and alar cartilages, and anastomosing with the angular branch, with the dorsal nasal branch of the ophthalmic, and with branches of the spheno-palatine artery.

$(j)$ The angular artery is the continuation of the external maxillary beyond the origin of the lateral nasal branch. It runs upwards, in the angular head of the quadratus labii superioris, to the medial commissure of the eye, where it anastomoses with the lateral nasal, and with the nasal and palpebral branches of the ophthalmic artery.

In addition to the above-named branches another branch, formerly called the inferior labial, springs from the anterior aspect of the external maxillary below the level of the alveolar border of the mandible. This vessel runs medially, under cover of the muscles of the lower lip, and it anastomoses with the mental branch of the inferior alveolar artery, with the inferior labial (O.T. inferior coronary), and with its fellow of the opposite side.

(4) Arteria Occipitalis.--The occipital artery (Figs. 759, 760) arises from the posterior aspect of the external carotid artery, below the posterior belly of the digastric muscle, and terminates near the medial end of the superior nuchal line of the occipital bone by dividing into medial and lateral terminal branches.

Course.-It commences in the carotid triangle and runs upwards and posteriorly, parallel with and under cover of the posterior belly of the digastric, to the interval between the transverse process of the atlas and the base of the skull, where it turns posteriorly in a groove on the lower surface of the mastoid portion of the temporal bone; as it leaves the groove it alters its direction and runs upwards and medially, on the superior oblique muscle, to the junction of the medial and intermediate thirds of the superior nuchal line of the occipital bone, where it pierces the deep fascia of the neck and enters the superficial fascia of the scalp.

Relations. - In the first or ascending part of its course the occipital artery crosses successively the internal carotid artery, the hypoglossal nerve, the vagus nerve, the internal jugular vein, and the accessory nerve; it is covered by the lower fibres of the posterior 
belly of the digastric and the anterior part of the stermo-mastoid muscle, and, close to its origin, it is crossed by the hypoglossal nerve. In the second, or more horizontal part of its course, it is still under cover of the sterno-mastoid and digastric, and lies, medially, against the rectus capitis lateralis, which separates it from the vertebral artery. In the third part of its course it rests upon the superior oblique and semispinalis capitis (O.T. complexus), and is under cover of the sterno-mastoid, the splenius capitis, and the longissimus capitis muscles. At its termination it is crossed by the great occipital nerve; it passes either through the trapezius or between the trapezius and the sterno-mastoid, and pierces the deep fascia of the neck before it enters the superficial fascia of the scalp.

Branches.-(a) Muscular branches go to the surrounding muscles. The sternomastoid branch is the most important of this group; it spriugs from the commencement of the occipital, is looped downwards across the hypoglossal nerve, and is continued downwards and posteriorly, below and anterior to the accessory nerve, into the sterno-mastoid muscle, where it anastomoses with the sterno-mastoid branch of the superior thyreoid artery.

(b) The meningeal are irregular branches given off from the occipital, anterior to the mastoid process. They enter the posterior fossa of the skull through the hypoglossal canal, or through the jugular foramen; they supply the upper part of the internal jugular rein, the transverse sinus, and the dura mater in the posterior fossa of the skull, and they anastomose with the middle meningeal and with meningeal branches of the ascending pharyngeal artery.

(c) The mastoid, a small and inconstant branch given off from the occipital posterior to the mastoid process. It enters the posterior fossa of the skull through the mastoid foramen, supplies the dura mater, and anastomoses with branches of the middle meningeal artery.

(d) The descending branch (O.T. princeps cervicis) is given off from the occipital upon the surface of the superior oblique. It passes medially to the lateral border of the semispinalis capitis, where it divides into superficial and deep branches. The superficial, branch runs over the semispinalis capitis, between it and the trapezius, and anastomoses with the superficial cervical artery. The deep branch runs between the semispinalis capitis and the underlying semispinalis cervicis, and anastomoses with branches of the vertebral and profunda cervicis arteries.

(e) The auricular is an inconstant branch which, as a rule, is only given off from the occipital when the posterior auricular artery is absent. It ramifies over the mastoid process, and supplies the medial surface of the auricle.

(f) The terminal branches (rami occipitales) are medial and lateral. They ramify in the superficial fascia of the posterior part of the scalp, anastomosing with the posterior auricular and superficial temporal arteries, and both are accompanied by branches of the great occipital nerre. The medial branch gives off a meningeal twig, which passes into the skull through the parietal foramen, to supply the walls of the superior sagittal sinus and to anastomose with the middle meningeal artery.

(5) Arteria Auricularis Posterior.-The posterior auricular artery (Figs. 759, 760) springs from the posterior aspect of the external carotid immediately above the posterior belly of the digastric muscle, and terminates between the mastoid process and the back of the auricle by dividing into mastoid and auricular branches.

Course and Relations.-Commencing at the upper border of the posterior belly of the digastric, it runs upwards and posteriorly, under cover of the posteromedial surface of the parotid gland, to the interval between the mastoid process and the external acoustic meatus. It is accompanied in the terminal part of its course by the posterior auricular branch of the facial nerve.|

Branches.-(a) Muscular branches are giren to the sterno-mastoid, the digastric, and the styloid group of muscles.

(b) Parotid branches pass to the lower and posterior part of the parotid gland.

(c) A stylo-mastoid branch is given off at the lower border of the external acoustic meatus. It runs upwards, by the side of the facial nerve, enters the stylo-mastoid foramen, and ascends, in the canalis facialis (Fallopius), to the upper part of the medial wall of the tympanum, where it terminates by anastomosing with the petrosal branch of the middle meningeal artery. It supplies branches to the external acoustic meatus, the mastoid cells, the restibule, and semicircular canals, the stapedius muscle, and a posterior tympanic branch which anastomoses with the anterior tympanic branch of the internal maxillary, forming, iu young subjects, a vascular circle around the membrana tympani ; other branches 
anastomose with tympanic branches from the internal carotid and the ascending pharyngeal arteries, and with the internal auditory branch of the basilar.

(d) The auricular branch ascends medial to the posterior auricular muscle. It gives branches to the auricle and to the scalp in the posterior part of the temporal region, which anastomose with the superficial temporal and occipital arteries. The auricular branches supply both surfaces of the anricle, piercing or turning round the margins of the cartilage to gain the lateral surface, and they anastomose with the anterior auricular branches of the superficial temporal artery.

(e) The occipital branch runs upwards and posteriorly along the insertion of the sterno-mastoid muscle. It supplies the sterno-mastoid and occipitalis muscles, and the skin, and it anastomoses with the occipital artery.

(6) Arteria Pharyngea Ascendens-The Ascending Pharyngeal Artery (Fig. 761).-This artery arises from the medial surface of the lower part of the external carotid, and its terminal branches are distributed to the wall of the pharynx and in the soft palate.

Course.-Commencing in the carotid triangle, usually as the first or second branch of the external carotid, it ascends on the wall of the pharynx to the apex of the petrous portion of the temporal bone.

Relations.--Medially it is in relation with the constrictor muscles of the pharynx. Posterior to it are the transverse processes of the cervical vertebræ, the sympathetic trunk, and the longus capitis. Laterally it is in relation with the internal carotid artery, and it is crossed by the stylo-pharyngeus muscle, the glossopharyngeal nerve, and the pharyngeal branch of the vagus.

Branches. - The branches of this artery are very irregular and inconstant, but the following have received names:-

(a) Pharyngeal Branches.-Small twigs which ramify on the walls of the pharynx and supply the middle and superior constrictor muscles, the palatine tonsil, and the lower part of the auditory tube (0.T. Eustachian). They anastomose with branches of the superior thyreoid, lingual, and external maxillary arteries.

(b) Prevertebral. - Small branches distributed to the prevertebral muscles and fascia, the deep cervical glands, and the large nerve trunks. They anastomose with the ascending cervical and vertebral arteries.

(c) Posterior Meningeal.-One or more small branches which enter the cranium by the hypoglossal canal, the jugular, or the lacerate foramen, and supply the dura mater. They anastomose with branches of the middle meningeal and vertebral arteries.

(d) Inferior Tympanic.-A small artery which accompanies the tympanic branch of the glossopharyngeal nerve to the tympanic cavity, where it anastomoses with the other tympanic arteries.

(e) Palatine.-A very variable artery which sometimes replaces the ascending palatine branch of the external maxillary artery. When present it springs from the upper part of the ascending pharyngeal artery, pierces the pharyngeal aponeurosis above the upper border of the superior constrictor muscle, and descends into the soft palate with the levator veli palatini muscle. It supplies the mucous membrane of the supero-lateral part of the pharyngeal wall and the tissues of the soft palate, and it anastomoses with the palatine branches of the internal maxillary, the external maxillary and the lingual arteries.

(7) Arteria Temporalis Superficialis (Fig. 759).-The superficial temporal artery, one of the terminal branches of the external carotid, commences between the upper part of the antero-medial surface of the parotid gland, and the neck of the mandible, and terminates in the scalp, from 25 to $50 \mathrm{~mm}$. ( 1 or 2 inches) above the zygomatic arch, by dividing into a parietal and a frontal branch.

Course.-The artery ascends over the posterior root of the zygoma, and passes into the superficial fascia of the temporal region. It is accompanied by the auriculo-temporal nerve and by the superficial temporal vein, which usually lies posterior to it. As it crosses the zygoma it is covered by the skin alone, and it may be easily compressed against the subjacent bone.

Branches.-(a) Parotid.-Small branches to the upper part of the parotid gland.

(b) Articular - to the mandibular articulation.

(c) Anterior Auricular.- Small branches to the lateral surface of the auricle and to the external acoustic meatus. They anastomose on the surface of the auricle with branches 
of the posterior auricular artery, and in the external acoustic meatus with branches of the internal maxillary artery.

(d) Transverse Facial. - A branch of moderate size which emerges from under corer of the upper part of the anterior border of the parotid gland, runs forwards across the masseter, below the zygoma and above the parotid duct, accompanied by zygomatic branches of the facial nerve, which may lie either above or below it. It is distributed to the parotid gland, the masseter, parotid duct, and the skin, and it terminates in branches which anastomose with the infra-orbital and buccinator branches of the internal maxillary artery and with the buccal and masseteric branches of the external maxillary artery.

(e) Middle Temporal. - A branch which usually springs from the commencement of the superficial temporal. It crosses the zygoma, pierces the temporal fascia and the temporal

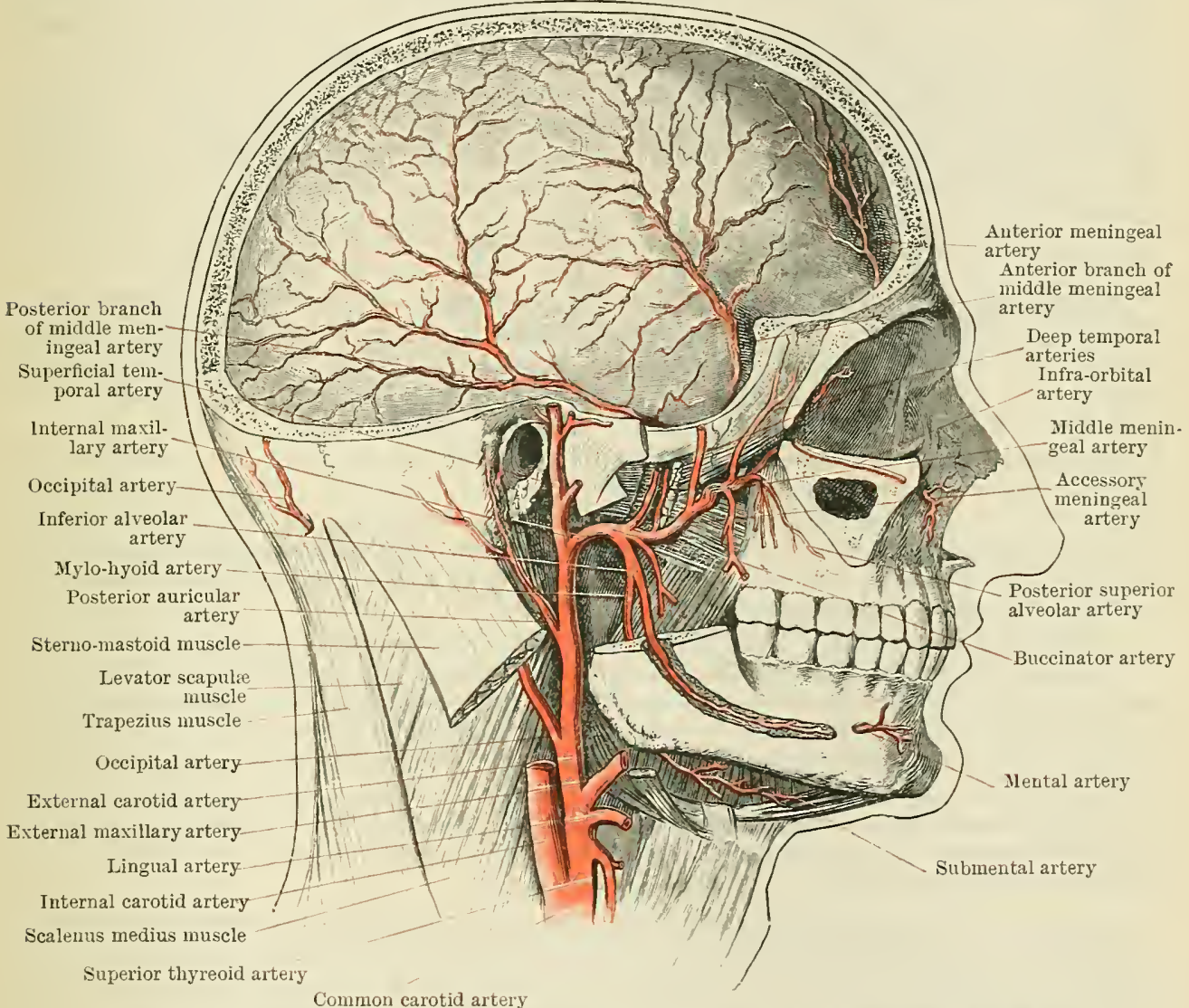

Fig. 760.--The External Carotid, Internal Maxillary, axd Mentngeal Arteries.

muscle, and terminates in the temporal fossa by anastomosing with the deep temporal branches of the internal maxillary artery.

(f) Zygomatico-orbital.- This branch may spring directly from the superficial temporal, but it is frequently a branch of the middle temporal. It runs anteriorly, above the zygoma, between the two layers of the temporal fascia. It supplies branches to the orbicularis oculi, and anastomoses, through the zygomatic bone and round the outer margin of the orbit, with the lacrimal and palpebral branches of the ophthalmic artery.

(g) The frontal branch runs forwards and upwards, in a tortuous course, through the superficial fascia of the scalp towards the frontal tuberosity, lying at first upon the temporal fascia, and then upon the galea aponeurotica. It supplies the frontalis and the orbicularis oculi, and anastomoses with the lacrimal and supra-orbital branches of the ophthalmic artery, with the parietal terminal branch of the superficial temporal, and with its fellow of the opposite side.

(h) The parietal branch, less tortuons than the frontal, runs upwards and posteriorly in the superficial fascia of the scalp. It anastomoses, anteriorly, with the frontal terminal branch, posteriorly with the posterior: auricular and occipital arteries, and, across the 
median line, with its fellow of the opposite side. It supplies the skin and fascia, and the anterior and superior muscles of the auricle.

(8) Arteria Maxillaris Interna.-The internal maxillary artery commences between the antero-medial surface of the parotid gland and the neck of the mandible, and terminates in the pterygo-palatine fossa.

Course and Relations.-Although the internal maxillary artery is only a short trunk it has many important relations, in the consideration of which it is convenient to divide the ressel into three parts. The first part extends from the back of the neck of the mandible into the infratemporal fossa, as far as the lower border of the external pterygoid muscle. It lies between the spheno-mandibular ligament and the neck of the mandible, along with the auriculo-temporal nerve and the internal maxillary vein. The second part is in the infratemporal fossa, and runs upwards and anteriorly. It may lie on the lateral or the medial side of the lower head of the external pterygoid muscle. In the former case it is situated between the temporal and external pterygoid muscles, and in the latter between the external pterygoid muscle and the branches of the mandibular division of the trigeminal nerve. The third part passes between the upper and the lower heads of the external pterygoid, through the pterygo-maxillary fissure and into the pterygo-palatine fossa.

Branches.-From the first part.-(a) Deep auricular. A small branch which arises from the commencement of the artery and passes upwards to the external acoustic meatus. It supplies the mandibular joint, the parotid gland, the exterual acoustic meatus, and the superficial surface of the tympanic membrane. It anastomoses with branches of the superficial temporal and posterior auricular arteries.

(b) The anterior tympanic, a variable and small branch. It runs upwards and posteriorly, traverses the petro-tympanic fissure (Glaserian), and enters the tympanum through its lateral wall. In the tympanic cavity it anastomoses with tympanic branches from the interual carotid and ascending pharyngeal arteries, and with the stylo-mastoid branch of the posterior auricular, forming with the latter, in young subjects, a circular anastomosis around the tympanic membrane.

(c) Middle Meningeal. - The largest branch of the internal maxillary. It ascends between the external pterygoid muscle laterally and the spheno-mandibular ligament and the tensor veli palatini medially; passes between the two roots of the auriculo-temporal nerve and through the foramen spinosum, and enters the middle fossa of the cranial cavity. Before it enters the skull it lies posterior to the third division of the trigeminal nerve, and is accompanied by a vein which also passes through the foramen spinosum. In the middle cranial fossa it passes for a short distance anteriorly, in a groove on the great wing of the sphenoid, between the dura mater and the bone, and divides into anterior and posterior terminal branches.

Branches.-(i.) Superficial Petrosal.-A small brauch which arises from the middle meningeal soon after it enters the cranium. It passes through the hiatus canalis facialis and anastomoses with the stylo-mastoid branch of the posterior auricular artery ; it also sends some small branches into the tympanic carity.

(ii.) Ganglionic.-Minute branches which supply the semilunar ganglion and the roots of the fifth cerebral nerve.

(iii.) Superior Tympanic.-A small twig which reaches the tympanic cavity through the canal for the tensor tympani muscle, or through the petro-squamous suture.

(iv:) Orbital__-An anastomosing branch which arises occasionally from the anterior terminal branch. It passes through the superior orbital fissure into the orbit, and anastomoses with the lacrimal artery.

(v.) Anterior terminal, the larger of the two terminal branches, passes upwards along the great wing of the sphenoid to the sphenoidal angle of the parietal bone, where it is sometimes enclosed in a distinct bony canal; it is continued upwards, a short distance behind the anterior border of the parietal bone, almost to the vertex of the skull, sending branches forwards into the anterior, and backwards towards the posterior cranial fossa.

(vi.) The posterior terminal branch passes posteriorly from the great wing of the sphenoid to the squamous part of the temporal bone, beyond which it ascends to the middle of the inner surface of the parietal bone. It sends branches upwards to the vertex, and backwards towards the posterior cranial fossa.

By means of its various branches the middle meningeal artery anastomoses with its fellow of the opposite side, with meningeal branches from the occipital, ascending pharyngeal, oph thalmic, and lacrimal arteries; also with the stylo-mastoid branch of the posterior anricular, the accessory meningeal artery, throngh the substance of the temporal bone, and with the deep temporal 
arteries. The anterior and posterior branches of the middle meningeal arteries and their ramifications are separated from the bone by corresponding veins.

(d) An accessory meningeal branch may arise either directly from the first part of the internal maxillary or from its middle meningeal branch. It passes upwards, on the medial side of the external pterygoid muscle, enters the middle fossa of the skull through the foramen ovale, supplies the semilunar ganglion and the dura mater, and terminates by anastomosing with branches of the middle meningeal and internal carotid arteries.

(e) The inferior alveolar is a branch of moderate size which passes downwards, between the spheno-mandibular ligament and the mandible, to the mandibular foramen. It is accompanied by the inferior alveolar nerve, which lies in front of it. After entering the foramen it descends in the mandibular canal, and terminates at the mental foramen by dividing into mental and incisive branches.

Branches.-Before it enters the mandibular foramen it gives off two branches.

(i.) The lingual, a small twig, to the buccal mucous membrane, which accompanies the lingual nerve. (ii.) The mylo-hyoid, a small branch which is given off immediately above the mandibular foramen. It pierces the spheno-mandibular ligament, and descends in the mylo-hyoid groove, in company with the mylo-hyoid nerve, to the floor of the mouth, where it anastomoses, on the superficial surface of the mylo-hyoid muscle, with the submental branch of the external maxillary artery.

In the mandibular canal the following branches are given off:-

(i.) Molar branches to the molar teeth. (ii.) Premolar branches to the premolar teeth. (iii.) The incisive terminal branch, which supplies the incisor and canine teeth and anastomoses with its fellow of the opposite side. (iv.) The mental terminal branch, which passes through the mental foramen, emerges beneath the quadratus labii inferioris, and anastomoses with its fellow of the opposite side, with the inferior labial, and with the submental arteries.

From the second part.-(a) The masseteric, a small branch which passes laterally, through the mandibular notch, to the deep surface of the masseter muscle. It anastomoses in the substance of the muscle with branches of the transverse facial and with the masseteric branches of the external maxillary artery.

(b) Deep Temporal.-Two in number, anterior and posterior. They ascend, in the temporal fossa, between the temporal muscle and the squamous portion of the temporal bone, supplying the muscle and anastomosing with the temporal and lacrimal arteries, and, through the substance of the temporal bone, with the middle meningeal artery.

(c) Small pterygoid branches supply the internal and external pterygoid muscles.

(d) The buccinator branch, a long, slender branch which passes obliquely forwards and downwards with the buccinator nerve. It supplies the buccinator muscle, the skin and mucous membrane of the cheek, and anastomoses with the buccal branches of the external maxillary artery.

From the third part.--(a) A posterior superior alveolar branch descends in the infratemporal fossa, on the posterior surface of the maxilla, and ends in branches which supply the molar and premolar teeth and the mucous membrane of the maxillary sinus; they also give twigs to the gums and to the buccinator muscle.

(b) An infra-orbital branch commences in the pterygo-palatine fossa. It enters the orbit through the inferior orbital fissure, and runs forwards in the infra-orbital groove and canal to the infra-orbital foramen, through which it emerges on the face beneath the quadratus labii superioris. Whilst in the infra-orbital groove it gives branches to the inferior rectus and the inferior oblique muscles and the lacrimal gland. In the infra-orbital canal it gives small twigs to the incisor and canine teeth (aa. alveolares superiores anteriores) and to the maxillary sinus. In the face it sends branches upwards to the lower eyelid, to the lacrimal sac, and to the frontal process of the maxilla; these anastomose with branches of the ophthalmic and external maxillary arteries; other branches run downwards to the upper lip, where they anastomose with the superior labial artery; lastly, some branches run laterally into the cheek to unite with the transverse facial and the buccinator arteries.

(c) The descending palatine runs downwards through the pterygo-palatine fossa, enters the pterygo-palatine canal, and becomes the great palatine artery, which supplies the mucous membrane of the roof of the mouth. As it descends it gives off the artery of the pterygoid canal several small twigs which pass through the accessory palatine canals to supply the soft palate, and to anastomose with the ascending palatine and tonsillar branches of the external maxillary and with the ascending pharyngeal artery. The great palatine artery, which is the continuation of the descending palatine, rums forwards in the roof of the mouth, medial to the alveolar process, to terminate in a small branch which ascends through the incisive formen and anastomoses with the posterior artery of the 
septum nasi, which is a branch of the spheno-palatine artery; in its course forwards in the roof of the mouth it supplies the gums and the mucous membrane of the hard palate, and also the palatine and maxillary bones.

(d) The artery of the pterygoid canal is a long, slender branch, usually given off from the descending palatine; it runs backwards through the pterygoid canal with the corresponding nerve (Vidian), and supplies branches to the upper part of the pharynx, to the levator and tensor veli palatini muscles, and to the auditory tube. One of the latter branches passes along the wall of the auditory tube to the tympanic cavity, where it anastomoses with the other tympanic arteries.

(e) The pharyngeal is a small artery which runs backwards, with the pharyngeal branch of spheno-palatine ganglion, through the pharyngeal canal to the roof of the pharynx. It supplies the upper and posterior part of the roof of the nose, the roof of the pharynx, the sphenoidal sinus, and the lower part of the auditory (Eustachian) tube, and anastomoses with the pterygoid branch of the internal carotid.

$(f)$ The spheno-palatine branch springs from the termination of the internal maxillary artery. It passes medially through the spheno-palatine foramen into the nasal cavity, where it gives off $(a)$ a branch to the sphenoidal sinus, and $(b)$ a branch which replaces the pharyngeal artery and has a similar course and distribution. Then it divides into lateral and septal posterior nasal branches. The lateral posterior nasal branches supply the lateral wall of the nasal cavity and the sinuses which open through it, and they anastomose with the posterior and anterior ethmoidal arteries and the lateral nasal branch of the external maxillary. The septal posterior nasal branch accompanies the posterior septal nerve across the roof of the nasal cavity and then anteriorly and downwards in the groove on the vomer, and it anastomoses with the great palatine artery and the septal branch of the superior labial.

\section{ARTERIA CAROTIS INTERNA.}

The internal carotid artery (Figs. 759, 761, and 764) commences at the termination of the common carotid, opposite the upper border of the thyreoid cartilage, and terminates in the middle fossa of the skull, close to the commencement of the stem of the lateral fissure (Sylvius), where it divides into the middle and anterior cerebral arteries.

Course.-From its origin in the carotid triangle it ascends to the base of the skull, lying first in the carotid triangle, medial to the anterior border of the sterno-mastoid, and then between the areolar tissue behind the lateral border of the pharynx medially and the posterior belly of the digastric and the styloid process and its muscles laterally. At its commencement it lies postero-lateral to the external carotid, but as it ascends it gradually passes to the medial side of the external carotid, from which it is separated by the styloid process, the stylopharyngeus muscle, the glosso-pharyngeal nerve, and the pharyngeal branch of the vagus.

At the base of the skull it enters the carotid canal, in which it ascends, anterior to the tympanum and the cochlea, and then turns antero-medially to the apex of the bone where it enters the foramen lacerum, through which it ascends, along the side of the body of the sphenoid, to the middle fossa of the cranium.

In the middle fossa it runs forwards, in the lateral wall of the cavernous sinus, to the small wing of the sphenoid; there it turns backwards along the medial border of the anterior clinoid process, which it grooves. At the posterior extremity of the process it turns upwards to its termination at the medial end of the stem of the lateral fissure (Sylvius), below the medial part of the anterior perforated substance.

Relations. - The relations of the various parts of the artery require separate consideration.

In the Neck.-Posterior.-The longus capitis (O.T. rectus capitis anticus major), the prevertebral fascia, and the sympathetic trunk separate it from the transverse processes of the cerrical vertebræ, and postero-lateral to it are the internal jugular vein and the vagus nerve. The accessory and the glossopharyngeal nerves are also postero-lateral to the artery for a short distance, in the upper part of the neck, and intervene between it and the internal jugular vein. Medial or deep to the internal carotid is the external 
carotid artery for a short distance below, and afterwards the wall of the pharynx, the areolar tissue posterior to the wall of the pharynx, the ascending pharyngeal artery, the pharyngeal plexus of veins, and the external and internal laryngeal nerves. Just before it enters the temporal bone the levator palati muscle is to its medial side. Lateral or superficial to it are the sterno-mastoid, skin, and fasciæ, and it is crossed under cover of the sterno-mastoid, from below upwards, by the hypoglossal nerre, the occipital artery, and the posterior auricular artery. It is also crossed superficially, between the lastmentioned arteries, by the digastric and stylo-hyoid muscles, which separate it from the parotid gland, and below the digastric it is covered by the lower part of the postero-medial surface of the gland. Passing obliquely across its anterior lateral surface, and separating

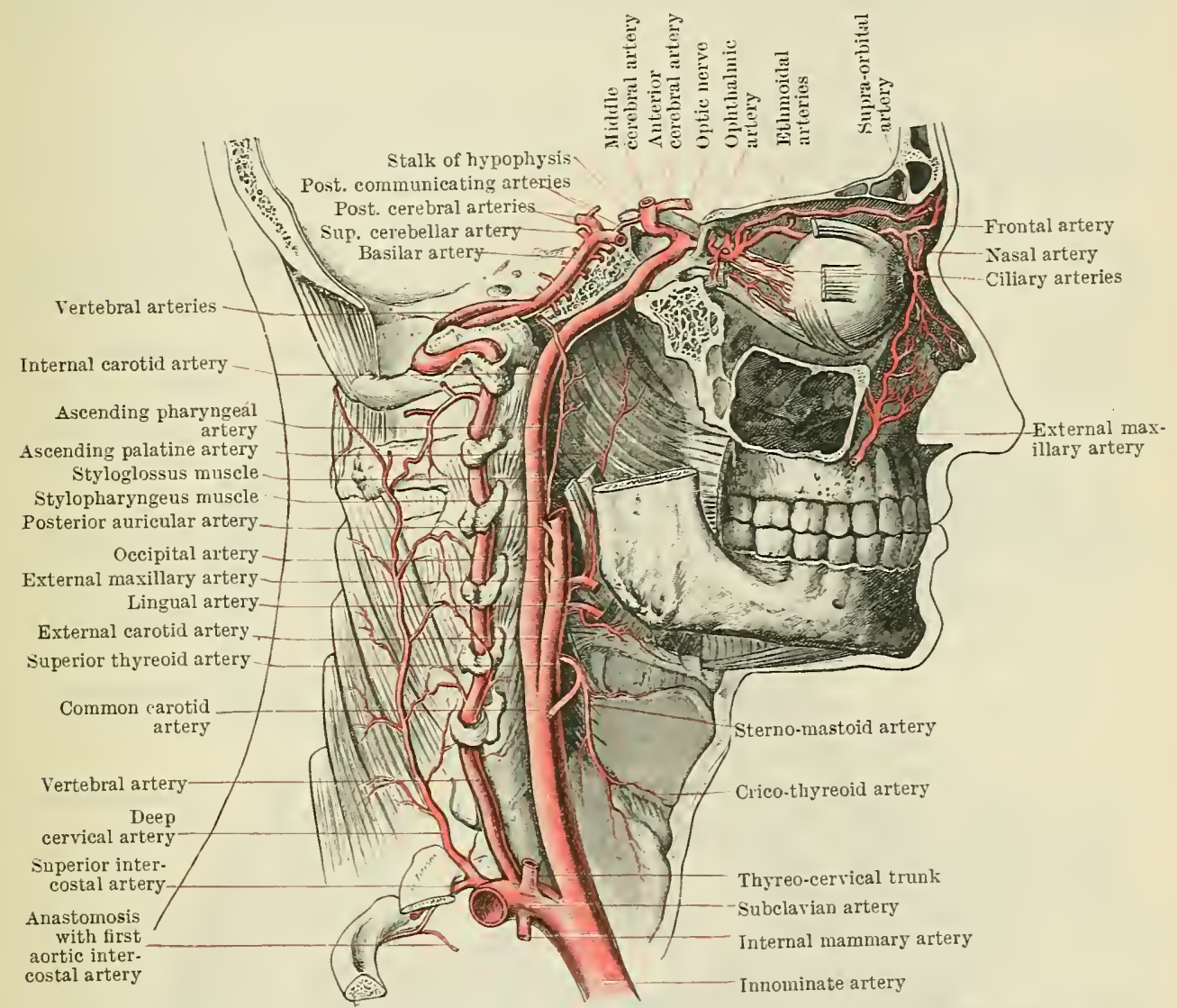

Fig. 761.-The Carotid, Subclayia, and Vertebral arteries aid their Main Braxches.

it from the exterual carotid artery, are the following structures, viz., the stylo-pharyngeus the styloid process, or the styloglossus muscle, and the glossopharrngeal nerve, the pharyngeal branch of the vagus, and some sympathetic twigs.

In the Carotid Canal. - The artery, as it passes upwards, is antero-inferior to the cochlea and the tympanum; postero-medial to the auditory (Eustachian) tube and the canal for the tensor tympani; and below the semilunar ganglion. The thin lamina of bone which separates it from the tJmpanum is frequently perforated, and that between it and the semilunar ganglion is frequently absent. In its course through the canal it is accompanied by small veins and sympathetic nerres. The veins receive tributaries from the tympanum, and communicate above with the cavernons sinus and below with the internal jugular vein. The nerres are branches of the nervus caroticus internus, which is the upward continuation of the sympathetic trunk; they form a plexus, called the internal carotid plexus, around the artery.

As it enters the cavity of the cranium the internal carotid artery pierces the external layer of the dura mater and passes between the lingula and the sixth cerebral nerve laterally, and the posterior petrosal process of the body of the sphenoid medially.

In the Cranial Cavity.-The artery runs forwards, in the lateral wall of the cavernous 
sinus, in relation with the oculo-motor, trochlear, the ophthalmic division of the trigeminal, and the abducens nerves laterally, and with the endothelial wall of the sinus medially. When it reaches the lower root of the small wing of the sphenoid it turns upwards to the medial side of the anterior clinoid process, pierces the inver layer of the dura mater, and comes into close relation with the inferior surface of the optic nerve immediately posterior to the optic foramen. It then turns abruptly backwards below the optic nerve, and on the medial side of the anterior clinoid process which it frequently grooves; inclining laterally, it runs between the optic and oculo-motor nerves, and below the anterior perforated substance, to the medial end of the stem of the lateral fissure (Sylvius), where it turns upwards, at some distance from the lateral side of the optic chiasma, and, after piercing the arachnoid, divides into its two terminal branches, the anterior and middle cerebral arteries.

\section{Branches of the Internal Carotid Artery.}

Branches are given off from the internal carotid in the temporal bone and in the cranium, but, as a rule, no regular branches are given off in the neck.

In the Temporal Bone-(1) A carotico-tympanic branch, very small, perforates the posterior wall of the carotid canal, and anastomoses in the tympanum with the stylo-mastoid artery and with the tympanic branches of the internal maxillary and ascending pharyngeal arteries.

(2) A small and inconstant branch which accompanies the nerve of the pterygoid canal (Vidian); it anastomoses with a branch of the descending palatine artery.

In the Cranium.-(1) Cavernous, small branches to the walls of the cavernous sinus and to the third, fourth, fifth, and sixth cerebral nerves.

(2) Minute twigs which supply the sernilunar ganglion.

(3) Hypophyseal branches pass to the hypophysis (O.T. pituitary body).

(4) Meningeal branches ramify in the dura mater of the middle cranial fossa, anastomosing with the branches of the middle and accessory meningeal arteries.

(5) Arteria Ophthalmica.-The ophthalmic artery (Fig. 761) springs from

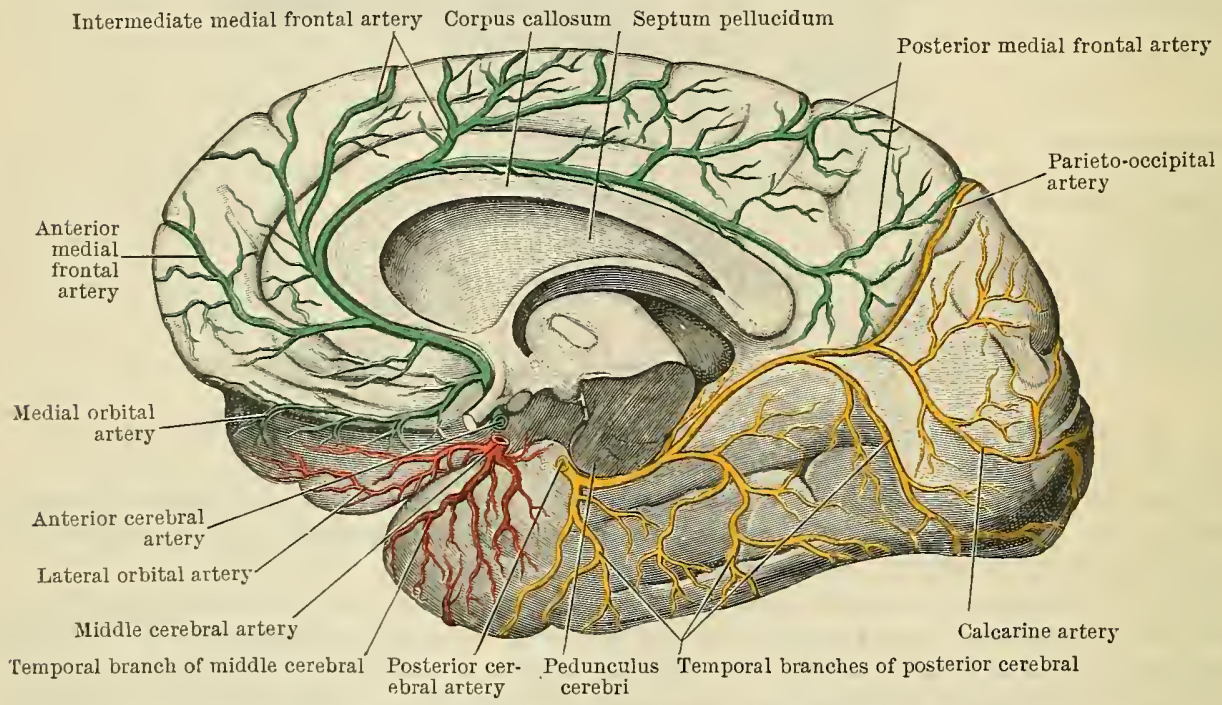

Fig. 762.-Distribution of the Cerebral Arteries on the Medial and Inferior Surfaces of the Cerebral Hemispheres.

The anterior cerebral artery is coloured green, the middle cerebral artery red, and the posterior cerebral artery orange.

the antero-medial side of the internal carotid as it turns upwards on the medial side of the anterior clinoid process. It passes forwards and laterally, below the optic nerve and through the optic foramen into the orbital cavity. In the orbit it runs forwards, for a short distance, on the lateral side of the optic nerve, and it is in relation laterally with the ciliary ganglion and the lateral rectus 
muscle; turning upwards and medially, it crosses, between the optic nerve and the superior rectus, to the medial wall of the orbit, where it turns forwards to terminate at the anterior boundary of the cavity by dividing into frontal and dorsal nasal branches. It is accompanied at first by the naso-ciliary nerve, and in the terminal part of its course by the infra-trochlear nerve.

Branches.-The branches of the ophthalmic artery are numerous. (a) The posterior ciliary, usually six to eight in number, run forwards at the sides of the optic nerve; they soon diride into numerous branches which pierce the posterior part of the selera; the majority terminate in the chorioid coat of the eye as the short posterior ciliary arteries, but two of larger size, the long posterior ciliary arteries, run forwards, one on each side of the eyeball, almost in the horizontal plane, between the sclera and the chorioid coat, to the periphery of the iris, where they divide. The resulting branches anastomose together and form a circle at the periphery of the iris, from which secondary branches run inwards and anastomose together in a second circle near the papillary margin of the iris.

(b) The central artery of the retina arises near to, or in common with, the preceding vessels. It pierces the infero-medial aspect of the optic nerve, about $12 \mathrm{~mm}$. (half an inch) posterior to the sclera, and runs in its centre to the retina, where it breaks up into terminal branches.

(c) Anterior meningeal. - A small branch which passes backwards through the superior orbital

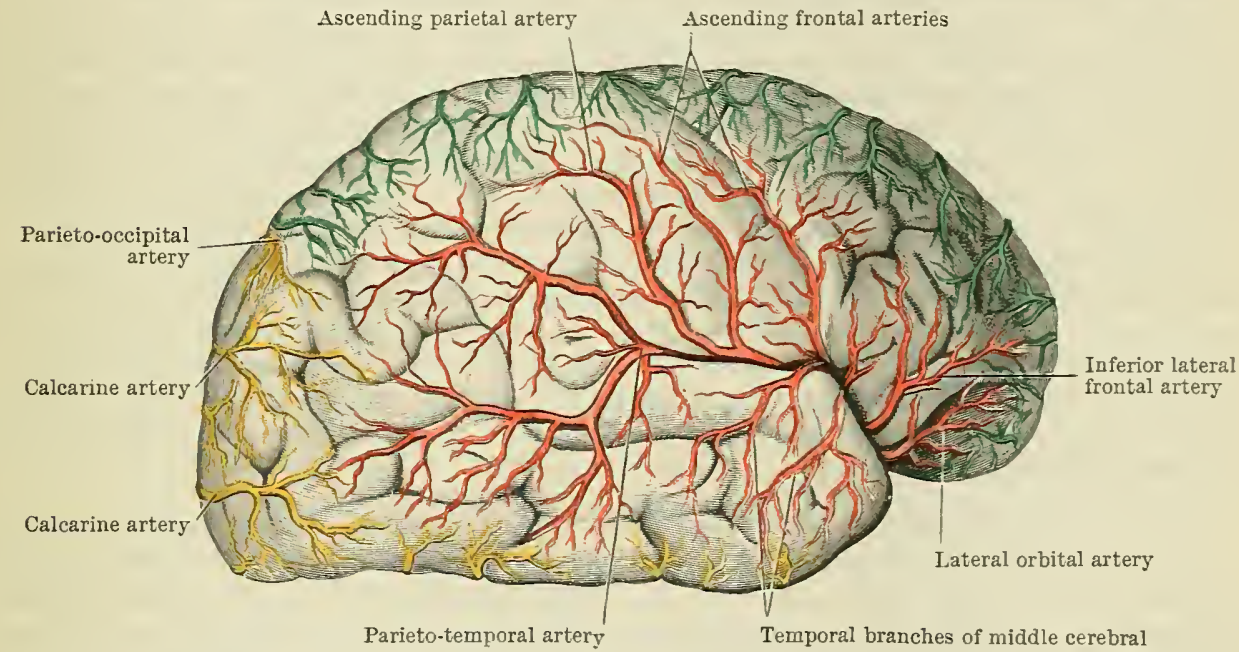

Fig. 763.-Distribution of Cerebral Arteries on the Covvex Strface of the Cerebrdi.

Anterior cerebral artery is coloured green, the middle cerebral red, and the posterior cerebral orange.

fissure into the middle fossa of the cranium, where it anastomoses with the middle and accessory meningeal arteries, and with the meningeal branches of the internal carotid and lacrimal arteries.

(d) The lacrimal artery arises from the ophthalmic on the lateral side of the optic nerre. It runs forwards, along the upper border of the lateral rectus, to the upper lateral angle of the orbit, and in its course gives off glandular branches to the lacrimal gland, muscular branches to the lateral and superior recti, palpebral branches to the upper eyelid and the upper and lateral part of the forehead, temporal and zygomatic branches, which accompany the zygomatico-temporal and zygomatico-facial branches of the zygomatic (temporo-malar) nerve, to the face and the infra-temporal fossa respectively; anterior ciliary branches, which perforate the sclera behind the corneo-scleral junction and anastomose with the posterior ciliary arteries; and a recurrent meningeal branch, which passes backwards, through the lateral part of the superior orbital fissure, to anastomose, in the middle fossa of the skull, with the middle meningeal artery.

(e) Muscular.-These branches are usually arranged in two sets, lateral and medial. The former supply the upper and lateral, and the latter the lower and medial orbital muscles. They anastomose with musenlar branches from the lacrimal and the supra-orbital ressels, and they give off anterior ciliary branches.

(f) The supra-orbital branch is given off as the ophthalmic artery crosses above the optic nerve. It passes round the medial borders of the superior rectus and levator palpebræ museles, and runs forwards, between the levator and the periosteum, to the supra-orbital notch, accompanying the frontal nerve and its supra-orbital branch. Passing through the notch it reaches the scalp, and, perforating the frontalis muscle, anastomoses with the frontal branches of the superficial temporal and ophthalmic arteries.

(g) Anterior and posterior ethmoidal branches arise from the ophthalmic as it runs formards along the medial botudary of the orbit. They pass medially, between the superior oblique and the medial rectus. The posterior, which is much the smaller of the two, traverses the posterior ethmoidal canal, and supplies the posterior ethmoidal cells and the posterior and upper part of 
the lateral wall of the nasal cavity. The anterior ethmoidal artery passes through the anterior ethmoidal canal with the anterior ethmoidal nerve, enters the anterior fossa of the skull, and crosses the lamina cribrosa of the ethmoid to the nasal slit, throngh which it reaches the nasal carity, where it descends, with the external branch of the nasal nerve, in a groove on the posterior surface of the nasal bone, and, finally, passes between the lateral cartilage and the lower border of the nasal bone to the tip of the nose. It supplies branches to the membranes of the brain in the anterior cranial fossa as well as to the anterior ethmoidal cells, the frontal sinus, the anterior and upper part of the nasal muco-periosteum, and the skin on the dorsum of the nose.

(h) Palpebral branches, upper and lower, are given off near the termination of the ophthalmic. They are distributed to the upper and lower eyelids, and they anastomose with the lacrimal, supra-orbital, and infra-orbital arteries.

(i) The dorsal nasal terminal branch passes out of the orbit above the medial tarsal ligament. It pierces the palpebral fascia, and terminates on the side of the nose by anastomosing with the angular branch of the external maxillary artery.

(j) The frontal terminal branch pierces the palpebral fascia at the upper and medial part of the orbit, and ascends, with the supra-trochlear nerve, in the superficial fascia of the anterior and medial part of the scalp, anastomosing with its fellow of the opposite side and with the supra-orbital artery.

(6) The posterior communicating artery arises from the internal carotid near its termination. It runs backwards, below the optic tract and anterior to the pedunculus cerebri, and, passing above the oculomotor nerve, joins the posterior cerebral artery forming part of the circulus arteriosus (Willis). It gives branches to the optic chiasma, the optic tract, the pedunculus cerebri, the interpeduncular region, the internal capsule, and the optic thalamus. The posterior communicating artery varies much in size; it may be small on one or both sides, sometimes it is very large on one side; occasionally it replaces the posterior cerebral artery, and it sometimes arises from the middle cerebral artery.

( 7 ) The chorioidal is a small branch, which also arises near the termination of the internal carotid; it passes backwards and laterally, between the pedunculus cerebri and the uncus, to the lower and anterior part of the chorioidal fissure which it enters, and it terminates in the chorioidal plexus in the inferior comn of the lateral ventricle. It supplies the optic tract, the pedunculus cerebri, the uncus, the posterior part of the internal capsule, the tail of the caudate nucleus, part of the lentiform nuclens, and the amygdaloid nucleus.

(8) Arteria Cerebri Anterior.-The anterior cerebral artery is the smaller of the two terminal branches of the internal carotid. It passes forwards and medially, above the optic chiasma and immediately in front of the lamina terminalis, to the commencement of the longitudinal fissure, where it turns round the genu of the corpus callosum, and runs backwards to the parietal lobe of the brain. At the commencement of the longitudinal fissure it is closely connected with its fellow of the opposite side by a wide but short anterior communicating artery, and in the remainder of its course it is closely accompanied by its fellow artery of the opposite side.

Branches.-Branches of all the cerebral arteries are distributed both to the basal ganglionic masses of the brain and to the cerebral cortex ; they therefore form two distinct groups which do not communicate with one another-(a) central or basal; $(b)$ cortical.

The branches of the anterior cerebral include :

(a) Central or basal branches.-The antero-medial basal arteries, a small group of vessels, constitute the basal branches of the anterior cerebral artery; they pass upwards into the base of the brain in front of the optic chiasma, and supply the rostrum of the corpus callosum, the lamina terminalis, the head of the caudate nucleus, the anterior part of the lentiform nucleus and internal capsule, the columns of the fornix, the septum pellucidium, and the anterior commissure.

(b) Cortical branches. - (b1) Medial orbital, one or more small branches which supply the medial orbital convolntion, the gyrus rectus, and the olfactory lobe.

$\left(b^{2}\right)$ Anterior medial frontal, one or more branches which are distributed to the anterior and Jower part of the medial surface of the superior frontal gyrus, and to the anterior portions of the superior and middle frontal gyri on the lateral surface of the hemisphere.

$\left(b^{3}\right)$ An intermediate medial frontal is distributed to the posterior part of the medial lateral surfaces of the superior frontal gyrus and to the upper parts of the anterior and posterior central gyri.

$\left(b^{4}\right)$ The posterior medial frontal runs backwards to the præcuneus. It supplies the corpus callosum, the præcuneus, and the upper part of the superior parietal lobule. 
(9) Arteria Cerebri Media.-The middle cerebral artery is the larger of the two terminal branches, and the more direct continuation of the internal carotid artery. It passes laterally, in the stem of the lateral fissure (Sylvius), to the surface of the insula, and it divides, in the posterior part of the circular sulcus (Reil), into parieto-temporal and temporal terminal brauches.

Branches.-(a) The central or basal, which constitute the antero-lateral basal arteries, are numerous and very variable in size. These arise at the base of the brain, in the region of the anterior perforated substance. Two sets, known as the medial and the lateral striate arteries, are distinguishable.

$\left(a^{1}\right)$ The medial striate arteries pass upwards through the two medial segments of the lentiform nucleus (globus pallidus) and the internal capsule to terminate in the caudate nucleus. They supply the anterior portions of the lentiform and caudate nuclei and of the internal capsule.

$\left(a^{2}\right)$ The lateral striate arteries pass upwards through the lateral segment (putamen) of the lentiform nucleus, or between it and the external capsule, and ther form two sets: an anterior, the lenticulo-striate, and a posterior, the lenticulo-optic; both sets traverse the lentiform nucleus and the internal capsule, but the lenticulo-striate arteries terminate in the caudate nucleus, and the lenticulo-optic in the thalamus. One of the lenticulo-striate arteries, which passes in the first instance round the lateral side of the lentiform nucleus, and afterwards through its substance, is larger than its companions; it frequently ruptures, and is known as the "artery of cerebral hæmorrhage."

(b) Cortical branches are given off as the middle cerebral artery passes orer the surface of the insula at the bottom of the lateral fissure, as follows :-

$\left(b^{1}\right)$ The lateral orbital runs forwards and laterally, and is distributed to the lateral part of the orbital surface of the frontal lobe and to the inferior frontal gyrus. grri.

$\left(b^{2}\right)$ The inferior lateral frontal, which supplies the inferior and middle frontal

$\left(b^{3}\right)$ The ascending frontal, which turus round the upper margin of the lateral fissure, and is distributed to the anterior central gyrus and to the posterior part of the middle frontal gyrus.

$\left(b^{4}\right)$ The ascending parietal branch emerges from the lateral fissure (Sylvius) and passes upwards along the posterior border of the posterior central gyrus, supplying that gyrus and the superior parietal lobule.

$\left(b^{5}\right)$ The temporal branch passes out of the lateral fissure, and turns downwards to supply the superior and middle temporal gyri.

$\left(b^{6}\right)$ The parieto-temporal branch continues backwards, in the direction of the main stem of the middle cerebral artery, and emerges from the posterior end of the lateral fissure; it supplies the inferior parietal lobule, part of the lateral surface of the occipital lobe, and the posterior part of the temporal lobe.

\section{Arteria Vertebralis.}

The vertebral artery (Figs. 757 and 761 ) is the first branch given off from the subclavian trunk; it arises from the upper and posterior part of he tparent stem, opposite the interval between the anterior scalene and the longus colli muscles, and terminates at the lower border of the pons (Varolii) by uniting with its fellow of the opposite side to form the basilar artery.

Course and Relations.-The vertebral artery is divisible into four parts.

The first part runs upwards and backwards, between the scalenus anterior and the lateral border of the longus colli, to the foramen in the transverse process of the sixth cervical vertebra. It is surrounded by a plexus of sympathetic nerve fibres, is covered anteriorly by the vertebral and internal jugular veins, and it may be crossed anteriorly by the inferior thyreoid artery. On the left side the terminal part of the thoracic duct also passes anterior to it. The second part runs upwards through the foramina in the transverse processes of the upper six cervical vertebræ. As far as the second cervical vertebra its course is almost vertical; as it passes through the transverse process of the epistropheus, however, it is directed obliquely upwards and laterally to the atlas. It is surrounded by a plexus of sympathetic nerve fibres, and also by a plexus of veins. The artery lies anterior to the trunks of the cervical nerres, and medial to the intertransverse muscles. The third part 
emerges from the foramen in the transverse process of the atlas, between the anterior division of the sub-occipital nerve medially and the rectus capitis lateralis laterally, and runs almost horizontally backwards and medially, round the lateral and posterior aspects of the superior articular process of the atlas. In this course it enters the sub-occipital triangle, where it lies in the groove on the upper surface of the posterior arch of the atlas (sulcus arteriæ vertebralis). It is separated from the bone by the sub-occipital nerve, and is overlapped superficially by the adjacent borders of the superior and inferior oblique muscles. Finally, this part of the

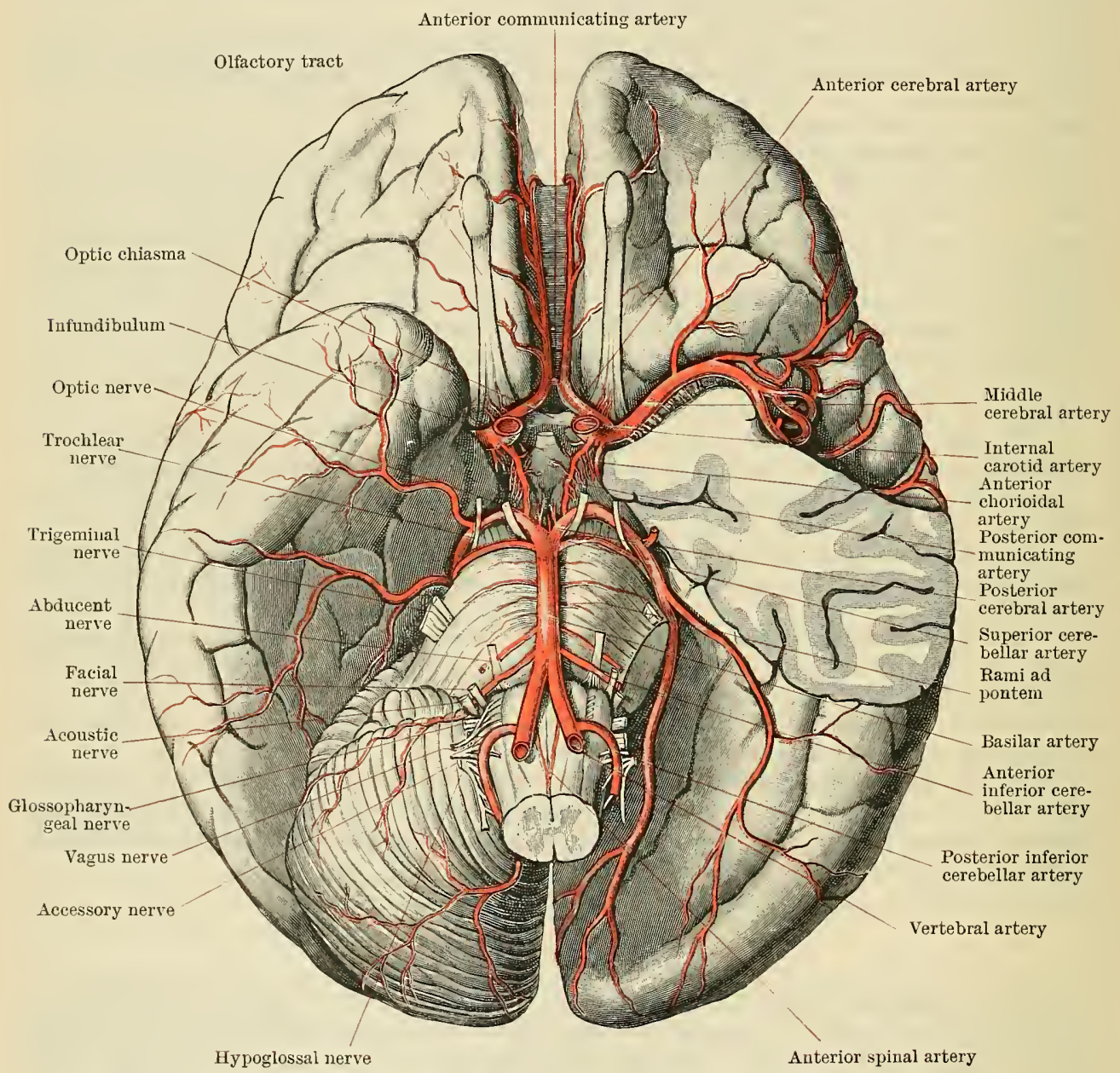

Fig. 764.-The Arteries of the Base of the Brain. The Circulds arteriosus (Willis).

artery passes anterior to the oblique ligament of the atlas and enters the vertebral canal.

The fourth part pierces the spinal dura mater and runs upwards into the cranial cavity. It passes between the roots of the hypoglossal nerve posteriorly and the first dentation of the ligamentum denticulatum anteriorly, pierces the arachnoid, and, gradually inclining to the front of the medulla oblongata, reaches the lower border of the pons, where it unites with its fellow of the opposite side to form the basilar artery.

Branches.--From the first part.-As a rule there are only a few small muscular twigs from this portion of the artery.

From the second part.-(1) Muscular branches which vary in number and size. They supply the deep muscles of the neck, and anastomose with the profunda cervicis, the ascending cervical, and the occipital arteries. 
(2) Spinal branches pass from the medial side of the second part of the vertebral artery through the intervertebral foramina into the vertebral canal, where they give off twigs which pass along the roots of the spinal nerves to reinforce the anterior and posterior spinal arteries; they supply the bodies of the vertebrae and the intervertebral fibrocartilages, and they auastomose with corresponding arteries above and below.

From the third part.-(1) Muscular branches to the sub-occipital muscles.

(2) Anastomotic branches which unite with the descending branch (O.T. princeps cervicis) of the occipital and with the profunda cervicis artery.

From the fourth part.-(1) Meningeal. - One or two small branches given off before the vertebral artery pierces the dura mater. They ascend into the posterior fossa of the skull, where they anastomose with meningeal branches of the occipital and ascending pharyngeal arteries, and occasionally with branches of the middle meningeal artery.

(2) Posterior Spinal.-The posterior spinal branch springs from the vertebral directly after it has pierced the dura mater. It runs downwards upon the side of the medulla oblongata and the spinal medulla, either in front of or behind the posterior nerve-roots. It is a slender artery, which is continued to the lower part of the spinal medulla by means of reinforcements from the spinal branches of the vertebral and intercostal arteries. It gives off branches to the pia mater, which form more or less regular anastomoses on the medial and lateral sides of the posterior nerve-roots, and it terminates below by joining the anterior spinal artery.

(3) The anterior spinal branch arises near the termination of the vertebral. It runs obliquely downwards and medially, in front of the medulla oblongata, and unites with its fellow of the opposite side to form a single anterior spinal artery, which descends along the anterior median fissure of the spinal medulla, and is continued as a fine vessel along the filum terminale. The anterior spinal artery is reinforced as it descends by anastomosing twigs from the spinal branches of the vertebral, intercostal, and lumbar arteries. It gives off branches which pierce the pia mater and supply the spinal medulla, and it unites below with the posterior spinal arteries.

(4) The posterior inferior cerebellar is the largest branch of the vertebral artery. It arises a short distance below the pons and passes obliquely backwards round the medulla oblongata, at first between the fila of the hypoglossal nerve, and then between the fila of the accessory and vagus nerves, into the vallecula of the cerebellum, where it divides into lateral and medial terminal branches.

The trunk of the artery gives branches to the medulla oblongata and to the chorioid plexus of the fourth ventricle. The medial terminal runs backwards between the inferior vermis and the lateral lobe of the cerebellum; it supplies principally the former structure, and anastomoses with its fellow of the opposite side. The lateral branch passes laterally on the lower surface of the hemisphere and anastomoses with the superior cerebellar artery.

Arteria Basilaris.-The basilar artery is formed by the junction of the two vertebral arteries; it commences at the lower border and terminates at the upper border of the pons (Varolii), bifurcating at its termination into the two posterior cerebral arteries.

Course and Relations.-It runs upwards, in the median part of the cisterna pontis, in a shallow groove on the front of the pons, behind the sphenoidal section of the basi-cranial axis and between the two abducent nerves.

Branches.-(1) Pontine, a series of small arteries which pass across the front and round the sides of the pons, supplying it, the brachia pontis (O.T. middle peduncles of the cerebellum), and the roots of the trigeminal nerve.

(2) The internal auditory, a pair of long but slender branches which accompany the acoustic nerve. Each enters the corresponding internal acoustic meatus with the facial and acoustic nerves, and, passing through the lamina cribrosa, is distributed to the internal ear.

(3) The anterior inferior cerebellar, two branches which arise, one on each side, from the iniddle of the basilar artery. They pass backwards on the anterior parts of the lower surfaces of the lateral lobes of the cerebellum, and anastomose with the posterior inferior cerebellar branches of the vertebral arteries.

(4) The superior cerebellar branches, two in number, arise near the termination of the basilar. Each passes laterally at the upper border of the pons, directly below the oculo-motor nerve of the same side, and, turning round the lateral side of the pedunculus cerebri, below the trochlear nerve, reaches the upper surface of the cerebellum, where it 
divides into a medial and a lateral branch. The medial branch supplies the upper surface of the rermis and the anterior medullary relum. The lateral branch is distributed over the upper surface of the lateral lobe, anastomosing at its margin with the inferior cerebellar arteries.

(5) Arteriæ Cerebri Posteriores.-The posterior cerebral arteries (Figs. 762 and $764)$ are the two terminal branches of the basilar. They run backwards and upwards, between the peduncles of the cerebrum and the uncinate gyri and parallel to the superior cerebellar arteries, from which they are separated by the oculomotor and trochlear nerves. Each posterior cerebral artery is connected with the internal carotid by the posterior communicating artery; it gives branches to the inferior surface of the cerebrum, and is continued backwards, beneath the splenium of the corpus callosum, to the calcarine fissure, where it divides into calcarine and parieto-occipital branches, which pass to the lateral surface of the occipital lobe. It supplies the medial and tentorial surfaces of the occipital lobe and the posterior part of its lateral surface.

Branches.-(A) Central or basal.-This group includes $\left(a^{1}\right)$ A postero-medial set of small ressels which pass on the medial side of the corresponding cerebral peduncle to the posterior perforated substance. They supply the peduncle, the posterior part of the thalamus, the corpora mamillaria, and the walls of the third ventricle.

$\left(a^{2}\right)$ A postero-lateral set of small ressels which pass round the lateral side of the peduncle. They supply the corpora quadrigemina, the brachia, the pineal body, the peduncle, the posterior part of the thalamus, and the corpora geniculata.

$\left(a^{3}\right)$ A posterior chorioidal set of small branches which pass through the upper part of the chorioidal fissure, and, after entering the posterior part of the tela chorioidea of the third ventricle, end in the chorioid plexus in the body of the lateral ventricle and the upper part of its inferior cornu. They also supply the body and corresponding crus of the fornix.

(B) Cortical.- $\left(b^{1}\right)$ The anterior temporal, frequently a single branch of variable size, but not uncommonly replaced by several small branches. It supplies the anterior parts of the uncus and the fusiform gyrus.

$\left(b^{2}\right)$ The posterior temporal is a larger branch than the anterior. It supplies the posterior part of the uncinate gyrus, the greater part of the fusiform gyrus, and the lingual gyrus.

$\left(b^{3}\right)$ The calcarine branch is the continuation of the posterior cerebral artery along the calcarine fissure, it is especially associated with the supply of the visual area of the cortex of the brain. It supplies the cuneus, the lingual gyrus, and the posterior part of the lateral surface of the occipital lobe.

$\left(b^{4}\right)$ The parieto-occipital branch, smaller than the calcarine, passes along the corresponding fissure to the cuneus and præcuneus.

Circulus Arteriosus (Willis) (Fig. 764).-The cerebral arteries of opposite sides are intimately connected together at the base of the brain by anastomosing channels. Thus, the two anterior cerebral arteries are connected with one another by the anterior communicating artery, whilst the two posterior cerebrals are in continuity through the basilar artery from which they arise. There is also a free anastomosis on each side between the carotid system of cerebral arteries and the vertebral system by means of the posterior communicating arteries, which connect the internal carotid trunks and posterior cerebral arteries.

The vessels referred to form the so-called circulus arteriosus (O.T. circle of Willis) which is situated at the base of the brain, in the interpeduncular and chiasmatic subarachnoid cisterns. It encloses the following structures: the posterior perforated substance, the corpora mamillaria, the tuber cinereum, the infundibulum, and the optic chiasma. The "circle" is irregularly polygonal in outline, and is formed posteriorly by the termination of the basilar and by the two posterior cerebral arteries, postero-laterally by the posterior communicating arteries and the internal carotids, antero-laterally by the anterior cerebral arteries, and in front by the anterior communicating artery.

It is stated that this free anastomosis equalises the flow of blood to the various parts of the cerebrum, and provides for the continuation of a regular blood-supply if one or more of the main trunks should be obstructed. 


\section{ARTERIES OF THE UPPER EXTREMITY.}

The main arterial stem of each upper extremity passes through the root of the neck, traverses the axillary space, and is continued through the arm to the forearm. In the forearm it runs only a short distance, terminating opposite the neck of the radius by bifurcating into the radial and ulnar arteries, which run through the forearm to the hand. That portion of the common trunk which lies in the root of the neck is known as the subclavian artery, the part in the axillary space is termed the axillary artery, whilst the remaining part is called the brachial artery.

\section{ARTERIE SUBCLAVIE.}

On the right side the subclavian artery (Figs. 759 and 761) commences at the termination of the innominate artery, posterior to the sterno-clavicular articulation, whilst that on the left side arises from the arch of the aorta, behind the upper half of the manubrium sterni.

The right artery is about $75 \mathrm{~mm}$. (3 inches) long, and it. lies in the root of the neck. The left artery is about $100 \mathrm{~mm}$. (4 inches) long, and is situated not only in the root of the neck, but also in the superior mediastinal part of the thorax. In the root of the neck each artery arches laterally, across the apex of the lung and behind the anterior scalene muscle, and is divided into three parts, which lie respectively to the medial side, posterior, and to the lateral side of the muscle. The extent to which the arch rises above the lerel of the clavicle varies considerably, and not uncommonly it reaches the level of the lower part of the thyreoid body. The first parts of the subclavian arteries differ materially from each other both in extent and relations. The relations of the second and third parts are similar on the two sides.

The first part of the left subclavian artery springs from the arch of the aorta, posterior to the commencement of the left common carotid and on the left side of the trachea. It ascends almost vertically, in the superior mediastinum, to the root of the neck, where it arches upwards and laterally to the medial border of the scalenus anterior muscle.

Relations.-Posterior.-In the superior mediastinum it is in relation with the lung and pleura.

Anterior. - In front are the left vagus, the left superior cardiac branch of the sympathetic, the left inferior cardiac branch of the vagus, the left phrenic nerve, and the left common carotid artery. It is also crossed obliquely by the left vagus nerve, and it is overlapped on the left side by the left lung and pleura.

Medial.-Medially it is in relation, from below upwards, with the trachea, the left recurrent nerve, the osophagus, and the thoracic duct, the latter lying in a posterior plane.

Laterally it is closely invested by the left pleura, and it ascends in a groove on the medial aspect of the left lung.

As it turns laterally, at the root of the neck, it lies behind the commencement of the left innominate vein, and the termination of the left vertebral vein, the phrenic nerve, the sterno-thyreoid and sterno-hyoid muscles, the anterior jugular vein, and, more superficially, the sterno-mastoid muscle and the deep cervical fascia; the thoracic duct arches obliquely over it; and it lies in front of the apex of the pleural sac and lung.

The first part of the right subclavian artery (Fig. 761) extends from the back of the right sterno-clavicular articulation to the medial border of the scalenus anterior. It is thus limited to the root of the neck.

Relations.-Posterior.-Behind this part of the artery, and intervening between it and the upper two thoracic vertebræ, are the recurrent nerve, the posterior part of the ansa subclavia, and the apex of the right plemral sac. Anterior.-In front it is in relation with the right vagus, the cardiac branches of the vagus and the sympathetic, the anterior portion of the ansa subclavia, the internal jugular and vertebral veins, and more superficially the sterno-hyoid and stemo-thyreoid muscles, the anterior jngular vein, the sternal end of the clavicle, the sterno-clavicular ligaments, and the stemo-mastoid muscle. The recurrent nerve passes below it and inter venes between it and the apex of the pleural sac. 
The second part of the subclavian artery, on each side, extends from the medial to the lateral border of the scalenus anterior, behind which it lies.

Relations.-Posteriorly and below it is in relation with the pleural sac. Anteriorly it is covered by the anterior scalene and the sterno-mastoid muscles. The anterior scalene separates it from the subclavian vein, which lies at a slightly lower level, from the transverse cervical and transverse scapular arteries, from the anterior jugular vein, and, on the right side, from the phrenic nerve.

The third part of the subclavian artery is the most superficial portion. It extends from the lateral border of the anterior scalene to the outer border of the first rib, lying partly in the clavicular portion of the posterior triangle of the neck and partly behind the clavicle and the subclavius muscle.

Relations. - It rests upon the upper surface of the first rib. Immediately posterior to it is the lowest trunk of the brachial plexus, which separates it from the middle scalene muscle. Anterior to it, and at a slightly lower level, lies the subclavian vein. The external jugular vein crosses the medial part of this portion of the artery in its course to join the subclavian vein, and just before its termination it receives the transverse cervical and transverse scapular veins ; these vessels also pass superficial to the artery, which is thus covered superficially by venous trunks; it is also crossed vertically, behind the veins, by the nerve to the subclavius muscle. The lateral section of this part of the artery lies posterior to the clavicle and the subclavius muscle. It is crossed anteriorly by the transverse scapular artery, but the layer of deep cervical fascia which binds the posterior belly of the omo-hyoid to the posterior border of the subclavian groove intervenes between the two vessels. More superficially the third part of the artery is covered by the superficial layer of the deep fascia, the supra-clavicular branches of the cervical nerves, the platysma, and the skin.

\section{Branches of the Subclavian Artery.}

(1) The vertebral artery is distributed almost entirely to the head and neck, and its chief function is to supply the posterior part of the brain. Its description has therefore been given with that of the other cerebral arteries (see p. 905).

(2) Truncus Thyreocervicalis.-The thyreo-cervical trunk (Figs. 758 and 759) arises close to the medial border of the scalenus anterior, from the upper and front part of the subclavian artery, directly above the origin of the internal mammary artery. After a short upward course of about $4 \mathrm{~mm}$. (two lines), it ends, under cover of the internal jugular vein, by dividing into three branches-viz., the inferior thyreoid, the transverse cervical, and the transverse scapular.

(A) Arteria Thyreoidea Inferior.-The inferior thyreoid artery (Fig. 759) ascends along the anterior border of the scaleuus anterior, and turns medially, opposite the cricoid cartilage, to the middle of the posterior border of the lateral lobe of the thyreoid gland; it then curves medially and downwards, and descends to the lower end of the lobe, where it divides into ascending and inferior terminal branches.

Relations.-Posterior are the vertebral artery, and the longus colli muscle; the recurrent nerve passes either anterior or posterior to the vessel, opposite the lower border of the thyreoid gland. It is covered anteriorly by the carotid sheath, which contains the common carotid artery, the internal jugular vein, and the vagus nerve; the middle cervical ganglion of the sympathetic lies in front of the artery as it bends medially; and on the left side the thoracic duct also passes in front of it.

Branches.- It gives off the following branches :-

(a) Muscular.-Numerous small branches pass to the scalenus anterior, the longus colli, the infra-hyoid muscles, and the inferior constrictor of the pharynx.

(b) The ascending cervical usually springs from the inferior thyreoid near its origin, though not uncomnonly it arises separately from the thyreo-cervical trunk. It ascends, parallel with and medial to the phrenic nerve, in the angle between the longus capitis and the scalenus anterior, to both of which it gives branches. It also gives off spinal branches which pass through the intervertebral foramina to the vertebral canal, and it anastomoses with branches of the vertebral, occipital, ascending pharyngeal, and deep cervical arteries. 
(c) Esophageal. -- Small branches given to the walls of the œsophagus, which anastomose with the œsophageal branches of the thoracic aorta.

(d) Tracheal branches are distributed to the trachea; they anastomose with branches of the superior thyreoid and with the bronchial arteries.

(e) An inferior laryngeal branch accompanies the recurrent nerve to the lower part of the larynx. It enters the larynx, at the lower border of the inferior constrictor, gives branches to its muscles and mucous membrane, and anastomoses with the laryngeal branch of the superior thyreoid artery.

(f) The ascending terminal branch supplies the posterior and lower part of the thyreoid gland, and anastomoses with branches of the superior thyreoid artery.

(g) The inferior terminal branch is distributed to the lower and medial part of the thyreoid gland. It anastomoses with its fellow of the opposite side and with branches of the superior thyreoid artery.

(B) Arteria Transversa Colli.-The transverse cervical artery (Figs. 759 and 761) runs upivards and posteriorly, from the thyreo-cervical trunk, across the posterior triangle of the neck to the anterior border of the trapezius, where it divides into a ramus ascendens (O.T. superficial cervical) and a ramus descendens (O.T. posterior scapular). It is very variable in size, and not infrequently the ramus descendens arises separately from the third part of the subclavian.

Immediately after its origin, under cover of the internal jugular vein, it crosses the scalenus anterior, lying superficial to the phrenic nerve and under cover of the sterno-mastoid muscle; on the left side it is also crossed, superficially, by the terminal part of the thoracic duct. Passing from beneath the sterno-mastoid, it enters the lower part of the posterior triangle of the neck, where it lies upon the trunks of the brachial plexus, and, as it runs upwards and backwards to its termination, it passes medial to the posterior belly of the omo-hyoid.

Not uncommonly the ascending branch forms a separate ressel which springs from the thyreo-cervical trunk and takes the conrse deseribed, whilst the descending branch arises from the third part of the subclavian artery and lies at a lower level. In such cases the upper of the two vessels is called the superficial cervical artery and the lower the transverse cervical artery. If the superficial cervical artery is absent it is replaced by the ascending branch of the transverse cervical.

Branches.--(a) Small muscular branches to the surrounding muscles.

(b) The ascending branch, usually a slender branch, passes beneath the trapezius; it runs upwards, superficial to the levator scapule and upon the splenius, and anastomoses with the descending branch of the occipital artery, and it sends branches downwards which accompany the accessory nerve and anastomose with the descending branch and transverse scapular arteries.

(c) The descending branch runs downwards, deep to the levator scapulæe and the rhomboid muscles, close to the vertebral border of the scapula. It runs parallel with, and a short distance away from, the dorsal scapular nerve (O.T. nerve to the rhomboid muscles), and it sends branches in to the supraspinous, the infraspinous, and the subscapular fossæ, which anastomose with branches of the transverse scapular and subscapular arteries. It also sends branches backwards, through and between the rhomboid muscles, which anastomose with the ascending branch of the transverse cervical and with the posterior branches of the intercostal arteries.

(C) Arteria Transversa Scapulæ.-The transverse scapular artery (O.T. suprascapular) springs from the thyreo-cervical trunk and terminates in the infraspinous fossa of the scapula. As a rule it is smaller than the transverse cervical artery.

Commencing behind the internal jugular vein, it crosses the scalenus anterior and phrenic nerve, and is covered superficially by the sterno-mastoid and the anterior jugular vein; on the left side it lies behind the termination of the thoracic duct also. Continuing behind the clavicle, and crossing superficial to the third part of the subclavian artery and the cords of the brachial plexus, it reaches the scapular notch and passes over the superior transverse ligament. Then it descends, with the suprascapular nerve, through the supraspinous fossa and beneath the supraspinatus muscle, and passing through the great scapular motch, deep to the inferior transverse ligament, enters the infraspinous fossa, where it anastomoses with the circumflex scapular branch of the subscapular artery and with branches of the descending branch of the transverse cervical artery. 
Branches.-(a) Muscular, to the sterno-mastoid, the subclavius, and the muscles on the dorsum of the scapula.

(b) The medullary, a small branch to the clavicle.

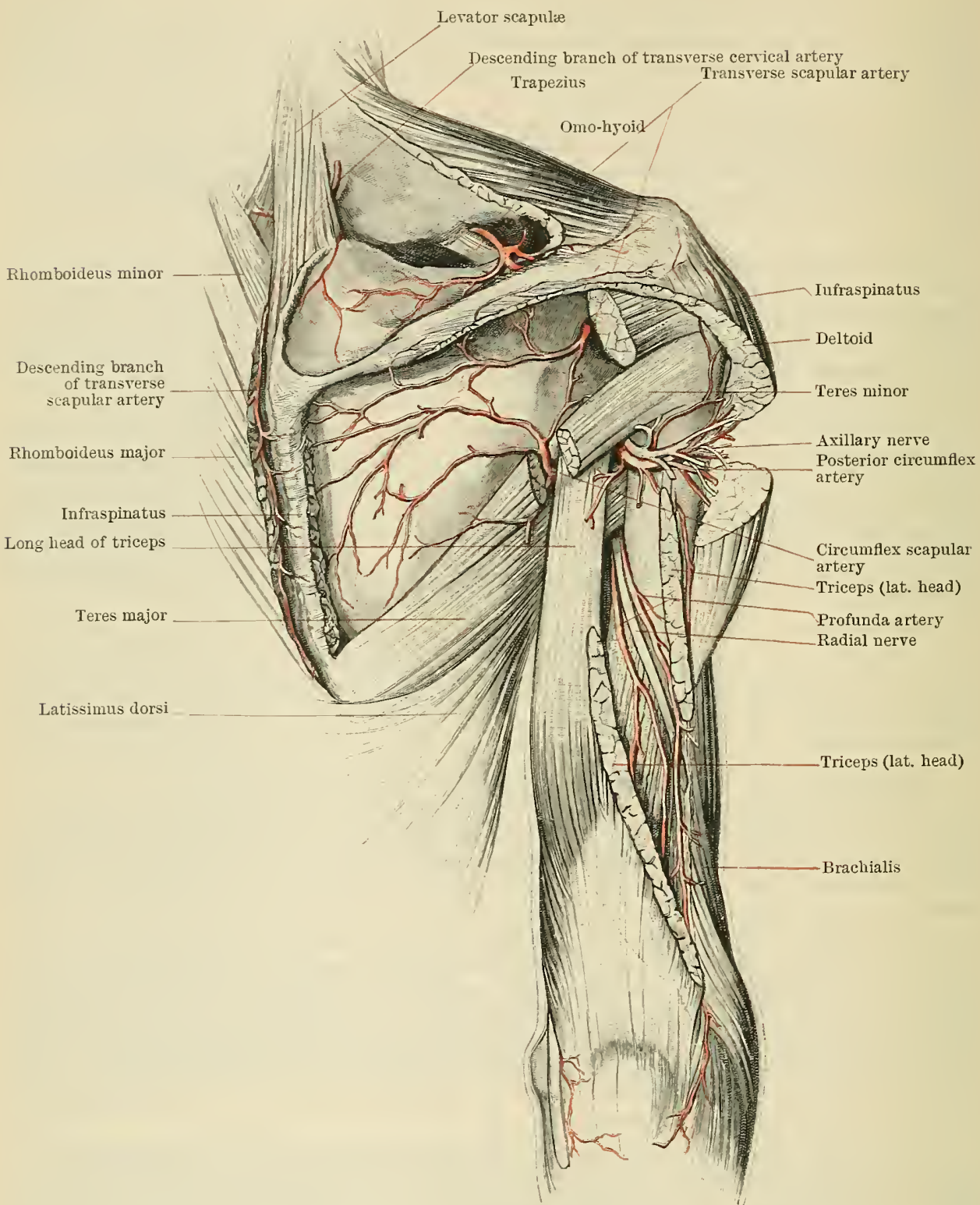

Fig. 765.-Dissection OF THE BACK OF THE SHOUlder AND ARM, showing the anastomosing vessels on the dorsum of the scapula, and the posterior humeral circumflex and the profunda arteries.

(c) The suprasternal, to the stemal end of the clavicle and the sterno-clavicular joint.

(d) Acromial branches, which ramify over the acromion, anastomosing with the acromial branches of the thoraco-acromial and the posterior circumflex arteries.

(e) Articular, to the acromio-clavicular and shoulder-joints.

$(f)$ The subscapular, which is given off as the artery passes over the superior transverse ligament. It passes down into the subscapular fossa, gives branches to the subscapularis, and anastomoses with the branches of the subscapular artery and the descending brauch of the transverse cervical artery. 
(g) Supraspinous, which ramify in the supraspinous fossa, supplying the muscle, and anastomosing with the descending branch of the transverse cervical.

(h) Terminal branches ramify in the infraspinous fossa, and anastomose with the circumflex scapular and with branches of the descending branch of the transverse cervical artery.

(3) Arteria Mammaria Interna.-The internal mammary artery (Fig. 761) arises from the lower and anterior part of the subclavian, at the medial border of the scalenus anterior and immediately below the origin of the thyreo-cervical trunk. It terminates behind the medial extremity of the sixth intercostal space by dividing into the musculo-phrenic and the superior epigastric arteries.

The artery passes at first dowwwards, forwards, and medially, lying upon the pleura, and behind the innominate vein, the sternal extremity of the clavicle, and the cartilage of the first rib; it is crossed obliquely, from the lateral to the medial side, by the phrenic nerve, which usually passes anterior to it. From the cartilage of the first rib it descends vertically, about $12 \mathrm{~mm}$. (half an inch) from the border of the sternum, and lies, in the upper part of its course, in front of the pleura, and, in the lower part, in front of the transversus thoracis. It is covered anteriorly by the cartilages of the upper six ribs, the intervening intercostal muscles, and the terminal portions of the intercostal nerves; and it is accompanied by two venæ comites, which unite together above, and on its medial side, to form a single trunk which terminates in the innominate vein.

Branches.-(a) The pericardiaco-phrenic (O.T. comes nervi phrenici) is a long slender branch which is given off from the upper part of the internal mammary. It accompanies the phrenic nerve, through the superior and middle mediastina, to the diaphragm, where it anastomoses with the inferior phrenic and musculo-phrenic arteries. In its course downwards the artery gives off numerous small branches to the pleura and pericardium, which anastomose with offsets of the mediastinal and pericardial branches of the aorta and internal mammary arteries, and also with the bronchial arteries, forming the widemeshed subpleural plexus of Turner.

(b) Anterior mediastinal branches, small and numerous, pass to the areolar tissue of the anterior mediastinum and supply the areolar tissue and the sternum.

(c) Thymic.-Small twigs which supply the thymus.

(d) Bronchial.-One or several small branches which pass to the lower end of the trachea and to the brouchi.

(e) The intercostal are two in number in each of the upper six intercostal spaces. They pass laterally for a short distance either between the pleura and the internal intercostal muscles or between the transversus thoracis and the internal intercostal muscles; they then pierce the internal intercostal muscles, and ramify between them and the external intercostal muscles, anastomosing with the aortic and superior intercostal arteries and their collateral branches.

$(f)$ The perforating branches, one in each of the upper six intercostal spaces, are small vessels which pass forwards, with the anterior, branches of the thoracic nerves, piercing the internal intercostal muscle, the anterior intercostal membrane, and the pectoralis major, to terminate in the skin and subcutaneous tissue. They supply twigs to the sternum, and those in the third and fourth spaces, usually the largest of the series, give off branches to the mammary gland.

(g) The musculo-phrenic, or lateral terminal branch of the internal mammary artery, runs downwards and laterally from the sixth intercostal space to the tenth costal cartilage. In the upper part of its course it lies upon the thoracic surface of the diaphragm, but it pierces the muscle about the level of the eighth costal cartilage, and terminates on its abdominal surface. Its branches are :-

(i.) Muscular, which supply the diaphragm and anastomose with the superior and inferior phrenic arteries.

(ii.) Intercostal branches, two in each of the seventh, eighth, and ninth intercostal spaces; they are distributed in the same manner as the corresponding branches of the internal mammary artery, and terminate by anastomosing with the artic intercostals and their collateral branches.

(h) The superior epigastric, or medial terminal branch of the internal mammary artery, descends into the anterior wall of the abdomen. It leares the thorax, between the sternal and costal origins of the diaphragm, and enters the sheath of the rectus, lying first behind, and then in the substance of the rectus muscle. It terminates by anastomosing with branches of the inferior epigastric artery. Its branches are:- 
(i.) Muscular, to the rectus, to the flat muscles of the abdominal wall, and to the diaphragm.

(ii.) Anterior Cutaneous.-These branches pierce the rectus and the anterior portion of its sheatl. They accompany the anterior terminal branches of the lower thoracic nerves, and terminate in the subcutaneous tissues and skin of the middle portion of the anterior abdominal wall.

(iii.) Xiphoid, a small branch which crosses the front of the xiphoid process to anastomose with its fellow of the opposite side. It supplies the adjacent muscles and skin.

(iv.) Hepatic branches of small size pass backwards in the falciform ligament to the liver, where they anastomose with branches of the hepatic artery.

(4) Truncus Costocervicalis.-The costo-cervical trunk (Fig. 761) springs from the posterior aspect of the second part of the subclavian artery on the right side and from the first part on the left side. It runs upwards and backwards, over the apex of the pleural sac, to the neck of the first rib, where it divides into superior intercostal and deep cervical branches.

Branches-(a) Arteria Cervicalis Profunda.-The deep cervical branch sometimes arises from the subclavian artery directly; but more commonly it springs from the costocervical trunk at the upper border of the neck of the first rib. It runs backwards, like the posterior branch of an intercostal artery, passes between the first thoracic and last cervical nerves, and between the transverse process of the last cervical vertebra and the neck of the first rib, to the back of the neck; there it ascends, between the semispinalis capitis (O.T. complexus) and the sernispinalis cervicis muscle, to terminate by anastomosing with the descending branch of the occipital artery. It anastomoses also with branches of the ascending cervical and vertebral arteries, supplies the adjacent muscles, and sends a spinal branch, through the intervertebral foramen between the last cervical and the first thoracic vertebræ, into the vertebral canal, where it anastomoses with the spinal branches of the vertebral and intercostal arteries.

(b) Arteria Intercostalis Suprema. - The superior intercostal branch descends, anterior to the neck of the first rib, between the first thoracic nerve laterally and the first thoracic ganglion of the sympathetic trunk medially and, at the lower border of the neck of the rib, it gives off the intercostal artery of the first space; then, crossing anterior to the neck of the second rib, it becomes the posterior intercostal artery of the second intercostal space. The first two posterior intercostal arteries run laterally, each in its own space, lying first between the pleura and the posterior intercostal membrane, and then between the internal and external intercostal muscles. The branches terminate by anastomosing with anterior intercostal branches of the internal mammary artery. Each gives off muscular branches to the intercostal muscles, a nutrient branch to the rib below which it lies, and a collateral branch which runs along the lower border of the space and terminates by anastomosing with an anterior intercostal branch of the internal mammary artery.

\section{ARTERIA AXILLARIS.}

The axillary artery, which lies in the axillary space, is the direct continuation of the subclavian artery, and it becomes the brachial artery.

It commences at the external border of the first rib, at the apex of the axillary space. It passes distally, with a lateral inclination, along the lateral wall of the space, i.e. to the medial side of the shoulder-joint and the humerus, to the lower border of the teres major, where it becomes the brachial artery. A line drawn from the middle of the clavicle to the medial border of the prominence of the coracobrachialis and biceps muscles, when the arm is abducted until it is at right angles with the side, indicates the position and direction of the artery.

The position and direction, however, and to a certain extent the relations of the axillary artery, are modified by changes in the position of the upper extremity. With the arm hanging by the side the axillary artery describes a curve with the concavity directed downwards and medially, and the vein is to its medial side. When the arm is at right angles with the side, the axillary artery is almost straight; it lies closer to the lateral wall of the axilla, and the vein overlaps it antero-medially. When the arm is raised above the level of the shoulder the axillary artery is curved over the head of the humerus, and the vein lies still more in front of it.

For descriptive purposes the artery is divided into three parts: the first part 
lies above, the second behind, and the third part below the pectoralis minor muscle.

Though it is the usual custom to describe three parts of the axillary artery, -a division which is perhaps of practical interest in so far as it emphasises the fact that the axillary artery is surgically accessible above the pectoralis minor,it is to be noted that the upper border of the pectoralis minor is frequently exactly opposite the external border of the first rib, at the point where the axillary artery

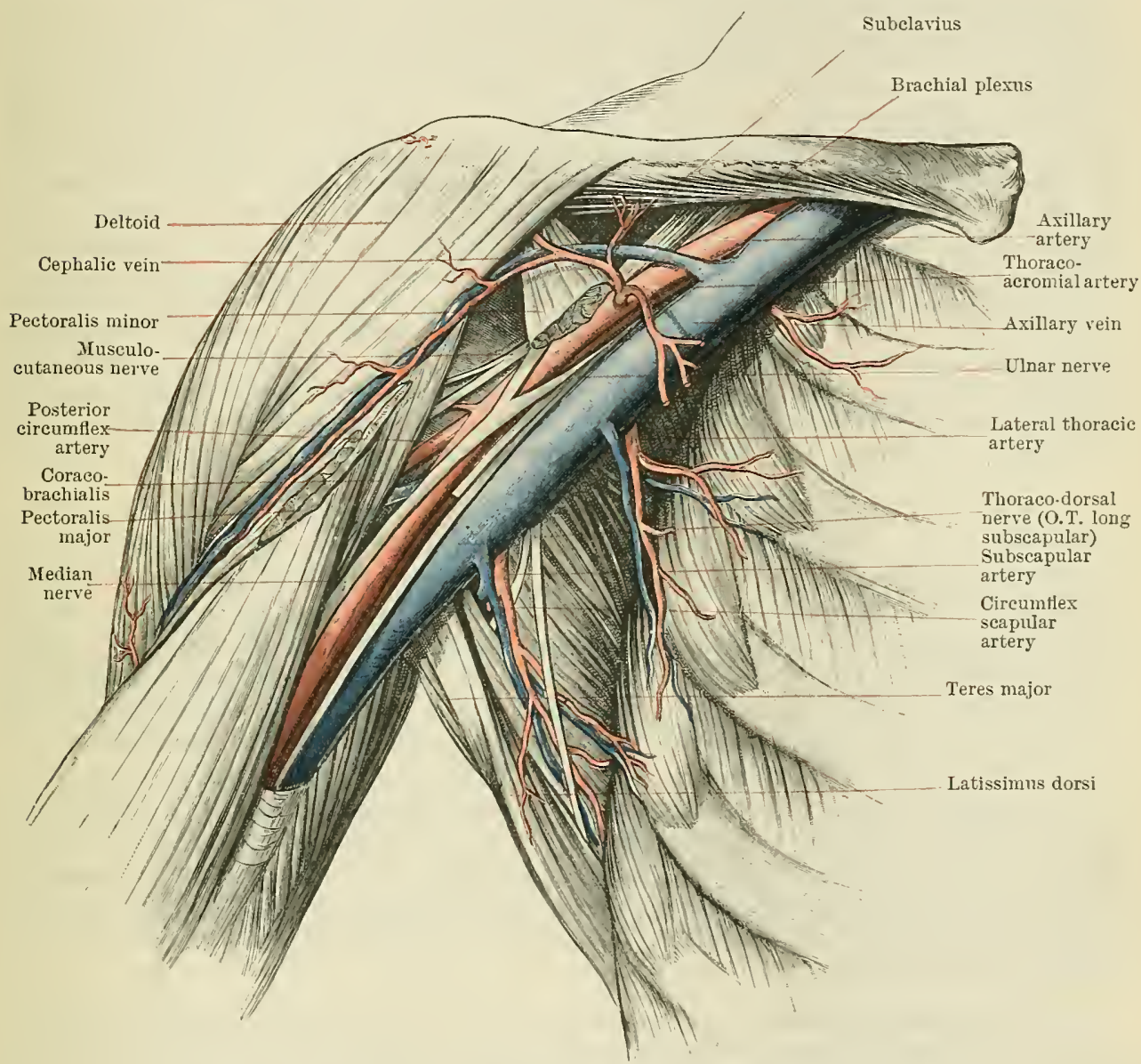

Fig. 766.-The Axillary Artery and its Branches and Relations.

begins. In the strict sense, therefore, no part of the artery is above the pectoralis minor.

Relations of the First Part-Posterior.-The first part of the artery is enclosed, together with the vein and the cords of the brachial plexus, in a prolongation of the cervical fascia known as the axillary sheath, posterior to which are the upper serration of the serratus anterior muscle, the contents of the first intercostal space, the medial cord of the brachial plexus, the medial anterior thoracic and the long thoracic nerves, the latter descending vertically between the artery and the serratus anterior. Anterior.-It is covered in front loy the costo-coracoid inembrane. The membrane intervenes between the artery and the cephalic vein, the branches of the lateral anterior thoracic nerve, the branches of the thoraco-acromial artery with their accompanying veins, and the clavicular part of the pectoralis major muscle, superficial to which are the deep fascia, the platysma, the supra-clavicular branches of the cervical plexus, and the superficial fascia and the skin. Posterior to the costo-corncoid membrane the artery is crossed by a loop of communication between the lateral and medial anterior thoracic nerves. Lateral.-Above and to the lateral side are the lateral and posterior cords of the brachial plexus and the lateral 
anterior thoracic nerve. Below and to the medial side is the axillary rein, the medial anterior thoracic nerve intervening.

Relations of the Second Part-Posterior.-Behind this portion of the artery are the posterior cord of the brachial plexus and a layer of fascia which separates it from the subscapularis muscle. Anterior.--In front is the pectoralis minor, and, more superficially, the pectoralis major, the fascir and skin. Lateral.-To the lateral side lies the lateral cord of the brachial plexus. Medial.-On the medial side the medial cord of the plexus lies in close relation to the artery, and intervenes between it and the axillary vein.

Relations of the Third Part-Posterior. - The third part of the artery rests posteriorly upon the lower border of the subscapularis, the latissimus dorsi, and the teres major. It is separated from the fibres of the subscapularis by the axillary (O.T. circumflex) and radial (O.T. musculo-spiral) nerves, and from the latissimus dorsi and teres major by the radial nerve alone. Anterior.-It is crossed in front by the medial head of the median nerve. In its upper half it lies under cover of the lower part of the pectoralis major, the fasciæ and skin, whilst its lower part, which is superficial, is covered by skin and fascire only. Lateral.-To the lateral side lie the median and musculo-cutaneous nerves and the coraco-brachialis muscle. Medial.-To the medial side is the axillary vein. The two vessels are, however, separated by two of the chief branches of the medial cord of the brachial plexus. In the angle between the vein and the artery, and somewhat in front of the latter, lies the medial cutaneous nerve of the forearm (O.T. internal cutaneous nerve); in the angle behind is the ulnar nerve. The medial cutaneous nerve of the arm (O.T. lesser internal cutaneous) lies medial to the vein, and the venæ comites of the brachial artery ascend along the medial side, to terminate in the axillary vein at the lower border of the subscapularis muscle.

\section{Branches of the Axillary Artery.}

(1) Arteria Thoracalis Suprema.-The supreme thoracic artery (Fig. 760) is a small branch which arises from the first part of the axillary at the lower border of the subclavius. It runs downwards and medially, across the first intercostal space, pierces the medial part of the costo-coracoid membrane, and supplies branches to the subclavius, the pectoralis major and minor, and to the serratus anterior (O.T. magnus) and the intercostal muscles; it anastomoses with branches of the transverse scapular, the internal mammary, and the thoraco-acromial arteries.

(2) Arteria Thoracoacromialis.--The thoraco-acromial artery (Fig. 766) arises near the upper border of the pectoralis minor, from the second part of the axillary artery. It is a very short trunk, of considerable size, which passes forwards, pierces the costo-coracoid membrane, and terminates, deep to the clavicular portion of the pectoralis major, by dividing into four terminal branches-clavicular, pectoral, deltoid, and acromial.

(a) The clavicular branch is a long slender artery which runs upwards and medially to the sterno-clavicular joint, anastomosing with the supreme thoracic, with branches of the transverse scapular, and with the first perforating branch of the internal mammary artery. It supplies the adjacent muscles and the sterno-clavicular articulation.

(b) The pectoral is a large branch which descends between the two pectoral muscles, to both of which it gives branches, and it anastomoses with the intercostal and lateral thoracic arteries.

(c) The deltoid branch runs distally in the groove between the pectoralis major and the deltoid, where it lies by the side of the cephalic vein, as far as the insertion of the deltoid. It anastomoses with the acromial branch and with the anterior circumflex artery, and it gives branches to the pectoralis major and deltoid muscles and to the skin.

(d) The acromial branch runs upwards and laterally, across the tip of the coracoid process, to the acromion, where it anastomoses with the deltoid branch, with the acromial branches of the transverse scapular, and with the posterior circumflex arteries. It gives branches to the deltoid.

(3) Arteria Thoracalis Lateralis.-The lateral thoracic curtery arises from the second part of the axillary, and descends, along the lower border of the pectoralis minor, to anastomose with the intercostal and subscapular arteries and with the pectoral branch of the thoraco-acromial. It supplies the adjacent muscles, and sends mammary branches to the lateral part of the mammary gland. 
(4) Arteria Subscapularis.-The subscapular artery is the largest branch of the axillary artery. It arises from the third part of the artery, opposite the lower border of the subscapularis, along which it descends, giving branches to the muscle and to the medial wall of the axillary space. After a short course it divides into two terminal branches, the circumflexa scapulæ and the thoracodorsalis.

(1) The circumflex scapulæ is frequently the larger branch. It arises about $37 \mathrm{~mm}$. (one and a half inches) from the commencement of the subscapular trunk, and passes backwards into the triangular space between the subscapularis above, the teres major below, and the long head of the triceps laterally. Turning round, and usually grooving; the axillary border of the scapula, under cover of the teres minor, it enters the infraspinous fossa, where it breaks up into branches which anastomose with branches of the descending branch of the transverse cervical artery and the transverse scapular arteries. Whilst it is in the triangular space the artery gives off an infrascapular branch which passes into the subscapular fossa and terminates by anastomosing with the branches of the descending branch of the transverse cervical and the transverse scapular arteries. It gives off, in the same situation, a descending branch also, which runs downwards, to the lower angle of the scapula, between the teres major and minor muscles, and small branches are given to the deltoid and long head of triceps.

(2) The thoraco-dorsal continuation of the subscapular trunk accompanies the thoracodorsal nerve (O.T. long subscapular) along the axillary border of the scapula to the wall of the thorax, where it anastomoses with the lateral thoracic artery and with branches of the intercostal arteries.

(5) Arteria Circumflexa Humeri Posterior.-The posterior circumflex artery arises from the third part of the axillary artery and passes backwards, accompanied by the axillary nerve, through an intermuscular cleft, the so-called quadrilateral space, which is bounded by the teres minor and subscapularis above, the teres major below, the long head of the triceps medially, and the humerus laterally. It turns round the surgical neck of the humerus, under cover of the deltoid muscle, and terminates in numerous branches which supply the deltoid. As a rule it is an artery of large size, only slightly smaller than the subscapular.

Branches.-(a) Muscular to the teres major and minor, the long and lateral heads of the triceps, and the deltoid; $(b)$ An acromial branch, which ascends to the acromial process, where it anastomoses with the acromial branches of the transverse scapular and the thoraco-acromial arteries; (c) A descending branch, which ruus distally, along the lateral head of the triceps, to anastomose with the profunda artery ; $(d)$ Articular to the shoulder-joint; (e) Nutrient to the head of the humerus; $(f)$ Terminal, which supply a large portion of the deltoid, and anastomose with the anterior circumflex and thoraco-acromial arteries.

(6) Arteria Circumflexa Humeri Anterior.-The anterior circumflex artery is a small branch which is given off from the third part of the axillary close to, or in common with, the posterior circumflex. It passes laterally, posterior to the coraco-brachialis and the two heads of the biceps, round the front of the surgical neck of the humerus, and terminates by anastomosing with the posterior circumflex. At the intertubercular groove it gives a well-marked branch which accompanies the long head of the biceps, supplying the sheath of the tendon, and giving branches to the shoulder-joint. It also gives muscular branches to the adjacent muscles, one of which runs distally along the tendon of insertion of the pectoralis major.

\section{ARTERIA BRACHIALIS.}

The brachial artery is the direct continuation of the axillary. It commences at the lower border of the teres major, and terminates in the cubital fossa, at the level of the neck of the radius, by dividing into the radial and ulnar arteries.

The general course of the brachial artery is distally and laterally, along the medial side of the arm. Its position and that of the axillary artery may be 
indicated on the surface, when the arm is abducted, by a line drawn from the middle of the clavicle to the centre of the bend of the elbow.

Relations-Posterior.-It lies, successively, anterior to the long head of the triceps, the radial (O.T. musculo-spiral) nerve and the profunda vessels intervening; the medial

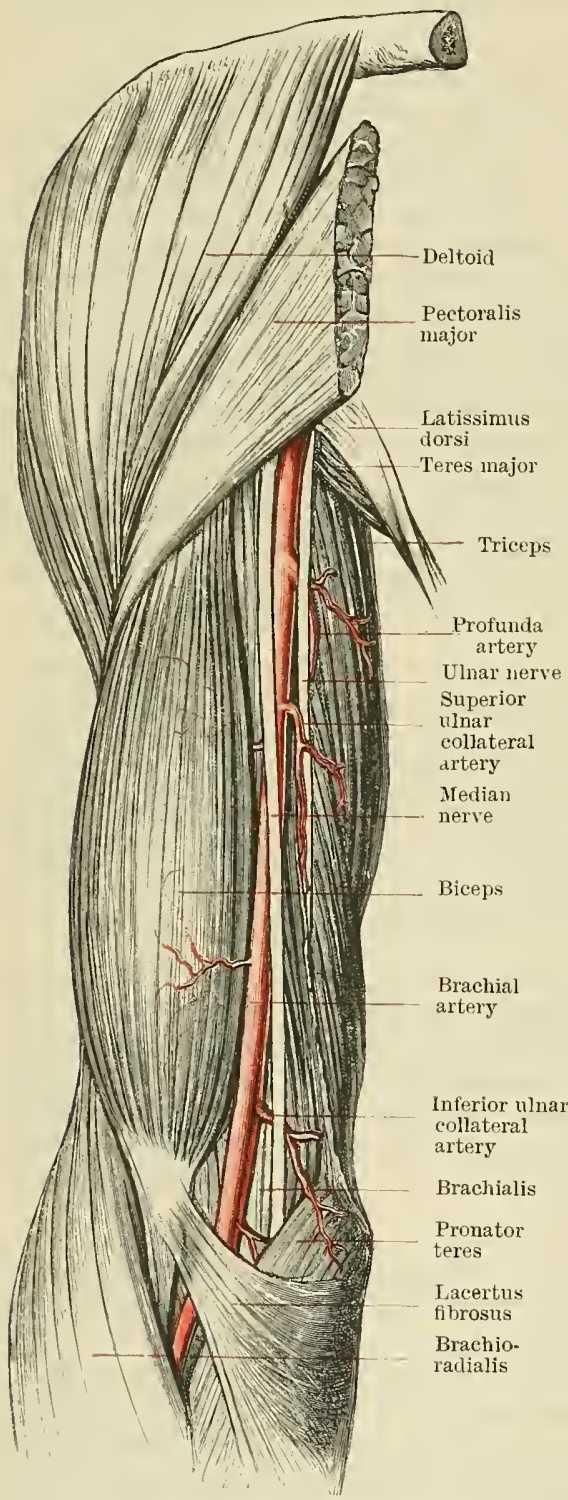

Fig. 767.-The Brachial Artery and its Branches. head of the triceps; the insertion of the coracobrachialis ; and the brachialis. Anterior.-It is overlapped anteriorly by the medial border of the biceps, is crossed at the middle of the arm by the median nerve, and, in addition, it is covered by deep and superficial fascia and by skin. In the cubital fossa a thickened portion of the deep fascia, the lacertus fibrosus (O.T. semilunar or bicipital fascia), separates it from the median basilic vein and the volar branch of the medial cutaneous nerve of the forearm, both of which lie in the superficial fascia. Lateral.To the lateral side it is in relation proximally with the median nerve, and distally with the biceps. Medial.-To the medial side it is in relation, in the proximal part of its extent, with the basilic vein, the medial cutaneous nerve of the forearm, the medial cutaneous nerve of the arm, and the ulnar nerve, and in the distal part with the median nerve. Two venæ comites, a medial and a lateral, accompany the artery, and communications between these pass across the vessel.

\section{Branches of the Brachial Artery.}

(1) Arteria Profunda Brachii. - The profunda artery of the arm (O.T. superior profunda) is a large branch which arises from the postero-medial aspect of the brachial soon after its commencement. It rums distally and laterally, with the radial (O.T. musculo-spiral) nerve, in the radial sulcus (O.T. musculo-spiral groove), and divides, at the back of the humerus, into two terminal branches, anterior and posterior. Not infrequently this division takes place at a higher level, and the artery appears double. The anterior terminal branch accompanies the radial nerve through the lateral intermuscular septum, and passes distally, between the brachio-radialis and the brachialis, to the front of the lateral epicondyle, where it anastomoses with the radial recurrent artery. The posterior terminal branch continues distally, behind the lateral intermuscular septum, and anastomoses, posterior to the lateral epicondyle, with the interosseons recurrent artery and with the inferior ulnar collateral artery.

Whilst they are posterior to the humerus one of the terminal branches gives off-(a) a slender medial collateral twig, which descends in the substance of the medial head of the triceps to the back of the elbow, where it anastomoses with the inferior ulnar collateral artery; $(b)$ a nutrient branch, which enters a foramen on the posterior surface of the humerus; and (c) an ascending branch, which anastomoses with the descending branch of the posterior circumflex artery.

(2) Muscular branches are given to the biceps, coraco-brachialis, brachialis, triceps, and pronator teres. 
(3) Nutrient.-A small artery which arises from the middle of the brachial and enters the nutrient foramen on the antero-medial surface of the body of the humerus.

(4) Arteria Collateralis Ulnaris Superior.-The superior ulnar collateral artery (O.T. inferior profunda) is smaller than the profunda, with which it sometimes arises by a common trunk; usually, however, it springs from the postero-medial aspect of the middle of the brachial. It runs distally and posteriorly, with the ulnar nerve, through the medial intermuscular septum, and then, passing more vertically, reaches the back of the medial epicondyle of the humerus, where it terminates by anastomosing with the dorsal and volar ulnar recurrent and inferior ulnar collateral arteries.

(5) Arteria Collateralis Ulnaris Inferior.-The inferior ulnar collateral artery (O.T. anastomotic) arises from the medial side of the brachial artery about $50 \mathrm{~mm}$. (2 inches) above its termination. It runs medially, posterior to the median nerve and anterior to the brachialis. Then it pierces the medial intermuscular septum, and turns laterally, between the medial head of the triceps and the posterior surface of the bone, to the lateral epicondyle. It supplies the adjacent muscles and anastomoses, anterior to the medial epicondyle, with the volar ulnar recurrent, behind the medial epicondyle with the dorsal nlnar recurrent and the superior ulnar collateral, at the middle of the back of the humerus with the medial collateral branch of the profunda, and posterior to the lateral epicondyle with the posterior terminal branch of the profunda and the interosseous recurrent artery.

\section{ARTERIA RADIALIS.}

The radial artery (Figs. 768,769 , and 770) is the smaller of the two terminal branches of the brachial artery, but it is the more direct continuation of the parent trunk. It commences in the cubital fossa, opposite the neck of the radius, and terminates in the palm of the hand, by anastomosing with the deep branch of the ulnar artery, and thus completing the deep volar arch (O.T. palmar).

The trunk is divisible into three parts.

The first part lies in the volar part of the forearm. It runs distally and somewhat laterally to the apex of the styloid process of the radius. The second part curves round the lateral side of the wrist and across the back of the os multangulum majus to reach the proximal end of the first interosseous space. The third part passes forwards, through the first interosseous space, to the palm of the band, where it joins the deep branch of the ulnar artery.

Relations of the First Part-Dorsal.-It passes successively across the volar aspects of the following structures: the tendon of insertion of the biceps, the supinator, the pronator teres, the radial portion of the flexor digitorum sublimis, the flexor pollicis longus, the pronator quadratus, and the volar ligament of the wrist-joint.

Volar.-The artery is covered superficially, in the proximal half, by the volar border of the brachio-radialis; in the remainder of its extent it is covered only by skin and fasciæ.

To the radial side are the brachio-radialis, and the superficial branch of the radial nerve (O.T. radial nerve). The nerve lies quite near to the artery in its middle third. 'To the ulnar side are the pronator teres proximally and the flexor carpi radialis distally. Two venæe comites, one on each side, accompany the artery.

Branches of the First Part.-(1) The radial recurrent arises in the cubital fossa. It springs from the lateral side of the radial on the volar surface of the supinator. It runs towards the radial border of the forearm, passes between the superficial and deep divisions of the radial (musculo-spiral) nerve, and then runs proximally to the lateral epicondyle of the humerus, where it anastomoses with the anterior terminal branch of the profunda. The radial recurrent supplies numerous muscular branches to the brachio-radialis, the supinator, the extensor carpi radialis longus, and the extensor carpi radialis brevis.

(2) Muscular branches to the muscles on the radial side of the volar aspect of the forearm.

(3) The superficial volar branch (Fig. 768) is a slender vessel which arises a short distance proximal to the wrist and rums distally across the ball of the thumb. It usually pierces the superficial muscles of the thenar eminence, and terminates either in their substance or by uniting with the ulnar artery and completing the superficial arch of the palm of the hand. 
(4) A volar carpal branch passes ulnarwards, between the flexor tendons and their synovial sheaths, and the radial attachments of the volar carpal ligaments. It anastomoses with the volar carpal branch of the ulnar artery to form the volar earpal arch,

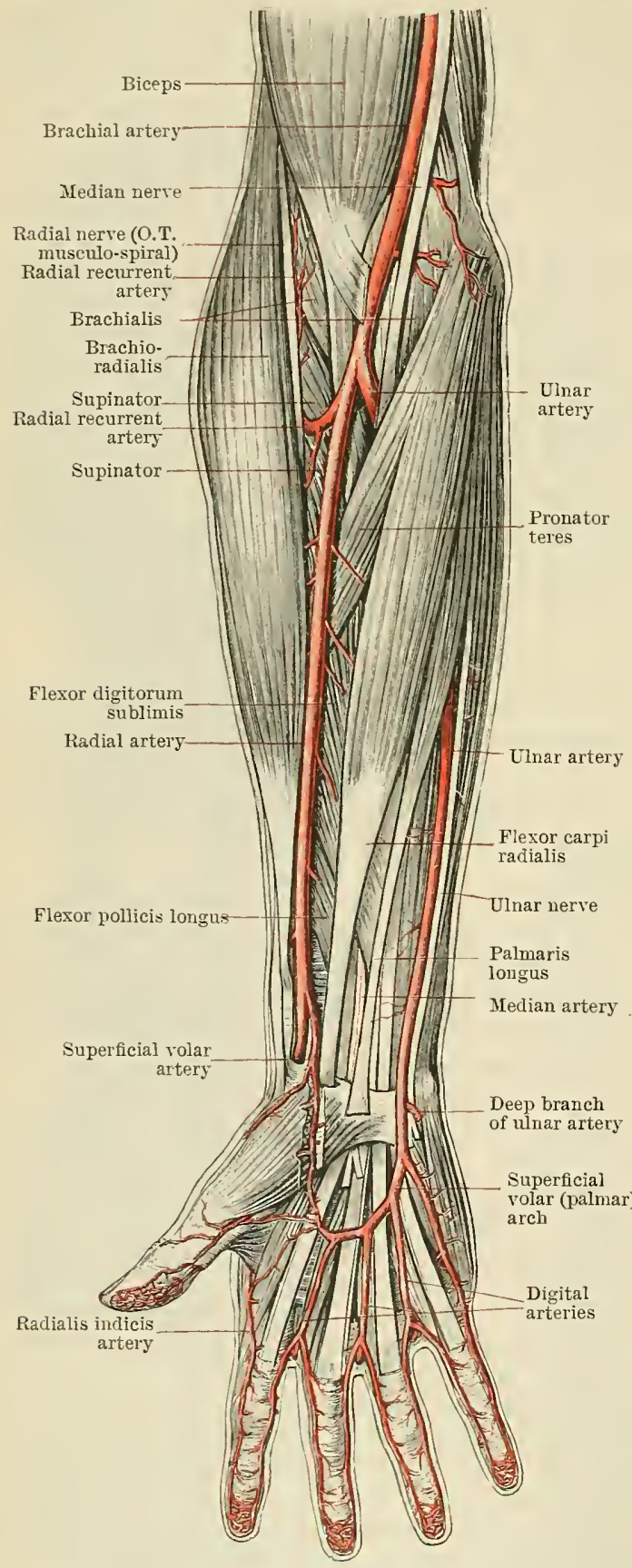

Fig. 768. - Superficial Dissection of the VoLaR Aspect OF THE FOREARM AND HAND, showing the radial and ulnar arteries and the superficial volar arch with its branches. the fourth and fifth digits, respectively.
Each dorsal metacarpal artery is connected with the deep volar (palmar) arch by a proximal perforating branch which passes through the proximal part of the corresponding interosseous space, and with a digital branch from the superficial volar (palmar) arch by a distal perforating branch which passes through the distal part of the space. the volar interosseous artery and from the deep rolar arch.

Relations of the Second Part.-As it curves round the radial side and the dorsum of the wrist, the radial artery lies upon the radial collateral ligament of the intercarpal joint and upon the back of the os multangulum majus. It is crossed by the abductor pollicis longus, the extensor pollicis brevis, and the extensor pollicis longus; more superficially it is covered by skin and fascia, in which are the cephalic vein and some filaments of the superficial branch of the radial nerve.

Branches of the Second Part-(1) Dorsales Pollicis. - Two small arteries which run along the borders of the dorsal aspect of the thumb; they supply the skin, tendons, and joints, and anastomose with the volar digital arteries.

(2) Dorsalis Indicis Radialis.A slender artery which runs distally, on the ulnar head of the first dorsal interosseous muscle and along the dorsal aspect of the radial border of the index-finger.

(3) and (4) The first dorsal metacarpal and the dorsal radial carpal arise by a common trunk which crosses deep to the extensor pollicis longus.

(a) The metacarpal branch passes distally, on the dorsal aspect of the second dorsal interosseous muscle, and divides, opposite the heads of the metacarpal bones, into two dorsal digital branches which supply the adjacent sides of the index and middle fingers. (b) The dorsal carpal branch runs ulnarwards on the dorsal carpal ligaments, deep to the extensor tendons, to anastomose with the dorsal carpal branch of the ulnar artery, and to complete the dorsal carpal arch which receives the terminations of the volar and dorsal interosseous arteries. The dorsal carpal arch gives off the second and third dorsal metacarpal arteries, which run distally, on the dorsal aspects of the third and fourth dorsal interosseons muscles, as far as the heads of the metacarpal bones, where each divides into two dorsal digital branches for the adjacent sides of the third and fourth and

and it receives communications from 
Relations of the third part. - The third part of the radial artery passes volarwards, between the two heads of the first dorsal interosseous muscle, to reach the palm, where it turns ulnarwards, deep to the proximal oblique part of the adductor muscle of the thumb, and, after passing through the proximal fibres of the transverse part of the adductor pollicis, or between the adjacent borders of the oblique and transverse parts of the muscle, it unites with the deep branch of the ulnar artery, completing the deep rolar (palmar) arch.

Branches of the third part.(1) The princeps pollicis branch is given off as soon as the radial artery enters the palm. It runs distally, on the volar aspect of the first metacarpal bone, between the adductor and the opponens pollicis, and under corer of the long flexor tendon, and divides, near the distal end of the bone, into collateral branches which run along the sides of the thumb and anastomose with the dorsales pollicis arteries.

(2) The volaris indicis radialis is a branch which runs distally between the ulnar head of the first dorsal interosseous muscle and the adductor of the thumb and along the radial side of the index-finger to its tip, supplying the adjacent tissues; not uncommonly it anastomoses with the superficial volar (palmar) arcli.

\section{ARTERIA ULNARIS.}

The ulnar artery (Figs. 768 and 769) is the larger terminal branch, but the less direct continuation of the brachial artery. It commences in the cubital fossa, opposite the neck of the radius, and terminates in the palm of the hand, where it anastomoses with the superficial volar artery to form the superficial volar (palmar) arch.

From its origin it runs obliquely, distally, and ulnarwards, deep to the muscles arising from the medial epicondyle, to the junction of the proximal and middle thirds of the forearm, where it comes into relation with the ulnar nerve; it then passes directly distally, on the radial side of the ulnar nerve, to the wrist; crosses anterior to the main part of the transverse carpal ligament, on the radial side of the pisiform bone, and enters the palm of the hand to form the main part of the superficial volar (palmar) arch.

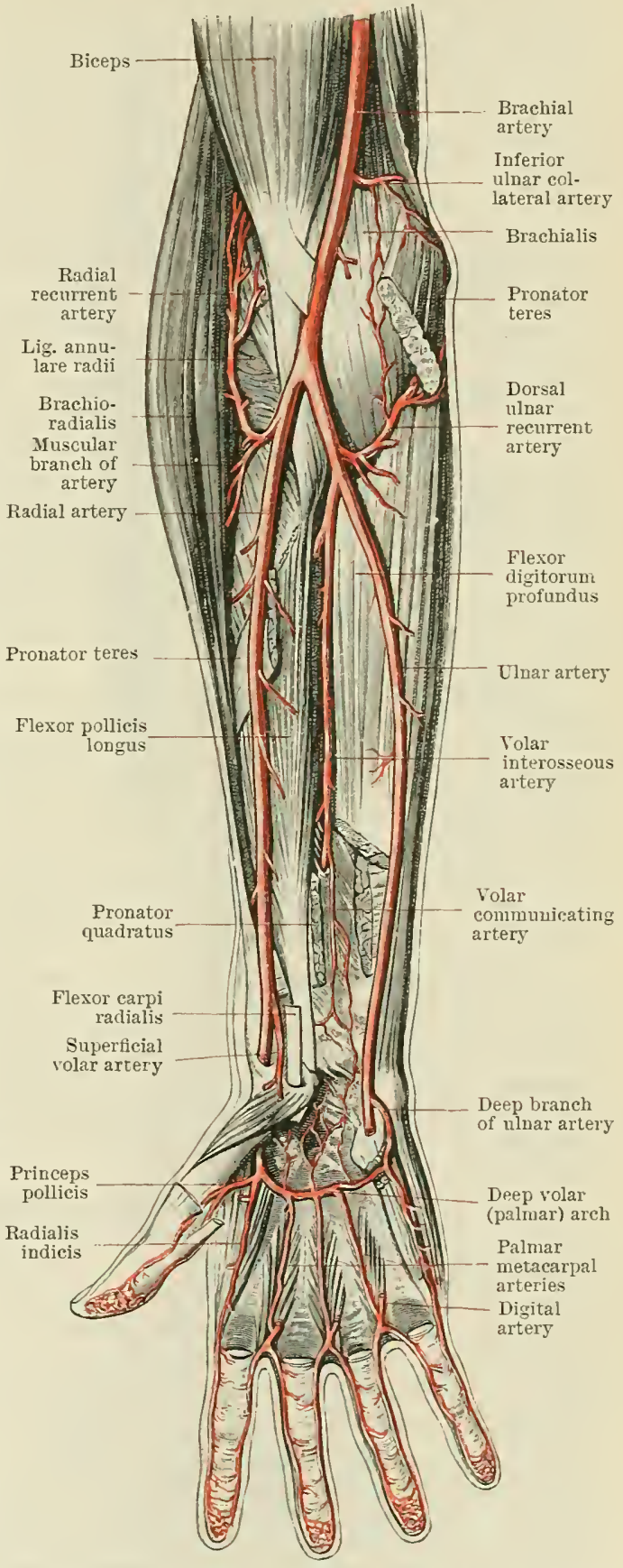

Fig. 769.-Deep Dissectiox of the Froxt of the FOrEary AND HAND, showing the radial and ulnar arteries and their branches and the deep volar arch and its branches. 
the flexor digitorum profundus, and the transverse carpal ligament (O.T. anterior annular). Tolar.-On its volar aspect it is crossed, in the oblique part of its course, by the pronator teres, the median nerve, which is separated from the artery by the deep head of the pronator teres, the flexor digitorum sublimis, the flexor carpi radialis, and the palmaris longus. In the middle third of the forearm it is overlapped by the volar border of the flexor carpi ulnaris, and in the distal third it is covered by skin and fascire only. A short distance proximal to the wrist the palmar cutaneous branch of the ulnar nerve lies volar to it, and as it crosses the transverse carpal ligament, it is bound down by a fascial expansion from the tendon of the flexor carpi ulnaris. Two venæ comites, which frequently communicate with one another, lie one on each side of the artery. On the radial side there is also, in its distal two-thirds, the flexor digitorum sublimis. On its ulnar side are the flexor carpi ulnaris and the ulnar nerve.

Branches.-(1) The volar ulnar recurrent is a small branch which arises in the cubital fossa, frequently in common with the dorsal ulnar recurrent. It passes proximally, to the anterior aspect of the medial epicondyle, under cover of the pronator teres, and anastomoses with branches of the superior and inferior ulnar collateral arteries.

(2) The dorsal ulnar recurrent branch, larger than the volar, arises in the cubital fossa, from the ulnar side of the ulnar artery, and ascends on the brachialis and under cover of the muscles which arise from the medial epicondyle, to the posterior aspect of that prominence, where it passes between the humeral and olecranoid heads of the flexor carpi ulnaris, and anastomoses with the superior and inferior ulnar collateral arteries. It gives branches to the adjacent muscles and to the elbow-joint.

(3) The common interosseous artery, a short trunk which springs from the radial and dorsal aspect of the ulnar artery in the distal part of the cubital fossa. It passes dorsally, towards the proximal border of the interosseous membrane, and divides into volar and dorsal interosseous branches.

(3a) The volar interosseous artery runs distally, on the volar surface of the interosseous membrane, between the adjacent borders of the flexor pollicis longus and the flexor digitorum profundus, to the proximal border of the pronator quadratus, where it pierces the interosseous membrane, and runs distally, first on the dorsal surface of the membrane, deep to the extensor pollicis longus and extensor indicis proprius, and then on the dorsal surface of the radius, in the groove for the extensor digitorum communis; and it terminates, on the dorsum of the carpus, by joining the dorsal carpal arch. It is accompanied on the volar aspect of the interosseous membrane by the volar interosseous nerve, and, after it has pierced the membrane, by the dorsal interosseous nerve.

Branches.-(a) Nutrient to the radius and ulna; (b) Muscular to the adjacent muscles; (c) The volar communicating, a slender branch which passes distally, deep to the pronator quadratus and on the volar surface of the interosseous membrane, to anastomose with the volar carpal arch; (d) Small anastomotic branches are given on the dorsum of the forearm to anastomose with the dorsal interosseous artery; (e) The median artery (0.T comes nervi mediani) is a long slender branch which arises from the proximal part of the volar interosseous artery and runs with the median nerve to the palm, where it anastomoses with recurrent branches of the superficial volar arch.

(3b) The dorsal interosseous artery is usually smaller than the volar interosseous. It passes dorsally between the proximal border of the interosseous membrane and the oblique cord, and then between the supinator and abductor pollicis longus (O.T. ext. oss. met. poll.), after which it runs distally, between the superficial and deep muscles on the dorsum of the forearm, to the wrist, where it anastomoses with the volar interosseous artery and with the dorsal carpal arch. As it crosses the abductor pollicis longus it is accompanied by the dorsal interosseous nerve, but in the remainder of its course it is separated from the nerve by the deep muscles.

Branches. - (a) An interosseous recurrent branch is given off at the dorsal margin of the distal border of the supinator. It runs proximally, on the dorsal surface of the supinator, under cover of the anconeus, to the back of the lateral epicondyle of the humerus, where it anastomoses with the posterior terminal branch of the profunda and with branches of the inferior nhar collateral artery. (b) Muscular branches to both superficial and deep muscles on the dorsum of the forearm. (c) Cutaneous branches to the skin on the dorsum of the forearm and the wrist.

(4) The volar carpal branch of the ulnar artery is a small branch given off proximal to the transverse carpal ligament; it passes towards the radial side, deep to the flexor tendons and their sheaths, on the volar surface of the proximal attachments of the volar radio-carpal ligament, and anastomoses with the volar carpal branch of the radial to form the volar carpal arch. 
(5) The dorsal carpal branch of the ulnar artery arises from the ulnar side of the ulnar artery immediately proximal to the pisiform bone. It passes dorsally, deep to the ulnar flexor and extensor of the carpus, to the dorsum of the carpus, where it unites with the dorsal carpal branch of the radial to form the dorsal carpal arch.

(6) Profunda. - This branch passes distally between the abductor and flexor brevis digiti quinti, and, turning towards the radial side, deep to the flexor brevis, the opponens digiti quinti, and the flexor tendons and their sheaths, joins the termination of the radial artery to complete the deep volar (palmar) arch.

\section{THE ARTERIAL ARCHES OF} THE WRIST AND HAND.

Arcus Carpeus Volaris - The Volar Carpal Arch (Figs. 768 and 769).--The volar carpal arch lies on the volaraspect of the volar carpal ligaments deep to the flexor tendons and their synovial sheaths. It is formed by the union of the volar carpal branches of the radial and ulnar arteries, and it receives the communicating branch from the volar interosseous artery and recurrent branches from the deep volar arch. The branches of distribution which pass from it supply the ligaments and synovial membrane of the radio-carpal and intercarpal joints.

Arcus Carpeus Dorsalis. - The Dorsal Carpal Arch. (Fig. 770).-.This arch lies on the dorsal carpal ligaments deep to the extensor tendons and their sheaths. It is formed by the union of the dorsal carpal branches of the radial and ulnar arteries, and receives the terminations of the volar and dorsal interosseous arteries.

\section{Branches.-(a) Articular}

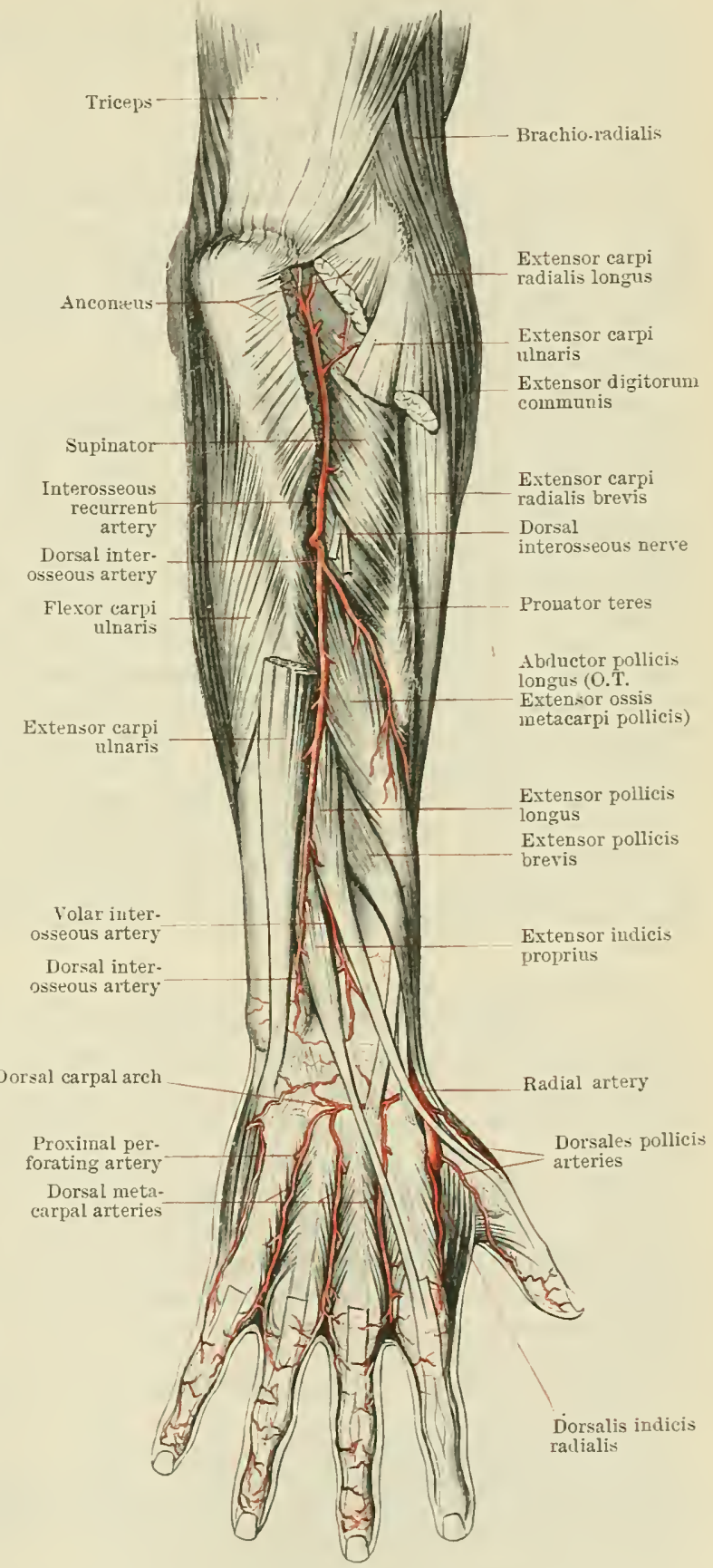

Fig. 770.-ThE DORSAL Ixterosseous ArTERY AND THE SECOND PART OF THE RADial ARtery, with their Braxches.

to the adjacent articulations.

(b) Dorsal metacarpal, two slender branches which run distally, along the third and fourth dorsal interosseous muscles, to the clefts of the fingers, where each divides into dorsal digital branches. They communicate near their origins with the deep rolar arch by the proximal perforating arteries, and near their terminations with the volar digital vessels through the distal perforating arteries. Their digital terminal branches rum 
distally, on the dorso-lateral aspects of the fingers which bound the third and fourth interosseons spaces, and they anastomose with the proper rolar digital branches of the rolar digital arteries.

Arcus Volaris Superficialis.-The superficial volar arch (Fig. 768) includes the terminal portion of the ulnar artery, and is usually completed on the radial side by the superficial volar, or by the volaris indicis radialis or the princeps pollicis branches of the radial artery. It extends from the ball of the little finger to the ulnar border of the superficial head of the flexor pollicis brevis, and reaches distally to a line drawn across the palm at the level of the distal border of the fully abducted thumb. It is covered by the integuments and the central portion of the palmar aponeurosis, and, on the ulnar side of the palm, by the palmaris brevis. It is accompanied by venæ comites. It is in contact dorsally with the flexor brevis and opponens digiti quinti, and with the common digital branches of the ulnar and median nerves, as well as with the flexor tendons and the lumbrical muscles.

Branches.--Four volar common digital arteries arise from the convexity of the arch. The most ulnar of the four passes along the ulnar border of the little finger, accompanied by the common digital branch of the ulnar nerve; the other three pass distally superficial to the common digital nerves, one along the middle of each of the ulnar three interosseous spaces towards the interdigital clefts, just proximal to which each common digital artery divides into two proper digital arteries which supply the contiguous sides of the fingers bounding the cleft. As the proper digital branches pass along the sides of the fingers they lie superficial to the corresponding proper digital nerves, and supply branches to the joints, to the flexor tendons and their sheaths, and to the skin and subcutaneous tissues on the volar surface; they give off dorsal branches also which anastomose with the dorsal digital arteries and supply the tissues on the dorsal aspects of the second and terminal phalanges. Some of the dorsally directed branches form a plexus in the matrix of the nail. In the pulp of the finger-tips anastomosing twigs join to form arches from which numerous branches are given off to the skin and subcutaneous fat.

Each of the three most radial proper digital arteries is joined, immediately proximal to its division, by a volar metacarpal artery from the deep volar arch and a distal perforating artery from a dorsal metacarpal artery. The most ulnar digital artery is joined by a branch which comes either from the most ulnar volar metacarpal artery or from the deep volar arch.

Arcus Volaris Profundus. - The deep volar arch (0.T. deep palmar) (Fig. 769) extends from the base of the metacarpal bone of the little finger to the proximal end of the first interosseous space, and is formed by the terminal part of the radial artery anastomosing with the profunda branch of the ulnar. It is from 12 to $18 \mathrm{~mm}$. (half to three-quarters of an inch) proximal to the level of the superficial volar arch. It lies deeply in the palm, in contact with the proximal ends of the metacarpal bones and their ligaments and on the origin of the interossei muscles, and deep to the flexor tendons and their synovial sheaths.

Branches. - $(a)$ The proximal perforating : three small arteries which pass dorsally through the nluar three interosseous spaces, and between the origins of the dorsal interosseous muscles. They anastomose on the dorsum of the hand with the dorsal metacarpal arteries.

(b) Small irregular recurrent branches pass proximally and unite with the volar carpal arch.

(c) The articular to the adjacent articulations.

(d) The volar metacarpal arteries are three vessels which pass distally, on the interosseous muscles of the three ulnar interosseous spaces, deep to the flexor tendons. They terminate by anastomosing with the volar digital arteries just before the latter vessels divide into proper volar digital branches.

(e) The communicating, a small irregular branch which passes ulnarwards between the flexor tendons and the short muscles of the little finger to anastomose with the ulnar proper volar digital artery.

\section{BRANCHES OF THE DESCENDING THORACIC AORTA.}

The branches given off from the thoracic portion of the descending aorta are distributed chiefly to the walls of the thorax and to the thoracic viscera. They 
contribute also to the supply of the spinal medulla and its membranes, and to that of the vertebral column and of the upper part of the abdominal wall. The branches, which are numerous and for the most part arranged in pairs, are as follows :-

$$
\text { Visceral. }\left\{\begin{array}{l}
\text { Bronchial. } \\
\text { Esophageal. } \\
\text { Pericardial. } \\
\text { Nediastinal. }
\end{array}\right.
$$$$
\text { Parietal. }\left\{\begin{array}{l}
\text { Intercostal. } \\
\text { Subcostal. } \\
\text { Superior phrenic. } \\
\text { The vas aberians. }
\end{array}\right.
$$

\section{Visceral Branches of the Descending Thoracic Aorta.}

1. Arteriæ Bronchiales.-The bronchial branches of the thoracic aorta are usually two in number-an upper and a lower-and both pass to the left lung. The upper left bronchial artery arises from the front of the aorta opposite the fifth thoracic vertebra; the inferior left bronchial artery usually takes origin near the lower border of the left bronchus. Both vessels are directed downwards and laterally to the back of the bronchus which they accompany, and, dividing similarly, they follow its ramifications in the lung. They not only supply the walls of the bronchial tubes and the substance of the lungs, but also give branches to the bronchial glands, the pulmonary vessels, the pericardium, and the osophagus.

As a rule there is only one right bronchial artery. It arises either from the first right aortic intercostal artery or from the upper left bronchial artery. More rarely it springs directly from the aorta. In its course and distribution it corresponds to the bronchial arteries of the left side.

2. Arteriæ Esophageæ.-The œsophageal branches are variable; usually four or five small branches spring from the front of the aorta and pass forwards to the œesophagus, in the walls of which they ramify, anastomosing above with branches of the left bronchial and inferior thyreoid arteries, and below with oesophageal branches of the left gastric and the phrenic arteries.

3. The pericardial branches are three or four small irregular ressels which are distributed on the surface of the pericardium.

4. Small mediastinal branches pass to the areolar tissue and glands in the posterior mediastinum, and to the posterior part of the diaphragm.

\section{Parietal Branches of the Descending Thoracic Aorta.}

1. Arteriæ Intercostales-The Intercostal Arteries.-There are nine pairs of aortic intercostal arteries which usually arise separately, though not uncommonly a pair may take origin by a common trunk from the back of the aorta. They are distributed to the lower nine intercostal spaces, to the vertebral column, to the contents of the vertebral canal, and to the muscles and skin of the back. The first three on each side give branches to the mammary gland also. The arteries of opposite sides closely correspond, but, since the aorta in the thoracic region lies on the left of the vertebral column, the right intercostal arteries cross the front of the column, posterior to the oesophagus, the thoracic duct, and the vena azygos, and are longer than the left arteries. In other respects the courses of all the aortic intercostal arteries are almost identical. As each artery runs postero-laterally, across the side of the vertebral column, to an intercostal space, it passes posterior to the pleura, and is crossed, opposite the head of a rib, by the sympathetic trunk. The lower arteries are crossed by the splanchnic nerves also, and those on the left side are crossed by the hemiazygos or accessory hemiazygos veins.

As each- artery passes laterally between the neck of two adjacent ribs, it gives off a posterior branch. Then it ascends to the upper border of the space, and, passing either behind or in front of the corresponding intercostal nerve, is continued along the space, in the costal groove. In the space, as far as the angle of the rib, it lies between the pleura and the posterior intercostal membrane, and, in this part of its course, it is embedded in the endothoracic fascia. Then it is continued forward between the internal and external intercostal muscles. In the 
costal groore the artery lies between the corresponding vein above and the intercostal nerve below, and it terminates anteriorly by anastomosing with an anterior intercostal branch of the internal mammary or of the musculo-phrenic artery. The lower two intercostal arteries, on each side, extend beyond their spaces into the abdominal wall, and anastomose with branches of the superior epigastric, subcostal, and lumbar arteries. The first right aortic intercostal artery frequently gives off the right bronchial artery.

Branches.-(a) The posterior branch passes backwards, accompanied by the posterior branch of a spinal nerve, medial to the anterior superior costo-transverse ligament, between the necks of the ribs which bound the space, and between the adjacent transverse processes, to the vertebral groove, where it divides into a medial and a lateral cutaneous terminal branch. The medial cutaneous branch passes backwards and medially either over or through the multifidus, giving branches to the muscles between which it passes and to the vertebral column. The lateral branch runs laterally under cover of the longissimus dorsi to the interval between it and the iliocostalis dorsi. It terminates in the skin of the back, after giving branches to the adjacent muscles. Before it divides, each posterior branch gives off muscular branches, and a spinal branch which passes through the corresponding intervertebral foramen, and enters the vertebral canal, to the contents and walls of which it is distributed. It divides into three branches-neural, post-central, and pre-laminar. The neural branch divides into two branches which run medially, on the roots of the spinal nerve, pierce the dura mater and arachnoid, and divide into branches some of which pass to the membranes of the spinal medulla, whilst others are continued on to reinforce the posterior and anterior spinal arteries. The post-central branch divides into ascending and descending branches which, anastomosing with similar branches above and below, form a series of vertical arches on the backs of the bodies of the vertebræ. The arches of opposite sides are connected by short transverse anastomoses. The pre-laminar branch is small, and its ascending and descending branches are distributed in a similar though less regular manner on the posterior wall of the vertebral canal.

(b) A collateral branch which arises near the angle of the rib. It descends to the lower border of the intercostal space, along which it runs forward to anastomose in front, like the termination of the trunk, with a separate anterior intercostal branch of the internal mammary or musculo-phrenic artery. The collateral branches of the lower two intercostal arteries on each side are inconstant; when present they are small, and terminate in the abdominal wall.

(c) Muscular branches to the adjacent muscles are given off both by the main trunk and its collateral branch.

(d) A lateral cutaneous offset accompanies the lateral cutaneous branch of the intercostal nerve.

In addition to the secondary branches above-named, the trunk of the first aortic intercostal on each side anastomoses with the superior intercostal, and may supply the whole or the greater part of the second intercostal space. The upper three or four aortic intercostals on each side give branches to the mammary gland which anastomose with branches of the lateral thoracic and internal mammary arteries. Longitudinal anastomoses between adjacent trunks and also between adjacent posterior branches of intercostal arteries sometimes exist near the necks of the ribs, or near the transverse processes. These longitudinal anastomoses are of consiclerable morphological interest.

2. The subcostal arteries are the last pair of parietal branches given off from the thoracic aorta. They are in series with and are very similar to the aortic intercostal arteries, but are situated below the last ribs. Each gives off a posterior branch which behaves in the same manner as the posterior branch of an ordinary aortic intercostal artery. The trunk runs along the lower border of the twelfth rib in company with the last thoracic nerve. It passes below the areus lumbocostalis lateralis (O.T. ligamentum arcuatum externum) to the abdomen, and there crosses anterior to the quadratus lumborum, and posterior to the kidney and the adjacent part of the colon. It next pierces the aponeurosis of origin of the transversus abdominis, and runs between the transversus and the internal oblique muscles, anastomosing with the lower intercostal arteries, with the lumbar arteries, and with branches of the superior epigastric artery.

3. Superior phrenic branches are given off from the lower part of the thoracic aorta. They are small vessels which ramify on the upper and posterior surfaces of 
the diaphragm, and anastomose with branches of the pericardiaco-phrenic and musculo-phrenic arteries.

4. The vas aberrans is a variable and inconstant branch of the thoracic aorta; it represents the dorsal roots of the fourth and sixth right aortic arches of the embryo. When present it arises from the front and right side of the upper part of the descending aorta near the upper left bronchial artery, and passes upwards and to the right behind the asophagus; it frequently anastomoses with the right superior intercostal artery, and it may be enlarged and form the first part of the right subclavian artery.

\section{BRANCHES OF THE ABDOMINAL AORTA.}

The branches of the abdominal portion of the aorta are distributed almost entirely to the walls and contents of the abdominal cavity, but some supply swall branches to the vertebral column, and to the contents of the vertebral canal, and others are prolonged into the pelvis minor. They are divisible into visceral and parietal groups, both of which include paired and single (unpaired) vessels.

$$
\text { Visceral. }\left\{\begin{array}{l}
\text { Paired. }\left\{\begin{array}{l}
\text { Suprarenal. } \\
\text { Renal. } \\
\text { Spermatic or ovarian. } \\
\text { Single. }
\end{array} \begin{array}{l}
\text { Coeliac axis. } \\
\text { Superior mesenteric. } \\
\text { Inferior mesenteric. }
\end{array}\right.
\end{array}\right.
$$$$
\text { Parietal. }\left\{\begin{array}{l}
\text { Paired. }\left\{\begin{array}{l}
\text { Inferior phrenic. } \\
\text { Lumbar. } \\
\text { Common iliac. }
\end{array}\right. \\
\text { Single, Middle sacral. }
\end{array}\right.
$$

\section{The Paired Visceral Branches of the Abdomisal Aorta.}

1. Arteriæe Suprarenales (Fig. 773).--There are tbree pairs of suprarenal arteries - the superior, middle, and inferior. Of these the middle only arise directly from the aorta; the superior spring from the inferior phrenic, and the inferior from the renal arteries.

The middle suprarenal arteries are two small branches which arise, posterior to the pancreas, from the sides of the aorta, close to the origin of the superior mesenteric artery. They run, one on each side, laterally and upwards, upon the crura of the diaphragm and just above the renal arteries, to the suprarenal glands, to which they are distributed, and they anastomose with the superior and inferior suprarenal arteries.

2. Arteriæ Renales.-The renal arteries (Fig. 773) arise, one on each side, from the aorta, about $12 \mathrm{~mm}$. (half an inch) below the origin of the superior mesenteric artery and opposite the second lumbar vertebra.

Both arteries are of large size, and the right is frequently slightly lower in position than the left. Each artery runs almost transversely to the hilus of the corresponding kidney. It passes anterior to the crus of the diaphragm and the upper part of the psoas muscle. The left artery lies posterior to the pancreas; the right vessel passes behind the inferior vena cava, the head of the pancreas, and the descending part of the duodenum. The renal vein usually lies below and anterior to the artery, but near the kidney the vein not infrequently occupies a posterior position.

On reaching the hilus of the kidney each artery divides into three branches, two of which pass anterior to the pelvis renalis, and between it and the renal vein, and the third posterior to the pelvis. In the renal sinus these primary branches break up into numerous secondary branches which enter the kidney substance between the pyramids.

Branches.-The following branches are given off by each renal artery, in addition to the terminal branches:-

(a) Inferior suprarenal, which passes upwards to the lower part of the suprarenal gland.

(b) Ureteral._Small branches to the upper part of the ureter, which anastomose with branches of the internal spermatic or ovarian arteries.

(c) Peri-nephric. - Small branches to the fatty capsule of the kidney, which anastomose with the lumbar arteries.

(d) Glandular offsets, either from the main trunk or from some of its branches, pass to the lumbar lymph glands. 
3. Arteriæ Spermaticæ Internæ.-The internal spermatic arteries are present in both sexes; in the male they are called the testicular arteries and in the female ovarian arteries. In each sex they are long slender vessels which spring from the front of the aorta a short distance below the origins of the renal arteries.

3a. The Testicular Arteries.-Each testicular artery runs downwards and forwards on the anterior surface of the psoas major to the abdominal inguinal ring, where it comes into relation with the ductus deferens. It accompanies the ductus deferens through the inguinal canal to the testis, to which it is distributed.

Relations-Posterior:-The right artery passes in front of the inferior vena cava, and as each artery descends, on the anterior surface of the psoas major, it passes in front of the corresponding genito-femoral nerve and the ureter.

Anterior.-Each artery is in relation anteriorly with the peritoneum to which it is attached; but crossing in front of the right artery and intervening between it and the peritoneum are the third part of the duodenum, the right colic and the ileo-colic arteries, the terminal part of the superior mesenteric artery, and the cæcum. Crossing anterior to the left artery are the left colic and sigmoid branches of the inferior mesenteric artery and the iliac colon.

In the lower part of the abdominal portion of its course each testicular artery is accompanied by two veins, which issue from the pampiniform plexus in the inguinal canal and enter the abdomen through the abdominal inguinal ring, but at a higher level the two veins usually fuse into a single stem.

As it enters the inguinal canal each spermatic artery passes in front of the inferior epigastric artery, and the lower end of the external iliac artery; and as it runs downwards and medially, in the canal, it is accompanied by the ductus deferens, and is more or less enclosed in the meshes of the pampiniform venous plexus. At the lower end of the canal it passes through the subcutaneous inguinal ring and descends through the scrotum, lying antero-lateral to the ductus deferens in close association with the anterior group of testicular veins. At the upper end of the testis it breaks up into branches, some of which are distributed to the testis and others to the epididymis.

Branches.-In the abdominal part of its course each testicular artery gives off :-

(a) Ureteral branches, to the abdominal part of the ureter.

(b) Peri-nephric twigs, to the peri-nephric fat.

(c) Peritoneal branches, which are distributed to the peritoneum.

(d) Glandular branches, which supply blood to the lumbar lymph glands.

Its terminal branches are the testicular and epididymal twigs already mentioned.

3b. Ovarian Arteries.-The course and the relations of each ovarian artery, as far as the level of the brim of the pelvis minor, are the same as the relations of the corresponding testicular artery; but at the level of the upper end of the external iliac artery each ovarian artery turns medially, crosses anterior to the upper ends of the extermal iliac artery and vein, and enters the upper part of the broad ligament of the uterus. In the broad ligament it runs medially, below the uterine tube, to the level of the ovary. There it turns backwards and passes between the layers of the mesovarium, where it breaks up into terminal branches which enter the ovary through the hilus in its anterior border. As it lies in the broad ligament each ovarian artery is accompanied by the pampiniform plexus of ovarian veins. In the lower portion of the abdominal part of its course it is accompanied by two veins, which issue from the pampiniform plexus at the brim of the pelvis minor, and unite at a higher level into a single trunk.

Branches. - (a) In the abdominal part of its course the branches of the ovarian artery are the same as those of the testicular artery.

In the pelvic part of its course it gives off:-

(a) Tubal branches, to the walls of the uterine tube.

(b) Branches to the round ligament of the uterus.

(c) Uterine branches, which pass towards the uterus to anastomose with the branches of the uterine artery.

\section{The Unpaired or Single Visceral Branches of the Abdominal Aorta.}

1. Arteria Cœliaca.-The coliac artery (Figs. 771 and 773) arises from the front of the abdominal aorta, immediately below the aortic orifice of the diaphragm and between its crura. It is a short but wide vessel which runs almost horizontally 
forwards for a discance of about $12 \mathrm{~mm}$. (half an inch), and terminates by dividing into three large branches-the left gastric, the hepatic, and the splenic.

Relations. - The short trunk lies behind the omental bursa, and runs forwards below the caudate lobe of the liver and above the upper border of the pancreas and the splenic vein. It is surrounded by the cœliac plexus of the sympathetic, and has the right cœliac ganglion to its right side and the left cœliac ganglion to its left side.

Branches.- (a) The left gastric (O.T. coronary) is the smallest branch of the coeliac artery. It runs obliquely upwards and to the left, and reaches the lesser curvature of the stomach close to the osophagus. It then turns sharply forwards, downwards, and to the right, and runs towards the pyloric end of the stomach to anastomose with the right gastric branch of the hepatic artery. In the first part of its course the artery lies posterior to the omental bursa; it then

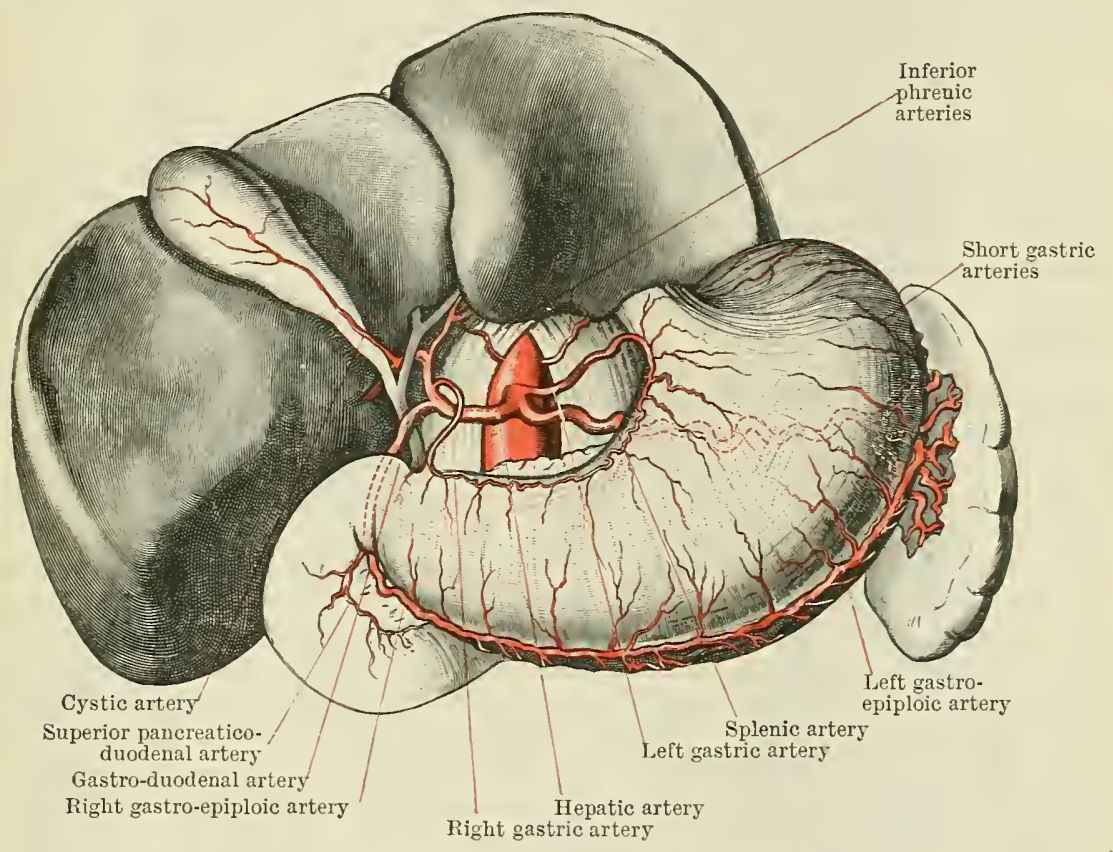

Fig. 7i1.-The Celiac Artery axd its Branches.

passes into the left gastro-pancreatic fold, and is continued between the layers of the lesser omentum.

Branches.-(i.) Esophageal.-When the left gastric artery reaches the stomach it gives off an cesophageal branch which passes upwards, on the cesophagus, and breaks up into branches which anastomose with œsophageal branches of the thoracic aorta and with branches of the inferior phrenic. (ii.) Gastric branches are distributed to both surfaces of the stomach. They anastomose with branches of the short gastric of the splenic, and with branches of the gastroepiploic arterial arch on the greater curvature of the stomach.

(b) Arteria Lienalis.-The splenic artery (Fig. 771) is the largest branch of the coliac artery. It runs a more or less tortuous course behind the stomach and the omental bursa, and along the upper border of the pancreas. It lies anterior to the left suprarenal gland and the upper end of the left kidney, and passes forwards between the two layers of the lieno-renal ligament, in which it divides into from five to eight terminal branches which enter the hilus of the spleen and supply the splenic substance. It is accompanied by the splenic vein, which lies below it.

Branches.-(i.) Pancreatic.-Numerous small branches are given off to the pancreas. A larger branch (pancreatica magna), occasionally present, enters the upper border of the pancreas, about the junction of its middle and left thirds, and runs from left to right in 
the substance of the pancreas, a little above and posterior to the pancreatic duct. Both the small and large arteries supply the substance of the pancreas, and anastomose with one another and with branches of the pancreatico-duodenal arteries.

(ii.) The short gastric branches (O.T. vasa brevia), four or five in number, are given off either from the terminal part of the splenic artery or, more commonly, from some of its terminal branches. They pass between the layers of the gastro-splenic ligament to the left part of greater curvature of the stomach, and anastomose with the osophageal, the left gastric, and the left gastro-epiploic arteries.

(iii.) The left gastro-epiploic branch arises from the front of the splenic, close to its termination, and passes forwards, between the layers of the gastro-splenic ligament, to the left end of the lower part of the greater curvature of the stomach, along which it is continued, from left to right, between the layers of the greater omentum. It ends by anastomosing with the right gastro-epiploic artery, and it gives off numerous gastric branches to both surfaces of the stomach, which anastomose with the short gastric and with branches of the left and right gastric arteries. Long slender omental branches pass to the omentum and anastomose with branches of the colic arteries.

(c) Arteria Hepatica. - The hepatic artery (Fig. 771) runs along the upper border of the head of the pancreas to the right gastro-pancreatic fold of peritoneum, in which it turns forwards to the upper border of the first part of the duodenum. It then passes upwards, between the layers of the hepato-duodenal ligament, anterior to the portal vein and to the left of the bile duct, and reaches the porta hepatis (O.T. transverse fissure), where it divides into right and left branches.

Branches.-(i.) The right gastric artery is a small branch which arises opposite the upper border of the first part of the duodenum. It runs to the pylorus, between the layers of the lesser omentum, and then turns to the left along the smaller curvature of the stomach. It gives branches to both surfaces of the stomach, and terminates by anastomosing with the left gastric artery.

(ii.) The gastro-duodenal artery.-This branch of the hepatic arises just above the upper border of the first part of the duodenum, descends behind it and terminates opposite its lower border. In its course it lies between the neck of the pancreas and the first part of the duodenum, and anterior to the portal vein. The bile duct is on its right side. The vessel ends by dividing into the right gastro-epiploic and the superior pancreatico-duodenal arteries. The right gastro-epiploic artery is the larger of the two terminal branches of the gastro-duodenal; it passes from right to left, along the greater curvature of the stomach, between the layers of the greater omentum, and unites with the left gastro-epiploic branch of the splenic artery. From the arterial arch so formed branches pass upwards on both surfaces of the stomach, to anastomose with branches of the right and left gastric arteries. Other branches pass downwards in the greater omentum, and anastomose with branches of the colic arteries. The superior pancreatico-duodenal artery runs a short course to the right, between the duodenum and the head of the pancreas, and divides into anterior and posterior terminal branches, which descend, the former in front of and the latter behind the head of the pancreas, to anastomose with similar branches of the inferior pancreatico-duodenal artery. They supply the head of the pancreas, anastomosing in it with the pancreatic branches of the splenic artery; branches are given also to the second part of the duodenum and to the bile duct.

(iii.) Terminal branches. - The right hepatic artery passes either in front of or behind the hepatic duct and behind the cystic duct, to the right end of the porta hepatis, where it divides into two or more branches which enter the substance of the liver and accompany the branches of the portal vein and the hepatic duct. As it crosses above the junction of the hepatic and cystic ducts, the right hepatic artery gives off a cystic branch. The cystic artery runs downwards and anteriorly, along the cystic duct, to the gall-bladder, where it divides into anterior and posterior branches; the anterior passes downwards between the gall-bladder and the visceral surface of the liver, to both of which it gives offsets; the posterior branch is distributed on the posterior surface of the gall-bladder, between it and the peritoneum. The left hepatic artery is longer and narrower than the right. It runs to the left end of the porta hepatis, gives one or two branches to the caudate lobe, crosses the fossa of the umbilical vein, and breaks up into branches which terminate in the substance of the left lobe of the liver. 
2. Arteria Mesenterica Superior.-The superior mesenteric artery (Figs. 772 and 773) springs from the front of the aorta, about $12 \mathrm{~mm}$. (half an inch) below the origin of the cœliac artery and opposite the first lumbar vertebra.

It passes obliquely downwards and forwards, crossing anterior to the left renal vein, the uncinate process of the head of the pancreas, and the third part of the duodenum; opposite the latter it enters the root of the mesentery, in which it

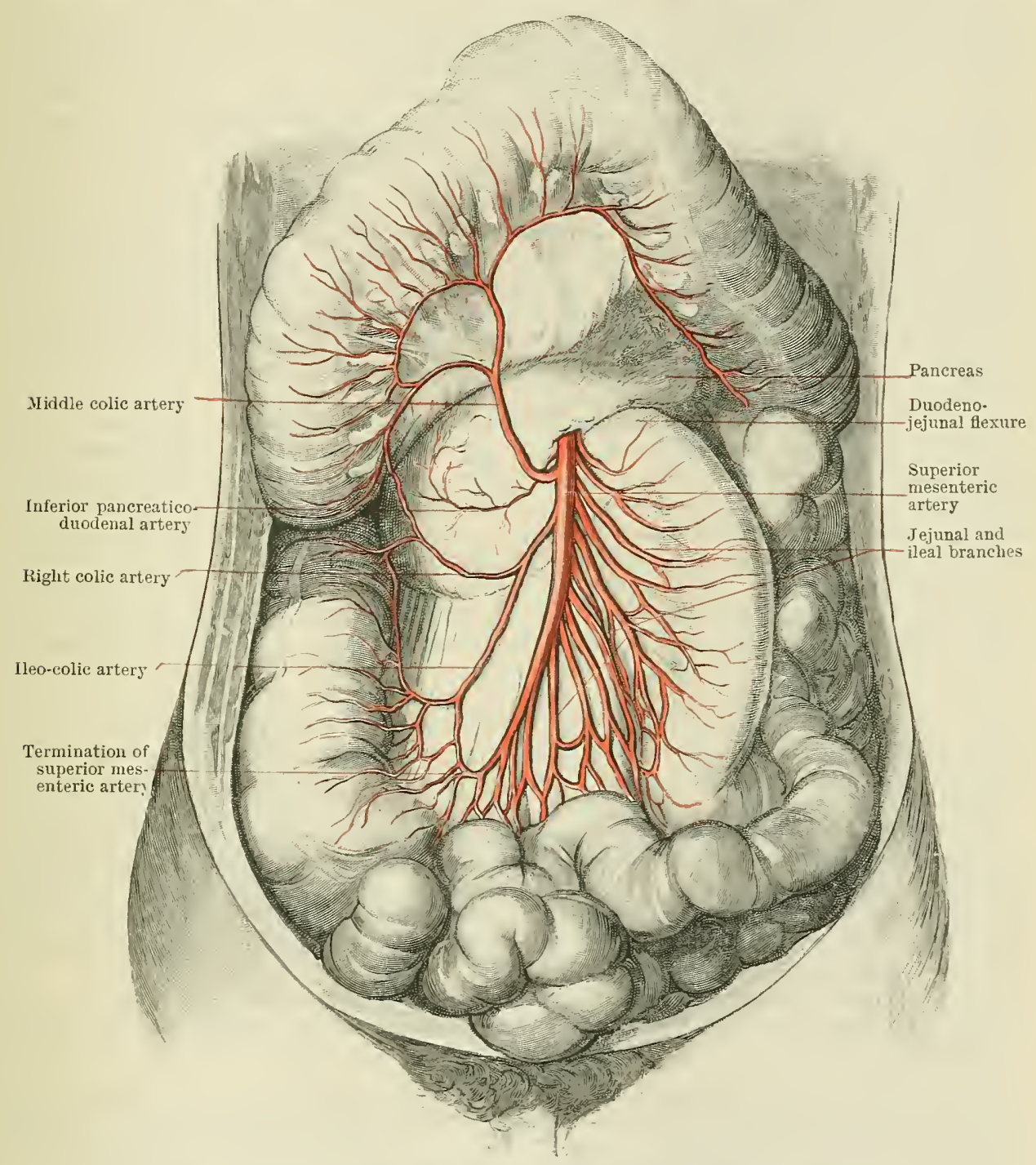

Fig. 772.-The Superior Mesexteric Artery and its Braxches.

continues to descend, curving obliquely from above downwards and to the right, to the right iliac fossa, and crossing, in this part of its course, obliquely in front of the aorta, the lower part of the inferior vena cava, the right ureter, and the right psoas major muscle. At its origin it lies posterior to the neck of the pancreas and the splenic vein; where it passes in front of the duodenum it is crossed anteriorly by the transverse colon, and in the lower part of its extent it is behind the coils of small intestine.

Branches.-It gives off numerous branches which supply the dnodenum and the pancreas in part, the whole of the small intestine below the duodenum, and the large intestine nearly as far as the left colic flexure. 
The branches are as follows:-

(a) The intestinal branches to the small intestine, varying from ten to sixteen in number, are separable into two groups, jejunal and ileal; they spring from the convexity of the superior mesenteric artery, and pass obliquely forwards and downwards, between the layers of the mesentery, each dividing into two branches which anastomose with adjacent branches to form a series of arcades, from which secondary branches are given off. This process of division and union is repeated three or four times; thus four or five tiers of arches are formed, from the most distal of which terminal branches are given off to the walls of the jejunum and ileum. Branches from the successive arcades are also given off to the mesenteric lymph glands. The terminal branches anastomose together in the walls of the gut, forming a vascular network, which communicates above with the inferior pancreatico-duodenal artery and below with the terminal branch of the superior mesenteric trunk. The arterial loops and branches are accompanied by corresponding veins, lymphatics, and nerves.

(b) The inferior pancreatico-duodenal artery. This branch arises either from the trunk of the superior mesenteric, at the upper border of the third part of the duodenum, or from the first jejunal branch. It runs to the right, between the head of the pancreas and the third part of the duodenum, and terminates by dividing into two branches, anterior and posterior, which ascend, the former in front, and the latter behind the head of the pancreas; they supply the head of the pancreas, the second and third parts of the duodenum, and they anastomose with the similar branches of the superior pancreatico-duodenal artery.

(c) The middle colic artery is a large branch which springs from the front of the superior mesenteric as it enters the root of the mesentery. It runs downwards and forwards, in the transverse mesocolon, and terminates by dividing into two branches, right and left, which anastomose respectively with the right and left colic arteries, forming arcades from which secondary and tertiary loops are derived, the terminal branches being distributed to the walls of the transverse colon.

$(d)$ The right colic artery springs from the right or concave side of the superior mesenteric, either alone or in the form of a common trunk which divides into right colic and ileo-colic branches. It runs to the right, posterior to the peritoneum on the posterior wall of the abdomen, and in front of the right psoas major, the ureter, and the internal spermatic vessels, towards the ascending colon, near which it divides into an ascending and a descending branch. The former passes upwards, and anastomoses, in the transverse mesocolon, with the middle colic artery. The latter descends to anastomose with the upper branch of the ileo-colic, and from the loops thus formed branches are distributed to the walls of the ascending colon and the beginning of the transverse colon.

(e) The ileo-colic artery arises by a common trunk with the right colic, or separately from the right side of the superior mesenteric, and passes downwards and to the right, behind the peritoneum, towards the lower part of the ascending colon, where it terminates by dividing into an ascending branch which anastomoses with the lower branch of the right colic, and a descending branch which communicates with the colic terminal branches of the superior mesenteric trunk.

(f) Terminal. - The lower end of the superior mesenteric artery divides into five branches-(i.) ileal, (ii.) appendicular, (iii.) anterior ileo-cæcal, (iv.) posterior ileo-cæcal, and (v.) colic.

The ileal branch turns upwards and to the left in the lowest part of the mesentery, and anastomoses with the intestinal arteries. The appendicular branch passes behind the terminal portion of the ileum, and through the mesentery of the vermiform process to the vermiform process, upon which it ends. The anterior ileo-cæcal crosses the front of the ileo-cæcal junction in a fold of peritoneum; the posterior ileo-cæcal crosses the ileo-cæcal junction posteriorly, and the colic runs upwards to the ascending colon. The ileo-cæcal branches supply the walls of the cæcum, and, like the colic branch, anastomose with branches of the ileo-colic artery. In some cases the majority or all of the above terminal branches spring from the ileo-colic.

3. Arteria Mesenterica Inferior. - The inferior mesenteric artery (Fig. 773) arises from the front of the aorta towards the left side, $37 \mathrm{~mm}$. (an inch and a half) above the bifurcation; it passes downwards and slightly to the left, lying posterior to the peritoneum and anterior to the left psoas major muscle, to the upper and left border of the left common iliac artery, where it becomes the superior hæmorrhoidal.

Branches.-(a) The left colic artery arises from the left side of the inferior mesenteric near its origin, and almost immediately divides into an upper and a lower 
branch. The upper branch runs upwards and to the left towards the left colic flexure, and to the lower pole of the left kidney, where it divides into (i.) a branch which enters the transverse mesocolon, and, turning medially, terminates by joining the left branch of the middle colic artery, and (ii.) a descending branch to the upper part of the descending colon. The lover branch passes to the left, behind the peritoneum, and divides into upper and lower divisions; the upper anastomoses with the descending division of the upper branch and supplies the lower part of the descending colon. The lower division supplies the iliac colon, and its branches anastomose with the branches of the upper division and with the branches of the sigmoid arteries. Both branches of the left colic artery lie immediately behind the peritoneum, and each branch crosses anterior to the ureter and the internal spermatic vessels.

(b) The sigmoid branches, usually two in number, arise from the convexity of the inferior mesenteric, and pass downwards and to the left to the lower part of the iliac colon and to the pelvic colon. They lie posterior to the peritoneum, and anterior to the psoas major, the ureter, and the upper part of the iliacus. They terminate by dividing into branches which anastomose with the terminal twigs of the lower branch of left colic above and with branches of the superior hæmorrhoidal below, forming a series of arches from which branches are distributed to the lower part of the iliac colon and the pelvic colon.

(c) The superior hæmorrhoidal artery is the direct continuation of the inferior mesenteric. It enters the mesentery of the pelvic colon, crosses the front of the left common iliac artery, descends into the pelvis minor as far as the third piece of the sacrum, or, in other words, the junction between the pelvic colon and the rectum, and divides into two branches which pass downwards on the sides of the rectum. Half-way down the rectum each of the two terminal branches of the superior hrmorrhoidal artery divides into two or more branches which pass through the muscular coats and terminate in the submucous tissue, where they divide into numerous small branches which pass vertically downwards, anastomosing with one another, with offsets from the middle hæmorrhoidal branches of the internal iliac arteries, the inferior hæmorrhoidal branches of the internal pudic arteries, and with branches from the middle sacral artery.

The superior hæmorrhoidal artery supplies the mucous membrane of the pelvic colon and the rectum and the muscular coats of the pelvic colon.

\section{Parietal Branches of the Abdominal Aorta.}

1. Arteriæ Phrenicæ Inferiores.-The inferior phrenic arteries (Fig. 773), right and left, are of small size; they arise, either separately or by a common trunk, from the aorta, immediately below the diaphragm, to the abdominal surface of which they are distributed. Diverging from its fellow, each artery runs upwards and laterally on the corresponding crus of the diaphragm-that on the right side passing posterior to the inferior vena cava, that on the left side posterior to the cesophagus-and just before reaching the central tendon of the diaphragm each divides into medial and lateral terminal branches. The medial branch runs forwards and anastomoses with its fellow of the opposite side, forming an arch, convex forwards, along the anterior border of the central tendon of the diaphragm. Offsets from this arch anastomose with the pericardiaco-phrenic, musculo-phrenic, and internal mammary arteries. The lateral branch passes laterally towards the lower ribs, and anastomoses with the musculo-phrenic and lower intercostal arteries.

In addition to supplying the diaphragm each inferior phrenic artery frequently gives a superior suprarenal branch to the suprarenal gland of its own side, and occasionally small hepatic branches which pass through the coronary ligament to the liver. Further, the left artery gives branches to the asophagus which anastomose with œesophageal branches of the aorta and of the left gastric artery, whilst from the artery of the right side, minute branches pass to the inferior vena cava.

2. Arteriæe Lumbales.-The lumbar arteries correspond to the intercostal branches of the thoracic aorta. They are in series with them, their distribution is very similar, and, like the intercostals, they arise, either separately or by common trunks, from the posterior aspect of the aorta.

There are ustually four pairs of lumbar arteries, but occasionally a fifth pair arises from or in common with the middle sacral artery. 
From their origins the lumbar arteries pass laterally and posteriorly, on the front and sides of the bodies of the upper four lumbar vertebræ, to the intervals between the adjacent transverse processes, bejond which they are continued into the lateral part of the abdominal wall.

Each artery lies on the body of the corresponding lumbar vertebra. In its back-

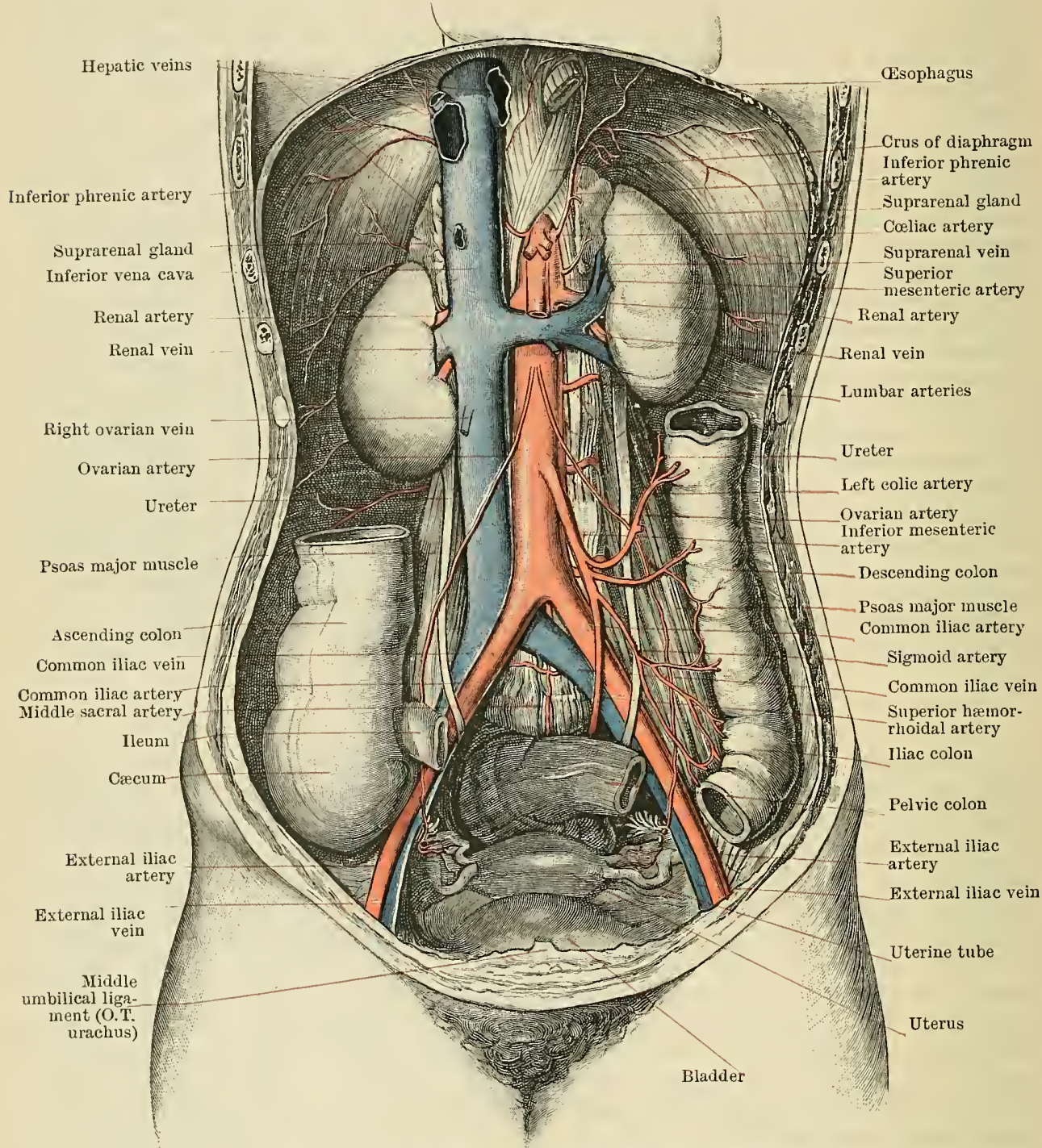

Fig. 773. - The Abdominal Aorta and its Branches.

ward course, and while still in relation with the vertebral body, it is crossed by the sympathetic trunk, and then, after passing medial to and being protected by the fibrous arches from which the psoas major muscle arises, it runs behind the muscle and the lumbar plexus. The upper two arteries, on each side, also pass posterior to the crura of the diaphragm. Beyond the interval between the transverse processes of the vertebræ each artery turns laterally and crosses the quadratus lumborum - the last usually passing anterior to, and the others posterior to the muscle; it then pierces the aponeurosis of origin of the transversus, and proceeds forwards in the lateral abdominal wall, in the interval between the transversus and internal oblique muscles. The lumbar arteries anastomose with one another, with the lower intercostal and subcostal arteries, and 
with branches of the superior and inferior epigastric and of the deep circumflex iliac and ilio-lumbar arteries.

Fine twigs also pass from the lumbar arteries to the extra-peritoneal fat; these anastomose with corresponding branches from the inferior phrenic and ilio-lumbar arteries, and with small branches from the hepatic, renal, and colic arteries, to form the subperitoneal plexus of Turner.

The abdominal aorta lies but little to the left of the median plane, and consequently the right lumbar arteries are scarcely longer than the left. On the right side the arteries pass behind the inferior vena cava, the upper two arteries being separated from that vessel by the right crus of the diaphragm. The upper two right arteries also pass posterior to the cisterna chyli and the lower end of the azygos vein.

Branches.-Dorsal.-Each lumbar artery gives off, opposite the interval between the vertebral transverse processes, a dorsal branch of considerable size. It is analogous with and is distributed like the posterior branch of an aortic intercostal artery (p. 925). Muscular branches are given off, both from the main trunk and its dorsal branch, to the adjacent muscles.

3. Arteria Sacralis Media. - The middle sacral artery (Fig. 773) is a single median vessel. It is commonly regarded as a caudal aorta and as the direct continuation of the abdominal aorta. It is, however, of small size, and almost invariably arises from the back of the aorta, about $12 \mathrm{~mm}$. (half an inch) above its bifurcation. It descends anterior to the lower two lumbar vertebræ and to the sacrum and coccyx, and ends, opposite the tip of the last-named bone, by anastomosing with the lateral sacral arteries to form a loop from which branches pass to the coccygeal glomus. Opposite the fifth lumbar vertebra it is crossed anteriorly by the left common iliac vein, below which it is covered by peritoneum and coils of small intestine as far as the third segment of the sacrum, and in the rest of its extent it is posterior to the rectum. It is accompanied below by venæ comites, which, however, unite above to form a single middle sacral vein.

As it lies anterior to the last lumbar vertebra it gives off on each side a lumbar branch, the arteria lumbalis ima, which is distributed like an ordinary lumbar artery, and as it descends in front of the sacrum it distributes small parietal branches laterally which anastomose with the lateral sacral arteries. These usually give off small spinal offsets which enter the anterior sacral foramina. Small and irregular visceral branches pass to the rectum and anastomose with the superior and middle hæmorrhoidal arteries.

\section{ARTERIA ILIACE COMMUNES.}

4. The common iliac arteries (Figs. 773 and 774 ) are the terminal branches of the abdominal aorta. They commence opposite the middle of the body of the fourth lumbar vertebra a little to the left of the median plane. Each artery passes downwards and laterally, across the bodies of the fourth and fifth lumbar vertebræ and the intervening intervertebral fibro-cartilage, and it terminates, at the level of the lumbo-sacral articulation and anterior to the corresponding sacro-iliac joint, by dividing into external iliac and hypogastric (U.T. internal iliac) branches.

The direction of each common iliac is indicated by a line drawn from the bifurcation of the aorta to a point midway between the symphysis pubis and the anterior superior spine of the ilium.

The angle included between the two diverging trunks is about $60^{\circ}$ in the male and about $68^{\circ}$ in the female.

The right artery is, for obvious reasons, a little longer than the left; the former being about $50 \mathrm{~mm}$. (two inches) and the latter $43 \mathrm{~mm}$. (one and three-quarter inches) in length.

Relations.--Anterior.-Both arteries are covered anteriorly by peritoneum, and are separated by it from coils of the small intestine. Communicating branches between the 
aortic and hypogastric plexuses of the sympathetic pass in front of the arteries, each of which is often crossed, anteriorly, near its termination by the corresponding ureter.

The left artery is crossed, in addition, by the superior hæmorrhoidal vessels.

Posterior.-Behind the artery, of each side, are the bodies of the fourth and fifth lumbar vertebræ, and the intervening intervertebral fibro-cartilage, the sympathetic trunk, and the psoas major muscle. These relationships, however, are much closer on the left side than on the right. The right common iliac, except at its lower end, where it is in contact with the psoas major, is separated from the structures named by the terminations of the right and left common iliac veins and the commencement of the inferior vena cava. The left common iliac, which is not so separated, lies on the medial border of the psoas major. Somewhat deeply placed, in the areolar tissue between the psoas major and the lumbar vertebræ, are the obturator nerve, the lumbo-sacral trunk, and the ilio-lumbar artery, which form posterior relations to the common iliac artery of the corresponding side.

Lateral. - The lateral relations of each artery are coils of small intestine, and the commencement of the inferior vena cava lies to the lateral side of the upper part of the right artery.

Medial.-On the medial side of the right common iliac artery are the right common iliac vein below, and the left common iliac vein above. The last-named vein lies on the medial side of the left common iliac artery.

Branches.-The external iliac and the hypogastric are the only branches.

\section{ARTERIA HYPOGASTRICA.}

The hypogastric artery (O.T. internal iliac) (Figs. 773,774 , and 777 ) in the foetus is the direct continuation of the common iliac trunk. It supplies numerous branches to the pelvis, runs upwards on the anterior abdominal wall to the umbilicus as the umbilical artery, and is prolonged through the umbilical cord to the placenta. One of its pelvic branches - the inferior glutæal (O.T. sciatic)-is at first the main artery of the inferior extremity, but subsequently another branch is given off which becomes the chief arterial trunk of the lower limb. This branch is the external iliac artery; it soon equals and ultimately exceeds the hypogastric in size, and it is into these two vessels that the common iliac appears to bifurcate.

When the placental circulation ceases and the umbilical cord is severed, the umbilical part of the hypogastric trunk which extends from the pelvis minor to the umbilicus atrophies, and is afterwards represented almost entirely by a fibrous cord, known as the obliterated umbilical artery. It is only at its proximal end that the atrophied part remains pervious, and there it forms the commencement of the superior vesical artery. The permanent hypogastric is a comparatively short vessel. Owing to the arrangement of some of its branches it appears to end in an anterior and a posterior division, the former of which is to be regarded as the continuation of the vessel, whilst the latter is simply a common stem of origin for some of the branches.

With this explanation the artery may be described in the usual manner.

It arises from the common iliac opposite the sacro-iliac and at the level of the lumbo-sacral articulation, and descends into the pelvis minor, to terminate, as a rule, opposite the upper border of the greater sciatic notch, in two divisionsanterior and posterior-from each of which branches of distribution are given off. The artery measures about $37 \mathrm{~mm}$. (one and a half inches) in length, and is the medial of the two terminal branches of the common iliac artery.

Relations. - Anterior. - Each hypogastric artery is covered antero-medially by peritoneum, behind which the corresponding ureter descends along the anterior border of the artery. The pelvic colon crosses from the front to the medial side of the left artery, and the terminal part of the ileum bears the same relation to the right artery.

Posterior to it are the hypogastric vein and the commencement of the common iliac vein ; still more posteriorly are the lumbo-sacral trunk and the sacro-iliac joint.

Lateral.--On its lateral side the external iliac vein separates it from the psoas major muscle above. At a lower level the obturator nerve, embedded in a mass of fat, intervenes between the hypogastric artery and the lateral wall of the pelvis. On its medial side it is crossed by some of the tributaries of the hypogastric vein, and it is covered by peritoneum. 


\section{Branches of the Posterior Division.}

The posterior terminal division gives off the ilio-lumbar and lateral sacral arteries, and is continued as the superior glutæal artery. No visceral branches are derived from this division.

1. Arteria Ilio-lumbalis.-The ilio-lumbar artery runs upwards and laterally across the upper margin of the pelvis minor to the iliac fossa. It passes anterior to the sacro-iliac articulation, between the lumbo-sacral trunk and the obturator nerve, and posterior to either the lower part of the common or the upper part of the external iliac vessels, and the psoas and iliacus muscles.

In the iliac fossa it divides into an iliac and a lumbar branch. The iliac branch anastomoses with branches of the deep circumflex iliac and obturator arteries. It also gives off offsets to the iliacus, and supplies a large nutrient branch to the ilium. A lumbar branch ascends behind the psoas major to the crest of the ilium. It supplies the psoas and quadratus lumborum, and anastomoses with the lumbar and deep circumflex iliac arteries; it also gives off a spinal branch, which enters the intervertebral foramen between the fifth lumbar vertebra and the sacrum, and is distributed like the spinal branches of the lumbar and the aortic intercostal arteries.

2. Arteriæ Sacrales Laterales.-There is sometimes only a single lateral sacral artery on each side; more commonly there are two, superior and inferior.

Both branches run downwards and medially, on the front of the sacrum. The inferior passes anterior to the piriformis and the sacral nerves, and descends, on the lateral side of the sympathetic trunk, to the coccyx, where it terminates by anastomosing with the middle sacral. The superior branch reaches only as far as the first or the second anterior sacral foramen; then it enters the sacral canal. It anastomoses with the lower branch and with the middle sacral artery. Transverse branches are given off by the lateral sacral arteries to the piriformis, and to the sacral nerves. Spinal offsets are also given off, which pass through the anterior sacral foramina to the sacral canal ; they supply the membranes of the spinal medulla, the roots of the sacral nerves, and the filum terminale, and anastomose with other spinal arteries. They then pass backwards through the posterior sacral foramina, and anastomose on the back of the sacrum with branches of the superior and inferior glutæal arteries.

3. Arteria Glutæa Superior-(Figs. 774 and 776).-After giving off the iliolumbar and lateral sacral branches, the posterior division of the hypogastric artery is continued as the superior glutæal artery. This is a large vessel which pierces the pelvic fascia, and passes backwards, between the lumbo-sacral trunk and the first sacral nerve. It leaves the pelvis through the upper part of the greater sciatic foramen, above the piriformis muscle, and enters the buttock, where it divides, under cover of the glutæus maximus and between the adjacent borders of the piriformis and glutæus medius muscles, into superficial and deep branches.

(a) The superficial branch divides at once into numerous rami, some of which supply the glutæus maximus, whilst others pass through it, near its origin, to the overlying skin. The branches freely anastomose with branches of the inferior glutæal, internal pudendal, medial circumflex, deep circumflex iliac, and lateral sacral arteries.

(b) The deep terminal branch, accompanied by the superior glutæal nerve, runs forwards between the glutæus medius and minimus, and, after giving a nutrient branch to the ilium, subdivides into upper and lower branches. The upper branch, runs forwards along the origin of the glutæus minimus from the anterior curved line of the ilium, and passes beyond the anterior margins of the glutæus medius and minimus to anastomose, under cover of the tensor fascir latæ, with the ascending branch of the lateral circumflex artery. It amastomoses with the deep circumflex iliac artery also, and it supplies muscular branches to the adjacent muscles. The lower branch passes more directly forwards, across the glutæus minimus, towards the trochanter major, along with the branch of the superior glutæal nerve which supplies the tensor fasciæ latæ. It supplies the glutæal muscles, and anastomoses with the ascending branch of the lateral circumflex artery.

Before leaving the pelvis the glutial artery gives muscular branches to the pelvic diaphragm and the obturator internus, small neural branches to the roots of the sacral plexus, and nutrient branches to the hip-bone. 
Branches OF THE ANTERior Division.

The anterior division gives off both parietal and visceral branches, and is continued as the umbilical artery, which for the greater part of its extent is completely obliterated. The parietal branches are the obturator, the internal pudendal, and the inferior gluteal. The visceral branches include the superior and inferior vesical, and the middle hæmorrhoidal arteries in the male. In the female the anterior division of the hypogastric artery gives off similar visceral branches, and, in addition, a uterine and a vaginal branch.

\section{Visceral Branches.}

1. Arteria Vesicalis Superior.-The superior vesical artery arises from the incompletely obliterated posterior part of the umbilical artery, as it lies at the side of the bladder. It passes medially to the upper part of the urinary bladder and divides into numerous branches which anastomose with the other vesical arteries, and it also gives small branches to the urachus, and often to the lower part of the ureter. It may in addition give off a middle vesical branch, and not infrequently the long slender artery to the ductus deferens arises from it.

2. Arteria Umbilicalis.-Atrophy of that portion of the umbilical artery which extends from the anterior division of the hypogastric to the umbilicus has already been referred to. The atrophy is complete between the umbilicus and the origin of the superior vesical artery, but between that origin and the apparent ending of the hypogastric in its two divisions it is incomplete, and the lumen of the vessel, though greatly diminished in size, remains patent. It is from this incompletely obliterated portion that the superior vesical artery arises. The completely obliterated part of the umbilical artery is reduced to a fibrous cord which runs along the side of the bladder to its apex, and then ascends, on the posterior surface of the anterior abdominal wall, to the umbilicus. In the latter part of its course it is known as the ligamentum umbilicale laterale. As it passes along the wall of the pelvis it is external to the peritoneum, and it is crossed by the ductus deferens in the male, and by the round ligament in the female.

3. Arteria Vesicalis Inferior.-The inferior vesical artery is a very constant branch which runs medially, upon the upper surface of the levator ani, to the base of the bladder. It also gives branches to the seminal vesicles, the ductus deferens, the lower part of the ureter and the prostate, and it anastomoses with its fellow of the opposite side, with the other vesical arteries, and with the middle hæmorrhoidal artery.

4. Arteria Deferentialis.-The artery to the ductus deferens may arise from either the superior vesical or the inferior. It is a long slender vessel which accompanies the ductus deferens to the testis, where it anastomoses with the testicular artery. It also anastomoses with the external spermatic branch of the inferior epigastric artery.

5. Arteria Hæmorrhoidalis Media.-The middle hæmorrhoidal artery is an irregular branch which arises either directly from the anterior division of the internal iliac or from the inferior vesical branch; more rarely it springs from the internal pudendal artery. It runs medially, and is distributed to the muscular coats of the rectum; it also gives branches to the prostate, the seminal vesicle, and the ductus deferens, and it anastomoses with its fellow of the opposite side, with the inferior vesical, and with the superior and inferior hæmorrhoidal arteries.

6. Arteria Vaginalis. - The vaginal artery may arise either directly from the anterior division of the hypogastric or from a stem common to it and the uterine artery, and it may be represented by several branches.

It runs downwards and medially, on the floor of the pelris, to the sides of the ragina, and divides into numerous branches which ramify on the anterior and posterior walls of the passage. The corresponding branches of opposite sides anastomose and form anterior and posterior longitudinal vessels, the so-called azygos arteries. They also anastomose above with the cervical branches of the uterine artery, and below with the perineal branches of the internal pudendal. 
In addition to supplying the vagina, small branches are given to the bulb of the vestibule, to the base of the bladder, and to the rectum.

7. Arteria Uterina.-The uterine artery arises from the anterior division of the internal iliac, either separately or in common with the vaginal or middle hæmorrhoidal arteries. It runs medially and slightly forwards, upon the upper surface of the levator ani, to the lower border of the broad ligament, between the two layers of which it passes medially, and arches above the ureter about threequarters of au inch from the uterus. It passes above the lateral fornix of the vagina to the side of the neck of the uterus, and then ascends towards the fundus, but at the level of the uterine tube it turns laterally, below the tube and between the layers of the broad ligannent, and anastomoses with the ovarian artery. It supplies the uterus, the upper part of the vagina, the medial part of the uterine tube, and gives branches to the round ligament of the uterus. It anastomoses with its fellow of the opposite side, and with the vaginal, the ovarian, and the inferior epigastric arteries, along the round ligament of the uterus.

\section{Parietal Branches of the Anterior Division.}

1. Arteria Obturatoria.-The obturator artery (Figs. 774 and 777) runs anteriorly and downwards along the lateral wall of the pelvis minor, just below its upper margin, to the obturator foramen, through the upper part of which it passes. It terminates, immediately on entering the thigh, by dividing into anterior and posterior terminal branches, which skirt round the margin of the obturator foramen deep to the obturator externus muscle. It is accompanied, in the whole of its course, by the obturator nerve and vein, the nerve being above the artery and the vein below it.

To its lateral side is the pelvic fascia, which intervenes between it and the upper part of the obturator internus muscle, whilst on its medial side it is covered by peritoneum. The ureter intervenes between the posterior part of the artery and the peritoneum. When the bladder is distended it also comes into close relation with the lower and anterior part of the artery. In the female the ovarian vessels and the broad ligament are on the medial side of the obturator artery.

Branches.-All the branches except the terminal are given off before the artery leaves the pelvis. They include:-(a) Muscular branches to the obturator internus, levator ani and ilio-psoas muscles. (b) A nutrient branch to the ilium, which passes deep to the ilio-psoas muscle, supplies the bone, and anastomoses with the ilio-lumbar artery. (c) A vesical branch or branches pass medially to the bladder beneath the lateral false ligament. (d) A pubic branch ascends on the posterior surface of the pubis, and anastomoses with its fellow of the opposite side and with the pubic branch of the inferior epigastric. It is given off just before the artery leaves the pelvis, and in its upward course it may pass either on the lateral or medial side of the external iliac vein, whilst not infrequently it runs on the medial side of the femoral ring. In the latter case it is important in relation to femoral hernia; this importance is emphasised when, as sometimes happens, the obturator artery arises as an enlarged pubic branch of the inferior epigastric artery instead of from the hypogastric. (e) Terminal.-The anterior terminal branch runs forwards, and the posterior backwards around the margin of the obturator foramen. They lie on the obturator membrane, under cover of the obturator externus, and they anastomose together at the lower margin of the foramen. Both give off offsets which anastomose with the medial circumflex artery, and twigs of supply to the adjacent muscles. The posterior branch also gives an acetabular branch to the hip-joint, which passes upwards, through the acetabular notch on the medial side of the transverse ligament, to supply the ligamentum teres and the head of the femur.

2. Arteria Pudenda Interna.-The internal pudendal artery (Figs. 774 and 775 ) arises from the anterior division of the hypogastric, close to the origin of the inferior gluteal artery, which slightly exceeds it in size. It runs downwards and backwards, to the lower part of the greater sciatic foramen, lying anterior to the piriformis muscle and the sacral plexus, from both of which it is separated by the pelvic fascia. At the lower border of the piriformis it pierces the pelvic 
fascia, passes between the piriformis and coccygeus muscles, and leaves the pelvis to enter the buttock. It is accompanied by venæ comites, the inferior glutæal vessels and nerves, the pudendal nerve, and the nerve to the obturator internus. In the buttock it lies on the spine of the ischium, under cover of the glutzus maximus, and between the pudendal nerve and the nerve to the obturator internus, the former being medial to it. It next passes through the lesser sciatic foramen and enters the perineum, in the anterior part of which it terminates by dividing into the profunda artery of the penis and the dorsal artery of the penis.

In the first part of its course in the perineum the artery lies in the lateral fascial wall of the ischio-rectal fossa, where it is enclosed in a canal in the fascia

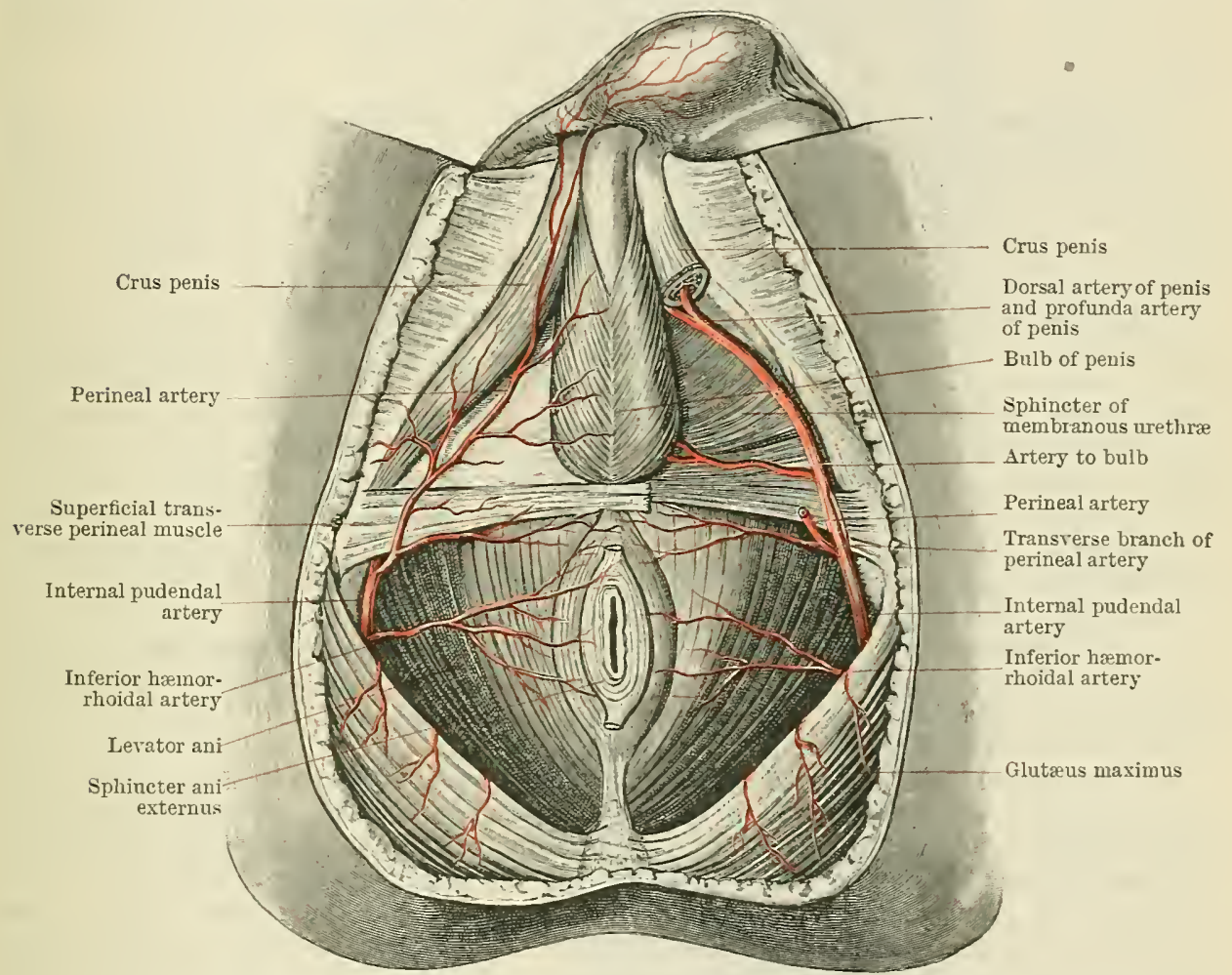

Fig. 775.-The Perineal Distribution of the Internal Pudendal Arteri in the Male.

(Alcock's canal). This canal, which is situated about one and a half inches above the lower margin of the tuberosity of the ischium, contains also the pudendal veins and the terminal parts of the pudendal nerve, viz., the dorsal nerve of the penis, which lies above the artery, and the perineal division, which lies below the vessel. From the ischio-rectal fossa the internal pudendal artery is continued forwards between the two layers of the fascia of the urogenital diaphragm (O.T. triangular ligament of the urethra), and close to the ramus of the pubis. About half-aninch below the arcuate ligament it turns somewhat abruptly forwards, pierces the inferior fascia of the urogenital diaphragm, and immediately divides into its terminal branches, viz., the profunda artery and the dorsal artery of the penis. The division sometimes takes place whilst the artery is still between the layers of the urogenital diaphragm.

Branches. - In the pelvis it gives small branches to the neighbouring muscles and to the roots of the sacral plexus.

In the buttock.-(a) Muscular branches are distributed to the adjacent muscles. Anastomotic branches unite with branches of the superior and inferior gluteal, and medial circumflex arteries. 
In the ischio-rectal fossa.-(c) The inferior hæmorrhoidal artery pierces the wall of the fascial canal, and runs obliquely forwards and medially. It soon divides into two or three main branches, which may arise separately from the pudendal; they pass across the space to the anal passage. The artery anastomoses in the walls of the anal passage with its fellow of the opposite side, and with the middle and superior hæmorrhoidal arteries; it anastomoses with the transverse perineal arteries also; and it supplies cutaneous twigs to the region of the anus, and others, which turn round the lower border of the glutieus maximus, to supply the lower part of the buttock.

(d) The perineal artery arises in the anterior part of the ischio-rectal fossa, pierces the base of the fascia of the urogenital diaphragm, and divides into long slender posterior scrotal branches in the male, and posterior labial branches in the female. These branches are continued forwards, in the urethral triangle, to the scrotum, deep to the superficial perineal fascia. They anastomose with their fellows of the opposite side, with the transverse perineal and the external pudenclal arteries, and supply the muscles and subcutaneous structures of the urethral triangle.

(e) The transverse perineal artery is a small branch which arises either directly from the internal pudendal or from its perineal branch. It runs medially along the base of the fascia of the urogenital diaphragm (0.T. triangular lig.) to the central point of the perineum, where it anastomoses with its fellow of the opposite side, with the perineal artery, and with the inferior hæmorrhoidal arteries. It supplies the sphincter ani, the bulbo-cavernosus or sphincter vaginæ, and the anterior fibres of the levator ani.

In the urethral triangle.-(f) The artery to the bulb, a branch which is usually of relatively large size, is given off between the fascial layers of the urogenital diaphragm. It runs transversely along the posterior border of the sphineter of the membranous urethræ, and then, turning forwards a short distance from the side of the urethra, it pierces the inferior fascia of the urogenital diaphragm and enters the substance of the bulb. It passes onwards in the corpus cavernosum urethræ to the glans, where it anastomoses with its fellow and with the dorsal arteries of the penis.

It supplies the sphincter of the membranous nrethræ, bulbo-urethral gland (Cowper), the corpus cavernosum urethræ, and the penile part of the urethra. In the female this artery supplies the bulb of the vestibule.

(g) The profunda artery of the penis (O.T. artery of the corpus cavernosum) in the male, and of the clitoris in the female, is usually the larger of the two terminal branches. Immediately after its origin it enters the crus penis, and runs forwards in the corpus cavernosum penis, which it supplies.

(h) The dorsal artery of the penis in the male, and of the clitoris in the female, passes forwards between the layers of the suspensory ligament, and runs along the dorsal surface of the penis, with the dorsal nerve immediately to its lateral side, whilst it is separated from its fellow of the opposite side by the deep dorsal vein, which lies in the median plane. It supplies the superficial tissues on the dorsal aspect of the penis, sends branches into the corpus cavernosum penis to anastomose with the profunda artery of the penis, and its terminal branches enter the glans penis, where they anastomose with the arteries to the bulb. It anastomoses also with the external pudendal branches of the femoral.

\section{Arteria Glutæal Inferior.-The inferior glutæaI artery (O.T. sciatic), (Figs. 774} and 776 ) arises from the hypogastric artery, either separately or by a common trunk with the internal pudendal artery. It descends a little postero-lateral to the internal pudendal vessels, pierces the pelvic fascia, runs backwards between the first and second, or second and third sacral nerves, and, passing between the piriformis and coccygeus muscles, leaves the pelvis through the lower part of the greater sciatic foramen, and enters the buttock just below the piriformis. In the buttock it descends posterior and to the medial sicle of the sciatic nerve beneath the glutæus maximus, and posterior to the obturator internus, the two gemelli, the quadratus femoris, and upper part of the adductor magnus muscles, to the proximal part of the thigh.

Below the lower border of the glutæus maximus the artery is comparatively superficial, and having given off its largest branches, it runs distally as a long slender vessel with the posterior femoral cutaneous nerve.

Branches-In the pelvis.- Small and irregular branches supply the adjacent viscera and muscles and the sacral nerves; they anastomose with branches of the internal pudendal and lateral sacral arteries. 
In the buttock.-(a) Muscular branches are given off to the muscles of the buttock and to the proximal parts of the hamstring muscles. They anastomose with the internal pudendal, medial circumflex, and obturator arteries. (b) The coccygeal branch arises immediately after the artery leaves the pelvis. It runs medially, pierces the sacro-tuberous ligament and the glutreus maximus, and ends in the soft tissues over the posterior aspect of the lower part of the sacrum and of the coccyx. It gives several branches to the glutæus maximus, and anastomoses with branches of the glutæal and lateral sacral arteries. (c) An anastomotic branch passes laterally, superficial or deep to the sciatic nerve, towards the greater trochanter of the femur. It anastomoses with branches of the glutæal, internal pudendal, medial and lateral circumflex, and the first perforating arteries, taking part in the formation of the so-called "crucial anastomosis."

Cutaneous branches, accompanying twigs of the posterior cutaneous nerve of the thigh, pass round the lower border of the glutæus maximus muscle to the integument. (e) The a. comitans $n$. ischiadici is a long slender branch which runs distally on the surface, or in the substance of the sciatic

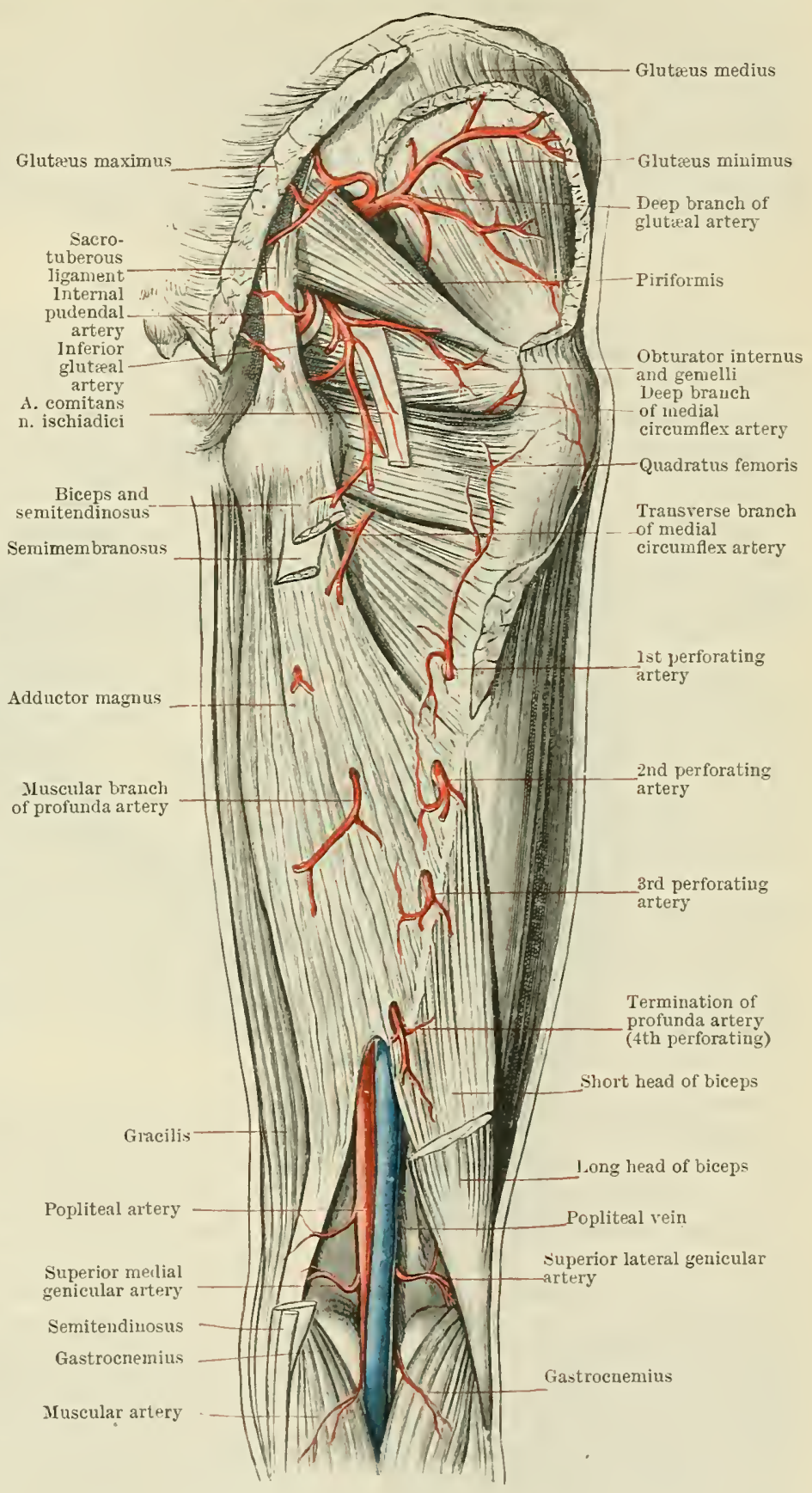

Fig. 7T6. - IHE ARTERIES OF THE ButTock AND THE BACK OF THE THIGH ANU KNEE. nerve. It supplies the nerve, and anastomoses with the perforating arteries and with the termination of the profunda femoris artery. 


\section{ARTERIES OF THE INFERIOR EXTREMITY.}

The main artery of each lower limb is continued from the corresponding common iliac artery. It descends as a single trunk as far as the lower border of the popliteus, and ends there by dividing into the anterior and posterior tibial arteries. Distinctive names are, however, applied to different parts of the artery, corresponding to the several regions through which it passes. Thus in the abdomen it is called the external iliac artery, in the proximal two-thirds of the thigh it receives the name of the femoral artery, whilst its distal part, which is situated on the flexor aspect of the knee, is termed the popliteal artery.

\section{ARTERIA ILIACA EXTERNA.}

The external iliac artery extends from a point opposite the sacro-iliac joint, at the level of the lumbo-sacral articulation, to a point below the inguinal ligament (Poupart's), midway between the anterior superior spine of the ilium and the symphysis pubis, where it becomes the femoral artery. Its length is about 87 to $100 \mathrm{~mm}$. (three and a half to four inches), and in the adult it is usually somewhat larger than the hypogastric artery.

It runs forwards and laterally, along the superior aperture of the minor pelvis, resting upon the fascia iliaca, which separates it above from the medial border, and below from the anterior surface of the psoas major muscle; and it is enclosed with its accompanying vein in a thin fascial sheath.

Relations.-Anterior.-It is covered in front by peritoneum, which separates it on the left side from the iliac colon, and coils of small intestine, and on the right side from the terminal portion of the ileum, and sometimes from the vermiform process. The ureter, descending behind the peritoneum, sometimes crosses the front of the artery near its origin, and in the female the ovarian vessels cross the upper part of the artery. Near its lower end the artery is crossed anteriorly by the external spermatic branch of the genito-femoral nerve and by the deep circumflex iliac vein. In the male this part of the artery is crossed also by the ductus deferens, and in the female by the round ligament of the uterus. Several iliac lymph giands lie in front and at the sides of the external iliac artery, and almost invariably one of these is directly anterior to its termination.

Posterior.-The fascia iliaca and psoas major muscle lie behind the artery. Near its upper end the obturator nerve and the external iliac vein are posterior to the vessel.

Lateral. - On its lateral side is the genito-femoral nerve. Medial.-To the medial side of its lower part is the external iliac vein.

Branches.-In addition to small branches to the psoas major muscle and to the lymph glands, two named branches of considerable size spring from the external iliac artery, viz., the inferior epigastric and the deep circumflex iliac.

(1) Arteria Epigastrica Inferior.-The inferior epigastric artery (Figs. 774 and 777 ) arises, immediately above the inguinal ligament, from the front of the external iliac. It lies in the extra-peritoneal fat, it curves forward from its origin, turns round the lower border of the peritoneal sac, and runs upwards and medially, along the medial side of the abdominal inguinal ring and along the lateral border of the medial inguinal fossa ; it then pierces the transversalis fascia, passes over the semicircular fold (Douglas) and enters the sheath of the rectus abdominis muscle. For a short distance it ascends posterior to the rectus, but it.soon penetrates the substance of the muscle, and breaks up into branches which anastomose with terminal offsets of the superior epigastric branch of the internal mammary artery and with the lower intercostal arteries. At the abdominal inguinal ring, in the male, the ductus deferens, the testicular vessels, and the external spermatic branch of the genitofemoral nerve hook round the front and lateral side of the artery, the ductus deferens turning medially behind it; whilst in the female the round ligament of the uterus and the external spermatic branch of the genito-femoral nerve occupy the corresponding positions.

Branches. - (a) Muscular branches, which spring mainly from the lateral side of the artery, supply the rectus, the pyramidalis, the transversus, and the oblique muscles of 
the abdominal wall, and anastomose with branches of the deep circumflex iliac, the lumbar, and the lower intercostal arteries. (b) Cutaneous branches, which pass from the front of the inferior epigastric, pierce the rectus abdominis and the anterior part of its sheath, and terminate in the subcutaneous tissues of the anterior abdominal wall, where they anastomose with corresponding branches of the opposite side and with branches of the superficial epigastric artery. (c) The external spermatic in the male (artery of the round ligament of the uterus in the female) is small. It descends throngh the inguinal canal and anastomoses with the external pudendal and the scrotal branches of the perineal artery, and in the male with the internal spermatic artery also. In the male it accompanies the spermatic funiculus, supplying its coverings, including the cremaster. In

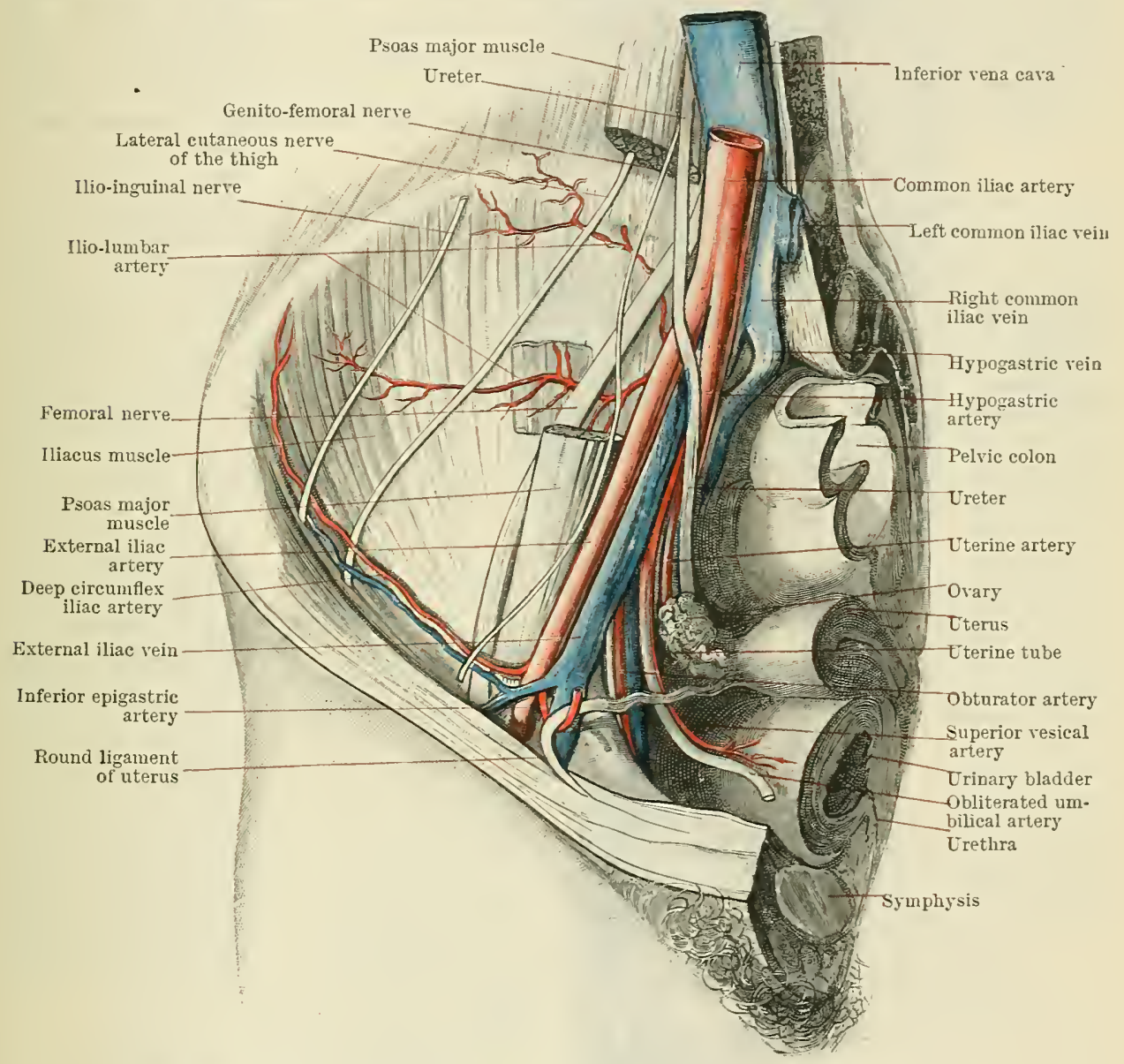

Fig. 777.-The Iliac ayd Hypogastric Arteries axd Veins in the Fearale.

the female it runs with the round ligament. (d) The pubic branch descends, either on the lateral or the medial side of the femoral ring, to anastomose with the pubic branch of the obturator artery; it anastomoses also with its fellow of the opposite side. Sometimes when the obturator branch of the hypogastric artery is absent, the pubic branch of the inferior epigastric artery enlarges and becomes the obturator artery, which descends to the obturator foramen either on the lateral or the medial side of the femoral ring. In the latter case the artery may be injured in the operation for the relief of a strangulated femoral hernia.

(2) Arteria Circumflexa Ilium Profunda.-The deep circumflex iliac artery (Figs. 774 and 777) springs from the lateral side of the external iliac artery, nsually a little below the inferior epigastric, and immediately above the inguinal ligament. It runs laterally and upwards to the anterior superior spine of the ilimm. In this part of its course it lies just above the lower border of the inguinal ligament, and is enclosed in a fibrous canal formed by the union of the transversalis and iliac 
fascix. A little beyond the anterior superior spine it pierces the transversus abdominis, and is continued backwards, between the transversus and the internal

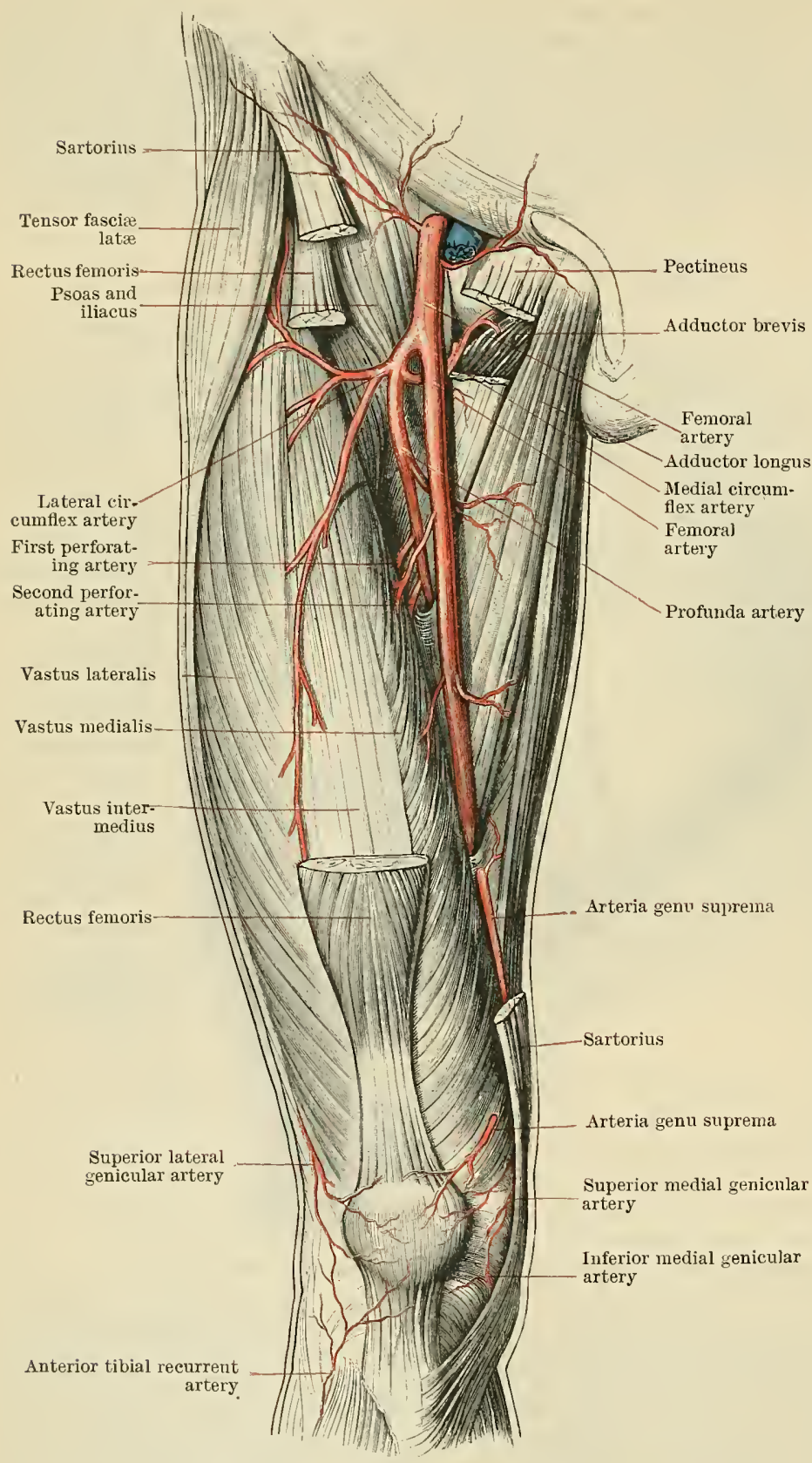

Fig. 778. - The Femoral Artery and its Bratches. oblique, to terminate by anastomosing with branches of the ilio-lumbar artery.

Branches.-- (a) Muscular to the upper parts of the sartorius and the tensor fasciæ latæ, and to the muscles of the abdominal wall. One of the latter branches is frequently of considerable size; it pierces the transversus muscle a short distance anterior to the anterior superior spine of the ilium, and ascends vertically, between the transversus and the internal oblique, anastomosing with the lumbar and the epigastric arteries. (b) Cutaneous branches pierce the internal and external oblique muscles. They terminate in the skin over the crest of the ilium, and they anastomose with the superior glutæal, the superficial circumflex iliac, and the ilio-lumbar arteries.

\section{ARTERIA}

FEMORALIS.

The femoral artery (Figs. 778 and 779) is the continuation of the external iliac into the thigh. It commences at the lower

border of the inguinal ligament (O.T. Poupart's), passes through the proximal twothirds of the thigh, and terminates at the opening in the adductor magnus. At one time it was customary to speak of the first one and a half inches, as far as the origin of the profunda branch, as the common femoral, and to say that it divided into the superficial and deep femoral branches, of which the former was the direct continuation of the common trunk. The morphology and development of the vessel gives no support for such terminology. 
Course.-Its general direction is indicated by a line drawn from the point of origin, midway between the anterior superior spine of the ilium and the symphysis pubis, to the adductor tubercle, the thigh being flexed, abducted, and rotated laterally.

In its proximal half the femoral artery lies in the femoral trigone (O.T. Scarpa's triangle), and is comparatively superficial; at the apex of the trigone it passes deep to the sartorius, enters the adductor canal (Hunter's), and is thus more deeply placed.

At their entry into the femoral trigone both the artery and its vein are enclosed, for a distance of $31 \mathrm{~mm}$. (one and a quarter inches), in a funnel-shaped fascial sheath formed of the fascia transversalis anteriorly and the fascia iliaca posteriorly. This is called the femoral sheath; it is divided, by antero-posterior septa, into three compartments, of which the lateral is occupied by the femoral artery and lumbo-inguinal branch of the genito-femoral nerve; the intermediate compartment contains the femoral vein: and the medial compartment constitutes the femoral canal.

Relations.-Anterior.-In the femoral trigone the femoral artery is covered superficially by skin and fasciæ, by superficial sub-inguinal lymph glands and small superficial vessels. The anterior part of the femoral sheath and the fascia cribrosa are in front of the proximal part of the artery, and the fascia lata is in front of the distal part. Near the apex of the triangle the artery is crossed by the medial cutaneous nerve, and not infrequently by a tributary of the great saphenous vein. Posterior.-It is in relation, posteriorly, proximo-distally, with the posterior part of the femoral sheath, the pubic or pectineal portion of the fascia lata and the psoas major, the pectineus, and the proximal part of the adductor longus muscles. The nerve to the pectinens passes between the artery and the psoas major; the femoral vein and the profunda artery and vein intervene between it and the pectineus, and the femoral rein also separates it from the adductor longus.

The femoral rein, which lies on a plane posterior to the artery in the lower part of the femoral trigone, passes to its medial side above, where it is separated from the artery by the lateral septum of the femoral sheath. On the lateral side of the artery is the femoral nerve (O.T. anterior crural) proximally ; more distally the saphenous nerve and the nerve to the vastus medialis are coutinued on the lateral side. The lumbo-inguinal branch of the genito-femoral nerve is anterior and to the lateral side proximally, as it runs for a short distance in the femoral sheath.

In the adductor canal the artery has posterior to it the adductor longus and the adductor magnus, whilst anterior and to the lateral side is the rastus medialis. The femoral rein is also posterior to the artery, but lies to its lateral side distally and to its medial side proximally. Anterior to the artery is the fascial roof of the canal, with the obturator or sub-sartorial plexus of nerves and the sartorius muscle. The saphenous nerve enters the adductor canal with the artery, and runs first on its lateral side, then anterior, and lastly on its medial side.

Branches. - The femoral artery gives off the following branches :-

(1) Superficial branches.

(a) The superficial circumflex iliac.

(b) The superficial epigastric.

(c) The superficial external pudendal.

(2) Muscular.

(3) The deep external pudendal.

(4) The profundi.

(5) The arteria genu suprema.

(a) Arteria Circumflexa Ilium Superficialis.-The superficial circumflex iliac springs from the front of the femoral artery just below the inguinal ligament. It pierces the femoral sheath and the fascia lata, lateral to the fossa ovalis (O.T. saphenous opening), and runs, in the superficial faseia, as far as the anterior superior spine of the ilium. It supplies the lateral set of sub-inguinal glands and the skin of the groin, and it sends branches through the fascia lata which anastomose with the deep circumflex iliac and supply the upper parts of the sartorius and tensor fascix latie muscles.

(b) Arteria Epigastrica Superficialis.-The superficial epigastric artery arises near the preceding. It pierces the femoral sheath and the fascia cribrosa, 
and passes upwards and medially, between the superficial and deep layers of the superficial fascia of the abdominal wall, towards the umbilicus. It supplies the sub-inguinal glands and the integument, and anastomoses with its fellow of the opposite side, with the inferior epigastric, and with the superficial circumflex iliac and superficial external pudendal arteries.

(c) Arteria Pudenda Externa Superficialis.-The superficial external pudendal artery also springs from the front of the femoral artery, and, after piercing the femoral sheath and the fascia cribrosa, runs upwards and medially towards the

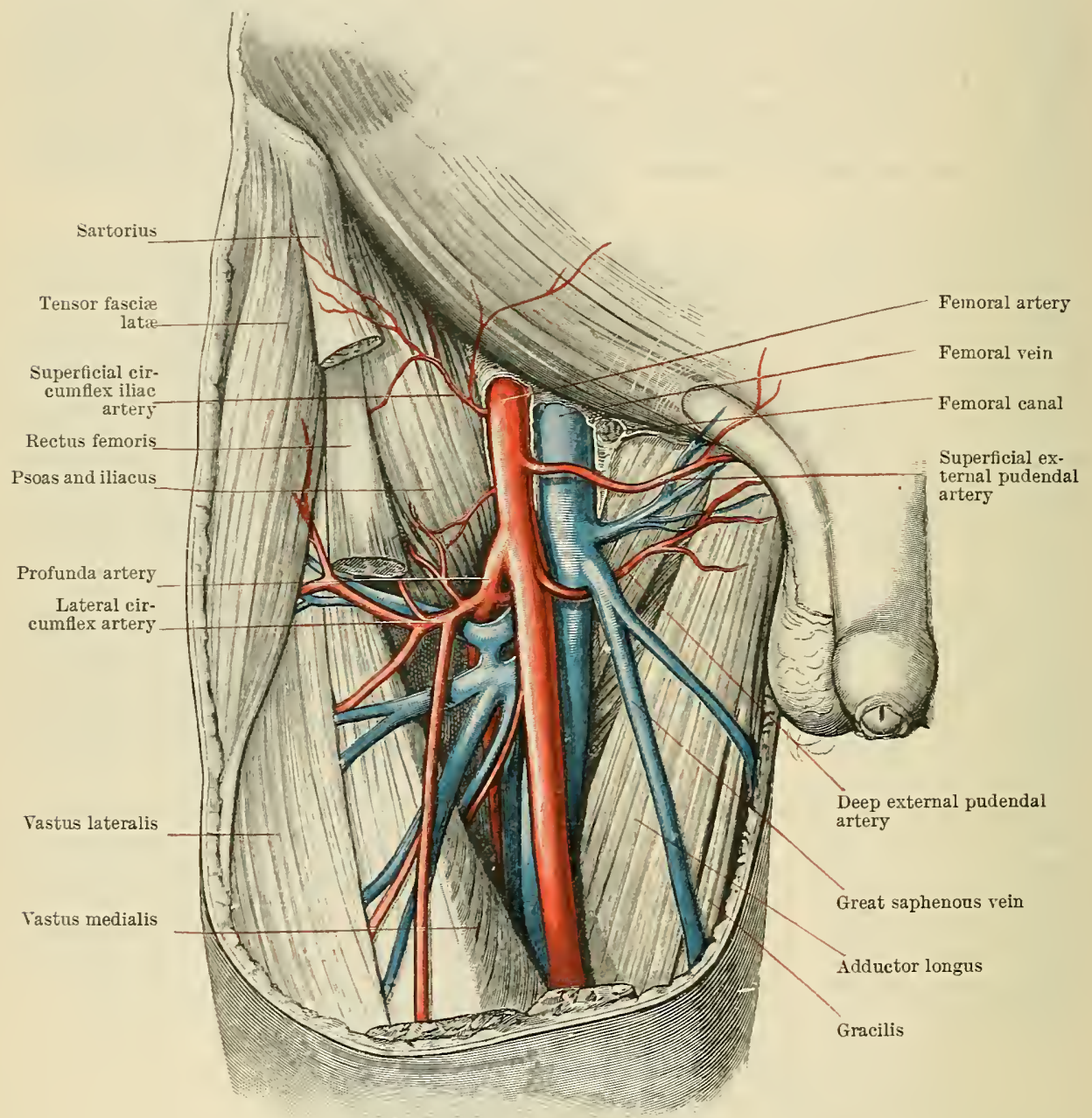

Fig. 779.-The Fearoral Vessels in Femoral 'Trigone.

pubic tubercle, where it crosses superficial to the spermatic cord and divides into terminal anterior scrotal or labial branches according to the sex. It supplies the integument of the lower part of the abdominal wall, the root of the dorsum of the penis in the male, and the region of the mons Veneris in the female, and it anastomoses with its fellow of the opposite side, the deep external pudendal, the dorsal artery of the penis, and the superficial epigastric artery.

(2) Rami Musculares.-The muscular branches are distributed to the pectineus and the adductor muscles on the medial side, and to the sartorius and the vastus medialis on the lateral side.

(3) Arteria Pudenda Externa Profunda.-The deep external pudendal artery arises from the medial side of the femoral. It runs medially, anterior to the pectineus, and either anterior or posterior to the adductor longus, to the medial 
side of the thigh; it then pierces the deep fascia, and terminates in the scrotum, where it anastomoses with the posterior scrotal branches of the perineal and the anterior scrotal branches of the superficial external pudendal arteries, and with the external spermatic branch of the inferior epigastric artery. In the female it terminates in the labium majus.

(4) Arteria Profunda Femoris.-The profunda artery (Fig. 778) is the largest branch of the femoral artery. It arises about $37 \mathrm{~mm}$. (an inch and a half) distal to the inguinal ligament, from the lateral side of the femoral artery. Curving backwards and medially, it passes posterior to the femoral artery, and runs distally, close to the medial aspect of the femur, to the distal third of the thigh, where it perforates the adductor magnus and passes to the back of the thigh. Its termination is known as the fourth perforating artery. As the profunda descends it lies anterior to the iliacus, the pectineus, the adductor brevis, and the adductor magnus. It is separated from the femoral artery by its own vein, by the femoral vein, and by the adductor longus muscle.

Branches.-(a) Muscular branches are given off from the profunda, both in the femoral trigone and whilst it lies between the adductor muscles; many of them terminate in the adductors, others pass through the adductor magnus, and terminate in the hamstrings, where they anastomose with the transverse branch of the medial circumflex and with the proximal muscular branches of the popliteal artery.

(b) The lateral circumflex artery (Figs. 778 and 779) spriugs from the lateral side of the profunda, or occasionally from the femoral artery proximal to the origin of the profunda. It runs laterally, anterior to the iliacus and between the superficial and deep branches of the femoral nerve, to the lateral border of the femoral trigone ; then, passing posterior to the sartorius and the rectus femoris, it terminates by dividing into three terminal branches - the ascending, the transverse, and the descending. Before its termination it supplies branches to the muscles mentioned and to the upper part of the crureus.

(i.) The ascending terminal branch runs proximally and laterally, posterior to the rectus femoris and the tensor fasciæ latæ, along the linea intertrochanterica, to the anterior borders of the glutæi, medius and minimus, between which it passes to anastomose with the deep branches of the superior glutæal artery. It supplies twigs to the neighbouring muscles, anastonıoses with the glutæal, the deep circumflex iliac, and the transverse branch of the lateral circumflex arteries, and, as it ascends along the linea intertrochanterica, it gives off a branch which passes between the two limbs of the ilio-femoral ligament into the hip-joint. (ii.) The transverse terminal branch is small; it runs laterally between the vastus intermedius and the rectus femoris, passes into the substance of the vastus lateralis, winds round the femur, and anastomoses with the ascending and descending branches, with the perforating branches of the profunda, and with the inferior glutwal and medial circumflex arteries. (iii.) The descending terminal branch runs distally, posterior to the rectus and along the anterior border of the vastus lateralis, accompanied by the nerve to the latter muscle. It anastomoses with the transverse branch, with twigs of the inferior perforating arteries, with the arteria genu suprema of the femoral, and with the superior lateral genicular branch of the popliteal artery.

(c) The medial circumflex artery (Fig. 778) springs from the medial and posterior part of the profunda, at the same level as the lateral circumHex, and runs backwards, through the floor of the femoral trigone, passing between the psoas major and the pectineus; crossing the upper border of the adductor brevis it is continued backwards, below the neck of the femur, and passes between the adjacent borders of the obturator externus and the adductor brevis to the upper border of the adductor magnus, where it divides into two terminal branches, a transverse and a profunda branch (O.T. ascending).

Branches.-(i.) An acetabular branch is given off as the artery passes below the neck of the femur. It ascends to the acetabular notch where it anastomoses with twigs from the posterior branch of the obturator artery, and it sends branches into the acetabular fossa and along the ligamentum teres to the head of the femur. (ii.) A superficial branch, which passes medially, anterior to the pectineus and between the adductors brevis and longus. (iii.) Muscular branches are given off to the neighbouring muscles. The largest of these branches usually arises immediately before the termination of the artery ; it runs distally, on the anterior aspect of the addnctor magnus, and auastomoses with the muscular branches of the profunda artery. (iv.) The profunda terminal branch (ascending) passes mpwards and laterally, between the obturator externus and the quadratus femoris to the trochanteric fossa of the femur, where it anastomoses with branches of the superior and inferior glutæal arteries. (v.) The transverse terminal branch runs backwards, between the lower border of the quadratus femoris and the upper border of the adductor magnus, to the hamstring muscles. It anastomoses, in front of the distal part of the 
glutæus maximus, with the inferior glutæal and first perforating arteries and with the transverse branch of the lateral circumflex, and, in the substance of the hamstrings, with the muscular branches of the profunda.

(d) The perforating arteries (Fig. 780), including the terminal branch of the profunda,

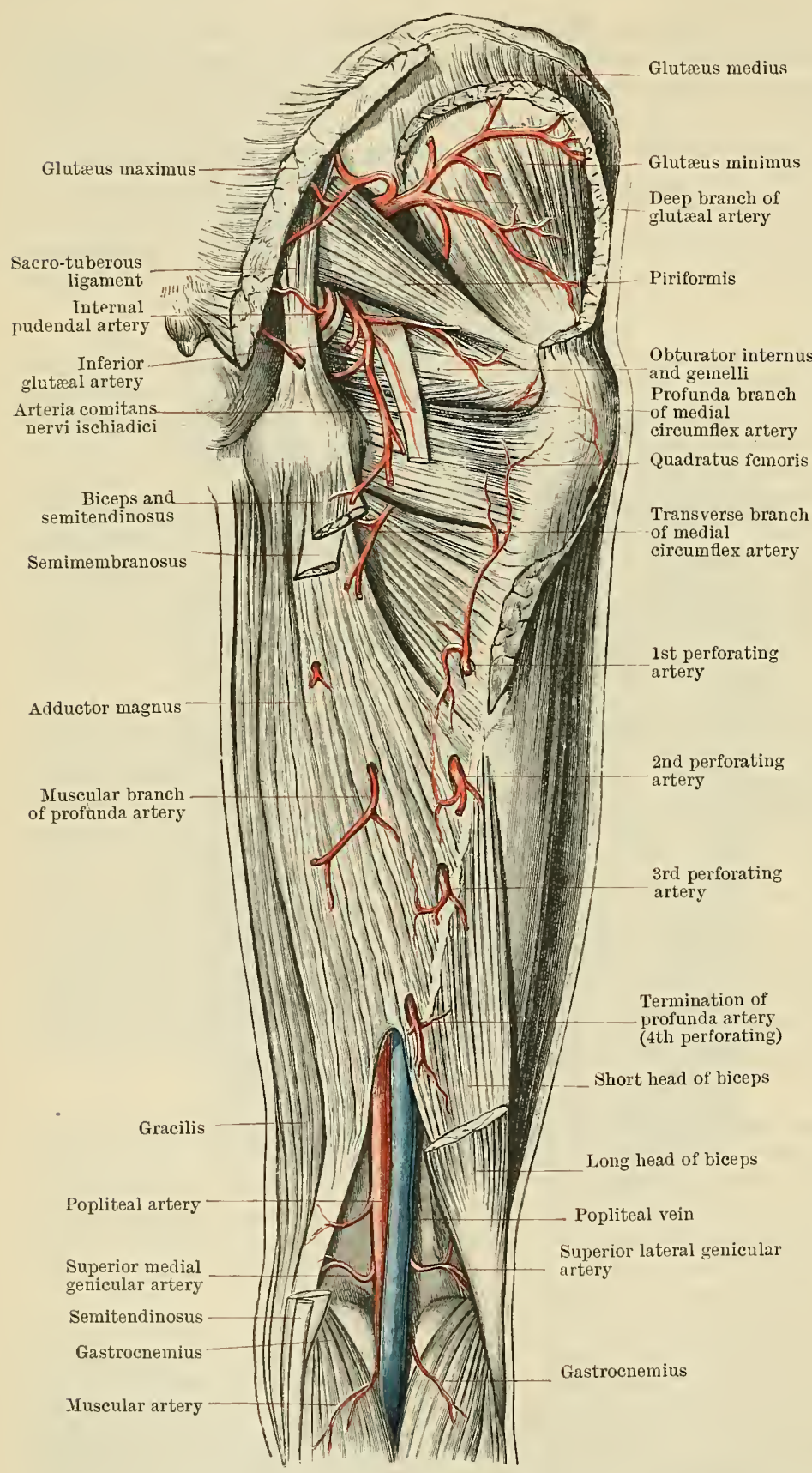

Fig. 780.-The Arteries of the Buttock and the Posterior Aspect OF THE Thigh AND KNEE. are four in number. They curve posterolaterally, round the posterior aspect of the femur lying close to the bone, and anterior to the wellmarked tendinous arches which interrupt the continuity of muscular attachments ; their terminal branches enter the vastus lateralis and anastomose, in its substance, with one another, with the descending branch of the lateral circumflex, with the arteria genu suprema, and with the superior lateral genicular branch of the popliteal.

The first perforating artery pierces the insertions of the adductors brevis and magnus, and some of its branches anastomose, anterior to the glutæus maximus, with the inferior glutæal, with the transverse branch of the medial circumflex, and with the transverse branch of the lateral circumflex, forming what is known as the crucial anastomosis.

The second perforating artery pierees the adductor's brevis and magnus, and then passes between the glutrus maximus and the short head of the biceps femoris into the vastus lateralis. It anastomoses with its proximal and distal fellows, and with the medial circumflex and the proximal muscular branches of the popliteal artery.

The third and fourth perforating arteries pass through the adductor magnns and the short head of the biceps femoris into the vastus lateralis. Their anastomoses are similar to those of the second perforating.

A nutrient branch to the femur is given off either from the second or third perforating 
artery, usually the former; an additional nutrient branch may also be supplied by the first or fourth perforating arteries.

(5) The arteria genu suprema (O.T. anastomotic) arises near the termination of the femoral artery, in the distal part of the adductor canal, and divides, almost immediately, into a superficial, saphenous, and a deep (musculo-articular) branch; indeed, very frequently the two branches arise separately from the femoral trunk.

(a) The saphenous branch passes through the distal end of the adductor canal with the saphenous nerve, and appears superficially, on the medial side of the knee, between the gracilis and the sartorius. It gires twigs to the integument of the proximal and medial part of the leg, and it anastomoses with the inferior medial genicular artery. (b) The musculo-articular branch runs towards the knee, in the substance of the vastus medialis, along the anterior aspect of the tendon of the adductor magnus. It anastomoses with the superior medial genicular, and it sends branches laterally, one on the surface of the femur and another along the proximal border of the patella, to anastomose with the descending branch of the lateral circumflex, the fourth perforating artery, the superior external genicular, and the anterior tibial recurrent.

\section{ARTERIA POPLITEA.}

The popliteal artery is the direct continuation of the femoral. It commences at the proximal and medial part of the popliteal fossa, under cover of the semimembranosus, and terminates at the distal border of the popliteus muscle, and on a level with the distal part of the tuberosity of the tibia, by dividing into the anterior and the posterior tibial arteries.

From its origin the artery passes distally, with a lateral inclination, to the interspace between the condyles of the femur, whence it is continued rertically to its termination.

Relations. - Anterior. - It is in contact in front and proximo-distally with the popliteal surface of the femur, the posterior part of the capsule of the knee-joint, and the fascia covering the posterior surface of the popliteus.

Posterior.-The artery is overlapped behind by the lateral border of the semimembranosus proximally; it is crossed about its middle by the popliteal vein and the tibial (O.T. internal popliteal) nerve, the vein intervening between the artery and the nerve; whilst in the distal part of its extent it is overlapped by the adjacent borders of the two heads of the gastrocnemius, and is crossed by the nerves to the soleus and popliteus and by the plantaris muscle.

Lateral._-On its lateral side it is in relation proximally with the tibial nerve and the popliteal vein, then with the lateral condyle of the femur, and distally with the lateral head of the gastrocnemius and the plantaris.

Medial.-On the medial side it is in relation proximally with the semimembranosus, in the middle with the medial condyle of the femur, and distally with the tibial nerre, the popliteal vein, and the medial head of the gastrocnemius. Popliteal lymph glands are arranged irregularly around the artery.

Branches.-(1) Muscular branches are given off in two sets, proximal and distal.

The proximal muscular branches are distributed to the distal parts of the hamstring muscles, in which they anastomose with branches of the profunda artery.

The distal muscular, or surul, arteries enter the proximal parts of the gastrocnemius, the plantaris, the soleus, and the popliteus muscles, and they anastomose with branches of the posterior tibial artery and the lower genicular arteries.

(2) The genicular branches are five in number-viz., superior and inferior lateral, superior and inferior medial, and a median branch.

(a) The superior lateral genicular artery (a. genu superior lateralis) passes laterally, proximal to the lateral condyle, behind the femur and in front of the biceps tendon, into the vastus lateralis, where it anastomoses with the arteria genu suprema, the descending branch of the lateral circumflex, and the fourth perforating artery ; it also sends branches distally to anastomose with the inferior lateral genicular and with the anterior tibial recurrent.

(b) The superior medial genicular artery passes medially, proximal to the medial condyle, behind the femur, and anterior to the tendon of the adductor magnus, into the vastus medialis. It anastomoses with branches of the arteria genu suprema and of the superior lateral genicular artery. 
(c) The inferior lateral genicular artery runs laterally, across the popliteus muscle and auterior to the plantaris and the lateral head of the gastrocnemius; then, turning forwards, it is joined by the inferior lateral genicular nerve, and passes to the medial side

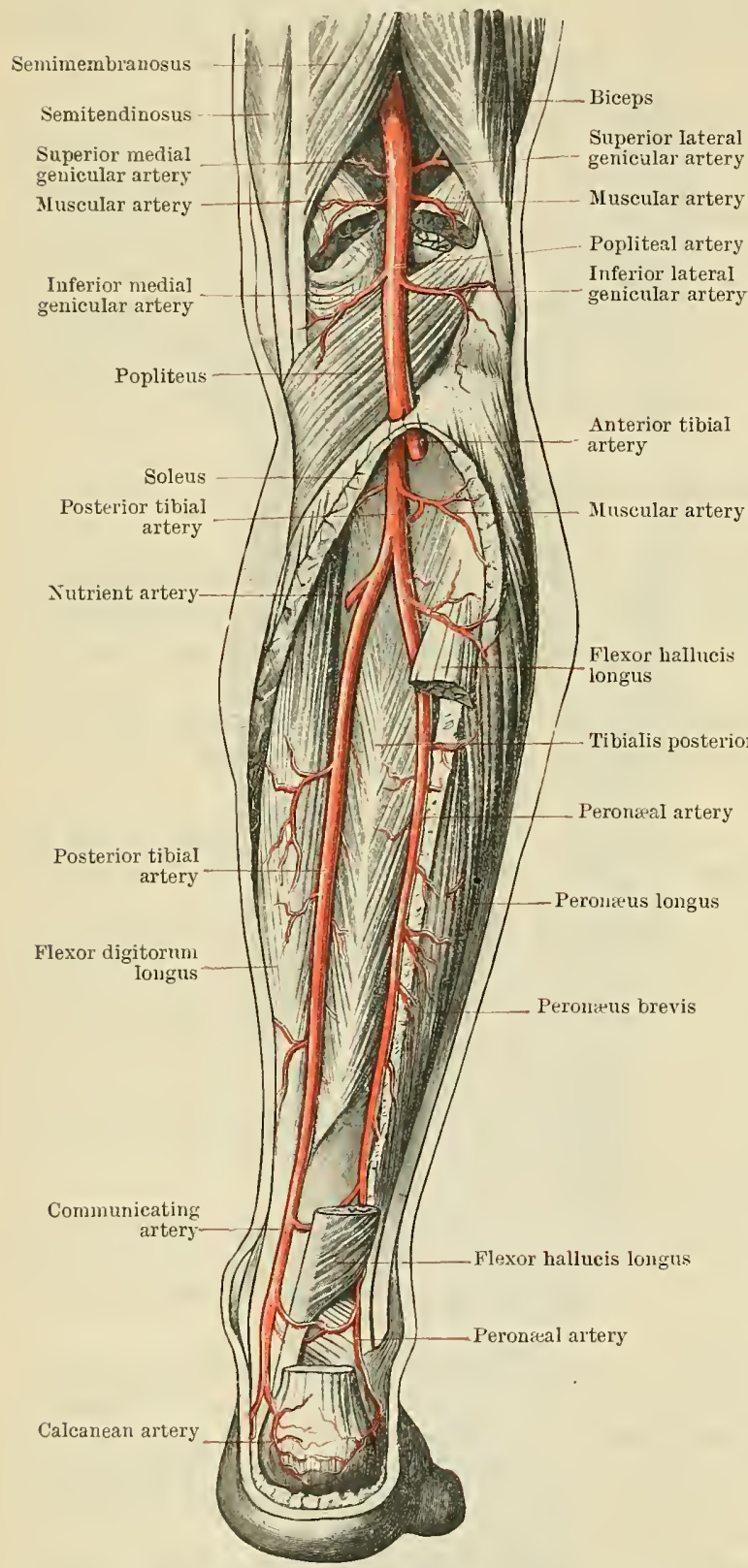

Fig. 781. - The Popliteal and Posterior Tibial Arteries AND THEIR BRANCHES. of the fibular collateral ligament. It terminates by anastomosing with its fellow of the opposite side and with the superior lateral genicular and anterior tibial recurrent arteries.

(d) The inferior medial genicular artery passes medially, distal to the medial condyle of the tibia, along the proximal border of the popliteus and in front of the medial head of the gastrocnemius, to the medial side of the knee, where it turns forwards, between the bone and the tibial collateral ligament, and terminates anteriorly by anastomosing with its fellow of the opposite side, with the recurrent branch of the anterior tibial artery, and with the superior medial genicular artery.

(e) The arteria genu media passes directly forwards from the front of the popliteal artery, pierces the central part of the posterior surface of the capsule of the knee-joint, and enters the intercondylar fossa. It supplies branches to the crucial ligaments and to the synovial membrane, and is accompanied by the medial genicular branch of the tibial nerve, and sometimes by the genicular branch of the obturator nerve.

(3) Cutaneous branches are distributed to the skin over the popliteal fossa. One of these, the superficial sural artery, runs along the middle of the back of the calf with the medial sural nerve.

\section{Arteria Trbialis Posterior.}

The posterior tibial artery, the larger of the two terminal branches of the popliteal, commences at the distal border of the popliteus and terminates midway between the tip of the medial malleolus and the most prominent part of the heel, at the distal border of the laciniate ligament (O.T. internal annular). It ends by dividing into the medial and the lateral plantar arteries, which pass onwards to the sole of the foot.

The posterior tibial artery runs distally and medially in the posterior part of the leg, between the superficial and deep layers of muscles, and covered posteriorly by the deep intermuscular fascia which intervenes between them. 
Relations.-Anterior.-It is in contact anteriorly, and proximo-distally, with the tibialis posterior, the flexor digitorum longus, the posterior surface of the tibia, and the posterior ligament of the ankle-joint.

Posterior. - The artery is crossed abont $37 \mathrm{~mm}$. (an inch and a half) distal to its origin by the tibial nerve. Elsewhere it is in contact with the intermuscular fascia which binds down the deep layer of muscles. More superficially the proximal half of the artery is covered by the fleshy parts of the soleus and gastrocnemius muscles, between which is the plantaris; the distal half of the artery is much nearer the surface, and is covered only by skin and fascir, except at its termination, where it lies deep to the laciniate ligament and the origin of the abductor hallucis.

Lateral and Medial.-The artery is accompanied by two renæ comites, one on each side. The tibial nerve lies at first on the medial side of the vessel, then crosses posterior to it, and is continued distally on its lateral side. In the most distal part of its course the artery is separated from the medial malleolus by the tendons of the tibialis posterior and the flexor digitorum longus, whilst the tendon of the flexor hallucis longus lies postero-lateral to it.

Branches.-The posterior tibial gives off numerous branches, the largest of which, the peroneal, forms one of the chief arteries of the leg. The branches include-

(1) Two large muscular branches which are distributed to the soleus, the tibialis posterior, the flexor digitorum longus, and the flexor hallucis longus. They anastomose with the deep sural branches of the popliteal artery and the lower medial genicular artery.

(2) A fibular branch passes laterally to the neck of the fibula, where it anastomoses with the inferior lateral genicular and the deep sural arteries, and supplies the adjacent muscles.

(3) The peronæal artery (Fig: 781 ) is the largest branch of the posterior tibial. It arises about $25 \mathrm{~mm}$. (an inch) below the distal border of the popliteus, curres laterally across the proximal part of the tibialis posterior to the medial crest of the fibula, along which it passes to the distal part of the interosseous space. About $25 \mathrm{~mm}$. (an inch) proximal to the ankle-joint it gives off a perforating branch and then passes, posterior to the tibio-fibular syndesmosis and lateral malleolus, to the lateral side of the heel and the foot. It supplies the ankle, the tibio-fibular syndesmosis, and the talo-calcanean joint, and anastomoses with the medial calcanean branch of the lateral plantar artery, and with the tarsal and arcuate branches of the dorsalis pedis.

As the peronaal artery passes laterally from its origin it lies posterior to the tibialis posterior, and is covered posteriorly by the deep intermuscular fascia and by the soleus. As it descends along the medial crest of the fibula it lies in a fibrous canal between the tibialis posterior in front and the flexor hallucis longus behind. The peronæal artery is accompanied by two renae comites, and is crossed anteriorly and posteriorly by communicating branches between them.

Branches.-(a) Muscular branches are clistributed to the soleus, tibialis posterior, flexor hallucis longus, and the peronzeal muscles. Some pass through the interosseous membrane and supply the anterior muscles of the leg.

(b) A nutrient branch enters the nutrient foramen of the fibula.

(c) A communicating branch passes across the back of the distal end of the shaft of the tibia, about $25 \mathrm{~mm}$. (an inch) above the tibio-fibular syndesmosis, to anastomose with the posterior tibial artery.

(d) The perforating branch passes forwards at the junction of the distal border of the interosseous membrane and the interosseous tibio-fibular ligament, and runs, in front of the ankle, to the dorsum of the foot, where it anastomoses with the lateral malleolar branch of the anterior tibial artery and with the tarsal branch of the dorsalis pedis; it also supplies branches to the tibio-fibular syndesmusis, to the ankle-joint, and to the peronæus tertins.

(4) The nutrient branch, the largest of the nutrient group of arteries to long bones, springs from the proximal part of the posterior tibial, pierces the tibialis posterior, and enters the nutrient foramen on the posterior surface of the tibia. In the interior of the bone it divides into proxinal and distal branches, the former passing towards the proximal extremity of the bone, and the latter towards the distal extremity. Before entering the tibia the nutrient artery gives small muscular branches.

(5) A communicating branch unites the posterior tibial to the peronceal artery about $25 \mathrm{~mm}$. (an inch) above the tibio-fibnlar syndesmosis. It passes posterior to the shaft of the tibia and anterior to the flexor hallucis longus.

(6) Cutaneous branches are distributed to the skin of the medial and posterior part of the leg.

(7) A posterior medial malleolar branch is distributed to the medial surface of the medial malleolus, anastonosing with a corresponding branch of the anterior tibial artery. 


\section{Plantar Arteries.}

(8) The medial and lateral plantar arteries are the terminal branches of the posterior tibial artery. They arise, under cover of the origin of the abductor hallucis muscle, midway between the tip of the medial malleolus and the most prominent part of the medial side of the os calcis.

Arteria Plantaris Medialis.-The medial plantar artery is the smaller of the two terminal branches of the posterior tibial artery. It passes forwards, along the

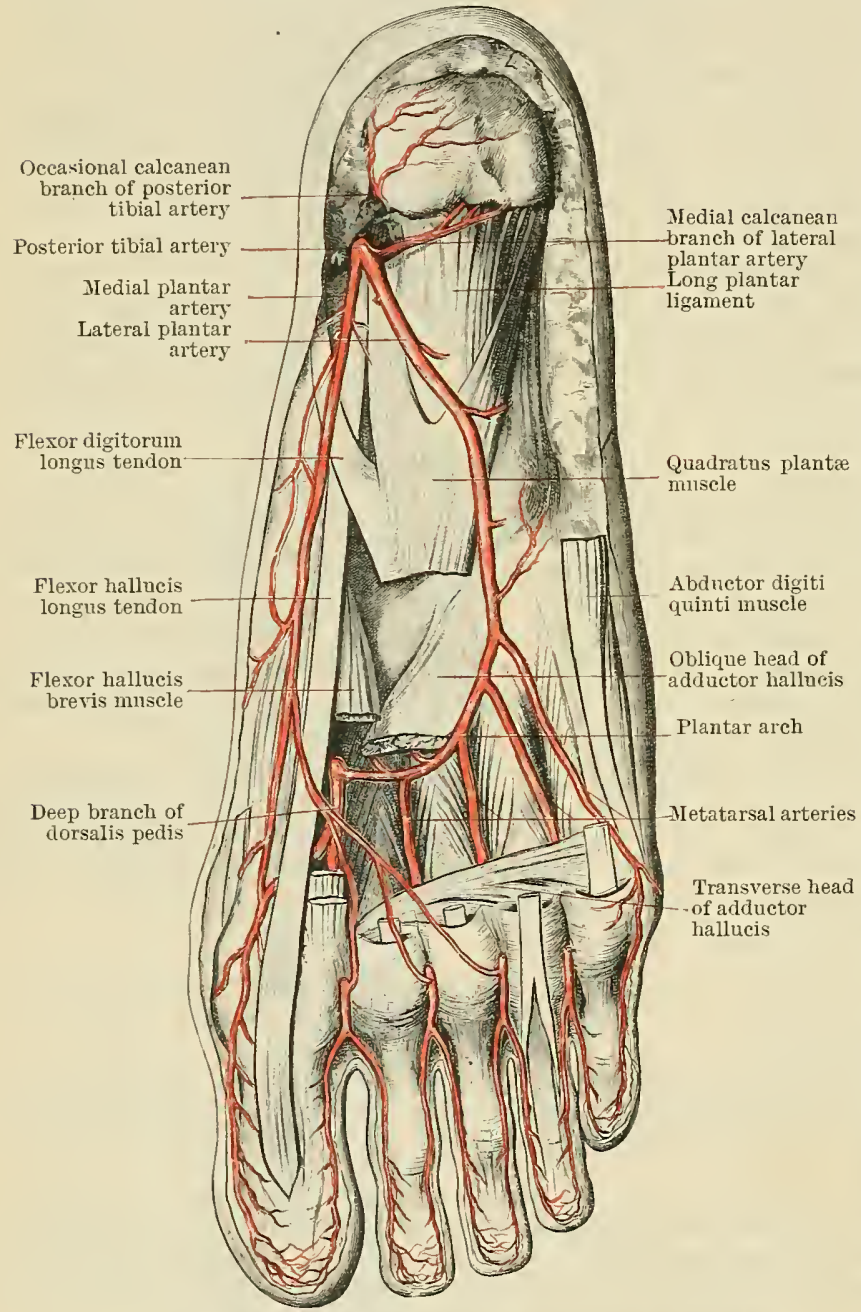

Fig. 782.-The Plantar Arteries and their Branches. medial side of the foot in the interval between the abductor hallucis and the flexor digitorum brevis, to the head of the first metatarsal bone, where it terminates by uniting with the plantar digital branch of the dorsalis pedis, which is distributed to the medial side of the great toe. In its course forwards it gives off a superficial branch, which ramifies on the superficial surface of the abductor hallucis, and branches to the adjacent muscles and articulations, and to the subjacent skin; it also gives three digital branches which anastomose, at the roots of the medial three interdigital clefts, with the medial plantar metatarsal arteries. Some of the cutaneous branches of the medial plantar artery anastomose, round the medial border of the foot, with the medial cutaneous branches of the dorsalis pedis artery.

Arteria Plantaris

Lateralis. - The lateral plantar artery is the larger of the two terminal branches of the posterior tibial artery. It runs forwards and laterally, first between the flexor digitorum brevis superficially and the quadratus plantæ deeply, and then, in the interval between the flexor digitorum brevis and the abductor digiti quinti, to the medial side of the base of the fifth metatarsal bone, where it turns abruptly medially and, gaining a deeper plane, passes across the bases of the metatarsal bones and the origins of the interossei, and above the oblique head of the adductor of the great toe, to the lateral side of the base of the first metatarsal bone, where it terminates by anastomosing with the dorsalis pedis artery. The last part of the artery is convex forwards and forms the plantar arch, which is completed by the profunda branch of the dorsalis pedis.

Branches. - Between its origin and the base of the fifth metatarsal the lateral 
plantar artery gives off $(a)$ the medial calcanean branch, which is distributed to the skin and the subcutaneous tissue of the heel.

(b) Muscular branches to the abductor hallucis, flexor digitorum brevis, quadratus plantæ, and abduetor digiti quinti.

(c) Cutaneous branches to the skin of the lateral side of the foot.

Between the base of the fifth metatarsal bone and the first interosseous space it forms the plantar arch, and gives off $(d)$ four plantar metatarsal branches; $(e)$ three posterior perforating arteries to the dorsal metatarsal arteries; and $(f)$ articular branches to the tarsal joints.

The fifth or most lateral metatarsal branch runs along the lateral side of the little toe, supplying the skin, joints, and the flexor tendons with their synovial sheaths. The medial three plantar metatarsal branches, second, third, and fourth, run formards on the plantar surfaces of the interossei, the medial two lying dorsal to the oblique head of the adductor of the great toe, and all three passing dorsal to the transverse head of the adductor. At the bases of the interdigital elefts the second, third, and fourth plantar metatarsal arteries divide into plantar digital arteries which rum along the plantar aspects of adjacent toes, and supply skin, joints, and the flexor tendons and sheaths. Opposite the last phalanx of each toe the digital arteries of opposite sides of the toe anastomose together.

The posterior perforating arteries are three in number; they pass dorsalwards through the three lateral intermetatarsal spaces, between the heads of the dorsal interosseous muscles, and terminate by uniting with the corresponding dorsal metatarsal arteries. Anterior perforating branches which communicate with the dorsal metatarsal arteries are given off from two or three of the plantar metatarsal arteries just before they divide.

The articular branches are numerous and irregular; they supply the joints and ligaments of the tarsus on its plantar aspect.

\section{Arteria Tibialis Anterior.}

The anterior tibial artery, the smaller of the two terminal divisions of the popliteal, commences opposite the distal border of the popliteus muscle, and terminates in front of the ankle, where it is continued into the dorsal artery of the foot.

Course and Relations.-From its origin, at the back of the leg, the artery passes anteriorly between the two slips of the proximal part of the tibialis posterior and above the proximal border of the interosseous membrane. It then runs distally, resting, in the proximal two-thirds of its course, against the anterior surface of the interosseous membrane and, subsequently, on the distal part of the tibia and the anterior ligament of the ankle-joint. In the proximal third of the anterior compartment of the leg it lies between the extensor digitorum longus laterally and the tibialis anterior medially; in the middle third it is between the extensor hallucis longus and the tibialis anterior; in the distal third the extensor hallucis longus crosses in front of the artery and reaches its medial side, and the most distal part of the vessel lies between the tendon of the extensor hallucis longus on the medial side and the most medial tendon of the extensor digitorum longus on the lateral side.

The deep peronreal nerve (O.T. anterior tibial) is at first well to the lateral side of the artery, but it soon passes in front of the ressel, and it lies in front of the middle third of the artery; more distilly the nerve is usually found on the lateral sicle again, and at the ankle it interrenes between the artery and the most medial tendon of the extensor digitorum longus.

Two renæ comites, with numerous intercommunications, accompany the artery.

Obviously the anterior tibial artery is, at least in its proximal part, deeply placed; moreover, its lateral muscular boundaries overlap it. In the greater part of its extent it is, however, easily accessible from the surface; and beyond being crossed by the nerve and tendon, as already described, is only covered, in addition, by skin, fascia, and the transverse crural ligament.

Branches.-Close to its origin the artery gires off fibular and posterior tibial recurrent branches; after it reaches the front of the leg it gives off anterior tibial recurrent, muscular, entaneous, medial malleolar, and lateral malleolar branches. 
(1) The fibular branch is a small ressel which may arise separately from the anterior tibial artery, or by a common stem with the posterior tibial recurrent; occasionally it springs from the lower end of the popliteal artery, or from the posterior tibial.

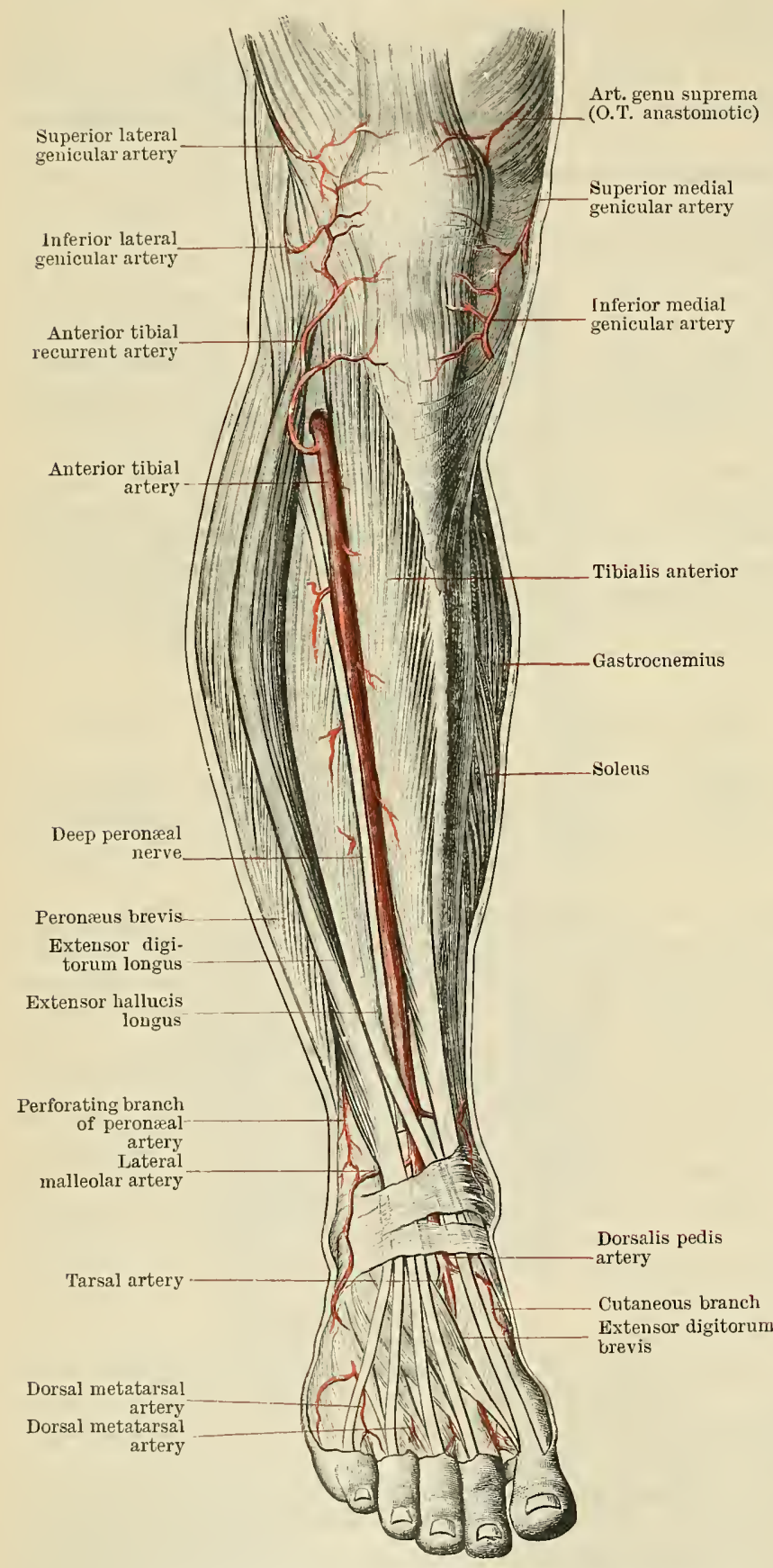

Fig. 783.-The Anterior Tibial Artery and its Branches. It runs upwards and laterally, behind the neck of the fibula and through the fibres of the soleus, and it terminates in branches which supply the soleus, the peronæus longus, and the skin of the proximal and lateral part of the leg. It anastomoses with the inferior lateral genicular artery.

(2) The posterior tibial recurrent branch, also small, and not always present, runs upwards, anterior to the popliteus muscle, to the back of the knee-joint. It anastomoses with the inferior genicular branches of the popliteal, and gives branches to the popliteus muscle and the proximal tibio-fibular articulation.

(3) The anterior tibial recurrent branch arises from the anterior tibial artery in front of the interosseous membrane. It runs proximally and medially, between the proximal part of the tibialis anterior and the lateral condyle of the tibia, accompanied by the recurrent articular branch of the common peronæal nerve, and, after supplying the tibialis anterior and the proximal tibio-fibular articulation, it pierces the deep fascia of the leg; it is connected with the anastomoses round the knee-joint, formed by the genicular branches of the popliteal artery, the descending branch of the lateral circumflex artery, and the arteria genu suprema.

(4) The muscular branches are distributed to the muscles of the front of the leg, and a few small branches also pass backwards to the deep surface of the tibialis posterior muscle.

(5) The cutaneous branches supply the skin of the front of the leg.

(6) The medial anterior malleolar branch arises from the lower part of the anterior tibial artery, and is smaller than its companion on the lateral side. It runs medially, posterior to the tibialis anterior tendon, ramifies over the medial malleolus, anastomosing with branches of the posterior tibial artery, and is distributed to the skin and to the ankle-joint. 
(7) The lateral anterior malleolar branch, more constant and larger than the medial, passes laterally, posterior to the extensor digitorum longus and peronæus tertius, towards the lateral malleolus. It anastomoses with the perforating branch of the peronæal artery and with the tarsal artery, and supplies the ankle-joint and the adjacent articulations.

Dorsalis Pedis Artery.-The dorsal artery of the foot is the direct continuation of the anterior tibial; it commences opposite the front of the ankle-joint, and extends to the posterior extremity of the first interosseous space, where it divides into the first dorsal metatarsal and the profunda branch.

It is covered superficially by skin and fascia, including the cruciate ligament, and it is crossed, just before it reaches the first interosseous space, by the most medial tendon of the extensor digitorum brevis. It rests upon the anterior ligament of the ankle, the head of the talus, the talo-navicular ligament, the dorsum of the navicular bone, and the dorsal naviculo-cuneiform and the inter-cuneiform ligaments between the first and second cuneiform bones. On its lateral side is the medial terminal branch of the deep peronæal nerve (O.T. anterior tibial), which intervenes between it and the extensor digitorum brevis and most medial tendon of the extensor digitorum longus. On its medial side it is in relation with the tendon of the extensor hallucis longus. Two venæe comites, one on each side, accompany the artery.

Branches. - On the

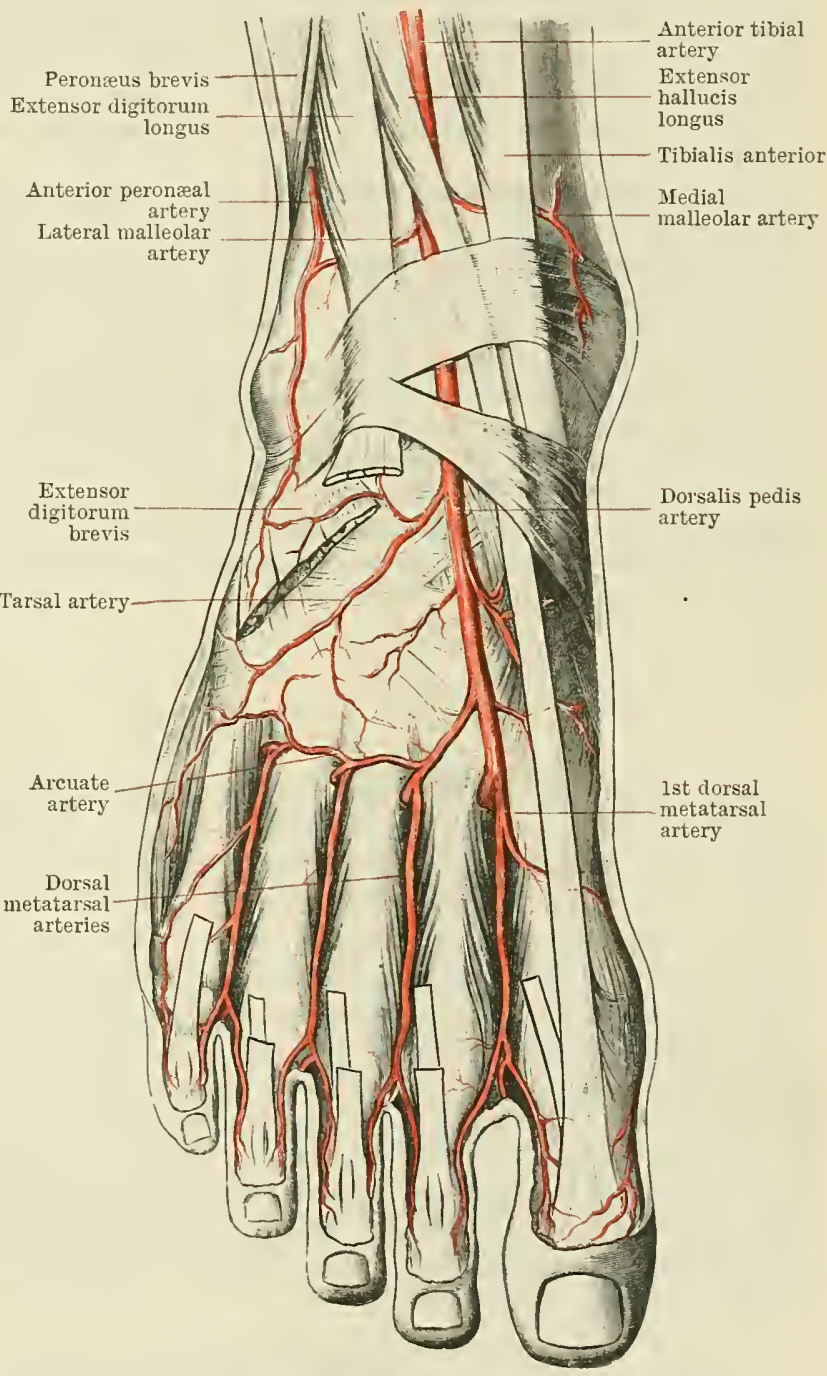

Fig. 784.-The Dorsalis Pedis Artery and its Branches. dorsum of the foot the dorsalis pedis artery gives off cutaneous branches, lateral and medial tarsal branches, the arcuate branch, and the first dorsal metatarsal and the profunda branch.

(1) Cutaneous branches, two or three in number, are distributed to the skin on the dorsum and medial side of the foot; they anastomose with branches of the medial plantar artery.

(2) The tarsal branches, medial and lateral.-The medial tarsal branches are small vessels given off from the medial side of the artery. They pass to the medial borders of the foot and anastomose with branches of the medial plantar artery. The lateral tarsal branch is given off opposite the head of the talus; it runs laterally, deep to the extensor digitorum brevis, supplying that muscle and the tarsal joints, and it anastomoses with the perforating branch of the peronseal, the arcuate, and lateral plantar arteries, and with the lateral malleolar artery. 
(3) The arcuate artery arises opposite the first cuneiform bone. It runs laterally, on the bases of the metatarsal bones, deep to the long and short extensor tendons, supplies the extensor brevis, and anastomoses with branches of the lateral tarsal and lateral plantar arteries. It gives off three dorsal metatarsal arteries, second, third, and fourth, which run forwards on the muscles which occupy the lateral three interosseous spaces to the clefts of the toes, where each divides into two dorsal digital branches for the adjacent sides of the toes bounding the cleft to which it goes. The lateral side of the little toe receives a branch from the most lateral dorsal metatarsal artery. Each dorsal metatarsal artery gives off a posterior perforating branch, which passes through the posterior part of the intermetatarsal space, between the heads of the dorsal interosseous muscle, to anastomose with the plantar arch, and an anterior perforating branch, which passes through the anterior part of the space to anastomose with the corresponding plantar metatarsal artery.

(4) The first dorsal metatarsal artery is continued forwards from the dorsal artery of the foot, and runs on the dorsal surface of the first dorsal interosseous muscle. It ends by dividing into dorsal digital branches for the adjacent sides of the first and second toes. Before it divides it usually gives off a dorsal digital branch which passes, deep to the tendon of the extensor hallucis, to the medial side of the great toe.

(5) The profunda branch passes through the posterior end of the first intermetatarsal space, between the two heads of the first dorsal interosseons muscle, to the plantar aspect of the foot, where it unites with the lateral plantar artery and completes the plantar arch. As it unites with the lateral plantar artery it gives off the first plantar metatarsal artery (O.T. arteria magna hallucis), which passes forwards, along the first intermetatarsal space, to the base of the first interdigital cleft, where it divides into plantar digital arteries for the adjacent sides of the great and second toes; before it divides it gives off a plantar digital artery to the medial side of the great toe.

\section{VENA}

Veins commence at the terminations of the capillaries. They converge towards the heart, and unite with one another to form larger and still larger vessels, until finally seven large trunks are formed which open into the atria of the heart. Three of these, the superior vena cava, the inferior vena cava, and the coronary sinus, belong to the systemic circulation; they contain venous blood, and open into the right atrium. The remaining four belong to the pulmonary circulation; they return oxygenated blood from the lungs, and open into the left atrium.

In addition to the systemic and pulmonary veins, there is also a third group of veins, constituting the portal system, in which blood from the abdominal part of the alimentary canal, and from the spleen and pancreas, is conveyed to the liver. The portal system is further peculiar in that it both begins and ends in capillaries. From its terminal capillaries in the liver the hepatic veins arise, and as these open into the inferior vena cava the blood of the portal system is finally poured into the general systemic circulation. The hepatic veins also receive blood supplied to the liver by the hepatic arteries.

\section{VEN $A$ PULMONALES.}

The terminal pulmonary veins (Figs. 750 and 757), two on each side, open into the left atrium of the heart. Their tributaries arise in capillary plexuses in the walls of the pulmonary alveoli. By the union of the smaller veins larger vessels are formed which run along the anterior aspects of the bronchial tubes, and, uniting together, ultimately form a single efferent vessel in each lobe, which passes into the root of the lung. Thus there are five main pulmonary veins, but, immediately after entering the root of the lung, the vessels from the upper and middle lobes of the right lung join together, and so only four terminal pulmonary veins open into the left atrium of the heart. Neither the main stems nor their tributaries possess valves.

Relations. - In the root of the lung the upper pulmonary vein, on each side, lies below and in front of the pulmonary artery. The lower pulmonary vein on each 
side is in the lowest part of the root, and it is in a plane posterior to that in which the upper vein lies.

On the right side the upper pulmonary rein passes behind to the superior rena cava, and the lower passes behind the right atrium. They both terminate in the upper and posterior part of the left atrium close to the interatrial septum.

On the left side both upper and lower pulmonary veins cross anterior to the descending aorta, and they terminate in the upper and posterior part of the left atrium near its left border.

All four pulmonary veins perforate the fibrous layer of the pericardiun, and receive partial coverings of the serous layer before they enter the atrium.

\section{SYSTEMIC VEINS.}

The systemic veins return blood to the right atrium of the heart through the superior vena cava, the inferior vena cava, and the coronary sinus. The two firstnamed receive blood from the veins of the body and limbs and from most of the abdominal and pelvic viscera. The coronary sinus receives blood from the veins of the walls of the heart alone.

General Arrangement.-The veins of the body wall and limbs form two groups -(1) the superficial veins; (2) the deep reins.

The superficial veins, which commence in the capillaries of the skin and subcutaneous tissues, lie in the superficial fascia, and are very numerous. They frequently anastomose with one another, and they also communicate with the deep veins, in which, after piercing the deep fascia, they terminate. They may or may not accompany superficial arteries.

The deep veins accompany arteries, and are known as vence comites. The large arteries have only one accompanying vein, but with the medium-sized and small arteries there are usually two venæ comites, which anastomose freely with each other by short transverse branches of communication.

Visceral veins usually accompany the arteries which supply viscera in the head, neck, thorax, and abdomen. As a rule there is only one vein with each visceral artery, and, with the exception of those which enter into the formation of the portal system, they terminate in the deep systemic veins.

\section{SINUS CORONARIUS ET VENE CORDIS.}

The coronary sinus (Fig. 750) is a short, but relatively wide, renous trunk which receives the majority of the veins of the heart. It lies in the inferior portion of the coronáry sulcus, between the left atrium and the left ventricle, and it is covered superficially by some of the muscular fibres of the atrium.

It terminates in the lower and posterior part of the right atrium, between the orifice of the inferior vena cava on the right, and the right atrio-ventricular oritice anteriorly; an imperfect valve, consisting of one cusp, called the valve of the coronary sinus (Thebesius), is situated at the right margin of the opening of the sinus into the atrium.

The apertures of the tributaries of the coronary sinus, except those of the great and small cardiac veins, are not provided with ralves, and the valves of the two veins mentioned are often incompetent.

Tributaries. - (1) The great cardiac vein (Fig. 754) commences at the apex of the heart. It ascends in the anterior interventricular sulcus to the coronary sulcus: it then turns to the left, and, passing round the left margin of the heart, into the inferior part of the coronary sulcus, terminates in the left extrenity of the coronary sinus. It receires tributaries from the walls of both ventricles and from the wall of the left atrimn. It receives also the left marginal vein; this vein commences at the lower extremity of the left margin of the heart, along which it ascends to its termination.

(2) The small cardiac vein is very variable; as a rule it commences at the inferior margin of the heart and passes to the right to the coronary sulcus in which it turns to the left, on the inferior surface of the heart, and terminates in the right extremity of the coronary sinus. It receives tributaries from the walls of the right atrium and the right ventricle. 
(3) The oblique vein of the left atrium (Marshall) (Fig. 750) is a small venous channel which descends obliquely, on the posterior wall of the left atrinm, and terminates in the coronary sinus. Its orifice is not provided with a valve. It is of special interest, inasmuch as it represents the left superior vena cava of some other mammals, and is developed from the left duct of Cuvier.

(4) The inferior cardiac vein of the left ventricle runs along the inferior surface of the left ventricle and ends in the coronary simus.

(5) The middle cardiac vein commences at the apex of the heart, and, passing posteriorly, in the inferior interventricular sulcus, terminates in the coronary sinus near its right extremity. It receives tributaries from the inferior parts of the walls of both ventricles.

Veins of the Heart which do not end in the Coronary Sinus.- $(a)$ The anterior cardiac veins are two or three small vessels which ascend on the anterior wall of the right ventricle to the coronary sulcus, where they either end in the right atrium or terminate in the small cardiac vein. (b) The venæ minimæ cordis.-A number of small veins, which commence in the substance of the walls of the heart and terminate directly in its cavities, principally in the atria; some few, however, open into the ventricles.

\section{VENA CAVA SUPERIOR AND ITS TRIBUTARIES.}

The superior vena cava (Figs. 756 and 757) returns the blood from the head and neck, the upper extremities, the thoracic wall, and a portion of the upper part of the wall of the abdomen. It is formed, at the lower border of the first right costal cartilage, by the union of the two innominate veins, and it descends, with a slight convexity to the right, to the level of the third right costal cartilage, where it opens into the upper and posterior part of the right atrium. It is about $75 \mathrm{~mm}$. (three inches) long; in the lower half of its extent it is enclosed within the fibrous layer of the pericardium, and it is covered in front and on each side by the serous layer.

Relations. - It is overlapped anteriorly by the margins of the right lung and pleural sac and by the ascending aorta. The lung and pleura intervene between it and the second and third costal cartilages, the internal intercostal muscles in the first and second intercostal spaces, and the internal mammary vessels. It is in relation posteriorly with the right margin of the trachea, the right vagus nerve, the vena azygos, which opens into it at right angles, the right bronchus, the right pulmonary artery, and the upper right pulmonary vein. On its left side are the ascending portion of the aorta, and the commencement of the innominate artery, whilst on the right side it is in close relation with the right pleura, the phrenic nerve and the pericardiaco-phrenic (O.T. comes nervi phrenici) vessels intervening.

Tributaries.-In addition to the two innominate veins, by the union of which it is formed, the superior vena cava receives only one large tributary, viz., the vena azygos; but several small pericardial and mediastinal veins open into it.

\section{Vena Azygos and its Tributaries.}

The vena azygos (O.T. vena azygos major) (Fig. 798) commences either from the posterior aspect of the inferior vena cava, at the level of the right renal vein, or as the direct upward continuation of an anastomosing channel which connects together the lumbar veins of the right side, and which is known as the right ascending lumbar vein. It ascends through the aortic orifice of the diaphragm, and is continued upwards through the posterior mediastinum. In the upper part of its course, it first passes posterior to the root of the right lung, and then arches anteriorly, above the root, to its termination in the posterior part of the superior vena cava, immediately before the latter vessel pierces the pericardium and at the level of the second costal cartilage. It frequently possesses imperfect valves.

Relations. - In the abdomen it lies on the anterior surfaces of the bodies of the upper lumbar vertebræ, posterior to the right crus of the diaphragm and the inferior vena cava, and to the right side of the cisterna chyli.

In the thorax it lies on the anterior surfaces of the bodies of the lower eight thoracic vertebræ, the intervening fibro-cartilages, and the anterior longitudinal ligament; and anterior to 
the right aortic intercostal arteries. In the lower part of the posterior mediastinum the right pleura and lung lie anterior to it; at a higher level it is overlapped by the right margin of the osophagus, and immediately before its termination it is crossed by the root of the right lung:

On its left side it is in relation, in the greater part of its extent, with the thoracic duct and, as it arches anteriorly over the root of the lung, with the right vagus nerve and the trachea. About the level of the seventh thoracic vertebra it receives the accessory hemiazygos vein, whilst at the level of the eighth thoracic vertebra the hemiazygos vein opens into it.

In addition to the two veins last mentioned it receives the right posterior intercostal veins, except that from the first space but including the right superior intercostal vein, the right subcostal vein, and, through the ascending lumbar vein, the upper right lumbar veins. It also receives the right bronchial veins and some small osophageal, pericardial, and mediastinal tributaries.

Tributaries. - (1) The vena hemiazygos accessoria (O.T. vena azygos minor superior) is formed by the union of the fourth, fifth, sixth, seventh and eighth left posterior intercostal veins. It lies on the left sides of the bodies of the fifth, sixth, and seventh thoracic vertebræ, and the intercostal arteries. It crosses the vertebral column, from left to right, opposite the body of the seventh thoracic vertebra, passing posterior to the aorta, œsophagus, and thoracic duct; and it terminates either in the vena azygos or in the vena hemiazygos. In addition to its intercostal tributaries it receives the left bronchial veins, and some small posterior mediastinal veins, and it communicates with the left superior intercostal vein.

(2) The vena hemiazygos commences in the epigastric region of the abdomen. At its origin it is connected either with the left ascending lumbar vein or with the left renal vein. After piercing the left crus of the diaphragm it ascends on the left sides of the bodies of the lower thoracic vertebræ, and, opposite the seventh or eighth thoracic vertebra, it turns to the right, crosses the front of the vertebral column, posterior to the aorta, cesophagus, and thoracic duct, and terminates in the vena azygos. As it ascends, on the bodies of the vertebræ, it lies lateral to the aorta, and medial to the roots of the splanchuic nerves, and anterior to the lower left intercostal arteries. Through the left ascending lumbar vein it receives blood from the upper lumbar veins of the left side; the left subcostal vein, the lower three posterior intercostal veins, and small mediastinal tributaries also terminate in it.

(3) The bronchial veins do not quite correspond to the bronchial arteries, and they are not found on the walls of the smallest bronchi. On each side the tributaries run, anterior or posterior to the bronchial tubes to reach the root of the lung, where they unite, as a rule, into two small trunks; those of the right side open into the vena azygos, and those of the left into the accessory hemiazygos vein, or into the left superior intercostal rein. On both sides they are joined by tracheal and posterior mediastinal veins. Some few small bronchial veius, including most of those from the smaller tubes, open into the pulmonary veins.

(4) Venæ Intercostales. - There are two sets of intercostal veins, the anterior and the posterior.

The anterior intercostal veins are tributaries of the interual mammary or of the musculo-phrenic veins, and are described with those ressels (pp. 962, 963).

The posterior intercostal veins (Fig. 798) are eleven in number on each side. A single vein runs in each intercostal space; it is situated in the costal groove, above the corresponding artery.

On the right side the posterior intercostal vein of the first space accompanies the superior intercostal artery across the front of the neck of the first rib, and terminates in the vertebral or imiominate vein. The second, third, and fourth intercostal reins of the right side unite together to form a common trunk, the right superior intercostal vein, which terminates by joining the vena azygos. The fifth to the eleventh posterior intercostal veins of the right side open separately into the vena azygos.

On the left side the first posterior intereostal rein follows a course similar to that taken by the corresponding vein on the right side, and terminates in the left vertebral or innominate vein. The second, third, and sometimes the fourth posterior intercostal veins of the left side unite to form the left superior intercostal vein, which runs from behind forwards along the left or anterior aspect of the aortic arch. It passes obliquely between the left ragus and phrenic nerres, crosses the root of the left subclavian artery, and ends in the lower border of the left inmominate vein. The fifth, sixth, serenth, and eighth, and sometimes the fourth posterior intercostal reins of the left side terminate in the accessory hemiazygos vein, and the ninth, tenth, and eleventh end in the hemiazygos vein. 
Each posterior intercostal vein is provided with valves, both at its termination and along its course, which prevent the blood flowing towards the anterior aspect of the thoracic wall. Its tributaries are derived from the adjacent muscles and bones, and a short distance from its termiuation it receives a posterior tributary which passes to it between the transverse processes of the vertebræ. This posterior vessel is formed by the union of small veins which issue from the muscles of the back, from the anterior and posterior spinal plexuses which lie respectively in front of the bodies and behind the arches of the vertebræ, and by venous channels which issue through the intervertebral foramina; the latter vessels commence in the vertebral canal, where they are connected with the anterior and posterior spinal veins.

\section{Vente ANonyme.}

The innominate veins (Figs. 756 and 757) are two in number, right and left. They return blood from the head and neck, the upper extremities, the upper part of the posterior wall of the thorax, the anterior wall of the thorax, and the upper part of the anterior wall of the abdomen. Each innomiuate vein commences behind the medial end of the clavicle of the corresponding side, and is formed by the union of the internal jugular and subclavian veins; the two innominate veins terminate by uniting together, at the lower border of the first costal cartilage of the right side, to form the superior vena cava. To reach this point the left vein has to pass from left to right behind the manubrium sterni, and it is therefore about three times as long as the right vein. The innominate veins do not possess valves.

The right innominate vein is a little more than $25 \mathrm{~mm}$. ( 1 inch) in length. It descends almost vertically to the lower border of the first costal cartilage, and terminates in the superior vena cava.

Relations. - It is in relation anteriorly with the medial end of the clavicle and the sterno-hyoid and sterno-thyreoid muscles. It partly overlaps the innominate artery, which lies to its left side, and it is in front of the internal mammary artery, the right vagus nerve, and the upper end of the right pleural sac. The phrenic nerve and the accompanying vessels run along its right side, and intervene between it and the right pleural sac.

Tributaries. - In addition to the veius by the union of which it is formed, the right innominate vein receives the right vertebral and internal mammary veins, and sometimes the right inferior thyreoid vein and the first right posterior intercostal vein. The right lymphatic duct also opens into it.

The left innominate vein passes from left to right, with a slight obliquity downwards, behind the upper part of the manubrium sterni, to the lower border of the first right costal cartilage, where it terminates in the superior vena cava. It is about 60 to $75 \mathrm{~mm}$. (3 inches) long.

Relations.-It is covered anteriorly, in the greater part of its extent, by the sternohyoid and sterno-thyreoid muscles, but at its right extremity it is slightly overlapped by the right pleura, and in the median plane the remains of the thymus intervene between it and the posterior surface of the sternum. It rests, posteriorly, upon the left pleura, the left internal mammary artery, the left subclavian artery, the left phrenic, and the left vagus nerves, the left superior cardiac branch of the sympathetic, the inferior cervical branch of the left vagus, the left common carotid artery, the trachea, and the innominate artery.

Its lower border is in relation with the arch of the aorta, and on its upper border it receives the inferior thyreoid vein of one or both sides.

Tributaries.-It receives the vertebral, internal mammary, inferior thyreoid, superior intercostal veins of its own side, the first left posterior intercostal vein, and some pericardial, thymic, anterior bronchial, and anterior mediastinal veins. Sometimes the right inferior thyreoid vein joins it, but usually this vessel terminates in the right innominate vein or in the commencement of the superior vena cava.

The thoracic duct opens iuto it just at the angle of junction of the internal jugular and subclavian veins.

Venæ Mammariæ Internæ-The Internal Mammary Veins._Each internal mammary artery is accompanied by venæ comites; they commence by the union of the venæ comites of the superior epigastric and musculo-phrenic arteries, between the sixth costal cartilage and the transversus thoracis; and at the upper part of the thorax 
they fuse into a single vessel which enters the superior mediastinum and ends in the innominate vein of the same side.

The tributaries of the internal mammary veins are- $(a)$ The venæ comites of the superior epigastric and musculo-phrenic arteries, which in their turn receive tributaries which correspond with the branches of the arteries they accompany. (b) Six anterior perforating veins which accompany the corresponding arteries, one lying in each of the upper six intercostal spaces. (c) Twelve anterior intercostal veins from the upper six intercostal spaces, two veins lying in each space with the corresponding branches of the internal mammary artery. (d) Small and irregular pleural, muscular, mediastinal, and sternal veins.

The internal mammary veins are provided with numerous valves which prevent the blood from flowing downwards.

Venæ Epigastricæ Superiores-The Superior Epigastric Veins.-The venæ comites of the superior epigastric artery receive tributaries from the substance of the rectus abdominis, the sheath of the muscle, and the superjacent skin and fascia; they pass, with the artery, between the sternal and costal origins of the diaphragm, and terminate in the internal mammary veins.

Musculo-phrenic Veins.-The venæ comites of the musculo-phrenic artery commence in the abdomen, pass through the diaphragm with the artery, and terminate in the internal mammary veins. They receive as tributaries the anterior intercostal veins of the serenth, eighth, and ninth intercostal spaces, and small venules from the substance of the diaphragm and walls of the abdomen.

Venæ Vertebrales-The Vertebral Veins correspond only to the extra-cranial parts of the vertebral arteries. Each commences by the union of offsets from the intraspinal venous plexuses, and, issuing from the vertebral canal, passes across the posterior arch of the atlas, with the vertebral artery, to the foramen in the transverse process of the atlas. In the foramina in the cervical transverse processes, a plexus of venous channels surrounds the artery. At the lower part of the neck these channels unite to form a single trunk which issues from the foramen in the transverse process of the sixth cervical vertebra, and descends, in the interval between the longus colli and scalenus anterior muscles, to terminate in the upper and posterior part of the innominate vein, where it possesses a uni- or bi-cuspidate valve.

Relations. - In the first part of its course the vein lies in the sub-occipital triangle. The second, plexiform portion, is in the canal formed by the foramina in the transverse processes of the cervical vertebræ, and, with the artery, which it surrounds, lies anterior to the trunks of the cerrical spinal nerves. The third part, in the root of the neck, is between the longus colli and scalenus anterior muscles, in front of the first part of the vertebral artery, and behind the internal jugular vein.

Tributaries. - In addition to the offsets from the intraspinal venous plexuses by the union of which it is formed, each vertebral vein receives the following tributaries:- $(a)$ Small vessels which issue from the muscles, ligaments, and bones of the deeper parts of the neck, and the lower and posterior part of the head. (b) Offsets from the intraspinal venous plexuses which pass out of the vertebral canal by the intervertebral foramina. (c) The ascending cervical vein, a ressel which is formed by the union of tributaries which issue from a venous plexus on the anterior aspects of the bodies and roots of the transverse processes of the cervical vertebra. This ressel accompanies the ascending cervical artery, and terminates in the lower part of the vertebral vein, immediately after the latter has issued from the foramen in the sixth cervical transverse process. (d) The deep cervical vein; this commences in the sub-occipital triangle from a venous plexus with which the vertebral and occipital veins communicate. It descends, posterior to the transverse processes of the cervical vertebre, in company with the profunda cervicis artery, turns forwards at the root of the neck, between the transverse processes of the sixth and seventh cervical vertebra or between the latter and the neck of the first rib, and opens into the vertebral vein. It receives blood from the muscles, ligaments, and bones of the back of the neck. (e) The posterior intercostal vein from the first intercostal space sometimes opens into the vertebral vein.

Occasionally the venous plexus around the vertebral artery ends below in two terminal trunks, anterior and posterior, instead of one. In these cases the second terminal ressel lies behind the lower part of the vertebral artery, passes through the foramen in the transverse process of the seventh cervical vertebra, and turns forwards on the lateral side 
of the artery to join the anterior trunk, thus forming a common terminal vein which ends in the usual manner.

Venæ Thyreoideæ Inferiores.-Each inferior thyreoid vein commences by the union of a series of tributaries which issue from the isthmus and the corresponding lateral lobe of the thyreoid gland. The two veins descend, along the front of the trachea, into the superior mediastinum, where the right inferior thyreoid vein terminates in the junction of the two innominate veins, and the left in the upper border of the left innominate vein; or the two veins unite to form a single trunk, which ends usually in the left innominate vein, but occasionally in the right. In their descent through the neck the inferior thyreoid veins frequently anastomose together, and sometimes these anastomoses are so frequent and irregular that a venous plexus is formed in front of the lower cervical portion of the trachea.

\section{VEINS OF THE HEAD AND NECK.}

Vena Jugularis Interna (Figs. 756, 787, 800 and 801).-Each internal jugular vein commences in the posterior compartment of the jugular foramen, as the direct continuation of the transverse sinus, and terminates behind the medial part of the clavicle, by uniting with the subclavian vein of the same side to form the innominate vein.

At its commencement it is dilated, forming the superior bulb of the jugular vein, and in this situation it lies postero-lateral to the internal carotid artery and the last four cerebral nerves. As it descends it accompanies first the internal and then the common carotid artery; inclining forwards during its descent, it gradually passes from its original position, behind and to the lateral side of the internal carotid artery, and lies more completely to the lateral side of the internal and common carotid arteries, and, indeed, somewhat overlaps the latter anteriorly. This is more especially the case on the left side, for both internal jugular veins trend slightly towards the right as they descend; consequently, at the root of the neck, the right vein is separated from the right common carotid artery by a small interval filled with areolar tissue, whilst the left vein is more directly in front of the corresponding common carotid artery.

A dilatation, the inferior bulb, is present at the inferior extremity of the vein, and this is bounded either above or below by a valve of two or three semilunar cusps. Sometimes both the superior and inferior ends of the bulb are bounded by valves.

Relations. - The vein lies anterior to the transverse processes of the cervical vertebræ, the rectus capitis lateralis, longus capitis, and scalenus anterior muscles, the ascending cervical artery, which runs upwards in the interval between the attachments of the two latter muscles, and the phrenic nerve; the suprascapular and the transverse cervical arteries intervene between it and the scalenus anterior. At the root of the neck the vein lies in front of the first part of the subclavian artery and the origins of the vertebral artery and the thyreo-cervical trunk, and on the left side it is anterior to the terminal part of the thoracic duct.

On the antero-medial side of the internal jugular vein, immediately below the skull, are the internal carotid artery and the last four cerebral nerves; in the rest of its extent it is in relation medially first with the internal and then with the common carotid artery, whilst to its medial side and somewhat posteriorly, between it and the large arteries, lies the vagus nerve.

Each internal jugular vein is covered superficially, in the whole of its length, by the sterno-mastoid muscle; near its upper end it is crossed by the styloid process, the stylopharyngeus and stylo-hyoid muscles, and the posterior belly of the digastric, whilst in its lower half, the omo-hyoid, the sterno-hyoid, and the sterno-thyreoid muscles are superficial to it, beneath the sterno-mastoid. Just below the transverse process of the atlas, and under cover of the sterno-mastoid, the vein is crossed, on its lateral side, by the accessory nerve and by the occipital artery ; about the middle of its course it is also crossed by the communicans cervicis nerve, and near its lower end by the anterior jugular vein; the latter vessel, however, is separated from it by the sterno-hyoid and sternothyreoid muscles. Superficial to the vein are numerous deep cervical lymph glands. 
Tributaries. - (a) A vein from the cochlea and (b) the inferior petrosal sinus joins it near its commencement. (c) Pharyngeal branches from the venous plexus on the wall of the pharynx. (d) Emissary veins from the cavernous sinus. (e) The common facial vein, which receives the anterior and posterior facial veins. $(f)$ The lingual veins, which return part of the blood from the tongue. $(g)$ The vena comitans hypoglossi, which accompanies the hypoglossal nerve. (h) The superior thyreoid vein, which accompanies the corresponding artery. (i) The middle thyreoid vein, which passes backwards from the lateral lobe of the thyreoid gland and crosses the middle of the lateral aspect of the common carotid artery. ( $j)$ The occipital vein occasionally terminates in the internal jugular vein. In many cases, however, it ends in the sub-oceipital plexus, which is drained by the vertebral and deep cervical veins (see p. 963).

The common facial vein is formed by the union of the anterior and posterior facial veins. It accompanies the first part of the external maxillary artery in the carotid triangle, and terminates in the anterior border of the intermal jugular vein. Just before it disappears beneath the sterno-mastoid, the common facial vein frequently gives off a large branch which descends along the anterior border of the sterno-mastoid to the supra-sternal fossa, where it joins the anterior jugular vein.

The anterior facial vein (Fig. 785) commences at the medial commissure of the eyelids as the angular vein, which is formed by the union of the supra-orbital and frontal veins. It passes downwards and backwards on the face, to the lower and anterior part of the masseter muscle, which it crosses, lying in the same plane as the external maxillary artery, but following a much straighter course. After crossing the lower border of the mandible it passes across the submaxillary triangle, superficial to the submaxillary gland, and separate from the external maxillary artery, which here lies in a deeper plane. It terminates, a short distance below the angle of the mandible, by uniting with the posterior facial vein to form the common facial vein.

The anterior facial vein receives tributaries correspouding with all the branches of the external maxillary artery, except the ascending palatine and the tonsillar, which have no accompanying veins, the blood from the region which they supply being returned for the most part through the pharyngeal plexus. The anterior facial vein also communicates with the pterygoid plexus around the external pterygoid muscle, by means of an anastomosing channel, called the deep facial vein, which passes posteriorly, between the masseter and buccinator muscles, into the infra-temporal fossa.

The posterior facial vein, see p. 968 .

The inferior thyreoid veins have already been described (see p. 964).

Venæ Subclaviæ.-The subclavian vein of each side is the direct continuation of the main vein of the upper extremity, the axillary vein; but through its tributary, the external jugular vein, it also receives blood both from the head and neck.

From its commencement, at the external border of the first rib, it runs medially, below and anterior to the corresponding artery from which it is separated by the lower part of the scalenus anterior muscle, and it terminates, behind the medial end of the clavicle, in the innominate vein of the corresponding side. As it passes medially it forms a slight curve, the convexity of which is directed upwards.

Each subclavian vein possesses a single bicuspid valve which is situated immediately to the distal side of the opening of the external jugular vein.

Relations. - The subclavian vein is in relation unteriorly with the posterior layer of the costo-coracoid membrane, which separates it from the subclavius muscle, and the nerve to the subclavius, and with the back of the medial end of the clavicle, from which it is partly separated, however, by the fibres of the stemo-hyoid and stemo-thyreoid muscles.

It is closely attached, anteriorly, to the posterior surface of the costo-coracoid membrane; consequently it is expanded when the clavicle is moved forwards, an arrangement which constitutes a distinct danger when operations are being performed in the neighbourhood of the vein; for, in the event of the ressel being wounded, forward movement of the clavicle may cause air to be sucked into the rein, with fatal results.

Posterior to the vein, and on a higher plane, is the first part of the subclavian artery. but it is separated from the second part by the scalenus anterior. As soon as it reaches the medial border of the anterior scalene the subclavian vein unites with the internal jugular vein, immediately anterior to the interual mammary artery. 
The upper surface of the first rib is below the vein.

Tributaries. - Whilst the subclavian vein is the direct continuation of the axillary vein, and receives, therefore, the blood from the upper extremity, it has, as a general rule, only one named tributary, viz., the external jugular vein.

Vena Jugularis Externa.-The external jugular vein (Fig. 785) is formed on the superficial surface of the sterno-mastoid muscle, a little below and posterior to the angle of the jaw, by the union of the posterior auricular vein with a branch from the posterior facial vein (O.'T. temporo-maxillary). In many cases the branch

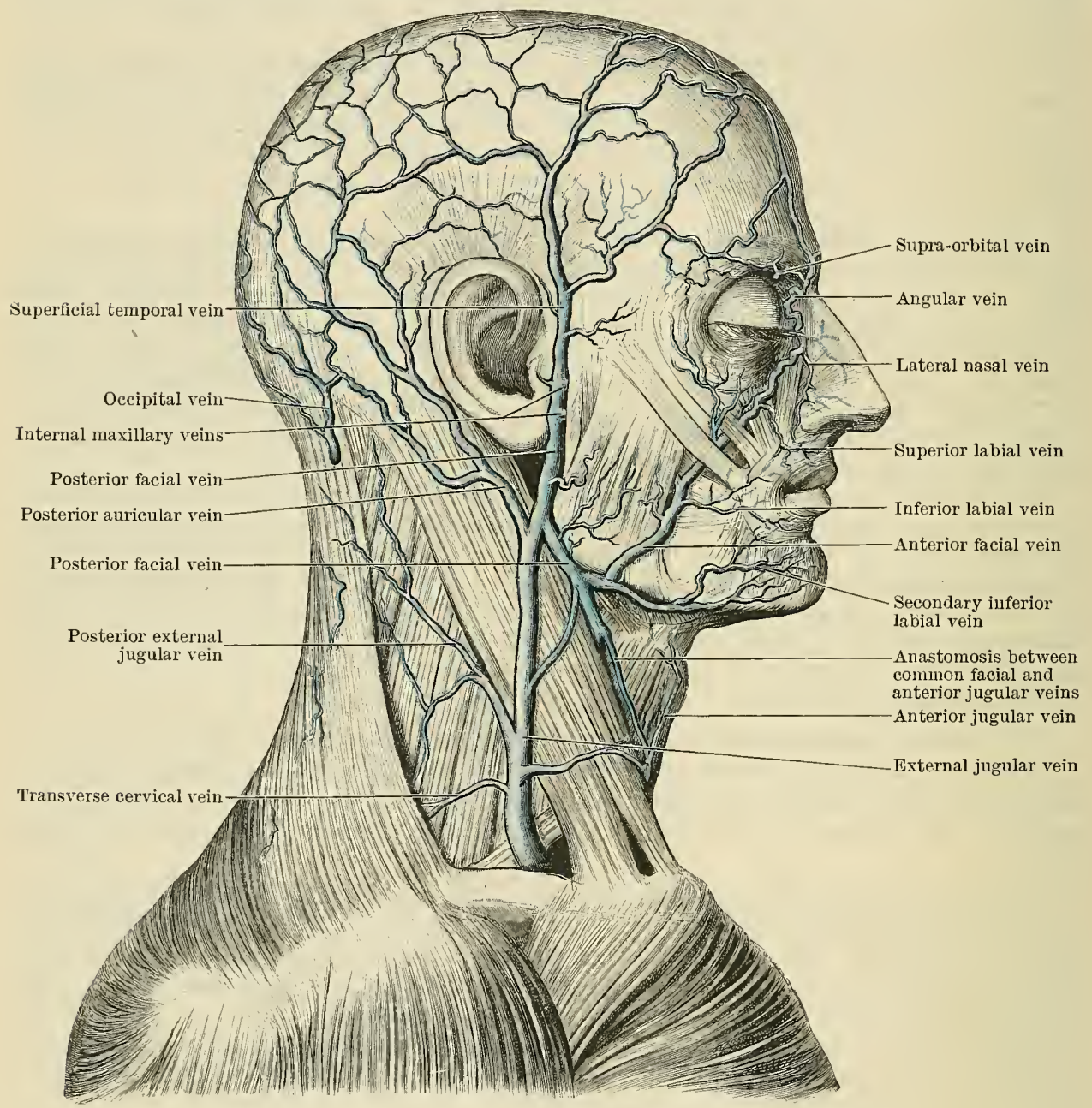

Fig. 785. - Superficial Veins of the Head and Neck.

from the posterior facial vein is so preponderantly large that it is more correct to describe the external jugular vein as commencing as a branch of the posterior facial vein. After its formation the external jugular vein descends, with a slight obliquity backwards, to the anterior part of the subclavian portion of the posterior triangle of the neck, where it pierces the deep fascia, and, after crossing in front of the third part of the subclavian artery, terminates in the subclavian vein.

Whilst on the surface of the sterno-mastoid muscle it is covered by the superficial fascia, and platysma muscle, and it lies parallel with the great auricular nerve; after crossing the nervus cutaneus colli (O.T. trans. cervical) it reaches the posterior border of the sterno-mastoid, where it receives a tributary called the posterior external jugular vein, which commences in the superficial tissues of the upper and back part of the neck, and runs downwards and forwards, across the 
roof of the upper part of the posterior triangle, to its termination in the external jugular vein.

As the external jugular vein pierces the deep cervical fascia in the subclavian triangle, its wall is closely attached to the margin of the opening through which it passes; and as it is crossing in front of the third part of the subclavian artery it is joined by the transverse scapular, transverse cervical, and anterior jugular veins.

There are usually two valves in the lower part of the vein-one, at its termination, which is generally incompetent, and a second at a higher level.

Tributaries.-In addition to the posterior auricnlar vein and the branch from the posterior facial vein by which it is formed, the external jugular vein receives the posterior external jugular vein, which has already been described, the transverse cervical and transverse scapular veins from the region of the shoulder, and the anterior jugular vein. Occasionally the cephalic vein also opens into it.

The posterior auricular vein (Fig. 785 ) receives tributaries from the posterior parts of the parietal and temporal regions and from the medial surface of the auricle. It is considerably larger than the posterior auricular artery, which it accompanies only in the scalp. At the base of the scalp it leaves the artery and descends in the superficial fascia, over the upper part of the sterno-mastoid, to open into the commencement of the external jugular vein.

The transverse cervical and transverse scapular veins accompany the corresponding arteries; not infrequently they open directly into the subclavian vein.

The anterior jugular vein commences in the submental region, and is formed by the union of small veins from the lower lip and chin. It descends in the superficial fascia, at a variable distance from the median plane, perforates the superficial layer of the deep fascia a short distance above the sternum and enters the suprasternal space (Burns) between the first and second layers of the deep fascia. In the space it anastomoses with its fellow of the opposite side and receives a communication from the common facial vein. Then it turns laterally, between the sterno-mastoid superficially and the sterno-hyoid, sterno-thyreoid, and scalenus anterior muscles deeply, and terminates in the external jugular vein at the posterior border of the sterno-mastoid.

The external jugular vein sometimes receives the occipital vein or a communication from it.

\section{The Veins of the Scalp.}

The veins which drain the blood from the superficial parts of the scalp are the frontal, the supra-orbital, the superficial temporal, the posterior auricular, and the occipital. The blood from the deeper part of the scalp, in the region of the temporal fossa, on each side, passes into the deep temporal veins, which are tributaries of the pterygoid plexus.

The frontal and supra-orbital veins receive blood from the medial and anterior part of the scalp. They unite together, near the medial commissure of the eyelids, to form the angular vein; before the union is effected the supra-orbital rein sends a branch backwards, through the supra-orbital notch, into the orbital cavity, where it terminates in the ophthalmic vein, and as this branch passes through the notch it receives the frontal diploic vein (p. 969).

The superficial temporal vein is formed by frontal and parietal tributaries which accompany the corresponding branches of the superficial temporal artery. They drain the lateral frontal, the superficial part of the temporal, and the anterior part of the parietal region of the scalp, and unite to form a single trunk which descends to the upper border of the zygoma, immediately anterior to the auricle, where it terminates in the posterior facial vein (see p. 968).

The posterior auricular vein drains the posterior portions of the temporal and parietal areas of the scalp. It runs downwards, across the mastoid portion of the temporal bone, and terminates in the external jugular vein (see above).

The occipital vein (Fig. 785) receives tributaries from the medial and posterior part of the parietal region and from the occipital region. As a rule it pierces the occipital origin of the trapezius, and, passing into the sub-occipital triangle, terminates in a plexus of veins which is drained by the vertebral and deep cervical veins. It sometimes communicates with the external jugular vein, and occasion- 
ally an offset from it accompanies the corresponding artery and ends in the internal jugular vein.

It generally receives the mastoid emissary vein; one of its tributaries receives the parietal emissary vein, and occasionally an emissary vein from the confluens sinuum (O.T. torcular Herophili) opens into it.

\section{The Veins of the Orbit, the Nose, and the Infra-temporal Region.}

The veins of these three regions are closely associated together; for although the orbital blood is returned for the most part to the cavernous sinus by the ophthalmic vein, the latter vein is closely connected with the pterygoid plexus, which lies in the infra-temporal region.

Veins of the Orbit.- The veins of the orbit correspond, with the exception of the naso-frontal vein, with the branches of the ophthalmic artery, and they gradually converge, as they pass backwards in the orbit, until they form two main trunks, a superior ophthalmic vein and an inferior ophthalmic vein; these terminate, separately or by a single trunk, in the anterior end of the cavernous sinus, to which they pass through the superior orbital fissure, and between the two heads of the lateral rectus muscle.

The superior ophthalmic vein communicates, at the supero-medial angle of the orbit, with the angular vein, and it receives the naso-frontal vein which accompanies the frontal nerve. The inferior ophthalmic vein communicates, through the inferior orbital fissure, with the pterygoid plexus.

Veins of the Nose.-The veins of the walls of the nasal cavity end partly in the ethmoidal tributaries of the superior ophthalmic vein, partly in the septal affluent of the superior labial and in the lateral nasal veins, both of which are tributaries of the anterior facial vein; but the majority of the veins of the nose, both from the septal and lateral walls, join together to form a spheno-palatine vein which passes through the spheno-palatine foramen and the pterygo-palatine fossa, and terminates in the pterygoid plexus.

Plexus Pterygoideus and the Vena Maxillaris Interna.-The pterygoid plexus of veins lies in the infra-temporal and pterygoid fossæ. It covers the lateral surface of the internal pterygoid muscle, and surrounds the external pterygoid. It receives tributaries which correspond with and accompany the branches of the internal maxillary artery - viz., spheno-palatine, pharyngeal, vein of pterygoid canal (Vidian), infra-orbital, posterior superior alveolar, descending palatine, buccinator, two or three deep temporal, pterygoid, masseteric, and inferior alveolar veins, and the middle meningeal vein. It communicates, superiorly, with the cavernous sinus through the foramen ovale; anteriorly with the inferior ophthalmic vein through the inferior orbital fissure; and between the masseter and the buccinator with the anterior facial vein by the deep facial anastomosing branch. It also communicates posteriorly and medially, on the medial side of the internal pterygoid, with the pharyngeal plexus, and it terminates posteriorly in the internal maxillary vein.

The internal maxillary vein is a short vessel which accompanies the first part of the internal maxillary artery, between the spheno-mandibular ligament and the neck of the mandible. Between the neck of the mandible and the antero-medial surface of the parotid gland it joins the upper part of the posterior facial vein. Occasionally the internal maxillary vein is double, and sometimes it is represented by several channels.

The posterior facial vein is formed, immediately above the zygomatic arch, by the union of the superficial and middle temporal veins. It crosses the zygomatic arch, dips deep to the upper part of the parotid gland, and, whilst lying between the antero-medial surface of the gland and the posterior border of the mandible, it receives the internal maxillary vein or veins. Then it descends, through the substance of the parotid, and, emerging from its lower end at the angle of the mandible, it passes forwards and downwards to unite with the anterior facial vein in the formation of the common facial vein.

Whilst it is in the substance of the parotid it gives off a comparatively large 
branch, which emerges from the lower and posterior part of the gland and forms the main commencing tributary of the external jugular vein.

\section{VENOUS SINUSES AND VEINS OF THE CRANIUM AND OF ITS CONTENTS.}

The venous channels met with in the cranial walls and cranial cavity are:-

(1) The diploic veins, which lie in the spongy tissue between the outer and inner tables of the cranial bones.

(2) The meningeal veins, which accompany the meningeal arteries in the outer layer of the dura mater.

(3) The veins of the brain, which lie between the folds of pia mater and in the subarachnoid space.

(4) The cranial venous sinuses, channels which are situated between the outer and inner layers of the dura mater; they receive the blood from the terminal cerebral veins.

\section{Diploid and Mentygeal Veins.}

Venæ Diploicæ. - The diploic veins are anastomosing spaces in the spongy tissue of the flat bones of the skull; they are lined with endothelium. The number of efferent vessels which emerge from these spaces is not constant, but usually there are at least four on each side-viz., a frontal, two temporal, anterior and posterior, and an occipital.

The frontal diploic vein is one of the most constant; it drains the anterior part

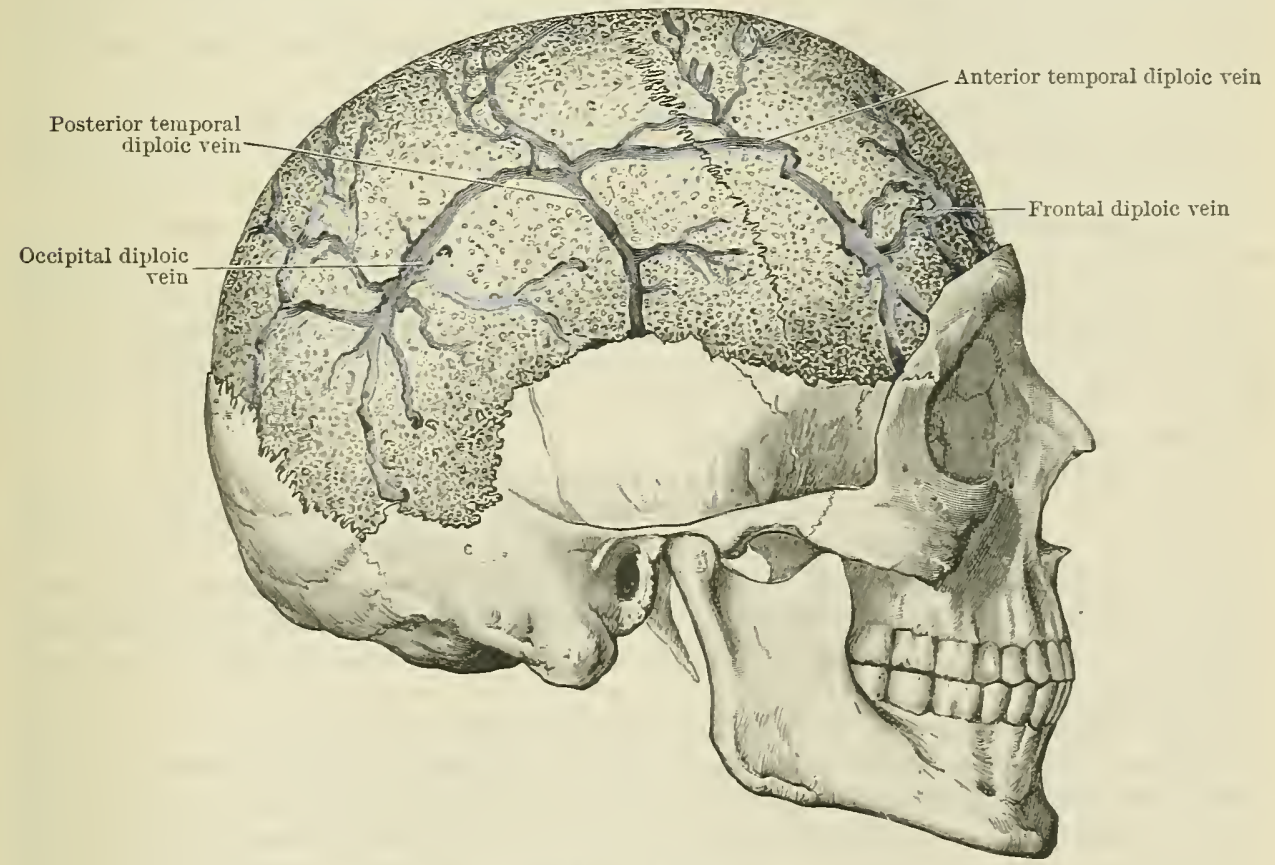

Fig. 786.-The Veiss of the Diplö̈.

of the frontal bone, and, passing through a small aperture in the upper margin of the supra-orbital notch, terminates in the supra-orbital vein.

The anterior temporal diploic vein drains the posterior part of the frontal bone and the anterior part of the parietal bone; it pierces the great wing of the sphenoid, and terminates either in the spheno-parietal sinus or in the anterior deep temporal vein.

The posterior temporal diploic vein drains the posterior part of the parietal bone; it runs downwards to the posterior inferior angle of the parietal bone 
and terminates in the transverse sinus, to which it passes either through a foramen in the inner table of the parietal bone or through the mastoid foramen.

The occipital diploic vein is usually the largest of the series; it drains the occipital bone, and terminates either externally in the occipital vein or internally in the lateral sinus.

Venæ Meningeæ.-The meningeal veins commence in two capillary plexuses, a deep and a superficial. The deep plexus is a wide-meshed network in the inner layer of the dura mater. Its efferent vessels terminate in the superficial plexus. The superficial plexus lies in the outer layer of the dura mater. It consists of numerous vessels of uniform calibre which frequently anastomose together, and terminate in two sets of efferents; of these, one set ends in the cranial blood sinuses, and the other accompanies the meningeal arteries. The efferent meningeal veins are peculiar, inasmuch as they do not alter much in size as they approach their terminations. They lie external to the arteries in the grooves in the inner wall of the cranium, and are very liable to be torn when the bones are fractured (Wood Jones).

\section{Veins OF THE BRAIN.}

The veins of the brain include the veins of the cerebrum, of the mid-brain, of the cerebellum, of the pons, and of the medulla oblongata. They do not possess valves.

Venæ Cerebri-The Veins of the Cerebrum.-The cerebral veins are arranged in two groups, $(a)$ the deep and (b) the superficial.

The deep veins issue from the substance of the brain. The superficial veins lie upon its surface in the pia mater and the subarachnoid space. The terminal trunks of both sets pierce the arachnoid membrane and the inner layer of the dura mater, and open into the cranial venous sinuses.

(a) The deep cerebral veins are the chorioid veins, the venæ terminales, the internal cerebral veins, the great cerebral vein (Galen), the vein of the septum pellucidum and the inferior striate veins.

Each chorioid vein is formed by the union of tributaries which issue from the chorioid plexus in the body and inferior horn of a lateral ventricle. It ascends along the lateral border of the tela chorioidea of the third ventricle (O.T. velum interpositum), and passes forwards in the lateral border of that fold of pia mater to the interventricular foramen (Monro), where it receives efferents from the chorioid plexus of the third ventricle, and unites with the vena terminalis to form the internal cerebral vein (Galen).

The vena terminalis (O.'T. vein of corpus striatum), on each side, is formed by the union of tributaries which issue from the corpus striatum and from the thalamus. It runs forwards between the two bodies, in a groove in the floor of the lateral ventricle, and, after receiving tributaries from the walls of the anterior horn of the ventricle, and the vein of the septum pellucidum, it terminates at the apex of the tela chorioidea, where it joins the chorioid vein to form the internal cerebral vein (Galen).

Each internal cerebral vein (Galen) commences at the apex of the tela chorioidea, near the interventricular foramen (Monro), by the union of the vena terminalis with the chorioid vein. The two veins run backwards between the layers of the tela, receiving tributaries from the chorioid plexuses of the third ventricle and from the fornix and corpus callosum, and they terminate, beneath the splenium of the corpus callosum, by uniting to form the great cerebral vein (Galen).

The great cerebral vein (Galen) passes backwards and slightly upwards from its origin, and ends in the anterior extremity of the straight sinus. In addition to the two internal cerebral veins, by the union of which it is formed, it receives tributaries from the posterior parts of the gyrus cinguli of each side, from the pineal and quadrigeminate bodies, from the medial and inferior surfaces of the occipital lobes of the brain, and from the upper surface of the cerebellum. It also receives the basal vein of each side (see p. 971). 
An inferior striate vein descends, on each side, from the substance of the corpus striatum, and, after passing through the anterior perforated substance, ends in the basal vein (see below), which, as already stated, is a tributary of the great cerebral vein.

(b) The superficial cerebral veins are more numerous and of larger calibre. than the cerebral arteries. They lie upon the surface of the cerebrum, drain blood from the cerebral cortex, and they are divisible into two sets, the superior and the inferior.

The superior cerebral veins, twelve or more in number, lie in the pia mater and subarachnoid space on the upper and lateral aspect of the cerebral hemispheres. They run upwards and medially, to the margin of the longitudinal fissure where they receive tributaries from the medial surface of the hemisphere, and they terminate in the superior sagittal sinus or in the lateral lacunar expansions of the sinus. The anterior veins of this set are small and run transversely, but the posterior are large and run obliquely forwards and medially; they are embedded for some distance in the wall of the sinus, and their orifices are directed forwards against the blood stream.

The inferior cerebral veins lie on the lower and lateral aspects of the cerebral hemispheres; they run downwards and medially, and terminate in the sinuses which lie at the base of the skull-viz., the cavernous, the superior petrosal, and the transverse sinuses. One of these veins, the superficial middle cerebral vein (O.T. superficial Sylvian), runs along the posterior horizontal limb and stem of the lateral fissure (Sylvius) to the cavernous sinus; occasionally it is united by an anastomotic loop, known as the great anastomotic vein (Trolard), with the superior sagittal sinus, and sometimes by the posterior anastomotic vein with the transverse sinus.

The anterior cerebral vein of each side lies in the longitudinal fissure, and accompanies the corresponding anterior cerebral artery; it receives tributaries from the corpus callosum and the gyrus cinguli. Turning downwards, round the genu of the corpus callosum, it reaches the base of the brain, and terminates in the basal vein.

The deep middle vein (O.T. deep Sylvian) lies deeply in the lateral fissure (Sylvius); it anastomoses freely with the superficial middle vein, receives tributaries from the insula and the adjacent opercula, and terminates in the basal vein.

The basal vein commences at the anterior perforated substance; it is formed by the union of the anterior cerebral vein with the deep middle vein and with the inferior striate vein. Passing backwards round the pedunculus cerebri, it terminates in the great cerebral vein (Galen). Its tributaries are derived from the tuber cinereum, the corpus mamillare, the posterior perforated substance, the uncus, the inferior cornu of the lateral ventricle, and the pedunculus cerebri.

Veins of the Mid-brain.-The veins of the mid-brain terminate for the most part either in the great cerebral vein (Galen) or in the basal veins.

Cerebellar Veins.-These veins also are divisible into two groups, the superficial and the deep. The former are quite independent of and much more numerous than the arteries. They form two sets, the superior and the inferior.

The superior superficial cerebellar veins terminate in a single median or vermian efferent vessel which is sometimes double, and in several lateral efferents. The superior vermian vein runs anteriorly and ends in the great cerebral vein (Galen). The lateral superior cerebellar veins terminate in the transverse sinuses or in the superior petrosal sinuses.

The inferior superficial cerebellar veins also form a small rermian and numerous lateral efferents; the former runs backwards and joins either the straight sinus or one of the transverse sinuses, and the latter end in the inferior petrosal and occipital sinuses.

The deep cerebellar veins issue from the substance of the cerebellum and terminate in the superficial veins.

Veins of the Pons.- The deep veins from the substance of the pons pass forwards to its anterior surface, where they become superficial, and, anastomosing together, form a plexus which is drained by superior and inferior efferent veins. 
The superior efferent veins join the basal vein; the inferior efferent veins either unite with the cerebellar veins, or they open into the superior petrosal sinus.

Veins of the Medulla Oblongata.-Deep veins of the medulla oblongata issue from its substance and end in a superficial plexus. This plexus is drained by an anterior and a posterior median vein and by radicular veins.

The anterior median vein is continuous below with the corresponding vein of the spinal medulla; it communicates above with the plexus on the surface of the pons.

The posterior median vein is continuous below with the posterior median vein of the spinal medulla, from which it ascends to the lower end of the fourth ventricle, where it divides into two branches which join the inferior petrosal sinus or basilar plexus.

The radicular veins issue from the lateral parts of the plexus and run with the roots of the last four cerebral nerves; they end in the inferior petrosal and occipital sinuses or in the upper part of the internal jugular vein.

\section{Sinus Dure Matris.}

The venous sinuses of the cranium are spaces between the layers of the dura mater; and they are lined with an endothelium which is continuous with the endothelium of the veins. They receive the veins of the brain, communicate frequently with the

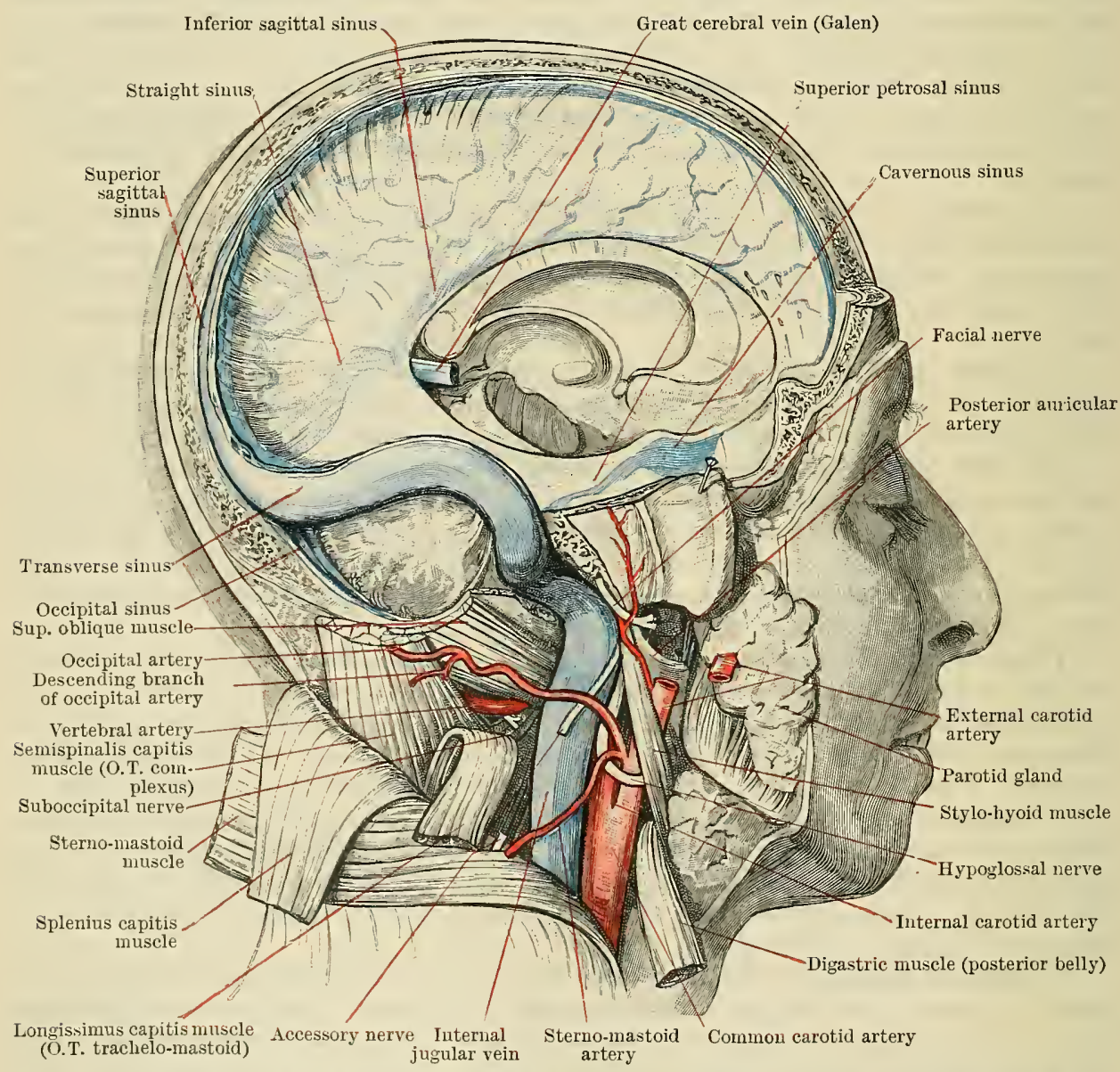

FIG. 787.-Dissection of THE HEAD AND NECK, showing the cranial blood sinuses and the upper part of the internal jugular vein.

meningeal veins and with veins external to the cranium, and terminate directly or indirectly in the internal jugular vein. Some of the cranial blood sinuses are unpaired, others are paired. 
superior sagittal sinus are the superior cerebral veins, and it communicates on each side by small openings with a series of spaces in the dura mater, the lacunæ laterales, into which the arachnoideal granulations project. It also communicates, by emissary veins, which pass through the foramen cæcum and through each parietal foramen, with the veins on the exterior of the cranium. Its cavity, which is triangular in transverse section, is crossed by several fibrous strands called the chordæ Willisii.

Sinus Sagittalis Inferior.-The inferior sagittal sinus lies usually in the posterior two-thirds of the lower free margin of the falx cerebri. It terminates posteriorly by joining with the great cerebral vein (Galen) to form the straight sinus. It receives tributaries from the falx cerebri and from the medial surface of the middle third of each cerebral hemisphere.

Sinus Intercavernosi. - The anterior intercavernous sinus is a small transverse channel which crosses from one cavernous sinus to the other in the anterior borders of the diaphragma sellæ.

The posterior intercavernous sinus also connects the two cavernous sinuses together. It lies in the posterior border of the diaphragma sellæ.

The anterior and posterior intercavernous sinuses and the intervening parts of the cavernous sinuses form collectively the circular sinus.

Plexus Basilaris. - The basilar plexus (O.T. basilar sinus) is situated in the dura mater on the basilar part of the occipital bone. It connects the posterior ends of the cavernous or the anterior ends of the inferior petrosal sinuses together, and communicates below with the anterior spinal veins.

Sinus Rectus.-The straight sinus is formed by the union of the inferior sagittal sinus with the great cerebral vein (Galen). It runs downwards and backwards, along the line of union between the falx cerebri and the tentorium cerebelli. As a general rule it turns to the left at the internal occipital protuberance, dilates somewhat, and becomes continuous with the left transverse sinus, its dilatation being united with the corresponding dilatation on the lower end of the superior sagittal sinus, the "confluens sinuum," by a transverse anastomosing channel. Occasionally the straight sinus terminates in the right lateral sinus, and in that case the superior sagittal sinus ends in the left transverse sinus. It receives some of the superior cerebellar veins and a few tributaries from the falx cerebri.

Paired Sinuses.-There are six pairs of sinuses, viz., the transverse, the occipital, the cavernous, the superior petrosal, the inferior petrosal, and the spheno-parietal.

Sinus Transversi (O.T. Lateral Sinuses).-Each transverse sinus commences at the internal occipital protuberance, the right usually as the continuation of the superior sagittal, and the left as the continuation of the straight sinus. Each passes laterally in the postero-lateral part of the attached border of the tentorium cerebelli and in a groove in the occipital bone. From the lateral angle of the occipital bone it passes to the posterior inferior angle of the parietal bone, which it grooves; then it leaves the tentorium and turns downwards on the inner surface of the mastoid portion of the temporal bone; from the latter it passes to the upper surface of the jugular process of the occipital bone, and turns forwards and then downwards into the jugular foramen, where it becomes continuous with the internal jugular vein.

Its tributaries are some of the superior and inferior cerebellar veins, a posterior diploic vein, and the superior petrosal sinus. It is connected with the veins outside the cranium by emissary veins which pass through the mastoid foramen and the condyloid canal.

Sinus Occipitales. - The occipital sinuses lie in the attached border of the falx cerebelli and in the dura mater along the postero-lateral boundaries of the foramen magnum; frequently they unite above and open by a single channel into the commencement of either the right or the left transverse sinus, but their upper extremities may remain separate, and then each communicates with the commencement of the transverse sinus of its own side. On the other hand either the right or the left sinus may be absent. They open below into the terminal part of the corre- 
sponding transverse sinuses, and they communicate with the posterior spinal veins. Each occipital sinus is an anastomosing channel between the upper and lower extremities of the transverse sinus of the same side, and each receives a few inferior cerebellar veins.

Sinus Cavernosi. - The cavernous sinuses lie at the sides of the body of the sphenoid bone. Each sinus commences anteriorly at the medial end of the superior orbital fissure, where it receives the corresponding ophthalmic veins, and it terminates, at the apex of the petrous portion of the temporal bone, by dividing into the superior and the inferior petrosal sinuses. Its cavity, which is irregular in size and shape, is so divided by numerous fibrous strands that it assumes the appearance of cavernous tissue; and in its lateral wall are embedded the internal carotid artery with its sympathetic plexus, the oculomotor, the trochlear, the ophthalmic and maxillary divisions of the trigeminal and the abducent nerves. Its tributaries are the spheno-parietal sinus and the inferior cerebral veins, including the middle cerebral vein (O.T. superficial Sylvian vein). It communicates with the opposite cavernous sinus by means of the anterior and posterior intercavernous sinuses; with the pterygoid plexus, in the infra-temporal fossa, by an emissary vein which passes either through the foramen ovale or through the foramen Vesalii; with the internal jugular vein by sinall venous channels which accompany the internal carotid artery through the carotid canal, and by the inferior petrosal sinus; with the transverse sinus by the superior petrosal sinus; and through the superior ophthalmic vein with the angular vein.

The spheno-parietal sinuses are lodged in the dura mater on the under surfaces of the small wings of the sphenoid bone close to their posterior borders. Each sinus communicates with the middle meningeal veins, receives veins from the dura mater, and terminates in the anterior part of the corresponding cavernous sinus.

Sinus Petrosi Superiores.-Each superior petrosal sinus commences at the apex of the petrous portion of the temporal bone, in the posterior end of the corresponding cavernous sinus, and it runs backwards and laterally, in the attached margin of the tentorium cerebelli, above the trigeminal nerve. It grooves the superior angle of the petrous portion of the temporal bone, at the lateral end of which it terminates in the transverse sinus, at the point where the latter is turning downwards on the medial surface of the mastoid portion of the temporal bone. It receives inferior cerebral, superior cerebellar, tympanic, and diploic veins.

Sinuus Petrosi Inferiores.-An inferior petrosal sinus commences at the posterior end of each cavernous sinus; it runs backwards, laterally, and downwards, in the posterior fossa of the cranium, in a groove formed by the lower angle of the petrous part of the temporal bone and the adjacent border of the basilar part of the occipital bone, to the anterior compartment of the jugular foramen of the same side, through which it passes. It crosses the last four cerebral nerves either on their lateral or on their medial sides, and it terminates in the internal jugular vein. Its tributaries include inferior cerebellar veins and veins from the internal ear, which pass to it through the internal acoustic meatus, the aquaductus cochler, and the aqueductus vestibuli.

Emissaria.-The emissary veins are veins which convey blood from the blood sinuses in the interior of the cranium to the veins which lie outside the walls of the cranium. They may be single veins, or plexiform channels surrounding other structures which are passing through the walls of the cranium.

(1) Frontal.- In the child, and sometimes in the adult, an emissary vein passes from the anterior end of the superior sagittal sinus through the foramen cæcum. Its lower end divides into two channels which either terminate in the veins of the roof of the nasal cavities or they perforate the nasal bones and join the angular veins.

(2) Parietal. - The parietal emissary reins, one on each side, pass through the parietal foramina, from the superior sagittal sinus to the occipital reins.

(3) Occipital.-An occipital emissary vein is only occasionally present. It passes from the "confluens sinumm" through the occipital protuberance to one of the tributaries of an occipital vein, and it receives the occipital diploic vein.

(4) Condyloid. When the condyloid canals are present in the occipital bone each is traversed by a condyloid emissary vein, which connects the lower end of the corresponding transverse sinus with the plexus of reins in the sub-occipital triangle.

(5) Emissary Plexus of the Foramen 0vale.-This plexus surrounds the mandibular nerve, as it passes through the foramen ovale, and connects the cavernous simus with the corresponding 
pterygoid plexus in the infratemporal fossa. If the foramen Vesalii is present, the plexus of the foramen ovale is replaced or supplemented by an emissary vein which passes through it.

(6) Internal Carotid Plexus.-The internal carotid plexus accompanies the internal carotid artery throngh the carotid eanal of the temporal bone, and connects the cavernous sinus either with the pharyngeal plexus or with the upper part of the internal jugular vein.

(7) Plexus of the Hypoglossal Canal.-As the hypoglossal nerve passes through the hypoglossal canal (O.T. anterior condyloid foramen) it is accompanied either by a venous plexus or by a large vein which comnects the veins of the medulla oblongata and the lower part of the occipital sinus with the upper end of the internal jugular vein, or with the extra-crauial part of the inferior petrosal sinus.

\section{VerTebral VeINS.}

The vertebral veins include-

(1) The basi-vertebral veins.

(2) The external vertebral plexuses.
(a) anterior
,
"

(b) posterior

(3) The internal vertebral plexus.

(4) Vertebral longitudinal sinuses.

(5) Intervertebral veins.

Venæ Basivertebralis.-The basi-vertebral veins are venous channels enclosed by endothelial walls which lie in the interiors of the bodies of the vertebræ. They communicate anteriorly with the plexuses of veins on the anterior surfaces of the bodies of the vertebræ, and they converge, radially, towards the posterior surfaces of the bodies of the vertebræ where they open into the transverse anastomoses between the longitudinal vertebral sinuses.

Plexus Venosi Vertebralis Externi. - The external vertebral plexuses, $(a)$ anterior and (b) posterior.

(a) The anterior external vertebral plexuses are formed by anastomosing venous channels which lie on the anterior surfaces of the vertebræ. They communicate with the basi-vertebral veins and with the intervertebral veins.

(b) The posterior external vertebral plexuses lie around the postero-lateral aspects of the vertebræ, in the vertebral grooves, around the spines, the articular and the transverse processes of the vertebræ. They communicate with the internal plexuses and with the intervertebral veins, and they open into the vertebral, intercostal, and lumbar veins.

Sinus Vertebrales Longitudinales.-The Longitudinal Vertebral Sinuses.-The veins in the interior of the vertebral canal form a network, the vertebral venous network, which lies external to the dura mater and covers the internal surfaces of the arches of the vertebre. The network communicates laterally with the intervertebral veins, posteriorly with the posterior external venous plexuses, whilst anteriorly it receives the basi-vertebral veins. In the anterior part of the network, on the posterior surfaces of the bodies of the vertebræ and at the sides of the posterior longitudinal ligament, there are two large longitudinal channels, the anterior longitudinal vertebral sinuses. Two less marked longitudinal channels, the posterior longitudinal vertebral sinuses, can sometimes be distinguished running along the internal surfaces of the vertebral arches.

The anterior longitudinal vertebral sinuses communicate above with the basilar plexus, the terminal parts of the transverse sinuses, and with the network of veins which accompanies each hypoglossal nerve through the hypoglossal canal.

The posterior longitudinal vertebral sinuses, when they are well established, communicate above with the occipital sinuses.

Venæ Intervertebrales. - The Intervertebral Veins.-The internal vertebral venous network is drained not only above into the cranial venous sinuses by the longitudinal vertebral sinus, but also by a series of intervertebral veins which pass through the intervertebral foramina. In the cervical region the intervertebral veins open externally into the vertebral veins, in the thoracic region into the intercostal veins, in the lumbar region into the lumbar veins, and in the sacral region into the lateral sacral veins. The intervertebral veins convey blood both from the internal vertebral venous plexus and also from the anterior and the posterior external vertebral plexuses. 


\section{The Veins of the Spinal Medulla.}

The veins of the spinal medulla issue from the substance of the spinal medulla, and terminate in a plexus in the pia mater. In this plexus there are six longitudinal channels-one antero-median, along the anterior fissure, two antero-lateral, immediately behind the anterior nerve-roots, two postero-lateral, immediately posterior to the posterior nerve-roots, and one postero-median, dorsal to the posterior septum. Radicular efferent vessels issue from the plexus, and pass along the nerve roots to communicate with the internal vertebral venous network. The veins of the spinal medulla vary very much in size, but they are largest on the lower and on the posterior portions.

The postero-median and antero-median veins are continued above into the corresponding veins of the medulla oblongata.

The antero-lateral and postero-lateral veins pour their blood partly into the median veins and partly into the radicular veins; indeed, the greater part of the blood from the spinal medulla is returned by the radicular veins.

\section{THE VEINS OF THE SUPERIOR EXTREMITY.}

The veins of each upper limb are divisible into two sets-viz., superficial and deep. Both sets open eventually into a common terminal trunk which is known as the axillary vein. This vein is, therefore, the chief efferent vein of the upper extremity. It is continued as the subclavian vein to the innominate vein, through which its blood, together with that from the corresponding side of the head and neck, reaches the superior vena cava.

\section{The Deep Veins of the Upper Extremity.}

The deep veins of the upper limb, with the exception of the axillary vein, are arranged in pairs, venæ comites, which accompany the different arteries and are similarly named. So far as these veins are concerned it will be sufficient to state that they are provided with valves, that they are situated one on each side of the artery with which they are associated, and that they are usually united together by numerous transverse anastomoses which cross the line of the artery. The axillary vein, however, requires more detailed consideration.

\section{Vena Axillaris.}

The axillary vein (Figs. 766 and 806) commences as the direct continuation of the basilic vein, opposite the lower border of the teres major muscle. It passes upwards and medially, through the axilla, along the medial side of the axillary artery, and terminates at the external border of the first rib by becoming the subclavian vein. It possesses one or more bicuspid valves of which one is usually situated opposite the lower border of the subscapularis muscle.

Relations.-Its anterior relations are similar to those of the axillary artery, but, in addition, the vein is crossed anteriorly, under cover of the clavicular part of the pectoralis major, by the pectoral branches of the thoraco-acromial artery, and by branches of the medial anterior thoracic nerve, and it receives anteriorly, just above the upper border of the pectoralis minor, the termination of the cephalic rein.

Posterior to it are the muscles which form the posterior wall of the axilla, the axillary fat, and the first serration of the serratus anterior. The long thoracic nerve intervenes between it and the serratus anterior, and the subscapular and thoraco-dorsal nerves and the subscapular artery pass between it and the subscapularis.

It is separated from the axillary artery in the distal part of its extent by the ulnar nerre and medial cutaneons nerves of the forearm, in the middle of its course by the medial cord of the brachial plexus, and in the proximal part of the axilla, behind the costo-coracoid membrane, by the medial anterior thoracic nerve. To its medial side lie the lateral set of axillary glands, and, in the distal part of the axilla, the medial cutaneous nerve of the arm. 
Tributaries. - In addition to tributaries corresponding with the branches of the axillary artery, it receives the venæ comites of the brachial artery, at the lower border of the subscapularis, and the cephalic vein, which joins it opposite the upper border of the pectoralis minor muscle.

\section{The Superficial Veins of the Superior Extremity.}

The superficial veins of the upper limb commence in the superficial fascia of the palm and dorsum of the hand and of the digits.

The Veins of the Digits and Hand.-The proper volar digital veins are two or more fine longitudinal channels which lie in the superficial fascia of the volar

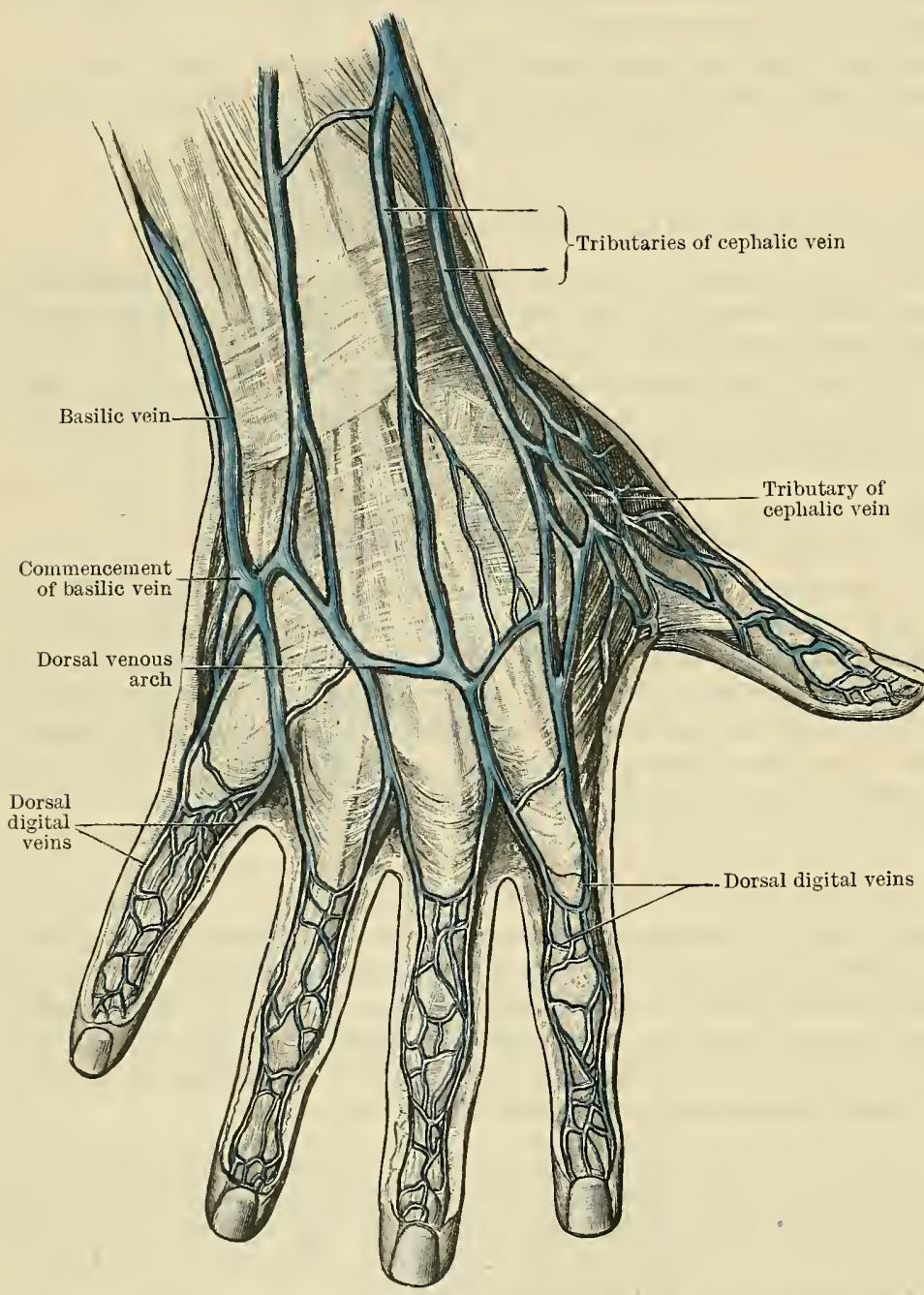

Fig, 789. - Superficial Veins on the Dorsdm of the Hand and Digits. aspects of the digits. They communicate, proximally, with a fine venous network which lies in the superficial fascia of the palm, and, at the proximal ends of the interdigital clefts, by means of intercapitular veins, which pass dorsally between the heads of the metacarpal bones, they open into the proper dorsal digital veins.

The proper dorsal digital veins, two in each digit, anastomose freely together on the dorsal aspects of the digits. At proximal ends of the interdigital clefts they communicate, through the intercapitular veins, with the proper volar digital veins, and then they unite together to form an indefinite series of dorsal metacarpal veins which terminate, a little

distal to the middle of the dorsum of the hand, in a dorsal venous arch.

The Veins of the Forearm and Arm.-The veins of the forearm emerge from the dorsal venous arch and from the volar venous plexus, and they vary considerably in number and in size. As a rule there are two main longitudinal channels, the cephalic vein on the radial side and the basilic vein on the ulnar side. In some cases there is an additional median vein on the volar aspect of the forearm.

The cephalic vein commences in the radial end of the dorsal venous arch. It receives the metacarpal veins of the thumb, turns round the radial margin of 
the distal part of the forearm, and runs proximall $y$, parallel with the volar border of the brachioradialis muscle, to the cubital region. There, frequently much reduced in size, it turns laterally and runs, along the lateral border of the prominence of the biceps, to the interval between the deltoid and pectoralis major, along which it ascends to the delto-pectoral triangle. At the delto-pectoral triangle it turns medially, between the pectoralis minor and the pectoralis major, to the anterior aspect of the costo-coracoid membrane, which separates it froin the front of the first part of the axillary artery; then, turning backwards, it pierces the costo-coracoid membrane and ends in the axillary vein. In a few cases instead of piercing the costocoracoid membrane it crosses the front of the clavicle, deep to the platysma, pierces the deep cervical fascia, and joins the lower part of the external jugular vein.

As it runs proximally, on the volar aspect of the forearm, a number of tributaries join its lateral border. Some of these commence in the dorsal venous arch of the hand and others in the superficial fascia of the dorsal aspect of the forearm.

In the cubital region it is connected with the basilic vein by a large obliquely placed anastomosing channel, the median cubital vein, which runs along the medial border of the distal part of the biceps prominence, superficial to the lacertus fibrosus which separates it from the distil part of the brachial artery. In the delto-pectoral triangle it is joined by tributaries which correspond with the acromial and pectoral branches of the thoraco-acromial artery.

The median cubital vein not only connects together the cephalic and basilic veins but it receives also the profunda vein which pierces the deep fascia and connects it with the deep veins of the forearm, and one or more superficial veins, of varying size which pass, proximally, along the volar aspect of the forearm.

In many cases the median cubital vein is relatively very large, and in such cases the more proximal part of the cephalic vein, which lies in the arm, is a comparatively small vessel.

The basilic vein commences in the ulnar end of the dorsal venous arch of the hand. It runs along the dorsal aspect of the forearm to the junction of the proximal and middle thirds, where it turns round

Subclavius

Costo-coracoid membrane
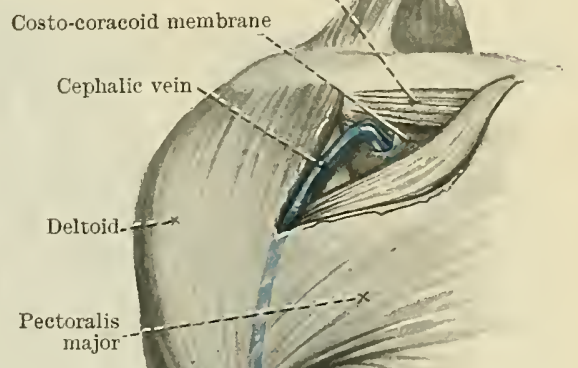

major
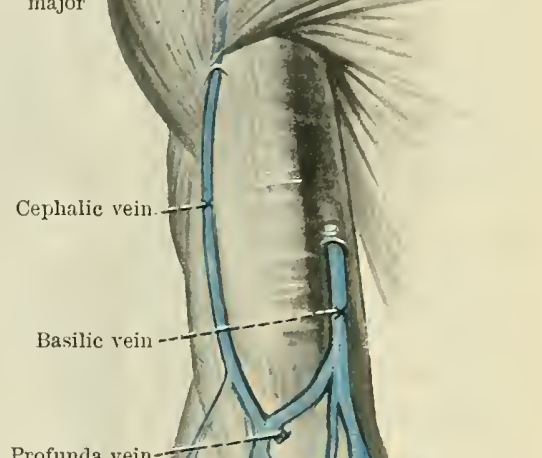

Profu
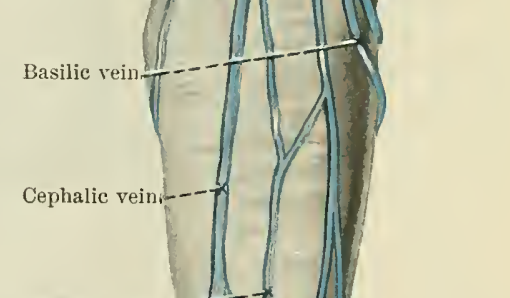

Medi

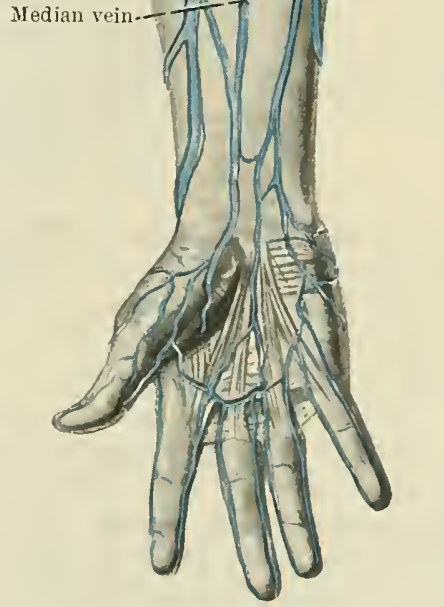

Fig. 790.-SUPERficlal VeINs oN the Flesor Aspect OF the UPpER Extremity. the ulnar border of the forearm, and runs, anterior to the medial epicondyle of the humerus, to the medial bicipital groove. At the middle of the arm, it pierces the deep fascia. After piercing the fascia, it runs proximally, along the medial border of the brachial artery, to the axilla, and there becomes the axillary vein. 
As it runs proximally, in the forearm, it is joined by tributaries from both the rolar and dorsal aspects and, in the cubital region, by the median cubital

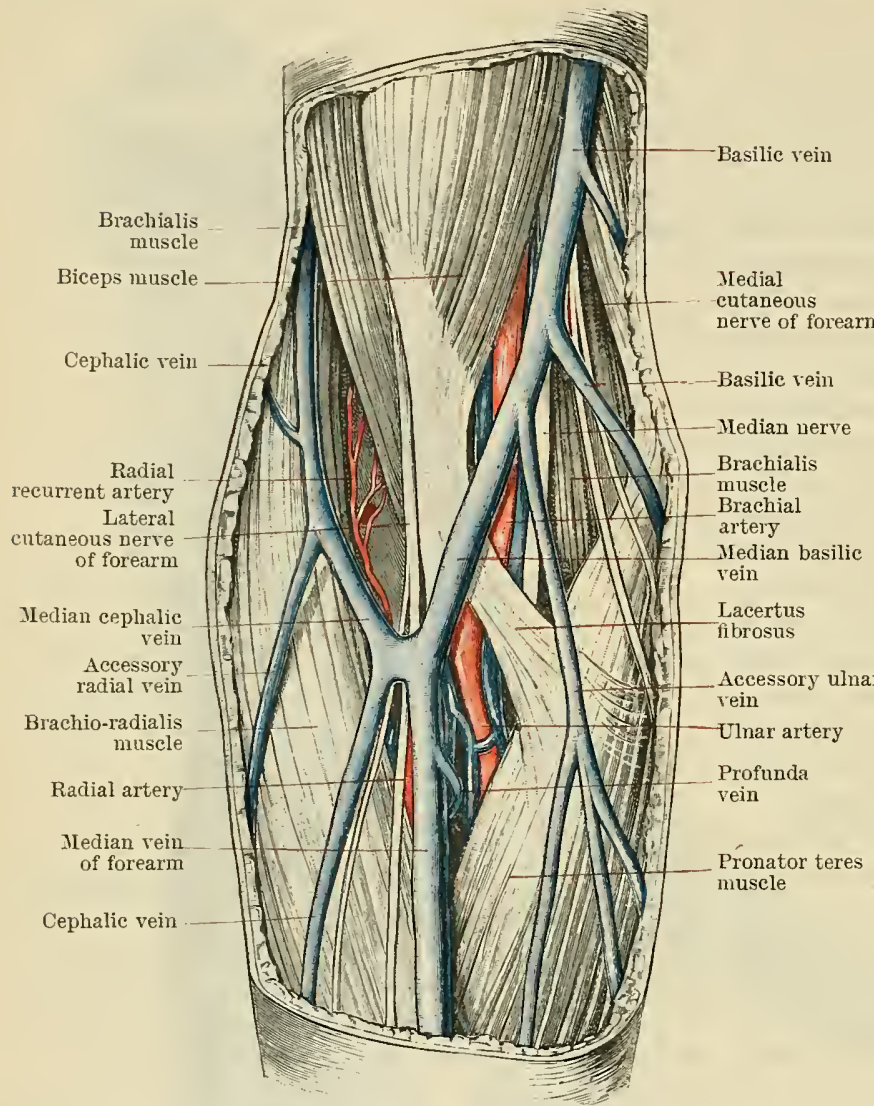

Fig. 791.-Superficial Veins at the Bend of the Elbow. vein which connects it with the cephalic vein.

The Median Vein of the Forearm.-In a certain number of cases a vein, which commences in the palmar venous plexus, runs along the middle of the volar aspect of the forearm to the cubital region. This is the median vein of the forearm. At the bend of the elbow it receives the profunda vein and then divides into two branches, the median cephalic and the median basilic veins (Fig. 791). The median cephalic vein runs along the lateral bicipital sulcus and joins the cephalic vein. The median basilic passes along the medial bicipital sulcus and joins the basilic vein. When the median vein of the forearm is present the median cubital vein is absent.

When venesection is performed in the forearm it is either the median cubital vein or, in its absence, the median basilic vein which is opened.

\section{VENA CAVA INFERIOR AND ITS TRIBUTARIES.}

The inferior vena cava (Fig. 792) is a large venous trunk which receives the whole of the blood from the lower extremities, and the greater part of the blood from the walls and contents of the abdomen and pelvis. It commences opposite the right side of the body of the fifth lumbar vertebra, behind and to the right of the right common iliac artery. It ascends through the abdomen, anterior and to the right of the vertebral column and the right crus of the diaphragm, and it pierces the cupola of the diaphragm, between the middle and right sections of the central tendinous leaflet, at the level of the eighth thoracic vertebra. It then enters the middle mediastinum, pierces the fibrous pericardium, and terminates in the lower and posterior part of the right atrium. Its intra-thoracic portion is very short, and its intra-pericardial portion, which is still shorter, is covered anteriorly and on its right and left sides by the parietal portion of the serous layer. Attached to the inferior and anterior margin of its atrial orifice is. the valve of the inferior vena cava (Eustachian). This is a remnant of an important fold of endocardium by which, in the foetus, the blood from the inferior vena cava is directed, through the foramen ovale, into the left atrium.

Relations. - The inferior vena cava is in relation posteriorly with the bodies of the 
lower lumbar vertebræ and the corresponding part of the anterior longitudinal ligament, the anterior portion of the right psoas major muscle, the right lumbar sympathetic trunk, the roots of the right lumbar arteries, the right crus of the diaphragm, the right renal artery, the right suprarenal artery, the right coliac ganglion, the right inferior phrenic artery, and the medial and upper portion of the right suprarenal gland.

Anterior to it, from below upwards, are the following structures-- the right common iliac artery, the lower end of the mesentery and the superior mesenteric artery, the right

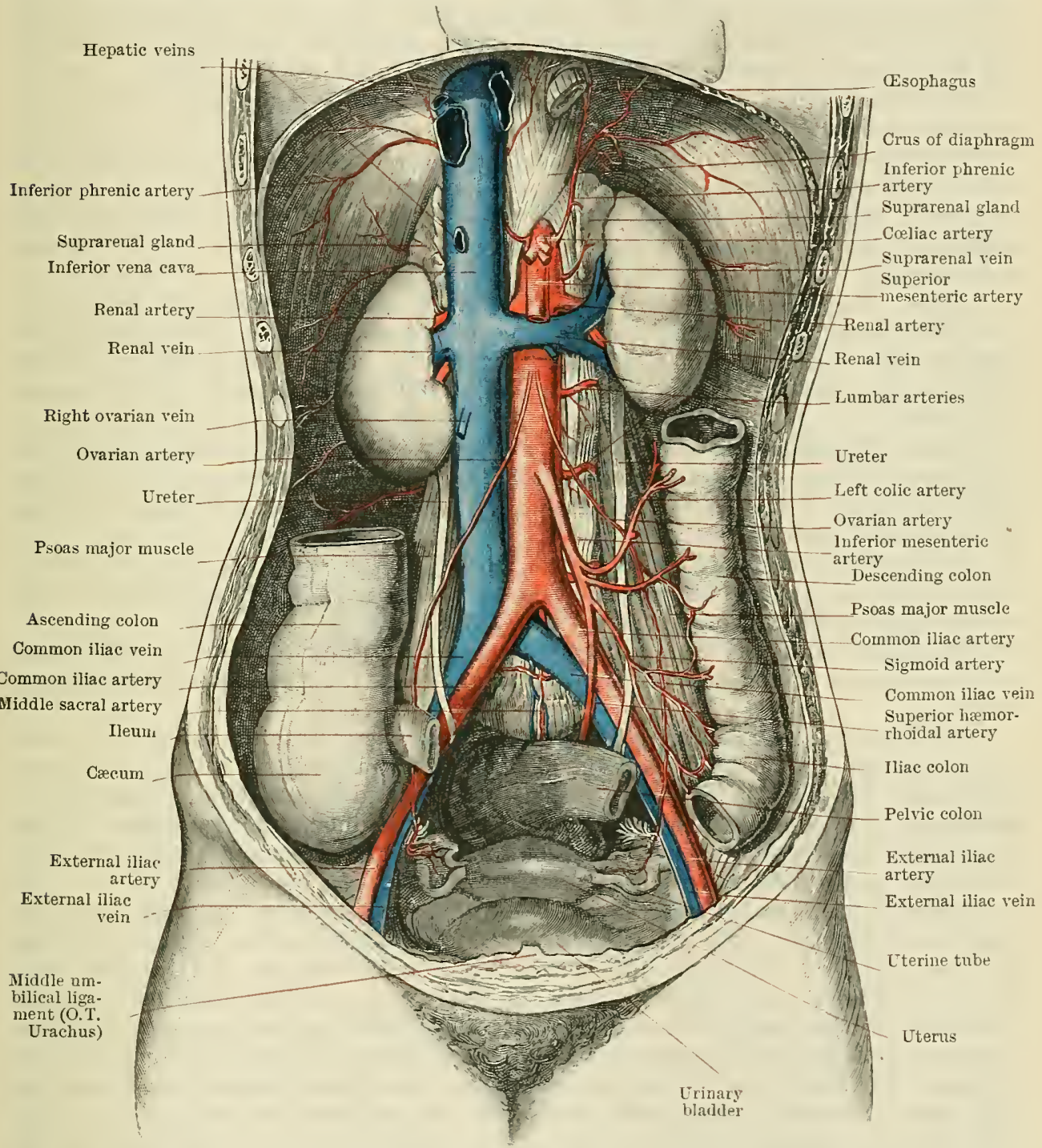

Fig. 792.-The INferior Vexa Cava axd its Tributaries.

internal spermatic artery and the third part of the duodenum, the head of the pancreas, the portal vein and the first part of the duodenum, the foramen epiploicum. and the posterior surface of the liver. More superficially are coils of small intestine, the great omentum, and the transverse colon and mesocolon.

To its left side are the aorta and the right crus of the diaphragm.

On its right side, below, is the right ureter, whilst at a higher level the right kidney is separated from the rein by a short interval only.

Tributaries. - In addition to the two common iliac veius, by the union of which it is formed, and through which it receives blood from the pelvis and from the lower extremities, the inferior vena cava receives the following tributaries:- The hepatic reins, the 
right inferior phrenic vein, the right suprarenal vein, the right and left renal veins, the right internal spermatic vein, and the right and left lumbar veins.

Venæ Hepaticæ (Fig. 792).-The hepatic veins convey blood which has passed through the liver from the portal veins and from the hepatic artery, and they open into that portion of the inferior vena cava which lies immediately below the diaphragm, and behind the right lobe of the liver. They form two groups, an upper group of two or three large trunks, and a lower group of smaller veins.

The upper group occasionally consists of only two veins, a right and a left; more frequently there are three vessels, a right, a left, and a middle vein, and in the latter case the middle vein issues from the caudate lobe (Spigelian).

The veins of the lower group vary in number from six to twenty; they return blood from the right and caudate lobes.

The hepatic veins commence in the interiors of the lobules of the liver as central veins; these issue from the upper and posterior aspects of the lobules, and unite together to form interlobular veins; and the latter, uniting with one another, as they converge towards the posterior surface of the liver, form the larger hepatic veins.

Venæ Phrenicæ Inferiores.-The inferior phrenic veins are formed by tributaries which issue from the substance of the diaphragm. The right inferior phrenic vein terminates in the upper part of the inferior vena cava. The left vein passes posterior to the cesophagus, and usually terminates in the left suprarenal vein.

Venæ Suprarenales.-A single suprarenal vein issues from the hilus on the anterior surface of each suprarenal gland; the right vein terminates in the inferior vena cava; the left usually ends in the left renal vein, but sometimes it opens directly into the inferior vena cava.

Venæ Renales.-Each renal vein is formed by the union of five or six tributaries which issue from the hilus of the kidney, where they lie anterior to or are intermingled with the corresponding arteries.

The right renal vein is about $25 \mathrm{~mm}$. (one inch long); it passes posterior to the second part of the duodenum, and terminates in the right side of the inferior vena cava.

The left renal vein is about $75 \mathrm{~mm}$. long. It crosses anterior to the left psoas major, the left crus of the diaphragm, and the aorta immediately below the superior mesenteric artery. It lies behind the pancreas and the ascending part of the duodenum, and, running above the third part of the duodenum, terminates in the left side of the inferior vena cava. The left testicular or ovarian vein, according to the sex, and almost invariably the left suprarenal vein, open into it.

Venæ Lumbales.- There are usually four lumbar veins on each side, one with each lumbar artery; the vein with the subcostal artery is not included in this number. By their anterior and posterior branches the lumbar veins drain the lateral and posterior walls of the abdomen. The anterior branches commence in the lateral walls of the abdomen, where they communicate with the superior and inferior epigastric veins. The posterior divisions issue from the muscles of the back, in the lumbar region, and receive tributaries from the spinal plexuses. The main stems pass forwards on the bodies of the vertebræ; on each side they run postero-medial to the psoas major muscle, whilst those of the left side also pass posterior to the aorta. They terminate in the posterior part of the inferior vena cava. Not uncommonly the corresponding veins of opposite sides unite together to form a single trunk which enters the back of the inferior vena cava. All the lumbar veins of each side are united together by a longitudinal anastomosing vessel, the ascending lumbar vein.

The Ascending Lumbar Vein.-Each ascending lumbar vein passes upwards, between the psoas major and the roots of the transverse processes of the lumbar vertebræ. It commences in the lateral sacral vein of the same side, anastomoses with the ilio-lumbar vein, connects the lumbar veins together, receives tributaries from the anterior external vertebral plexus and anastomoses with the inferior vena cava and the renal vein. The right ascending lumbar vein terminates in the azygos and the left in the hemiazygos vein. 
Venæ Testiculares.-The testicular veins on each side issue from the testis and epididymis and form a plexus, the pampiniform plexus. The plexus is one of the constituents of the spermatic cord, and consists of from eight to ten veins, most of which lie anterior to the ductus deferens; it passes upwards in the inguinal canal, and, near the abdominal inguinal ring, terminates in two main trunks which ascend with the corresponding testicular artery for some distance, receiving tributaries from the ureter; ultimately the two veins unite together and a single terminal vein is formed. The terminal testicular vein on the right side opens into the inferior vena cava, that on the left side into the left renal vein. The left testicular vein is longer than the right, the left testis being lower than the right, and the termination in the left renal vein being at a higher level than the termination of the right vein in the inferior vena cava. The testicular veins, on each side, lie anterior to the psoas major muscle and the ureter. They are covered by peritoneum, and they are crossed on the right side by the termination of the ileum and the third part of the duodenum, and on the left side by the iliac colon and the lower part of the pancreas. They are provided with valves, one of which usually lies at the terminations of each vein, but, occasionally, the valve at the orifice of the left testicular vein is absent.

Venæ Ovaricæ.-The ovarian veins, on each side, issue from the hilus in the anterior border of the ovary. They pass between the layers of the broad ligament, where they anastomose freely and form the pampiniform plexus, which extends laterally towards the upper margin of the pelvis minor. From the plexus two veins are formed which accompany the corresponding ovarian artery; they pass anterior to the external iliac artery, and then upwards, behind the peritoneum and anterior to the psoas major muscle and ureter. The veins of the right side, like the corresponding testicular veins, also pass behind the termination of the ileum and the third part of the duodenum; whilst the left veins, near the margin of the pelvis minor, pass behind the commencement of the pelvic colon.

The two veins on each side ultimately fuse together to form a single terminal vein which ends, on the right side in the inferior rena cava, and on the left side in the left renal vein.

\section{Vene Iliace COMnunes.}

The common iliac veins (Figs. 777 and 792), right and left, are formed by the union of the corresponding external iliac and hypogastric veins. Each commences at the superior aperture of the pelvis minor, immediately posterior to the upper part of the hypogastric artery of its own side, and both vessels pass upwards to the right side of the body of the fifth lumbar vertebra, at the upper part of which, posterior and lateral to the right common iliac artery, they unite together to form the inferior vena cava.

The right common iliac vein is much shorter than the left; it passes anterior to the obturator nerve and the ilio-lumbar artery, and at first posterior and then somewhat to the lateral side of the corresponding common iliac artery.

The left common iliac vein is much longer than the right, and is also placed more obliquely. It passes upwards and to the right, anterior to the bocly of the fifth lumbar vertebra, and the middle sacral artery. For some distance it runs along the medial side of the left common iliac artery, and then passes posterior to the right common iliac artery. It also passes posterior to the mesentery of the pelvic colon and the superior hæmorrhoidal vessels.

Tributaries.-Each common iliac vein receives the corresponding external iliac, hypogastric and ilio-lumbar veins. The left common iliac vein receives, in addition, the middle sacral vein.

The ilio-lumbar veins receive tributaries from the iliac fossa, from the lower parts of the vertebral muscles, and from the vertebral canal. There is a single vein on each side which accompanies the corresponding artery. It passes posterior to the psoas major muscle and terminates in the common iliac vein.

Vena Sacralis Media.-The venæe comites of the middle sacral artery commence by the union of tributaries which issue from the venous plexus in front of the sacrum, 
through which they communicate with the lateral sacral veins and receive blood from the interior of the sacral canal. They unite above into a single middle sacral vein, which terminates in the left common iliac vein.

Vena Hypogastrica.-The hypogastric vein (Fig. 777) is a short trunk formed by the union of tributaries which correspond to all the branches of the hypogastric artery, with the exception of the umbilical and the ilio-Iumbar branches.

It commences at the upper border of the greater sciatic notch, and ascends to the aperture of the minor pelvis; there it unites with the external iliac vein to form the common iliac vein. It lies immediately postero-medial to the hypogastric artery, is crossed laterally by the obturator nerve, and is in relation medially, on the left side with the pelvic colon, and on the right side with the lower part of the ileum.

Tributaries.-The tributaries, which are numerous, are conveniently divisible into extra-pelvic and intra-pelvic groups.

The extra-pelvic tributaries are all parietal, and include the obturator, internal pudendal, inferior, and superior glutæal veins.

Obturator Vein.-This vein is formed by the union of tributaries which issue from the hip-joint and from the muscles of the proximal and medial part of the thigh. It enters the pelvis minor through the obturator canal, runs backwards, along the lateral wall of the pelvis minor, lying medial to the pelvic fascia, immediately below the corresponding artery, and, passing between the hypogastric artery on the lateral side and the ureter on the medial side, it terminates in the hypogastric vein.

Inferior Glutæal Veins (O.T. Sciatic).-The venæ comites of the inferior glutæal artery commence in the subcutaneous tissues on the back of the thigh; they ascend with the artery, and pass into the buttock on the deep aspect of the glutæus maximus, where they receive numerous tributaries from the surrounding muscles. Entering the pelvis, through the greater sciatic foramen, they unite into a single vessel, which terminates in the lower and anterior part of the hypogastric vein below the termination of the obturator vein.

Superior Glutæal Veins (O.T. Glutæal).-The venæ comites of the superior glutæal artery are formed by tributaries which issue from the muscles of the buttock. They accompany the artery through the greater sciatic foramen, and terminate in the hypogastric vein; they frequently unite together before reaching their termination.

Internal Pudendal Veins. - The venæ comites of the internal pudendal artery commence by tributaries which emerge from the pudendal plexus, which lies below and posterior to the arcuate ligament of the pubis and constitutes the anterior part of the prostatic plexus. They receive blood from the corpus cavernosum penis, or the corpus cavernosum clitoridis, by the deep vein of the penis or clitoris. They follow the course of the internal pudendal artery, and usually join together into a single vessel (the internal pudendal vein) which terminates in the internal iliac vein. They receive as tributaries the veins from the bulb, the perineal and inferior hæmorrhoidal veins, and veins from the muscles of the buttock.

The inferior hæmorrhoidal veins, which commence in the substance of the external sphincter of the anus and in the walls of the anal canal, anastomose with the middle and superior hrmorrhoidal veins, and consequently connect the lowest parts of the portal and vena caral systems together.

The intra-pelvic tributaries of the internal iliac vein are either (a) parietal or (b) visceral; the former comprises the lateral sacral veins, the latter includes the efferent vessels from the plexuses around the several pelvic viscera.

(a) Parietal: Lateral sacral veins accompany the corresponding arteries, and terminate on each side in the postero-medial wall of the hypogastric vein.

(b) Visceral tributaries are derived from the rectum and from the plexuses associated with the uterus, vagina, bladder, and prostate. They include the middle hæmorrhoidal, the uterine, the vaginal, and the vesical veins.

The middle hæmorrhoidal veins are very irregular; sometimes they cannot be distinguished. When present they are formed by tributaries which commence in the submucous tissue of the rectum, where they communicate with the superior and inferior hæmorrhoidal veins in the hæmorrhoidal plexus; they pass through the muscular coat, and fuse together to form two middle hæmorrhoidal veins, right and left, each of which runs laterally, beneath the peritoneum, on the upper surface of the levator ani, to terminate in the hypogastric vein. In the male each middle hæmorrhoidal vein receives tributaries from the seminal vesicle and ductus deferens of its own side. 
Uterine Plexuses and Veins.-The uterine plexuses lie along the lateral borders of the uterus; they receive tributaries, which are entirely devoid of valves, from the uterus; and they communicate above with the ovarian, and below with the raginal plexuses.

The uterine veins, usually two on each side, issue from the lower parts of the uterine plexuses, above their communications with the vaginal plexuses. At first the uterine vein, on each side, lies in the medial part of the base of the broad ligament, above the lateral fornix of the vagina and the ureter; then it passes backwards, accompanying the corresponding artery, in a fold of peritoneum which lies between the back of the broad ligament and the recto-nterine fold; finally it ascends in the fioor of the ovarian fossa, and terminates in the corresponding hypogastric vein.

Vaginal Plexuses and Vaginal Veins.-The vaginal plexuses lie at the sides of the vagina. They receive tributaries from the walls of the vagina, and communicate with the uterine plexuses above, and with the veins of the bulb below; anteriorly, with the vesical plexus; and posteriorly with the veins which issue from the middle and lower parts of the hæmorrhoidal plexus. A single vaginal vein issues from the upper part of the vaginal plexus on each side; it accompanies the corresponding artery, and terminates in the hypogastric vein.

Superior Vesical Plexus.-The superior vesical plexus of veins lies on the outer surface of the muscular coat of the bladder, at the fundus and the sides. It receives tributaries from the mucous and muscular walls, and its efferent vessels terminate in the prostatico-vesical plexus in the male, and in the inferior vesical plexus in the female.

Prostatico-vesical Plexus.-This plexus is distributed around the prostate and the neck of the bladder, and is enclosed between the proper fibrous capsule of the prostate and its sheath of recto-vesical fascia. Anteriorly it is continuous with the pudendal plexus which receives the dorsal vein of the penis; postero-superiorly it communicates with the superior vesical plexus, and receives tributaries from the seminal vesicles and deferent ducts. One or more efferent vessels pass from it on each side and open into the corresponding hypogastric vein.

The inferior vesical plexus of the female, which represents the prostatico-vesical plexus of the male, surrounds the upper part of the urethra and the neck of the bladder. It is continuous with the pudendal plexus which receives the dorsal vein of the clitoris, and its efferent vessels terminate in the hypogastric vein.

Dorsal Veins of the Penis.-There are two dorsal veins of the penis - the superficial and the deep.

The superficial dorsal vein receives tributaries from the prepuce, and runs backwards, immediately beneath the skin, to the symphysis, where it divides into two branches which terminate in the superficial external pudendal veins.

The deep dorsal vein lies on the dorsum of the penis deep to the deep fascia. It commences in the sulcus behind the glans, by the union of numerous tributaries from the glans and the anterior parts of the corpora cavernosa penis; and it runs backwards in the mid-dorsal line, in the sulcus between the corpora cavernosa penis, from which it receives many additional tributaries. At the root of the penis the vein passes between the two layer's of the suspensory ligament, and then between the arcuate ligament and the deep transverse ligament of the perineum, where it lies above the membranous part of the urethra. It terminates by dividing into two branches which join the pudendal plexus.

The dorsal vein of the clitoris in the female has a similar course to that of the deep dorsal vein of the penis in the male. It terminates in the pudendal plexus.

\section{THE VEINS OF THE LOWER EXTREMITY.}

The veins of the lower extremity, like those of the upper extremity, are arranged in two groups, the superficial and the deep; and in the lower as in the upper limb the deep veins are associated with the arteries as venæ comites, whilst the trunks of the superficial veins, which lie, at first, in the subcutaneous tissues ultimately terminate in the deep veins. There is, therefore, a general similarity in the arrangement of the veins of the upper and the lower limbs, but there are differences in the details of the arrangement which are of some importance. Thus, in the upper extremity, there are two deep veins with each artery from the fingers to the root of the limb, where a single trunk, the axillary vein, is formed; but in the lower extremity each main artery has two venæ comites only as far as the middle of the limb, where a single trunk is frequently formed. This vessel, the popliteal 
vein, is the commencement of the main venous stem of the lower extremity; it is continued proximally, through the thigh, as the femoral vein, and along the upper margin of the pelvis minor as the external iliac vein, which terminates by uniting with the hypogastric vein to form the common iliac vein.

Further, the superficial veins of the upper limb are more numerous than those of the lower limb, for in the arm there are two main superficial veins, and in the thigh only one.

In the upper limb the blood which passes through the superficial veius is poured into the efferent trunk vein at the root of the limb-that is, into the axillary vein ; but in the lower limb the blood from the superficies of the lateral parts of the leg and foot passes into the commencement of the main efferent vein, the popliteal vein, at the middle of the limb-that is, in the region of the knee, whilst the blood from the superficial parts of the medial aspect of the lower limb is poured into the femoral vein near the root of the limb in the upper part of the femoral trigone.

In addition to the above-mentioned differences in the general arrangement of the veins of the upper and the lower extremities, it must be noted also that in the upper extremity all the blood of the limb, both that from the shoulder-girdle region as well as that from the free portion of the limb, is returned to the main efferent venous trunk; but in the lower extremity the greater part of the blood from the region of the pelvic girdle, and a considerable portion from that of the thigh, is returned by the glutæal, obturator, and pudendal veins to the hypogastric vein, which is not the main efferent vein of the lower extremity.

\section{The Deep Veins of the Lower Extremity.}

All the arteries of the lower limb, except the popliteal and femoral trunks, are accompanied by two vence comites. They usually lie one on each side of the artery; they are connected with each other by transverse channels which pass across the line of the artery, and they are provided with numerous valves.

Vena Poplitea.-The popliteal vein (Fig. 780) is formed, at the distal border of the popliteus muscle, by the union of the venæ comites of the anterior and posterior tibial arteries. At its commencement it lies to the medial side of and somewhat superficial to the popliteal artery, and to the lateral side of the tibial (O.T. internal popliteal) nerve. As it runs through the popliteal fossa it gradually inclines towards the lateral side of the artery, and in the middle of the space it is directly posterior to the artery, separating the artery from the tibial nerve, which is still more posterior, whilst at the proximal end of the space it is to the lateral side of the artery, and still between it and the tibial nerve. It then passes through the adductor magnus muscle and becomes the femoral vein.

The popliteal vein, which is provided with two or three bicuspid valves, is closely bound to the artery by a dense fascial sheath. Not uncommonly there are one or more additional satellite veins which anastomose with the popliteal vein, and in these cases the artery is more or less completely surrounded by venous trunks.

Tributaries.-In addition to the venæ comites of the anterior and posterior tibial arteries, it receives tributaries which correspond with the branches of the popliteal artery, and it also receives one of the superficial veins of the leg, viz., the small saphenous vein.

Vena Femoralis.-The femoral vein is the direct continuation of the popliteal vein. It commences at the junction of the middle and distal thirds of the thigh, at the opening in the adductor magnus muscle. It then ascends, through adductor canal (Hunter's), and through the femoral trigone, and terminates, a little to the medial side of the middle of the inguinal ligament (Poupart's), by becoming the external iliac vein.

In the adductor canal it lies at first postero-lateral to the femoral artery, and anterior to the adductors magnus and longus which separate it from the profunda vessels. In the distal part of femoral trigone it is postero-medial to the artery, and immediately anterior to the profunda vein which separates it from the profunda artery, but in the proximal part of the femoral trigone it is directly on 
the medial side of the femoral artery. About $37 \mathrm{~mm}$. (one and a half inches) below the inguinal ligament it enters the middle compartment of the femoral sheath, through which it ascends to its termination, lying between the compartment for the femoral artery on the lateral side and the femoral canal on the medial side.

It usually contains two bicuspid valves-one near its termination and the other just proximal to the entrance of its profunda tributary.

Tributaries.-It receives tributaries which correspond with the branches of the femoral artery and the larger of the two superficial veins of the lower extremity, viz., the

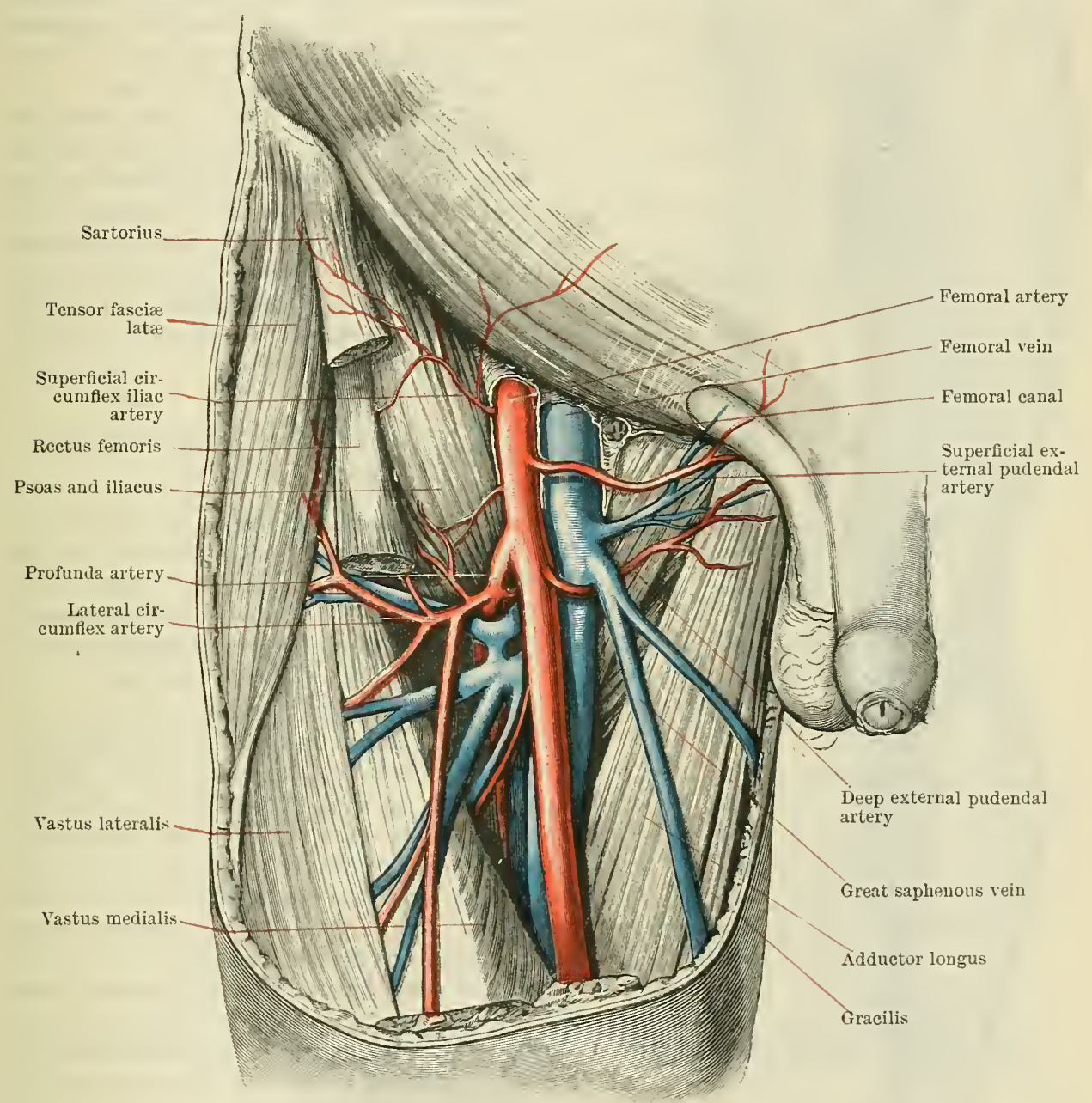

Fig. 793.-The Femoral Vessels in the fesioral Trigone.

great saphenous vein, which enters the femoral vein where that vessel lies in the middle compartment of the femoral sheath, and, not uncommonly, the medial and lateral circumflex veins.

Vena Iliaca Externa.-The external iliac vein (Figs. 773,774 , and 777 ) is the upward continuation of the femoral vein. It commences, on the medial side of the termination of the external iliac artery, immediately posterior to the inguinal ligament, and ascends along the aperture of the pelvis minor, to a point opposite the sacro-iliac joint, and at the level of the lumbo-sacral articulation, where it ends, immediately behind the hypogastric artery, by joining the hypogastric vein to form the common iliac vein. It lies, at first, on the medial side of the external iliac artery, but on a somewhat posterior plane, and then directly posterior to the 
artery, whilst just before its termination it crosses the lateral side of the hypogastric artery, and separates that vessel from the medial border of the psoas major muscle. In its whole course the vein lies anterior to the obturator nerve.

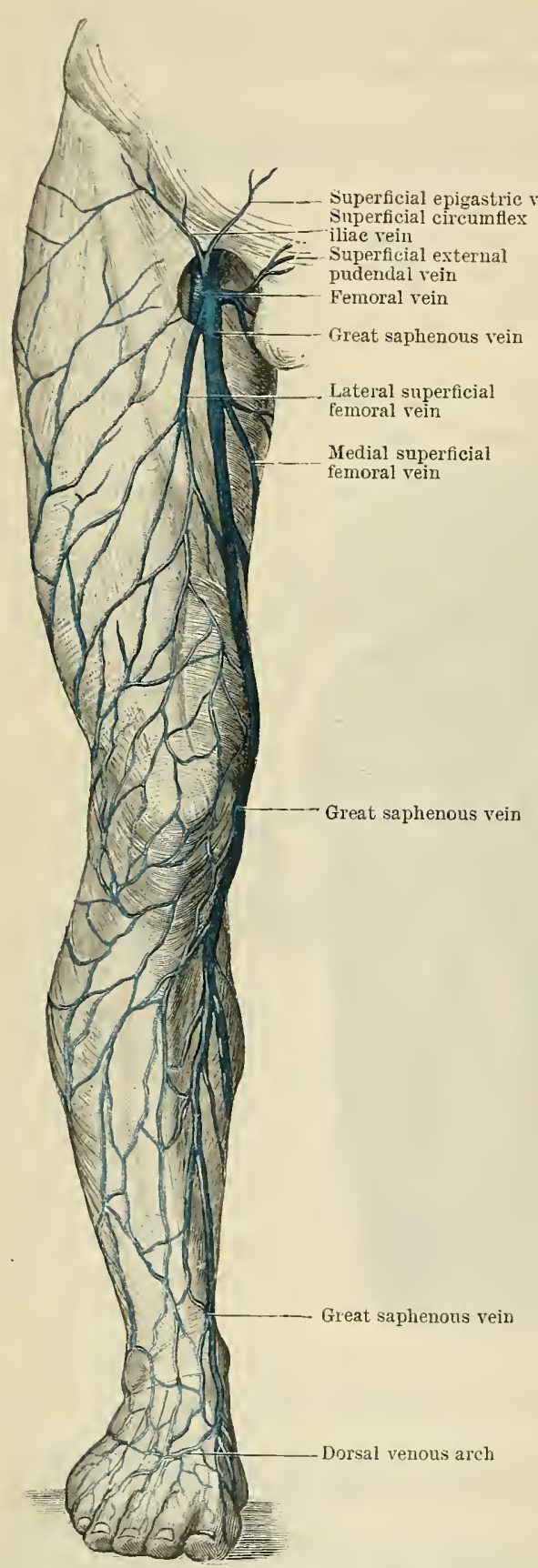

Fig. 794.-The Great Saphenods Vein and its Tributaries.

It is nsually provided with one bicuspid valve; sometimes there are two, but both are usually incompetent. Its tributaries correspond to the branches of the external iliac artery; that is, the deep circumflex iliac and inferior epigastric veins open into it, close to its commencement, whilst, in addition, it frequently receives the pubic vein.

The pubic vein forms a communication between the obturator vein and the external iliac vein. It varies in size, and may form the main termination of the obturator vein, from which it arises. Commencing in the obturator canal, it ascends, along the pubic branch of the inferior epigastric artery, to reach the external iliac vein.

\section{The Superficial Veins of the INFERIOR EXTREMITY.}

The superficial veins of the lower limb terminate in two trunks, one of which, the small saphenous vein, passes from the foot to the popliteal space; whilst the other, the great saphenous vein, extends from the foot to the groin.

The superficial veins of the sole of the foot form a fine plexus, immediately under cover of the skin, from which anterior, medial, and lateral efferents pass. The anterior efferents terminate in a transverse arch which lies in the furrow at the roots of the toes, and the medial and lateral efferents pass round the sides of the foot to the great or small saphenous veins. The transverse arch receives also small plantar digital veins from the toes, and it communicates by intercapitular veins with the veins on the dorsum of the foot.

The superficial veins on the dorsal aspect of each toe unite to form two dorsal proper digital veins, which run along the borders of the dorsal surface. The proper dorsal digital veins of the adjacent borders of the interdigital clefts unite, at the apices of the clefts, to form four dorsal metatarsal veins which terminate in the dorsal venous arch. The dorsal digital vein from the medial side of the great toe ends in the great saphenous vein, and that from the lateral side of the little toc terminates in the small saphenous vein.

Arcus Venosus Dorsalis Pedis.-The dorsal venous arch lies in the subcutaneous tissue, between the skin and the dorsal digital branches of the superficial peronæal 
nerve, opposite the distal parts of the shafts of the metatarsal bones. It ends medially by uniting with the medial dorsal digital vein of the great toe to form the great saphenous vein, and laterally by joining the lateral dorsal digital vein of the little toe to form the small saphenous vein. The dorsal venous arch receives the dorsal metatarsal veins; interdigital efferents from the plantar transverse arch; and numerous tributaries from the dorsum of the foot, which anastomose freely together forming a wide-meshed dorsal venous plexus, open into it posteriorly.

Vena Saphena Magna. - The great saphenous vein is formed by the union of the medial extremity of the dorsal venous arch with the medial dorsal digital vein of the great toe. It passes anterior to the medial malleolins, crosses the medial surface of the distal third of the shaft of the tibia, and ascends, immediately posterior to the medial margin of the tibia, to the knee, where it lies just posterior to the medial condyle of the femur; continuing proximally, with an inclination forwards and laterally, it gains the proximal part of the femoral trigone, where it perforates the fascia cribrosa and the femoral sheath to reach its termination in the femoral vein. In the foot and leg it is accompanied by the saphenous nerve, and for a short distance distal to the knee by the superficial or saphenous branch of the arteria genu suprema. In the thigh, branches of the medial cutaneous nerve (O.T. internal) lie in close relation with it. It contains from eight to twenty bicuspid valves.

Tributaries. - It communicates freely, through the deep fascia, with the deep intermuscular veins. In the foot, it receives tributaries from the medial part of the sole and from the dorsal renous plexus. As it ascends in the leg it is joined by tributaries from the dorsum of the foot, the medial and posterior parts of the heel, the front of the leg and the back of the calf, and it anastomoses freely with the small saphenous vein. In the thigh it receives numerous tributaries, some of which usually converge to form two superficial femoral veins. Of these, one, the lateral, ascends from the lateral side of the knee and terminates in the great saphenous vein about the distal part of the femoral trigone; the other, the medial,

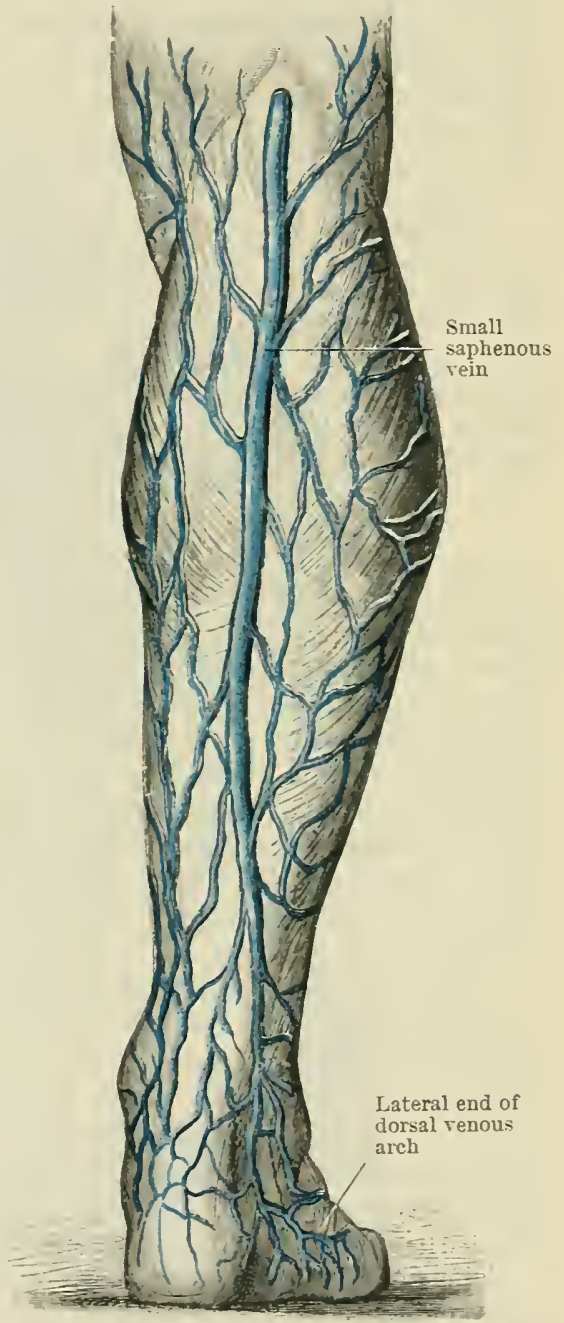

Fig. 795.-The Syall Saphexods TeIN AND ITS TRIBUTARIES. ascends from the posterior aspect of the thigh along its medial side to terminate in the great saphenous vein near the fossa oralis (O.T. saphenous opening). In many cases the medial superficial femoral vein communicates distally with the short saphenous rein, and when this condition exists the medial superficial femoral vein is called the accessory suphenous vein. The last tributaries to enter the great saphenous vein are the superficial circumflex iliac, superficial epigastric, and superficial external pudendal veins. They accompany the corresponding arteries, and terminate in the great saphenous rein immediately before it perforates the fascia cribrosa.

The superficial circumflex iliac vein receives blood from the lower and lateral part of the abdominal wall and the proximal and lateral parts of the thigh. The superficial epigastric rein drains the lower and medial part of the abdominal wall, and the superficial external pudendal vein receives blood from the dorsum of the penis and the scrotum in the male, and from the labium majus in the female. 
Vena Saphena Parva.-The small sphenous vein is formed by the union of the lateral extremity of the dorsal venous arch with the lateral dorsal digital vein of the little toe. At first it passes posteriorly, along the lateral side of the foot and distal to the lateral malleolus, lying on the peronæal retinacula (O.T. ext. ann. lig.), in company with the nervus suralis; then it passes posterior to the lateral malleolus, and along the lateral border of the tendo calcaneus, still in company with the nervus suralis, to the middle of the calf, proximal to which it is continued in the superficial fascia, accompanied by the superficial sural artery, to the distal part of the popliteal fossa, where it pierces the deep fascia, and terminates in the popliteal vein. It communicates, round the medial side of the leg, with the great saphenous vein, and through the deep fascia with the deep veins, and it contains from six to twelve bicuspid valves.

Tributaries.-It receives tributaries from the lateral side of the foot, from the lateral side and back of the heel, from the back of the leg, and occasionally a descending tributary from the back of the thigh. Just before it pierces the popliteal fascia it frequently gives off a small branch which ascends round the medial side of the thigh and unites with the medial superficial femoral vein to form the accessory saphenous vein. In this way a communication is established between the great and small saphenous veins, which may become enlarged, and not uncommonly it constitutes the main continuation of the small saphenous vein.

\section{THE PORTAL SYSTEM.}

The portal system includes the veins which convey blood from almost the whole of the abdominal and pelvic parts of the alimentary canal, and from the spleen and pancreas, to the liver. The tributaries of origin of these veins agree closely with the terminal branches of the corresponding arteries. They are single vessels, which for some distance accompany the corresponding arteries, and are similarly named. The larger or terminal veins, however, leave their associated arteries; the inferior mesenteric vein joins the splenic vein, and the latter unites with the superior mesenteric vein to form the portal vein, which passes to the liver. These veins, together with their tributaries, constitute the portal system. Al] the larger vessels of this system are devoid of valves, but valves are present in the tributaries.

Vena Portæ.-The portal vein is a wide venous channel, about $75 \mathrm{~mm}$. (three inches) long, which conveys blood from the stomach, from the whole of the intestine, except the terminal portion of the rectum, and from the spleen and pancreas to the liver. Unlike other veins, it ends like an artery, by breaking up into branches which ultimately terminate in capillaries in the substance of the liver; from these capillaries, which also receive the blood conveyed to the liver by the hepatic artery, the hepatic veins arise; and since these open into the inferior vena cava, the portal blood ultimately reaches the general systemic circulation.

The portal vein commences by the union of the superior mesenteric and the splenic veins, posterior and to the left of the neck of the pancreas, and either anterior to the left border of the inferior vena cava, at the level of the body of the first lumbar vertebra, or in front of the upturned extremity of the processus uncinatus of the head of the pancreas. It ascends, anterior to the inferior vena cava and posterior to the neck of the pancreas and the first part of the duodenum, to the lower border of the epiploic foramen (Winslow), where it passes forwards, in the right gastro-pancreatic fold of peritoneum, and enters the lower border of the gastro-hepatic ligament. Continuing its upward course, it lies posterior to the bile-duct and hepatic artery, and anterior to the epiploic foramen (Winslow); it ultimately reaches the right end of the porta hepatis, where it ends by dividing into a short and wide right and a longer and narrower left branch. Just before its termination it enlarges, forming the sinus of the portal vein.

The right branch generally receives the cystic vein and then enters the right lobe of the liver, in which it breaks up into numerous branches which terminate in the portal capillaries around the periphery and in the substance of the liver lobules.

The left branch runs from right to left along the porta hepatis, giving off 
branches to the caudate and quadrate lobes; it crosses the umbilical fossa, and ends in the same manner as the right branch, but in the substance of the left lobe of the liver.

As it crosses the umbilical fossa, the left branch of the portal vein is joined anteriorly by the round ligament of the liver, a fibrous cord which is the remains of the left lateral umbilical vein of the fœtus. One or more small veins which accompany the ligamentum teres connect the left branch of the portal vein with the superficial veins round the umbilicus. Somewhat to the right of the attachment of the round ligament anteriorly, a fibrous cord springs from it

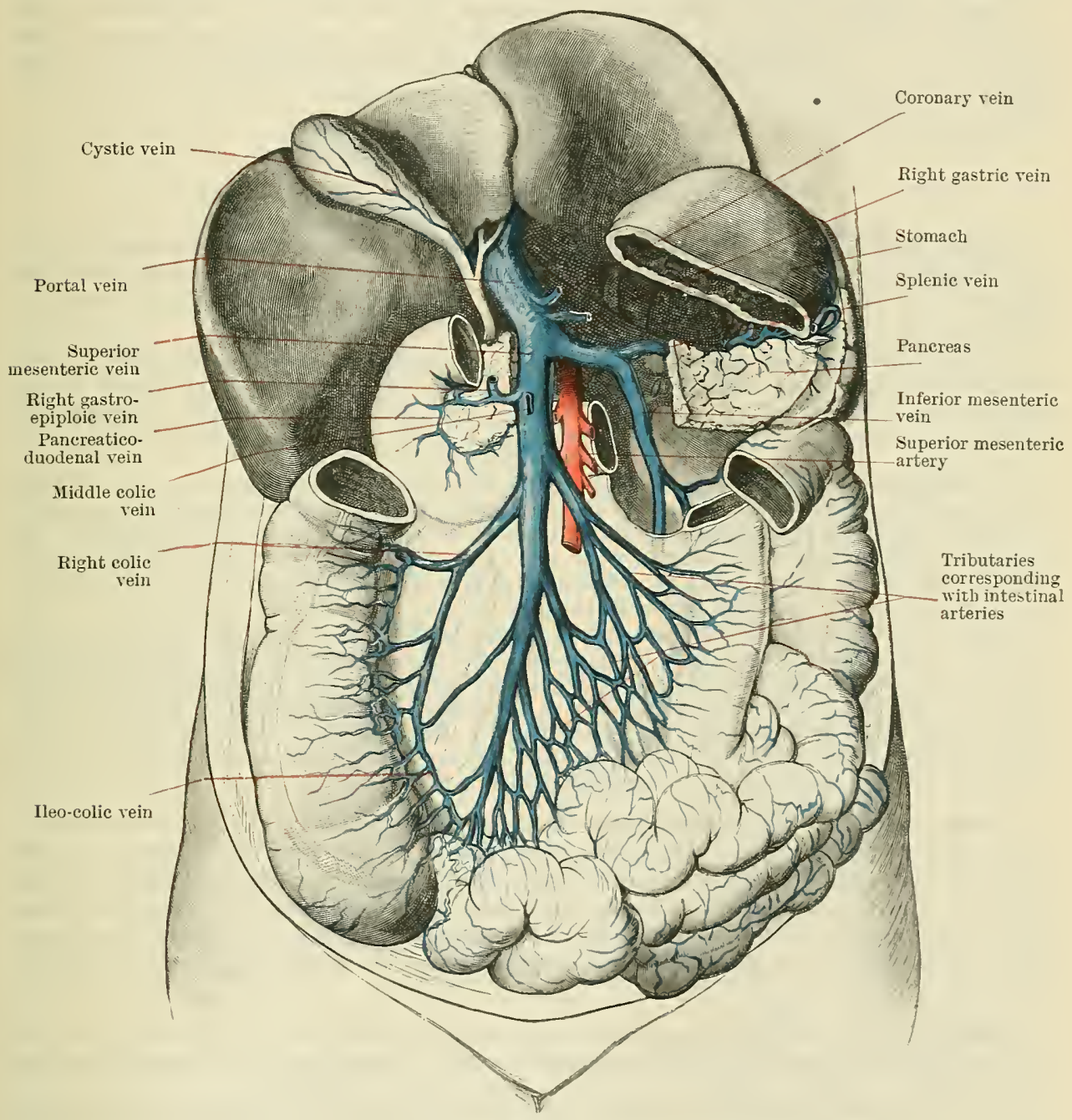

Fig. 796.-The Portal Vein and its Tribotaries.

posteriorly and connects it with the upper part of the inferior vena cava; this cord is the ligamentum venosum. It is the remains of the ductus venosus, a blood-vessel of the fotus, through which blood, carried from the placenta by the umbilical vein, passed into the inferior vena cava without going through the liver.

The portal vein is accompanied by numerous lymph ressels, and it is surrounded, in the lesser omentum, by filaments of the hepatic plexus of nerves.

Tributaries.- Soon after its formation the portal vein receives the coronary and right gastric veins, and the cystic vein opens into its right branch.

Vena Coronaria Ventriculi.- The coronary vein commences in the lesser omentum by the union of tributaries from both surfaces of the stomach. It runs to the left 
between the layers of the lesser omentum, and along the lesser curvature of the stomach, with the left gastric artery, to the œesophagus, where it receives œesophageal tributaries. It then turus posteriorly, in the left gastro-pancreatic fold, and reaches the posterior wall of the abdomen, where it again changes its direction to run from left to right, behind the omental bursa, to the right gastro-pancreatic fold, at the root of which it opens into the portal vein.

The right gastric vein is a small vessel which is formed by the union of tributaries from the upper parts of both surfaces of the stomach. It runs from left to right along the right portion of the lesser curvature, between the layers of the lesser omentum, and terminates in the portal vein, after that vessel has entered the lesser omentum.

Vena Cystica.-The cystic vein is formed by the union of tributaries which accompany the branches of the cystic artery on the anterior and posterior surfaces of the gall-bladder; it ascends along the cystic duct and, as a rule, terminates in the right branch of the portal,vein. Some small veins pass directly from the gall-bladder into the substance of the liver.

\section{The Mesenteric and Splenic Veins.}

Vena Mesenterica Superior.-The superior mesenteric vein commences in the right iliac fossa in connexion with the lower part of the ileum. It ascends along the right side of the superior mesenteric artery, in the root of the mesentery, forming a curve with the convexity to the left.

As it ascends it passes anterior to the right ureter, the lower part of the inferior vena cava, the third part of the duodenum, and the uncinate process of the head of the pancreas; and, after passing behind the root of the transverse mesocolon, it terminates, behind the neck of the pancreas, by uniting with the splenic vein to form the portal vein.

Its tributaries correspond with the branches of the superior mesenteric artery. It is formed by the union of the ileo-cæeal and appendicular veins. Anteriorly and towards the left side it receives intestinal tributaries (venæ intestinales) from between the layers of the mesentery; the right colic and ileo-colic veins enter its right side; the middle colic vein joins it anterior to the lower border of the head of the pancreas, and close to its termination it receives the right gastro-epiploic and the pancreatico-duodenal veins.

The right gastro-epiploic vein runs from left to right along the lower border of the stomach, and between the two anterior layers of the greater omentum. It receives tributaries from both surfaces of the stomach, and near the pylorus turns posteriorly in the right gastro-pancreatic fold of peritoneum, passes in front of the neck of the pancreas, and ends in the superior mesenteric vein.

The pancreatico-duodenal vein receives tributaries from the head of the pancreas and the adjacent parts of the duodenum; it ascends along the superior pancreatico-duodenal artery, and terminates in the upper part of the superior mesenteric vein.

Vena Lienalis. - The splenic vein is formed by the union of five or six tributaries which issue from the hilus on the gastric surface of the spleen. It passes posteriorly and medially, in the lieno-renal ligament, to the kidney, then, turning to the right, it runs behind the upper border of the pancreas and below the splenic artery ; it crosses the front of the abdominal aorta, immediately below the origin of the coliac artery, and terminates, behind the neck of the pancreas, by joining the superior mesenteric vein to form the portal vein.

Tributaries.-It receives the vasa brevia or short gastric veins, the left gastro-epiploic vein, the pancreatic veins, and the inferior mesenteric vein. Occasionally the coronary vein terminates in it.

The short gastric veins are a series of small venous channels which gather blood from the region of the left portion of the greater curvature of the stomach; they pass backwards towards the spleen, in the gastro-splenic ligament, and terminate either in the trunk of the splenic vein or in one of its main tributaries.

The left gastro-epiploic vein runs from right to left along the lower border of the stomach between the layers of the greater omentum. At the left extremity of the lower part of the greater curvature of the stomach it enters the gastro-splenic ligament, throngh which it passes towards the hilus of the spleen, and it terminates in the commencement of the splenic vein. It receives tributaries from both surfaces of the stomach.

The pancreatic veins issue from the substance of the pancreas, and terminate directly in the splenic vein.

The inferior mesenteric vein commences, as the superior hæmorrhoidal vein, in the venous plexus which lies between the muscular and mucous coats of the rectum. The superior hæmorrhoidal vein drains the greater part of the blood from the hæmorrhoidal plexus, through which it communicates with the middle and inferior hæmorrhoidal veins. It ascends, in company with the superior hæmorrhoidal artery and between the layers of the pelvic mesocolon, 
to the aperture of the pelvis minor, where it passes in front of the left common iliac artery and becomes the inferior mesenteric vein.

The inferior mesenteric vein runs upwards, on the left of the aorta, behind the peritoneum and in front of the left psoas major muscle and the left internal spermatic artery. Near its termination it crosses in front of the left renal vein, and, passing behind the body of the pancreas, ends in the splenic vein. Occasionally it terminates in the angle of union of the superior mesenteric and splenic veins.

Tributaries.-In addition to the superior hæmorrhoidal vein, of which it is the direct continuation, the inferior mesenteric vein receives sigmoid tributaries from the iliac and pelvic colon, and the left colic vein from the descending colon and left colic flexure.

\section{THE LYMPH VASCULAR SYSTEM.}

The vessels of the lymph vascular system, vasa lymphatica, contain a colourless fluid, rich in white corpuscles, which is called lymph.

In many respects the lymph vessels resemble blood-vessels, especially veins, and, like the veins, many of the lymph vessels, but not all, contain numerous valves, which control the direction of the circulation. Unlike the veins, however, the lymph vessels communicate directly with the great serous cavities of the body, by openings called stomata; and also unlike the veins, the continuity of the lymph vessels is interrupted by interposed nodular aggregations of lymphoid tissue which are known as lymph glands.

The corpusculated fluid called lymph, which fills the interiors of the lymph vessels, is partly collected from the serous cavities, through the stomata already mentioned, and, in part, it passes into the vessels from the surrounding tissues. It is carried by the lymph vessels to the veins; for the smaller lymph vessels gradually unite together to form larger and larger channels until, ultimately, all the lymph passes into two main trunks - the thoracic duct, which terminates in the commencement of the left innominate vein, and the right lymphatic duct, which ends in the beginning of the right innominate vein.

Obviously, therefore, all the lymph vessels are afferent inasmuch as they carry the lymph towards the great central vessels, but it is customary to speak of some of the lymph vessels as vasa afferentia and others as vasa efferentia, the former heing vessels which carry lymph to lymph glands, and the latter, those which convey the lymph from more peripheral towards more central glands.

The lymph vessels merely collect and convey lymph; the lymph glands probably serve in part as filters and in part as the sources of origin of some of the lymph corpuscles, which are called lymphocytes and become white blood corpuscles when they enter the blood stream.

In its course from the tissues to the bloodvessels the greater part, if not the whole, of the lymph passes through one and generally through more than one lymph gland.

All parts of the body which possess blood-ressels, except the central nerrous 
system, the eye and the internal ear, are plentifully provided with lymph channels, which are divided, according to their positions, into superficial and deep vessels.

The superficial lymph vessels lie in the skin and subcutaneous tissues; they frequently accompany the superficial veins and, in the limbs, they join the deep vessels in definitely localised situations.

The deep lymph vessels drain the Iymph from all parts of the body which lie internal to the deep fascia; they tend to accompany the blood-vessels of the various parts and organs.

The lymph glands also are divided into superficial and deep groups. The former lie in the superficial fascia and are comparatively few in number. They are associated more particularly with the superficial lymph vessels of the limbs. The deep lymph glands of the limbs are also comparatively few in number, but those of the head, neck, and trunk are very numerous.

Vasa Lymphatica.-The smaller lymphatics are channels of various shapes but of greater calibre than the blood capillaries. They anastomose freely together, forming lymphatic plexuses.

Their walls are formed by a single layer of endothelial cells of irregular shape and sinuous outline, which are in close contact, externally, with the tissue elements amidst which they lie. In some cases lymph vessels, or plexuses of lymph vessels, surround the blood-vessels forming perivascular lymph channels. It has been generally believed that such perivascular channels are numerous in the central nervous system, but the researches of Bruce tend to show that, whilst the lymphocytes travel along the walls of the blood-vessels of the central nervous system, they pass along cleft-like spaces in the adventitial sheaths, and not in distinct perivascular channels.

As the lymph vessels attain a larger size their walls are strengthened by the deposition of a layer of elastic fibres on the outer surface of the endothelial coat. The fibres run longitudinally, and in some cases fuse together to form a fenestrated elastic membrane.

The walls of all the largest lymph vessels, like those of the blood-vessels, are formed by three tunics, external, middle, and internal. The tunica intima consists of a layer of endothelium covered externally by elastic fibres or fenestrated elastic membrane. The tunica media is formed of transverse and oblique unstriped muscle fibres intermingled with elastic fibres. The tunica externa consists of longitudinal connective tissue elements with which are intermingled oblique and longitudinal unstriped muscle fibres; the latter feature being peculiarly characteristic, for it is not met with in the blood vascular system, except in the walls of the large veins.

Biscupid valves formed by semilunar folds of the tunica intima are extremely numerous in the lymph vascular system. They are either absent or they are few and incompletely developed in the small vessels and the lymph plexuses, but they are very prevalent in the larger vessels; consequently when the latter are injected they assume a modulated outline. Valves are present also at the entrances of the great lymph channels into the venous system.

Lymphoglandulæ.-Lymph glands are globular, ovoid, flattened, or irregular bodies, and each gland presents a localised depressed area which is known as the hilus. They vary considerably in size, some being no larger than a pin's-head, whilst others are as large as a bean. In colour they are usually grayish pink, but the tint varies with the position, vascularity, and state of activity of the gland. The glands of the lung are generally blackened by the deposition of carbonaceous material in their substance, and those of the liver and spleen frequently have a brownish hue. The glands of the mesentery are creamy or white whilst the chyle is rapidly passing through them, but when the absorption of food-material from the intestine ceases they become a rosy pink.

The lymph glands are embedded in the connective tissues, some lying superficially in the subcutaneous tissues, but the majority more deeply and usually at the sides of the great blood-vessels. As a rule, they are arranged in groups of from two to fifteen, but a few of those which lie in the subcutaneous tissues are solitary.

They form centres to which afferent lymphatic vessels converge, and from which efferent vessels pass onwards to other glands or to the larger lymph channels. 
The student should therefore acquaint himself with the various groups of glands, with their afferents and efferents, and with the exact position and relations of the large lymphatic trunks; he will then be in a position to understand the course which minute organisms or particles, which have gained access to the lymph spaces, may take as they are carried in the lymph stream; and he will realise that such structures may either be entangled in the glands through which the lymph passes, or, having escaped all obstructions, that they will finally enter the veins at the root of the neck. At the same time, if he bears in mind the existence of the numerous anastomoses between the lymph vessels, he will have no difficulty in appreciating that variations from any regular course may not infrequently occur, and his clinical experience at a later period will show that such variations are by no means uncommon.

Structure of Lymph Glands.-Lymph glands consist of (1) a skeleton or framework, (2) lymph sinuses, and (3) lymph follicles and cords; and each gland is separable into cortex and medulla. The cortex lies immediately internal to the capsule, except at the hilus, where it is absent. The medulla forms the internal part of the gland, and reaches the surface at the hilus.

(1) The skeleton or framework consists of a capsule and of primary, secondary, and tertiary trabeculæ.

The capsule is formed of white fibrous tissue, interspersed with elastic fibres, and in some cases with unstriped muscular fibres.

The primary trabeculce spring from the deep surface of the capsule and radiate through the cortex into the medulla. In the cortex they are flattened lamellæ, but as they reach the medulla they break up into flattened, rounded, and angular bands which unite freely together; their structure is the same as that of the capsule, and from their surfaces the secondary trabeculæ are given off. The secondary trabeculce spring from the surfaces of the primary trabeculæ, cross the lymph sinuses and enter the follicles of the cortex and the cords of the medulla, where they terminate by dividing into tertiary trabeculæ. As they cross the lymph sinuses they unite together freely, forming a fine mesh-work through which the lymph passes in its course from the afferent to the efferent vessels. The secondary trabeculæ consist of fine strands of fibrous tissue devoid of nuclei, and their surfaces are covered with endothelial cells. The tertiary trabeculce are finer and more delicate than the secondary trabeculæ, from the terminations of which they spring, but they have a similar structure. They unite together, forming a fine network in the lymph cords and follicles, and the spaces of the network are filled with lymph corpuscles.

(2) The lymph sinuses lie internal to the capsule and around the primary trabeculæ which form their boundaries on one side, whilst on the other they are limited by the lymph cords and follicles. They are traversed by the secondary trabeculæe, and their channels are thus converted into a kind of sponge-work through which the lymph stream flows. In the cortical parts of the glands they form more or less cylindrical channels, but in the medulla they become moniliform. Afferent vessels enter the sinuses of the cortex, and the efferent vessels emerge from the medulla at the hilus.

The lymph follicles lie in the cortical portions of the lymph glands, where they form the inner boundaries of the lymph sinuses. They consist of dense masses of lymphoid cells, embedded in a stroma formed by the tertiary trabeculx, and they are continuous internally with the lymph cords of the medullary substance.

The lymph cords are continuous with the lymph follicles, and have the same structure, but they lie in the medullary portions of the glands; they are cord-like and not nodular in shape, and they form the peripheral boundaries of the lymph sinuses of the medulla.

The Blood-Vessels of the Lymph Glands.-Blood-vessels are distributed to the capsule and through the capsule to the primary trabeculæ of the glands; but the main blood-ressels to each gland enter the hilus and ramify in the lymph cords and follicles, amidst the tertiary trabeculæ which are connected with the walls of the vessels.

Hæmal Lymph Glands.-In various parts of the body, but more particularly in the retro-peritoneal region, and especially along the line of the abdominal aorta, a number of bodies may be found which have all the ordinary structural characters of lymph glands, but they differ from lymph glands inasmuch as some of their sinuses contain blood. These structures are called hæmal lymph glands. The siuuses of the hæmal lymph glands which contain lymph are in continuity with lymphatics, whilst the blood-filled sinuses open into blood-vessels. It is stated that communications exist between the blood and the lymph containing sinuses of the hæmal lymph glands, but the evidence ou this point is not quite satisfactory.

Hæmal Glands.-The term "hæmal gland" is applied to nodules possessing the structure of ordinary lymph glands, but which contain only blood in their sinuses: they probably belong, however, as their development shows, to the lymph vascular and not to the blood vascular system (see p. 1042). 


\section{THE TERMINAL LYMPH VESSELS.}

The terminal lymph vessels are the thoracic duct and the right lymphatic duct.

Ductus Thoracicus. - The thoracic duct is by far the larger and the longer of the two terminal lymph vessels. It commences in the epigastric region of

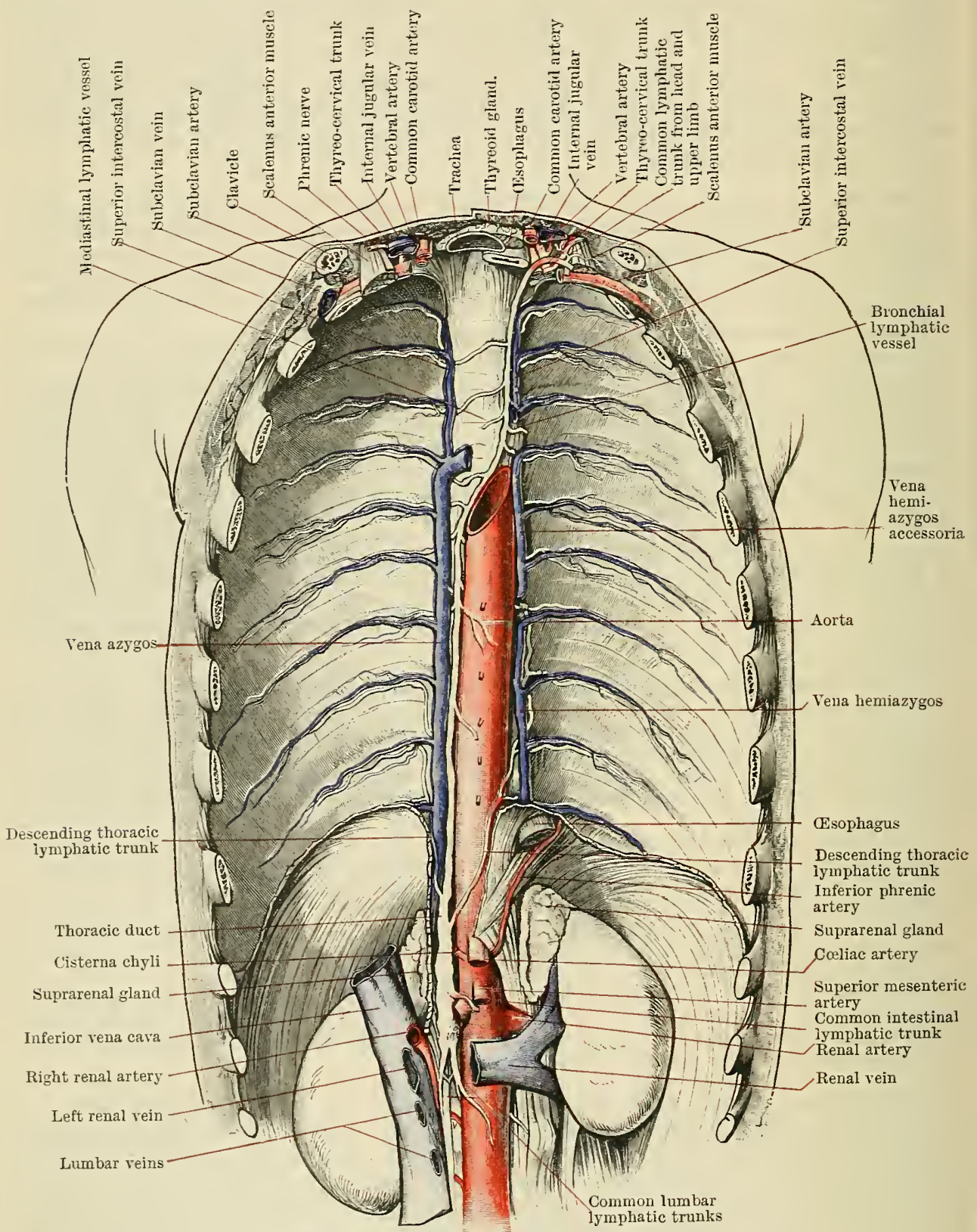

Fig. 798.-The Thoracic DUCt and its Tributaries.

the abdomen as an elongated ovoid dilation - the cisterna chyli-which measures 6 to $8 \mathrm{~mm}$. ( $\frac{1}{4}$ to $\frac{1}{3}$ in.) in its broadest diameter, and from 50 to $75 \mathrm{~mm}$. ( 2 to $3 \mathrm{in}$.) in length. The cisterna chyli lies between the aorta and the lower part of the vena azygos, posterior to the right crus of the diaphragm, and opposite the first and second lumbar vertebræ. Passing upwards from the cisterna, the thoracic duct traverses the aortic opening of the diaphragm and enters the posterior 
mediastinum, through which it ascends, lying anterior to the vertebral column and to the right of the median plane, to the level of the fifth thoracic vertebra; it then crosses somewhat abruptly from the right to the left of the median plane, and ascends through the superior mediastinum to the root of the neck, where it turns laterally, between the vertebral and common carotid arteries, and it terminates, at the medial border of the scalenus anterior, by joining the left innominate vein at its commencement.

Length and Diameter.-The total length of the duct averages about $45 \mathrm{~cm}$. (18 inches). It is dilated at both its origin and termination. As a rule it is narrowest opposite the fifth thoracic vertebra, but its calibre is very variable, and sometimes the thoracic portion is broken up into a series of anastomosing channels. The widest portion of the tube is usually the cisterna, but occasionally this dilatation is entirely absent. The dnct is provided with several valves, formed by semilunar folds of the tunica intima, arranged in pairs, and the most perfect of these is situated at or near the orifice of communication with the left innominate vein.

Relations. - In the abdomen the cisterna chyli lies anterior to the upper two lumbar vertebræ and the corresponding lumbar arteries, between the aorta on the left and the rena azygos and the right crus of the diaphragm on the right. In the posterior mediastimum the thoracic duct is separated from the vertebral column and the anterior longitudinal ligament by the right aortic intercostal arteries and the transverse parts of the hemiazygos and accessory hemiazygos veins; it is covered, in front, in the lower part of its extent by the right pleural sac, and in the upper part by the œsophagus; to its right is the vena azygos, and to its left the descending aorta. In the superior mediastinum it passes forwards from the vertebral column, and it is separated from the left longus colli muscle by a mass of fatty tissue; the cesophagus lies in front of it in this region, but the left margin of the duct projects beyond the osophagus, and is in relation anteriorly, and from below upwards, with the termination of the arch of the aorta, the left subclavian artery and the pleura. As the duct enters the root of the neck it passes behind the left common carotid artery, whilst to its right and somewhat anteriorly is the œsophagus, and the left pleura is still in association with its left border.

At the root of the neck it arches laterally above the apex of the pleura sac and the first part of the left subclavian artery. It passes anterior to the vertebral artery and vein, the roots of the inferior thyreoid, transverse cervical, and transverse scapular arteries, the medial border of the scalenus anterior and the left phrenic nerve, and posterior to the left carotid sheath and its contents.

Tributaries. - The cisterna chyli commonly receives five tributaries. Truncus Intestinalis.-The intestinal trunk, which is formed by the efferents of mesenteric and upper pre-aortic glands, and conveys lymph from the lower and anterior part of the liver, the stomach, the small intestine, the spleen, and the pancreas. (2) Two trunci lumbales, one on each side; they are formed by the efferents of the lumbar glands. They carry lymph from the lower extremities, from the deep portions of the abdominal and pelvic walls, the large intestine and the pelvic viscera, and from the kidneys, suprarenal glands, and genital glands. (3) Two descending lymphatic trunks, one on each side, each of which is formed by the efferent vessels from the corresponding lower intercostal glands; these descend to the cistema through the aortic opening of the diaphragm. Occasionally they unite to form a single trunk, and in others they, or the tributaries from which they are usually formed, open directly into the thoracic duct (Figs. 797, 798).

In its course through the posterior mediastium the thoracic duct receives efferents from the upper and posterior part of the liver, and from the posterior mediastinal and osophageal glands; the latter carry lymph from the csophagus, the pericardium, and the left side of the thoracic wall.

In the superior mediastinum the ressels which open into it are derived from the upper left intercostal glands; it receives lymph also from the heart and lungs by efferents from the left peritracheo-bronchial glands and the intertracheobronchial glands, though as a rule the efferents of these glands unite with the internal mammary lymphatic to form a common trunk which may open either into the thoracic duct or into the innominate rein. In the superior mediastinum, therefore, it may receive lymph from the upper and median part of the abdominal wall, 
the liver, the diaphragm, the wall of the thorax, and the mammary gland of the left side, the thymus, the pericardium, the left lung, and the left part of the heart.

At the root of the neck, just before its termination, it receives the efferents from the glands of the left upper extremity, which frequently unite to form a subclavian trunk, and the left jugular trunk, which conveys the lymph from the left side of the head and neck; but either of these vessels or both of them may end separately in the innominate vein.

Ductus Lymphaticus Dexter.-The right lymphatic duct (Fig. 798) is not always present. It is a short trunk, from 12 to $17 \mathrm{~mm}$. (half to three-quarters of an inch) in length, which lies at the right side of the root of the neck along the medial border of the scalenus anterior, and it is formed by the confluence of (1) the right jugular trunk, (2) the right subclavian trunk, and (3) the right broncho-mediastinal trunk, which carries lymph from the bronchial, posterior, and anterior mediastinal and sternal glands. It thus receives lymph from the right side of the head and neck, the right upper limb and the right side of the trunk, including the upper part of the thoracic wall, the right lung and pleura, the right half of the heart and pericardium, the right side of the diaphragm, and the upper surface of the liver. As a rule, the right lymphatic duct is not present as a definite stem, and the right jugular trunk carrying the lymph from the head and neck, the right subclavian trunk bearing lymph from the right upper extremity, and the right broncho-mediastinal trunk, end separately in the upper part of the right innominate vein, but any two of the three main trunks of the right side may unite together. The right broncho-mediastinal trunk may also communicate below with the thoracic duct.

\section{LYMPH GLANDS OF HEAD AND NECK.}

\section{THE LYMPH GLANDS OF THE HEAD.}

All the lymph glands of the head are extracranial.

Lymphoglandulæ Occipitales.-The occipital lymph glands, two or three in number, lie in or deep to the deep fascia upon the upper part of the trapezius muscle, or, if the trapezius is small, upon the upper part of the semispinalis eapitis or on the splenius muscle. They receive afferent vessels from the occipital region of the scalp and from the superficial parts of the upper and back portion of the neck. Their efferents terminate in the deep cervical glands. Some of the lymph vessels of the occipital region pass directly to the deep cervical glands (Fig. 799).

Lymphoglandulæ Auriculares Posteriores.-The posterior auricular lymph glands (O.T. mastoid) lie on the upper part of the sterno-mastoid muscle and on the mastoid portion of the temporal bone, and they are bound down by a sheathing of deep cervical fascia. They receive afferent vessels from the posterior part of the parietal region of the scalp, and from the medial surface of the auricle. Their efferents join the superficial and the deep cervical glands (Fig. 799).

Lymphoglandulæ Faciales Profundæ.-The deep facial lymph glands are very variable both in number and size; they lie in association with the internal maxillary artery on the external pterygoid muscle, or on the adjacent part of the wall of the pharynx. Their afferent vessels are derived from the orbit, the temporal fossa, the infra-temporal fossa, the palate, the nose, and the cerebral meninges. Their efferent vessels open into the upper deep cervical glands.

Lymphoglandulæ Auriculares Anteriores.-The anterior auricular lymph glands (O.T. parotid) lie both superficial and deep to the parotid fascia on the lateral surface of the parotid gland. They receive afferents from the frontal and the temporal regions of the scalp, from the eyebrow, the upper and lower eyelids, the upper part of the cheek, the root of the nose, and the lateral surface of the auricle. Their efferents pass to the superficial and the upper deep cervical glands, and to the parotid lymph glands (Fig. 799).

Lymphoglandulæ Parotideæ. - The parotid lymph glands (O.T. deep parotid glands) lie embedded in the deeper parts of the parotid gland. They receive afferents 
from the external acoustic meatus, the tympanum, the soft palate, the posterior part of the nose, and the deeper portions of the cheek. Their efferents open into the upper deep cervical glands.

The Superficial Facial Lymph Glands.-Several lymph glands, or groups of lymph glands, have been found in the region of the face but, apparently, they are irregular, both in occurrence and in position. Those which appear to be most frequently found are: Infra-orbital, which lie along the angle between the nose and the cheek, and below the margin of the orbit. Their afferents are derived from the

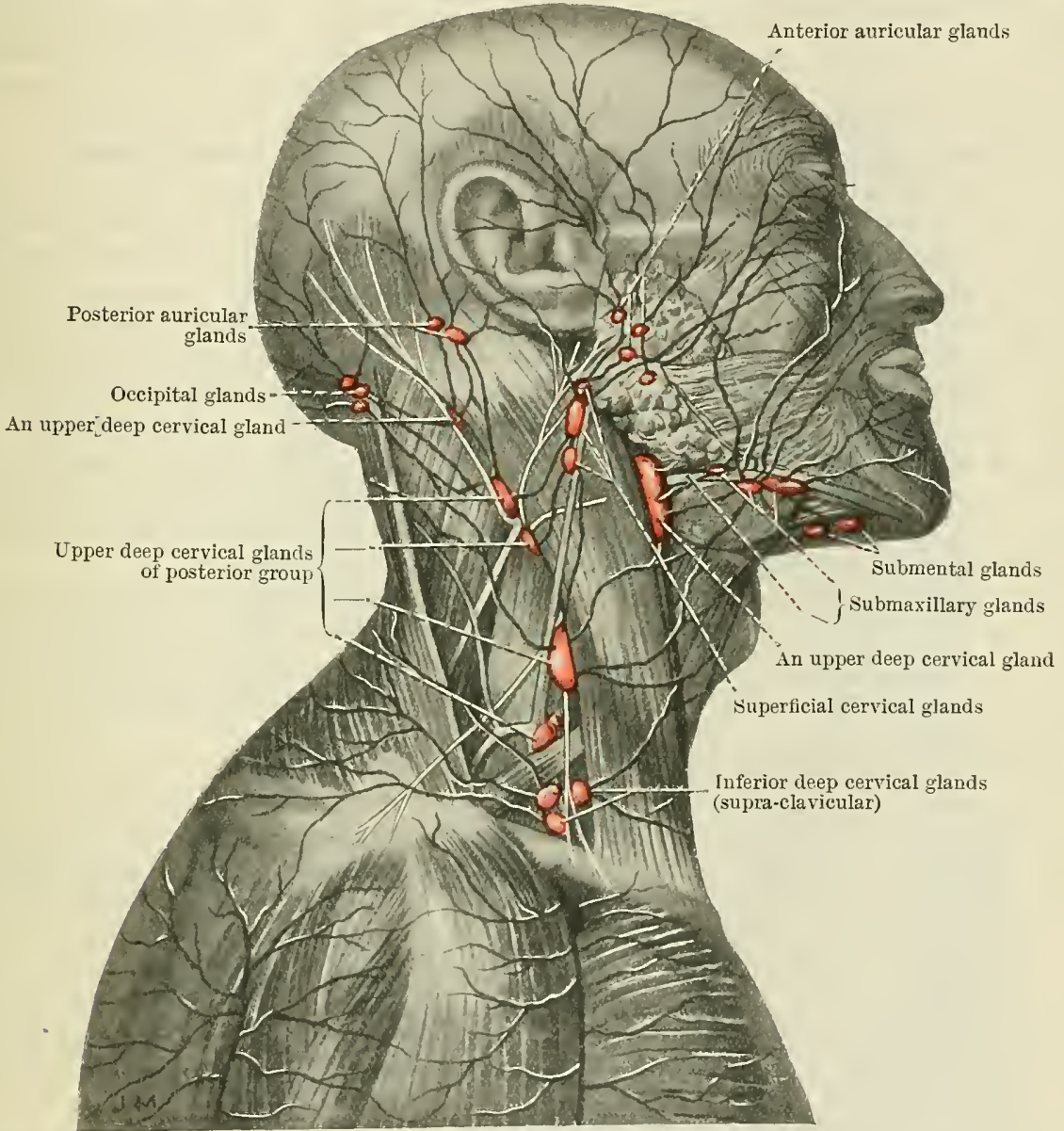

Fig. 799.-Lymph Gtands of the Head and Neck as seen when the Stenno-Mastoid Is in its USUAL POSITION. The occipital and the posterior and anterior auricular glands are inserted in accordance with descriptions. The other glands were present in one or other of the two bodies from which the drawing was made. Compare Fig. 801.

surrounding parts; and their efferents pass to the anterior auricular and the submaxillary lymph glands. Buccinator lymph glands have been found on the superficial surface of the anterior part of the buccinator, both anterior and posterior to the anterior facial vein. Those posterior to the vein usually lie close to the point where the parotid duct turns medially round the anterior border of the masseter. They receive lymph from the eyelids and cheeks, and transmit it to the anterior auricular glands. Supra-mandibular lymph glands lie superficial to the mandible at the anterior border of the masseter, between the anterior facial vein and the external maxillary artery. They receive lymph from the region of the lower lip, and transmit it to the anterior auricular and superficial cervical glands.

Lymphoglandulæ Linguales. - The lingual lymph glands lie between the genioglossi muscles and, on the lateral surfaces of the hyo-glossi and genio-glossi muscles, 
deep to the mylo-hyoid muscles; they are simply small lymph nodules interposed in the course of the lymphatics which are passing from the tongue and the floor of the mouth to the deep cervical glands.

\section{THE LYMPH GLANDS OF THE NECK.}

Lymphoglandulæ Cervicales Superficiales.-The superficial cervical lymph glands lie on or are embedded in the deep fascia along the course of the external jugular vein, superficial to the sterno-mastoid (Fig. 799). They receive afferent vessels from the superficial tissues of the neck, the posterior and anterior auricular, and the submaxillary lymphatic glands. Their efferent vessels terminate in the upper deep cervical glands and the supra-clavicular glands. The uppermost superficial cervical glands are sometimes described as infra-auricular glands.

Lymphoglandulæ Submaxillares.-The submaxillary lymph glands vary in number from three to six. They lie under cover of the deep fascia of the neck in the angle between the lower border of the mandible and the submaxillary gland, and the largest of the series is usually situated near the point where the external maxillary artery turns round the lower border of the mandible (Fig. 800). Occasionally some smaller gland nodules are found on the deep surface of the submaxillary gland, but these are comparatively rare. The afferent vessels of the submaxillary lymph glands carry lymph from the side of the nose, the upper lip, the lateral part of the lower lip, the anterior third of the border of the tongue, the gums, the submaxillary and sublingual glands, and the adjacent parts of the floor of the mouth. The efferents descend over the superficial surface of the submaxillary gland, and terminate in the upper deep cervical glands, more particularly in those in the immediate neighbourhood of the termination of the common carotid artery.

Paramandibular Lymph Gland.- This term is applied to one or more lymph glands which lie inside the capsule of the submaxillary gland, in close relation with the gland or embedded in its substance. They receive lymph from the gland and the adjacent parts of the mouth and transmit it to the submaxillary and deep cervical glands.

The Submental Lymph Glands lie below the chin superficial to the mylo-hyoid muscles and between the anterior bellies of the two digastric muscles. There are usually two on each side, a medial or superior close to the median plane, and a lateral or inferior on the anterior border of the anterior belly of the digastric. They are apt to become enlarged in diseased conditions of the middle part of the lower lip, the adjacent part of the gums, the anterior part of the floor of the mouth, the tip of the tongue, and the skin beneath the chin, for their afferent vessels drain those parts. The efferents from this group of glands pass partly to the submaxillary lymph glands, and partly to a deep cervical gland situated on the superficial surface of the internal jugular vein at the level of the cricoid cartilage (Figs. 799, 800, 801).

Lymphoglandulæ Retropharyngeæ.-The retro-pharyngeal lymph glands lie posterior to the upper part of the pharynx, embedded in the fascia covering the superior constrictor muscle. They are separable into two groups, lateral and median.

The lateral retro-pharyngeal glands, 1-3, appear to be constant both in children and adults. Each lateral gland, or group of glands, lies at the level of the atlas, anterior to the upper part of the longus capitis, and posterior to the internal carotid artery.

The median retro-pharyngeal glands, commonly present in children and frequently absent in adults, lie at the same level as the lateral glands, but in the median plane. They are irregular in number and size.

The retro-pharyngeal lymph glands receive lymph from the adjacent muscles and bones, from the nasal part of the pharynx, from the auditory tube and tympanum, and from the posterior parts of the nasal cavities. Their efferents pass to the medial and the lateral deep cervical glands.

Lymphoglandulæ Cervicales Anteriores.-The lymph glands of the anterior part of the neck are separable into two groups, superficial and deep.

The superficial anterior cervical lymph glands are very irregular in number and 
size. When they are present they lie in association with the anterior jugular veins. The exact origin of their afferents and the terminations of their efferents are unknown, but it is probable that they receive lymph from the superficial tissues of the anterior parts of the neck, and transmit it to the lower deep cervical glands.

The deep anterior cervical lymph glands are-

(a) Infra-hyoid glands, which lie anterior to the hyo-thyreoid membrane. They receive lymph from the region of the epiglottis and transmit it to the deep cervical glands. They are not constantly present.

(b) The prelarynyeal gland, which lies either anterior to the cricoid cartilage or to the crico-thyreoid ligament. Its occurrence is very constant. It receives

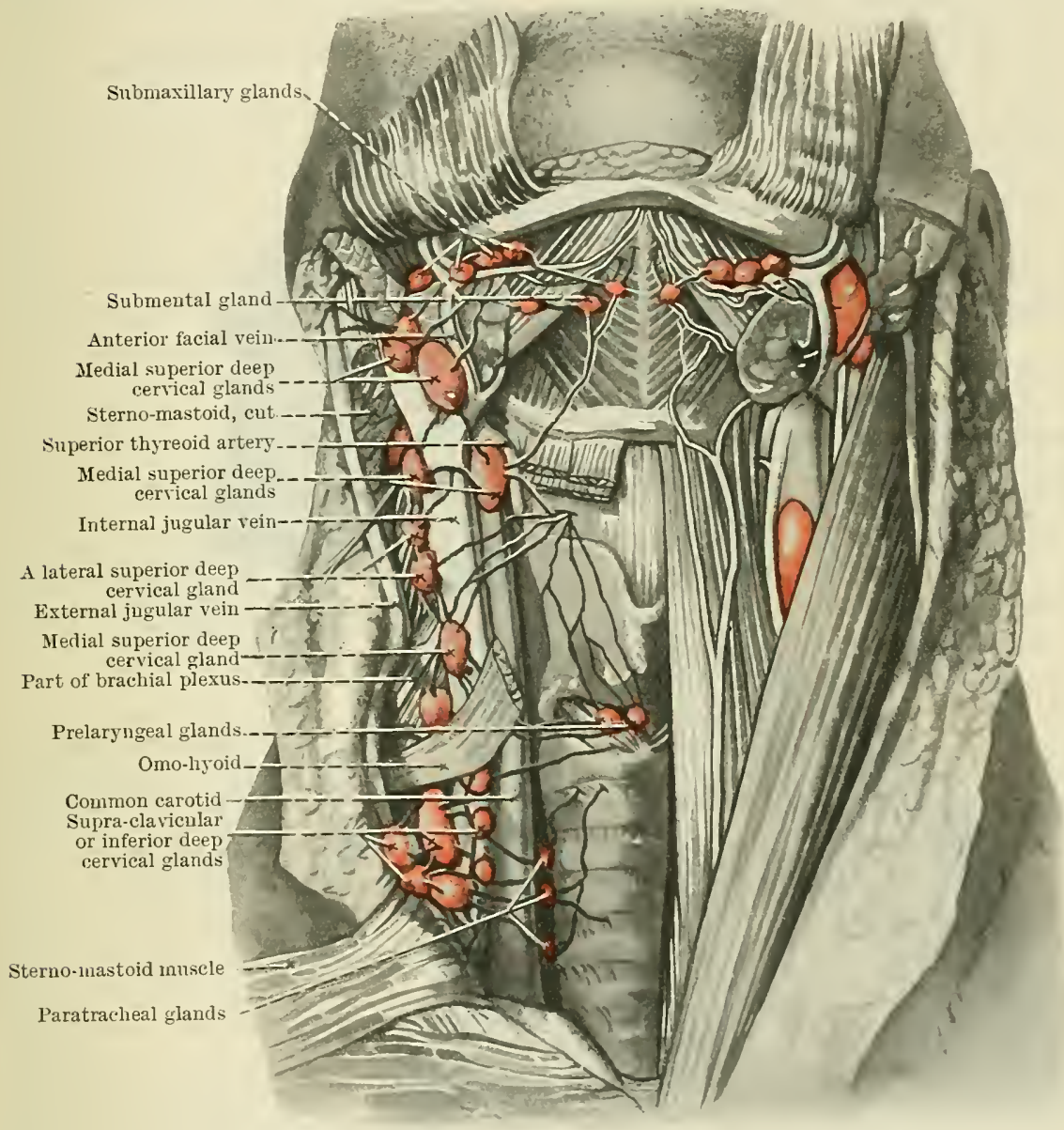

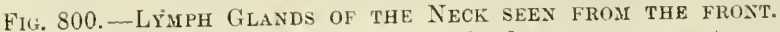

Infra-hyoid glands and pretracheal glands were not present.

lymph from the anterior part of the larynx and from the isthmus and the adjacent parts of the lateral lobes of the thyreoid gland. Its efferents terminate in the deep cervical and the pretracheal glands.

(c) The pretracheal lymph glands are numerous small nodules which lie along the inferior thyreoid veins. They receive lymph from the trachea, the lower part of the larynx, and from the lateral lobes and the isthmus of the thyreoid gland; and they transmit it to the lower deep cervical glands.

(d) The paratracheal lymph glands lie along the sulcus between the larynx and the trachea anteriorly and the pharynx and cesophagus posteriorly, in association with the branches of the superior and inferior thyreoid arteries and the recurrent nerves. They receive lymph from the adjacent parts and transmit it to the deep cervical glands (Fig. 800). 
Lymphoglandulæ Cervicales Profundæ Superiores et Inferiores.-The deep cervical lymph glands lie in the anterior and posterior triangles of the neck and under cover of the sterno-mastoid muscle. They form a more or less continuous sheet of gland nodules and inter-communicating lymph vessels; but the glands are divided into two main groups, the $(a)$ superior, and $(b)$ inferior, and each group is separable into (1) medial, and (2) lateral components.

(a) The Superior Deep Cervical Lymph Glands.-(1) The medial group of upper deep cervical lymph glands lies on the superficial surface of the internal jugular vein and in the carotid triangle of the neck. One of the largest, which is closely associated with the tongue, lips, gums, cheeks, and the outer part of the nose, is

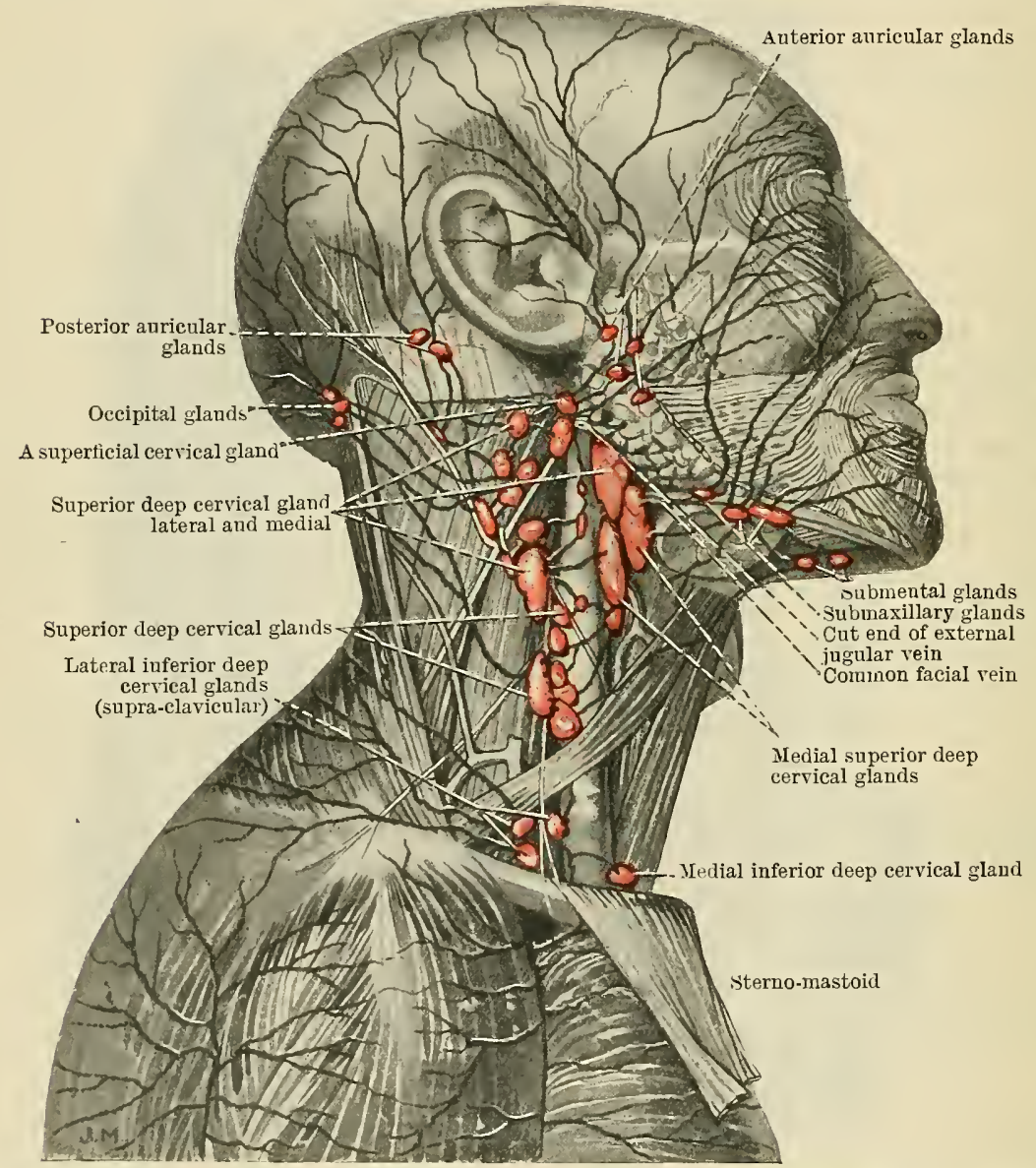

Fig. 801.-Lympe Glands of the Head and Neck as seen after the Removal of the SternoMastom Muscle. The anterior and posterior auricular and the occipital glands are inserted in accordance with descriptions. The other glands were present in one or other or in both the bodies from which the figure was made. Compare Fig. 799.

frequently situated in the region of the union of the common facial vein with the internal jugular veiu. The lowest gland of the group, which receives a communication from the submental glands, lies on the lateral surface of the internal jugular vein immediately above the omo-hyoid muscle. The highest members of the group may be under cover of the postero-medial surface of the parotid gland, in association with the posterior belly of the digastric muscle. (2) The members of the lateral group of superior deep cervical lymph glands lie under cover of the posterior part of the upper portion of the sterno-mastoid, and in the upper part of the posterior triangle of the neck. They are embedded in the fat-laden fascia which covers the roots of the cervical plexus and the upper part of the brachial plexus, 
and the levator scapulæ and the scalene muscles, and several of them are in close relation with the accessory nerve (Fig. 801).

The superior deep cervical glands are connected by afferent vessels with the various groups of glands which lie in the regions of the pharynx, the face, and the upper part of the neck. They receive lymph, therefore, from the nose, the mouth, the tongue, the upper parts of the pharynx and larynx, the tonsil, the upper part of the thyreoid gland, the submaxillary, sublingual, and parotid salivary glands, and from the interior of the cranium. Their efferents pass either to the inferior deep cervical glands or to the jugular lymph trunk. In some cases the medial and lateral members of the superior group are connected with the corresponding members of the lower group only, but in other cases the medial or lateral members of the superior group may be connected with both the medial and the lateral members of the inferior glands.

The inferior deep cervical lymph glands (Figs. 800, 801), which are also termed the supra-clavicular glands, are situated below the level of the omo-hyoid muscle. (1) The members of the medial group lie in relation with the lower part of the internal jugular vein, opposite the interval between the sternal and the clavicular heads of the sterno-mastoid. They receive afferents from the members of the upper medial group and from the pretracheal and the paratracheal glands and from the upper part of the thorax. Their efferents unite with some of the efferents of the upper medial group and pass with them to the jugular lymph trunk.

(2) The members of the lateral group of inferior deep cervical glands lie in the subclavian triangle, in the fatty tissue superficial to the lower part of the brachial plexus and the third part of the subclavian artery. They receive lymph from the lower parts of the neck, from the upper part of the thorax, and from the upper lateral glands. They receive lymph also from the deep parts of the mammary gland, and they are in communication with the axillary glands. Their efferents join the jugular lymphatic trunk.

\section{THE LYMPH VESSELS OF THE HEAD AND NECK.}

The lymph vessels and the head and neck may be separated into two groups, intracranial and extracranial.

Intracranial Lymph Vessels and Lymph Spaces.-The cerebro-spinal fluid which fills the ventricles of the brain, the central canal of the spinal medulla, and the subarachnoid and subdural spaces, differs in chemical constitution from true lymph; nevertheless it plays the part of lymph, to some extent, and there can be little doubt that some of it eventually passes into lymph vessels; therefore it may be considered as a modified form of lymph. The fluid is secreted by the chorioid plexuses of the cerebral ventricles, and it passes through the medial and lateral foramina of the fourth ventricle into the cerebello-medullary subarachnoid cistern. Part of the fluid transudes through the arachnoideal granulations into the superior sagittal and other cerebral blood sinuses; and part, probably, passes by osmosis into the subdural space and thence into the meningeal lymphatics, by which it is conveyed to the exterior of the cranium.

Cerebral Lymph Channels. - It appears probable that the so-called peri-vascular and pericellular lymph spaces which have so frequently been described in the central nervous system are merely artifacts produced by unsatisfactory methods of preparation. Nevertheless, the fluid which pervades the cerebral substance must have some exit, and it is not unlikely that it passes, with the lymphocytes, through cleft-like intercommunicating spaces in the adventitial coats of the blood vessels, similar to those demonstrated by Bruce in the case of the spinal medulla, and so reaches the pia-mater and subaraclinoid space; that is, it runs along the walls of the arteries, enters the meningeal lymphatics, and passes through them to the exterior of the cranium and where it enters the extracranial lymph vessels. The above statements are based upon Bruce's researches and the fact that the lymph vessels of the nose, the ear, and the deep lymph vessels of the neck have been injected from the subdural space.

The Superficial Lymph Vessels of the Head.-(1) The superficial lymplatics from the frontal and anterior temporal regions of the head accompany the branches of the superficial temporal artery and terminate in anterior auricular glands, from which efferents pass to the parotid, the superficial cervical, and to the medial glands of the superior deep cervical gromp.

(2) The lymphaties of the posterior temporal and parietal region run to the posterior auricular glands. It is stated that they sometimes communicate directly with the lateril glands of the superior deep cervical group.

(3) The lymphatics from the occipital part of the scalp pass along the branches of the occipital artery and terminate in the occipital glands, which transmit the lymph to the lateral superior deep cervical glands. 
The Superficial Lymph Vessels of the Neck. - The majority of the lymph vessels from the skin and the subcutaneous tissues of the upper part of the neck pass to the inferior deep cervical glands, but some end in the occipital glands and others in the superior deep cervical glands.

The superficial lymph channels of the lower part of the neck terminate in the axillary glands.

The Lymph Vessels of the Eyelids and the Conjunctiva.-The lymph vessels which drain the region of the eyelids and the conjunctiva form two groups, a medial and a lateral. (a) The medial vessels pass from the superficial and deeper parts of the medial portions of the superior and inferior eyelids and, following the course of the angular and the external maxillary arteries, they pass to the submaxillary lymph glands. The more superficial vessels lie anterior, and the deeper vessels posterior to the orbicularis oculi. Both groups may be connected with infra-orbital and the anterior buccinator glands. (b) The lymph vessels from the lateral parts of the eyeluds pass posteriorly along the line of the transverse facial artery. They end in the anterior auricular and the parotid lymph glands. In some cases they become connected also with the buccinator and superficial cervical glands.

Lymph Vessels of the Eyeball.-It is doubtful if any true lymph vessels exist in the eyeball. Lymph spaces have been described in association with the coats of the eyeball, and lymph vessels are stated to exist in the chorioid coat, but their existence is uncertain. The sinus venosus scleræ (Schlemm), formerly locked upon as a lymph channel, is probably a venous canal. If lymph vessels are absent then the fluids in the tissues and spaces of the eye must pass into

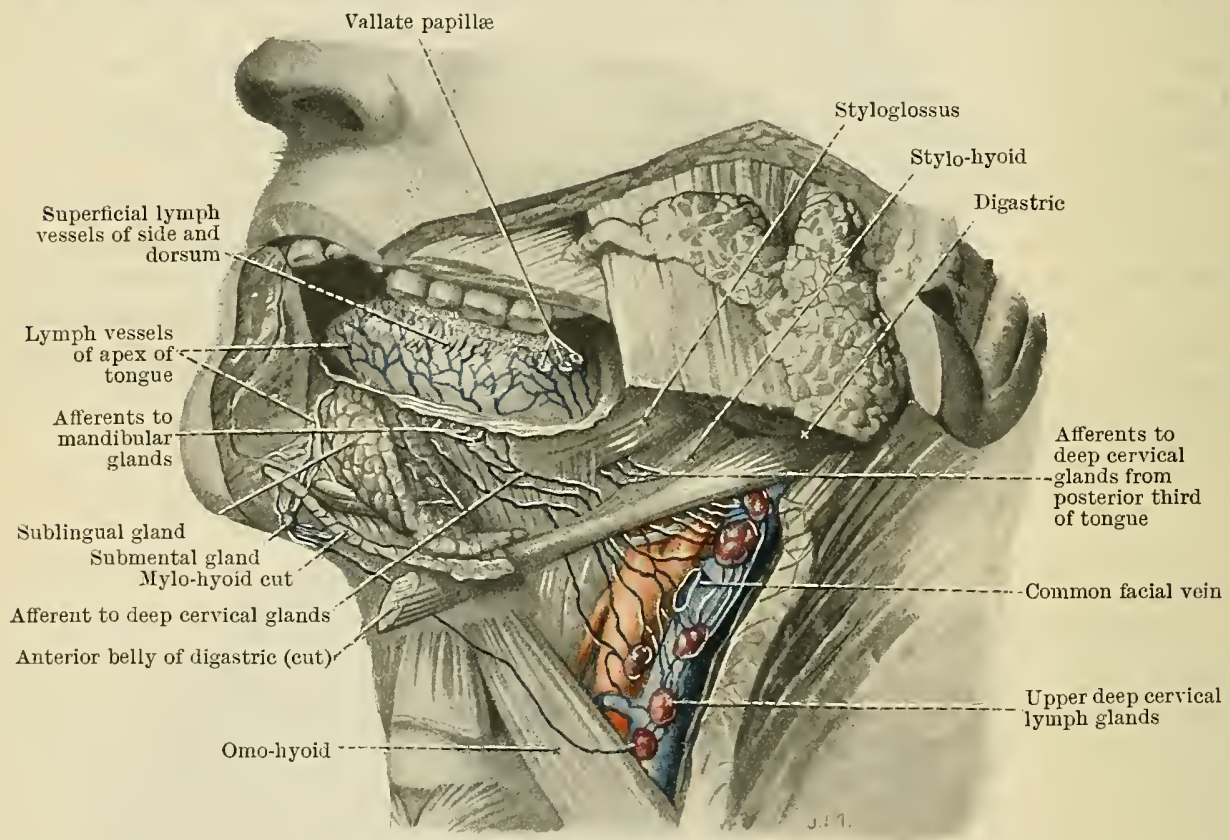

Fig. 802.-LxMrh Vessels of the Tongue.

the capillaries of the veins, unless channels exist in the adventitia of the vessels similar to those described by Bruce in the spinal medulla.

The Lymph Vessels of the Far.-The lymph vessels from the upper and lateral parts of the auricle end in the anterior auricular glands. Those from the lower part of the auricle go to the upper superficial cervical glands. The lymph channels from the medial surface of the auricle end in the posterior auricular glands, but in a few cases they establish direct communication with the superior deep cervical glands.

The lymph vessels of the external acoustic meatus end in the anterior and posterior auricular glands.

The lymph vessels of the middle ear pass in two directions. Those from the more laterally situated parts of the walls of the cavity join the vessels of the external acoustic meatus aud terminate in the posterior auricular glands. The lymph vessels which drain the more medial parts of the middle ear and the auditory tube terminate in the lateral retro-pharyngeal glands.

It is doubtful if any lymph vessels exist in the internal ear. It is possible that the perilymph drains into the subarachnoid space of the posterior fossa of the skull along the line of the ductus endolymphaticus and that the endolymph reaches the subarachnoid space along the fibres of the acoustic nerve.

The Lymph Vessels of the Nose.-The lymph vessels from the external part of the nose form two groups, superior and inferior. The superior group accompany the vessels from the lateral parts of the eyelids and end in the anterior auricular glands. The inferior group accompanies the angular and the external maxillary arteries, and the majority of the vessels end 
in the submaxillary glands, but in some cases one or more vessels of this group pass to the upper superficial cervical glands.

The Lymph Vessels of the Nasal Muco-periosteum. - The ressels from the anterior part of the nasal muco-periosteum accompan $\mathrm{T}$ the vessels of the lower portion of the external part of the nose and end in the submaxillary glands. Those from the posterior part of the muco-periosteum end partly in the medial superior deep cervical glands, and partly in the lateral retro-pharyngea] glands.

There is little definite knowledge regarding the lymph vessels of the accessory sinuses of the nose, but it is probable that they follow the lines of the bloodvessels which supply the mucoperiostem of the cavities.

The Lymph Vessels of the Lips.-The ressels from the skin of the medial part of the lower lip pass to the submental glands and, occasionally, direct to the superior deep cervical glands. The ressels from the deeper parts of the lower lip unite with those from the upper lip and end in the submaxillary glands, but some of the superficial vessels of the upper lip may end in the superficial cervical glands.

The Lymph Vessels of the Cheeks. - The majority of the

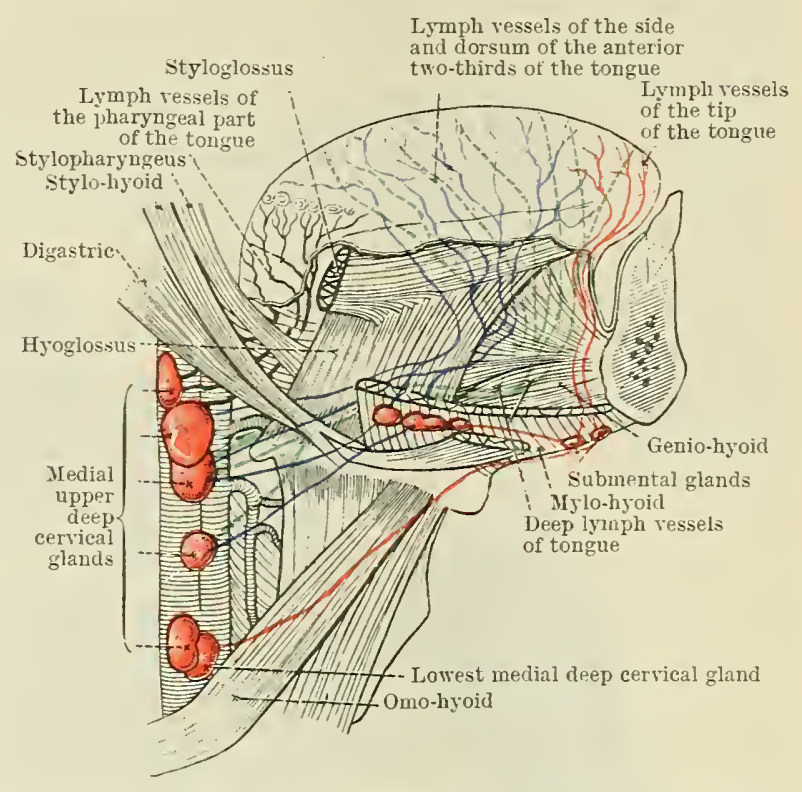

Fig. 803.-Diagram of Side-view Origins axd Terminatioxs of THE LyMPh Tessels of the Toxgue. (After Poirier, modified.)

superficial and deep lymph ressels of the cheeks pass to the submaxillary glands, but in some cases they communicate directly with the superficial or with the superior deep cervical glands. They may communicate also with the buccinator glands.

The Lymph Vessels of the Gums. - The ressels from the onter part of the anterior portion

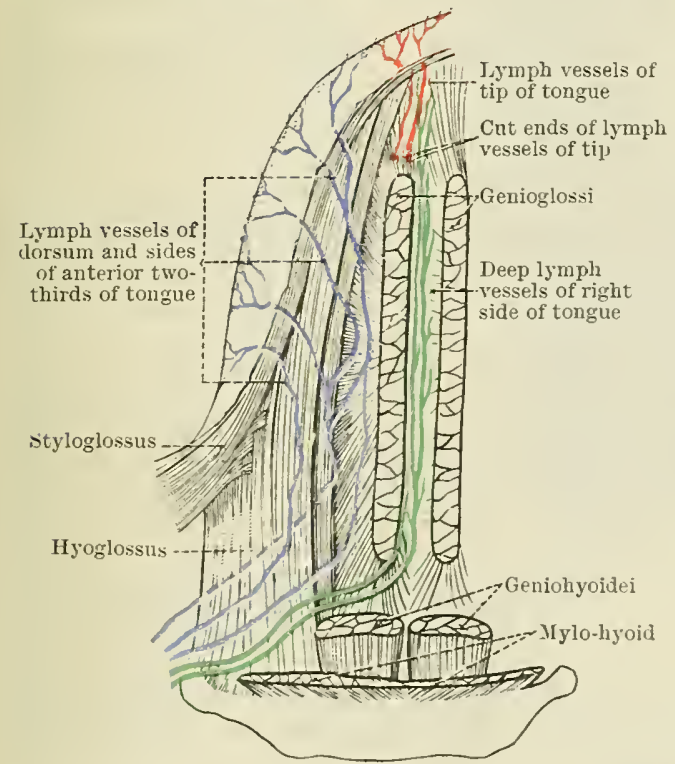

Fig. 804. - Dlagray of LyMph Vessels of Axterior TWO-THIRDS OF TONGUE, SEEX FROM BELOW: (After Poirier, modifiecl.)

The Lymph Vessels of the Tongue. - The lymph ressels of the tongue form three groups(1) anterior, (2) middle, (3) posterior. 'The anterior and midrle gromps commumcate freely with each other and with their fellows of the opposite side, but the posterior group have little or no communication with the middle gromp (1) The anterior lymph vessels drain the tip and the mental glands. Those from the posterior part, together with the vessels fiom the outer part of the gum of the maxilla, terminate in the submaxillary glands. The ressels of the gum of the maxilla may also communicate with the buccinator glands.

The ressels from the inner part of the gum of the mandible end in the submaxillary glands; those of the inner part of the gun of the maxilla, together with the ressels of the hard and the soft palate, end in the medial superior deep cervical glands.

The Lymph Vessels of the Teeth. It is known that lymph vessels exist in connexion with the teeth of the mandible as well as with the mandible itselt; but their terminations are not definitely established. It is probable that they end in the submaxillary or the superior deep cervical glands.

The lymph ressels of the teeth of the maxilla pass partly into the infra - orbital canal and so to the face, where they join the vessels from the lateral parts of the eyelids, and terminate in the anterior auricular and submaxillary glands. The remaining vessels of the maxillary teeth nd in the submaxillary glands.

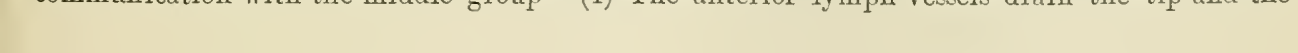


lower surface of the anterior free portion of the tongue. The main trunks pierce the mylohyoid muscle and end in the submental glands. (2) The middle group of lymph vessels of the tongue drain the anterior two-thirds, exclusive of the tip, and they terminate partly in the submaxillary glands and partly in the medial superior deep cervical glands. Small lingual glands are intercalated in the course of some of these ressels. (3) The posterior lymph vessels drain the portion of the tongue which lies in the anterior wall of the pharynx posterior to the papillæ vallate; they pass to the medial smperior deep cervical glands. (4) The lymph vessels from the deeper central portions of the tongue go mainly to the upper deep cervical glands.

The Lymph Vessels of the Salivary Glands.-The lymph vessels of the parotid gland terminate in the parotid and superior deep cervical lymph glands. The lymph vessels of the submaxillary gland terminate, according to Most, not in the submaxillary lymph glands but in the medial superior deep cervical glands. Practically nothing is known of the lymph vessels of the sublingual gland.

The Lymph Vessels of the Pharynx.-From the upper part of the pharynx, and from the posterior wall and lateral borders of the middle and lower parts, the lymph stream flows to the median line posteriorly. There the larger vessels pierce the walls of the pharynx, then they turn laterally and end in the lateral retro-pharyngeal glands.

From the lower and anterior part of the pharynx, that is, from the region of the piriform recesses and the adjacent part of the larynx, the lymph vessels pass along the course of the laryngeal branch of the superior thyreoid artery, pierce the hyo-thyreoid membrane and

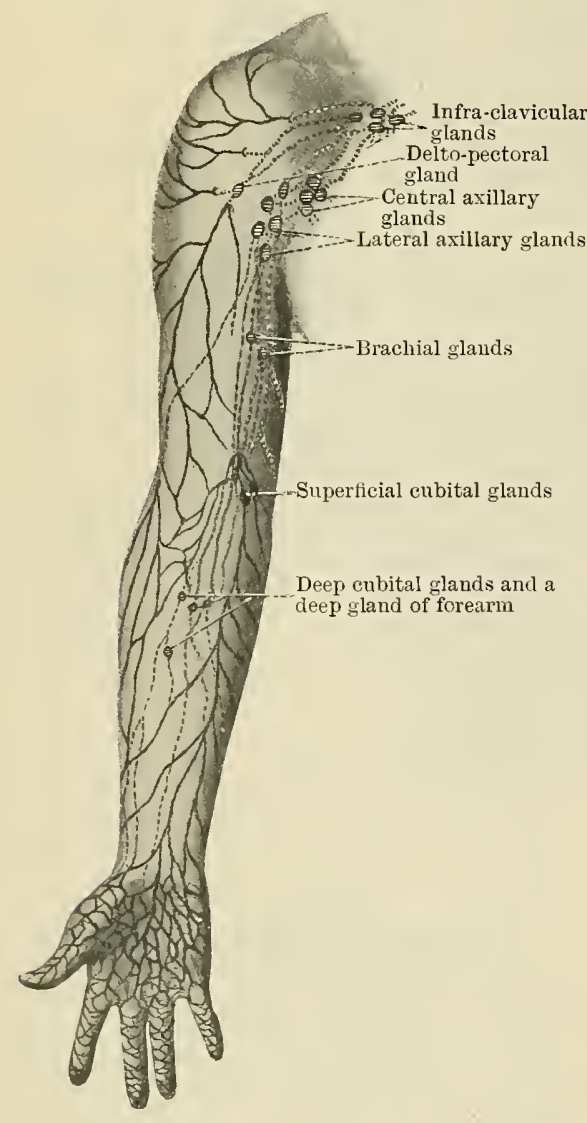

F1G. 805.--SCHEMA OF THE LyMPH Vessels AND GLands of the UpPER Extremity. terminate in the medial superior deep cervical glands; they may be connected also with the infra-hyoid, and with the prelaryngeal glands.

The lymph vessels of the palatine tonsil and the adjacent parts of the glosso-palatine and pharyngo-palatine arches pierce the lateral wall of the pharynx and end in a gland, or group of glands, which lies on the lateral surface of the internal jugular vein, immediately below the posterior belly of the digastric at the level of the angle of the mandible.

The Lymph Vessels of the Thyreoid Gland.-The lymph vessels of the thyreoid gland form a plexus common to both lobes and the isthmus, therefore the lymph can pass from the lobe of one side to the terminal glands of the opposite side. The terminal vessels end in the prelaryngeal, the pretracheal, the paratracheal, the superior and inferior deep cervical, and the upper mediastinal glands.

The Iymph Vessels of the Larynx.-The lymph plexus of the larynx is separable into upper and lower portions; they are connected together on the posterior wall of the cavity, but are separated, laterally and anteriorly, by the plice vocales which contain extremely few lymph vessels. The efferent stems of the upper part pass mainly along the laryngeal branch of the superior thyreoid artery, and they end in the superior deep cervical glands, but are frequently connected also with the infra-hyoid glands. The efferent vessels from the lower part of the larynx form two subordinate groups. Those from the anterior region pierce the median crico-thyreoid ligament and end in the prelaryngeal, the pretracheal, and the deep cervical glands. The efferents from the posterior region pierce the crico-tracheal membrane and end in the paratracheal glands (Fig. 800).

The Lymph Vessels of the Cervical Part of the Trachea and Esophagus. - The terminal vessels of the cervical part of the trachea and the adjacent portion of the osophagus and the paratracheal and the inferior deep cervical glands. From the mpper part of the trachea some vessels pass to the prelaryngeal glands also.

\section{LYMPH GLANDS OF THE SUPERIOR EXTREMITY.}

The lymph glands of the upper extremity form two groups-(1) superficial, (2) deep.

(1) Lymphoglandulæ Cubitales Superficiales.—The superficial cubital lymph 
glands, one or two in number, lie on the medial side of the basilic vein, a short distance proximal to the medial epicondyle of the humerus. They receive lymph from both aspects and from the ulnar border of the forearm, and their efferents pass to the deep glands of the arm.

(2) Lymphoglandulæ Cubitales Profundæ.-Occasionally small glands are found in association with the arteries of the forearm, but in most cases the lymph from the deeper parts of the hand and forearm, below the region of the elbow, passes to the deep cubital glands or to the brachial or axillary glands.

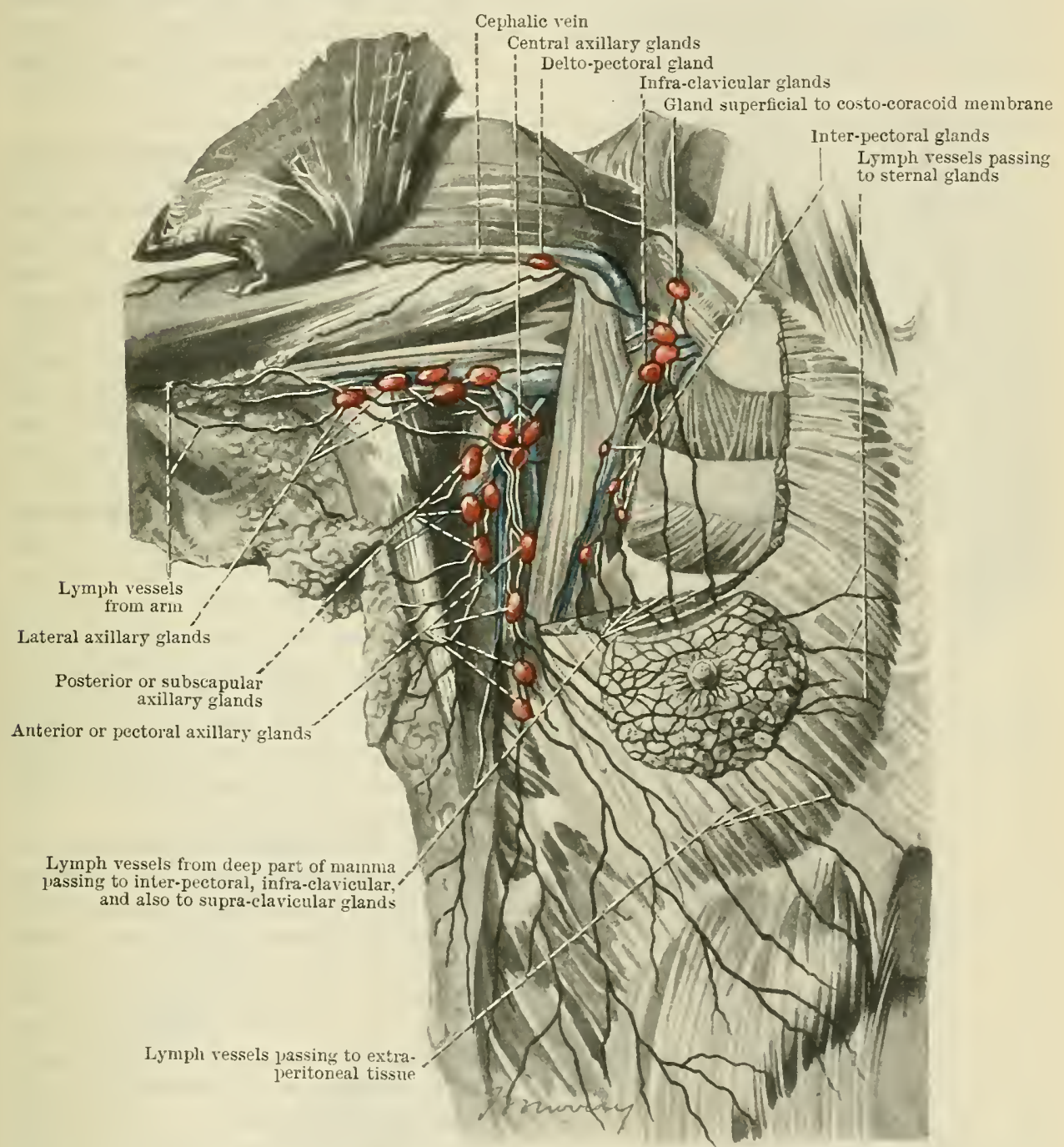

Fig. 806.-Dissection of Axilla axd Axterior Part of Thoracic ITall, showixg Lymph Glaxds AND Vessels. (Semi-diagrammatic.)

The deep cubital lymph glands lie anterior to the elbow in the neighbourhood of the terminal part of the brachial artery. They receive many of the deep lymph vessels of the forearm and their efferents pass to the brachial and axillary glands.

Brachial lymph glands, irregular in number and size, are found along the course of the brachial artery. Their afferents are derived from the forearm, from the deep cubital and superficial cubital glands, from adjacent parts, and from the elbowjoint. Their efferents end in lateral group of axillary glands.

In addition to the glands which lie along the course of the brachial artery other deep glands are occasionally met with in the arm. (1) One in the sulcus 


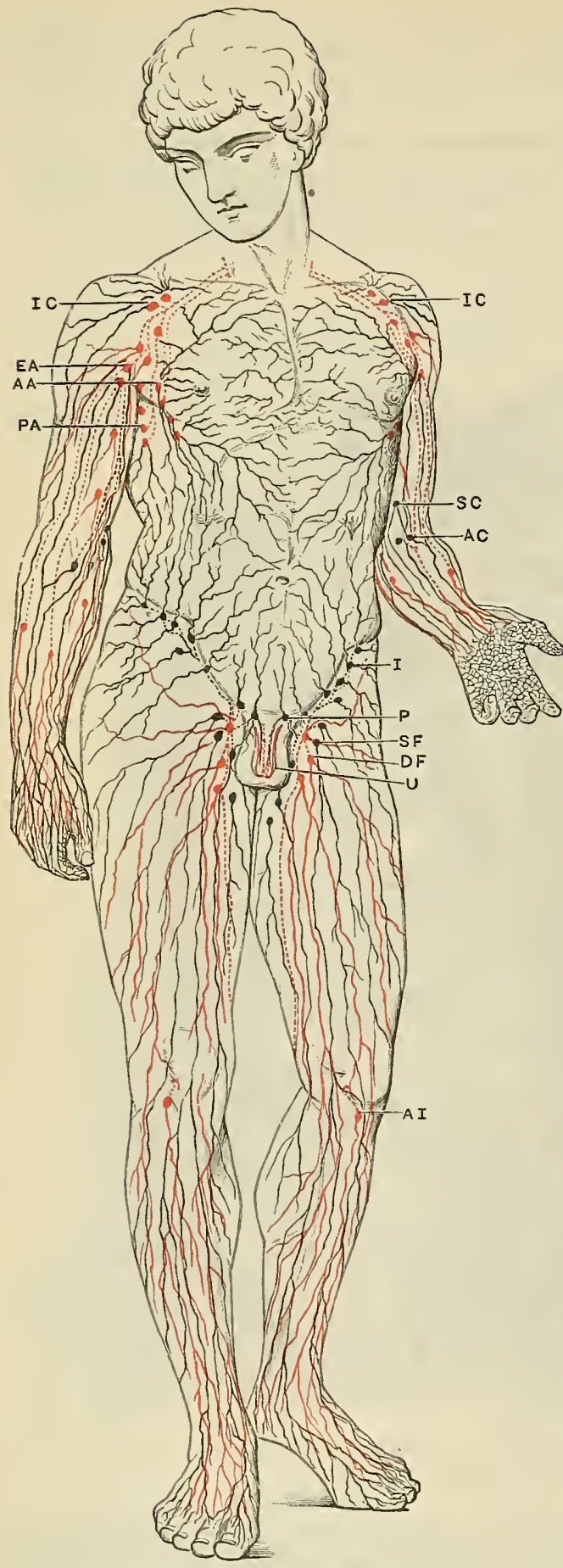

between the brachioradialis and the brachialis; (2) another in the radial sulcus. When they are present both of these glands receive lymph from the ligaments of the elbow-joint as well as from other adjacent soft parts.

Lymphoglandulæ Axillares. ${ }^{1}$ The axillary lymph glands lie in the region of the axilla, where they form several groups, some of which are practically constant, whilst others are very variable.

(a) The lateral or brachial group of axillary lymph glands, 1-7, lie in relation with the lateral boundary of the axillary space along the line of the great axillary vessels. They receive the lymph from the greater part of the upper extremity. Their efferents anastomose with the lymph vessels of the central glands; some terminate in the inferior deep cervical glands and others pass directly to the subclavian lymph trunk (Fig. 806).

(b) The posterior or subscapular lymph glands lie in relation with the posterior wall of the axilla, along the line of the subscapular vessels. Their afferents are the vessels of the lateral and posterior walls of the body, above the level of the umbilicus, and lymph vessels from the lower and posterior part of the neck. Their efferents join the lateral, the central, and the infraclavicular axillary glands (Fig. 806).

(c) The anterior or pectoral group of axillary lymph glands, 2-4, lie along the line of the lateral thoracic artery, in the angle between the lower border of the pectoralis major and the serratus anterior. They extend from the third to the sixth intercostal space, sometimes in a single and sometimes in a double row. Occasionally one or two outlying members of this group, called the paramammary glands, are found on the superficial surface of the pectoralis major. The afferents of the

1 The B.N.A. axillary lymph glands are the lateral glands of the axilla, but, as the other groups mentioned also lie in the axillary region, the general term "axillary" is used here to include all the groups.

Fig. 807.-SUPERfictal LiYMPH Vessels OF THE TRUNK, AND THE LyMph GLands and Vessels-SUPERFicial AND DEEP-OF THE LIMBS (diagranmatic). All super-

ficial lymph vessels are printed black; the deep lymph vessels throughout are coloured red. Afferent vessels are represented by continuous lines; efferent and interglandular vessels by dotted lines.

A.A. Anterior axillary glands. E.A. Lateral axillary glauds.

A.C. Superficial cubital glands. I. Superficial subinguinal glands.

A.I. Superficial tibial glands. I.C. Infra-clavicular or subclavian glands.

D.F. Deep subinguinal glands. P. Pubic glands.
P.A. Posterior axillary glands. S.C. Superficial cubital glands.

S.F. Subiuguiual glands.

U. Urethral lymphatics. 
anterior glands are derived from the anterior wall of the body above the umbilicus from the lateral two-thirds of the mamma. Their efferents pass to the central, lateral, and infra-clavicular axillary glands (Fig. 806).

(d) The central axillary lymph glands, 2-6, lie in the central part of the axilla, and frequently along the line of the intercosto-brachial nerve. They receive afferents from the anterior, the subscapular, and the lateral glands. Their efferents pass to the infra-clavicular glands (Fig. 806).

(e) The subpectoral group of axillary, lymph glands, 3-14, is formed by several small glands which lie posterior to the pectoralis minor and anterior or medial to the axillary artery. They receive lymph from the glands situated at a lower level and from the lateral wall of the thorax. Their efferents pass to the infra-clavicular glands.

$(f)$ The infra-clavicular group of axillary lymph glands, 1-11, lies in the region between the upper border of the pectoralis minor and the clavicle, along the medial side of the axillary artery. They receive efferents from the arm, from the other groups of axillary glands, and directly from the mamma and the pectoral muscles, along the line of the pectoral branches of the thoraco-acromial artery, and from the inter-pectoral glands. Their efferents pass to the inferior deep cervical glands and to the subclavian lymph trunk (Fig. 806).

(g) A delto-pectoral lymph gland is occasionally found in the groove between the deltoid and the pectoralis major muscles. It receives afferents from the superficial parts of the arm and the shoulder, and gives efferents to the subclavian trunk and to the infra-clavicular glands.

(h) Small inter-pectoral lymph glands are sometimes found between the great and small pectoral muscles. They are connected with the lymph vessels which pass from the posterior part of the mamma to the infra-clavicular glands (Fig. 806).

\section{THE LYMPH VESSELS OF THE SUPERIOR EXTREMITY.}

The lymph vessels of the upper extremity, like the glands, form two groups-(1) superficial, and (2) deep.

(1) The superficial lymph vessels lie in the skin and the subcutaneous tissues. They commence in cutaneous plexuses which are finest and most dense on the palmar aspects of the fingers and hand. The efferents from the volar digital plexus of each finger pass to the dorsum of the digit. There they unite to form dorsal digital vessels, 2-4, which run to the dorsum of the hand where they unite together to form new vessels.

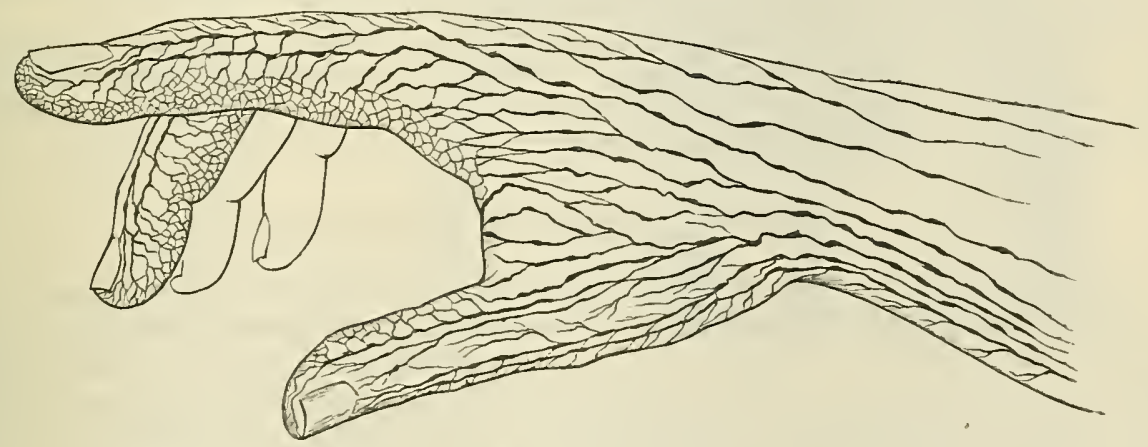

Fig. 80.5.-Seperficial Lymphatics of the Digits and of the Dorsal Aspect of the Haxd.

The efferents from the volar plexus of the hand rum proximally, distally, and to the lateral and medial margins of the hand. The lateral efferents, as they turn round the lateral border of the hand, join the efferents of the thumb. The medial elferents turn round the medial border of the hand, and join the efferents of the little finger. The afferents which run proximally are few and variable; when they are present they lie alung the line of the superficial median vein of the forearm. The efferents which run distally pass to the interdigital clefts where they turn dorsally and join the vessels on the dorsum of the hand (Figs. 807, 808).

As the superficial lymphatics pass towards the elbow they tend to form two main streams(1) a lateral stream which accompanies the cephalic vein, and (2) a medial stream which accompanies the basilic vein. The lymph vessels which commence on the dorsum of the hand and furearm converge to one or other of the two main groups of vessels. In the region of 
the elbow the ressels of the two streams anastomose together and some pass through the fascia and join the deep cubital glands.

As they pass from the forearm to the arm, the majority of the lymph vessels converge towards the medial side. Some join the superficial cubital glands, but others pass those glands and accompany their efferents, along the basilic vein, to the axilla where they join the lateral group of axillary glands. There is, however, a varying number of lymph vessels, from the lateral stream of the forearm, which accompany the cephalic vein in the arm. Some of these terminate in the delto-pectoral gland, if it is present, but, whether it is present or not, some pass directly to the infra-clavicular glands.

The superficial lymph vessels of the arm terminate, for the most part, in the lateral group of axillary glands.

The deep Iymph vessels of the upper extremity accompany the deeper blood-vessels. Some of the lymph vessels of the hand and forearm end in the deep glands, which are occasionally present in the forearm, but the majority either end in the deep cubital glands, or they pass directly to the lateral group of axillary glands.

The Lymph Vessels of the Mamma.-As the mamma is a modified skin gland, and as it is embedded in the superficial fascia, the lymph vessels which issue from it pass first into the superficial fascia and thence into the deep fascia. Having traversed the deep fascia, more or less obliquely, they either end in lymph glauds or enter and traverse other layers of the body wall.

The main outflow of lymph from the substance of the mamma is towards the areola, where a subcutaneous plexus of lymph vessels is formed. From this plexus two or more main vessels of large size pass laterally (Fig. 806), pierce the deep fascia and join the anterior group of axillary glands. There are, however, other groups of vessels by which lymph may pass from the namma. Some vessels issue from the medial border of the gland and run along the lines of the neighbouring anterior perforating branches of the internal mammary artery to the anterior ends of the intercostal spaces, where they pass through the deeper parts of the thoracic wall and end in the sternal lymph glands. Clinical evidence (Sampson Handley) has shown that some vessels pass from the lower and medial part of the gland and pass to the angle between the seventh rib and the xiphoid process, where they pierce the fibrous layers of the abdominal wall and join the lymph vessels in the extra-peritoneal fascia of the upper part of the abdomen. It is through these vessels that cancer cells not uncommonly travel from the mamma to the abdomen (Fig. 806).

Lymph vessels pass also from the deep part of the mammary gland, through the deep fascia and the pectoralis major, and then ascend, along the line of the pectoral branches of the thoraco-acromial artery, to the infra-clavicular region, where they terminate either in the inter-pectoral or the infra-clavicular glands, or in both groups. It is possible that some of these vessels, after piercing the costo-coracoid membrane, may pass directly to the inferior deep cervical glands (Fig. 806).

It is stated, further, that some of the lymph vessels which issue from the mamma pierce the whole thickness of the thoracic wall and join the lymph vessels which lie in the endo-thoracic fascia, which intervenes between the ribs and the intercostal muscles externally and the pleural membrane internally.

\section{THE LYMPH GLANDS OF THE THORAX.}

The lymph glands of the thorax form 5 named groups, with subdivisions.

(1) Lymphoglandulæ Sternales.-The sternal lymph glands form two groups each of which lies at the margin of the sternum along the line of the corresponding internal mammary artery. The glands are variable in number (4-18) and in size. They receive afferents from the upper part of the muscles of the abdominal wall, from the diaphragm, from the anterior part of the wall of the thorax, and from the medial portion of the mamma. Their efferents communicate with the upper anterior mediastinal glands and with the inferior deep cervical glands, and they terminate on the right side in the right lymphatic or the right broncho-mediastinal duct and on the left in the thoracic duct. Occasionally, also, they end directly in the internal jugular or the subclavian vein.

(2) Lymphoglandulæ Intercostales.-The intercostal lymph glands are lateral and medial. The lateral glands lie in the posterior parts of the intercostal spaces, the medial are placed in front of the heads of the ribs. Their afferents are derived from the boundaries and contents of the spaces. The efferents of the glands of the upper spaces pass either to the posterior mediastinal glands or to the thoracic 
duct. Those of the lower spaces, on each side, form a descending trunk which passes through the aortic opening of the diaphragm and ends in the cisterna chyli.

(3) Lymphoglandulæ Mediastinales Anteriores. - The anterior mediastinal lymph glands form two groups, a lower and an upper. The lower group consists of 3 or 4 glands, and is situated, posterior to the sternum, in the lower part of the anterior mediastinum. It receives afferents from immediately adjacent parts and from the liver and the diaphragm. Its efferents communicate with the upper anterior mediastinal glands, and they end, for the main part, in the broncho - mediastinal trunk.

The upper group consists of from 8 to 19 glands which lie posterior to the manubrium sterni and anterior to the thymus and the great vessels of the superior medias tinum. Their afferents are derived from the lower group of anterior mediastinal glands, from the pericardium, the heart, the thymus, the thyreoid gland, and from the sternal glands. Their efferents pass mainly to the broncho-mediastinal trunk, but they communicate with the medial inferior deep cervical glands and possibly also with the thoracic duct. 
(4) Lymphoglandulæ Mediastinales Posteriores.-The posterior mediastinal lymph glands, S-12, lie along the descending part of the thoracic aorta and the thoracic part of the asophagus. They receive afferents from the diaphragm, the

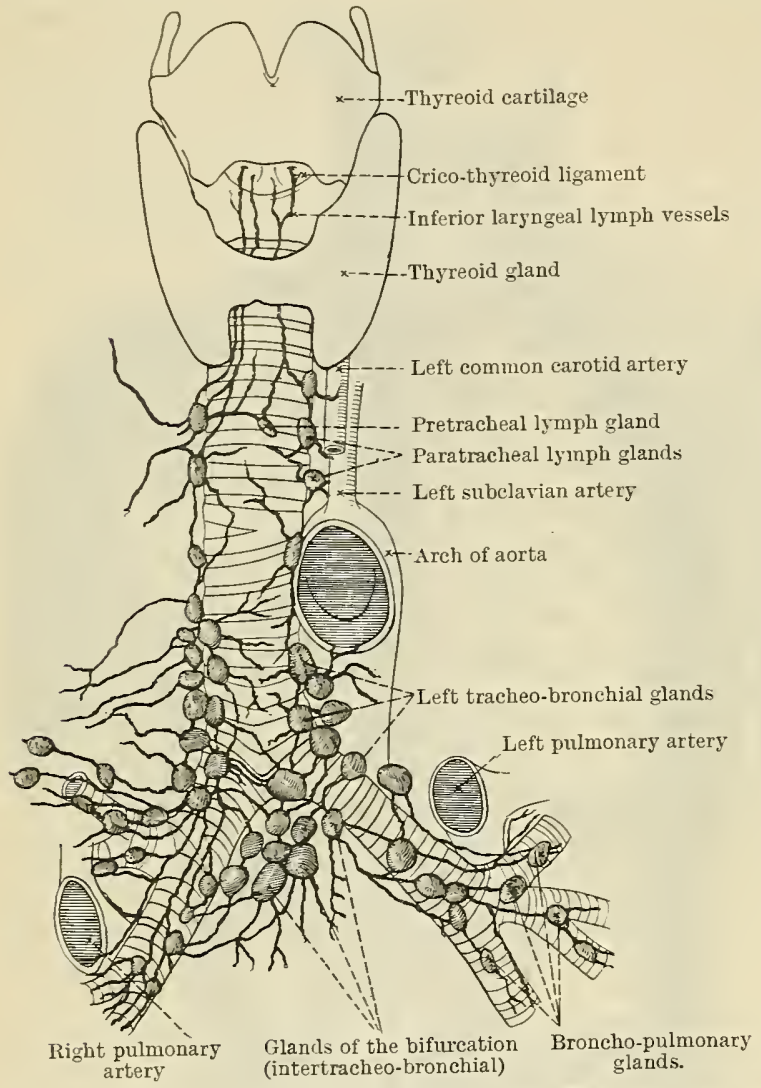

Fig. 810.--The Glands in Reiation to the Trachea and the Main Bronchi. pericardium, the cesophagus, and other immediately adjacent tissues. Some of their efferents join the thoracic duct, others the broncho-mediastinal trunk, and some pass to the bronchial glands.

(5) Lymphoglandulæ Bronchiales.-Under the term bronchial lymph glands are included all the lymph glands which are closely associated with the walls of the intrathoracic part of the trachea and with the main bronchi and their intra-pulmonary branches. The glands are extremely numerous, and they are conveniently classified, by Bartels, into four groups-(1) tracheo-bronchial right and left; (2) the glands of the bifurcation, also called intertracheo-bronchial; (3) bronchopulmonary: (4) pulmonary. At birth and for some years afterwards they are pink in colour, but later they become blackened by the deposit of carbonaceous particles derived from the atmosphere.

(1) The Tracheo-Bronchial Lymph Glands are those which are situated in the lateral angle between the trachea and the bronchus, on each side. On the right side they vary in number from 5 to 9 , on the left from 3 to 6 . Those on the left are in close relation with the left recurrent nerve. Their afferents are derived from the other groups of bronchial glands and from the adjacent parts of the trachea and bronchi. They are connected with the anterior and posterior mediastinal glands. Their efferents pass to the broncho-mediastinal trunk and also to the inferior deep cervical glands. They are associated, also, by interglandular vessels, with the paratracheal glands.

(2) The Lymph Glands of the Bifurcation (intertracheo-bronchial) lie below the trachea, in the angle between the two main bronchi. They are situated between the roots of the great vessels anteriorly and the cesophagus and the aorta posteriorly. Their afferents are derived from the broncho-pulmonary glands and from adjacent parts: their efferents terminate in the tracheo-bronchial glauds. They are connected with the posterior mediastinal glauds.

(3) The Broncho-Pulmonary Lymph Glands.-Each group of broncho-pulmonary glands, right and left, lies in the hilus of the corresponding lung, in the angles between the branches of the bronchial tube. They vary cousiderably in number, and they receive afferents, either directly or through the pulmonary glands, from the lung substance. They also receive afferents from the pleura; and their efferents pass to the tracheo-bronchial glands and to the glands of the bifurcation.

(4) The Pulmonary Lymph Glands lie in the lung substance and usually in the angles between two bronchial tubes. Their afferents are derived from the lung substance, and their efferents pass to the broncho-pulmonary glands. 


\section{THE LYMPH VESSELS OF THE THORAX.}

The lymph ressels of the thorax form two main groups-(a) the ressels of the thoracic wall, and $(b)$ the vessels of the contents of the thorax.

(a) The Lymph Vessels of the Thoracic Wall are the intercostal lymph vessels and the lymph vessels of the diaphragm.

(1) The Intercostal Lymph Vessels receire lymph from the ribs and from the content of the intercostal spaces, and they terminate in the intercostal and sternal glands. Communications are said to exist between the intercostal ressels and the glands of the axilla.

(2) The Lymph Vessels of the Diaphragm.-The lymph vessels from the anterior part of the diaphragm pass to the lower sternal and anterior mediastinal glands, and those from the posterior part to the posterior mediastinal glands.

(b) The Lymph Vessels of the Contents of the Thorax are:-

(1) The Lymph Vessels of the Heart, which follow the courses of the coronary arteries, and pass to the anterior mediastinal glands.

(2) The Lymph Vessels of the Pericardium, which terminate in adjacent glands.

(3) The Lymph Vessels of the Thymus, some of which pass to the anterior mediastinal glands, some to the tracheo-bronchial glands, others to the medial inferior deep cervical glands.

(4) The Lymph Vessels of the Thoracic Part of the Esophagus, which are separable into upper and lower groups. The upper pass to the bronchial, the posterior mediastinal, and the lower deep cervical glands. The lower group end in the glands situated at the cardiac end of the stomach. The two groups anastomose together.

(5) The Lymph Vessels of the Pleura. -The ressels from the apical parts of the parietal portion of the pleura pass to the adjacent lymph trunks or their tributaries. The vessels from the posterior part of the parietal pleurd join the intercostal glands, and those from the anterior part end in the sternal glands.

The Lymph Vessels of the Lungs and the Visceral Pleura pass to the broncho-pulmonary glands.

\section{THE LYMPH GLANDS OF THE INFERIOR EXTREMITY.}

The lymph glands of the inferior extremity, like those of the upper, are separable into a superficial and a deep group.

The Superficial Lymph Glands lie, almost entirely, in the subinguinal region, though occasionally one or more may be situated abore the level of the inguinal ligament, and therefore in the inguinal region. On this account they are separated in the B.N.A. into inguinal and subinguinal groups. Both groups lie in the superficial fascia.

Lymphoglandulæ Inguinales. - The inguinal lymph glands, when they exist, are merely scattered members of the subinguinal group which lie above the level of the inguinal ligament. They receive afferents from the lower and anterior part of the abdominal wall. Their efferents terminate either in the superficial or the deep subinguinal glands.

Lymphoglandulæ Subinguinales Superficiales. -The superficial subinguinal glands (Figs. 811, 817) form two groups, a proximal and a distal, each of which is separable into medial and lateral parts; but the various members of the groups are intimately connected together by communicating vessels.

The proximal group lies along the line of the inguinal ligament. It may extend from the anterior superior spine of the ilium to the pubic tubercle. Its lateral members leceive afferents from the lower and

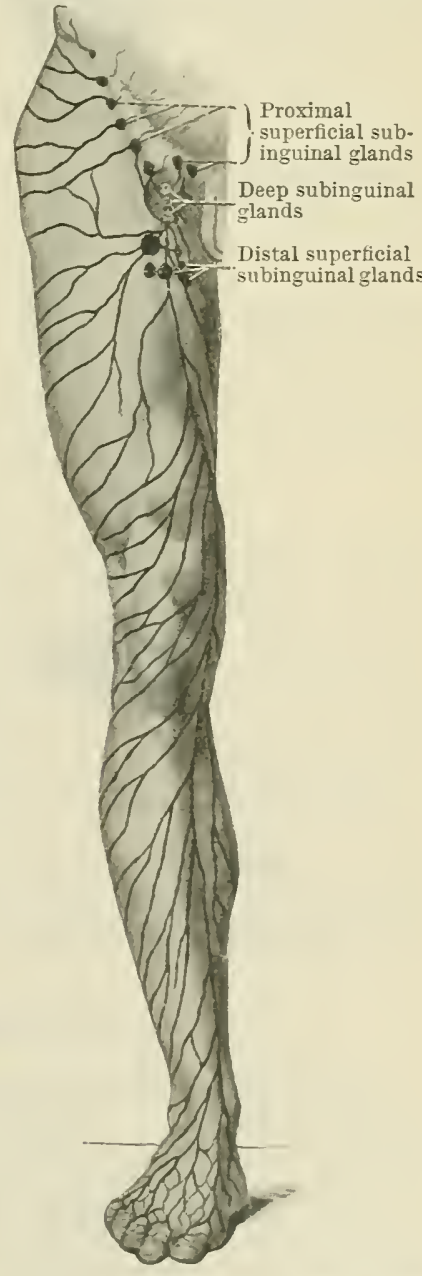

Fig. 811. -Diagrair OF THE LyMPH Vessels aNd Lrarph Glajds of THE LOWER EXTRFMITT. lateral part of the abdominal wall, from the buttock, and the proximal and lateral part of the thigh. 
The more medial members of the proximal group receive afferents from the anal canal, the perineum, the scrotum, the penis, and the pubic region in the male,

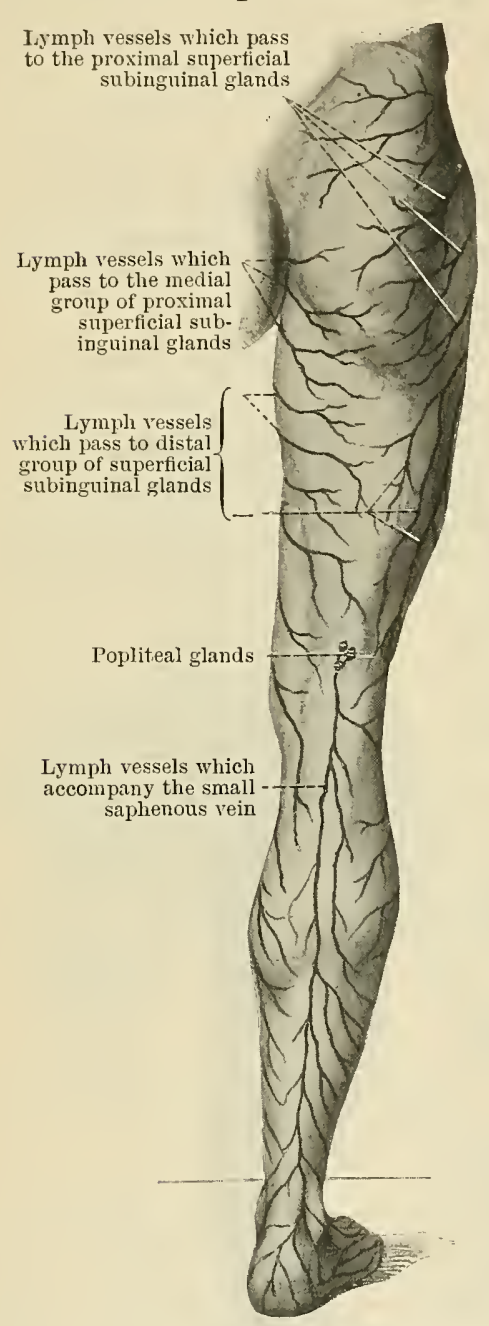

FIG. 812.-DIAGRAM OF THE LYMPH Vessels of the Posterior Part of THE Lower Extremity. and from the corresponding parts, including the lower part of the vagina, in the female.

The distal group of superficial subinguinal glands lies along the line of the proximal part of the great saphenous vein-some on its lateral and some on its medial side. They receive afferents bearing lymph from the superficies of the greater part of the inferior extremity, with the exception of the lateral part of the foot, the heel, and a part of the posterior aspect of the leg.

The efferents of both proximal and distal groups of subinguinal glands pass to the deep subinguinal glands.

The Deep Lymph Glands of the inferior extremity are the popliteal and the deep subinguinal glands. Occasionally a deep gland is met with in the leg in relation with the proximal third of the anterior tibial artery.

Lymphoglandulæ Popliteæ.-The popliteal lymph glands (Fig. 812) lie in the popliteal fossa. One is usually situated, comparatively superficially, at the point where the small saphenous vein pierces the deep fascia and enters the fossa. It receives afferents, which accompany the small saphenous vein, from the lateral part of the foot, the heel, and the posterior part of the calf. Its efferents pass to the deeper glands.

The deeper glands lie in the fat around the popliteal vessels and are sometimes separated into inter-condylar and supra-condylar groups. Their afferents are derived from the more superficial gland and from the deeper tissues of the leg and foot. Their efferents pass to the deep subinguinal glands.

Lymphoglandulæ Subinguinales Profundæ. -The deep subinguinal glands (Figs. 807, 811, 817) lie in the femoral trigone. They are small glands, three to seven in number, which are difficult to demonstrate. Some of them lie in the femoral canal, the most proximal being situated in or close to the femoral ring. Their afferents are the efferents of the other glands of the lower extremity, and, in addition, vessels from the deeper parts of the penis or the clitoris. Their efferents pass to the external iliac glands.

\section{THE LYMPH VESSELS OF THE INFERIOR EXTREMITY.}

The arrangement of the superficial lymph vessels of the toes and the foot is very similar to that met with in the fingers and the hand. From lymph plexuses on the plantar aspect vessels pass to the dorsum of the foot and toes, where they unite into a number of vessels, the majority of which accompany the great saphenous vein and terminate in the distal gronp of superficial subinguinal glands. Some of the lymph from the lateral part of the plantar surface and from the lateral border of the foot, and the lymph from the heel enters vessels which accompany the small saphenous vein; they end either in the more superficial gland of the popliteal fossa or in the deeper glands of that region (Fig. 812).

With the exception of the lymph vessels from the lateral and posterior part of the leg, which accompany the smail saphenous vein to the popliteal glands, all the superficial lymph vessels of the leg, thigh, and buttock pass to the superficial subinguinal glands; those from the leg and thigh mainly to the glands of the distal group; those of the buttock chiefly to the lateral glands of the proximal group. 
The deep lymph vessels of the inferior extremity accompany the deep blood-vessels. Many of the vessels from the leg and foot end in the popliteal glands, but some pass directly to the deep subinguinal glands. The deep vessels of the more proximal parts of the inferior extremity end in the deep suljinguinal glands and in the hypogastric glands.

\section{THE LYMPH GLANDS OF THE ANTERIOR ABDOMINAL WALL.}

Some lymph glands are regularly, and others are occasionally present in the anterior wall of the abdomen. Those fairly regularìy present are :-

The inferior epigastric lymph glands, 3-6, which lie along the course of the inferior epigastric artery. Their afferents are from the deep part of the umbilicus and their efferents pass to the inferior external iliac glands.

The Pubic Gland or Glands.-One or more small glands which lie anterior to the suspensory ligament of the penis or clitoris. Their afferents are vessels from the superficial parts of the penis or clitoris, and their efferents end in the proximal superficial subinguinal glands.

The occasional glands are :-

(1) A superior epigastric gland which sometimes lies in the superficial fascia of the median part of the epigastric region. Its afferents are from the adjacent parts and its efferents pass to the sternal glands. It is probably very rare.

(2) Circumflex iliac glands, $2-4$, which lie along the course of the deep circumflex iliac artery.

(3) An umbilical gland which lies in the extra-peritoneal tissue below the umbilicus. When it is present it receives vessels from the umbilicus and its efferents go to the external iliac glands.

(4) Supra-umbilical glands, 1-2, small glands which lie in the extra-peritoneal tissue above the umbilicus. Its afferents are from the region of the umbilicus. The efferents probably pass to the inferior anterior mediastinal glands.

\section{THE LYMPH VESSELS OF THE ANTERIOR WALL OF THE ABDOMEN.}

The superficial lymph vessels of the upper part of the anterior wall of the abdomen go, for the most part, to the anterior or pectoral group of axillary glands; but some pierce the wall of the lower part of the thorax and end in the sternal glands.

The superficial lymph vessels of the lower part of the anterior wall of the abdomen terminate in the proximal group of superficial subinguinal glands.

The deep lymph vessels of the upper part of the anterior abdominal wall accompany the superior epigastric vessels and terminate in the sternal glands; but some may be connected with the supra-umbilical glands if they are present.

The deep lymph vessels of the lower part of the anterior wall of the abdomen accompany the inferior epigastric vessels, and end in the inferior external iliac glands or the inferior epigastric glands.

\section{THE LYMPH VESSELS OF THE EXTERNAL GENITALS.}

The lymph vessels of the scrotum in the male and of the labia majora in the female pass to the proximal superficial subinguinal glands, and mostly to the medial group.

The superficial lymph vessels of the penis go to the medial glands of the proximal subinguinal group:

The deep lymph vessels of the penis, including those of the penile portion of the urethra, end either in the medial glands of the proximal subinguinal group or in the deep subinguinal glands.

The termination of the lymph vessels of the clitoris is similar to that of the lymph ressels of the penis.

\section{LYMPH GLANDS OF THE PELVIS AND ABDOMEN.}

The lymph glands of the pelvis are separable into visceral and parietal groups.

\section{The Visceral Glands of the Pelvis.}

Lymphoglandulæ Vesicales.-The lymph glands of the urinary bladder form an anterior and two lateral groups.

(a) The anterior lymph glands of the bladder are variable in number. They lie in the retro-pubic fat and receive afferents from the anterior and antero-lateral parts of the bladder wall. Their efferents go to the external iliac glands.

(b) The lateral lymph glands of the bladder lie along the course of the umbilical artery on each side. Their afferents are derived from the lateral parts of the bladder and their efferents end in the external iliac glands.

Lymphoglandulæ Anorectales.-The ano-rectal lymph glands (2-8) lie in the lower part of the pelvis minor in relatinn with the ampullary part of the rectum, 
between its muscular wall and its external fibrous coat. Their afferents are derived from the muscular and mucous coats of the rectum and from the upper part of the anal canal, and their efferents pass to the superior hæmorrhoidal glands.

Lymphoglandulæ Parauterinæ. -The para-uterine lymph glands (1-6), lie at the sides of the neck of the uterus in the bases of the broad ligaments. They receive afferents from the neck of the uterus and the efferents pass to the hypogastric glands.

Lymphoglandulæ Hæmorrhoidales Superiores.-The superior hæmorrhoidal lymph glands lie along the course of the superior hæmorrhoidal artery in the pelvic meso-colon. They receive afferents from the walls of the rectum, and from the ano-rectal glands. Their efferents go to the inferior mesenteric glands.

\section{The Parietal Lymph Glands of the Pelvis.}

Lymphoglandulæ Sacrales.-The sacral lymph glands, variable in number, lie along the anterior aspect of the sacrum, between the anterior sacral foramina.

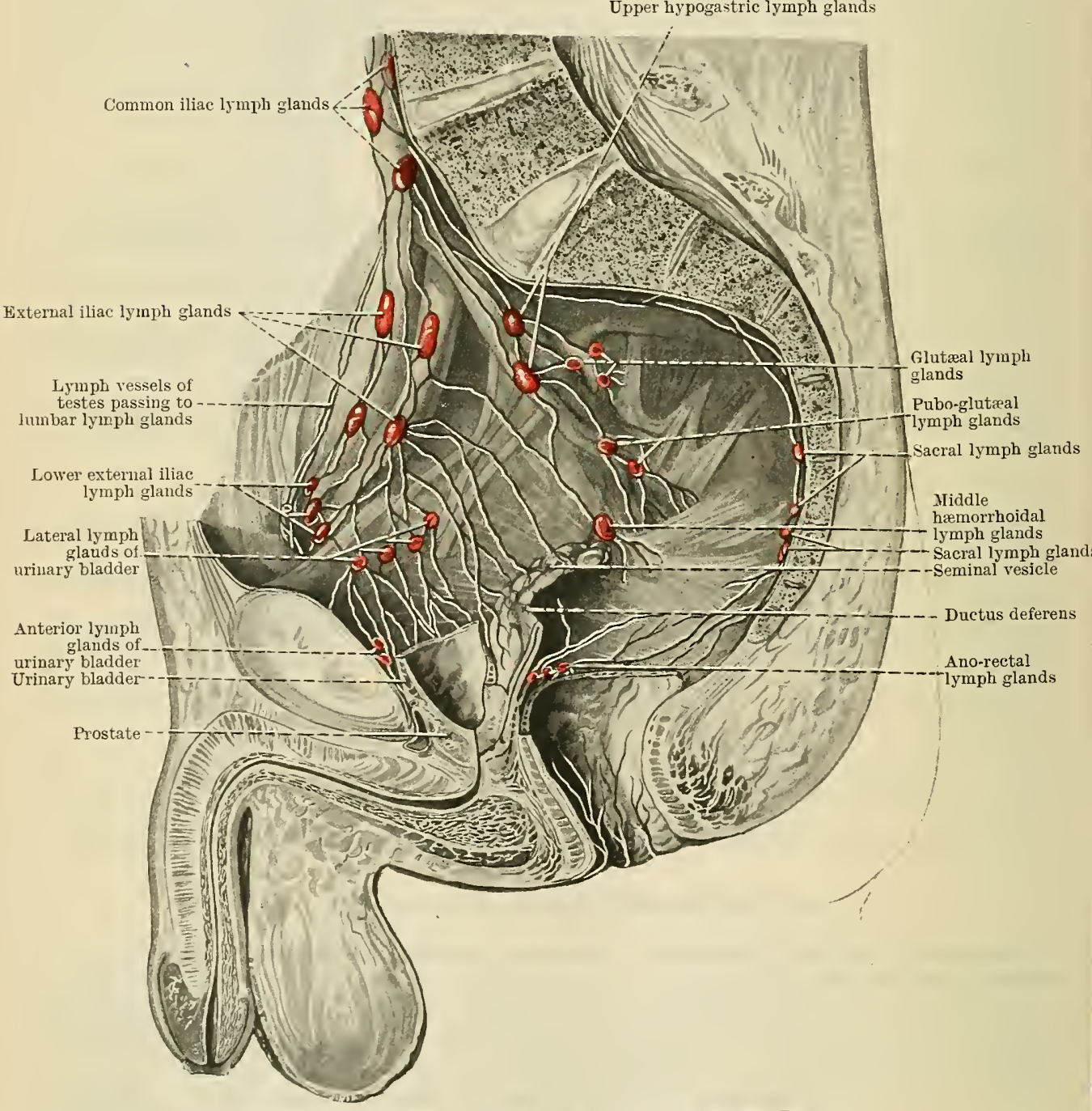

Fig. 813.-Diagray of the Lyiph Glando of the Pelis.

Their afferents are from the rectum, the prostate, and the adjacent parts of the wall of the pelvis. Their efferents end in the sub-aortic, the aortic, and the hypogastric glands. 
Lymphoglandulæ Subaorticæ.-The subaortic lymph glands (1-3) lie on the anterior aspect of the fifth lumbar vertebra. Their afferents are from the sacral glands, the hypogastric glands, and the external iliac glands. Their efferents go to the aortic glands (Fig. 817).

Lymphoglandulæ Hypogastricæ.-The hypogastric lymph glands form right and left groups, which are associated with the corresponding hypogastric vessels. As a rule they lie near the origins of the main branches of the hypogastric artery, or iu the angles between the branches, and some are, therefore, separable into a number of groups.

The Glutæal Lymph Glands lie in relation to the superior glutæal artery and receive afferents from the glutæal region. Their efferents pass to the common iliac glands.

The Pubo-gluteal Lymph Glands (1-2) lie in relation to the origins of the inferior glutæal and internal pudendal arteries. They receive afferents from the thigh and perineum and their efferents end in the common iliac glands.

The Middle Hæmorrhoidal Gland lies more medially than the other glands of the group, close to the lateral wall of the rectum at the point where the middle hæmorrhoidal artery breaks up into its terminal branches. It receives afferents from the rectum and gives efferents to the other hypogastric and to the external iliac glands.

The Inter-iliac Glands lie in the angle between the external iliac and the hypogastric arteries, and cannot be clearly disassociated from the medial external iliac glands. They receive afferents from the lower parts of the genito-urinary organs. Their efferents pass to the common iliac glands.

The Obturator Gland lies at the inner end of the obturator canal, above the obturator vessels. It receives afferents from the upper and medial parts of the thigh and its efferents join the inter-iliac and common iliac glands.

Lymphoglandulæ Iliacæ.-The iliac lymph glands are separable into a lower group, associated with the external iliac artery, lymphoglandulæ iliacæ externæ, and an upper group, the lymphoglandulæ iliacæ communes.

The External Iliac Glands.-According to Poirier and Cuneo, the external iliac lymph glands form three chains, lateral, intermediate, and medial, which lie, respectively, at the lateral side, anterior to, and at the medial side of the external iliac vessels. The three lowest members of the group, that is the lowest member of each chain, lie in close relation to the abdominal aperture of the femoral ring, and are frequently spoken of as supra-femoral glands. They receive afferents from the superficial subinguinal and the deep subinguinal glands, from the urethra and the deeper parts of the penis, and from the portions of the abdominal wall supplied by the deep circumflex iliac and inferior epigastric arteries. Their efferents end in the upper glands of the external iliac group.

The higher members of the external iliac lymph glands receive afferents from the membranous part of the urethra, the prostate, the bladder, the vagina, and the neck of the uterus. They are connected by anastomoses with the hypogastric glands, particularly the middle hæmorrhoidal gland, and their efferents pass to the common iliac glands.

The Common Mliac Lymph Glands.-The glands of the common iliac group are sometimes separated into a lateral and intermediate and a medial series. The lateral and intermediate groups are quite distinct, the former lying along the lateral margin of the artery and the latter posterior to it, but the medial group is not clearly defined from the sub-aortic group already mentioned. Indeed the sub-aortic group may be looked upon as constituted by the medial common iliac glands of opposite sides.

The common iliac glands receive afferents from the external iliac and the hypogastric glands, and consequently from practically the whole of the pelvic contents, except the oraries of the female.

\section{THE LIMPH VESSELS OF THE PELVIC VISCERA.}

The Lymph Vessels of the Urethra of the Male.-It has been pointed out that the lymph vessels of the greater part of the penile portion of the urethra are said to pass to the deep subinguinal glands. The lymph ressels of the bulbar and membranous parts of the 
urethra have not yet been satisfactorily demonstrated, but it is stated that they pass to the hypogastric glands, to the medial supra-femoral gland of the external iliac group, and to the higher glands of the external iliac group. The lymph vessels of the prostatic part of the nrethra unite with the other lymph vessels of the prostate.

The Lymph Vessels of the Prostate pass to the anterior and lateral vesical glands, to the external iliac glands, to the hypogastric glands, and to the sacral and hæmorrhoidal glands. They anastomose with the lymph vessels of the bladder and the deferent duct.

The Lymph Vessels of the Urethra of the Female have terminations corresponding with those of the vesseis of the membranous and prostatic portions of the urethra of the male.

The Lymph Vessels of the Seminal Vesicle, on each side, pass to the medial glands of the external iliac group.

The Lymph Vessels of the Ductus Deferens, on each side, anastomose with those of the seminal vesicle, and they pass to the hypogastric and external iliac glands.

The Lymph Vessels of the Urinary Bladder.-Many of the Jymph vessels from the anterolateral aspect of the urinary bladder pass to the corresponding anterior and lateral vesical lymph glands and, through them, become connected with the external iliac and hypogastric glands, but some apparently pass directly to the hypogastric lymph glands.

The lymph vessels from the superior, and many from the posterior part of the bladder, on

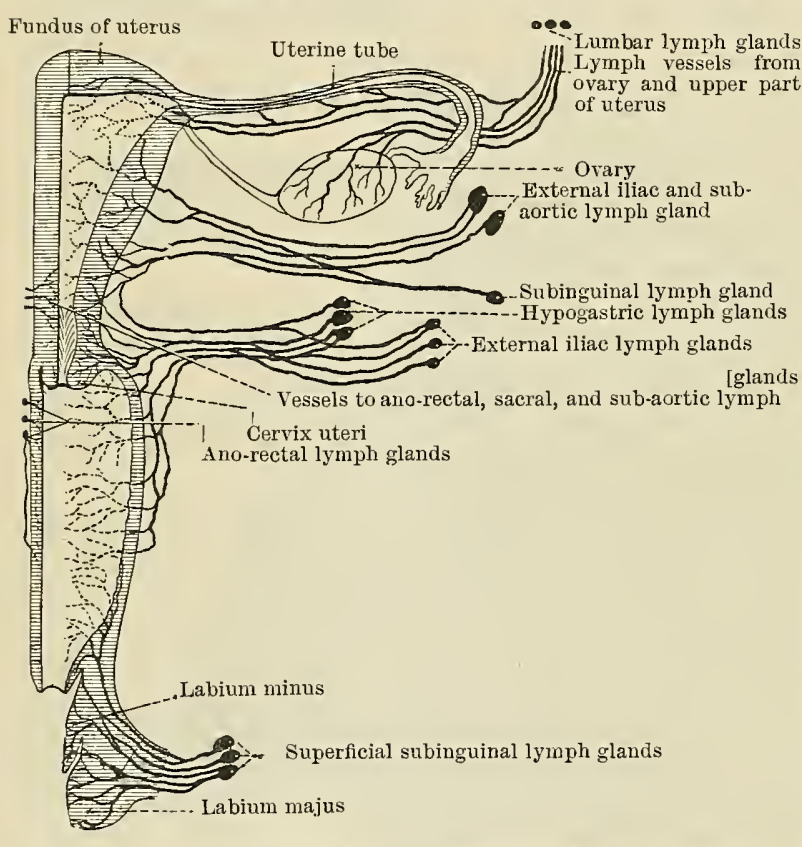

Fig. 814.-Diagram of Lymph Vessels of Female Genital ORGANS. each side, end in the external iliac and hypogastric glands, but some from the posterior part pass directly to the sub-aortic glands.

The Lymph Vessels of the Ureter.-Litt]e is known of the lymph vessels of the ureter except that those of its lower extremity anastomose with the lymph vessels of the urinary bladder. It is suggested that the vessels pass to the nearest lymph glands.

The Lymph Vessels of the Vagina.-The lymph vessels of the lower part of the vagina anastomose with the lymph vessels of the labia minora and so transmit lymph to the superficial subinguinal glands. The lymph vessels of the upper parts of the vagina pass to the hypogastric glands and also, with the lymph vessels of the cervix uteri, to the external iliac glands. Some of the lymph vessels from the posterior wall of the vagina terminate in the ano-rectal glands.

The Lymph Vessels of the Uterus. - The Lymph Vessels of the Lower Part of the Uterus. The majority of the lymph vessels from the lower part of the uterus, including the cervix, unite with the lymph vessels of the upper part of the vagina and pass to the hypogastric glands including the inter-iliac group (p. 1017). Some pass to the external iliac glands, and others from the lower and posterior part become associated with the ano-rectal, the sacral, and the sub-aortic glands.

The Lymph Vessels of the Body of the Uterus rum in several directions. The most important outflow is along the upper part of the broad ligament, below the uterine tube, to the region of the ovary where there is an anastomosis with the ovarian lymph vessels. Afterwards the lymph vessels of this stream cross the brim of the pelvis minor and ascend to the lumbar lymph glands. The accessory ontflows are to the external iliac glands; to the sub-aortic glands; and, along the round ligament, to the superior group of sub-inguinal glands.

The Lymph Vessels of the Uterine Tube accompany the vessels of the main ontflow from the body of the nterns, and those from the ovary, and pass to the lumbar lymph glands.

The Lymph Vessels of the Ovaries. - The lymph vessels of each ovary accompany the ovarian artery and some of the uterine lymph vessels, along the mpper part of the broad ligament, to the brim of the pelvis minor and then upwards to the lumbar lymph glands.

The Lymph Vessels of the Testis and Fpididymis.-The testis and the epididymis are not normally pelvic organs in the adult, bnt their lymph vessels may be considered here, inasmuch as the testes correspond, morphologically, with the ovaries. The lymph vessels of each testis and its epididymis accompany the testicular arteries and ascend to the lumbar region where they terminate in the lumbar lymph glands.

The Lymph Vessels of the Rectum.-.The lymph vessels of the rectum and the upper part of the anal canal pass for the most part along the middle and superior hæmorrhoidal vessels. 
Those which accompany the branches of the middle hæmorrhoidal artery, on each side, pass to the corresponding middle hæmorrhoidal gland of the hypogastric group; whilst the lymph vessels of the rectum which accompany the branches of the superior hæmorrhoidal artery become associated with the ano-rectal, the sacral, and the inferior mesenteric lymph glands.

\section{THE LYMPH GLANDS OF THE ABDOMEN.}

The lymph glands of the abdomen are separated into visceral and parietal groups. The visceral groups are those more directly associated with the lymph vessels which issue from the walls of the atidominal part of the alimentary canal, although they may lie posterior to the peritoneum in relation to the posterior wall of the abdomen. The parietal glands lie in relation with the abdominal part of the aorta and the inferior vena cava and the adjacent parts of the posterior abdominal wall.

\section{Visceral Lymph Glands of the Abdomen.}

Lymphoglandulæ Gastricæ.-The gastric lymph glands are arranged in two main groups, the lymphoglanduloc superiores which lie in association with the arteries of the smaller curvature, and the lymphoglandula inferiores associated with the greater curvature. Jamieson and Dobson have separated the superior gastric glands into several subdivisions.

Lymphoglandulæ Gastricae Superiores.- (a) The Anterior Left Gastric Glands (lower coronary glands, J. and D.). The anterior left gastric glands lie between the layers of the lesser omentum along the course of the left gastric artery. They receive afferents from the greater part of the lesser curvature of the stomach and the adjacent parts of its anterior and posterior walls, and they send efferents to the posterior left gastric glands.

(b) The Right Paracardial Glands are essentially members of the anterior left gastric group which lie to the

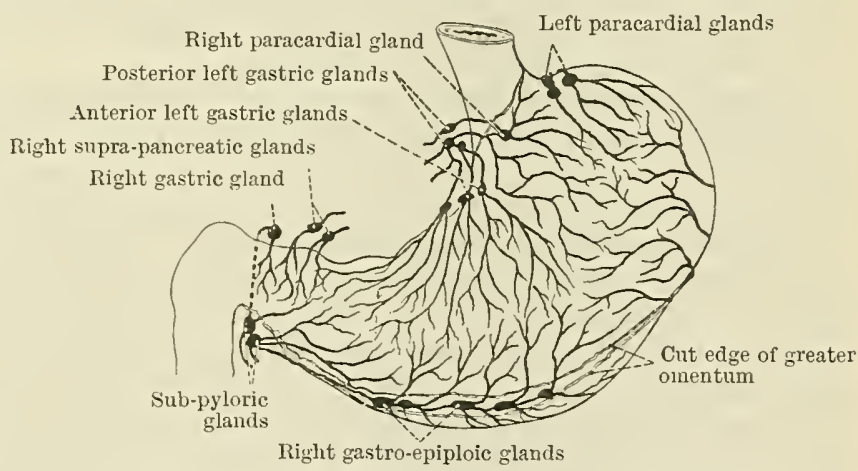

Fig. 815. - Lipaph Vessels and Glands of the Stomach. (After Jamieson and Dobson, modified.) right of the cardiac orifice of the stomach. Their afferents are derived from the cardiac part of the stomach and their efferents go to the posterior left gastric glands.

(c) The Left Paracardial Glands lie to the left of the osophageal orifice. They receive afferents from the adjacent parts of the cardiac portion of the stomach, and their efferents end in the posterior left gastric glands.

(d) The Posterior Paracardial Glands lie on the posterior aspect of the stomach, between the layers of the gastro-phrenic ligament. Their afferents are from the neighbouring parts of the cardia and their efferents go to the posterior left gastric glands.

(e) The Posterior Left Gastric Glands (upper coronary, J. and D.) lie around the left gastric artery as it passes forwards through the left gastro-pancreatic fold of peritoneum. They receive afferents from the previously mentioned groups of gastric glands and direct afferents from the cardiac portion of the stomach. Their efferents pass to the middle supra-pancreatic glands of Jamieson and Dobson (cerliac glands, B.N.A.).

$(f)$ The Right Gastric Gland (pyloric of J. and D.) is a small gland, occasionally present, which lies immediately above the pylorus or the first part of the duodenum, 
in association with the right gastric artery. It receives afferents from the pylorus, and its efferents end in the sub-pyloric glands.

(g) I'he Right Gastro-epiploic Glands lie along the lower part of the greater curvature of the stomach, in association with the right gastro-epiploic artery. Their afferents are from the adjacent parts of the anterior and posterior surfaces of the stomach and their efferents pass to the sub-pyloric glands.

(h) The Left Supra-pancreatic Glands of Jamieson and Dobson (lymphoglandulæ pancreaticolienales, B.N.A.) lie along the course of the splenic artery and in the gastro-splenic ligament: they receive afferents from the left part of the stomach and from the spleen. Their efferents pass to the middle supra-pancreatic glands.

(i) The Right Supra-pancreatic Glands (J. and D.) lie in relation with the stem of the hepatic artery as it passes through the right gastro-pancreatic fold. They receive afferents directly from the pyloric part of the stomach and the liver, and give off efferents to the middle supra-pancreatic glands.

(j) The Sub-pyloric Glands (J. and D.). The sub-pyloric lymph glands lie at the right border of the omental bursa, in the angle between the superior and descending parts of the duodenum, between the head of the pancreas posteriorly and the peritoneum of the posterior wall of the great sac anteriorly. Their afferents are from the right gastro-epiploic glands, the right gastric gland, and from the pyloric portion of the stomach. The efferents pass to the middle supra-pancreatic glands.

(k) The Biliary Lymph Glands ( $J$. and D.) lie along the line of the bile duct. They receive afferents from the gall-bladder and liver. One of the lower glands of the group, which lies posterior to the head of the pancreas, close to the lower end of the bile-duct, is associated, by direct afferents, with the upper part of the pylorus. Their efferents pass to the right and middle supra-pancreatic glands.

The highest member of the series is associated with the cystic artery and the gall-bladder and is called the cystic gland.

Lymphoglandulæ Hepaticæ (B.N.A.) The Hepatic Lymph Glands of the Basle nomenclature are a few small glands which lie in the region of the porta hepatis, between the layers of the lesser omentum; they receive afferents from the liver and give efferents to the right supra-pancreatic glands (J. and D.).

Lymphoglandulæ Mesentericæ (B.N.A.)-The Mesenteric Lymph Glands lie between the layers of the mesentery, where they form three main groups: $(a)$ a series of juxta-intestinal glands which lie close to the walls of the small gut; (b) an intermediate series of larger glands which lie in relation with the trunks of the rami intestinales of the superior mesenteric artery; and (c) a terminal group of large glands which lie round the upper part of the stem of the superior mesenteric artery. They receive lymph from all parts of the small intestine, from the cæcum, the vermiform process, the ascending colon, the transverse colon, and the part of the descending colon. Their efferents unite to form a common intestinal trunk, which enters the cisterna chyli.

The Lymph Glands of the Cæcum and the Vermiform Process and the Terminal part of the Ileum.-The lymph glands particularly associated with the terminal part of the ileum, the cæcum and its vermiform process, according to Jamieson and Dobson, are (1) the ileal, (2) the anterior ileo-colic, (3) the posterior ileo-colic, and (4) the appendicular. All those glands give off vessels which pass to the larger ileo-colic glands which lie along the ileo-colic branch of the superior mesenteric artery.

The Ileal Glands lie in the lower part of the mesentery. They receive afferents from the lower part of the ileum and give efferents to the main ileo-colic glands.

An Appendicular Lymph Gland is sometimes met with in the mesentery of the vermiform process. When it is present it may be associated with the vessels which pass from any part of the vermiform process. - Its efferents pass to the main ileocolic glands.

The Anterior Ileo-colic Glands, 1-4, lie in the anterior ileo-colic fold of peritoneum. Their afferents are derived from the anterior part of the cæcum and the root of the vermiform process, and efferents pass to the main ileo-colic glands.

The Posterior Ileo-colic Glands, more numerous than the anterior, lie in the 
angle between the ileum and the cæcum, and in the angle between the ileum and the ascending colon. Their afferents are from the posterior part of the cæcum and the root of the vermiform process. Their efferents pass to the main ileo-colic glands.

The Lymph Glands of the Colon, according to Jamieson and Dobson, may be considered as forming four groups, epicolic, paracolic, intermediate, and main.

The Epicolic Glands are small nodules which lie in the appendices epiploicæ and in relation with the wall of the gut. The paracolic glands lie along the medial borders of the ascending and descending colon, the iliac parts of the colon; along the upper border of the transverse colon, and on the mesenteric border of the pelvic colon. The intermediate glands lie along the branches of the colic arteries and the main groups are situated

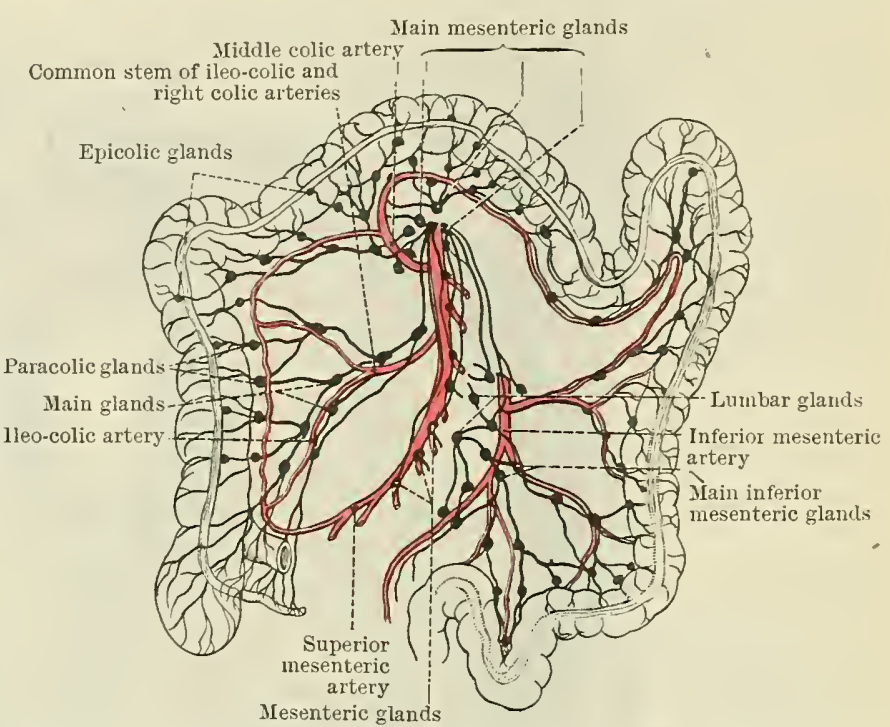

Fig. 816.-Diagram of the Limph Glands and Lymph Vessels of the Large Intestine. (After Jamieson and Dobson.)

around the stems from which the colic arteries arise. The lymph gathered by the lymph plexuses in the walls of the gut passes through one or more of the groups of glands, and that which issues from the main group, in association with the ileo-colic and middle colic arteries, enters the main mesenteric glands which surround the upper part of the superior mesenteric artery. It is then carried by the efferents of these glands to the common intestinal lymphatic trunk. The lymph from the descending, the iliac, and the pelvic parts of the colon passes to the intermediate groups of inferior mesenteric glands and thence, for the main part, to the lumbar glands, but some of the efferents from the upper intermediate inferior mesenteric glands pass to the main group of superior mesenteric glands.

The lymph glands associated with the middle colic artery and its branches are the lymphoglandulæ mesocolicæ of the Basle nomenclature.

The Main Glands of the Inferior Mesenteric Group receive lymph from the intermediate left colic glands and transmit it to the lumbar glands through which it passes, by the lumbar lymph trunks, to the cisterna chyli; but some of the lymph from the upper intermediate left colic glands passes to the main mesenteric glands, and so to the common intestinal lymph trunk.

The Middle Supra-pancreatic Lymph Glands of Jamieson and Dobson correspond fairly closely with the lymphoglandulæ coliacæ of the Basle terminology. They lie at the upper border of the pancreas around the cceliac artery. Their afferents are from the right and left supra-pancreatic glands, from the posterior left gastric glands, and from the subpyloric glands. They are connected by intermediate channels with the superior mesenteric glands, and they give efferents to the common intestinal lymph trunk and also to the common lumbar trunks.

Lymphoglandulæ Lumbales, B.N.A.-The Lumbar Lymph Glands lie behind the peritoneum of the posterior wall of the abdomen, in association with the aorta, the inferior vena cava, the psoas and quadratus lumborum muscles, and the crura of the diaphragm. Those which are situated on the anterior aspect of the aorta are frequently spoken of as pre-aortic glands and those situated more laterally as para-aortic glands.

The afferents of the lumbar lymph glands are (1) the efferents of the common 
iliac glands, (2) efferents from the sub-aortic glands, (3) efferents from the sacral glands, (4) some efferents from the hypogastric glands, (5) efferents from the main inferior mesenteric glands, (6) the lymph vessels from the testes and epididymicles and their coverings in the male, and from the ovaries, the uterine tubes, and the upper part of the uterus in the female, (7) lymph vessels from the

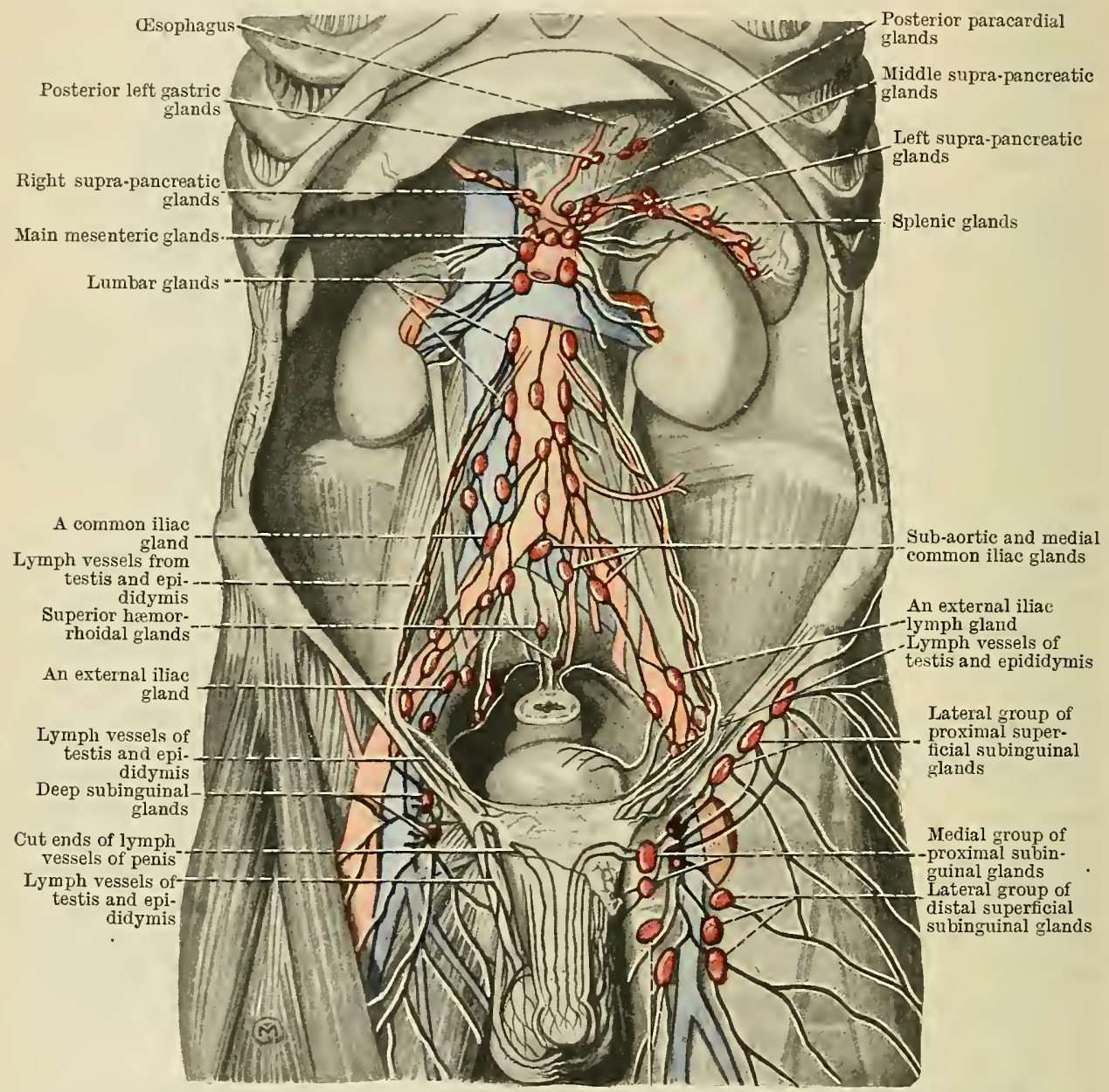

Medial group of distal superficial subinguinal glands

Fig. 817.--Semi-diagrammatic view of the Limph Glands and Vessels of the Proximal Parts

of the Lower Extremities, the Pelvis Major and the Posterior Part of the Abdonex.

kidneys, (8) lymph vessels from the suprarenal glands, (9) lymph vessels from the muscles of the back and of the posterior wall of the abdomen.

The efferents of the lumbar glands form two common lumbar lymph trunks, which pass to the cisterna chyli.

\section{THE LYMPH VESSELS OF THE ABDOMINAL VISCERA AND THE SUPERIOR AND POSTERIOR WALLS OF THE ABDOMEN.}

The Lymph Vessels of the Abdominal Part of the Alimentary Canal.-The lymph vessels in the walls of the alimentary canal form four plexuses: (1) a mucous plexus, in the mucous membrane, (2) a submucous plexus, in the submucous tissue, (3) a muscular plexus, between the two muscle coats, (4) a subserous plexus which lies in the areolar tissue between the peritoneal covering and the outer muscular coat. The four plexuses communicate freely with each other. The lymph is eventually collected from the subserous plexus and carried to the various groups of lymph glands. The vessels which carry away the lymph from the sub- 
serous plexuses of the various parts of the alimentary canal are spoken of in the following account as the lymph vessels of those parts.

The Lymph Vessels of the Stomach.-The lymph ressels of the stomach communicate freely with the lymph vessels of the oesophagus on the one hand and those of the duodenum on the other.

From the point of view of lymph outflow the area of each surface of the stomach may be divided into four parts. First a small right portion of the region of the pyloric canal, and, second, the remaining larger portion which is subdivided into three parts by two lines: (1) A line from the apex of the fundus to the pyloric canal along the junction of the upper and right two thirds with the left and lower third, (2) a line, parallel with the cesophagus, dividing the left and lower part into left and right portions (J. and D.). It must be understood, however, that the lymph vessels of the varions areas communicate freely with each other (Fig. 815).

The Lymph Vessels of the Region of the Pyloric Canal pass (a) partly to the anterior left gastric glands, $(b)$ partly to the right supra-pancreatic lymph glands, and $(c)$ partly to the lower biliary group of lymph glands. If the right gastric gland is present some of the vessels of the upper pyloric region go to it, and in some cases vessels from the pyloric region pass directly to the posterior left gastric lymph glands.

The Lymph Vessels from the Right Upper Area of the larger portion of the stomach pass $(a)$ to the anterior left gastric lymph glands, $(b)$ to the posterior left gastric lymph glands, $(c)$ to the paracardial lymph glands.

The Lymph Vessels from the Left Section of the Left and Lower Portion of the stomach pass along the gastro-splenic ligament to the splenic glands, which are occasionally present near the hilus of the spleen, and partly to the left supra-pancreatic lymph glands.

The Lymph Vessels from the Right Part of the Lower and Left Area follow the course of the right gastro-epiploic artery and terminate in the sub-pyloric glands.

The Lymph Vessels of the Duodenum are apparently few and difficult to inject; they commminicate with those of the stomach above and the jejumum below, and the collecting vessels which pass from the subserous plexus end in the biliary, the sub-pyloric, and the mesenteric lymph glands.

The Lymph Vessels of the Jejunum and Ileum, with the exception of those from the terminal part of the ileum, pass to the mesenteric lymph glands. The lymph vessels from the terminal part of the ileum go to the ileo-colic lymph glands.

The Lymph Vessels of the Cæcum, the Vermiform Process, and the Ascending Colon pass to the ileo-colic lymph glands, either directly or after having traversed glands which lie nearer to the walls of the various parts of the gut.

The Lymph Vessels of the Right Colic Flexure and the Transverse Colon pass to the meso-colic and the superior mesenteric lymph glands.

The Lymph Vessels of the Left Colic Flexure, the Descending Colon, the Iliac Colon, and the Pelvic Colon pass to the inferior mesenteric lymph glands. From these glands the greater part of the lymph is conveyed to the lumbar lymph glands, but part passes to the mesenteric lymph glands and part to the common intestinal lymph trunk.

The Lymph Vessels of the Liver.-The lymph vessels of the liver are described as forming superficial and deep groups. The superficial vessels pass to subserous plexuses from which collecting vessels arise.

The collecting vessels from the superior, anterior, and right lateral surfaces converge to a series of posterior and anterior efferent trunks.

The posterior collecting trunks form three groups: (1) a right group, which runs through the right triangular ligament of the liver and then downwards aud medially on the posterior wall of the abdomen, to the middle supra-pancreatic lymph glands; (2) the middle group runs towards the inferior vena cava, passes with it through the diaphragm, and ends in the posterior mediastinal lymph glands; (3) the left group passes through the left triangular ligament to the posterior left gastric glands and the posterior paracardial glands.

The anterior collecting trunks are inferior and superior. The inferior pass from the anterior part of the right lobe, turn roumd the lower border, and end in the hepaticlymph glands. The superior group pass to the falciform ligament. Some turn posteriorly towards the inferior vena cava, pass through the diaphragm with it and end in the posterior mediastinal ly mph glands ; others turn forwards and downwards to the round ligament, which they accompany to the porta hepatis where they join the hepatic glands. The remaining ressels pass upwards to the anterior part of the diaph ragm which they perforate, and they end in the anterior mediastinal glands.

The superficial collecting vessels of the inferior surface of the right lobe pass $(a)$ backwards to the inferior vena cava and along that vessel to the posterior mediastinal glands, $(b)$ to the cystic gland of the biliary chain. T'he collecting vessels of the lower part of the left lobe end in the hepatic glands. The collecting vessels of the candate lobe pass partly to the posterior mediastinal glands, along the inferior vena cava; and partly to the hepatic lymph glands in the porta hepatis.

The Deep Lymph Vessels of the Liver pass to ascending and descending collecting trunks. The ascending trunks follow the hepatic veins and the inferior vena cava and end in the posterior mediastinal lymph glands. The descending collectors accompany the bile-ducts, the branches of the portal vein, and the branches of the liepatic artery, and terminate in the hepatic lymph glands.

The Lymph Vessels of the Gall Bladder.-The lymph vessels from the gall bladder terminate chiefly in the cystic gland but some pass to other members of the biliary chain. 
The Lymph Vessels of the Pancreas.-The efferent vessels from the pancreas end in the adjacent glands, that is, some pass to the sub-pyloric, some to the supra-pancreatic, some to the mesenteric glands, and some to the posterior left gastric lymph glands.

The Lymph Vessels of the Spleen.-The collecting vessels from the spleen pass to the splenic lymph glands which occasionally lie near the hilus of the spleen and the left suprapancreatic lymph glands.

The Lymph Vessels of the Kidneys.-The lymph vessels of each kidney run along the renal blood-vessels and terminate in the lumbar glands, especially in the pre-and para-aortic lymph glands.

The Lymph Vessels of the Ureters.-The lymph vessels from the abdominal part of each ureter pass to the lumbar and the common iliac and the sub-aortic lymph glands.

The Lymph Vessels of the Suprarenal Glands anastomose with the vessels of the kidneys and pass to the lumbar and to the posterior mediastinal lyniph glands.

The Lymph Vessels of the Diaphragm.-The collecting lymph vessels from the diaphragm pass to the thoracic lymph glands, that is, to the anterior and posterior mediastinal lymph glands, and lower sternal glands.

The Lymph Vessels of the Posterior Wall of the Abdomen terminate in the lnmbar lymph glands. 


\section{DEVELOPMENT OF THE BLOOD-VASCULAR SYSTEM.}

\section{The Arteries and the Heart.}

In the general account of the development of the primitive vascular system and the establishment of the fœtal circulation, given in a previous chapter, it was pointed out that the germ of the whole blood-vascular system appears in the wall of the yolk-sac as a series of strands of cells which constitute the angioblast. Some of the angioblast cells remain in situ and form the blood-vessels of the walls of the yolk-sac and the corpuscular contents of the blood-vessels; other angioblastic cells wander into the embryonic area and form the bloodvessels of the embryo; whilst still others become located in the developing liver and other organs, where they become foci for the formation of new blood corpuscles.

The first bloodvessels developed in the embryonic area are the primitive aortæ. They

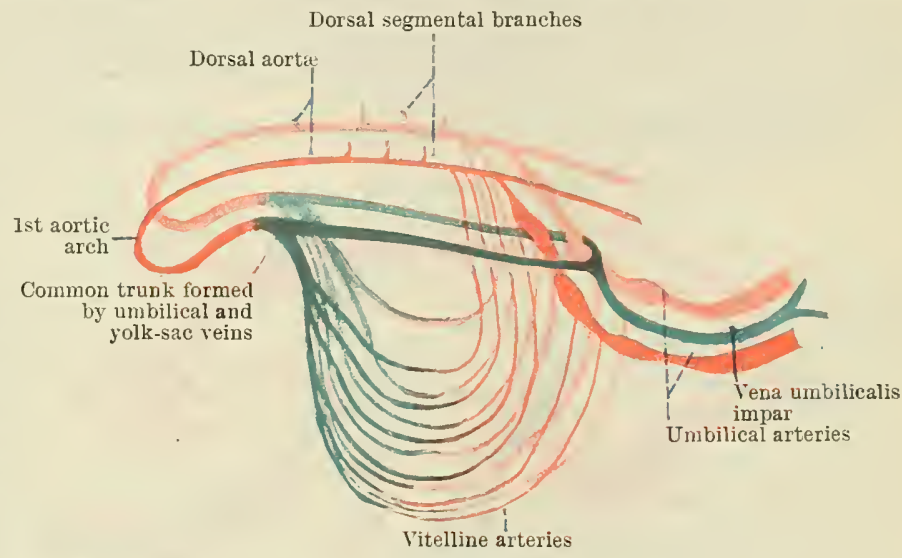

Fig. 818. - SeheMa of CrRCUlation of aN EMBryo, 1.35 nM. LONG, With Six Somites. (After Felix, modified.) appear, either just before the embryonic area begins to be folded into the form of the embryo or as the folding is commencing, in the pericardial or anterior region of the embryonic area, where they are continuous with the earlier-formed vessels on the wall of the yolk-sac. From the pericardial region they extend caudalwards, one on each side of the notochord, and as they pass candalwards they give off a series of dorsal and ventral branches. The dorsal branches are

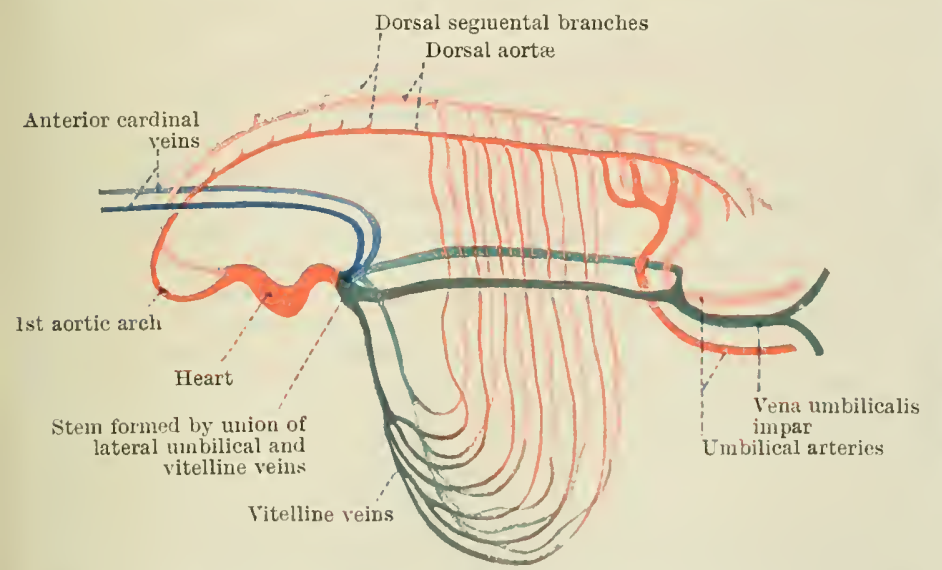

Fig. 819. - Schema of Vasedlar System of an Embrio, $2 \cdot 6$ mis. LONg, with Focrteex Somites. (Arteries after Felix, modified.) intersegmental in arrangement; they lie in the intervals between the mesodermal somites The ventral branches are more irregular, and are not strictly segmental in arrangement; moreover, they are not only distributed to the wall of the alimentary canal, but they also pass across it to the yolk-sac. Further, those which are situated nearest the tail anastomose together, on the side wall of the hind-gut area, forming a plexus, and it is from this plexus, on each side, that the umbilical artery is prolonged along the bodystalk to the chorion (Figs. $818,819)$.

As the head fold forms, the cephalic part of each primitive aorta is bent into the form of in loop, and the whole vessel assumes a hook-shaperl form. The long or dorsal limb of the look, which lies along the dorsal wall of the primitive alimentary canal, is the primitive dorsal aorta; 
the bend of the hook is the first aortic arch; and the short ventral limb of the hook, which lies in the ventral wall of the fore-gut and the dorsal wall of the pericardium, is the primitive ventral aorta, which is continuous, at the anterior margin of the umbilical orifice, that is at its candal end, with a venous ressel, the vitelline vein, which is carrying blood from the yolk-sac to the embryo.

The condition described is that found in embryos about $1.4 \mathrm{~mm}$. long, possessing six mesodermal somites (Fig. 818).

In embryos in which the mesodermal somites have increased to fourteen pairs the posterior, or caudal, portions of the primitive ventral aortæ have fused together to form a single heart (Fig. 819).

The Primitive Heart.-The primitive heart lies in the dorsal wall of the pericardium and, therefore, in the ventral wall of the fore-gut. As it grows more rapidly in length than the wall to which it is attached, it bends upon its long axis and bulges ventrally into the interior of the pericardium. As it projects into the pericardium it pushes before it the immediate bounding wall of the pericardial cavity, which thus becomes converted into the visceral pericardium. The visceral pericardium surrounds the heart, and passes from its dorsal border to the ventral wall of the fore-gut as a donble layer which constitutes the dorsal mesocardium.

The portion of each primitive ventral aorta which lies cephalwards of the heart forms the ventral root of the first aortic arch. At this stage the primitive dorsal aortæ are still separate from one another, and each gives off a series of dorsal intersegmental branches and a series of ventral branches which pass across the side walls of the primitive gut on their way to the wall of the yolk-sac. The candally situated ventral vessels, as in the earlier stage, form a plexus on the side walls
of the primitive gut from

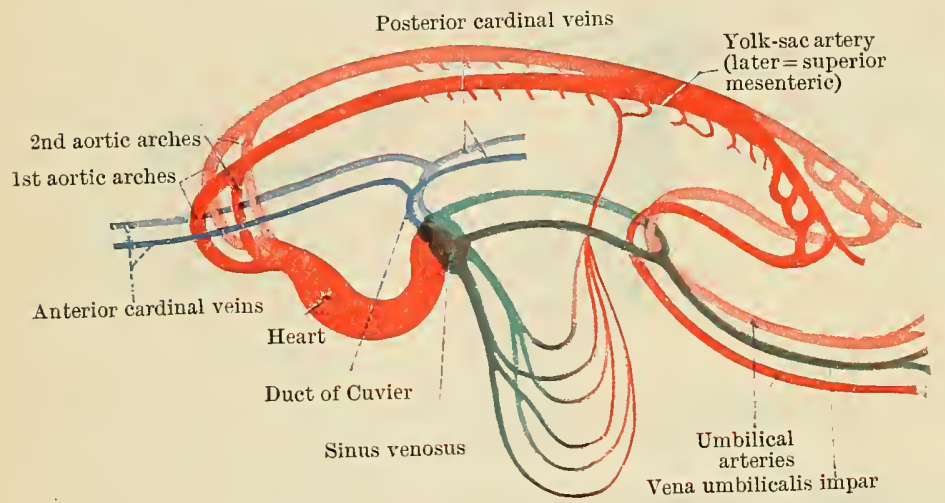

Fig. 820.-Schema of Vascular System of an Embryo with TwentyTHREE SOMITES. (Arteries atter Felix, modified.) which the umbilical arteries arise (Fig. 819).

When the embryo has attained a length of $2.5 \mathrm{~mm}$, and possesses about twentythree mesodermal somites, the two primitive dorsal aortæ have fused together, from the tenth to the sixteenth somite, forming in the region of fusion a single dorsal aorta, which becomes the descending aorta of the adult.

At a slightly later stage the fusion of the two primitive dorsal aortæ extends caudalwards to the level of the twenty-third somite, where one of the ventral branches of each primitive
Still vessel becomes enlarged and forms the origin of the stem of the primitive umbilical artery. Still
later the comparatively small continuations of the primitive dorsal aortæ, which are continued caudalwards from the twenty-third somite to the end of the cautal the twenty-third body somite. the middle sacral artery - the dorsal aorta, as such, terminating at the twenty-thire veins are present on each

The Primitive Veins.-In embryos $1.4 \mathrm{~mm}$. long two prim the vitelline veins. The lateral side in the body of the embryo-the lateral umbilical veins and the vitelline veins. umbilical veins are the divisions of the vena umbilicalis impar, the yolk-sac (Fig. 819). During placenta to the embryo; and the vitelline veins return blood $.6 \mathrm{~mm}$. additional veins appear. As the time in which the embryo increases from $1.4 \mathrm{~mm}$. to $26 \mathrm{~mm}$ adannels are formed to return the body and head of the embryo become larger din with the more rapid development of the blood from them to the heart, and in association with the mor sapid appear are the anterior cephalic portion of the embryo the first entirely intra-embryonic veins to appear are the anterio or
cardinal veins, one on each side, which retnrn blood from the head, and from the cephalic or anterior portion of the body of the embryo. These veins are present in embryos possessing fourteen mesodermal somites, and each terminates in the common trunks formed by the union of the vitelline and umbilical veins of the same side (Fig. 819).

A little later the posterior cardinal veins, one on each side, develop in the caudal or posterior part of the body. They join the anterior cardinal veins at the level of the caudal end of the heart, and the common trunk formed by the union is the duct of Cuvier, which opens directly in to the caudal part of the heart. In the meantime the venous trunk, produced by the union of the lateral umbilical with the vitelline vein, and into which the anterior cardinal vein opened, is absorbed into the heart; therefore, when the ducts of Cuvier are formed, six vessels, three on each side, open into the caudal portion of the heart-the vitelline veins, the lateral umbilical veins, and the ducts of Cuvier. Whilst these changes in the veins are taking place, two additional aortic arches are formed, one on each side. They spring from the cephalic extremity of the heart, immediately caudal and somewhat dorsal to the ventral roots of the first arch; and they terminate, dorsally, in the dorsal aortæ (Fig. 820). 
The Aortic Arches and their Ventral and Dorsal Roots. - The aortic arches are the ressels which connect the ventral portions of the primitive ventral aortæ with the primitive dorsal aortæ. Six such arches are formed on each side. They spring from the ventral aortæ or from the heart, they pass round the lateral walls of the fore-gut, in the branchial arches, and they terminate, in relation with the dorsal wall of the pharynx, in the primitive dorsal aortæ. All six arches are not present at the same time, for as the more caudally situated arches are formed those situated more cephalwards disappear (Figs. 821, 822). Five pairs of arches, the first four and the sixth, are present in embryos $5 \mathrm{~mm}$. long; but by the time the length of the embryo has increased to $7 \mathrm{~mm}$. the first two arches on each side have begun to disappear, and the very transitory fifth arch has been formed (Fig. 822).

The first aortic arch, on each side, is part of the primitive aorta, and is formed as the head fold is developed and the fore-gut is enclosed. It passes through the mandibular or first branchial arch, and connects the eephalic parts of the ventral and dorsal portions of the primitive aortæ together (Fig. 821). When the number of mesodermal somites has increased to twenty-three pairs and the embryo is about $2.5 \mathrm{~mm}$. long, a second pair of aortic arches has appeared. They spring from the cephalic end of the heart, dorsal to the ventral roots of the first arches, and pass through the hyoid or second pair of branchial arches to the dorsal aortæ.

In embryos $5 \mathrm{~mm}$. long the number of

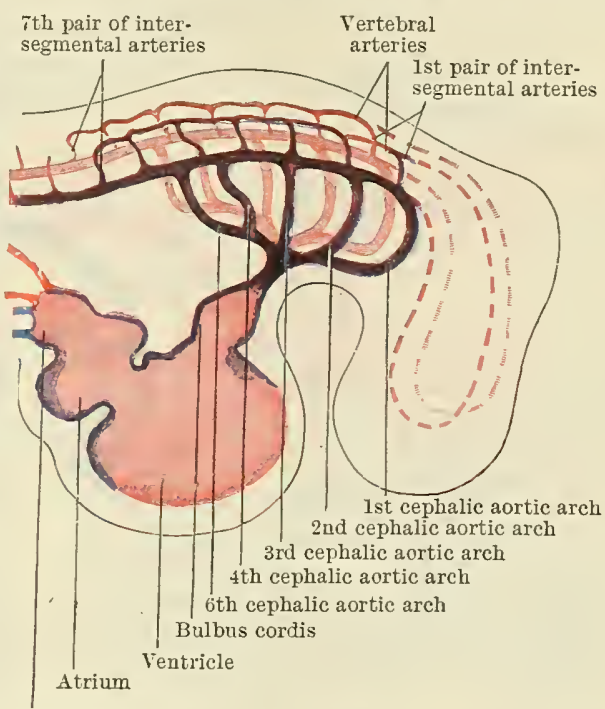

Sinus venosus

Fig. 821. - Schema of the Stage of Five Aortic Arches. The cardinal veins and ducts of Cuvier are not shown. aortic arches has increased to five on each side - the first four and the sixth, the fifth appearing later, between the fourth and the sixth. At the period when five pairs of arches are present only four vessels spring from the cephalic end of the heart, which is now called the bulbus cordis; they are, on each side, an anterior stem which forms the ventral roots of the first and second arches, and a posterior stem common to the third, fourth, and sixth arches (Fig. 821). Up to this period the head lies quite close to the thorax, and a distinct neck can scarcely be said to exist.

As the neck appears and the head is moved away from the thorax the third and fourth aortic

2nd arches atrophied 3 rd arehes

4th arches

5 th arches

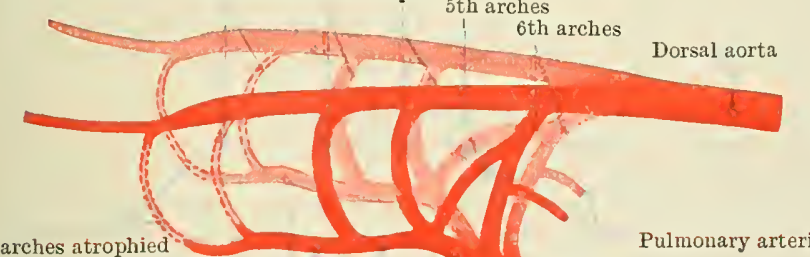

1st arches atrophied

External carotids

Ventral root of 3rd arch

Ventral root of 4 th and 5th arches

Truncus arteriosus arches also move headwards and are transposed from the posterior to the anterior stem, which is simultaneously elongated. When the transposition is completed the condition depicted in Fig. 822 is attained; the most cephalic, or anterior, part of each dorsal aorta is connected with the cephalic end of the heart by the sixth aortic arch; and by the first, second, third, and fourth arches it is connected with a rentral vessel which springs from the cephalic end of the heart. The portion of each dorsal aorta which is caudal to any given arch is called the dorsal root of the arch,

Fig. 822.-Schema of Aortic Arehes of Ax Embryo, 9 mir. Long. (After Tandler, modified.) The second and third arches have atrophied and the transitory fifth has appeared.

and the portion of the ventral stem which lies caudal to any arch is the ventral root of that arch. The sixth arch has no ventral root, for it arises directly from the heart. Its dorsal root converges towards and meets its fellow of the opposite side about the level of the tenth mesodermal somite, where the two fuse together to form the single dorsal aorta, which becomes the descending aorta of the adult, and which extends caudalwards to the level of the twenty-third somite, where it gives off the umbilical arteries and becomes the middle sacral artery.

By the time the embryo has attained a length of $7 \mathrm{~mm}$. the first two arches have partly disappeared, only their dorsal and ventral extremities being left, and the transitory fiftli arch has 
been formed. It runs from the ventral root of the fourth arch to the dorsal part of the sixth arch (Fig. 822), persists for a short time, and then disappears.

At a still later period the dorsal roots of the third arches on both sides and the dorsal roots of the fourth and sixth arches on the right side disappear. The vessels which remain form

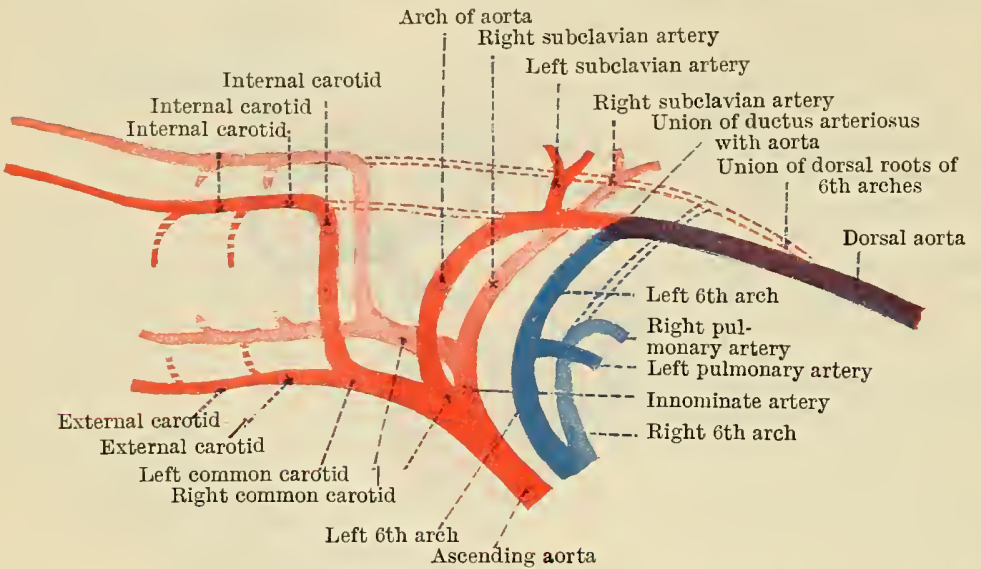

Fig. 823.-Schema of part of the Arterial System of a Fetus seen from the Left SiDE. Parts of the first and second arches, the dorsal roots of the third arches, the dorsal part of the right sixth arch, and the dorsal roots of the right fourth and fifth arches have atrophied. The position of the fifth arch is not indicated; see Fig. 822

becomes the common carotid. The ventral root of the fourth arch on the right side is converted into the innominate artery, and the fourth arch of the right side forms part of the right subclavian artery, i.e. a portion of that part of the right subclavian artery which lies medial to the vertebral artery. On the left side the ventral root of the fourth arch, and the fourth arch itself and its dorsal root, take part in the formation of the arch of the aorta, and the dorsal root of the sixth arch is converted into the most cephalward or anterior portion of the thoracic part of the descending aorta; the remainder of the descending aorta being formed by the earlier fusion of the primitive dorsal aortæ. Occasionally the dorsal roots of the fourth and sixth arches on the right sidepersist (see p. 1051), and in such cases the right subclavian artery, of which they form a part, springs from the descending aorta at the level of the fifth thoracic vertebra. It is probable, therefore, that the portion of the descending aorta formed from the dorsal roots of the left fourth and sixth arches is a comparatively small part. The left subclavian artery, which springs from the aortic arch, in the adult, is an intersegmental artery which sprang originally from the primitive dorsal aorta. It may be presumed, therefore, that that portion of the aortic arch which lies dorsal to the origin of the left subclavian artery is formed from the dorsal roots of the fourth and sixth arches of the left side-a presumption which is strengthened by the fact that the ligamentum arteriosum, which is a remnant of the left sixth arch, is attached to the opposite border of the aortic arch immediately dorsal to the origin of the left subclavian artery.

The sixth arch on the right side forms part of the extra-pulmonary portion of the right pulmonary artery, the remainder of the extra-pulmonary part of the artery being derived from a branch given off from the right sixth arch to the lung bud.

The ventral part of the left sixth arch becomes absorbed into the stem of the pulmonary artery; therefore the left pulmonary artery is merely the branch from the left sixth arch to the lung bud.

The dorsal part of the left sixth arch forms, during fœtal life, the ductus arteriosus, which carries the venous blood from the right ventricle of the heart to the aorta. After birth it is converted into the ligamentum arteriosum.

The Branches of the External Oarotid Artery.- All the typical branches of the external carotid artery are present in embryos $15.5 \mathrm{~mm}$. long; little is known, however, regarding the details of their development. It is probable that the internal maxillary artery and its branches are evolved partly from the ventral part of the first aortic arch and partly from an anastomosis with the branches of a temporary stapedial artery, which develops from the dorsal end of the second arch; but it is not known whether the other branches of the external carotid spring as offsets from the ventral roots of the first or second arches or from the ventral parts of the arches themselves.

The Descending Aorta. - The greater part of the descending aorta is formed by the fusion of the primitive dorsal aortæ. In embryos about $2.6 \mathrm{~mm}$. long, possessing twenty-three mesodermal somites, the primitive dorsal aortæ are fused together from the tenth to the sixteenth segment (Fig. 820). At a later period the fusion is continued caudalwards to the twenty-third body segment-the level of the fourth lumbar vertebra-where the common iliac arteries arise. Still later the small terminal portions of the primitive dorsal aortæ fuse together to form the unpaired middle sacral artery, which terminates at the extremity of the coccygeal region.

If the three somites which lie nearest the head end, in embryos possessing twenty-three somites, 
are cephalic somites, then the point of commencement of the median aorta would be situated at the level of the seventh body somite, that is, at the situation of the future seventh cervical vertebra. The position of the anterior point of fusion of the primitive dorsal aortæ is indicated in the adult by the origin of the abnormal right subclavian artery, and is situated at the level of the fifth thoracic vertebra; therefore the anterior end of that part of the descending aorta which is formed by the process of the primitive dorsal aortæ must move caudalwards during the developmental period.

The Branches of the Dorsal Aortæ.-Each primitive dorsal aorta gives off a series of dorsal, lateral, and ventral branches. The dorsal branches are distributed to the neural tube and body wall; the lateral branches to the primitive excretory organs - the Wolffian bodies; and the ventral branches pass to the alimentary canal, the yolk-sac, and to the placenta.

The dorsal branches are intersegmental in arrangement, and when they first appear they pass dorsally, in the intervals between the mesodermal somites, supplying the walls of the neural tube and the adjacent mesoderm and nerve ganglia. After a time each primitive dorsal intersegmental artery gives off a ventral branch which passes first laterally and then ventrally in the body wall, towards the ventral median line. At this time each intersegmental artery consists of a stem and a dorsal and a ventral branch. As the ventral part of the body increases in size more rapidly than the neural tube and the vertebral region, the ventral branch of each primitive intersegmental artery soon exceeds in size the dorsal continuation, and simultaneonsly the stem of each primitive intersegmental vessel enlarges. Thus it is that the stems of the intersegmental arteries and their lateral branches become the trunks of the intercostal and lumbar arteries, whilst the dorsal continuation of each primitive vessel is reduced to the position of a posterior ramus.

The dorsal branches of the intersegmental arteries become connected together by longitudinal anastomosing channels, some of which lie ventral and others dorsal to the rudiments of the transverse processes of the vertebræ. Each ventral branch of an intersegmental artery, as it passes towards the mid-ventral line, gives off a lateral branch to the tissues of the lateral part of the body wall, and at its termination it becomes connected, by longitudinal anastomosing channels, with its more cephalward and caudal neighbours. The lateral branches also become connected by longitudinal anastomoses.

The dorsal branch of each intersegmental artery gives off a neural ramus to the walls of the neural tube, which divides into dorsal and ventral neural branches; these accompany the posterior and anterior roots of the spinal nerves. As the dorsal and rentral neural branches approach the median plane, those of each side become connected together by a longitudinal plexus of fine vessels, and on the ventral surface of the neural tube the longiturlinal plexuses of opposite sides are connected together at or near the median plane.

The permanent arteries derived partially or wholly from the primitive dorsal intersegmental arteries and their branches and anastomoses are: (1) The intercostal and lumbar arteries and their posterior or dorsal rami; (2) the subclavian and axillary arteries and their continuations in the upper extremities; (3) the vertebral arteries; (4) the spinal arteries; (5) the basilar artery; (6) the superior intercostal arteries; (7) the internal mammary and the superior and. inferior epigastric arteries.

In the cervical region the stems of the first six intersegmental arteries disappear, but the seventh persists and forms, on each side, a portion of the stem of the corresponding subclavian artery. The dorsal branch of the serenth segmental artery and the anastomoses, between it and the first six dorsal branches, which pass rentral to the true transverse processes of the cervical vertebræ, form the vertical part of the vertebral artery of the adult. The neural ramus of the first cervical segmental artery and its preneural branch form the part of the rertebral artery which lies on the atlas and passes to the vential surface of the medulla oblongata. The cranial or upward prolongation of the rertebral to its union with the basilar is dereloped from the network of vessels which connects the medial ends of the preneural arteries. 
The ventral branch of the seventh cervical segmental artery on each side forms the trunk of the subclavian artery, from the origin of the vertebral to the origin of the internal mammary, and that part of the internal mammary which extends from its origin to the upper margin of the first costal cartilage. The remainder of the internal mammary artery, and the superior and inferior epigastric arteries, are derived from a Iongitudinal anastomosis which forms between the terminal extremities of the ventral branches of the intersegmental arteries.

The lateral ranus of the ventral branch of the seventh cervical intersegmental artery forms the trunk of the subclavian artery beyond the origin of the internal mammary branch, and from its prolongation into the upper extremity are formed the main arterial stems of the upper limb.

The superior intercostal arteries are derived from longitudinal anastomoses which connect together the lateral rami of the rentral branches of the intersegmental arteries, on the inner sides of the dorsal parts of the ribs.

The anterior and posterior spinal arteries are derived from plexiform anastomoses which form on the dorsal and rentral aspects of the neural tube between the terminal ends of the dorsal and ventral neural branches of the neural rami of the posterior divisions of the intersegmental arteries.

The lateral branches of the primitive dorsal aortæ supply structures derived from the intermediate cell tract, and from them are formed the renal, the suprarenal, the inferior phrenic, and the internal spermatic and ovarian arteries.

The ventral branches of the primitive dorsal aortæ are not definitely segmental or intersegmental in arrangement. In the early stages they pass not only to the gut wall but also, beyond it, to the wall of the yolk-sac. They are connected together by longitudinal anastomosing channels which lie in the dorsal mesentery of the gut and also upon the wall of the gut itself. As the yolk-sac atrophies the prolongations of the ventral branches which pass to its walls disappear and, simultaneously, the portions of the corresponding vessels of opposite sides which lie in the mesentery, dorsal to the gut, and the longitudinal anastomoses which connect them, fuse together to form unpaired stem-trunks from which the three great vessels of the abdominal part of the alimentary canal are derived, namely, the cœliac, the superior mesenteric, and the inferior mesenteric arteries; but the original stem of each of these three important vessels is not that which eventually forms its origin from the abdominal part of the aorta, for the cœliac artery, which originally arose opposite the seventh cervical segment, wanders caudalwards to the twelfth thoracic segment as the roots of origin of the ventral vessels which are situated nearer the head disappear; and in the same manner the superior mesenteric is transposed from the level of the second thoracic to the level of the first lumbar segment, and the inferior mesenteric wanders from the twelfth thoracic to the third lumbar segment.

The Umbilical and Iliac Arteries.-It was pointed out, in the account of general features of embryology, that the umbilical arteries which carry blood to the placental area of the chorion arise, in a human embryo about $1.38 \mathrm{~mm}$. long, about the level where the fourth cervical mesodermal somite will be developed at a later stage. They spring from plexuses formed, on

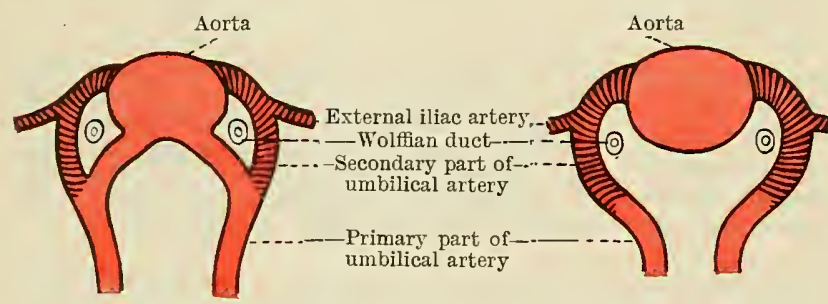

Fig. 825.-Diagay shoming the Formation of the Secondary Parti of the Primitive Uabilical Artery. the lateral walls of the caudal part of the primitive gut, by the anastomosis of some of the most caudally situated ventral or vitelline branches of the primitive dorsal aorta. The origins of the arteries are gradnally moved caudally as the embryo grows, until, eventually, they spring from the primitive dorsal aorta, opposite the twenty-third body somite, that is the fourth lumbar segment. As each umbilical artery passes from its origin on the ventral wall of the primitive dorsal aorta to the body-stalk it lies to the medial side of the Wolffian duct. The ventral origin is, however, bnt temporary; for, by the time the embryo has attained a length of $5 \mathrm{~mm}$, and the primitive dorsal aortæ have fused to form the permanent descending aorta, a new vessel has arisen on each side from the lateral part of the caudal end of the aorta. This new vessel passes ventrally, to the lateral side of the Wolffian duct, and then unites, on a plane ventral to the aorta, with the primitive umbilical artery of the same side. After the union has taken place the ventral origin of the umbilical artery disappears, and the primitive umbilical artery then arises from the side of the caudal end of the aorta. From the newly formed vessel which now constitutes the only origin of the umbilical artery, the inferior glntæal artery, which is the primitive main artery of the lower limb, arises. At a later period, and at a more dorsal level, a second branch arises from the dorsal root of origin of the umbilical artery; this is the second main vessel of the lower extremity, which becomes the external iliac and the femoral arteries of the adult. As soon as the external iliac artery is formed that portion of the umbilical stem which lies dorsal to it becomes the common iliac artery, and the more ventral part, which descends into the pelvis minor, becomes the hypogastric artery. But that portion of the original umbilical artery which runs along the side of the pelvis minor to the ventral wall of the abdomen, then cephalwards to the umbilicus and through the umbilicus to the placenta, is still called the umbilical artery. After birth, when the placental circulation ceases, the greater part of the intra-abdominal portion of the umbilical artery atrophies and 
becomes converted into the lateral umbilical ligament, but a portion of the part which lies in the pelvis minor remains pervious and from it springs the superior vesical artery.

The Arteries of the Limbs.-Our knowledge of the development of the arteries of the limbs is still very deficient, but during the last few years some investigations have been made and certain facts have been established. The very earliest stages of development have not yet been seen in the human subject, but it is not probable that they differ, in any essential respects, from those found in other mammals; therefore it may be assumed that the upper limb is supplied, at first, by a number of branches which spring from the sides of the primitive dorsal aortæ. As development proceeds the number of the vessels is reduced until only one remains. This loses its direct connexion with the aorta and becomes attached to the seventh segmental artery forming the ventral branch of that vessel, and the lateral division of the branch; the ventral continuation, past the lateral branch, being, apparently, a later formation. In the earlier stages the portion of the artery which lies in the free part of the limb does not consist of a single stem but of a plexiform series of vessels which only gradually become reduced to a stem. When the stem is definitely established it is divisible into subclavian, axillary, brachial, and volar interosseous portions. The median, the radial, and the ulnar arteries are of later formation.

In the case of the lower limb the earliest known artery is the primitive inferior glutæal, which springs from the secondary root of origin of the umbilical artery. It is converted into the inferior glutæal and popliteal arteries of the adult. The external iliac and femoral arteries are parts of a later formation which arises from the cephalic aspect of the secondary root of the umbilical artery above the origin of the inferior glutieal. This secondary ressel anastomoses distally, at the level of the proximal part of the popliteal fossa, with the primitive inferior glutæal, and, afterwards, the proximal part of the primitive inferior glutæal undergoes a certain amount of atrophy. The developmental history of the arteries of the leg and foot is not definitely known.

The Heart.-The rudi-
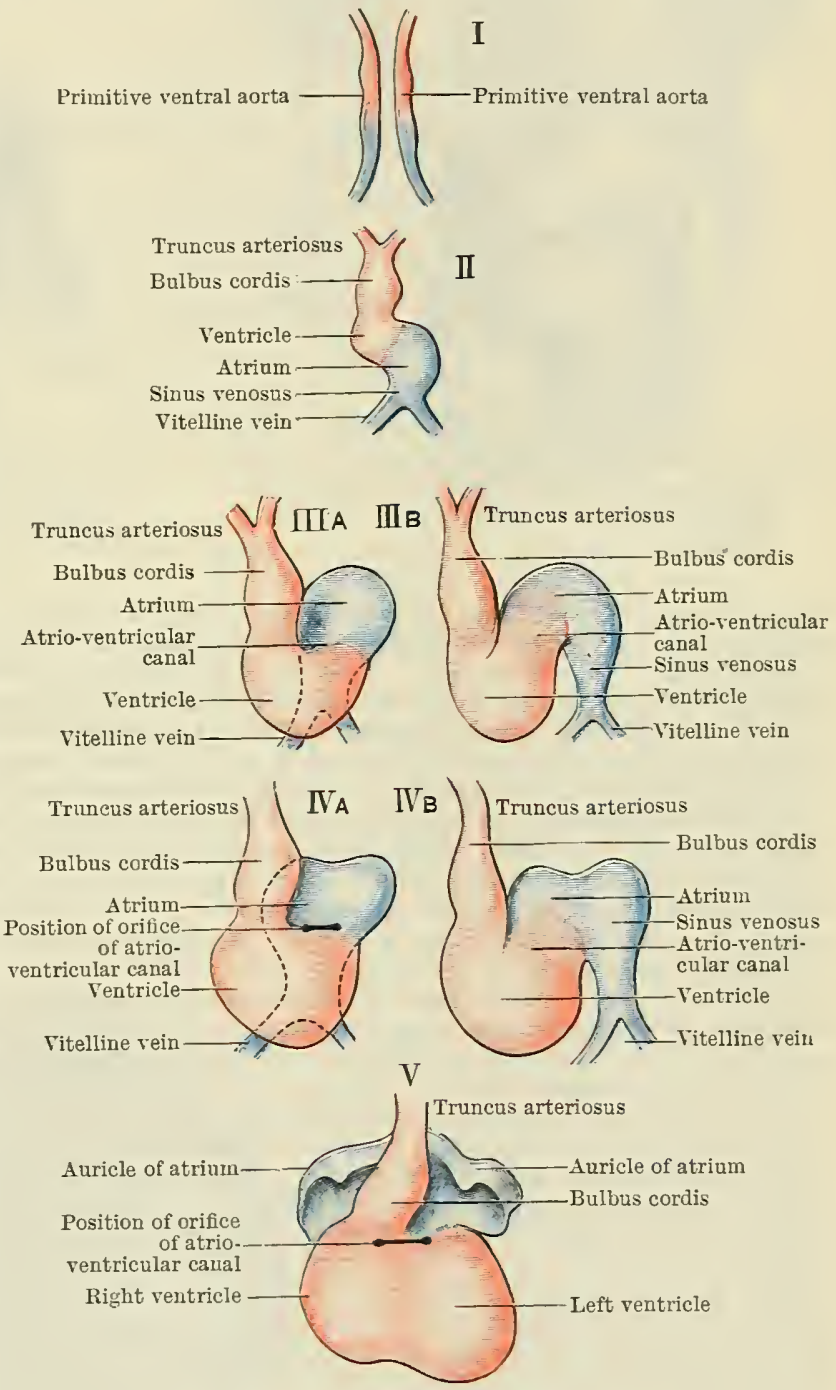

F1G. 826.-Development of the Heart.

Diagram showing the changes of form and external appearances at different stages. Moclified from His's models. III.B and IV.B are side views; the other figures represent the heart as seen from the front. ments of the heart are the caudal portions of the primitive ventral aortæ, which lie in the ventral wall of the fore-gut and the dorsal wall of the pericardium; therefore the heart may be said to consist, at first, of two tubes; these two tubes fuse, and the heart is then a single median tube, separated by constrictions into five compartments which, from the caudal to the cephalic end, are the sinus venosus, the atrium, the ventricle, the bulbus cordis, and the truncus arteriosus. The constricted region between the atrium and the ventricle is called the atrio-ventricular canal.

At a later stage the longitudinal tube becomes folded on its long axis and at the same time twisted. The caudal limb of the loop thus produced is formed by the sinus venssus, the atrium, and part of the ventricle; and the cephalic limb by the remainder of the rentricle, the bulbus cordis, and the short truncus arteriosus. Subsequently, for a time, the rentricular and bulbar 
part of the cephalic limb of the loop become placed transversely (Fig. 827), but after a short period its ventricular extremity again passes caudally until the original cephalic limb of the loop lies to the right and somewhat ventral to the original dorsal limb. Still later, the bulbus cordis is partly absorbed into the truncus arteriosus and partly into the ventricle; the right segment of the sinus venosus is absorbed into the atrium, and the left segment forms the coronary sinus. At a still later period the atrium is divided, by intra-atrial septa, into right and left atria. The atrio-ventricular canal becomes converted into the right and left atriorentricular apertures. The ventricle, including the absorbed portion of the bulbus cordis, is

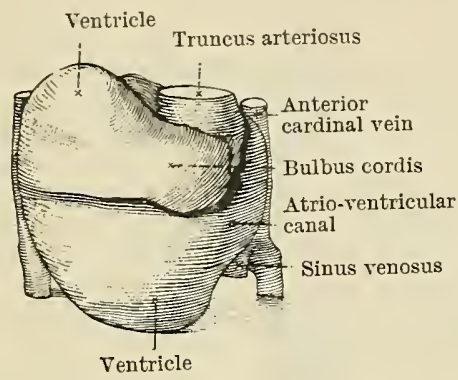

Fig. 827.-Ventral View of a Model of The Heart of a HuMan EMbryo $2 \cdot 5$ Mm. LONG. (Meyer's collection. Modelled by Professur P. Thompson.)

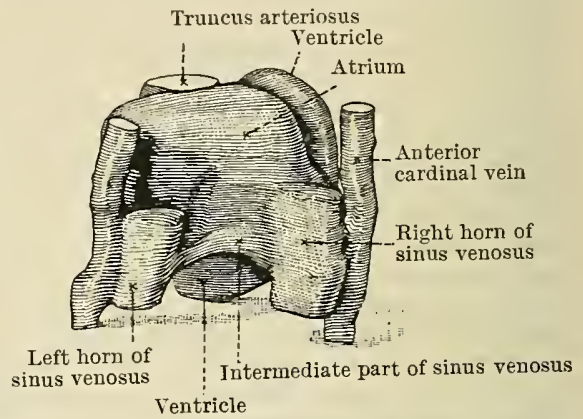

Fig. 828.-Dorsal View of a Modet of the Heart of a HuMan EMbryo 2.5 M. LONG. (Heyer's collection. Modelled by Professor P. Thompson.)

separated into the right and left ventricles of the adult heart; and the truncus arteriosus, and the part of the bulbus cordis which becomes incorporated with it, is separated into the ascending aorta and the pulmonary artery. Thus, from the embryonic heart are eventually produced the adult heart, the ascending aorta, the pulmonary artery, and the coronary sinus.

The main outlines of the transformation of the simple tubular heart of the young embryo into the four-chambered heart of the adult are, therefore, comparatively simple, but the details of the process are intricate and some of them are still imperfectly understood.

The Sinus Venosus.-In embryos possessing fourteen mesodermal somites the primitive single heart, formed by the fusion of the caudal portions of the primitive ventral aortæ, receives at its caudal end two venous stems, each of which is the common termination of the lateral umbilical vein, the vitelline vein, and the anterior cardinal veins of the same side (Fig. 819). At a later period, after the heart has begun to fold on its longitudinal axis, the two common venous stems are absorbed into the heart and form its most caudal section, the sinus venosus, which consists of a right and a left cormu, united by an intermediate segment. In the meantime, however, the posterior cardinal veins have appeared and have united with the anterior cardinals. After this union occurs the portion of the anterior cardinal vein ventral to the point of union becomes the duct of Cuvier. At this period, therefore, each cornu of the sinus venosus receives three veins -the vitelline vein, the lateral umbilical vein, and the duct of Cuvier.

As development proceeds the left vitelline vein and the left lateral umbilical vein lose their connexion with the left horn of the sinus venosus and pour their blood into the liver, through which it reaches the cephalic end of the right vitelline vein. The latter in the meantime has become the only outflow from the liver to the heart, and it ultimately forms the terminal part of the inferior vena cava. In association with these changes the right horn of the sinus venosus becomes considerably larger than the left horn (Fig. 828), and the left horn and the intermediate portion of the sinus become reduced to the form of a comparatively narrow channel which opens into the right horn, whilst the latter opens into the dorsal part of the atrial chamber, by a cleftlike aperture which is bounded by right and left lateral lips called the right and left venous valves (Figs. 829, 830).

As the right horn of the sinus venosus is absorbed into the right part of the corsal portion of the atrium the caudal or lower portion of right venous valve becomes the valve of the inferior vena cava and the valve of the coronary sinus. The cephalic or upper portion is united with a septal projection into the cavity of the atrium called the septum spurium, and forms with it the crista terminalis of the completed heart, which indicates, therefore, the line of union of the right horn of the sinus with the atrium proper. The left venous valve becomes incorporated with the interatrial septum, and the angle in the posterior wall of the sinus venosus which indicates the line of union of the right cornua and the intermediate part of the sinus appears in the dorsal all of the right atrium, where it unites with the dorsal part of the caudal or inferior portion of the septum secundum of the atrium, and takes part in the formation of the limbus ovalis.

Whilst these changes have been proceeding the right duct of Cuvier has become the lower part of the superior vena cava, the intermediate part of the sinus venosus and the left cornu are transformed into the coronary sinus, and the left duct of Cuvier has become the oblique vein of the left atrium. Thus when the changes mentioned are completed the right part of the atrium receives the superior and the inferior vena cava and the coronary sinus. 
The perforations eventually blend together to form the secondary foramen ovale of the interatrial septum. As soon as the septum primum is completed the primitive atrium is divided into the permanent right and left atria, each of which communicates through the secondary foramen

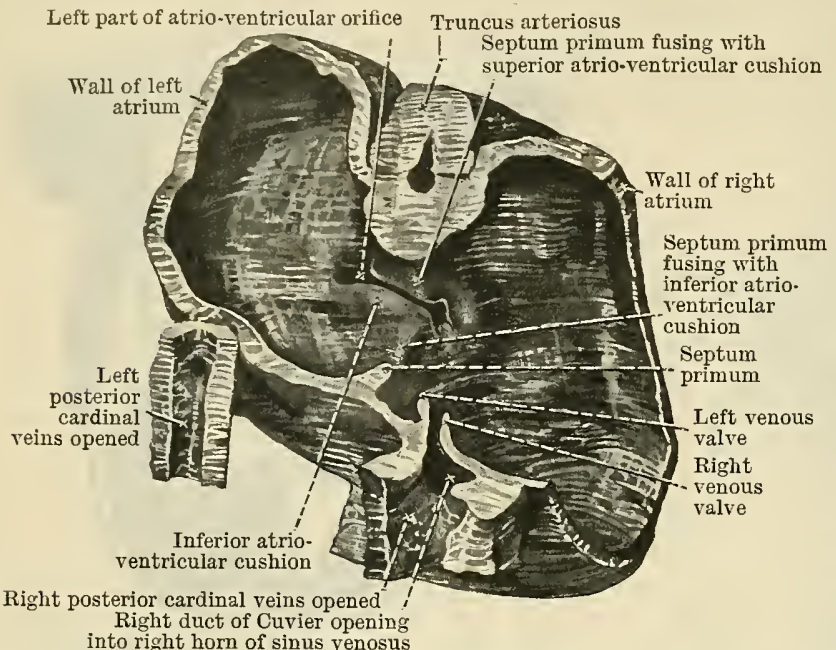

Fig. 831.-View of the Interiors of the Right and Left Atria or a HUMaN EMBryo 5.5 MM. LONG. (Edinburgh University collection. Modelled by C. C. Wang.) ovale, with the atrium of the opposite side and with the corresponding portion of the ventricle through an atrioventricular aperture which is completely separate from its fellow of the opposite side.

As the ventral border of the septum primum fuses with the endocardial cushions of the atrio-ventricular canal, the septum secundum appears immediately to the right of the septum primum. It grows from the dorsal and cephalic (superior in adult) walls of the atrium. As the septum secundum develops, the right cornu of the sinus venosus is absorbed into the atrium, the left venous valve fuses with the septum primum or disappears, and the angle between the right horn and the intermediate part of the sinus appears in the caudal part of the dorsal wall of the right atrium. As the septum secundum increases in size its cephalic part grows first ventrally and then caudally and lastly dorsally; consequently the free border soon becomes concave and the concavity of its margin is directed dorsally.

Both extremities of the free margin of the septum secundum fuse with the right lateral surface of the septum primum, and the more ventrally situated part of the border, growing along the

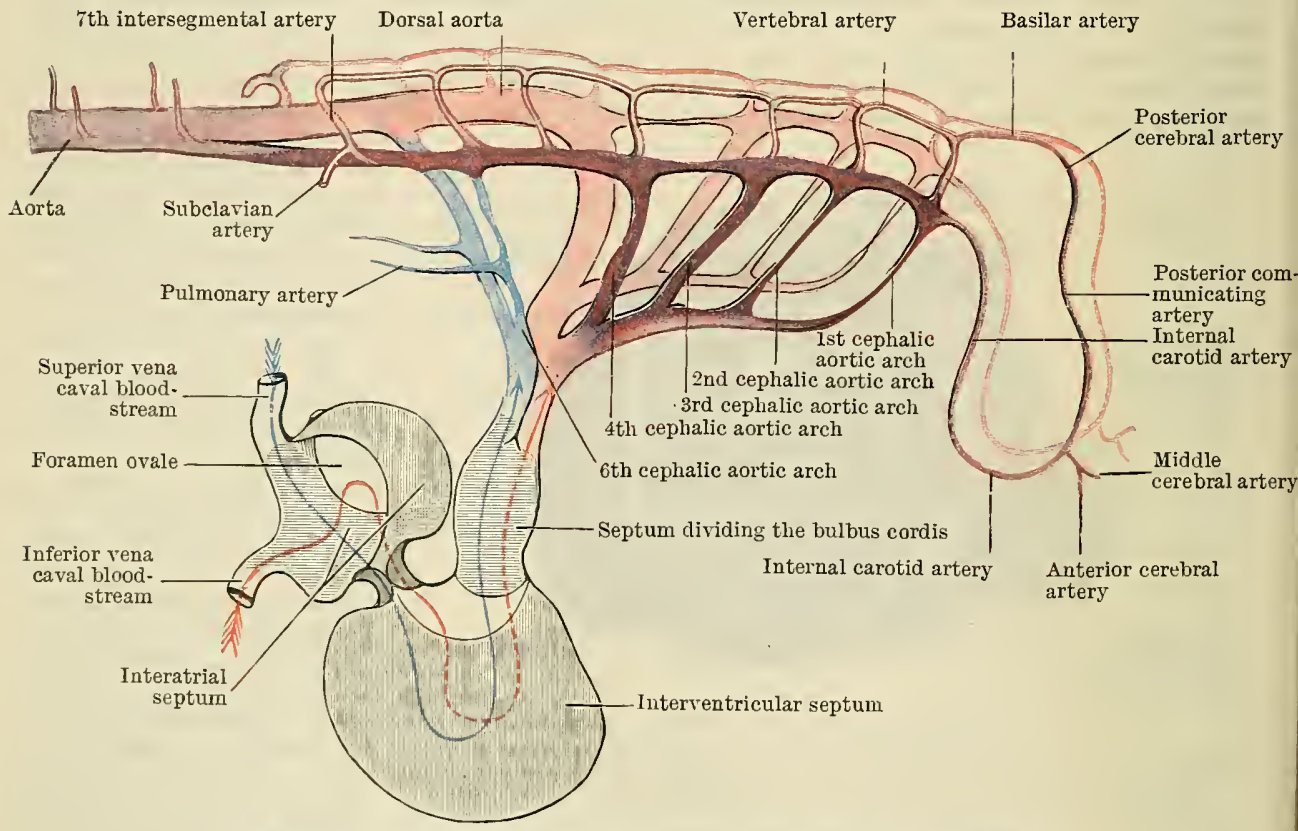

Fig. 832. -Development of the Heart and the Main Arteries.

Diagram of the heart, showing the formation of its septa, and of the cephalic portion of the arterial system

septum primum, fuses with the angle between the right horn and the intermediate part of the sinus venosus forming with it the lower part of the limbus fossæ ovalis of the fully developed heart. The remainder of the limbus is formed by the thickened free margin of the septum secundum.

As soon as the septum secundum passes beyond the level of the foramen ovale that portion 
of the dorsal part of the septum primum which is not yet fused with the septum secundum acts as a flap valve, permitting blood to pass from the right to the left atrium, but preventing its return. This condition persists until birth, when the thickened free margin of the septum secundum fuses with the right lateral face of the septum primum, and the foramen ovale of the fœtus becomes the fossa ovalis of the child. The fossa ovalis is bounded rentrally and caudally (anteriorly and inferiorly) by the limbus fossæ ovalis, which is formed mainly by the originally free margin of the septum secundum, but to a small extent also by the angle between the right cornu and the intermediate part of the sinus venosus.

The Division of the Primitive Ventricle, the Bulbus Cordis, and the Truncus Arteriosus. - Two facts have already been pointed out with regard to the bulbus cordis ; firstly, that it forms part of the cephalic or anterior limb of the early loop-sliaped heart, and secondly, that it disappears by being absorbed partly into the ventricle and partly into the truncus arteriosus. The part absorbed into the ventricle enters into the formation of that part of the ventricle which afterwards becomes the right ventricle of the completed heart, and the part absorbed into the truncus arteriosus lengthens that trunk.

The division of the elongated truncus arteriosus into the pulmonary artery and the ascending aorta is a complicated process in which three factors are associated: (1) a proximal and (2) a distal set of endocardial swellings in the bulbar part of the truncus aorticus, which are known as the proximal and distal bulbar swellings, and (3) a septum called the aorto-pulmonary septum, which appears at the cephalic end of the truncus aorticus, growing from the angle between the orifices of the more dorsally situated sixth aortic arches, and the orifices of the two stems which form the ventral roots of the first four aortic arches. The three sets of elements are, at first, entirely distinct from one another, but ultimately they blend together to form a spiral septum by which the lumen of the truncus arteriosus is divided into two channels. One of these channels communicates with the right ventricle and the other with the left ventricle. After the septum is completed it is cleft longitudinally into two parts, and so the truncus is divided into two vessels, the pulmonary artery which communicates with the right rentricle, and the aorta which is connected with the left ventricle.

The proximal bulbar swellings, which take part in the separation of the truncus into pulmonary artery and aorta are prolonged into the ventricular region as the ventral part of the bulbus cordis is absorbed into the ventricle, consequently the septum which they form by theix fusion is prolonged into the ventricular chamber, and helps to separate that cavity into two parts, by fusing with the dorsal end of the cephalic or anterior portion of the interventricular septum.

The interventricular septum appears as a semilunar ridge on the inner surface of the ventral part of the wall of the ventricle. At a later period its position is marked on the outer surface of the ventricle by the interventricular sulcus (Fig. 829) which persists in the completed heart. As the interventricular septum increases in height it fuses with the fused endocardial cushions which divided the atrio-ventricular canal into right and left parts, and with the ventral border of the bulbar septum which projects into the dorsal part of the rentricular chamber. The completed interventricular septum consists, therefore, of two distinct parts : a ventral part formed by the proper interventricular septum, and a dorsal part formed by the lower portion of the fused bulbar endocardial cushions. The two parts can be distinguished quite easily in the adult heart, for the interventricular septum is muscular, and it forms by far the greater part of the permanent septum, whilst the bulbar part of the septum, being developed from endocardial thickenings, is membranous, and it forms the small pars membranacea of the permanent septum, which lies between the aortic vestibule of the left ventricle and the upper part of the right rentricle and the adjacent lower part of the right atrimm.

\section{DEVELOPMENT OF THE VEINS.}

Simultaneously with the formation of the arteries, by which blood is distributed to the embryo and to all parts of the zygote, and in a similar manner, a series of ressels is developed by means of which the blood is returned to the heart. These ressels are the primitive veins; they form two main groups which make their appearance at different periods.

The first group consists of (1) the vitelline veins, and (2) the umbilical veins which return the blood from the placenta.

The second group consists of (1) the anterior cardinal veins, (2) the posterior cardinal veins, the (3) ducts of Cuvier, and (4) the subcardinal veins.

The ducts of Cuvier, one on each side, are the common stems by which the blood of the anterior and posterior cardinal veins is conveyed to the primitive heart. The anterior cardinal vein returns blood from the head and neck and fore limbs. The posterior cardinal veins carry blood from the body walls, the Wolffian bodies, and the hind limbs. The subcardinal veins also are closely associated with the return of blood from the Wolffian bodies.

The veins of the first group are largely transitory. The umbilical veins entirely disappear as blood channels, but a part of the left lateral umbilical vein is recognisable in the adult as the ligamentum teres of the liver. Portions of the intra-embryonic parts of the vitelline veins, and anastomoses which form between them, remain as the portal vein, its right and left branches, and the upper end of the inferior vena cava.

The anterior cardinal veins, and a transrerse anastomosis which forms between them in the more cephalward or upper portion of the thoracic region, are converted into the (1) cavernous sinuses of the cranium, (2) the internal jugular reins, (3) the innominate veins, (4) the upper part of the superior vena cara, and (5) the upper part of the left superior intercostal vein. The 
other renous channels of the cranium and the head and neck and the rpper extremities are later formations.

The right duct of Cuvier forms the inferior half of the superior vena cava, and the left duct of Cuvier becomes the oblique vein of the left atrium.

The posterior cardinal veins take part in the formation of the inferior vena cava, the azygos, hemiazygos, and accessory hemiazygos reins, and the hypogastric veins. The right subcardinal takes part in the formation of the inferior vena cava, and an anastomosis between the right and left subcardinal veins forms a large part of the left renal vein.

The Vitelline and Umbilical Veins and their Association with the Formation of the Portal System and the Upper End of the Inferior Vena Cava.-The vitelline veins, left and

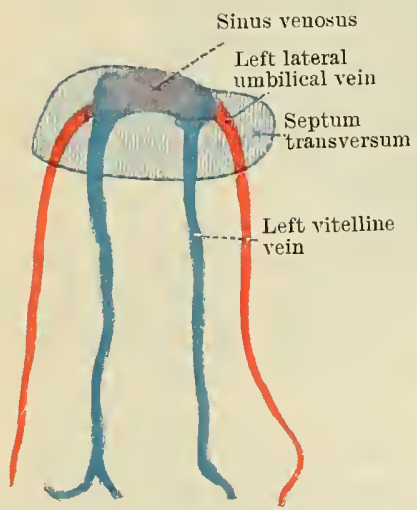

1

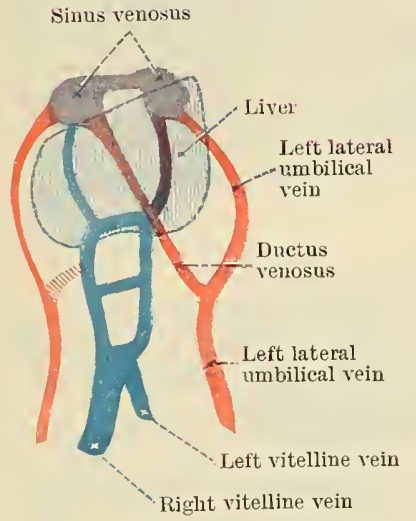

2

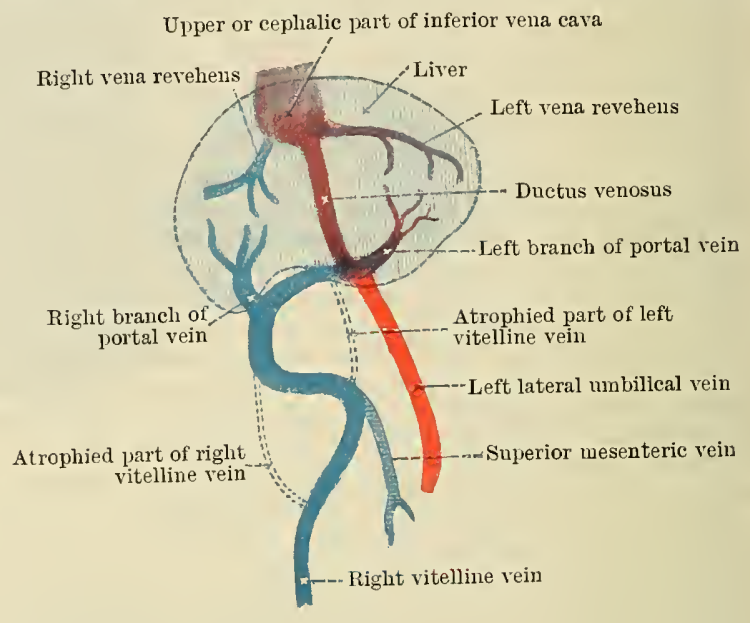

3

Upper or cephalie part of inferior vena cava

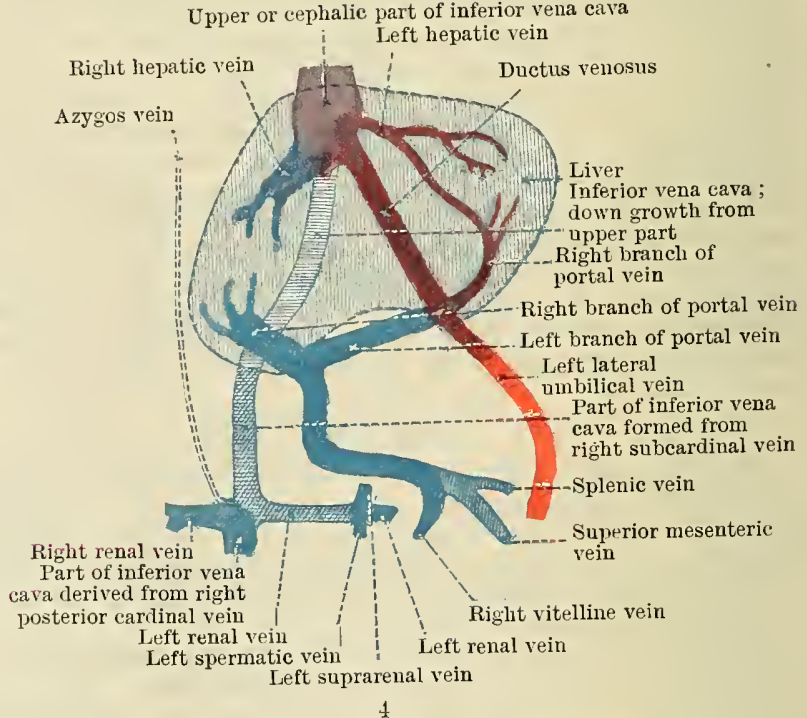

4

Fig. 833.--Schenata, showing four stages of the development of the portal system and part of the inferior vena cava.

right, pass over the wall of the yolk-sac, and, later, along the sides of the vitello-intestinal duct and the duodenum towards the caudal end of the heart. For a time each unites with the corresponding lateral umbilical vein to form a common stem, but at a later period each vitelline vein opens separately into the corresponding cornu of the sinus venosus of the heart.

The umbilical veins are three in number-the vena umbilicalis impar, which passes first along the body stalk, and later along the umbilical cord, and divides into the right and left lateral umbilical veins, which run, in the edges of the body wall, along the margin of the umbilical orifice to their union first with the corresponding vitelline veins, and later with the corresponding cornua of the sinus venosus of the heart.

On their way to the heart, both the vitelline and the lateral umbilical veins pass through 
the mass of mesoderm, called the septum transversum, which lies in the cephalic margin of the umbilical orifice and at the caudal end of the pericardium. The septum transversum afterwards takes part in the formation of the diaphragm, the liver, the falciform ligament of the liver and the lesser omentum. As the liver is formed from it the cardiac ends of the vitelline and lateral umbilical veins become enclosed in the liver substance, and pour their blood into a number of freely communicating channels or sinusoidal spaces, which form by far the greater portion of the liver in the early stages of its development.

Whilst the formation of the sinusoidal spaces is occurring in the liver, the parts of the foregut have been defined, and the vitelline veins, as they approach the growing liver, pass along the sides of the duodenum and become connected around it by three transverse anastomuses, two of which lie ventral and one dorsal to the duodenum. Cephalwards of these anastomoses each vitelline vein is broken up by the formation of the sinusoidal channels in the liver substance, into a caudal part, the vena advehens, which enters the liver substance, and a cephalic part, the vena revehens, which passes from the liver to the heart. After a time the left vena revehens loses its direct connexion with the heart, moves across towards the right, and opens into the cephalic end of the right vena revehens. When this change has occurred all the blood passing to the liver by the vitelline veins reaches the heart by the cephalic extremity of the right vena revehens, which now becomes the upper end of the inferior vena cava. This also receives the ductus venosus - a new channel, which is evolved from the sinusoidal spaces, and carries the major part of the blood from the left lateral umbilical vein to the upper end of the inferior vena cava.

In the meantime degeneration takes place in the ventral and caudal parts of the vitelline veins and the loops formed by the three transverse anastomoses between them. The ventral parts of the veins disappear with the degeneration of the yolk-sac, and the right half of the caudalward and the left part of the more cephalward situated loops also disappear. Simultaneously the superior mesenteric vein, which has been evolved in association with the formation of the intestine from the mid-gut, opens into the left vitelline vein caudal to the dorsal transverse anastomosis, and, a little later, the splenic vein enters at the same point. The final result is the formation of the permanent vena portæ, which is formed from (1) the cephalic end of the left limb of the caudal loop between the vitelline veins; (2) the dorsal anastomosis between the vitelline veins; $(3)$ the right limb of the cephalic loop formed by the vitelline veins. The right branch of the portal vein is the right vena advehens. The left branch of the portal vein is formed from the left vena advehens, and the most cephalward of the two ventral anastomoses between the vitelline reins. It is connected with the ligamentum teres of the liver, because the left lateral umbilical vein, which opened at one time into the left horn of the sinus renosus of the heart, and afterwards into the sinusoids of the liver, finally becomes connected with the left vena advehens, at the level of the cephalward ventral anastomosis between the two vitelline veins; and it is connected with the ductus venosus so that a channel may exist by which the blood from the placenta can pass to the right vena revehens without much admixture with the venous blood passing to the liver through the left branch of the portal vein and the left vena advehens. Therefore the ductus venosus is developed from the sinusoidal spaces of the liver when the left lateral umbilical vein is transferred to the left vitelline vein.

The venæ revehentes, which transfer the blood from the liver to the heart, are the cephalic ends of the primitive vitelline veins. The left vena revehens, as already stated, eventually loses its connexion with the heart and ends in the right vena revehens, which receives the ductus venosus also. The right vena revehens thus becomes the only channel by which blood is returned to the heart from the alimentary canal and from the placenta: that is, it becomes the npper or cephalic end of the inferior vena cava. The stems of the right and left venæ revehentes become the right and left hepatic veins which convey to the inferior vena cava the blood which was carried from the alimentary canal to the liver by the portal vein and its branches.

The sinusoidal spaces become reduced to the blood capillaries of the liver, and the ductus venosus which, during fœtal life, conveyed the greater part of the placental blood to the inferior vena cava becomes reduced, after birth, to the ligamentum venosum, which connects the left branch of the portal vein with the upper end of the inferior vena cava.

As the cephalic part of the right ritelline vein is transformed from the right vena revehens into the upper end of the inferior vena cava, an outgrowth passes caudally from it, along the dorsal aspect of the liver; this becomes connected, at its caudal end, with the right subcardinal vein, and it forms that part of the inferior vena cava which lies in the groove on the dorsal aspect of the right lobe of the liver:

The Umbilical Veins. - In the earliest stages of development there are three umbilical reins, the vena umbilicalis impar and the left and right lateral umbilical veins. The vena umbilicalis impar and the left lateral vein persist until birth, and a remuant of the latter is found, in the adult, as the ligamentum teres of the liver; the right lateral rein disappears entirely at an early stage of development.

The vena umbilicalis impar passes from the placenta to the caudal boundary of the umbilical orifice, where it terminates in the left and right lateral umbilical veins. Each of the latter unites, for a time, with the corresponding vitelline vein; then it becomes directly connected with the corresponding cornu of the sinus venosus of the heart, and still later with sinusoidal spaces of the liver. The right lateral umbilical vein lias also a temporary secondary connexion with the right vitelline vein, but at an early period it undergoes atrophy and all parts of it completely disappear.

The left lateral umbilical vein, which is connected first with the left vitelline vein, next with the heart, still later with the liver, and finally with the left vitelline again, at the point where 
the latter becomes the left rena adrehens, persists until birth and, after the disappearance of the right lateral umbilical vein, it conveys the blood from the placenta to the liver, where part of the placental blood passes into the left rena adrehens and so through the left rena revehens to the inferior rena cava, and part passes into the ductus renosus, by which it reaches that portion of the cephalic part of the right vena advehens which becomes the cephalic or upper end of the permanent inferior vena cava.

After birth when the placental circulation ceases the left lateral umbilical vein becomes the ligamentum teres of the liver.

The Ductus Venosus.-The ductus venosus is developed as the right lateral umbilical vein loses its direct connexion with the liver and becomes united to the left rena advehens. It is formed from the sinusoidal spaces of the rudimentary liver and connects the commencement of the left rena advehens with the cephalic part of the right vena revehens. It forms the more direct channel by which blood from the placenta is passed to the heart through that part of the right vena revehens which becomes the upper end of the inferior vena cava. After birth it is converted into the fibrous ligamentum venosum, which connects the left branch of the portal vein with the upper end of the inferior vena cava.

The Anterior Cardinal Veins. - The anterior cardinal veins are the veins by which the blood is returned to the heart from the head and neck and, ultimately, that from the upper extremities, although the primitive veins of the upper extremities are, in the first place, tributaries of the posterior cardinal veins.

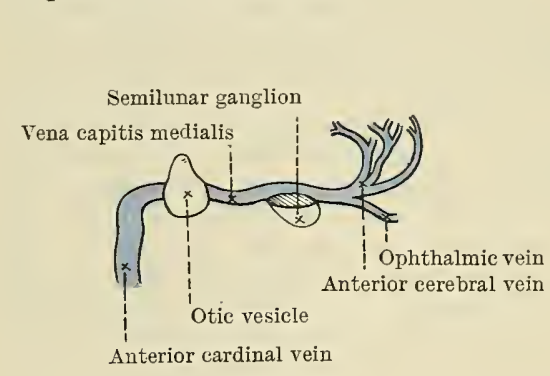

A.

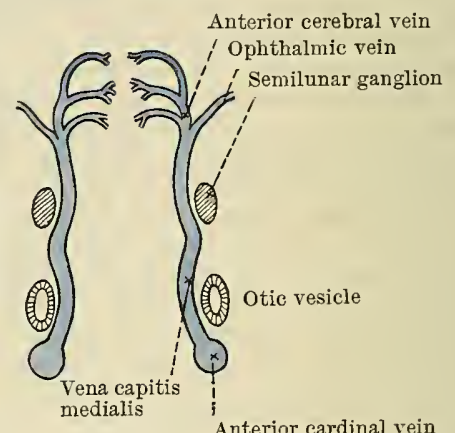

$\mathrm{B}$

Fig. 834. - Schema of the Development of the Primitive Cerebral Veins and Cranial Blood Sinuses. A, side view ; B, dorsal view. Stage I. (After Mall, modified.)

Each anterior cardinal vein may be separated into two parts - the intra-cranial and the extracranial. From the intra-cranial portions and their associated tributaries and anastomoses are developed some of the cranial blood sinuses and their tributaries; and from the extra-cranial portions and their anastomoses are formed the internal jugular veins, the innominate veins, the upper or cephalic parts of the superior vena cava and the left superior intercostal vein.

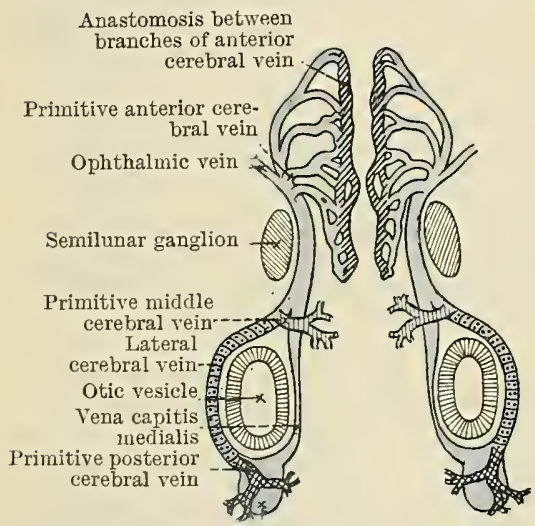

Anterior cardinal vein

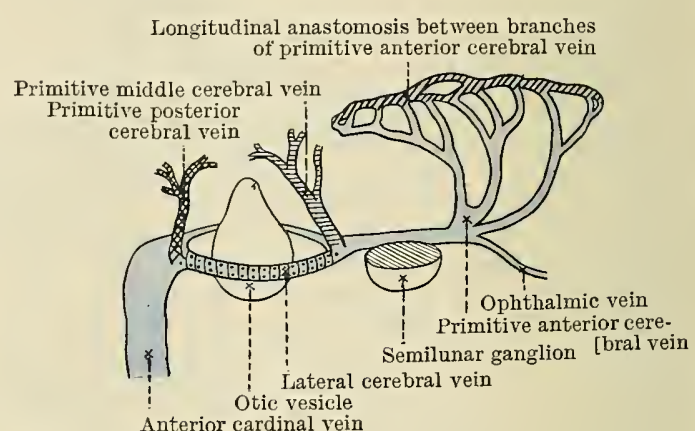

Anterior cardinal vein

Fig. 835. - Schema of the Development of the Primitive Cerebral Vein and the Cranial Blood Sinuses. A, dorsal view; B, side view. Stage II. (After Mall, modified.)

The intra-cranial portion of each anterior cardinal vein is called the vena capitis medialis, because it lies to the medial side of the otic vesicle and the fifth cerebral nerve. The cerebral extremities of the veins of opposite sides are associated with the developing cerebral hemispheres, 
and each receives tributaries from the corresponding hemisphere and from the optic resicle of the same side.

After a short time an anastomosing channel appears which connects the intra-cranial part of each anterior cardinal vein with the extra-cranial part. This channel is called the vena capitis

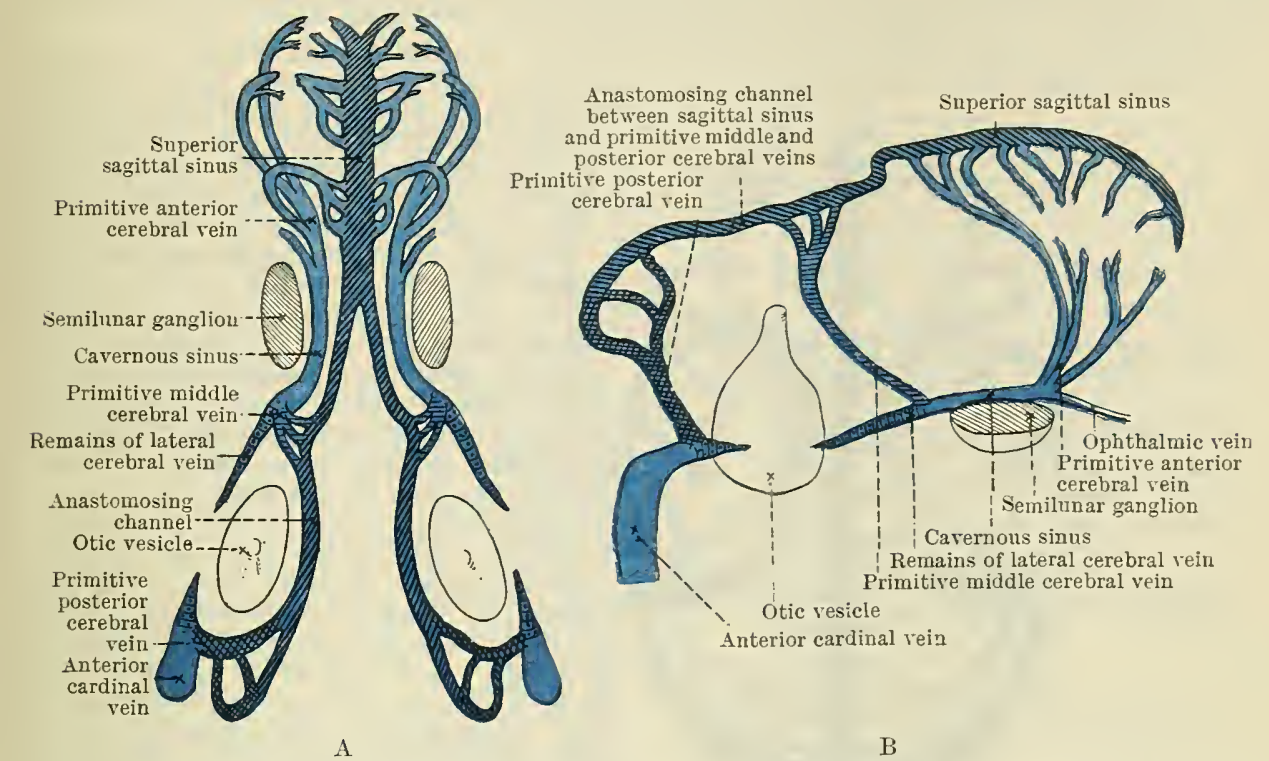

Fig. 836. - Schema of the Defelopmext of the Primitive Cerebral Teixs axd the Craxial Blood Sinuses. Stage In. A, dorsal view ; B, side view. (After Mall, modified.)

lateralis. It arises from the intra-cranial portion of the anterior cardinal vein, immediately caudal (posterior) to the semilunar ganglion of the trigeminal nerve; passes lateral to the otic vesicle, and leaves the cranium with the facial nerve. The caudal part of the intra-cranial portion of the anterior cardinal vein, which lies medial to the otic vesicle, then disappears. The part of the anterior cardinal vein which lies medial to the semilunar ganglion persists, and, up to the point where the vein from the optic vesicle joins it, it becomes the cavernous sinus. The remainder of the intra-cranial part of the anterior cardinal vein, which receives numerous. tributaries from the cerebral hemisphere, then becomes the primitive anterior cerebral vein, and the vein from the optic resicle becomes the ophthalmic vein.

In the meantime, however, two outgrowths are projected dorsally from the vena capitis lateralis, one from its junction with the intra-cranial part, and the other from its junction with the extra-cranial part of the anterior cardinal vein. The anterior of the two lies anterior to the otic vesicle, and passes towards the cerebellar part of the hind-brain and is known as the primitive middle cerebral vein. The other lies posterior or candal to the otic resicle and passes towards the caudal part of the hind-brain; it is called the primitive posterior cerebral vein. Subsequent to the formation of the primitive middle and posterior cerebral veins the lateral cerebral vein disappears. After the condition above described is evolved, the tributaries which join each anterior cerebral rein become connected together, along the dorsal border of the hemisphere of the cerebrum by a longitudinal anasto-

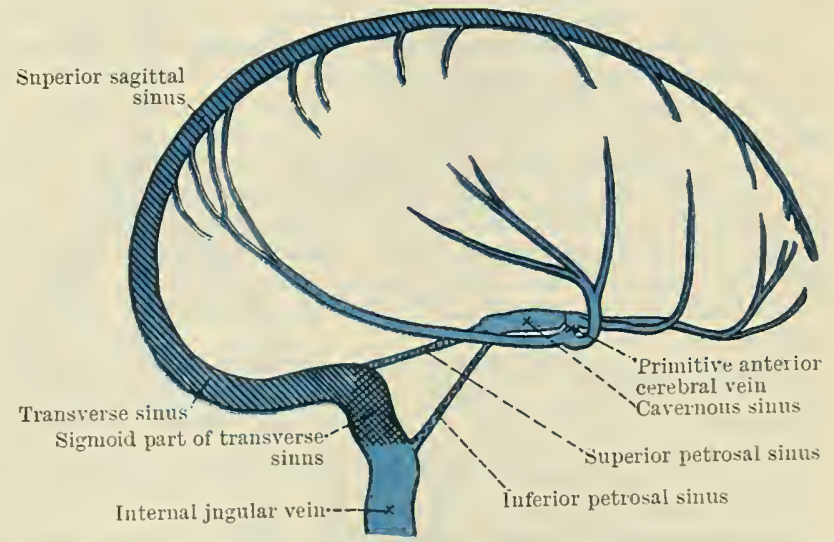
mosis which is the forerunner of

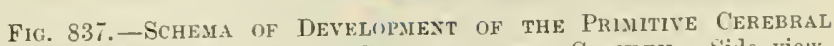
Veiss and the Blood sinuses of the Craxiox. Side view. Stage 1v. (After Mall, modified.)

the superior sagittal sinus. The superior sagittal sinus is therefore primitively double, but the right and left lateral halves soon fuse together to form a single median vessel. In the meantime, however, the tributaries which comnect each half of the sagittal sinus with the corresponding 
anterior cerebral vein atrophy in the middle parts of their lengths. The upper portions then become the superior cerebral veins, which terminate in the superior sagittal sinus, and the lower portions become the inferior cerebral veins. These open into the primitive anterior cerebral vein which lies in the lateral fissure of the hemisphere and becomes the medial cerebral vein of the adult. Tery conmonly one of the intercommunicating tributaries persists in the whole of its length and so becomes the great anastomotic vein (Trolard).

The dorsal longitudinal anastomosis extends caudally on each side, beyond the fusion by which the nredian unpaired sagittal sinus is formed, and comnects the sagittal sinus with the tributaries of

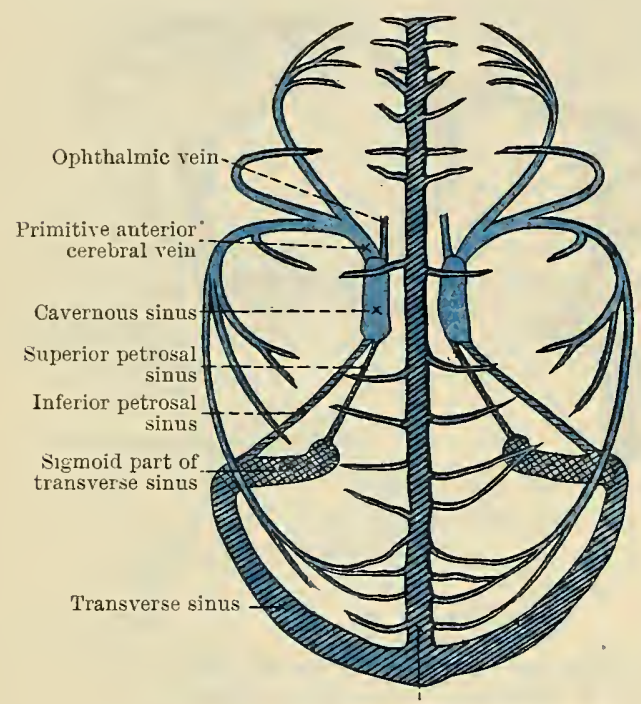

Superior sagittal sinus

Fig, 838.-SChena of the Development of the Primltive Cerebral Veins and the Cranial Blood Sinusfs, Stage IV. Dorsal view. (After Mall, modified.) the primitive middle and the posterior cerebral veins. This portion of the anastomosis becomes displaced caudally and laterally by the extending cerebral hemispheres, and it becomes converted, on each side, into the horizontal part of the transverse sinus, the sigmoid part of the transverse sinus being formed from the primitive posterior cerebral vein. At the same time the primitive middle cerebral vein becomes the superior petrosal sinus; and the inferior petrosal sinus is formed as a new structure which lies in the position of the original vena capitis medialis, but does not appear to be formed from it.

The extra-cranial parts of the anterior cardinal veins become connected together, in the upper or cephalic part of the thoracic region, by a transverse anastomosis which becomes the greater part of the left innommate vein. A short distance cephalwards of this transverse connexion, the primitive vein of the upper limb ultimately opens into the anterior cardinal vein. The portion of the anterior cardinal vein of the right side, which lies between the entrance of the limb vein and the transverse anastomosis, becomes the right innominate vein (Fig. 839), and the corresponding part on the left side forms the commencement of the left innominate vein.

The part of the extra-cranial portion of each anterior cardinal vein which lies cephalwards of the entrance of the limb vein forms the internal jugular vein; and the part of the right anterior cardinal vein which lies candalwards of the transverse anastomosis becomes the npper or cephalic part of the superior vena cava, whilst the corresponding portion of the left vein is converted into the upper part of the left superior intercostal vein (Fig. 839).

The external jugular vein is a new formation which receives for a time the cephalic vein of the upper extremity; but the cephalic vein, which is a secondary vessel, is eventually transposed to the axillary vein, which is a part of the primitive upper limb vein.

The Posterior Cardinal Veins, the Subcardinal Veins, and the Inferior Vena Cava.The posterior cardinal veins appear later than the anterior cardinal veins and they terminate cephalwards in the ducts of Cuvier. They lie dorsal to the Wolffian bodies and they become connected with each other, dorsal to the descending aorta, by numerous transverse anastomoses.

The subcardinal veins appear later than the posterior cardinals. They lie along the ventral borders of the Wolffian bodies and they are connected not only by dorso-ventral anastomoses with the posterior cardinal veins, but also by transverse anastomoses with each other. The majority of both sets of anastomosing vessels ultimately disappear, but two remain ; one which joins the right subcardinal to the right posterior cardinal, at the level of the right renal vein; and one which connects the subcardinal veins together, across the ventral surface of the aorta, at the same level.

After a time an anastomosis is formed between the right subcardinal vein and the cephalic end of the right vena revehens, dorsal to the liver, by the candal outgrowth of an anastomosing offset from the right vena revehens. As soon as the anastomosis is completed the blood from the caudal portion of the body and from the lower limbs is short circuited to the heart, and extensive changes occur in the primitive posterior cardinal veins, into which in the meantime the veins from the lower extremities have opened.

The Posterior Cardinal Veins. - The right posterior cardinal vein, cephalwards of the right renal vein, becomes the vena azygos. Between the right renal vein and the entrance of the lower limb vein it forms the candal or lower part of the inferior vena cava and the right common iliac vein; the remainder of the right posterior cardinal vein becomes the right hypogastric vein.

Two of the transverse anastomoses between the posterior cardinal veins form the transverse parts of the hemiazygos and accessory hemiazygos veins; others become converted into those parts of the left Iumbar veins which lie dorsal to the aorta, and one, which lies opposite the fifth lumbar somite, becomes the greater part of the left common iliac vein. 


\section{DEVELOPMENT OF THE VEINS.}

Portions of the left posterior cardinal vein remain as the left hypogastric vein, the hemiazygos and the accessory hemiazygos veins and the lower part of the left superior intercostal vein.

The tributaries of the right posterior cardinal vein become the right intercostal, subcostal, and the right lumbar veins. The right renal vein is also one of its tributaries. The tributaries of the left posterior cardinal become the left intercostal and subcostal veins, and ther form those

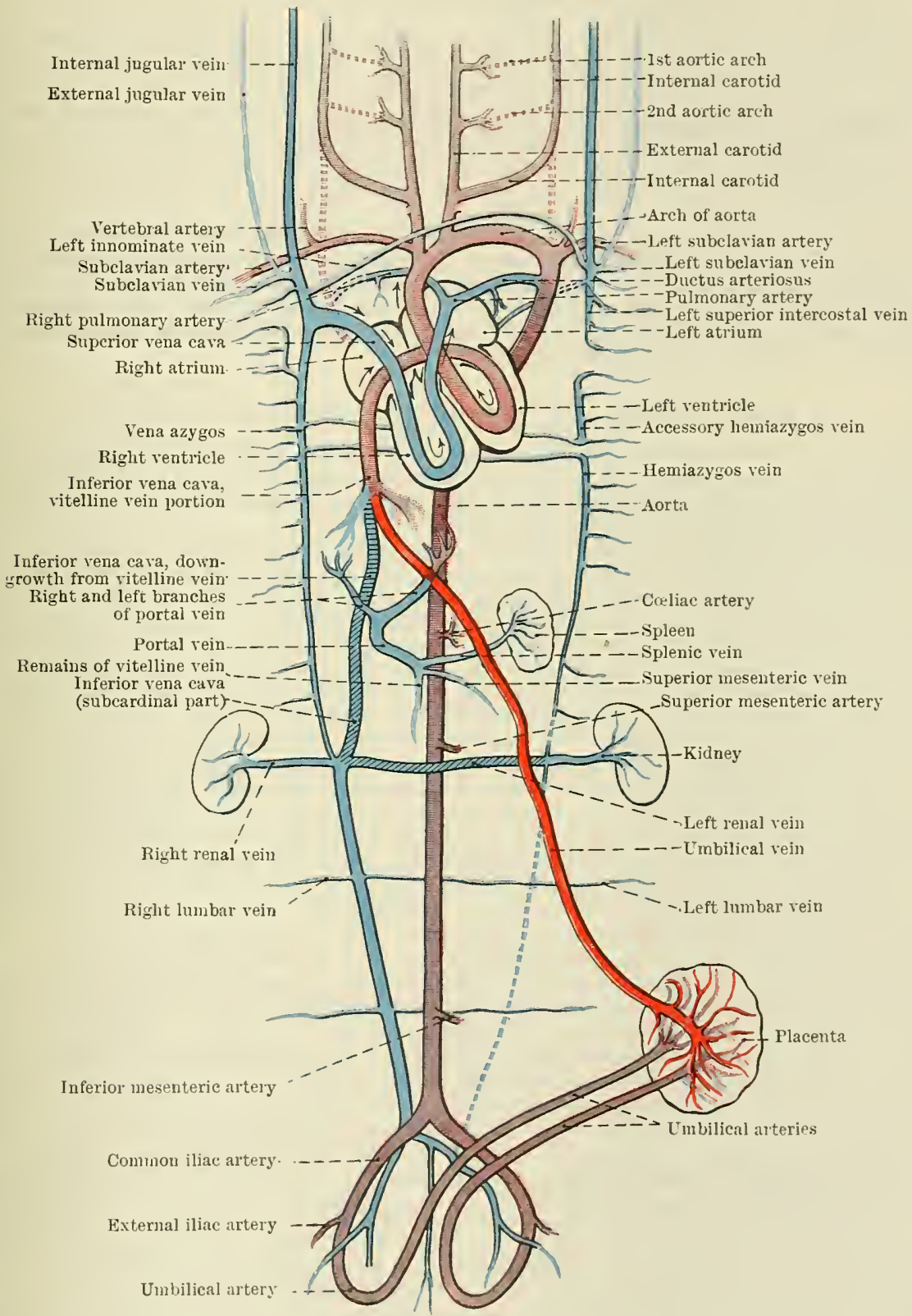

Fig. 839.-Diagram of the Course of the Fotal Circulatiox.

parts of the left lumbar veins which lie to the left of the vertebral column, and the corresponding part of the left renal vein (Fig. 839).

The Subcardinal Veins. - The only important parts of the snbcardinal system which remain in the adult are a portion of the right subcardinal rein, one of its anastomoses with the right posterior cardinal vein, and a transverse anastomosis between the subcardinal veins. The last forms the part of the left renal vein which crosses the front of the aldiominal part of the aorta, and the first two form that part of the inferior vena cava which extends fiom the liver to the entrance of the renal reins.

The Inferior Vena Cava,-It follows, from wint hits been said, that the inferior vena cava is 
a composite ressel derived from five sources:(1) the cephalic end of the right vitelline vein; (2) a caudal outgrowth from the cephalic part of the right vitelline vein; (3) a portion of the right subeardinal vein; (4) an anastomosis between the right subcardinal vein and the right posterior cardinal vein; and (5) a portion of the right posterior cardinal vein.

The Veins of the Extremities.-The primitive veins of the extremities are superficial veins which run along the corresponding borders of the two limbs, i.e. the ulnar border of the upper and the fibular border of the lower limb.

The primitive vein of the upper extremity, which becomes the basilic vein, the axillary vein, and the subclavian vein in different regions, opens at first into the posterior cardinal vein, afterwards into the duct of Cuvier, and finally into the anterior cardinal vein.

The cephalic vein of the upper extremity appears at a later period and, in the first instance, joins the external jugular vein, the primitive termination being occasionally retained in adult life. At a later period its terminal extremity is transferred to the axillary vein.

The deep veins which accompany the arteries are the latest venous formations of the extremities.

The primitive vein in the lower extremity becomes the small saphenous vein, which is continued proximally, as the inferior glutæal vein, to that part of the posterior cardinal vein which later becomes the hypogastric vein. The great saphenous vein and the femoral vein appear later and are continued to the posterior cardinal vein as the external iliac vein. After the external iliac vein joins the posterior cardinal vein the part of the latter vessel which lies caudal to the point of union is called the hypogastric vein.

\section{THE DEVELOPIENT OF THE LYMPH VASCULAR SYSTEM.}

Very little is known regarding the origin of the vessels of the lymph vascular system in man, but during recent years numerous investigations have been made with the object of discovering the various phases of the development of the lympl vascular system in other mammals; some of the main points are however still subjects of dispute.

It is generally admitted that the terminal parts of the great lyuph vessels, that is, the terminal part of the thoracic duct and the right lymphatic duct, are derived from venous channels, which, for a time, lose their connexion with the larger veins and become modified into terminal lymph sacs which obtained a secondary union with the great veins at the root of the neck; but regarding the origin of the thoracic duct and the cisterna chyli and the peripheral lymph vessels there is, as yet, no agreement. According to Florence Sabin, and those who agree with her, the peripheral lymph vessels are outgrowths from a series of lymph sacs of which the two cervical, a retro-peritoneal, a cisterna chyli, and two posterior sacs, lying along the inferior glutæal veins, are recognised in human embryos of about $24 \mathrm{~mm}$. length. The origin of these sacs, in the human embryos, has not been proved, but it appears probable that the cervical sacs are derived as in other mammals from venous capillary vessels. There is no agreement, however, concerning the origin of the other sacs, for whilst, on the one hand, Florence Sabin appears to believe that they have an origin like that of the jugular lymph sacs and that the thoracic dnct is developed in the same manner, Huntington, on the other hand, believes that, with the exception of the jugular or cervical lymph sacs, all the other lymph vessels, including the thoracic duct, are developed neither as outgrowths from ly mph sacs nor by the modification of venous capillaries, but by the formation of endothelial lined spaces in the mesodermal tissues. The spaces are at first entirely closed but afterwards attain union with each other and with the terminal lymph vessels.

According to the view upheld by Florence Sabin and her supporters, the lymph vessels are outgrowths of lymph spaces derived from the venous systen, and are, therefore, lined with endothelium which is genetically the same as that in the veins. According to Huntington this is not the case ; for his observations lead him to believe that the endothelium of the lymph vessels is formed, in situ, from the mesodermal cells, and it has, therefore, no direct genetic connexion with the endothelinm of the veins, which is derived from the original angioblast. The evidence brought forward by the supporters of the opposite views is interesting and instructive upon many points, and the balance at present appears to be in favour of Huntington's contention.

The Development of Lymph Glands. - Lymph glands are developed from plexuses of lymph vessels. The transformation is brought about by the aggregation of numerous lymphocytes in the connective tissue strands of the plexuses and the transformation of the lumina of the vessels into the peripheral and central portions of the lymph sinus. The stroma, the capsule, and the proper substance of a lymph gland are therefore formed from the fibro-cellular reticulum of the lymphatic plexus, and the eavity of the lymph sinus is formed from the lumina of lymph capillaries. The rudimentary lymph glands possess blood vascular as well as lymphatic capillary networks, and if the blood vascular network preponderates over the lymph vascular the developing gland has a reddish appearance and is known as a hæmal gland. Such glands are found in man (Schäfer) as well as in other mammals, and it would appear from the recent observations of S. v. Schumaker that hæinal glands are merely rudimentary forms of true lymph glands (Arch.f. mikr. Anat. H. 2., 1912).

\section{MORPHOLOGY OF THE VASCULAR SYSTEM.}

In conformity with the general plan of the vertebrate body, the vascular system is essentially segmental in character. This is obvious, even in the adult, in the intercostal and lumbar vessels. It is distinguishable, though less obvious, in the vessels of the head and neck and of the pelvis. 
The segmental arteries and veins form a series of bilaterally symmetrical vessels, each of which is united to the vessels of adjacent segments by intersegmental channels, which anastomose with one another, through the portions of the segmental vessels which they connect together, and thus form longitudinal trunks. The longitudinal trunks are mainly, though not exclusively, intersegmental. From them the main stem ressels of the individual are formed, and from or to these latter the segmental vessels appear to proceed as branches or tributaries.

In the course of development the longitudinal trunks become the most important trunks in the individual, and they are formed before the segmental vessels make their appearance.

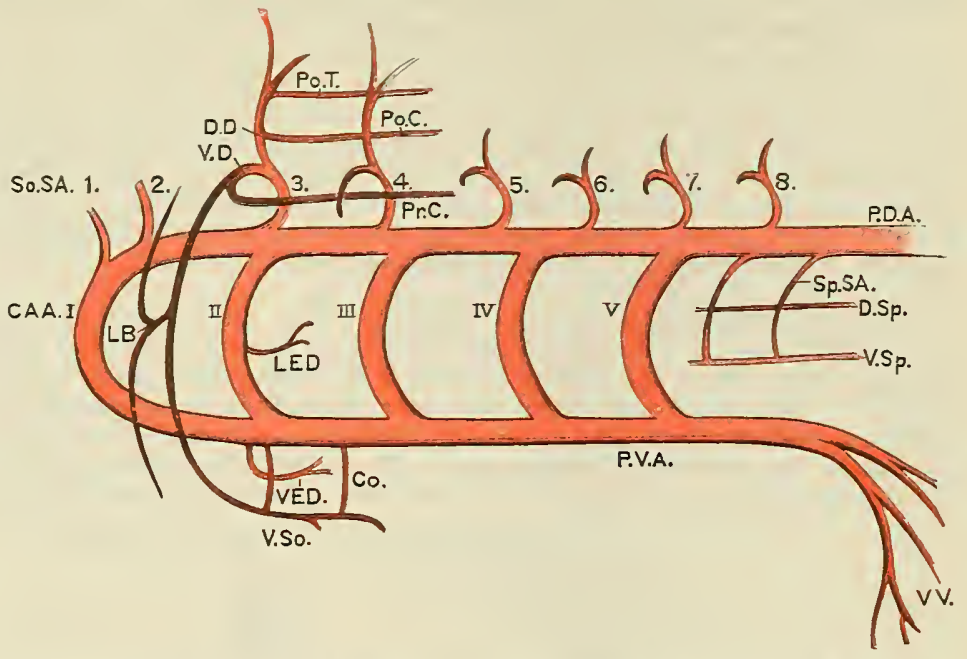

Fig. 840.-Diagram of the Cephalic Aortic Arches, and of the Segmextal and Intersegmental Arteries in the Region in front of the Uybilious.

C.A.A. I, II, III, IV, V. The cephalic Po.C. Post-costal anastomosis. aortic arches.

Co. Anastomosing ressel between the primitive ventral aorta and the ventral somatic anastomosis.

THE SEGMENTAL ARTERIES AND THEIR ANASTOMOSES.

D.D. Dorsal division of a somatic intersegmental artery.

D.Sp. Dorsal splanchnic anastomosis.

The main longitudinal trunks are the primitive aortæ. The descending aorta is formed, in the

L.B. Lateral branch of rentral division of somatic intersegmental artery.

L.E.D. Branch to lateral enteric diverticulum.

P.D.A. Primitive dorsal aorta.
Po.T. Post-transverse anastomosis.

Pr.C. Pre-costal anastomosis.

P.V.A. Primitive ventral aorta.

So.S.A. 1, 2, 3, 4, 5, 6, 7, 8 . Somatic intersegmental arteries.

Sp.S.A. Splanchnic arteries.

V.D. Ventral division of a somatic intersegmental artery.

V.E.D. Branch to ventral enteric diverticulum.

V.V. Vitelline ressels.

V.So. Ventral somatic anastomosis.

V.Sp. Ventral splanchnic anastomosis. greater part of its extent, by the fusion of the dorsal parts of the prinitive aortæ, and from it the

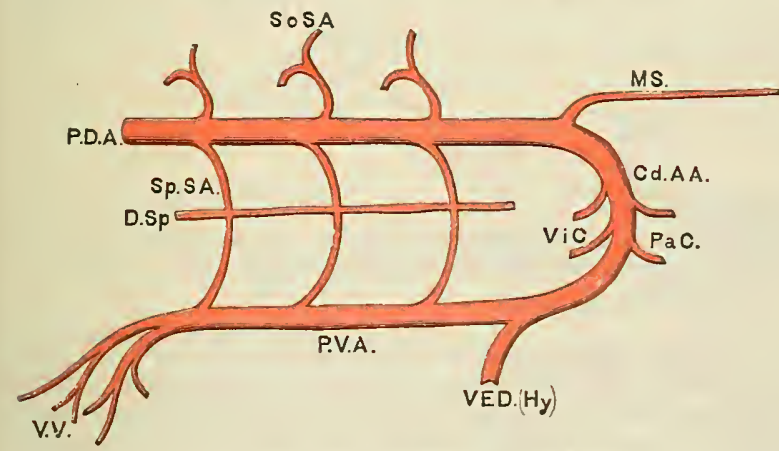

Fig. 811.-Diagran of the Arteries in the Region caddal TO THE UMBILICLS.

Cd.A.A. Caudal aortic arch.

D.Sp. Dorsal splanchnic anastomosis.

M.S. Middle sacral artery:

Pa.C. Parietal branch from V.E.D. $(\mathrm{Hy})$. Branch to a ventral candal arch.

P.D.A. Primitive dorsal aorta.

P.V.A. Primitive ventral aorta.

So.S.A. Somatic segmental arteries.

Sp.S.A. Splanchnic segmental arteries.

intersegmental, lateral, and ventral arteries arise in pairs.

In a typical segment of the body of the embryo there are three arteries on each side. One arises from the dorsal surface of the primitive dorsal aorta, i.e. from the dorsal longitudinal trunk, and runs laterally and ventrally in the tissues developed from the somatic mesoderm ; it is distributed to the body wall, including the vertebral column and its contents, and is termed a somatic intersegmental artery. A second ressel arises from the side of the primitive dorsal aorta; it is distributed to the structures developed from the intermediate cell mass, viz., the suprarenal gland, the kidney, and the ovary or the testis, and it is accordingly termed a lateral or an intermediate visceral artery. The third artery, which is known as the splanchnic artery, springs from the ventral surface of the aorta. It runs in the tissues developed from the splanchnic

mesoderm, and supplies the wall of the alimentary canal.

The somatic intersegmental arteries form, in the early embryo, a regular series of paired vessels throughont the cervical, thoracic, lumbar, and sacral regions. It is, however, only in the 
thoracic and lumbar regions that their original characters are retained. The paired vessels pass dorsally, by the sides of the rertebræ, and divide into dorsal and ventral branches which accompany the corresponding anterior and posterior divisions of the spinal nerves.

The ventral branches run ventro-laterally between the ribs, in the thoracic region, and in corresponding positions in the lumbar region, and together with the stems they form the main parts or trunks of the vessels in the thoracic and lumbar regions. They are connected together, near their commencements, by a series of pre-costal anastomoses which pass in front of the necks of the ribs, and they are also connected together, near their terminations, by ventral anastomosing channels which run, in the thoracic region, behind the costal cartilages, and in the lumbar region behind or in the substance of the rectus abdominis muscle. Each ventral branch gives off a lateral offset which is distributed like the lateral cutaneous branch of a spinal nerve, and together with the stem of the intersegmental artery it forms the trunk of an intercostal or lumbar artery in the adult.

The dorsal branches, which are present before the ventral branches, run dorsally between the transverse processes of the vertebræ, and form the posterior branches of the intercostal arteries and the dorsal branches of the lumbar arteries of the adnlt; they are connected, behind the necks of the ribs, by post-costal anastomoses, and again, behind the transverse processes of the vertebræ, by post-transverse anastomosing channels. Moreover, each dorsal branch, as it passes by the corresponding intervertebral foramen, gives off a spinal offset which enters the spinal canal, along the corresponding nerve-root, and divides into a dorsal, a ventral, and a neural branch. The

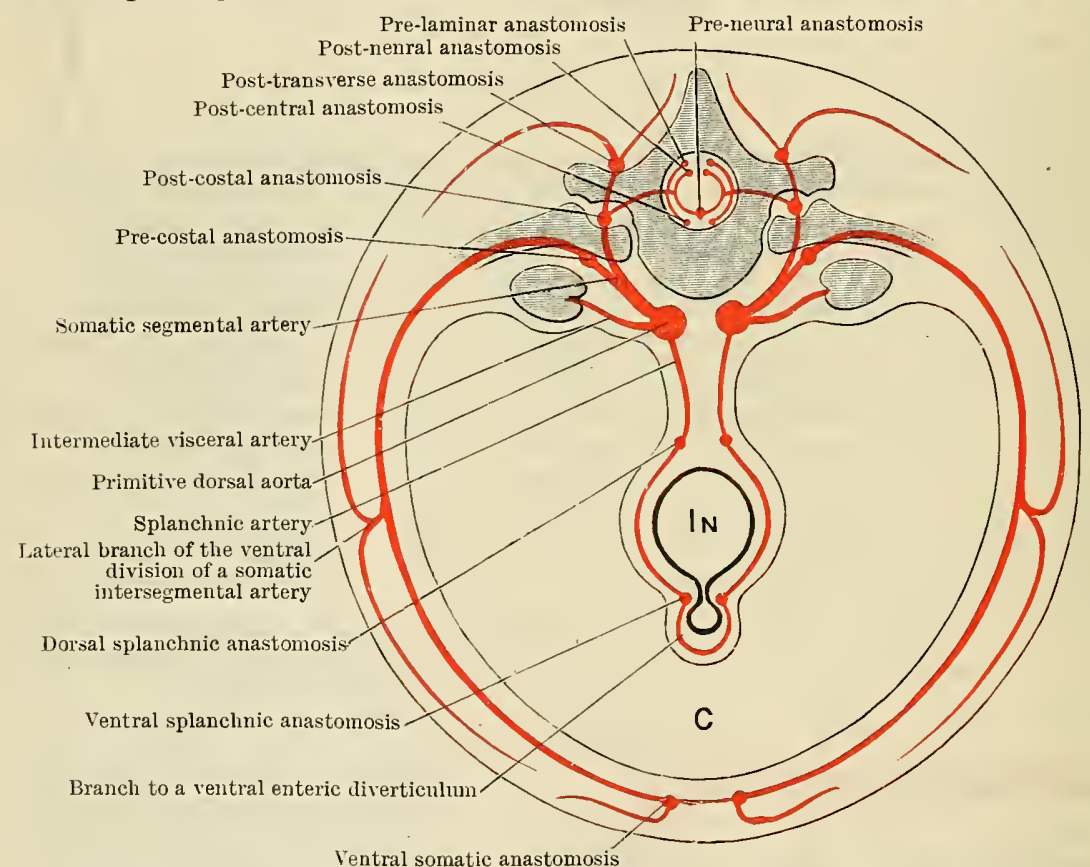

Fig. 842.-Diagram showing the Arrangement and Communications of the Segmental and Intersegnental Arteries at an early Stage of Development.

C, Colom ; In, Intestine.

dorsal branches of these spinal arteries are connected together along the ventral surfaces of the laminæ by pre-laminar anastomoses, and the ventral branches are united on the dorsal surfaces of the vertebral bodies (or centra) with their fellows above and below by post-central anastomoses; they are also united with their fellows of the opposite side by transverse communicating channels. The neural branches of the spinal arteries divide similarly into dorsal and ventral branches; the dorsal branches of each side are connected together by post-neural anastomoses, which form the posterior spinal arteries; and the ventral branches unite, in the median line, both with their. fellows above and below and with those of the opposite side, forming a single longitndinal pre-neural trunk, the anterior spinal artery.

In the thoracic and lumbar regions of the body the somatic segmental arteries persist, and form the interestal and lumbar arteries. These vessels spring from the dorsal aspect of the descending aorta, usually in pairs. The corresponding vessels of opposite sides, however, occasionally fuse together at their origins, simnltaneously with the fusion of the dorsal longitndinal trunks to form the descending aorta, and then the arteries of opposite sides arise by common stems.

The pre-costal anastomoses between the ventral branches of the somatic segmental arteries. are only represented in the thoracic region by the superior intercostal arteries; in the lumbar region they disappear entirely. The anastomoses between the anterior ends of the rentral. 
branches of the somatic segmental arteries persist as the internal mammary and superior and inferior epigastric arteries.

The lateral offsets of the ventral branches are represented by the cutaneous arteries which accompany the lateral cutaneous branches of the spinal nerves, and the lateral branch of the seventh somatic intersegmental artery forms the greater part of the arterial stem of the upper limb.

The post-costal and post-transverse anastomoses usually disappear in the thoracic and lumbar regions, but the post-costal anastomoses occasionally persist in the upper thoracic region, and take part in the formation of the vertebral artery, which in such cases arises from the first or second intercostal artery. In some carnivores the post-costal longitudinal vessels persist in the upper thoracic region, and form, on each side, a trunk which is connected with the first aortic intercostal, and which supplies the first five intercostal spaces.

The pre-laminar, the postcentral, and the pre- and postneural anastomoses persist, the latter two aiding in the formation of the thoracic and lumbar portions of the anterior and posterior spinal arteries respectively.

It is in the cervical region, however, that the most interesting changes occur. The first six pairs of somatic intersegmental arteries
lose their connexions with the dorsal roots of the aortic arches, i.e., in other words, with the longi-
tudinal anastomosing chamnels in this region. The seventh pair,

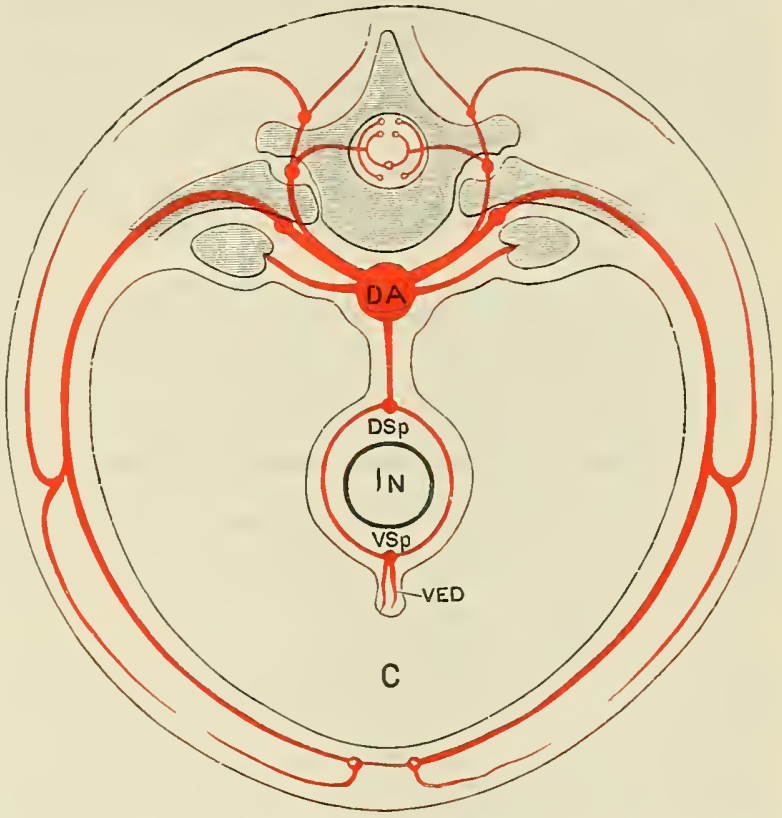

Fig. 843. - Diagram of the Segmextal axd Interseguental Arteries at a Later Perlod of Developient than 15 F1G. 842 .

C, Coelom ; D.A, Dorsal aorta ; D.Sp, Dorsal splanchnic anastomosis ; IN, Intestine; V.E.D, Branch to rentral enteric diverticulum; T.Sp, Ventral splanchnic anastomosis. however, persist in their entirety; and from them are formed, on the right side, a portion of the subclavian trunk, and on the left side the whole of the subclavian stem from its commencement up to the origin of the vertebral artery. On each side the ventral branch of the seventh intersegmental artery forms

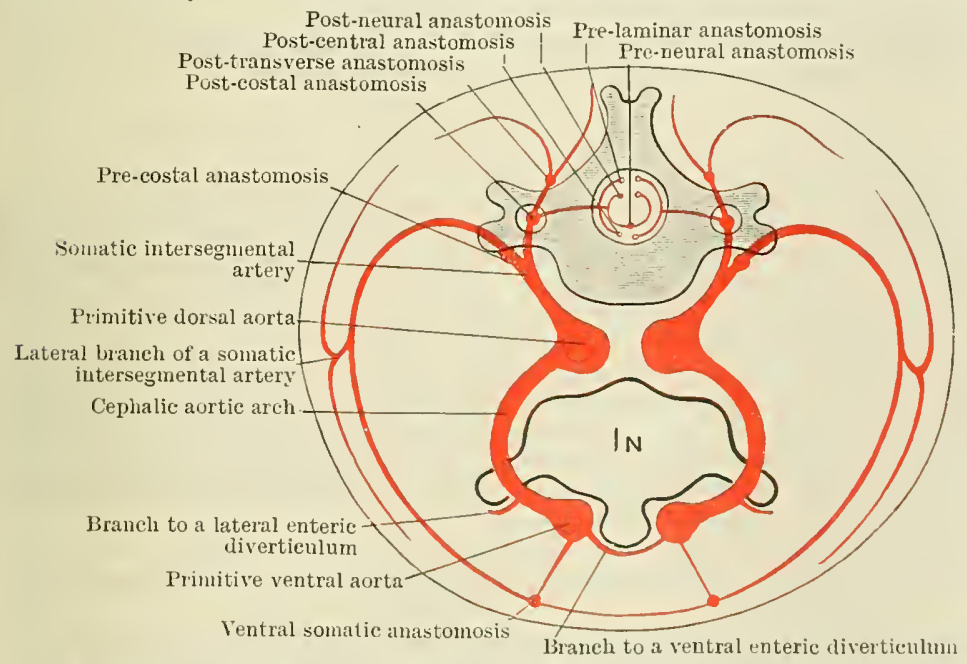

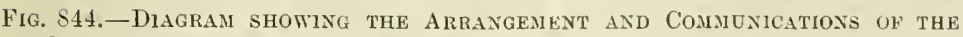
Segmextal, Arteries in the Region of the Cephalic Aortic Arches. IN, Intestine. which is continued into the upper limb, caudal or postaxial to the shoulder girdle. The thyreocervical trumk and the superior intercostal artery, both branches of the sulvelavian artery, are 
persistent pre-costal anastomoses, and the ascending cervical artery belongs to the same series of ressels. The rertebral artery, which appears as a branch of the subclavian in the adult, is, morphologically, somewhat complex. The first part represents the dorsal branch of the seventh somatic intersegmental artery; the second part, that passing through the cervical transverse processes, consists of the persistent post-costal anastomoses between the dorsal branches of the first seven intersegmental arteries; a third part, that lying on the arch of the atlas, is the spinal branch of the first somatic intersegmental artery and its neural continuation; whilst finally the upper part of the vertebral artery, the part in the cranial cavity, appears to represent a prolongation of the pre-neural anastomoses, which still farther upwards are probably represented by the basilar artery. As already stated, the post-costal auastomoses below the seventh intersegmental artery occasionally persist, and in such cases the vertebral may lose its connexion with the subclavian, and spring from one or other of the posterior branches of the upper intercostal arteries.

The profunda cervicis artery is to be regarded as a remnant of the post-transverse longitudinal anastomoses.

The origin of the seventh somatic intersegmental artery from the dorsal longitudinal trunk is, at first, some distance caudal to the sixth aortic arch, but, simultaneously with the elongation of the neck and the retraction of the heart into the thoracic region, it is shifted cephalwards until it is opposite the dorsal end of the fourth aortic arch.

The middle sacral artery is formed by the fusion of two vessels, each of which springs from the dorsal surface of the aorta. It is regarded as the direct continuation of the descending aorta.

The lateral or intermediate visceral arteries supply the organs derived from the intermediate cell mass. They form a somewhat irregular series of vessels in the adult, but presumably in the primitive condition there was a pair in each segment of the body; many of these disappear, however, and the series is only represented in the adult by the suprarenal, the right renal, part of the left renal, and the testicular or ovarian arteries-possibly, also, by some of the branches of the hypogastric arteries.

The splanchnic arteries arise in the embryo from the ventral aspects of the primitive dorsal aortæ, and are not strictly either segmental or intersegmental in arrangement. They are distributed to the walls of the alimentary canal. Each anastomoses with its immediate neighbours on the dorsal wall and the ventral walls of the gut.

After the fusion of the dorsal longitudinal trunks to form the descending aorta, the roots of each pair of the splanchnic arteries fuse into a common stem, or either the right or left artery altogether disappears, whilst at a later period the majority of the splanchnic arteries lose their direct connexion with the descending aorta; those which retain their connexion are the cœliac artery and the superior and inferior mesenteric arteries.

The bronchial and œsophageal arteries are later formations. They appear to correspond morphologically with the more primitive splanchnic arteries, but the developmental history is not known.

The left gastric branch of the cœliac artery, as it passes from its origin to the small curvature of the stomach, represents a right splanchnic artery; the remainder of the left gastric artery and the right gastric branch of the hepatic are remnants of the ventral anastomoses between the splanchnic arteries cephalwards of the umbilicus.

The splenic artery is a branch given off from a splanchnic artery to an organ developed in the mesogastrium, and the hepatic is a branch from the ventral splanchnic anastomoses to the hepatic diverticulum from the wall of the duodenal portion of the fore-gut.

The superior and inferior mesenteric arteries represent at their origins splanchnic branches, and in the remainder of their extent they represent the dorsal anastomoses on the gut wall.

\section{The Aorta, Pulmonary Artery, and other Chiej Stem Vessels.}

The heart and the majority of the great arterial trunks of the body, including the aorta, the innominate, part of the right subclavian, the common, external, and greater parts of the internal carotids, and the pulmonary arteries, are all modified portions either of the primitive aortæ or of the aortic arches. The developmental changes, which result in the formation of the vessels named, are described in the preceding chapter, and the morphology of these vessels is obviously the same as that of the trunks from which they are derived.

It will be sufficient, therefore, to point out that the primitive aortæ may be regarded as the greatly enlarged pre-central or pre-vertebral longitudinal anastomoses between the successive intersegmental arteries of each side; obviously, therefore, each primitive aorta, like the rest of the longitudinal anastomoses, consists chiefly of segmental elements. The origins of the intersegmental vessels enter into its formation only in so far as they connect the segmental vessels together, and so complete the longitudinal anastomoses.

The first cephalic aortic arches are simply portions of the primitive aortæ. The other aortic arches have possibly a different morphological significance, but their exact nature is not definitely settled.

The second, third, fourth, fifth, and sixth cephalic aortic arches of each side are developed in the undivided mesoderm of the head region, caudal to the first arch. They spring from the part of the primitive aorta which, after the head fold is formed, lies on the ventral aspect of the foregut, and they extend, at the side of the pharyngeal part of the fore-gut, to the dorsal aorta. Thus, in some respects they may be looked upon as segmental vessels. In addition to the vessels already mentioned, there are given off from the ventral aorte and the aortic arches a series of branches which supply ventral and lateral diverticula from the alimentary canal; these are represented in the adult by the superior thyreoid, the thyreoidea ima. 
Iliac Arteries and their Branches.-The common iliac arteries are formed from the secondary roots of the umbilical arteries, and their exact morphological position is uncertain. The true morphological position of the hypogastric arteries is not yet defined. They also are parts of the secondary roots of the umbilical arteries, and they give off both somatic and splanchnic branches; therefore they do not correspond either with somatic intersegmental or with splanchnic arteries. The branches of the hypogastric artery are arranged in two groups(1) a visceral set which supplies the walls of the hind-gut and the genital organs, and (2) a parietal set which is distributed to the body wall and to the hind-limbs. The branches distributed to the gut probably represent the splanchnic vessels, more or less homologous with ordinary splanchnic branches of the primitive aortæ, and the parietal branches are possibly the homologues of intersegmental arteries.

\section{The Limb Arteries.}

In all probability the ressels of both the upper and the lower limbs are derived originally from several somatic intersegmental arteries, the majority of which, however, have atrophied. The upper limb is supplied in man by the lateral offset from the ventral branch of the seventh somatic segmental artery. It passes into the extremity caudal to the shoulder girdle, courses through the arm, enters the cubital fossa, and is continued through the forearm, in the early stages, as the volar interosseons artery, which terminates in the deep part of the palm, in the deep volar arch. At a later period, phylogenetically, a median artery appears as a branch of the parent stem, and it terminates in a superficial volar arch; still later the radial and ulnar branches are formed. The latter grow rapidly, soon exceeding in size the parent stem, and they terminate in the superficial and deep volar arches. The interosseous and median arteries decrease, and generally lose their direct connexions with the volar arches. The dorsal interosseous artery is also a secondary branch from the parent stem, and the digital arteries are offsets from the volar arterial arches.

The chief arteries of the lower extremities spring directly from the secondary roots of the umbilical arteries, and may be looked upon as being essentially intersegmental; whether they represent the whole or only parts of typical somatic intersegmental arteries, however, is not clear.

The arteries of the lower limbs certainly show no very obvious indications of division into dorsal and ventral branches, though such indications are not entirely wanting. In their comparative absence it is supposed that the dorsal branches have been either suppressed or incorporated with the coinmon stems; that similarly the ventral branches and their lateral offsets are indistinguishably fused, and that probably both are represented in a limb artery.

The original stem vessel of the lower limb is the inferior glutæal artery, which is continued distally, caudal to the pelvic girdle, into the popliteal and peroneal arteries, and so to the plantar arch. Subsequently the external iliac artery is given off from the secondary root of the umbilical artery, dorsal to the origin of the inferior glutæal, and, passing into the limb cephalward of the pelvic girdle, it becomes the femoral artery. This vessel ultimately unites with the proximal part of the popliteal artery, and after this communication is established the distal part of the inferior glutæal atrophies and loses its connexion with the popliteal, which henceforth appears to be the direct continuation of the femoral trunk; therefore, whilst the main artery of the upper limb is formed by the prolongation of the lateral branch of one segmental artery, the corresponding vessel of the lower extremity is developed from representatives of, probably, two somatic segmental arteries, the external iliac and femoral trunks being the representatives of one, whilst the popliteal and its continuation, the peroneal, are parts of
another.

The first main artery of the leg, phylogenetically, is the peroneal, which is continued into the plantar arch; after a time, howerer, the posterior and anterior tibial branches are given off from the stem, over which, as a rule, they soon preponderate in size, and they terminate in the plantar arch, whilst the parent trunk diminishes and loses its direct connexion with the arch.

The peroneal artery corresponds in position and development with the common interosseous trunk and the volar interosseous artery in the forearm. The posterior tibial apparently corresponds with the median artery; it develops in a similar way, and has similar relations to homologous nerves, the tibial nerve representing the combined median and ulnar nerves of the upper extremity.

The anterior tibial artery represents the dorsal interosseous, whilst the radial and ulnar arteries of the upper extremity are not represented in the lower limb.

\section{MORPHOLOGY OF THE VEINS.}

Two dorsal longitudinal vessels, one on each side, connect the successive intersegmental veins together. They do not, however, in any part of their course, fuse together to form a single vessel comparable to the descending aorta.

Of these dorsal longitudinal vessels, that on the right side greatly enlarges, and from it the main stem vessels which return blood from the body walls, the head and neck, and the limbs, are almost entirely formed. The left dorsal longitudinal vessel remains relatively small-in parts, indeed, it altogether disappears - and the blood conveyed to it by the corresponding inter- 
segmental veins is transmitted, across the median plane, to the chief functional stem by later developed and superadded transverse communicating channels, which are formed between the more primitive longitudinal anastomoses.

The primitive dorsal longitudinal anastomosing channels include on each side-(1) the anterior cardinal vein, (2) the posterior cardinal vein, and (3) the duct of Cuvier ; the last-named vessel, which opens into the sinus venosns of the primitive heart, is, originally, part of the anterior cardinal vein; it becomes enlarged and receives a special name after the mion of the posterior with the anterior cardinal vein.

The cardinal veins return blood not only from the limbs and body wall, but they are also, in the early stages, the only vessels by which blood is returned from the derivatives of the intermediate cell tract, i.e. the kidneys, the genital glands, and the suprarenal glands. At a later period other longitudinal anastomoses, called the subcardinal veins, appear, and into these a large part of the blood from the derivatives of the intermediate cell tract is poured. It is from these vessels, and from the transverse communications which are established between the cardinal and subcardinal veins of opposite sides, that the chief veins of the head and neck and the body are formed; there is in addition, however, a later-formed vessel, the upper part of the inferior vena cava, which is developed independently of the veins previonsly mentioned. Moreover, it must not be forgotten that the veins of the extremities are, like the extremities themselves, secondary structures, and that they are developed at a later period than the veins of the trunk, with which, however, they ultimately communicate.

In the light of these facts the morphology of the chief veins of the head and neck, the trunk and limbs may now be considered.

The cavernous sinuses are remnants of the anterior cardinal veins. The other blood sinuses of the cranium are either secondarily formed vessels, or anastomoses between the tributaries of the anterior cardinal veins, or anastomoses between those tributaries and other newly formed veins.

The internal jugular veins are also portions of the anterior cardinal veins.

The right innominate vein is a part of the right anterior cardinal vein. A small part of the left innominate vein is formed from the left anterior cardinal vein, the greater part is derived from a transverse anastomosis between the two anterior cardinal veins.

Other remnants of the anterior cardinal veins are the upper parts of the superior vena cava and left superior intercostal vein.

The basilic vein and its prolongations, the axillary vein and the subclavian vein, are derived from the ulnar or post-axial primitive veins of the upper extremities. The external jugular vein is a secondary formation, and the cephalic vein is the radial or pre-axial vein of the upper extremity which opens first into the external jugular vein and at a later period into the axillary vein.

The superior vena cava represents the lower part of the anterior cardinal vein and the right duct of Cuvier, and the oblique vein of the left atrium represents the left duct of Cuvier.

The azygos vein is the upper or cephalic part of the right posterior cardinal vein, and the vertical parts of the hemiazygos and accessory hemiazygos veins are remnants of the left posterior cardinal vein, whilst the transverse portions of the hemiazygos and accessory hemiazygos veins represent transverse anastomoses between the posterior cardinal veins.

The inferior vena cava is a compound structure representing parts of five different structures. Its upper end is the transformed cephalic end of the right vitelline vein. The portion posterior to the liver is a secondary outgrowth from the right vitelline vein. The part between the liver and the right renal vein represents a part of the right subcardinal vein and an anastomosis between it and the posterior cardinal vein, and the remainder is a portion of the right posterior cardinal vein.

The right common iliac vein is a part of the right posterior cardinal vein, but the left is a compound structure. Its lower part probably represents a portion of the left posterior cardinal vein, but the greater part is a persistent transverse anastomosis between the posterior cardinal veins.

The hypogastric veins are remnants of the posterior cardinal veins.

The popliteal and the inferior glutieal veins are remnants of the primitive fibular vein of the lower limb, and the external iliac vein is the trunk formed by the union of the tibial and the deep veins of the lower limb which are secondary formations.

Visceral Veins. - The portal vein represents portions of both vitelline veins and of the middle anastomosis between them.

The right gastric vein is a splanchnic ventral longitudinal anastomosing vein. The left gastric vein is partly a ventral and partly a dorsal splanchnic longitudinal anastomosis, and the superior and inferior mesenteric veins are dorsal splanchnic longitudinal venous anastomoses, the splenic vein being merely a tributary from a lymphoid organ developed in the dorsal meso-gastrium.

The anterior facial vein is a combination of somatic and splanchnic veins of several segments, and the internal maxillary vein is probably of similar nature. The thyreoid and bronchial veins return blood from organs developed from diverticula from the walls of the alimentary canal ; they are, therefore, more or less modified splanchnic veins; so also apparently are the vesical and the middle and inferior hæmorrhoidal veins.

The cardiac veins are simply "vasa vasorum," and they belong therefore to the splanchnic group of vessels, but it is impossible to say whether they are segmental or intersegmental. The coronary sinus into which they open is a portion of the sinus venosus of the heart, and therefore of an originally segmental vessel. 
The hepatic veins are parts of the primitive vitelline veins; and the pulmonary veins are splanchnic veins returning blood from a diverticula of the gut.

It is noteworthy that some parts of the splanchnic venous system, i.e. the portal vein and the coronary sinus, are portions of the most primitive rascular system, and that others, - the thyreoid, bronchial, mesenteric, vesical, and hæmorrhoidal veins-appear to belong to a somewhat secondary group of splanchnic veins of combined segmental and intersegmental character ; moreover, some of the secondary group of reins open into the primary splanchnic veins, e.g. the superior and inferior mesenteric into the portal vein; some open into the dorsal longitudinal anastomosing veins, e.g. the vesical and hæmorrhoidal veins open into the cardinal veins, which are intersegmental anastomoses; others again open into the internal jugular, which is part of the anterior cardinal vein.

Veins of the Limbs. - The veins of the limbs, like the arteries, were probably at one time intersegmental in character, but we have no indisputable proof that this was the case. Looked at from an embryological standpoint, the nost primitive limb veins are a superficial distal arch and a post-axial trunk vein in each extremity; at a later period digital veins are connected with the distal arch, and a pre-axial trunk is formed. In the upper extremity the distal arch and its tributaries remain as the dorsal venous arch and the digital veins, and the post-axial vein becomes the basilic, axillary, and subclavian veins. The pre-axial vein of the upper extremity is represented in the adult by the cephalic vein; the latter vessel originally terminated in the external jugular vein, above the clavicle, the union with the axillary portion of the post-axial vessel being a secondary condition; the primary condition is, however, frequently retained in man, and is constant in many monkeys. The anastomosis between the pre-axial and post-axial veins in the region of the elbow, and the connexion of the anastomosing channels, is brought abont by newly-formed vessels of secondary character.

The distal arch in the lower extremity and the tribntaries connected with it remain in the adult as the dorsal venous arch of the foot and the digital veins. The post-axial vein becomes the small saphenous vein, which was originally continued proximally as the popliteal and inferior glutæal veins to the hypogastric portion of the posterior cardinal vein.

The pre-axial vein of the lower limb becomes the great saphenous vein, which is continued proximally to the cardinal portion of the left common iliac rein as the proximal part of the femoral and the external iliac reins.

The venæ comites of the arteries in both the upper and lower extremities are secondarily developed vessels which become connected with the upper portions of the pre-axial venous trunks.

\section{ABNORMALITIES AND VARIATIONS OF THE VASCULAR SYSTEM.}

Abnormalities are of special interest to the anatomist because of their morphological significance, and the vascular system is, perhaps more than any other, rich in such abnormalities, many of which are of great practical importance.

With the exception of those irregularities which are directly due to the effect of morbid conditions and external influences, all abnormalities are the result of modifications of normal developmental processes. The exceptions referred to are, howerer, very numerous; thus disease and external influences may lead to the obliteration of vessels, a condition which is invariably associated with the enlargement of collateral vessels, and it will be obvious that abnormalities so produced may occur in almost any situation.

Abnormalities which are determined by, or are dependent upon, modifications of the usual developmental processes are of greater interest. In the human subject they are generally due either to the retention of conditions which, normally, are only transitory in ontogenetic development, or to the acquirement of conditions which, though not as a rule present at any time in man, occur normally in some animals.

There are, in addition, other variations from the normal, such as the division of the axillary artery into radial and ulnar branches; the higher or lower division of the brachial artery; the formation of "vasa aberrantia," e.g. of long slender vessels connecting the axillary or brachial to the radial, ulnar, or interosseous arteries; the altered position of certain ressels, e.g. the transference of the subclavian artery to the front of the scalenus anterior, or of the uluar artery to the front of the superficial flexor muscles; all of which, though undoubtedly due to alterations of ordinary developmental processes, still do not represent any known conditions met with, either temporarily or permanently, in man or in other animals. Their occurrence cannot at present be adequately explained, and their retention in the adult is entirely dependent upon their utility.

To the first and the last of these different grouns of abnormalities it is not necessary to refer further, whilst with regard to the rest it will be sufficient to indicate those of greatest importance. They can only, however, be fully understood and explained on the basis of a comprehensive knowledge of the development and morphology of the vascular system, to the chapters on which the reader is referred. 


\section{ABNORMALITIES OF THE HEART.}

The heart may be transposed from the left to the right side of the body, a condition which is usually associated with general transposition of the viscera, and with the presence of a right instead of a left aortic arch.

The external form of the heart does not as a rule vary much, but occasionally the apex is slightly bifid, a character it normally possesses at an early stage of its development, and which is retained in the adult in many cetaceans and sirenians. The internal conformation of the heart deviates from the normal much more frequently; more particularly is this the case with regard to the septa which separate the right from the left chambers. The interatrial septum may be entirely absent, as in fishes; it may be fenestrated and incomplete, as in some 'amphibians; or the foramen ovale may remain patent, as in amphibians and reptiles.

The interventricular septum may be absent, as in fishes and amphibians, or incomplete, as in reptiles; when incomplete, it is usually the "pars membranacea septi" which is deficient, but perforations are occasionally fonnd in the muscular portion.

The communication between the infundibular part of the right ventricle and the body of the ventricle may be constricted or the infundibular part may be entirely cut off from the remainder of the cavity.

\section{ABNORMALITIES OF ARTERIES.}

The pulmonary artery and the aorta may arise by a common stem, as in fishes and some amphibians, and the common stem may spring either from the right or the left ventricle, or from both. In these cases the truncus arteriosus has remained undivided, and the normal position of the interventricular septum in relation to the lower orifice of the aortic bulb has been altered.

Again, owing to malposition of the aortic septum, the pulmonary artery may spring from the left ventricle and the aorta from the right ventricle. In some cases the root of the pulmonary artery is obliterated, and the blood passes to the lungs along the patent ductus arteriosus.

Occasionally the arch of the aorta is on the right side instead of the left, a condition which is normal in birds. More rarely there are two permanent aortic arches, right and left, as in reptiles ; the cophagus and trachea in these cases are enclosed in a vascular collar, the two arches unite dorsally, and the beginning of the descending aorta is double. Quite independent of this condition, however, the two primitive dorsal aortæ sometimes fail, either altogether or partially, to unite together, and the descending aorta is accordingly represented, to a corresponding extent, by two tubes. A more common, though still rare, form of double aorta is that due to the persistence, in whole or in part, of the septum formed by the fused walls of the primitive dorsal aortæ from which the descending aorta is developed.

The length of the descending aorta is determined largely by the extent to which fusion of the two primitive aortæ takes place. Accordingly, when this deviates from the normal, the termination of the descending aorta is at a correspondingly higher or lower level than usual, and resulting from this the lengths of the common iliac arteries are almost invariably proportionately modified. The bifurcation of the aorta may be as low as the fifth lumbar vertebra; less frequently it is higher than usual; it is rare, however, to find it as high as the third, and still more rare to find it at the level of the second, lumbar vertebra.

The aorta, instead of bifurcating into two common iliac arteries, may terminate in a common iliac artery on one side and a hypogastric artery on the opposite side, the external iliac artery on the irregular side arising, at a higher level, as a branch of the aortic stem. This arrangement approaches the condition met with in carnivores and many other mammals, in which the aorta bifurcates into two hypogastric arteries, the external iliacs arising from the aorta at a higher level as lateral branches; it is probably due either to a fusion of the secondary roots of the umbilical arteries of opposite sides.

\section{The Branches of the Aorta.}

The coronary or cardiac arteries may arise by a single stem. When arising separately both may spring from the same aortic sinus; or again, their interventricular and circunflex branches may arise as distinct vessels from a single aortic sinus. This variability is not very remarkable, seeing that the arteries in question are merely enlarged "vasa vasorum" raised to a position of special importance by the development of the heart.

The branches of the arch of the aorta are sometimes increased and sometimes decreased in number.

The highest number recorded is six, viz, right subclavian, right vertebral, right common carotid, left common carotid, left vertebral, and left subclavian. Apparently this condition is the result of the absorption into the arch of the innominate artery and of the roots of the subclavian arteries, to points beyond the origins of the vertebrals. By variations of this process of absorption other combinations may be produced; thus, instead of the roots of the subclavian arteries being absorbed, the right common carotid and innominate arteries may alone be absorbed, in which case the five following branches spring separately from the arch of the aorta: right subclavian, right external carotid, right internal carotid, left common carotid, and left subclavian. The trunk most commonly absorbed is the initial part of the left subclavian; the 
number of branches then arising from the arch of the aorta is four, the additional vessel being the left vertebral, which arises between the left common carotid and the left subclavian. Occasionally the usual three branches from the arch are increased to four by the formation of a new vessel, the "thyreoidea ima." This may be placed between the innominate and left carotid trunks, in which case it represents a persistent ventral visceral branch from the ventral root of the fourth left aortic arch; in other cases the thyreoidea ima springs from the innominate artery and represents a ventral visceral branch of the ventral root of the fourth right arch. Very rarely the right vertebral artery arises separately, and forms a fourth branch of the arch of the aorta, the rest of the branches being normal. This condition cannot be accounted for by any modification of the ordinary developmental processes. It may possibly be due to the persistence of an irregular or unimportant anastomosis between the ventral root of an aortic arch and the seventh somatic segmental artery.

Decrease in the number of branches from the arch of the aorta is most frequently due to fusion of the ventral roots of the fourth aortic arches, the result being that a stem is formed common to the right subclavian and the right and left common carotid arteries; whilst the left subclavian, arising separately, is the only other branch which springs from the arch of the aorta.

If the fusion of the ventral roots proceeds further and includes those of the third arches, the result, as regards the branches given off from the arch of the aorta, is the same, viz., there is a common stem for the right subclavian and both carotids, and a separate left subclavian trunk; but the common stem now gives off the right subclavian artery, and then continues as a single vessel for some distance before it divides into the two common carotids, of which the left crosses in front of the trachea. This arrangement is common in many quadrumana and in some other mammals.

It is only in rare cases when the number of branches from the arch of the aorta is reduced to two, that these consist of a right subclavian artery and of a single stem common to the two carotids and the left subclavian arteries. In such cases, however, the right common carotid crosses in front of the trachea, and the variation is one of practical importance. This does not appear to exist as a normal condition in any mammal. Probably it is due to fusion of the ventral roots of the fourth aortic arches, with absorption of the left fourth arch and the left subclavian into the stem so formed, whilst the right subclavian is relatively displaced. The two common carotids may arise by a common stem, and the left subclavian arise separately from the arch of the aorta, whilst the right subclavian springs from the descending aorta. This arrangement probably results from the disappearance of the fourth right arch, the fusion of the ventral roots of the fourth arches of opposite sides and the persistence of the dorsal roots of the right fourth and sixth arches.

Sometimes two innominate arteries, right and left, replace the usual three branches of the arch of the aorta. This is the normal arrangement in bats, moles and hedgehogs. It is obviously the result of the disappearance of that portion of the arch which intervenes between the left carotid and left subclavian arteries, and the consequent fusion of these two vessels.

In a similar way may be explained the rarer condition in which the three ordinary branches of the arch arise by one single stem, which divides into right and left innominate arteries. In most ruminants, in the horse and in the tapir, this arrangement is constant.

It will be evident that other combinations and modifications may be met with in the branches of the arch of the aorta as the result of fusions and absorption.

The right subclavian or the right vertebral may spring from the commencement of the descending aorta.

The bronchial arteries obviously correspond to splanchnic arteries and their continuations to diverticula from the walls of the gut; therefore the usual origin of the right bronchial artery from the first right aortic intercostal artery must result from the persistence of an anastomosis between a splanchnic artery and the first part of a somatic intersegmental artery; the origin of the right from the upper left bronchial artery, which sometimes occurs, is due to the fusion of the roots of two splanchnic arteries. The occasional origin of a bronchial vessel from an internal mammary artery can result only from the persistence and enlargement of an anastomosis between a splanchnic artery and the ventral branch of a somatic segmental artery. The origin of a bronchial branch from a subclavian artery may have the same or a different significance on opposite sides of the body. A bronchial artery arising from the left subclavian artery corresponds with the origin of the right bronchial artery from the first aortic intercostal artery; it is due to the persistence of an anastomosis between a splanchnic artery and the root of a somatic intersegmental artery ; and the origin of a bronchial artery from a right subclavian artery may be due to a similar cause. It may, on the other hand, be due to the enlargement of an anastomosis between a splanchnic branch of the descending aorta and a splanchnic branch of the fourth right aortic arch. When, as occasionally happens, the bronchial artery arises from the inferior thyreoid, it is due to the persistence and enlargement of an anastomosis between splanchnic arteries.

Intercostal Arteries.-Variations of the intercostal arteries are not very common, but they are significant and interesting. Corresponding ressels of opposite sides may arise from a common stem which has been formed by the fusion of the roots of two somatic intersegmental arteries after or simultaneously with the fusion of the primitive dorsal aortre. The number of intercostal arteries may be reduced, one artery supplying two or more intercostal spaces; in these cases the roots of origin of some of the somatic intersegmental arteries in the thoracic region have disappeared, and the precostal anastomoses between their ventral branches liave persisted.

Occasionally the number of the aortic intercostal arteries is increased, an additional artery 
being given to the second intercostal space, which is usually supplied by the superior intercostal arters; this is brought about by the persistence of the root of the tenth somatic intersegmental artery and the disappearance of the precostal anastomosis between the ventral branches of the ninth and tenth somatic intersegmental arteries. Very rarely the first aortic intercostal artery sends a branch upwards between the necks of the ribs and the transverse processes of the upper thoracic region; this branch supplies the upper intercostal spaces, the superior intercostal artery being small or absent, and it terminates by becoming the profunda cervicis artery. It is due to the persistence of the postcostal anastomoses in the upper thoracic region, and is a repetition of a condition regularly present in some carnivores.

There are no very important variations of the œsophageal, pericardial, and mediastinal arteries.

Lumbar Arteries. - Variations of the lumbar arteries are very similar to those of the intercostal arteries, and they are due to similar canses. The lumbar arteries of opposite sides may arise by common stems from the back of the aorta; and the last pair of lumbar arteries mar arise in common with the middle sacral artery. Further, a lumbar artery may have its area of distribution extended into the adjacent segment.

The inferior phrenic arteries are very variable; they may arise by a common trunk either from the cœliac artery or from the aorta; they may arise separately either from the aorta or from the cœliac artery and more commonly from the latter vessel; or again, one may spring from the aorta or cœliac artery, and the other from the coronary, renal, or even from the superior mesenteric artery.

The middle sacral artery usually springs from the back of the aorta above its bifurcation; it may be considerably above, or more rarely it may spring directly from the bifurcation. Not infrequently it arises from the last lumbar artery or from a stem common to the two last lumbar arteries, and occasionally it arises from a common or internal iliac artery. Sometimes it gives off the last pair of lumbar arteries, and, in a few cases, an accessory, renal, or a hæmorrhoidal branch arises from it. The vessel is not always present, it may be double, entirely or in part, and it may bifurcate at its termination.

The renal arteries frequently deviate from the normal arrangement. The arteries of opposite sides may spring from a common stem, or there may be two or more renal arteries on one or both sides. The accessory arteries are more common on the left than on the right side, and an accessory artery arising below the ordinary vessel is more common than one arising above it.

Accessory renal arteries may be derived not only from the aorta, but also from the common iliac or hypogastric arteries; they have been described as arising also from the inferior phrenic, spermatic, lumbar, or middle sacral arteries, and even from the external iliac artery. As the kidney is developed in the region of the first sacral vertebra, and afterwards ascends to its permanent position, it is not surprising that it occasionally receives arteries from the main stem of more than one of the segments of the body throngh which it has passed, and it is usually found that the lower the position of the kidney in the abdomen the more likely it is to receive its arteries from the lower part of the aorta or from the common iliac arteries. The accessory renal arteries which spring from the inferior phrenic, the spermatic, and lumbar arteries can only be the result of the persistence and enlargement of anastomosing channels between the renal and either another intermediate-visceral, or a somatic artery.

The testicular or ovarian arteries may be double on one or both sides; the arteries of opposite sides may spring from a common trunk, or they may rise from the renal or suprarenal arteries. The right artery may pass behind instead of in front of the inferior vena cava. The spermatic and ovarian arteries arise from the upper lumbar portion of the aorta, because the testes and ovaries are developed in and obtain their arterial supply in that region, and the vessels are elongated as the testes and ovaries descend to their permanent positions. The occurrence of two spermatic arteries on one side is probably an indication that the testis was developed in at least two segments of the body, and the origin of a spermatic artery from a renal or suprarenal artery is due to the obliteration of the root of the original vessel and the enlargement of an anastomosis between the intermediate visceral arteries of adjacent segments.

The cœliac artery may be absent, its branches arising separately from the aorta or from some other source. Sometimes it gives off only two branches, usually the left gastric and splenic, and occasionally it gives four branches, the additional branch being either a second left gastric artery or a separate gastro-duodenal artery.

The hepatic artery may spring directly from the aorta or from the superior mesenteric artery, and the left hepatic artery arises occasionally from the left gastric artery. Accessory hepatic arteries are not uncommon, and they originate either from the left gastric, superior mesenteric, renal, or inferior mesenteric artery.

The left gastric artery is occasionally double; it may spring directly from the aorta, and it may give off the left hepatic or an accessory hepatic artery.

The splenic artery may arise from the middle colic, from the left hepatic, or from the superior or inferior mesenteric artery.

The superior mesenteric artery may be double, and it may supply the whole of the alimentary canal from the second part of the duodenum to the end of the rectum, the inferior mesenteric artery being absent. In addition to its ordinary branches it may give off a hepatic, a splenic, a pancreatic, a gastric, a gastro-epiploic or a gastro-duodenal branch. Very rarely it gives off an omphalo-mesenteric branch, which passes to the region of the umbilicus and becomes connected with capillary vessels in the falciform ligament of the liver. 
The inferior mesenteric artery may give hepatic, renal, or middle colic branches; occasionally it is absent, being replaced by branches of the superior mesenteric, and sometimes, as in ruminants and some rodents, its left colic branch does not anastomose with the middle colic artery.

All these variations of the nnpaired visceral branches of the abdominal aorta are merely due to modifications of the usual processes by which the ressels are developed.

The hepatic, splenic, and left gastric arteries may arise directly from the aorta, a condition which is due to the retention of a greater number of the splanchnic arteries than usual. A double superior mesenteric artery results from the persistence of both the right and left splanchnic vessels from which the superior mesenteric artery is formed, these remaining separate instead of fusing together. All the other variations are the results of the obliteration of the usual channels, combined with the enlargement of anastomoses which exist both between the splanchnic arteries of adjacent segments and between the splanclinic and intermediate visceral arteries.

\section{The Arteries of the Head and Neck.}

Innominate Artery.-From what has already been said with reference to the branches of the arch of the aorta, it will be noted that the innominate artery may be absent. On the other hand there may be two innominate arteries, a right and a left, each ending in corresponding common carotid and subclavian trunks, and the two ressels may themselves arise by a common stem.

The branches given off by the innominate artery may be increased in number, or the innominate may vary from the normal only as regards length. As a consequence of such modifications in length, the origins of the right common carotid and right subclavian arteries may be situated at a higher or lower level than usual, whilst, in the absence of the innominate artery, both these branches may arise directly from the aorta.

Common Carotid Arteries.-When the right common carotid artery arises separately from the arch of the aorta, it may be the first, or, much more rarely, the second branch. In the former case the fourth right aortic arch has been obliterated, and the right subclavian artery springs from the descending aorta; in the latter case either the innominate stem has been absorbed into the arch of the aorta, or the ventral root of the fourth right aortic arch has fused with part of an elongated fourth left arch.

Whether arising as the first or second branch, the origin may be to the left of the median plane, and the trunk may pass in front of the trachea, or behind the csophagus, before it ascends into the neck.

The left common carotid artery varies, as regards its origin, much more frequently than the right vessel; not uncommonly, and apparently because of the fusion of the ventral roots of the fourth aortic arches, it arises from a stem common to it and to the right common carotid and right subclavian arteries.

Both common carotids may vary as regards their termination. They may divide at a higher or lower level than usual, the former more commonly than the latter; whilst in a few exceptional cases the common carotid does not divide, but is continued directly into the internal carotid, and from this the branches usually given off by the external carotid are derived.

This arrangement is probably due to obliteration of the ventral roots of the first and second aortic arches, the arches persisting and being divided into the branches which generally arise from their ventral extremities.

Ustally the common carotids give off no branches, but not infrequently one or more of the branches of the external carotids arise from them.

The external carotid artery may be absent, or it may, in rare cases, arise directly from the arch of the aorta. The number of its branches may be diminished either by fusion of their roots or by transference to the internal or common carotid arteries. On the other hand, the number of its branches may be increased ; thus, the sterno-mastoid artery, the hyoid branch usually given off by the superior thyreoid artery, or the ascending palatine branch of the external maxillary, may arise from it. Sometimes the branches may arise in the usual way, but may deriate from the course generally taken; more particularly is this the case with the internal maxillary artery, which may pass either between the heads, or entirely lateral or medial to both heads of the external pterygoid muscle.

The internal carotid artery is rarely absent. Occasionally it springs from the arch of the aorta, and in its course through the neck it may vary somewhat in length and in tortuosity. One or more of the branches usually derived from the external carotid artery may arise from it, and it sometimes gives off a large meningeal branch to the posterior fossa of the skull. Its posterior communicating branch may replace the posterior cerebral artery; on the other hand, the upper part of the internal carotid may be absent, and the posterior communicating artery may become the middle cerebral artery. The anterior cerebral branch of the internal carotid may be absent, or rather it may arise from the corresponding artery of the opposite side; or there may be three anterior cerebral arteries, the third arising from the auterior communicating artery which connects the two anterior cerebrals together. The ophthalmic artery, as it traverses the orbit, may pass either above or below the optic nerve. It is occasionally replaced by a branch of the middle meningeal artery.

The vertebral artery may have a double origin-one from the subclavian, and one from the inferior thyreoid artery or from the aorta. 
The right rertebral may arise from the common carotid or from the arch of the aorta. Occasionally it springs from the descending aorta, an arrangement associated with the persistence of the dorsal roots of the fourth and fifth right arches.

The left vertebral artery not infrequently springs from the arch of the aorta, arising between the left common carotid and left subclavian arteries; this is evidently due to the absorption of the stem of the serenth segmental artery into the aortic arch. Very exceptionally the left vertebral is a branch of an intercostal artery.

In its course upwards either vertebral artery may enter the vertebrarterial foramen of any of the lower six cervical vertebra.

The cases in which it does not enter one of the lowest of these are apparently associated with its formation in part from the precostal instead of from the postcostal anastomosing channels.

The artery may enter the vertebral canal with the second instead of with the first cervical nerve, or, after leaving the foramen in the transverse process of the third vertebra, it may divide into two branches, one of which accompanies the second and the other the first cervical nerve; the two branches unite together again in the vertebral canal to form a single trunk.

Sometimes, though rarely, it gives off superior intercostal and inferior thyrèid branches. The upper end of one of the vertebrals is sometimes very small, or it may be entirely wanting; in the latter case the basilar artery is formed by the direct continuation of the opposite vertebral.

The basilar artery may be double in part or the whole of its extent, or its cavity may be divided by a more or less complete septum. It may terminate in one instead of two posterior cerebral arteries, the missing vessel being supplied by the enlargement of the posterior communicating branch of the internal carotid.

\section{The ARTERIES OF THE UPPER Limb.}

Subclavian Arteries.-The variations, so far as regards the origins of the subclavian arteries, have already been mentioned (p. 1051). Other interesting modifications are met with in respect of its position and branches.

The subclavian artery may reach as high as 25 or $37 \mathrm{~mm}$. (1-1 $\frac{1}{2}$ in.) above the clavicle, though as a rule it does not reach higher than $19 \mathrm{~mm}$. above that bone. On the other hand, it may not rise even to the level of the upper border of the clavicle. These differences appear to be associated with the descent of the clavicle and sternum, which occurs as age increases.

The artery may pass in front of or through the scalemus anterior instead of behind it, or the vein may accompany it behind the muscle.

The branches of the subclavian artery may be modified with reference to their points of origin; thus, those of the first part may be further medial or lateral than usual, the transverse scapular or some other branch of the thyreo-cervical trunk may arise separately from the third part of the subclavian, and not nncommonly the descending branch of the transverse cervical artery is a branch of this part. The abnormalities of the vertebral branch have already been described; those of the thyreo-cervical trunk and its branches are numerons but not important.

The internal mammary artery, usually a branch of the first part of the subclavian, is very variable as regards its origin. It may arise from the second or third parts, or from the thyreocervical, or it may spring from the aorta, or from the innominate or axillary arteries. All these variations are due to obliteration of the normal origin and the opening up of anastomoses. The internal mammary artery sometimes descends in front of the cartilages of one or more of the lower true ribs; and occasionally it gives off a large lateral branch (a. mammaria lateralis) which descends on the inner side of the chest wall, close to the mid-axillary line, -a point of importance in paracentesis.

A few cases have also been noticed in which a bronchial artery has arisen from the internal mammary.

The superior intercostal branch of the costo-cervical trunk may be absent, and the profunda cervicis branch may arise directly from the subclavian trunk. The superior intercostal is sometimes formed from a postcostal instead of a precostal primitive channel. In such cases it passes between the necks of the ribs and the transverse processes of the vertebræ instead of, as usual, in front of the necks of the ribs.

The axillary artery does not vary much as regards its origin or course. Its relations may be modified by the existence of a muscular or tendinous "axillary arch," which, passing from the latissimus dorsi to the pectoralis major, crosses the distal part of the artery superficially ; and a further interesting modification is associated with an anomalous arrangement of its branches. Occasionally the sub-scapular, circumflex, and profunda and superior ulnar collateral arteries arise from the axillary by a common stem. In these cases the chief branches of the brachial plexus are grouped round the common stem instead of round the main trunk. This is due to the persistence of a different part of the original vascular plexus.

Sometimes the axillary artery divides into the radial and ulnar arteries, and more rarely the interosseous artery may spring from it.

Obviously there is no brachial artery when the radial and ulnar arteries are formed by the division of the axillary; its place is taken by the two abnormal vessels which, as a rule, are separated by the median nerve as they run through the arm; the radial is usually more superficial than the ulnar, and crosses laterally in front of it at the bend of the elbow.

The brachial artery is rarely prolonged beyond its usual point of bifurcation; not uncommonly, however, it bifurcates at a more proximal level. Of the two terminal branches of the brachial, one may divide into radial and interosseous, the other forming the ulnar; or one may divide into 
radial and ulnar, whilst the other is the interosseous artery. Occasionally the brachial artery terminates by dividing into three branches-viz., the radial, the ulnar, and the interosseons. In any case, the branch which gives origin to or becomes the interosseous was, in all probability, the original trunk.

Division of the brachial artery at a more proximal level than usual occurs most commonly in the proximal third of the arm, and least commonly in the distal third; the resulting trunks are often united near the bend of the elbow by a more or less oblique anastomosis.

In cases of proximal division of the brachial artery the radial branch may pierce the deep fascia of the arm near the bend of the elbow, and passes distally in the forearm immediately deep to the skin ; in other cases the radial runs deeper, and passes behind the tendon of the biceps. The ulnar branch sometimes runs, on the medial intermuscular septum, towards the medial epicondyle, and then laterally towards the middle of the bend of the elbow, under a band of fascia from which the proximal fibres of the pronator teres arise, or round the supracondylar process of the humerus if it is present. Hore commonly the ulnar branch runs distally towards the medial epicondyle, and crosses superficial to the flexor muscles or deep to the palmaris longus; and in a few cases it is subcutaneous. In rare cases the ulnar artery accompanies the ulnar nerve behind the medial epicondyle; in these cases it has obviously been formed by enlargement of the ordinary superior ulnar collateral and dorsal ulnar recurrent arteries.

Instead of following its usual course along the brachialis muscle, the brachial artery may accompany the median nerve behind a supracondylar or epicondylic process, or ligament, as in many carnivores; it may pass in front of the median nerve instead of behind it. It may give off a "vas aberrans" or a median artery, and any of its ordinary branches may be absent.

The vas aberrans given off from the brachial artery usually ends in the radial artery, sometimes in the radial recurrent, and rarely in the ulnar artery.

The ulnar artery may be absent, being replaced by the median artery or the interosseous artery, and it may terminate in the deep instead of in the superficial volar arch. It rarely arises more distally than usual, and when it arises at a more proximal point it most commonly passes superficial to the muscles which spring from the medial epicondyle. Moreover, in these cases it frequently has no interosseous branch, the latter vessel springing from the radial artery, and in all probability variations of this description are produced by the nInar artery taking origin from the main trunk, which is represented by the radio-interosseous vessel, at a more proximal level than usual. Even when it commences in the usual way the ulnar artery may pass superficial to the muscles arising from the medial epicondyle, and in these cases its interosseous and recurrent branches spring from the radial artery.

The volar and dorsal interosseous arteries may arise separately from the ulnar instead of by a common interosseous trunk. The recurrent branches of the ulnar may spring from the interosseous, and the interosseous itself may be a branch of the radial.

The small median artery, the companion artery of the median nerve, usually a branch of the volar interosseous, may spring from the axillary, brachial, or ulnar arteries; it may be much larger than usual, and it may terminate either by breaking up into digital branches, or by joining one or more digital branches of the superficial volar arch or the arch itself.

The radial artery may be absent, its place being taken by branches of the ulnar or interosseons arteries; it may arise from the axillary, or, more proximal than ustal, from the brachial. It may terminate in muscular branches in the volar part of the forearm, or as the superficial volar, or in carpal branches; the distal portion of the artery, in these cases, is usually replaced by branches of the ulnar or interosseous arteries. Occasionally the radial divides some distance proximal to the wrist into two terminal branches, one of which gives off the carpal branches, and becomes the superficial volar, whilst the other crosses superficial to the extensor tendons and passes to the dorsum of the wrist.

The radial artery may run a superficial course, or, and especially when it commences at a more distal level than usual, it may pass deep to the pronator teres and the radial origin of the flexor digitorum sublimis. In some cases it passes to the dorsum of the wrist across the brachioradialis, and in others it lies superficial, instead of deep to, the extensor tendons of the thumb.

Its brauches may be diminished or increased in number. The radial recurrent may spring from the brachial or nlnar arteries, or may be represented by several branches from the proximal part of the radial. The dorsal artery of the index digit may be large, and may replace the princeps pollicis and the volaris indicis radialis. On the contrary, the dorsal carpal artery and dorsal digital branches of the radial may be small, or the former may be replaced by branches of the metacarpal arteries, and the latter by the proximal perforating branches of the deep volar arch.

The princeps pollicis and volaris indicis radialis arteries may be absent, their places being taken either by branches of the superficial volar arch or by the dorsalis indicis radialis artery.

The superficial volar arch is sometimes absent; its branches are then given off from the deep arch. On the other hand, it may be larger than normal, and it may be completed on the radial side by the volaris indicis radialis, the princeps pollicis, or the comes nervi mediani arteries.

The deep volar arch is much more rarely absent than the superficial arch. When absent its branches are supplied by the superficial arch, the proximal perforating arteries, or the volar carpal areh.

\section{The Iliac Arteries and their Branches.}

The common iliac artery may be longer or shorter than usual, a modification which is largely, though not altogether, determined by the point at which the bifurcation of the aorta 
takes place. If exceptionally long, it is usually tortuous. In rare cases in man the artery is absent. It occasionally gives off the middle or a lateral sacral artery, and ilio-lumbar, spermatic, or accessory renal branches may arise from it.

The hypogastric artery raries as regards length. It is usually longer, and arises at a higher level when the common iliac is short. In rare cases it has been found to arise from the aorta without the intervention of a common iliac. Frequently it does not, even in appearance, end in anterior and posterior divisions, but obviously forms a single trunk, as in the fotus, from which the several branches are given off.

The visceral branches vary much in number and size, and the middle hæmorrhoidal may not be present, its place being taken by branches from the vesical arteries. A renal branch sometimes arises from the hypogastric artery.

The ilio-lumbar branch may arise from the common iliac instead of from the hypogastric artery ; the superior glutæal and inferior glutæal arteries may arise by a common stem, or the superior gluteal may be absent, and its place taken by a branch from the femoral artery; the inferior glutæal artery may, as in the fœtus, constitute the main artery of the lower limb, and rum distally to become continuous with the popliteal artery. Probably the arteria comitans nervi ischiadici represents the original continuity of these two ressels. Occasionally the lateral sacral arteries do not arise from the hypogastric trunks.

In some instances the obturator artery arises from the inferior epigastric artery instead of from the hypogastric. The condition is apparently due to obliteration of the usual origin of the obturator artery and to the subsequent enlargement of the anastomosing pubic branches of the obturator and inferior epigastric arteries. The course of the abnormal obturator artery is of importance. From its origin it descends, into the pelvis minor, on the medial side of the extermal iliac vein, and in the majority of cases on the lateral side of the crural ring, but in three-tenths of the cases, and more frequently in males than in females, it descends on the medial side of the ring.

The obturator artery sometimes gives off an accessory pudendal branch which passes along the side of the prostate, pierces the urogenital diaphragm, and terminates by dividing into the profunda artery of the penis and the dorsal artery of the penis. When this occurs the internal pudendal artery is small, and it terminates in the artery to the bulb. Occasionally the accessory pudic arises from the external pudendal artery in the pelvis, or from one of the vesical arteries.

The external iliac artery may be much smaller than usual, especially if the inferior glutæal artery persists as the main vessel of the lower limb. It may give off two deep circumflex iliac branches, a dorsal artery of the penis, a medial circumflex artery of the thigh, or a vas aberrans, and its deep circumflex iliac and inferior epigastric branches may arise at higher or lower levels than usual.

\section{The Arteries of the Lower Limb.}

The femoral artery is small, and ends in the profunda aud circumflex branches, when the inferior glutæal artery forms the principal vessel of the lower limb. The profunda branch, which arises usually from the lateral side of the felnoral trunk, about $37 \mathrm{~mm}$. (1 $\frac{1}{2}$ in.) distal to the inguinal ligament, may commence at a more proximal or a more distal level, and from the back or the medial side of the femoral trunk. In rare cases when the profunda arises from a more proximal level than usual it may cross anterior to the femoral vein, above the entrance of the great saphenous vein, after which it passes distally and laterally posterior to the femoral vessels (Johnston, Anat. Anz., Bd., 42, 1912). Absence of the profunda has been noted, and in these cases the branches usually given off by it spring directly from the femoral artery.

The femoral artery may be double for a portion of its extent, or it may be joined by a vas aberrans given off from the external iliac artery. In addition to its ordinary branches, it may furnish one or both of the circumflex arteries of the thigh, and sometimes it gives off, near the origin of the profunda, a great saphenous artery, such as exists normally in many mammals. This vessel runs distally through femoral trigone and the adductor canal, and accompanies the saphenous nerve to the medial side of the foot.

The deep circumflex iliac, the obturator, and the inferior epigastric arteries are occasionally given off from the femoral.

The popliteal artery may exceptionally form the direct continuation of the inferior glutæal artery. It sometimes divides at a more proximal or more distal level than usual, and the division may be into either two or three branches; if three terminal branches are present, they are the anterior and posterior tibial and the peroneal arteries, and if only two, either the anterior and posterior tibial, or the anterior tibial and the peroneal arteries.

Occasionally the artery is double for a short portion of its course, and it has been found to cross first posterior to the medial head of the gastrocnemius to the medial side of the knee, and then anterior to the medial head of the gastrocnemius to regain the popliteal fossa. The number of its branches may be reduced, or they may be increased by the addition of a vas aberrans which connects it with the posterior tibial artery. Its superficial sural branch may enlarge to form a well-marked small saphenous artery.

The posterior tibial artery may be small or altogether absent, its place being taken by branches of the peroneal artery; again, it may be longer or shorter than usual, in conformity with the more proximal or more distal division of the popliteal trunk. The peroneal artery is large, if either the anterior or the posterior tibial artery is small. The perforating branch of the peroneal is almost invariably large when the anterior tibial artery is small; in some cases, 
indeed, it replaces the whole of the dorsalis pedis continuation of the latter vessel; in others, however, only the lateral tarsal and arcuate branches are so replaced. The peroneal sometimes arises from a stem common to it and the anterior tibial artery.

The anterior tibial artery may be absent, its place being taken by branches of the posterior tibial and peroneal arteries. It is longer than normal when the popliteal artery divides at a more proximal level than usual, and in these cases it may pass either posterior or anterior to the popliteus muscle. Occasionally the anterior tibial artery and its dorsalis pedis continuation are larger than normal, and the terminal part of the dorsalis pedis takes the place, more or less completely, of the lateral plantar artery.

The medial plantar artery is sometimes very small, and it may be absent; its place is taken by branches of the dorsalis pedis or lateral plantar arteries. The lateral plantar artery also may be small or absent, the plantar arch being formed entirely by the dorsalis pedis.

\section{ABNORMALITIES OF VEINS}

Abnormalities or variations of veins are as frequently met with as those of arteries, and they are due to similar causes.

\section{The Superior Vena Cava.}

The superior vena cava may develop on the left side instead of on the right. This peculiarity is due to the persistence of the left duct of Cuvier instead of that on the right side, and it is associated with absence of the coronary simus, which is replaced by the lower part of the left superior vena cava. An exceptional case is recorded in which the opening of the coronary sinus into the heart was obliterated, and the cardiac veins terminated in a trunk which passed upwards to the left innominate vein. This trunk was obviously formed by enlargement of the left duct of Cuvier and the lower part of the left anterior cardinal vein. Not very uncommonly, as the result of the persistence of both ducts of Cuvier, there are two superior venæ cavæ, the transverse anastomosis which usually forms the left innominate vein being small or entirely absent. In these cases the left innominate vein descends in the left part of the superior mediastinum, crosses the aortic arch, is joined by the left superior intercostal vein, and becomes the left stuperior vena cava; which descends anterior to the root of the left lung, and terminates in the lower and back part of the right atrium. It receives the great cardiac vein, and, turning to the back of the heart, replaces the coronary sinus. This arrangement is normal in many mammals. Occasionally in man the left superior vena cava terminates in the left atrium, and the coronary sinus, which represents a part of the sinus venosus, has been seen to have a similar ending; both these abnormal endings must be the result of malposition of the interatrial septum.

The vena azygos may be formed on the left side; it then arches over the root of the left lung, and terminates in the left end of the coronary sinus. This is the normal arrangement in some mammals, and it is due to the persistence of the left posterior cardinal vein and the left duct of Cuvier.

Occasionally the azygos vein is the only vessel by which blood is returned to the heart from the lower limbs and the lower parts of the body walls. In such cases that portion of the inferior vena cava which usually extends from the right renal vein to the heart is absent and the azygos vein is the direct continuation of the inferior vena cara. This condition probably results from the absence of those parts of the inferior vena cava which are usually formed from the right vitelline and the right subcardinal veins, and to the enlargement of the whole of the suprapelvic portion of the right posterior cardinal vein.

The hemiazygos and the accessory hemiazygos veins may be absent. In these cases each left intercostal vein opens separately into the rena azygos. On the other hand the hemiazygos and the accessory hemiazygos veins may form a continuous trunk which may open by a transverse anastomosis into the azygos vein, or it may join the left innominate vein. When the hemiazygos and the accessory hemiazygos veins form a single trunk, which receives the left intercostal veins and opens into the left innominate vein, the condition is due to the persistence of the whole of the thoracic part of the left posterior cardinal vein and of the lower part of the left anterior cardinal vein.

Cases also occur in which the thoracic part of the posterior cardinal vein is represented by three instead of two stems, either the hemiazygos or the accessory hemiazygos rein being represented by two vessels.

The internal jugular vein may be either smaller or larger than normal. In either case compensatory changes in size occur in the transverse sinus and internal jugular vein of the opposite side, or in the external and anterior jugular veins of the same side.

The external jugular vein is sometimes absent, or it may be smaller than usual; in both cases either the anterior or the internal jugular vein is enlarged. In some of the cases in which the external jugular vein is small it receives no communication from the posterior facial rein, but is merely the continuation of the posterior auricular vein. On the otler liand, it may be enlarged, and receive the whole of the posterior facial vein.

The anterior jugular vein may be absent, or it may be unusually large, espacially in the lower part of its extent, and after it has received an occasional tributary from the common facial vein. 
The posterior facial vein may terminate entirely in the common facial vein, or in the external or the internal jugular vein. It may be very small, and occasionally it is absent.

Variations of the cranial blood sinuses are not numerous. One transverse sinus may be absent or very small, when, as a rule, that of the opposite side is enlarged. The inferior sagittal, the occipital, or the spheno-parietal sinuses may be absent, and there may be an additional petrosquamous tributary to the transverse sinus. The petro-sqnamous sinus, when present, is the remains of a sinus which crossed the temporal bone, passed through the post-condyloid foramen and terminated in the lateral cerebral vein. In the human adult, in rare cases, it pierces the skull behind the condyle of the mandible, and terminates in the posterior facial vein. This is the normal arrangement in some mammals.

\section{The Vhins of the Upper Extremity.}

The superficial veins of the forearm are extremely variable; any of them may be absent, but most commonly it is the median or the cephalic vein which is wanting. The median cephalic and the cephalic veins may be small or absent, and, on the other hand, the cephalic vein may be larger than usual. Moreover the cephalic vein may end in the external jugular vein, its original termination; or it may be connected with the external jugular vein by an anastomosing channel which sometimes passes over the clavicle and sometimes throngh that bone.

The basilic vein is sometimes larger and sometimes smaller than usual, and it may pierce the fascia of the arm at a more proximal or at a more distal level than usual.

The venæ comites of the arteries of the upper extremity generally terminate at the lower border of the subscapularis, where they join the axillary vein, but they may end above or below the position of their usual termination.

The subclavian vein sometimes passes behind instead of in front of the scalenus anterior muscle, and it has been seen passing between the clavicle and the subclavius muscle.

\section{The Inferior Vena Cava.}

The lower part of the inferior vena cava is sometimes absent, in which case the common iliac veins ascend, one on the right and the other on the left of the aorta, to the level of the second lumbar vertebra, where the left common iliac vein receives the left renal vein, and then crosses in front of or behind the aorta to fuse with the corresponding vein of the right side; in such cases, therefore, the inferior vena cava commences at the level of the second lumbar vertebra, and it represents only the upper and last-formed part of the ordinary vessel; the common iliac veins, each of which receives the lumbar veins of its own side, are exceptionally long, and they may or may not be united at the pelvic brim by a small transverse anastomosing channel. Cases of this kind are sometimes described as partial doubling of the inferior vena cava.

Occasionally the inferior vena cava does not terminate in the right atrinm, but is continuous with the vena azygos, which is much enlarged, all the inferior caval blood being then carried to the superior vena cava. In these cases the hepatic veins open directly into the right atrium without communicating with the inferior vena cava.

The lower part of the inferior vena cava sometimes lies to the left instead of to the right of the aorta; this condition is associated with a long right common iliac vein, which crosses obliquely from right to left to join the shorter left common iliac vein. After receiving the left renal vein the misplaced inferior vena cava crosses in front of the aorta, reaching the right side at the level of the second or first lumbar vertebra. In other cases, however, the left inferior vena cava continues upwards through the left crus of the diaphragm, usurping the place of a greater or smaller part of the hemiazygos vein; having entered the thorax, it may cross to the opposite side and terminate in the vena azygos, or it may continue upwards on the same side, and after arching over the root of the left lung, descend behind the left atrium to terminate in the right atrium in the situation of the coronary sinus. In this group of cases also the hepatic veins open separately into the right atrium.

The inferior vena cava may lie ventral instead of dorsal to the right internal spermatic artery, in which case the lower part of the vessel has been derived from the subcardinal vein instead of from the posterior cardinal vein. (Johnston, Journ. of Anat. and Phys. xlvii. 1913.)

The tributaries of the inferior vena cava are also subject to variation. Additional renal, spermatic, ovarian, or suprarenal veins may be present. Two or three lumbar veins of one or both sides may unite into a common trunk which terminates in the inferior vena cava, and the hepatic veins may open separately, or after fusing into a common trunk, into the right atrium near the opening of the inferior vena cava.

No explanation of the variations of the inferior vena cava and its tributaries is necessary, beyond the statement that they are due to persistence of portions of the cardinal and subcardinal veins which usually disappear, and to the persistence of transverse anastomoses and tributaries which usually atrophy, or to modifications of those which ordinarily take part in the formation of the inferior vena caval system.

The left common iliac vein is short and the right long when the inferior vena cava lies on the left side. The common iliac veins may be absent, the hypogastric veins uniting to form the commencement of the inferior vena cava, into which the external iliac veins open as lateral tributaries. 


\section{The Veins of the Lower Extremity.}

The great saphenous vein is not subject to much variation, but the small saphenous vein may terminate by joining the great saphenous, or, after piercing the deep fascia in the distal part of the thigh, it may ascend and join the inferior glutæal vein or one of the tributaries of the profunda vein.

The venæ comites are generally described as terminating in the lower extremity, at the distal part of the popliteal fossa, but they may ascend as far as the femoral trigone; as a matter of fact, one or more small additional veins usually accompany the popliteal and femoral arteries, although as a rule there is only one large popliteal and one large femoral vein.

In a few cases the popliteal vein does not pierce the distal part of the adductor magnus, but ascends behind that muscle and becomes continuous with the profunda vein, the femoral artery being unaccompanied by any large vein during its passage through the adductor canal.

\section{ABNORMALITIES OF THE LYMPHATICS.}

Variations of the glands and smaller vessels of the lymphatic system are so common that they can hardly be regarded as abnormalities; variations of the larger vessels, however, are comparatively rare. This is especially the ease with respect to the two terminal trunks, the thoracic duct and the right lymphatic duct, the abnormalities of which are interesting and important.

When the arch of the aorta is on the right side instead of on the left side, the thoracic duct terminates usually in the right innominate vein, in which case it receives the tributaries which usually open into the right lymphatic duct, whilst the corresponding area on the left side is drained by lymphaties terminating in a left lymphatic duct which opens in to the commencement of the left innominate vein. A similar arrangement of the terminal lymphatic trunks sometimes occurs even when the arch of the aorta is in its normal position on the left side. In either case the thoracic duct may commence in the usual way, and after reaching the level of the fifth thoracic vertebra continue upwards on the right side, instead of crossing to the left side of the vertebral column; more rarely it commences on the left side and crosses over to the right at a higher level.

In one case in which the thoracic duct opened into the right innominate vein, instead of the left, no trace of a lymphatic duct was discovered on the left side.

Occasionally the thoracic duct commences and terminates in the usual manner, but crosses the vertebral column immediately after its origin and ascends on the left side.

Not uncommonly there is no distinct eisterna chyli, in which ease the terminal lymphatic vessels of the abdomen merely unite to form a larger vessel which does not present any obvious dilatation, and from which the thoracic duct is continued. The terminal lymphatic trunk may open into the internal jugular vein, previous to its junction with the subclavian, instead of into the commencement of the innominate vein.

Occasionally the thoracic duct is double, either in the whole or in part of its extent, and sometimes it breaks up into a plexus of vessels which may reunite into a single trunk in the upper part of the thorax. Both the thoracic duct and the right lymphatic duct may, before terminating, divide into branches which, though sometimes reuniting on each side into a single trunk, not infrequently open separately into the great veins at the root of the neck.

As a rule the thoracic duct joins the commencement of the left innominate vein, but it may end in the internal jngular, vertebral, or subclavian veins of the left side; whilst very rarely, it opens into the vena azygos. 



\title{
THE RESPIRATORY SYSTEM.
}

\section{THE ORGANS OF RESPIRATION AND VOICE.}

\author{
By the late D. J. Cunningham, F.R.S., \\ Professor of Anatomy, University of Edinburgh. \\ Revised by Richard J. A. Berry, F.R.C.S., \\ Professor of Anatomy, University of Melbourne.
}

THE organs of respiration are the larynx and trachea, which, together, constitute a median air-passage ; the two bronchi or branches into which the inferior end of the trachea divides; and the two lungs to which the bronchi conduct the air. In connexion with the lungs there are also the pleural membranes-two serous sacs which line the portions of the thoracic cavity which contain the lungs, and at the same time give a thin coating to those organs.

The larynx opens above into the inferior or caudal part of the pharynx, and the air which passes in and out from the air-passages likewise traverses the pharynx, the nasal cavity, and also the oral cavity if the mouth be open. This connexion between the digestive and respiratory systems is explained by the fact that the respiratory apparatus is secondarily developed, as an outgrowth, from the ventral aspect of the primitive fore-gut of the embryo. In most mammals the superior or cranial aperture of the larynx opens into the part of the pharynx which lies dorsal to the nasal cavities. In man, however, the superior opening of the larynx is placed below, that is inferior or caudal to, the communication between the mouth and pharynx, and both nasal and oral breathing may be carried on with very nearly equal ease.

\section{LARYNX.}

The larynx or organ of voice is the upper part of the air-passage, specially modified for the production of voice. Above it opens into the pharynx, whilst below its cavity becomes continuous with the lumen of the trachea or windpipe.

Position and Relations of the Larynx.-In the natural position of the neck, and whilst the organ is at rest, the larynx is placed on the ventral side of the bodies of the fourth, fifth, and sixth cervical vertebræ. Its highest point, represented by the tip of the epiglottis, extends to the inferior border of the body of the third cervical vertebra, whilst its lowest limit (the inferior border of the cricoid cartilage) usually corresponds to the inferior border of the body of the sixth cervical vertebra. From the vertebral column the larynx is separated, not only by the prevertebral muscles and the prevertebral fascia, but also by the dorsal wall of the pharynx-indeed the dorsal surface of the larynx forms the inferior part of the ventral wall of the pharynx, and is covered by the lining mucous membrane of that section of the alimentary canal.

The larynx lies below the hyoid bone and the tongue, and in the interval between the great vessels of the neck. It forms a more or less marked projection on the ventral side of the neck, and, in the median plane, it approaches very closely to the surface, being merely covered by skin and the two layers of fascia. Laterally 
it is more deeply placed. Thus, it is overlapped by the sterno-cleido-mastoid muscle, and is covered by the two strata of thin ribbon-like muscles which are attached to the thyreoid cartilage and the hyoid bone; and it is hidden, to some extent, by the upper prolongations of the lateral lobes of the thyreoid gland.

The position of the larnyx is influenced by movements of the head and neck. Thus it is elevated or raised when the head moves dorsally, and depressed when the chin is carried downwards towards the chest. Again, if the finger is placed upon it during deglutition, it will be noted that the larynx moves to a very considerable extent. The pharyngeal muscles attached to it, and more especially the stylo-pharyngeal muscles, are chiefly responsible for bringing about these movements. During singing, changes in the position of the larynx may also be noted, a high note being accompanied by a slight upward movement, and a low note by a similarly slight downward movement of the organ.

The position of the larynx is not the same at all periods of development and growth. In the fœtus, shortly before birth, it lies much nearer the head, and its inferior border corresponds to the inferior border of the fourth cervical vertebra. Its permanent position is not reached until the period of puberty is attained (Symington). This downward movement of the larynx has been stated to be due to the rapid and striking growth of the facial part of the skull (Symington). It is very doubtful, however, if the facial growth has any influence in this direction. In the anthropoid ape, in which the face forms a much greater part of the skull than in man, and in which, in the transition from the infantile to the adult condition, the facial growth is even more striking than it is in man, the larynx occupies a relatively higher position in the neck. In the early stages of growth all the thoracic viscera undergo a gradual subsidence. The larynx in its downward movements follows these. Indeed, it cannot do otherwise, seeing that the bifurcation of the trachea between infancy and puberty moves downwards towards the caudal end of the body more than the depth of one thoracic vertebra.

General Construction of the Larynx.-The wall of the larynx is constructed upon a somewhat complicated plan. There is a framework composed of several cartilages. These are connected together, at certain points, by distinct joints and also by elastic membranes. Two elastic cords, which stretch in a ventro-dorsal direction from the ventral to the dorsal wall of the larynx, form the groundwork of the vocal folds (O.T. true vocal cords). Numerous muscles also are present. These operate upon the cartilages of the larynx, and thereby not only bring about changes in the relative position of the vocal folds, but also produce different degrees of tension of these folds. The cavity of the larynx is lined with nucous membrane, under which, in certain localities, are collected masses of mucous glands.

\section{CARTILAGINES LARYNGIS.}

Three single cartilages and three pairs of cartilages enter into the construction of the laryngeal wall. They are named as follows :-

$$
\text { Single cartilages }\left\{\begin{array} { l } 
{ \text { Thyreoid. } } \\
{ \text { Cricoid. } } \\
{ \text { Epiglottis. } }
\end{array} \quad \text { Paired cartilages } \left\{\begin{array}{l}
\text { Arytænoids. } \\
\text { Corniculate cartilages } \\
\text { (Santorini). } \\
\text { Cuneiform cartilages. }
\end{array}\right.\right.
$$

Cartilago Thyreoidea. - The thyreoid cartilage, the largest of the laryngeal cartilages, is formed of two quadrilateral plates termed the laminæ, which meet ventrally at an angle, and become fused along the median plane. Dorsally the laminæ diverge from each other, and enclose a wide angular space which is open dorsally. The ventral borders of the laminx are fused only in their inferior parts. Above they are separated by a deep, narrow $V$-shaped median notch, called the incisura thyreoidea or thyreoid notch. In the adult male the angle formed by the meeting of the ventral borders of the two laminæ, especially in its upper part, is very projecting, and with the margins of the thyreoid notch, which lies above, constitutes a marked subcutaneous prominence in the neck, which receives the name of the prominentia laryngea (O.T. Adam's Apple). 
The angle which is formed by the meeting of the two laminæ of the thrreoid cartilage raries to some extent in different individuals of the same sex, and shows marked differences in the two sexes and at different periods of life. In the adult male the average angle is said to be $90^{\circ}$; in the adult female it is $120^{\circ}$; whilst in the infant the laminæ meet in the form of a gentle curve, convex ventrally.

The dorsal border of each lamina of the thyreoid cartilage is thick and rounded, and is prolonged beyond the superior and inferior borders in the form of two slender cylindrical processes, termed cornua. The superior cornu is longer than the inferior cornu. It is directed upwards, towards the head, with a slight dorso-medial inclination, and ends in a rounded extremity, which is joined to the tip of the great cornu of the hyoid bone by the lateral hyo-thyreoid ligament. The inferior cornu is shorter and stouter than the superior cornu. As it proceeds downwards it curres slightly towards the median plane, and upon the medial face of its extremity it shows a circular flat facet, by means of which it articulates with a similar facet on the lateral aspect of the cricoid eartilage.

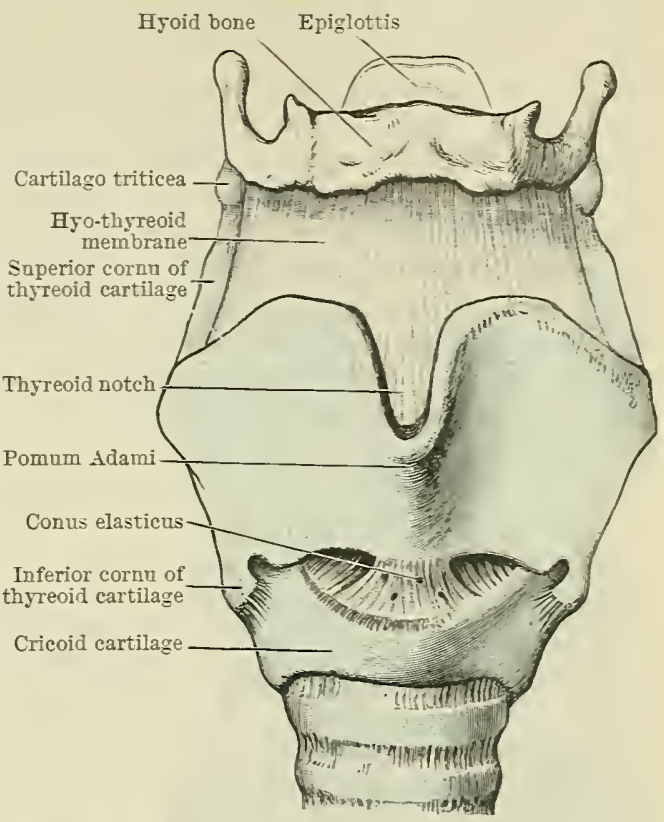

Fig. 845.-Textral Aspect OF the Cartilages AXD LIGAMENTS OF THE LARYXX.

The superior border of each lamina is for the most part slightly convex, and ventrally it dips suddenly to become continuous with the margin of the thyreoid notch. Dorsally, where it joins the superior cornu, it exhibits a shallow notch or concavity. The inferior border is almost straight, but it is marked off by a

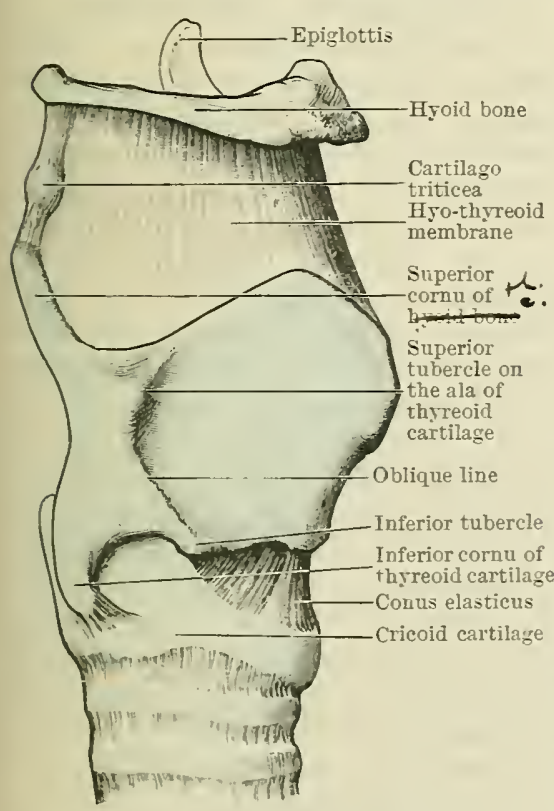

Fig. \$46.-Profile Viem of the Cartilages AND Liganexts OF thE LARTAx. projection, termed the inferior thyreoid tubercle, into a short dorsal part, which shows a shallow concarity close to the inferior cornu and a longer part which lies ventral to the tubercle, and is also concare, but to a less degree.

The lateral surface of each lamina is dirided into two unequal areas by the linea obliqua. This line begins above at the superior thyreoid tubercle, a prominence situated immediately below the superior border, and a short distance rentral to the root of the superior cornu. From this the oblique line proceeds forwards and downwards to end in the inferior tubercle on the inferior border of the lamina. The area which lies dorsal to the oblique line is much smaller than that which lies on its ventral side. It is covered by the inferior constrictor muscle of the pharynx. The larger ventral area is for the most part corered by the thyreohyoid muscle. To the oblique line are attached the sterno-thyreoid and thrreo-hyoid muscles. The medial surface of the lamina of the thyreoid cartilage is smooth and slightlr concare.

Cartilago Cricoidea.-The cricoid cartilage is shaped like a signet-ring. Dorsally there is a broad, thick plate, somewhat quadrilateral in form, termed the lamina; whilst ventralls and laterally the circumference of the ring is completed by a curved band, called the arch. The 
lumen of the ring enclosed by these parts is circular below, but the upper part of the ring is compressed laterally, so that the lumen becomes elliptical. The upper border of the lamina presents a Iaintly marked median notch. On either side of this there is an oval facet which looks more laterally than upwards; it articulates with the base of the arytænoid cartilage. The dorsal surface of the lamina is divided by an elevated median ridge into two depressed areas which give attachment to the posterior crico-arytænoid muscles. The ventral part of the arch of the cricoid is in the form of a narrow band, but as it proceeds dorsally towards the lamina its upper border rises rapidly, and in consequence the arch becomes much broader. The inferior border of the cricoid is nearly straight, although it frequently presents a median ventral projection and two lateral projections. It is joined to the first ring of the trachea by an elastic membrane-the crico-tracheal ligament. On the lateral surface of the cricoid cartilage, at the place where the arch joins the lamina, a vertical ridge runs

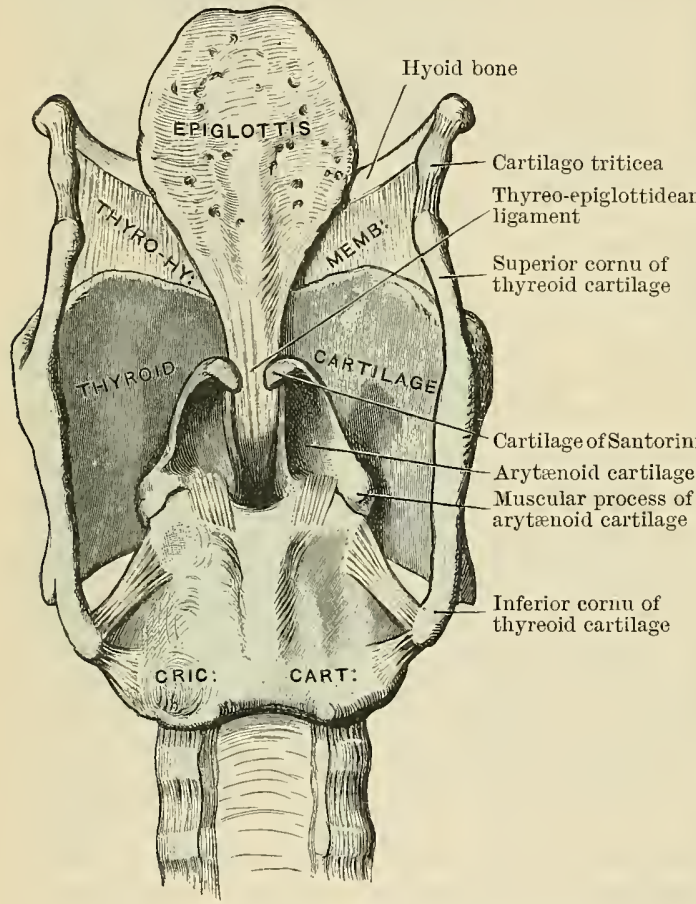

Fig. 847.-Dorsal Aspect of the Cartilages AND LIGAMENTS OF THE LARYNX. downwards from the arytænoid articular facet. On this, a short distance from the inferior border of the cartilage, a prominent circular articular facet is visible, for articulation with the inferior cornu of the thyreoid cartilage (Fig. 848, p. 1067). The medial surface of the cricoid cartilage is smooth, and is lined with mucous membrane.

The narrow band-like part of the arch of the cricoid cartilage lies below the inferior border of the thyreoid cartilage, whilst the lamina is received into the interval between the dorsal portions of the laminæ of the thyreoid cartilage.

Cartilagines Arytænoideæ. The arytænoid cartilages are placed one on either side of the median plane, and rest upon the upper border of the lamina of the cricoid cartilage, in the interval between the dorsal portions of the laminæ of the thyreoid cartilage. Each presents a somewhat pyramidal form, the pointed apex of which is directed upwards, and at the same time curves dorsally and medially.

It supports the corniculate cartilage (Santorini). Of the three surfaces, the medial one faces the corresponding surface of the opposite cartilage, from which it is separated by a narrow interval; another looks dorsally; whilst the third is directed laterally and ventrally. The medial surface, which is the smallest of the three, is triangular in outline. It is narrow, vertical, and even, and is clothed with the lining mucous membrane of the larynx. The dorsal surface is smooth and concave in the craniocaudal direction; it lodges and gives attachment to the arytænoideus transversus muscle. The ventro-lateral surface is the most extensive of the three (Fig. 848, p. 1067). Its middle part is marked by a deep depression in which is lodged a mass of mucous glands. Upon this surface of the arytænoid cartilage the vocalis and thyreoarytænoid muscles are inserted, whilst a small tubercle a short distance above the base gives attachment to the ventricular ligament-the feeble supporting ligament of the ventricular fold (O.T. false vocal cord). The three surfaces of the arytrenoid cartilages are separated from each other by a ventral, a dorsal, and a lateral border. The lateral border is the longest, and it pursues, as it is traced from the apex to the base, a sinuous course. Reaching the base of the cartilage, it is prolonged laterally 
and dorsally in the form of a stout prominent angle or process, termed the processus muscularis. Into the ventral side of this process is inserted the crico-arytænoideus lateralis muscle; whilst into its dorsal aspect the crico-arytænoideus dorsalis (posterior) muscle is inserted. A small nodule of yellow elastic cartilage, called the sesamoid cartilage, is frequently found on the lateral border of the arytænoid cartilage, where it is held in position by the investing perichondrium. The ventral border of the arytæenoid is vertical, and at the base of the cartilage is prolonged ventrally into a small sharp-pointed process called the processus vocalis, which receives this name because it gives attachment to the vocal ligament or supporting band of the vocal fold (O.T. true vocal cord). The base of the arytænoid cartilage presents on its inferior surface, particularly in the region of the processus muscularis, an elongated concave facet for articulation with the facet on the superior border of the lamina of the cricoid cartilage.

Cartilagines Corniculatæ (Santorini).-The corniculate cartilages are two minute conical nodules of yellow elastic cartilage which surmount the apices of the arytænoids, and prolong the upper curved ends of these cartilages in a dorsomedial direction. Each corniculate cartilage is enclosed within the dorsal part of the corresponding ary-epiglottic fold of mucous membrane.

Cartilagines Cuneiformes (Wrisbergi).-The cuneiform cartilages are not always present. They are two minute rod-shaped pieces of yellow elastic cartilage, each of which occupies a place in the corresponding ary-epiglottic fold immediately ventral to the arytænoid cartilage and the corniculate cartilage of Santorini. On the superficial surface of each a collection of mucous glands is present, and this tends to make the cartilage stand out in relief under the mucous membrane.

Cartilago Epiglottica.--The epiglottis is supported by a thin, leaf-like lamina of yellow fibro-cartilage, the epiglottic cartilage, which is placed dorsal to the root of the tongue and the body of the hyoid bone, and ventral to the aperture of the larynx. When divested of the mucous membrane, which covers it dorsally and also to some extent ventrally, the epiglottic cartilage is seen to present the outline of a bicyclesaddle, and to be indented by pits and pierced by numerous perforations. In the pits, glands are lodged, whilst through the foramina, blood-vessels and, in some cases, nerves pass. The broad end of the epiglottic cartilage is directed upwards, and is free. Its margins are, to a large extent, enclosed within the ary-epiglottic fold. The ventral surface is free only in its upper part. This part is covered with mucous membrane, and looks towards the pharyngeal part of the tongue. The dorsal surface is covered throughout its whole extent with the lining mucous membrane of the laryngeal cavity. The inferior pointed extremity is carried downwards in the form of a strong fibrous band, termed the thyreo-epiglottic ligament.

Ossification of the Cartilages of the Larynx. - The thyreoid and cricoid cartilages and the greater part of the arytænoid cartilages are composed of the hyaline variety of cartilage. The apical parts, and also the vocal processes of the arytænoid cartilages, the corniculate cartilages of Santorini, the cuneiform cartilages, and the epiglottis, are formed of yellow fibro-cartilage, and at no period of life do they exhibit any tendency towards ossific change. The thyreoid, cricoid, and basal portions of the arytænoids, as life advances, become more or less completely transformed into bone. In males over twenty years of age, and in females over twenty-two years of age, the process will usually be found to have begun (Chievitz). It is impossible, however, by an examination of the laryngeal cartilages, to form an estimate of the age of the individual, although in old age it is usual to find the thyreoid, cricoid, and the hyaline parts of the arytænoids completely ossified. It would appear that the process is somewhat slower in the female than in the male. The thyreoid is the first to show the change; then, but almost at the same time, the cricoid ; and lastly, a few years later, the arytænoids.

\section{ARTICULATIONS, LIGAMENTS, AND MEMBRANES OF THE LARYNX.}

Crico-thyreoid Joints. - These are diarthrodial joints, and are formed by the apposition of the circular facets on the tips of the inferior cornua of the thyreoid cartilage with the elevated circular facets on the sides of the cricoid cartilage. An articular capsule surrounds each articulation, and this is lined with a 
synovial layer (stratum synoviale). On the dorsal aspect of the joint a strengthening band is present in the capsule. The movements which take place at the crico-thyreoid joints are of a twofold character, viz., gliding and rotatory. In the first case the thyreoid facets glide upon the cricoid surfaces in different directions. The rotatory movement is one in which the thyreoid cartilage rotates to a slight extent around a transverse axis which passes through the centres of the two joints.

Crico-arytænoid Joints.-These also are diarthrodial articulations. In each case there is a joint cavity surrounded by an articular capsule, which is lined with a synovial layer. The cricoid articular surface is convex, whilst that of the arytænoid is concave; both are elongated or elliptical in form, and they are applied to each other so that the long axis of the one intersects or crosses that of the other at an acute angle. In no position of the joint do the two surfaces accurately coincide-a portion of the cricoid facet is always left uncovered. The capsule of the joint is strengthened dorsally by a band which is inserted into the dorsomedial part of the base of the arytænoid cartilage, and plays a somewhat important part in the mechanism of the joint; it effectually arrests excessive ventral movement of the arytænoid cartilage.

The movements which take place at the crico-arytænoid joints are of a twofold kind, viz., gliding and rotatory. The ordinary position of the arytænoid during easy, quiet breathing is one in which it rests upon the lateral part of the cricoid facet. By a gliding movement it can move upon the cricoid facet, and advance towards the median plane and its fellow of the opposite side. The gliding movements, therefore, are of such a character that the two arytænoid cartilages approach or retreat from each other and from the median plane. In the rotatory movement the arytænoid cartilage revolves around a vertical axis. By this movement the vocal process is swung laterally or medially, so as to open or close the rima glottidis.

The joint between the arytænoid and the corniculate cartilage (Santorini) may either partake of the nature of an amphiarthrosis or of a diarthrosis. The tips of the two corniculate cartilages can generally be made out to be connected to the upper border of the lamina of the cricoid cartilage by a delicate $Y$-shaped band of connective tissue termed the ligamentum corniculopharyngeum.

Hyothyreoid Membrane.-This is a broad membranous and somewhat elastic sheet which occupies the interval between the hyoid bone and the thyreoid cartilage. It is not equally strong throughout. It presents a central thick portion and cord-like right and left dorsal margins, whilst in the intervals between these it is thin and weak (Figs. 845 and 846, p. 1063). The central thickened part, or the ligamentum hyothyreoideum medium, is largely composed of elastic fibres. Below it is attached to the margins of the thyreoid notch, whilst above it is fixed to the dorsal part of the upper border of the body of the hyoid bone. The upper part of its ventral surface, therefore, is placed dorsal to the dorsal hollowed-out surface of the body of the hyoid bone; a synovial bursa of variable extent is placed between them, and in certain movements of the head and larynx the upper border of the thyreoid cartilage mores towards the head on the dorsal side of the hyoid bone. On either side of the strong central part the byothyreoid membrane is thin and loose, and is here attached below to the upper border of the thyreoid cartilage, and above to the medial aspect of the great cornu of the hyoid bone. It is pierced by the internal ramus of the superior laryngeal nerve and by the superior laryngeal vessels. The dorsal border of the hyothyreoid membrane on each side is thickened, round, and cord-like, and is chiefly composed of elastic fibres; it is termed the ligamentum hyothyreoideum laterale, and extends from the tip of the great cornu of the hyoid bone to the extremity of the upper cornu of the thyreoid cartilage. In this ligament there is usually developed a small oval cartilaginous or bony nodule, which receives the name of the cartilago triticea. The deep surface of the lateral part of the hyothyreoid membrane is covered with the pharyngeal mucous membrane, and its central part lies ventral to the epiglottis, but separated from it by a mass of adipose tissue (Fig. 851, p. 1070).

Conus Elasticus.-The conus elasticus, formerly known as the crico-thyreoid membrane, is a very important structure, which it is convenient to consider in three 
parts, viz., one median and two lateral, all of which are directly continuous with each other, and differ only in the nature of their upper connexions. The median part (crico-thyreoid ligament) of the conus elasticus is strong, tense, and elastic. It is triangular in shape, and is attached by its broad base to the upper border of the arch of the cricoid cartilage, whilst its apex is fixed to the medial part of the lower border of the thyreoid cartilage (Fig. 845, p. 1063). It is pierced by minute apertures, and is crossed superficially by the crico-thyreoid branch of the superior thyreoid artery. The median part of the conus elasticus, therefore, closes, ventrally, the interval between the cricoid and thyreoid cartilages. The lateral part on each side presents very different connexions. It is not attached to the inferior border of the thyreoid cartilage, but slopes upwards and medially on the inner side of the thyreoid lamina, and thus diminishes materially the transverse or frontal width of the cavity of the larynx. Its attachments are very definite. Inferiorly it is fixed to the superior border of the cricoid cartilage immediately subjacent to the lining mucous membrane of the larynx; above it is directly continuous with the vocal ligament or supporting band of the vocal fold. This ligament, indeed, may be looked upon as constituting the superior thickened free border of the lateral part of the conus elasticus. Ventrally the lateral part of the conus elasticus is attached to the inferior half of the medial surface of the lamina of the thyreoid cartilage, close to the angle, and dorsally to the inferior border of the processus vocalis of the arytænoid cartilage. In contact with the outer surface of the lateral part of the conus elasticus, and separating it from the thyreoid lamina, are the lateral cricoarytænoid muscles; the inner surface is clothed with the lining mucous membrane of the larynx.

Ligamentum Vocale.-The vocal ligament (O.T. inferior thyreo-arytænoid lig.) is formed in connexion with the superior border of the conus elasticus, and con-

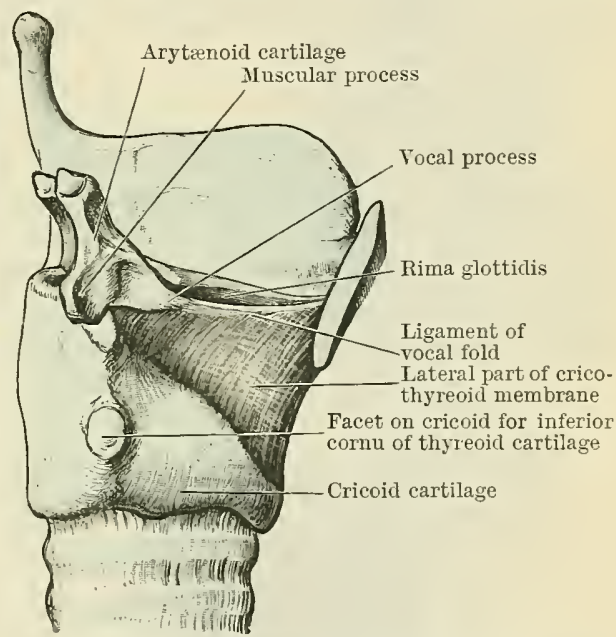

Fig. 848. - Dissection TO SHOW THE CONCS ELAsticus. The right lamina of the thyreoid cartilage has been removed.

stitutes the supprorting ligament of the vocal fold (O.T. true vocal cord). It is attached ventrally, close to its fellow of the opposite side, to the middle of the angular depression between the two laminæ of the thyreoid cartilage. From this it stretches dorsally, and becomes incorporated with the tip and superior border of the processus vocalis, which projects ventrally from the base of the arytænoid cartilage. The vocal ligament is composed of yellow elastic fibres, and embedded in its ventral extremity there is frequently a minute nodule of elastic cartilage. Its medial border is sharp and free, and is clothed with mucous membrane, which in this position is very thin and tightly bound down to the ligament.

Ligamentum Ventriculare.-The ventricular ligament supports the ventricular fold (O.T. false vocal cord). It is weak and indefinite, but somewhat longer than the vocal ligament. Ventrally it is attached to the angular depression between the two laminæ of the thyreoid cartilage, above the vocal ligament and close to the attachment of the thyreo-epiglottic ligament; it extends dorsally to be fixed to a tubercle on the ventro-lateral surface of the arytænoid cartilage, a short distance above the processus vocalis. It is composed of connective tissue and elastic fibres which are continuous with the fibrous tissue in the ary-epiglottic fold.

Epiglottic Ligaments.-The epiglottis is bound by ligaments to the base of the tongue, to the wall of the pharynx, to the hyoid bone, and to the thyreoid cartilage. The glosso-epiglottic fold is a prominent median fold of mucous membrane which proceeds from the middle of the ventral free surface of the epiglottis to the root of the tongue. The pharyngo-epiglottic folds are similar 
elevations of mucous membrane which proceed from the lateral margins of the epiglottis to the lateral walls of the pharynx at the side of the tongue. Between the two layers of mucous membrane which form each of these folds is a certain amount of elastic tissue. By the three folds the depression between the root of the tongue and the epiglottis is marked off into two fossæ, termed the epiglottic valleculæ. From the lateral margins of the epiglottis there also pass off the plicæ aryepiglotticæ to the arytænoids.

The ligamentum hyoepiglotticum is a short, broad elastic band, somewhat broken up by adipose tissue, which connects the ventral surface of the epiglottic cartilage to the upper border of the hyoid bone (Fig. 853, p. 1073). The ligamentum thyreoepiglotticum is strong and thick (Fig. 855, p. 1075). Composed mainly of elastic tissue, it proceeds downwards from the inferior pointed extremity of the epiglottic cartilage, and is attached to the angular depression between the two laminæ of the thyreoid cartilage below the median notch.

A triangular interval is left between the ventral surface of the epiglottis and the hyo-thyreoid membrane. This is imperfectly closed above by the hyoepiglottic ligament, and contains a pad of soft fat (Fig. 851, p. 1070).

\section{CAVUM LARYNGIS.}

The cavity of the larynx is smaller than might be expected from an inspection of its exterior. On looking into its interior through the laryngeal aperture it is seen to be subdivided into three portions by two pairs of elevated folds of mucous membrane, which extend ventro-dorsally (antero-posteriorly), and project medially from each lateral wall of the cavity. The upper pair of folds are the ventricular folds (O.T. false vocal cords); the lower, more definite pair, are the vocal folds (O.T.

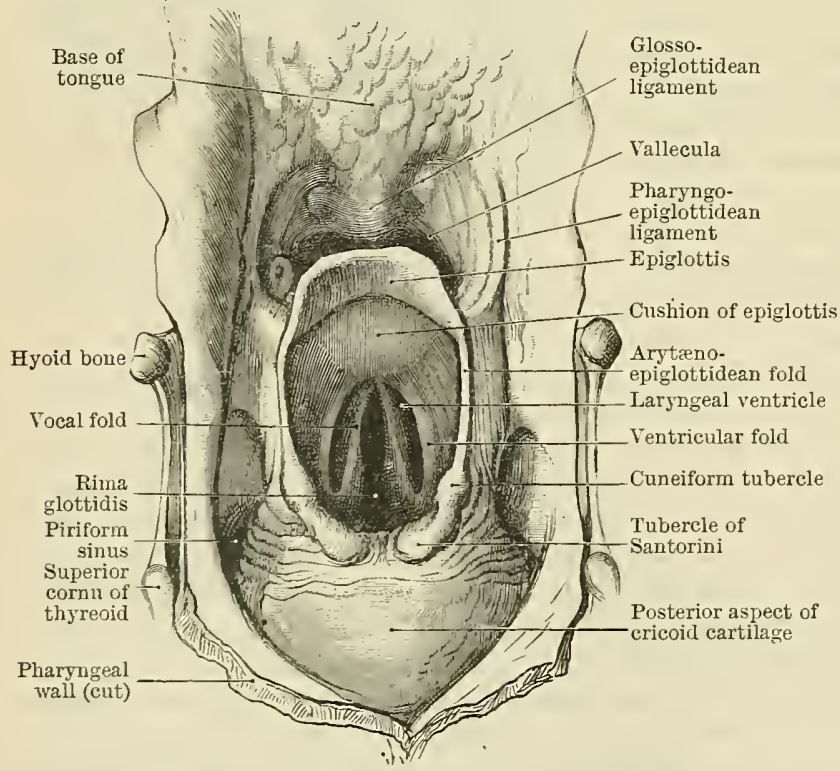

Fig. 819.-Aditus Laryigis, exposed by the ReMotal of the DORSAL WALL OF THE LARYNX. true vocal cords) (Fig. 849). The latter are the chief agents in the production of the voice, and the larynx is so constructed that changes in their relative position and in their degree of tension are brought about by the action of the muscles and the recoil of the elastic ligaments.

\section{Aditus Laryngis. -} The laryngeal aperture is a large obliquely placed opening which slopes rapidly in a dorsal and downwards direction and looks upwards and dorsally into the laryngeal part of the pharynx. Somewhat triangular in outline, the basal part of the aperture, placed superiorly and ventrally, is formed by the

free border of the epiglottis. The opening rapidly narrows as it runs downwards, and it ends in the interval between the two arytænoid cartilages. The sides of the aperture are formed by two sharp and prominent folds of mucous membrane called the ary-epiglottic folds which stretch between the lateral margins of the epiglottis ventrally and the arytænoid cartilages dorsally. The two layers of mucous membrane which compose the ary-epiglottic folds, enclose between them some connective tissue, muscular fibres belonging to the ary-epiglottic muscles, and in their dorsal parts the cuneiform and corniculate cartilages, which latter surmount 
the arytænoid cartilages. These small nodules of cartilage raise the dorsal part of the ary-epiglottic fold in the form of two rounded eminences, termed respectively the tuberculum cuneiforme [Wrisbergi] and the tuberculum corniculatum [Santorini].

On either side of the laryngeal opening there is, in the pharynx, a small recess directed downwards which presents a wide entrance, but rapidly narrows towards the bottom. It is termed the recessus piriformis, and is of importance to the surgeon, because foreign bodies introduced into the pharynx are liable to be caught in this little pocket. On the medial side the recessus piriformis is bounded by the arytænoid cartilage and the ary-epiglottic fold, whilst on the lateral side it is limited by the inner surface of the laminæ of the thyreoid cartilage, clothed with the pharyngeal mucous membrane.

Vestibulum Laryngis. - The vestibule of the larynx is the uppermost compartment of the cavity of the larynx. It extends from the laryngeal aperture to the ventricular folds. In its inferior part it exhibits a marked lateral compression. Its width, therefore, diminishes in the vertical direction, whilst, owing to the obliquity of the laryngeal aperture, its depth rapidly diminishes ventrodorsally. Ventrally it is bounded by the dorsal surface of the epiglottis, clothed with mucous membrane. This wall passes obliquely from its superior end in an inferior ventral direction, and becomes narrower as it approaches the ventral or anterior ends of the ventricular folds. The superior part of the dorsal surface of the epiglottis is convex, owing to the manner in which the upper margin is curved ventrally towards the tongue; caudal to this there is a slight concavity, and still more caudally a marked bulging or convexity, over the superior part of the thyreo-epiglottic ligament. This swelling is called the tuberculum epiglotticum, and it forms a conspicuous object in laryngoscopic examination of the larynx. Each lateral wall of the vestibule of the larynx is formed by the medial surface of the corresponding aryepiglottic fold. For the most part it is smooth and slightly concave, and it diminishes considerably in vertical depth as it passes dorsally. In its dorsal part the mucous membrane stands out in two elongated vertical elevations, placed one dorsal to the other (Fig. 849, p. 1068).

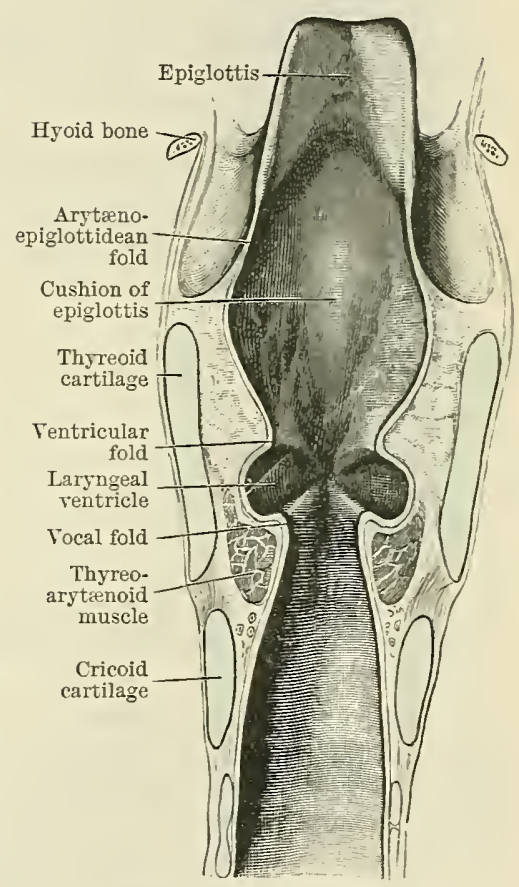

Fig. 850.-FrONTAL SECTION THROCGH THE LARYNX TO SHOW ITS COMPARTMENTS.

The more ventral elevation is formed by the subjacent cuneiform cartilage with the mass of glands associated with it; the more dorsal elevation is produced by the upper part of the arytænoid cartilage and the corniculate cartilage (Santorini). A shallow groove (philtrum ventriculi of Merkel) passes downwards between these rounded elevations, and terminates below by running into the interval between the ventricular and vocal cords. The ventral elevation ends below in the dorsal extremity of the ventricular fold; the arytænoid or dorsal elevation, in its inferior part, bends round the dorsal end of the ventricle of the larynx and becomes lost in the vocal fold. The dorsal wall of the laryngeal vestibule is narrow, and corresponds to the interval between the upper parts of the two arytænoid cartilages. Its width, to a large extent, depends on the position of these cartilages, and when they are placed near each other the mucous membrane which covers this wall is thrown into longitudinal folds.

The middle compartment of the larynx is much the smallest of the three. It is bounded above by the ventricular fold and below by the vocal folds, whilst it communicates between these folds with the vestibule on the one hand and the inferior compartment on the other. 
The ventricular folds (O.T. false vocal cords) are two prominent folds of mucous membrane which extend ventro-dorsally on the lateral walls of the

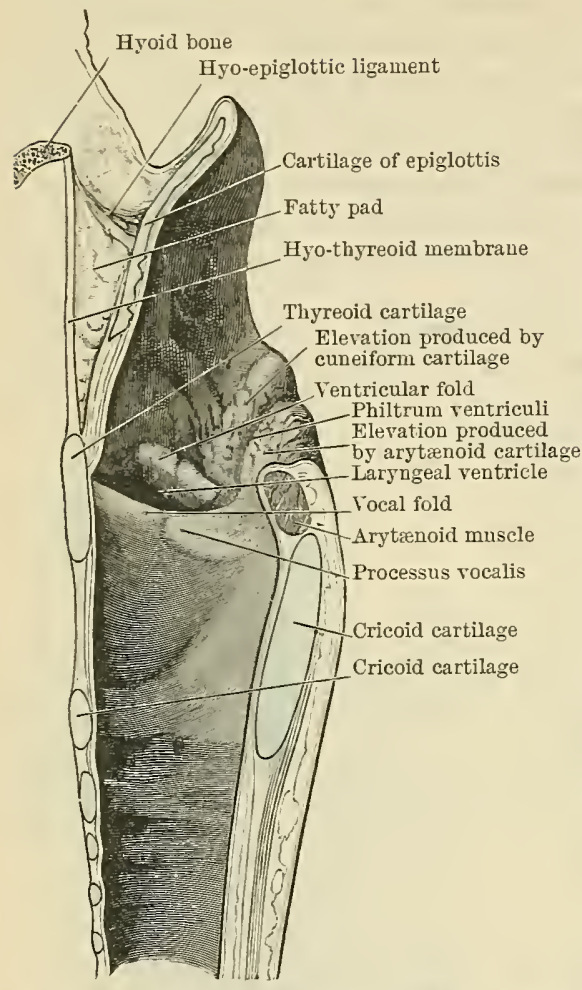
Mediax Plate to show the Odter Wall of the Pight HalF.
Fig. 851.-SEction THROdGH LARYNx IN THE

laryngeal cavity. Ventrally they reach the angle between the two laminæ of the thyreoid cartilage, but dorsally they do not extend so far as the dorsal wall of the larynx. They come to an end at the inferior extremity of the elongated swelling produced by the cuneiform cartilage. The ventricular fold is soft and somewhat flaccid, and presents a free border which is slightly arched-the concavity looking downwards. Within the fold of mucous membrane which forms this fold are contained: (1) the feeble ventricular ligament; (2) numerous glands which are chiefly aggregated in its middle part; and (3) a few muscle fibres.

The interval between the ventricular folds is sometimes termed the rima vestibuli (O.T. false glottis), and is considerably wider than the interval between the two vocal folds, which is called the rima glottidis. It follows from this that when the cavity of the larynx is examined from above the four folds are distinctly visible, but when examined from below the vocal folds alone can be seen.

The vocal folds (O.T. true vocal cords), placed below the ventricular folds, extend from the angle between the laminæ of the thyreoid cartilage ventrally, to the vocal processes of the arytænoid cartilages dorsally. The vocal fold is sharp and prominent, and the mucous membrane which is stretched over it is very thin and firmly bound down to the subjacent ligament. In colour it is pale, almost pearly white, whilst dorsally the point of the processus vocalis of the arytænoid, which stands out clearly in relief, presents a yellowish tinge. In cross-section the vocal fold is prismatic in form, and its free border looks upwards as well as medially.

The vocal folds are the agents by means of which the voice is produced. The ventricular folds are of little importance in this respect; indeed, they can in great part be destroyed and no appreciable difference in the voice result.

Rima Glottidis. - This name is applied to the elongated fissure by means of which the middle compartment of the larynx communicates with the lower compartment. It is placed somewhat below the middle of the laryngeal cavity, of which it constitutes the narrowest part. Ventrally it corresponds to the interval between the vocal folds; dorsally it corresponds to the interval between the bases
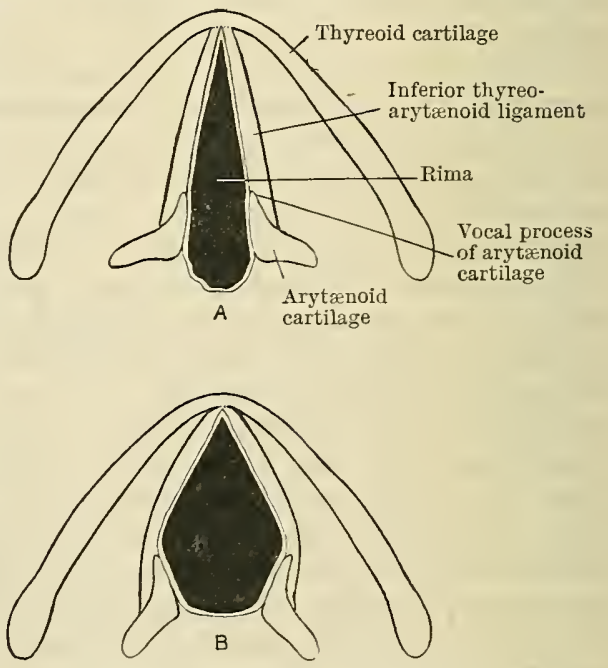

Fig. 852.-Diagram of Rima GLottidis.

A. During ordinary easy breathing. B. Widely opened. and vocal processes of the arytænoid cartilages. It is composed, therefore, of two distinct parts: (1) a narrow ventral portion, between the vocal folds, involving 
more than half of its length, and called the pars intermembranacea of the rima glottidis; (2) a broader, shorter portion, between the arytænoid cartilages, and termed the pars intercartilaginea. By changes in the position of the arytænoid cartilages the form of the rima glottidis undergoes constant alterations. In ordinary easy breathing it is somewhat lanceolate in outline. The pars intermembranacea presents under these conditions the form of an elongated triangle with the base directed dorsally, and corresponding to an imaginary line drawn between the points of the vocal processes of the arytænoid cartilages, whilst the pars intercartilaginea is somewhat quadrangular. When the glottis is opened widely the broadest part of the fissure is at the extremities of the vocal processes of the arytænoids, and here the side of the rima glottidis presents a marked angle. The two vocal folds, on the other hand, may be approximated to each other so closely, as in singing a high note, that the pars intermembranacea is reduced to a linear chink.

The length of the rima glottidis differs very considerably in the two sexes, and upon this depends the different character of the voice in the male and female. According to Moura, the following are the average measurements in the quiescent condition of the rima :-

Male-Length of entire rima glottidis, $23 \mathrm{~mm} .\left\{\begin{array}{l}\text { pars intermembranacea, } 15.5 \mathrm{~mm} . \\ \text { pars intercartilaginea, } 7.5 \mathrm{~mm} .\end{array}\right.$ Female-Length of entire rima glottidis, $17 \mathrm{~mm} .\left\{\begin{array}{l}\text { pars intermembranacea, } 11.5 \mathrm{~mm} . \\ \text { pars intercartilaginea, } 5.5 \mathrm{~mm} .\end{array}\right.$

By stretching the vocal folds, however, the length of the rima glottidis in the male may be increased to $27.5 \mathrm{~mm}$., and in the female to $20 \mathrm{~mm}$.

The position of the rima glottidis may be indicated on the surface by marking a point on the middle line of the neck $8.5 \mathrm{~mm}$. below the thyreoid notch in the male and $6.5 \mathrm{~mm}$. in the female. This is the average position (Taguchi).

Ventriculus Laryngis (Morgagnii).-The lateral wall of the larynx, in the interval between the ventricular and the vocal folds, exhibits a marked pocketlike depression or recess called the ventricle of the larynx. The ventricle passes upwards so as to undermine somewhat the ventricular fold, and its mouth is somewhat narrower than its cavity. Ventrally it reaches to the angle between the laminæ of the thyreoid cartilage, whilst dorsally it ends at the ventral border of the arytænoid cartilage.

Under cover of the ventral part of the ventricular fold a small slit-like aperture may be detected; this leads upwards from the laryngeal ventricle into a small diverticulum of mucous membrane, termed the appendix ventriculi laryngis, which passes upwards between the ventricular fold and the lamina of the thyreoid cartilage. The laryngeal appendix is of variable extent, but as a rule it ends blindly at the level of the upper border of the thyreoid cartilage.

Sometimes the appendix ventriculi laryngis extends much higher up, and may even reach the dorsal part of the great cornu of the hyoid bone. This is of interest when considered in connexion with the extensive laryngeal pouches of the anthropoid apes.

The lowest compartment of the cavity of the larynx leads caudally into the trachea. Above it is narrow and compressed laterally, but it gradually widens out until it becomes circular, in correspondence with the trachea, with which it is continuous. It is bounded by the sloping medial surfaces of the conus elasticus (O.T. crico-thyreoid membrane) and by the medial aspect of the cricoid cartilage-both covered with smooth mucous membrane. In the operation of laryngotomy the opening is made through the crico-thyreoid ligament in the ventral wall of the compartment.

Tunica Mucosa Laryngis.-The mucous membrane which lines the larynx is continuous above with the lining of the pharynx, and below with the mucous membrane of the trachea. Over the dorsal surface of the epiglottis it is closely adherent, but elsewhere, above the level of the vocal folds, it is loosely attached by submucous tissue which extends into the ary-epiglottic folds. As it passes over the vocal folds the mucous membrane is very thin, and is tightly bound down.

It is important to bear these facts in mind, because, in certain inflammatory conditions, the lax submucous tissue in the upper part of the larynx is liable to become infiltrated with fluid, pro- 
ducing what is known as œdema glottidis. This may proceed so far as to cause occlusion of the upper part of the cavity. The close adhesion of the mucous membrane to the vocal folds, however, prerents the odema extending beyond the level of the rima glottidis, and the surgeon is thus able to relieve the patient by making an opening through the ventral part of the conus elasticus into the cavity of the larynx.

Above the level of the rima glottidis the laryngeal mucous membrane is extremely sensitive, and when touched by a foreign body there is an immediate response in the shape of an explosive cough. In the lower compartment of the larynx the mucous membrane is lined with columnar ciliated epithelium. Over the vocal folds this is replaced by squamous epithelium. In the ventricle of the larynx and in the inferior part of the vestibule of the larynx the columnar ciliated epithelium again reappears. The upper part of the epiglottis and the upper parts of the lateral walls of the vestibule are covered with squamous epithelium similar to that present in the mouth and pharynx.

The mucous membrane of the larynx has a plentiful supply of acinose glands, and in only one place, viz., over the surface of the vocal folds, are these completely absent. For the most part the glands are aggregated in groups. The following are the localities in which these groups are especially noticeable: (1) On the dorsal surface of the epiglottis, many of the glands piercing the cartilage; (2) around the cuneiform cartilage, where they are chiefly responsible for the elongated elevation seen in this part of the wall of the vestibule; (3) in the ventricular folds and over the wall of the laryngeal vestibule and the appendix ventriculi laryngis.

\section{MUSCULI LARYNGIS.}

Of the several muscles attached to the cartilages of the larynx all do not physiologically belong to the larynx, as, for example, the inferior constrictor muscles of the pharynx, which, though attached to both cricoid and thyreoid cartilages, belong to the muscles of the pharynx, as do also the stylo-pharyngeus muscles inserted in part into the thyreoid cartilage.

The true physiological muscles of the larynx may be divided into two great groups, extrinsic and intrinsic. The extrinsic laryngeal muscles comprise all muscles passing to the os hyoideum, which is physiologically a part of the laryngeal apparatus, as well as the m. sterno-thyreoideus. They have already been described in the section on muscles.

The intrinsic laryngeal muscles are twenty-one in number, ten paired and one unpaired. They may be roughly classified physiologically as follows :-

A. Constrictor muscles of the larynx, including the adductors of the vocal foldsMm. cricoarytænoidei laterales. Paired.

Mm. thyreoarytænoidei. Paired.

M. arytænoideus transversus. Unpaired.

Mm. arytænoidei obliqui. Paired.

Mm. aryepiglottici. Paired.

B. Dilator muscles of the larynx, including the abductors of the vocal folds-

$\mathrm{Mm}$. cricoarytænoidei posteriores. Paired.

Mm. thyreoepiglottici. Paired.

C. Muscles modifying the tension of the vocal cords--

Mm. cricothyreoidei. Paired.

IIm. vocales. Paired.

Mm. ventriculares. Paired.

Mm. thyreoarytænoidei (also constrictors). Paired.

The mm. cricoarytænoidei laterales are a pair of triangular muscles, each of which lies in the lateral wall of the larynx upon the conus elasticus and concealed by the lamina of the thyreoid cartilage, the thyreoid gland, and the infrahyoid muscles.

Each muscle arises from the upper border and the lateral surface of the arch of the cricoid cartilage as far dorsally as the facet which supports the base of the arytænoid cartilage, and also from the latera, part of the conus elasticus. 
From this origin the muscular fibres run dorsally and upwards, and converge to be inserted into the ventral surface of the processus muscularis of the arytænoid cartilage. The muscle is not infrequently inseparable from the (external) thyreo-arytæenoid muscle.

By its action the lateral crico-arytænoid muscle draws the processus muscularis of the arytænoid cartilage ventrally and downwards, thus turning the processus vocalis of the same cartilage medially, and tending thereby to stretch the vocal fold and to approximate it to its fellow of the opposite side, thus assisting in closure of the rima glottidis. Its nerve supply is the anterior ventral branch of the inferior laryngeal nerve.

The IMm. Thyreoarytænoidei (O.T. Thyreoarytænoideus Externus).Each thyreo-arytænoid muscle is a paired, thin, quadrangular muscle, which is only separable from the $\mathrm{m}$. vocalis, with which it forms a common mass, by artificial means.

It lies in the lateral wall of the larynx immediately to the medial side of the lamina of the thyreoid cartilage, and lateral to the appendix ventriculi laryngis, the $\mathrm{m}$. vocalis, and the conus elasticus; its inferior border is in contact with the lateral crico-arytænoid

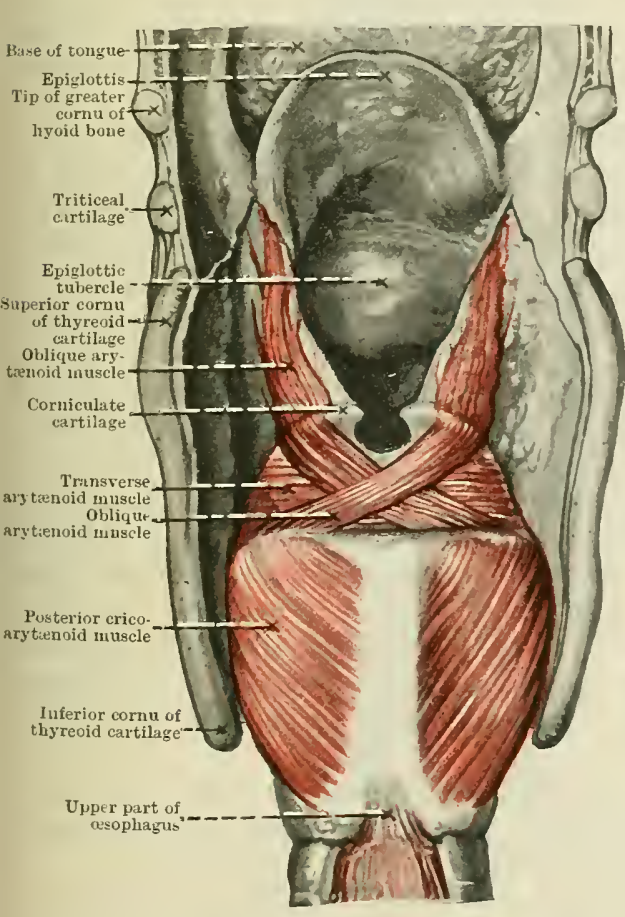

Fig. 854.-Dissection OF THE MUUscles ON THE Dorsal Aspect of the LARTNx.

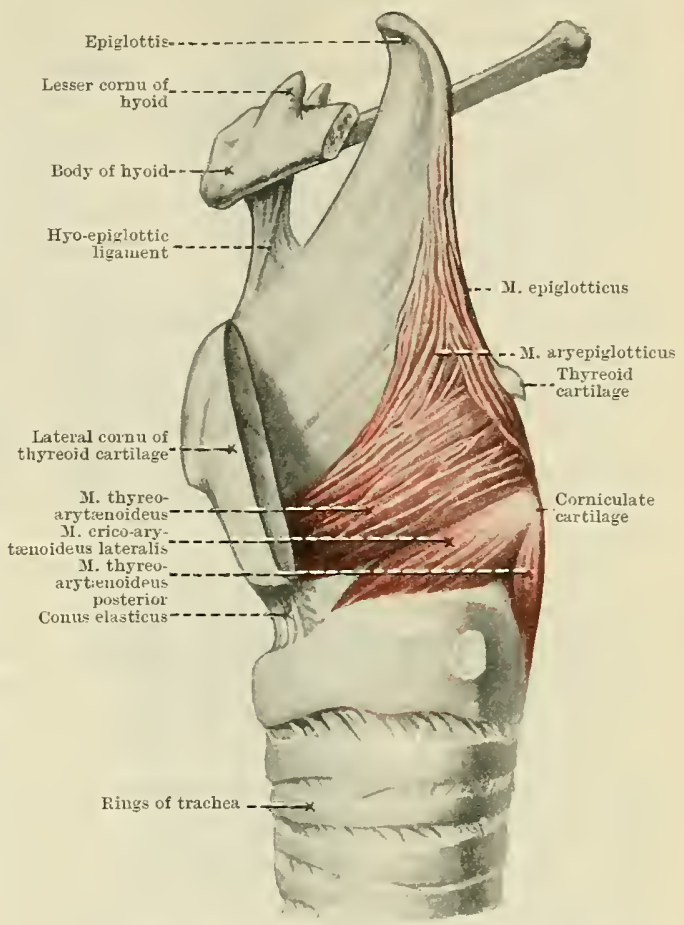

Fig. 853.-Dissection of the MUscles OF THE LATERAL WALL OF THE LARYNX.

muscle, whilst its superior border extends farther upwards than the vocal fold, and is in contact with the inferior border of the thyreo-epiglotticus.

It arises from the inferior half of the medial surface of the lamina of the thyreoid cartilage, close to its ventral angle, and also from the lateral part of the conus elasticus. The muscular fibres pass dorsally and upwards to be inserted into the lateral border and muscular process of the arytænoid cartilage; some of the fibres, however, turn round this cartilage and become continuous with the arytænoideus obliquus. The upper fibres of the thyreo-arytænoideus vary very greatly in their development and arrangement.

By its action the muscle rotates the arytrenoid cartilage and draws it ventrally in such a way that its vocal process is carried ventrally and medially and the vocal fold is rendered somewhat flaccid. The muscle thus antagonises the crico-thyreoideus. The main action of the muscle must, however, be that of a constrictor of the supraglottic region of the larynx. 
The nerve supply is the anterior branch of the inferior laryngeal nerve.

The $\mathrm{m}$. arytænoideus transversus is a thick, oblong, unpaired muscle which lies in the dorsal wall of the larynx and bridges across the interval between the two arytænoid cartilages. The ventral surface of the muscle is in contact with the dorsal concave surfaces of the arytænoid cartilages, and between them with the mucous membrane of the larynx. Its dorsal surface is partly concealed by the arytænoidei obliqui and by the submucous tissue of the pharynx. The inferior border extends to the lamina of the cricoid cartilage, and its upper border does not quite reach the apices of the arytænoid cartilages.

The attachments of the muscle are, on both sides, to the dorsal surface of the processus muscularis and the lateral edge of the arytænoid cartilages. All the fibres run in a frontal (coronal) direction, and some turn round the arytænoid cartilage to become continuous with the thyreo-arytænoideus. It is in this way that the latter muscle becomes a sphincter of the glottis.

By its action the arytænoideus transversus approximates the arytænoid cartilages, thereby tending to close the pars intercartilaginea of the rima glottidis. Its assistance in the sphincter action of the thyreo-arytænoideus has already been pointed out.

The muscle is innervated by the posterior or dorsal rami of the inferior laryngeal nerve of both sides.

The $\mathrm{mm}$. arytænoidei obliqui are a pair of muscles which lie in the dorsal wall of the larynx, immediately dorsal to the arytænoideus transversus and ventral to the submucous tissue of the pharynx.

Each muscle consists of a bundle of muscular fibres which arise from the dorsal aspect of the processus muscularis of the corresponding arytænoid cartilage. From their origins the two fleshy slips proceed upwards and medially, and cross each other in the median plane like the two limbs of the letter $X$. Reaching the apex of the arytænoid cartilage of the opposite side, many, but not all, of the fibres are inserted there, but others receiving a fresh attachment arise from the apex of the arytænoid cartilage as the $\mathrm{m}$. aryepiglotticus, and extend ventrally and upwards in a series of arches within the ary-epiglottic fold to terminate in the thyreo-epiglottic ligament and the lateral margin of the epiglottic cartilage ; and as the muscle approaches the latter structure its fibres are joined by the fibres of the thyreo-epiglotticus. With its superior border are also commingled some fibres from the m. stylo-pharyngeus.

Action.-The arytænoideus obliquus and aryepigloticus combined, act as a rudimentary sphincter muscle for the aditus and the vestibulum laryngis, that is for the superior aperture of the larynx, inasmuch as they extend from the base of one arytænoid cartilage to the arytænoid cartilage of the opposite side, and then on to the epiglottis within the ary-epiglottic fold.

The two muscular slips are innervated by the corresponding anterior rami of the inferior laryngeal nerves.

The mm. cricoarytænoidei posteriores are a pair of triangular muscles, each of which lies on the dorsal surface of the lamina of the cricoid cartilage, under cover of the tela submucosa of the pharynx. They arise by a broad origin from the medial and inferior part of the depression on the dorsal surface of the lamina of the cricoid cartilage at the side of the median ridge; from this origin its fibres converge upwards and laterally to be inserted into the dorsal surface and apex of the processus muscularis of the arytænoid cartilage. In pursuing their course from origin to insertion the muscular fibres display very different degrees of obliquity. The most superior fibres are short and nearly horizontal; the intermediate fibres are the longest and are very oblique; whilst the most inferior fibres are almost vertical in their direction.

By its action the crico-arytænoideus posterior draws the muscular processes of the arytænoid cartilages medially and dorsally, swings the vocal processes and the vocal folds laterally, and thereby opens the rima glottidis.

The muscle is innervated by the posterior ramus of the inferior laryngeal nerve.

The mm. thyreoepiglottici are a pair of thin, oblong, very variable muscles, 
which lie in the lateral walls of the larynx. Each is bounded below by the thyreo-arytænoideus, medially by the thyreo-epiglottic ligament and the appendix ventriculi laryngis, and laterally by the lamina of the thyreoid cartilage. It constitutes what was formerly described as the uppermost fibres of the thyreo-arytænoideus externus muscle.

Each thyreo-epiglotticus arises from the medial surface of the lamina of the thyreoid cartilage, immediately above the origin of the thyreo-arytænoideus. From this origin the fibres run in arches upwards and dorsally to be inserted partly into the margin of the aryepiglottic fold, and partly into the lateral margin of the epiglottis, being intermingled with the fibres of the aryepiglotticus.

By its action the thyreo-epiglotticus widens the aditus and the vestibulum laryngis. Its innervation is derived from the ventral ramus of the inferior laryngeal nerve.

The $\mathrm{mm}$. cricothyreoidei are a pair of quadrangular muscles, broader and

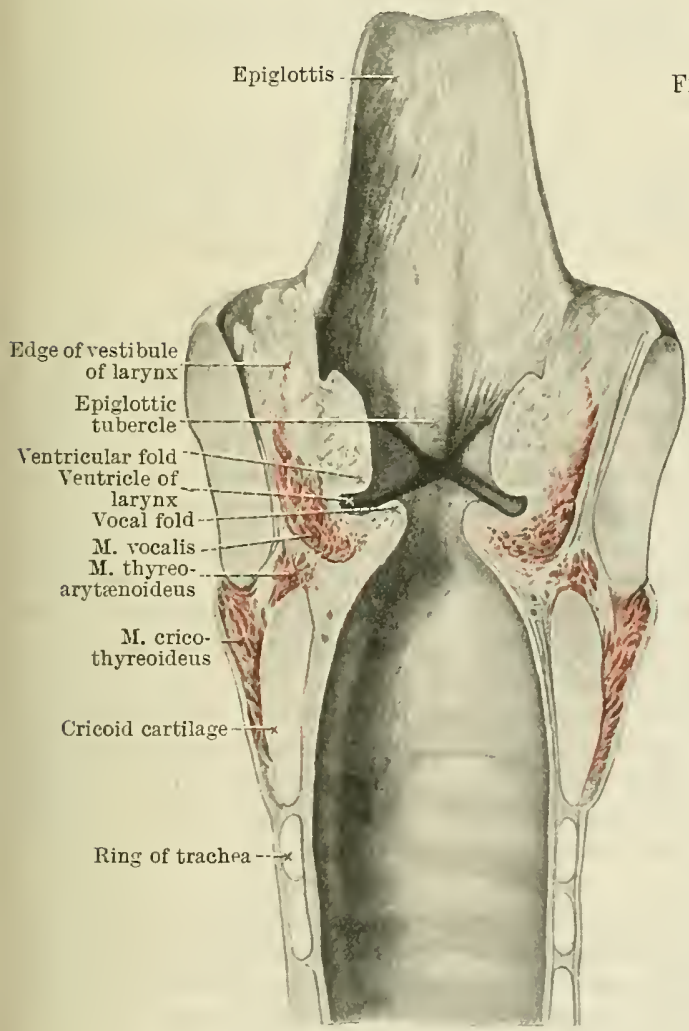

Fig. 856.-Frontal Section of the Laryxi, SHOWING MUSCLES.

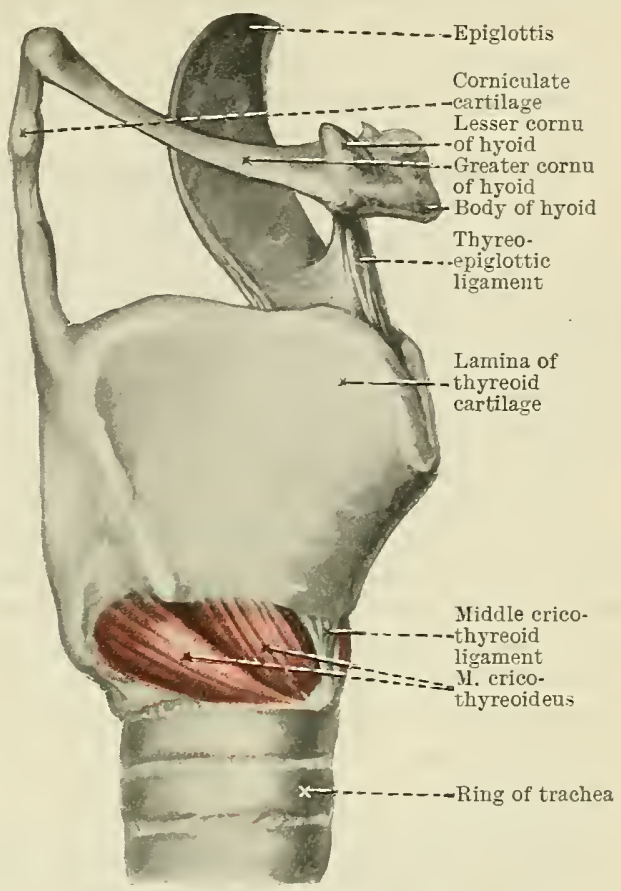

Fig. 855.-The Crico-Thyreoid Muscle of the Right Side.

thicker above than below. They lie on the cricoid cartilage and bridge over the crico-thyreoid interval, and are therefore the only intrinsic laryngeal muscles which are visible in an ordinary dissection of the neck. Each is covered laterally and in part by the thyreoid gland and the sternothyreoid and the sterno-hyoid muscles. Between the two muscles of opposite sides there is an intermediate triangular area left in which the crico-thyreoid ligament is visible.

Each crico - thyreoideus arises from the lower border and lateral surface of the arch of the cricoid cartilage, and from this origin its fibres radiate dorsally and upwards to be inserted into the inferior border and medial surface of the lamina of the thyreoid cartilage, as far as its inferior cornu, and also into the inferior cornu itself. As a general rule each muscle is divided into two parts, viz., (1) a pars recta composed of those fibres which are inserted into the lamina of the thyreoid cartilage; and (2) a pars obliqua formed of those fibres which are inserted into
the inferior cornu. The muscle is closely associated with the inferior constrictor 
muscle of the pharynx, and sometimes shows a certain amount of continuity with it.

The general action of the crico-thyreoideus is to render the vocal fold tense, as is more fully set forth in the paragraph dealing with the actions of the intrinsic laryngeal muscles as a whole.

The innervation is derived from the external ramus of the superior laryngeal nerve.

The IMm. Vocales (O.T. Internal Thyreo-arytænoid Muscles).-The vocalis muscle of each side is a triangular, somewhat prismatic muscle, which forms with the thyreo-arytænoideus a common muscular mass separable only with difficulty into its two constituent portions. The $\mathrm{m}$. vocalis lies within the vocal fold closely applied to the lateral aspect of the ligamentum vocale, and receives its prismatic form from this adaptation. Of its three surfaces, the medial lies adjacent to the ligamentum vocale and the conus elasticus; the upper surface is bounded by the labium vocale and the entrance to the ventricle of the larynx; whilst the lateral surface is bounded by, and is in contact with, the thyreo-arytænoideus.

The in. vocalis arises from the inferior part of the angular depression between the two laminæ of the thyreoid cartilage, and also from the corresponding vocal fold, whence the fibres run dorsally to be inserted into the lateral aspect of the vocal process and the depression on the ventro-lateral surface of the arytænoid cartilage. The greater thickness of the $\mathrm{m}$. vocalis dorsally than ventrally is due to the fact that whilst all its fibres are attached dorsally to the arytænoid cartilage, only a certain proportion obtain attachment ventrally to the thyreoid cartilage. The remainder are attached at irregular intervals to the lateral margin of the vocal fold itself.

It follows that the action of the muscle is to draw the vocal process of the arytænoid cartilage ventrally, thereby relaxing the vocal fold and ligament.

The innervation is derived from the anterior ramus of the inferior laryngeal nerve.

The $\mathrm{m}$. ventricularis is composed of several bundles of fibres, visible under the microscope, which pass in a vertical direction from the lateral edge of the arytænoid cartilage to the lateral margin of the cartilage of the epiglottis. There are also intermingled with it fibres from the thyreo-arytænoideus and aryepiglotticus.

Action of the Intrinsic Laryngeal Muscles.-By the action of the intrinsic laryngeal muscles the position and tension of the vocal folds are so influenced that, during the passage of air through the larynx, the tone and the pitch of the voice is determined. Tension of the vocal folds is produced by the contraction of the two crico-thyreoid muscles. The straight portions of the muscles pull the inferior border of the thyreoid cartilage downwards, whilst the oblique portions, through their insertion into the inferior cornua, draw the thyreoid cartilage ventrally, thereby increasing the distance between the angle of the thyreoid cartilage and the vocal processes of the arytænoid cartilages. When the crico-thyreoid muscles cease to contract, the relaxation of the cords is brought about by the elasticity of the ligaments. The thyreo-arytænoid muscles must be regarded as antagonistic to the crico-thyreoid muscles. When they contract they approximate the angle of the thyreoid cartilage to the arytænoid cartilages, and still further relax the vocal folds; and when they cease to act the elasticity of the ligaments of the larynx again restores the state of equilibrium. They also act as constrictors of the supraglottic region of the larynx. The vocales muscles, by the attachments of their fibres into the vocal folds, may tighten portions of these folds, but their main action is relaxation of the vocal folds and ligaments.

The width of the rima glottidis is regulated by the arytænoideus transversus, which draws together the two arytænoid cartilages, and this may be done so effectually that the medial surfaces of these cartilages come into contact; the pars intercartilaginea of the rima glottidis is thus completely closed. The crico-arytænoideus lateralis and posterior also modify the width of the rima glottidis. When they act together they assist the arytænoideus transversus in closing the glottis, but when they act independently they are antagonistic muscles. Thus the crico-arytænoideus posterior draws the muscular processes of the arytænoid cartilages dorsally and medially, and swings the vocal processes and the vocal folds laterally, and thereby opens the rima. The 
lateral crico-arytænoid muscles act in exactly the opposite mauner. By drawing the muscular processes of the arytænoid cartilages ventrally and medially, they approximate the vocal processes and close the rima glottidis. The actions of the other muscles have been sufficiently described already.

Closure of the Larynx during Deglutition.-The muscles of the larynx have, however, another function to perform besides vocalisation and regulating the amount of air passing to and fro through the glottis. During deglutition it is requisite that the communication between the pharyux and larynx should be closed, to prevent the fluid or solid parts of the food entering the respiratory passages. In the process of closing the laryngeal entrance the epiglottis stands erect, whilst the dorsal wall formed by the arytænoids is carried ventrally, the arytænoid cartilages are closely approximated, glide ventrally, and are then inclined towards the epiglottis. The result of this is that the laryngeal opening is converted into a $T$-shaped fissure. The median limb of the $T$ is formed by the interval between the closely applied arytruoid cartilages, whilst the cross limb, which lies ventrally, is bounded ventrally (anteriorly) by the epiglottis and dorsally by the aryepiglottic folds. The apices of the arytænoid cartilages, with the comiculate cartilages (Santorini), are pressed against the tubercle of the epiglottis, whilst the lateral margins of the epiglottis are pulled dorsally so as to make the transverse limb of the fissure distinctly concave in a dorsal direction. The muscles chiefly concerned in producing these movements are the thyreo-arytænoid and the transverse arytænoid muscles. These form a true sphincter vestibuli. The thyreo-epiglottic and aryepiglottic muscles also come into play. They pull upon the epiglottis so as to produce tight application of its tubercle to the arytenoid cartilages and the corniculate cartilages (Santorini), and they also curve its margins dorsally so as to increase its dorsal concavity.

Vessels and Nerves of the Larynx.-Two branches of the vagus nerve, viz., the superior laryngeal and the recurrent (laryngeal) nerves, supply the larynx. The superior laryngeal
divides into the internal and external laryngeal branches. The external laryngeal nerve supplies the crico-thyreoid muscle; whilst the internal laryngeal nerve enters the larynx by piercing the lateral part of the hyothyreoid membrane to supply the laryngeal mncous membrane. The recurrent nerve reaches the larynx from the thoracic direction, and, by its terminal inferior laryngeal branch, supplies all the intrinsic laryngeal muscles with the exception of the crico-thyreoid.

The superior laryngeal artery, a branch of the superior thyreoid, accompanies the internal laryngeal nerve; whilst the inferior laryngeal artery, which springs from the inferior thyreoid, accompanies the inferior laryngeal nerve. These two vessels ramify in the laryngeal wall and supply the mucous membrane, the glands, and muscles.

Growth-Alteration and Sexual Differences in the Larynx.-A considerable amount of variation may be noticed in the size of the larynx in different individuals. This is quite independent of stature, and explains to a great extent the difference in the pitch of the voice in different persons. But quite apart from these individual variations, there is a marked sexual difference in the size of the larynx. The male larynx is not only absolutely, but also relatively, larger than the female laryux in all its diameters, but more particularly in the ventro-dorsal diameter; and to a large extent the increase in that direction is produced by the strong development of the prominentia laryngea in the male. The greater ventro-dorsal diameter of the male larynx necessarily implies a greater length of the vocal folds and a lower or deeper tone of the voice in the male than in the female.

In a newly born child the larynx, in conparison with the rest of the body, is somewhat large (C. L. Merker), and it continues to grow slowly and uniformly up to the sixth year of childhood. At this period there is a cessation of growth until puberty is reached, and then a stage of active growth supervenes. Up to this time the larynx in both sexes is similar in its dimensions, and although the growth which now occurs affects both the male and the female larynx, it is much more rapid and much more accentuated in the male than in the female. As a result of this the voice of the male "breaks" and assumes its deep tone.

It is interesting to note that the growth activity of the laryux at puberty is intimately connected with the development of the sexual organs. In a male subject who has been castrated when young the larynx attains a size which exceeds that of the female only to a small degree, and the high pitch of the voice is retained.

\section{Appearance of the Interior of the Larynx when examined by the Laryngoscope.}

When the cavity of the larynx is illuminated and examined by laryngoscopic mirrors, the parts which surround the superior aperture of the larynx, as well as the interior of the organ, come into view. Not only this, but when the vocal folds are widely separated it is possible to inspect the interior of the trachea as far as its bifureation. 
In such an examination the arched npper border of the epiglottis is a conspicuous object, whilst, dorsal to this, the bulging on the ventral wall of the vestibule, formed by the tubercle of the epiglottis, may also be a feature of the picture. The median glosso-epiglottic fold with the epiglottic vallecula on either side of it, can also be inspected in the interval between the epiglottis and the base of the tongue. The sharp aryepiglottic folds are clearly visible, and in the dorsal portion of each of these can be seen the two prominent tubercles which are formed by the enclosed cuneiform and corniculate cartilages. Dorsal to these tubercles is the dorsal wall of the pharynx, whilst to their lateral side the deep piriform
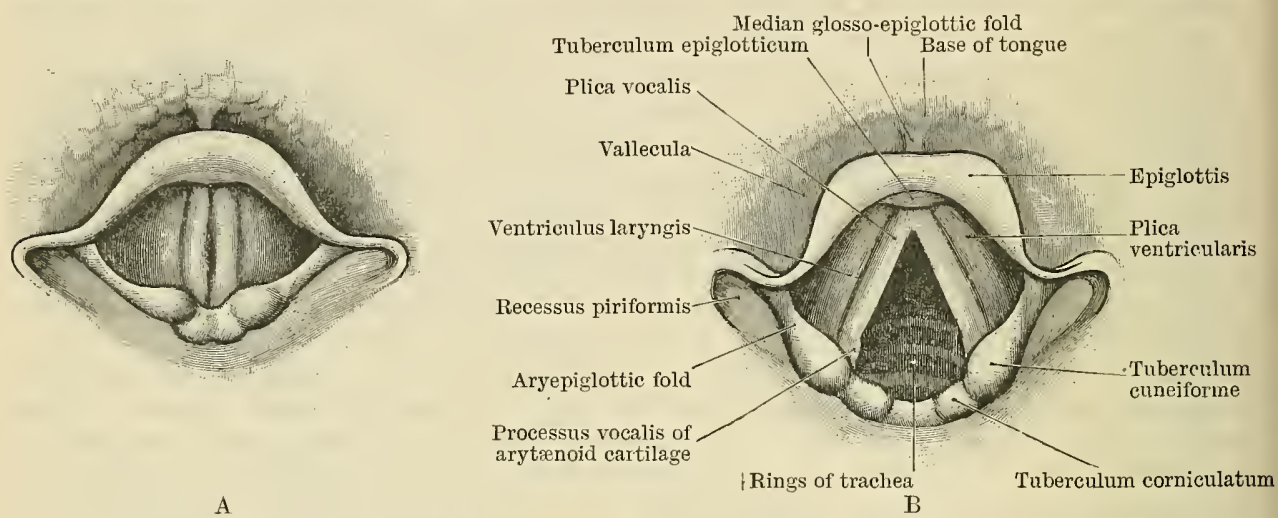

Fig. 857.-CAVity of THE LARYNx, as seen by means of the laryngoscope.

A. Rima glottidis closed.

B. Rima glottidis widely opened.

recess may be seen. In the interior of the larynx the ventricular and 'the vocal folds are easily recognised, and the interval between the two, or, in other words, the entrance into the laryngeal ventricle, appears as a dark line on the lateral wall of the larynx. The ventricular folds are red and fleshy-looking; the vocal folds during phonation are tightly stretched and pearly whitethe white colour being usually more apparent in the female than in the male. The outline and yellowish tinge of the vocal process at its attachment to the vocal fold, and the outline of the ventral part of the base of the arytænoid cartilage to a slight extent as well, can be made out in a successful laryngoscopic examination. The vocal folds during ordinary inspiration are seldom at rest, and with the laryngoscope their movements may be studied. It should be borne in mind that the picture afforded by the laryngoscope does not give a true idea of the level at which the different parts lie. The cavity appears greatly shortened, and its depth diminished.

\section{TRACHEA.}

The trachea or windpipe is a wide tube which is kept permanently patent by a series of cartilaginous rings embedded in its wall. These rings are deficient dorsally, and consequently the tube is not completely cylindrical: its dorsal wall is flattened. The trachea begins at the inferior border of the cricoid cartilage, opposite the inferior margin of the sixth cervical vertebra. From this it extends through the neck into the superior mediastinum of the thorax, and it ends at the level of the superior border of the fifth thoracic vertebra by dividing into the right and left bronchi. The length of the trachea in the male is from four to four and a half inches, and in the female from three and a half to four inches, but even in the same individual it varies considerably in length with the movements of the head and neck.

The inferior end of the trachea is fixed in position. This is a necessary provision to prevent dragging on the roots of the lung during movements of the head and neck. The remainder of the tube is surrounded by a quantity of loose areolar tissue, and possesses a considerable amount of mobility. Further, its wall is highly elastic, and thus when the head is thrown back the tube elongates through stretching, and when the chin is depressed its length is diminished by the recoil of its wall.

The trachea does not present an absolutely uniform calibre thronghout its whole length. About its middle it exhibits a slight expansion or dilatation, and from this the calibre diminishes towards both extremities. Close to the bifurcation it is again slightly expanded (Braune and Stahel). 
These differences in the calibre of the tube are determined by the surroundings of the trachea. The cervical part is narrowed owing to its being clasped by the thyreoid gland. Further, a short distance above its bifurcation an impression, sometimes strongly marked, is usually seen on the left side of the trachea. This is due to the close contact of the aortic arch as it passes dorsally against this part of the tube. It is evident therefore that the second slight diminution in calibre which is described by Braune and Stahel is produced by the proximity of the aorta. Lejars gives the average ventro-dorsal diameter of the trachea in the living person as $11 \mathrm{~mm}$., and the transverse diameter as $12.5 \mathrm{~mm}$. In the dead subject the lumen of the tube is considerably greater.

The trachea adheres rigorously to the median plane except towards its termination, where it deviates very slightly to the right. As it passes downwards it recedes rapidly from the surface. This is due to its following the curvature of the vertebral column, from which it is separated by the œsophagus alone.

Relations of the Trachea.-In the study of the relations of the trachea it is convenient to consider it in the two stages of cervical and thoracic.

When the chin is held so that the face looks directly forwards the cervical part of the trachea measures from 2 to $2 \frac{1}{2}$ inches in length ; but when the head is thrown dorsally or backwards the length is considerably increased. It is clasped by the thyreoid gland, the isthmus of which is applied to its ventral surface, and covers the second, third, and fourth rings; while on each side the lateral lobe of the thyreoid gland is applied to the lateral surface of the trachea and extends downwards to the fifth or sixth ring. On

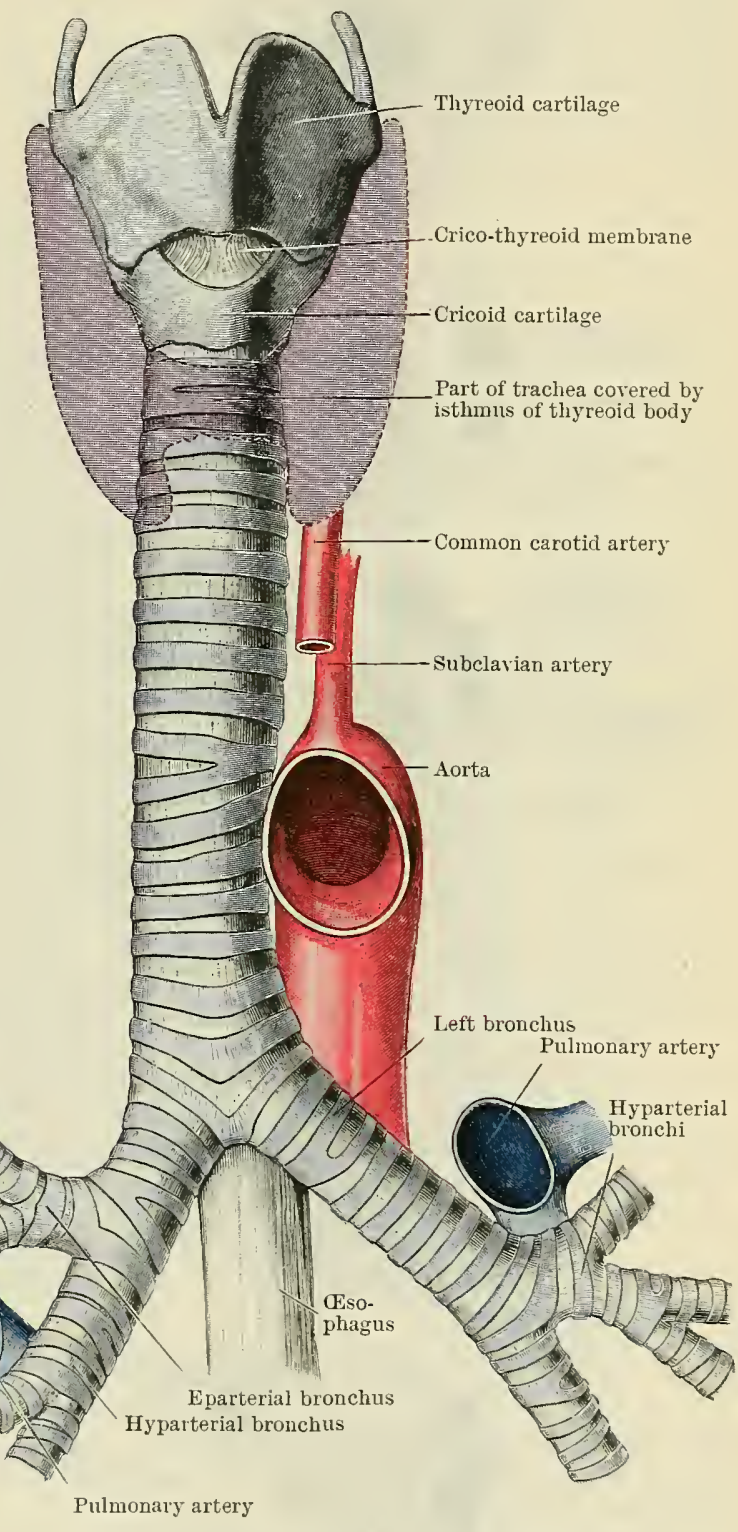

Fig. 858.-The Trachea axd Broschi.

The thyreoid glind is indicated by a dotted line and a purple tint.

either side of the cervical part of the trachea is the common carotid artery, whilst the recurrent nerve passes upwards in the groove between the trachea and the œsophagus. Dorsally the trachea is in relation to the œsophagus, which intervenes between it and the bodies of the vertebræ and deviates somewhat to the left as it passes downwards.

In addition to the isthmus of the thyreoid gland two thin muscular strata, composed of the sterno-hyoid and the sterno-thyreoid muscles, as well as the deep 
cervical fascia and integument, separate the cervical part of the trachea from the surface. In the median plane of the neck there is a narrow diamond-shaped space between the medial margins of these muscles, within which the trachea is covered merely by the integuments and fascix. It is important to note that in the inferior
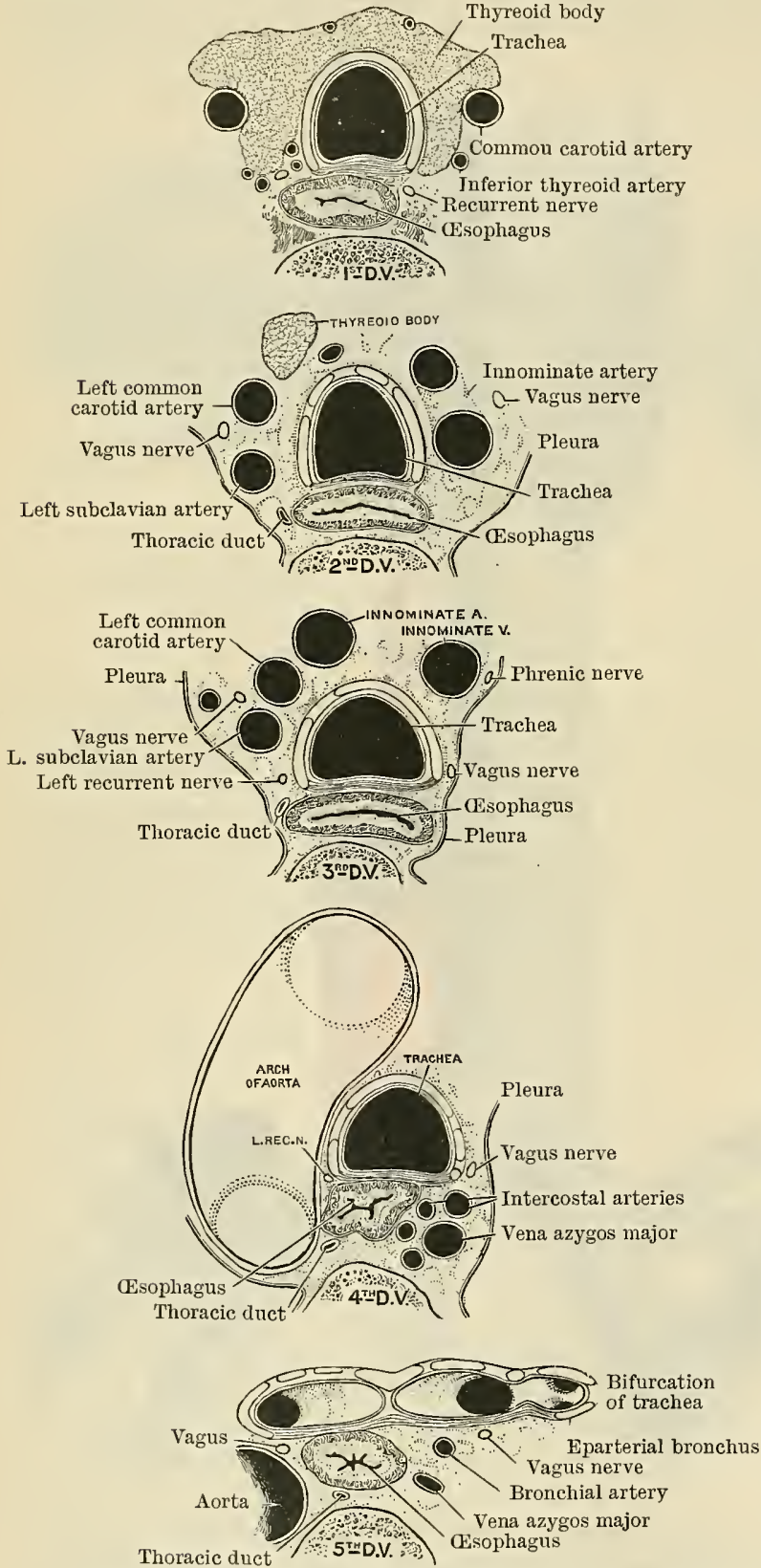

Fig. 859.-TRansverse Sections through the trachea and its immediate surronndings at the level of each of the upper five thoracic vertebræ.

right, and the left common carotid to the left. Ventral to these vessels are the left innominate vein and the remains of the thymus. On the right side the thoracic part of the trachea is in relation to the right vagus nerve, and is clothed by the right mediastinal pleura; on the left side are the left subclavian artery and the left recurrent nerve. fascia is in two layers-viz., a strong stratum applied to the ventral surface of the sterno-hyoid and sterno-thyreoid muscles, and a weaker superficial layer stretching across between the two sterno-cleido-mastoid muscles. Dorsalto these muscular and fascial layers the inferior thyreoid veins pass downwards on the ventral surface of the trachea, and sometimes the occasional thyreoidea ima artery passes upwards on the ventral aspect of the tube. At the superior border of the manubrium sterni the innominate artery may be seen crossing the trachea obliquely.

The thoracic part of the trachea is situated in the dorsal part of the superior mediastinum, being separated from the bodies of the vertebræ by the œsophagus alone. Immediately above its bifurcation the deep cardiac plexus of nerves is placed on the ventral and lateral sides of the trachea. At the level of the fourth thoracic vertebra the aortic arch is very intimately related to it, lying first on the ventral side of the tube, and thereafter on its left side. The three great vessels which spring from the aortic arch are also placed in close proximity to the trachea. The innominate and the left common carotid arteries lie at first ventral to the trachea, and then gradually diverging as they proceed upwards, come to lie on either side of it - the innominate to the

part of the neck the cervical 
Structure of the Wall of the Trachea.-The walls of the trachea and bronchi are composed of (1) a fibro-elastic membrane in which the cartilaginous rings are embedded; (2) within this, and on the dorsal aspect of the tube, a layer of muscular tissue, termed the musculus trachealis ; and (3) the lining mucous membrane.

The fibro-elastic membrane is strong and dense, and, passing round the whole circumference of the tube, becomes continuous above with the perichondrium which invests the cricoid cartilage. Embedded in its substance are the series of cartilaginous rings. These vary in number from 15 to 20 , and are composed of hyaline cartilage. They are horseshoe-shaped, the dorsal fourth of the circumference being deficient, so that dorsally each ring ends in two rounded extremities. The outer surface of the tracheal ring is flat and even, and does not project much beyond the level of the membrane in which

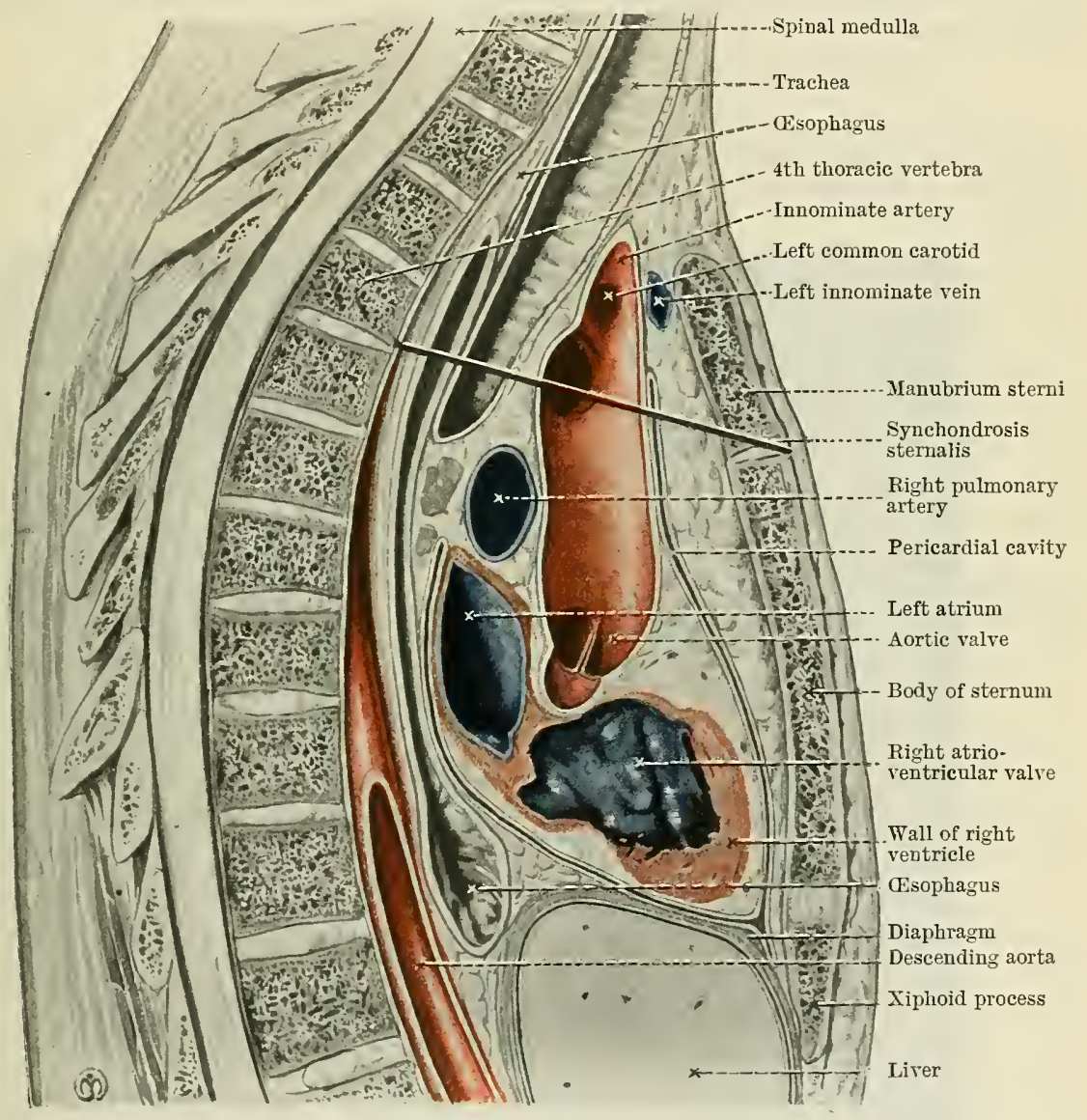

Fig. 860. - Sagittal Section throdgh the Thorax of an Old Man. The superior border of the manubrium sterni and the bifurcation of the trachea are lower than in the average adult.

it is embedded; the inner surface, however, is convex in the vertical direction, and consequently it bulges slightly into the lumen of the tube. The intervals between the rings are somewhat narrower than the rings themselves, and neighbouring rings frequently show a more or less complete fusion, whilst others present other irregularities, such as a tendency to bifurcate. The lowermost ring is specially adapted to the tracheal bifurcation. In the median plane, ventrally, it inclines downwards, and from this median peak a cartilaginous strip is carried backwards in the fork between the two bronchi.

The $\mathrm{m}$. trachealis is a continuous layer of involuntary muscular tissue placed in the dorsal part of the wall of the trachea internal to the fibro-elastic membrane. The muscular bundles are arranged transversely, and are attached to the extremities of the rings, and also to the inner surfaces of the rings for a short distance beyond their extremities. In the intervals between the rings the transverse muscular bundles are attached to the fibro-elastic membrane. It is evident that, by its contraction, this muscle will reduce, in a marked degree, the lumen of the tube. 
The mucous membrane is laid smoothly over the interior of the tube upon a layer of submucous areolar tissue. Lymph tissue enters largely into the composition of the tracheal mucous membrane, and its inner surface is lined with columnar ciliated epithelial cells. The action of the cilia exercises an important influence in producing an upward movement of the mucus which is present on the surface of the mucous membrane.

Numerous longitudinal bundles of elastic tissue are present in the dorsal wall of the trachea, more particularly in its inferior part, between the mucous membrane and the trachealis muscle.

In connexion with the mucous membrane there is a plentiful supply of acinous mucous glands. These are placed in the submucous tissue, and also, on the dorsal aspect of the tube, on the exterior of the trachealis as well as amidst its muscular bundles. They send their ducts to the surface of the mucous membrane, where they open by trumpetshaped mouths.

\section{BRONCHI.}

The two chief bronchi proceed obliquely downwards and laterally from the termination of the trachea, each towards the hilus of the corresponding Iung. Like the

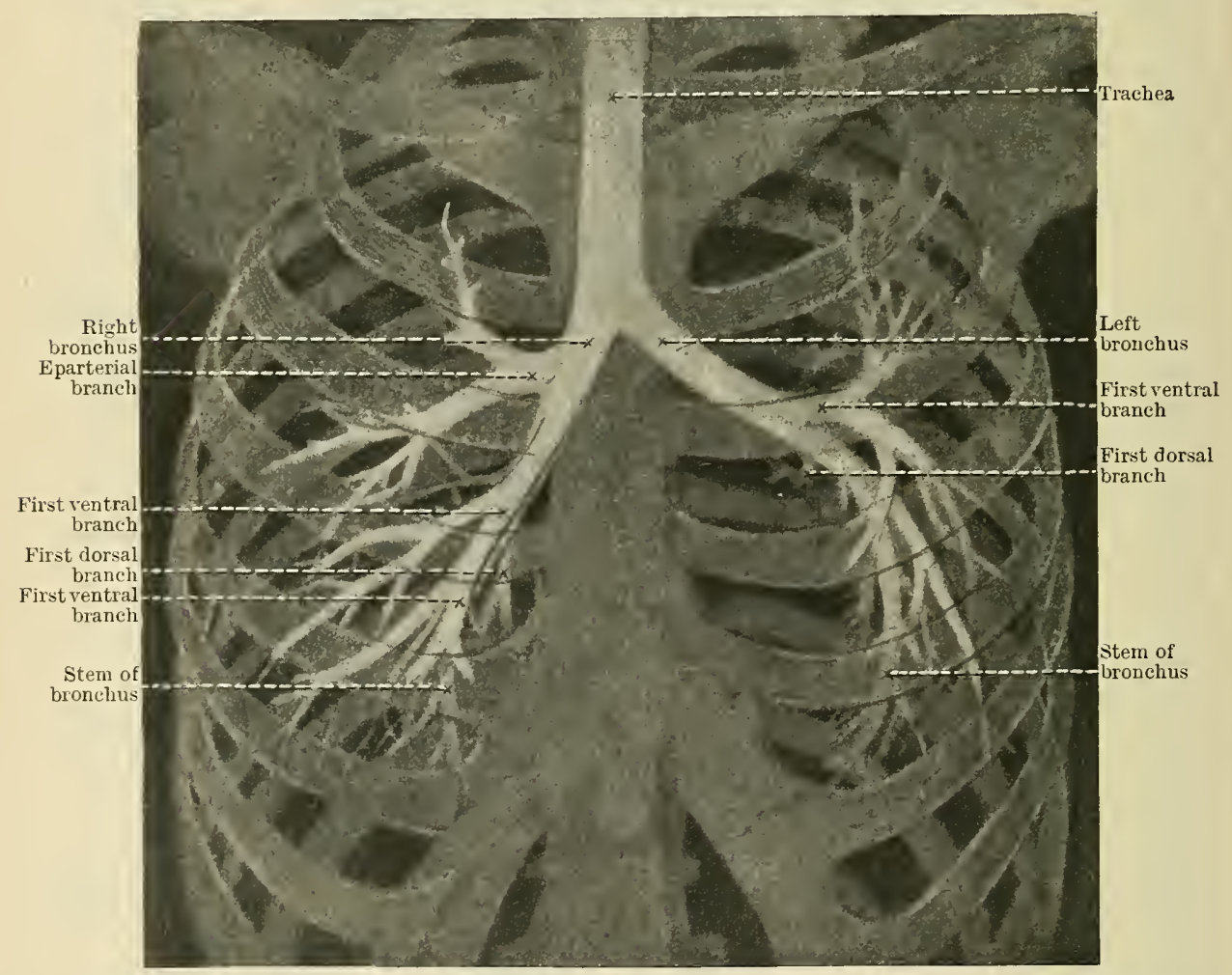

Fig. 861.-Drating of a Stereoscopic Skiagraph of the Trachea and Bronchi injected with Starch aNd Red Lead.

trachea, they are kept permanently patent by the presence of cartilaginous rings in their walls. These rings are deficient dorsally, so that the bronchi exhibit a flattened dorsal surface, in every respect similar to the trachea. The two bronchi differ from each other, not only in the relations which they present to surrounding structures, but also in length, in width, and in the direction which they pursue (Fig. 858, p. 1079).

The first collateral branch of the right bronchus (ramus bronchialis eparterialis) arises much nearer the trachea than the first branch of the left bronchus. This difference determines the length of the primary divisions of the trachea, and, although there is much variation in the matter, it may be said that, as a rule, the 
left bronchus is at least twice as long as the right bronchus. According to Henle there are from six to eight rings in the right, and from nine to twelve rings in the left, bronchus. A marked difference is also noticeable in the calibre of the two tubes. The right bronchus is wider than the left in the proportion of 100 to 78.4 (Braune and Stahel), and this asymmetry is clearly due to the fact that the right lung is more bulky than the left. The right bronchus, as it passes towards the hilus of the right lung, takes a more vertical course than the left bronchus. It therefore lies more in the line of the trachea, and to this, as well as to its greater width, is due the greater tendency which foreign bodies exhibit, when introduced into the trachea, to drop into the right bronchus, in preference to the left. The average angle which the right bronchus forms with the median plane is $24.8^{\circ}$, whilst the angle formed by the left bronchus with the median plane is $45.6^{\circ}$. The more horizontal course of the left bronchus is probably determined by the marked projection of the heart to the left side of the median plane (Merkel).

Relations of the Bronchi. - Arching above the right bronchus, from behind forwards, is the vena azygos, whilst arching above the left bronchus, from before backwards, there is the arch of the aorta. Occupying the interval between the bronchi there is a cluster of bronchial lymph glands, and an irregular chain of similar glands is carried along each tube towards the hilus of the lung. On the dorsal aspect of each bronchus the vagus nerve breaks up into the plexus pulmonalis posterior, whilst the left bronchus, as it proceeds downwards and laterally, crosses the ventral surfaces of the csophagus and descending thoracic aorta. The most interesting relation is, however, that presented on each side by the corresponding pulmonary artery. On the left side the pulmonary artery crosses ventral or anterior to the left bronchus on the superior side of its first collateral branch, and then turns round its lateral side to gain its dorsal aspect. All the left bronchial branches, therefore, are placed inferior to the left pulmonary artery, and are in consequence termed hyparterial. The right pulmonary artery, on the other hand, crosses ventral to the continuation of the right bronchus, inferior to its first collateral branch. This branch is therefore termed the eparterial bronchus, whilst all the others are classified as hyparterial.

Structure of the Walls of the Bronchi.-The walls of the bronchi present a structure similar to that seen in the trachea.

\section{CAVUM THORACIS.}

The cavity of the thorax is divided into two large lateral chambers, which contain the lungs, by a median partition termed the mediastinal septum, which extends from the vertebral column to the ventral thoracic wall. From the fact that each of these chambers is lined by an extensive and separate serous membrane called the pleura, they receive the name of the pleural cavities.

Septum Mediastinale.-The mediastinal septum is built up of several structures which lie in, or in close proximity to, the median plane. The more important of these are the heart, enveloped in its pericardium, the thoracic aorta, with the great vessels which spring from its arch, the pulmonary artery, and the great veins in the neighbourhood of the heart, the thymus or its remains, the trachea, oesophagus, and thoracic duct, and the vagi and phrenic nerves.

Cavum Pleuræ.-The pleural cavities, in which the two lungs lie, comprise much the larger part of the thoracic cavity. Each pleural cavity is bounded inferiorly by the corresponding cupola of the diaphragm; and as the right cupola rises to a higher level than the left, the right pleural cavity presents a smaller vertical depth than the left. Ventrally, the wall of each pleural chamber is formed by the costal cartilages and the sternum; laterally, by the bodies of the ribs and the intercostal muscles as far as the costal angles; dorsally, by the portions of the ribs, with the intervening intercostal muscles, which lie medial to the costal angles; and medially, by the bodies of the vertebræ and the mediastinal septum, which completely shuts off the one chamber from the other.

The mediastinal septum is not uniformly median in position. Owing to the 
marked projection of the heart to the left side, and to the position of the thoracic aorta on the left side of the median plane, the left pleural chamber, although it is deeper than the right, is greatly reduced in width. The two pleural cavities, therefore, are very far from being symmetrical in form, and consequently the mediastinal septum tends to extend to the left of the median plane of the body.

Each pleural cavity is completely lined by a separate serous membrane termed the pleura. The portion of this membrane which clothes the mediastinum or intervening partition forms the lateral boundary of an area termed the mediastinal or interpleural space, within which the parts which build up the mediastinal septum are placed.

\section{PLEURA.}

The pleura of each side not only lines the corresponding pleural cavity, but at the pulmonary root, it is prolonged on to the lung so as to give it a complete investment. It is customary, therefore, to recognise a pulmonary or investing part (pleura pulmonalis) and a parietal or lining part (pleura parietalis). The inner surface of the pleura (i.e. that surface which is turned towards the interior of the cavity) is coated with squamous endothelium, and presents a smooth, glistening, and polished appearance; further, it is moistened by a small amount of serous fluid.

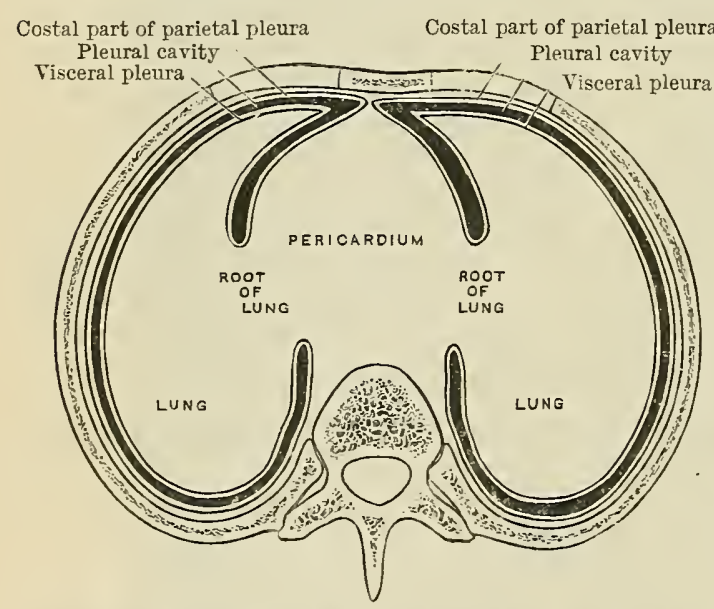

Fig. 862.-Diagram showing Arrangement of Pletrai Sacs as seen it Traxsterse Section.
In consequence of this the surface of the lung covered by pulmonary pleura can glide on the wall of the cavity, lined as it is by parietal pleura, with the least possible degree of friction. In the pathological condition known as pleurisy the inner surface of the pleura becomes roughened by inflammatory exudation, and the so-called "friction sounds" are heard when the ear is applied to the chest.

Pleura Pulmonalis.-The pulmonary pleura is very thin, and is so firmly bound down to the surface of the lung that it cannot be detached without laceration of the pulmonary substance, and then only in small pieces. It dips into the fissures of the lungs, lines them down to the very bottom, and thus completely separates the different lobes of the lungs from each other. The pulmonary pleura becomes continuous with the mediastinal pleura at the root of the lung, and also through the ligamentum pulmonale.

Pleura Parietalis.-Different names are applied to the parietal pleura as it lines the different parts of the wall of the eavity in which the lung lies. Thus there are the costal pleura, the diaphragmatic pleura, the mediastinal pleura, and the cupula pleurce; but it must be borne in mind that these terms are merely used for convenience in description, and that the portions of the pleura so designated are all directly continnous with each other.

The cupula pleuræ or the cervical pleura rises into the root of the neck, through the superior aperture of the thorax, and forms a dome-shaped roof for the pleural cavity. Its highest point or summit reaches the level of the inferior border of the neck of the first rib; but owing to the great obliquity of the first costal arch, this point is placed from one to two inches above to the ventral or anterior extremity of the first rib, and from a half to one and a half inches above the clavicle. The cupula pleurre is supported on the lateral side by the scalenus anterior and scalenus medius muscles, whilst the subclavian artery, arching laterally, lies in a groove on its medial and ventral aspects a short distance below its summit. 
At a lower level the innominate and subclavian veins also lie upon its medial and ventral aspects.

The cupula pleuræ is strengthened and held in place by an aponeurotic expansion, first described by Sibson, which is spread over it, and is attached to the internal concare margin of the first rib. This fascia is derived from a small muscular slip which takes origin from the transverse process of the serenth cervical rertebra.

Pleura Costalis. - The costal pleura is the strongest and thickest part of the parietal pleura. It lines the internal surfaces of the costal arches and of the intervening intercostal muscles. Ventrally it reaches the sternum, whilst dorsally it passes from the ribs over the sides of the bodies of the vertebræ. It is easily detached from the parts which it covers, except as it passes from the heads of the ribs on to the vertebral column. Here it is somewhat tightly bound down.

Pleura Diaphragmatica. The diaphragmatic pleura covers that portion of the thoracic surface of the diaphragm which lies to the lateral side of the base

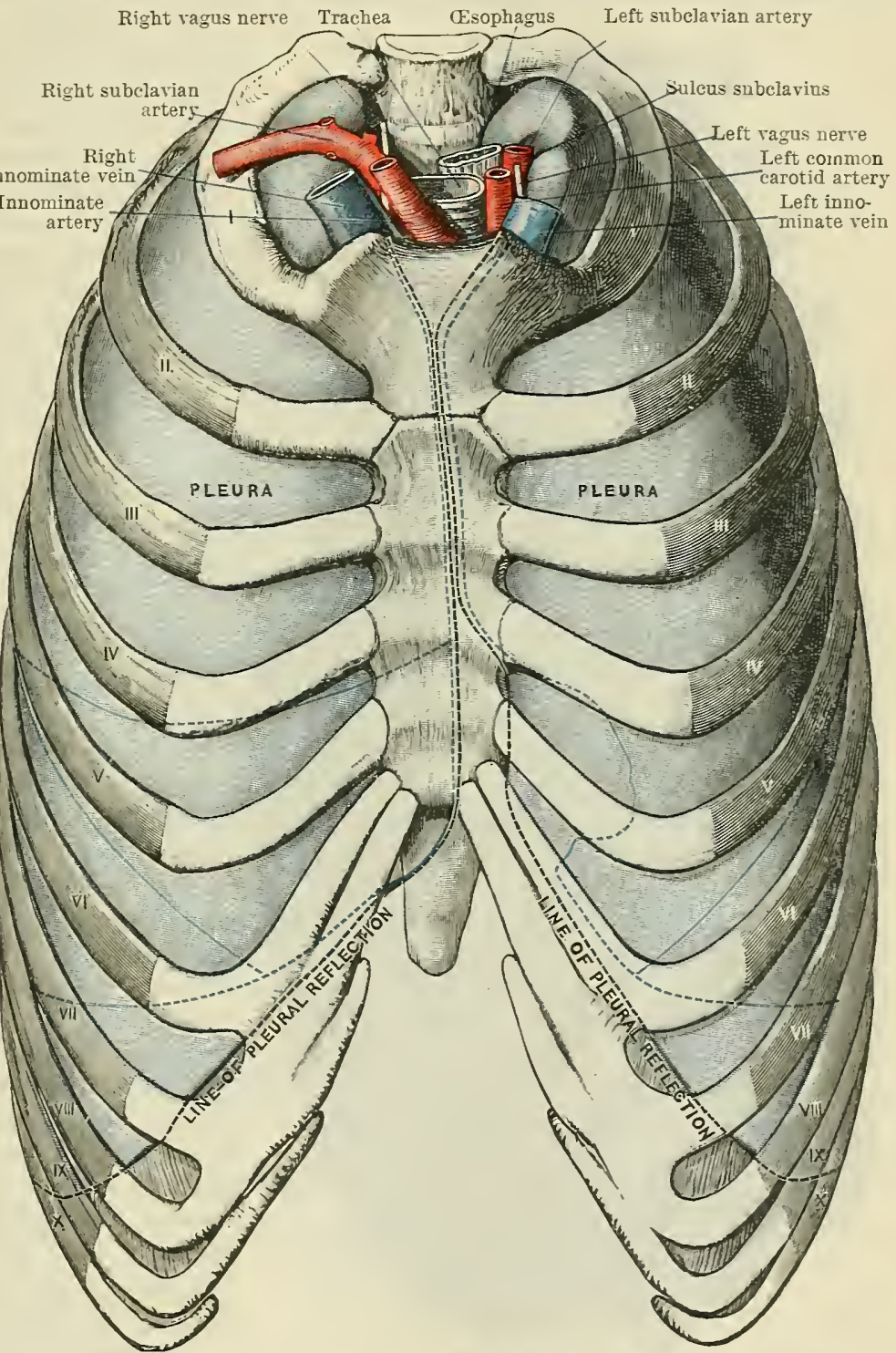

Fig. S63.-Dissection of a SUbJect hardesed br Formatis Injectios, to show the relations of the two pleural sacs, as viewed from the front. The anterior and diaphragmatic lines of pleural reflection are exhibited by black dotted lines, whilst the outlines of the lungs and their fissures are indicated by the blue lines. of the pericardium, but it does not dip down to the bottom of the narrow interval between the thoracic wall and the diaphragm. In other words, a strip of the thoracic surface of the diaphragm adjoining its costal attachment is left uncorered.

Pleura Mediastinalis.-The mediastinal pleura extends from the dorsal surface of the rentral thoracic wall to the rertebral column, and clothes the side of the mediastinal septum, which intervenes between the two pleural cavities. It is continuous with the costal pleura of its own side, both ventrally and dorsally, along two lines which are respectively termed the sternal and vertebral lines of 
pleural reflection; whilst inferiorly it becomes continuous with the diaphragmatic pleura, of its own side, at the base of the pericardium.

Above the root of the lung the mediastinal pleura passes directly from the sternum to the vertebral column. In this region the left mediastinal pleura is applied to the arch of the aorta and the phrenic and vagus nerves; to the left innominate vein, the left superior intercostal vein and the left common carotid and

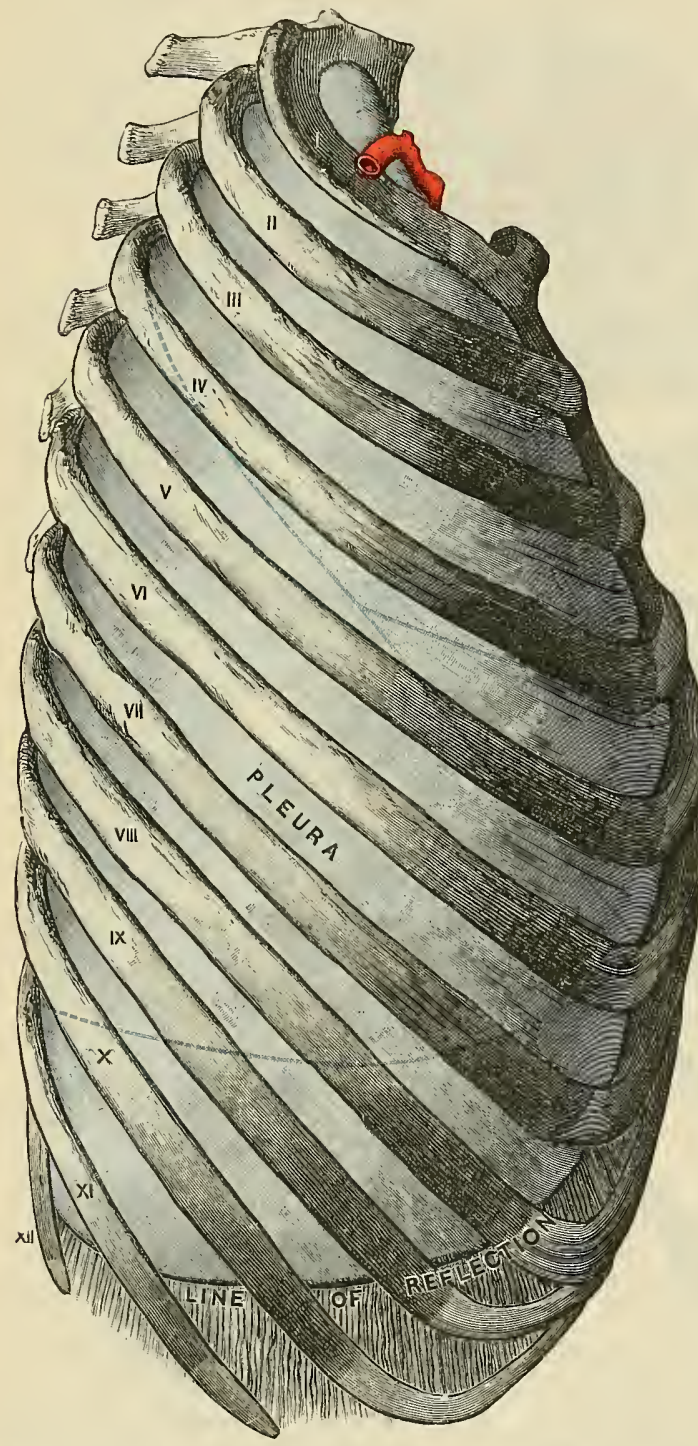

Fig. 864.--Lateral View of the Pight Pleural Sac in a SUbJect hardened by Formalin InJection. The blue lines indicate the outline of the right lung, and also the position of its fissures. the left side it passes dorsally over the thoracic aorta, and to a small extent over the lower end of the asophagus, in the region immediately adjoining the diaphragm, ventral to the thoracic aorta.

Lines of Pleural Reflection.-These are three in number-viz., the sternal, the vertebral, and the diaphragmatic. The pleural cavities are not symmetrical. The left is longer and narrower than the right, and it thus happens that the lines of pleural reflection do not accurately correspond on the two sides of the body. Further, although the 
vertebral line of reflection is fairly constant, the other two reflection-lines are subject to marked variations in different subjects. Consequently the following description must be regarded as merely giving the average condition.

The vertebral line of pleural reflection is that along which the costal pleura is continued ventrally from the vertebral column to become the mediastinal pleura. On the right side, above the root of the lung, the pleura passes from the bodies of the vertebræ on to the right side of the trachea; whilst lower down, and dorsal to the pericardium, it passes from the vertebral bodies on to the œesophagus. On the left side, and above $\mathrm{I}$ the arch of the aorta, the pleura along this line of reflection is carried from the vertebral column on to the osophagus and thoracic duct; below that level it passes on to the thoracic aorta. In the superior part of the chest the right and left lines of reflection are placed well apart from each other, and about equidistant from the median plane. As they are traced downwards they approach more closely to each other and deviate to the left, so that whilst the reflection on the right side takes place from the ventral aspect of the vertebral bodies, on the left' side it takes place from the left aspect of the vertebral column. This is due to the position of the thoracic aorta.

The sternal line of pleural reflection is that along which the costal pleura leaves the ventral thoracic wall to become the mediastinal pleura. The lines differ somewhat on the two sides, and in both cases show a tendency to deviate to the left (Fig. 863, p. 1085). In the vicinity of the manubrium sterni the two pleural sacs are separated from each

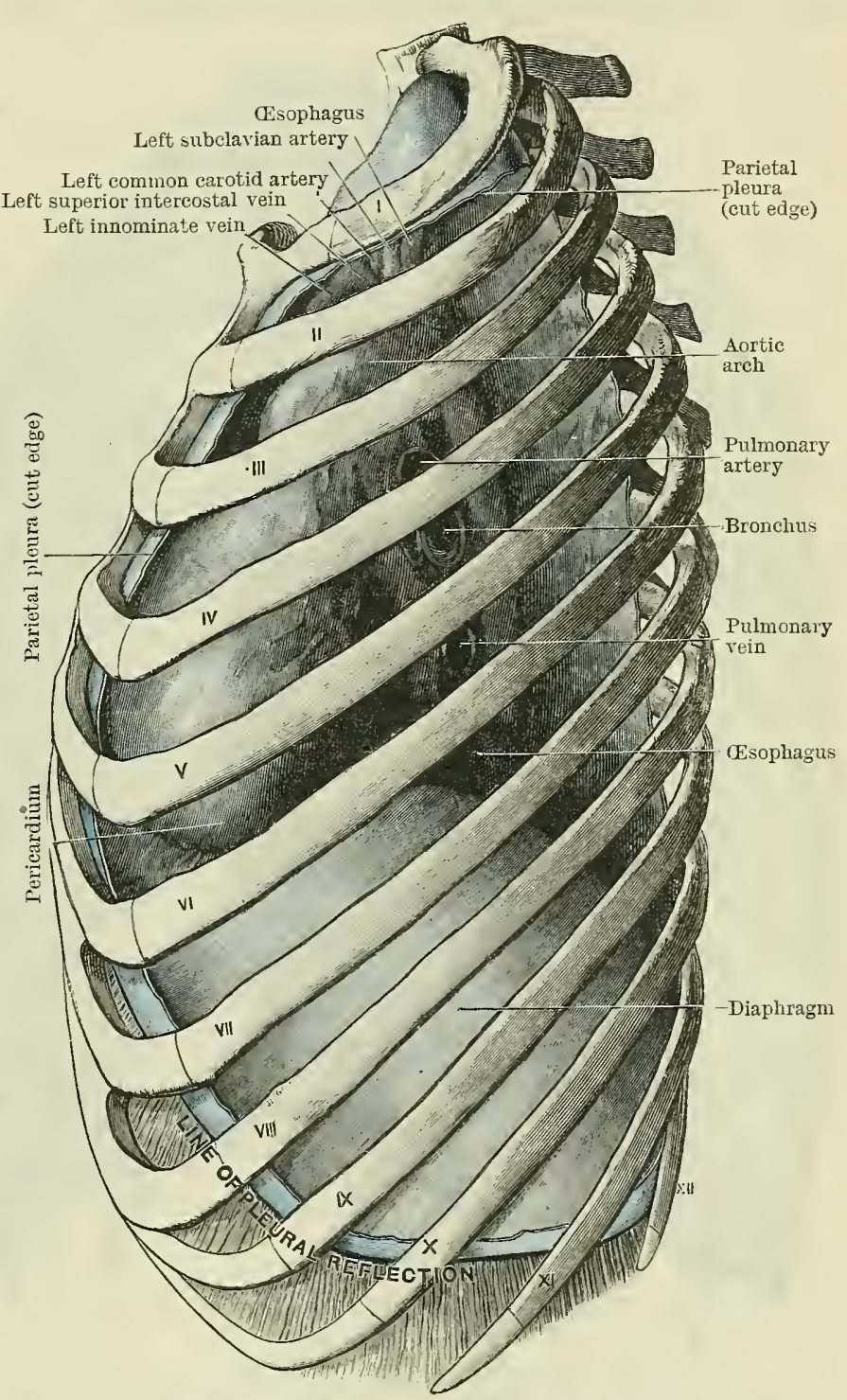

Fig. 865.-Left Pledral Sac in a SUbject hardened by Formatin INJECTION, opened into by the removal of the costal part of the parietal pleura. The lung has also been removed so as to display the mediastinal pleura.

other by an angular interval. The lines of reflection at the superior thoracic aperture or inlet correspond to the sterno-clavicular joints. From these points the lines, as they are traced downwards, converge behind the manubrium, until at last they meet at its inferior border. Here the two sacs come into contact with each other, and the lines of reflection coincide. From this they proceed downwards on the back of the body of the sternum, with a slight deviation to the left of the median plane, until a point immediately above the level of the sternal attachments of the fourth costal cartilages is reached, and here the two sacs part company. The line of reflection of the right pleura is continued downwards in a straight line to the xiphoid process, where the 
sternal reflection-line passes into the right diaphragmatic reflection-line. Opposite the sternal attachment of the fourth costal cartilage the reflection-line of the left pleura deviates laterally, and is continued downwards at a variable distance from the right pleura. A small triangular area of pericardium is thus left uncovered by pleura, and therefore in direct contact with the ventral chest-wall. Leaving the sternum, the reflection-line of the left pleura passes downwards, parallel and close to the left margin of the sternum, dorsal to the fourth intercostal space, the fifth costal cartilage and the

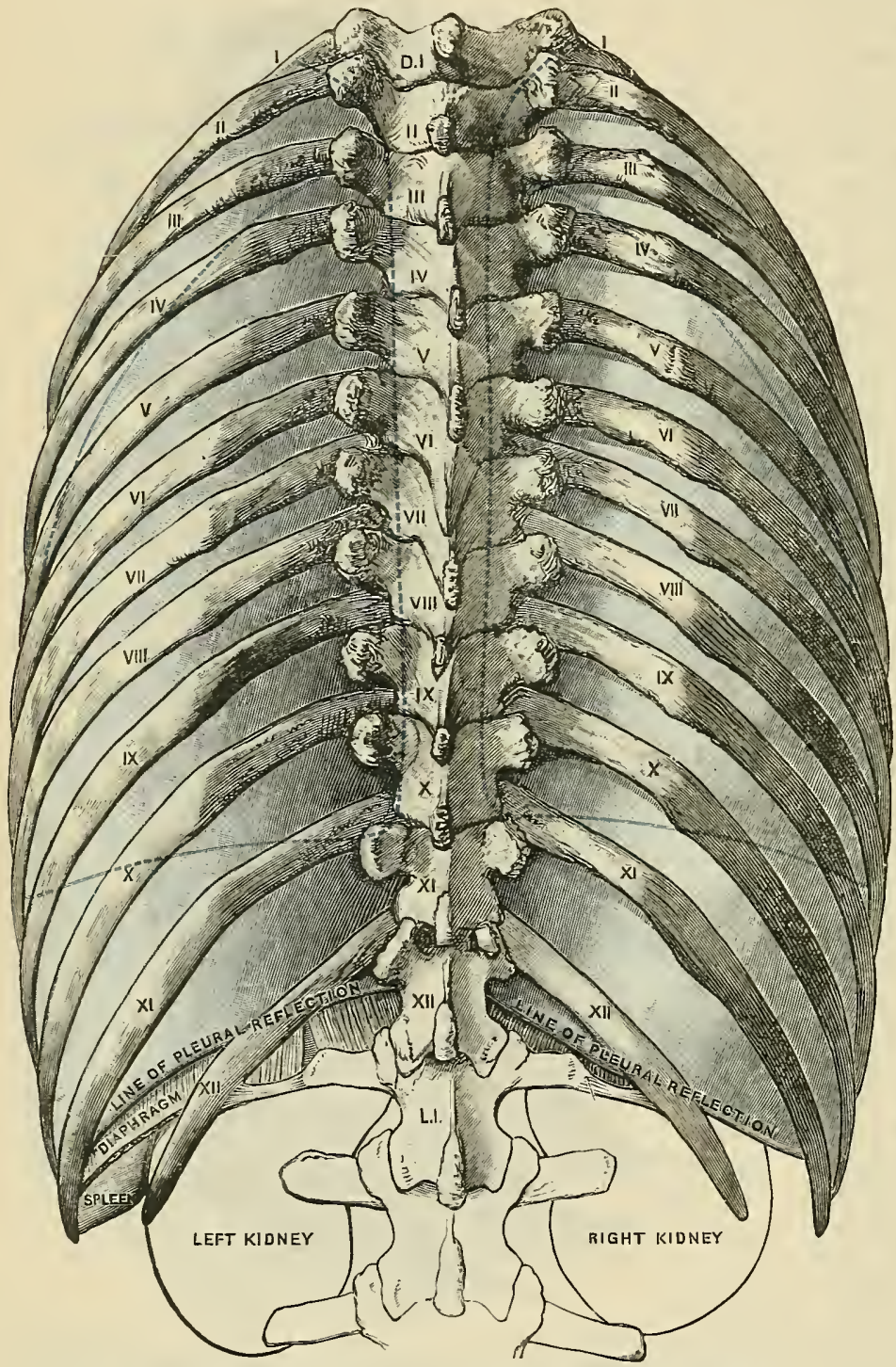

Fig. 866.-Dissection of the Pleural Sacs from Behind.

The blue lines indicate the outlines and the fissures of the lings.

fifth intercostal space, to the sixth costal cartilage. Here it turns laterally and downwards, and passes into the diaphragmatic reflection-line of the left side.

From the back of the sternum the right pleura is reflected, in the superior part of the chest, on to the remains of the thymus, the right innominate vein and the vena cava superior, and, inferior to this, directly on to the ventral aspect of the pericardium. The left pleura is reflected from the back of the manubrium sterni on to the left innominate vein and the aortic arch, and, inferior to this, directly on to the ventral side of the pericardium.

The diaphragmaticline of reflection is that along which the pleura leaves the thoracic wall and is reflected on to the thoracic surface of the diaphragm. This reflection takes place along a curved line, which, except as it approaches the vertebral column, is placed a short distance above the in-

ferior border of the thoracic wall. It differs somewhat on the two sides of the body.

On the left side the diaphragmatic line of reflection proceeds downwards along the ascending part of the sixth costal cartilage, crosses the ventral end of the sixth intercostal space and the descending part of the cartilage of the seventh rib (Fig. 865). Still continuing to pass downwards, it crosses the eighth costal arch at the junction between its cartilaginous and bony portions. This is a fairly constant relation on both sides of the body, and it should be noted that a vertical line-the mamillary line,-drawn downwards from the nipple of the breast, intersects the line of pleural reflection, close to the point where it presents this relation to the eighth costal arch. Beyoud this point 
the line of diaphragmatic reflection is carried downwards and laterally across the extremities of the bony portions of the ninth and tenth ribs. As it crosses the tenth rib, or, it may be, as it proceeds across the tenth intercostal space, the line of pleural reflection reaches its lowest point, and it is important to observe that this point lies in the mid-lateral line (i.e. in a vertical line drawn on the side of the chest, midway between vertebral column and sternum). From this, as it curves dorsally towards the vertebral column, it passes slightly upwards. Thus it cuts across the eleventh rib and reaches the twelfth rib. The relation which it presents to the twelfth rib varies in accordance with the length of that rib. When the last rib is not abnormally short the pleura clothes its medial half, and the line of reflection falls below this portion of the rib, so as to reach the vertebral column, midway between the capitulum of the last rib and the transverse process of the first lumbar vertebra (Fig. 866). Here, therefore, the line of diaphragmatic reflection falls below the inferior border of the thoracic wall; and this is a point of practical importance, because in operations upon the kidney the incision cannot be carried above the level of the transverse process of the first lumbar vertebra and the lateral lumbo-costal arch without the risk of wounding the pleura. On the right side the line of diaphragmatic pleural reflection differs from that on the left chiefly ventrally (Fig. 864, p. 1086). Here it passes at a lower level, and proceeds laterally and downwards from the dorsum of the xiphoid process along the dorsal aspect of the seventh costal cartilage, and then behind the eighth costal arch, as a rule at the same point as on the left side, viz., the junction of its cartilaginous and bony parts. From this on to the vertebral column the relations are so similar to those of the left side that a separate description is unnecessary.

It is commonly stated that the left pleural sac reaches a lower level than the right. In certain cases there is no doubt that it does, but this condition is by no means the rule. In those cases where the two pleural sacs do not reach the same level at their lowest points, it is sometimes the right and sometimes the left pleura which oversteps the mark.

As already stated, the lowest point which the pleura attains is usually found, on both sides, in the mid-lateral line where the diaphragmatic reflection-line crosses the tenth rib or the tenth intercostal space. This point can be very readily ascertained on the surface by drawing a horizontal line round the trunk at the level of the lowest part of the extremity of the spinous process of the first lumbar vertebra, and noting where it is intersected by the mid-lateral line. In the majority of cases the point of intersection will correspond with the lowest part of the pleural sac. Another horizontal line opposite the spine of the twelfth thoracic vertebra will give the level of the diaphragmatic pleural reflection in the mamillary line. ${ }^{1}$

Along the line of the diaphragmatic reflection a strong fascia passes from the uncovered part of the diaphragm, and from the costal cartilages to the surface of the costal pleura, so as to hold it firmly in its place. It may be termed the phrenicopleural fascia.

\section{MEDIASTINUM.}

The term mediastinum is applied to the interval between the mediastinal portions of the two pleural sacs. Ventrally it is bounded by the sternum, and dorsally by the vertebral column. It is customary to subdivide this space in a purely arbitrary manner into four portions, termed respectively the superior or cranial, the ventral or anterior, the middle, and the dorsal or posterior part, according to the relations which they present to the pericardium.

The superior mediastinum is that part of the general area which lies above the level of the pericardium. Its boundaries are as follows:-Ventrally, the manubrium sterni, with the attached sterno-hyoid and sterno-thyreoid muscles; dorsally, the bodies of the first four thoracic vertebræ; below, an imaginary and oblique plane, which extends from the inferior border of the manubrium sterni to the inferior border of the fourth thoracic vertebra; laterally, the mediastinal pleura.

Within the superior mediastinum are placed (1) the aortic arch and the three

1 The above description represents the average results which have been obtained from the study of the pleura in a large number of subjects, eight of which were specially hardened by formalin or other re-agents for the purpose. For many of the dissections I have to thank my former assistant, Dr. H. St. J. Brooks, and for others I am indebted to Professor C. J. Patten of Sheffield.-D. J. C. 
great arteries which spring from it; $(2)$ the innominate veins and part of the vena cava superior; (3) the trachea, osophagus, and thoracic duct; (4) the phrenic, vagi, and cardiac nerves, and the left recurrent nerve; $(5)$ the thymus.

The middle mediastinum is the wide part of the area which contains the pericardium, and lies below the superior mediastinum. In addition to the pericardium and its contents the middle mediastinum contains the phrenic nerves and their accompanying vessels.

The ventral mediastinum is that part of the interpleural region which lies between the pericardium dorsally and the body of the sternum ventrally. In its superior

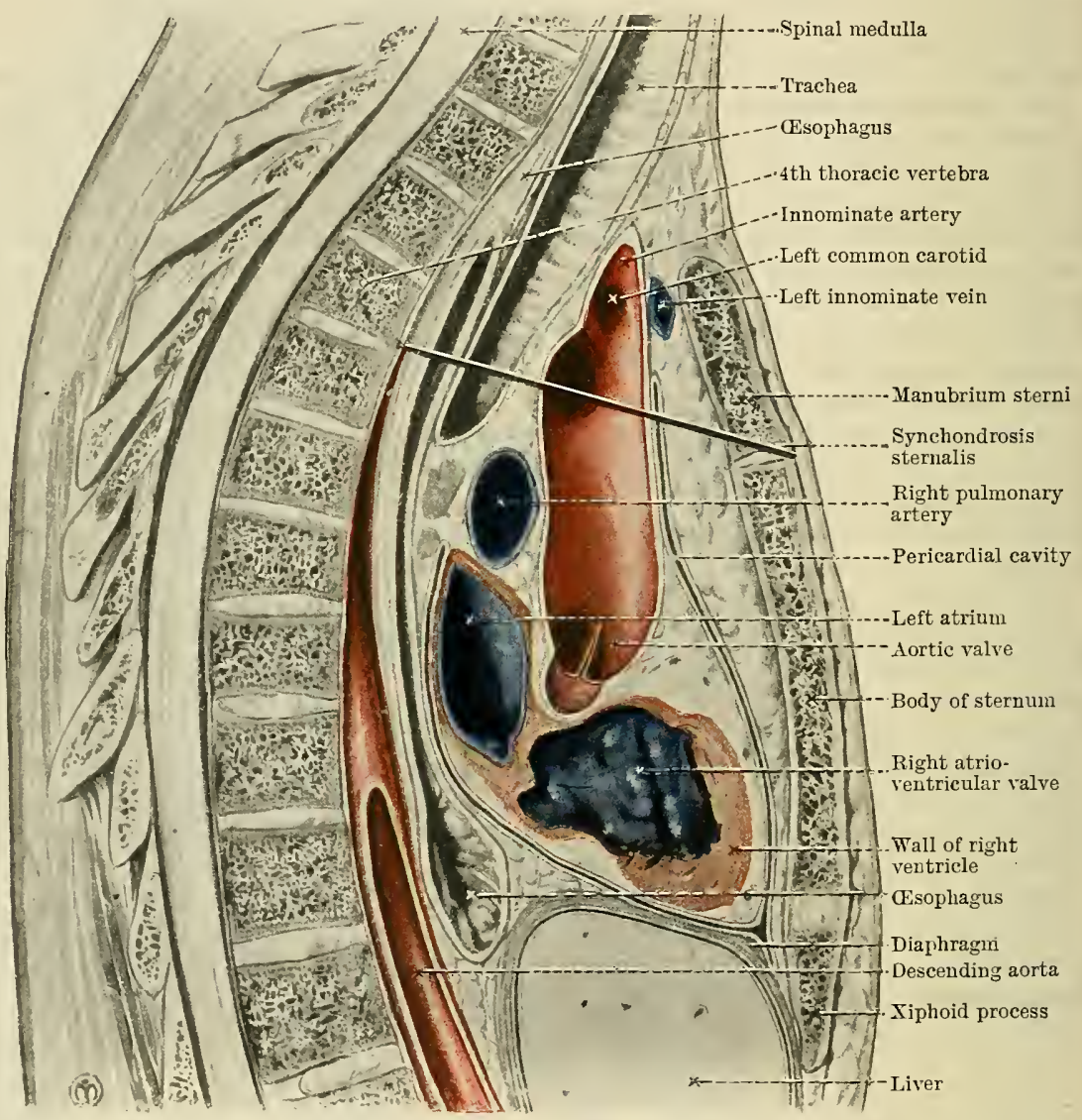

Fig. S67.-Sagittal Section through the Thorax of an Old Man. The superior border of the manubrium sterni and the bifurcation of the trachea are lower than in the average adnlt.

part this region can hardly be said to exist, seeing that there the two pleural sacs come into contact with each other on the ventral aspect of the pericardium; but below the level of the sternal ends of the fourth costal cartilages the left pleura falls short of the right pleura, and an interval is apparent. The only contents to be noticed in the ventral mediastinum are a few lymph glands and some areolar tissue, in which ramify some lymph vessels, and some minute twigs from the internal mammary artery.

The dorsal mediastinum is that part of the interpleural region which is situated dorsal to the pericardium. It may be regarded as an inferior continuation of the more dorsal part of the superior mediastinum, and many of the structures in the one are prolonged into the other. The arbitrary superior limit of the dorsal mediastinum is the inferior border of the fourth thoracic vertebra. Ventrally it is bounded by the pericardium and the vertical part of the diaphragm. Dorsally it is limited by the bodies of the last eight thoracic vertebræ and on each lateral side by the mediastinal pleura. It contains the descending 
thoracic aorta with the aortic intercostal arteries, the azygos and hemiazygos veins, the thoracic duct and the oesophagus, with the two vagi.

Structure of the Pleura. - The pleura on each side is a closed sac, and, like other serous membranes, is attached to the wall of the cavity which it lines and to the surface of the viscus which it covers. It is composed of a thin connective-tissue stratum, in which bundles of fibres cross each other in various directions, and intermixed with which there is a considerable quantity of elastic tissue. On the internal surface of this there is a continuous coating of thin endothelial cells placed edge to edge. The pleura so formed is attached to the parts which it lines and invests by a small amount of areolar tissue termed the subserous layer. In the case of the pulmonary pleura the subserous tissue is continuous with the areolar tissue in the substance of the lung, and this accounts for the tight manner in which the membrane is bound down.

The pleura is plentifully supplied with blood. This is conveyed to it by minute twigs from the intercostal arteries, the internal mammary artery, and the bronchial arteries. Lymph vessels are also particularly abundant in the pleura and in the subserous layer, and it is by these that excess of fluid is conveyed from its cavity. Many lymph vessels communicate directly with the cavity by meaus of excessively minute orifices termed stomata. Dybkowsky has shown that the lymph vessels and stomata of the pleura are not equally distributed throughout the membrane. Over the ribs and on the mediastinal pleura they are absent.

\section{PULMONES.}

The Lungs. - When healthy and sound each lung lies free within the corresponding pleural cavity, and is attached only by its root and the ligamentum pulmonale. It is uncommon, however, in the dissecting room, to meet with a perfectly healthy lung. Adhesions between the pulmonary and parietal layers of pleura, due to pleurisy, are generally present.

Like the cavities in which they are placed, the two lungs are not precisely alike. The right lung is slightly larger than the left, in the proportion of about 11 to 10 . The right lung is also shorter and wider than the left lung. This difference is due partly to the great bulk of the right lobe of the liver, which forces the right cupola of the diaphragm to a higher level than the left cupola, and partly to the heart and pericardium projecting more to the left than to the right, thus diminishing the width of the left lung.

The lung is light, soft, and spongy in texture; when pressed between the finger and thumb it crepitates, and when placed in water it lloats. The elasticity of the pulmonary tissue is very remarkable. A striking demonstration of this is afforded when the thoracic cavity is opened, and the atmospheric pressure acting upon the interior and exterior of the lung is equalised. Under these conditions the organ immediately collapses to about one-third of its original bulk, and it becomes impossible in such a specimen to study its proper form and dimensions.

The surface of the adult lung presents a mottled appearance. The ground colour is a light slate-blue, but scattered over this there are numerous dark patches of various sizes, and also fine dark intersecting lines. The coloration of the lung differs considerably at different periods of life. In early childhood the lung is rosy-pink, and the darker colour and the mottling of the surface, which appear later, are due to the pulmonary substance, and particularly its interstitial areolar tissue, becoming impregnated, more or less completely, with atmospheric dust and minute particles of soot.

At every breath foreign matter of this kind is inhaled, but only a small proportion of it reaches the lung tissue. The greater part of it becomes entangled in the mucus which coats the mucous membrane of the larger air-passages, and is gradualiy got rid of along with the mucus through the activity of the cilia attached to the lining epithelinm. By the constant upward sweep of these a current towards the pharynx is established. The fine dust and soot particles which reach the finer recesses of the lungs, and ultimately the interstitial tissue, are partly conveyed away. by the lymph ressels to the bronchial glands, which in consequence become, in many cases, quite black. The colour of the lung, therefore, depends, to some extent, upon the purity of the atmosphere which is inhaled, and it thus happens that in coalminers the surface of the lung may be very nearly uniformly black. 
The fotal lung differs in a marked degree from the lung of an individual who has breathed. After respiration is fully established, the lung soon comes to occupy almost the whole space allotted to it in the pleural cavity; in the fœetus, on the other hand, the lung is packed away at the dorsal aspect, and occupies a relatively much smaller amount of space in the thoracic cavity. Further, it is firm to the touch, and sinks in water. It is only when air and an increased supply of blood are

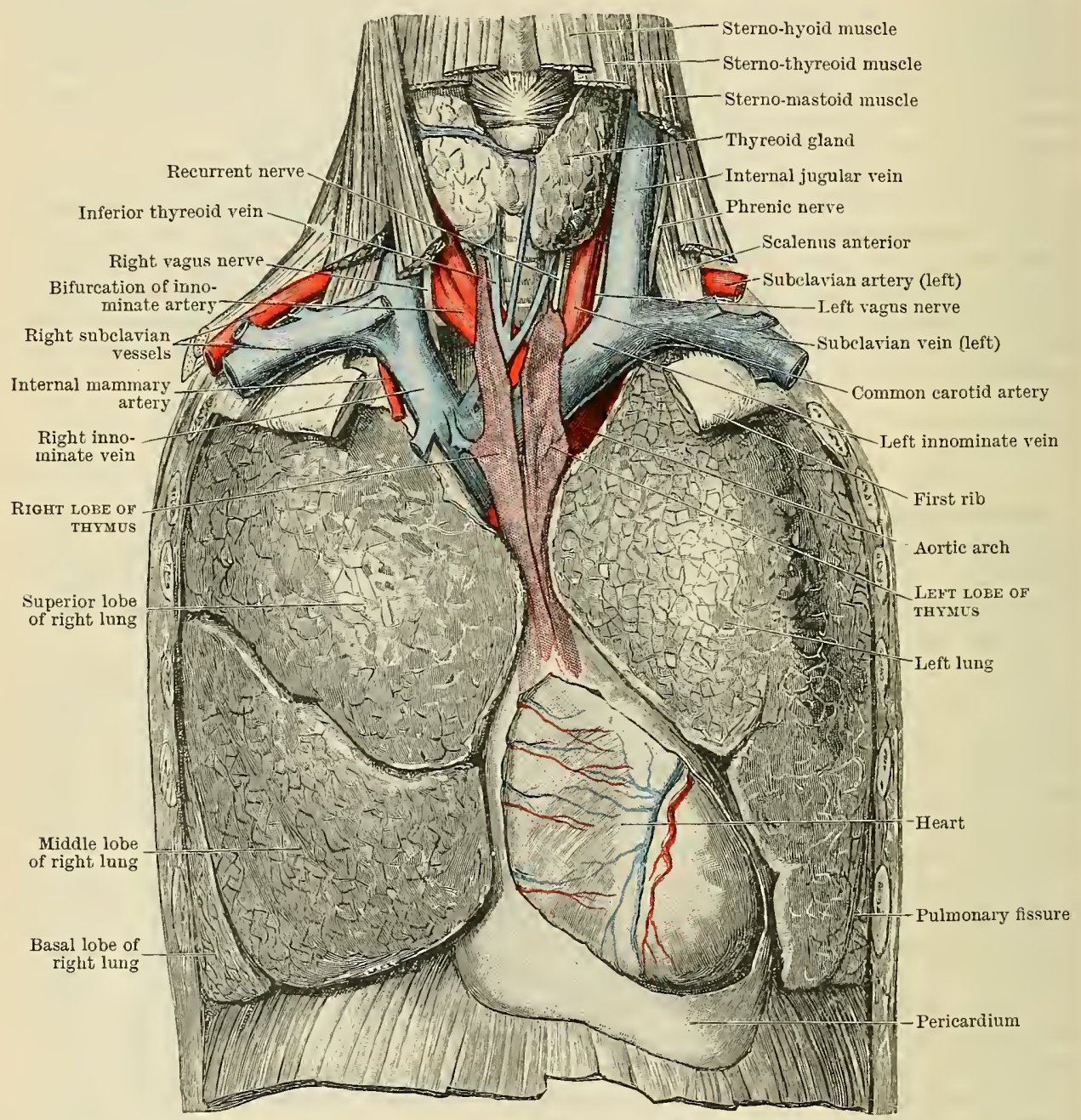

Fig. 868.-Dissection of Thorax and Root of the Neck From the front to show the Relations of the Lungs, Pericardium, and Thymos.

introduced into the lung that it assumes the soft spongy and buoyant qualities which are characteristic of the adult lung.

Form of the Lungs.-The lungs are accurately adapted to the walls of the pleural chambers in which they are placed, and in the natural state they bear on the surface impressions and elevations which are an exact counterpart of the irregularities on the walls of the cavity in which they lie.

When care has been taken to harden it in situ, each lung presents for examination an apex, diaphragmatic, mediastinal, and costal surfaces, and ventral (anterior) and inferior borders.

The apex pulmonis is blunt and rounded, and rises above the level of the oblique first costal arch to the full height of the cupula pleuræ. It therefore protrudes above, through the superior aperture of the thorax, into the root of the 
neck. The subclavian artery arches laterally on its medial and ventral aspects a short distance below its summit, and a groove, the sulcus subclavius, corresponding to the vessel, is apparent upon it. At a lower level on the apex pulmonis a shallower and wider groove upon its medial and ventral aspects marks the position of the innominate vein. Although these vessels impress the lung they are separated from it by the cupula pleuræ.

The diaphragmatic surface, or base of the lung, presents a semilunar outline, being curved around the base of the pericardium. It is adapted to the thoracic surface of the diaphragm, and is consequently deeply hollowed out. As the right cupola of the diaphragm passes further upwards than the left, the basal concavity of the right lung is deeper than that of the left

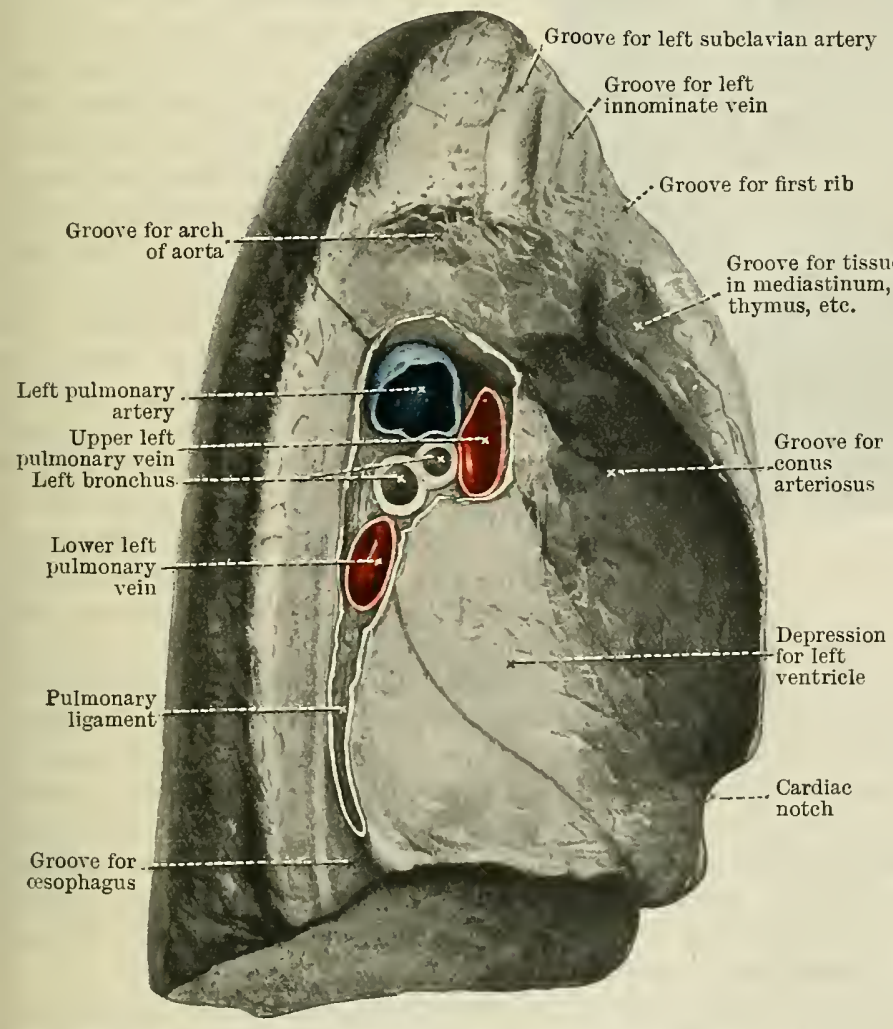

Fig. 870.- Medial Strface of a Left LUNG hardened iN sit?.

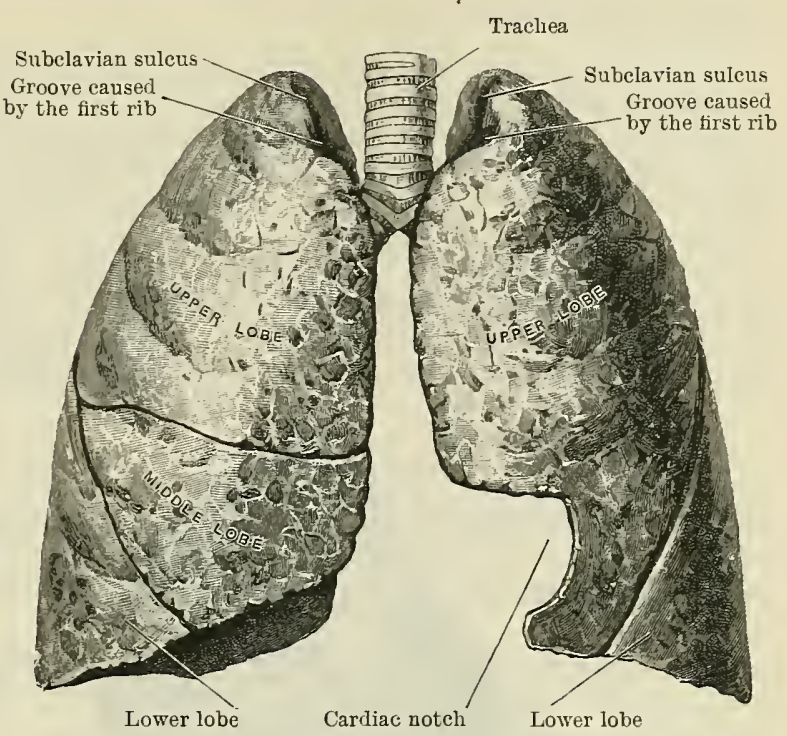

Fig. 869.-The Trachea, Broxchi, and Lujgs of a Child, HARDENED BY FORMALIN INJECTION. dorsally, the diaphragmatic surface of each lung is limited by a thin salient margin, called the inferior border or margin, which extends downwards for some distance in a narrow pleural recess, the sinus phrenicocostalis, between the diaphragm and the chest-wall. This inferior border of the lung extends further downwards on the lateralsideand dorsally than it does ventrally, but it falls considerably short of the bottom of the phrenicocostal sinus. Thus, after expiration, it reaches the inferior border of the sixth rib in the mamillary line; the eighth rib, in the axillary or mid-lateral line; whilst dorsally it proceeds medially along a straight horizontal line so as to reach the vertebral column at the level of the extremity of the spine of the tenth thoracic vertebra. During respiration the thin inferior border moves freely in a vertical direction within the phrenico- 
costal sinus, but even after the deepest breath it never reaches the extreme lower limit of this recess.

The diaphragmatic surfaces of the lungs establish important relations with certain of the viscera which occupy the costal zone of the abdominal cavity, the diaphragm alone intervening. Thus the diaphragmatic surface of the right lung rests upon the right lobe of the liver; whilst that of the left lung is in relation to the left lobe of the liver, the fundus of the stomach, the spleen, and in some cases to the left colic flexure.

The costal surface is extensive and convex. It is accurately adapted to that part of the wall of the pleural cavity which is formed by the costal arches and the intervening intercostal muscles, and it presents markings corresponding to these. Thus the imprint of the ribs appear as shallow oblique grooves, while the

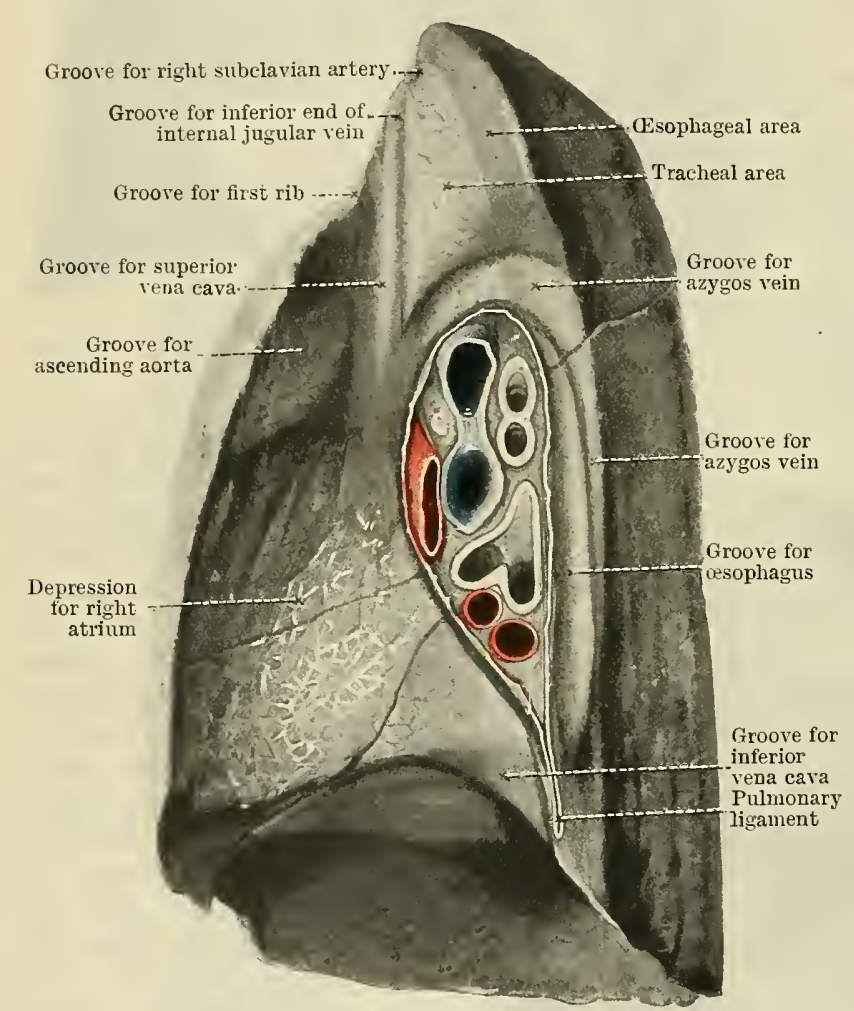

Fig. 871. -The Medial Surface of a Right Lung hardened is situ. intercostal spaces show as elongated intervening bulgings.

The mediastinal surface presents a smaller area than the costal surface. It is applied to the mediastinal septum, and presents markings in accordance with the inequalities upon this (Figs. 870 and 871 ). Thus it is deeply hollowed out in adaptation to the pericardium upon which it fits. This pericardial concavity comprises the greater part of the mediastinal surface, and owing to the greater projection of the heart to the left side, it is much deeper and more extensive in the left lung than in the right lung. Above and dorsal to the pericardial hollow is the hilus of the lung. This is a wedge-shaped depressed area, within which the blood-vessels, nerves, and

lymph vessels, together with the bronchus, enter and leave the organ. Amidst these structures there are also some bronchial glands. The hilus is surrounded by the reflection of the pleura from the surface of the lung on to the pulmonary root. Dorsal to the hilus and pericardial area there is on each lung a narrow strip of the mediastinal surface of the lung which is in relation to the lateral wall of the dorsal mediastinum. On the right lung this part of the surface is depressed, and corresponds to the œsophagus; on the left lung it presents a broad longitudinal groove, which is produced by the contact of the lung with the thoracic aorta, and also, close to the base, a small flattened area ventral to this which is applied to the cesophagus where it pierces the diaphragm.

The portion of the mediastinal surface of the lung which lies above the hilus and pericardial hollow is applied to the lateral aspect of the superior mediastinum, and the markings are accordingly somewhat different on the two sides. On the left lung a broad deep groove, produced by the aortic arch, curves dorsally above the hilus, and becomes continuous with the aortic groove on the dorsal part of the mediastinal surface. From this a narrower, deeper, and 
much more sharply marked groove runs upwards, and laterally over the apex pulmonis a short distance from the summit. This is the sulcus subclavius, and it contains the left subclavian artery when the lung is in place. Ventral to this a shallow wide groove, also leading to the ventral aspect of the apex, corresponds to the left innominate vein. In the right lung the hilus is also circumscribed above by a curved groove, but this is narrow and more distinctly curved than the aortic groove on the left side. It lodges the vena azygos as it turns ventrally to join the vena cava superior. From the ventral end of the azygos sulcus a wide shallow groove extends upward to the inferior part of the anterior aspect of the apex pulmonis. This is produced by the apposition of the lung with the vena cava superior and the right innominate vein. Close to the summit of the apex there is also, on its medial aspect, a sulcus for the superior end of the innominate artery.

In addition to the hilus, it must now be evident that the mediastinal surface of each lung presents three areas which correspond respectively with (1) the middle mediastinum (i.e. the pericardial hollow), (2) the dorsal mediastinum, and (3) the superior mediastinum; and that in each of these districts impressions corresponding to structures contained within these portions of the interpleural space may be noticed.

The dorsal part of the lung at the junction of the costal and mediastinal surfaces is thick, long, and rounded. It forms the most bulky part of the organ, and occupies the deep hollow in the thoracic cavity which is placed on either side of the vertebral column.

The ventral border or margo anterior of the lung is short, and exceedingly thin and sharp. It begins abruptly immediately below the groove on the apex for the innominate vein, and extends to the base, where it becomes continuous with the sharp inferior border. The thin ventral part of the lung is carried ventrally and medially, ventral to the pericardium, into the narrow pleural costomediastinal sinus, dorsal to the sternum and costal cartilages. The ventral border of the right lung fills up this recess completely, and in the upper part of the chest is separated from the corresponding border of the left lung only by the two layers of mediastinal pleura which are reflected from the sternum to the pericardium. The ventral border of the left lung, in its lower part, shows a marked deficiency or notch, the incisura cardiaca, corresponding to the apex of the heart, and where this exists the lung margin leaves a considerable portion of the pericardium uncovered, and fails to fill up completely the costo-mediastinal sinus of the pleural cavity. During respiration the ventral margin of the left lung at the incisura cardiaca advances and retreats to a small extent in this pleural sinus, ventral to the pericardium.

Fissures and Lobes of the Lung.-The left lung is divided into two lobes by a long deep fissure, the incisura interlobaris, which penetrates its substance to within a short distance of the hilus. On the upper and lower sides of the hilus this fissure cuts right through the lung and appears on the mediastinal surface. Viewed from the costal surface, it begins dorsally about two and a half inches below the apex, about the level of the vertebral end of the third rib, and is continued downwards and ventrally in a somewhat spiral direction to the diaphragmatic surface of the lung, which it reaches a short distance from its ventral end. The lobus superior lies above and rentral to this cleft. It is conical in form, with an oblique base, and the apex and the whole of the rentral border of the lung belong to it. The lobus inferior lies below and dorsal to the fissure. It is the more bulky of the two, and includes almost the entire diaphragmatic surface and the greater part of the thick dorsal part of the lung.

In the right lung there are two incisure interlobares, which subdivide it in to three lobes. One of the incisuræ interlobares is very similar in its position and relations to the fissure in the left lung. It is directed, however, rather more vertically, and ends somewhat farther from the median plane. It separates the lobus inferior from the lobus medius and lobus superior. The second incisura interlobaris begins in the main fissure at the dorsal part of the ling, and proceeds ventrally, to end at the ventral border of the lung at the level of the fourth costal 
cartilage. The middle lobe of the right lung is triangular or wedge-shaped in outline.

Variations.-Variations in the pulmonary fissures are fairly common. Thus, it sometimes happens that the middle lobe of the right lung is imperfectly eut off from the lobus superior. Supernumerary fissures also are not infrequent, and in this way the left lung may be cut into three lobes, and the right lung into four or even more lobes. The occurrence of the lobus azygos in the right lung is a variation of some interest, seeing that such a lobe is constant in certain mammals. It is a small accessory lobe, pyramidal in form, which makes its appearance on the lower part of the mediastinal surface of the right lung. In certain cases the vena azygos is enclosed within a fold of pleura, and is sunk so deeply in the pulmonary substance of the right ling that it marks off a small accessory lobe.

\section{RADIX PULMONIS.}

The term root of the lung is applied to a number of structures which enter and leave the lung at the hilus on its mediastinal surface. They are held together by an investment of pleura, and constitute a pedicle which attaches the lung to the mediastinal wall of the pleural cavity. The phrenic nerve passes downwards a short distance ventral to the pulmonary root, whilst the vagus nerve breaks up into the dorsal or posterior pulmonary plexus on its dorsal aspect under cover of the investing pleura. The delicate ventral or anterior pulmonary plexus is placed ventral to the root of the lung under cover of the pleura, whilst from the inferior border of the root of the lung the ligamentum pulmonale extends towards the diaphragm. These relations are common to the pulmonary root on both sides of the body, but there are others which are peculiar to each side. On the right side the vena cava superior lies ventral to the pulmonary root, whilst the vena azygos arches over its upper border. On the left side the aorta arches above the root of the lung, whilst the descending thoracic aorta passes dorsal to it.

Constituent Parts of the Pulmonary Root.-The large structures which enter into the formation of the pulmonary root are (1) the two pulmonary veins, (2) the pulmonary artery, (3) the bronchus. But in addition to these there are one or more small bronchial arteries and veins, the pulmonary nerves and the pulmonary lymph vessels, and some bronchial glands.

The pulmonary nerves come from the vagus nerve and also from the sympathetic system. They enter the lung and follow the air-tubes through the organ. The bronchial arteries are small vessels which carry blood for the supply of the lung-tissue. They arise from the aorta or from an intercostal artery, and vary in number from one to three for each lung. In the root of the lung they lie on the dorsal aspect of the bronchus, and they follow the air-tubes through the organ. Part of the blood conveyed to the lung by the bronchial arteries is returned by the pulmonary veins; the remainder is returned by special bronchial veins which open on the right side into the vena azygos, and on the left side into the vena hemiazygos.

The lymph-vessels of the lungs are numerous and well developed, and are divided into two groups, superficial and deep.

The superficial lymph-vessels form a network on the surface of the lung and eventually terminate by four or five vessels in the broncho-pulmonary glands of the hilus. It is usually stated that the superficial lymph vessels communicate freely with the deep. This, however, is denied by Miller, who maintains that anastomoses between the two systems of vessels are very rare. A specimen of secondary carcinoma of the lung in the Pathology Museum of the University of Melbourne shows a direct continuation of the disease through the lung-substance from the surface to the tubes by way of the lymph vessels, and would thus tend to disprove Miller's assertion.

The deep lymph-vessels are subdivided into bronchial accompanying the bronchi and vascular accompanying the blood-vessels. Both systems communicate freely together, and at the level of the hilns terminate in the broncho-pulmonary glands.

The pulmonary or broncho-pulmonary lymph-glands, found at the hilus, are usually numerons and variable in size. They are sitnated either just outside the lung or within the lung-substance itself.

From these broncho-pulmonary glands the lymph-flow is continued onward from the lung, partly directly into the thoracic duct, aud partly by a more circuitous route as follows :-

From the broncho-pulmonary lymph-glands vessels pass on to the tracheo-bronchial glands situated at the angles produced by the bifureation of the trachea into the two bronchi. Of these glands there are, therefore, three groups, an inferior and right and left superior. From these glands the lymph-flow is continued npwards through the tracheal lymph-glands lying on either side of the trachea into the deep cervical lymph-glands, and thence into the thoracic duct.

The bronchus in the root of the lung lies dorsal to the great pulmonary vessels. 
The pulmonary artery occupies a different position on the two sides, in relation to the main or undivided part of the bronchus. On the right side it is placed below it, whilst on the left side it crosses the bronchus and occupies a higher level in the pulmonary root. The two pulmonary veins on both sides lie at a lower level in the root of the lung than the pulmonary artery and bronchus, whilst the superior of the two veins occupies a plane ventral to the pulmonary artery (Figs. 870 and S71).

Distribution of the Bronchial Tubes within the Lungs. - The two lungs are not symmetrical; the right lung is subdivided into three lobes, and the left lung is cleft into two lobes. The bronchi exhibit a corresponding want of symmetry. The right bronchus, as it approaches the pulmonary hilus, gives off two branches for the superior and middle lobes of the right lung respectively, and then the main stem of the tube enters the inferior lobe. The left bronchus sends off a large branch to the superior lobe of the left lung, and then sinks into the inferior lobe. The first branch of the right bronchus, for the superior lobe, leaves the main stem about one inch from the trachea. The first branch of the left bronchus, on the other hand, takes origin about twice that distance from the trachea.

The relation of the pulmonary artery to the bronchial subdivisions is different on the two sides. On the right side it turns dorsally to reach the dorsal aspect of the bronchus inferior to the first, and superior to the second, bronchial branch.

On the left side the pulmonary artery turns dorsally above the level of the first bronchial branch. On the right side, therefore, the first bronchial branch is placed above the pulmonary artery, and in consequence it is termed the eparterial bronchial ramus; all the others lie below the artery, and are termed hyparterial bronchial rami. On the left side there is no eparterial branch; they are all hyparterial.

When the main stem of the bronchus is followed into the inferior lobe of each lung, it is seen to travel downwards and dorsally in the pulmonary substance

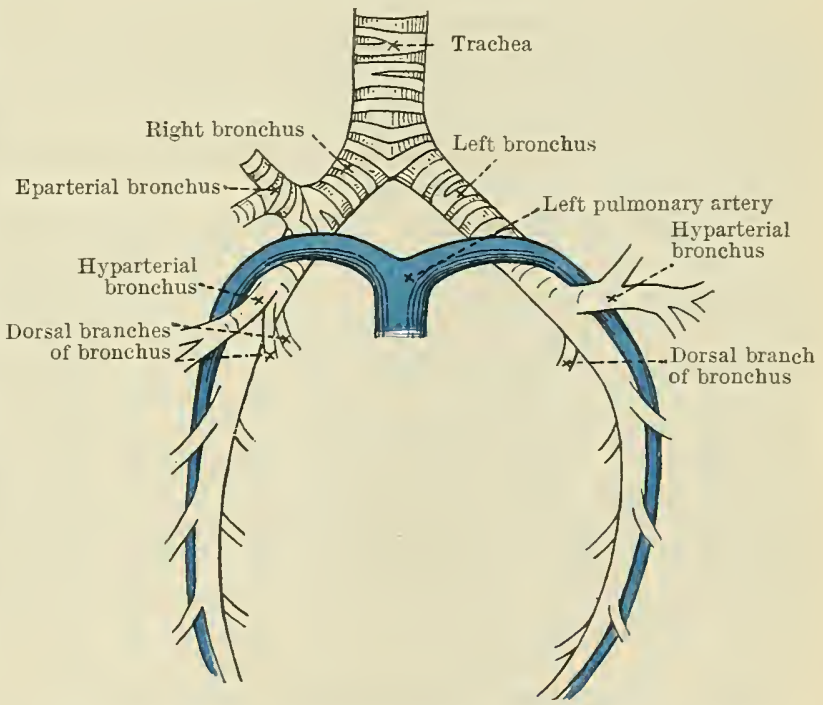

Fig. 872.-DiagraM of the Relatioxs of THE PulMoNaRy ARtery to THE BRoxchi. until it reaches the thin dorsal part of the diaphragmatic surface of the lung which lies between the diaphragm and the thoracic wall, and there it ends. As it proceeds through the inferior lobe it gives off a series of large ventral and a series of smaller dorsal branches. As a rule these are three in number in each case, and the dorsal and ventral branches do not arise opposite to each other, but alternately, one from the dorsum, and then another, after a slight interval, from the ventral surface of the tube. The first hyparterial division on each side (i.e. the branch to the middle lobe of the right lung and the branch to the superior lobe of the left side) is generally regarded as the first member of the ventral group.

It was Aeby who first recognised the existence in each lung of a main or stem bronchus giving off a ventral and dorsal series of branches, and who drew the distinction between the eparterial and hyparterial bronchial rami. A consideration of these relations led this author to conclude that the eparterial bronchus and the superior lobe of the right lung have no morphological equivalents on the left side of the body. In other words, he was led to believe that the middle lobe of the right lung is the homologue of the superior lobe of the left lung. Hasse, who has also investigated the subject, endorsed this view, with certain modifications and additions; and the hypothesis, either in its original state as presented by Aeby, or as subsequently modified by Hasse, has been, until lately, very generally accepted by anatomists. More recent research, 
however, has seriously affected the stability of this conclusion. Narath contends that the distinction between the eparterial bronchus of the right side and the hyparterial bronchi of both sides is not one of fundamental importance, and that a branch which arises from the first hyparterial bronchus on the left side and turns upwards into the apex of the left lung is the direct equiralent of the eparterial bronchus of the right side. This he terms the apical bronchus, and he believes that it represents the first dorsal branch of the left stem-bronchus. Huntington, in a very convincing paper, strougly supports the contention of Narath, and holds that, except "for purposes of topography, we should abandon the distinction between eparterial and hyparterial bronchi." With Narath he regards the eparterial bronchus as a secondary branch which has migrated in an upward direction on the main stem. According to Huntington, therefore, Aeby's proposition should be amended as follows:-

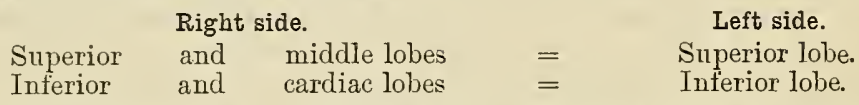

The cardiac lobe mentioned in this table is the occasional azygos lobe to which reference has already been made, and it is interesting to note that, whilst the lobe in question as a separate entity is rarely seen in the human lung, the bronchus which corresponds to it is always present in the pulmonary substance as an accessory branch, which proceeds from the main stem as it traverses the inferior lobe of the right side. It receives the name of the cardiac bronchus.

\section{StruCTURE OF THE LUNG.}

The lung is constructed so that the blood which reaches it through the pulmonary artery is brought into the most intimate relation with the air which enters it through the trachea and bronchi. An interchange of materials between the blood and the air is thus rendered possible, and the object of respiration is attained. As a result of this interchange the dark, impure blood, which flows into the lung through the pulmonary artery, is rendered bright red and arterial.

Lobules of the Lung.-A thin layer of subpleural connective tissues lies subjacent to the continuous coating which the lung receives from the pulmonary pleura. From the deep surface of this subpleural layer fine septal processes penetrate into the substance of the lung, and these, with the connective tissue which enters at the hilus upon the vessels and bronchi, constitute a supporting framework for the organ. The lung is lobular, and on the surface the small polygonal areas which represent the lobules are indicated by the pigment present in the connective tissue septa which intervene between them. Although no pigment is present, the lobular character of the lung is particularly well marked in the fœtus, and with a little care the surface lobules in the fotal lung can be separated from each other by gently tearing through the intervening connective tissue. The lobules thus isolated are piriform or pyramidal in form. The broad bases of these lobules abut against the subpleural layer, whilst each of the deep narrow ends receives a minute division from the bronchial system of tubes. The lobules which lie more deeply in the substance of the organ are not so large, and are irregularly polygonal in form.

The Lung Unit.-The unit of lung-structure is the lung-lobule. This comprises a terminal bronchus with its air-spaces, blood-ressels, lymph vessels, and nerves.

The terminal bronchus of the lung-nnit is attained as follows:-The larger branches of the bronchi, as they traverse the lung, give off numerous divisions, which, by repeated branching, ultimately form a system of tubes which pervade the entire organ. At first the bronchial divisions come off at rery acute angles, but as the finer ramifications are reached this character becomes much less apparent. The ramifications of these bronchi are termed bronchioles, which by subdivision give rise to the respiratory bronchiole of the lung-unit.

Within the lung unit the respiratory bronchiole gives off a series of terminal bronchi or alveolar ducts, each of which leads to a group of air-spaces termed atria. Each one of these atria communicates, in its turn, with a further and secondary series of air-spaces termed air-sacs or alveolar saccules, the walls of which are pouched out to form the very numerous alveoli or air acells of the lung-unit.

Structure of the Bronchi.- When the large bronchi enter the lung they become cylindrical, and lose the flattening on the dorsal aspect which is characteristic of the primary bronchi outside the lung. They possess the same coats as are present in the case of the trachea and primary bronchi, but as the tubes become smaller by repeated divisions, these coats become correspondingly thinner and finer. Certain marked differences also in the manner in which the constituents of these coats are arranged become apparent.

In the external fibro-cartilaginous coat the cartilage is no longer present in the form of incomplete rings, but in irregular plates or flakes dejosited at various points around 
the wall. As the tubes diminish, these cartilaginous deposits show a corresponding reduction in size, until at last, in bronchi of $1 \mathrm{~mm}$. diameter, they disappear altogether. The glands in relation to the tubes for the most part cease to exist about the same point. The muscular or middle coat, which in the trachea and primary bronchi is confined to the dorsal wall of the tube, forms a continuous layer of circularly arranged bundles in the bronchi as they ramify within the lung. Spasmodic contraction of the muscular coat gives rise to the serious symptoms which accompany asthmatic affections. The muscular fibres of the middle coat may be traced as far as the atria, on the walls of which they are present in considerable numbers. The mucous lining of the tubes becomes greatly thinned as it is followed into the smaller bronchioles. It contains a large number of longitndinally arranged elastic fibres, and is disposed in longitudinal folds, so that when the tube is cut across the lumen presents a stellate appearance. The mucous membrane is lined with ciliated columnar epithelium.

Structure of the Atria and Alveoli.-The walls of the atria and alveoli are exceedingly fine and delicate, but, nevertheless, constituents continuous with those observed in the three coats of a bronchus are found entering into their construction. The epithelium is reduced to a single layer. Further, it is no longer columnar and ciliated, but it has become flat and parement-like. Two kinds of epithelial cells may be recognised-(1) a few small granular polygonal cells, arranged singly or in groups of two or three, (2) more numerous thin cells of large size and somewhat irregular in outline. Outside the epithelium is a delicate layer of faintly fibrillated connective tissue. This is strengthened by a network of elastic fibres, which is specially well marked around the mouths of the alveoli, and is also to some extent carried over the walls of the air-cells. Muscular fibres also are present on the walls of the atria, but it is questionable if any are prolonged over the air-cells.

Pulmonary Vessels. - The pulmonary artery, as it traverses the lung, divides with the bronchi, and closely accompanies these tubes. The resultant branches do not anastomose, and for the most part they lie above and dorsal to the corresponding bronchi. The fine terminal divisions of the artery join a dense capillary plexus which is spread orer the alveoli or air-cells. This vascular network is so close that the meshes are barely wider than the capillaries which form them. In the partition between adjacent alveoli there is only one layer of the capillary network, and thus the blood flowing through these vessels is exposed on both aspects to the action of the air in the air-cells. The radicles of the pulmonary vein arise in, and carry the blood fiom, the pulmonary capillary plexus. Each afferent arteriole supplies the blood which flows through the capillaries spread over a number of neighbouring alveoli, and in like manner each afferent venous radicle drains an area corresponding to several adjoining air-cells. At first the veins run apart from the arteries, but after they have attained a certain size they join them and the bronchi. As a rule the pulmonary veins are placed on the inferior and ventral aspects of the corresponding bronchi.

\section{Developient of the Respiratory Apparatus.}

The larynx, trachea, bronchi, and lungs all arise as an outgrowth from the ventral aspect of the foregut. The first indication of a respiratory tract occurs in the human embryo early in the third week, on or about the fifteenth day of development, and when the embryo is but little more than $3 \mathrm{~mm}$. in length. At this period a median longitudinal groove makes its appearance on the rentral wall of the foregut, extending thereon from the primitive pharynx well towards the primitive stomach, and deepening gradually as it passes caudalwards.

The cranial end of the respiratory tube becomes enlarged and forms the larynx, the intermediate portion forms the trachea, and the caudal end bifurcates in the floor of the groove into two tubes-the future bronchi were already indicated by slight bulgings before the two tubes divide-which grow candalwards on either side of the heart, into a mesodermic mass, from which the connective tissue of the future lungs is ultimately dereloped. The respiratory tube is lined with entoderm continuous with the entodermal lining of the foregut.

The groove becomes deeper and constricted, its lateral margins approximate, and finally meet dorsally, and the groove separates off from the foregut as a distinct tube. This differentiation necessarily results in the production of two tubes or canals, a ventral one forming the respiratory tube, and a dorsal one the osophagus. The separation of the tro tubes commences at the caudal end and proceeds cranialwards towards the pharynx, into which both the csophagus and the respiratory tube open. 
The Larynx.-The rudiment of the larynx appears, at the cranial or pharyngeal end of the primitive respiratory tube, about the twenty-fifth day, and before the trachea separates off from the œesophagus in the form of two lateral swellings-the arytænoid swellings, which lie caudal to the fourth visceral pouches, and possibly represent rudimentary fifth branchial arches (Kallius). These arytænoid swellings are connected by a ventral median ridge which intervenes between the ventral ends of the third visceral arches. At this period the site of the future larynx is represented at the pharyngeal end of the respiratory tube by a $U$-shaped ridge which surrounds the tube cranially and laterally, and is known as the furcula.

The cranial or anterior portion of the furcula forms a median elevation from which the epiglottis is developed, whilst the lateral portions of the furcula-the arytænoid swellings-eventually form the ary-epiglottic folds. On the medial side of the latter, about the fourth month, a furrow marks the future site of the ventriculus laryngis [Morgagini], the margins of which later become the vocal folds.

About the eighth week the cartilaginous framework of the larynx is indicated by mesoblastic condensations of the connective tissue around the now slit-like rima glottidis; and at this period the rudimentary arytænoids, the cricoid and the cartilages of the trachea are all continuous laterally.

The epiglottic cartilage is developed, as stated, in the anterior portion of the furcula, and chondrifies relatively late. It may possibly represent a rudiment of the cartilage of the sixth branchial arch, and according to Göppert it is at first continuous dorsally with the cuneiform cartilages, which, therefore, are derivatives of the epiglottic cartilage.

The thyreoid cartilage is laid down in the form of two separate lateral mesoblastic plates, in each of which chondrification proceeds from two centres, ventral and dorsal, which probably represent the cartilages of the fourth and fifth branchial arches. As development proceeds the sheets of cartilage formed from these centres fuse, and eventually extend ventrally to fuse with their fellows of the opposite side, in the median plane. Chondrification is completed comparatively late, and when incomplete it results in the formation of an abnormality-the thyreoid foramen. The superior cornu of the thyreoid cartilage is at first continuous with the greater cornu of the os hyoideum, and the remains of this cartilaginous connexion is seen in the presence of the cartilago triticea in the lateral hyothyreoid ligament of the adult.

The pro-cartilaginous rudiments of the cricoid and arytænoid cartilages are at first continuous with each other, but later become differentiated by the appearance of separate cartilaginous centres for the arytænoids, and an incomplete ring, for a time deficient dorsally, for the cricoid. The cricoid thus resembles developmentally a tracheal ring, with which it probably corresponds morphologically. Chondrification proceeds in the cricoid by two centres, one on each lateral side. These centres unite ventrally, but dorsally fusion does not take place until much later, and is finally completed by an extension of chondrification from the lateral into the dorsal plate. The cricoid thus differs from the tracheal ring, in having its chondrification completed dorsally, whereas this never takes place in the tracheal ring.

The arytrenoid, cartilages are, as stated, at first continuous with the cricoid cartilage by fibrous tissue, but become eventually completely separated from it by the appearance of one chondrification centre for each arytænoid.

The corniculate cartilages (Santorini) are merely portions of the arytænoid cartilages separated off by segmentation; whilst the cuneiform cartilages (Wrisbergi) are, as previously stated, derivatives of the epiglottic cartilage.

The Trachea. - The trachea is developed from the intermediate portion of the median longitudinal groove. Originally, both this portion of the primitive respiratory tube and the œsophageal portion of the primitive alimentary canal were of equal length; but as development proceeds both tubes lengthen, the latter more rapidly than the former, so that eventually the lung rudiments no longer lie on the ventral and lateral sides of the primitive stomach, but come to lie on the cephalic side of that viscus, and are separated from each other by the csophagus dorsally and the heart and pericardium ventrally. In this way, that is by unequal growth, it comes about that the trachea in the adult is shorter than the œsophagus, though originally both were of equal length.

The cartilaginous rings of the trachea are developed like the cricoid cartilage, with the difference that in the trachea the process of chondrification does not extend into their dorsal portions, and hence, in the adult, the $\mathrm{C}$-shaped rings of the trachea are deficient dorsallyan arrangement which admirably adapts itself to the functional uses of both trachea and œsophagus. 
The Lungs.- The lungs are developed from the two diverticula of the caudal end of the median longitudinal groove and the mesodermal tissue into which these grow. Originally single, this caudal end soon becomes bilobed and ponches out on each side into two lateral diverticula, which represent the primitive bronchi and lungs. From the first the right pulmonary diverticulum or vesicle is slightly the larger of the two. Both diverticula elongate, and almost immediately undergo a subdivision-the right into three vesicles, and the left into two resicles-thus early indicating the three lobes of the right lung and the two lobes of the left lung. As the primitive respiratory tube lies in the median plane in the dorsal attachment of the septum transversum, the pulmonary diverticula grow laterally and dorsally into the dorsal parietal recesses, that is into the future pleural cavities, carrying before them a covering of mesoblast. From this mesoblast are derived the blood-vessels and other tissues which build up the lung, whilst the entodermal cells which form the lining membrane of the primitive respiratory tube eventually develop into the epithelial lining of the air-passages, and are embedded within the surrounding mesoderm. The main entodermal subdivisions continue to branch and re-branch, pushing their way into the pulmonary mesoblast, until the complete bronchial tree is formed.

The primary pulmonary diverticula increase in size and complexity as additional outgrowths arise by the subdivision of the enlarged terminal part of each diverticulum. Their mode of subdivision is very characteristic, and from the first the various branches are bulbous or flask-shaped at their extremities. These bifurcate, and although at first the two main subdivisions appear, in each case, of equal importance, one grows out as the continuation of the main bronchial stem-the future hyparterial bronchus-whilst the other remains as a branch. When the ramification of the entudermal tubes into the lung-mesoderm is complete, the small terminal flask-shaped extremities of the various branches represent the atria of the lung.

This repeated bifurcation results, as just stated, in the formation of a main bronchus which traverses the entire length of the lung, and into which numerous secondary bronchi open. The latter, from the manner in which they arrange themselves around the main stem of the pulmonary artery, are divided into dorsal and ventral. These alternate with each other, and usually number four in each series; not infrequently the third dorsal bronchus fails to develop. In the left lung the first dorsal bronchus arises, not from the main tube as on the right side, but from the first ventral bronchus-an arrangement which probably results from the fusion on the left side of the superior and middle lobes of the left lung into one, namely, the so-called lobus superior of the adult left lung.

The secondary bronchi elongate, and give rise to the tertiary bronchi, and these in turn to lesser bronchi, and so on down to the terminal bronchi, with their atria, air-sacs, and air-cells of the lung-muit. At first the lung-unit is devoid of air-cells, but between the sixth month and full term the alveolar saccules and air-cells make their appearance on the alveolar ducts; and it is thus clear that the epithelial lining of the entire system of bronchial subdivisions and ramifications is derived originally from the entodermal lining of the primitive foregut. By the close of the fourth month of fœtal life the columnar cells lining the trachea and bronclii have become ciliated.

At first the diverticula of the respiratory tube are surrounded by thick masses of mesoblastic tissue, but as development proceeds the latter fails to keep pace with the former, and hence the mesoblastic tissue becomes greatly reduced in amount and in thickness. Coincidently, this mesoblast becomes vascularised, and thus rich plexuses of blood-vessels come to surround the terminal divisions of the epithelial tubes-an arrangement obviously adapted to the interchange of gases from air to blood and vice versa.

The rudiments of the developing lungs grow dorsally on each side of the oesophagus into the fissure-like portion of the colom which occupies the thoracic region. They push before them the endothelial lining of the cœlom, and thus come to acquire their covering of pulmonary pleura. By the development of the diaphragm and the pericardium the pleural portions of the colom become cut off from the peritoneal cavity and from each other. 



\title{
THE DIGESTIVE SYSTEM.
}

\author{
Retised AND LARgely Rewrittex
}

By David Waterston.

\section{APPARATUS DIGESTORIUS.}

The Digestive System.-The physical characters and the chemical composition of much of the food taken into the body are such that it cannot at once be utilised by the organism. Before it can be absorbed and used in nutrition it requires to be acted upon, both chemically and mechanically. The performance of these mechanical and chemical changes is known as digestion.

The term apparatus digestorius (digestive system) is applied collectively to the organs which are concerned in this process, in the reception of food into the body, and in the excretion of the undigested or unabsorbed residue.

The simple form of digestive system which is found in many of the lower animals consists of a hollow tube, passing through the interior of the body, from an anterior or mouth aperture, to a posterior or anal orifice. The wall and lining membrane of the tube are so constructed as to act mechanically and chemically upon the food in its interior.

In man, a tube of this kind forms the basis of the digestive system. It extends from the mouth through the neck, thorax, abdomen, and pelvis to the anal orifice. But the tube, originally simple, has become modified, in different directions in different parts, for the performance of the various stages of the complex processes of digestion, absorption, and excretion.

The principal modifications which it has come to present are the following:-

(1) The tube is very greatly elongated, so that its total length measures from seven to eight times the length of the trunk. This is effected by the tube being thrown into folds or coils, especially in that part known as the small intestine.

(2) Certain portions of the wall of the tube have become modified in structure for the performance of special digestive changes. Thus in the month there are found the teeth and tongue, for mastication or triturition of food and for deglutition, or swallowing. Further on in the course of the tube is found a dilated chamber, the stomach, in whose wall special glands, called gastric glands, are present, which produce the gastric juices; while in the succeeding portion, or small intestine, are found the villi-very numerous papillary projections of minute size, whose function is largely that of absorption.

(3) Certain special accumulations or masses of glandular tissue, producing secretions useful in digestion, are found situated altogether outside of the wall of the tube, but communicating with its interior by neans of ducts, through which these secretions are conveyed.

The chief of such masses of glandular tissue are the salivary glands, which aré placed in the head and neck, and communicate with the mouth; and the liver and pancreas, which lie in the abdomen, and are connected with the duodenum.

These glandular masses, though lying exterial to the wall of the tube, have been developed as outgrowths from it, and the ducts represent the stalks of connexion. 
The digestive system, then, may be considered to present the following parts :I. The alimentary canal, or digestive tube.

II. Special organs, found in the wall of this canal.

III. Accessory glands, placed external to the wall of the tube.

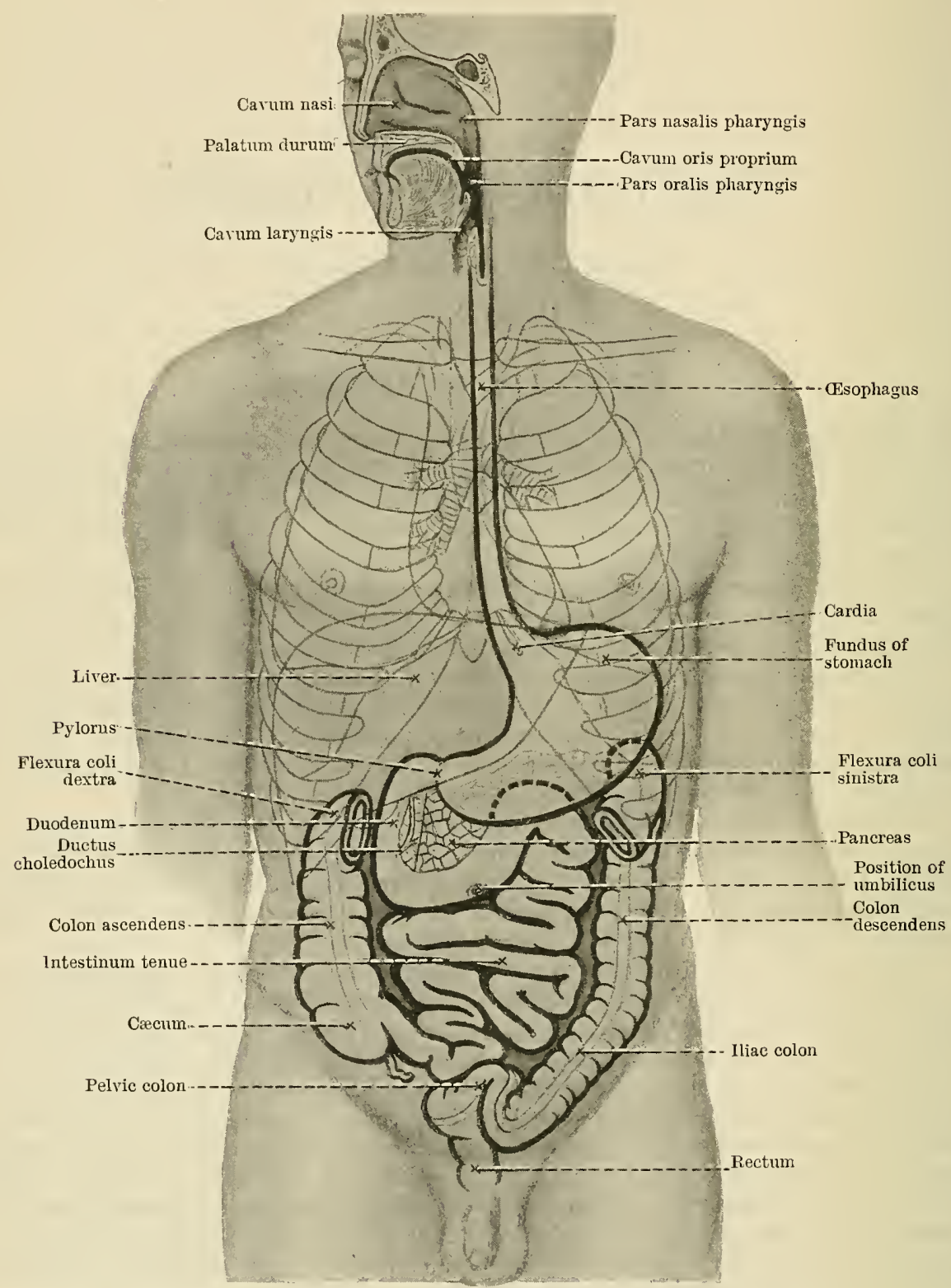

Fig. 873. -Diagram of the General Arrangeuent of the Digestive System.

The processus vermiformis is seen hanging down from the cæcum. The transverse colon is not represented, in order that the duodenum and pancreas, which lie behind it, may be seen.

The greater part of the digestive system is found in the abdomen, and hence, in this section, the abdominal cavity, together with its lining membrane the peritoneum, falls to be described.

I. Alimentary Canal.-The alimentary canal, taken as a whole, measures, when fully extended, about 30 feet (9 metres) in length, and consists (Fig. 873) of the 
following parts in order:-mouth, pharynx, œsophagus, stomach, small and large intestines. The term tubus digestorius is applied to the whole of the canal below the lower end of the pharynx. The mouth cavity is the first division of the tube. It is separated from the nasal cavities above by the palate, and opens posteriorly into the pharynx. This latter is an expanded portion of the canal lying posterior to the mouth, nasal cavity and larynx, the mouth opening into it through the isthmus of the fauces, the nasal cavity through the choanæ (O.T. posterior nares); whilst lower down, immediately below the base of the tongue, the aperture of the larynx is found in its anterior wall. Opposite the lower border of the larynx, the pharynx is continued into the cesophagus, a long and comparatively straight portion of the digestive tube, passing through the neck and thorax to the abdomen, which it reaches by piercing the diaphragm. Immediately after entering the abdomen the tube expands into a pear-shaped dilated chamber, the stomach. This is followed by over 20 feet of small intestine, the junction of the two being marked by a constriction, the pylorus. The small intestine presents three more or less arbitrary divisions-namely, (a) the duodenum, a part about 10 inches in length, curved somewhat like a horse-shoe, and closely united to the posterior abdominal wall; $(b)$ the jejunum, which includes the upper two-fifths, and (c) the ileum, the lower three-fifths of the small intestine beyond the duodenum. The jejunum and ileum are connected to the posterior abdominal wall by the mesentery, a fan-shaped fold of connective tissue covered by the peritoneum, or lining membrane of the abdominal cavity.

The terminal part of the ileum opens into the side of the large intestine,

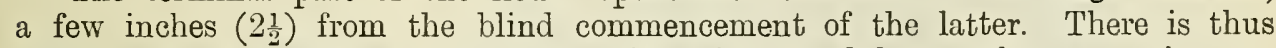
formed at the beginning of the great intestine a cul-de-sac, the cæcum, in connexion with which is found a small worm-shaped diverticulum, the vermiform process.

The orifice through which the ileum opens into the large intestine is guarded by the valve of the colon (O.T. ileo-cæcal valve), which prevents the return of its contents from the large into the small bowel. After the creum comes the ascending colon, which runs up in the right side of the abdomen. This is succeeded, in order, by the transverse colon crossing from right to left, the descending colon running down on the left side of the abdomen, and the iliac colon, lying in the left iliac fossa. Beyond this are the pelvic colon, which lies in part or entirely within the pelvis minor (O.T. true pelvis), the rectum, and the anal canal.

The rectum lies within the small pelvis, and the anal canal, the terminal part, is a short channel passing between the muscles which form the pelvic floor, to open on the surface at the anal orifice.

The term colon sigmoideum includes the portion named above as pelvic colon, and the term colon descendens the descending and iliac colon.

II. Special Organs found in the Wall of the Tube.-In the mouth are found the teeth, gums, tongue, and behind them, in the pharynx, are the palatine tonsils. The teeth, 32 in number in the adult, are portions of the mucous membrane of the mouth and of the subjacent tissue, calcified on the surface, and specially formed for mastication, that is, the division and triturition of the food which take place in the mouth before the bolus, as the resulting mass is termed, can be swallowed. They are rooted in the jaws and partly surrounded by the gums.

The tongue is a muscular organ, useful alike in mastication, deglutition, and speech. It is covered by epithelium, which in places is modified so as to form taste corpuscles, which are the end organs of the gustatory sense.

The roof of the mouth is formed by the palate, which separates the mouth from the nose. It consists of a bony part in front called the hard palate, and a movable sheet called the soft palate behind.

The palatine tonsils are two large masses of lymph tissue, found one on each side of the wall of the pharynx, just posterior to the mouth. They form the most prominent portions of an almost complete ring of lymph tissue placed around the circumference of the tube at this level. 
III. Accessory Digestive Glands.-The largest of these is the liver (hepar), which occupies the upper and right portion of the abdominal cavity, immediately below the diaphragm, and its secretion-the bile-is conveyed into the duodenum by the bile duct (ductus choledochus). The pancreas, next in size, lies across the front of the vertebral column, with its right end or head resting in the concavity of the duodenum, into which its secretion flows through the pancreatic duct. The salivary glands consist mainly of three large paired glands, parotid, submaxillary, and sublingual (glandula parotis, submaxillaris, and sublingualis), and their ducts, which convey the saliva, open into the mouth. The saliva is a mechanical lubricant, which facilitates swallowing and the movements of the tongue in speaking and masticating, and also plays an important part in the chemical processes of digestion.

\section{CAVUM ORIS.}

1. Parts.-Rima oris, vestibulum oris, cavum oris proprium.

2. Boundaries.-1. Labia oris-their structure.

2. Buccæ-their structure.

3. Palatum, palatum durum, palatum molle-arrangement and structure.

4. Isthmus faucium.

3. Structures found in the Mouth.-Gingivæ, gums.

Dentes, teeth.

Lingua, tongne.

4. Glandulæ oris, buccal and salivary glands.

The mouth is the upper expanded portion which forms the first division of the alimentary canal. It lies between the maxillæ and mandible, bounded externally by the lips and the cheeks, and roofed in by the palate. It contains the teeth and greater part of the tongue; and the ducts of the salivary glands open

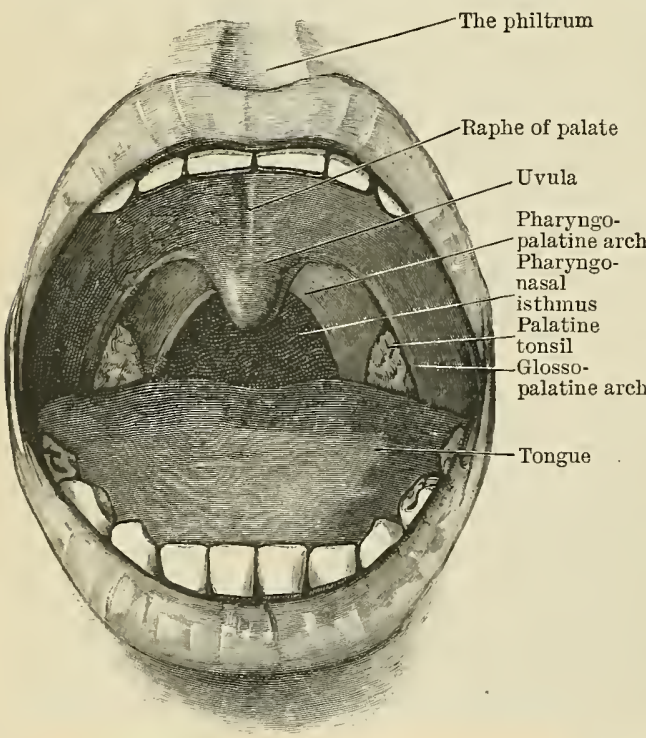

Fig. 874. - Open Modth SHowing Palate aND PalatiNe ToNsils.

It also shows the two palatine arches, and the pharyngonasal isthmus through which the naso-pharynx above communicates with the oral portion of the pharynx below. into it. The cavity is divisible into two portions, the vestibule and the cavity proper of the mouth. These are separated from one another by the alveolar ridges, gums, and teeth of the maxillæ and mandible. The cavity of the mouth narrows at the back to a slight constriction, marked by a vertical fold on each side, called the arcus glosso-palatinus (O.T. anterior pillar of the fauces), and between them the cavity of the mouth is continuous with that of the pharynx.

Rima Oris.-The aperture of the mouth is bounded above and below by the corresponding lips, which, by their junction at the sides, form the labial commissures. In a state of rest, with the lips in apposition, the rima appears as a slightly curved line, corresponding in length to the interval between the first premolar teeth, and in level to a line drawn across just below the middle of the upper incisor crowns. The shape of the rima varies with every movement of the lips, from the resting linear form, curved like the conventional bow, to a circular or oval shape when the mouth is widely open, or the "pursed-up" condition produced by the contraction of the orbicularis oris muscle.

Vestibulum Oris.-The vestibule of the mouth lies immediately internal to the 
aperture of the mouth. It is that portion of the cavity which occupies the interval between the lips and cheeks externally, and the teeth and gums internally.

In the normal resting condition, when the mouth is closed and the lips and the teeth are in contact, its cavity is practically obliterated by the meeting of its walls, and it becomes merely a slit-like interval, with a narrow roof and floor formed by the reflection of the mucous membrane, from the deep surface of the lips and cheeks to the corresponding gum. This reflection is interrupted in the median plane by a small but prominent fold of the mucous membrane, the frenulum, which connects the back of each lip to the frout of the gum. The upper frenulum is the better developed, and is readily brought into view by everting the lip. The frenulum of the lower lip is not always present.

On the outer wall of the vestibule, opposite the crown of the second upper molar, upon a variably developed eminence, is placed the small opening of the duct of the parotid gland, which conveys the saliva from the parotid gland to the mouth.

When the teeth are in contact the vestibule communicates with the cavity of the mouth only through the small and irregular spaces left between the opposing teeth, and posteriorly, on either side, by a wider but variable aperture between the last molars and the ramus of the mandible.

Advantage is some-

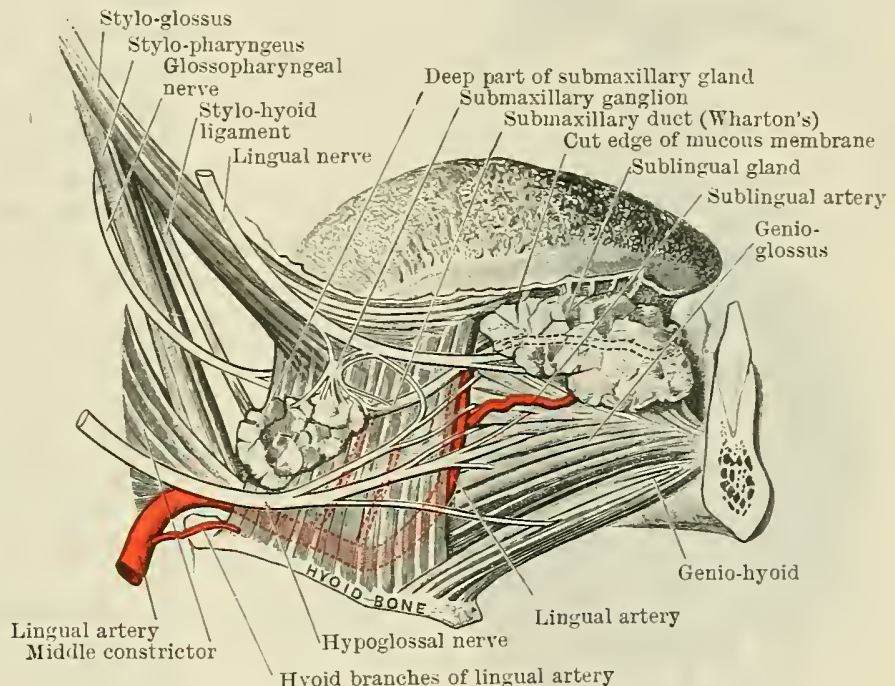

Fig. 875.-Dissection of Stbmaxillati Regiox. times taken of the presence of this aperture for the introduction into the cavity of the month of liquid food in certain cases-trismus, anchylosis, etc-in which the jaws are rigidly closed.

On the outer wall of the vestibule, the anterior border of the masseter can be distinctly felt with the finger, when the muscle is thrown into a state of contraction. Still further back, the front of the coronoid process, bearing the lower part of the insertion of the temporal muscle, can also be made out. The spheno-mandibular ligament, which corresponds to, and is felt along with, the anterior border of the internal pterygoid muscle, is distinguishable as a pliant ridge when the finger is carried from the front of the coronoid process behind the last molar tooth into the cavity of the mouth.

In addition to the duct of the parotid, the dncts of numerous small glands which are embedded in the lips and cheeks open into the restibule.

Under normal conditions, as pointed out above, the lips and cheeks lie against the teeth and gums, obliterating the cavity of the vestibule, and helping, with the aid of the tongue, to keep the food between the grinding surfaces of the molar teeth during mastication. In facial palsy, however, owing to the paralysis of their muscles, and particularly of the buccinator muscle, the lips and cheeks fall away from the dental arches, and allow the food to pass out from between the teeth and to accumulate in the vestibule.

Cavum Oris Proprium.-The cavity proper of the mouth is the space situated within the dental arches, extending backwards to the glosso-palatine arches (O.T. anterior pillars of the fauces). Its boundaries consist of a roof, a floor, and a margin, formed by the teeth and gums. The roof is formed by the hard palate and the anterior portion of the soft palate, while the floor is formed by the anterior part of the tongue in the middle, and on each side by the reflection of the mucous membrane from the side of the tongue to the mandible.

On each side of the tongue, and in front of it, when it is at rest, there is only a slit or sulcus between the tongue and the gums, into which the ducts of the submaxillary and sublingual glands open. 
If, however, the tongue is raised, there is exposed a limited space, to which the term sublingual space is more usually applied (Fig. 876).

The term "floor of the mouth," or sublingual region, is frequently applied to the muscular and other structures, especially the mylo-hyoid muscles, which fill in the interval between the two halves of the body of the mandible. These structures, with the hyoid bone, form the basis upon which the tongue and the mucous membrane of the sublingual space are supported, and they extend from the symphysis menti in front to the body of the hyoid bone behind.

The sublingual region (Fig. 876) is covered by the mucous membrane between the deep surface of the gum and the inferior aspect of the tongue. When the tip of the tongue is raised the membrane forms in the median plane a prominent fold,

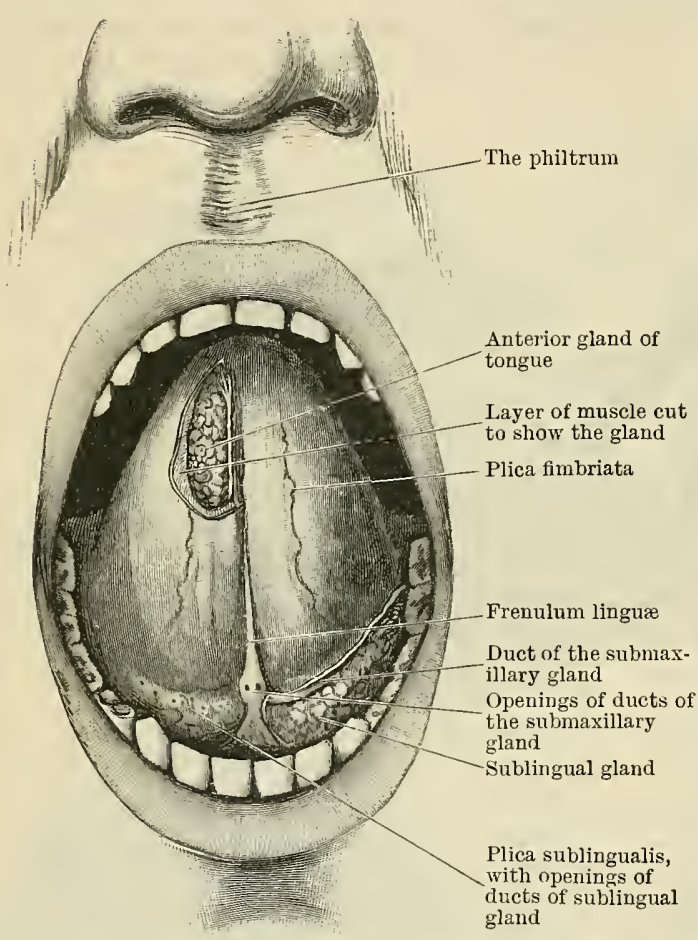

Fig. 876.--Open Modth with Tongue raised, AND the Sublingual and Anterior Glands exposed.

The sublingual gland of the left side has been laid bare by removing the mucous membrane; to expose the anterior lingual gland of the right side a thin layer of muscle, in addition to the mucous membrane, has been removed. A branch of the lingual nerve is seen running on the medial aspect of the gland. The profunda vein is faintly indicated on this side also.

the cavum oris can be increased to a considerable size even by the simulan the teeth are in contact. Finally, the soft plateons descent of the mandible and hyoid bone with the tongue, and the ascent of

Labia Oris.-The lips are the two movable folds, covered superficially by skin, and on their deep surface by mucous membrane, which surround the rima oris. The meeting of the lips at each side constitutes the commissure, and bounds the (angulus oris) angle of the mouth. Laterally they are prolonged into the cheeks, with which they are continuous. The junction of the lips and cheek is marked on the surface by the sulcus naso-labialis, which passes downwards and laterally from the margin of the nose towards the angle of the mouth, while the sulcus mento-labialis separates the lower lip from the chin. The upper lip presents on its superficial surface a well-marked vertical groove, the philtrum, bounded by two distinct ridges descending from the columella nasi (Fig. 876); inferiorly the groove 
widens out, and terminates opposite a slight projection-the labial tubercle-on the free edge of the upper lip. This tubercle is particularly well developed in children, and is chiefly responsible for the characteristic curve of the rima oris. The lower lip is usually longer and more mobile than the upper lip.

For the manner in which the various muscles enter into the formation of the lip, see section on the Muscles (pages 450 to 451 ).

The lips include within them the greater part of the orbicularis oris muscle, which surrounds the aperture of the mouth, and in each lip the following series of structures can be recognised from the external to the internal surface:-(1) The skin, which is closely beset with hairs, small and fine in the child and female, long and stout in the adult male. (2) A layer of fatty superficial fascia continuous with the fascia of the face generally. (3) The orbicularis oris muscle, continuous at its periphery with the various muscles converging towards the mouth. A number of its fibres, or those of the muscles joining it, pass through the superficial fascia and are attached to the skin, thus establishing a close connexion between the skin and the muscle. (4) The submucous tissue, which is occupied by an almost continuous layer of racemose glands-the labial glands. These open into the vestibule, and their secretion is said to be mucous. (5) The mucous membrane of the mouth, covered by stratified squamous epithelium. Between the orbicularis and mucous membrane, but nearer to the former, that is, in the deeper part of the submucosa, the labial artery is found a short distance from the free margin of the lip, running to meet its fellow of the opposite side.

The free margin of the lip is covered by a dry and otherwise modified mucous membrane. It begins where the integument changes colour at the outer edge of the lip, and ends posteriorly just behind the line along which the two lips meet when closed, where it passes into the ordinary moist mucous membrane of the vestibule. It presents numerous simple vascular papillæ, and its nerves terminate in special end organs, hence the acute sensitiveness of this part. In the child, at birth, the margin of the lip is divided by a very pronounced groove or fissure into an outer and an inner zone, differing considerably in their appearance.

When the tongue is pressed firmly against the back of the lips and moved about, the labial glands can be distinctly felt through the mucous membrane, giving the impression of a knobby or irregular surface. The glands, which are about the size of hemp-seeds and can be readily displayed by removing the mucous membrane, are more numerous in the lower than in the upper lip. Stoppage of their ducts, with the resulting distension of the glands, gives rise to "mitcous cysts," a well-known pathological condition.

Blood-vessels, Nerves, and Lymph-vessels.-The lips receive a free blood stupply, the lower lip from the inferior labial, and the upper from the superior labial branches of the external maxillary artery.

The nerve supply of the lips is derived from the trigeminal nerve, that of the upper through the infra-orbital branch of the maxillary division, and that of the lower from the mental branch of the inferior alveolar branch of the mandibular division, while the buccinator branch of the mandibular division supplies the region of the angle. The lymph-vessels of the upper lip pass with the external maxillary artery to the submaxillary lymph-glands lying in the submaxillary triangle, while those from the lower lip pass in part to the same glands, and in part to the submental glands lying on the mylo-hyoid muscles, above the hyoid bone.

Buccæ.-The cheeks resemble the lips in structure, being formed of corresponding layers, but the place of the orbicularis oris muscle is taken by the buccinator muscle. They are covered externally by the skin and internally by the mucous membrane. Under the skin lies the fatty superficial fascia of the face, through which the parotid duct (O.T. Stenson's duct) runs inwards to pierce the buccinator. Here too are placed some of the muscles of facial expression. Near the end of the duct are found four or five mucous glands, as large as hemp-seeds. These are known as the molar glands; their ducts pierce the cheek and open into the vestibule. Beneath the superficial fascia lies the buccinator muscle, covered by the thin bucco-pharyngeal fascia. Deeper still is the submucosa, which, like that of the lips, coutains numerous racemose buccal glands. And finally the mucous membrane is reached (Fig. 876).

An important constituent of the cheek of the infant is the corpus adiposum buccæ (O.T. sucking pad), an encapsuled mass of fat, distinct from the surrounding superficial fascia, which lies on the onter side of the buccinator, and passes backwards into the large recess between that innscle and the overlying anterior part of the masseter. This fatty mass, which is relatively more 
dereloped in the child than in the adult, strengthens the cheek, and helps it to resist the effects of atmospleric pressure during the act of sucking. In the adult the remains of the pad can be distinctly made out under the anterior border of the masseter.

Some small superficial lymph-glands lie on the superficial surface of the buccinator, communicating with the vessels of the lips, while their efferent vessels pass onwards towards the parotid region.

Palatum.-The palate forms the roof of the mouth, and separates the mouth from the nasal cavities and nasal part of the pharynx.

It is not confined to the mouth, but extends backwards also into the cavity of the pharyux, forming the division between the oral and the nasal pharynx. It terminates behind in a free conical projection, the uvula. It consists of two distinct portions, an anterior, forming the anterior two-thirds, which has a bony foundation (palatine processes of the maxillæ and the horizontal parts of the palatine bones), and a posterior, forming the posterior third, with a fibrous basis ; and they are termed the hard and the soft palate respectively. The palate is arched antero-posteriorly, and also transversely. The latter curvature is the more pronounced in the hard palate, but the shape and curvature of this portion depend upon the configuration of its bony foundation.

The hard palate is, on the whole, horizontal in direction, both transversely and anteroposteriorly. The soft palate is, on the other hand, during rest, as, for instance, in quiet nasal breathing, very oblique in direction, and it shuts off the mouth from the nasal and largely from the oral parts of the pharynx. When, however, the soft palate is raised by the action of its muscles, it more nearly continues backwards the plane of the hard palate, and it projects across the cavity of the pharynx, forming a nearl $\Gamma$ complete partition between the oral and the nasal parts of the pharynx. In this position it prevents food from passing upwards into the nasal part of the pharyux and nose.

Traversing the middle of the palate is seen a faint central ridge or raphe (Fig. 877), indicating its original development from two lateral halves. This raphe is continued posteriorly along the soft palate to the base of the uvula, and in front it ends in a slight elevation, the papilla palatina (O.T. incisive pad). From the anterior end of the raphe a series of transverse ridges of mucous membrane, about six in number, run laterally, just behind the incisor teeth; they are known as the plicæ palatinæ, and are composed of dense fibrous tissue. Sometimes a small pit, which will admit the point of a pin, is seen on each side immediately posterior to the central incisor teeth, and about $2 \mathrm{~mm}$. from the median plane. These pits correspond to the inferior openings of the incisive canals, with which they are occasionally continuous.

Palatum Durum, - The hard palate consists of a horizontal plate formed by the palatine processes of the maxillæ and the horizontal parts of the palatine bones,

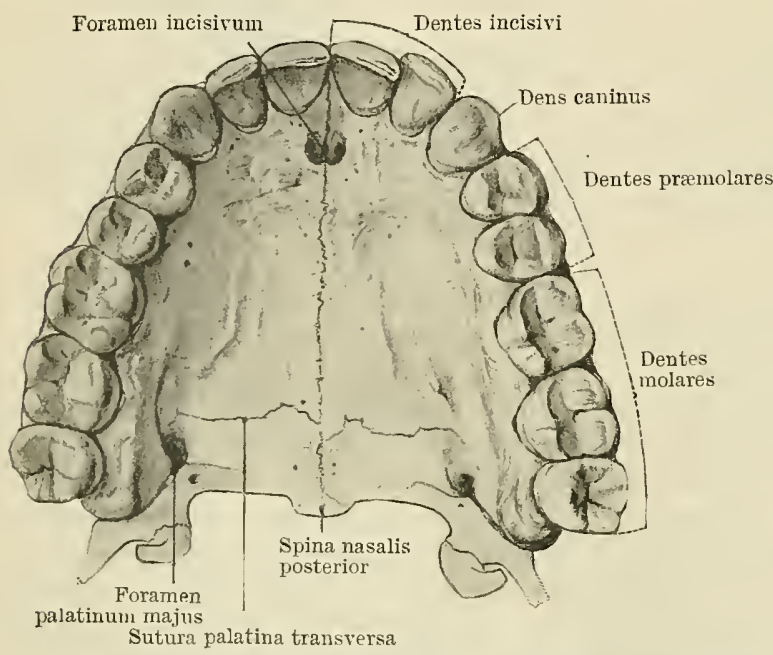

Fig. 877. - The Hard Palate and Upper Permanent Teeth, SEEN FROM BELOW. covered on eachsurface,superiorand inferior, by periosteum. The periosteum of the inferior surface is thick, and is in turn covered by a quantity of dense fibrous tissue firmly united both to the periosteum and to the mucous membrane. This dense tissue contains in its posterior half a large number of racemose palatine glands, and it also contains the larger nerves and blood-vessels of the palate. The mucous membrane covering the superior surface is largely ciliated in character, and forms the floor of the nasal cavity, while that on the inferior surface is a stratified squamous epithelium.

Palatum Molle.-The soft palate is attached anteriorly to the posterior margin of the hard palate. Its lower and posterior margin is free, and forms an arch, extending from one side of the pharynx to the other, but the arch is interrupted 
in the centre by the conical projection of varying size called the uvula, which hangs down from its inferior margin. Laterally the soft palate is intimately connected on each side with two prominent folds, called the palatine arches. The exact relationship of the soft palate to these is as follows. The free posterior margin of the soft palate passes into the pharyngo-palatine arch (O.T. posterior pillar of the fauces), which passes downwards for some distance on the lateral wall of the pharynx.

The glosso-palatine arch (O.T. anterior pillar of the fauces), on the other hand, passes below into the side of the tongue. Traced upwards, it runs on to the inferior surface of the soft palate, and is continuous with the margin of the uvula.

The two palatine arches on each side are $7-8 \mathrm{~mm}$. apart, and on the lateral wall between each pair is a fossa or depression which is occupied in part by the palatine tonsil. This region belongs properly to the pharynx, and will be described in detail when that part is dealt with, but at the present stage the relation of this fossa of the tonsil to the soft palate should be carefully noticed.

The superior surface of the soft palate forms a continuation backwards and downwards of the floor of the nasal cavity, and constitutes the floor of the nasal part of the pharynx. It is covered by a prolongation of the nasal mucous membrane, partly ciliated in character. The inferior surface is arched, and forms the backward prolongation of the roof of the mouth.

In the fœtus the whole of the epithelial covering of the soft palate is ciliated, but after birth the ciliated epithelium is largely replaced by stratified squamous epithelium, except at the margin of the palate.

Structure.-The framework of the soft palate is formed of a strong fibrons sheet, called the palatine aponenrosis. To it several muscles are attached. These structures, together with fibrous tissue, gland-vessels, and nerves, are covered by mucous membrane on each surface.

The palatine aponenrosis, which is confined to the anterior part of the soft palate, is in the form of a thin flat sheet, constituting a common tendon for the palatine muscles which are attached to (or blended with) its posterior margin. Its anterior margin is united to the posterior edge of the horizontal parts of the palatine bones. With the exception of the aponeurosis of the tensor veli palatini which passes into its lateral part, the muscles do not, as a rule, reach further forwards than to within 8 or $10 \mathrm{~mm}$. of the posterior edge of the hard palate.

The muscles entering into the formation of the soft palate are the $\mathrm{mm}$. pharyngo-palatini, uvulæ, levatores veli palatini, tensores veli palatini, and glossopalatini. For the details of the attachments and arrangement of these muscles, see p. 466.

The anterior part of the soft palate for $S$ or $10 \mathrm{~mm}$. ( $\frac{1}{3}$ in.) contains practically no muscular fibres; it is composed of the palatine aponeurosis, covered by an extremely thick layer of glands on the inferior surface and by mucous membrane on both surfaces. This anterior portion is much less movable than the rest of the soft palate, and forms a relatively horizontal continuation backwards of the hard palate, stretching across between the two medial pterygoid laminæ. It is upon this portion chiefly that the tensor veli palatini muscles act. The posterior and larger part contains muscular fibres in abundance, slopes strongly downwards, and is freely movable, being the portion upon which the remaining palatine muscles act.

The mucous membrane of the inferior surface of the palate, which is covered by stratified squamous epithelium, is firmer and more closely adherent in front, near the rugæ, than behind, near the soft palate.

Mucons glands, the orifices of which can be seen as dots with the naked eye, are extremely abundant in the soft palate, and in the posterior half of the hard palate, except near the raphe. They are wanting in the anterior part of the palate, where the mucous membrane is particularly dense.

The plicæ palatinæ (which correspond to more strongly developed ridges in carnivora, etc.) are very well marked in the child at birth, althongh, perhaps, relatively less distinct in the foetus of five or six months; in old age they become more or less obliterated and irregular. At birth, also, and in the foetus, the incisive pad at the anterior end of the raphe is continned orer the edge of the gum into the frenulum of the upper lip.

The uvula, already referred to, is a conical projection, very variable in length, which is continued downwards and backwards from the middle of the posterior border of the soft palate. It is composed chiefly of a mass of racemose glands and connective tissue corered by mucous membrane, and containing a slender prolongation of the uvular muscle in its upper part.

The vessels of the palate are :-

(1) Branches from the descending palatine artery, a branch of the internal maxillary artery.

Of these, some small vessels, the lesser palatine arteries, emerge from the foramina palatini 
ninora, and are distributed to the tonsil and palate, and anastomose with branches of the ascending pharyngeal artery.

The largest branch, greater palatine artery, emerges through the foramen palatinum majus, and runs forwards over the lateral margin of the hard palate, about $\frac{1}{4}$ in. from the alveolar margin, as far as to the foramen incisivum, where it anastomoses with the naso-palatine artery.

(2) Posterior nasal septal artery, a small vessel which enters through the foramen incisivum.

(3) Ascending palatine artery, from the external maxillary, which anastomoses by a ramus tonsillaris with the descending palatine.

(4) Branches from the ascending pharyngeal artery, which enter the soft palate.

(5) Branches from the rami dorsales linguæ of the lingual artery, which pass in the glossopalatine fold to the palate tonsil and soft palate.

The nerves are all derived from branches from the spheno-palatine ganglion.

(1) Nervi palatini. The most important of these is the nervus palatinus anterior, which passes through the foramen palatinum majus, and divides in the roof of the mouth into branches which rum in grooves on the hard palate, and extend forwards nearly to the incisor teeth.

The others are the nn. palatini medius and posterior, which emerge from the foramina palatina minora, and are distributed to the hard and soft palate.

(2) N. nasopalatinus (Scarpæ). This nerve sends branches to the palate through the foramen incisivum, which join with branches from the anterior palatine nerves.

For the motor nerves to the muscles of the soft palate, see p. 467 .

The lymph-vessels of the palate pass beside the tonsil and the isthmus of the fauces to the upper deep cervical lymph-glands.

Isthmus Faucium.-The isthmus of the fauces is the aperture through which the mouth communicates with the oral part of the pharynx (Fig. 878). It is

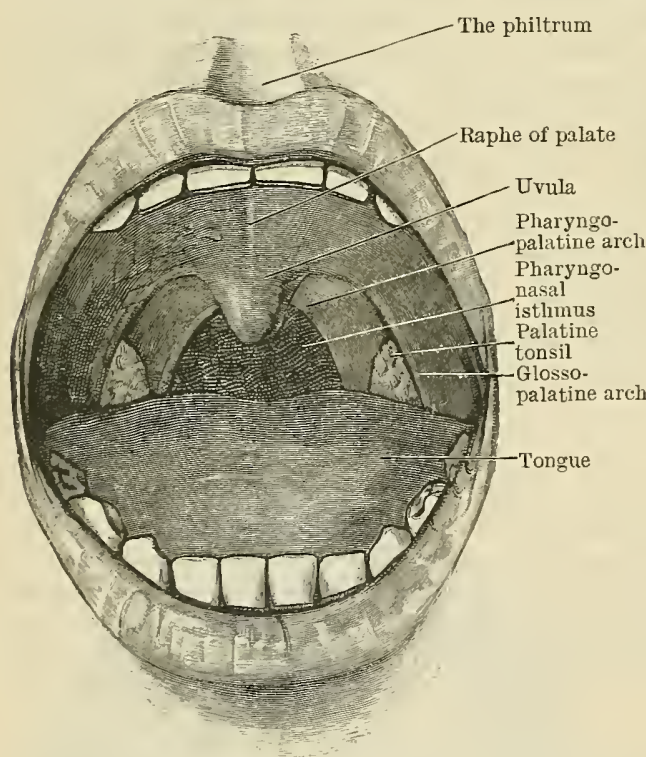

Fig. 878. - Open Motth showing Palate axd Palatixe ToNsils.

It also shows the two palatine arches, and the pharyngonasal isthmus throngh which the nasal part of the pharynx above communicates with the oral portion of the pharynx below. bounded at the sides by the glossopalatine arches, above by the inferior surface of the soft palate, and below by the dorsum of the tongue; in width it corresponds pretty closely to the cavum oris.

The arcus glosso-palatini (O.T. anterior pillars of the fauces) are two prominent folds of mucous membrane which bound the isthmus of the fauces laterally (Fig. 878). Each contains a glosso-palatine muscle in its interior. They are continuous above with the inferior surface of the soft palate, a little way (about $8 \mathrm{~mm}$.) anterior to its free edge, and near the base of the uvula, and they pass downwards and slightly anteriorly to join the tongue a little behind the middle of its lateral border.

The arcus pharyngo-palatini (O.T. posterior palatine arches) are two vertical folds of mucous membrane which pass from the soft palate to the side wall of the pharynx. Each contains a muscle, the pharyngo-palatinus. The pharyngo-palatine arches are described in connexion with the tonsil (p. 1145).

Gingivæ.--The gums are composed of the red firm tissue which covers the alveolar borders of the maxillæ and mandible, and surrounds the necks of the teeth. In structure they consist of dense fibrous tissue, inseparably united to the periosteum, covered by mucous membrane. They are richly supplied with blood-vessels, but sparsely with nerves, and are covered by stratified squamous epithelium. Around the neck-or more correctly the base of the crown -of each tooth, the gum forms a free overlapping collar, and at this part particularly it is closely beset with small papillæ, visible to the naked eye.

In thickness it usually measures from 1 to $2 \mathrm{~mm}$. 


\section{DENTES.}

Each tooth is a calcified papilla of the mucous membrane of the mouth, and consists like that membrane of two chief portions-namely, the substantia eburnea or ivory (O.T. dentine) derived from the connective tissue, and the substantia adamantina or adamant (O.T. enamel) from the epithelial layer of the mucous membrane. The substantia eburnea constitutes the chief mass of the tooth, whilst the substantia adamantina forms a cap for the portion which projects above the gum. There is also found in the teeth another special tissue-the substantia ossea (O.T. cement), a form of modified bone-encasing the roots, which are formed chiefly of substantia eburnea.

Both ivory and adamant, but particularly the latier, are the hardest and most resistant structures in the body, and are thus specially fitted for the functions which they have to perform.

Dentes Decidui and Dentes Permanentes (Deciduous and permanent teeth).-The mouth of the infant at birth contains no teeth, although a number, partly developed, lie embedded in the jaws beneath the gum. Some six months later, teeth begin to appear, and by the end of the second year a set, known as the deciduous teeth (O.T. milk teeth), twenty in number, has been "cut." Then follows a pause of about four years, during which no visible change takes

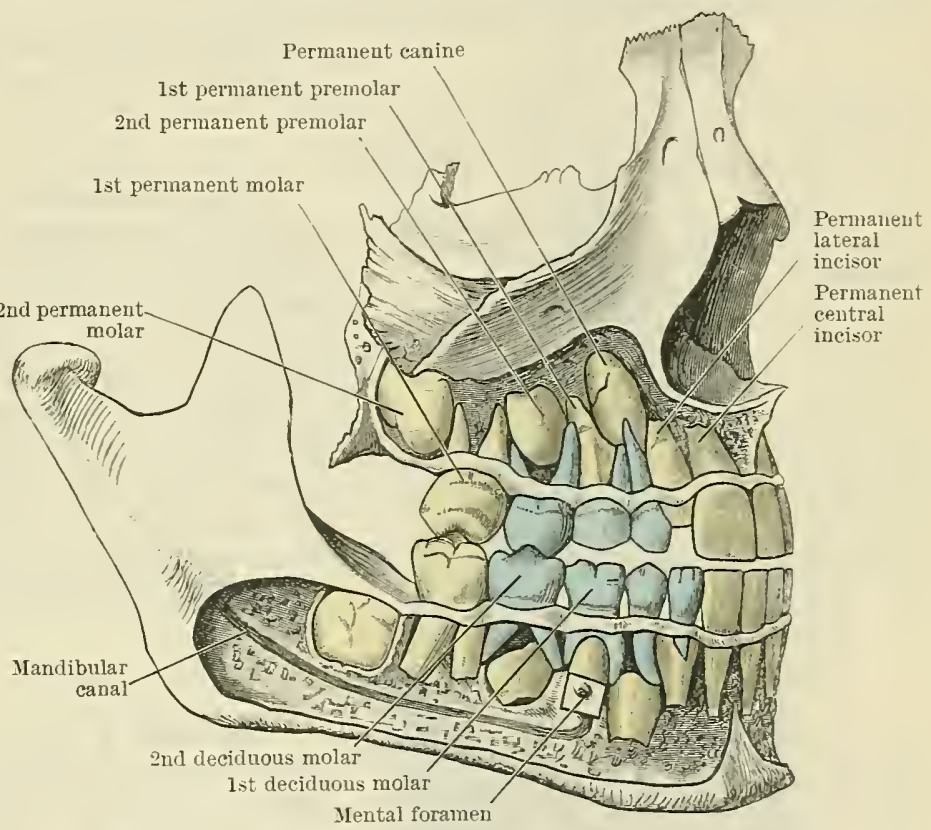

Fig. S79. - TeEth of a CHILd OVER SETEN YeARs old (modifiel from Testut).

By removing the bony outer wall of the alveoli, the roots of the teeth which have been erupted, and the permanent teeth which are still emhedded in the mandible and maxilla, have been exposed. The deciduous teeth are coloured blue, the permanent teeth yellow. It will be seen that the first permanent molars have appeared, the central and lateral deciduous incisors have been replaced by the corresponding permanent teeth in the maxilla, but the deciduous canine and molars have not yet been shed. In the mandible the central deciduous incisor has been replaced by the permanent central; the lateral has not yet been shed, but its permanent successor is making its way up to the surface on its lingual side. In addition, the canine and two molars of the decidnous set persist. The position of the crowns of the permanent teeth between the roots of the deciduous molars, and the deep situation occupied by the permanent canines, should be notecl. Observe also the absorption of the root of the lower lateral incisor.

place in the mouth, although in reality an active preparation for further development is going on beneath the gum.

At the end of this period, namely, about the sixth year, the next stage in the production of the adult condition begins. It consists in the eruption of four new teeth-the first permanent molars—one on each side, above and below, behind those of the deciduous set. This is followed by the gradual falling out of the twenty teeth which have occupied the mouth since the second year (Fig. 879), and the substitution for them of twenty new teeth, which take up, one by one, the vacancies created by the dropping out of each of the deciduous set. Finally, the adult condition is attained by the eruption of eight additional teeth-the 2nd and 3rd molarstwo on each side, above and below, behind those which have already appeared. All of these-the permanent teeth-have appeared by the end of the twelfth or thirteenth year, except the four dentes serotini (O.T. wisdom teeth), which are usually 
cut between the seventeenth and twenty-fifth year, but are often delayed until a very much later period, and occasionally never appear.

The set of teeth which, as indicated above, begin to appear in the infant about the sixth month, are known as the deciduous teeth (O.T. temporary, or milk teeth); whilst those which succeed them and form the adult equipment are the permanent teeth.

The deciduous teeth are twenty in number, and are named as follows in each jaw, beginning at the median plane :- dentes incisivi, or incisor teeth, central and lateral; dens caninus, or canine tooth; dentes molares, or molar teeth, first and second ; or more briefly, two incisors, one canine, two molars. This is conveniently expressed by the "dental formula" for the deciduous teeth in man, which shows the number

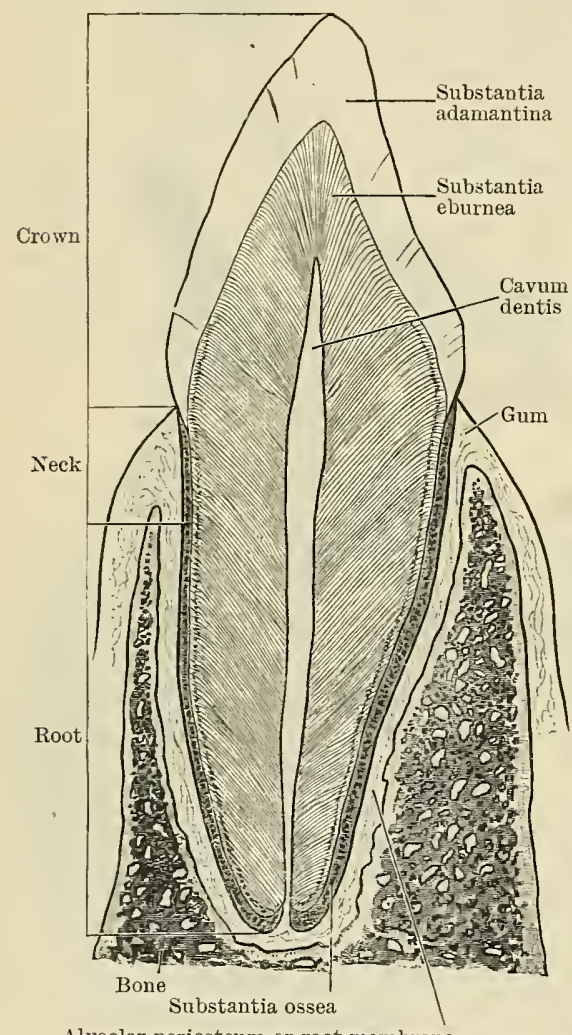

Alveolar periosteum or root-membrane

Fig. 880.--Vertical Section of Canine Tooth, to illustrate its various parts, and its structure. of each class of teeth above and below on one side of the mouth, viz: :-

$$
\text { i. } \frac{2}{2}, c \cdot \frac{1}{1}, m \cdot \frac{2}{2}=20 \text {. }
$$

The permanent teeth, thirty-two in number, are named dentes incisivi, or incisor teeth, a central and a lateral; dentes canini, or canine teeth; dentes præmolares, premolar (O.T. bicuspid) teeth; dentes molares, molar teeth; and are arranged as follows in each jaw, beginning at the median plane :-central incisor, lateral incisor, canine, 1st premolar, 2nd premolar, 1st molar, 2nd molar, and 3rd molar or dens serotinus (O.T. wisdom tooth). The dental formula for the permanent set in man is thus:-

$$
i . \frac{2}{2}, c . \frac{1}{1}, p m . \frac{2}{2}, m \cdot \frac{3}{3}=32 \text {. }
$$

General Form and Structure. $-A$ tooth consists (Fig. 880) of (1) the corona dentis or crown, the portion projecting above the gum. It varies in shape in the different teeth, and in all, except the incisors and canines, bears on its masticating surface a number of tubercles, the tubercula coronæ (O.T. cusps), varying in number from two to five in the different teeth; (2) the collum dentis or neck, the faintly constricted part surrounded collar-wise by the gum, which connects the crown with (3) the radix dentis or root, the portion of the tooth which is embedded in the alveolus of the jaw. In the majority of teeth, namely, in all except the molars, the root, as a rule, is single, or nearly so, and consists of a long, tapering, conical, or flattened piece, perfectly adapted to the alveolus in which it lies. In the molar teeth (and in some of the others occasionally) the root is divided into two or three tapering or flattened roots or fangs. At the apex of each root there can be made out, even with the naked eye, a minute opening, the foramen apicis, through which the vessels and nerves enter the tooth.

On making a section of a tooth (Fig. 880), it will be seen that the interior of the body is occupied by a cavity of some size, called the cavum dentis or tooth cavity, which is filled in the natural state by the soft and sensitive tissue known as the pulpa dentis or tooth pulp. The tooth cavity gradually narrows, and is prolonged into each root of the tooth as a slender tapering passage, the canalis radicis (root-canal), which opens at the apical foramen already referred to. Through these root-canals, which also contain some pulp, the vessels and nerves, which enter at the apex, pass to the interior of the tooth.

Short diverticula of the pulp cavity are prolonged into the bases of the tubercles 
in the molar and premolar teeth, and in the incisors also there are similar slight prolongations of the eavity towards the angles of the crown.

The roots of the teeth are embedded in the alveoli or sockets of the jaws, to which they are accurately adapted, and firmly united (Fig. 880) by a highly vascular layer of connective tissue-the periosteum alveolare. This is attached to the wall of the alveolus on the one hand and to the root of the tooth on the other, whilst above it is continuous with the connective tissues of the gum.

So accurately are the root and the alveolus adapted to each other over their whole extent, and so firmly does the periosteum bind then together, that, under normal conditions, the tooth is quite firmly fixed in the bone, and no movement of the root within the alveolus can take place; the vessels and nerves entering at the apex are thus secured against pressure or strain.

When, however, the alveolar periosteum is inflamed it becomes swollen and exquisitely sensitive; the tooth, as a result of the swelling, is pushed partly out of its socket, its crown projects above those of its neighbours, and strikes against the opposing tooth when the mouth is closed, giving rise to much pain and discomfort.

The neck, although the term is useful, can scarcely be recognised as a distinct constriction in the permanent teeth; it corresponds to the line along which the gum and alveolar periostenm meet, or along which the gum is united to the tooth; but, as already pointed out, the gum does not stop at the neck, but forms a free fold which surrounds the base of the crown collar-wise for a short distance. The ontline of the margin of the gum opposite the labial and lingual surfaces of the crown is usually concave, but opposite the contact surfaces of the tooth it is convex, and reaches much nearer to the edge of the crown than on the other surfaces.

In the incisors and canines the tooth cavity, which is about $\frac{1}{8}$ to $\frac{1}{4}$ the diameter of the tooth, passes very gradually into the root-canal (Fig. 880 ), so that it is difficult to say where one ends and the other begins. The reverse is the case in the molars, whilst the premolars are somewhat variable in this respect.

Tartar is a hard calcareous deposit from the saliva (salivary calculns), often found on the teeth near their necks. It is composed of lime salts, and its deposit is largely determined by the presence of organisms (leptothrix, etc.) in the mouth.

\section{DENTES PERMANENTES.}

The permanent teeth (Figs. 881 and 882) are thirty-two in number, sixteen above and sixteen below, or eight in each half of either jaw; and, although they can be grouped under four heads-incisors, canines, premolars, and molars-the individual teeth differ so much in their characters that each tooth requires a separate description.

Descriptive Terms.-Before describing the permanent teeth, it is requisite that certain terms which are employed to denote the surfaces of the teeth should be defined. This is a matter of some importance, seeing that the terms medial and lateral, anterior and posterior, cannot, owing to the curvature of the dental arches, be properly applied to all the teeth in the same sense. The terms given below have been adopted seeing that they are free from the danger of misconception.

The part of a tooth which comes in contact with the teeth of the opposite jaw is known as the facies masticatoria (grinding or masticating surface) (Fig. 883). The surface in contact with or looking towards its predecessor in the row is known as the facies medialis in incisors and canines, facies anterior in premolars and molars; the opposite surface, namely, that which looks towards its successor in the row, is known as the facies lateralis in iucisors and canines, facies posterior in molars and premolars. The surface which looks towards the tongue is the facies lingualis (lingual surface), and that looking in the opposite direction, i.e. towards the lips and cheek, the facies labialis (labial surface). The portion of a tooth which touches its neighbour in the same row is known as the facies contacta (contact surface).

Dentes Incisivi (Figs. 881 and 882).-The incisor teeth, four in number in each jaw, are used specially for cutting the food, hence their name. The crown of each is chisel-shaped, and presents a labial surface which is convex in all directions, a concave lingual surface, and a chisel-like edge, which, when first cut, is surmounted by three small tubercles separated by two grooves. These tubercles, however, are soon worn down, and the edge becomes straight or nearly so. Owing to the fact that the upper incisors overlap those in the mandible, the 
cutting edge is worn away, or becomes bevelled, on the lingual aspect in the former, but on the labial aspect or summit in the latter. The upper, and particularly the central upper incisors, are of large size, and slope somewhat forwards ; whilst the lower incisors, all of nearly equal size, are much smaller-being

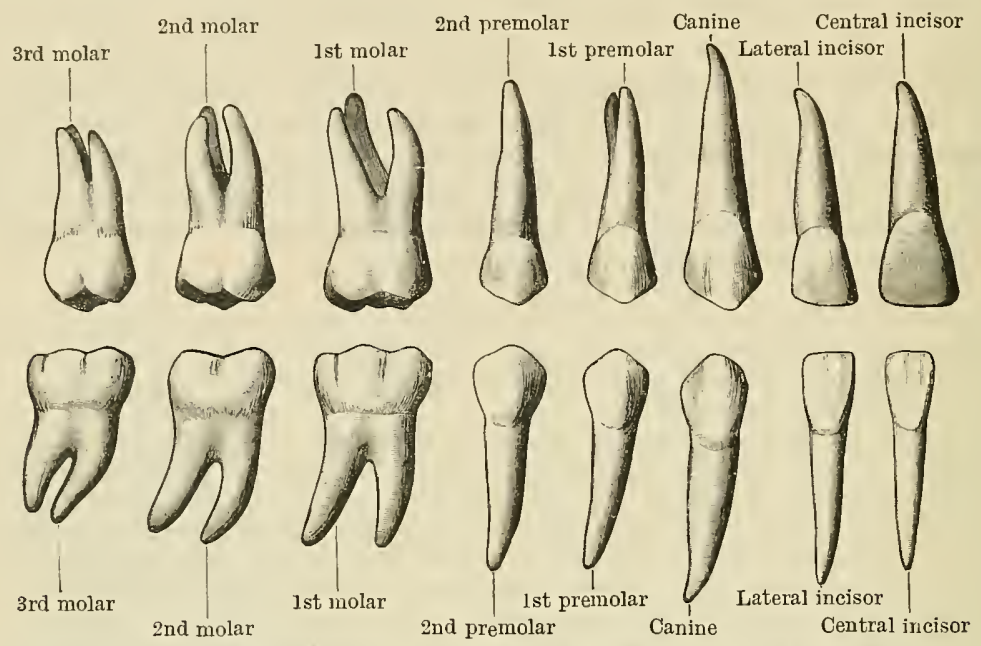

Fig, 881.-The Permanent Teeth of the Right Side, Labial Aspect.

The upper row shows the upper teeth, the lower row the lower teeth. The wide vertical "labial ridge" is distinct on the upper canine and premolar teeth.

the smallest of all the teeth-and are placed vertically. The roots of the incisors are single, though a groove is occasionally seen on each side, suggesting a division.

The central upper incisors are very much larger than the upper lateral incisors (Fig. 881), but in the lower jaw the opposite is the case, the lateral incisors being slightly the larger. In all incisors

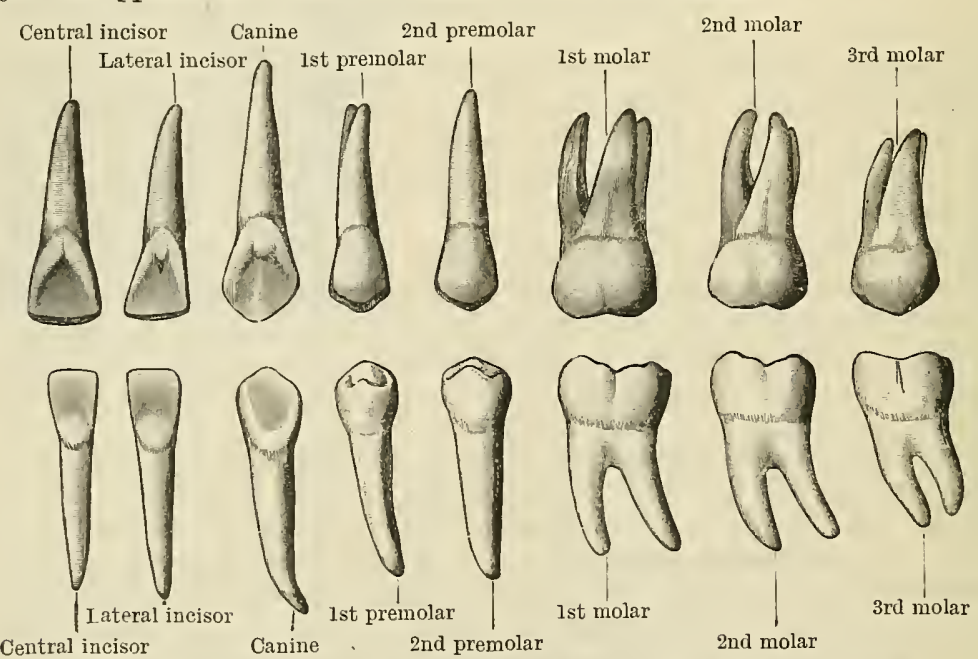

Fig. 882. - The Permanent Teeth of the Right Side, Lingual Aspect.

The upper row shows the upper teeth, the lower row the lower teeth. The cingulum is distinct on the upper incisors and both canines, the lingual tubercle on the upper lateral incisor and the upper canine.

the lateral angle of the crown is more rounded than the medial. The concave lingual surface of the crown in the upper incisors is usually limited towards the gum by a $\wedge$-shaped ridge (Fig. 882), known as the cingulum. The two limbs of the $\wedge$ are continued up along the sides of the lingual surface, whilst the apex is turned towards the gum; and here, particularly in the lateral incisor, there is often developed a small lingual tubercle (Fig. 882). The cingulum is rarely found on the lower incisors.

The roots of the upper incisors and canines are conical and rounded (the lateral incisors and canines not so distinctly as the central incisors) (Fig. 881), whilst those of the mandible are flattened from side to side (medio-laterally). 
Dentes Canini. - In the four canine teeth, which succeed the incisors in each row (Figs. 881 and 886), the crown is large and conical, corresponding closely in general form to a very large central incisor with its angles cut away, so that the crown assumes a pointed or conical shape. The labial surface is convex, the lingual usually somewhat concave. The root is single and long, particularly in the upper canine, the root of which is longer than that of any other tooth, and produces the canine eminence on the anterior surface of the maxilla. The upper canines are larger than the corresponding lower teeth, behind which they bite; and they are sometimes known as the "eye teeth."

The upper canine presents on its lingual surface a well-marked cingulum, and often a distinct lingual tubercle; in addition, there is usually a median ridge running from the point of the crown to the apex of the cingulum, which is separated from the lateral part of the cingulnm on each side by a slight depression. These points are neither so well marked, nor so constant, in the lower as in the upper canine.

Of the two margins sloping away from the apex of the crown, the lateral is the longer in both teeth. After it has been a little worn the lower canine is less distinctly pointed than the upper; its root is also more flattened. On the labial surface of the crown, of both canines and premolars, a wide low vertical ridge (labial ridge) can generally be made out (Fig. 882); it is most distinct on the canine and first upper premolar.

\section{Dentes Præmolares} (Figs. 881 and 882). - The premolar teeth, eight in number, two in each jaw above and below, are placed posterior to the canines, and anterior to the molars, as the name indicates. The crown, which, unlike that of the incisors and canines, is flattened antero-posteriorly, is characterised by the presence of two tubercles (O.T. cusps) (Fig. 883). One of the tubercles, the larger, is placed on the labial, the other on

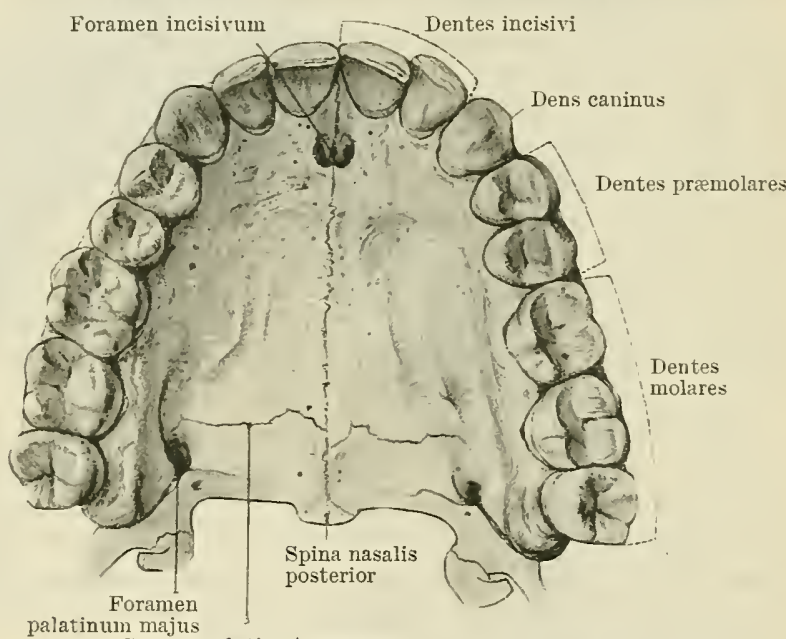

Sutura palatina transversa

Fig. 883.-The Hard Palate and Upper Pervanent Teeth, VIEWED FROM BELOW.

the lingual side. The labial and lingual surfaces are both convex. The root is single, but it is, as a rule, flattened antero-posteriorly and grooved, showing in this a tendency to division, which often actually takes place in the first upper premolar. The upper premolars are easily distinguished by the fact that their two tubercles are large and are separated from one another by a distinct antero-posterior fissure (Fig. 883); whilst in the lower premolars, on the other hand, the separation between the two tubercles is not effected by a continuous fissure as in the upper teeth, but by two dimple-like depressions separated by a ridge which joins the two tubercles (Fig. 884). In the upper premolars, therefore, the two tubercles are separated by a fissure, in the lower they are united by a ridge.

The first upper premolar is often slightly larger than the second; the reverse is the case in the mandible. The labial surface of the crown is usually somewhat larger than the lingual surface in all premolars. As a general rule in the lower premolars the labial surface of the crown is sloped medially near the masticating surface. The first can usually be distinguished from the second by the fact that, while the lingual tubercle and surface are smaller than the labial in the first premolar, they are nearly of the same size in the second. In addition, the root of the first upper premolar is bifid or nearly so, and its labial ridge is fairly distinct, but is indistinct in the second. In the first lower premolar the lingual tubercle and surface are very small, in fact the tubercle is quite rudimentary. It should, however, be added that it is often extremely difficult to identify the various premolars.

Dentes Molares.-The molar teeth are twelve in number-three on each side 
above and below-and are distinguished as first, second, and third molars. The last in each jaw is also known as the dens serotinus. All the molars are characterised by the large size of the crown and the possession of three or more trihedral tubercles on the masticating surface (Figs. 883 and 884). They are the largest of all the teeth, but they diminish in size, as a rule, from the first to the third. In shape the crown is more or less quadrangular, with convex labial and lingual surfaces. The roots are either two or three in number, but frequently in the last molars they are united to a varying degree.

The molars of the maxilla and mandible differ so considerably in their further details that they must be considered separately. They may be most readily distinguished from one another by the fact that normally the upper molars possess three roots (Figs. 881 and 882), whilst the lower molars bave two at most. The number of tubercles, though not so reliable a guide as the form of the root, is also generally sufficient to distinguish them. In the upper molars there are either three or four tubercles, whilst in the lower the number is most commonly five (see, however, below).

In the upper molars, the crown, viewed from the masticating surface (Fig. 883), is rhomboidal in shape (i.e. quadrangular with the angles not right angles). The labial and the lingual surfaces are convex. The number of tubercles is either four or three. On the first there are invariably four-two on the labial and two on the lingual side-the anterior lingual of these being connected with the posterior labial by an oblique ridge (Fig. 883), which is also found on the second and third molars when these bear four distinct cusps. The second upper molar has either four or three tubercles in about an equal proportion of European skulls, whilst in the third the number is much more frequently three than four. The roots in the upper molars are three in number (except, occasionally, when the three roots of the third are confluent), two being labial, and the third lingual (Figs. 881, 882, and 885 ).

In the lower molars, the crown, viewed from above (Fig. 884), is somewhat cubical. The labial and lingual surfaces are convex, as in the upper molars. The first, as a rule, bears five tubercles, two being on the labial side, two on the lingual, and the fifth behind and lateral, that is, between the two posterior tubercles and somewhat to the labial side. The second has usually only four tubercles; a fifth, however, is sometimes present. The third has either four or five, the former number more frequently than the latter.

The roots of the lower molars are two in number, each wide, grooved, and flattened antero-posteriorly. One root is anterior, the other posterior, and both are usually recurved in their lower portions (Fig. 885). As in the corresponding teeth of the maxilla, the roots of the lower last molars are often more or less united into a single mass.

The chief characters of the upper and lower molars may be summarised thus :-

The first molar is usually larger than the second, and the second than the third. The upper molars are directed downwards and laterally; whilst the lower molars, which the former partly overlap, slope upwards and medially, with the result that the labial tubercles of the lower molars lie in the groove separating the lingual from the labial tubercles of the upper teeth (Fig. 886, p. 1120). As a result of this overlapping, the labial edge of the crown is sharp and the lingual edge rounded in the upper molars; whilst the lingual edge is sharp and the labial edge rounded in the lower set.

The fissures which separate the cusps on the grinding surfaces of the molar teeth are generally continued as faint grooves on the labial and lingual surfaces.

Upper Molars. - The crowns, as already stated, are rhomboidal in shape, and when viewing their masticating surfaces, as in Fig. 883, if the planes of separation between them be prolonged, they would strike the median plane near the posterior part of the hard palate; in other words, their anterior and posterior surfaces are not in transverse but in oblique planes, sloping strongly postero-medially, and converging in that direction. A knowledge of this is useful in determining the side to which an upper molar belongs, as is the fact that the anterior labial root is broader than the posterior (Fig. 882).

As regards the number of tubercles (Fig. 883):-The first upper molar has four tubercles in practically all skulls (99 per cent); occasionally, indeed, ańother, but very rudimentary, tubercle is present on the lingual side of the antero-lingual tubercle. The second molar has either three or four in an almost equal proportion of Europeans, but more frequently four, taking the teeth of all nations together. (According to Topinard, four are present in 66 per cent of all races, 
and in 58 per cent of European, Semitic, and Egyptian skulls; according to Zuckerkandl, in 73.5 per cent of the lower races and 45.6 per cent of Europeans.) The third upper molar has three tubercles much more frequently than four amongst Europeans (four only in 36 per cent, although it has four more frequently in certain lower races). It should be remarked that, while there are practically always fonr tubercles in the first molar, still there is a tendency to the disappearance of the postero-lingual one, which tendency grows more pronounced as we pass backwards to the second and third molars. The other tubercles are practically constant.

The three roots of the upper molars (Figs. 881, 882, and 885) are, a large palatine, subcylindrical in shape, and two labial roots, smaller and flattened from before backwards. The palatine root, which is placed opposite the posterior labial root, is often united to one of the others. The lower part of the maxillary sinus generally extends down between the palatine and the two labial roots (Fig. 879, p. 1113), but the latter project on its floor more frequently than the palatine root. In the last molars the three roots are frequently more or less united into a single conical process (Fig. 881).

Lower Molars.-The crowns are more massive than those of the upper molars, and are elongated antero-posteriorly (Fig. 884). A crucial groove separates the four chief tubercles from

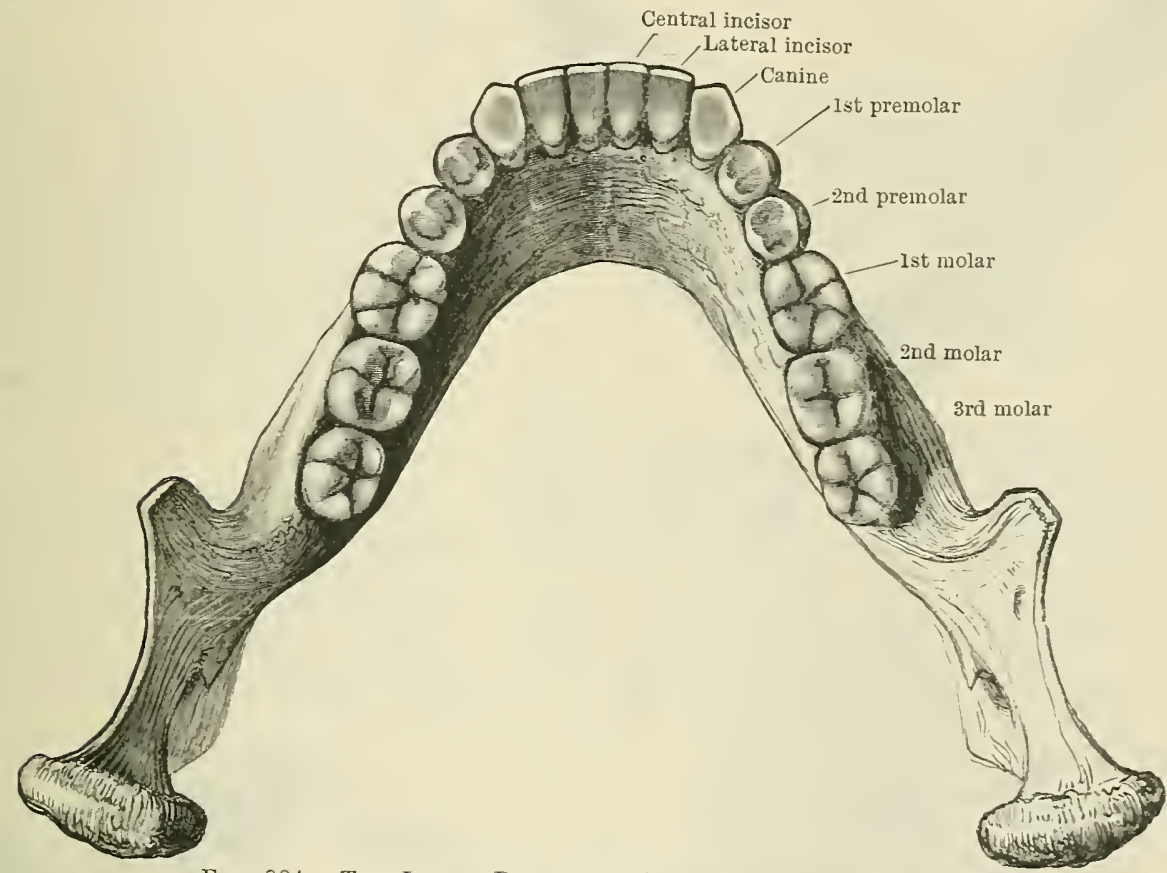

Fig. 884.-The Lower Permaxent Teeth, niewed from abote.

one another; this bifurcates behind to enclose the fifth, which lies slightly to the labial side of the middle of the tooth. The number of tubercles present in the lower molars is as follows:The first has usually five (62 per cent of all races, 61 per cent of Europeans); the second has four, as a rule (five in only 24 per cent of all skulls); the lower dens serotinus has four a little more frequently than five (five in 46 per cent of all skulls), but like the upper last molar tooth it is extremely variable.

The roots of the lower molars (Fig. 881), two in number, are flattened from before backwards, and very wide. The anterior of these has two root-canals; the posterior but one (Fig. 885). The dens serotiuus has commonly two roots like its fellows; occasionally the two are united. In determining the side to which a lower molar belongs, it should be remembered that the deep part of the root is generally curved backwards, and also that the blunter margin of the crown (see above) and the fifth tubercle, if present, are on the labial side.

Arrangement of the Teeth in the Jaws.-The teeth are arranged in each jaw in a curved row-the arcus dentalis-of approximately a semi-oval form (Figs. 884 and 885). The curve formed by the upper teeth, arcus dentalis superior, however, is wider than that formed by the lower set, arcus dentalis inferior, so that when the two are brought in contact the upper incisors and canines overlap their fellows in front, and the labial tubercles of the upper premolars and molars overlap the corresponding ones of the lower teeth (Fig. 886, p. 1120). It will also be seen that, as a rule, the teeth in one jair are not placed exactly opposite their fellows, but rather opposite the interval between two teeth, in the other jaw 
(Fig. 886). This arrangement is brought about largely by the great width of

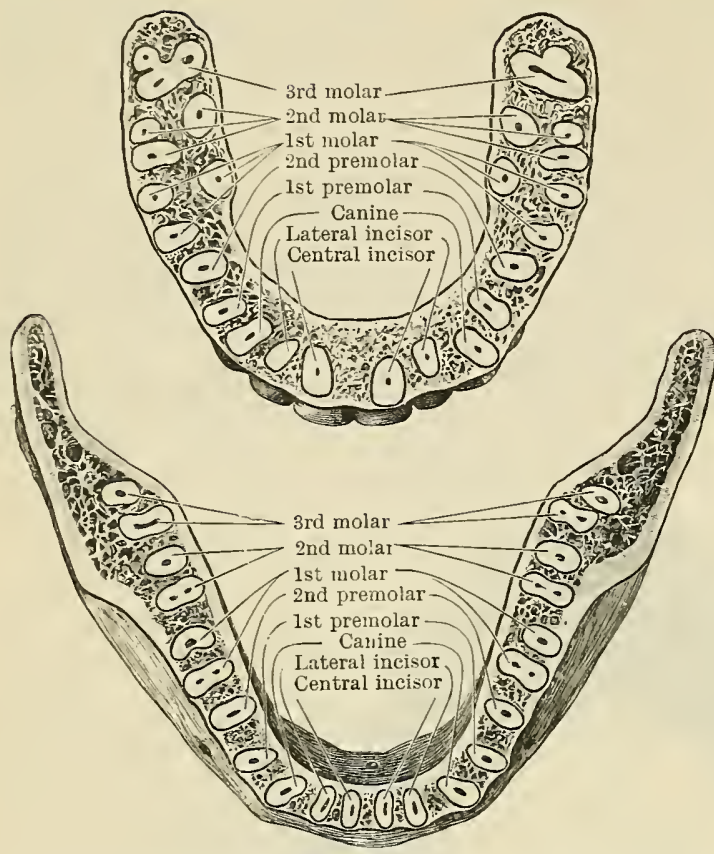

Fig. 885. - Horizontal Sections through both the MaxILLA AND NANDIBLE to show the roots of the teeth. The sections were carried through the bones a short distance from the edge of their alveolar borders. The upper figure shows the upper teeth, the lower figure the lower teeth. Note the flattened roots of the lower incisors, the two root-canals in the anterior root of each lower molar, and the confluence of the three roots of the upper last molars. the upper central incisors as compared with their fellows of the mandible, which throws the upper canines and the succeeding teeth into a position behind that of the same-named teeth of the lower set. But as the lower molars are larger in their antero-posterior diameter than those of the upper row - and this remark applies particularly to the third molars - the two dental arches terminate behind at approximately the same point.

The upper dental arch is said to form an elliptical, the lower a parabolic curve (Figs. 884 and 885). The line formed by the masticating surfaces of the upper teeth, as seen on profile view (Fig. 886), is usually somewhat convex, owing largely to the failure of the third molar to descend into line with the others. Similarly the line of the lower teeth is as a rule concave.

In both jaws the crowns of the front teeth are higher (longer) than those of the inolars.

Period of Eruption of the Permanent Teeth. - Although there is considerable variety in the dates at which the various permanent teeth appear above the gums, the order of eruption is practically constant in different individuals, and is as follows:-Before any of the deciduous teeth are lost the first permanent molars appear behind the 2nd deciduous molars. Next the central deciduous incisors fall out, and their places are taken by the permanent teeth of the same name; then follow the remaining teeth in the following order: Lateral incisors, 1st premolars, 2nd premolars, canines, 2nd molars, and 3rd molars. It will be observed that the eruption of the canine is delayed until the two premolars, which succeed it in the row, are cut, so that it breaks the otherwise regular order of eruption. The 1st molar is sometimes popularly known, owing to the date of its eruption, as the "six-year-old tooth," and the 2nd molar as " the twelve-year-old tooth."

The dates at which the eruption usually takes place may be

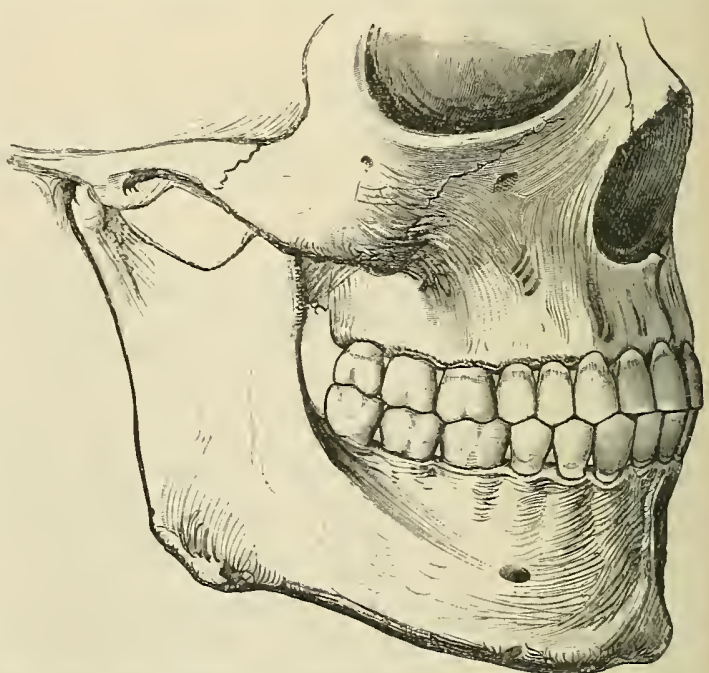

Fig. 886. - To show the relation of the upper to the lower teeth when the mouth is closed. The manner in which a tooth of one row usually strikes against two teeth of the opposite row, and the resulting interlocking of the teeth, are to be noted.

simply stated as follows for the lower teeth; those of the upper jaw appear a little later :- 
Ist molars appear soon after the 6 th year.

Central incisors appear soon after the $T$ th year.

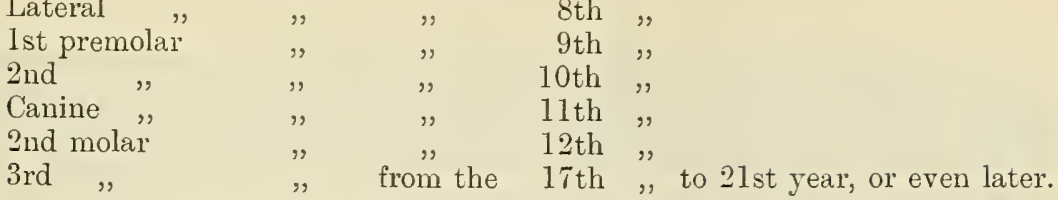

Variations in the Number of the Teeth.-The presence of an additional tooth is by no means uncommon. It may appear in connexion with the incisor, premolar, or the molar groups. A distinction is drawn between "supernumerary" or imperfect additions to the dentition and "supplemental" teeth which correspond in size with those with which they are associated. When a supplemental incisor appears it has an interesting bearing upon the solution of the much-debated point as to which incisor has disappeared from the primate dentition. A fourth molar is occasionally present.

\section{Dentes Decidui.}

The deciduous teeth (O.T. temporary or milk) are twenty in number, ten above and ten below, or five in each half of each jaw-namely, two incisors, one canine, and two molars. They may be distinguished from the permanent teeth by their smaller size, their well-marked and constricted necks, and, in the case of the molars, by the wide divergence of their roots (Fig. 887). Otherwise they correspond so closely to the samenamed teeth of the permanent set, that they require no separate description, except in the case of the molars. The first upper molar has but three tubercles on its crown-two lateral and one medial; the first lower molar has fourtwo lateral and two medial, and the crowns of both are flattened from side to side. The second molars of the maxilla have four, those of the mandible five tubercles each. In every case the second are much larger than the first

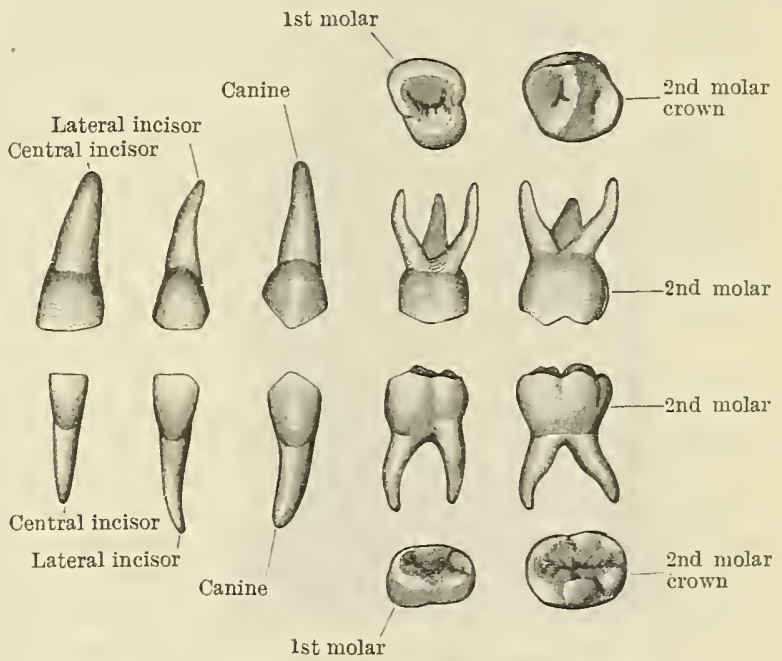

Fig. 887.-The Decideots Teeth of the Left Side.

The masticating surfaces of the two upper molars are shown above. In the second row the upper teeth are viewed from the outer or labial side. In the third row the lower teeth are shown in a similar manner; and below are the masticating surfaces of the two lower molars. In the specimen from which the first upper molar was drawn the two labial tubercles were not distinctly separated, as is often the case. molars. The tubercles are sharper and are separated by deeper fissures or fossæ than those of the permanent teeth, whilst the roots of the deciduous molars, except for their greater divergence, agree with those of the permanent set.

The marked constriction at the neck of the decidnous teeth (Fig. 887) is due to a great thickening of the cap of adamant on the crown, and its abrupt termination as the neck is reached. The adamant, too, is much whiter as a rule than in the permanent teeth. It should be added that the labial surface of the canines and molars departs very markedly from the vertical; it slopes strongly inwards towards the mouth cavity as it approaches the masticatory surface of the crown, which latter is, as a result, much reduced in width.

The divergence of the roots in the deciduous molars allows the crowns of the permanent premolars to fit in between them before the former molars are shed. 


\section{Structure of the Teeth.}

As mentioned above, the teeth are composed of three special tissues, substantia adamantina or adamant (O.T. enamel), substantia eburnea or ivory (O.T. dentine), and substantia ossea (O.T. crusta petrosa or cement), in addition to the pulp which occupies the tooth cavity. The chief mass of the tooth is formed of substantia eburnea, which surrounds the tooth cavity and extends from crown to root; outside this is a covering of substantia adamantina on the crown, and a layer of substantia ossea on the root.

The substantia adamantina is the dense, white, glistening layer which forms a cap, thickest over the tubercles, for the portion of each tooth projecting above the

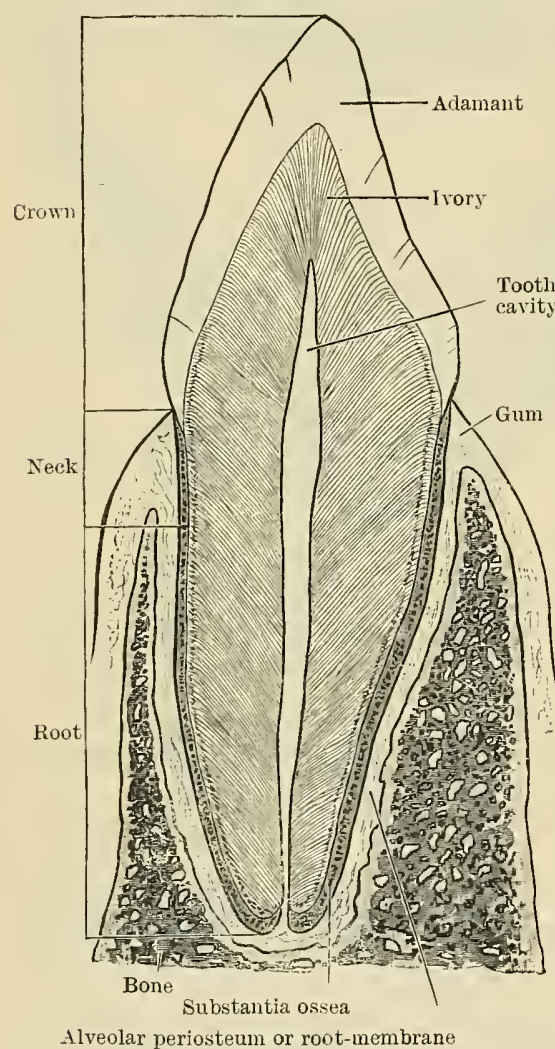

Fig. 888. - Vertical Section of Canine Tooth to illustrate its various parts, and its structure. gum (Fig. 888). At the neck it ceases gradually, being here slightly overlapped by the substantia ossea.

It is composed chiefly of phosphate and carbonate of lime (phosphate of calcium 89.82 per cent, carbonate of calcium 4.37 per cent, magnesium phosphate 1.34 per cent, a trace of calcium fluoride, other salts 88 per cent), and has generally been considered to contain about 3.6 per cent of organic substance; but this Tomes has recently shown to be inaccurate: "That which has heretofore been set down as organic matter is simply water combined with the lime salts. The substantia adamantina is to be regarded as an inorganic substance composed of lime salts, which have been deposited in particular patterns and formed under the influence of organic tissues, which have themselves disappeared during its formation."

The adamantine substance consists of calcified microscopic prisms, prismata adamantina, radiating from the surface of the ivory, on which their inner ends lie, to the surface of the crown, on which they terminate by free ends. These prisms are hexagonal in shape, solid, and of considerable length, for most of them reach from the ivory to the surface of the crown without interruption. The prisms, which are calcified themselves, are held together by the smallest possible amount of calcified matrix (Tomes). In old teeth the cap of adamantine substance is often worn away over the tubercles, the ivory is then exposed, and is easily recognised by its yellowish colour, which contrasts strongly with the whiteness of the adamant.

Whilst adjacent adamantine prisms are in general parallel to one another, they do not usually take a straight, but rather a wavy course, and in alternate layers they are often inclined in opposite directions, thus giving rise to certain radial striations seen by reflected light (Schreger's lines). Certain other pigmented lines, more or less parallel to the surface, are also seen in the adamant (brown striæ of Retzius). They are dne to true pigmentation (Williams), and mark the lines of deposit of the adamant during its development. The adamantine prisms are more or less tubular in certain animals-viz., in all marsupials except the wombat, in the hyrax, certain insectivora, and certain rodents.

Cuticula dentis (O.T. Nasmyth's membrane) is an extremely thin ( $\frac{1}{20000}$ of an inch) cuticular layer which covers the adamant of recently-cut teeth, and is very indestructible, resisting almost all reagents. Two chief views are held as to its origin. One that it is the last formed layer of adamant, which has not yet been calcified, and therefore the final product of the adamant cells. The other that it is produced by the outer layer of cells of the adamant organ. This latter seems to be the more probable view.

Substantia eburnea or ivory (O.T. dentine) is the hard and highly elastic substance, yellowish white in colour, which forms the greater part of the mass of every tooth (Fig. 888). Like the adamant it is highly calcified, but it differs from it in containing 
a very considerable amount of organic matter and water incorporated with its salts, which are chiefly phosphate and carbonate of lime.

Fresh human ivory contains 10 per cent of water, 28 per cent of organic and 62 per cent of inorganic material. The organic matter is composed chiefly of collagen, and to a less extent of elastin. The organic matter consists of (1) calcium phosphate (with a trace of fluoride), (2) calcium carbonate, and (3) magnesium phosphate, the percentages present in dried dentine being $66 \cdot 72,3 \cdot 36,1 \cdot 08$ respectively.

Ivory consists of a highly calcified organic matrix, which is itself practically structureless, although everywhere traversed by tubes-the canaliculi dentales, or dentinal canaliculi-which give to this tissue a finely striated appearance, the striæ usually running in wavy lines. The canaliculi begin by open mouths on the wall of the pulp cavity, whence they run an undulating, and at the same time a somewhat spiral course, towards the periphery of the ivory. They give off fine anastomosing branches, and occasionally divide into two. Somewhat reduced in size, they usually end in the outer part of the ivory.

The canaliculi dentales are generally described as being lined by special sheaths (dentinal sheaths of Neumann) which are composed of a most resistant material, and possibly are calcified. It should be mentioned that the presence of these sheaths as separate structures is doubted by some authorities, who hold that the part described as the sheath is only a modified portion of the ivory which forms the tubules.

The canaliculi dentales are occupied by processes, prolonged from the outermost cells of the pulp-the odontoblasts. These processes are called after their discoverer, Tomes' fibrils (dentinal fibrils), and they are probably sensory in function.

The concentric lines of Schreger, frequently seen in the ivory, are due to bends in successive canaliculi along regular lines running parallel to the periphery of the ivory. Other lines (the incremental lines of Salter), dne to imperfect calcification, are found arching across the substance of the ivory, chiefly in the crown. There must also be mentioned the interglobular spaces, intervals left in the ivory, as a result of imperfect calcification, bounded by the fully calcified surrounding tissue, the contour of which is in the form of a number of small projecting globules. These interglobular spaces are very numerous in the outer or "granular layer" of the ivory, particularly beneath the osseous substance.

The substantia ossea (O.T. cement) is a layer of modified bone which encases the whole of the tooth except its crown. It begins as a very thin stratum, slightly overlapping the adamant at the neck. From this it is continued, increasing in amount, towards the apex, which is formed entirely of this substance. It is relatively less in amount in the child, and increases during life. In places the ivory seems to pass imperceptibly into the substantia ossea (the "granular layer" marking the junction of the two, and some of the canaliculi dentales are continuous with the lacunæ of the substantia ossea. Like true bone, it is laminated, it possesses lacunæ, canaliculi, and, when in large masses, it may even contain a few Haversian canals.

The pulpa dentis occupies the tooth cavity and the root-canals of the teeth. It is composed of a number of branched connective tissue cells, the anastomosing processes of which form a fine network, containing in its meshes a jelly-like material, in addition to numerous vessels and nerves, but no lymph-vessels. The most superficial of these cells are arranged in the young tooth as a continuous layer of columnar, epitheliumlike cells, lying on the surface of the tooth pulp against the ivory; they are known as odontoblasts, for they are the active agents in the formation of the ivory. From the outer ends of these odontoblasts processes are continued into the canaliculi dentales, where they have been already referred to as Tomes' fibrils. The vessels of the tooth pulp are numerous, and form a capillary plexus immediately within the odontoblasts. The nerves form rich'plexuses throughout the pulp, but their exact mode of ending is unknown.

The periosteum alveolare is a layer of connective tissue free from elastic fibres, but well supplied both with blood-vessels and nerves, which fixes the root of the tooth in the alveolus, being firmly united by perforating fibres of Sharpey, to the substantia ossea on the one hand, and to the bone of the alveolus on the other. It establishes a communication between the bone of the jaw and the substantia ossea, and it is continuous. with the tissue of the gum. Its blood comes chiefly from the arteries, which subsequently enter the apical foramina for the supply of the tooth pulp, but in part also from the vessels of the surrominding bone and of the gum (hence the relief obtained in dental periostitis by lancing the gum). 


\section{LINGUA.}

The tongue is a large mobile mass, which occupies the floor of the mouth and forms the anterior wall of the oral part of the pharynx (Fig. 889). It is composed chiefly of muscular tissue, and is covered by mucous membrane.

Whilst the sense of taste resides chiefly in its modified epithelium, the tongue is also an important organ of speech, and, in addition, it assists in the mastica-

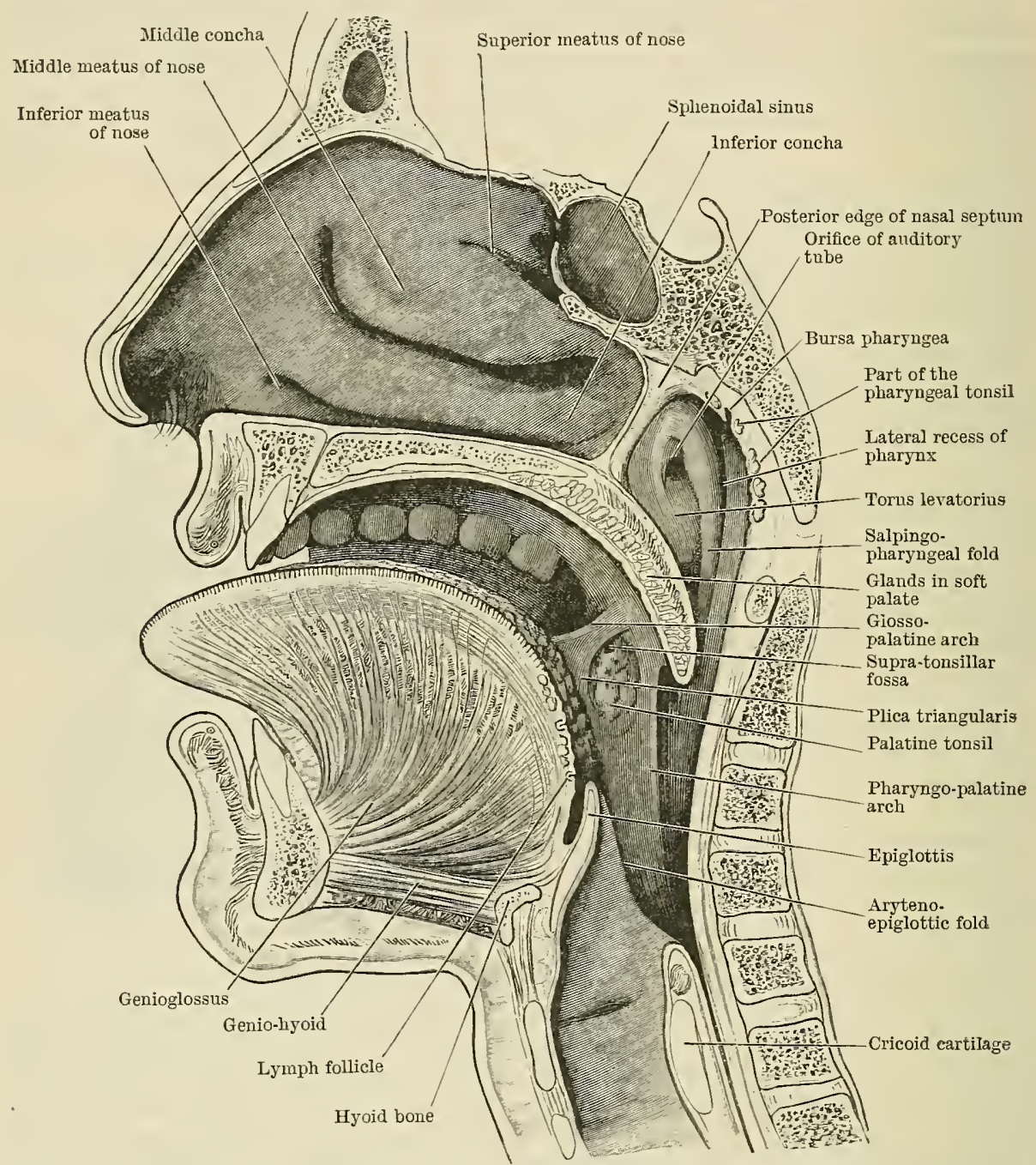

Fig. 889.-Sagittal Section through Mouth, Tongde, Larynx, Pharynx, and Nasal Cavity.

The section was slightly oblique, and the posterior edge of the nasal septum has been preserved. The specimen is viewed slightly from below, hence the apparently low position of the inferior concha.

tion and deglutition of the food-functions which it is well fitted to perform, owing to its muscular structure and great mobility. In length it measures about three and a half inches (9 cms.), when at rest, but both its length and width are constantly varying with every change in the condition of the organ, an increase in length being always accompanied by a diminution in width, and vice versa.

In describing the tongue we distinguish the following parts: the corpus linguæ (body), made up chiefly of striped muscle, and forming the mass of the organ; the dorsum linguæ (Fig. 890), which looks towards the palate and pharynx, and is free 
in its whole extent; the base, the posterior wide end which is attached to the hyoid bone; the apex lingur, the pointed and free anterior extremity; the margo lateralis, which is free in its anterior half or more, i.e. in front of the attachment of the anterior palatine arch (Fig. 890). Finally, the unattached portion on the inferior aspect, seen when the apex is turned strongly upwards (Fig. 892), constitutes the facies inferior, or inferior surface; whilst the thick posterior portion, fixed by muscles and mucous membrane to the hyoid bone and mandible, is known as the radix linguæ or root.

The dorsum of the tongue, when the organ is at rest, is strongly arched antero-posteriorly in its whole length (Fig. 889), the greatest convexity corresponding to the attachment of the glosso-palatine arch. When removed from the body

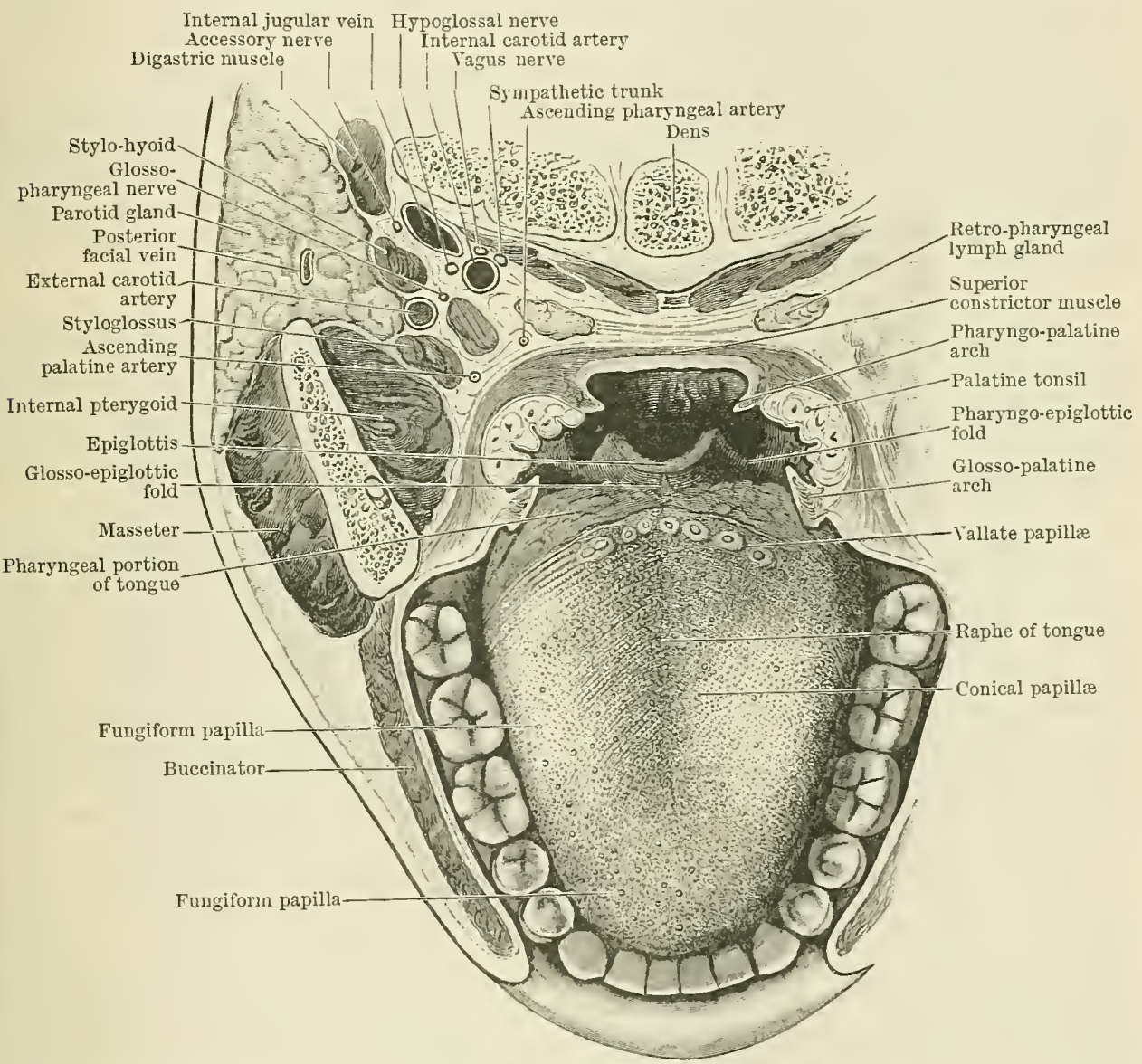

Fig. 890.-Horizontal Section throdgh Modth and Pharrxx at the Level of the Palatine Tonsils. The stylopharyngeus muscle, which is shown immediately to the medial side of the external carotid artery, and the prevertebral muscles, are not indicated by reference lines.

the tongue, unless previously hardened in situ, loses its natural shape, and appears as a flat, elongated oval structure, which gives a very erroneous idea of its true form and connexions.

Both in structure and in function, as well as in embryological history, the dorsum lingure is divisible into two areas-an anterior or oral part, which lies nearly horizontally on the floor of the mouth, and constitutes about two-thirds of the length of the whole tongue (Fig. 890); and a posterior or pharyngeal part, the remaining third of the organ, which is placed nearly vertically, and forms the anterior wall of the oral pharynx (Fig. 889). The separation between these two parts, which differ in appearance as well as in direction, is indicated by a distinct $V$-shaped groove, called the sulcus terminalis (Fig. 890), the apex of which is 
directed backwards, and corresponds to a depression on the surface of the tongue, the foramen cæcum, whilst its diverging limbs pass laterally and forwards towards the attachments of the glosso-palatine arch. The foramen cæcum is the remains of a tubular downgrowth formed early in embryonic life, in the floor of the primitive pharynx, from which the isthmus of the thyreoid gland is developed (see p. 44).

The anterior portion presents a velvety surface and is covered with innumerable papillæ; the taste-buds are situated in it, and it is horizontal in position. It is developed from the tissues of the floor of the pharynx behind the first visceral arch. The posterior portion, on the other hand, has a smooth glistening surface, contains numerous serous glands and small lymph follicles, and is more vertical in position. It is developed from the tissue covering the ventral ends of the second and third visceral arches (see p. 45).

The anterior or oral portion of the dorsum linguæ (Fig. 890) is convex, both from before backwards and from side to side in the resting condition of the organ (Fig. 893). It usually presents a slight median depression, sulcus medianus, in the form of an irregular crease, which ends posteriorly near the foramen cæcum. The mucous membrane of this portion of the dorsum is thickly covered with the prominent and numerous papillæ linguales which give this portion of the tongue its characteristic appearance.

On the pharyngeal part of the tongue there are also small papillary projections of the corium, but the epithelium fills up all the intervals between the papillæ, and, as it were, levels off the surface, so that none are visible to the eye as projections above the general level. Over the anterior part of the tongue, on the contrary, the projections of the corium are large and prominent, and the intervals between them, while they are covered, yet are not filled up, by the epithelium, so that the projections stand out distinctly and independently, and in places attain a height of nearly $2 \mathrm{~mm}$. above the general surface.

The posterior or pharyngeal portion of the dorsum linguæ (Fig. 889), nearly vertical in direction, forms the greater portion of the anterior wall of the oral part of the pharynx (Fig. 890). Its surface is free from evident papillæ, but is thickly studded with rounded projections, each presenting, as a rule, a little pit, visible to the naked eye, at its centre; the great majority of these folliculi linguales (lingual follicles, Fig. 889), are similar to the lymph follicles found in the palatine tonsils; some few are said to be mucous glands; all are covered by a smooth mucous membrane, and they combine to give to this region a characteristic nodular appearance. To this collection of follicles the name tonsilla lingualis is applied.

The mucous membrane of this portion of the tongue is separated from the muscular substance by a submucous layer in which the lymph follicles and the mucous glands lie embedded (Fig. 893). At the sides it is continuous with the tunica mucosa covering the palatine tonsils and the side wall of the pharynx; whilst posteriorly it is reflected on to the front of the epiglottis, forming in the middle line a prominent fold, the plica glosso-epiglottica mediana (Fig. 889), at each side of which is a wide depression, the vallecula.

On each side is a pharyngo-epiglottic fold, which passes from the side of the epiglottis, upwards along the wall of the pharynx, upon which it is soon lost.

Papillæe of the Tongue (Fig. 891).-These are formed by variously shaped projections of the corium of the mucous membrane, covered by thick caps of epithelium. They are of three main varieties: 1, Conical and filiform (papilloe conicce, p. fliformes); 2, Fungiform and lenticular (papille fungiformes et p. lenticulares); and 3 , Vallate and foliate (papilloe vallatce et p. folicitce).

The conical and filiform papillæ (Fig. 891) are the smallest and most numerous, forming as they do a dense crop of minute projections all over the anterior twothirds of the dorsum, and also upon the superior part of the margin and tip, of the tongue. Posteriorly they are arranged in divergent rows running laterally and forwards from the raphe, parallel to the limbs of the sulcus terminalis. More anteriorly, the rows become nearly transverse, and near the tip irregular. Each 
papilla is composed of a conical projection of the corium, beset with microscopic papillæ like those of the skin, and covered by a thick long cap of stratified squamous epithelium.

In many of them the cap of epithelium is broken up into several long slender hair-like processes, giving rise to the variety known as filiform papillce. The cap of epithelium is being constantly shed and renewed, and an excessive or diminished rate of shedding or renewal, coupled with the presence of various fungi, gives rise to the several varieties of "tongue" found in different diseases.

The conical papillæ are longer and larger than the filiform, and have a wider base. They are situated on the dorsum among the filiform papillæ, and resemble them in their structure.

The conical and filiform papillæ are probably of a prehensible or tactile nature, and are highly developed, and horny, in carnivora.

The fungiform and lenticular papillæ (Fig. 890) are larger and redder, but less numerous than the first variety, and they are found chiefly near the tip and margins of the tongue, comparatively few being present over the dorsum generally.

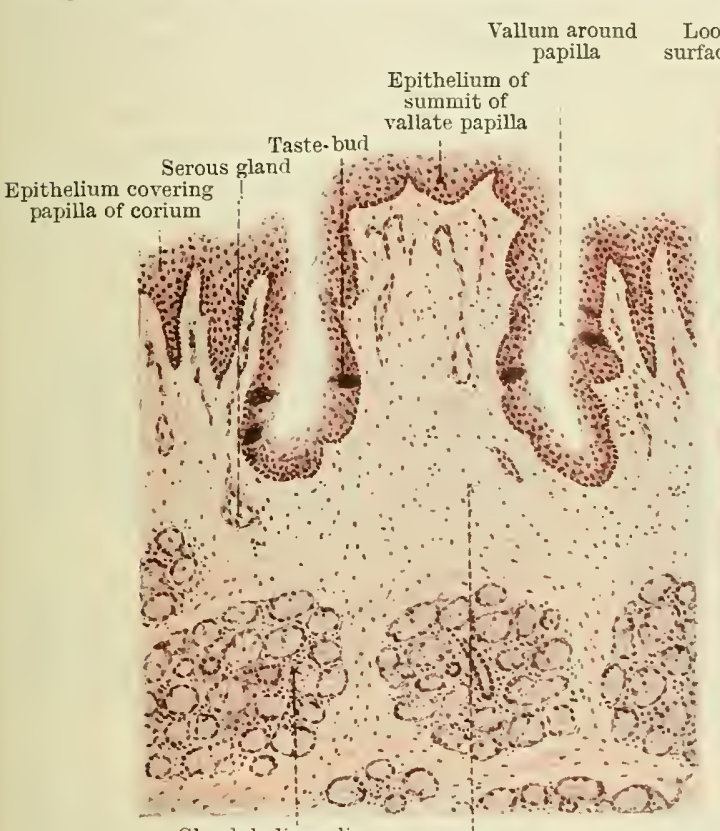

Glandula lingualis
FiG. 891.
A

Blood-ressel

A. Section of a papilla vallata of tongue.

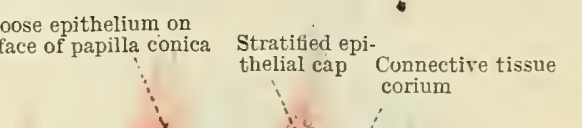

Each is in shape like a "puff-ball" fungus, consisting of an enlarged rounded head, attached by a somewhat narrower base. As in the case of the conical papilla, the corium is studded over with microscopic papilla, which are buried in the covering of squamous epithelium and do not appear on the surface. Most of the fungiform papillæ, if not all, appear to be furnished with taste-buds, and they are probably intimately connected with the sense of taste. The lenticular papillæ are placed on the margin of the tongue. They are flatter than the fungiform papillæ, and do not contain taste-buds.

The vallate papillæ (O.T. circumvallate) (Fig. 891), much the largest of all the papillæ of the tongue, are confined to the region immediately in front of the sulcus terminalis and foramen cæcum. Usually about nine to fourteen in number, they are arranged in the form of the letter $V$, with the apex posteriorly, just in front of and parallel to the sulcus terminalis. One or two of the papillæ are usually placed at the apex of the $\mathrm{V}$, immediately anterior to the foramen cæeum. In appearance a vallate papilla resembles very closely the impression left by pressing the barrel of a small pen on soft wax (Fig. 891). Each is composed of a cylindrical 
central part ( 1 to $2.5 \mathrm{~mm}$. wide), slightly tapering towards its base, and flattened on its crown, which projects a little above the general surface of the tongue. This is surrounded by a deep, narrow, circular trench or fossa, the outer wall of which is known as the vallum. The vallum appears in the form of an encircling.collar very slightly raised above the adjacent surface (Fig. 891).

As in the case of the other forms, the vallate papillæ are made up of a central mass of corium, beset with numerous microscopic papillæ on the crowns, but not on the sides, and covered over, as are the surfaces of the fossa and vallum, by stratified squamous epithelium. Into the fossæ open the ducts of some small serous glands (Fig. 891 A).

On the sides of the vallate papillæ, as well as upon the opposed surface of

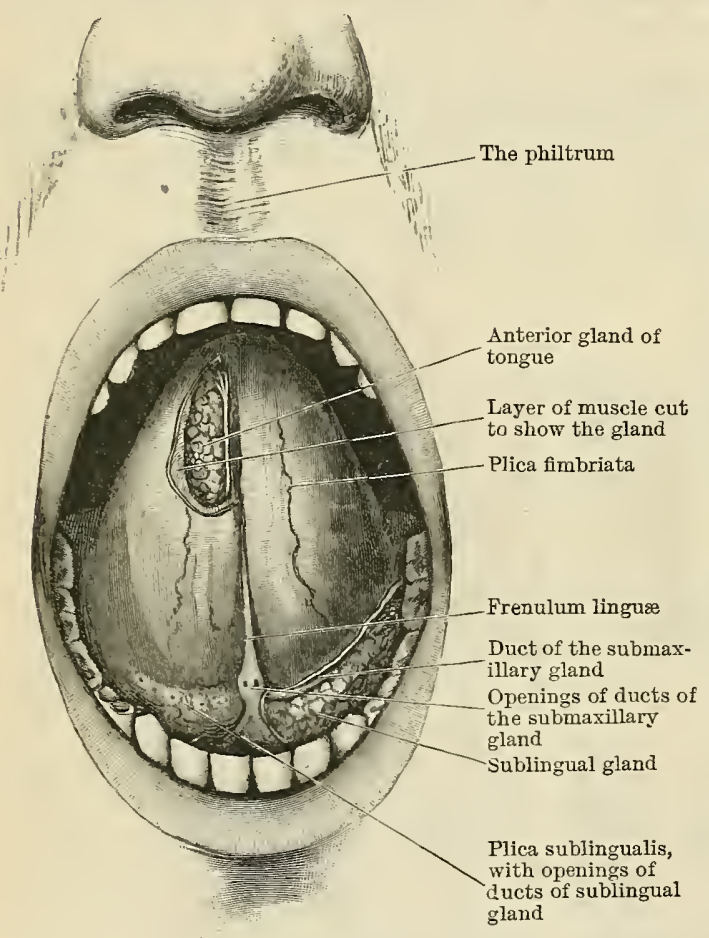

Fig. 892.-OPEN Mouth with Tongue RaIsed, AND THE Sublingual and Axterior Lingual Glands Exposed.

The sublingual gland of the left side has been laid bare by removing the mucous membrane; to expose the anterior gland of the right side a thin layer of muscle, in addition to the mucous membrane, has been removed. A branch of the lingual nerve is seen running on the medial aspect of the gland. The vena profunda linguæ is faintly indicated on this side also. the vallum, are found, in considerable numbers, the structures known as taste-buds, the special end-organs of the nerves of taste.

Just anterior to the glossopalatine arch, on the margin, are usually seen about five or six distinct vertical folds, forming the folia linguæ, which are beset with taste-buds. They correspond to the papillæ foliatæ on the side of the tongue in certain animals (rabbit, hare, etc.), in which they form an important part of the organ of taste.

The apex and the margin of the tongue in front of the attachment of the glosso-palatine arch are free, and lie in contact with the teeth when the tongue is at rest.

On the superior half or more of the margin and apex, papillæ are present as on the dorsum ; but on the inferior part they are absent, and the surface is covered by smooth mucous membrane.

The inferior surface of the tongue, which is exposed by turning the apex of the organ upwards, is limited in extent (Fig. 892), and is free from visible papillæ, the surface being covered by a smooth mucous membrane. Running along its middle, except near the tip, is a depression, from which a fold of mucous membrane, the frenulum lingur, passes down to the floor of the mouth, and on towards the posterior aspect of the mandible. At each side of the frenulum, and a short distance from it, the large profunda linguæ vein is distinctly seen through the mucous membrane. Further out still are situated two indistinct, fringed folds of mucous membrane, the plicæ fimbriatæ, which converge somewhat as they are followed forward towards the tip, near which they are lost.

From the inferior surface of the tongue the mucous membrane passes across the floor of the mouth to the medial surface of the gum, with the mucous covering of which it becomes continuous. 
run towards the tip; the arteries, however, are deeply placed in the substance of the tongue, at a distance of 3 to $6 \mathrm{~mm}$. from the inferior surface. The plicæ, which are more distinct at birth and in the fotus, are said to correspond to the under tongue found in the lemurs.

The root of the tongue is the portion of the inferior aspect which is connected by muscles and mucous membrane to the mandible and hyoid bone. It is of very considerable extent, and is, with the base, the most fixed part of the organ. It is also the situation at which the vessels, nerves, and the extrinsic muscles enter.

Structure of the Tongue.-The tongue is chiefly composed of striped muscular tissue, with a considerable admixture of fine fat. A median septum of connective tissue occupies the central part of the organ. In addition, there are vessels, nerves, glands, and lymph tissue, the whole being covered over by mucous membrane, except at the root (Fig. 893).

The muscular tissue is derived partly from the terminations of the extrinsic musclesnamely, the hyoglossus, styloglossus, genioglossus, glossopalatinus, and chondroglossus; and also largely from the intrinsic muscles - namely, the longitudinalis superior, longitudinales inferiores, the transversus linguæ, and the verticalis linguæ. These are so arranged that they form a cortical portion, made up chiefly of longitudinal fibresderived above from the longitudinalis superior and the hyoglossus, at the sides from

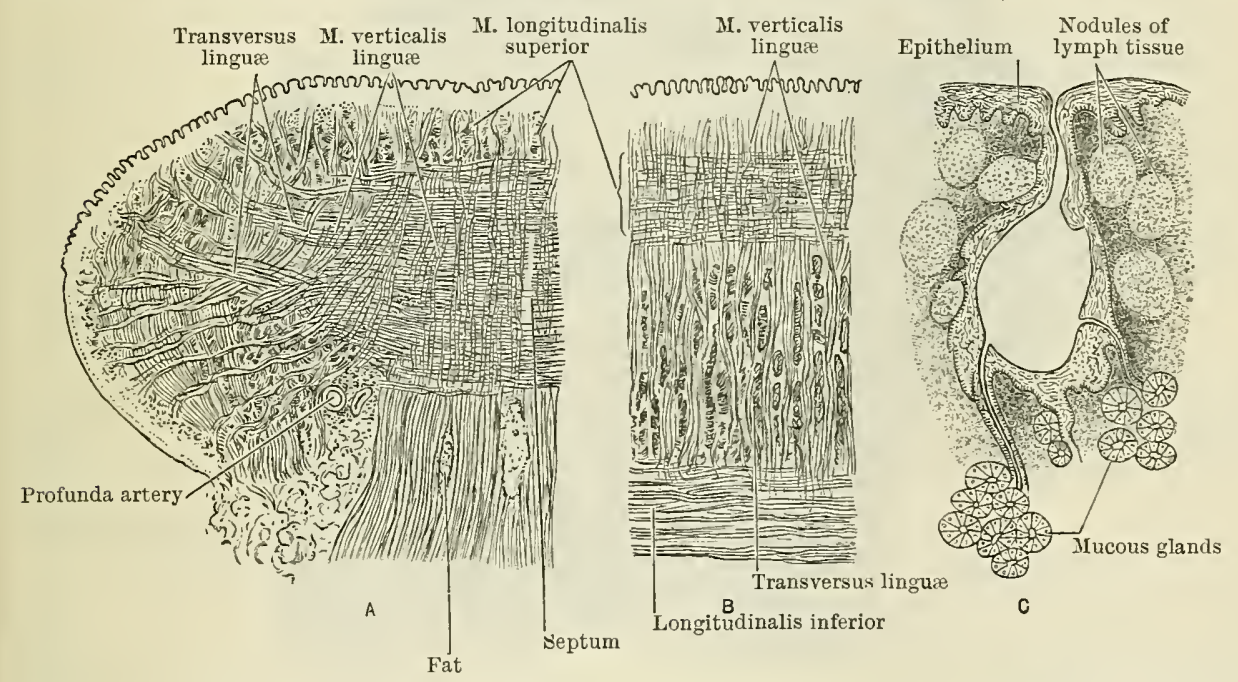

Fig. 893.-A, Transverse, and B, Longitudinal Vertical Section throdgh the Tongue (Krause); C, A Lymph Foliole from Posterior Part of the Tongue. (Macalister, slightly modified.)

the styloglossus, and below from the longitudinales inferiores. This cortex surrounds a central or medullary portion, divided into two lateral halves by the septum, and formed in great part by the transverse and vertical fibres, and also by the fibres of the genioglossi ascending to the dorsum. The muscular fibres derived from these various sources end by being inserted into the deep surface of the mucous membrane.

The detailed description of the extrinsic and intrinsic muscles will be found on page 462 .

The septum is a median fibrous partition found in the medullary portion only, and easily exposed by separating the two genioglossi on the inferior surface of the tongue. Anteriorly it usually extends to the apex ; whilst posteriorly it grows gradually narrower, and expanding transversely at the same time, it passes into a broad sheet (the hyoglossal membrane) which is united to the upper border of the hyoid bone, and gives attachment to the posterior fibres of the genioglossus. From the sides of the septum the fibres of the transverse muscle of the tongue arise.

The mucous membrane on the anterior two-thirds of the dorsum, and on the free margins, is firm and closely adherent to the underlying muscular substance, the fibres of which are inserted into it. On the posterior third of the dorsum, and on the inferior surface, it is neither so firm nor so closely united to the muscular substance, from which it is separated in both of these situations by a layer of submucous tissue. 
The mucous membrane of the tongue, like that of the rest of the mouth, is covered by stratified squamous epithelium.

Glandulæ Linguales. -Numerous small racemose glands are found scattered beneath the mucous membrane of the posterior third of the tongue; and a small collection of similar glands is present at the margin, opposite the vallate papillæ. Small serous glands are also found embedded in the dorsum near the vallate papillæ, into the fossæ of which their ducts open (Fig. 891).

The chief collections of glandular tissue in the tongue, however, are found embedded in the muscle of the under surface, a little way posterior to the apex, on each side of the middle line (Fig. 892). They are known as the glandulæ linguales anteriores of Blandin or Nuhn.

These glands are displayed after removing, from the under surface of the tongue, the mucous membrane and a layer of muscle fibres abont $2 \mathrm{~mm}$. thick which is composed of fibres of the styloglossus and the longitudinalis inferior muscles a little distance behind the apex. The anterior lingual glands are oval in shape, often partly broken up by muscular fibres, and they measure from $\frac{1}{2}$ to $\frac{3}{4}$ in. (12 to $19 \mathrm{~mm}$.) in length. They are mixed serous and mucous glands, and they open by three or four very small ducts on the inferior surface of the tongue.

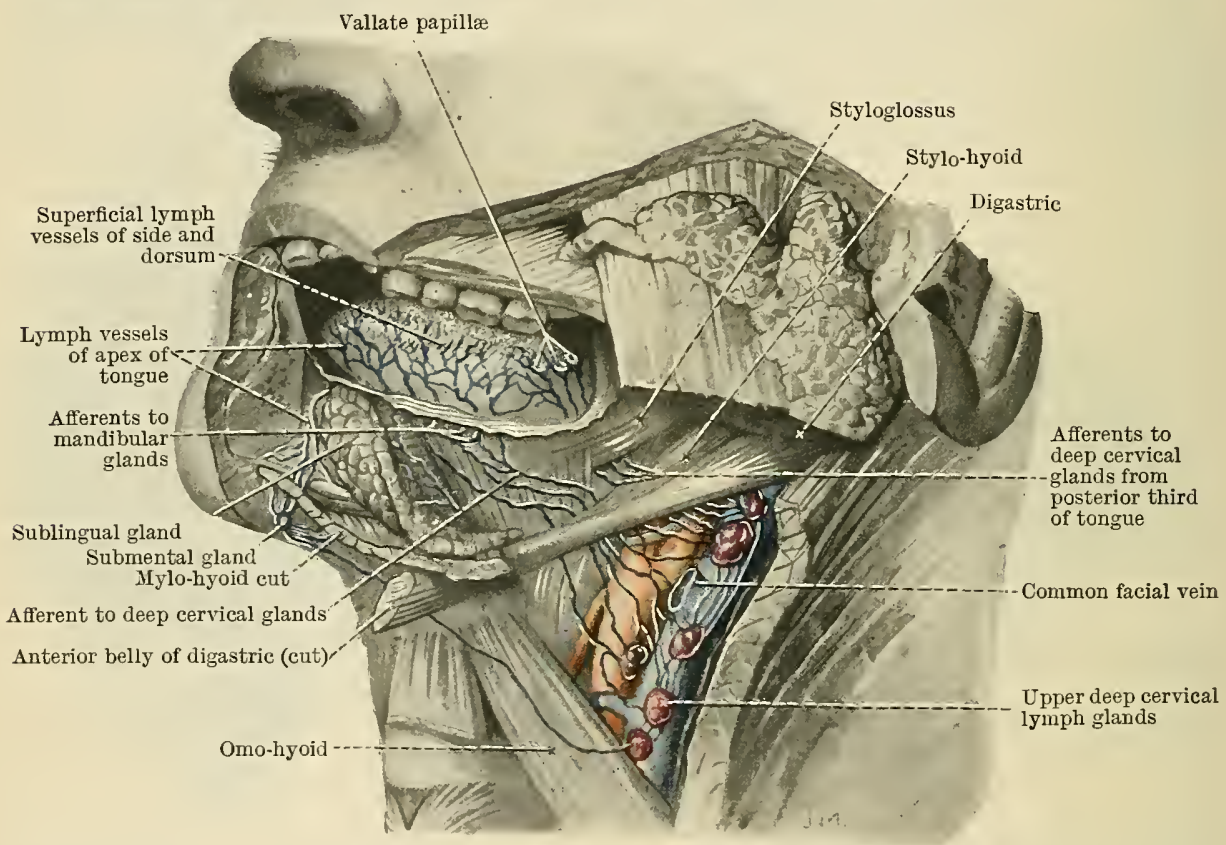

Fig. 894.-Lymph Vessels of the Tongue (after Poirier and Cuneo, modified).

Vessels. - The chief artery is the lingual. This vessel passes forwards on each side medial to the hyoglossus muscle, and then is continued on to the apex-between the genioglossus on the medial side and the longitudinalis inferior laterally-under the name of the a. profunda linguæ. Anteriorly it is covered by the fibres of the longitudinalis inferior, and lies $\frac{1}{8}$ to $\frac{1}{4}$ in. from the surface. Near the apex the arteries of opposite sides are connected by a branch which pierces the septum; but otherwise, with the exception of capillary anastomosis, they do not communicate. The rami dorsales linguæ of the lingual artery are distributed to the pharyngeal part of the tongue, whilst some twigs of the ramus tonsillaris of the external maxillary artery are also distributed in the same region.

The veins are: The $v$. profunda linguæ, the chief vein, which lies beneath the mucous membrane at the side of the frennlum, and runs backwards over the hyoglossus with the hypoglossal nerve; two venæ comites, which accompany the lingual artery; and two dorsalis linguæ veins from the back of the tongue. These either unite and form a common trunk, or open separately into the internal jugular vein.

The lymph-vessels of the tongue take their origin in an extensive lymph network in the submncous coat, and a smaller network connected with the first, in the muscular substance of the tongne. The network at the apex, including the tip, margins, and front of the dorsum, is drained by some two to four vessels on each side, which pass downwards by the margin of the genioglossus muscle and pass outwards to the inferior deep cervical lymph glands. These vessels may be connected with the submental lymph glands also.

From the margins and dorsum of the tongue, behind the former area, and extending back to the vallate papillæ, lymph-vessels pass to the submaxillary lymph glands, and also, on the hyo- 
glossus muscle, to the upper deep cervical lymph glands, especially to some glands near the bifurcation of the common carotid artery. From the posterior part of the tongue the lymphressels pass laterally on each side below the palatine tonsil, and thence follow the course of the tonsillar lymph-vessels to the upper deep cervical lymph glands. Some central vessels, from the median portion of the tongue, pass downwards to the submaxillary glands, and also to the upper deep cervical glands, on the lateral side of the internal jugular vein.

Nerves.-The nerves which supply the tongue are: (1) The hypoglossal nerve, the motor nerve of the tongue, which enters the genioglossus and passes up in its substance to the intrinsic muscles, in which it ends. (2) The lingual nerve, a branch of the mandibular nerre, which is accompanied by the chorda tympani branch of the facial nerve. The lingual, after crossing the hyoglossus, breaks up and enters the longitudinalis inferior and genioglossus muscles, and thus makes its way upwards to the mucous membrane of the anterior two-thirds of the tongue-the lingual itself conferring common sensation on this part, the chorda tympani probably carrying to it taste fibres. (3) The glosso-pharyngeal nerve passes forwards beneath the upper part of the hyoglossus muscle, and sends its terminal branches to the mucous membrane of the posterior third of the tongue, supplying the papillæ vallatæ, and the part of the tongue behind these, with both gustatory and common sensory fibres. (4) The internal laryngeal nerve also distributes a few fibres to the posterior part of the base of the tongue, near the epiglottis.

\section{GLANDULA.}

Numerous organs, differing widely in structure, function, and development, are commonly included under the term glands. It may indicate any of the following structures :-

(1) Glands producing a visible fluid or semi-fluid secretion, which is discharged from the cells of the gland, either directly or by a duct, on to a free surface, where it is useful chemically or mechanically, or by which it is drained away. Glands of this type connected with the alimentary canal are, serous and mucous glands, salivary glands, gastric and intestinal glands, the liver and pancreas.

(2) The so-called ductless glands, which possess no ducts, but secrete some substances, which are directly and gradually transmitted from the cells of the gland to the blood or lymph stream, and are of use in the general metabolism of the body. Such structures are the thyreoid gland, the suprarenals, the parathyreoids, and the hypophysis cerebri.

(3) Cytogenic or cell-producing glands, not always epithelial, and usually with no distinct duct, consist of aggregations of special cells, enclosed in a more or less definite framework of connective tissue, freely supplied with blood-and lymph-vessels. Glands of this type are concerned in the production, from the cells in the glands, of special cells, which are liberated from the gland tissue, and pass away from it. Such glands are lymph glands, the bone marrow, and the reproductive glands-testes and ovaries.

In structure they present wide differences.

Glands may also be classified according to their development, and on this basis the following groups are recognised:-

(1) Glandulæ epitheliales, developed from epithelial cells. These may $(a)$ possess a duct, in which case they are termed glandulæ evehentes; or (b) they may be constituted as ductless glands, and they are then termed glandulæ clausæ. To this last group belong the thyreoid gland, the hypophysis, and the suprarenal glands.

(2) Glandulæ vasculares, developed in connection with vessels, and not containing epithelial cells. This group includes all the lymph glinds, the lymph nodules found in the intestine, the tonsils, the thymus, and the spleen.

In the following paragraphs only the true glands of the alimentary system -namely, the glands of epithelial origin, claracterised by the possession of duets - are considered.

Such glands may be defined as epithelial organs used for the secretion or excretion of some particular substance or substances from the body. They usually consist of a number of cells, and there may be different kinds of cells in a gland. 
The simplest form of this type of gland is a portion of an epithelial surface, continuous with adjacent portions of the surface, but involuted from the surface to which it originally belonged.

The simplest form in which this involution occurs is as a single pocket, of uniform size throughout, forming a simple tubular gland. Of this kind are the intestinal glands in the wall of the small intestine.

In other cases there may be a bag-like enlargement of the end of the gland, forming a sort of pocket, called an alveolus (alveolus, small stomach or bag), and this type of gland is known as the simple alreolar gland. It does not exist in the alimentary canal.

Sometimes the lower part or fundus of the gland does all the secretion, and the upper part forms a tube or duct that carries the secretion to the surface.

When the outgrowth forming the gland remains undivided, the gland is known as a simple gland. It may, on the other hand, break up into two or more branches, and it then is known as a compound gland, and this compound gland may be tubular, alveolar, or of a mixed tubular and alveolar form.

When the fundus of the gland at the extremities of the ducts becomes a highly differentiated saccular region, consisting of several enlargements (alveoli)

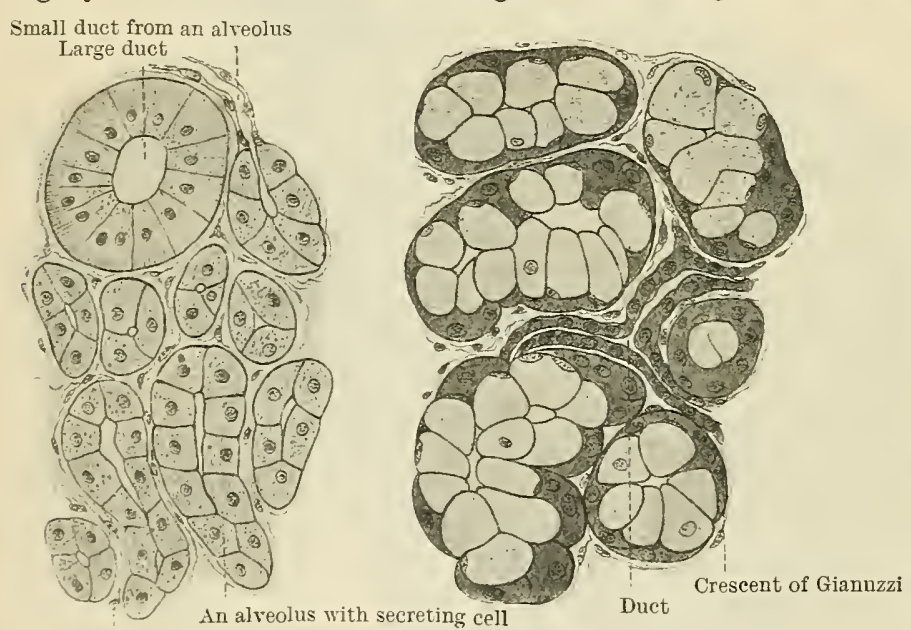

Connective tissue

Fig. 895. - Section of a Serods Gland ox the left, a Mucous Glaxd ON THE RIGHT SIDE (Böhm and v. Davidoff.)

In the serous gland the granular secreting cells and the centrally-placed nuclens should be noted. The relatively clear cells, with the dark crescents of Gianuzzi, are distinctive in the mucous gland.

branches more or less freely according to the size of the gland. The terminal divisions of the ducts end finally in specialised secreting parts, the acini or alveoli, quite distinguishable from the ducts or conducting parts. In typical acinous glands the acini or alveoli are distinctly saccular ; in other glands, such as the pancreas, this is not the case, the acini being long and narrow. Accordingly, the term alveolo- or acino-tubular has been introduced and applied to glands of this latter type, which is usually made to include the pancreas, and Brunner's duodenal glands. ${ }^{1}$

It should be added that the term acino-tubular is by some anthors used exclusively instead of acinous for all racemose glands.

The foregoing may be summarised in tabular form thus :-

I. Simple glands.-Duct undivided.

(a) Simple tubular (undilated at end)-e.g. intestinal glands and certain gastric glands.

(b) Simple alveolar (dilated at end) - not met with in alimentary canal.

II. Compound glands.--Duct divided.

(a) Compound tubular, branched elongated tubes, no acini-e.g. most gastric glands.

(b) Compound acinous or alveolar (racemose glands), branched duct with saccular acini on terminal branches-e.g. salivary glands; the mucous glands of the mouth, tongue, palate, pharynx, and cesophagus.

1 Some authorities consider the duodenal glands of Brunner to belong to the class of compound tubular glands (Heidenhain, Watney, Jonnesco, etc.). 
(c) Acino-tubular, branched duct, with elongated narrow acini on terminal branchese.g. pancreas, Brunner's glands.

General Structure of Glands. - Whilst the small glands, such as those of the mouth and pharynx, are placed in the mucosa or submucosa close to the point at which their ducts open on the surface, the large glands forming distinct masses, often lie at a considerable distance from the points at which their ducts open, and are generally surrounded by special capsules.

Each of these large glands of the acinous type, such as the parotid or submaxillary, presents the following general arrangement. The gland is made up, as can be seen with the unaided eye, of a number of masss, often as large as peas, which are surrounded and held together by connective tissue. These are known as lobes, and to each a branch of the duct passes. The lobes are in turn made up of a number of smaller masses-lobules - each having a special branch of the lobar duct. These again are composed of smaller lobules, and so on to a varying degree. Finally, the smallest are made up of a terminal branch of the duct, with a cluster of acini or alveoli developed upon it.

The acini or alveoli, the special secreting portions of the gland, are composed of a basement membrane, often fenestrated or basket-like, formed of flattened cells, on the outer side of which the blood-and lymph-vessels lie. The inner surface of this membrane is lined by the secreting epithelial cells, usually polygonal in shape, which almost completely fill the alveolus. A small lumen, however, is left, into which the secretion of the cells is shed; thence it passes into the duct of the lobule, and thus to the main duct.

The blood-and lymph-vessels, on entering the gland, break up and run, branching as they go, in the connective tissue which conveys them to all parts of the gland.

\section{GLaNDUl瓜 Salivales.}

Salivary Glands.-This term is generally understood to include only the three large masses of glandular tissue found on each side of the face and upper part of the neck-namely, the parotid, submaxillary, and sublingual glands. But, as previously pointed out, numerous other small glands of a similar nature are found in the lips, cheeks, palate, tongue, etc. These have already been sufficiently described, and require no further mention.

Glandula Parotis.-The parotid gland is the largest of the salivary glands, and lies on the side of the face, below and in front of the ear, and is prolonged inwards deeply from the surface.

It forms a lobulated mass, of a yellowish or light reddish-brown colour, with a large triangular superficial surface. From this mass a process of the gland passes medially posterior to the upper part of the ramus of the mandible below the base of the skull almost to the side wall of the pharynx. It is known as the processus retromandibularis.

The superficial surface extends upwards nearly to the zygoma, and downwards as far as to the angle of the mandible. It is prolonged anteriorly on the superficial surface of the masseter muscle in the form of a process, often triangular in shape, called the facial process, while at the back it comes into contact with the cartilaginous external acoustic meatus, the front of the sterno-mastoid muscle, and the mastoid process.

Processus Retromandibularis.-This portion of the gland occupies a deep fossa, called the parotid fossa, of considerable size, which has two nearly vertical sides, an anterior and posterior. These sides converge towards one another and meet deeply, and so form the apex of the fossa. This fact is well brought out by a horizontal section through the head about the middle of the gland (Fig. 896).

From this it will be seen that the posterior wall of the fossa is formed, medial to the sterno-mastoid muscle, by the posterior belly of the digastric and the stylohyoid muscles, with the occipital artery, and more deeply still, by the root of the styloid process and the carotid sheath and its contents, and especially by the internal jugular vein separating the gland from the vertebral column.

The anterior wall of the fossa is formed by the ramus of the mandible and the masseter and internal pterygoid muscles.

Fascia Parotideomasseterica.-The parotid recess is covered over on the one hand, 
and lined on the other, by fascia. The covering layer is specially known as the fascia parotideomasseterica ( $0 . T$. parotid fascia) and both it and the lining layer are derived from the deep cervical fascia, which divides to enclose the gland. The parotideo-masseteric fascia is connected, on the surface, above to the zygoma ; posteriorly, to the acoustic meatus and anterior border of the sterno-mastoid; below, it is continuous with the deep cervical fascia, and anteriorly it passes over the masseter, and blends with the fascia buccopharyngea. The fascia forms a lining for the recess, and is united above to the periostenm over the acoustic meatus and posterior part of the glenoid fossa; medially it is

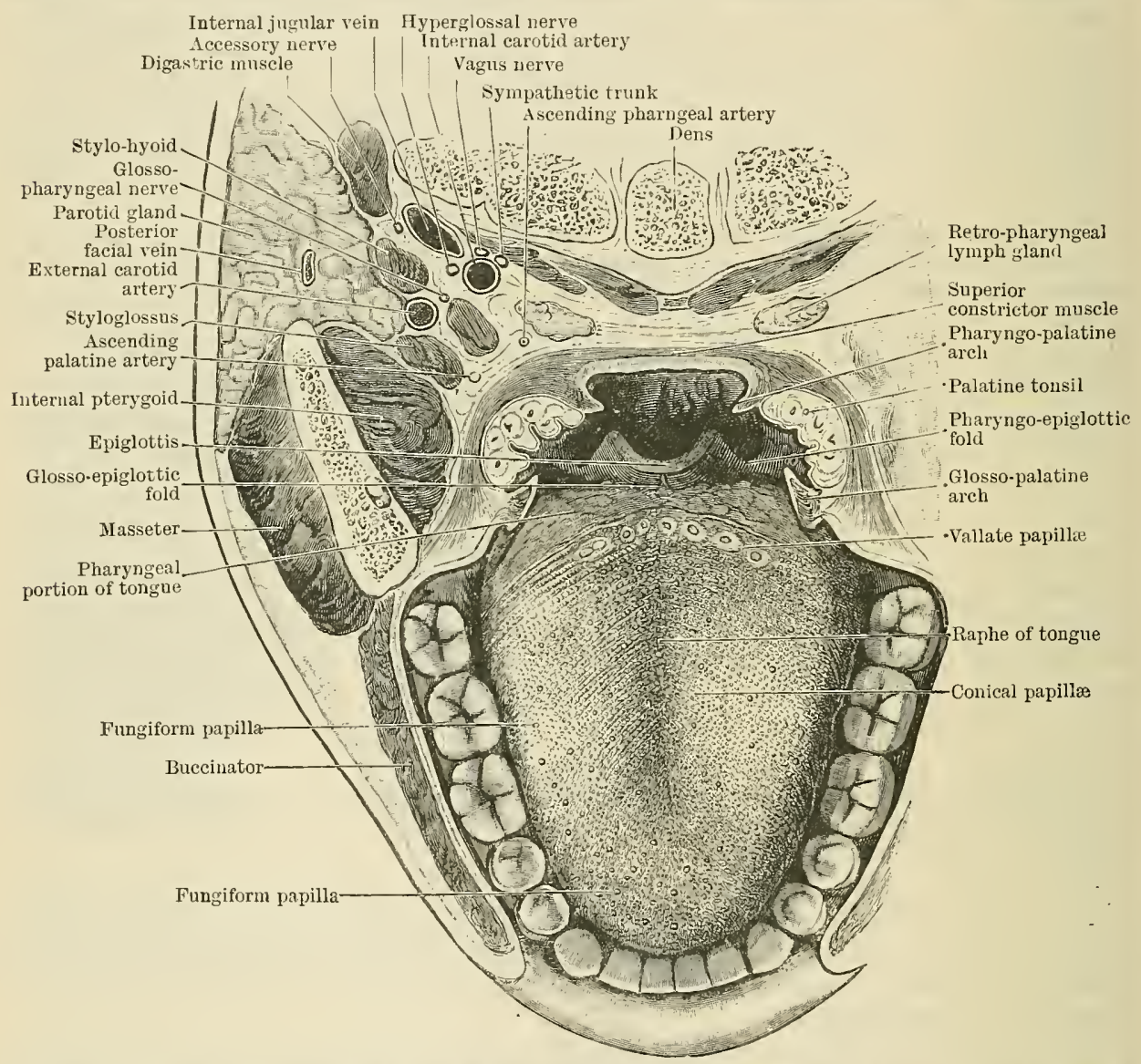

Fig. 896. - Horizontal Section throdgh Modth and Pharynx at the Level of the Palatine Tonsils.

The stylopharyngeus, which is shown immediately to the medial side of the external carotid artery, and the prevertebral muscles, are not indicated by reference lines.

connected to the styloid process; whilst below it joins the deep cervical fascia. Taken together, the two layers form a definite capsule which completely encloses the gland. In connexion with the lower and anterior part of this capsule is developed a special flat band, the stylo-mandibular ligament, which passes downwards and laterally from the styloid process to the angle of the mandible. It separates the anterior part of the parotid gland from the posterior border of the internal pterygoid muscle; perhaps occasionally, also, from the upper and posterior part of the submaxillary gland.

Shape and Relations of the Parotid Gland.-The main mass of the parotid gland is three-sided (Fig. 896), the three surfaces being superficial, anterior, and posterior.

Superficial Surface. - This surface is somewhat triangular in form, and irregular in outline. Its long posterior border lies in front of the external acoustic meatus, and the stemo-mastoid muscle. Its superior border lies below the zygomatic arch, and the inferior border passes irregularly upwards and anteriorly to 
join it. The apex, directed anteriorly, is formed by the facial process of the gland, and lies on the masseter muscle, and the duct of the gland issues from it, or just below it.

This superficial surface is frequently prolonged beyond the limits of the parotid fossa, and passes downwards over the digastric muscle. It may descend beyond the angle of the mandible, and come into immediate relation with the posterior part of the submaxillary gland, from which it is separated merely by a thin layer of the deep cervical fascia.

Deep Portion of the Gland.-This portion of the gland presents an anterior surface looking forwards, deeply concave, and a posterior surface, irregular in outline, directed backwards and medially.

These surfaces meet medially at the medial border, which may lie so deeply as to be in contact with the side wall of the pharynx. The lower part of the styloid

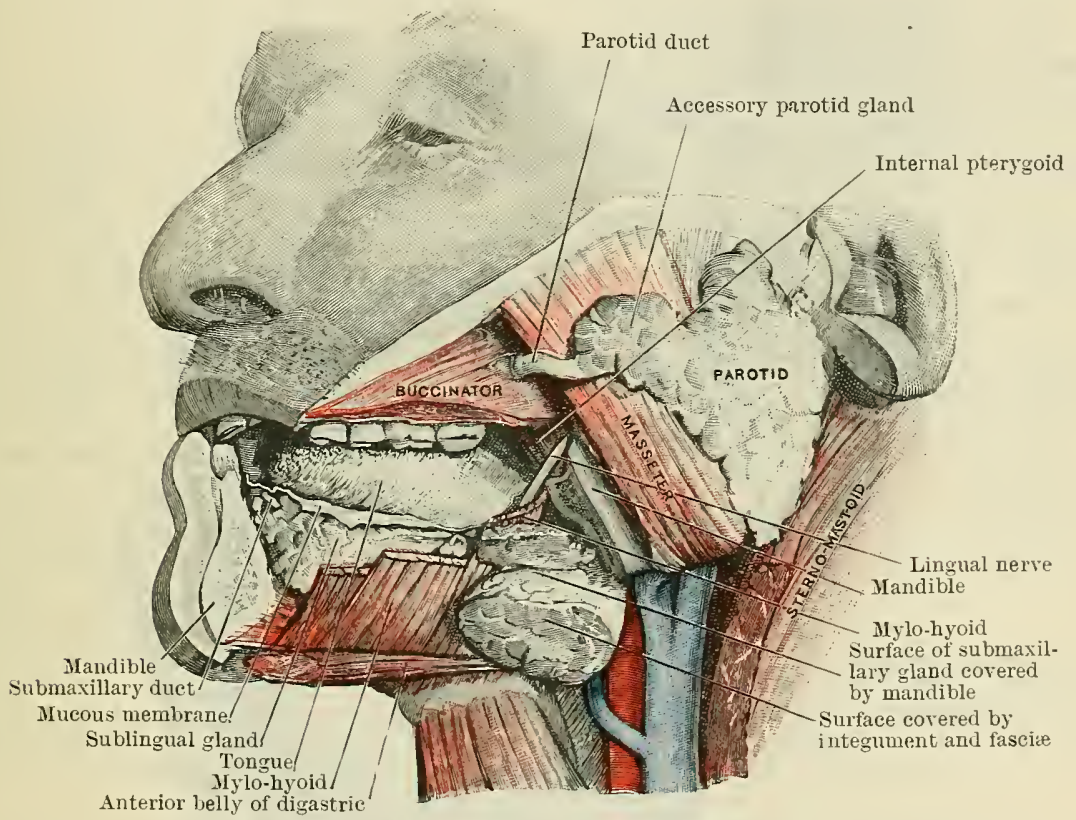

Fig. 897.-The Salivari Glands and their Ducts.

process in many cases lies in contact with the inferior part of this border, and in such cases the process, together with the styloglossus and stylopharyngeus muscles, separates the medial border from the pharynx. The superior and inferior borders, at the union of the anterior and posterior surfaces, are irregular in outline, and indefinite.

The relations of these two surfaces are as follows:-

The anterior surface is wrapped round the ramus of the mandible, and extends on to the muscles which cover this portion of the bone laterally and medially, that is, on to the masseter and internal pterygoid muscles respectively.

The posterior surface, in contact with the posterior wall of the fossa, is moulded upon the structures which form that wall. It is in contact, from the surface medially, with the stermo-mastoid muscle, the mastoid process, the external acoustic meatus, the posterior belly of the digastric muscle, the internal jugular vein, and the root of the styloid process and the styloid muscles. It is often deeply grooved by the posterior belly of the digastric.

The posterior surface is occasionally prolonged medially beyond the lower portion of the styloid process, towards the pharynx. In such cases, the lower part of the styloid process lies in a groove on the posterior surface of the gland, and is not in contact with its medial border as described above.

The gland frequently gives off processes which pass into the intervals between the structures bounding the fossa. Occasionally from its superior end a small 
process termed the glenoid lobe is found, passing into the posterior or tympanic part of the glenoid cavity.

Another runs into the interval between the sterno-mastoid and digastric muscles; and a pharyngeal process is occasionally found running medially anterior to the styloid process towards the side of the pharynx.

A pterygoid extension, between the two pterygoid muscles, cannot properly be said to exist.

Embedded in the superficial surface there are usually found several small rounded lymph glands, which can be recognised from the gland tissue by the difference in their colour.

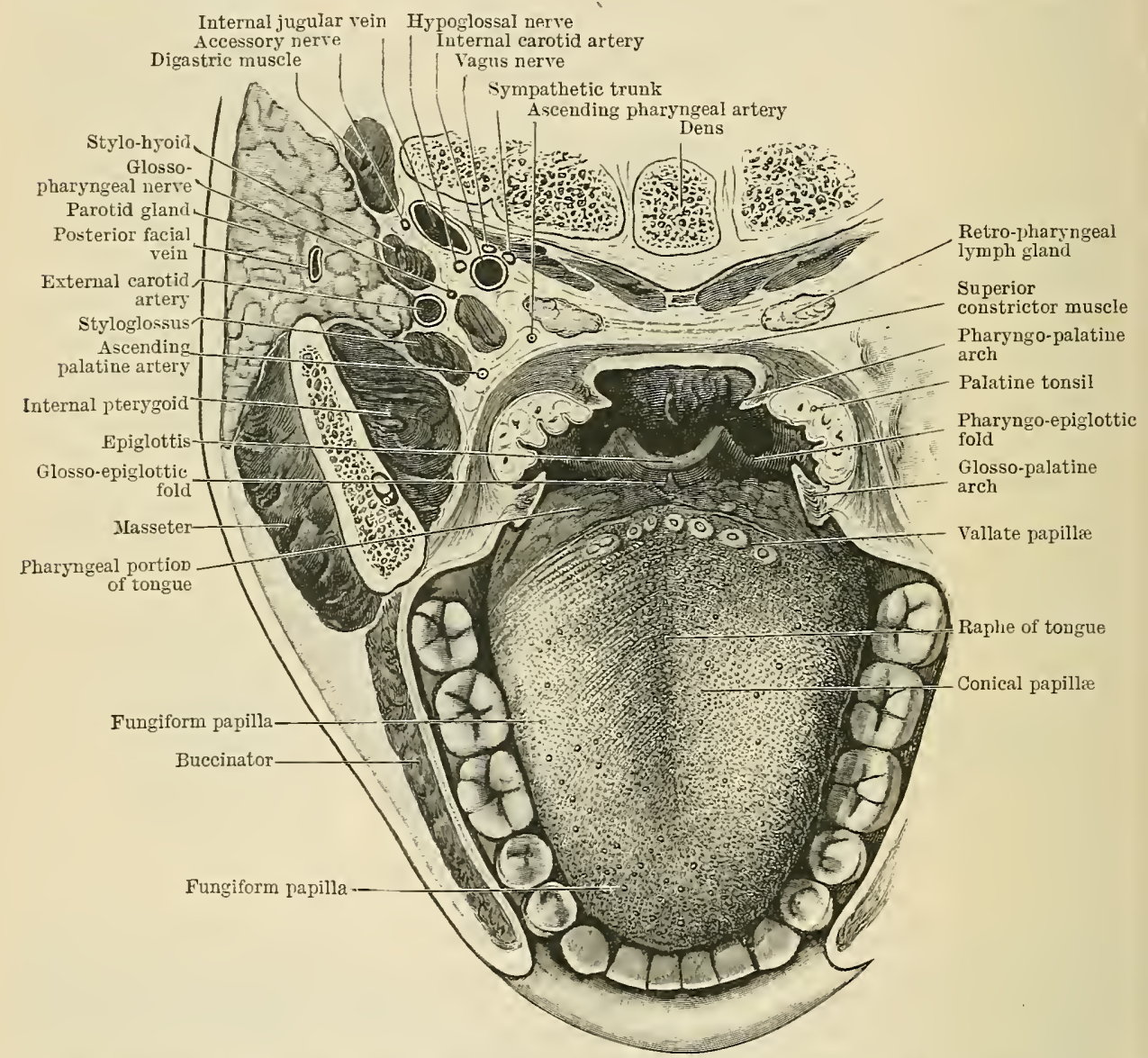

Fig. 893.-Horizoxtal Sectiox throtgh Moeth axd Pharyxy at the Letel of the Palatine Toxsils.

The prevertebral muscles and the stylopharyngeus (which is shown just at the medial sile of the external carotid artery) are not indicated by reference lines.

The facial process of the gland-often of considerable size-is a flat and somewhat triangular portion which runs forwards from the upper part of the front of the gland, and overlaps the masseter muscle to a varying extent; from its most anterior part the parotid duct emerges, and a separated portion of this process, often found lying immediately above the duct, is known as the glandula parotis accessoria (O.T. socia parotidis).

Ductus Parotideus (Stenonis).--The parotid duct (O.T. Stenson's) leaves the anterior border of the gland at its most prominent part (Fig. 897). It first runs forwards across the masseter, below the accessory parotid gland, and accompanied by branches of the facial nerve, and the transverse facial artery, which is commonly some distance above, though its relation is variable. Having crossed the masseter, it turns abruptly round the anterior border of this muscle and runs 
inwards through the fat of the cheek, practically at right angles to the first part of its course, to reach the buccinator, which it pierces. Then passing for some distance ( 5 to $10 \mathrm{~mm}$.) between the buccinator and the mucous membrane, it opens into the vestibule of the mouth by a very small orifice, on a variably developed papilla, opposite the crown of the second upper molar tooth.

The course of the duct, which is fairly constant, can be marked on the side of the face by drawing a line from the inferior edge of the acoustic meatus to a point midway between the ala of the nose and the red of the lip; the middle third of this line corresponds fairly accurately, on the surface, to the course pursued by the duct.

The duct measures from $1 \frac{1}{2}$ to $2 \frac{1}{2}$ inches ( 38 to $62 \mathrm{~mm}$.) in length, and $\frac{1}{8}$ inch ( 3 to $4 \mathrm{~mm}$.) in diameter. The calibre of the duct is very much greater than that of its orifice, which only admits a fine bristle, and for this reason the duct may; to some extent, be looked upon as a reservoir for the saliva, as well as a duct for its conveyance. In the child it pierces the "sucking pad" on its way to the mouth.

A number of vessels and nerves are found in intimate relation to the parotid gland.

These are: (1) The external carotid artery and its two terminal branches. This artery lies at first in a groove in the inferior and deep aspect of the gland. It then enters the gland substance and lies deeply in it, as far mp as to the neek of the mandible, when it divides into its two terminal branches. The superficial temporal artery passes onwards and emerges from the superior superficial part of the gland, and the internal maxillary artery turns inwards and emerges from the deep part of the anterior surface.

The transverse facial artery is given off in the substance of the gland, and emerges from it between the zygomatic arch and the duct.

The posterior facial vein descends in the substance of the gland superficially, and divides in it in to the two terminal branches which emerge from the inferior part of the gland.

The facial nerve enters the posterior surface of the gland, slightly below its middle, and runs forwards and laterally, dividing into its main branches within the gland, and lying superficially to the external carotid artery and posterior facial vein. Communicating branches from the auriculo-temporal and great auricular nerves to the facial also traverse the gland substance.

Vessels and Nerves.-The arteries which supply the gland arise from the external carotid artery, and from the branches of this artery in relation to the gland.

The veins join the posterior facial vein and its tributaries. The lymph vessels pass to both the superficial and the deep cervical glands; there are also a few small parotid lymph glands, which lie on the surface of the superior and inferior part of the parotid beneath the capsule. Some are said to be embedded in the substance of the parotid itself.

The nerves are derived (a) from the auriculo-temporal, great amicular, and facial, and (b) from the plexus caroticis externus. The fibres of the sympathetic are mainly vaso-constrictor.

The secretory fibres to the gland, arising in the brain-stem, pass out through the glossopharyngeal nerve, and pass from it through the lesser superficial petrosal nerve to the otic ganglion, and from that ganglion to the gland in the auriculo-temporal nerve.

Glandulæ Submaxillares.-The submaxillary glands are next in size to the parotid, and resemble them in their lobulation and colour. Each is placed partly in the submaxillary triangle and partly under cover of the mandible (Fig. 897).

In each gland two portions may be recognised, a somewhat superficial larger part, the body, lying in the submaxillary triangle, and a smaller deep part, the deep process, which springs from the middle of the deep surface of the body.

The superficial part, like the parotid, presents a superficial convex surface, which projects below the mandible, in the submaxillary triangle, but it frequently extends beyond the limits of that space, and overlaps the digastric muscle.

This surface looks downwards and laterally, and is covered by the deep cervical fascia and the platysma and crossed superficially by the anterior facial vein.

Deeply to this surface the body of the gland is wedged upwards, between the medial surface of the mandible and the mylo-hyoid and hyoglossus muscles. It thus presents two surfaces, a lateral, which is in contact with the submaxillary fossa of the mandible, and a medial, related to the mylo-hyoid, hyoglossus, the posterior belly of digastrie, and stylo-hyoid muscles.

The deep process passes still further medially, around the posterior free margin of the mylo-hyoid muscle, and comes to lie between the mylo-hyoid and hyoglossus muscles.

Embedded in the substance of the gland are found a few submaxillary lymph glands, which are of importance from the connexion they have with the lymph vessels of the lip and of a portion of the tongue. 
major (O.T. duct of Bartholin), is very rare, and must be considered as an exceptional condition in man, althougl normal in the ox, sheep, and goat. The same may also be said of ducts from the sublingual, which are described as opening into the submaxillary duct.

Vessels and Nerves.-The arteries are derived from the sublingual artery, a branch of the lingnal, and from the submental, a branch of the external maxillary. The nerves come from the lingual, chorda tympani, and the external maxillary plexus, through a branch of the submaxillary ganglion which joins the lingual, and is conveyed by it to the gland. The secretory fibres run in the chorda tympani nerve, and thence through the submaxillary ganglion to the gland.

The glandula lingualis anterior (Blandini, Nuhni) has been described with the tongue.

Structure of the Salivary Glands (Fig. 900).- Each of the principal salivary glands consists of a number of lobules, loosely united together by connective tissne. From each of them one or more ducts emerge. Each duct when traced onwards divides into branches, which terminate in a group of saccular or tubular alveoli.

The epithelium lining the ducts is columnar in character, bnt becomes flattened at the junction with the alveoli.

The epithelium lining the alveoli shows different characters in different glands. In the parotid, and the small salivary glands of the vallate papillæ in which the secretion is watery or albuminous, the cells are uniform in character, and of small size. When the gland is at rest, the cells are filled with small granules, which when the secretion is poured out are transformed into the gland ferment (ptyalin). After secretion, only the deeper parts of the cells show the presence of granules. The nuclei are rounded, and lie near the centre of the cells. In the sublingual, labial, buccal, and other glands of the mouth and palate the secretion is of a mucous character and the cells are larger, and the nuclei are placed deeply. The -cells appear clear and swollen unless special methods of preparation are employed. In such cases, e.g. when examined in serum, the cells are seen to contain large and distinct granules of mucigen which in secretion are transformed into mucus.

In the submaxillary gland and the anterior lingual gland both varieties of cells are present. In these cases, the larger, clear mucous cells line the cavity of the alveolus, and the smaller granular serons cells are arranged upon the basement membrane, deeply to the former cells, in crescentic masses, termed the crescents or demilunes of Gianuzzi. They communicate with the cavity of the alveolus by small channels between adjacent mucous cells.

After secretion, the mucous cells become smaller, and stain more deeply than when loaded with mucigen before secretion.

\section{PHARYNX.}

The pharynx is the expanded upper portion of the alimentary canal which lies posterior to and communicates with the mouth, the larynx, and the nasalicavities, and is continuous inferiorly with the superior end of the cesophagus or gullet (Fig. 901).

It extends from the base of the skull above to the level of the sixth cervical vertebra (Fig. 903), and the lower border of the cricoid cartilage below.

Its total length varies from 5 to $5 \frac{1}{2}$ inches $(12.5$ to $14.0 \mathrm{~cm}$.).

The inferior portion alone, that is, the parts lying opposite and inferior to the opening of the mouth, is functionally a part of the alimentary canal, for the portion above the level of the soft palate is used for respiration only. It is, however, convenient to study the structure and relations of the whole of the pharynx at once.

Structurally the pharynx is a fibro-muscular bag, of conical form, wide above and narrow below. The wall of the superior part of the pharynx, in the region of the base of the skull, is firmly attached to the surrounding bony structures, especially around, the orifice of the choanæ, and hence in this superior portion of the pharynx there is a permanent cavity containing air.

The lower portion gradually assumes a more tubular form, and the anterior and posterior walls approach one another, so that below the level of the opening of the larynx they are in contact with one another, and the cavity, except during the passage of food, is reduced to a slit.

Dimensions of the Pharynx.-From the fornix pharyngis, the highest part of the roof, to the superior surface of the soft palate at its junction with the hard palate, measures about $1_{4}^{\frac{1}{4}}$ inches, or $3 \mathrm{cms}$. The vertical extent of the oral part of the pharynx is about $2 \frac{1}{4}$ inches, or $6 \mathrm{cms}$., and that of the laryngeal part is about $2 \frac{3}{4}$ inches, or $7 \mathrm{cms}$.

The inferior end of the pharynx is usually about $5 \frac{1}{2}$ to $6 \frac{1}{2}$ inches from the margins of the incisor tooth, in a line passing throngh the cavities of the mouth and of the oral and laryngeal parts of the pharynx.

The other diameters are as follows: the antero-posterior diameter (depth) of the superior 
segment (nasal portion), from the posterior margin of the septum of the nose at its inferior part horizontally backwards, measures 15 to $18 \mathrm{~mm}$., and that of the middle segment, from the glossopalatine arches to the posterior wall, about $10 \mathrm{~mm}$. Below this level, the anterior and posterior walls gradually approach one another, until, below the laryngeal orifice, they are in contact with one another.

The transverse width of the pharynx also varies considerably. Immediately below the base of the skull the cavity is wide, as there is on each side a deep lateral recess, and it measures $35 \mathrm{~mm}$., or rather more than $1 \frac{1}{4}$ inches.

Opposite the middle of the soft palate the cavity narrows, and measures transversely $25 \mathrm{~mm}$., or 1 inch.

It again widens out below this level, and expands to a width of $45 \mathrm{~mm}$., opposite the inferior margin of the laryngeal opening, where on each side there is a wide recess, called the piriform recess.

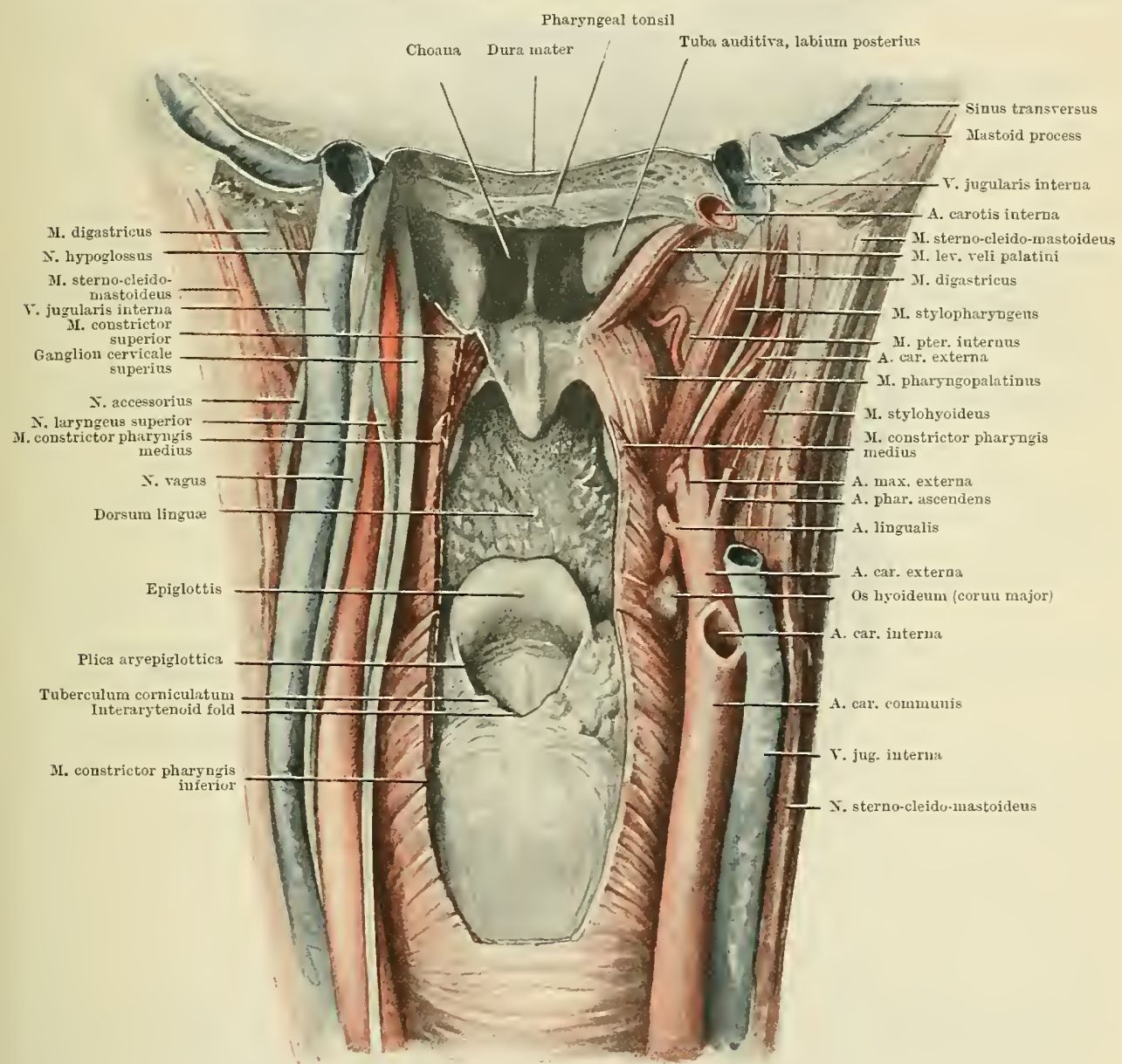

Fig. 901.-Interior of Pharsix and Strectures in relatios to its Lateral Walls, VIEWED FROM BEHIND.

Cavum Pharyngis.-The cavity of the pharynx is partially intersected by the soft palate, which is attached anteriorly to the hard palate, and laterally to the lateral walls of the pharynx. This sheet, sloping obliquely backwards and downwards, cuts into the cavity of the pharynx (Fig. 901), and, falling short of the posterior wall, incompletely divides it into two, namely, an upper part, pars nasalis (O.T. naso-pharynx), and a lower part or pharynx proper. This lower portion is further subdivided into the pars oralis (O.T. oral pharynx) lying behind the mouth and tongue, and the pars laryngea (O.T. laryngeal pharynx) behind the larynx.

The aperture left between the soft palate and the posterior wall of the pharynx, through which the nasal part of the pharynx communicates with the inferior divisions of the cavity, is called the isthmus pharyngonasalis.

The pharynx presents seven openings by which it communicates with 
neighbouring cavities (Fig. 901)., These are the two choanæ (O.T. posterior nares) on the anterior wall of the pars nasalis, and the two tubæ auditivæ (O.T. Eustachian tubes) on its lateral walls; the isthmus of the fauces leading into the mouth from the oral part; the orifice of the larynx on the anterior wall of the laryngeal part of the cavity; and finally, the opening of the osophagus at its inferior end.

Pars Nasalis (O.T. Naso-Pharynx) (Figs. 901 and 902).-Although morphologically and developmentally this is a portion of the true pharynx, it is functionally an annexe to the respiratory portion of the nasal cavities, and both anatomically and

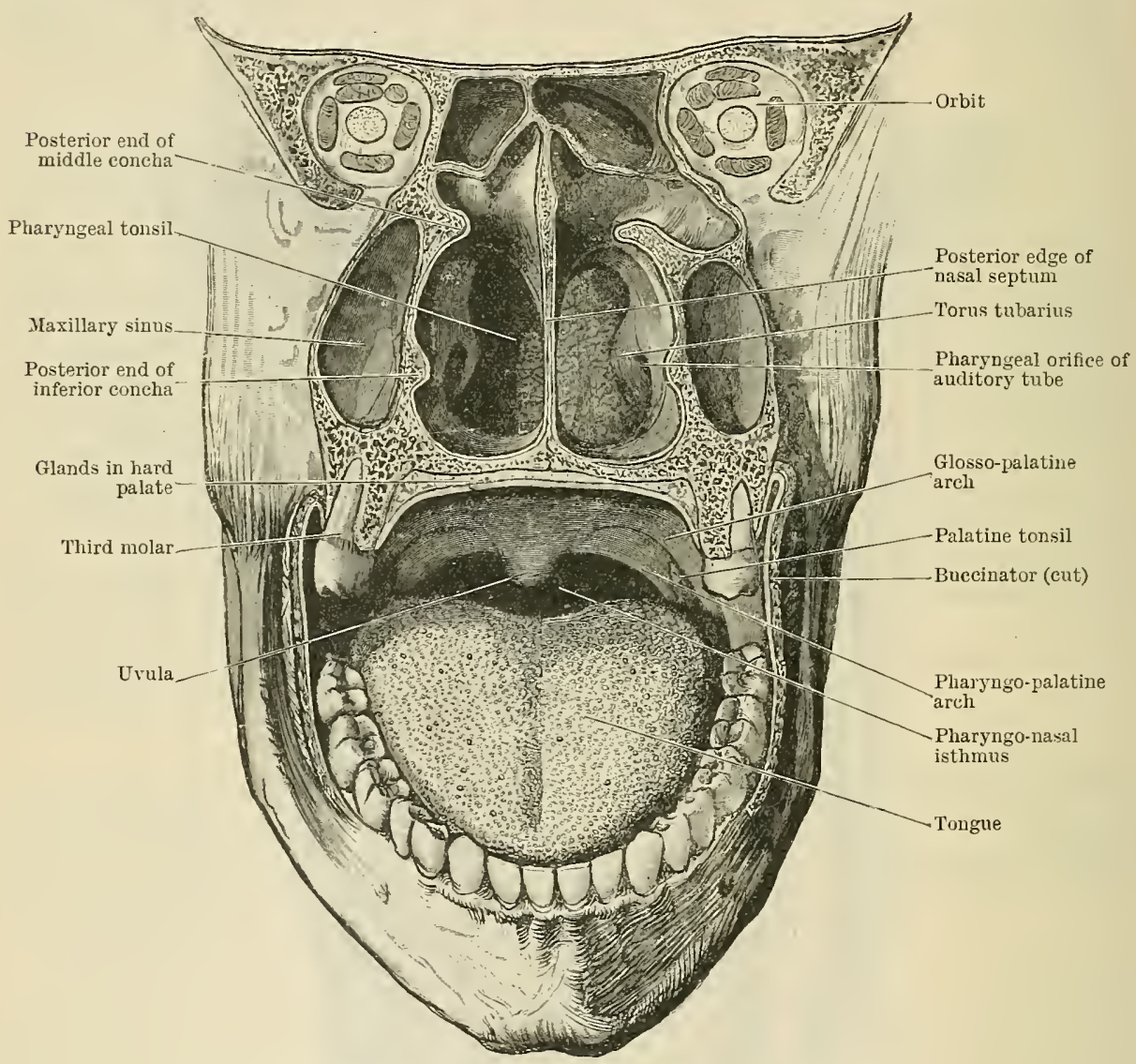

Fig. 902.-The Nasal Part of the Pharyni from the Front.

A frontal section was made through the upper part of the head; this passed immediately in front of the posterior edge of the nasal septum, and extended into the mouth below. Through the choanæ, the nasal part of the pharynx is seen. The prominence of the posterior margin of the ostium pharyngeum of the auditory tube, and the lymph nodnles constituting the pharyngeal tonsil, should be noted. The palatine arches and tonsils, and an unusually wide pharyngo-nasal isthmus, are also seen.

functionally it is distinctly marked off from the digestive tube. It differs from the rest of the pharynx in that its cavity remains, under all conditions, a distinct open chamber incapable of obliteration, owing to the fact that all its walls, with the single exception of the floor, are practically immovable.

The cavity of the pars nasalis is irregular in shape, and is enclosed by six walls-namely, anterior, posterior, two lateral, a floor and a roof or vault.

These walls all merge into one another, and the lines of separation between them are arbitrary. Through the anterior wall, which slopes upwards and backwards, open the choanæ (O.T. posterior nares), separated from each other by the nasal septum. The margins of the choane form the line of separation between the pars nasalis and the cavity of the nose. This separation is occasionally marked by a furrow or fold on the lateral wall, called the naso-pharyngeal furrow. 
The posterior wall is nearly vertical, and may be considered to extend upwards as far as to the level of the body of the sphenoid bone, where it becomes continuous with the rounded vault forming the roof.

The roof lies under the body of the sphenoid, and on each side it extends downwards to the superior margin of the orifice of the auditory tube. It slopes from in front downwards and backwards to meet the posterior wall at the junction of the basilar part of the occipital and sphenoid bones immediately anterior to the pharyngeal bursa - a small median recess in the pharyngeal wall, found constantly in the child and occasionally in the adult.

The lateral walls are occupied by the pharyngeal opening of the auditory tube, and posterior to them, by a vertical slit-like depression leading into a recess, the recessus pharyngeus (Rosenmülleri).

The floor is formed by the upper surface of the soft palate.

Between the floor and the posterior wall is the aperture, the isthmus pharyngonasalis, through which the pars nasalis communicates with the cavity of the pharynx proper.

When the soft palate is raised, this communication becomes closed, by contact of the soft palate with the posterior wall, and the floor of the pars nasalis is complete.

A number of important structures are found in the walls of the pars nasalis.

In the posterior part of the roof, and superior part of the posterior wall, there is a considerable accumulation of lymph tissue, known as the pharyngeal tonsil. It is most distinct in the child, and becomes indistinct, or entirely disappears, in adult life. It extends from the body of the sphenoid down as far as to the margin of the occipital bone, and, laterally, as far as to the superior part of the lateral wall. The mucous membrane which covers it is thickened and thrown into transverse folds.

In connexion with the inferior part of the pharyngeal tonsil, there is found, constantly in the child and occasionally in the adult, a small median recess which runs upwards and backwards in the wall of the pharynx for some distance, and is known as the bursa pharyngea (Fig. 903). The origin and morphological significance of this pouch are not yet solved.

Enlargement of the lymph tissue here occurs frequently in children, and the swollen lymph nodules are known as adenoids. The enlargement may become so great as to fill up a great part of the cavity of the nasal part of the pharynx.

Ostium Pharyngeum Tubæ Auditivæ. - On each lateral wall is placed the pharyngeal orifice of the auditory tube (O.T. Eustachian tube), an opening of a somewhat triangular form, with a characteristic infundibular or funnel-like appearance (Fig. 903). It is bounded superiorly and posteriorly by a prominent rounded ridge, the torus tubarius (O.T. Eustachian cushion). This ridge is due to the projection of the cartilage, which surrounds the auditory tube superiorly and posteriorly, but is absent inferiorly and anteriorly. The prominence of the posterior margin (labium posterius) as contrasted with the anterior margin (labium anterius) of the orifice, and the direction of the tube itself, which runs posteriorly and laterally (from the pharynx to the tympanum), greatly facilitate the introduction of a Eustachian catheter.

The exact position of the orifice is of importance. It is situated on the lateral wall of the pars nasalis, a short distance (about $\frac{1}{3}$ to $\frac{1}{2}$ inch) behind the posterior end of the inferior concha, and immediately above the level of the hard palate (Figs. 902 and 903).

A slight ridge of the mucous membrane descends from the inferior end of the torus tnbarius on the lateral wall of the pharynx, and gradually becomes lost. This is known as the plica salpingopharyngea. Another less-developed ridge, the plica salpingopalatina, passes from the anterior border of the ostium pharyngeum downwards and forwards to join the palate. In front of the latter lies the indistinct groove, the naso-pharyngeal groove, which indicates the separation of the nasal cavity from the nasal part of the pharynx.

The levator veli palatini in descending runs parallel to the tuba anditiva, and along its lower border. As it enters the palate, it produces, particularly when in a state of contraction, an elevation just below the pharyngeal orifice of the tube, known as the torus levatorius (Figs. 902 and 903), which in its upper portion abuts against the lower part of the orifice, and forms its base when that opening assumes its usual triangular shape. 
Occasionally the osteum pharyngeum is of an oval or slit-like form, with sloping edges, but the triangular shape described above is much more conimonly found.

Immediately posterior to each osteum pharyngenm is seen the recessus pharyngeus (O.T. lateral recess of the pharynx or fossa of Rosenmuiller), a nearly vertical depression of considerable depth (Figs. 903 and 905), which runs outwards in the form of a flattened pouch or diverticulum.

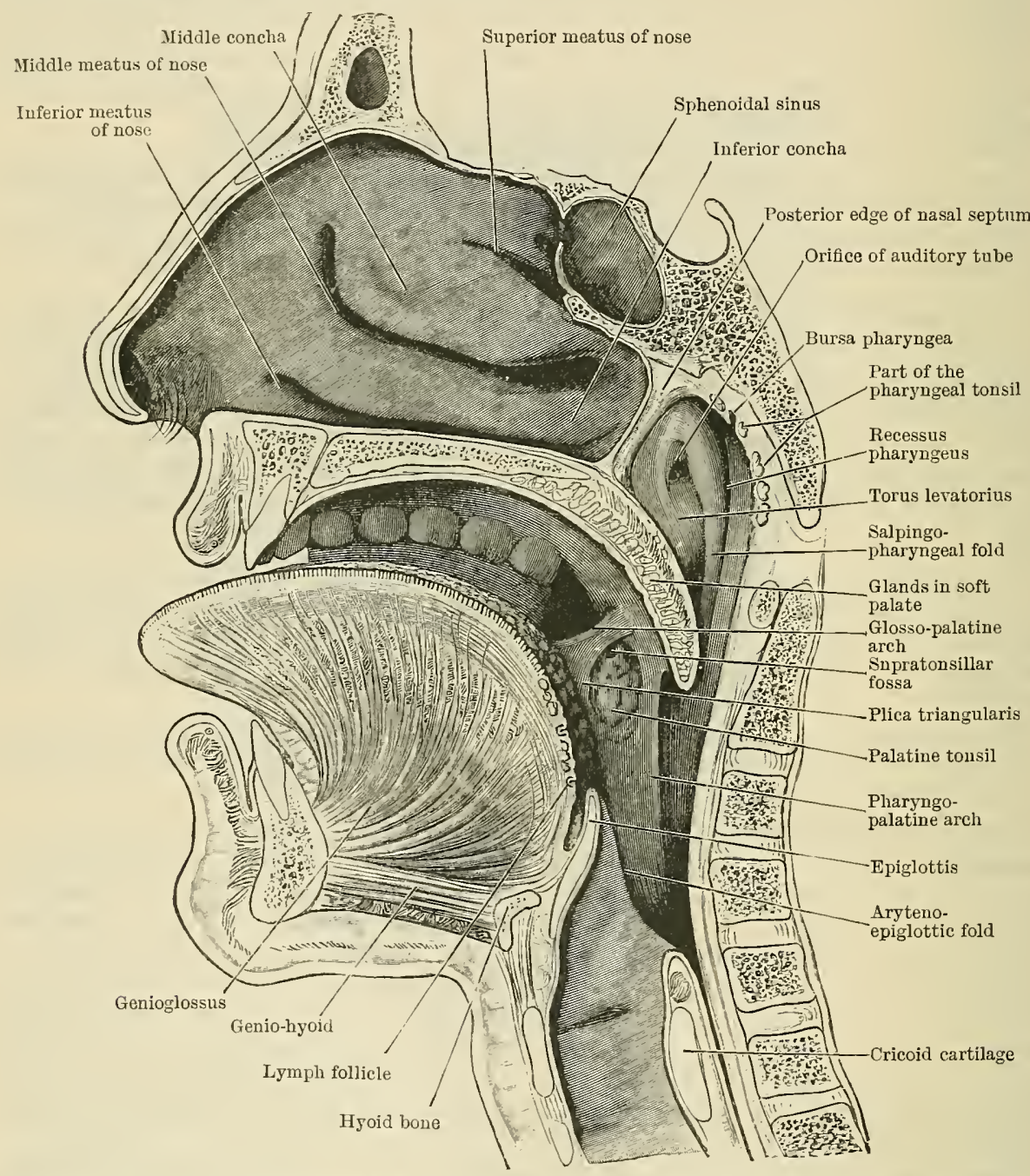

Fig. 903.-Sagittal Section throcgh Modth, Tongue, Larynx, Pharyni, and Nasal Cavity.

The section is slightly oblique, and the posterior edge of the nasal septum has been preserved. The specimen is viewed slightly from below, hence, in part, the low position of the inferior concha.

The pharyngeal recesses project outwards over the superior margin of the superior constrictor, below the petrons portion of the temporal bone, and correspond in position to the sinus of Morgagni on each side (ef. description of pharyngeal wall, p. 1143). The recess has been considered to be the remains of the inner or pharyngeal portion of the second visceral cleft, the lower part of which is represented in the supra-tonsillar fossa, but more probably it is not connected with any of the visceral clefts, but makes its appearance after they have disappeared.

Pars Oralis. - The oral part of the pharyux lies behind the mouth, between the soft palate above and the superior aperture of the larynx below. On its anterior aspect is the isthmus of the fauces, leading into the mouth. Below this the vertical pharyngeal portion of the tongue forms the anterior wall. Its lateral wall 
(Fig. 903) presents a triangular area, sinus tonsillaris, bounded anteriorly by the glosso-palatine arch, posteriorly by the pharyngo-palatine arch, and below by the sides of the tongue in its pharyngeal portion. This area is occupied in the greater part of its extent by the tonsil. Above the tonsil there is a depression, the fossa supratonsillaris (Fig. 903), which is of considerable clinical interest.

The arcus pharyngopalatinus (O.T. posterior pillar of the fauces) is a prominent fold of mucous membrane, containing in its interior the pharyngopalatinus muscle. It springs from the posterior edge of the soft palate, and, passing downwards and slightly backwards, ends inferiorly on the lateral wall of the pharynx (Fig. 903). The two pharyngo-palatine arches form the lateral boundaries of the pharyngonasal isthmus, and the orifice can be modified in size by the contraction of the pharyngo-palatine muscles.

The arcus glossopalatinus is described on p. 1111.

The isthmus pharyngonasalis is the very oblique and somewhat triangular orifice through which the oral part communicates with the nasal part of the pharynx (Fig. 904). It differs considerably in size and shape in different individuals, being in some so small that the nasal part can be explored from the mouth only with very great difficulty; whilst in others it is of much larger dimensions (Fig. 905 ) and affords ample space for the rhinoscopic examination of the nasal part of the pharynx and the posterior part of the nasal cavities.

In general it may be described as triangular in shape, the sides corresponding to the pharyngo-palatine arches, and the base, which is behind, being formed by the posterior wall of the pharynx. The apex of the triangle

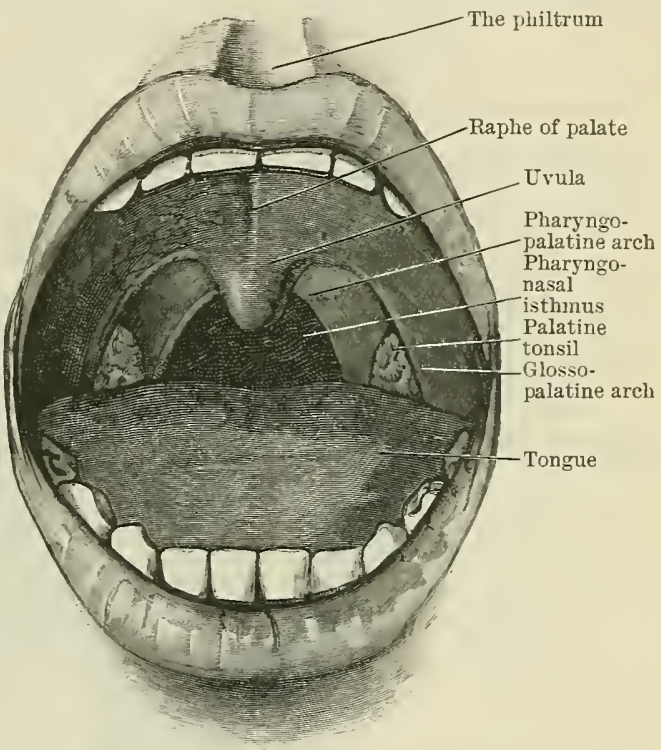

Fig. 904.-Open Mouth showing Palate and Palatine ToNsILS.

It also shows the two palatine arches, and the pharyngonasal isthmus through which the nasal part above communicates with the oral part of the pharyns below. is directed towards the soft palate, and is encroached upon, and overlapped from below by the uvula, which assists in the closure of the orifice (Fig. 902).

By the contraction of the pharyngo-palatine muscles, which are enclosed within the pharyngo-palatine arches, the sides of the isthmus can be approximated, like two curtains, and its size correspondingly diminished. When, at the same time, the urula and soft palate are elevated, and the whole pharynx in this region is narrowed by the contraction of the superior constrictor, the aperture can be completely closed, and the oral separated from the nasal part of the pharynx, as in the acts of swallowing and vomiting.

Tonsillæ Palatinæ.-The palatine tonsils are two large, oval masses of lymph tissue which are embedded in the lateral walls of the oral part of the pharynx, between the glosso-palatine and pharyngo-palatine arches (Fig. 904). As already pointed out, there is in this region a triangular interval (the sinus tonsillaris). The greater part of this interval is occupied by the tonsil. In its superior part, however, above the tonsil, there is usually found a variably developed depression already referred to as the fossa supratonsillaris.

The tonsillar sinus is bounded anteriorly by the glosso-palatine arch, passing from the inferior surface of the soft palate to the side of the tongue. Posteriorly it is bounded by the more vertical pharyngo-palatine arch, passing from the margin of the uvula to the lateral wall of the pharynx. The inferior boundary is formed by the margin of the tongue, while the narrow apex above passes up to the side of the soft palate. The tonsil occupies the inferior part of this sinus. 
From the posterior surface of the glosso-palatine arch a thin triangular fold of mucous membrane, called the plica triangularis, passes backwards. Its base corresponds to the glosso-palatine arch, its superior border is free, and passes downwards and backwards, frequently overlapping the tonsil. Its lower border is attached to the side of the tongue. It covers, medially, the inferior part of the tonsillar fossa.

The palatine tonsil presents very different forms in different individuals.

It may project from the fossa into the cavity of the pharynx, or it may be flat and limited to the tonsillar fossa. In some cases the plica triangularis is fused with the free surface of the tonsil, and the lymph tissue may in some cases be developed on the median surface of that plica.

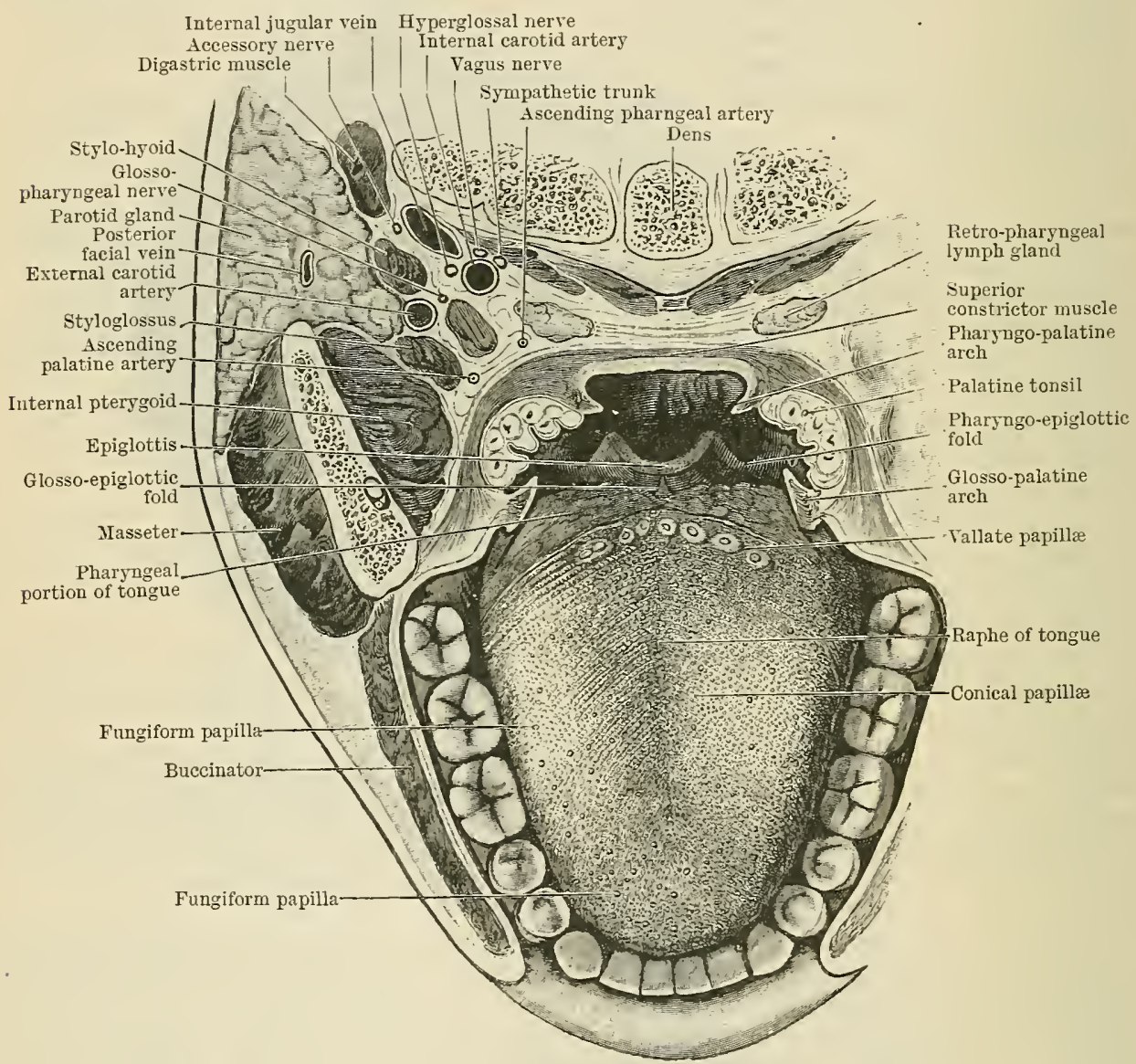

Fig. 905.-Horizontal Section throdgh Modth ard Phartix at the letel of the Palatixe Tonsils. The stylopharyngeus, which is shown immediately to the medial side of the external carotid artery, and the prevertebral muscles, are not indicated by reference lines.

The palatine tonsils are oval in shape, with the long axes directed vertically, and each presents a medial and a lateral surface, and a superior and inferior pole, and an anterior and posterior margin.

The medial surface is prominent and free, studded with small pit-like depressions, the fossulæ or crypts of the tonsil.

The lateral, or attached surface, is enclosed in a distinct fibrous capsule, connected with the pharyngo-basilar fascia, and this capsule separates the tonsil from the superior constrictor muscle of the pharynx.

The superior pole is rounded and blunt, and presents numerous fossulæ. The inferior pole projects downwards towards the tongue. The anterior margin looks towards the glosso-palatine arch, and is often overlapped by the plica triangularis, the posterior margin is directed towards the pharyngo-palatine arch. 
Relations of the Tonsil.-The lateral relations of the tonsil consist of the fibrous capsule and the superior constrictor musele. Lateral to the pharyngeal wall lies the internal pterygoid muscle, and behind it a region filled with connective tissue, containing blood-vessels and nerves.

The nearest and most important ressel is the external maxillary artery, which, especially if tortnous, has a very close relation to the pharyngeal wall at this leve].

The ascending palatine and tonsillar branches of the artery are also in close relation.

The internal carotid artery and internal jugular vein lie considerably further back $\frac{3}{4}$ to 1 inch) and to the lateral side, and the external carotid artery is still more lateral.

The ascending pharyngeal artery is well behind the tonsil.

The size of the palatine tonsils is extremely variable, but as a rule, in early life, they measure something under 1 inch (20 to $22 \mathrm{~mm}$.) from above downwards, about $\frac{3}{4}$ inch (18 to $20 \mathrm{~mm}$.) antero-posteriorly, and $\frac{1}{2}$ inch (12 to $15 \mathrm{~mm}$.) mediolaterally.

The arteries of the palatine tonsil are derived from the ascending palatine and tonsillar branches of the external maxillary artery, the ascending pharyngeal branch of the external carotid, and the dorsalis linguæ of the lingual. The veins pass to the tonsillar plexus, on the lateral side of the tonsil, which is an offshoot of the pharyngeal venous plexus.

Nerves.-The palatine tonsil receives a special branch from the glossopharyngeal; this unites with branches from the pharyngeal plexus to form a small plexus tonsillaris which supplies the organ.

The lymph vessels are extremely numerous. They begin in a plexus which surrounds each follicle, whence vessels pass to the lateral surface of the tonsil. Thence they pass through the wall of the pharynx, and pass to the deep cervical glands in the neighbourhood of the greater cornu of the hyoid bone, behind and inferior to the angle of the mandible.

Structure of the Palatine Tonsils.--Each palatine tonsil is composed of masses of small rounded lymph cells with a delicate connective tissue reticulum. These resemble in structure the folliculi linguales, $q \cdot v$.

Upon its medial surface it is covered with epithelium, continuous with the epithelium covering the adjacent parts of the wall of the pharynx. This surface is very irregnlar, and on section crypts, termed fossulae tonsillares, are seen to be formed by deep infoldings of the epithelial wall. On its lateral surface, the lymph tissue is invested by a connective tissue capsule.

Pars Laryngea. - The laryngeal part of the pharyngeal cavity lies posterior to the larynx (Fig. 903). It is wide above, where it is contiuuous with the oral portion, and maintains a considerable width until within about an inch of its termination, where, posterior to the cricoid cartilage it narrows rapidly and passes down to join the osophagus. Except during the passage of food, the anterior and posterior walls of this latter part are in contact, and its cavity is reduced to a inere transverse slit (Fig. 906).

The anterior wall of the laryngeal portion of the pharynx is formed in its whole extent by the posterior surface of the larynx, of which the following parts are seen from the pharyngeal cavity (Fig. 901):-The epiglottis above; below this the superior aperture of the larynx, bounded at the sides by the ary-epiglottic folds; lateral to these folds is seen on each side a deep recess, the recessus piriformis (Fig. 905). Lower down still, the posterior surfaces of the arytenoid and cricoid cartilages, covered by muscles and mucous membrane, are visible.

Its posterior and lateral walls are directly continuous with the corresponding walls of the oral portion, and present no features which require special notice.

The recessus piriformis (O.T. sinus pyriformis) is a deep depression, seen on each side between the ary-epiglottic fold and the lamina of the thyreoid cartilage. When viewed from above, as in laryngoscopic examinations, it appears of a piriform shape, the wider end being directed upwards and forwards. When viewed from behind, the recess is boat-shaped and elongated in the vertical direction. Its lateral wall is formed by the thyreoid cartilage and thyreo-hyoid membrane, covered with mucous membrane; its medial wall by the ary-epiglottic fold, and slightly, below, by the superior part of the cricoid cartilage.

Relations of the Pharynx.-In considering the relations of the pharynx, it is at once evident that these are very different in the superior and inferior portions.

1. Throughout its whole extent it lies anterior to the cervical region of the vertebral column, and is separated from the bodies of the vertebre and the intervertebral fibro-cartilages by the loose areolar tissue of the prevertebral or retropharyngeal space, posterior to which lie the anterior longitudinal ligament of the vertebral column, the longus capitis and longus colli muscles. 
2. In the neck, laterally, it is in contact with the superior part of the thyreoid gland, the carotid sheath, and especially the common and external carotid arteries, and, more posteriorly, the internal carotids.

The branches arising from the inferior part of the external carotid are also in close relation to the pharyngeal wall, viz., the superior thyreoid and lingual arteries in the lower part, while the external maxillary artery, as it passes under the digastric and stylo-hyoid muscles, comes into contact with the superior constrictor, and the ascending pharyngeal artery runs upwards by the side of the pharyngeal wall.

3. The relations of the cranial portion are more complex, but are of great importance. Reference to Fig. 906 will help to elucidate them. At the upper

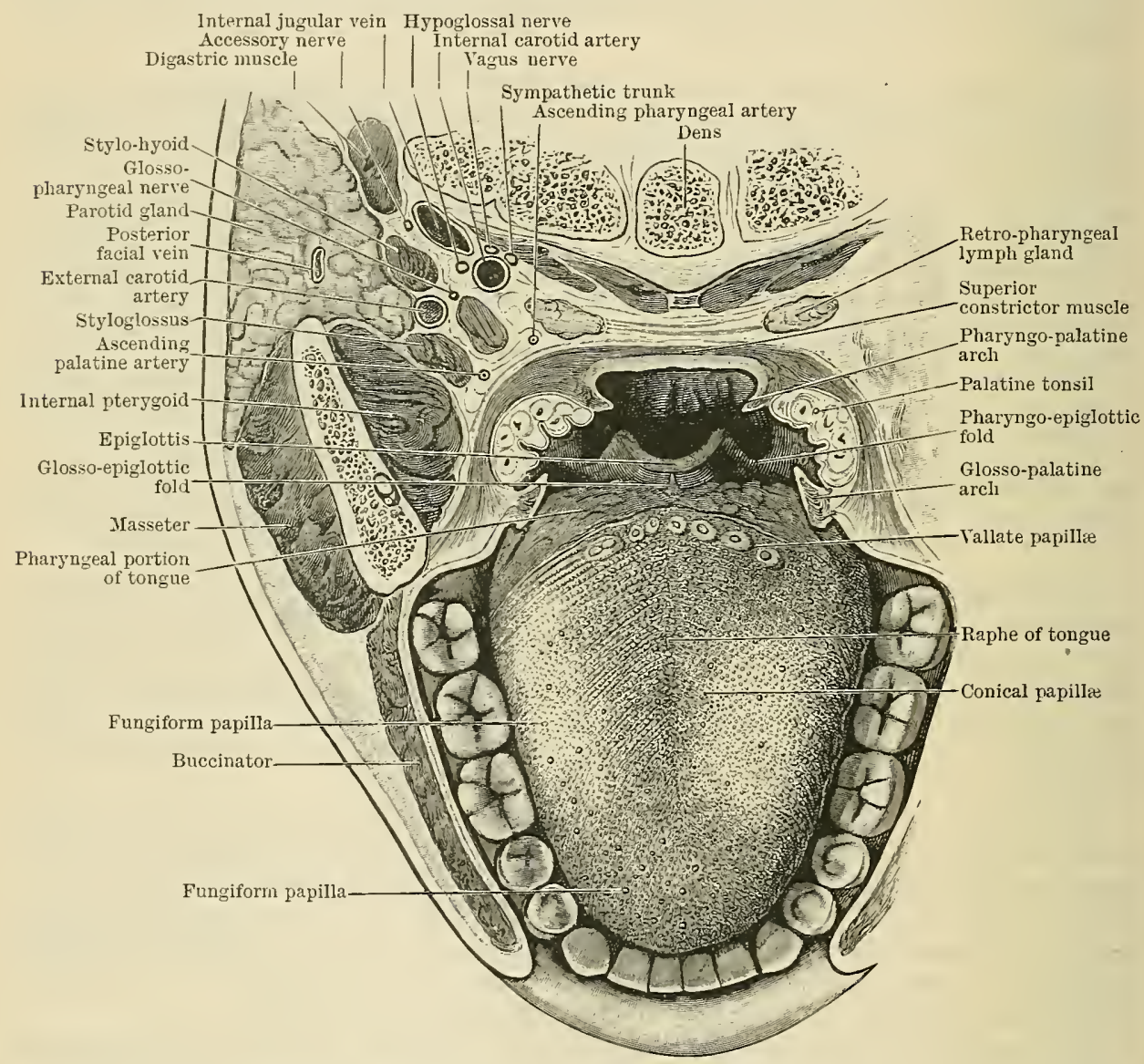

Fig. 906. - Horizontal Sectiox throdgh Modth and Pharynx at the Level of the Palatine Tonsils.

The stylopharyngeus, which is shown immediately to the medial side of the external carotid artery, and the prevertebral muscles, are not indicated by reference lines.

part, the wall of the pharynx is related to the internal pterygoid muscles, separated from them by the levator and tensor veli palatini muscles. As each internal pterygoid passes posteriorly and downwards to its insertion, it diverges away from the pharynx, and a triangular space is left between its medial surface and the wall of the pharynx. The styloid process, and the muscles which arise from it, project downwards into this space, and lying beside them are numerous vessels and some nerves. Thus, the styloglossus and stylopharyngeus come into contact with the lateral wall, and with the latter the glosso-pharyngeal nerve. The ascending palatine and tonsillar branches of the external maxillary artery ascend in close relation to the pharyngeal wall.

The internal carotid artery lies rather further back, with the vagus, accessory, and hypoglossal nerves. 
The external carotid lies more superficially, and is here separated by a considerable interval from the pharyngeal wall.

Lastly, a process of the parotid gland may insert itself on the medial aspect of the internal pterygoid, and come in to contact with the pharynx.

The pharyngeal plexus of nerves lies in contact with the lateral wall.

Structure of the Pharyngeal Wall.-The wall of the pharynx is strong and mobile; it is firmly fixed above to the base of the skull, but below that level it is not attached firmly to any surrounding structures, except to the hyoid bone and the skeleton of the larynx, and hence the inferior end can easily be displaced from side to side in the neck.

The wall is composed of a strong fibrous membrane, called the fascia pharyngobasilaris (O.T. pharyngeal aponeurosis), lined internally by mucous membrane, and covered incompletely on its outer surface by a series of three overlapping muscles, the constrictor muscles of the pharynx.

These muscles are themselves covered externally by a thin layer of fibrous tissue or fascia, which passes anteriorly, at its superior part, on to the surface of the buccinator muscle, and is called the fascia buccopharyngea.

Externally to this fascia the wall of the pharynx is in contact with loose cellular tissue by which it is connected to and separated from adjacent structures.

With the wall of the pharynx are associated several accessory muscles, viz., the muscles of the soft palate and the stylopharyngeus and pharyngo-palatine muscles, which blend with the wall but are also attached to the larynx (see p. 466).

The fibrous aponeurosis which forms the principal constituent of the pharyngeal wall is firmly attached (round the margins of the openings into the pharynx) to other structures as follows:- -

Above, it blends with the periosteum covering the basilar portion of the occipital bone in front of the pharyngeal tubercle, and body of the sphenoid bone, and on each side it extends out to the angular spine of the sphenoid and the apex of the petrous part of the temporal bone.

Laterally it is attached to the structures which lie on each side of the orifices of the nose, mouth, and larynx. As it descends it gradually becomes thinner, and is eventually lost.

The fascia pharyugo-basilaris is particularly strong in the superior part, where there is an area on each side which is not covered by the superior constrictor muscle. This area forms the sinus of Morgagni, and here the tuba auditiva and tensor and levator veli palatini muscles pass through the wall.

Mucous Membrane of the Pharynx.-The superficial layer of the mucous membrane of the pharynx consists, in the lower part, of a stratified squamous epithelium, while in the upper or nasal portion it is in part composed of ciliated epithelium. In the superior part of the pharynx and in the lateral wall, there are found large masses of lymph tissue, constituting the pharyngeal tonsil in the roof, and the palatine tonsil on each side. The same tissue is found in considerable amount in the pharyugeal recess and on the pharyngeal portion of the dorsum of the tongue.

There are also numerous racemose glands, of the mucous type, in the walls of the pars nasalis, and in the soft palate, and in the ary-epiglottic folds.

Pharyngeal Muscles.-For the details of the attachment and relations of these muscles, see pp. 464-467.

Externally to the pharyngeal muscles lies the fascia buccopharyngea.

The fascia pharyngobasilaris, which is thick above and thin below, and the fascia bucco-pharyngea, which is thin above and stouter below, are practically blended into one layer above, near the base of the skull, where the muscular coat is absent. Lower down they are separated by the constrictors, and become two distinct sheets. They are strengthened in the median plane posteriorly by a fibrous band descending from the pharyngeal tubercle.

Vessels and Nerves of the Pharynx.-The arteries of the pharynx are derived from-1, the ascending pharyngeal; 2 , the ascending palatine branch of the external maxillary; 3 , the descending palatine from the internal maxillary, with a few twigs from the dorsalis linguæ, tonsillar (of external maxillary), the artery of the pharyngeal canal, and the pterygo-palatine branch of the internal maxillary. The veins go to the pharyngeal venous plexus, which is found between the constrictors and the fascia pharyngobasilaris. The plexus communicates with the pterygoid plexus above and with the internal jngular or common facial vein below.

The lymph vessels of the pharynx pass chiefly to the superior set of deep cervical glands. 
2. In the neck, laterally, it is in contact with the superior part of the thyreoid gland, the carotid sheath, and especially the common and external carotid arteries, and, more posteriorly, the internal carotids.

The branches arising from the inferior part of the external carotid are also in close relation to the pharyngeal wall, viz., the superior thyreoid and lingual arteries in the lower part, while the external maxillary artery, as it passes under the digastric and stylo-hyoid muscles, comes into contact with the superior constrictor, and the ascending pharyngeal artery runs upwards by the side of the pharyngeal wall.

3. The relations of the cranial portion are more complex, but are of great importance. Reference to Fig. 906 will help to elucidate them. At the upper

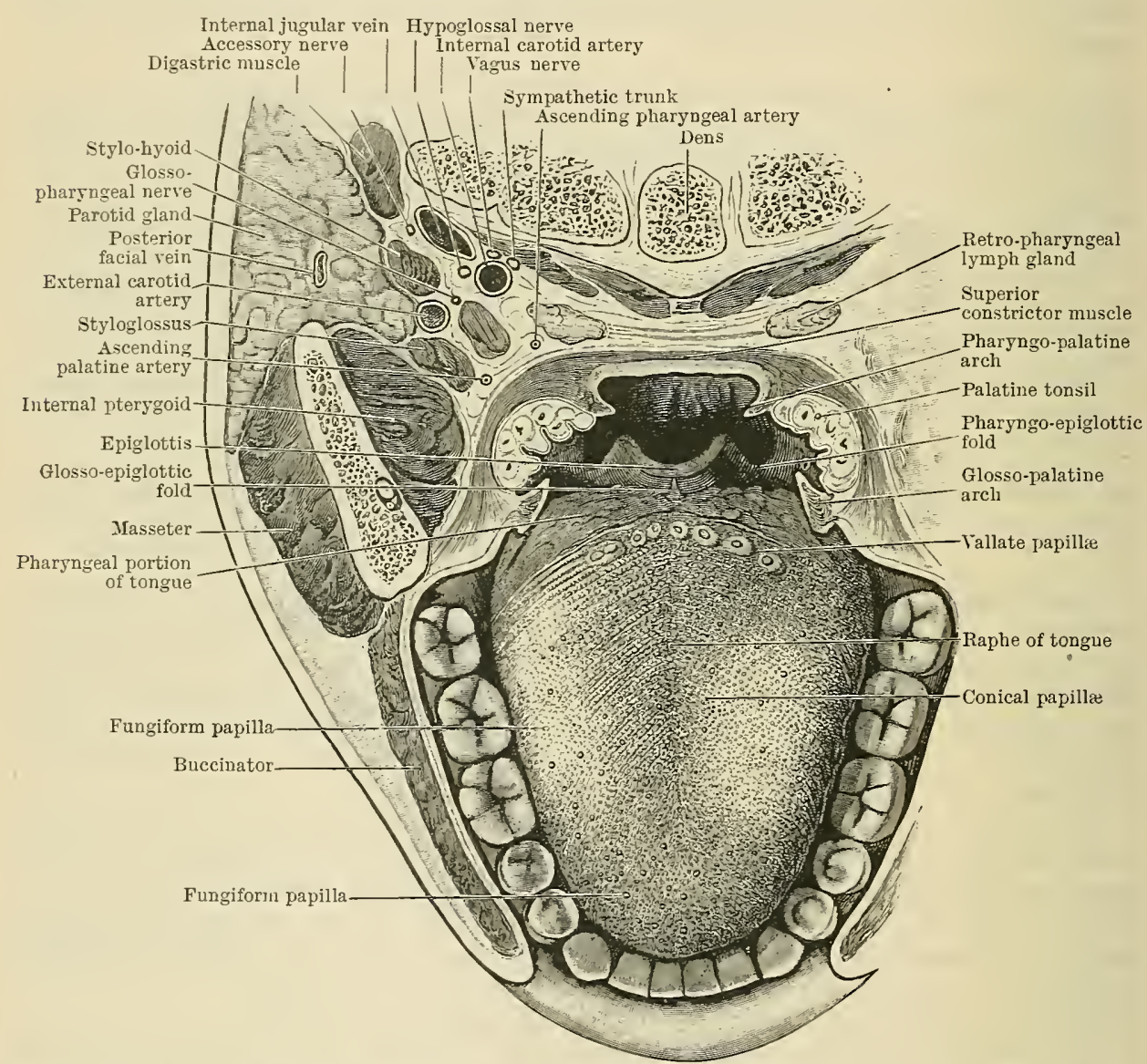

Fig. 906. - Horizontal Section throcgh Modth and Pharixy at the Level of the Palatise Tonsils. The stylopharyngeus, which is shown immediately to the medial side of the external carotid artery, and the prevertebral muscles, are not indicated by reference lines.

part, the wall of the pharynx is related to the internal pterygoid muscles, separated from them by the levator and tensor veli palatini muscles. As each internal pterygoid passes posteriorly and downwards to its insertion, it diverges away from the pharynx, and a triangular space is left between its medial surface and the wall of the pharynx. The styloid process, and the muscles which arise from it, project downwards into this space, and lying beside them are numerous vessels and some nerves. Thus, the styloglossus and stylopharyngeus come into contact with the lateral wall, and with the latter the glosso-pharyngeal nerve. The ascending palatine and tonsillar branches of the external maxillary artery ascend in close relation to the pharyngeal wall.

The internal carotid artery lies rather further back, with the vagus, accessory, and hypoglossal nerves. 
The external carotid lies more superficially, and is here separated by a considerable interval from the pharyngeal wall.

Lastly, a process of the parotid gland may insert itself on the medial aspect of the internal pterygoid, and come into contact with the pharynx.

The pharyngeal plexus of nerves lies in contact with the lateral wall.

Structure of the Pharyngeal Wall.-The wall of the pharynx is strong and mobile; it is firmly fixed above to the base of the skull, but below that level it is not attached firmly to any surrounding structures, except to the hyoid bone and the skeleton of the larynx, and hence the inferior end can easily be displaced from side to side in the neck.

The wall is conposed of a strong fibrous membrane, called the fascia pharyngobasilaris (O.T. pharyngeal aponeurosis), lined internally by mucous membrane, and covered incompletely on its outer surface by a series of three overlapping muscles, the constrictor muscles of the pharynx.

These muscles are themselves covered externally by a thin layer of fibrous tissue or fascia, which passes anteriorly, at its superior part, on to the surface of the buccinator muscle, and is called the fascia buccopharyngea.

Externally to this fascia the wall of the pharynx is in contact with loose cellular tissue by which it is connected to and separated from adjacent structures.

With the wall of the pharynx are associated several accessory muscles, viz., the muscles of the soft palate and the stylopharyngeus and pharyngo-palatine muscles, which blend with the wall but are also attached to the larynx (see p. 466).

The fibrous aponeurosis which forms the principal constituent of the pharyngeal wall is firmly attached (round the margins of the openings into the pharynx) to other structures as follows:-

Above, it blends with the periosteum covering the basilar portion of the occipital bone in front of the pharyngeal tubercle, and body of the sphenoid bone, and on each side it extends out to the angular spine of the sphenoid and the apex of the petrous part of the temporal bone.

Laterally it is attached to the structures which lie on each side of the orifices of the nose, mouth, and larynx. As it descends it gradually becomes thinner, and is eventually lost.

The fascia pharyngo-basilaris is particularly strong in the superior part, where there is an area on each side which is not covered by the superior constrictor muscle. This area forms the sinus of Morgagni, and here the tuba auditiva and tensor and levator veli palatini muscles pass through the wall.

Mucous Membrane of the Pharynx.-The superficial layer of the mucous membrane of the pharynx consists, in the lower part, of a stratified squamous epithelium, while in the upper or nasal portion it is in part composed of ciliated epithelium. In the superior part of the pharynx and in the lateral wall, there are found large masses of lymph tissue, constituting the pharyngeal tonsil in the roof, and the palatine tonsil on each side. The same tissue is found in considerable amount in the pharyngeal recess and on the pharyngeal portion of the dorsum of the tongue.

There are also numerous racemose glands, of the mucous type, in the walls of the pars nasalis, and in the soft palate, and in the ary-epiglottic folds.

Pharyngeal Muscles.-For the details of the attachment and relations of these muscles, see pp. 464-467.

Externally to the pharyngeal muscles lies the fascia buccopharyngea.

The fascia pharyngobasilaris, which is thick above and thin below, and the fascia bucco-pharyngea, which is thin above and stouter below, are practically blended into one layer above, near the base of the skull, where the muscular coat is absent. Lower down they are separated by the constrictors, and become two distinct sheets. They are strengthened in the median plane posteriorly by a fibrous band descendiug from the pharyngeal tubercle.

Vessels and Nerves of the Pharynx.-The arteries of the pharynx are derived from-1, the ascending pharyngeal; 2 , the ascending palatine branch of the external maxillary; 3 , the descending palatine from the internal maxillary, with a few twigs from the dorsalis linguæ, tonsillar (of external maxillary), the artery of the pharyngeal canal, and the ptersgo-palatine branch of the internal maxillary. The veins go to the pharyngeal venous plexus, which is found between the constrictors and the fascia pharyngobasilaris. The plexus communicates with the pterygoid plexus above and with the internal jugular or common facial vein below.

The lymph vessels of the pharynx pass chiefly to the superior set of deep cervical glands. 
Those from the superior part of the posterior wall join a few post-pharyngeal glands which are found on each side between the pharynx and the rectus capitis anterior muscle. These latter glands, which are large in the child, small in the adult, but apparently always present (Fig. 906 ), are of considerable clinical interest, as they often form the starting-point of post-pharyngeal abscess. For fuller details see section on Lymph Glands.

The nerves of the pharynx, both motor and sensory, are derived chiefly from the pharyngeal plexus, which is formed by branches of the vagus, glosso-pharyngeal, and sympathetic. The soft palate and the neighbourhood of the palatine tonsil are supplied by the palatine branches of the spheno-palatine ganglion. The tonsil receives a branch from the glosso-pharyngeal direct. The vault of the pharynx, and the region around the orifice of the tuba auditiva, as well as the orifice itself, are supplied by the spheno-palatine ganglion. Finally, the internal laryngeal nerve supplies the mucous membrane of the back of the larynx, where it forms the anterior wall of the laryngeal portion of the pharynx.

\section{CESOPHAGUS.}

The œsophagus or gullet is the portion of the digestive canal which intervenes between the pharynx above and the stomach below. With the exception of the

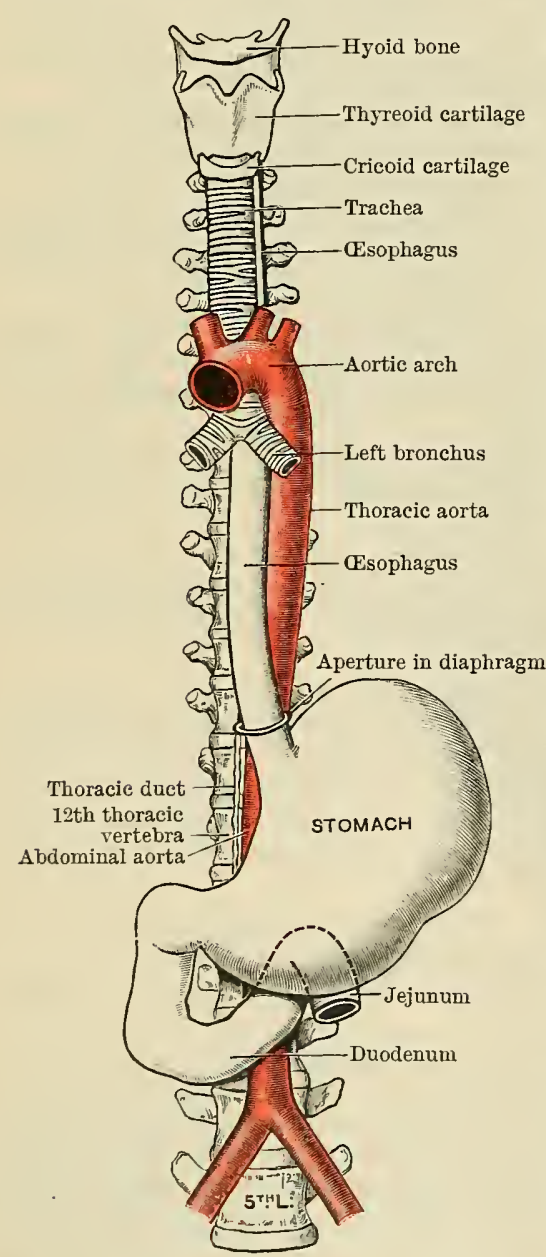

Fig. 907.-Diagram to Show the Cotrse of THE CESOPHAGCS.

pylorus, it is the narrowest, and at the same time one of the most muscular parts of the whole alimentary tube.

It extends from the termination of the pharynx, at the inferior border of the cricoid cartilage and opposite the sixth cervical vertebra, to the cardiac orifice of the stomach, opposite the eleventh thoracic vertebra. Between these two points it traverses the inferior part of the neck, the whole length of the thorax, and, having pierced the diaphragm, it enters the abdomen, and immediately afterwards joins the stomach. In this course it does not adhere to the median plane of the body, but twice leaves it, and curves to the left. The first of these curvatures corresponds to the inferior part of the neck and the superior part of the thorax, where the œsophagus projects beyond the left margin of the trachea to the extent of $\frac{1}{6}$ or $\frac{1}{4}$ inch (4 to $6 \mathrm{~mm}$.). It returns to the median plane at the level of the fourth thoracic vertebra posterior to the aortic arch. Lower down, posterior to the pericardium, it again passes to the left, and at the same time anteriorly, in order to reach the osophageal opening in the diaphragm (which is placed anterior to and to the left of the aortic opening), and it maintains this direction until the stomach is reached. It leaves the median plane at the seventh thoracic vertebra, crosses anterior to the aorta at the level of the eighth thoracic vertebra, and traverses the diaphragm at the level of the tenth.

In addition to the curvatures just described, it is also curved in the anteroposterior direction, in correspondence with the form of the vertebral column upon which it, in great part, lies.

In length it usually measures about ten inches $(25 \mathrm{~cm}$.).

Its breadth, where the tube is widest, varies between half an inch (13 mm.) in the empty contracted condition and an inch or more (25 to $30 \mathrm{~mm}$.) in the fully distended state. 
When seen in sections of the frozen body (Fig. 908), the œsophagus usually appears either as a flattened tube with a transverse slit-like cavity, or as an oval or rounded canal with a more or less stellate lumen. The former condition is more common in the neck, owing to the pressure of the trachea, and the latter in the thorax.

When exposed in the ordinary postmortem examination soon after death, it has rather the appearance of a solid muscular rod or band than of a hollow tube.

The œesophagus presents three distinct constrictions, one situated at its beginning, another at the point where it is crossed by the left bronchus, and the third where it passes through the diaphragm. The two upper constrictions are of the same size, and will admit without injury an instrument with a maximum diameter of $\frac{4}{5}$ inch $(20 \mathrm{~mm}$.). At each of these points the tube is flattened from before backwards.

The œsophagus varies in length in different individuals, from 8 to 14 inches $(20$ to $35 \mathrm{~cm}$.). The distance from the upper incisors to the beginning of the œsophagus averages about 6 inches $(15 \mathrm{~cm}$.).

During life the cerrical portion is said, under ordinary circumstances, to be closed and flattened from before backwards by outside pressure, whilst the thoracic portion may be open owing to the negative pressure in the thorax. The passage into the stomach is also said to be open (Mickulicz), but this is doubtful.

The size at the two constrictions, when the tube is fully distended, is $23 \mathrm{~mm}$. transversely, and $17 \mathrm{~mm}$. antero-posteriorly. The other parts vary in diameter between 26 and $30 \mathrm{~mm}$. (Jonnesco).

In its first curvature to the left the divergence is greatest opposite the third thoracic rertebra. The second inclination to this side begins about the seventh thoracic vertebra, and continues to the end of the cesophagus, being considerably increased as the diaphragm is approached.

Relations of the Esophagus.-The relations (Fig. 908) differ so widely in the neck and thorax that they must be described separately for each of these regions.

In the Neck.-Anteriorly lies the trachea - to the posterior membranous wall of which the cesophagus is loosely connected by areolar tissue-and in the groove at each side, between the trachea and cesophagus, the recurrent nerve ascends to the larynx (Fig. 908, A). Posteriorly lie the vertebral column and the longus colli muscles, from which the asophagus is separated by the prevertebral layer of the cervical fascia. Laterally are placed the carotid sheaths with their contained ressels, and the lateral lobes of the thyreoid gland and the inferior thyreoid arteries. Owing

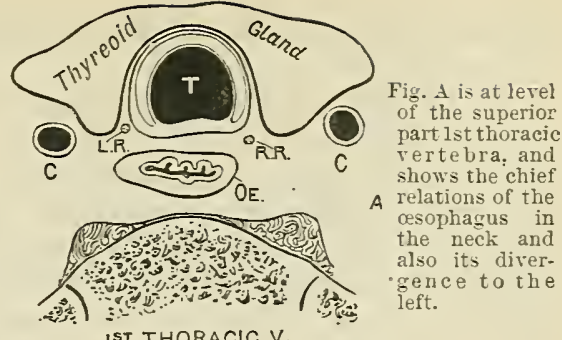

IST THORACIC V.

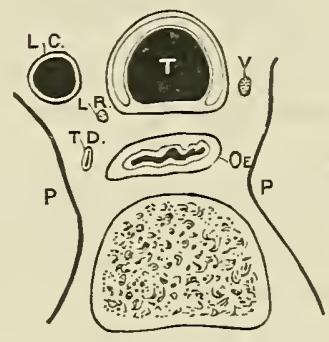

Fig. B, at the 3rd thoracic verte-

$B$ bra, shows the thoracic duct lying on left side of the ceso. phagus.

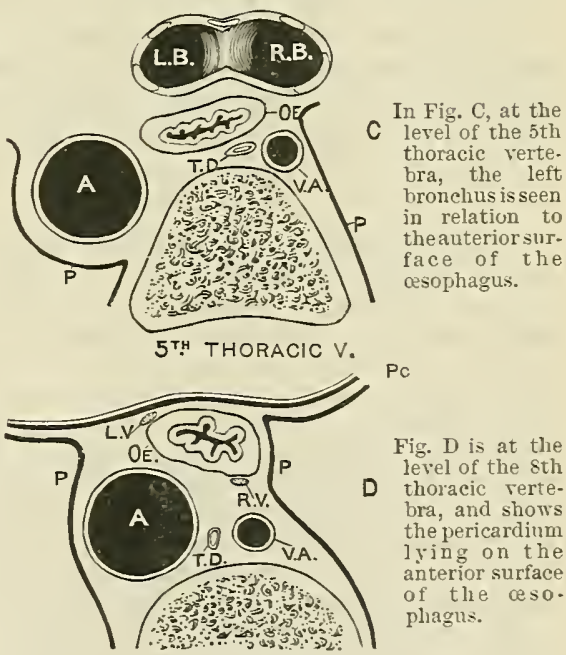

8T. THORACIC V.

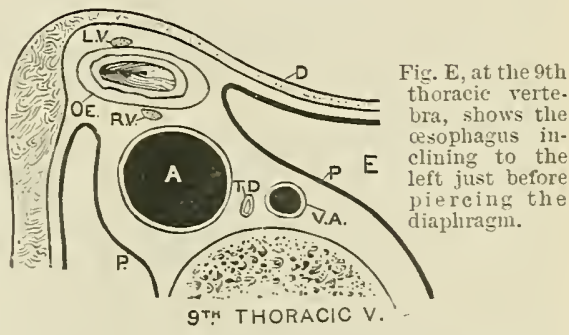

Fig, 908.-Tracixgs froy Frozex SEctioxs TO SHOW THE RELATIONS OF THE ESOPHAGUS at the levels of the 1st, 3rd, 5tb, Sth, and 9 th thoracic rertebra, respectively.

A, Aorta ; C, Common carotid artery ; D, Diaphragm L.B, Left bronchus; L.C, Left subclaviau artery L.R, Left recurrent nerre: L.V, Left vagus; $O E$ Esophagus ; P, Pleura ; Pc, Pericardium ; R.B, Right bronchus; R.R, Right recurrent nerve R.V, Right ragus; T, Trachea; T.D, Tlioracic duct; V.A, Vena azygos. 
to the deviation of the tube to the left in the inferior part of the neck, its relation to the carotid sheath and thyreoid gland is much more intimate on the left than on the right side.

In the Thorax.-The oesophagus passes successively through the superior and posterior mediastina, in the former lying close to the vertebral column, but in the latter advancing somewhat into the thoracic cavity and coming into contact with the back of the pericardium. The trachea still lies anteriorly as far as its bifurcation at the level of the fifth thoracic vertebra. Immediately below this the cesophagus is crossed by the left bronchus (Fig. 908, C), and in the rest of its thoracic course it lies in the closest relation to the back of the pericardium. Posteriorly, in the upper part of the thorax, it rests on the longus colli muscle and the vertebral column; but below the bifurcation of the trachea, as already explained, it advances into the cavity of the posterior mediastinum, and is soon separated from the rertebral column by the vena azygos, the thoracic duct, the upper six aortic intercostal arteries of the right side, and in its lower part by the thoracic aorta as well.

On its left side, in the upper part of the thorax, lie the left pleura and the left subclavian artery, with the thoracic duct in a plane posterior to the artery; in the middle region, the aorta, and lower down the left pleura again, for a little way, before the cesophagus pierces the diaphragm. On the right side the tube comes into relation with the arch of the vena azygos, whilst the right pleura clothes it both below and abore that level.

The two vagus nerves, after forming the anterior and posterior pulmonary plexuses descend to the œsophagus, where they form, by uniting with one another and with the branches of the sympathetic, the anterior and posterior csophageal plexuses. Lower down the left nerve winds round to the anterior, whilst the right turns to the posterior surface of the cesophagus, and in this relation they pass with the tube through the diaphragm to reach the stomach.

The diaphragmatic portion, about half an inch in length ( 1 to $1.5 \mathrm{~cm}$.), corresponds to the portion of the tube which lies in the cesophageal orifice (or canal) of the diaphragm. The plane of this orifice is very oblique or almost vertical, and its abdominal opening looks forwards and to the left, and but little downwards. Above and in front, where it is bounded either by the posterior edge of the central tendon or by a few decussating fibres of the muscular portion of the diaphragm, which meet behind the tendon, the csophageal orifice has practically no length, and consequently the œsophagus here passes into the abdominal cavity immediately after leaving the thorax. At the sides and behind, on the other hand, the decussating bands from the two crura, which embrace the orifice, are so arranged that they turn a flat surface (not an edge) towards the opening, and thus, posteriorly and laterally, the orifice or canal is of some length; and on these aspects there is a portion of the tube in contact with the diaphragm for a distance of 1 to $1 \frac{1}{2} \mathrm{~cm}$. But this contact takes place not around a horizontal line, but in a very oblique plane corresponding to that of the orifice.

The csophagus, in passing through the orifice, is comnected to its boundaries by a considerable amount of strong connective tissue, but it is extremely difficult, or impossible, to demonstrate any direct naked-eye connexion between the osophageal muscular fibres and those of the diaphragm.

The anterior or right boundary of the œsophageal orifice, formed of fibres derived from both crura of the diaphragm, is strongly developed and prominent, and usually lies in the cesophageal groove, on the back of the left lobe of the liver, which groove is rarely due to the pressure of the œsophagus alone.

The pars abdominalis of the œsophagus is very short, for immediately after piercing the diaphragm the tube expands into the stomach. However, when the empty stomach is drawn forcibly downwards, a portion of the front and left side of the tube, about half an inch in length ( 1 to $1: 5 \mathrm{~cm}$.), is seen, to which the above term is applied. This part is covered with peritoneum, derived from the great sac in front and on the left, whilst its right and posterior surfaces are uncovered. It is generally described as lying against the œsophageal groove and the left triangular ligament of the liver in front, but it never actually comes in contact with the latter of these structures, which is attached to the upper surface of the left lobe of the liver by one edge, and to the diaphragm, over an inch in front of the œsophagus, by the other. As regards the former, the œsophageal groove of the liver is generally occupied by the prominent right margin of the cesophageal orifice of the diaphragm and occasionally by the cesophagus as well. Possibly this margin is so strongly developed and so prominent in order that it may bear the pressure of the liver off the gullet, which otherwise might be interfered with in its dilatation during the passage of food.

When the stomach is fully distended the abdominal part of the œsophagus almost disappears, being absorbed into the stomach in its distension.

The portion of the cesophagus which adjoins the stomach is sometimes described as consisting of two parts, namely, the ampulla phrenica and the antrum cardiacum. The former is a 
fusiform expansion of the tube, of variable length and girth, which lies within the thorax immediately above the point where the gullet is grasped between the two muscular margins of the cesophageal opening and the diaphragm. It lies in the lowest part of the posterior mediastinum where this is bounded anteriorly by the back of the diaphragm.

The antrum cardiacum is another name for the abdominal portion of the œsophagus. It is funnel-shaped, and expands towards the stomach.

Relation of the Aorta to the Esophagus.-The arch of the aorta, passing back to reach the vertebral column, crosses to the left side of the csophagus; consequently the descending thoracic aorta lies at first to its left; lower down, however, as the aorta passes on to the anterior aspect of the vertebral column, and the gullet inclines forwards and to the left, the aorta comes to lie posteriorly, and then, as the diaphragm is approached, it lies not only posteriorly, but also somewhat to the right of the œsophagus (Figs. 907 and 908).

Relation of the Thoracic Duct to the Esophagus. - The thoracic duct, lying to the right of the aorta below, is not directly related to the œsophagus (Fig. 908, E); but higher up (Fig. 908, D and E) it lies posterior to it. About the level of the aortic arch the duct passes to the left, and above this (Fig. 908, B and A) will be found on the left side of the csophagus, and on a plane somewhat posterior to it.

Relation of the Pleural Sacs to the Esophagus.-Above the level of the arches of the aorta and of the vena azygos, between which the osophagus descends, the pleuræ, though not lying in immediate contact with the csophagus, are separated from it only by a little connective tissue, and on the left side also, behind the subclavian artery, by the thoracic duct (Fig. $908, \mathrm{~B})$. Here, in thin bodies, the left pleura is very close to the œsophagus, and the thoracic duct, lying on its left side, may occasionally be seen through the pleural membrane. Below the arch of the azygos vein the right pleura clothes the right side of the csophagus-and very often even a considerable portion of its posterior surface too, thus forming a deep recess behind it - almost as low down as the opening in the diaphragm. On the left side, below the level of the aortic arch, the left pleura comes in contact with the gullet, only for a short distance, just above the diaphragm (Fig. 908, E).

Variations. - The chief anomalies found in the csophagus are: (1) Annular or tubular constrictions; (2) diverticula, of which the most interesting-known as "pressure pouches"-are usually situated on the posterior wall close to its junction with the pharynx, and these sometimes require surgical interference; (3) doubling in part of its course; and (4) communications between the trachea and œsophagus.

Structure of the Esophagus (Fig. 911). - The oesophageal wall is composed of three proper coats-(1) tunica muscularis, (2) tela submucosa, and (3) tunica mucosa. In addition, it is surrounded by an onter covering of areolar tissue (4) tunica adventitia, by which it is loosely connected to the various structures related to it in its course. This loose covering permits of its free movement and of its increase in size, or of its diminution, during the act of swallowing.

The tunica muscularis is composed of two layers - an outer of longitudinal, and an inner of circular fibres. The longitudinal layer is highly developed, and, unlike the condition usually found in the digestive tube, it is as stout as, or in places stouter than, the circular layer. Its fibres form along the greater length of the tube an even covering ontside the circular layer, and below they are continued into the longitudinal fibres of the stomach. Above, near the superior end of the cesophagus, the longitudinal fibres of each side, separating at the back, pass round towards the anterior aspect and form two longitudinal bands (Fig. 909), which run up on the front of the tube, and are attached by a tendinous band to the superior part of the posterior surface of the cricoid cartilage (Fig. 909).

The circular muscular fibres, though not forming such a thick layer as the longitudinal fibres, are nevertheless well developed. Below, they are continued into both the circular and oblique fibres of the stomach. Above, they pass into the inferior fibres of the inferior constrictor of the pharynx.

The muscular fibres are entirely of the striated variety at the superior end of the œsophagus. Soon unstriped fibres begin to appear, increasing in number as we descend. In the inferior half or two-thirds, only unstriped muscle is found.

The longitudinal fibres for about the superior fifth of the tube are entirely striped; in the second fifth striped and unstriped are mixed; whilst in the inferior three-fifths unstriped fibres alone are present. The circular fibres are entirely striated for the first inch; after this unstriped fibres appear; and in the inferior two-thirds, only unstriped muscle fibres are found.

The longitudinal fibres are often joined by slips of unstriped muscle, or elastic fibres, which spring from various sources, including the left pleura (m.pleuro-cesophageus) (constant, Cumningham), the bronchi ( $m$. broncho-asophageus), back of trachea, pericardium, aorta, etc. These slips assist in fixing the œsophagus to the surrounding structures in its passage through the thorax, and have been aptly compared to the teudrils of a climbing plant (Treitz).

The tela submucosa, composed of areolar tissue, is of very considerable thickness, in 
order to allow of the expansion of the tube during swallowing. It connects the mucous

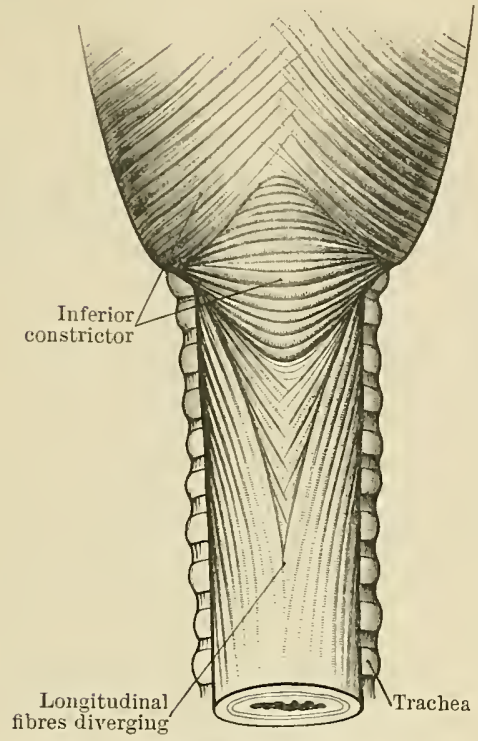

Fig. 909. - Dissection to show the arrangement of the muscular fibres on the posterior aspect of the cesophagus and pharynx. Traced upwards, the longitudinal inuscular fibres of the cesophagus are seen to separate posteriorly ; passing round to the sides, they form two longitudinal bands which meet anteriorly and are united to the cricoid cartilage, as showu in the next figure.

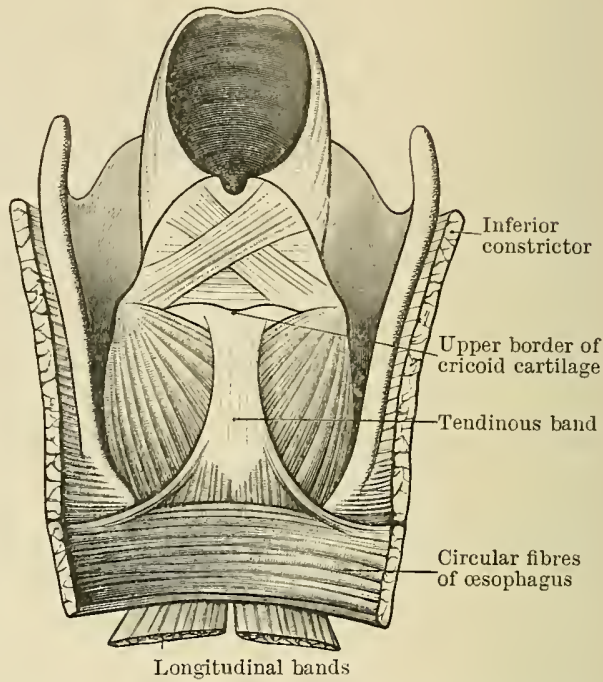

Fig. 910.- - The Inferior Part of the Pharynx aNd the Superior Part of the Esophagus have been slit up from behind, and the mucous membrane removed to show the muscular fibres. The two longitudinal bands are seen passing round to the front to be attached by a common tendon to the superior border of the cricoid cartilage. See explanation of last figure.

membrane loosely to the muscular coat, and admits of the former being thrown into folds

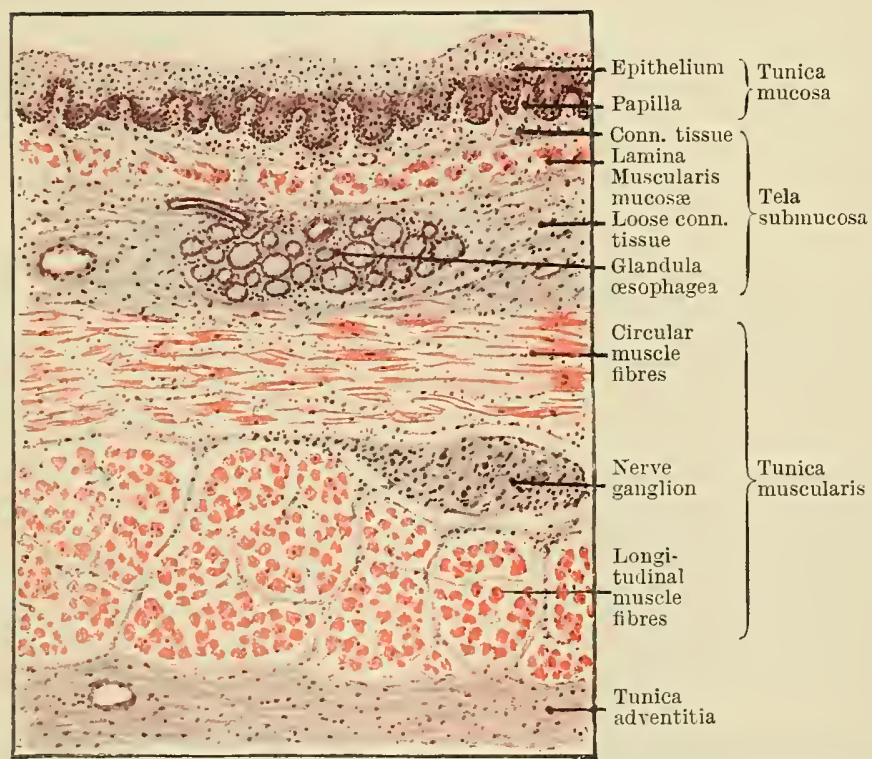

Fig. 911.-Transverse Section of Wald of Humax Esophagus. when empty. In this coat are contained the numerous racemose mucous glands (glandulæ œsophageæ) which open into the cavity of the œsophagus (Fig. 911).

The tunica mucosa is of a grayish - pink colour, much paler than that of the pharynx, and of a firm and resistant texture. It is covered with a thick stratified, squamous epithelium, on the surface of which the openings of numerous glands are found. Below, its junction with the gastric mucous membrane is indicated by a distinct, irregularly dentated or crenated line, which runs transversely round the tube. In carefully preserved specimens the smooth mucous membrane of the œsophagus above this line contrasts strongly with the mammillated gastric mucous membrane below.

Owing to the inelasticity of this coat, and the fact that it is but loosely comnected to 
the muscular coat by the submucosa, it is thrown into a series of longitudinal folds when the œsophagus is empty and contracted; hence the stellate lumen often seen in sections of the gullet.

Glands.-Numerous racemose mucous glands, the glandulæ œsophageæ, large enough to be distinctly seen with the naked eye, are found in the submucosa. They are pretty evenly distributed over the whole tube, and do not appear to be more numerous towards either end. In addition to these, other glands, resembling closely those of the cardiac end of the stomach, are found in the mucous membrane of certain portions of the osophagus. They are entirely confined to the mucosa, and do not extend beyond the lamina muscularis mucosæ. These glands are specially numerous at both the upper and lower ends of the tube.

Vessels and Nerves.-Its arteries consist of numerous small branches derived, in the neck, from the inferior thyreoid, in the thorax, from the bronchial arteries and thoracic aorta, and in the abdomen, from the left gastric artery, and also from the left inferior phrenic.

The veins form a plexus on the exterior of the osophagus, from which branches pass, in the lower part of the tube, to the coronary vein of the stomach, and, higher up, to the azygos, and thyreoid veins. There is thus established on the lower part of the cesophagus a free com. munication between the portal and systemic veins.

The lymph vessels pass to the inferior set of deep cervical glands in the neck, and to the posterior mediastinal glands, many of which, of large size, are seen around the tube, in the thorax.

The nerves are derived from the recurrent, and from the cervical sympathetic in the neck, from the vagus and sympathetic nerves in the thorax.

\section{THE ABDOMINAL CAVITY.}

As the remaining parts of the digestive system lie within the abdomen it will be necessary to describe that cavity, and to refer briefly to its lining membranethe peritoneum-before passing on to the consideration of the viscera which are contained within it.

The abdomen is that portion of the trunk which lies below the diaphragm. It consists of a wall, composed in part of bones, muscles, tendons, fascia, etc., enclosing a large cavity, in which lie the greater part of the digestive, urinary, and generative systems of organs, as well as blood-vessels, nerves, and other structures. The greater part of the wall, and the surfaces of the viscera, are clothed by a continuous smooth membrane, the peritoneum. The cavity is completely filled by these organs. They lie in contact with one another, and when the organs are in situ the so-called carity is merely a potential space between the peritoneal surfaces of adjacent viscera. When air is admitted, as, for instance, by opening the abdominal wall in any place, the viscera fall away from one another and a space is formed, in place of the capillary interval which exists under normal conditions between them.

In the following description, the term abdomen or abdominal cavity is used to indicate the region enclosed by the muscular and bony walls, and the term peritoneal cavity the potential space inside the peritoneal membrane between the viscera.

Shape.-In general shape the cavity is of a somewhat oval form, with the long axis directed vertically. The superior end is wider than the inferior. It is strongly flattened from before backwards, and is encroached upon in the median plane posteriorly by the projection forwards of the vertebral column.

On transverse section, it will be noticed that the front of the vertebral column lies at no great distance from the back of the anterior abdominal wall (usually $2 \frac{1}{2}$ to 3 inches), while on each side of the vertebral column there is a deep recess, occupied by the kidneys and portions of the intestine.

The abdominal cavity is divisible into the abdominal cavity proper and the pelvis minor. Vertical section of the trunk shows that the pelvis minor (O.T. true pelvis) lies below and behind the abdominal cavity, and forms a funnel-shaped termination for it, whose long axis is directed downwards and backwards.

As the walls of these two regions are markedly different, the boundaries will be considered separately.

Boundaries of the Abdomen Proper.-The eavity is limited above by the concave vault of the diaphragm, which is dome-shaped and presents a right and a left cupola 
separated by an intervening depression. Into the right cupola fits the greater part of the liver; in the left lie a part of the stomach and spleen. On the superior surface of each cupola is placed the base of the corresponding lung, whilst between them, on the depression, rests the inferior surface of the heart.

During expiration, the right cupola ascends almost to the level of the right nipple; it is bighest at a point about one inch medial to the nipple line, and here it reaches the superior border of the fifth rib, or even the middle of the fourth intercostal space. On the left side it is one-half to one inch $(12-25 \mathrm{~mm}$.) lower, and in the median plane it crosses the inferior extremity of the body of the sternum about the level of the sixth rib cartilage.

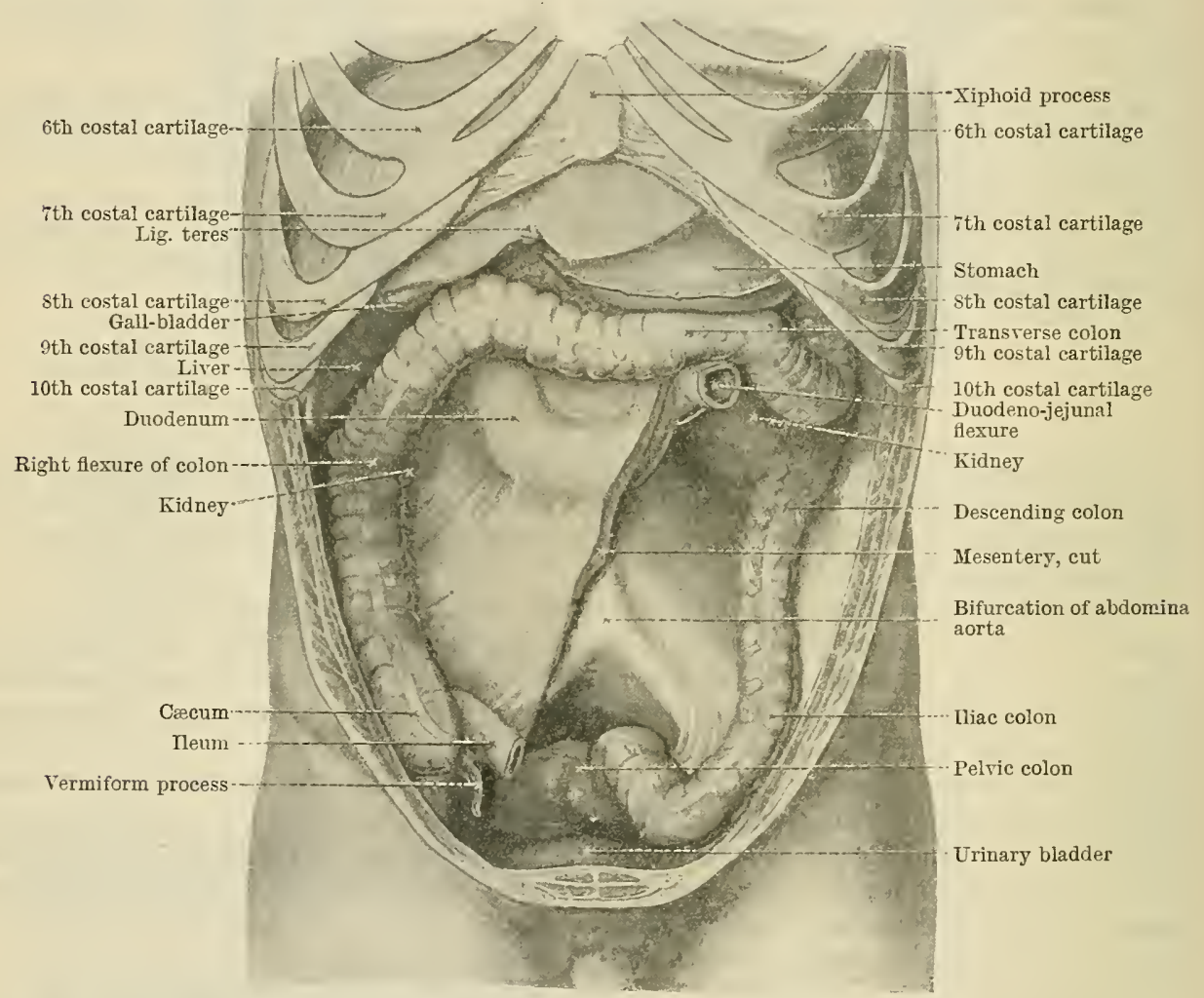

Fig. 912.-The Cotrse of the LARge Ixtestixe. The jejunum and ileum have been removed.

Below, the cavity is continued in to the cavity of the pelvis minor.

The anterior wall is formed by the aponeuroses of the three flat abdominal muscles, obliquus externus, obliquus internus, and transversus abdominis, together with the two recti, which latter constitute powerful braces for the wall, on each side of the median plane.

Anteriorly, below the junction of abdomen and pelvis, lies the pubic symphysis. The body of the pubis looks upwards as well as posteriorly, and appears to form a support or floor for the viscera contained within the anterior part of the abdominal cavity.

The lateral walls are formed by the muscular portions of the obliqui and transversi muscles, and below by the iliac bones and the iliacus muscles.

Finally, the cavity is limited posteriorly by the lumbar portion of the vertebral column with the crus of the diaphragm and psoas major muscle on each side, and the quadratus lumborum still more laterally. The iliac bones also enter into the formation of the inferior portion of the posterior wall.

The superior portion of the cavity lies under cover of the ribs, which afford considerable protection to this part of the abdomen, particularly laterally and 
posteriorly, in which latter position the cavity is furtber protected by the vertebral column. Anteriorly, on the other hand, the ribs are wanting below the sternum, and here the abdominal wall is formed only of aponeuroses and muscles. But even at the sides and back there is a considerable zone, usually one to two inches wide, between the lower ribs above and the crest of the ilium below, which has no bony support except that afforded by the rertebral column.

Whilst the circumference of the diaphragm is attached to the inferior part of the thoracic framework anteriorly and laterally, and to the lumbar vertebræ posteriorly, the central portion of the dome, on the other hand, namely, the central tendon, is placed high up, under cover of the ribs, and in a more or less horizontal plane. As a result, the peripheral muscular part slopes upwards and medially from the circumference of the thoracic framework to the central tendon, and lies for a considerable distance in contact with the deep surface of the ribs; thus the diaphragm comes to form, not only the roof of the cavity, but it also enters into the formation of the lateral, posterior, and, to a lessextent, of the anterior walls; and almost as much of the cavity of the abdomen as of the thorax lies under shelter of the ribs.

Owing to the fact that the boundaries of the abdomen are formed chiefly of muscles, it follows that its walls are capable of contraction to a very considerable extent, and the size of the cavity can consequently be altered in all directions. Its chief changes in form are due to the descent or elevation of the diaphragm, the contraction or relaxation of the anterior and lateral walls, and the raising or lowering of the pelvic floor.

The superior aperture of the pelvis (Figs. 234 and 235, p. 236), which separates the two natural divisions of the cavity, is formed behind by the base of the sacrum, at the sides by the linea terminalis of each hip bone, and in front by the pubic crests and the symphysis pubis. In the erect position it usually makes an angle of about 55 to 60 degrees with the horizontal. The two portions of the abdominal cavity which the superior aperture separates meet at an angle, the abdomen proper running almost vertically upwards from it, whilst the pelvic cavity slopes backwards and slightly inferiorly.

The pelvic cavity is bounded in front and at the sides by the portions of the hip bones below the level of the linea terminalis. These bony walls are partly clothed, in front and laterally, by the obturator internus muscles, and internal to these by the parietal portion of the pelvic fascia, as low down as the arcus tendineus. The posterior wall is formed by the front of the sacrum, covered on each side by the piriformis muscle. This wall (as represented by the piriformes muscles) meets the lateral wall at the anterior border of the greater sciatic foramen; through this foramen the piriformis passes out, thus closing up what would otherwise be a large aperture in the parietes of the cavity. The floor is composed of the two pairs of muscles which form the pelvic diaphragm, namely, the levatores ani and coccygei-covered by the visceral layer of the endopelvic fascia. These muscles pass on each side, from the lateral wall of the pelvis, downwards and medially towards the median plane, and present a concave superior surface towards the pelvic cavity.

Within the muscles forming its walls, the abdomen is lined by an envelope of fascia, which separates the muscles from the extraperitoneal connective tissue and peritoneum. This aponeurotic layer is distinguished in different localities as:(1) the fascia transversalis on the anterior and lateral walls, lining the deep surface of the transversalis muscle and continuous above with the fascia clothing the inferior surface of the diaphragm; (2) the fascia iliaca on the posterior wall, covering the psoas and iliacus muscles; (3) the fascia diaphragmatica, covering the inferior surface of the diaphragm; and (4) the fascia endopelvina, lining the pelvis.

Apertures.-Certain apertures are found in the walls of the abdomen, some of which lead to a weakening of the parietes. These are: the three openings in the diaphragm for the passage of the inferior vena cava, the cesophagus, and the aorta respectively; the apertures in the pelvic floor, through which the rectum, the urethra, and the vagina in the female, reach the surface; the inguinal canal, through which the spermatic funiculus (or round ligament) passes, in leaving the abdominal cavity; and lastly, the femoral canal, a small passage which runs down from the abdomen along the medial side of the femoral vessels. The two latter 
particularly constitute on each side weak points in the abdominal wall, through which a piece of intestine occasionally makes its way, giving rise to inguinal or femoral hernia respectively. Similar protrusions may also occur at other points in the abdominal wall, and also through apertures in the pelvic wall.

Tela Subserosa (O.T. Extraperitoneal or Subperitoneal Connective Tissue).Between the fascia which covers the deep surfaces of the abdominal muscles, and the peritoneum which lines the cavity, there is found a considerable quantity of connective tissue, generally more or less loaded with fat, which is known as the tela subserosa. This is part of an extensive fascial system which lines the whole of the body cavity, outside its various serous sacs, and is continued on the several vessels, nerves, and other structures which pass from the trunk into the limbs and neck.

In the abdomen it is divisible into a parietal and a visceral portion, both composed of loose connective tissue. The former lines the cavity, whilst the latter passes forwards between the layers of the mesenteries and other peritoneal folds to the viscera. These two portions of the extraperitoneal tissue are perfectly continuous with one another, and contain in their whole extent a vascular plexus, through which a communication is established between the vessels of the abdominal wall, on the one hand, and those of the contained viscera on the other.

The parietal portion is thin and comparatively free from fat over the roof and anterior wall of the abdomen, and here the peritoneum is more firmly attached than where the tissue is fatty and large in amount. In the pelvis, on the other hand, the tissue is loose and fatty, and, as such, it is continued up for some inches on the anterior abdominal wall above the pubes, to permit of the ascent of the bladder during its distension, in the interval between the peritoneum and the anterior abdominal wall. Here also the urachus and the obliterated umbilical arteries will be found passing up in its substance. On the posterior wall the tissue is large in amount and fatty, particularly where it surrounds the great vessels and the kidneys.

From this parietal portion the visceral expansions are derived, in the form of prolongations around the various branches of the aorta. These expansions are connected with the areolar coats of the blood-vessels and are conducted by them into the mesenteries and other folds of the peritoneum, and thus reach the viscera.

The chief uses of this tissue are: (1) to unite the peritoneum to the fascial and muscular layers of the abdominal wall; (2) to connect the viscera to these walls and to one another in such a loose manner that their distension or relaxation may not be interfered with. This would not be the case if the connecting medium were firm or rigid; (3) in addition, it is a storehouse of fat, forms sheaths for the vessels and nerves, and establishes, through its vascular plexus, communication between the parietal vessels and those distributed to the abdominal viscera.

Subdivision of the Abdomen Proper.-Owing to the large size of the cavity, and in order to localise more correctly the position of the various organs contained within it, the abdomen proper is artificially subdivided by two horizontal and two sagittal planes (Fig. 913).

Of the two horizontal planes, one divides the trunk at the level of the lower border of the tenth costal cartilage; this is known as the subcostal plane, and the line where it intersects the abdominal wall is the subcostal line. The second horizontal plane is at the level of the highest point of each iliac crest which is visible from the front; this point corresponds to the tubercle seen on the lateral lip of the crest, about two inches posterior to the superior anterior spine, and can be easily located; the line and plane are consequently known as the intertubercular line and plane respectively.

The sagittal planes are drawn, one on each side, perpendicularly upwards from a point on the inguinal ligament midway between the superior anterior spine and the symphysis pubis. These planes and the corresponding lines are known as the lateral planes and lines respectively.

By the two horizontal planes the abdomen is divided into three zones, a superior or costal, a middle or umbilical, and an inferior or hypogastric zone. By the two 
perpendicular planes each of these is subdivided into three parts, a central and two lateral. Thus, in the upper zone, we get a hypochondriac region or hypochondrium on each side, and an epigastric region or epigastrium in the centre. Similarly, the umbilical zone is divided into right and left lumbar regions, with an umbilical region between. And the hypogastric zone has a hypogastric region or hypogastrium in the centre, with right and left iliac regions at the sides.

In addition, the portion of the abdominal wall above the body of the pubis is known as the suprapubic region, and that immediately above the inguinal ligaments as the inguinal region.

The three central divisions, namely, the epigastric, umbilical, and hypogastric

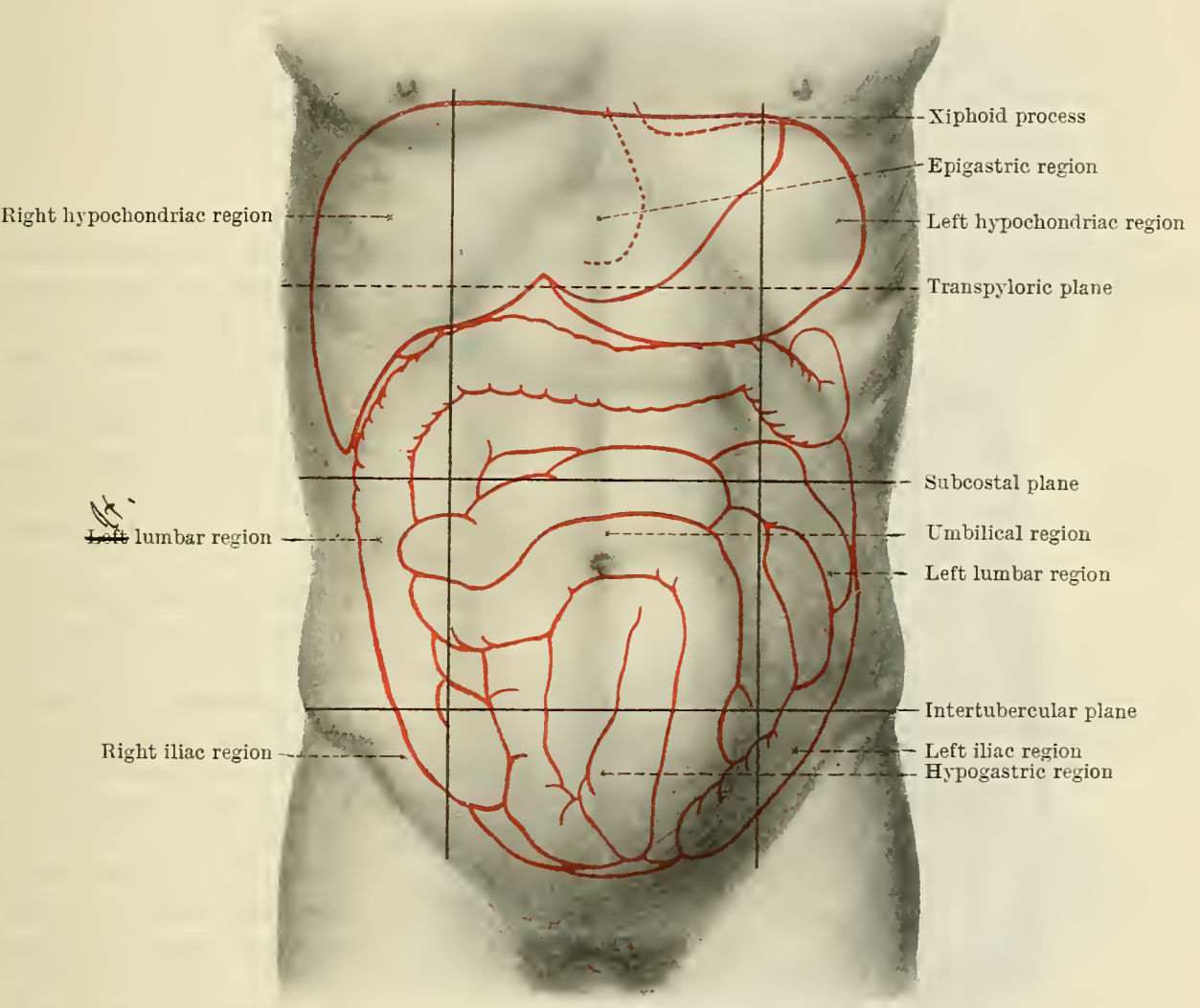

Fig. 913.-Planes of Subdinision of the Abdoninal Cajity, and Outline Tracing of the Liner, Stomach, and Intestine in Relation to the Anterior abdominal Wall.

The oblique position of the stomach and the high position of the transverse colon are largely due to the fact that the subject was in the horizontal position.

regions, can conveniently be further subdivided by the median sagittal plane, passing through the middle of the body, into right and left halves.

The superior horizontal, or subcostal, plane passes posteriorly, through the superior part of the third lumbar vertebra, or the fibro-cartilage between the second and third lumbar vertebræ. The intertubereular plane cuts through the niddle or superior part of the fifth lumbar vertebra.

The inferior margin of the tenth costal cartilage frequently corresponds to the most dependent part of the thoracic framework. Often, howerer, the eleventl costal cartilage descends $\frac{1}{4}$ to $\frac{1}{2}$ inch lower. Nevertheless, the tenth cartilage is selected in drawing the subcostal plane, for two chief reasons, namely, it is visible from the front as a rule, and it is comparatively fixed, whilst the eleventh, being a floating rib, is much more movable, is variable in length, and more difficult to locate.

Another plane which is of some practical value is the transpyloric plane (Addison). This is a horizontal plane which is taken to intersect the trunk at the level of the first lumbar vertebra. That level is ascertained during life by taking the mid-point of a line drawn on the surface of the trunk from the superior border 
of the sternum to the crest of the pubis. The same level is obtained usually, but not so accurately, by taking the mid-point of a line drawn from the xiphi-sternal articulation to the umbilicus.

Contents of the Abdomen.-The following structures are found within the abdominal and pelvic cavity:-

1. The greater part of the alimentary canal, viz., stomach, small intestine, and large intestine.

2. Digestive glands: the liver and pancreas.

3. Ductless glands: the spleen and the two supra-renal glands.

4. Urinary apparatus: the kidneys, ureters, bladder, and part of urethra.

5. The internal generative organs according to the sex.

6. Blood and lymph vessels, and lymph glands.

7. The abdominal portion of the cerebro-spinal and sympathetic nervous systems.

8. Certain fotal remains.

9. The peritoneum-the serous membrane which lines the cavity, and is reflected over most of its contained viscera.

\section{PERITON EUM.}

The arrangement of the peritoneum is so complicated, and its relations to the abdominal contents so intricate and detailed, that it will be expedient to postpone

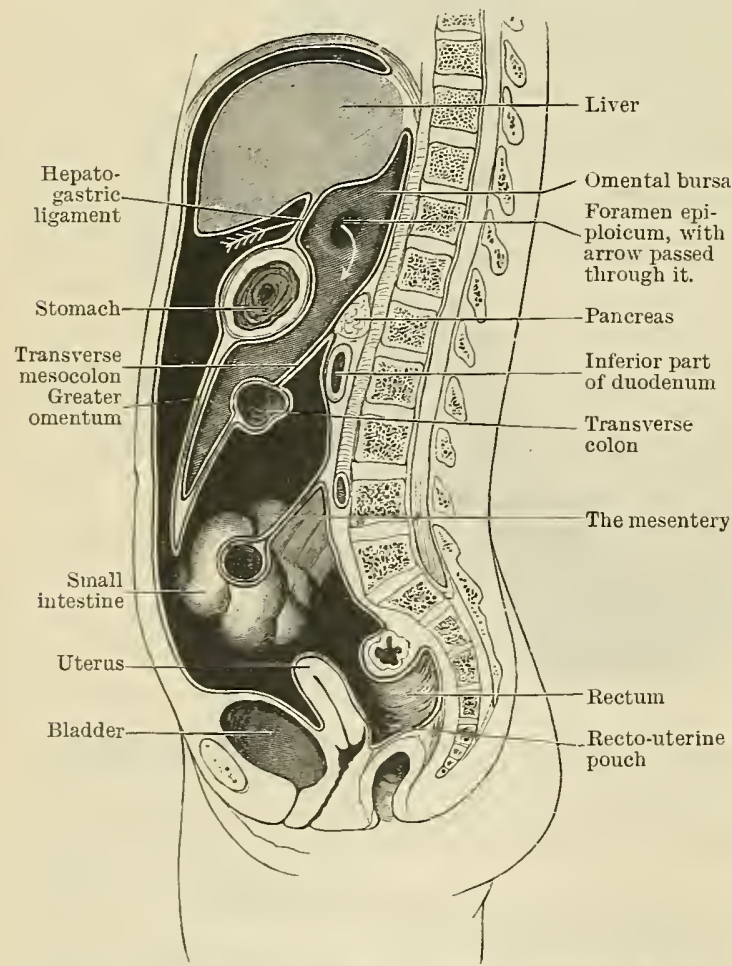

Fig. 914.--Diagramiatic Median Section of Female Body, to show the peritoneum on vertical tracing. The great sac of the peritoneum is black and is represented as being much larger than in nature; the bursa omentalis is very darkly shaded ; the peritoneum on section is shown as a white line; and a white arrow is passed through the foramen epiploicum from the great sac into the bursa omentalis. brane secretes only sufficient moisture to lubricate its surface, otherwise the sac is perfectly empty, and its opposing walls lie in contact, thus practically obliterating its cavity.

The use of these lubricated and highly polished serous linings, found in the

the various organs, with their special peritoneal relations, have been separately considered. Nevertheless, it will be necessary to give here a general account of the disposition of the membrane, and to refer to some of the folds which it forms in passing from organ to organ, or from these to the abdominal wall.

The peritoneum is the serous membrane which lines the abdominal cavity and invests most of the abdominal viscera, to a greater or less degree. Like the pleuræ, pericardium, and other serous sacs, its walls are composed of a thin layer of fibrous tissue, containing numerous elastic fibres, covered over on the side turned towards the cavity of the sac by a layer of flattened endothelial cells forming the tunica serosa. Like them, too, the peritoneum in the male is a completely closed bag, but in the female this is not the case, for the ostium abdominale of each uterine tube opens into the sac, whilst the ostium uterinum of that tube communicates with the interior of the uterus, and thus, indirectly, with the exterior of the body. Normally the mem- 
abdomen and certain other cavities, is to facilitate the movements of the contained viscera during any changes in size or form which they or their containing cavity may undergo. As a result of this arrangement, notwithstanding the tonic pressure of the abdominal wall on its contents, the stomach and intestines are free to move with the greatest ease and the least degree of friction, when any change takes place either in the organs themselves or in their surroundings.

The peritoneum is a thin glistening membrane, which may aptly be compared to a coat of varnish applied to the inner aspect of the abdominal walls, and to the surface of the contained viscera, except where these are directly applied to the walls or to one another. It forms throughout its entire extent a continuous and distinct sheet, but it is united so intimately to the viscera, and follows the irregularities of their walls so closely, that it appears at first sight to be a superficial layer of these walls, rather than a separate membrane. Outside the peritoneum lies the tela subserosaalready describedby which the peritoneum is connected more or less intimately to the fascial lining of the abdominal walls and to the abdominal viscera.

The portion of peritoneum which lines the walls of the cavity is known as the peritoneum parietale and that which clothes the viscera as the peritoneum viscerale.
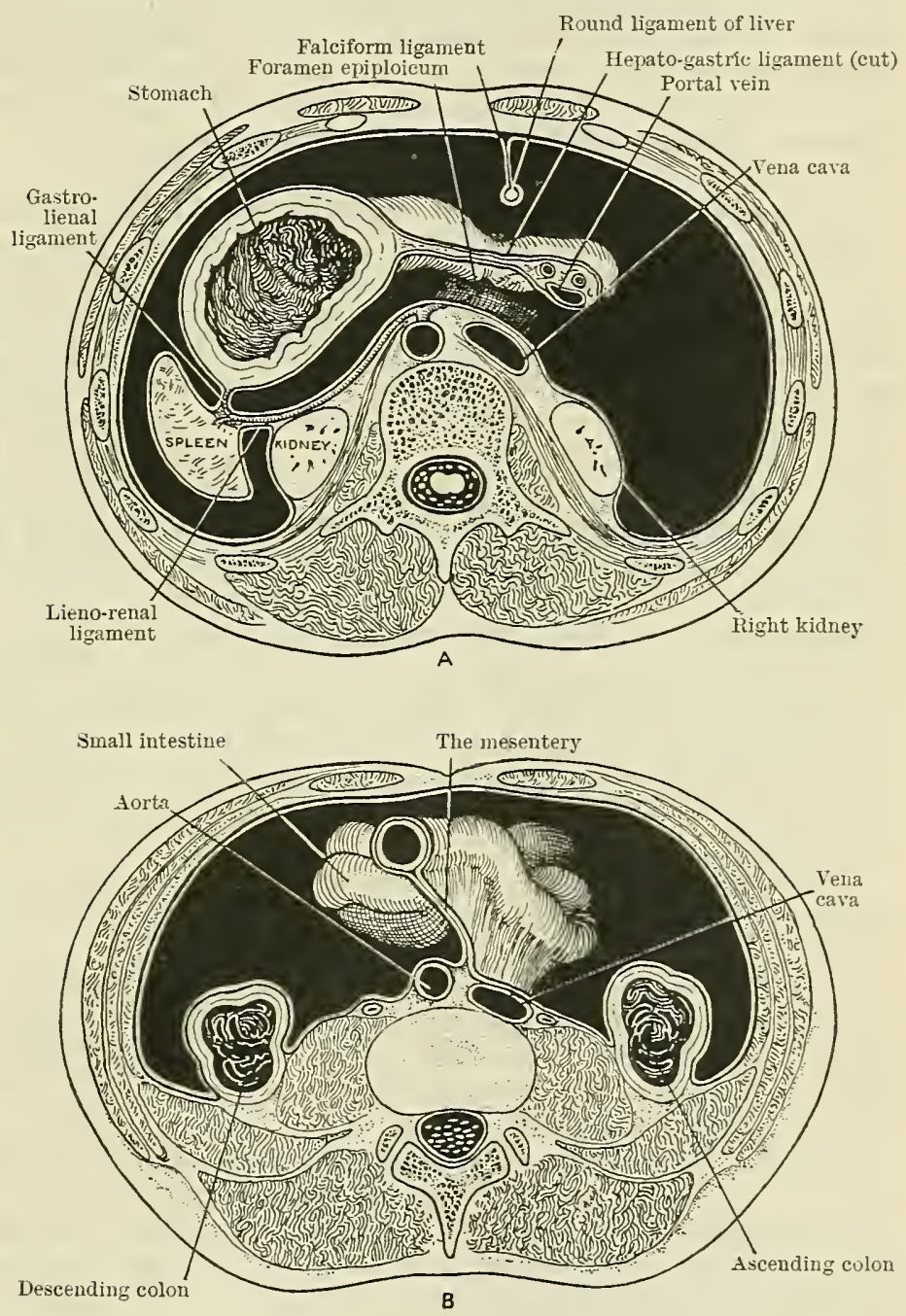

Fig. 915.-Diagramiatic Transverse Sectioys of AbDomex, to show the peritoneum on transverse tracing. A, at level of foramen epiploicum; B, lower down. In A note, one of the short gastric arteries passing to the stomach between the layers of the gastro-lienal ligament, and also the foramen epiploicum leading into the bursa omentalis which lies behind the stomach.

If we trace the peritoneum, beginning in front, we find that it lines the deep surface of the anterior abdominal wall, and is continued upwards to the inferior surface of the diaphragm (Fig. 914), the greater portion of which it covers. From the posterior part of the diaphragm it is reflected or carried forwards on to the superior surface of the liver. From the liver it can be traced over the stomach, intestines, and other abdominal viscera to the pelvis. In like manner, when traced laterally from the anterior wall, the membrane will be found to line the sides of the cavity, and passing backwards to clothe the posterior abdominal wall, and the 
viscera lying upon it (Fig. 914). It should be pointed out that all the abdominal viscera are either directly fixed by connective tissue to the posterior abdominal wall, or connected by blood-vessels with it. In the former case the peritoneum is reflected directly from the wall on to the viscera; in the latter it runs along the blood-ressels to reach the viscera, which it clothes, and then returns to the wall on the opposite sides of the vessels, which it thus encloses in a fold.

Whilst the greater part of the general peritoneal cavity lies anterior to the various abdominal viscera, covering them over and dipping down between them, it should be mentioned that there is a special diverticulum derived from it, situated mainly behind the stomach, and covering its posterior surface; this is known as the bursa omentalis (O.T. small sac), and it will be described in detail later on. The aperture through which one sac communicates with the other is termed the foramen epiploicum (Winslowi) (O.T. foramen of Winslow).

In passing from organ to organ, or from these to the abdominal wall, the peritoneum forms numerous folds, the principal ones being as follows :-

(1) Omentum Majus.-The greater omentum hangs down like an apron from the transverse colon, in front of the coils of the jejunum and ileum. It consists embryologically of four layers of peritonemm, two anterior and two posterior, which are usually, in the adult, adherent to one another. The four layers form a thin, translucent, and often perforated membrane. The two anterior layers were originally connected with the stomach above, and passed down in front of the transverse colon, but as development proceeds they become adherent to the anterior surface of the transverse colon. The fold which extends from the stomach to the colon is termed the gastro-colic ligament. If the two anterior layers be separated from the two posterior and from the front of the transverse colon, a cavity is formed, continuous with the bursa omentalis, and the anterior layers of the great omentum are directly continuous with the layers of the gastro-colic ligament. This condition is that usually described in English text-books as the normal adult condition and is represented in Fig. 914, where the gastro-colic ligament is separated from the transverse colon, and passes in front of the transverse colon directly into the anterior layers of the omentum majus, and the great omentum thus descends from the stomach above.

(2) Omentum Minus.-The lesser omentum is a fold passing from the inferior surface of the liver to adjacent organs. It consists of two, or occasionally three, portions :-

(a) The ligamentum hepatogastricum, a wide peritoneal fold, extending from the left end of the porta hepatis, the fossa of the ductus venosus, and partly also from the concave surface of the left lobe of the liver and the caudate process, to the lesser curvature of the stomach, where it is continued into the peritoneal coats of the anterior and posterior surfaces of that organ.

(b) The ligamentum hepatoduodenale passes from the porta hepatis to the pars superior of the duodenum. On the left this fold is continuous with the hepatogastric ligament, on the right it ends in a rounded margin. Traced downwards, the layers of peritonem which form it clothe the commencement of the dnodenum on two sides, and are continued into the transverse mesocolon, and into the dundeno-renal ligament.

(c) The ligamentum hepatocolicum is an occasional fold passing from the region of the gall-bladder to the transverse colon and right colic flexure.

(3) Ligamentum Gastrolienale.-The gastro-splenic ligament (O.T. gastro-splenic omentum) is a double layer of peritoneum extending between the fundus of the stomach and the hilus of the spleen, and continuous below with the gastro-colic ligament.

(4) The ligamentum gastrocolicum extends from the greater curvature of the stomach to the transverse colon. It consists of two layers of peritoneum, continuous above with the layers on the anterior and posterior surfaces of the stomach, and below with the anterior layers of the great omentum.

In English text-books this is not usually recognised as a separate ligament, but is considered to be a portion of the great omentum, and to pass downwards in front of the transverse colon. It will be found, however, that the arrangement in the adult is usually that described above. 
Mesenteries are folds of peritoneum which unite portions of the intestine to the posterior abdominal wall, and convey to them their vessels and nerves. There are several mesenteries, e.g. the mesenterium (mesentery proper), which connects the jejunum and ileum to the posterior abdominal wall, the mesocolon transversum (transverse mesocolon), the mesocolon pelvinum (pelvic mesocolon), and occasionally others.

Other folds, specially named, but described elsewhere, are the ligaments of the liver, the so-called "false ligaments" of the bladder, the lieno-renal ligament, and the broad ligament of the uterus.

\section{VENTRICULUS.}

The stomach is the large dilatation found on the digestive tube immediately after it enters the abdomen (Figs. 916 and 920). It constitutes a receptacle in which the food accumulates after its passage through the osophagus, and in it take place some of the earlier processes of digestion, resulting in the conversion of the food into a viscid soup-like mixture, known as chyme. The chyme as it is formed is allowed to escape intermittently through the pylorus, into the small intestine, where the digestive processes are continued.

The form and the position of the stomach present great variations, not only among different individuals, but also in the same individual at different times. The degree to which it is filled, the size and position of adjacent organs, the condition of the abdominal walls, and even the assumption of the erect or the recumbent attitude can influence its shape and relations.

Of recent years, examination of the stomach by $\mathrm{X}$-rays has afforded information, otherwise unattainable, of the shape and position of the stomach in life, and of the changes which it undergoes. The results obtained by this method have modified considerably current conceptions regarding the stomach in the living. A necessary preliminary to the proper comprehension of these appearances is a careful study of the stomach as it presents itself to anatomical examination.

General Shape and Position.-In shape, the stomach may be described as an irregularly piriform or conical organ, with a wide end directed upwards and backwards, lying deeply in the hollow of the diaphragm, mainly in the left hypochondriac region, and a narrow tapering extremity which passes downwards and forwards, and is bent over to the right side, in the epigastric region.

The long axis of the organ forms a spiral curve, directed downwards, anteriorly and to the right, and finally backwards.

The superior end, or fundus, is almost always dome-shaped, and is distended with gas, and its wall is thinner and more flaccid than that of the lower portion, which is thicker and somewhat cylindrical in shape.

The walls of the stomach are composed of an inner thick layer of mucous membrane (tunica mucosa), supported by submucous tissue (tela submucosa), a muscular coat, consisting of three layers, more or less complete, of muscle fibres (tunica muscularis), rumning in different directions, covered externally by a serous, peritoneal investment (tunica serosa). The special characters of each of these walls will be described later.

The stomach presents the following parts for examination :-

Two surfaces, an anterior (paries anterior) directed at the same time forwards and to the left, and a posterior (paries posterior) which looks posteriorly and also to the right. These surfaces meet above and to the right at the lesser curvature, curvatura minor, and below at the greater curvature, curvatura major. At the superior end of the lesser curvature the osophagus enters the stomach, at the cosophageal opening, while at the inferior the stomach passes into the duodenum at the pylorus. The dome-shaped portion to the left of the cesophagus is the fundus, while the remainder of the stomach is divisible into the body, corpus ventriculi, and the pyloric portion, pars pylorica.

The cesophageal opening is termed the cardia, and the portion of the stomach adjacent to it the pars cardiaca, while the inferior orifice is termed the pylorus, and the portion of the stomach adjacent to it is the pars pylorica, a dilated portion of 
A

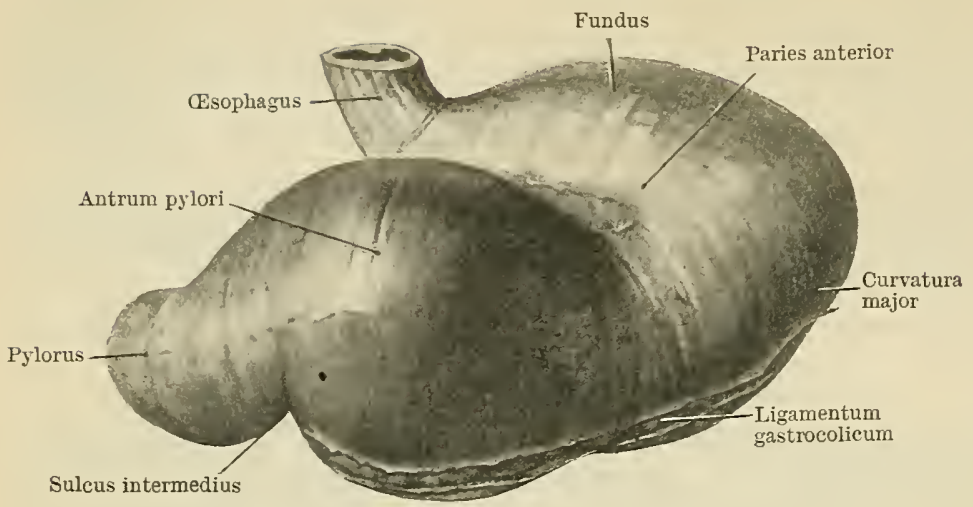

B

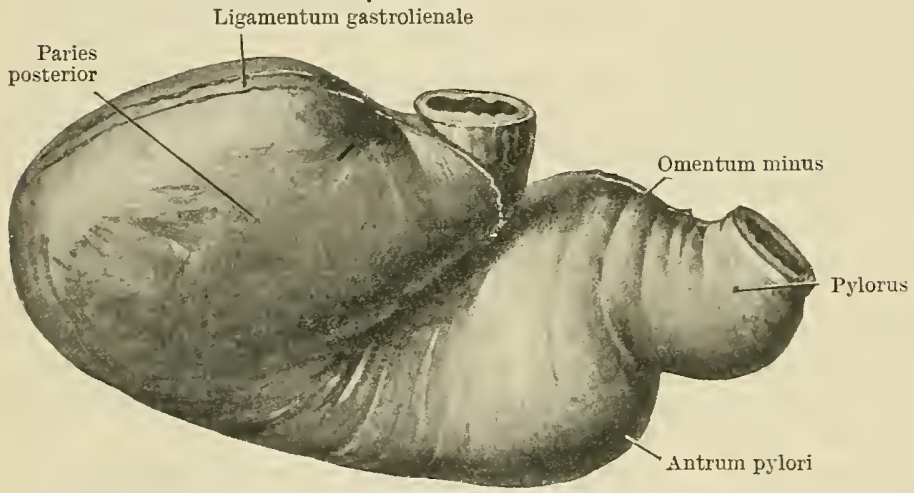

C

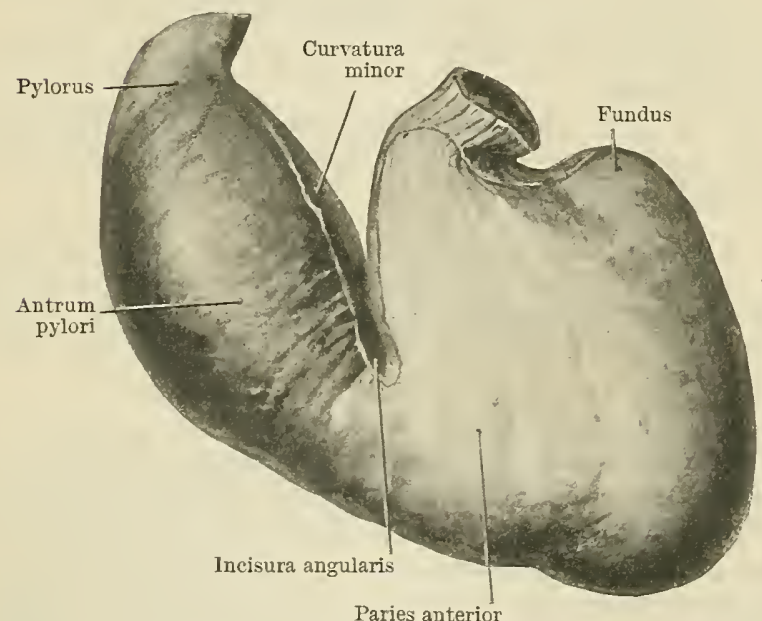

Fig. 916. - Three Views of a Stomach Fixed bX Formalin Injection IN SitU.
A. From the front.
B. From the back.
C. From above.

The orientation of the stomach was determined by inserting long pins into it in the sagittal, frontal, and transverse planes. These views show the comparatively horizontal position of the stomach associated with the horizontal posture of the trunk. They also show the partial division into chambers produced by temporary constrictions of the stomach wall fixed by the action of formalin. which forms the antrum pyloricum.

Cardia. - The opening is situated at the superior end of the lesser curvature, on the right side of the fundus, and more on the anterior than the posterior surface of the stomach.

Around this opening the muscular walls of the œsophagus and the mucous membrane become continuous with corresponding coats of the stomach wall. The longitudinal muscular coat passes onwards into a longitudinal set of fibres, and the circular csophageal fibres pass into the circular muscular coat. The whitish-coloured stratified squamous epithelium of the osophagus is continuous with the pinkish-coloured columnar epithelial wall of the stomach, and the junction is marked by a sharp irregular line running round themargin of the opening.

The orifice itself is oval or angular rather than round, being compressed from side to side.

To the right of the orifice, the right margin of the cesophagus 
merges with a slight curve into the lesser curvature of the stomach, while on the left side there is a deep notch, the incisura cardiaca, between the inferior end of the cesophagus and the fundus, in which lies a strong projecting ridge of the right crus of the diaphragm.

This notch on the outer surface produces a fold in the interior of the stomach, which may assist in closing the csophageal opening, and this, with the decussating fibres of the diaphragm, and the strengthened circular fibres of the inferior end of the œesophagus, forms a kind of sphincter for this orifice which serves to prevent regurgitation from the stomach under ordinary condition.

The cardia is very deeply placed, and lies about four inches behind the sternal end of the seventh left costal cartilage, at a point one inch from its junction with the sternum. Posteriorly it corresponds to the level of the eleventh thoracic vertebra.

Owing to the fixation of the œsophagus by its passage through the diaphragm, and the close connexion between the stomach and the diaphragm, near the cardia where the peritoneum is absent, this is the most fixed part of the whole organ. The object of this immobility is evidently to maintain a clear passage for the food entering the stomach.

Pylorus.-The pyloric orifice or pylorus is the aperture by which the stomach communicates with the duodenum. It is placed at the extremity of the pyloric end of the stomach, and its position is indicated upon the surface of the stomach by a slight annular constriction which is most marked at the curvatures.

Its position is also indicated by an arrangement of blood-ressels at the pyloric ring, which is nearly constant. On the peritoneal surface a thick rein passes upwards from the lower side somewhat more than half-way on the anterior surface, and from the upper border a second vein reaches downwards in the same line, nearly, if not quite, meeting the first (W. J. Mayo).

The pyloric constriction marks the junction of stomach and duodenum, and here the various coats of these portions meet with one another. The peritoneal covering of the stomach is continued onwards on to the first part of the duodenum.

The muscular fibres have here a special arrangement, which is due to the presence of a mechanism for arresting the escape of food from the stomach before it has undergone digestion. The longitudinal fibres of the stomach (stratum longitudinale) are in part continued onwards into the longitudinal fibres of the duodenal coat, but many of them bend inwards into the thickened ring around the opening, where they spread out in diverging bundles, which interlace with the most superficial of the circular fibres, and some of them reach and terminate in the subjacent submucosa.

The circular muscular fibres of the stomach (stratum circulare) are not continuous directly with those of the duodenum. On the contrary, at the orifice they become very much increased in number, and they form a thick ring, or sphincter, which is separated from the circular muscular coat of the duodenum by a fibrous septum.

The length of this sphincteric ring is not easily estimated, for while it is sharply marked off from the duodenum there is no sharp line of demarcation on the gastric side. There the ring gradually merges into the circular muscular coat of the cylindrical pyloric canal.

When this canal is contracted, its wall is nearly as thick as the sphincteric ring.

The gastric mucous membrane (tunica muscosa) is continued into the mucous membrane of the duodenum at the distal margin of the sphincter. The junction cannot be recognised by superficial inspection. The gastric mucosa is considerably thickened where it covers the sphincter muscle. When examined post-mortem in the ordinary way, the aperture, viewed from the duodenal side, is somewhat oval in form. When seen from the opposite side, it presents an irregular or stellate appearance, owing to the fact that the rugæ of the gastric mucous membrane are continued up to the orifice.

The orifice is directed horizontally backwards, and to the right. When the stomach is full, however, it looks almost directly backwards, or even slightly to the left side. 
The pylorus rests on the neck of the pancreas below and posteriorly, and is overlapped by the liver above and anteriorly. When the stomach is empty the pylorus is usually placed near (i.e. within $\frac{1}{2}$ inch, $12 \mathrm{~mm}$. of) the median plane, below the left lobe or sometimes the quadrate lobe of the liver, and at the level of the first lumbar vertebra, or the fibro-cartilage between this and the second lumbar. During distention it is pushed over beneath the quadrate lobe for a variable distance, but very rarely more than $1 \frac{1}{2}$ or 2 inches to the right of the median plane. Its average position can be marked on the surface of the body by the intersection of two lines; one drawn horizontally half-way between the top of the sternum and the pubic crest (Addison), the other drawn vertically a little way $\left(\frac{1}{2}\right.$ inch, $12 \mathrm{~mm}$.) to the right of the median plane.

During the earlier stages of gastric digestion the sphincter pylori is strongly contracted and the aperture firmly closed, but it opens intermittently to allow of the passage of properly digested portions of the food. As digestion advances the sphincter probably relaxes somewhat; but in hardened bodies a really patent pylorns is rarely or never found, which would seem to

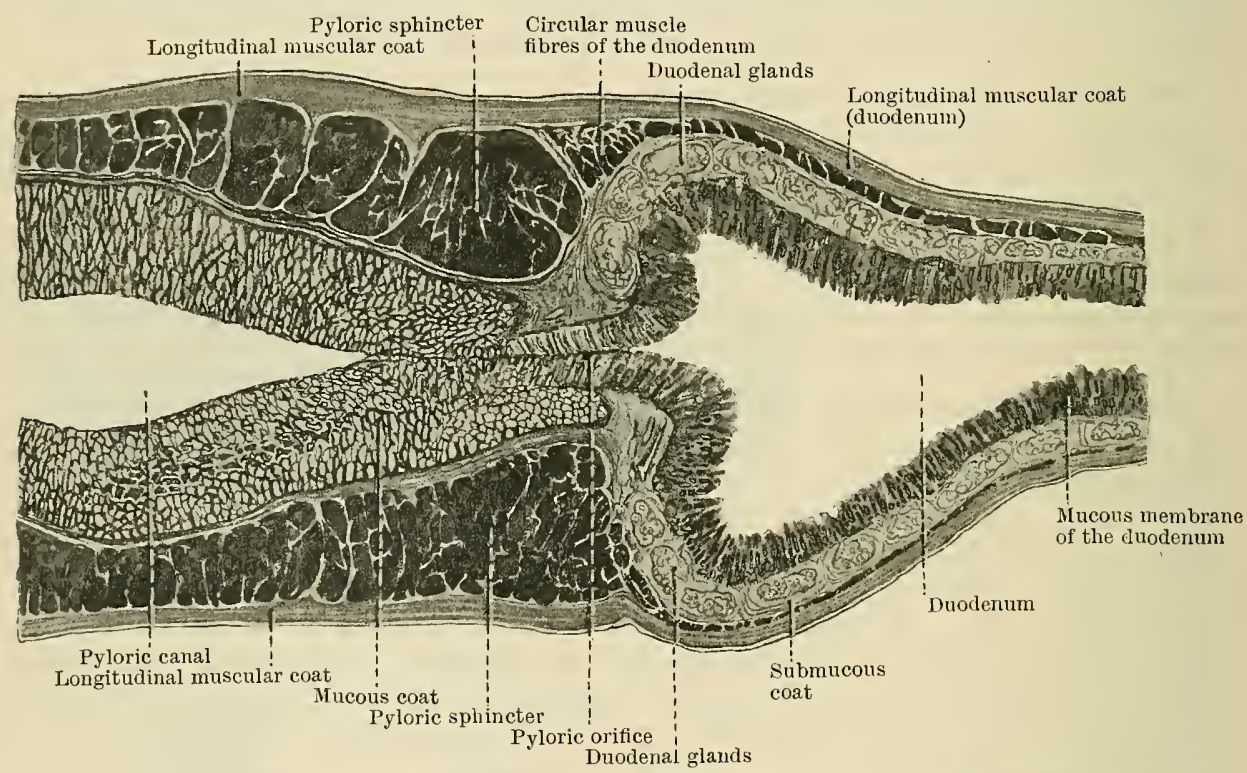

Fig. 917.-Longitudinal Section throdgh the Pyloric Canal and Commencenent of the DUODENum in a New-BORN Child. (From Stiles.)

indicate that the pylorus is normally closed, or nearly so, and that its opening is an active rather than a passive condition, as in the case of the anal canal.

As regards its size, the pylorus is stated to be about $\frac{1}{2}$ inch $(12.5 \mathrm{~mm}$.) in diameter, but there is no doubt that this represents neither its full size nor its calibre when at rest. Foreign bodies with a diameter of $\frac{3}{4}$ to 1 inch have been known to pass through the pylorus without giving rise to trouble, even in children. On the other hand, when at rest, with an empty stomach and duodenum, the aperture is practically closed.

Curvatura Ventriculi Minor.-The lesser curvature is directed towards the liver, and corresponds to the line along which a double fold of peritoneum called the hepato-gastric ligament is attached to the stomach, between the pyloric and ossophageal orifices (Fig. 916). This fold connects the stomach and liver, and between its two layers the gastric vessels run along the curvature of the stomach.

While this border is on the whole concave, it consists of two portions which meet and form a sharp angle, called the incisura angularis, situated nearer the pyloric than the cardiac end, though its position varies with the condition of the stomach. The superior or left portion is nearly vertical, and continues the direction of the right margin of the cesophagus, while the inferior, distal, or right portion is more nearly horizontal, when viewed from the front. The depth and acuteness of the angle between these two segments varies with the degree of distension of the stomach. When the pyloric portion of the stomach is full, the distal portion of the lesser 
curvature becomes distended, and this portion of the border becomes convex in outline.

The lesser curvature does not form a straight line along the surface of the stomach, for at the left end it turns forwards somewhat on to the anterior surface of the stomach, to the place where the cardiac orifice is situated. In length, the lesser curvature measures some 3 to 4 inches.

Curvatura Ventriculi Major.-The greater curvature of the stomach is usually over three times as long as the lesser curvature, and corresponds to a line drawn from the cardia over the summit of the fundus (Fig. 916), and then along the most projecting portion of the stomach as far as the pylorus. In general, it is directed to the left and forwards, but at its beginning, near the cardia, it of course looks in a different direction. The great curvature corresponds in the greater part of its length to the attachment of the gastro-splenic and gastro-colic ligaments,folds of peritoneum passing to the spleen and to the transverse colon respectively; and in close relation to it, between their layers, run the right and left gastro-epiploic vessels.

This border of the stomach, like the lesser curvature, does not present a uniformly curved outline. Towards the pylorus a notch is often found, called the sulcus intermedius. The portion to the right of this sulcus is known as the pyloric canal.

On the left side of this notch, the greater curvature bulges forwards, forming a chamber called the antrum pylori, and the projecting rounded prominence which it forms is, in some phases of digestion, marked off from the rest of the body of the stomach by a temporary indentation. Other indentations which are sometimes found on the greater curvature, or the body of the stomach, are probably due to temporary peristaltic waves of contraction.

\section{Paries Anterior.-The an-} terior surface of the stomach is

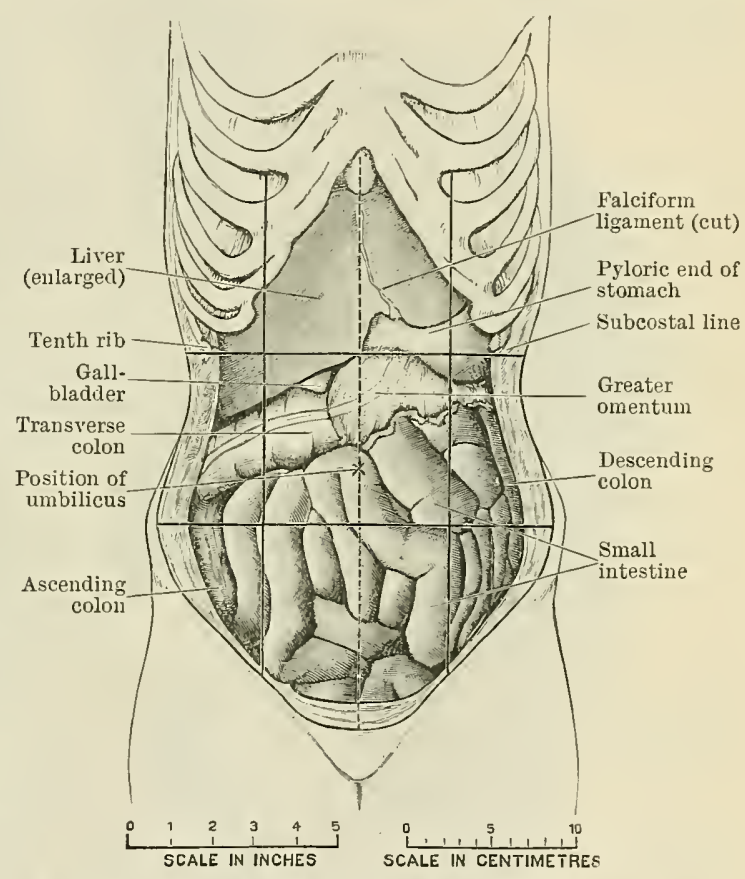

Fig. 918. - Abdomen of Female, showing Displacements RESUlTiNg FRos Tight LACING.

The liver is much enlarged, and extends on the left side to the ribs, where it was folded back on itself for over an incl. The pyloric end of the stomach and the beginning of the duodenum are quite superficial below the liver, and all the viscera are displaced downwards. (From a photograph of a body hardened by injections of formalin.) more convex and more extensive than the posterior. It lies, when the organ is distended, in contact with the inferior surface of the left lobe of the liver medially, the vault of the diaphragm laterally, and the anterior abdominal wall below (Fig. 916). When the stomach is empty, on the other hand, the transverse colon doubles up anteriorly to it, and separates this surface from the liver and diaphragm and abdominal wall.

Paries Posterior.-The posterior surface looks downwards and posteriorly. It is more flattened than the anterior, and is moulded by the structures upon which it rests.

Thus, to the left is a flattened area, passing on to the fundus, which is in contact with the diaphragm and the spleen. To the right of the fundus, the posterior surface is divisible into two horizontal areas, a superior and an inferior, separated by a slight ridge. The superior portion, nearly vertical, lies in contact with the left kidney and supra-renal gland and diaphragm, and the inferior portion, more horizontal, is in contact with the pancreas, transverse mesocolon, and transverse 
colon. These structures constitute the posterior wall of the bursa omentalis of the peritoneal carity.

Between the two surfaces, the wall comes into contact with the splenic artery as it runs along the superior border of the pancreas.

The different portions into which the stomach may be divicled are as follows:-

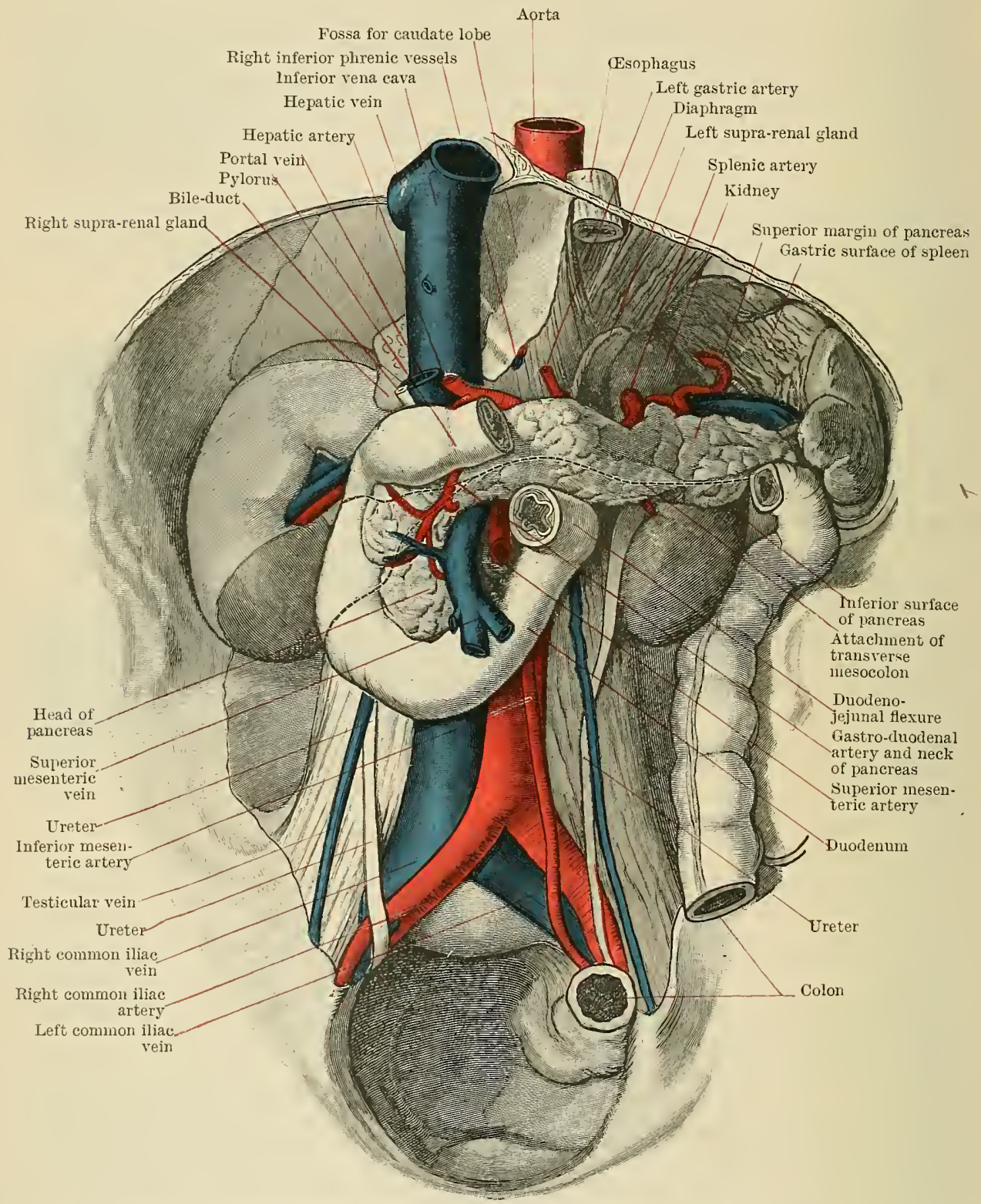

Fig. 919.-The Viscera and Vessels on the Posterior Abdoninal Wall.

The stomach, liver, and most of the intestines have been removed. The peritoneum has been preserved on the right kidney, and also, the fossa for the caudate lobe. In taking out the liver, the vena cava was left behind. The stomach bed is well shown. (From a body hardeued by chromic acid injections.)

Fundus Ventriculi. - The fundus is that portion of the stomach which lies above a horizontal plane drawn through the cesophageal opening. It is rounded or domeshaped. This shape seldom alters, whatever the condition of the stomach may be. It is usually filled with gas.

Corpus Ventriculi.-The body of the stomach extends from the fundus to 
the incisura angularis on the lesser curvature, and to the notch on the greater curvature already described. It forms a rounded chamber, capable of great distension, but when the stomach is empty it contracts to a narrow tube-like structure. As the stomach is seldom completely empty, the body usually tapers from the fundus to the proximal end of the pyloric portion.

Pars Pylorica.-The pyloric portion of the stomach extends from the incisura angularis in the lesser curvature, and a variable and inconstant notch on the greater curvature, as far as to the pyloric orifice.

It differs from the body of the stomach in being more tubular in shape, and possessing thicker walls.

It has been divided anatomically into two portions, the pyloric canal and the antrum pyloricum respectively.

The pyloric canal is a short more or less tubular portion rather more than an inch in length, extending from the sulcus intermedius on the greater curvature to the pyloric constriction. The proximal portion, called the pyloric antrum,

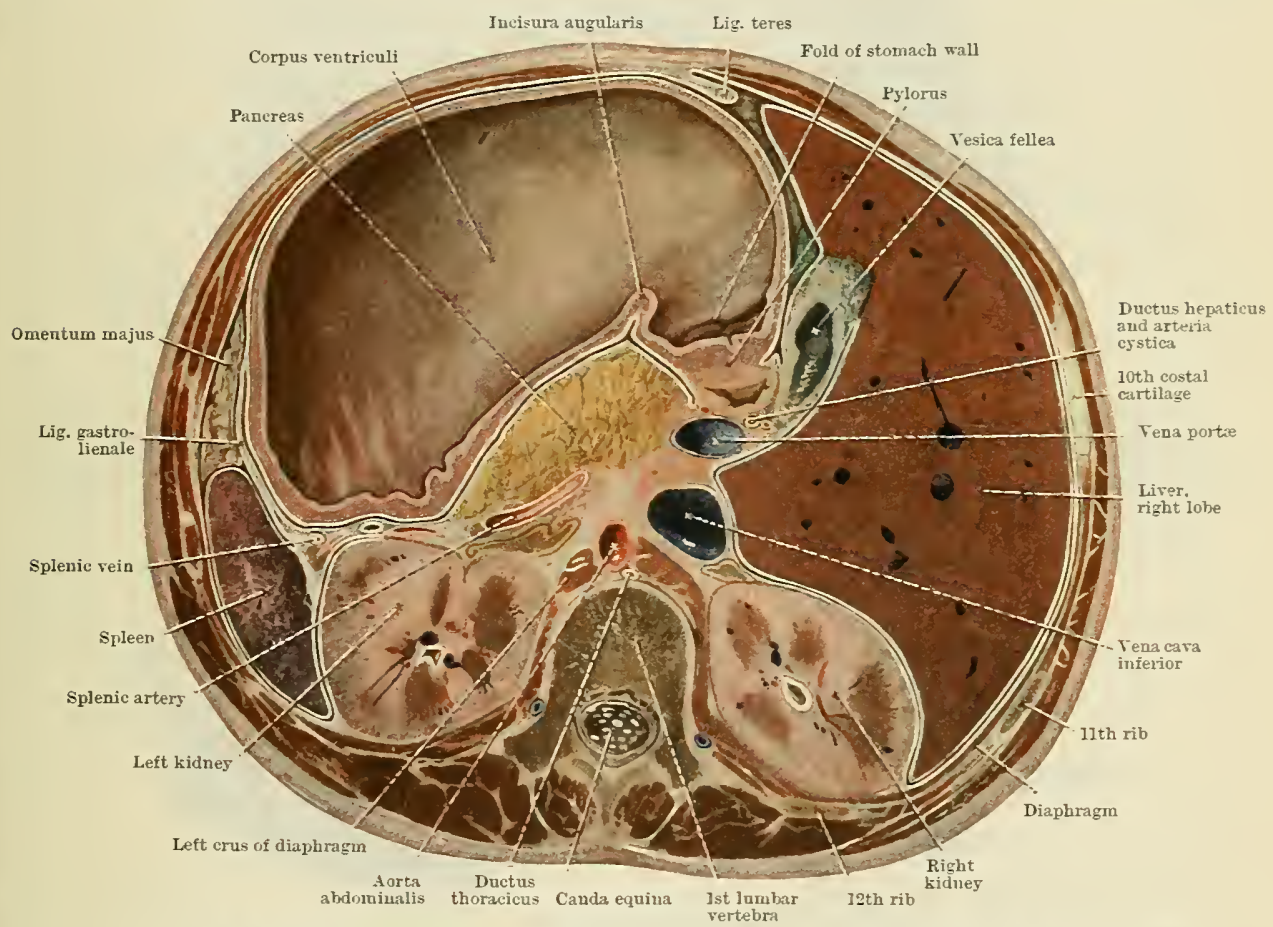

Fig. 920.-Traxsterse Sectior of the Trenk at the Level of the first Lembar Vertebre. Showing relations of stomach, pancreas, kidneys, etc. From a subject ten years old.

is more expanded. It is not clearly demarcated from the body of the stomach by any constant line of aivision on the greater curvature. On the lesser curvature it extends from the incisura angularis to the pyloric canal, and it is occasionally pouched outwards on the side of the greater curvature so as to form a chamber or pouch, the "camera princeps" of His.

\section{RELATIONS AND CONNEXIONS OF THE STOMACH.}

When the stomach has been remored, after the body has been hardened, a chamber or recess is exposed, known as the stomach chamber. It is (Figs. 920 and 921) a space in the upper and left portion of the abdominal cavity which is completely occupied by the stomach when that organ is distended, but into which the transverse colon also passes, doubling up in front of the stomach, when it is empty.

The chamber presents an arched roof, an irregularly sloping floor, and an anterior wall. The roof is formed partly by the visceral surface of the left lobe of the lirer, and in the rest of 
its extent by the left cupola of the diaphragm, which arches gradually downwards behind aud on the left to meet the floor.

The floor or "stomach bed" (Fig. 921) is a sloping shelf on which the posterior surface of the stomach rests, and by which it is supported. The bed is formed posteriorly by the superior pole of the left kidney (with the supra-renal gland) and the gastric surface of the spleen; anterior to this, by the wide anterior surface of the pancreas; and more anteriorly still, by the transverse mesocolon running forwards above the small intestine, from the anterior edge of the pancreas to the transterse colon (Fig. 921), which completes the floor anteriorly.

Finally, the anterior wall of the stomach chamber is formed by the abdominal wall, between the ribs on the left and the liver on the right side.

This chamber is completely filled by the stomach, when that organ is distended. When, on the other hand, the stomach is empty and contracted, it still rests on the floor, or stomach bed, but occupies only the inferior portion of the chamber, whilst the rest of the space is filled by the transverse colon, which turns gradually upwards as the stomach retracts, and finally comes to lie both above and in front of that organ and immediately beneath the diaphragm-a fact to be remembered in clinical examinations of this region.

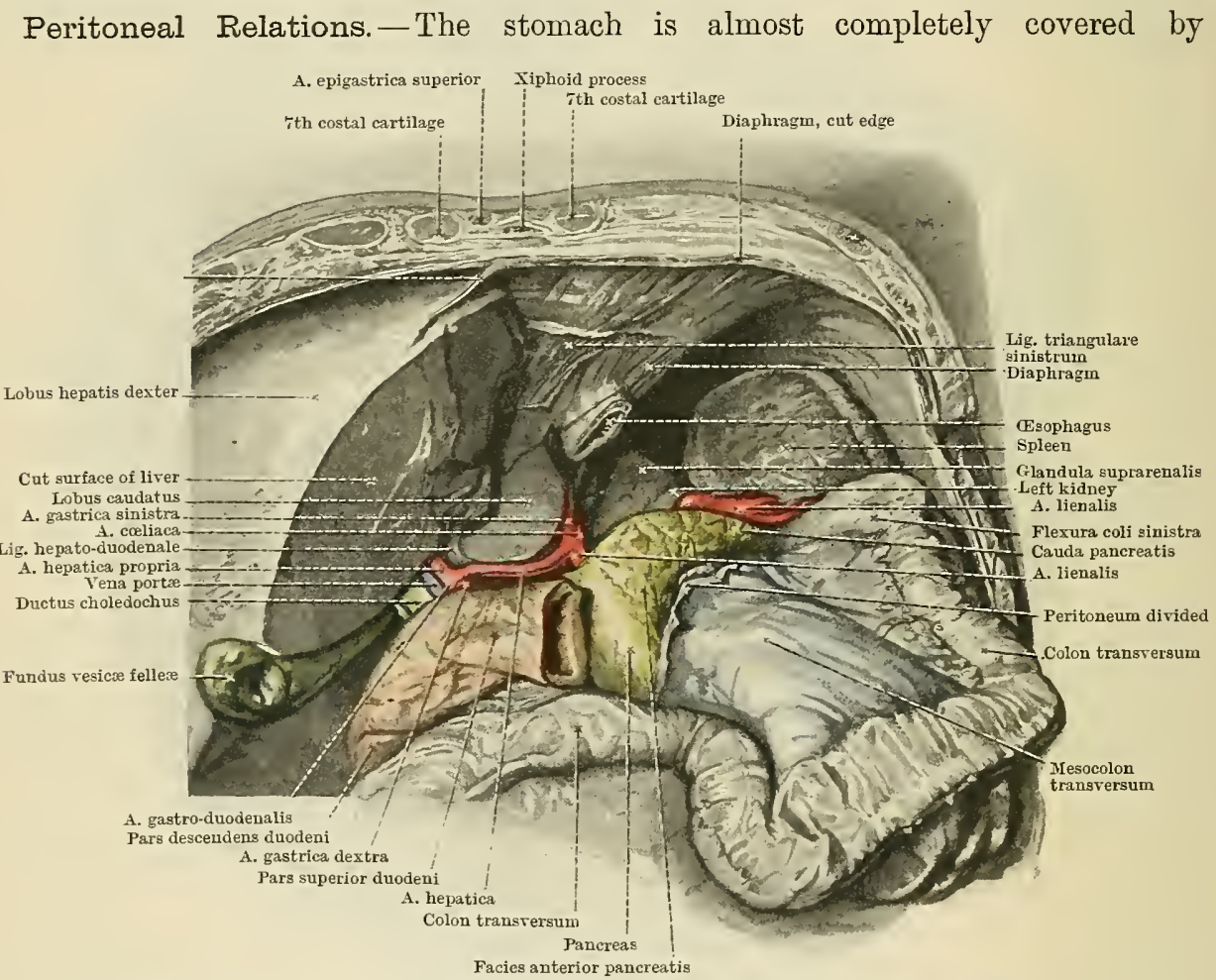

Fig. 921.-Stomach Chamber viewed frodr the Front and fron Below.

From the specimen figured in Fig. 912, after removal of the stomach.

peritoneum-the anterior surface being clothed by that of the general peritoneal sac, and the posterior surface by the anterior layer of the bursa omentalis (see p.1162). From the small curvature the hepato-gastric ligament extends to the liver, whilst to the greater curvature the gastro-lienal and gastro-colic ligaments are attached. Finally, a small peritoneal fold, known as the gastro-phrenic ligament, is found running from the stomach up to the diaphragm along the left side of the œsophagus.

A small irregularly triangular area (Fig. 919), about 2 inches wide and $1 \frac{1}{2}$ inches from above downwards, during moderate distension of the stomach, on the inferior surface below and to the left of the cardia, is uncovered by peritoneum, and over it the organ is in direct contact with the diaphragm, occasionally also with the superior extremity of the left kidney and the suprarenal gland. From the left angle of this "uncovered area "the attachment of the gastro-lienal ligament starts; and at the right angle the left gastric artery passes on to the stomach.

The margins of this fold on the right enclose the left gastric artery, and constitute a fold called the left gastro-pancreatic fold.

The right gastro-pancreatic fold is a fold of peritoneum passing from the right extremity of 
the superior part of the pancreas to the first part of the duodenum. It encloses the hepatic artery.

Size and Capacity of the Stomach.-Probably no organ in the body varies more in size within the limits of health than the stomach. Moreover, as its tissues change so rapidly after death, measurements made on softened and relaxed organs are not only worthless but quite misleading. Consequently it is difficult, perhaps impossible, to arrive at a correct estimate of its size and capacity.

The length of the stomach in the fully distended condition is about 10 to 11 inches (25 to $27.5 \mathrm{~cm}$.), and its greatest diameter not more than 4 to $4 \frac{1}{2}$ inches (10 to $11.2 \mathrm{~cm}$.); whilst its capacity in the average state rarely exceeds 40 ounces, or 1 quart.

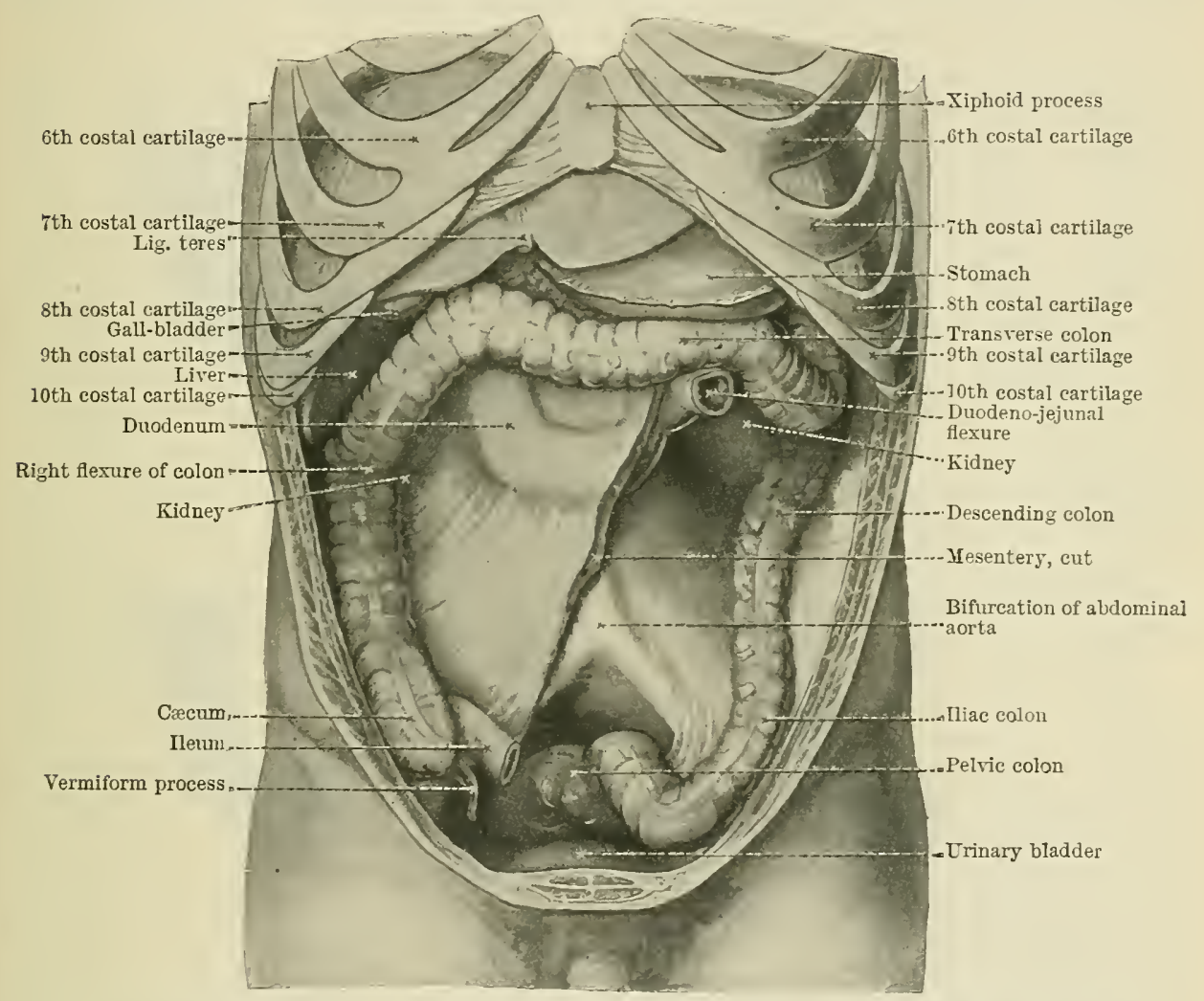

Fig. 922. -The Course of the Large Ixtestixe. The jejunum and ileum have been removed.

The length has been estimated by different authorities at from 10 to $13 \frac{1}{2}$ inches (26 to 34 $\mathrm{cm}$.); its diameter, from $3 \frac{1}{4}$ to 6 inches $\left(8\right.$ to $15 \mathrm{~cm}$.); and its capacity from $1 \frac{1}{2}$ to 5 pints. The measurements of the capacity given by Dr. Sidney MIartin are probably the most accurate: he states that the capacity varies between 9 and 59 oz., with an average of from 35 to 40, or a little over a litre.

The distance in a direct line from the cardiac to the pyloric orifice varies from 3 to 5 inches $\left(7.5\right.$ to $12.5 \mathrm{~cm}$.), and that from the cardia to the summit of the fundus from $2 \frac{1}{2}$ to 4 inches $(6 \cdot 2$ to $10.0 \mathrm{~cm}$.).

As regards the weight, the average of twelve wet specimens freed from their omenta was found to be $4 \frac{3}{4}$ oz. (135 grms.), with a maximum of 7 oz. (198.45 grms.) and a minimum of $3 \frac{1}{2} \mathrm{cz}$. (99.22 grms.). Glendinning gives the weight as $4 \frac{1}{2} \mathrm{oz}$.

In the child at birth the stomach is scarcely as large as a small hen's egg, and its capacity is about 1 oz. $(28.3$ grms.). In shape it corresponds pretty closely to that of the adult, and the fundus is well developed. It is vertical in position.

Displaced Stomach (Fig. 918).- As a result of disease, or of constriction of the superior part of the abdomen, the stomach is occasionally displaced in position and distorted in shape, so that instead of rumning obliquely forwards, downwards, and to the right, it is placed nearly vertically along the left side of the vertebral column, in which direction it has a very considerable length. Its inferior part bends rather suddenly, and runs upwards 
and to the right to join the pylorus, which is often placed quite superficially below the liver. As a result of the displacement, the left extremity of the pancreas is pushed downwards from the horizontal until it almost assumes a vertical position. The narrowing and inversion of the inferior margin of the thoracic framework at the same time constricts the stomach about its middle, and may lead to a bilocular condition.

Hour-glass or Bilocular Stomach.-This is a condition of the organ, by no means rare, in which the stomach is more or less completely separated into two divisions-a cardiac and a pyloric-the normal arrangement in certain rodents and other animals. As a rule the former division is the larger, but occasionally the two are nearly equal, or the pyloric portion may exceed the cardiac in size. Sometimes the condition is temporary, and the result of a vigorous contraction of the circular muscular fibres at the seat of constriction. In other cases it is
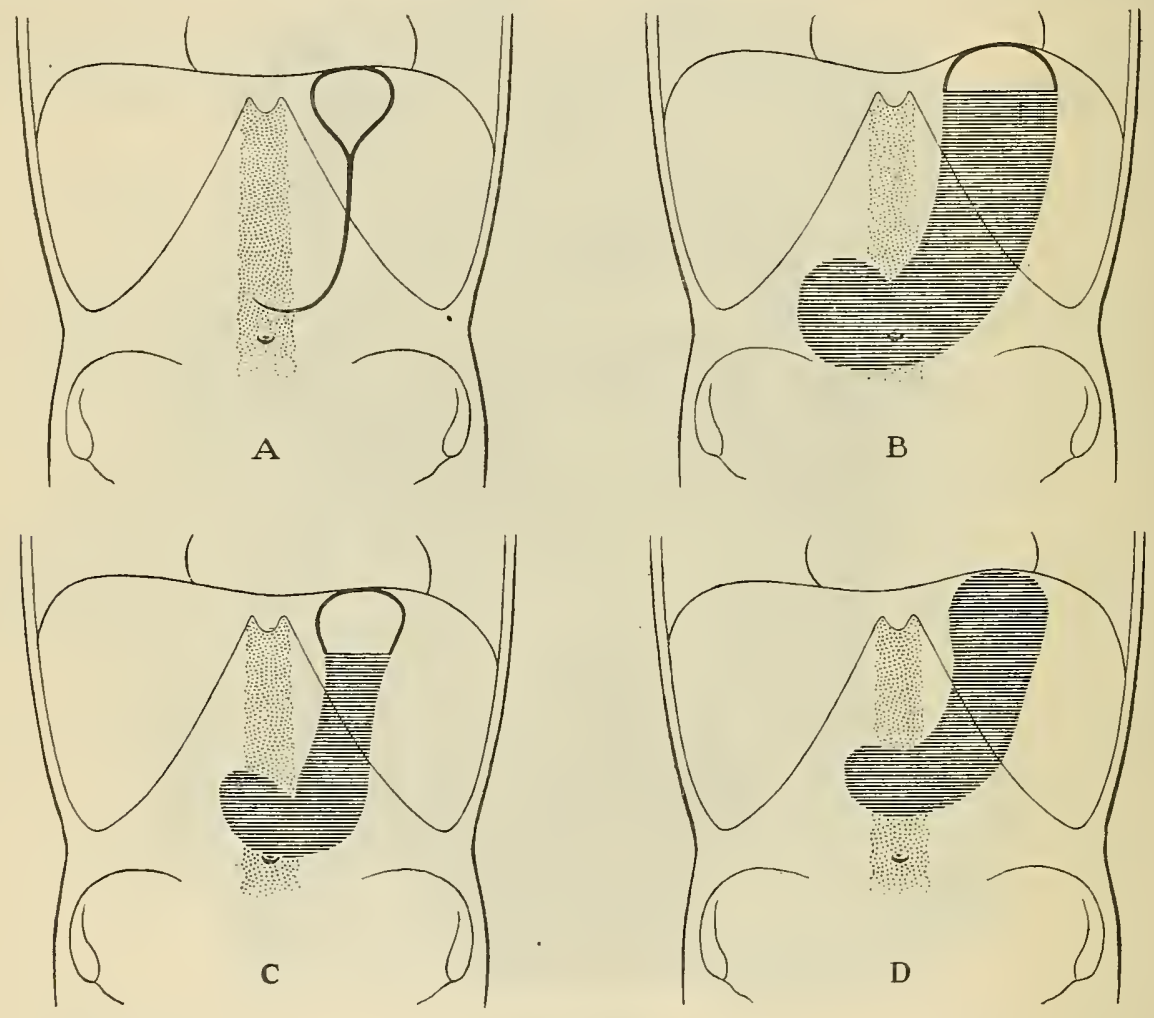

Fig. 923.

A. Empty stomach in vertical position as defined by the $\mathrm{X}$-rays.

B. Filled stomach in vertical position as seen with the $X$-rays.

C. Half-filled stomach in vertical position as seen with the X-rays.

$D$. Half-filled stomach in horizontal position as seen with the $\mathrm{X}$-rays.

permanent, and may be due to cicatricial contraction after gastric ulcer, or to some other pathological condition. The condition is more frequent in the female than the male, and is rarely found in the foetus or child.

Position of the Stomach.-When empty, or nearly so, the stomach lies in the left hypochondrium and left part of the epigastrium, with its fundus directed posteriorly towards the diaphragm, its long axis lying almost in a horizontal plane and its pyloric part running to the right to join the duodenum. In this state the whole organ is narrow and attenuated, particularly the pyloric part, which is contracted, and resembles a piece of thick-walled small intestine.

When distended, both the cardiac and pyloric parts become full and rounded (Fig. 923). It still lies within the hypochondriac and epigastric regions; but in exceptional cases, or in extreme distension, it may pass down below the subcostal plane and reach into the umbilical and left lumbar regions. As a result of the 
general increase in length which takes place during distension, the pylorus is moved a variable distance to the right beneath the quadrate lobe of the liver, and at the same time the long axis of the whole organ becomes much more oblique, running forwards, downwards, and to the right. Finally there is developed a special dilatation of the pyloric part, known as the antrum pylori, which in extreme distension is carried so far to the right that it may even reach to the hypochondrium.

Shape and Position of the Stomach as seen by X-Ray Examination.-Examination of the stomach by means of X-rays after a "bismuth meal" has given important information about the shape and position of the stomach in the living, and about the changes which occur as the stomach fills and empties.

These examinations corroborate, in great part, the conclusions which have been arrived at by the study of formalin specimens so far as the shape of the stomach, and its division into parts, is concerned. In regard, however, to the position and direction of the stomach, X-rays show that the stomach in the living, and especially in the erect attitude, is more vertical than it is after death, and when the body is examined in the horizontal position. In the upright position, in fact, the long axis of the organ appears to be nearly vertical. The general shape and position of the stomach in the vertical position, moderately distended, is shown in Fig. 923. From this it will be seen that not only is the body of the stomach nearly vertical, but that the greater curvature reaches down to the umbilicus, and may descend even beyond it. The pyloric part is directed upwards, as well as backwards, and the pylorus is not usually the lowest point of the stomach.

The other anatomical features of the stomach described above are well brought out. Thus the fundus is a hemispherical dome, lying to the left of the terminal portion of the cesophagus, and continuous in outline with the body of the stomach. It usually contains gas, and appears translucent to X-rays. The body is of uniform outline, and the pyloric part is marked off from it by the incisura angularis, on the lesser curvature. Further, the pyloric part shows division into pyloric antrum and pyloric canal. The incisura angularis and sulcus intermedius are distinct.

The position of the stomach is greatly influenced by attitude and by the condition of the abdominal muscles. Contraction of the abdominal muscles can elevate the stomach from 5 to $13 \mathrm{~cm}$., or 2 to 5 inches, and the change from the horizontal to the erect attitude alters the height of the inferior border from 2 to $10 \mathrm{~cm}$. This sinking which occurs in the alteration from the horizontal to the erect attitude, accounts largely for the differences found between the stomach seen in the postmortem room or on the operating table and the stomach displayed by means of X-rays. Thus, if the stomach figured on p. 1167 be considered fixed at the cardiac end, and somewhat fixed at the pylorus, and the pyloric antrum and greater curvature should sink downwards, the shape, as seen from the front, would closely resemble the $\mathrm{X}$-ray appearances found often in the living.

The empty stomach is a contracted tubular organ, except at the fundus, where it appears to be always dilated. When food is taken, when the individual is standing or sitting, it runs down to the point where the gastric walls are in contact with one another. The distal portion of the stomach dilates for some distance, or at least as far as the pyloric canal.

As the stomach becomes filled the whole of the body of the organ becomes dilated, but the fundus and cardiac portion more particularly so, and these two latter regions act as a storehouse.

There is no definite division of this portion from the remainder of the stomach by a permanent sphincter, but the peristaltic waves of contraction begin about the middle of the organ, and form a fleeting constriction between the two parts.

As peristalsis goes on, the tubular pyloric part relaxes somewhat. The waves of peristalsis here become so deep as to divide this portion into chambers. The food substances are forced through the pylorus by successive waves of peristalsis, and in the form, usually, of jets which impinge against the posterior aspect of the duodenal wall.

Should there be undigested masses, the pyloric valve relaxes to allow them also to pass into the duodenum. 


\section{Structure of the Stomach.}

The stomach wall is composed of four coats-namely, from without inwards: (1) Tunica serosa, (2) tmnica muscularis, (3) tela submucosa, and (4) tunica mucosa (Fig. 924). Tunica Serosa.-This coat is formed of the peritoneum, the relations of which to

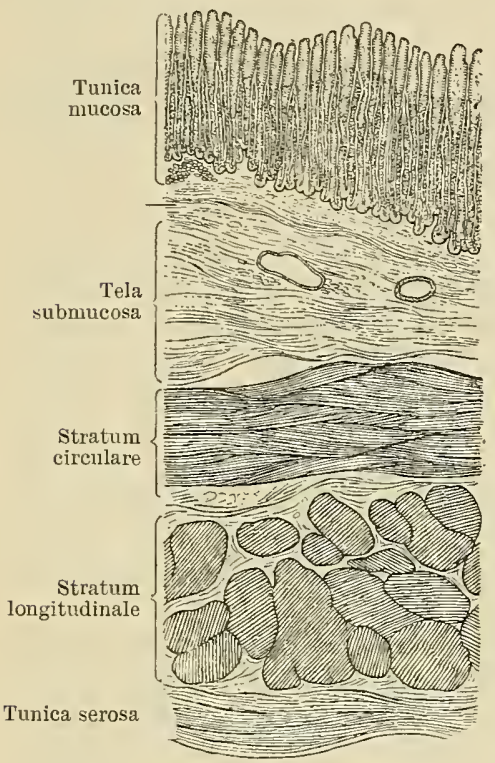

the stomach have already been described. It is closely attached to the subjacent muscular coat, except near the curvatures, where the connexion is more lax; and it confers on the stomach its smooth and glistening appearance.

Tunica Muscularis.--The muscular coat, which is composed of unstriped muscle, is thinnest in the fundus and body, much thicker in the pyloric portion, and very highly developed at the pylorus. It is made up of three incomplete layers-au external, stratum longitudinale; a middle, stratum circulare; and an internal of oblique muscular fibres, fibra obliquce.

The stratum longitudinale consists of longitudinal fibres, continuous with those of the osophagus on the one hand, and those of the duodenum on the other (Fig. 926, A). They are most easily demonstrated on the lesser curvature, where they can be traced down from the right side of the œsophagus. Over the greater curvature and on the two surfaces they are present as an extremely thin and irregular sheet. Towards the pylorus the longitudinal fibres grow much thicker, and also much tougher and more closely united, and they take part

Fig. 924.-T'RaNsterse SectioN throdgh THE WaLl OF A HUMaN Stomach. $\times 250$. in the formation of the pyloric valve.

A specially condensed band of these can be often made out both on the front and back at the antrum pylori, the form of which is said to be due to their presence. These bands are known as the ligamenta pylori (pyloric ligaments).

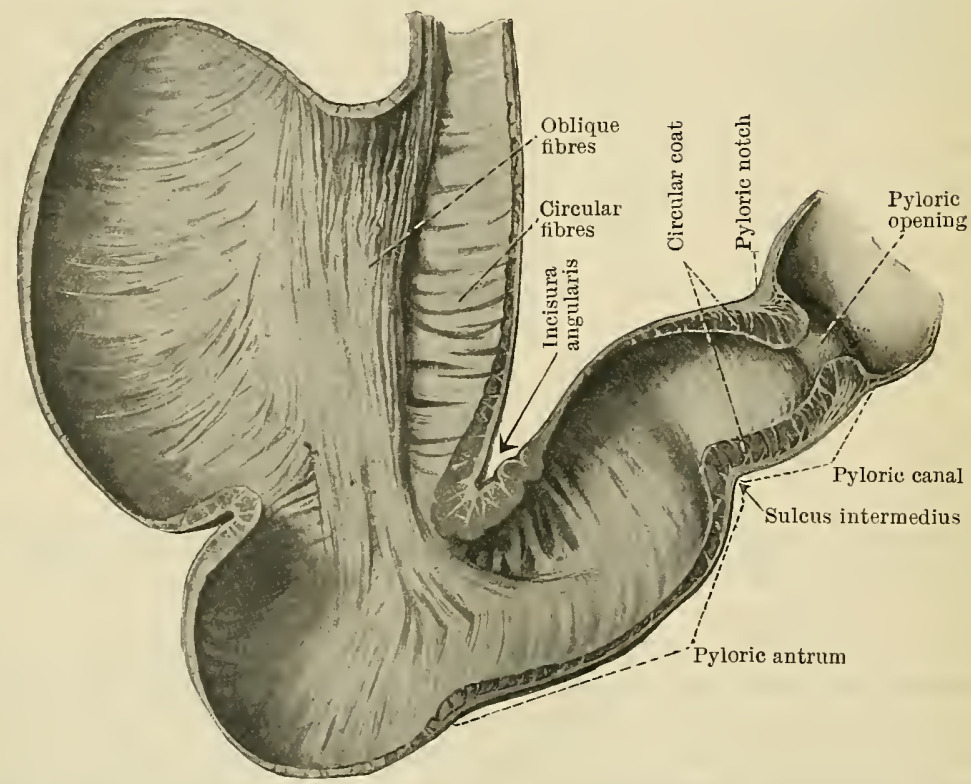

Fig. 925.-Muscular COAT of the Stomach, seen from within after removal of the mucous and submucous layers. The auterior half of the stomach is shown, viewed from behind (Cunningham).

The stratum circulare is composed mainly of circular fibres, continuous with the more superficial of the circular fibres at the lower end of the cesophagus (Fig. 925). They begin as a set of $U$-shaped bundles which loop over the lesser curvature at the right of 
the cardia, and pass downwards and to the left on both surfaces. Further to the right these looped fibres are succeeded by circles which surround the organ completely. Traced towards the narrow end of the stomach, the circular bundles grow thicker, and at the pylorus they undergo a further increase, giving rise to the pyloric sphincter which surrounds the orifice as a thick muscular ring.

The fibrce obliquae, forming the inner layer, consist of fibres which are arranged on the fundus and adjacent parts of the stomach, in much the same manner as those of the middle layer are on the body and pyloric part of the organ (Fig. 926, C). They are continuous above with the deeper circular fibres of the inferior end of the œesophagus, and form U-shaped bundles which loop over the stomach immediately to the left of the cardia, and run very obliquely downwards and to the right for a considerable distance on both surfaces of the organ. These looped fibres, as they pass to the left, gradually become less oblique, and finally form circles which surround the wide end of the stomach completely, even as far as the summit of the fundus. The oblique fibres can be most readily shown by removing the circular fibres on either surface below the cardia. When traced towards the right, they will be found to terminate by turning down and joining the fibres of the circular layer.

Tela Submucosa. - The submucous coat is a layer of strong but loose connective tissue, which lies between and unites the muscular and mucous coats (Fig. 924). It is more loosely attached to the muscular and more closely to the mucous coat, and it forms a bed in which the vessels and nerves break up before entering the mucous membrane.

Tunica Mucosa. - If examined in the fresh state soon after death, the mucous coat is of a reddish-gray colour and of moderate consistence. When examined some time after death, the colour turns to a darker gray, and the whole membrane becomes softer and more pulpy. It is thicker (over $2 \mathrm{~mm}$.) and firmer in the pyloric than in the cardiac part,
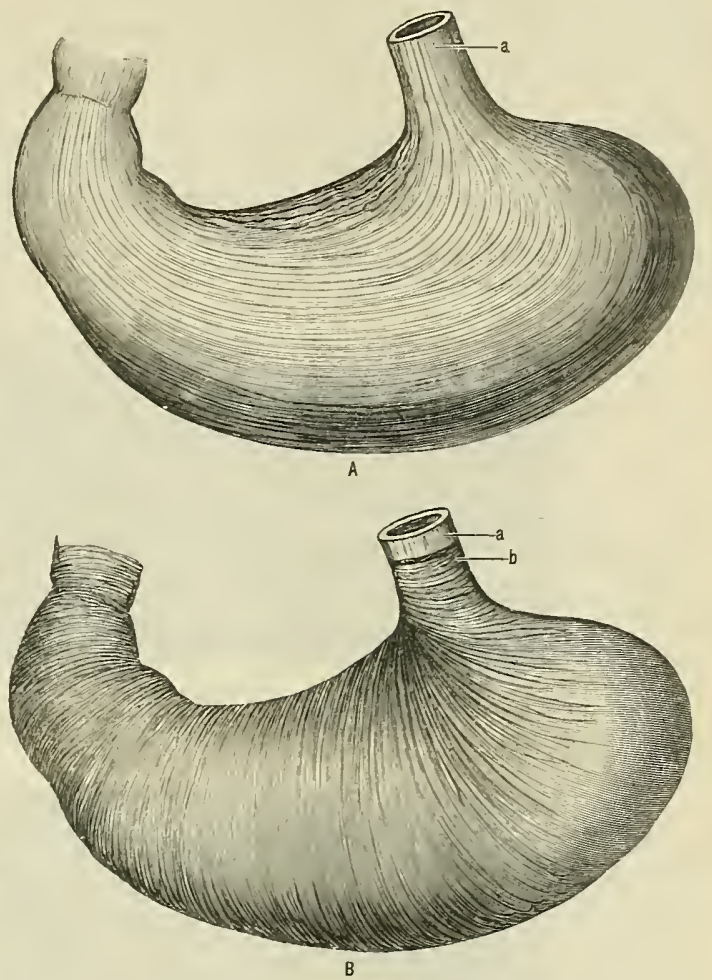

B

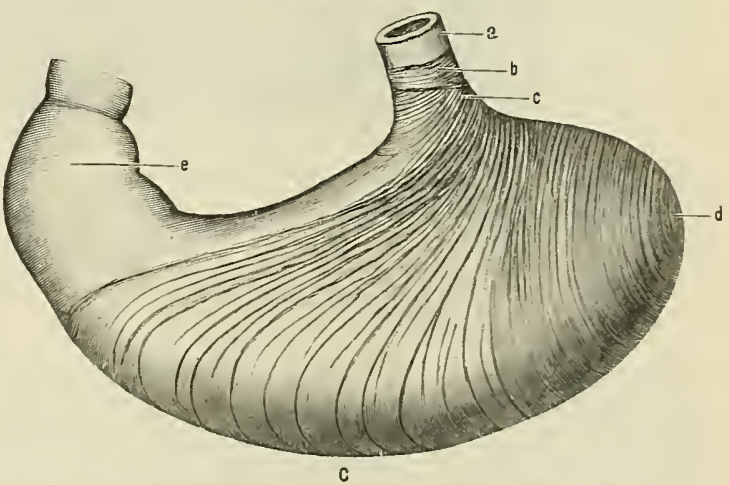

Fig. 926. -The Three Layers of the Mcsctlar CoAT of THE Sтомдсн. A, Exterual or longitudinal layer; $B$, Middle or circular layer; $C$, Internal or oblique layer. $a$, Longitudinal fibres of osophagus ; $b$, Superficial circular fibres of cesophagus passing into circular fibres of stomach in B; $c$, Deep circular fibres of csophagus passing into oblique fibres of stomach in $\mathrm{C}$; $d$, Oblique fibres forming rings at the fundus ; $e$, Submucosa. and is thinnest at the fundus, where it often shows sigus of post-mortem digestion. When the stomach is empty all three outer coats, which are extensile, contract; whilst the inextensile mucons coat, as a result of its want of elasticity, is thrown into numerous prominent folds or ruga, which project into the interior and, as it were, occupy the cavity of the contracted organ. These are, in general, longitudinal in direction, with numerous cross branches, and they are largest and most numerous along the greater curvature. They disappear when the stomach is distended.

When the surface of the mucous coat is examined in a fresh stomach, it is seen to 
be marked out into a number of small, slightly elevated, polygonal areas, arece gastricae, by numerous linear depressions; the mucous membrane is consequently said to be mamillated (Fig. 927, A). These little areas, which measure from 1 to $6 \mathrm{~mm}$. in diameter, are beset with numerous small pits, foveolce gastricce, about $2 \mathrm{~mm}$. wide, which are the mouths of the gastric glands, and they are so closely placed that the amount of surface separating them is reduced (particularly in the pyloric portion, where the gland mouths are widest) to a series of elevated ridges, plicae villosce, resembling villi on section. Although the gland mouths cannot be seen with the naked eye; a very slight magnification is sufficient to show them clearly; it is also possible to see the gland tubes leading off from the bottom of each (Fig. 927, B).

Minute Structure of the Mucous Coat. - In structure the mucous coat consists of an epithelial covering composed of long columnar cells, and of numerous tubular glands, glanduloe
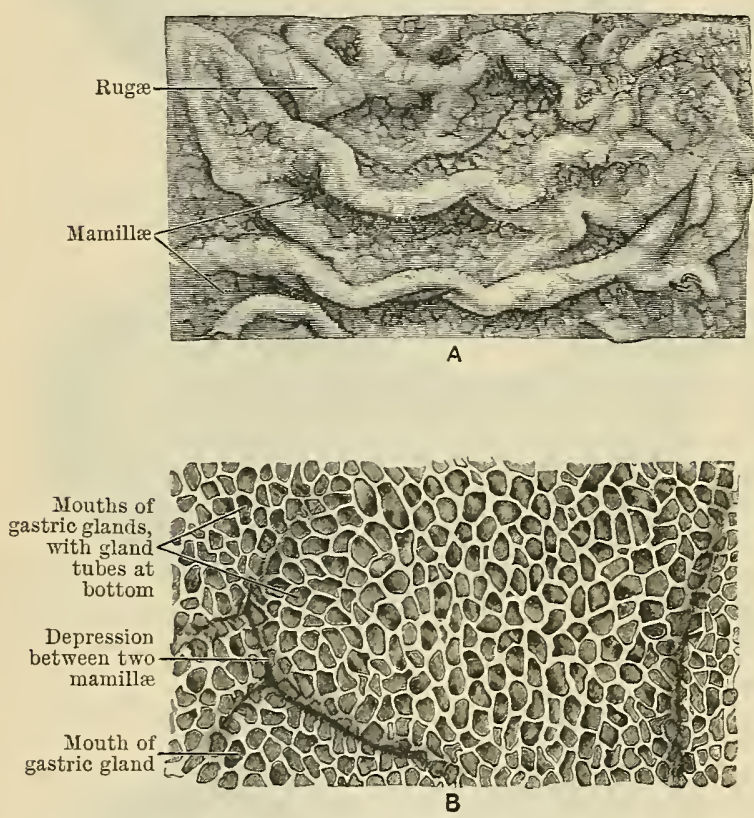

Fig. 927.-Mucous Menibrane of the Stomach. A, Natural size ; B, Magnified 25 diameters. In A the rugæ and the mamillated surface are shown. In $B$ the gland mouths (foveolæ gastricæ), with the gland tubes leading off from some of them, and the ridges separating the mouths (plicæ villosæ) are seen.

(3) Pyloric glands are found in the pyloric portion of the stomach. These consist of a short duct, terminated in a group of short but tortuons gland tubules. These tubules are lined with short columnar or polyhedral cells, similar to the central cells of the fundus glands.

Blood-vessels. - The arteries of the stomach are all derived ultimately from the coeliac artery. The gastric artery arises from this trunk direct. Having reached the lesser curvature and given off an œsophageal branch, it divides into two large branches, which run, one on each side of the organ, along this curvature, and join below with two similarly-disposed arteries derived from the right gastric branch of the hepatic. From the two arches thus formed, four or five large branches pass to each surface of the stomach, and soon pierce the muscular coat. Along the greater curvatúre several smaller branches reach the stomach from the right and left gastro-epiploic arteries, which are branches respectively of the gastro-duodenal and the splenic, and run in the gastro-colic ligament close to its attachment to the stomach. Finally, four or five aa. gastricee breves, branches of the splenic, are distributed to the fundus of the stomach, which they reach by passing forwards between the layers of the gastro-lienal ligament. At first the arteries lie beneath the peritoneum; very soon, however, they pierce the muscular coat, which they supply, and, reaching the submucosa, break up to form a close network of vessels. From these arise numerous small branches, which enter the mucous membrane and form capillary plexuses around the glands as far as the surface.

The veins begin in the capillary plexuses around the glands; uniting, they form a network in the submucosa, from which arise branches that pierce the nusscular coat, and finally end in the following veins: the right gastro-epiploic, which joins the superior mesenteric; the left gastroepiploic, and four or five veins corresponding to the aa. gastrica breves, which join the splenic ; the $v$. coronaria ventriculi, which runs along the lesser curvature from right to left, and joins 
the portal vein. These veins contain numerous valves which, though competent to prevent the return of blood in the child, are rarely so in the adult.

The lymph vessels of the stomach arise in an extensive plexus in the mucous membrane around the gastric glands. They then join a plexus of vessels in the tela submucosa, from which some vessels pass at intervals to join another plexus of vessels, subserous in position; piercing the muscular coats obliquely in their course. The efferent vessels pass mainly from the subserous plexus, and are arranged in three main groups, which pass in different directions, and drain three different areas of the stomach wall.

One set of vessels is connected mainly with the whole of the lesser curvature, from fundus to pylorus, and the adjacent half or two-thirds of the anterior and posterior surfaces of the stomach. These vessels pass to the superior gastric glands, along the lesser curvature, and, in company with the left gastric artery, to the cœliac glands.

The second set of vessels drains an area which includes the greater curvature below the fundus, and the adjacent portions of the anterior and posterior surfaces of the stomach. These vessels pass with the right gastro-epiploic artery to some inferior gastric glands which lie below and behind the pylorms, and thence they pass with the hepatic artery to the cœliac glands.

The third set of vessels drains the region of the fundus. The vessels from this area pass in the gastro-lienal ligament to the spleen, where they are connected with some splenic glands, and pass onwards, along the superior border of the pancreas, to the cœliac glands also.

The superior and inferior gastric glands and the splenic glands are the first glands interposed in the course of the lymph vessels. The ceeliac glands form the second set.

The nerves are derived from the two vagus nerves and from the ganglia coeliaca of the sympathetic. The vagi nerves pass throngh the diaphragm with the cesophagus, the left lying on its anterior, the right on its posterior aspect; in this way they reach the anterior and posterior surfaces of the stomach respectively. Here they unite with the sympathetic fibres from the cœliac plexus, which pass to the stomach with the branches of the celiac artery. The nerve fibres, which are chiefly non-medullated, form two gangliated plexuses, those of the myenteric plexus and the submucous plexus, in the muscular and submucons coats respectively.

The development of the stomach is described with that of the intestines on p. 47.

\section{INTESTINUM TENUE.}

The small intestine is the portion of the digestive tube which is placed between the stomach and the beginning of the large intestine. It commences at the pylorus, where it is continuous with the stomach, and ends at the valvula coli by joining the large intestine. It occupies the greater portion of the abdominal cavity below the liver and stomach (Fig. 913), and is found in the umbilical, hypogastric, and both lumbar regions; also, but to a less extent, in the other regions of the abdomen, and in the pelvic cavity.

In length, the small intestine nsually measures over 20 feet. According to Treves, it is $22 \frac{1}{2} \mathrm{ft}$. in the male, 23 in the female, whilst Jonnesco gives the average lengtl at $24 \mathrm{ft} .7$ ins., or $7 \frac{1}{2}$ metres. In form it is cylindrical, with a diameter varying from nearly two inches $(47 \mathrm{~mm}$.) in the duodenum to a little over an inch $(27 \mathrm{~mm}$.) at the end of the ileum; there is thus a gradual diminution in its size from the pylorus to the valvula coli.

The small intestine is relatively longer in the child than in the adult; at birth it is to the total height of the child as 7 to 1 , whilst in the adult the proportion is as 4 to 1 . Notwithstanding Treves' results, it is generally held that the small gut is relatively longer in the male than the female.

While the former figures, 20 to 22 feet, represent the entile length of the intestine in its most extended form, after death, when muscular tonus has disappeared, it is probable that during life the length is not so great. The muscular coats, both longitudinal and circular, are more or less contracted, and probably the total length during life may be estimated as 15 to 17 feet.

In formalin-hardened bodies the small bowel rarely measures more than 12 or 13 feet in length. Similarly its diameter is often reduced in places to $\frac{1}{2}$ or $\frac{3}{4}$ inch $(12.5$ to $18.7 \mathrm{~mm}$.), although the greater part of the gut may retain its usual width: these narrow parts have apparently been fixẹ in a state of contraction.

The small intestine is divided more or less arbitrarily into three parts (Fig. 873) -namely, the duodenum, constituting the first eleven inches, distinctly marked off from the rest by its fixation and the absence of a mesentery; the intestinum jejunum ("empty intestine") which comprises the upper two-fifths, and the intestinum ileum ("twisted intestine") the lower three-fifths of the remainder. The two latter parts pass imperceptibly into one another, and the line of division drawn between them is entirely artificial; however, if typical parts of the two-namely, the beginning of the jejunum and the end of the ileum-are selected, they differ so 
much in size and in the appearance presented by their lining mucous membrane, that they can be distinguished from one another without difficulty.

Both the jejunum and ileum are irregularly disposed in the form of crowded loops or coils (Fig. 913) which are comnected to the posterior abdominal wall by a great fan-shaped fold of peritoneum, containing their vessels and nerves, and known as the mesentery. Hence the name of intestinum tenue mesenteriale is applied to them. The mesentery is of such a length that the coils are able to move about freely in the abdominal cavity, and consequently the position occupied by any portion of the tube, with the exception of the beginning of the jejunum and the ending of the ileum, can never be stated with certainty. Nevertheless, it may be said that, in general, the jejunum occupies the superior and left portions of the cavity below the stomach, the ileum the inferior and right divisions, its terminal part almost always lying in the pelvis, just before it joins the large gut.

According to Mall, the most usual arrangement is to find the proximal coils of the jejunum on the left side, and high up. Then the tube crosses the vertebral column below the duodenum, and a few coils are placed on the right side. It then crosses to the left side again, and several coils are formed, some of which may descend into the pelvis. Thence it passes again to the

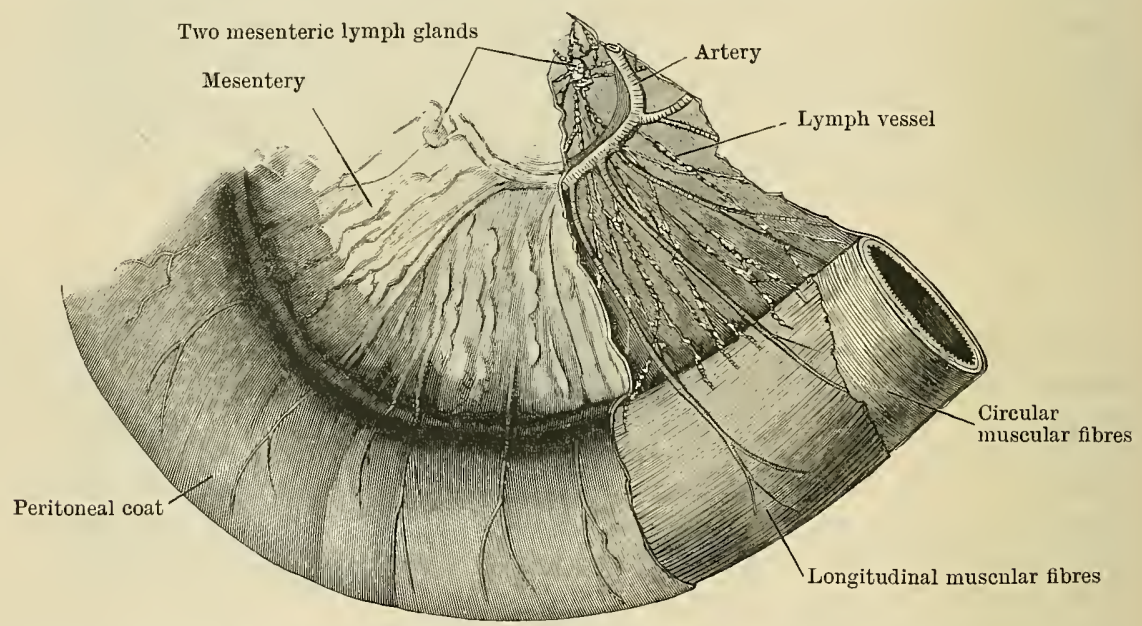

Fig. 928.-A Portion of Silall Intestine, with Mesentery and Vessels.

The peritoneal coat has been removel from the right half, and the two layers of the muscular coat exposed.

right side, where it is coiled up, and then finally descends into the pelvis. The terminal portion almost always lies in the pelvis, just before it ascends to join the large intestine.

As the coats of the large and small intestine agree in many particulars, it will be convenient to describe the general structure of the intestines here. Subsequently, any peculiarities of structure in particular regions will be described with the corresponding division of the tube.

\section{STRUCTURe OF the INTESTINES.}

The wall of the intestines, like that of the stomach, is made up of four coats, which are named from without inwards-tunica serosa, tunica muscularis, tela submucosa, and tunica mucosa (Figs. 928 and 929).

1. Tunica Serosa.-This is formed of peritoneum, and confers on the intestines their smooth and glossy appearance. It varies in the extent to which it clothes the different divisions of the tube, giving the duodenum, the ascending, descending, and iliac colons, and the rectum only a partial covering; whilst it clothes the jejunum and ileum, the cxcum, the transverse and the pelvic colons completely. The detailed arrangement of this coat will be given with the description of each division of the intestinal tube.

2. Tunica Muscularis.-This consists of unstriped muscle arranged in two layers 
-an outer stratum longitudinale, in which the fibres run longitudinally, and an inner stratum circulare, in which they are circularly disposed. The muscular coat is thicker in the duodenum than in any other part of the small intestine, and it gradually diminishes in thickness until the end of the ileum is reached. On the other hand, in the large intestine, it is thickest in the rectum and thinner towards the beginning of the colon.

The stratum longitudinale of this coat is much thinner than the underlying stratum circulare. In the small intestines it forms a complete sheet, continuous all round the gut (Fig. 928), but thickest at its free margin; whilst in the large intestine it is divided up into three longitudinal bands known as the tcenice coli, which will be more fully described in connexion with the colon.

The stratum circulare, much thicker than the longitudinal layer, is composed of bundles of muscular fibres arranged circularly round the tube (Fig. 929), and forming in all parts a continuous sheet. Unlike the longitudinal fibres, those of the circular layer take part in the formation of the valves of the pylorus and colon.

3. Tela Submucosa. - This is a loose but strong layer of areolar tissue connecting the muscular and mucous coats, on which chiefly depends the strength of the intestinal wall. In addition to forming a bed in which the ressels break up before entering the mucous coat, it contains the glandulce duodenales (Brunneri) (Fig. 929), and, in both small and large intestines, the bases of the solitary lymph nodules lie in it (Fig. 929).

4. Tunica Mucosa. - The mucous membrane constitutes the inner coat of the intestine. It is everywhere composed (Fig. 929) of the following parts:-(1) A layer of striated, columnar, epithelial cells, resting on (2) a basement membrane. Outside this lies (3) a layer of retiform tissue, containing a considerable number of scattered lymph cells. This layer is limited towards the tela submucosa by (4) an extremely thin sheet of unstriped muscle, the lamina muscularis mucosæ, which is not visible to the naked eye. The mucous membrane is very vascular, particularly in the small intestine. It is thicker in the duodenum than in the jejunum, and thicker in this latter than in the ileum.

Throughout both the small and large intestines the substance of the mucous membrane is closely beset with innumerable (small microscopic) tubular glands, known as the glandulæ intestinales [Lieberkühni] (O.T. glands or follicles). In shape they are minute straight tubes, like diminutive testtubes. Their mouths open on the free surface of the mucous membrane: their closed ends lie in the deeper part of the mucous coat, and their cavities are lined with colummar epithelium. They open on the surface between the bases of the villi of the small intestine, and in the large gut their orifices are found all over the surface of the nonvillous mucous membrane.

Certain special developments of the
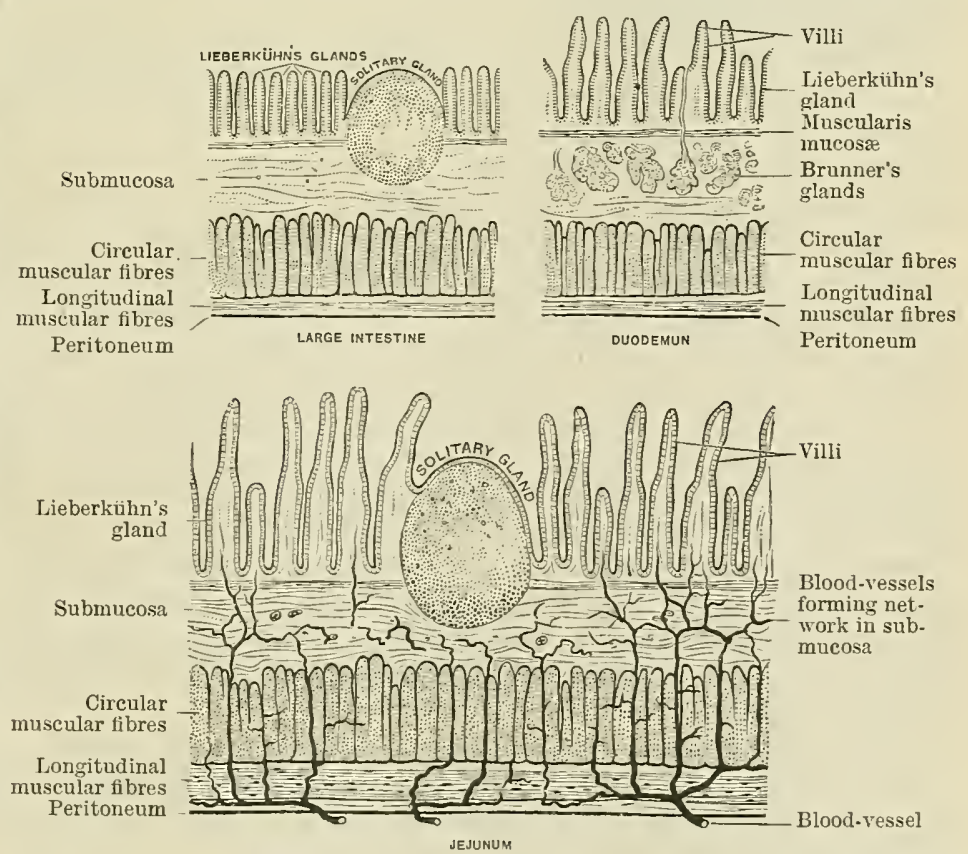

Fig. 929.-Diagraur to show the structure of the large intestine, the duodenum, and the jejunum.

mucous coat, found in particular regions of the intestinal tube, must next be considered: these are the (1) villi intestinales; (2) plicæ circulares [Kerkringi] (O.T. valvulæ conniventes); (3) noduli lymphatici solitarii (O.T. solitary glands); and (4) noduli lymphatici aggregati [Peyeri] (O.T. Peyer's patches).

Villi Intestinales. - If the mucous membrane of any part of the small in- 
testine is examined, it is seen to present a soft, velvety, or fleecy appearance (Fig. 930, B); this is due to the presence of an enormous number of minute processes, known as villi, which cover its surface.

They are minute cylindrical or finger-like projections of the tunica mucosa
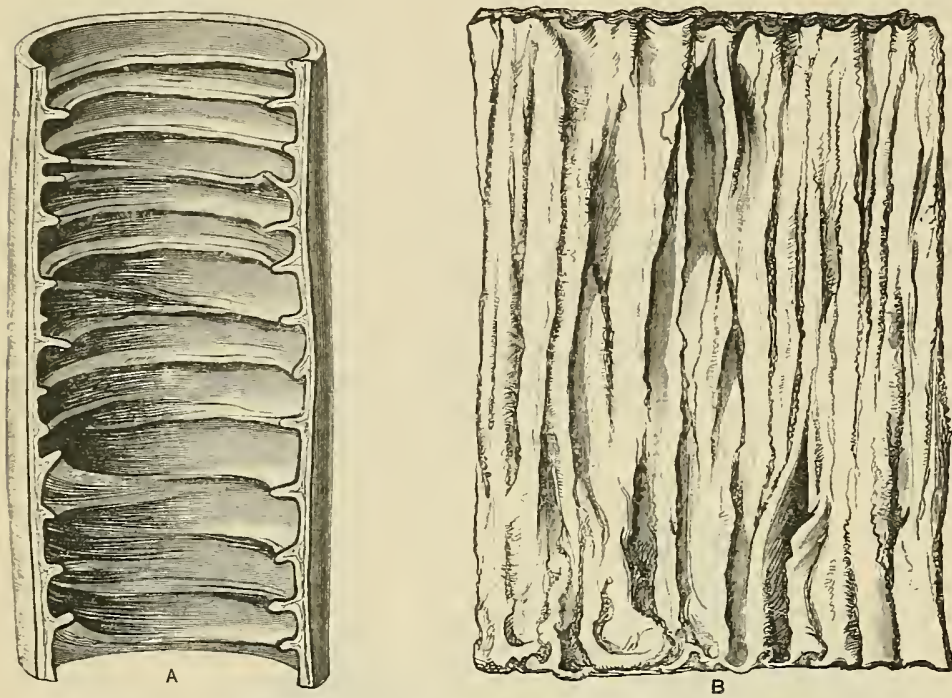

Fig. 930.-Plic E Circolares (natural size).

A, as seen in a portion of jejunum which has been filled with alcohol and hardened; $B$, a portion of fresh intestine spread out under water.

(Fig. 929) about $\frac{1}{30}$ th or $\frac{1}{40}$ th of an inch $(1.2$ to $1.6 \mathrm{~mm}$.) in height, and barely visible to the naked eye, which are closely set all over the surface of the lining membrane of the small intestine. Beginning at the edge of the pyloric valve, they are broad but short in the duodenum, and grow narrower as they are followed down through the intestine to the valvula coli, at the edge of which

they cease. They are found, not only on the general surface of the mucous membrane, but also upon the plicæ circulares, and, while they are not present over the solitary lymph nodules, they are found in the intervals between the individual nodules of the aggregated nodules.

They play an important part in the absorption of the products of digestion which takes place in the small intestine.

Plicæ Circulares [Kerkringi].-When the intestine is empty and contracted, its mucous membrane is thrown into effaceable folds or rugæ, which disappear on distension. But in addition to these, there are found in certain portions of the small intestine a series of large, permanent transverse folds, which are not effaceable; these are known as plicæ circulares (Fig. 930). These are usually more or less crescentic in shape, and resemble a series of closely placed shelves running transversely around the gut. They rarely form more than two-thirds of a circle; sometimes, however, they present a circular or even a spiral arrangement, the spiral extending little more than once round the tube, as a rule. Occasionally they bifurcate at one or both ends; sometimes, too, short irregularly directed branches pass off from them. They are usually about 2 to 3 inches $(5$ to $7.5 \mathrm{~cm}$.) in length, and their breadth, that is their projection into the cavity, may be as much as $\frac{1}{3} \mathrm{rd}$ of an inch $(8 \mathrm{~mm}$.), whilst in thickness, as seen when cut across, they measure about $\frac{1}{8}$ th inch $(3 \mathrm{~mm}$.).

They are composed of two layers of the tunica mucosa, with a prolongation from the tela submucosa between, to bind the two together. They are covered with villi, and are permeated by intestinal glands. Their use is to increase the amount of surface available for secretion and absorption.

Plicæ circulares are not found in the upper part of the duodenum. They begin at a distance varying from 1 to 2 inches $(2.5$ to $5 \mathrm{~cm}$.) from the pylorus. At first they are small, irregular, and scattered; but they are larger lower down, and at the opening of the bile duct ( 4 inches from the pylorus) they are distinct and prominent. In the rest of the duodenum, and in the superior half of the jejunum, they are highly developed, being large, broad, and closely set. In the inferior half of the jejunum they become gradually smaller and fewer. Passing down into the ileum, they 
become still smaller and more irregular, and, as a rule, they practically cease a little below the iniddle of the ileum.

Often patches of plicæ circulares, much reduced in size, can be traced to within a short distance of the valvula coli. According to Sappey, Luschka, and others, they usually reach to within two or three feet of the end of the ileum.

Noduli Lymphatici Solitarii.-The solitary lymph nodules are minute masses of lymph tissue, opaque and of a whitish colour, found projecting on the surface of the mucous membrane throughout the whole length of both the small and large intestines.

Isolated lymph cells are found in abundance scattered through the connective-tissue layer of the intestinal mucous membrane generally; in places these cells are gathered together to form little nodules, supported by a framework of retiform tissue, and surrounded by a lymph space which communicates below with the lymph vessels of the tela submucosa. Such a collection of lymph cells constitutes a solitary nodule. They are usually of a rounded or oval shape (Fig. 931), the wide end resting in the tela submucosa, the nodule itself piercing the lamina muscularis mucosæ, and the narrow end projecting slightly above the general surface of the mucous membrane. In size they vary from $\frac{1}{40}$ th to $\frac{1}{8}$ th of an inch ( 6 to $3.0 \mathrm{~mm}$.), but their average bulk is about that of a small grain of sago, to which they bear some resemblance.

As already mentioned, they are present throughout the small and large intestines, being particularly abundant in the vermiform process and cæcum. In the small intestine they are found on the plicæ circulares, as well as upon the general surface of the mucous membrane between them.

Noduli Lymphatici Aggregati.-These lymph nodules (O.T. Peyer's patches) consist of a large number of minute lymph nodules grouped closely together so as to form a slightly elevated area, usually of an oblong form, on the surface of the mucous membrane (Fig. 931). In length they vary from half an inch (12 $\mathrm{mm}$.) or less to three or four inches $(100 \mathrm{~mm}$.), and

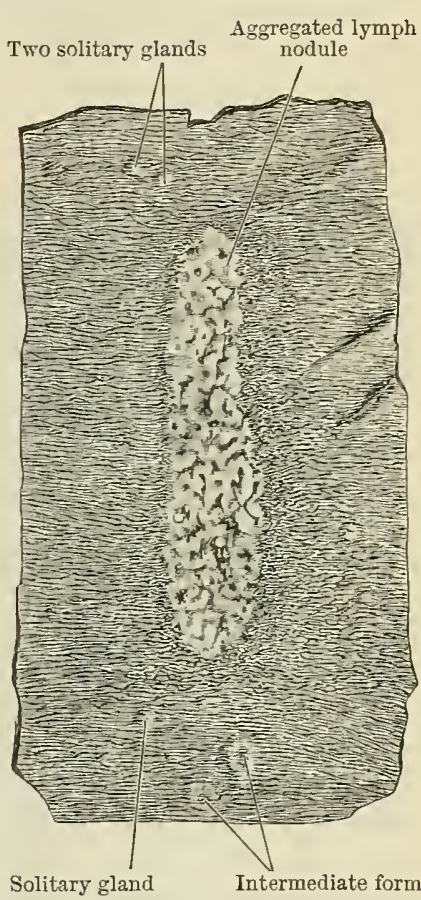

Fig. 931. - Noduli LyMPHatici AgGregati and Solitari, from intestine of child two years old (natural size).

Near the lower border are seen a few sinall patches made up of two or three lymph nodules; they are marked "intermediate form.' in width they commonly measure from a third to half an inch (8 to $12 \mathrm{~mm}$.). Their number is variable, but in the average condition about 30 or 40 are found. They are best marked in young subjects, where they form considerable elevations above the general surface, and may be as many as 45 in number. After middle life they atrophy, and in old age, although usually to be found, they are indistinct, occasionally being marked by little more than a dark discoloration of the mucous membrane. They are invariably situated along the surface of the intestine opposite the line of mesenteric attachment, with their long axis corresponding to that of the bowel. Consequently, in order to display them, the tube must be slit up along its attached or mesenteric border.

These aggregated nodules are entirely confined to the small intestine, being largest and most numerous in the ileum, particularly in its inferior part, where they usualiy assume an oblong shape; in the inferior half of the jejunum they are small, circular, and few in number; in its superior part they are rare; and, although their presence has been noted in the inferior portion of the duodenum, they may be said to be absent, as a general rule, from this division of the intestine.

The plicæ circulares stop at the margins of the aggregated nodules, and are not continued across them; but villi are found on the surface of the aggregated nodules, in the intervals between the individual lymph nodules. 
The chief bowel lesion in typhoid fever is found in these aggregated and in the solitary nodules.

When the surface of one of these nodules from a child's intestine (in which these structures are particularly well developed) is carefully examined, it is seen to be made up, not of a series of separate, rounded nodules gromped together, but rather of a number of wavy, irregular, and branching ridges connected with one another by cross branches (Fig. 981), the whole recalling in miniature the appearance of a raised map of a very mountainous district in which the chief chains run irregular courses, and are joined to one another by connecting ridges.

Small patches, intermediate in form between solitary and aggregated nodules, and consisting of two or three lymph nodules, are also usually present.

\section{DUODENUM.}

The duodenum, the portion of the digestive tube which immediately succeeds the stomach, is the first part of the small intestine, and differs from the rest of that tube in having for the greater part no mesentery, and hence it is closely fixed to the posterior abdominal wall. The ducts of the liver and pancreas open into it, and some special glands are found in its wall, known as the duodenal glands of Brunner.

Shape and Divisions.-The duodenum begins at the pylorus, about the level of the first lumbar vertebra, and ends at the left side of the first or second lumbar vertebra (Fig. 932). Between these two points it pursues an irregular course, which has some resemblance to the outline of a horse-shoe. It is made up of three main parts, namely:-(1) The pars superior, which begins at the pylorus, passes posteriorly and to the right beneath the liver, and ends at the neck of the gall-bladder by turning down forming the flexura superior and joining (2) the pars descendens. This begins at the neck of the gall-bladder, runs down on the posterior abdominal wall, on the right of the vertebral column, behind the transverse colon (Fig. 932), and ends opposite the third or fourth lumbar vertebra. There it turns to the left, and passes into (3) the pars inferior. This portion at first runs more or less transversely to the left, across the vena cava, aorta, and vertebral column (pars horizontalis), and then ascends as far as the inferior surface of the pancreas (pars ascendens). There, at the level of the first or second lumbar vertebra, it bends abruptly forwards, forming the duodeno-jejunal flexure (Fig. 932), and passes into the jejunum. The junction of the pars descendens and pars inferior constitutes the flexura inferior.

Taking the whole of the duodenum together, it forms an irregular horseshoeshaped curve, with the opening directed upwards and to the left, and the ends reaching to within about two inches of one another. Within the concavity of the curve the head of the pancreas is placed.

The incomplete ring which the duodenum makes does not all lie in the sanie plane; for, whilst its greater part is placed in a frontal plane, the superior part, and the commencement and termination of the inferior part, lie more in a sagittal plane (Fig. 932).

Position and Size. - As a rule, a little more than half of the duodenum lies in the epigastrium; the remainder-namely, about the inferior third of the descending portion and the adjoining two-thirds of the inferior portion-are placed in the umbilical region. With the exception of the terminal ascending portion of the third part, the whole of the duodenum lies to the right of the median plane.

Its length is usually about 11 inches $(27.5 \mathrm{~cm}$.), its first portion being the shortest and its third portion the longest. Its diameter varies considerably, and may be stated to average about $1 \frac{1}{2}$ inches when empty, but it may be as much as two inches when distended.

Relations. Pars Superior.-The superior part (O.T. first portion) begins at the pylorus opposite the first lumbar vertebra. From this it runs to the right, and then posteriorly, beneath the liver, when the stomach is empty, but directly backwards when it is full; and ends at the neck of the gall-bladder by turning inferiorly and passing into the descending part. Its length varies from about $1 \frac{1}{2}$ to 2 inches $(3.7$ to $5.0 \mathrm{~cm}$.), and is said to be greater when the stomach is empty than when distended. 
Its relations are as follows:--It forms the inferior boundary of the foramen epiploicum, and above this foramen it is in relation to the candate process of the liver, while the quadrate lobe of the liver hangs downwards over it and to the right. The hepatic artery is in contact for a short distance with the superior border. Below, it rests on the head and neck of the pancreas. The portal vein, gastro-duodenal artery, and the bile-duct lie in contact with it on the left

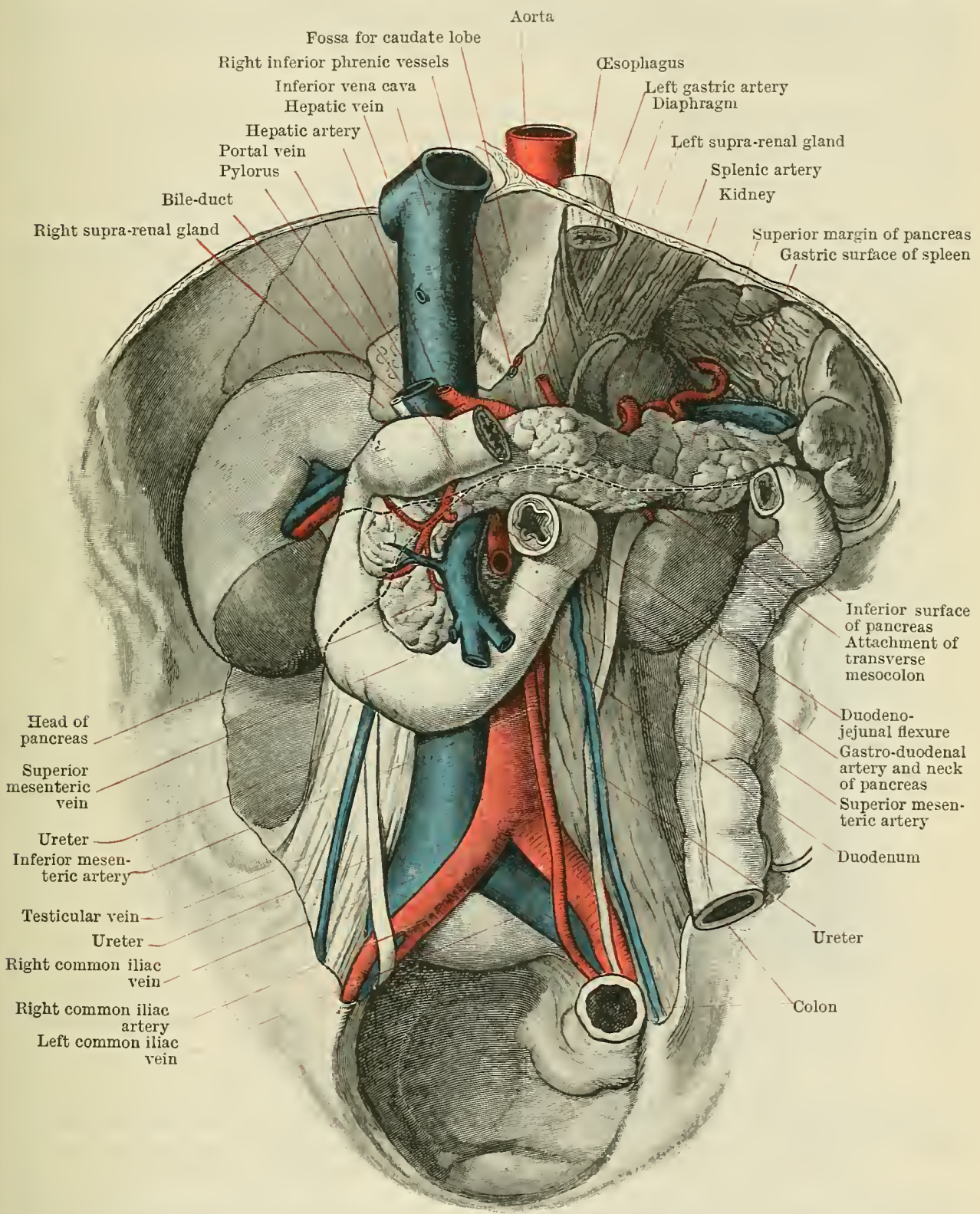

Fig 932.-The Viscera aid Vessels on the Posterior abdominal Wall.

The stomach, liver, and most of the intestines have been removed. The peritoneum has been preserved on the right kidney, and the fossa for the caudate lobe. In taking out the liver, the vena cara was left behind. The stomach bed is well shown. (From a body hardened by injection of chromic acid.)

side, and behind them the duodenum comes into contact with the right aspect of the inferior vena cava. The superior pancreatico-duodenal and the right gastro-epiploic vessels pass forwards below its inferior margin.

Its peritoneal relations are similar to those of the pyloric end of the stomach for abont an inch. It is therefore at first invested by peritoneum on the right and left aspects, and the peritoneum passes upwards from its superior border as the right portion of the lesser omentum, forming the hepato-duodenal ligament, while from its inferior border the descending folds of the 
peritoneum pass downwards. The peritonenm is reflected from off the left surface on to the pancreas and abdominal wall, forming a told known as the right gastro-pancreatic fold, while the peritoneal corering of the right side is continned onwards along the whole of this part of the duodenum.

Pars Descendens. - The descending part (O.T. second portion) begins at the neck of the gall-bladder, passes down behind the transverse colon, and ends at the right side of the third or fourth lumbar vertebra. In length it measures $3 \frac{1}{2}$ or 4 inches $(8.7$ to $10 \mathrm{~cm}$.).

Its relations are as follows:- It lies on the right of the vertebral column and the inferior vena cava, from the first to the third or fourth lumbar vertebra, and is anterior to the pelvis

Top of omental bursa

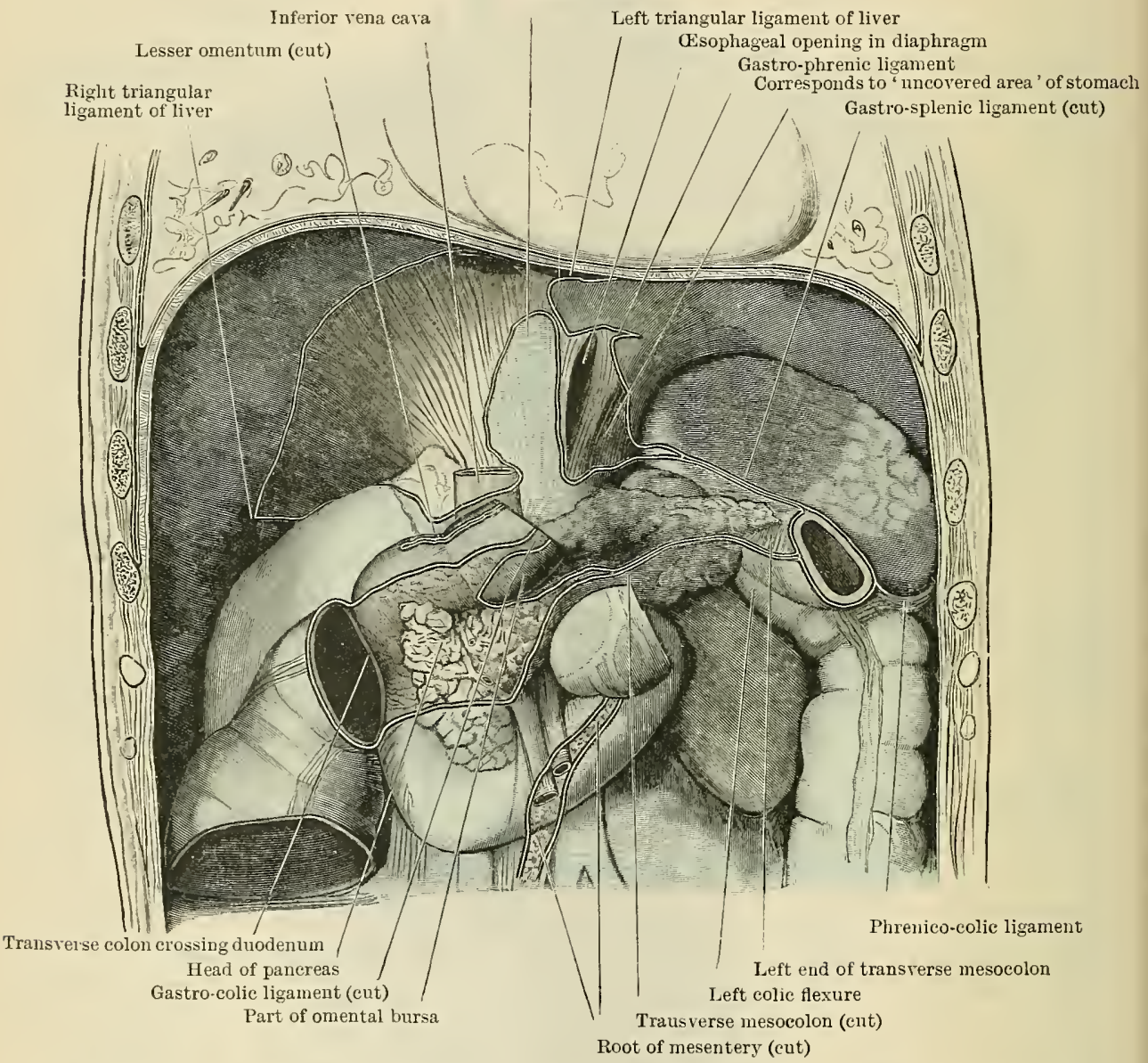

Fig. 933.-The Peritoneal Relations of the Duodenum, Pancreas, Spleen, Kidneys, etc.

From a body hardened by injections of formalin. In removing the liver, stomach, and intestines the lines of the peritoneal reflections were carefully preserved. The peritoneum is coloured blue.

of the right kidney, the right renal vessels, and ureter, and also to a varying extent the front of the right kidney itself; while, below the level of these structures, it rests upon the psoas major muscle.

The lateral aspect is in contact with the sloping inferior surfaces of the liver in its superior part, and with the right flexure of the colon below.

Peritoneal Relations. - The anterior aspect is covered by peritoneum, except about its middle, where the root of the transverse mesocolon crosses the duodenum. Occasionally, and not infrequently, the transverse colon has no mesentery, but is itself in direct contact with the wall of the duodenum. In other cases, the colon is in contact with the peritoneal surface of the dnodenum, below the line of reflection of the transverse mesocolon.

The head of the pancreas is in contact with its concave left margin, and occasionally overlaps it anteriorly and posteriorly; and along the margin of the pancreas, both anteriorly and posteriorly, are branches of the superior and inferior pancreatico-duodenal vessels, the veins often forming a dense network on the posterior aspect. 
The bile-duct, after passing down behind the superior part of the duodenum, descends between the head of the pancreas and the descending part, nearly as far as its middle; here it is joined by the pancreatic duct, and the two, piercing the wall of the duodenum obliquely, open by a common orifice on its inner aspect, about 3 to 4 inches $(8.7$ to $10 \mathrm{~cm}$.) beyond the pylorus.

Pars Inferior. - The inferior part (O.T. third portion) begins at the right side of the third or fourth lumbar vertebra. It is described in two parts, par's horizontalis, transverse in direction, and pars ascendens, and it shows that arrangement in Fig. 933.

The pars horizontalis runs more or less transversely to the left across the inferior vena cava (Fig. 933) for one or two inches, and the pars ascendens passes very obliquely, or even vertically, upwards in front of the aorta and left psoas major muscle. Finally, having reached the inferior surface of the pancreas, it bends forwards, and passes into the jejunum.

Anteriorly, it is crossed (about the junction of its two divisions) by the superior mesenteric vessels, and also by the root of the mesentery (Fig. 933). On each side of this it is covered by coils of small intestine. Posteriorly, the pars horizontalis lies over the vena cava inferior ; the pars ascendens on the aorta, the left renal vein and occasionally also the artery, and the left psoas major muscle, all of which separate it from the vertebral column. Above, it is closely applied in its whole extent to the head of the pancreas. The left side of the pars ascendens, which is free, lies in contact with some coils of the small intestine.

Peritoneal Relations. - The inferior part of the duodenum is covered by peritoneum on its anterior surface thronghout, except where it is crossed by the superior mesenteric vessels and the root of the mesentery which contains them (Fig. 933). In addition, its ascending part is also clothed by this membrane on its left side.

The attachment of the root of the mesentery begins above quite close to the duodeno-jejunal flexure, on the front of the duodenum; from this it runs down on the anterior aspect of the ascending part, and finally leaves the duodenum about the union of the two divisions of its third portion.

Duodenal Fossæ.-In the neighbourhood of the pars ascendens are found three well-known fossæ of the peritoneum which are of some surgical interest; these are the superior and inferior duodenal and the paraduodenal fossæ (Fig. 934). Other rarer forms are occasionally present.

When the ascending part of the duodenum is drawn over to the right, and the angle between its left side and the posterior abdominal wall examined, one or two triangular folds of peritoneum will generally be found crossing over this angle from the duodenum to the abdominal wall. Each fold has one edge attached to the duodenum, another to the parietal peritoneum at the left of the duodenum, whilst the third is free, and bounds the opening of a small pouch which lies behind the fold, the recessus duodeno-jejunalis. Of these folds, the upper is termed the plica duodeno-jejunalis, and it is situated near the termination of the duodenum, with its apex directed up and its free margin down. It sometimes contains between its two layers the termination of the inferior mesenteric vein. Behind it lies a prolongation from the recessus duodeno-jejunalis termed the superior duodenal fossa. Its opening looks downwards, and will usually admit the tip of a finger (Fig. 934). The second, known as the plica drodeno-mesocolica, is placed lower down, at the side of the same part of the duodenum. Its free border is directed upwards, as is the mouth of the inferior duodenal fossa, which lies behind it. This latter is larger aud more constant than the superior duodenal fossa, and is present in 75 per cent of bodies, whilst the superior is present in 50 per cent (Jonnesco).

Paraduodenal Fossa (fossa of Landzert). - This fossa, which is best seen in the 
infant, is placed some distance to the left of the ascending part of the dnodenum. It is produced by the inferior mesenteric vein raising up a fold of peritoneum, as it runs medially along the side of the fossa, and then above it (see Fig. 934, where the vein, but not the fossa, is shown). It is limited below by a special fold (the mesenterico-meso-

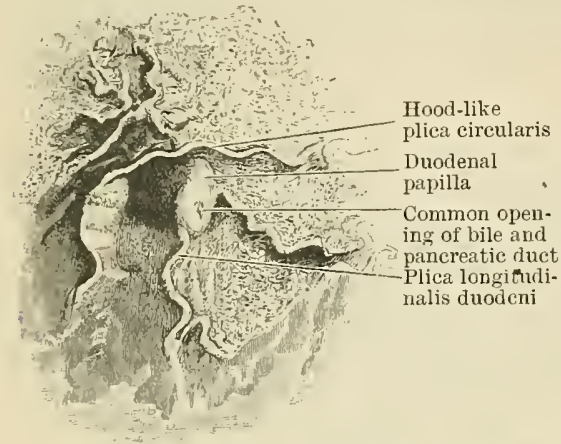

F1G. 935̆.-The Papilla DUOdexi in the INTERIOR OF THE DUODENUM. colic fold). According to Moynihan, this is the only fossa to the left of the duodenum capable of developing into the sac of a hernia; and when this occurs, the inferior mesenteric vein always lies in the anterior margin of the orifice of the sac (accompanied for some distance by the ascending branch of the left colic artery).

Peritoneal Relations of the Duodenum. - Whilst the relations of the peritonemm to the second and third portions of the duodenum are nsually described as in the foregoing account, it should perhaps be pointed out, that it is not really the front, but the right half of the circumference of the descending portion which has a serous coat. Similarly, it is the inferior and anterior half of the circumference of the horizontal portion of the inferior part which is clothed by peritonenm, whilst considerably more than half of the circumference of its ascending portion is covered; for the peritoneum forms a fold rumning in behind this portion, in addition to covering its left side and half its anterior aspect.

Interior of Duodenum. - No plicæ circulares are found in the duodenum for an inch or two beyond the pylorus. They then begin; at first as low, scattered, and irregular folds; further down, they gradually become larger, more regular and more numerous; and by the time the middle of the descending part is reached they have attained a considerable development. In the inferior part of the duodenum the folds are large, prominent, and closely set.

On the inner aspect of the descending portion, about its middle-namely, $3 \frac{1}{2}$ or 4 inches $(8.7$ to $10 \mathrm{~cm}$.) beyond the pylorus-is seen a prominent papilla, on which the bile and pancreatic ducts open by a common orifice (Fig. 935). This is known as the papilla duodeni (Santorini).

The papilla duodeni is placed beneath, and protected by, a prominent, hood-like plica circullaris, which is situated immediately above it. From its lower margin a firm ridge of the mucous membrane, the plica longitudinalis duodeni, descends for a considerable distance, and acts as a frenum, which fixes the papilla and directs its apex somewhat downwards (Fig. 935). The papilla is prominent, and nipple or dome-shaped, and at its summit is placed the small orifice, which will usually admit the point of a pencil; the whole bears a close resemblance to the nozzle of a perfume-spray.

Nearly an inch higher up, and invariably on the ventral side of the papilla (sometimes as much as a $\frac{1}{2}$ to $\frac{3}{4}$ inch distant), is seen a second and smaller papilla, the caruncula minor of Santorini, at the point of which is placed the very small orifice of the accessory pancreatic duct. This second papilla seems to be constantly present, althongh sometimes so small that it may easily escape detection unless carefully sought for. When well developed, it may have a hood-like plica circularis and a little frenulum, like those of the bile papilla.

Structure of the Duodenum.-The tunica serosa, which is incomplete, has already been described in detail, in connexion with each part of the duodenum.

The tunica muscularis is well developed, and is pierced by the bile and pancreatic ducts, but otherwise calls for no special description.

The tela submucosa differs from that of the rest of the small intestine, in that it contains, especially in the superior half of the duodenum, the glandulæ duodenales [Brunneri]. These are small acino-tubular glands, closely resembling the pyloric glands of the stomach, which lie in the submucous coat, and send their ducts through the muscularis mucosæ to open on the surface between the glandulæ intestinales, or sometimes into these glands themselves (Fig. 929). They can be exposed by removing the peritoneal and muscular coats, and also some of the submucosa, when they appear as little round or flattened masses of a reddish-gray colour, varying in size from $\frac{1}{50}$ th to $\frac{1}{12}$ th of an inch in diameter $(.5$ to $2.0 \mathrm{~mm}$.). They form an almost continuous layer as far as the opening of the bile duct; beyond this they diminish progressively, and completely disappear near the duodeno-jejunal flexure.

The tunica mucosa, which is thicker in the duodenum than in any other part of the small intestine, is covered throughout with broad short villi. 
Various Forms of Duodenum.-Three different types of duodenum have been described(1) The annular, in which the curves separating the various parts are open, and the two extremities come fairly close to one another. (2) The U-shaped, in which the horizontal part of the inferior part is very long, and the ascending part nearly vertical; and (3) the $V$-shaped duodenum, in which the horizontal portion of the inferior part is very short or absent.

Vessels and Nerves.-The duodenum receives its blood from the superior and inferior pancreatico-duodenal arteries, branches of the gastro-duodenal and superior mesenteric arteries respectively. The blood is returned by the corresponding veins, the superior of which opens into the superior mesenteric, and the inferior into the beginning of the portal vein.

The lymph vessels of the duodenum follow for the most part the course of the blood-vessels.

From the anterior surface, lymph vessels pass aloug the course of the inferior pancreaticoduodenal artery, and communicate with lymph glands found along the course of that vessel. Thence they pass to the inferior cœliac glands, beside the origin of the superior mesenteric artery.

The vessels from the posterior aspect accompany the superior pancreatico-duodenal artery, communicate with the inferior gastric glands, and terminate in the coeliac glands.

The nerves come from the solar plexus of the sympathetic.

Flexura Duodenojejunalis. - When the ascending part of the duodenum reaches the inferior surface of the pancreas, at a point opposite the left side of the first or second lumbar vertebra, it turns abruptly forwards, downwards, and to the left, and passes into the jejunum. This abrupt bend is known as the duodeno-jejunal flexure. Unlike the rest of the duodenum, which is subject to considerable variations in position in different individuals, the duodeno-jejunal flexure is fixed by a thin band of unstriped muscle, which is attached above to the strong connective tissue around the cœliac artery, as well as to the left crus of the diaphragm. This band passes posterior to the pancreas, and inferiorly it joins the muscular coat of the duodenum at the flexure. It is known as the m. suspensorius duodeni (O.T. muscle of Treitz).

The duodeno-jejunal flexure is occasionally directed to the right, and it lies at a variable distance from the root of the transverse mesocolon. When the attachment of the transverse mesocolon is low, the duodeno-jejunal flexure is in contact with it.

Duodenal Pouches or Diverticula.-Occasional diverticula are found passing from the duodenal wall in different directions. Such diverticula may be hernial protrusions of the mucous and submucous coats through the muscnlar wall, termed false diverticula, or they may be "true" diverticula, in which all the coats are represented.

They are usually situated on the aspect of the duodenum which is in contact with the pancreas, and frequently in the neighbourhood of the orifice of the bile duct.

Some of these appear to be due to the pressure from the interior of the duodenum, while others, and the majority of the true diverticula, are rather congenital in origin, and are probably associated with the diverticula which give rise to the liver and pancreas.

\section{HEPAR.}

The liver is the large glandular organ which secretes the fluid called bile (fel). It occupies the superior and mainly the right portion of the abdominal cavity, and lies immediately below the diaphragm.

Its secretion is conveyed away from it by the hepatic ducts and the bile-duct to the duodenum. With the bile duct there is connected a pear-shaped diverticulum, the gall-bladder (vesica fellea), which lies in contact with the liver, and which serves apparently for the temporary storage of bile.

In addition to secreting bile, the liver plays an important part in the metabolism of both the carbohydrate and nitrogenous materials absorbed from the intestine which are conveyed to it by the portal vein, and it also has to do with the production and the destruction of some of the blood-cells.

Physical Characters. - The liver is a large irregularly shaped mass, of a reddish-brown colour, soft and pliant to the touch, somewhat readily lacerated, and highly vascular.

It is of uniform consistence throughout, and little of its internal structure can be made out by naked-eye examination. If, however, a torn surface be examined, the liver tissue is seen to be somewhat granular. Under the investing peritoneum the surface is somewhat mottled.

This mottled or granular appearance is due to the lobules (lobuli hepatis) of 
which the liver is composed. Each lobule is a small irregular or polygonal area, measuring from $\frac{1}{2}$ th to $\frac{1}{12}$ th of an inch in diameter, or 1 to $2 \mathrm{~mm}$., with a partial covering of fine connective tissue, forming a delicate stroma.

In the adult, the liver weighs from 3 to $3 \frac{1}{4}$ pounds, or about $\frac{1}{40}$ th of the body weight, and it is somewhat heavier in the male than in the female, its weight in the former being from 50 to 55 ounces and in the latter 43 to 48 ounces. The ratio to the body weight is the same in both sexes. In the fotus and child it is relatively very large and heavy. At birth it occupies the greater part of the abdominal cavity, and constitutes from $\frac{1}{20}$ th to $\frac{1}{18}$ th of the body weight. In the young fotus the ratio is even larger.

The average size of the liver may be briefly expressed as follows:-It measures in the transverse direction about seven inches $(17.5 \mathrm{~cm}$.) ; in the vertical, six to seven inches $(15$ to $17.5 \mathrm{~cm}$.) ; and in the antero-posterior, on the right side where greatest, about six inches $(15 \mathrm{~cm}$.$) . Its$

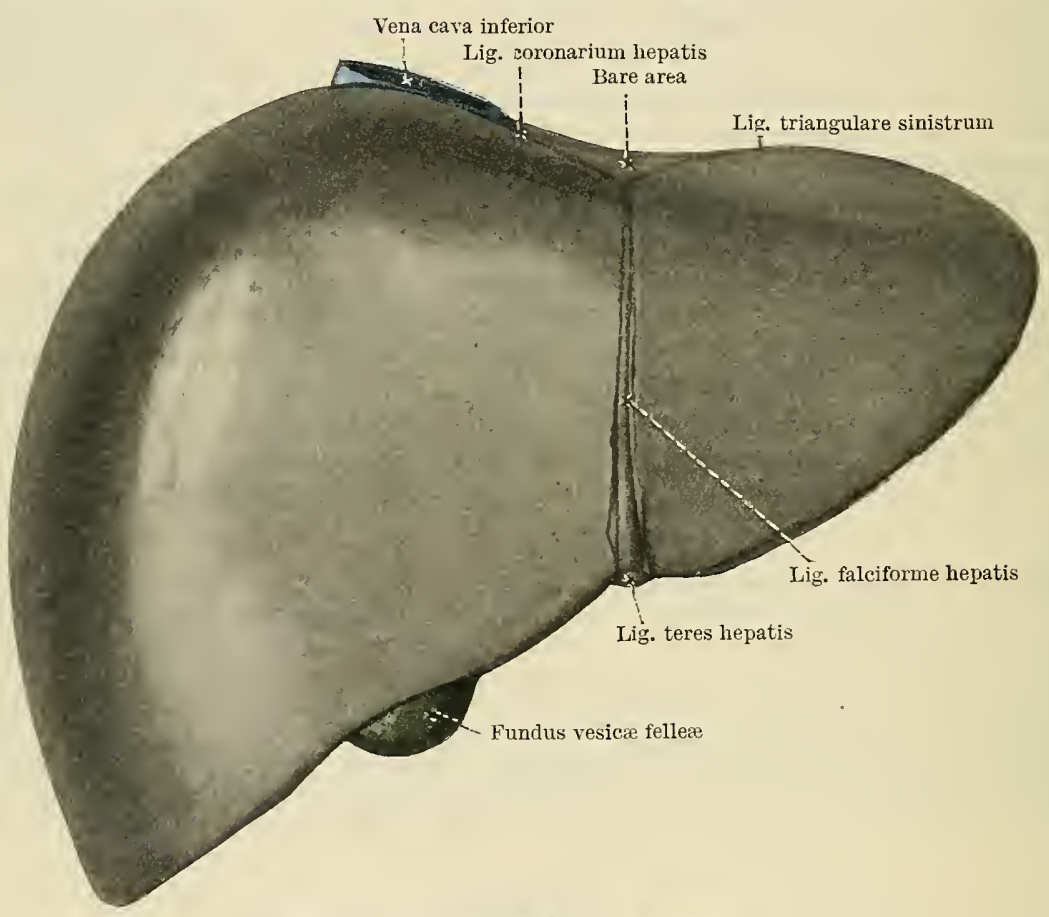

FIG. 936. - LIVER VIEWED FROM THE FRONT.

greatest width, measured obliquely from side to side along the inferior or visceral surface, is ten inclies $(25 \mathrm{~cm}$.).

The liver is capable of being greatly distended by fluid forced into its blood-vessels. Its surface then becomes tense, and the consistence of the whole organ becomes much firmer.

Shape.-If the liver is hardened in situ and then removed from the body, it will be found to present a form which is fairly constant, but which is modified by the shape and size of the adjacent viscera, and hence shows minor variations in different individuals.

If the liver has not been hardened, it does not retain, after removal, the shape and form which it had when it lay in the abdomen, but tends to collapse into a flattened cake-like mass.

The description of the shape, surfaces, and borders given below is drawn from examination of specimens hardened in situ.

The liver possesses three principal surfaces, a superior, a posterior, and an inferior, known as the facies superior, posterior, and inferior.

The facies superior is in contact chiefly with the rounded vault of the abdominal cavity, and hence it is uniformly rounded and convex.

The facies posterior, directed backwards, is in contact with the structures 
forming the superior portion of the posterior abdominal wall. It is deeply indented by the projecting vertebral column, and it is flat in the vertical axis.

The facies inferior is directed obliquely downwards and posteriorly, is in contact with a number of the abdominal viscera, especially the right kidney, stomach, duodenum, and colon, and its general configuration is influenced to a marked degree by the shape and position of these organs.

This surface is sometimes termed the visceral, in contrast to the other two surfaces which constitute the parietal surface of the organ.

The parietal and visceral surfaces are marked off from one another by the inferior margin of the liver. Posteriorly, this margin is indistinctly marked and corresponds to the inferior edge of the posterior area, or back, of the parietal surface: it is in contact with the right kidney, and runs along the course of the eleventh rib. At the right side the margin is stout but distinct, and usually corresponds to, or projects a little way below, the inferior border of the thoracic

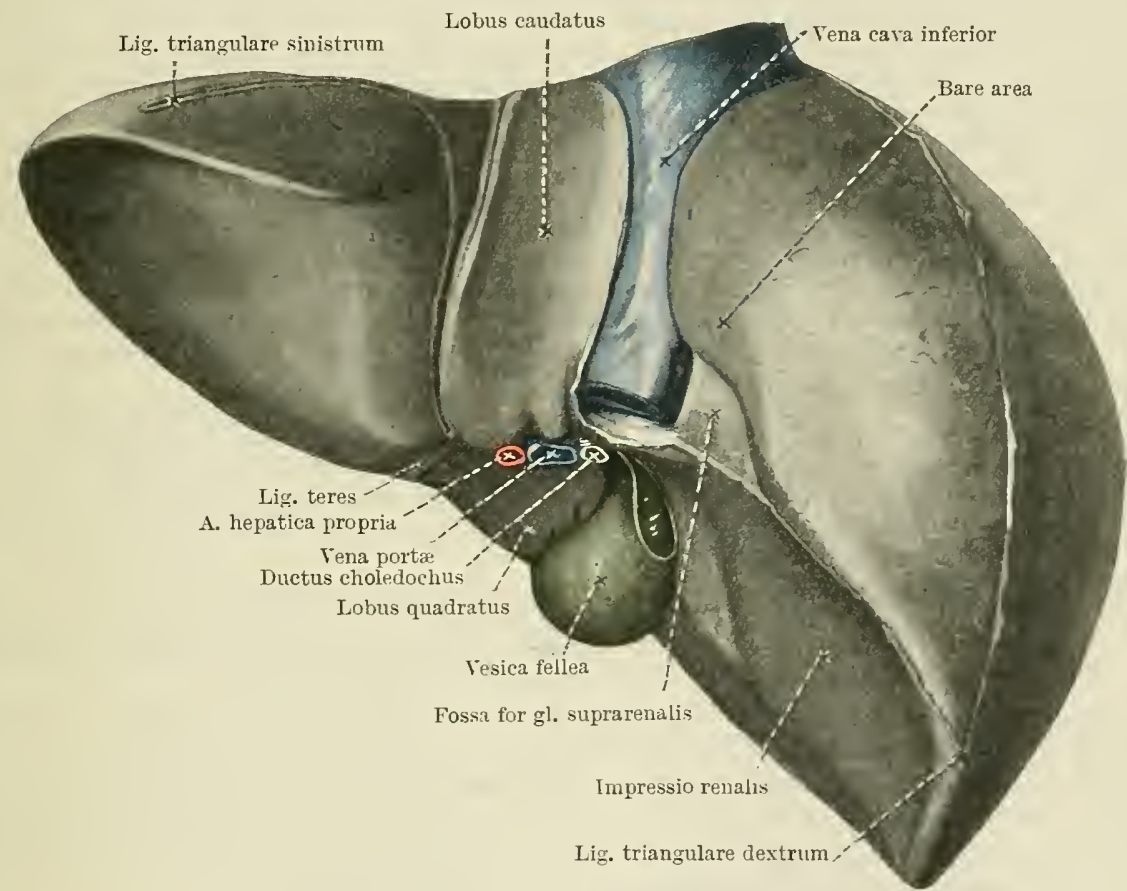

Fig. 937. - THE LIVER VIEWED FROM BEHLND.

framework. Anteriorly, the border is thin and sharp, and passes obliquely upwards from the right to the left side behind the anterior abdominal wall. This portion forms the margo anterior. Its direction corresponds to a line drawn from a point half an inch (12 mm.) below the margin of the ribs (tip of tenth costal cartilage) on the right side to a point an inch below the nipple on the left. It extends down in the median plane to a point half-way between the body of the sternum and the umbilicus. This portion of the lower border usually, but not invariably, presents one or two notches. The incisura umbilicalis, the more constant of the two (Fir. 936), is situated at the anterior end of a cleft on the inferior surface, known as the fossa sagittalis sinistra (see p. 1191), and corresponds to the inferior part of the attachment of the ligamentum teres hepatis. It is usually placed from one to two inches $(2.5$ to $5.0 \mathrm{~cm}$.) to the right of the median plane. The second notch, less frequently present, corresponds to the fundus of the gall-bladder, and is called the incisura vesicæ felleæ.

At its left extremity the margo anterior turns posteriorly around the edge of the left lobe, and ends at a groove on the posterior surface, in which the osophagus lies, termed the impressio œsophagea. 
The division between the superior surface and the posterior surface is not marked by a border of any prominence, but by an indefinite margin which runs transversely from side to side.

The superior surface may be further divided into three areas, a superior, an anterior, and a right, following the general direction of these portions of the surface, but they are not clearly marked off from one another by borders.

Their arrangement is as follows:-

The superior area of the superior surface lies in contact with the roof of the abdomen; it is convex on each side, and depressed near the median plane. The two convexities, of which the right is the more prominent, fit into the two cupolæ of the diaphragm; whilst the central depression, depressio cardiaca, corresponds to the position of the heart. This area (with the exception of a small triangle at its posterior part, between the separating layers of the ligamentuma falciforme) is completely covered by peritoneum, and on it the division of the liver into right and left lobes is indicated by the attachment of the ligamentum falciforme.

The anterior area of the superior surface is triangular in shape, and after death is usually flattened, owing to the falling in of the anterior abdominal wall. In part it lies in contact with the diaphragm, which separates it from the rib-cartilages on each side, but at the subcostal triangle it comes into direct relation with the anterior wall of the abdomen, for a distance ustally of two or three inches below the xiphi-sternal articulation. It has a complete peritoneal covering, and gives attachment, as far down as the umbilical notch at the inferior border, to the ligamentum falciforme, which connects it to the anterior abdominal wall.

The anterior passes gradually into the upper and right areas, but it is distinctly separated from the visceral surface by the sharp margo anterior of the organ. The umbilical notch is often continued upwards for some distance on the surface as a slit-like fissure.

The right area of the superior surface is convex and extensive, and lies in contact with the diaphragm, which separates it from the inner surface of the lower ribs, and also above from the inferior margin of the lung and pleura. Though sharply marked off by the margo anterior from the visceral surface, it passes without distinct limits into the other areas of the parietal surface. It is completely covered by peritonenm.

The superior surface is smooth and shows no fissures, but the line of attachment of the ligamentum falciforme is taken as dividing the liver on this surface into a right and a left lobe.

Upon the posterior surface and inferior surface there are several clefts or depressions upon the surface of the liver, termed fossæ or fissures, which further subdivide the surfaces into lobes.

These fossæe, it should be noted, do not indicate any deep division of the liver into separate parts, but are only indentations upon the surface.

Porta Hepatis.-(1) The gate of the liver (O.T. portal or transverse fissure) is the equivalent in the liver of the hilus of other glands. It is a slit-like depression, where the vessels enter the gland, and whence the ducts emerge.

It is placed on the inferior surface, runs transversely from right to left, and measures about 2 to $2 \frac{1}{2}$ inches in length. It is bounded anteriorly and posteriorly by prominent margins, and through it the hepatic artery, vena portæ, and plexus hepaticus of nerves enter the liver, and the hepatic ducts and many of the lymph vessels leave. To the anterior and posterior margins of the fissure are attached layers of peritoneum which constitute part of the lesser omentum.

The various structures found in the porta hepatis are arranged in the following way. The vena portæ lies posteriorly, and divides, in the fissure, into right and left branches, which run to right and left. The neck of the gall-bladder, with the cystic duct coming from it, lies at the right extremity of the fissure, and there the cystic duct bends downwards between the layer of the hepato-duodenal ligament.

The right and left bile ducts lie at their respective ends of the porta hepatis, and converge towards each other at the right extremity and lie anterior to the corresponding branches of the hepatic artery, and to the right side of the main vessel at their junction in the hepato-duodenal ligament. The nerves mainly invest the arteries, and the lymph vessels lie in the connective tissue which invests all these structures.

Two or three lymph glands are occasionally found in the porta hepatis, especially at the right end, near the neck of the gall-bladder, and when enlarged, they may press upon the ducts, and interfere with the passage of the bile.

The intervals between the vessels and other structures are filled in by loose connective tissue, which is continued inwards with the vessels as the fibrous capsule of Glisson.

When the porta hepatis is opened up, it is found to extend on the left as far as to the fossa venæ umbilicalis. 
(2) Fossa Venæ Umbilicalis (O.T. Umbilical Fissure).-This is a deep crevice-like fissure, situated in the inferior surface, running from before backwards, parallel to the gall-bladder, but about 1 to $1 \frac{1}{2}$ inches to its left side. It begins in front at the margo anterior, which it intersects, and runs backwards to the left extremity of the porta hepatis. Within this fissure lies a rounded cord-like structure, the ligamentum teres hepatis, the remains of the left umbilical vein of the foetus. The fissure is often crossed by a bridge of liver tissue, the pons hepatis, which may even extend for the whole length of the fissure, and conceal the round ligament from view.

(3) Fossa Ductus Venosi (O.T. Fissure of the Ductus Venosus).-At the posterior termination of the fossa venre unbilicalis the ligamentum teres is usually attached to the left branch of the portal vein. Beyond that point it is continued backwards as a fine fibrous band, the lig. venosum (Arantii), which runs onwards to join the vena cava inferior. This fibrous cord lies in a groove on the posterior aspect of the liver, called the fossa of the ductus venosus.

The umbilical vein and the ductus venosus in the fœtus serve to convey the blood back from the placenta to the inferior vena cava.

The umbilical fossa and the fossa for the ductus venosus together form a continuous fossa on the inferior and posterior surfaces which divide them into a right and left lobe. This fossa is known as the fossa sagittalis sinistra, in contrast to the porta hepatis, and to the fossa sagittalis dextra, lying to the right of two fossæ which is made up of:

(4) Fossa Vesicæ Felleæ.-The fossa of the gall-bladder is a slight depression which begins (often as a notch) at or near the margo anterior of the liver, and runs backwards and to the left, as far as the porta hepatis (Fig. 938). Its surface is uncovered by peritoneum as a rule, and in it lies the gall-bladderthe two being united by areolar tissue.

(5) Fossa Venæ Cavæ.-The fossa of the vena cava is a deep groove, on the posterior surface, between the caudate and right lobes, in which the superior part of the vena cava inferior is embedded, immediately before it pierces the diaphragm.

The depressions for the gall-bladder and the vena cava are rightly called fossæ. In hardened specimens it will be seen that the fossa of the umbilical vein, the porta hepatis, and the fossa of the ductus venosus are really fissure or crevice-like.

Taken together, the five fossæ are arranged somewhat in the form of the letter A (Fig. 938); the two lower divisions of the diverging limbs being formed by the fossa venr umbilicalis and the fossa vesicæ felleæ respectively, and the cross-piece by the porta hepatis - all of which are placed on the inferior surface. The two upper divisions of the limbs are represented by the fossa ductus venosi and that of the vena cava, which meet above and are both placed on the posterior surface. The latter of these two-namely, the fossa of the vena cava, represented by the right upper division of the A-does not join the cross-piece (the porta hepatis), but is separated from it below by a narrow ridge of liver substance-the processus caudatus (Fig. 938).

To the right of the $A$ is the lobus hepatis dexter, to its left the lobus hepatis sinister.

The interior of the $A$ is filled by the lobus quadratus anteriorly and the lobus caudatus [Spigeli] posteriorly, while the processus caudatus cuts across the stem of the A behind the cross-piece, and connects the lobus caudatus (Spigeli) to the lobus hepatis dexter.

Lobi Hepatis (Lobes of the Liver).-As has been pointed out, the attachment of the ligamentum falciforme to the superior surface of the liver divides that aspect of the organ into right and left lobes. Similarly, upon the inferior surface, the fossa sagittalis sinistra is taken as dividing this aspect into right and left lobes.

Lobus Hepatis Sinister. - The left lobe is much smaller and flatter than the right, and forms only about one-fifth of the whole mass.

Lobus Hepatis Dexter.-Its inferior and posterior surfaces of the right lobe are intersected by the three additional fosse described above, and by then it is subdivided into other parts, which also are called lobes. These are the lobus caudatus [Spigeli] with the processus caudatus, and the lobus quadratus. 
(1) The Lobus Quadratus.-This is a quadrilateral area upon the inferior surface, extending from the margo anterior in front to the porta hepatis behind. On the right, it extends as far as the fossa of the gall-bladder, and on the left to the fossa of the umbilical rein. The surface is flattened or concave, and is mainly in contact with the pyloric part of the stomach and the duodenum.

(2) The Lobus Caudatus [Spigeli] (O.T. Spigelian Lobe).--This is a prominent rather quadrilateral area on the facies posterior of the liver, between the fossa for the inferior vena cava on its right, and the fossa for the ductus venosus on its left side.

Its superior limit is formed by the terminal part of the ductus venosus, as it bends to the right to join the vena cava inferior, while below it is free and forms the posterior boundary of the porta hepatis.

This extremity is often cut into by a notch or fissure (in which the cœliac artery lies, particularly in the foetus), which marks off a larger and more prominent left part, the processus papillaris, projecting downwards behind the porta hepatis, and a smaller right part, the processus caudatus, which connects it (Fig. 938) with the facies inferior of the right lobe.

The posterior surface of the caudate lobe is free; it is placed vertically, and looks backwards and slightly medially. The lobe has also another surface, which is hidden when in the body and in the hardened liver by the folding of the left lobe across it. By this folding there is formed a deep fossa (fossa of the ductus venosus), at the bottom of which will be found the remains of the ductus venosus.

(3) The processus caudatus (O.T. caudate lobe) is merely a narrow bridge of liver tissue, which connects the caudate lobe with the right lobe proper. It is limited anteriorly by the porta hepatis, and posteriorly by the fossa for the inferior vena cava. It forms the superior boundary for the epiploic foramen, and when the finger is placed in the foramen it rests against the caudate process, and has a vein on either side, i.e. in front and behind, separated by a fold of peritoneum.

Facies Posterior (Posterior Surface).-This portion of the parietal surface is directed backwards, and lies in contact with the diaphragm, as the latter passes down on the posterior abdominal wall. It is very irregular in shape, and presents the following parts:-(1) The "uncovered area" of the right lobe; (2) the suprarenal impression; (3) the fossa of the vena cava; (4) the caudate lobe, separated by the fossa of the ductus venosus from (5) the osophageal groove, which belongs to the left lobe.

(1) The "uncovered area" of the right lobe (Fig. 938) is a considerable portion of the posterior surface of the right lobe-varying from $1 \frac{1}{2}$ to $2 \frac{1}{2}$ inches $(3 \cdot 7$ to $6.2 \mathrm{~cm}$.) in width, and from 3 to 4 inches $(7.5$ to $10 \mathrm{~cm}$.) in transverse measurement-which is devoid of peritoneum. Over this uncovered portion, which looks more medially than backwards, the liver and diaphragm are in direct contact, and are united by areolar tissue; here too is established a communication by small veins between the portal circulation of the liver and the systemic circulation of the diaphragm.

(2) Impressio Suprarenalis.-On the "uncovered area," immediately to the right of the vena cava, is a triangular impression (Fig. 938), produced by a portion of the right suprarenal gland, which projects upwards from the superior extremity of the right kidney, between the diaphragm and liver.

(3) Fossa Venæ Cavæ.-At the left extremity of the "uncovered area" the inferior vena cava lies vertically, embedded in a fossa of the liver substance, between the caudate lobe on the left and the adjacent part of the uncovered area on the right, both of which project over the sides of the vein, almost hiding it from view (Fig. 938); sometimes they actually meet and form a pons hepatis across the back of the vein.

(4) Lobus Caudatus [Spigeli]. - This has already been described, see above. The superior recess of the omental bursa separates the posterior surface of the caudate lobe from the diaphragm, which latter, in turn, separates it from the aorta just before that vessel enters the abdomen.

(5) The Impressio Esophagea, or œesophageal groove, is situated on the posterior surface of the left lobe, to the left of the superior end of the caudate lobe, but 
separated from it by the fossa of the ductus venosus. The groove leads down into the gastric impression on the inferior surface of the left lobe (Fig. 938), and, when in the body, lies in contact with the prominent right or anterior margin of the cesophageal orifice of the diaphragm (see p. 1152 and Fig. 912), sometimes also with the cesophagus itself.

Facies Inferior (Inferior Surface).-This is an irregular, obliquely sloping surface (Fig. 938), which looks downwards, posteriorly, and to the left, and rests upon the stomach, lesser omentum, intestines, and right kidney. The division into right and left lobes is indicated on this surface by the left sagittal fossa, which passes from the umbilical notch at the anterior border back to the porta hepatis, and thence backwards as the fissure of the ductus venosus.

The inferior surface of the left lobe is directed downwards and posteriorly, and

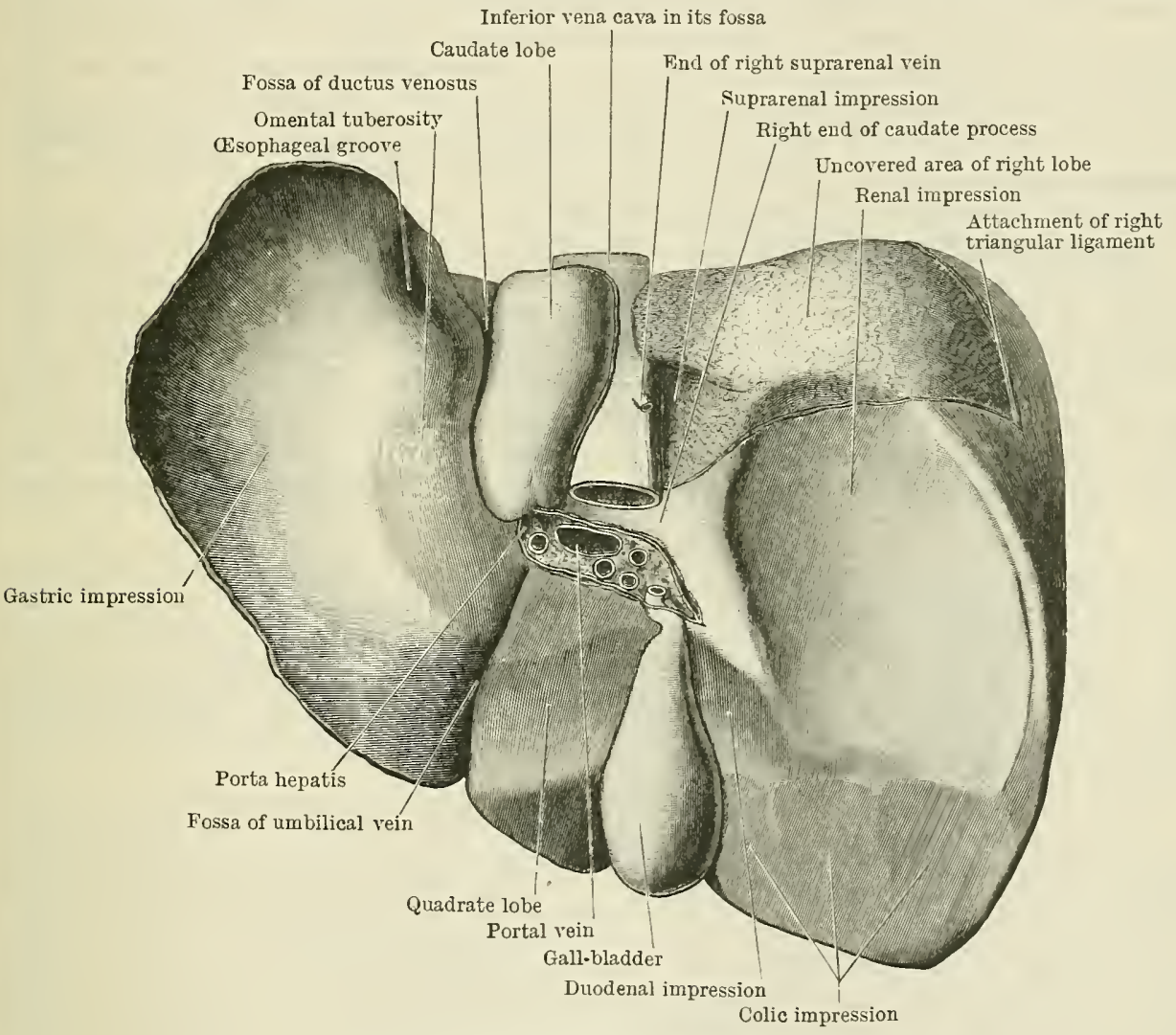

Fig. 938.-INferior Surface of the Liver.

rests on the superior surface of the stomach, in front of the cardia; also on the lesser curvature with its attached lesser omentum. The part which rests upon the anterior surface of the stomach is rendered concave by the pressure of that organ (Fig. 938), and is known as the impressio gastrica; whilst the portion to the right of this, being free from the pressure of the stomach, projects backwards over the lesser curvature against the lesser omentum in the form of a smooth rounded prominence, and is known as the tuber omentale.

The inferior surface of the right lobe may be divided into two portions by the line of the gall-bladder, which extends forwards in its fossa to the anterior sharp margin of the liver (Fig. 936).

(a) To the left of the line of the gall-bladder are found from before backwards:The lobus quadratus, porta hepatis, and processus caudatus.

The quadrate lobe is of an oblong shape, the antero-posterior diameter being the greatest. Its surface is generally concave, and is related to the pylorus and the adjacent parts of the stomach and duodenum, when the former is distended. When the stomach is empty, however, the 
pylorus usually lies beneath the right portion of the left lobe, and the superior part of the duodenum lies beneath the quadrate lobe, the transverse colon also coming in contact with it anteriorly (Fig. 938).

(b) The surface to the right of the gall-bladder, which is more extensive than that on its left, is entirely occupied by three impressions, produced by the underlying viscera-namely: (1) The impressio colica lies in front and to the right of the gall-bladder. It is formed by the right flexure of the colon and the beginning of the transverse colon. (2) Behind this is the impressio renalis, larger than the preceding, which is produced by the superior half or two-thirds of the right kidney. It is placed behind the colic impression just as the kidney itself is placed behind the colon. The superior end of the renal impression is frequently uncovered by peritoneum (Fig. 938), that is to say, the "uncovered area" of the right lobe extends down over the impression for a little way. This impression is very deep, and accommodates nearly the whole thickness of the kidney. In many hardened specimens it would appear to belong more to the posterior part of the parietal than to the inferior or visceral surface. (3) To the medial side of the renal impression, and near the neck of the gall-bladder, is placed the narrow impressio duodenalis, which lies in contact with the descending part of the duodenum down to the point at which it is crossed by the colon.

Surface Markings of the Liver.-The limits even of the normal liver are very variable, but, taking the average condition in the male, they may be marked out on the anterior surface of the body by the following method:- Three points are determined-(a) half an inch $(12.5 \mathrm{~mm}$.) below the right nipple; (b) half an inch $(12.5 \mathrm{~mm}$.) below the right margin of the thorax (or below the tip of the tenth rib); and $(c)$ one inch $(25 \mathrm{~mm}$.) below the left nipple. If these points are joined by three lines, slightly concave towards the liver, they will give the outline of the organ with sufficient accuracy for all ordinary purposes. (For variations in position see p. 1195.)

To state the matter somewhat more in detail:-If the two "nipple points" $(a)$ and $(c)$ be joined by a line, slightly convex upwards on each side, but a little depressed at the centre corresponding to the position of the heart, and crossing the inferior end of the sternum about the level of the sixth cartilage, it will mark the superior limit. A line, convex upwards, from the right nipple point $(a)$ to the subcostal point $(b)$ will indicate the right limit, while the inferior limit is marked by a line, convex downwards, drawn from the subcostal point $(b)$ to the left nipple point $(c)$, and passing through a point half-way between the umbilicus and the inferior end of the body of the sternum, in the medial line.

The line indicating the superior limit of the liver is elevated on each side, corresponding to the cupolæ of the diaphragm, and depressed in the centre beneath the heart. On the right side where highest, namely, about one inch $(25 \mathrm{~mm}$.$) , medial to the mammary line, it reaches during$ expiration to the superior border of the fifth rib; on the left side it is one-half to three-quarters of an inch (12 to $18 \mathrm{~mm}$.) lower ; and it crosses behind the sternum at the level of the sixth sternocostal junction-or sometimes lower. It must be remembered, however, that, whilst the liver reaches up to the levels just given, it does so only at the highest part of its convex parietal surface, and is separated from the ribs all round by the thin lower margin of the lung (which extends down between the chest wall and diaphragm to the sixth rib in front, to the eighth in the midlateral line, and to the level of the tip of the spine of the tenth thoracic vertebra behind), so that, in percussing over the liver, its dulness is obscured by the resonance of the lungs above these points.

From the back, the superior margin of the liver rises as high as to the superior margin of the eighth rib or to the inferior margin of the scapula on the right side. On the left, it rises to the inferior margin of the eighth rib, and terminates about an inch medial to the inferior angle of the scapula.

The inferior margin slopes upwards along the eleventh rib of the right side, along a line leading to the superior part of the tenth thoracic vertebra. On the right side the liver extends vertically in the mid-axillary line from the sixth to the eleventh ribs.

Variations in Size, Form, and Position.-Few organs will be found to vary more in size in different bodies than the liver ; these variations, however, are very frequently to be looked upon as pathological. But even the normal, healthy liver may vary in weight from 48 to 58 ounces in the adult male, and from 40 to 50 ounces in the female.

Variations in form and position doubtlessly take place physiologically, as a result of the conditions of fulness or emptiness of the adjacent viscera; for, though the liver, like the other solid abdominal organs, has an intrinsic shape of its own, this is capable of modification within certain limits by the varying pressure of the surrounding parts. Thus, distension of the stomach, or of a portion of the transverse colon lying in the stomach chamber, may push the liver over to the right, so that it may hardly reach the median plane, and at the same time it increases its vertical 
depth. On the other hand, a distended state of the small intestines, with a contracted stomach and colon, may have the opposite effect, flattening it from below upwards and enlarging it in the transverse direction.

Variations in form and position due to malformations of the thoracic framework, either congenital or acquired, are very common, particularly in females as a result of tight-lacing, which presses the lower ribs inwards. Sometimes in these cases the constriction of the waist lies chiefly below the liver. The organ is then forced up against the diaphragm, filling its whole vault, and extending across to the left abdominal wall, where its left margin may lie in the interval between the diaphragm and the spleen. But more commonly it would seem that the liver is caught by the constriction : its upper part is then closely pressed into the vault of the diaphragm, which, owing to the narrowing of the thorax, is unable to accommodate the whole organ, so that its inferior part is crushed down for a considerable distance into the umbilical zone of the abdomen (Fig. 918, p. 1167), particularly on the right side. Often, too, a wide, tongue-like process (the so-called "Reidel's lobe") descends from the inferior margin, lateral to the gallbladder. This process, which when rery large may reach to the iliac crest, is sometimes found in men, although more common in women, and is liable to be mistaken for a tumour. A somewhat similar process occasionally descends from the left lobe.

Again, in apparently healthy bodies the liver may extend up on the right side almost to the fourth rib; whilst in other cases it may be as low as the sixth rib, or even lower. Nor is it rare-particularly in females - to find the anterior border projecting two or three inches $(5.0$ to 7.5 cm.) below the margin of the thorax on the right side (Fig. 918, p. 1167).

Reference should be made here to certain grooves often seen on the liver. Some of these are found running obliquely low down at the right side where the liver is in contact with the ribs; they are particularly common in females, and are due to the pressure of the ribs resulting from tight-lacing. Grooves of a different kind are found at the superior part of the parietal surface ; where the liver is in contact with the diaphragm; these usually run radially, that is, in the direction of the muscular fibres of the diaphragm, and are apparently produced by a wrinkling, or irregular contraction, of the diaphragm. At least, ridges of the diaphragm are found lying in the grooves, and these ridges or wrinkles would seem to be responsible for the production of the grooves,

Finally, the liver may present certain congenital irregularities in the direction of additional fossæ and lobes, which reproduce the conditions found in the higher apes, and are very commonly present in the fœtus (Thomson). Or the liver may be divided up into a large number of distinct lobes, as in most other animals.

Changes in position have been already referred to in connexion with variations in form ; there need only be added here that the liver ascends and descends at every expiration and inspiration respectively, and that it also descends, but very slightly, in changing from the reclining to the erect posture. Occasionally, without any evident cause, the liver and diaphragm are found to occupy a higher or lower position than usual.

Fization of the Liver.-At first sight it is not easy to understand the means by which the liver maintains its position in the abdomen (and the same remark applies, perhaps, to other solid abdominal organs). The falciform ligament gives it no support, as it is quite lax when in the body. Nor can it be said that its ressels, except perhaps the hepatic reins, assist. However, on considering the conditions under which the viscera are placed in the abdominal cavity the problem becomes less difficult.

The abdomen is a closed cavity, with a firm framework to its superior part, a tightly stretched diaphragm for its roof, and muscular walls all round. Into the concarity of this roof the parietal surface of the liver is fitted witl perfect accuracy, so that the two are in absolute contact, and cannot be separated without producing a vacuum, unless some other structure is in a position to fill the space. But there is hardly any other viscus movable enough to pass up over the front of the liver into the vault of the diaphragm, so that atmospheric pressure alone is probably sufficient to retain the organ in situ, as in the case of the hip joint. In addition, the abdominal muscles are always in a condition of tonic contraction or "tone," which gives rise to an intraabdominal pressure. This is effective in all directions, and consequently there is a considerable pressure on all the abdominal walls. The liver, being in absolute contact with the roof, may be considered a part of this wall, and it is consequently affected by this pressure which helps to sustain it. Add to this, the support which the organ receives from the intestines, the stomach, and the pancreas; from the coronary and triangular ligaments ; from the connexion of the back of the right lobe by areolar tissue to the diaphragm; and, finally, from the inferior vena cara embedded in the liver and sending its hepatic reins forwards to all parts of the organ, just before the vein itself is firmly attached to the margins of the caval orifice in the central tendon of the diaphragm, and we will probably find sufficient cause for the maintenance of the organ in its position in the abdominal cavity.

Relation to Peritoneum.-The relation of the liver to the peritoneum is somewhat complex in its details. The greater part of the liver is covered with peritoneum, forming the tunica serosa, but there is an area of some size upon its superior and posterior aspects where it is directly in contact with the diaphragm, and round the margins of this area the peritoneum passes from liver to diaphragm. This is known as the bare area, and the peritoneum round this area is known as the ligamentum coronarium (coronary ligament). Further, the liver is attached to the 
anterior portion of the diaphragm, and to the abdominal wall as low as to the umbilicus by a double fold of peritoneum which forms a sort of mesentery for it. This fold, known as the ligamentum falciforme, runs forwards from and is continuous with the folds of peritoneum which limit the bare area, and the whole forms a sort of meso-hepaticum.

The peritoneum is also reflected off from the margins of the porta hepatis and from the fossa for the ductus venosus, and passes thence to the lesser curvature of the stomach and the first part of the duodenum, forming the omentum minus, The liver may, in fact, be regarded as lying inside a peritoneal fold which stretches from the lesser curvature of the stomach below to the diaphragm and anterior abdominal wall above. This fold is embryologically the ventral mesentery of the stomach, or ventral meso-gastrium, and its original simple character has become complicated by the growth of the liver within it and by the rotation which the stomach undergoes to the right side at its inferior part.

The various ligaments of the liver are as follows:-

(1) Ligamentum Falciforme Hepatis.-The falciform ligament of the liver is a crescentic fold of peritoneum, which is attached by its convex border to the inferior surface of the diaphragm, and to the anterior abdominal wall (an inch or more to the right of the median plane) to within a short distance ( 1 to 2 inches, 2.5 to $5 \mathrm{~cm}$.) of the umbilicus. Its concave border is attached to the superior surface of the liver; below this level it presents a free rounded edge, stretching from near the umbilicus to the umbilical notch of the liver, and it contains within its layers a stout fibrous cord, the round ligament.

Near the posterior part of the superior surface of the liver the two layers of which the falciform ligament is composed separate, and enclose a triangular area on the posterior surface, in front of the superior end of the vena cava, uncovered by peritoneum. Traced backwards, the right layer passes into the superior layer of the coronary ligament, the left into that of the left triangular ligament. It is the remains of a part of the ventral mesentery of the embryo, and has no supporting or suspensory action on the liver of the adult.

(2) Ligamentum Coronarium Hepatis.--The coronary ligament consists of the folds of peritoneum which are reflected from the liver to the diaphragm at the margins of the uncovered area of the right lobe. The name of right triangular ligament has been given to its pointed right extremity (Fig. 938).

The coronary ligament consists of a superior and an inferior layer. The superior is formed by the prolongation to the right of the right layer of the falciform ligament. The inferior layer is formed by the continuation of the inferior layer of the right triangular ligament to the left side, and by the reflection from the margin of the caudate lobe by the side of the inferior vena cava (see Fig. 938).

(3) Ligamentum Triangulare Dextrum. - The right triangular ligament (O.T. right lateral ligament) is merely the pointed right extremity of the coronary ligament, where the superior and inferior layers become continuous with one another.

(4) Ligamentum Triangulare Sinistrum.-The left triangular ligament (O.T. left lateral ligament) is a considerable triangular fold, derived from the left layer of the falciform ligament, which is attached by one border to the superior surface of the left lobe near its posterior border, and by the other to the diaphragm, for a distance of several inches as a rule.

Its attachment to the diaphragm lies nearly altogether to the left of the osophageal orifice and abont $\frac{3}{4}$ inch $(18 \mathrm{~mm}$.) anterior to the plane of this opening.

Two other structures, termed ligaments, are not peritoneal folds, but obliterated bloodvessels, namely the ligamentum teres hepatis or round ligament and the ligamentum venosum (Arantii).

(5) Ligamentum Teres Hepatis. - The round ligament of the liver is a stout fibrous band which passes from the umbilicus posteriorly and superiorly, within the free margin of the falciform ligament, to the umbilical notch of the liver, and thence upwards and backwards in the umbilical fossa, to join the left branch of the portal vein. It is the remains of the left umbilical vein which, before birth, carries the arterial blood from the placenta to the body of the fotus (Fig. 88).

(6) Ligamentum Venosum Arantii.-The venous ligament of Arantius (O.T. obliterated ductus venosus) is a slender fibrous cord, which passes from the left branch of the portal vein, nearly opposite the attachment of the round ligament, upwards in the fossa 
bearing its name, to be connected with the inferior vena cara as it leares the liver. In the fœetus this structure is a considerable vessel, which convers some of the blood brought to the porta hepatis by the left umbilical vein directly backwards to the vena cava. At the time of birth the ductus venosus and umbilical vein cease to carry blood, their cavities become obliterated, and they are converted into fibrous cords.

(7) The omentum minus is a fold of peritoneum which extends from the liver to the lesser curvature of the stomach to the duodenum.

It is attached above to the margins of the porta hepatis, and also to the bottom of the fossa of the ductus venosus. Below, it is connected to the lesser curvature of the stomach, where its two layers separate to enclose that organ, and also to the upper border of the duodenum for an inch or more beyond the pylorus. Between its layers, close to its right or free border, are contained the bile duct, the hepatic artery, the portal rein, and the nerves and lymph vessels passing to and from the porta hepatis (Fig. 939). Its central part is wide, but it is narrow at each end. Of the two ends, the right is free, and

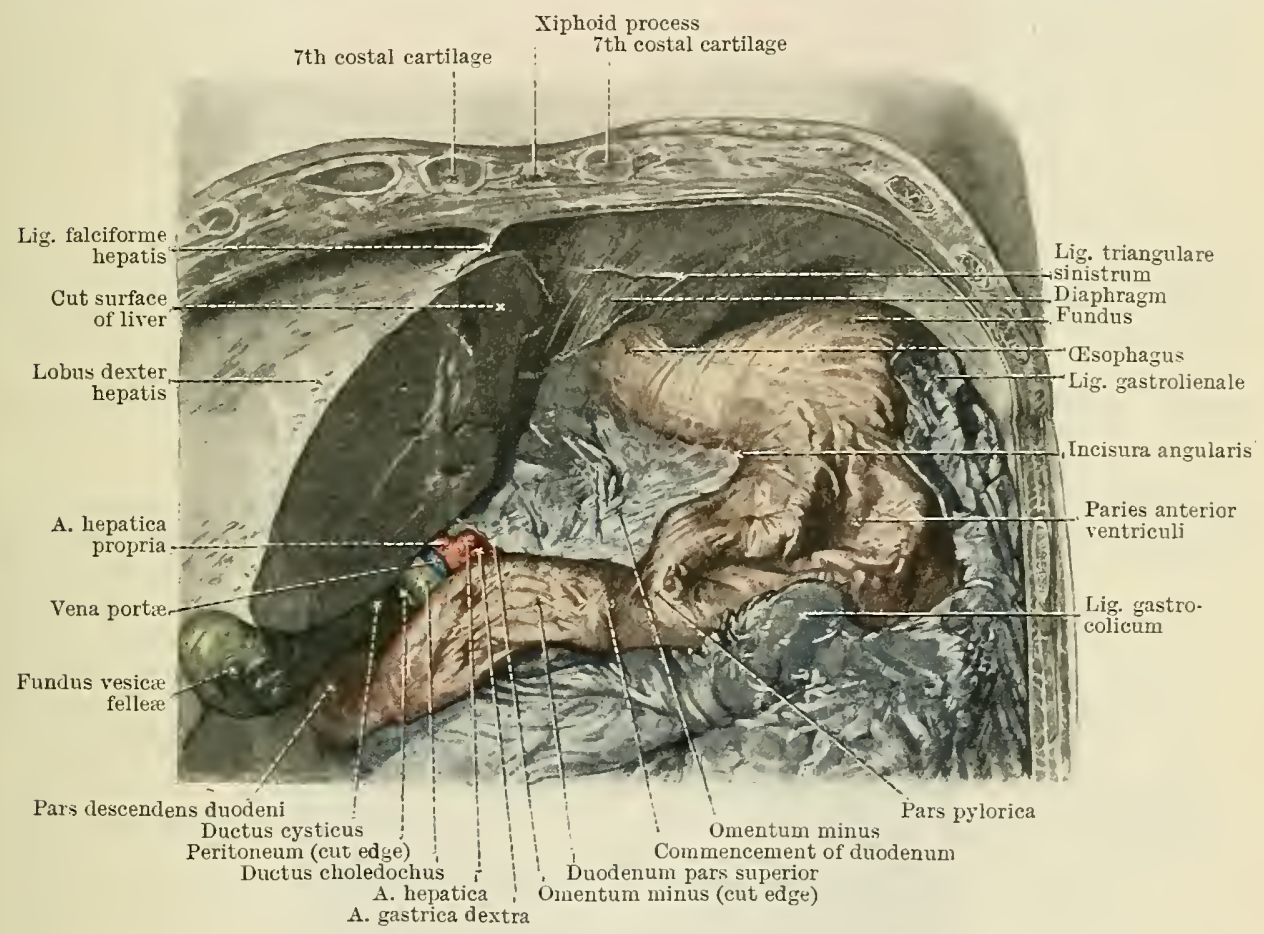

Fig. 939.-The Lesser Onentum.

The left lobe of the liver has been removed, and also the anterior layer of the hepato-duodenal ligament. The view is taken looking upwards as well as posteriorly.

stretches from the liver to the duodenum, forming the anterior boundary of the foramen epiploicum. The left end is very narrow, and is attached to the diaphragm between the esophageal and caval openings. The portion of the lesser omentum passing between the liver and the stomach is known as the ligamentum hepatogastricum, that between the liver and the duodenum as the ligamentum hepatoduodenale.

The reflection from the liver to the superior part of the right kidney (a portion of the inferior layer of the coronary ligament) is termed the hepato-renal ligament.

The "bare area" of the liver is triangular in shape, and measures about 3 inches in its greatest vertical extent, and some 5 inches transversely. It is in contact with the diaphragm, a portion of the right suprarenal gland, and the inferior vena cava. It is bounded above and below by the superior and inferior folds of the coronary ligament, and on the left by the attachment of peritoneum to the margin of the caudate lobe. It is prolonged upwards for a short distance on the superior surface of the liver, in front of the inferior vena cava, between the layers of the falciform ligament as they diverge from one another. 


\section{Structure of the Liver.}

The liver is invested by an onter tunica serosa described in connexion with the peritoneum. Within this is a thin capsula fibrosa [Glissonii] (O.T. Glisson's capsule)

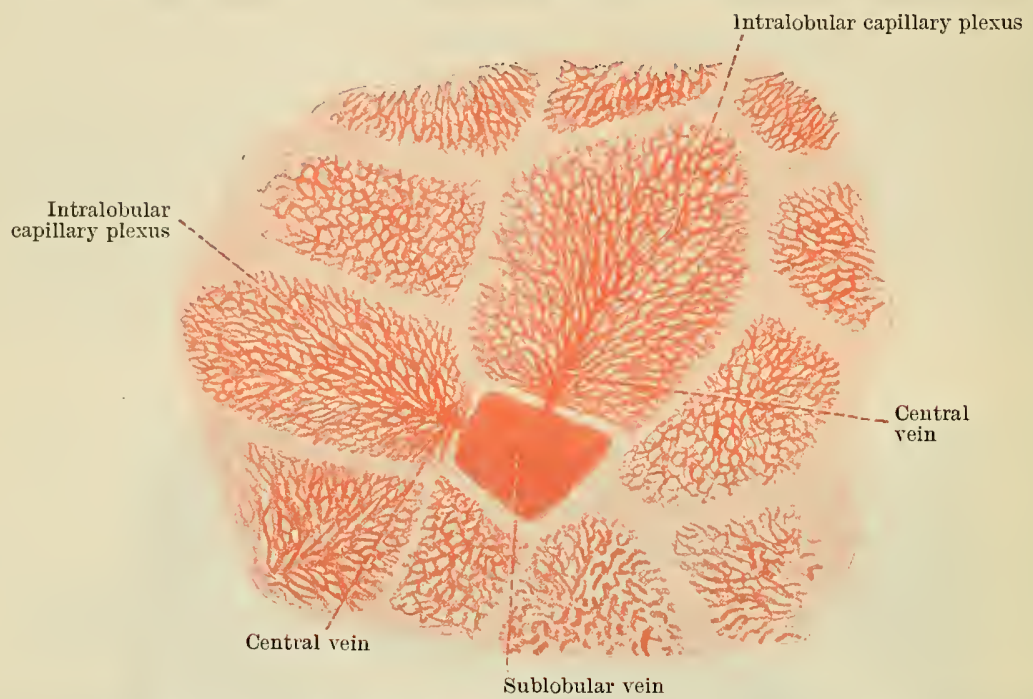

Fig. 940.--Liver of a Pig injected from the Hepatic Vein by T. A. Carter. (From a specimen left in the Anatomical Department of Edinburgh University by Sir William Turner.)

of delicate fibrous tissue, which is most evident where the serous coat is absent. In the neighbourhood of the porta hepatis it is particularly abundant, and here it surrounds
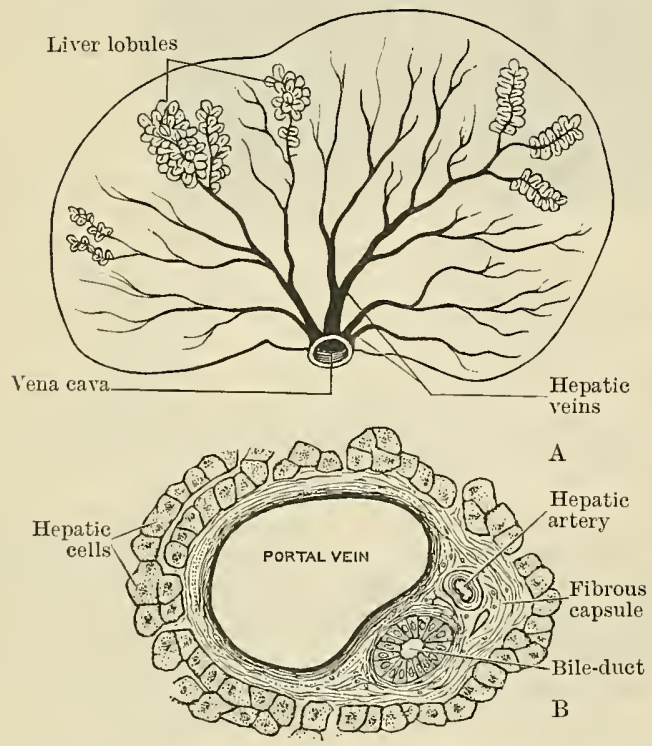

Fig. 941.-Diagranis illustrating the Structure OF THE LIVER.

A, Arrangement of liver lobules around the sublobular branches of the hepatic vein; B, Section of a portal canal, showing its contained branches of the portal vein, hepatic artery, and bile-duct, surrounded by a prolongation of Glisson's fibrous capsule. the vessels entering the porta, and accompanies them through the portal canals in the liver substance. This coat is continuous with the fine areolar tissue which pervades the liver, surrounding its lobules and holding them together.

The liver substance proper is made up of an enormous number of small lobules $\frac{1}{25}$ th to $\frac{1}{12}$ th inch ( 1 to $2 \mathrm{~mm}$.) in diameter, closely packed, and held together by a small amount of connective tissue. In man the lobules are not completely separated from one another all round their circumference, but coalesce in places; the reverse is the case in certain animals such as the camel and the pig. The lobules are arranged around the branches of the hepatic veins, to form the compact mass of the liver, in the following manner:-

The hepatic veins radiate from the inferior vena cava, at the posterior surface of the liver, to all parts of the organ, dividing and re-dividing until the vessels are reduced to branches of a very small size, known as sublobular veins - the whole arrangement may be aptly compared so far to the branching of a tree (Fig. 941, A). On all sides

there open into these sublobular veins numerous closely crowded vessels - the venæ centrales (0.T. intralobular veins) (which, following our simile, may be compared to an enormous 
number of thorns growing out on all sides from the sublobular twigs of the tree). On each of these little central veins there is impaled, as it were, a lobule. These little conical lobules, with their central veins running through them, are so numerous and so closely packed together, that they give rise to the practically solid liver tissue.

The lobules are surrounded by the venæ interlobulares, branches of the portal vein, from which numerous twigs enter the lobule on all sides, and converging, join the central vein (Fig. 940). This runs through the centre of the lobule (Fig. 941, A), and opens at its base into a sublobular vein. The sublobular veins, uniting and growing larger by constant additions, finally form the hepatic veins, which open into the vena cava.

Hepatic Cells.- In the intervals between the branches of the capillaries, running from the interlobular to the central veins (Fig. 940), are placed the polygonal-shaped epithelial, hepatic cells. Between the cells run the ductus biliferi (O.T. bile canaliculi) which, passing out of the lobule (Fig. 941), join the ductus interlobulares, and these uniting, finally end in the hepatic ducts.

The liver cells are very intimately connected both with the blood capillaries and the radicles of the bile-ducts. From both sets of vessels minute channels pass into the interior of the hepatic cells, forming intracellular canals. The blood plasma is thus brought into very intimate relation with the plasma of the hepatic cells, and the small fine intracellular biliary canaliculi facilitate the secretion of bile by the cells.

\section{VESSELS OF THE Liver.}

Like many other glands, the liver presents, as has been seen, a hilus, or slit-like fissure, upon its surface, where vessels are found, and where the ducts emerge. In the liver, the hilus is placed upon the inferior aspect, and is represented by the porta hepatis.

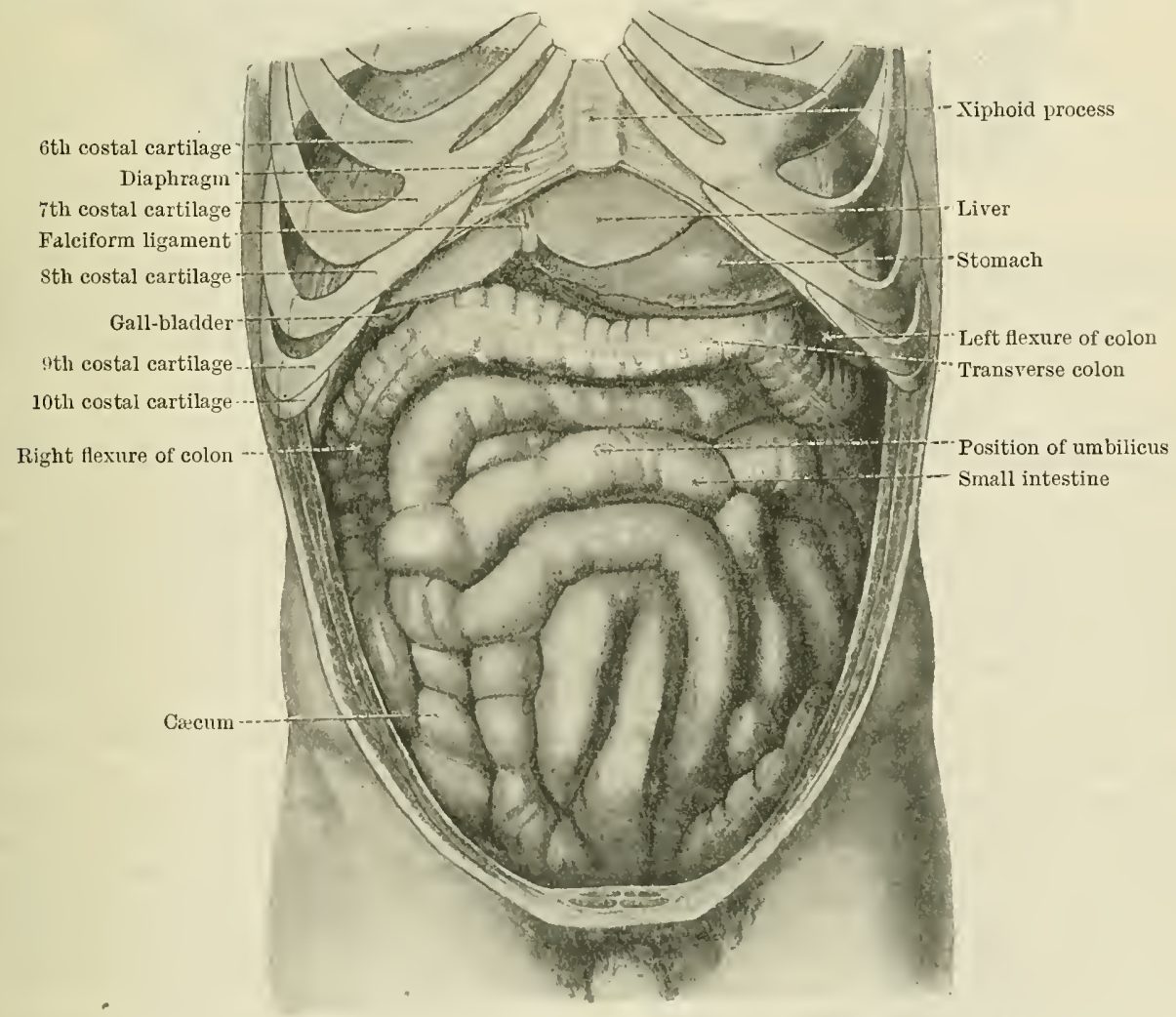

Fig. 942.-The Abdominal Viscera, after remotal of the Omentom Majus AND THE LIG, Gastrocolicem.

The blood-ressels here are all afferent, conveying blood to the liver. The blood is conveyed away from the liver by various channels which emerge from its posterior aspect (venæ hepaticæ) and enter the vena cava inferior, which is partially embedded in the substance of the liver in this region. 
The circulation within the liver is, therefore, arranged differently from that of other glands, and in order to understand properly the structure of the liver, it is necessary to give some account of the relatious which it presents to the blood vessels which pass to and from it.

The vena portæ and the arteria hepatica propria pass up to the liver between the two layers of the hepato-duodenal ligament, anterior to the foramen epiploicum. Here they are accompanied by the bile-duct, which lies to the right, whilst the artery is placed to the left, and the portal vein posterior to both. In this order they enter the porta hepatis, and there becoming rearnanged, so that the vein lies behind, the artery in the middle, and the duct in front. Each breaks up into two chief branches-a right and a left-and several smaller ones, which enter the liver substance, surrounded by a prolongation of the connective tissue coat of the liver (O.T. Glisson's capsule). Within the organ the three vessels run and divide together, so that every branch of the portal vein is accompanied by a corresponding (but much smaller) branch of the hepatic artery and of the hepatic duct : and the three, surrounded by a prolongation of the fibrous capsule,

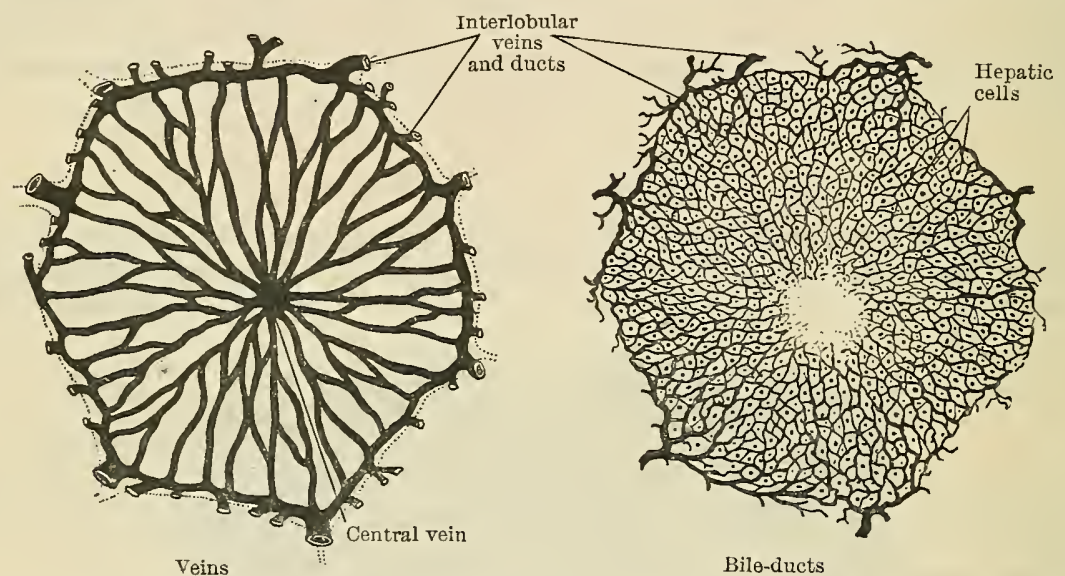

FIG. 943.-DiAgram illustrating the arrangement of the blood-vessels (on left) and of the hepatic cells and bile-ducts (on right) within a lobule of the liver. The first diagram shows the interlobular veins running around the outside of the lobule, and sending their capillaries into the lobnle to join the central vein. In the second diagram the bile capillaries are seen, with the hepatic cells between them, radiating to the periphery of the lobule, where they join the interlobular bile-ducts.

and accompanied by branches of the hepatic nerves and lymph vessels, run in special tunnels of the liver substance, which are known as portal canals (Fig. 941, B).

The hepatic artery has but a small part to play in the hepatic circulation within the liver, and it is distributed in the following way. Reaching the porta hepatis of the liver it breaks up into branches which accompany the branches of the bile-ducts and of the portal vein into the interior, and it supplies minute branches, known as the vaginal and capsular branches, to the fibrous tissue which accompanies these vessels, and which also invests the surface of the liver. The terminal branches of the artery end in the branches from the portal vein which go to the liver lobules.

The portal vein within the liver divides like an artery into numerous branches, which pass in all directions in company with small branches of the bile-ducts.

Finally, the small terminal branches form an elaborate meshwork, whose vessels anastomose freely with one another, around the periphery of the liver lobules, and are known as interlobular vessels. From this meshwork small capillary-like channels pass into the interior of each lobule between columns of liver cells, towards a channel placed in the centre of the lobule, called the central vein. From the central veins the blood is carried into larger channels or sublobular veins, which pass to the hepatic veins, and so to the inferior vena cava.

The hepatic veins, formed by the union of the sublobular vessels, gradually unite with one another, and run towards the inferior vena cava. Their mode of termination is variable, but presents the following general arrangement:- - The left lobe is drained by a vessel which joins the superior part of the inferior vena cava. The right lobe is drained by one or two vessels which join the superior part of the inferior vena cava, and by a series of small vessels, 4 to 12 in number, which pass from the inferior portion of the right lobe to the inferior vena cava. The caudate lobe and central portion of the liver are drained by 
ressels which mostly pass to the inferior part of the inferior vena cava. The hepatic veins and their branches are not accompanied by branches of the bile-ducts, and are surrounded by a very small amount of connective tissue.

The lymph vessels of the liver are arranged in a superficial and a deep set:- -1 . The superficial set lies beneath the peritoneum on both $(a)$ the visceral and $(b)$ the parietal surfaces of the organ. (a) The vessels from the visceral surface pass chiefly to the hepatic glands, which lie between the layers of the lesser omentum; but some of them, from the posterior surface on the right lobe, join the lumbar glands, and others, from the posterior surface on the left lobe, go to the cœliac glands. (b) The vessels from the inferior surface pass in various directions. Those from the adjacent parts of the right and left lobes pass up in the falciform ligament, and pierce the diaphragm to reach the anterior mediastinal glands, and eud finally in the right lymphatic duct. Those from the anterior part of this surface pass down to the inferior aspect, and join the hepatic glands in the lesser omentum. The lymph vessels from the back of the right lobe pierce the diaphragm between the layers of the coronary ligament, and join some glands in the thorax around the upper end of the inferior cava; others run in the right triangular ligament, and either pierce the diaphragm and end in the anterior mediastinal glands, or, turning down, join the coeliac group.

2. The deep lymph vessels accompany either $(a)$ the portal or $(b)$ the hepatic veins. (a) The former set pass out through the porta hepatis and join the hepatic glands, the efferent vessels of which join the cœliac glands. (b) Those which accompany the hepatic veins pierce the diaphragm with the vena cava, and having formed connexions with the group of glands at its superior end, within the thorax, turn down and join the beginning of the thoracic duct.

The nerves, which are chiefly of the non-medullated variety, are derived from the left vagus and the coliac plexus of the sympathetic. The branches of the former pass from the front of the stomach up between the layers of the lesser omentum to the lirer. Those of the latter pass from the coliac plexus along the hepatic artery-forming the hepatic plexus-to the porta hepatis, where they enter the liver with the blood-vessels. They are distributed chiefly to the walls of the vessels and of the bile-ducts.

\section{THE GALL-BLADDER AND BILE-PASSAGES.}

Under this heading we have to consider the hepatic ducts, the gall-bladder, the cystic duct, and the bile-duct.

The excretory ducts of the liver (Fig. 943) begin within the hepatic cells as minute channels. Thence they run between the hepatic cells (Fig. 943), and are known as the ductus biliferi.

Outside the lobules these join (Fig. 943) the ductus interlobulares which, by uniting, form larger and larger ducts, and finally end in two, or more, chief branches, a larger from the right, and a smaller from the left lobe, which unite immediately after leaving the liver to form the ductus hepaticus.

As a rule, five or six ducts leave the liver at the porta hepatis; these generally unite into right and left main ducts; sometimes they all converge towards, and unite at the beginning of the hepatic duct. It is interesting to note that the ducts from the candate lobes and process join the left branch of the main duct.

Ductus Hepaticus. - The hepatic duct is formed within the porta hepatis by the union of right and left chief ducts (Fig. 944), and passes downwards, with an irregular course, and, just beyond the porta hepatis, is joined by the cystic duct (Fig. 944) to form the ductus choledochus or bile-duct (O.T. common bile-duct). In length it usually measures about 1 to $1 \frac{1}{1}$ inch $(25$ to $31 \mathrm{~mm}$.), and in breadth, when thattened out, nearly $\frac{1}{4}$ inch $(6 \mathrm{~mm}$.), or about as much as a goose quill. It lies, practically altogether, within the porta hepatis.

Vesica Fellea (Gall-bladder).-The gall-bladder, with the cystic duct, may be looked upon as a diverticulum of the bile-duct, enlarged at its extremity to form a reservoir for the bile. It is pear-shaped, and lies obliquely on the inferior surface of the liver (Fig. 944). The wide end, or fundus, usually reaches the anterior border of the liver-where there is sometimes a notch to receive it-and comes in contact with the anterior abdominal wall (Fig. 944). The corpus (body) runs backwards, upwards, and to the left, lying in the fossa of the gall-bladder, and near the porta hepatis passes rather abruptly into the narrow neck. The collum (neck) is curved medially towards the porta hepatis, in the form of the italic letter $s$, and when distended it presents on its surface a spiral constriction which is continued into the beginning of the cystic duct, and is due to a series of crescentic folds placed somewhat spirally round the interior of its cavity forming the valvula spiralis (Heisteri). Haring arrived near the porta hepatis, much reduced in size, it passes into the cystic duct.

As a rule the gall-bladder is covered by the peritoneum of the inferior surface 
of the liver, except on its superior aspect, which is united to the fossa of the gallbladder by areolar tissue. Sometimes, but rarely, this surface is covered also,

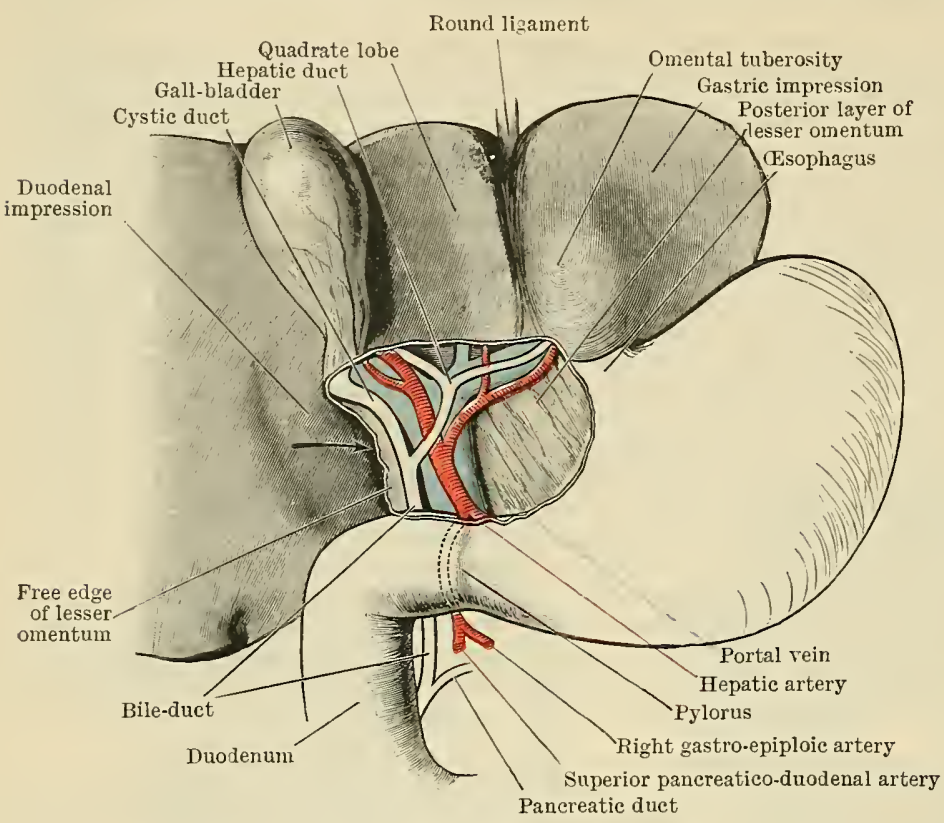

Fig. 944.-Strectures between the Layers of the Lesser Omentum. and the gallbladder is then suspended from the liver by a short peritoneal ligament. The fundus usually lies in contact with the anterior abdominal wall, at or immediately beneath the point where the right vertical lateral plane meets the lower margin of the ribs (i.e. in the angle between the lateral border of the right rectus muscle and the inferior margin of the ribs). Above, the gall-bladder lies against the liver; and below, it rests on the transverse colon in front, and behind, near its neck, on the duodenum.

In some cases the fundus of the gall-bladder does not reach the anterior border of the liver or the abdominal wall. In others it may be moved considerably to the right of the vertical lateral plane-possibly as a result of distension of the stomach and colon-or as a result of tightlacing, it may be moved to the left, and may then lie near the median plane and far below the ribs (Fig. 918, p. 1167).

Its total absence, as well as the presence of two distinct gall-bladders, and several other irregularities in form, have been recorded.

Its size is usually about 3 inches $\left(75 \mathrm{~mm}\right.$.) in length, and 1 to $1 \frac{1}{4}$ inches $(25$ to $31 \mathrm{~mm}$.) in diameter. Its capacity varies between 1 and $1 \frac{1}{2}$ fluid ounces.

Structure of Gall-bladder.-The wall of the gall-bladder is composed of an outer coat of peritoneum, the tunica serosa, usually incomplete; a middle coat of unstriped muscle intermixed with fibrons tissue, the tunica muscularis ; and an inner coat of mucous membrane, the tunica mucosa, which is covered with columnar epithelium, and is raised into a number of smali ridges, the plica tunica mucosce, which confer on it a reticulated appearance. The mucous membrane is always deeply stained with bile when the gallbladder is opened after death.

The cystic artery which supplies it with blood arises from the hepatic artery itself, or its right division, and divides into two branches, which run on the sides of the gall-bladder. The veins join the vena portæ, and the nerves come from the sympathetic plexus on the hepatic artery.

Ductus Cysticus.- The cystic duct, about half the diameter of the hepatic duct (3 mm.), but usually slightly longer ( $1 \frac{1}{4}$ to $1 \frac{1}{2}$ inches: 31 to $37 \mathrm{~mm}$.), begins at the neck of the gall-bladder, and running an irregular course posteriorly and medially joins the hepatic duct at the mouth of the porta hepatis, to form the bile-duct. The spiral constriction found in the neck of the gall-bladder is continued into the beginning of this duct. Sometimes the cystic duct joins the right hepatic duct instead of the hepatic duct proper.

Ductus Choledochus. - The bile-duct (O.T. common bile-duct) begins at the mouth of the porta hepatis, where it is formed by the union of the hepatic and cystic ducts. From this it passes downwards, anterior to the foramen epiploicum, lying between the two layers of the lig. hepato-duodenale with the portal vein behind 
and the hepatic artery to its left. It next descends posterior to the superior part of the duodenum (Fig. 944), and then between the pancreas and descending part of the duodenum. Finally, it meets the pancreatic duct, and the two, running together, pierce the medial wall of the descending part of the duodenum very obliquely, and open by a common orifice on the papilla duodenalis about $3 \frac{1}{2}$ or 4 inches $(8 \cdot 7$ to $10 \mathrm{~cm}$.) beyond the pylorus (see p. 1185).

The length of the bile-duct is about 3 inches (75 mm.), and its diameter, which is very variable, is generally about $\frac{1}{4}$ inch ( 6 to $7 \mathrm{~mm}$.).

Structure of the Excretory Ducts. - With the exception of the peritoneal coat, which is absent, the hepatic, cystic, and bile-ducts agree with the gall-bladder in general structure. The tunica mucosa contains a large number of mucous-producing glands, the glandulæ mucosæ biliosæ.

The bile and pancreatic ducts, in piercing the wall of the duodenum, run obliquely through its coats for about $\frac{1}{2}$ or $\frac{3}{4}$ of an inch (12 to $18 \mathrm{~mm}$.), and, as a rule, do not unite until they have almost reaclied the opening on the duodenal papilla (Fig.

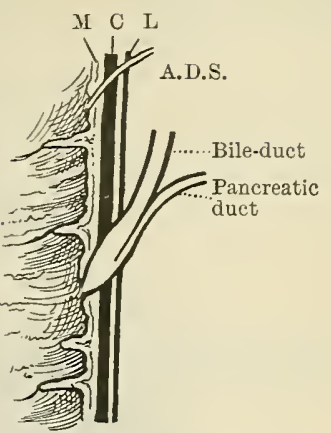

F1G. 945.-DLAGRAM SHOWIXG THE Bule aNd PaNcreatic DUCts PIERCING THE WALL OF THE DUODENCM OBLIQUELY.

A.D.S., Accessory pancreatic duct (of Santorini); C, Circular muscular fibres; L, Longitudinal muscular fibres; M, Mucous coat.

945). This orifice is very much smaller than either duct, and the short and relatively wide common cavity which precedes it is sometimes known as the "ampulla of Vater." Occasionally the cystic and hepatic ducts open into the duodenum separately.

\section{PANCREAS.}

The pancreas is an elongated glandular mass which lies transversely on the posterior abdominal wall, with its right end resting in the concavity of the duodenum (Fig. 946), and its left end touching the spleen. It secretes a digestive fluid-the pancreatic juice-which is conveyed to the duodenum by the pancreatic duct, and which constitutes one of the chief agents in intestinal digestion.

The absence of a true capsule, and the distinct lobulation of the gland, give the pancreas a very characteristic appearance (Fig. 948).

Position.-The greater part of the gland lies in the epigastrium, but the tail and adjacent part of the body extend into the left hypochondrium.

The head is placed opposite the second and upper part of the third lumbar vertebra, whilst the body runs to the left, about the level of the first lumbar vertebra. It should be added, that very often the inferior portion of the head projects some distance below the subcostal plane, and thus lies in the umbilical region.

In shape the pancreas, when hardened in situ, is very irregular (Fig. 946), its right end being flattened and hook-like, whilst the rest of the organ is prismatic and three-sided. It may, perhaps, in general form be best compared to the letter $J$ placed thus $\subset$, particularly if the stem and hook of the letter are thickened.

The gland is divisible into a head (caput) with a processus uncinatus, a body (corpus), and a tail (cauda). The head corresponds to the hook of the $\tau$, and runs downwards and to the left along the descending and transverse portions of the duodenum. The stem of the $\tau$ represents the body of the gland, and the thin left extremity of the body forms the tail. The narrow part connecting the head and body is the neck (Symington).

When removed from the body without previons hardening, the pancreas loses its true form, and becomes drawn out into a slender, elongated, tongue-shaped mass, with a wider end turned towards the duodenum, and a narrow end corresponding to the tail.

Its total length, when fixed in situ, is about 5 or 6 inches (12.5 to $15 \mathrm{~cm}$.); after removal, if not previously hardened, it is easily extended to a length of 8 inches $(20 \mathrm{~cm}$.).

Its weight is usually about 3 ounces (87 grammes).

Relations.-The general position and relations of the pancreas may be briefly 
expressed as follows:- The head (Fig. 946) lies in the concavity of the duodenum, with the vena cava inferior and abdominal aorta behind it; the body crosses the

Aorta

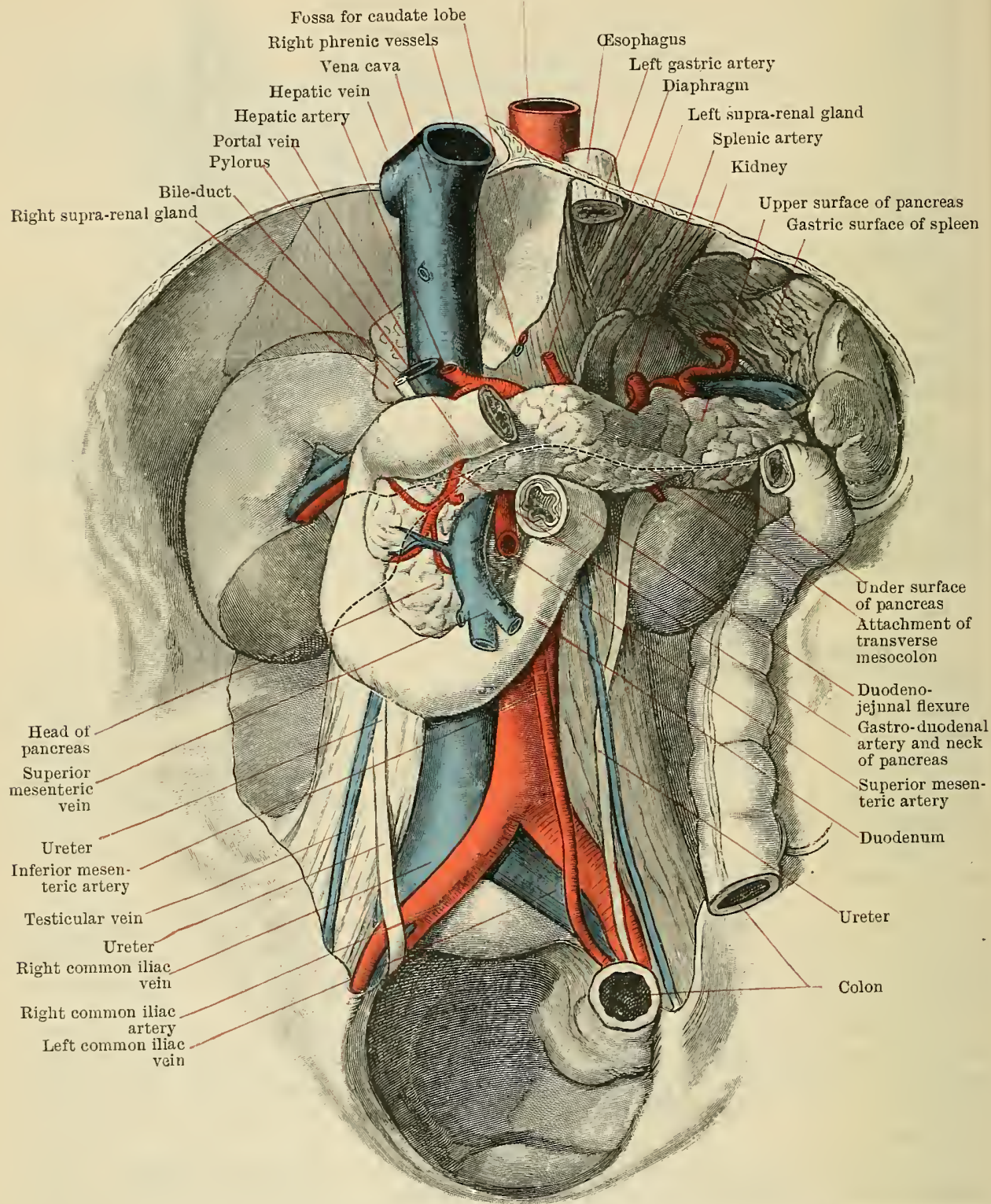

Fig. 946.-The Viscera and Vessels on the Posterior Abdominal Wall.

The stomach, liver, and most of the intestines have been removed. The peritoneum has been preserved on the right kidney, and the fossa for the caudate lobe. In taking out the liver, the inferior vena cava was left behind. The stomach bed is well shown. (From a body hardened by chromic acid injections.)

left kidney and supra-renal gland; and the tail touches the inferior part of the spleen. The greater part of the organ lies behind the stomach, which must be detached from the gastro-colic ligament, and turned upwards, in order to expose it.

In describing the detailed relations, each part of the organ will require to be considered separately.

Caput Pancreatis.- The head of the pancreas is the large flattened and somewhat disc-shaped portion of the gland which lies in the concavity of the duodenum, extending along its second and third portions almost as far as the duodenal-jejunal flexure. Above, 
in its right half, it is continuous with the neck; whilst to the left of this it is separated from the neck by a deep notch, incisura pancreatis, in which lie the superior mesenteric vessels (Fig. 946). Its right and inferior borders are moulded on to the side of the duodenum, which lies in a groore of the gland substance--the bile-duct being interposed as far down as the middle of the descending part of the duodenum. The posterior surface of the head is applied to the front of the vena cava inferior; it also lies on the right renal vessels and the left renal vein, and, at its left end, on the aorta as well. Its anterior surface is in contact above and on the right with the beginning of the

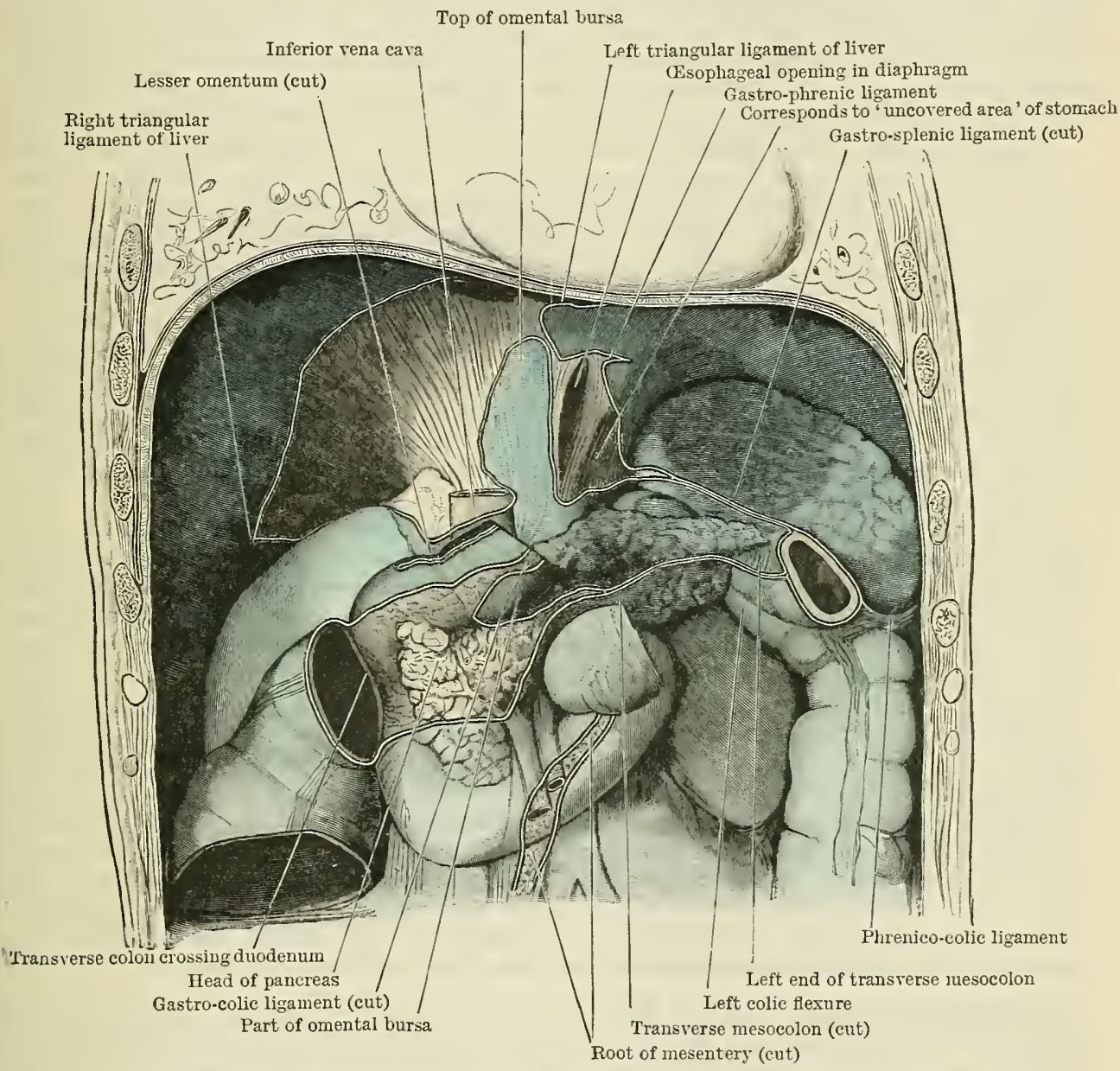

Fig. 947. - The Perituneal Relations of the Deodenum, Pancreas, Spleen, Kidneys, etc.

transverse colon (Fig. 947), without the interposition of the peritoneum as a rule. Below this it is clothed by peritoneum, and is corered by the small intestine.

The superior mesenteric vessels, after passing forward through the pancreatic notch, descend in front of that portion of the head (processus uncinatus) which runs to the left along the third part of the duodenum. The superior pancreatico-duodenal vessels run downwards, and break up on the front of the head (Fig. 946).

The neck (Fig. 946) is a comparatively attenuated portion of the gland which lies in front of the portal vein, and connects the head to the body. Springing from the npper portion of the head, it runs forwards, upwards, and to the left for about I inch (25 mm.), and then passes into the body.

The neck is about $\frac{3}{1}$ inch $\left(18 \mathrm{~mm}\right.$.) in width, and less than $\frac{1}{2}$ inch $(12.5 \mathrm{~mm}$.) in thickness. In front and to its right lie the first part of the duodenum and the pylorus; behind and to the left it rests upon the beginning of the portal vein, which is formed under cover of its lower border by the union of the splenic and superior mesenteric veins. It has a partial covering of peritoneum on its anterior surface; and its beginning is generally marked off from the head by the gastro-duodenal artery, with its continuation the superior pancreatico-dnodenal, which lies in a groove of the gland substance between the head and neck. 
Corpus Pancreatis.-The body is of a prismatic form, largest where it lies in front of the left kidney, and usually somewhat tapering towards the tail (Fig. 948). Beginning at the termination of the neck, it runs backwards and to the left across the front of the left kidney, beyond which its extremity or tail comes in contact with the spleen. When hardened in situ it presents three surfaces-anterior, inferior, and posterior-all of which are of nearly equal width (namely, about $1 \frac{1}{4}$ inches: $31 \mathrm{~mm}$.).

Facies Anterior.-The anterior surface is widest towards the left end; it looks upwards and forwards (Fig. 947), and forms a considerable portion of the stomach-bed. This surface is completely covered by peritoneum, derived from the posterior wall of the bursa omentalis, which latter separates the pancreas from the posterior surface of the stomach. Towards its right extremity it usually presents an elevation or prominence where the body joins the neck. This projects against the back of the lesser omentum when the stomach is distended, and is consequently known as the tuber omentale.

Facies Inferior.-The inferior surface, which, like the anterior, is, as a rule, widest towards its left end, looks downwards and slightly forwards. It is completely covered by peritoneum, continuous with that forming the posterior layer of the transverse mesocolon (Fig. 947). It lies in contact with the duodeno-jejunal flexure towards its right end, with the left flexure of the colon near its left end, and with a mass of small intestine (jejunum, which is always found packed in beneath it) in the rest of its extent.

Facies Posterior.-The posterior surface looks directly backwards, and is entirely destitnte of peritoneum. It is connected by areolar tissue to the posterior abdominal wall with the orgaus lying upon it. From right to left these are: the aorta with the origin of the superior mesenteric artery, the left renal vessels, the left supra-renal gland, and the left kidney. In addition, the splenic artery runs its tortuous course to the left along the superior border of the pancreas, whilst the splenic vein runs, behind the gland, at an inferior level than the artery.

The three surfaces of the body of the pancreas are separated by three borders. The margo anterior is the most prominent, and gives attachment to the transverse mesocolon (Fig. 947). It is, as it were, squeezed forward, by the pressure of the stomach above and the small intestine below, into the interval between these two sets of viscera, thus following the line of least resistance (Cunningham). Towards the neck this border is no longer prominent, but becomes rounded off, so that here the superior and inferior surfaces are confluent.

The cœliac artery projects over the margo superior, and sends its hepatic branch to the right, resting upon it, whilst the splenic artery runs to the left along it (Fig. 947). The margo inferior calls for no special description.

Cauda Pancreatis.- The tail of the pancreas is the somewhat pointed left end of the body, which is in contact with the inferior portion of the gastric surface of the spleen. It usually presents an abrupt, blunt ending, in which case it is related to the spleen in the manner just described; or it may be elongated and narrow, when it bends backwards around the lateral aspect of the kidney, and beneath the base of the spleen. In either case it is in near relation below with the left flexure of the colon (Fig. 947).

Peritoneal Relations of the Pancreas.-The posterior surface of the pancreas is entirely free from peritoneum. The other surfaces derive their peritoneal covering from the prolongation of the two layers of the transverse mesocolon, which is attached to the anterior border of the gland, from the tail to the neck. At this border the two layers separate (Fig. 914, p. 1160), the anterior-derived from the bursa omentalispassing backwards and upwards over the anterior surface; the posterior-derived from the large sac-turning downwards and backwards along the inferior surface.

As the transverse mesocolon is followed to the right it is, as a rule, found to terminate near the neck of the pancreas (Fig. 947). Beyond this, the posterior surface of the colon is generally free from peritoneum, and is connected by areolar tissue to the anterior aspect of the head of the gland. Below the level of the colon the head is covered by the continuation downwards of the peritoneum from the inferior surface of that gut. Often, however, the transverse mesocolon is continued to the right as far as the right colic flexure, and the anterior surface of the head is then completely covered by peritoneum.

Ducts of the Pancreas. - Almost invariably two ducts are found in the interior of the pancreas - the ductus pancreaticus [Wirsungi] or pancreatic duct.proper and the ductus pancreaticus accessorius [Santorini], accessory pancreatic duct (O.T. duct of Santorini).

The pancreatic duct [Wirsungi] begins near the tip of the tail by the union of small ducts from the lobules forming that part of the organ. From this it pursues 
a rather sinuous or zigzag course (Fig. 948) through the axis of the gland, at first running transversely to the right, until the neck is reached, then bending downwards towards the head. Here it approaches the descending part of the duodenum, and meeting the bile-duct, the two pierce the medial wall of the gut obliquely (for $\frac{1}{2}$ to $\frac{3}{4}$ of an inch, 12 to $18 \mathrm{~mm}$.), and open, by a common orifice on the duodenal papilla, about $3 \frac{1}{2}$ or 4 inches ( 8.7 to $10 \mathrm{~cm}$.) beyond the pylorus (see p. 1203).

In its course through the gland the duct receives numerous branches, which join it, as a rule, nearly at a right angle. These ducts, as well as the main duct itself, are easily recognised by the whiteness of their walls, which contrasts with the darker colour of the gland tissue. The main duct receives branches from all portions of the pancreas, and towards its termination attains a considerable size (namely, $\frac{1}{10}$ th to $\frac{1}{6}$ th of an inch- 2.5 to $4 \mathrm{~mm}$.- - when flattened out, or somewhat larger than a crow quill).

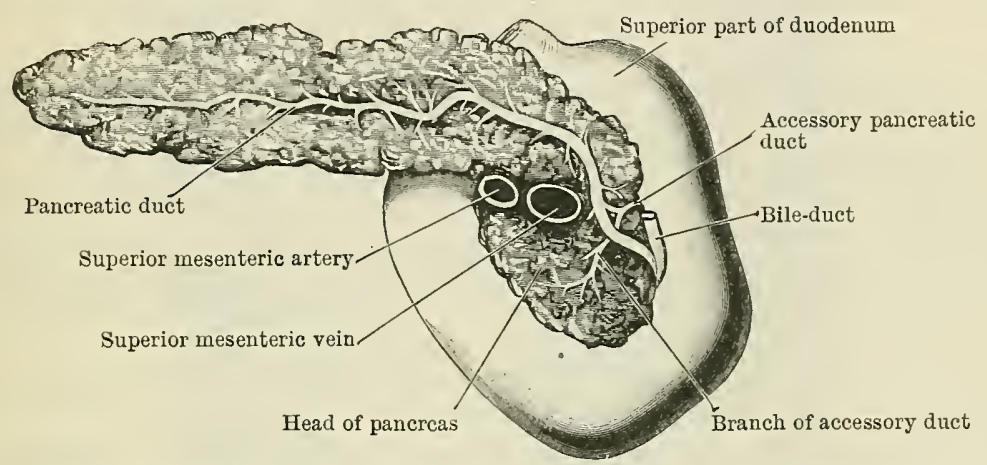

Fig. 948.-Posterior Aspect of the Pancreas and Ddodendm, with the pancreatic duct exposed.

The superior mesenteric vessels are also shown in section, passing forwards, surrounded by the recurved portion of the head of the pancreas.

The pancreatic accessory duct (O.T. duct of Santorini) is a small and variably developed duct (Fig. 948) which opens into the duodenum about $\frac{3}{4}$ of an inch above and somewhat anterior to the pancreatic duct. From the duodenum it runs to the left and downwards, and soon divides into two or more branches, one of which joins the pancreatic duct, the others pass down and receive the ducts from the lower part of the head. It is generally supposed that the current flows from this into the main duct, and not into the duodenum, as a rule, except in early life.

Physical Characters and Structure of the Pancreas.-The pancreas is of a reddish cream colour, soft to the touch, and distinctly lobulated. The lobules are but loosely held together by their small ducts and by loose areolar tissue; for, as already pointed out, the pancreas is devoid of a regular capsule, and possesses instead merely an adventitious coat of fine connective tissue.

The gland belongs to the class of acino-tubular glands, its alveoli or acini being elongated like those of the duodenal glands; otherwise it corresponds very closely to a serous salivary gland, the general structure of which will be found on p. 1140 . The secretion is termed succus pancreaticus.

Variations.-The chief variations found are:-(1) A separation of the part of the head, known as the uncinate process, which then forms a lesser pancreas. (2) A growth of the pancreas around the duodenum, which it may practically encircle for a short part of its course. And (3) an opening of its duct into the duodenum, independently of the bile-duct. An accessory pancreas (pancreas accessorium) is also sometimes found in the wall of the stomach or of the jejunmm. Diverticula of the duodenum, already described (p. 1187), ought perhaps to be mentioned in this connexion.

Vessels. - The arteries of the pancreas are:-(1) The superior pancreatico-duodenal, a branch of the gastro-duodenal artery, which runs down on the front of the head (Fig. 946), sending branches laterally to the duodenum, as well as numerous twigs into the substance of the pancreas. (2) The inferior pancreatico-duodenal, a branch of the upper part of the superior mesenteric artery; or from the root of one of the rami jejunales; it runs upwards and to the right across the back of the head, and sends branches to it and to the duodenum, one of which runs between the head and the duodenum. These two pancreatico-duodenal arteries anastomose around the inferior border of the head. (3) Pancreatic rami from the splenic artery, are several (3 to 5) fair-sized branches 
which come off from the splenic as it runs behind the superior border of the gland; they enter the pancreas immediately, and traverse its substance from above downwards, some sending branches in both directions along the course of the pancreatic duct.

The veins are: (I) The pancreatico-duodenal veins (Fig. 947), of which some pass downwards and to the left, on the front of the head, and join the superior mesenteric ; while others cross the back of the head, and open into the superior mesenteric; (2) several small pancreatic veins which join the splenic.

The lymph vessels pass chiefly with the splenic lymph vessels to the cœliac glands; some also are connected with a few glands which lie near the upper end of the superior mesenteric vessels. All the lymph of the organ passes ultimately to the cœliac glands.

The nerves, which are almost entirely non-medullated, come from the plexus coliacus, through the hepatic and splenic plexuses.

\section{INTESTINUM TENUE MESENTERIALE.}

\section{Intestinum JeJUNUM AND INTestinum Ileum.}

The upper two-fifths, that is, about 8 feet, of the small intestine beyond the duodenum, are known as the intestinum jejunum. The succeeding three-fifths, which usually measure about 12 feet, constitute the intestinum ileum. The ileum opens into the large intestine at the junction of the cæcum and ascending colon, where its orifice is guarded by the valvula coli.

Both the jejunum and ileum are connected to the parietes by a large fold of peritoneum - the mesentery - which conveys vessels and nerves from the posterior abdominal wall to these divisions of the intestine.

The part of the tube to which the mesentery is connected is known as the mesenteric or attached border; the opposite side is the free border.

Mesenterium. - The mesentery is a broad fan-shaped fold, composed of two layers of peritoneum, which connects the small intestine to the posterior wall of the abdomen. The long free border of the fold contains the intestine within it (Fig. 949). The other, or attached border, known as the radix mesenterii (root of the mesentery), is comparatively short, being only 6 or 7 inches long; but it is much thicker than the part near the gut, for it contains between its layers a considerable amount of fatty extra-peritoneal tissue, in addition to the large vascular trunks passing to the intestine. The root is attached to the posterior abdominal wall along an oblique line, extending approximately from the left side of the second lumbar vertebra to the right iliac fossa (Fig. 949). In this course its line of attachment passes from the duodeno-jejunal flexure down over the front of the terminal part of the duodenum, then obliquely across the aorta, the inferior vena cava, the right ureter, and psoas major muscle, to reach the right iliac region.

The unattached border of the mesentery is frilled out to an enormous degree, so that, while the root measures but 6 or 7 inches, the free border is extended to some 20 feet, thus resembling a fan, one border of which may be twenty or thirty times as long as the other. The length of the mesentery, measured from its root to the attached edge of the intestine directly opposite, usually measures at its longest part about 6 inches ( 8 or 9 inches, Treves and Lockwood).

Between the two layers of the mesentery (Fig. 928) are contained $(a)$ the jejunal and ileal branches of the superior mesenteric vessels, accompanied by the mesenteric nerve plexus and lymph vessels; (b) the mesenteric lymph glands, which vary from 40 to 150 in number; (c) a considerable amount of fatty connective tissue, continuous with the extra-peritoneal areolar tissue; and (d) the intestine itself.

The peritoneum from the right side of the mesentery passes out on the posterior abdominal wall to clothe the ascending colon, and, above, it is connected by a fold with the transverse mesocolon. That of the left side, similarly, passes across the parietes to the descending and iliac portions of the colon.

The mesentery begins above, immediately beyond the ending of the duodenum-that is, in the angle of the duodeno-jejunal flexure-and it ends below in the angle between the ileum and ascending colon. It is very short at each end, but soon attains the average length. Its longest part goes to the portion of the small intestine situated between two points, one six feet, the other eleven feet from the duodenum (Treves).

Whilst the root of the mesentery pursues at its attachment an almost straight line from one end 
to the other, if cut across a very short distance from the posterior abdominal wall, it will here be found to form a wavy or undulating line. Further away still this condition becomes more and more marked; and finally, if the bowel is removed by cutting through the mesentery close to its attachment to the intestinal wall, it will be seen that its free edge is not only undulating, but is frilled or plaited to an extreme degree. When shown in this way, it is found that the plaiting or. folding is not quite indiscriminate, but that the main folds, of which there are usually six, run alternately to the right and left. As a rule, the first fold runs to the left from the duodeno-jejunal flexure, and goes to a coil of jejunum which lies under the transverse mesocolon, and helps to support the stomach. The second fold passes to the right, the third to the left, and so on up to the fifth and sixth, which are usually small. From the margins of these primary folds secondary folds project in all directions, and from these again even a third series may be formed.

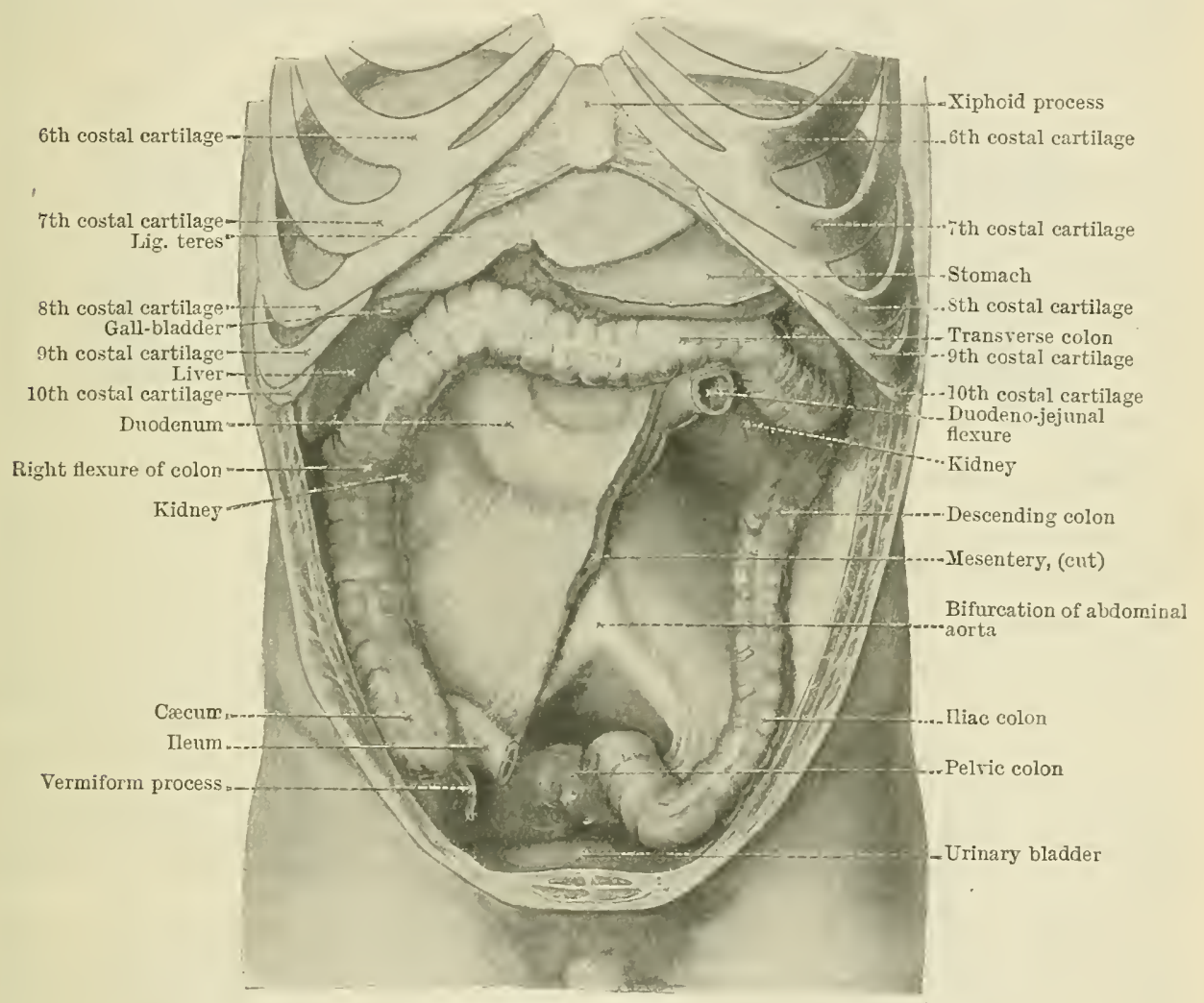

Fig. 949.-ABdomex, AFter removal of Syall INtestine.

This order is of course by no means constant, but if the intestine is removed from a hardened body in the way suggested, without disturbing the mesentery, it will be found to be arranged with more or less regularity, on some such plan as that indicated.

Differences between Jejunum and Ileum.--If the small intestine is followed down from the duodenum to the cæcum no noticeable change in appearance will be found at any one part of its course, to indicate the transition from jejunum to ileum; for the one passes insensibly into the other. Nevertheless, a gradual change takes place, and if typical parts of the two, namely, the upper portion of the jejunum and the lower portion of the ileum, be examined, they will be found to present characteristic differences, which are set forth in the following table:-

\section{Jejunum.}

Wider, $1 \frac{1}{2}$ to $1 \frac{1}{4}$ inch in diameter: Wall, thicker and heavier. Redder and more vascular. Plica circulares, well developed. Noduli lymphatici aggregati [Peyeri], few and small.

\section{Ileum.}

Narrower, $1 \frac{1}{4}$ to 1 inch in diameter.

WVall, thinner and lighter.

Paler and less vascular.

Plica circulares, absent or very small.

Toduli lymphatici aggregati [Peyeri], large and numerous. 
The villi are also said to be shorter and broader in the jejunum, more slender and filiform in the ileum (Rauber).

The terminal portion of the ileum, after crossing the superior aperture of the pelvis, runs upwards, and also slightly backwards and to the right, in close contact with the cæcum, until the ileo-cæcal orifice is reached.

Diverticulum Ilei (O.T. Meckel's Diverticulum). -This is a short finger-like protrusion which is found springing from the lower part of the ileum in a little over 2 per cent of the bodies examined. It is usually about 2 inches long, and of the same width as the intestine from which it comes off. Most commonly it is found about $2 \frac{3}{4}$ feet from the valvula coli, and opposite the termination of the superior mesenteric artery. As a rule, its end is free; but occasionally it is adherent either to the abdominal wall, the adjacent viscera, or the mesentery, and in such cases it may be the cause of strangulation of the intestine.

The diverticnlum is due to the persistence of the proximal portion of the vitelline (or vitellointestinal) duct, which connects the primitive intestine of the embryo with the yolk sac. In shape it may be cylindrical, conical, or cord-like, and it may present secondary diverticula near its tip. It arises most frequently from the free border of the intestine, but it sometimes comes off from the side. It runs at right angles to the gut most commonly, but it may assume any direction, and it is often provided with a mesentery. In 3302 bodies specially examined with reference to its existence, it was present in 73 , or $2 \cdot 2$ per cent, and it appeared to be more common in the male than in the female. In 59 out of the 73 cases its position with reference to the end of the ileum was examined: its average distance from the ileo-cæcal valve was $32 \frac{1}{2}$ inches measured along the gut, the greatest distance being 12 feet, and the smallest 6 inches. In 52 specimens the average length was $2 \cdot 1$ inches, the longest being $5 \frac{1}{4}$ inches, the shortest $\frac{1}{2}$ inch. The diameter usually equals that of the intestine from which it springs; but occasionally it is cord-like, and pervious only for a short way; on the other hand, it may attain a diameter of $3 \frac{3}{4}$ inches.

Vessels and Nerves of the Jejunum and Ileum.-The arteries for both the jejunum and ileum - the jejunal and ileal-come from the superior mesenteric, and are contained between the two layers of the mesentery. After breaking up and forming three tiers of arches, the terminal branches (Fig. 772, p. 931) reach the intestine, where they bifurcate, giving a branch to each side of the gut. These latter run transversely round the intestines, at first under the peritoneal coat; soon, however, they pierce the muscular coat and form a plexus in the submucosa, from which numerous branches pass to the mucous membrane, where some form plexuses around the intestinal glands whilst others pass to the villi. The veins are similarly disposed, and the blood from the whole of the small intestine beyond the duodenum is returned by the superior mesenteric vein, which joins with the splenic to form the portal rein.

The lymph vessels of the small intestine (known as lacteals) begin in the villi, and also as lymph sinuses surrounding the bases of the solitary nodules; a large plexus is formed in the submucosa, a second between the two layers of the muscular coat, and a third beneath the peritoneum. The vessels from all these pass up in the mesentery, being connected on the way with the numerous (from 40 to 150) mesenteric glands, and finally unite to form the truncus intestinalis, which opens into the cisterna chyli.

The nerves come from the cœliac plexus, through the superior mesenteric plexus, which accompanies the superior mesenteric artery between the layers of the mesentery, and thus reaches the intestine. Some of the fibres are derived ultimately from the right vagus. The nerve-fibres are non-medullated, and form, as in other parts of the canal, two gangliated plexuses-the myenteric in the muscular coat, and the submucosal in the submucosa.

Structure.-The tunica serosa is complete in all parts of the jejunum and ileum. The tunica muscularis is thicker in the jejunum, and grows gradually thimner as it is traced down along the ileum. The tela submucosa contains the bases of the solitary nodules (Fig. 929), but otherwise calls for no special remark. The tunica mucosa is thicker and redder above in the jejunum, thinner and paler in the ileum. It is covered throughout by villi intestinales, which are shorter and broader in the jejunum, longer and narrower in the ileum. In its whole extent it is closely beset with intestinal glands, and numerous solitary nodules are seen projecting on its surface. Aggregated lymph nodules are particularly large and numerous in the ileum; they are fewer, smaller, and usually circular in the jejunum. Finally, the mucous membrane forms plicæ circulares, which are much more prominent in the jejunum; they are smaller and fewer in the superior part of the ileum, and usually disappear a little below its middle.

\section{INTESTINUM CRASSUM.}

The ileum is succeeded by the intestinum crassum (large intestine), which begins on the right side, some $2 \frac{1}{2}$ inches below the ileo-creal junction, and comprises the following parts:- 
1. Cæcum.-The cæcum is a wide, short cul-de-sac, consisting of the portion of the large bowel below the valvula coli. It lies in the right iliac region, and from its medial and posterior part a worm-shaped outgrowth, the vermiform process, is prolonged (Fig. 951).

2. Colon Ascendens. - The ascending colon ascends vertically in the right lumbar region as far as the inferior surface of the liver: here the gut bends to the left, forming the flexura coli dextra (O.T. hepatic flexure), and then passes transversely across the abdomen, towards the spleen, as the transverse colon.

3. Colon Transversum.-The transverse colon, a loop of intestine which passes across the abdominal cavity in an irregular looped manner. It ends at the inferior extremity of the spleeu. There it turns downward, forming the flexura coli sinistra (O.T. splenic flexure), and passes into the descending colon.

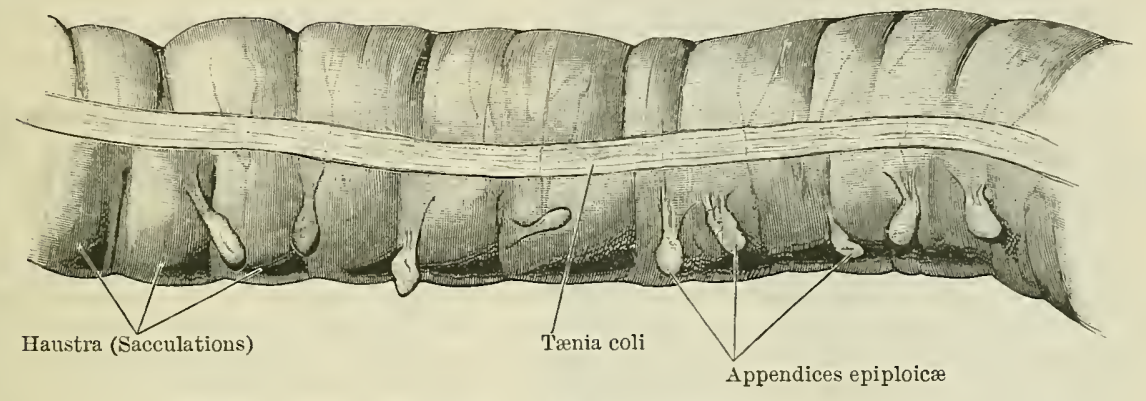

FIG. 950.-LARGE INTESTINe.

A piece of transverse colon from a child two years old. The three chief characteristics of the large intestinesacculations, tæniæ, and appendices epiploicæ-are shown.

4. Colon Descendens. - The descending colon runs down on the left side, from the splenic flexure to the rectum.

It is usually divided into the following parts :-

(a) Descending colon, which extends down to the crest of the ilium.

(b) The iliac colon extends from the crest of the ilium to the superior aperture of the pelvis, where it is succeeded by the pelvic colon.

(c) The pelvic colon is a large loop of intestine which is usually found in the pelvis. The iliac and pelvic portions of the colon taken together are sometimes described as the colon sigmoideum.

5. Intestinum Rectum. - The rectum, the terminal part of the large bowel, succeeds the pelvic colon, and ends in the anal canal, which opens on the surface at the anal orifice.

In its course the large bowel is arranged in an arched manner around the small intestine, which lies within the concavity of the curve (Fig. 912).

In length, the great intestine is equal to about one-fifth of the whole intestinal canal, and usually measures between 5 and $5 \frac{1}{2}$ feet $(180$ to $195 \mathrm{~cm}$.). Its breadth is greatest at the cæcum, and from this-with the exception of a dilation at the rectum-it gradually decreases to the anus. At the cæcum it measures, when distended, about 3 inches $(75 \mathrm{~mm}$.) in diameter; beyond this it gradually diminishes, and measures only $1 \frac{1}{2}$ inches $(37 \mathrm{~mm}$.) or less in the descending and iliac divisions of the colon.

The large intestine, with the exception of the rectum and vermiform process, may be easily distinguished from the regularly cylindrical small intestine by $(a)$ the presence of three longitudinal bands-the tæniæ coli-running along its surface (Fig. 950); (b) by the fact that its walls are sacculated; and (c) by the presence of numerous little peritoneal processes, known as appendices epiploicæ, projecting from its serous coat. In addition, the larger intestine is usually wider than the small, but reliance cannot be placed on this character, for the jejunum is oftenindeed, generally -wider than the empty and contracted descending colon.

Tæniæ Coli.-In the large bowel, unlike the small, the longitudinal fibres of the muscular coat do not form a complete layer, continuous all round the tube, 
but, on the contrary, are broken up (Fig. 950) into three bands, known as the tæniæ coli. These bands, which are about $\frac{1}{4}$ inch $(6 \mathrm{~mm}$.) wide, begin at the base of the vermiform process, and run along the surface of the gut at nearly equal distances from one another until the rectum is reached. Here they spread out and form a layer of longitudinal muscular fibres, which is continuous all round the tube (see p. 1229). The bands are about one-sixth shorter than the intestine to which they belong; consequently, in order to accommodate the bowel to the length of the tæniæ, the gut is tucked up, giving rise to a sacculated condition (Fig. 950). Three rows of pouches or saccules are thus produced, along the length of the tube, between the tæniæ. If the tæniæ be dissected off, the sacculations largely disappear, the intestine becomes cylindrical, and at the same time about one-sixth longer.

The appendices epiploicæ (Fig. 950) are little processes or pouches of peritoneum, generally more or less distended with fat, except in emaciated subjects, which project from the serous coat along the whole length of the large intestine, with the exception of the rectum proper.

When the interior of a piece of distended and dried large intestine is examined, its saccules appear as rounded pouches, haustra, separated by crescentic folds, plicæ semilunares coli, corresponding to the creases on the exterior separating the saccules from one another.

The position of the three tæniæ on the intestines is as follows :-On the ascending, descending, and iliac colons one tænia lies on the anterior aspect of the gut, and two on the posterior aspect, namely, one to the lateral (postero-lateral), the other to the medial side (postero-medial). It is chiefly along the first of these (the anterior) that the appendices epiploicæ are found. On the transverse colon their arrangement is different, but is rendered exactly similar by turning the great omentum, with the colon, up over the thorax. On the transverse colon in the natural position, the anterior tænia of the ascending and descending colons becomes the posterior (or postero-inferior) termed tcenia libera, the postero-lateral becomes auterior or tonia omentalis, and the postero-medial becomes superior in position and is termed tcenia mesocolica. The anterior and postero-lateral tæniæ of the iliac colon pass below on to the front of the pelvic colon and rectum.

In formalin-hardened bodies portions of the large intestine, but particularly of the descending and sigmoid colons, are often found fixed in what appears to be a state of contraction, when they are reduced to a diameter of about $\frac{5}{8}$ or $\frac{3}{4}$ of an inch (16 to $19 \mathrm{~mm}$.). Under similar conditions parts of the small intestine are found correspondingly reduced.

The appendices epiploicæ, although generally said to be absent in the fœtus, can be distinctly seen as early as the seventh month, but at this time they contain no fat.

Structure of the Large Intestine.-The tunica serosa is complete on the vermiform process, cæcum, transverse colon, and pelvic colon; incomplete on the ascending, descending, and iliac divisions of the colon and on the rectum. It will be described in detail with each of these portions of the intestine.

The tunica mucosa is of a pale, or yellowish, ash colour in the colon, but becomes much redder in the rectum. Unlike that of the small intestine, its surface is smooth, owing to the absence of villi, but it is closely studded with the orifices of numerous large intestinal glands. Solitary lymph nodules are also numerous, particularly in the vermiform process (Fig. 955).

Vessels and Nerves.-The cæcum and vermiform process receive their blood from the ileo-colic artery; the ascending colon from the right colic artery; and the transverse colon from the middle colic artery, which lies in the transverse mesocolon. These are all branches of the superior mesenteric. The descending colon is smpplied by the left colic, and the iliac and pelvic colons by the sigmoid arteries, branches of the inferior mesenteric. The rectum derives its blood from the three hæmorrhoidal arteries, which will be described with that division of the gut.

The veins correspond largely to the arteries, and join the inferior and superior mesenteric vessels, which send their blood into the portal vein.

The lymph vessels of the large intestine arise from plexuses in the submucous and subperituneal coats, as in other parts of the alimentary canal.

The deeper vessels escape chiefly along the entering blood-vessels, those from the lateral aspects passing behind the intestine.

The vessels pass medially to a series of glands lying along the medial border of the intestine ("paracolic" glands (Jamieson)); thence they pass along the lines of the main arteries, passing then to glands disposed at intervals ahout these vessels (intermediate and main glands). The lymph ressels from the lower half of the descending, and from the iliac and pelvic colons, join the left lymph trunk of the lumbar glands. Those of the rectum and cæcum will be described later. 
Nerves.-The nerves come from the superior mesenteric plexus, an offshoot of the cœliac plexus, and from the inferior mesenteric, a derivative of the aortic plexus. The arrangement is similar to that of the nerves of the small intestine.

\section{INTESTINUM CACUM AND PROCESSUS VERMIFORMIS.}

Intestinum Cæcum.-After leaving the pelvic cavity, as already described, the terminal portion of the small intestine passes upwards, backwards, and to the right, and opens, by the ileocæcal orifice, into the large intestine some $2 \frac{1}{2}$ inches from its lower end. The portion of the large gut which lies below the level of this orifice is known as the intestinum cæcum. In shape (Fig. 951) it is a wide, asymmetrical, or lop-sided cul-de-sac, furnished with the tæniæ and sacculations usually found in the large, intestine. Its lower end or fundus is directed downwards and medially, and usually rests on the right psoas major muscle, close to the brim of the pelvis; whilst the opposite end is directed upwards and laterally, and is continued into the ascending colon.

Its asymmetrical form is due to the fact that the lateral and medial portions of the organ undergo an unequal

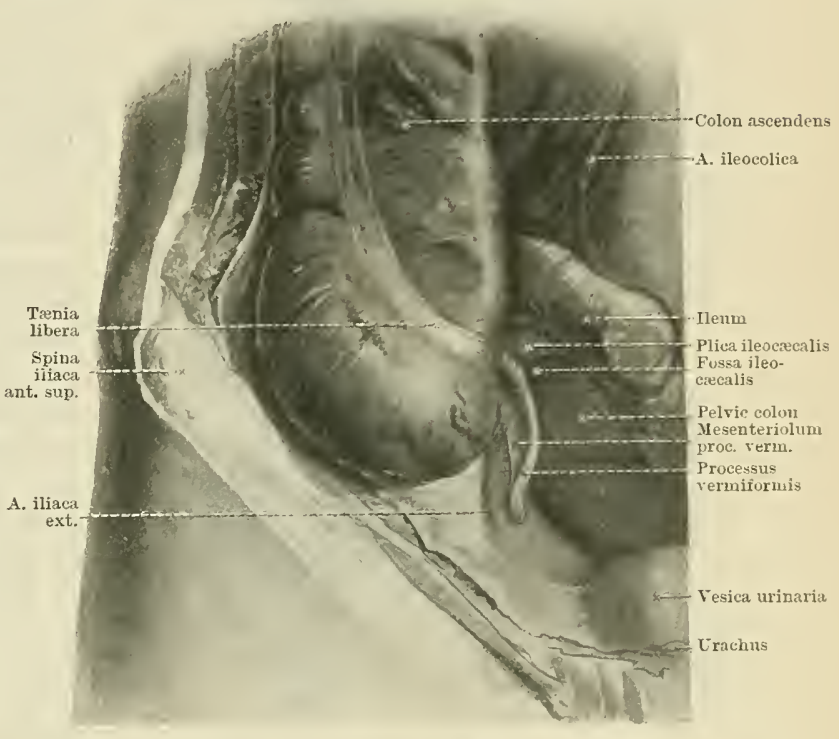

Fig. 951. - The Cacom and Vermiform Process from the front. development in the child. The medial (or medial and posterior) section lags behind, whilst the lateral (or lateral and anterior) division grows much more rapidly, and, projecting downwards, soon comes to form the inferior end or fundus of the cæcum. As a result the original extremity of the gut, with the vermiform process springing from it, is hidden away behind and to the medial side of the fundus.

In length the distended cæcum usually measures about $2 \frac{1}{2}$ inches $(60 \mathrm{~mm}$.); whilst its breadth is usually more, and averages about 3 inches $(75 \mathrm{~mm}$.).

Position. - It is usually situated almost entirely within the right iliac region of the abdomen, immediately above the lateral half or third of the inguinal ligament; but its inferior end projects medially in front of the psoas major and reaches the hypogastrium (Fig. 951). On the other hand, it is sometimes found high up in the right lumbar region (owing to the persistence of the foetal position), or hanging over the pelvic brim and dipping into the pelvic cavity to a varying extent.

In the great majority of cases the cæcum is completely covered with peritoneum on all aspects, and lies quite free in the abdominal cavity. In a small proportion, namely, about 6 or 7 per cent of bodies, the posterior surface (probably as a result of adhesions) is not completely covered, but over a greater or less portion of its extent is bound down to the posterior abdominal wall by connective tissue.

Relations.-Posteriorly, the cæcum rests on the ilio-psoas muscle; generally, too, on the vermiform process and the femoral nerve. Anteriorly, it usually lies in contact with the omentum and anterior abdominal wall; but when the cæcum is empty, the small intestine intervenes. Its lateral side is placed immediately above the lateral half or third of the inguinal ligament (Fig. 951), whilst the medial side has the termination of the ileum lying in contact with it. On the medial and posterior aspect, but more on the former than the latter, the small intestine joins the cæcum. On the same aspect, and usually from 1 to $1 \frac{1}{2}$ inches (25 to $37 \mathrm{~mm}$.) lower down, the vermiform process comes off. 
The interior of the cæcum corresponds in general appearance to that of the large intestine; but it presents two special features on the posterior part of its medial wall, namely, the ileo-cæcal orifice, guarded by the valvula coli (O.T ileocæcal valve), and below this the small opening of the processus vermiformis, both
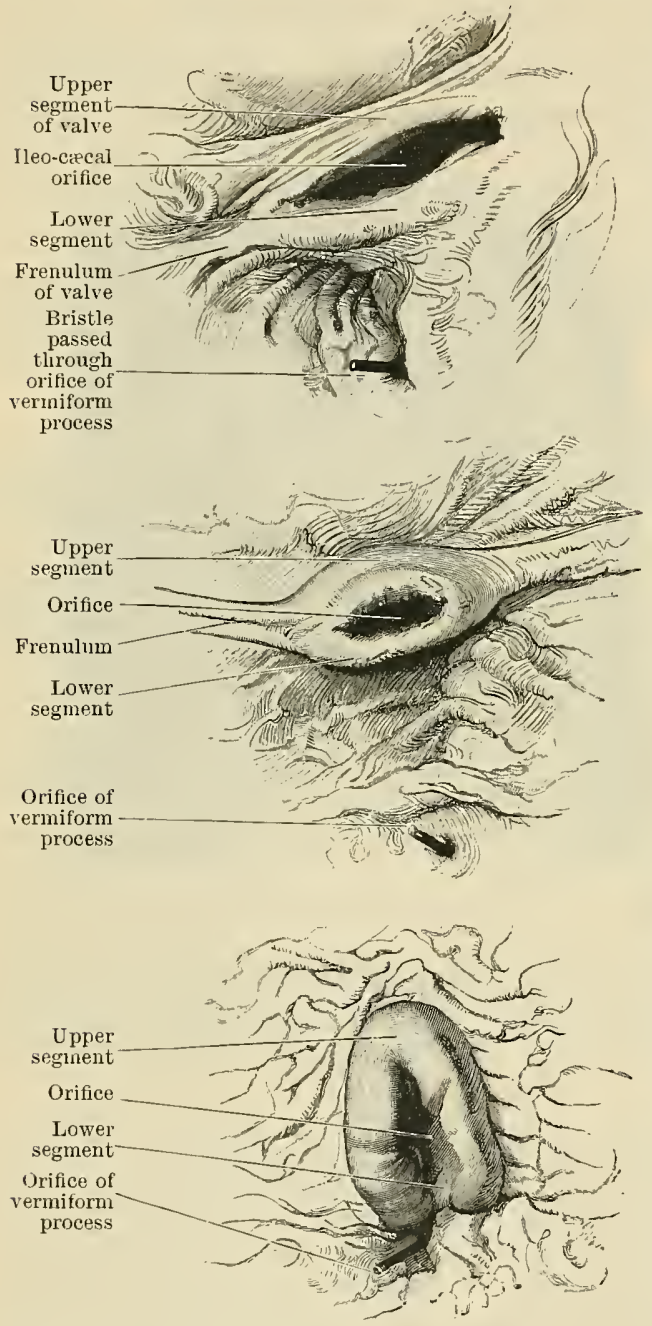

Fig. 952. - Three Forms of Valvula Coli, from bodies hardened by intra-vascular injections of formalin.

The hardening was not so complete in the case of the highest of the three valves represented. In each a bristle is passed through the orifice of the vermiform process. stretch, and, pulling upon the two segments of the valve, they bring them into apposition, and effect the closure of the orifice.

The position of the valvula coli, in the average condition, may be indicated on the surface of the body by the point of intersection of the intertubercular and vertical lateral lines. A point 1 to $1 \frac{1}{2}$ inches $(2.5$ to $3.7 \mathrm{~cm}$.) lower down would correspond to the orifice of the vermiform process.

In bodies hardened in situ with formalin, the valve and orifice present an entirely different appearance (see Fig. 952, in which three different forms of hardened valves are shown), suggesting, much more closely than in the dried state, the appearance of telescoping or inversion mentioned above. In them also the two segments of the valve are much thicker and shorter, but they can 
always be distinguished, and are found to bear the same relation to one another as in the dried condition, although this may be obscured by foldings or rugæ. The aperture may be slit-like or rounded, with sloping or funnel-shaped edges; the frenula are not so prominent at times; but the whole valve projects much more abruptly into the cavity of the cæcum than in the distended and dried specimen.

Structure of the Valvula Coli.-Each labium of the valve is formed of an infolding of all the coats of the gut, except the peritoneum and the longitudinal muscular fibres, and consequently consists of two layers of mucous membrane, with the submucosa and the circular muscular fibres between, all of which are continuous with those of the ileum on the one hand and of the large intestine on the other. The surface of each labium turned towards the small intestine is covered with villi, and conforms in the structure of its mucous membrane to that of the ileum; whilst the mucous membrane of the opposite surface resembles the mucous coat of the large bowel.

In the dried specimen the superior labium usually projects further into the cavity of the cæcum than the inferior, so that the aperture appears to be placed between the edge of the inferior segment and the inferior surface of the superior.

There is little doubt that the efficiency of the valvula coli is largely due to the oblique manner in which the ileum enters or invaginates the large intestine; this oblique passage alone, as in the case of the ureter piercing the wall of the bladder, would probably be sufficient to prevent a return of the cæcal contents. In the great majority of cases, when in position within the body, the ileum is perfectly protected from such a return, although when the parts are removed, and then distended with fluid, this fluid often passes throngh the valve, and reaches the small intestine. Still, the efficiency of such a test, applied when the parts are deprived of their natural supports, cannot be relied upon.

The size of the segments of the valve, as seen in the dried

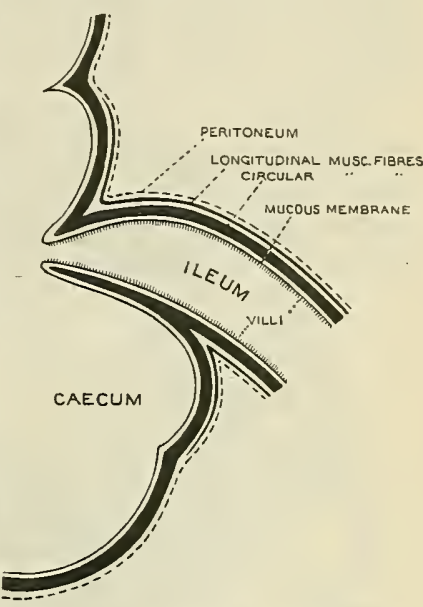

Fig. 953. - Diagramiatic Section THROUGH THE JUNCTION OF THE ILEUM WITH THE CÆCUM, TO SHOW THE Formation OF THE YaLvula Coli. condition, varies considerably; they are sometimes very imperfect; and even the absence of both has been recorded. But here again there is danger of falling into error, through examining the parts under such artificial conditions.

Types of Cæcum.-Three chief types of cæcum may be distinguished-the fotal type, conical in shape and nearly symmetrical, with the inferior end gradually passing into the vermiform process; the infantile, in which the passage from the cæcum to the vermiform process becomes more abrupt, the lateral wall more prominent, and the whole sac more asymmetrical; and the lopsided adult form, as described above, which is the condition found in 93 or 94 per cent of adults.

Structure.-Nothing in the arrangement of the mucous and submucons coats calls for special notice. The tæniæ or longitudinal bands of the muscular coat all spring from the base of the vermiform process (Fig. 954); the anterior runs up on the front, medial to the main prominence of the creum; the postero-lateral runs up behind this prominence; whilst the postero-medial passes directly upwards behind the ileum (Fig. 954). The longitudinal fibres on the superior aspect of the ileum partly join the posteromedial tænia; those on the anterior and posterior aspects join the circular fibres of the large gut.

The serous coat has, in connexion with it, certain folds and fossæe which are described at p. 1218.

Processus Vermiformis (Fig. 954). - The vermiform process (O.T. appendix, or vermiform appendix) is a worm-like tubular outgrowth which springs from the medial and posterior part of the creum about 1 to $1 \frac{1}{2}$ inches $(2.5$ to $3.75 \mathrm{~cm}$.) below the ileo-crcal orifice. From this point it generally runs in one of three chief directions, namely-(1) over the brim, into the pelvis; (2) upwards behind the cæcum; or (3) upwards and medially, thus pointing towards the spleen; each of which has been considered to be the normal position by one or more observers. In the first of these situations it is quite evident as it hangs over the pelvic brim; in order to expose it in the second, the cæcum must be turned upwards; whilst, in the third position, it lies behind the end of the ileum and its mesentery, and these must be raised up in order to display it. In addition to the positions just mentioned, it 
has been found in almost every possible situation in the abdomen which its length and the extent of its mesentery would allow it to attain. In every case the anterior tænia of the cæcum, which is always distinct, offers the surest guide to the vermiform process, and its base can be located with certainty by following this trnia to the back of the cæcum (Fig. 954).

Its size is almost as variable as its position. Taking the average of numerous measurements, its length may be given as about $3 \frac{1}{2}$ inches (92 mm., Berry), and its breadth as $\frac{1}{4}$ inch ( $6 \mathrm{~mm}$., Berry). On the other hand, it has been found as long as 9 inches $\left(230 \mathrm{~mm}\right.$.), and as short as $\frac{3}{4}$ inch $(18 \mathrm{~mm}$.). Even its absence has been recorded (Fawcett), but this must be looked upon as an extremely rare occurrence.

Its lumen or cavity is variable in its development, and is found to be totally or partially occluded in at least one-fourth of all adult and old bodies examined. This is looked upon as a sign of degeneracy in the process of gradual obliteration, which it is by many considered to be undergoing, in the human species. It opens into the cavity of the cæcum on its medial, or medial and posterior aspect

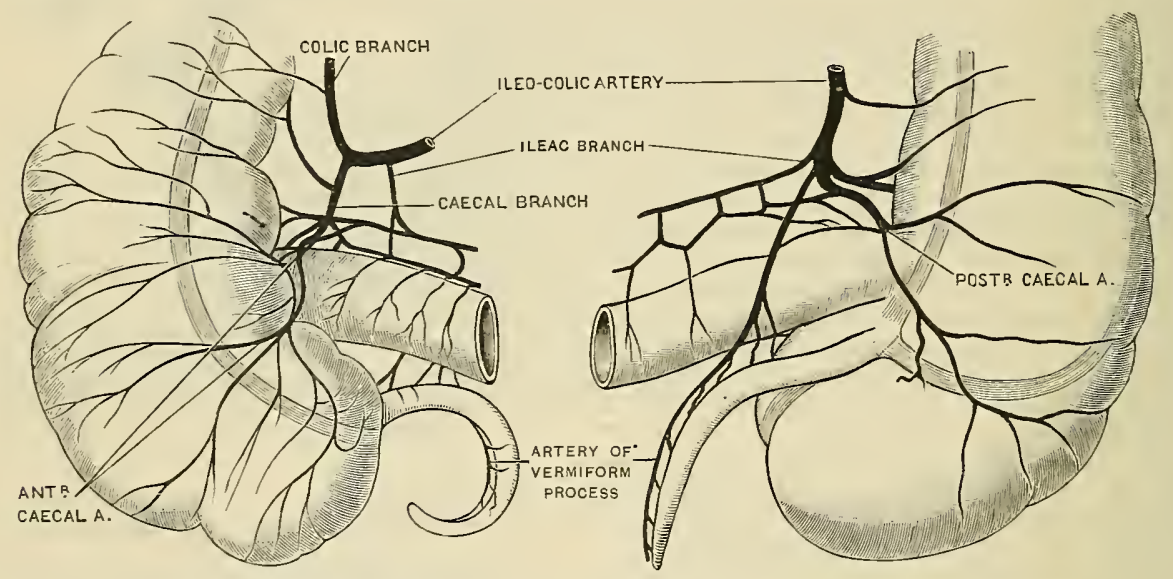

Fig. 954.-The Blood-Supply of The Cafcum ANd Veruiform Process.

The illustration to the left gives a front view ; in that to the right the creum is viewed from behind. In the latter the artery of the process, and three tæniæ coli springing from the base of the vermiform process should be specially noted. (Modified from Jonnesco).

(Fig. 952), at a point 1 to $1 \frac{1}{2}$ inches $(2.5$ to $3.8 \mathrm{~cm}$.) below, and somewhat posterior to the ileo-cæcal orifice. These are the relative positions of the two orifices, as seen from the interior of the cæcum; viewed from the exterior, the base of the vermiform process is within $\frac{3}{4}$ inch of the lower border of the ileum. This apparent difference is due to the fact that the ileum adheres to the medial side of the cæcum for a distance of nearly 1 inch before it opens into it.

Sometimes the orifice of the vermiform process has a crescentic fold or valve, the valvula processus vermiformis placed at its superior border; but it is probably of very little functional importance, for the aperture of the process is usually so small that its cavity is not likely to be invaded by the contents of the cæcum.

The vermiform process is completely covered with peritoneum, and has a considerable mesentery, the mesenteriolum processus vermiformis (O.T. meso-appendix), which extends to its tip as a rule, and connects the process to the inferior surface of that part of the mesentery proper which goes to the inferior extremity of the ileum.

The vermiform process is relatively, to the rest of the large intestine, longer in the child at birth than in the adult, the proportion being about 1 to 16 or 17 at birth and 1 to 19 or 20 in the adult. (The difference is certainly not as great as stated by Ribbert, who makes the proportion 1 to 10 at birth and 1 to 20 in the adult.) The process attains its greatest length and diameter during adult and middle age, and atrophies slowly after that time. It is said to be slightly longer in the male than in the female.

Total occlusion of its carity is found in 3 or 4 per cent of bodies; it is then converted into a fibrous cord. Partial occlusion is present in 25 per cent of all cases, and in more than 50 per cent 
of those over 60 years old, whilst it is unknown in the child. This frequency of occlusion, the physiological atrophy which takes place after middle life, the great variations in length, and other signs of instability, have been considered to point to the retrogressive character of the vermiform process.

A vermiform process is found only in man, the higher apes, and the wombat, although in eertain rodents a somewhat similar arrangement exists. In carnivorous animals the cæcum is very slightly developed; in herbivorous animals (with a simple stomach) it is, as a rule, extremely large. It has been suggested that the rermiform process in man is the degenerated remains of the herbivorous cæcum, which has been replaced by the carnivorous form. Another and perhaps more probable view regards the process as a lymph organ, having the same functions as lymph nodules, and, like these, undergoing degeneration after middle life (Berry).

In the fotus and child, as well as in the adult with the infantile type of cæcum, the vermiform process springs from the true apex, not from the mesial and posterior aspect.

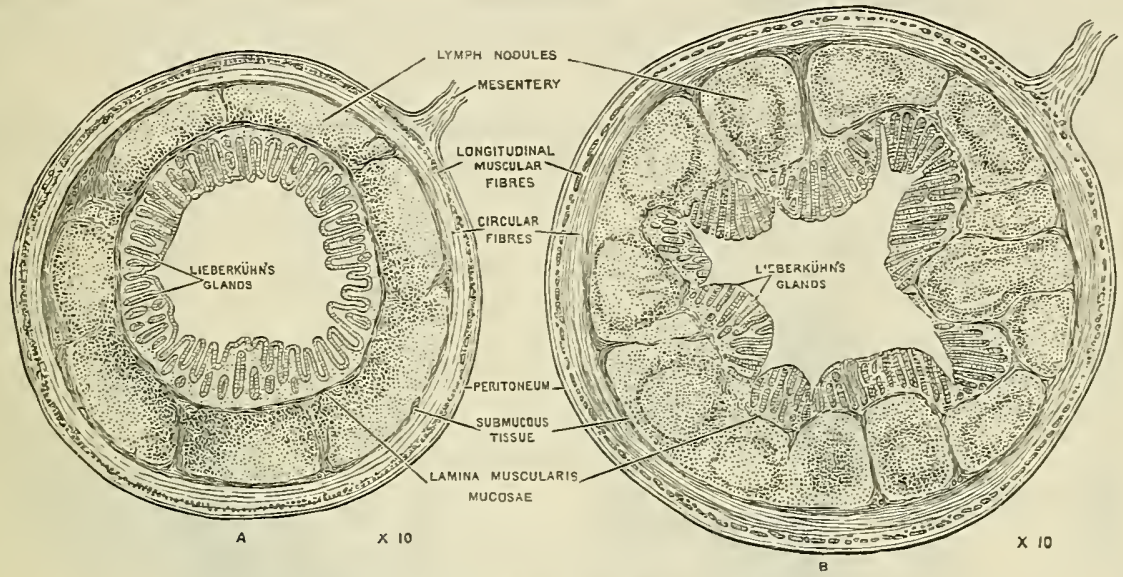

F1G. 955.-Strecture of the Vermiform Process.

A. From a child two years old.

B. From a male, age 56 .

It will be observed that the tela submucosa is almost entirely occupied by lymph nodules and patches. The lamina muscularis mucosi is very faint, and lies quite close to the bases of the intestinal glands. The longitudinal layer of muscular fibres forms a continuous sheet.

Foreign bodies, although reputed to find their way very easily into the vermiform process, are rarely found there after death. On the other hand, concretions or calculi, formed of micus, fæces, and various salts, are often present (Berry).

Structure (Fig. 95̃).-The tunica serosa is complete, and forms a perfect investment for the process. The tunica muscularis, unlike that of the rest of the large intestine, has a continuous and stout layer of longitudinal fibres, which passes at the root of the process into the three truire coli (Fig. 954). The layer of circular fibres is well dereloped. The tela submucosa is almost entirely occupied by large masses of lymph tissue surrounded by sinus-like lymph spaces. Owing to the large size of these lymph nodules, the areolar tissue of the submucosa is compressed against the inner surface of the muscular coat, and forms a well-marked fibrous ring, which sends processes at intervals between the lymph masses towards the mucous membrane. These lymph nodules, which correspond to solitary lymphoid nodules, have, owing to their great number, been almost completely crushed out of the mucosa (in which they chiefly lie in the intestine) into the submucosa.

The mucous coat corresponds to that of the large intestine in its general characters, but the intestinal glands are fewer, and irregular in their direction; the lamina muscularis mucosæe is thin and ill-defined; it lies just internal to the lrmphoid nodules of the submucosa, and immediately outside the base of the intestinal glands. Some few lymph nodules lie in the mucous coat also.

Blood-vessels of the Cæcum and Vermiform Process (Fig. 954). - These parts are supplied with blood by the ileo-colic artery. This gives off, near the upper angle formed by the junction of the ileum with the small intestine- $(a)$ an anterior cceal artery, which passes down on the front of the ileo-cæcal junction to the cæcum, and breaks up into numerous branches for the supply of that part; (b) a posterior coecal artery, similariy disposed on the back ; and (c) the artery for the vermiform process. The last-named branch passes down behind the ileum (Fig. 954), then enters the mesentery of the process, and running along this near its free border, sends off several branches across the little mesentery to the process, before finally ending in it. The course of the artery behind the ileum is said to render it subject to pressure from frecal masses in that gut, and thus to predispose to an interference with the blood supply of the rermiform process, and to morbid changes in it. 
The lymph vessels of the excum and vermiform process arise mainly from networks in the mucous and serous coats.

The first of these networks communicates with a lymph sinus which is found at the base of the lymph nodules in the process, and the vessels from it pierce the muscular coats, and pass in company with the blood-vessels. They are connected with mucons lympl glands found near the ileo-excal junction, especially on the posterior and medial aspect, in the angle between the ileum and colon.

Small isolated glands may be found lying in close contact with the medial part of the cæcum, on its anterior and posterior aspects. From these glands, the lymph stream is directed upwards and medially towards the coliac and lumbar glands. The lymph vessels of the vermiform process may also communicate with the lymph nodes in the iliac fossa, and also, it has been stated, with the lymph vessels of the right ovary.

Cacal Folds and Fossæ.-The peritoneum in the neighbourhood of the cæcum forms certain fossæ, of which the most interesting and important are- $(a)$ the fossa cæcalis; $(b)$ the recessus ileocæcalis inferior; $(c)$ the recessus ileocæcalis superior; and (d) the recessus retrocæecalis.

(a) The fossa cæcalis (Fig. 956, B) is only occasionally present, and can be exposed by turning the cæcum and adjacent part of the ileum upwards. It is a fossa in the
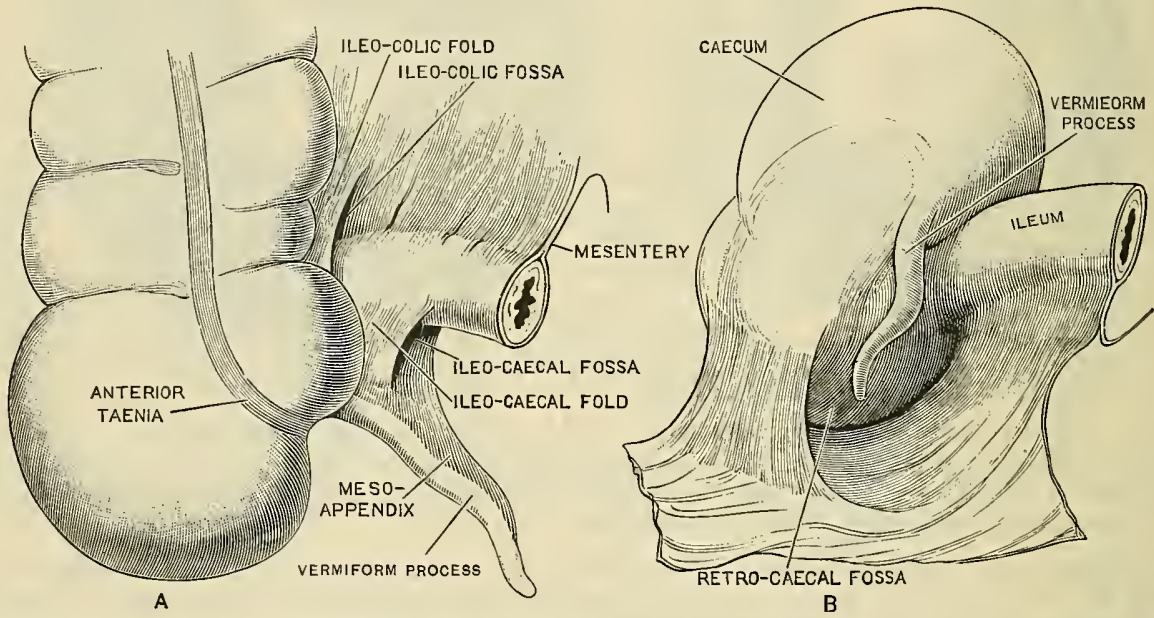

Fig. 956.-The Cecal Folds and Fossw.

In $\mathrm{A}$, the creum is viewed from the front; the mesentery of the vermiform process is distinct, and is attached above to the inferior surface of the portion of the mesentery going to the end of the ileum. In $B$, the cæcum is turned upwards to show a retro-cæcal fossa, which lies behind it and behind the beginning of the ascending colon.

parietal peritoneum on the posterior abdominal wall, open above, in which the lower end of the cæcum occasionally lies. It is produced by the plica caecalis, a peritoneal fold which passes from the surface of the iliacus to the right lateral aspect of the cæcum. Two forms, lateral and medial, are described; the first lies behind the lateral part of the ascending colon, immediately above the cæcum; the second behind its medial part. These fossæ are specially interesting because, when present, they frequently lodge the vermiform process (see Fig. 956, B), a condition which is said to favour the production of appendicitis.

$(\zeta$ and c) Recessus Ileocæcales and Plica Ileocæcalis.-If the vermiform process is drawn down, and the finger run towards the cæcum, along the inferior border of the terminal part of the ileum, its point will generally run into a fossa situated in the angle between the ileun and cæcum (Fig. 956, A), which is known as the recessus ileocacalis inferior. The fold which bounds the fossa in front is the plica ileoccecalis (O.T. the "bloodless fold of Treves"). It passes from the ileum to the front of the mesentery of the vermiform process, which forms the posterior wall of the fossa.

The plica ileocæcalis contains some unstriped muscle fibres continuous with the longitudinal muscle coat of the cæcum, and some fat especially at its free margin.

The recessus ileocæcalis inferior is bounded in front by the lower end of the ileum, to the right by the cæcum, above by the plica ileocæcalis, below by the root of the mosenteriolum of the processus vermiformis, while it is open to the left or medially.

Similarly, if the finger is run out along the superior border of the ileum towards the cæcum, it will usually lodge in a smaller fossa, the recessus ileocacalis superior, which is 
bounded in front by a small peritoneal process, the ileo-colic fold (Fig. 956, A), containing the anterior cæcal artery.

The recessus ileocæcalis superior lies at the upper margin of the opening of the ileum into the colon, and is bounded behind by the ileum, to the right by the cæcum.

(d) Recessus Retrocæcalis.--This is an occasional recess which passes upwards between the ascending colon and the posterior abdominal wall. Its orifice looks downwards or to the left, and lies in the fossa crecalis behind the crecum.

\section{COLON.}

Colon Ascendens.-The ascending colon begins about the level of the intertubercular plane, opposite the ileo-cæcal orifice, where it is continuous with the cæcum. From this it runs upwards and somewhat posteriorly, with a slight concavity to the left, until it reaches the inferior surface of the liver, where it bends forwards and to the left, and passes into the right flexure of the colon (Fig. 957). In its course it lies in the angle between the quadratus lumborum, and the more prominent psoas major medially (Fig. 957).

It is situated chiefly in the right lumbar region, but it extends slightly into the hypochondrium above; and, although it usually begins about the level of the intertubercular plane, still with a low position of the cæecum it will extend further down, and may occupy a considerable part of the iliac region.

Its length is extremely variable, depending upon the extent to which the cæecum has descended from the position it occupied during development, viz., in contact with the under surface of the liver.

It is from 5 to 8 inches long, and it is wider and more prominent than the descending colon. It generally presents several minor curves or flexures, and it often has the appearance of being pushed into a space which is too short to accommodate it.

Relations.- Anteriorly, it is usually in contact with the abdominal wall, but the small intestine frequently intervenes, particularly above (Fig. 957). To its medial side lie the coils of the small bowel and the psoas major; to the lateral side is the lateral wall of the abdomen. Its posterior surface, which is free from peritoneum as a rule (Fig. 968), is connected by areolar tissue to the iliacus muscle as far up as the crest of the ilium, to the quadratus lumborum above this, and finally to the inferior part of the right kidney.

In the great majority of cases only the two sides and the anterior surface are covered with peritoneum, the posterior surface being destitute of a serous coat (Fig. 968). In a small proportion of bodies, however, the ascending colon is provided with a complete peritoneal coat and a mesentery, but this latter is so short that it admits of but a slight amount of movement in the gut.

On the lateral aspect of the cæcum and colon there are occasionally found small peritoneal pockets termed recessus paracolici.

Like the cæcum, the ascending colon is frequently found distended with gas or fæces after death, hence in part its large size and prominence as compared with the descending colon, which is generally empty.

Flexura Coli Dextra.-The right (O.T. hepatic) flexure of the colon is the bent piece of the large intestine between the end of the ascending colon and the beginning of the transverse colon (Figs. 947 and 957).

When the ascending colon reaches the inferior surface of the liver, it bendsusually acutely, sometimes obtusely - forwards and to the left on the anterior surface of the right kidney, and on reaching the front of the descending portion of the duodenum, passes into the transverse colon.

The flexure is placed between the descending duodenum medially and the anterior thin margin of the liver, or the lateral abdominal wall, laterally; above, it corresponds to the colic impression on the liver, and posteriorly it rests on the kidney. Its peritoneal relations are similar to those of the ascending colon.

Colon Transversum.-This is the long and looped portion of the large intestine 
which lies between the right and left flexures. It begins at the end of the right flexure, at the point where the colon passes forwards from the anterior surface of the kidney, and, turning to the left, crosses the descending duodenum (Fig. 957). It runs at first transversely to the left, and for the first few inches is comparatively fixed, being united to the front of the descending part of the duodenum and the head of the pancreas either by a very short mesentery or by areolar tissue. Immediately beyond this a long mesentery is developed, which allows the colon to hang down in front of the small intestine, at a considerable distance from the posterior abdominal wall. This portion of the colon is therefore very mobile, and consequently its position is very variable, and is influenced by posture and by the condition of the other viscera. Towards its left extremity the mesentery shortens again, thus bringing the gut towards the tail of the pancreas (Fig. 957), along which it runs upwards into the left hypochondrium, under cover of the stomach, as Iar as the inferior end of the spleen, where it passes into the left (O.T. splenic) flexure (Fig. 942). Its two ends lie in the right and left hypochondriac regions respectively, whilst its middle portion hangs down into the umbilical, or even the hypogastric region.

Its average length is about 19 or 20 inches $(47.5$ to $50.0 \mathrm{~cm}$.), that is, more than twice the distance, in a direct line, between its two extremities. This great length is accounted for by the curved and somewhat irregular course which the bowel pursues.

Relations. - The greater part of the transverse colon lies behind the greater omentum, which must consequently be turned upwards in order to expose it. Above, it is in contact, from right to left (Fig. 957), with the liver and gall-bladder (which also descend in front of the colon), the stomach, and, near its left end, with the tail of the pancreas and inferior end of the spleen (Fig. 947). Anteriorly are placed the omentum and the anterior abdominal wall; towards its termination the stomach also is anterior. Posteriorly, it first lies in contact with the descending duodenum and head of the pancreas; beyond this, where it hangs down, the small intestine is placed below and posteriorly, and it is connected to the posterior abdominal wall (more correctly, to the anterior border of the pancreas) by the transverse mesocolon. It is also loosely connected to the stomach by the lig. gastrocolicum which is attached to its anterior surface. The transverse mesocolon and the gastro-colic ligament are described with the peritoneum, p. 1242.

The transverse colon is completely covered with peritoneum, with the exception of the first few inches of its posterior surface, which are often, if not usually, uncovered.

The state of the peritoneal covering on the posterior surface of the first part of the transverse colon would seem to depend, in some degree, on the extent to which the liver passes downwards on the right side. With a small high liver no mesentery is present, and the posterior surface is devoid of peritoneum; on the other hand, when the liver is enlarged in the vertical direction, it pushes the colon downwards before it, and brings the upper line of the peritoneal reflection from its back, into contact with the lower, thus giving rise to the mesentery. In the fotus of three or four months every part of the colon is supplied with a long mesentery; subsequently this, as a rule, disappears at the beginning of the transverse colon, but it may be reproduced in the manner stated.

Flexura Coli Sinistra (Left Flexure of the Colon (O.T. Splenic Flexure))- The terminal portion of the transverse colon runs upwards (also posteriorly and to the left) until the inferior end or base of the spleen is reached; here it bends sharply, forming the left flexure, and runs down into the descending colon. The flexure is placed deeply in the left hypochondrium, posteriorly to the stomach, and in contact with the base of the spleen. It lies at a higher level than the right colic flexure, and is connected to the abdominal parietes by the phrenico-colic ligament, which helps to maintain it in this position.

Ligamentum Phrenicocolicum (Fig. 947).- This is a triangular fold of peritoneum, with a free anterior border, which is attached medially to the left flexure and laterally to the diaphragm opposite the ninth to the eleventh rib. (Owing to the fact that the base of the spleen rests upon it, the ligament has also received the older name of sustentaculum lienis.) 
The phrenico-colic ligament is formed in the fotus from the left margin of the greater omentum (Jonnesco).

The peritoneal covering of the left colic flexure is similar to that of the descending colon.

Colon Descendens.-The descending colon is much narrower and less obtrusive than the ascending colon: indeed in a large number of cases it is found firmly contracted. It begins in the left hypochondrium at the left flexure, passes down on the left side of the abdomen, and ends in the lumbar region, opposite the crest of the ilium, by passing into the iliac colon. Its course is not quite straight, for it first curves downwards and medially along the lateral border of the left kidney, and then descends almost vertically to the iliac crest (Fig. 957).

Its length is usually from 4 to 6 inches (10 to $15 \mathrm{~cm}$.), and its width, which is less than that of the ascending colon, about $1 \frac{1}{2}$ inches $(37 \mathrm{~mm}$.).

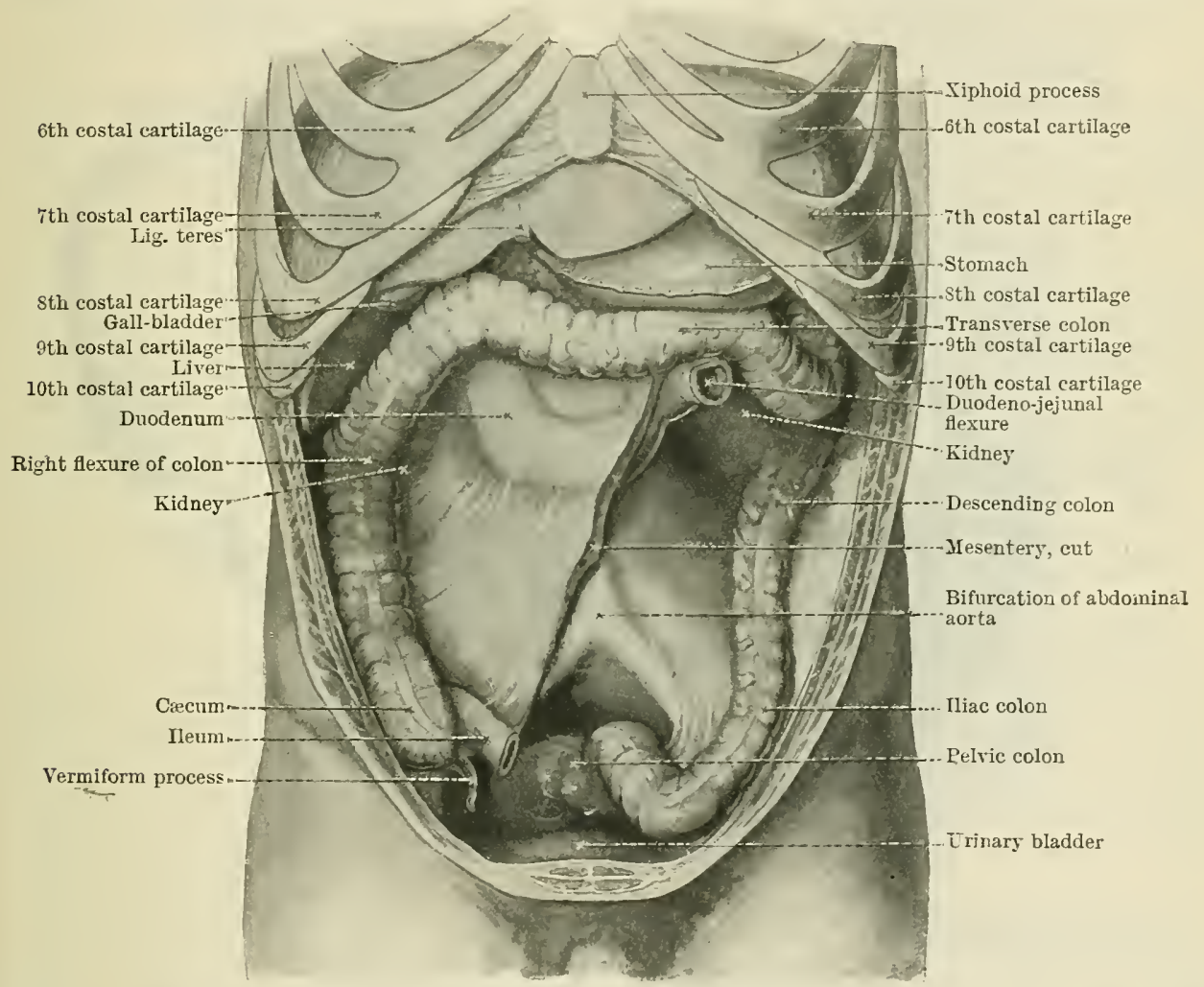

Fig. 957.-The Abdoninal Viscera after the Removal of the Jejuscm aNd Ileuvi (from a photograph of the same body as depicted in Fig. 912). The transverse colon is much more regular than usual.

Relations.-The descending colon first lies in contact with the lateral border of the left kidney; below this it is placed, like the colon of the opposite side, in the angle between the psoas and quadratus Inmborum muscles. Posteriorly, it rests upon the lower part of the diaphragm above, and on the quadratus lumborum below. Anteriorly (and somewhat laterally also, except when the bowel is distended) are placed numerous coils of small intestine, which hide the colon completely from view, and compress it against the posterior abdominal wall. To its medial side lies the inferior part of the kidney above, the psoas major below.

In the great majority of bodies only the front and sides of the descending colon are covered with peritoneum (Fig. 968); the posterior surface, being destitute of a serous coat, is connected to the posterior wall of the abdomen by areolar tissue. In a small proportion of cases, on the other hand, the serous coat is complete, and the colon is furnished with a short mesentery.

Up to the fourth or fifth month of fœtal life the descending colon has a complete investment of peritoneum and a long mesentery. After the fifth month the mesentery adheres to, and soon 
blends with, the parietal peritoneum on the posterior abdominal wall, and is completely lost as a rule. The persistence of this mesentery, in a greater or less degree, explains the occasional presence of a descending mesocolon in the adult.

Iliac Colon.-This corresponds to the portion of the "sigmoid flexure" which lies in the iliac fossa, and it has no mesentery. It is the direct continuation of the descending colon, with which it agrees in every detail, except as regards its relations. Beginning at the crest of the ilium, it passes downwards and somewhat medially, lying in front of the iliacus muscle. A little way above the inguinal ligament it turns medially over the psoas major, and ends at the medial border of this muscle by dipping into the pelvis and becoming the pelvic colon (Fig. 958). It usually measures about 5 or 6 inches $(12.5$ to $15 \mathrm{~cm}$.) in length, but it varies considerably in this respect.

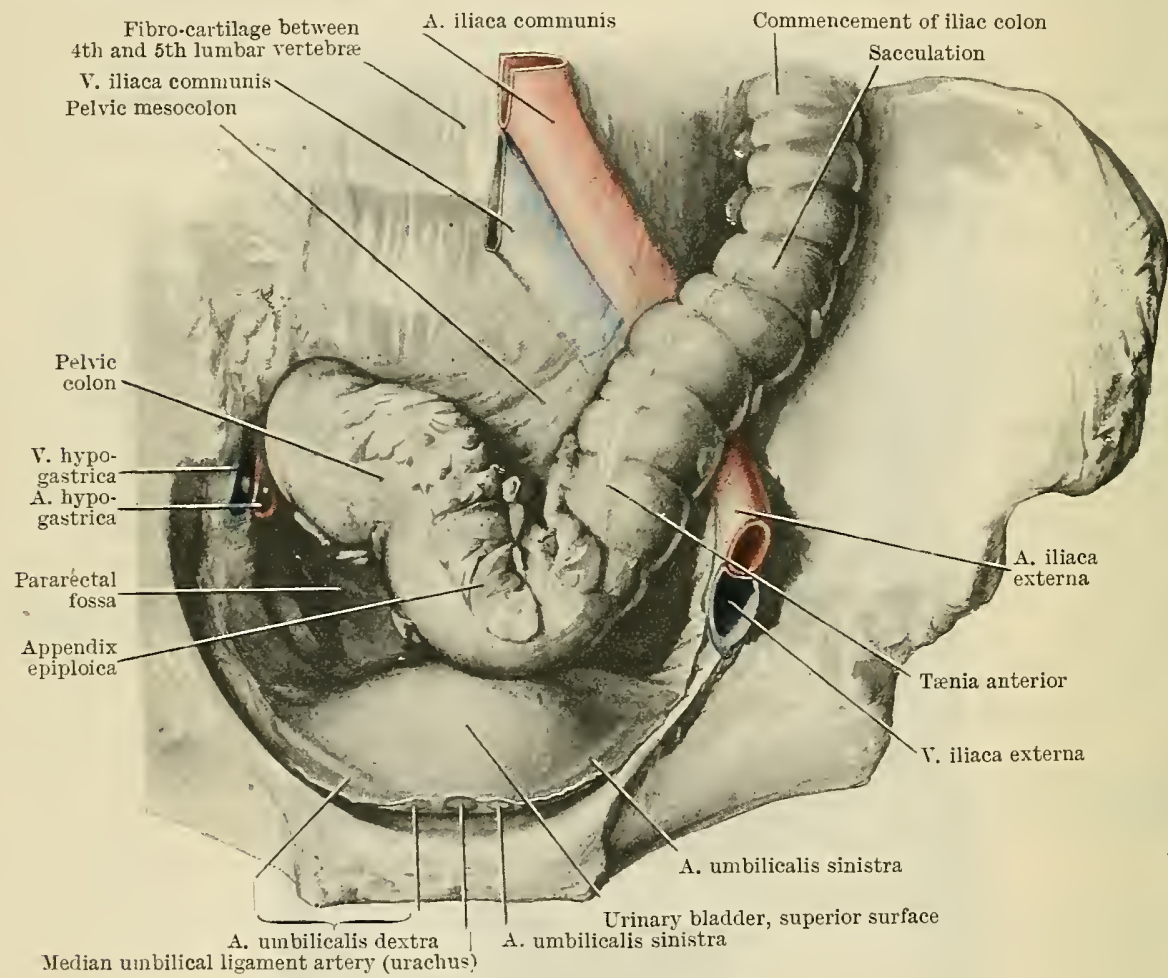

Fig. 958.-The Iliad and Pelvic Colon in situ.

Relations.-Posteriorly, it lies upon, and, as a rule, is connected by areolar tissue to, the front of the ilio-psoas muscle. It also crosses the left ureter, the left internal spermatic vessels, and the femoral nerve. Anteriorly, it is usually covered by coils of small intestine, which hide it from view; but when distended, or when it occupies a lower position than usual, it comes into direct contact with the anterior abdominal wall. As a rule ( 90 per cent of bodies-Jonnesco), it is covered with peritoneum only on its anterior and two lateral surfaces. Occasionally (10 per cent of cases) it is completely covered, has a short mesentery ( 1 inch, 2 to $3 \mathrm{~cm}$.$) , and is slightly movable.$

In its course it passes down over the iliac fossa near its middle, generally forming a curve with its concavity directed medially and upwards, and having reached a point $1 \frac{1}{2}$ or 2 inches $(4$ to $5 \mathrm{~cm}$.) above the inguinal ligament, it turns medially across the psoas major towards the pelvic cavity. Occasionally the iliac colon occupies a lower position than this, and runs along the deep surface of the inguinal ligament, immediately behind the anterior abdominal wall.

Pelvic Colon.-The pelvic colon is a large coil of intestine, which begins at the medial border of the left psoas major muscle, where it is continuous with the iliac 
colon, and ends at the level of the third sacral vertebra by passing into the rectum. Between these two points it has a well-developed mesentery, and forms a large and variously shaped coil, which usually lies in the cavity of the pelvis (93 per cent).

Whilst the loop of the pelvic colon is very irregular in form, the following may be given as perhaps its most common arrangement. Beginning at the medial margin of the left psoas major, it first plunges over the brim into the pelvis, and crosses this cavity from left to right; it next bends backwards and then returns along the posterior wall of the pelvis towards the median plane, where it turns down and passes into the rectum (Figs. 957 and 958).

Relations. - In its passage into the pelvis it crosses the external iliac vessels; in ruming from left to right across the cavity, it rests on the bladder or uterus, according to the sex; whilst above it lie the coils of the small intestine.

It is completely covered by peritoneum, and is furnished with an extensive mesentery - the pelvic mesocolon - which permits of considerable movement.

In cases where the pelvic colon is unusually long (Fig. 957), in returning from the right side of the pelvis it crosses the median plane, going even as far as the left wall, and then turns back a second time towards the middle of the sacrum, where it joins the rectum at the usual level, thus making an S-shaped curve within the pelvis. On the other hand, when the loop is short (a not infrequent occurrence), all its curves are abridged, and it fails to pass over to the right side, but runs more or less directly backwards after entering the pelvis.

From what has been said it will be seen that the loop of the pelvic colon is subject to numerous and considerable variations, which are chiefly dependent upon its length and that of its mesentery, and also upon the state of emptiness or distension of itself and of the other pelvic viscera. When the intestine is long the loop is more complex; when short, more simple. When the bladder and rectum are distended, or when the pelvic colon itself is much distended, it is unable to find accommodation in the pelvis minor, and consequently it passes up into the abdominal cavity, almost any part of the lower half of which it may occupy. But, as already stated, in the great majority of cases (92 per cent, according to Jonnesco) it is found after death lying entirely within the pelvic cavity.

In length, the pelvic colon generally measures about 16 or 17 inches (40 to $42.5 \mathrm{~cm}$.), but it may be as short as 5 inches (12 cm.), or as long as 35 inches $(84 \mathrm{~cm}$.$) .$

The pelvic mesocolon, which corresponds to both the sigmoid mesocolon and the mesorectum, is a fan-shaped fold, short at each extremity, and long in its middle portion (Figs. 957 and 958). Its root is attached along an inverted $V$-shaped line, one limb of which runs up close to the medial border of the left psoas major, as high as the bifurcation of the common iliac artery (or often ligher); here it bends at an acute angle, and the second limb descends over the sacral promontory and along the front of the sacrum to the middle of its third piece, where the mesentery ceases, and the pelvic colon passes into the rectum. When the pelvic colon ascends into the abdominal cavity this mesentery is doubled up on itself, the side which was naturally posterior beconing anterior.

Recessus Intersigmoideus. - When the pelvic colon with its mesentery is raised upwards, a small orifice will usually be found beneath the mesentery, corresponding to the apex of the $V$-shaped attachment of its root to the posterior abdominal wall. This orifice leads into a fossa which is directed upwards, and will often admit the last joint of the little finger. It is known as the intersigmoid fossa, and is due to the imperfect blending of the mesentery of the descending colon of the fotus with the parietal peritoneum. The ureter is found lying behind the apex of this fossa. In the fotus this mesentery is well developed, and extends from the region of the vertebral column out towards the descending colon. After a time it begins to unite with the underlying parietal peritoneum; but in the region of the intersigmoid fossa the union is rarely perfect, hence the presence of the fossa.

In the child at birth only the terminal part of the pelvic colon lies in the pelvis. This is chiefly owing to the small size of the pelvic cavity in the infant. Beginning at the end of the iliac colon, the pelvic colon generally arches upwards and to the right across the abdomen towards the right iliac fossa, where it forms one or two coils, and then passes down over the right side of the pelvic brim into the pelvic cavity. In cases of imperforate anus, it is important to remember, in connexion with the operation for forming an artificial anus, that, whilst the iliac colon is found in the left iliac region, the pelvic colon ("sigmoid flexure") usually lies on the right side, and passes over the right portion of the brim to enter the pelvis.

Structure of the Pelvic Colon.-Only the arrangement of the muscular coat need be referred to. As the tæniæ of the descending colon are followed down, it will be found that the posterolateral band gradually passes on to the front, and unites with the anterior trenia to form a broad band, which occupies nearly the whole width of this bowel in its lower portion. The posteromedial truia spreads out in a similar manner on the back; so that in the inferior half of the pelvic colon the longitudinal layer of the muscular coat is complete, with the exception of a narrow part on each side; here the circular fibres come to the surface, and the intestine presents 
a series of small sacculations. These, however, disappear, and the longitudinal fibres, although thicker in front and behind, form a continuous layer all round, as the rectum proper is approached.

\section{INTESTINUM RECTUM.}

Intestinum Rectum.-The rectum is the portion of the large bowel which intervenes between the pelvic colon above and the anal canal-the slit-like passage through which it communicates with the exterior (Fig. 961).

Unlike the portion of the bowel which immediately precedes it, the rectum has but a partial covering of peritoneum, and is entirely destitute of a mesentery; sacculations, too, which are so characteristic of the large intestine, cannot properly be said to be present.

The rectum begins at the termination of the pelvic mesocolon, namely, about the

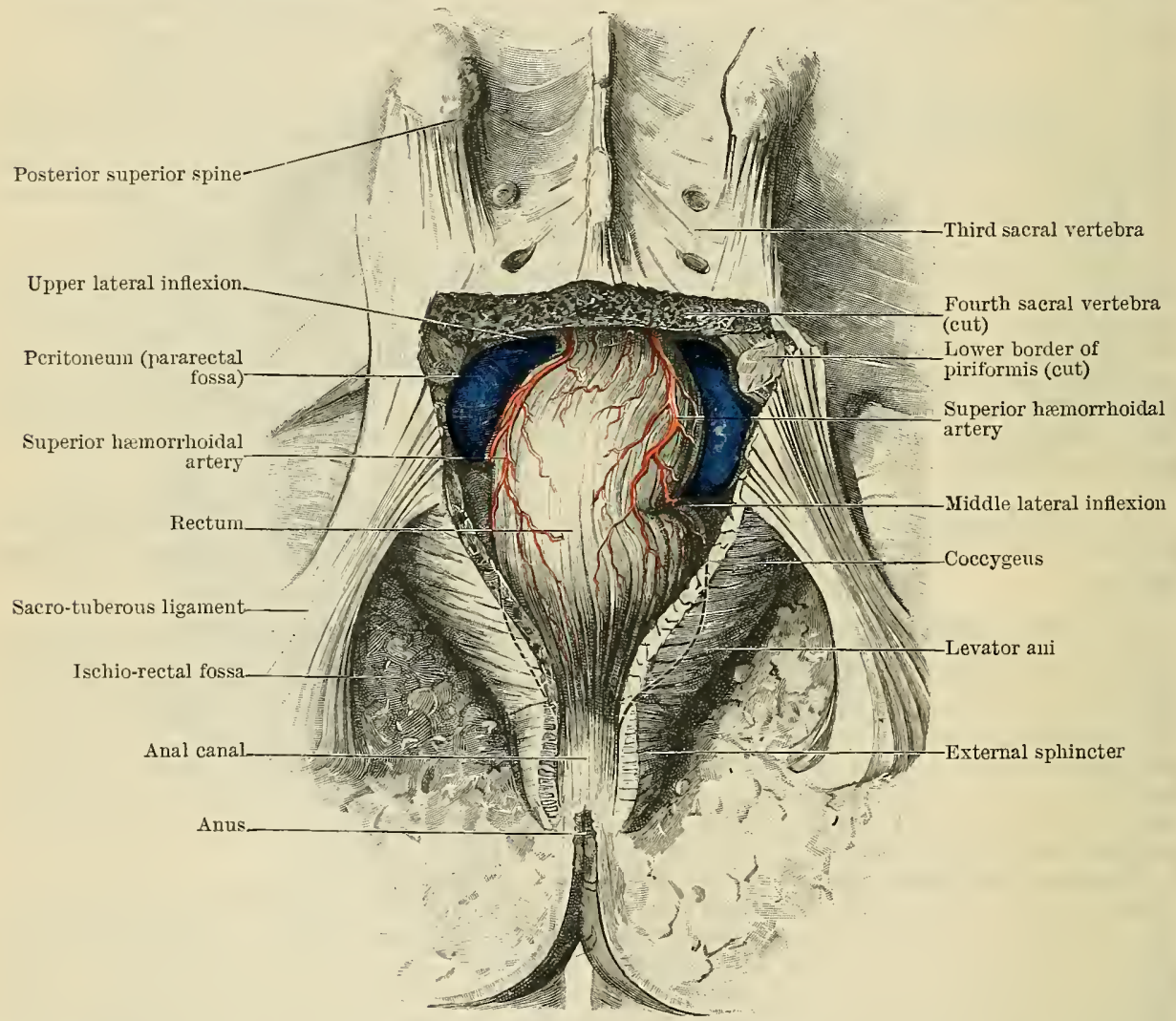

Fig. 959.-The Rectum From Behind.

The sacrum has been sawn across through the 4 th sacral vertebra, and its inferior part removed with the coccyx. The posterior portions of the coccygei, levatores ani, and of the external sphincter have been cnt away. The "pinching in " of the lower end of the rectum by the medial edges of the levatores ani, resulting in the formation of the flattened anal canal, is suggested in the illustration, which has been made from a formalin-hardened male body, aged 30. The lateral inflexions of the rectum, corresponding to the plicæ transversales recti, are also shown.

level of the third sacral vertebra, and ends, where the bowel pierces the pelvic floor, opposite the inferior and posterior part of the prostate in the male, or at a point $1 \frac{1}{2}$ inches $(3.7 \mathrm{~cm}$.) in front of, but at a more inferior level than, the tip of the coccyx in both sexes. It first descends along the front of the sacrum and coccyx, following the curve of these bones; beyond the coccyx, it rests, for about $1 \frac{1}{2}$ inches $(3.7 \mathrm{~cm}$.), on the posterior part of the pelvic floor, here formed by the union of the two levatores ani; and finally, having reached the inferior part of the prostate, it bends rather abruptly posteriorly and inferiorly, and, piercing the pelvic floor, passes into the anal canal (Fig. 959). 
Its general direction is downwards, but this varies at its two extremities, being downwards and posteriorly above, downwards and strongly anteriorly below:

Curvatures. - The rectum is far from straight, notwithstanding its name, for it is curved in both the antero-posterior and the transverse planes. Viewed from the side, it forms a gentle curve, with the convexity posteriorly, which extends from the beginning of the rectum to the back of the prostate, and fits into the hollow of the sacrum and coccyx (flexura sacralis). At the back of the prostate a second curve (flexura perinealis) is formed where the rectum joins the anal canal; this has its convexity directed forwards, whilst its concavity

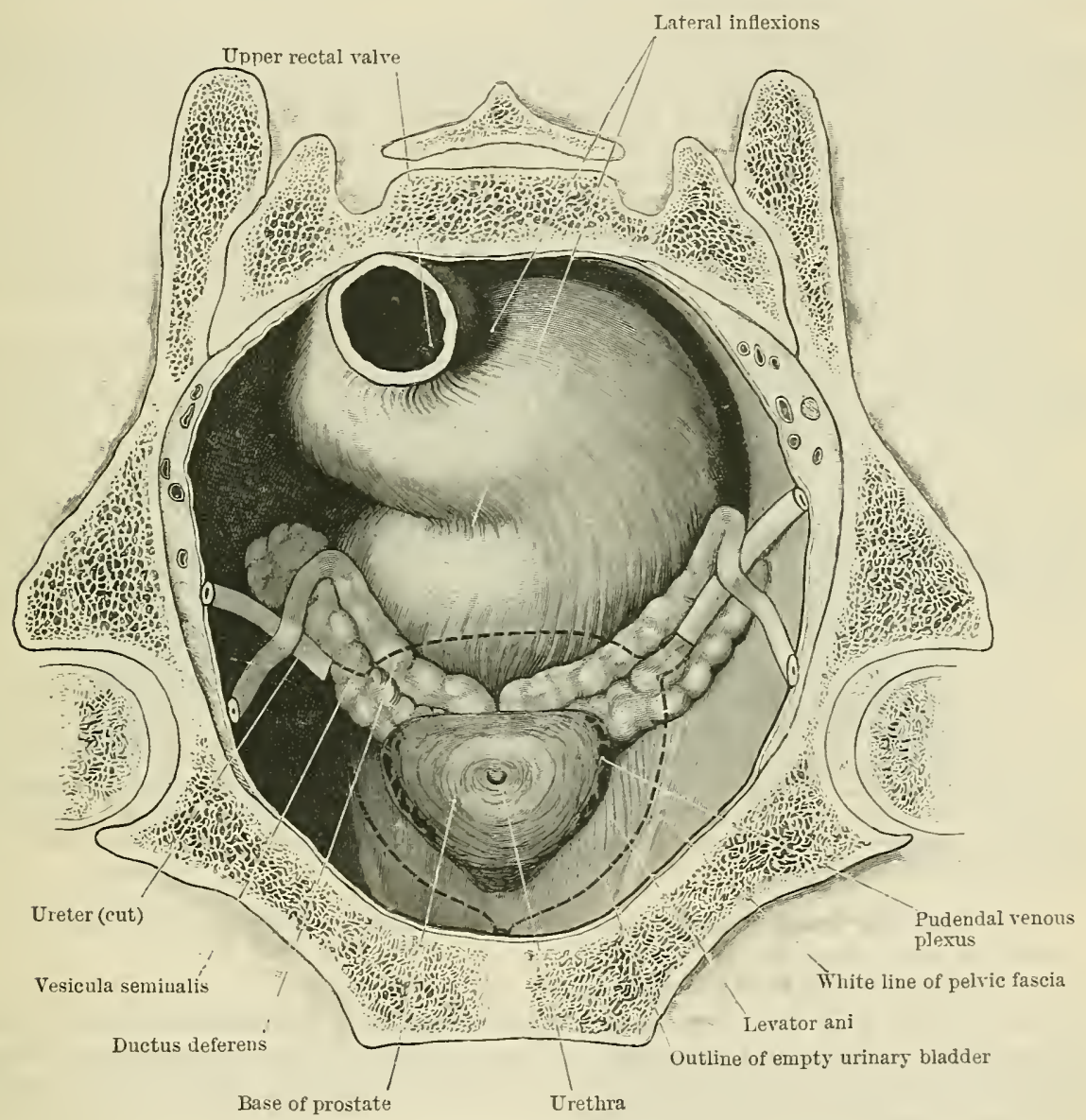

Fig. 960.-Distended REctuM IN SITt.

From a formalin-hardened male body, age 56. The peritoneum and extra-peritoneal tissue have been removed, after sawing the pelvis along a plane passing through the superior part of the symphysis pubis in front and the lower part of the second sacral vertebra behind. The bladder. which was empty and contracted, has also been removed, but its form is shown by a dotted line. The rectum was rery much distended, and almost completely occupied the pararectal fossa.

embraces the ano-coccygeal body-the mass of muscular and connective tissue which lies between the tip of the coccyx and the anal canal.

When viewed from the front the rectum is seen to be regularly folded from side to side in a zigzag fashion, the folding being slightly marked when the rectum is empty, but becoming much more distinct with distension (Figs. 960 and 961). In other words, when viewed from this aspect it presents, in the majority of cases, three more or less distinct lateral flexures or inflexions. Of these the upper and lower have their concavities directed to the left as a rule; the third flexure, which is the best marked, lies between the other two, but on the right side. Not infrequently, however, two are found on the right and one on the left side. The flexures, which 
are marked on the exterior by a crease, appear in the interior as three prominent crescentic shelves (Fig. 960), known as the plicæ transversales recti (O.T. Houston's valves), which help to support the fæcal contents when the rectum is distended.

This folding is maintained by the arrangement of the longitudinal muscular fibres, the majority of which are accumulated in the form of two wide bands, one on the front, the other on the back of the bowel. These two bands, which are continuous with, and comparable in their functions to, the trniæ of the colon, are shorter than the other coats of the rectum ; hence they give rise, as in the case of the colon, to a folding or sacculation of the tube, which can be effective only at the sides where the longitudinal fibres are fewest, for the front and back are occupied by the thickened longitudinal bands (see p. 960).

In addition to supporting the freces, these foldings greatly increase the capacity of the rectum without unduly dilating the tube. When the rectum is empty (Fig. 961) its course is comparatively straight, its lateral flexure being but slightly marked, and its whole calibre very much reduced. In this condition it occupies only a small portion of the posterior division of the pelvic cavity near the median plane, and at each side, between it and the lateral wall of the pelvis, is a large fossa of the peritoneum (the!pararectal fossa, p. 959), which, when the bowel is empty, contains a mass of small intestine or pelvic colon (Figs. 959 and 961). When the rectum is distended the lateral flexures become much more marked, and the gnt, projecting alternately to each side, passes out beneath the peritoneum, obliterating the pararectal fossæ (Fig. 960), and fills the greater part of the posterior division of the pelvis - a condition which could not be brought about with a straight rectum without an enormous increase in all the diameters of the tube.

According to Jonnesco, the rectum begins - that is, the pelvic mesocolon ceases-most frequently opposite the fibro-cartilage between the third and fourth sacral vertebræ. It is our experience that the mesocolon ends more frequently above than below the third sacral vertebra-often, indeed, at the level of the second (Birmingham).

At its superior end the rectum, following the curve of the sacrum, slopes downwards and at the same time slightly backwards; its middle portion is practically vertical, but the terminal third or more is directed downwards and forwards at an angle varying from $45^{\circ}$ to $60^{\circ}$ with the horizontal. The pelvic floor, npon which this latter part rests, forms here a similar angle with the horizontal. The bend which the bowel makes behind the inferior end of the prostate, where the rectum passes into the anal canal, is, as pointed out above, abrupt, and usually approaches a right angle, so that the anal canal itself slopes downwards and backwards at an angle of nearly $45^{\circ}$ with the horizontal.

Not uncommonly the abrupt curve, at the junction of the rectum with the anal canal, presents in front a knuckle-like projection (well seen on median section), immediately above the canal. It is most marked in females, and sometimes appears as if the bowel were doubled back upon itself at this point. The floor of the pouch thus formed may dip down in front, even below the level of the upper aperture of the anal canal. This condition is most common in multiparæ, and is evidently due to the relaxed condition of the pelvic structures, and the slight support afforded by the perineal body to this part of the gut in these, and the great capacity and shallowness of the pelvis in the female.

In length the rectum usually measures about 5 or 6 inches $(12.5$ to $15.0 \mathrm{~cm}$.), but it may be much longer.

Its diameter is smallest above, near the junction with the pelvic colon, and is greatest below, near the anal canal, where there is a special enlargement known as the ampulla recti (rectal ampulla). When empty the rectum measures little over an inch $(2.5 \mathrm{~cm}$.) in diameter, but in a state of extreme distension it may be as much as 3 inches $(7.5 \mathrm{~cm}$.) in width.

Peritoneal Relations of the Rectum (Figs. 959, 961).-As a rule the superior two-thirds of the rectum has a partial covering of peritoneum-anteriorly and at the sides at first, later on anteriorly only-whilst the lower third has no peritoneal investment whatsoever. When the mesocolon ceases at the end of the pelvic colon, its two layers separate and leave the posterior aspect of the rectum destitute of peritoneum. Very soon the membrane quits its sides also, and is then found on the front only; so that the greater part of the rectum lies behind or beneath the pelvic peritoneum, as it were, and is capable of expanding and contracting without being in any way hampered by its partial peritoneal coat.

From the front of the rectum the peritoneum is carried forwards to the base of the bladder in the male, forming the floor of the excavatio recto-vesicalis (rectovesical or recto-genital pouch, Fig. 961). In the female it passes to the superior part of the posterior wall of the vagina, forming the floor of the excavatio recto-uterina [cavum Douglasi] (O.T. pouch of Douglas, Fig. 961). At each side, in both sexes, it passes from the front of the rectum on to the posterior wall of the pelvis, forming the bottom of a large fossa, seen at the sides of the rectum when that bowel 
is empty, and known as the pararectal fossa. With distension this fossa is encroached upon by the enlarging bowel, and soon is obliterated.

The level at which the reflection of the peritoneum takes place from the front of the rectum is of considerable practical importance in connexion with operations in this region. As a general rule this reflection, that is, the bottom of the recto-vesical pouch, is placed at a distance of 1 inch $(2.5 \mathrm{~cm}$.) above the base of the prostate, or about 3 inches above the anus, but the level is subject to considerable variation, being as a rule relatively much higher in well-developed muscular or fatty subjects, whilst in emaciated bodies, owing to the thinness of the structures forming the pelvic floor, it is usually lower.

The bottom of the recto-vesical pouch may reach down in an extreme case to within an inch $(2.5 \mathrm{~cm}$.) of the anus, whilst it is not at all rare to find it within 2 inches $(5.0 \mathrm{~cm}$.$) of that orifice ;$ on the other hand, it may be considerably higher than normal, sometimes being placed at a dis-

Second sacral vertebra

Ending of pelvic mesocolon

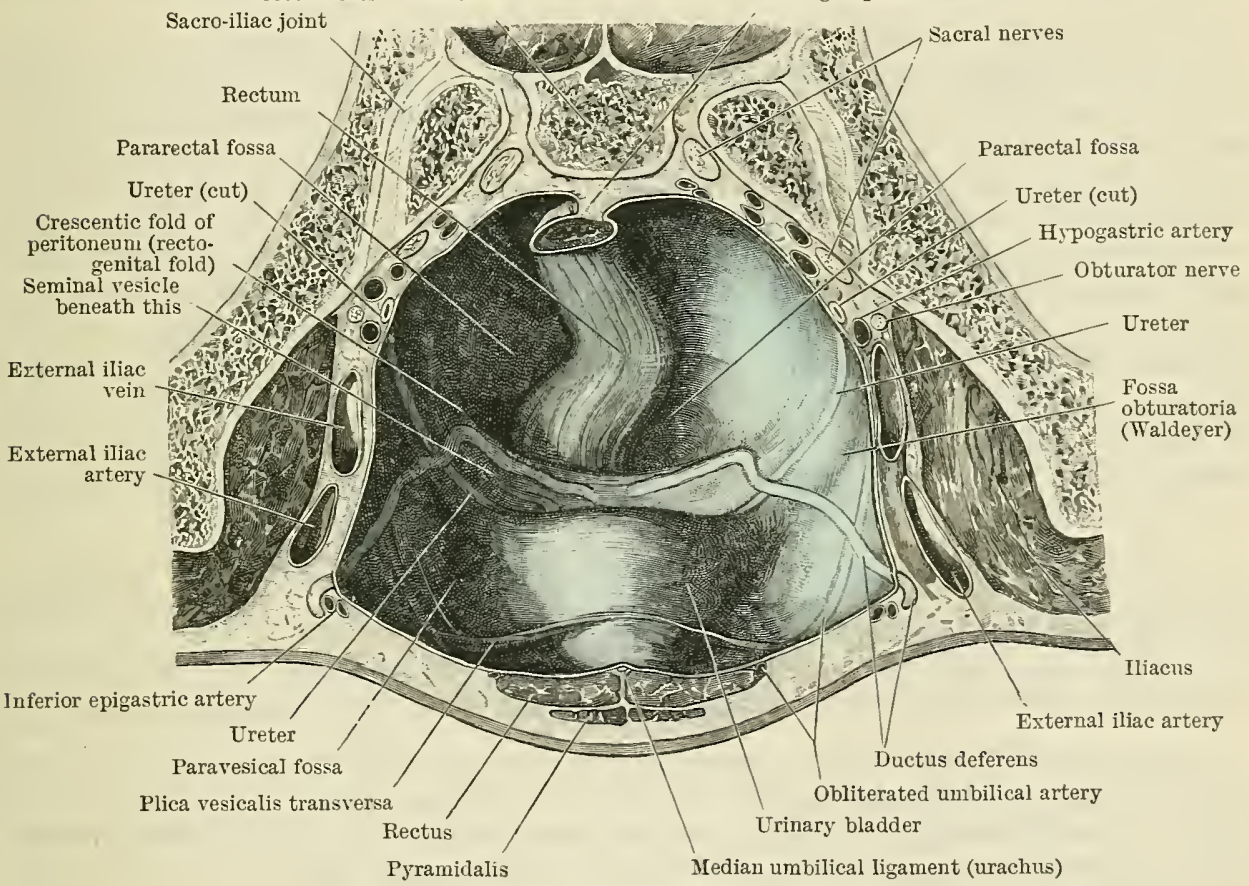

Fig. 961.--The Peritonedm of the Pelvic Catity.

The pelvis of a thin male subject, aged 60, was sawn across obliquely. Owing to the absence of fat the rarions pelvic organs are visible through the peritoneum, though not quite so distinctly as presented here.

The urinary bladder and rectum are both enpty and contracted ; the paravesical and pararectal fosse, as a result, are very well marked.

tance of 4 or $4 \frac{1}{2}$ inches $\left(10^{\circ} 0\right.$ to $11 \cdot 2 \mathrm{~cm}$.) from the anus. It should also be added that the level is generally beliered to be somewhat raised by distension of the rectum and bladder, and lowered by emptying these viscera.

In the child at birth, the peritoneum extends down to the base of the prostate (Srmington), and is thus lower in relation to the bladder; but this may be partly accounted for by the high position of this organ in the child.

As a rule it will be found that 2 inches $(5.0 \mathrm{~cm}$.) of the front of the rectum, exclusive of the anal canal, are entirely free from peritoneum, and it is this and the adjacent portion of the bowel which, being free from the restraining influence of the peritoneum, is most distensible, and forms the rectal ampulla. Including the anal canal, $3 \frac{1}{2}$ inches $(8 \cdot 7 \mathrm{~cm}$.) of the rectum, measured along the front of the tube, have no serous covering. On the other hand, the back is free from peritoneum for 5 or 6 inches $(12.5$ to $15.0 \mathrm{~cm}$.) -or sometimes much more-above the anus.

It is also of interest to notice that the connexion of the peritoneum to the rectum varies in its character at different parts:-Above and in front it is closely adherent, and can be removed only with the greatest difficulty; at the sides and below the connexion is mucl looser. As a result, the peritoneum can be stripped off the rectum in its inferior third or half without much difficulty, whilst in its superior portion this is nut the case-an arrangement which admits of the free expansion of the rectal ampulla. 
General Relations of the Rectum (Figs. 959 and 960).-Posteriorly, the rectum rests on the front of the sacrum and coccyx, and below these upon the posterior part of the pelvic floor-here formed by the meeting of the two levatores ani in the anococcygeal raphe. When much distended it also comes into relation on each side with the lower part of the piriformis and the sacral plexus. The bowel is separated from these structures by a very considerable amount of comnective tissue, arranged (apparently in several layers) around the tube. In this tissue the two chief branches of the superior hæmorrhoidal vessels lie behind the superior part of the bowel, but lower down they are placed in relation to its sides.

At its sides above are the pararectal fossæ and their contents (pelvic colon, or ileum); below this the rectum is in contact with the coccygei and levatores ani muscles, which run backwards to the coccyx on each side of the bowel. The branches of the superior hæmorrhoidal vessels are also found running down on its muscular coat, as far as the middle of the rectum, where they pierce the wall of the bowel.

Anteriorly, in the male the rectum is separated from the bladder, to within an inch of the prostate, by the recto-vesical pouch of peritoneum, which usually contains some coils of small intestine. Below the reflection of the peritoneum the front of the bowel is in contact with the posterior aspect of the bladder, the deferent ducts, vesiculæ seminales, and the posterior aspect of the prostate gland (Fig. 960 ), from all of which it is separated by the recto-vesical layer of the pelvic fascia.

The lower portions of the rectum and bladder in the male are separated by the recto-vesical fascia only, over a narrow triangular area which measures about an inch $(2.5 \mathrm{~cm}$.) in vertical height. The base of this triangle corresponds to the reflection of the peritoneum from one organ to the other, and the apex to the union of the sides formed by the deferent ducts, which lie very close to one another except above, near the base of the triangle, where they diverge rather abruptly (Fig. 960). Through this triangle the operation of tapping the bladder from the rectum used to be performed.

The resiculæ seminales, unless when of a small size, slope laterally and posteriorly round the front and sides of the distended rectum (Fig. 960), which they thus embrace, as it were, withiu their grasp.

The ureters, as they run medially towards the base of the bladder, lie close in front of the deferent ducts, and are not far separated from the distended rectum (see Fig. 960).

In the female the rectum is separated from the posterior surface of the uterus and the upper end of the vagina by the recto-uterine pouch and the intestine which it usually contains. Below the peritoneal reflection it is in direct contact with the posterior vaginal wall, to which it is connected loosely above, but more closely below.

The portion of the rectum below the level of the peritoneal reflection is surrounded by the rectal fascia, a layer of connective tissue which is derived from the visceral layer of the pelvic fascia.

In the child the rectum, or at least its superior part, is relatively larger, and it pursues a much straighter course than in the adult. As pointed out above, its peritoneal covering likewise descends lower at birth, and reaches as far as the base of the prostate.

\section{PARS ANALIS RECTI-ANAL CANAL.}

Pars Analis Recti.-In order to reach the exterior, it is necessary for the lower end of the bowel to pierce the floor of the pelvis. This it does by passing through the narrow interval left between the medial borders of the levatores ani muscles (Fig. 963). As it passes between them, the two muscles pinch in the tube, and by the apposition of its lateral walls obliterate its cavity, reducing it to a mere slit-like passage. This passage, through which the rectum communicates with the exterior, is the "anal canal" (Symington).

The term pars analis recti refers, strictly, to the lower half only of this canal, which is lined by squamous epithelium, and shows the columnæ rectales. 
Formerly this terminal portion of the tube was described as the "third part of the rectum," and, like the rest of that bowel, it was supposed to form a reservoir for the retention of the fæces. It is probable that only when the rectum is distended is the superior part of the anal canal occupied by the wedge-shaped lower end of the contained fæcal mass.

The anal canal begins where the rectum proper terminates, namely, at the level of the levatores ani muscles, opposite the inferior part of the prostate. When the distended rectum is cut across near its inferior end, in a hardened body, and the cavity examined from the interior, a distinct projection, formed by the medial border of the levator ani (O.T. puborectalis, or sphincter recti portion), is seen on each side, indicating the superior limit of the canal. It is said that these ridges can also be felt during life by the finger introduced into the rectum. Below, the anal canal ends at the anus, or anal orifice, by opening on the exterior.

Its length is usually from 1 to $1 \frac{1}{2}$ inches $(2 \cdot 5$ to $3 \cdot 7 \mathrm{~cm}$.), being greater when the bowel is empty, and less when it is distended. Its antero-posterior diameter when closed varies between $\frac{1}{2}$ and $\frac{3}{4}$ inch $(12$ to $19 \mathrm{~mm}$.).

The direction of the anal canal, as already pointed out, is downwards and posteriorly, often forming an angle of nearly $45^{\circ}$ with the horizontal, although it is usually somewhat nearer to the vertical.

Relations. - It is surrounded by both the external and internal sphincters, and above also by the borders of the levatores ani, these muscles forming a muscular cylinder around it (Fig. 963). On each side is situated the ischiorectal fossa with its contained fat, which allows of the distension of the canal during the passage of fæces. Posteriorly is placed a mass of mixed connective and muscular tissue, known as the ano-coccygeal body (Symington), which intervenes between it and the coccyx. Finally, anteriorly, it lies close behind the bulb of the urethra and the base of the urogenital diaphragm in the male, and a sound in the urethra can be easily felt by the finger introduced into the anal canal, particularly in thin bodies. In the female it is separated from the vagina by the wedge-shaped mass of fatty and muscular tissue known as the "perineal body."

Structure of the Rectum and Anal Canal.-The wall of the rectum is made up of four coats, viz. :- l. The outer coat, formed in part by peritoneum (already described), and, where the peritoneum is absent, of connective tissue which can be dissected off in several layers. In this connective tissue the hæmorrhoidal vessels run until they pierce the wall of the tube. In it also, at the back and sides of the rectum, are found embedded a number of rectal lymph glands.

2. The tunica muscularis, which is much thicker than in any other portion of the intestine, is composed of two stout layers of unstriped muscle - an outer longitudinal and an inner circular - like that of the intestine generally. The longitudinal fibres, although present all round, are chiefly accumulated on the front and back of the tube (see p. 1212), where they form two broad bands; at the sides they are reduced to a thin layer, the deepest fibres of which are folded in and take part in the formation of the rectal valves.

Where the rectum pierces the floor of the pelvis, the outer layer of longitudinal fibres is united to the deeper portion of the levator ani, partly by tendinous fibres and partly by an interchange of muscular fibres, between the levatores and the muscular coat of the rectum. Below, the longitudinal fibres pass between the external and internal sphincter muscles, or through the latter to join the skin around the anus.

In sagittal sections of the pelvis near the median plane there can generally be seen a distinct band of red, longitudinally arranged, muscular fibres, which descends on each side from the front of the coccyx to blend with the longitudinal fibres on the back of the rectum. This band is the rectococcygeus muscle. It is composed of striped fibres above, but becomes unstriped below.

Some unstriped muscular fibres which are found descending in the subcutaneous tissue of the lower part of the anal canal, to join the skin around the anus, have been described by Ellis as the corrugator cutis ani. According to Roux, they are some of the longitudinal fibres of the rectum which have passed through the internal sphincter to the submucous tissue, and then descended to the skin. The front of the rectum at the perineal flexure is, in the male, connected to the back of the membranous urethra by a band of muscle, termed the rectourethralis.

The circular fibres form along the whole length of the tube a contimnous layer, which is doubled inwards to assist in the formation of each rectal valve, and is thickened below to form the internal sphincter of the anus. The sphincter ani internus, as just pointed out, is formed by a great, and rather sudden, increase of the circular muscular fibres, which begins at the superior end of the anal canal. It surrounds the camal for about an inch $(2.5$ to $3.0 \mathrm{~cm}$.), and terminates at its junction with the skin. 
3. The tela submucosa is composed of loose areolar tissue, which allows of a free morement of the mucons layer on the muscular coat, and which also admits, under certain abnormal conditions, of a prolapse of the mucous membrane through the anal orifice. The hemorrhoidal plexus of veins is contained in this layer.

4. The tunica mucosa must be considered separately in the rectum and pars analis recti. 'That of the rectum is redder in colour than the mucous membrane of the colon, as a result of its greater vascularity. It is also thicker, and owing to the looseness of the underlying submucosa, is thrown into numerous irregular rugæ when the rectum is empty; these disappear when the bowel is distended, and there then become evident three (sometimes more, sometimes less) crescentic folds, which are much less noticeable in the empty state, and which have been already referred to as the plicre transversales recti. Lymph nodules and intestinal glands are present; but these latter are not so numerous as in the colon, although their calibre is greater.

The mucous membrane of the pars analis recti presents a number of vertical ridges known as the columnce rectales (Morgagnii); between the lower ends of these are found a series of small semilunar folds which connect the lower ends of these columns together and are called the anal valves (Fig. 962). Above the level of the anal valves the canal is lined by a modified mucous nembrane resembling that of the rectum; the portion below the valves (i.e. the lower 12 to $16 \mathrm{~mm}$. of the canal) is covered by modified skin, continuous with that around the anus.

The term annulus hamorrhoidalis is applied to the segment enclosed by the sphincter externus muscle. It extends from the region of the rectal sinuses to the anal orifice, and in its wall is found the large venous plexus, termed the plexus hoemorrhoidalis.

The mucous membrane of the rectum presents a characteristic punctated appearance, which is due to the presence of a considerable number of rounded depressions, such as might be made by firmly pressing a finely pointed pencil against the membrane. These rectal pits are tubular in form, and have an accumulation of lymph tissue at the bottom of each, the whole appearance being such as might be produced if a small solitary nodule were drawn down from the surface into the intestimal wall.

Plicæ Transversales Recti (O.T. Rectal Valves, or Valves of Houston).-These are crescentic shelf-like folds which project into the cavity of the rectum on its lateral aspects (Fig. 960). They are composed of an infolding of the mucous, submucous, and greater part of the circular muscular coats, and their form is preserved by the relative shortness of the anterior and posterior bands of longitudinal muscular fibres. They are produced, as pointed out above, by the projection, into the interior of the bowel, of the creases on the exterior which result from the lateral inflections of the rectum. In the majority of cases three are present (there may be four, five, or, it is said, even more), but often the lowest of the three is small or absent; or all the valves may be ill-developed and indistinct. When median sections of the empty rectum are examined, the valves are not easily seen, as they then project but slightly, and are almost completely hidden amongst the numerous rugæ of the mucous coat. They are most evident in a distended rectum which has been hardened in situ; they can also be seen during life, per anum, with the aid of a rectal speculum.

As a rule two valves are found on the left and one on the right side; this latter is generally the largest, and is situated a little above the level of the peritoneal reflection, viz., 3 or $3 \frac{1}{2}$ inches $(7 \cdot 5$ to $8 \cdot 7 \mathrm{~cm}$.) above the anus; the other two valves are found about 1 to $1 \frac{1}{2}$ inches $(2 \cdot 5$ to $3.7 \mathrm{~cm}$.) higher up and lower down respectively. The valves are distinctly marked in the fœtus, and seem to constitute an essential part of the human rectum, their use being to support the contents of the rectum, which they break up into segments, each supported by a valve. They are said to interfere sometimes with the introduction of an enema tube.

Columnæ Rectales [Morgagnii].-The mucous membrane of the pars analis recti, or lower portion of the anal canal, presents a number ( 5 to 10 ) of permanent vertical folds, separated by grooves, and known as the columnæ rectales (O.T. columns of Morgagni) (Fig. 962). They are usually $\frac{1}{3}$ to $\frac{1}{2}$ inch ( 8 to $12 \mathrm{~mm}$.) in length, $\frac{1}{8}$ to $\frac{1}{4}$ inch (3 to $6 \mathrm{~mm}$.) in width, and they extend down to within $\frac{1}{2}$ or $\frac{2}{3}$ inch (12 to $20 \mathrm{~mm}$.) of the anal aperture. They are formed by infoldings of the mucous membrane, containing in their interior some bundles of longitudinal muscle and also, as a rule, an artery and a vein. 
Very often the contained vein presents an enlargement, or a knob-like tortuous plexus in the lower part of the column; below this the plexus is continued down external to the mucous membrane of the lower zone of the anal canal into the anal veins. This portion has accordingly been described as the hæmorrhoidal zone of the anal canal. Sometimes the columns are very indistinct; occasionally no trace of them can be found, although in the fœus they are usually well marked.

\section{Anal Valves. - If a} probe be passed downwards along the groove which separates two adjacent columnæ rectales (Fig. 962), its point will usually catch in a small crescentic fold which joins the lower ends of the two columns. These little folds,

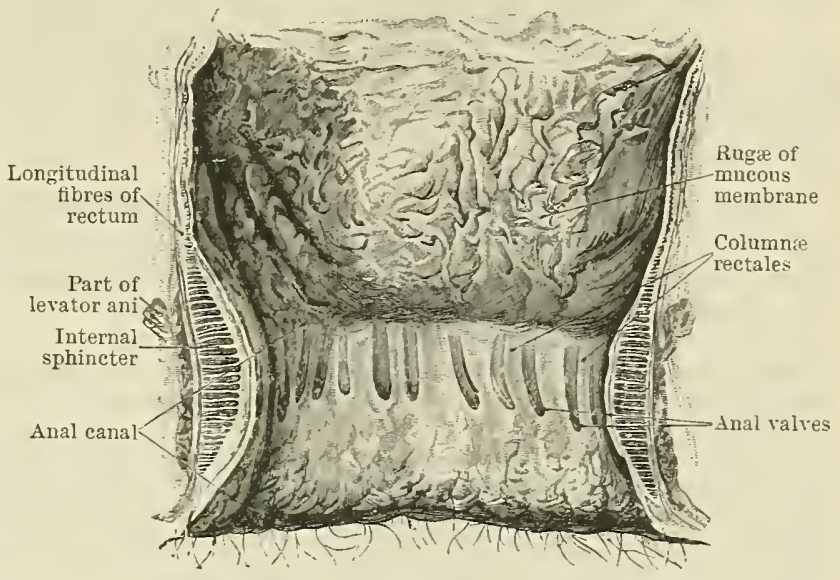

Fig. 962.-T'he Ixterior of the Axal Caxal axd Lower Part of Rected,

Showing the columnæ rectales, and the anal ralres between their lower ends. The columns were more numerous in this specimen than usual.

which resemble in miniature the segments of the semilunar valves of the heart, are the anal valves. They project inwards and upwards, and behind each is found a little pocket-like sinus (sinus rectalis).

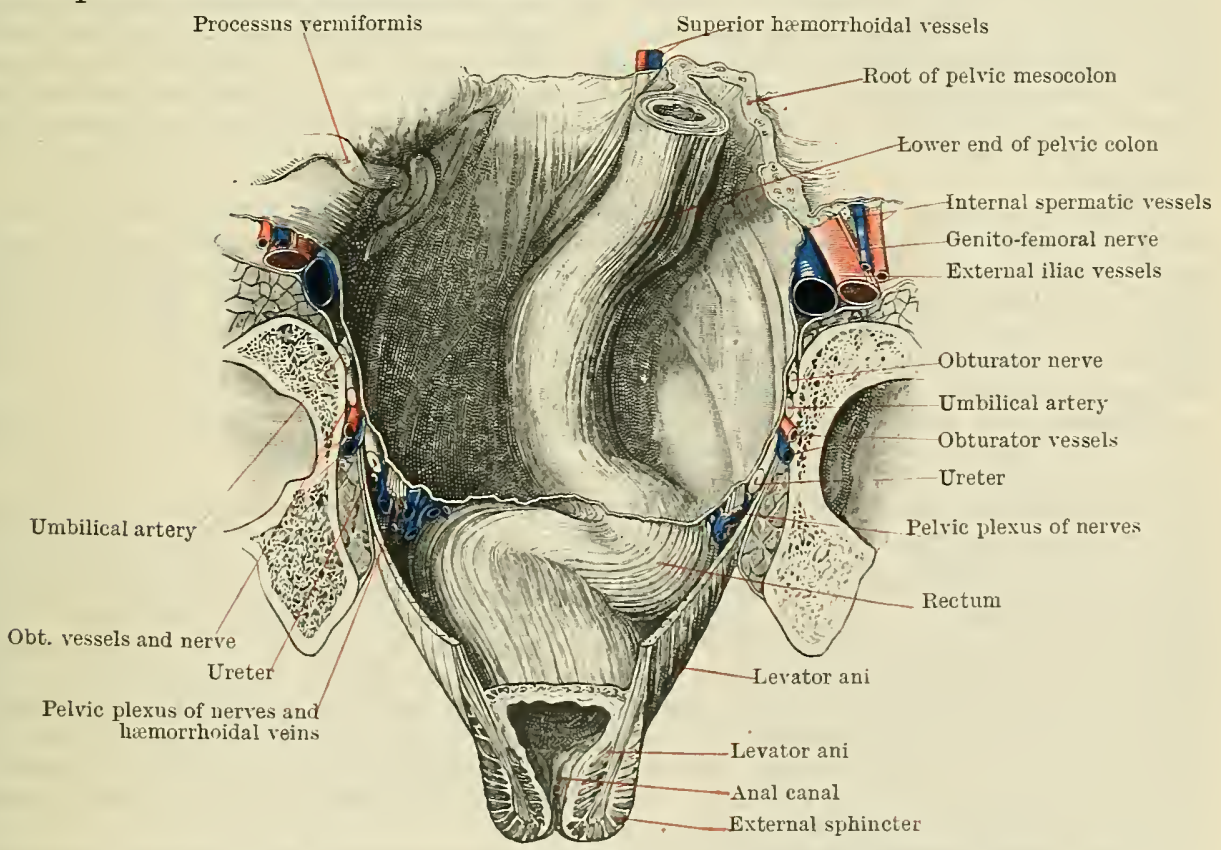

Fig. 963.-Dissection of the Rector froy the Front lx a Specimex hardexed by Formalix IXIJEcTION.

The front wall of the pelvis has been remored, and the bladder, prostate, and seminal vesicles taken away.

These valves were first described by Morgagni. Recently the view has been adranced by Ball that they are the remains of the embryonic cloacal or anal membrane; and he explains the production of "painful fissure of the anus" by the tearing down of one of them during defreation by hardened masses of fæces.

The epidermis is continued in a thin and modified form from the exterior up along the anai canal as far as the superior end of the columnæ rectales; and the view is pretty generally held that 
only this lower portion of the anal passage is formed from the proctodrum in the embryo. The junction of the skin with the mucous membrane is indicated by a fine wavy line ("white line" of Hilton-ano-cutaneous line of Hermann) which runs around the bowel at the level indicated. The mucous nembrane of the region immediately above the anal valves is of a more or less transitional nature; glands are absent from it, and over the columnæ rectales it is covered with stratified epithelium, the superficial cells of which are flattened, whilst in the grooves between the columns the epithelium is columnar. In the upper zone of the anal canal the mucous membrane gradually approaches to the rectal type, but the intestinal glands and lymph nodules are few and scattered.

Anus or Anal Orifice.-At the inferior aperture of the anal canal, the modified skin of its lower zone passes into the ordinary skin. A little way outside the orifice, hairs, sebaceous glands, and large modified sweat-glands appear, the last being termed glandulæ circumanales.

Action of the Sphincters.-In connexion with the anal canal are found three musclesnamely, the paired levatores ani, the external sphincter, and the internal sphincter-the action of which may be briefly referred to here.

Levator Ani.-The fibres of the levator which arise from the pubis (pubo-coccygens or sphincter recti portion) pass backwards on each side of the beginning of the anal canal, and, in great part, meet behind the passage. These two muscular bands-which are but a little distance apart at their origin, and are actually united behind the bowel-are closely approximated during the contraction of the muscles, like the limbs of a clamp, and, pressing on the sides of the anal canal, they assist in closing the upper part of that passage, whilst at the same time drawing it slightly towards the pubes. There is little doubt that the levator ani in this way acts as one of the chief sphincters of the bowel; and it should be noticed that it is placed where its action would be most effective, namely, opposite the point at which the rectum is narrowed or "pinched in " to form the anal canal. In addition to its sphincter action the muscle supports the expanded bowel immediately above the anal canal, and in this way sustains the weight of the fæces when the rectum is distended. It is probably relaxed during defæcation, except perhaps at the completion of the act. The muscle is under the control of the will.

The m. sphincter ani externus forms a muscular cylinder around the inferior two-thirds of the anal canal, with (except in the case of some of its inner fibres) an anterior and a posterior attachment. When the muscle contracts, its fibres are tightly stretched between its two attachments, and the space between them is reduced to a narrow antero-posterior slit. By this action the anal canal is flattened from side to side and closed, so that, whilst the levator ani is the sphincter of the upper aperture of the anal canal, the external sphincter closes its inferior and greater part. It is under the control of the will, but under ordinary circumstances it is in a state of tonic contraction.

The $\mathrm{m}$. sphincter ani internus is merely a thickening of the circular muscular coat at the inferior end of the bowel. It is continuous with the circular fibres of the gut, not only in structure, but probably also in action, its chief use being to empty the anal canal completely, after the passage of each fæcal mass. Owing to the fact that the canal is an antero-posterior slit, not a circular orifice, and that the internal sphincter forms a muscular ring around it, acting alone, it is scarcely competent to keep the sides of the canal in apposition, and probably it acts rather as a detrusor than a true sphincter of the anal passage.

Vessels.-The rectum and anal canal receive their blood supply from three chief sources, namely, the three hæmorrhoidal arteries; to these another less important, though constant, source may be added-the middle sacral artery.

1. The superior hæmorrhoidal artery, the principal artery of the rectum, is the prolongation of the inferior mesenteric. At first it descends in the root of the pelvic mesocolon until the rectum is reached. Here it divides into two chief branches which run downwards and forwards around the sides of the rectum-the right, usually the larger, lying more posteriorly, the left more anteriorly, and the two, as it were, embracing the bowel between them. From these two arteries come off secondary branches (about five to eight in all), which pierce the muscular coat about the middle of the rectum, and then descend in the submucosa as a series of longitudinally running "terminal branches" as far as the anal valves, above the level of which one is usually found beneath each of the rectal columns. These terminal branches give off numerous twigs in their course, which form a hæmorrhoidal plexus in the submucosa by anastomosing with one another, and also with branches of the middle, and, in the inferior part of the bowel, of the inferior hæmorrhoidal artery.

2. The middle hæmorrhoidal arteries, two in number-one on each side - are usually branches of the hypogastric or of the internal pudendal; they run on the wall of the inferior part of the rectum, and each breaks up into four or five small branches, some of which supply the muscular wall of the inferior part of the rectum, whilst the others pierce the muscular coat near the superior end of the anal canal, and join in the submucosa with the plexus formed by the superior hæmorrhoidal artery already described.

3. The inferior hæmorrhoidal arteries, generally two or three in number on each side, arise at variable levels from the internal pudendal. They are distributed to the levatores ani and the sphincters. Other branches pierce the sphincters and break up in the submucosa into a close network which supplies the inferior part of the anal canal, and communicates above with the plexus formed by the superior and middle hæmorrhoidal arteries. The inferior hæmor- 
rhoidal artery is distributed chiefly on the posterior, and the middle hæmorrhoidal chiefly on the anterior aspect of the lower part of the bowel.

4. One or more small branches of the middle sacral artery reach the posterior surface of the rectum, where they are distributed chiefly, if not solely, to the muscular coat.

Anastomosis of the Hæmorrhoidal Arteries.-The superior and middle hæmorrhoidal arteries anastomose freely in the hæmorrhoidal plexus of the submucosa, and also by a few large branches on the exterior of the bowel: some perforating branches of the middle sacral and inferior hæmorrhoidal arteries also join the plexus in the submucous layer at the lower part of the rectum. In addition, small branches of these several arteries unite with one another in the muscular coat. It should be remarked that the superior hæmorrhoidal arters supplies both the muscular and mucous coats in the superior part of the rectum, but the muscular coats in the inferior part are supplied by the middle and inferior hæmorrhoidal vessels only.

Veins of the Rectum and Anus.-These form two chief plexuses of large ressels deroid of valves, namely, the internal hæmorrhoidal plexus situated in the submucous coat, and the external hæmorrhoidal plexus in the outer coat. The internal hæmorrhoidal plexus takes origin near the margin of the anus in a number of small (anal) veins, which are radially disposed beneath the skin of the anus, and communicate below with the rootlets of the inferior hromorrhoidal vein over the external sphineter. These anal veins, traced upwards, join together, and are joined by others from the surrounding parts to form larger and often tortuous vessels, which ascend in the columnæ rectales, where they frequently present ampullary enlargements, varying in size up to that of a small pea, which are said to be the starting-points of hæmorrhoids. Passing upwards, the reins are known as the "terminal veins"; they communicate freely with one another, forming the plexus, and unite into still larger vessels, which pierce the muscular coat about the middle of the rectum, and join to form the superior hrmorrhoidal vein.

From the inferior part of the internal hæmorrhoidal plexus numerous vessels pass through the external sphincter to join a venous network on the outer surface of that muscle, from which the inferior hæmorrhoidal veins arise. This network, as pointed out above, also communicates with the internal hæmorrhoidal plexus, through the anal veins which descend from the latter beneath the skin of the anal canal, to the exterior of the sphincter.

The various veins which pass ont through the walls of the rectum unite freely on its exterior to form a rich venous plexus (external hæmorrhoidal plexus), throngh which the three hæmorrhoidal vessels are brought into free communication with one another. Passing off from this plexus, the superior hæmorrhoidal joins the left colic vein and forms with it the inferior mesenteric vein, which opens into the splenic; the middle hæmorrhoidal joins the hypogastric, from which the blood passes through the common iliac to the vena cava inferior; and the inferior hæmorrhoidal joins the internal pudendal, a tributary of the hypogastric rein. Thus, on the rectum, a free anastomosis is established between the reins of the portal and systemic circulations.

Lymph Vessels.-Most of the lymph ressels of the rectum pass to the lymphoglandulx sacrales, of which some lie close to the muscular coat on the side of the rectum along the superior hæmorrhoidal vessels, while others, four or five in number, and of a larger size, lie in front of the promontory of the sacrum, between the layers of the pelvic mesocolon. The glands of opposite sides are connected with one another by the middle sacral plexus and with the hypogastric and mesocolic lymph glands. The efferent ressels from these pass to the lumbar glands. Some of those from the lower part of the anal canal join the cutaneous lymph ressels round the anus, and pass with them to the inguinal and subinguinal glands. A few of the lymph vessels from the lower portion of the rectum are said (by Quenu) to join the hypogastric glands.

Nerves.-The nerves of the rectum come partly from the sympathetic and partly from the cerebro-spinal system. The sympathetic fibres are derived from the inferior mesenteric plexus, through the superior hæmorrhoidal nerve and the corresponding plexus, and from the upper and lower divisions of the hypogastric plexus, the former accompanying the superior hæmorrhoidal, the latter the middle hæmorrhoidal vessels, to the rectum. The cerebro-spinal fibres arise from the second, third, and fourth sacral nerves soon after these leave the sacral foramina (and constitute the "pelvic splanchnics" of Gaskell). They run forward in the pelvic connective tissue, and joining the pelvic plexuses, reach the side of the rectun. Fibres of the inferior hæmorrhoidal branches of the pudendal nerve (third and fourth sacral) are also distributed to the lower part of the anal canal as well as to the external sphincter.

It has been shown by experiments on animals, that the cerebro-spinal nelves from the second, third, and fourth sacral) convey motor impulses to the longitudinal fibres, but iuhibitory impulses to the circular muscular fibres. In like manner the branches from the sympathetic convey motor fibres (derived from some of the lumbar rami communicantes) to the circular muscle, and inhibitory fibres to the longitudinal muscle of the rectum.

The reflex centre which governs the action of the sphincters and the muscular filbres of the rectum ("defreation centre") is sitnated in the lumbar region of the cord, and appears to be capable of carrying ont the whole act of defecation eren when separated from the brain.

Variations. - The best known anomalies found in connexion with the rectun are those classed under the term imperforate anus or atresia ani. The atresia may be simply due to a partial or complete persistence of the anal membrane (see p. 42), which separates the proctodæum from the hind-gut in the embryo (atresia ani simplex); or the lind-gut may be deficient in its lower part, when there is a considerable interval between the proctodæum and the gut (defectus recti partialis, vel totalis); or the rectum may open into the vagina, the uterus, the 
bladder, or the ureters, when usually no anus is evident; or finally the cloaca may persist. Other forms are also described, but the foregoing are those most commonly found.

For the development of the rectum and anus, see pp. 39 and 42.

\section{PERITON AUM.}

An introductory sketch of the peritoneum was given on p. 1160 ; subsequently, when describing the abdominal viscera, an account of its detailed relations to each of these was included. We shall here consider the membrane and its folds as parts of one continuous whole; and we shall also describe its arrangement as seen on horizontal and vertical sections of the abdomen.

As already explained, the peritoneum is the serous membrane which, on the one hand, lines the abdominal cavity, and on the other forms a more or less complete covering for the contained viscera. The portion which lines the walls of the cavity is known as the parietal peritoneum, that which clothes the viscera as the visceral peritoneum. The membrane is connected to both walls and viscera by a layer of areolar tissue-tela subserosa, the extra or subperitoneal connective tissue-which is considerable in amount in certain regions, whilst it is reduced to a mere trace in others, particularly on the viscera. (The subperitoneal tissue is described at p. 475 .)

The peritoneal cavity is described as consisting of two portions-the general peritoneal or great sac and the bursa omentalis. The great sac is opened when the anterior abdominal wall is removed or incised, and the peritoneum which encloses it lines the greater portion of the wall of the abdominal cavity, and invests most of the abdominal viscera; the omental bursa lies chiefly on the posterior aspect of the stomach, and is much smaller. It must be clearly understood that these two sacs are not two separate cavities, but simply subdivisions of one great cavity; for the omental bursa is merely a recess of the greater sac, from which it has become partly shut off largely by changes that take place in the position of the adjacent viscera during their development. If the general peritoneal cavity is compared to a bag, the bursa omentalis might be represented as a pocket lying behind, and opening into it by a narrow orifice-the foramen epiploicum [Winslowi].

Speaking generally, the great sac lines the walls of the abdominal cavity, and it also covers the various organs which receive a peritoneal investment, except the back of the stomach, the caudate lobe of the liver, the left supra-renal gland, the upper surface of the pancreas, and also parts of the spleen, left kidney, and transverse colon; all of these, as well as the parietes behind the caudate lobe, are clothed by the bursa omentalis.

The general peritoneal cavity is placed between the parietes anteriorly and the abdominal viscera posteriorly. It is composed of two layers, an anterior which lines the anterior abdominal wall, and a posterior which mainly covers the viscera; but this posterior layer is carried forwards by the viscera, so that the two layers come in contact, and the cavity of the sac is practically obliterated.

The anterior layer of the peritoneum covers the anterior abdominal wall completely, from the diaphragm above to the pelvis below. Over the greater part of its extent the connexion of the serous membrane to the wall is by a small amount of fatty extra-peritoneal connective tissue; but below, near the pubic region, the fat is more abundant, and the connexion between the two becomes much looser. This is to allow of the movement of the peritoneum, which takes place here during distension of the bladder. As the bladder enlarges it passes up in the extraperitoneal tissue of the lower part of the anterior abdominal wall, off which it raises the peritoneum, so that, in the fully distended condition, the anterior surface of the bladder is in contact with this wall, without the interposition of peritoneum, for a distance of two inches $(5.0 \mathrm{~cm}$., or occasionally more) above the pubes (Fig. 964).

Running up in this fatty subserous tissue are found five cord-like structures, one placed in the median plane, and two at each side. These are $(\alpha)$ the lig. umbilicale medium (O.T. urachus) - the remains of the allantois of the fotus-which in the adult is a slender fibrous band connected to the umbilicus above, and to the 
apex of the bladder below, where it usually becomes much stouter. Lateral to the urachus, and some distance from it (Fig. 965), will be found, in the same fatty tissue, (b) two stouter fibrous cords, the obliterated arteriæ umbilicales (O.T. obliterated hypogastric arteries), forming the plica umbilicalis lateralis dextra and sinistra. Traced upwards, these also become more slender, and approach the urachus, along with which they are connected to the umbilicus. Below, Lesser omentum they grow thicker, and can be followed backwards along the side wall of the pelvis to the hypogastric arteries, which they join. (c) More laterally still, the inferior epigastric arteries are seen running upwards and medially from the external iliac trunk on each side.

When the anterior abdominal wall is examined from behind, it will be seen that these five structures, which lie on the front of the peritoneum, carry that membrane inwards towards the abdominal cavity in the form of five more or less distinct ridges, known as the plica umbilicalis media, plicæ umbilicales laterales, and plicæ epigastricæ, respectively. In relation to these are found on each side three peritoneal fossæ, known as the foveæ inguinales (O.T. inguinal pouches or fossæ).

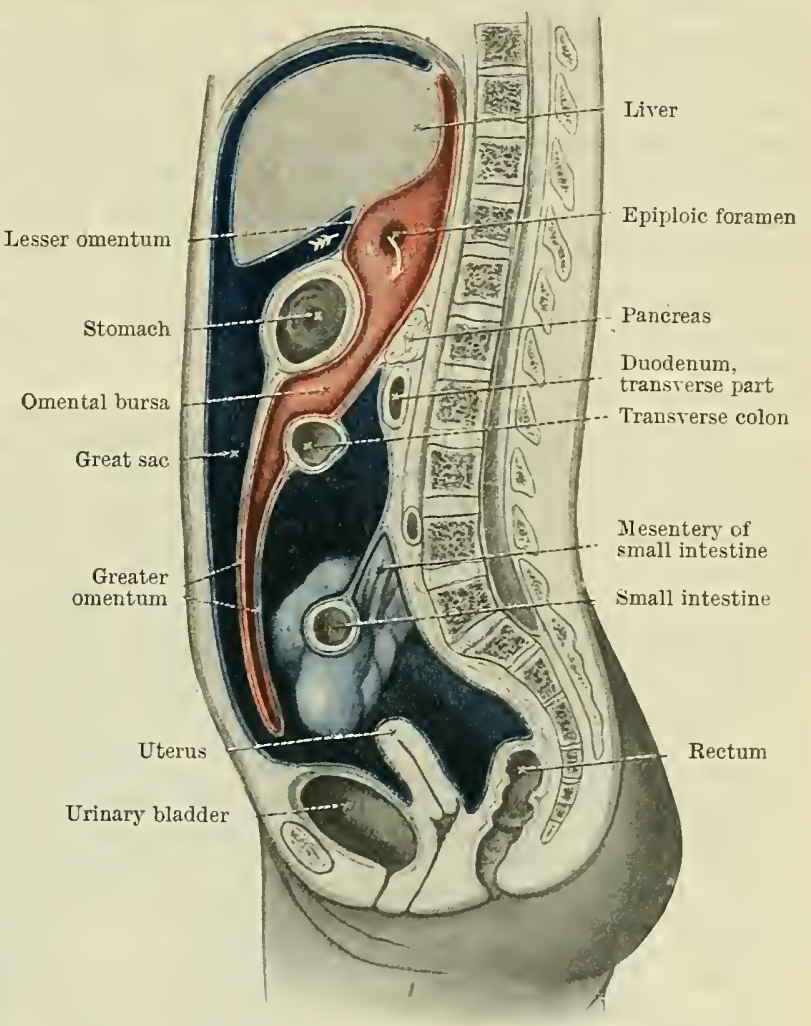

Fig. 964.-Diagramatic Median Section of Female Body, to show the peritoneum on vertical tracing. The great sac of the peritoneum is blue and is represented as being much larger than in nature; the bursa omentalis is coloured red; the peritoneum in section is shown as a white line: and a white arrow is passed through the epiploic foramen from the great sac into the bursa omentalis.

The fovea inguinalis lateralis lies lateral to the inferior epigastric artery, and corresponds to the position of the abdominal inguinal ring. At its bottom is often found a dimple-like depression of the peritoneum, indicating the point from which the processus vaginalis passed down, in connexion with the descent of the testicle. The forea inguinalis medialis is situated between the inferior epigastric and the obliterated umbilical arteries; whilst the fovea supravesicalis lies to the medial side of the obliterated umbilical artery, namely, between it and the urachus.

Between the inferior epigastric artery laterally, the margin of the rectus abdominis muscle, and the inguinal ligament below is a small triangular region, called Hesselbach's triangle. The obliterated umbilical artery, in passing upwards, crosses this triangle, dividing it into a lateral and a medial part. The middle inguinal fossa corresponds to the lateral division of the triangle, and the medial fossa to its medial division.

Still another fossa of the peritoneum is seen in this region, just beneath the medial part of the inguinal ligament, corresponding to the position of the femoral ring, and consequently known as the fovea femoralis. It may be added that the ductus deferens crosses the lateral part of the fovea femoralis, and the obliterated nmbilical artery its medial part. The significance of those fossæ is referred to in connexion with the applied anatomy of the inguinal and femoral regions.

Near the median plane, above the umbilicus, the peritoneum is carried back from the anterior abdominal wall and diaphragm to the parietal surface of the liver in the form of a crescentic fold, the falciform ligament of the liver (described with the liver), which connects the liver to the abdominal wall. This fold lies somewhat to the right of the median plane, and extends almost as low down as the umbilicus. 
It consists of two layers of peritoneum, between which, in the lower border of the fold, runs the round ligament of the liver-the remains of the umbilical vein of the fœetus.

Posterior Wall of the General Peritoneal Cavity.-The peritoneum clothing the anterior abdominal wall is continued on to the inferior surface of the diaphragm. Thence it is reflected on to the superior surface of the liver, and here the anterior becomes the posterior wall of the great sac. The peritoneum on the posterior wall first clothes the superior surface of the liver, then turns round its anterior border, and is continued back on the inferior surface as far as the attachment of the lesser omentum, where it quits the liver and passes down, as the anterior layer of the lesser omentum, to the lesser curvature of the stomach and the duodenum.

The line of reflection of the peritoneum from diaphragm to liver is interrupted near the median plane by the falciform ligament. The portion lying to the right of this fold forms the superior layer of the coronary ligament; that to the left of it, the superior layer of the left triangular ligament of the liver.

The extent to which the peritoneum passes uninterruptedly back on the inferior surface of the liver varies according as it is traced at the right, the left, or the middle portion of the liver. It clothes the right portion as far back as the inferior edge of the uncovered area of the liver, where it is reflected on to the posterior wall of the abdomen and the superior extremity of the right kidney (constituting the hepato-renal ligament), as the inferior layer of the coronary ligament. On the left portion it is continued back as far as the posterior border of the left lobe-or even a little way on to its superior surface-whence it passes to the diaphragm as the inferior layer of the left triangular ligament. The middle region of the under surface it clothes only as far as the porta hepatis and the fossa of the ductus venosus ; from these the peritoneum is carried down as the anterior layer of the lesser omentum.

The peritoneum, which passes back on the inferior surface of the diaphragm to the left of the liver, is continued down on the posterior abdominal wall, behind the fundus of the stomach and the spleen, until the left kidney is reached. It covers the superior and lateral part of the kidney, and is then carried forward as the lieno-renal ligament to the spleen, around which it passes -clothing its renal, phrenic, and gastric surfaces-as far as the hilus (Fig. 966); from this it is carried to the stomach as the left layer of the gastro-splenic ligament. Similarly, the inferior layer of the left triangular ligament is continued down on the posterior part of the diaphragm to the œsophagus, the anterior and left sides of which it clothes. It also forms a little fold at the left of the œesophagus, known as the gastro-phrenic ligament (see p. 1241 and Fig. 969).

At the right side, the portion of the peritoneum which forms the inferior layer of the coronary ligament is carried down over the right kidney (and inferior part of the supra-renal gland) to the duodenum and right colic flexure, over both of which it passes.

We shall now follow down the peritoneum forming the posterior wall of the general peritoneal cavity - which we have already traced to the stomach-as seen in a sagittal section (Fig. 964).

Having reached the lesser curvature of the stomach, it passes down over the front of that organ, clothing it completely as far as the greater curvature. From this it descends, and is usually adherent to the transverse colon, forming the anterior layer of the gastro-colic ligament. Thence it passes onwards as the most anterior fold of the greater omentum. Arrived at the inferior border of the greater omentum, the membrane returns on itself, and passes upwards towards the transverse colon, forming the posterior layer of that omentum. After meeting and covering the posterior aspect of the transverse colon (Fig. 964), it is then continued, as the posterior layer of the transverse mesocolon, up to the posterior abdominal wall, which it reaches at the anterior border of the pancreas (Fig. 969).

From the anterior border of the pancreas it is continued downwards again, clothing first the lower part of that organ, then the front of the third portion of the duodenum, and below this the posterior abdominal wall. From this latter, however, it is soon carried forwards again by the branches of the superior mesenteric vessels, passing to the small intestine. Running out along these, it forms the superior (or more correctly the right) layer of the obliquely placed mesentery (Fig. 964): on reaching the small bowel at the border of the mesentery, it invests that tube, giving it its serous coat, and then returns-as the inferior, or left, layer of the mesentery - to the posterior abdominal wall, on which it runs down, covering the great vessels near the median plane, and the psoas major muscle and ureter at each side, to enter the pelvis. The mesentery is described at p. 1208 .

Pelvic Peritoneum.- The detailed arrangement of the peritoneum in the pelvic 
cavity is somewhat complicated, and is fully described in connexion with the several pelvic organs. A general account will suffice here.

Having passed over the superior aperture all round, it enters the pelvis, and covers its walls as low as the pelvic floor, across which it passes to the various organs. Behind, it invests completely, and forms a mesentery (pelvic mesocolon) for, the pelvic colon, as far down as the third sacral vertebra. Here the colon joins the rectum proper, and the complete investment of the bowel ceases.

As the end of the pelvic colon is approached the two layers of its mesocolon become shorter, and when the rectum is reached, they separate, leaving its posterior surface uncovered, whilst the bowel is clothed in front and at the sides. Lower down, the membrane leaves the sides, and finally, at a point which is usually about 3 inches $(7.5 \mathrm{~cm}$., see p. 1224) above the anus, it leaves the anterior surface of the bowel, and in the male is carried on to the posterior part of the bladder (here covered

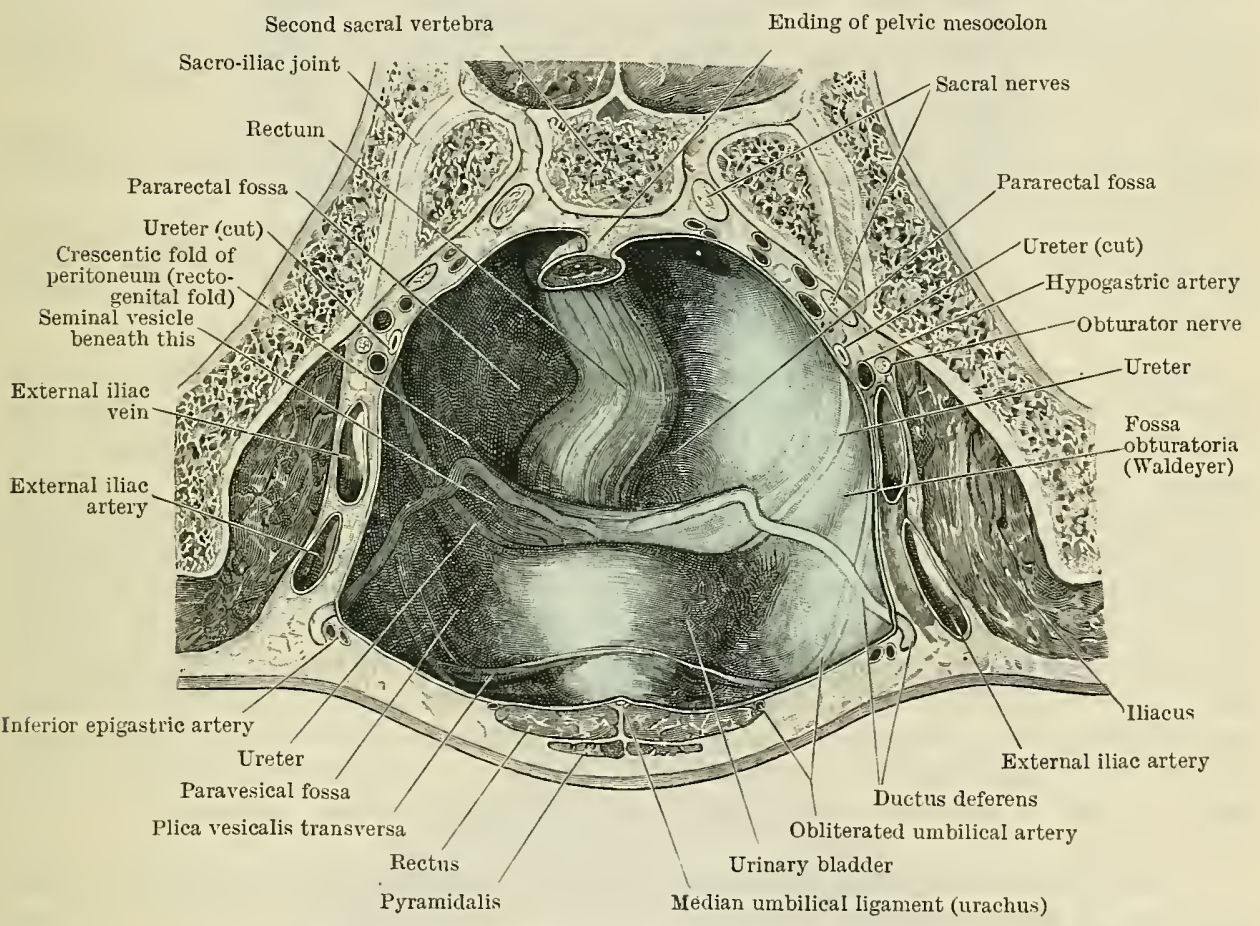

Fig. 965.-The Peritoneum of the Pelfic Cavity.

The pelvis of a thin male subject aged 60 was sawu across obliquely. Owing to the absence of fat the various pelvic organs are visible through the peritoneum, though not quite so distinctly as representel here. The urinary bladder and rectum were both empty and contracted ; the paravesical and pararectal fossæ, as a result, are very well marked.

by the seminal vesicles and deferent ducts), forming the floor of the excavatio rectovesicalis (recto-vesical pouch), found between these organs. It then covers the superior surface of the bladder, and passing off from its sides to the walls of the pelvis, constitutes the so-called false ligaments of that organ. From the apex of the bladder it is carried on to the anterior abdominal wall by the middle umbilical ligament, thus forming the plica pubovesicalis (O.T. the superior or anterior false ligament of the bladder).

In the female (Fig. 964), the peritoneum, on leaving the rectum, passes to the posterior wall of the vagina, the superior portion of which it covers. From this it is continued up over the posterior surface and fundus of the uterus, and down on its anterior surface as far as the junction of the cervix and body (Fig. 964). Here it passes from the uterus to the bladder, which it partly covers, as in the male, and is then carried on to the anterior abdominal wall. Between the rectum behind, and the uterus and vagina in front, is situated the excavatio rectouterina [cavum Douglasi] (O.T. pouch of Douglas), the entrance of which is limited on each side 
by a fold passing from the cervix of the uterus around the sides of the pouch towards the rectum; these are the plicæ rectouterinæ [Douglasi] (O.T. folds of Douglas), and they contain in their interior the musculi rectouterini (O.T. utero-sacral ligaments), two bands of fibrous tissue with plain muscle fibres intermixed, which pass from the cervix of the uterus, backwards on each side of the rectum, to blend with the connective tissue on the front of the lower part of the sacrum.

Similarly, in front of the uterus, between it and the bladder, is found the much smaller excavatio vesicouterina (utero-vesical pouch). Finally, the peritoneum is prolonged as a wide fold from each margin of the uterus to the side wall of the pelvis, constituting the ligamentum latum uteri (broad ligament of the uterus), within which are contained the uterine tube, the ovary, the ligamentum teres, and other structures (see pp. 1315 et seq.).

When the bladder is empty, there is seen at each side, between it and the pelvic wall, a considerable peritoneal depression-the paravesical fossa (Fig. 965). This fossa is traversed by a peritoneal fold - the plica vesicalis transversa-which is found running transversely laterally from the superior surface of the empty bladder, and, when well marked, passing to the neighbourhood of the abdominal inguinal ring.

Above the bladder, on each side of the middle umbilical ligament, is found the internal inguinal fovea already referred to (p. 1235). Both of these fossæ are practically obliterated by distension of the bladder.

Similarly, there is seen at each side of the empty rectum, on the posterior pelvic wall, a large depression, which may be known as the pararectal fossa (Fig. 965). When the rectum is empty and contracted, these fossæ are occupied by intestine; during distension, the rectum, increasing in width, expels the intestine and practically obliterates the fossæ.

Transverse Tracing of the Peritoneum.-If the peritoneum is followed transversely around the abdomen, just above the level of the iliac crest (Fig. 968), few difficulties will be encountered. From the anterior abdominal wall it passes round on each side to the back, lining the lateral and posterior walls. Passing medially on the posterior wall, it meets the colon-ascending on the right side, descending on the left-over which it is carried, in each case covering the bowel in front and at the sides only, and leaving the posterior surface bare, as a rule. Sometimes, however, the covering is complete, and a short mesentery is formed. It is next continued medially over the psoas muscles, the ureters, and the great vessels, on the front of which it meets the superior mesenteric artery and vein running downwards to the intestines. From both sides it passes forwards on these vessels, forming the right and left layers of the mesentery; and finally, having reached the intestine, it clothes it completely, and the two portions become continuous on the bowel.

A transverse tracing at a higher level would include the bursa omentalis ; it will, therefore, be well to study this portion of the peritoneal cavity before describing such a tracing.

Bursa Omentalis (O.T. Lesser Sac of the Peritoneum).-The omental bursa, as already pointed out, is a diverticulum of the great sac. It lies behind the stomach and adjacent organs, and communicates with the general cavity by a constricted passage, called the foramen epiploicum [Winslowi]. If the general cavity is compared, as already suggested, to a bag, the anterior layer of which clothes the anterior and lateral walls of the abdomen, and the posterior layer the viscera lying on the posterior wall, the bursa omentalis would correspond to a pocket lying behind the stomach, lesser omentum and part of the liver, and opening into its cavity by a narrow mouth, on the right side, just below the liver. From this opening the pocket passes to the left behind the lesser omentum and stomach, as far as the spleen, up behind the caudate lobe of the liver, and down behind the stomach and gastro-colic ligament.

As in the case of the general peritoneal cavity, it will, of course, be understood that the two walls of the bursa omentalis and the boundaries of the epiploic foramen are normally in contact. We shall first consider this opening, and then trace the layers of the small sac.

Foramen Epiploicum (Winslowi) (Fig. 966).-This, the constricted passage which leads from the general peritoneal cavity into the bursa omentalis, is found just below and behind the porta hepatis. It is bounded anteriorly by the free right 
border of the hepato-duodenal ligament, passing up from the superior part of the duodenum to the porta hepatis, and containing between its two layers the portal vein, hepatic artery, and bile-duct. Posteriorly, lies the inferior vena cava, covered, of course, by peritoneum. Above, is placed the caudate process of

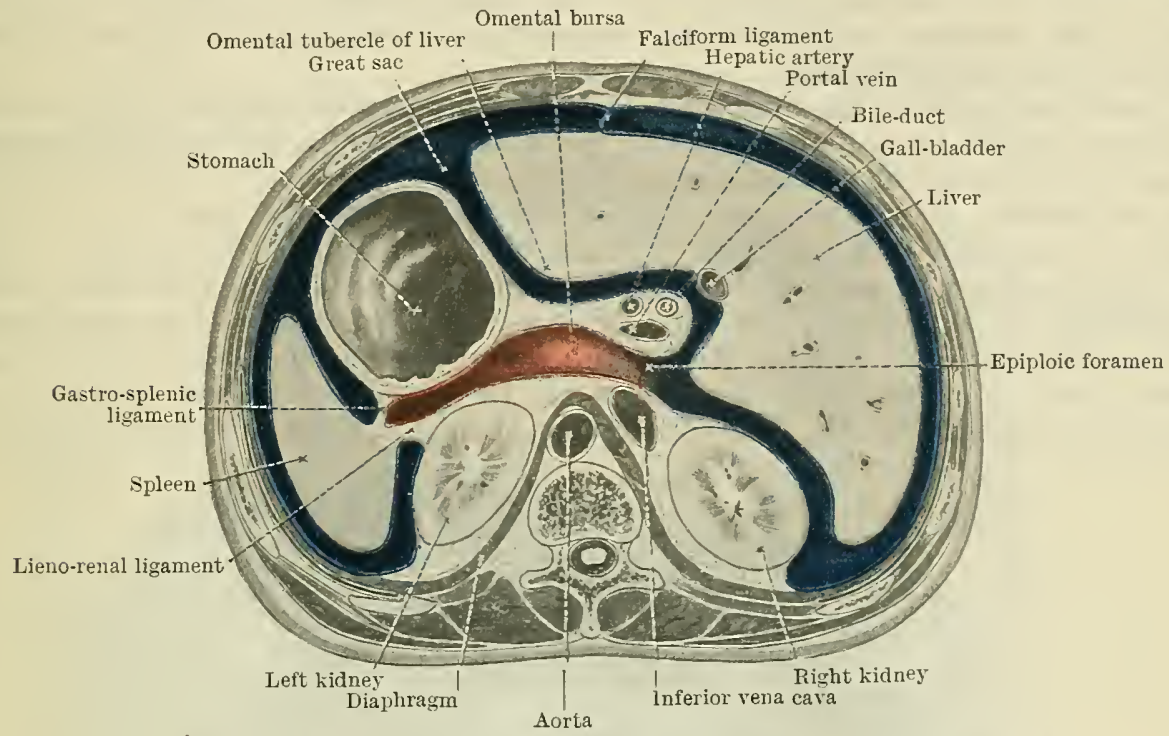

Fig. 966.-Trassierse Section of Abdomex at level of Epiploic Foramex.

the liver. And below, lies the superior part of the duodenum, with the hepatic artery running forwards and to the right beneath the foramen, before turning up into the lesser omentum. It should be remembered that, normally, the various boundaries of the foramen lie in contact, and that its cavity can only be said to exist as such when its walls are drawn apart.

Beyond the foramen epiploicum is a small portion of the omental bursa

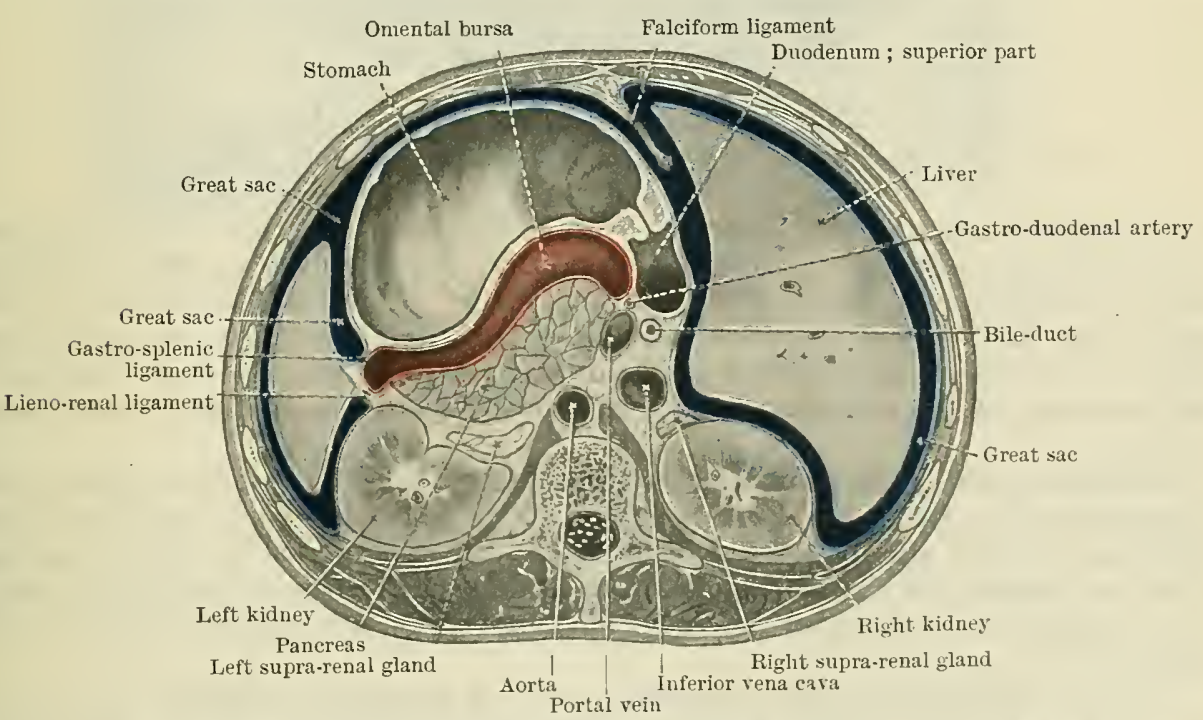

Fig. 967.-Traysterse Section of Abdomex manedately below Eptploic Foramex.

termed the vestibulum bursæ omentalis, lying below the processus candatus of the caudate lobe of the liver, and above the superior part of the duodenum and the head of the pancreas. The anterior wall of this portion is formed by the hepatoduodenal ligament, with the bile-duct, hepatic artery, and portal rein. The 
vestibule is continued beyond a fold termed the plica gastropancreatica into the true bursa omentalis, which presents two main parts, the recessus superior and recessus inferior. The recessus superior passes from the vestibule upwards behind the porta hepatis to the dorsal surface of the lobus caudatus. Posteriorly it is in contact with the diaphragm and aorta. The recessus inferior extends medially in front of the pancreas, and behind the stomach, and passes to the left towards the spleen as the recessus lienalis.

The recessus inferior omentalis and the vestibulum bursæ omentalis communicate with one another by a rounded orifice, which is constricted by the sickle-shaped forward projecting fold, the plica gastropancreatica. This fold is an elevation of the peritoneum of the posterior wall of the omental bursa, raised up by the arteries of the stomach as they pass forwards to that organ from the posterior wall.

As the peritoneal wall of the omental bursa is described in two main parts, an anterior and a posterior, it will be necessary to follow each of these separately. Above, the peritoneum forming the anterior wall clothes the caudate lobe; it then passes down (from the posterior margin of the porta hepatis, and the fossa of the ductus venosus) to the lesser curvature of the stomach and the duodenum

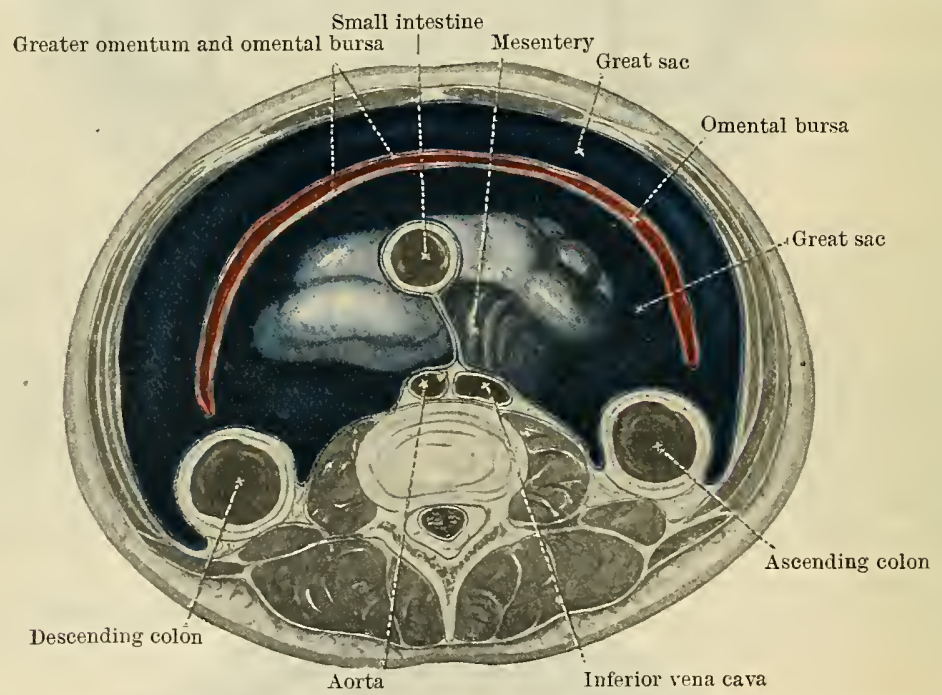

Fig. 968. - Traysverse Section of Abdomen through the Fourth Lumbar Vertebre.

as the posterior layer of the lesser omentum. Continued on from this, it clothes the posterior (or visceral) surface of the stomach as far as the greater curvature, with the exception of the small "uncovered area" below and to the left of the cardia (Fig. 969), but it does not actually come in contact with the osophagus itself, the back and right side of which are uncovered. On the left, it is reflected from the back of the stomach to the spleen as the deeper layer of the gastro-lienal ligament.

From the greater curvature of the stomach it is continued down, forming the posterior layer of the gastro-colic ligament as far as to the transverse colon. In some cases it is not attached to the colon, but is continued onwards as the posterior of the two anterior layers of the omentum, and in such cases at the inferior part of the omentum it meets and becomes continuous with the posterior layer of the small sac.

The peritoneum forming the posterior wall of the bursa omentalis, in passing through the epiploic foramen, clothes the front of the inferior vena cava (Fig. 969); beyond this, it covers the eœliac artery, and passes upwards to line the slight depression on the posterior abdominal wall (diaphragm), against which the caudate lobe rests. Then, passing over to the left, it covers the superior surface of the pancreas, the top of the left kidney and suprarenal gland, and the medial part of the gastric surface of the spleen (Fig. 969). From the anterior border of the 
pancreas it is prolonged anteriorly and downwards-as the anterior or upper layer of the transverse mesocolon-to the transverse colon (Fig. 969). Here it usually joins the gastro-colic ligament, but in English text-books it is described, and here it is figured, as being continued down as the anterior layer of the posterior fold of the greater omentum, almost to its inferior border, where it becomes continuous with the anterior layer of the omental bursa already described.

The transverse tracings at the level of the epiploic foramen and pylorus are shown in Figs. 966 and 967 , and can be easily followed without any further description than is there given.

Top of omental bursa

Inferior rena cava

Lesser omentum (cut)

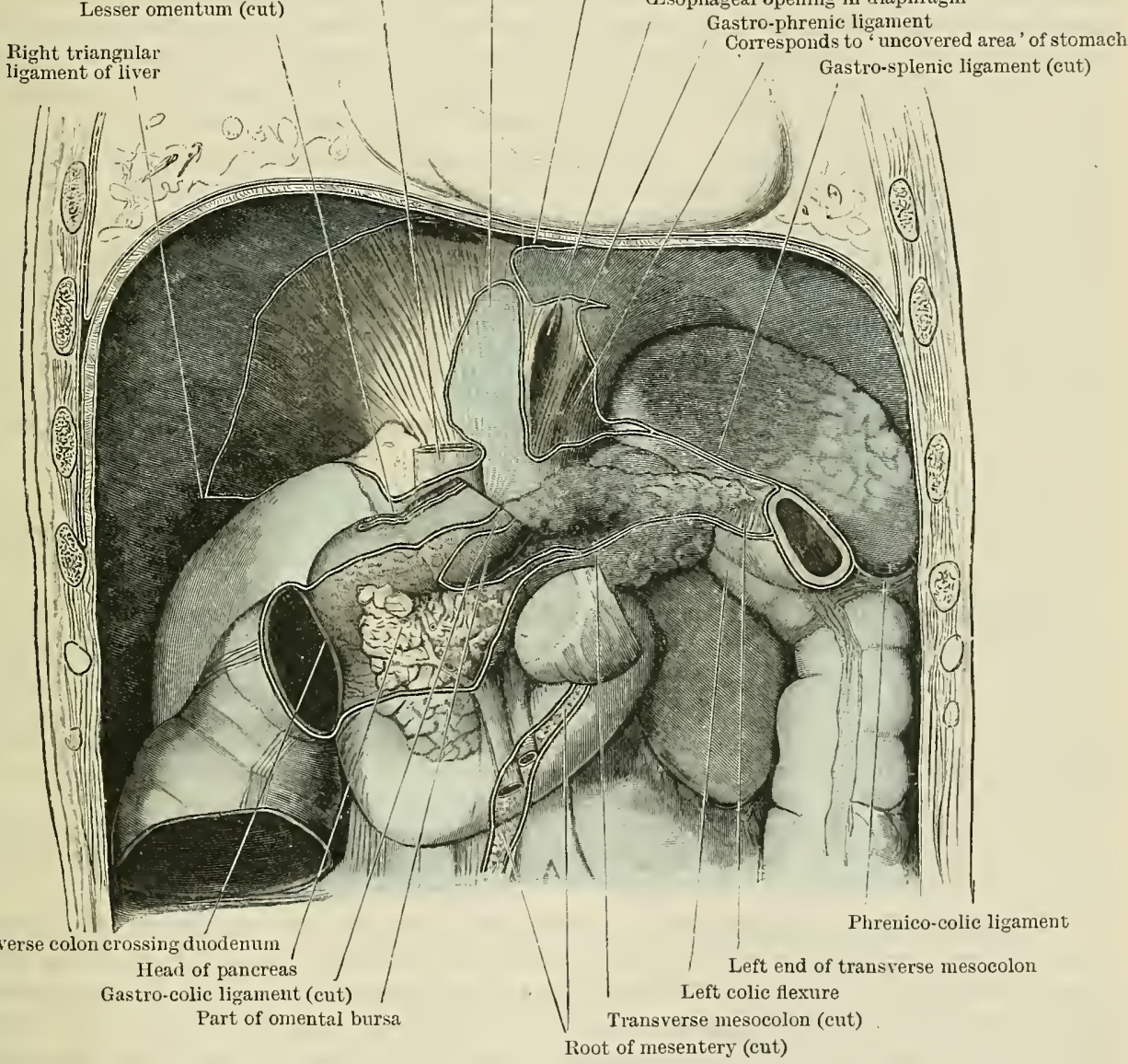

Fig. 969.-The Peritoneal Relations of the Duodenum, Pancreas, Spleex, Kidneys, etc.

The lesser omentum is described at p. 1162 ; it need only be pointed out now that it is composed of two layers, the anterior belonging to the general peritoneal cavity, and the posterior belonging to the omental bursa; and both layers are extremely thin-sometimes even cribriform.

The greater omentum is a large apron-like fold of peritoneum, usually more or less loaded with fat, which is suspended from the transverse colon, and hangs down in front of the intestines to a variable extent. When the abdomen is carefully opened withont disturbing the viscera, it is rare to find the greater omentum evenly spread over the front of the intestines. More commonly it is folded in between some of the coils of intestine, or tucked into the left hypochondrium; or perhaps it is carried upwards in front of the stomach by a distended transverse colon. The gastro-colic ligament continues the anterior layers of the greater omentum upwards to the stomach, and the gastro-lienal ligament continues them 
between the spleen and stomach. The greater omentum is thus commonly described as extending between the greater curvature of the stomach above and the transverse colou below, not taking the shortest course from one of these to the other, but hanging down as a loose fold between the two, and containing between the anterior and posterior folds a cavity continuous with the omental bursa (Fig. 968).

This is the condition in the embryo, but in the adult the anterior fold usually becomes adherent to the colon, and, below it, also to the posterior fold, and hence the carity becomes largely obliterated. If the gastro-colic ligament be included as part of the greater omentum, and the embryonic condition is retained, as is usually described in English text-books, the greater omentum may be said to consist of two folds, each formed of two layers, one derived from each sac of the peritoneum. The anterior or descending fold begins at the greater curvature of the stomach, where it is formed by the meeting of the two layers from the anterior and posterior surfaces of that organ respectively; from this it descends to the front of the transverse colon. Leaving the colon, or passing anteriorly to it, see Fig. 964, the two layers proceed to the lower border of the omentum, where, turning back (Fig. 964), they pass up as the posterior or ascending fold. This runs upwards until it meets the transverse colon; here its two layers separate to enclose and cover that colon-and the greater omentum properly so called ceases. Its two layers, however, unite at the superior margin of the colon (Fig. 964) to form the transverse mesocolon, which is continued upwards and posteriorly to the anterior border of the pancreas. Here the layers of the transverse mesocolon again separate-the superior running upwards over the anterior surface of the pancreas to the posterior abdominal wall and lining the omental bursa; the lower passing downwards on the posterior abdominal wall, as already explained.

The greater omentum is continued to the right for a short distance $(25 \mathrm{~mm}$.) along the inferior border of the duodenum. At the left end it shurtens very much, and is directly continued into the gastro-lienal ligament; the spleen, as it were, being introdnced between the two layers instead of the colon.

Functions of the Greater Omentum.-Numerous uses have been assigned to the great omentum; the chief seem to be: (1) To act as a movable and easily adjustable packing material, capable of filling all temporarily-produced spaces in the abdomen. In this respect it may be compared with the Haversian fatty pads in joints. (2) It probably, to some extent, prevents the passage of the small intestines up into the stomach chamber, and helps to keep them from getting entangled there. (3) It is a storehouse of fat. (4) It is said to be "the great protector against peritoneal infectious invasions." Being freely movable, it can pass to almost any part of the abdomen, and there "build up barriers of exudations to check infection."

Mr. Lockwood has made the interesting observation (in connexion with the contents of herniæ) that, in bodies under forty-five years of age, the omentum can rarely be drawn down below the level of the pubic tubercle ; in older bodies the reverse is the rule.

The gastro-lienal ligament is a short fold composed of two layers, an anterior lining the general peritoneal sac, and a posterior lining the omental bursa (Fig. 966). It is attached by one margin to the fundus and greater curvature of the stomach, and by the other to the gastric surface of the spleen just in front of the hilus. Between its two layers the vasa brevia of the splenic artery pass from the spleen to the stomach. Below and in front, its layers are continued into the corresponding layers of the gastro-colic ligament; above and behind, they separate at the "uncovered area" of the stomach (Fig. 969).

Minor Folds of Peritoneum.- The phrenico-colic ligament, passing from the left flexure of the colon to the diaphragm opposite the 10 th or 11 th ribs, has been described, and also the mesentery of the vermiform process, the lieno-renal and hepato-renal ligaments.

\section{DEVELOPMENT OF THE DIGESTIVE SYSTEM.}

In the section on General Embryology it has been pointed out that the alimentary canal is formed from three separate parts. (1) A middle large entodermal portion, and (2) two smaller ectodermal parts, one anterior, the oral sinus or stomodæum, and one posterior, the proctodæum. 
It has been further shown that these three portions are at first separated from one another by septa, the pharyngeal membrane and the proctodeal membrane, respectirely, but these septa disappear at an early date, and the three parts are thrown into continuity.

There is thus formed a tube, the primitive alimentary canal, extending through the body from the mouth aperture in front to the anal orifice posteriorly.

The entodermal segment of the primitive alimentary canal is divided into three portions as follows :-

(1) That portion which is enclosed within the head fold is termed the foregut; the portion within the tail fold is termed the hindgut; and the intermediate portion is termed the midgut. The midgut at first lies opposite the communication with the yolk sac, and the other portions cephalic to and caudal to this level.

From the foregut are formed the posterior part of the mouth, the pharynx, csophagus, stomach, and the greater part of the duodenum. From the mid and hindgut are formed the rest of the small intestine, and the whole of the large intestine, as far as to the "white line" of the anal orifice. There is no sharp limit between the mid and hindgut or between the portions of the intestinal canal formed from them.

The different parts of this tube become modified in their structure, so as to form special organs, and in many regions outgrowths occur in the form of hollow diverticula, from which the accessory glands are formed, which lie outside the wall of the original tube. Organs such as the liver, pancreas, and salirary glands arise in this way.

It should be stated here, also, that this primitive intestinal tube forms the basis, not only of the alimentary canal and its associated organs, but it also is the source from which many other organs, not ultimately connected with digestion, are formed.

Thus the respiratory tract below the lerel of the orifice of the larynx is formed as an outgrowth from the ventral wall of the primitire foregut, and remains permanently connected with it at that point, thongh in structure and function it becomes rery different from the tube from which it is derired.

Other structures also, namely, the thyreoid gland, the parathyreoid glands, and the thymus, are formed from the alimentary canal as direrticula, but they erentually loose their connexion with the wall of the tube, and become specialised in function and in structure.

Furthermore, the allantois, a diverticulum from the hindgut, plays an important part in the formation of the urinary bladder, and with a part of the primitive hindgut is cut off from the primitive cloaca to form the urinary bladder and a portion of the urethra.

The development of these organs not connected with the alimentary canal in the adult will be found in the sections dealing with them.

Development of Mouth and Pharynx.-The development of the mouth and of the pharynx from the oral sinus and anterior part of the foregut are intinately associated with one another, and with the formation of the mouth and nose.

The stomodeum or oral sinus first appears as a depression situated between the primitive forebrain above and the pericardial region below.

The floor of this depression is formed by the pharyngeal membrane, which consists of ectoderm and entoderm only, mesoderm being absent; the membrane separates the oral sinus from the anterior end of the foregut, but at an early stage it ruptures and disappears.

The mouth carity of the adult is formed in part from the oral sinus, and in part from the anterior end of the foregut, or primitive pharynx. The line of division between the portions of the mouth derived from these two parts is difficult to trace, on account of the rery extensive changes which occur after the pharyngeal membrane has disappeared, and which are associated with the formation of the face and of the nose. The portion of the mouth cavity derived from the primitive pharynx is lined with entoderm, and that from the oral sinus with ectoderm. The position of the original pharyngeal membrane may be represented by an imaginary plane extending from the anterior part of the body of the sphenoid to the base of the alreolar process of the mandible on its lingual surface.

Thus the cavity of the nose is derived from the upper part of the oral sinus, while the floor of the mouth is formed from the pharynx. The adamant (O.T. enamel) of the teeth and probably the secreting epithelium of the parotid gland are ectodermal structures, while the epithelium of the tongue and submaxillary and sublingual glands is entodermal in origin.

The ectodermal or oral sinus portion of the mouth, then, gires origin to the lips, teeth, and parotid glands; while in the pharyngeal portion are dereloped the tongue, submaxillary and sublingual glands.

The upper lip is formed from the tissues covering the frontal and maxillary processes (see development of face). 
The lower lip similarly is formed from the tissues corering the mandibular arches.

$\mathrm{By}$ an ingromth of epithelium from the surface of the frontal and maxillary processes into the subjacent mesoderm and by subsequent desquamation of the superficial layers, a groore is formed between the lips and cheeks, on the one hand, and the alveolar ridges on the other. This groore when deepened forms the restibule of the mouth, and is termed the alveolo-labial sulcus, or labial groore.

The surface corered with mucous membrane becomes ererted, to form the red portion of the lips, and at birth is divided into an outer smooth portion, and an inner portion whose surface is rillous, termed pars villosa. The distinction between these two parts disappears shortly after birth.

Several explanations of the formation of the philtrum or groore on the front of the upper lip have been put forward; most probably it is produced by the union of the margins of the two processus globulares with one another, the floor of the groove being formed by their line of union, and the ridges bounding the groore at the sides corresponding to the medial portions of the globular processes.

The parotid glands are formed as outgrowths of the epithelium in the outer wall of the alreolo-labial sulcus.

The outgrowth in each side has been found in embryos $8 \mathrm{~mm}$. long. It is at first a furrow. The posterior part of the furrow becomes closed off from the mouth carity and forms a tube, which grows backwards for some distance on the surface of the first risceral arch.

The terminal portion of the tube formed in this way gires rise to a number of buds, which diride repeatedly, and form the lobules of the gland.

These are at first solid, and the alreoli do not become hollowed until about the twentr-second week.

The epithelium of the terminal buds forms the secreting glandular epithelium, while that of the stalk forms the lining epithelium of the duct.

\section{DEVELOPMENT OF THE TEETH.}

A tooth may be described as a calcified papilla of the mucous membrane, composed of two chief parts-namely, the substantia adamantina formed by the epithelial layer, and the substantia eburnea by the connective tissue lajer of the mucous membrane. The details of the process by which such a tooth is developed from the two layers of the mucous membrane are both numerous and intricate, and can be but briefly described here.

In lower rertebrates (sharks, rars, etc.), teeth which correspond essentially, both in structure and development, to those of mammals are found on the surface of the body, and are known as dermal teeth. The following outline of the development of the dermal tooth of a shark may assist in rendering the derelopment of the human teeth more intelligible:-

First, a papilla is formed from the corium or connective tissue layer of the skin (Fig. 970, B), and this papilla is corered over by the epithelial layer.

Tert, the superficial (connective tissue) cells of the papilla begin to form a laser of irory on the surface of the papilla (Fig. 970, C), which it soon encases, the remaius of the papilla persisting in the interior as the future tooth pulp. At the same time the deepest cells of the epithelium deposit a laver of adamant outside the ivory over the summit of the papilla (Fig. 970, C), and subsequently the two-adamant and irorybecome inseparably united, thus giving rise to the substance of the tooth.

At a later period the epithelium corering the summit disappears and the tooth comes to the surface; this constitutes its eruption (Fig. 970, D).

In the case of the mammalian tooth a sinilar process takes place, not, however, on the surface, but deep domn in the substance of the gum, into which a downgrowth of epithelium has preriously taken place. This epithelial downgromth spreads out in the substance of the jaw, and into it the papilla grows up, and goes through the other changes described abore, as if the whole process took place on the surface.

Development of Human Teeth.-The following is a brief summary of the chief erents in the derelopment of a human tooth. For conrenience in expression and terms, the description refers to the development of a lower tooth. The upper teeth are, of course, dereloped in a manner exactly similar.

1. The first distinct evidence of the derelopment of the teeth is ' to be found in a thickening of the mouth epithelium, at the site of the future gum, and a resulting downgrowth of its deeper portion into the substance of the primitire jaw (Fig. 971, I.). This epithelial downgromth is continued along the whole length of the gum, and is known as 
the dental lamina or tooth-band (Zahnleiste). The dental lamina divides into two plates, a lateral vertical and a medial more horizontal in direction. The medial plate is the portion from which the teeth are formed, and is termed the dental ledge. On the under surface of the dental ledge there soon appears a series of knob-like projections-one for each of the milk teeth (Fig. 971, II.) - which are known as adamant germs or adamant organs. These organs are connected with the epithelium of the dental ledge by a constricted part, and although at first knob-like, they soon become bell-shaped owing to the invagination of the lower surface of the knobs, so that each may now be compared to an inverted egg-cup.

2. As soon as the adamant organs begin to assume a cup-like shape, the cellular connective tissue of the jaw beneath grows up and projects into the cavity of the cup (Fig. 971, III.) in the form of a papilla-the papilla dentis. The arrangement, pursuing our simile, may now be compared to an egg fitting into its cup - the papilla representing the egg, and the adamant organ the cup (Fig. 971, III.).

3. The two layers of cells which are thus brought in contact, namely, the epithelial cells lining the concavity of the adamant organ, and the superficial cells of the tooth papilla, become elongated or columnar, and undergo other changes, preliminary to the production of the adamant by the former - which are now called adamant cells or ameloblasts - and the ivory by the latter, which are known as odontoblasts.

4. The odontoblasts, that is the layer of columnarshaped connective tissue cells lying on the surface of the dental papilla, begin to form at their outer ends a layer of ivory (Fig. 971, IV.). Similarly, the adamant cells lining the cup begin to form at their inner surface a layer of adamant on the top of the layer of ivory (Fig. 971, IV.), to which it adheres: in each case the deposit taking place first at the summit of the tooth.

5. The formation of these tissues proceeds apace, the ivory increasing at the expense of the papilla, the adamant similarly encroaching on the cup or
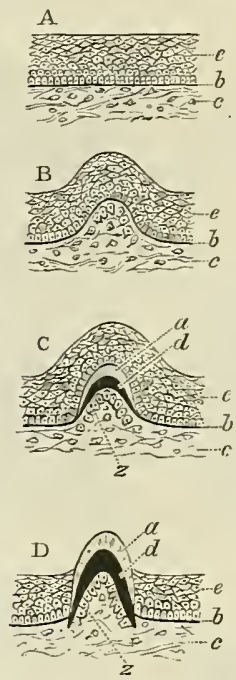

A, Section of skin showing epithelium $\ell$, basement membrane $b$, and connective tissue layer $c$.

$B$ shows the papilla of the connective tissue layer growing up covered by the epithelial layer.

In $\mathrm{C}$ the superficial cells of the papilla $z$ begin to deposit irory $d$ over the papilla, and at the same time the depest cells of the deepest cells of the epithelium deposit adamant $\alpha$.

Fig. 970.-DLAGRAM TO ILLCSTRATE THE DeVElopMext OF a Dermal ToOth I THE S'HARK.

In all figures- $a$, adamant; $b$, basement meubrane; $c$, connective tissue layer of skin; $d$, irory; $e$, epithelium; and $z$, superficial cells of papilla.

adamant organ; and in each case the two layers of cells-odontoblasts and adamant cells -which produced the deposits, retiring gradually from one another, as the space between them becomes occupied by the newly formed tissues (Fig. 971, V.).

The remains of the dental papilla persist as the pulp of the tooth, which is corered even in the adult by the odontoblasts, and occupies the tooth cavity, i.e. the central part of the tooth to which the formation of ivory has not extended.

6. Turning now to the jaw itself: The connective tissue of the gum surrounding the tooth germ (as the developing tooth with its adamant organ and dental papilla are called) early becomes condensed and vascular (Fig. 971, V.), and later on forms a membranous bag-the tooth-sac or follicle-which completely shuts off the developing tooth from the surrounding structures. On the floor of this sac the tooth germ sits, the base of its dental papilla being continuous with the tissue of the floor of the sac, and the young tooth being enclosed by the sac, as a kernel is enclosed by its shell.

7. Reverting to the tooth: When the crown is completed the deposit of irory, but not of adamant, is continued downwards to form the root. The root is composed chiefly of ivory continuous above with that of the crown, and like it formed by the odontoblasts of the dental papilla. As the ivory is deposited, and the root is being built up, the connective tissue of the tooth-sac comes to surround the root more closely, and deposits on its surface, after the manner of a periosteum, a layer of bone, the substantia ossea. After this layer has been formed, the connective tissue of the sac persists as the alveolar periosteum. The development of the root takes place rery slowly, and its lower end is not completed as a rule for some time after the eruption of the tooth has taken place.

8. During the development of the teeth the ossification of the jaw has been going on, and as it grows up on each side, the young teeth, enclosed in their tooth-sacs, come to lie in an open bony groove, which is subsequently divided by septa into compartments - the alveoli-for the individual tooth-sacs. The bone continuing to grow after birth, these 
compartments become more perfect, but are never entirely closed in over the crowns of the teeth. During the eruption of the teeth the upper and anterior part of these bony cells is absorbed; subsequently, however, it is re-formed around each tooth when it has taken its final position.

9. Eruption.-Long before the root is completed, the crown, by some force which is not properly understood, but which does

I. Shows the downgrowth of the dental lamina D.L from the surface epithelium E and the berinning of the adamant germ E.G.

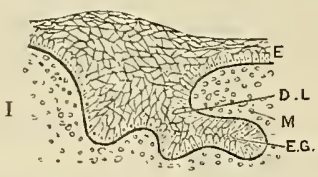

II. Shows the further growth of the adamant germ and its invagination.

III. The adamant germ is more invaginated, and its inner layer of cells becomes columnar. $A$, the dental lamina, grows thinner, but near its posterior or lingual edge there is an enlargement R.G which is the reserve germ for a permanent tooth. The superficial cells of the ivory papilla $\mathrm{P}$ are becoming columnar.
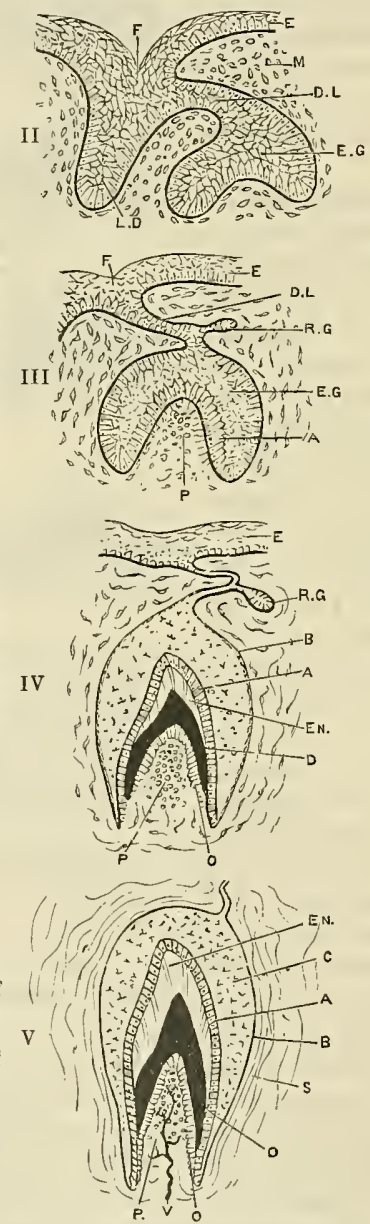

Fig. 971.-DIAGRAM TO ILLUSTRATE DEvElopMent OF A TOOTH.

A, Inner layer of adamant germ; B, Onter layer; C, Remains of intermediate cells; D, Ivory; D.L, Ivory lamina; E Epithelium; E.G, Adamant germ ; EN, Adamant; F, Dental furrow ; L. D, Labio-dentaI furrow; M, Connective tissue cells O, Odontoblasts; $P$, Ivory papilla; R.G, Reserve germ; V, Blood-vessel.

\section{dental lamina is completed by the end of the seventh week.} not seem to depend on additions to the root, is pushed through the top of the tooth-sac, and-the upper and anterior wall of the roomy alveolus having been absorbed at the same time-onwards through the gum until the month is reached. Later on, when the tooth has assumed its final position, the alveolus, as already stated, is re-formed, and closely embraces the completed root.

10. After the adamant organs of the deciduous teeth have been formed on the inferior aspect of the dental lamina, as described above, the neck of epithelium by which the lamina is still connected with the surface becomes broken up into a cribriform sheet. Its free posterior border, on the other hand, continues to grow backwards in the tissue of the gum towards the cavity of the mouth (Fig. 971, III. and IV.), and at a later date there appear on its under surface, near the free edge, and behind the several developing milk teeth, the adamant organs-or so-called "reserve germs"for the corresponding permanent teeth, which are developed from these in exactly the same manner as the deciduous teetl described above.

In connexion with the development of the permanent molars, which have no corresponding teeth in the deciduous set, there takes place a prolongation backwards of the posterior extremity of the dental lamina into the tissue of the jaw, behind the last deciduous molar. On the inferior aspect of this prolongation, which has no direct connexion with the surface epithelium, adamant organs are formed for the permanent molars, and their further development goes on in the manner described for the other teeth.

The dates at which some of the chief events in the development of the teeth occur may be briefly given :-The thickening of the epithelium, the first sign of the future teeth, begins about the sixth week of fœtal life, and the

The dental papillæ for the eight front teeth appear and become surrounded by their adamant organs about the tenth week, and the papilla for the first permanent molar about the seventeenth week.

The first traces of calcification, and the formation of the tooth-sacs, take place about the fifth month of foetal life.

Eruption of Deciduous Teeth.-The period at which the eruption of the milk teeth takes place is extremely variable, and no two observers seem to agree upon the question. 
The following, according to Tomes, may be taken as representing the average. The lower central incisors appear first, usually between the sixth and ninth months; then follows a rest of a few months. Next come the four upper incisors, followed by a rest of a few months. Then the lower lateral incisors and the four first molars erupt, succeeded by a rest of a few months. Next appear the canines, and finally the four second molars, which are all cut by the end of the second year.

The following statement is simple, and perhaps is sufficient for all ordinary purposes. The deciduous teeth usually appear in the following order:-Central incisors, lateral incisors, first molars, canines and second molars; the eruption commences between the sixth and the ninth month, and is usually completed by the twenty-fourth-the lower teeth, as a rule, preceding the upper.

Formation of Adamant and Ivory.-Different opinions are held as to the method in which the substantia adamantina is produced by the cells concerned in the process. One view maintains that it is secreted and shed out by the cells (Kölliker). According to the other view, part of the substance of the cells is actually converted or transformed into adamant (Tomes). In connexion with this latter view, which seems to receive more support at present, Tomes has discovered that there projects from the base of each cell, towards or into the most recently formed enamel, a fibrillar process, which has received the name of Tomes' process, and he holds that the substantia adamantina is formed by calcification taking place in or aronnd the process.

Similarly, two views are held as to the prodnction of ivory by the odontoblasts; one, that the odontoblasts secrete the matrix ivory, and the other, that their substance is actually converted into the matrix of the ivory. The odontoblasts, when active, are branched columnarshaped cells, and from their outer ends one or more processes extend towards and into the ivory; between these processes a matrix appears - produced probably by the odontoblasts - and soon this matrix becomes calcified. In this way the ivory is formed, and the process is repeated until its full thickness is attained. The branches of the odontoblasts, encased in ivory, just mentioned, are the Tomes' fibrils already described; the canals in which they lie are the dental canaliculi; and the fibrils themselves are concerned in the production of the sheaths of Neumann which line the tubes.

The tooth-sacs, when fully developed, are large and distinct fibrous bags which lie in the alveoli of the maxilla and mandible, and are continuous above with the tissue of the gum. On the lingual side of the sacs of the deciduous teeth are found the germs of the permanent teeth, surrounded by their own sacs. These latter are at first very small, and are partly embedded in the posterior wall of the decidnous tooth-sacs, but subsequently they come to lie in distinct but incomplete bony cavities of their own. The bone surrounding the tooth-sacs, temporary and permanent, is always wanting over the summit of the sac, and the band of connective tissue by which the sac is connected with the overlying gum tissue, through the deficiency, is known as the gubernaculum dentis.

These points are easily demonstrated on the mandible of a child at birth, particularly when the tissues have been allowed to soften a little. If, in such a specimen, the gum and periosteum be reflected upwards from the labial and lingual surfaces of the mandible, and freed as far as the superior border of the jaw, the gum, with the tooth-sacs depending from it like small bags, can be pulled away out of the bony groove of the jaw ; and if the operation has been successfully performed, the tooth-sacs of the three front permanent teeth may be seen, varying in size from a small pin's-head to a hemp-seed, hanging down behind the superior part of the corresponding deciduous sacs. As already explained, the tooth-sacs are produced simply by a condensation of the connective tissue around the developing tooth, the condensation going on to the formation of a distinct membranous bag.

Formation of Alveoli and Eruption.-At first the developing teeth lie in an open bony groove or channel between the labial and lingual plates of the young jaw. This groove is subsequently divided up into separate compartments for the sacs of each of the deciduous teeth. As development proceeds these compartments or alveoli surround the sacs more completely, but never actually close over the summit. When the eruption of the deciduous teeth is about to take place, the anterior wall and roof of the alveolus are absorbed; the tooth passes through the sac and appears above the gum, and then the alveolus, which up to this was much too large to give actual support, is re-formed more closely around the tooth. Meanwhile the root, which was only partly formed at the time of the eruption, continues to be added to, possibly for a few years more, and, as it grows, the alveolus is completed around it. When the permanent tooth, or as much of it as is then formed, is about to be erupted, it makes its way from its own bony cell through the posterior wall of the alveolus of its temporary predecessor; the ront of the deciduous tooth undergoes absorption at the same time, but quite independently of pressure from the permanent tooth. The alveolus, now occupicd by both teeth, is again much enlarged 
by absorption, particularly in front; what remains of the temporary tooth is shed; the permanent tooth passes onwards through the enlarged alveolus, and, making its way to the surface, appears above the gum. After some time, when the tooth has taken its final position, the alveolus is again re-formed, first around its neck, and later on, as the root is built up, around it also, and thus the tooth is permanently fixed.

What the force is which causes the eruption, is a question that has not been answered satisfactorily. That the growth of the root pushes up the crown was formerly the favourite explanation. For several reasons, unnecessary to detail, this view is now discarded, and a theory which attributes the impelling force to the blood pressure is looked upon with more favour, although even this is not altogether satisfactory. (See Tomes' Dental Anatomy, 5th Edition, page 211.)

\section{Morphology of the Teeth.}

In most vertebrates below mammals all the teeth are alike in form ; such a dentition is said to be homodont. In the majority of mammals, on the other hand, the teeth are arranged in groups of different size and form; such a dentition is heterodont.

Again, mammals have, neglecting exceptional cases, but two functional sets of teeth ; they are consequently said to be diphyodont. Most vertebrates below mammals, on the other hand, have a continuous succession of teeth throughout life, and hence are said to be polyphyodont.

Seeing that practically all lower vertebrates are provided with simple conical teeth, the evolution of the multi-tuberculate mammalian molar has given rise to much speculation. The jaws of the earliest fossil mammals found are furnished with tri-tubercular teeth, the three tubercles being placed in an antero-posterior line; by a rotation of two of the tubercles to the lingual or labial side, as the case may be (a condition found in certain other fossil skulls), we arrive at a tri-tubercular form, from which the transition to an ordinary mammalian molar is not difficult. As to how the tri-tubercular tooth arose from the simple cone, two different views are advanced : one, that it was formed by the union of several conical teeth as a result of the shortening of the jaw and the crowding of the teeth together; the other, that the single conical tooth developed on its crown two subsidiary tubercles, one in front and the other behind, and that these tubercles growing larger, the tooth assumed the tri-tubercular form.

The complete or typical mammalian dentition, in its highest development, as in the horse, is represented by the following formula : i. $\frac{3}{3}, c . \frac{1}{1}, \mathrm{pm} . \frac{4}{4}, \mathrm{~m}$. $\frac{3}{3}=44$. In the dentition of man, therefore, one incisor and two premolars are wanting. Different views are held as to which teeth have been suppressed-most probably they are the second incisors, and the first and second or first and last premolars.

In general it may be said that the dentition of the lower races differs from that of the higher, in that the dental arches are squarer in front, the teeth larger and more regular, the canines stronger, the last molars better developed, and the tubercles on the molars more perfect, in the lower than in the more civilised races. It may be mentioned, however, that the teeth of a savage man, if seen in the mouth of a European, would be looked upon as an "exceedingly perfectly formed set of teeth" (Tomes).

To express the proportion in size of the crowns of the premolars and molars to that of the skull in different races, Flower compared the distance from the front of the first premolar to the back of the last molar, in situ, with the distance from the front of the foramen magnum to the naso-frontal suture (basi-nasal length), in the form of a "dental index"-

$$
\text { Thus : } \frac{\text { Length of teeth } \times 100}{\text { Basi-nasal length }}=\text { Dental index, }
$$

and by this means he has divided the various races into microdont (index 42 to 43 , Europeans, Egyptians, etc.), mesodont (index 43 to 44, Chinese, American Indians, Negroes, etc.), and macrodont (index 44 and upwards, Australians, Melauesians, etc.).

\section{Development of Primitive Pharynd and Pharyngeal Portion of the} MouTh.

The anterior blind termination of the foregut in the head region constitutes the primitive pharynx.

Its roof is formed by the tissues covering the under aspect of the mid- and fore-brain, and its floor by the tissues overlying the heart and pericardium. The lateral wall on each side is a lamina of tissue extending from the floor to the roof, continuous in front with the bucco-pharyngeal membrane which forms the anterior wall of the pharynx and separates it from the stomodeum.

In the roof are formed the tissues which form the hinder part of the base of the skull.

In the lateral wall and in the floor extensive changes occur, comnected with the appearance of structures known as the visceral arches and pouches, and with the origin of numerous structures from them and the development of the tongue, 
Tongue.-The tongue is formed in two portions, anterior and posterior, in the floor of the pharynx.

The anterior portion, forming the anterior two-thirds of the organ, is formed from the tissues on each side of the tuberculum impar, which grow up and enclose that elevation, and from the tuberculum itself. Evidence of this bilateral origin of the tongue is found in those cases of bifid tongue which occur, though rarely.

The hinder portion, forming the posterior third of the tongue, is formed from the tissues covering the inner ends of the second arch and a portion of the third.

These arches, as has been pointed out, meet and fuse in a common mass in front of the furcula, in the floor of the sinus arcuatus.

Between the ridge which they form and the tuberculum impar in front, a slight median depression is found, from which the median thyreoid diverticulum is formed, and which persists as the foramen cœcum of the tongue. On each side of this depression a groove runs obliquely outwards and upwards (the sulcus terminalis) immediately behind the region of the vallate papillæ, and marks the union of the anterior and posterior portions of the tongue.

The tongue mass formed by the union of these different parts increases in size, rises upwards from the floor of the pharynx, and projects forwards.

The tissue forming its interior becomes transformed into the muscular substance of the tongue, and is derived largely from the first branchial region, and not from the musculature of the visceral arches.

The investing epithelium of the anterior two-thirds gives rise to the papillæ and the taste buds, while that covering the posterior portion remains smooth. The papillæ appear about the third month as elevations of the corium, covered with epithelium.

The vallate papillæ are formed by ingrowths of the epithelium in rings, around a central core. The superficial layers of the epithelium desquamate and form the trench surrounding the papilla.

Submaxillary and Sublingual Glands.-These glands are formed in the alveololingual groove in the floor of the primitive pharynx, immediately behind the first arch, by outgrowths somewhat similar to those described in connexion with the parotid (q.v.).

The submaxillary outgrowth occurs about the fifth week, and the sublingual, several in number, on the outer side of it at the ninth week.

Palatine Tonsil.--The glosso-palatine arch arises in the position occupied earlier by the second visceral arch, behind which, in the embryo, lies the pharyngeal portion of the second visceral cleft. The dorsal extremity of this cleft enlarges, and forms a recess termed the sinus tonsillaris. From the lower and greater part of the sinus tonsillaris the palatine tonsil is developed; the upper part of the sinus persists, however, as the supratonsillar fossa. The palatine tonsil at first is a smooth depression of the mucous membrane. About the fourth month of fœtal life downgrowths of the epithelium take place, which are afterwards converted into the tonsillar crypts. Subsequently lymph cells accumulate around the downgrowths and form the lymph tissue, which constitutes the mass of the organ. The plica triangularis is formed from a tubercle, which becomes flattened, and forms a fold on the anterior and medial aspect of the inferior part of the palatine tonsil.

\section{Development of Esophagus, Stomach, And Intestines.}

Esophagus.-The oesophagus is formed from the foregut. The lengthening of the thoracic region of the trunk, which occurs with the growth and development of the heart and lungs, causes this portion of the alimentary tube to become greatly lengthened. The entodermal lining forms the epithelial layer, and the mesoderm the other coats of the osophagus.

Stomach.-As early as the fourth week, the foregut exhibits a fusiform enlargement in the region of the developing heart, which is the first evidence of the differentiation of the stomach: this enlargement takes the form first of an outgrowth on the dorsal border to form the fundus. Soon, however, as the diaphragm is being formed, the stomach descends into the abdomen, and its dorsal wall-the future greater curvature -begins to grow more rapidly than the ventral wall. As a result the whole organ becomes somewhat curved, and its inferior end is carried forwards from the posterior abdominal wall, giving rise to the curvature of the duodenum. The excessive growth of its posterior wall causes the stomach to turn over on to its right side, which now becomes posterior or dorsal. In this rotation the upper or cardiac portion moves to the left of the median plane, and the whole organ assumes an oblique direction across 
the abdomen. Already, at the fiftl or sixth week, the adult form of the stomach is clearly indicated.

This rotation of the stomach around its long axis, which is accompanied by a rotation of the lower end of the csophagus, explains the asymmetrical position of the two vagi. In the adult the left nerve is foumd on the front of the stomach, which was originally the left side of the organ; similarly, the right nerve lies on the back, which was originally the right side.

Intestines. - At first there is no separation into large and small intestines; the primitive canal simply forms a slender tube, with a convexity towards the umbilical orifice, through which the vitelline duct passes to the yolk sac. Later, the tube increases in length, and in embryos of 11 or $12 \mathrm{~mm}$. an outgrowth of the canal appears, which represents the future cæcum, and indicates the separation into large and small intestines. Growing longer, the intestine forms a large loop with the vitelline duct springing from its apex (Fig. 973), and the superior mesenteric artery running down between the layers of its mesentery. At the same time the two extremities of the coil approach one another, and form a narrow neck to the loop, as shown in Fig. 973. There now takes place a change which entirely modifies the position of the parts-this is a rotation of the whole loop, with its mesentery, around the superior mesenteric artery as an axis (Fig. 973). The result of this rotation is that the original right side of the loop of gut and mesentery becomes the left side; and the beginning of the large intestine is carried across the duodenum (Fig. 973), thus explaining the passage of the transverse colon in front of the second part of the duodenum in the adult. At the same time the crcum comes to lie near the middle of the abdomen below the liver, a position in which it is found during the third month. Subsequently, it passes farther to the right; and finally, descending, comes to occupy its adult position.

The small intestine continues to grow in length, and, as a result, is thrown into coils, which become more and more complex as the length increases, until the adult condition is attained. The terminal portion of the large bowel retains its position on the left side, and passes down to the anus.

Formation of Gastric and Intestinal Glands, etc.-The epithelial lining of the intestinal tube is composed, at first, of a single layer of cells, and the inner surface is smooth. In the second month the epithelium increases rapidly, and as a result its surface is thrown into folds and furrows, arranged irregularly. Mesenchymal tissue passes into the interior of the folds, and also blood capillaries. Those folds appear first in the stomach, especially

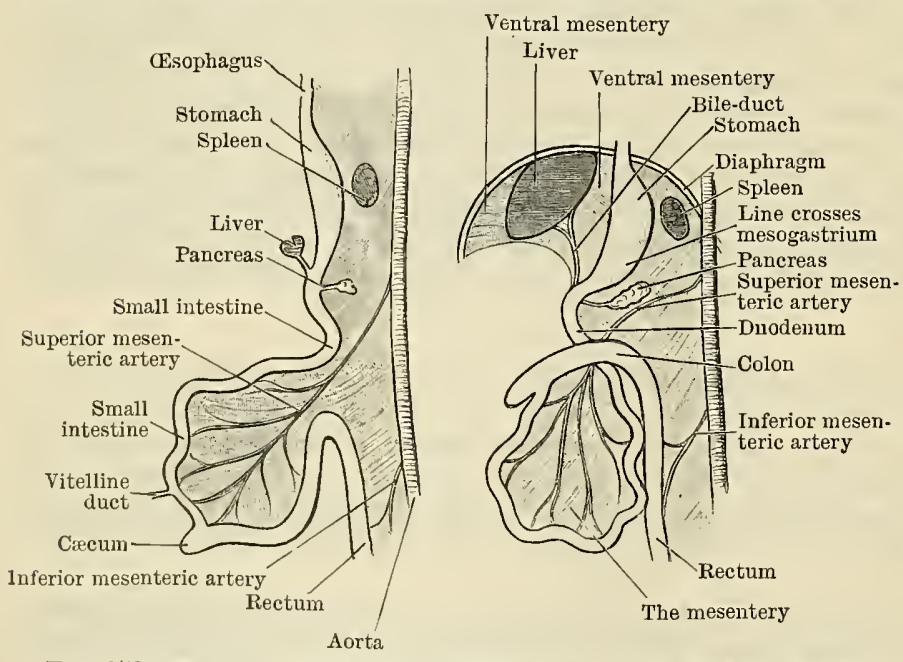

Fig. 972.-Two Diagrams to illustrate the Development of the IntestinaL CANAL. in the regions of the curvatures, and later in the duodenum and small intestine, and then in the large intestine, where they are formed first in the rectum and last in the vermiform process. In the stomach the folds are arranged so as to surround small isolated depressions, which afterwards become the foveolæ gastricæ. In the small intestine isolated elevations are found, in place of continuous folds, and at a later stage new elevations are formed between the primary ones. These papillary elevations form the villi. In the large intestine, the arrangement resembles that in the stomach. The glands of the stomach and
intestine, viz., the gastric and duodenal glands, and the intestinal glands in the small intestine are formed by an active proliferation of the epithelium at the bottom of the furrows, and at first the cells forming them are everywhere of a similar character, and 
become differentiated later on. This formation begins in the stomach about the end of the third month.

The intestinal glands of the large intestine represent merely furrows between adjacent elevations, and are not due to an active proliferation of cells at the base of the furrows, and hence a distinction may be drawn between the two, and be expressed by using the term intestinal glands for the depressions of the small intestine and intestinal follicles for those of the large intestine.

According to v. Nagy, whose description has been followed above, the glandular epithelium of the gastric glands begins to assume its differentiated form in different parts, i.e. cardiac and pyloric glands, towards the fifth month of development.

Cæcum and Vermiform Process.-The cæcum first appears in the embryo, at about the fifth week, as a small outgrowth of the wall of the primitive gut (midgut), not yet differentiated into small and large intestines. At this time the outgrowth is of the

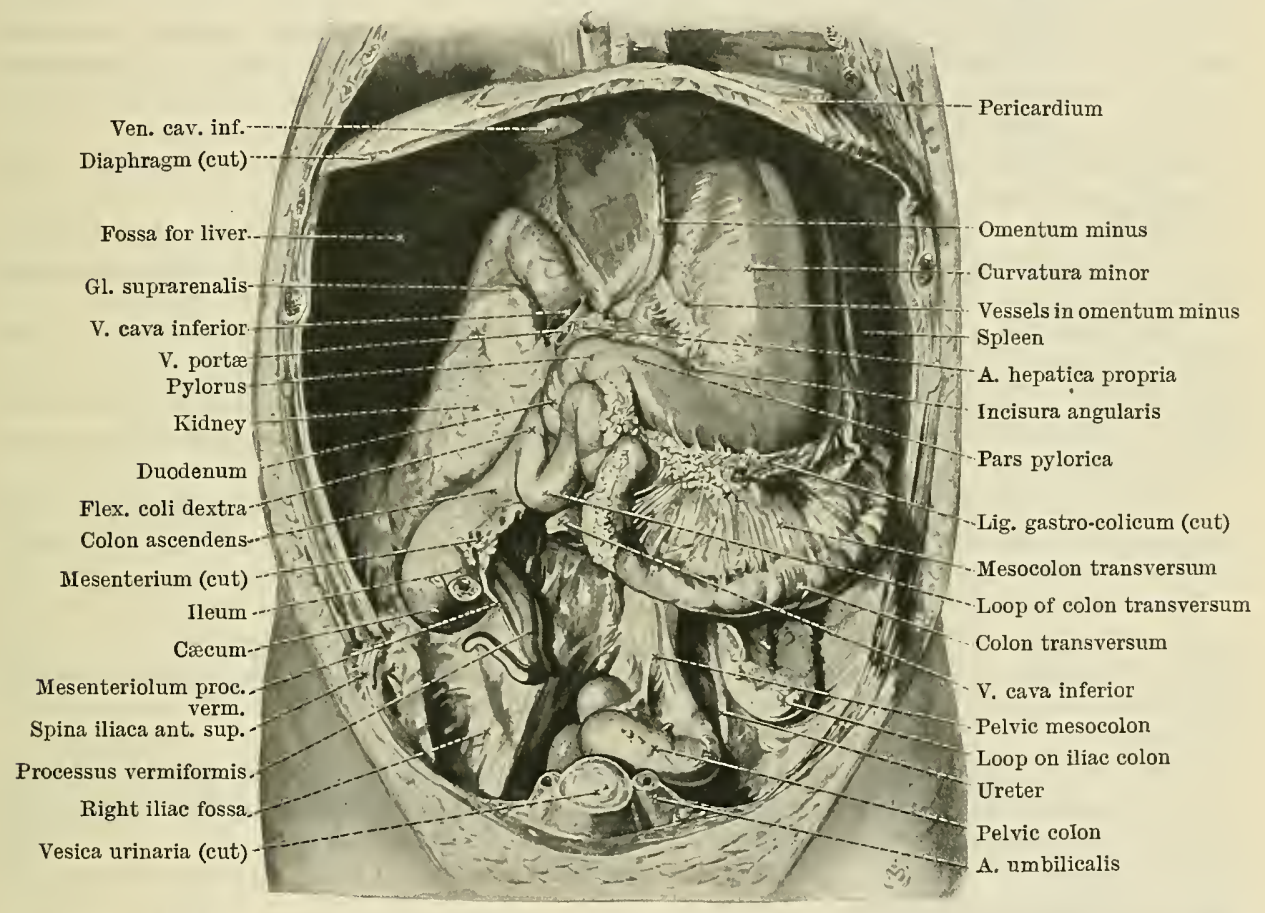

Fig. 973.-The Abdominal Viscera in the Newly Born Child. The liver and the jejunum and ileum have been removed. The vertical stomach, the large supra-renal gland, the high position of the cæcum, and the whole arrangement of the large intestine are typical of the condition found at birth, and differ, as can be seen, largely from the adult condition.

same size throughout, and is practically equal to the intestines in diameter. About the eleventh week, whilst the large and small bowels are still of the same width, it has increased very considerably in length (being equal to about five times the diameter of the small intestine, and thus being relatively as long as in the adult); but even at this early date the basal portion, for about one-fifth of its length, is quite as wide as the intestine, whilst the remaining four-fifths of the outgrowth-the future vermiform process-is only about one-half or one-third the diameter of the gut. From this it is seen that the distal portion of the outgrowth, which subsequently becomes the vermiform process, begins to lag behind even at this early period of its development.

The basal portion continues to expand with the gut; the distal part grows rapidly enough in length, but otherwise enlarges very slowly, so that, towards the end of fœtal life, the cæcum has attained a conical shape, the wider end joining the ascending colon, the narrow end tapering gradually and passing into the vermiform process. This form, known as the infantile type of cæcum, is retained for some time after birth, or eren may (in 2 or 3 per cent of cases) persist throughout life.

As early as the sixth or seventh month of foetal life the wall of the terminal portion of the small intestine adheres to the medial side of the crecum for some distance below the ileo-creal orifice. And this connexion, which is rendered more intimate by the passage 
of two folds of peritoneum, one on the front, the other on the back, between the two parts, profoundly modifies the subsequent growth of the cæcum, and determines very largely its adult form. For, when the creum begins to expand, the medial aspect is prevented, by its connexion with the termination of the ileum, from enlarging as freely as the rest of the wall; in consequence of this the lateral part grows and expands much more rapidly, producing the lop-sided appearance already referred to, and soon comes to form the lowest part or fundus of the cæcum, and the greater part of its sac; whilst the original apex, with the vermiform process springing from it, anchored, as it were, to the end of the ileum, is thrust to one side, and finally lies on the medial and posterior aspect of the cæcum, a little way below, and usually posterior to, the end of the ileum.

The position of the cæcum varies at different periods of fœtal life. About the eleventh or twelfth week it lies immediately beneath the liver, and to the left of the median plane ; it then gradually travels to the right, crossing the descending part of the duodenum, and is found lying on the right side, just beneath the liver, at the fourth month. From this it descends slowly to its adult position, which it usually approaches towards the end of foetal life, but it may not actually reach it until some time after birth. An imperfect descent gives rise to the lumbar position of the cæcum, or an excess in this direction to the pelvic position (referred to on p. 1213).

Rectum.-The rectum and anal canal are formed from the posterior portion of the hindgut, and from the proctodeum.

The primitive elosed chamber becomes divided by a vertical septum into anterior and posterior portions. The anterior, with the allantois growing from it, forms the sinus urogenitalis, the posterior forms the rectum.

The proctodeum is separated from the rectum by the proctodeal membrane, but this membrane disappears, and thus the rectum comes to open on the surface.

The rectim and anal canal at first form a single continuous straight tube, which passes downwards in front of the comparatively straight anterior surface of the sacrum to the anal orifice.

This is the condition which the parts present at birth. After birth, the bony pelvis undergoes great enlargement. The sacrum and coccyx become curved, and the anteroposterior diameter of the pelvis increases very considerably.

The urinary bladder and, in the female, the uterus-both organs at birth lying mainly in the abdomen-descend into the pelvic cavity. The anal orifice appears to be moved further forwards in the perineum, through the bending of the sacrum and coccyx, and the rectum is pushed back into the hollow of the sacrum. Hence the "flexura sacralis" is formed.

The "flexura perinealis" is formed by the junction of the curved rectum with the straight vertical or backwardly directed passage formed by the intestine as it passes through the tissues of the pelvic floor.

The increase in the thickness of the pelvic floor gives to the anal canal the length which it attains in the adult.

\section{Development of the Peritoneum.}

At first the primitive alimentary canal is suspended from the dorsal wall of the embryo, along the medial plane, by a simple dorsal mesentery, which extends along the whole length of the tube, and is common to all its divisions-a condition found in the adult stage of many reptiles. There is also present, in the upper part of the cavity, after the stomach and liver descend into the abdomen, a ventral mesentery (Fig. 972), which connects the stomach and duodenum to the back of the liver, and, passing on, connects the front of the liver to the anterior abdominal wall and diaphragm. The portion of this ventral mesentery, between the stomach and liver, becomes the lesser omentum; its anterior portion, between the liver and the abdominal wall, forms the falciform ligament (Fig. 972); and, in its inferior margin, the umbilical vein runs from the umbilicus to the liver.

The portion of the dorsal mesentery lying behind the stomach is known as the mesogastrium. At first it is relatively short; but with the growth of the posterior wall of the stomach, and the turning of that organ over on its right side, the mesogastrium becomes elongated, and is folded on itself, forming more or less of a pouch, directed downwards and to the left. The wall of this pouch becomes in part the greater omentum, and the cavity enclosed by it forms the greater part of the omental bursa. In the rotation of the stomach and the accompanying passage of the lesser omentum from an antero-posterior to a more or less transverse direction, a portion of the cavity of the 
abdomen is, as it were, caught in behind the stomach and lesser omentum. This portion of the cavity becomes the upper part (vestibule) of the omental bursa, and at first it communicates with the general cavity by a wide opening to the right of the lesser omentum; but the growth of the liver, encroaching upon the opening, and other causes, reduce it to a relatively small size, and it forms the foramen epiploicum in the adult.

The greater omentum is, as pointed out above, a bag-like growth of the lower part of the mesogastrium, which passes downwards and to the left in front of the transverse colon. As shown in Fig. $975, \mathrm{~A}$ and $\mathrm{B}$, it is first entirely unconnected with the transverse colon and mesocolon; but about the third or fourth month it becomes united to both, and the adult condition is established (Fig. 975, C).

It would appear that the growth of the inferior

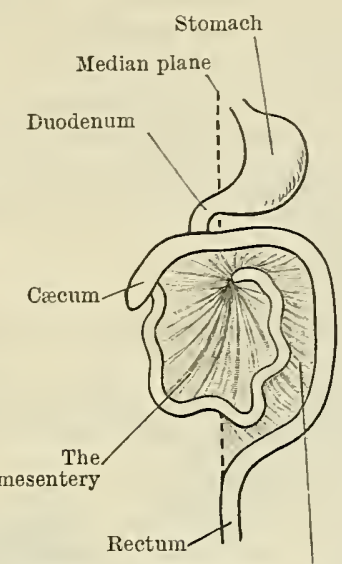

Mesentery of descending colon

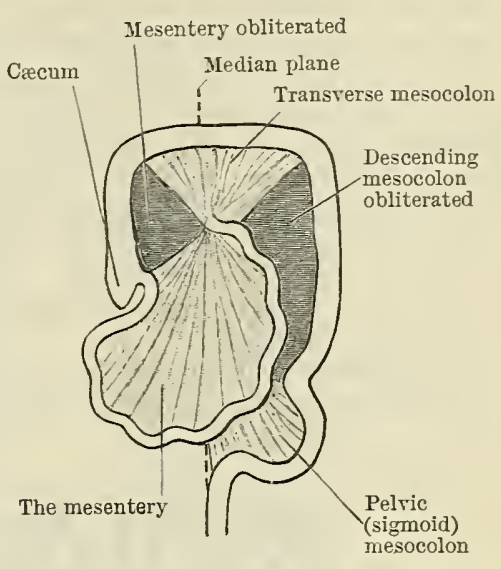

Fig. 974.-Two Diagrams to illustrate the Development of the MESENTERIES.

In the first figure the rotation of the intestinal loop and the continuous primitive mesentery is shown. In the second figure (to the right), which shows a more advanced stage, the portions of the primitive mesentery (going to the ascending and descending colons) which dis. appear, through their adhesion to the posterior abdominal wall, are shaded dark; the portions which persist are lightly shaded. part of the omental bursa, and of the greater omentum, is primarily due to a proliferation of the cells over a limited area of the mesogastrium, and a resulting folding of this layer downwards and to the left.

In the upper part of the mesogastrium the spleen is developed, and the portion of this fold which intervenes between the stomach and spleen forms the gastro-lienal

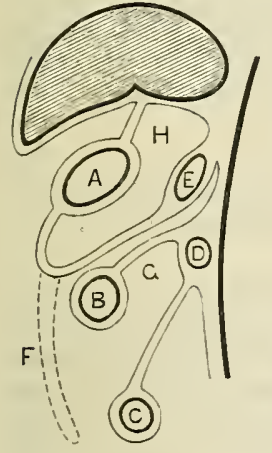

A

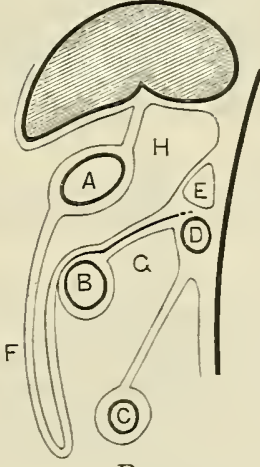

B

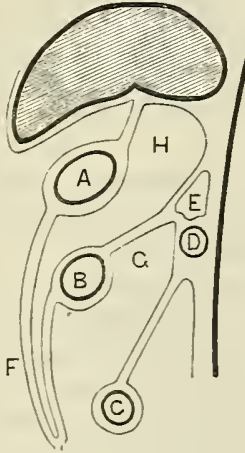

C
Fig. 975.-Diagrans to illustrate the Developient of the Greater Omextum (after Hertwig).

A, shows the beginning of the greater omentum and its independence of the transverse mesocolon; in $\mathrm{B}$, the two come in contact; and in $\mathrm{C}$, they have fused along the line of contact. (According to Lockwood, the two layers of the fold shown in A, running in between the greater omentum and transverse mesocolon, instead of fusing, as shown in B, are drawn out-unfolded-producing the condition shown in C.) A, stomach ; B, transverse colon ; C, small intestine ; D, duodenum ; E, pancreas ; F, greater omentum; G, placed in great sac; $\mathrm{H}$, in omental bursa. the duodenum, and a fan-shaped portion of the general mesentery, lying within the concavity of the loop, is partially cut off; this, later on, forms the mesentery proper in the adult. At first it is continuous by its right border with the mesentery of the 
ascending colon, a part of the primitive mesentery (which is similarly continued into the mesentery of the transverse, descending, iliac, and pelvic colons). Subsequently, as shown by the darkly shaded parts in Fig. 974 , the back of the mesenteries of the ascending, descending, and iliac portions of the colon adheres to the posterior abdominal wall, and these mesenteries become lost; whilst the mesenteries of the transverse and pelvic portions of the colon remain free, and persist in the adult.

At the same time, the mesentery proper (which was at first attached only at its narrow neck, between the duodenum and transverse colon, and below this was continuous on the right with the ascending mesocolon) now acquires a new attachment to the posterior abdominal wall through the absorption of the ascending mesocolon (Fig. 974), and the adult condition is attained.

\section{Development of the Liver and Pancreas.}

The glandular tissue of the liver and pancreas, and the epithelial linings of the ducts of these organs, including the gall-bladder and cystic duct, are formed from protrusions of

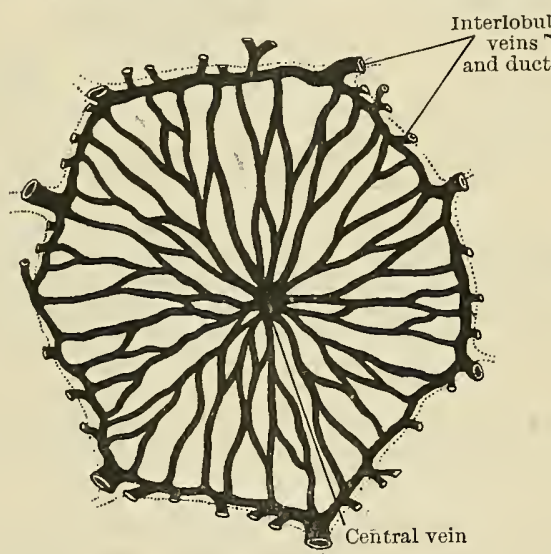

Veins

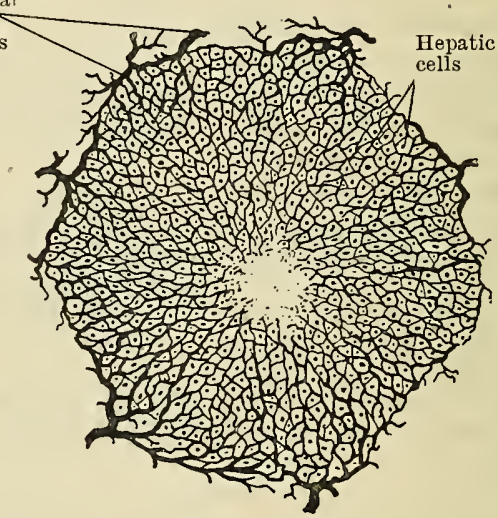

Bile-ducts

Fig. 976.-DiagraM illustrating the arrangement of the blood-vessels (on left) and of the hepatic cells and bile-ducts (on right) within a lobule of the liver. The first diagram shows the interlobular veins running around the outside of the lobule, and sending their capillaries into the lobule to join the central vein. In the second diagram the bile capillaries are seen, with the hepatic cells between them, radiating to the periphery of the lobule, where they join the interlobular bile-ducts.

the endothelial wall of the foregut, below the stomach. The connective tissue framework of the glands is formed from the mesodermic tissue into which the protrusions grow.

The process of formation is as follows :-

1. Liver.-A longitudinal groove appears on the interior of the ventral wall of the foregut, close to its union with the midgut, at about the third week. This groove appears on the external surface of the gut as a projection, which rapidly increases in size and grows forwards and upwards towards the lower part of the septum transversum. This septum is a mass of mesodermic tissue which lies in front of the foregut, just below the heart, and which is attached to the anterior and lateral walls of the trunk. It conveys the umbilical and vitelline veins as they pass to the sinus venosus.

The liver band grows into the lower (caudal) portion of the septum transversum, and sends out strands of cells termed trabeculæ, which come into contact with the vessels in the septum, and enclose them.

By the growth of capillary vessels, from the vitelline and umbilical veins, and of the trabeculæ, a spongy network is produced, the framework of which is formed by branching and anastomosing trabeculæ, while the spaces of the network represent portions of the lumen of the vessels, and are filled with blood. This form of vascular network is known as a "sinusoidal circulation."

The trabeculæ become hollowed out, and are reduced in size, so that eventually a minute channel is formed in the centre of each of them, surrounded by a single layer of cells. The lumen of the channel forms a bile capillary, and the cells surrounding it form the secreting cells of the liver lobule.

The bile capillaries of adjacent trabeculæ meet and unite, and converging together 
constitute the bile-ducts within the liver. Adjacent trabeculæ become arranged into the form of a lobule, each with a vascular channel in its interior, which communicates with the vascular network in the surface of the lobule by capillary intervals between adjacent trabeculæ.

The central vein becomes a tributary of a hepatic vein, and the capillary network becomes the terminal distribution of branches of the portal vein.

The proximal portion of the original hollow diverticulum becomes the bile-duct, and the gall-bladder and cystic duct are formed by an evagination from it.

As the liver increases in size, it begins to project down from the inferior part of the septum transversum into the ventral mesentery, so that now, instead of being situated within the septum, it looks like an appendage of its inferior surface. In other words, the septum begins to differentiate into two parts-an inferior, the liver, and a superior, which constitutes the

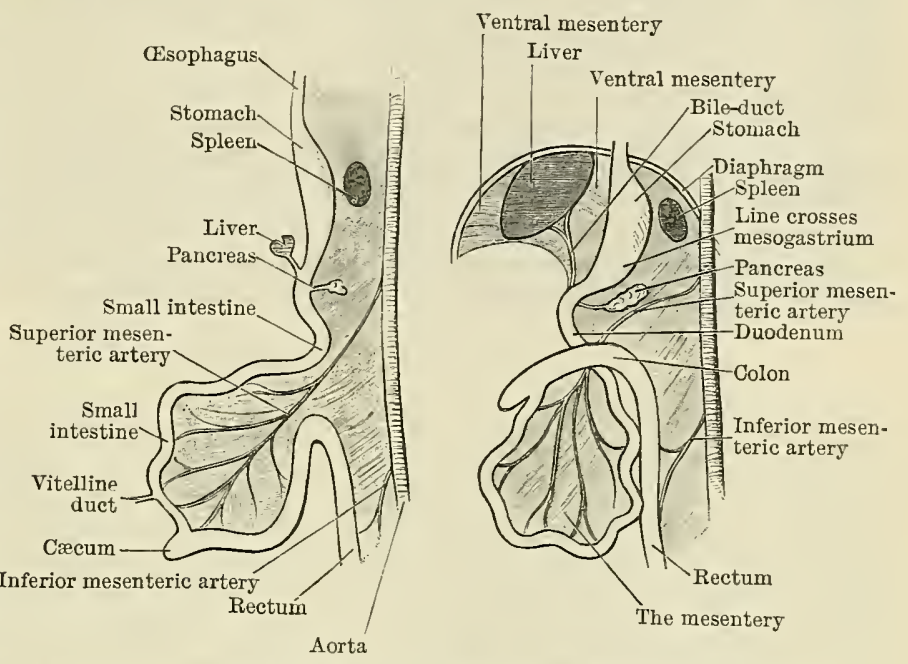

Fig. 977.-Two Diagrams to illustrate the Development of the InTESTINAL CANAL.

The figure to the right shows the rotation of the intestinal loop around the superior mesenteric artery. In both figures the parts are supposed to be viewed from the left side.

greater portion of the diaphragm, both of these having been at first one continuous mass. In the course of development the separation of the two becomes more marked, and finally is complete everywhere except at the coronary and lateral ligaments behind, and at the falciform ligament in front, where they are still connected.

As the liver separates off from the future diaphragm, and descends into the abdomen, it lies between the layers of the ventral mesentery-a fold which connects the stomach

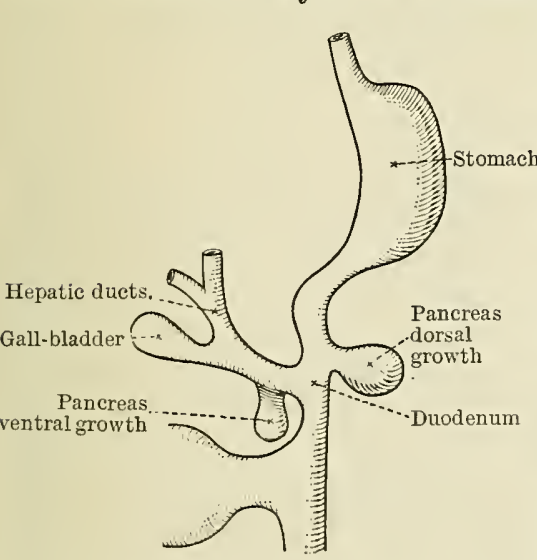
and duodenum with the anterior abdominal wall. This is divided by the liver into two parts - a lower, stretching from the front (lesser curvature) of the stomach to the liver, which becomes the lesser omentum; and an upper, stretching from the liver to the diaphragm and anterior wall of the abdomen, which forms the falciform ligament.

2. Pancreas.-The pancreas is developed at a very early period in man (being present in embryos of $5 \mathrm{~mm}$.) from two outgrowths from the alimentary canal, a dorsal and a ventral.

The dorsal rudiment is an outgrowth from the dorsal aspect of the intestine, anterior to the origin of the hepatic outgrowth. The ventral rudiment grows at a later stage from the root of the hepatic bud in the form of two ventral offshoots, one on either side. That on the left side, however, soon disappears.

Fig. 978.-Diagrail of the Origin of the

Through the rotation of the duodenum around its long axis, the dorsal and rentral rudiments approach one another and become fused, and their ducts open on the left side of the duodenum. 'The connecting stalk between the ventral rudiment and the hepatic bud becomes the main duct of the pancreas, while the connexion of the dorsal outgrowth with the duodenum remains as the accessory pancreatic duct. In embryos of the fifth week, a large dorsal pancreatic rudiment is present, and also a smaller ventral rudiment, which opens into the duodenum in common with the bile-duct, and lies on the right of 
the rena portæ. In the sixth week, these two rudiments meet and unite with one another, forming a long slender glandular mass which passes backwards within the dorsal mesogastrium (meso-duodenum) between the vertebral column and the greater curvature of the stomach. The pancreas so formed follows the changes which occur in the position of the stomach and of the dorsal mesogastrium. Consequently its free dorsal extremity comes to be directed to the left, while the right extremity or head is included within the hollow of the curve formed by the duodenum. At first it possesses a dorsal mesentery, a part of the dorsal mesogastrium, but from the fifth month this disappears, coincidently with the rotation of the gland into the transverse axis of the body.

The lower part of the head, the body, and tail of the gland arise from the ventral element, and the upper part of the head from the dorsal bud.

The primary diverticula give off buds, lined with cylindrical epithelium, and these in turn gire off other buds, and the process goes on until the mass of the gland is formed.

The islets of Langerhans are formed at a very early stage, from the entodermal lining cells of the branching diverticula which form the gland acini.- 


\title{
THE URINO-GENITAL SYSTEM.
}

\author{
By A. Francis Dixon.
}

\section{THE URINARY ORGANS.}

THE kidneys, or glands which secrete the urine, are a pair of almost symmetrically placed organs, situated in the posterior part of the abdominal cavity, one on each side of the lower movable portion of the vertebral column. The fluid, or urine, secreted by the kidneys is received into the upper expanded portions of a pair of long tubes, the ureters, and by them it is conducted to the bladder, which is placed within the pelvic cavity. From the bladder the urine is passed, during micturition, along a passage called the urethra to the exterior. In the male the urethra is a relatively long passage, and traverses the prostate gland and the whole length of the penis; in the female it is a short tube, and opens on the surface just above the vaginal orifice.

\section{THE KIDNEYS.}

The kidney (ren), when removed from a fresh subject, presents a bean-shaped contour. It is of a dark brown-red colour, and is surrounded by a thin glistening capsule, the tunica fibrosa, which gives to the whole organ a uniformly smooth surface. The kidney is not a solid body, but contains a cavity called the sinus renalis, the opening into which, termed the hilus renalis, is situated on the medial and anterior part of the organ. Each kidney measures about $4 \frac{1}{2}$ inches in length, 2 inches in width, and about $1 \frac{1}{4}$ inches in thickness, and is placed so that its long axis is nearly vertical. The weight of the adult kidney is about $4 \frac{1}{2}$ ounces. In the freshly removed kidney the superior and inferior ends are smoothly rounded, and the extremitas superior or superior end is usually a little more bulky than the extremitas inferior or inferior end. The margo lateralis or lateral border, which is opposite to the hilus, is rounded and convex, while the margo medialis or medial border, on which the hilus is placed, is concave from above downwards. These two borders separate the facies anterior or anterior surface from the facies posterior or posterior surface of the kidney.

The capsule, which envelops the whole organ, divides in the region of the hilus into two layers, one of which is continued over the lips of the hilus into the interior of the kidney, and lines the walls of the renal sinus. The other layer is prolonged to form a tubular sheath for the vessels and nerves of the kidney before they pass through the hilus to enter the sinus, within which they break up into branches. These branches, piercing the wall of the sinus, enter the substance of the kidney. The upper expanded portion of the ureter leaves the sinus through the hilus in company with the blood-vessels and nerves.

Position of the Kidneys. - The precise level of the kidney in the abdominal cavity is subject to a considerable amount of variation, and, further, it is usual to find a difference in the level of the right and left kidney in the same individual. Most frequently the left kidney is on a somewhat higher level than the right, but in many cases the kidneys are found to occupy the same level, or, the more usual condition being reversed, the right kidney is a little higher than the left. 
If a line be drawn round the body at the level of the lowest part of the thoracic wall, the whole, or almost the whole, of the left kidney will be found to lie above the level of the subcostal plane so determined. It is, therefore, situated in the subcostal zone of the abdominal cavity. The right kidney, however, although it lies for the most part in the subcostal zone, usually projects at its inferior part somewhat below the subcostal plane, and hence lies to some extent in the umbilical zone. It is often stated that the kidneys are placed on a somewhat lower level in the female than in the male subject.

By far the greater part, usually two-thirds or more, of the kidney lies to the medial side of a line drawn vertically upwards through the middle point of the inguinal ligament.

The posterior aspect of the kidney is closely applied against the muscles attached to the bodies of the last thoracic and upper three lumbar vertebræ, and is placed in front of the last rib and of the transverse processes of the upper three

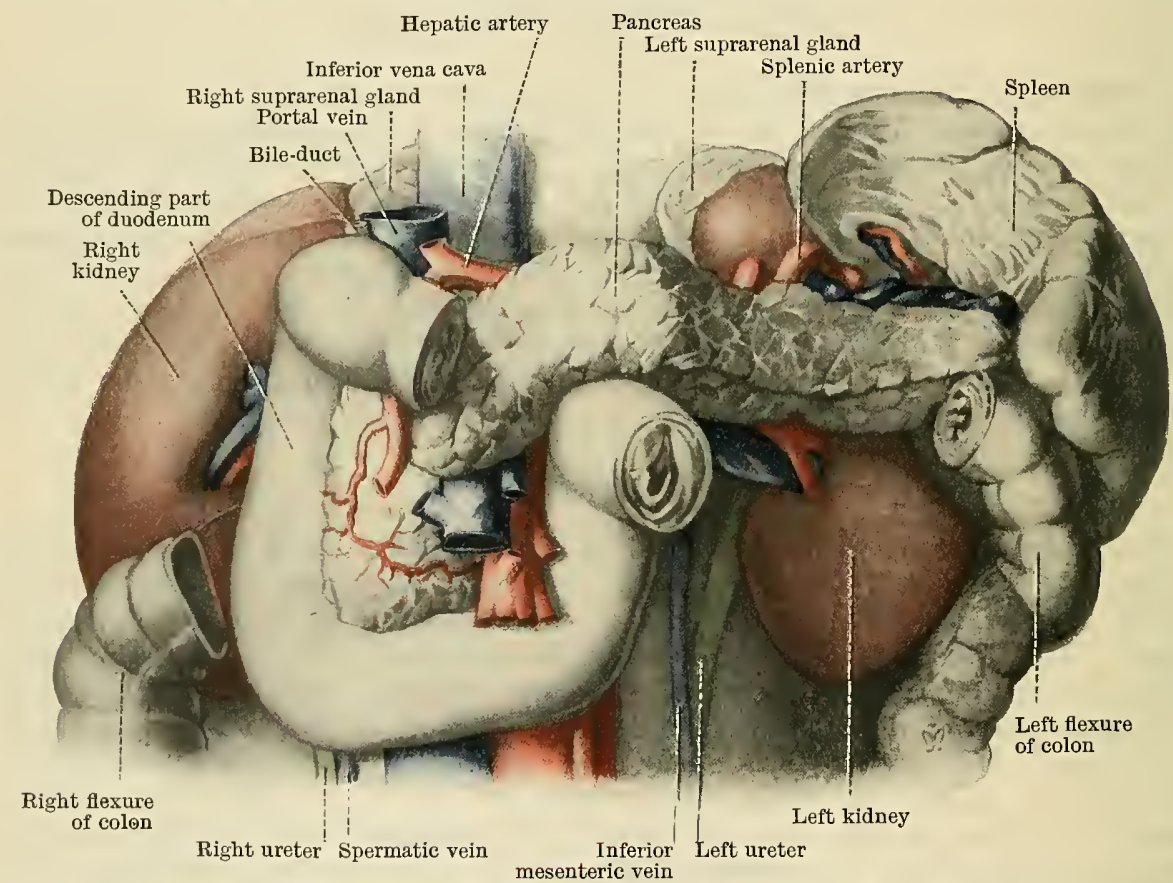

Fig. 979.-Dissection to show the Relationships of the Kidneys. The greater part of the stomach has been removed by an incision made close to the pylorus. The transverse colon has been taken away, and the small intestine has been cut across close to the duodeno-jejunal flexure.

A model prepared by the late Professor Birmingham has been made use of in this drawing.

lumbar vertebræ. In some cases, more frequently on the left side of the body, the eleventh rib also lies behind the upper part of the kidney. The relationship of the kidney to the lower two ribs is, however, very inconstant, owing partly to the great variability in size and inclination of these bones.

The inferior end of the kidney is usually situated from $1 \frac{1}{4}$ to 2 inches above the highest part of the crest of the ilium; the interval between the kidney and the ilium being usually greater on the left side of the body.

Sometimes the inferior end of the kidney lies on the same level as, or only a short distance above, the iliac crest; this condition is sometimes due to the crest rising to a higher level than usual, the kidney occupying its normal position in relation to the vertebral column. It is important to remember that during life the kidney moves upwards and downwards, following the respiratory movements of the part of the diaphragm against which it rests.

The long axis of each kidney is somewhat oblique, its superior end approaching nearer to the median plane than the inferior. The surface of the kidney, which is applied against the muscles forming the posterior wall of the abdomen, looks, 
as a whole, backwards and medially, and that which projects into the abdominal cavity forwards and laterally. Hence it happens that the lateral border lies on a posterior plane to the medial border. The kidney is rotated in this manner on its long axis to such a degree that the medial margin and hilus are scarcely visible from behind, and only a limited view of the lateral border can be obtained from the front (Figs. 979 and 980).

The kidneys are placed behind the peritoneum, and project into the posterior part of the abdominal cavity. Each is surrounded by a considerable amount of loose tissue, often loaded with fat; the fatty tissue, or capsula adiposa, being present in greater quantity round the margins of the kidney, and only to a less extent in front of and behind the organ. In this fat the renal vessels and nerves lie before they enter the kidney, and the adipose tissue is continued, along with the vessels, through the hilus into the renal sinus, where it fills up all the space unoccupied by the vessels and nerves.

Embedded in the soft fatty tissue surrounding the kidney is a layer of fibrous

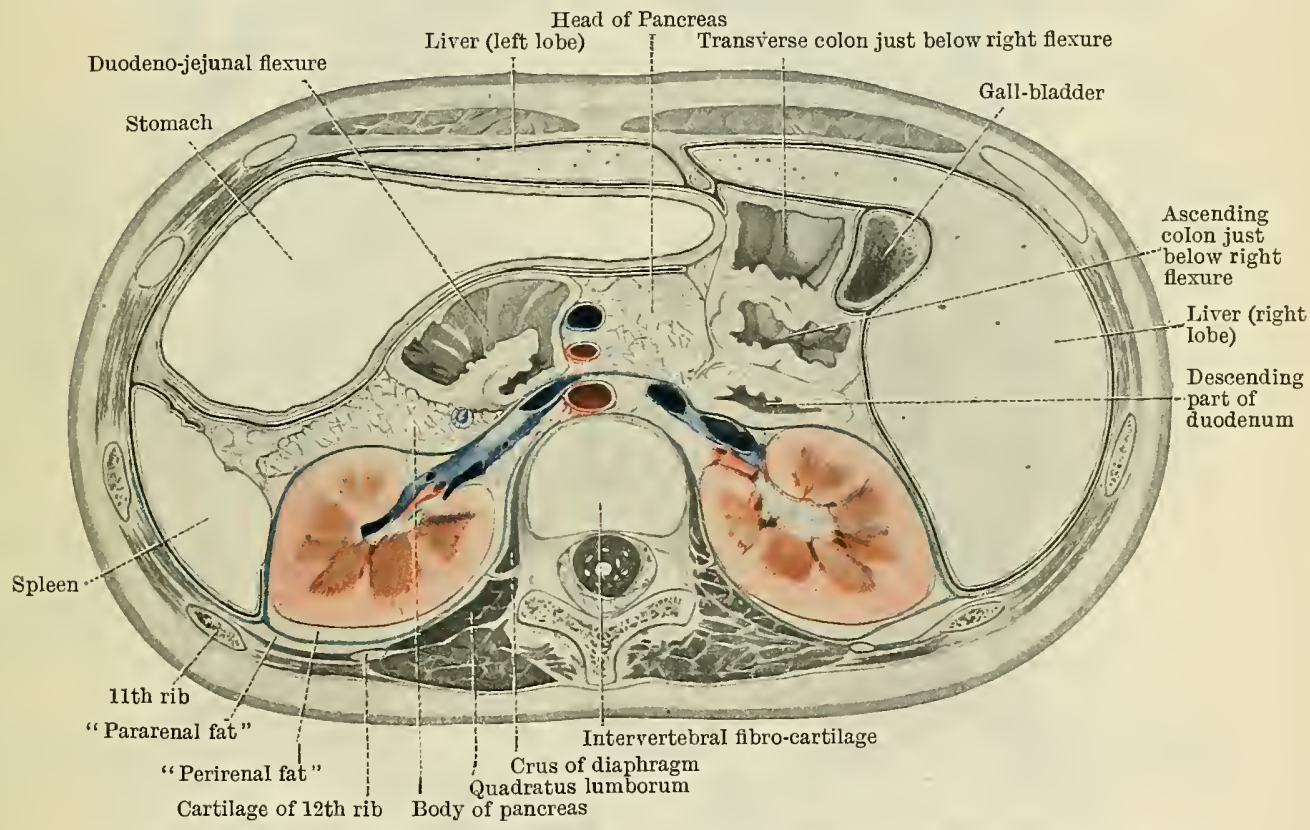

Fig. 980.-Transverse Section through the Body of a Child. The position and relationships of the kidneys are well seen, and the arrangement of the fascia renalis is indicated. The fascia is coloured green.

tissue to which the term fascia renalis is applied. This fascia surrounds the kidney and a considerable amount of its fatty capsule in the form of a loose sheath, in which may be distinguished anterior and posterior walls. The sheath is open inferiorly and medially, but closed above and to the lateral side of the kidney by the apposition of its walls. Laterally, the anterior and posterior walls of the sheath come into contact and are connected with the retro-peritoneal tissue. Medially they remain distinct, and the anterior wall is continued across the median plane, in front of the renal vessels and the aorta, to join the corresponding layer of the opposite side, while the posterior wall fuses with the fascia covering the psoas and quadratus lumborum muscles. Inferiorly, below the level of the kidney, the anterior and posterior layers of the renal fascia remain separate, and can be traced downwards into the iliac fossa. Above the level of the kidney and the suprarenal gland the layers of the renal fascia unite and join the fascia covering the diaphragm. It has been suggested that the terms "tunica adiposa" and "perirenal fat" should be restricted to the loose fatty tissue enclosed along with the kidney within the sheath of renal fascia, and that, the term "pararenal body," or "fat," should be used to denote the tissue outside the sheath. The fibrous capsule of the kidney is joined to the loose sheath formed by 
the renal fascia by numerous connective tissue strands. These traverse the perirenal fat and undoubtedly assist in fixing the kidney in its place. The pararenal fat is present in greatest quantity behind the inferior part of the kidney, and in this position the layer of fibrous tissue, separating the two masses of fat and forming the posterior layer of the sheath of renal fascia, is usually well marked.

Fixation of the Kidney.-The kidney is not held in its place by any distinct ligaments, or special folds of peritoneum, but its fixation depends, to a large extent, on the pressure and counter-pressure which is exerted upon it by neighbouring structures, and on its connexions with the fascia renalis above described.

Posterior Relations and the Posterior Surface of the Kidney.-The muscles of the posterior abdominal wall on which the kidney rests are the psoas major, the

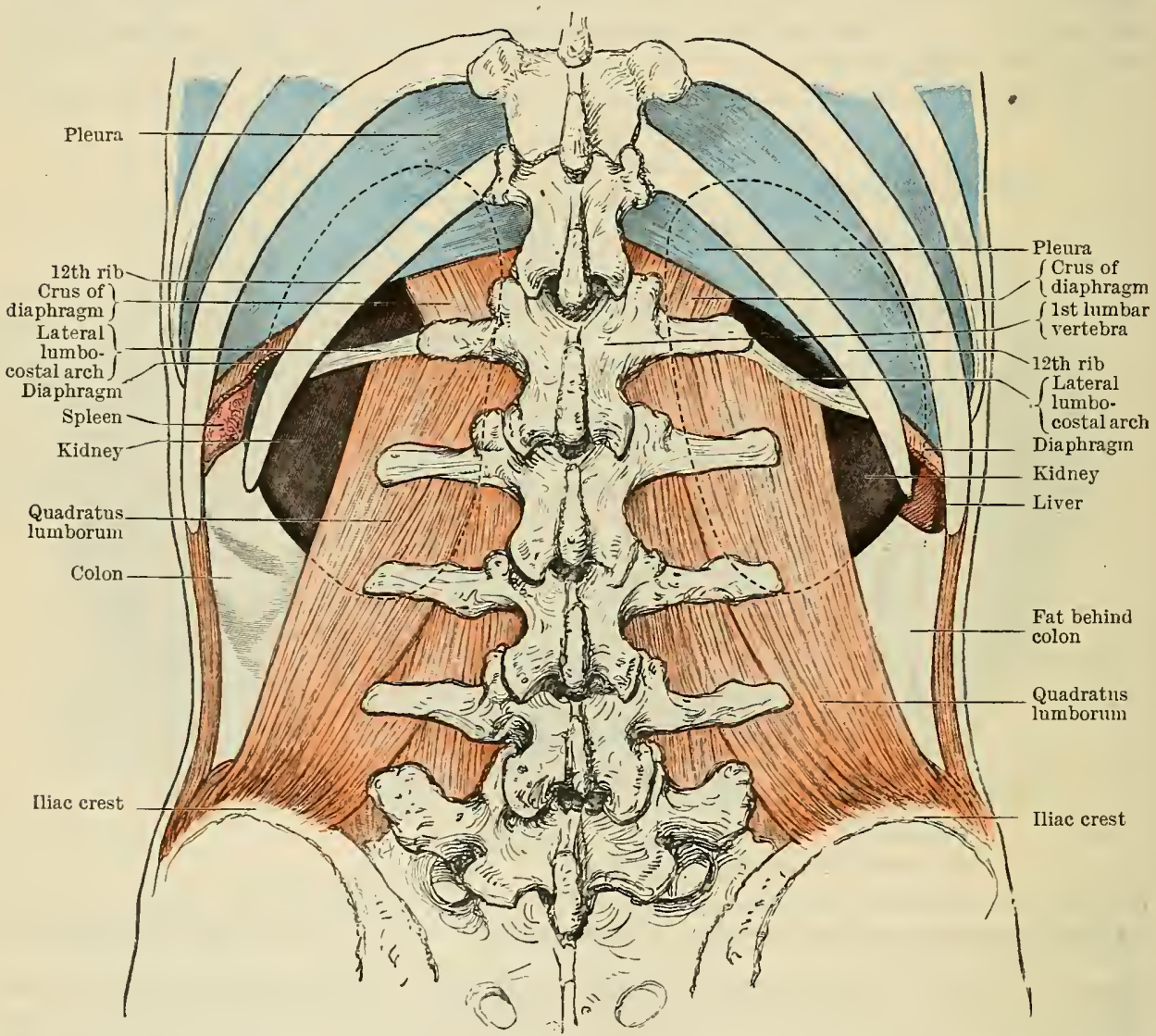

Fig. 981.-The Posterior Relationships of the Kidneys. The dotted lines indicate the contours of the kidneys. The drawing is made from a model prepared by the late Professor Cunningham.

quadratus lumborum, the diaphragm and the tendon of the transversus abdominis. The abdominal surfaces of these muscles do not lie on the same plane, but slope towards one another, and thus the bed on which the kidney rests is not flat. When but little fat is present, the posterior aspect of the kidney adapts itself to the inequalities of the surface against which it is placed, and so we may find on a kidney which has been carefully fixed and hardened before it has been disturbed, areas marked off for the different planes of these muscles. When such a kidney is in position, slight ridges or elevations separating these areas correspond to the angles along which the different muscular planes meet. These ridges can be observed in the hardened kidney, after its removal from the body, but usually they are not sharply defined, the angles between the muscular planes being very obtuse.

A kidney removed from the body after having been hardened in situ (Fig. 982) 
presents an area along the medial part of its posterior surface adapted to the anterior aspect of the psoas major muscle. This part of the posterior surface looks medially and slightly posteriorly. More laterally there is a larger area which rests against the quadratus lumborum and looks more directly backwards. These two areas are separated by a rounded ridge which fits into the angle between the muscles mentioned. Beyond the area in contact with the quadratus lumbortum is the thick lateral border of the kidney, which rests for the most part on the tendon of the transversus abdominis and on the diaphragm.

Towards the superior end of the kidney the posterior surface slopes somewhat forwards and rests upon the diaphragm. Indeed the superior part of the kidney is, as a whole, bent slightly forwards, following that part of the arch of the diaphragm on which it rests, and thus a narrow interval is left, in which the pleural cavity passes down behind the superior end of the kidney (Fig. 981). This relation-

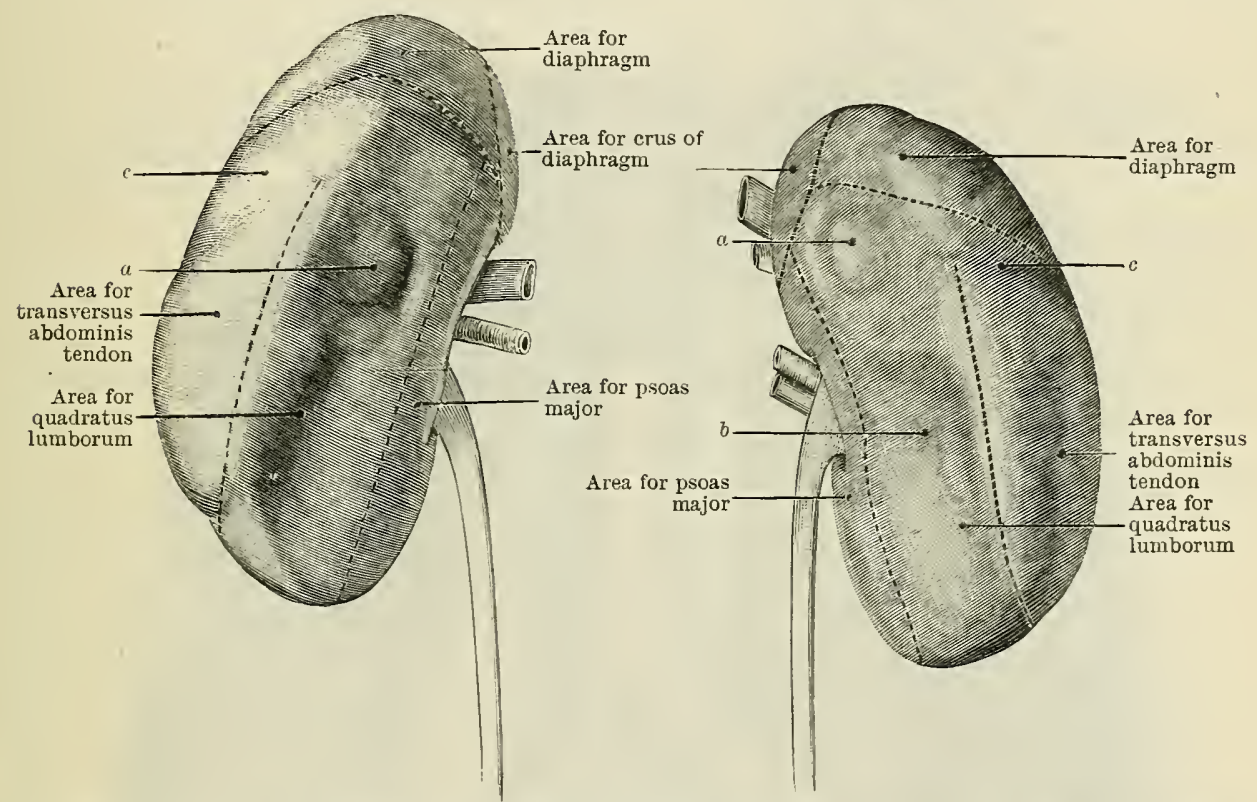

Fig. 982.-The Posterior Aspect of the Kidneys. Same specimen as Fig. 9S1. The dotted lines mark out the areas in contact with the various muscles forming the posterior abdominal wall.

a. Depression corresponding to the transverse process of the first lumbar vertebra.

b. Depression corresponding to the transverse process of the second lumbar vertebra.

c. Depression corresponding to the twelfth rib.

ship of the pleural cavity to the kidney is of great importance in connexion with surgical operations performed through a lumbar incision. The portions of the diaphragm to which the kidney is applied are the crus and the parts arising from the last rib and lumbo-costal arches.

The posterior relationships of the kidney are well seen in Fig. 981.

In addition to these surfaces, or "facets," for the muscles with which it is in contact, the posterior aspect or outer border of the kidney often shows a groove for the last rib, another for the lateral lumbo-costal arch, and two or three depressions for the tips of the transverse processes of the upper two or three lumbar vertebræ. In some cases also faint narrow grooves are to be seen for the nerves which pass downwards and laterally between the kidney and quadratus lumborum-namely, the last thoracic nerve and the ilio-hypogastric and ilio-inguinal nerves.

It is probable that some at least of the depressions on the posterior aspect of the kidney are produced after death, and are caused by the weight of the other abdominal organs pressing the kidney backwards against the more resisting structures of the abdominal wall, at a time when the muscles behind the kidney have become flaccid. When much fat is present the posterior aspect of the kidney is more uniformly convex.

The lateral border in its middle and inferior part is rather a surface than a border, and looks for the most part directly backwards. It rests on the diaphragm and on the anterior surface of the tendon of the transversus abdominis, to the 
lateral side of the quadratus lumborum muscle. The lateral border is narrowest above, and widest just below its middle point, corresponding to the greater thickness of the kidney at this level.

In many ways it would be more satisfactory to apply the term facies muscularis or muscular surface collectively to the areas above described as "posterior surface" and "lateral border"; in like manner the term facies visceralis, or visceral surface, might be suitably applied to the so-called anterior surface of the organ. The edge separating the visceral from the muscular surface is the actual lateral edge or border of the kidney.

Anterior Relations and the Anterior Surface of the Kidney.--The anterior relations of the kidneys not only differ on the two sides of the body, but also many

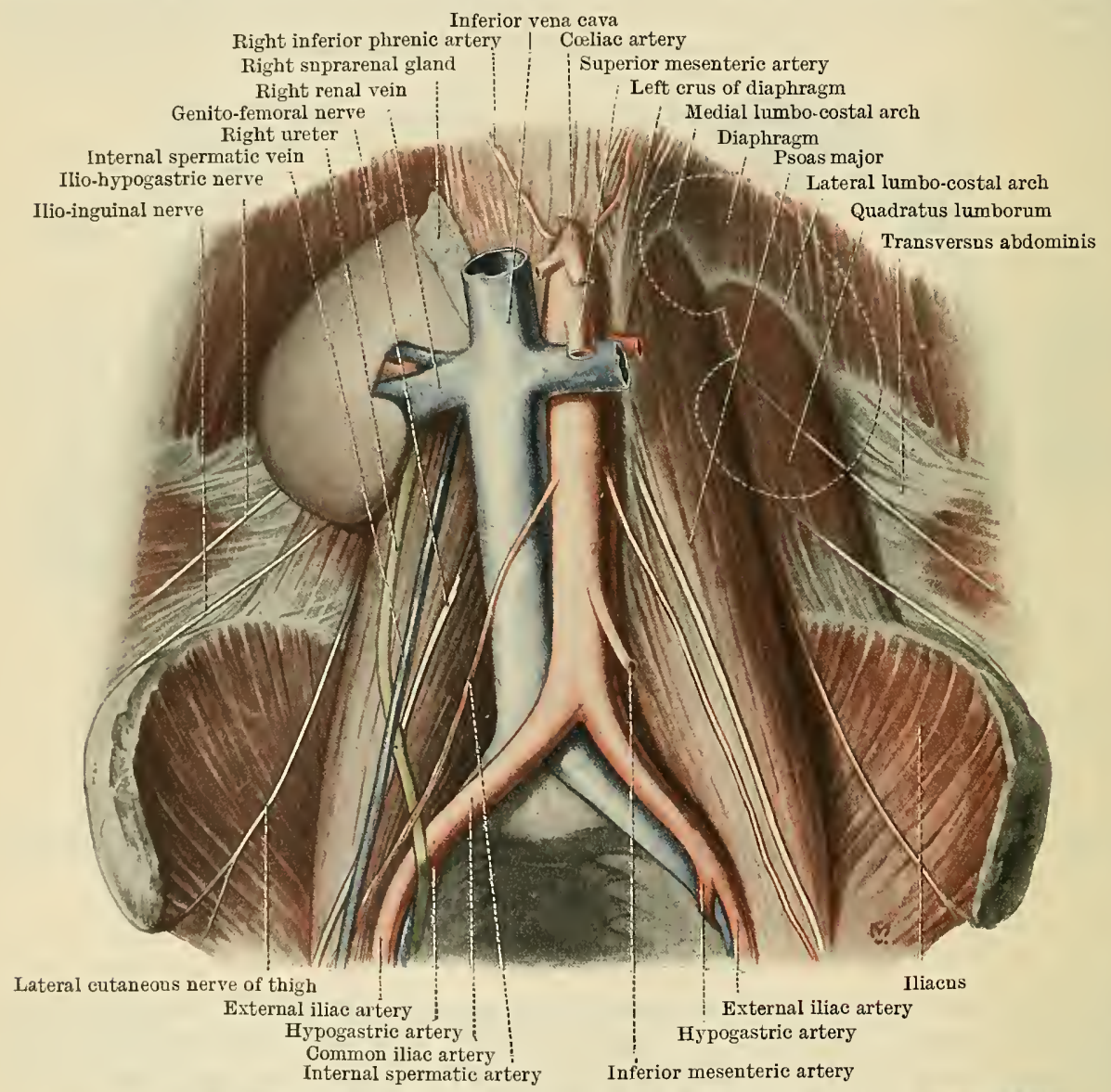

Fig. 983.-Dissection to ShOW the ReLationships of the Kidneys aNd OF the URETERS to the Musclees facing the Posterior Abdoninal Wall.

of the structures related to the anterior surface of each kidney undergo frequent changes in position during life. Hence it is not possible to give more than a general account of the anterior relationships of the kidneys.

Right Kidney. - A small area on the superior part of the anterior surface of the right kidney is in relation to the corresponding suprarenal gland (Fig. 983). The rest of the superior part of the anterior surface is in contact with the visceral surface of the liver, which is often hollowed out to form a fossa for the kidney. The suprarenal gland is bound to the kidney by connective tissue, while the part of the kidney in relation to the liver is, like the liver itself, covered by peritoneum, and thus the two organs, although closely applied, are really separated by a part of the general peritoneal cavity. Immediately anterior to the inferior end of the right kidney are usually found two parts of the alimentary canal-namely, the descending part of the duodenum and the right flexure of the colon, or the 
commencement of the transverse colon. The part of the kidney related to the duodenum lies to the medial side of the area which touches the colon, but the exact amount of the kidney in contact with each of these two parts of intestine varies much in different subjects. Frequently the colon and the kidney are both covered by peritoneum where they are in contact, but the duodenum is bound down to the kidney by connective tissue. In addition to the structures mentioned, some portion of the ileum, or of the jejunum, is often found in contact with a small part of the right kidney near its inferior end.

In some cases the peritoneal membrane does not cover the whole of the surface in contact with the liver, and then the superior part of the hepatic area of the kidney is, like the anterior aspect of the suprarenal gland, bound by connective tissue to the "uncovered" area on the posterior aspect of the liver.

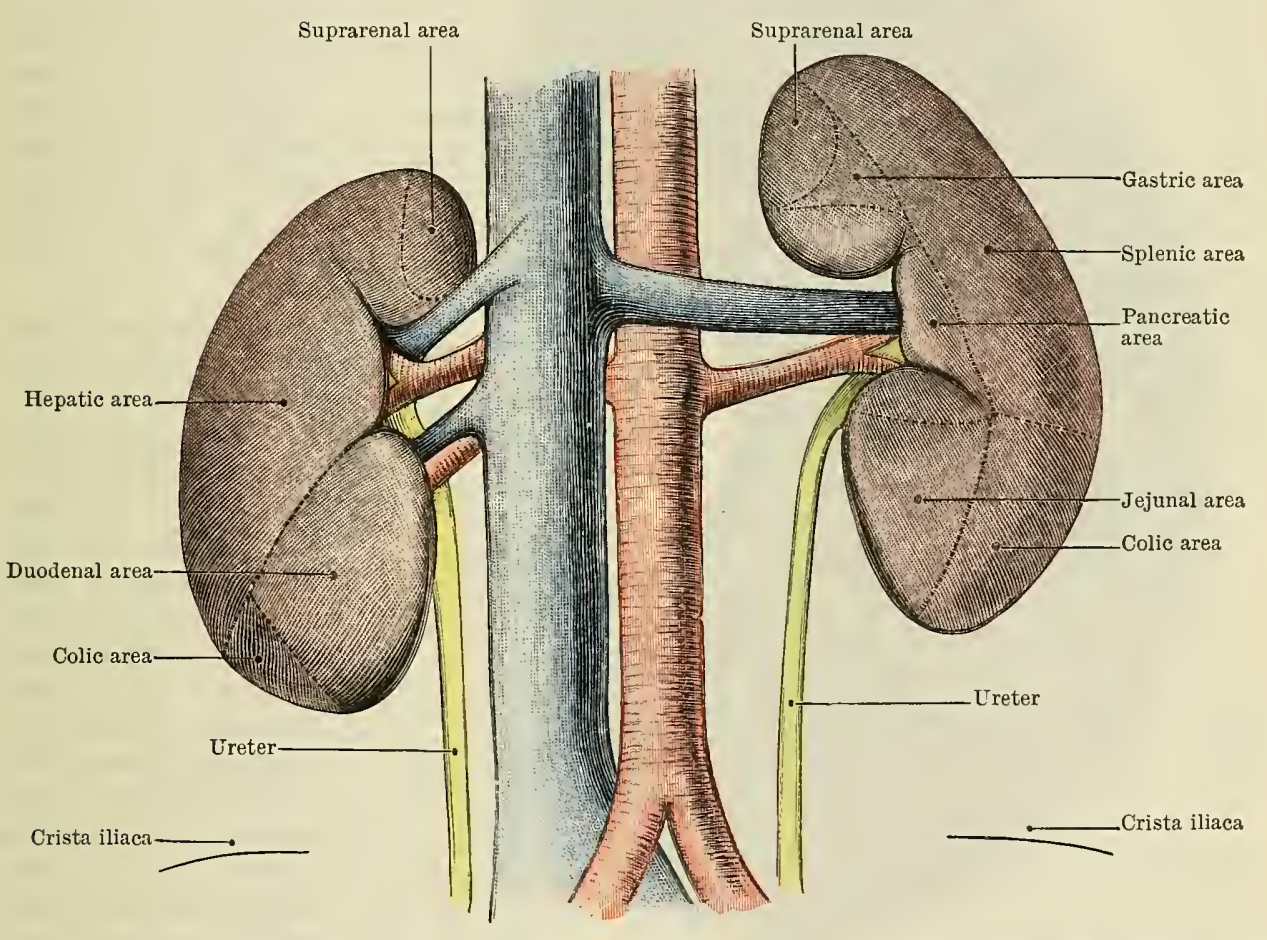

Fig. 984.-Anterior Aspect of the Kidneys and Great Vessels. The drawing was made, before removal of the organs, from a specimen in which the viscera had been hardened in situ. The dotted lines mark out the areas which were in contact with the various other abdominal viscera.

Left Kidney.-The extreme superior and medial part of the anterior aspect of the left kidney is united by connective tissue to the lower part of the left suprarenal gland, and the area immediately below this is in contact with the stomach and the pancreas. The latter, like the suprarenal gland, is bound down to the kidney by comnective tissue, but the stomach is separated from the area with which it is in apposition by a portion of the omental bursa. The area in actual contact with the stomach is a small somewhat triangular district situated above the level at which the pancreas is related to the kidney. The superior and lateral part of the anterior aspect of the kidney is related to the spleen, the two organs being separated by a portion of the general peritoneal cavity, except along the area where spleen and kidney are connected by the lieno-renal ligament. The anterior surface of the inferior end of the left kidney is related, towards the medial side, to a part of the jejunum, and towards the lateral side to the left flexure of the colon or to a part of the descending portion of the colon. In most cases, however, the colon lies against the posterior abdominal wall to the lateral side rather than on the anterior surface of the left kidney. 
The right and left colic arteries, or their branches, as they pass laterally to reach the colon, are often related to the anterior aspects of the corresponding kidneys. The splenic vessels pass laterally in front of the left kiduey (Fig. 979).

The anterior surface of a kidney which has been hardened in situ is, like the posterior surface, not uniformly rounded, but marked by a series of impressions corresponding to the different structures which lie in contact with it. In the case of each kidney, the most prominent region on the anterior surface lies below the level of the middle of the kidney, and corresponds to the thickest part of the organ.

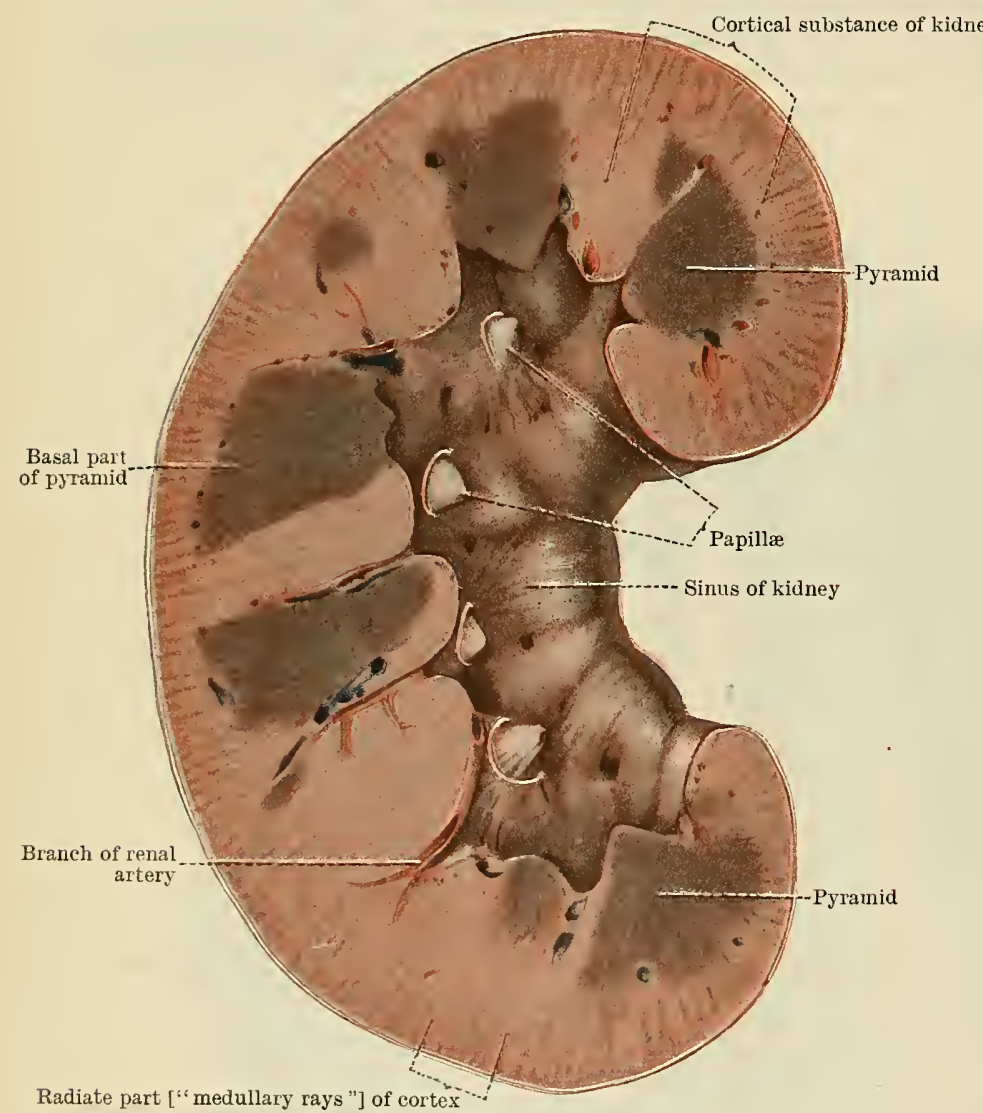

Fig. 985.-Longitudinal Section through the Kidney.

The vessels and fat have been removed to give a view of the wall of the kidney sinus. The points where the vessels enter the kidney substance are seen as holes in the sinus wall.

The relative sizes of these three areas or impressions vary much in different specimens.

On the left lidney, also, three more or less defined, flattened impressions slope towards the borders of the organ from the most prominent part of the anterior surface. One of these, on the superior and lateral part of the kidney, is the splenic impression; another, extending downwards to the lower end of the kidney, is for the jejunum, or for the jejunum and colon; the third, above and in the region of the hilus, is called the impressio gastrica, and corresponds to the position of the overlying stomach. Only a small portion of this impression is in direct contact with the stomach, since the pancreas and a part of the suprarenal gland intervene between the stomach and the kidney (Fig. 979).

It is common to find the left kidney thicker and less flattened antero-posteriorly than the right, the impressions, or "facets," upon its surface being at the same time better marked. With this probably is to be associated the fact that floating kidney is more rarely met with on the left than on the right side of the body. 
Extremities of the Kidney.-The kidney, fixed and hardened in situ, is usually more pointed at its inferior than at its superior end. The latter is wider from side to side, and often somewhat flattened from before backwards. The superior end of the kidney is bent somewhat forwards and rests upon the diaphragm, which separates it from the inferior part of the pleural cavity.

Sinus Renalis.--The sinus of the kidney (Fig. 985), into which the hilus opens, is a narrow space, having its long axis corresponding to that of the kidney. The thick walls of the sinus cavity are formed by the substance of the kidney, and are lined by a part of the fibrous kidney capsule which enters the sinus over the lips of the hilus. The floor of the sinus is not even, but presents a series of small projecting conical elevations called papillæ renales, which vary from six to fifteen in number. Radiating from each papilla are a number of somewhat raised bars, or ridges, of kidney substance, separated by depressed areas. The blood-vessels and nerves enter and leave the kidney by piercing the wall of the sinus where it is formed by these little depressed areas (Fig. 985). The rounded summit of each renal papilla is pierced by a number of minute openings called foramina papillaria, which are the terminal apertures of the secreting tubules of which the kidney is mainly composed. These openings all lie close together, and give rise to the so-called area cribrosa upon the apex of the renal papilla. The urine secreted by the kidney escapes through the foramina papillaria into the subdivisions (or calyces) of the kidney duct or ureter.

Kidney in Section.-Sections through the kidney (Fig. 985) show that it is composed to a large extent of a number of conical masses, known as pyramides renales or pyramids. These together constitute the substantia medullaris or medulla of the kidney, and are arranged with their bases directed towards the surface, and their apices projecting into the renal sinus, where they form the papillæ renales already mentioned. The pyramids are more numerous than the papillæ, two or three usually ending in each papilla in the middle part of the kidney, and sometimes as many as six or more in each papilla near the superior and inferior ends of the organ. The bases of the pyramids do not reach the surface of the kidney, but are separated from it by a thin layer of kidney substance called the cortex, or substantia corticalis of the kidney. The cortical substance not only covers over the bases of the pyramids, but also sends in prolongations, called columnæ renales or renal columns, between the pyramids, towards the sinus. The medullary part of the kidney exhibits in section a striated appearance, while the cortical part is more granular and usually different in colour. The outer part of each pyramid is called the basis pyramidis, and appears in section to be composed of alternate dark and light streaks, while the inner, or papillary part, is often of a lighter colour, and more uniformly and faintly striated.

In sections of the kidney the larger blood-vessels are seen, after they have entered the kidney substance, to lie between the pyramids; and some of their main branches are visible passing across the bases of the pyramids.

In the foetus and young child, and sometimes, though much less distinctly, in the adult, the surface of the kidney is marked by a number of grooves dividing it into polygonal areas. These represent the lobes, lobi renales or reniculi, of which the kidney is originally composed, and each corresponds to one papilla with its pyramids and surrounding cortical substance.

An examination, with an ordinary pocket lens, of a section through the kidney shows that the lighter striæ of the bases of the pyramids are coutinued into the cortex. As they pass through the cortex towards the surface of the kidney the striæ become less distinct, and appear, when cut longitudinally, as separate raylike prolongations carried outward from the bases of the pyramids. These parts of the cortex, which seem, in this way, to be continuations of the medulla, are called "medullary rays" and constitute the pars radiata; the portions which intervene between them form what is known as the pars convoluta or "labyrinth." The appearance presented by the cortex of the kidney in section varies much according to the plane in which the section has been taken. If the section passes through, and lies parallel to the axis of a pyramid, the radiate part met 
with will appear as isolated streaks directed from the base of the pyramid towards the surface of the kidney, and separated from one another by narrow strips, or intervals, of the convoluted part. On the other hand, in sections made at right angles to the axis of a pyramid, or cutting this axis obliquely, the convoluted

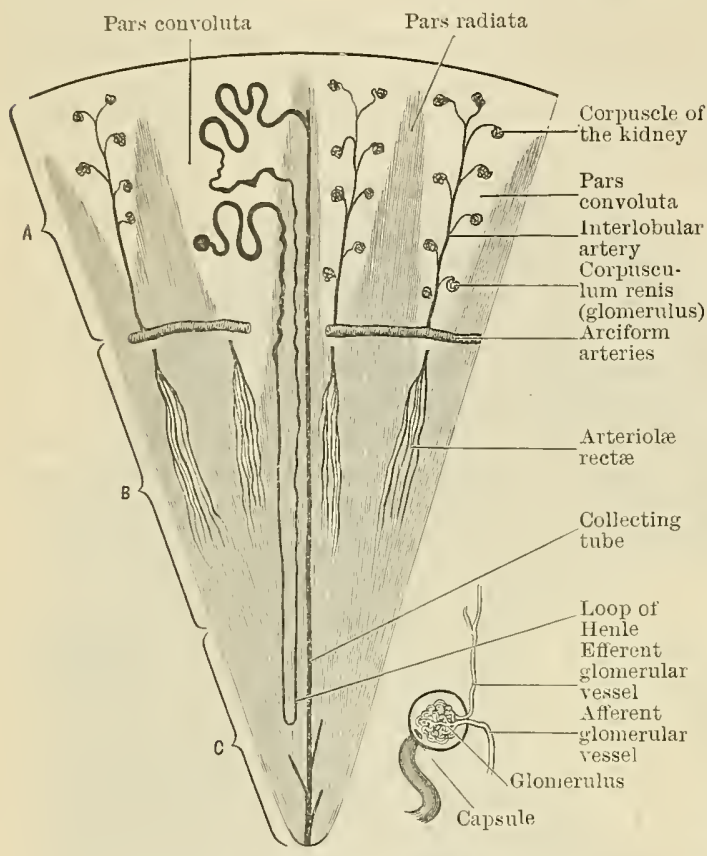

Fig. 986.-Diagramatic Represextation of the Structures Forming a Kidney Lobe.

In the middle part of the figure the course of one of the kidney tubules is indicated, and in the lateral parts the clisposition of the larger arteries. A, Cortex; B, Basal portion; and $C$, Papillary portion of pyramid.

The cliagram at the right-liand side of the lower part of the figure illustrates the comnexions of the structures composing a renal corpuscle. in the convoluted portion of the kidney cortex, where they may be recognised as minute red points just visible to the unaided eye and best marked when the renal vessels are congested. The part of the tubule leading from the capsule-first convoluted tubule-is very tortuous, and lies within the convoluted part of the cortex. Passing from the convoluted part, the tubule enters a radiate part, in which its course becomes less complicated, and here it receives the name of spiral tubule. From the radiate part the tubule enters the basal portion of the pyramid, and, diminishing in diameter, it pursues a straight course towards the apex of the pyramid, forming the so-called descending limb of Henle's loop. Within the apical portion of the pyramid the tubule suddenly bends upon itself, forming the loop of Henle, and reversing its direction, it passes back again through the base of the pyramid into the radiate part of the cortex as the ascending liml, of Henle's loop. This ascending limb exhibits a slight spiral twisting. Leaving the radiate part, the tubule once more enters the convoluted part of the cortex, where its outline becomes so uneven that the name irregulur tubule is applied to it. While still within the convoluted part, its contour having acquired a nore uniform appearance, the tubule receives the name of second convoluted tubule; this latter finally ends in a short junctional tubule, which passes back into a radiate part of the cortex and joins a collecting tube. Each collecting tube receives numerous kidney tubules, and pursues a straight course through the radiate part of the cortex and the pyramid. Finally, several collecting tubes, uniting together, form an excretory tube, which opens on the summit of a renal papilla into a calyx of the ureter by one of the foramina papillaria already described. In microscopic sections the various portions of the kidney tubule may be distinguished by the position which they occupy and by the character of the lining epithelium.

Connective Tissue of the Kidney. - The tubules and the blood-vessels forming the substance of the kidney are all united together by a very small amount of comnective 
tissue, which completely surrounds each tubule and blood-vessel, and binds it to its neighbours. It has been found possible to obtain an accurate idea of the arrangement of this connective tissue by submitting thin sections of the kidney to the action of certain digestive fluids. When this is done the tubules and blood-vessels are removed, and the connective tissue stroma is left behind. The connective tissue thus revealed is seen to form a continuous network, the spaces in which faithfully reproduce the outlines and the arrangement of the kidney tubules. The network of the stroma is continuous with the capsule of the kidney.

Vessels of the Kidney. - The renal artery comes directly from the aorta, and is very large in proportion to the size of the organ to which it conveys blood. Its main branches, as they approach the kidney to enter the lilus, lie between the tributaries of the renal vein in front and the ureter behind. Within the sinus of the kidney the branches of the renal artery become arranged in a dorsal and a ventral group, the dorsal vessels lying behind, the ventral ones in front of the subdivisions of the ureter. The ventral group of vessels supplies the part of the kidney which forms the anterior and lateral walls of the sinus; the distribution of the dorsal group is for the most part restricted to the portion of the kidney which lies behind, and to the rnedial side of the sinus.

Entering the substance of the kidney in the manner described above (p. 1265), the larger arteries lie in the intervals between the pyramids, and are called the arteriæ interlobares renis or interlobar arteries. These vessels dividing, form a series of incomplete arterial arches, the arteriæ arciformes, which pass across the bases of the pyramids. Although we speak of arterial arches, it must be understood that no anastomosis between the branches of the interlobar arteries actually takes place, but that each artery which enters the wall of the kidney sinus has an isolated distribution and possesses the characters of an "end artery." Each arterial arch gives off a number of vessels which pass through the convoluted part of the cortex towards the surface of the kidney. These are known as the arteriæ interlobulares, and lie at very regular intervals. From them a number of short branches arise, termed vasa afferentia, each of which proceeds to the dilated extremity, or capsule, of a uriniferous tubule. Here the vas afferens breaks up into a much convoluted capillary mass, called a glomerulus, which is contained within the invagination of the capsule. The little vein which issues from the glomerulus, or vas efferens, instead of running directly into a larger vein, breaks up, after the manner of an artery, into capillaries which supply the tubules of the convoluted and radiate parts of the kidney cortex. Hence almost all the blood which supplies the tubules of the cortical part of the kidney passes in the first instance through the glomeruli. The tubules of the bases of the pyramids also receive their blood-supply through vasa efferentia derived from the glomeruli which lie near. The little vessels passing from these glomeruli break up into bundles of fine arteries, which give the bases of the pyramids their coarsely striated appearance. They are known as arteriolæ rectæ, and, like the arteriæ interlobulares, are very conspicuous in injected preparations of the kidney.

The fibrous capsule of the kidney receives minute branches from the interlobular arteries, some of which, piercing the capsule, communicate by capillaries with the vessels of the tunica adiposa.

Veins corresponding to the interlobular arteries and arteriolæ rectæ collect the blood from the capillaries surrounding the tubules, and unite to form a series of complete arches across the bases of the pyramids. From these venous arcades vessels arise, which traverse the intervals between the pyramids and reach the sinus of the kidney, where they unite to form the dorsal and ventral tributaries of the renal vein. Some small veins in the superficial part of the cortex communicate through the fibrous capsule with minute veins in the capsula adiposa. Issuing from the kidney simus, the veins run a direct course to end in the inferior vena cava.

Nerves of the Kidney. - The nerves of the kidney accompany the branches of the artery, and are derived from the renal plexus. Their minute branches form regular net-like plexuses on the walls of the fine arteries and kidney tubules, and the presence of nerve terminations occurring among the epithelial cells lining the tubules has within recent years been demonstrated.

From clinical evidence it wonld appear that the nerve fibres which supply the kidney are portions of the tenth, eleventh, and twelfth thoracic nerres.

Variations. - A marked difference in the size of the two kidneys is sometimes observed, a small kidney on one side of the hody being usually compensated for by a large kidney on the opposite side. Cases of complete absence of one or other kidney are recorded.

A few cases are on record in which an extra kidney was foind in the right or left side. 
Traces of the superficial lobulation of the kidney, present in the fœtus and young child, are often retained in the adult.

Horse-shoe kidney is not an infrequent abnormality. In these cases the two kidneys are united at their inferior ends, across the median plane, by a connecting piece of kidney substance. The amount of fusion between the two kidneys varies much; it is sometimes very complete, while in other cases it is but slight, the connexion being chiefly composed of fibrous tissue.

In very rare cases the kidney appears to be almost entirely surrounded by peritoneum and to be attached to the abdominal wall by a kind of mesentery, enclosing the vessels and nerves passing to the hilns. The condition is believed to be congenital.

Not very infrequently one or both kidneys are found at a much lower level than usual, and occupying a position in the iliac fossa or the pelvic cavity. This condition, when congenital, is associated with an arrest in the normal change in position, relative to surrounding structures, which the kidney experiences during development. In such cases the kidney does not receive its blood-supply from usually placed renal arteries, but from vessels which arise from the lower end of the aorta, or from the iliac, or the middle sacral artery. These congenitally abnormally situated kidneys do not usually possess the typical ontline of the normal organ, but vary much in shape, and the hilus is often directed downwards or backwards and not inwards.

In some mammalian animals, such as the bear, the ox, the porpoise, ete., the kidneys are composed of a number of completely isolated lobes, each of which corresponds to one papilla, its pyramids and surrounding cortex; while in others, such as the horse, the fusion of the lobes is more complete even than in the human kidney, and a single mass represents the united papillæ.

\section{The Duct of The KiDney.}

The duct of the kidney is called the ureter, and begins above in a thin-walled funnel-shaped expansion called the pelvis renalis, which is placed partly within and partly outside the sinus of the kidney. Towards the level of the inferior end of the kidney the part of the pelvis which lies outside the sinus diminishes in 'calibre, and forms a tube-like duct, the ureter, which conveys the urine to the bladder.

Pelvis of the Kidney.-Within the sinus of the kidney the pelvis lies among the larger renal vessels. It is formed by the junction of two, or more rarely three, thin-walled tubes, the calyces majores, each of which has a number of branches. These latter, called calyces renales minores, are short, and increase in diameter as they approach the sinus wall, to which they are attached. Their wide, somewhat funnel-like ends enclose the renal papillæ, and receive the urine, wlich enters them through the foramina papillaria. The calyces are usually about eight in number, one calyx sometimes surrounding two or even three papillæ. The portion of the pelvis that lies outside the kidney has in front of it, in addition to the renal vessels, on the right side the descending part of the duodenum, and on the left side a part of the pancreas and sometimes the duodeno-jejunal flexure (Fig. 979).

Ureter.-The ureter is the vessel which carries the urine from the pelvis of the kidney to the bladder. It is a pale-coloured thick-walled duct with a small lumen. While in situ it has a total length of about ten inches, and lies throughout its whole course in the subperitoneal tissue, behind the peritoneum, to which it is closely connected. In its superior part the ureter lies in the abdominal cavity, and in its inferior part in the pelvic cavity (Figs. 983 and 988).

The normal ureter, in the flaccid condition, measures after its removal from the body eleven to fourteen inches.

The pars abdominalis, or abdominal portion of the ureter, about five or five and a half inches in length, is directed downwards and slightly medially, and lies upon the psoas major muscle. Certain structures are related to the ureters in a similar manner on each side of the body ; for instance, the abdominal portion of each ureter is crossed very obliquely, on its anterior aspect, by the internal spermatic vessels, and behind each ureter the genito-femoral nerve passes downwards and laterally (Fig. 983). Other structures are related to the duct of the right or left side alone; on the right side the descending part of the duodenum lies in front of the upper part of the ureter, and the line of attachment of the mesentery crosses it lower down, just before the ureter enters the pelvic cavity. On the left side the line of attachment of the mesentery of the pelvic colon crosses the ureter.

Crossing the common iliac; or the external iliac artery, the ureter enters the pelvis. The left ureter usually crosses the common iliac artery, and the right 
ureter, in most cases, lies across the external iliac; but this arrangement is by no means constant. The course and position occupied by the abclominal portion of the ureter is well seen in Fig. 983.

In X-ray photographs, the shadow cast by the abdominal portion of the ureter when the latter has been rendered opaque, is seen to fall immediately in front of the tips of the transrerse processes of the lower lumbar vertebre.

The pars pelvina or pelvic portion of the ureter is about four or four and a half inches in length, and passes downwards on the lateral wall of the pelvis, immediately beneath the peritoneum, describing a curve which is convex backwards and laterally (Fig. 988). The most convex portion of this curve lies close to the deepest part of the greater sciatic notch (Fig. 988). As it descends upon the lateral wall of the pelvis the ureter forms the posterior boundary of the triangular district known as the obturator triangle. The lower limit of this triangle is formed by the ductus deferens, and the upper and anterior boundary by the external iliac vessels and the pelvic brim (Fig. 988).

In its course within the pelvis the ureter lies in front of the hypogastric artery, and crosses the medial aspect of the obturator nerve and vessels and of the obliterated umbilical artery. About the level of the spinaischiadica, or ischial spine, the ureter is crossed from before backwards by the ductus deferens, and from this point on wards it is not so intimately related to the peritoneum. It now bends some-

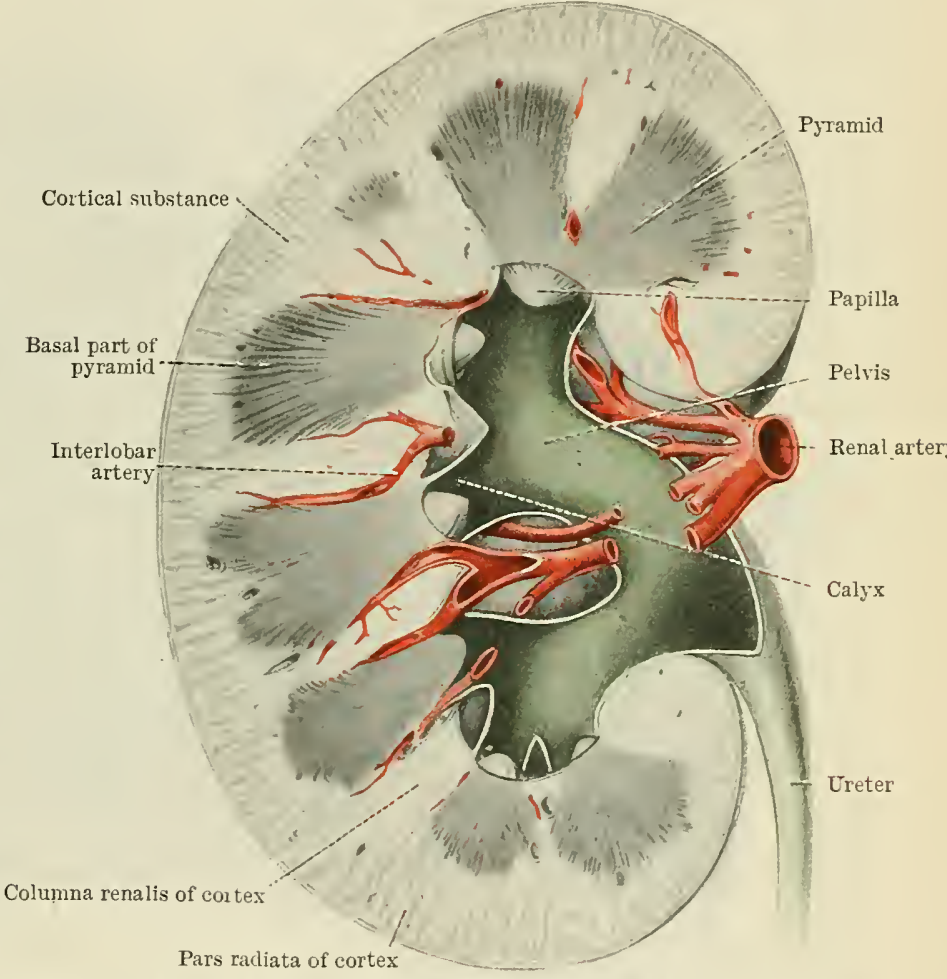

Fig. 987.-Longitudisal Section of the Kidney, opexing up the Kidney Sincs.

The pelvis of the kidney and some of its calyces have been laid open as they lie within the sinus.

what medially and forwards, to reach the lateral angle of the bladder, and comes into relationship with the upper end of the vesicula seminalis, in front of which it lies. The ductus deferens having crossed the ureter also turns medially, and as it does so it lies at a higher level and on a posterior plane to the ureter. The inferior end of the ureter is surrounded by a dense plexus of veins which brings the vesical plexus into communication with the hypogastric vein. The great nerve cord which connects the hypogastric plexus with the pelvic plexus, also comes into relationship with the lower part of the pelvic portion of the ureter, in the region where the latter is crossed by the ductus deferens (Fig. 988).

When the right and left ureters reach the bladder they are a little more than two inches apart. They pierce the bladder wall very obliquely, and are embedded within its muscular tissue for nearly three-quarters of an inch of their length. Finally, they open into the bladder by two small slit-like apertures which are of a valvular nature, and prevent a backward passage of fluid from the bladder. It is probable, however, that an exaggerated idea of the valvular nature of the openings of the ureters into the bladder is obtained by an examination of the parts in the dead subject. When the bladder is empty the openings of 
the ureters are placed about one inch apart, but when that viscus is distended they are often two inches, or more, distant from one another. As the ureter pierces the bladder wall the muscular fibres of the bladder and ureter remain quite distinct, and so the nreter, remaining a thick-walled tubular structure, appear's to pass through a gap in the muscular wall of the bladder. The mucous coat alone of the ureter becomes continuous with that of the bladder.

The canal of the ureter is not uniform throughout, but is somewhat constricted in certain places, corresponding to the regions where the ureter is most sharply curved or changes its direction. These more constricted parts of the tube are described as occurring one in the middle of the abdominal portion, one at the

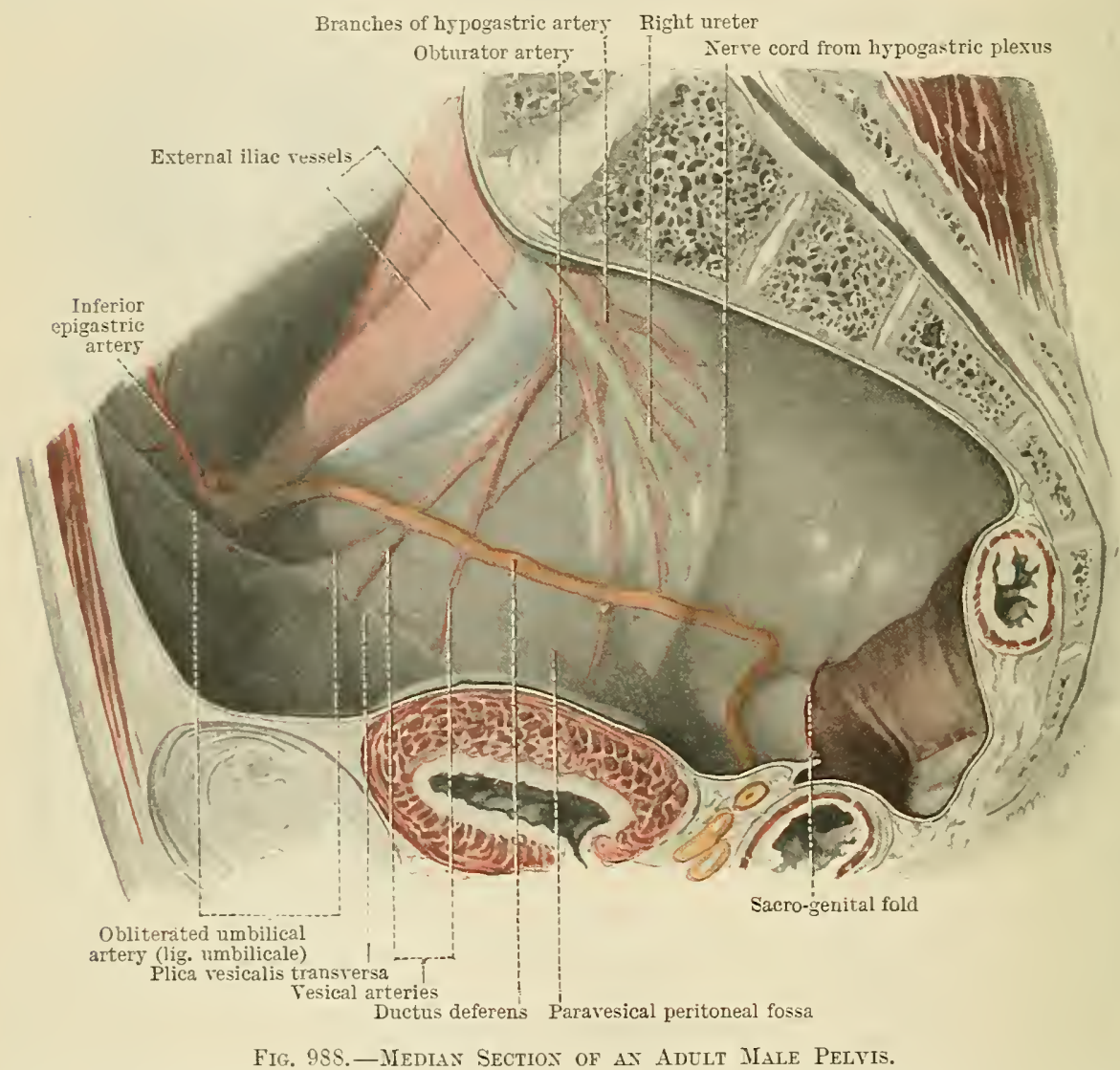

The coils of the small intestine and of the colon which lay within the pelvis have been lifted ont in order to give a riew of the lateral wall of the pelvic carity.

junction of the abdominal and pelvic portions, and one in the pelvic part of the ureter. Also just before the ureter joins the pelvis of the kidney and just as it reaches the bladder wall its lumen is usually somewhat constricted.

In the female, the ureter, near its termination, passes beneath the lower part of the broad ligament of the uterus, and lies to the lateral side of the cervix uteri and the upper part of the lateral wall of the vagina. It is accompanied in the inferior part of its course by the uterine artery, which crosses it on its anterior aspect not far from its termination (Fig. 1002). Higher up it lies in the peritoneal ridge which forms the posterior boundary of the fossa ovarica, a posterior subdirision of the obturator fossa (Fig. 1002).

\section{StruCTURE OF THE URETER.}

The wall of the ureter, which is thick and of a whitish colour, is composed of mucous, muscular, and fibrous coats. The tunica mucosa or mucous coat possesses an epithelium composed of many layers of cells, those nearest the surface being of 
large size. When the canal is empty the mucous coat is thrown into numerous longitudinal folds, and so its lumen exhibits a stellate outline in transverse section. The submucous tissue varies much in thickness in different parts of the ureter, and contains some elastic fibres. The unstriated muscle fibres which compose the tunica muscularis or muscular coat are collected into bundles which are separated by a considerable amount of connective tissue, and are arranged, some longitudinally, some circularly. In the upper part of the ureter a relatively large amount of connective tissue is present deep to, and among the bundles of muscle fibres which are arranged in three distinct strata-an inner longitudinal, an intermediate circular, and an outer longitudinal. In the middle part of the vessel the same layers may be recognised, but the circularly disposed bundles of fibres are more numerous than higher up. In the lower part of the ureter the connective tissue is relatively scanty and the inner longitudinal fibres lie close to the lining epithelium; in this region also the longitudinal folds of the mucous coat become fewer and less marked. A short distance above the point where it reaches the bladder, the wall of the ureter becomes much thickened by the addition of a number of coarse bundles of longitudinally arranged muscle fibres, which are applied to the outer surface of the muscular coat. These muscle fibres form the so-called "sheath of the ureter," and are continued on the superficial aspect of the vessel as it passes through the bladder wall. In the portion of the ureter which traverses the wall of the bladder (pars intramuralis) nearly all the fibres of the muscular coat are disposed longitudinally, i.e. in a direction parallel to that of the vessel. The muscle fibres lie close beneath the epithelium, and end just where the mucous coats of the bladder and ureter become continuous. The tunica adventitia or outer fibrous coat of the ureter varies in thickness at different levels, and in its lower part blends with the connective tissue which lies among the muscle fibres forming the sheath of the ureter just mentioned.

The mucous membrane of the calyces and of the pelvis of the kidney possesses an epithelium resembling that of the ureter. Where each renal papilla projects into one of the calyces a deep circular recess, or fornix, is formed between the wall of the calyx and the sloping side of the papilla; at the bottom of this recess the epithelium of the calyx becomes continuous with that covering the papilla. At the foramina papillaria the epithelium joins that of the kidney tubules. The muscular fibres in the wall of the calyces and of the pelvis are collected into loosely arranged bundles separated by wide intervals occupied by fibrous connective tissue. As in the ureter, the outermost and innermost fibres run in a longitudinal, the intermediate ones in a circular direction. The circularly arranged fibres alone form a distinct layer.

Vessels and Nerves of the Ureter.-The abdominal part of the ureter receives its blood-supply from the renal and internal spermatic arteries; the pelvic portion is supplied by the superior vesical and middle hæmorrhoidal vessels.

The nerves of the ureter reach it through the renal, the spermatic, and the interiliac, or hypogastric, plexuses.

Variations.-The ureter is sometimes represented by two tubes in its upper portion. In rarer cases it is double throughout the greater part of its extent, or even in its whole length from the pelvis of the kidney to the bladder. In such eases there may be two openings into the bladder. Asymmetry as regards such abnormalities is very common.

Variations in the form of the pelvis of the kidney are of frequent occurrence. Most usually the pelvis divides into two large subdivisions, one of which passes in the direction of the upper, the other in that of the lower pole of the kidney. In some cases these branches come off directly from the ureter without the intervention of a pelvis, or a marked subdivision may lead to the formation of two pelves.

\section{VESICA URINARIA.}

The vesica urinaria or urinary bladder is a hollow muscular organ situated in the anterior part of the pelvic cavity, above and behind the symphysis pubis. It lies in front of the rectum, from which it is separated in the male by the seminal vesicles and the terminal portions of the ductus deferentes, and in the female by the vagina and uterus. The ureters, which convey the fluid secreted by the kidneys, open into the lower and under part of the bladder about half an inch from the median plane. 
The urethra, or canal by which the urine reaches the surface, leads from the bladder, its aperture lying in the median plane, not far from the openings of the ureters, but on a lower and anterior plane. The size and shape of the bladder, the thickness of its wall, and also to a great extent its relations, vary with the amount of distension, or contraction, of the organ. When the bladder is empty, or only slightly distended, it lies within the pelvic cavity; as it becomes filled with urine it rises above the pubis, and crossing the pelvic brim, enters the

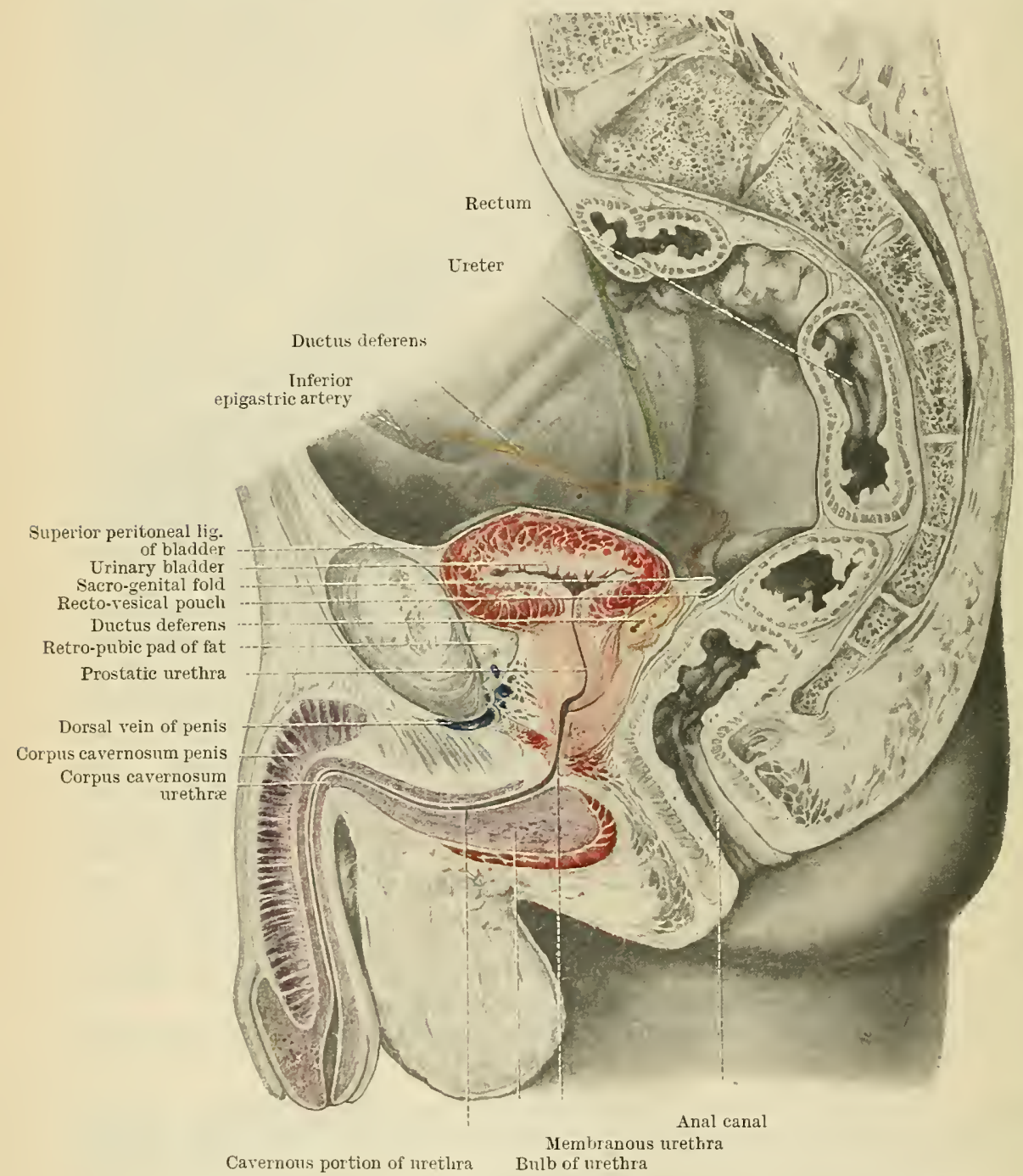

Fig. 989.- Median Section throdgh the Pelvis of an Adult Male Subject.

The uriuary bladder is empty and firmly contracted. The coils of small intestine have been removed to afford a view of the lateral wall of the pelvic cavity.

abdominal cavity. These changes affect chiefly the upper part of the bladder, which becomes altered in shape and size, and acquires new connexions and relations; the lower portion varies but slightly with the amount of distension of the organ (see Figs. 989 and 990). The upper part of the bladder is covered by peritoneum, which is reflected on to it from the anterior abdominal wall in front, from the sides of the pelvis laterally, and, in the male, across the seminal vesicles and terminal parts of the ductus deferentes from the rectum behind. In the female the peritoneum passes on to the bladder posteriorly from the anterior surface of the uterus. The peritoneum dips down posteriorly for a certain distance between the bladder and 
rectum in the male, forming the recto-vesical or recto-genital pouch; in the female a slit-like peritoneal depression, called the utero-vesical pouch, intervenes between the anterior surface of the uterus and the bladder (Fig. 996). The inferior part of the bladder lies below the peritoneum, and is for the most part directed towards the pelvic floor. In the median plane it is supported by the symphysis pubis and the retro-pubic pad of fat; farther back in the male it rests upon the prostate and on the lower part of the rectum, from the latter of which it is separated by the vesiculæ seminales and the terminal parts of the ductus deferentes. In the female it rests

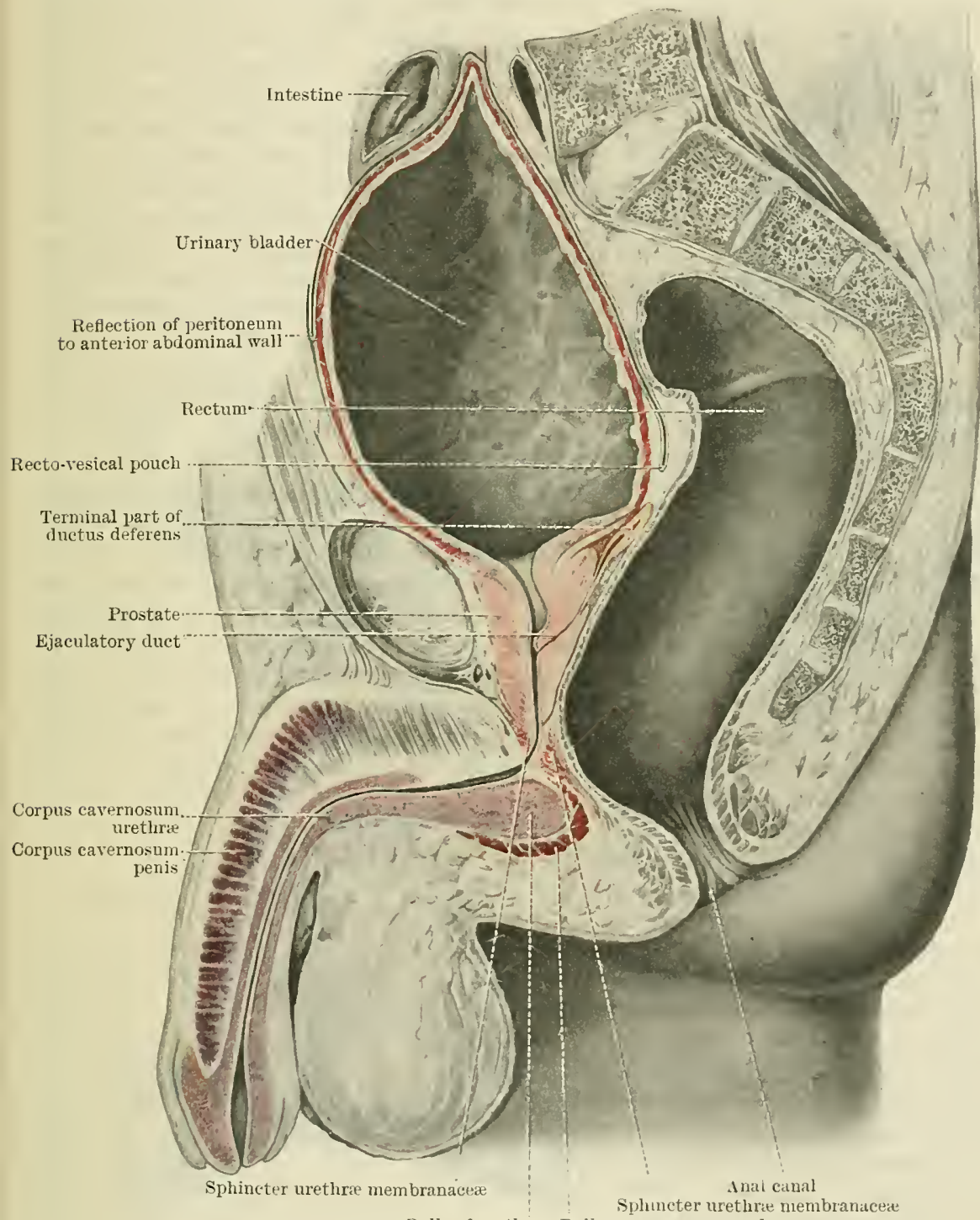

Bulb of urethra Bulbo-carernosus muscle

Fig. 990. - Mededay Section of the Pelvis of an adult Male Subject.

The urinary bladuler and rectum are both greatly disteuled.

upon the anterior wall of the vagina. Laterally the bladder is supported by the levatores ani muscles, and farther from the median plane it rests on each side on the obturator internus; it is separated from the layer of the pelvic fascia covering these muscles by loose areolar tissue.

The opening of the urethra, orificium urethræ internum or internal urethral orifice, is placed in, or near, the part of the bladder wall which lies lowest in the pelvic cavity. The term neck, or cervix, is often applied to this region, the 
bladder appearing as if it were suddenly constricted to form the urethra. The portion of the bladder wall posterior to the urethral orifice, which is directed in the male towards the anterior wall of the rectum and lies below and in front of the recto-vesical pouch, is called the fundus vesicæ or base of the bladder; it is closely related to the seminal vesicles and ampullæ of the ductus deferentes. The corresponding part of the bladder in the female rests against the anterior wall of the vagina. The term vertex vesicæ, or apex of the bladder, is applied to the portion which lies nearest to the upper border of the symphysis when the organ is empty,

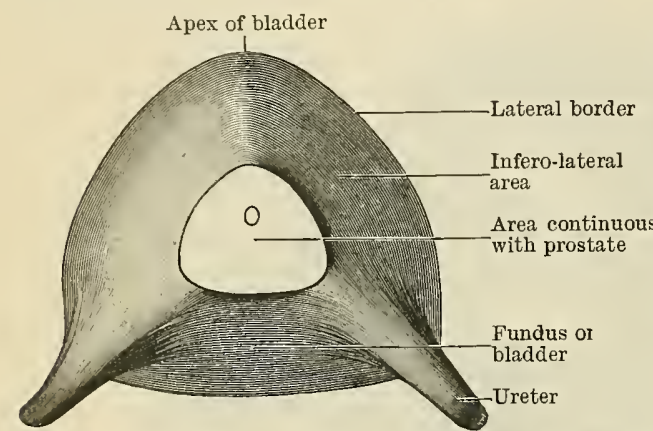

Fig. 991.-Inferior Aspect of the empty Male URINARY BLADDER. From a subject in which the viscera had been hardened in situ.

The prostate has been severed from the bladder, and the white area in the drawing indicates the position where the two structures were continuous.

and rises high above the pubis into the abdominal cavity when the bladder is distended. Connected with the vertex of the bladder is a fibrous cord, the ligamentum umbilicale medium, or urachus, which passes upwards, in the median plane, on the posterior aspect of the anterior abdominal wall, and reaches the umbilicus. It represents the passage which in the embryo comnects the developing bladder with the allantois. The part of the bladder connecting the apex with the base, and not sharply marked off from either, is called the corpus vesicæ, or body of the bladder.

Position of the Urethral Orifice. -During the various changes in shape and size which the bladder undergoes, the region of the internal urethral orifice remains almost fixed in position. The urethral orifice lies immediately above the prostate, and behind and slightly below the level of the upper margin of the symphysis pubis, from which it is distant about two to two and a half inches. It can be easily reached by a finger introduced into the bladder through the abdominal wall above the symphysis pubis. It is usually placed half an inch to one inch above the level of a plane passing through the lower margin of the symphysis and the lower end of the sacrum, but in some cases it is found to be somewhat lower. In the female it normally occupies a lower level than in the male. The comparatively slight variations in the level of the internal urethral orifice which do occur, depend partly upon the quantity of fluid contained in the bladder, and partly upon the amount of distension of the lower portion of the rectum. When the bladder is very much distended this region lies at a slightly lower level in the pelvis than it does when the organ is empty; on the other hand, distension of the lower part of the rectum raises, to some extent, the level of the urethral orifice. Since the position of the internal urethral orifice varies, in the manner just described-with the condition of the rectum and of the bladder-it

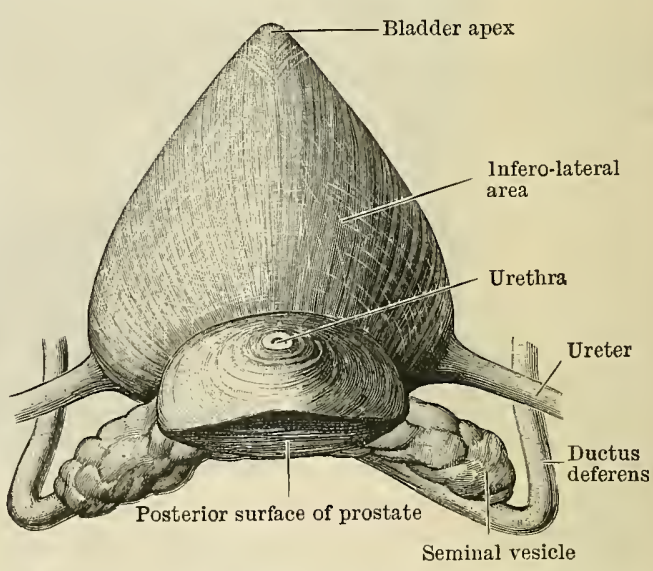

Fig. 992.-The Urinary Bladder, Prostate, and Seminal Vesicles, VIewed from Below.

Taken from a subject in which the viscera were hardened in situ. Same specimen as Fig. 993, A. The bladder contained but a small amount of fluid.

follows that it lies at its lowest limit when the bladder is full and the rectum empty, and at its highest level when the bladder is empty and the rectum distended.

Inferior Aspect of the Bladder.- The lower part of the bladder, which is directed towards the pelvic floor, changes, as we have seen, but slightly with the varying amount of distension of the viscus. When the organ has been carefully hardened 
before its removal from the body, it is possible to map out on its inferior aspect three convex triangular areas, which may be distinguished from one another by the directions in which they look. The three areas approach one another in the region of the urethral orifice, where, in the male, a portion of the inferior aspect of the bladder wall is structurally continuous with the upper part of the prostate. Posterior to the urethral orifice is a triangular district, directed downwards and backwards, and related, in the male, to the seminal vesicles and the terminal portions of the ductus deferentes which, together with the recto-vesical layer of the pelvic fascia, intervene in this position between the bladder and the rectum. This triangular area of the bladder wall is known as the fundus, or postero-inferior surface of the bladder, and in the female it is directed against the anterior wall of the vagina. The rest of the inferior aspect of the bladder is formed by two infero-lateral areas, or surfaces, which meet in the median plane in front of the urethral orifice, and are directed for the most part downwards and laterally (see Fig. 993). Each of these areas extends backwards to join the fundus or postero-inferior surface, along a rounded border which lies between the point where the ureter reaches the bladder and the urethral orifice. The infero-lateral part of the bladder wall rests on the areolar tissue covering the fascia of the levator ani and the obturator internus muscles, and, nearer the median plane, upon the os pubis and retro-pubic pad of fat.

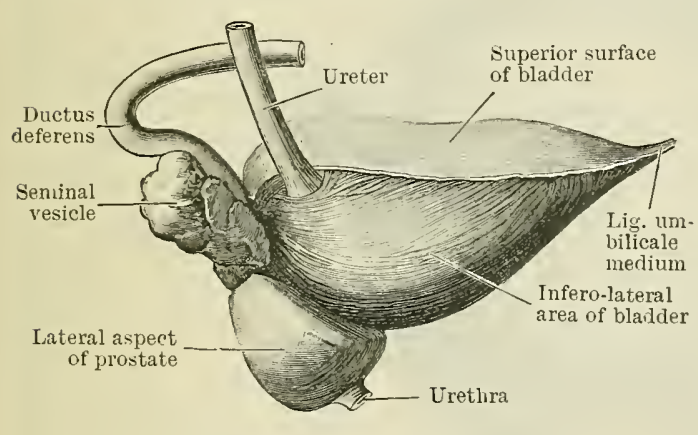

A

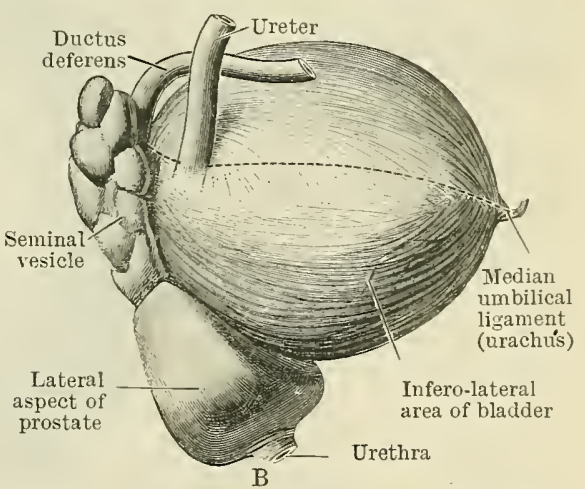

B

Fig. 993. - The Urinary Bladder, Prostate, and Vesicula Seminalis, viewed from the Lateral Aspext.

Drawn from specimens in which the viscera were hardened before removal from the body. In A the bladder contained but a very small quantity of fluid; in $\mathrm{B}$ the quautity was somewhat greater. In $\mathrm{A}$ the peritonenm is shown covering the superior surface of the bladder, and its cut edge is seen where it is reflected along the lateral border of the organ. In $\mathrm{B}$ the level of the peritoneal reflexion is indicated by a dotted line.

The three rounded borders which mark off the three triangular areas on the inferior aspect of the bladder, just described, extend from the region of the urethral orifice to the bladder apex, and to the points where the ureters reach the bladder wall (see Fig. 993).

Shape and Relations of the Empty Bladder.-When the bladder is empty, or nearly so, it has, roughly speaking, the shape of an inverted tetrahedron, whose apex corresponds to the point where the urethra leaves the organ, while the base of the tetrahedron is formed by the superior surface of the bladder. The three basal angles of the tetrahedron correspond to the bladder apex and to the two lateral angles of the bladder, or points where the ureters join the organ. The three surfaces, which meet inferiorly at the urethral orifice, are only marked off from one another by rounded borders, but as long as the organ is empty, or nearly so, they are separated by distinct borders from the smperior surface. These three areas have been already described as the infero-lateral surfaces and the base of the bladder (Figs. 991 and 992). Their relations have also been indicated. The superior surface of the empty bladder looks upwards into the pelvic cavity ; it is convex when the organ is contracted, concave when relaxed. This surface is covered by peritoneum, and its ontline, which is approximately triangular, is determined by lateral aud posterior borders (Fig. 993). The lateral borders of the empty bladder are sharply marked, and extend from the bladder apex to the lateral angles 
of the bladder, or points where the ureters join the organ. They separate the superior surface from the infero-lateral portions of the inferior aspect of the bladder wall (Fig. 993, A). The posterior border stretches across between the lateral angles of the bladder, and separates the superior from the basal surface of the viscus. The superior surface is related in the male to coils of intestine; in the female it is also related to the anterior surface of the uterus. The lateral border of the empty bladder lies against the pelvic fascia just above, or at the level of the arcus tendineus of the levator ani muscle. The ductus deferens crosses the lateral wall of the pelvis parallel to it, but at a considerabily higher level. In median section the cavity of the empty and relaxed bladder often presents the appearance of a $Y$-shaped chink, the stem of the $Y$ being represented by the urethra as it leaves the organ, and the two limbs by the narrow intervals between the superior surface and the under parts of the bladder wall which lie in front of and behind the urethral orifice. This relaxed form is sometimes described as the diastolic condition of the empty bladder, and is found associated with a bladder wall of but little thickness, and with a concave upper surface. The condition is usually the result of an escape of fluid after death, when the bladder wall has lost the power of contracting. It certainly does not

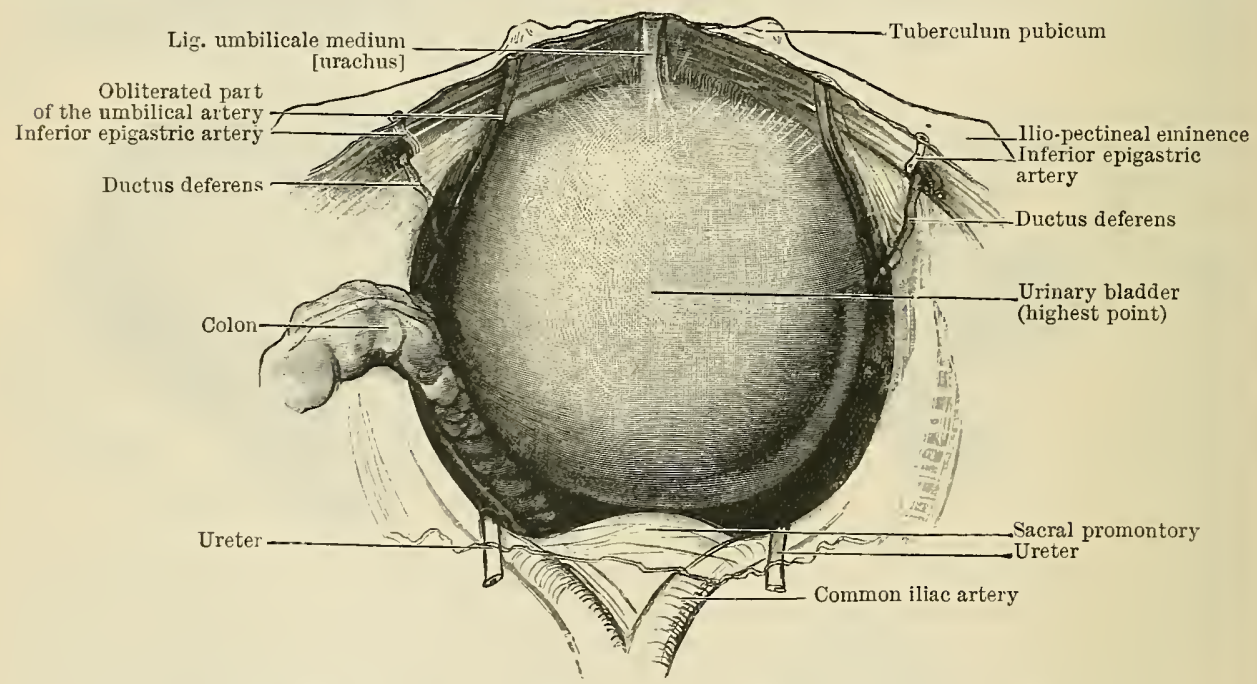

Fig. 994.-VIEW LOOKING INTO THE PELVIS FROM ABOVE AND SOMEWHAT BEHIND.

The bladder has been artificially distended.

represent a normal condition of the organ in the living. The normal empty bladder is strongly contracted, and its wall is thick and firm. A distinctly Y-shaped appearance is not presented by its cavity in median section, but the interior of the organ is seen as a simple narrow interval continuous with the canal of the urethra.

Distended Bladder.-As the bladder fills with fluid the superior wall is raised upwards from the infero-lateral and basal walls, and, at the same time, the borders separating the superior from the other surfaces of the bladder become at first more rounded and then nearly obliterated. The lateral borders of the bladder becoming in this manner opened out, give rise to so-called lateral surfaces in the distended organ. These surfaces, however, are not sharply marked off, and are directly continuous with the superior surface. During distension, also, the angles present in the empty condition of the organ become rounded as the entire bladder wall becomes more uniformly convex. The general shape of the bladder becomes altered during distension; the tetrahedral form of the empty organ is lost, and the bladder as it becomes filled assumes first a somewhat spherical, then an oval contour. During distension the enlarging bladder comes to occupy more and more of the pelvic cavity, displacing upwards the portions of the colon and small intestine which may lie in the pelvis when the organ is empty. Until all the available pelvic space has been filled up, the form 
of the distended bladder is spherical, or oval, with the larger end directed downwards and backwards. When the pelvic wall prevents further expansion of this portion, the outline of the organ may become an oval with the larger end directed upwards and forwards into the abdominal cavity. The highest part of the distended bladder lies at some distance above the pelvic brim, and does not correspond to the attachment of the urachus at the apex, but to a point farther back (Fig. 994). As the superior wall of the bladder is raised up during distension it earries with it the peritoneum, and thus the reflexion of that membrane, from the anterior abdominal wall on to the apex of the bladder, comes to lie one and a half inches, or even higher, above the upper margin of the symphysis pubis (Fig. 990). It is, therefore, possible to puncture, or open into the distended bladder, through the anterior abdominal wall above the symphysis pubis, without at the same time opening into the peritoneal cavity. In a similar manner the line of reflexion of the peritoneum, from the side wall of the pelvis on to the lateral aspect of the bladder, is raised higher during distension, and may come to correspond, in part, to the level of the ductus deferens, or to that of the obliterated part of the umbilical artery. On the other hand, the level of the reflexion of the peritoneum from the rectum towards the basal aspect of the bladder does not appear to vary much with the distension, or contraction, of the organ (compare Figs. 989 and 990), and thus the fossa between the bladder and rectum becomes relatively very deep when the bladder is full. The bladder in normal distension may contain nearly one pint, but in most cases the organ is emptied when its contents reach from six to ten ounces. Under abnormal or pathological conditions the bladder capacity may be very much increased.

Varying Relationships, according to the degree of Distension of the Bladder. -When the bladder is distended the obliterated part of the umbilical artery may cross forwards against its side, but when it is empty the obliterated vessel at its nearest point often lies as much as one and a quarter inches above the lateral border of the organ. The ductus deferens, during a part of its course, is in contact with the lateral wall of the distended bladder, but when the organ is empty it lies above and parallel to the lateral border, only coming into relationship with the basal surface of the bladder beyond the point where it crosses the ureter. The side wall of the distended bladder is closely related to the obturator vessels and nerves.

Interior of the Bladder. - The mucous membrane lining the bladder is loosely connected to the muscular coat, and when the bladder is contracted the mucous lining of the upper wall is thrown into a number of prominent wrinkles or folds (Fig. 995). At one place only the mucous membrane is firmly connected to the subjacent muscular coat, and the inner surface of this part of the bladder wall is smooth and free from wrinkles. This smooth area corresponds to a triangular surface behind the urethral orifice, called the trigonum vesicæ, and to the part of the bladder wall which immediately surrounds the opening. The apex of the triangle lies at the beginning of the urethra, and the base is formed by a line drawn between the openings of the ureters into the bladder. Just behind the urethral opening the bladder wall sometimes bulges slightly into the cavity, owing to the presence of the middle lobe of the prostate, which lies beneath the mucous coat in this position. When well marked, as it often is in old people, this bulging is termed the uvula vesicæ. Stretching across between the openings of the ureters there is usually to be seen a smooth ridge, due to the presence of a bundle of transversely disposed muscle fibres, which lies within this part of the bladder wall, beneath the mucous membrane. This ridge has been called the "torus uretericus." It may be deficient near the median plane, and it is curred so as to be convex forwards. The lateral portions of the ridge which lie outside the openings of the ureters are called the plicæ uretericæ, and are produced by the terminal parts of the ureters as they traverse the bladder wall and lie beneath the mucous coat of the bladder (Fig. 995). In old people the region behind the trigonum is usually distinctly depressed and forms a shallow fossa, sometimes called the retro-ureteric fossa. A less distinct shallow depression may sometimes be observed on each side of the trigone. Round the urethral orifice are a number of minute radially disposed folds which, disappearing into the urethra, become continuous with the longitudinal folds of the mucous membrane of the first part 
of that canal. The ureters pierce the bladder wall very obliquely, and so the minute orificium ureteris, or opening, of each has an elliptical outline. The lateral boundary of each opening is formed by a thin, crescentic fold, which, when the bladder is artificially distended in the dead subject, acts as a valve in preventing water or air from entering the ureter. Hence the term "valvula ureteris" is sometimes used to designate the fold. In the empty bladder the urethral orifice and the openings of the two ureters lie at the angles of an approximately equilateral triangle, whose sides are about one inch in length. When the bladder is distended the distance between the openings may be increased to one and a half inches or more.

Bladder in the Female. - In the female the bladder is related posteriorly to

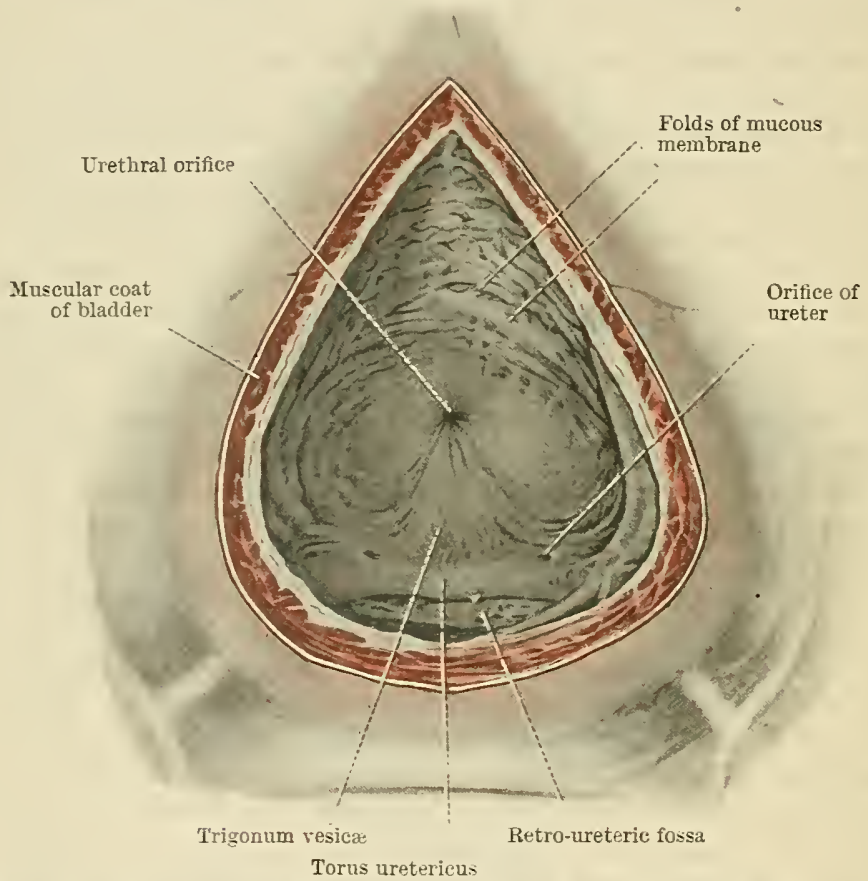

Fig. 995.-EMptr axd Coxtracted Urisary Bladder, opesed dP BY the Plemofal of its Upper Wali..

The peritoneum is seen spreading out from the lateral and posterior borders of the organ. Compare with Fig. 1000.

the uterus and upper part of the vagina. The anterior surface of the uterus in its upper part is separated from the upper surface of the bladder by the shallow uteroresical pouch of peritoneum, but the two organs are nevertheless normally in apposition. So close is this relationship that the upper surface of the bladder very often shows a slight concavity, due to contact with the convex anterior wall of the uterus. The lower part of the uterus and upper part of the vagina are not separated by peritoneum from the basal surface of the bladder, but are in actual apposition with it (Fig. 996). Thus, below the level of the utero-vesical pouch, the female bladder is related in much the same manner to the uterus and anterior wall of the vagina as the male bladder is related to the vesiculæ seminales and ductus deferentes. The apex of the bladder, where the urachus is attached, often lies on a lower level than in the male, so that the organ, even when distended, rises less freely into the abdomen. The bladder as a whole is placed deeper in the pelvis than in the male, and the internal urethral orifice lies just abore, or just below, a line drawn from the lower margin of the symphysis to the lower end of the sacrum (p. 1274). The lower level of the internal urethral orifice is probably correlated with the absence of a distinct prostate in the female. It is probable that as regards capacity no difference exists between the bladder in the male and in the female; the conflicting results arrived at by different observers are probably due to the faulty methods which have been employed in estimating the capacity of the organ. 
Bladder in the Newly Born Infant and in the Child.-At birth the empty

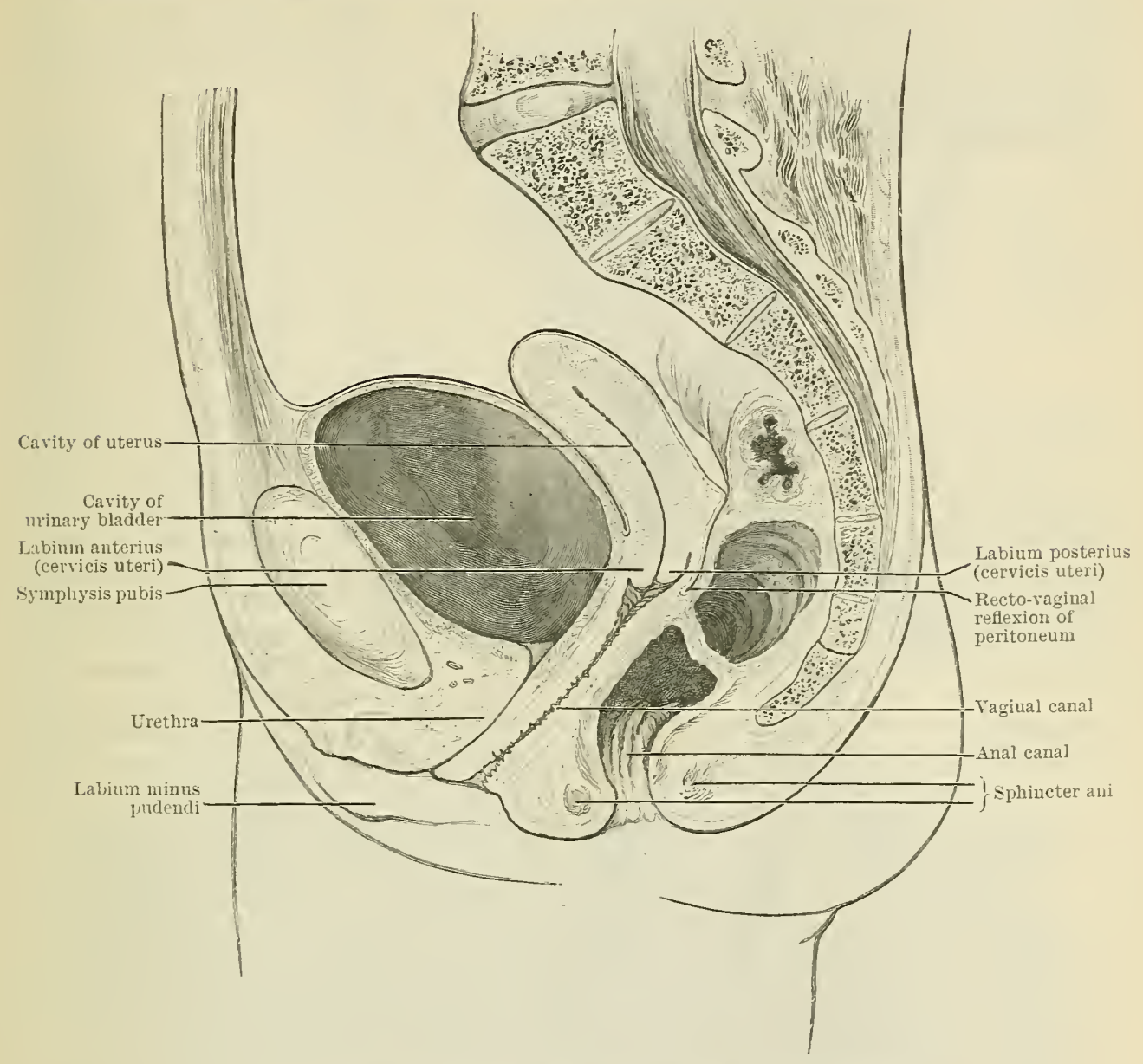

Fig. 996.-Mediax Sectiox of the Peltis in ax Adelt Fedrale.

The cavity of the uterus is indicated diagrammatically.

bladder is spindle- or torpedo-shaped, and its long axis, which extends from the point of attachment of the urachus to the internal urethral orifice, is directed downwards and backwards (Fig. 997). The lateral and posterior borders seen in the adult organ cannot be recognised at birth, nor is there any part of the bladder wall directed downwards and backwards, as is the basal surface of the adult organ. In the foetus and young child the bladder occupies relatively a much higher level than it does in the adult, and, even when empty, it extends upwards into the abdominal cavity. Its anterior aspect is in contact with the posterior surface of the anterior abdominal wall. At birth the peritoneum forming the recto-vesical

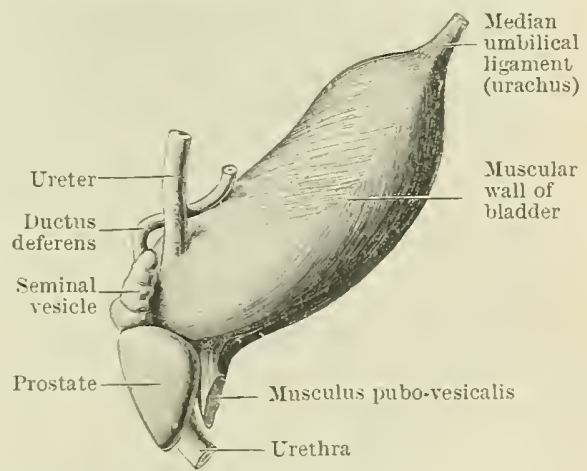

Fici. 997.-The URINARY BLADDER OF A TEmLY BORI MALE C'HILD, viewed from the side.

The drawing is from a specimen which had been hardened in situ. pouch covers the whole of the posterior surface of the bladder, and reaches as low as the upper limit of the prostate. The intermal urethrial orifice is placed at a high level, and sinks gradually after birth (Fig. 998, A). In the newly born child this 
opening lies on a level with the upper margin of the symphysis pubis, and the openings of the ureters lie almost on a level with the plane of the pelvic brim. The obliterated portious of the umbilical arteries are more intimately related to the bladder in the foetus and child than in the adult, and lie close against its sides as they pass upwards towards the umbilicus (Fig. 999).

Peritoneal Relations and Connexions of the Bladder.-We have already

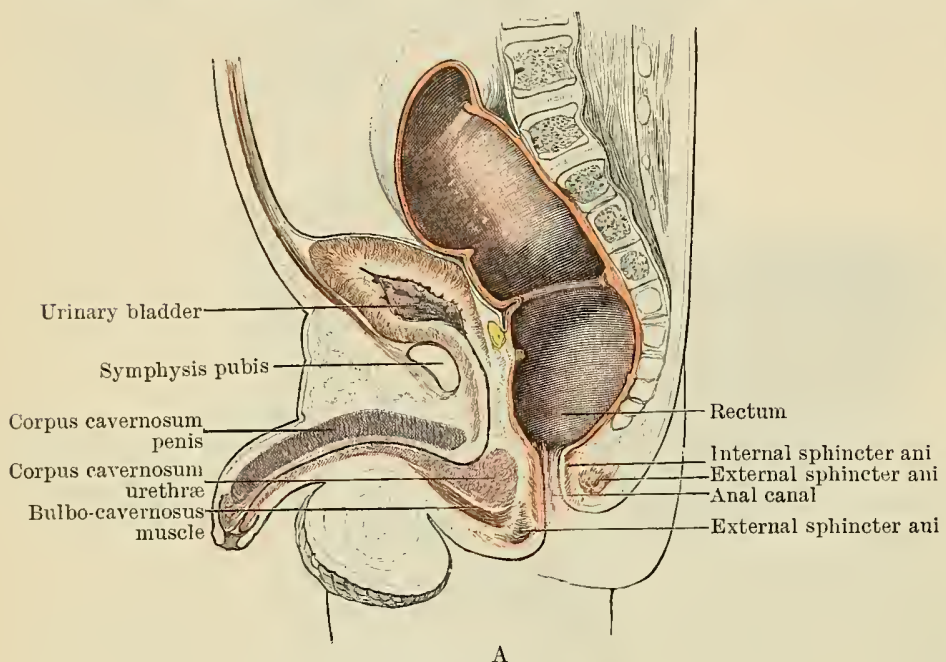

A

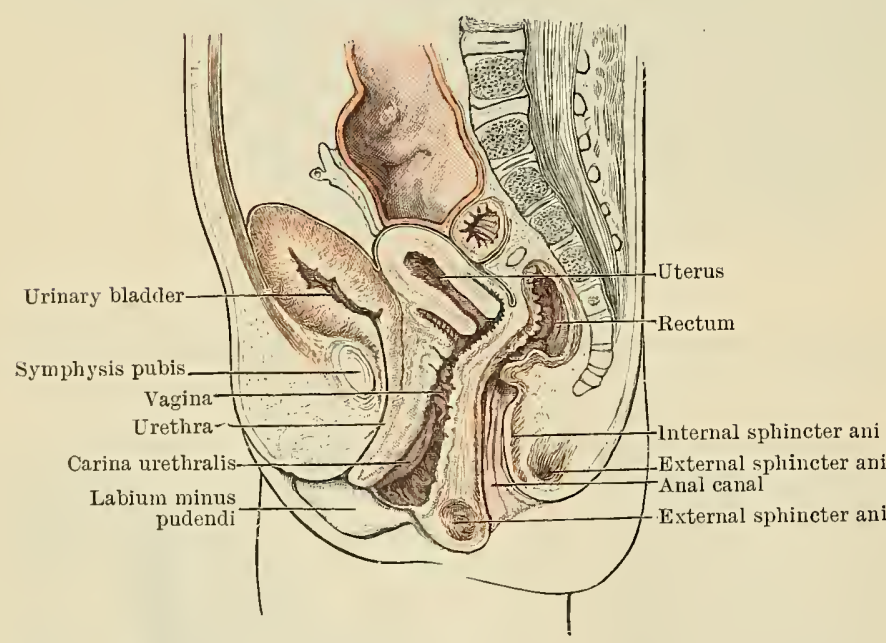

B

Fig. 998. - Median Section throdgh the Pelvis of newly born Child.

A, Male, and B, Female. seen that the superior surface of the empty bladder is covered by peritone $\mathrm{um}$, which leaves it along the lateral border on each side to reach the pelvic wall at about the level of the arcus tendineus or white line of the pelvic fascia. To this peritoneal reflection the term lateral false (or peritoneal) ligament is often applied. The lateral ligaments of opposite sides are continuous in front at the bladder apex, where the peritoneum is conducted over the fibrous cord of the urachus to reach theanterior abdominal wall, forming the socalled superior false (or peritoneal) ligament. When the bladder is empty the level of this anterior reflection lies just behind, or just below, the upper margin of the symphysis pubis. When the bladder becomes filled the level of the peritoneal reflection forming the superior false ligament is raised upwards, and may reach a point two inches, or more, above the upper margin of the symphysis pubis. Similarly, the line along which the lateral peritoneal ligament reaches the pelvic wall is also carried upwards in distension of the bladder, and may reach the level of the ductus deferens and of the obliterated umbilical artery.

When the bladder is empty the peritoneum is carried downwards upon the side wall of the pelvis as low as the lateral border of the organ, and lines a shallow depression which receives the name of paravesical fossa. This peritoneal fossa lies below the level of the obturator peritoneal fossa (p. 1269), from which it is separated by the ductus deferens. As the bladder fills, the peritoneum is raised off this part of the pelvic wall, and certain structures, such as the obturator vessels and nerve 
and the ductus deferens, which lie on the lateral wall of the pelvis, come into direct relationship with the lateral aspect of the distended bladder.

Posteriorly the peritoneum leaves thesuperior surface of the empty bladder at its posterior border, and iscarried backwards, forming a kind of horizontal shelf, or fold, for a distance of about half an inch, giving at the same time a partial covering to the ductus deferentes and superior ends of the seminal vesicles. The peritoneum then suddenly dips downwards to

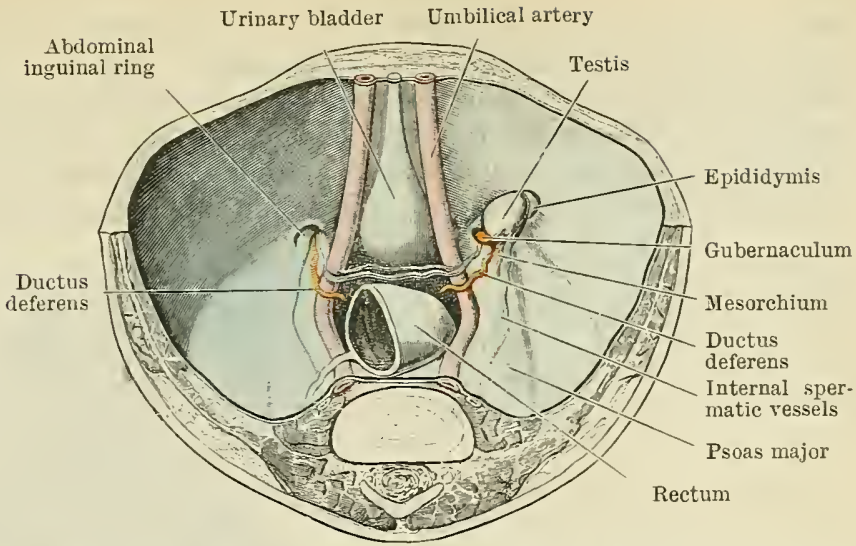

Frg. 999.- VIEW LOOKING FRON ABOVE INTO THE PELTIS AND LoweR Part of the AbDominal Cavity in a Fetus of abott the SEVENTH MoNTH.

On the left side, which represents a slightly more advanced condition than the right, the testis has entered the inguinal canal ; on the right side the testis is still within the abdominal cavity.

reach the bottom of the recto-vesical, or recto-genital, pouch, where it is reflected on to the anterior surface of the rectum (Fig. 1001). As a rule, no part of the

Median umbilical ligament (urachus) Urinary bladder

Plica vesicalis transversa

Paravesical peritoneal fossa

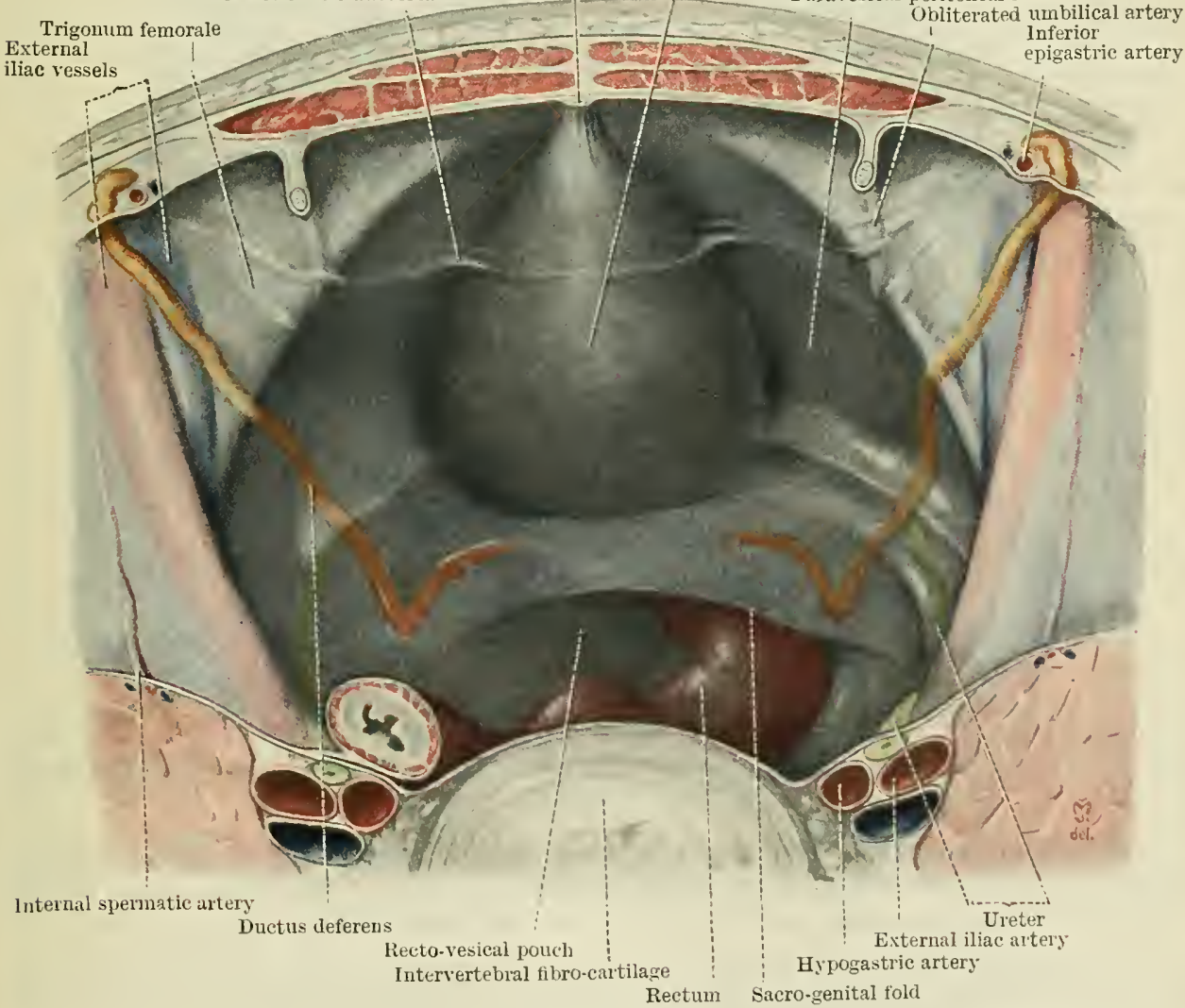

Fig. 1000.-View looking into the Male Peltis from above and somenhat behind.

From a specimen in which the bladder was firmly contracted and contained but a small amount of thid. The paravesical fossa is seen on each side of the blatder. The deep peritoneal ponch in front of the rectum is bounded on eacli side by crescentic sacro-genital folds or "posterior false ligaments of the bladder," which meet together in the median plane some distance behind the posterior border of the bladder. 
basal surface of the contracted and empty bladder receives a covering from the peritoneum, since the seminal vesicles and terminal portions of the ductus deferentes intervene as they lie in the anterior wall of the recto-vesical or rectogenital pouch. When the bladder is distended the posterior border, separating the upper and basal surfaces, is rounded out, and the peritoneum forming the horizontal shelf, just described, is taken up (compare Figs. 989 and 990). It is

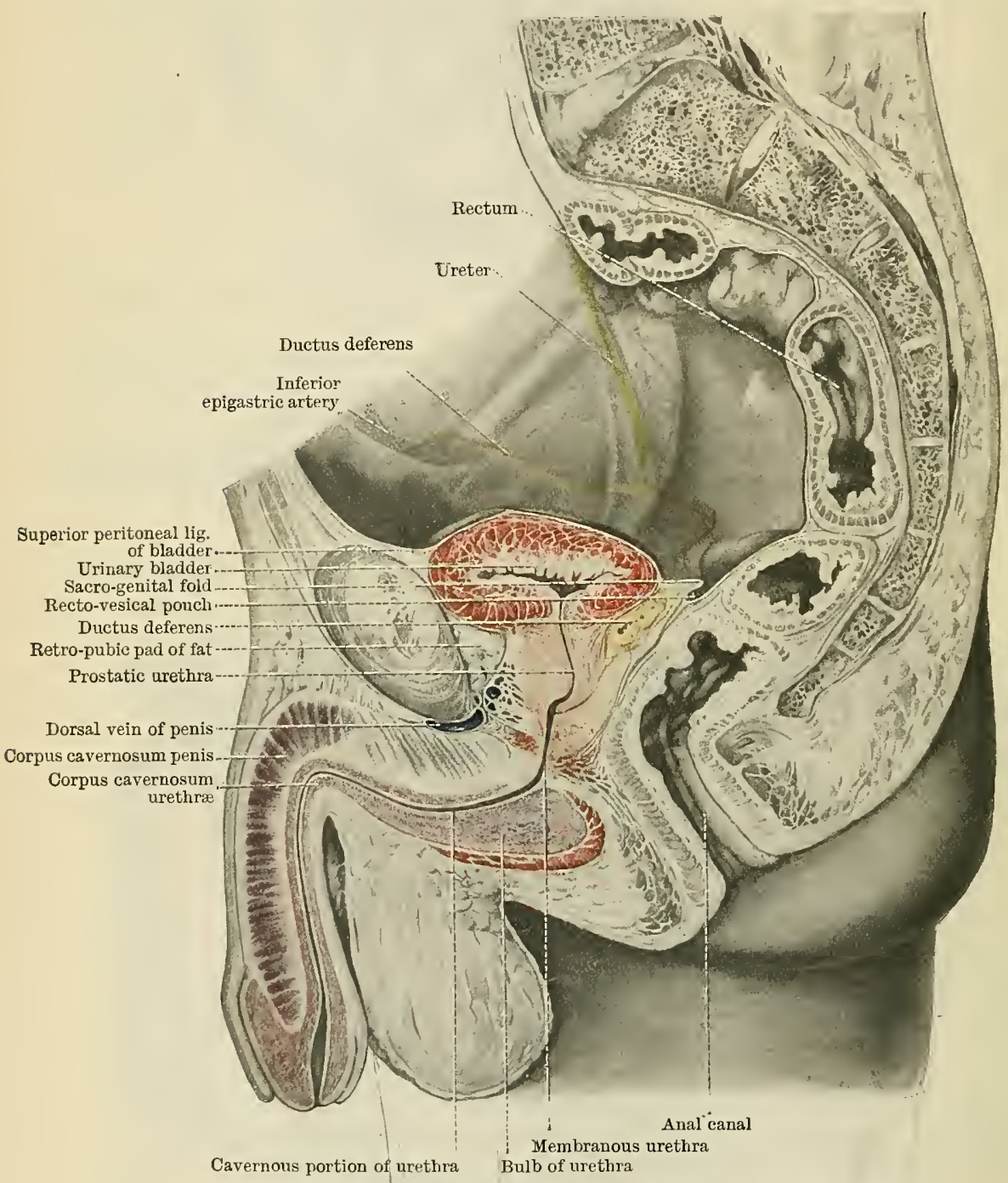

Fig. 1001.- Median Section of the Pelvis in an adult Male.

The coils of small intestine which lay within the pelvis have been lifted out in order to give a view of the lateral wall of the pelvic cavity.

to be specially noted that the level of the peritoneal reflection, forming the bottom of the recto-vesical pouch, does not vary much, as regards its relationship to the prostate, during distension and contraction of the bladder (Figs. 989 and 990).

An examination of median sections of the pelvis shows the great danger run by the ampullæ of the ductus deferentes in any operation for reaching the bladder throngh the anterior wall of the rectum, and the difficulty in avoiding injury to the peritoneum.

The term "posterior false (or peritoneal) ligament" is often applied to the somewhat variable crescentic fold of peritoneum which bounds on each side the entrance to the recto-vesical or recto-genital pouch, and which often unites with 
the fold of the opposite side across the median plane, behind the posterior border of the bladder and the ductus deferentes. These folds represent the plicæ rectouterinæ or folds of Douglas in the female, and are to be regarded as connexions of the ductus deferentes rather than of the bladder; hence the term sacro-genital folds is applicable to these structures in both sexes. The folds are seen in Figs. 990 and 995.

The peritoneum corering the upper surface of the empty or partly distended bladder often exhibits a transversely disposed fold or wrinkle, to which the term plica vesicalis transversa has been applied. This fold, when well developed, can be traced on to the side wall of the pelvis, where it traverses the pararesical fossa, and in some cases it is found to cross the pelvic brim and to be directed towards the abdominal inguinal ring (Fig. 995).

In the female the peritoneum is reflected posteriorly from the upper surface of the bladder on to the anterior aspect of the uterus.

Fixation of the Bladder.-When the ligamentum umbilicale medium, or fibrous cord of the urachus, which binds the bladder apex to the anterior abdominal wall, and the peritoneal folds, already described as the false ligaments, are severed, the bladder is easily moved about, except in its lower and basal parts. Anteriorly it is connected to the pubis, and laterally to the fascial lining of the pelvis by loose areolar tissue only, which permits free movement during expansion and contraction. The lower fixed part of the bladder is chiefly held in place by processes of the pelvic fascia, continuous with those forming the capsule of the prostate. The fascial connexions constitute the true ligaments of the bladder, and are described as pubo-prostatic or anterior ligaments, reaching the bladder from the pubis in front, and lateral ligaments, reaching the bladder from the fascial lining of the side wall of the pelvis.

In addition to the urachus and the peritoneal and the true ligaments already mentioned, the bladder is supported and fixed in position, in the region of its basal surface, by the dense fibrous and unstriped muscular tissue which surrounds the seminal vesicles, the terminal portions of the ductus deferentes and the ureters.

Laterally the strands of connective tissue and the bundles of muscle fibres forming this support pass backwards and are continued into the fascia which surrounds the branches of the hypogastric artery. Muscle fibres connected with the bladder wall are also found within the pubo-prostatic ligaments, through which they are attached to the pubis.

In the female the basal part of the bladder wall is supported and held in place by its connexion with the anterior wall of the ragina. The region of the urethral orifice is the most firmly fixed part of the bladder wall in both sexes.

Structure of the Bladder Wall.-The wall of the bladder from without inwards is composed of a serous, a muscular, a submucous, and a mucous coat. The tunica serosa or serous coat, formed by peritoneum, is incomplete, and covers only the upper and posterior parts of the distended bladder (Fig. 993).

A considerable amount of fibrous connective tissue surrounds the tunica muscularis or muscular coat, and penetrating it, divides it into numerous coarse bundles of muscle fibres. All the muscle fibres are of the unstriped variety, and the bundles which they form are arranged in three very imperfectly separated strata called external, middle, and internal. The stratum externum is for the most part made up of fibres which are directed longitudinally, and it is best marked near the median plane on the upper and under aspects of the bladder. Farther from the median plane, on the sides of the bladder, the fibres composing the external stratum rum more obliquely, and their directions frequently cross one another. In the male, many of the fibres of the external stratum are attached both anteriorly and posteriorly to the prostate, and in the female the corresponding fibres join the dense tissue which in this sex forms the upper part of the wall of the urethra. Other fibres of this stratum on each side of the body join the lower part of the symphysis pubis and constitute the musculus pubovesicalis, which lies in the substance of puboprostatic ligament. Lastly some fibres of the external stratum blend posteriorly with the anterior aspect of the rectum and receive the name of musculus rectovesicalis. The stratum medium is composed of fibres which for the most part rum circularly, and forms the greater part of the thickness of the muscular coat. In the region of, and 
behind, the urethral orifice the bundles of fibres are finer and more densely arranger, and surround the opening in a plane which is directed obliquely downwards and forwards. This part of the middle stratum is often spoken of as the "sphincter vesicæ." Inferiorly the fibres of the sphincter vesicæ are continuous with the muscular tissue of the prostate in the male, and with the muscular wall of the urethra in the female. In other parts of the bladder the bundles of the middle stratum are coarser and separated by intervals filled by connective tissue. The stratum internum is a thin layer of fibres directed for the most part longitudiually.

The tela submucosa or submucous coat is composed of areolar tissue, but contains numerous fine elastic fibres.

The tunica mucosa or mucous coat is loosely attached, by means of the submucous layer, to the subjacent muscular coat, except in the region of the trigonum vesicæ, where the muscular fibres lie close beneath, and are firmly adherent to the mucous membrane. Over the trigonum the mucous coat is always smooth and flat; elsewhere it is thrown into folds when the bladder is empty. The mucous membrane of the bladder is continuous with that of the ureters and urethra. The epithelium, covering it, varies much in appearance in different conditions of the organ, and is of the variety known as transitional stratified epithelium. The appearance of the mucous coat is described on p. 1277 .

Vessels and Nerves of the Bladder.-The bladder receives its blood supply on each side from the superior and inferior vesical arteries. The inferior vesical artery arises from the hypogastric artery, and the superior vesical arises from the umbilical artery just before it becomes obliterated. The largest veins are found just above the prostate, and in the region where the ureter reaches the bladder. They form a dense plexus which pours its blood into tributaries of the hypogastric vein, and communicates below with the pudendal venous plexus.

The lymph-vessels from the bladder join the iliac group of lymph-glands.

The nerve supply of the bladder is derived on each side from the vesical plexus, the fibres of which come from two sources, namely (1) from the upper lumbar nerves through the hypogastric plexus, and (2) from the third and fourth sacral nerves. The fibres from the latter sources join the vesical plexus directly.

\section{THE URETHRA.}

The urethra is the channel which serves to convey the urine from the bladder to the exterior. In the male it consists of two portions, a proximal part, less than one inch in length, extending from the bladder to the points where the ducts of the reproductive glands join the canal, and a much longer distal portion which serves as a common passage for the secretion of the kidneys and for the generative products. An account of the male urethra follows the description of the male reproductive glands and passages (see p. 1304). In the female the urethra is more simple in its arrangement, and represents only the proximal part of the male canal. It is a short passage leading from the bladder to the external urethral orifice-an aperture placed within the rima pudendi or urino-genital cleft, immediately above and in front of the opening of the vagina.

Urethra Muliebris.-The female urethra is a canal of about one to one and a half inches in length which follows a slightly curved direction downwards and forwards, below and behind the lower border of the symphysis pubis. As it leaves the pelvis the urethra pierces the urogenital diaphragm and its fasciæ, and the part of the passage which lies between the superior and inferior layers of fascia is surrounded by the fibres of the sphincter urethræ membranaceæ muscle. Except during the passage of fluid the canal is closed by the apposition of its anterior and posterior walls. The orificium urethræ externum or external orifice is placed between the labia minora, immediately in front of the opening of the vagina, and lies about one inch below and behind the clitoris (Fig. 1002). The opening is slit-like, and is bounded by slightly marked lateral lips. The posterior wall of the urethra, except in its upper part, is very intimately connected with the anterior wall of the vagina. The mucous lining of the canal is raised into a number of slightly marked longitudinal folds, one of which, more distinct than the others, and placed upon the posterior wall of the passage, receives the name of crista urethralis. 
Structure.-The wall of the female urethra is thick and contains much fibrous tissue, which passes without any sharp line of demarkation into the surrounding mass of connective tissue. The tunica muscularis or muscular coat of the urethra is continuous above with that of the bladder, and is composed of layers of circularly and longitudinally disposed smooth muscle fibres arranged to form outer and inner strata. Within the muscular coat the wall of the urethra is very vascular, and the canal itself is lined by a pale mucous membrane which is thrown into longitudinally directed folds, one of which is the crista urethralis mentioned above. The epithelium of the canal, in its upper part, is of the transitional variety, like that of the bladder; in its lower part it becomes scaly. Numerous minute glands, the glandulæ urethrales, and pit-like depressions

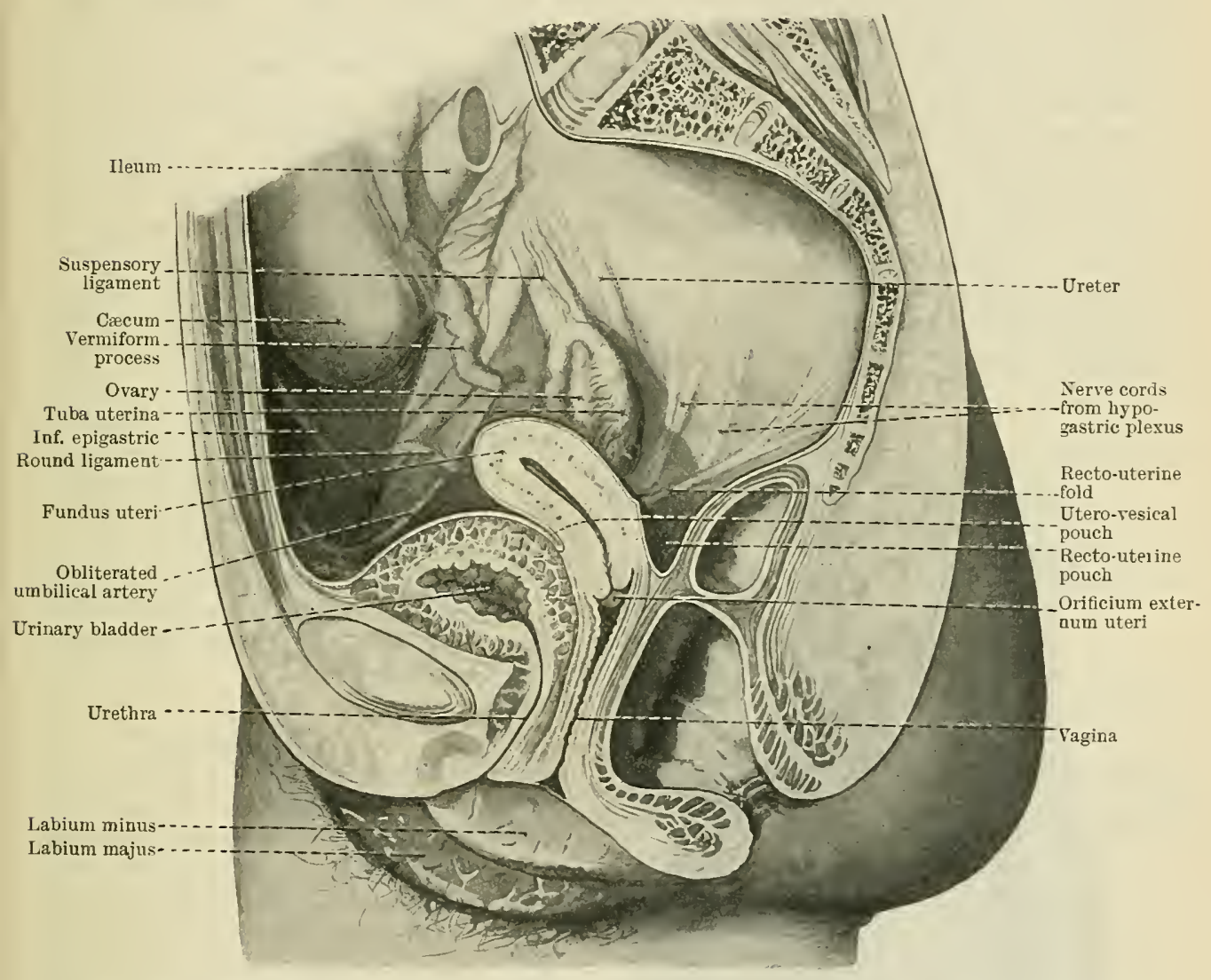

Fig. 1002.-Median Section throdgh the Female Pelvis. Drawn for the most part from a model of a dissection by Professor Edward H. Taylor.

(lacunæ urethrales) open into the urethral canal. One group of these glands on each side possesses a minute common duct known as the ductus paraurethralis, which opens into the rima pudendi or urino-genital cleft by the side of the urethral orifice. It is believed that these latter glands represent the prostatic glands of the male subject. The vascular layer which lies between the muscular coat and the mucous membrane contains elastic fibres, and in appearance resembles erectile tissue. Striped muscle fibres are present on the outer aspect of the muscular coat of the urethra. In the upper part of the canal these fibres form a complete ring-like sphincter, but in the middle and lower parts the striped muscle fibres though present in front are absent on the posterior wall of the urethra, as at this level they pass backwards on the outer aspect of the ragina, and enclose this latter passage together with the urethra in a single loop of muscle tissue. The lower fibres, therefore, form a urino-genital sphincter. 


\section{THE MALE REPRODUCTIVE ORGANS.}

We have here to describe (1) the testes or essential reproductive glands of the male, together with their (2) coverings and (3) ducts, (4) the prostate, (5) the bulbourethral glands, (6) the external genital organs, and (7) the male urethra.

The reproductive glands of the male, or testes, are a pair of nearly symmetrical oval-shaped bodies situated in the scrotum. The duct of each gland, at first much twisted and intertwined, forms a structure known as the epididymis, which is applied against the posterior and lateral part of the testis. From the epididymis the excretory duct, or ductus deferens, passes upwards towards the inferior part of the anterior abdominal wall, which it pierces very obliquely, to enter the abdominal cavity. Here each ductus deferens is covered by the peritoneum, and almost at once crossing the pelvic brim, enters the pelvis. The duct now runs on the lateral wall of the pelvis towards the base of the bladder, where it comes into relation with a branched tubular structure termed the vesicula seminalis. Joined by the duct of the vesicula seminalis, the ductus deferens forms a short canal called the ejaculatory duct, which terminates by opening into the prostatic part of the urethra. The prostate, a partly glandular, partly muscular structure, surrounding the first part of the urethra, and also a pair of small glandular bodies called the bulbo-urethral glands, are accessory organs connected with the male

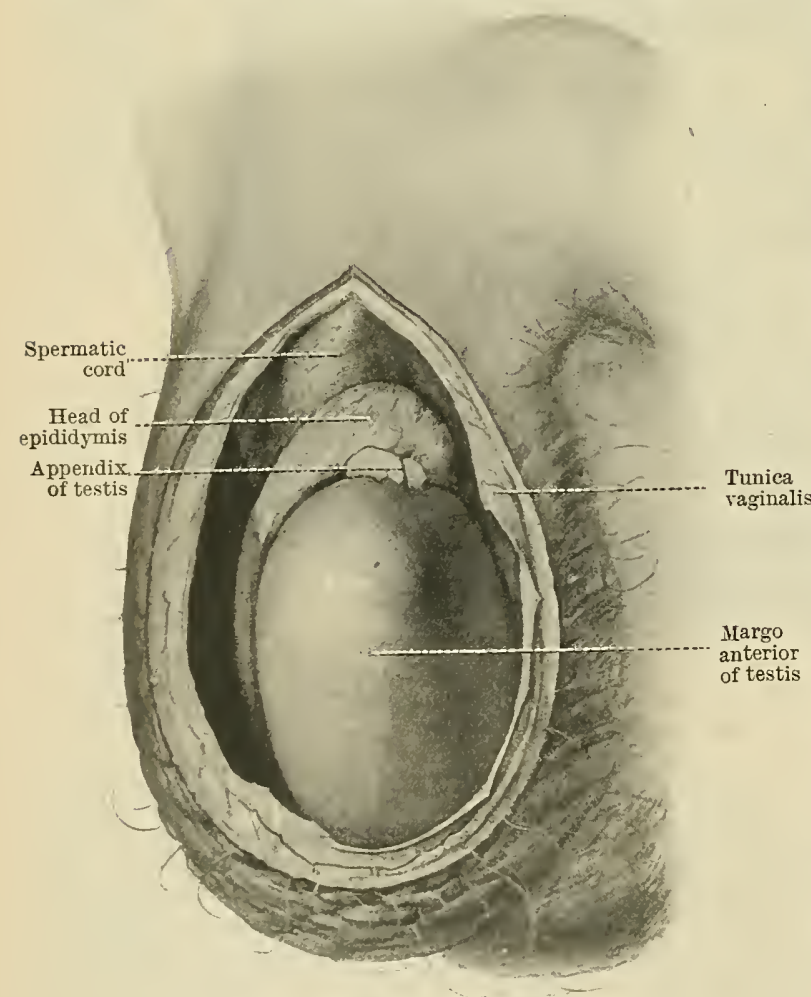

Fig. 1003.-Right Testis AND EPIDidyais, Exposed by the Remotal of the ANTerior Wall of the Scrotum. reproductive system. The ducts of the bulbo-urethral glands and those of the prostate, like the ejaculatory ducts, open into the urethra, which thus serves not only as a passage for urine, but also for the generative products. The external genitals are the penis and scrotum.

\section{THE TESTIS.}

The male reproductive glands, the testes, are a pair of somewhat oval, slightly flattened bodies of a whitish colour, measuring about an inch and a half in length, one inch from before backwards, and rather less in thickness. Each testis is placed within the cavity of the scrotum in such a manner that its long axis is directed upwards, slightly forwards, and laterally, and usually the left gland occupies a lower level than the right. The testis (Fig. 1003) has two somewhat flattened surfaces, one of which, called the facies lateralis, or lateral surface, looks backwards as well as laterally; the other, the facies medialis, or medial surface, looks forwards as well as medially, and is usually the more flattened. The two surfaces are separated by two rounded borders, one of which, the margo anterior, is the more convex and free; while the other, the margo posterior, is less rounded, and by it the organ is suspended within the scrotum. The epididymis and the lowest portion of the funiculus spermaticus, or spermatic cord, are 
attached to the posterior border of the testis. Each border ends above in the superior extremity, and below in the inferior extremity of the testis. Owing to an obliquity of the long axis of the gland, the superior extremity of the testis lies on an anterior and lateral plane to the inferior.

Epididymis. - The epididymis is a somewhat crescentic structure, which is curved round the posterior border of the testis and overlaps to some extent the posterior part of the lateral surface of that organ. The superior, somewhat swollen part of the epididymis, is called the caput epididymidis or head, and overhangs the superior end of the testis, to which it is directly connected by numerous emerging ducts, by connective tissue, and by the serous covering of the organ. The inferior and smaller end is termed the cauda epididymidis or tail, and is attached by loose areolar tissue and by the serous covering to the inferior end of the testis. The intermediate part, the body, or corpus epididymidis, is applied against, but is separated from, the posterior part of the lateral surface of the testis by an involution of the serous covering of the organ, which forms an intervening pocket termed the sinus epididymidis (O.T. digital fossa).

The main mass of the epididymis is composed of an irregularly twisted canal, the ductus epididymidis, which forms the first part of the duct of the testis.

Minute sessile, or pedunculated, bodies are often found attached to the head of the epididymis or to the superior end of the testis. These are called appendices of the epididymis and testis (O.T. hydatids of Morgagni), and have a developmental interest. The minute body which lies on the superior end of the testis represents the free end of Müller's duct in the embryo and the fimbriated end of the uterine tube of the female ; it is usually sessile. Above the head of the epididymis, and in front of the lower part of the spermatic cord, there may also be present a small rudimentary body called the paradidymis. This is rarely seen in the adult, and is best marked in young children.

Tunica Vaginalis.-The cavity within which the testis and epididymis are placed is lined by a smooth serous membrane-the tunica vaginalis - which resembles in appearance and structure the peritoneum from which it is originally derived. The cavity is considerably larger than the contained structures, and extends not only down to a lower level than the testis, but also reaches upwards to a higher level than the gland. The sac, or cavity, tapers as it is traced upwards, and above the level of the testis the funiculus spermaticus or spermatic cord bulges forwards into its posterior part. The tunica vaginalis lines the cavity for the testis, and is reflected from the posterior wall of the scrotal chamber over the testis and epididymis, giving a covering to each. The part of the membrane lining the cavity is called the lamina parietalis or parietal portion of the tunica vaginalis, while the part clothing the testis and epididymis is termed the lamina visceralis or visceral portion. Between the lateral surface of the testis and the body of the

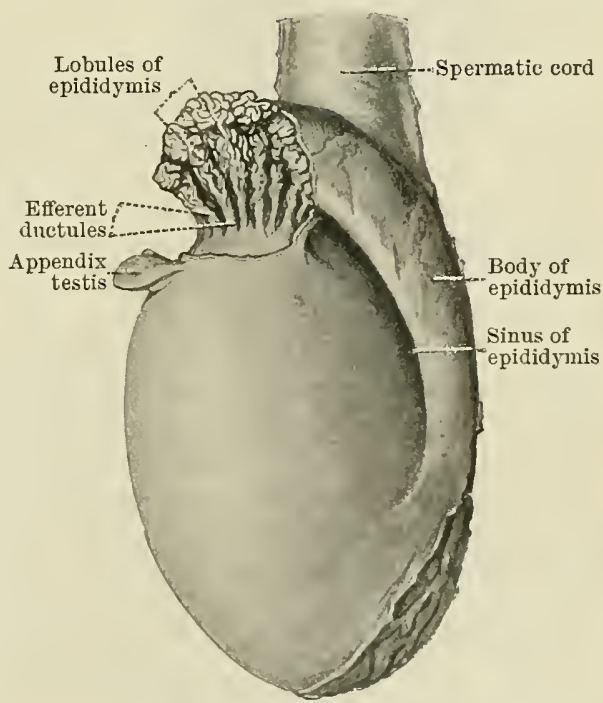

Fig. 1004.-Left Testis ANd Epididyuis.

A part of the tunica vaginalis has been removed in order to show the ductuli etferentes and lobuli epididymidis. epididymis, the visceral part of the tunica vaginalis dips in and lines a narrow interval called the sinus epididymidis (O.T. digital fossa). The entrance to the sinus is limited above and below by short crescentic folds of the tunica vaginalis, which pass from the testis to the head and tail of the epididymis. These folds are spoken of as the superior and inferior ligaments of the epididymis. In three positions the surface of the testis receives no covering from the tunica vaginalis-superiorly 
where the globus major is attached, inferiorly where the cauda epididymidis is in contact, and posteriorly where the blood-vessels and nerves enter the organ from the funiculus spermaticus or spermatic cord.

Structure of the Testis and Epididymis.-Beneath the serous tunica vaginalis the testis is invested by an external coat, composed of dense white inelastic fibrous tissue called the tunica albuginea, from the deep surface of which a number of slender fibrous bands or septa dip into the gland. These-the septula testis-imperfectly divide the organ into a number of wedge-shaped parts called lobuli testis (Fig. 1005). All the septa end posteriorly in a mass of fibrous tissue which is

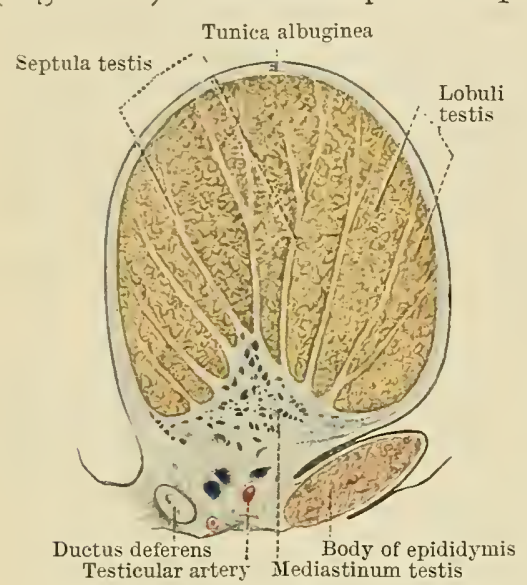

Fig. 1005.-TRANSVERSE SECtion OF THE TEsTIS AND EPIDIDYMIS. directly continuous with the tunica albuginea, and which projects forwards into the testis along its posterior border. This structure receives the name of mediastinum testis, or corpus Highmori, and is traversed by an exceedingly complicated network of fine canals, into which the minute tubules which compose the substance proper of the testis open. The mediastinum is also pierced by the arteries, veins, and lymph vessels of the testis. These vessels enter the posterior border of the organ, and traversing the mediastinum, spread out on the fibrous septa which radiate towards all parts of the deep surface of the tunica albuginea. In this way a delicate network of vessels (tunica vasculosa) is formed on the deep surface of the tunica albuginea and on the sides of the septa.

The mediastinum, the septa, and the tunica albuginea form a framework enclosing a number of imperfectly isolated spaces which are filled by a loosely packed substance of a light brown colour called the parenchyma testis.

The parenchyma is composed of enormous numbers of much-convoluted seminiferous tubules, called tubuli seminiferi contorti, and completely fills up the intervals between the septa. The minute tubules look like fine threads to the unaided eye, and are but loosely held together by a small amount of connective tissue. Usually three or four tubules are found in each lobule of the gland, and the total number in the testis has been estimated at about 600 . The seminiferous tubules, after a course of about two feet in length, pass towards the mediastinum testis and unite at acute angles, to form a smaller number of slender tubes which run a straight course. These latter are called tubuli seminiferi recti, and open into a complicated network of fine canals situated in the substance of the mediastinum, called the rete testis. The tubules are much more twisted and convoluted in the cortical part of the gland, near the tunica vaginalis, than in the region of the mediastinum, and often give off side branches which, according to some observers, may effect anastomoses between the tubules. It appears doubtful, however, if the seminiferous tubules of the testis do really anastomose.

Microscopic sections show that the walls of the seminiferous tubules are composed of a basement membrane and of an epithelial lining, formed of several layers of cells. Certain cells of this epithelium are, in the adult, constantly undergoing transformation into spermatozoa, and the appearance of the tubules in section varies much, according to age and to the greater or less activity of the epithelial cells.

The secretion of the seminiferous tubules is carried through the tubuli seminiferi recti into the rete testis, and leaves the latter, to reach the canal of the epididymis, through from fifteen to twenty minute tubules called ductuli efferentes testis or efferent ductules. These latter pierce the tunica albuginea and enter the caput epididymidis where it is in direct contact with the superior extremity of the testis. Each efferent ductule is at first straight, but soon becomes much convoluted, and forms a little conical mass of twisted tubule, called 
a lobule of the epididymis (O.T. conus vasculosus). . Within the head of the epididymis the little canals finally open into the single much-convoluted tube which constitutes the chief bulk of the epididymis, and is called the duct of the epididymis. This canal, which is not less than 19 or 20 feet in length, may be said to begin in the head of the epididymis, and to end, after an extraordinarily tortuous course, at the tail by becoming the ductus deferens (Fig. 1006).

In most cases one or more slender convoluted diverticula from the duct of the epididymis may be found near its lower end. These receive the name of ductuli aberrantes, and one of them which is very constantly present often measures a foot or more in length.

Minute Structure.-The duct of the epididymis and the efferent ductules are lined by a ciliated epithelium, the cilia of which maintain a constant current towards the ductus deferens. The duct of the epididymis possesses a muscular coat composed of an inner stratum of transversely and an outer stratum of longitudinally directed fibres. The wall, at first thin, becomes much thicker as the ductus epididymidis approaches the ductus deferens.

Vessels and Nerves of the Testis.-The testis is supplied by the internal spermatic artery, a branch of the aorta. This slender vessel, after

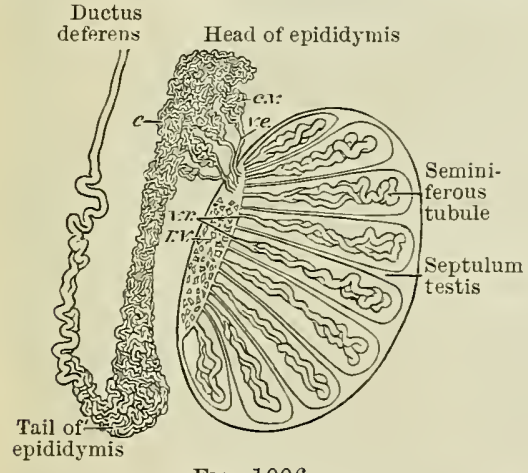

F1G. 1006.

DIAGRaM to illustrate the structure of the testis and epididymis. $\begin{array}{ll}\text { c. Duct of epididymis, } & \text { v.e. Ductuli efferentes testis. } \\ \text { c.v. Lobuli of epididymis. } & v . r . \text { Tubuli seminiferi recti. }\end{array}$ r.t. Rete testis.

a long course, reaches the posterior border of the testis, where it breaks up into branches which enter the mediastinum testis, and are distributed along the septa and on the deep surface of the tunica albuginea.

The veins issuing from the posterior border of the testis form a dense plexus, called the plexus pampiniformis, which finally pours its blood through the spermatic vein, on the right side, into the inferior vena cava; on the left side the spermatic vein joins the left renal vein.

The nerves for the testis accompany the internal spermatic artery, and are derived through the aortic and renal plexuses from the tenth thoracic segment of the spinal medulla. The afferent fibres from the epididymis appear to reach the spinal medulla through the posterior roots of the eleventh and twelfth thoracic and first lumbar nerres. The arteries and nerves of the testis communicate with those on the lower part of the ductus deferens, namely, with the artery of the ductus deferens and with twigs from the hypogastric plexus.

The lymph-vessels of the testis pass upwards in the spermatic cord, and end in the lumbar lymph-glands.

\section{DUCTUS DEFERENS.}

The ductus deferens (O.T. vas deferens) is the direct continuation of the duct of the epididymis. Beginning at the inferior extremity of the epididymis, it ends, after a course of nearly 18 inches, by opening as the ejaculatory duct into the prostatic or first part of the urethra. The duct in parts of its course is somewhat convoluted, and the actual distance traversed by it is not more than 12 inches. Placed in the first instance outside the abdominal cavity, the ductus deferens ascends 
within the scrotum towards the lower part of the anterior abdominal wall, which it reaches not far from the median plane. During this part of its course the duct, together with the ressels and nerves of the testis, is surrounded by a number of loose coverings derived from certain layers of the abdominal wall, and the cord-like structure so formed is termed the funiculus spermaticus or spermatic cord. The ductus deferens, together with the accompanying vessels and nerves, now passes through the abdominal wall in an oblique passage, to which the name canalis inguinalis is applied. Within the abdomen the duct lies immediately beneath the peritoneum, and soon crossing over the pelvic brim, it enters the pelvis, on the side wall of which it proceeds backwards towards the base of the bladder. Here, near the median plane, the ductus deferens is joined by the duct of the correspond-

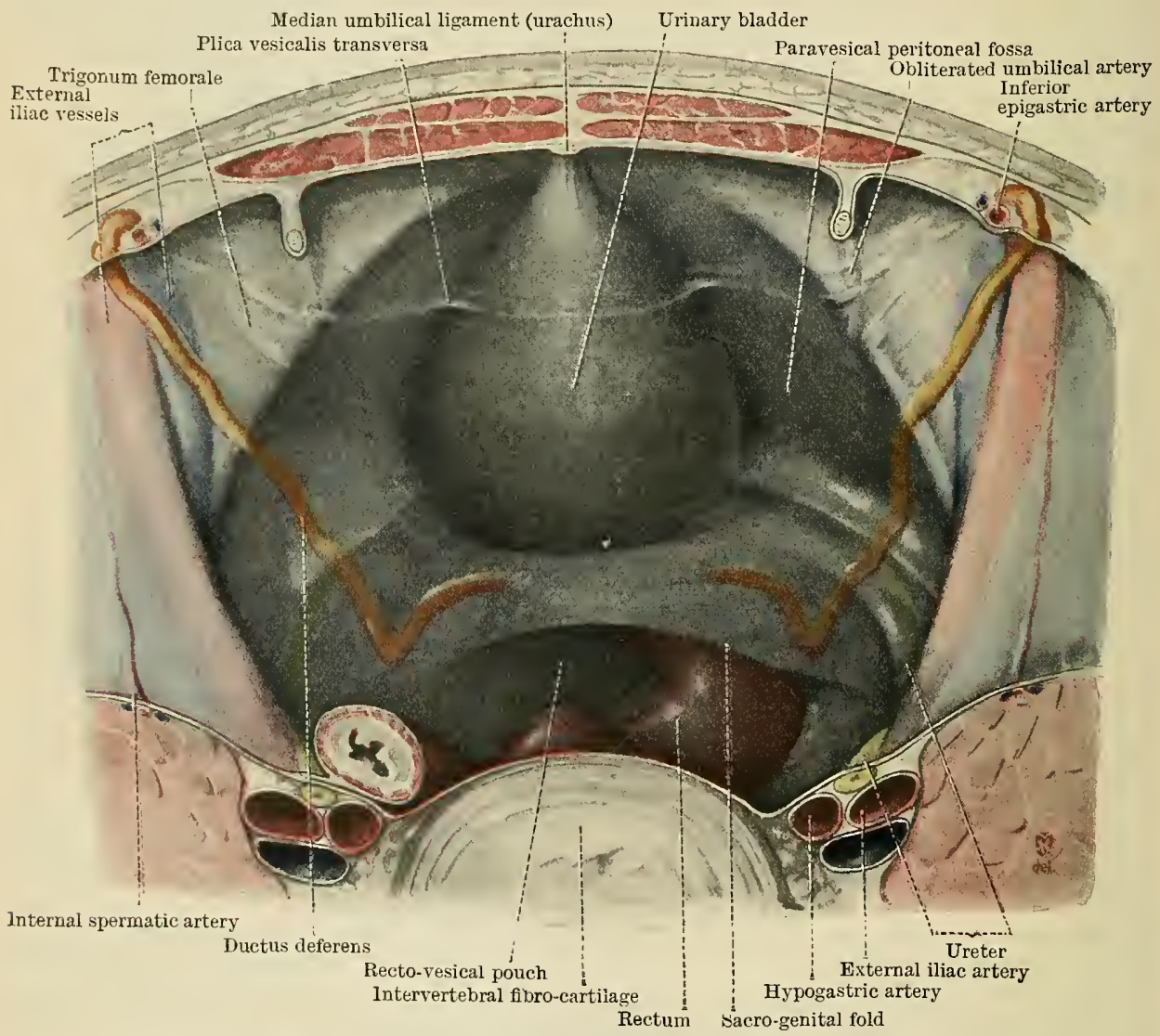

Fig. 1008.-View of the Male Pelvis seen from above and Behind. The course of the ductus deferens is well seen.

ing vesicula seminalis, and the ejaculatory duct, thus formed, having traversed the prostate, opens into the urethra.

At first the ductus deferens, like the canal from which it takes its origin, is very tortuous, but soon increasing in thickness, the duct becomes less twisted, and passes upwards along the medial side of the epididymis, behind the testis, to enter the spermatic funiculus (Fig. 1007). Its course is now almost vertically upwards towards the pubic tubercle, near which, crossing the medial part of the inguinal ligament [Pouparti], the duct enters the inguinal canal by the subcutaneous inguinal ring (Fig. 1017). Of the structures composing the funiculus spermaticus the duct is the most posterior, and it can be readily distinguished, even in the undissected subject, by its hard firm feel, when it is taken between the finger and thumb. In the inguinal canal the ductus deferens is directed outwards, upwards, and a little backwards to the abdominal inguinal ring, where, at a point half an inch above the inguinal ligament, and midway between the symphysis pubis and the anterior 
superior iliac spine, it enters the abdomen. The distance between the point where the cord enters the inguinal canal to the point where it leaves it to enter the abdomen is about one and a half inches. While passing from the subcutaneous to the abdominal inguinal ring the ductus deferens, together with the other structures of the funiculus spermaticus, rests upon the upper grooved surface of the inguinal ligament, and is placed behind the aponeurosis of the external oblique and some of the lower fibres of the internal oblique muscle. From before backwards the duct rests, in the first instance, upon the falx aponeurotica or conjoined tendon of the internal oblique and transversus abdominis muscles, and farther laterally upon the fascia transversalis. Above the funiculus are some arching fibres of the internal oblique muscle, which enter the falx. As the ductus deferens leaves the inguinal canal by the abdominal inguinal ring, it turns round the inferior

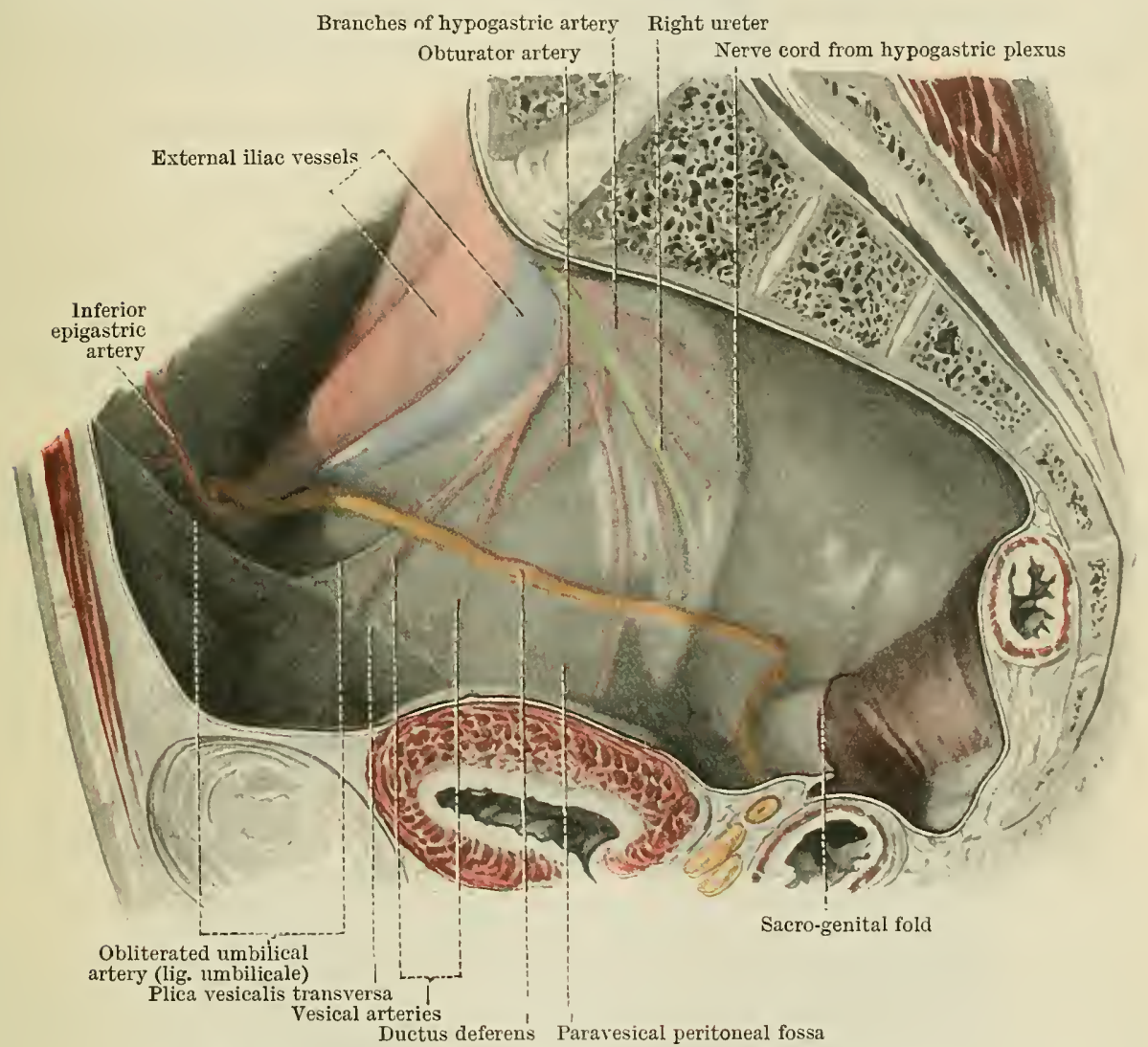

Fig. 1009.- Median Section of the Pelvis in an Adult Male.

The coils of small intestine and colon which lay within the pelvis have been lifted out in order to give a view of the side wall of the pelvic cavity.

epigastric artery on its lateral and posterior aspect. Completely changing the direction of its course, the duct now runs for a short distance backwards, medially, and upwards, beneath the peritoneum, to a point one and a half to two inches from the pubic tubercle, where it crosses the ilio-pectineal line and enters the pelvis. In this part of its course the duct usmally lies at first in front of the external iliac vessels, and then in the floor of a little triangular fossa, the trigonum femorale, between these vessels and the pelvic brim (Fig. 1009). On the lateral wall of the pelvis the ductus deferens is continued backwards, and a little downwards and medially, in the direction of the ischial spine, and lies immediately beneath the peritoneum, through which it can usually be seen shining. In the pelvic part of its course the ductus deferens crosses on the medial side of (1) the obliterated part of the umbilical artery, (2) the obturator nerve and vessels, (3) the vesical vessels, and (4) the ureter (Fig. 1009). 
Beyond the ureter the duct takes a somewhat sudden bend, and passes downwards and medially towards the median plane, beneath the peritoneum of the pelvic floor. Reaching the interval between the base of the bladder in front and the rectum behind, the ducts of opposite sides occupy the angle formed between the vesiculie seminales (Fig. 1012). As they approach one another each duct becomes somewhat tortuous, sacculated, and dilated, and assumes a general resemblance in structure to a portion of the seminal vesicle. This dilated part of the ductus deferens is termed the ampulla ductus deferentis. As it turns medially the duct lies a short distance behind the ureter, and immediately in front of the free edge of the peritoneal fold (sacro-genital) which bounds the recto-vesical or recto-genital pouch of the peritoneum. Just above the base of the prostate the ductus deferens becomes once more a narrow canal, and in this position it is joined by the duct of the corresponding seminal vesicle to form the ductus ejaculatorius, which, after a short course downwards, forwards, and medially through the prostate, opens into the urethra.

In some cases the ductus deferens crosses the obliterated umbilical artery before it enters the pelvic cavity; it normally does so in the fœtus.

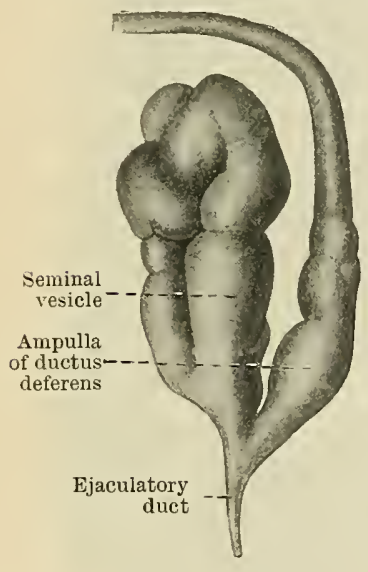

A

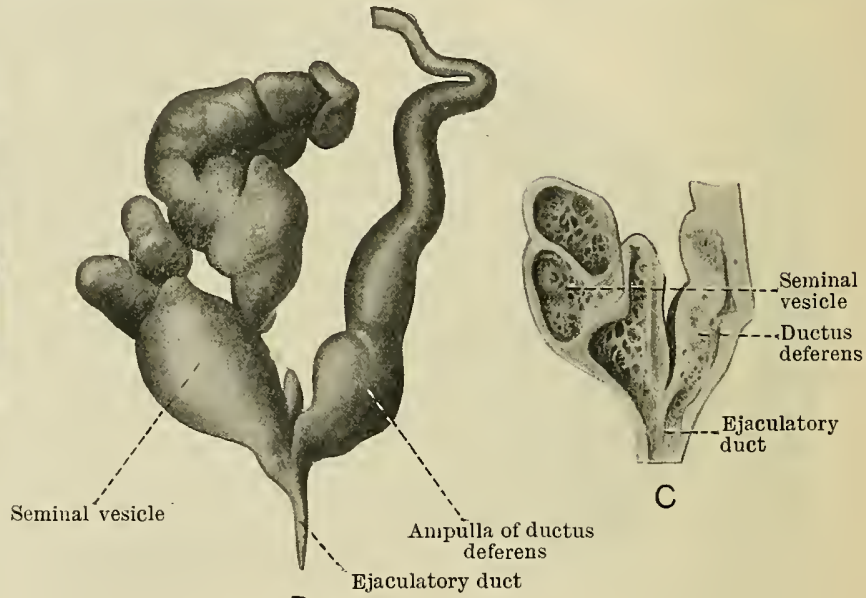

B

FIG. 1010.

$A$ and B. Drawings illustrating the seminal vesicle and the ampulla of the ductus deferens taken from two different subjects.

C. The seminal vesicle and ductus deferens have been cut into to show the pitted structure of their walls.

Ductus Ejaculatorius (O.T. common ejaculatory duct).-The ejaculatory duct is a very slender canal, formed by the union of the ductus deferens with the duct of the corresponding seminal vesicle. It is less than one inch in length, and lies very close to its fellow of the opposite side as it passes through the prostate behind its median lobe. The ducts open by slit-like apertures into the first part of the urethra, one on each side of the utriculus prostaticus. They are well seen in sections through the upper part of the prostate (Fig. 1011).

The mucous membrane of the duct is thrown into numerous complicated folds, and in connexion with it are a number of remarkable minute diverticula, which are enclosed within the muscular coat of the duct.

Vesiculæ Seminales.-The seminal vesicles are a pair of hollow sacculated structures placed in front of the rectum and behind the bladder (Fig. 1012). Each vesicle is usually about two inches in length, and has its long axis directed downwards, medially, and somewhat forwards. The superior extremity of the vesicle, which is partly covered by peritoneum, is large and rounded, and lies at a considerable distance from the median plane, behind the inferior end of the ureter. The peritoneum of the recto-vesical or recto-genital pouch separates the upper end of the seminal vesicle from the rectum; below the peritoneal cavity the vesicle 
and rectum are more intimately related. The vesicle tapers towards its inferior end, which is placed close to the median plane and immediately above the prostate. Inferiorly, the vesicle becomes constricted to form a short duct, the ductus excretorius, which joins the lateral side of the corresponding ductus deferens at an acute angle to form the ejaculatory duct. The medial side of each vesicle is related to the ductus deferens, and the lateral side, when the bladder is empty, lies close to the sloping pelvic floor. The seminal vesicle often assumes a more vertical position when the bladder is distended; amore horizontal direction when the bladder is empty. Its superior end

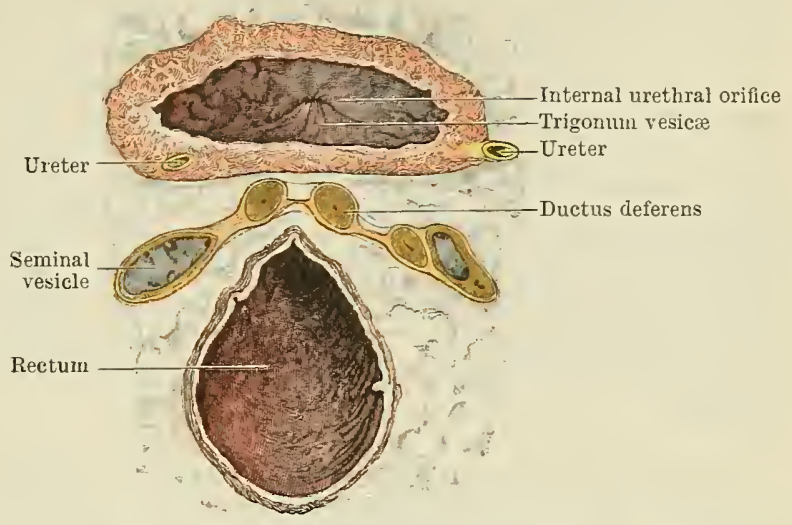

Fig. 1011. - Horizontal Section throdgh the Rectum aNd URINARY BLADDER aT THE LeVEL at Which the URETERS PIERCE THE BLADDER WALL.

From a specimen in the Surgical Museum, Trinity College, Dublin. is sometimes found to be curved backwards against the side of the rectum. In

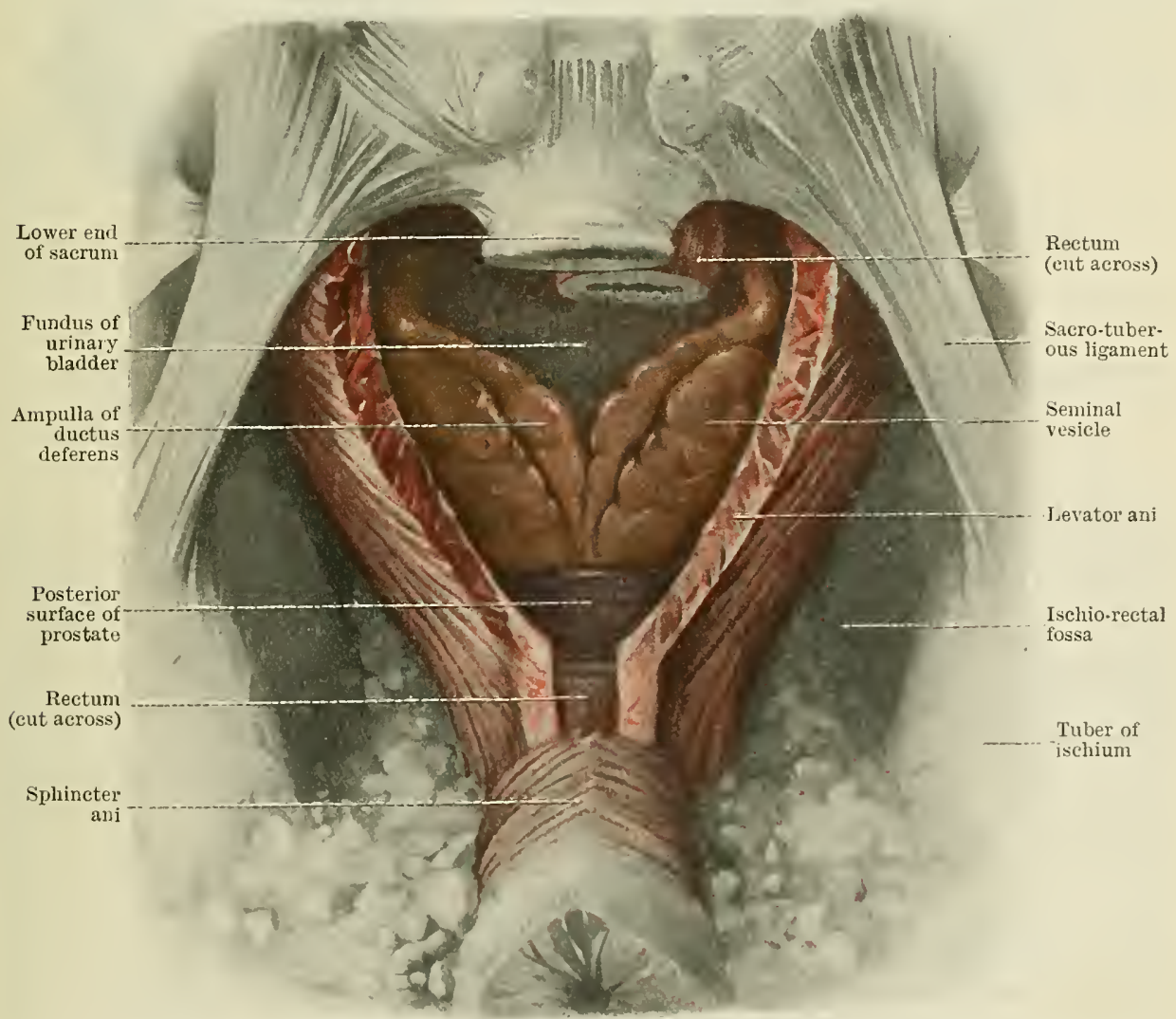

Fig. 1012. - Dissection to display the Posterior Aspect of the Vesicula Seminales, the Aupullat of the Ductes Deferentes, and the Prostate. The coccyx and portions of the levatores ani have been removed, also a considerable portion of the rectum.

some cases the seminal vesicles are much smaller than usual, and may be less than one inch in length. Frequently they are asymmetrical as regards size and 
shape. The seminal vesicles are more intimately related to the wall of the bladder than to that of the rectum. Their superior ends are, as we have seen, separated from the rectum by a portion of the recto-vesical pouch of peritoneum, and lower down the septum of fascia which intervenes between the vesicula seminales and the rectum is denser than that which separates them from the bladder.

Each resicula seminalis is in reality a tube bent in a tortuous manner on itself, and if the dense connectire tissue which envelops it be taken away, the length of the tube when untwisted may be found to be as much as five inches. The tube is closed above, and a rariable number of short tortuous branches come off it at different levels. The blind end of the tube usually lies at the superior and lateral extremity of the seminal vesicle, but in some cases the tubular vesicle is so bent upon itself that the blind terminal part lies against the side of the issuing duct. The derelopment of the resiculæe seminales shows that they are to be regarded as diverticula of the ductus deferentes, from which they originally arise as small pouches.

The dense tissue in which the seminal resicles are embedded contains much unstriped muscle tissue, which sweeps round in the side wall of the recto-resical ponch. Inferiorly this tissue is attached to the capsule of the prostate. The large reins coming from the prostatic and vesical plexuses are closely related to the seminal resicles.

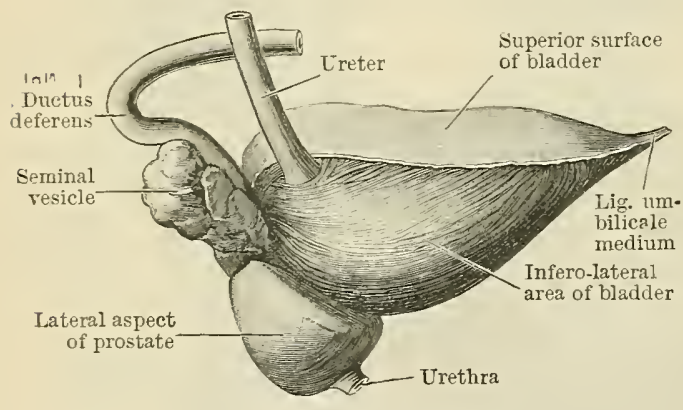

A

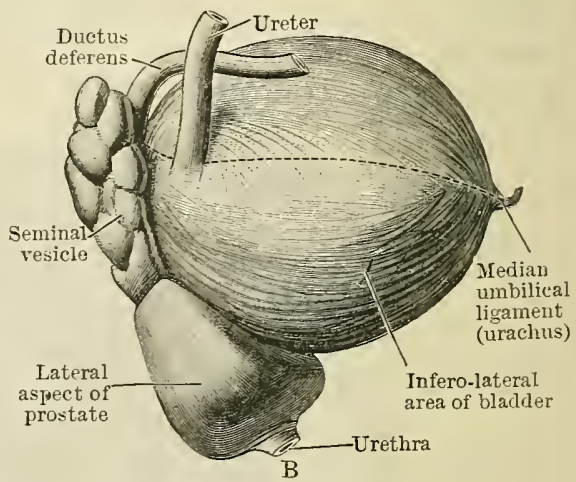

Fig. 1013. - The Urivart Bladder, Prostate, and Seminal Vesicle riewed from the side. Drawn from specimens hardened in situ.

In A the bladder contained but a small amount of tluid; in B the quantity was somewhat greater.

\section{Structure of the Ductus Deferens and of the Vesicula Seminalis.-} Except near its termination, where it is dilated to form the ampulla, the ductus deferens is a thick-walled tube with relatively a rery small lumen. The hard cord-like sensation which the ductus deferens conveys to the touch is due to the thickuess and toughness of its wall, which is composed of three layers-an outer fibrous tunica adventitia, an intermediate tunica muscularis, and an inner tunica mucosa. The thickness of the wall is due to the great development of the middle or muscular coat, which is composed of an intermediate layer of circularly and an inner and outer layer of longitudinally directed unstriped muscular fibres. Of these layers the middle one is by far the thickest, and forms the chief part of the thickness of the wall of the ductus deferens. The mucous membrane of the duct exhibits a number of slight longitudinal folds and possesses a ciliated epithelium. The ampulla, or terminal part, possesses a much thinner wall, and, as the surface of its mucous membrane has a number of ridges separating depressed areas, the lining of this part of the tube presents a pitted or honeycombed appearance. The wall of the vesicula seminalis resembles that of the ampulla in being thin, and in haring a mucous lining with meven honeycomb-like ridges and depressions. In it the same coats are to be recognised as in the ductus deferens, but the muscular layer is much thinner, and the strata composing it less regularly arranged.

The seminal resicles are not present in all mammals, and in those in which they do occur their relative size and form vary much. Among the carnivora, marsupials, and some other groups of mamnals, the seminal resicles do not occur ; in some other animals, snch, for instance, as the hedgehog, they are relatively of enormons size. 
Vessels and Nerves of the Ductus Deferens and of the Vesicula Seminalis. -The ductus deferens receives its arterial supply from the superior or inferior vesical artery. The artery to the duct accompanies that structure, supplying it as far as the testis, where it ends by anastomosing with branches of the internal spermatic artery. The vesicula seminalis is supplied by the inferior vesical artery. The nerves of the ductus deferens and vesicula seminalis are derived from the hypogastric plexus. In lower animals the nerves for the seminal vesicles are derived from the nerve roots of the second, third, and fourth lumbar nerves.

\section{Descent of the Testis.}

The peculiar course pursued by the ductus deferens in the adult, and the manner in which it is related to the anterior abdominal wall, are rendered clear by a study of the arrangement of the parts in the fœtus. The testes until nearly the end of intra-uterine life are placed in the abdominal carity. Lying at first on the posterior wall of the abdomen at the level of the upper two lumbar vertebræ, and just below the level assumed at this time by the permanent kiduey, the testis is held in place by a fold of peritoneum or mesentery, called the mesorchium. As growth goes on the testis is found to occupy a lower level in the abdominal cavity; in the third month it lies in the iliac fossa, and in the seventh it is situated near the abdominal inguinal ring. Meauwhile a blind pouch or diverticulum of the peritoneal membrane, termed the processus vaginalis peritonæi, has grown downwards and inwards through the anterior abdominal wall towards the scrotum, deriving as it goes a covering from each of the layers of the abdominal wall through which it passes. The testis with its mesorchium enters the diverticulum of the $a b$ dominal cavity, and descends within it until the scrotum is reached. At a later stage, the connexion between the part of the processus vaginalis that lies

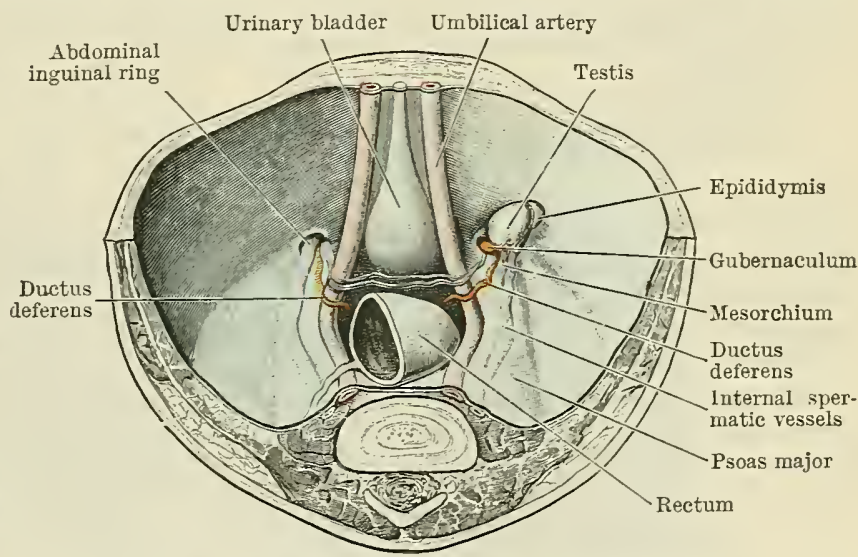

Fig. 1014.-View looking from above nNto the Pelvis and Lower Part of the Abdominal Cavity in a Fotus of abott the SEVENTH MONTH.

On the left side, which represents a slightly more advanced condition than the right, the testis has entered the inguinal canal; on the right side the testis is still within the abdominal carity.

in the scrotum and the peritoneal lining of the abdomen becomes lost by the obliteration of the upper part of the pouch. Thus the part of the processus vaginalis that persists in the scrotum becomes the parietal portion of the tunica vaginalis; while the visceral part of that membrane is the primitive peritoneal covering of the testis and epididymis (Figs. 1014 and 1015).

Often a small fibrous band-the "ligamentum vaginale"-may be found in the adult passing through the inguinal canal and joining the peritoneum superiorly in the region of the abdominal inguinal ring. Sometimes this band is connected below with the tunica vaginalis, but more often it does not reach so far downwards. When present it represents the obliterated portion of the processus vaginalis, and is therefore known as the rudimentum processus vaginalis.

In other rare cases the processus vaginalis may persist after birth as a channel freely open to the abdominal cavity above, or the passage, becoming closed at intervals, may give rise to one or more cysts within the coverings of the spermatic cord.

It sometimes happens that the descent of the testis is arrested, and then, either failing to enter the processus vaginalis, the testis remains withiu the abdominal carity; or entering the processus vaginalis, it fails to reach the scrotum, and lies in the inguinal canal. The term "cryptorchism" is frequently applied to such cases.

In connexion with the descent of the testis a remarkable cord-like structure-the gubernaculum testis [Hunteri] - must be mentioned. The gubernaculum arises for the most part within a peritoneal fold which, at an early time in the derelopment of the foetus, may be seen stretching from the inguinal region to the Wolffian duct (future duct of the testis) and inferior end of the mesonephros or primitive kidney. This peritoneal 
fold, termed the plica inguinalis (or plica inguino-mesonephrica), is joined from above by a less marked fold (the plica testis inferior) which extends downwards from the inferior end of the testis, which, at this time, is situated in the abdomen close to the inner aspect of the mesonephros. Within both these folds smooth muscular and fibrous tissue arises and gives origin to a continuous band, or ligament-the gubernaculum testis. The gubernaculum is, therefore, to be regarded as originally composed of two portions - a part developed within the plica inguinalis, and a part formed within the plica testis inferior. It is interesting to note that in the female the representatives of these two parts
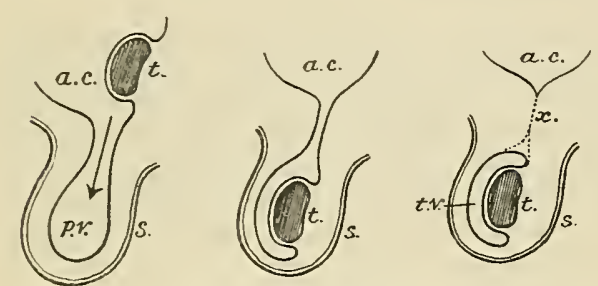

Fig. 1015.-Diagran to illustrate the descent of the testis and the manner in which the tunica vaginalis is derived.

a.c. Abdominal cavity. p.v. Processus vaginalis. t. Testis.

$$
\begin{aligned}
& \text { s. Scrotumu. } \\
& t . v \text { Tunica vaginalis. } \\
& x . \quad \begin{array}{l}
\text { Rudimentum pro- } \\
\text { cessus vaginalis. }
\end{array}
\end{aligned}
$$
of the gubernaculum remain separate throughout life, and constitute the round ligament of the uterus and the ligament of the ovary. The gubernaculum, when it is at its greatest development (about the sixth month), is rounded and cord-like, and is attached above to the lower end of the testis, while inferiorly it is fixed near the inguinal region. In the lower part of its course it is closely related to, and is partly covered by, the peritoneum of the processus vaginalis. Striped muscular fibres are present in the lower part of the gubernaculum, and have their origin from the muscles of the inguinal part of the anterior abdominal wall. As the testis enters the processus vaginalis the gubernaculum atrophies, but at birth a short part of the gubernaculum may still be found passing downwards towards the inferior part of the scrotum and lying below the level of the tunica vaginalis. It is considered by some anatomists that the movement downwards of the testis may be partly due to a pull caused by the shrinking of the gubernaculum as it atrophies.

In some mammals, such as the elephant, the testes remain permanently within the abdominal cavity; while in others, such as the rabbit and the hedgehog, the peritoneal pouches remain widely open throughout life, and the testes are periodically withdrawn into the abdomen.

\section{Funiculus Spermaticus (Spermatic Cord).}

The testis in its course downwards through the abdominal wall into the scrotum takes with it its duct-the ductus deferens-blood and lymph vessels, and nerves of supply. All these lie together in the inguinal canal as they traverse the abdominal wall, and when they leave the canal by the subcutaneous inguinal ring they extend downwards to the posterior border of the testis. The ductus deferens, the spermatic vessels, and the nerves and lymph vessels of the testis, loosely connected together, form the funiculus spermaticus, or spermatic cord. At the abdominal inguinal ring its constituent parts separate from one another, and the funiculus may therefore be considered to extend from the abdominal inguinal ring to the posterior border of the testis. The structures which form the funiculus spermaticus are enclosed within a number of coverings derived from the layers of the anterior abdominal wall, and these, when the constituents of the funiculus reach the posterior border of the testis, surround the tunica vaginalis, and so form a part of the wall of

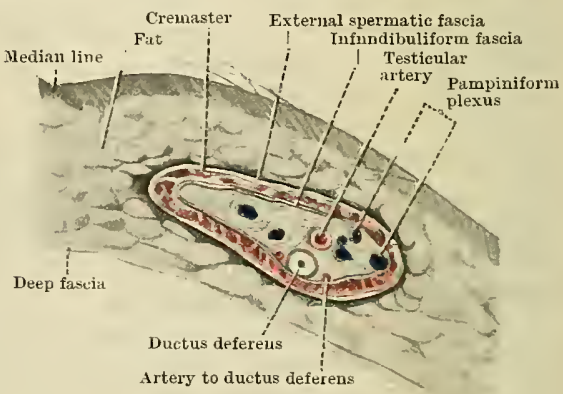

Artery to ductus deferens

Fig. 1016. - Transverse Section of the Funiculus Spermaticus, OR SPermatic Cord, JUst BELOW THE SUbCUTANEOUS INgUiNaL RING.

the scrotum. The sheaths or coverings of the cord derived from the abdominal wall are three in number, and are named intercolumnar fascia, fascia cremasterica, and infundibuliform fascia. The intercolumnar fascia is the most superficial of the three sheaths, and is derived from the aponeurosis of the external oblique muscle, 
with which it is continuous round the margins of the subcutaneous inguinal ring. The fascia cremasterica consists partly of muscular fibres derived from the inferior portion of the internal oblique muscle, and partly of delicate connective tissue. The muscular fibres constitute the cremaster muscle and passing down over the funiculus, form a series of loops round the testis and tunica vaginalis. The infundibuliform fascia is derived from the fascia transversalis of the abdomen. It passes downwards as a continuous sheath over the funiculus, and encloses its various structures, together with a certain amount of areolar tissue derived from the subperitoneal tissue of the abdominal wall and some smooth muscle fibres.

In addition to the structures enumerated above, the artery to the ductus deferens, the extemal spermatic (O.T. cremasteric) artery, and the genital branch (n. spermaticus externus) of the genito-femoral nerve, accompany the structures forming the funiculus spermaticus.

\section{SCROTUM}

The scrotum, in which the testes are placed, varies much in appearance in different subjects, and even in the same individual at different times. As the

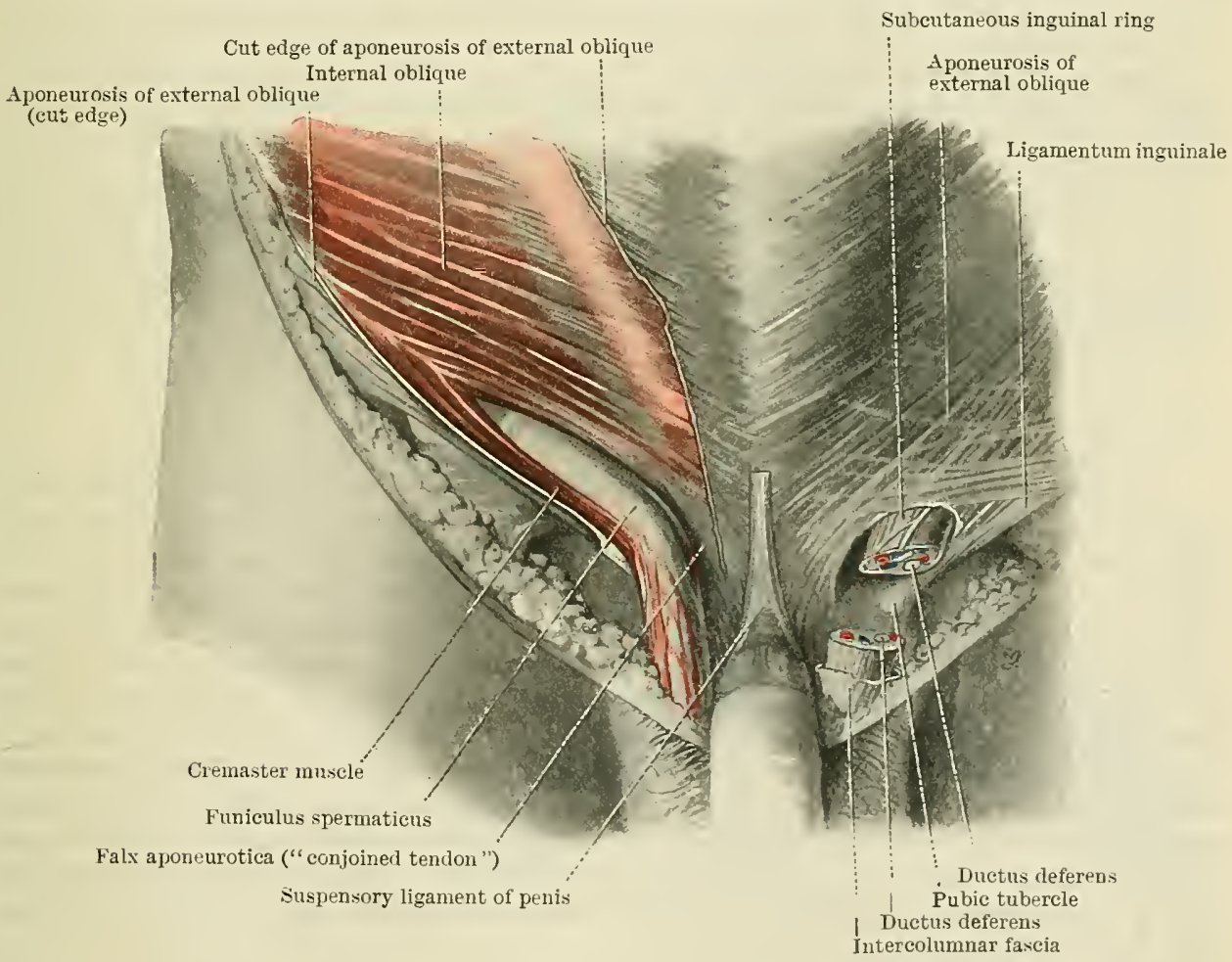

Fig. 1017.-Dissection to show the Funiculus Speruaticus as it issues from the Subcutaxeots Inguinal Ring. On the right-hand side of the figure the funiculus has been cut across, and the structures composing it are seen in section. On the left-hand side of the figure the external oblique muscle has been removed.

result of cold or of exercise, the wall of the scrotum becomes contracted and firm, and the skin covering it wrinkled; at other times the wall may be relaxed and flaceid, the scrotum then assuming the appearance of a pendulous bag. The left side of the scrotum reaches to a lower level than the right, in correspondence with the lower level of the testis on that side of the body. The skin covering the scrotum is of a darker colour than the general skin of the body, and is covered with hair. It is marked in the median plane by the raphe scroti, which is continued backwards towards the anus, and forwards on to the inferior, or urethral, surface of the penis. The difference in the appearance of the scrotum at different times is due to the amount of contraction or relaxation of a layer of 
muscular fibres, constituting the tunica dartos, situated in the superficial fascia. When this muscular layer is contracted, the scrotum becomes smaller and somewhat globular, and the skin is thrown into folds or wrinkles called rugæ; when it is relaxed, the scrotum is flaccid and pendulous, and the skin becomes more smooth and even. The layer of fascia which contains the smooth muscle fibres can be shown to be continuous superiorly with the superficial fascia of the penis, and with the deep layer of the superficial fascia of the abdomen, and to be attached laterally to the bones forming the pubic arch. The muscle fibres are arranged in a thick layer of interlacing bundles, and many of the deeper fibres are continued into the septum scroti, which divides the scrotum into two cavities, one for each testis. The wall of each of these cavities is formed by the corresponding tunica vaginalis, infundibuliform fascia, fascia cremasterica, and intercolumnar fascia; while the skin, the superficial fascia, and the superficial part of the dartos muscle form coverings which are common to the whole scrotum, and enclose both cavities. The layer of tissue immediately beneath the dartos tunic is made up of exceedingly loose and easily stretched areolar connective tissue, and in it, as throughout in the superficial fascia of the scrotum, there is an entire absence of fat.

The scrotum in the fotus contains no cavity, but, like the labia majora in the female, it is composed entirely of vascular connective tissue.

Vessels and Nerves of the Scrotum. - The scrotum receives its vascular supply from the posterior scrotal branches of the perineal divisions of the internal pudendal arteries, which reach it from behind, and from the external pudendal branches of the femoral artery, which reach its upper and anterior part.

The nerves of the scrotum are derived on each side from the posterior scrotal branches of the perineal division of the pudendal nerve, from the perineal branch of the posterior cntaneous nerve of the thigh, and from the ilio-inguinal nerve. The branches from the pudendal and posterior cutaneous nerves reach the scrotnm from behind, while the ilio-inguinal supplies its upper and anterior part. The nerve fibres for the dartos muscle fibres are believed to have their origin from the hypogastric plexus.

\section{PENIS.}

The penis is composed chiefly of erectile tissue, and is traversed by the canal of the urethra. The surface nearest to which the canal of the urethra lies is called the facies urethralis, or urethral surface; the opposite and more extensive aspect is the dorsum penis. The erectile tissue is for the most part disposed in three longitudinal columns, which in the body of the organ are placed side by side, while at the root of the penis they separate from one another, and become attached to the fascia inferior of the urogenital diaphragm and to the pubic arch. Two of these masses of erectile tissue, placed one on each side of the median plane, and forming the dorsum and sides of the penis, are called the corpora cavernosa penis, while the third, which is called the corpus cavernosum urethræ (O.T. corpus spongiosum), is situated in the median plane near the urethral surface. The corpus cavernosum urethræe is the part of the penis which is traversed by the urethra, and it is considerably smaller than the corpora cavernosa penis, which form the chief bulk of the organ.

In the corpus penis, or body of the penis, each corpus cavernosum penis is placed close to the median plane, and presents a rounded surface, except where it is flattened by contact with its fellow of the opposite side. The corpora cavernosa penis are separated on the anterior or dorsal surface by a shallow groove, and on the posterior or urethral aspect by a deeper and wider furrow, in which lies the corpus cavernosum urethræ (Fig. 1018). Towards the distal end of the penis the corpus cavernosum urethræ appears to expand, and, spreading towards the dorsal surface of the organ, it forms a kind of conical cap, the glans penis, which covers over the blunt rounded termination of the corpora cavernosa penis. The prominent margin of the glans, called the corona glandis, projects dorsally and laterally beyond the extremities of the corpora cavernosa penis. The glans is traversed by the terminal part of the urethra, which ends near the summit of the glans in a slit-like opening called the orificium urethræ externum, or external urethral orifice. The united corpora cavernosa penis end in a blunt conical extremity, the apex of which is 
received into a hollow in the base of the glans. The skin covering the body of the penis is thin, delicate, and freely movable, and, except near the root of the organ, is free from hairs; on the urethral aspect of the penis the skin is marked by a median raphe, continuous with the raphe of the scrotum. Traced towards the base of the glans, the skin forms a free fold called the præputium, or prepuce, which overlaps the glans to a variable extent. From the deep surface of the prepuce the skin is reflected on to the terminal part of the penis, along a line just proximal to the corona glandis, and is continued over the entire glans to the external urethral orifice. A small median fold, the frenulum præputii, passes to the deep surface of the prepuce from a point immediately below the orificium urethræ externum. The skin covering the glans is firmly attached to the underlying erectile tissue, and here, as well as on the deep surface of the prepuce, it presents some resemblance to mucous membrane.

Sometimes minute sebaceous glands, glandulæ præputiales, are found in very variable numbers on the glans and inner surface of the prepuce; the secretion from these when they are present may help to form the smegma præputii, which tends to collect in the groove between the glans and the prepuce. The main source of the smegma is to be found in the desquamated and broken-down epithelial cells derived from the surface of the glans and prepuce.

At the radix penis, or root, the three component parts of the organ separate from one another (Fig. 1018). The corpora cavernosa, diverging from each other laterally, at first become somewhat swollen, and then, gradually tapering, gain a firm, fibrous attachment to the periosteum on the medial surface of the pubic arch. These diverging parts of the corpora cavernosa are called the crura penis, and each is covered by the corresponding ischio-cavernosus muscle. The corpus cavernosum urethræ lying between the crura becomes enlarged, and forms a somewhat spherical mass which receives the name bulbus urethræ. The bulb varies much in size in different individuals, and is attached to the under surface of the fascia inferior of the urogenital diaphragm,

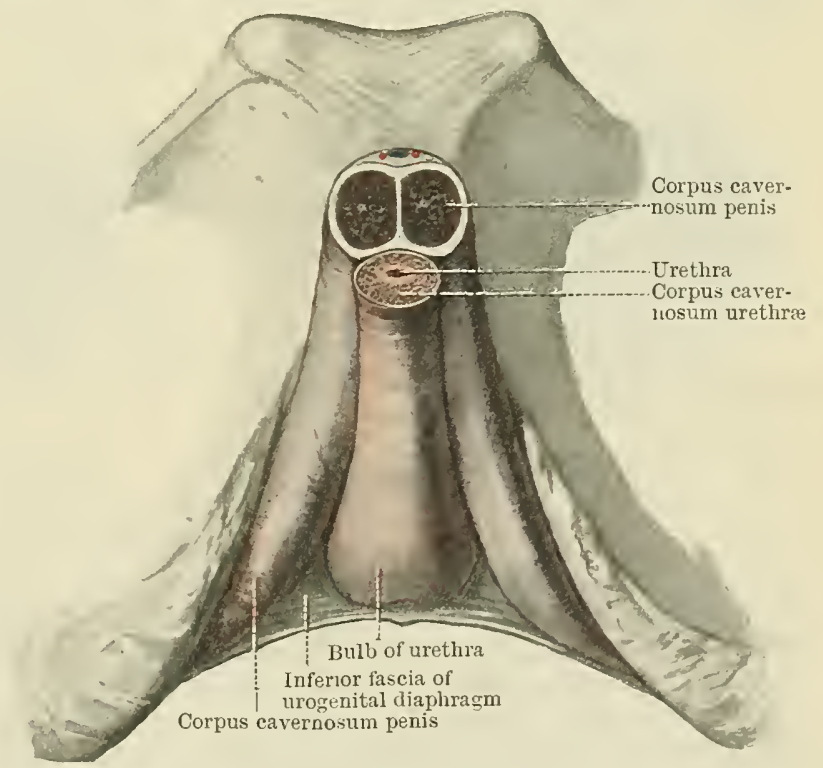

Fig. 1018.-StrRectures composing the Radix PeNis.

The corpus penis is seen in section. against which it rests. The posterior part and under surface of the bulb usually show a median notch or groove-an indication that the bulb is originally composed of two symmetrical portions, which during development have become fused in the median plane. These two portions are termed the hemispheria bulbi urethræ, and are best seen in subjects whose tissues have been hardened by intravascular injection. A slightly marked median septum, situated within the bulb tissue, indicates on a deeper plane the line along which fusion has taken place. The canal of the urethra, piercing the fascia inferior of the urogenital diaphragm, enters the bulb obliquely a short distance in front of its posterior extremity (Fig. 1024). Covering the superficial surface of the bulb is the bulbo-cavernosus muscle.

A somewhat triangular band of strong fibrous tissue, called the ligamentum suspensorium penis, is attached to the front of the symphysis pubis, and extends to the fibrous capsule of the penis, with which it becomes continuous (Fig. 1017). 
Structure of the Penis. - Each corpus cavernosum penis is enclosed by a dense white fibrous coat-tunica albuginea corporum cavernosorum, which, fusing with the corresponding coat of the opposite side, forms a median septum penis. The septum is rerr incomplete, especially near the terminal part of the penis, where it is interrupted by a number of nearly parallel slit-like perforations; hence the term "septum pectiniforme" is often applied to it (Figs. 1019 and 1020). Through these openings the erectile tissue of the corpora cavernosa of opposite sides is continuous.

The fibrous coat contains some elastic fibres, and may be divided into an outer layer of longitudinally directed fibres and an inner layer of circular fibres, some of which latter are continued into the septum. Numerous fibrous strands, called trabeculæ corporum cavernosorum, proceed from the deep surface of the tunica albuginea, and
stretching across the interior of the corpus carernosum, form a fine sponge-like framework whose interspaces communicate freely with one another, and are filled with blood. These blood-containing spaces lead directly into the veins of the penis, and like the reins have a lining of flat endothelial cells. The size of the penis varies with the amount of blood in this cavernous tissue. The structure of the corpus cavernosum urethræ resembles that of the corpora cavernosa penis, but the fibrous coat is much thinner and more elastic, and the trabeculæ are finer (Fig. 1019).

The glans penis is also composed of cavernous tissue which communicates by a rich venous plexus, situated on the ventral aspect of the urethra, with the corpus spongiosum urethræ. No strongly marked tunica albuginea is present, and the erectile tissue is practically bounded by the firmly adherent skin. Surrounding the urethra, which in this part of the penis is represented by a laterally compressed slit-like passage, is a mass of fibro-elastic tissue which forms a kind of median septum within the glans. This septum

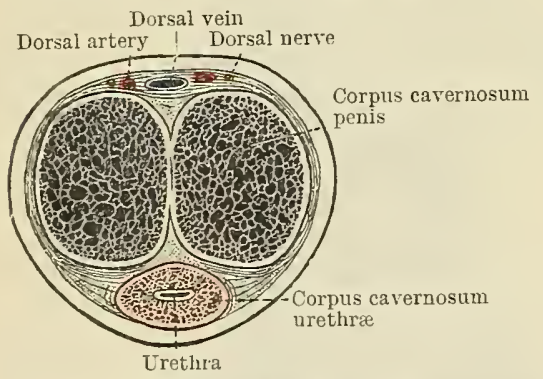

Fig. 1019. - Transterse Section through the Body of THE PENis.

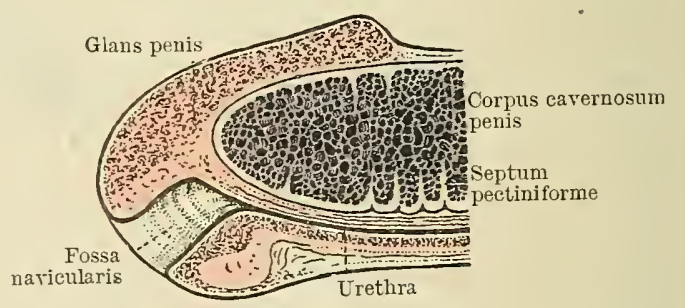

Fig. 1020.-A Longitudinal Section of the Terminal Portion of the Penis.

is continued backwards to join the sheath of the conical end of the corpora cavernosa, and rentrally it gives attachment to the frenulum of the prepuce. It imperfectly divides the erectile tissue of the glans into right and left portions, which, however, freely communicate dorsally. From the septrum, trabeculæ pass out in all directions into the tissue of the glans.

Loosely surronnding the corpora cavernosa penis and the corpus cavernosum urethræ is a fibrous sheath containing numerous elastic tissue fibres. This sheath is termed the fascia penis, and reaches as far as the base of the glans, where it becomes fixed to the floor of the groove limited by the corona glandis. In its proximal part the sheath gives insertion to many of the fibres of the bulbo-cavernosus and ischio-cavernosus muscles.

Superficial to the fascia penis is a layer of extremely lax areolar tissue, and more superficial still is a prolongation of the tunica dartos of the scrotum, covered by the delicate skin of the penis. Numerous sebaceous glands are present in the skin, especially on the urethral aspect of the penis.

In some mammals, such as the walrus, dog, bear, baboon, etc., a bone called the os penis is developed in the septum which intervenes between the corpora cavernosa penis.

Vessels and Nerves of the Penis.-The penis receives its arterial supply from iranches of the internal pudendal artery. The erectile tissue of the corpora cavernosa penis is supplied chiefly by the deep arteries of the penis, while that of the corpus cavernosum urethræ receives its arterial supply from the artery to the bulb. Branches of the dorsal artery of the penis piercing the fibrous coat of the corpora cavernosa penis furnish additional twigs to the erectile tissue of these structures. The glans receives its chief blood-supply from branches of the dorsal artery. The small branches of these arteries run in the trabeculæ of tine erectile tissue, and the capillaries, into which they lead, open directly into the cavernous venous spaces. As they lie in the finer trabeculæ the smaller branches often present a peculiar twisted appearance, and hence the nane arteriæ helicinæ is sometimes applied to them. 
The veins with which the cavernous spaces communicate, carry the blood, for the most part, either directly into the pudendal plexus, or into the dorsal vein and so to the pudendal plexns. The dorsal vein of the penis begins in tributaries from the glans and prepuce, and lies in the groove between the corpora cavernosa penis as it ascends to pass beneath the arcuate ligament of the pubis to join the pudendal plexus. On each side of it lies the dorsal artery, and still farther from the median plane lies the dorsal nerve (Fig. 1019).

The lymph-vessels of the penis are arranged in a deep and superficial series, and end in the medial glands of the inguinal group of lymph-glands.

The nerve-supply of the penis is derived from the pudendal nerve and from the hypogastric and pelvic plexuses. The branches of the pudendal are the dorsal nerve of the penis, and branches from the perineal nerves. These supply the cutaneons structures of the penis, while the sympathetic filaments from the hypogastric and pelvic plexuses, which reach the penis throngh the prostatic nerve plexus, end in the erectile tissue.

\section{PROSTATA.}

The prostata, or prostate, is a partly glandular, partly muscular organ of a dark brown-red colour which surrounds the beginning of the urethra in the male. It lies within the pelvis behind the pubes, and is enclosed by a dense sheath derived from the pelvic fascia. Through the various connexions of this sheath the prostate is firmly fixed within the pelvic cavity. The ejaculatory ducts traverse the prostate in their course downwards and forwards to join the urethra as it

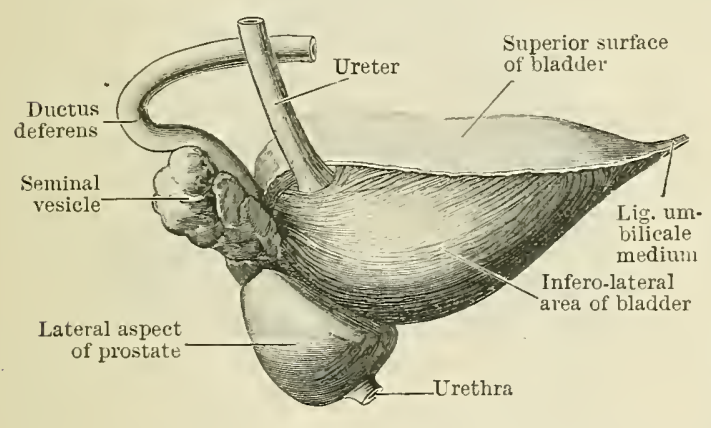

A

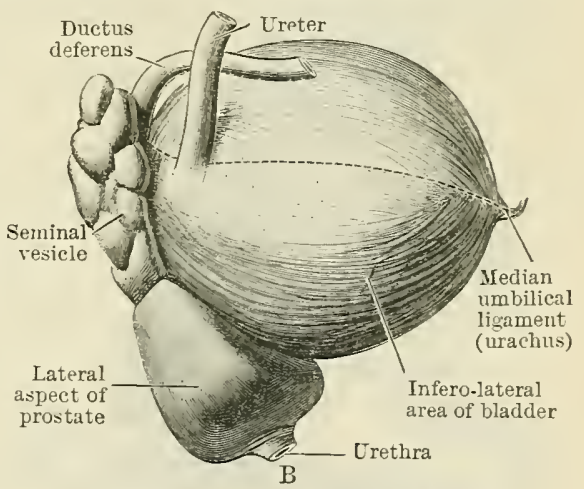

Fig. 1021.-Urinary Bladder, Prostate, and Seminal Vesicles viewed from the Side.

descends through the gland (Fig. 1023). The size of the prostate varies considerably in different individuals, but its transverse, or longest, diameter is usually from one and a quarter to one and a half inches; its antero-posterior diameter about three-quarters of an inch; and its vertical diameter about one and a quarter inches. Superficially the prostate is separated from the bladder by deep wide lateral grooves directed downwards and forwards, and by a narrow posterior groove which is horizontal.

In connexion with the prostate we describe an apex which is directed downwards, a base looking upwards, a posterior, and two lateral surfaces. The general outline of the organ has been often compared with that of a Spanish chestnut. The upper surface, or basis prostatæ, is directed upwards against the inferior aspect of the bladder, in the neighbourhood of its urethral opening. The greater part of this surface is structurally continuous with the bladder wall, only a narrow portion remains free on each side, and forms the lower limit of the deep groove which marks the separation of the bladder and prostate (Fig. 1021). The lateral surfaces of the prostate are convex and prominent, especially in their posterior and upper portions, and rest against the fascia covering the levator ani muscle. They are directed for the most part laterally, downwards, and somewhat forwards, and meet together in front in a rounded anterior border, sometimes called the "anterior surface," or "facies anterior," of the prostate. Posteriorly the prostate presents a flattened somewhat triangular posterior surface, directed backwards and downwards 
against the anterior wall of the rectum, from which it is separated by a layer of the pelvic fascia. This flattened facies posterior is separated on each side from the lateral surfaces by a rounded border which, beginning above at the prominent lateral part of the prostate, ends below at the apex of the organ. The apex prostatæ points downwards, and is in relation to the sphincter urethræ membranaceæ muscle, from which it is separated by the fascia superior of the urogenital diaphragm. From the apex the rounded anterior border, which separates the lateral surfaces, passes upwards in the median plane behind the symphysis pubis and retropubic pad of fat. This border is interrupted in its lower part by the passage of the urethra.

Then the sheath formed by the pelvic fascia is stripped off the prostate the organ has a more rounded outline, and the surfaces just described are not so clearly defined. The anterior border may now appear to be rather a surface than a border, and the antero-posterior diameter of the whole organ is considerably reduced.

The urethra enters the prostate at a point near the middle of its upper surface, and leaves it at a point situated on its anterior border, just above and in front of the apex. As it descends, the urethra describes a curve which is concave forwards, and in median section it is seen to lie, on the whole, nearer to the posterior surface than to the anterior border of the gland.

The ejaculatory ducts, entering a slit-like interval, or hilus, situated just in front of the border which separates the base from the posterior surface of the prostate,

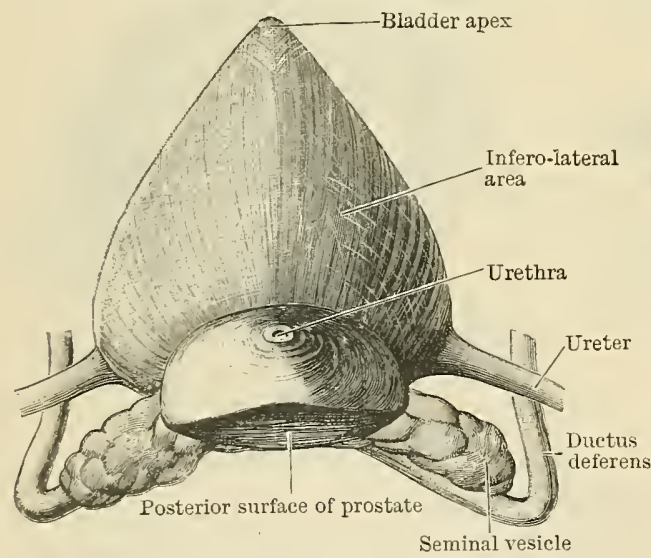

Fig. 1022.-Prostate, URixari Bladder, AND SEMINAL VESICLES SEEN FROM BELOW.

Drawn from a specimen hardened in situ. The lateral surfaces of the prostate are seen one on each side of the urethra and in front of the posterior surface. run downwards, medially, and forwards, to open into the prostatic portion of the urethra very close to one another. The somewhat wedge-shaped portion of the prostate, which lies between these ducts and the posterior aspect of the urethra, receives the name of lobus medius (Fig. 1023). The base of this middle lobe projects upwards against the bladder, and is continuous with the part of the bladder wall lying immediately behind the urethral orifice. When hypertrophied, as it often is in old people, the middle lobe of the prostate may cause a considerable elevation in the cavity of the bladder, to which the term uvula vesicæ is applied. This elevation possesses considerable surgical interest (p. 1277).

The rest of the prostate is described as being composed of two large lateral lobes, which are, however, not marked off from one another superficially.

In front of the prostate, between it and the pubis, is a rich venous plexus-plexus pudendalis-in which the dorsal vein of the penis terminates. This plexus is continued backwards, on each side, round the lateral aspect of the prostate, and joins the large thin-walled veins which are collected for the most part in the deep sulcus between the bladder wall and the prostate, and form the prostatico-vesical plexus. Most of the veins forming this plexus lie partly within and partly outside the dense fibrous sheath of the prostate, which is derived from the visceral pelvic fascia (Figs. 1023 and 1024).

Fibrous Sheath of the Prostate.-The sheath of the prostate is formed by the visceral pelvic fascia, and closely invests the gland on its lateral and posterior aspects. Inferiorly at the apex of the prostate the sheath becomes continuous with the fascia superior of the urogenital diaphragm, which lies above the sphincter urethræ membranaceæ muscle, and is attached to the pubic arch. In front two thickened bands pass forwards from the anterior aspect of the sheath, one on each side of the median plane, to reach the back of the lower part of the pubis, where 
they are attached to the periosteum. These constitute the pubo-prostatic ligaments, and contain smooth muscle fibres, as well as dense connective tissue. Some of the muscle fibres in connexion with the pubo-prostatic ligaments, passing upwards as well as backwards, gain the bladder wall, and are spoken of as the pubo-vesical muscles. Below the pubo-prostatic ligaments the medial edges of the levatores ani muscles pass medially and almost meet together in front of the apex of the prostate. When followed backwards, the medial edges of these muscles are seen to closely embrace the apex of the prostate. This layer forms a part of the wall of the retro-pubic space which lies in front of the prostate and below the bladder (Fig. 1024).

Between the pubo-prostatic ligaments there is a shallow fossa, or depression, the floor of which is formed by a thin layer of fascia connecting the anterior aspect of the sheath of the prostate with the back of the pubis. On each side of the body the lateral aspect of the sheath of the prostate is continuous with the strong fascia which covers the pelvic surface of the levator ani muscle. When the fibrous sheath of the prostate is traced upwards beyond the level of the upper margin of the gland it becomes thinned out and joins the fascial covering of the bladder. Posteriorly the

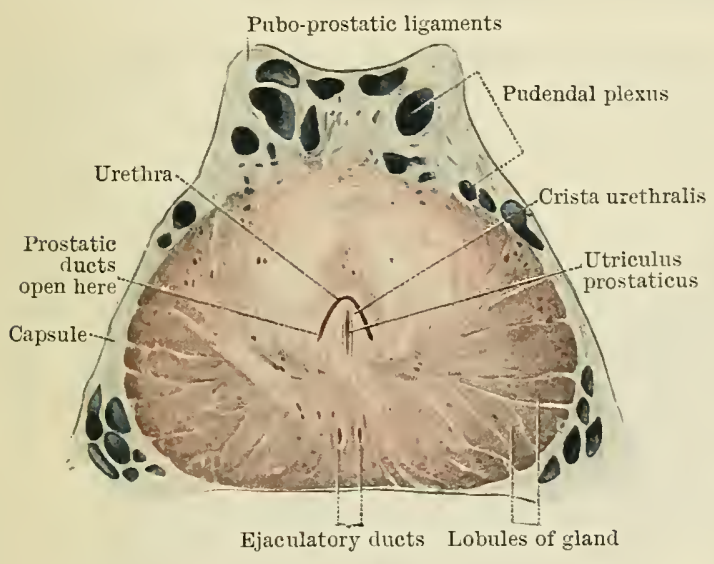

A

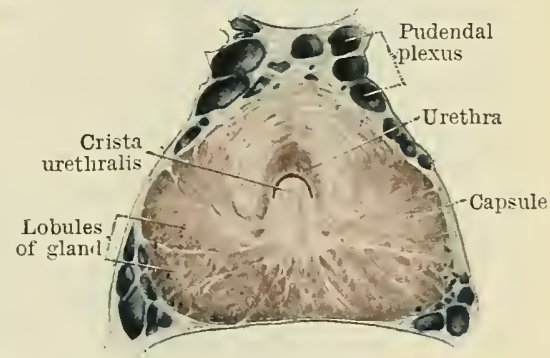

$\mathrm{B}$

Fig. 1023, A and B.-Horizontal Sections throvgh the Prostate. Section A lies at a higher level than B.

upward prolongation of the sheath is continuous with the fascial layers which enclose the ampullæ of the ductus deferentes and the seminal vesicles, and it is adherent to the peritoneum of the recto-vesical pouch. In this position it is often spoken of as the recto-vesical fascia.

Structure of the Prostate.-Beneath the fibrous sheath of the gland the superficial part of the prostate is seen to be largely composed of matted interlacing bundles of smooth muscle and connective tissue fibres, which form a kind of capsule for the deeper parts of the organ. This layer, or capsule of the prostate, is not sharply defined, but from its deep aspect fibrous and muscular strands pass inwards, courerging towards the posterior wall of the urethra, to become continuous with the mass of smooth muscular tissue which surrounds this canal as it traverses the prostate. These somewhat radially arranged strands divide the prostate into a number of incompletely defined lobules, of which there appear to be about fifty. The yellowish-coloured glandular tissue, or corpus glandulare, which forms the lobules is composed of minute, slightly branched tubules, the walls of which in certain places show numerous saccular dilatations. In the upper portion of the gland the tubules are slightly dilated and shorter than in the lower part, where they are longer and more convoluted. The glandular tubules lead into the minute prostatic ducts, which open into the urethral canal as it traverses the prostate. The ductus prostatici number abont twenty or thirty, and open for the most part into a groove on each side of the median elevation, or crista urethralis, in the posterior wall of the urethra (Fig. 1023 A).

The bulk of the glandular tissue is situated at the sides of and behind the urethra. In front of the upper part of the prostatic portion of the urethra there is a mass of 
smooth muscular fibres, which is continued upwards and backwards on the sides of the urethra to form a part of the "sphincter vesicæ." At a lower level striped muscular tissue, which is continuous with the deep part of the sphincter urethræ membranaceæ muscle, occupies a position in front of the urethral canal.

The muscular tissue of the prostate is to be regarded as the thickened muscular layer of the wall of the urethra, broken up and invaded by the prostatic glands which arise and are developed from the lining layer of the canal during embryonic life.

In old age the prostate frequently undergoes a hypertrophy, which may affect chiefly the glandular tissue, or the entire organ. Not infrequently calcareous concretions are found embedded in the prostate.

Vessels and Nerves of the Prostate.-The prostate receives its blood-supply from branches of the hæmorrhoidal and inferior vesical arteries, while the large plexus of veins-plexus pudendalis - which surrounds it, and into which the veins of the penis open, communicates with the vesical plexus, and drains into the hypogastric veins. In old people the veins of the prostate usually become much enlarged.

The nerves of the prostate are derived from the hypogastric plexus.

\section{GLANDULE BULBO-URETHRALES.}

The bulbo-urethral glands (O.T. glands of Cowper) are a pair of small bodies placed in relation to the second, or membranous, part of the urethra. They are each about the size of a pea, and are of a yellowish-brown colour. Situated in the space between the two fasciæ of the urogenital diaphragm, they lie below the level of the apex of the prostate, and above that of the bulbus urethræ (Figs. 1024 and 1026). Each gland is made up of a number of closely applied lobes or lobules, and is of the compound racemose type. The ductules of the gland unite to form a single ductus excretorius, which pierces the bulbus urethræ, and, after a relatively long course, ends by opening into the cavernous portion of the urethra by a minute aperture. The secreting acini are lined with columnar epithelium.

The glands receive their arterial supply from the artery to the bulb.

In old age these glands are often difficult to find without a microscopic examination.

\section{URETHRA VIRILIS.}

The urethra in the male is a channel of about eight inches in length leading from the bladder to the external urethral orifice at the extremity of the glans penis. The canal serves not only for the passage of urine, but it also affords an exit for the seminal products, which enter. by the ejaculatory ducts, and for the secretion of the prostatic and bulbo-urethral glands. In addition, numerous minute glandulæ urethrales pour their secretion into the urethra.

As it passes from the internal urethral orifice, to its external opening, the urethra describes a somewhat $\backsim$ shaped course, and it is customary to divide it into certain sections, which have received distinctive names. The first part of the urethra lies within the pelvic cavity, and has a somewhat vertical course as it traverses the prostate. Turning more forwards, the urethra passes below the pubic arch, and pierces the fibrous layers which form the pelvic wall in this region. Leaving the pelvic cavity, the canal enters the bulbus urethræ, where the latter is attached to the fascia inferior of the urogenital diaphragm, and throughout the rest of its course it lies in the erectile tissue of the corpus cavernosum urethræ and of the glans penis. The part of the urethra which lies embedded in the prostate is called the pars prostatica, or prostatic portion; the short part which pierces the pelvic wall is called the pars membranacea, or membranous portion, and the part surrounded by the corpus cavernosum urethræ receives the name of pars cavernosa, or cavernous portion. Of these three sections of the urethra the cavernous portion is much the longest, and the membranous is the shortest. 
Pars Prostatica Urethræ Virilis.-The prostatic part of the male urethra descends through the prostate from the base towards the apex, describing a slight curve which is concave forwards. It is about one inch in length,

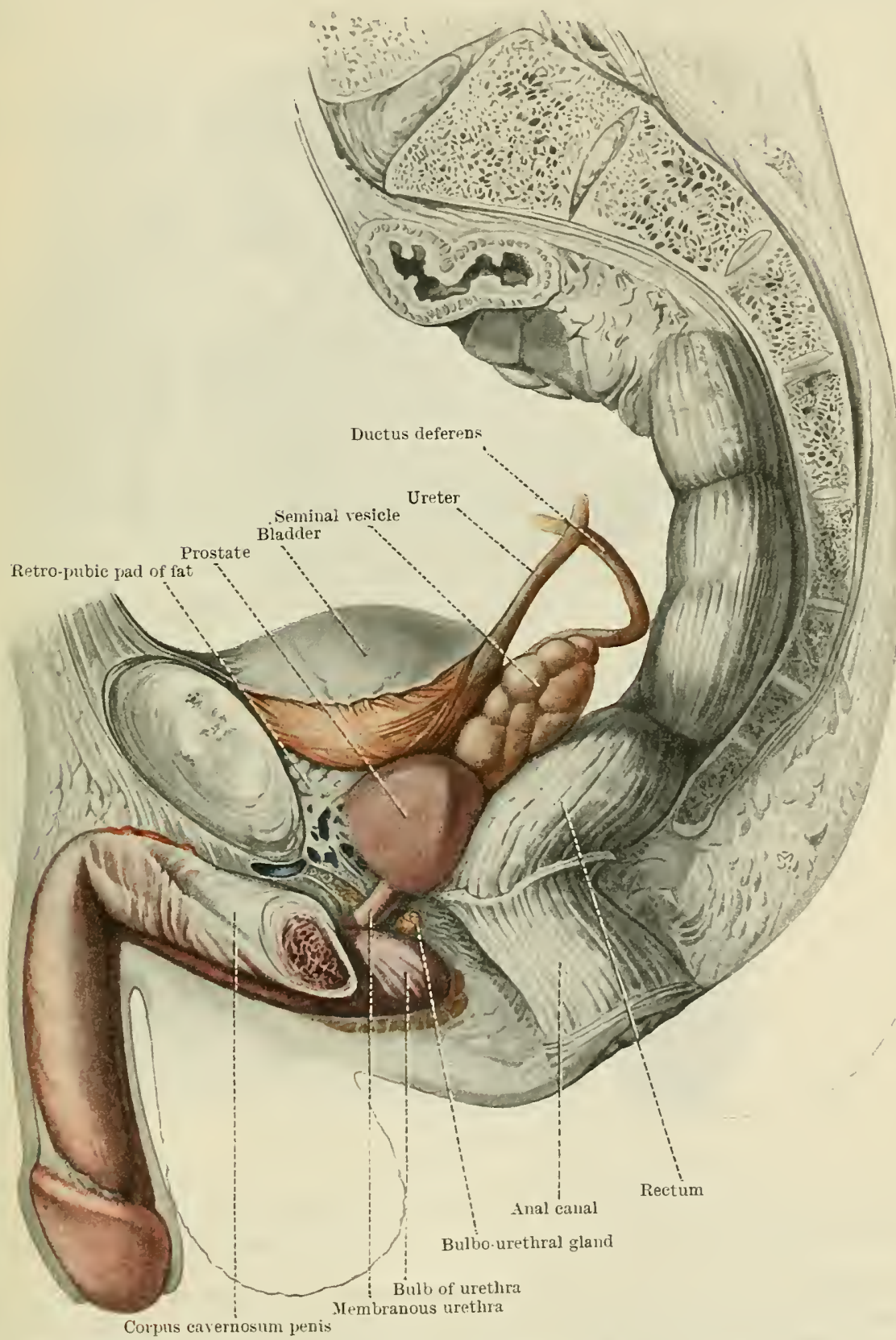

Fig. 1024. - Dissection of the Male Pelic Orgats axd of thr Pexis, FROM THE SIDE.

The dorsal rein of the penis and the pulendal venous plexus are coloured blue.

and is narrower above and below than in its middle portion, which is, indeed, the widest part of the whole urethral canal. Except while fluid is passing, the canal is collapsed, and the mucous membrane of the anterior and posterion walls is in contact, and thrown into a series of longitudinal folds. When distended, the middle, or widest part of the canal, may normally have a diameter 
of about one-third of an inch. The posterior wall, often termed the "floor" of the prostatic urethra, presents a distinct median ridge or elevation called the crista urethralis (Fig. 1026). This projects forwards into the urethra to such an extent that the canal in transverse section presents a somewhat crescentic outline. In the depressions, or! grooves, on each side of the crista urethralis

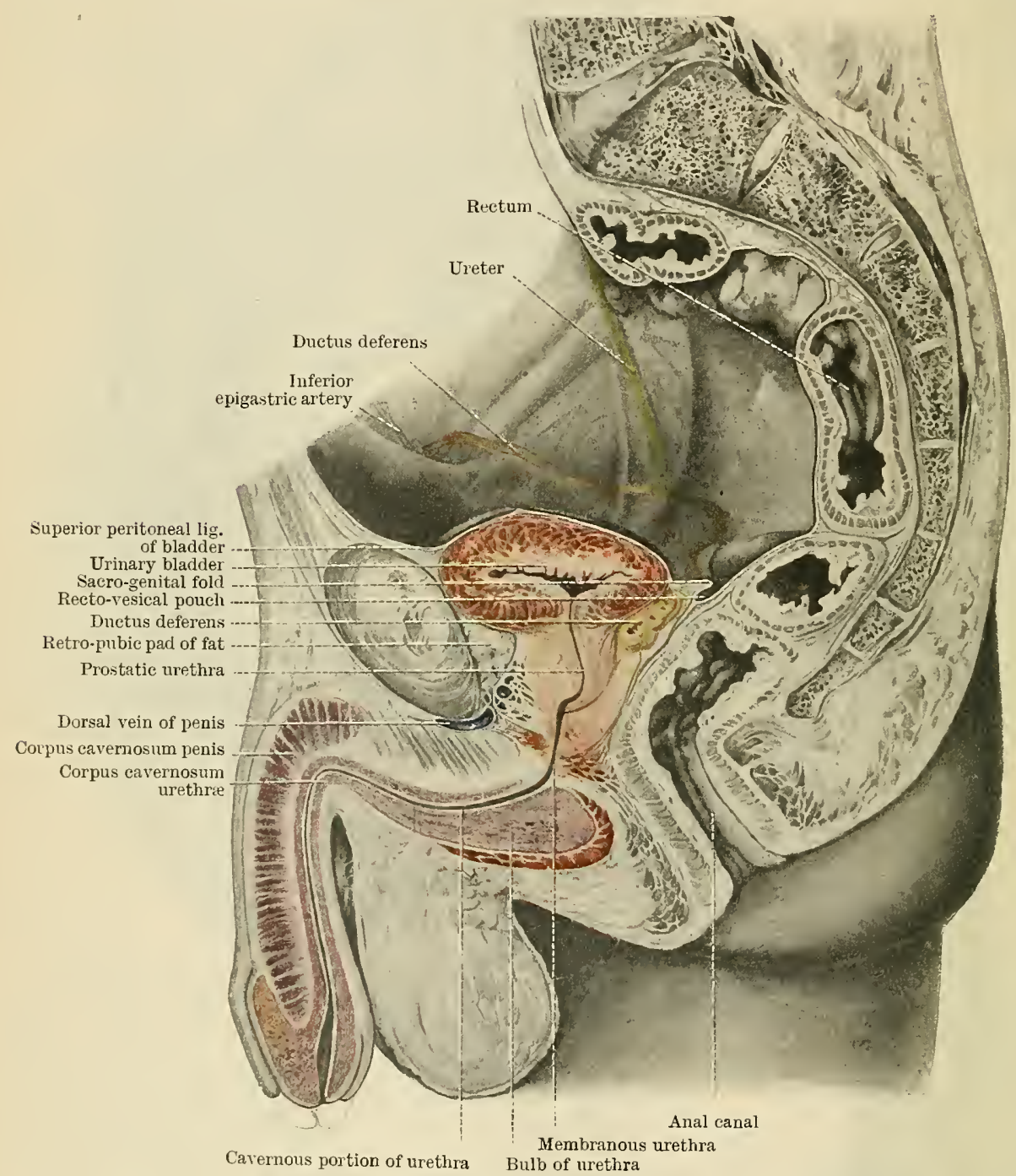

Fig. 1025.-Adult Male Pelvis in Median Section.

The urinary bladder is empty and firmly contracted. The urethra is opened up in its entire length.

the numerous ducts of the prostatic glands open by minute apertures. Some few ducts from the middle part of the gland open nearer the median plane, on the sides of the urethral crest. On the summit of the crista urethralis is a slit-like opening which leads backwards and upwards for a distance of about a quarter of an inch, as a blind pouch, in the substance of the prostate. This little cavity is known as the utriculus prostaticus, and represents the fused posterior ends of the Müllerian ducts, from which the uterus and vagina of the female are developed. The term uterus masculinus is therefore sometimes applied to this little pouch. On each side of the mouth of the utricle is the much more minute opening of the ejaculatory duct. When traced upwards towards the bladder, the urethral crest, diminishing in height, becomes indistinct, 
but in it can often be traced as a slight median ridge as far as the uvula vesicæ. When followed in the opposite direction the ridge becomes less marked, and can be followed on the urethral wall into the membranous portion of the canal, where it divides into a pair of inconspicuous folds or elevations, which gradually fade out into the urethral wall (Fig. 1026).

The curvature and, to a less degree, the length of the prostatic urethra depends upon the amount of distension of the bladder and of the rectum (compare Figs. 989 and 990).

Pars Membranacea Urethræ.-The second, or membranous portion, of the

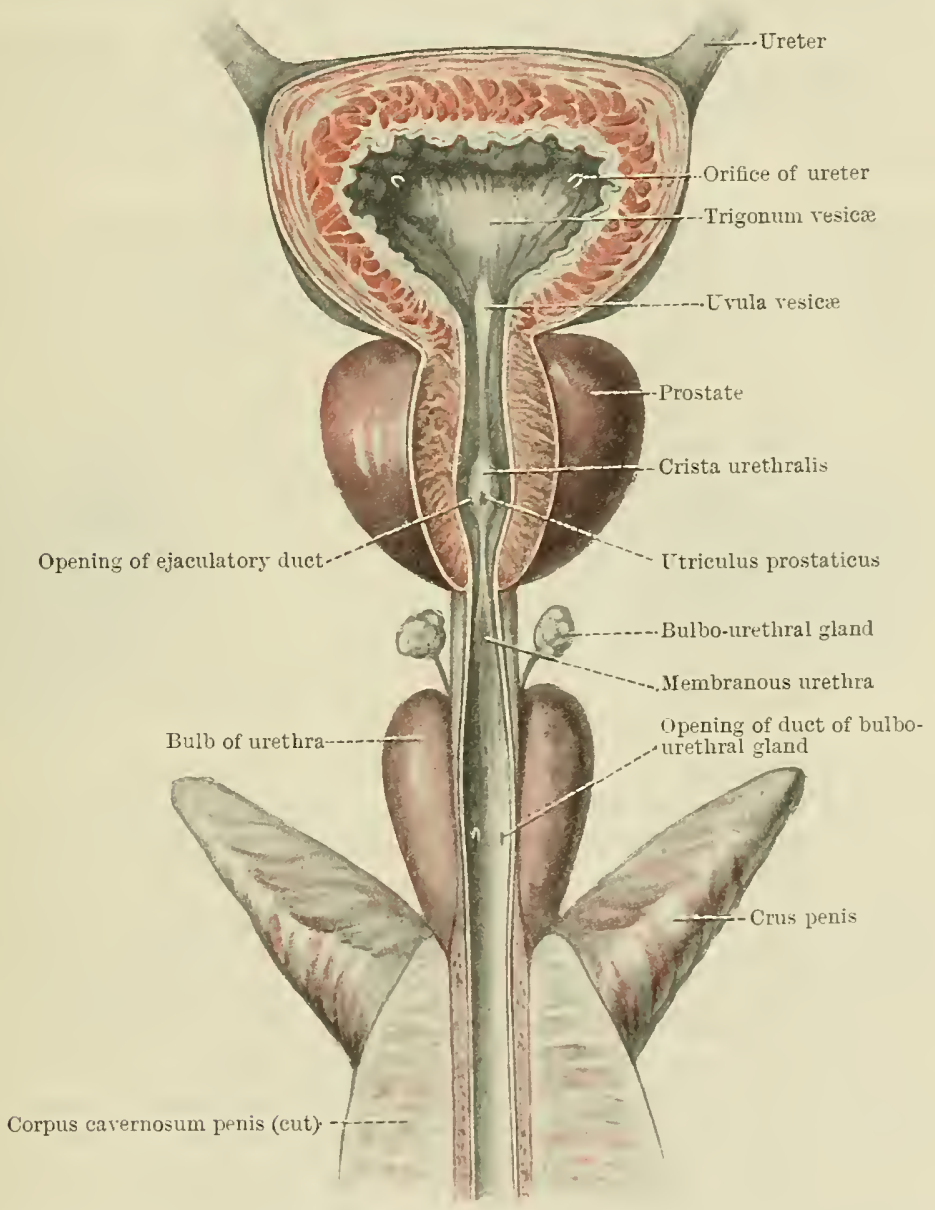

Fig. 1026.-Dissection showixg the Trigoxum Vesic.e and the Posterior Wall or floor of the Urethra ix its Prostatic, Mesibraxocs, ayd the Upper Part of its Careryous Subdisions.

The canal has been opened up by remoring its anterior and upper wail.

urethra leads downwards and forwards from the apex of the prostate to the bulbus urethræ, and is the shortest and narrowest of the three subdivisions of the canal, its length being somewhat less than half an inch. It begins at the superior fascia of the urogenital diaphragm, a layer of pelvic fascia which lies abore the sphincter urethræ membranaceæ muscle. Here it is continuous with the prostatic portion of the urethra. It ends, having pierced the inferior fascia of the urogenital diaphragm, by becoming continuous with the cavernous portion of the urethra. Placed in front of the rectum, it lies about one inch behind and below the arcuate ligament of the pubis (or sub-pubic ligament). It is surrounded by fibres of the sphincter urethræ membranaceæ muscle, and behind it, on each side of the median plane, lies the bulbo-urethral gland. The posterior part of the bulbus 
urethræ projects backwards and overlaps the posterior wall of the membranous part of the urethra to a considerable extent (Fig. 1024).

The membranous portion of the urethra is the most firmly fixed and least dilatable part of the passage.

A slight medial elevation, which is continuous above with the crista urethræ, projects into the canal from its posterior wall, and becoming less marked as it is traced downwards, is often seen to divide into two faint ridges. When the canal is empty other longitudinal folds or ridges are usually to be seen on the mucous membrane, but these become obliterated when the passage is distended. The lumen of the empty tube, in transverse section, presents a stellate outline.

It is important to note that the terminal portion of the pars membranacea urethræ, where it is overlapped posteriorly by the urethral bulb, lies in front of the urogenital diaphragm. It is considerably wider than the upper part of this subdivision of the canal, and is very thin-walled. This is the part of the canal which is most liable to rupture (Figs. 1024 and 1026).

Pars Cavernosa Urethræ.-The third, or cavernous portion, of the urethra is much the longest of the three subdivisions. It begins at a point about half an inch in front of the posterior end of the bulbus urethræ, and ends at the external urethral orifice on the glans penis. Its proximal, or perineal, portion has a fixed position and direction, while its distal part varies with the position of the penis. The canal is about six inches in length, and is related throughout its whole extent to the erectile tissue of the corpus cavernosum urethræ and of the glans penis. Directed at first forwards through the bulbus urethræ, the canal turns downwards and forwards at the point where it comes to lie in front of the lower part of the symphysis pubis (Fig. 1025). This bend in the direction of the canal, roughly speaking, corresponds to the place of attachment of the suspensory ligament to the dorsum of the penis. When the penis is drawn upwards towards the front of the abdomen, the direction of the terminal half of the canal is, of course, changed, and at the same time the whole length of this subdivision of the urethra becomes more uniformly curved.

The urethra passing obliquely downwards and forwards enters the bulb at a point nearly half an inch from its posterior extremity. Immediately after the canal has pierced the fascia inferior of the urogenital diaphragm its posterior aspect becomes surrounded by the erectile tissue of the bulb, but the anterior wall remains uncovered for a distance of about a quarter of an inch (Fig. 1025). The wall of the urethra is here very thin, and the passage is more readily dilatable than in other parts. In this region the urethral wall may readily be torn through, if undue force is used, or if the handle is depressed too soon when attempting to pass an instrument into the narrower more fixed part of the canal. The urethra lies at first in the upper part of the erectile tissue, but as it passes forwards it sinks deeper, and comes to occupy the middle part of the corpus cavernosum urethræ (Fig. 1025). In the glans, on the other hand, the erectile tissue lies on the dorsal and lateral aspects of the urethra. Like the other parts of the urethral passage, the pars cavernosa is closed except during the passage of fluid, the closure being effected by the apposition of its dorsal and ventral walls except in the portion of the canal which lies in the glans penis, where the lateral walls of the canal come into contact. Thus the lumen of the first part of the canal, when empty, is represented in cross section by a transverse slit, and that of the terminal part by a vertical slit (Fig. 1027). The cavernous part of the urethra does not present a uniform calibre throughout, but is narrower in its intermediate part, where it traverses the corpus cavernosum urethræ, than it is in those portions of its course which are surrounded by the bulb and the glans. The terminal dilated part of the passage is termed the fossa navicularis urethræ, and opens on the surface by the vertically placed slit-like orificium urethræ externum, or external urethral orifice, which is bounded by lateral lips, and is the narrowest and least dilatable part of the whole urethral canal.

The ducts of the bulbo-urethral glands open by very minute apertures in the inferior wall of the proximal part of the cavernous portion of the urethra. Before 
opening into the canal, they lie for some distance immediately beneath its mucous membrane. A number of little pit-like recesses, called the lacunæ urethrales, also open into the cavernous part of the urethra, and are so disposed that their openings lead for the most part obliquely into the canal in the direction of its external orifice.

In some cases a somewhat ralve-like fold of the mucous membrane, the valvula fossæ navicularis, is found in the upper wall of the urethra in the region of the fossa navicularis. The free edge of this fold is directed towards the external urethral orifice, and may engage the point of a fine instrument introduced into the urethra.

Structure.-The mucous membrane of the urethra contains numerous elastic fibres and varies in thickness in different parts of the canal. In many positions it show's distinct longitudinal folds and also minute depressions or pits-the lacunæ urethrales, already mentioned. The lining epithelium is composed of many layers of cells, and is continuous through the internal urethral orifice with the epithelinm of the bladder, which at first it closely resembles. In the region of the fossa navicularis the lining cells, which throughout the careruous portion of the canal are of a columnar type, become flat and scaly.

Numerous minute glands-glandulæ urethrales - open into the urethra. These are most plentiful in the upper, or anterior, wall, but they also occur in smaller numbers in the floor and side walls. They are most numerous in the anterior half of the carernous portion of the canal, and in the membranous subdivision of the urethra.

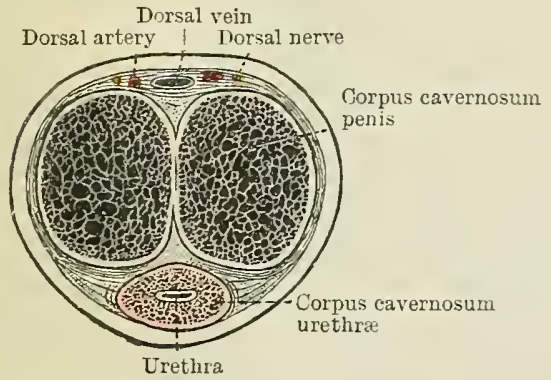

A

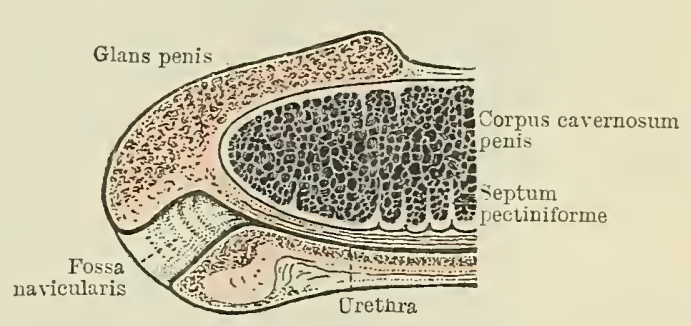

B

Fig. 1027.-A, Transterse Section throdgh the Body of the Pexis. B, Loxgitudixal Section of the Terdicil Portioy of the Pexis.

The larger glands are deeply placed beneath the mucous coat, and communicate with the urethra by long slender obliquely placed branched ducts. The smaller glands lie in the mucous coat and form flask-like depressions with very short ducts. The ducts of some of the glands open into the lacunæ, but many of the latter have no connexion with the urethral glands.

Frequently two or more elongated ducts belonging to some of the larger glands open into the urethra quite close to its termination. These are sometimes spoken of as paraurethral ducts, and may be traced backwards for some distance beneath the mucous membrane forming the roof of the urethra. Morphologically they do not correspond to the ducts which in the female have received the same name.

The muscular wall in the upper part of the urethra consists of smooth muscle fibres directed for the most part longitudinally, but some circularly arranged fibres are also present. It is probable that throughout the greater part of the cavernous urethra a muscular coat is not represented.

Round the begimning of the urethra there is an obliquely placed band of circularly arranged smooth muscle fibres, which is continued downwards and forwards from below the anterior part of the trigone of the bladder. The lower and anterior fibres of this band lie in the anterior wall of the upper part of the prostatic urethra. The band is sometimes spoken of as the sphincter vesice interuus. At a lower level, in front of the prostatic urethra, is a band of striped nuscular fibres which is continuous inferiorly with the inner circularly disposed part of the sphincter urethre membranacer.

Like the latter it is probably to be regarded as a part of a primitive roluntary urogenital sphincter muscle, such as is represented also in the female subject. 


\section{THE FEMALE REPRODUCTIVE ORGANS.}

The reproductive glands in the female are a pair of ovaries placed laterally in the cavity of the pelvis. In connexion with each ovary is an elongated passage or tube-the tuba uterina, uterine, or Fallopian tube-which leads to the uterus and opens into its cavity. There is no direct continuity between the ovary and the uterine tube, such as exists between the other glands of the body and their ducts, but the ova, when shed from the ovary, pass into the open end of the tube, and are thus conducted to the uterine cavity. The uterus is a hollow muscular organ which

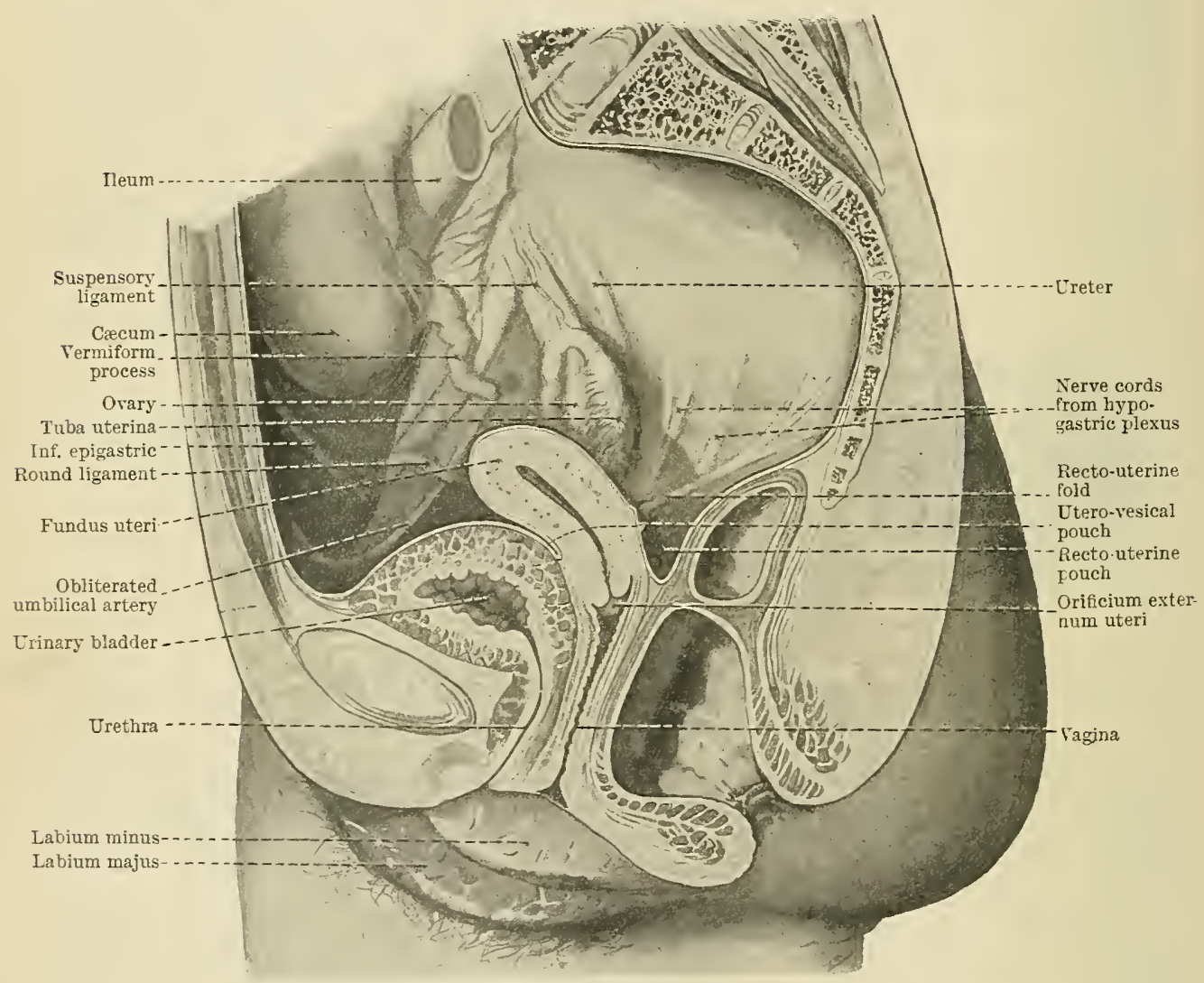

Fig. 1028.- Median Section throdgh the Female Pelvis.

Drawn for the most part from a model made from a dissection by Professor Edward H. Taylor.

occupies a nearly median position in the pelvis; it is joined by the uterine tubes above, and it communicates with the rpper part of the vagina below. The ovum, having passed through the tube, reaches the cavity of the uterus, and in it, if fertilisation has taken place, the ovum undergoes its development into the embryo and fotus. The vagina is the passage which leads from the uterus to the exterior, and has its external opening behind that of the urethra, within the rima pudendi or urino-genital space. In connexion with the urino-genital space are a number of structures which are included under the term external genital organs, and which represent in the female the various parts of the penis and scrotum in the male. These are the labia majora and the mons Veneris, the labia minora, the clitoris, and the bulbus vestibuli. The larger vestibular glands, placed one on each sicle of the lower part of the vagina, are accessory organs of the female reproductive system, and are represented by the bulbo-urethral glands in the male. 


\section{OVARIUM.}

The ovary is a solid body, flattened from side to side, and about the size and shape of a large almond. Its length is usually between one and one and a half inches, and the thickness from side to side between a quarter and half an inch. In the adult the ovary is placed against the lateral wall of the pelvic cavity, and is connected by peritoneal folds with the broad ligament of the uterus and with the lateral wall of the pelvis. The position occupied by the ovary within the pelvic cavity is fairly constant, although these ligaments do not hold the organ firmly fixed in any definite place.

In the ovary we recognise two extremities-a superior extremity, larger and more rounded, and an inferior extremity, somewhat pointed. The term extremitas

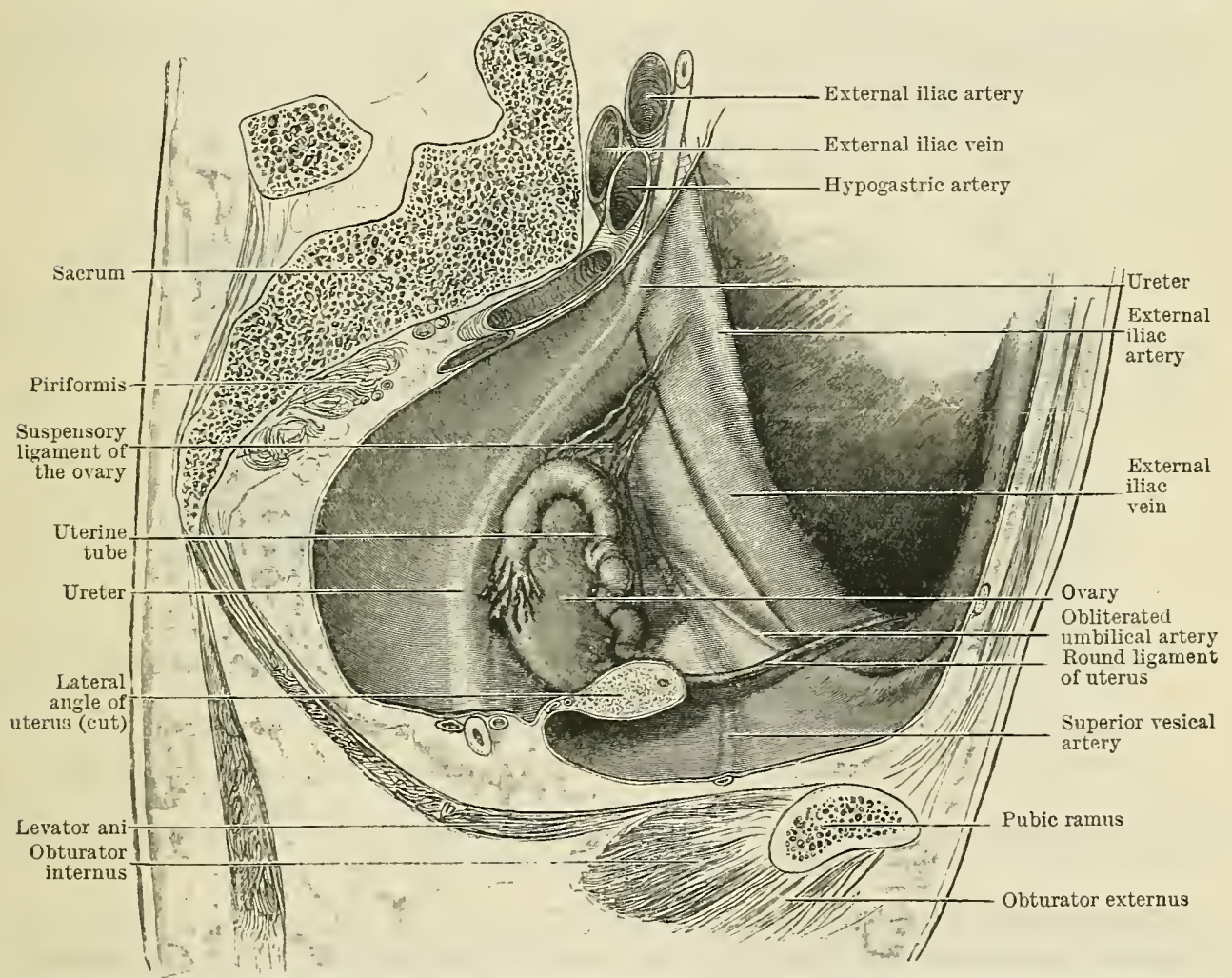

Fig. 1029.-Side WALl of The Female Pelvis, showing the position of the ovary and its relation to the uterine tube. The pelvis has been cut in section parallel to, but at some distance from, the median plane.

tubaria is applied to the superior end of the ovary, as it is most intimately connected with the uterine tube; the term extremitas uterina is used with reference to the inferior extremity, since this part of the ovary is connected with the uterus by a fibrous cord, termed the ligament of the ovary. The flattened surfaces of the ovary are called facies medialis and facies lateralis, and the borders separating them margo mesovaricus or mesovarian border, and margo liber or free border. The free border is convex; while the mesovarian, which is straighter and narrower, is connected by a very short peritoneal fold, the mesovarium, with the posterior layer of the broad ligament of the uterus. The vessels and nerves enter the ovary at this mesovarian border, which is therefore often termed the hilus of the ovary.

Position and Relations of the Ovary.-When the ovary occupies its most usual, or typical, position the long axis of the gland is vertical. Its lateral surface lies against the wall of the pelvis, and its medial surface looks medially towards the pelvic cavity. The peritoneum of the pelvic wall, where the ovary lies 
against it, is depressed to form a little fossa termed the fossa ovarii, within which the ovary is placed. In the floor of this fossa are the obturator nerve and vessels. The tubal extremity of the ovary lies below the level of the external iliac vessels, and its uterine extremity is placed just above the level of the peritoneum covering the pelvic floor. The fossa ovarii, in which the ovary lies, extends as far forwards as the obliterated umbilical artery, and backwards as far as the ureter and uterine vessels. Thus the mesovarian border of the ovary lies just behind the line of the obliterated umbilical artery, and the free border is on a plane anterior to the ureter (Fig. 1029). The medial surface of the ovary is almost completely covered by the uterine tube, which, passing upwards on it near its mesovarian border, arches over the tubal extremity, and then turns downwards in relation to the free border and posterior part of the medial surface (Fig. 1029).

In some cases the ovary is found to lie behind, or more rarely in front, of the fossa described above, and its long axis may be oblique instead of vertical. The above description, however, corresponds to the typical position of the organ in women who have not borne children. When

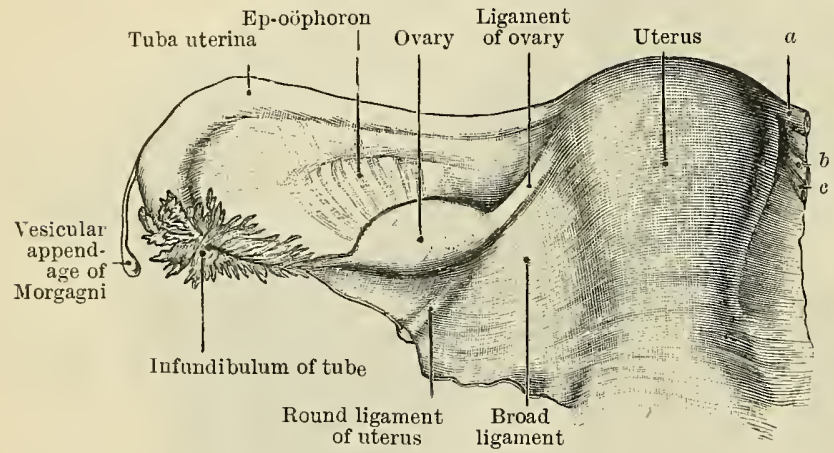

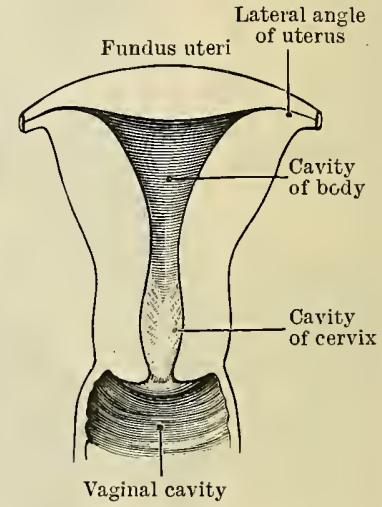

B

Fig. 1030.-A, The Posterior Aspect of the Uterus and Broad Ligament (the broad ligament has been spread out).

$a, b$, and $c$, the isthmus tubæ, the ligament of the ovary, and the round ligament of the right side cut short.

B, Diagrammatic Representation of the Uterine Cavity opened up fromi its Anterior Aspect.

the uterns is much inclined towards the right side of the body the left ovary has its long axis directed obliquely downwards and medially, the right gland remaining vertical.

Connexions of the Ovary.-When the ovary is in position a small somewhat triangular peritoneal fold passes upwards from its tubal extremity, and becomes lost in the peritoneum covering the external iliac vessels and the psoas major muscle (Fig. 1028). This fold has received the name of ligamentum suspensorium ovarii, and is a portion of the superior and lateral part of the broad ligament of the uterus, which here contains between its two layers the ovarian vessels and nerves as they pass down into the pelvis to reach the hilus of the ovary. The vessels and nerves entering the ovary along its mesovarian border are enclosed in a sheath of peritoneum derived from the posterior layer of the broad ligament. In this way the ovary is connected along the whole length of its anterior border by a very short mesentery, or mesovarium, to the posterior aspect of the broad ligament (Fig. 1030). The uterine extremity of the ovary is connected with the lateral angle of the uterus by a ligament called the ligamentum ovarii proprium or ligament of the ovary. This has the form of a rounded cord enclosed between the peritoneal folds of the broad ligament, and is attached to the uterus, behind and below the point of entrance of the uterine tube. It is chiefly composed of smooth muscle fibres continuous with those of the uterus. The tubal extremity of the ovary is directly connected with one of the largest of the fimbrix surrounding the abdominal end of the uterine tube, which receives the name fimbria ovarica, or ovarian fimbria of the tube (Fig. 1030). 
Descent of the Ovary.-Like the testes, the ovaries at first lie in the abdominal cavity, and only later assume a lower position. At birth the ovary lies partly in the abdominal, and partly in the pelvic cavity; soon, however, it takes up a position entirely within the pelvis minor. As in the male a gubernaculum is present in the early stages of development. The ligament of the ovary represents the upper part of the gubernaculum which is developed within the plica testis inferior in the male, and the round ligament of the uterus represents the inferior part, which is formed within the plica inguinalis (see p. 1295). It is a rare abnormality for the ovary, instead of entering the pelvis, to take a course similar to that of the testis, and pass through the inguinal canal into the tissue of the labium majus.

Structure of the Ovary.-The ovary is for the most part composed of a connective tissue, called the stroma ovarii, richly supplied by blood-vessels and nerves. The stroma contains very numerous spindle-shaped connective tissue fibres, and some elastic tissue. The surface of the ovary is covered by a layer of epithelium, which is composed of columnar cubical cells, and is continuous with the epithelium of the peritoneum forming the mesovarium. The ovarian epithelium is a persistent portion of the germinal epithelium of the embryo which covers the genital ridges, and from which the ova and other cells of the Graafian follicles are derived. The position in which it becomes continuous with the peritoneum can usually be distinguished as a fine white line near the hilus of the ovary. Shining through the epithelium of the fresh ovary (except

Down-growths of epithelium Ovum with its investing cells Germinal epithelium

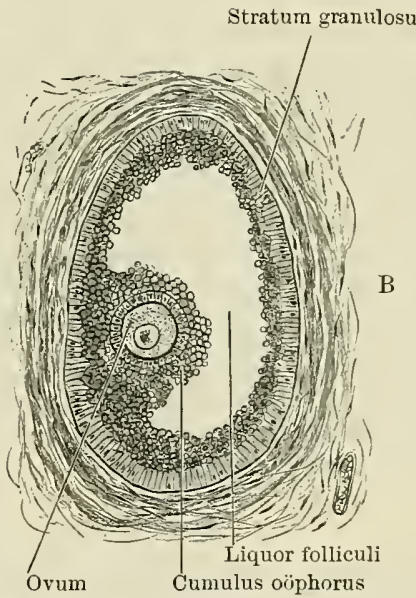

Nests of epithelial cells

Ovarian stroma

Vesicular ovarian follicle

WHICH THE OVARIAN (GRAAFIAN) Follicles ARISE DURING THE DEVELOPMENT OF THE OVARY. B. DIAGRAM ILLUSTRATING THE Structure of a Pipe or Vesicular Ovarian (Graafian) Follicle.

in old age) are usually to be seen a variable number of small vesicles-the folliculi oöphori vesiculosi (0.T. Graafian follicles), in which the ovula, or ova, are contained. The number of follicles visible, and also the size which each follicle reaches before it ruptures and sheds its contents, is by no means constant. When a follicle ruptures and discharges the ovum its walls at first collapse, but later the cavity becomes filled with extravasated blood and cellular tissue of a yellowish colour. The resulting structure, called a corpus luteum, slowly degenerates unless impregnation has taken place, in which case it develops and becomes larger during pregnancy. As it atrophies the cells of the corpus luteum disappear, and the structure, losing its yellow colour, receives the name of corpus albicans. After a time the corpus albicans completely disappears. Owing to the periodic rupture of the Graafian follicles, the surface of the ovary, which is at first smooth and even, becomes in old age dimpled and puckered.

A section through the ovary, especially in young children, presents in its superficial part a somewhat granular appearance, which is due to the presence of enormous numbers of small follicles, or collections of epithelial cells, embedded in the connective tissue near the surface of the ovary. The larger follicles lie deeper in the stroma, but when they become fully developed they pass towards the surface, where the ripe follicles are often seen slightly projecting and ready to burst. In the deepest part of the ovary the blood-vessels are most numerous, and here also some smooth muscle fibres are to be found.

The ova and the other cells that compose the Graafian follicles are derived originally from the germinal epithelium which covers the developing ovary in the embryo. The epithelium, at first simple, grows down into the underlying tissue in the form of branching 
tube-like processes, or "egg tubes." This takes place during fœtal development, and the branching cellular processes so formed become broken up, within the stroma, into little nests or clumps of cells, each of which becomes a Graafian follicle. From the beginning some cells of the egg tubes are larger than the others; these become the future ova, while the cells round them become the investing cells of the follicle. The investing cells, at first flattened, form a single layer round each ovum. Later becoming columnar, as the follicle increases in size and sinks more deeply in the stroma, these cells divide in such a manner that the ovum becomes surrounded by a double layer of cells. Fluid-liquor folliculi-accumulates between the two cellular layers, except at one place where the inner cells surrounding the ovum remain attached to the outer layer or stratum granulosum. To the inner cellular mass enclosing the ovulum, or ovum, the term cumulus oöphorus, or discus proligerus, is applied (Fig. 1031). The ripe follicle contains a relatively large amount of fluid, and the surrounding stroma becomes differentiated to form for it a theca folliculi, or capsule. This capsule is composed of an inner more vascular layer, the tunica interna, and an outer more fibrous layer, the tunica externa. There is reason to believe that in the human subject the formation of ova and follicles ceases before birth, and that the appearances which have led to the belief that they may originate during the first years of extra-uterine life have been due to pathological conditions. In the young child there are enormous numbers of small follicles in the superficial parts of the ovary, but in old age none are found in this situation.

The appearance and structure of the ripe ova are described on pp. 13-16.

Vessels and Nerves of the Ovary.-The ovarian arteries, corresponding to the internal spermatic arteries of the male, are a pair of long slender vessels which spring from the anterior aspect of the aorta, below the level of origin of the renal vessels. Each gains the pelvis in the fold of peritonetum forming the suspensory ligament of the ovary, and enters the ovary at its mesovarian border, or hilus. The ovarian artery anastomoses freely near the hilus with other vessels derived from the uterine arteries. The blood is returned by a series of communicating veins, similar to the plexus pampiniformis in the male.

The nerves of the ovary are derived chiefly from a plexus which accompanies the ovarian artery, and which is continuous above with the renal plexus. Other fibres are derived from the inferior part of the aortic plexus, and join the plexus on the ovarian artery (plexus arteriæ ovaricæ). The afferent impulses from the ovary reach the central nervous system through the posterior root fibres of the tenth thoracic nerve.

The lymph-vessels of the ovary join with those from the upper part of the uterus, and end in the lumbar lymph-glands.

\section{TUBE UTERINÆ.}

The uterine tubes (O.T. Fallopian tubes) are a pair of ducts or passages which convey the ova, discharged from the Graafian follicles of the ovaries, to the cavity of the uterus. Each tube is about four and a quarter inches in length, and opens at one end into the pelvic cavity near the ovary, and at the other end by a smaller opening into the lateral part of the uterine cavity. The tube is enclosed in a fold of peritoneum called the mesosalpinx, which is a portion of the broad ligament of the uterus.

The opening of the tube into the pelvic cavity-or ostium abdominale - is of small size, being only about $2 \mathrm{~mm}$. in diameter when its walls are relaxed, and much narrower when the muscular coat of the tube is contracted. This opening is placed at the bottom of a funnel-like expansion of the tube called the infundibulum tubæ uterinæ, the margins of which are produced into a number of irregular processes or fimbriæ tubæ. The presence of these fimbriæ, many of which are branched or fringed, has given the name fimbriated extremity to this end of the uterine tube. The surface of the fimbriæ which looks into the cavity of the infundibulum is covered by a mucous membrane continuous with that lining the tube, while the outer surface is clothed by peritoneum. The mucous surfaces of the larger fimbriæ present ridges and grooves which are continued into the folds and furrows of the mucous coat of the tube. One of the fimbriæ, usually much larger than the rest, is connected either directly or indirectly with the tubal extremity of the ovary, and to it the name fimbria ovarica, or ovarian fimbria, is applied. The part of the tube continuous with the infundibulum, and into which the ostium abdominale leads, is called the ampulla tubæ uterinæ. This, the widest and longest portion of the uterine tube, is usually tortuous and of varying diameter, being in some places slightly constricted, and in others distended. The wide, thin-walled ampulla ends in the narrower, thicker-walled, and much shorter isthmus tubæ uterinæ 
which joins the lateral angle of the uterus. The last portion of the canal, or pars uterina, is embedded in the substance of the uterine wall, which it traverses to reach the cavity of the uterus (Fig. 1032, B). The opening into the uterus, or ostium uterinum tubæ, is smaller than the ostium abdominale, being about $1 \mathrm{~mm}$. in diameter. The lumen of the canal gradually increases in width as it is traced outwards from the uterus towards the ovary.

Course of the Uterine Tube.-Traced from the lateral angle of the uterus the uterine tube is directed at first horizontally in a lateral direction towards the uterine extremity of the ovary. It then passes upwards in relation to the medial side of the mesovarian border of the ovary, until it reaches the tubal extremity, where, arching backwards, it descends along the posterior or free border, resting against the medial surface of the ovary (Fig. 1028). As the uterine tube describes this loop it often covers almost the entire medial surface of the ovary. The fimbriated end of the tube is applied against the free border and inferior part of the medial surface of the ovary, and from it the ovarian fimbria pass upwards to gain attachment to the tubal extremity of the gland.

The fimbriated end of the uterine tube lies in the abdominal cavity until the ovary in its descent has entered the pelvis.

Structure of the Uterine Tubes.-The wall of each tube, which is surrounded by a covering of peritoneum or tunica serosa, is composed of a number of concentric layers or coats. Immediately beneath the peritoneum is a layer of loose connective tissue, the tunica adventitia, in which lie mauy vessels and nerves. Beneath this is the tunica muscularis, composed of two strata of smooth muscle fibres-a more superficial thin stratum of longitudinally arranged fibres, the stratum longitudinale, and a deeper thicker layer, the fibres of which are circularly disposed, the stratum circulare. Deeper is a submucous layer or tela submucosa, and then the lining membrane or tunica mucosa. In the part of the tube near the uterus the muscular layer is thicker than towards the other end, and in the isthmus it forms the chief part of the wall. The mucous membrane, on the contrary, is thickest towards the fimbriated"end, and here it forms the chief part of the tube wall. The stratum of circular muscle fibres is especially well developed near the uterus. The mucous membrane is thrown into numerous longitudinal folds, the plicæ tubariæ, which in the ampulla are exceedingly complex, the larger ones being beset on the surface by smaller folds. In transverse sections of this part of the tube the folds of the mucous membrane look like large branching processes projecting into, and almost completely filling up, the lumen of the tube. The mucons membrane is corered by a ciliated epithelium, the cilia of which tend to drive the contents of the tube towards the uterus. The epithelium is continuous with that of the uterus, and at the fimbriated end joins the peritoneum.

Vessels and Nerves of the Uterine Tube.-The uterine tube receives its chief blood-supply from a ramus tubarius of the uterine artery, but it also receives small branches derived from the ovarian artery. The veins of the tube pour their blood partly into the uterine and partly into the ovarian veins. The lymph-vessels join the lumbar group of lymph-glands. The nerves are derived from the plexus that supplies the ovary, and also from the plexus in comnexion with the uterus. The afferent fibres appear to belong to the elerenth and twelfth thoracic and the first lumbar nerves.

\section{EP-OÖPHORON AND PAR-OÖPHORON.}

These are two rudimentary structures found between the layers of the broad ligament.

The ep-oöphoron (often called the organ of Rosenmiuller), or parovarium, lies in the mesosalpinx between the uterine tube and the ovary. In the adult it consists of a number of small rudimentary blind tubules lined by an epithelium. One of these tubules - the ductus epoöphori longitudinalis (O.T. duct of Gärtner)-lies close to, and runs nearly parallel with, the uterine tube. It is joined by a number of the other tubules, or ductuli transversi, which enter it at right angles from the neighbourhood of the ovary. The longitudinal duct is a persistent portion of the Wolffian duct, and represents the canal of the epididymis in the inale, while the tubules which join it are derived from the mesonephros and represent the efferent ductules of the testis (and probably also the ductuli aberrantes of the duct of the epididymis). The ep-oöphoron is best seen by holding up to the light the part of the broad ligament in which it lies. 
One or more small pedunculated cystic structures, called appendices vesiculosi (O.T. hydatids of Morgagni), are often seen near the infundibulum of the uterine tube. These are supposed to represent portions of the upper end of the Wolffian duct.

The par-oöphoron is a collection of rudimentary tubules also enclosed by the layers of the mesosalpinx, but lying nearer the uterus than the ep-oöphoron. These very rudimentary tubules represent the paradidymis in the male, and are derived from the part of the mesonephros which lies nearer the caudal end of the body of the embryo. Thongh sometimes visible in the child at birth, the paroöphoron in the adult can only be made out with the aid of a lens.

\section{UTERUS.}

The uterus, or womb, is a hollow, thick-walled, muscular organ placed within the pelvis between the bladder in front and the rectum behind. The ova discharged from the ovary enter the uterus through the uterine tubes, and, if fertilisation has taken place, undergo their development within it. In form the uterus is somewhat pear-shaped, the wide upper end of the organ projecting freely upwards and forwards into the pelvic cavity, while the lower more constricted part is connected with the vagina. The usual length of the adult uterus (when non-pregnant) is three inches, its greatest breadth is nearly two inches, and its maximum thickness is about one inch. In the description of the uterus we distinguish between an upper larger portion, somewhat flattened from before backwards, composed of fundus and body, and a lower more cylindrical part called the cervix (Fig. 1032).

The part of the uterus that lies above the level of a line joining the points of entrance of the uterine tubes is called the fundus uteri. The fundus is convex from before backwards and from side to side, its anterior and posterior aspects being directly continuous with the anterior and pcsterior surfaces of the body of the organ.

The corpus uteri, when seen from in front or from behind, has a somewhat triangular outline, and lies below the fundus, with which it is continuous. The base of the triangle is directed upwards and is formed by a line joining the lateral angles of the uterus, or points of entrance of the uterine tubes, and the sides of the triangle correspond to the lateral borders of the uterus, which extend on each side from the lateral angle to the cervix. The margo lateralis or lateral border separates on each side the facies vesicalis (or anterior surface) from the facies intestinalis (or posterior surface) of the body. Both these surfaces are rounded, but the intestinal is much the more convex. The vesical surface rests against the upper aspect of the bladder, from which usually it is separated only by the layers of peritoneum forming the utero-vesical pouch. The intestinal surface forms the chief part of the anterior wall of the deep recess situated between the uterus and rectum, and is usually in contact with some part of the small intestine or the pelvic colon. The broad ligament passes laterally on each side of the uterus from the lateral border of the organ.

The cervix uteri is cylindrical, and at its commencement it is sometimes marked off from the body by a slight constriction. Its length is about one inch, and its inferior end, tapering somewhat, enters the upper part of the vagina. The cervix is attached to the margin of the opening in the vaginal wall, through which it passes, and in this way a portio supravaginalis is marked off from a portio vaginalis of the cervix. In the vaginal portion of the cervix there is an opening - the orificium externum uteri (O.T. external os uteri) - through which the cavity of the uterus communicates with that of the vagina. In the uterus which has never been pregnant this opening is nearly circular, but in women who have borne children it is usually a transverse slit with a somewhat irregular outline. In front of, and behind, this opening the cervix forms two lips, an anterior and a posterior, the labium anterius and the labium posterius. The anterior lip is thicker, and slightly more rounded; it is placed upon a lower level than the posterior lip, which is slightly longer and thinner. The cervix enters the vagina through the upper part of its anterior wall in such a manner that the external orifice of the uterus is directed backwards and downwards against the upper part of the posterior vaginal wall (Fig. 1033). 
Cavity of the Uterus. - In comparison with the size of the organ, the cavum uteri is of small size owing to the great thickness of the uterine wall. In the body, the cavity is merely a narrow chink between the anterior and posterior walls, which are almost in contact (Fig. 1033). When, however, the uterus is opened from above downwards in frontal section of the organ, the cavity of the body has a triangular outline (Fig. 1032). The base of the triangle is directed upwards, and corresponds to a line drawn between the openings of the uterine tubes, while the apex is directed downwards towards the cervix. The sides of the triangle are convex inwards towards the cavity. The cavity of the body becomes continuous with that of the cervix by an opening called the orificium internum uteri (O.T. internal os uteri), which is a little smaller and more circular than the external orifice of the uterus. The cavity of the cervix, canalis cervicis uteri, or cervical canal, extends Irom the internal orifice of the uterus, where it joins the cavity of the body, to the external orifice, where it opens into the vagina. It is a somewhat spindle-shaped passage, which is narrower above and below than in its middle part; sections show also that its antero-posterior diameter is shorter than its transverse one, owing to an approximation of its anterior and posterior walls. In the body of

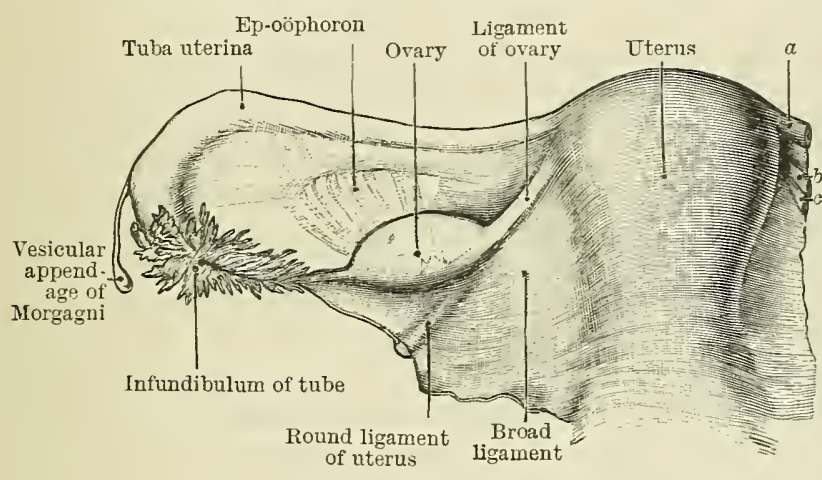

A

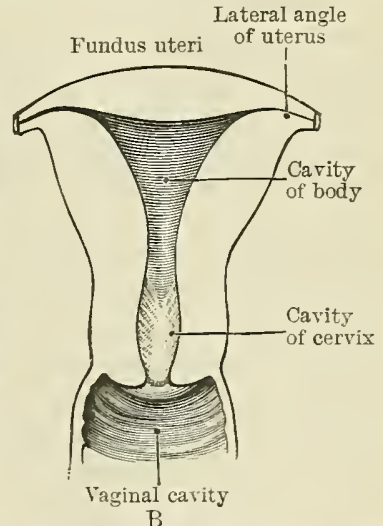

B

Fig. 1032.-A. The Posterior Aspect of the Uteros and Broad Liganent (the broad ligament has been spread out).

$a, b$, and $c$, the isthmus tubæ, the ligament of the ovary, and the round ligament of the right side cut short.

B. Diagrammatic Representation of the Uterine Cavity opened up from its ANterior Aspect.

the uterus the walls of the cavity are smooth and even, but in the cervical canal the mucous membrane forms a remarkable series of folds, called the plicæ palmatæ (O.T. arbor vitæ uterinæ). These consist of an anterior and a posterior longitudinally directed fold or ridge, from which a large number of secondary folds, or rugæ, branch off obliquely upwards and laterally (Fig. 1032, B).

Connexions of the Uterus and its Relations to the Peritoneum.-In addition to the uterine tubes at its upper lateral angles, and the vagina below, the uterus possesses other important connexions. Some of these are simply peritoneal folds passing from the uterus to neighbouring structures; others contain fibrous connective tissue, or smooth muscle fibres.

The peritoneum covering the fundus of the uterus is continued down over the vesical surface as far as the junction of the body and cervix, where it leaves the uterus to be reflected on to the bladder, forming the utero-vesical fold, or "anterior ligament of the uterus." The peritoneal recess between the bladder and the uterus is called the excavatio vesicouterina, or utero-vesical pouch. Below the level of this pouch the anterior aspect of the cervix is connected by loose tissue with the posterior, or basal, part of the bladder. Posteriorly the peritoneum covers the whole of the uterus, except the small portion of the cervix which projects into the upper part of the vagina. The peritoneum covering the intestinal surface of the uterus is continued to such a depth that it invests a small portion of the upper part of the posterior wall of the vagina before it is reflected on to the rectum, to form the recto-vaginal fold (Fig. 1033). The deep pouch between the uterus and 
vagina in front and the rectum behind is called the excavatio rectouterina, or rectouterine pouch of Douglas, and its entrance is bounded on each side by a crescentic peritoneal fold, which passes from the posterior surface of the cervix uteri to the posterior wall of the pelvis, and ends near the side of the rectum. These crescentic folds are called the plicæ rectouterinæ, or recto-uterine folds of Douglas, and each contains between its layers a considerable amount of fibrous and smooth muscular tissue. A few of these fibres, which are continuous with the uterine wall, pass backwards to reach the rectum and constitute the musculus rectouterinus; others are said to gain an attachment to the front of the sacrum, and form a utero-sacral ligament. In many cases the recto-uterine folds become continuous with one another across the median plane behind the cervix uteri, and form, in this position, a transverse ridge termed the torus uterinus. The recto-uterine pouch of the female represents the recto-vesical pouch of the male, and the folds which bound it laterally, namely, the recto-uterine folds, correspond to the sacro-genital folds (sometimes called posterior false ligaments of the bladder) in the male sex.

The peritoneum of the vesical and intestinal surfaces, leaving the uterus along each lateral border to reach the side wall of the pelvis, forms the broad ligament of the uterus.

The ligamentum latum uteri, or broad ligament, is a wide peritoneal fold which passes from the lateral border of the uterus to the pelvic wall, and contains between its layers several important structures (Fig. 1032). The plane of the medial part of the ligament is determined by the position of the uterus. When the uterus is normally placed, the ligament has an anterior surface which looks downwards as well as forwards, and a posterior one which looks upwards and backwards. Near its attachment to the pelvis the ligament is placed more vertically. The free edge of the ligament contains the uterine tube, and follows the course pursued by that structure. Thus, in the undisturbed condition of parts, it at first passes horizontally laterally towards the uterine extremity of the ovary, where it ascends to arch over the tubal pole of the ovary on its medial side. Owing to the course pursued by the uterine tube round the ovary, the broad ligament forms a kind of curtain over the gland, and the ovary lies in a little pocket formed by the broad ligament, to which the name of bursa ovarica is applied (Figs. 1028 and 1029). This bursa ovarica is not to be confused with the fossa ovarii, or depression on the side wall of the pelvis, against which the ovary is usually placed.

The various structures in connexion with the broad ligament are most easily demonstrated when the ligament is spread out as flat as possible.

The ovary is connected with the posterior layer of the broad ligament by a very short mesentery, called the mesovarium, which, passing to the hilus, encloses the ovarian vessels and nerves as they reach the ovary. The part of the broad ligament which slings the uterine tube is called the mesosalpinx. When the ligament is spread out, the mesosalpinx has the form of a narrow triangle, the apex of which is at the lateral angle of the uterus, while the upper side is formed by the uterine tube, and the inferior one by the ligament of the ovary and the ovary itself. The narrow base of the triangle is directed laterally. Between the layers of this part of the broad ligament are situated the ep-oöphoron, or parovarium, and the par-oöphoron (Fig. 1032). The part of the broad ligament below the level of the mesosalpinx is termed the mesometrium, and contains, especially in its lower part, a considerable amount of fatty connective tissue, the parametrium, and unstriped muscle fibres. The ureter and the uterine vessels lie in the lowest part of the broad ligament where it joins the pelvic floor. The fibrous and smooth muscle tissue which lies in the lower part of the broad ligament, immediately below the uterine artery, forms what is known as the lateral cervical ligament of the uterus. It is continuous with the dense tissue surrounding the branches of the hypogastric artery, and in vertical antero-posterior section has a triangular outline near its attachment to the cervix uteri.

The highest part of the attached lateral portion of the broad ligament forms the ligamentum suspensorium ovarii or suspensory ligament of the ovary, and contains between its layers the ovarian vessels and nerves as they enter or leave the pelvis.

The ligamentum ovarii proprium, or ligament of the ovary, is a rounded fibrous 
cord, of about one inch in length, which is attached by its lateral end to the uterine pole of the ovary, and by its medial end to the lateral angle of the uterus immediately below and behind the entrance of the uterine tube. This ligament, which is largely composed of unstriped muscle fibres continuous with those of the uterus, is enclosed in a slight fold derived from the posterior layer of the broad ligament.

The ligament of the ovary represents the upper portion of the gubernaculum which appears in the embryo.

The ligamentum teres uteri, or round ligament of the uterus, is a narrow flat band attached to the uterus just in front of, and a little below, the opening of the uterine tube. Near the uterus it contains numerous smooth muscle fibres, which are continuous with those of the uterus; more laterally it is chiefly composed of fibrous connective tissue. Lying in the anterior part of the broad ligament, it reaches the pelvic wall, and is then directed forwards and slightly upwards to cross the obliterated umbilical artery and the pelvic brim. After it has reached the pelvic wall its course is comparable to that of the ductus deferens in the male, and, like the latter, it leaves the abdomen to traverse the inguinal canal (Figs. 1028 and 1029). It finally ends in the subcutaneous tissue and skin of the labium majus. Its terminal part is composed of connective tissue only.

In some cases a small diverticulum of the peritoneal cavity can be traced accompanying the round ligament through the abdominal wall. This is called the processus vaginalis peritonei (O.T. canal of Nuck), and corresponds to the processus vaginalis of the male (p. 1294).

The round ligament of the uterus represents the lower portion of the gubernaculum testis which appears in the male embryo (see pp. 1294 and 1313).

Position and Relations of the Uterus.-The position occupied by the uterus in the pelvis is not always the same, but varies with the conditions of the neighbouring organs. The lower cervical part is, however, much more firmly fixed in place than the body and fundus, which possess a considerable amount of mobility. Usually the level of the external orifice of the uterus will be found to correspond to that of a horizontal plane passing through the upper margin of the symphysis pubis. The uterus rarely lies exactly in the median plane of the body, but usually bends to one or other side, most frequently towards the right. The vesical surface of the uterus rests against the bladder, and follows the rising or falling of its superior wall as that organ becomes filled or emptied. When the bladder is empty the long axis of the uterus points forwards and upwards, and the organ is said to be in an anteverted position. Also, the long axis of the uterus is bent on itself where the body joins the cervix, and so the organ is said to be anteflexed. The anteflexion is due to the fact that the more rigid cervix is fixed, while the movable upper part of the uterus sinks forwards, following the bladder wall. With the empty condition of the bladder the angle formed between the long axis of the uterus and that of the vagina is about a right angle. When the bladder becomes filled, the anteversion and anteflexion of the uterus become less marked, owing to the body and fundus being pushed backwards. Finally, if the, rectum is empty and the bladder very much distended, the uterus is pushed so much backwards that the long axis of the organ may nearly correspond to that of the vagina. The uterus is then said to be retroverted. Superiorly a part of the peritoneal cavity intervenes between the vesical surface of the uterus and the bladder, but lower down the two organs are separated merely by a small quantity of connective tissue. The intestinal surface of the uterus looks into the pouch of Douglas, and is usually, like the fundus, in relation to some loops of the small intestine or pelvic colon. Laterally the uterus is related to the broad ligaments. The terminal parts of the ureters pass downwards, medially, and a little forwards on the lateral aspects of the cervix, but are separated from it by an interval of about three-quarters of an inch. The lowest part of the cervix is, as we have seen, enclosed within the cavity of the vagina.

On each side of the cervix uteri and upper part of the vagina there is an interval in which lie numerous large vessels. These are surrounded by loose fatty tissue, which is continued upwards for a considerable distance between the layers of the broad ligament. This loose tissue, which is of surgical importance, has received the name parametrium. 
Structure of the Uterus. - The thick uterine wall is composed of three chief layers, which are termed respectively the serous, the muscular, and the mucous coats.

The tunica serosa, serous coat, or perimetrium, is derived from the peritoneum, and covers the whole organ except the part of the cervix which projects into the vagina and the anterior surface of its supra-vaginal portion. At the lateral borders it is continued into the broad ligaments. Over the fundus and body of the uterus the serous coat is very firmly adherent to the deeper layers, and cannot be easily peeled off without tearing either it or the underlying muscular tissue. Near the lateral borders the peritomeum is less firmly attached, and over the posterior aspect of the cervix it may readily be stripped off without injury to the underlying structures.

The tunica muscularis or muscular coat is composed of unstriped fibres, and forms the chief part of the uterine wall. Inferiorly the muscular coat of the uterus becomes continuous with that of the vagina. The more superficial layer of the muscular coat sends prolongations into the recto-uterine folds, into the round and broad ligaments of the uterus, and into the ovarian ligaments. Other fibres join the walls of the uterine tubes. The main branches of the blood-vessels and nerves of the uterus lie among the muscle fibres. In the deeper layers of the muscular coat a considerable amount of connective tissue and some elastic fibres are to be found. The muscular coat of the cervix, or tunica muscularis cervicis, contains more connective and elastic tissue than that of the body, and hence the greater firmness and rigidity of the cervical part of the uterus.

The deeper and thicker part of the muscular tissue of the uterus is considered by some anatomists to represent a muscularis mucosæ, and is therefore described as part of the mucous coat. The deep and superficial portions of the muscular coat are, howerer, quite continuous, and there is no representative of a submucous vascular layer of tissue such as in the alimentary canal separates the muscular coat from the muscularis mucose. In the uterus the blood-ressels lie in the muscular coat.

The tunica mucosa or mucous coat in the body of the uterus is smooth and soft, and covered by colımnar ciliated epithelium. Simple tubular glands, glandulæ uterinæ, also lined by a ciliated epithelium, are present in the mucous membrane, and penetrate in their deeper parts into the muscular coat. In the cervix of the uterns the mucous coat is firmer and nore fibrous than in the body, and its surface is not smooth, but presents a number of peculiarly disposed ridges which have been already described. Like the mucous membrame of the body of the uterus, that of the cervix is covered by a ciliated epithelium which passes into squamous epithelium just inside the external orifice of the uterus. The cervix uteri possesses, in addition to unbranched tubular glands, resembling those present in the body, numerous somewhat branched glands, the glandulæ cervicales uteri. Both kinds of glands are lined by ciliated epithelium. In many cases little clear retention cysts, "ovules of Naboth," are to be seen in the cervical mucous membrane. These arise as a result of obstruction at the mouths of the glands.

Difference in the Uterus at Different Ages.-At birth the cervix uteri is relatively larger than in the adult organ, and its cavity is not distinctly marked off from the interior of the body by an internal orifice. At this time also the plicæ palmatæ extend throughout the whole length of the uterus. The organ grows slowly until just before puberty, when its growth is rapid for a time. As the body increases in size the mucous membrane becomes smooth and the plicæ palmatæ become restricted to the cervix. In women who have borne children the cavity remains permanently somewhat wider and larger than in cases where the uterus has never been pregnant.

In old age the uterine wall becomes harder and has a paler colour than it possesses in the young subject.

Variations.-In rare cases the uterus may be divided by a septum into two distinct cavities, or its lateral angles may be produced into straight or curved processes, called "horns" or cornua. The latter abnormality recalls the appearance of the bicornuate uteri of some animals. Both the above conditions arise from an arrest in the fusion of the two separate trbes-the Mitllerian ducts-which normally unite in the embryo to form the uterus.

Periodic Changes in the Uterine Wall.-At each menstrual period a remarkable series of changes occurs which results in a periodic shedding of the superficial parts of the uterine mucous membrane. For a few days before menstruation begins, the mucous membrane gradually thickens and becomes more vascular, while at the same time its surface becomes uneven. Soon the superficial parts of the 
mucous membrane disintegrate and hæmorrhage takes place from the small superficial blood-vessels. In this way a hæmorrhagic discharge is caused, and the superficial parts of the uterine mucous membrane are shed at each period. When menstruation is over the mucous membrane is rapidly regenerated.

Pregnant Uterus. - The pregnant uterus increases rapidly in size and weight, so that from being three inches in length and one ounce in weight, it becomes by the eighth month about seven or eight inches in length and sometimes as much as two pounds in weight. In shape the uterus is now oral or rounded, with a thick wall composed chiefly of muscle fibres arranged in distinct layers. The rounded fundus is very prominent. The round ligaments are stronger and better marked, and the layers of the broad ligament become separated in their medial parts by the growth of the uterus between them. The blood-vessels, especially the arteries, are very large and tortious. The changes which occur in the mucous membrane of the pregnant uterus are intimately connected with the manner in which the developing fotus receives its nutrition, and have been noticed on pp. 56 et seq.

Vessels and Nerves of the Uterus.-The nterus receives its arterial supply mainly from the uterine arteries, which are branches of the hypogastric arteries, and also from the ovarian arteries, branches of the aorta. The vessels derived from these two sources communicate freely with one another. Each uterine artery, reaching the side of the lower part of the uterus, divides into a large branch which passes upwards to supply the body and fundus, and a much smaller branch which passes downwards to supply the cervix. The ressels distributed to the body and fundus have an exceedingly tortuous course. The branches of the uterine artery, having entered the muscular coat, break up within its deeper layers into smaller twigs which supply the muscular tissue and the mucous coat. The small uterine branch from the ovarian artery reaches the uterus in the region of the lateral angle. During pregnancy the arteries become enormously enlarged.

The thin-walled veins form a plexus which pours its blood into the tributaries of the hypogastric vein.

The nerves of the uterus are derived chiefly from a plexus placed in the neighbourhood of the cervix uteri, to which the term plexus uterovaginalis or "cervical ganglion" is applied. Superiorly this plexus is continuous with the hypogastric plexus, but it also receives fibres from the third and fourth sacral nerves. In addition to fibres from the plexus uterovaginalis, the uterus receives fibres directly from the hypogastric plexus, and also from the plexus vesicalis.

Clinical observations indicate that afferent impulses reach the central nervous system from the uterus through the posterior roots of the tenth, eleventh, and twelfth thoracic nerves, the first lumbar, and the second, third, and fourth sacral nerves.

The numerous lymph-vessels coming from the body of the uterus join those from the ovary, and end for the most part in the lumbar lymph-glands. Along the course of the round ligament of the uterus there are a few lymph-vessels which establish a connexion between the lymph-network surrounding the uterus and the inguinal lymph-glands. The lymphvessels from the cervix uteri end in the gland placed near the bifurcation of the common iliac artery.

\section{VAGINA.}

The vagina is a passage about three inches in length, open at its lower end, and communicating above with the cavity of the uterus. The passage is directed downwards and forwards, describing a slight curve which is convex backwards. The axis of the vagina forms with that of the uterus an angle which is open forwards. This angle is usually somewhat greater than a right angle, but varies with the condition of the neighbouring viscera (p. 1319). The vagina is wider in its middle part than it is at either end, and normally its anterior and posterior walls are in contact. In transverse section the lower part is usually an $\mathrm{H}$-shaped cleft, the middle part a simple transverse slit, while the lumen of the upper portion, into which the cervix uteri projects, is more open. The lower part of the cervix uteri has the appearance of entering the vagina through the upper portion of its anterion wall (Fig. 10:33). As more of the posterior than of the anterior part of the cervix projects into the vagina, a deeper recess is formed between the vaginal wall and the cervix behind than in front or laterally. The term anterior formix is often applied to the angle, or recess, in front; posterior fornix to the deeper angle behind, and lateral fornix to the recess on each side of the cervix uteri, between it and the wall of the vagina. The anterior wall of the vagina (paries anterior) is shorter than the posterior (paries posterior), the former being about three inches in length, 
the latter about three and a half inches. At its lower end the vagina opens into the rima pudendi, the opening being situated behind the orifice of the urethra and the clitoris, and between the labia minora. The opening is partly closed in the virgin by a thin crescentic or annular fold, called the hymen, torn fragments of which persist round the opening, as the carunculæ hymenales, after the fold itself has been ruptured.

Relations of the Vagina.-The anterior wall of the vagina in its upper part lies against the base of the bladder, but is separated from it by loose connective

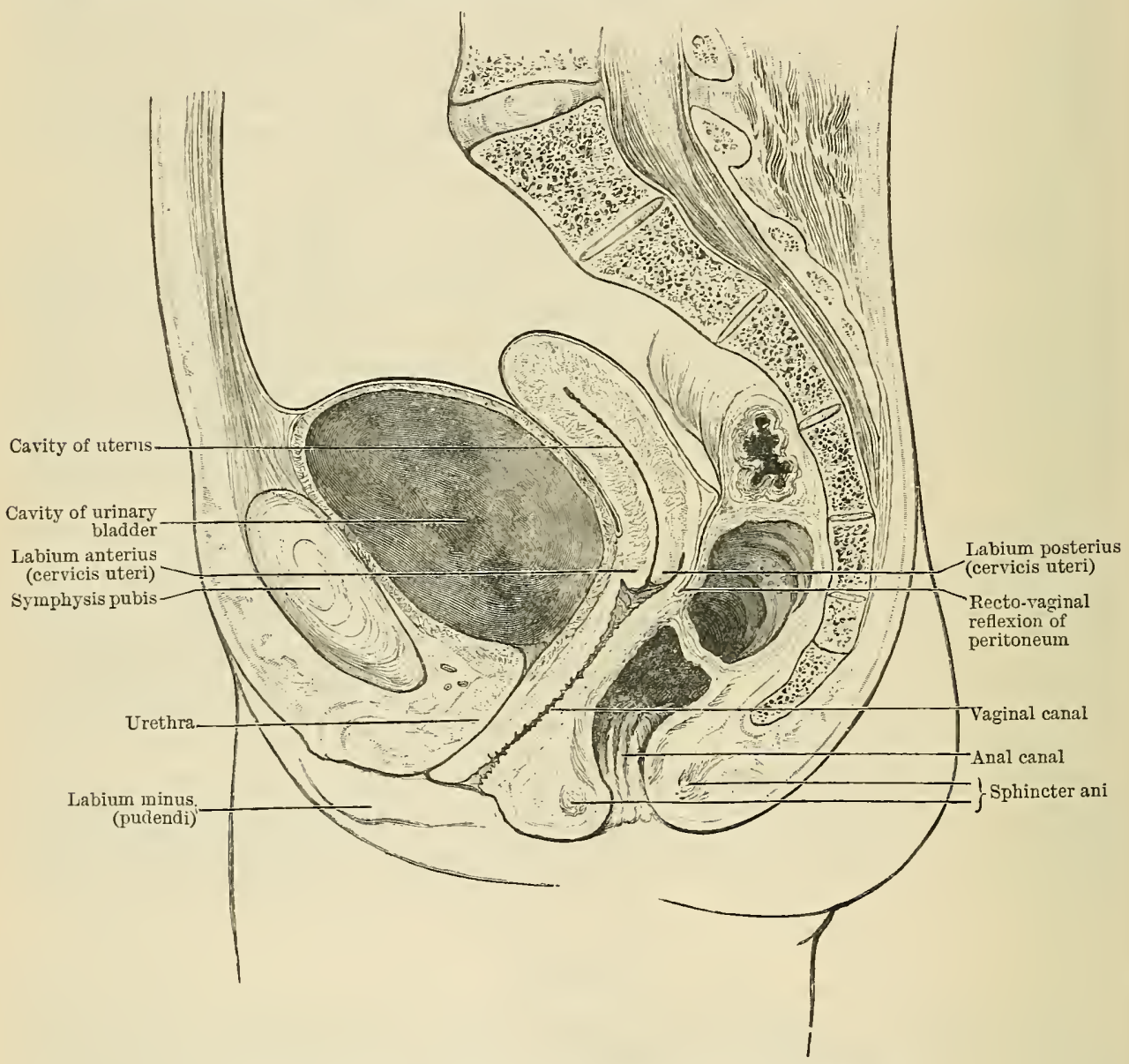

Fig. 1033.-Median Section of the Pelvis in ax Adult Female.

The cavity of the uterus is indicated diagrammatically.

tissue. Lower down, the anterior wall in the median plane is intimately connected with the urethra (Fig. 1033). Near the median plane, the posterior wall in its upper portion is covered for a distance of about a quarter of an inch by the peritoneum, which here forms the anterior boundary of the deepest part of the recto-uterine pouch. The depth to which the peritoneum of this pouch descends practically corresponds to the level of the spina ischiadica. Lower down, the posterior wall lies close against the rectum, from which it is separated by a layer of the pelvic fascia. As, however, the orifice of the vagina is approached, the rectum and vagina become separated by a considerable interval, which is occupied by a mass of fibrous and fatty tissue, often called the "perineum " or "perineal body." At the sides the vagina is supported by the levatores ani muscles. The terminal part of the ureter lies not far from the lateral wall of the upper part of the vagina, as it passes from above and behind downwards, medially and a little forwards to reach 
the bladder. Near its termination the vagina pierces the fascia inferior of the urogenital diaphragm, and is related laterally to the bulbus vestibuli, the larger vestibular glands, and the bulbo-cavernosus (sphincter vaginæ) muscle.

Structure of the Vagina.-The vaginal wall has a distinct tunica muscularis, composed of unstriped muscle fibres, most of which are longitndinally disposed. Towards

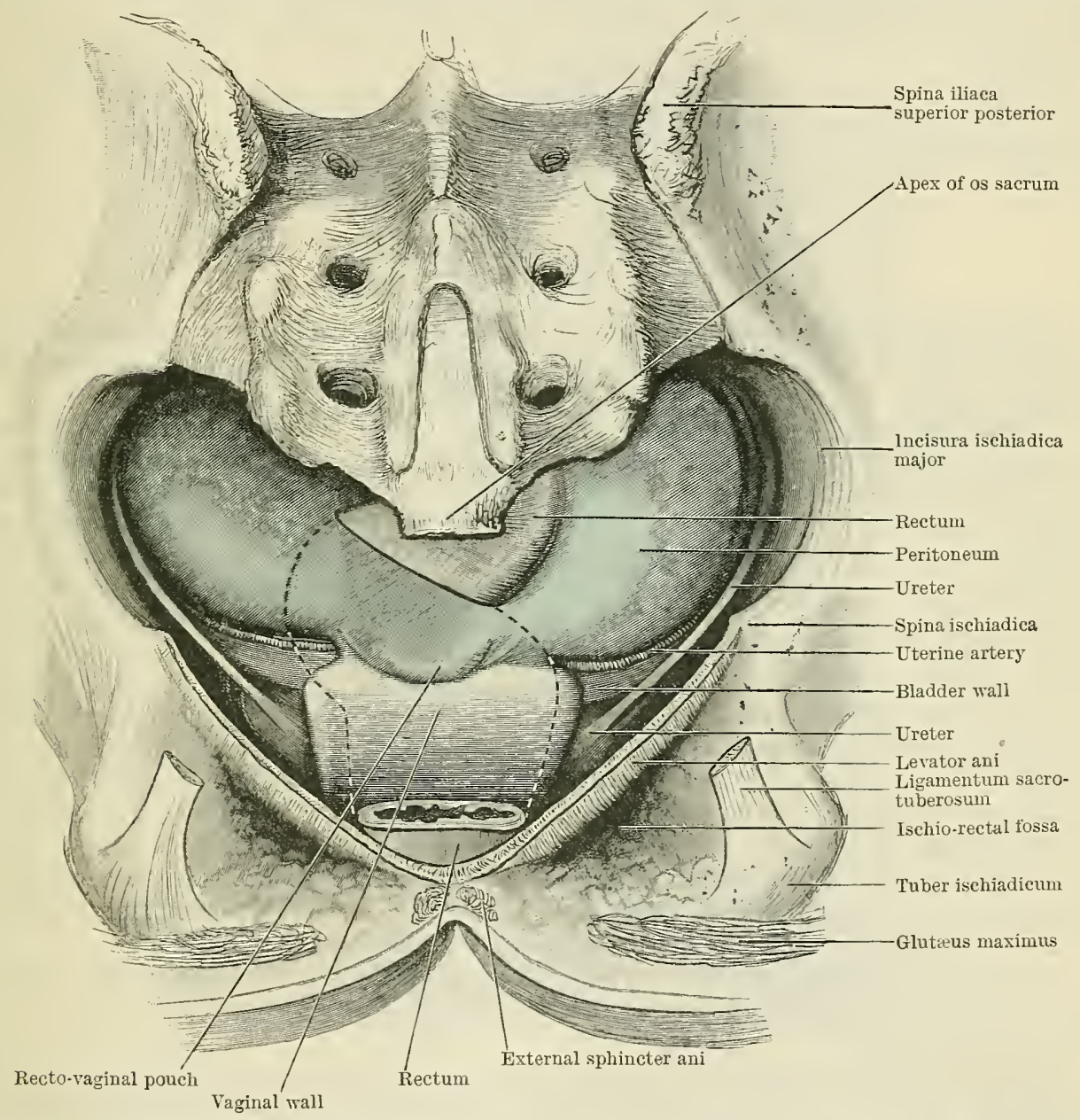

Fig. 1034.-Posterior Aspect of the Vagina, the Base of Bladder, and the Recto-vaginal Podch of Peritonedi.

The coccyx and the ligamentum sacrotuberosum and ligamentum sacrospinosum, together with the muscles attacherl to them, have been removed. The levatores ani have been separated along the median raphe, and drawn laterally. A considerable portion of the rectum has been removed, but the position which it occupied is indicated by the dotted lines. The peritoneum is indicated by a blue colour. The rectovaginal pouch is probably not quite so deep as usual. The triangular interval between the ureter ancl uterine artery was filled by a mass of fibro-muscular tissue, forming the lateral cervical ligament of the uterus.

the lower end of the passage circularly disposed bundles of striped muscle fibres, some of which are continuons with those forming a part of the urethral wall, are found in the muscular coat. The thick tunica mucosa, which has a stratified scaly epithelium, is corrugated, and presents a number of transverse ridges or elevations called rugæ vaginales. In addition to these transverse rugæ, a slightly marked longitudinal ridge, or column, is to be seen on the anterior and on the posterior wall of the vagina. These receive the name columnæ rugarum, and, like the transverse rugæ, are best seen in joung subjects and in the lower part of the vagina. The urethral canal lies in close relationship to the anterior column of the vagina in its lower part, and hence this portion of the anterior column is sometimes called the carina urethralis. 
Within the tunica mucosa are to be found small collections, or nodules, of lymphtissue.

The vaginal wall is surrounded by a layer of loose vascular connective tissue containing utumerons large communicating veins.

Vessels and Nerves of the Vagina.-The blood-stupply of the vagina is for the most part derived from the vaginal artery, the vaginal branch of the uterine artery, the vaginal branches of the middle hæmorrhoidal artery, and from the branches of the internal pudendal. The veins form a plexus surrounding the vaginal wall, and drain their blood into the tributaries of the hypogastric.

The lymph-vessels from the upper part of the vagina join the hypogastric group of glands, while those from the lower part end in the superficial inguinal glands.

The nerves of the vagina are derived from the plexus uterovaginalis and from the plexus vesicalis. Other fibres are derived directly from the third and fourth sacral nerves.

\section{THE FEMALE EXTERNAL GENITAL ORGANS. (PUDENDUM MULIEBRE.)}

The term pudendum muliebre, or vulva, is applied collectively to the female external genital organs, i.e. to the labia majora and the structures which lie between them.

Labia Majora.-The labia majora represent the scrotum in the male, and form the largest part of the female external genital organs. They form the lateral boundaries of the rima pudendi or urino-genital cleft, into which the urethra and vagina open. Each labium is a prominent rounded fold of skin, narrow behind where it approaches the anus, but increasing in size as it passes forwards and upwards to end in a median elevation, the commissura labiorum anterior, or the mons pubis or Veneris. The mons Veneris lies over the symphysis pubis, and, like the labia majora, it is composed.chiefly of fatty and areolar tissue, and is covered with hair. The lateral convex surface of each labium majus is covered by skin containing numerous sebaceous glands and resembling that of the scrotum in the male, but the medial flatter surface is smooth, and presents a more delicate integumentary covering. In some cases the posterior narrow ends of the labia majora are connected across the middle line in front of the anus by a slight transverse foldthe commissura labiorum posterior or posterior commissure.

Usually, especially in young adult subjects, the labia majora are the only visible parts of the external genital organs, since they are in contact with one another, and completely enclose the structures within the rima pudendi.

The round ligament of the uterus ends in the fatty tissue of the labium majus. The superficial subcutaneous tissue resembles that of the scrotum, but contains no muscular fibres.

The nerve-supply corresponds with that of the scrotum, the anterior part of each labium being supplied by the branches of the ilio-inguinal nerve, and the posterior part by branches from the internal pudendal and by the perineal branch from the posterior cutaneons nerve of the thigh. The blood-vessels of the labia majora are derived from the external pudendal arteries and from the perineal branches of the internal pudendal vessels.

Labia Minora.-The labia minora pudendi (O.T. nymphæ) are a pair of much smaller and narrower longitudinal folds, usually completely enclosed within the cleft between the labia majora. Diminishing in size, and becoming less marked in their posterior parts, the labia minora end by gradually joining the medial surfaces of the labia majora. In the young subject, a slightly raised transverse fold is usually seen connecting the posterior ends of the labia minora; to this fold the term frenulum labiorum pudendi (O.T. fourchette) is applied. Traced forwards, each labium minus divides into two portions, a lateral and a medial. The lateral portions of the two labia unite over the glans clitoridis, and form for it a fold or covering called the præputium clitoridis. The medial portions, uniting at an acute angle, join the glans and form the frenulum clitoridis. The skin of the labia minora resembles the integument on the medial or deep surface of the labia majora, being smooth, moist, and pink in colour. The medial surfaces of the labia minora are in contact with one another; their lateral surfaces are applied against the medial aspects of the labia majora. 
The openings of the urethra and vagina are placed in the median plane, in the interval between the labia minora, which must be separated to bring them into view.

The vestibulum vaginæ, or vestibule, is the name applied to the cleft that lies between the labia minora and behind the glans clitoridis. In its floor are the openings of the urethra, the vagina, and the minute ducts of the larger vestibular glands.

The term fossa navicularis is the part of the vestibule placed behind the vaginal opening and in front of the frenulum labiorum pudendi.

The orificium urethræ externum, or external urethral orifice, lies immediately in front of that of the vagina, and is about one inch behind the glans clitoridis. The opening has the appearance of a vertical slit, or of an inverted $V$ shaped cleft, the slightly prominent margins of which are in contact. On each side of the urethral orifice there may sometimes be seen the minute opening of the ductus paraurethra lis the frenulum labiorum is seen stretching across behind the fossa navicularis and in (see p. 1285).

The orificium vaginæ, or vaginal

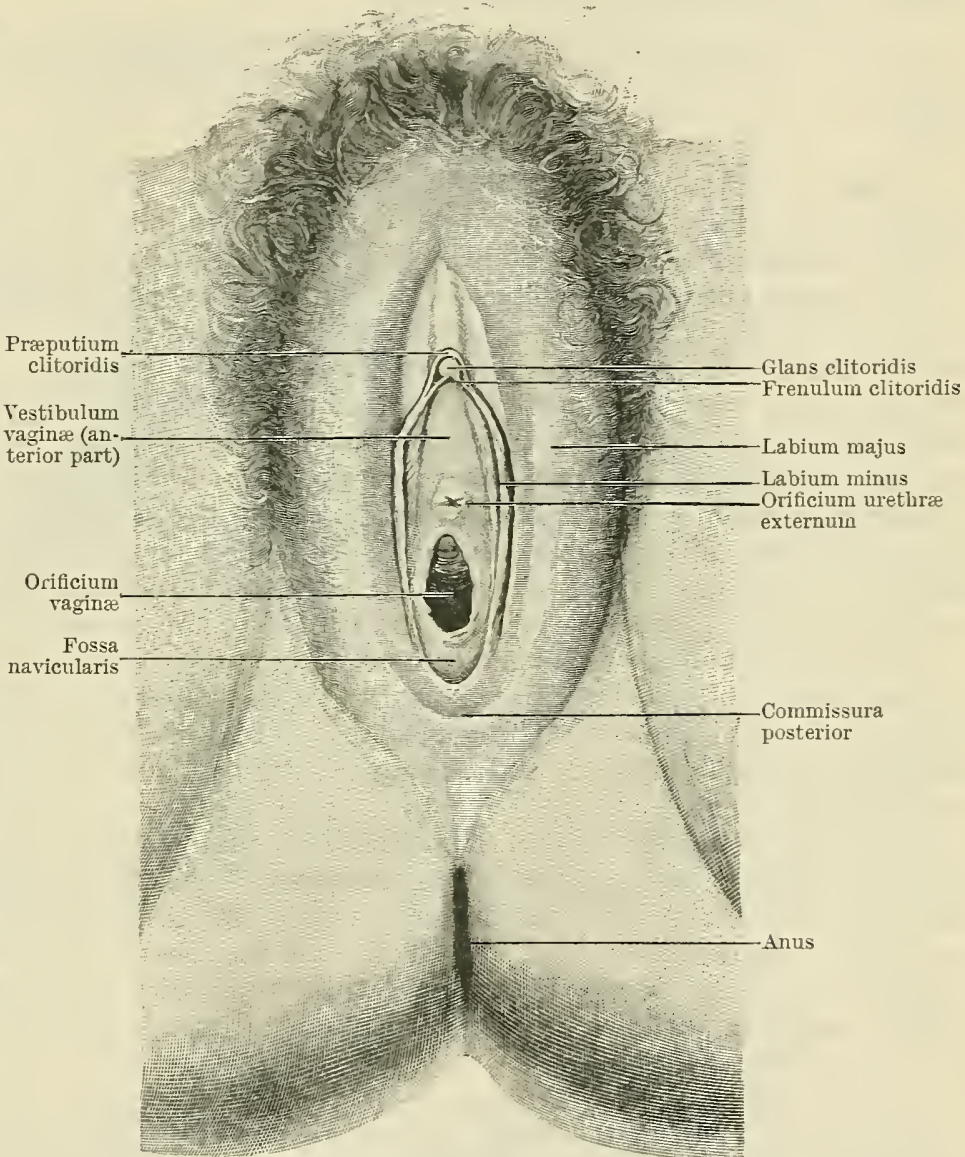

Fig. 1035.-Female Exterial Gexital Orgais. front of the posterior commissure. The ducts of the larger vestibular glands open in the intervals between the vaginal orifice and the medial edges of the labia minora.

opening, lies further back and below the orifice of the urethra. The appearance of the opening varies with the condition of the hymen-a membrane which in the young subject partly closes the aperture. When the hymen is intact the opening is small, and is only seen when the membrane is put on the stretch. When the hymen has been ruptured the opening is much larger, and round its margins are often seen small projections-carunculæ hymenales-which are to be looked upon as persistent fragments of the hymen.

The hymen is a thin membranous fold, partially closing the lower end of the vagina, and msually perforated somewhat in front of its middle point. The position of the opening gives the fold, when stretched, a crescentic appearance. The opening in the hymen is sometimes cleanly cut, sometimes fringed. The membrane is not stretched tightly across the lower end of the vagina, but is so ample that it projects downwards into the rima pudendi, and the parts of its upper surface are in contact with one another on each side of the opening. The opening is thus a median slit whose margins are normally in contact. The upper 
surface of the hymen is directly continuous with the vaginal wall, and on it are to be seen slight ridges continuous with the vaginal rugæ.

Developmentally the hymen appears to be a portion of the vagina.

On each side of the vaginal opening, and close against the medial side of the attached margin of the labium minus, is the minute opening of the duct of the glandula vestibularis major (O.T. Bartholin's gland). This is usually just large enough to be visible to the unaided eye.

Numerous minute mucons glands, the glandulæ vestibulares minores, open on the surface of the mucous membrane of the vestibule, between the urethral and vaginal orifices. The opening of the ductus paraurethralis at the side of the urethral orifice has been already noted, p. 1285 .

Clitoris.-The clitoris is the morphological equivalent of the penis, and is composed of a body and two crura. Upon the summit of the body is a minute glans. Unlike the penis, the clitoris is not traversed by the urethra.

The corpus clitoridis is composed for the most part of erectile tissue resembling that of the penis in the male. It is about an inch or an inch and a half in length, and is bent upon itself, forming an angle open downwards. The body of the clitoris tapers towards its distal end, which is covered by the glans clitoridis. The organ is enclosed in a dense fibrous coat, and is divided by an incomplete septum, the septum corporum cavernosorum, into two symmetrical and somewhat cylindrical portions, the corpora cavernosa clitoridis. These represent the corpora cavernosa penis of the male, and diverge from one another at the root of the clitoris to form the crura clitoridis. A ligamentum suspensorium clitoridis passes from the fibrous coat of the body of the clitoris to the symphysis pubis (Fig. 1036).

The glans clitoridis is a small mass of erectile tissue which is fitted over the pointed end of the body. It possesses, like the glans penis, which it represents, a very sensitive epithelium. The præputium, or fold of skin which covers it, and the frenulum clitoridis, which is attached to it inferiorly, are continuous with the labia minora (Fig. 1036).

The crura clitoridis diverge from the body posteriorly, and are attached to the sides of the pubic arch. Each is continuous with one of the corpora cavernosa, and has a firm fibrous sheath, which is covered by the corresponding ischio-cavernosus or erector clitoridis muscle. In structure the crura and body of the clitoris resemble the corpora cavernosa penis, while the glans more closely resembles the bulbus vestibuli, with which it is continuous through a structure known as the pars intermedia.

In the seal and some other animals, a bone, which represents the os penis of the male, is developed in the septum of the clitoris. This bone receives the name os clitoridis.

Arteries and Nerves of the Clitoris.-Each crus receives a branch, the arteria profunda clitoridis, from the internal pudendal, while the glans is supplied by branches of the arteria dorsalis clitoridis.

The nerve-supply of the clitoris is derived partly from the hypogastric sympathetic plexus and partly from the dorsal nerves of the clitoris, which are branches of the pudendal nerves.

Bulbus Vestibuli.-The bulbus vestibuli is a mass of erectile tissue, in the female, which corresponds developmentally to the corpus spongiosum urethræ of the male. In the female the fusion of the two halves of this structure is not nearly so complete as in the male, for the vagina and urethra separate the bulbus vestibuli into two lateral portions which are only slightly connected in front by a narrow median part called the pars intermedia. Each lateral portion of the bulb is thick and massive posteriorly, and more pointed in front where it joins the pars intermedia. It rests against the lateral wall of the vagina, and upon the superficial aspect of the fascia inferior of the urogenital diaphragm. It represents onehalf of the corpus cavernosum urethræ of the male. Superficially it is covered by the bulbo-cavernosus muscle. The pars intermedia lies above the opening of the urethra, and becomes continuous with the tissue of the glans clitoridis.

The bulbus vestibuli is for the most part composed of minute convoluted bloodvessels, held together by a very small amount of connective tissue. These vessels frequently anastomose with one another, and those of each lateral half communicate with the vessels of the pars intermedia and the glans clitoridis. 
The blood-supply of the bulb is derived on each side by the arteria bulbi restibuli, a branch of the internal pudendal.

\section{Glandule Vestibulares Majores.}

The glandulæ vestibulares majores (O.T. glands of Bartholin) are placed one on each side of the lower part of the vagina, and represent the bulbo-urethral glands in

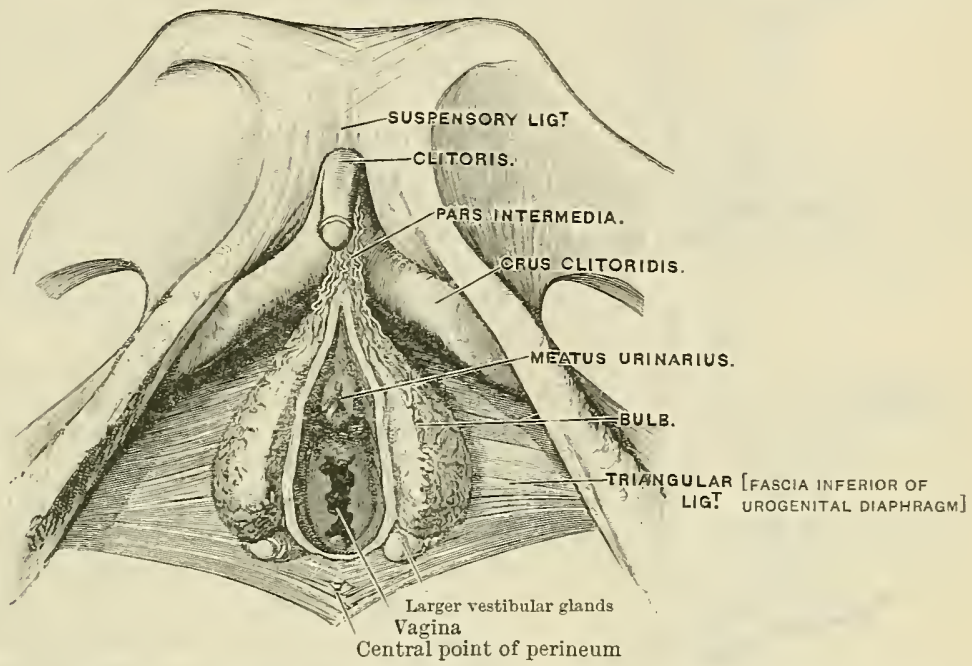

Fig. 1036.-Dissection of Female Perineum to show the Clitoris, the Bulb of the Vestibule, AND the LaRger Vestibelar Glaids (D. J. Cunuingham).

the male. They are often overlapped by the posterior ends of the bulbus vestibuli, and are covered by the bulbo-cavernosus muscle. Each is about the size and shape of a small bean, and possesses a long slender duct which opens into the rima pudendi in the angle between the attached border of the labium minus and the vaginal opening.

\section{DEVELOPMENT OF THE URINO-GENITAL ORGANS.}

\section{The Urino-genital Passages.}

General Account.-In tracing the developmental history of the urino-genital passages we may for convenience begin with an embryo of fifteen days old. Abont this time a duct, which runs in a longitudinal direction, and occupies a position on the lateral side of the protovertebral somites, begins to develop on each side of the body. With the exception of the anterior portion of the cloaca and the proximal part of the allantois, this duct, which has received the name of primary excretory or Wolffian duct, is the earliest formed structure from which, or in connexion with which, the parts of the adult urino-genital system arise.

The Wolffian duct serves as the canal, or duct, for the primitive secretory organsthe pronephros and the mesonephros of the embryo. With the atrophy of these the duct suffers modification, yet both sexes in the adult possess structures which have their embryonic origin from the Wolffian duct. In the male the duct of the epididymis, the ductus deferens, and the ejaculatory duct, are to be looked npon as directly developed from the Wolffian duct of the embryo; while in the female the longitudinal duct of the ep-oöphoron and the appendices vesiculosi are rudimentary structures haring a like origin. Further, the ureter and its pelvis arise in both sexes as an ontgrowth from the Wolffian duct (Fig. 1037). In the male the vesicula seminalis is developed as a diverticulum of the Wolftian duct.

The primitive secretory organs, the pronephros and the mesonephros, develop in connexion with the anterior part of the Wolffian duct (p. 48), and, during the early life of the embryo, the latter of these is a most important structure. Eren in the embryo 
the pronephros is a restigial organ, and its development in all higher vertebrates is very incomplete. It disappears almost as soon as it is formed, and it is replaced by the far more important mesonephros. With the development of the permanent kidney the mesonephros atrophies, yet some of its tubules persist in the adult. The ductuli

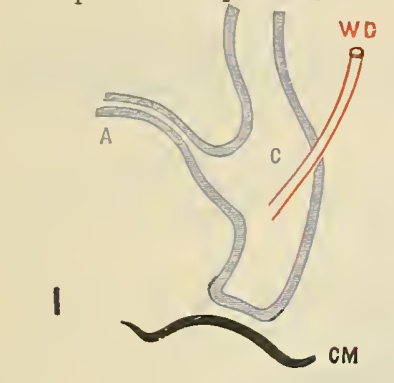
efferentes, the ductuli aberrantes, and the rudimentary paradidymis (organ of Giraldés) in the male, and the rudimentary tubules of the ep-oöphoron and of the par-oöphoron in the female, are structures which owe their origin to the tubules of the mesonephros.

Soon after the formation of the Wolffian ducts two other longitudinally disposed canals, called the Müllerian ducts, are developed. These open at their cephalic ends into the body cavity, and at their caudal ends, nnlike the Wolffian ducts, they unite with one another in the median plane. From them are formed, in the female-the uterine tubes, the uterus, and the WD $\begin{aligned} & \text { vagina; and in the male-the appendices of the testis } \\ & \text { Kand the utriculus prostaticus. }\end{aligned}$ A The Wolffian and Wüllerian ducts open at their

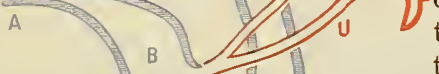
the cloaca, which in the course of development becomes transformed into the bladder and the urino-genital canal of the embryo. The developing ureter at first arises as a diverticulum from the Wolffian duct, at a short distance from the point where the latter joins the cloaca. Soon, however, the ureters acquire independent openings into the cloaca, which become gradnally shifted further from one another and from those

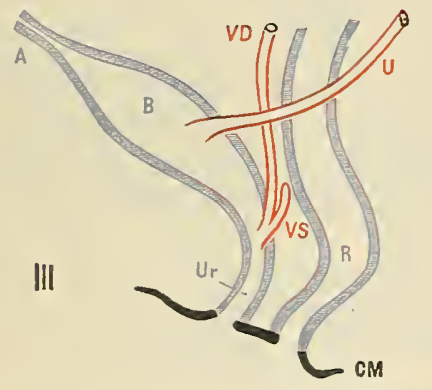

Fig. 1037.-DIAGRaM to ILLǓstrate THE MANTER IN WHICH THE URETER, THE DUCTUS DEFERENS, AND THE URINARY BLADDER ARISE IN THE EMBRYO.

The structures developed from the cloaca are indicated in blue, those from the Wolffian duct in red, and the ectoderm in black.

The manner in which the rectum and bladder become separated and acquire openings into the ectodermal cloacal fossa is shown in II. and III. (A. H. Young and A. Pobinson).

$\begin{array}{lll}\text { A. Allantois. } & \text { R. Rectum. } \\ \text { B. Blarlder. } & \text { Ur. Urogenital canal. } \\ \text { C. Cloaca. } & \text { U. Ureter. } \\ \text { C.I. Ectoderm of } & \text { VD. Ductus deferens. } \\ \text { F. Ploacal fossa. } & \text { VS. Seminal vesicle. } \\ \text { Pelvis of kiduey. WD. Wolffian duct. }\end{array}$
of the Wolffian ducts. The ureters are now found to open into the anterior portion of the cloaca which lies nearer to the head of the embryo than the part with which the Wolffian ducts are connected. This cephalic portion of the anterior subdivision of the cloaca which receives the ureters becomes the bladder and the upper part of the urethra. The caudal part, lying below the level of the entrance of the Wolffian ducts, is called the urogenital canal, and is represented in the adnlt male by the lower part of the prostatic and by the membranous portions of the urethra; in the female by the lower part of the urethra and the part of the urino-genital fissure which immediately surrounds the openings of the urethra and vagina (Figs. 10441045). The united Müllerian ducts open into the lower part of the cloaca or urogenital canal between the Wolffian ducts of opposite sides. In the male the position of this opening, which is represented in the adult by the orifice of the utriculus prostaticus, remains almost unchanged; in the female, on the other hand, a downgrowth from the fused Müllerian ducts gives origin to a new passage, the vagina, which establishes an opening behind that of the urethra in the urinogenital fissure of the adult.

After the complete separation of the cloaca into anterior or urino-genital and posterior or rectal subdivisions, the rectum establishes a communication with the exterior in the floor of the shallow depression known as the ectodermal cloacal fossa. At a little later time the urino-genital canal also joins this fossa at a point in front of the opening of the rectum. The ectodermal cloacal fossa lies in front of the vestigial tail, and extends forwards as far as a tnbercle known as the cloacal tubercle, which later gives rise to the genital eminence and a pair of elevations called the labio-scrotal folds. The genital eminence becomes converted into the clitoris or penis according to the sex. The labioscrotal folds extending backwards on each side form the labia majora of the female, and, 
fusing posteriorly, give rise to the scrotum in the male. In the female the slit-like opening of the urino-genital canal retains its position, and its margins becoming elongated, form the labia minora. The raginal opening arises, as we have seen, by a downgrowth of the fused Müllerian ducts which lies in front of the rectum and behind the primitive urino-genital canal. The latter becomes the urethra in the female. In the male the slitlike opening of the urino-genital canal is prolonged anteriorly by an active growth at the base of the genital eminence, and its margins uniting, give rise to the penile portion of the urethra.

\section{The Wolffian Duct and Embryonic Secretory Organ.}

The Wolffian Duct.-The Wolffian duct arises in the mesoblast, about the fifteenth day, as a solid cord of cells occupying a position immediately to the lateral side of the protorertebral somites and to the medial side of the body cavity (Fig. 1038). Then first recognised the duct lies immediately beneath the epiblast, and as it grows backwards to reach the cloaca it is often found to be intimately connected with the epiblast. This close connexion of the duct with the epiblast, in the early stages, is by some authorities supposed to indicate a primitive epiblastic origin of the canal, but by others, and apparently with more reason, to be a trace of the opening of ducts on the surface of the body, such as exists in connexion with the excretory organs of lower animals. During the third week the cellular cord which represents the Wolffian duct acquires a lumen, and about the end of the same week the duct Fig. 1038. - Trassverse Section throdgh the Trunk of a Hemas in its growth reaches the

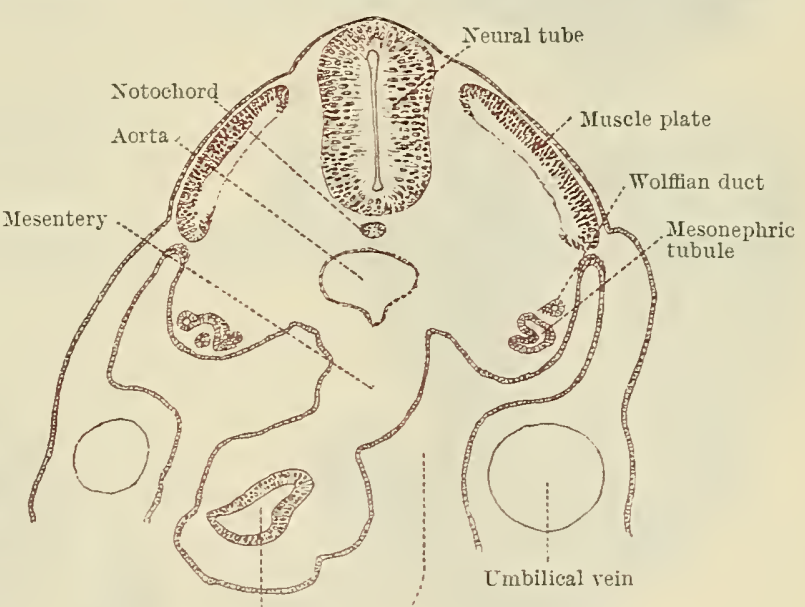

Alimentary canal Bods carity cloaca. As soon as the cloaca has become divided into dorsal and rentral subdirisions, the Wolffian duct is seen to end in the caudal part of the rentral subdivision, which becomes the bladder and uro-genital canal (Fig. 1040).

The mesonephros or Wolffian body is dereloped in the mesoblast of the "intermediate cell mass," immediately adjoining the Wolffian duct, and consists of a number of transversely arranged canals or tubules, each of which opens by one end into the Nolffian duct, while its other extremity ends blindly. These transrerse tubules, like the canal into which they open, are at first solid cellular structures, and only later acquire a distinct lumen. Increasing rapidly in size and number, the tubules become twisted and tortuous, and the blind end of each dilates to form a capsule invaginated upon itself and containing a bunch of capillary blood-ressels similar to the glomeruli of the adult kidney. It would appear that primitively one tubule is developed in the portion of the intermediate cell mass (nephrotome) corresponding to each mesoblastic somite, but, in higher vertebrates at all erents, such a correspondence between the number of somites and the number of tubules cannot be demonstrated. In the posterior part of the mesonephros the number of tubules is very numerous, and greater than the number of segments in this region. The tubules of the mesonephros arise in all segments from the sixth cervical to the third lumbar. The tubules in the anterior part atrophy and clisappear at a rery early time, even while others are being formed towards the hind end of the embrro. When at its greatest development (fifth to eighth week) the mesonephros forms a relatively large glandular mass, composed of tubules resembling in a general way those of the adult kidney, which projects into the dorsal part of the body carity, and extends from the region of the liver to the caudal end of the body cavity. Along its lateral aspect lies the Wolfian duct. 
In anamniate rertebrates, fishes, and amphibia, the mesonephros persists as the secretory organ of the adult.

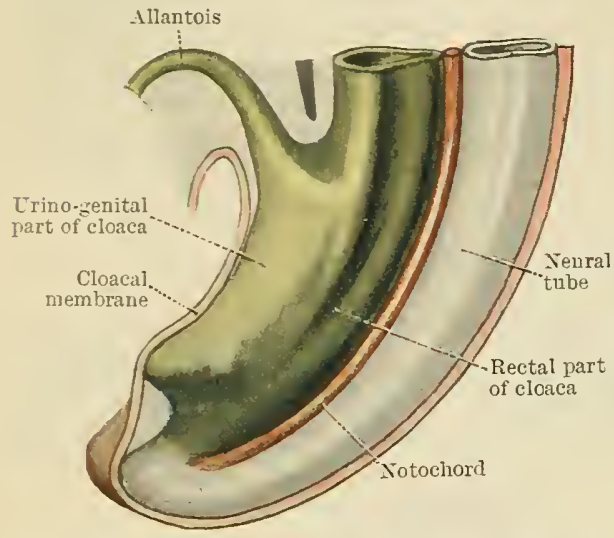

Fig. 1039.-TAIL Exd of HoMaA EMbryo BEFore THE TIMe at THICH THE WOLFfaN DUCts REACH THE CLOACA. (Drawn from a model constructed by Prof. F. Keibel.)

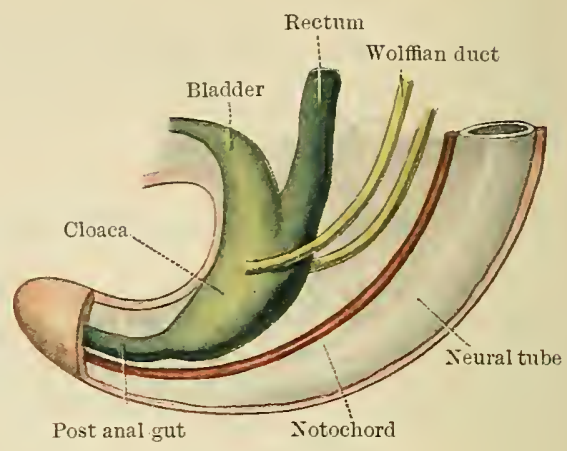

F1G. 1040.-Tail Exd of Humax Embryo. The Wolffian ducts open into the anterior part of the cloaca. (Drawn from a model constructed by Prof. F. Keibel.)

Pronephros.-From what is known regarding the development of lower animals, it seems certain that the Wolffian duct originally served as the duct of the still earlier secretory organ-

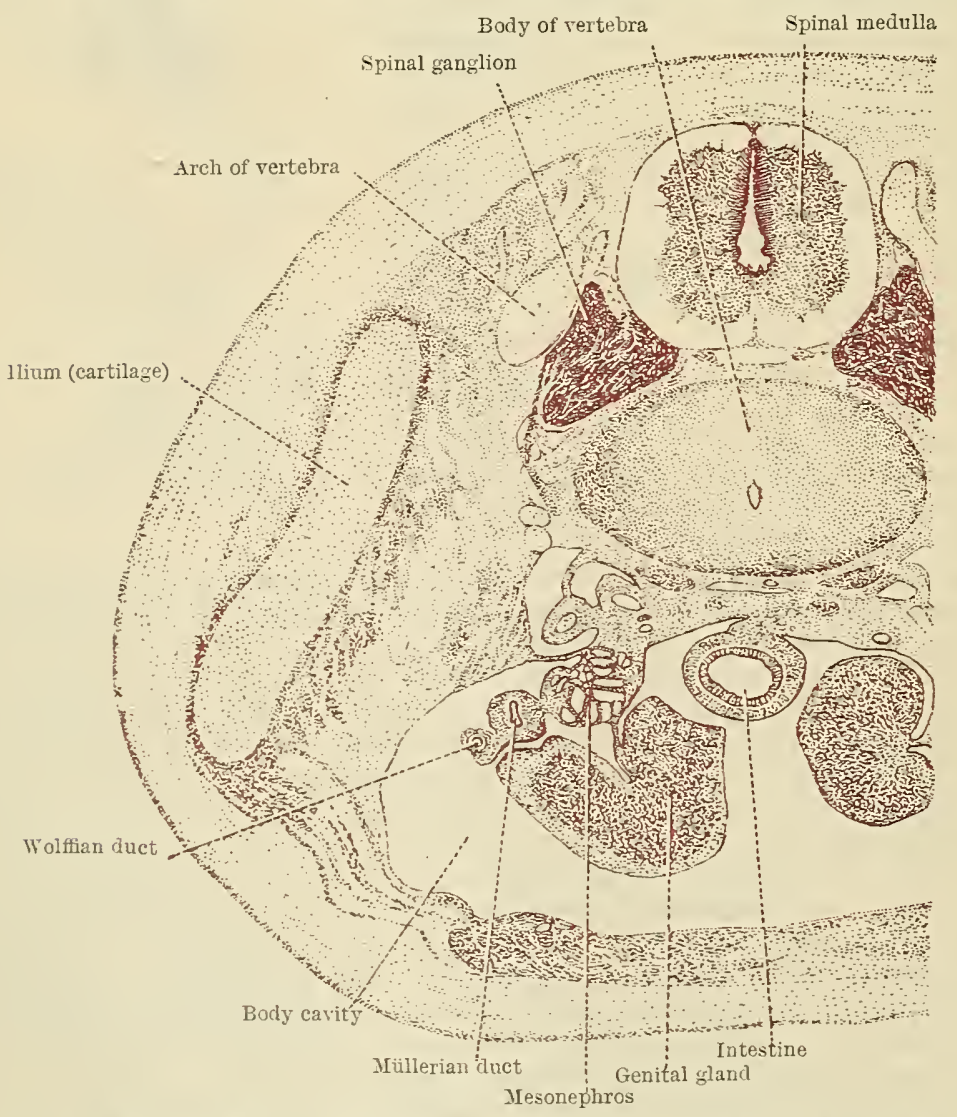

Fig. 1041.-Transterse Sectlon throtgh the Loter Part of the Trixk of a Hudas Embryo of ABOUT 7 WeEks. (Specimen in the possession of Prof. J. Symington.)

the Pronephros. In man the pronephros arises nearer to the head end of the embryo than the later formed mesonephros, and its tubules can only with difficulty be distinguished 
from those of the later appearing mesonephros. The tubules of the pronephros arise in all the segments from the fifth cervical to the third lumbar.

As the permanent kidney, or metanephros, is developed the mesonephros atrophies; a portion of it, however, is retained in the male, and forms the excretory apparatus of the testis. The Wolffian duct becomes the canal of the epididymis and the ductus defereus of the adult (see p. 1334). In the female, when the permanent kidney is formed, the mesonephros and its duct undergo atrophy to a greater extent than in the male, and they are ouly represented in the adult by the vestigial structures present in the broad ligament of the uterus (see pp. 1315 and 1316).

\section{The Ureter and Permanent Kidney.}

The ureter arises as a tubular diverticulum from the Wolffian duct close to the point where the latter joins the cloaca (Figs. 1039 and 1042). This diverticulum is seen first during the fourth week, and grows from behind forwards, dorsal to the body cavity. Even in its very early condition the portion of the outgrowth which lies nearest to the Wolffian duct, and from which the adult ureter is developed, is more slender than the distal part, which becomes brauched, and grows out to form the pelvis and calyces of the ureter. From the calyces numerous collecting tubules grow out into the developing kidney and acquire connexions with the glandular or uriniferous tubules of the kidney. The uriniferous tubules of the kidney arise independently of the ureter in a backward prolongation of the tissue which, further forward, gives origin to the tubules of the mesonephros. The tissue in which the permanent kidney tubules arise lies behind the third lumbar segment. The blind distal end of each tubule soon dilates to form a capsule which, becoming invaginated ou itself, encloses a tuft of capillary blood-vessels. The renal corpuscles arising in this manner are found in the human kidney as early as the eighth week.

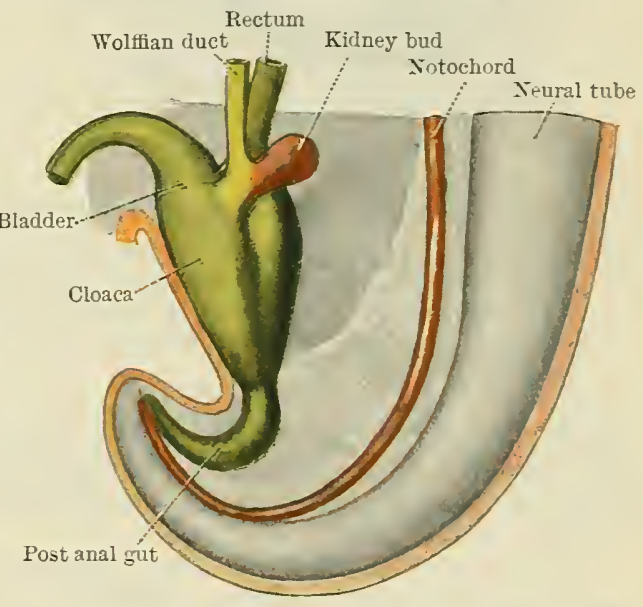

Fig. 1042.-Tall Exd of a Huyax Eybryo about 25 DAYS OLD.

The cloaca is dividing into rectal and urino-genital subdivisions. The ureter is arising as a bud from the Wolffian duct. (Drawn from a model constructed by Prof. F. Keibel.)

As regards their origin in the embryo we distinguish between the collecting tubules and their branches, and the uriniferons secretory tubules of the kidney. The former arise from the calyces of the ureter, and hence are derived from the Wolffian duct; the latter are formed in mesoderm, known as the metanephric cell mass, which is continuous at its anterior end with the tissue from which the mesonephros is derived. The short junctional tubules of the adult lie in the regiou where these developmentally distinct portions of the kidney unite.

As the ureter increases in length, it becomes separated from the Wolffian duct, and acquires a distinct opening into the anterior part of the cloaca nearer the head of the embryo than that of the Wolffian duct. This part of the cloaca receiring the ureters becomes the bladder. The kidney is at first a distinctly lobulated body, and shows at birth, and sometimes eren in the adult, distinct traces of its original subdirision into lobule.

The metanephric cell mass, in which the uriniferous tubules arise, lies at first on the medial side of the bud-like outgrowth, which represents the ureter; at a later time it comes to lie dorsally. As the ureter grows towards the head end of the embryo the cell mass which gives rise to the uriniferous tubules follows it; hence the metanephric tissue ceases to lie to the caudal end of the mesonephros. As the ureter divides to form the calyces, the metanephric cell mass becomes broken up into cap-like portions, one for each branch of the ureter, and later one for each of the collecting tubes which grow out from the calyces.

The formation of uriniferous tubules within the nephrogenic cell mass is continued until a few days after birth. 


\section{THE BLADDER.}

The main portion of the bladder is formed from the superior (cranial) part of the anterior subdivision of the cloaca. This at an early time becomes flattened dorso-ventrally, and prodnced laterally into two horn-like projections in the region where the Wolffian

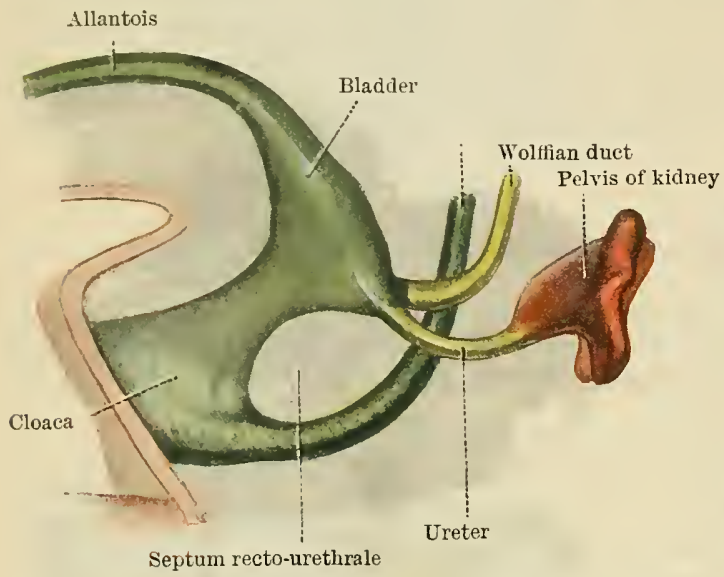

Fig. 1043.-Tail End of Human Embryo about 33 Days Old.

The cloaca is becoming separated into rectal and urino-genital portions by the formation of the septum recto-urethrale. The ureter has acquired a separate opening into the anterior division of the cloaca. (Drawn from a model constructed by Prof. F. Keibel.) ducts open (Fig. 1043). Inferiorly it becomes constricted to form the urino-genital canal. Little by little the lower ends of the Wolffian ducts open out and are absorbed into the wall of the developing bladder and soon it comes about that the ureters, which originally were outgrowths of the Wolffian ducts, open directly into the bladder. The openings of the ureters become shifted latterally, but the final position of the openings of the Wolffian ducts is close to the median plane in the upper prostatic part of the urethra. The bladder has therefore a double origin :-its main portion is derived from the endodermal cloaca; its smaller basal part arises from the opened-out lower ends of the IVolffian ducts. The latter portion approximately corresponds to the trigonum vesicæ of the adult, and must be regarded as having its source from the mesoderm. The extreme cephalic end of the anterior part of the cloaca tapers gradually, and beyond the umbilicus is continuous with the allantois. This part of the cloaca loses its lumen about the fifth week, and from it is derived the fibrous cord of the urachus, which in the adult reaches from the bladder apex to the umbilicus.

The cavity of the urachus is sometimes not lost so early, and in rare cases it has been found persisting in the child or adult as a pervious channel extending from the apex of the bladder to the umbilicus. Here it may open on the surface of the body.

\section{The Male Urethra.}

The first part of the male urethra has a similar origin as the basal part of

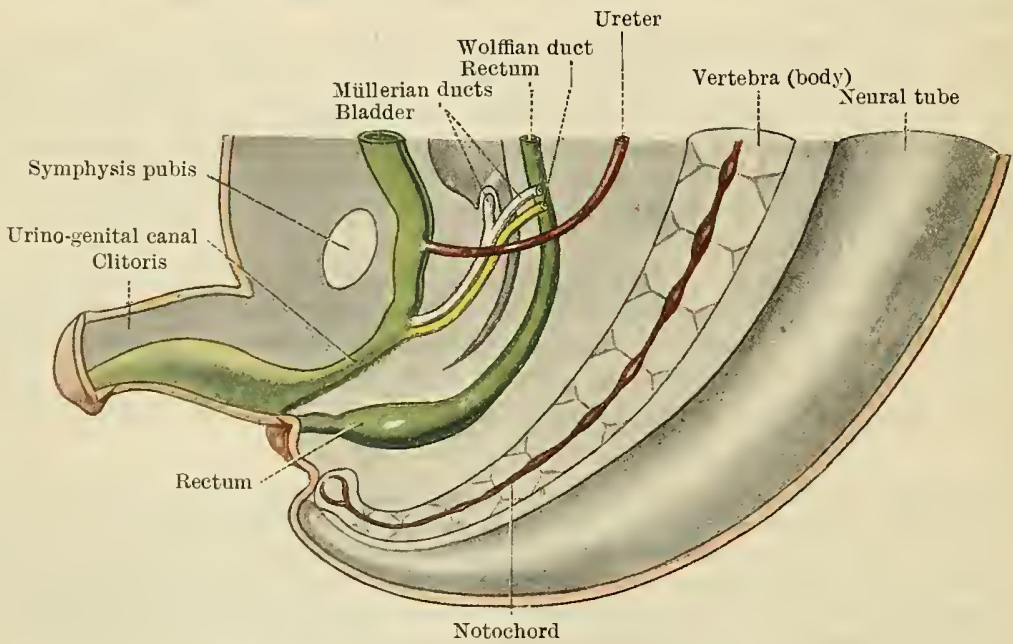

Fig. 1014. - Tall End of Female Human Embryo about 9 WeEks Old.

The rectum lias acquired an opening and the endoderm of the urino-genital canal is continued into the genital eminence (clitoris). (Drawn from a model constructed by Prof. F. Keibel.) 
the bladder, and is derived from the ends of the Wolffian ducts (see above, p. 1332). The remaining portion, beyond the openings of the ductus deferentes of the adult, is derived from the urino-genital canal, or caudal subdivision of the anterior part of the cloaca. The urino-genital canal is early subdivided into a pelvic part lying within the future pelvic cavity and a penile part which occupies the region in which the corpus spongiosum urethrse is developed. The latter part of the urino-genital canal becomes filled with closely and irregularly packed cells, which later on breaking down, re-establish the canal and give origin to a slit-like opening in the region in front of the auus. The canal for some time opens at a rhomboidal fossa situated in the groove at the base of the glans. In the glans penis a septum of densely packed cells passes forwards from this fossa and is known as the urethral septum. At a later stage these cells also break down and form a groove, the lips of which unite and enclose the terminal portion of the urethra. It is doubtful if any of the male urethra owes its origin to the ectoderm, but there is some evidence to show that the urethral septum is to be regarded as ectodermal, in which case the part of the canal which traverses the glans must have a like origin.

\section{The Female Urethra.}

In the female the part of the urethra near the internal urethral orifice is developed from the inferior ends of the Wolffian ducts and has a similar origin to the basal portion of the bladder. The inferior part of the passage is derived from the urino-genital canal. When the urino-genital canal opens on the surface it is continued forwards as a sulcus on the genital eminence, as in the male sex. The margins of the slit-like opening do not unite, but form the labia minora of the adult, and the sulcus which appears on the glans clitoridis is closed without forming a canal. At first the fused caudal ends of the Müllerian ducts open into the urino-genital canal, but later on a downgrowth, which is at first solid, establishes a connexion between these ducts and the surface immediately in front of the rectum and behind the opening of the urino-genital canal. This new connexion becomes the vagina, and the urino-genital canal the urethra. By some embryologists it is believed that a shortening and spreading out of the inferior portion of the urino-genital canal, to form a part of the urino-genital cleft of the adult, is responsible for bringing the opening of the fused Müllerian ducts to the surface. If this latter view is accepted, the female urethra corresponds to the part of the male passage which lies above the opening of the utriculus prostaticus.

\section{The Sexual Glandos.}

Sexual Glands.-In the development of the sexual glands, male and female, a differentiated thickened portion of the peritoneal epithelium is first recognised. This specialised epithelium, which has received the name of germinal epithelium, is situated to the medial side of the mesonephros and of the Wolffian and Müllerian ducts. Here it covers a longitudinally disposed ridge or elevation called the genital ridge. The germinal epithelium is not strictly limited to this ridge, but extends to some extent beyond its limits. The genital ridge is soon found to have numerons epithelial cells embedded in its connective-tissue stroma which appear to originate, in both sexes, by a proliferation from the deep surface of the germinal epithelium covering the ridge. From these epithelial cells the seminiferous tubules of the male, and Graafian follicles with their contained ova of the female are developed. The tissue which gives rise to the genital ridge occurs in all the body segments from the sixth thoracic to the second sacral, but the cephalic end of the ridge atrophies before the germinal epithelium can be recognised in the more caudal segments, and only about one-fourth of the ridge gives origin to the permanent sexual gland. The part of the genital ridge which persists appears to correspond to three or four segments in the region of the 4 th or 5 th lumbar to the 1 st or 2 nd sacral segments.

In the male, as early as the thirty-third day, the epithelial cells embedded in the stroma of the developing testis have become arranged into a network of anastomosing cords within which certain larger cells are seen to be irregularly scattered. These larger cells have received the name of primitive sperm cells, and are relatively few in number. They undergo frequent division, and in the later stages are not to be distinguished from the other cells of the cords. The cellular cords undergo direct transformation into the seminiferous tubules of the testis, the tubuli recti and the rete testis. At a very early stage the superficial part of the stroma of the developing testis becomes lenser, and gives origin to the tunica albuginea. The tissue surrounding the cellular cords becomes converted into the septula testis and the mediastinum. A lumen can first be recognised in the seminiferous tubules in the seventh month. The rete testis becomes connected 
secondarily with the ductuli efferentes which are derived from the tubules of the mesonephros, and thus the mesonephric or Wolffian duct becomes the passage for the secretion of the testis.

In the female large epithelial cells are found in the stroma of the developing ovary, beneath the germinal epithelium, as early as the thirty-third day. These primitive ova are much more numerous than the primitive sperm cells of the male, and form a very characteristic feature of the developing ovary. At first they lie isolated, but later-about the fifth week-they become surrounded by other smaller cells having a like origin from

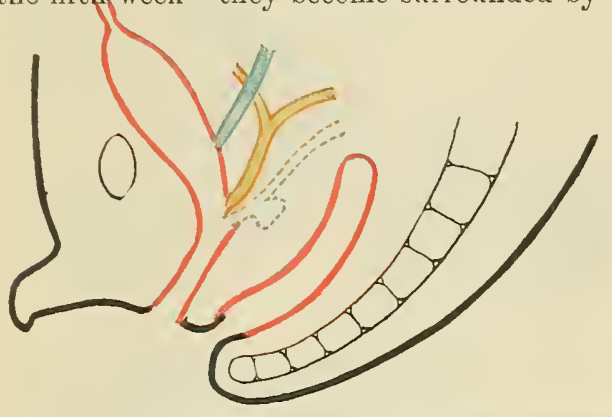

Frg. 1045.-The URINo-genital PASsages at THF INDIFFERENT STAGE OF DEVELOPNENT. the germinal epithelium. Each primitive ovum surrounded by its cells becomes a primitive follicle, the further development of which has already been described ( $p$. 1318). During the later stages the epithelium has the appearance of growing down into the stroma in the form of long branching cellular processes which break up into little nests of cells to form the future follicles (p. 131s). The proliferation of cells from the surface epithelium goes on until the seventh month, but it is extremely doubtful if any new ova arise in the later months of gestation or after birth.

Ureter, green solid outline. WVolffian duct, green dotted outline. The origin of the vesicula seminalis is indicated. Mitllerian ducts, orauge. Rectum, bladder, and urino-genital canal, red.

\section{The Generative Ducts.}

Generative Ducts. - As has been already stated, the male ducts arise from the Wolffian, and the female from the Müllerian ducts of the embryo. Both sexes at first possess well-developed Wolffian and Müllerian ducts, which are arranged in a very definite manner: The Wolffian ducts communicating directly with the tubules of the mesonephros lie at first parallel to, and at a considerable distance from one another. As they pass towards the caudal end of the embryo they approach one another, and each becomes enclosed in a fold of peritoneum called the plica urogenitalis. Nore caudally the ducts become closely approximated to each other, are embedded in a cord-like mass of connective tissue, to which the term genital cord is applied. They finally open into the anterior subdivisiou of the cloaca (Fig. 1042).

The Müllerian ducts, opening freely into the body cavity at their cephalic ends, lie to the lateral side of the Wolffian ducts. As they are traced caudally they cross the Wolffian ducts and enter the genital cord, within which they unite and form a canal, which occupies the median plane, and opens into the anterior subdivision of the cloaca, between the Wolffian ducts (Fig. 1042). The manner in which the ureters become separated from the Wolffian ducts has already been described.

Ducts in the Male.-The seminiferous tubules of the testis become connected with the Wolffian duct through a fusion of certain tubules of the mesonephros with the

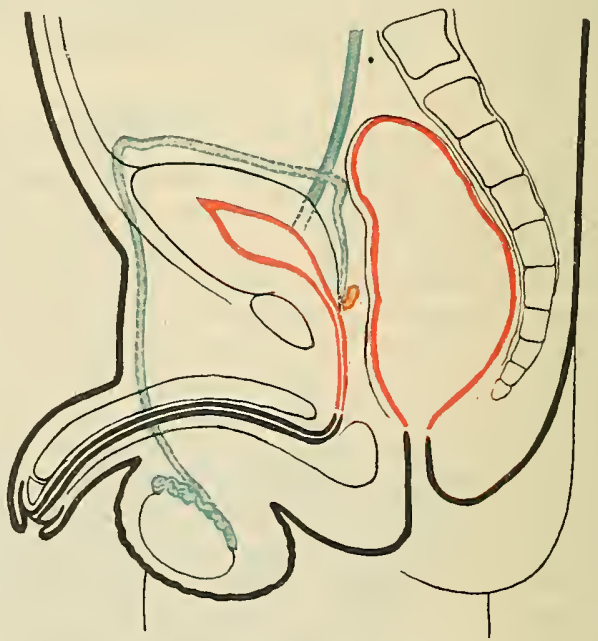

Fig. 1046. -The Unino-genital Passages in THE MALE.

Ductus deferens, dotted green outline. Ureter, solid green outliue. Utriculus prostaticus, orange. Bladder and pelvic part of urethra, red. Penile portion of urethra, black.

rete testis. The connexion is definitely established in the third month. The number of tubules taking part varies considerably, but corresponds to the number of ductuli efferentes found in the adult. The connecting tubules becoming much convoluted, just as they join the Wolffian duct, form the lobuli of the epididymis. The canal of the epididymis is directly formed from the cephalic part of the Wolffian duct, and the ductus 
deferens from the more caudal portion. The ductuli aberrantes and the rudimentary tubules of the paradidymis are to be looked upon as persistent tubules, of a more caudal portion of the Wolffian body, which have failed to become connected with the tubules of the testis.

The seminal vesicles are dereloped in the third month as evaginations which arise from the Wolffian ducts, near their caudal extremities. Each at first has the appearance of a longitudinal groove in the wall of the ductus deferens, which closes over and becomes cut off from the main tube except at the point where later on the duct of the seminal vesicle joins the ductus deferens.

The Mitllerian ducts atrophy in the male embryo, but the appendices of the testis are vestigial remains of their cephalic portions, while the utriculus prostaticus represents the candal fused portions which, in the embryo, occupy the genital cord.

Ducts in the Female.-The Miillerian ducts in the female retain their openings into the body cavity, and their anterior portions become the uterine tubes. Their fused posterior parts, which at first join the urino-genital canal, give rise to the uterus and vagina. The manner in which the original position of the opening of the Müllerian ducts becomes shifted, by the formation of a new passage or by the shortening of the nrinogenital canal, has already been mentioned (p. 1333). The final position of the opening is in the urino-genital cleft of the adult.

The vaginal portion of the fused Miillerian ducts is at first relatively very short, and at the point where it opens into the urino-genital canal a slight fold appears, which is the future hymen. The vagina increases rapidly in length as its opening moves downwards towards the urino-genital cleft. In the human embryo during the third month the closely applied Nüllerian ducts, which higher up have fused to form the uterus, are represented at their inferior ends by a pair of rapidly elongating solid cellular cords, which at a later stage break down to form the vagina.

The Wolffian ducts and the mesonephros atrophy in the female, but traces of them are to be found in the ep-oöphoron and par-oöphoron of the adult. In the fotus the Wolffian duct can be traced along the side of the nterus as far as the upper end of the vagina.

Prostate. - The glandular portion of the prostate arises as a series of solid outgrowths from the epithelium of the urinogenital canal during the third month. The outgrowths, which are at first simple, become branched and finally acquire a lumen. They are arranged in three groups-an

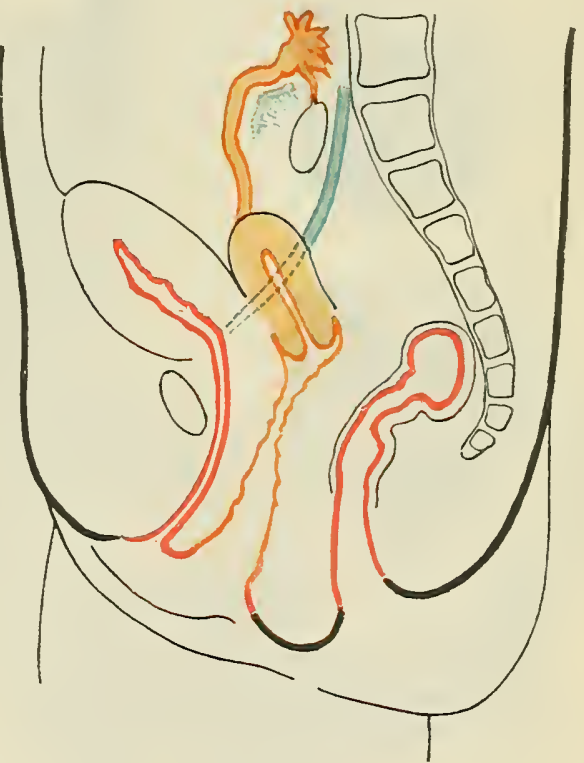

Fig. 1047.-The Urixo-gexital Passages in the Female.

Derivations of the Miillerian duct, orange. Ureter, green solid ontline. The ep-oöphoron is indicated in green near the opening of Mitllerian duct and near the ovary.

upper and a lower dorsal, and a ventral group. The glands of the ventral group soon became reduced in number and often completely disappear; those of the upper dorsal group form the chief part of the gland.

The prostatic glands arise in both sexes, but in the female, where they are known as para-urethral glands, they are few in number and not densely packed as in the male. The muscular tissue of the prostate is derived from the muscular wall of the urethra.

The bulbo-urethral glands arise in the third month, and appear to be developed from the epithelium of the urino-genital canal.

The larger vestibular glands in the female arise as epithelial outgrowths in the same manner as the bulbo-urethral glands.

\section{External Genital Organs.}

The external genital organs are developed in the region of the ectodermal cloacal fossa, and those of the male and female cannot be distinguished from one another in the earlier stages. The fossa at first extends on the rentral aspect of the body almost 
from the tail to the umbilical cord. At its cephalic end is a tubercle known as the cloacal tubercle, and behind lies the coccygeal tubercle. Immediately in front of the latter the anus is formed, and between this opening and the cloacal tubercle the urino-genital canal opens on the surface by a median slit-like aperture, the primitive urino-genital opening.

The cloacal tubercle early becomes subdivided into an apical genital eminence which occupies the middle line and lies at the cephalic end of the slit-like urino-genital opening, and a basal portion which lies nearer to the umbilicus and also curves round the sides of the genital eminence. At a later time the basal part is continued to form a prominent fold on each side of the extodermal cloacal fossa. These folds are called the labio-scrotal folds and, in the female, give rise to the labia majora. The lateral margins of the primitive urino-genital opening give origin to the labia minora, and the genital eminence becomes the clitoris. On the clitoris at a very early date a relatively large glans is marked off by a surrounding sulcus. In the male the scrotal folds grow backwards, and meeting behind the primitive urino-genital opening, fuse together. In this way the opening is pushed forwards. The genital eminence elongates rapidly owing to a growth at its basal part, and
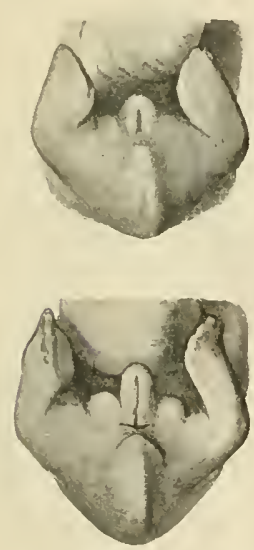

Fig. 1048.-Exterial GejtTal Organs, Human Embryos. Indifferent stage. A. Embryo of $20 \mathrm{~mm}$. B. Slightly larger.

The genital eminence and the labio-scrotal folds are well seen.

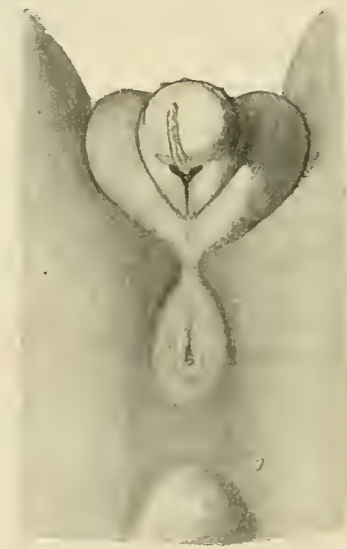

Fig. 1049.-External GenitaL Organs, Male Embryo.

Formation of scrotum. The labioscrotal folds, formerly best marked at the sides of the genital eminence, have grown backwards and united behind the primitive urino-genital opening, to form the raphe scroti. The genital folds embrace the base of the genital eminence or penis. The glans is very prominent.

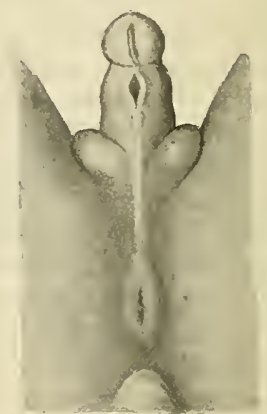

Fig. 1050.-External Genital Organs, Male Embryo.

Behind the glans penis the urethra opens iu a diamond-shaped fossa in the posterior wall of which the median raphe ends. The prepuce is formed behind the constriction which marks off the glands, and as it grows forwards the constriction disappears.

A little horn-like process of epithelium is present on the summit of the genital eminence.

a sulcus which is formed on its cloacal aspect gradually becomes converted into a canal by the closure of the lateral lips of the primitive urino-genital opening. Soon the urinogenital opening is found to lie nearer the apex than the base of the eminence, which has now given rise to the penis. For some time the opening in the male lies at the base of the glans penis and is somewhat rhomboidal in outline. At a later time, owing to the breaking down of a dense septum of epithelial cells which appears within the glans, a sulcus and finally a canal arises within this part of the penis and thus the terminal part of the urethra is formed. When the opening at the base of the glans is closed the continuous urethral passage is established. The main portion of the urethra is endodermal in origin, but there is some evidence to indicate that the part which traverses the glans has its origin from the ectoderm.

\section{THE MAMMARY GLANDS.}

The mammæ or breasts are accessory organs connected with the female reproductive system. Each gland is situated in the superficial fascia covering the anterior aspect of the thorax, and usually extends from the level of the second or third to that of the sixth rib. The hemispherical projection formed by the gland 
lies upon the superficial aspect of the pectoralis major and to a less extent upon the serratus anterior muscle. Near the summit of each mammary elevation, and usually at the level of the fourth or fifth rib, is placed the wart-like nipple or papilla mammæ, which is pierced by the minute openings of the lactiferous ducts and is surrounded by a coloured circular area of skin called the areola. The skin covering the nipple is thrown into numerous wrinkles, and on the areola exhibits many minute rounded projections due to the presence of underlying cutaneous glands. These have received the name of glandulæ areolares, and are considered to represent rudimentary portions of the mamma. The colour of the nipple and areola varies with the complexion of the individual, but in young subjects they are usually of a somewhat rosy-pink colour, which changes to a deep brown during the second and third months of first pregnancy. Also during pregnancy the areola increases in size and its glands become more marked. The nipple contains a considerable number of unstriped muscle fibres, and becomes firmer and more prominent as a result of mechanical stimulation.

The size and appearance of the mammæ vary much, not only in the different races of mankind, but also in the same individual under different conditions. In the young child the mammæ are small, and there is little difference between those of the male and female. Their growth is slow until the approach of puberty, and then the female mammæ increase rapidly in size. At each pregnancy the mammæ become large, and they attain their greatest development during lactation. The size of the mamma depends partly on the amount of superficial fat and partly on the amount of glandular tissue present.

\section{Structure of the Mamma.} - The mamma is composed of a mass of glandular tissue traversed and supported by strands of fibrous connective tissue, and covered by a thick layer of fat. The glandular tissue, to which the term corpus mammæ is applied, forms a somewhat conical mass whose apex corresponds to the position of the nipple while its base is loosely connected to the fascia covering the pectoralis major and serratus anterior

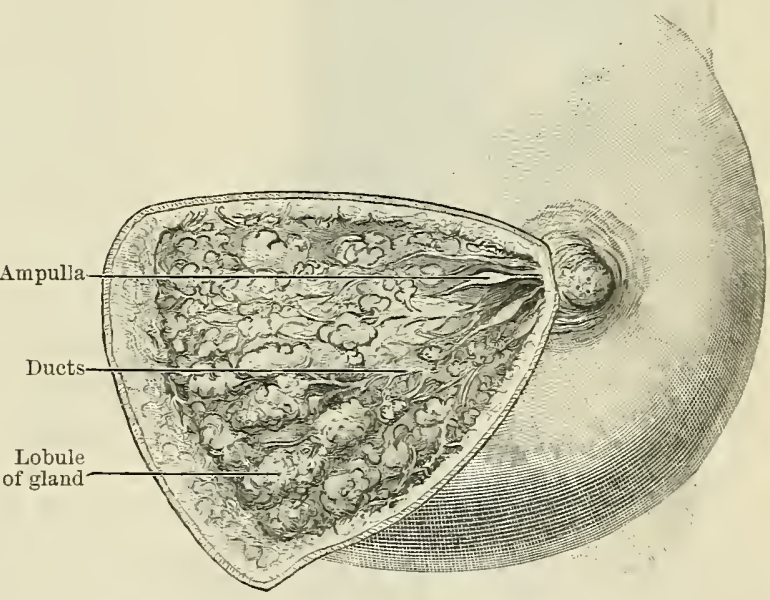

Fig. 1051.-Dissectiox of the Mama. muscles. In section the corpus mammæ is readily distinguished from the surrounding fat by its firmer consistency and by its pinkish-white colour. The corpus mammæ is composed of lobes and lobules, and its superficial aspect and edges are very uneven, the inequalities of its surface being filled up by processes of the fatty tissue which forms a covering for the gland. This fatty covering is incomplete beneath the areola, and here the lactiferous ducts pass into the nipple. The gland is composed of fifteen to twenty lobes, or lobi mamma, which radiate from the nipple, each lobe being quite distinct from the others and possessing its own duct. The lobes are subdivided into secondary lobes and lobules, bound together and supported by a considerable amount of connective tissue which forms the stroma of the gland.

The alveoli of the gland and the secretory epithelium lining them vary much under different conditions. At puberty the corpus mammæ is chiefly composed of connective tissue stroma and the ducts of the gland. At this time the alveoli are small and few in number. During lactation, when the gland is fully functional, the alveoli are enlarged, distended with fluid, aud much more numerous. The epithelial cells are uubical and filled with fat globules. When the gland is not secreting, the alveoli become small and reduced in number 
while the cells of the lining epithelium, which are now small and glandular, do not contain fat globules.

The ducts, or ductus lactiferi, passing towards the nipple, become enlarged to form small spindle-shaped dilatations, called ampullce, or sinus lactiferi ; then becoming once more constricted, each duct passes, without communicating with its neighbours, to the summit of the nipple, where it opens.

In the male subject the various parts of the mamma are represented in a vestigial condition.

The presence of milk-glands is characteristic of the class mammalia, and the

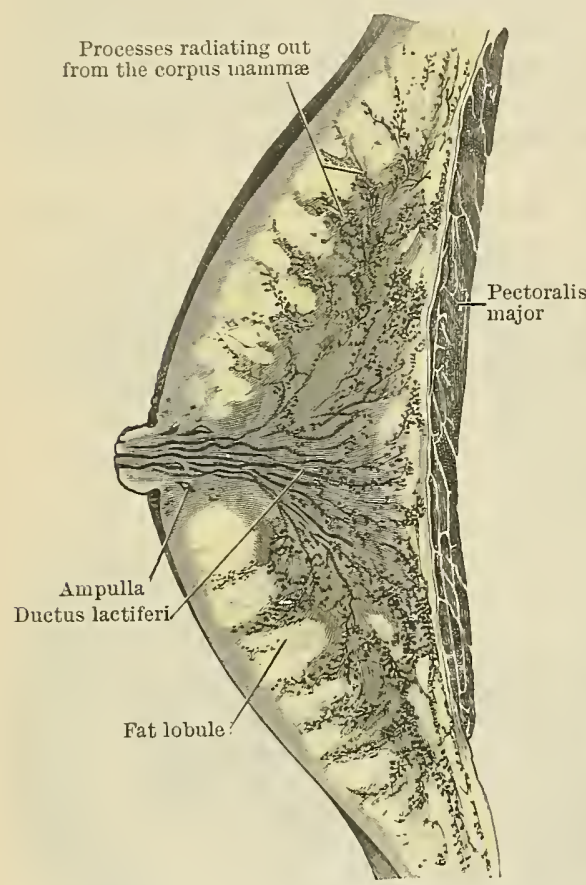

Fig. 1052.- Section throvgh a Mamiary Gland. Prepared after immersion in nitric acid as recommended by Mr. Harold Stiles. (D. J. Cunningham.) number of pairs of glands in each group of animals bears some relation to the number of young usually produced at each birth.

Variations.-Asymmetry in the development of the mammæ is very common-the left mamma being very often larger than the right. Absence of one or both inammæ is a very rare abnormality, which may or may not be associated with absence of the nipples. When one nipple only is present it is usually the left. The presence of supernumerary glands or nipples is not very uncommon, and a large number of examples are recorded. The term polymasty has been applied to cases in which more than the normal number of mammæ are present, and polythely to those in which additional glands, in a restigial condition, are represented by accessory nipples. Usually the accessory glands, or nipples, are present on the anterior aspect of the thorax, and in most instances they occur below and a little to the medial side of the normal site. When the abnormal glands are found above the normal site they generally lie further from the median plane. Much more rarely accessory glands have been found on the abdomen, in the axilla, or in some other situation, including even the dorsal aspect of the trunk. As many as three extra pairs of mammæ have been found in the same individual, and cases in which the probable representatives of mammary glands were even more numerous have been recorded. Asymmetry is very common in these abnormal structures. It is interesting to note that examples of polymasty and polythely occur in the male rather more frequently than in the female. In some women the accessory breasts have yielded milk during lactation; in most cases the abnormal organs are very rudimentary, and represented only by a minute nipple or pigmented areola. These cases of polymasty and polythely are supposed to represent a reversion to an ancestral condition, in which more than two mammary glands were normally present, and in which probably many young were produced at each birth. In this connexion it is interesting to observe that usually the accessory glands occur in positions normally occupied by mammæ in lower animals. In the course of the development of the mammæ in man, specialised areas of the epidermis, similar to those which give origin to the mammæ, have been observed both superior and inferior to the region in which the adult mammæ are developed. These areas appear to be present normally, but in most cases they disappear at an early stage in the history of the embryo. In some other mammals rudimentary mammæ may occur, as, for instance, in lemurs and in some cows.

A slight functional activity of the mammary glands of the male at birth and about the time of puberty is stated to be not a very uncommon occurrence.

Vessels and Nerves of the Mamma. - The breast receives its arterial supply from the perforating branches of the internal mammary artery and fron the external mammary branches of the lateral thoracic. Additional supply is sometimes derived from some of the intercostal vessels. The veins coming from the gland portr their blood into the axillary and internal mammary veins. Some small superficial veins from the breast join tributaries of the external jugular.

The lymph vessels of the breast are very numerons, and form extensive lymph spaces round the alveoli of the gland. These freely anastomose with the lymph vessels of the skin and more especially with the vessels of a very large anastomotic circle deep to the skin of the nipple. The lymph vessels coming from the deep parts of the mamma for the most part join the lymph glands of the axilla. They first run directly towards the deep surface of the breast, where they enter the fascial lymph vessels contained in, or lying deep to, the fascia of the pectoralis major. These fascial vessels end for the most part in the axillary glands. It is important to remember 
that while the majority of the lymph vessels first reach the lymph glands lying on the lateral border of the pectoralis major, some free vessels may "short circuit" to glands (1) in the floor of the axilla, (2) along the circumflex vessels, (3) even to glands along the axillary vein. Yet other lymph vessels of the breast may reach first the glands in the costo-coracoid space. Some ressels from the medial part of the breast, following the course pursued by the perforating arteries, may join the lymph glands situated along the course of the internal mammary artery, but these vessels are fortunately often absent. It is also to be remembered that a few probably irregular communications exist across the middle line with the lymph vessels of the opposite breast; and further that lymph vessels from the infero-medial area of the breast regularly join the fascial lymph vessels of the upper part of the sheath of the rectus abdominis, and through these make communication with the lymph ressels of (1) the round ligament of the liver, (2) the peritoneum generally, and ultimately with the abdominal lymph glands. The surgical importance of the facts regarding the lymphatic drainage of the breast cannot be exaggerated.

The nerve-supply of the gland is derived from the intercostal nerves of the fourth, fifth, and sixth intercostal spaces. Along the course of these nerves sympathetic filaments reach the breast from the thoracic part of the sympathetic cord.

\section{DEVELOPMENT OF THE MAMME.}

The mammæ are developed as downgrowths of the ectoderm into the underlying mesoblastic tissue. In the human embryo a thickened raised area of the ectoderm is to be recognised in the region of the future mamma at the end of the fourth week. This thickened ectoderm becomes depressed in the underlying mesoblast, and thus the mammary area soon becomes flat, and finally sunk below the lerel of the surrounding epidermis. The mesoblast, where it is in contact with this downgrowth of the ectoderm, is compressed, and its elements become arranged in concentric layers, which, at a later stage, give rise to the connective-tissue stroma of the gland. The depressed mass of ectoderm cells soon becomes somewhat flask-shaped, and grows out into the surrounding mesoblast as a number of solid processes, which represent the future ducts of the gland. These processes, by dividing and branching, give rise to the future lobes and lobules, and much later to the alveoli. The mammary area becomes gradually raised again in its central part to form the nipple. A lumen is only formed in the different parts of this branching system of cellular processes at birth, and with its establishment is associated the secretion of a fluid resembling milk, which often takes place at this time. The ampullæ appear as thickenings on the developing ducts before birth.

In those animals which possess a number of mammary glands-such as the cat, pig, etc.- the thickening of the ectoderm, which is the first indication of the development of these structures, takes the form of a pair of ridges extending from the level of the forelimb towards the inguinal region. These converge posteriorly, and at their terminations lie not far from the middle line. By the absorption of the intermediate portions the ridges become divided up into a number of isolated areas, in connexion with which the future glands arise. Somewhat similar linear thickenings of the ectoderm have also been recognised in the human embryo, and the usual positions assumed by the accessory glands when present, leads us to suspect that in all probability the ancestors of man possessed numerous mammæ arranged, as in lower animals, in lines converging towards the inguinal region. 



\title{
THE DUCTLESS GLANDS.
}

\author{
Originalit Bi the late D. J. C'Tninghay, F.R.S., \\ Late Professor of Anatomy, Tniversity of Edinburgh;
}

\author{
Revised Axd Rewrittey by A. C. Geddes, M.D., F.R.S.E., \\ Professor of Anatomy, Royal College of Surgeons in Ireland.
}

THE title, the ductless glands, denotes a group of organs whose function is to elaborate a special product and to discharge it into the blood or lymph. These activities constitute the act of internal secretion.

The group includes the hypophysis and the pineal body, which are described with the brain; the suprarenal glands, which are compound organs and are the principal representatives of two important systems of glandular tissue called respectively the chromaphil and cortical systems; the glandulæ caroticæ, which are outlying parts of the chromaphil system; the thyreoid and parathyreoid glands, and the thymus, which are developed from the entodermal lining of the embryonic pharynx; the spleen and the glomus coccygeum, which are associated with the circulatory system.

Physiologically, the liver, pancreas, gastric and intestinal mucous membranes; the kidners, prostate, and testes; the uterus, ovaries, corpus luteum, and possibly some other organs form internal secretions, and act therefore as "ductless glands" in addition to fulfilling their more obvious functions. Anatomically, the lrmph and hæmo-lymph glands are "ductless glands;" but it is not customary to speak of them as such.

\section{THE CHROMAPHIL AND CORTICAL SYSTEMS AND THE SUPRARENAL GLANDS.}

\section{A. The Chromaphil System.}

\section{(Syroxyus: Chromophil, Chromaffin, Phcoochrome, Phä̈chrome System.)}

The chromaphil system is composed of a number of discrete masses of tissue which produce and discharge adrenin (læro-adrenalin, $\mathrm{C}_{9} \mathrm{H}_{13} \mathrm{NO}_{3}$ (Aldrich)). The name chromaphil is given to the tissne because the cells forming it contain granules which, in the presence of chromium salts, stain to any tint between bright yellow and dark brown. The distribution of the masses of tissue forming the system is shown in Fig. 1053. There are (i.) a series of isolated masses, the paraganglia, associated singly or in groups with the ganglia of the sympathetic nervous system, (ii.) a number of masses, chromaphil bodies of the sympathetic plexuses (aortic bodies) in close relation to the abdominal sympathetic plexuses, (iii.) the glandulie caroticre, and (iv.) the medullary portions of the suprarenal glands.

(i.) The paraganglia are rounded masses of chromaphil tissue, 1-3 mm. in diameter, placed inside, half inside, or immediately ontside the capsules of the ganglia of the sympathetic system. Typically one paraganglion, exceptionally a pair of paraganglia, is associated with each ganglion of the gangliated trunks and with each ganglion of the coliac, renal, suprarenal, aortic, and hypogastric plexuses. Inconstantly, paraganglia 
are associated with the ganglia of the cardiac and inferior mesenteric plexuses. They have been reported in association with ganglia situated upon the surface of the suprarenal glands, upon the surface and in the sinus of the kidney, in relation to the ureter, the prostate, the epididymis, the ovary, the paroöphoron, and the retro-peritoneal Pacinian corpuscles, but have not been discorered in association with the ganglia of the branches of the nervus trigeminus.

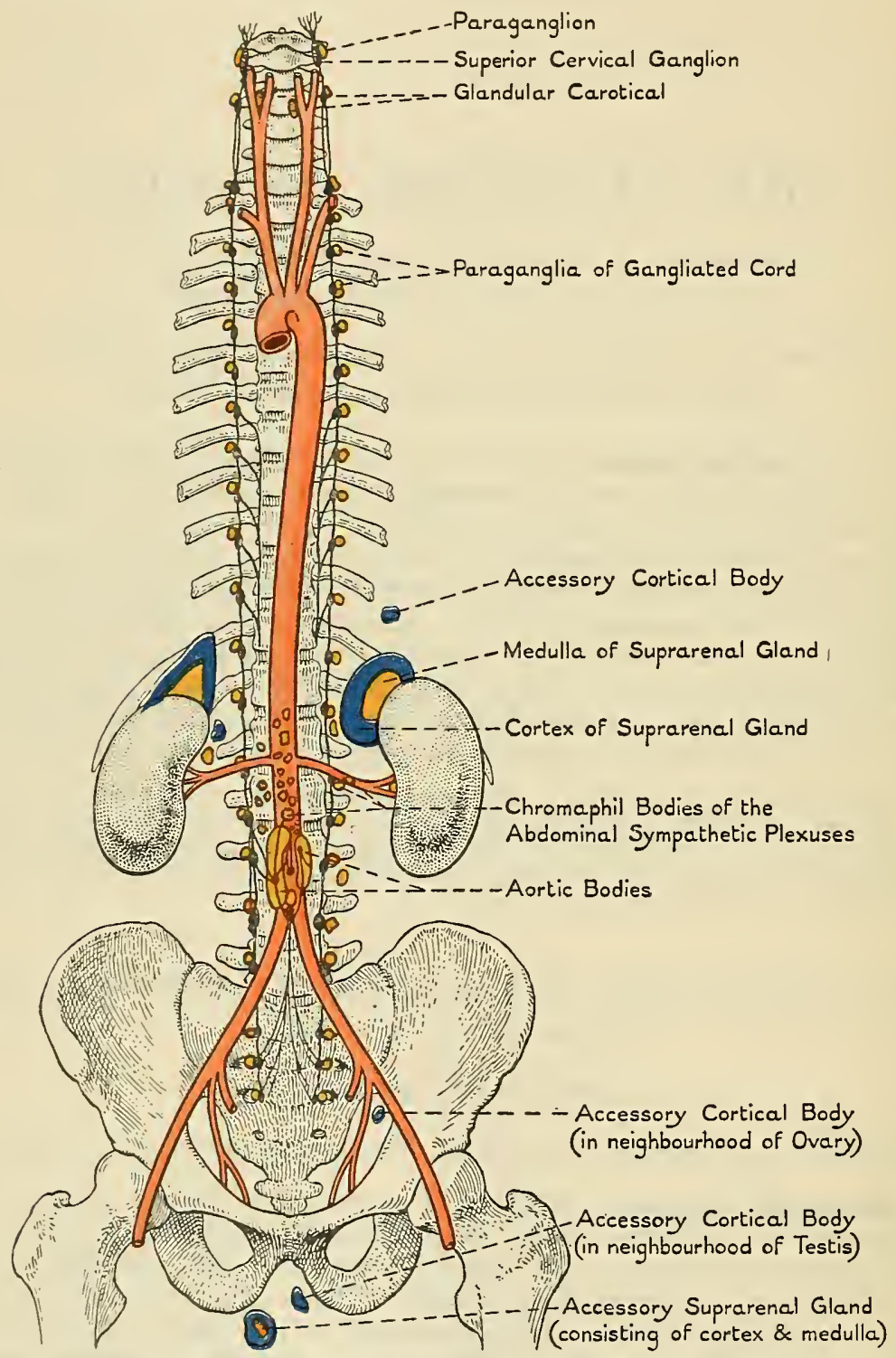

Fig. 1053.-Dlagram of the Chromaphil and Cortical Systems. Modified from Swale Vincent. Chrornaphil tissues $=$ yellow ; cortical tissue $=$ blue.

(ii.) The Chromaphil Bodies of the Sympathetic Plexuses.-From seven to seventy masses of chromaphil tissue are developed in relation to the abdominal sympathetic plexuses independently of the ganglia and in addition to the paraganglia. Of these, the most important are the two aortic bodies, which lie one on either side of the aorta in the region of the origin of the inferior mesenteric artery. In the new-born child they are smooth brownish structures, $8-11 \mathrm{~mm}$. in length, not infrequently united by an isthmus superiorly (Zuckerkandl). They degenerate as life advances, ceasing to be risible soon after puberty, but remaining discoverable, microscopically, until about the age of forty. 
(iii.) The glandula carotica (B.X.A. glomus caroticum; O.T. intercarotid body) is a bilateral paired organ situated in close but slightly variable relation to the bifurcation of the common carotid artery. Frequently it lies deep to the bifurcation ; sometimes it is wedged in between the internal and external carotids at their commencement; sometimes it is placed between them at a slightly higher level. Its shape varies with its position. When free from pressure it is oval: when compressed by the internal and external carotids it is wedge-shaped. On the average, its height is $7 \mathrm{~mm}$., its breadth 1.5-5 mm. Not infrequently it is split into two or more nodules. Its colour is grayish, yellowish, or brownish red.

Structure. - The glandula carotica is built up of nodules of chromaphil tissue surrounded and supported by fibrous tissue. The nodules are penetrated by a mass of sinus-like blood capillaries and surrounded by large lymph ressels. Scattered nerve-cells are present, and the whole organ is permeated by non-medullated nerve-fibres, which establish intimate connexion with the chromaphil cells.

(iv.) The medullary portions of the suprarenal glands, althongh belonging to the chromaphil system, are described below (p. 1346).

Development of the Chromaphil System. - All cluromaphil tissue develops in intimate relation with the sympathetic nervous system. It is not derived from the sympathetic tissue nor is the sympathetic tissue derived from it. Both are the descendants of a primitive, indifferent, sympatho-chromaphil blastema, which in a $16-\mathrm{mm}$. embryo occupies the regions corresponding to those occupied by the sympathetic system of the adult. It is composed of tightly packed deeply staining cells about $5 \mu$ in diameter. The ancestry of these cells can be traced back with strong probability to the cells of the neural crest (see Development of the Sympathetic Nervous Srstem).

The differentiation of chromaphiloblasts from sympathoblasts begins when the embryo is about $18 \mathrm{~mm}$. in length, but is not completed until late in gestation, if then. The process is marked by an increase in size of the chromaphil formative cells and by a diminution in the inteusity of their reaction to ordinary stains. Later, the specific chrome reaction derelops, but the exact stage at which this occurs is mknomn. It is important to note that if any cells in an area differentiate, all do. The result is that, in spite of their intimate relations and common origin, an intermixture of chromaphil and sympathetic cells is extremely rare.

The first of the chromaphil masses to differentiate are the aortic bodies. They are prominent structures in a 20 -mm. embryo. Later, the paraganglia of the sympathetic plexuses develop, and last the paraganglia of the gangliated trunk.

The development of the glandnla carotica requires special description. It takes origin from a strand of sympatho-chromaphil blastema, which extends rentrally from the region of the superior cervical sympathetic ganglion, deep to the internal carotid artery or between the internal and external carotids. Differentiation begins when the embryo is about $20 \mathrm{~mm}$. in length, and is completed by the time it is $30 \mathrm{~mm}$. long. In connexion with the development of the glandula, there is a peculiar thickening of the wall of the internal carotid artery near the developing g]and. In the dog a similar thickening of the wall of the internal carotid artery takes place, although in that animal the glandula lies beside the external carotid. Further, in a $45-\mathrm{mm}$. fœtus in which the glandula is fully differentiated the thickening is still present. These facts show that in the higher animals the thickening has no connexion with the development of the glandula, though the association of chromaphil bodies with blood-vessels in cyclostomata and elasmobranchs (see Comparative Anatomy of the Chromaphil and Cortical Systems) compels cantion in excluding the possibility of there being at least some phylogenetic relation between the two. It has frequently been stated, and is ridely held, that the glandula carotica is developed from or receives some contribution from the entoderm of the third pharyngeal pouch. This is not the case (see Parathyreoid Glands, Development).

\section{B. The Cortical Systey.}

The cortical system is composed of several masses of glandular tissue peculiarly rich in lipoids. Its function is undetermined. The distribution of the masses is shown in Fig. 1053. There are (i.) the cortical portions of the suprarenal glands, (ii.) accessory cortical bodies. These are described below (see Accessory Suprarenal Glands and Cortical System, Development).

\section{Glandule Suprarenales.}

The suprarenal glands (O.T. suprarenal bodies or capsules, adrenal glands) are compound organs consisting of a capsule of cortical substance enclosing a medulla of chromaphil tissue. Typically, there are two suprarenal glands, a right and left, placed in the epigastric region, one on each sicle of the vertebral 
column. Ther lie in the same plane as, and in intimate relation to, the superomedial aspects of the kidness. Their colour is yellowish brown; their size raries within wide limits. To some extent it depends upon the cause of death-being large in subjects dead of acute septic intoxication, small after sudden death from riolence. Arerage dimensions are: height, $5 \mathrm{~cm}$; breadth, $3 \mathrm{~cm}$; thickness, slightly under $1 \mathrm{~cm}$. : weight about $7 \mathrm{gm}$.
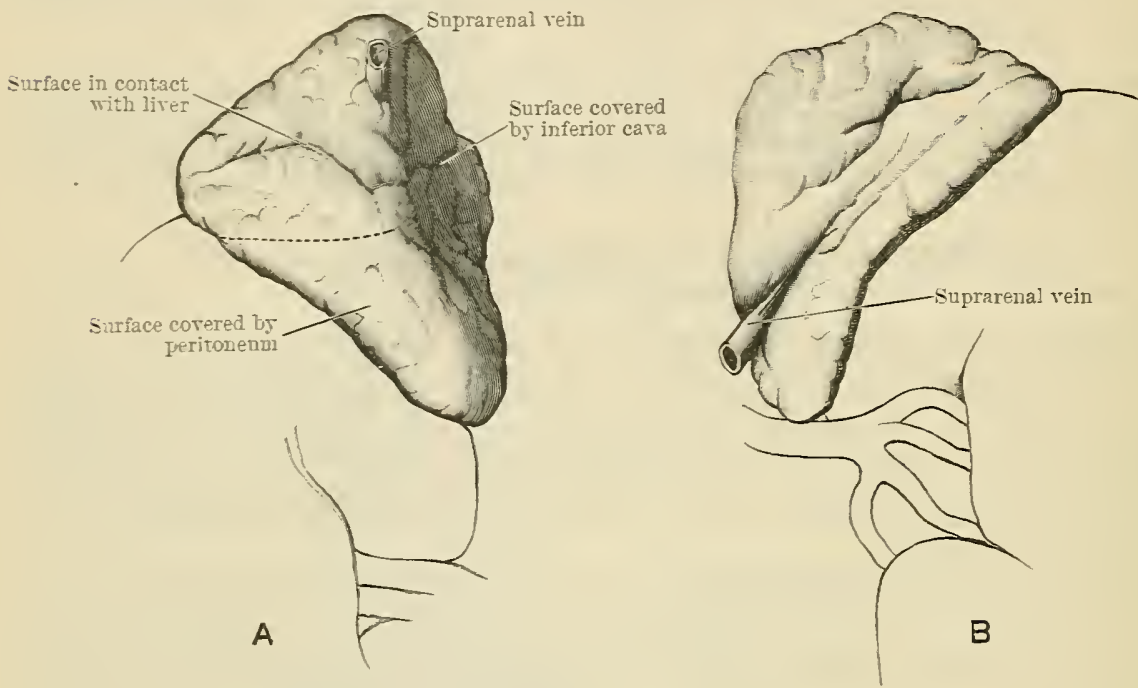

FIG. 1054.

A. Anterior surface of right suprarenal gland. B. Anterior surface of left suprarenal gland. The superior and medial parts of each kidney are indicated in outline. On the right gland the dotted line indicates the superior limit of the peritoneal covering.

Piarely only one gland is present; occasionally one is quite small, the other unusually large; as a rule.they are unequal in size, the left being more frequently the larger. Sometimes the two glands are fused (cf. horse-shoe kidney). Frequently there are accessory glands. These derelop in the neighbourhood of the main gland, and usually remain there, but may become attached, early in embryonic life, to organs which subsequently change their position. As a result, they may be found not only beside the main gland but also in
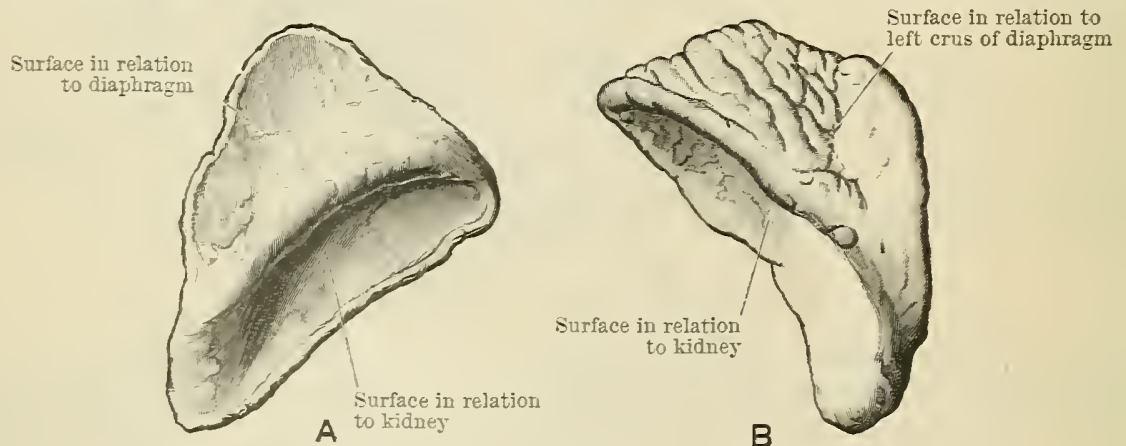

FIG. 1055

A. Posterior surface of right suprarenal gland. B. Posterior surface of left suprarenal gland.

the ligamentum latum, on the spermatic cord, or even attached to the epididymis. Like the main glands, accessory suprarenals are compounded of cortex and medulla, and require to be distinguished from chromaphil bodies and accessory cortical bodies, which may be found in any of the positions in which accessory suprarenal glands occur.

Forms and Relations.- The suprarenal glands possess fairly constant forms and relations. The right gland is flat and triangular in outline. It is moulded, antero-laterally 
by the liver ; antero-medially by the vena cava inferior ; postero-medially by the diaphragm above, and by the kidney below. In a formalin-hardened specimen these areas are separated by prominent ridges. Near the apex of the gland within the area of contact with the rena cava inferior there is a short fissure, the hitus. From this emerges a rein which immediately joins the rena cara. The left gland is also flat, but is semilunar in outline. It is moulded antero-laterally, by the stomach above, and by the pancreas

Medulla of suprarenal gland Cortex of suprarenal gland

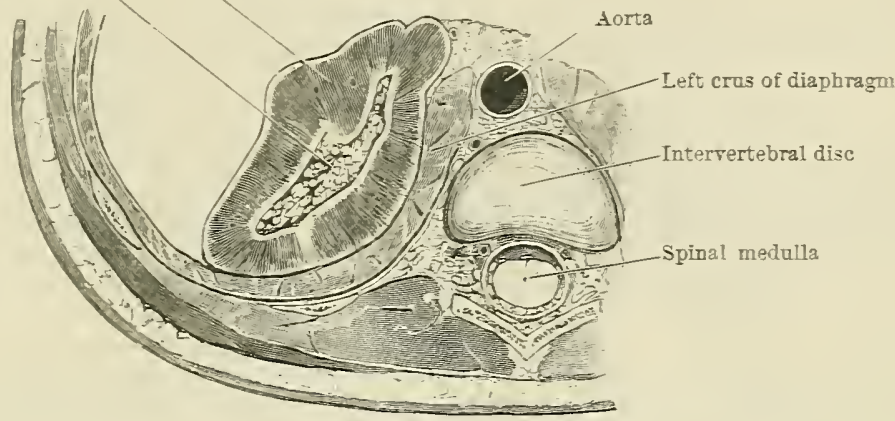

Fig. 1056. -Traisterse Sectiox throdgh the Supraresal Glayd of a New-bory Child IN SITU.

below; postero-medially by the diaphragm above, and by the kidney below. Upon the anterior surface, near its lower end, is a well-marked fissure, the kilus. From this emerges a vein which almost immediately joins the left renal rein.

The relations of the right and left glands to the kidneys are different. The right lies like a cap upon the superior pole of the right kidner; the left is in contact with the antero-medial border of the left kidney from the hilus to the superior pole. The relation

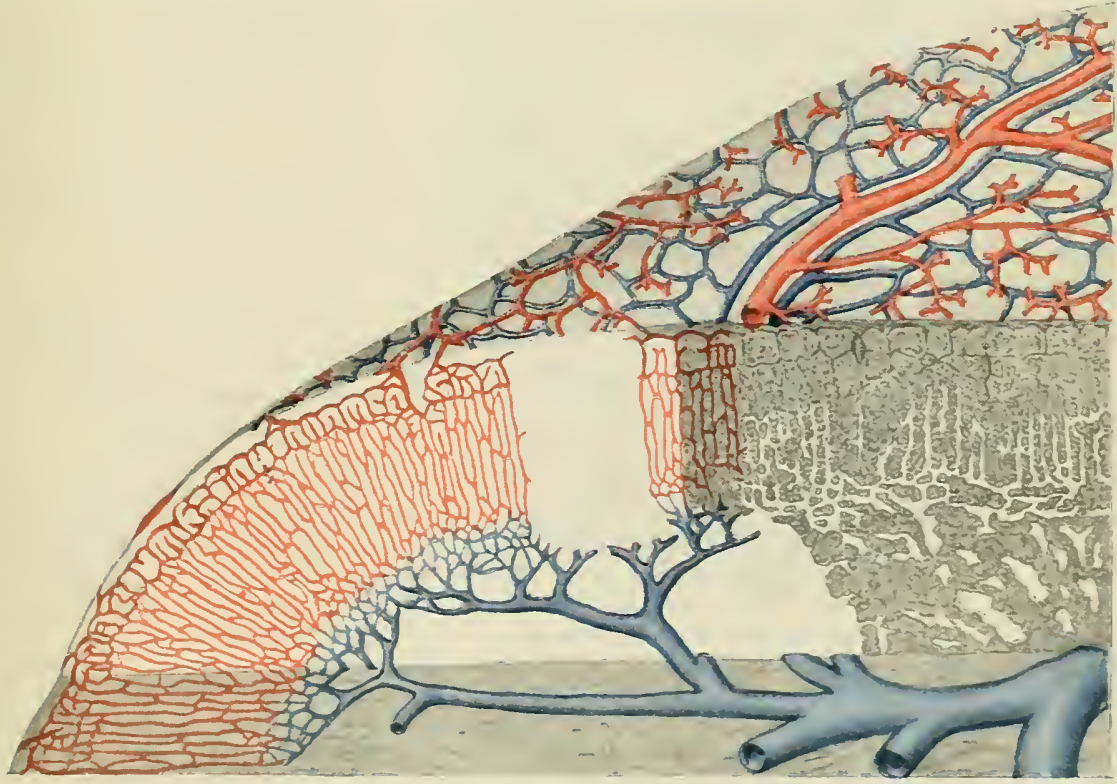

Fig. 1057.-Reconstrectiox of Adrexal of a Dog. (From J. Marshall Flint.)

The upper part shows the arrangement of blood-vessels upon the surface of the gland, the lower part their arrangement within its substance.

of the glands to the peritoneum is not only different but variable. On the right side the peritoneum may cover the lower part of the antero-lateral surface of the gland; or this part may be in contact with the duodenum, in which case a small area about the middle of the surface may be covered by peritoneum; or the peritoneum may not come into relation with the gland at all. On the left side the upper part oi the anterior surface is commonly covered by the peritoneum of the omental bursa, the lower part being 
crossed by the pancreas and splenic vessels. Sometimes these structures lie at a lower level, when the whole antero-lateral surface is covered by peritoneum of the omental bursa.

Blood and Lymph Vessels.-Typically, each gland receives three arteries: one direct from the aorta, one from the inferior phrenic, and one from the renal artery; and is drained by one vein, which emerges at the hilus, the right to join the vena cava inferior, the left to join the left renal vein. Numerous lymph vessels pass from the suprarenal glands to the lateral nortic lymph glands.

Nerves.-The nerves passing to and from the glands constitute the suprarenal plexuses. They comnect with the renal and coliac plexuses and with the coliac ganglia, and include numerous fibres from the greater splanchnic nerves, with a smaller number from the vagus and phrenic nerves. Most of them are medullated, but lose their sheaths on passing into small ganglia in, or just within, the fibrous capsule of the gland. Thereafter they pass to the chromaphil tissue of the medulla, either directly, or after first supplying the cortex.

Structure.-A suprarenal gland consists of a highly vascular central mass of chromaphil tissue, the medulla, enclosed within a thick capsule of cortical substance, the cortex, which in turn is enclosed within a capsule of fibrous tissue, tunica fibrosa. From the deep aspect of the fibrous tunic trabecule pass inwards to support the glandular tissue. In the superficial part of the cortex the trabeculæ interlace freely to enclose rounded loculi, anon glomerulosa; in the intermediate part they run vertically to the surface to enclose columnar spaces, zonc fasciculata; in the deepest part of the cortex they, become broken $u p$ and form a reticulum, zona reticulata.

The cortex consists of polyhedral cells arranged in the interstices of the fibrous trabeculæ. These cells contain a lipoid substance, which is present in sufficient quantity to give the cortex a yellow colour.

The medulla is formed of a spongework of cell columns bounding anastomosing venous sinuses. The cells are large, contain numerous granules, and possess the specific chromaphil reaction. In a fresh gland the medulla is of a dark red colomr owing to the presence of blood in its sinuses.

The blood-vessels enter at numerous points in the fibrous capsule and run in the trabeculæ, forming a network around the cell masses and columns of the zona glomerulosa and zona fasciculata. In the zona reticulata the blood-vessels open up to form a veuous plexus, which is continued through large sinuses in the medulla to reach a central vein. This is the vein which emerges at the hilus.

Development of the Cortical System and of the Suprarenal Glands.-The cortical system is a derivative of the colomic epithelium (mesoderm). The first indication of its development is given, when the embryo is about $6 \mathrm{~mm}$. in length, by the rapid proliferation of the epithelial cells placed between the mesonephros and the root of the mesentery. Numerous buds form and penetrate the mesenchyme at the sides of and ventral to the aorta. In an 8-mm. embryo these buds have already lost their connexion with the colomic epithelium. By the time the embryo is $9 \mathrm{~mm}$. long the developing cortical masses are vascularised. In man the greater part of the tissue thus formed is ultimately included in the cortex of the suprarenal glands, but small masses may escape, either at this stage or subsequently, to form independent cortical bodies.

In 12-mm. embryos the developing suprarenal glands lie in a caudalward continuation of the dorsal portion of the pleuro-peritoneal membrane called the suprarenal ridge, and are composed of cortical tissue only. When the embryo is about $20 \mathrm{~mm}$. in length sympatho-chromaphil cells, destined to form the medulla of the gland, begin to migrate into the developing cortex. The two kinds of tissue are in contact in 10-12 mm. enbryos, but penetration of cortical masses by sympatho-chromaphil cells has not been observed earlier than the stage mentioned.

At first the immigrating cells are scattered in numerous columns and strands, and it is not until the embryo is about $10 \mathrm{~cm}$. in length that they begin to reach the central vein and to form a true medulla. When the process of immigration ceases is unknown, probably not until after birth.

The final specialisation of the cortex is a late phenomenon, and does not take place until long after birth. The zona reticularis develops early and is recognisable in a $15-\mathrm{mm}$. enıryo; the zona glomerulosa is not formed until the second or third year, but is represented until then by a layer of small incompletely specialised cells immediately under the fibrous capsule.

During fœtal life the cortex is relatively enormous. This is due to a great proliferation of the cells of the fotal zona reticularis, which differ from the adult cells of the same zone in not containing lipoids. This fotal cortex begins to undergo a fatty degeneration soon after birth, and by the end of the first year has disappeared. The new cortex which replaces it develops from the small, superficially placed, incompletely specialised cells already referred to.

Comparative Anatomy of the Chromaphil and Cortical Systems.-A knowledge of the main facts of the comparative anatomy of the chromaphil system is a help to understanding its distribution in man. Chromaphil tissue is first recognised with certainty in the cyclostomata, in which it is arranged in thin strips on the walls of the larger arteries and their branches. In elasmobranchs chromaphil bodies are present and are arranged segmentally on branches of the aorta in close relation to the ganglia of the sympathetic chain. Cortical tissue is also recognisable in the cyclostomata, in which it is arranged in small lobulated masses in the walls of the posterior cardinal veins and renal arteries. Even in this rudimentary form it is rich in lipoids. In the rays (elasmobranchs) the cortical system is represented by a pair of yellowcoloured, rod-shaped structures in the region of the kidney. In batrachians the chromaphil and cortical representatives first begin to come together. In the frog the actrenals are golden yellow 
streaks on the ventral surface of the kidney. The greater part of these are made up of columns of cortical cells, but at the borders or ends of the cell columns masses of chromaphil cells occur: This arrangement is transitional between the complete independence of the chromaphil and cortical systems in elasmobranchs and the partial inclusion of chromaphil tissue within cortical characteristic of the higher mammals (Swale Vincent). But even in man the union of the systems is far from complete. All the chromaphil tissue except the medulla of the suprarenal gland lies ont of touch with cortical substance. It appears therefore (i.) that the paraganglia of the sympathetic trmnk are homologous with the segmental chromaphil bodies of elasmobranchs; (ii.) that the chromaphil bodies of the abdominal plexuses are a new formation confined to the higher vertebrates; (iii.) that the inclusion of chromaphil tissne within a capsule of cortical, as in the suprarenal glands, is a still later development confined to the highest classes of animals.

\section{THE DUCTLESS GLANDS OF ENTODERMAL ORIGIN.}

A group of ductless glands, (i.) the thyreoid gland, (ii.) the parathyreoid glands, (iii.) the thymus, and two pairs of inconstant, apparently functionless structures, (iv.) the cervical thymus glands, and (v.) the ultimo-branchial bodies, are developed from the entodermal lining of the embryonic pharynx.

\section{(i.) Glandula Thyreoidea.}

The thyreoid gland (O.T. thyroid body) is placed in the neck, firmly bound by fibrous tissue to the anterior and lateral aspects of the upper part of the trachea and to the sides of the larynx. It is yellowish red, soft, and vascular. It varies in size with age, sex, and general nutrition, being relatively large in youth, in females, and in the well nourished. In women it increases temporarily with menstruation and pregnancy. Its a verage dimensions are, height $5 \mathrm{~cm}$., breadth $6 \mathrm{~cm}$., weight $25 \mathrm{gm}$; ; but these measurements are of little value because of the range of variation.

Conventionally, the thyreoid gland is said to consist of two conical lateral lobes united across the middle line by a narrow strand of gland tissue, the isthmus. To many thyreoids this description is inapplicable. In men and thin elderly spinsters the gland is not uncommonly horse-shoe shaped; in young well-nourished women and in pregnancy its general contour

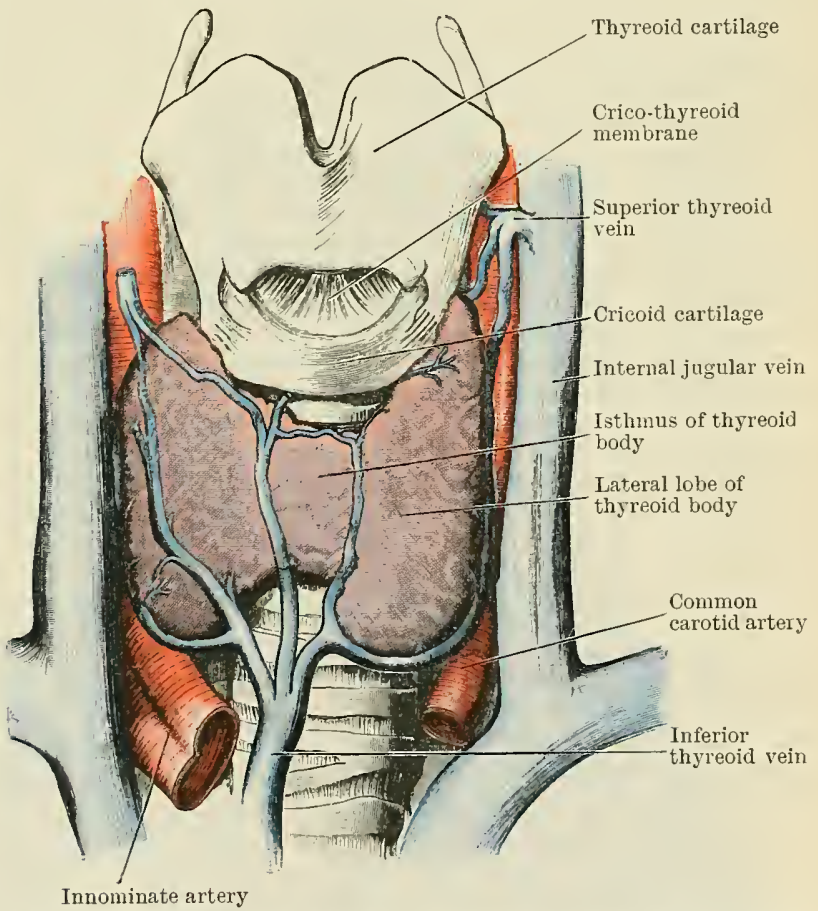

Fig. 1058. - Dissection of the Thyreoid Body and of the Parts IN IMMEDIATE RELATION TO IT. suggests a sphere, deeply notched superiorly to accommodate the larynx and deeply grooved posteriorly for the trachea and œsophagus. Rarely, the gland is in two parts. Not infrequently, it is asymmetrical. In about 40 per cent of specimens a process of gland tissue, the pyramidal lobe, extends from the upper border of the isthmus, upwards, in front of the cricoid and thyreoid cartilages, towards the hyoid bone. This process is seldom median, lying more often on the left than on the right. In rare cases, it is double. Less rarely, it is double below and single above. Sometimes it is represented by a strip of fibrous tissue ol a narrow muscle (lig. suspensorium, or m. levator, glandulæ thyreoideæ).

Small oval accessory thyreoid glands are common in the region of the hyoid bone, and are occasionally met with in relation to the lateral lobes.

The relations of the gland are variable, depending upon its size and its relative level. 
In a majority of cases the isthmus covers the second, third, and fourth rings of the trachea, but it may corer the cricoid cartilage, or the fourth, fifth, and sixth tracheal rings. Anteriorly, the gland is clothed by the pretracheal fascia, which separates it from the sterno-thyreoid, sterno-hyoid, and omo-hyoid muscles. Extensions of this fascial layer form an indefinite capsule for the gland. Postero-medially, the thyreoid gland is moulded by the sides of the trachea and lower part of the larynx, and, when large, comes into contact, behind them, with the pharyux and osophagus. Postero-laterally, it is in relation to the common carotid arteries, and when large is in intimate relation to the recurrent nerves. Further, it has important relations to the parathyreoid glands (see Parathyreoid Glands, Relations).

Blood and Lymph Vessels. - The blood supply is effected through the superior thyreoid arteries, branches of the external carotids, and through the inferior thyreoid arteries, branches of the thrreo-cervical trunks. Occasionally a fifth artery is present, the thyreoidea ima, a branch of the innominate. The pyramidal lobe, if well developed, receives a special branch from one of the superior thyreoids, usually the left. These arteries are remarkable for their large size and for the frequence and freedom of their anastomoses. An anastoniosing trunk courses $11 p$ the posterior aspect of the lateral lobe, uniting the inferior and superior thyreoid arteries. It is of interest in connexion with the recognition of the parathyreoid glands. Typically, three pairs of veins drain the gland. The upper two pairs, the superior and middle thyreoid veins, join the internal jugulars; the lower pair, the inferior thyreoid veins, join the left innominate. These vessels take origin from a venous plexus on the surface of the gland or, in the case of the inferior, from a downward extension of the plexus in front of the trachea. When the gland is very large, accessory veins are present, sometimes in considerable numbers. Most of these pass to the internal jugulars. A free, transverse, venous anastomosis is effected along the borders of the isthmus through the superior and inferior communicating veins.

The lymph vessels anastomose freely in the substance and on the surface of the gland. Most pass direct to the deep cervical lymph glands, a few descend in front of the trachea to the pretracheal lymph glands.

Nerves.-The nerves are derived from the middle and inferior cervical ganglia of the sympathetic. They accompany the blood-vessels.

Structure.-The gland is enclosed in a fibrons capsule (tumica propria) which sends prolongations inward to form a framework for the gland tissue proper. This consists of spheroidal vesicles, $.04 \mathrm{~mm}$. to $1 \mathrm{~mm}$. in diameter, lined with cubical epithelinm, and filled with "colloid." The size, shape, and cellular characters of the vesicles vary with diet and environment. The vesicles are surrounded by networks of blood capillaries and of lymph vessels.

Development. - The thyreoid gland takes origin from a single median outgrowth from the pharyngeal floor (entoderm). It is recognisable as a shallow bay in a $1 \cdot 8$-nm. embryo, practically simultaneously with the demarkation of the foregut. As the bud grows its end expands whilst its stalk narrows to form the thyreo-glossal duct.

In a $4-\mathrm{mm}$. embryo an elevation is present round the pharyngeal opening of the duct. This is the tuberculum impar. It migrates forwards, the duct backwards, so that in a $5-\mathrm{mm}$. embryo the duct opens into the furrow immediately caudal to the tuberculum (see Tongue, Development). At abont this stage the duct begins to obliterate. This process proceeds slowly and is seldon quite complete, a vestige of the duct, the foramen crecum of the tongue, remaining in the adult.

While these processes are proceeding growth and lateral expansion of the bud continue. It becomes bilobed and has a divided lumen, and all the while it undergoes a continuous relative displacement caudalwards. Soon its lumen disappears. In a $9-\mathrm{mm}$. embryo the developing thyreoid gland is a transverse bar composed of transversely rlisposed cell columns. At about the tenth week of development, 55-mm. embryo, the formation of vesicles commences but is not completed until after birth. The remaining changes are due to simple growth and the moulding effects of the pressure of surrounding structures.

The thyreoid gland does not arise in any of its parts from any of the pharyngeal pouches (see Ultimo-branchial Bodies).

The developmental history of the gland affords a ready explanation of its variations in the aduIt. Thus the development of a pyramidal lobe and its variations, partial and complete duplication, are due to the development of gland tissue from that part of the thyreo-glossal duct which has a doulble lumen and the more оr less complete fusion or separation of the masses thus formed. Accessory thyreoid glands near the hyoid bone are the result of a similar process in connexion with isolated remuants of the duct.

The occurrence in the adult of a duct leading from the foramen cæcum to, or towards, the hyjoid bone (lingual duct) is due to a persistence of the upper part of the thyreo-glossal duct. Similarly, thyreo-glossal cysts are due to the persistence of short intermediate lengths of the duct.

\section{(ii.) Glandula Parathyreoidez.}

The parathyreoid glands (O.T. parathyroid bodies; Synonyms: epithelial bodies, parathymic glands, branchiogenic glands) are finely granular, yellowish brown, lenticular or spheroidal structures, from 2 to $20 \mathrm{~mm}$. in diameter and from 
01 to $3 \mathrm{gm}$. in weight. Most commonly they are lenticular, $5-7 \mathrm{~mm}$. in length, 1-2 mm. in thickness, and from 01 to $1 \mathrm{gm}$. in weight. Normally there are two pairs of parathyreoids, distinguished by the Poman numerals IV. and III. to signify that they develop from the fourth and third pharyngeal pouches. Sometimes, in course of development, the parathyreoid buds divide so that more than four, five to twelve, glands may be present: the numerals are then applied to the groups of glands formed from the pouches.

Parathyreoid IV. is commonly embedded in the tunica propria of the thrreoid gland and lies posterior to the lateral lobe of that organ, about its middle. Parathrreoid III., similarly embedded, usually lies on the posterior aspect of the inferior extremity of the lateral lobe of the thyreoid gland. As a rule the anastomosing channel, which connects the inferior and superior thyreoid arteries (see Thyreoid Gland, Blood Supply), passes near both parathyreoids and furnishes the best guide to their discovery, but the range of the exceptional positions which the glands may occupy is wide. Thus, parathyreoid IV. may be found (1) behind the pharynx or cesophagus, $(2)$ in the fibrous tissue at the side of the larynx, above the level of the thyreoid gland, (3) behind any part of the lateral lobe of the thrreoid gland or even embedded in the thrreoid substance (internal parathyreoid); whereas parathyreoid III. may be found (I) near the bifurcation of the common carotid artery, (2) behind any part of the lateral lobe of the thrreoid gland, (3) on the sides of the trachea, or (4) in the thorax.

Blood-vessels. - The blood supply of each parathyreoid is effected by a single artery which enters the gland at its hilus. It may spring from any branch of the inferior or superior thyreoid arteries, but most commonly is a branch of the large anastomosing channel already referred to.

Structure.-The parathyreoids are built up of intercommunicating tràbeculæ of epithelial cells with strands of vaseular connective tissue between them. The cells are of two kinds, one clear, the other, the minority, containing oxyphyl granules. Sometimes they surround spaces recalling thyreoid resicles but there is no formation of " colloid," except possibly after thyreoidectomy.

Development. - The parathyreoid bodies develop from the dorsal diverticula of the third and fourth pharyngeal pouches. The first indication of their development is a proliferation and thickening of the epithelium on the cranial and lateral aspects of the diverticula. This is present in both the third and fourth ponches in 9-10 mm.embryos but appears to be ratier irregular in the time of its

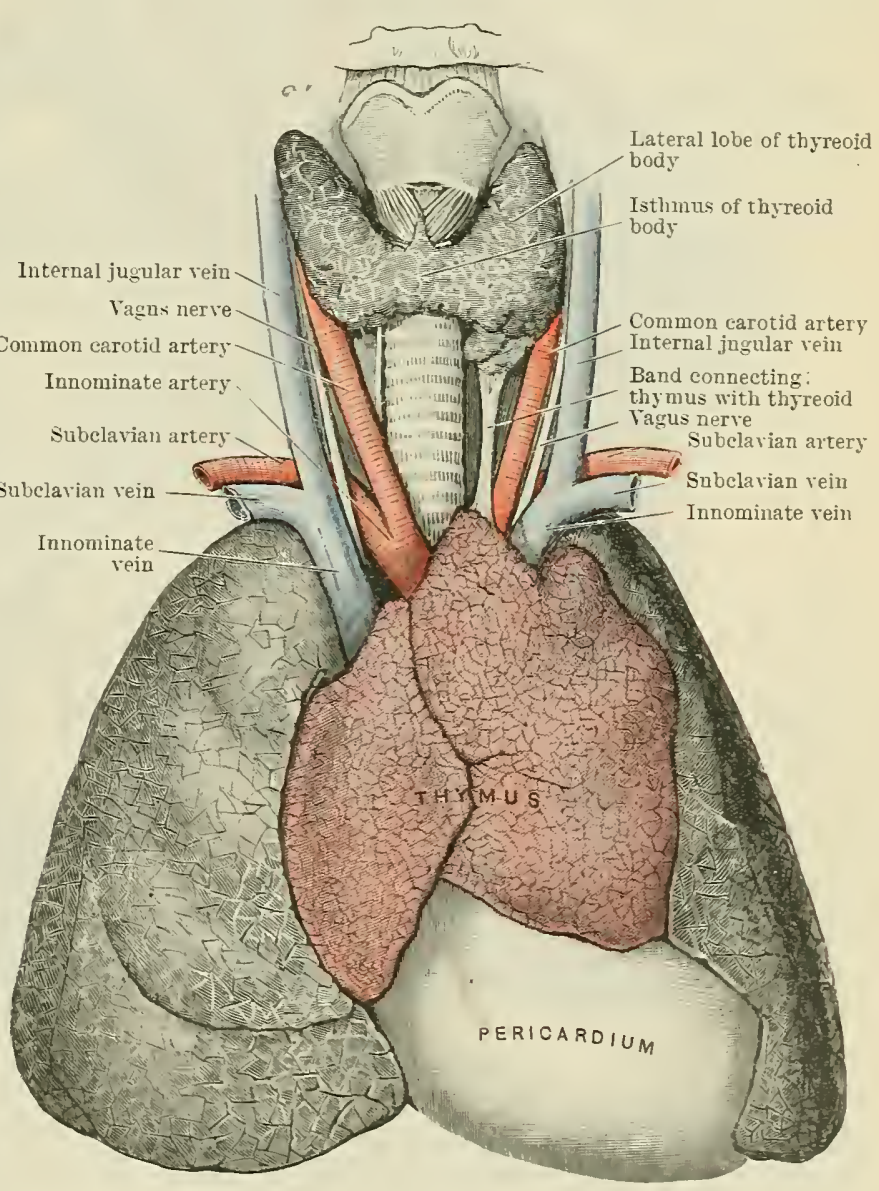

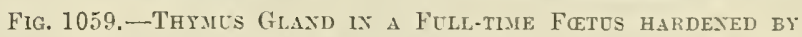
FORMALIT-LYJECTION. appearance. The cells forming it are vactolated, difficult to stain, and indistinct in outline. Cords of cells grow out from the thickening and fibrous tissue penetrates between the outgrowing cords, which soon lose their connexion with the pharmx. The differentiation of the two kinds of cells takes place after birth. 
Parathyreoid III. is normally drawn by the thymus as it migrates caudal to parathyreoid IV. As a rule it halts at the level of the inferior extremity of the lateral lobe of the thyreoid gland, but may continue its descent into the thorax or may not descend at all. In the latter case it remains near the bifurcation of the common carotid artery, where it is apt to be confused with the glandula carotica. It is from this confusion that the idea, that the chromaphil glandula carotica arises from the third pharyngeal pouch, has obtained a foothold in anatomical teaching.

\section{(iii.) Thymus.}

Strictly, there are two thymus glands, a right and a left, but they are so closely bound to one another that it is customary to speak of them as a unit,

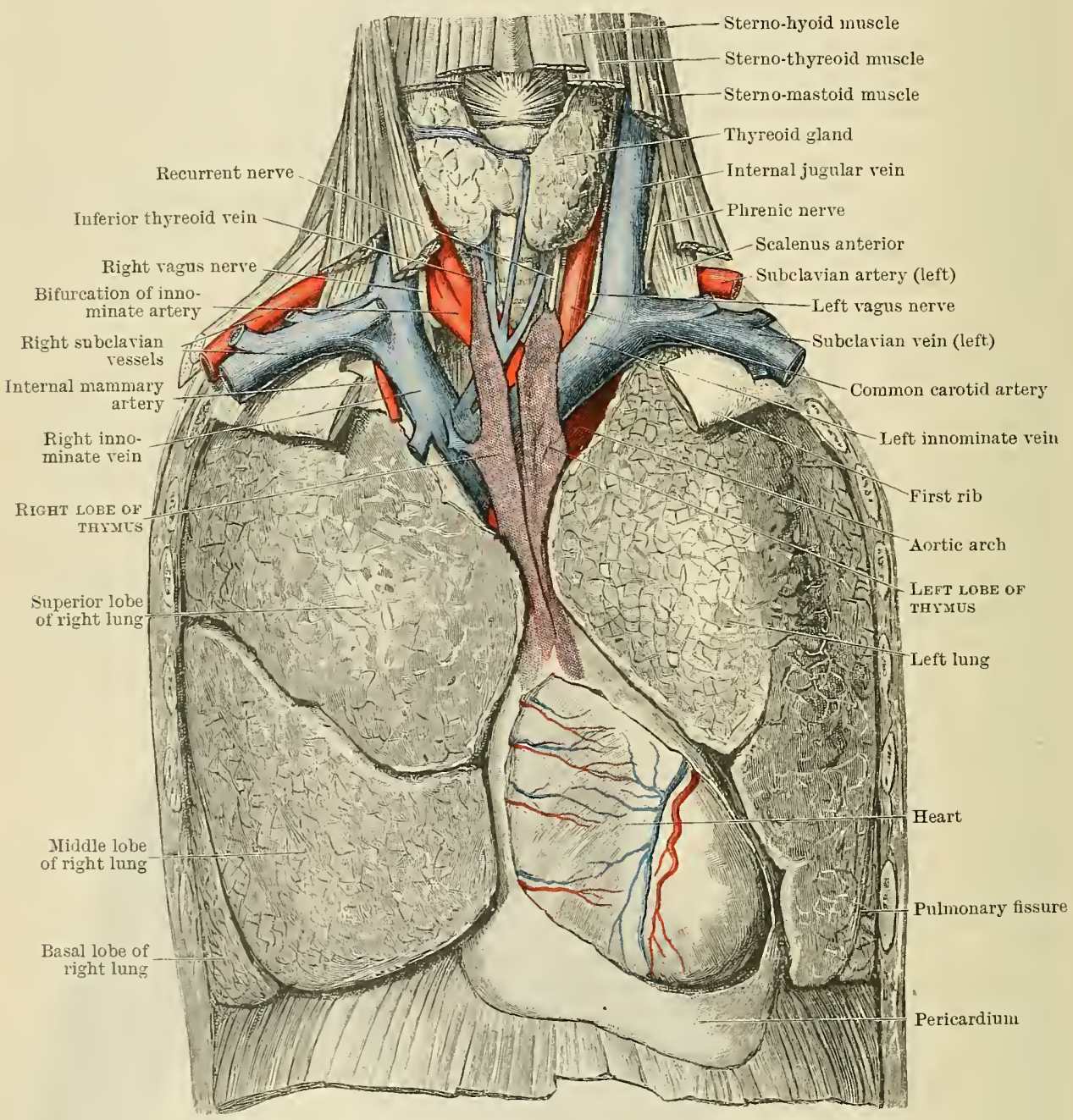

Fig. 1060.-Dissection to show the Thymus Gland in an Adult Female.

the thymus. This is an irregular pinkish mass of glandular tissue placed in the lower part of the neck and in the superior and anterior mediastina. Its size varies, relatively and absolutely, with age, sex, and nutrition, being relatively largest in infancy, absolutely largest at puberty; larger in females and the well nourished than in males and the emaciated; large in healthy adults accidentally killed; small in persons, even children, who have died of a slow wasting disease. It is supposed that it undergoes a premature permanent involution as the result of severe illness even though, to all appearance, the individual completely recovers. 
It is impossible to say what should be the normal dimensions of the gland at the various ages. In some new-born babes it weighs as little as 2 or $3 \mathrm{gm}$., in others as much as $15-17 \mathrm{gm}$. At puberty it may be difficult to find, or may weigh as much as $40 \mathrm{gm}$. After the age of fifty it may require careful dissection to discover, or may be quite large. When large it fills all the space available between the pleural sacs laterally and the back of the sternum and the pericardium and greatt vessels in front and behind; when small it is embedded in fat and fibrous tissue. The shape of the gland varies with its size and the age of the individual. In infants with short thoraces it is broad and squat; in adults with long thoraces it is drawn out into two finger-like strands. The details of its shape are determined by its size and by the structures upon which it is moulded, viz., the pericardium and the great ressels of the superior mediastinum and the root of the neck. One or both of its lobes may be connected by a strand of fibrous tissue to the tunica propria of the thyreoid gland.

Blood and Lymph Vessels. - The blood supply of the thymus is effected through inconstant branches of the inferior thyreoid and internal mammary arteries. Its veins are irregular and join the inferior thyreoid, internal mammary, and innominate veins. Its lymph ressels are large and pass to glands close to the organ.

Its nerves are minute and are derived from the ragus and srmpathetic. The branches of the vagus descend directly to the thymus from about the level of the thrreoid cartilage; the sympathetic fibres run with the blood-ressels. The fibrous capsule of the thymus receives small irregular branches from the phrenic nerves, but these do not supply the gland tissue in any way.

Structure. - The thymus is invested by a fibrous capsule which sends septa into its substance to divide it into lobules. The lobules are similarly divided into follicles (secondary lobules) about $1.5 \mathrm{~mm}$. in diameter. Each follicle consists of a medulla not quite completely surrounded by a cortex. In a general way, the structure of the cortex resembles a lymph gland, but the reticulum, instead of being fibrous, is syncytial. The spaces of the reticulum are crowded with lrmphocytes, but there are no germinal centres. The medulla resembles the cortex, but the reticulum is coarser and contains cell nests, the concentric corpuscles of Hassall. As age advances the thymus undergoes involution. This process is marked by an increase of fibrous tissue and a rednced cellularity. The number of lymphocytes and of concentric

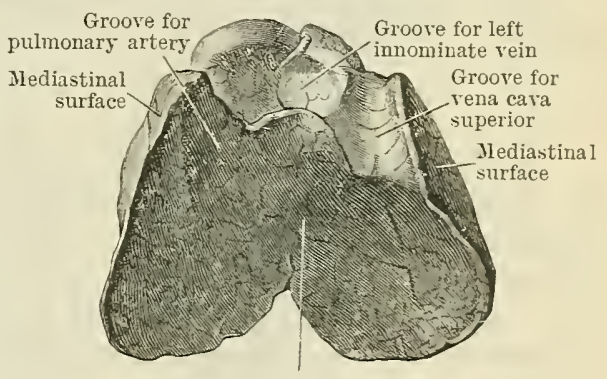

Pericardial surface

Fig. 1061.-DeEp Surface of ThyMUS, TAKex FROM A FETCS HARDEAED BY FORIALIAINJECTION. corpuscles varies with nutrition.

Development. - As has been stated, there are in reality two thymus glands, a right and a left; these arise from the ventral diverticula of the third pharyngeal pouches. The first indications of the dereloping glands, cylindrical elongations of the direrticula, are present in 5-mm. embryos; the wills of the cylinders, more particularly their dorsal parts, soon thicken. Coincidently the necks of the pharyngeal pouches become constricted to form the pharrngobranchal ducts III. These soon disappear when the thymus rudiments lose all comiexion with the pharynx. At this time the upper prarts of the rudiments still have a lumen; the lower parts are solid. Soon the lumen vanishes; the solid parts thicken and the dereloping thymus migrates caudalwards to reach the pericardium at the $15-1 m$ m. stage. As a result of the migration the upper part gets drawn out and finally disappears. It is in this process that parathyreoid III. is involved. It is attached to the upper part of the migrating thrmus, the part which disappears. The relative time of this disappearance determines the permanent level of parathyreoid III., for until it happens that gland is dragged in the wake of the thrmus (see Parathyreoids, Development of). Sometimes a small detached mass of thymus formative tissue inay persist beside parathyreoid III., and may differentiate to form an Accessory Cervical Thymus III.

During migration and after, the cells continue to proliferate and the thrmus rudiment increases in mass. At the 40-mm. stage lymphocytes begin to appear in it. Differentiation of cortex and medulla is visible at the $45 \mathrm{~mm}$. stage. The details of the process of thymic histogenesis are undetermined. It is beliered that the syncytial reticulum and concentric corpuscles are of entodermal origin, but whether the lymphocytes arise in situ or are immigrants is unknown.

\section{(iv.) The Cervical Thymes Testiges.}

Small masses of thymus tissue are frequently found in close relation to parathyreoids IV. They are developed from the rentral diverticula of the fourth pharyngeal pouches in a manner generally similar to that in which the main thymus gland derelops. Not 
infrequently they are embedded in the thyreoid gland, internal thymus. Less frequently they are sansage-shaped bodies, $5.25 \mathrm{~mm}$. in length, lying at the sides of the trachea. sometimes they are long enough to extend into the thorax, where they come into relation with the main thymus gland. Rarely they migrate into the thorax and develop to form consiclerable portions of the main thymus gland, which then consists of four developmentally distinct parts. Cervical Thymus Vestiges IV. require to be distinguished from the Accessory Cervical Thymus Glands III., which are sometimes found in close relation to parathyreoids III. (see Thymus Gland, Development).

\section{(v.) The Ultimo-Branchial Bodies.}

The fifth pharyngeal pouches give rise to a pair of gland rudiments called ultimobranchial bodies. Their fate is not known; it is possible that they may become the strands of parathyreoid-like tissue occasionally present in the lateral lobes of the thyreoid ; more frequently, apparently, they degenerate and leare no vestiges.

Their chief interest is that, for long, they were erroneously regarded as the rudiments of the lateral lobes of the thyreoid gland.

\section{THE DUCTLESS GLANDS ASSOCIATED WITH THE VASCULAR SYSTEM.}

Two ductless glands of mesodermal origin are associated with the vascular system. They are (i.) the spleen, (ii.) the glomus coccygeum.

\section{(i.) LIEN.}

The spleen is a soft, highly-elastic, contractile organ of purplish colour, placed in the upper left posterior part of the abdominal cavity, partly in the epigastrium, mainly in the left hypochondrium. It is moulded by the diaphragm, kidney, stomach, and, sometimes, colon. Its dimensions vary widely, but on the average are: length, $12 \mathrm{~cm}$; breadth, $7 \mathrm{~cm}$; thickness, $4 \mathrm{~cm}$; weight, $160 \mathrm{gm}$. Its shape is modified by the relaxation, distension, and contraction of the neighbouring hollow viscera; its position and the details of its moulding, by the attitude of the individual.

When the stomach is contracted and the colon distended, the spleen has the form of an irregular tetrahedron; when the conditions of the hollow viscera are reversed, the form of a segment of an orange. These are the extremes of a series of forms which the spleen presents when hardened in situ. In the recumbent posture the long axis of the spleen corresponds in direction with the posterior part of the tenth rib; in the erect attitude the long axis is frequently vertical, more especially in adult females.

Surfaces, Borders, and Angles of the Spleen.-The surfaces of the spleen are the facies diaphragmatica, facies renalis, facies gastrica, and, in the tetrahedral form only, facies basalis (colica). Their contour is fairly constant. The diaphragmatic surface is convex, moulded to the curve of the diaphragm; the renal is slightly concave, moulded to the kidney; the basal is flat or slightly concave, moulded by the colon; the gastric, deeply concave, moulded by the stomach. The gastric surface is interrupted by an irregular, not infrequently divided, slit, the hilus, through which the branches of the splenic artery enter and the tributaries of the splenic vein leave the gland. On the same surface, behind the hilus, there is a depression for the tail of the pancreas.

The borders of the spleen are margo anterior, between the gastric and diaphragmatic surfaces; margo posterior, between the diaphragmatic and renal surfaces; margo intermedius, between the renal and gastric surfaces. When present the basal surface is separated from the diaphragmatic by the margo inferior; from the gastric and renal by the margines intermedii, anterior and posterior.

The anterior border of the spleen is almost invariably notched; most frequently there are two motches, but there may be six or seven. Sometimes the posterior borcler also is notched. Rarely, the notches on the borders are joined by fissures extending across the diaphragmatic surface.

The angles of a tetrahedral spleen are: superior, at the junction of the diaphragmatic, 
gastric, and renal surfaces; anterior, at the junction of the diaphragmatic, gastric, and basal surfaces; posterior, at the junction of the diaphragmatic, renal, and basal surfaces; intermediate, at the junction of the renal, gastric, and basal surfaces. In a spleen of orange-segment form there are but two angles, a superior and an anterior. The superior is bounded in the same way as in the tetrahedral form; the anterior, by the diaphragmatic, gastric, and renal surfaces. In all spleens, but most commonly in those of oblique, irregularly tetrahedral form, the superior angle may curve forward as a blunt hook.

The spleen is entirely covered with peritoneum and is moored by two peritoneal folds, the lieno-renal and gastro-splenic ligaments (pp. 1162 and 1236). Inferiorly it is supported by the peritoneal phrenico-colic ligament (p. 1242 ).

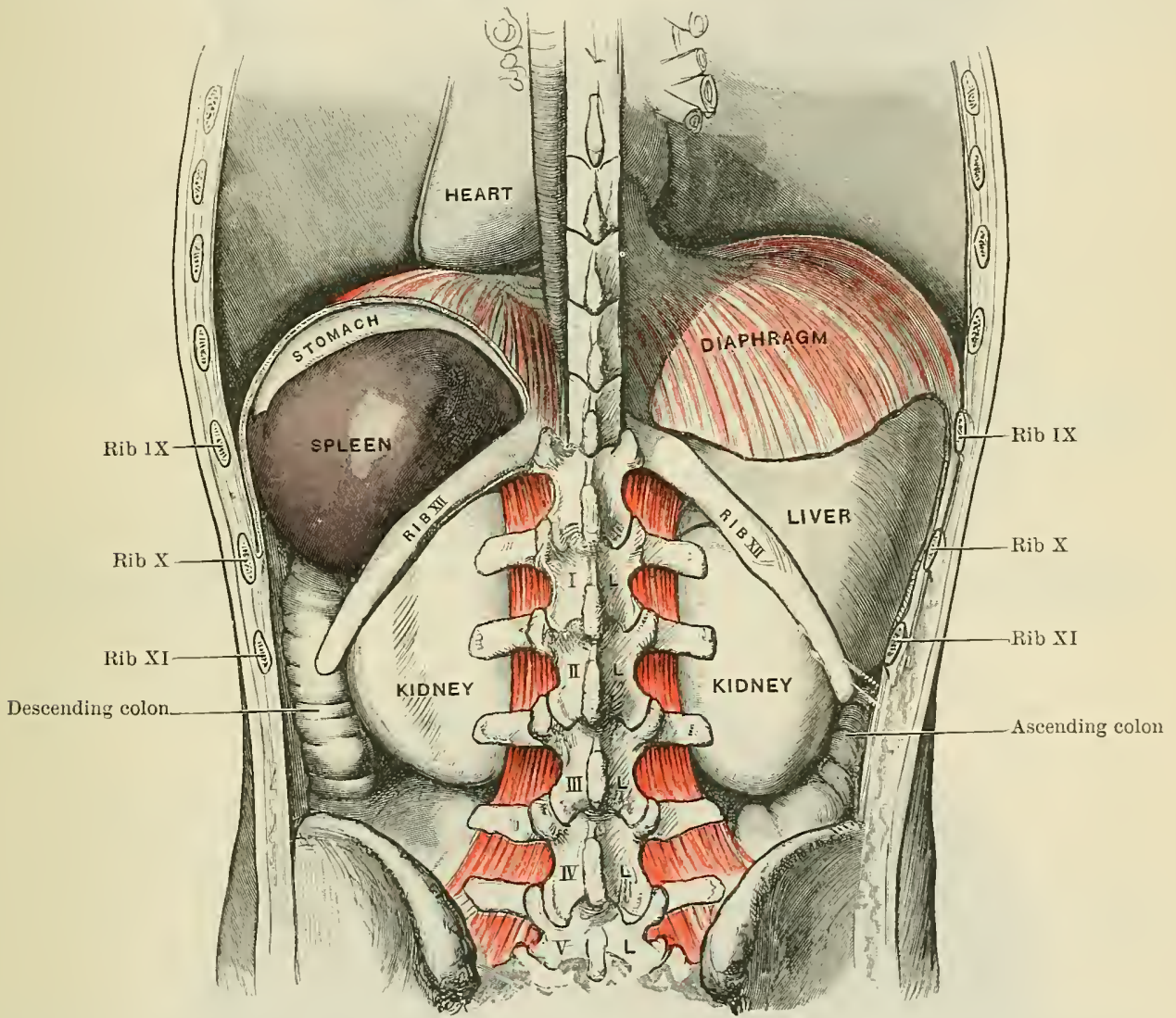

Fig. 1062.-Dissection of the Spleen, Liver, and Kidneys fron Behind, in a SubJect hardened by FordaLin-INJECTION.

Small globular accessory spleens are often present. As a rule they are attached to the gastro-splenic ligament near the splenic hilus.

Blood and Lymph Vessels.-The spleen receives its blood from the splenic artery, which passes through the lieno-renal ligament. Before reaching the gland it breaks up into six or more branches which enter the hilus independently. The vein of the spleen, the splenic vein, is formed in the lieno-renal ligament by the nnion of several unnamed tributaries which emerge from the hilus. The lymph vessels also leave the spleen at the hilus. They are small and come from the capsule and trabeculæ only, not from the glandular part of the organ.

Nerves. - The nerres are almost entirely non-medullated and come from the cœliac plexus. They accompany the splenic artery and its branches.

Structure.-The spleen is composed of a soft substance called pulp, supported by fibrons trabeculæa and enclosed within a fibrous capsule, tunica propria, which, in turn, is enclosed within a peritoneal capsule, tunica scrosa. Embedded in the pulp are nodules of lymph tissue, noduit lymphatici lienales (O.T. Malpighian corpnscles).

The tunica serosa closely invests the organ, except where it is reflected on to the lieno-renal and gastro-splenic ligaments and at the hilus. It is very firmly bound to the tunica propria.

The tunica propria is stont and strong but highly elastic. It is composed mainly of fibrous 
tissue but includes many elastic and muscle fibres. From its deep surface, more especially at the hilus, strong trabeculie pass into the organ to support the blood-ressels and nerves.

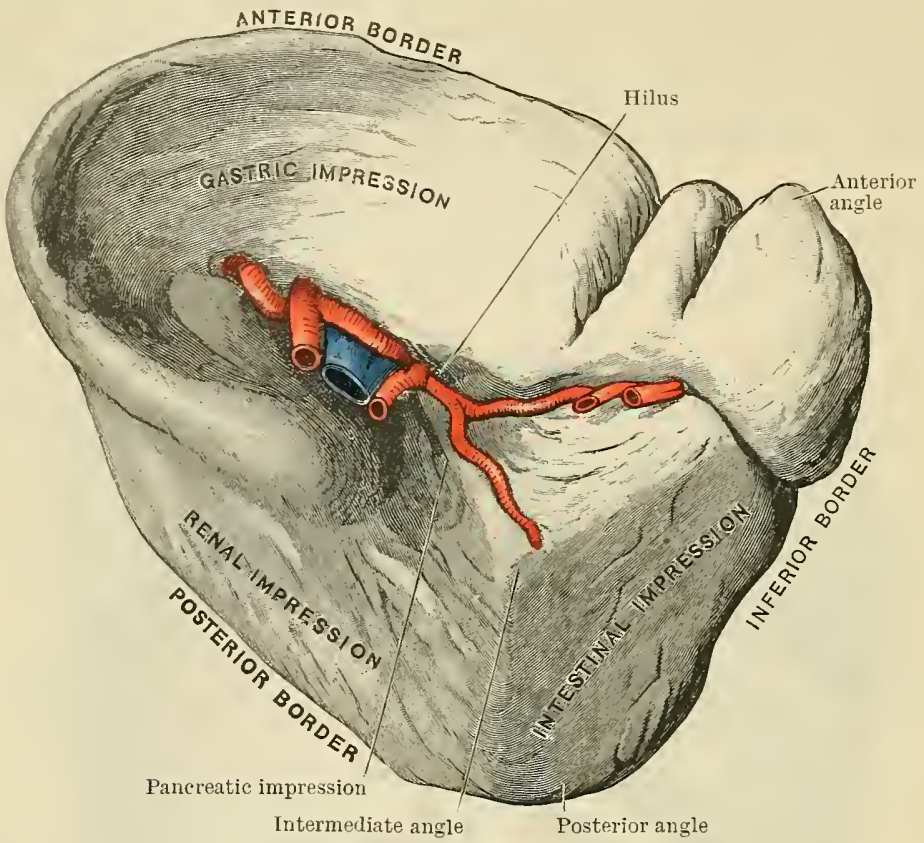

Fig, 1063.-The Spleex-Visceral Aspect.

The pulp is a spongework of fine fibres covered, at places entirely concealed, by branched connective-tissue corpuscles, reticulum cells. Associated with these, occupying some of the

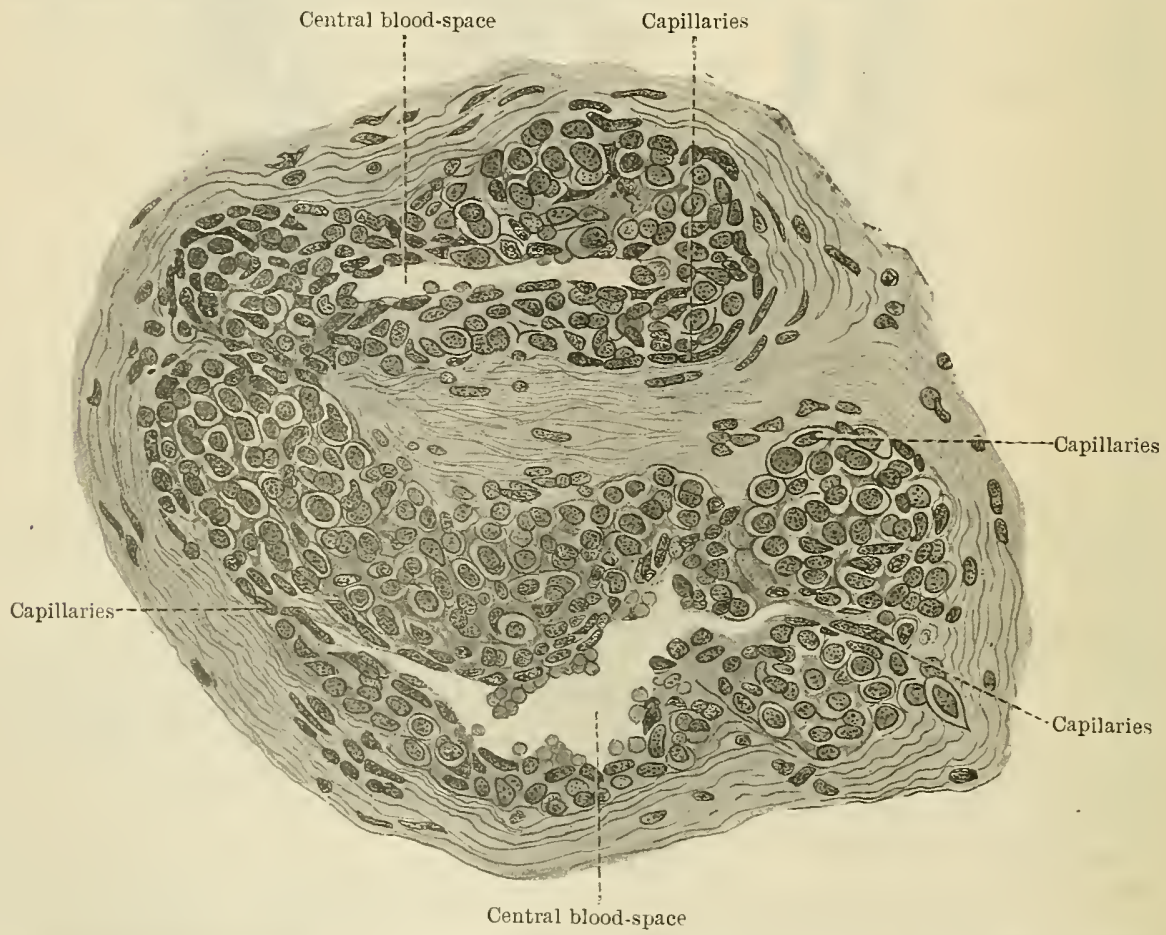

Fig. 1064. - Section throdgh Glomes Coccxgedn (highly magnified). From J. W. Thomson Walker. smaller spaces of the spongework, are cells like very large leucocytes, spleen phagocytes. These are amœeboid and often contain the debris of red blood corpuscles. 
The arteries enter at the hilus, run in the trabeculæ, and branch freely. The smaller arteries have a lymphoid sheath developed in their walls. This replaces the fibrous sheath which the larger arteries receive from the trabeculæ. Every here and there the lymploid sheath expands symmetrically or asymmetrically to form a lymphatic nodule (nodulus lymphaticus lienalis). Many of the nodules thus formed are quite small; others are visible to the naked eye as white specks, but, however large or small they may be, each contains a network of capillaries. Towards their termination the arteries lose their sheaths and become reduced to simple tubes of endothelial cells; gaps appear in their walls and finally the cells forming them become continuous with the reticulum cells of the pulp. The veins begin in the same way as the arteries end. The pulp is, therefore, the modified capillary system of the spleen.

Development. - The spleen is mesodermal in origin. The first indication of its development, in a 9-mm. embryo, is a thickening of the dorsal mesogastrium. In 10-12 $\mathrm{mm}$. embryos the cœlomic epithelium over the splenic rudiment is several layers thick. Soon the deeper layers of the thickening are transformed into mesenchyme and the epithelium is reduced again to a single layer. The first vascularisation of the spleen is effected by a capillary network. Out of this the intra-splenic arteries and veins differentiate. The undifferentiated capillaries between them form capillary tufts or spherules. These become transformed into the pulp. The exact method of this transformation is undetermined, but during its progress great numbers of red blood cells are produced. The lymphatic nodules are developed in the later part of fœtal life, and with their contaiued lymphocytes differentiate from the tunica adventitia of the arteries.

\section{(ii.) Glomus Coccrgeun.}

The glomus coccygeum is a small body, $2-2.5 \mathrm{~mm}$. in diameter, placed immediately anterior to the tip of the coccyx, upon a branch of the middle sacral artery. Usually it is accompanied by a group of smaller bodies of similar structure and arterial relation.

Structure. - The glomus is enclosed in a fibrous capsule and consists of round or polyhedral cells with large nuclei lining a considerable blood space, which is an anastomosing channel between an artery and a vein.

Development. - The glomus develops from the capillary network of the region of the tip of the embryonic tail. At first

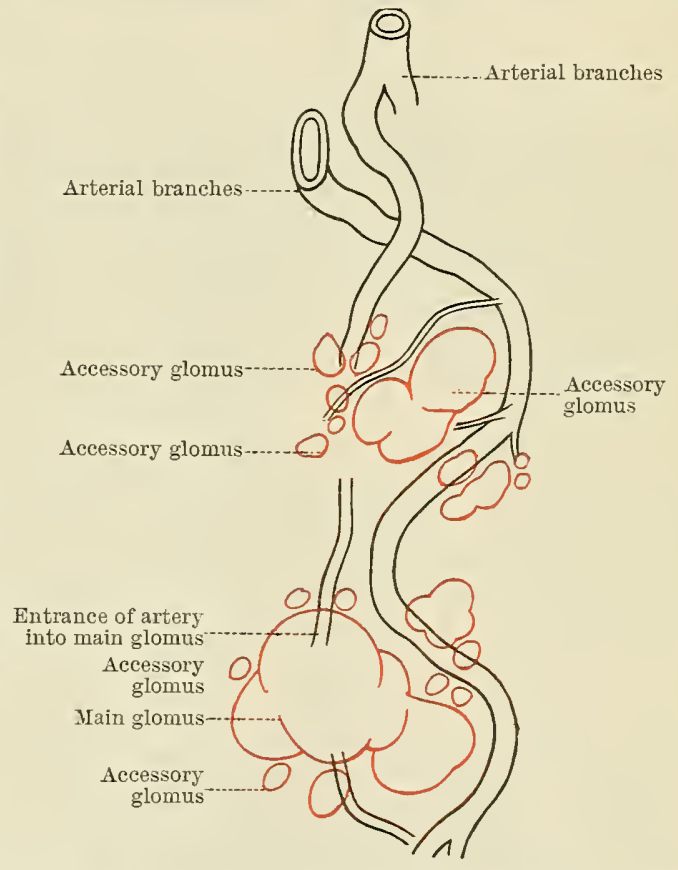

FIG. 1065.- ScheMA OF THE RELATION PRESENTED BY THE GLOMUS COCCYGEUM AND ITS ACCESSORY OUTLING parts to The Brasches of the Middle SACral ARTERY. (Reconstructed from serial sections through the region.) From J. W. Thomson Walker.

the capillary walls differentiate as if to form an artery, then the cells of the middle coat, instead of forming muscle, assume an epithelioid character.

The position of the glomus coccygeum at the posterior end of the axis of the body, and the fact that its blood-spaces form a wide arterio-venous anastomosis, suggest that it is a sort of safety-valve on the peripheral circulation. No evidence that it produces an internal secretion has, as yet, been obtained, and in spite of frequent statements to the contrary it contains no chromaphil cells (Stoerk). 



\title{
SURFACE AND SURGICAL ANATOMI.
}

\author{
Bi Harold J. Stiles, F.R.C.S.
}

\section{THE HEAD AND NECK.}

THE CRANIUM.

Scalp.-The first and third layers of the scalp, namely, the skin and the epicranius muscle, are firmly united by fibrous processes which pass from the one to the other through the second or subcutaneous fatty layer. Intervening between these three layers and the pericranium is a loose cellular layer which supports the small vessels passing between the scalp proper and pericranium. The thin pericranium, although regarded anatomically as periosteum, possesses very limited bone-forming properties; over the vertex it is readily separated from the skull-cap, except along the lines of the sutures, where it gives off intersutural processes to join the endosteal layer of the dura.

The free blood-supply of the scalp is for the purpose of nourishing its abundant hair follicles and glands. The main vessels lie in the dense subcutaneous tissue, and are superficial, therefore, to the epicranius (Fig. 1066). The arteries supplying the frontal region are derived from the internal carotid, while those for the remainder of the scalp spring from the external carotid. These two sets of vessels anastomose freely with one another, and freely also across the median plane; hence the failure of ligature of the external carotid to cure cirsoid aneurysm of the temporal artery.

Wounds of the scalp bleed freely, and the vessels are difficult to ligature on account of the adhesion of their walis to the dense subcutaneous tissue. In extensive flap wounds and in diffuse suppuration beneath the epicranius there is little danger of sloughing of the scalp. Abscesses and hæmorrhages superficial to the epieranius are usually limited on account of the density of the subcutaneous tissue. Hæmorrhage beneath the epicranius is seldom extensive on account of the small size of the vessels, but suppuration in this situation may rapidly undermine the whole muscle; incisions to evacuate the pus shonld be made early, and parallel to the main vessels of the scalp. Extravasation of blood beneath the pericranium leads to a hæmatoma which is limited by the sutures.

The veins of the scalp communicate with the intra-cranial venous sinuses(1) directly through their anastomoses with the large emissary veins, namely, the parietal, which opens into the superior sagittal sinus, and the mastoid and condyloid, which open into the transverse sinus; (2) through the anastomoses of the frontal and supra-orbital veins with the ophthalmic vein, which opens into the cavernous sinus; (3) through the veins of the diplöe, which connect the reins of the scalp and the pericranium on the one hand with those of the dura mater and the venous sinuses on the other; (4) through small veins which pass from the pericranium through the bones and the intersutural membranes to the dura. It is along these various channels that pyogenic infection may extend, from the scalp and pericranium, through the bone to the dura mater and renous sinuses, and from the latter to the cerebral veins, the pia-arachnoid, and the substance of the brain. More rarely the infection spreads from the cranial cavity along the emissary reins to the scalp.

The lymph vessels of the anterior part of the scalp join the external maxillary lymph vessels ; those of the temporal and parietal regions open in to the pre-auricular and parotid lymph glands, situated in front of and below the ear, and into the post-auricular or mastoid glands, situated upon the insertion of the stermo-mastoid muscle. The lymph vessels of the occipital region open in to the occipital glands, which lie close to the occipital artery where it becomes superficial in the scalp. 
Bony Landmarks of the Cranium.-At the root of the nose is the frontonasal suture (nasion); a little above it is the glabella, a slight prominence which connects the superciliary arches. About 1 in. below the posterior pole of the

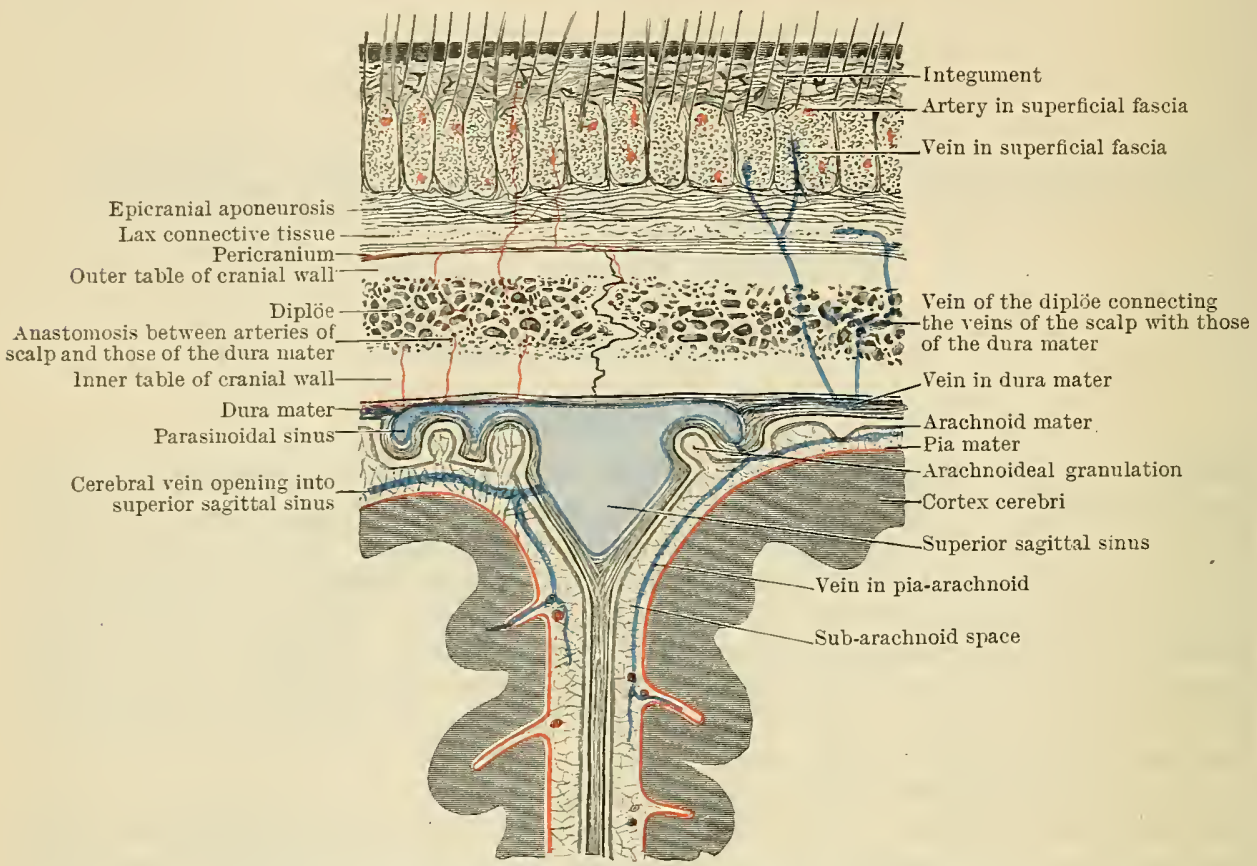

Fig. 1066.-Diagramiatic Representation of a Coronal Section through the Scalp, Cranidm, Meninges, and Cortex Cerebri (modified from Cunningham).

cranium, and 2 in. above the spine of the epistropheus, is the external occipital protuberance (inion). In the child the protuberance is not developed; its position may be defined by taking a point at the junction of the upper and middle thirds of a line extending from the posterior pole of the skull to the spine of the epistropheus. About a third of the distance from the nasion to the inion is the bregma or junction of the coronal and sagittal sutures; with the head in the natural erect posture the bregma corresponds to the middle of a line carried across the vertex between the pre-auricular points of the zygomatic arches.

At birth the position of the bregma is occupied by the anterior fontanelle, a rhomboidal membranous area which generally becomes ossified at about the eighteenth month. The size and date of closure of the fontanelle, as well as its tension and pulsation, are all points to be carefully noted in the clinical examination of children.

The lambda, or junction of the sagittal and lambdoidal sutures, situated $2 \frac{1}{2}$ in. above the inion, can generally be felt through the scalp; a line drawn from it to the posterior border of the root of the mastoid process corresponds to the lambdoidal suture. In the adult the parieto-occipital fissure of the brain lies opposite, or a few millimetres in front of, the lambda; in the child, however, the fissure may be as much as $1 \mathrm{in}$. in front of it.

Crossing the supra-orbital margin close to its medial angle, a finger's-breadth from the medial line, are the supra-trochlear nerve and the frontal branch of the ophthalmic artery; the latter nourishes the flap in the operation of rhinoplasty. At the junction of the medial and intermediate thirds of the supra-orbital margin, 1 in. from the medial line, is the supra-orbital notch or foramen, the guide to the supra-orbital vessels and nerves. A little above the level of the lateral canthus of the eyelid is the fronto-zygomatic suture, immediately above which is the lateral angular process of the frontal bone. At the posterior end of the suture the zygomatico-temporal branch of the orbital nerve pierces the temporal fascia to reach the scalp. Half an inch above the suture is the lower margin of the cerebral hemisphere; while half an inch below the suture is a small tubercle on the posterior border 
of the zygomatic bone; a line drawn from this tubercle to the lambda gives the line of the superior temporal sulcus and of the descending cornu of the lateral ventricle.

The zygomatic arch, an important landimark, is horizontal when the head is in the natural position, and is on the same level as the inferior margin of the orbit and the inion; its superior border is at, or not infrequently a little above, the level of the lower lateral margin of the hemisphere. The superior border of the zygoma may be traced backwards immediately above the tragus and the external acoustic meatus to become continuous with the ridge formed by the supra-mastoid portion of the temporal crest. The part of the posterior root of the zygoma which lies immediately in front of the superior end of the tragus constitutes a valuable landmark which may with advantage be termed the pre-auricular point of the zygoma, while by the term post-auricular point is understood that point upon the supra-mastoid crest which lies immediately behind, and a finger's-breadth below, the upper attachment of the auricle. The temporal vessels and the auriculo-temporal nerve cross the zygoma at the pre-auricular point, and it is here that the pulsations of the temporal artery may be felt during the administration of an anæsthetic, or the vessel compressed for the purpose of checking bleeding from the temporal region of the scalp. The termination of the auriculo-temporal nerve in the neighbourhood of the parietal tuber is often the seat of a neuralgic pain in irritative conditions about the external acoustic meatus, the latter being supplied by this nerve.

Two inches vertically above the pre-auricular point is the inferior end of the central sulcus of Rolando. Two inches vertically above the middle of the zygomatic arch is the pterion (spheno-parietal suture), a point which cannot be felt, but which is nevertheless of topographical importance, as it overlies the lateral point (the point where the lateral fissure of the brain breaks up into its three branches) and the anterior branch of the middle meningeal artery.

The frontal tuber (better marked in the child) overlies the middle frontal convolution. The parietal tuber, which varies considerably in the definiteness with which it can be recognised, overlies the termination of the posterior horizontal limb of the lateral fissure of the brain, and therefore also the supra-marginal convolution, which is named by Turner the convolution of the parietal tuber. The part of the temporal crest which intervenes between the lateral angular process and the coronal suture lies a little above the level of the inferior frontal sulcus. The highest part of the temporal crest crosses the Rolandic area at the junction of its middle and lower thirds, that is to say, at the junction of the motor areas for the arm and face. In the child the temporal muscle, which is relatively much smaller than in the adult, reaches only a short distance above the squamous suture, and, therefore, only as far as the level of the inferior end of the central sulcus of Rolando.

The thickness of the skull-cap varies at different parts and in different individuals. The inner table is only half the thickness of the outer table, but both possess the same degree of elasticity. When the vault is fractured from direct violence, the inner table is more extensively fissured than the outer table, because the elements of the latter are compressed, while those of the former are stretched apart. The weak areas at the base of the skull through which fractures are liable to extend are: in the anterior cranial fossa, the orbital parts of the frontal bone, and the cribriform plate of the ethmoid; in the middle cranial fossa, the region of the glenoid carity of the temporal bone, and of the foramen ovale of the sphenoid; in the posterior fossa, the fossæ of the occipital bone. The strong petrous part of the temporal is weakened by the tympanic cavity and by the deep jugular fossa.

Cranio-Cerebral Topography. - Of the many methods which have been devised for mapping out the relations of the cranial contents to the scalp, that intrcduced by Professor Chiene is, probably, the most useful from a clinical point of view; no figures or angles have to be remembered, and the primary surface lines are drawn from bony points which are not variable, whilst the secondary lines are drawn, for the most part, between mid-points of the primary lines. The method is as follows (Figs. 1067 and 1068):-

"The head being shaved, find in the medial line of the skull between the glabella $(G)$ and the external occipital protuberance $(O)$ the following points :-

"First, the mid-point (M); second, the three-quarter point(T); third, the sereneighth point (S). 
"Find also the lateral angular process (E), and the root of the zygoma (preauricular point) (P), immediately above and in front of the external acoustic meatus. Having found these five points, join EP, PS, and ET. Bisect EP and PS at N and R. Join MN and MR. Bisect also AB at C, and draw CD parallel to AM."

The line MA correspouds to the superior and inferior precentral sulci, and may therefore be termed the pre-central line. The origins of the superior and inferior frontal sulci may be indicated by trisecting MA at the points $\mathrm{K}$ and $\mathrm{L}$, the latter point being at the level of the temporal crest.

The line ET, termed the oblique or lateral line, intersects the pre-central line at the point $A$, which overlies the pterion, and corresponds therefore to the lateral point of the lateral cerebral fissure and to the anterior division of the middle meningeal artery. AC overlies the posterior horizontal limb of the lateral fissure of the brain, which terminates at the level of the temporal crest, in the inferior part of the triangle HCB. This triangle contains the parietal tuber, and may, therefore, be termed the supra-marginal triangle. The termination of the lateral line, at the three-quarter sagittal point $\mathrm{T}$, overlies the parieto-occipital fissure.

By joining TR, RO, a triangle is mapped out which delimits the surface of the occipital lobe; the line TR corresponds to the lambdoidal suture, while RO corresponds to, or lies a little above, the tentorium and the upper border of the transverse sinus.

$\mathrm{CD}$, the post-central line, corresponds to the superior post-central sulcus, and lies a little behind the inferior post-central sulcus.

The parallelogram AMDC overlies the Rolandic area, i.e. the anterior central convolution and the posterior central convolution, separated by the central sulcus of Rolando.

The pentagon ABRPN maps out the temporal lobe, with the exception of its apex, which is directed downwards, forwards, and inwards, a finger's-breadth in front of the point $\mathrm{N}$.

A finger's-breadth below $A B$ is the superior temporal sulcus, the posterior extremity of which turns upwards to terminate at B, the point which indicates, therefore, the position of the angular gyrus.

The central sulcus of Rolando may be mapped out upon the scalp by drawing a line downwards and forwards for a distance of $3 \frac{3}{8} \mathrm{in}$. from a point half an inch behind the mid-sagittal point $M$ at an angle of $67^{\circ}$ to the sagittal line (Hare). This angle may readily be found by Chiene's plan of folding a sheet of paper first to half a right angle and again to a quarter of a right angle $\left(45^{\circ}+22.5^{\circ}=67 \cdot 5^{\circ}\right)$. According to Cunningham, the average angle which the fissure makes with the sagittal line is $70^{\circ}$.

Krönlein's scheme for projecting the more important cerebral areas on the surface of the cranium is as follows:-A base line, the same as that advocated by Reid, is drawn from the infra-orbital margin backwards through the centre of the external acoustic meatus to the occipital region, which it strikes a little below the inion. A second horizontal line is drawn backwards parallel to it from the supraorbital margin. Three vertical lines are now projected between these two parallels: the anterior from the centre of the zygomatic arch, the middle from the preauricular point to the zygoma, the posterior from the posterior border of the base of the mastoid process. The latter is prolonged upwards to the sagittal line on the cranial vault, and the direction of the central sulcus of Rolando is obtained by drawing a line from this point obliquely downwards and forwards to the point where the anterior vertical meets the superior horizontal line (Sylvian point). The inferior extremity of the sulcus corresponds to the point where the middle vertical line, prolonged upwards, meets the Rolandic line. The Sylvian line is obtained by bisecting the angle formed by the Rolandic line and the superior horizontal line.

The topographical distribution of function in the cerebral cortex is shown in Fig. 1068, in which the areas worked out by Grünbaum and Sherrington in the anthropoid apes have been transferred to the human brain. The above observers have shown that, while the motor area occupies the whole length of the anterior central convolution and of the central sulcus of Rolando (with the exception of its very extremities), it nowhere extends on to the exposed surface of the posterior central convolution; nor does it extend as far down on the medial surface of the hemisphere as the sulcus cinguli. Extirpation of the hand area, for example, is 
followed by severe paralysis of the hand, but the use and power of the hand is regained in a few weeks; ablations, on the other hand, of even large portions of the posterior central convolution do not give rise even to transient paralysis.

In some of the animals experimented on, the motor area was found to extend to the deeper part of the posterior wall of the central sulcus of Rolando. Anteriorly it extended into the pre-central sulci as well as into the occasional sulci which cross the pre-central gyrus; indeed the hidden part of the motor area fully equals in

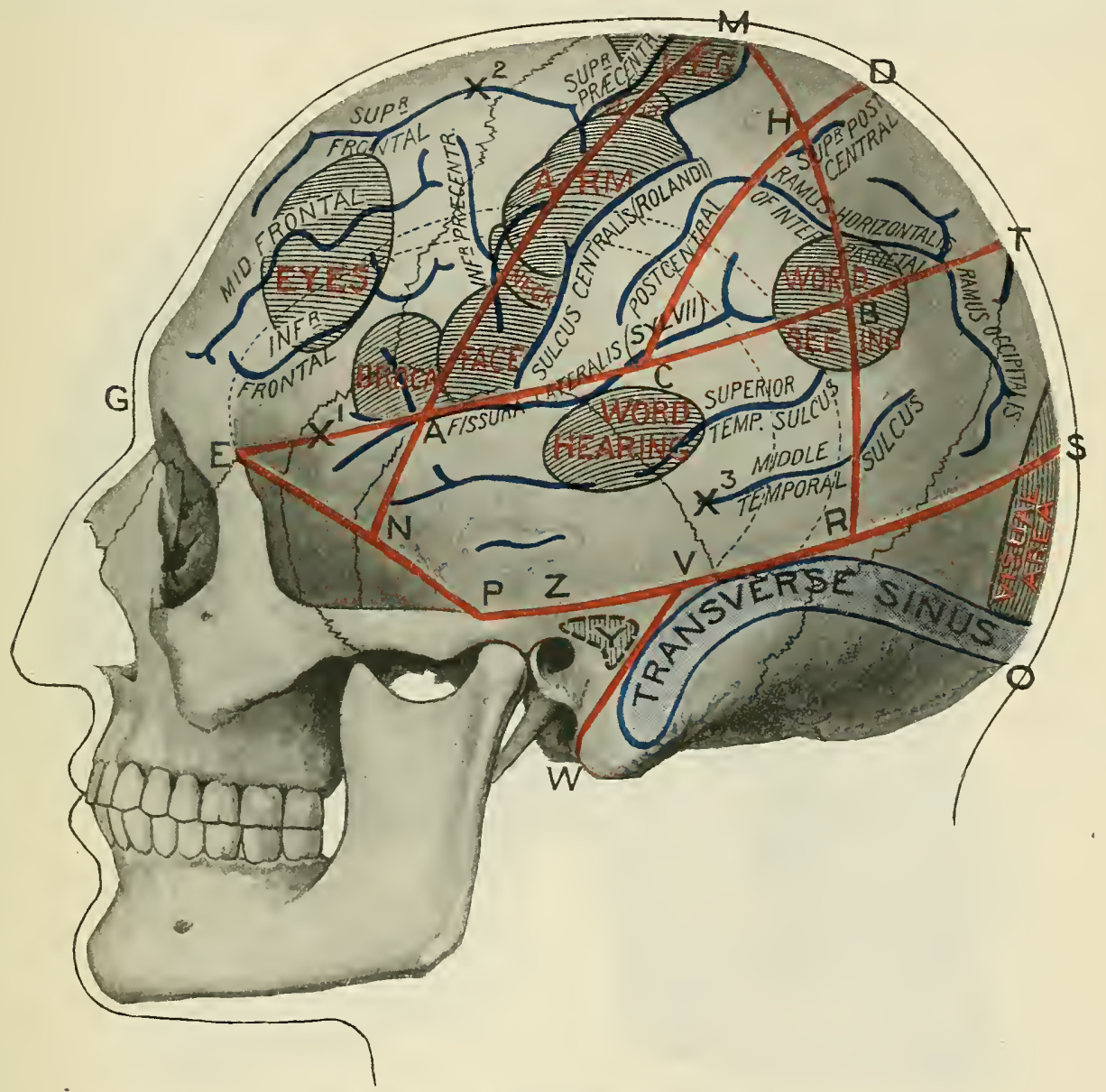

Fig. 1067.-Cranio-Cerebral 'Topography.

Shows relations of the motor and sensory areas to the gyri, and to Chiene's lines.

G. Glabella.

O. External occipital protuberance (inion).

II. Mid-point between $\mathrm{G}$ and $\mathrm{O}$.

T. Mid-point between $\mathrm{M}$ and $\mathrm{O}$.

S. Mid-point between ' $\mathrm{T}$ and $\mathrm{O}$.

E. Zygomatic process of frontal.

P. Root of zygoma (pre-auricular point).

N. Mid-point of EP.

R. Mid-point of PS.
C. Mid-point of AB.

CD is drawn parallel to AM.

Z. Post-auricular point.

VW. Guide to anterior limit of transverse sinus.

T. Tympanic antrum.

*1. Site at which subarachnoid space may be opened.

*2. Site for draining lateral ventricle (Kocher).

*3. Site for draining lateral ventricle (Keen).

extent that contributing to the free surface of the hemisphere. The motor areas extend a little in front of the superior and inferior pre-central sulci, which cannot therefore be regarded as physiological boundaries.

Reference to Fig. 1068 shows that, of the main areas, that for the lower extremity occupies the upper third of the motor region, that for the upper extremity the middle third, while the face occupies the inferior third. The relative topography of the chief subdivisions of these main areas is shown in Fig. 1069. It must be remembered, however, that there exists much overlapping of the adjacent areas.

The body of the lateral ventricle, which is equal in length to the posterior 
horizontal ramus of the lateral cerebral fissure, occupies a level midway between it and the temporal erest. The anterior horn of the ventricle is opposite the lower part of the coronal suture while the posterior horn is opposite the posterior part of the temporal crest. The inferior horn corresponds to the second temporal convolution.

The lateral ventricle may be tapped or drained from above, by traversing brain tissue for a depth of 4 to $5 \mathrm{~cm}$. through the superior frontal sulcus, $1 \frac{1}{4} \mathrm{in}$. (two fingers'-breadth) in front of the point $K$, the instrument being directed downwards and backwards (Kocher).

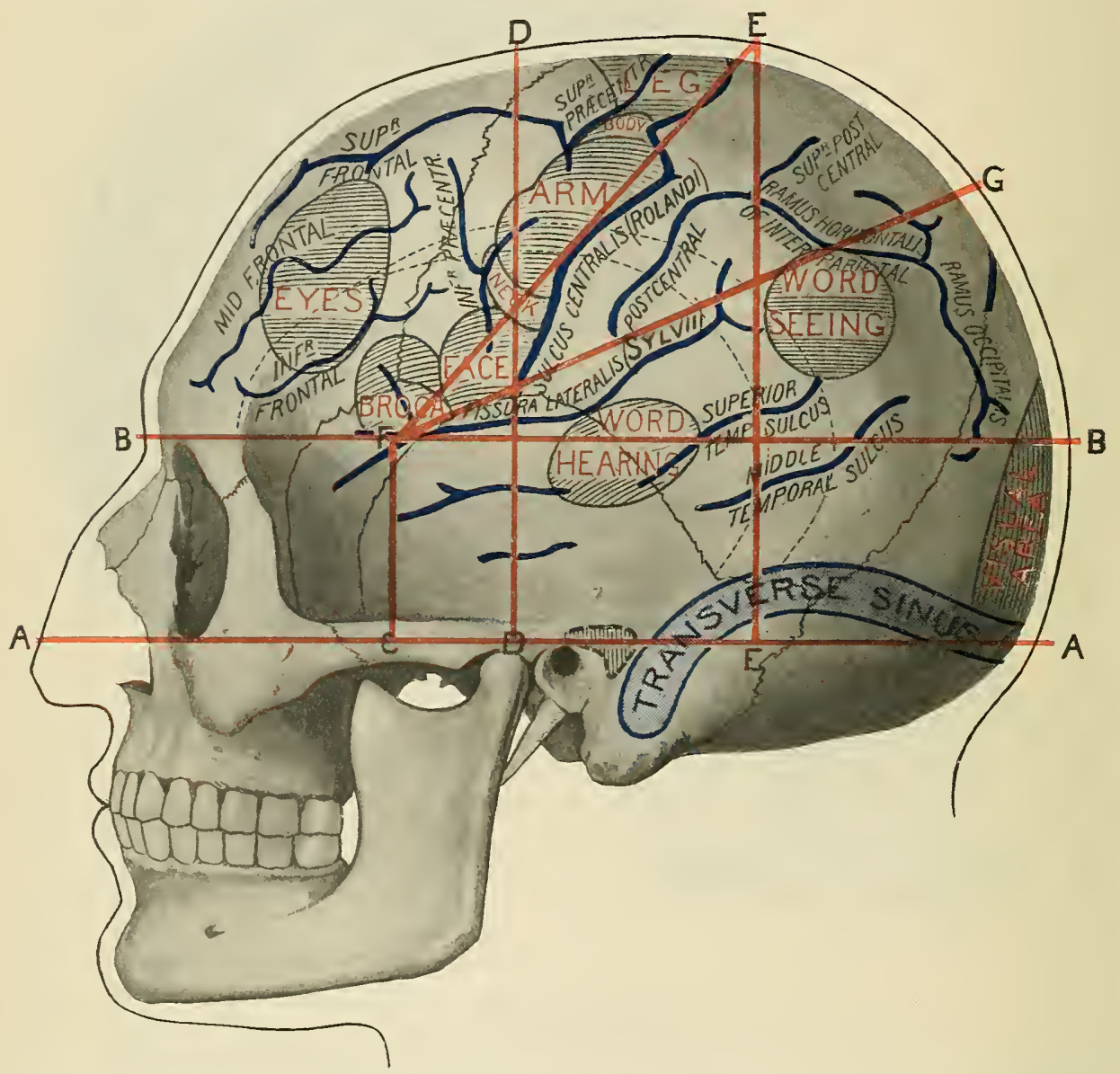

Fig. 1068. - Schene showing Relative Topography of the Chief Subdivisions of the Motor Area (adapted from Griinbaum and Sherrington). Guiding lines (Chiene's), red; sulci, blue.

Keen drains the ventricles through an opening $1 \frac{1}{4}$ in. behind the external acoustic meatus and the same distance above Reid's base-line (a line drawn backwards from the inferior margin of the orbit through the centre of the external acoustic meatus), the instrument being passed into the brain towards the summit of the opposite auricle. If the ventricle be not distended it will be reached at a depth of two inches from the surface.

To open the subarachnoid space, the pin of a small trephine is placed over the mid-point of the line EA; the dura is incised as it crosses the stem of the lateral fissure of the brain from the frontal lobe to the anterior extremity of the temporal lobe. Care must be taken to keep in front of the middle meningeal artery.

The cisterna magna, situated between the back part of the under surface of the cerebellum and the medulla oblongata, may be reached by turning down a flap of soft parts, and removing a circle of bone immediately above the foramen magnum. The 
fourth ventricle may be opened up by making a somewhat larger trephine opening and separating the posterior extremities of the tonsillar lobes of the cerebellum.

To expose the lateral hemisphere of the cerebellum, trephine over the centre of a line drawn from the tip of the mastoid process to the external oscipital protuberance.

To expose both lobes of the cerebellum a flap is turned downivards by carrying a curved incision between the bases of the mastoid processes, the centre of the incision reaching upwards to a little above the inion. The occipital arteries are

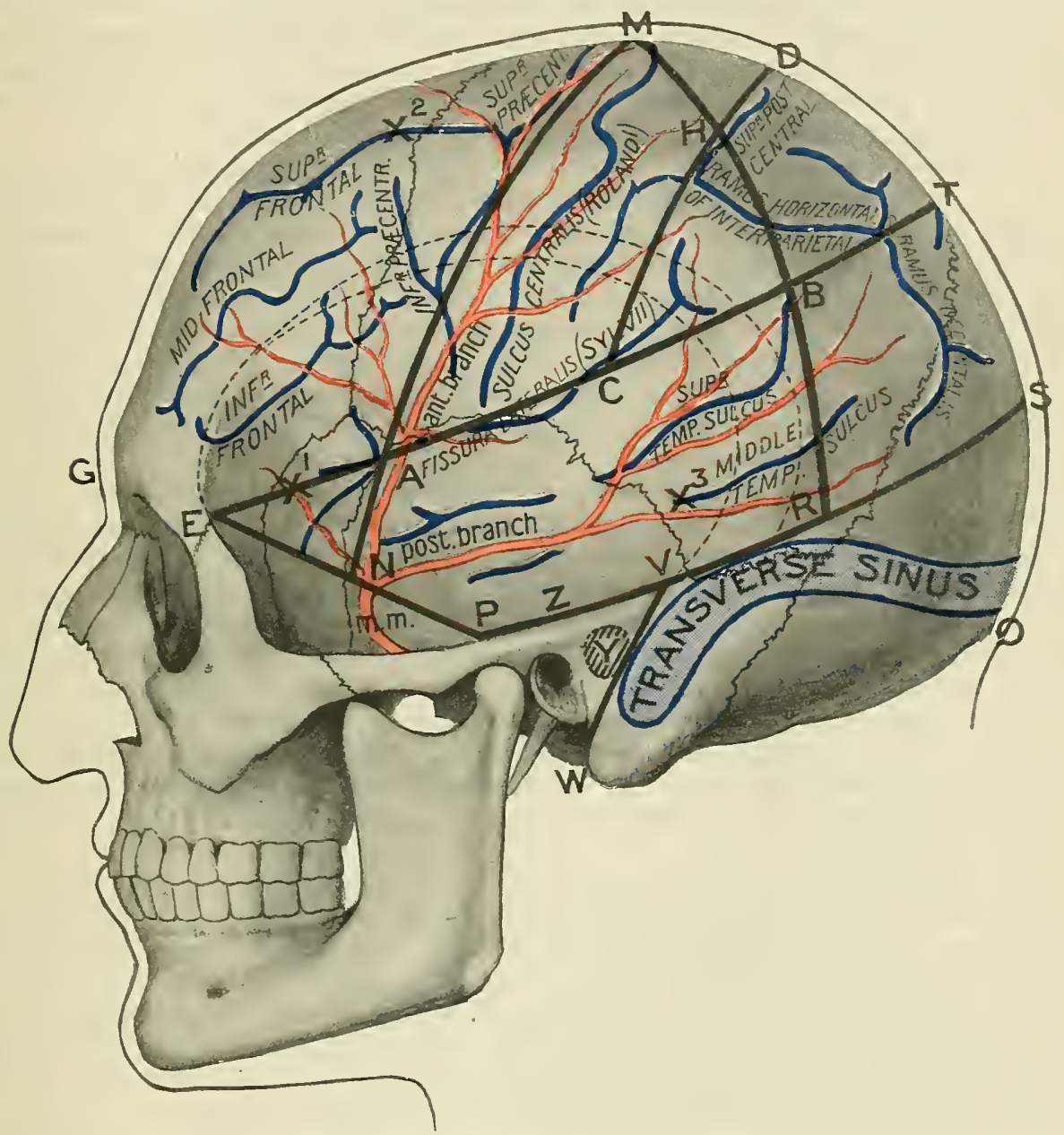

Fig. 1069.-Cranio-Cerebral Topography.

Guiding lines (Chiene's), deep black; sutures, fue black; meningeal arteries, red ; sulci, blue.

G. Glabella.

O. External occipital protuberance (iniou).

M. Mid-point between $G$ and $O$.

T. Mid-point between $M$ and $O$.

S. Mid-point between $T$ ' and $\mathrm{O}$.

E. Zygomatic process of frontal.

P. Root of zygoma (pre-auricular point).

N. Nid-point of EP.

R. Nid-point of PS.
C. Mid-point of AB.

MA is divided into thirds at $\mathrm{K}$ and $\mathrm{L}$.

$\mathrm{CD}$ is drawu parallel to AM.

Z. Post-auricular point.

VW. Guide to anterior limit of transverse sinus.

Y. Tympanic antrum.

*1. Site at which subarachnoid space may be opened.

*2. Site for draining lateral ventricle (Kocher).

*3. Site for draining lateral ventricle (Keen).

divided, but the anterior extremities of the incision should, if possible, be kept behind the mastoid emissary veins. As the flap contains the suboccipital muscles the bone itself may be removed. If more room is required, the opening in the bone may reach above the level of the transverse sinuses without wounding them as they can be displaced along with the dura. The occipital sinus is divided between two ligatures. After dividing the dura the lateral lobe of the cerebellum may be displaced towards the median plane so as to enable the finger to be passed 
between it and the posterior surface of the petrous portion of the temporal bone as far as the acoustic nerve, which occupies the angle between the cerebellum and the pons.

Meningeal Arteries. - When the calvaria is removed the meningeal arteries are found to adhere firmly to the dura. Of these vessels the middle meningeal artery is the only one of surgical importance. It is frequently lacerated in fractures of the skull; the blood is generally extravasated between the dura and the bone, and the bleeding point lies beneath the clot. After entering the cranial cavity through the foramen spinosum, the main trunk, which is usually about $1 \frac{1}{2}$ in. in length, runs laterally and slightly forwards to bifurcate into anterior and posterior divisions at a point a finger's-breadth above the middle of the zygomatic arch, viz., at or close behind the point $N$. When the main trunk is short the bifurcation takes place opposite the middle of the zygomatic arch.

The anterior and larger division passes upwards, with a slight forward convexity, a little behind the spheno-squamosal suture and across the pterion to the sphenoid angle of the parietal bone. From this point the vessel is continued upwards and slightly backwards behind the coronal suture; it gives off branches which ascend over the motor area. The position and general direction of the anterior branch may be said to correspond to the line LN; it follows, therefore, that the artery will be encountered in trephining over the lower and anterior part of the Rolandic area, especially over the motor centres for the tongue and face.

The posterior division passes almost horizontally backwards towards the mastoid angle of the parietal bone.

To expose the trunk of the vessel and its bifurcation, the trephine is applied immediately above the middle of the zygomatic arch. To expose the anterior division the pin of the trephine may be applied at the point $A$, which strikes the artery as it crosses the pterion and grooves the sphenoidal angle of the parietal bone. The inferior segment of the disc of bone removed is much thicker than the superior, as it involves the prominent ridge which passes from the tip of the great wing of the sphenoid on to the sphenoidal angle of the parietal bone. At the sphenoidal angle of the parietal bone, the artery frequently runs in a canal for a distance of half an inch. It follows, therefore, that a considerable thickness of bone has to be sawn through at the inferior segment of the circle before the disc can be removed, and during the removal bleeding may occur from the artery as it lies in the canal.

Vogt localises the anterior division at a point a thumb's-breadth behind the tubercle on the posterior border of the malar bone and two fingers'-breadth above the zygoma. Krönlein trephines at a point $1 \frac{1}{4} \mathrm{in}$. behind the lateral angular process, on a line drawn from the supra-orbital margin backwards parallel to Reid's base-line. If the centre of the trephine be placed at the mid-point of the line LA, the anterior division will be reached above the canal and the ridge at the sphenoidal angle of the parietal; should the bleeding-point be lower down, the trephine opening may be enlarged downwards along the line LN.

The course of the posterior division may be indicated upon the surface by drawing a line backwards from the point $\mathrm{N}$ parallel to $\mathrm{PR}$, that is to say, a finger'sbreadth above the zygoma and the supra-mastoid crest.

When the frontal branch of the anterior division is injured, the clot is in the fronto-temporal region, and involves more especially the motor area for the face, and, on the left side, Broca's convolution; when the anterior division is wounded, the clot, which is larger, involves the parietotemporal region, and the motor symptoms are due to pressure upon the centres for the arm and face; in injuries to the posterior division the clot overlies the parieto-occipital region, and the localising symptoms are sensory (Krönlein). In more extensive meningeal hæmorrhage the clot may cover the greater part of the hemisphere.

The superior sagittal sinus, which enlarges as it extends backwards, occupies the medial plane of the vertex from the glabella to the internal occipital protuberance, where it opens into the confluens sinuum, and becomes continuous usually with the right transverse sinus. Opening into the sinus, especially in the posterior part of the parietal region, are the para-sinoidal sinuses, into which arachnoideal granulations project. In opening the skull over the posterior part of the vertex, the edge of the trephine should be kept at least three-quarters of an inch from the median plane. 
The transverse sinus may be mapped out on the surface by drawing a line, slightly convex upwards, through a point a little above the inion to the asterion ( $1 \frac{1}{2}$ in. behind and 1 in. abore the centre of the external acoustic meatus) at, or a little in front of, the point $R$, and thence in a downward and forward direction to a point $\frac{3}{4}$ in. inferior and posterior to the centre of the external acoustic meatus, where it finally curves medially and forwards to open into the jugular bulb, which occupies the jugular foramen. According to Moorhead the highest part of the sinus lies a finger's-breadth above the middle of a line extending from the inion to the middle of the external acoustic meatus. The anterior border of the descending or mastoid portion of the sinus may be mapped out by drawing a line VW from a point a finger's-breadth behind the post-auricular point of the temporal crest to the anterior border of the tip of the mastoid process. In wounds of the sinus the hæmorrhage is rery free, owing to the inability of its walls to collapse, but the bleeding is easily controlled by plugging.

Of the cerebral arteries, the middle supplies almost the whole of the motor area, and one of its lenticulo-striate branches, which enters the brain at the anterior perforated space, is called "the artery of cerebral hcemorrhage" from the frequency of its rupture in apoplexy. The extravasated blood involves the motor part of the internal capsule. The postero-medial central branches of the posterior cerebral artery, which enter the brain at the posterior perforated substance, supply the thalamus and walls of the third ventricle; hæmorrhage from one of these branches is apt to rupture into the ventricle. The postero-lateral central branches of the posterior cerebral artery supply the thalamus, and when one of these vessels ruptures the hæmorrhage is apt to invade the posterior or sensory part of the internal capsule.

Semilunar Ganglion.- The topography of the semilunar ganglion is of importance in relation to its surgical extirpation for trigeminal neuralgia. The ganglion is situated in the dura at the apex of the petrous portion of the temporal bone, at the medial part of the middle fossa of the base of the skull. The surgeon reaches it by an extra-dural route through an opening in the anterior and lower part of the temporal fossa immediately above the zJgomatic arch. The bone is removed down to or, even better, beyond the level of the infra-temporal crest, which forms the boundary line between the lateral and basal portions of the cranium. By temporarily resecting and depressing the zygomatic arch a portion of the floor of the middle fossa, internal to the infra-temporal crest, can be removed. The dura is separated from the fossa so as to admit of the ligature of the middle meningeal artery immediately after its entrance into the cranium through the foramen spinosa. By separating the dura still further in a medial and forward direction, the mandibular division of the trigeminal nerve is exposed as it enters the foramen ovale, and, after it, the smaller maxillary division, as it passes in a forward and slightly downward direction to enter the foramen rotundum. To expose the ganglion itself and the trunk of the nerve the dura is then carefully separated in a backward and medial direction; in doing this care must be taken not to wound the carernous sinus and the trochlear and abducent nerves which lie in its lateral wall. The oculo-motor nerre and the carotid artery are less likely to be injured. The ganglion has a grayish-red corer and a felted surface, while the trunk of the nerre is almost white, and striated longitudinally. After dividing the mandibular and maxillary divisions of the nerve close to their foramina of exit, the ganglion is seized with forceps and removed by twisting it away from its root and the first division.

Ear.-The skin covering the outer surface of the auricle is tightly bound down to the perichondrium, hence inflammations of it are attended with little swelling but much pain. The posterior auricular artery, which ascends along the groove at the posterior attachment of the auricle, is immediatel 5 anterior to the incision for opening the mastoid antrum.

The external acoustic canal, the general direction of which is medially, formards upwards, and downwards, possesses rarious curves of practical importance. The highest part of the upward convexity, which is also the narrowest part of the canal, is situated at the centre of its osseous portion; bejond this the floor sinks to form a recess in which foreign bodies are liable to be imprisoned. Of the two horizontal 
curves the lateral is convex forwards, the medial concave forwards. The skin of the osseous portion of the canal is thin and fused with the periosteum, hence when chronically inflamed it is liable to give rise to secondary periostitis and osseous narrowing of the canal.

The relations of the osseous walls of the canal are of importance to the surgeon. The whole of the upper wall and the upper half of the posterior wall, developed from the squamous portion of the temporal bone, consist of two layers of

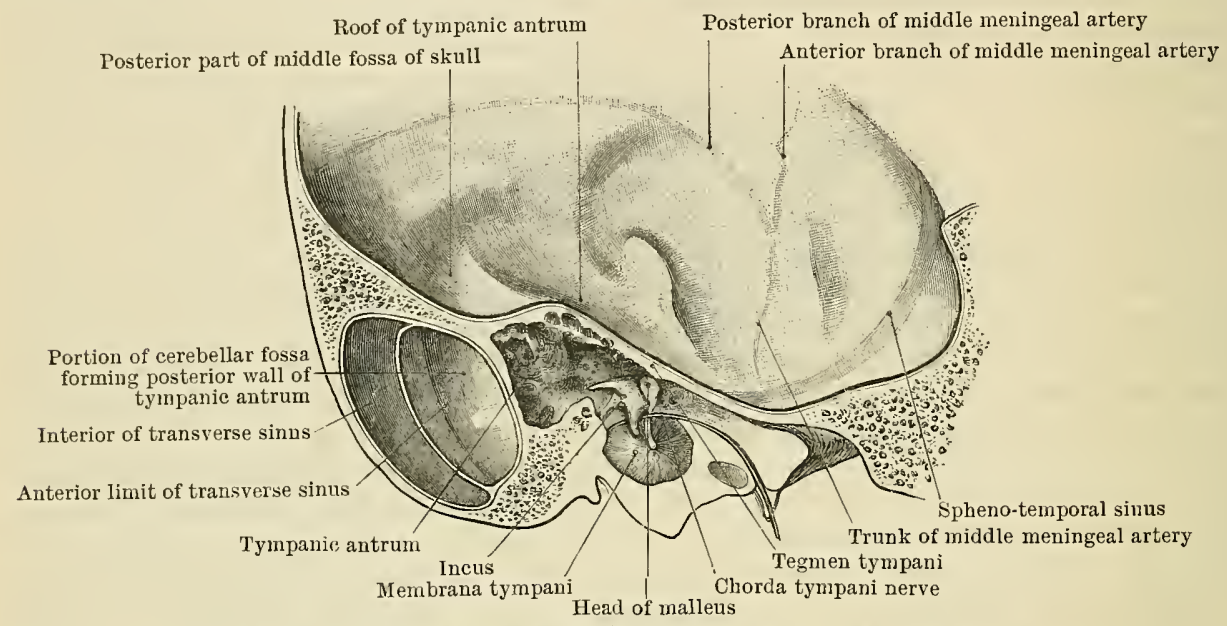

Fig. 1070.-View of the Lateral Wall of the Middle Ear.

Section through the left temporal bone of a child, to show the relations of the tympanum and tympanic antrum to the middle and posterior fossi of the skull.

compact bone, a superior and an inferior, which are continuous, the former with the inner table, the latter with the outer table of the skull. The superior plate passes inwards to the petro-squamosal suture, where it becomes continuous with the lateral edge of the tegmen tympani, which roofs over the tympanic attic and the mastoid antrum; the lower plate bends downwards and inwards at its deepest part to form the lower and lateral wall of the tympanic attic and the anterior part of the lateral wall of the antrum (Trautmann). It follows, therefore, that when the mastoid antrum is abnormally small, due to sclerosis of the bone, or when it is encroached upon by a far-forward transverse sinus, it, along with the tympanic attic, can be opened by perforating the junction of the upper and posterior walls of the osseous canal, the instrument being directed medially and slightly upwards. Upon the upper and posterior segment of the external acoustic process is the suprameatal spine; this small but important process, developed from the squamous portion,

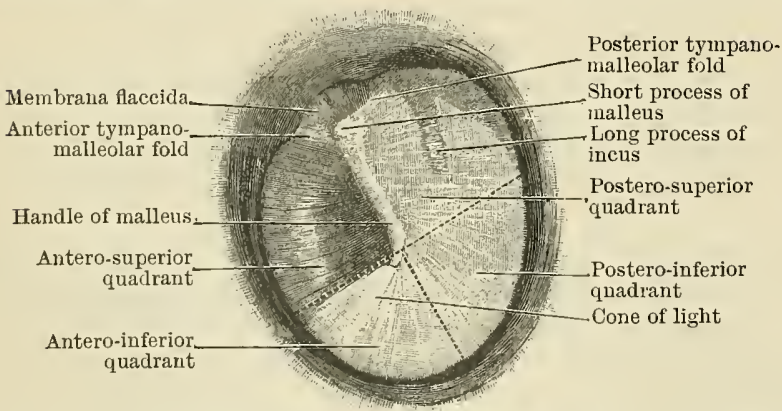

Fig. 1071. - Lefe Tympanic Membrane (as viewed from the external aeoustic meatus), $\times 3$. (From Howden.) can usualiy be distinctly made out in the living subject by pressing upwards and backwards with the forefinger placed in the external acoustic meatus.

The lower half of the posterior wall of the osseous canal (posterior part of the tympanic plate) is fused with the anterior part of the mastoid process, and closes the lower and anterior set of mastoid cells (border cells).

Anteriorly and inferiorly the osseous canal is related respectively to the temporomandibular articulation and the parotid gland; hence it follows that blows upon the 
chin may fracture the tympanic plate as well as the base of the skull, that pain on mastication is usually complained of in acute inflammatory affections of the meatus and middle ear, and that in young children, in whom the tympanic plate is incompletely ossified, suppurative inflammation is liable to extend from the ear to the parotid region.

Clinically, to obtain a view of the membrana tympani a speculum and a reflecting mirror are employed; the auricle is pulled upwards, backwards, and laterally in order to

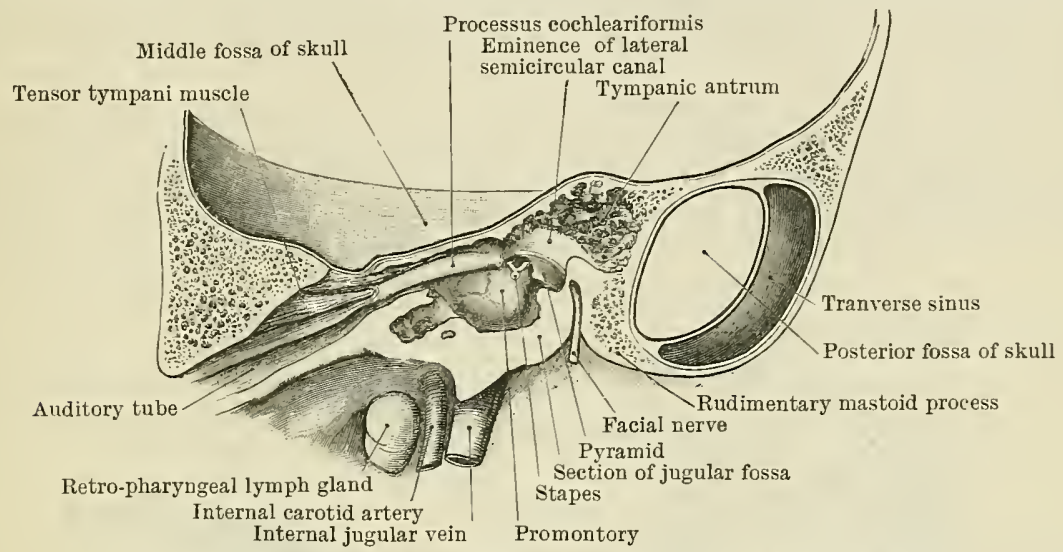

Fig. 1072.-View of the Labyrinthine Wall of the Middle Ear.

Section through the left temporal bone of a child, to show the relations of the tympanum and tympanic antrum to the middle and posterior fossæ of the skull.

straighten the cartilaginous part of the canal. The healthy membrane is pearly gray, semiopaque, slightly concave outwards, and obliquely placed, being inclined laterally, especially above and behind.

The handle and short process of the malleus, both embedded in the membrana tympani, are the only objects distinctly seen when the healthy ear is examined with the speculum.

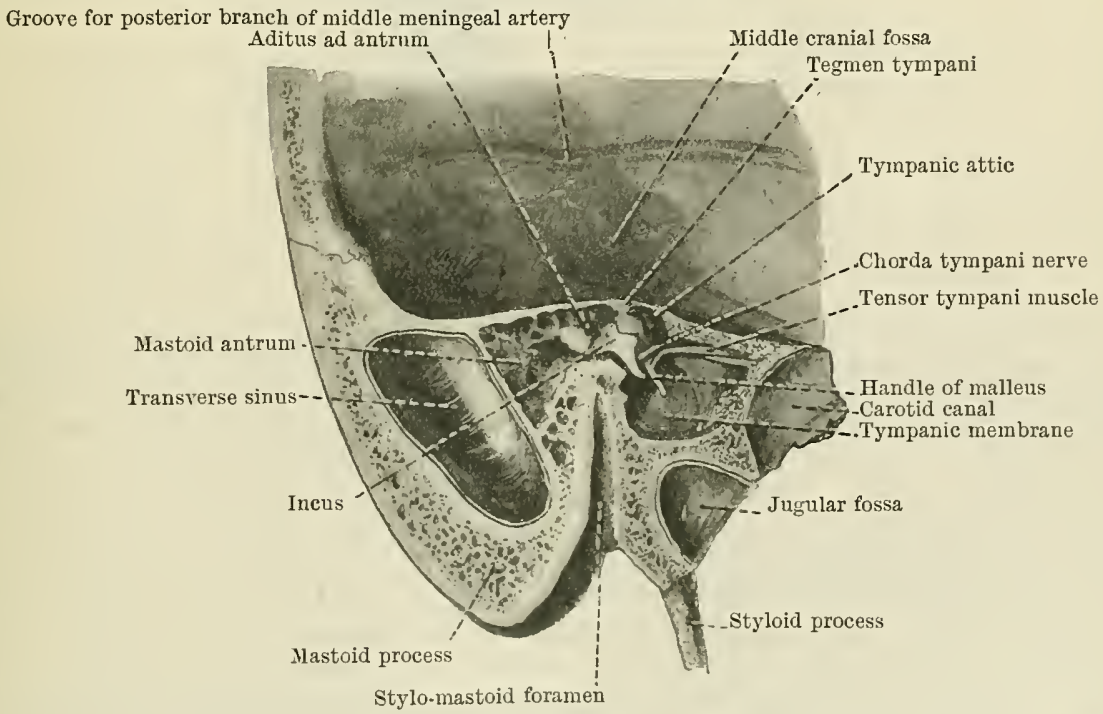

Fig. 1073. - Section throdgh Left Temporal Bose, showing Tympanic Wali of Trupasic Cavits, ETC.

The short process of the malleus projects laterally, and presents itself, therefore, as a distinct knob-like projection at the superior part of the membrane ; passing forwards and backwards from this process are the anterior and posterior folds of the membrana tympani ; they form the lower limit of Shrapnell's membrane, and correspond to the line of the chorda tympani nerve. The handle of the malleus, situated at the junction of the two upper quadrants, is seen passing downwards and backwards to the point of maximum 
concavity of the membrane (umbo), situated a little below its centre (Fig. 1071); passing downwards and forwards from the umbo is the triangular cone of reflected light, to which too much importance must not be attached, since its appearances vary considerably in healthy ears. Normally, the long process of the incus is but faintly visible, and still less so are the promontory and fenestra rotunda; in the condition of Eustachian obstruction, however, in which the membrane is indrawn, these structures, along with the folds of the drum-head, become more distinct.

In performing the operation of paracentesis of the tympanic membrane the posteroinferior quadrant is the site chosen for making the puncture, as, in addition to providing good drainage, it is farthest removed from important structures, especially the chorda tympani nerve.

In order to understand the clinical importance of the parts seen through the translucent membrane, it is necessary to study the relative position of the structure of the "mesotympanum," that is to say, that part of the tympanum which lies opposite the tympanic membrane. If the tympanic plate and the tympanic membrane be carefully removed so as to leave the ossicles and chorda tympani nerve in position, it will be seen

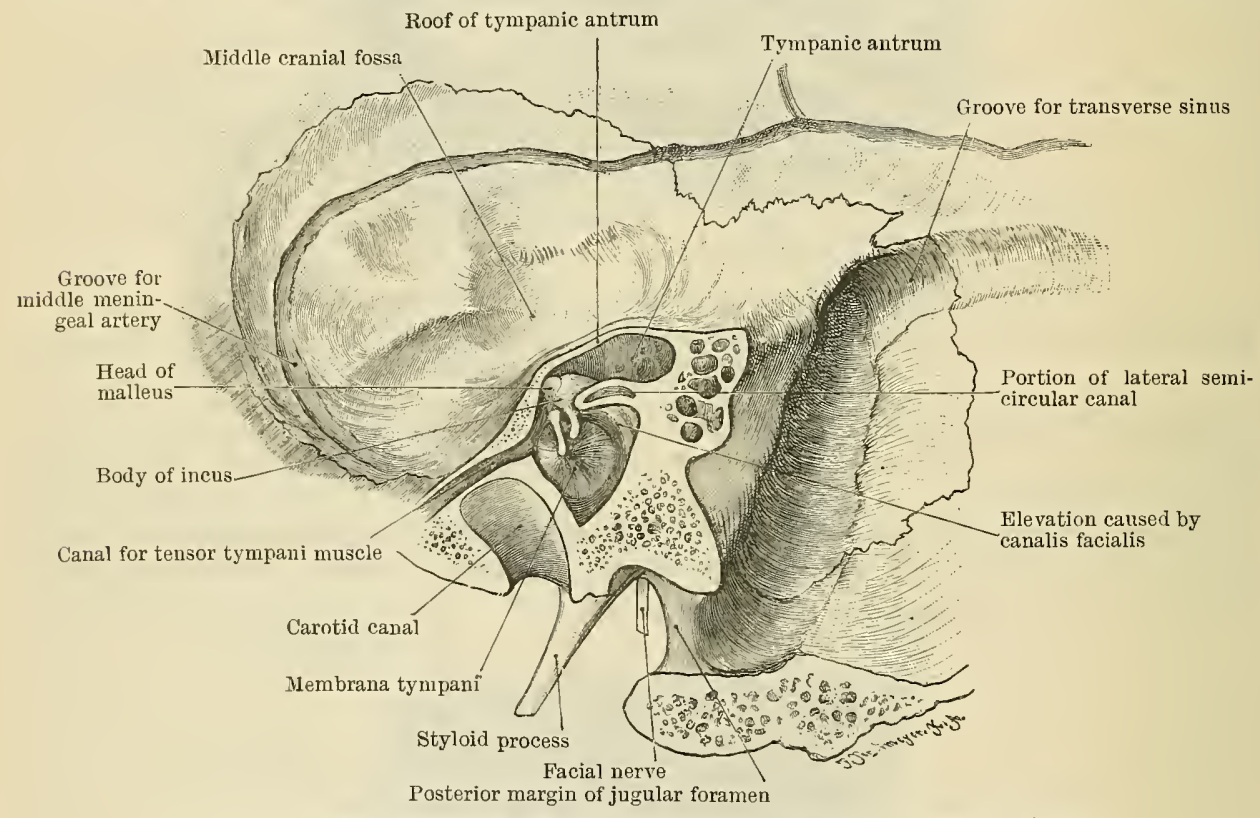

Fig. 1074.-Section throdgh Petrods Portion of Temporal Bone of Adult.

Showing the relation of the tympanum to the middle and posterior fossæ of the skull.

that the head of the malleus and the body and short process of the incus are altogether above the tympanic membrane, and that they occupy the tympanic attic or epitympanic space (Fig. 1074). At the junction of the two upper quadrants of the membrane is the handle of the malleus, which is directed downwards, backwards, and medially. The lateral process of the malleus is directed laterally a little below the deepest part of the roof of the osseous external acoustic canal. Opposite the postero-superior quadrant are the long limb of the incus, which descends behind and almost parallel to the handle of the malleus, and the stapes, which is directed medially and slightly backwards to the fenestra ovalis. The chorda tympani nerve runs from behind forwards between the lateral surface of the superior part of the long limb of the incus and the medial surface of the neck of the malleus. At the deepest part of the roof of the osseous canal, above the chorda tympani nerve and the short process of the malleus, is a notch (notch of Rivinus), which is occupied by the flaccid and highest portion of the membrana tympani (Shrapnell's membrane). Opposite the postero-inferior quadrant of the drum-head is the promontory of the cochlea, below and behind which is the fenestra rotunda. Opposite the anterosuperior quadrant are the processus cochleariformis, the tendon of the tensor tympani, and the passage leading towards the auditory tube.

The labyrinthine wall of the tympanic cavity is related to the internal ear. The tegmental wall is separated from the middle fossa of the skull and the under surface of the temporal lobe of the brain by the tegmen tympani-a thin plate of bone, which is continued 
anteriorly to form the roof of the osseous portion of the auditory tube, while posteriorly it roofs over the mastoid antrum. Laterally the tegmen is limited by the petrosquamous suture, which may remain unossified for some years after birth, thus affording a channel along which pyogenic infection may spread from the middle ear to the meninges and brain. Infection may also spread along the small veins which convey blood from the tympanum to the superior petrosal and transverse sinuses.

The jugular vall of the tympanum is formed mainly by the bone forming the jugular fossa, which is occupied by the bulb of the internal jugular vein. When the transverse sinus is large and unusually far forward the bulb is likewise large, and the fossa, which is consequently deeper, may arch up into the jugular wall of the tympanic cavity, from which it may be separated merely by a thin and translucent plate of bone which occasionally shows an osseous deficiency. In cases where this condition existed the jugular bulb has been wounded in the operation of paracentesis of the tympanic membrane.

Anteriorly the tympanic cavity leads into the auditory tube, which brings it into communication with the nasal part of the pharynx. In the child the auditory tube is shorter, wider, and more horizontal than in the adult, hence inflammations are more liable to spread along it to the tympanum.

Above the level of the membrana tympani is the epitympanic recess, which communicates posteriorly by means of a triangular opening (aditus ad antrum) with the tympanic antrum; the base of the triangle, directed upwards, is formed by the tegmen tympani ; its apex, directed downwards, is formed by the meeting of the medial and lateral walls. The opening will admit an instrument half a $\mathrm{cm}$. in diameter. The epitympanic recess contains from before backwards the head of the malleus, the body and short limb of the incus, the latter projecting backwards into the aditus. When these structures are covered with inflamed mucous membrane or granulations, drainage from the mastoid antrum into the tympanum proper is interfered with. The boundaries of the aditus, important surgically, are as follows: superiorly, the tegmen tympani ; medially, an eminence of compact bone, containing the lateral semicircular canal, inferior and anterior to which is a second smaller prominence, corresponding to that portion of the facial canal which curves immediately above and behind the fenestra ovalis. The wall of the facial canal is here thin and not infrequently deficient, in which case inflammation may readily spread from the tympanum to the facial nerve. The lateral wall of the aditus is formed by the deepest part of the upper and lateral wall of the osseous external acoustic meatus.

The posterior wall of the tympanum, below the aditus ad antrum, is formed by diplöic bone which contains the descending portion of the facial canal.

The tympanic antrum is to be considered, developmentally as well as anatomically, as an extension upwards and posteriorly of the tympanum (Fig. 1073). Its anatomy and relations will be best understood by studying it in the child, in whom it is relatively larger than in the adult. Situated above and posterior to the tympanic cavity proper, its lateral wall is formed by a triangular plate of bone which descends behind the external acoustic process from the squamous portion. Posteriorly, this triangular plate is separated from the petro-mastoid element by the petromastoid suture, which overlies the posterior part of the antrum and transmits small veins to the surface. The suture does not become completely ossified until a year or two after birth, and remains of it may frequently be detected in the adult bone. The anterior and superior portion of the triangular plate turns medially at an angle to form the upper and posterior wall of the rudimentary osseous canal, as well as the floor of the epitympanic recess.

In the adult the lateral wall of the mastoid antrum is formed by a plate of bone, from $\frac{1}{2}$ to $\frac{3}{4}$ in. in thickness, which occupies the triangular and somewhat depressed area between the ridge extending posteriorly and slightly upwards from the posterior root of the zygoma (supra-mastoid portion of temporal crest), and the superior and posterior quadrant of the osseous external acoustic meatus; upon the latter is the supra-meatal spine, immediately posterior to which, upon the floor of the above triangle, is a crescentic depression, the fossa mastoidea. The lateral wall of the antrum is felt through the skin as a slight depression immediately behind the auricle, and immediately inferior to the ridge formed by the supra-mastoid crest; below the depression is the prominence corresponding to the insertion of the sterno-mastoid muscle. Trautmann has pointed out, however, that the supramastoid erest, which varies considerably in its obliquity, is sometimes situated a little above the level of the roof of the antrum, and that it is safer, therefore, to 
take the level of the superior border of the osseous meatus as the guide in order to avoid opening the middle fossa of the skull. In children the supra-mastoid crest is not developed, so that if the operator mistake the posterior root of the zygoma for the crest, he will open into the middle fossa of the skull immediately in front of the attic. The upper and posterior quadrant of the osseous meatus is therefore the only reliable guide to the antrum in the child.

The medial wall is formed by a thick plate of spongy bone which separates the antrum from that portion of the posterior fossa lying between the aqueduct of the restibule and the groore for the sigmoid portion of the transverse sinus, and which contains the posterior semicircular canal.

The roof, which slopes downwards and forwards, is formed by the posterior and thinnest part of the tegmen tympani.

The floor is on a lower level than the aditus, and is therefore unfavourably placed for natural drainage.

The mastoid process begins to develop in the second year. As development adrances the diplöe surrounding the antrum in the child becomes excavated to

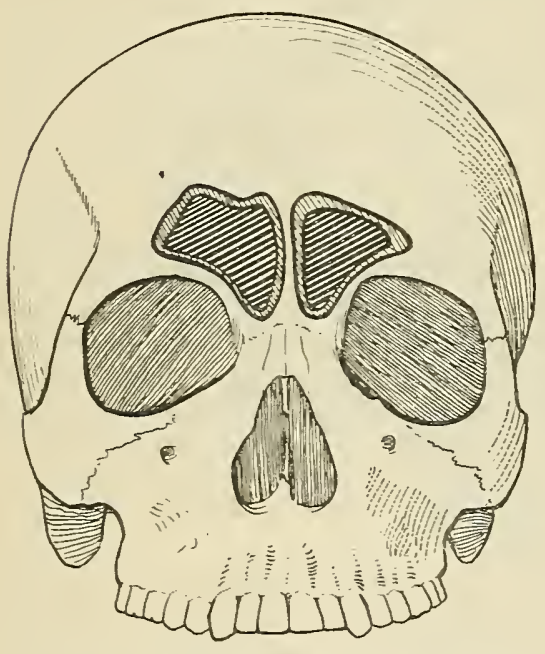

Fig. 1075. - Frovital Siruses of Average Dimexsions, wth a Media Septum (Logan Turner).

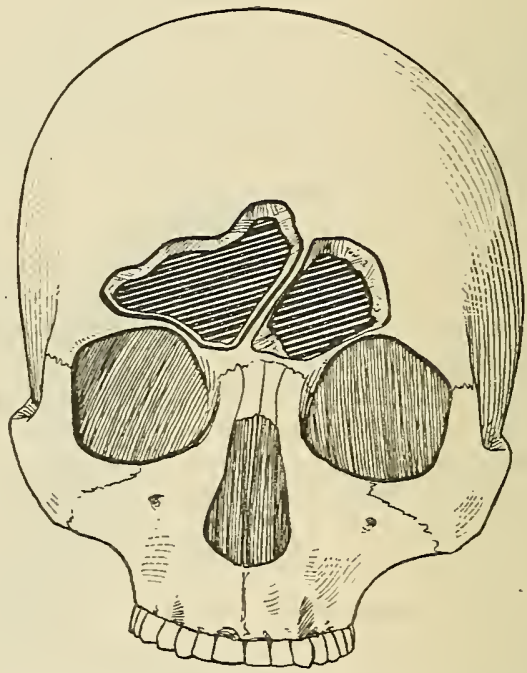

Fig. 1076. - A Large Right Frontal SiNus with Septum oblique to the LEFT (Logan Turner).

form the mastoid cells, which radiate from the antrum, and either directly or indirectly communicate with it by small openings. In the pneumatic type of mastoid the whole of the process j.s excavated by these cells, which extend upwards into the squamous portion, forwards to the posterior wall of the osseous meatus (border-cells), and backwards into the occipital bone. Pus retained within the "border-cells" may bulge into, and rupture through, the posterior wall of the osseous meatus. Less frequently the mastoid cells are absent, the bone consisting either of osseous tissue similar to that of the diplöe, or of dense bone (sclerosed type).

The mastoid process is grooved upon its medial surface by the sigmoid portion of the transverse sinus. The average distance of the foremost part of the sinus from the supra-meatal spine is $1 \mathrm{~cm}$. The right sinus usually receives the superior sagittal sinus, and when this is the case it is larger and farther forward than the left; in extreme cases it may reach to within 2 or $3 \mathrm{~mm}$. of the meatus. The average minimum distance of the transverse sinus from the outer surface of the mastoid is about $1 \mathrm{~cm}$., but when the sinus is large and far forward the thickness may be reduced to 1 or $2 \mathrm{~mm}$.

The facial nerve, after entering the facial canal at the bottom of the internal acoustic meatus, lies immediately above and behind the fenestra ovalis, between it and the prominence of the lateral semicircular canal ; thence it descends almost vertically in the mastoid wall of the tympanum $\frac{1}{8}$ in. posterior and medial to the 
inferior half of the deepest part of the posterior wall of the external osseous canal and emerges through the stylo-mastoid foramen.(Fig. 107:3).

In the infant, in consequence of the absence of the mastoid process, the exit of the facial nerve from the stylo-mastoid foramen is unprotected and exposed upon the lateral rather than upon the basal surface of the skull at a point immediately behind the posterior segment of the tympanic horse-shoe. It follows, therefore, that, in infancy, the incision to expose the antrum should not be curred too far downwards and forwards, otherwise the facial nerve may be divided. In the infant the position of the tympanic antrum is relatirely higher than in the adult, because in the former the upper wall of the osseous canal inclines towards the vertical plane instead of being horizontal. The lymph vessels from the auricle and external acoustic meatus open into the mastoid and parotid lymph glands, the latter receiving also the lymph from the middle ear. The efferent vessels from these glands open into the superior sub-sternomastoid glands; hence it is that these groups of glands are so frequently found to be diseased secondary to tuberculosis of the middle ear; and care must be taken not to mistake an abscess in one of the mastoid glands for subperiosteal mastoid suppuration associated with middle-ear disease.

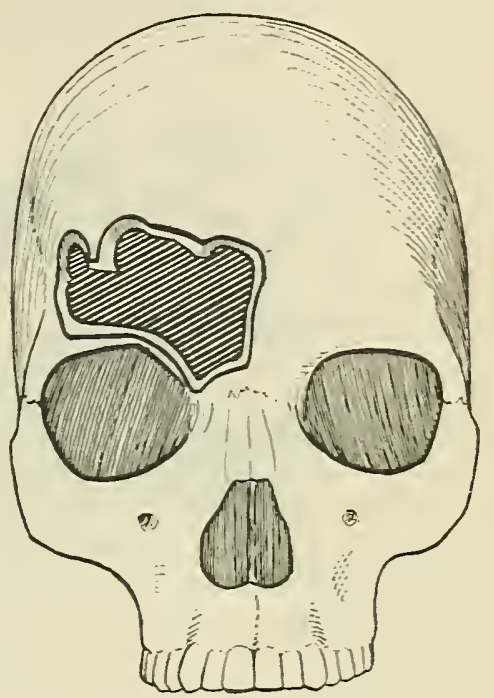

Fig. 107\%. - Right Frostal Sists of VERT LARGE DIJEFsiosis; LEFT SIMUS CMOPENED (Logan Turner).

To open the tympanic antrum the surgeon makes a curved incision a little behind the attachment of the auricle, and chisels or drills away the bone immediately abore and behind the postero-superior quadrant of the external osseous meatus. In this operation the middle fossa of the skull is aroided by keeping below the supra-mastoid crest; the transverse sinus, by keeping close to the external acoustic canal and by chiselling obliquely to the surface in opening the mastoid cells; the descending portion of the facial nerve is avoided by not encroaching upon the inferior half of the deepest part of the posterior wall of the osseous canal. In extending the operation from the trmpanic antrum through the aditus into the epitympanic recess, the lateral semicircular canal and the curve of the facial nerve, which lie in relation to the medial wall of the aditus, are liable to injury, and must be protected either by a curred probe, or better by Stacke's protector, passed from the antrum through the aditus into the tympanic carity.

The frontal air sinuses are two cavities situated immediately abore the root of the nose between the two tables of the frontal bone. Each sinus at its most dependent part communicates, by means of the naso-frontal duct, either directly with the middle meatus of the nose, or indirectly with that channel through its infundibulum A bony-septum, rarely incomplete, separates the two sinuses; it is usually medial in position below, but it may deviate to one or other side abore (Figs. 1075 and 1076).

The sinuses vary considerably in their size and shape, independently of the degree of derelopment of the glabella and superciliary arches (Fig. 107T). According to Logan Turner, the dimensions of an average-sized sinus are : height, $1 \frac{1}{4} \mathrm{in}$., from the lower end of the fronto-maxillary suture vertically upwards; breadth, 1 in., from the medial septum horizontally laterally; depth, $\frac{3}{4}$ in., from the anterior wall backwards along the orbital roof. The sinus may exist merely as recesses limited to a small area of bone above the nose, or it may extend uprards on to the forehead for more than two inches; laterally it may be limited by the bony wall of the temporal fossa, while posteriorly it may reach as far back as the optic foramen. The anterior wall is thickest, but the thickness mas rary from 1 to $5 \mathrm{~mm}$. The floor is the thinnest wall, hence when pus is retained within the carity, it tends to point at the superior and medial angle of the orbit. Intra-cranial suppuration may arise in connexion with sinus disease by extension through the roof 
or the posterior wall. The muco-periosteal lining, which readily strips from the bone, is thin and pale, and provided with mucous-secreting glands.

In many indiriduals, by the aid of trans-illumination, the extent of the sinuses and the position of the interrening septum may be mapped out upon the forehead. For this

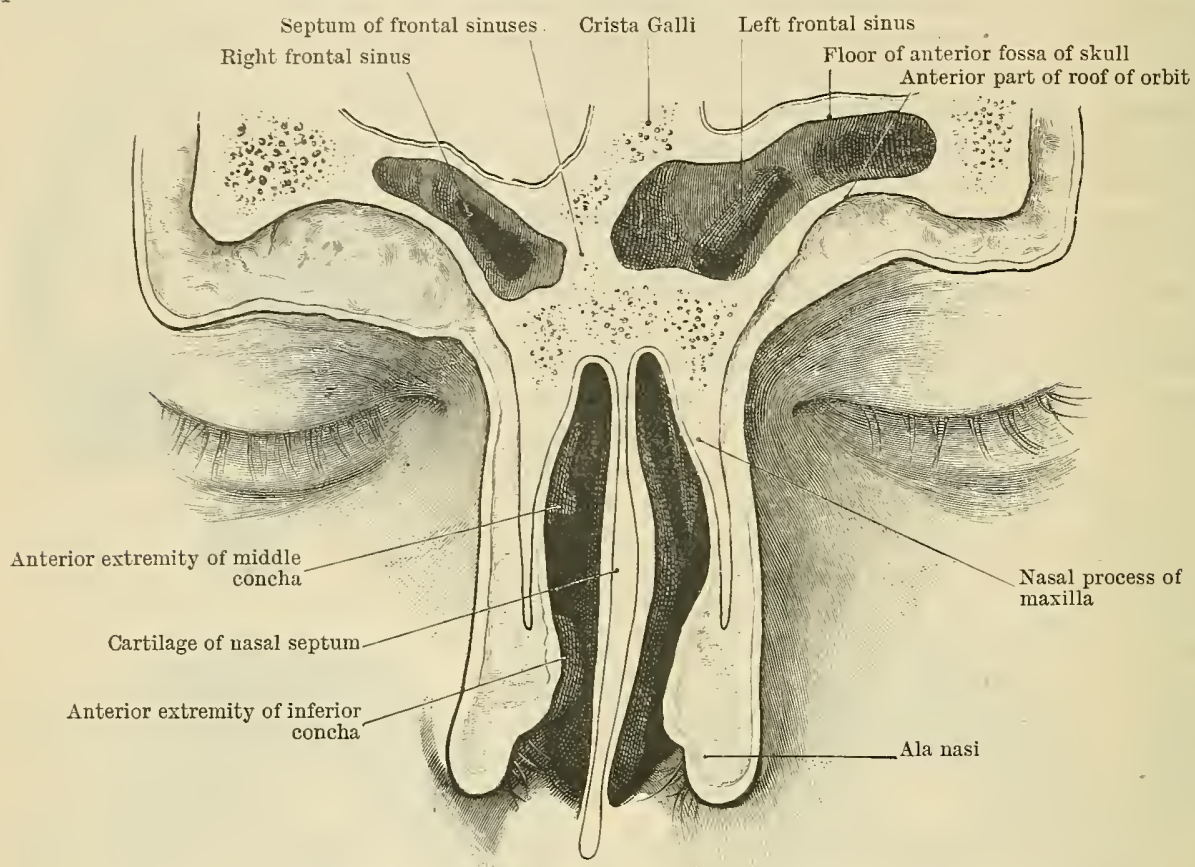

Fig. 1078.--Vertical Frontal Section throdgh the Nose and Frontal Sinuses.

purpose a small electric lamp is placed against the floor of the sinns, beneath the medial third of the supra-orbital margin.

The skiagraphic appearances of the frontal sinuses are of importance clinically and give more information than trans-illumination. Antero-posterior skiagrams show the vertical extent of the sinus, the degree of asymmetry, and the presence or absence of recesses with their intervening septum. An orbital expansion is indicated by a welldefined shadow with a sharply-defined upper margin, extending laterally parallel to and immediately above the medial half or more of the supra-orbital margin. A profile skiagram shows not only the height of the sinuses but also their antero-posterior diameter, as well as the degree to which they extend backwards between the roof of the orbit and the floor of the anterior fossa of the skull. While it is exceptional to meet with frontal sinuses before the age of five years, they are almost invariably present by the seventh or eighth year.

In exploring the sinus, the opening in the bone should be made close to the median plane, immediately above the root of the nose. In marked cases of deviation of the septum one sinus may extend so far across the medial plane of the forehead as to reduce the other to a mere slit; in such cases the surgeon may fail to open the diseased sinus when the operation is performed through the anterior wall. The sinus frequently contains incomplete partitions, which give rise to the formation of pockets and recesses usually found towards the lateral angle of the sinus; when dealing with chronic suppuration of the sinuses, special attention should be paid to these recesses as well as to the backward extension of the cavity along the orbital roof. The anterior ethmoidal cells are closely related to the thin medial or uasal portion of the floor of the sinus and its duct of exit; hence suppuration very frequently co-exists in both cavities. In some cases pus flows directly from the frontal sinus and infundibulum along the hiatus semilunaris into the maxillary sinus, which opens into the back part of the hiatus. Killian's operation for the cure of chronic suppuration in the sinus consists in the removal of its anterior and inferior walls, the supra-orbital margin being left to prevent the falling in of the eyebrow. By removing the frontal process of the maxilla good access may at the same time be obtained to the etlimoidal cells and free drainage established between the frontal sinus and the nasal cavity. 
In an antero-posterior skiagram of the skull, the light shadows formed by the ethmoidal cells are seen to occupy the well-defined area bounded on either side by the still lighter shadow of the orbital cavities and above by the dense horizontal shadow of the cribriform plate, which occupies the frontier line between these sinuses and the frontal sinuses. Anteriorly the ethmoidal area is overlapped by the vertical shadow caused by the frontal processes of the maxillæ and by the ridges of the lacrimals. Not infrequently the ethmoidal cells will be seen to extend into the roof of the orbit, while inferiorly and laterally they come into close relation to the superior and medial angle of the shadow formed by the maxillary sinus. The comparative transparency of the area of the ethmoidal cells is accounted for by the fact that it is superimposed upon that of the sphenoidal sinuses.

In a profile skiagram the ethmoidal area is seen to extend from the frontal process of the maxilla backwards across the orbits to the sphenoidal sinuses, with which they are contiguous. This area is crossed about its middle by the vertical shadow caused by the lateral margin of the orbit. In front of this, and occupying, therefore, the light area of the orbital cavity, are the anterior ethmoidal celis; while behind it are the posterior ethmoidal cells. In a profile view of the skull, the posterior ethmoidal cells, the sphenoidal sinuses, and the hypophyseal fossa all lie from before backwards in the axis of those rays which pass through the thinnest portion of the cranial box, namely, the anterior part of the temporal fossa; hence the possibility of being able to identify them even in a skiagram taken from a living subject.

The sphenoidal sinuses are so deeply placed behind the upper half of the piriform aperture of the nares that their outlines cannot be identified in an antero-posterior skiagram. If the sinuses be filled with bismuth before the skiagram is taken, it will be seen that they produce a well-defined and slightly oval black shadow, about the size of a shilling, situated opposite the superior half of the piriform aperture, the superior limit of the shadow reaching just up to the transverse curvilinear line already referred to, while laterally the sliadow reaches $\frac{1}{2} \mathrm{~cm}$. medial to the inferior half of the medial margin of the orbit (Logan Turner).

In a profile skiagram of the skull the light shadow produced by the sphenoidal sinus is seen immediately inferior and in front of the characteristic well-defined cupshaped sharlow formed by the concave floor of the hypophyseal fossa. Inferiorly the sinus area is bounded and to some extent overlapped and obliterated by the dense shadow which corresponds from without medially to the eminentia articularis and the horizontal portion of the great wing of the sphenoid, that is to say, to the floor of the middle fossa of the base of the skull. This dark shadow is continuous posteriorly with that which is caused by the dense petrous portion of the temporal bone. Anteriorly is the shadow of the posterior ethmoidal cells (blurred by that produced by the vertical portion of the great wing of the sphenoid), while posteriorly it is limited by the shadow produced by that portion of the body of the sphenoid which lies inferior to the dorsum sellæ.

\section{Hypophysis CEREBRI.}

The topography of the sella turcica, which lodges the hypophysis cerebri, is of importance now that surgery has succeeded in dealing with certain tumours and enlargements of this organ. The fossa hypophyseos lies immediately behind the superior part of the sphenoidal sinuses, and, in a medial sagittal section of the skull, the anterior half of the fossa is seen to project into what would correspond to the supero-posterior angle of the sinuses. The more the sphenoidal sinuses project backwards, beneath the sella turcica, the thinner is the plate of bone which separates the sinus from that part of the posterior fossa of the base of the skull which supports the pons. When, on the other hand, the sphenoidal sinuses are small and do not extend backwards below the sella turcica, the latter may be difficult to identify. In order to reach the hypophysis surgeons have abandoned the intra-cranial route, partly on account of the damage produced in the brain, and partly because, when the hypophysis 
enlarges, it frequently does so by projecting downwards towards the sphenoidal sinuses rather than upwards into the cranial cavity.

The sphenoidal sinuses constitute the surgeon's guide to the hypophysis. To reach them he traverses the upper portions of both nasal cavities, removing, from before backwards, the upper portion of the septum nasi, the superior and middle conchæ, and the anterior and posterior ethmoidal cells. The rostrum sphenoidale, situated at the superior and most posterior part of the nasal septum, serves as a guide to the anterior wall of the sphenoidal sinuses; after removing it the sinuses are opened up by removing their anterior walls and the septum. The hypophysis is then exposed by breaking down the anterior portion of the floor of the sella turcica, which forms a bullous-like projection into the superior and posterior part of the sinuses. In making the opening from the sphenoidal sinuses into the hypophyseal fossa, the surgeon must keep strictly to the median plane, so as to avoid opening into the cavernous sinus; if the roof of the sinus be penetrated in front of the fossa the optic chiasma would be injured and the cranial carity opened, while if the posterior wall of the sinus be penetrated below the level of the fossa hypophyseos the cancellated tissue of the body of the sphenoid would be opened into, and if the sinus happened to extend unusually far back, the anterior part of the posterior fossa of the base of the skull wonld be opened into opposite the basilar artery and the ventral surface of the pons.

According to Stanley Gibson, the average distance from the nasion to the anterior superior margin of the sphenoidal sinus is $1 \frac{3}{4}$ inches, while the distance from the anterior superior boundary of the sinus to the anterior superior margin of the sella turcica is a little more than $\frac{1}{2}$ inch, so that the total distance from the nasion to the hypophysis is from $2 \frac{1}{4}$ to $2 \frac{1}{2}$ inches. The average distance from the anterior nasal spine to the hypophysis is $7.8 \mathrm{~cm}$. (practically $3 \mathrm{in}$.). The floor of the hypophyseal fossa is on a level with a plane projected backwards from the nasion to the inion. The fossa measures $\frac{1}{2}$ inch in its antero-posterior diameter.

In a profile skiagram of the skull, the ontline of the cup-shaped sella turcica is marked out by a crescentic linear shadow, the anterior and posterior horns of the crescent being represented by the shadows of the anterior and posterior clinoid processes. Below and in front of the fossa the outlines of the sphenoidal sinuses may be distinctly traced.

Enlargements of the hypophysis cerebri can often be clearly demonstrated by an increase in the depth and antero-posterior diameter of the skiagraphic outline of the sella turcica, and by the unusual extent to which the fossa encroaches upon the sphenoidal sinus.

\section{THE FACE.}

The skin of the face is thin, vascular, and rich in sebaceous and sweat glands; it is intimately connected with the subcutaneous tissue, in which are imbedded the facial muscles as well as the main blood-vessels. Owing to its elasticity and to the presence of the main blood-vessels in the lax subcutaneous tissue, the face is an admirable site for plastic operations, as the flaps do not necrose in spite of considerable tension. The laxity of the tissues accounts for the marked swelling which attends odematous and inflammatory conditions about the face. Whenever possible, incisions should be made along the line of the natural furrows and creases of the skin, so as to render the resulting cicatrix less noticeable.

The bony landmarks of the face which may be readily palpated are: the superciliary ridges and the glabella, the nasion (fronto-nasal junction), the bridge of the nose, the osseous piriform opening and the nasal spine, the supra- and infra-orbital margins, the lateral and medial angular processes, the anterior part of the temporal crest, the zygomatic bone, the zygomatic arch, and the region of the canine fossa of the maxilla.

Immediately inferior to the root of the zygoma, and in front of the superior part of the tragus, is the condyle of the mandible. By pressing with the point of the finger upon the condyle while the mouth is being widely opened, the bone will be 
felt to glide forward, while the finger sinks deeply into the hollow corresponding to the glenoid fossa. The close relation of the first part of the internal maxillary artery to the medial aspect of the neck of the jaw must be kept in mind in operations calling for disarticulation or excision of the condyle. The ascending ramus of the mandible is sandwiched between the masseter and the pterygoid muscles, and can be removed without opening into the mouth. Passing downwards from the condyle, one can palpate the anterior and posterior borders of the ascending ramus and the angle and body of the mandible. The anterior border of the coronoid process is felt in front of the upper part of the anterior border of the masseter, immediately below the anterior part of the zygomatic aroh.

The pulsation of the external maxillary artery may be felt as the vessel crosses the inferior margin of the mandible at the anterior border of the masseter, $1 \frac{1}{4}$ in. in front of the angle of the jaw. To map out the course of the artery upon the face, draw a line from this point to a point $\frac{1}{2}$ in. lateral to the angle of the mouth, and thence to a point a little behind the ala nasi and along the side of the nose to the medial angle of the orbit. The external maxillary vein lies posterior to the artery, and takes a straighter course from the medial palpebral commissure to the anterior inferior angle of the masseter. The ressel is devoid of ralves, hence infective phlebitis and thrombosis are liable to spread along it to the cavernous sinus by way of the ophthalmic and pterygoid veins.

A line projected downwards from the supra-orbital notch (junction of medial and intermediate thirds of the supra-orbital margin) to the inferior border of the mandible opposite the interval between the two lower bicuspid teeth, will cross the infra-orbital and mental foramina, the former $\frac{1}{4}$ in. below the infra-orbital margin, the latter midway between the superior and inferior borders of the mandible. In performing the operation of neurectomy for the relief of trigeminal neuralgia, these foramina furnish the guides to the correspondingly-named branches of the fifth nerve. It should be remembered that the nerves in question, after emerging from their respective foramina, lie, in the first instance, beneath the facial muscles. The supra-orbital and infra-orbital nerves are not infrequently represented each by two branches, one of which passes through an accessory foramen situated lateral to the normal opening. Neurectomy of the inferior alveolar nerve is performed by trephining the ascending ramus of the mandible midway between its anterior and posterior borders, on a level with the crown of the last molar tooth, the nerve being reached as it enters the inferior alveolar canal: the lingual nerve, which lies a little anterior to the inferior alveolar, can be exposed through the same opening.

The relations of the maxillary and mandibular divisions of the trigeminal nerve have become of increased importance to the surgeon since the introduction of the treatment of trifacial neuralgia by the injection of alcohol into these nerves immediately after their exit from the cranial cavity. According to Symington, in order to reach the maxillary nerve as it lies in the pterygo-palatine fossa, the skin should be punctured immediately below the zygomatic arch, about $4 \mathrm{~cm}$. in front of the anterior wall of the external acoustic meatus. The needle should be directed inwards with a slight inclination upwards and backwards. After perforating the masseter and temporal muscles, the instrument enters the fatty tissue of the pterygo-palatine space, embedded in which is the internal maxillary artery and some veins. By passing the needle still more deeply, it is made to penetrate between the two heads of the external pterfgoid muscle through the pterygo-palatine fissure into the pterygo-palatine fossa. If the instrument be passed too far forwards it will strike the maxillary tuberosity; if too far backwards, the lateral pterygoid lamina. The cedema of the eyelids which not infrequently follows the operation is due to some of the fluid passing upwards into the orbit through the inferior orbital fissure. The distance from the skin to the nerve, as it lies in the pterygo-palatine fossa, is practically 2 in. Should the needle, after perforating the masseter, strike the coronoid process of the mandible, the latter may be depressed by opening the mouth.

The mandibular nerve is injected immediately bejond its exit from the foramen ovale, which lies $4 \mathrm{~cm}$. from the skin in the same rertical frontal plane 
as the eminentia articularis. When the mouth is opened widely the condyle of the mandible travels forwards and can be distinctly felt immediately below the eminence. To avoid entering the temporo-mandibular joint the needle is introduced through the skin immediately below the zygoma, a little in front of the eminence. It is pushed inwards and slightly backwards through the sigmoid notch of the mandible, and thence through, or immediately above, the external pterygoid muscle into the nerve. Symington points out that "the chief dangers connected with this operation are dependent upon the needle being passed in too far. Thus if it be directed straight inwards beyond the depth of the nerve $(4 \mathrm{~cm}$.) it would penetrate the tensor veli palatini and the auditory tube and open on the lateral wall of the naso-pharynx; or, if directed somewhat upwards, it might pass through the foramen ovale, and even reach the cavernous sinus and the internal carotid artery, as the medial boundary of the foramen slopes upwards and inwards."

The facial nerve, after emerging from the stylo-mastoid foramen, is embedded in the parotid gland, where it is superficial to the external carotid artery; the nerve can be rolled under the finger as it crosses the posterior border of the ascending ramus of the jaw at the level of the lower margin of the tragus; incisions continued along the ramus above this point should be only skin deep if the nerve is to be avoided. To expose the trunk of the nerve an incision is made from the anterior border of the mastoid process to the angle of the mandible. Incisions upon the cheek should, whenever possible, be planned so as to run parallel with the branches of the nerve; these radiate from the inferior end of the tragus. The nerve may be paralysed by wounds of the cheek and by malignant tumours of the parotid, as also by intra-cranial and middle-ear lesions.

The parotid gland is surrounded by a fascial envelope, the strongest portion of which is continued from the deep cervical fascia over its superficial aspect to become attached to the zygoma (Fig. 1085); hence abscesses in the parotid tend to burrow deeply towards the pterygo-palatine space and the superior part of the pharynx (Fig. 1085); the pus should therefore be evacuated by Hilton's method, through an early incision over the angle of the mandible. A study of the relations of the gland explains the surgical difficulties which attend its complete removal.

The parotid duct can be rolled beneath the finger as it crosses the masseter, rather less than a finger's breadth below the zygoma. After winding over the anterior border of the muscle it soon pierces the buccinator, and opens into the mouth opposite to the second molar tooth of the maxilla. The duct corresponds to the intermediate third of a line drawn from the inferior margin of the concha to a point midway between the ala nasi and the margin of the upper lip.

Superficial to the parotid and a little in front of the tragus is the pre-auricular lymph gland, which is frequently found to be inflamed in children suffering from eczematous conditions of the eyelids, face, scalp, and external ear. In opening an abscess connected with this gland eare must be taken to make the incision as low down as possible, so as to avoid the parotid duct.

The deep parotid lymph glands which lie partly in the substance of, and partly beneath, the inferior part of the parotid, form the highest group of the upper carotid set of deep cervical glands. They are especially liable to become infected secondary to tuberculous disease of the middle ear and to malignant affections about the root of the tongue, the fauces, and the naso-pharynx. In removing them it is generally impossible to avoid dividing the infra-maxillary branch of the facial nerve, which pierces the cervical fascia immediately inferior and posterior to the angle of the jaw. This nerve supplies the platysma and the depressor labii inferioris muscles, so that its division gives rise to inability to depress the lower lip on the affected side. At the same operation some trouble may be caused by bleeding from the temporomaxillary vein and its divisions, which traverse the substance of the gland.

Eyelids.-The skin of the eyelids, more especially of the upper, is very thin and connected with the orbicularis oculi muscle by delicate and lax subcutaneous tissue destitute of fat; hence the marked swelling which occurs in a "black eye" and in cdema of the lids. Along the anterior edge of the free margins of the lids are the eyelashes and the orifices of the sebaceous glands, suppurative inflammation of which gives rise to a "stye"; along the sharp posterior edge of the free margins 
are the minute orifices of the tarsal glands. These glands, embedded in the deep surface of the tarsi, are seen through the palpebral conjunctiva as a row of parallel, yellowish, granular-looking streaks. From the deep position of the glands it follows that the skin over a Meibomian cyst is freely movable, and that to reach the cyst an incision should be made through the conjunctival surface of the lid.

The palpebral conjunctiva is closely adherent to the ocular surface of the tarsi; at the fornix it is loose and contains small lymph follicles, which become hypertrophied in the condition known as granular conjunctivitis. The ocular conjunctiva is thin, transparent, and loosely attached to the sclera, so that in operating upon the eye a fold of the membrane can be picked up with forceps to steady the eyeball.

In inflammatory affections of the eye the state of those ressels which are risible gives important information as to the seat of the mischief. For example, in inflammation of the conjunctiva the posterior conjunctival vessels (derived from the palpebral arteries), scarcely visible normally, appear as a close network which fades away towards the corneal margin ; these vessels move freely with the conjunctiva, and do not disappear under pressure. In superficial inflammations of the cornea the anterior conjunctival vessels (the most superficial of the terminal branches of the anterior ciliary arteries) are seen to spread in a freely branching manner into its superficial layers. In iritis and deep inflammations of the cornea there is a pink circumcorneal zone of vascular dilatation consisting of delicate straight vessels which disappear under pressure and do not move with the conjunctiva; they are the subconjunctival (episcleral) terminations of the anterior ciliary arteries; in health they are invisible.

Lacrimal Apparatus.--The lacrimal gland, situated behind the lateral part of the supra-orbital margin, cannot be felt unless enlarged. By everting and raising the upper eyelid, the accessory (palpebral) portion of the gland is seen to project beneath the lateral third of the fornix, in which situation also the minute orifices of the lacrimal ducts may be detected. By gently drawing downwards the lower lid, the small punctum lacrimale is seen situated upon a slight papillary elevation of its margin about $4 \mathrm{~mm}$. from the medial palpebral commissure; the corresponding orifice of the upper lid is placed a little nearer the commissure. Normally the puncta are directed towards, and accurately applied to, the ocular conjunctiva immediately lateral to the lacrimal caruncle. By drawing the lids laterally the medial palpebral ligament is put upon the stretch, and can be felt as a narrow tense band passing transversely medially to be attached to the nasal process of the maxilla. The ligament is a guide to the position of the lacrimal sac, which it crosses a little above its centre. Continuous with the inferior end of the lacrimal sac is the naso-lacrimal duct, which passes downwards and slightly backwards and laterally, to open into the inferior meatus of the nose, under cover of the anterior end of the inferior concha. The lacrimal sac and naso-lacrimal duct each measure about $\frac{1}{2}$ in. in length; the latter is slightly contracted at its commencement and termination, and it is in these situations that pathological strictures of the duct are commonest. Spontaneous rupture of an abscess of the lacrimal sac almost invariably occurs just below the medial palpebral ligament; it is in this situation that the abscess should be opened, the incision being made a little lateral to the angular termination of the external maxillary artery.

The canaliculi lacrimales, which convey the tears from the puncta to the lacrimal sac, run for the first $1-2 \mathrm{~mm}$. almost vertically to the free margins of the lids, and thence parallel to them. Between the canaliculi is the lacrimal caruncle. In the various morbid conditions which give rise either to misdirection of the puncta or to stricture at any part of the lacrimal drainage apparatus, overflow of the tears (epiphora) is the chief symptom. In passing a probe along a canaliculus the instrument, in consequence of the bend upon the duct, is passed at first vertically to the margin of the lid, and afterwards parallel to it, until the point is felt to strike against the medial wall of the lacrimal sac; to pass the instrument onwards along the naso-lacrimal duct the handle is rotated forwards and upwards through a quarter of a circle, and then pushed gently downwards and slightly backwards and laterally into the inferior meatus of the nose. 
The tarsi are attached to the periosteum of the orbital margins by the orbitotarsal ligaments which shut off the communication between the subcutaneous tissue of the eyelids and the fatty tissue of the orbital cavity. In fracture of the anterior fossa of the base of the skull involving the orbital part, the blood extends forwards between the periosteum and the musculo-fascial envelope of the orbit and appears under the conjunctiva.

To obtain free access to the cavity of the orbit, the surgeon first enlarges the palpebral fissure by making a horizontal incision from the lateral palpebral commissure to the lateral margin of the orbit, and then, after everting the eyelid, divides the conjunctiva along the fornix of the upper or lower lid, or of both, as may be desired.

Nose.-To examine the anterior nares (anterior rhinoscopy) a strong light is reflected into the nostril, which is dilated by means of a nasal speculum. The anterior extremity of the inferior concha appears as a rounded body projecting from the lateral wall of the nose; in turgescence of its erectile tissue it is liable to come in contact with the nasal septum and so occlude the nostril. The inferior meatus, situated between the inferior concha and the floor of the nasal fossa, is brought into view by tilting forwards the head. The inferior aperture of the nasolacrimal duct is concealed from view by the anterior part of the inferior concha. The floor of the nose is horizontal and placed on a slightly lower level than the anterior nares. The septum, generally more or less deviated to one or other side, is seen when the head is slightly rotated away from the side to be examined. The anterior extremity of the middle concha, which lies a little behind and medial to the lower-medial angle of the orbital margin, is seen when the patient's head is thrown well back; between it and the septum is a slit-like interval (olfactory cleft). By rotating the patient's head towards the corresponding shoulder the anterior part of the middle meatus is brought into view; pus in this situation may originate from the frontal, the anterior ethmoidal, or the inaxillary sinuses, all of which open into the hiatus semilunaris of the middle meatus.

To make a satisfactory digital exploration of the anterior part of the nasal cavities, it is necessary to divide the columella and the cartilaginous septum with a strong pair of scissors, one blade being introduced into each nostril (Kocher); blood spurts from the small arteries of the septum, but the bleeding soon ceases. When these vessels, which are derived from the superior coronary arteries, are the source of the hæmorrhage in epistaxis, the bleeding can be arrested either by compressing the coronary arteries, by plugging the anterior nares, or by grasping the cartilaginous part of the nose firmly between the finger and thumb.

The maxillary sinus or antrum of Highmore, situated in the maxilla, is a pyramidal cavity with its base formed by the lateral wall of the nose and its apex directed towards the zygomatic bone. The cavity is lined by a thin mucoperiosteal membrane, easily separable from the bone; in the mucous layer are numerous mucous glands from which cysts may develop. The floor of the antrum, which is at or a little below the level of the floor of the nose, is separated from the roots of the bicuspid and molar teeth by a plate of bone of varying thickness. When this plate is thin and devoid of spongy bone, the floor of the sinus sinks below the level of the floor of the nose, and suppuration at the roots of one of the teeth above mentioned is in these circumstances very liable to extend to the sinus. In a sinus of average dimensions the line of union of the nasal and facial walls of the cavity corresponds externally to the lateral edge of the canine ridge (Logan Turner). The nasal orifice is situated at the highest part of the sinus, and is therefore unfavourably placed for natural drainage; it opens into the posterior and lower part of the infundibulum, which in its turn communicates with the middle meatus of the nose through the hiatus semilunaris. In old age there is frequently a second communication between the sinus and middle meatus, the opening being situated posterior to and below the normal orifice ; when this accessory osteum exists, pus from the antrum may drain backwards into the nasal part of the pharynx (Logan Turner). In empyema of the sinus the opening to evacuate and drain the cavity may be made (1) through the alveolus of the second bicuspid or of the first or second molar tooth, the first molar being the site of election; 
(2) through the canine fossa, lateral to the prominence caused by the root of the canine tooth; or (3) through the lateral wall of the inferior meatus of the nose.

In an antero-posterior skiagram of the skull, the shadow of the maxillary sinus presents a pyramidal outline, the base corresponding to the floor of the orbit and the rounded apex to the alveolar recess of the sinus. Sometimes the floor of the sinus extends medially, below the floor of the nose, into the palatine process of the maxilla so as to form a distinct palatine recess. The medial outline of the sinus area is formed by the foreshortened shadow of the nasal wall of the sinus and the lateral pterygoid lamina, while laterally it is outlined by the zygomatic bone. The petrous portion of the temporal bone throws a deep shadow across the superior half of the sinus. In taking the skiagram, therefore, the head should be placed in such a position that this shadow is raised as much as possible into the orbits. In the living subject the inferior and medial portion of the outline of the maxillary sinus is considerably obscured by that caused by the cervical portion of the vertebral column (Killian).

In a profile skiagram of the facial region of the dried skull, the shadow of the outline of the maxillary sinus is well defined. It is represented below by the dense horizontal shadow of the hard palate which crosses the tips of the roots of the molar teeth. Above it is limited anteriorly by the dark curved shadow of the floor of the orbit, while above and posteriorly is the shadow of the posterior ethmoidal-cell area. Behind the maxillary area are the vertical linear shadows of the pterygoid laminæ overlapped by that of the coronoid process of the mandible. The anterior part of the sinus area is overlapped and to a considerable extent obscured by the shadow caused by the denser and somewhat triangular shadow of the zygomatic bone.

Lips.-In compressing the coronary arteries, it must be remembered that they run beneath the mucous surface of the lips a short distance from their free margins. The lips are abundantly supplied with mucous glands which can be felt immediately beneath the mucous membrane nearer their attached than their free borders; the glands are a frequent source of mucous cysts; occasionally they are enlarged congenitally, giving rise to one form of hypertrophy of the lip.

Hare-lip is due to failure of the union of the superficial parts of the medial nasal subdivision of the fronto-nasal process with the maxillary process (Fig. 1079). The deformity is spoken of as complete or incomplete according as the cleft extends into the nostril or merely involves a portion of the lip. The fissure may involve the lip only, or it may include the alveolar process of the maxilla; in the latter case the cleft may or may not be associated with a cleft of the palate. Lastly, the hare-lip may be single or double, according as the deficiency has occurred on one (usually the left) or both sides.

Fig. 1080, taken from a coronal section through the head of a human embryo at the seventh week, shows how the mouth is shut off from the nasal cavities by the growth inwards from the deep aspect of the maxillary process of two horizontal plates (palatine processes) which unite in the medial line with each other and with the inferior border of the septum of the nose; the latter, which develops as a downgrowth from the primitive basis cranii, is continuous anteriorly with the two medial nasal processes which form the premaxillæ and the medial portion of the upper lip. The various degrees of cleft palate

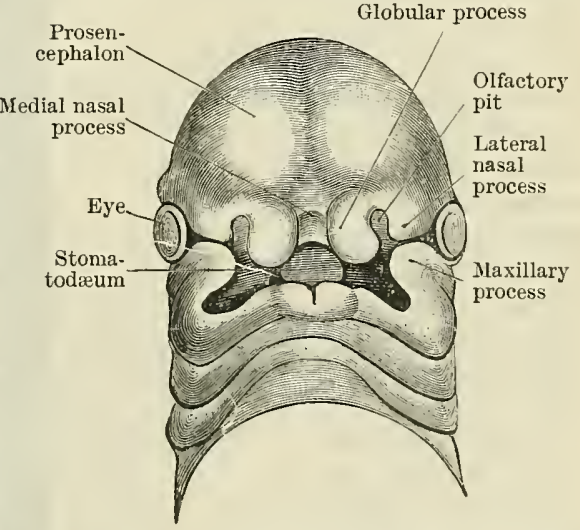

Fig. 1079.-Head of Human Embryo about 29 DAYS OLD, showing the division of the lower part of the medial frontal process into the two globular processes, the intervention of the olfactory pits between the medial and lateral nasal processes, and the approximation of the maxillary and lateral nasal processes, which, however, are separated by the oculo-nasal sulcus (from His). are due to the more or less complete failure of union of the palatine processes with each other and with the premaxillary part of the medial nasal processes. The cleft in the soft palate, which is always medial, may be either partial or complete, and may or may 
not extend forwards into the hard palate. The cleft in the latter is spoken of as single or double according to whether the palatal processes have failed to unite with the lower edge of the nasal septum on one, or on both, sides. When the cleft extends forwards

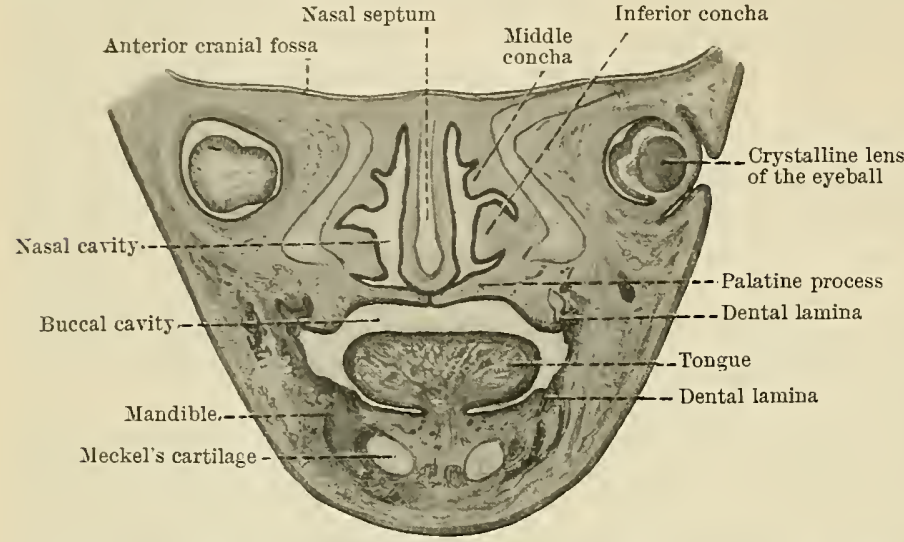

Fig. 1080.-Coronal Section throdgh the face of a Human Embrio AT the SEVenth WeEk.

through the alveolar process to become continuous with a cleft of the lip, the medial (premaxillary) edge of the cleft is usually projected forwards in advance of the lateral (maxillary) edge. Before proceeding to repair the cleft in the lip, the projecting premaxillary edge is forced back into line with the maxillary edge.

In what is known as a complete double cleft palate, the palatine processes fail to

join the nasal septum and the premaxillæ on both sides; the result is a wide median cleft which communicates with both nasal cavities. The free inferior border of the vomer extends along the middle of the cleft to be continuous anteriorly with the rounded premaxillary mass; the latter, along with the central portion of the upper lip, is projected forwards between the two labial clefts, often to such an extent that it appears to spring from the tip of the nose (Fig. 1081). In operating on such a double harelip the first step is to get rid of the premaxillary projection. This is done, not by removing it altogether, but by removing a triangular portion of the septum of the nose behind it, so as to allow of its being bent back into line with the alveolar processes of the maxillæ. The base of the triangular piece of bone should not be taken from the

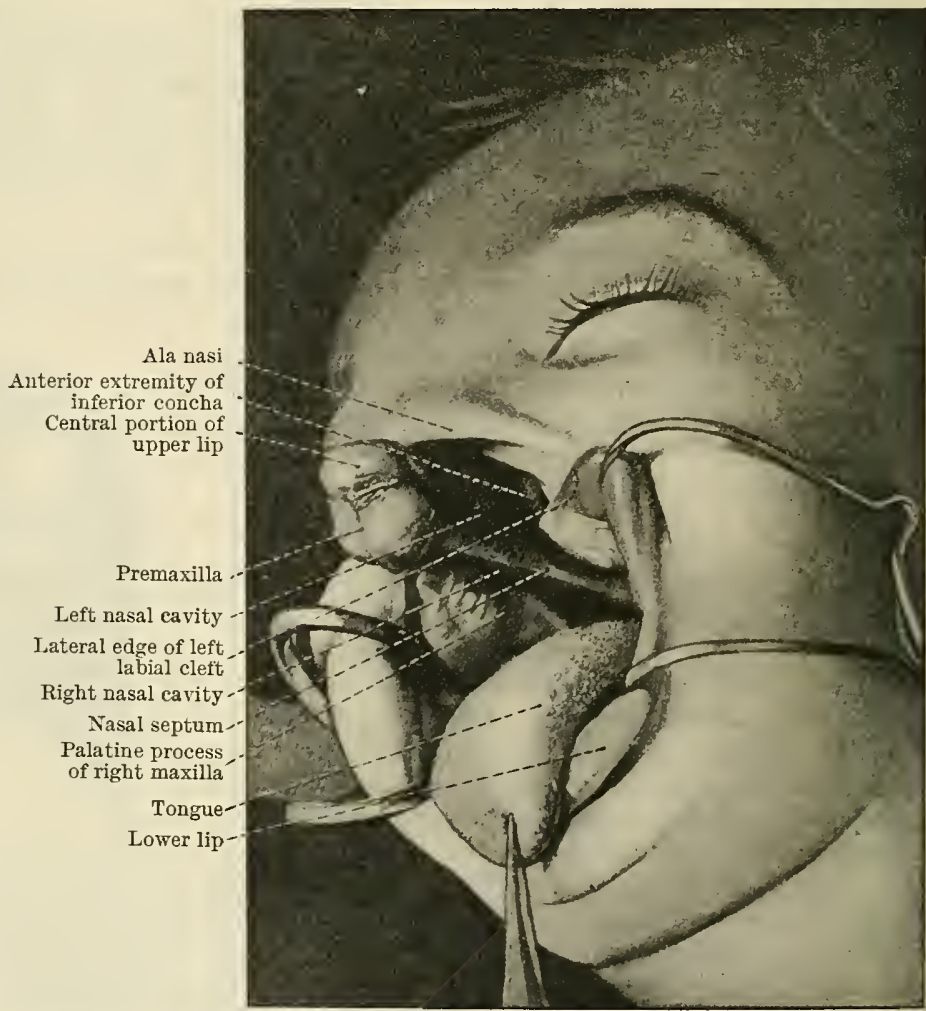

Fig. 1081.-From a Photograph showing Double Complete Hare-lip and Cleft Palate.

constricted portion of neck of the premaxillary projection, but should consist of the oliveshaped thickening situated immediately behind the neck. This thickening is crossed by the transverse suture uniting the premaxilla with the anterior extremity of the 
vomer (Fig. 1082). If the premaxillary projection be removed altogether, there is nothing left to support the upper lip, and the result is an ugly deformity, due to the comparative protrusion and redundancy of the lower lip.

Teeth. - The milk teeth begin to appear from the sixth to the eighth month, the first to emerge being the lower central incisors. The first dentition is completed about the thirtieth month. Delayed dentition is generally due to rickets. Of the permanent set the first to erupt are the first molars, which appear at the end of the sixth or seventh year; the third molars, the last to appear, may erupt any time between the eighteenth and

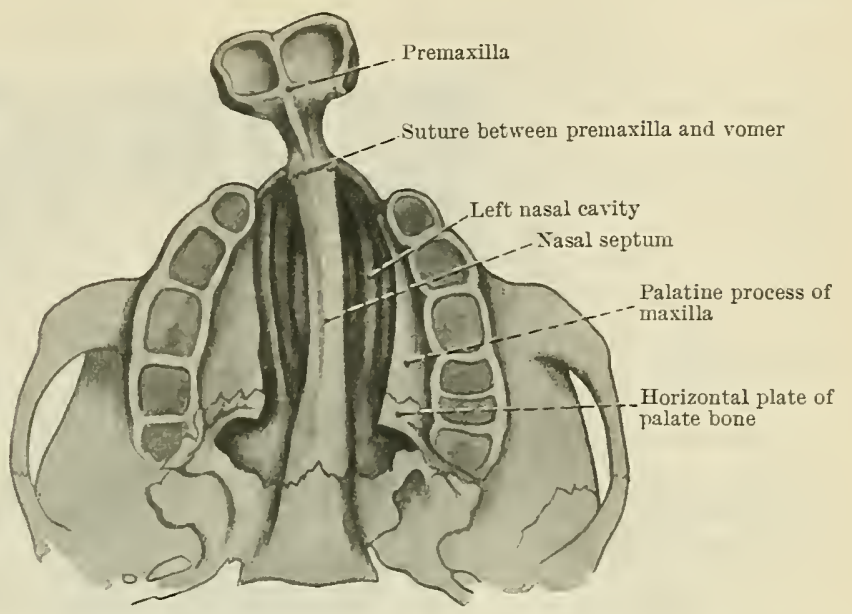

Fig. 1082.- Shows Arraxgenext of Bones is Double Clefr Palate (Handbook of Practical Surgery, Bergmann, Bruns, and Mikulicz).

the twenty-fifth year, or even later. As the permanent teeth push their way towards the surface, absorption of the roots of the first set takes place, which either fall out of their own accord or are easily removed. Loss of the permanent teeth is followed by absorption of the alveolar margin of the jaw. The tooth sockets are lined by a thin periosteum, which is anatomically continuous with the pulp tissue of the teeth on the one hand and the dense fibrous tissue of the deep layer of the gum on the other.

The upper incisors and canines and the lower bicuspids have cylindrical roots, hence in extracting these teeth they should be first loosened by a slight rotatory movement; the roots of the lower incisors and canines and of the upper bicuspids are flattened, so that they must be loosened by a lateral movement. The roots of the third molars are convergent, generally welded together and curved backwards, especially in the mandible. The first and second upper molars have three roots which are often divergent.

Tongue.-For practical purposes, as well as on developmental and structural grounds, it is convenient to divide the tongue into an anterior two-thirds-the oral part, and a posterior third-the pharyngeal part (Fig. 1085). At the junction of the two portions, immediately behind the median vallate papilla, is the foramen cæcum, which represents the remains of the upper or pharyngeal extremity of the thyreo-glossal duct. Congenital cysts and fistulce which develop from persistent remains of this tract are always medial; those arising from the upper or lingual portion of the tract are situated above the hyoid bone, whereas those developed from the lower or thyreoid portion are situated below the hyoid bone. The liability of these cysts and fistulæ to recur after operation is due to the fact that part of the epithelial tract lies in the substance of the hyoid bone.

The mucous membrane covering the pharyngeal part is much more sensitive than that covering the oral, hence in using a tongue depressor the instrument should, except under special circumstances, rest only upon the latter region, otherwise a reflex arching of the tongue will be set up, which prevents the operator from obtaining a satisfactory view of the throat. Scattered over the pharyngeal part are clusters of lymph follicles (lingual tousils), which appear on the surface as a number of nodular umbilicated elevations provided with little crypts into which mucous glands open (Fig. 1085). The lingual tonsils are liable to chronic inflammation and hypertrophy, conditions which are often accompanied by a varicose condition of the reins which lie immediately beneath the mucous membrane containing the palatoglossus muscle. To obtain a satisfactory riew 
of the lingual tonsils in the living subject the laryngoscopic mirror must be employed.

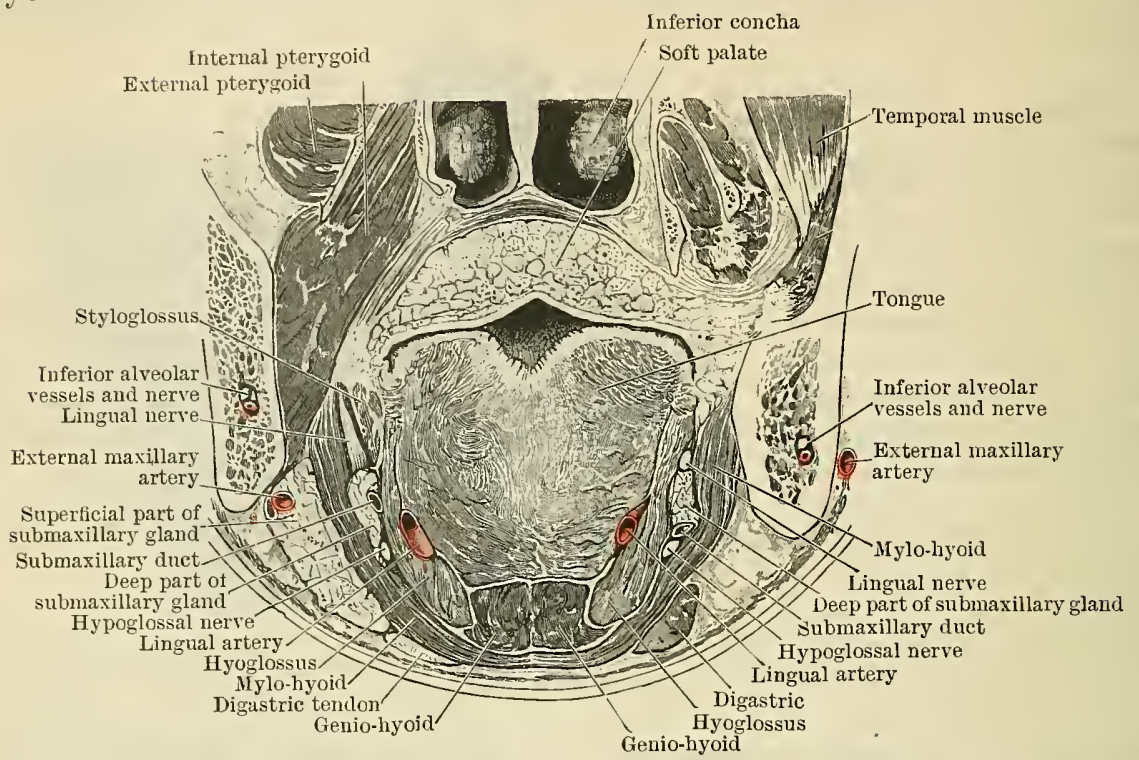

Fig. 1083.-Coronal Section throdgh the Tongue and Submaxillary Region in a Plane behind the Molar TeEth (from Cunningham).

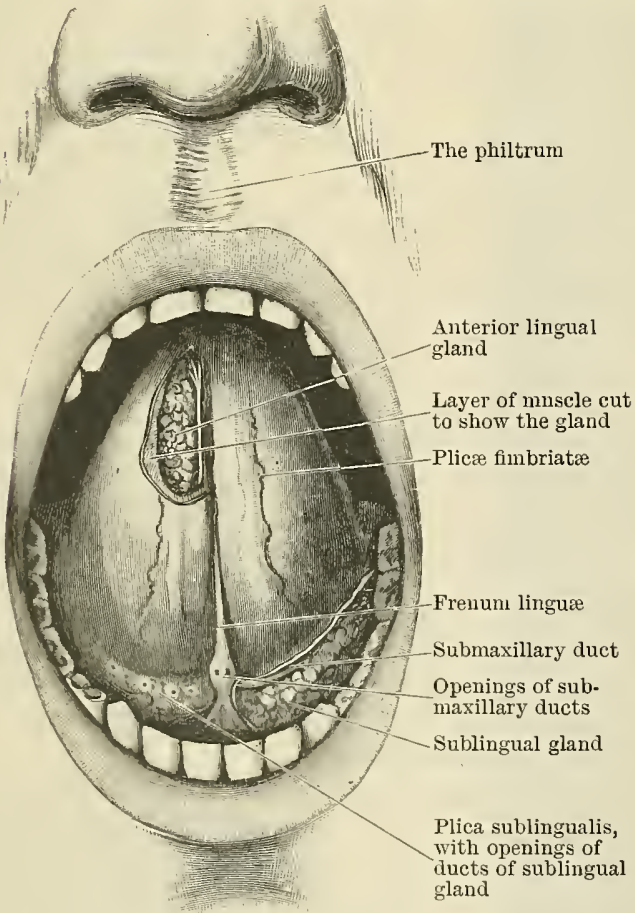

Fig. 1084. - Open ModTh with Tongue raised and the Sublingual and ANTerior Lingual Glands exposed.

The sublingual gland of the left side has been laid bare by removing the mucous membrane; to expose the anterior lingual gland of the right side a thin layer of muscle, in addition to the mucous membrane, has been removed. A branch of the lingual nerve is seen running on the medial aspect of the gland. The ranine vein is faintly indicated on this side also (from Birmingham).
The pair of mucous glands situated on the inferior surface of the tongue a little behind its tip, and known as the anterior lingual glands, are of interest in that they occasionally give rise to mucous cysts similar to those which develop in connexion with the labial glands (Fig. 1084).

The muscular bundles of the tongue are separated by a quantity of loose connective tissue, rich in blood- and lymph vessels (Fig. 1083); hence acute inflammatory œdema of the substance of the tongue may be attended with a degree of swelling sufficient to obstruct the respiratory passage.

The main blood-vessels of the tongue run from behind forwards, nearer its inferior than its superior surface (Fig. 1083); incisions into the substance of the tongue to reduce swelling and tension should, therefore, be made longitudinally upon the dorsum. Bleeding from the lingual artery, divided in the substance of the tongue, is temporarily arrested by passing the finger behind the base of the tongue and hooking it well forward, so as to compress the vessel against the medial surface of the mandible. 
On account of the very slender anastomosis between the vessels of the two halves of the tongue, scarcely any bleeding occurs when the organ is split in the median plane.

According to Poirier, the collecting trunks which arise from the lymph networks in the mucous membrane and muscular substance of the tongue may be divided into four groups:-(1) Apical trunks which open partly into the submental glands and partly into a gland of the internal jugular chain lying immediately above the anterior belly of the omo-hyoid muscle. (2) Marginal trunks which pass, some lateral to the sublingual gland and through the mylo-hyoid muscle, to join the most anterior of the submaxillary lymph glands; others pass medial to the sublingual gland, in front of and behind the hyoglossus muscle, to join the glands of the internal jugular chain. The more anterior their lingual origin the lover in the chain is the gland to which they pass. (3) The basal trunks, from the posterior third of the tongue, pass from before backwards towards the inferior extremity of the tonsils, where they pierce the superior and middle constrictors of the pharynx, and, after surrounding the lingual artery, open into a gland placed on the internal jugular vein immediately below the posterior belly of the digastric. (4) The central trunks, which descend in the middle line between the genio-glossi, pass beneath the hyoglossus and mylo-hyoid muscles into the submaxillary space, and thence in front of the hyoid bone (having embraced the tendon of the digastric) to join the glands of the internal jugular chain.

Between the tongue and the lingual surface of the gums is the alveolo-glossal sulcus, crossed in the median plane by the frenum linguæ, which passes upwards to the inferior surface of the tongue (Fig. 1084). Immediately on either side of the lower part of the frenum is the orifice of the submaxillary duct. A little external to the frenum the ranine veins are seen lying immediately under the thin mucous membrane; to the lateral side of the veins are the ranine arteries and the lingual nerves, both of which lie deeper than the veins, and are therefore not visible.

The mucous membrane at the anterior part of the floor of the alveolo-glossal sulcus is thrown into a slight elevation, which overlies, and is caused by, the sublingual salivary gland. The duct of the submaxillary gland and the lingual nerve lie beneath and to the medial side of the sublingual gland.

In dividing a shortened frenum for "tongue-tie" the deep lingual vessels and the orifices of the submaxillary ducts must be avoided. Behind the frenum linguæ are the anterior borders of the genio-glossi, which descend to the superior genial tubercles. In operations necessitating the removal of the region of the symphysis of the jaw, or the separation of the origins of the genio-glossi, the tongue must be kept forward, otherwise the patient will be suffocated by the organ falling backwards over the entrance to the larynx. In removing a small salivary calculus from the floor of the mouth the calculus should be fixed with the finger against the lingual surface of the jaw before cutting down upon it.

When the teeth are clenched the vestibule of the mouth communicates behind the last molars with the oral cavity proper through an opening which barely admits a medium-sized catheter. Hence, when the jaws cannot be separated it is generally necessary to feed the patient through a tube passed along the floor of the nose.

By opening the mouth widely and taking a deep inspiration, the soft palate is elevated, and the glosso-palatine and pharyngo-palatine arches are rendered prominent. The glosso-palatine arches are seen to spring from the anterior surface of the soft palate, close to the base of the uvula, and to arch downwards and laterally in front of the tonsils to end at the posterior extremity of the lateral border of the tongue. The pharyngo-palatine arches are really the continuation of the lower free border of the soft palate downwards behind the tonsils to become attached to, and lost upon, the postero-lateral wall of the pharynx. Together with the lower edge of the soft palate and the base of the tongue they bound a hemispherical opening (pharyngeal isthmus), through which is visible the oral portion of the mucous membrane covering the posterior wall of the pharyix.

The palatine tonsils (Fig. 1085) lie one on each side of the isthmus, between the palatine arches; they are situated opposite the angle of the jaw, but they cannot 
be felt from the outside. Each tonsil is covered on its free surface by mucous membrane upon which are seen the orifices of the tonsillar crypts; the lateral or deep surface is covered by a layer of fibrous tissue which forms an imperfect capsule to the organ. According to Merkel, the internal carotid artery is situated $1.5 \mathrm{~cm}$. behind the lateral margin of the tonsil, which is separated from the superior constrictor by a quantity of loose cellular tissue and fat, so that the gland can be grasped with a volsellum and pulled forward without dragging the vessel with it. The tonsil receives its blood-supply mainly from a small vessel derived from the anterior palatine artery; when this branch is larger than usual and adherent to

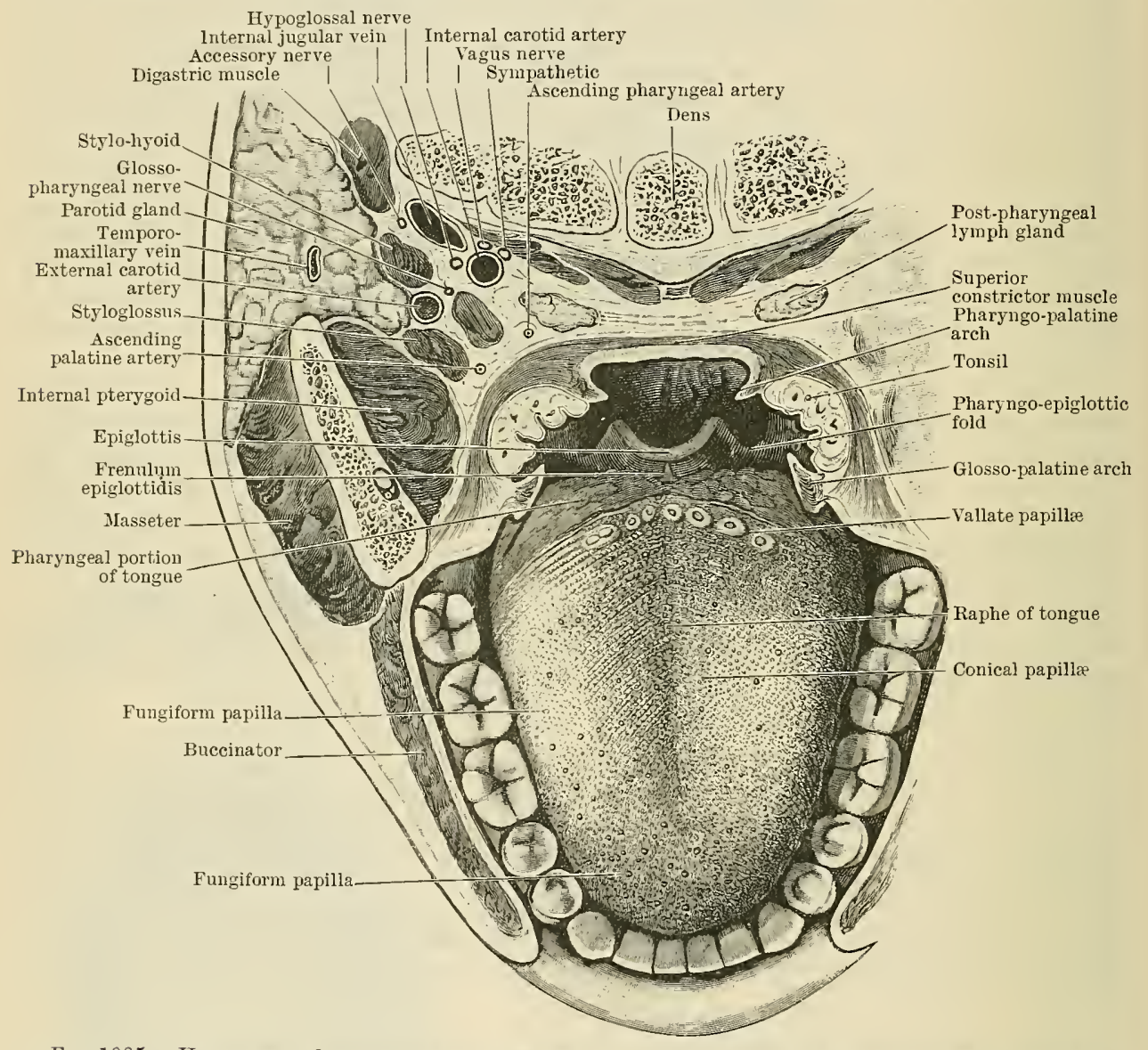

Fig. 1085. - Horizontal Section throdgh Modth and Pharynx at the Level of the Tonsils.

The stylopharyngeus, which is shown immediately to the inuer side of the external carotid artery, and the prevertebral muscles, are not indicated by reference lines (from Birmingham).

the capsule of the tonsil the bleeding which attends the operation of removal of the tonsils may be considerable. The hæmorrhage can be arrested by pressing the bleeding point outwards against the internal pterygoid and the ramus of the jaw. If the bleeding be from a spurting vessel of larger size, its source, according to Merkel, is probably the external maxillary artery, which has been wounded as it arches upwards beneath the digastric and stylo-hyoid muscles to within a short distance from the lateral surface of the tonsil. In children and adolescents the tonsils are frequently hypertrophied; the enlargement may be either general, more towards the medial line, downwards along the pharynx, or upwards behind the soft palate; to expose and thoroughly remove the last-mentioned variety of enlargement the upper part of the glosso-palatine arch must be divided.

The mucous membrane and the periosteum of the hard palate are so closely united as to form practically one membrane. The greater palatine arteries, after 
leaving the larger palatine foramina, run forward in shallow grooves in the hard palate, close to its alveolar margin. In the operation for cleft palate (staphylorraphy), in order to secure nourishment for the muco-periosteal flaps, the lateral incisions should be made lateral to these vessels.

Secondary hæmorrhage after the operation for cleft palate is treated by plugging the greater palatine foramen, which lies a little medial to the last molar tooth about $\frac{1}{3}$ in. in front of the hamular process, which can be felt at the superior extremity of the fold of mucous membrane containing the pterygo-maxillary ligament. In the closure of a wide cleft of the soft palate the tension of the tensor veli palatini muscle is got rid of by chipping off the hamulus with a small chisel introduced at the posterior extremity of the lateral relief incisions.

Nasal Part of the Pharynx.-To explore the superior or nasal part of the pharynx the finger should be hooked upwards behind the soft palate. Anteriorly, the finger readily detects the sharp posterior border of the vomer, the posterior nares, and the posterior extremity of the middle and inferior conchæ. The roof of the space is formed by the basilar part of the occipital bone, while upon the posterior wall is a transverse bony ridge caused by the projection of the anterior arch of the atlas. Upon the lateral walls of the nasal part of the pharynx are the openings of the auditory tubes, situated $\frac{1}{2}$ in. behind the posterior extremities of the inferior conchæ. The orifices, bounded superiorly and posteriorly by a prominent margin, are directed downwards and forwards, and, therefore, in a direction favourable to the passage of the Eustachian catheter. Behind the prominent posterior margin of the orifice is a lateral recess of the pharynx known as the fossa of Rosenmiiller, in which the point of the Eustachian catheter is apt to become engaged. Upon the roof and posterior wall of the pharynx, down to the level of the anterior arch of the atlas, and extending laterally as far as the orifices of the auditory tubes, is a collection of adenoid tissue, the pharyngeal tonsil. Hypertrophy of this tissue constitutes the condition known as "adenoids," the harmful effects of which are due to their interference with nasal respiration. Upon the centre of the pharyngeal tonsil is an orifice leading into a small recess into which numerous mucous glands open. The structures felt in the post-nasal space may be rendered visible by reflecting the light upon a small mirror placed immediately behind and below the soft palate (posterior rhinoscopy). The inferior part of the inferior concha is obscured from view by the bulging of the superior surface of the soft palate.

In plugging the posterior nares, it is important to remember that these openings measure nearly one inch in the vertical and half an inch in the transverse direction. In the child, owing to the small size of the face, the vertical diameter of the nasopharynx is relatively much smaller than in the adult.

The lymph vessels from the nasal. fossæ and pharynx, including the faucial and pharyngeal tonsils, join the sub-parotid and superior deep cervical glands, one of which lies medial to the carotid vessels between the lateral recess of the pharynx and the prevertebral fascia. In children suppuration originating in this gland is the commonest cause of a retro-pharyngeal abscess.

In the adult the four upper cervical vertebræ can be explored from the mouth, while in the child the finger can also reach as far down as the sixth rertebra and the back of the cricoid cartilage.

\section{THE NECK.}

The general envelope of deep cervical fascia, along with the processes and partitions which proceed from its deep surface, subdivides the neck in to compartments which limit and determine the spread of pus. The most important compartment is the central or visceral compartment, bounded anteriorly by the pretracheal fascia, posteriorly by the prevertebral fascia, and laterally by the fascia forming the rascular compartment. Posteriorly, this compartment extends from the base of the skull downwards into the posterior mediastinum; anteriorly, it extends from the hyoid bone into the anterior part of the superior mediastinum. Abscesses in the visceral compartment are either secondary to disease of the ljmph glands or organs it 
contains, or the result of a primary suppurative cellulitis. A tubercular abscess originating in one of the retropharyngeal lymph glands (Fig. 1085) lies in front of the prevertebral fascia, and points towards the posterior wall of the pharynx; abscesses secondary to disease of the cervical vertebræ lie behind the prevertebral fascia, and spread laterally behind the vascular compartment; they point behind the sterno-mastoid, and should be opened through an incision at the posterior border of the muscle, the surgeon keeping to the anterior aspect of the transverse processes in order to avoid the structures in the vascular compartment (Chiene).

In front of the visceral compartment is a small muscular compartment containing the infra-hyoid muscles; anterior to it again, in the region of the supra-sternal notch, is the small supra-sternal compartment, containing the lower part of the

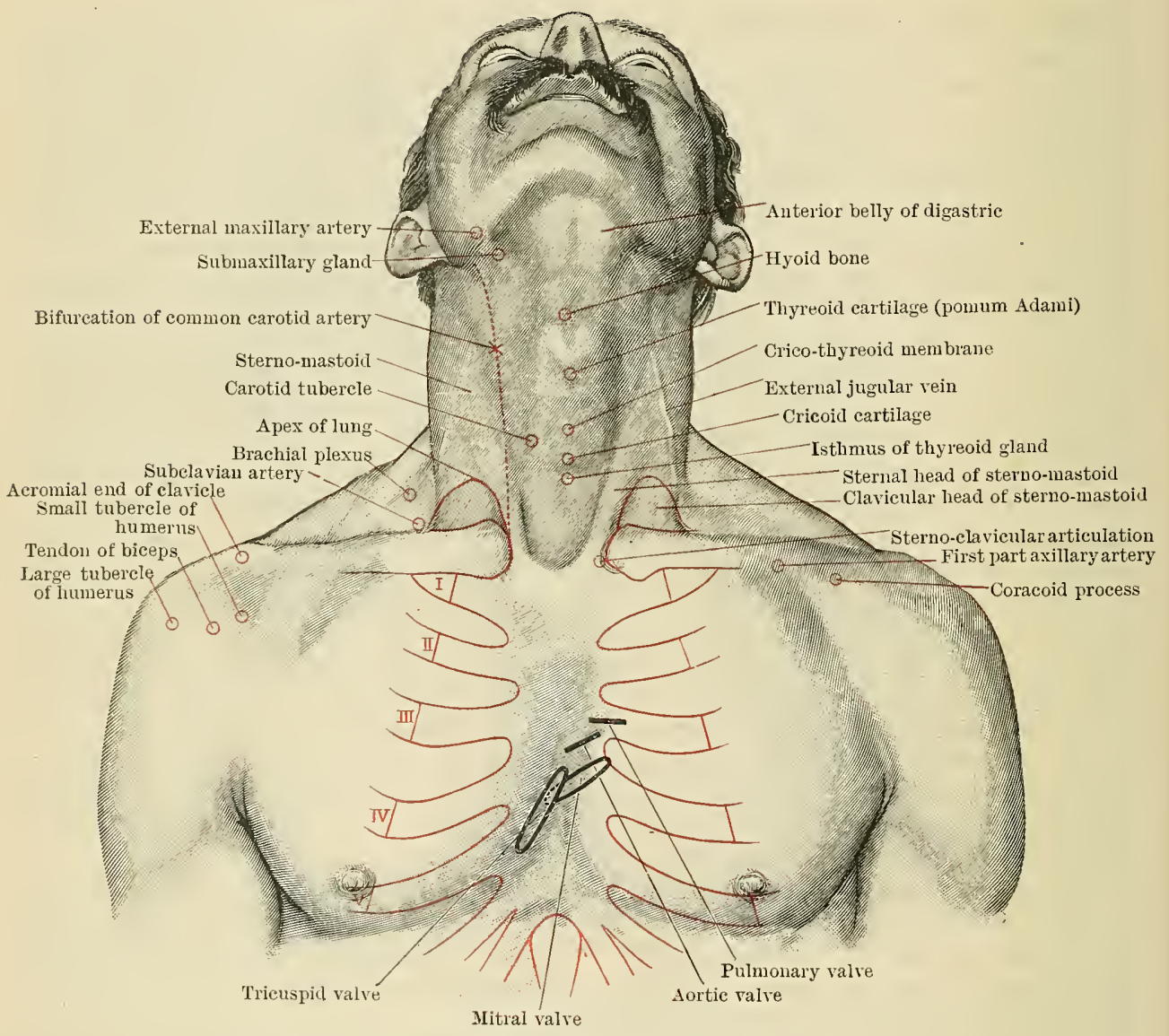

Fic. 1086.-Anterior Aspect of Neck and Shoulders.

anterior jugular veins, along with their transverse communicating branch, a little fat, and one or two lymph glands.

The vascular compartment contains the carotid vessels, and the internal jugular vein, and the following nerves, viz.: the vagus, the first part of the hypoglossal, the descendens hypoglossi, and the superior part of the accessory. These structures are enveloped in a thin fascial tube, the carotid sheath. The sheath is surrounded by cellular tissue in which are embedded the carotid chain of lymph glands; normally they may be readily separated from the sheath of the internal jugular vein, to which, however, they become adherent when inflamed. A few small lymph glands lie within the sheath. The cervical sympathetic trunk and the inferior thyreoid artery lie in the cellular space between the posterior wall of the carotid sheath and the prevertebral fascia; they can be reached through an incision along the posterior border of the sterno-mastoid muscle, this muscle, along 
with the carotid sheath and its contents, being retracted well forwards. In approaching the trunk of the inferior thyreoid artery from the front the sterno-mastoid and carotid sheath are retracted backwards and the dissection is continued through the cellular interval between it and the sheath (outer capsule) of the thyreoid gland, which is formed by the splitting of the pretracheal fascia.

A glandular abscess in this compartment usually points upon the surface, adhesions being formed, first, between the gland and the fascia, and, subsequently, between the latter and the cutaneous structures. In diffuse suppurative cellulitis of this compartment the pus burrows towards the root of the neck, and may reach either the mediastinum or the axilla.

Medial Line of the Neck.-The body of the hyoid bone divides the median plane of the neck into supra- and infra-hyoid portions. Above the hyoid bone is the submental triangle, with its apex at the inferior border of the symphysis menti and its

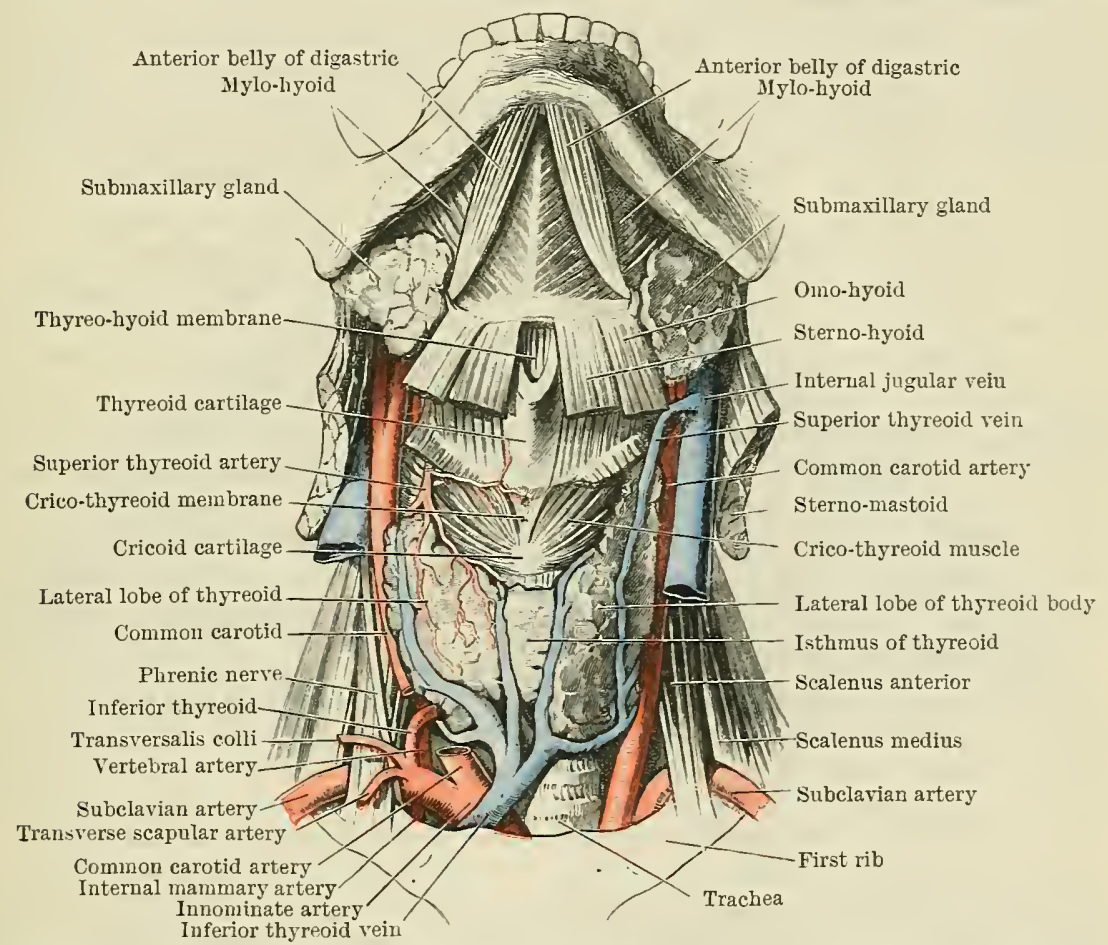

Fig. 1087.-Dissection of the Front of the Neck. The lower portions of the sterno-mastoil muscles have been remored, and the lower part of the right common carotid artery cut away to show the deeper parts (from Cunningham).

sides formed by the anterior bellies of the digastrics. In the floor of the triangle are the anterior portions of the mylo-hyoid muscles, separated by the median raphe (Fig. 1087). The most important structures in the triangle are the submental lymph glands, which can usually be felt a little above the body of the hyoid bone. In children they are a frequent seat of abscess secondary to impetigo of the lower lip and chin. About $1 \mathrm{in}$. below the hyoid bone is the pomum Adami, more prominent in the male than in the female. On either side of the pomum Adami are the alæ of the thyreoid cartilage, while between the latter and the hyoid bone is the thyreo-hyoid membrane. In the operation of sub-hyoid pharyngotomy the epiglottis and the superior opening of the larynx are reached by passing through the anterior wall of the pharynx at the level of the thyreo-hyoid membrane. The structures divided from without medially are: the integuments, the sternohyoid, omo-hyoid, and thyreo-hyoid muscles, the medial portion of the thyreo-hyoid membrane, along with a layer of fat between it and the lower part of the epiglottis, and, finally, the glosso-epiglottidean ligament and fold of mucous membrane. The incision must not be extended too far on either side of the 
median plane for fear of wounding the superior laryngeal vessels and nerve which pierce the thin lateral portions of the thyreo-hyoid membrane.

The wound in suicidal cut-throat is generally at this level. The more important structures which are usually divided are: more or less of the left stemo-mastoid muscle, the superior thyreoid vessels, the thyreo-hyoid membrane, the base of the epiglottis, and, less frequently, the carotid vessels, the internal jugular vein, and the superior laryngeal nerve. When the wound is above the hyoid bone, the lingual and external maxillary vessels and the muscles of the tongue are the more important structures injured.

At the level of the middle of the anterior border of the thyreoid cartilage is the rima glottidis.

In the operation of thyreotomy care is taken to divide the thyreoid cartilage exactly in the median plane so as to avoid injuring the vocal folds.

A little more than an inch below the prominentia laryngea is the anterior arch of the cricoid cartilage, which may be readily felt, and, when the neck is extended, often seen; it lies a little below a point midway between the lower margin of the chin and the superior border of the sternum. Above the cricoid is the crico-thyreoid membrane; in the operation of laryngotomy only the middle portion of the membrane is divided, in order to avoid injury to the crico-thyreoid muscles. The small crico-thyreoid branch of the superior thyreoid artery lies close to the inferior border of the thyreoid cartilage. Below the cricoid cartilage is the trachea, which recedes as it descends, so that it lies $1 \frac{1}{2}$ in. from the surface at the level of the superior border of the sternum. The isthmus of the thyreoid gland lies in front of the second, third, and fourth rings of the trachea (Fig. 1087); not infrequently, however, it reaches up to the cricoid. Immediately in front of the trachea, below the isthmus of the thyreoid, is the pretracheal fat, containing one or two lymph glands and the inferior thyreoid veins, each represented by one or more branches which converge as they descend. The pretracheal lymph glands receive afferent vessels from the larynx and thyreoid body, while their efferent vessels open into the inferior carotid glands. In the adult the innominate artery crosses the front of the trachea at the level of the superior border of the sternum; in the child, however, it not infrequently crosses half an inch higher, a relation which must be remembered in performing the operation of low tracheotomy.

In the operation of high tracheotomy the upper three rings of the trachea are divided. The incision, which should be medial, divides the integuments, the tributaries of the anterior jugular veins, the general envelope of deep cervical fascia, and, after passing between the depressor muscles of the hyoid bone, the pretracheal fascia, which descends from the cricoid to enclose the isthmus of the thyreoid gland. By dividing this fascia transversely below the cricoid, the isthmus may be pulled downwards and the upper rings of the trachea exposed. In some cases it is necessary either to divide the isthmus or to extend the incision upwards through the cricoid cartilage. In opening the trachea, the edge of the knife should be directed upwards so as to avoid injuring the vessels at the upper border of the isthmus. The anterior jugular veins are in danger of being wounded if the skin incision is not strictly medial. In low tracheotomy the trachea below the isthmus is opened; it is a more troublesome operation on account of the depth of the trachea and the presence in front of it of the large inferior thyreoid veins and of the transverse anterior jugular vein. In children the difficulty is increased by the higher position of the innominate artery and left innominate vein, by the presence of the thymus gland, and by the shortness of the neck.

Thyreoid Gland.-The thyreoid gland, which is moulded on and adherent to the anterior and lateral aspects of the upper part of the trachea and to the lower and posterior portions of the alæ of the thyreoid cartilage, is covered by the infrahyoid muscles and overlapped by the sterno-mastoid. The posterior borders of the lateral lobes come in contact with the osophagus and lower part of the pharynx, while posteriorly they partially overlap the carotid sheath.

The thyreoid gland, like the prostate, possesses in addition to its own proper capsule an outer capsule or sheath derived from the cervical fascia. The capsule proper, like that of the liver, is inseparably connected with the gland. The sheath, on the other hand, is formed by the middle (pretracheal) layer of deep cervical fascia, which splits to enclose the thyreoid. - Between the true capsule and the 
sheath is a loose cellular interval which is crossed by branches of the thyreoid arteries and veins on their way to and from the gland. The arteries traverse the space directly, while many of the veins (accessory thyreoid veins of Kocher) ramify for some distance on the surface of the capsule before they pierce the sheath.

In excising one of the lateral lobes, the surgeon reaches the gland through the median plane in the interval between the infra-hyoid muscles. If, in order to obtain more room, it is found necessary to divide the depressor muscles on one or both sides, this should be done towards their upper attachments, as their nerves of supply, derived from the ansa hypoglossi, enter the muscles nearer their lower attachments. By freely dividing the middle layer of cervical fascia where it forms the anterior portion of the sheath of the thyreoid, the gland can be brought out of the wound and so mobilised that the main vessels may be brought into view and ligatured.

The superior thyreoid vessels are brought into view by freeing and drawing forwards the superior pole of the gland. As the inferior thyreoid arteries arch medially behind the carotid artery they lie in the cellular interval between the carotid sheath and the pretracheal fascia. Immediately after piercing the posterior part of the sheath of the gland the vessel divides into two or more branches which pierce the capsule to enter its substance. The recurrent nerve, which also

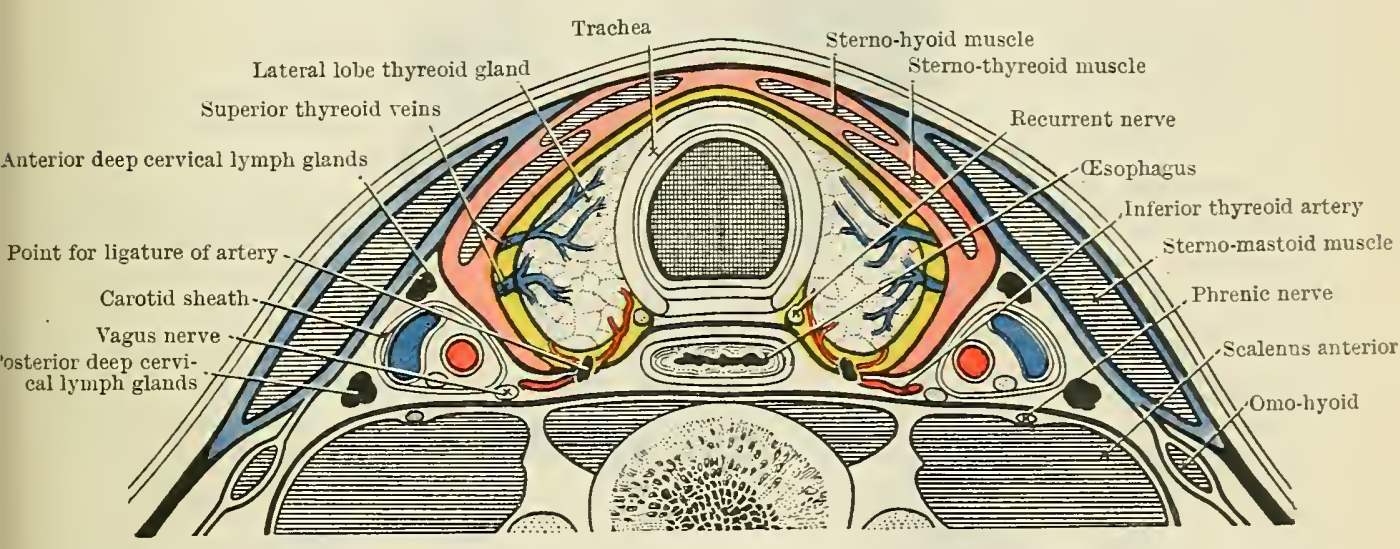

Fig. 1088.-A Diagram of the Relations of the Cervical Fascia to the Thyreoid Glaxd.

Blue = deep cervical fascia (sterno-mastoid layer). Red=outer capsule of thyreoid gland (pretracheal layer of cervical fascia). Yellow=capsule proper of the thyreoid gland.

lies between the posterior part of the sheath and the postero-medial aspect of the lateral lobe, ascends either posterior to the inferior thyreoid artery or between its main divisions.

The parathyreoids can generally be distinguished from the thyreoid tissue itself; and from the lymph glands, by their grayish-yellow colour as well as by their smooth and shining surfaces. The superior parathyreoids are found usually, one on each side, at the posterior borders of the lateral lobes, about opposite the cricoid cartilage. They are in close relation to the pharyngo-cesophageal junction, from which they are separated by the posterior part of the sheath of the thyreoid gland. The inferior parathyreoid glands, which are supplied by a small vessel from one of the branches of the inferior thyreoid artery, occupy the same cellular interval at the posterior aspect of the inferior pole of the gland, a little lateral to the inferior thyreoid artery and the recurrent nerve. It is this close relationship of the recurrent nerve and the inferior parathyreoid glands to the posterior aspect of the lateral lobes of the thyreoid gland which has induced surgeons, in excising one of the lobes, to make the resection intracapsular at the posterior aspect of the gland, the posterior part of the capsule along with a layer of thyreoid substance being left behind, attached to the trachea. In this way injury to the recurrent nerve and inferior parathyreoid gland is avoided, as the branches of the inferior thyreoid artery are ligatured after they have pierced the capsule. De Quervain, on the other hand, prefers to ligature the main trunk of the inferior thyreoid 
artery before it pierces the sheath, that is to say, as it lies in the cellular tissue between the carotid sheath and the prevertebral fascia. In order to reach the vessel in this situation the surgeon should keep outside the sheath of the thyreoid gland, between it and the carotid sheath which is retracted laterally along with the infra-hyoid muscles. When the inferior thyreoid artery has been ligatured the posterior branch of the superior thyreoid artery furnishes a sufficient blood-supply to the inferior parathyreoid gland.

Triangles of the Neck. - The lateral aspect of the neck may be divided into an anterior and a posterior triangle by the sterno-mastoid muscle; the former is further subdivided into digastric, carotid, and muscular triangles by the digastric and omo-hyoid muscles. The posterior triangle is subdivided into occipital and subclavian portions by the posterior belly of the omo-hyoid.

The sterno-mastoid muscle forms one of the most important superficial land-

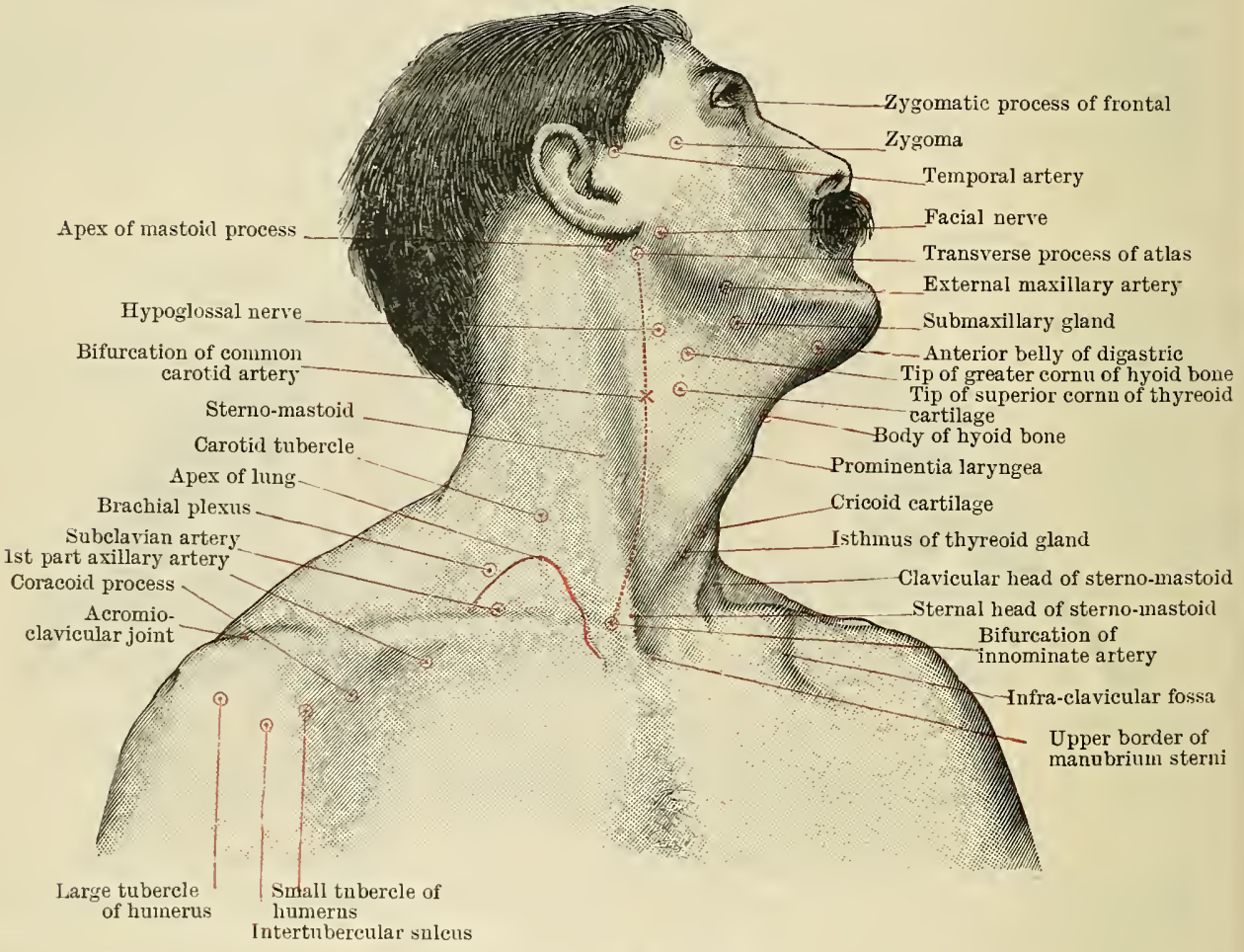

FIG. 1089. - SIDE OF THE NECK.

marks of the neck. The anterior border of the muscle, the more distinct of the two, may be felt along its whole extent. Between the prominent sternal origin and the broad ribbon-like clavicular origin is a slight triangular depression which overlies the inferior part of the internal jugular vein.

By dividing the cervical fascia along the anterior and posterior borders of the muscle the surgeon is able to retract it backwards and forwards so as to obtain free access to the structures deep to it. If the posterior fibres of the muscle are divided at their clavicular and mastoid attachments the muscle can be still more freely mobilised. In dividing the fascia along its posterior border the cutaneous branches of the cervical plexus are generally divided, but care is taken not to injure the accessory nerve. Should it be found necessary to remove the upper third or more of the muscle, the divided end is stitched to the levator scapulie or to the scalenus medius, according to the amount resected. In dividing the muscle completely across at the lower part of the neck, as is done, for example, in congenital wry-neck, the close relation of the anterior and external jugular veins to its corresponding borders must be kept in mind. After division of the muscle, 
the lower part of the anterior belly of the omo-hyoid is seen, lying upon that part of the carotid sheath which overlies the internal jugular vein.

Digastric Triangle. - This triangle is subdivided into an anterior or submaxillary portion and a posterior or parotid portion by a process of the deep cervical fascia, known as the stylo-mandibular ligament. In the anterior portion is the submaxillary gland, which is overlapped by the posterior half of the inferior border of the mandible and reaches down to the greater cornu of the hyoid bone. The anterior facial vein passes downwards and backwards superficial to the gland, while the external maxillary artery, embedded in its deep surface, arches upwards under cover of the angle of the mandible, where it approaches the tonsil, being separated from it, however, by the superior constrictor of the pharynx. The lingual artery may be ligatured in the digastric triangle, where it lies behind the hyoglossus a little above the greater cornu of the hyoid bone; the superficial guides to the vessel are the inferior border of the submaxillary gland, and the hypoglossal nerve and lingual vein, which lie upon the hyoglossus, the latter being recognised by the vertical direction of its fibres. The floor of the digastric triangle is formed, from before backwards, by the mylo-hyoid, hyoglossus, and superior constrictor of the pharynx. The lymph glands of this space receive their lymph from the face, lips, teeth and gums, tongue, and floor of the mouth; hence the frequency with which they become the seat of abscess formation and malignant enlargement. To palpate them the surgeon stands behind the patient and thrusts the fingers well upwards under cover of the mandible, the patient's chin being a little depressed so as to relax the cervical fascia.

Carotid Triangle.-The central landmark of this triangle is the greater cornu of the hyoid bone, the tip of which, when the fascia is relaxed, may be readily felt, immediately in front of the anterior border of the sterno-mastoid, at a point corresponding to the centre of a line drawn from the tip of the mastoid process to the prominentia laryngea. The deep cervical fascia holds the superior part of the sterno-mastoid forwards towards the angle of the mandible, so that, with the fascia undivided, the anterior border of the sterno-mastoid overlaps the internal jugular vein and the bifurcation of the common carotid artery.

The course of the carotid vessels is indicated upon the surface by a line extending from the superior end of the sterno-clavicular articulation to a point midway between the angle of the mandible and the tip of the mastoid process; a point upon this line, at the level of the superior border of the thyreoid cartilage, overlies the bifurcation of the common carotid. The anterior belly of the omo-hyoid crosses the common carotid at the level of the cricoid cartilage. The pulsations of the carotid vessels may be felt in the hollow between the larynx and the anterior border of the sterno-mastoid. In the carotid triangle the external carotid lies medial and anterior to the interual carotid. The seat of election for ligation of the external carotid is between its superior thyreoid and lingual branches, a finger's-breadth below the tip of the greater cornu of the hyoid bone; the difficulty in the operation is due to the plexus of veins (formed by the common facial, lingual, and superior thyreoid veins) which overiies the artery. The lingual and external maxillary arteries frequently arise from a common trunk which must not be mistaken for the external carotid. The superior thyreoid artery arises opposite the upper cornu of the thyreoid cartilage, which may be distinctly felt 1 in. below the tip of the greater cornu of the hyoid bone. The vessel and its companion vein are common sources of hæmorrhage in cut-throat. The guide to the lingual artery, in the carotid triangle, is the tip of the great cornu of the hyoid bone, above which it forms an arch, crossed by the hypoglossal nerve. The vessel enters the digastric triangle by passing beneath the tendons of the stylo-hyoid and digastric muscles. When ligature of the artery is called for, it is usually necessary to secure the vessel as it lies in the carotid triangle so that the ligature may be applied on the proximal side of its dorsalis linguæ branch.

From a surgical point of view the internal jugular vein is the most important structure in the anterior triangle. In the carotid division of the triangle it overlaps the carotid vessels, and its sheath lies close beneath the general envelope of deep cervical fascia from which it is separated by a loose cellular interval. About 
the level of the hjoid bone it receives the large common facial vein, while at an inferior level it receives the superior and middle thyreoid veins which are often greatly enlarged in goitres.

By the term deep cervical glands is included a broad chain of lymph glands which is closely related to the internal jugular vein, and which stretches from the transverse process of the atlas to the root of the neck. The chain is in reality made up of subsidiary glandular groups, each of which receives its lymph vessels from fairly well-defined areas. In the first place, the chain may be divided into an upper and a lower portion, the former situated above the bifurcation of the common carotid artery, the latter below it. Each of these divisions is again subdivided into a medial and a lateral chain.

Of the four groups, the superior anterior is the most important, as it is there that disease first manifests itself in the vast majority of cases. The reason for this predilection is the fact that this group of glands, in addition to receiving efferent lymph vessels from the glands of the circular chain, receives also lynph vessels directly from the nasal part of the pharynx, including the palatine and pharyngeal tonsils. These latter structures are now known to provide the chief portals of entrance through which the tubercle bacilli reach the efferent lymph vessels. Wood, of Philadelphia, has succeeded in tracing the lymph vessels from the tonsils directly into one of the glands of this group, namely, that situated a little below the angle of the mandible, under cover of the anterior border of the sterno-mastoid immediately below the posterior belly of the digastric. The relations of the deep surface of this gland are important. It lies upon the anterior surface of the internal jugular, in the angle between it and the common facial vein. It plays such an important rôle in tuberculous adenitis that it is now termed by surgeons the tonsillar lymph gland. In the great majority of cases it is the first gland in the neck to show signs of tuberculous enlargement. When the superior medial deep cervical glands become enlarged they form a swelling which projects from beneath the sterno-mastoid forwards into the carotid division of the anterior triangle. The mass soon becomes adherent to the general envelope of deep cervical fascia, and, if the disease is allowed to run its course, the latter becomes perforated, with the result that a subcutaneous tuberculous abscess soon develops. The glands are also liable to become adherent to the digastric muscle, and to the stylo-mandibular ligament, which separates them from the submaxillary lymph glands. The most important adhesions, however, from the surgeon's point of view, are to the common facial and internal jugular veins.

The superior lateral group of deep cervical glands lies postero-lateral to the internal jugular upon the origins of the splenius and the levator scapulæ muscles. They are smaller in size than the medial group, but when enlarged they may form a swelling which projects across the posterior triangle as far as the trapezius. They are embedded in a quantity of fibro-fatty tissue which supports the accessory nerve and the cervical plexus. Wood has shown that the lymph vessels from the pharyngeal tonsil, after piercing the posterior wall of the pharynx, pass downwards and outwards behind the sheath of the great vessels to enter the glands situated deeply, just below the tip of the mastoid process.

The inferior medial group forms a somewhat narrow chain, which is continued down the anterior aspect of the internal jugular as far as its junction with the subclavian. Above the bifurcation of the common carotid artery this chain is continuous with the superior medial jugular group, while, below, it comes into relation with the superior mediastinal glands.

The inferior lateral group of deep cervical glands is continuous above with the superior lateral group. Like the superior lateral group, they lie altogether behind the internal jugular vein, upon the levator scapulæ, the scalenus medius, and the brachial plexus. The most inferior glands of the group, viz., the supraclavicular, are subdivided into a superficial and a deep cluster by the omo-hyoid muscle and the middle layer of deep cervical fascia. They receive their afferent vessels from the subclavicular group of axillary glands.

The hypoglossal nerve is deeply placed in the carotid triangle, being overlapped by the internal jugular vein and the inferior border of the posterior belly of the 
digastric muscle. It crosses forwards in front of the occipital and internal and external earotid arteries immediately below the origin of the superior sterno-mastoid branch of the first-mentioned vessel. The vagus nerve descends vertically within the carotid sheath, behind and between the carotid vessels and the internal jugular vein; care must be taken not to include it when ligaturing the common carotid or internal jugular. Surgically, the accessory is the most important nerve in the anterior triangle; it enters the substance of the sterno-mastoid muscle $1 \frac{1}{2}$ in. below the tip of the mastoid process. A portion of the nerve is resected in the treatment of spasmodic wry-neck, and it is always exposed in the removal of the carotid group of deep cervical glands. The course of the nerve may be mapped out upon the surface by drawing a line from a point midway between the tip of the mastoid process and the angle of the mandible to a little above the middle of the posterior border of the sterno-mastoid muscle, and thence across the posterior triangle to the anterior border of the trapezius, beneath which it passes at the level of the seventh cervical spine. The deeper guides to the nerve are the posterior belly of the digastric, and the internal jugular vein, which it crosses very obliquely from above downwards and backwards, below and in front of the transverse process of the atlas (felt as a distinct bony landmark midway between the tip of the mastoid and the angle of the mandible). The cervical sympathetic lies in the posterior wall of the vascular compartment of the neck, and may be reached by an incision along the posterior border of the sterno-mastoid: the anterior surfaces of the roots of the transverse processes of the vertebræ are the deep guides to the nerve.

The cervical plexus, which lies behind the superior half of the sterno-mastoid upon the levator scapulæ and scalenus medius muscles, may be exposed through an incision along the posterior border of the upper half of the sterno-mastoid muscle. The phrenic nerve, the most important branch of the cervical plexus, arises one inch above the carotid tubercle and descends almost vertically upon the scalen us anterior; it is overlapped by the lateral margin of the internal jugular vein. Although frequently exposed by the surgeon in removing the lower carotid group of deep cervical glands, the phrenic nerve is protected from injury by being covered by the prevertebral fascia.

The muscular or lower carotid triangle is an important triangular intermuscular space bounded by the anterior border of the sterno-mastoid, the anterior belly of the omo-hyoid, and the sterno-hyoid. Behind this space, and forming, as it were, its floor, is a still deeper space bounded by the longus colli and scalenus anterior muscles. It may with advantage be termed the prevertebral intermuscular triangle, or, from the fact that it contains the vertebral artery, it may be termed the vertebral arterial triangle. At its apex is the prominent anterior tubercle of the transverse process of the sixth cervical vertebra. By making an incision along the anterior border of the left sterno-mastoid muscle, and passing through this triangle, the surgeon reaches, in order from before backwards, the internal jugular vein, the common carotid artery, the vagus, the thoracic duct, the middle cervical ganglion of the sympathetic, the inferior thyreoid artery, the vertebral vessels, the recurrent nerve, and the cesophagus. The most important bony landmark in this triangle is the prominent anterior tubercle of the transverse process of the sixth cervical vertebra. The common carotid artery may be compressed against this tubercle, which is therefore termed the "carotid tubercle." It is the most important guide to the vertebral artery, which enters the foramen in the transverse process of the sixth cervical vertebra.

The cervical portion of the œsophagus, which begins at the level of the cricoid cartilage, descends behind, and a little to the left of, the trachea. To expose it, the surgeon, after passing through the above-mentioned muscular triangle, divides the pretracheal fascia, and passez between the trachea and the carotid sheath domn to the longus colli muscle medial to the inferior thyreoid artery and vertebral vessels. The lower pole of the lateral lobe of the thyreoid gland is retracted medially along with the trachea. The œsophagus lies in the loose cellular tissue in front of the prevertebral fascia; hence it can be mobilised sufficiently to admit of its being brought to the surface. The oesophagus may also be exposed through an incision in the median plane, the trachea, which is freely movable, being displaced to 
the right side. In opening the oesophagus care must be taken not to injure the recurrent nerve, which ascends in the groove between it and the trachea, and also that the loose submucous cellular interval must not be mistaken for the lumen of the tube. The recurrent nerve must be avoided also in operations connected with the thyreoid gland; it is most liable to be injured during the application of a ligature to the inferior thyreoid artery, which arches medially in front of the nerve to reach the posterior surface of the gland.

\section{The Thoracic Duct.}

The thoracic duct, after entering the root of the neck between the oesophagus and the pleura, ascends to about an inch above the clavicle. At this level it arches laterally behind the lower part of the carotid sheath in front of the vertebral vessels. Great care must therefore be taken not to injure the duct in removing the lymph glands which lie in the loose cellular tissue behind the inferior part of the internal jugular vein, between it and the vertebral vein at the medial border of the scalenus anterior. In addition to these glands a few small lymph glands lie adjacent to the lateral aspects of the cervical portions of the trachea and oesophagus. They receive their afferent vessels from the larynx, trachea, œsophagus, and thyreoid gland.

\section{Posterior Triangle.}

The roof of the posterior triangle is formed by the general envelope of deep cervical fascia, while the fascia which covers the muscles forming its floor, as well as that covering the brachial nerve trunks and the subclavian artery, is a lateral continuation of the prevertebral fascia. The lateral deep cervical and supraclavicular lymph glands are embedded in the cellular tissue between these two layers of fascia. In removing these glands, every endeavour should be made to preserve the motor nerves. The accessory nerve, after entering the posterior triangle at the junction of the superior and middle thirds of the posterior border of the sterno-mastoid muscle, crosses the triangle superficially, and parallel to the levator scapulæ. It leaves the triangle by passing under cover of the anterior border of the trapezius at the junction of its middle and inferior thirds. The lesser occipital nerve curves round the accessory from below upwards superficially just at the posterior border of the muscle; it furnishes, therefore, a useful guide to the position of this important motor nerve.

The dorsalis scapulæ nerve (O.T. nerve to the rhomboids) crosses the triangle, inferior to the accessory, and enters the septum between the levator scapulæ and scalenus medius muscles.

The supra-scapular nerve is seen arising from the lateral edge of the upper trunk of the brachial plexus, a little above the posterior belly of the omo-hyoid muscle. The loops of the cervical plexus lie under cover of the upper part of the sterno-mastoid muscle, between it and the origins of the levator scapulæ and the upper part of the scalenus medius muscles.

The posterior belly of the omo-hyoid, which forms the superior boundary of the subclavian division of the posterior triangle, passes beneath the posterior border of the sterno-mastoid at a point about one inch above the clavicle. The external jugular vein, usually visible through the skin, runs in a line from the angle of the jaw to the middle of the clavicle; it is the vessel which is generally opened to relieve the right side of the heart in asphyxia. The lumen of the vein is kept patent where it pierces the fascia of the subclavian triangle; hence a wound of the vein in this situation is liable to be followed by the suction of air into the circulation during inspiration. The third part of the subclavian artery can be compressed against the.first rib by pressing downwards and backwards, immediately above the clavicle, a little behind the posterior border of the sterno-mastoid muscle. To map out the course of the subclavian artery in the neck, draw a line, convex upwards, from the superior border of the sterno-clavicular articulation to the middle of the clavicle, the highest part of the arch to reach from $\frac{1}{2}$ to 1 in. above the bone. To ligature the vessel in the third part of its course, an angular incision is made along 
the middle of the superior border of the clavicle and the inferior part of the posterior border of the sterno-mastoid muscle. The most important guides to the vessel are the posterior belly of the omo-hyoid, the lateral border of the scalenus anterior, and the scalene tubercle of the first rib. The close relation of the vessel to the lowest trunk of the brachial plexus and to the cervical pleura must be kept in mind. In the rare instances in which a cervical rib is present the subclavian artery lies either in front of it, or arches above it, according to the degree of development of the rib. The subclavian vein lies below, and anterior to, the artery, altogether under cover of the clavicle.

Entering the posterior triangle from behind the lateral border of the scalenus anterior are the trunks of the brachial plexus. They lie upon the scalenus medius, and can be felt through the skin immediately above and behind the third part of the subclavian artery. The anterior ramus of the fifth cervical nerve supplies the rhomboids, the abductors and lateral rotators of the arm, and the flexors and supinators of the forearm; that of the sixth the serratus, the adductors and medial rotators of the arm, and the extensors and pronators of the forearm; that of the seventh the flexors and extensors of the wrist; that of the eighth the flexors and extensors of the fingers; that of the first thoracic all the small muscles of the hand. The carotid tubercle lies between the anterior rami of the sixth and seventh cervical nerves. The fifth and sixth cervical nerves are those which suffer most when the plexus is injured by forcible depression of the shoulder while the head is bent to the opposite side, such as occurs, for instance, in the "Obstetrical Paralyses" of Duchenne.

To expose the trunks of the brachial plexus an incision is made from the junction of the middle and inferior thirds of the posterior border of the sternomastoid downwards and laterally to the junction of the lateral and intermediate thirds of the clavicle.

The relation of the lowest trunk of the brachial plexus to the first rib is important in relation to those forms of brachial neuritis in which the motor and sensory symptoms indicate pressure on the anterior ramus of the first thoracic nerve. Wood Jones has shown that the sulcus for the subclavian artery on the superior surface of the first rib frequently lodges the lowest trunk of the brachial plexus as well as the artery, and that the more the first thoracic nerve contributed to the plexus the deeper is the sulcus. In two cases the writer has cured the neuralgia and the partial paralysis of the intrinsic muscles of the hand supplied by the first thoracic nerve by removing the portion of the first rib containing the "sulcus nervi brachialis." The symptoms were due to the portion of the first thoracic nerve which goes to join the brachial plexus being stretched and pressed upon by the first rib as it crosses its inner edge to join the eighth cervical nerve. Although similar symptoms may be produced by the first thoracic nerve being stretched across a cervical rib, the surgeon must not expect to find this anomaly in all cases; and when a skiagram has been obtained, care must be taken not to mistake a well-developed posterior tubercle of the transverse process of the seventh cervical vertebra for a foreshortened view of a rudimentary cervical rib.

In the median line of the neck posteriorly is the nuchal furrow, at the bottom of which are the cervical spines and the ligamentum nuchæ. At the superior part of the furrow, about two inches below the external occipital protuberance, is the large spine of the epistropheus, which can be distinctly felt; a line drawn from it laterally and slightly upwards to the transverse process of the atlas corresponds to the position of the inferior oblique muscle and, therefore, to the inferior margin of the sub-occipital triangle. The course of the deep part of the greater occipital nerve may be mapped out byidrawing a line from the centre of the above-mentioned line to a point one inch lateral to the external occipital protuberance. In the floor of the suboccipital triangle is the posterior arch of the atlas upon which the vertebral artery lies.

\section{THE THORAX.}

For the convenience of topographical description, clinicians, by the use of vertical and transverse lines, have arbitrarily divided the surface of the chest into 


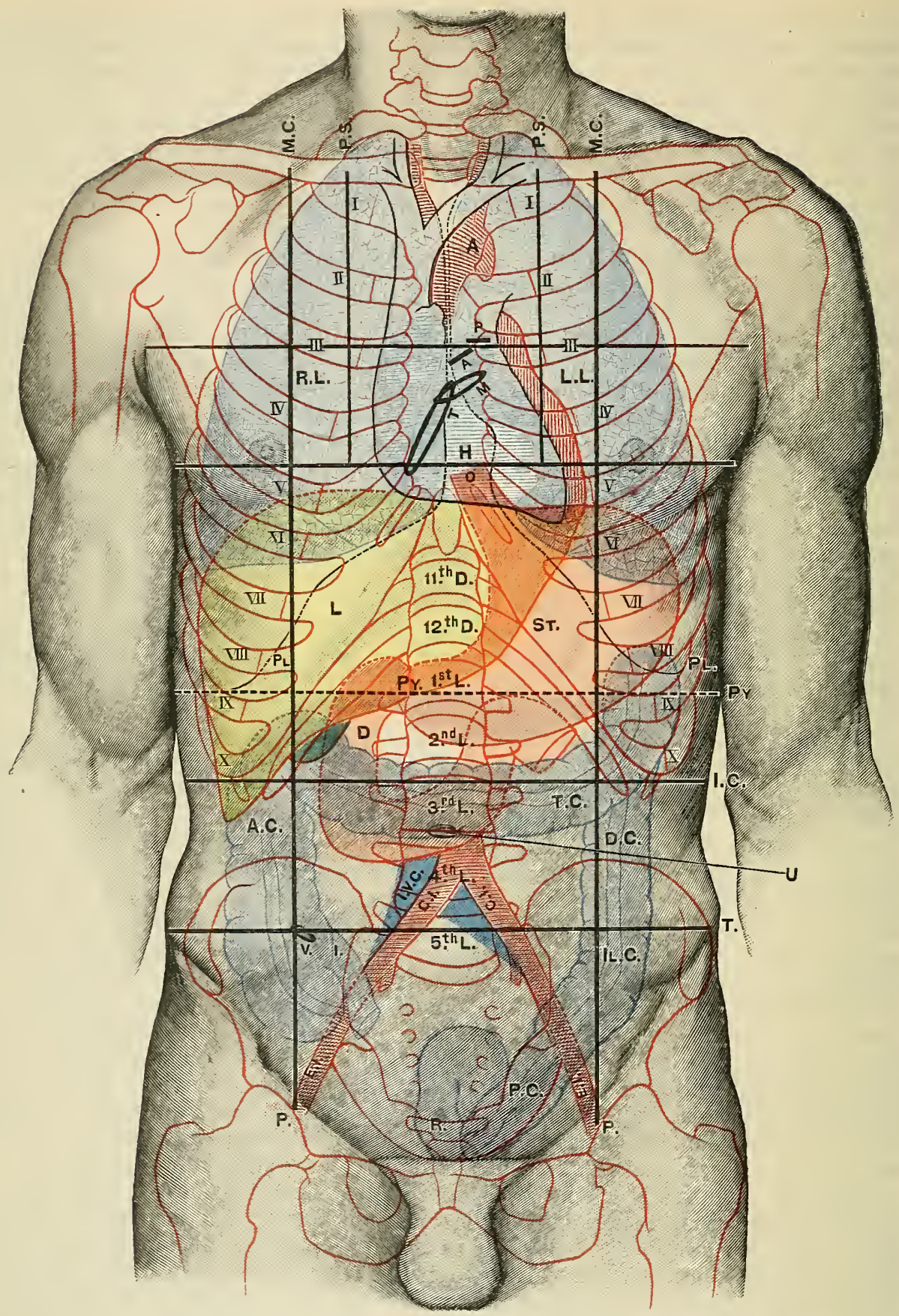

Fig. 1090. - ANterior Aspect of Trunk, showing Surface Topography of Viscera

M.C. Mid-clavicular line.

P.S. Para-sternal line.

P. InguinaI vertical line.

I. C. InfracostaI line.

T. Intertubercular line.

Py. Transpyloric line of Addison.

A. Aorta.

H. Heart.

P. Pulmonary orifice.

A. Aortic orifice.

M. Mitral orifice.
T. Tricuspid orifice.

R.L. Right lung.

L.L. Left lung.

Pl. Pleura,

L. Liver.

O. Esophagus.

St. Stomach.

Py. Pylorus.

D. Duodenum

I. Ileum.'

V. Valve of the colon.
A.C. Ascending colon.

T.C. Transverse colon.

D.C. Descending colou.

II. C. Iliac colon.

P.C. Pelvic colon.

R. Rectum.

C.I. Common iliac artery

E.I. External iliac artery.

I.V.C. Inferior vena cava.

U. Umbilicus. 
certain definite regions or areas. The vertical lines are: the mid-sternal, the lateral sternal, the para-sternal, the mammary or mid-clavicular, the anterior, mid, and posterior axillary, and the scapular. The position of the mid-and lateral sternal lines is sufficiently indicated by their names.

The mammary, better termed the mid-clavicular, is drawn vertically downwards from the centre of the clavicle, or, what comes to practically the same thing, from a point midway between the centre of the jugular notch and the tip of the acromion. In the male this line usually lies $\frac{1}{2}$ to $\frac{3}{4}$ in. medial to the centre of the nipple, which is usually placed over the fourth interspace, or fifth rib, four inches from the median plane. In the child the nipple may be as high as the inferior border of the third rib. In the female the position of the nipple is so variable that it is of no topographical value. In a well-proportioned subject, the mid-clavicular line, if prolonged downwards, will be found to be continuous with the vertical or lateral inguinal line, which crosses the costal margin at the tip of the ninth costal cartilage.

The para-sternal line, drawn midway between the lateral sternal and midclavicular, crosses the costal margin opposite the tip of the eighth costal cartilage.

The anterior, the mid, and the posterior axillary lines are drawn downwards from the anterior fold, the apex, and the posterior fold of the axilla, respectively.

The scapular line is drawn perpendicularly through the inferior angle of the scapula.

Of the two transverse lines, the superior, which separates the infra-clavicular and supra-sternal regions from the mammary and infra-sternal regions, is drawn at the level of the third chondro-sternal articulation; the inferior, which separates the mammary and infra-mammary regions, is drawn at the level of the sixth chondrosternal articulation.

The lateral area of the chest is divided into a superior, or axillary, and an inferior or infra-axillary region, by a horizontal line drawn at the level of the sixth rib.

In muscular subjects there is a well-marked median furrow, the sternal furrow, between the sternal origins of the pectoralis major muscles. The medial part of the inferior border of each of these muscles forms a curved prominence which, overlying the fifth rib, corresponds to the junction of the mammary and infra-mammary regions. Below this prominence is the infra-mammary region, which forms a somewhat flat surface, corresponding to the upper part of the rectus muscle. In the axillary and infra-axillary regions are the prominences caused by the digitations of origin of the serratus anterior, the first to appear below the pectoralis major being that which springs from the fifth rib.

The superior border of the sternum lies in the same horizontal plane as the inferior border of the body of the second thoracic vertebra, the distance between the two being about two inches. The junction of the manubrium and the body of the sternum forms a slight prominence or angle, known as the angulus sterni (Ludovici), which, although not usually visible, may always be felt. The angulus lies in the same plane as the body of the fifth thoracic vertebra.

The xiphi-sternal junction corresponds to the fibro-cartilage between the ninth and tenth thoracic vertebræ. Immediately inferior to the xiphi-sternal articulation is the infra-sternal notch, formed by the junction of the seventh costal cartilages with the sternum. Inferior to the notch is the epigastric fossa or triangle, bounded laterally by the seventh costal cartilages. The apex of the triangle forms an angle which varies considerably according to the shape of the chest, the average being about $70^{\circ}$. Not infrequently the eighth costal cartilage articulates with the sternum.

Fracture of the sternum is rare, and generally occurs at or close to the junction of the manubrium and the body; it may occur either from direct violence, or indirectly along with fracture of the rertebral column. Unlike that of the ribs, the periosteum covering the sternum is firmly adherent to the bone.

The ribs, which in well-nourished subjects cause no surface prominences, are readily visible in thin persons; in the obese they are very difficult to feel. In counting the ribs from the front, the second may always be identified by its relation to the angulus sterni. The first rib is to a large extent under cover of the clavicle. The inferior border of the pectoralis major and the first visible digitation of the 
serratus anterior afford reliable guides to the fifth rib. The infra-sternal notch is the guide to the medial end of the seventh costal cartilage. The second and third costal cartilages are almost horizontal; below this the cartilages ascend with increasing obliquity, that of the sixth being the first to present a distinct angle. The anterior end of the second intercostal space is the widest, while those of the fifth and sixth are very narrow.

The costo-chondral junctions may be indicated on the surface by a line drawn from the superior end of the para-sternal line to a point a finger's breadth posterior to the angle of the tenth costal cartilage.

The internal mammary artery crosses behind the medial ends of the superior five intercostal spaces, about half an inch from the edge of the sternum; as it descends it approaches a little nearer to the sternum. The ressel is accompanied by two veins which unite to form a single vein opposite the second interspace.

This artery is occasionally injured in punctured wounds of the chest. At the second or third intercostal space it is easily ligatured through a transverse incision, but at a lower level it is generally necessary to resect a portion of one of the costal cartilages.

\section{THE LUNGS AND PLEURE.}

The apex of the lung extends upwards into the root of the neck for a distance of one to two inches superior to the anterior extremity of the first rib, and is mapped out by a curved line drawn from the superior border of the sterno-clavicular articulation across the sterno-mastoid to the junction of the medial and intermediate thirds of the clavicle, the highest part of the curve reaching from $\frac{1}{2}$ to $1 \frac{1}{2}$ in. above the clavicle. The apex of the right lung reaches half an inch higher than that of the left lung. Intimately related to the apex of the cervical pleura are the subclavian artery and the inferior cervical ganglion of the sympathetic.

Both the cervical pleura and the subclavian artery may be injured by one of the fragments in a fracture of the clavicle; the scaleni muscles, however, affording considerable protection to the pleura. In ligaturing the third part of the subclavian artery, care must be taken not to injure the cervical pleura.

To delineate the anterior border of the right lung, draw a line from the superior border of the sterno-clavicular articulation to the centre of the manubrium sterni, and from thence vertically downwards, in or slightly to the left of the median plane to the level of the sixth or seventh costal cartilage, or, it may be, even to the infrasternal notch (Fig. 1091).

The anterior border of the left lung is mapped out by a corresponding line as far as the fourth costal cartilage; thence it is directed laterally along the inferior border of the fourth costal cartilage to the para-sternal line; it then passes inferiorly and slightly laterally across the fourth interspace, and curves medially behind the fifth costal cartilage and fifth interspace to reach the superior border of the sixth costal cartilage in the para-sternal line. The inferior part, therefore, of the anterior surface of the right ventricle is uncovered by lung and gives a completely dull note on percussion; this area is spoken of as the area of "superficial or absolute cardiac dulness."

The level of the inferior border of the lung is practically the same on both sides ; it is mapped out by a line extending laterally from the inferior extremity of the anterior border to the sixth costal cartilage in the mid-clavicular line, and thence in a slightly curved direction, with the convexity downwards, across the lateral aspect of the chest to the tenth thoracic spine. This line crosses the eighth rib in the mid-axillary line and the tenth rib in the scapular line (Figs. 1091 and 1092).

To indicate the position of the oblique fissure a line is drawn from the second thoracic spine across the interscapular region to the root of the spine of the scapula, and thence downwards and laterally across the infraspinous fossa, to end at the inferior border of the lung opposite the sixth costal cartilage, a little medial to the mammary line. When the arm is raised above the level of the shoulder, and the hand placed on the back of the head, the inferior angle of the scapula is rotated upwards and forwards so that the vertebral margin practically corresponds with the line of the oblique fissure. 
The transverse fissure of the right lung is mapped out by drawing a line from the anterior border of the lung, at the level of the fourth costal cartilage, laterally and slightly upwards to join the middle of the oblique fissure.

Pleuræ.-The line of reflection of the right pleura from the back of the sternum may be said to correspond to the anterior border of the right lung.

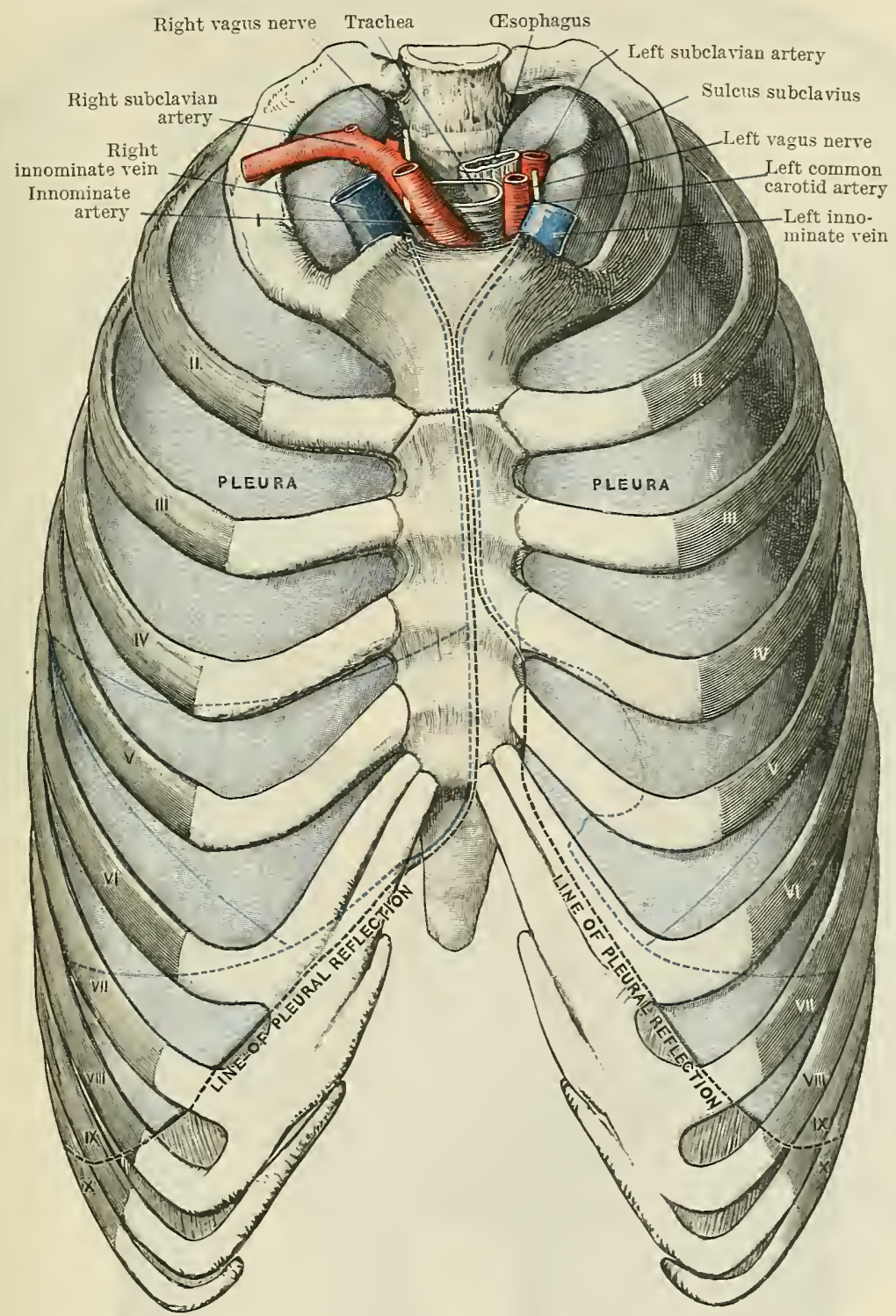

Fig. 1091.-Dissection of a SUbJect HaRdexed br Formalry Injection, to show the relations of the two pleural sacs as viewed from the front. The anterior and diaphragmatic lines of pleural reflection are exhibited by black dotted lines, whilst the outlines of the lungs and their fissures are indicated by the blue lines. (From Cunningham.)

On the left side, the pleural reflection corresponds to the anterior border of the left lung as far as the inferior edge of the fourth chondro-sternal junction, from which point it diverges slightly and descends, behind the left border of the sternum, to the sixth costal cartilage (Fig. 1091). It is only occasionally that the anterior extremities of the fifth and sixth interspaces are uncovered by pleura.

The right costo-diaphragmatic reflection (see Figs. 1091 and 1093) is indicated on the surface by a line drawn from the sixth or seventh chondro-sternal junction (sometimes the infrasternal notch) downwards and laterally to a point two inches 


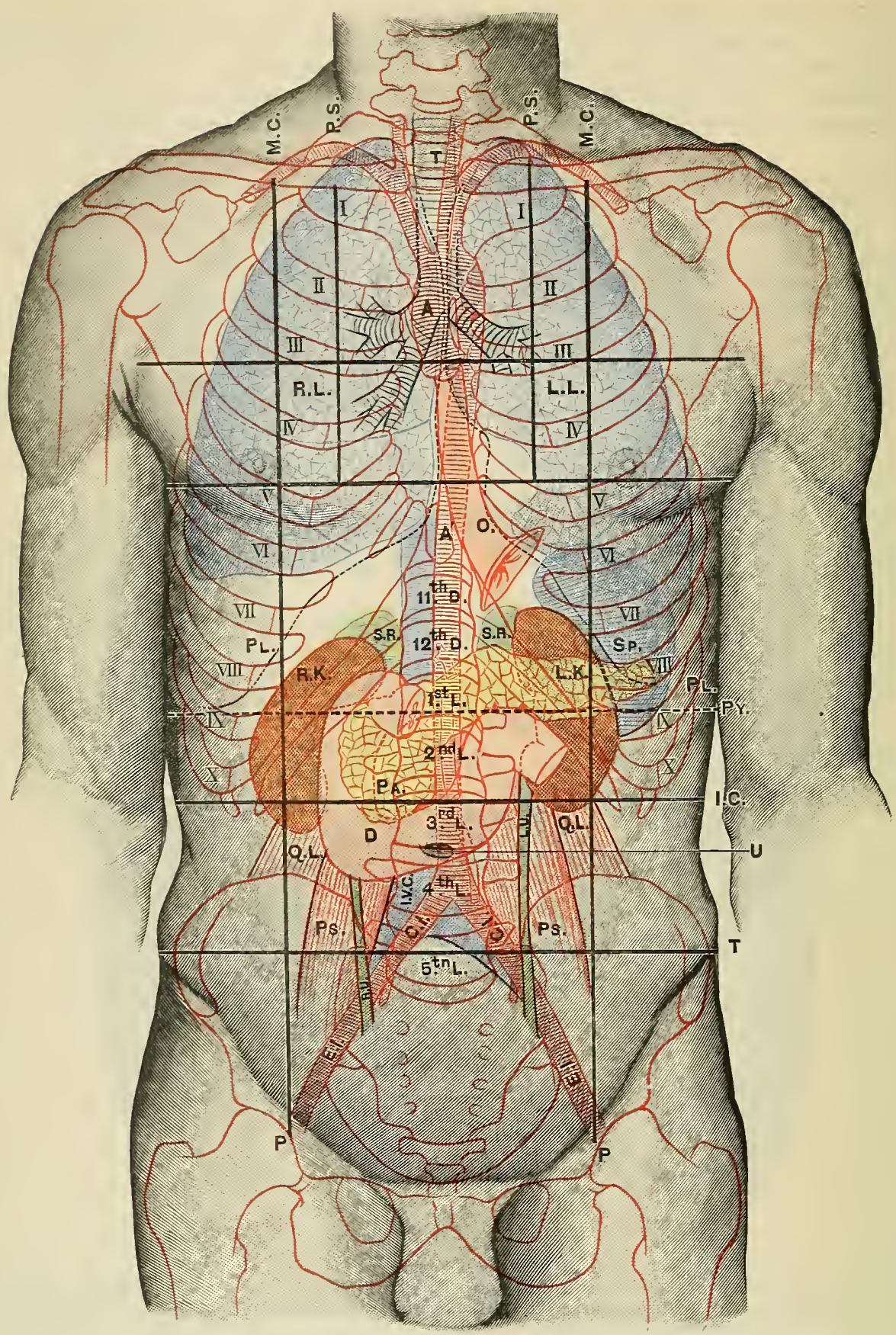

Fig. 1092.-Axterior Aspect of Trunk, Showing Surface Topography of Viscera.

M.C. Mid-clavicular line.

P.S. Para-sternal line.

P. Inguinal vertical line.

I.C. Infracostal line.

T. Intertubercular line.

Py. Transpyloric line.

T. Trachea.

A. Aorta.

R.L. Right lung.
L.L. Left lung.

Pl. Pleura.

O. Esophagus.

R.K. Right kidney.

L.K. Left kidney.

Sp. Spleen.

S.R. Suprarenal gland.

$\mathrm{Pa}$. Pancreas.

D. Duodenuín.
Q.L. Quadratus lumborum.

P.S. Psoas major.

R.U. Right-ureter.

L.U. Left ureter.

C.I. Common iliac artery.

E.I. External iliac artery.

I. V.C. Inferior vena cava.

U. Umbilicus. 
vertically above the angle of the tenth costal cartilage; from this point the line is carried with a slightly downward curve across the lateral aspect of the chest to the twelfth rib at the lateral margin of the sacro-spinalis; thence it passes below the twelfth rib and reaches the vertebral column at the level of the superior border of the twelfth thoracic spine. The relation of the costo-diaphragmatic reflection to the seventh, eighth, and ninth costal arches may be conveniently expressed by stating that it lies a little in front of the costo-chondral junction of the seventh, opposite that of the eighth, and a little behind that of the ninth.

The left costo-diaphragmatic reflection is indicated by a line drawn from a point opposite the sixth costal cartilage, a finger's breadth from its junction with the sternum, to a point one and a half inches vertically above the angle of the tenth costal cartilage, and thence to the vertebral column, as on the right side, but at a slightly inferior level.

The costo-diaphragmatic reflection reaches its lowest limit a little behind the mid-axillary line two inches vertically above the tip of the eleventh costal cartilage, a level which may be readily indicated, according to Cunningham, by a point in the mid-axillary line intersected by a horizontal line drawn round the trunk at the level of the lowest part of the extremity of the first lumbar spine (Fig. 1092). The same author localises the level of the diaphragmatic pleural reflection in the mammary line at the point where this line is intersected by another horizontal line at the level of the spine of the last thoracic vertebra.

The relations of the pleura to the twelfth rib are of importance to the surgeon, especially in connexion with operations on the kidney (Figs. 1094 and 1095). When this rib is not abnormally short, the pleural reflection crosses it opposite the lateral border of the sacro-spinalis muscle; hence an incision may be carried deeply as far as the apex of the angle formed by the twelfth rib and the lateral border of the sacro-spinalis

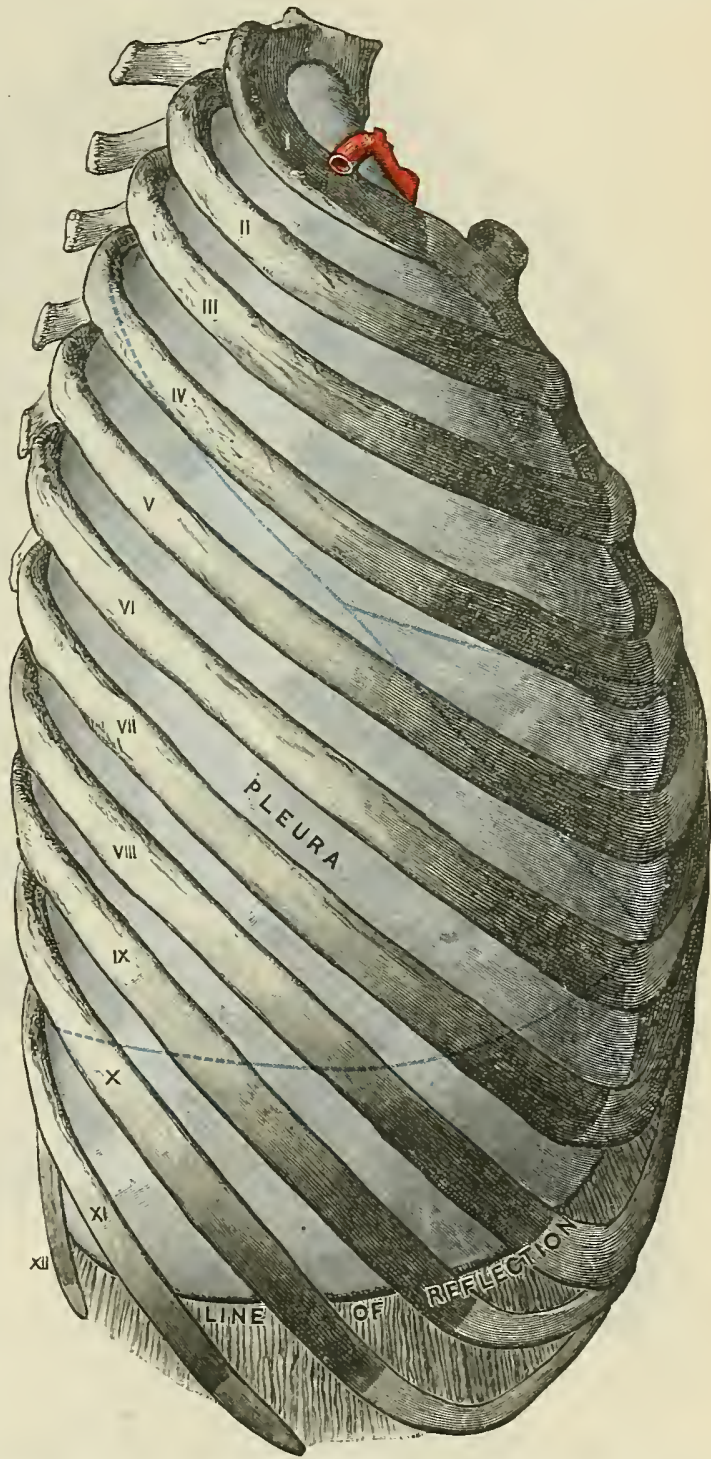

Fig. 1093.-Lateral View of the Right Plecral Sac is a ScBject hardened by Foryalis Isjection. The blue lines indicate the ontline of the right lung, and also the position of its fissures. (From Cunningham.) without entering the pleura. When, howerer, the twelfth rib does not reach the lateral border of the sacro-spinalis, an incision carried upwards into the apex of the angle between this muscle and the eleventh rib is certain to wound the pleura (Melsom). It is important, therefore, to count the ribs from above downwards, in order not to mistake the elerenth for the twelfth, when the latter is rudimentary.

Medial to the lateral edge of the sacro-spinalis the pleural reflection lies below the level of the twelfth rib, and not infrequently descends as far as the transverse process of the first lumbar vertebra. 
On the right side the posterior mediastinal pleura, as it passes from the posterior aspect of the pericardium, backwards, to the front of the vertebral column, sweeps over the right side of the œsophagus; hence malignant ulcers of the œsophagus are more likely to invade the right pleura than the left. On the left side the posterior mediastinal pleura passes from the lateral aspect of the bodies of the vertebre on to the left side of the aorta. Hence, to evacuate pus from the posterior mediastinum, there is less risk of opening the pleura if the space is entered from the left side of the vertebral column.

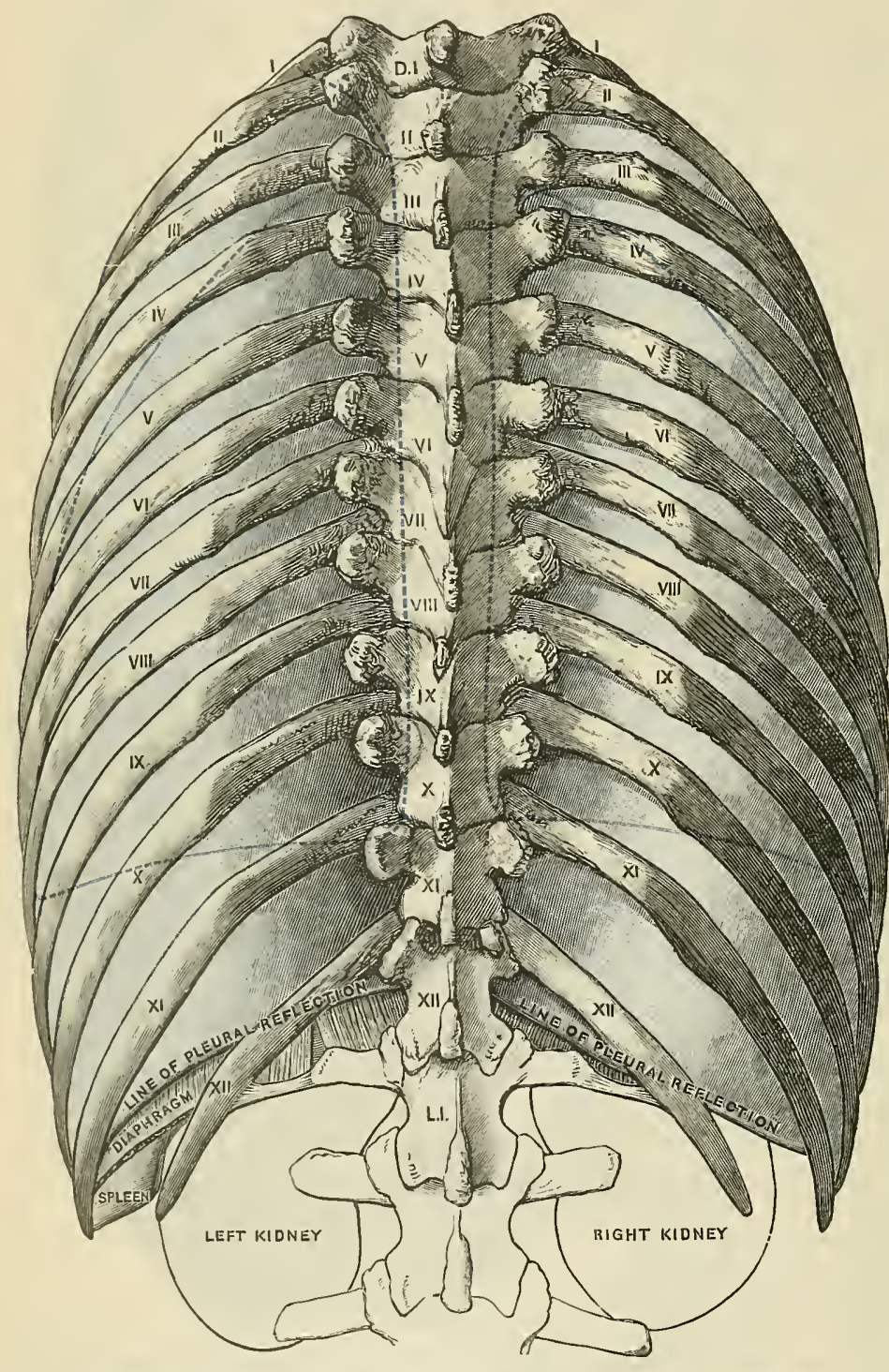

Fig. 1094.-Dissection of the Pleural Sacs from Behind.

The seat of election for tapping the pleura (paracentesis pleurce) is the sixth or seventh costal interspace, a little in front of the posterior axillary fold. To allow of the introduction of a tube to drain away the pus from the pleural cavity in empyema, a portion of one of the ribs (sixth to ninth) is resected. The intercostal vessels and nerves, which lie in the groove at the inferior border of the rib, are avoided by removing the portion of bone subperiosteally. If the chest is opened in the scapular line, care must be taken not to resect either the seventh or the eighth ribs, which are exposed when the arm is elevated, but are overlapped by the inferior angle of the scapula when the arm is lowered.

Anteriorly, the bifurcation of the trachea lies opposite, or a little below, the angulus sterni, while pos-

The blue lines indicate the outlines and the fissures of the lungs. (From Cunningham.) teriorly it lies a little below the level of the root of the spine of the scapula, opposite the fourth thoracic spine. The bifurcation takes place one vertebra higher in the infant than in the adult (Symington).

The septum between the right and the left bronchus lies a little to the left of the middle of the trachea, and the right bronchus is wider and more nearly in a line with the trachea than the left bronchus; hence the greater tendency of foreign bodies to enter the right bronchus. 
The roots of the lungs are situated opposite the fourth, fifth, and sixth thoracic spines, midway between them and the vertebral margins of the scapulæ.

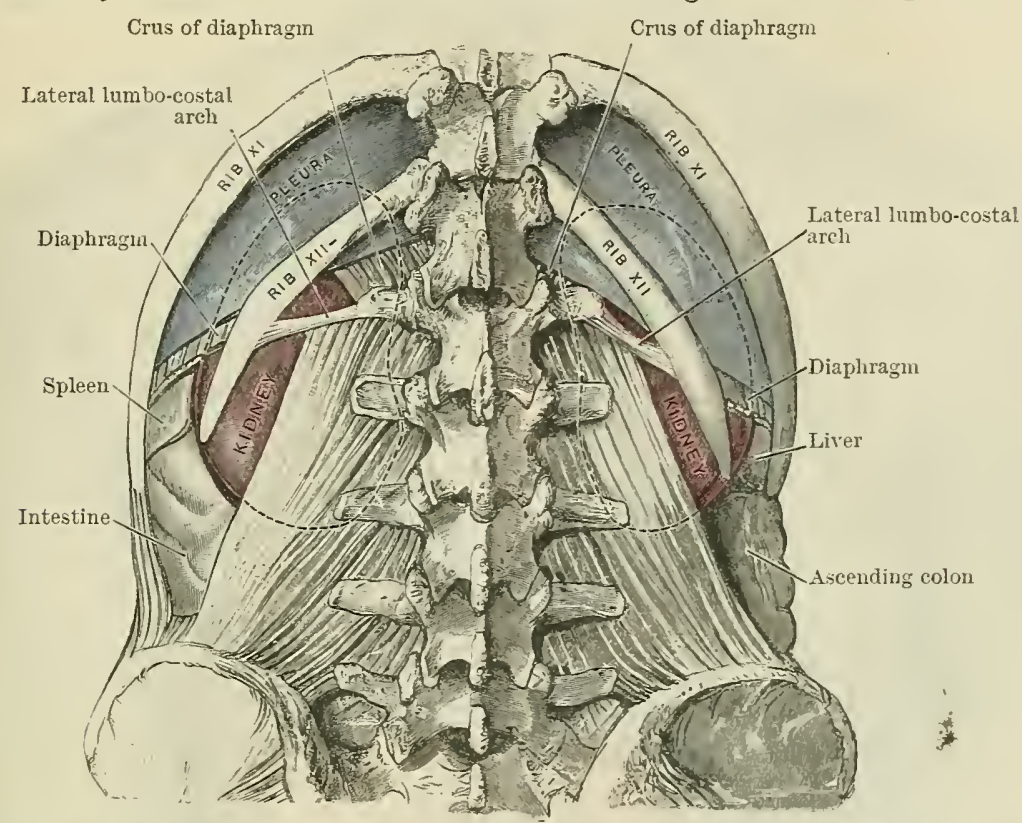

Fig. 1095.-Dissection fron beHIND to Show the relation of the two Pleural SaCs to the KidNeYs. Outlines of superior portions of the two kidneys are indicated by dotted lines. (From Cunningham.)

The lower end of the trachea, the bronchi, the vagi, and the left recurrent nerve, are all more or less surrounded by lymph glands, which, when enlarged, may exert injurious pressure upon them.

\section{THE HEART AND GREAT VESSELS.}

Viewed from the front, the outline of the precordial area, like that of the pericardial sac, is roughly triangular, the base of the triangle being below and the apex above. The boundaries are delineated upon the surface as follows :-

The right side of the triangle, formed by the right atrium, is indicated by drawing a line slightly convex laterally from the superior end of the third to the sixth costal cartilage, a finger's breadth from the edge of the sternum; the curve attains its maximum opposite the fourth intercostal space, where it reaches one and a half inch from the median plane.

The base of the triangle, formed by the margo acutus of the right ventricle and to a very slight extent by the apical portion of the left ventricle, is almost horizontal, and corresponds to a line drawn from the inferior extremity of the right side of the triangle to the apex of the left ventricle, which lies behind the fifth left intercostal space, three and a half inches from the median plane, and half an inch medial to the mid-clavicular line. The base line crosses the xiphoid process at its junction with the body of the sternum.

The left side of the triangle, formed by the margo obtusus of the left ventricle, is indicated by a slightly curved line extending from the apex of the heart upwards to the inferior edge of the second interspace, a finger's breadth from the sternum, the convexity of the curve being directed laterally and slightly superiorly.

The truncated apex of the triangle, which lies behind the sternum at the level of the second intercostal space, corresponds to the highest part of the heart, namely, where the auricles embrace the aorta and pulmonary artery.

The anterior part of the right auriculo-ventricular groove is mapped out by a line drawn from the median plane, opposite the inferior border of the third right costal cartilage, downwards and laterally to the sixth right chondro-sternal junction; the line should be slightly convex upwards and to the right. The right auricle lies at, or a little to the left of, the median plane, at the level of the second 


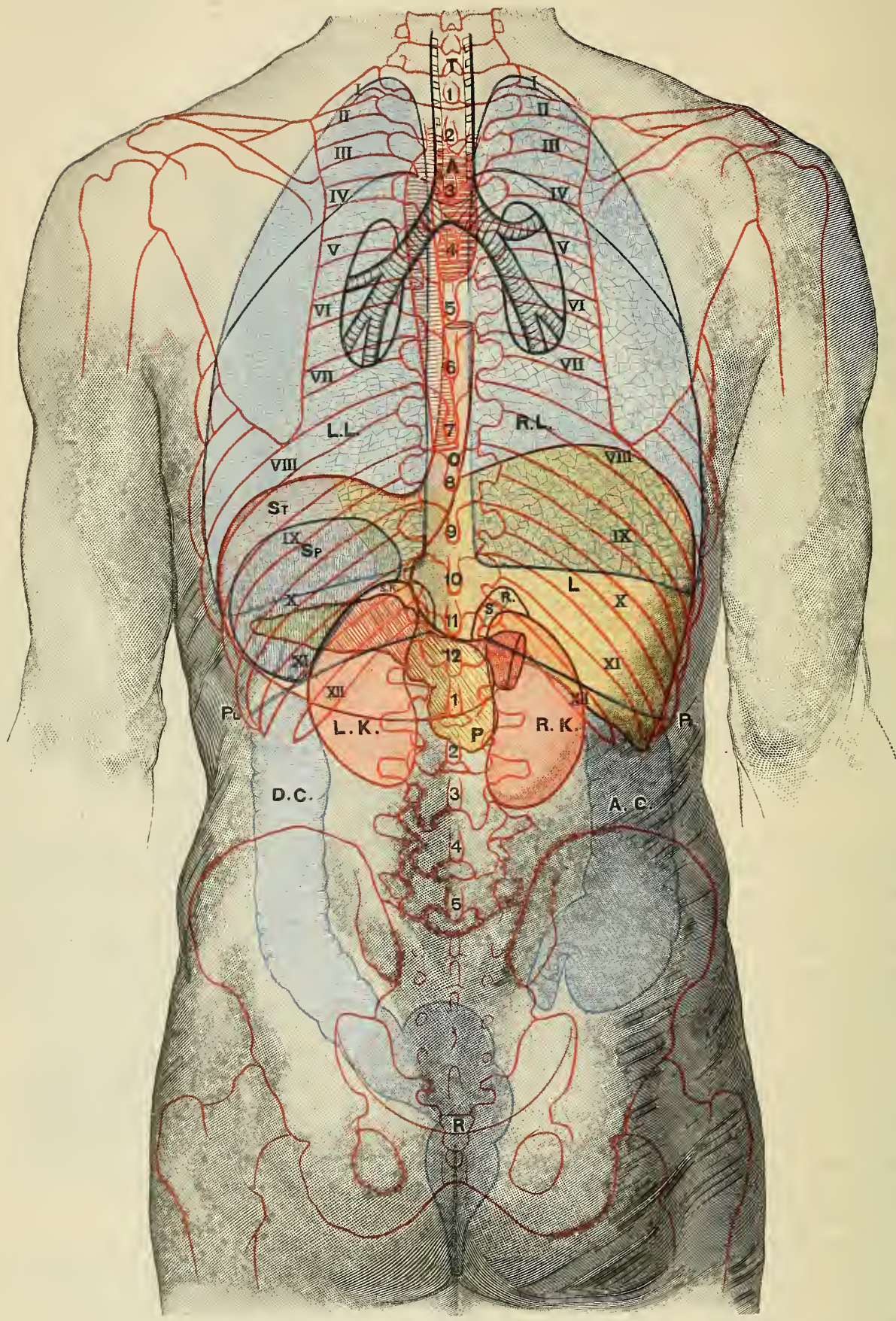

Fig. 1096.-Posterior Aspect of Trunk, showing Surface Topography of Viscera.

T. Trachea.

A. Aorta.

L. L. Left lung.

R.L. Right lung.

St. Stomach.
Sp. Spleen.

L. Liver.

S.R. Suprærenal gland.

I.K. Left kiduey.

R.K. Right kidney.
P. Pancreas.

P1. Pleura.

D.C. Descending colon.

A.C. Ascending colon.

R. Rectum. 
intercostal space and the superior border of the third costal cartilage. The left auricle lies behind the second left intercostal space, close to the edge of the sternum.

The diaphragmatic or inferior surface of the heart rests upon the diaphragmatic or basal part of the pericardium. The base, or true posterior surface, of the heart is formed mainly by the left atrium, which is moulded posteriorly upon the cesophagus, the aorta, the bronchi, and the bronchial glands, the pericardium intervening. The left atrium extends behind the right atrium for a considerable distance to the right of the median plane.

In a radiographic examination in cases of general visceroptosis, the diaphragm, which should rise and fall opposite the xiphisternal junction will be seen to be an inch or more lower down, while the heart is seen to hang more vertically than normal (cardioptosis).

In determining the position of the cardiac orifices and their valves it is to be remembered that they are all situated to the left of the right auriculo-ventricular groove, and that they lie in the following order from above downwards-viz., pulmonary, aortic, mitral, and tricuspid. When delineated on the surface they will be seen to lie within an ellipse whose long axis extends from the superior border of the third left to the sixth right chondro-sternal junction.

The pulmonary orifice, directed upwards and slightly posteriorly and to the left, lies opposite the superior border of the third left chondro-sternal junction; the aortic orifice, directed upwards, posteriorly, and to the right, lies further from the surface, behind the left half of the sternum, opposite the inferior border of the third costal cartilage; the mitral orifice lies at an inferior level, behind the left half of the sternum, opposite the fourth rib; the orifice of the opening is directed downwards, forwards, and to the left. The tricuspid orifice, situated nearer the anterior wall of the chest than the mitral, lies very obliquely behind the right half of the sternum at the level of the fourth and fifth cartilages and intervening space.

Although the first and second sounds of the heart are heard all over the cardiac area, the sounds produced by the individual valves are heard most distinctly, not directly over their anatomical situation, but over the area where the cavity in which the valve lies approaches nearest to the surface. Hence the mitral sound is best heard over the apex (mitral area), the tricuspid over the inferior part of the body of the sternum (tricuspid area), the aortic over the second right costal cartilage (aortic area), and the pulmonary over the second left intercostal space (pulmonary area).

In tapping the pericardium (paracentesis pericardii) the pleura will be avoided by making the puncture through the fifth or sixth left intercostal space as close as possible to the edge of the sternum. When, however, the pericardial sac is distended with fluid, the pleura is pushed laterally, and will therefore escape injury if the puncture is made at a safe distance lateral to the internal mammary vessels, viz., one inch lateral to the left border of the sternum.

To establish free drainage in suppurative pericarditis, the sixth left costal cartilage must be resected and the internal mammary vessels ligatured; the transversus thoracis and the pleural reflection are then pushed aside and the pericardium exposed and incised.

The ascending aorta lies behind the sternum, opposite the second and third ribs, and, unless dilated, does not project beyond its right border. The superior border of the aortic arch lies at or a little above the centre of the manubrium sterni; in the child the vessel may reach as high as the superior border of the manubrium.

The innominate and left common carotid arteries diverge from either side of the median plane between the upper part of the manubrium sterni and the front of the trachea. A pin pushed directly backwards immediately above the middle of the supra-sternal notch will strike the medial border of the innominate artery a little below its bifurcation.

The pulmonary artery lies behind the left border of the sternum opposite the second interspace and the second costal cartilage.

The left innominate vein lies behind the superior part of the manubrium sterni, the right behind the medial end of the right clavicle. The superior vena cava lies immediately to the right of the margin of the sternum, opposite the first and second interspaces and the intervening second rib; its opening into the right atrium, behind the third chondro-sternal articulation, corresponds to the centre of the root of the right lung. 

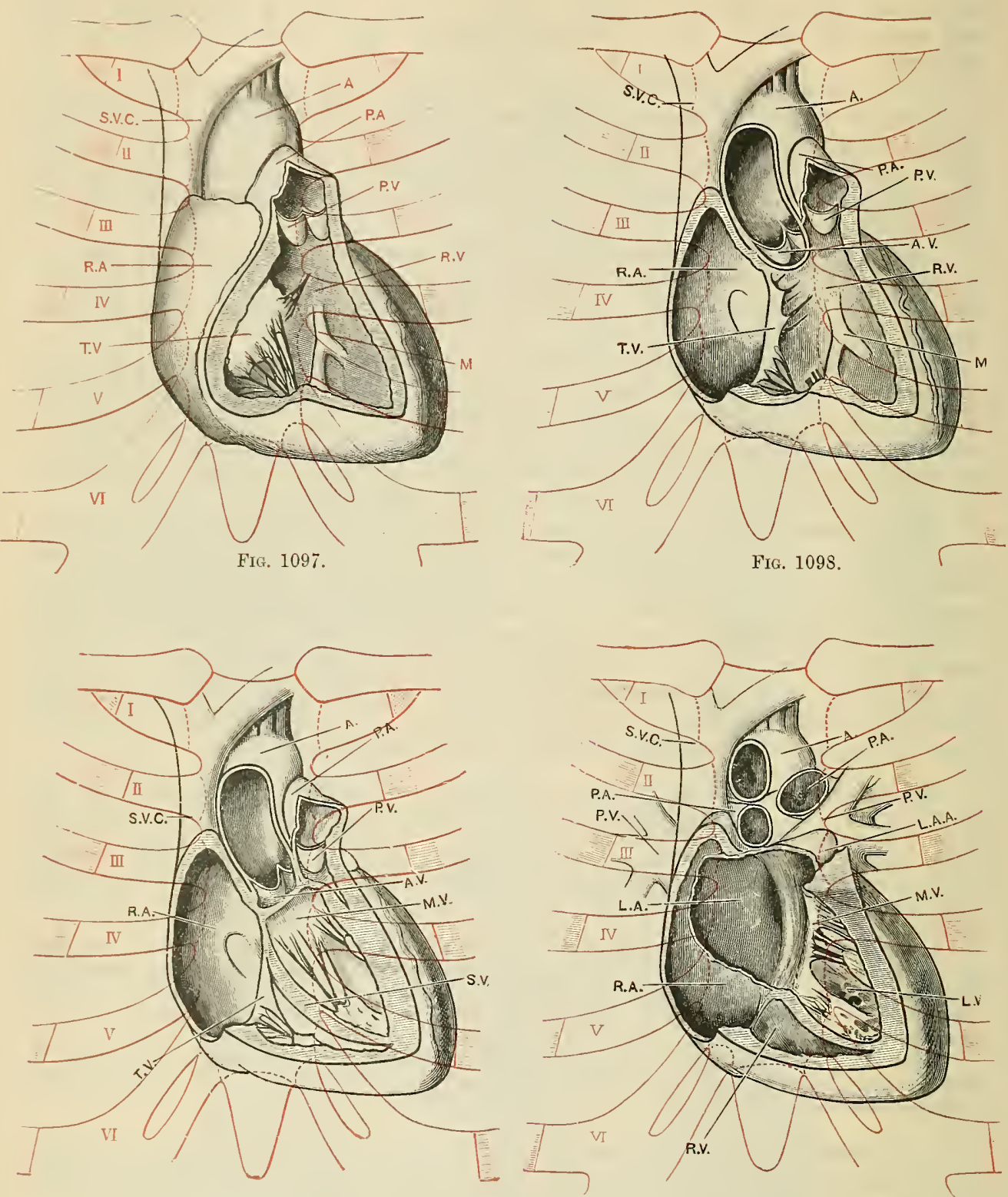

FIG. 1099.

FIG. 1100.

From photographs of a formalin-hardened subject, with the heart dissected in situ, to show the relations of its cavities and valves to the anterior wall of the thorax.

In Fig. 1097 the anterior wall of the right ventricle has been removed and the pulmonary artery opened.

In Fig. 1098 the anterior walls of the ascending aorta and of the right atrium have been removed; also the anterior cusp of the tricuspid valve.

In Fig. 1099 the greater part of the interventricular septum has been removed, exposing the anterior cusp of mitral valve.

In Fig. 1100 the ascending aorta, anterior cusp of mitral valve, trunk of pulmonary artery, and interauricular septum have been removed; the cavities of the left atrium and left ventricle are exposed, also the left auricle and posterior cusp of mitral valve.

R.A. Right atrium.

R.V. Right ventricle.

L.A. Left atrium.

L.A.A. Left auricle.

S.V. Interventricular septum.
P.A. Pulmonary artery.

P.V. Pulmonary valve.

A. Aortic arch.

A.V. Aortic valve.

T.V. Tricuspid valve.
M. V. Mitral valve.

S.V.C. Superior veua cava.

P.V. Pulmonary vein.

M. Moderator band. 


\section{ESOPHAGUS.}

The average length of the esophagus in the adult is $10 \mathrm{in.}(25 \mathrm{~cm}$.); the distance from the incisor teeth to its commencement is $6 \mathrm{in}$; to the point or level where it is crossed by the left bronchus, 9 in.; to the œsophageal opening of the diaphragm, 14 to $15 \mathrm{in}$; to the cardiac orifice of the stomach, 16 in. These measurements, which are of great importance in diagnosing the seat of oesophageal obstructions, should be marked off from below upwards upon all cesophageal bougies and probangs. Posteriorly, the cesophagus extends from the level of the sixth cervical spine to that of the tenth thoracic, a little to the left of which is the situation at which the stethoscope is placed in order to hear the sound produced by the passage of fluid into the stomach.

Clinically it is important to bear in mind the relation of the csophagus to the trachea and left bronchus, to the left recurrent nerve, to the bronchial and posterior mediastinal glands, to the descending thoracic aorta, and to the right posterior mediastinal pleura. Ulcers of the esophagus are liable to open into either the trachea, the left bronchus, or the right pleura.

The veins of the inferior end of the csophagus open partly into the systemic veins and partly into the portal system; like those at the inferior end of the rectum they are liable to become varicose in conditions which give rise to chronic interference with the portal circulation.

The lymph vessels of the upper part of the œsophagus open into the inferior deep cervical glands, the remainder into the posterior mediastinal glands.

The œsophagus is very distensible in the transverse but not in the antero-posterior direction, hence the most useful forceps for removing foreign bodies from the csophagus are those which open laterally.

\section{THE ABDOMEN.}

\section{THE ANTERIOR ABDOMINAL WALL.}

The configuration of the abdomen varies with the age, sex, obesity, and muscular development of the individual. In the child it is wider above than below, while the reverse is the case in the adult female. It is most prominent in the region of the umbilicus, which is situated, normally, below the mid-point between the infrasternal notch and the symphysis pubis, usually a little below the level of the highest part of the iliac crest, and opposite the middle of the body of the fourth lumbar vertebra. In the obese, and especially when the abdominal muscles have lost their tone, the umbilical region becomes prominent and more or less pendulous, so that the umbilicus may come to lie considerably below the normal level. In the child it is relatively lower than in the adult, in consequence of the undeveloped state of the pelvis.

In spare subjects the inferior end of the body of the sternum, the xiphoid process, and the costal margin, can readily be traced. The slight depression or notch formed by the seventh costal cartilages and the inferior border of the body of the sternum is termed the infrasternal notch. Below the notch, and bounded on each side by the seventh, eighth, and ninth costal cartilages, is the infracostal angle, which varies considerably according to the shape of the chest; it is relatively wider in the child than in the adult. The inferior border of the curve of the tenth costal cartilage is easily recognisable, and was selected by Cunningham as the level of the plane of separation (infracostal plane) between the upper and middle abdominal zones.

The anterior abdominal wall is limited below by the fold of the groin and the crest of the pubes. In a spare muscular subject the recti, the furrows corresponding to the inscriptiones tendineæ (O.T. lineæ transversæ) and the supra-umbilical portion of the linea alba, can be readily made out. When the outline of the rectus is not visible the lateral border may be indicated by a line drawn from the tip of the ninth costal cartilage to the mid-point of a line joining the umbilicus and the anterior superior iliac spine, and from thence to the pubic tubercle. In the angle between the lateral border of the rectus and the ninth costal cartilage, on the right side, is a slight triangular depression which overlies the fundus of the gall-bladder. Between the inferior part of the lateral border of the rectus and the prominence above the anterior part of the iliac crest, caused by the lower 
muscular fibres of the exterual oblique, is another slight triangular depression, which correspouds to the inferior and narrow part of the aponeurosis of the external oblique muscle.

Close above, and almost parallel to, the medial half of the inguinal ligament is the inguinal canal, traversed by the spermatic funiculus (Fig. 1101); the latter can be felt to emerge at the subcutaneous inguinal ring immediately above the pubic tibercle. The abdominal and subcutaneous inguinal rings have been fully described elsewhere: the former is triangular in shape, with its apex directed superiorly and laterally, and its base immediately above the pubic crest. By invaginating the skin of the scrotum the little finger may be passed through the ring into the canal. It is to be noted that the neck of an inguinal hernia lies above the pubic tubercle, whereas the neck of a femoral hernia emerges below the medial end of the inguinal ligament, lateral to the pubic tubercle. The abdominal inguinal ring, an opening in the fascia transversalis, lies half an inch above a

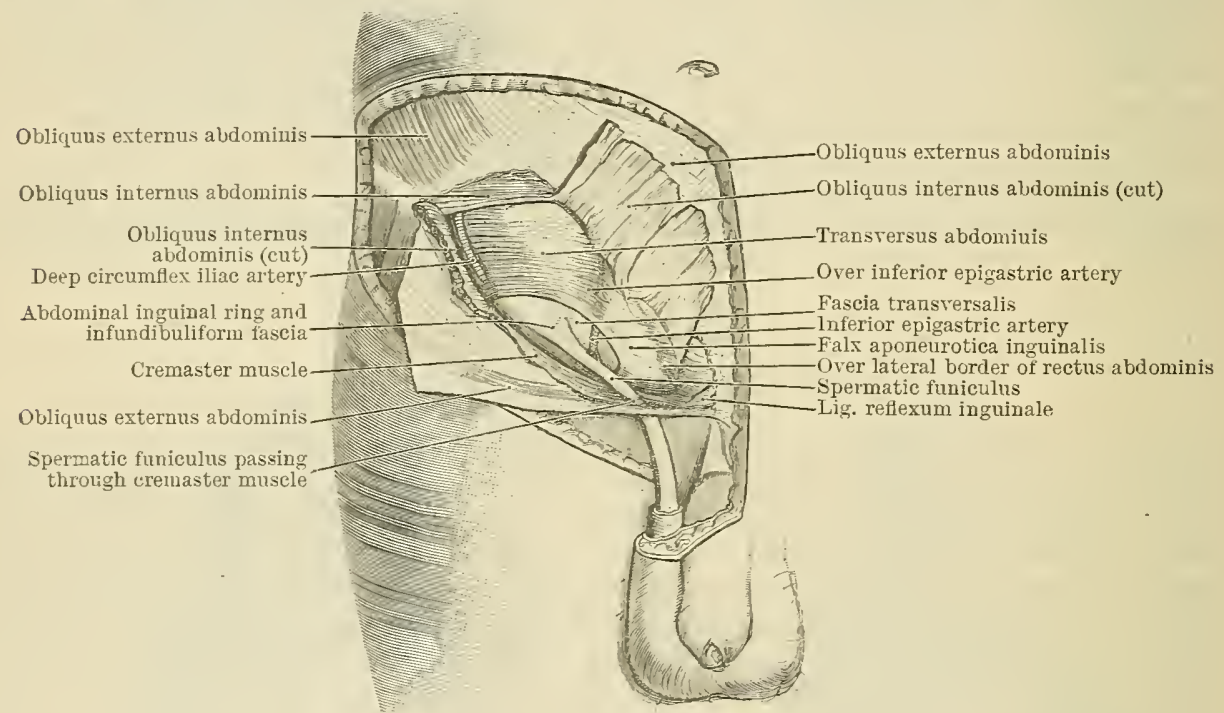

FIG. 1101.--The GroIx. The structures seen on reflection of part of the obliquus internus abdominis

(A. M. Paterson).

poiut a little medial to the middle of the inguinal ligament. The inferior epigastric artery may be mapped out by drawing a line from a point midway between the superior anterior iliac spine and the symphysis pubis towards the umbilicus. The vessel, together with the medial third of the inguinal ligament and the inferior part of the lateral border of the rectus, bounds a triangle known as Hesselbach's triangle. As the inferior epigastric artery passes superiorly and medially to disappear behind the falx aponeurotica inguinalis and the lateral border of the rectus, it lies behind the spermatic funiculus immediately medial to, and below, the abdominal inguinal ring. The floor of Hesselbach's triangle is formed throughout by the fascia transversalis, superficial to which, over the medial half or so of the triangle, is the falx aponeurotica inguinalis. An oblique inguinal hernia leaves the abdomen at the abdominal inguinal ring and traverses the whole length of the inguinal canal; its coverings are therefore the same as those of the spermatic funiculus, and the neck of the sac lies lateral to the inferior epigastric artery, hence this variety of hernia is also termed lateral inguinal hernia. A direct inguinal hernia, on the other hand, instead of traversing the whole length of the inguinal canal, pushes before it that part of its posterior wall which is formed by the floor of Hesselbach's triangle. The neck of the sac, therefore, lies medial to the inferior epigastric artery, and this variety of hernia may be termed a medial inguinal hernia. If a direct hernia makes its way through the medial part of Hesselbach's triangle, it derives a covering from the 
falx inguinalis, as well as from the fascia transversalis; if through the lateral part of the triangle, the lateral edge of the falx inguinalis curves round the medial side of the neck of the sac. To relieve the constriction at the neck of the sac, in the case of an oblique inguinal hernia, the edge of the knife is directed superiorly and laterally to avoid the inferior epigastric artery, while in a direct hernia the artery is avoided by dividing the constriction in a superior and medial direction. In an oblique inguinal hernia the sac lies within the infundibuliform fascia (fascia propria of the hernia), whereas in a direct hernia the fascia propria is derived from the fascia transversalis of Hesselbach's triangle. The extraperitoneal fat which covers the outer surface of the hernial sac is sometimes hypertrophied to such an extent as to amount to a fatty tumour.

In a large proportion of children, at birth, the vaginal process of peritoneum, which connects the tunica vaginalis testis with the abdominal peritoneum, is still patent, especially on the right side. Should the bowel force its way along the patent process a congenital inguinal hernia arises. In the majority of the cases of congenital inguinal hernia it will be found that the tunica vaginalis testis has been shut off by closure of the lower part of the vaginal process, only the superior part remaining patent and forming the sac of the hernia.

In the child the persistence of a patent vaginal process can almost invariably be detected by rolling the cord between the finger and thumb; after the ductus deferens and spermatic vessels have slipped away from one's grasp the edge of the sac can be felt to follow them. In regard to the operation for the cure of inguinal hernia, it should be borne in mind that in the acquired form the hernia produces the sac, whereas in the congenital variety the sac is the cause of the hernia; it follows, therefore, that in the operation for acquired hernia the closure of the canal is as important as the removal or obliteration of the sac, while in a congenital hernia the most essential part of the operation is the closure of the neck of the sac, and as the muscular and fascial apparatus forming the walls of the canal are often well developed (especially in children), they should be interfered with as little as possible. A patent vaginal process may persist during adult life without any bowel descending into it; on the other hand, years after birth, bowel may suddenly enter it. In practically all oblique inguinal herniæ, which develop suddenly in children as well as in adolescents and young adults, the sac is of congenital origin.

In the ordinary form of hydrocele the fluid is confined to the tunica vaginalis testis, but when the vaginal portion of the processus vaginalis remains patent, the hydrocele may extend upwards into the inguinal canal, and may or may not communicate with the general peritoneal cavity. In the condition known as encysted hydrocele of the cord the patent funicular process is shut off both from the tunica vaginalis testis and from the peritoneal cavity.

\section{Abdominal Incisions.}

Before proceeding to deal with the abdominal cavity reference must be made to some anatomical points connected with the more typical incisions made by surgeons in opening the abdomen.

Incisions in the Median Plane.-Median line incisions through the linea alba have the advantage of being comparatively bloodless and rapid of execution, of dividing no motor nerves, and of enabling the surgeon to expose a wide area of the abdomen. Unless special precautious are taken, however, they are more liable to be followed by a ventral hernia.

Above the umbilicus the linea alba is comparatively broad, so that the edges of the recti are separated by a distinct interval, which may be of considerable width in obese subjects and multiparous women. Beneath the linea alba is the transrersalis fascia, which is so thin and adherent that the two structures form practically a single layer. The extraperitoneal fat, which forms a comparatively thick stratum, must not be mistaken for omentum. The peritoneum presents itself as a thin, bluish, semi-transparent membrane. If it is necessary to prolong the iucision downwards below the level of the umbilicus, it should skirt its left margin so as to 
avoid the round ligament of the liver. If, in closing a median supra-umbilical laparotomy wound, the surgeon merely sutures the edges of the stretched linea alba without opening into the rectal sheaths, a hernia may result. To ensure against it the medial borders of the recti are exposed by opening into their sheaths along each edge of the wound. In closing the wound, the deepest suture (continuous) includes on each sicle the posterior layer of the rectal sheath along with the split linea alba, the transversalis fascia and the peritoneum. This gires a substantial "first line of defence." The next suture takes up some of the fibres of the medial edges of the recti, along with the anterior layer of their sheaths. The skin is sutured separately. By the above procedure the edges of the recti are brought into actual contact and a double-layered linea alba is fashioned, one layer behind the margins of the recti and the other in front of them.

Below the umbilicus the medial edges of the recti are practically in contact, so that an incision between them opens into the rectal sheath on both sides.

The nearer the opening into the abdomen approaches the symphysis pubis, the more likely is the bladder to be encountered; this applies more especially in children in whom the bladder extends higher up out of the pelvis. Before opening the abdomen, therefore, by a low median incision, the bladder should be emptied; in supra-pubic cystotomy, on the other hand, it is intentionally filled so as to elevate the peritoneum (superior false ligament of the bladder) well above the symphysis. Below this peritoneal layer is the space of Retzius, occupied by a pad of extra-peritoneal fat which must be separated by blunt dissection before the bladder wall is actually exposed. In opening the bladder the pre-vesical veins, which ramify on its surface, are avoided as far as possible. Above the pubes the fascia transversalis recedes somewhat from the posterior surface of the recti, leaving behind it a cellular interval which must not be mistaken for the space of Retzius.

If a transverse incision is added to the inferior end of a supra-umbilical median incision, free access may be obtained to the hypochondriac as well as to the epigastric region. Before dividing the fibres of the rectus, however, the anterior layer of the sheath is stitched to them to prevent their retraction. In dividing the posterior layer of its sheath the terminal portions of the ninth and tenth intercostal nerves need not be injured as they run in a transverse direction.

Incisions through the- Recti. - In opening the abdomen by longitudinal incisions through the recti, the superior epigastric artery will be encountered above the umbilicus, and the inferior epigastric below it. The nearer the opening approaches the lateral border of the rectus, the more will its nerve-supply be injured. Above the level of the umbilicus, the posterior layer of the rectal sheath is well developed; and in closing the wound it is included in the same suture as the transversalis fascia and the peritoneum, the three together forming a most efficient "first line of defence." The higher up and further out the incision is made through the rectus, the more will the posterior layer of the sheath be found to be made up of transverse muscular fibres prolonged inwards from the transversus abdominis muscle. Below the level of the umbilicus, the posterior layer of the rectal sheath is much thinner, and where it ceases, namely, about midway between the umbilicus and the pubes, it constitutes what is known as the fold of Douglas. Below this level, therefore, the " deep closure" of a laparotomy wound through the rectus is less secure than is the case at a higher level. It is all the more important, therefore, to see that the edges of the anterior layer of the sheath are accurately sutured.

Incisions Lateral to the Rectus.-Longitudinal incisions lateral and parallel to the lateral border of the rectus are as far as possible to be avoided, firstly, because they divide the motor nerves, and, secondly, because the abdominal wall is almost entirely aponeurotic, and, therefore, a hernia is liable to result.

Incisions lateral to the rectus, above the level of the umbilicus, are generally made more or less parallel to the costal margin. Such incisions give excellent access to the gall-bladder and bile-ducts. The fibres of the external oblique muscles are divided transversely; but, fortunately, those of the internal oblique and transversus muscles may be divided more or less parallel to the fibres. The abdominal portions of the eighth, ninth, and tenth thoracic nerves which course, 
between the two deep muscles, run in a medial and slightly downward direction, so that it is practically impossible to aroid dividing one or other of them.

In the iliac regions, to reach the crecum and relmiform process on the right side, and the pelvic colon on the left side (colostomy), it is customarr, by using what is known as the "gridiron incision," to split the three abdominal muscles in the direction of their fibres. The external oblique is split in the direction of the shin incision, which is made obliquely from above downwards and medially. After retracting the edges of this muscle the fibres of the internal oblique and transversalis muscles are split horizontally. The abdomen is then opened by diriding the transtersalis fascia and peritoneum. If a comparatively large opening is required the branch of the deep circumflex iliac artery, which ascends between the internal oblique and transversus muscles, a little medial to the anterior superion iliac spine, is divided and ligatured, while the ilio-hypogastric and ilio-inguina! nerves are to be avoided. If it is necessary to extend the incision in a media direction, the lateral part of the anterior layer of the sheath of the rectus is opened and the rectus muscle retracted medially; while the inferior epigastric artery now exposed, is pushed aside or ligatured before the opening in the fascia trans. versalis and peritoneum is enlarged.

\section{Distribution of Sexsory Nerves in Axterior Abdomixal Wall.}

A knowledge of the segmental distribution of the sensory fibres of the anterior rami of the lower intercostal nerves enables us to appreciate the significance of the so-called girdle pain often associated with lesions of the spinal meduila and its nerve-roots. In tuberculous disease of the vertebral column, for example, the girdle pain may be an early symptom of the disease, and when present it affords a valuable guide to the situation of the disease in the vertebral column. The seventh thoracic nerve supplies the skin at the level of the epigastric triangle, the eighth and ninth, that between it and the umbilicus, the tenth that at the lerel of the umbilicus, the eleventh and twelfth that between the umbilicus and groin.

\section{THE ABDOMINAL CAVTTY.}

Subdivisions of the Abdominal Cavity.-To simplify the topography of the abdominal viscera the abdomen is arbitrarily divided into nine regions by two horizontal and two vertical planes. Of the two horizontal planes, the superior or infracostal plane is at the level of the lowest part of the tenth costal cartilages; the inferior or intertubercular plane is at the level of the tubercles of the iliac crests. The two vertical planes correspond upon the surface to a line drawn vertically upwards on each side from a point midway between the superior anterior iliac spine and the pubic symphysis. Superiorly, these vertical planes generally strike the tip of the ninth costal cartilages. The subdivisions of the superior zone are termed the epigastric and right and left hypochondriac regions, of the middle zone the umbilical and right and left lumbar regions, of the inferior zone the hypogastric and right and left iliac regions. The epigastric, umbilical, and hrpogastric regions may be further divided into right and left halres by the median plane. The xiphisternal junction is on a level with the fibro-cartilage between the ninth and tenth thoracic vertebræ. The infracostal plane passes through the superior part of the third lumbar vertebra; the intertubercular plane through the fifth lumbar vertebra, about one inch above the sacral promontory. The umbilicus is situated usually from one to two inches above the intertubercular line.

In the method of surface topography employed by Addison the plane of separation between the superior and middle abdominal zones is placed midway between the superior border of the manubrium sterni and the superior border of the pubic symphysis. It will be found to lie at or near the mid-point between the xiphisternal junction and the umbilicus. Posteriorly, this plane strikes the inferior border of the first lumbar vertebra, and it passes so constantly through the pylorus that it may with advantage be termed the transpyloric plane.

The peritoneal cavity may be regarded as a large and complicated lymph sac which is intimately related to the abdomimal viscera, and more especially to the 
gastro-intestinal canal. Inflammatory infections of the peritoneum are therefore almost always secondary to lesions of the viscera. The peritoneal lymph sac is brought into direct communication with the subperitoneal lymph vessels of the diaphragm through stomata which open upon the peritoneum covering the abdominal surface of that muscle. With the object, therefore, of diminishing septic absorption after operations for peritonitis, the patient is kept in the half-sitting posture, and pelvic drainage is established. The healthy peritoneum, in virtue of the vital action of its endothelial cells, is endowed with great absorptive properties, and, when irritated,

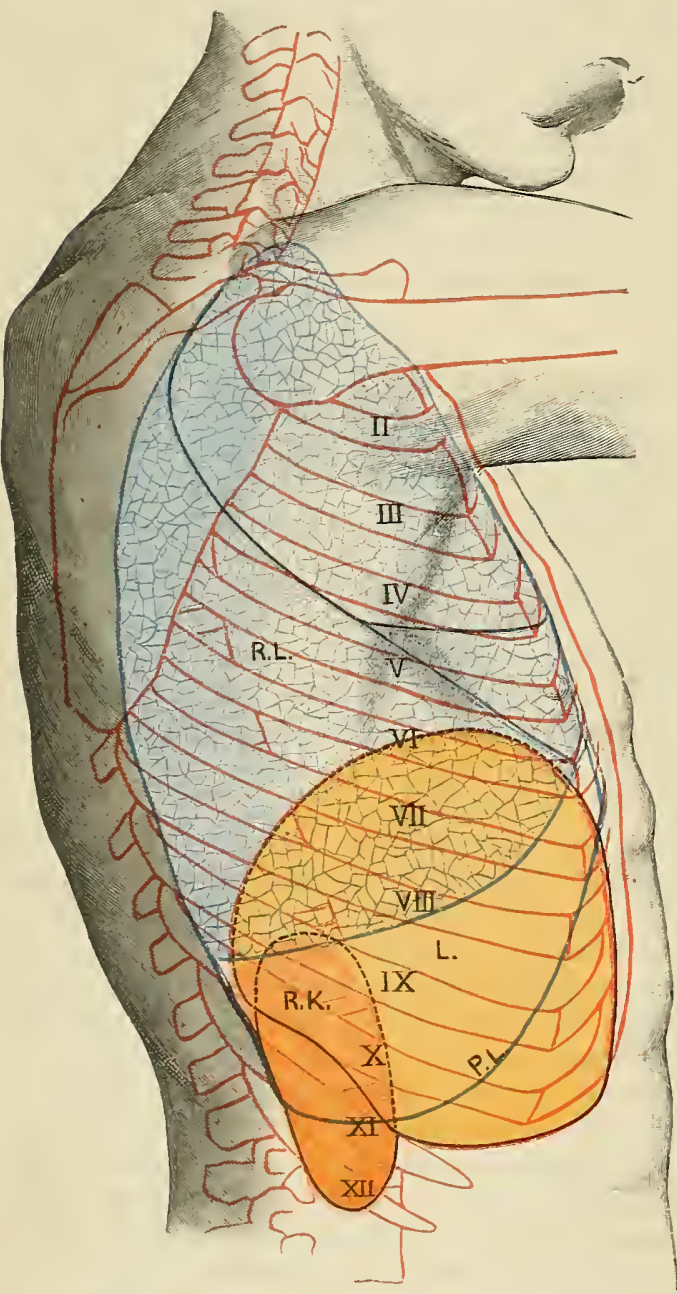

Fig. 1102.-Lateral Aspect of Trunk, showing Surface TOPOGRAPHT OF VISCERA.
R.L. Right lung.
R.K. Right kidney.
L. Liver.
P.L. Pleura.

has the power of throwing out an abundant exudation, the cellelements of which are actively phagocytic.

The reflection of the peritoneum and its relations to the various organs have been fully described in the section on the Digestive System.

The attachment of the transverse mesocolon to the posterior abdominal wall is at the level of the second lumbar vertebra, and lies, therefore, a little above the infracostal plane. The attachment, which ascends slightly as it passes from right to left, crosses the right kidney, the descending part of the duodenum, and the head of the pancreas, after which its attachment follows the superior border of the pancreas. The peritoneal subdivision above this attachment is roofed in by the diaphragm, and includes the superior part of the great sac, and, behind it, the larger portion of the omental bursa. The organs related to this area of the peritoneum are the liver, along with the bile-ducts and gallbladder, the stomach and part of the duodenum, the spleen, the pancreas, the upper parts of the kidneys, and the suprarenal glands. Suppuration connected with any of these organs is liable to spread upwards under the cupola of the diaphragm, producing what is known as subphrenic abscess.

The attachment of the mesentery of the small intestine extends from the left side of the second lumbar vertebra downwards to the right iliac fossa. The attachment may be mapped out on the surface by drawing a line from a point on the transpyloric line, one inch to the left of the median plane, to the mid-point of a line drawn horizontally between the right superior anterior iliac spine and the median plane.

Subdivisions of the Peritoneal Cavity.-From the surgical point of view the peritoneal cavity may be arbitrarily divided into four great subdivisions : namely, a supracolic, a right infracolic, a left infracolic, and a pelvic. All these subdivisions communicate freely with one another behind the anterior abdominal wall, as well as on each side, along the gutter-like channels in the loins. It is along these lateral gutters that pus readily makes its way from the upper part of 


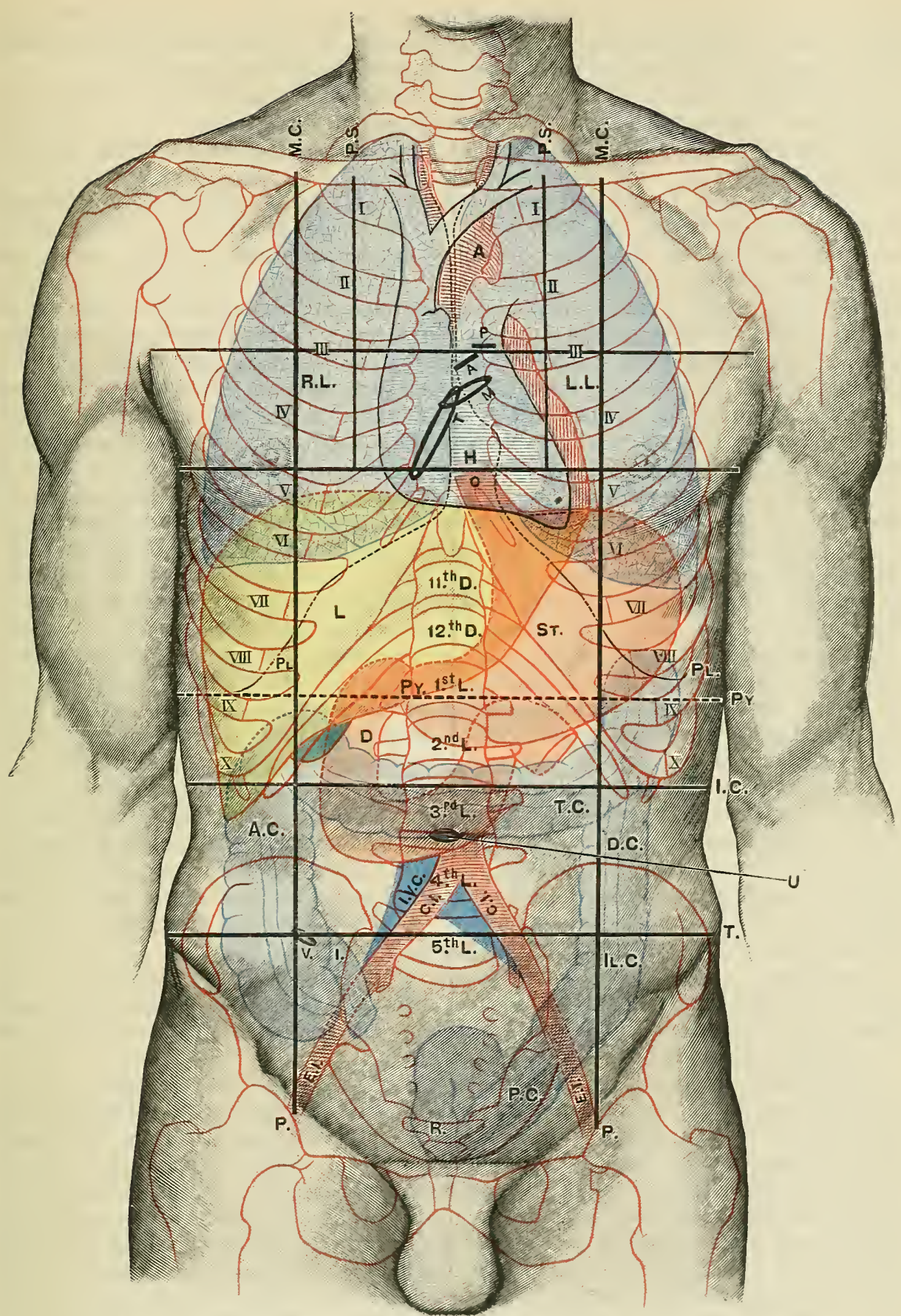

Fig. 1103.-Anterior Aspect of Trunk, Showiyg Surface Topography of Viscera.

M.C. Mid-clavicular line.

P.S. Para-sternal line.

$\mathrm{P}$. Inguinal vertical line.

I.C. Infra-costal line.

T. Intertubercular line.

Py. Transpyloric line of Addison.

A. Aorta.

H. Heart.

P. Pulmonary orifice.

A. Aortic orifice.

M. Mitral orifice.
T. Tricuspid orifice.

R.L. Right lung.

I.L. Left Lung.

Pl. Pleura.

L. Liver.

o. Esophagus.

St. Stomach.

Py. Pylorus.

I. Duodenum.

I. Ileum.

V. Valve of the colon.
A.C. Ascending colon.

T. C. Transverse colon.

D.C. Descending colon.

Il.C. Iliac colon.

P.C. Pelvic colon.

R. Rectum.

C.I. Common iliac artery.

E.I. External iliac artery.

I.V.C. Inferior vena cava.

U. Unbilicus. 
the abdomen along the lumbar regions into the iliac regions, and thence into the pelvis: and, on the other hand, the pus may ascend from the pelvis along the same channels, especially when the patient is in the recumbent posture.

The highest (subphrenic) region of the supracolic compartment is further subdivided into a right and left portion by the falciform ligament. .

The omental bursa may be looked upon as a diverticulum of the first-mentioned subdivision.

The subphrenic lymph plexus communicates, by means of lymph vessels which pierce the diaphragm, with the subpleural plexus on its superior surface; hence pus confined under tension in either of these spaces is liable to give rise to secondary infection of the corresponding pleural cavity. By adhesions of the transverse colon and greater omentum to the anterior abdominal wall, the supracolic subdivision of the peritoneal cavity may become more or less completely shut off from the rest of the abdomen. Suppuration in the right half of the phrenicocolic subdivision is generally secondary to leakage from an ulcer of the first part of the duodenum or to disease of the gall-bladder and bile-ducts; while the left half of the space is more usually infected from the stomach. The best method of draining the supracolic subdivision of the peritoneal cavity is to pass a tube through the hepato-renal pouch of Morrison. The entrauce to this pouch lies lateral to the gall-bladder between the inferior margin of the liver above and the right flexure of the colon below. The bottom of the pouch is formed by the reflection of the peritoneum from the superior part of the kidney on to the fascia transversalis covering the aponeurosis of origin of the transversus abdominis muscle below the tip of the twelfth rib. To drain it, a tube is introduced into it either from the wound in the anterior abdominal wall, or, still better, through a puncture opening made through the loin lateral to the kidney, in the angle between the twelfth rib and the lateral border of the sacro-spinalis muscle. Another drainage route is by a tube passed from the wound in the anterior abdominal wall into the omental bursa, through either the gastro-hepatic ligament or the great omentum.

The right infra-colic subdivision lies above and to the right of the mesentery of the small intestine. It is bounded, above, by the right and middle two-thirds of the transverse colon and the corresponding part of its mesentery, while laterally it is limited by the cæcum and ascending colon. At its right inferior angle are the ileo-cæcal junction and the vermiform process; at its right upper angle is the right flexure of the colon, while at its left upper angle is the inferior part of the duodenum, crossed by the superior mesenteric vessels.

The organs related to this subdivision are, in addition to the parts of the large intestine already mentioned, coils of small intestine, the inferior third of the right kidney, the right ureter, the inferior half of the descending and the horizontal part of the inferior portions of the duodenum.

Suppuration in connexion with the organs in this area involves more especially the right lumbar region, and may extend upwards along the colon into the subdiaphragmatic region, or downwards into the pelvis minor. To drain this region a tube is introduced into the right lumbar region either through the anterior abdominal wall or through a stab-wound in the loin lateral to the ascending colon.

The left infra-colic subdivision, which lies below and to the left of the mesentery, narrows as it passes upwards and reaches to a higher level than the right infra-colic subdivision. Inferiorly, it is directly continuous at the superior aperture of the pelvis with the peritoneal cavity of the pelvis minor. Above, it is bounded by the left third of the transverse colon and its mesentery, and, still more posteriorly, by the inferior surface of the body of the pancreas; laterally it is bounded by the descending and iliac portions of the colon. At its right upper angle is the duodenojejunal flexure, lying immediately to the left of the vertebral column, in the angle between it and the inferior surface of the pancreas. At its left superior angle is the left flexure of the colon, while at its left inferior angle is the junction of iliac with pelvic colon. This subdivision of the peritoneal cavity, in addition to containing the majority of the coils of the small intestine, is related to the inferior third of the left kidney, the left ureter, the lower part of the abdominal aorta and vena cava, and the inferior mesenteric and common iliac vessels. Drainage of this 
subdivision may be established through the left loin, or by a tube introduced down to the bottom of the pelvis, namely, into the recto-vesical pouch in the male, and into or through the recto-vaginal pouch (pouch of Douglas) in the female.

On account of the oblique manner in which the mesentery proper is attached to the posterior abdominal wall, it follows that in order to examine the organs related to the right infra-colic subdivision of the abdomen, the coils of small intestine should be displaced downwards and to the right, while to investigate the left infra-colic subdivision they should be carried upwards and to the right.

\section{ABDOMINAL VISCERA.}

Liver.-The anterior margin of the liver, as it crosses the costal angle, can readily be determined by palpation and light percussion; it passes from the eighth left to the tip of the tenth right costal cartilage, and crosses the median plane at the level of the transpyloric line. In the mid-axillary line it reaches down to a point a little below the most inferior part of the tenth right costal cartilage. Above the left costal margin the anterior margin passes upwards and to the left to join the left border of the liver at the fifth interspace in the mammary line. The highest part of the liver, which corresponds also to the highest part of the right arch of the diaphragm, reaches, during expiration, to the level of the fourth intercostal space in the mammary line. To the right of the median plane the superior surface of the liver is too far removed from the anterior wall of the chest, and overlapped by too thick a layer of lung substance, to be accurately determined by percussion. Behind the sternum the superior surface reaches to the level of the sixth chondrosternal junctions. To the left of the median plane the superior limit of the liver cannot be determined by percussion since it merges into the cardiac dulness. The base or right lateral surface extends from the level of the seventh to the level of the eleventh rib in the mid axillary line and is separated by the diaphragm from the lower part of the right lung and pleura.

The falciform ligament of the liver lies, as a rule, a little to the right of the median plane.

The anterior surface of the liver may be reached throngh a median incision, extending downwards from the diphoid process, or by an oblique incision, a finger's breadth below and parallel to the right costal margin. To obtain free access to the superior surface the eighth and ninth costal cartilages must be resected; the seventh cartilage should, if possible, be avoided; otherwise the pleural cavity may be opened into. Division of the round and falciform ligaments allows of greater downward displacement of the liver. To reach the upper part of the lateral surface of the right lobe, portions of the seventh and eighth ribs should be resected in the midaxillary line, and both the pleural and peritoneal cavities must be traversed.

Gall-Bladder.-The relation of the fundus of the gall-bladder to the surface of the body is subject to considerable variation. Normally it is situated behind the angle between the ninth costal cartilage and the lateral border of the rectus; exceptionally, it is pendulous and suspended from the liver by a more or less distinct mesentery; or it may be elongated and drawu downwards by adhesion to the duodenum or colon. When displaced downwards it is liable to be mistaken for a movable kidney, but may be distinguished from it by the fact that although it may be pushed backwards into the lumbar region it returns at once to its habitual position, immediately behind the anterior abdominal wall, as soon as it ceases to be manipulated.

The cystic duct is enclosed in the right extremity of the superior border of the gastro-hepatic ligament. It is about an inch and a half in length, is sharply bent upon itself close to its origin at the neck of the gall-bladder. It joins the hepatic duct at a very acute angle. The passage of a probe along the normal duct is rendered difficult by the marked flexure at its commencement, as well as by the folded condition of its mucous membrane; hence also the frequency with which calculi become impacted at the neck of the gall-bladder. In excising the gall-bladder, it is an advantage to ligature and divide the cystic artery and duct before proceeding to detach the organ from the inferior surface of the liver. 
The bile-duct, about three and a half inches in length, lies, in its superior third, close to the right free border of the gastro-hepatic ligament. When cutting into this, the most accessible part of the duct, it should be drawn forward by the finger introduced behind it, through the epiploic foramen; the portal vein, which must be aroided, lies posterior and a little to the left of the duct. The middle third of the duct lies a little to the right of the commencement of the gastroduodenal artery behind the superior part of the dnodenum about a finger's breadth from the pyloro-duodenal junction. The inferior third of the duct, which passes downwards and to the right, is intimately related to the pancreas; in about two out of three instances it is so embedded in the posterior aspect of its head that it cannot be freed by blunt dissection. Close to its termination the duct is joined by the main pancreatic duct of Wirsung, the two opening separately, but close together, at the bottom of a diverticulum, which pierces the wall of the duodenum obliquely, and opens at the summit of a small papilla situated at the inferior part of the medial wall of the descending part of the duodenum, about four inches from the pylorus. When a calculus becomes impacted in the ampulla there is retention of the pancreatic as well as of the biliary secretion. Frequently, however, the gland possesses an accessory pancreatic duct (duct of Santorini) which opens into the duodenum at a higher level than the main duct, with which it also communicates. A calculus in the ampulla may be reached either by opening the duodenum from the front (trans-duodenal route), or by freeing the duodenum and gaining access to the duodenum from behind (retro-duodenal route). In the latter instance an incision is made, lateral to the right border of the descending part of the duodenum, through that portion of the peritoneum which passes upwards and to the right from the superior layer of the transverse mesocolon, over the superior part of the pars descendens of the duodenum on to the anterior surface of the right kidney. By blunt dissection directed medially behind the duodenum, this organ, along with the adjacent part of the head of the pancreas, can be separated from the kidney and vena cava, and folded over towards the left like a door on its hinges. In freeing the bile-duct from the posterior aspect of the head of the pancreas a vein of considerable size will be encountered; this vein, which returns the blood from the pancreatic-duodenal system of arteries, lies close to the bile-duct as it ascends behind the head of the pancreas to open into the commencement of the vena portæ. Of the lymph glands related to the bile passages it is to be remembered that one lies at the neck of the gall-bladder, another at the junction of the cystic and hepatic ducts, while a third lies close to the termination of the bile-duct. When these glands are enlarged and indurated, care must be taken not to mistake them for impacted gall-stones.

Stomach.-The stomach lies almost entirely within the left half of the epigastric region and in the left hypochondriac region. The cardiac orifice, which lies 1 in. below and to the left of the osophageal opening in the diaphragm, is about 4 in. from the surface, and corresponds, on the anterior surface of the body, to a point over the seventh left costal cartilage 1 in. from the median plane. The pylorus, which is generally partly overlapped by the anterior margin of the liver, lies in, or a little to the right of the median plane; when the stomach is empty it generally lies in the median plane, when distended it may reach two, or even three inches to the right of the median plane. Passing from the superior to the inferior border of the pylorus opposite its junction with the duodenum is the anterior pyloric vein of Mayo. This vein affords a useful visible guide to the position of the pylorus. Another guide is furnished by the ring-like thickening of the pyloric sphincter which projects into the commencement of the duodenum (like the cervix uteri into the vagina), and can be readily palpated through its thin wall. The pyloric portion of the stomach is practically bisected by a horizontal plane which passes through the abdomen at the level of a point midway between the jugular notch of the sternum and pubic symphysis (Addison); it lies, therefore, three to four inches below the infra-sternal notch, midway between it and the umbilicus, opposite the first lumbar vertebra. The highest part of the fundus of the stomach corresponds to the left vault of the diaphragm, and lies at the level of the fifth rib in the mammary line, a little above and behind the 
apex of the heart. The greater curvature crosses behind the left costal margin opposite the tip of the ninth costal cartilage, that is to say, where the transpyloric line intersects the vertical inguinal line. The lowest part of the great curvature, situated generally in the median plane, extends down to, or a little above, the infracostal plane, about two inches above the umbilicus. The lesser curvature and the adjacent part of the anterior wall of the stomach are overlapped by the anterior margin of the liver.

Radiography of Stomach. - Radiograms of the stomach, taken after a "bismuth meal," show that the form and position of the stomach in the living subject differ considerably from that which it presents in the cadaver.

In the cadaver, owing to loss of muscular tone, it presents itself as a more or less empty pear-shaped bag with collapsed and flaccid walls. The same applies to a large extent to the stomach as seen in the operating room, its normal tonicity being almost entirely held in abeyance by the anæsthetic.

In the living subject, the form and position of the stomach are found to vary not only according to the amount of food it contains, but also according to whether the patient occupies the erect or the recumbent posture. The most reliable as well as the most useful, information regarding the form, the position, and the motor activity of the stomach is obtained by "screen" examinations and radiograms taken with the patient in the erect posture. When examined in this way, after partly filling the stomach with a "bismuth meal," the organ is seen to possess a distinctly $\mathrm{J}$-shaped form. The stem of the $\mathrm{J}$, which is represented by the body of the stomach, lies immediately and entirely to the left of the vertebral column. The fundus, which is slightly more expanded than the body, reaches up to the left cupola of the diaphragm; it is represented in the skiagram as a light semilunar shadow, the horizontal inferior margin of which corresponds to the superior limit of the bismuth. This clear semilunar area is due to the rising up of the gaseous contents of the stomach to the highest part of the cavity. The cardiac orifice is seen to lie opposite the left side of the fibro-cartilage between the tenth and eleventh thoracic vertebræ. The shadow of the curved pyloric portion of the stomach, after crossing the left side of the vertebral column opposite the third and fourth lumbar vertebra, ascends as the pyloric canal to join the duodenum at or a little to the right of the median plane, opposite the second (not infrequently the third) lumbar vertebra. The pylorus itself is represented by a light disc due to a break in the continuity of the bismuth, caused by contraction of the pyloric sphincter. The lowest portion of the greater curvature, which generally lies at or a little to the left of the median plane, reaches, in the erect posture, down to the level of the middle or inferior border of the fourth lumbar vertebra, or, in other words, to the umbilicus and the highest part of the iliac crest.

As more food enters the stomach its capacity is increased by lateral expansion rather than by any elevation of its fundus or downward expansion of its greater curvature. The normal tonic action of the gastric muscle is able to hold up the meal against the action of gravity to the level of the cardiac orifice.

When, as not infrequently happens, the normal muscular tonicity of the stomach is lost, the bismuth meal is no longer held up against the action of gravity, but at once sinks to the most dependent part of the stomach where it lies as in a flaccid sac, and gives rise to a crescentic shadow which may reach down almost, or even quite, to the level of the pubes.

In gastroptosis, and in general visceroptosis, the whole stomach may be displaced downwards without any great loss of its tonicity.

During a "screen" examination after a bismuth meal, the peristaltic movements of the stomach can be seen to pass in distinct wave-like indentations from left to right along the greater curvature, and to increase in force as they approach the pylorus.

When the stomach is hypertrophied and dilated, as a result of pyloric obstruction, the peristaltic waves are more pronounced, and the bismuth shadow extends well over to the right of the median plane, owing to the dilated pyloric antrum and pyloric canal being carried over to the right, in front of the superior part of the duodeuum. The stomach tends, therefore, to lose its somewhat J-shaped 
tubular form, and the axis of its body becomes more oblique. In the infant and young child the stomach is flask-shaped rather than $\mathrm{J}$-shaped, and its axis is less vertical than in the adult. The elongated form of the adult stomach is acquired as a result of the erect posture.

It must be remembered that the only really fixed part of the stomach is the region of the cardia, so that the form and position of the organ may be considerably intluenced by the condition of the neighbouring organs. For example, it may be displaced downwards and to the left by enlargement of the liver, upwards by distension of the intestines, and to the right by distension of the left colic flexure.

Overlying the stomach is an important surface area known to clinicians as the semilunar space of Traube. This space, which yields a deeply tympanitic note on percussion, is bounded above by the inferior margin of the left lung; below, by the left costal margin; to the right, by the anterior margin of the left lobe of the liver; behind and to the left, by the anterior border and anterior basal angle of the spleen. The line of the costo-diaphragmatic pleural reflection crosses the space about midway between its superior and inferior limits. The tympanitic area of the space is diminished superiorly by pleuritic effusion, towards the right by enlargement of the liver, and towards the left by enlargement of the spleen.

Perforation of an ulcer on the anterior wall of the stomach leads to extravasation into the greater sac of the peritoneum, while if the perforated ulcer is on the posterior wall, extravasation takes place into the omental bursa. The close relation of the splenic artery and its branches to the posterior wall of the stomach explains the severe hæmorrhage which is sometimes caused by a posterior gastric ulcer. The surgeon may reach the posterior wall of the stomach through the gastro-colic ligament, or, after throwing upwards the greater omentum and transverse colon, by traversing the transverse mesocolon; by the former route the posterior wall of the stomach is reached through the anterior wall of the omental bursa, in the latter through its posterior wall.

When a partial resection of the stomach for malignant disease is performed, the bleeding is controlled by ligaturing the main vessels at an early stage of the operation. These are the right and left gastrics at the lesser curvature, the gastroduodenal behind the first part of the duodenum, and the right and left gastroepiploics at the greater curvature. The left gastric should be ligatured as near the cardia as possible so that the whole chain of lymph glands along the lesser curvature may be removed. Care is taken to remove also all the glands which lie behind the first part of the duodenum in relation to the gastro-duodenal artery and head of the pancreas, as well as those along the right half of the greater curvature in relation to the right gastro-epiploic artery. If the disease has spread to the retro-peritoneal lymph glands, surrounding the cœliac artery, above the pancreas, the chances of a permanent recovery are very remote.

In the classical "no-loop" gastro-enterostomy operation a longitudinal opening in the commencement of the jejunum is anastomosed by suturing it to an opening in the posterior wall of the stomach, near the greater curvature. The jejunum is applied to the stomach in such a way that it maintains its normal direction, namely, obliquely upwards and to the left. To bring the surfaces of the two organs in contact, surgeons are in the habit of protruding the posterior wall of the stomach through an opening made in the transverse mesocolon, on the proximal side of the arch formed by the middle and left colic arteries. A better plan, however, is to make an opening also into the omental bursa through the gastro-colic ligament a little below the gastro-epiploic vessels, and then to bring the jejunum into contact with the posterior wall of the stomach by pushing it (the jejunum) upwards through the opening in the transverse mesocolon. By this plan the posterior wall of the stomach along with the jejunum can be protruded through an opening in the gastro-colic ligament, and can be more easily delivered out of the abdominal cavity.

When the posterior wall of the stomach and transverse colon are held down by adhesions, a long loop of jejunum is brought up in front of the greater omentum and transverse colon and anastomosed to the anterior wall of the stomach.

The Duodenum.-The duodenum is the widest, thickest, and most fixed part 
of the small intestine. For descriptive purposes it is divided by anatomists into three parts. From the surgical standpoint it may with advantage be subdivided into a supra-colic and an infra-colic portion, the former, comprising the superior and the upper half of the descending part, being situated above the attachment of the transverse mesocolon; while the latter, comprising the lower half of the descending part along with both subdivisions of the third part, being situated below this attachment. To expose the supra-colic portion the greater omentum and the transverse colon must be pulled downwards, while to expose the infra-colic portion they are thrown upwards along with the transverse mesocolon.

The first portion proper (pars superior) lies in the right part of the epigastric region medial to the gall-bladder, where it is overlapped by the quadrate lobe of the liver. As regards its blood-supply, it occupies the frontier zone between the cœliac and superior mesenteric vascular areas, and the vessels which supply it vary considerably in their size and mode of origin.

This peculiarity of its blood-supply may partly account for the relative frequency with which this portion of the intestine is found to be the seat of ulceration. The first inch or so the duodenum possesses some degree of mobility, being surrounded by the same two layers of peritoneum which invest the stomach. Beyond this it is in direct contact posteriorly and inferiorly with the pancreas, while descending behind it are the common bile-duct and the gastro-duodenal artery. The relations must be borne in mind in performing the operation of pylorectomy. When an ulcer of the superior part perforates, extravasation takes place, in the first instance, into the supra-colic compartment of the peritoneum, thence into its hepato-renal pouch, and subsequently down along the ascending colon into the right iliac fossa,-hence the possibility of mistaking the condition for an acute appendicitis. Perforation of the ulcer, however, is often prevented by the duodenum becoming adherent especially to the gall-bladder, to the omentum, or to the transverse colon.

If the finger is passed upwards, backwards, and to the left, immediately above the first part of the duodenum and behind the right free border of the lesser omentum, it will pass through the foramen epiploicum into the omental bursa of the peritoneum.

The second portion of the duodenum (pars descendens) descends in the epigastric and umbilical regions a little medial to the right lateral plane. The attachment of the transverse mesocolon crosses it about its middle, while posteriorly it lies in front of the hilus and medial border of the right kidney, from which it is separated by loose areolar tissue. The procedure necessary to mobilise this portion of the duodenum has been referred to already.

The horizontal portion of the inferior part of the duodenum occupies the superior part of the umbilical region, and crosses the median plane about one inch above a line joining the highest part of the iliac crests; behind its commencement is the superior part of the right ureter.

The ascending portion of the inferior part of the duodenum crosses the infracostal plane, and ascends upon the left side of the vertebral column opposite the second and third lumbar vertebra.

The duodeno-jejunal flexure, which lies in the transpyloric plane one inch to the left of the median plane, is the landmark which the surgeon makes for when he wishes to identify the commencement of the jejunum (Fig. 946, p. 1204). To find the flexure the greater omentum and transverse colon should be thrown upwards and the finger passed along the inferior layer of the transverse mesocolon to the left side of the vertebral column. The flexure lies in the angle or recess formed by the left side of the second lumbar vertebra and the inferior surface of the body of the pancreas. With the finger in this recess the commencement of the jejunum may be hooked forward a little to the left of the superior mesenteric vessels at the root of the mesentery. In connexion with the duodeno-jejunal junction is the inferior duodenal fossa of Jonnesco, formed by a fold of peritoneum which stretches from the left side of the fourth or ascending part of the duodenum upwards to become attached to the peritoneum of the posterior abdominal wall close to the medial border of the left kidney. The free edge of the fold and the mouth of the 
fossa look upwards. This is one of the situations at which an internal hernia sometimes develops, the sac, as it enlarges, extending further and further into the extra-peritoneal tissue on the posterior abdominal wall. Should strangulation occur, the inferior edge of the orifice must be divided in a downward direction, in order to avoid the inferior mesenteric vein which curves round the anterior and superior aspects of the orifice (Treves).

Jejunum and Ileum.-To expose the coils of the jejunum and ileum completely, the greater omentum, along with the transverse colon and the greater curvature of the stomach, must be turned upwards. On account of the oblique attachment of the mesentery, the greater number of the coils lie in the left infra-colic peritoneal compartment, where they extend upwards to the left of the vertebral column as far as the attachment of the transverse mesocolon and the inferior surface of the pancreas; here they lie in front of the inferior pole of the left kidney, in the angle of the left colic flexure.

The only certain means which the surgeon has of distinguishing the superior from the inferior coils of small intestine is by their relation to the duodenojejunal flexure and the ileo-cæcal junction. Occasionally the plicæ circulares
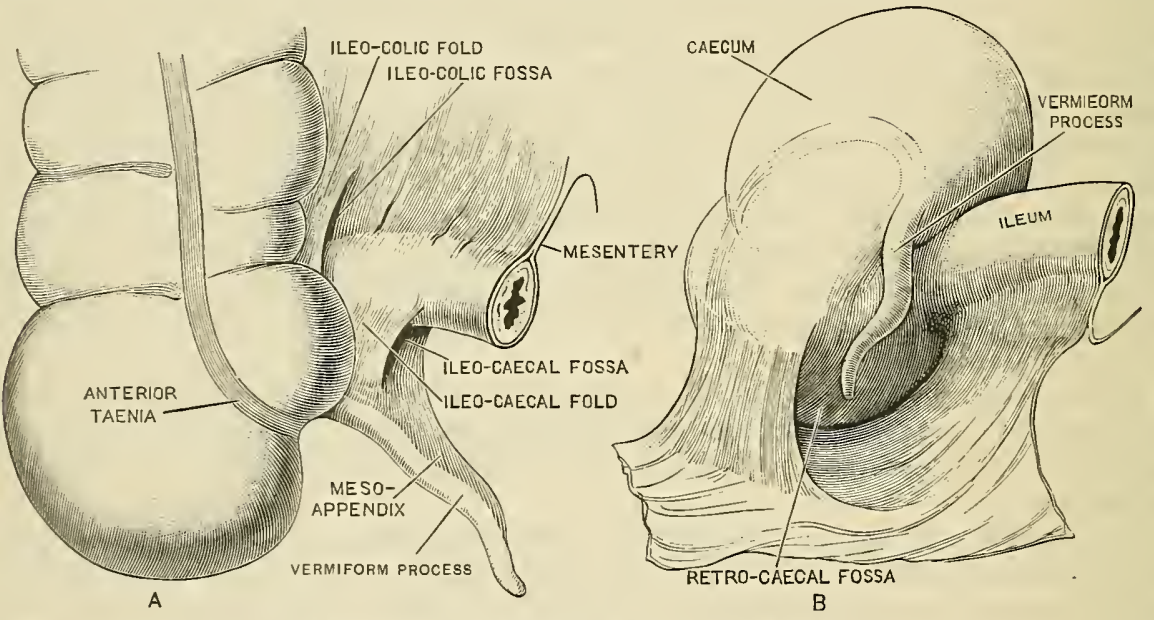

Fig. 1104. - The CACAL Folds and Foss

In $A$, the cæcum is viewed from the front; the mesentery of the vermiform process is distinct, and is attached above to the inferior surface of the portion of the mesentery going to the end of the ileum. In $B$, the cæcum is turned upwards to show a retro-cæcal fossa, which lies behind it, and the beginning of the ascending colon (from Birmingham).

and the aggregated lymph nodules can be seen from the peritoneal aspect and the jejunum and ileum thereby respectively identified. The terminal portion of the ileum, which is attached by the inferior end of the mesentery to the superior part of the right lateral wall of the pelvis minor, crosses over its superior aperture, and ascends along the medial edge of the cæcum before opening into it. The terminal loop of the ileum may be hooked up by passing the finger along the medial side of the cæcum downwards over the medial border of the psoas major and the external iliac vessels into the pelvis minor.

Meckel's diverticulum, which is due to persistent patency of the proximal portion of the vitelline duct, is situated usually from two to three feet above the valve of the colon; its average length is two inches. Springing from the anti-mesenteric border of the ileum, its termination is usually free, but it may be adherent either to the anterior abdominal wall, to the mesentery, or, more rarely, to one of the adjacent viscera. When its termination is fixed it may give rise to strangulation of the intestine.

Cæcum.-The cæcum occupies the right iliac region and extends from the superior anterior spine of the ilium to the superior aperture of the pelvis minor. When empty, it is generally more or less completely overlapped by small intestine, and frequently also by the greater omentum. When partly distended, the cæcum comes 
in contact with the anterior abdominal wall immediately above the lateral half of the inguinal ligament. In the normal condition it is completely surrounded by peritoneum, and can, therefore, along with the vermiform process, be readily delivered out of the abdomen. In chronic constipation, associated with intestinal atony, the cæcum is thin-walled, dilated, abnormally movable, and often prolapses into the pelvis.

The position of the ileo-cæcal valve corresponds, on the surface of the body, to the medial angle between the intertubercular and right lateral lines, while the orifice of the vermiform process is one inch lower. It is to be noted that the lower end of the ileum protrudes somewhat into the cæcum, and that its circular muscular fibres are prolonged into the flaps of the colic valve. Both of these anatomical arrangements favour the occurrence of intussusception. In infants, other predisposing causes are: (1) the relatively rapid enlargement of the lumen of the large intestine as compared with the small; (2) the greater mobility of the crcum; and (3) the frequent presence of a mesentery to the ascending colon.

Vermiform Process.-The vermiform process (O.T. vermiform appendix), which springs from the postero-medial aspect of the cæcum, one inch below the ileo-crcal junction, is provided with a well-developed "meso-enteriole" derived from the posterior aspect of the lowest part of the iliac mesentery. It is this portion of the posterior layer of the mesentery which sometimes develops a band-like thickening, which, by dragging upon the inferior end of the ileum, produces the kink to which attention has been directed by Arbuthnot Lane. The artery of the vermiform process is the only vessel which supplies the process; it occupies the free border of the meso-enteriole and gives off several branches which pass between its two layers to reach the organ. In amputating the vermiform process the artery is ligatured on the proximal side of its first branch in order to control the bloodsupply to the stump of the process. The fact that the vermiform process is supplied by a single artery predisposes it to gangrene should the vessel become thrombosed, or should the circulation in it be interfered with by kinking as a result of adhesions.

The vermiform process will generally be found to pass either upwards and inwards behind the lower end of the ileum, or downwards and inwards so as to overhang the external iliac vessels at the superior aperture of the pelvis minor; less frequently it ascends in the pouch behind the commencement of the ascending colon. When, as not infrequently happens, the retro-cæcal fossa is prolonged upwards to form a pouch behind the colon, the vermiform process almost invariably ascends into it, and should it be diseased, it may give rise to a retro-cæcal abscess. The abscess may perforate the posterior wall of the cæeum, or it may ulcerate through the posterior peritoneum; in the

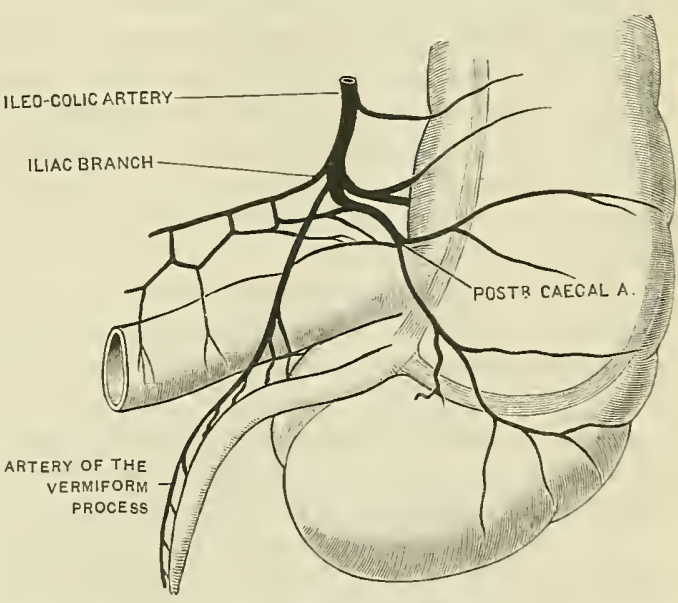

Fig. 1105.-The BLOOd-Suppty of THE Cactu ANd TERMIFORM PROCESS.

The illustration gives a view of the cæcum from behind. The artery of the vermiform process, and the three tænia coli springing from the base of the process, should be specially noted (modified by Birminghan from Jomnesco).

latter case the suppuration may spread upwards, in the loose fatty sub-peritoneal tissue behind the colon, into the lumbar and perinephric regions; and it may reach even the under surface of the diaphragm and form a subphrenic abscess. When, in the course of its development, the creum has failed to complete its descent, the vermiform process may lie in the lumbar region in relation to the inferior pole of the lidney. When it dips downwards into the pelvis minor it may become adherent to the pelvic colon, the rectum, or the bladder, and in the female to the nterine tube or the ovary. To find the rermiform process, the best plan 
is simply to pull the cæcum out of the wound, and if the parts are normal the process will be delirered along with it; if, on the other hand, the crecum and rermiform process are tacked down by adhesions, the vermiform process is best discorered by following the anterior tænia coli to the root of the process.

Ascending Colon.-The ascending colon, after crossing the iliac crest, lies deeply in the right lumbar region upon the fascia covering the quadratus lumborum and the adjacent aponeurotic origin of the transversus abdominis. Between the bowel and the fascia is a quantity of loose cellular tissue and fat, which may be the seat of a large abscess, secondary, (1) more especially, to disease of the colon itself, (2) to disease of a retro-colic vermiform process, or (3) to disease of the right kidney. This cellular tissue is directly continuous above with a thin layer lining the inferior surface of the diaphragm; hence the suppurative process may extend upwards, giving rise to one form of subphrenic abscess. In some cases the ascending colon is completely surrounded by peritoneum, and it may even be provided with a distinct mesentery. The latter condition is almost invariably present in infants suffering from extensive ileo-crcal intussusception. After the invagination has been reduced the mesentery proper is seen to be continuous, through the ascending mesocolon, with the mesentery of the transverse colon.

In order to resect the ascending colon the surgeon mobilises it by dividing the peritoneum along its line of reflection from the lateral aspect of the colon on to the abdominal wall. The colon, along with the posterior peritoneum medial to it, is then stripped, from the lateral side towards the median plane, off the quadratus lumborum, the psoas, and the inferior pole of the right kidney. While this is being done, the branches of the ileo-colic and right colic vessels which pass laterally to supply the gut are secured, and the lymph vessels and associated lymph glands are removed along with the bowel. As the peritoneum is stripped off, care must be taken not to injure the important structures which lie behind it, namely, the duodenum; the ureter, and the spermatic vessels.

The flexura colica dextra reaches upwards beneath the tenth costal cartilage into the most inferior part of the right hypochondrium, where it lies immediately to the right of the gall-bladder, between the liver and the inferior half of the anterior surface of the kidney. Posteriorly, it is separated from the anterior surface of the right kidney by a quantity of loose cellular tissue; hence by dividing the peritoneum to the right side of the flexure it can readily be mobilised and separated from the kidney.

Transverse Colon. - The transverse colon crosses the lower part of the umbilical region immediately below the greater curvature of the stomach. In cases of chronic constipation it may form a $U$-shaped or $V$-shaped loop, extending down to the level of the pubes. When this is the case the natural kinking at the right and left colic flexures become more acute, and tend, therefore, to aggravate the constipation. In such cases the right and left portions of the transverse colon often lie parallel and close to the ascending and descending colon, respectively, like the barrels of a gun.

The transverse colon receives its blood-supply from the arch formed by the middle and left colic arteries. The arch lies in the posterior wall of the bursa omentalis between the two layers of the transverse mesocolon. In resecting portions of the stomach for malignant disease, the surgeon removes also the glands which lie between the two layers of the gastro-colic ligament in relation to the right gastro-epiploic vessels. At this step of the operation care must be taken not to endanger the blood-supply of the transverse colon by injuring the middle colic artery.

The left colic flexure is more acute and more fixed than the right flexure; and it is situated at a higher level as well as more deeply. A tumour originating in this portion of intestine lies generally under cover of the left costal margin, and is therefore difficult to palpate. To expose the left colic flexure, the omentum along with the transverse colon and the body of the stomach is turned upwards. To mobilise it for the purpose of resection the surgeon must divide: (1) the phrenicocolic ligament, which attaches it to the diaphragm opposite the eleventh rib; (2) the left border of the greater omentum, which attaches it to the stomach; and (3) the left portion of the transverse mesocolon, which attaches it to the left extremity of the pancreas. 
Descending Colon.-The descending colon, like the ascending, is deeply placed in the lumbar region and is related to the inferior half of the lateral border of the left kidney. It is less frequently provided with a mesentery than is the ascending colon.

Iliac Colon.-The iliac colon commences at the junction of the posterior and middle thirds of the iliac crest, and ends at the superior aperture of the pelvis minor by joining the pelvic colon. It possesses no mesentery and is connected to the fascia covering the iliacus and psoas major muscles by loose areolar tissue. Towards its termination it turns inwards immediately above and parallel to the inguinal ligament, and at its junction with the pelvic colon it lies in front of the external iliac artery. Although, as a rule, it is entirely overlapped by coils of small intestine, it can frequently be felt by firm palpation at the lateral part of the left iliac fossa, because its muscular wall is comparatively thick and generally contracted.

Pelvic Colon.-The pelvic colon, in consequence of possessing a well-cleveloped mesentery, forms a freely movable loop which, though usually confined to the pelvis minor, may, when distended, rise well up into the abdomen. It is this section of the large intestine which is opened for the purpose of making an artificial anus in malignant disease of the rectum.

The pelvic colon varies considerably in length, the average being sixteen or seventeen inches. It is relatively longer and of greater calibre in the child than in the adult. It is the part of the large intestine especially involved in the condition known as megalocolon or Hirschsprung's disease-a congenital abnormality in which the large intestine is greatly dilated and hypertrophied.

When the pelvic colon is thrown upwards and to the right so as to spread out its mesentery, the latter is seen to be attached in an inverted $V$-shaped manner to the posterior wall of the pelvis. At the apex of the $V$ is a small peritoneal pouch the (inter-sigmoid fossa), situated just in front of the ureter as it crosses the termination of the common iliac artery to enter the pelvis minor. This fossa is one of the situations at which an internal retro-peritoneal hernia may originate. The mouth of the fossa looks downwards and to the left, while above and to its right is the sigmoid artery. The fossa affords a guide to the commencement of the pelvic portion of the left ureter. On account of the $V$-shaped attachment of this mesentery it is convenient to speak of the pelvic colon as possessing an ascending or proximal and a descending or distal limb. At the junction of the proximal limb with the termination of the iliac colon is a more or less well-marked flexure (the "last kink" of Arbuthnot Lane). It is to the proximal limb of the pelvic colon that the divided inferior end of the ileum is anastomosed in the short-circuiting operation of ileo-sigmoidostomy.

In the author's operation of transplanting the ureters into the large intestine for incontinence of urine, the result of epispadias in the female, and of ectopia vesice in either sex, the left ureter is implanted into the ascending limb of the pelvic colon and the right ureter into its descending limb.

By dividing the attachment of the mesentery of the pelvic colon in the operation of excision of the rectum, the pelvic colon may be mobilised sufficiently to allow of its being brought down and sutured to the skin in the sacral region or even to the anal region. Further, the mobility of the pelvic colon is such that after resection of the descending and iliac colon and mobilisation of the left colic flexure, the divided ends of the bowel can be sutured together without undue traction.

After operations on the female genital organs by the abdominal route-for example, after abdominal hysterectomy - the surgeon makes use of the pelvic colon and its mesentery by spreadiug them ont over the pelvis so as to roof it in, and so prevent any of the coils of small intestine from becoming adherent in the pelvis.

Kidneys. - The kidneys lie behind the peritoneum, and extend higher up than is often supposed, and laterally they do not extend so far away from the rertebral column as is almost invariably depicted; hence it is that, unless enlarged, the kidneys can seldom be felt through the abdominal wall. The right kidney as a rule lies a 


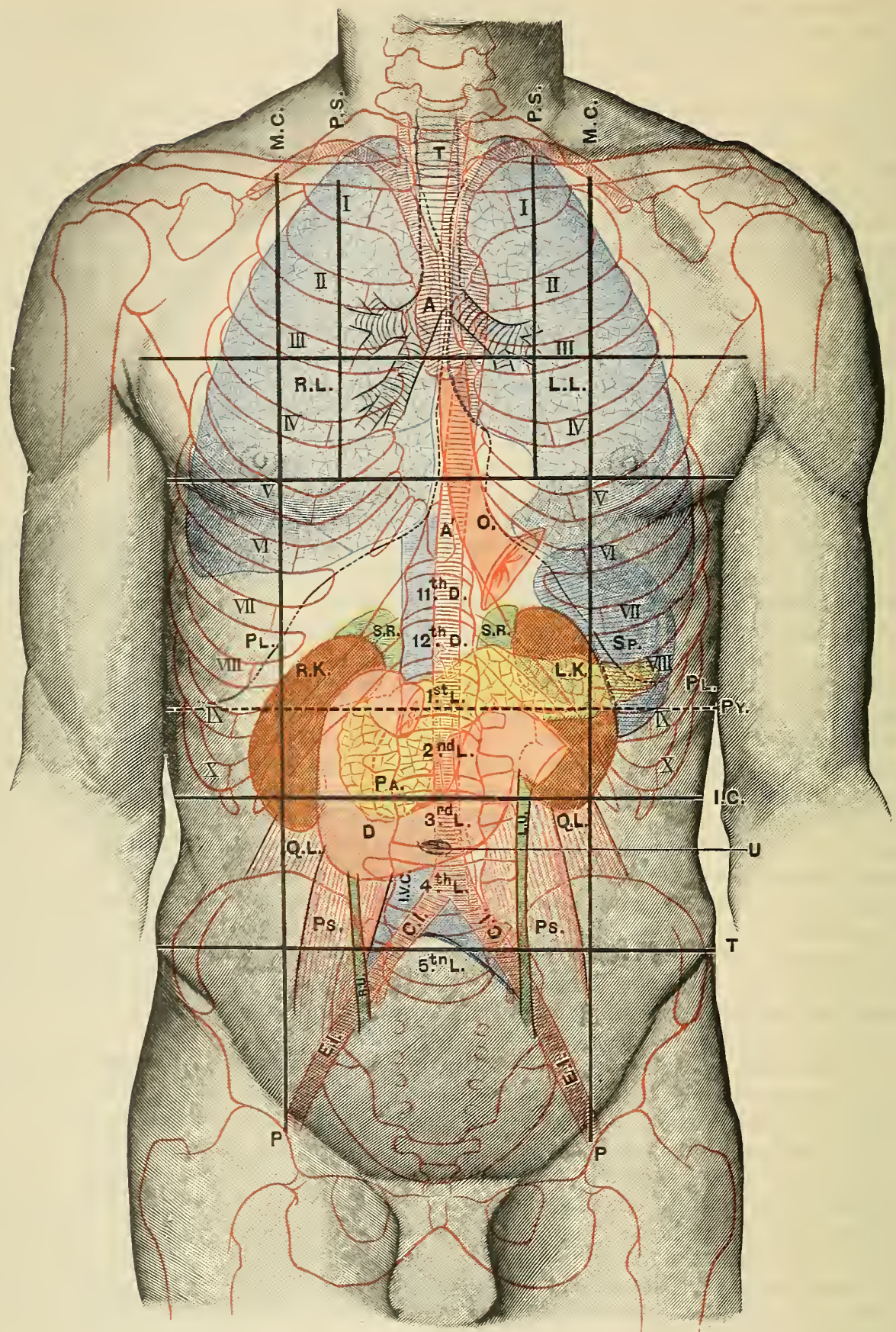

Fig. 1106.-Anterior Aspect of Trunk, showing Surface Topography of Viscera.

M. C. Mid-clavicular line.

P.S. Para-sternal line.

P. Inguinal vertical line.

I.C. Infra-costal line.

T. Inter-tubercular line.

Py. Transpyloric line.

T. Trachea.

A. Aorta.

R. L. Right lung.
L. L. Left lung.

Pl. Pleura.

O. Esophagus.

R.K. Right kidney.

L.K. Left kidney.

Sp. Spleen.

S. R. Suprarenal gland.

$\mathrm{Pa}$. Pancreas.

D. Duodenum.
Q.L. Quadratus lumborun.

Ps. Psoas major.

R.U. Right ureter.

L.U. Left ureter.

C.I. Common iliac artery.

E.I. External iliac artery.

I. T.C. Inferior rena cava.

U. Umbilicus. 
little lower than the left, as well as a little further away from the median plane. The hilus of the right kidney lies 2 in: from the median plane; that of the left $1 \frac{1}{2}$ in. from the median plane. For practical purposes the hilus of the kidney may be regarded as opposite a point on the anterior abdominal wall a finger's breadth medial to the tip of the ninth costal cartilage; and a line joining the two hili crosses the vertebral column opposite the fibro-cartilage between the first and second lumbar vertebræ, that is to say, a little below the transpyloric line. The highest point of the kidney is situated two inches from the median plane, on a lerel with a line crossing the abdomen midway between the xiphisternal and transpyloric planes. The lovest point of the kidney reaches down to, or a little below, the infra-costal plane.

The student should make himself familiar with the feel of the parts in relation to the kidneys, as far as they can be made out by introducing the hand through a median abdominal incision.

The superior half of the anterior surface of the right kidney is felt, at the bottom of the hepato-renal peritoneal pouch, by passing the hand deeply into the right hypochondrium, between the anterior margin of the liver and the right flexure of the colon. The inferior half is palpated by passing the hand deeply into the highest part of the right infra-colic peritoneal cornpartment; its free peritoneal surface lies in the angle of the right flexure of the colon. The second portion of the duodenum overlaps both the supra- and infra-colic portions of the medial border of the right kidney. When the right kidney is excised by the abdominal route, the peritoneum is divided lateral to the ascending colon and right colic flexure, and these structures, along with the descending part of the duodenum, are stripped off the organ in a medial direction, until the hilus and the renal vessels are reached.

The left kidney is crossed transversely, about its middle, by the body of the pancreas and the splenic vessels. To palpate the supra-pancreatic portion, the hand is passed through the left portion of the gastro-colic ligament, upwards behind the stomach, into the superior part of the omental bursa. The spleen will be felt to overlap the lateral border of the kidney. To palpate the infra-pancreatic portion of the organ, which is covered by the peritoneum continued downwards from the attachment of the inferior layer of the transverse mesocolon, the hand is passed deeply into the upper part of the left infra-colic peritoneal compartment as far as the angle of the left flexure of the colon. This area of the kidney is overlapped by coils of small intestine, while passing transversely outwards in front of it are the left colic artery and its branches. When the left kidney is excised by the transperitoneal route, the left colic flexure and the descending colon are mobilised by dividing the peritoneum lateral to them so as not to injure the left colic artery.

In addition to their true fibrous capsules, the kidneys are surrounded by and enveloped in a well-marked fatty capsule. Outside this perinephric fat is a more or less well-defined fibrous envelope, known as the renal fascia or fascia of Gerota, which forms, as it were, a sheath to the organ. Hence, just as in the case of the prostate and thyreoid glands, the kidney possesses, in addition to its true capsule, a sheath derived from the neighbouring fasciæ. The anterior and posterior layers of the sheath remain distinct at the medial border of the kidney and are prolonged, the one in front of, and the other behind the renal vessels. The two layers remain separate also for some distance below the inferior pole of the kidney, and it is into this downward extension of the fascial compartment that the kidney descends in the condition known as movable kidney. Above and laterally the sheath joins the fascial lining of the diaphragm and transversus muscles respectively. Outside the perinephric fascia is a second layer of fat sometimes spoken of as the paranephric fat.

When the inferior pole of the kidney receives a special blood supply, either directly from the aorta, or from the renal artery, the abnormal vessel may, by passing either in front or behind the superior part of the ureter, cause the latter to be so kinked over the vessel as to cause a secondary hydronephrosis.

Brodel has shown that the branches of the renal artery are distributed to the cortex of the kidney in an anterior and a posterior group; hence, in splitting the 
kidney substance to reach the renal pelvis, the incision should be made along the frontier line between the two vascular areas, viz., about half an inch behind and parallel to the lateral border of the kidney.

The ureters lie behind the peritoneum covering the psoas major muscles; they descend almost vertically in the umbilical region $1 \frac{1}{2}$ in. from the median plane. At the level of the intertubercular plane they lie in front of the termination of the common iliac arteries, and then pass down into the pelvis minor, in front of the hypogastric arteries.

The ureter possesses a well-developed muscular wall so that it is well adapted for suturing, while its rich blood supply favours rapid healing. Its abdominal portion is supplied by the renal and internal spermatic arteries; its pelvic portion by the superior vesical, the inferior vesical, and the middle hæmorrhoidal arteries. By their anastomosis they form a continuous and somewhat tortuous chain which is generally visible beneath the peritoneum along the whole course of the tube.

In reading skiagrams with a view of ascertaining the presence or absence of calculi in the abdominal portion of the urinary tract, Hurry Fenwick makes use of a line projected vertically upwards from the highest part, i.e. the centre, of the iliac crest to the twelfth rib. As this line corresponds to the lateral limit of the kidney, it follows that a "calculus shadow" close to the medial side of this line will generally occupy one of the calyces and be situated, therefore, towards the cortex, while if the shadow be situated close to the tips of the transverse processes of the vertebræ, the calculus will usually be found either in the pelvis of the kidney or in the abdominal portion of the ureter. The other points to be kept in mind in reading the radiogram are that the pelvis of the kidney lies opposite the interval between the transverse process of the first and second lumbar vertebræ, and, secondly, that the abdominal portion of the ureter descends in the line of the tips of the transverse processes of the second, third, fourth, and fifth lumbar vertebrr.

Pancreas.-The head of the pancreas sccupies the curve of the duodenum, and lies in the lowest part of the right half of the epigastric region, on a level with the second lumbar vertebra. The neck, which crosses the median plane opposite the fibro-cartilage between the first and second lumbar vertebræ, lies in the transpyloric plane, while the body lies immediately above that plane. The tail lies in the left hypochondriac region. The relations of the pancreas to the transverse mesocolon and to the neighbouring viscera have already been sufficiently referred to.

After opening the abdomen in the median line, the pancreas is best exposed by passing through the gastro-colic ligament; access to the organ through either the hepato-gastric ligament or the transverse mesocolon is more limited and therefore less satisfactory.

A pancreatic cyst gives rise to a tumefaction of the abdomen either in the epigastric or in the umbilical region, depending on whether it pushes the hepatogastric ligament before it and develops between the liver and stomach, or whether it extends forwards below the stomach. In severe contusions of the abdomen the pancreas may be ruptured against the vertebral column.

Vessels of the Abdomen.-The commencement of the abdominal aorta and the coliac artery are situated two fingers' breadth above the transpyloric plane. The superior mesenteric artery arises a finger's breadth above the transpyloric plane, the renal arteries a finger's breadth below it. The inferior mesenteric artery arises midway between the transpyloric and the intertubercular plane-that is to say, about $1 \mathrm{in.} \mathrm{above} \mathrm{the} \mathrm{level} \mathrm{of} \mathrm{the} \mathrm{umbilicus.} \mathrm{The} \mathrm{abdominal} \mathrm{aorta} \mathrm{bifurcates} \mathrm{in,} \mathrm{or} \mathrm{a} \mathrm{little}$ to the left of, the median plane, on a level with the highest part of the iliac crest, and about $\frac{3}{4}$ in. below the level of the umbilicus.

The inferior vena cava lies immediately to the right of the aorta; its most important surgical relation is the right ureter, which lies close to its right side.

The common and external iliac arteries may be mapped out by drawing a line, curved slightly laterally, from a point opposite the bifurcation of the aorta to a point midway between the superior anterior iliac spine and the pubic symphysis: the superior third of this line corresponds to the common iliac, the inferior twothirds to the external iliac.

In ligaturing the common iliac artery, or the superior part of the external iliac, 
the close relation of the ureter must be borne in mind, while in ligaturing the inferior part of the external iliac it is the internal spermatic (or ovarian vessels) and the ductus deferens which have to be avoided.

The common iliac veins lie mainly to the right of the corresponding arteries, the left vein, however, crossing behind the right artery to join its fellow to form the inferior vena cava.

The fact that the left common iliac vein passes behind the right common iliac artery to reach the vena cava would seem to afford a sufficient explanation for the much greater frequency with which thrombosis of the femoral vein is met with on the right side as compared with the left side.

The great vessels upon the posterior abdominal wall, along with the adjacent lymph vessels and glands, lie in the tela subserosa, and therefore within the general fascial envelope of the abdomen. Abscesses originating from the retroperitoneal lymph glands are therefore like perinephric abscesses, extra-peritoneal but intra-fascial; abscesses of vertebral origin, whether lumbar, iliac, or psoas, are, on the other hand, extra-fascial. Abscesses connected with the vermiform process are primarily intra-peritoneal; occasionally they ulcerate through the parietal peritoneum and burrow in the extra-peritoneal fat.

\section{THE MALE PERINEUM.}

The male perineum is a heart-shaped space, the osseous boundaries of which are the same as those which form the inferior aperture of the pelvis. A line drawn transversely across the perineum between the anterior part of the tuberosities of the ischium crosses the median plane, immediately in front of the anus, and divides the space into an anterior or urogenital triangle and a posterior or rectal triangle.

The urogenital triangle is subdivided into a superficial and a deep compartment by the inferior fascia of the urogenital diaphragm; in the superficial compartment is the root of the penis, 'which gives rise to a longitudinal fulness upon the surface. Anteriorly, the surface of the urogenital triangle is continued on to the scrotum, whilst laterally a distinct groove separates it from the medial surface of the thighs. The central point of the perineum (common tendon of the perineal muscles) is continuous with the centre of the base of the fascie of the urogenital diaphragm, and lies a finger's breadth in front of the anus. Immediately in front of it, and about $1 \mathrm{in}$. from the centre of the anus, is the posterior edge of the bulb of the corpus cavernosum urethræ. The superficial compartment of the urogenital triangle is bounded below by the perineal fascia of Colles, which is attached posteriorly to the base of the fascia of the urogenital diaphragm, and laterally, on each side, to the margins of the pubic arch. Anteriorly, the fascia of Colles passes on to the scrotum, the penis, and spermatic funiculi, to become continuous with the fascia of Scarpa upon the anterior surface of the abdomen.

When the urethra is ruptured below the inferior fascia of the urogenital diaphragm, the course of infiltration of the extravasated urine is determined by these attachments; at first, therefore, the urine is confined within this compartment, but gradually travels forwards, under the fascia of Colles, on to the inferior part of the anterior abdominal wall; it is prevented from passing into the front of the thigh by the attachment of Scarpa's fascia to the fascia lata, a little distal to the inguinal ligament.

The deep compartment of the urogenital division of the perineum corresponds to the interval between the inferior and superior fasciæ of the urogenital diaphragm. The most important structures which this compartment contains are the membranous part of the urethra, the bulbo-urethral glands, the internal pudendal vessels, and the artery to the bulb.

The membranous part of the urethra lies one inch behind the inferior border of the pubic symphysis. When this division of the urethra is ruptured, the extravasated urine, after filling the deep compartment, may reach the superficial compartment by bursting through the inferior fascia of the urogenital cliaphragm where the vessels pierce it; or it may penetrate the superior fascia, infiltrate the perivesical 
connective tissue and the space of Retzius, and ultimately ascend on the anterior abdominal wall between the fascia transversalis and the parietal peritoneum.

The bulbo-urethral glands, which lie immediately behind the membranous part of the urethra, are overlapped by the bulb of the urethra, from which they are separated by the inferior fascia of the urogenital diaphragm. The internal pudendal artery lies just within the margin of the pubic arch. The artery to the bulb runs transversely medially $\frac{1}{4}$ in. above the base of the urogenital diaphragm, i.e. above the level of a line drawn from the front of the tuberosities to the central point of the perineum.

The male urethra measures about eight inches from the external to the internal orifice; the narrowest portion is at the external orifice; a second narrowing occurs at the urogenital diaphragm. It is behind these constrictions that a calculus is liable to become impacted. The most dependent part of the urethra is the bulbous portion, and it is in this situation that an organic stricture is most frequently met with. The membranous part of the urethra, situated between the two fasciæ of the urogenital diaphragm, is surrounded by the sphincter urethræ membranaceæ muscle, which, when thrown into spasm, may firmly grip an instrument as it is passed into the bladder. Rupture of the urethra from a fall on the perineum generally involves the bulbous portion. A false passage made during the passage of an instrument generally traverses the floor of the urethra at the urogenital diaphragm; to prevent this the point of the instrument should always be directed upwards, and the handle at the same time depressed as soon as the instrument is felt to encounter the resistance of the inferior fascia of the urogenital diaphragm. When the prostate is hypertrophied the prostatic part of the urethra is elongated, and the internal orifice may look directly forwards, while if the lateral lobes are unequally enlarged it may deviate laterally. Patients with prostatic hypertrophy are seldom able to completely empty the bladder, on account of the dependent well which exists behind the prostate.

Cystoscopic Examination of the Bladder.-On making a cystoscopic examination of the bladder special attention is paid to the trigone, as most of the pathological lesions are associated with this region. At its anterior angle is the internal urethral orifice, while at its postero-lateral angles are the small oblique slit-like orifices of the ureters, surrounded by a very slight lip-like elevation of the mucous membrane. At the base of the trigone the mucous membrane is raised into a smooth transverse ridge which stretches between the ureteric openings, with a slight forward convexity. The elevation is caused by a bundle of transverse muscular fibres, continuous with the longitudinal fibres of the ureters. The distance of the ureteric orifices from one another is rather more than an inch, while their distance from the internal urethral orifice is slightly less than an inch.

The urine is ejected into the bladder intermittently at intervals of a minute or so. During each ejection the ureteric orifice is seen to pucker up, and as it relaxes the gush of urine takes place in the form of a characteristic whirl "resembling an injection of glycerine into water." The mucous membrane of the trigone is closely connected with the subjacent muscular wall, so that it presents a smooth appearance; whereas over the rest of the bladder it is thrown into folds owing to the looseness of the submucous tissue. Further, the mucous membrane of the trigone presents a pink injection, while over the rest of the bladder it is of a pale straw colour. This contrast is due to the difference in the arrangement of the bloodvessels; over the trigone they are larger, more numerous, and form a close network; hence, when this surface is inflamed, the congested vessels form a continuous vascular layer. Over the rest of the bladder one sees, here and there in the mucous membrane, small segments of fine vessels giving off a cluster of short branches, the finer anastomoses of which are not visible when the mucous membrane is healthy.

The form and shape of the trigone in women may be distorted by prolapse of the bladder, by alterations in the size and position of the cervix, and by the presence of fibroids. In the male, distortion is usually due either to the enlargement of the prostate or to disease of the vesiculæ seminales.

When the normal bladder is comfortably filled, the bladder walls appear almost smooth, but when the bladder contracts the delicate muscular trabeculæ 
become visible through the mucous membrane. When the bladder is hypertrophied as the result of urinary obstruction the muscular trabecula become greatly hypertrophied, and stand out prominently, even when the bladder is full. The spaces between the trabeculæ may become so deeply pitted as to lead to the formation of little pockets, known as false diverticula.

THE PROSTATE.

The operation of prostatectomy has proved so successful in removing urinary complications associated with enlargement of the prostate that a fresh impetus has been given to the study of the anatomy of the gland from the surgical point of view. With the body erect the base of the prostate lies in a horizontal plane at the level of the middle of the symphysis pubis, while its apex lies $\frac{1}{2}$ in. behind and below the sub-pubic angle. It follows, therefore, that the vesical orifice and the base of the prostate are within easy reach of the finger introduced through a supra-pubic cystotomy incision. The anterior surface of the prostate lies about $\frac{3}{4}$ in. behind the pubes, to which it is connected by the pubo-prostatic ligaments. Above these ligaments is the space of Retzius, occupied by fatty tissue which passes upwards in front of the anterior wall of the bladder between the umbilical arteries as far as the umbilicus, while laterally it extends on each side, between the peritoneum and pelvic fascia, as far back as the hypogastric arteries. The posterior surface of the prostate is related to that part of the rectal ampulla immediately above the anal canal, and is therefore accessible to palpation per rectum. Between the rectum and the posterior part of the sheath of the prostate (formed by the recto-vesical layer of pelvic fascia) is a loose cellular interval, which is taken advantage of in the operation of excision of the rectum, and in exposing the posterior surface of the prostate in the operation of perineal prostatectomy. The lateral surfaces of the prostate cannot be felt through the rectum; they are related to the anterior or pubo-rectal fibres of the levatores ani, from which they are separated by the lateral portion of the fascial envelope of the gland.

The prostate substance is made up of branching tubular glands supported by a fibro-muscular stroma. The gland tissue is most abundant in the posterior and lateral aspects of the organ; anteriorly the stroma is more abundant and extends backwards from the capsule to the urethra to form a sort of anterior commissure. By the term "capsule" of the prostate is understood the immediate or proper envelope of the gland; this envelope consists of parallel layers of fibromuscular tissue, continuous with, and forming part of, the stroma of the organ. In some instances it is so thin that the gland tissue reaches almost to its surface, while in other instances it is so thick as to deserve to be regarded as forming the cortical portion of the gland. By the term "sheath" of the prostate is meant the fibrous envelope derived from the pelvic fascia; the veins of the pudendal plexus lie between its lamellæ.

In what is known as "senile" hypertrophy of the prostate the organ may be uniformly enlarged, or the enlargement may affect chiefly one or other of the lateral lobes, one or both of which may enlarge more particularly in an upward direction so as to project into the bladder. This intra-vesical overgrowth may take the form either of a more or less pedunculated projection situated immediately behind the internal urethral orifice, or it may surround the orifice to form a prominent ring-like elevation. As the intra-resical growth enlarges, it makes its way torrards the bladder within the ring of the splineter vesicæ, and, having pushed before, or separated, the internal longitudinal fibres of the bladder, it comes nitimately to be separated from the cavity of the bladder by mucous membrane only. In the operation of supra-pubic prostatectomy the true capsule of the prostate is at once reached by simply tearing throngh the mucous membrane immediately behind the vesical orifice. By keeping close to the capsule, the entire organ, including the capsule, may be enncleated from its sheath. As the latter is markedly thicker and denser in the hypertrophied than in the normal prostate, this enucleation can be accomplished without injuring the veins of the pudendal plexus. As a rule, the only part where any difficulty in the enucleation is encountered is anteriorly, where the capsule is more intimately comnected with the sheath by the interposition of a layer of striated longitudinal muscular fibres which pass from the urethra to be continnous with the outer 
longitudinal fibres of the bladder. In "total" prostatectomy, practically the whole of the prostatic urethra is remored along with the gland. In some instances, instead of remoring the entire prostate and its capsule along with the prostatic urethra, the surgeon, by working within the capsule, is able to enucleate each lateral glandular mass either separately or united to its fellow in the form of a horse-shoe shaped mass, the urethra and the anterior commissure being left more or less intact. The cavity, which is left behind after the removal of the prostate, at once contracts owing to the approximation of the bladder and rectum antero-posteriorly, and of the levatores ani laterally.

In perineal prostatectomy the posterior surface of the prostate is exposed by making a horse-shoe shaped incision with the convexity reaching forwards to a point immediately behind the bulb; laterally, the incision sinks into the ischio-rectal fossæ, its extremities ending at the anterior part of the ischial tuberosities (Fig. 1108). After reflecting the skin and subcutaneous tissue, the incision is carried through the central point of the perineum.

The bulb, the superficial transverse perineal muscles, and the inferior fascia of the urogenital diaphragm are now retracted forwards, and the fibres of the recto-urethral muscle (which connect the anterior wall of the rectal ampulla with the constrictor urethræ) are divided; this allows the anal canal and the inferior end of the rectum to be retracted backwards. The dissection is now carried in a forward direction, between the anterior borders of the levatores ani, towards the prostate, so as to strike the loose non-rascular space which intervenes between the posterior part of the prostatic sheath and the thin fascia outside the muscular wall of the rectum. The posterior surface of the prostate, covered by its true capsule, is reached by incising the fascial sheath. The prostate, along with its true capsule and the urethra, may either be enurcleated entire from the sheath, or the true capsule may be incised as well as the sheath, and the adenomatous masses removed separately. The operation is greatly facilitated by pulling the prostate down into the wound byia special retractor (Young) inserted into the bladder through a median incision into the floor of the membranous part of the urethra.

The epididymis, which can be felt behind the testis as an elongated curved body applied vertically to its posterior margin, is especially involved in gonorrhoal and tubercular infections of the testis. Occupying the posterior part of the spermatic funiculus is the ductus deferens, which, when grasped between the finger and thumb, feels like a piece of whip-cord. The spermatic veins form a plexus in the substance of the cord, known as the pampiniform plexus; a varicose condition of these veins gives rise to the condition known as varicocele. In operating for varicocele the veins are reached by dividing, in succession, all the coverings of the cord; the deepest covering, viz., the infundibuliform fascia, derived from the fascia transversalis, forms a well-marked fibrous envelope which immediately surrounds the veins and other constituents of the funiculus. Besides the internal spermatic artery, the testis receives its blood supply from the artery accompanying the ductus deferens and from the external spermatic branch of the inferior epigastric.

The marked swelling which attends adema and homatoma of the scrotum is due to the loose and delicate character of the cellular tissne which occupies the space between the dartos muscle and the subjacent membrane derived from the intercolumnar fascia.

The anus is situated in the rectal division of the perineum about $1 \frac{1}{2} \mathrm{in}$. in front of and below the tip of the coccyx. The skin around the orifice is pigmented and thrown into radiating folds. The painful linear crack or ulcer, known as fissure of the anus, generally occupies one of the furrows at the posterior margin of the anus. The skin of the anus is provided with large sebaceous and sweat glands, which are occasionally the site of small and very painful anal abscesses.

On making a rectal examination it will be observed that the finger, before it reaches the cavity of the rectum, traverses the narrow or sphincteric portion of the rectum, appropriately named by Symington the anal canal. This canal, which is directed from below upwards and forwards, extends from the anal orifice to the ampulla of the rectum; it is from one to one and a half inches in length; its upper end is on a level with the medial borders of the pubo-rectal portions of the levatores ani.

External homorrhoids are developed from the anal folds situated outside the white line corresponding to the muco-cutaneous junction; internal piles are developed from the veins of the mucosa at the upper part of the anal canal. 
In the superior half of the anal canal are the rectal columns of Morgagni. According to Ball, fissure of the anus is generally caused by the tearing downwards of one of the posterior rectal sinuses (Fig. 1107) during the passage of a scybalous mass.

According to Birmingham, the pubo-coccygeal fibres of the levator ani close the superior part of the anal canal, whilst the external sphincter closes the remaining part. The internal sphincter, according to the same author, acts probably as a detrusor, its use being to empty the anal canal completely after the passage of the frecal mass.

Ischio-rectal Fossa. - The apex of the ischiorectal fossa (Fig. 1108), formed by the attachment of theinferior fascia of the pelvic diaphragm (anal fascia) to the obturator portion of the parietal pelvic fascia, is directed upwards towards the pelvis, and lies $2 \frac{1}{2} \mathrm{in}$. from the surface. The showing the rectal columns of Morgagni and the rectal sinuses between their medial wall of the fossa is bounded by the levator

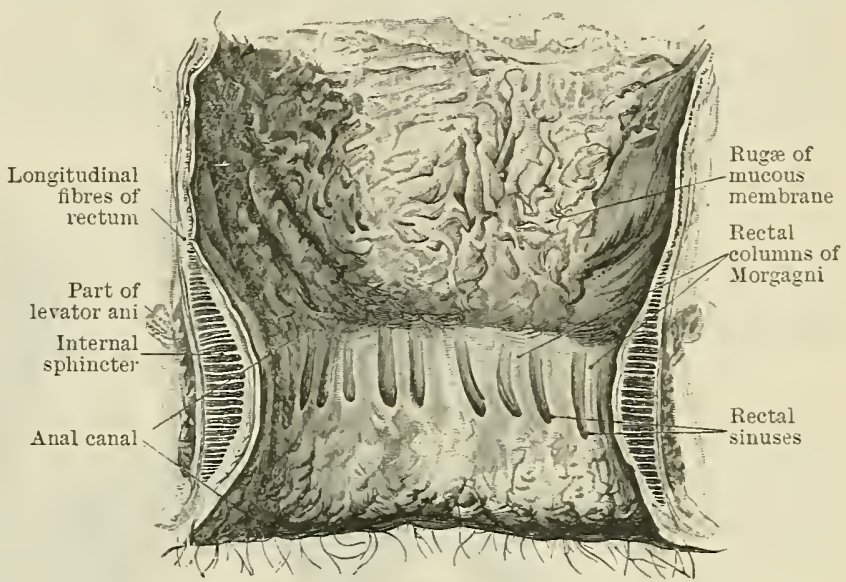

Fig. 1107.-The Ixterior of the Axal CANal axd Ixferior Part OF THE PECTUM. than usual. (From Birmingham.)

ani and coccygeal muscles covered by the anal fascia (Fig. 1108); the lateral wall by the obturator internus muscle covered by the obturator fascia. An abscess in the ischio-rectal fossa should be opened early, otherwise it is liable to burst through the medial wall into the rectum; should it open also upon the skin surface a complete "fistula in ano" is formed. When a "fistula in ano" results from the bursting of a submucous abscess of the anal canal the track of the fistula runs either medial to or through the fibres of the internal and external sphincter muscles, and the external or skin opening is, as a rule, close to the anus, while the internal opening is generally within the upper end of the anal canal. Occasionally the ischio-rectal abscess perforates the lerator ani towards the apex of the fossa; it then burrows into the peri-rectal cellular tissue of the pelvis, and opens into the ampulla of the rectum. In other cases, again, the abscess starts in the peri-rectal tissue internal to the levator ani, and either bursts into the rectal ampulla or through the levator ani into the ischio-rectal fossa, and so reaches the surface. Or the pus may burrow between the rectum and coceyx, whence it may pass outwards through the greater sciatic foramen, behind the parietal pelvic fascia, into the buttock; or, by piercing the visceral layer of the pelric fascia, may reach the tela subserosa of fatty tissue of the pelvis and ascend in it to form an iliac abscess.

The lymph ressels from the skin of the anus pass along the perineo-femoral folds to the most medial glands of the groin, both superficial and deep subinguinal. According to Poirier and Cunéo, those from the region of the white line end in the hypogastric glands which lie in front of the hypogastric artery, while those which issue from the mucous membrane of the upper part of the anal canal and the rectum proper traverse a few minute glands (ano-rectal glands of Gerota) placed between the muscular and fibrous coats of the rectum, along the superior hæmorrhoidal vein and its two branches, and pass thence to the sacral glands which lie internal to the anterior sacral foramina.

Digital Examination of Rectum.-In making a rectal examination the finger should be carried forwards from the tip of the coccrx so as to enter the anus from behind. The finger is then gently pressed upwards and slightly forwards through the sphineteric region, in the axis of the anal canal, until it reaches the carity of the rectum, the inferior 
part of which is dilated to form the ampulla. The transverse folds of the rectum or ralves of Houston, three in number, project into the cavity of the bowel in the form of prominent crescentic shelves, which are produced by the three permanent or true flexures into which the rectum is thrown (Birmingham); the inferior valve, which may be sufficiently prominent to impede the passage of the finger, must not be mistaken for a pathological condition. Through the anterior wall the finger can palpate from below upwards the bulb of the urethra, the membranous part of the urethra, the bulbo-urethral glands (when inflamed and enlarged), the apex and lateral lobes of the prostate, the resiculæ seminales, and the external trigone of the bladder. With the left forefinger in the rectum, an instrument passed into the bladder can be distinctly felt as it traverses the mem-

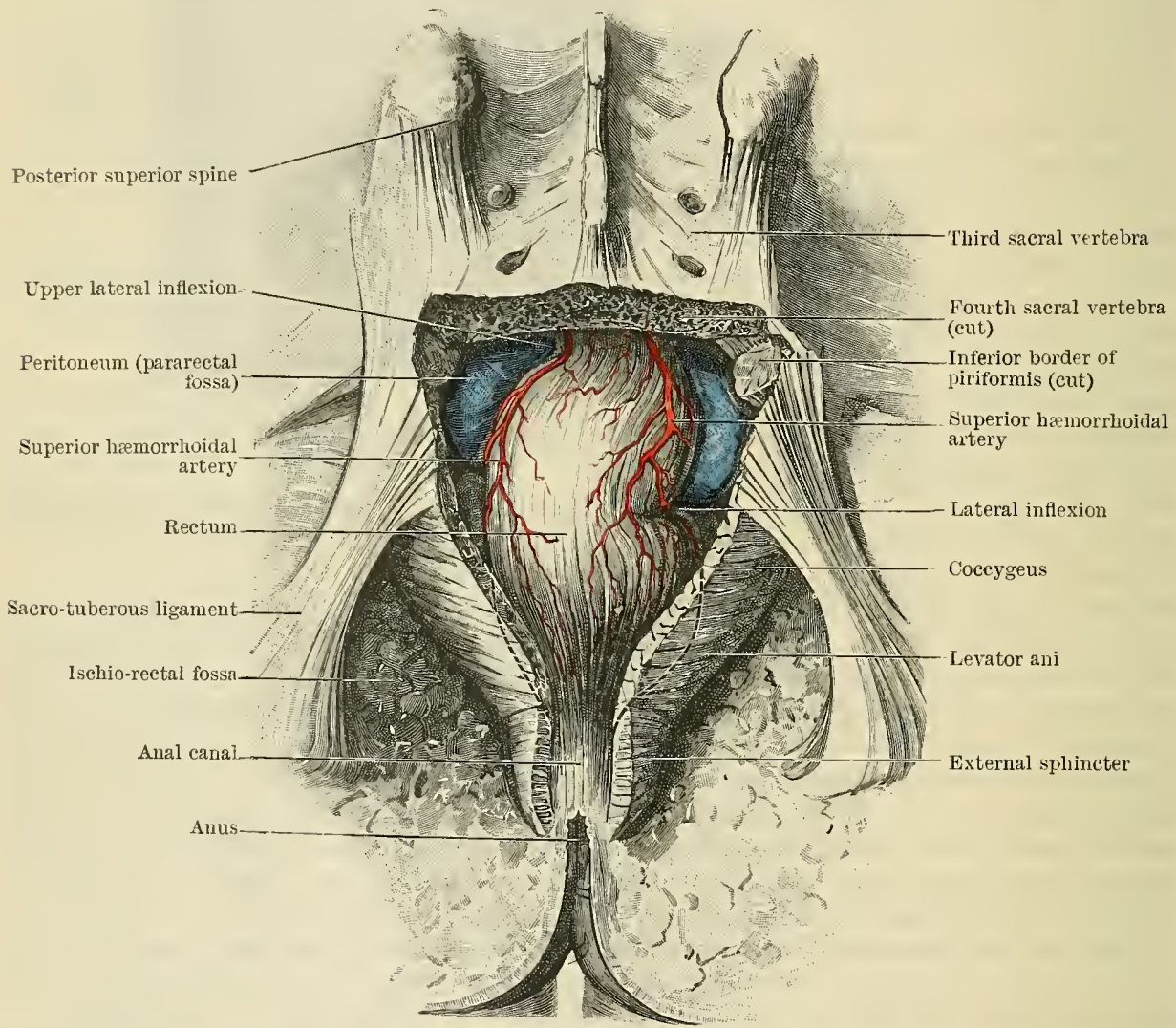

FIG. 1108.-The Rectum hrom Behind.

'The sacrum has been sawn across through the 4th sacral vertebra, and its inferior part removed with the coccyx. The posterior portions of the coccygei, levatores ani, and of the external sphincter have been cut away. The "pinching in" of the inferior end of the rectum by the medial edges of the levatores ani, resulting in the formation of the flattened anal canal, is suggested in the illustration, which has been made from a formalin-hardened male body, aged thirty. The lateral inflections of the rectum, corresponding to Houston's rectal valves, are also shown. (From Birmingham.)

branous urethra; as it lies in the prostatic urethra it is separated from the finger by the prostate. Hence, when a false passage is made through the bulbous or membranous portion of the urethra, the instrument, if pushed onwards towards the bladder, will be felt immediately outside the rectum between it and the prostate. In the child, owing to the rudimentary condition of the prostate, the instrument is distinctly felt close to the rectum, as it lies in the prostatic as well as in the membranous portion of the urethra. When the prostate is not enlarged the tip of the finger can just reach the external trigone, which is most distinctly felt when the bladder is full. The vesiculæ seminales, indistinctly felt when healthy, may be readily palpated when enlarged and indurated from disease. Through the lateral wall of the rectum may be palpated the ischio-rectal fossa, the bony wall of the pelvis minor, and, when enlarged, the hypogastric lymph glands; through the posterior wall the hollow of the sacrum and coccyx, and the lymph glands lying in the retrorectal cellular tissue. 
In the child rectal examination enables one to palpate, in addition to the structures in the cavity of the pelvis minor, those which occupy the lower segment of the abdomen. When the bladder is empty even a small calculus can be readily felt by recto-abdominal palpation.

The distance of the apex of the recto-vesical pouch of peritoneum from the anus varies considerably, according to the degree of distension of the bladder and rectum; when both are empty it reaches to about 2 in. from the anus; when both are distended it is at least one inch higher (Fig. 1108).

Examination by Sigmoidoscope.-In introducing the sigmoidoscope into the pelvic colon the direction of the anal canal and the curve of the rectum must be borne in mind; as the instrument traverses the anal canal it must be directed forwards as well as upwards, after which it is pushed onwards, in a backward and upward direction, towards the hollow of the sacrum; while, finally, in order to reach the pelvic colon, it is again directed forwards and a little to the left so as to clear the promontory of the sacrum. The instrument is more difficult to pass in women, on account of the greater abruptness of the curvature of the sacrum in the female as compared with the male.

When examined with the sigmoidoscope the mucous membrane of the rectum is seen to possess a deep red colour, and an excellent view is obtained of the rectal valves of Houston. The most conspicuous fold, known as the plica transversalis, projects from the right lateral wall about the level of the recto-vesical peritoneal reflection, i.e. about three inches from the anus. The highest valve, situated at the colo-rectal junction, gives rise to a distinct narrowing which must not be mistaken for a stricture. The pulsations of the left common iliac artery can generally be seen to be communicated to the postero-lateral wall of the pelvic colon about four inches from the anus.

Removal of the Rectum.-In removing the rectum and anal canal for malignant disease, an incision is carried round the anus and then upwards and backwards over the coccyx and inferior half of the sacrum. The ano-coccygeal raphe is divided longitudinally and the coccyx (either alone or along with more or less of the lower part of the sacrum) is excised by dividing the structures attached to its margins, viz., the inferior fibres of the glutæus maximus, the coccygeus, and the sacro-tuberous and sacro-spinous ligaments (O.T. greater and lesser sacro-sciatic). The parietal pelvic fascia, here very thin and adherent, is removed along with the bone. The middle sacral artery is ligatured. This is now seen, stretching across the floor of the wound, a well-defined sheet of fascia, viz., the rectal Iayer of the visceral pelvic fascia, which is divided longitudinally and stripped to either side off the posterior surface of the rectum; in doing this the branches of the middle hæmorrhoidal arteries, and, higher up, the two divisions of the superior hæmorrhoidal are encountered and ligatured. Anteriorly, the anal canal is detached from the central point of the perineum, after which the anterior surface of the rectum is freed from below upwards from the urogenital diaphragm containing the membranous urethra, the posterior surface of the prostate, the trigone of the bladder and the vesiculæ seminales and the ductus deferentes. This procedure is facilitated by the existence of a cellular interval between the anterior wall of the rectum and the strong recto-vesical layer of visceral pelvic fascia, which forms the posterior part of the sheath of the prostate, and, higher up, encloses the vesiculæ seminales and ductus deferentes. In order to strike this cellular interspace, the surgeon, after dividing the central point of the perineum transversely, deepens the incision down to the apex of the prostate. In doing this he divides a band of muscular fibres (recto-urethral muscle) which passes from the anterior wall of the lowest part of the rectal ampulla to blend with the sphincter urethræ muscle surrounding the urethra at the apex of the prostate. It is these recto-urethral fibres, which, by pulling forwards the ampulla, bring it into close relation with the urethra; hence it is especially at this stage of the operation that great care must be taken not to open into the rectum or to wound the urethra. After exposing the apex of the prostate the next step is to retract the anal canal well backwards and to define the anterior or pubo-prostatic borders of the levator ani muscle. These muscles are then divided, on each side, 
a little above their insertion into the rectum. The posterior surface of the prostate, corered with recto-resical fascia, is now exposed.

By continuing the separation of the rectum upwards in the cellular plane above mentioned, the bottom of the recto-vesical pouch of peritoneum is reached; it can usually be stripped for some distance off the rectum, without opening into the peritoneal cavity. In freeing the rectum laterally, bands of connective tissue containing branches of the middle and superior hæmorrhoidal vessels are divided. If the tumour is situated at the superior part of the rectum, the recto-vesical pouch of peritoneum is freely opened in a transverse direction. The colo-rectal junction is then mobilised by dividing the sacral attachment of the pelvic mesocolon and securing the superior hæmorrhoidal artery. After dividing the rectum well above the tumour, the opening into the peritoneal cavity is closed by suturing together the anterior and posterior walls of the recto-vesical pouch. If a permanent colostomy has been established, the divided bowel is closed; if not, a sacral anus is made.

\section{FEMALE PELVIS.}

On opening the abdomen by a median incision extending from the umbilicus to the pubes, and looking into the pelvis minor from above, after displacing some coils of the small intestine upwards, the fundus of the uterus, directed forwards and a little upwards, is seen resting upon the superior surface of the bladder. Behind the uterus is the rectum, and between the two the recto-uterine pouch of Douglas, containing the pelvic colon and the inferior part of the ileum. The ovary lies a little below the level of the superior aperture of the pelvis minor upon a triangular shelf, bounded in front by the broad ligament, behind and medially by the uterosacral ligament, and behind and laterally by the pelvic wall. When the vermiform process overhangs the superior aperture of the pelvis minor its tip may come into close relation with the right ovary, a condition, which often leads to a difficulty in distinguishing an inflammation of that ovary from appendicitis. The round ligaments are seen passing forwards and laterally from the anterior aspect of the cornua of the uterus to the abdominal inguinal rings, which lie.immediately in front and to the medial side of the terminations of the external iliac arteries. Inferiorly and at the medial side of the round ligament, as it leaves the pelvis, is the inferior epigastric artery. By pulling the uterus upwards the attachments of the broad ligament to the floor and lateral walls of the pelvis are brought into evidence, as also are the utero-vesical and recto-vaginal peritoneal pouches; the former is shallow, while the deepest part of the latter covers the upper fourth of the posterior wall of the vagina, and comes into relation, therefore, with the posterior fornix.

The utero-vesical peritoneal reflection takes place at the level of the junction of the body of the uterus with the cervix. The anterior wall of the cervix comes into relation, therefore, with the superior part of the base of the bladder, from which, however, it is separated by a layer of loose connective tissue. It is the existence of this cellular plane which enables the surgeon to separate the bladder readily from the uterus in the operation of hysterectomy.

While the anterior wall of the vagina is firmly united to the urethra, its posterior wall, on the other hand, can be readily separated from the rectum, in consequence of the interposition between the two organs of the recto-vaginal fascia.

The ureter crosses the brim of the pelvis in front of the bifurcation of the common iliac artery $1 \frac{1}{2}$ in. lateral to and a little below the centre of the sacral promontory. The corresponding point on the anterior abdominal wall is at the junction of the lateral and middle thirds of a line joining the anterior superior spines of the ilium.

After crossing the termination of the common iliac artery from lateral to medial side, the ureter dips vertically into the pelvis minor behind the peritoneum covering the hypogastric artery. It then courses medially in the parametric cellular tissue below the base of the broad ligamenta. In this position it lies a little above the lateral fornix of the vagina, about three-quarters of an inch lateral to the superior part of the cervix uteri; finally, just before it pierces 
the lateral angle of the bladder, it lies in front of the antero-lateral aspect of the upper part of the vaginal wall.

The relation of the pelvic portions of the ureters are of special importance in the female as their close relation to the cervix uteri and upper part of the vagina renders them liable to injury, more especially in the operation of hysterectomy performed for malignant disease of the uterus.

The uterine artery, in the first part of its course, passes downwards and forwards a little anterior and lateral to the ureter. At the level of the orificium internum uteri it takes a medial direction and passes along the inferior border of the broad ligament, and crosses, above and in front of the inferior part of the ureter, from lateral to medial side; it then passes above the lateral fornix of the ragina and finally ascends close to the side of the body of the uterus, and ends by anastomosing with the ovarian artery below the isthmus of the uterine tube.

The ovarian artery enters the pelvis minor between the layers of that portion of the broad ligament known as the infundibulo-pelvic ligament; it is here that the vessel may be most readily ligatured in abdominal hysterectomy, and in ovariotomy.

The lymph vessels from the inferior part of the vagina pass to the superficial vaginal and sacral glands, while those from the rest of the vagina, from the cervix uteri and from the body of the uterus, pass to the hypogastric, the external iliac, and the sacral glands. The hypogastric glands are situated on the lateral wall of the pelvis in close relation to the origins of the branches of the hypogastric artery. The sacral glands form a chain along the medial side of the anterior sacral foramina. The lymph vessels from the fundus of the uterus, and from the ovary, terminate in the glands around the aorta.

The external genitals are fully described elsewhere. The external orifice of the urethra, surrounded by a slight annular prominence of the mucous membrane, is situated about $1 \mathrm{in}$. behind the clitoris, immediately above the centre of the base of the vestibule - a smooth triangular area at the anterior part of the vulva, with its sides formed by the labia minora and its base by the anterior margin of the ostium vaginæ. In passing a catheter the instrument is directed along the forefinger (introduced just within the ostium vaginæ with the palmar surface towards the symphysis pubis) to the base of the smooth restibule, where it is tilted slightly upwards so as to bring its point opposite the urethral orifice.

The larger vestibular glands, about the size of a bean, are placed on each side of the posterior third of the orifice of the vagina, below the urogenital diaphragm. Their ducts, nearly one inch in length, open posteriorly between the hymen and the posterior commissure (fossa navicularis). Abscesses and cysts not infrequently develop in connexion with these glands. The bulbs of the vestibule are two piriform collections of erectile tissue situated on each side of the vestibule, between the bulbo-cavernosus muscle and the inferior fascia of the urogenital diaphragm. Rupture of these bodies gives rise to the condition known as pudendal homatocele.

The cervix uteri projects downwards and backwards. into the roof of the vagiua so as to leave a distinct fornix between the two. The relations of the fornix are of so much practical importance that for descriptive purposes it is customary to subdivide it into an anterior, a posterior, and two lateral portions. The anterior fornix, which is shallow, is related to the base of the bladder and to the utero-vesical pouch of peritoneum. The posterior fornix, which is deeper, extends upwards for some little distance in front of the anterior wall of the lowest part of the pouch of Donglas. The septum between the two is formed merely by the wall of the vagina; hence the readiness with which the pelvis may be drained by puncturing it and pulling a tube through the opening from the pelvis into the vagina.

The lateral fornix lies below the medial part of the base of the broad ligannent. An incision carried through it would therefore open into the parametric cellular tissue and would expose the uterine artery as it passes transversely to the uterus, after crossing above and in front of the lower part of the ureters.

Vaginal Examination.-In making a vaginal examination the patient should be placed in the dorsal position, with the thighs well flexed ; the index-finger of the right hand is now carried along the fold of the buttock towards the median plane, where it will impinge against the posterior aspect of the introitus vaginæ, whence it is inserted 
upwards and backwards into the canal; to render the examination more thorough the middle finger also may be introduced. When the uterus is in its normal position the vaginal part of the cervix uteri is felt as a knob-like body projecting downwards and backwards into the upper part of the canal. In nulliparæ the os uteri is a small transverse slit, whereas in women who have borne children it is larger and more or less fissured. Ahove and behind the cervix is the posterior fornix, which is in close proximity to the recto-uterine pouch of Douglas; this pouch, though normally empty, is the frequent site of displaced abdominal and pelvic organs, and collections of intra-peritoneal effusions and exudations. A loaded rectum can be detected through the vagina by the characteristic way in which the contents can be pitted by the finger. In front of the cervix is the shallow anterior fornix, through which may be felt the body of the uterus and the base of the bladder, while through the inferior half of the anterior vaginal wall the urethra may be detected as a cylindrical, cord-like thickening which may be rolled against the inferior border of the symphysis. The ureter, especially if enlarged, can be recognised through the antero-lateral fornix, by compressing it against the pubic bone.

By the bimanual examination the pelvic organs are steadied and pushed downwards towards the inferior aperture of the pelvic by the pressure of the left hand applied in the hypogastric region, so that they can be more readily reached and palpated by the finger placed in the vagina with its palmar aspect directed upwards. The ovary may be felt as a firm body about the size of the end of the thumb by pushing the fingers well up into the lateral fornix towards the lateral wall of the pelvis. In health the ovaries are freely movable. The healthy uterine tubes cannot, as a rule, be felt per vaginam.

Examination of Interior of Bladder.-The whole of the interior of the bladder in the female can be readily seen by reflecting light into it through a speculum introduced into the empty bladder after dilating the urethra. The patient is placed in the genupectoral position, so that the bladder may become inflated with air, the coils of intestine being displaced upwards. In the distended condition of the bladder the mucosa has a dull white or straw-coloured appearance, except in the region of the trigone, which shows a pale pink injection. The ureteral orifices placed a little more than one inch apart and connected by a slight transverse ridge (inter-ureteric fold), present the appearance of fine oblique slits situated upon small and somewhat injected elevations of the mucosa.

Rectal Examination.-By rectal examination the finger can palpate, from below upwards, the recto-vaginal septum, the cervix uteri, the posterior fornix of the vagina, the apex of the recto-uterine pouch of Douglas, and the body of the uterus. By washing out the rectum and introducing a speculum into the bowel, with the patient in the genupectoral position, the rectum becomes inflated with air; the finger can now feel very distinctly the posterior surface of the uterus and the uterine tubes, and by running the finger laterally, along the prominent fold formed by the utero-ovarian ligament, the ovary is also very distinctly felt.

\section{THE BACK.}

Median Line of the Back.-In the median line of the back is the vertebral furrow, which is deepest in the inferior thoracic and superior lumbar regions, where the sacro-spinales muscles are most prominent. Over the superior sacral region, where the sacro-spinales muscles are tendinous, is a flattened area'forming an equilateral triangle, the angles of which correspond respectively to the posterior superior spines of the two iliac bones and the third sacral spine. The vertebral spines can be palpated at the bottom of the vertebral furrow; they become more distinct when the spine is flexed, and, as pointed out by Holden, they become mapped out by reddened areas when friction is applied along the furrow. The identification and counting of the spines will be facilitated if it is remembered that the first thoracic is more prominent than the vertebra prominens (seventh cervical), that the third thoracic is on a level with the root of the spine of the scapula, the seventh thoracic its inferior angle, the fourth lumbar with the highest part of the iliac crest, and the second sacral with the posterior superior iliac spine.

Lateral Region of the Back.-Above the spine of the scapula is the suprascapular region, which is padded by a thick mass of muscle consisting of the supraspinatus and levator scapulæ, covered by the superior part of the trapezius; the two latter muscles may be thrown into relief by shrugging the shoulders.

In the interscapular region are the rhomboid muscles which are thrown into prominence by bracing back the shoulders. 
Below the inferior angle of the scapula the last five ribs can readily be felt lateral to the sacro-spinales muscle; when the twelfth rib does not reach beyond this muscle, the eleventh rib will be mistaken for it, unless the ribs are counted from above downwards.

The inferior border of the trapezius is indicated by a line extending upwards and laterally from the twelfth thoracic spine to the root of the spine of the scapula; the superior border of the latissimus dorsi by a line extending from the sixth thoracic spine transversely laterally across the angle of the scapula. Between these two muscles and the inferior part of the vertebral margin of the scapula is a triangular area, the floor of which is formed by the rhomboideus major muscle and the sixth costal interspace.

The lateral border of the sacrospinalis is indicated on the surface by drawing a line from a point on the iliac crest $3 \frac{1}{2} \mathrm{in}$. (four fingers' breadth) from the median line, upwards and slightly laterally to the angles of the ribs. The lateral border of the quadratus lumborum, which passes upwards and slightly medially, lies a little lateral to that of the sacrospinalis at the crest, and a little medial to it at the twelfth rib.

The anatomy of the muscles and fasciæ which complete the abdominal wall between the last rib and the iliac crest is of great importance in connexion with operations in the region of the loin. The space between the last rib and the iliac crest varies greatly according to the length of the rib, and according to the general shape of the chest and slope of the ribs as a whole. As a rule, the tip of the twelfth rib lies about two inches vertically above the centre of the iliac crest. From a surgical point of view the costo-iliac space may be said to be limited medially by the lateral edge of the sacrospinalis, and, more deeply, by the tips of the transverse processes of the lumbar vertebræ, while laterally it is bounded by the posterior free border of the external oblique, and, more deeply, by the line of reflection of the peritoneum from the colon on to the lateral wall of the abdomen. The space is roofed over by the latissimus dorsi, except below, where a narrow triangular interval is left between its lateral border and the posterior border of the external oblique, the base of the triangle being formed by the crest of the ilium, a little behind its centre. This triangle, known as the "triangle of Petit," represents a weak area through which a lumbar abscess may come to the surface, and through which a lumbar hernia occasionally develops. On removing the latissimus dorsi and the lower part of the thin serratus posterior inferior, another triangle will be exposed, which constitutes a second weak area in the loin; it is bounded above by the last rib, medially by the lateral border of the sacrospinalis, and laterally by the posterior muscular fibres of the internal oblique; the floor of the triangle is formed by the aponeurosis of origin of the transversus abdominis muscle. At the lateral border of the quadratus lumborum this aponeurosis splits into three layers to form two compartments, the anterior enclosing the quadratus lumborum and the posterior the sacrospinalis.

Kidneys. - The superior limit of the kidney is indicated by a line drawn transversely across the loin opposite the eleventh thoracic spine, the inferior limit by a line on a level with the third lumbar spine. The superior extremity reaches to the eleventh rib; the lower, which lies immediately lateral to the tip of the transverse process of the third lumbar vertebra, reaches to within $1 \frac{1}{2}$ to 2 in. of the erest of the ilium. About a third of the kidney lies above the inferior margin of the twelfth rib. The left kidney usually lies about $\frac{1}{2}$ in. higher than the right. The most lateral point of the lateral border lies 4 in. from the median plane, while the hilus lies $1 \frac{1}{2}$ in. lateral to it in front of the interval between the tips of the transverse processes of the first and second lumbar vertebræ.

The psoas major muscle intervenes between the postero-medial surface of the kidney and the transverse processes, and protects the organ from injury by a blow directed from the front. Between the superior end of the kidney and the eleventh and twelfth ribs is the diaphragm and the posterior costo-diaphragmatic reflection of the pleura (Fig. 1110). The relations of the pleura to the last rib have alreads been considered (p. 1401).

Posteriorly the course of the superior part of the ureter may be indicated by a line drawn vertically upwards from the superior posterior iliac spine to the lerel of the second lumbar spine; the deep guides are the tips of the transrerse processes of the second, third, and fourth lumbar vertebræ, corered by the psoas major muscle. 
Exposure of Kidney from behind.-In exposing the kidney from the loin, by a vertical incision between the lateral border of the sacrospinalis and the free posterior border of the external oblique muscle, the following structures are divided from without inwards:-(1) the integuments; (2) the lower fibres of the latissimus dorsi and serratus posterior inferior muscles; (3) the middle layer of the Iumbar aponeurosis, just lateral to the sacrospinalis compartment, and parallel to the lateral fibres of the quadratus lumborum muscles; (4) the anterior layer of the lumbar aponeurosis (which forms the aponeurotic origin of the transversus muscles), and the transversalis fascia; (5) the paranephric fat; (6) the perinephric fascia; (7) the perinephric fat surrounding the true capsule of the kidney. The kidney may be readily mobilised and brought to the surface by shelling it out of its fatty capsule

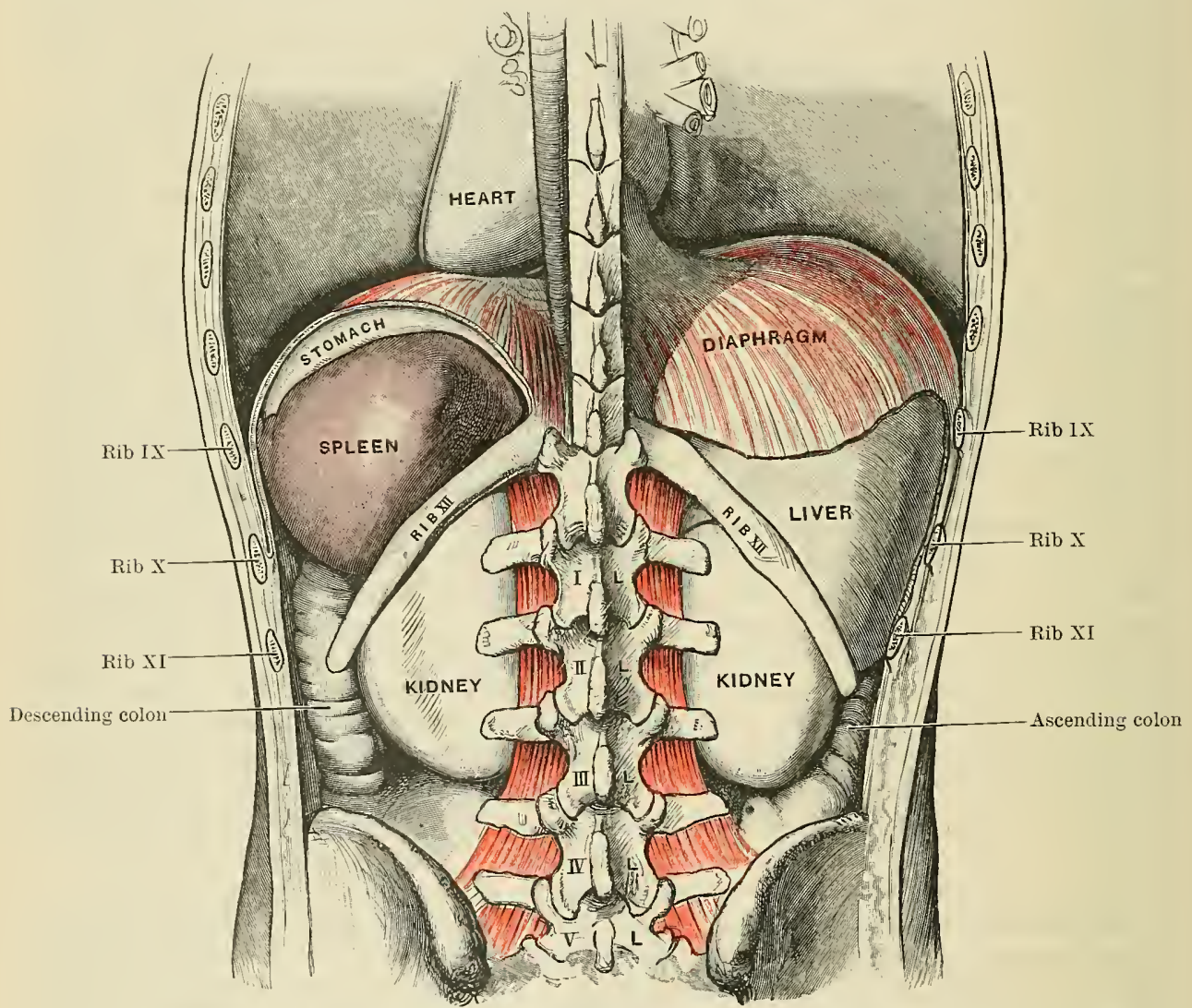

Fig. 1109.-Dissection of the Spleen, Liver, and Kidneys from BeHind, in a Subuect hardened BY Formalin InJECTION. (From Cunningham.)

with the finger. Better access to the renal vessels can be obtained if the incision is made a little nearer the median plane, so as to open into the sacrospinalis compartment. This allows of the muscle itself being retracted medially more efficiently.

In exposing the kidney by an oblique incision in the loin, the latissimus dorsi and serratus posterior inferior muscles are divided at the medial part of the wound, while at its lateral part the posterior fibres of the external and internal oblique muscles are divided; next, the aponeurotic origin of the transversus muscle and the transversalis fascia are split so as to expose the extra-peritoneal fat and the peritoneum, as it is reflected from the ascending colon on to the lateral aspect of the abdominal wall. The latter structures are then stripped forwards and medially off the anterior surface of the kidney, until the hilus and renal vessels are reached. The sacrospinalis and quadratus lumborum muscles are retracted well medially, and it is often necessary to divide the lateral fibres of the quadratus muscle. 
The upper part of the ureter is exposed by extending the division of the abdominal muscles still further downwards and forwards into the iliac region. After stripping the peritoneum off the quadratus and psoas muscles, the ureter will be found to cling to the deep surface of the membrane. Care is taken not to injure the internal spermatic or ovarian vessels, which cross the ureter superficially, and from the medial to the lateral side. The ureter is surrounded by a quantity of loose cellular tissue, and, owing to an abundance of elastic fibres in its adventitious coat, is very elastic, so that it can be readily pulled up to the surface.

To deliver an enlarged kidney out of the loin, it is generally necessary to prolong the incision upwards so as to divide the lateral lumbo-costal arch; and it may be necessary to divide, fracture, or resect the twelfth rib also. In doing this it is not always possible to avoid opening into the lowest part of the pleural sinus, which descends in front of the medial half of the rib.

In operating on the kidney, the last thoracic, and the ilio-hypogastric and ilio-inguinal nerves, which lie between it and the quadratus lumborum, must not be injured; the last thoracic nerve should be retracted upwards and laterally, the other two downwards and medially.

A needle passed through the medial extremity of the eleventh intercostal space will transfix the suprarenal gland.

The pus of a perinephric abscess occupies the fatty layer of the tela subserosa (perinephric fat), and lies, therefore, within the fascial envelope of the abdomen; the pus in a psoas abscess, on the other hand, lies external to the fascia. In opening a psoas abscess from behind, a vertical incision is made in the angle formed by the lateral border of the sacrospinalis and the crest of the ilium; in the deeper part of the dissection the surgeon should keep close to the front of the transverse process of the fourth lumbar vertebra.

Diaphragm, Liver, Stomach, and Large Intestine.-Posteriorly the right arch of the diaphragm and the right lobe of the liver extend upwards to the level of the angle of the scapula (eighth rib), while the left arch and the fundus of the stomach lie one inch lower (eighth interspace); the central tendon reaches up to the eighth thoracic spine. The right lobe of the liver is covered posteriorly by the eighth to the twelfth ribs, and is overlapped by the base of the right lung as far as a line drawn horizontally laterally from the tenth thoracic spine; hence, posteriorly, the superior limit of the liver cannot be defined by percussion, and its inferior limit merges into the dulness of the loin muscles and kidney.

The cardiac orifice of the stomach lies one inch to the left of the ninth thoracic spine. The cardiac portion, overlapped by the ninth to the twelfth ribs, extends upwards to the level of the eighth thoracic spine, one inch below the inferior angle of the scapula. The pyloric portion crosses the median plane opposite the first and second lumbar spines, the pylorus itself being situated one inch to the right of the first lumbar spine. The lesser curvature lies to the left of and below the tenth, eleventh, and twelfth thoracic spines.

Viewed from behind, the large intestine, on both sides, overlaps the lateral border of the kidneys and lies parallel to the lateral border of the sacrospinalis muscles. The peritoneum is reflected from the colon on to the posterior abdominal wall along a line drawn vertically upwards from the centre of the iliac crest. The left flexure of the colon, which reaches up to the level of the twelfth thoracic spine and the tenth rib, lies about five inches above the iliac crest. The right flexure lies on a level with the first lumbar spine.

Spleen.-The spleen, situated in the left hypochondrium, behind the cardiac end of the stomach, is overlapped by the ninth, tenth, and eleventh ribs, the long axis of the organ corresponding approximately to that of the tenth rib. Between the superior third of the spleen and the chest wall (pleura and diaphragm intervening) is the base of the left lung, the inferior margin of which crosses the organ horizontally at the level of the tenth thoracic spine. The costo-diaphragmatic reflection of the pleura reaches down as far as the inferior angle of the spleen. The superior limit of the organ cannot therefore be defined by percussion; and unless enlarged, or displaced downwards, the spleen cannot be punctured from behind without traversing the pleural as well as the peritoneal cavity. 
Of the three angles of the spleen, the posterior or vertebral lies at the same level as the inferior margin of the lung, $1 \frac{1}{2}$ in. lateral to the tenth thoracic spine. The

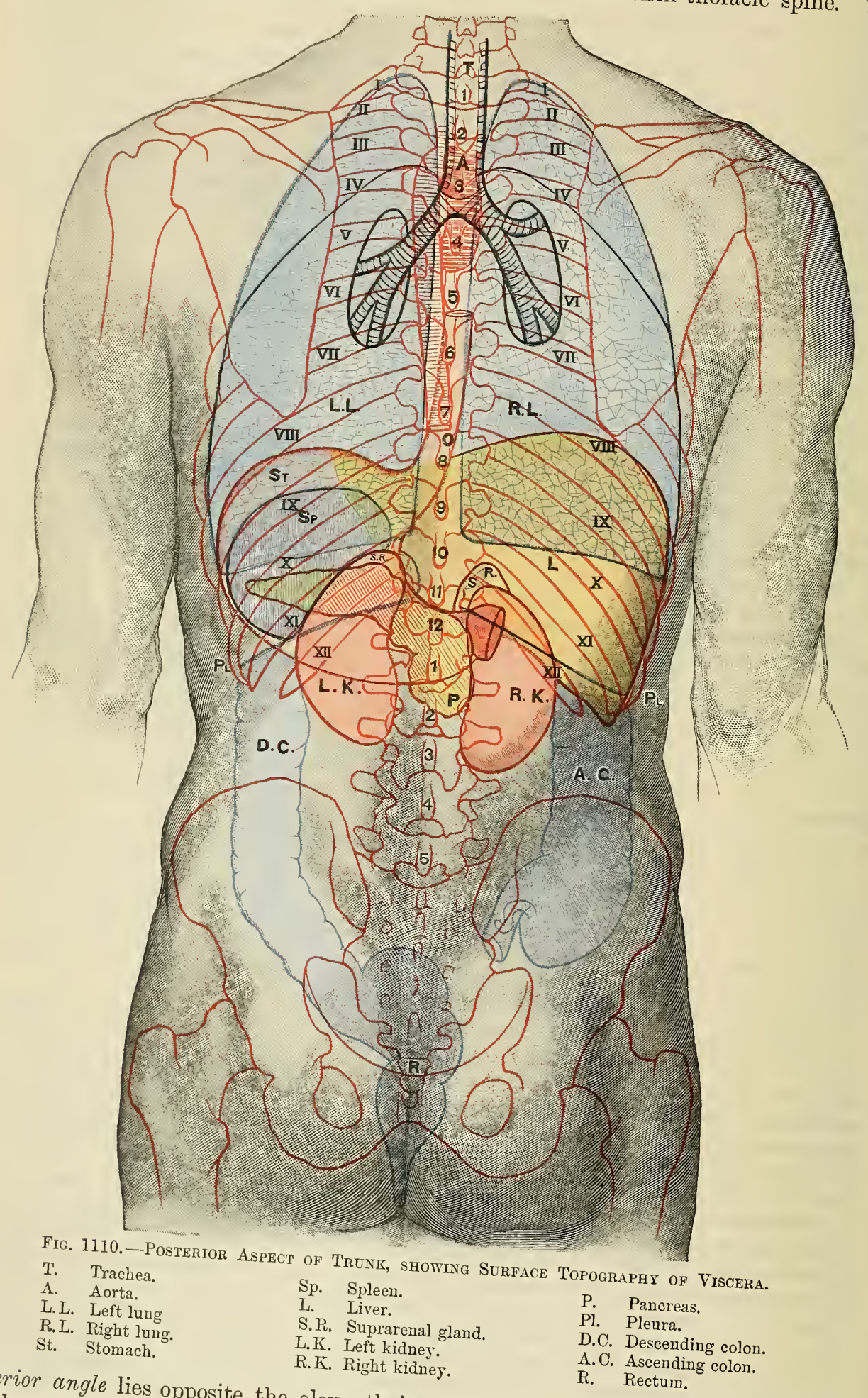
inferior angle lies opposite the eleventh intercostal spact lumbar spine, in a line drawn vertically intercostal space on a level with the first 
centre of the iliac crest. This angle is situated behind the superior part of the descending colon immediately lateral to the middle of the lateral border of the kidney. The anterior angle is at the level of the ninth interspace in the midaxillary line. Having placed a mark on the skin opposite these three angles the organ is mapped out on the surface as follows:-The posterior margin is obtained by joining the posterior and inferior angles; this margin, which gives the key to the position of the spleen, will be found to follow the eleventh intercostal space. The short inferior margin corresponds to a line joining the anterior and the

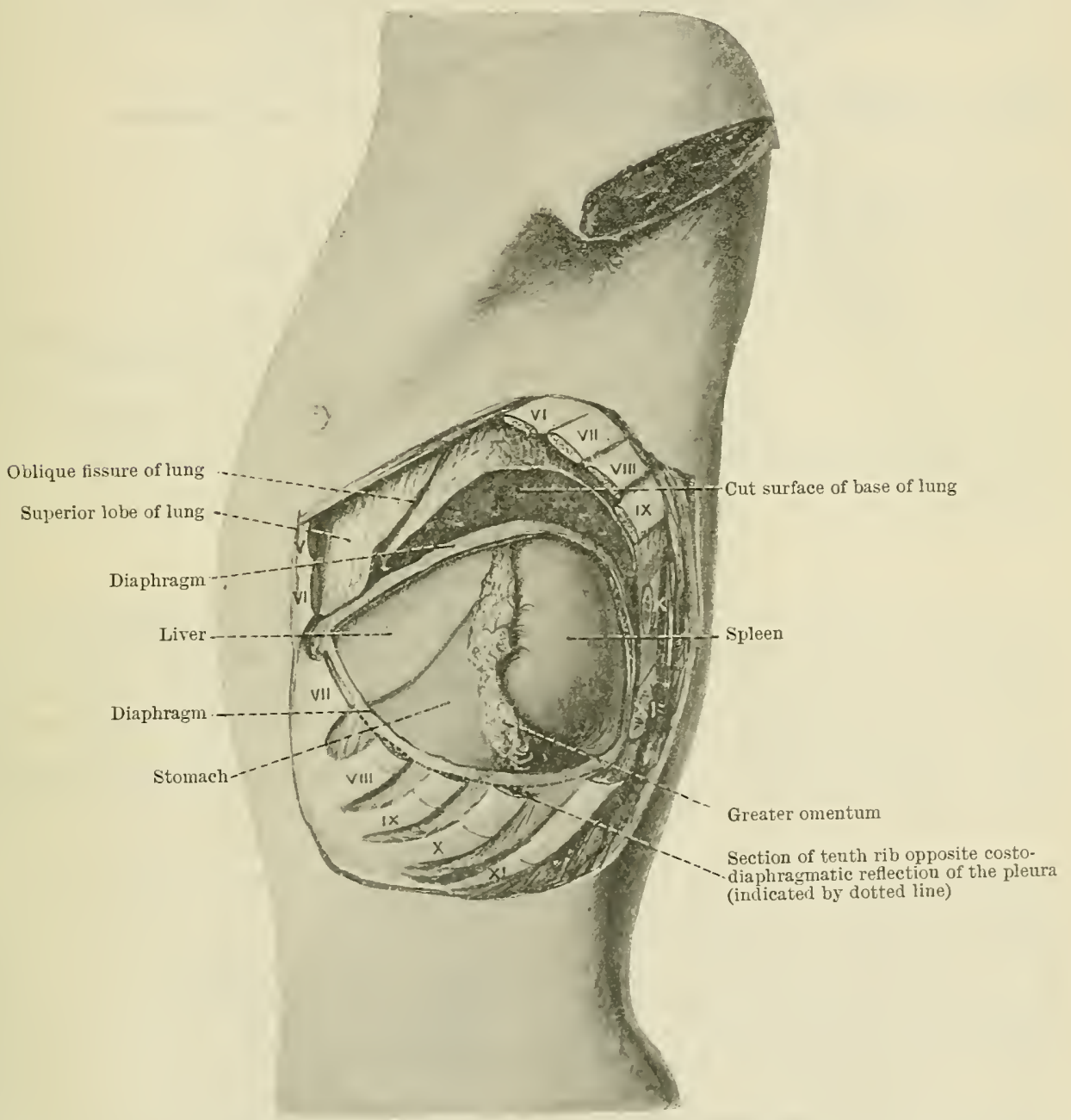

Fig. 1111.-Dissection of the Left Hrpochondrium to Show the Relations of the Spleex to the Lateral Wall of the Chest, the Dlaphragi, aNd the ADJACENT Viscera. In addition to the portions of ribs, there has been removed a part of the base of the left lung, and a window has been made in the diaphragm almost down to the level of the costo-diaphragmatic reflection of the pleura.

inferior angles; it is related to the left flexure of the colon. Commencing at the vertebral angle, the anterior margin is at first arched, the summit of the arch reaching to the level of the upper border of the ninth rib in the scapular line: thence it is continued downwards and forwards across the posterior axillary line as the "anterior crenated border" to the anterior angle. The upper arched portion lies parallel to and about one inch below the highest part of the fundus of the stomach. The only parts of the splenic outline which can be defined by percussion are the lower crenated part of the anterior margin, the anterior angle, and the short postero-inferior or colic border; and it is these parts which may be felt below the costal margin when the organ is considerably enlarged. 
In excising the spleen it is important to remember that the splenic vessels lie between the two layers of the lieno-renal ligament, and not in the gastro-lienal ligament which contains the short gastric vessels. In a floating spleen these two peritoneal ligaments are elongated to form a distinct pedicle.

Pancreas.-The head of the pancreas lies opposite the last thoracic and first lumbar spines; the tail lies at the same level as the left flexure of the colon, a little above the inferior basal angle of the spleen.

\section{Table indicating the Level of the More important Structures in Relation to the Spines of the Vertebræ.}

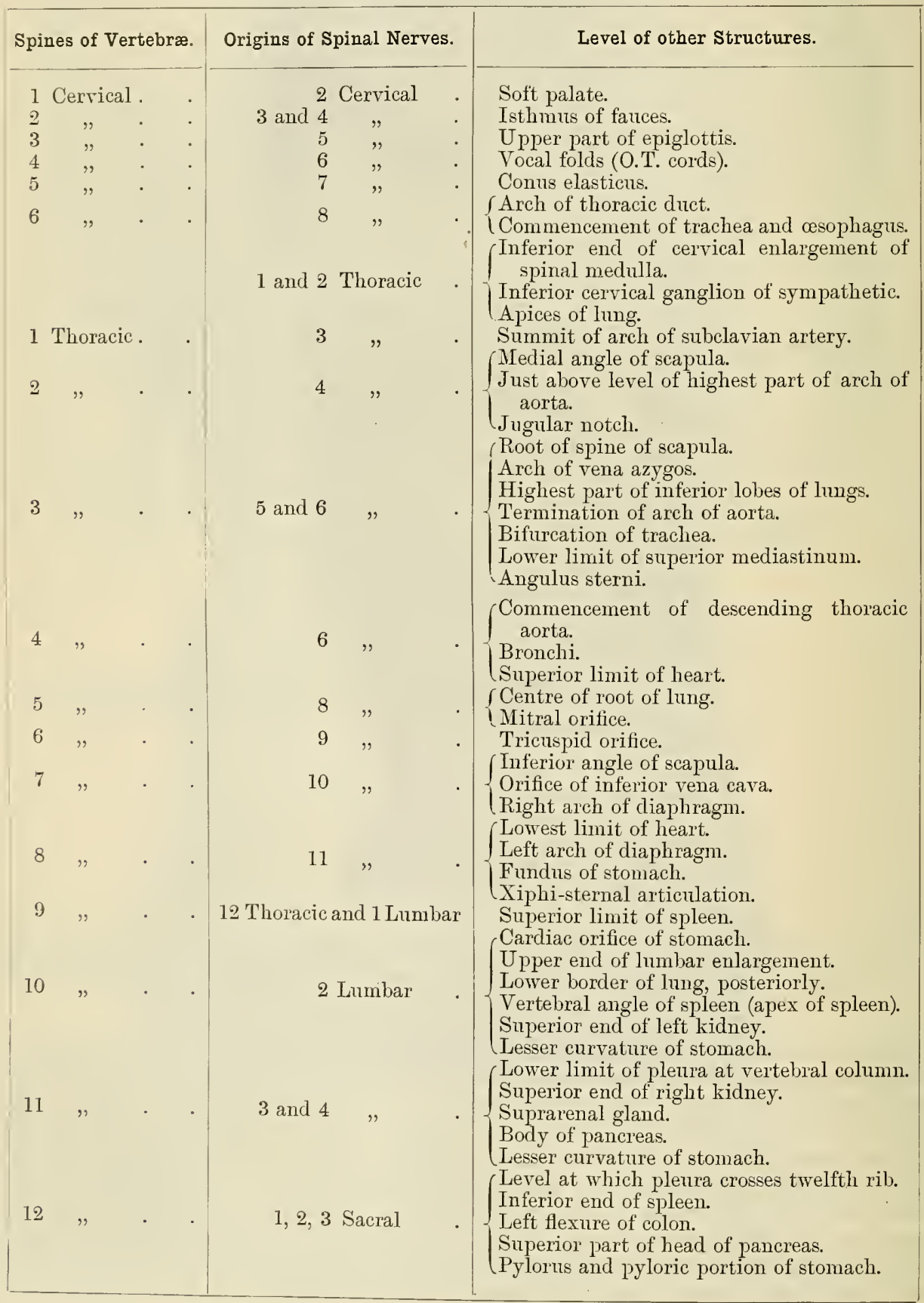


Table indicating the Level of the yore important Structures in relation to the Spines of the Vertebr.

Spines of Vertebræ. Origins of Spinal Nerves.

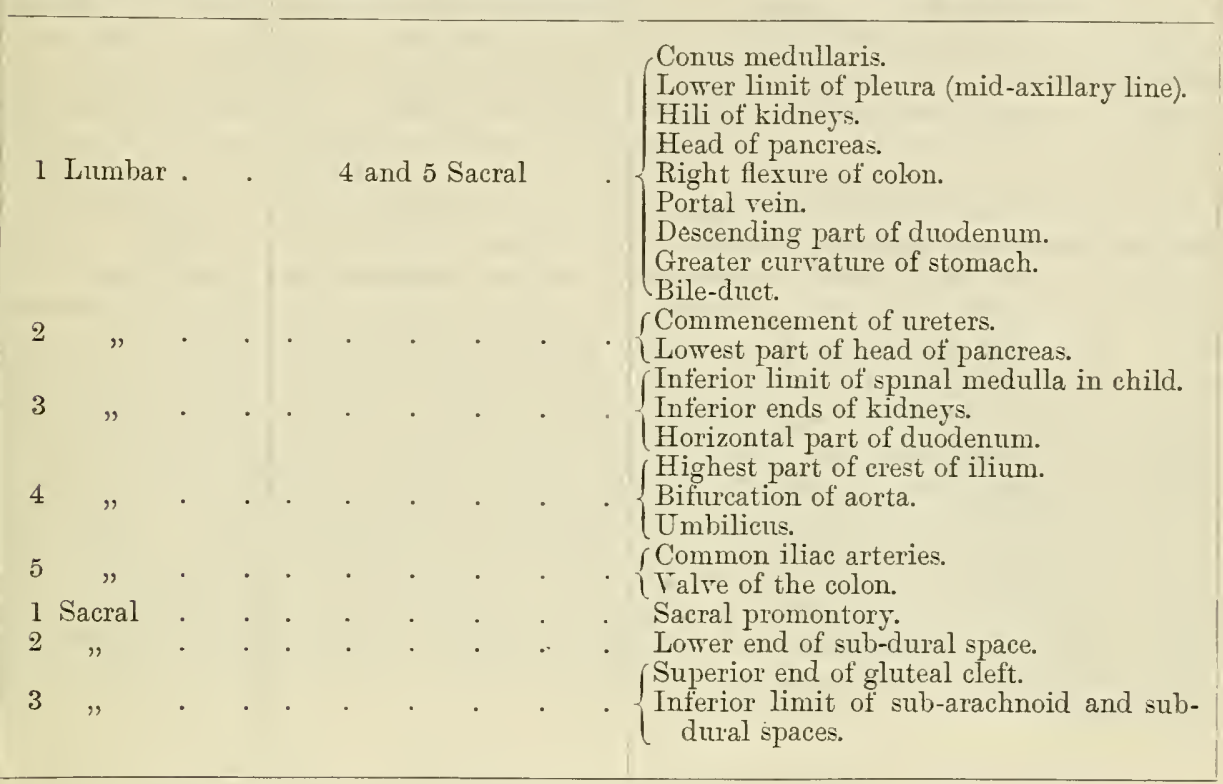

Level of other Structures.

Conus medullaris.

Hili of kidneys.

Head of pancreas.

Right flexure of colon.

Portal rein.

Greater curvature of stomach.

Lowest part of head of pancreas.

Inferior limit of spinal medulla in child.

Inferior ends of kidneys.

Umbilicus.

Common iliac arteries.

Talve of the colon

dural spaces.

Spinal Medulla. - The spinal medulla ends opposite the inferior border of the first lumbar spine; in the infant it reaches to the interval between the second and third lumbar spines. The cervical enlargement, which corresponds to the lower four cervical and the first two thoracic segments, ends opposite the seventh cervical spine. The lumbar enlargement lies opposite the last three thoracic spines. The five lumbar segments are opposite the ninth, tenth, and eleventh thoracic spines, while the five sacral segments extend from the lower border of the eleventh thoracic to the lower border of the first lumbar spine.

The sub-dural space extends down to the level of the second sacral spine. In performing the operation of lumbar puncture (Quincke) a fine trochar and cannula are introduced into the sub-arachnoid space below the level of the spinal medulla, the puncture being made $\frac{1}{4}$ to $\frac{1}{2}$ in. to one side of the interspinous ligament in the interval between the third and fourth or fourth and fifth lumbar spines. The instrument should be directed medially towards the median plane and very slightly upwards. In the adult the distance of the dura mater from the surface is about 2 in., in the infant $\frac{3}{4}$ in.

Fracture-dislocations of the spine are commonest in the lower cervical and thoracico-lumbar regions; that is to say, where the movable cervical and lumbar regions join the more fixed thoracic region. The vertebral column above the injury is generally displaced forwards, so that the spinal medulla is often sererely lacerated or completely torn across by the superior end of the portion of the column below the fracture. It is important to remember that in consequence of the shortness of the spinal medulla as compared with the rertebral column, the origins of the spinal nerves are at a higher level than their exits from the vertebral canal. The distance between their origins from the spinal medulla and their exits through the intervertebral foramina becomes greater the further down we descend, the lowest nerve trunks runuing almost vertically downwards. The cervical nerves leave the vertebral canal above the vertebrie after which they are named (except the eighth, which is above the first thoracic vertebra); the thoracic, lumbar, and sacral nerves, on the other hand, leare the canal below the correspondingly named vertebræ. 
To understand the effect of lesions of the spinal medulla, it is necessary to be familiar with the sensory and motor distributions of the various spinal segments (see Figs. 609, p. 693 , and 607, p. 688). Transverse lesions of the spinal medulla above the fifth cervical spine (that is, above the fibro-cartilage between the fourth and fifth cervical vertebræ) are quickly fatal, owing to paralysis of respiration, as the phrenic nerve arises mainly from the fourth segment. In transverse lesions of the cervical enlargement the cutaneous insensibitity does not extend higher than a transverse line at the level of the second intercostal space. The diagnosis of the particular segment involved is arrived at by testing the motor and sensory functions of each segment. The sensory areas corresponding to the lower four cervical and the first two thoracic segments occupy the upper extremities, and are placed in numerical order from the lateral to the medial side of the limb. The sensory area corresponding to the second, third, and fourth cervical segments occupy the occipital region of the scalp, the back of the auricle, and the masseteric region, the whole of the neck, and the shoulders and upper part of the chest down to a horizontal line at the level of the anterior end of the third intercostal space. In a total transverse lesion of the spinal medulla in the thoracic region, the superior limit of the anæsthesia is horizontal, and reaches to the level of the terminations of the anterior rami of the spinal nerves which arise from the spinal segment opposite the vertebral injury. Hence the superior limit of the anæsthesia is at a much inferior level than that of the injured vertebra. For example, a fracture-dislocation at the level of the eighth thoracic vertebra involves the origin of the tenth thoracic nerve which ends at the level of the umbilicus. The sensory zone corresponding to the fifth thoracic segment is at the level of the nipples, that of the seventh thoracic segment is at the level of the xiphoid process, that of the tenth at the level of the umbilicus, while that of the twelfth reaches down, anteriorly, to the superior border of the symphysis. The sensory areas corresponding to the lumbar and sacral segments are seen in Figs. 627, p. 725, and 629 , p. 733 .

\section{THE UPPER EXTREMITY.}

\section{THE SHOULDER.}

The bony landmarks of the shoulder must be systematically examined in all injuries about this region. The medial extremity of the clavicle is prominent; its articulation with the sternum forms essentially a weak joint, which is liable to be dislocated, especially from blows upon the lateral part of the shoulder which drive the medial end of the clavicle forwards against the weak anterior sterno-clavicular ligament. The body of the clavicle, subcutaneous throughout, is weakest at the junction of its two curves; it is in this region that the bone is so frequently fractured as the result of force transmitted through it to the trunk. The displacement of the lateral fragment varies according to whether the break takes place medial or lateral to the coraco-clavicular ligament; in the former case the weight of the upper extremity, acting through the coraco-clavicular ligament, pulls the lateral fragment downwards; when the fracture is lateral to the ligament, the lateral end of the clavicle rotates forwards, but there is no downward displacement. The lateral end of the clavicle is on a plane posterior to its medial end, so that the shoulder is braced backwards away from the thorax; hence in fractures of the clavicle, both medial and lateral to the coraco-clavicular ligarnent, the point of the shoulder rotates forwards and medially. The acromio-clavicular articulation is somewhat difficult to feel ; the groove which corresponds to it runs in the sagittal direction, and lies $1 \frac{1}{4}$ in. medial to the lateral border of the acromion, and immediately lateral to a slight prominence upon the lateral extremity of the clavicle. When this joint is dislocated the clavicle almost invariably overrides the acromion, and the summit of the shoulder presents a somewhat conical or "sugar-loaf" appearance.

The tip of the acromion looks directly forwards, and lies a finger's breadth lateral to and a little in front of the lateral extremity of the clavicle. The lateral border of the acromion can readily be followed to its junction with the spine of the scapula, and the latter to its root, which is situated on a level with the third thoracic spine. The medial border of the acromion and the posterior border of the lateral end of the clavicle meet at an angle into which the point of the finger can 
be pressed. The medial angle of the scapula, covered by the trapezius and the supraspinatus muscles, is too deeply placed to be palpated distinctly. The inferior angle, and the vertebral border, from the root of the spine downwards, form visible prominences which are readily felt; the inferior angle overlies the seventh intercostal space on a level with the seventh thoracic spine, while the vertebral border lies a little medial to the angles of the ribs.

To elicit crepitus in a transverse fracture of the scapula below the spine, the surgeon stands behind the patient and grasps the upper fragment by placing the forefinger upon the coracoid and the thumb upon the spine, while, with the other hand, he grasps the inferior angle; the two fragments are then moved the one upon the other.

The tip of the coracoid process may be felt by pressing the finger firmly upon the anterior border of the deltoid at a point one inch below the junction of the middle and lateral thirds of the clavicle. Medial to the coracoid is a triangular depression which corresponds to the superior end of the interval between the clavicular fibres of the pectoralis major and deltoid muscles. Behind this triangular depression are the termination of the cephalic vein, a lymph gland, the first part of the axillary vessels, and the cords of the brachial plexus. By firm pressure in this situation the pulsation of the axillary artery can be felt, and by further pressure the circulation in the vessel can be arrested by compressing the artery against the second rib. The first part of the axillary artery may be cut down upon either by a transverse incision through the clavicular origin of the pectoralis major, or by a longitudinal incision in the interval between this muscular slip and the deltoid. The companion vein lies in front of, as well as to the thoracic side of, the artery, thus adding to the difficulty of exposing the vessel. In fractures of the middle third of the clavicle the subclavian vessels are protected by the soft pad formed by the subclavius muscle.

The proximal extremity of the humerus, covered by the deltoid, gives rotundity to the shoulder. The greater tubercle projects beyond the acromion, and constitutes the most lateral bony landmark of the shoulder. When the head of the bone is dislocated, the lateral border of the acromion then becomes the most lateral bony landmark, and the shoulder presents a square contour. The lesser tubercle, small but conical, can be felt through the deltoid. Pointing directly forwards, it lies one inch lateral to and a little below the level of the tip of the coracoid process. In examining the proximal extremity of the humerus for fracture, the tubercles should be grasped between the finger and thumb of one hand, while the flexed elbow is rotated with the other hand. The head of the humerus has the same direction as the medial epicondyle; its distal part can be palpated through the axilla, the arm being meanwhile abducted, to bring the head in contact with the inferior surface of the capsule. It is through this, the weakest part of the capsule, that the head is driven in the common varieties of dislocation of the shoulder, viz., those due to forcible abduction. The proximal epiphysis of the humerus includes the head and the greater part of the tubercles. The capsule is attached mainly to the epiphysis; hence, in children, we find that separation of the proximal epiphysis takes the place of dislocation. Disease in the proximal end of the diaphysis does not necessarily involve the cavity of the joint. The intertubercular sulcus of the humerus, which lies immediately lateral to the lesser tubercle, may be mapped out upon the surface by drawing a line, two inches in length, distally along the axis of the humerus from the tip of the acromion. When there is effusion into the joint, the arm becomes slightly abducted, and there is fulness in front, along the line of the long tendon of the biceps. With the elbow at the side the lower part of the capsule of the shoulder-joint is loose and folded upon itself to form a dependent pocket; if, after an injury, the arm is retained too long in this position, the patient may be mable to abduct the arm, in consequence of the formation of adhesions in and around the pouch. To evacuate pus from the shoulder-joint, the integuments, deltoid, and capsule should be cut into by an incision passing vertically distally from the tip of the acromion. 


\section{THE ANILLA.}

The anterior fold of the axilla, formed by the inferior border of the pectoralis major, extends from the fifth rib to the middle of the anterior border of the deltoid. With the arm abducted, the interval between the sternal and clavicular fibres of the pectoralis major is indicated by a slight groove extending inferiorly and laterally from the medial end of the clavicle. The sternal fibres, along with the pectoralis minor, are remored in a complete operation for malignant disease of the breast, the pectoral branches of the thoraco-acromial artery being secured as they cross the interval between the sternal and clavicular portions of the greater pectoral. The posterior fold of the axilla, formed by the latissimus dorsi and the teres major muscles, is on a lower level than the anterior fold, and leaves the chest a little in front of the inferior angle of the scapula. Between the two folds, and running in the long axis of the limb, from the axilla to the middle of the arm, is the prominence of the coraco-brachialis muscle. The pulsations of the third part of the axillary artery may be felt in the furrow, immediately behind this prominence, at the junction of the anterior and middle thirds of the lateral wall of the axilla.

Female Mamma.-The breast tissue proper is arranged to form a central portion, the corpus mammce, and a peripheral portion, made up of branching processes which radiate into the paramammary fat and become continuous ultimately with the connective tissue septa of the subcutaneous fatty tissue. The mamma, therefore, has no distinct capsule. In the young adult nullipara, the corpus mammæ is compact and well defined, and contains but little intramammary fat, while the peripheral processes are relatively small. In multipara, the corpus mammæ contains more fat, and the peripheral processes extend more widely into the paramammary fat.

The arrangement and extent of the parenchyma can be well seen by treating the breast with a 5 per cent solution of nitric acid. If slices of the fresh organ are placed in this solution for a few minutes and then washed under running water, the albumen of the epithelial cells of the parenchyma is coagulated, while the connective tissue is rendered translucent and somewhat gelatinous. The ultimate lobules of the parenchyma now appear as little ( 1 to $2 \mathrm{~mm}$.), dull, opaque, white, sago-like bodies, arranged in grape-like clusters around the finer branches of the ducts.

The parenchyma is prolonged into the peripheral processes, into the suspensory ligaments of Cooper, and into the loose retromammary cellular tissue and pectoral fascia. The breast tissue, therefore, has a much wider distribution than was formerly supposed. Vertically, it extends from the second rib to the sixth costal cartilage at the angle where it begins to ascend towards the sternum; horizontally, from a little medial to the lateral border of the sternum, opposite the fourth rib, to the fifth rib in the mid-axillary line. The medial hemisphere of the mamma rests almost entirely on the pectoralis major; at its lowest part it slightly overlies the upper part of the aponeurosis covering the rectus abdominis muscle. The superior quadrant of the lateral hemisphere rests upon the greater pectoral, on the edge of the lesser pectoral, and to a slight extent on the serratus anterior, upon which it extends upwards into the axilla as high as the third rib, where it comes into relation with the thoracic group of axillary lymph glands. The remainder of the lateral hemisphere rests almost entirely upon the serratus anterior, except the lowest part, which overlaps the digitations of the external oblique arising from the fifth and sixth ribs. It follows, therefore, that fully one-third of the whole mamma lies inferior and lateral to the axillary border of the pectoralis major muscle. The surgeon must cut beyond the above limits if he wishes to remove the whole of the mammary tissue.

The axillary fascia resists the spontaneous ruptnre of an axillary abscess, which, therefore, tends to spread upwards beneath the pectorals, and towards the root of the neck. To open the abscess the incision should be made upon the medial wall, behind, and parallel to, the lateral thoracic artery, which runs under cover of the anterior fold. The axillary lymph glands rary greatly in size and number; many are no larger than a pin's head. In the female some of them undergo an adipose functional involution, whereby they come to resemble fat lobules. In health, one or two glands can usually be felt by thrusting the fingers upwards and medially beneath the anterior fold, the arm 
being only slightly abducted, so as not to stretch the axillary fascia. The central group (Leaf), imbedded in the fat immediately beneath the axillary fascia, become inflamed in poisoned wounds of the upper extremity. The same group, along with the pectoral group (related to the medial wall of the axilla, at the inferior border of the pectoralis minor), are usually the first to become diseased in malignant affections of the breast. When the disease is more advanced the posterior (subscapular) and the apical (subclaricular) groups are generally affected as well; and Rotter has shown that in a considerable porportion of cases diseased glands are to be found in the retro-pectoral fascia, i.e. between the pectoralis major and minor and, above the latter muscle, on the first intercostal space in relation to the supreme thoracic artery. In operating for malignant disease of the breast, the surgeon removes, in addition to the whole breast and the greater part of the skin over it, both pectoral muscles (with the exception of the clavicular fibres of the pectoralis major),

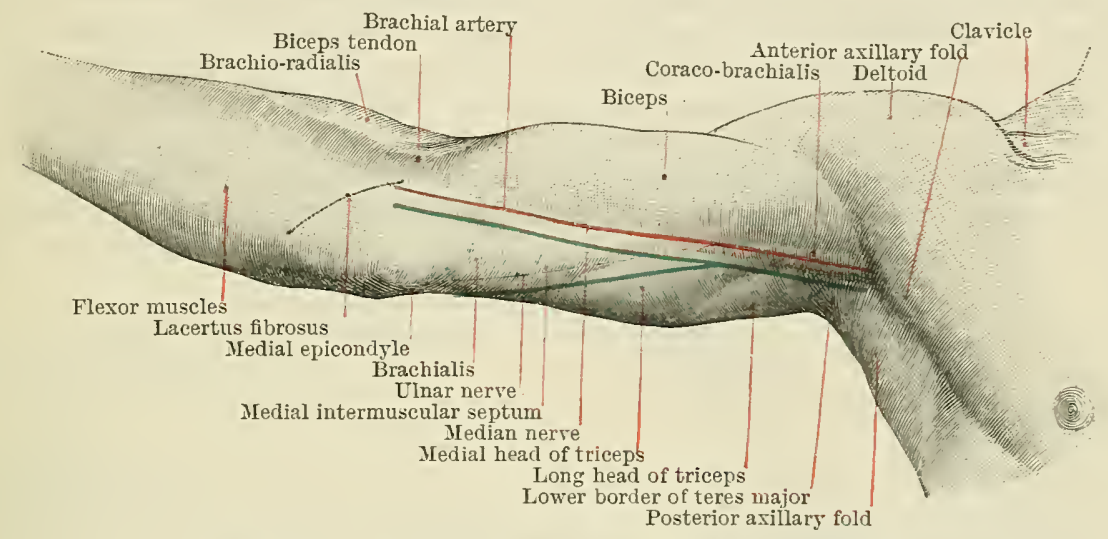

Fig. 1112. - Axilla, Txier Aspect of ArM Axd Elbow.

all the axillary lympl glands, and, as far as possible, all the fat and fascia, including the sheath of the axillary vein. It must be remembered that the distal part of the axillary vein lies immediately underneath the deep fascia of the lateral wall of the axilla; in cleaning the medial wall the long thoracic nerve must not be injured; and in removing the posterior group of lymph glands the thoraco-dorsal nerve, which accompanies the subscapular vessels, must be avoided, as it is doubly important to retain the action of the latissimus dorsi after remoring the pectorals. The writer has so frequently met with disease in these retro-pectoral glands, that he is convinced of the necessity of remoring the pectoral muscles.

\section{THE ARM.}

The anterior and posterior borders of the deltoid may be traced from the shoulder girdle to the insertion of that muscle. The surface relations of the anterior border have already been referred to; the posterior border forms a rell-marked and important landmark as it crosses the angle between the axillary margin of the scapula and the proximal part of the shaft of the humerus. By making an incision along this part of the posterior border of the deltoid, and retracting the edge of the muscle upwards and laterally, we expose the surgical neck of the humerus, and the quadrilateral opening in the posterior wall of the axilla, transmitting the posterior circumflex artery of the humerus and the axillary nerve; a little more distally is the radial nerve. The coraco-brachialis, the guide to the proximal half of the brachial artery, forms a prominence occupying the proximal half of the medial bicipital furrow. Traced distally the medial bicipital furrow widens out into an elongated triangle. This triangle which may be termed the medial supracondylar triangle, becomes continuous distally with the medial part of the triangle in front of the bend of the elbow, and is limited posteriorly by the medial intermuscular septum, which may be felt as a cord-like band extending proximally from the medial epicondrle: the floor of the space is formed by the medial part of the brachialis. Within the triangle are the following important structures, enumerated from the lateral to the medial sicle, viz.: the brachial artery, the median nerve, the distal part of the basilic 
vein, the medial cutaneous nerve of the forearm, and the superficial cubital lymph glands, two or three in number. Extending proximally from the lateral epicondyle to the insertion of the deltoid is the lateral intermuscular septum, which is pierced at the junction of its proximal and middle thirds by the radial nerve. Between the lateral intermuscular septum and the lateral edge of the biceps is the ill-defined lateral bicipital furrow, the floor of which is formed by a strip of the brachialis, and, nearer the elbow, by the brachio-radialis and extensor carpi radialis longus.

The posterior compartment of the arm is occupied by the triceps, the long head of which can be traced proximally to the axillary margin of the scapula, in front of the posterior border of the deltoid and behind the posterior fold of the axilla. The lateral head of the triceps, after emerging from under cover of the distal part of the posterior border of the deltoid, is continued obliquely along the lateral aspect of the arm as a well-marked muscular elevation. Proximal to the olecranon is the strap-like tendon of insertion of the triceps, which, when the elbow is fully flexed, forms an admirable posterior splint in supracondylar fractures of the humerus.

The brachial artery, slightly overlapped in the proximal half of the arm by the coraco-brachialis and in the distal half by the biceps, can be felt pulsating throughout the whole length of the anterior part of the medial bicipital furrow. The

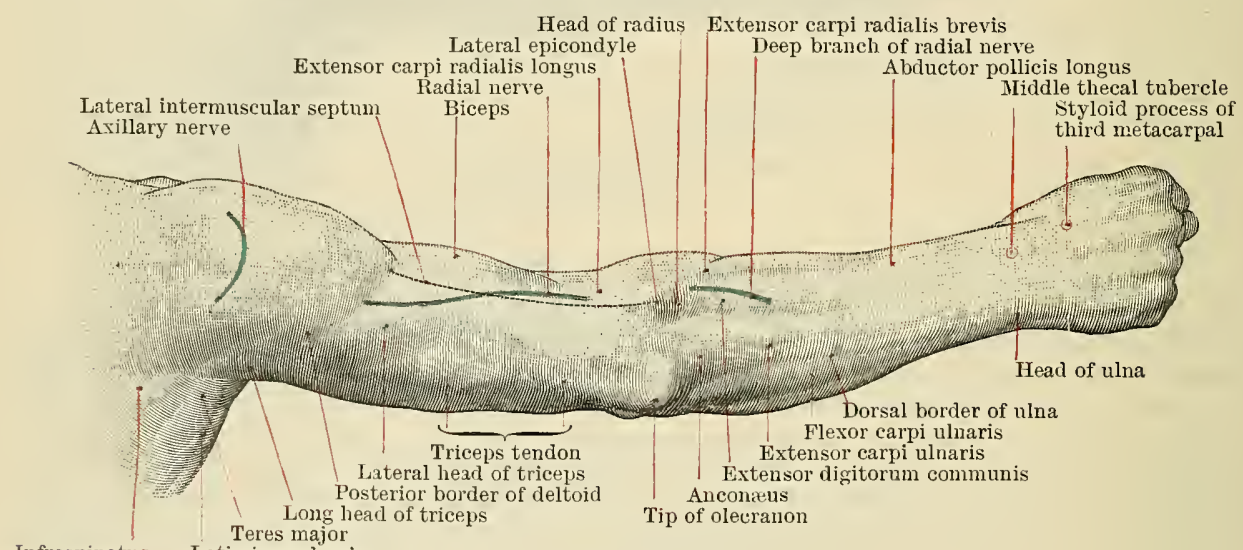

Infraspinatus

Latissimus dorsi

Fig. 1113.-Dorsal Aspect of Arm.

course of the vessel may be mapped out upon the surface by drawing a line from the medial border of the coraco-brachialis, at the level of the posterior fold of the axilla, distally to a point (opposite the neck of the radius) $\frac{1}{2} \mathrm{in}$. distal to the middle of the bend of the elbow. In ligaturing the vessel, the edges of the coraco-brachialis and biceps muscles, together with the median nerve, furnish valuable guides to the artery, the mobility of which is often a source of trouble in performing the operation.

The basilic vein, which is superficial to the deep fascia in the distal third of the arm, is visible in the medial supracondylar triangle and the distal part of the medial bicipital groove. The cephalic vein ascends a little anterior and medial to the lateral edge of the triceps to reach the interval between the deltoid and pectoralis major.

The surface guide for the median nerve is the same as that for the brachial artery. The ulnar nerve is indicated superficially by a line extending from the lateral wall of the axilla, immediately posterior to the prominence of the coracobrachialis, to the back of the medial epicondyle; in the proximal half of the arm the nerve lies close behind the brachial artery under cover of the basilic vein, while in the distal half it lies a little posterior to the medial intermuscular septum, partially imbedded in the fibres of the medial head of the triceps. To map out the course of the radial nerve, first mark the point where it pierces the lateral intermuscular septum, viz., the junction of the proximal and middle thirds of a line extending from the insertion of the deltoid to the lateral epicondyle; from this 
point draw a line obliquely distally and forwards to the front of the lateral epicondyle, where the nerve divides into its superficial and deep branches. To map out the nerve as it lies in the radial groove, draw a line from the same point obliquely proximally across the prominence formed by the lateral head of the triceps to the junction of the posterior fold of the axilla with the arm. In fractures of the humerus in the neighbourhood of the insertion of the deltoid, the nerve is not infrequently lacerated, or so involved in the callus as to produce the condition known as "drop-wrist," the result of paralysis of the extensor muscles of the forearm. To cut down upon the nerve, commence the incision a little distal to the point where it pierces the lateral intermuscular septum, and carry it obliquely proximally and slightly backwards through the lateral head of the triceps.

The shaft of the humerus, nowhere subcutaneous, is most readily manipulated in the region of the insertion of the deltoid, proximally along the lateral head of the triceps, and distally behind the lateral supracondylar ridge. The surgical neck, situated between the tubercles and the attachments of the muscles inserted into the region of the intertubercular sulcus, is related to the lateral wall of the axilla, and is on a level with the junction of the proximal and middle thirds of the deltoid; at the same level are the circumflex vessels and the axillary nerve.

The shaft may be cut down upon with least injury to soft parts: (1) in its proximal third, anteriorly, by an incision extending distally through the anterior fibres of the deltoid, parallel, and a little lateral, to the intertubercular sulcus; the sheath of the biceps will thus be avoided, and the small, anterior circumflex artery will be the only vessel divided. (2) In the proximal third, posteriorly, by an incision through the posterior fibres of the deltoid, the bone being reached just lateral to the origin of the lateral head of the triceps, thus avoiding the radial nerve ; the circumflex vessels and the axillary nerve will be exposed at the proximal part of the wound. (3) In the distal third, by an incision extending upwards from the back of the lateral epicondyle a little to the medial side of the lateral intermuscular septum.

\section{THE ELBOW.}

In injuries about the elbow the diagnosis rests mainly upon the relative positions of the bony points, which are, therefore, of great importance. The epicondyles of the humerus are both subcutaneous and upon the same level, the medial being the more prominent. In the extended position of the elbow the tip of the olecranon is on a level with a line joining the epicondyles; when the forearm is flexed the olecranon descends, and when full flexion is reached it lies 1 in. distal to the epicondyles, and in a plane anterior to the posterior surface of the distal end of the humerus. The head of the radius, which lies nearly 1 in. below the lateral epicondyle, is best manipulated from behind by placing the thumb upon it, while the semi-flexed forearm is being alternately pronated and supinated. Upon the lateral part of the posterior aspect of the extended elbow is a distinct dimple, which overlies the radio-humeral articulation; this dimple, along with the hollows on each side of the olecranon, becomes effaced in synovial thickenings and effusions into the joint. The coronoid process is situated too deeply to be distinctly felt. The distal epiphysis of the humerus includes the articular portion of the distal extremity and the lateral epicondyle; it is, therefore, small and almost entirely intra-articular, so that foci of disease in its neighbourhood soon invade the cavity of the joint. The medial epicondyle ossifies as a separate epiphysis which unites with the distal end of the diaphysis. In interpreting skiagrams of the elbow of children about six years of age and upwards, care must be taken not to mistake the centre of ossification in the lateral portion of the distal epiphysis of the humerus for a fracture. In the commonest dislocation of the elbow, viz., with backward displacement of both bones of the forearm, the normal relative position of the bony points is lost, whereas in a transverse supracondvlar fracture the normal relations are maintained. In the child the head of the radius is relatively smaller, and less firmly kept in position by the annular ligament than in the adult, so that it is liable to be partially dislocated, giving rise to the condition known as "pulled elbow." 
To evacuate pus from the elbow-joint a vertical incision should be made over the dorsal aspect of the joint, immediately lateral to the olecranon.

The median vein is seen to bifurcate in to the median basilic and median cephalic veins $\frac{1}{2} \mathrm{in}$. distal to the middle of the bend of the elbow; opposite the same point, but beneath the deep fascia, is the bifurcation of the brachial artery. The median basilic and median cephalic veins diverge as they ascend one on each side of the biceps tendon; the larger of the two veins, viz., the median basilic, is usually selected for the operations of venesection and transfusion. When the elbow is flexed the biceps tendon can be traced vertically through the centre of the bend of the elbow almost to its insertion. Passing distally and medially from the medial

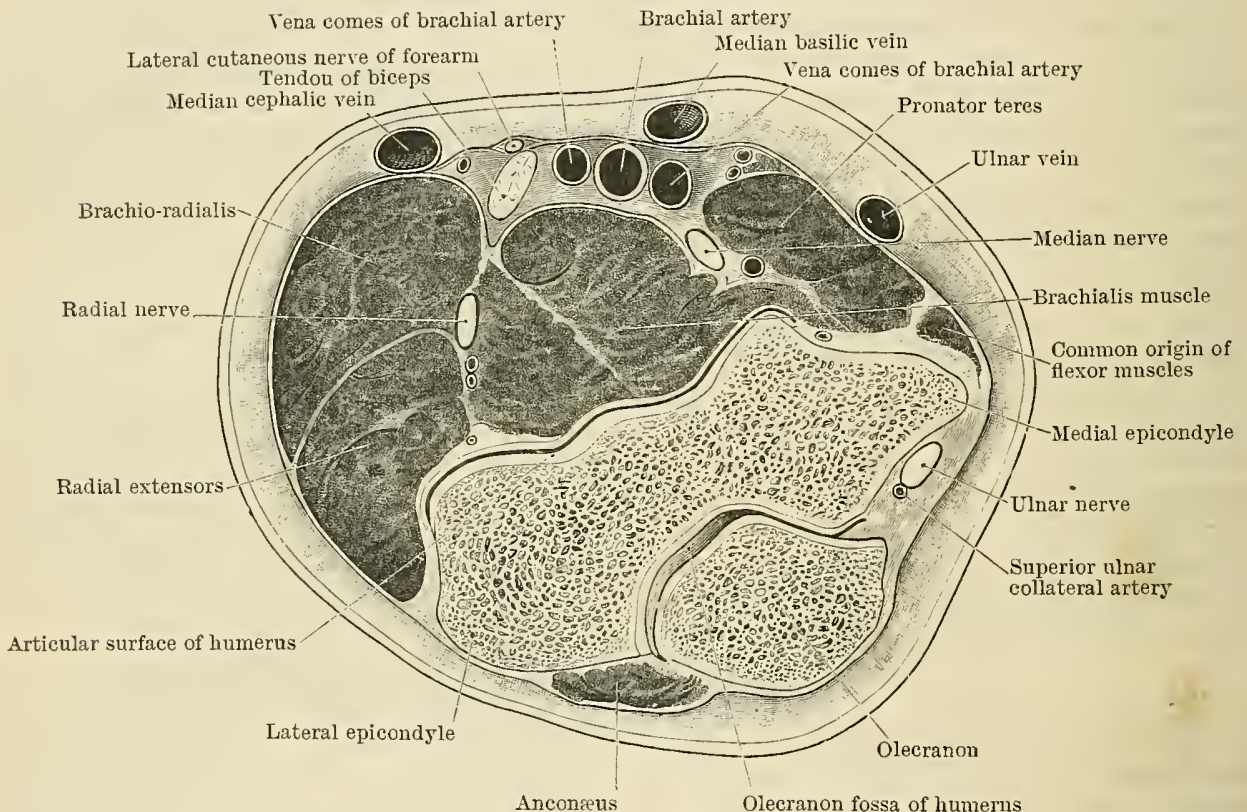

Fig. 1114. - Transverse Section throdgh the Bend of the Elbow.

edge of the tendon is the lacertus fibrosus, which separates the median basilic vein from the brachial artery. If the finger nail is insinuated beneath the medial edge of the lacertus fibrosus the point of the finger will rest upon, and feel the pulsations of, the brachial artery. The median nerve descends through the space a little medial to the brachial artery. The bifurcation of the radial nerve takes place in front of the lateral epicondyle under cover of the brachio-radialis. The ulnar nerve can be rolled beneath the finger upon the back of the medial epicondyle; its position renders it liable to injury in severe fractures about the elbow; and in excising the joint care must be taken not to injure the nerve.

\section{THE FOREARM AND HAND.}

The proximal half of the radius is deeply placed; the distal half, however, is easily palpated. The anterior border of its distal extremity is felt as a prominent transverse ridge, situated 1 in. proximal to the thenar eminence; immediately distal to the ridge is the radio-carpal articulation. The tip of the styloid process, situated nearly $\frac{1}{2}$ in. more distal than that of the ulna, is deeply placed at the lateral side of the wrist, in the hollow between the extensor tendons of the first and second phalanges of the thumb. Upon the middle of the posterior surface of the distal end of the radius is the dorsal radial tubercle, which intervenes between the extensor pollicis longus and the short radial extensor of the wrist; the tubercle can be distinctly felt, and may be taken as a guide to the proximal end 
of Lister's dorso-radial incision for excision of the wrist. The dorsal border of the ulna is subcutaneous throughout, and may be felt along the interval between the flexor and extensor carpi ulnaris muscles. Upon the ulnar side of the dorsal aspect of the wrist, when the forearm is in the prone position, there is a well-marked rounded prominence formed by the distal extremity of the ulna, anterior to which is the styloid process, the deep groove between the two being occupied by the tendon of the extensor carpi unlnaris.

The carpal bones are built up so as to form an arch, converted by the transverse carpal ligament into a tunnel for the transmission of the flexor tendons. At each extremity of the arch the two bony points to which the ligament is attached furnish important landmarks. These bony points are: laterally, the tuberosity of the navicular and the ridge of the greater multangular bone; medially, the pisiform and the hamulus of the os hamatum. The tuberosity of the navicular is felt immediately proximal to the root of the thenar eminence, midway between the tendons of the abductor pollicis longus and the flexor carpi radialis; $\frac{1}{2}$ in. distal to the tuberosity of the navicular is the ridge of the greater multangular bone, felt deeply beneath the medial part of the thenar eminence. At the root of the hypothenar eminence, and crossed by the crease which separates the forearm from the hand, is the pisiform bone, proximal to which is the tendon of the flexor carpi ulnaris, passing to be inserted into it. The hamulus of the os hamatum is felt deeply beneath the radial side of the hypothenar eminence, and a full finger's breadth distal and lateral to the pisiform.

The bases of the first, third,

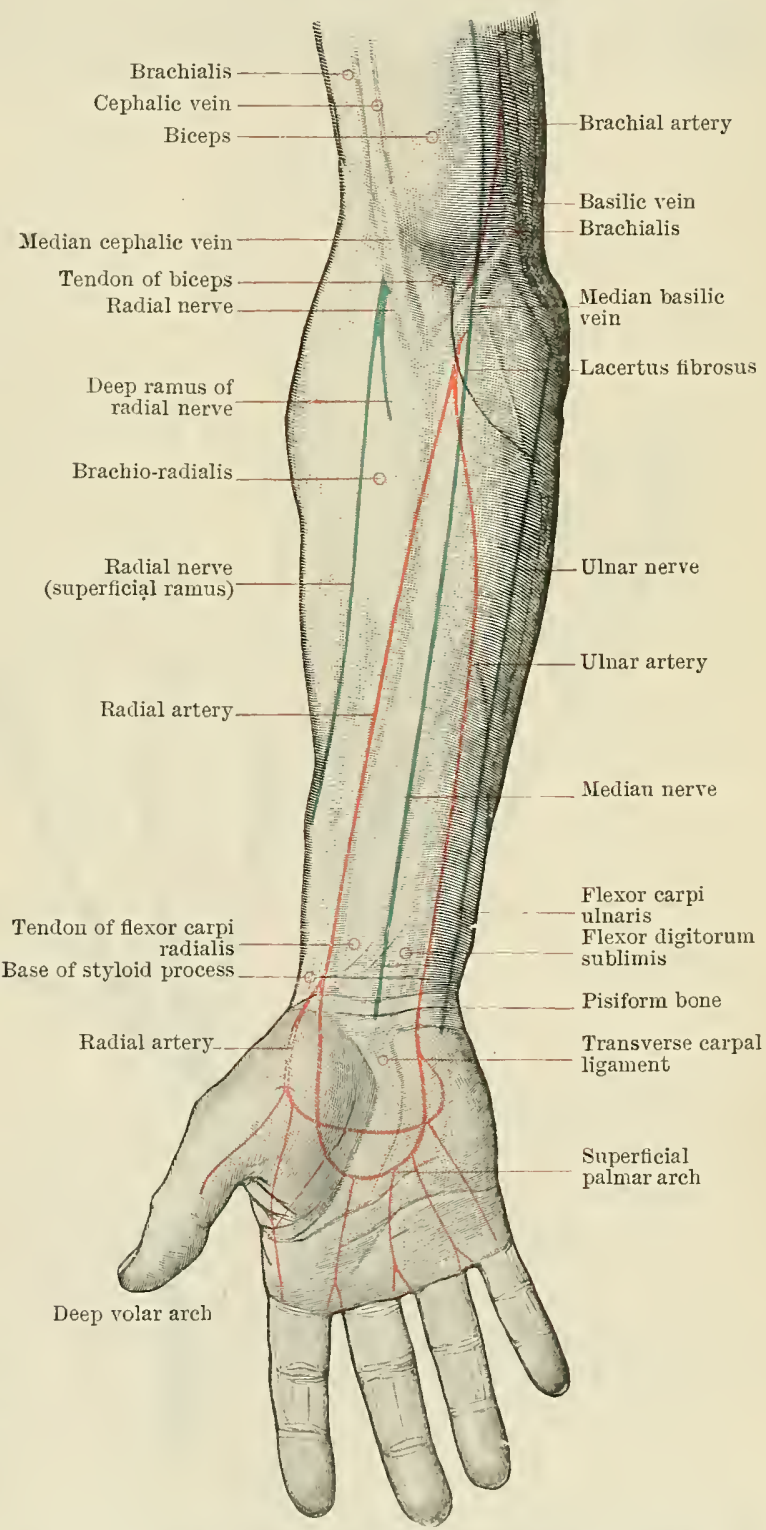

Fig. 1115.-Bexd of Elbow, Tolar Surface of Forearm, AND HAND. and fifth metacarpals, all of which can be readily identified on the dorsal aspect, furnish a sufficient guide to the line of the carpo-metacarpal articulations. At the base of the third metacarpal is a tubercle, which can be felt projecting from its dorsal aspect at a point $1 \frac{3}{4}$ in. vertically distal to the tubercle upon the back of the distal end of the radius. This metacarpal tubercle marks the insertion of the extensor carpi radialis brevis, the favourite site for the development of a "ganglion," which may frequently be ruptured by pressing it firmly against the tubercle. Anteriorly, the carpo-metacarpal articulations correspond to the distal border of the transverse carpal ligament. 
The prominences of the knucliles are formed entirely by the heads of the metacarpal bones. Anteriorly, the metacarpo-phalangeal articulations are situated $\frac{3}{4}$ in. proximal to the level of the web of the fingers; posteriorly, the joints may be felt as a groove immediately proximal to the projecting ridge at the base of the first phalanges. A well-marked crease crosses obliquely over the anterior aspect of the metacarpo-phalangeal joint of the thumb. To cut into the first interphalangeal joints from the front, incise along the most proximal of the creases in front of the joints; whereas to cut into the terminal joints, incise along the most distal of the creases in

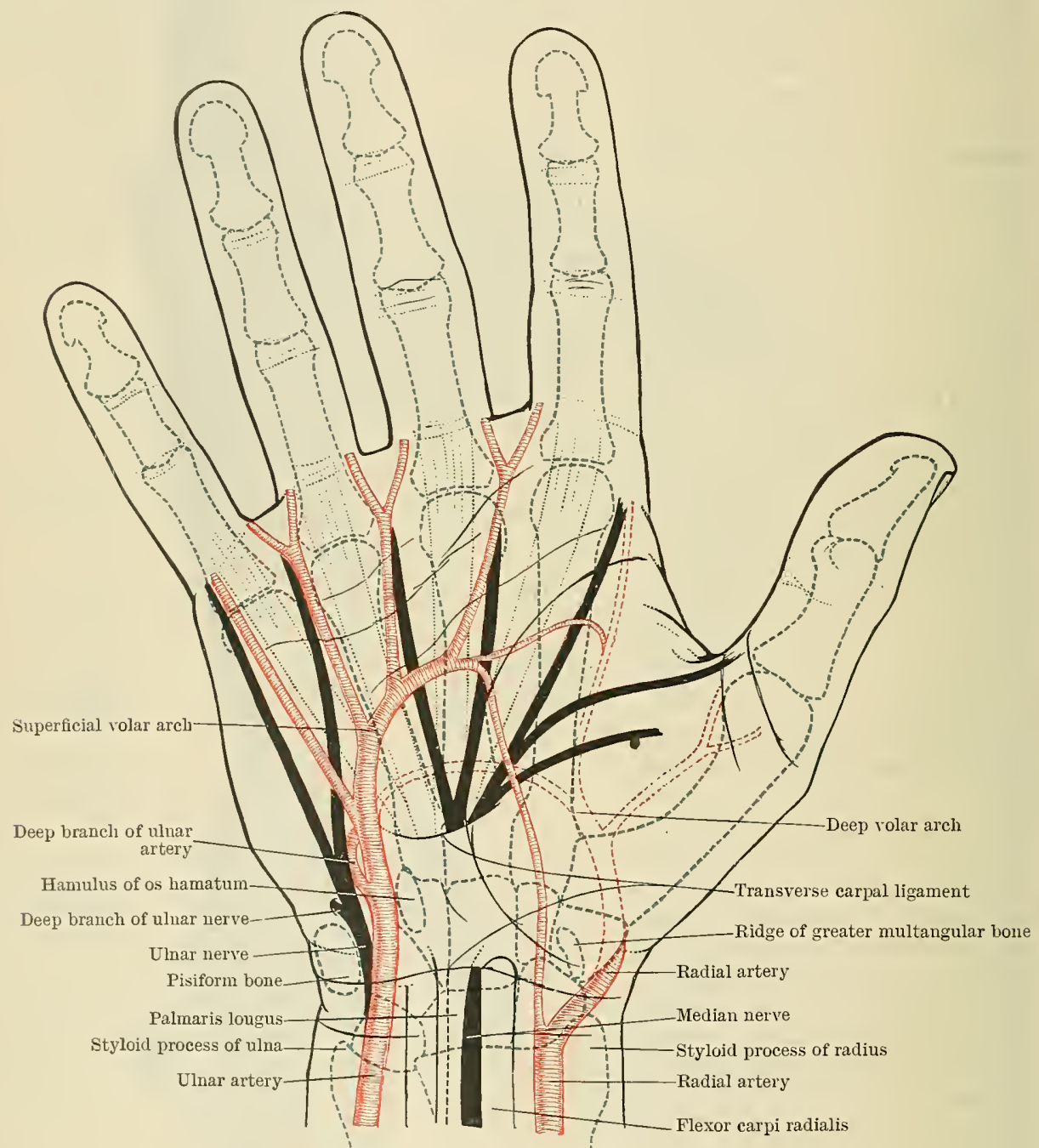

Fig. 1116.-PALM OF HÁND.

front of the joints. Dorsally, the first and the terminal interphalangeal articulations are opposite the most distal of the various creases overlying the joints.

The most important muscular landmarks upon the front of the forearm are the brachio-radialis, the flexor carpi radialis, and the pronator teres. The brachioradialis is thrown into prominence by flexing the semi-prone forearm against resistance. At the junction of the proximal and middle thirds of the forearm the pronator teres passes beneath the brachio-radialis; between the two is the radial artery. The tendon of the flexor carpi radialis forms a prominent landmark descending along the middle of the volar aspect of the forearm towards the ridge of the multangular magus; the tendon of the palmaris longus, when present, is seen to its medial side. 
At the dorsum of the forearm the intermuscular septum between the radial and common extensors corresponds to the proximal part of a line extending from the lateral epicondyle of the humerus to the tubercle on the dorsum of the distal end of the radius. The dorsal interosseous nerve, at the point at which it emerges from the substance of the supinator muscle, will be found at the bottom of this septum, 2 in. distal to the head of the radius; below this point the septum is the best line along which to cut down upon the posterior surface of the radius. Winding across the distal third of this surface is an oblique prominence caused by the abductor pollicis longus and extensor pollicis brevis muscles.

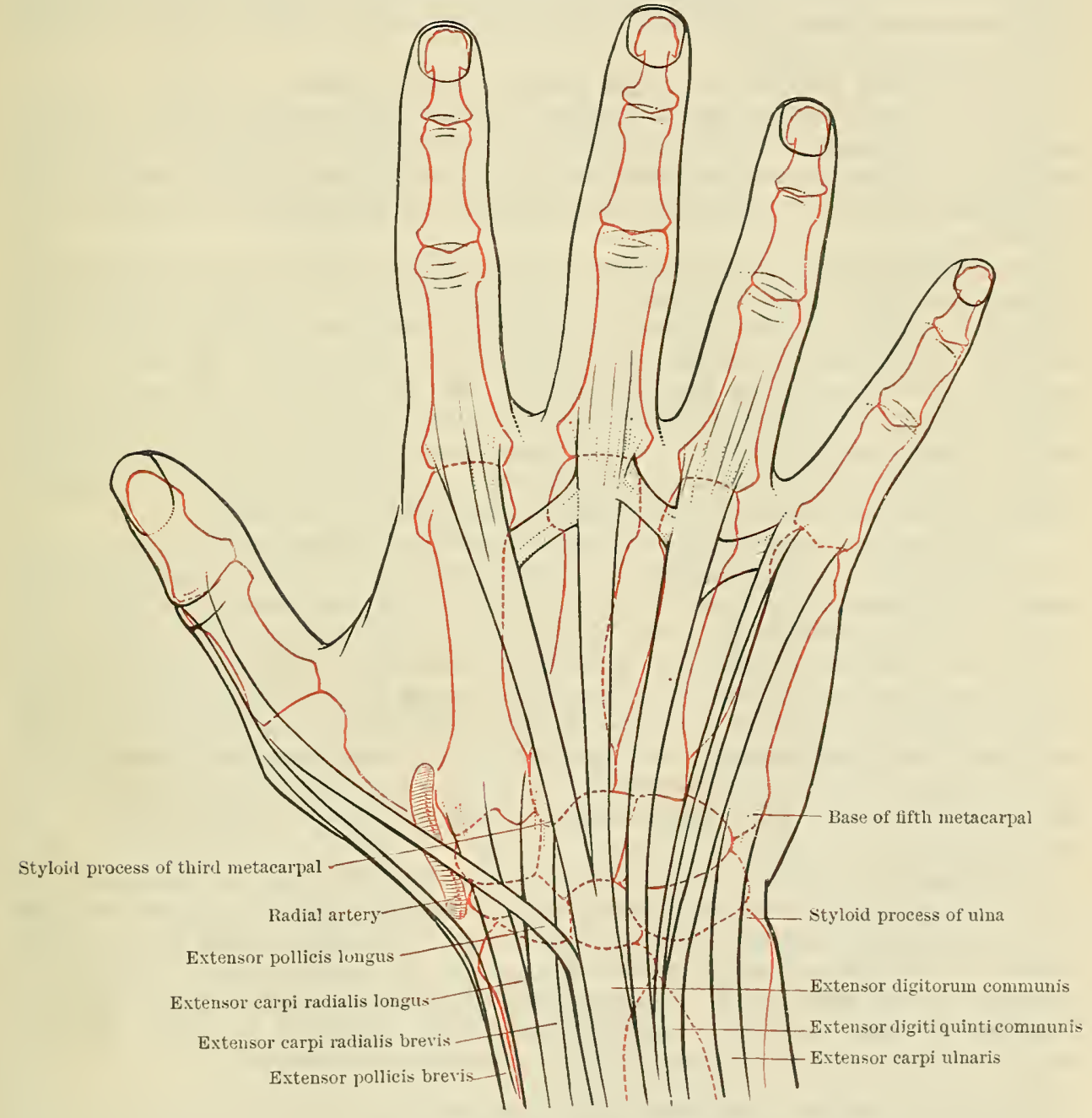

Fig. 1117.-DORSAL AsPect OF HAND.

The flexor sheaths of the palm and of the digits are of surgical importance in consequence of their liability to suppurative inflammation. The common flexor sheath begins $1 \frac{1}{2}$ in. proximal to the transverse carpal ligament, under which it extends to a little below the middle of the palm. The digital flexor sheaths extend from the bases of the terminal phalanges to the level of the distal transverse crease of the palm, opposite the necks of the metacarpal bones, with the exception of the sheath of the little finger, which is continuous with the common flexor sheath of the palm. The sheath of the flexor pollicis longus extends from the base of the teiminal phalanx proximally to a point about 1 in. proximal to the transierse carpal ligament; it frequently communicates with the common flexor sheath. From this anatomical arrangement it follows that suppuration in the sheaths of the little finger and 
thumb is specially liable to spread upwards into the palm, and thence underneath the transverse carpal ligament into the forearm.

The pulsations of the radial artery can readily be felt in the distal third of the forearm, midway between the lateral border of the radius and the tendon of the flexor carpi radialis. The course of the vessel is indicated upon the surface by a line extending from the bifurcation of the brachial ( $\frac{1}{2}$ in. distal to the middle of the bend of the elbow) to the tubercle of the navicular, around which, and distal to the tip of the styloid process, the artery winds to the dorsum of the radial side of the wrist; in the latter situation the vessel, after passing beneath the extensor tendons of the thumb, dips into the palm through the proximal extremity of the first interosseous space. Incisions for opening or resecting the wrist are planned so as to avoid the ressel.

The proximal third of the ulnar artery is deeply placed, and takes a curved course from the bifurcation of the brachial towards the medial part of the anterior surface of the forearm; the distal two-thirds of the vessel correspond to the distal two-thirds of a line drawn from the front of the medial epicondyle to the radial border of the pisiform bone. The course of the ulnar nerve corresponds to the whole of the above line.

The median nerve in the forearm may be mapped out by a line extending from a point midway between the centre of the bend of the elbow and the medial epicondyle, to a point midway between the styloid processes; in the distal third of the forearm the line follows the medial border of the tendon of the flexor carpi radialis. To evacuate pus spreading deeply up the front of the forearm, the incisions should be made on either side of the line corresponding to the median nerve. The superficial branch of the radial nerve winds to the dorsum of the forearm round the lateral border of the radius beneath the tendon of the brachioradialis, at the junction of the middle and distal thirds of the forearm.

The summit, or most distal part of the superficial palmar arch, corresponds to the mid-point of a line extending from the middle of the most distal transverse crease of the wrist to the root of the middle finger; a line drawn from the radial border of the pisiform bone across the hamulus of the os hamatum, and thence in a curved direction distally and laterally to this point, corresponds to the main or proximal part of the arch; the first and fourth digital branches overlie the fifth and third metacarpal bones respectively, while the second and third overlie the fourth and third interspaces respectively. The deep arch lies almost transrersely, midway between the distal border of the transverse carpal ligament and the superficial arch. The radialis indicis corresponds to the radial border of the index-finger.

The ulnar nerve and the commencement of its two divisions lie immediately to the medial side of the superficial palmar arch, so that the pisiform and the hamulus of the os hamatum are the guides to the nerve. The median nerve emerges from beneath the transverse carpal ligament opposite the medial edge of the thenar eminence, while the digital branches to the thumb follow its distal margin. Incisions for the removal of foreign bodies may therefore be made into the thenar with greater freedom than into the hypo-thenar uminence.

Incisions to evacuate deep-seated pus in the palm may be made in one or more of the following situations: (1) over the distal two-thirds of the second metacarpal bone ; (2) over the distal half of the fourth metacarpal bone ; (3) from the proximal part of the first incision an opening may be made through the first interosseous space on to the dorsum, care being taken to keep below the radial artery; (4) a longitudinal incision between the median and ulnar nerves, on the proximal side of the superficial palmar arch. At the wrist a longitudinal incision may be made immediately to the ulnar side of the palmaris longus tendon, thus falling between the lines of the median nerve and the ulnar artery. To open the digital flexor sheaths, incisions are made along the middle of the palmar surface of the fingers, opposite the first and second phalanges. The proper digital vessels and nerves pass distally along the sides of the fingers, nearer the fiexor than the extensor surfaces. In cutting down upon the dorsal aspects of the phalanges, the incisions should be made to one or other side of the extensor tendon, preferably upon the ulnar side, to avoid division of the insertions of lumbrical muscles. The subcutaneous tissue of the 
palmar aspect of the terminal phalanges is connected by fibrous processes with the periosteum; hence the frequency of necrosis of the terminal phalanx in suppurative inflammations in this region.

\section{THE LOWER EXTREMITY.}

THE BUTTOCK.

The region of the hip or buttock extends from the crest of the ilium above to the gluteal fold below. The highest point of the iliac crest, situated a little posterior to its middle, is on a level with the fourth lumbar spine; the anterior superior spine of the ilium is directed forwards, and belongs to the groin, which it limits externally; the posterior superior spine, situated at the bottom of a dimple or small depression, is on a level with the second sacral spine, and corresponds, therefore, to the middle of the sacro-iliac joint. Two and a half inches behind the anterior superior spine is a prominence upon the outer lip of the iliac crest ; this prominence, which is termed the tubercular point, is the most lateral part of the crest, and has been referred to in dealing with the surface anatomy of the abdomen. A hand's breadth below the tubercle of the crest is the greater trochanter of the femur, the most lateral bony landmark of the hip; its anterior and posterior borders are best felt between the fingers and thumb, while the limb is slightly abducted to relax the ilio-tibial tract, and if the thigh is now rotated, it will be noted that the trochanter rotates round the segment of a circle, the radius of which is formed by the head and neck of the femur; in nonimpacted fractures of the neck of the femur the trochanter rotates round the segment of a much smaller circle. Nelaton's line, drawn from the anterior superior spine to the most prominent part of the ischial tuberosity, crosses the hip at the level of the proximal border of the greater trochanter; this line is employed to ascertain the presence or absence of upward displacement of the trochanter. Chiene demonstrates the relative height of the trochanters by stretching two tapes across the front of the pelvis, one between the anterior superior spines, and the other between the proximal borders of the trochanters; the lower tape will converge towards the upper on the side of the upward displacement. A line prolonging the anterior border of the greater trochanter vertically upwards touches the iliac crest at the tubercular point. The sciatic tuberosity, in the erect posture, is overlapped by the distal border of the gluteus maximus; its most prominent part is felt a little proximal to the medial part of the gluteal fold. If the hip is rotated medially, the lesser trochanter of the femur may be felt by deep palpation proximal to the lateral end of the gluteal fold ; it corresponds to the interval between the distal border of the quadratus femoris and the proximal border of the adductor magnus, and therefore, also, to the level of the medial circumflex artery of the thigh.

The lower border of the glutæus maximus lies a little above the gluteal fold medially, crosses it about its middle, and is continued distally and laterally to meet the proximal end of the furrow of the lateral intermuscular septum, at the junction of the proximal and middle thirds of the femur. The medial borders of the two great gluteal muscles are separated by the deep gluteal cleft, which extends upwards and backwards from the perineum to the level of the fourth sacral spine, where it opens out into the triangle upon the back of the sacrum. Anteriorly the buttock is limited by the prominence of the tensor fasciæ latæ muscle, which extends distally and somewhat backwards from the anterior end of the crest, to join the ilio-tibial tract distal to the root of the greater trochanter.

The superior giuteal artery reaches the buttock immediately below the upper border of the greater sciatic foramen, opposite a point corresponding to the junction of the upper and middle thirds of a line drawn from the posterior superior iliac spine to the upper border of the greater trochanter. To expose the ressel the incision should be made along this lime, which has the advantage of rumning parallel to the fibres of the glutæus maximus, as well as parallel to the interval between the glutæus medius and piriformis muscles. 
The sciatic nerve enters the buttock at a point corresponding to the junction of the upper and middle thirds of a line drawn from the superior posterior iliac spine to the sciatic tuberosity; from this point the nerve passes dowuwards and slightly laterally upon the ischium to a point midway between its sciatic tuberosity and the greater trochanter. The spine of the ischium and the pudendal vessels are situated opposite the junction of the lower and middle thirds of the above line. The vessels and nerves which enter the buttock through the greater sciatic foramen below the piriformis, may be exposed through an incision below and parallel to that ahove described for exposing the superior gluteal artery, viz., an incision corresponding to the middle two-fourths of a line extending from the upper end of the gluteal cleft to the root of the greater trochanter; the deep landmarks are the lower border of the piriformis and the root of the sciatic spine.

\section{THE BACK OF THE THIGH.}

The hamsoring muscles, and especially the tendon of the biceps and semitendinosus, are thrown into prominence either by standing on tiptoes with the knees slightly flexed, or by flexing the leg against resistance. By throwing the

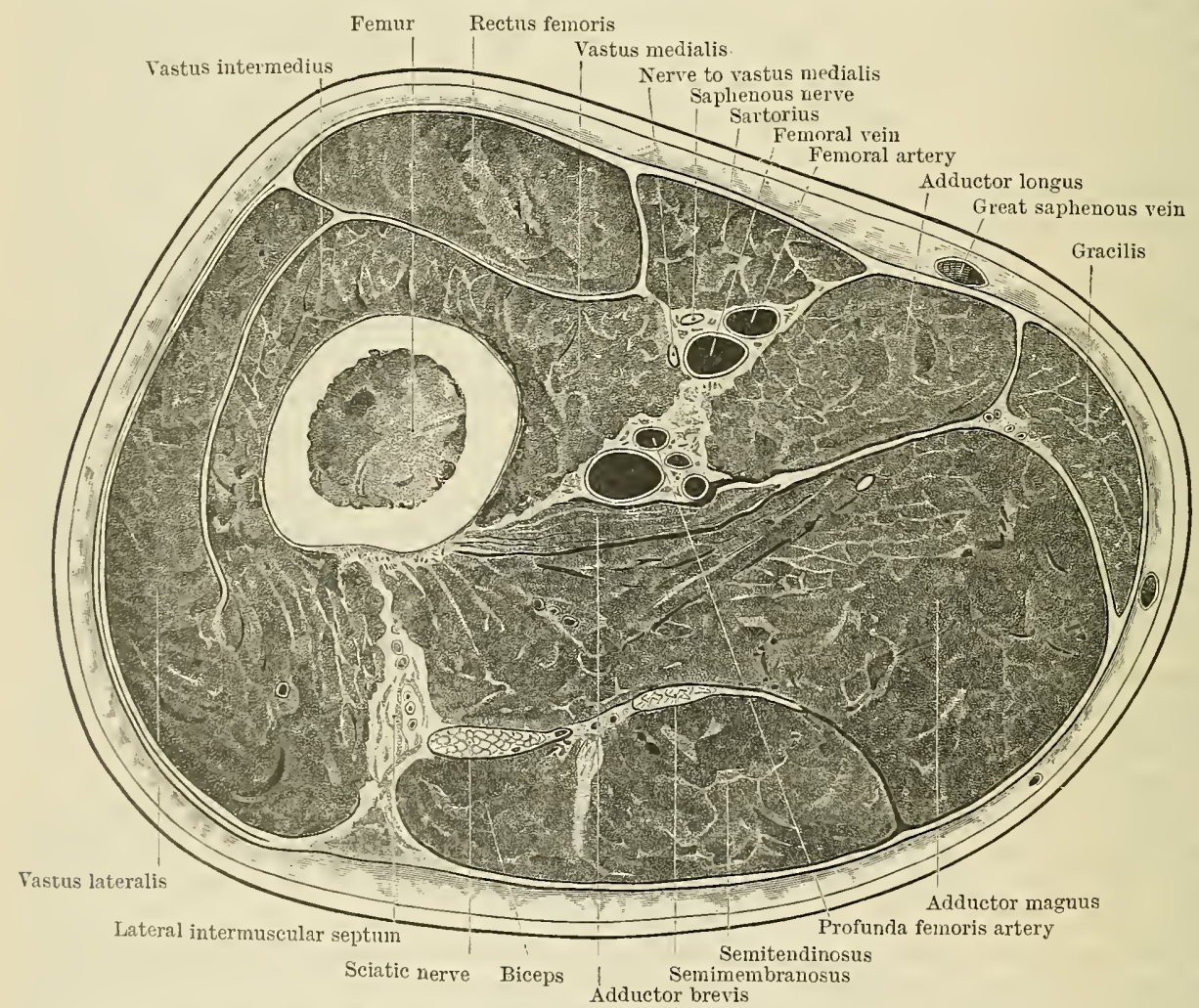

Fig. 1118. - Section throdgh Thigh at the Level of the proxinal part of the adductor Canal.

hamstrings into action, the line of the lateral intermuscular septum of the thigh is indicated by a well-marked furrow, extending from the lower edge of the insertion of the glutæus maximus to the lateral aspect of the knee; behind this furrow is the biceps femoris, and in front of it is the large vastus lateralis, covered by the strong ilio-tibial tract of the fascia lata. The shaft of the femur may be cut down upon along the whole length of this furrow with least injury to the soft parts; the popliteal surface of the femur and deep-seated popliteal abscesses are most conveniently reached through the lower part of the same incision.

The course of the sciatic nerve corresponds to the proximal half of a line 
extending from a point midway between the sciatic tuberosity and the greater trochanter to the centre of the popliteal fossa. The nerve enters the thigh under cover of the lateral border of the biceps, whereas the posterior cutaneous nerve of the thigh which takes the same line, descends superficial to the biceps, between it and the fascia lata. In the operation of stretching the sciatic nerve it is cut down upon immediately distal to the lower border of the gluteus maximus. The surgeon, standing on the side of the patient opposite to the leg to be operated upon (Chiene), makes an incision in the line of the nerve through the integuments and fascia lata, and, sweeping the index-finger round the lateral border of the

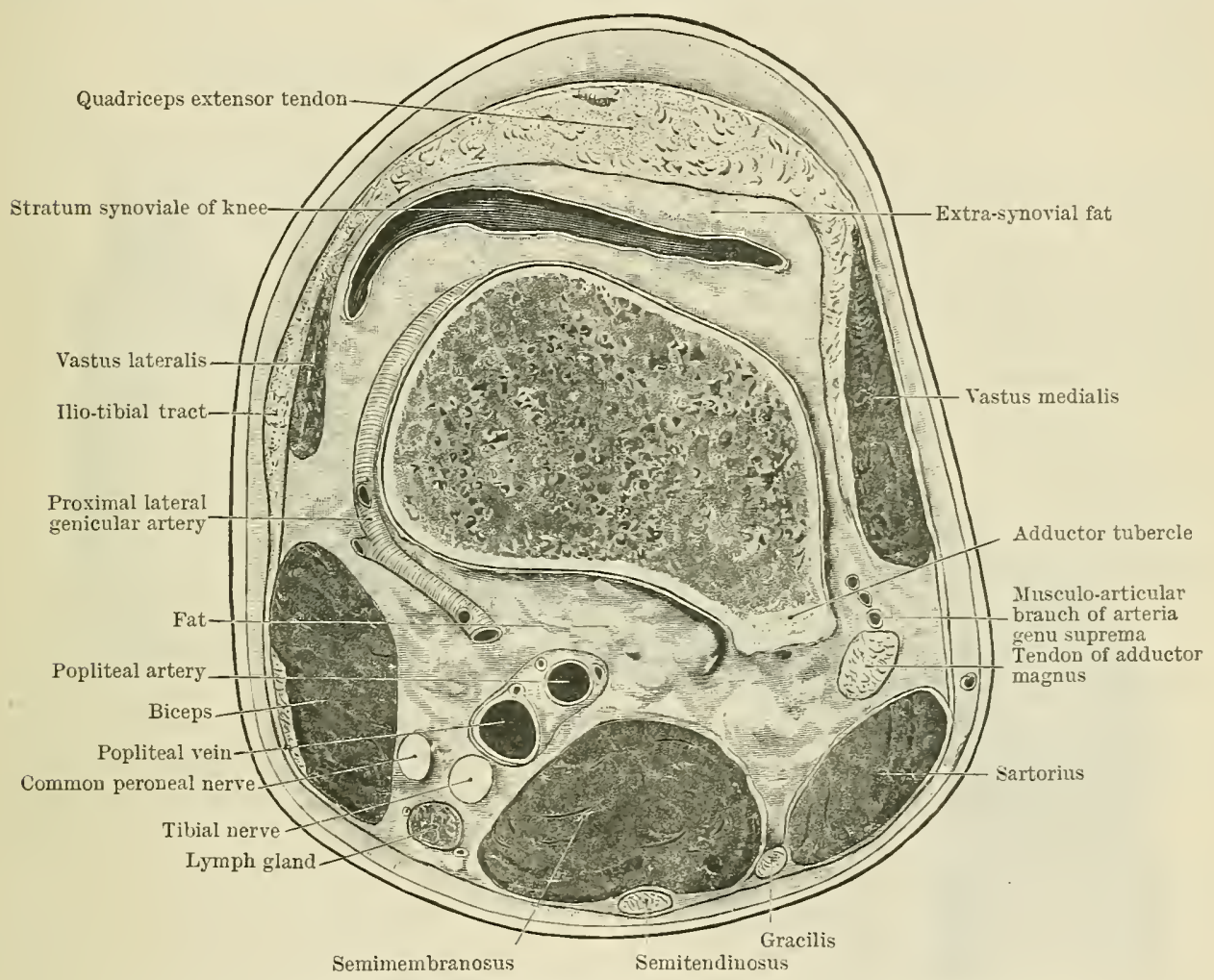

F1G. 1119.-Section throdgh the Thigh imaediately proximal to the Patella.

biceps, hooks up the nerve as it lies between that muscle and the adductor magnus.

The common peroneal nerve may be rolled under the finger as it passes distally immediately behind the tendon of the biceps and the head of the fibula; so close is the nerve to the tendon that the tendon should be divided, in cases where this is necessary, by the open method rather than subcutaneously.

Abscesses may reach the flexor compartment of the thigh from varions sources, viz. : (1) from the posterior aspect of the hip-joint; (2) from the pelris through the greater sciatic foramen; (3) from one or other of the burse under the gluteus maximus; (4) from the front of the hipjoint by passing backwards under the tensor fascize lata; or by winding backwards beneath the neck of the femur, and through the interval between the quadratns femoris and the adductor magnus, (5) from the iliac fossa under the inguinal ligament into the fascial trigone, and thence to the back of the thigh by one or other of the routes already mentioned ; 6 ) the pus may spread proximally from the popliteal surface of the femur, the knee, a popliteal gland, or from a bursa.

\section{THE POPLITEAL FOSSA.}

When the knee is extended the popliteal fascia is put upon the stretch, and obliterates the hollow of the popliteal fossa; by flexing the knee the fascia is relaxed, and the fingers may be pressed deeply into the proximal or femoral 
division of the fossa; as a rule, the pulsations of the popliteal artery can be felt. Beneath the semitendinosus is the fleshy semimembranosus, which bulges into the space and orerlaps the proximal part of the popliteal artery. Between the semimembranosus and the medial head of the gastrocnemius is the most important bursa in the popliteal region; it not infrequently becomes distended with fluid, and then presents usually a more or less sausage-shaped outline; according to Holden, the bursa communicates with the cavity of the knee-joint in one subject out of five.

To map ont the line of the popliteal vessels and the tibial nerve, draw a line

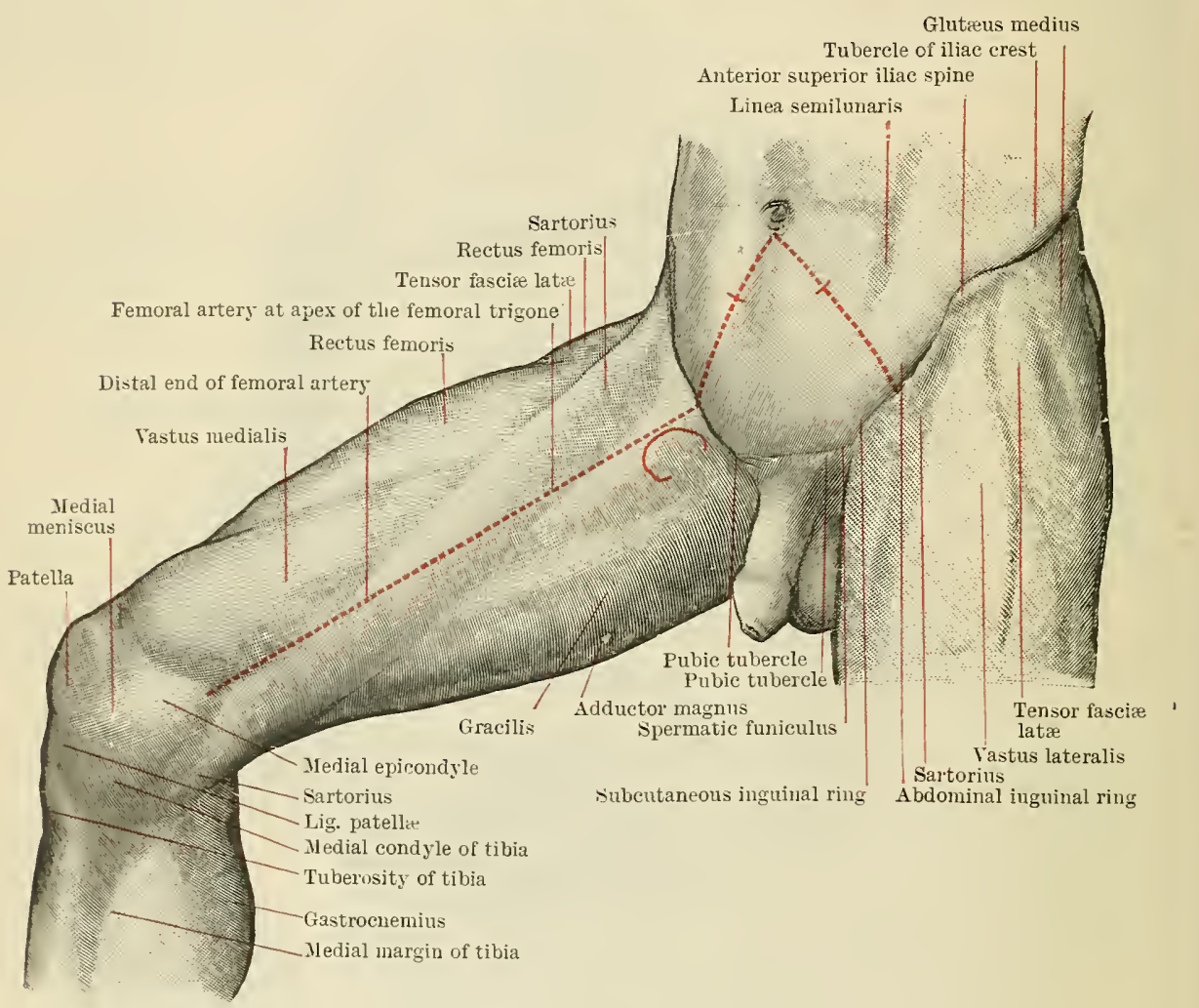

Fig. 1120.-The Thigh ANd Grols.

from a point a little medial to the proximal angle of the space to a point midway between the condyles of the femur, and thence distally along the middle of the space to the level of the distal part of the tuberosity of the tibia. The tibial nerve lies immediately beneath the deep fascia; the artery is separated from the popliteal surface of the femur by a quantity of fat. The popliteal lymph glands lie beneath the popliteal fascia, one upon the tibial nerve, the others deeply in the space (Leaf).

\section{THE FRONT OF THE THIGH.}

Between the front of the thigh and the abdomen is the fold of the groin, at the bottom of which the inguinal ligament can be felt as a tense band, stretching from the anterior superior spine of the ilinm to the pubic tubercle. The anterior superior spine looks directly forwards; comparative measurements of the inferior extremities are made by stretching a tape from it to the tip of one or other of the malleoli, care being taken that the pelvis is horizontal, and the limbs in corresponding positions. The pubic tubercle is felt under the proximal and lateral part of the mons Veneris and at a corresponding point in the male; between the tubercle and the symphysis is the crest of the pubis, the two crests together 
forming a rounded subcutaneous bony ridge. A line extending from the pubic tubercle horizontally laterally across the front of the thigh crosses the front of the hip-joint at the level of the inferior part of the head of the femur. The cord-like tendon of the adductor longus is readily felt, and a point about 1 in. below the pubic tubercle is selected for performing the operation of subcutaneous tenotomy of the tendon.

The centre of the fossa ovalis is situated $1 \frac{1}{2} \mathrm{in}$. distal and lateral to the pubic tubercle; it overlies the medial (hernial) and intermediate (venous) compartments of the femoral sheath; behind the lateral border of the opening is the arterial compartment of the sheath; crossing over the distal border is the termination of the great saphenous vein. A femoral hernia makes its way into the thigh beneath the proximal edge of the opening. The course of the great saphenous vein in the thigh is indicated by a line extending from the adductor tubercle of the medial epicondyle of the femur to the distal part of the fossa ovalis.

The horizontal or subinguinal chain of lymph glands can usually be felt along, and a little distal to, the line of the inguinal ligament; when the glands are inflamed the surgeon should not neglect to examine the buttocks and anus as well as the external genitals. The vertical or femoral chain lies in close relation to the upper end of the great saphenous vein. Deeper glands also are met with beneath the fascia cribrosa, close to the medial side of the femoral vein, and there is generally one in the femoral canal. To clear out the glands in the groin an incision should be made parallel to, and a finger's breadth distal to the whole length of the inguinal ligament.

To map out the course of the femoral artery, the thigh being slightly flexed and rotated laterally, draw a line from the mid-point between the anterior superior iliac spine and the symphysis pubis to the adductor tubercle at the proximal and posterior part of the medial epicondyle; rather less than the proximal third of this line corresponds to the femoral artery in the femoral trigone, while rather more than its middle third corresponds to the artery as it lies in the adductor canal. The seat of election for ligature of the vessel is at the apex of the femoral trigone. To compress the femoral, pressure should be made directly backwards against the ilio-pectineal eminence, and not against the head of the femur; to compress the femoral in the adductor canal, pressure should be made laterally against the medial surface of the shaft of the femur.

On the lateral aspect of the thigh the fascia lata is thick, aponeurotic, and loosely attached to the vastus lateralis; hence the tendency of abscesses to travel distally beneath it towards the knee. The sartorius, which forms the most important muscular landmark of the thigh, may be thrown into prominence by maintaining the thigh unsupported, flexed, and slightly rotated laterally. Observe that in the proximal third of the thigh it forms the lateral boundary of the femoral trigone; in the middle third it is placed over the adductor canal; while in the distal third it lies in front of the medial hamstrings. Lateral and adjacent to the proximal part of the sartorius is the prominence of the tensor fasciæ latæ, which, as it passes to its insertion, diverges from the sartorius; in the angle between the two the tendon of the rectus may be felt as it overlies the distal part of the anterior aspect of the articular capsule of the hip.

The medial aspect of the distal half of the shaft of the femur may be conveniently cut down upon through the rastus medialis, where it comes to the surface between the sartorius and rectus muscles; the incision should be made in the direction of a line extending from a point midway between the medial border of the patella and the adductor tubercle, to the anterior superior iliac spine.

The front of the hip-joint may be reached through an incision from the anterior superior iliac spine distally, along either the medial or the lateral border of the sartorius; in the former case the deeper part of the dissection passes between the iliacus and the medial border of the rectus, while in the latter case the joint is reached lateral to the rectus tendon, between it and the anterior borders of the gluteus medius and minimus muscles. The ascending branch of the lateral circumflex artery of the thigh crosses the capsule parallel to, and immediately above, the intertrochanteric line. The ilio-psoas crosses the anterior and the medial part of the capsule; between the two is a bursa, which frequently communicates with the joint through the thin part of the capsule medial to the ilio-femoral ligament; it is by way of this commumication that a psoas abscess occasionally gives rise to secondary tubercular disease of the 
hip-joint. One of the commonest sitnations to meet with an abscess in hip-joint disease is in the cellular tissue and fat under the tensor fasciæe latæ; or the pus may pass below and to the medial side of the neck of the femur, and thence along the course of the medial circumflex artery of the thigh to the back of the thigh. To tap or explore the hip-joint, the puncture should be made in the interval between the sartorius and the tensor fasciæ latæ, 2 to 3 in. distal to the superior anterior iliac spine; if the instrument is then pushed upwards, medially and posteriorly beneath the tendon of the rectus, it will pass throngh the capsule a little above the anterior intertrochanteric line. Regarded from the point of view of dislocation, the regions of the acetabular notch and of the inferior part of the capsule are the weak points in the joint; it follows, therefore, that abduction farours dislocation by bringing the head of the femur into relation with these two weak areas.

THE KNEE.

With the linee extended and the quadriceps relaxed, the patella can be readily outlined and moved from side to side upon the femoral condyles. When the

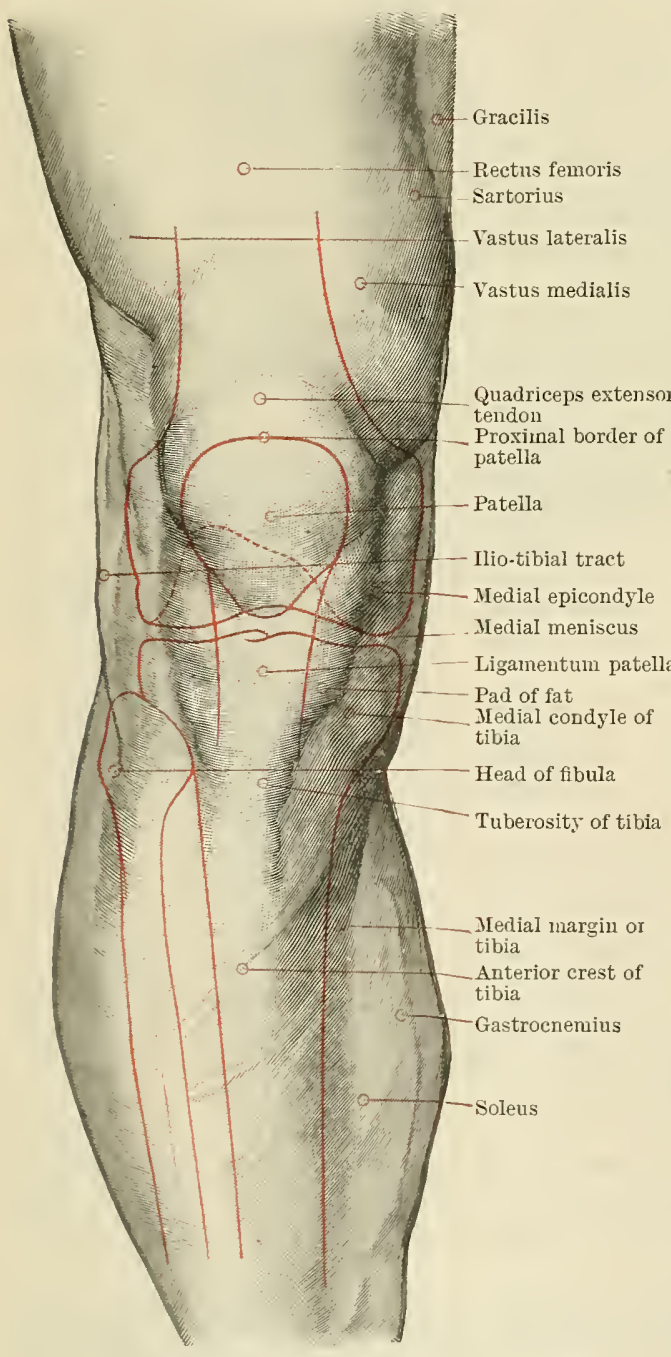

Fig. 1121.-Axterior Aspect of KNeE. quadriceps is contracted its tendon springs forwards and is felt as a tense band above the patella; while the lig. patellæ, which has become tense and prominent, may be traced to the distal part of the tuberosity of the tibia. In front of the distal part of the patella and of the proximal part of the lig. patellæ is the pre-patellar bursa, into which effusion takes place in the condition known as housemaid's knee. Beneath and on each side of the ligamentum patellæ is a well-circumscribed pad of fat, palpation of which gives rise to a feeling closely resembling true fluctuation. In extension, only the distal pair of articular facets of the patella are in contact with the trochlear surface of the femur. In semiflexion the midldle pair of facets rests upon the trochlea; in this position the medial margin of the medial condyle, the proximal border of the medial condyle of the tibia, and the distal part of the patella are all distinctly visible, and together bound a triangular depression, which overlies the line of the joint and contains the anterior part of the medial meniscus; it is in this triangle that the surgeon searches for a displaced or thickened medial meniscus, for a loose body, and for "lipping" of the edge of the articular cartilage in chronic osteo-arthritis. A similar, but less well-defined, triangle may be felt immediately lateral to the distal edge of the patella. When the quadriceps is thrown into sudden or violent contraction, as in preventing oneself from falling backwards, the patella may be transversely fractured at the moment of partial flexion. In full flexion almost the whole of the trochlear surface of the condyles is exposed to palpation, covered, however, by the stretched quadriceps tendon. 
The proximal part of the medial surface of the medial condyle is overlapped by the muscular prominence of the distal fibres of the vastus medialis. Leading proximally from the medial condyle is a slight furrow, corresponding to the interval between the distal part of the vastus medialis and the sartorius; at the bottom of the furrow the cord-like tendon of the adductor magnus may readily be felt, and followed to its insertion into the adductor tubercle; the latter, situated at the junction of the medial supra-condylar ridge with the proximal and posterior part of the medial condyle, marks the level of the epiphyseal cartilage. Anteriorly and posteriorly the epiphyseal cartilage lies just proximal to the highest part of the articular cartilage.

Disease of the distal end of the diaphysis of the femur generally invades the popliteal surface of the femur and the popliteal fossa rather than the cavity of the knee-joint. In Macewen's operation for knock-knee, the incision (through which the osteotome is introduced to divide the femur) is carried down to the bone through the vastus medialis a little proximal to the medial condyle, a finger's breadth proximal to the summit of the trochlea, to avoid injury to the epiphyseal cartilage, and the same distance in front of the adductor tendon, to avoid injury to the musculo-articular branch of the arteria suprema genu.

Distal to the medial condyle is the subcutaneous medial condyle of the tibia, across which the tendons of the sartorius, gracilis, and semitendinosus pass to their insertion. Between these tendons and the medial head of the gastrocnemius is a groove which winds distally and forwards from the popliteal space; an incision along this groove will expose the great saphenous vein and saphenous nerve and the superficial or saphenous branch of the arteria suprema genu.

On the lateral side of the knee is the ilio-tibial tract, which, after crossing and obscuring the line of the joint, is attached to the lateral condyle of the tibia. By semiflexion of the knee the posterior border of the tract is thrown into relief, and a well-marked furrow intervenes between it and the prominent tendon of the biceps; the distal part of the shaft of the femur and the popliteal surface may be reached through an incision along this furrow. Under cover of the ilio-tibial tract, as it crosses the line of the joint, are the lateral meniscus, the distal lateral genicular artery, and the fibular collateral ligament. The head of the fibula, and the tendon of the biceps passing to be inserted into it, are rendered distinctly visible by semiflexing the knee; the former lies on a level with the tuberosity of the tibia, $1 \frac{1}{2}$ in. posterior and a little distal to the most prominent part of the lateral condyle of the tibia. Immediately distal to the head of the fibula is the termination of the common peroneal nerve, which is liable to be contused from blows, and in fractures of the neck of the fibula.

The synovial layer of the knee-joint extends distally, anteriorly, as far as the level of the proximal border of the tibia; posteriorly, it dips distally for a short distance behind the popliteal notch of the tibia, to form a small cul-de-sac, the close relation of which to the popliteal artery must be borne in mind in performing the operation of excision of the knee. Anteriorly, the synovial layer extends proximally beneath the quadriceps in the form of a pouch, which reaches nearly two inches proximal to the articular surface of the femur; posteriorly, there is no extension of the synovial cavity proximal to the condyles; at the sides of the knee the synovial layer covers the anterior third of the superficial surface of each condyle.

In effusion into the knee-joint the hollows become obliterated, the patella is floated up, and fluctuation may be obtained proximal, distal, and to either side of the patella.

To pass a tube through the knee-joint for drainage, two short rertical incisions should be made-one on each side of the joint at the level of the proximal part of the patella, and a finger's breadth behind its lateral edges. In arthrectomy of the knee for tubercular disease, the subsynovial fat facilitates the separation of the supra-patellar pouch from the distal and anterior part of the shaft of the femur ; to expose the pouches posterior to the condyles, the cruciate ligaments must be divided.

\section{THE LEG.}

The medial surface of the tibia is subcutaneous throughout; hence the seat of a fracture of the shaft is, as a rule, easily felt, and the distal extremity of the proximal fragment is liable to perforate the skin. The skin over the distal half of this 
surface is the commonest seat of varicose and callous ulcers, which are frequently prevented from healing by adhesion of the floor of the ulcer to the periostenm.

The shaft of the fibula, situated on a plane posterior to that of the tibia, is, with the exception of the triangular subeutaneous surface proximal to the lateral malle-

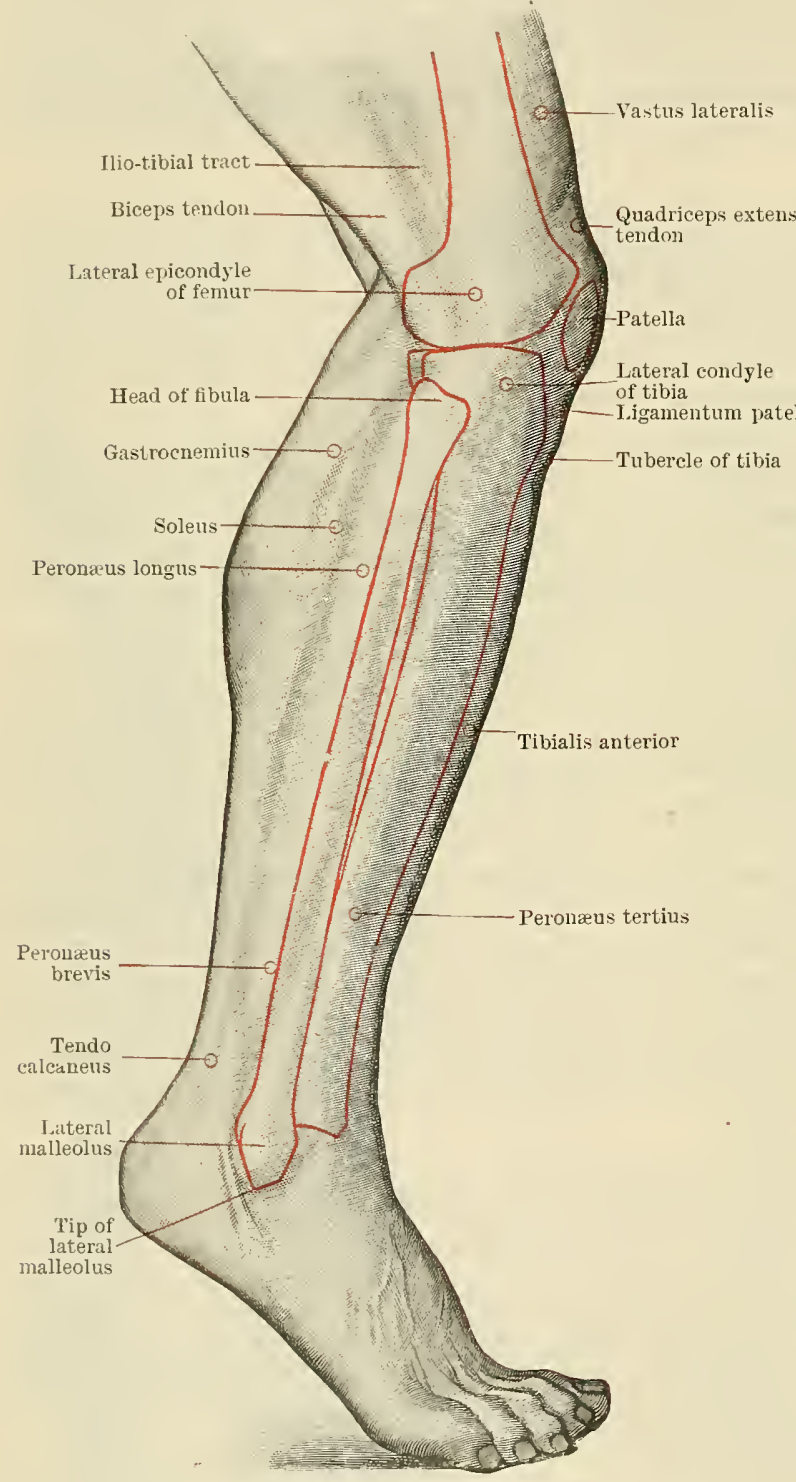

Fig. 1122.- Lateral Aspect of Knee axd Leg.

olus, deeply placed amongst the muscles. To examine the fibula, the surgeon should stand on the opposite side of the patient and manipulate the bone along the line of the intermuscular septum between the peronæi and the muscles of the calf.

The greater fulness of the antero-lateral surface of the leg, as compared with its medial surface, is due to the presence of the extensor and peroneal groups of muscles. When these groups are thrown into action, the individual muscles are mapped out upon the surface by the grooves corresponding to their intermuscular septa. The posterior peroneal septum is seen as a well-marked furrow, extending from the posterior aspect of the head of the fibula to the hollow behind the lateral malleolus; in front of it are the peronæi muscles, the longus giving rise to a prominence on the proximal half of the leg, while the brevis is prominent on the distal half; behind the septum is a prominence formed by the lateral border of the soleus, which projects beyond that of the gastrocnemius.

It is along the line of the posterior peroneal intermuscular septum that incisions should be made to

expose the fibula; to avoid the superficial peroneal nerve, however, the incision must not extend to a more proximal level than $1 \mathrm{in.} \mathrm{distal} \mathrm{to} \mathrm{the} \mathrm{head} \mathrm{of} \mathrm{the}$ fibula.

The furrow between the extensors and the two peronæi, the anterior peroneal septum, is much less distinct, and runs in a line from the anterior border of the head of the fibula to the anterior border of the lateral malleolus; the cutaneous portion of the superficial peroneal nerve corresponds to the distal half of this line. At the junction of the middle and distal thirds of the leg the extensor muscles incline medially over the anterior aspect of the tibia.

The anterior tibial artery reaches the front of the interosseous membrane 2 in. distal to the tuberosity of the tibia; in the proximal two-thirds of its course it lies 
upon the interosseous membrane, while in its distal third it winds on to the front of the tibia, to terminate at a point opposite the ankle-joint, midway between the two malleoli. Incisions to expose the ressel should strike the lateral border of the tibialis anterior, which corresponds to a line drawn from a point midway between the lateral condyle of the tibia and the head of the fibula, to the termination of the vessel.

When the muscles of the calf are thrown into action, a groove is seen between the two heads of the gastrocnemius, the fleshy fibres of which extend a little distal to the middle of the leg. The fleshy fibres of the soleus extend to the junction of the middle and distal thirds of the leg, and project beyond the margins of the gastrocnemius. The narrowest part of the tendo calcaneus is situated opposite the bases of the malleoli, and it is here that the tendon is divided in the operation of tenotomy. The small saphenous vein, which lies a little to the lateral side of the tendon, gradually reaches the middle of the ealf, along which it runs proximally to the middle of the popliteal fossa. The great saphenous vein and the saphenous nerve lie along the medial margin of the tibia.

The course of the posterior tibial artery is mapped out by drawing a line from the distal angle of the popliteal fossa, at the level of the distal border of the tuberosity of the tibia, to a point midway between the medial malleolus and the tendo calcaneus. To expose the vessel in the proximal half of the leg, an incision is made parallel to and $\frac{1}{2}$ in. posterior to the medial margin of the tibia; after retracting the medial border of the gastrocnemius and dividing the tibial origin of the soleus, the artery is found lying on the tibialis posterior. In exposing the artery below the soleus, divide two layers of deep fascia and keep the knife directed towards the tibia.

The peroneal artery is given off $3 \mathrm{in}$. distal to the head of the fibula; incisions to expose the ressel are made in the direction of a line extending from the posterior border of the head of the fibula to a point midway between the lateral malleolus and the tendo calcaneus.

\section{THE FOOT AND ANKLE.}

The tip of the lateral malleolus is situated $\frac{1}{4}$ in. distal and $\frac{3}{4}$ in. more posterior than that of the medial malleolus. Proximal to the lateral malleolus is

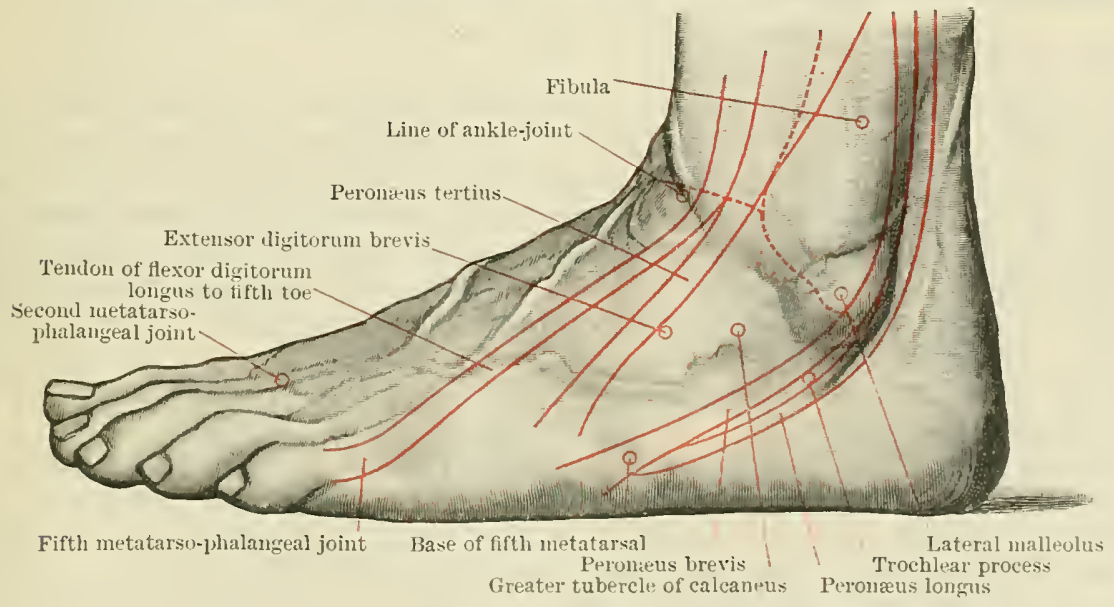

Fig. 1123.--LAteral Aspect of Foot AND AXKLe.

the triangular subcutaneous surface of the fibula, the apex of which corresponds to the lower end of the extensor-peroneal intermuscular septum.

The line of the ankle-joint can be felt on either side of the extensor tendons, and when the foot is extended the anterior part of the proximal articular surface of the talus forms a visible prominence distal to the anterior crest of the distal end 
of the tibia. The small posterior surface of the talus is felt distal and posterior to the medial malleolus, at the anterior part of the hollow between it and the heel. In effusions into the ankle-joint the hollows in front and behind the malleoli are obliterated, and the extensor tendons are raised from the front of the joint.

A finger's breadth distal to the tip of the medial malleolus is the sustentaculum tali; $1 \frac{1}{4}$ in. in front of the sustentaculum, and midway between the dorsal and plantar margins of the medial aspect of the foot, is the tuberosity of the navicular (the medial landmark in Chopart's amputation), which is generally visible, and always distinctly palpable. The calcaneo-taloid joint lies immediately above the sustentaculum, while close above it the tendon of the tibialis posterior may be rendered visible, as it extends from behind the tip of the medial malleolus to the tuberosity of the navicular. An inch and a half in front of the tuberosity of the navicular is the joint between the first cuneiform and the first metatarsal; the ridge at the base of the first metatarsal furnishes a good guide to the articulation. The first metatarso-phalangeal joint lies a little in front of the middle of the ball of the great toe.

A finger's breadth rertically below the tip of the lateral malleolus is the trochlear process of the calcaneus, and midway between the two is the calcaneotaloid joint; the trochlear process is, when present, a trustworthy guide to the level at which the two peronæi tendons cross the lateral surface of the calcaneus. The

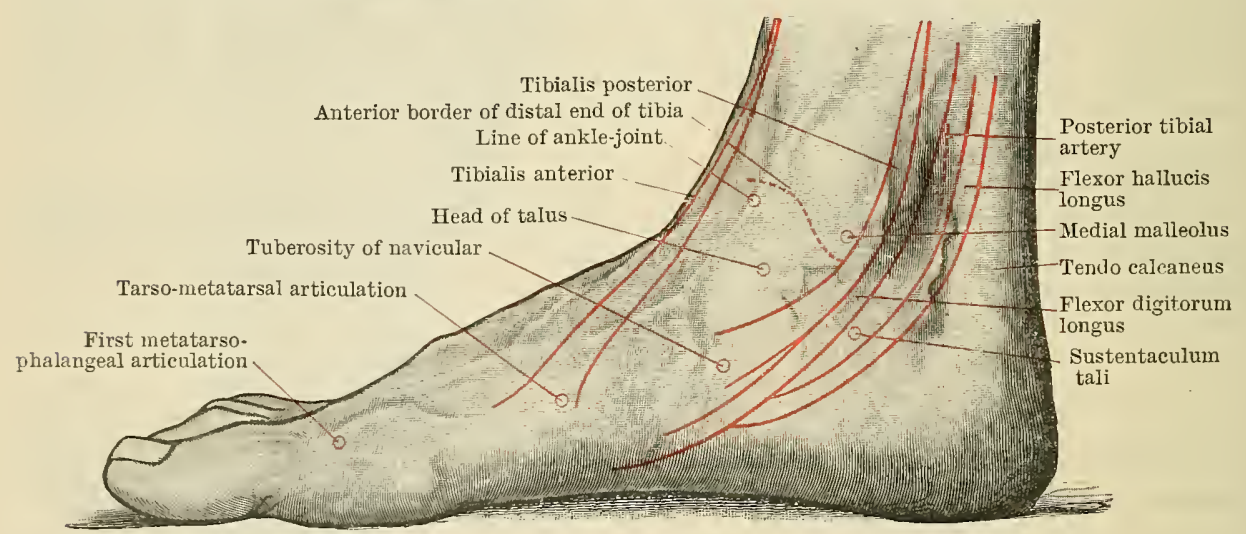

Fig. 1124.- Medial Aspect of Foot and ANkle.

greater process of the calcaneus is felt in the triangular interval between the tendons of the peronæus brevis and tertius; the calcaneo-cuboid joint-the lateral landmark in Chopart's amputation-is placed a little in front of the mid-point between the tip of the lateral malleolus and the base of the fifth metatarsal bone. To open the lateral tarso-metatarsal articulations, the knife, entered behind the projecting base of the fifth metatarsal bone, should be directed forwards as well as medially. On the dorsum of the foot the tarsal joints are obscured by the extensor tendons. The synovial layer of the ankle-joint is prolonged on to the neck of the talus, and care must be taken to avoid opening the ankle-joint in performing Chopart's amputation.

The line of the tarso-metatarsal joints extends nearly 1 in. further forwards on the medial than on the lateral border of the foot; between these points the jointline takes a zigzag course on account of the second metatarsal bone extending backwards between the first and third cuneiform bones. The joint between the second metatarsal and second cuneiform is nearly $\frac{1}{2} \mathrm{in}$. behind that between the first metatarsal and first cuneiform, and nearly $\frac{1}{4}$ in. behind that between the third metatarsal and the third cuneiform. The strong transverse interosseous ligament (Lisfranc's ligament), which connects the lateral surface of the first cuneiform with the base of the second metatarsal, must be divided in the tarso-metatarsal amputation of Lisfranc. In order to preserve the insertions of the two tibial and the three peroneal muscles it is advisable, when possible, 
instead of disarticulating at "Lisfrane's joint," to saw through the metatarsal bones just in front of their bases.

The metatarso-phalangeal articulations are situated $1 \mathrm{in}$. behind the web of the toes. In disarticulating a toe, the transverse metatarsal ligament, which unites the heads of the metatarsal bones, should not be injured.

The tendon of the tibialis posterior may be felt, and, by inverting the foot, seen, as it extends from behind the tip of the medial malleolus to the tuberosity of the navicular; it crosses the talus immediately above the sustentaculum tali.

In the commonest form of club-foot, viz., talipes equino-varus, the tuberosity of the navicular is approximated to the medial malleolus, so that tenotomy of the tendon should be performed through a puncture a little distal to the tip of the medial malleolus; if the knife, after dividing the tendon, is carried down to the bone, the plantar calcaneonavicular ligament will be divided and the talo-navicular joint opened, a procedure which is called for before the foot can be brought into good position.

Crossing the front of the ankle-joint, from medial to lateral side, are the following tendons: viz., the tibialis anterior, the largest and most prominent; the extensor hallucis longus, the extensor digitorum longus, and the peronæus tertius. The extensor digitorum brevis gives rise to a fleshy pad which overlies the dorsal aspect of the calcaneo-cuboid joint. When the foot is everted, the tendon of the peronæus brevis may be seen extending from the tip of the lateral malleolus to the base of the fifth metatarsal bone; immediately below it is the tendon of the peronæus longus, which, as it winds round the cuboid, is obscured by the fleshy fibres of the abductor digiti quinti muscle. The abductor hallucis muscle, although described along with the sole, forms a fleshy pad along the medial border of the foot below the sustentaculum tali.

An incision, extending from the tuberosity of the navicular to the middle of the medial border of the heel, will expose the various tendons, vessels, and nerves, as they pass from the medial malleolus into the sole, beneath the abductor hallucis.

The dorsalis pedis artery may be mapped out on the surface by drawing a line from a point opposite the ankle-joint, midway between the tips of the two malleoli, to the posterior end of the first interosseous space; the vessel may be compressed against the medial column of the tarsal bones. The great saphenous vein and the saphenous nerve lie between the anterior border of the medial malleolus and the tendon of the tibialis anterior; the small saphenous vein and the nervus suralis take the same course as the tendon of the peronæus brevis.

The medial plantar vessels and nerves lie along the medial intermuscular septum, which corresponds to a line drawn from the inferior surface of the medial tubercle of the calcaneus to the interval between the first and second toes. The lateral plantar vessels and nerves may be exposed by an incision along the lateral intermuscular septum, which runs in a line extending from the middle of the inferior surface of the heel to the fourth toe (Kocher); to map out the course of the plantar arch, draw a line across the sole from the medial side of the base of the fifth metatarsal bone to the proximal end of the first interosseous space. 



INDEX. 



\section{INDEX.}

Note. - The B.N.A. nomenclature, alone, is inclnderl in the index, as references to the Engli-h terms will be found in the text. Figures in heary trpe refer to the pages on which structures are mast exhanstively describerl.

\author{
Abdomen, 1155 \\ apertures of, 1157 \\ boundaries of, 1155 \\ cavity of, 1155, 1411 \\ contents of, 1160 \\ fasciæe of, $474,485,489$ \\ intertubercular lines of, $115 \mathrm{~s}$ \\ lymph vessels of, 1015 \\ muscles of, 475 \\ planes intertubercular, 1158 \\ planes subcostal, 1155 \\ regions of, 1159,1411 \\ shape of, 1155 \\ subcostal line of, 1158 \\ subdivision of abdomen proper, $115 \mathrm{~s}$ \\ surface and surgical anatomy of, $1+15$ \\ tela subserosa of, $115 \mathrm{~s}$ \\ zones of, 1159,1411 \\ Abdominal aorta, $\$ \$ 5$ \\ surface and surgical anatomy of, $1 \pm 26$ \\ Abdominal cavity, 1155, 1411 \\ apertures of, 1157 \\ boundaries of, 1155 \\ fascize of, $474,455,459$ \\ pelvic portion of, 485 \\ subdivisions of, $1159,1+11$ \\ vessels, position of, 1426
}

Abdominal incisions, abore umbilicus, 1409

below umbilicus, $1 \pm 10$

in iliac regions, $1+11$

lateral to recti, $1 \neq 10$

median, 1409

throngh the recti, $1 \pm 10$

Abdominal inguinal ring, 1408 surgical anatomy of, 1408

Abdominal wall, fascire of, $\downarrow \bar{\top} 4.485,489$ inuscles of, 475 part of sympathetic, 761 surgical anatomy ot, 1107

Abducens nerre, 781

derelopment of, 683

morphology of, 795

nucleus of, 568,600

origin of, deep, 600 superficial, 600,781

Abduction, 401

Abductor canal, $11 \pm$

Abductor ballucis muscle, 432,434 action of, $43 \pm$
Abrluctor hallueis muscle, nerre-supply of, $43 \pm$ surgical anatoms of, $1 \pm 6.5$

Abrluctor pollicis brevis muscle, 39 ?

action of, 392

nerre-supply of, 39?

longus muscle, 399

quinti digiti muscle of hand, 393

action of, 393

nerre-supply of, 393

quinti digiti muscle of foot, 433

action of, 433

nerre-supply of, \pm 33

tberrant arteries, $105 \div$

Abnormalities of arteries. 105.

of heart, 1050

anterior tibial, $105 \%$

axillars, $105 t$

basilar, $105 \pm$

brachial, $105 \pm$

common carotid. 1053

external carotid, 10.53

external iliac, 1056

femoral, 1056

hypogastric, 10.56

iliac common, 1055

inferior mesenteric arters, 10.53

innominate, 10.53

internal carotid, 10.5.3

internal mammary, 10.5 1

obturator, 10.56

popliteal, 10.56

posterior tibial, 1056

radial, 1055

subclarian, $105 . t$

superior intercostal, 1054

ulnar, 1055

rertebral, $10.5 \pm$

Abnormalities of the lymph veseds. 1059

Alnormalities of the vascular ststem, 10 49

of the heart, 1050

aorta, 1050

branches of the arch of the sorta. $105 \mathrm{n}$

bronchial arteries, 1051

ceeliac, 1052

coronars arteries, 1050

gastric, 1052

hepatic, 1052

interostal arteries, $105 \mathrm{l}$

lumbar arteties, 105: 
Abnormalities of the heart, phrenic inferior, 1052

pulmonary artery, 1050

renal, 1052

sacral middle, 1052

splenic, 1052

superior mesenteric, 1052

testicular, 1052

Abnormalities of veins, superior vena cava, 1057

facial, posterior, 1058

hemiazygos veins, 1057

jugular, anterior, 1057

external, 1057

internal, 1057

of lower extremity, 1059

of upper extremity, 1058

vena azygos, 1057

vena cava inferior, 1058

Abscesses of the scalp, 1357

abdominal, 1427

in back of thigh, 1457

Accessory nerve, 726

central part of, 595

nucleus ambiguus, 595, 596

nucleus of origin of, 595

spinal part of, 595

surgical anatomy of, 1393

Accessory processes of vertebræ, 96

Acetabular artery, of obturator, 940 ; of medial cireumflex of thigh, 949

Acetabular fossa, 234

Acetabulum, 234

part of cell, 8

Achromatic spindle, 10, 13

substance, 8, 10

Acini, 1132

Acino-tubular glands, 1132

Acinous glands, 1132

Aconstic area and fibre tracts, 656 development of, 622

meatus of ear, external, 1ymph vessels of, 1004 radiation, 643,656

Acoustic nerve, 784

area acustica, 604

cochlear nerve, 604

central connexions of, 606

development of, 683

Deiter's nucletıs, 605

divisions of, 604

dorsal cochlear nuclens of, 604

lateral nucleus, 605

origin of, 604

roots of, 784

superior nuclens, 605

vestibular nerve, 604

ventral cochlear nucleus, 604

spinal ganglion of, 604

vestibular ganglion of, 604

vestibular nerve, dorsal vestibular nucleus, 604

principal nucleus of, 604

restibular nerve, nucleus of descending tract, 605

Bechterew's nucleus, 605

Acromial angle, 203

artery, $9 \mathbf{i} 6$

morphology of, 297

Acromio-clavicular joint, 318

ligaments of, 319

movements at, 319,373

surgical anatomy of, 1444

topography of, 1444
Acromion, 200

surgical anatomy of, 1444

Actions of muscles of forearm, 401 of leg and foot, 435

of thigh, 421

Adamant, 1113, 1122

development of, 1247

formation of, 1247

cells, 1245, 1247

cuticle, 1122

germs, 1245

organs, 1245

prisms, 1122

Addison's transpyloric plane, 1411

Adduction, 401

Adductor brevis muscle, 412

actions of, 412

nerve-supply of, 412

hallucis muscle, 434

action of, 434

nerve-supply of, 434

longus muscle, 411

actions of, 412

nerve-supply of, 412

surgical anatomy of, 1459

tenotomy of, 1459

magnus muscle, 412

actions of, 413

nerve-supply of, 413

relations, 413

surgical anatomy of, 1461

minimus muscle, 413

pollicis muscle, oblique part, 393 action of, 393 . nerve-supply of, 393

transverse part, 393 action of, 393

nerve-supply of, 393

Adduetor tubercle of femur, 242, 412 surgical anatomy of, 1459, 1461

Adenoids, 1385

Aditus ad antrum, Appendix A, 271 snurgical anatomy of, 1365

laryngis, 1068

Adrenin, 1341

Adrentitious ligaments, 305

Equator bulbi oculi, 807

lentis, 820

Affenspalte, 660

Agger nasi, 803

Aggregated lymph glands, 1181

Agitator caudæ muscle, 415

Air-cells, ethmoidal, 140, 804, 1373

surgical anatomy of, 1372

of ling, 1099, 1101

mastoid, 133, 836, 1370

sturgical anatomy of, 1370

Air-sinuses, 84, 183

frontal, 270,1371

maxillary, 148, 188, 1378

nasal, 185

sphenoidal, 135, 183, 1373

Akanthion, 285

Akrocephalic skulls, 286

Ala cinerea, 551

lobuli centralis cerebelli, 575

magna ossis sphenoidalis, 134 nasi, 799

parva ossis sphenoidalis, 135

sacralis, 98

vomeris, 144

Alar dens, 92 
Alar dens, ossification of, 105

ligaments, 311 of apex of, 311

Alar lamina of neural tube, 682

alar ligaments of epistropheus, 92 folds of knee, 348

process of ethmoid, 140

sulcus of nose, 799

Albumen of ovum, 14

Alecithal ovum, 14

Alimentary canal, 1104

accessory digestive glands, 1106

anal canal, 1105

aperture of larynx, 1105

ascending colon, 1105

cæcum, 1105

descending colon, 1105

development of, 41, 1249

duodenum, 1105

ileum, 1105

iliac colon, 1105

isthmus of the fances, 1105

jejunum, 1105

mouth cavity, 1105

œsophagus, 1105

palate, $110 \tilde{\jmath}$

pancreas, 1106

parts of, 1105

pelvic colon, 1105

pharynx, 1105

primitive entodermal development of, 38

rectum, 1105

salivary glands, 1106

special organs found in walls of, 1105

stomach, 1105

transverse colon, 1105

valve of colon, 1105

rermiform process, 1105

Alisphenoids, 136

development of, 138

Allantoic arteries, 65

body-stalk, 54

diverticulum, 38

stalk, 54

veins, 68

Allantois, 38

Allelomorphs, 19

Alveolar arch, 148, 1119

artery, anterior superior, 899 inferior, 899

posterior superior, 899

canal, inferior, 156, 157 posterior, 147

ducts of lungs, 1101

glands, 1133

index, 287

nerve, anterior superior, 77

inferior, 780

middle inferior, 777

posterior superior, 775

point, 285

process, 148

veins, 968

Alveoli of glands, 1133

of jaws, 156

development of, 149, 157

pulmonum, 1101

of the teeth, 1119

Alveolo-dental periosteum, 1115, 1123

Alveolo-glossal sulcus, 1383

Alveus, $62 T$

Ameloblasts, 1245
Amitosis, 9

Amnion, 54, 55

cavity of, 54,60

distention of, $\check{5} 5$

false, 22

fluid, 63

fold, 22

formation of, 54,60

true, 22

Amphiarthroses, 300

development of, 304

Ampulla ductus deferentis, 1292

duodeni, 1186

lacrimalis, 825

of lactiferous ducts, 1338

membranacea, 848

ossea lateralis, posterior, superior, 844

of rectum, 1226, 1227

of semicircular canals, osseous, 844; membranous, 848

of uterine tube, 1314

Amygdala (tonsil), 1145

of cerebellum, 575

Amygdaloid nucleus, 641

tubercle, 636

Anal canal, 1228

columns of, 1230, 1231

derelopment of, 48

hæmorrhoidal ring of, 1233

orifice of, 1232

relations of, 1229

sinuses of, 1231

tendinous areh of, 491

transverse folds of, 1230

surgical anatomy of, 1430

tunica mucosa of, 1230

ressels of, 1233

white line of, 1430

veins, 1233

Anal part of rectum, 1228

course of, 1229

relations of, 1229

structure of, 1229

Anal valves, 1231

Analogy, 2

Anaphase, 10, 14

Anapophysis, 284

Anastomoses, arterial segmental, 1042

Anastomosis, 943, 951

Anastomotic arterial branches of brachial, 919 of femoral, 951

of inferior gluteal, 943

vein of Trolard, 971

of vertebral, 907

Anatomical neck of humerus, 205

Anatoms, I

surgical, 1357

systematic, 4

topographical, 4

Anconæus muscle, 398 action of, 398

nerve-supply of, 398

Angeiology, 3

Angle or Angulus-

acromial, 203

cephaIo-auricular, 828

facial, 286

frontalis of parietal bone, 119

inferior lateral, of sacrum, 99

inferior, scapulix, 201

infracostal, 1407

infrasternal, 114 
Angle or Angulus, of jaw, surgical anatomy of, 1392

difterences in, due to age, 158

lateralis scapulæe, 201

of mandible, 155

mastoideus of parietal bone, 119

medialis scapulæe, 201

occipitalis of parietal, 119

pubis, 217

of rib, $97,98,99,100$

sacro-Tertebral, 109

sexual differences in, 238

sphenoidalis of parietal bone, 119

of the sternum, 107

Angular artery, 894

gyrus, 665

surface anatomy of, 1360

processes of frontal bone, $115,160,166$

surface and surgical anatomy of, 1364

spine of sphenoid, 136

vein, 967,969

Animal cell, structure of, 7

Animal cells, reproduction of, 8

division of, 9

amitotic, 9

mitotic, 9

Ankle, surface and surgical anatomy of, 1464

Ankle-joint, 351

effusions into, 1464

line of, 1463

movements of, 353,436

muscles producing, 436

nerves of, 731,733

synovial layer of, 1464

surgical anatomy of, 1464

tendons abont the, 1465

Annectant gyri of calcarine fissure, 660, 661

of interparietal sulcus, 664

of parieto-occipital fissure, 662

grrus, deep, of central fissure, 663

Annular ligament of base of stapes, 841 of the radius, 326

plexus of cornea, 810

Annuli fibrosi cordis, 879

Annulus femoralis, 405

fibro-cartilagineus of membrana tympani, 834 fibrosus, 307

inguinalis abdominalis, 481, 483, 1408

inguinalis subcutaneus, 477, 1408

tympanicus, 142

Ano-coccygeal body, 1224

plexus, 738

Ano-cutaneous line, 491

Ansa hypoglossi, 698, 699, 794

lenticularis, 641

thyreo-hyoid branch of, 795

peduncularis, 545

lingual branches of, 795

subcla via, 759

Ante-cubital lymph glands, 759

Anterior ethmoidal artery, 903 cells, 1373

skiagraphs of, 1373

surgical anatomy of, 1372

Anterior rami of spinal nerves, 692

Antibrachium, 382, 1450

Anticlinal vertebra, 101

Antihelix, 828

derelopment of, 52

fossa of, 828

Antithesis in muscular action, 452

Antitragicus muscle, 829
Antitragus, 828

development of, 52

Antrum, maxillary, 149, 804, 1378

pyloricum, 1169,1173

changes in, during digestion, 1173

Antrum, tympanic, 191, 834, 836

development of, 44,842

formation of, 842

relation of, to tympanum, 836

surface and surgical anatomy of, 1369, 1371

Antrum, tympanic, in frontal section of skull, 191

openings into, $834,836,1369,1371$

relation of molar teeth to, 1113, 1119

surgical anatomy of, 1378

Anus, 1232

development of, 48

imperforate, 1223

sphincter ani externus, 1232

surgical anatomy of, 1430

Aorta, 884

abdominal, 885 ; surface and surgical anatomy of, 1426

branches of, 886,927

paired visceral, 927

parietal, 933

unpaired visceral, 928

relations of, 886

ovarian, 928

branches of, 928

suprarenal, 927

branches of, 927

internal spermatic, 928

renal, 927

testicular, 928

branches of, 928

relations of, 928

abnormalities of, 1050

arch of, 884

abnormalities of, 1050

branches of, 885

abnormalities of, 1050

development of, $968,1027,1028$

relations, 885

surface anatomy of, 1405

ascending, 884

branches of, 884

development of, 68

relations, 884

surface anatomy of, 1405

bifurcation of, 1050

variations in, 1050

descendens, 884

branches of, 924

abnormalities of, 1050

formation of, 67,1027

morphology of, 1016

descending, 885

branches, 885

relations, 885

development of, 67,1027

great sinus of, 884

parietal intercostal, 926

subcostal, 926

primitive, branches of, 1027

development of, 67,1027

dorsal, 65

formation of, 1027

morphology of, 1046

subdivision of, 884

ventral, 65

relations of, 884 
Aorta, sinuses of, 884

superior phrenic, 926

thoracic, 885

descending, 885

branches of, 924

vas aberrans of, 927

rentral, 1026, 1027

visceral, bronchial, 925

mediastinal, 925

œsophageal, 925

pericardial, 925

Aortic arches, 67, 1405 development of, 67,1027

first aortic arch, 65 morphology of, 1016

first cranial, 1027

abnormalities of, 1050

branches of, 67

development of, $67,1027,1028$

dorsal roots of, 67

morphology of, 67,1046

segmental branches of, 1043

ventral roots of, 67

area, 1405

bulb, abnormalities of, 1050

division of, 1035

septum of, 1035

cusp of mitral valve, 878

opening of diaphragm, 473

opening of heart, 878,884

surface anatomy of, 1405

plexus, 762,765

valve, 878

vestibule, 843

Aortico-renal ganglion, 764

Apertura externa aquædnctus cochleæ, 129, 845 externa aquæductus vestibuli, 843

lateralis ventriculi quarti, 553

measurement of, 287

medialis ventriculi quarti, 553

pelvis (minoris) inferior, 237

superior, 236

piriformis, 163

superior canaliculi tympani, 129

thoracis inferior, 114; superior, 114

tympanica canaliculi chordæ, 834

Aperture of abdominal cavity, 1157

Aperture, laryngeal, 1068

A pex auriculæ (Darwini), 828

capituli fibulæ, 250

colnmnæ posterioris, 523

corun columnie posterioris, 523

of heart, 872

of lung, 1092, 1398

ossis sacri, 99

patellæ, 245

prostatæ, 1302

Apical bronchus, 1098

Aponeurosis, 364

epicranial, 447,449

iutercostal, 470

of palate, 1111

palmar, 384

pharyngeal, 1149

plantar, 423

vertebral, 437

A pophysis, submalleolar, 282

Apparatus digestorius, 1103

lacrimal, 824, 1377

respiratorius, 1061

urinogenitalis, 1257

Appendages of skin, 858
Appendices of auricles, $874,875,1032$

epiploicæ, 1211, 1212

testis, 1287

resiculosi (MIorgagni), 1287

Appendicular artery, 932, 1421

lymph gland, 1020, 1023

muscles, 365

sheleton, 82

morphology of, 294

vein, 1421

Appendix epididymidis, 1287

ventriculi laryngis, 1071

Aquæductus cerebri, 542, 545, 581, 581, 618 restibuli, 843

Aqureductus cochleæ, 129, 845

development of, 37,592

vestibuli, external aperture of, 131

Aqueous humour, 821

Arachnoid of the brain, 670,671

spinal medulla, 670

granulationes arachnoideales, 672

spinalis, 670

functions of, 673

Arachnoideal villi, 672

Arbor vitæ cerebelli, 577

Arch, alveolar, superior, 148

anterior, of atlas, 91

aortic, 884

abnormalities of, 1050

branches of, 67

caudal, 68

cephalic, 67,1405

development of, $67,1027,1028$

arterial, of wrist and hand, 923

branches of, 923

dorsal carpal arch, 93ㅡ

volar carpal arch, 923

carpal, anterior (volar), 923, 924

branches of third part of, 921 princeps pollicis, 921

rolaris indicis radialis, 921

dorsal, 920

relations of third part, 921

dental, 146, 1119

femoral, deep, 405

superficial, 405

glosso-palatine, 1111, 1112, 1145

hyoid, 43

muscles produced from, 496

nerve of, 796

mandibular, 43

branchial muscles produced from, 496

muscles produced from, 496

nerve of, 796

palmar, deep, 923, 924

abnormalities of, 1055

morphology of, 1055

surgical anatomy of, 1454

superficial, 923,924

abnormalities of, 1055

morphology of, 1055

surgical anatomy of, 1454

pharyngo-palatine, 1111, 1112, 1145

plantar, 954

abnormality of, 1057

morphology of, 1057

surgical anatomy of, 1465

posterior, of atlas, 91

thyreo-hroid, 42, 43

musclès produced from, 496

nerve of, 796 
Arch, transverse (osseous), of foot, 361

transverse, venous, of foot, 988

venous, dorsal, of foot, 988

morphology of, 1049

of hand, 978

morphology of, 1049

vertebral, 88

of fifth lumbar, variation in, 275

ossification of, 104, 105

serial homology of, 283

rolar superficial, 924

branches of, 924

deep, 924

branches of, 924

zygomatic, 167, 169

surgical anatomy of, 1364, 1365, 1375

Arches, aortic, 67,1405

alveolar, 148, 1119

dorsal roots of, 1027

segmental brallches of, 1042

surface anatomy of, 1405

ventral roots of, 1027

arterial, of wrist and hand, 924

axillary, 371

ner.ve-supply of, 371

of fauces, 1111, 1145

of foot, 361

superciliars, 116, 1374

tarsal, of eyelids, 823

visceral, 42,43

muscles produced from, 496

relation of, to cerebral nerves, 796,798

Architecture of bones-

bones of foot, 274

carpus, 272

clavicle, 271

femur, 273

fibula, 274

frontal bone, 270

hip-bone, $2 \% 3$

humerus, 272

lacrimal, 271

mandible, 271

maxilla, 271

metacarpus, 272

occipital bone, 270

parietal bone, 270

patella, 274

phalanges, 272

radius, 272

rilus, 270

scapula, 271

sphenoid, 271

stemum, 270

temporal, 271

tibia, 274

ulna, 272

vertebræ, 270

vomer, 271

zygomatic, 271

Arcuate eminence, 130, 133

fibres, internal, 556, 560, 561

development of, 566

external, 548, 563, 566

development of, 566

posterior external, 563

ligament of pubis, 338

nucleus of medulla, 551, 554

development of, 566

Arcus lumbo-costalis Iateralis (Haller $\mathrm{i}$ ), 472 medialis (Halleri), 472

senilis, 810
Arcus, superciliary, 116

tarseus inferior et superior, 823

tendineus $\mathrm{m}$. levatoris ani, 491

Area of absolute cardiac dulness, 1398 acustica, 656,657

amniotic, 54

aortic, 1405

bucco-pharyngeal, 27, 42

chorionic, 21

cochleæ, 844

embryonic, 22

facial, 846

mitral, 1405

motor, of the brain, 663

nervi facialis fundi meatus, 846

olfactory, 622

paracentral anterior, 666

intermedius, 666

posterior, 666

parasplenalis, 665

parastriata, 660

parieto-occipital, 665

pars intermedia, 657

circumambiens, 657

pericardial, 27,65

peristriata, 660

piriformis, 624

of Rablet, 624

placental, 56

postrema, 551

precentral, 666

pulmonary, 1405

sensory, 662

striata, 659

temporalis polaris, 657

tricuspid, 1405

vascular, 64

vestibularis inferior et superior, $846^{\circ}$

visual, 658

Areas of Flechsig, 564

Areola mammæ, 1337

Areolar coat of liver, 1198

Areolar glands, 1337

Arlt, sinus of, 825

Arm, development of, 39

fasciæ of, 378

intermuscular septa of, 378

lateral bicipital furrow of, 1448

lymph vessels of, 1006

medial bicipital furrow of, 1447

medial supracondylar triangle of, 1447 muscles of, 378

surface and surgical anatomy of, 1447

Arrectores pilorum, 861

Arteria hyaloidea, 819

Arterial arches of wrist and hand, 923

Arteriola macularis inferior et superior, 818

nasalis retinæ inferior et superior, 818

temporalis retinæ inferior et superior, 818

rectæ, 1269

Arterioles, capillary, 868

Artery or Arteries; Arteria or Arteriæ, 868, 882

aberrant, 1054

abnormalities of, 1050

acetabular, of medial circumflex of thigh, 949

acetabuli (obturator), 940

acromial, 916

allantoic, 65

alveolar anterior superior, 899 
Artery or Arteries-continued

alveolar inferior, 899

posterior superior, 899

anastomotic of inferior ulnar collateral, of brachial, 919

of arteria suprema genı, 951

of inferior gluteal, 942

of vertebral, 910

angular, 894

anonyma, 888

appendicular, 1421

arciform, 1269

articular, art. genu media, of popliteal, 952 of deep volar arch, 924

of dorsal carpal arch, 923

of lateral plantar arch, 357

lateral, of popliteal, 95

surgical anatomy of, 1461

of medial circumflex, 949

medial, of popliteal, 951

auditiva interna, 852

auditory, internal, 853

auricular, deep, 898

of occipital, 895

posterior, 895

branches, 895

auricular, 896

occipital, 896

stylo-mastoid branch of, 895

course and relations, 895

surgical anatomy of, 1365

axial skeleton, 82

axillary, 914

abnormalities of, 1054

branches of, 916

supreme thoracic artery, 916

course of, 914

formation of, 1047

relations of first part, 915

of second part, 916

of third part, 916

sirgical anatomy of; 1445

basilar, 907

abnormalities of, 1054

loranches, 907

auditory internal, 907

cerebellar anterior inferior, 907 superior, 907

pontine, 907

colurse and relations, 907

formation of, 1046

morphology of, 1046

bicipital, 917

blood-vessels of, 870

brachial, 917

abnormalities of, 1054

bifurcation of, 1450

branches of, 918

inferior uInar collateral, 919

muscular, 918

nutrient, 919

profunda artery of the arm, 918

superior ulnar collateral, 919

colırse of, 917

formation of, 1047

relations of, 918

surgical anatomy of, 1448

branches of external maxillary, 894

augular, 894

buccal, 894

lateral nasal, 894
Artery or Arteries-continued

bronchial, 1096

abnormalities of, 1051

morphology of, 1016

buccal, of external maxillary, 894

of internal maxillary, 899

buccinator, 899

bulbi urethræ, 942

surgical anatomy of, 1427

vestibuli (vaginæ), 9.12

cæcal, 932

calcaneal, medial, 955

calcarine, 908

canalis pterygoidii (Vidii), 900

capsular, of liver, 933

carotico-tympanic, 902

carotid, common, 889

abnormalities of, 1053

formation of, 67

morphology of, 1046

surgical anatomy of, 1396, 1389, 1391

external, 891

abnormalities of, 1053

branches, 891

course, 891

development of, 67

morphology of, 1046

relations, 891

surgical anatomy of, 1391

intermal, 900

abnormalities of, 1053

branches of, 902

anterior cerebral, 901

branches of, 904

anterior medial frontal, 904

antero-medial basal, 904

medial orbital, 901

carotico-tympanic, 902

cavernous, 902

hypophyseal, 902

meningeal, 902

posterior communicating, 904

course, 900

chorioidal, 904

development of, 67

morphology of, 1016

left, 889 relations, 900,901

abnormalities of, 1053

cervical portion of, 889

relations of, 889

thoracic portion of, 889

right common, 890

abnormalities of, 1053

relations of, 890

carpal, radial, dorsal, 920

volar, 920

ulnar, dorsal, 923

volar, 922

cavernous, 902

central, of middle cerebral, 905

of posterior cerebral, 908

centralis retinæ, 903

cerebelli inferior anterior, 907

posterior, 907

superior, 907

cerebral, anterior, 904

abnormalities of, 1053

branches of, 904

anterior medial frontal, 904

antero-medial basal, 901

intermediate medial frontal, 904 
Artery or Arteries-continued

cerebral, anterior, branches of, medial orbital, 904

posterior medial frontal, 904

cerebral, middle, 905

branches of, 905

ascending frontal, 905

parietal, 905

inferior lateral frontal, 905

lateral striate, $90 \tilde{5}$

orbital, 905

medial striate, 905

pirieto-temporal, 905

temporal, 905

cerebral, posterior, 908

branches of, 908

calcarine, 908

chorioidal posterior, 908

parieto-occipital, 908

postero-lateral, 908

temporal anterior, 908

posterior, 908

cervical, ascending, 910

ascending of transverse cerebra], 1320

branches ascending, 911

descending, 911

morphology of, 1045

deep, 914

morphology of, $10 \pm 6$

transverse, 911

cervical portion of left, 889

course of, 889

relations of, 889

chorioidal, anterior, 904

posterior, 908

ciliary, 903

anterior, 813, 903

long, 813

posterior, 903

short, 903

circumflex, anterior, of humerus, 917

lateral of thigh, 919

surgical anatomy of, 1447

iliac, deep, 945

branches of, 946

course of, 946

superficial, 947

surgical anatomy of, 1447

medial, of the thigh, 949

posterior, of humerus, 917

surgical anatomy of, 1447

of the scapula, 917

clavicular, 916

coccygeal, 935

coliac, 928

abnormalities of, 1052

branches of, 929

gastric left, 929

branches of, 929

left gastro-epiploic, 930

splenic, 929

branches of, 929

pancreatic, 930

short gastric, 930

morphology of, 1016

relations of, 929

surgical anatomy of, 1418

colic, 932

colica dextra, 932

media, 932

sinistra, 932

collateralis ulnaris inferior, 919
Artery or Arteries-continued

collateralis ulnaris superior, 919

comitans nervi mediani, 922

nervi phrenici, 913

common digital, of foot, 955

of hand, 924

communicating, anterior, 904 of volar interosseous, 922

of deep rolar arch, 924

peroneal, 953

posterior, 904

abnormality of, 1054

tibial, 953

coronary, right, of heart, 887; left, 887

abnormalities of, 1050

of external maxillary, 894

surgical anatomy of, 1379

of stomach, 929

abnormalities of, 1052

morphology of, 1046

of corpus cavernosum penis, 942

costo-cervical trunk, 914

branches of, 914

deep cervical artery, 914

superior intercostal artery, 914

crico-thyreoid, 892

cystic, 930

deferential, 939

diaphragmatic, of aorta, 933

of comitans nervi phrenici, 913

of inferior phrenic, 933

of superior phrenic, 914, 926

digital, of foot, 955,958

of hand, 920, 924

morphology of, 147

surgical anatomy of, 1454

digital plantar, 954

volar digital arteries, 924

proper digital arteries, 924

dorsal metatarsal arteries, 958 abnormalities of, 1055

linguæ, 892

pedis, 957

branches of, 957

course of, 957

surgical anatomy of, 1465

penis, 942

pollicis, 920

radialis, 920

dorsal of radial, 920

dorsalis clitoridis, 942, 1428

arcuate branch of, 958

of dnctus deferens, 939,945

elastic lamina of, 868

endothelium of, 868

epigastric, inferior, 944

branches of, 944

formation of, 1030

morphology of, 1045

surgical anatomy of, 1408

superficial, 947

superior, 913

ethmoidal, anterior, 903

posterior, 903

external iliac, 945

branches of, 945

pubic, 945

spermatic, 945

external maxillary, 893

branches, 893

ascending palatine, 893 
Artery or Arteries-continued

external maxillary, branches, inferior labial, 894

masseteric, 894

submaxillary, 893

submental, 894

superior labial, 894

tonsillar, 893

course, 893

formation of, 1028

relations, 893

surgical anatomy of, $1375,1379,1391$

external spermatic of inferior epigastric, 945 facial transverse, 897

femoral, 946

abnormalities of, 1056

anastomotic branches of, 951

branches, 947

course, 947

circumflex acetabular branch of medial, 949

circumflex lateral branches of, 949 medial, 949

deep, 405

morphology, 1046

superficial, 405

formation of, 1031

morphology of, 1047

relations, 947

sheath, 947

surgical anatomy of, 1459

fibular, 953

frontal, of ophthalmic, 904

surgical anatomy of, 1358

frontal, of superficial temporal, 897

ganglionic, of middle meningeal, 898

of internal carotid, 902

gastric, 929

morphology of, 1046

short, 930

gastro-duodenal, 930

gastro-epiploic left, 930

right, 930

genu suprema anterior, 951

branches of, 951

gluteal, inferior, 942

abnormalities of, 1056

branches of, 943

anastomotic, 943

coccygeal, 943

comitans nervi ischiadici, 934

cutaneous, 943

muscular, 943

formation of, 1031

morphology of, 1047

superficial, incisions to expose, 1455

stuperior, 938

branches of, 938

surgical anatomy of, 1455

hæmorrhoidal, inferior, 1232

middle, 939, 1232

superior, 1232

of head and neck, 888

helicine, of the corpus cavernosum penis, 1300

hepatic, 930

abnormalities of, 1052

branches of, 930

gastric right, 930

gastro-duodenal, 930

gastro-epiploic right, 930

pancreatico-duodenal, superior, 930
Artery or Arteries-continued

hepatic, branches of, terminal, 930

of inferior phrenic, 933

morphology of, 1046

hyaloid, 826

branches of, 937

of anterior division, 939

of posterior dirision, 938

hyoid of lingual, 892

hypogastric, 936

course of, 936

relations of, 936

hypophyseal, 902

ileo-cæcal, 932

ileo-colic, 932

iliac, common, 935

abnormalities of, 1056

course of, 935

morphology of, 1047

relations of, 935

surgical anatomy of, 1426

external, 944

abnormalities of, 1056

formation of, 1031

morphology of, 1047

surgical anatomy of, 1426

hypogastric, 936

abnormalities of, 1056

branches of, 937

morphology of, 1047

ilio-lumbar, 938 abnormality of, 1056

of inferior extremity, 944

branches of, 944

course, 944

external iliac, 944

relations, 944

infra-hyoid, 892

infra-orbital, 899

infra-scapular of cireumflex scapulie, 917

innominate, 888

abnormalities of, 1050, 1051

branches, 888

colurse, 888

development of, 1028

morphology of, 1046

relations, 888

surgical anatomy of, 1405

intercostal, 925

abnormalities of, 1051

formation of, 1014

morphology of, 1044

anterior, 913

superior, 914

abnormalities of, 1050

morphology of, 1044, 1046

interlobar, of the kidney, 1267

interlobulare, of the kidney, 1267

intermediate visceral, 1013, 1046

interosseous, of dorsal carpal arch, 923

of hand, 922

common, 922

dorsal, 922

abnormality of, 1051

formation of, 1031, 1047

morphology of, 1017

volar arch, 923

abnormalities of, 1051

formation of, 1047

inorphology of, 1045

interosseous recurrent, 922

intersegmental, 1043 
Artery or Arteries-continued

intestinal, 932

jejunal, 932

labial inferior, 894

posterior (rulvæ), 942

superior, 894

lacrimal, 903

laryngeal inferior, 911

superior, 892

lateral sacral, 938

lienal, 929

ligamenti teretis uteri, 945

lingual, 892

alveolar, 892

branches, 892

course, 892

development of, 1028

dorsalis linguæ, 892

relations, 892

sublingual, 893

surgical anatomy of, 1382, 1383, 1391

of lower limb, 944

abnormalities of, 1056

formation of, 1031

morphology of, 1047

lumbar, 933

abnormalities of, 1052

formation of, 1029

of ilio-lumbar, 938

lymph vessels of, 870

morphology of, 1044

lumbar, lowest, 935

macular, 818

malleolar, lateral anterior, 957

medial anterior of anterior tibial, 956 of posterior tibial, 953

mammary, external (lateral thoracic), 916

internal, 913

abnormalities of, 1054

branches, 913

intercostal, 913

musculo-phrenic, 913

pericardiaco-phrenic, 913

smaller, 913

superior epigastric, 913

course, 913

formation of, 1030

morphology of, 1044,1045

surgical anatomy of, 1398

masseteric, 899

mastoid, of occipital, 895

of posterior auricular, 895

maxillary, external, 893

intermal, 898

abnormalities of, 1053

branches, 898

alveolar posterior superior, 899

anterior tympanic, 898

auricular deep, 898

descending palatine, 899

infra-orbital, 899

middle meningeal, 898

pharyngeal, 900

pterygoid canal, artery of, 900

spheno-palatine, 900

course and relations, 898

development of, 1028

surgical anatomy of, 1398

median, 834

abnormality of, 1055

morphology of, 1031

mediastinal, anterior, 913
Artery or Arteries-continued

mediastinal, of aorta, 925

meningeal, anterior, of ophthalnic, 903

media, 898

posterior (asc. phar.), 896

meningeal, of internal carotid, 902

accessory, 899

middle, 898

surgical anatomy of, 1359, 1360, 1364

of occipital, 895

of vertebral, 907

mesenteric, inferior, 932

abnormalities of, 1053

branches, 932

colic, left, 932

hæmorrhoidal superior, 933

sigmoid, 933

morphology of, 1046

surgical anatomy of, 1426

superior, 931, 1205

abnormalities of, 1052

appendicular, 932

branches of, 931

colic, middle, 932

right, 932

ileæ, 932

ileo-cocal, 932

ileo-colic, 932

intestinal, 932

morphology of, 1046

pancreatico-duodenal inferior, 932

surgical anatomy of, 1426

terminal, 932

metacarpal, 920, 923

metatarsal, 958

dorsal, 920, 923

musculo-phrenic, 913

mylo-hyoid, 899

nasal, lateral, 894

of retina, 818

naso-palatine, 900

nerves of, 870

of nose, 899,900

nutritiæ ossium (nutrient, of bones), 87

clavicle, 912

femur, 950

fibula, 953

hip-bone, 940

humerus, 919

radius, 922

ulna, 922

obturator, 940

abnormalities of, 1056

branches of, 940

occipital, 895,896

branches, 895

auricular, 895

descending, 895

mastoid, 895

meningeal, 895

sternomastoid, 895

terminal, 895

course, 894

of posterior auricular, 896

relations, 894

œsophageal, of aorta, 926

morphology of, 1046

of coronary, 929

of inferior thyreoid, 911

ophthalmic, 902

abnormalities of, 1053

branches of, 903 
Artery or Arteries-continued,

ophthalmic, branches of, anterior meningeal of, 903

central artery of retina, 903

ethmoidal, 903

lacrimal, 903

palpebral, 904

posterior ciliary, 903

supra-orbital, 903

terminal, 904

course of, 902

orbital, of middle meningeal, 898

of superficial temporal, 897

ovarian, 928

abnormalities of, 1052

morphology of, 1046

surgical anatomy of, 1427, 1438

palatine, ascending, 893

of ascending pharyngeal, 896

descending, 899

surgical anatomy of, 1384

palpebral, 904

pancreatic, 930, 1207

of hepatic, 930, 1207

of splenic, 930,1207

of superior mesenteric, 932, 1207

pancreatica magna, 930, 1207

pancreatico-duodenal inferior, 932, 1207

superior, 930, 1205, 1207

parietal, of superficial temporal, 897

parieto-occipital, 821

parotid, of posterior auricular, 895

of superficial temporal, 896

pectoral, of thoraco-acromial, 916

penis, 1300

perforating, anterior, of foot, 955,958 posterior, 955,958

distal, of hand, 920

proximal, 920,924

of internal mammary, 913

of peroneal, 953

of profunda femoris, 950

pericardiaco-phrenic, 913

pericardial, of internal mammary, 913

of aorta, 925

perineal, 942

transverse, 942

perirenal, 935

peroneal, 953

abnormalities of, 1056

formation of, 1031

morphology of, 1047

surgical auatomy of, 1463

pharyngeal ascending, 896

branches, 896

inferior tympanic, 806

palatine, 896

pharyngeal, 896

posterior meningeal, 896

prevertebral, 896

course, 896

derelopment of, 1028

relations, 896

phrenic, inferior, 933

abwormality of, 1052

plantar, lateral, 954

branches of, 955

medial, 954

abnormalities of, 1057

course of, 954

surgical anatomy of, 1465

popliteal, 951
Artery or Arteries-continued

popliteal, abnornalities of, 1056

branches of, 951

art. genu media, 952

inferior genicular arteries, 952

superior genicular arteries, 951

formation of, 1047

morphology of, 1047

relations of, 951

surgical anatomy of, 1458

presegmental, 66

prevertebral, of ascending pharyngeal, 896

primitive vitelline, 56

princeps cervicis, 895

pollicis, 921

abnormality of, 1055

profunda brachii superior, 918

linguæ, 892

penis, 942

perforating, 950

course of, 950

first, 950

second, 950

third and fourth, 950

of ulnar, 923

pterygoid, 899

pterygo-palatine, 899

pubic, of inferior epigastric, 945

of obturator, 852

pudendal, internal, 940

branches of, 940

bulb artery of, 942

course of, 940

hæmorrhoidal inferior, 942

penis, dorsal artery of, 942

penis, profunda artery of, 942

perineal, 942

perineal transverse, 942

pudendal, superficial, external, 948

deep external, 948

surgical anatomy of, 1428

pulmonary, 882

abnormalities of, 1050

development of, 68

left branch of, 883

relations, 884

morphology of, 1046

relations of, 882

right branches of, 882

branches of, 882

relations, 882

surface anatomy of, 1408

pyloric, 930

morphology of, 1046

radial, 919

abnormalities of, 1055

branches of first part, 919

raclial recurrent, 919

superficial volar, 919

volar carpal, 920

branches of second part, 920 dorsal metacarpal, 920

dorsal of the thumb, 920

dorsalis indicis radialis, 920

formation of, 1047

morphology of, 1047

relations of first part 919

of second part, 920

surgical anatomy of, 1454

indicis, 921

abnormalities of, 1055

surgical anatomy of, 1454 
Artery or Arteries-continued recurrent, of deep palmar ar'ch, 924

interosseous, 922

radial, 919

abnormalities of, 1055

tibial, anterior, 956 posterior, 956

ulnar, 929

renal, 927

abnormalities of, 1425

morphology of, 1046

surgical anatomy of, 1425

of round ligament, 945

sacral, lateral, 938

morphology of, 943

of retina, 814

middle, 935

abnormalities of, 1052

morphology of, 68

of scalp, 1357

scapular, circumflex, 917

branches of, 912

course of, 911

descending branch of transverse cervical, 911

scrotal posterior, 942

segmental, 66, 1043

anastomoses of, 1043

dorsal branches of, 1044

terminal, 913

somatic, 1043

splanchnic, 1043

septal, of nose, 900

sheath of, 870

sigmoid, 933

somatic intersegmental, 1043

spermatic, internal, 928

abnormalities of, 1052

morphology of, 1046

spheno-palatine, 900

spinal, formation of, 1029

of ilio-lumbar, 938

of intercostals, 926

of lateral sacral, 938

of vertebral, 907,908

splanchnic, 1043, 1046

splenic, 929

abnormalities of, 1052

morphology of, 1046

stapedial, 1028

stemomastoid, of occipital, 895

of superior thyreoid, 892

of stomach, 928

striate, lateral, 905

medial, 905

structure of, 868

stylo-mastoid, 895

subclavian, left, first part of, 909 lelations, 909

right, first part of, 909

relations, 909

second part of, 910

relations of, 910

thirr part of, 910 relations of, 910

abnormalities of, 1050, 1051, 1054

branches of, 910

thyreo-cervical trunk, 910

vertebral artery, 910

development of, 67,1028

morphology of, 1045, 1046

surgical anatomy of, 1394
Artery or Arteries-continued

subcostal, 926

sublingual, 893

submaxillary, 893

submental, 894

subscapular, 912, 917

of transverse scapular, 912

branches of, 917

circumflex scapulæ, 917

thoraco-dorsal, 917

superficial petrosal, 898

volar, 924

supraorbital, 903

surgical anatomy of, 1358

suprarenal inferior, 927

middle, 92

superior, 933

supraspinons, 912, 913

suprasternal, 912

sural, 952

systemic, 884

tarsal, lateral, 957

temporal, deep, 899

posterior, 899

middle, 897

of posterior cerebral, 908

of retina, 818

temporal, snperficial, 896

branches, 896

froutal, 897

middle temporal, 897

parietal, 897

transverse facial, 897

zygomatico-orbital, 897

conrse, 896

development of, 1030

surgical anatomy of, 1359

testicular, 928

thoracic lateral, 916

supreme, 828

thoraco-acromial, 916

branches of, 916

thoraco-dorsal, 917

thyreoid, inferior, 910

branches of, 910,911

ascending cervical, 910

inferior laryngeal, 911

osophageal tracheal, 911

relations of, 910

terminal, 911

surgical anatomy of, 1389

superior, 891

conl'se, 891

morphology of, 1045

branches, 892

crico-thyreoid, 892

relations, 891

sterno-mastoid, 892

superior laryngeal, 892

terminal, 892

surgical anatomy of, 1389

thyreoidæ ima, 888

morphology of, 1045

tibial, anterior, 955

abnormalities of, 1057

branches of, 955

anterior tibial recurrent, 956

fibular, 956

lateral anterior malleolar, 957

medial anterior malleolar, 956

posterior tibial recurrent, 956

course and relations of, 955 


\section{INDEX.}

Artery or Arteries--continued

tibial, anterior, course and relations of, formation of, 1031

morphology of, 1047

surgical anatomy of, 1462

posterior, 952

abnormalities of, 1056

branches of, 953

fibular, 953

peronral, 953

branches of, 953

communicating, 953

nutrient, 953

posterior malleolar (medial), 953

formation of, 1031

morphology of, 1047

relations of, 953

surgical anatomy of, 1463

incisions to expose, 1463

recurrent, 956

of tongue, 1130

of tonsil, 1147

tonsillar, of external maxillary, 893, 1147

tracheal, 911

transversa colli, 911

scapulæ, 911

transverse, of basilar, 907

transverse cervical artery, 911

ascending branch, 911

descending branch, 911

tunica externa of, 868

intima of, 868

of arteries, 868

media of, 868

tympanic, of internal carotid, 902

tympanica anterior (of int. maxillary), 898

inferior (of asc. phar.), 896

posterior (of stylomastoid), 895

superior (of middle meningeal), 898

ulnar, 921

abnormalities of, 1055

branches, 922

common interosseous, 922

dorsal interosseous, 922

branches of, 922

ulnar recurrent, 922

volar interosseous, 922

branches of, 922

ulnar recurrent, 922

formation of, 1031

morphology of, 1047

surgical anatomy of, 1454

umbilical, 939

of foetus, 65,939

primitive, 65

of the upper extremity, 909

of upper $\operatorname{limb}, 909$

abnormalities of, $105 \pm$

formation of, 1047

morphology of, 1047

obliterated, 939

ureteral, of internal spermatic and ovarian, 928

of renal, 927

uterine, 940

surgical anatomy of, 1435

of ovarian, 928

tube, arteries of, 928

ragina vasis of, 869

vaginal, 939

of vermiform process, 1217, 1421
Artery or Arteries-continued,

vertebral, 905

abnormalities of, 1053

anastomotis of, 905

branches of, 906

anastomotic, 907

anterior spinal, 907

cerebellar posterior inferior, 907

meningeal, 907

muscular, 906, 907

posterior spinal, 907

spinal, 907

course and relations, 905

development of, 1029

morphology of, 1045,1046

surgical anatomy of, 1395

vesical, inferior, 939

middle, 940

of obturator, 940

superior, 939

vesico-vaginal, 939

visceral, intermediate, 1043, 1046

vitelline, primitive, 66

zygomatico-orbital, 897

Arthrectomy of the knee joint, 1461

Arthrodia, 301

Arthrology, 3, 299

Articular disc, 302

processes of atlas, 91

of cervical vertebræe, 90

of coccyx, 99

of epistropheus, 92

of lumbar vertebræ, 95

of sacrum, 97,98

serial homology of, 283

of thoracic vertebræ, 94

of twelfth dorsal vertebræ, 95

tubercle of temporal bone, 125, 167

Articulatio or Articulationes-

acromio-clavicular, 318

sturgical anatomy of, 1444

topography of, 1444

atlanto-epistropheal, 309

atlanto-occipital, 310

of auditory ossicles, 840

calcaneo-cuboid, 357

between bodies of vertebræ, 306

ligaments of, 357

surgical anatomy of, 1464

carpal, 329

distal row of, 330

proximal row of, 330

synovial strata of, 331

transverse carpal, 330

carpo-metacarpal of fingers, 332

ligaments of, 332

synovial stratum of, 332

of thumb, 332

costo-chondral, 315

costo-transverse, 314

costo-vertebral, 313

coxæ, 339

articular surfaces of, 339

capsule of, 340

ligaments of, 340 .

morements of, 342

synovial stratum of, 341

crico-arytænoid, 1066

crico-thyreoid, 1065

cubiti, 323

fibrous stratum of articular capsule of, 324 
Articulatio or Articulationes-continued cubiti, ligaments of, 324

movements at, 325

synovial pads of fat of, 325

layer of, 325

cuneo-cuboid, 358

cuneo-naricular, 357

of fingers, 334

of the foot, 351

genn, 342

articular surfaces of, 342

different parts of, $3 \pm 3$

ligaments of, 344

menisci of, 347

movements of, 348

patellar surfaces in, 343

synovial stratum of, 348

of hand, 329

of heads of ribs, 313

humero-radial, 323

humero-ulnar, 323

of humerus, 320,326

incudo-malleolar, 810

incudo-stapedial, 840

intercarpal, 329

interchondral, 315

intercoccygeal, 309

intercuneiform, 358

intermetacarpal, 332

movements at, 334

intermetatarsal, 360

interphalangeal, 334

articular capsule of, 331

of foot, 361

ligaments of, 334

movements of, 334

synovial stratum of, 334

intertarsal, 354

ligaments of, 354

movements at, 361

talo-calcaneal, 354

mandibular, 312

articular disc of, 312

movements of, 313

synovial stratum of, 312

metacarpo-phalangeal, 333

ligaments of, 333

movements at, 334

surgical anatomy of, 1454

metatarso-phalangeal, 360

movements at, 361

surgical anatonly of, 1464,1465

of pelvis, 335

sacro-lumbar, 335

sacro-iliac, 335

articular capsule of, 336

articular cavity of, 336

ligimients of, 336

of pisiform bone, 331

carpo-metacarpal, 332

intermetacarpal, 332

of the thumb, 332

articular capsule of, 332

movements of, 332

synovial stratum of, 332

radiocarpal, 328

articular capsule of, 328

movements at, 329

surgical anatomy of, 1450

synovial stratum of, 329

radio-ulnar, 327

distal joint of, 327
Articulatio or Articulationes-continued radio-ulnar, proximal, 326

synovial stratum of, 327

triangular meniscus of, 327

sacro-coccygeal, 308

sacro-iliac, 335

topography of, 1455

of shoulder, bursæ of, 322

fibrous stratum of capsule, 321

intra-capsular structures, 322

ligaments of, 321,322

synovial stratum of, 322

stermo-clavicular, 317

articular disc of, 318

movements at, 319,373

surgical anatomy of, 1444

sterno-costal, $\mathbf{3 1 5}$

of sternum, 317

talo-calcaneal, 354

talo-calcaneo-navicular, 355

ligaments of, 355

talo-crural, 351

ligaments of, 352

movements of, 353

synovial stratum of, 353

talo-navicular, 355

tarsal transverse, 357

tarso-metatarsal, 359

intermediate, 359

lateral, 359

medial, 359

surgical anatomy of, 1464

tibio-fibular, 349

articular capsule of, $\mathbf{3 4 9}$

ligaments of, 350

of toes, 361

transverse tarsal, 357

cuneo-navicular, 357

articular capsule of, 358

synovial stratum of, 358

Articulations between vertebral arches, 307

Arytæno-epiglottic folds, 1068 development of, 45

muscle, 1074

Arytænoid cartilage, 1064

development of, 44

ossification of, 1065

processus muscularis of, 1065 vocalis of, 1065

sesamoid cartilages of, 1065

muscle, 1074

action of, 1076

Aryvocalis muscle, 1076

action of, 1076

Ascending aorta, surface markings of, 1405

Ascending branch of transverse cervical artery, 1320

Ascending colon, surgical anatomy of, 1422

Ascending degeneration of nerves, 532

palatine artery, 893

Ascultation, triangle of, 366

Association areas, 645

Association fibres, 648

of cerebral hemispheres, 648

intersegmental, 538

long, 648

of medulla oblongata, 556, 560

short, 648

of spinal medulla, 534, 538

Asterion, 165, 171, 285

Asymmetry, 4

Atlanto-epistropheal joint, 309 
Atlanto-epistropheal joint, morements at, 311

Atlanto-occipital joint, 310

Atlas, 91

anterior arch of, 91

arches of, 91

articular facets of, 91

fovea dentis of, 91

lateral masses of, 91

ossification of, 104

posterior arch of, 91

tubercle of, 91

serial homology of, 283

transverse ligament of, 310

process of, 91

surgical anatomy of, 1393

tubercle of, 91

Atresia ani, 48

Atria of heart, 873

Atriæ and alveoli (of lung), structure of the, 1097

Atrio-ventricular apertures, 877

mitral, 877

tricuspid, 877

sulcus, 871

surface anatomy of, 1403

Atrium dextrum, 873

crista terminalis, 874

fossa ovalis, 874

interior of, 874

musculi pectinati, 874

valve of the vena cava, 874

meatus nasi, 830

of primitive heart, 1033

sinistrum, 875

Atrium left, 875

mitral orifice, 876

Atrium right, foramen ovale, 875

tricuspid orifice of, 874

tuberculum intervenosum, 875

valve of the coronary sinus, 875

valve of the inferior vena cava, 875

venæ cordis minimæ, 874

Attic, tympanic, 1368, 1369

Auditory area of cerebral cortex, 656

artery, internal, 853

epithelium, development of, 50

labjrinth, 843

meatus, external acoustic, 830

blood-vessels of, 832

ceruminous glands of, 832

development of, 52

foramen of Huschke of, 832

isthmus of, 830

lymph vessels of, 832

nerves of, 832

structure of, 831

surgical anatomy of, 1365

variation in, 278

internal acoustic, 845

absence of, 278

nerve, acoustic, 852

organ, 827

ossicles, 838

articulations of, 840

derelopment of, 8.1

incus, 840

ligaments of, 841

malleus, 839

stapes, 840

pit, 853

radiation, 643,656
Auditory teeth of Huschke, 850

tube, 837,838

blood-ressels of, 838

bony part of, 837

canal of, $128,837,838$

cartilaginous part of, 837

catheter, passage of, 1385

in child, 838

cushion of, 1143

development of, 44,52

dilator muscle of, 838

dilator tubæ muscle, 838

facia salpingo-pharyngea, 838

groove for, 138

isthmus of, 837

lamina membranous of, 838

nerves of, 838

ostium pharyngeum of, 838,1143 tympanicum of, 834

pars cartilaginea of, 837

ossea of, 128, 837

pharyngeal orifice of, 837,838

processus tubarius of, 838

sulcus of, 838

surgical anatomy of, $1368,1369,1385$

tonsil of, 838

torus tubarius of, 838

tympanic orifice of, 837

vesicle, 506

A uricle, 827

antihelix of, 828

antitragus, 828

apex of, 828

cartilage of, 829

cauda helicis, 829

fissure antitrago-helicine, 829

incisura terminalis, 829

isthmus of, 829

ponticulus, 829

sulcus antihelicis transversus, 829 cruris helicis, 829

concha of, 827

crura of, 828

crus helicis of, 827

cymba conchæ of, 827

development of, $44,52,76,78$

fossa triangularis of, 828

helix of, 827

incisura intertragica, 828

ligaments of, 829

lobule of, 828

muscles of, 829

antitragicus, 829

helicis major, 829

minor, 829

obliquus auricule, 830

tragicus, 829

transversus auriculiu, 830

nerves of, 830

scapha of, 828

skin of, 830

spina helicis, 829

structure of, 829

tragus, 828

tubercle of, 828

tuberculum supratragicum, 828

vessels of, 830

Auricles, 874, 875, 1032

Anuicula, 827

(cordis) dextra, 874

sinistra, 875

Auricular artery, deep, 830,898 
Auricular artery of occipital, 895 posterior, 895 surgical anatomy of, 1365 cartilage, 829

index, 828

inuscle, anterior, 449

posterior, 449

superior, 449 nerve-supply of, 449

nerves, 830

of auriculo-temporal, 779

great, 695,696

morphology of, 700

posterior, 783

of vagus, 788

septum, 1033

surface of ilium, 230

of sacrum, 99

rein, posterior, 967

Auriculo-temporal nerve, 779

Auriculo-ventricular groove, position of, 1403

Auscultation, triangle of, 366

Axial line, dorsal, of limbs, 741, 1397 ventral, of limbs, 741, 1397

muscles, 365,437

skeleton, 82

Axilla, 1446

folds of, 1446

lymph glands of, 1008

surgical anatomy of, 1446

Axillary arches, 371 nerve-supply of, 371

artery, 914

abnormalities of, 1054

formation of, 1047

surgical anatomy of, 1445

fascia, 369

folds, 1446

lines, 1397

lymph glands, 1447

margin of scapula, 201

nerve-supply of, 371

region, 1446

sheath, 1447

vein, 977

development of, 1042

morphology of, 1049

surgical anatomy of, 1447

Axis, basi-cranial, 183

cylinder, 509

lentis, 820

optic, 807

pelvis, 237

Axis-ligament of mallens, 811

Axon, 508, 680

Azygos lobe of lung, 1096

veins, 960

Bacillary layer of retina, 817

Back, fasciæ of, 365,437

muscles of, 365,437

actions of, 366,445

nerve-supply of, 365

superficial muscles of, 365

regions of, 1437

surgical anatomy of, 1436

of thigh, surgical anatomy of, 1456

vertebral furrow of, 1436

Baillarger, bands of, 644

Ball-and-socket joint, 301, 303

Bands of Baillarger, 644

Bands of Meckel, 841
Banderella of Giaconimi, 629

Bar, branchial, 42

hyoid, 43, 159

pharyngeal, 42

thyreo-hyoid, 44, 159

Barbula hirci, 830

Bartholin, duct of, 1140

Basal cells of olfactory mucous membrane, 804

ganglia of cerebral hemispheres, 637

lamina, 682,684

layer of placenta, 57,58

plate, 31

vein, 97

Base of cranium, 179

of heart, 871

of mandible, 155

Base-line of Reid, 1360

Basement membrane, 1133

Basi-cranial axis, 183

Basihyal, 159

Basilar artery, 907 abnormalities of, 1054

morphology of, 1046

groove, 128

membrane of cochlea, 849,850

part of occipital bone, 120, 123

development of, 124

sinus, 974

sulcus of pons, 548

venous plexus, 975

Basilic vein, 979

Basion, 178, 183, 285

Basiotic bone, 278

Basi-pharyngeal canal, 175

Basis cerebri, 540

cochleæ, 844

cordis, 871

cranii, 179

mandibulæ, 155

modioli cochleæ, 844

ossis hyoidei, 158

pedunculi, 591

stapedis, 840

Basi-sphenoid, 139

Basket-cells, 580

Bechterew, nucleus of, 605

Beraud, valve of, 825

Bertin, bones of, 139

Biasterionic width of skull, 286

Biaxial joints, 303

Biceps brachii muscle, 380

femoris muscle, 418

Bicipital artery, 917

furrow, 1447, 1448

groove, 206

topography of, 1445

sulci, surgical anatomy of, 1448

Bifurcation of aorta, 1050 of trachea, 1078

Bigelow, Y-shaped ligament of, 340

Bile canaliculi, 1199

Bile duct, 1202

development of, 1254

level of, 1443

relation of, to duodenum, 1185

retro-dnodenal exposure of, 1416

surgical relations of, 1416

termination of, 1186, 1203

papilla, 1186, 1203

Bimanual examination, 1436

Bismuth meal, 1417 
Bistephanic diameter of skull, 286

Biventer cervicis muscle, 442

Biventral lobule of cerebellum, 575

Bladder, gall, 1201

urinary, 1271, 1278

capacity of, 1277

cystoscopic examination of, 1428

trigoma of, 1428

development of, 1328, 1332

distended, 1276

diverticula of, 1429

empty, 1275

in female, 1278

fixation of, 1283

in infant, 1279

inferior aspect of, 1274

infero-lateral areas of, 1275

interior of, 1277

examination of, 1428

lateral false ligaments of, 1280

ligaments of, false, 1282

anterior, 1283

lateral, 1283

structure of, 1283

lymph vessels of, 1284

nerves of, 1284

in newly born. infant and child, 1279

peritoneal relations and connexions of, 1280

plicæ uretericæ of, 1277

shape and relations when empty, 1275 distended, 1276

sphincter of, 1284

structure of, 1283, 1284

superior false ligaments of, 1280

torus uretericus, 1277

trigonum vesicæ of, 1277

urachus of, 1280, 1283

development of, 1332

ureteral orifices of, 1278

examination of, 1428

urethral orifice of, 1273,1274

uvula vesicæ of, 1277

varying relationships, 1277

vessels and nerves of, 1284

Blastula, 21

Blind spot, 815

Blood capillaries, 867

development of, 64

islands, 64

Blood corpuscles, mesamoboids, 64

blood plastids, 64

erythrocytes, 64

ichthyoid cells, 64

nucleated colourless corpuscles, 64 sauroid blood cells, 64

Blood-vascular system, primitive formation of, 64

abnormalities of, 1049

development of, 64,1025

morphology of, 1042

Blood-cessels of rectum and anus, 1232

anastomoses of, 1233

development of, 64

Body, para-thyreoid, development of, 44 ultimo-brachial, 14

cavity, 22, 27

polar, 15, 19

stalk, 38,54

vitelline, 18

Wolffian, 1329

Bone or Bones, 81
Bone or Bones, air-spaces of, 82

articular surface of, 83

of Bertin, 139

blood-supply of, 87

bregmatic, 277

(analiculi of, 84

cancellar tissue of, 83

carpal, 217

cartilage, 83

of skull, 290

compact tissue of, 83

composition of, 82

descriptive terms, 82

diaphysis of, 85

diploe, 84

epiphyses of, 85

pressure and traction, 85

epiphyseal line of, 85

epipteric, 132, 145

of face, 146

flat, 82

of foot, 254

frontal, 115

fundamental lamellæ of, 84

growth of, 86,87

of hand, 217

Haversian systems of, 84

of head, 115

hip, 228

irregular, 82

lamellæ of, 84

interstitial, 84

long, 82

of lower limb, 228

lymph vessels of, 87

marrow of, 83

medullary cavity of, 83

membrane, 83 ,

of skull, 292

metacarpal, 223

metatarsal, 265

of middle ear, 838

nerves of, 87

number of, 82

ossification of, 84,85

in cartilage, 86

in membrane, 85

osteoblasts of, 85

periosteal membrane of, 84

periosteum of, 83

primary centre of, 84

primordial, 292

secondary, 292

sesamoid, of metacarpo-phalangeal joints, 228

of metatarso-phalangeal joint, 269

of peronæus longus, 269,427

short, 82

of skull, 115

strength of, 83

structure of, 83

microscopic, 84

sutural, 145,146

tarsal, 254

thigh, 239

of thorax, 113

of upper limb, 197

vascular supply of, 87

of vertebral columm, 87

Boundaries of abdominal carity, II55

Bowman, elastic lamina of, 810

anastomotic branches of, 919 
Bowman, surgical anatomy of, 1448

Brachia conjunctiva, 33, 542, 587

quadrigemina inferius, 582 superius, 582

Brachial artery, 917

branches of, 702

muscular of, 702

pars supraclavicularis of, 702

branches of, 701

communications with sympathetic, 700

composition of, 700

ligature of, 1448

plexus, 700

position of, 700

pars infraclavicularis of, 703

primary cords of, 700

secondary cords of, 701

Brachialis muscle, 381

action of. 381

nerve-supply of, 381

Brachio-radialis muscle, 396

action of, 396

nerve-supply of, 396

Brachium conjunctivum, 512, 569, 578

quadrigeminmm inferius, 582 superior, 582

Brachycephaly, 284

Brachyfacial skulls, 286

Brachy-kerkic limbs, 289

Brachy-knemic limbs, 289

Brachy-uranic skulls, 287

Brain, 512, 589

aqueduct of, 584

dèvelopment, 37,592

arteries of, 904, 905

development of, 33,514

flexures of, 514

lymph vessels of, 1003

meninges of, 667

mesencephalon, 33, 514, 516, 581

nature of the, 512

nerve-cells of, 584

nerve-fibres of, 588

neuroglia of, 511

Brain, prosencephalon, 514, 607 development of, 33,514

rhombencephalon, 514, 515

development of, 33,515

isthmus of, 515

veins of, 970

resicles, primitive, 33

weight of, 667

Branchial arches, 43

luars, 42

ducts, 43

muscles derived from, 496

produced from, 466

nerves of, 795-797

pouches, 42

relation of, to cerebral nerves, 796-798

Breast, 1336

bone, 106

Bregma, 172, 285 topography of, 1223

Bregmatic bone, 277 fontanelle, 194

Broad ligament of uterus, 1318

bursa ovarica of, 1318 sturgical anatomy of, 1434

Bronchi (dexter et sinister), 1082 apical, 1098

cardiac, 1098
Bronchi (dexter et sinister), cartilaginous rings of, 1082

development of, 1099

differences in calibre and direction in, 1083

dorsal branches in lumg, 1097

eparterial, 1097

external branch of right, 1082

fibro-cartilaginous coat of, 1083

hyparterial, 1083, 1097

meninges of, 667

mucous membrane of, 1083

muscular coat of, 1081

relations of, 1083

in root of lung, 1097

structure of, 1098

topography of, 1402

weight of the, 667

Bronchial arteries, 1096

abnormalities of, 1051

arches, 496

bar, 42

morphology of, 1046

lymph glands, 1012, 1096

tube, distribution of, within the lung, 1097 veins, 961

morphology of, 1048

Bronchioli, 1097

Brunner, glands of, 1179

Buccæ, 1109

fatty body, 1109

lymph vessels, 1005

Buccal branch of external maxillary artery, 894 of internal maxillary, 899

glands, 1109

lymph glands of, 1005, 1109

Buccinator artery, 899

-muscle, 451

action of, 452

nerve-supply of, 452

nerve of serenth, 784

nerve of trigeminal, 779

Bucco-pharyngeal area, 27, 42

fascia, 1149

membrane, 25, 27

Buds, taste, 854, 1128

$\lim b, 39$

Bulb, aortic, 884

abnormality of, 1050

division of, 1035

septum of, 1035

of corpus spongiosum, 1308

of eye, 807

equator of, 807

fascia of, 807

optic axis of, 807

poles of, 807

sulcus scleræ of, 807

tunics of, 807

of hair root, 860

of jugular vein, 964

olfactory, 622,623

of posterior cormu of lateral rentricle, 635

of urethra, 942, 1308

artery of, 942

sturgical anatomy of, 1427

of ragina, 1326

of restibule, 912,1326

artery, 942

surgical anatomy of, 1427

Bulbo-cavernosus muscle, 487

Bulbo-urethral glands, 1286, 1304

Bulbus, anterior chamber of, 813 
Bulbus, anterior chamber of, development of, 825 aortæe, 884

bursa of, 452,807

coats of, 807

cornu posterius, 635

dimensions of, 807

equator of, 807

fascia of, 807

lymph vessels of, 1004

muscles of, 453

nerves of, 773

nervous tmic of, 808,814

oculi, 806

olfactorins, 622,623

optic axis of, 807

pili, 860

poles of, 807

posterior chamber of, 813

refracting media of, 819

sclero-corneal junction of, 806

shape of, 807

stileus scleræ of, 809

tunica vasculosa of, 810

urethræ, 1308

vestibuli, 1326

Bulla ethmoidalis, 185, 803

Bundle, medial longitudinal, 588

Burdach, column of, 522,533

Burns, space of, 967

Bursa or Bursæ, 364

anterior wall of, 1240

of coraco-clavicular ligament, 319

of eyeball, 452, 807

of tlexor carpi radialis, 386

under hyoid bone, 1066

of ilio-psoas, 410, 341

surgical anatomy of, 1459

at knee-joint, 348

surgical anatomy of, 1460

of muscles of arm, 378-382

of back, stiperficial, 365-369

of back of forearm, 396-400

of back of leg, 428-431

of back of thigh, 419-421

of buttock, 415-418

of front of leg, 424-426

of front of thigh, 406-414

of shonlder, 323, 324

omental, 1162, 1238

gastro-pancreatic folds of, 1240

lienal folds of, 1240

of peroneal muscles, 427

pharyngea, 1143

posterior wall of, 1240

præpatellaris subcutanea, $1+60$

recessus superior of, 1240

inferior of, 1240

at shoulder-joint, 323

subacromial, 323

subcutaneolls, 364

Bursa or Bursæ, subtendinous, 364

subscapular, 323

thecal, varieties of, 303

vestibulum, 1238

Buttock, fasciæ of, 402

bony points of, 1455

muscles of, 414

actions of, $415-418$

nerve-supply of, $415-418$

surgical anatomy of, 1455
Cæcal folds, 1218

fossæ, 1218

Cæcum, 1213

development of, 48

dimensions of, 1213

fœtal, 48, 1217

ileo-cæcal orifice of, 1214

infantile, 1217

position of, 1213

relations of, 1213

structure of', 1215

surgical a natomy of, 1421

types of, 1215, 1217

valve of, 1214

vermiform process of, 1215

vessels of, 1217

Cæecum cupulare cochleæ, 849

vestibulare, 849

Calamus scriptorius, 550

Calcaneal medial artery, 955

Calcanean facets, 259 nerve, medial, 731

Calcaneo-cuboid joint, 357 surgical anatomy of, 1464

ligaments of, 357

finctions of, 361 position of, 1464

Calcaneo-fibular ligament, 352

Calcaneo-metatarsal ligament, 423

Calcaneo-navicular ligaments, 355

function of, 355

sturgical anatomy of, $146 t$

Calcaneo-taloid joint, 354 position of, 1464 surgical anatomy of, 1464

Calcaneus, 259

facets of, 259

plantar surface of, 209

processes of, 259

sustentaculum of, 260

trochlear process of, 260

tuber of, 260

Calcar avis, 635, 659

femorale, 274

Calcarine artery, 908 fissure, 660

Calyces renales, 1268 development of, 1331

Camera octrli, 820

anterior, 821

posterior, 821 princeps of $\mathrm{His}, 1169$

Canal or Canalis

adductor (Hunteri), 405, 414

alimentary, 1104 primitive, 41

alveolar, 147

development of, 1327, 1331

inferior, 147

of epididymis, 1289

anal, 1228

development of, 48

orifice of, 1232

relations of, 1229

sinuses of, 1231

surgical anatomy of, $1 \pm 30$

valves of, 1231

vessels of, 1233

for Arnold's merve, 129

atrio-rentricular, 1033

auditory, 128, 176, 837

basi-pharyngeal, 175 
Canal or Canalis-continued

earotica, 129, 176, 177

relation of, to tympanum, 271

variation in, 278

central of cochlea, 846

of meclulla oblongata, 564

of spinal medulla, 564

development of, 35

of cervix uteri, 1317

condyloid, 177

cranio-pharyngeal, 135

closure of, 290

ethmoidal, in anterior cranial fossa, 179

on ethmoid, 140

on frontal, 116

in the orbit, 162

facialis, 129, 130, 833

hiatus of, 130

condition of, at birth, 133

femoral, 405

Haversian, 84

of Huguier, 125

relation of, to tympanum, 834

hyaloid, 826

development of, 826

hypoglossal, 177

infraorbital, 147, 162

inguinal, 483

surgical anatomy of, 1408

innominate, 137

lacrimal, membranous, 825

development of, 827

osseous, 143, 147, 187

mandibular, 156

musculo-tubarins, 128, 176, 837

of naso-lacrimal duct, 143, 147, 187

neural, 88

neurenteric, 23, 26

of Nuck, 1319

obturator, 338

palatine, anterior, 149

greater, 151

lesser, 152

superior openings of, 152

of Petit, 819

pharyngeal, 138, 152, 175

plenro-pericardial, 72

portal, 1200

pterygo-palatine, 147, 151

1)terygoid, 138, 180, 192

jyloric, 1169,1173

radicis dentis, 1114, 1115

reuniens, 51, 854

sacral, 99

semicircular ducts, 847

spheno-vomerine, 279

spiralis cochlese, 845

of Stenson, 1109

for tensor tympani muscle, 128

tympanic, 129

urogenital, 1328

vertebral, 88

zygomatico-orbital, 154

zygomatico-temporal, 154

Caraaliculus or Canaliculi, bile, 1199

of bone, 84

carotico-tympanic, 129

innominate, 137

mastoid, 129

tympanic, 129

Canine fossa, 146

teeth, 1115
Canine teeth, eruption of, 1120

Caninus muscle, 451

action of; 454

Capillaries, 867

blood, structure of, 868

Capillary arterioles, 868

lymph vessels, 1042

veins, 867

Capitular process, 284

Capitulum of humerus, 208

of mandible, 156

of radius, 214

of nlna, 214

Capsula adiposa of kidney, 1259

articularis of joints, 302

externa, 644

fibrosa (Glissoni), 1198

interna, 642

pars frontalis, 642

anterior limb of, 642

occipitalis, 642

posterior limb of, 642

Capsular arteries of liver, 933

of inferior suprarenal, 927

of middle suprarenal, 927

of superior suprarenal, 933 morphology of, 1043, 1046

Capsule, external, 644

of Glisson, 1198

glomerular, 1266

internal, 642

acoustic radiation fibres of, 643,656

anterior limb of, 642

cerebro-spinal tract of, 462

fasciculus cerebro-rubricus of, 643

fronto-pontine fibres of, 642

genu of, 642

lenticulo-caudate part of, 642

lenticulo-thalamic part of, 642

optic radiation fibres of, 643,658

posterior limb of, 642

retro-lenticular part of, 643

sublenticular part of, 642

temporo-pontine fibres of, 643

of joints, 302

of lens, 819

Caput angulare m. quadrati labii superioris, 451 epididymidis, 1287

infraorbitale $\mathrm{m}$. quadrati labii superioris, 451 of posterior column of spinal medulla, 523 zygomaticum m. quadrati labii superioris, 451

Cardia, 1164

topography of, 1416, 1417, 1439

Cardiac bronchus, 1098

dulness, 1398

ganglion of Wrisberg, 790

lobe of lung, 1098

nerves inferior, of sympathetic, 759

middle, 759

superior, 757

of vagus, 789

notch of lung, 1095

plexus, 790

portion of stomach, 1163, 1172, 1173

Cardiac veins, 959

Cardinal veins, anterior, 1038

morphology of, 1048

posterior, 1040

Carina vaginalis, 1323

Carotid artery, common, 889

abnormalities of, 1053 
Carotid artery, common, development of, 67 morphology of, 1046

surgical anatomy of, 1386, 1389, 1391

left, 889

abnormalities of, 1053

right, 890

abnormalities of, 1053

external, 891

abnormalities of, 1053

development of, 67

morphology of, 1046

surgical anatomy of, 1391

internal, 900

abnormalities of, 1053

development of, 67

morphology of, 1053

canal, 129

relation of, to tympanum, 271

variation in, 278

glomus, 1343

groove, 135

lymph glands, 1009

plexus, 757, 758

sheath, 447

triangle, 1390, 1391

tubercle, 1393

Carpal arch, dorsal, 923

volar, deep, 924

volar, superficial, 924

artery, anterior radial, 919 ulnar, 921

posterior radial, 920

ulnar, 921

bones, 217

architecture of, 272

ossification of, 223

variations in, 280

joints, 329

movements at, 334

nerves to, 705,713

synovial stratum of, 331

transverse, 380

Carpale, os, 280

Carpo-metacarpal of finger joints, 332

Carpus, as a whole, 222

bones of, 217

bony parts about the, 1451

ossification of, 223

Cartilage - Cartilago-Cartilagines-

alares minores, 800

alaris major, 800

lateral crus of, 800

medial crus of, 800

articular, 83

arytienoid, 1064

auricular, 829

bones, 86

of skull, 290

corniculate, 1065

costal, 113

joints of, 315

topography of, 1407

cricoid, 1063

development of, 1100

ossification of, 1065

surgical anatoiny of, 1388

cuneiform, 961, 1068

epiglottic, 1065

larynx, 1064

development of, 1100

meatus acustici, 829
Cartilage-Cartilago--Cartilagines-continued of Meckel, 157, 841

nasal, 800

greater alar, 800

lateral, 800

lesser alar, 800

of septum, 800

processus sphenoidalis of, 801

vomerine, 801

nasi, 800

lateralis, upper, 800

parachordal, 290

of pinna, 829

prechordal, 290

of Reichert, 159

of Santorini, 1065

semilunar, 347

surgical anatomy of, 1460, 1461

of septum of the nose, 800

sesamoid, of arytænoid, 1065

sesamoid, of the nose, 800

tarsal, 1378

thyreoid, 1062

development of, 1100

ossification of, 1065

surgical anatomy of, 1388

tracheal, 1081

triticea, 1066

vomero-nasalis (Jacobsoni), 801

xiphoid, 108, 109

Cartilaginous cranium, 290

vertebral column, 103

Caruncula lacrimalis, 821

Carunculæ hymenales, 1322

myrtiformes, 1322

Catheter, passage of female, 1435

Canda epididymidis, 1287

equina, 519

fasciæ dentatie, 629

helicis, 829

Caudal arches, 68

fold, 38,48

nerves, 678

Caudate lobe of liver, 1192

nucleus, 635, 637

Cavernous arteries, 902

plexus, 759,766

sinus, 975

Cavitas glenoidalis, 201

Cavity, amniotic, 54, 55

mandibular, of temporal bone, 125, 167 condition of, at birtll, 133

nasal, development of, 50

of scapula, 201

segmentation, 21

sigmoid, of ulna, 211

Cavum abdominis, 1155

articulare, 300

conche, 827

dentis, 1114

epidurale, 669

Meckelii, 771

medullare, 83

nasi, 183,801

oris, 1106

proprium, 1107

pelvis, 237,1157

peritonæi, 1412

pharyngis, $11 \pm 1$

plewre, 1083

Retzii, 493

septi pellucili, 628, 632 
Cavum subarachnoideale, 671

subdurale, 670

thoracis, 1083

mediastinnm, dorsal, 1090

ventral, 1090

tympani, 832

nteri, 1317

Cell, period of life, 10

period of resting stage, 10

Cell-body, 8

Cell-mass, inner, 21

intermediate, 21

history of, 21

Cells, basal, of olfactory mucons nembrane, 804 basket, 580

body of, 8

ethmoidal, 140, 804

relation of, to orbit, 1373

to nasal fossæ, 1373

surgical anatomy of, 1372

germinal, 502

of neural tube, 36

lymph, 906

of marrow, 83

mastoid, 133, 1370

surgical anatomy of, 1370

nerve, $16,497,506$

nucleus of, 8

olfactory, 804, 805

reproduction of, 8

reproductive, 11

spermatocytes, 16

supporting, 16

Cellulæ ethmoidales, 140, 804

mastoideæ, 836

Cement (substantia ossea), 1123

development of, 1245

Central arteries of middle cerebral, 905

of posterior cerebral, 908

of retina, 903

canal of medulla oblongata, 564

gray matter of medulla oblongata, 564

gyri, 654

hemispheres, 620

development of, 621,623

longitudinal fissures of, 621, 623

lobule of cerebellum, 575

lymph vessels of hand, 1009

point of perineum, 1427

sulcus of insula, 654

Central bone of wrist, 290

Centrioles, 8

medullary, of cerebral hemispheres, 644,647 of ossification, 85,86

Centrolecithal ovum, 14

Centrosome, 7, 8, 10, 11, 12

Centrum tendineum, 472

of vertebra, 88

Cephalic aortic arches, 65, 68, 1027, 1028, 1029, 1030, 1034

morphology of, 1046

flexure of brain, 514

fold, 37

index, 284

myotomes, 30

part of sympathetic, 756

somites, 28

vein, 978

Cephalo-auricular angle, 828

variations in, 830

Cerato-hyal, 159

Cerebellar artery, anterior inferior, 907
Cerebellar artery, anterior superior, 907 posterior inferior, 907

tract, 534, 536, 578

spino-cerebellar anterior, 536,537 posterior, 537

antero-lateral superficial, 536

Cerebellar veins, 971

Cerebello-olivary tract, 556,563

Cerebellum, 570

alæ lobuli centralis, 575

amygdala of, 575

arbor vitæ of, 577

arrangement of gray and white matter of, 576

association fibres of, 578

biventral lubule, 575

brachium conjunctivum of, 569

clivus monticuli of, 575

commissural fibres of, 578

connections of peduncular fibres, 578

corpus dentatum of, 576

culmen declivi, 575

development of, 33

fissure, postnodular, of, 571

horizontal, of, 573

post-tonsillar, 573

pyramidal of, 573

supra-pyramidal, 573

fissures of, 571, 572, 573

prima, 572

secunda, 572, 573

development of, 571

flocculns, 571, 575

folium vermis of, 572

furrowed band of, 576

gray matter of, 576

hemispheres, lateral, of, 571, 574

surgical anatomy of, 1363

incisura anterior, 574

posterior, 574

inferior vermis of, 574

lingula cerebelli, 575

lobe, lateral, of, 571

lobes of, 575

lobes on inferior surface of, 575

lobes on superior surface of, 575

lobules of, 575

centralis, 575

gracilis, 576

medullary velum of, anterior, 549

minute structure of, 579

posterior, 576

monticulus, 574

nodulus, 571

notches of, 514

origin of, 515

nucleus emboliformis of, 577

dentatus, 576

fastigii, 577

globosus, 577

paraflocculus, 571

peduncles of, 577

brachium conjunctivum, 577,578 pontis, 577,578

restiform, 577,578

origin of fibres of, 578

in sections of pons, 576

posterior inferior lobule, 575

postlunar sulcus of, 573

pyramid of, 576

roof nucletis of, 577

structure and connexions of, 576 
Cerebellum, sulcus valleculare, 575 development of, 571

superior vermis of, 574

tonsil of, 573,575

tuber of, 575

vermis of, 575

uvula of, 507,576

vallecula of, 574

vermis of, 572,574

white matter of, 576

Cerebral artery, anterior, 904 abnormalities of, 1053

middle, 905

posterior, 908

surgical anatomy of, 1365

cortex, 644,646

association centres of, 645

fibres of, 648

auditory area of, 656

band of Baillarger of, 644,645

of Bechterew of, 645

of Martinotti of, 645

commissural fibres of, $6 \pm 7$

connexion of, with thalamus, 612

gray layers of, 645

layer of polymorphic cells of, 645 of pyramidal cells of, 645

lymph vessels, 1003

nerve-fibres of, 645

olfactory area of, 625

projection filures of, 651

stratum zonale of, 645

stria of Gennari of, 614

structure of, 644

thickness of, 644

topography of, 1359

vesicles, 514

visual area of, 658

white layers of, 644

hemispheres, 620

association fibres of, 648

basal ganglia of, 637

borders of, 647

claustrum of, $6 \pm 1$

commissural fibres of, 647

corpus callosum of, 629

cortex of, 644

development of, 34

external configuration of, 646

fimbria of, 627

fissures of, 653

form of, 646

frontal pole of, $6+7$

general structure of, $6 \pm 4$

gray matter of, 644

groove for transverse sinus on, 647

gyri of, 654

impressio petrosa of, $6 \pm 7$

incisura longitudinalis, 540

intermal capsule of, 612

intimate structure of, 644

island of Reil of, 854

lateral fossa of, 655

level of lower margin of, 135!)

limen insulæ of, 654

lobes of, 665

medulla of, 645

merves, list of, 678,767

development of, $68: 2$

nuclei of, 637,638

occipital pole of, $6+7$

opercula of, 685
C'erebral hemispheres, poles of, (j47

jorimary ulfactory fimetion of, 51:

projection fibres of, 651

Rolandic :mgle of, $66 \%$

sejtum jellucidum of, 628

development of , $(j 28$

structure of, 644

sulci of, 653

surfaces of, 646

sturgical anatomy of, $13(j)$

temporal pole of, 647

veins, 970

veutricles of, $5 \pm 9,6 j 16,6: 32$

vesicles, 511

white mitter of, 6.17

Cerebral nerves, 767

lst nerve, olfactory, 767

2nd nerve, optic, 768

3rd nerve, uculo-notor, 769

4th nerve, trochlear, 770

5th nerve, trigeminal, 771

6th nerve, abducens, $7 \& 1$

7 th nerve, facial, 781

8th nerve, acoustic, 784

9 th nerve, glossopharyngeal, 785

10th nerve, vagus, $786^{\circ}$

11th nerve, accessoly, 791

12th nerve, hypoglossal, 793

abducens nerve, nuclens of, 600

accessory nerve, nucleus of, 595

acoustic nerve, 604

deep connexions of, 592

dorsal, nuclei of, 597

facial nerve, intripontine course of, $5 ! 99$

nuclei of, 598

glossopharyngeal, nuclei of, 5.96

gustatory nuclei of, 597

nervus intermelius, nuclei of, 595

nnclei of, lateral somittic, 593

medial somatic, 592

of origin, or notor nutelei wi." 592

splanchnic, 5!):3

terminal, 593

nucleus of ly yoglosisil nerve, 594

oculomotor nerve', 603

trigeminil nerve", nuelei of, 600

trochlear nerve, 602

vigus, nuclei of, $596^{\circ}$ splanchnic nuclei of, $5 ! 14$ tractus solitaus, $59 \%$

Cerebro-spinal fluid, 1003

nervous system, 497

ganglionie part of, 511

gray matter of, 512

inedullary part of, . 50 ;

nerve-etls of, ior;

nerve-fibres of, 508

$110 \mathrm{v} v \mathrm{e}$ 's of, 50.5

netrroglia of, 511

netroms of, 503

white malter of, 512

C'rehrum, 620

firentisl region of the, (itis)

partelat region of the, fitid

suleus circular ris uf, 654

Cermmen, 8:32

('eruminous glames, 8.32

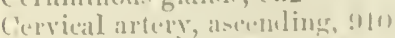

morpholing of, 10 ti

(अe.), 914

morpholugy of, 10.16 
Cervical artery, transverse, 911

cinal of uterus, 1317

fascia, 447

surgical anatomy of, 1385

Hexure of neural tube, 514,515

of brain, 514

ganglion, inferior, 759

surgical anatomy of, 1393, 1398

middle, 759

superior, 756

glands of uterus, 1320

lymph glands, 1000

surgical anatomy of, 1392

nerves, 688, 692

posterior rami of, 688

first, 688

second, 689

third, 690

fourth to sixth, 690

pleura, 1398 seventh and eighth, 690

plexus, 694

communicating branches of, 697

deep branches of, 696

morphology of, 700

muscular branches of, 696

ribs, 93, 275, 1375

serial homology of, 283

sympathetic, 756

development of, 681

surgical anatomy of, 1393

veins, 964

vertebræ, 90, 93

Cervicis ileocostalis muscle, 440 descendens nerve, 794

Cervix columnæ posterioris, 523

uteri, 1316

arbor vitæ of, 1317

glands of, 1320

mucous membrane of, 1320

muscular coat of, 1320

supra-vaginal portion of, 1316

vaginal portion of, 1316 surgical anatomy of, 1434

Chamæcephalic skulls, 286

Chamæprosope, 286

Chamber, anterior, of eye, 813 development of, 825 endothelium of, 810

posterior, of eye, 813 recesses of, 818

Cheek bone, 153

Cheeks, 1109

buecal fatty body, 1109

glands of, 1109

lymph vessels of, 1005

Chest, 1395

Chiasma opticum, 619

Chiene's lines, 1359

Choanæ, 175, 185, 190

surgical anatomy of, 1246

Chondro-cranium, 290

Chondro-epitrochlearis muscle, 371

Chondro-glossus muscle, 462 action of, 463

Chopart's amputation, 1464

Chorda obliqua (of forearm), 328

tympani nerve, 782 origin of, 598

Chordæ tendineæ, 877

Willisii, 974

Chordal portion of skull, 290
Chorioid, 810

development of, 825

fissure, 637

lamina basalis of, 811,812

chorio-capillaris of, 81$]$

supra-chorioidea of, 811

vasculosa of, 811

nerves of, 814

pigment of, 814

plexus of lateral ventricle, 621

proper tissue of, 811

spatium perichorioidale of, 808

stratum intermedium of, 811

tapetum of, 812

Chorioid plexuses of fourth ventricle, 553, 636 development of, 552

of lateral ventricle, 635

development of, 635

of inferior horn of, 636

of third ventricle, 617

Chorioidal artery, anterior, 904 posterior, 908

fissure of eye, 826

development, 826

of brain, 636

veins, 970

Chorioidal fissure, $621,637,675,826^{\circ}$

Chorion, 21, 53, 57

frondosum, 60

læve, 54, 60

Chorionic area, 21

plate, 58

vesicle, 55

villi, 58

absorbing, 59

anchoring, 59

Chromaffin cells, 32

Chromatin, 8

organs, 32

skein, 10

Chromogenic cells, 1331-32

Chromophil bodies, 1342

system, 1341

development of, 1343

Chromosomes, 8, 10, 11

object of the reduction of, 18

Chyme, 1163

Chymus, 1163

Cilia, 823

Ciliary arteries, 903 anterior, 813, 903

long, 813

posterior, 903

short, 903

body, 812

orbiculus of, 812

border of iris, 814

bundle of orbicularis palpebrarum, 450

ganglion, 773

development of, 699

morphology of, 701

motor root, 773

sensory root, 773

splanchnic efferent fibres of, 604

sympathetic root of, 773

glands, 861

Ciliary muscle, 813

nerves, distribution of, on comea, 808

in chorioid and iris, 814

innervation of, 604

entrance of, into eyeball, 814

long, 814 
Ciliary nerves, short, 814

processes, 812

veins, 814

Cinerea ala, 551

Cingulum, 649

extremitatis inferioris, 228

superioris, 197

of teeth, 1116

Circular sinus, 974

sulcus, 654

Circulation, fœtal, development of, 63,71

Circulus arteriosus, 908

major of iris, 813

minor of iris, 813

tonsillaris, 1147

Circum-anal glands, 1280

Circumduction, movement of, 303, 323, 436

Circumflex artery, anterior, of the humerus, 917

lateral, of the thigh, 919

surgical anatomy of, 1447

medial, of the thigh, 949

posterior, of the humerus, 903

surgical anatomy of, 1447

iliac artery, deep, 945 surgical anatomy of, 1445 superficial, 947

vein, deep, 988

Circumflex ilii vein, superficial, 989

Circumflex nerve, 710

surgical anatomy of, 1447

Cisterna basalis, 672

cerebello-medullaris, 671

chiasmatis, 672

chyli, 996, 997

interpeduncularis, 672

magna, 671

surgical anatomy of, 1362

pontis, 672

Cisternæ subarachnoideales, 671

Classification of joints, 299

Claudius, cells of, 850

Claustrum, 641

Clava, 547

Clavicle, 197

acromial end of, 199

architecture of, 271

articulations of, 317

coracoid tubercle of, 198

costal tuberosity of, 199

deltoid tubercle, 198

morphology of, 199

ossification of, 199

shaft, 198

surgical anatomy of, 1444

variations in, 279

Clavicular artery, 916

facet of sternum, 107

nerves, 695

morphology of, 1700

Cleft, bronchial, 42

gluteal, 1455

olfactory, 1378

palate, 1379

pharyngeal, 42

urogenital, 1324

visceral, 42

nerves of, 796,798

stages of, at different ages, 42, 44, 52

Cleido-mastoid muscle, 458

Cleido-occipital muscle, 458

Clinoid process, anterior, 135
Clinoid process, middle, 135

posterior, 135

Clitoris, 1326

arteries of, 1326

body of, 1326

bone of, 1326

corpora cavernosa of, 1326

crura of, 1326

development of, 1336

dorsal vein of, 942

frenulum of, 1326

glans of, 1326

prepuce of, 1326

septum corporum cavernosum of, 1326

suspensory ligament of, 1326

vessels and nerves of, 1326

Clivus monticuli cerebelli, 575

Cloaca, 48

entodermal, 39

Cloacal fossa, 48

membrane, 39

Closing month, muscles of, 458

Club-foot, 1465

Co-aptation in joints, 303

Coccygeal artery, 935

ganglion, 753, 763

glomus, 1355

nerves, 691

plexus, 738

vertebræ, 99

Coccyx, 99

cornula of, 99

ossification of, 106

Cochlea, 844

aquæductus cochleæ, 845

area, 844

auditory teeth of Huschke of, 830

base of, 844

basilar membrane of, 849,850

canales spirales cochler, 845

crista basilaris of, 849

crista semilunaris, 845

cripula of, 844

development of, 51

duct, 848,849

foramen centrale, 844

foramina nervosa of, 849

ganglion spirale cochler, 845

hair cells of, 851

hamulus laminæ spiralis, 845

helicotrema of, 845

lagena of, 849

lamina spiralis ossea, 845

lamina spiralis secundaria, 845

ligament spira.l of, 849

limbus laminæe spiralis of, 819

membrana basilaris of, 845

membrana restibularis of, 849

membranous, 848

modiolus of, 844

prominentia spiralis of, 849

scala tympani, 845

scala vestibuli, 845

spiral canal of, 845

spiral organ of, 849,850

stria vascularis of, 849

sulcus spiralis externus, 849

sulcus spiralis internus of, 819

tractus spiralis formminosus, 841

tumnel of Corti, 850

vas prominens of, 849

Cochlear nerve, 785 


\section{Cochlear nucleus, 604} development of, 684

Cochleariform process, 128

Cocum, folds ancl fosse of, 1218

Cocliac artery, 928

abnormalities of, 1052

morphology of, 1046

surgical anatomy of, 1426

ganglia, 763

Tymph glands, 1021

plexus, 763, 765

Colom, 22, 71

embryonic, $27,71,72$

extra-embryonic, 22, 53, 57, 71

Colic arters, left, 932

middle, 932

right, 932

impression of liver, 1189, 1192

lymph glands, 1021

vein, left, 993

middle, 992

right, 992

Collar bone, 197

Collateral digital artery of foot, 955 of hand, 924

Collateral eminence, 637

fissure, 662

nerve-fibres, 534

Collecting tubules, renal, 1266

Colles, perineal fascia of, 1427

Colliculi, origin of, 516

inferiores, 585

functions of, 586

nervi optici, 814

stratum griseum of, 586

lemnisci of, 586

opticum of, 586

zonale of, 586

superiores, 620

functions of, 586

Colon, 1211

appendices epiploicæ of, 1211, 1212

ascending, 1211, 1219

length, 1219

position, 1219

relations, 1219

topography of, 1422

cæclum of, 1211

descending, 1211, 1221

length of, 1221

relations of, 1221

topography of, 1423

dimensions of, 1211

haustra of, 1212

iliac, 1222

course of, 1222

relations of, 1222

topography of, 1423

left flexure of, 1211

level of, 1439

topography of, 1422

mesentery of, 1219

nerves of, 1213

pelvic, 1222

length of, 1223

mesentery of, 1219

in new-bom child, 1223

position of, at birth, 1223

relations of, 1223

structure of, 1223

surgical anatomy of, 1423

variations in course of, 1223
Colon, plicr semilunares of, 1212

right flexure of, 1211

level of, 1439

topography of, 1422

sacculi of, 1212

sigmoid flexure of, 1211

sigmoideum (pelvic), 1222

structure of, 1212

tæniæ of, 1179

transverse, 1219

position of, 1220

relations of, 1220

topography of, 1422

vessels of, 1212

Column anterior of spinal medulla, 528

of Burdach, 522, 533

of fornix, 615

of Goll, 522, 533

lateralis, 529

posterior, 537

vertebralis, 87

Columnæ carneæ, 877

griseæ, 523

rectales, 1230

renales (Bertini), 1265

rugarum vaginæ, 1323

Columns of Bertin, 1265

membranous vertebral, 102

of fornix, 34, 615

posterior, of spinal medulla, neck of, 523

of the rectum, 1230

of spinal medulla, 523

Comitans nervi ischiadici, 943

nervi mediani, 922

nervi phrenici, 913

"Comma tract," 533

Commissural cords of sympathetic, 755

fibres, cerebellar, 578 cerebral, 616, 631

Commissure, anterior, of brain, 616, 628, 647

anterior gray, 539

dorsal, of brain, 34

gray, 539

of Gudden, 619, 769

habenularum, 615

of the hippocampus, 627,648

labiorum anterior, 1324

posterior, 1324

of lips, 1108

medial and lateral, of eye, 821

olfactory portion of, 647

of optic tract, 619

development of, 609

palpebrarum, 821

lateralis, 821

medialis, 821

posterior, 539

of brain, 614,615

cerebri, posterior, 631

of vulva, 1324

of spinal medulla, 539

temporal portion of, 647

white, anterior, 539

posterior, of brain, 631

development of, 609

Common iliac artery, ligature of, 1426

peroneal nerve, surgical anatomy of, 1461

Communicating artery, anterior, of brain, 904 
Communicating artery, of deep palmar arch, 924

peroneal, 953

posterior, of brain, 904

abnormalities of, 1054

tibial, 953

of volar interosseons, 922

Compact tissue of bone, 83

Compound glands, 1132

Compressor bulbi muscle, 487

hemispheriorum bulbi, 487

naris muscle, 450

urethræ membranace muscle, 488

Concentric corpuscles of Hassall, 135 I

Concha amriculæ, 827

nasalis inferior, 142

media, 141

superior, 141

Conchæ, ethmoidal, 141

inferior, 142 ossification of, 143

sphenoidales, 139

Condyle of femur, lateral, 243

medial, 243

of humerus, 207

of jaw, 156

occipital, 122

third, 278

Condylic foramina, 122, 123, 124

fossa, 122

surface of tibia, 247

Condyloid joints, 301

Cone of attraction, 20

bipolars of retina, 817

granules of retina, 817

retinal, 817

development of, 827

Confluens sinuum, 968, 973

inferior ophthalmic vein, 968

superior ophthalmic vein, 968

Congenital diaphragmatic hernia, 473

Coni vasculosi, 1289

development of, 1204

Conical papillæ, 1126

Conjugal ligament of ribs, 314

Conjunctiva, 823

fornices of, 823

nerves of, 823,824

ocular, 821

palpebral and bulbar, 823

plica semilunaris of, 821

surgical anatomy of, 1377

vessels of, 823,824

Connexions, central, of olfactory nerves, 623

of the corpus striatum, 639

of thalamus, 612

Comoid ligament, 319

functions of, 319

tubercle, 198

Constrictor muscles of pharynx, 464

actions of, 467

development of, 496

inferior, 465

middle, 464

nerve-supply of, 465

superior, 464

of urethra, 488

Conus arteriosus, 876

elasticus, 1066

level of, 1442

surgical anatomy of, 1388
Conus medullaris, 518

level of, 519

structure of, 526

vasculosus, 1289

Convoluted tubules of kidner, 1266

Convolutions of cerebrum, 653

Cor, 870

Coraco-acromial ligament, 320

Coraco-brachialis muscle, 378

action of, 380

nerve-supply of, 380

superior or brevis, 379

surgical anatomy of, 1446, 1447

Coraco-clavicular ligament, 319

Coraco-glenoid ligament, 322

Coraco-humeral ligament, 322

Coracoid process, 201

morphology of, 295

topography of, 1445

variations of, 280

Cord, gangliated, of sympathetic, 753 umbilical, 55

Cords of brachial plexus, 700

branches of, 702

formation of, 700

morphology of, 741

Corium, 857

papillæ of, 857

stratum papillare of, 857

reticulare of, 857

Cornea, 808

annular plexuses of, 810

anterior elastic lamina of, 810

arcus senilis of, 810

blood-vessels of, 810

bulb of, 635

cell spaces, 810

endothelium of anterior chamber, 810

filtration, angle of, 809

lacunæ, 810

ligamentum pectinatum of iris, 810

nerves of, 810

posterior elastic lamina of, $\$ 10$

scleral spur, 810

spatia anguli iridis of, 810

structure of, 809

substantia propria, 810

sulcus circularis, 809

vascular and nervous supply, 810

Cornicula laryngis, 1065

Cornu ammonis, 625, 626, 636

anterius ventriculi lateralis, 633

inferius ventriculi lateralis, 633

inferius fossæ ovalis, 403

majus oss. hyoidei, 159

minus oss. hyoidei, 159

posterius rentriculi lateralis, 635

superius fossæ ovalis, 403

Cornua coccygea, 99

sacralia, 97

of fossa ovalis, 403

of thyreoid cartilage, 1062

of uterus, 1320

Corona dentis, 1114

glandis, 1298

radiata, 631,644

Coronal suture, 164

synostosis of, $19 \%$

Coronary arteries of face, 894

surgical anatomy of, 1379

of heart, 887

abnormalities of, 1050 
Coronary arteries of stomach, 929 abnormalities of, 1052 morphology of, 1046

Coronary ligament of liver, 1195, 1196 plexus, 765 sintıs, 959

abnormalities of, 1057

development of, 1032 morphology of, 1049 opening of, 875

veins of heart, 959 of stomach, 991, 1176

Coronoid fossa of humerus, 208 process of jaw, 156

surface anatomy of, 1375

of ulna, 210

Corpora mamillaria, 541, 615 connexions of, 615 development of, 608 geniculate, origin of, 517 mediale, 582

pedumcles of, 615

relation of, to third ventricle, 616

quadrigemina, 542, 582

brachia of, 582

connexion of, with cochlear nerve, 586 with thalamus, 586

development of, 34

inferius, 585

connexion of, with lateral lemniscus, 590

lemniscus-fibres of, 586, 590

origin of, 516

structure of, 586

superius, 586

connexion of, with optic tract, 620

with optic radiation, 586,620

Corpus adiposum buccæ, 446

albicans of ovary, 1313

callosum, 628, 629, 647

absence of, 588,590

development of, 628

forceps major of, 631

geniculatum laterale, 620

genu of, 630

luteum, 1313

occipital part of, 631

radiation of, 631

rostrum of, 630

splenium of, 628,630

striæ longitudinales, mediales of, 630

lateralis of, 630

morphology of, 630

striatum, 622

superior surface of, 629

tapetum of, 631

trunk of, 630

cavernosum clitoridis, 1326

penis, 1298

inethræ, 1298

ciliare, 812

dentatum cerebelli, 576

epididymidis, 1287

fornicis, 629

geniculatum, laterale, 620

connexion of, with optic radiation, 620 with optic tract, 620

development of, 608

structure of, 613

mediale, 619

connexion of, with auditory radiation, 656 with lateral lemniscus, 607

with medial root of optic tract, 619
Corpus geniculatum, mediale, development of, 608

glandulare prostatæ, 1303

Highmori, 1288

hypothalamicum, 613

linguæ, 1124

luteum, 1313

mamillare, 34

mandibulæ, 155

maxillæ, 146

ossis ischii, 232

pubis, 233

sphenoidalis, 133

paraterminale, 626,628

pineale, 614

restiforme, 547

spongiosum penis, 1298, 1300

surface anatomy of, 1427

sterni, 106

striatum, 638

connexions of, 639

development of, 622

finctions of, 639

morphology of, 638

vein of, 635

trapezoideum, 606

of cerebellum, 576

of pons, 606

vertebræ, 88

vitreum, 819

Wolffi, 1329

Corpuscles, blood, origin of, 64

concentric, of Hassall, 1351

of Golgi and Mazzoni, 865

of Grandry, 864

of Krause, 863

lymph, 993

Malpighian, of spieen, 1353

of kidney, 1266

of Meissner, 865

of Pacini, 864

of Ruffini, 865

tactile, 863

of Wagner, 865

Corrugator cutis ani muscle, 486, 1229 supercilii muscle, 450

action of, 452

Cortex, cerebral, 644 renal, 1265

Corti, spiral ganglion of, 845, 852 organ of, 849,850

cells of Claudius of, 850,851 of Hensen of, 850, 851

development of, 853

hair-cells of, 850,851

lamina reticularis of, 850,851

membrana tectoria of, 850,851

pillars of, 850

rods of, 850

space of Nuel of, 852

supporting cells of, 850,851

fibres of, 851

phalangeal processes of, 851

tunnel of, 850

Cortical system, 1343

Corticifugal projection strands of brain, 652

Cortico-pontine tract, 653

in internal capsule, 642

in mid-brain, 591

in pons, 555

Costæ, 109

floating, 109 
Costæ spuriæ, 109

veræ, 109

Costal cartilages, 113 joints of, 315

topography of, 1407

demi-facets of dorsal vertebræ, 93

pleura, 1084, 1085

transverse epiphyses, 106

zone of abdomen, 1158

Costo-central joints, 313

Costo-chondral joints, 315 topography of, 1398

Costo-clavicular ligament, 318, 319

Costo-colic ligament, 1220

Costo-coracoid ligament, 369 membrane, 369

Costo-iliac space, 1437

Costo-sternal joints, 315

Costo-transverse joints, 314 ligaments, 314

Costo-vertebral joints, 313

Costo-xiphoid ligaments, 316

Cotyloid ligament, 340 notch, 232

absence of, 281

Coxa, 339

Cranial fossa, anterior, $179,183,188,189$ capacity, 284 middle, 180, 183, 190, 191 posterior, 182, 183

Cranio-cerebral topography, 1359 central sulcus of Rolando, 1360

lateral cerebral fissure, 1360

parieto-occipital fissure, 1360

Rolandic area, 1360

transverse sinus, 1360

Craniology, 284

Craniometry, 284

Cranio-pharyngeal canal, 135 closure of, 290

Cranium, 115

articulations of, with vertebral column, 310

base of, 179

bony landmarks of, 1358

capacity of, 284

cartilaginous, 290

cerebrale, 115

circumference of, 286

height of, 286

membranous, 290

sinuses of, 972

surgical anatomy of, 1357, 1359

thickness of, 1359

trabecular portion of, 290

veins of, 969,972

vertebral portion of, $290^{-}$

viscerale, 115

Cremaster muscle, 480 nerve-supply of, 484

Cremasteric artery of inferior epigastric, 944 of internal spermatic, 928

fascia, 480, 483, 1297

Crescents of Gianuzzi, 1132

Crest, anterior of fibula, 252 of tibia, 248

conchal, of maxilla, $1 \pm 8$

of nasal bones, 145

of palate, 151

ethmoidal, 151

falciform, 131

frontal, 117,179

iliac, 228, 238
Crest, iliac, interosseous crest of, 248 topography of, 1442, 1455

incisor, 149

infra-temporal, 137, 167, 168

interosseous, of fibula, 252

of radius, 215

of ulna, 212

lacrinal, posterior, 143

lateral, of fibula, 252

neural, $32,500,679$

obturator, 233

occipital, external, 121

internal, 121

pubic, 233

sexual difference of, 238

topography of, 1408

sacral, articular, 97

lateral, 98

medial, 97

spñenoidal, 135

supra-mastoid, 125

of tibia, anterior, 248

urethral, 1306

zygomatic, 154

Cribrous fascia, 403

lamina, 139

relation of, to cranial fossa, 179 to nasal fossæ, 184, 187

Crico-arytænoid joint, 1066 muscles, 1072, 1074 actions of, 1072, 1074

Cricoid cartilage, 1063

arch of, 1063

development of, 1100

lamina of, 1063

ossification of, 1065

surface anatomy of, 1388

Crico-thyreoid artery, 892

joint, 1065

muscle, 1075

action of, 1076

nerve of, 1076

Crista or Crista-

ampullaris, 848

anterior, of the tibia, 248

basilaris cochler, 849

conchalis, 148

cutis, 856

ethmoidalis, 151

of female urethra, 1284

galli, 140

of heads of ribs, 109

iliaca, 228, 238

infra-temporalis, $137,167,168$

intertrochanterica, 210

lacrimalis anterior, 148 posterior, 143

of male urethra, 1306

mallei, 840

nasal, 802

of the necks of the ribs, 109

neural formation of, 500

obturatoria, 233

sacral articular, 97

lateral, 98

media, 97

sphenoidal, 135

spina rum, 831

terminalis, $87 t, 1032$

development of, 1032

transversa, 846

tuberculi majoris et minoris, 206 
Crista or Cristre, vestiluli, 843

Crucial anastomosis, 943,950

Cruciate ligament of atlas, 311

of knee, 346

in movements of knee, 348

Crura antihelicis, 828

cerebri, 383

basis of, 583

cerebro-poutine filures of, 591

development of, 592

position and connexions of, 583

pyramidal fibres of, 591

red nuclens of, 588,613

tegmentum of, 583,586

relation of, to thalamus, $610,612,613$

to third ventricle, $610,612,614$

temporo-pontine fibres of, 591

clitoridis, 1326

of diaphragm, 471

formicis, 628

of penis, 1298

of strbentaneous inguinal ring, 477

Crus, 1461

anterius stapedis, 840

breve incudis, 840

common, of semicircular canals, 844

helicis, 827

inferior, of subentaneous ingninal ring, 477

intermedium of diaphragm, 471

lateral, of diaphragm, 471

longum incudis, 840

medial, of diaphragm, 472

posterius stapedis, 840

superior, of subentaneous inguinal ring, 477

Cryptorchism, 1295

Cryptozygous skulls, 171, 286

Crystalline lens, 819

Cubitus, 323

Cuboid bone, 763

morphology of, 295

peroneal groove of, 263

tuluercle of, 263

Culmen of cerebellum, 575

Cumulus oophorus, 1314

Cuneate funiculus, 533

gyrus, 661,662

nucleus, 533

Cuneiform bones of foot, 261

first, 261

second, 262

third, 263

molphology of, 295

ossification of, 265

Cuneiform cartilages, 1068

tubercle, 1069

Cuneo-culjoid articulation, 358

Cuneo-lingual gyri, 660

Cuneo-metatarsal ligaments, 359

Cuneus, 660, 661

Cup, optic, of optic vesicle, $33,825,826$ of retina, 815

Cupola of cochlea, 844 terminalis, 848

Cirved lines of occipital bone, 121

Cushion, endocardial, 1033

of epiglottis, 1068, 1069

Eustachian, 1143

levator, 1143

Cusps of cardiac valves, 877,878 of teeth, 1114

Cutaneous lamella, 30

Cuticula dentis, 1122
Cutis, 857

Cut-throat, 1388

Cuvier, duct of, 1026 abnormalities of, 1057 morphology of, 1048

Cylinder, axis, 507

Cymba conchæ, 827

Cystic artery, 930

duct of liver, 1202

surgical relations of, 1415

vein, 992

Cytolymph, 8

Cytoplasm, 8

Cyto-reticulum, 8

Dacryon, 285

Dartos muscle, 485

penis, 1300

Darwin, tubercle of, 828

Decidua, 56, 57

basalis, 57, 58, 62

capsularis, 57

layers of, 57

margiualis, 57

relation of ovum to, 57

vera, 57

Decidnons teeth, 1113, 1114, 1121 development of, 1244

Declive cerebelli, 575

Decussatio brachii conjunctivi, 548 of the pyramids, 545,557

fountain, 589, 591

of the lemnisci, 560

of lemniscus medialis, 560

motor, 545, 557

in optic commissure, 619

sensory, 562, 566

transverse, of pous, 578

Defrcation centre, 1233

Deferent duct, 1289, 1290 ampulla of, 1292

Degeneration, ascending, 532 descending, 532

WVallerian, 532

Deglutition, movements in, 467

Deiters, nucleus of, 605

supporting cells of, 857

Deltoid ligament, 352 muscle, 373

action and nerve-supply of, 374 topography of, 1447

tubercle, 207

Demilunes of Gianuzzi, 1132

Dendrites, 507, 509

of cells of cerebellum, 580,581

of cerebral cortex, 645

of spinal medulla, 528

of sympathetic ganglia, 704

development of, $36,504,512$

function of, 498

Dens serotinus, 146

Dental arches, 1119

formula, 1114

index, 287

lamina, 1244, 1245

Dentate nucleus, 576, 577

Dentes or Teeth, 1113

canine, 1117

corona of, 1114

deciduous, 1121

incisive, 1115

molar, 1117 
Dentes or Teeth, permanent, 1115 præmolar, 1117

Dentition, diphyodont, 1248

lieterodont, 1248

homodont, 1248

of lower races, 1248

polyphyodont, 1248

typical inammalian, 1248

Depression in presternum, 108

Depressor alæ nasi muscle, 450 septi muscle, 450

Dermal teeth, 1244

Dermic skull, 292

Dermis, 856

Descendens hypoglossi nerve, 698, 794

Descending degeneration, 532 palatine artery, 899

Descent of the testis, 1295 gubernaculum testis, 1295 processus vaginalis peritonei, 1295 rudimentum processus vaginalis, 1295

Descriptive terms, 4

Dentoplasm of ovum, 14

Development, 7 of adamant and ivory, 1247 of adamant organs, 1245 of alimentary canal, 41, 1249 of alveolar canal, 149, 157 of anal canal, 48 of anterior cardinal veins, 1038 of anterior commissure of medulla, 34 of aortic arches, $67,1027,1028$ of appendicular skeleton, 294 of arcuate fibres, 566 of arteries of the limbs, 1031 of atrio-ventricular canal, 1033 of anditory ossicles, 841 of anditory tube, 52 of the bladder, 1328, 1332 of blood-vascular system, 1025 of brain, 33, 34, 512, 514 of branches of dorsal aorta, 1029 of bulbo-urethral glands, 1335 of cerebellum, 33,571 of cerebral hemispheres, $34,512,621$ of cerebral nerves, 593, 682, 796 of chondro-cranium, 290 of chromaphil system, $13 \pm 3$ of cœecum and rermiform process, 1251 of cortical system, 1341 of dermal teeth, 1244 of descending aorta, 67,1028 of digestive system, 1242 of division of the atrium, 1033 of division of primitive ventricle, 1035 of dorsal maxillary process, 1252 of ducts of Cuvier, 1035 of ductus venosus, $103 \mathrm{~S}$ of ep-ö̈phoron, 1328 of external ear, 52,53 of external genital organs, 1328,1335 of eye, 825 of female urethra, 1333 of first blood-ressels, 1025 of foramen epiploicum, 1253 of gastro-intestinal glinds, 1250 of generative ducts, 1334

in the female, 1335

in the male, 1334

of genital eminence, 1335

of glomus caroticum, 1343

of glomus coceygeum, 1355
Derelopment of great anastomotic rein (of Trolard), 1040

of greater omentum, 1253

of hairs, 862

of head, 495

of heart, 65, 70, 1025, 1031

of hypophysis cerebri, 49

of interventricular septum, 1035

sulcus, 1035

of intestine, 1250

of joints, 304

of labyrinth, 853

of larger vestibular glands, 1335

of larynx, 1100

of left stperior intercostal rein, 1040

of limbs, 39

of liver, 1254

of lower lip, 12.44

of limbar veins, 1041

of lungs, 1101

of male urethra, 1332

of mamma, 1339

of medulla, 536

of mesencephalon, 33, 34, 592

of mesogastrium, 1252

of metencephalon of head, 495

of month, 1242

of muscles of limbs, 495

of nails, 862

of neck, 42

of nerve-cells, 35, 498

of nose, 49

of csophagus, 1249

of palate, 49

of pancreas, 1255

of parathyreoid glauds, 1349

of par-oöphoron, 1328

of parotid glands, 1244

of pericardium, 72,74

of peripheral nerves, 679

of peritoneum, 1252

of pharynx, 1242

of philtrum, 1244

of pinna, 52

of placenta, 56

of pons Varolii, 33, 514, 592

of portal system, 1036, 1037

of posterior cardinal reins, 1040

of primary foramen ovale, 1033

of primitive aorta, $6 \bar{i}, 102 \bar{T}$

of primitive cerebral reins, 1039

of prinitive dorsal aorta, 1025

of primitive pharynx, 1248

of primitive reins, 1026

of prostate, 1335

of quadrigeminal bodies, 34,592

of rectum, 1252

of renal veins, 1041

of respiratory apparatus, 1099

of salivary glands, 1249

of sebaceous glands, 862

of secondary foramen ovale, 1034

of sensory cells, 500

of septum primum, 1033

of septum secuudum, 1033

of sexual glauds, 1333

female, 1331

male, 1333

of sinus renosus, 1032

of skeletal muscles, 495

of skin, 861

ef spinal medulla, 31,33 
Derelopment of spinal nerres, 679 of spleen, 1253,1355

of stomach, 1249

of submaxillary and sublingual glands, 1249 of sudiferous glands, 862

of superior vena cara, 1040

of suprarenal glands, 32, 1343

of sympathetic system, 681

of teeth, 1244

of thymus gland, 1351

of thyreoid gland, 1348

of tongue, 1249

of tonsil, 1249

of trachea, 1100

of transverse sinus, 1040

of trmpanic cavity, 52

of umbilical and iliac arteries, 1030

of umbilical veins, 1036, 1037

of upper lip, 1242

of ureter and permanent kidney, 1331

of urino-genital organs, 1327

of reins, 1035

of venous valves, 1032

of rentral mesentery, 1252

of vitelline reins, 1036

Diagonal sulcus, 666

Diameter obliqua pelvis, 238

transversa pelvis, 238

Diaphragm, 471

actions of, 474

anomalies of, 473

arch of, 1439

central tendon of, 472

crura of, 471

development of, 74

external arcnate ligament, 472

foramen venæ cavæ of, 472

foramina in, 472

formation of, 74

hernia of, 473

hiatus aorticus of, 472

hiatus œsophageus, 473

internal arcuate ligament, 472

lumbo-costal arches of, 472

middle arcuate ligament of, 472

nerve-supply of, 474

openings in, 473

pars costalis of, 471

parts of, 471

pelvic, 493

relation of, to abdominal cavity, 1439

surgical anatomy from the back, 1439

Diaphragma sellæ, 669

urogenitale, 489, 491

Diaphragmatic arteries of aorta, 933

of inferior phrenic, 933

of musculo-phrenic, 913

of pericardiaco-phrenic, 913

ganglion, 765

line of pleura, 1088, 1399, 1401

lymph glands, 1011, 1013, 1024

pleura, 1085

plexus, 765

Diaphysis of bone, 85

Diapophysis, 284

Diarthroses, 301

development of, 304

Diencephalon, 541, 608

development of, 34

parts derived from, 609

Differences between jejunum and ilium, 1209

Digastric fossa, 155
Digastric muscle, 461

action of, 463

development of, 496 nerve-supply of, 461

triangle, 1391

Digestive system, 1103

derelopment of, 1242

modifications of, 1103

parts of, 1104

Digital arteries of foot, 955,958

of hand, 920,924

morphology of, 1047

surgical anatomy of, 1454

depressions, 105,108

flexor sheaths, 1453

sheaths of fingers, 388, 389

of toes, 430

veins of foot, 988

of hand, 978

morphology of, 1049

Digits, rudiments of the, 40

Digitus post minimus, 295

Dilatator pupillæ, 815

Dilator naris muscle, 450

tubæ muscle, 838

Diphyodont dentition, 1248

Diplöe of bone, 84

Diploic veins, 969

Dise, interpubic, 337

intervertebral, 307

optic, 815

tactile, 863

Discus articularis acromio-clavicularis, 319 mandibularis, 312

radio-ulnaris distalis, 327

triangular, of distal radio-ulnar joint, 327 sterno-clavicularis, 318

proligerus, 1314

Dislocation of the shoulder, 1445

Displaced medial meniscus, 1460

Diverticulum, allantoic, 38, 39, 54 ilei, 1210

Dolicho-cephalic skulls, 171, 285

Dolicho-facial skulls, 286

Dolicho-hieric sacrum, 289

Dolicho-kerkic limbs, 289

Dolicho-knemic limbs, 289

Dolicho-pellic pelves, 288

Dolicho-uranic skulls, 287

Dorsal arch, 924

axial line of limbs, 691

Dorsalis clitoridis artery, 942, 1428 nerve, 740

hallucis artery, 958

indicis artery, 920 abnormalities of, 1055

linguæ artery, 892

pedis artery, 957

position of, 1465

surgical anatomy of, 1465

penis artery, 941, 942

nerve, 740

pollicis artery, 920

Dorsiflexion, 303

Dorso-epitrochlearis muscle, 370

Dorsum sellæ, 134 development of, 139

Douglas, folds of, peritoneal, 1238, 1318 of sheath of rectus, 483 topography of, 1410

pouch of, 1237,1318

strgical anatomy of, 1435, 1436 
Drainage of left infra-colic compartment of peritoneum, 1414

of right infra-colic compartment of peritoneum, 1414

of supra-colic compartment of peritoneum, 1414

of ventricle of brain, 1362

Drop-wrist, 1449

Ductuli aberrantes, 1289

efferentes testis, 1288

transversi (of ep-oöphoroll), 1315

Duct or Ducts-Ductus-

alveolar, of lung, 1098

arteriosus, 68, 70, 71

abnormalities of, 1050

of Bartholin, 1140

bile, 1202

development of, 1255

level of, 1443

relation of, to duodenım, 1183

sturgical anatomy of, 1416

termination of, 1186, 1203

biliferi, 1201

choledochus, 1201, 1202

cochlear, 848, 849, 1201

development of, 854

of Cuvier, 69, 1026

abnormalities of, 1057

morphology of, 1048

cystic, of liver, 1202

surgical anatomy of, 1415

deferent, 1289,1290

ampulla of, 1292

arteries of, 939,945

development of, 1335

structure of, 1294

surgical anatomy of, 1433

ejaculatory, 1292

opening of, 1292

endolymphaticus, 51

development of, 854

epididymidis, 1287

epoöphori longitudinalis (Gärtneri), 1315

excretorius, glandulæ bulbo-urethralis, 1304

fronto-nasal, 804

hepatic, of liver, 1201

development of, 1255

interlobulares hepatis, 1199

development of, 1254

lactiferi mammæ, 1338

larger, of Santorini, 1207

lymph, right, 993

abnormality of, 1059

naso-lacrimal, 825, 1377,1378

development of, 49

surgical anatomy of, 1377

pancreatic termination of, 1186,1203

para-urethral, of urethra (female), 1285

parotid, 1109, 1136

surgical anatomy of, 1376

parotid opening of, 1107

pharyngo-branchial, 44

precervical, 43

prostatici, 1303

reuniens (Henseni), 847

development of, 51

of Rivinus, 1139

semicircular, 847

lateralis, posterior, superior, 844, 847 smaller, of Santorini, 1207

sublingual, 1108, 1138
Duct or Ducts-Ductus, sublingual larger, 1140 sublingual smaller, 1139

submaxillary, 1138

gland, 1108

surgical anatomy of, 1383

sudoriferus, 861

thoracic, 993

abnormalities of, 1059

surgical anatomy of, 1394

thyreo-glossal, 1348

utriculo-saccular, 847

renosus, 71

fissure of, 1191, 1196

ligament of, 1196

vitelline, 38,48 , 5็

ritello-intestinal, 48,55

remnant of, in adult, 1196

of Wirsung, 1206

Wolffian, 1329

Ductless glands, $13 \pm 1$

Ductus endo-lymphaticus, 51

associated with the rascular system, 1352

Duodenal folds, 1185

diverticula, 1187

fossæ, 1185

impression, 1194

pollch, 1187

ulcer, 1419

Duodeno-jejunal flexure, 1187

surgical anatoms, 1419

fossa, 1185,1419

Duodenum, 1177. 1182

ampulla of, 1186

ascending part of, 1182

caruncula of, 1186

descending part, 1182

derelopment, 47

diverticulum of, 1187

duodeno-jejunal flexure, 1182

first part of, 1082

glands of, 1186

horizontal part of, 1182

ileım, 1177

inferior part of, 1182

interior of, 1186

jejumal flexure of, 1177

nerves of, 1187

orifice of bile-duct in, 1186

papilla of, 1186

pars inferior, part of, 1185

level of, 1185

peritoneal relations of, 1186

plice longitudinales of, 1186

position and size, 1182

relations of, 1182

relations of descending part, 1184

relations of inferior pirt, 1185

second part of, $118 t$

shape and divisions of, 1182

structure of, 1186

superior part, 1182

surgical anatomy of, 1419

suspensory muscle of, 1187

rarious forms of, 1187

vessels and nerres of, 1187

Dura mater of the brain, 667

cranial, 667

diaphragma sellæ of, 668

encephali, 667

falx cerebelli of, 669

cerebri of, 668

lacunæ laterales of, 974 
Dura mater of the brain, layers of, 668 prolongations of, on nerves, 668 of the spinal mectulla, 669 spinalis, 669 venous blood-sinuses of, 668,972

Ear, 827

articulations of, 841

capsule, 131, 291

development of, 811

external, 827

development of, 52,53

meatus of, $8 \pm 5$

pima of, 827

incus, 840

interual, 843

development of, 50

internal ressels of, 853

ligament of, $8+1$

lymph vessels of the, 1001

malleus, 839

middle, 832

muscles of, extrinsic, 449

intrinsic, 841

ossicles, auditory, 838

semicircular canals, bony, 844

stapes, 840

surgical anatomy of, 1365

Ebmer, glands of, 855

Ectochondral ossification, 86

Ectoderm, 21, 23

neural, 22, 30

structures formed from, 33

surface, 39

Effusion in to the shoulder-joint, 1445 knee-joint, 1461

Egg-tubes, 1314

Ejaculatory duct, 1292, 1302, 1306

development of, 1304 opening of, 1306

Elastic lamina of arteries, 868 of Bowman, 810 of cornea, 810

Elbow, bony points about the, 1449 surgical anatomy of, 1449

Elbow-joint, 323

fat-pads of, 325

incisions into, 1449

movements at, 325

muscles acting on, 382, 401

nerves of, $705,709,711$

surgical anatomy of, 1449

synovial stratum of, 325

Ellipsoid joints, 301

Embolus of cerebellum, 577

Embryo, summary of, 39

ectoderm of, 39

entoderm of, 39,40

external features of, at different periods, 74

fold, head, 37

tail, 38

folding off of, from blastodermic vesicle, 37

folds, lateral of, 38

formation of the, 37

intermediate cell-tracts of, 30

lateral mesodermic plates of, 30

membranes of, 53-63

mesodermic somites of, 28,29

mutrition of, 53

period of the, 7

protection of, 5.3

Embryology, 1, 7
Embryonic area, 22

at different periods, 74, 79

Eminence, areuate, 130, 182

genital, 48

ilio-pectineal, 231, 233

oculate, 130

Eminentia arcuata, 130, 133

collateralis, 637

conchæ, 828

fossæ triangularis, 828

intercondyloidea, 247

medialis, 551

scaphæ, 828

Emissary veins, 975

Empyema of maxillary sinus, 1378

Enarthrodial joints, 301

Encephalon, 539

general appearance of, 539

connexions of parts of, 541

End-bulbs of Krause, 864

End organs, special, 863

articular bulbs, 864

corpuscles of Pacini, 864

genital corpuscles, 864

of Grandry, 864

of Golgi and Mazzoni, 865

of Krause, 863

neuro-muscular spindles, 866

nemro-tendinous spindles, 865

of Ruffini, 865

tactile corpuscles of Wagner and Meissner, 865

Endocardial cushions, 1033

Endocardium, 879

structure of, 879

Endochondral ossification, 86

Endolymph, 846

Endoskeleton, 81

Entoderm, 21, 22, 42

Eparterial bronchus, 1083, 1097

Ependyma, 632, 636, 637

Ependymal cells, 632 layer, 632

Epibranchial organs, 796, 797

Epicardium, 879

Epicondyles of humerus, 207 ossification of, 210 surgical anatomy of, 1449 of femur, 243

Epicondylic, 207 surface anatomy of, 1449

Epicondylic lines, 207 process of humerus, 210,280 ossification of, 210 ridges, 207

Epicranius musele, 448 action of, 449 nerve-supply of, 449

Epidermis, 857

appendages of, 858

development of, 861

Malpighian layer of, 857

stratum corium of, 857,859 filamentosum of, 859 germinativum of, 857 granulosum of, 858 mucosum of, 857 vessels and nerves of the, 859

Epididymal artery, 1289

Epididymis, 1286, 1287

aberrant ductules of, 1289 developinent of, 1327, 1331 
Epirlidymis, appendix of, 1287 canal of, 1289

development of, 1327,1334

caput of, 1287

canda of, 1287

corpus of, 1287

sinus of, 1287

structure of, 1288

surgical anatomy of, 1430

Epidural space, 667, 669

Epigastric artery, inferior, 944 formation of, 1030 surgical anatomy of, 1408 superficial, $94 \bar{\jmath}$

superior, 913

fossa, 1397

region, 1159, 1411

vein, inferior, 988 superficial, 986 superior, 963

Epigastrium, 1159

Epiglottic cartilage, 1065

Epiglottis, 1065

cartilage of, 1065

cushion of, 1068, 1069

in deglutition, 1077

development of, 45,1100

frenulum of, 1067

glands of, 1065

level of, $1+42$

ligaments, 1067

taste buds of, 1067

Epihyal, 159

Epiotic, 132

Epiphora, 1377

Epiphyses, 85

of bone, 85

development of, 34

distal of humerns, 1449

pressure and traction, 85

Epiphyseal line, 85

Epiploic foramen, 1163, 1238 surgical anatomy of, 1419

Epipteric bones, 132, 145

Epispinous process, 92

Episternal bones, 276

notch, level of, 1442

Epistropheus, 92

articular surface of, 92

body of, 92

dens of, 92

ossification of, 105

Epithalamus, 609, 614 development of, 35,608

Epitrichinm, 862

Epitrochleo-anconeus muscle, 398

Epitympanic recess, 1369

Eponychium, 859, 862

Ep-oöphoron, 1315, 1316

appendices vesiculosi of, 1315

development of, 1335

longitudinal dnet of, 1315

par-oüphoron, 1316

transverse ductules of, 1315

Erect position, 4

Erector clitoridis muscle, 488 penis muscle, 488

Eruption of teeth, 11:20

deciduons, 1246

permanent, 1120, 1121

Er'ythroblasts, 83

Ethmoid bone, 139
Ethmoid bone, alar processes of, 140 ossification of, 142

relation of, to cranial fossa, 179 to nasal fossæe, 184

to orbit, 163

rariations in, 278

Ethmoidal air-cells, 140, 804 surgical anatomy of, 1372, 1373

arteries, 903

canals, 116,140

in anterior cranial fossa, 179

crest, 151

foramen, anterior, 140, 163

posterior, 140, 163

notch of frontal, 116

plate, 292

process, of inferior concha, 143

Ethmo-turbinals, 141, 292

Ethno-romerine region, 292

Eutelolecithal ovum, 14

Eversion of foot, 436

Fxamination of interior of female bladder, 1436

Excavatio of papilla of optic nerve, 815

recto-uterine, 1318

recto-vesical, 1226, 1237

vesico-nterine, 1226, 1237, 1238, 1317

Excision of the knee-joint, 1461

Exoskeleton, 81

Expiration, 474

Exposure of lateral hemisphere of cerebellum, 1363

meningeal arteries, 1364

semilunar ganglion, 1365

Expression, facial, 452

Extension, morement of, 436

Extensor carpi radialis brevis muscle, 396 action of, 396 nerve-supply of, 396

longus muscle, 396 action of, 396 nerve-supply of, 396

ulnaris muscle, 398 action of, 398 nerve-supply of, 398

abductor pollicis longus muscle, 399 action of, 400 nerve-supply of, 400

metatarsi hallucis muscle, 426

digiti quinti proprius muscle, 398 action of, 398 nerve-supply of, 398

digitorum brevis muscle, 426 action of, 426 nerve-supply of, 426 topograplyy of, 1465

communis nulscle, 397 action of, 397 nerve-supply of, 397

longus muscle, 425 action of, 425 nerve-supply of, 425 topography of, 1465

hallucis longus muscle, 426 action of, 426 nerve-supply of, 426

indicis proprins in uscle, 400 action of, 400 nerve-supply of, 100

pollicis breris nunscle, 400,426 action of, 400 nerve-supply of, 100 
Extensor pollicis longus musele, 400 action of, 400 nerve-supply of, 400

External acoustic meatus, surgical anatomy of, 1366

capsule, 644

urethral orifice of female, 1326

Extraperitoneal tissue, 475

$$
\text { of pelvis, } 489
$$

Extravasation of urine, 485

Eye, 806

anterior chamber of, 813

arteries of, 823

camera of, 821

commissures, medial and lateral, 821

development of, 825

glands of, 823

layers of optic vesicle, 820

morements of, 454

pineal, 547

tarsus of, 821

Eyelashes, 822, 823

Eyelids, 821

blood-ressels of, 823

caruncula lacrimalis, 821

commissures, medial and lateral, 821

development of, 827

in fœtus, $76,78,79$

glands of Moll of, 823, 827

lacus lacrimalis of, 821

lymph ressels of, 824, 1004

mucous membrane of, 823

muscles of, 450

actions of, 454

nerves of, 824

palpebral medial ligament of, 822

superior, 822

inferior, 822

fissure, 821

lateral raphe, 822

papilla lacrimalis of, 821

plica semilunaris conjunctivæ, 821

septum orbitale of, 822

skin of, 823

surgical anatomy of, 1376

tarsal arches of, 823

glands of, 823

tarsi of, 821

third, 821

Eye-teeth, 1117

\section{Face, angle of, 286}

ascending part of, 599

buecal branches of, 784

cervical branch, 784

cerrico-facial division of, 784

colliculus facialis of, 599

development of, 683

emergent part of, 599

exposture of, trunk of, 1375

expression, 452

foramina, 1375

index, 286

intrapontine course of, 599

marginal branch of mandible, 784

method of reaching mandibular nerve, 1375

maxillary nerve, 1375

migration of nucleus of, 600

nerve, 781

nervus intermedius, nuclei of, 598

nucleus of, 567,598
Face, angle of, radicular part of, 599

relations of, to tympanic antrum, 1371

skeleton of, at birth, 196

somatic fibres of, 599

splanchnic-efferent fibres of, 598

surface markings of, 286

temporo-facial division of, 784

veins, 965

common, 965 surface anatomy of, 1375, 1391

deep, 965

zygomatic branches of, 784

bones of, 146

bony landmarks of, 1374

measurements of, 286

muscles of, 450

actions and nerve-supply of, 451

development of, 496

surgical anatomy of, 1374

Facial bones, 146

canal, 129, 130

meatus of, 130

Falciform crest, 131

ligament of fossa oralis, 403

of liver, 1196

development of, 1196, 1252

topography of, 1415

margin, 404

process of sacro-tuberous ligament, 337

False passages in trethra, 1428

Falx cerebelli, 669

cerebri, 668

inguinalis, aponeurotica, 479, 481 surgical anatomy of, 1408

Fangs of teeth, 1114

Fascia or Fasciæ of abdominal cavity, 474, 485, 489

of abdominal wall, 474

anal, 490

antibrachii, 382

of arm, 378

axillary, 369

of back, 365,437

brachii, 378

bucco-pharyngea, 1149

bulbi, 452,807

check ligaments of, 807 suspensory ligament of, 807

of buttock, superficial, 402

cervical, deep, 447, 1385

muscular compartments of, 1386

suprasternal compartment of, 1386

surgical anatomy of, 1385

vascular compartment of, 1386

visceral compartment of, 1385

cremasterica 480

cribrosa, 403, 405

cruris, 422

deep, of arm, 378

deep, of chest, 369

deep, of shoulder, 373

dentata, 625,626

diaphragmatis pelvis superior, 491

urogenitalis inferior, 338,489 superior, 491

fasciæ, 364

superficial, 364 deep, 364

of foot, 423

of forearm, 382

superficial, 382

deep, 382 
Fascia or Fasciæ of groin, 402 superficial, 402 deep, 403

of hand, 384

of head, 446

superficial, 446 deep, 447

iliaca, 1157

infundibuliform, $47 \tilde{x}$

intercolumnar, 477

lacertus fibrosus, 380

surgical anatomy of, 1448

lata, 403, 405

fossa ovalis of, 403

surgical anatomy of, 1459

of leg and foot, superficial, 422 deep, 422

lumbar, 437

lumbo-dorsal, 437

masseteric, 447,454

of neck, 1386, 1389

obturator, 489

of orbit, 452

palmar, 384

parotid, 447, 1133

pectinea, 403

pectoralis, 369

pelvis, 485,489

tendinous arch of, 491

penis, 1300

of perineum, 485

surgical anatomy of, 1427

pharyngo-basilar, 1149

phrenico-pleural, 1089

piriform, 489

plantar, 423

popliteal, 405

surgical anatomy of, 1457

of popliteus, 425

prævertebral, 448, 467, 1386

prostatæ, 493, 1429

rectal, 1228

recto-raginal, 493

recto-resical, 493

renal, 1259

salpingo-pharyngea, 838

of shoulder, 373

spernatic external, 477

internal, 475

superficial, of arm, 378

of chest, 369

temporal, 447

of thigh and buttock, 402

thyreoid, 1389

transversalis, 475

triangular, 478

of upper limb, 378

urethro-vaginal, 493

urogenital diaphragm inferior, 489

stperior, 491

Fasciculus or Fasciculi

anterior proprius, 538

antero-lateral superficial, 536

bulbo-spinal, 538

bulbo-thalamic, 591, 651

cerebello-spinal, 536

cerebro-pontine, 591

cerebro-spinal anterior, 536,539 lateral, $536,538,545$

circumolivary, 557

cuneatus, $\tilde{2} 26,533,559$

fate of walls of, 33
Fasciculus or Fasciculi, gracilis, 522, 526

intra-fascicularis, 533,559

lateralis (plexus brachialis), 701

lateralis proprius, 538

longitudinalis inferior, 650

medialis, $586-588$

superior, 650

niamillo-thalamic, 615

medialis (plexus brachialis), 701

occipito-frontal, superior, 651

oliro-spinal, 538

posterior (plexus brachialis), 701

proprins, 535

postero-lateral, 534

proprius anterior, 535 lateral, 535

pyramidal, 591

retroflexus, 591, 614

rubro-spinal, 538, 588 origin of, $516^{\circ}$

septo-marginal, 535

Eolitarius, 564, 596, 597, 598

spino-cerebellar, 531, 563

anterior, 537,578

posterior, 537

spino-tectal, 537

spino-thalamic, 535, 537, 545, 562, 591, 651

anterior, $53 \overline{7}, 538$

posterior, 537

spiralis of cochlear nerve, 852

strio-nigricus, 641

strio-rubricus, 641

strio-thalamicus, 641

tecto-bulbaris et spinalis, 591

tecto-spinal, 538, 562

origin of, 516

temporo-thalamic, 643

thalamo-mamillary, 612

thalamo-olivary, 556, 568

uncinate, 649

restibulo-spinal, 538,605

of Vicq d'Azyr, 612, 615

Fasciola cinerea, 629, 946

Fat-pads, synovial of joints, 302 of elbow-joint, 325

of hip-joint, 341

of knee-joint, 348

Fauces, 1112

arches of, glosso-palatine, 1112 pharyngo-palatine, 1112

isthmus of , 1112

level of, 1442

surgical anatomy of, 1383

Female pronucleus, 16, 20

Female reproductive organs, 1310

bulbus vestibuli, 1310

clitoris, 1310

external genital organs, 1310

labia majora, 1310

minora, 1310

large vestibular glands, 1310

mons veneris, 1310

ovary, 1310, 1311

rima pudendi, 1310

uterine tube, 1310

uterus, 1310

vagina, 1310

Femoral arch, deep, 405 superficial, 405

artery, 946

ligature of, 1459

surgical anatomy of, 1459 
Femoral canal, 405

fus:a, 1235

her'uia, 405

lympli glauds, 1013

ling, 405

septum, 405

sheath, 947

triangle, 414

rein, 985

superficial, 988

Femur, 239

irlductor tubercle of, $2 \pm 2,412$

architecture of, 273

courlrlar surface of, $2+4$

condyles of, 243

connexions of, 244

distal parts of shaft, 1459

epicondrles of, 243

forea capitis of, 240

greater trocantemr of, 241

head of, 239

homology of, 294

intertrochanteric crest of, 210

line of, $2 \pm 0$

lesser trocanteur of, 242

linea aspera of, 242

lower epiphrseal line of, 1462

neck of, $2 \pm 0$

autrient foramina of, 244

ossification of, 244

patellar surface of, 244

pectineal line of, 242

pilastered femur, 281

platymerie, 281

popliteal surface of, $2-24$

sexual differences of, 244

shaft of, 242

spinal line of, 242

third trocanteur of, 242,281

trochanteric fossa of, 241

variations in, 281

Fenestra ovalis s. vestibuli, 832

rotunda s. cochleæ, 833

Fenestrated membrane, 868

Fertilisation of ovum, 20

Fibræ ar'uatæ externæ, 566 internal, 560

development of, 566

circulares Mülleri, 813

lentis, 820

meridionales (Brueckei), 813

obliquæ ventriculi, 1174

Fibres, association, of spinal medulla, 534

commissural, of cerebellar, 578

cortico-striate, 653

cortico-thalamic, 612

intercolumnar, 477

internal arcuate, 560,561

of medulla oblongata, 556, 560

of Purkinjé, 879

thalamo-cortical, 612

Fibrils of irory, 1123

Fibrocartilages intervertebral, 306

Fibrous plate of fingers, 333

of toes, 361

tympanic, 831

Fibula, 250

auterior crest of, 252

apex of head, 250

architecture of shaft of, 250

connexions of, 253

incisions to expose the shaft of, 1462
Fibula, interosseous crest of, 252 lateral crest of, 252

malleolus lateral of, 253

medial crest of, 253

morphology of head of, 250

ossification of, 253

shaft, examination of, 1462

surface of, 252

variations in, 282

Fibular artery, 953

Fibulare, os, 295

Field, polar, 13

Filament, axial, 18

Filiform papillæ, 1126

Filtration angle of cornea, 809

Filum terminale, 518

Fimbria, 627

ovarica, 1312

tubæ uterinæ, 1314

Finger-cells, 857

Fingers, bones of, 226

movements of, 401

Fissure or Fissures-Fissura

angular, 665

anterior hyaloidea of eye, 826 median, of spinal medulla, 521 antitrago-helicine, 829

of anus, 1430

auricular, 127

posterior and lateral, 559

calcarine, 660

central of brain, 663

development of, 662,663

topography of, 1360, 1361

transitional gyri of, 663

centralis insulæ, 654

of cerebellum, 571

of cerebrum, $571,572,573$

chorioidal, of brain, $621,637,675$

development of, 621

chorioidal, of eye, 826

cinguli, 666

circular, 654

collateral, 661, 662

"complete," 646

of ductus venosus, 1191, 1197

floccular, of cerebellum, 572

development of, 573

frontal inferior, 665

middle, 665

superior, 665

fronto-marginal, 665

hippocampi, 626

horizontal, of cerebellum, 573

development of, 572

inferior orbital, 137, 147

interparietal proprius, 664

lateral, of the brain, 653

anterior ascending ramus of, 653 , 654

horizontal ramus, 654

ascending ramus, 654

development of, 655,656

posterior ramus, 653

rami of, 653

stem of, 653

terminal piece of, 665

topography of , 1359, 1360

longitudinal, of cerebrum, 540, 646 development of, 608

lunatus, 660

of lung, 1095 
Fissure or Fissures-Fissura, of medulla oblongata, $5 \pm 3$

occipital anterior, 665

lateral, 661

paramedial, 661

transverse, 664

olfactory, 666

orbital (of brain), 666

inferior, 137, 147, 162, 163, 189

ossa suturarum in connexion with, 146

Tariations in superior, 136, 162, 180

palpebral, 821

paracentral, 664

paramedial, 661

parapyramidal, 573

development of, 573

parietal superior, 665

parieto-occipital, 661

topography of, 1360

paroccipital, 661

petro-basilar, 130

petro-occipital, 176

petro-squamous, 131

petro-tympanic, 127,831

portal, 1190

post-central inferior, 661

superior, 664

post-lunar, 573

development of, 572

post-nodular, 571

development of, 571

post-tonsillar, 573

of cerebellum, 573

prae-cuneal, 665

pre-central inferior, 665

superior, 665

prima, of cerebellum, 572

pterygoid, 138

pterygo-maxillary, 168, 192

pterygo-palatine, 192

rhinal, 624

sagittal, of the lingual gyrus, 662

secundary, of cerebellum, 572

simial, 660

spheno-petrous, 175,176

of spinal medulla, 521,522

development of, 521

subparietal, 665

superior orbital, 160,180

superior temporal, 658

topography of, 1360

suprapyramidal, 573

development of, 572

temporal inferior, 658 middle, 658

transverse, of the brain, 674 of liver, 1180

tympano-mastoid, 127

numbilical, 1191

urogenital, 1329

vestibuli, 841

Fistula in ano, 1431

Flat bones, 82,85

Flechsig, areas of, 564

Flexiom, 377

Flexor carpi radialis muscle, 385

action of, 386

bursa, 386

nerve-supply of, 386

surface anatomy of, 1452

ulnaris muscle, 386

action of, 387
Flexor carpi ulnaris muscle, nerve-supply of, 387 caudæe muscle, 494

digiti quinti breris of foot, 435

action of, 435

nerve-supply of, 435

of hand, 394

action of, 394

nerve-supply of, 394

digitorum brevis, 433

action of, 433

nerve-supply of, 433

longus muscle, 430

action of, 430

nerve-supply of, 430

profundus, 388

action of, 389

nerre-supply of, 389

sublinis muscle, 388

action of, 388

nerve-supply of, 388

hallucis brevis muscle, 434 action of, 434

nerve-supply of, 431

longus muscle, 431 action of, 431 nerve-supply of, 431

pollicis brevis muscle, 393 action of, 393 nerve-supply of, 393

longus muscle, 390

action of, 390

nerve-supply of, 390

surgical anatomy of, 1153

sheath, common of hand, 1453

Flexura coli dextra, 1211

sinistra, 1211

Flexures of brain, 514

cephalic, of brain, 514

cervical, of brain, 514

colon iliac, 1211

pelric, 1211

sigmoid, 1211

duodeno-jejunal, 1182, 1187

topographical anatomy of, 1419

left, of colon, 1211, 1220

level of, 1412

topography of, 1422

perimeal, of rectum, 1224

pontine, of brain, 514

right, of colon, $1211,1220,1422$

level of, 1423

topography of, 142 2

sacral, of rectum, 1224

Floating ribs, 112

Floccular fissure of cerebellnum, 572 development of, 573

fossa, 131,133

Flocculus cerebelli, 571 derelopment of, 571

Floor, pelvic, 490 plate, 500, 502

Fœetus, circulation of, 71

estimate of age of, 78,79

external characters of, at different periods, it membranes of, 53, 62

period of the, 7

Fold or folds, ary-epiglottic, 1068

development of, 1100

axillary, 1446

ary-epiglottic, 1068

caudal, 38,74

cephalic, 38,74 
Fold or Folds, of Douglas, of sheath of rectus, 483

topography of, 1410

genital, 1333

glosso-epiglottic, 1067

gluteal, 1455

ilio-ciecal fold, 1218

labio-scrotal, 1328

of larynx, 1068

ary-epiglottic, 1068

ventricular, 1068

rocal, 1068

medullary, 23, 74

pharyngo-epiglottic, 1067

recto-genital, 1317

recto-uterine, 1317

of pelvic peritoneum, 1238, 1318

recto-vaginal, 1317

sacro-genital, 1283, 1318

salpingo-palatine, 838,1143

salpingo-pharyngeal, 838, 1143

semilunar of Doinglas, 483

transverse vesical, 1283

utero-vesical, 1317

ventricular, 1068

vestigial, of Marshall, 872, 882

vocal, 1068

Folds and fossæ about the cæcum, 1218

Folia of cerebellum, 571, 580

Folinm rermis of cerebellum, 572

Follicles, vesiculosi, 1313

development of, 1334

of hair, 860

of Lieberkühn, 1181

lymph, 995

primitive, of ovary, 1334

of teeth, 1245, 1246

Folliculi oophori primarii, 1331 vesiculosi, 1313

Folliculus pili, 860

Fontana, spaces of, 810

Fontanelle, anterior, 194

antero-lateral, 194

posterior, 194

postero-lateral, 194

sagittal, 194

Fonticulus frontalis, 194

mastoideus, 194

occipitalis, 194

sphenoidalis, 194

Foot, transverse areh of, 361

articulations of, 351

bones of, 254

architecture of, 274

morphology of, 295

ossification of, $265,267,268$

variations in, 282

fasciæ of, 4.23

lymph vessels of, 1014, 1015

mechanism of, 361

muscles of, $424,430,432-435$

actions and nerve-supplies of, 435,436

surgical anatomy of, 1463, 1467

Foot-plate of stapes, 840

Foramen apicis dentis, 1114

aperture median of fourth ventricle, 37

development of, 553

cæcum linguxe, 1126, 1348

development of, 44, 1249, 1348

cæcum of medulla oblongata, 544

of skull, 140

canalis condyloideus, 122
Foot, centrale cochlex, 844

condylic, anterior, 122, 123, 124

diaphragmatis (sellæ), 699

epiploicum, 1162, 1183, 1238

development of, 1253

surgical anatomy of, 1272

ethmoidal, 142, 179

posterius, 140, 163

of Huschke, 832

hypoglossi, 122

incisivum, 149,174

incisor, 149, 174

infraorbital, 146, 162

surface anatomy of, 1375

interventricular, $543,608,618,621,832$ development of, 608, 621

intervertebral, 89,95

ischiadicum majus, 229, 337

minus, 232, 337

jugular, 176, 177, 182

lacerum, 176, 180

of Magendie, 553

magnum, 123, 178, 182

plane of, 124

mandibular, 156

mastoid, 128

mental, 155

surface anatomy of, 1375

obturator, 234

of hip-bone, 228

occipital, 172, 178

optic, 180

abnormalities of, 278

ovale, 136, 169, 176, 180, 875

development of, 1033, 1034

persistence of, 1050

of sphenoid, 136, 176, 180

abnormality of, 278

palatine, larger, 151, 174 surgical anatomy of, 1384

lesser, 152, 174

parietal, 171

origin of, 277

quadratum, 473

rotundum, 136, 180

abnormality of, 278

of Scarpa, 149, 174

sciatic, greater, 229, 337

lesser, 232, 337

singulare cochleæ, 846

spheno-palatine, 185, 192

spinal, 90, 93, 95, 96

spinosum, 136, 169, 176, 180

abnormality of, 278

of Stenson, 149, 174

development of, 149

stylomastoid, 129, 177

absence of, 278

supraorbital, 116, 160

surface anatomy of, 1358

supratrochlear, of humerns, 280

transversarium, 90, 92, 93

serial homology of, 284

venæ cavæ, 472

vertebral, 90, 93, 95

of Vesalius, 136, 168, 180

zygomatico-facial, 153

zygomatico-orbital, 154

zygomatico-temporal, 154

Foramina alveolaria, 147

anterior of sacrum, 96

ethmoidal, 162 
Foramina interventricular, 618

inter'vertebral, 89

nervosa, 849

palatina minora, 152

papillaria of kidney, 1265

sacralia anteriora, 96

posteriora, 97

venarum minimarum cordis (Thebesii), 874, 960

Forearm, fasciæ of, 382

lymph ressels of, 1006

muscles of, 382

superficial veins of, 978

surgical anatomy of, 1450

Forearm and hand, 382

surgical anatomy of, 1450

Fore-brain, 514

development of the primitive, 33

second dilatation, 33

Fore-gut, 38

differentiation of the, 42

dorsal wall, developments of, 47

lateral wall of the, 42

branchial bars of, 42 pouches, 42

pharyngeal bars of, 42

pouches, 42

ventral wall, developments of, 44

Formatio reticularis of medulla oblongata, 564 alba, 564

grisea, 564

hippocampalis, 625

of pons, 564

of spinal medulla, 524

Formation of alveoli of teeth, 1246

Fornix, 625

body of, 629

columns of, 615,627

convexion of, with hippocampus, 625

crura of, 628

crus of, 628

development of, 628

columns of, 34

fimbria of, 628

pharyngis, 1145

vaginæ, 1321

Fossa or Fossæ, acetabuli, 284

anterior, 179

antihelix, 828

cæcalis, 1218

canina, 146, 179, 183, 188, 189

condylic, 122

coronoid, of humerus, 208

cranial, 179

anterior, 179, 188, 189

middle, 180, 190, 191

posterior, 182, 191

digastric, 155

ductus venosi, 1191, 1192

duodenal, inferior, 1185

superior, 1185

duodeno-jejumal, 1185, 1419

surgical anatomy of, 1419

epigastric, 1397

femoral, of peritoneum, 1235

floccular, 130, 133

for gall-bladder, 1191

glandulæ lacrimalis, 143, 162

glenoid, of scapula, 201, 202

of temporal bone, 125 condition of, at birth, 133 surgical anatomy of, 1445
Fossa or Fossæ of helix, 828

hypophyseos, $13 t$

development of, 291

liy potrochanterica, 281

ileo-cæcal, 1218

ileo-colic, 1218

iliaca, 231

incisor, 155

of mandible, 156

incudis, 840

inferior dtodenal, of Jonnesco, 1419

infraspinous, 202

infratemporal, 168

boundaries, 168

floor of, 169

inguinal, intermediate, 1235

lateral, 1235

medial, 1235

intercondyloid of femur, 243

anterior of tibia, $24 \overline{7}$

posterior of tibia, 247

interpeduncular, 180, 541

intersigmoid, 1223

surgical anatomy of, 1423

ischio-rectal, 1238

jugular, 177

condition of, at birth, 133

relation of, to jugular foramen, 177

to tympanum, 1369

lacrimal, 148,163

of Landzert, 1185

lateral, of brain, 655

for ligamentum teres of hip, 284 variation in, 281

mandibular, 167

mastoid, 1369

middle, 180

myrtiform, 146

nasal, 801

navicularis urethræ (Morgagni), 1308 surgical anatomy of, 1428

restibuli vaginæe, 1325

olecrani, 208

orbital, 160

ovalis, 403

of heart, 874

development of, 1033

ovarian, 1312

paraduodenal, 1185

pararectal, 1227, 1238

paravesical, 1238, 1280

patellar, 819

post-condylic, 177

posterior, 182

pterygoid, 174

pterygo-palatine, 170

radial, 208

retro-crecal, 1218

retro-colic, 1219

retro-mandibular, 1113

retro-ureteric, of bladder, $127 \%$

rhomboid, 550

of Rosenmiller, 1144

development of, 1144

surgical anatomy of, 1385

sacci lacrimalis, 825

scaphuid, 828

scaphoid of splenoid, 135, 175, 176

subarcuate, 130, 131

submaxillary, 155

supraspinous, 202

supratonsillar, 1145 
Fosia or Fosice, supratonsillar, development of, 1249

temporal, 166

lower part, 167

of testis, 1287

triangular auricule, 828

trochanteric of femur, 241

venæ caræ (inferioris), 1191, 1192 umbilical, 1191

rermiform, 278

vesicre felleæ, 1191

zJgomatic, 168, 175

Fossula fenestræe cochleæ, 129, 833 restibuli, 832

inferior, of internal acoustic meatus, 846 superior, of internal acoustic meatus, 846

Fossulæ tonsillares, 1146

Fountain decussation, 589, 591

functions of, 589

Fourchette, 1324

Fourth ventricle, 549

clava of, 579

obex of, 579

roof of, 578

Forea capitis femoris, 240

capituli radii, 214

centralis retinæ, 815

costalis inferior, 93

stiperior, 93

dentis, 91

femoralis, 1235

inferior of fourth ventricle, 550

inguinalis, 1235

lateral, 1235

medial, 1235

pterygoidea, 157

submaxillaris, 155

superior, of fourth ventricle, 551

supravesical, 1235

trochlearis, 117, 162

Foreæ articulares superiores atlantis, 91

Foveolæ gastricæ, 1176

Fracture of the clavicle, 1445

dislocations of the spine, 1443

of sternum, 1397

Frenula valvulæ coli, 1214

Frenulum clitoridis, 1326

epiglottidis, 1126

of Giacomini, 629

labii inferioris, 1106

superioris, 1106

labiorum pudendi, 1324

clitoridis, 1324,1326

linguæ, 1108, 1128

surgical anatomy of, 1383

præputii, 1299

veli, 582

development of, 542

Frenum labiorum pudenda, 1324

Front of thigh, surgical anatomy of, 1458 Frontal air sinuses, artery of ophthalmic,

exploration of, 1372

size of, 1371

skiagraphs of, 1372

of superficial temporal, 897

surgical anatomy of, 1358

surgical importance of, 1371

trans-illumination of, 1372

bone, 115

angular process of, $115,160,166$

architecture of, 270
Frontal bone, cerebral surface of, 117

crest of, 117,179

ethmoidal noteh of, 116

ossification of, 118

sexual differences in, 115

supercilialy arches of, 116

surgical anatomy of, 1364

tuberosities of, 115

variations in, 277

eminence, 115

difference in, due to sex, 193

relation of, to brain, 1360

gyrus, precentral, 665

inferior, 665

middle, 665

superior, 665

nerve, 772

plane, 5

process of maxilla, 148, I63

of zygomatic bone, 153

region of the brain, 665

sinus, 270

in coronal sections, 186

growth of, 118

at puberty, 197

relation of, to infundibulum, 141

to nose, 186

to orbit, 162

surgical anatomy of, 1371

suture, 160

topography of, 1360

vein, 967,969

Fronto-marginal suleus, 665

F'ronto-nasal process, 49

Fronto-pontine strand, 653

in crus cerebri, 591

in internal capsule, 642

Froriep's ganglion, 684, 796

Fundus of cæcum, 1213

meatus acustici interni, 845

of stomach, 1163, 1168

level of, 1442

surgical anatomy of, 1417

tympani, 832

uteri, 1316, 1434

ventriculi, 1163

vesicæ, 1274

Fungiform papillæ, 1127

Funicular cells, 504

process, 1409

Funiculus anterior, 538

cuneatus, 526, 533, 547

constitution of, 538

in section of medulla oblongata, 555

gracilis, 526,547

constitution of, 532

in section of medulla oblongata, 555

lateralis, of spinal medulla, 535

posterior, of spinal medulla, 533

separans, 551

spermaticus, 1296

coverings of, 1297

umbilical, 56

Furcula, 45

Furrow, bicipital, 1445

nuchal, 1395

sternal, 1397

vlnar, 213

vertebral, 1436

Furrowed band of cerebellum, 576

Galea aponeurotica, 447,449 
Galen, great veins of, 674

Gall-bladder, 1201

body of, 1201

development of, 1250

duct of, 1201

fundus of, 1201

neck of, 1201

spiral valve of, 1201

structure of, 1202

surgical relations of, 1415

variations in, 1202

Gallstones, impacted, 1415, 1416

Gametes, 11

female, 11

male, 11

Ganglia aberrantia, 685

essentials of, 498

primitive, 32

spinal, 685

sympathetic plexuses, 753

of trunk, sympathetic, 753

Gangliated cord of sympathetic, 753

Ganglion or Ganglia, aortico-renal, 764 basal, of central hemispheres, 637

of cardiac plexuses, 789,880

cardiac (TV risbergi), 790

of cerebral nerves, 678,767

cervical inferior, of sympathetic, 759

branches of, 759

surgical anatomy of, 1398, 1442

cervical middle of sympathetic, 759

branches of, 759

plexuses of, 759

splanchnic efferent fibres of, 604

superius, 759

of uterus, 1321

ciliary, 773

development of, 683,796

long root of, 773

morphology of, 796

roots of, 773

short root of, 770

sympathetic root of, 773

of vagus, 786,788

coccygeal, 753

cochlear, 554, 664, 785

coeliac, 763

of Corti, 845,852

diaphragmatic, 765

of Froriep, 796

geniculi of facial nerve, 598, 782

development of, 683 , 796

morphology of, 796

habenulæ, 614

impar, 753, 763

inferior cervical of sympathetic, 759

interpedunculare, 591, 614

relation of, to fasciculus retroflexus, 614

jugular of vagus, 786, 788

development of, 796

morphology of, 796

lumbar, 761, 762

mesenteric superior, 765

middle cervical of sympathetic, 759

nodosum of vagus, 786,788

development of, 684,796

morphology of, 796

olfactory, 622

morpholosy of, 622

otic, 781

development of, 684, 796

petrous, 785

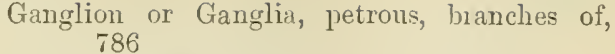
development of, 684, 796

morphology of, 796

phrenic, 765

sacral, 763

semilumar, 600, 772

development of, 683,796

morphology of, 7.96

of sensory nerves, 510

spheno-palatine, 775,777

development of, $683,795,796$

spinal, 685

aberrant, 685

cells of, 685

development of, 679

spiral, of cochlear, $785,845,852$

splanchnic, 761

submaxillary, 780

branches firom, 780

roots of, 780

superior cerrical, of sympathetic, 756

superius, of glossopharyngeal nerve, 785

development of, 684,796

morphology, 796

sympathetic, 504

cells of, 753

cervical superior, 756

branches of, 756

collateral, 75.4

development of, 681

gray rami of, 754

terminal, 754, 767

superior, of glossopharyngeal, 735

of the tendon sheath, 1451

thoracic, 759

central branches of, 761

first, 759

peripheral branches of, 761

plexuses of, 761

trunci sympathici, 753

vestibular, 853

development of, 683, 796

Ganglionic crest, 679

layer of retina, 816

of middle meningeal, 898

Gastric artery, 929

impression of liver, 1193

of kidney, 1264

lymph glands, 1019

ulcer, perforation of, $] \pm 18$

reins, 992, 1019

Gastrocnemius muscle, 428

action of, 429

nerve-supply of, 42.9

surface anatomy of, 1463

Gastro-colic ligament, 1241

Gastro-duodenal artery, 930

Gastro-enterostomy, 1418

Gastro-epiploic right artery, 930

veins, 992

Gastro-lienal ligament, 1162, 1170, 1236, 1240, 1242

development of, 1256

Gastro-phrenic ligament, 1170, 1236

Gelatinous marrow, 83

Gemellus inferior muscle, 418

superior muscle, 418

actions of, 418

nerve-supplies of, 418

General lumbar inclex, 248

Geniculate bodies, lateral, 620 
Geniculate bodies, lateral, derelopment of, 35, 608

internal structure of, 613

medial, 582

ganglion, 598, 782

Genio-glossus muscle, 462

action of, 463

nerve-supply of, 463

surgical anatomy of, 1383

Genio-hyoid muscle, 461 action of, 462

nerve-supply of, 462

Genital cord, 1331

eminence, $78,1328,1336$

fold, 1333

organs, development of, 1328

temale, 1334, 1335, 1336

male, 1333, 1335, 1336

ridge, 1333

Genito-femoral nerve, 722

Gennari, stria of, 644,659

Genu capsulæ internæ, 642

of central fissure of the brain, 663

of corpus callosum, 630

of facial nerve, 782

Germ cells, enamel, 1245 multiplication of, 12 primitive, 11

progenitors of, 21

nerve, 679

of tooth, 1245

Germinal cells, 502

of ovary and testis, 15, 17, 21

of spinal medulla, 30

epithelium, 21, 1333, 1334

layers, 7,21

vesicle, 14, 22

Giacomini, banderella of, 629

Gianuzzi, crescents of, 1132

Gingivæ, 1112

Ginglymus, 301

Girdle, pectoral, 203, 270 pelvic, 228, 273

Glabella, 160, 183, 285

surgical anatomy of, 1358, 1374

Glands or Glandulæ, 1131

acini of, 1133

acino-tubular, 1132

acinous, 1132

alveolar, 1133

alveoli of, 1133

anterior, of tongue, 1130

areolar, 1337

basement membrane of, 1132

buccal, 1109

bulbo-urethral, 1301

development of, 1335

ducts of, 1304

surgical anatomy of, 1248

carotid, $13+3$

ceruminous, 832,861

cervical, of the uterus, 1315

ciliary, 861

circum-anal, 1230

coccygeal, 1355

compound, 1132

cytogenic, 1131, 1132

digestive, 1106

ductless, 1341

duodenal, 1179, 1186

of Ebner, 855

epithelial, 1131
Glands or Glandulæ, general structure of, 1133

Haversian, 341

of intestine, 1179

of colon, 1212

of rectum, 1230

of small intestine, 1210

labial, 1109

lacrimal inferior, 824

superior, 824

surgical anatomy of, 1377

laryngeal, 1072

lingual, 1130

anterior, 1130

lymph, 993

mammary, 1336

molar, 1109

of Moll, 823, 827

mucous, 1131

nodules, lymph aggregate, 1179

olfactory, 804

palatine, 1110

parathyreoid, 1345

parotid, 1133

accessory parotid gland, 1136

deep part of the gland, 1135

duct of, 1136

facial process of, 1133,1136

immediate relations of, 1137

retro-mandibular process of, 1133

shape and relations of, 1134

smperficial surface, 1134

vessels and nerves of, 1137

præputial, 1299

prostatic, 1301, 1302, 1307

racemose, 1132

salivary, 1133

structure of, 1140

sebaceous, 861

serous, 1132

sexual, development of, 1333

shape and relations of, 1139

simple, 1132

solid, 1131

solitary, of large intestine, 1181

of. small intestine, 1179

structure of, 1132

sublingual, 1138

development of, 1243

surgical anatomy of, 1383

vessels and nerves of, 1140

submaxillary, 1137

development of, 1243

position and relation of, 1137

surgical anatomy of, 1391

ressels and nerves of, 1138

sudoriferous, 861

sudoriparous, 861

siprarenal, development of, 32, 1343

surgical anatomy of, 1437, 1442

sweat, 861

tarsal, 823

of Moll, 823

surgical anatomy of, 1377

thymus, 1350

thyreoid, 1347

accessory, 1349

of tongue, 1130

tubular, 1132

urethral, 1309

uterine, 1320

vascular, 1131 
Glands or Glandulæ, restibular, greater (Bartholini), 1326 surface anatomy of, 1435 lesser, 1326

Glans clitoridis, 1326 penis, 1298, 1336

Gleno-humeral ligament, 322

Glenoid fossa of scapula, 201, 202

fossa of temporal bone, 125, 154 condition of, at birth, 133 surgical anatomy of, 1375

labrum, glenoidale of, 320

Glisson (capsula fibrosa), 1198

Globular process, 49

Globus pallidus of lentiform nucleus, 639

Glomerular capsule, 1266

Glomerulus, olfactory, 623

renal, 1269

of sweat glands, 861

Wolffian, 1329

Glomus caroticum, 1343 development of, 1355 structure of, 1343, 1355 coccygeum, 1355

Glosso-epiglottidean folds, 1067

Glosso-palatine arch, 1111, 1112 muscle, 467 action of, 467 nerve-supply of, 467

Glossopharyngeal nerve, 785 nuclei of, 596

Glossopharyngeus muscle, 464

Glottis respiratoria, 1071 development of, 684

spuria, 1070

vera, 1070 pars intermembranacea, 1071

Glutæus maximus muscle, 415 actions of, 415,421 nerve-supply of, 415 surface auatomy of, 1455

medius muscle, 416

minimus muscle, 416 actions of, 417,421 nerve-supply of, 417

Gluteal artery, 942 surgical anatomy of, 1455

cleft, 1455

fold, 1455

lines of ilium, 230

surface of ilium, 230

veins, 984

Gnathic index, 287

Goll, column of, 522, 533

Gonion, 286

Gowers' tract, 535, 536, 546

Gracile funiculus, 547

lobule, 576

nucleus, 547, 559

Gracilis muscle, 411 action of, 411 nerve-supply of, 411

Granulationes arachnoideales, 672

Granule cells, 579

layers of retina, 817,818

Gratiolet's optic radiation, 658

Gray matter, central, of mid-brain, 584 of cerebellum, 576

of cerebral cortex, 644,645

cerebro-spinal, 36,512

of spinal medulla, 527-531

development of, 33,35
Gray matter of medulla oblongata, 33, 515 of thalamus, 36

Gridiron incision, 1411

Groin, 1405

fasciæ of, 402

Groove, alveolar process of, 148

anterior medial, of spinal medulla, 522

antero-lateral, of medulla oblongata, 544

for auditory tuke, 136

carotid, of sphenoid, 135

cerebral sinuses, 182

coronary, of heart, 871

topography of, 1403

costal, 110, 112

frontal process of, 148

for great superficial petrosal nerve, 130

for inferior petrosal sinus, 128

interosseous, of calcaneus, 259

of talus, 256

intertubercular, 206

interventricular, 872, 873, 1035

intervertebral, 89

lacrimal, 147

of lacrimal bone, 143, 163

of maxilla, 148, 163

longitudinal, of heart, 871

maxilla of, 148

for meningeal arteries, 117, 119, 126

on frontal bone, 117

on parietal, 119

on temporal, 126

mylo-hyoid, 156

development of, 158

naso-pharyngeal, 1143

nenral, 23, 24, 31

obturator, 234

abnormality of, 281

for occipital sinus, 183

œsophageal, of liver, 1192

of lung, 1094

olfactory, 140, 141, 179

optic, 135

palatine process of, 148

popliteal, 243

postero-lateral, of medulla oblongata, 541

primitive, 23

pterygo-palatine, of palate, 151

of sphenoid, 138

for radial nerve of humerus, 207

sacral, 97

subclavian, 111

for subclavius, 199

for superior petrosal sinus, 128, 182

for superior sagittal sinus, on cranial vault, 117

on frontal, 117

on occipital, 121

on parietal, 119

for transverse sinus, 121

on cerebral hemisphere, 647

on occipital bone, 121-122

on parietal, 119

on temporal, 128

partial absence of, 278

vertebral, of spinal column, 100

of thorax, 114

zygomatic process of, 148

Growth of bones, 86,87

Gubernaculum dentis, 1247 testis, 1295

Gudden's commissure, 769

Gullet, 1150 


\section{Gims, 1112}

lymph vessels of, 1005

Gustatory cells, 855

$$
\text { liair, } 855
$$

pore, 854

Grrus or Gyri, 650

angular, 665

topograpliy of, 1360

lreves, 654

central, anterior, 665

posterior, 662

of cerebral hemispheres, 653

cinguli, 666

cunei, 662

cuneo-lingualis, anterior, 660

posterior, 660

frontal, inferior, 665

middle, 665

superior, 665

topography of, 1360

of Heschl, 656

lingualis, 660

longi, 654

orbitalis anterior, 666

paracentral (lobule), 665

pararhinal, 658

parasplenalis (area), 665

parietal inferior (1obule), 664-665

superior (lobule), 664

parieto-occipital (area), 665

præcuneus, 662

precentral, 665

rectus, 666

supramarginal, 665

topography of, 1360

temporal, inferior, 658

medius, 658

parasplenal, 658

superior, 657

sulface anatomy of, 1360

transverse, 656

transitional, deep, of calcarine and parietooccipital fissure, 660

of central fissure, 663

of intraparietal, 664

transitivi cerebri, 663

\section{Habenula, commissure of, 615}

ganglion of, 614

Hæmal lymph glands, 995

Hematocele, pudendal, 1435

Hrmatoma of the scrotum, 1430

Hæmorrhages of the scalp, 1357

Hamorrhoidal arteries, inferior, $] 232$ middle, 939

superior, 1232

nerve, inferior, 738

plexus, 766

venotis, 985

veins, 981

Hæmorrhoids, 1430

Hair, 859

development of, 862

erector muscles of, 861

of fotus, 79

follicle of, 860

bulb of, 860

root sheaths of, 860

papilla of, 860

root of, 859

scapus of, 859
Hair, slıaft, 859

Hair-cells, anditory, 847, 848, 851

of cochlea, 851

Hair-follicles, 860

Hair's, gustatory, 855

olfactory, 805

Hamstring muscles, 418 surgical anatomy of, 1456

Hamulus of medial pterygoid lamina, 138, 175 surgical anatomy of, 1385

of lacrimal, 43

Hamulus cochleæ, 845

lacrimalis, 143

laminæ spiralis, 845

of os liamatum, 221

pterygoidens, 138

Hand, arterial arches of, 923

articulations of, 329

bones of, 217

architecture of, 272

morphology of, 295

ossification of, $223,226,227$

variations in, 280

fasciæ of, 384

movements of, 401

muscles of, 382,391

surgical anatomy of, 1450

Hard palate, 174

in frontal section of skull, 189

relation of, to surface, 164

Hare-lip, 1379

Hasner, valve of, 825

Hassall, concentric corpuscles of, 1351

Haustra coli, 1212

Haversian canals, 84

gland of hip-joint, 341

systems, 84

Head, arteries of, 888

bones of, 115

development of, 495

fasciæ of, 446

lymph vessels of, 1003 superficial, 1003

mesodermal somites of, 28, 29, 30, 496

movements of, 446

muscles of, 448

development of, 495

nerves of, 767

process, 24

segmental characters of, 293,496

surgical anatomy of, 1357

veins of, 964

Head-cap, of spermatozoon, 17

Heart, 870

abnormalities of, 1050

aortic cusp of, 1050

orifice of, 878,884

topography of, 1403

valve of, 878

vestibule of, 878

apex of, 872

abnormalities of, 1050

arteries of, 887

atria of, 874,875

development of, 70

left of, 875

right of, 873

structure of, 879

topography of, 1403

atrio-ventricular apertures of, 877

auricles of, 874,875 
Heart, amricles of, development of, 1032 left, 875

right, 874

surface anatomy of, 1404, 140.5

base of, 871

bulbus cordis of, 70

capacity of, 880

central fibro-cartilage of, 876,879

chambers of, 873

chordæe tendineæ of, 877

conus arteriosus of, 876

coronary groove of, 871 topography of, 1403

sinus of, 875,959

abnormalities of, 1057

development of, 1032

morphology of, 1049

opening of, 875

sulcus of, 871

crista terminalis of, 874

development of, 70, 75, 1025, 1031

diaphragmatic surface of, 872

endocardium of, $875,876,877,878$

structure of, 879

epicardium of, 879

fibrous rings of, $877,878,879$

foramen ovale of, 875 persistence of, 1050

foramina venarum minimarum, 874

fossa ovalis of, 874

development of, 1033, 1034

infundibulum of, 876

interauricular septum of, 873

abnormalities of, 1050

development of, 1032

interventricular septum of, 878

abnormalities of, 1050

development of, 1032

sulcus of, 873

limbus fossa ovalis, 874

lunulæ of valves of, 877

lymph vessels of, 880

margins of, 873

topography of, 1403

mitral orifice of, 878

level of, 1442

topography of, 1.05

valve of, 878

moderator band of, 877

musculi papillares of, 877 structure of, 879

pectinati of, 874

myocardium of, 878

nerves of, 880

nodulus valvulæ semilumaris, 877

orifices of pulmonal'y veins in, 875

of venæ cavæe in, 874,875

outline of physiology of, 870

pars membranacea septi of, 878 abnormalities of, 1050

primitive, 70

atrium of, 1033

development of, 1026

ludiments of, 65

venous valves of, 1032

pulmonary orifice of, 877 topography of, 1045

valve of, 877

development of, 1032

Purkinjé's fibres of, 879

relation of, to wall of thorax, $870,871,873$

semilunar valves of, 877
Heart, semilunar valves of, development of, 1032

septum primum of atrimm, 1033

secundum of atrium, 1033

sinus venosus, 1032

shape of, 870

sinus venosus of, 1032

development of, 70

size of, 880

sterno-costal surface of, 872

structure of, 878

atrio-rentricular bundle, 879

endocardium, 879

epicaldium, 879

fibres of, 879

sulcus, coronary, 871

sulcus terminalis of, 873,874

developmental significance of, 1032

surface and surgical anatomy of, 1403

Thebesian valve of, 874 development of, 1032

trabeculæ carneæ of, 877

transposition of, 1050

tricuspid orifice of, 874,877

level of, 1442

topography of, 140.5

valve of, 877

trigona fibrosa of, 876

truncus aorticus of, 70

tuberculum intervenosum, 875

valvula venæ cavæ inferioris, 875 development of, 1032

vascular supply of, 880

veins of, 959

morphology of, 1048

ventricles of, 876

development of, 70

structure of, 879

ventricular septun, 876

weight of, 880

Helicine arteries, 1300

Helicotrema, 845

Helix, 827

development of, 53

fossa of, 828

muscles of, 829

spine of, 828

tail of, 829

Helmholtz, ligaments, 841

Hemisphæria bulbi urethre, 1308

Hemispheres, cerebellar, 570 cerebral, 620

Henle, layer of, 860 loop of, 1266

Hensen, cells of, 8.50, 8.51

ductus reunieus of, 846 development of, 854

stripe of, 8.51

Hepatic artery, 930

cells, 1199

duct, 1201

derelopment of, 1254

lobules, 1198

lympli glands, 1020

plexus, 765

veins, 982

Hepato-duodenal ligament, 1152, 1183, 1197

Hepato-gastric ligament, 1162, 1170, 1197 development of, 1255

Hepato-renal ligament, 1197

Heredity, theory of, 19

Hernia, congenital inguinal, 1409 
Ilemia, diaphragmatic, 473 direct inguinal, 1 1408,1409 femoral, 405 medial, $1 \pm 09$ oblique inguinal, 1405,1409 surgical anatomy of, 1408, 1459 Heschl's conrolution, 656

Hesselbach's triangle, 1235, I408

Heterodont dentition, 1218

Hiatus aorticus, 472 canalis facialis, 130 condition of, at birth, 133

interosseus, 327

maxillaris, 804

œsophageus, 472

sacralis, 97

semilunaris, 186, 803 surgical anatomy of, 1378

Highmori, corpus, 1288

Hilus of kidney, 1251, 1258, 1437 topography of, 1425,1437 of lung, 1094 topography of, 1399 of lymph glands, 995 of nucleus dentatus, 510 of olivary nucleus, 556 of orary, 1311 of spleen, 1352 of suprareual gland, 1345

Hind-brain, 33, 514 parts derived from, 514

Hind-gut, 38, 48 deriratires of the, 48

Hinge-joints, 301 nutrient foramina of, 234 ossification of, 235

Hip-bone, 228 acetabulum of, 228 architecture, 273 canal, 137 connexions of, 234 ilium, 228 molphology of, 294 obturator foramen of, 228 ossification of, 235 rariations in, 281

Hip-joint, 339 disease, abscesses in, 1460 dislosation of, 1460 exposure of front of, 1459 motements at, 312 nerves to, $723,721,728,729$ surgical anatomy of, 1455,1159 synovial stratum of, 311

Hippocampal commissure, 627 fissure, 626

Hippocampus, 625, 626, 627, 636 connexion of, with fornix, 625 with thalamus, 625

fimbria of, 627 inversus, 629 olfactory bundle of, 627

Hirschsprung's disease, 1.23

Histology, 4

Homodont dentition, 1248

Honolog 5,2 of limb-bones, 294 of limb-girdles, 296 of scapula and ilium, 297 serial, 3 of vertebræ, 283

Homoplasy, 3
Horizontal fissure of cerebellum, 573 derelopment of, 573

Horse-shoe kidney, 1268

Hour-glass stomach, 1172

Housemaid's knee, 1460

Huguier, canal of, 125 relation of, to tympanum, 834

Humero-femoral index, 289

Humero-nlnar joint, 323

Humerus, 204

anatomical neck of, 205

architecture of, 272

capitulum of, 208

connexions of, 209

coronoid fossa of, 208

deltoid tuberosity of, 207

distal extremity of, 208

epicondyles of, 207

epiphyses of, 209

groove for radial nerve, 207

head of, 205

intertubercular groore of, 206

morphology of, 294

nutrient foramina of, 209

olecranon of, 208

ossification of, 209

sexual differences of, 209

shaft of, 206

surgical anatomy of, 1449

trochlea of, 208

tubercles of, 205

variations in, 280

Humour, aqueous, 821

ritreous, 819

Huschke, foramen of, 832

Huxley, layer of, 860

Hyaloid artery, 826

history of, 819

canal, 826

development of, 819

fossa, 819

membrane of, 819

Hyaloplasm, 8

Hydra, nervous system in, 497

Hydrocele, 1409

Hydronephrosis, caused by abnormal vessels, 1425

Hymen of vagina, 1322, 1325

carunculæ hymenales of, 1325

development of, 1335

Hyo-epiglottic ligament, 1068

Hyo-glossal membrane, 1129

Hyo-glossus muscle, 462 action of, 463

nerre-supply of, 463

Hyoid arch, 43

muscles derived from, 496

produced from, 496 nerve of, 796

artery, of lingual, 892

of superior thyreoid, 892

bar, 43,159

bone, 158

body of, 158

connexions of, 159

development of, 43,159

greater cornua of, 159

lesser cornua of, 159

movements of, 463

ossification of, 159

surgical anatomy of, 1387

Hyparterial bronchus, 1083, 1097 
Hypocartilaginous ring of membrana tympani, 834

Hypochondrium, 1159

Hypochordal bow, 103 spange, 936

Hypogastric artery, 936 abnornalities of, 1056

umbilical artery of, 939

relation of, to urachus, 939

nerves, 765,766

plexus, 766

region, 1159

vein, 984

zone, 1158

Hypogastrium, 1158

surgical anatomy of, 1392

Hypoglossal nerve, 793

development of, 34

nucleus of origin of, 594

Hypophyseal arter'y, 902

body, 615,616 development of, 34, 49

fossa, 134, 183, 291

Hypophysis cerebri, 615, 616 arteries of, 902

development of, $34,49,616,684$

fossa of , 134, 183, 291

infundibulum of, 616

method of exposure, 1374

skiagrams of the sella turcica, 1374

surgical anatomy of, 1373

Hypothalamic tegmental region, 613

Hypothalamus, development of, 35

origin of, 517

pars mamillaris, 608, 609

optica, 608,609

Hypotrochanteric fossa, 281

Hypsicephalic skulls, 286

Ileal artery, 932

Ileo-creal artery, 932

fold, 1218

fossa, 1218

glands, 1217

orifice, $1214_{j}$

valve, 1215

frenula of, 1214

sigmoidoscopy, 1423

structure of, 1215

tibial tract, surgical anatomy of, 1461

topography of, 1421, 1443

vein, 990

Ileo-colic artery, 932

fossa, 1218

veins, 990

Ileo-psoas, bursa, $3 \notin 1,410$

Ileum, 1208

diverticulum of, 1210

structure of, 1210

vessels and nerves of, 1210

Iliac arteries, 935

colon, 1222

topography of, 1423

crest, 228, 238

topography of, 1423, 1443

fascia, 1157

fossa, 231

lymph glands, 1017

morphology of, 1047

portion of fascia lata, 403

region, 1159

spine, anterior inferior, 229
Iliac spine, anterior superior, 228 surface anatomy of, 1455, 1458 posterior inferior, 229

superior, 229 sturface anatomy of, 1455

tuberosity, 230

veins, 983

Iliacus muscle, 410

action of, 411

nerve-supply of, 411

minor, 410

Ilio-capsularis muscle, 410

Ilio-coccygeus muscle, 494

Ilio-costalis cervicis muscle, 440

dorsi, 439

lumborum, 439

Ilio-femoral ligament, 340

Ilio-hypogastric nerve, 720

Ilio-inguinal nerve, 720

Ilio-lumbar artery, 938

abnormalities of, 1056

ligament, 337

inferior, 337

vein, 982

Ilio-pectineal eminence, 233

line, 231

Ilio-psoas muscle, 410

action of, 411

bursa of, 1459

nerve-supply of, 411

surgical anatomy of, 1459

Ilio-sacralis muscle, 494

Ilio-tibial tract, 404 relation of, to muscles, 416 surgical anatomy of, 1459

Ilio-trochanteric ligament, 340

Ilium, 228

anterior inferior spine of, 229

superior spine of, 228

arcuate line of, 231

auricular surface of, 230

crest of, 228

fossa of, 231

gluteal lines of, 230

surface of, 230

greater sciatic notch of, 229

morphology of, 297

posterior inferior spine of, 229

superior spine of, 229

tuberosity of, 230

Immovable joints, 299, 300

Imperforate anus, 1233

Impressio trigemini, 130

Impression, gastric, of kidney, 1264

hepatic, of kidney, 1264

splenic, of kidney, 1264

Impressiones digitatæe, 107

Incisions to evacuate pus in the palm, 1454

Incisive artery, 899

bundle, $45 \mathrm{l}$

centre, 150

fossa, 146

pad of palate, 1110

condition of, at birtll, 1111

papilla palatina, 1110

suture, 149

Incisor crest, 149

foramen, $149,17 t$

fossa, 155

nerve, 780

teeth, 1115, 1116

eruption of, 1121 
Incisura acetabuli, 234

cardiaca, 1095

cerebelli anterior, 574

posterior, 574

clavicularis, 107

ethmoidalis, 116

fibularis, 249

intertragica, 828

ischiadiea major, 232

minor, 232

jugularis ossis occipitalis, 122 sterni, 107

mandibulæ, 156

mastoidea, 128

nasalis, 115

pancreatis, 1205

parieto-nccipitalis, 662

radialis, 211

scapulæ, 201

semilunaris, 211

spheno-palatina, 152

supraorbitalis, 116

tentorii, 669

terminalis auris, 829

thyreoidea inferior, 1062 superior, 1062

ulnaris, 216

umbilicalis, 1189

vertebralis of cervical vertebræ, 90

inferior and superior, 89

of lumbar vertebrae, 95

of thoracic vertebræ, 93

Inclinatio pelvis, 237

Incremental lines in ivory, 1114

Incudo-malleolar joint, 840

Incudo-stapedial joint, 840

Incus, 840

articulations of, 840

development of, 841

ligaments of, 840

movements of, 840

processus lenticularis of, 840

Index, alveolar, 287

auricular, 828

cephalic, 286

dental, 287

facial, superior, 286

total, 287

gnathic, 287

humero-femoral, 289

innominate, 288

intermembral, 289

lumbar, 288

nasal, 287

orbital, 287

palato-maxillary, 287

pelvic, 288

platyknemic, 289

platymeric, 289

radio-humeral, 289

of sacrum, 99, 289

scapula, 288

superior facial, 286

thoracic, 114

tibio-femoral, 289

vertical, of skull, 287

Indices of skulls, 284

Indifferent cells, 36, 503

Induseum griseum, 629

Inferior alveolar canal, 147

gluteal arter5, 942

veins, 984
Infra-axillary region, 1397

Infraclavicular lymph glands, 1009

nerves, 703

region, 1397

Infracostal angle, 1397, 1407

muscles, 470

plane, 1407, 1411

Infraglenoid tuberosity, 201

Infrahyoid artery, 892

muscles, 459

action of, 460

nerve-supply of, 460

Inframammary region, 1397

Inframandibular nerve, 778

Infraorbital artery, 899

canal, 147, 162

relation of, to orbit, 162

rariations in, 279

foramen, 146, 162

topography of, 1375

margin, 146

nerve, 777

plexus, 777

suture, 279

vein, 968

Infrapatellar bursa, $3 \pm 5$

fat-pad, 348

Infrascapular artery, 917

Infraspinatus muscle, 375 action of, 375

nerve-supply of, 375

Infraspinous fossa, 202

Infrasternal depression, 108 notch, 1397, 1407

region, 1397

Infratemporal crest, 137, 167, 168 fossa, 168

Infratrochlear nerve, 773

Infundibuliform fascia, 475, 483, 1297

Infundibulo-pelvic ligament, 1435

Infundibulum, 186, 541, 803

development of, 616

ethmoidale, 141 relation of, to nasal fossæ, 185 to orbit, 163

fascia of, 475

of heart, 876

hypothalami, 615

of nose, 803

of pulmonary lobules, 1098

development of, 1099

relation of, to third ventricle, 617

renal, 1268

of uterine tube, 1314

Inguinal canal, 1290, 1291

abdominal inguinal ring of, 483

fascia of, 483

subcutaneous inguinal ring of, 483

surgical anatomy of, 1408

fossa, intermediate, 1235

lateral, 1235

medial, 1235

glands, 1013

hernia, surgical anatomy of, 1408, 1409

ligament, 477

region, 1458

rings, abdominal, 481, 483, 1408 position of, 1408

subcutaneous, 477, 1408

walls of, 483

Inion, 166, 171, 285

topography of, 1358 
Inner cell-mass, 21, 22

Innervation of muscles of limbs, laws of, 749 of skin of the limbs, 750

lower limb, 752

upper limb, 752

Innominate artery, 888

abnormalities of, 1050, 1051

development of, 1028

morphology of, 1046

topography of, 1405

veins, 1405

Inscriptones tendinal, 1407

Inscriptiones tendineæ, 482

Insertion of muscles, 361

Inspiration, 474

muscles of, 373

Insula, 655

development of, 6 5̆5

limen of, 654

opercula of, 655

sulcus centralis of, 654

Integument, 856

corium of, 8.57

papillæe of, 857

structure of, 857

Interarticular ligaments, 302

of costo-sternal joints, 316

of costo-transverse joints, 314

development of, $30 \pm$

of hip-joint, 339

menisci, 302

of acromio-clavicular joint, 319

function of, 319

development of, 304

of distal joint, 327

of knee, 347

of proximal radio-ulnar joint, 326

of temporo-mandibular joint, 312

Interauricular septum of heart, 874,875 abnormalities of, 1050

development of, 1033

sulcus of heart, 871

Intercavernous sinuses, 974

Intercentral articulations, 306

Interchondral joints, 315

Interclavicular ligament, 318 function of, 319

Intercoccygeal joints, 309

Intercolumnar fascia, 477,483

Intercondylic fossa of femur, 243 of tibia, 247

notch, 243

Intercostal aponeuroses, 470

arteries, 925

lymph glands, 1013

muscles, 470

action of, 474

nerve-supply of, 474

nerves, 713

spaces, 114

veins, 961

Intercosto-brachial nerves, 714 variations in, 716

Intercrural fibres, 477

Intercuneiform joints, 358

Interdigital veins of foot, 951 of hand, 924

Interglobular spaces of ivory, 1123

Interlobar fissures of lung, 1095

Intermaxillary suture, 148, 174

Intel'mediate visceral arteries, 1043, 1046 cutaneous nerve of thigh, 724
Intermedium, os, 295

Intermetacarpal articulations, 332 movements of, 334

Intermetatarsal articulations, 360

Intermuscular septa of arm, 378 of foot, 423

topography of, 1465

of leg, 422

of thigh, 403

topography of, I 459

Internal capsule, 610,642

anterior limb of, 642

cerebro-spinal tract in, $6 \pm 2$

genu of, $6 \pm 2$

lenticulo-caudate fibres of, 642

lenticulo-thalamic fibres of, $6+2$ motor tract of, 642

parts of, 642

posterior limb of, 612

retrolenticular fibres of, $642,6 \pm 3$

sublenticular fibres of, $6 \pm 2$

ear, 843

mammary artery, 913

ligature of, 1398

medial nerve of forearm, 709

cutaneous nerve of upper arm, 710 of thigh, 725

of profunda femoris, 950

surgical anatomy of, 1398

structure of pous, 565

Internasal suture, 145

Interolivary stratum, 556

Interosseous arteries, 922

of dorsal carpal arch of foot, 923

groove of calcaneus, 259

of talus, 256

ligaments, calcaneo-cuboid, 357

carpal, 329

carpo-metacarpal, 332

cuboideo-navicular, 357

cuneo-cuboid, 358

cuneo-metatarsal, 359

intercuneiform, 358

intermetatarsal, 360

talo-calcaneal, 355

tibio-fibular, 350

membrane of forearm, 327

chorda obliqua of, 328

hiatus interosseous of, 327

of the leg, 350

inuscles of foot, 432

action of, 435

nerve-supply of, $433-435$

of hand, 391

action of, 395

nerve-supply of, 392-39.;

ridge of fibula, 252

of tibia, 248

veins of hand, 978

Interparietal bone, 124

sulcus, 664

Interpeduncular fossa, $5 \neq 1$

gangliou, 614

relation of, to fasciculus retroflexus, 614

Interphalangeal joints of foot, 361 movements at, 361

of hand, 334

movements at, 331

position of, 1452

surgical anatony of, 1452

Interpleural space, 1089 
Interpubic fibro-cartilaginous lamina, 337

Interscapular region, 1436

Intersegmental association fibres of spinal medulla, 535

ressels, 1043

Intersigmoid fossa, 1223 surgical anatomy of, 1423

Interspinales muscles, 445

Interspinous ligaments, 308

Intertarsal joints, 358 movements at, 361 synovial strata of, 334

Iutertransversales muscles, 445

Intertransverse ligaments, 308

Intertrochanteric crest, 243

Intertubercular line, 1411 plane, 1411

Interventricular foramen, 618 sulcus of, 618

foramina, $543,618,621$

groores, $872,873,1035$

septum, 876, 878

abnormalities of, 1050

development of, 1035

sulcus, 872

Intervertebral cartilages, 306

dises, 306

foramen, 89,95

groove, 89

Intestinal arteries, 932

lymph trunks, 997

veins, 992,1210

Intestine, 1178

aggregated lymph nodules of, 1181

agminated glands of, 1181

basement membrane of, 1179

cæcum, 1211

circular folds of, 1180, 1209

colon, ascending, 1121

descending, 1211

transverse, 1211

development of, 1250

duodenal glands of, 1179, 1186

epithelium of, 1179

intestinal glands of, 1179, 1212

lamina muscularis mucosa, 1179

large intestine, 1121

appendices epiploicæ of, 1211-1212

divisions of, 1211

haustra of, 1212

length of, 1211

nerves of, 1211

plicæ semilunares, 1212

structure of, 1212

tæniæ of, 1211, 1212

topography of, 1419, 1421

vessels of, 1212

left flexure of colon, 1211

length of, 1177

lymph vessels of, 1212

inucous membrane of, 1179

of anal canal, 1229

of large intestine, 1212

of small intestine, 1210

structure of, 1210

muscular coat of, 1178

of anal canal, 1229

of large intestine, 1212, 1223

of rectum, 1226

of small intestine, 1210

structure of, 1210

pliea circularis of, 1180
Intestine, position of coils of, 1178, 1181, 1210 1212

rectum, 1211

retiform tissue of, 1179

right flexure of colon, 1211

rotation of hoop, 48

serous coat of, 1178

of large, 1212

of small, 1210

small intestine, 1177

coils of, 1208

divisions of, 1177

duodeno-jejunal flexure of, 1182 topography of, 1419

lacteals of, 1210

Meckel's diverticulum of, 1210

mesentery of, 1208

nerves of, 1210

topography of, 1419

vessels of, 1210

solitary lymph nodules of, 1181, 1210, 1212

structure of, 1178

submucous coat of, $1179,1212,1213$

surgical anatomy of, 1419

tela submucosa of, 1179

tunica mucosa of, 1179

villi of, 1179

Intestinum cæcum, 1213

crassum, 1210

ileum, 1208

jejunum, 1208

rectum, 1224

tenue, 1208

mesenteriale, 1178

Intracranial lymph vessels, 1003

Intrajugular process, 122

Intumescentia cervicalis, 519

lumbalis, 519

Inversion of foot, 361

museles producing, 436

Iris, 813

blood-vessels of, 813

ciliary margin of, 813

circulus arteriosus major, 813 minor, 813

dilator pupillæ of, 814

ligamentum pectinatum of, 810

muscular fibres of, 814

nerves of, 814

pupil of, 814

pupillary border of, 814

membrane of, 813

sphincter pupillæ of, 814

stroma of, 813

Irregular tubules of kidney, 1267

Ischial spine, 232 sexual differences of, 237 topography of, 1455

tuberosity, 232

sexual differences of, 238

topography of, 1455

Ischio-bulbosus muscle, 487

Ischio-capsular ligament, 341

Ischio-cavernosus muscle, 488

Ischio-coccygeus muscle, 495

Ischio-pubicus muscle, 488

Ischio-rectal fossa, 1238, 1431

Ischium, 232

acetabulum, notch of, 232

body of, 232

morphology of, 295

rami of, 232 
Ischilum, spine of, 232 tuberosity of, 232

Island of Reil, 654, 655

limiting sulcus of, 654 opercula of, 655

Isthmus of acoustic meatus, 830 of auditory tube, 827 of brain, 515

of cartilage of ear, 829

of fauces, 1112

level of, 1442

pharyngo-nasal, 1141, 1145

of pharynx, 1112

rhombencephali, 34

of thy reoid gland, 1347

topography of, 1338

of uterine tube, 1314

Iter chordæ anterius, $83 \pm$ posterius, 834

Ivory, 1113, 1123

development of, 1247

formation of, 1247

structure of, 1123

fibrils, 1123

development of, 1245

papilla, 1244, 1245

sheaths, 1123

development of, 1245

tubes, 1123

development of, 1245

Jacobson, nerve of, 786 vomero-nasal organ of, 802

Jaw, alveoli of, 148,155

formation of, 1123

mandible, 154

angle of, 156

body of, 154

condyle of, 156

coronoid process of, 156

movements of, 458

ramus of, 156

topography of, 1375

maxilla, 146

Jejunum and ileum, lymph vessels of, 1210

structure of, 1210

surgical anatomy of, 1420

vessels and nerves of, 1210

Joints, 299

development of, 304

abduction, 303

acromio-clavicular, 373

movements at, 319,373

topography of, 1444

adduction, 303

adipose tissue of, 302

amphiarthrodial, 300, 301

development of, 304

ankle, 351

surgical anatomy of, 1463

arthrodial, 301

articular capsules, 302 topography of, 1464 dises, 302

atlanto-epistropheal, 309

movements at, 311

of anditory ossicles, $8 \pm 0$

ball and socket, 301, 30:3

biaxial, 301

calcaneo-cuboid, 357

ligaments of, 357
Joints, calcaneo-cuboid, surgical anatomy of, 1464

topography of, 1464

calcaneo-taloid, $35 \pm$

surgical anatomy of, 1464

capsule of, 302

carpal, 329

movements at, $33 t$

carpo-metacarpal, 332

cavity of, 301

circumduction, 303

classification of, 299

of clavicle, 317

co-aptation in, 303

condyloid, 301

costo-central, 313

costo-chondral, 315

topography of, 1398

costo-sternal, 315

costo-transverse, 314

costo-vertebral, 313

ci一co-arytænoid, 1066

crico-thyzeoid, 1065

cubo-cuneiform, 357

cuneo-na vicular, 357

development of, 304

diarthrodial, 301

development of, 304

elbow, 323

enarthrodial, 301

extension, 303

finger, 334

flexion, 303

of foot, 351

nerves of, 731, 734

gliding, 303

hinge, 304

hip, 339

humero-radial, 323

humero-1llnar, 323

immorable, 299, 300

development of, 304

incudo-malleolar, 840

incudo-stapedial, 810

of inferior extremity, 339

interarticular ligaments, 302

intercarpal, 329

intercentral, 307

interchondral, 315

intercoccygeal, 309

intercuneiform, 358

intermetacarpal, 332

movements at, 334

intermetatarsal, 360

interneural, 307

interphalangeal, of foot, 334,361 movements at, 331, 361

of hand, 334

movements at, 334

topography of, 1452,1465

interpulic, 337,338

intertarsal, 354, 358

synovial strata of, 334

knee, 342

of larynx, 1065

Iumbo-sacral, 335

menisci, 302

metacarpo-phalangeal, 333

movements at, 334

surgical anatomy of, 1451

topography of, 1452

metatarso-phalangeal, 360 
Joints, metatarsal-phalingeal, movements at, 361

surgical anatomy of, $146 \pm, 1 \pm 65$

topography of, $146 t, 1465$

movable, 300

development of, $30 t$

morements at, 303

multiaxial, 301, 303

occipito-atloid, 309

movements at, 311

of pelvis, 335

pisi-cuneiform, 330

of pisiform bone, 331

radio-carpal, 328

surgical anatomy of, $1+50$

topography of, $1+56$

radio-humeral, 323

topography of, 1449

radio-ulnar, inferior, 327

superior, 326

rotation, 303

sacro-coccygeal, $30 \mathrm{~s}$

sacro-iliac, 335

cuboideo-navicular, 357

cineo-navicular, 357

topography of, 1455

scapulo-clavicular, 318

shoulder, 320

of spine with craninm, 310

sternal, 315

sterno-clavicular, 317

action of muscles on, 373

movements at, 319,373

surgical anatomy of, 1444

sterno-costal, 315

structures of, 302

synarthrodial, 301, 303

synovial stratum, 302

talo-calcaneal, 354

topography of, $146 \pm$

talo-calcaneo-navicular, 355

movements at, 361

tarsal, transverse, 357

movements at, 361

tarso-metatarsal, 359

movements at, 361

surgical anatomy of, 1464

temporo-mandibular, 312

of thorax, 313

tibio-fibular, syndesmosis, 349

articulation, 349

movements at, 350

toe, 361

transverse carpal, 330

tarsal, 357

uniaxial, 301

of upper extremity, 317

varieties of movements in, 303

of vertebral column, 305

wrist, movements at, 334

xiphisternal, 316

level of, 1397, 1407, 1442

Juga alveolaria, 155

Jigal point, 286

Jugular foramen, 176, 177, 182

tossa, 177

development of, 133

relation of, to jugular foramen, 177

to tympanum, 1369

ganglion, superior, 785

lymph trunk, 998

notch, 122
Jugular process, 122, 172, 177

tubercle, 122

veins, 966

primitive, 1038, 1039

remains of', in adult, 1038, 1039

Junctional tubules of kidney, 1266

Junctura ossium, 299

Karyokinesis (mitosis), 9

Karyolymph, 8

Karyoplasm, 8

Karyo-reticulum, 8

Keratin, 858

Kerkring, ossicle of, 124

Kidneys, 1257

abnormal vessels, 1425

adipose capsule of, 1259

anterior surface of, 1262

relations, 1262

arciform arteries of, 1267

area cribrosa of, 1265

arteries of, 1267

ascending limb of Henle's loop, 1266

irregular tubule, 1266

base of the pyramids, 1265

calyces, renal of, 1268

development of, 1331

capsula adiposa of, 1259

capsule of, 1259

collecting tube, 1266

columns of Bertin of, 1265

connective tissue of, 1266

convoluted part of, 1265

corpuscles of, 1266

cortex of, 1265

descending limb of Henle's loop, 1266

loop of Henle, 1266

development of, 1331

dimensions of, 1257

duct of, 1268

excretory tube, 1266

exposure of from behind, 1438

extremities of, 1265

fascia renalis of, 1259

first convoluted tubule, 1266

fixation of, 1260

foramina papillaria of, 1265

gastric impression of, 1264

glomeruli of, 1266

hepatic impression of, 1264

hilus of, 1257, 1258, 1425, 1437

topography of, 1437

horse-shoe, 1268

interlobular arteries, 1267

junctional tubule, 1266

lateral border of, 1261

left, 1263

lobes of, 1265

medullary substance of, 1265

nerves of, 1267

oblique incision for exposure of, 1438

papillæ of, 1265

papillary part, 1265

pararenal fat of, 1209

pars radiata, 1265

convoluta, 1265

pelvis of, 1268

perirenal fat of, 1259

surgical anatomy of, 1425

position of, 1257, 1423

from behind, 1437

posterior relations of, 1260 
Kidneys, posterior surface of, 1260

primitive, 1331

pyramids of, 1265

on section, 1265

relations of, 1262

anterior, 1262

left, 1425

posterior, 1260

light, 1262,1425

renal columns, 1265

corpuscles of, 1266

development of, 1333

reniculi, 1265

second convoluted tubule, 1266

sinus renalis, 1265

skingraphs of pelvis of, 1426

sinus of, 1257,1265

splenic impression of, 1264

surface impressions of, 1264

surgical anatomy of, 1264

tubules of, 1266

development of, 1333

tumica fibrosa of, 1257

ureter of, 1268

development of, 1331

variations in, 1267

vasa afferentia of, 1267

efferentia of, 1267

development of, 1331

veins of, 1267

vessels of, 1267

arteriolæ rectæ, 1267

interlobular arteries, 1267

rasa afferentia, 1267

visceral surface of, 1262

Kink, intestinal, of Arbuthnot Lane, 1423

Knee-joint, 342

alar folds of, 348

articular surfaces of, 342

bursæ connected with, 348

surgical anatomy of bursie, 1460

ligaments of, 344

menisci of, $3 \pm 7$

surgical anatomy of, 1160

movements at, 348

muscles producing, 421

nerves of, from femoral nerve, 724

from common peroneal nerve, 730

from obturator nerve, 724

from sciatic nerve, 728,729

from tibial nerve, 732

surgical anatomy of, 1460

synovial stratum of, 348

surgical anatomy of, 1461

Kunckles, prominences of, 1452

Kranse, corpuscles of, 863

end-bulbs of, $86 t$

Kronlein's method for cranio-cerebral topography, 1360

Labia majora, 1324

commissures of, 1324

development of, 1336

minora, 1321

oris, 1108

Labial artery, branch of exterual maxillary artery, 806

branch of superficial perineal artery, 1324 glands, 1109

nerves, 1321

veins, 1324

Labio-scrotal folds, 1328
Labium anterius orificii externi uteri, 1316 externum cristre iliacæ, 229

inferius, 1108

internum cristæ iliacæ, 228

posterius orificii externi uteri, 1316

superius, 1108

Labrum glenoidale of hip joint, 340

Labyrinth, membranous, 843

acoustic nerve in, 852

blood-vessels of, 853

cochlea of, 843

membranous, 846

development of, 853

endolymph of, 762

hair-cells of crista acustica of, 848

of maculæ of, 847

of spiral organ of Corti of, 847

mascula acustica utriculi, 816

membranous, 846

osseous, 843

otoconia of, 847

perilymph of, 816

recessus utriculi, $8+6$

saccule of, 846

saccus endolymphaticus of, 847

semicircular canal, ducts of, 844

membranous, 847

sinuses superior and inferior of, $8 \pm 6$

spiral organ of Corti of, 850

utricle of, 846

vestibule of, $8 \pm 3$

of ethmoid, 140

Labyrinth, osseous, 843

derelopment of, 853

ductus endolymphaticus of, 847

reuniens of, 847

utriculosaccular, $84 \overline{7}$

endolymph of, 846

membranous, 843

perilympli of, $8 \pm 6$

saccus endolymphaticus, 847

utricular sinus of, 847

Lacertus fibrosus, 380

Lachrimal bones, 143, 163

ossification of, 144

Lacrimal apparatus, 824, 137

ampulla of, 825

surgical anatomy of, 1377

artery, 816

bone, 143,163

relation of, to nasal fosse, 187 to orbit, 163

membranous, 825 development of, 827

caruncle, 821

crest, of lacrimal, anterior, 148 posterior, $1 \pm 3$

of maxilla, 148

ducts, 825

fossa, 148,163

gland, 821

inferior, 824

inferior portion of, 824

superior portion of, $82 \pm$

superior, 824

surgical anatomy of, 1377

groove, 143, 163

relation of, to orbit, i (i3)

of maxilla, 187

naso-lacrimal cluct, 8.25

nerve, 772

papillæ, 821 
Lacrimal, plica lacrimalis, of Horsner, 825 process, $1+3$

puncta lacrimalia, 8:25 sac, 825

derelopment of, 49

surgical anatomy of, 1377

sinus of Arlt, 825

sints of Maier, 825

valve of Beraud, 825

inferior part, 824

superior part, 824

Lacteals, 1210

Lactiferous ducts, 1338

Lacunæ of bone, 84

lateral sagittal, 974

urethral, 1309

Lacus lacrimalis, 821

Lagena cochleæ, 849

Lambda, 171, 285 topography of, 1358

Lambdoid suture, 171 topography of, 1360

Lamellæ, fundamental, 84 interstitial, 84

osseous, 84

Lamina or Laminæ, alar, 36

alar, 505

basal, 36, 505

basal, of chorioid, 812

basilar, of chorioid, 811, 812

chorio-capillaris, 811

development of, 608

terminalis, 616

cribrosa of ethmoid, 139

scleræ, 808

of temporal bone, 131

dental, 1245

elastic anterior, 810

posterior, 810

fibro-cartilaginous interpubic, 337

fibrosa, 139

fusca, processus pterygoidei, 808

lateralis terminalis, 137

development of, 33

medialis processus pterygoidei, 137

tubae auditivæ, 838

medullary, lateral and medial, of thalamus, 610,611

lateral, of lentiform nuclens, 639

of thalamus, 611

medial, of lentiform nucleus, 639

of thalamus, 611

membranacea tubæ auditivæ, 838

perpendicular of ethmoid, 139

plate of, 140

papyracea of, 140

uncinate process of, 141

quadrigemina, 584

reticularis, 851

septi pellucidi, 632

spiralis ossea, 845

sectundaria, 845

stprachorioidea, 811

of thyreoid cartilage, 1062

vasculosa of chorioid, 811

vertebral, $88,90,91,93,95$

Landzert, fossa of, 1185

Langhan's layer, 59

Lanugo, 862

Large intestine, 1210

Laryngotomy, 1388

Larynx, 1061
Larynx, action of intrinsic muscles of, 1076 aperture of, 1068

apex of, 1064

appendix of ventricle of, 1071

articulations of, 1065

ary-epiglottic folds of, 1068

arytænoid cartilages, 1064, 1074

oblique muscles of, 1074

base of, 1065

blood-vessels of, 911

cartilages of, 1062

development of, 1100

construction of, 1062

conus elasticus of, 1066

corniculate cartilages, 1065

crico-arytænoid joints, 1066

crico-thyreoid joints, 1065

cuneiform cartilages, 1065

tubercle of, 1065, 1069

in deglutition, 1077

development of, 1100

epiglottic cartilage, 1065

epithelium of, 1072

glands of, 1072

glottis, intercartilaginous part of, 1070

aperture of, 1068

cavity of, 1068

folds of, 1068

glottis, 1070

intermembranous part of, 1070

rima vestibuli of, 1070

growth-alterations of, 1077

hyo-thyreoid, membrane of, 1066

interior of, 1068

intrinsic muscles of, 1072

joints of, 1065

laryngoscopical appearance of, 1077

ligaments of, 1066

lowest compartment of, 1071

middle compartment of, 1069

mucous glands of, 1072

membrane of, 1071

muscles of, 1072

nerves of, 788,789

nucleus of, 598

ossification of, 1065

pars intermembranacea of rima glottidis, 1071

intercartilaginea, 1071

part of the pharynx, 1149

philtrum ventriculi of, 1069

position and relations of, 1061

processus muscularis of, 1065

vocalis of, 1065

sesamoid cartilage of, 1065

sexual differences in, 1077

surfaces of, 1064

tubercle of Santorini of, 1065, 1069

tuberculum epiglotticum of, 1069, 1073

ventricle of, 1071

piriformis of, recess of, 1069

ventricular folds of, 1070

ventricularis, 1076

vessels and nerves of, 1077

vestibule of, 1069

vocal folds of, 1070

inucous membrane of, 1071

relation of, to thyreo-arytænoideus muscle, 1073

topography of, 1387

vocalis muscles of, 1076

Lateral angle, inferior, of sacrum, 99 
Lateral collateral ligaments, of ankle, 352 of elbow, 324

of knee, 345

surgical anatomy of, 1160

of liver, 1196

of mandible, 312

relation of, to deep cervical fascia, 448

of patella, 344

of wrist, 328

commissures, 1106

fissure of the brain, 653

development of, 655

line, sense organs of, 501,796

mass of atlas, 91

of sacrum, 99

ossification of, 106

part of occipital, 113

derelopment of, 293

plantar vessels, position of, 1465

plates, mesodermic, 27

recess of fourth ventricle, 549

recesses of pharynx, 1144

transverse sinuses, venous, 974

grooves for, 121

morphology of, 1040

surgical auatomy of, 1357, 1358

veutricles, 632

Latissimus dorsi muscle, 366

action of, 368

nerve-supply of, 368

topography of, 1437

Lajers of blastoderm, 21 germinal, 21

Left colic flexure, 1220

surgical anatomy of, 1422

Leg, development of, 39

fasciæ of, 422

intermuscular septa of, 422

lymph tessels of, 1013

muscles of, 424

surgical anatomy of, 1461

Lemniscus, 560

connexion of, with cochlear mulei, 586

with geniculate body, 591

with quadrigeminal body, 590

with superior olive, 556

with thalamus, 562, 591

decussation of, 560

interolivary stratum of, 568

lateral, 570, 584, 585, 586, 590, 606

nucleus of, 606

medial, 560, 561, 568, 570, 586, 590, 613

in mid-brain, $568,570,585,590$

in pons, 590

Lens, crystalline, 819

axis of, 820

capsule of, 819

cortical substance of, 820

curvatures of, 820

development of, 826

at different ages, 820

epithelium of, 820

history of, 826

equator of, 820

fibres of, 820

history of, $8 \geq 6$

lamine of, 820

nucleus of, 820

poles of, 820

radii of, 820

refractive index of, 820

substance of, 820
Lens, crystalline, suspensory ligament of, 819 vascular tunic of, 826 resicle, 825

Lenticulo-optic artery, 905

Lenticulo-striate artery, 905

Lentiform nucleus, globus pallidus of, 638 , 639

medullary laminæ of, 639

process of incus, 840

putamen of, 639

sturfaces of, 638

Leptoprosope skulls, 286

Leptorhine skulls, 287

Lesions of the spinal medulla, 1444

Lesser multangular bone, 220, $295^{\circ}$

Levator ani muscle, 493 action of, 495

cushion, 1143

glandulæ thyreoideæ, 1347

palpebræ superioris muscle, 452

action of, 454

nerve-supply of, 454

prostatæ muscle, 494

scapulæ muscle, 368

action of, 368

nerve-supply of, 368

veli palatini muscle, 466

action of, 467

nerve-supply of, 467

Levatores costarum muscles, $4 \bar{\imath} 0$

action of, 474

nerve-supply of, 474

Lerel of structures in relation to spines of vertebræ, 1442

Lien, 1352

accessorius, 1353

artery of, 929

Lieno-renal ligament, 1236

development of, 1252

Ligament or Ligameuts, 302

acetabular transverse, 339

of acromio-clavicular joint, 319

adventitious, 305

alar, 311

of ankle-joint, anterior, 352

lateral, 3.52

posterior, 352

annular, of ankle (O.T.), 352

of radius, 326

of wrist (O.T.), 1451

surgical anatomy of, 1451

of stapes, 841

anterior costo-transverse, 314

covering atlanto-epistropleal, 309

of elbow-joint, 324

radio-ulnar, 327

sterno-cla ricular, 318

of apex of dens, 311

aponeurosis plantar, 423

arcuate micldle, 472

arcuate of pubis, 338

arteriosum, 68

atlanto-epistropheal, 309, 310

of joint, 309

of atlanto-occipital joint, 310

atlanto-occipital, 310

of atlas, transverse, 310

of auditory ossicles, $8+1$

auriculare anterins, 829

posterins, 829

superius, 829

basium ossium metacarpalium, 360 
Ligament or Ligaments-continued basium ossium metatarsalinm, 360

bifurcate, 356. (See Ligaments calcaneonavicular, calcaneo-cuboid)

of Bigelow, 340

of bladder, 1280, 1283, 1303

broad, of uterus, 1238

surgical anatomy of, 1434

calcaneo-cuboid, 357

calcaneo-fibular, 352

calcaneo-metatarsal, 423

calcaneo-navicular, plantar, 355

part of bifurcate, 356

function of, 355

surgical anatomy of, 1464

capituli costæ interarticulare, 1242 radiatum, 314

fibulæ, 350

capitulorum ossium metacarpalium transrersa, 333

metatarsalium transversa, 360

carpal, 329

carpo-metacarpal, 332

dorsal, 332

interosseous, 332

rolar, 332

collateral, of metacarpo-phalangeal joints, 333 of patella, 404

colli costæ, 315

columnæ vertebralis et cranii, 305

conjugal, of ribs, 314

conoid, 319

function of, $3 \bar{i} 9$

tubercle, 198

coraco-acromial, 320

coraco-clavicular, 319

coraco-glenoid, 322

coraco-humeral, 322

relation of, to pectoralis minor muscle, 322 corniculo-pharyngeal, 1066

coronary, 1195, 1196

of knee, 348

costo-clavicular, 318, 319

relations of, to movements of clavicle, 319

costo-colic, 1220

costo-coracoid, 369

of costo-sternal joints, 316

of costo-transverse joints, 314

costo-vertebral, 313

costo-xiphoid, 316

cotyloid, 340

of cranium, 313

crico-arytreuoid posterior, 1066

crico-thyreoid, 1067

cruciate of atlas, 311

$$
\text { genu, } 346
$$

cruciatum anterius (of knee), 346

posterius, 347

cruris, 423

relation of, to morements at knee, 348

cruciform, of atlas, 311

cuboideo-navicular, 357

cuneo-cuboid, 358

cuneo-metatarsal, 359

cuneo-navicular, 357,358

of apex of, 311

of dens, 92,311

deltoid, 352

denticulate, 518

of elbow-joint, 323

epiglottic, 1067
Ligament or Ligaments-continued falciform, 1196, 1235

development of, 1252

topography of, 1415

fibular collateral, 345

flara, 308

gastro-colic, 1162, 1170, 1242

gastro-lienal, 1162, 1170, 1236, 1240

gastro-phrenic, 1170, 1236

gleno-humeral, 322

glenoid, 322

glosso-epiglottic, 1067

of head of fibula, anterior, 350 posterior, 350

of heads of ribs, 313

hepato-duodenal, I162, 1183, 1197

hepato-gastric, 1162, 1170, 1197

hepato-renal, 1197

of hip-joint, 339

hyo-epiglottic, 1068

hyo-thyreoid, lateral, 1066

middle, 1066

ilio-femoral, 340

ilio-lumbar, 337

ilio-trochanteric, 340

of incus, 840

inferior transverse scapular, 320

infundibulo-pelvic, 1435

inguinal, 477

reflex (Collesi), 478

interarticular, 302 development of, 304

of costo-transverse joints, 314

of head of rib, 314

of hip-joint, 339

of sacro-coccygeal joint, 308

of sternal-costal joints, 316

iutercarpal dorsal, 330

interosseous, 330

volar, 320

interchondral, 317

interclavieular, 318

intercuneiform interosseous, 358

intermetatarsal, 360

interosseous, of carpal joints, 329

of carpo-metacarpal joints, 332

cuneo-cuboid, 358

of intertarsal joints, 357

of tarso-metatarsal joints, 359

of tibio-fibular joint, inferior, 350

interspinous, 308

intertransverse, 308

ischio-capsular, 341

relation of, to movements at hip-joint, 342

jugal, 314

of knee-joint, 344, 346

posterior, 345

topography of, 1458

laciniatum, 422

lacunar (Gimbernati), 405, 477

of larynx, 1066

of lateral malleolus, anterior, 351

distal, 351

interosseous, 351

posterior, 351

lateral radio-carpal, 328

latum uteri, 1318

lieno-renal, 1252

development of, 1253

of liver, 1196

longitudinal, of spine, 307 
Ligament or Ligaments-continued

longitudinal anterior, of spine, 307 posterior, of spine, 307

long plantar, 357

Iumbo-costal, 315

lumbo-sacral, 335

malleolar, 351

of malleus, 841

of mandibular joint, 312

medial ulno-carpal, 328

metacarpo-phalangeal, 333

metatarsal transverse, 360

metatarso-phalangeal, 360

morphology of, 305

of neck of rib, 315

nuchæ, 308

obliquum genu, $3 \pm 5$

occipito-epistropheal, 310

orbito-tarsal, 1378

of ossicles of ear, 841

of ovary, 1311

palmar, 328-332

palpebral, topography of, 1377

of evelids, 822

patellar, 345

collateral, 344

relation of, to fascia lata, 344

topography of, 1460

pectinatum of iris, 810

of pelvis, 336

of peritoneum, 1162, 1196

plirenico-colic, 1220, 1242

of pinna, 829

pisi-metacarpal, 328, 331

pisi-tunciform, 331

plantar, 355, 357

long, 357

popliteal, 312

posterior costo-transverse, 315

costo-sternal, 316

covering atlanto-epistropheal, 310

of elbow-joint, 324

obliquum gentr, 345

radial collateral, 32.5

radio-ulnar, 327

of radius, 326

sterno-clavicnlar, 318

ulnar collateral, $32 \pm$

pterygo-spinous, 313

pubic, anterior, 337

arcuate, 338

posterior, 337

superior, 337

pubo-capsular, 340

pubo-vesical, lateral, 49:3

middle, 493

pulmonale, 1086

of pylorus, 1174

radial collateral carpal, 331

radiate carpal, 330

of liead of rib, 314

sterno-costal, 316

radio-carpal, 328

radio-tulnar, 326

round, of liver, 1197

development of, 1255

of uterus, 1319

surgical anatomy of, 1434

sacro-coccygeal, 308

sacro-iliac, anterior, 336

interosseous, 336

long posterior, 336
Ligament or Ligaments-continued

sacro-iliac posterior, 336

short posterior, 336

sacro-spinous, $33 \overline{7}$

sacro-tuberous, 337

processus falciformis of, 337

of scapula, 320

of shoulder-joint, 321

spheno-mandibular, 312

development of, 158

spirale cochler, $8 \pm 9$

of stapes, 841

of sterno-clavicular joint, 318

relation of, to movements of clavicle, 319

sterno-costal, 315

sterno-pericardial, 881

stylo-hyoid, 313

development of, 159

stylo-mandibular, 313, 1131

relation of, to parotid fascia, 1134

superficial transverse metacarpal, 384

metatarsal, 423

superior transverse scapular, 320

supraspinous, 308

suspensory, of clitoris, 1326

check, 807

of fascia bulbi, 807

of lens, 819

of ovary, 1311

of penis, 1299

talo-calcaneal, 351-5

anterior, 354

interosseous, 355

lateral, 354

medial, 355

posterior, 355

talo-fibular, anterior, 352

posterior, 352

talo-navicular, 356

dorsal, 356

talo-tibial, 353

tarsal, of eyelids, 822

tarso-metatarsal, dorsal, 359

interosseous, . 359

plantar, 359

teniporo-mandibular, 312

teres femoris, 341

relation of, to morements at hip-joint, 342

of liver, 1196

of uterus, 1319

thyreo-arytænoid, 1067

thyreo-epiglottic, 1068

tibio-fibular, 349

tibio-naricular', 3.53

transverse, of acetabulum, 339

of atlas, 310

coraco-glenoid, 322 2

coraco-humeral, 322

cruris, $12: 3$

genu, $3 \pm 8$

gleno-liumeral, :322

of the liearls of the metacarial hones, 33:3

humeral, 321

metacarpal, 332

superficial, 384

metatar:al, 390

superficial, 423

pelris, 493

perineal, 338

scapulæ inferius, 320

superius, 320 
Ligameut or Ligaments-continued

trapezoid, 319

relation of, to morements of clavicle, 319

triangular, 1196

left, 1196

of tuhercle of rib, 315

of tympanic membrane, 834

ulnar collateral carpal, 331

utero-sacral, 1318

of uterus, 1318

bursa orarica of, 1318

raginal, 384

renæ caræ sinistræ, 882

venous, of Arantius, 1196

ventricular, of larynx, 1067

of vertebral column, 305

rocal, 1067

rolar access on, 333

Ligamentum, anterior longitudinal, 307 carpi dorsale, 383

transversorum, 382

collateral of patella, 409

denticulum, 675

gastro-colic, 1162

gastro-lienal, 1162

hepato-colic, 1162

hepato-duodenal, 1162

hepato-gastric, 1162

ovarii proprium, 1312

patellæ, 408

pectinatum iridis, 810

posterior longitudinal, 307

suspensorium ovarii, 1312

teres hepatis, 1191

umbilicale medium, 1235, 1274

rolar radio-carpal, 329

Limb-girdles, 295

Limb-plexuses, significance of, 753

Limbs, arteries of, morphology of, 1047

derelopment of, 39, 1031

dorsal axial line of, 751

morphology of, 297

of muscles of, 495

of nerve-plexuses of, 741

nature of, 741

lower borders of primitive, 742

upper borders of primitive, 741

plexuses, composition of, 742

formation of, 680

morphology of, 741

relation of nerves derived from lower, 743

derived from upper, 742

variations in position, 752

post-axial border of, 741,742

pre-axial border of, 741,742

segmental relations of, 741

surfaces of, 742

ventral axial line of, 751

Limbus alveolaris mandibulæ, 155 maxillæ, 148

fossæ ovalis, 874

laminæ spiralis, 849

Limen insulæ, 654

nasi, 802

Limiting sulcus of Reil, 654

Line or Linea, alba, 476

surgical anatomy of, 1409, 1410

ano-cutaneons, 1232

aspera of femur, 242

axillary, 741, 1397
Line or Linea, base, of Reid, 1360 of chest, 1397

dorsal axial, of limbs, 751

epicondylic, 207

epiphyseal, 85

gluteal anterior, 230

inferior, 230

posterior, 230

incremental, 1114

intercondyloid, 243

intermedia cristæ iliacæ, 228

intertrochanteric, 240

intertubercular, 1411

lateral cerebral, 1360

lateral sense-organs of, 796

mammary, 1397

mid-lateral, of thorax, 1089

mylo-hyoid, 156

of Nelaton, 1455

nuchal, 171

of occipital bone, 121

pectineal, of femur, 242

spinal, of femir, 242

superior, 121

suprema, 121

obliqua mandibulæ, 155

oblique, of tibia, 249

parasternal, 1397

pectinea, 231

of pleural reflection, 1399

popliteal, of tibia, 249

post-central, 1360

of Poupart, 1411

pre-central, 1360

scapular, 1397

of Schreger, 1128

semicircularis, 483

semilunaris, 482

spiral, of femur, 242

splendens, 675

sternal, 1397

subcostal, 1407

temporal inferior, 118

ossis frontalis, 116

superior, 118

tendinous arch of pelvic fascia, 491

terminalis, 231, 232

of pelvis, 231, 232

relation of, to small pelvis, 232

ventral axial, of limbs, 751

white, of anns, 1232

Lingual artery, 892, 1130

development of, 1028

surgical anatomy of, 1382, 1383, 1391, 1393

duct, 1139

glands, 1130

gyrus, 660

lymph glands, 1130

nerve, 1131

septum, 1129

tonsil, 1126

surgical anatomy of, 1383

tubercles of teeth, 1117

vein, 1130

Lingual veins, 965, 1130

surgical anatomy of, 1382

Lingualis muscle, inferior, 463

superior, 463

Lingula cerebelli, 575

mandibulæ, 156

sphenoidalis, 134 
Linin, 8

Lip, rhombic, 554

Lips, 1108

commissures of, 1108

development of, 1244

frenulum of, 1108

glands of, 1109

surgical anatomy of, 1379

lymph vessels of, 1005

mucous membrane of, 1109

nerves of, 1109

philtrum of, 1108

structure of, 1109

sulcus mento-labialis of, 1108

naso-labial of, 1108

surgical anatomy of, 1379

tubercle of, 1109,1379

vessels of the, 1109

Liquor folliculi, 1313

Lisfranc, ligament of, 1464

Lisfranc's amputation, 1464

joint, 1465

Lister's incision for excision of wrist, 1451

Liver, 1187

areolar coat of, 1198

arteries of, 1120

bile-ducts of, 1201

interlobular, 1201

capsule of Glisson of, 1190

cardiac depression of, 1190

candate lobe of, 1192

cells of, 1199

in child, 1195

colic impression of, 1194

congenital irregularities in, 1195

coronary ligament of, 1195, 1196

development of, 47, 1254

duodenal impression of, 1194

excretory ducts of, 1201

development of, 12.55

falciform ligament of, 1196 development of, 1252, 125.

topography of, $1+1 \tilde{5}$

fibrous coat of, 1198

fissures of, 1191

fixation of, 119.

form of, 1187

variations in, 1194

fossa ductus venosi, 1191 of gall-bladder, 1191, 1192

for ligamentum teres hepatis, 1191

sagittalis sinistra of, 1189

of umbilical rein, 1191

of venæ cavæ, 1191, 1192

vesicæ felleæ, 1191

gall-bladder, 1201

gastric, impression of, 1193

hepatic duct of, 1201

impressio colica, 1194

duordenalis, 1194

gastrica, 1193

oesophagea, 1189, 119.2

renalis, 1194

suprarenalis, 1192

incisura umbilicalis, 1189

resicæ felleæ, 1189

inferior margin of, 1189

surface of, 1193

interlobular ducts of, 1200

left sagittal fissure of, 1191

ligaments of, 1196

lobes of, 1191
Liver, lobes of, left, 1191

right, 1191

topography of, 141 ว

lobules of, 1198

lobus candatus, 1191, 1192

quadratus, 1191, 1192, 1193

lymph ressels of, 1201

margin, inferior, 1189

posterior, 1189

nerves of, 1201

notch of gall-bladder of, 1191, 1192

csophageal groove of, 1192

omental tuberosity of, 1193

parietal surface of 1188

peritoneal relations of, 1195

physical characters of, $118 \%$

pons hepatis of, 1191

porta hepatis, 1190,1196

portal canals of, 1200

position of, 1194

variations in, 1194

posterior surface of, 1192

processus caudatus, 1191, 1192

quadrate lobe of, 1193, 1194

relation to peritoneum, 1195

renal impression of, I19t

Riedel's lobe of, 1195

round ligament of, 1196

development of, 1191

serous coat of, 1196

shape of, 1188

size of, 1188

variations in, 1194

and weight of, 1188

structure of, 1198

suprarenal impression of, 1192

surface marking:, 1191, 1415

surgical anatomy from the back, $1+39$

tuberculum papillare of, 1192

tuber omentale of, 1193

umbilical fissure of, 1191

notch of, 1191

uncovered area of, 1192, 1196

variations in form and position, 1194

veins of, 980,990

central, 1198, 1200

interlobular, 1199, 1200

sublobular, 1198, 1200

ressels of, 1199

risceral surface of, 1193

weight of, 1188

Lobe or Lobus, anterior of hypophysis, 616

azrgos of lung, 1096

caudate, of liver, 119.1

centralis cerebelli, 575

cerebellar, 575

cerebial, 654

culmen cerebelli, 5i5

declive, of cerel.ellum, .57.5

frontal, of brails, 66.;

liepatis, 1191

insulie, 654

of limg, 1095

derelopment of, 1101

namme, $13: 37$

nodule, of eerelsellum, 572, 576

occipital, of brain, 660 topography of, 1360

olfactory, of liain, 624 development of, 624

relation of, to anterior conmuis-une, 626

parietal, of brain, 662 
Lobe or Lobus, piriform, 624

posterior, of hypophysis, 616

of prostate gland, 1306

pyramidal, of thyreoid gland, 1347

development of, 1348

pyramids of cerebellum, 576

quadrate, of liver, 1193

of Riedel, 1195

temporal, of brain, 656

topograpliy of, 1360

of testis, 1288

of thyreoid gland, 1347

tuber vermis, of cerebellum, 575

uvula, of cerebellum, 576

Lobule of auricle, 828

biventral, of cerebellum, 575

central, of cerebellum, 575

epididymidis, 1289

flocculus, of cerebellum, 575

gracile, 576

inferior parietal, 665

lingula, of cerebellum, 575

of lung, 1095

mammæ, 1337

paracentral, 664, 666

parietal, inferior, 664

superior, 664

posterior superior, 575

postero-inferior, 575

quadrate, 1193, 1194

tuber vermis, of cerebellum, 575

Locomotion, 436

Locus cœruleus, 551

Long bones, 82, 83, 84

Longissimus capitis muscle, 440

cervicis muscle, 440

dorsi muscle, 440

Longitudinal fissure, great, 621 development of, 621

medial bundle, 562, 570, 586, 588

connexions of, with lower visual centres, 589

in medulla oblongata, 562

in mesencephalon, $562,570,588$

in pons, 570

relation of, to abducens nerve, 588, 589

to oculo-motor and trochlear nuclei, 588

Longus capitis muscle, 468

colli muscle, 468

Loop of Henle, 1266

subclavian, 759

Lower extremity, 228

surgical anatomy of, 1455

Lumbar aponeurosis, 437

arteries, 933

abnormalities of, 1052

development of, 1029

morphology of, 1043

of aorta, 933

of ilio-lumbar, 938

ganglia, 761, 762

lymph glands, 102

trunk, 997

nerves, 719

posterior rami of first three, 690 of fourth and fifth, 691

\section{plexus, 719}

branches of, 720

muscular branches of, 720

position and constitution, 719

puncture, 1443

region, 1411, 1425, 1437
Lumbar rib, 104, 277, 284

sympathetic, 761

veins, 982

vertebræ, 95

Lumbo-costal ligament, 315

Lumbo-dorsal fascia, 437

Lumbo-sacral joint, 335

ligament, 335

plexus, 718

communications with sympathetic, 719

lumbar, 719

pudendal, 719

sacral, 719

trunk, 727

Lumbricales muscles of foot, 430

action of, 430

nerve-supply of, 430

of hand, 389

action of, 389

nerve-supply of, 389

Lung, 1091

air-cells of, 1101, 1099

development of, 1101

alveolar ducts of, 1101

anterior border, surface markings of, 1398 margin of, 1095

apex of, 1092, 1398

level of, 1398

topography of, 1398

atria, 1099

development of, 1101

azygos lobe of, 1096 sulcus of, 1095

blood-vessels of, 1099

bronchial tubes of, 1097

bronchioles of, 1099

cardiac lobe of, 1098

notch of, 1095

costal surface of, 1094

development of, 1101

diaphragmatic surface of, 1093

fissures of, 1095

topography of, 1398

fœtal, 1092

form of, 1092

hilus of, 1064

relations of, 1094

incisura cardiaca of, 1095

interlobaris of, 1095

variations of, 1096

inferior border, surface markings of, 1398 lobe of, 1095

ligamentum pulmonale of, 1086, 1087

lobes of, 1095

lobules of, 1098

lymph vessels of, 1096

mediastinal surface of, 1094

middle lobe of, 1096

nerves of, 791

oblique fissure, surface markings of, 1398

phrenico-costal sinus of, 1093

root of, 1096

constituent parts of, 1096

level of, 1403

relations of, 1096

topography of, 1403

structure of, 1098

sulcus subclavius of, 1093

superior lobe of, 1095

surgical anatomy of, 1398

units, 1098

variations in, 1096 
Lungs and pleuræ, surgical anatomy of, 1398

Limula unguis, 859

Lunulæ valvularum semilunarinm, 877

Lymph, 993

capillaries, 994

channels, perivascular, 994

cords, 995

corpuscles, 993

development of lymph vaseular system, 1042

duct, right, 993, 998 abnormalities of, 1059

follicles, 906

glands, 993

of abdomen, 1015, 1019

abdominal wall, 1015

aggregated, 1181

ano-rectal, 1015

anterior auricular, 998

surgical anatomy of, 1376

appendicular, 1020

auricular, 1020

posteriores, 998

axillary, 1008

anterior, 1008

posterior, 1008

surgical anatomy of, 1446

biliary, 1020

blood-vessels of, 995

brachial, 1007

bronchial, 1012

broncho-pulmonary, 1012

buccinator, 999

cervical, anterior, 1000

deep, inferior, 1001, 1003

superior, 1002

inferior lateral, 1392

medial, 1392

superficial, 1000

superior anterior, 1392

lateral, 1392

surgical anatomy of, 1392

circumflex iliac, 1015

of cœcum, 1020

cœliac, 1019

colic, 1021

of colon, 1021

epicolic, 1021

paracolic, 1021

suprapancreatic middle, 1021

common iliac, 1017

cubital, 1006

deep, 1006

superficial, 1006

delto-pectoral, 1009

diaphragmatic, 1011, 1013, 1014

of digastric triangle, 1000

epigastric, inferior, 1015

superior, 1015

external iliac, 1017

facial, deep, 998 superficial, 999

femoral, 1013

surgical anatomy of, 1459

follicles of, 995

gastric, 1019

left, 1019

right, 1019

anterior, left, 1019

biliary glands, 1020

inferiores, 1020

left para-cardial, 1019

supra-pancreatic, 1020
Lymph glands, gastric, posterior para-cardial, 1019

gastro-epiloic, 1020

para-cardial, 1019

supra-pancreatic, 1020

sub-pyloric glands, 1020

superiores, 1019

gastro-epiploic, left, 1020

right, 1020

gluteal, 1017

hæmal, 995

of head, 998 ?

hepatic, 1020

hypogastric, 1017

ileo-cæcal, 1020

ileo-cœlic, anterior, 1028

posterior, 1020

iliac, common, 1017 external, 1017

of the inferior extremity, 1013

infra-clavicular, 1009

infra-orluital, 998

infra-umbilical, 1015

inguinal, 1013

surgical anatomy of, 1459

intercostal, 1010, 1013

inter-iliac, 1017

interpectoral, 1009

intertracheo-bronchial, 1012

lateral aortic, 1012

axillary, 1008

lingutal, 999, 1130

of lower limb, 1013

lumbar, 1021

of the mamma, 1008, 1009

mediastinal, anterior, 1011

posterior, 1012

mesenteric, 1020

mesocolic, 1021

of the neck, 1000

nodules of spleen, 1353

obturator, 1017

occipital, 998

para-aortic, 1021

para-cardial, 1019

left, 1019

posterior, 1019

right, 1019

para-mandibular, 1000

para-tracheal, 1001

para-uterine, 1016

parotid, 998

pectoral axillary, 1008

surgical anatomy of, 1446

of pelvis, 1015

pharyngeal, 1000

lateral, 1000

median, 1000

surgical anatomy of, 1385

popliteal, 1014

surgical anatomy of, $145 \mathrm{~s}$

posterior anricular, 998

mediastinal, 1012

of posterior triangle, 1394

pre-aortic, 1021

pre-laryngeal, 1001

pre-tracheal, 1001

pubic, 1015

pubo-gluteal, 1017

pulmonary, 1012

rectal, 1016, 1017

retro-peritoneal, $1+27$ 
Lymph glauds, sacral, 1016

sinuses of, 995

sternal, 1010

structure of, 994, 995

sub-iortic, 1017

sub-clavicular, 1009

sub-inguinal deep, 1014

distal gromp, 1014

proximal group, 1012

superficial, 1013

sub-maxillary, 1000

surgical anatomy of, 1391

sub-mental, 1000

surgical anatomy of, 1391

sub-pectoral group of axillary, 1009

sub-pyloric, 1020

sub-scapular, 1008

surgical anatomy of, 1447

sub-sternomastoid, 1002

of superficial extremity, 1009

of the superior extremity, 1006, 1009

superior hæmorrhoidal, 1016

supra-clavicular, 1003

supra-hyoid, 1002

surgical anatomy of, 1392

supra-mandibular, 999

supra-pancreatic, 1020

left, 1020

right, 1020

supra-umbilical, 1015

of thorax, 1013

trabeculæ of, 995

tracheo-bronchial, 1012

umbilical, 1015

of upper limb, 1006

visceral, of abdomen and pelvis, 1015

of thorax, 1010

nodules, aggregated, 1181

solitary, 1181

spaces, 994

perivascular, 995

Lymph trunk, intestinal, 997

broncho-mediastinal, 998

common lumbar, 998

descending, 997

jngtlar, 998

lumbar, 997

retro-aortic, 998

right jugular, 998

subclavian, 998

of brain, 1003

vessels, 993

of abdomen, 1017, 1022

of abdominal cord, 1022

viscera, 1822

wall, 1015

abnormalities of, 1059

of anterior wall of abdomen, 1015

of anus, 1019

of arm, 1006

of blood-vessels, 870

of bones, 87

of breast, 1010

of buttock, 1014

capillary, 1042

central, of hand, 1009

cerelbral, 1003

of cheeks, 1005

deep, 1015

of ductus deferens, 1018

of ear, 1004

endothelium of, 994
Lymph vessels of external acoustic meatus, 1004

of external genitals, 1015

extra-cranial, 1003

of eyeball, 1004

of eyelids and conjunctiva, 1004

follicles, 995

of foot, 1014, 1015

of forearm, 1009

of gums, ] 005

of hand, 1009

of head and neck, 1003, 1004,

of heart, 880

of inferior extremity, 1014

intra-cranial, 1003

of larynx, 1006

lateral aortic, 1024

of leg, 1014

of lips, 1005

of lower limb, 1014

of ling, 1013

meningeal, 1003

of middle ear, 1004

of nasal muco-periosteum, 1005

of the nose, 1004

of ovaries, 1018

of pelvic viscera, 1017

of pharynx, 1006

of pleura, 1013

pre-aortic, 1024

of prostate, 1018

of rectum, 1018

of rectum and anus, 1233

of salivary glands, 1006

of scalp, 1003

superficial, 10]4

of head, 1003

of teeth, 1005

of testis, 1018

of thigh, 1014

of thorax, 1010

of the thyreoid gland, 1006

of tongue, 1005

surgical anatomy of, 1382

of trachea and œsophagus, 1006

tunica externa of, 994

interna of, 994

media of, 994

of upper limb, 1009

of ureter, 1018

of urethra, female, 1018

male, 1017

of urinary bladder, 1018

of uterine tube, 1018

of uterus, 1018

lower part, 1018

of vagina, 1018

valves of, 994

vasa afferentia, 993

efferentia, 993

lymphatica, 994

of vesicles, seminal, 1018

visceral, of abdomen and pelvis, 1017, 1022

walls of, 994

Lymph-vascular system, 993

development of, 1042

M. tensor stapedins, 811

tympaui, 841

Macewen's operations for knock-knee, 1461

Macrodont skulls, 288 
Macula acustica sacculi, 847 utriculi, 846

cribrosa inferior, $84 t$ media, 843 superior, 843

flava of vocal fold, 1070

lutea, 815 structure of, 817

Maculæ, structure of, 847

Macular artery, 818

Maier, sinus of, 825

Male pronucleus, 20

Malleolar arteries, 957 of anterior tibial, 956 of posterior tibial, 953

Malleolus, lateral, 253 topography of, 1463 medial, 249 topography of, 1463

Malleus, 839 articulations of, 840 development of, 841 ligaments of, 841 movements of, 842 surgical anatomy of, 1368

Mamillary bodies, 541, 615 development of, 608 line, 1397

process of vertebræ, 96 ossification of, 104

Mamma, 1336

development of, 1339

lymph vessels of, 1010

Mammæ accessoriæ, 1338

Mammary artery, 916 gland, 1336 alveoli of, 1337 ampullæ of lactiferous ducts, 1338 areola of, 1337 areolar glands of, 1337 development of, 1339 lactiferous ducts of, 1338 lobes of, 1337 lymph vessels of, 1338 nerves of, 1339 papilla or nipple of, 1337 sinus of lactiferous ducts, 1338 stroma of, 1337 structure of, 1337 supernumerary, 1338 surgical anatomy of, 1446 variations in, 1338 vessels of, 1338

line, 1397

lymph glands, 1008

region, 1397

veins, 977

Mandible, 154

alveoli of, 156

angle of, 155

architecture of, 271

base of, 155

body of, 155

capitulum of, 156

condition at birth, 158

coronoid process of, 156

differences in, due to age, 158

movements of, 313

neck of, 156

ossification of, 157

ramus of, 156

surgical anatomy of, 1392
Mandible, variations in, 279

Mandibular arch, 43

muscles derived from, 496

muscles produced from, 496

nerve of, 778

course and branches, 778

canal, 156

corpus, 155

foramen, 156

notch, 156

veins, 993

Mantle-layer of neural tube, 502

Manubrium mallei, 841

sterni, 107

Margin, falciform of fossa ovalis, 404

infraorbital, 146

liber of ovary, 1311

pupillary, 813

supraorbital, 115

Marginal artery of heart, 887

layer of neural tube, 502

veins of heart, 959

Narrow, 83

gelatinous, 83

red, 83

yellow, 83

Marrow-cells, 83

Marshall, oblique vein of, 872,960

vestigial fold of, 872,882

Massa lateralis of atlas, 91

development of, 608

intermedia of brain, 617

Masseter muscle, 454

action of, 458

nerve-supply of, 457

Masseteric artery, 899

border of zygomatic bone, 153

fascia, 447,454

nerve, 779

vein, 965

Mastication, muscles of, 457 actions of, 457

nerve-supply of, 457

Mastoid cells, 836

surgical anatomy of, 1370

angle of parietal bone, 120

artery, 895

border-cells, 1370

canal, 129

foramen, 128

fossa, 1369

process, 128

development of, 1370

growtli of, 1370

ossification of, 133

relation of, to transverse process, of atlas, 178

sexual differences in, 193

surgical anatomy of, 1370

Matrix unguis, 859

Naturation of ovum, 15

Maxillæ, 146

interior surfaces of', 146

antrum of, 149, 186, 804, 1378

architecture of, 271

body of, 146

conchit of, 148

connexions of, 149

infre-temporal stirfaces of, 147

nasal surfaces of, $1 \$ 7$

orbital surfaces of, 147

ossification of, 149 
Maxillæ, processes of, 148

relation of, to nasal fossie, 183

to infra-temporal fossa, 168

to orbit, 162

tuberosity of, 148

variations in, 279

Maxillary antrum, 149, 186 opening of, $149,186,188,804$

relations of, 149, 186, 187, 188

surgical anatomy of, 1378

arteries, 898

lymph glands, internal, 998

maxillary nerve, 775

process, 49, 50, 76, 149

of inferior concha, 143

of palate bone, 151

sinus, 149

development of, 150

ossification of, 149

relation of, to nasal fossæ, $148,149,162$, $185,186,188$

to orbit, 162

skiagraphs of, 1379

surgical anatomy of, 1379

vein, internal, 968

morphology of, 1048

Maximum occipital point, 285

Measurements and indices in anthropology, 281

humero-femoral index, 289

intermembral index, 289

of limb bones, 289

platyknemic index, 289

platymeric index, 289

radio-humeral index, 289

of skulls, 285

tibio-femoral index, 289

Meatus, acoustic external, 830

bony part, 830

cartilaginous part, 830

ceruminous glands of, 832

condition in infancy of, 831

development of, 52, 831

diameters of, 830

foramen of Huschke of, 832

isthmus of, 830

lymph ressels of, 832

nerves of, 832

structure of, 831

surgical anatomy of, 1365

variations in and absence of, 278

vascular and nervous supply of, 832

auditory, internal, 135, 845

absence of, 278

area of facial nerve, 816

vestibularis inferior, $8+6$

crista transversa, $8 \pm 6$

foramen singulare, 846

fossula inferior, 846

superior, $8 \pm 6$

fundus of, 845

superior vestibular area, $8+6$

tractus spinalis foraminosus, $8 \pm 6$

of nose, atrium of, 803

inferior, 804

bony, 185, 188

surgical anatomy of, 1378

middle, 803

bony, 185, 188

surgical anatomy of, 1378

superior, 803

bony, 185̃, 188
Meatus, urinarius, 1308, 1284

Mechanism of foot, 361 of pelvis, 338

Meckel, band of, 841

cartilage of, 157,841

diverticulum of, 1420

ganglion of, 777,778

derelopment of, 796

Medial longitudinal bundle of brain, 588 plantar artery, position of, 1465

Median artery, 834 abnormalities of, 1055 morphology of, 1047

nerve, 705

surgical anatomy of, at elbow, 1450

in forearm, 1454

in upper arm, 1447, 1448

plane, 4

veins, 980

position of, in forearnı, 1454

surgical anatomy of, 1450

Median basilic vein, 980

surgical anatomy of, 1450

Median cephalic vein, 980

abnormalities of, 1058

medial longitudinal bundle, 558, 562, 570

surgical anatomy of, 1450

Mediastinal arteries, of aorta, 925 of internal mammary, 913

lymph glands, 1011, 1012

pleura, 1085, 1086, 1401, 1402

space, 1089

veins, 961, 963

Mediastinum, 1089

thoracis, 1089

dorsal, 1090

bomudaries of, 1090

centres of, 1090

middle, 1090

superior, 1089

ventral, 1090

boundaries of, 1090

centres of, 1090

Medulla of bone, 83

of kidney, 1265

Medulla oblongata, 543

ala cinerea of, 551

anterior area of, 545

fasciculus proprius of, 545,558

relation of, to medial longitudinal bundle, 558

antero-lateral furrow of, 544

antero-median groove of, 543 areas of, $\tilde{5} 45,547$

arcuate fibres of, 556

anterior external, 563,548

external, 548

internal, 560

posterior external, 563

area acustica, 551

development of, 554

anterior, 545

lateral, 545

posterior, 547

postrema, 551

vestibularis, 551

association fibres of, 564

calamus scriptorius of, 550

central canal of, 564

chorioidal plexuses of fonrth ventricle, 552

lateral aperture of, 553

median aperture of, 553 
Medulla oblongata, clava of, 547 closed part of, 544

corpus ponto-bulbare of, 548

cuneate tubercle of, 547

decussation of the pyramids, 545

development of, $33,515,536$

eminentia medialis, 551

external arcnate fibres, 548

fasciculus olivaris pyramiclis, 548

fissures of, 543

foramen cæcum of, 544

fossa rhomboidea of, 544

fovea inferior of, 550 development of, 554

funiculus cuneatus of, 559,547

gracilis of, 559,547

separans, 551

gray matter of, 33,515

internal structure of, 551

lateral area of, 545

funiculus of, 564

recess of, 552

somatic column of, 551

lemniscus fibres of, 561

locus cœruleus, 551

medial longitudinal bundle in, 558, 562

somatic column of, 551

nuclei of, $551,555,559$

oliva of, 546

olivary eminence of, 546

olivo-cerebellar fibres of, 556

open part of, 544

origin of nerves from, 481

position and connexions of, 564

posterior area of, 547

postero-lateral furrow of, 544

postero-median fissure of, 544

pyramidal (cerebrospinal) tract in, 545 decussation of, 545

development of, 533

pyramids of, 545

raphe of, 554,561

development of, 554

restiform body of, 547,562

sections of, 555,563

spino-cerebellar tract of, 564 relation of, to restiform body, 563

striæ medullares of, 550

substantia reticularis of, 564 development of, 551

sulcus lateralis anterior of, 544 posterior of, 544

tractus solitarius of, 597 development of, 593

trigontm, hypoglossi of, 551

development of, 554

vagi, 551

development of, 5.54

tuberculum cinereum of, 547

veins of, 972

white matter of, $557,560,562$

Medulla ossium, 83

flava, 83

rubra, 83

Medullary arteries, 87

cavity, 83

centre of cerebral hemisphere, 644

corona radiata of, 644

conus arteriosus, 876

folds, 23,74

groove, 23
Medullary lamina, lateral, of lentiform nucleus, 639

of thalamus, 611

medial, of lentiform nucleus, 639

of thalamus, 611

rays, 1265

sheath, 508,532

velum, 549

Megacephalic skulls, 284

Megadont skulls, 288

Mregalocolon, 1423

Megaseme skulls, 287

Meissner, corpuscles of, 865

Melanin, 858

Iembrana atlanto-occipitalis anterior, 310 posterior, 310

basilaris cochleæ, $845,849,850$

substantia propria of, 850

vas spirale of, 850

zona arcuata of, 850

hyaloidea, 819 pectinata of, 850

hyothyreoid, 1066

interossea antibrachii, 327

cruris, 350

limitans retinæ externa, 818

$$
\text { interna, } 817
$$

obturatoria, 338

pupillaris, 813

development of, 826

sterni, 316,317

tectoria, 311

of organ of Corti, 851

tympani, 834

annulus fibro-cartilagineus of, 834

appearance of, on examination, 1367

blood-vessels of, $8: 35$

dendritic fibres of, 835

development of, 52

examination of, 1367

folds of, 835

lymph vessels of, 836

malleolar folds of, 835

membrana propria of, 835

nerves of, 836

otoscopic appearances of, 835

paracentesis of, 1368

pars flaccida of, 835

tensa of, $83 \tilde{y}$

secundaria, 833

stratum circulare of, 835

cutaneum of, 835

mucosum of, 835

radiatum of, 835

surgical anatomy of, 1367

tectoria of cochlea, 851

triangular cone of, 835

$u$ mbo of, 835

restibularis, $8: 33$

Membranæ deciduæ, 57

Membrane, anal, 42

anterior occipito-atloid, 310

bones, 85,292

of brain, development of, 37

bucco-pliaryngeal, 39, 41, 42

chorionic, 53

cloacal, 39, 42, 48

costo-coracoil, 369

relation of, to axillary artery, 915

fenestrated, 868

fotal, 53,62

hyoglossal, 1129 
Memlorane, liyothrreoid, 1066 surgical auatomy of, 1387

interosseons, of forearm, 327 of $\operatorname{leg}, 350$

of Nasmrth, 1122

nictitating, 821

nuclear, 8, 9

obturator, 338

periosteal, 83

posterior occipito-atloid, 310

of Reissner, 849

of Shrapnell, 835

surgical anatomy of, 1367

of spiual medulla, 518

Membranes, fotal, 53

of spinal medulla, 669,675

Membranous cranium, 292

labyrinth, 846

urethra, 1304, 1307

surgical anatomy of, 1427

Tertebral column, 29, 102

Meningeal arteries, 902

lymph ressels, 1003

reins, 970

Meninges of brain, 667

of knee, 347

lateralis, 347

medialis, 347

Meniscus, 302

of acromio-clavicular joint, 318, 319

development of, 304

interarticular, 302

of knee-joint, 347

surgical anatomy of, 1460, 1461

of pubis, 337

of radio-carpal joint, 327

of sterno-clavicular joint, 318

of temporo-mandibular joint, 312

Mental artery, 899

foramen, 155

topography of, 1375

nerve, 780

protuberance, 155

spines, 156

tubercles, 155

Mentalis muscle, 4.51

action of 451

Merkel, philtrum ventriculi of, 1069

Mesaticephalic skulls, 285

Mesencephalic root of trigeminal nerve, 601

Meseucephalon, 33, 514, 516, 542, 581

development of, $33,31,592$

interual structure of, 584

stratum griseum centrale of, 584

lamina quadrigemina of, 584

nerve cells of, 584

fibres of, 588

Mesenteric arteries, inferior, 932 superior, 931, 1205

ganglion, superior, 765

lymph glands, 1020

plexus, inferior, 932 superior, 766

veins, 992

Mesenterico-mesocolic fold, 1185

Mesenteriolum processus vermiformis, 1216

Mesentery, 1163

development of, 1252

dorsal, 1252

folds of, 1163

of intestine, 1208

contents of, 1208
Mesentery, of intestine, folds of, 1208 root of, 1208

primitive, 1254

structure of, 1252

surgical anatony of, 1426

of testis, 1295

ventral, 1255

of vermiform process, 1216

Mesocephalic skulls, 284

Mesocolic glands, 1021

Mesocolon ascendeus, 1219

descendens, 1220

development of, 1253, 1254

iliac, 1222

pelvic, 1223

sigmoid, 1223

transverse, 1206, 1220, 1242

attachment of, 1206

topography of, 1422

Mesoderm, 23, 24, 25, 28, 30

cephalic, 30

ecto-mesoderm, 21, 25

lateral plates of, 30

paraxial, 27,28

primary, 21

secondary, 23

differentiation of, 25

somatic, 27

somites of, 27

splanchnic, 27

structures formed from, 30

Mesodont skulls, 288

Mesoduodenum, 1185

Mesogastrium, 1252

Mesognathous skulls, 287

Mesometrium, 1318

Mesonephros, 1327

Mesorchium, 1295

Mesorectum, 1223

Mesorhine skulls, 287

Mesosalpinx of uterine tubes, 1314, 1318

Mesoseme skulls, 287

Mesotympanum, 1368

Mesovarium, 1312, 1318

Mesuranic skulls, 287

Metacarpal arteries, 920,923

bones, 223

architecture of, 272

fifth, 226

first, 224

fourth, 226

ossification of, 226

second, 225

shafts of, 223

surgical anatomy of, 1454

third, 225

variatious in, 280

ligament, superficial transverse, 333

tubercle, 1451

Metacarpo-phalangeal joints, 333 topography of, 1454

Metacarpus, 223

Metaphase, 10

Metatarsal artery, 955, 958

bones, 265

architecture, 275

fifth, 267

first, 266

fourth, 267

ossitication of, 267

second, 266

third, 267 
Metatarsal bones, variations in, 282

ligaments, trausverse, 360

-superficial, 423

Metatarso-phalangeal joints, 360 movements at, 361 position of, 1465 surgical anatomy of, 1464, 1465

Metatarsus, 265

Metathalamus, development of, 35, 608

Metencephalon, 33, 515

early changes in, 515

Metopic skulls, 172 suture, 118

Metrio-cephalic skulls, $286^{\circ}$

Meynert, decussation of, 591

Microcephalic skulls, 284

Microdont skulls, 288

Microseme skulls, 287

Mid-brain, 33, 581

aquæductus cerebri of, $581,58 \pm$ development of, 592

basilar part of, 565

brachium conjunctivum in, 587

central gray matter of, 584

cerebro-pontine fibres of, 591

corpora quadrigemina of, 582,586

corpus trapezoideum of, 567

deep origin of nerves from, 591

development of, 592

fasciculus retroflexus of, 591

fountain decussation of, 589,591

frenulum veli of, 582

development of, 592

ganglion interpedunculare of, 591

internal structure of, 565

lamina quadrigemina of, 584

lateral sulcus of, 584

lemniscus fibres of, 590

medial longitudinal bundle of, 568, 570, 588

nuclei of, $568,582,584,588$

oculo-motor sulcus of, 584

pedunculi cerebri, 583

pyramidal fibres of, 591

situation and connexions of, 581

stratum griseum centrale of, $\mathbf{5 8 4}$

intermedium of, 584

substantia nigra of, $58 \pm$

in hypothalamic region, 584, 614

tegmentum of, 586

veins of, 971

Mid-clavicular line, 1357

Mid-gut, 48

derivatives of the, 47

relation of, to Meckel's diverticulum, 1210, 1250

structures derived from, 47

Mid-sternal line, 1357

Middle-ear, 832

Migrations of nerve-cells, 554

Milk-teeth, 1121

eruption of, 1113

surgical anatomy of, 1381

Mitochondria, 8

Mitochondrial sheath, 18

Mitosis, 9

heterotype, 11

homotype, 9

Nitral area, 1405

cells, 623

orifice, 876,878

valve, 878
Mitral valve, cusps of, 878

level of, 1.142

topography of, 1405

Moderator band, 877

Modiolus, 844

Molar artery, 899

glands, 1109

teeth, 1117

development and eruption of, 1244, 1246

deciduous dentition of, 1121

Molecular layers of retina, 816,817

Moll, glands of, 823,827

Mons Veneris, 1324

Montgomery, glands of, 1337

Monticulus, $57 \pm$

Morgagni, appendices vesiculosi of, 1316 columns of, 1230

surgical anatoniy of, 1431

Morphology, 2

of aorta, 1046

of aortic arches, 1046

of appendicular skeleton, 294

of arteries, 1042

of cerebral nerves, 795

of cervical plexus, 700

of descending aorta, 1016

of head-muscles, 496

of ligaments, 305

of limb-girdles, 295

of limb-rnuscles, 495

of limb-plexuses, 741

of limbs, 294

of posterior rami of spinal nerves, 691

of primitive streak, 26

of pudendal plexus, 748

of scapula, 203

of segmental arteries, 1043

of skeletal muscles, 495

of skull, 293

of synpathetic system, 795

of tarsus, 295

of teeth, 1218

of vascular system, 1042

of veins, 1047

Morula, ㄹ

Moss-fibres, 581

Motor area of the brain, 663

face, 1361

lower extremity, $136 \mathrm{I}$

position of, 1360

upper extremity, 1361

Mouth, 1106

angle of the, 1108

aperture of, 1106

buccal glands of, 1109

cavity of, 1106

proper, 1107

corpus adipostum of, 1109

development of, 124 ?

floor of, 1107

labial glands of, 1109

molar glands of, 1109

nucous nembrane of, 1111

muscles of, 450

plica sublingualis of, 1108

primitive, 41

inof of, 1107, 1110

sublingual caruncle of, 1108

region of, 1108

restibule of, 1106

Movable joints, 300

kidner, 1425 
Movements at ankle-joint, 35:3, 436

at atlanto-occipital joints, 311

of anditury ossicles, 842

at carpo-metacarpil joint of thumb, 332

at claricular joints, 319

at elbow-joint, 3:5

of fingers, 401

of head, 446,464

of the hip-joint, 342,421

of liyoid bone, 464

at the joints of the foot, 361

of the joints of the hand, 334

in leaping, 437

in locomotion, 436

of lower $\operatorname{limb}, 436$

of pelvis, 446

of radio-car'pal joint, 329

of radius on ulna, 328

in respiration, 474

in running, 437

of shoulder girdle, $46 t$

at shoulder-joint, 323,377

in swallowing, 467

of thumb, 401

of thyreoid cartilage, 464

of the toes, 436

of tongue, $46 \pm$

of vertebral column, 309

in walking, 436

Mucous glands, 1131

Müllerian duct, 1328

development of, 1330

Multifidus spinæ muscle, 442 action of, 444

nerve-supply of, 444

Multitubercular teeth, 1248

Muscle or Muscles; Musculus or Musculi, 363

of abdominal wall, 474

actions of, 484

nerve-supply of, 484

abductor digiti quinti (of hand), 393, 433 action of, 393 nerve-supply of, 393,433

(of foot), 433 action of, 433 nerve - supply of,

hallucis, 432,434 433

action of, 434

nerve-supply of, 434

oblique head of, 434

surgical anatomy of, 1465

transverse head, 434

pollicis brevis, 392

action of, 392

nerve-supply of, 392

longus, 399

actions of, 400

nerve-supply of, 400

adductor brevis, 412

action of, 412

nerve-supply of, 412

hallucis, caput obliquunı, 434

action of, 434

nerve-supply of, 434

caput transversum, 434

action of, 434

longus, 411

nerve-supply of, 434

action of, 412
Muscle or Muscles-continued

adductor longus, nerve-supply of, 412 surgical a natomy of, 1459

magnus, 412

action of, 413

nerve-supply of, 413

relations, 413

surgical anatomy of, 1461

minimus, 413

adductor pollicis, 393

action of, 393

nerve-supply of, 393

oblique part, 393

transverse part, 393

pollicis, caput obliquum, 393 action of, 393 nerve-supply of, 393

caput transversum, 393 action of, 393 nerve-supply of, 393

agitator caudæ, 415

anconæus, 398

action of, 398

nerve-supply of, 398

of ankle-joint, 353,436

antitragicus, 829

appendicular, 365

of arm, 378

arrectores pilorum, 861

artieularis genu, 408

aryepiglotticus, 1074

action of, 1076

nerve-supply of, 1077

arytænoideus obliquus, 1074

transversus, 1074

auricularis anterior, 149

posterior, 449

superior, 449

nerve-supply of, 449

axial, 365,437

axillary arches, 371

of back, 438

serratus posterior inferior, 439

actions, 439 .

nerve-supply, 439

superior, 438

actions, 439

superficial, 365

nerve-supply, 439

action of, 381

insertion of, 380

nerre-supply of, 381

biceps brachii, 380

action of, 381

nerve-supply of, 381

surgical anatomy of, 1450

femoris, 418

action of, 420

nerve-supply of, 420

surgical anatomy of, 1460

biventer cervicis, 442

brachialis, 381

action of, 381

nerve-snpply of, 381

brachio-radialis, 396

action of, 396

nerve-supply of, 396

topography of, 1454

buccinator, 451

action of, 452

nerve-supply of, 452

bucco-pharyngens, 464 
Muscle or Muscles-continued

bucco-pharyngeus, actions of, in female, 488

nerve-supply of, 488

bulbo-cavernosus (female), 487

of buttock, 414

$$
\text { (male), } 487
$$

actions of, 415

nerve-supplies of, 415

caninus, 451

action of, 452

nerve-supply of, 452

cerato-pharyngens, 464

cervicalis ascendens, 440

action of, 442

nerve-supply of, 442

chondro-epitrochlearis, 371

chondro-glossus, 462

chondro-pharyngeus, 464

ciliaris, 813

cleido-mastoid, 458

cleido-occipitalis, 458

coccygeus, 495

actions, 495

nerve-supply, 495

compressor bulbi, 487

hemispherium bulbi, 487

naris, 450

urethræ membranaceæ, 488

constrictor pharyngis inferior, 465

development of, 496

nerve-supply of, 465

medius, 464

action of, 467

development of, 496

nerve-supply of, 465

superior, 464

action of, 464

development of, 496 nerve-supply of, 465

coraco-brachialis, 378

action of, 380

morphology, 379

nerve-supply of, 380

surgical anatomy of, 1446,1447

topography of, 1293, 1295

coraco-brachialis superior, 332

corrugator cutis ani, 486, 1229

supercilii, 450

action of, 487

nerve-supply of, 487

costo-coracoidells, 371

cremaster, 480

crico-arytænoidei, 1072, 1074

action of, 1072, 1074

crico-pharyngeus, 465

crico-thyreoideus, 1075

action of, 1076

nerve-supply of, 1077

dartos, 485

deltoideus, 373

action of, 374

nerve-supply of, 374

relations of, 374

topography of, 374

depressor alæ nasi, 450

development of, 495

diaphragm, 471

digastric, 461

action of, 458

development of, 496

nerve-supply of, 461
Minscle or Muscles-continued,

dilatator pupillæ, 814

dilator naris, 450

tubæ, 838

dorso-epitrochlearis, 370

with double nerve-supply, 750

of ear, extrinsic, 449

intrinsic, 829

epicranins, 448

action of, 449

nerve-supply of, 449

epitrochleo-anconeus, 398

erector clitoridis, 488

penis, 488

sacrospinalis, 439

action of, 442

nerve-supply of, 442

extensor carpi radialis brevis, 396

action of, 396

nerve-supply of, 396

longus, 396

action of, 396

nerve-supply of, 396

ulnaris, 398

action of, 398

digiti quinti proprius, 398

nerve-supply of, 398

action of, 398

nerre-supply, 398

digitorum brevis, 426

action of, 426

nerve-supply of, 426

topography of, 1465

digitorum communis, 397

action of, 397

nerve-supply of, 397

digitorum longus, 425

action of, 425

nerve-supply of, 425

topography of, 1465

hallucis longus, 426

action of, 426

additional slips of, 426

nerve-supply of, 426

topography of, 1465

indicis proprius, 400

action of, 400

nerve-supply of, 400

action, 375

nerve-supply, 400

pollicis brevis, 400,426 action of, 400 nerve-supply of, 400

pollicis longus, 400 action of, 400 nerve-supply of, 400

quinti digiti proprius, 398

extrinsic, 462

of eye, action of, 454

nerre-supply of, 454

of eyeball, molphology of, 4.52

of eyelids, 450

action of, 452

nerve-supply of, 452

of face, 450

derelopment of, 496

ficial, actions of, 451

nerve-supply of, 457

fasciculi of muscles, 363

flexor carpi radialis, $3 \& 5$

action of, 386

bursa of, 386 
Yuscle or Muscles-continned

flexor carpi radialis, nerve-supply of, 386 topography of, 1452

ulnaris, 386

action of, 387

nerve-supply of, 387

caudie, 494

digiti quinti brevis of hand, 394,435

of toot, action of, 394,435 nerve-supply of, $39 \pm, 435$

digitorum brevis, 433

action of, 433

nerve-supply of, 433

communis, 397

action of, 397

nerve-supply, 397

longus, 430

action of, 430

nerve-supply of, 430

profundus, 388

action of, 389

nerve-supply of, 389

sublimis, 388

action of, 388

nerve-supply of, 388

hallucis brevis, 434

action of, 434

nerve-supply of, 434

longus, 431

action of, 431

nerve-supply of, 431

pollicis brevis, 393

action of, 393

nerve-supply of, 393

longus, 390

action of, 390

nerve-supply of, 390

of foot, $424,430,432,435$

actions of, 435,436

nerve-supply of, 435,436

surgical anatomy of, 1463,1464

of forearm, 382

deep, 389,398

dorsal, 395

superficial, 385,395

on tront of leg and dorsum of foot, 424

frontalis, 148

galea aponeurotica, 449

actions, 449

nerve-supply, 149

gastrocnemius, 428

action of, $4: 29$

nerve-supply of, 429

topography of, 1462,1463

gemellus inferior, 418

action of, 418

nerve-supply of, 418

superior, 418

action of, 418

nerve-supply of, 418

genio-glossus, 462

action of, 463

nerve-supply of, 463

surgical anatomy of, 1383

genio-hyoid, 461

action of, 462

nerve-supply of, 462

glosso-palatine, 463, 467

action of, 467

nerve-supply of, 467

glosso-pharyngeus, 464

glutæus maximus, 415
Muscle or Muscles--continued glutæus maximus, action of, 415 nerve-supply of, 415 topography of, 1455 medius, 416 action of, 416 nerve-supply of, 416 ninimus, 416 action of, 417 nerve-supply of, 417

gracilis, 411

action of, 411

nerve-supply of, 411

hamstring, 418

topography of, 1456

of hand, 391

short, 382

of head, 448

of heart, 878

helicis major, 829

minor, 829

hyo-glossus, 462

action of, 463

nerve-supply of, 463

of hyoid bone, 459

iliacus, 410 action of, \pm 11 nerve-supply of, 411

minor, 410

ilio-capsularis, 410

ilio-coccygeus, 494

ilio-costalis, 439

cervicis, 440

dorsi, 439

lumbor'um, 439

ilio-psoas, 409

action of, 411

bursa of, 1459

nerve-supply of, 411

surgical anatomy of, 1459

ilio-sacralis, 494

infracostal, 470

infrahyoid, 459

action of, 460

nerve-supply of, 460

infraspinatus, 375

action of, 375

nerve-supply of, 375

insertion of, 364

intercostal external, 470

action of, 474

nerve-supply of, 474

internal, 470

action of, 474

nerve-supply of, 474

interosseous volar of hand, 394 action of, 395

dorsal, 395

nerve-supply of, 395

pedis, 435

action of, 435

nerve-supply of, 435

interspinal, 445

intertransverse, 445

intrinsic, of tongue, 463

ischio-bulbosus, 487

ischio-cavernosus, 488

actions of, 488

female, 488

male, 488

nerve-sipply of, 488

ischio-coccygeus, 494 
Muscle or Muscles-continued

ischio-pubicus, 488

labii inferioris, 451

laryngeal, 1072

on lateral side of leg, 426

latissimus dorsi, 366

action of, 368

nerve-supply of, 368

surgical anatomy of, 1437

levator ani, 490, 493, 1229, 1232 actions, 495 nerve-supply, 494

glandulæ thyreoideæ, 460

palatini reli, 466

action of, 467

nerve-supply of, 467

palpelbræ superioris, 452

action of, 453

nerre-supply of, 453

scapulæ, 368

action of, 368

nerve-supply of, 368

levatores costarum, 470

action of, 474

nerve-supply of, 474

of limbs, development of, 41

lingualis inferior, 462,463

superior, 463

of little finger, 393

longissimus capitis, 440

action of, 442

nerve-supply of, 442

cervicis, 440

dorsi, 440

longus capitis, 468

action of, 468

colli, 468

nerve-supply, 468

lumbricales, 389,430

of foot, 430

action of, 430

nerve-supply of, 430

of hand, 389

action of, 389

nerve-supply of, 389

Inasseter, 454

action of, 458

nerve-supply of, 457

of mastication, 454,457

action of, 457

nerre-supply of, 457

temporalis, 455

mentalis, 451

action of, 452

nerve-supply of, 452

morphology of, 495

of month, 450

of Miiiller, 454

multifidus (spinæ), 442

action of, $1+4$

nerre-supply of, $14 t$

mylo-hyoid, 461

action of, 463

nerve-supply of, 461

mylo-pharyngeus, 464

of neek, 458

of nose, 450

actions of, 452

nerve-supply of, 452

obliquus abdominis externus, 476
Mruscle or Minscles-continued

obliquus abdominis intermus, 487 action of, $48 t$ inferior (of eye), 453 nerve-supply of, 484

auriculæ, 830 superior (of eje), 453

capitis inferior, 444

action of, $44 t$

nerve-supply of, $44 t$

superior, 444

action of, 444

nerre-supply of, 444

obturator externus, 413

action of, 414

nerve-supply of, 414

internus, 418

action of, 418

nerve-supply of, 418

occipitalis, 448

omohyoid, 459

action of, 460

nerve-supply of, 460

surgical anatomy of, 1391, 1394

opponens digiti quinti, 393

action of, 394

nerve-supply of, 394

opponens pollicis, 392

action of, 393

nerve-supply of, 393

orbicularis oculi, 450

action of, 452

ciliary bundle of, 450

lacrimal part of, 450

nerve-supply of, 452

orbital part of, 450

palpebral part of, 450

orbicularis oris, 450,1100

action of, 452

inferior incisire bundle of, 451

naso-labial band of, 450

nerve-supply of, $t 52$

smperior incisire bundle of, 451

orbicnlaris palpebrarum, 452

ciliary arteries, 450

of orbit, 452

action of, $45 t$

development of, 496

nerve-supply of, $45 t$

orbitalis, 454

origin of, 364

palmaris brevis, 382

longus, 386

action of, 386

nerve-supply of, 386

papillares (of heart), $87 \%, 878$

structure of, 879

pectinati, 874

pectineus, 411

action of, 411

nerve-supply of, $t 11$

of pectoral region, 369

pectoralis najor, 369

action of, 370

nerre-supply of, 370

topography of, 1446

minimus, 371

minor, 371

action of, 371

nerve-supply of, 371

of pelvis, 493

perinenu, 486 
Muscle or Muscles-continued

peronæo-calcaneus, 431

externus, 427

peronæo-cuboidens, 427

peronæus accessorints, 427

brevis, 427

action of, 427

additional slips of, 427

nerre-supply of, 427

topography of, 1462

of tendon of, 1464, 1465

digiti quinti, 427

longus, 426

action of, 427

nerve-supply, 427

topography of, 1462

of tendon of, 1464, 1465

tertius, 425

action of, 426

nerve-supply of, 426

peroneal, 427 topograpliy of, 1465

pharyngo-palatinus, 465

action of, 467

nerve-supply of, 467

of pharynx, 464

action of, 467

development of, 496

nerve-supply of, 467

of pinna, 449,829

piriformis, 417

action of, 418

nerve-supply of, 417

plantaris, 429

action of, 429

nerve-supply of, 429

platysma, 448

action of, 448

development of, 496

nerve-supply of, 448

popliteus, 429

action of, 429

nerve-supply of, 429

minor, 429

on posterior aspect of leg, 428

procerus, 450

action of, 452

pronator quadratus, 390

action of, 391

nerve-supply of, 391

pronator teres, 385

action of, 385

nerve-supply of, 385

psoas major, 410

action of, 411

nerve-supply of, 410

surgical anatomy of, 1459

psoas minor, 410

action of, 411

nerve-supply of, 410

pterygoideus externus, 455

action of, 457

nerve-supply of, 457

internus, 4.57

action of, 457

nerve-supply of, 457

pterygo-pharyngeus, 464

pubo-cavernosus, 488

pubo-coccygeus, 494

pubo-rectalis, 494

pubo-vesicalis, 1283

pyramidalis abdominis, $48 \mathrm{I}$
Mnscle or Muscles-continued quadratus femoris, 418

action of, 418

nerve-supply of, 418

quadratus labii inferioris, 451

action of, 452

nerve-supply of, 452

septi, 450

triangularis, 451

quadratus labii superioris, 451

caput angulare, 451

infra-orbitale, 451

zygomaticum, 451

quadratus lumbortum, 485

actions of, 485

nerve-supply, 485

surgical anatomy of, 1437

quadratus plantæ of foot of, 431

action of, 431

nerve-supply of, 431

quadriceps femoris, 406

action of, 409

nerve-supply of, 409

recti (of eye), 453

recto-coccygeus, 1229

recto-urethralis, 1229

recto-uterine, 1238

recto-vesical, 1283

rectus abdominis, 481

capitis anterior, 468 action, 468

nerve-supply, 468

lateralis, 445,470

action of, 445,470

nerve-supply of, 445,470

major, 444

minor, 444

posterior major, 444

actions, 444

nerve-supply, 444

posterior minor, 444

actions, 445

rectus femoris, 407

nerve-supply, 445

action of, 409

nerve-supply of, 409

rectus inferior, 453

action of, 454

nerve-supply of, 454

rectus lateralis, 453

action of, 454

nerve-supply of, 454

rectus medialis, 453

action of, 454

nerve-supply of, 454

rectus superior, 453

action of, 454

nerve-supply of, 454

of respiration, 470,474

action of, 474

nerve-supply of, 474

rhomboid, action, 369

nerve-supply, 369

rhomboid major, 368

action of, 369

nerve-supply of, 369

rhomboid minor, 368

action of, 369

nerve-supply of, 369

of Riolan, 823

risorius, 4.51

action of, 452 
Muscle or Muscles-continued

risorius, nerve-supply of, 452

rotatores (dorsi), 445

rotatores (dorsi), action of, 445

nerve-supply of, 445

sacro-spinalis, 439

salpingo-pharyngeus, 465

nerve-supply of, 465

relation of, to salpingo-pharyngeal fold, 838

sartorius, 406

action of, 406

nerve-supply of, 406

topography of, 1459

scalenus anterior, 467

action of, 468

nerve-supply of, 468

medius, 467

action of, 468

nerve-supply of, 468

posterior, 467

action of, 468

of scalp, 448

nerve-supply of, 468

action of, 449

nerve-supply of, 449

semimembranosus, 420

action of, 421

nerve-supply of, 421

topography of, 1458

semispinalis capitis, 442

actions of, 442
nerve-supply of, 442
cervicis, 442
action of, 444
nerve-supply of, 444
dorsi, 442

semitendinosus, 419

action of, 420

nerve-supply of, 420

topography of, 1450

septi, 450

serratus anterior, 372

action of, 372

insertion, 372

nerve-supply of, 372

topography of, 1446

serratus posterior inferior, 439 action of, 439 nerve-supply of, 439

serratus posterior superior, 438 action of, 439 nerve-supply of, 439

of shoulder, 373

skeletal, 363

perimysium externum of, 363 internum of, 363

of soft palate, 466

actions, 467

developinent of, 496

nerve-supply of, 467

of sole of foot, 432,434

soleus, 429

action of, 429

nerve-supply of, 429

topography of, 1461, 1462

sphincter ani exterutis, 486, 1232 action of, 1232 nerve-supply of, 1233

inter'nus, 1229, 1232

pupilla, 814

pylori, 1166, 1174

recti, 1229
Muscle or Muscles-continued

sphincter ani, urethræ in female, 489 actions, 489

nerve-supply, 489

sphincter urethræ membranaceæ, 488

sphincter vaginæ, 487

sphincter vesicæ, 1284

spinalis dorsi, 442

splenius capitis, 439

action of, 439

nerve-supply, 430

splenius cervicis, 439

action of, 439

nerve-supply of, 439

stapedius, $84 \overline{1}$

sternalis, 370

nerve-supply, 370

sterno-clavicular, 372

sterno-cleido-mastoid, 372

action of, 458

nerve-supply of, 458

sterno-hyoid, 459

action of, 460

nerve-supply of, 460

sterno-mastoid, action of, 458

nerve-supply of, 458

surgical anatomy of, 1390

sterno-thyreoid, 459

action of, 460

nerve-supply of, 460

stylo-auricular, 830

stylo-glossus, 463

action of, 463

nerve-supply of, 463

stylo-hyoid, 461

action of, 462

development of, 496

nerve-supply of, 461

stylo-pharyngeus, 465

action of, 467

development of, 496

nerve-supply of, 465

subanconæus, 382

subclavins, 371

action of, 371

insertion, 371

nerve-supply of, 371

subcostal, 470

action of, 474

nerve-supply of, 474

subscapular, 377

actions, 377

nerve-supply of, 377

minor, 377

supercilii, 450

supinator, 398

action of, 399

nerve-supply of, 399

supra-hyoid, 460

action of, 462

nerve-supply of, 457,461

supraspinatus, 375

action of, 375

nerve-supply of, $\mathbf{3 7 5}$

suspensory of the duodenum, 1187

temporal, 455

action of, 4.58

nerve-supply of, 457

tensor fascia latie, 415

$$
\begin{aligned}
& \text { action of, } 416 \\
& \text { nerre-supply of, } 416 \\
& \text { topograplyy of, } 1459
\end{aligned}
$$


Inscle or MIuscles-continued

tensor fasciz suralis, 419

$$
\begin{aligned}
& \text { tarsi, } 450 \\
& \text { action of, } 452 \\
& \text { nerre-supply of, } 452 \\
& \text { trmpani, s } 41 \\
& \text { surgical anatomy of, } 1368 \\
& \text { veli palatini, } 466 \\
& \text { relation of, to auditory tube, } \\
& \quad 838 \\
& \text { surgical anatomy of, } 1385
\end{aligned}
$$

teres major, 376

action of, 377

nerve-supply of, 377

relations of, 377

minor, 375

action of, 376

nerve-supply of, 376

of medial side of thigh, 411

actions of, 411,414

nerve-supplies of, 411,414

on anterior aspect of thigh, 405

on posterior aspect of thigh, 418

thoracis, 470

actions of, 474

nerve-supplies of, 474

of thumb, 392, 393

actions of, 392,393

nerve-supplies of, 392, 393

thrreo-arytienoid, 1073

action of, 1076

nerve-supply of, 1077

thrreo-epiglottic, 1075

thyreo-hyoid, 460

action of, 460

nerve-supply of, 460

thyreo-pharyngeus, 465

tibialis anterior, 424

action of, $42 \pm$

nerve-supply of, $42 t$

topography of tendon, 1465

tibialis posterior, 431

action of, 431

nerve-supply of, 431

topography, 1465

tibio-fascialis anterior, 424

of tongue, 462

action of, 463

arrangement of, 462

derelopment of, 496

morphology of, 496

nerve-supply of, 463

surgical anatomy of, 1382

trachealis, 381, 1081

action, 381

insertion of, 381

nerve-supply, 381

tragicus, 829

transterse, of tongue, 463

transversus abdominis, 480

auriculæ, 830

perinei profundus, 488

superficialis, 487 actions of, 487 nerve-supply, 487

thoracis, 470

action of, 474

nerve-supply of, 474

trapezius, 365 aginæ, 489

action of, 366

nerre-supply of, 366
Mruscle or Muscles-continued trapezius, topography of, 1437

triangularis, 451 oris, 451

triceps brachii, 381

actions of, 382

insertion, 381

nerve-supply of, 382

origin, 381

topography of, $1 \pm 37$

femoris, 418

suræ, 428

of tympanic cavity, 841

of upper limb, 365

uvulæ, 466

nerve-supply of, 467

vastus intermedius, 408 action of, 409 nerve-supply of, 409

vastus lateralis, 407 action of, 409 nerve-supply of, 409 topography of, 1459

vastus medialis, 408 action of, 409 nerve-supply of, 409 topography of, $1+59$

verticalis linguæ, 463

vocalis, 1076

zygomaticus, 457 action of, 452

nerve-supply of, 452

caput zygomaticum of quadratus, 451 action of, 452 nerve-supply of, 452

Muscle-celis, 363

Muscle-plate, 30

Muscular process of arytænoid cartilage, 1065 1074

of vertebrx, 95,96

system, 363

triangle of neck, 1387

Musculo-cutaneous nerve, of arm, 704

Iusculo-phrenic artery, 913

vein, 963

Musculus recto-uterinus, 1318

Myelencephalon, 575

development of, 33

Myelin, 508

Myelinisation of nerves, 533

Myelospongium, 503

Mylohyoid artery, 899

groove, 156

muscle, $46 I$

action of, 463

nerve-supply of, 461

nerve, 780

ridge, 156

Myocardium, 878

Myoccle, 29

Myology, 368

Myotomes, 495

cephalic, 496

cervical, 796

number of, 496

Myrtiform fossa, 146

Naboth, ovules of, 1320

Nail, 858

bed of, 859

development of, 41, 862

eponychium, 859 
Nail, in fœtus, 78

lunula of, 859

matrix of, 859

papillæ of, 859

vallum of, 859

wall, 859

Nasal aperture, anterior, 163

arteries, 899, 900

bone, 145

ossification of, 145

relation of, to nasal aperture, 164 to nasal fossæ, 181

cartilages, 800

greater alar, 800

lateral, 800

lesser alar, 800

processus sphenoidalis of, 801

of septum, 800

vomero-nasal, 801

cavity, 801

duct of, fronto-nasal, $80+$

lymph vessels of, 806

nerve-supply of, 805

olfactory cleft of, 803

ostium maxillare, 804

crest, 802

limen nasi of, 802

relation of to nasal septum, 186

restibule of, 802

Nasal fossa, 801

agger nasi of, 803

atrium of, 803

basal cells of, 805

blood-vessels of, 805, 806

Bowman's glands of, 804

bulla ethmoidalis of, 803

cavernous tissue of, 806

development of, 50

epithelium of, 804,805

hiatus semilunaris of, 803

inferior meatus of, 804 surgical anatomy of, 1378

infundibulum of, 803

lateral wall of, 802

limen of, 802

lymph vessels of, 1004

middle meatus of, 803 surgical anatomy of, 1378

olfactory cells of, 804

part of, 802,803 mucons membrane of, 805

organ of Jacobson of, 802

orifices in, 801, 802, 803

recessus naso-palatinus of, 802

spheno-ethmoidalis of, 802

respiratory part of, 802,803 mucous membrane of, 804

sensory nerves of, 805

superior meatus of, 803

supporting cells of, 804

vestibule of, 802

Nasal index, 287, 799

laminæ, 50

muco-periosteum, 1005

naso-ciliary nerve, 773

noteh, of frontal bone, 115

of maxilla, 146, $14 \bar{\tau}$

part of frontal bone, 117

lateral, 49

median, 49

of the pharnyx, 1141, 114.2

development of, 1248
Nasal part of the pharynx, fossa of Rosenmiiller of, 1144

orifice of auditory tube, 1143

surgical anatomy of, 1383

tonsil of, 1145

pit, 798

septum, 802

bony, 175,185

development of, 40

spine, anterior, 146, 149, 164

topography of, $137 \pm$

of frontal bone, 116

posterior, 151, 174

veins, 968

Nasion, 285

Nasmyth, membrane of, 1122

Naso-facial angle, 799

Naso-frontal suture, 160

Naso-labial band, 450

Naso-lacrimal duet, 825

bony canal of, $143,148,186,188$

development of, 49

surgical anatomy of, $137 \mathrm{~T}$

Naso-palatine artery, 900

nerve, 778

recess, 802

Naso-pharyngeal groove, 1143

Navicular bone, of foot, 261 morphology of, 1464 position of tuberosity of, 1464

of hand, 218

surface anatomy of, 1451

variations in, 286

fossa, 138

Naviculo-cuboid joints, 357

Naviculo-cuneiform joints, 357

Neck, abscesses of, 1385

anterior triangle of, 1390

arteries of, 888

carotid triangle of, 1391

deep cervical glands, 1392

lateral muscles of, 467

development of, 42,47

digastric triangle of, 1391 surgical anatomy of, 1391

fasciæ of, 1386, 1389

fascial compartments of, 1385

infrahyoid region of, 1387, 1388

lymph ressels of, 1003

medial line of, 1387

muscles of, 458

muscular triangle of, 1383

nuchal furrow of, 1395

posterior triangle of, 1390

sub-occipital triangle of, 1395

suprahyoid region of, 1387

surgical anatomy of, 1385

triangles of, 1390

Nelaton, line of, 1455

Neopallium, 624, 628, 645

Nerve or Nerves; Nervus or Nervi

abducens, 781

course and communications, 781

deep connexions of, 600

derelopment of, 798

morplology of, 798

nucleus of, 600

relation of, to medial longitudinal bundle, 600

origin of, deep, 600

superficial, 781

accessory, 791 
Nerve or Nerres-continned accessory, morphology of, 797

deep origin of, 595

derelopment of, 592, 684

external ramus (spinal part) of, 791,793

derelopment of, 592, 684

morphology of, 797

internal ramus (accessory part) of, 791, 793

development of, 592, 684

morphology of, 797

medullary part of, 595

mucleus of, 595

superficial origin of, 596, 793

surgical anatomy of, 1393

accessory, obturator, 726

acusticus, 852

ampullary branches of superior and lateral, 785,853

central connexions of, 606

cochlear division of, 604

termination of, 852

development of, 552-554, 796, 798

in labyrinth, 852

morphology of, 796

nuclei of, 604

origin of, deep, 604

superficial, 784

utricular branch of, 785,853 nuclei of, 604

vestibular division of, 601

ganglion of, 853

termination of, 853

to adductor magnus muscle, from obturator, 723

from sciatic, 729

alveolar, anterior smperior, 777

inferior, 780

branches of, 780

mental nerve, 780

mylohyoid nerve, 780

middle stuperior, 777

posterior superior, 775

to ankle-joint, from deep peroneal, 731, 733

from tibial, 732

ano-coccygeal, 738

anterior supra-clavicular, 696 morphology of, 700

to arteries, 870

to articulations of foot, from deel' peroneal, 731

from lateral plantar, 735

from medial plantar, 734

from tibial, 733

of auditory tube, 838

auricular anterior of auriculo-temporal, 780 great, 695,696

morphology of, 700

posterior, 783

auricular branch of vagus, 788

auriculo-temporal, 779

meatal branches of, 780

morphology of, 700

parotid branches of, 780

axillary, 710

bigeminal, 727

of blood-vessels, 870

of bones, 87

to brachial artery, 765

buccal branch of facial, 784 of trigeminal, 779

to bulb of urethra, 740

calcanean, medial, 734
Nerve or Nerves-continued

canalis pterygoidei (Vidii), 777

cardiac, of vagus, 789 recurrent left, 789

right, 789

inferior, of sympathetic, 759

middle, 759 of vagus, 789

of sympathetic, 757,759

carotici externi, 757

$$
\text { of vagus, } 789
$$

carotico-tympanic, 759, 786

caroticus internus, 757

to carpal joints, 329

caudal, 691, 738

cells, 497, 506

cerebral, 767

afferent roots of, development of, 796 morphology of, 796

connexion of, with superior cervical ganglion, 756

deep connexions of, in cerebrum, 619 in medulla oblongata and pons, 592 in mesencephalon, 600

development of, 795

efferent roots of, development of, 796 morphology of, 796

general distribution of, 767

list of, 678,767

morphology of, 795, 796

motor nuclei of, 592

nuclei of origin of, 592

of termination of, 593

roots of, 767

segmental characters of, 795, 796

1st, olfactory, 767

2nd, optic, 768

3rd, oculomotor, 769

4th, trochlear, 770

5 th, trigeminal, 771

6th, abducens, 781

7th, facial, 781

8 th, acustic, 784

9th, glossopharyngeal, 785

10th, vagus, 786

11th, accessory, 791

12th, hypoglossal, 793

cervical, 692

anterior rami, 692, 700

descending, 696

first, 688,695

gray rami of, 692

chorda tympani, 782

branches of, to sublingual gland, 782, 1140 to submaxillary gland, 782, 1138

development of, 796

morphology of, 796

relation of, to lingual nerve, 780

to taste, 855

tympanic aperture of, 834

in tympanum, 782, 1368

ciliary, long, 773

short, 773

circumflex, 710

axillary, 710

surgical anatomy of, 1447

topography of, 1447

clunium inferiores, 737

coccygeus, 691

to coccygeus muscle, 738

cochlear, 785

deep origin of, 604 
Nerve or Nerves-continued.

common peroneal, $728,729,730$

branches of, 730

surgical anatomy, 1457

tibial, 732

surgical anatomy of, 1458

to constrictors of pharynx, from glossopharyngeal, 786

from vagus, 788

to corpus cavernosum penis, 740

to cremaster muscle, 722

cutaneous, of abdomen, 716,717

from ilio-inguinal nerve, 720

of lower limb, tables of, 747, 748

of upper limb, tables of, 744,745

cutaneus antibrachii dorsalis, 711 lateralis, 705 medialis, 709

brachii lateralis, 710 medialis, 710

colli, 696 posterior, 711

dorsalis intermedius, 731

lateralis suræ, 730

medialis, 731

femoris lateralis, 722

posterior, 737

suræ lateralis, 730

deep peroneal, 730

descendens hypoglossi, 698,794

to diaphragm, 699, 717

to digastric muscle, 780

digital, of foot, from deep peroneal, 731

from plantar, 734, 735

from superficial peroneal, 731

from sural nerve, 730

of hand, from median, 706

from superficial ramus of radial, 712

from ulnar, 709

to dilatator pupillæ muscle, 773

dorsal cutaneous nerves of the foot, 731

lateral, 731

medial, 731

dorsalis clitoridis, 740

dorsalis penis, 740

dorsalis scapulæ, 702

efferent, 504

of elbow-joint, 705, 709, 711

to epicranius muscle, 783

ethmoidal, anterior, 773

posterior, 773

of extemal acoustic meatus, 832

of eyelid, 824

facial, 781

in acoustic meatus, 782

afferent root of, 796

ascending part of, 599

auricular posterior, branches of, 783

branches of, 782

branches and communications of, 782

central connexions of, 600

cervico-facial division of, 784

communications of, 781

course of, 781

deep origin of, 599

development of, 796

efferent root of, 598

emergent part of, 598

facial branches of, 783

in facial canal, 782

geniculate ganglion of, 782

in infant, 600
Nerve or Nerves-continued

facial, intrapontine course of, 599

morphology of, 796

in neck, 783

n. intermedius of, 781

development of, 598

origin of, 598

relation of, to chorda tympani, 782, 796

to geniculate ganglion, 782, 796

to vestibular nerve, 781

nucleus of, 599

in parotid gland, 783

plexus parotidens, 783

roots of, 598,781

surgical anatomy of, 1376

temporal, 783

temporo-facial, 783

terminal rami of, 783

femoral, 724

articular branches of, 724

cutaneous branches of, 724

intermediate cutaneous nerve of thigh, 724

medial cutaneous nerve of thigh, 725

muscular branclies of, 724

saphenous nerve, 726

branches of, 726

to femoral artery, 723

to femur, 724

to fibula, 734

frontal, 772

furcalis, 727,753

variations of, 753

to gemelli muscles, 728

genital, external spermatic branch, 722

of genito-femoral, 722

lumbo-inguinal branch of, 722

genito-femoral, 722

glossopharyngeal, 785

afferent fibres of, 785

root of, 597,598

branches of, 785,786

communications of, 786

course of, 785

deep origin of, 596,598

development of, 796

efferent fibres of, 517

root of, 596,598

in jugular foramen, 786

morphology of, 796

in neck, 786

nucleus of, 596,598

relation of, to fourth ventricle, 596

petrous ganglion of, 786

roots of, 785

superficial origin of, 596

superior ganglion of, 785

tympanic nerve of, 786

gluteal, inferior, 729

of posterior cutaneous of thigh, 737

superior, 729

hæmorrhoidal, inferior, 738

to hamstring muscles, 728

of heart, 880

of hip-joint, $723,724,728,729$

from femoral, 724

from nerves of sacral plexus, 729

fiom obturator, 723

to humerus, 705

hypogastric, 766 
Nerve or Nerves-continued

hypogastric, of aortic plexus, 765,766

hypoglossal, 793

ansa hypoglossi of, 794

branches of, 794

communications of, 793

course of, 793

deep origin of, 594

descending branch of, 794

development of, 798

nucleus of, 594

recurrent branch of, 794

relation of, to fourth ventricle, 594

superficial origin of, 594

surgical anatomy of, 1392

ilio-liypogastric, 720

ilio-inguinal, 720

incisor, 780

infra-clavicular, 703

to infra-hyoid muscles, 794

infra-mandibular, 778

infra-orbital, of facial, 777

of trigeminal, 776

infra-trochlear, 773

intercostal, 713

intercosto-brachial, 716

intermedius, 781, 782

development of, 683

origin of, 598

relation of, to chorda tympani, 782

to geniculate ganglion, 782

to vestibule, 1326

to interossei muscles of foot, 734,735 of hand, 709

interosseous, of common peroneal, 731

interosseous, dorsal, 713 surgical anatomy of, 1453

interosseous, volar, 705

ischiadicus, 728

of knee-joint, from common peroneal, 729

from femoral, 724

from obturator, 724

from sciatic, 729

from tibial, 732

labial, 1324

anterior, 721

posterior, 739

lacrimal, 772

canals, 825

of large intestine, 1213, 1233

laryngeal, external, 788, 789

inferior, 789

morphology of, 797

internal, 788

in tongue, 1131

recurrent, 789

surgical anatomy of, 1389

superior, 788

morphology of, 797

surgical anatomy of, 1388

lateral cutaneous, of thigh, 722 of thorax, 716

to latissimus dorsi muscle, 713

to levator ani muscle, from perineal nerve, 739

from pudendal plexus, 738

to levator scapulæ muscle, 702

to levator veli palatini muscle, 467

lingual, 1131

surgical anatomy of, 1375

of glossopharyngeal, 780
Nerve or Nerves-continued

lingual, of glossopharyngeal, communications of, 780

morphology of, 796

of hypoglossal, 795

in tongue, 1131

of vagus, 788

long scrotal, 739

thoracic, 702

to longus colli muscle, 468

lumbar, 719

anterior rami, 719

posterior rami, 690

lumbo-inguinal branch of genito-femoral, 722

to lumbrical muscles, of foot, 734, 735 of hand, 706, 709

of lung, 791

mandibular, 778

marginal, of mandible, 784

masseteric, 779

buccinator, 779

deep temporal, 779

mastoid, 695

maxillary, 775

meatus acoustici externi, 780

medial cutaneous, of the arm, 710

of the calf, 732

branches of, 732

of forearm, 709

of thigh, 724, 725

median, 705

branches in the forearm, 705

in hand, 706

communications, 705, 707

course of, 705

cutaneous branches, 706

muscular branches, 705

palmar ramus, 705

surgical anatomy of, at elbow, 1451 in arm, 1448

volar interosseous nerve of forearm, 705

of membrana tympani, 836

meningeal, of vagus, 788

(middle), 775

mental, 780

to muscles of abdominal wall, 485

of arm, 381

of back, 439

of buttock, 418

of face, 452

of foot, 425

of forearm, 400

of hand, 400

of hyoid bone, 460

of iris, 814

of leg, 435

of lower limb, 718

of mastication, 457

of orbit, 454

of pectoral region, 369

of pelvis, 494

of perineum, 489

of pinna, 830

prevertebral muscles, 470

of shoulder, $375,376,377$

of soft palate, 786,788

of thigh, 418

of thorax, 474

of tongue, 463

between trunk and upper limb, 372

of upper limb, 700 
Nerve or Nerves-continued

musculo-cutaneons, 704

superficial peroneal, 731

variations of, 752

to mylo-hyoid, 780

naso-ciliary, 773

of infra-orbital, 777

lateral, 773

medial, 773

posterior inferior lateral, 778

superior lateral, 778

naso-palatine, 778

to obliqui abdominis muscles, 716

obturator, 722

accessory, 726

to obturator externus muscle, 723

internus muscle, 728

occipital, greater, 689

branch of posterior auricular, 783

occipital, small, 695

morphology of, 700

occipital third, 690

oculo-motor, 769

branches of, 770

comnunications of, 770

course of, 770

deep origin of, 603

development of, 796

morphology of, 796

superficial origin of, 769

œsophageal, from sympathetic, 760

from vagus, 789

olfactory, 767, 768, 805

bulb of, 623

development of, 622

morphology of, 797

structure of, 623

development of, 622

morphology of, 797

origin of, 624,628

termination of, 768

tract of, 623

development of, 622

ophthalmic, 772

branches of, 772

course of, 772

development of, 796

frontal, 772

lacrimal, 772

supra-orbital, 772

supra-trochlear, 773

optic, 768

development of, 825

morphology of, 797

origin of, 658

retinal portion of, 815

tract of, 619

orbital, of spheno-palatine ganglion, 778

zygomatic, of maxillary, 775

palatine, 778

anterior, 778

middle, 778

nasal posterior inferior lateral branches, 778

naso-palatine branches, 778

orbital branches of, 778

posterior, 778

palpebral, 824

to parotid gland, 1137

patellar, 726

perforans coccygeus major, 738

perforating cutaneous, 737
Nerve or Nerves-continued

pericardiac, 791

perineal, 737

of fourth sacral, 738

of posterior cutaneous nerve of thigh, 737

superficial, 739

to perineal muscles, 739

peripheral, development of, 679

peroneal anastomotic ramus, 730 superficial, 731

to peroneus brevis, 731

longus, 731

petrosal, deep, 758,777

superficial, external, 782

greater, 782

lesser, 782

smaller, 759, 786

pharyngeal, 778, 1150

of glossupharyngeal nerve, 786

of spheno-palatine ganglion, 778

of sympathetic, 756

of vagus, 788

phrenic, 699

branches of, 699

communications of, 699,702

surgical anatomy of, 1393

of pinna, 830

to piriformis muscle, 729

plantar, lateral, 734

surgical anatomy of, 1465

medial, 734

surgical anatomy of, 1465

posterior descending supra-clavicular, 696 morphology of, 700

to prevertebral muscles, 695

to psoas major muscle, 720

of pterygoid canal, 777

pterygoid, external, 779

internus, 778

pudendal, 738

pulmonary, 1096

from sympathetic, 761

from vagus, 789

to pyramidalis abdominis muscle, 717

to quadratus femoris muscle, 728

lumborum muscle, 720

radial, 710

collateral branches of, 711

course of, 711

cutaneus brachii posterior, 711

deep ramus of, 712

dorsal cutaneous nerve of forearm, 711

interosseous, 713

superficial rami of, 712

surgical anatomy of, $145 \pm$

topography of, at elbow, 1450

in arm, 710, 711

ulnar collateral nerve, 711

variations of, 752

to radio-carpal joint, 705

to radius, 705

ramus anastomoticus peronaus, 730

of rectum, 1233

recurrens (ragi), 788

recurrent tibial, 730

to rhomboids, 702

sacral, $691,727,735$

anterior rami of, 727,735

posterior rami of, 691

visceral branches of, 736

sacro-coccygeal, anterior, 738

posterior, 691 
Nerre or Nerres-continued saphenous, 726

surgical anatomy of, in foot, 1465

in leg, 1463

in thigh, 1461

sure lateralis, 730

medialis, 732

surgical anatomy of, 1465

to scaleni muscles, 695,697

to scalp muscles, 783

scapular, dorsal, 702

sciatic, 728

course of, 728

division of nerve to hamstrings, 728

nerve to short head of biceps, 728

surgical anatomy of, 1456

posterior cutaneous nerve of the thigh, 737 surgical anatomy of, 1456

scrotal anterior, 721

posterior, 739

segmental, of head, 796

to semicircular ducts, 785

sensory ganglion of, 510

to short head of biceps, 729

muscles of little finger, 709 of thumb, 706

to shoulder-joint, from axillary, 710

from supra-scapular, 703

of skin, 858

of small intestine, 1187

spermatic external, 722

spheno-palatine, 775

to sphincter ani muscle, 738,739 pupillæ muscle, 814

spinal, 685

anterior rami of, 685

classification of, 678

development of, 679

distribution of, general, 680, 687

to limb-muscles, 687

tu skin of limbs, 687

formation of, 680

ganglia of, 685

gray rami of, 680,681

of brachial plexus, 700

of cervical plexus, 694

of lumbo-sacral plexus, 719

of pudendal plexus, 719

of sacral plexus, 719

of thoracic, 714, 716, 717

morphology of rami, 681, 691, 741

number of, 678

origin of, 522,528

posterior rami, 687,691

recurrent branches of, 686

relation of, to meninges, 686

to vertebræ, 1442, 1443

roots of, 519

anterior, 519

development of, 679

posterior, 519

development of, 679

segmental disposition of, 687

size of, 678

somatic portion of, 680

splanchnic portion of, 680

visceral branches of, 680

white rami of, 687

development of, 681

of lumbar and sacral nerves, 719

of pudendal plexus, 719

of sacral plexus, 719
Nerve or Nerves - continued

spinal, white rami of thoracic, 714, 716 717

spinosus, 778

splanchnic, 761

greater, 761, 764

lowermost, 761,764

smaller, 761

stapedius, 782

to sterno-mastoid muscle, 696,793

from accessory, 793

of stomach, 1177

to stylo-pharyngeus muscle, 786

subclavins, 702

of sublingual gland, 1140

of submaxillary gland, 1138

suboccipital, 688

morphology of, 691

subscapular, 713

lower, 713

short, 713

supra-clavicular (descending cervical), 696

anterior, 696

middle, 696

morphology of, 700

posterior, 696

supra-orbital, 772

surgical anatomy of, 1358

supra-scapular, 703

variations of, 700,752

supra-trochlear, 773

surgical anatomy of, 1358

sural, of common peroneal, 730

lateral, of posterior cutaneous nerve of thigh, 737

medial, of tibial, 732

sympathetic, 753

of taste, 598

temporal, of auriculo-temporal, 780

deep, 779

of facial, 783

of orbital, 776

topography of, 1359

to tensor fasciæ latæ muscle, 729

tympani muscle, 835

tentorii, 772

veli palatini muscle, 786,788

to teres minor muscle, 710

thoracic, 713

anterior rami of, 713

cutaneous branches of, 714

of first, 714

of second, 714

of twelfth, 717

communications of, 714, 716, 717, 719

first, 713

lateral anterior, 703

long, 702

medial anterior, 703

muscular branches of, 703

of first, 714

of second, 714

of twelfth, 717

posterior rami of, 690

cutaneous branches of, 690

second, 690

twelfth, 690

thoraco-dorsal, 713

to tibia, 732

tibial, 729,732

communicating, 732

deep peroneal, 730 
Nerve or Nerves-continued

tibial, recurrent, 730

surgical anatomy of, 1458

to tibio-fibular joint, from common peroneal, 730

from tibial, 732

of tongue, 1136

of tonsil, 1149

to transversus abdominis, 481

thoracis musele, 470

to trapezius muscle, 366

from accessory, 793

trigeminal, 771

ascending root of, 601

deep origin of, 600

development of, 683

divisions of, 772

mandibular, 778

maxillary, 775

mesencephalic root of, 601

$$
\text { in pons, } 602
$$

morphology of, 796

motor root of, 601

development of, 683

morphology of, 796

nuclei of, 600

development of, 683

of mesencephalic root of, 602

in pons, 602

ophthalmic division of lranches, 772

semilunar ganglion of, 771

sensory root of, 600

development of, 683

morpliology of, 796

spiual tract of, 601

development of, 602

superficial origin of, 600,771

trochlear, 770

communications of, 771

coluse of, 770

deep origin of, 602

development of, 683

morphology of, 798

nucleus of, 602

stperficial origin of, 602,770

tympanic, 786,836

morphology of, 796

to ulna, 705

uluar, 708

collateral, 711

commrmicating, 708

course of, 708

surgical anatomy of, in al'us, 1448 at ellow, 1451

to utricle, 785

to uvular muscle, 786

vagus, 786

abdominal branches of', 789

afferent fibres of, 596 root of, 795

branches of, 789

cardio-inhibitory fibres of, 793

communications of, 788,789

deep origin of, 596

development of, 795

efferent fibres of, 596 loot of, 795

ganglion nodosum of, 788

in jugular foramen, 786

jugular ganglion of, 788

left, in thorax, 786

morphology of, 797
Nerve or Nerves-continut

vagus, in neck, 788

nuclens of, 597

relation of, to fouth ventricle, $55 \mathrm{I}$

right, in thorax, 786

roots of, 596

development of, 795

morphology of, 796

superficial origin of, 786

surgical anatomy of, 1393

termination of, in coats of stomach, 1177

in thorax, 786

viscero-motor fibres of, 793

vesical, 766

vestibular, 853

connexion of, with cerebellum, 604

deep origin of, 604

descending root of, 605

nuclens of, 604,605

relation of, to fouth ventricle, 551

zygomatic, of facial, 773, 775

zygomatico-facial, 776

of zygomatico-facial maxillary, 776

zygomatico-temporal, 776

Nel've-cells, 506

axons of, 507

bipolar, 510

cellulipetal processes of, 511

of cerebellum, 579

of cerebral cortex, $6 \pm 5$

dendrites of, 509

development of, 35,498

ganglionic, 510

of Golgi, in cerebral cortex, 645

processes of, 528, 529, 530, 531

of Purkinjé in cerebellum, 580, 581

radicular, 528

of spinal ganglia, 685

medulla, 529

of sympathetic ganglia, 753

unipolar, 510

Nerve-components, 505

Nerve-endiugs, 863

free, 863

special end organs, 863

Nerve-fibres, 508

afferent, 509

collateral, 512, 534, 535

efferent, 504, 509

medullated, 508

myelinisation of, 509

of lateral cerebro-spinal tract, 533

of medial lougitudinal fasciculus, 589

order of occurrence of, in spinal medulla, 533

of sellsuly, 532

nemolemma of, 508

non-medullated, 508, 75t

primitive sheath of, 508

somatic efl'er'ent, 505

splanchnic, afterent, 754,760

in thoracic region, 759

effurent, $505,754,760$

in thoracie region, $76 \mathrm{I}$

peripheral, 755

sympathetic, 7.54

cervical, 756

destinations of, 754

inedullated, 75t

non-medullated, 754

splanchuic, 754,756

terminations of, 504,509 
Nerve-fibres, Wallerian degeneration of, 532

Nerve-roots, 519

anterior origin of fibres of, 528

cerebral, 592

spinal, 519

derelopment of, 519

anterior, 519, 529

development of, 520

origin of, 529

relation of, to sympathetic, 754

posterior, $519,533,534,536$

development of, 520,536

in posterior funiculus of spinal medulla, 533

relation of, to sympathetic, 754

Nerrous system, 497

cerebro-spinal, 497

early stages of development, 30

elements of the, 497

of hydra, 497

scheme of the, 498

sympathetic, 753

Nervus furcalis, 753

intermedius, development of, 683

Nervus terminalis, 608

Neural arteries, of gluteal, 938

of intercostals, 926

canal, 31

crest, 32, 500, 679

ectoderm, 499, 501

fold, 31

groove, 23

plate, 30

syncytium, 504

tube, 31,33

alar and basal terminal, 36

alar lamina of, 505,682

in fore-brain, 608

in hind-brain, 552, 553, 554

in mid-brain, 592

relation of, to origin of nerves, 553 , 554,682

basal lamina of, 505, 682

in fore-brain, 608

in hind-brain, 553

in mid-brain, 592

relation of, to origin of nerves, 553, 554,682

central canal of, 564,565

development of cerebral nerves from, 682

of spinal nerves from, 679

differentiation of, 33

ependymal layer of, 502

fate of spinal portion, 35

flexures of, 514

floor-plate of, 402,520

germinal cells of, 35

histological differentiation of walls, 35

limiting membrane of, external, 35, 502

internal, 35, 502

mantle-layer of, 502

marginal layer of, 502

myelospongium of, 503

neuroblasts of, 503

perforations in wall of, 37

roof-plate of, 402,520

sulcus limitans of, 36

Neurenteric canal, 23, 26

Neurobiotaxis, 554

Neuroblasts, 36, 503

Neuro-central synchondrosis, 104

Neuroglia of brain, 511
Neuroglia of spinal medulla, 527

Neurolemma, 508

Neurology, 3

Neuro-muscular spindles, 866

Neuron, 503

Neurone theory, 503 objections to, 504

Neuropore, 31

anterior, 31,500

posterior, 31, 500

Neuro-tendinous spindles, 865

Nictitating membrane, 821

Nipple, 1337

Nodule of cerebellum, 571 development of, 571

Noduli aggregati of vermiform process, 1217 lymphatici aggregati, 1181 intestini recti, 1230

lienales, 1355

solitarii, 1181

valvularum semilunarium, 877

Nose, 799

ala of, 799

alar sulcus of, 799

arteries of, 805

bridge of, 799

cartilages of, 800

choanæ of, 175, 185, 196

surgical anatomy of, 1246

development of, 49

digital exploration of, 1378

external, 799

floor of, 804

fossæ of, 801

hiatus semilumaris of, 803

infundibulum of, 803

lateral wall of, 802

limen of, 802

lymph vessels of, 1004

meatuses of, 803

mucous membrane of, 804

muscles of, 450

action of, 452

nerve-supply of, 452

nasal index of, 799

nerves of, 805

olfactory part of, 804

outer parts of, 799

piriform openings of, 163

recessus spheno-ethmoidalis of, 802

respiratory part of, 804

septum of, 802 surgical anatomy of, 1378

veins of, 806

vestibule of, 802 .

vessels of, 805

Nostril, 799

Notch, acetabular, of ischium, 232 variations in, 281

cardiac, of liung, 1095

of cerebellum, 574

ethmoidal, 116

greater sciatic, of ilium, 229

infra-sternal, 1397, 1407

intercondylic, of femur, 243

jugular, 107

mandibular, 156

nasal, 115

pterygoid, 137

pterygo-palatine, 151

radial, 211

of Rivinus, 834 
Notch, of sacrum, 96

scapular, 201, 203

great, 202

sciatic, 229,232

semilumar, 211

of spleen, 1352

supraorbital, 116

suprasternal, 107

ulnar of radius, 215

umbilical, 1191

Notochord, 23, 24, 290

formation of, 24

remnants of, 25

Nuchal furrow, 1395

lines, 166, 171

of occipital bone, 121

plane of occipital bone, 121

Nuck, canal of, 1319

Nuclear juice, 8

layer of retina, 816,817

membrane, 8, 9

Nucleolus, $8,9,10$

false, 8

Nucleus, 8

Nucleus or Nuclei, of abducens nerve, 600 relation of, to medial longitudinal bundle, 588, 600

accessory, 560, 595

of acoustic nerre, 601-606

ambiguus, 595, 596

amygdalæ, 641

anterior, of thalamus, 612

arcuate, 552, 563

development of, 552

thalami, 612

of Bechterew, 605

caudate, 635,637

of cells, 8

during mitosis, 9, 13

segmentation, 10

central, of Luys, 612

cochlear, 554, 604

development of, 684

colliculi inferioris, 585

corporis geniculati lateralis, 613

medialis, 607

mamillary, 615

of corpus trapezoideum, 606

cuneate, 533, 547, 560

development of, 552

relation of, to arcuate filures, 560

of Deiters, 605

function of, 605

dentate, 576

dorsalis, 531

emboliform, of cerebellum, 577

of facial, 599

fastigii, 577

fertilisation of, 20

first segmentation, 21

formatio reticularis grisea, 564 alba, 564

of funiculus solitarius, 598

globosus, 577

glossopharyngeal, 596-598

relation of, to fourth ventricle, 596

gracilis, 547

relation of, to arcuate fibres, 560 to lemiscus, 559

hypoglossal, 594

relation of, to fourth ventricle, 594

hypothalamicus, 614
Ňcleus or Nuclei, intercalatus, 551

laryngeal, 598

of lateral lemniscus, 606

somatic efferent or intermediate, 506

lentiform, 638

lentis, 520

of Luys, 614

medial, of thalamus, 611

of medulla oblongata, 551

development of, 551,592

of mesencephalon, $584,585,586,588$

motor, 592

motorii nervi trigemini, 601

oculo-motor, 603

superior, 561, 606

pedicle of, 606

relation of, to corpus trapezoideum, 606

to lateral lemniscus, 606

to nucleus of lateral lemniscus, 606

olivary, accessory, 556

inferior, 556

relation of, to cerebello-olivary fibres, 556

surface elevation of, 547

superior, 567

of optic nerve, 620

of origin, 592

of origin of cerebral nerves, 592

development of, 592

pontis, 566

development of, 566

relation of, to transverse fibres of pous, 566 pulposus, 307

radicis descendentis nervi trigemini, 559

red, 613

roof, 577

relation of, to spino-cerebellar tract, 578

ruber, 586-588

origin of, 516

segmentation, 21

somatic afferent terminal, 506

efferent, 506

splanchnic afferent terminal, 506

efferent, 506

of tegmentum, 586

terminal, 505

of termination of nerves, 593

of thalamus, 611

tractus solitarii, 598

spinalis nervi trigemini, 559

trigeminal, 600

development of, 683

trochlear, 602

relation of, to medial longitudinal bundle 602

vagus, 596

relation of, to fourth rentricle, 596

vestibular, 554, 604

early importance of, 575

relation of, to fourtli ventricle, 604

Nuel, space of, 852

Number of bones, 265

Nutrient arteries, 87

Nymphre, 1324

Obelion, 171, 285

Obex, 579

Oblique chord, 328

line, anterior, of radius, 215

external, of mandible, 155

Oblique line of tibia, 249

vein of Marshall, 960

Obliquus externus abdominis muscle, 476 
Obliquus, inferior, of neck, 444 of orbit, 453

intemus abdominis muscle, 478

superior muscle of neck, 444

of orbit, 453

action of, 454

nerve-supply of, 454

Obliterated umbilical artery, 936

Obstetrical paralysis of Duchenne, 1395

Obturator artery, 940

abnormalities of, 1056

canal, 338

crest, 233

extermus muscle, 413

action of, 414

nerve-supply of, 414

fascia, 489

foramen, 234

gland, 1017

groove, 234

abnormalities of, 281

internus muscle, 418

action of, 418 nerve-supply of, 418

membrane, 338

nerve, 722

accessory, 726

plexus, 723

tubercle, anterior, 234

posterior, 234

vein, 984

Occipital angle of parietal bone, 119

arteries, 895

bone, 120

architecture of, 270

basilar part of, 123 ossification of, 124

cerebral surface of, 121

condyles of, 122 ossification of, 124

connexions of, 124

foramen magnum of, 123, 172, 178

lateral parts of, 121

morphology of, 290

nuchal lines of, 121

plane of, 121

ossification of, 124

relation of, to sutures, 165, 171

squamous part of, 121 ossification of, 124

variations in, 277

condyles, 122, 182

third, 278

crest, external, 121

internal, 121, 182

fontanelle, 293

lobe, 660

topography of, 1360

lymph glands, 998

nerves, 688-690

plane, 118

point, 183, 285

protuberance, external, 121, 178

internal, 121, 182

sinus, 183, 974

abnormalities of, 1058

sulcus, 661

triangle, 1395

vein, 965,967

Occipito-atloid joint, 309

movements at, 311

ligaments, 310
Occipito-epistropheal ligaments, 311

Occipito-frontal strand, 650

Occipito-mastoid suture, 165, 171

Oculo-motor nerve, 683

connexions of, 604

development of, 683

morphology of, 798

nucleus of, 603

splanchnic efferent nucleus of, 604

sulcus, 603

Oculo-nasal sulci, 49

Odontoblasts, 1245

processes of, 1247

Esophageal arteries of aorta, 925 of coronary, 929

of inferior thyreoid, 611

morphology of, 1046

groove of liver, 1189

of lung, 1094

opening of diaphragm, 473

orifice of stomach, 1163

plexus, 791

veins, 961

Esophagus, 1150

abdominal part of, 1152

cervical portion of, 1151 surgical anatomy of, 1393

constrictions of, 1151

development of, 45,1249

diaphragmatic part of, 1152

distensibility of, 1407

glands of, 1155

relations of, 1151, 1152, 1153

structure of, 1153

surgical anatomy of, 1407

thoracic part of, 1152

variations in, 1153

vessels and nerves of, 1155

Olecranon, 210

fossa, 208

topography of, 1449

of humerus, 208

Olfactory area, 500, 622

bulb, 622,623

development of, 622

morphology of, 622

structure of, 623

biundle, 627

cells, 805

cleft, 1378

ganglion, 622

morphology of, $6: 2$

glands, 804

glomeruli, 623

groove, 140, 141, 179

hairs, 805

lobe, 624

development of, 624

relation of, to anterior cerebral commissure, 626

nerve, 767, 768, 805

central commexions of, 623

development of, 682

neurones, 625

organ, 799

for receptive impressions, 625

pits, 49,682

sulcus, 666

tract, 622, 623

development of, 622

structure of, 623

triangle, 623 
Olfactory tubercle, 623

Oligolecithal ovum, 14

Olivary nucleus, 555

Olive of medulla oblongata, 547

Omental bursa, 1162, 1238

tuberosity of liver, 1193 of pancreas, 1206

Omentum, 1162

gastro-colic, 1162

gastro-hepatic, 1162

gastro-splenic, 1162

development of, 1253

relation of, to omental bursa, 1239

greater, 1162, 1241

development of, 1253

functions of, 1242

relation of, to duodenum, 1186

to omental bursa, 1239

to transverse colon, 1239

small, 1162, 1197, 1241

development of, 1253

omental birsa, 1239

relation of, to structure of, 1198

Omo-hyoid muscle, 459

action of, 394

nerve-supply of, 394

Ontogeny, 1

Oocyte, 12

of first order, 12

of second order, 15

Oogonia, 12, 15

Oolemma, 13

Opening of subarachnoid part of brain, 1362

Opercula insulæ, 655

orbital, 655

superior, 655

temporal, 655

Ophryon, 285

Ophthalmic artery, 902

abnormalities of, 1053

nerve, 772

morphology of, 797

veins, 968

Opisthion, 178, 183

Opponens digiti quinti muscle, 393 action of 394

nerve-supply of, 394

Opponens pollicis muscle, 392 action of, 393 nelve-supply of, 393

Optic axis, 807

chiasma, 541, 619

decussation in, 769

development of, $609,682,826$

morphology of, 798

commissure, 619

cup, 682, 826

of optic disc, 815

disc, 815

foramen, 180

abnormalities of, 278

groove, 135

nerve, 541, 768

deep connexions of, 620

development of, $33,609,682$

morphology of, 798

papilla, 815

in retina, 816

radiation, $6 \pm 3,658$

recess, 618

stalk, 682, 825, 826
Optic stalk, morphology of, 798

tract, $5 \pm 1,619$

ceutral connexions of, 619

cortical connexions of, 620

radiation, 620

vesicle, 825

pigmentary layer of, 825

Ora serrata, 815 structure of, 815

Oral part of the pharynx, 1144, 1145

Orbicularis oenli muscle, 450

Orbicularis oris muscle, 450 action of, 452 nerve-supply of , 452

Orbiculus ciliaris, 812

Orbit, 160, 162

fascia of, 452

floor of, 162

lateral wall of, 162

medial wall of, 163

muscles of, 452

action of, 454

morphology of, 496

nerve-supply of, 454

roof of, 160

veins of, 968

Orbital artery of middle meningeal, 898 of superficial temporal, 897

fossa, 160

gyri, 666

index, 287

margin, 115

sexual differences in, 193

part of frontal bone, 117,162

plate of ethmoid bone, 140, 163

process of palate bone, 152, 162, 170 .

of zygomatic bone, 154

septum, 822

sulcus, 666

wings of sphenoid, 135

Orbito-maxillary-frontal suture, 279

Orbito-nasal centre, 150

Orbito-sphenoids, 135, 138

Orbito-tarsal ligaments, 1378

Organ of Corti, 849,856

epibranchial, 796, 797

of lateral line, 796

of Ruffini, 865

of senses, 799

of taste, 854

vomero-nasal, of Jacobson, 802

Orifice, aortic, 878

topography of, 1405

external, of uter'us, 1316

interual, of uterus, 1317

uitral, 876, 878

level of, 1442

topograpliy of, 1105

pulmowary, 878

topography of, 1405

tricuspid, 877

level of, $14+2$

topography of, $1 \pm 05$

Origin of muscles, 36.1

Orthoceplialic skulls, 286

Orthognathous skulls, 287

Os or Ossa, breve, 82

calcaneus, 259

capitate, 221

inor'pliology of, 295

ossification of, 223

carpal, 280 
Os or Ossa, carpi, 217

ceutrale, 280

morphology of, 295

clitoridis, $13=6$

coceygis, 99

cordis, $\$ 76$

coxa, 228

cranii, 115

cuboid, 263

cuneiform, first, 261

second, 262

third, 263

ethmoid, 139

extremitatis inferioris, 228

superioris, 197

faciei, 146

fibular, 295

frontal, 115

greater cornu of hyoid, 159

greater multangular, 220

hamatum, 221

surface anatomy, 1451

variation in, 280

hyoidenm, 158

ilinm, 228

Incæ, 278

intercuneiform, 282

interfrontal, 277

intermetatarsal, 282

interparietal, 277

ischii, 232

Japonicum, 279

lacrimal, 143

lamina papyracea of ethmoid, 140 relation of, to orbit, 163

- variations in, 278

lesser cornu of hyoid, $\mathbf{1 5 9}$

lesser multangular bone, 220

longum, 82

lunatum, 218

metacarpals, 223

metatarsals, 265

multangulum majus, 220

minus, 220

nasal, 145

navicular, of the hand, 218

of the foot, 261

occipital, 120

odontoid, 275

orbicular, 840

palatine, 150

parietal, 118

penis, 1300

pisiform, 219

pubis, 233

radial, 295

sacrum, 96

sesamoid, 269

sphenoid, 133

subcapitular, 280

sustentaculi, 282

suturce, 145

tarsi, 254

temporal, 125

tibial, 295

trigonum, 282

triquetral, 219

ulnar, 295

Vesaleanum, 282

zygomatic, 153

Osseous labyrinth, 843

Ossicles, auditory, 838
Ossicles, auditory, articulations of, 840 development of, 841

epipteric, 146

joints of, 840

of Kerkring, 124

ligaments of, 841

movements of, 842

Ossification of bones, 84

of laryngeal cartilages, 1065

Osteoblasts of bone, 85

Osteology, 3, 81

descriptive terms of, 82

Ostium abdominale tubæ uterinæ, 1314 maxillare, 804

pharyngeum tubæ auditivæ, 837, 838 tympanicum tubæ auditivæ, 837 uterinum tubæ, 1315

Otic ganglion, 781

branches of, 781

development of, 684, 796

roots of, 781

vesicle, 51,853

Otoconia, 847

Ovarian artery, 928

fimbria, 1312, 1314

fossa, 1312

ligament, 1312

plexus, 765

vein, 1048

abnormalities of, 1058

morphology of, 1048

Ovary, 1311

bursa of, 1318

connexions of, 1312

corpora albicantia of, 1313

lutea of, 1313

descent of, 1313

development of, 1334

egg-tubes of, 1314

extremities of, 1311

tubal extremity, 1311

uterine extremity, 1311

free border, 1311

hilus of, 1311

ligament of, 1311, 1312

lymph vessels of, 1314

mesovarial border, 1311

nerves of, 765, 1314

ova of, 1313

position and relations of, 1311, 1312

primitive follicles of, 1313

stroma of, 1313

structure of, 1313

surgical anatomy of, 1435, 1436

suspensory ligament of, 1312

vesicular follicles of, 1313

vessels of, 1314

Ovules of Naboth, 1320

Ovum, 13

alecithal, 14

centrosome of, 14

cone of attraction, 20

deutoplasm of, 14

eutelolecithal, 14

fertilisation of, 20

maturation of, 15

nucleus of, 14

oligolecithal, 14

in ovary, 1313,1314

primitive, 1313, 1314

relation of, to decidua, 57

segmentation of, 15, 21 
Ovum, special characters of, 13

telolecithal, 14

Pacinian corpuscles, 864

Pad, 1110, 1111

infra-patellar, of knee-joint, 348

suctorial, 1109

Palate, 1110

aponeurosis, 466,1111

arches of, 1111, 1112

arteries of, 1111

bone, 150

horizontal part of, 151

orbital process of, 152

perpendicular part of, 151

relation of, to nasal fossæ, 183 to orbit, 162

to zygomatic fossa, 168

development of, 49,1379

foramen, larger, 151, 174 surgical anatomy of, 1384

lesser, 152, 174

glands, 1110

hard, 174, 1107, 1110

surgical anatomy of, 1384

incisive pad of, 1110, 1111

lymph vessels of, 1112

micous membrane of, 1111

muscles of, 466

derelopment of, 496

nerves of, 778,1112

papilla palatina of, 1110

plicæ palatinæ of, 1110

pyramidal process of, 152

raphe of, 1110

rugæ of, 1110, 1111

soft, 1107,1110

folds of, 1111

level of, 1442

mucous membrane of, 1111

muscles of, 1111

structure of, 1111

sphenoidal process of, 152 ossification of, 153

uvula of, 1111

veins of, 965

Palatine canal, anterior, 149

greater, 152

lesser, 152

superior openings of, 152

cleft, 1379

surgical anatomy of, 1379

process, 148,149

suture, median, 174

transverse, 174

taste-buds, 854

tonsils, 1106, 1145

primary hremorrhage after removal of, 1384 surgical anatomy of, 1584

Palato-ethmoidal suture, 162

Pallitım, 621

Palm, surgical anatomy of, 1454

Palmar arch, deep, 923, 924

abnormalities of, 1055

morphology of, 1055

surface anatomy of, 1454

superficial, 923,924

morphology of, 1047

surface anatomy of, 1454

fascia, 384

ligaments of carpal joints, 328

of carpo-metacarpal joints, 330
Palmar ligaments of metacarpo-phalangeal joints, 332

Palmaris brevis muscle, 382

longus muscle, 386 action of, 386

Palpebræ, 821 nerve-supply of, 386

Palpebral arteries, 823

fissure, 821

lateral raphe, 822

medial ligaments, 822 surgical anatomy of, 1376

nerves, 824

reins, 824

Pampiniform plexus, 983

Pancreas, 1203

accessory, 1207

body of, 1203, 1206

characters of, 1207

development of, 47

ducts of, 1206, 1207, 1255 termination of, $1186,1203,1207$ accessory, 1207

head of, 1203, 1204

lesser, 1207

lymph ressels of, 1207

margin, anterior, 1206

inferior, 1206

superior, 1206

neck of, 1203, 1205

nerves of, 1208

omental tuberosity of, 1206

parts, 1203

peritoneal relations of, 1206

position, 1203

processus uncinatus of, 1203

relations, 1203

shape, 1203

structure of, 1207

surface of, anterior, 1206

inferior, 1206

posterior, 1206

surgical anatomy of, 1426

from behind, 1439, 1442

tail of, 1203, 1206

variations in, 1207

ressels of, 1207

Pancreatic artery, 930, 1207

cysts, 1426

reins, 1208

Pancreatico-duodenal arteries, 930, 932, 1:205, 1207

vein, 1208

Panuiculus adiposus, 364

carnosus, 364

Papilla or Pajillæ, bile, 1186, 1203, 120 -

conical and filiform, 1127

corii, 857

dentis, 1244

duodeni, 1186, 1203, 1207

fungiform and lenticular, 1127

of integument, $85 \vec{i}$

of kidney, 1265

lacrimal, 821

lenticular, 1127

lingual, 1126

mammæ, 1337

of nail, 859

of optic nerve, 815

pili, 860

renal, 1265

of skin, 85. 
Papilla or Papilla, vallate, 1127

Paracentesis of the pericardium, 1405 of pleura, site for, 1402

of tympanic membrane, 1368

Paracentral lobule, 664, 666

Parachordal cartilages, 290

Paradidymis, 1287

origin of, 1335

Paraduodenal fossa, 1185

Paraflocculus, 571

Paramastoid process, 278

Parametrium, 1318, 1319

Paranephric fat, 1425

Parapophysis, 284

Parapyramidal fissure, 573

Pararectal fossa, 1227, 1238

Parasinoidal sinuses, 974

Parasternal line, 1397

Parathyreoid bodies, 44

glands, 1348

blood-vessels of, 1349

development of, 1349

number of, 1349

position of, 1349

structure of, 1349

surgical anatomy of, 1388

Para-mrethral duct, 1285, 1309

Paravesical fossa, 1238, 1280

Paraxial mesoderm, 27

Parenchyma testis, 1288

Paries carotica of tympanic eavity, 834 jugularis, 832

labyrinthica, 832

mastoidea, 834

membranacea, 834

tegmentalis, 832

Parietal artery, 897

bones, 118

angles of, 119

cerebral surface of, 119

ossification of, 120

relation of, to sutures, 171

surface of, 118

topography of, 1359

tuberosities of, 118

variations in, 277

foramen, 171

abnormality of, 277

gyri, 662

lobe, 662

region of the brain, 662

Parieto-mastoid suture, 164

Parieto-occipital artery, 908

fissure or fossa, 661,662

topography of, 1360

Parieto-temporal artery, 905

Paroccipital process, 278

Par-oöphoron, 1316, 1335

Parotid artery, of posterior auricular, 895 of superficial temporal, 896

duct, 1109,1376

surgical anatomy of, 1376

fascia, 447,1133

gland, 1133

accessory, 1136

development of, 1244

duet of, 1136

surgical anatomy of, 1376

nerves of, 1137

relation of, to external acoustic meatus, 1135,1366

surgical anatomy of, 1376
Parotid gland, vessels of, 1137

lymph glands, 998

Pars or part abdominalis of œsophagus, 1152

et pelvina s. sympathici, 761

analis recti, 1228

basilaris ossis occipitalis, 123

pontis, 565

cavermosa urethræ, 1308

centralis of lateral ventricle, 634

cephalica et cervicalis s. sympathici, 750

cervical of the csophagus, 1151

ciliaris retinæ, 815

development of, 826

convoluta of kidney, 1265

dorsalis pontis, 567

flaccida membranæ tympani, 835

frontalis eapsulæ internæ, 642

operculi, 655

iridica retinæ, 813,815

development of, 826

lacrimalis of orbicularis oculi, 450

laryngeal part of pharyux, 1147

mamillaris hypothalami, 609

membranacea of the urethra, 1307

nasal of the pharynx, 1142

occipitalis capsulæ internæ, 643

optica hypothalami, 609

retinæ, 815

oral of pharynx, 1144

orbitalis operculi, 655

parietalis operculi, 655

prostatic of the urethra, 1305

radiata of kidney, 1265

squamous of occipital bone, 121

temporalis operculi, 655

tensa membranæ tympani, 835

thoracalis of the csophagus, 1152

s. sympathici, 759

triangularis operculi, 655

Patella, 245

apex of, 245

articular surface of, 245

base of, 245

fracture of the, 1460

ligaments of, 344

relation of, to fascia lata, 404, 409, 422

to quadriceps (extensor) femoris, 409

ossification of, 245

topography of, 1460

Patellar plexus, 726

Pecten ossis pubis, 233

Pectinea fascia, 403

Pectineal line, 231

Pectineus muscle, 411

action of, 411

nerve-supply of, 411

Pectiniform septum of penis, 1300

Pectoral fascia, 369

girdle, 203, 270

lymph glands, 1008

muscles, nerve-supply of, 704

region, fascia, 369

muscles of, 369

ridge, 206

thoraco-acromial artery, 916

Pectoralis major muscle, 369

action of, 370

nerve-supply of, 370

minimus, 371

minor muscle, 371 action of, 371

nerve-supply of, 371 
Pedicles (O.T.) of vertebræ, 89, 90, 93, 95

Peduncles of cerebellum, 577

of cerebrum, 34

of corpora mamillaria, 615

olivary, 556

of pineal body, 614

development of, 6]4

Pedunculi cerebri, 541, 542, 583

basis pedunculi of, 583

origin of, 517

sulcus lateralis of, $58 t$

n. oculomotorii of, 584

tegmentum of, 583

Pelvic colon, 1222

topography of, 1423

diaphragm, 493

fasciæ, 489

floor, 490

girdle, 228, 273

morphology of, 295

mesocolon, 1223

part of sympathetic, 762

plexus, 766

Pelvis, 235

articulations of, 335

axis of, 237

cavity of, 489

conjugate diameter, 237, 238

diameters of, 237,238

dolichopellic, 288

fasciæ of, 489

female, surgical anatomy of, 1434

growth of, 238

inferior aperture of, 237

sexual differences in, 237

large, 235

ligaments of, 336

lymph vessels of, 1015

measurements of, 238

mechanism and movements of, 338

mesatipellic, 288

muscles of, 493

oblique diameter of, 237

peritoneum of, 1237

planes of, 238

platypellic, 288

position of, 237

renal, 1268

calyces majores of, 1268 minores of, 1268

development of, 133]

sexual differences in, 237

small, 236

superior aperture, 236

sexual differences in, 237

transverse diameter, 237

white line of, 491

Penis, 1298

artery of, 1300

bone of, 1300

bulbus urethre of, 1299

corona glandis of, 1298

corpora cavernosa of, 1299 structure of, 1300

corpus caveruosum urethre of, 1298 structure of, 1300

crura of, 1299

developnent of, $13: 36$

dorsal veiu of, 897

dorsum of, 1298

fascia of, 1300

fræenulum præputii, 1299
Penis, glandulæ præputiales, 1299 glans of, 1298

development of, 1336

hemispheria bulbi urethræ of, 1299

ligamentum suspensorium of, 1299

nerves of, 740

præputium, 1299

root of, 1299

bulbus urethræe of, 1299

crura of, 1299

septum of, 1300

structure of, 1300

suspensory ligament of, 1299

tunica albuginea of, 1300

vessels and nerves of, 1300

Perforated substance, 624

Perforating arteries, 950

cutaneous nerve, 737

Pericardiac nerve, 791

Pericardiaco-phrenic artery, 913

Pericardial area, 27, 65 arteries, of aorta, 925

of internal mammary, 913

Pericardium, 880

development of, 72,74

fibrous part of, 880

great oblique sinus of, 882

transverse sinus of, 882

paracentesis of, 1405

serous, 881

simuses of, 882

structure of, 882

restigial fold of, 882

Perichondrium, 85

Pericranium, 1357

Perilymph, $846^{\circ}$

Perimysium externum, 363 internum, 363

Perineal arteries, 942

body (female), 1322

fascia of Colles, 338, 1427

fold, 48

ligament, arcuate, 338

nerves, 737

Perinephric arteries, 927, 928

Perineum, 1427

central point of, 1427

fascia of, 485

male, surgical anatomy of, $1 \pm 27$

muscles of, 486

rectal triangle of, 1431

surgical anatomy of, $1+2 \tau$

urogenital diaphragm of, 338, 48.9, 491 triangle of, 1427

Period, pre-embryonic, 7 of embryo, 7

of fotus, ?

l'eriosteum, 83 relation of, to ossification, 85

alveolar, 1115, 1123

development of, 1245

Puripheral nerves, development of, 679

Peritoneal carity; $1+12$

left infira-colic compartment of, 1414

right infra-colic compartment of, 1414

subdivisions of, 1412

supra-colic compartment of hepato-remal pouch of Morrison, 1414

surgical anatomy of, 1.12

Perinephric absiess, 14:39

Peritonem, 1160, 1234

anterior larer of, 1234 
Peritoneum, bursa onentalis, 1234

derelopment of, 1252

duodenal fossie of, 1185,1186

duodeno-jejunal fossa of, 1185, 1186

femoral fossa of, 1235

folds of, 1162-1163, 1235-1242

foramen epiploicum, 1162, 1239

great sac of, 1234

inguinal fossæ of, 1235

intersigmoid fossa of, 1223

surgical anatony of, 1423

ligaments of, 1162, 1235-1242

surgical anatomy of, 1412

mesenterico-mesocolic fold of, 1186

mesenteries of, $1163,1208,1242$

omenta of, 1162,1241

functions of, 1242

omental bursa of, 1102, 1195, 1234, 1239

paraduodenal fossa of, 1186

pararectal fossa of, 1238

paravesical fossa of, 1238,1280

parietal and risceral, 1161

pelvic, 1237

wall of, 1236

posterior wall of, 1236

pouch of Douglas of, 1237, 1238, 1318

surgical anatomy of, 1434, 1436

processus vaginalis of, 1295,1319

recto-vesical pouch of, 1282, 1283 surgical anatomy of, 1434

relation of, to bladder, 1280

to cæclum, 1218

to colon, 1219, 1220, 1221

to duodenum, 1186, 1239, 1240

to kidney, 1262

to liver, 1195

to pancreas, 1206

to rectum, 1226

to spleen, 1353

to stomach, 1170

to nterus, 1317

surgical anatomy of, 1412

transverse tracing of, 1238

utero-vesical pouch of, 1317

visceral, 1161

Perivascular lymph-spaces, 994

Permanent teeth, 1115-1119

Peronæo-calcarieus muscle, 431

lateralis muscle, 427

Peronæo-cuboideus muscle, 427

Peronæus accessorius muscle, 427

brevis muscle, 427

action of, 427

digiti quinti muscle, 427

longus muscle, 426

action of, 427

tertius muscle, 425

action of, 426,953

Peroneal artery, 953

muscles, 1462

nerve, 731

retinaculum superior, 422

Perpendicular plate of ethmoid, 139, 185

Petit, canal of, 839

Petro-basilar fissure, 130

Petro-mastoid suture, 1369

Petro-occipital fissure, 176

Petrosal artery, 898

ganglion, 785

nerve greater superficial, origin of, 598

deep, 758, 777

superficial, external, 782, 899
Petrosal nerve, superficial, greater, 777 smaller, 759,786

process, 135

sinus, inferior, 975

superior, 975

Petro-squamous fissure, 131

suture, 125, 126

surgical anatomy of, 1369

Petro-tympanic fissure, 125, 133

Petrous ganglion, 785,786 part of temporal bone, 131

Phænozygous crania, 286

Phalangeal process of lamina reticularis, 851

Phalanges of foot, 267

of hand, 226

of rods of Corti, 851

ossification of, 227,268

Pharyngeal artery, ascending, 896 bar, 42 development of, 1028

nerves, 1150

of glosso-pharyngeal nerve, 786

of spheno-palatine ganglion, 778

of sympathetic, 756

of vagus, 788

orifice of auditory tube, 1143

plexus, 756, 786, 788

tubercle, 123

veins, 965

Pharyngo-branchial duct, 44

Pharyngo-epiglottic fold, 1067

Pharyngo-glossus, 464

Pharyngo-palatine arch, 1111, 1112

muscle, 465

action of, 467

nerve-supply of, 467

Pharyngotomy, sub-hyoid, 1387

Pharynx, 1140

aponeurosis of, 1149

auditory tubes of, 1142

boundaries of, 1143

bursa pharyngea, 1143, 1396

cavity of, 1141

choanæ, 1142

cushion of, 1143

orifice of auditory tube, 1143

development of, 1242

dimensions of, 1140

fascia pharyngo-basilaris, 1149 bucco-pharyngea, 1149

glands of, 1149

isthmus pharyngo-nasal, 1141, 1145, 1383

laryngeal part of the, 1141, 1147

lateral recesses of, 1144 development of, 1144

levator cushion of, 1143

lymph vessels of, 1006, 1149 surgical anatomy of, 1386

mucous membrane of, 1149

muscles of, $464-467$

action of, 467

development of, 496

nerve-supply of, 467

nasal part of the, 1141,1142

surgical anatomy of, 1385

naso-pharyngeal groove of, 1143

nerves of, 1150

openings of, 1142

oral part of the, $1141,1144,1145$

pharyngo-palatine arch of, 1145

plica triangularis of, 1146

recessus piriformis of, 1069 
Pharynx, recessus tonsillaris of, $11 \pm 5$ development of, 46

relations of, 1149

salpingo-palatine fold of, 1143

salpingo-pharyngeal fold of, 1143

structure of wall, 1149

supra-tonsillar fossa of, 1145

development of, 1144

tonsil of, palatine, $11.5,1146$

pliaryngeal, 1143

torus tubarins of, $11+3$

vault of, 1143

ressels and nerves of, 1149

Philtrum, 1108

ventriculi of Merkel, 1069

Phrenic artery, inferior, 933 ganglion, 765

nerve, 699

surgical anatom of, 1393 rein, 982

Phrenico-colic ligament, 1242

Phrenico-pleural fascia, 1089

Phylogeny, 1

Pia mater, 518

of the brain, 673

chorioid plexuses of, $553,611,617,635$

ligamentum denticulatum of, 675

linea splendens of, 675

of the spinal medulla, 675

tela chorioidea of, 673

of third ventricle, 674

Pigmentary layer of optic resicle, 825

Pillars of Corti, 850

Pineal bod $5,582,614$

development of, 608

morphology of, $6 \mathrm{I} 9$

tænia thalami of, 614

eye, 608

Pinna, 449

development of, 52

Piriform aperture, 163

measurement of, 287

surgical anatomy of, 1239

Piriformis fascia, 489

muscle, 417

action of, 418

nerve-supply of, 417,729

Pisi-cuneiform joints, 330

Pisiform bone, 219

morphology of, 295

ossification of, 223

surgical anatomy of, 1451

Pisi-metacarpal ligament, 331

Pisi-unciform ligament, 331

Pit, auditory, 50, 853

nasal, 798

olfactory, 49

rectal, 1230

Placenta, 54, $5 €$

basal layer of, 57,58

completion of the, 61

detachment of, 63

derelopment of, 56

fœtal, 60

maternal, 57, 60, 62

Placental area, 61, 63

Placode, dorso-lateral, 501 epibronclial, 501

Plane, frontal, 5 of greatest pelvic extension, 238 infra-costal, 140 $\bar{T}, 1411$

of least pelric extension, 238
Plane, median, 4 transpyloric, 1159

Plantar aponeurosis, 4£3

arch, 954

abnormalities, 1057

morphology of, 1047

position of, 1465

surgical anatomy of, 1465

artery, lateral, $95 \pm$

medial, 954

fascia, 423

lateral, 731

branches of, 735

deep branch of, 735

ligaments, 355

medial, 734

branches of, 734

nerves, 734

Plantaris muscle, 429 action of, 429

Planum nuchale, 166

occipitale, 166

popliteum, 2 42

sternale, 107

temporale, 118

Plate, basal, 31

floor, 31

mediulary, 513

neural, 31

roof, 31

Platyhieric sacım, 289

Platyknemia, 281, 289

Platyknemic index, 289

Platymeria, 289

Platymeric index, 289

Platypellic pelvis, 288

Platyrhine skulls, 287

Platysma muscle, 448 action of, 448

Pleura, pulmonary, 1084

Pleurie, 108 t

blood-ressels of, 913,926

cervical, 1398

costal, I085

cupula of, 1084

diaphragmatic, 1085, 1088

left costo-diaphragmatic reflection of, 1101

ligamentum julmonale of, 1086

lines of feflection of, 1086, 1399

lowest limit of, 1401

lymph ressels of, 1013

mediastinal, 1085, 1086, 1401, 1402

paracentesis of, 1403

parietal, 1081

pericardiac, 1086

phrenico-pleural fascia of, 1089

posterior mediastinil, $1+02$

pulmonary, 10.94

relation of, to kidney, 1401

to osophagus, 1152

to twelfth rib, $1 \pm 01$

right costo-diaphragmatie reflection of, 1399

sinus costo-mediastinalis of, 1094

phrenico-costalis of, 1093

stomata of, 1091

structure of, 1091

surgical anatomy of, 1399

vertebral line of, $109 \%$

Pleural cavity, 1083

reins, 963

Plenro-pericarclial canal, 72 
Plexus or Plexuses, annular, of cornea, 810 ano-coccrgeal, 738

aortic, 762,765

basilar renous, $97 \pm$

brachial, 700

communications of, 700

composition of, 700

infra-claricular branches of, 703

lateral cord of, 703

medial cord of, 703

morphology of, 742,743

position of, 700

posterior cord of, 701

primary cord of, 700

secondary fasciculi of, 701

supra-clavicular branches of, 702

surgical anatomy of, 1395

variations in, 752

cardiac, deep, 759, 789, 790, 791, 880

superficial, $757,789,880$

ca rotid, 757

external, 757

carernosus, clitoridis, 766

penis, 766

cavernous, 759,766

cervical, 694

ascending branches of, 695

branches of, 695

communications of, 697,698

cutaneous branches of, 695

descending branches of, 696

lateral branches of, 695,696

medial branches of, 695,697

morphology of, 700

muscular branches of, 696,697

posterior, 688,690

morphology of, 691

superficial cutaneous of, 695

chorioid, of fourth rentricle, 553,636 development of, 552

of lateral rentricle, 635 of inferior horu of, 636 development of, 635

of third rentricle, 617

coccygeal, 738

coliac, of sympathetic, 761, 763, 765

coronary, 765

anterior, 791

posterior, 791

deferential, 765

dental, superior, 775

diaphragmatic, 765

fundamental, of cornea, 810

hæmorrhoidal, 766

external venous, 984

internal venous, 984

hepatic, 765

hypogastric, 763, 1321

of sympathetic, 766

inferior mesenteric, 765

infra-orbital, 777

of limbs, 680

composition of, 742

development of, 743

distribution of nerves of, 750

formation of, 680

morphology of, 741

significance of, 753

trunks of, 742

variations in, 752

vesical, 1321

lumbar, 719
Plexus or Plexuses, lumbar, connexions of, with sympathetic, 719

constitution of, 719

subdivisions of, 720

variations in, 752

mesenteric, inferior, 732

superior, 766

myenteric of intestines, 1185,1210

of stomach, 1177

obturator, 723

œsophageal, 787, 788

anterior, 791

posterior, 791

ovarian, 765

pampiniform, 983

patellar, 726

pelvic, of sympathetic, 766

pharyngeal, 788

ascending, of sympathetic, 756

venous, 965

posterior cervical, 689

morphology of, 692

sacral, 691

morphology of, 692

post-vertebral venons, 976

prostatic, 766

(sympathetic), 766

prostatico-vesical (venous), 985

pterygoid (venous), 968

pudendal, 735

branches of, 736

morphology of, 740

position and constitution of, 735

pulmonary, 781

anterior, 791

posterior, 787, 791

renal, 765

sacral, 727

anteriur branches of, 727

articular branches of, 729

commmications of, with sympathetic, 727

muscular branches of, 728,729

position and constitution of, 727

terminal branches of, 729

spermatic, 765

splenic, 765

subclavian, of sympathetic, 759

subepithelial, of cornea, 810

submucons, of intestine, 1177

subperitoneal (Turner), 935

subpleural (arterial), 913

superior mesenteric, 765

suprarenal, 765

thyreoid, 759

tonsillar, 1147

tympanic, 759

uterine, 765,766

venous, 985

utero-vaginal, 985, 1321

vaginal venous, 766,985

vertebral venous, 976 external (venous), 976

resical, 766 of sympathetic, 759

venous inferior, 985

superior, 985

Plica or Plicæ, alares of knee-joint, 348

aryepiglottic, 1068

circular, of intestine, 1180

duodeno-jejunal, 1185

duodeno-mesocolic, 1185 
Plica or Plicæ, fimbriata, 1108, 1128 glosso-epiglottic lateral, 106 ' median, 1067, 1126

ileo-cæcal, 1218

inguinal, 1296

lacrimal, of Hasuer, 82.)

longitudinal, of duodenum, 1186

palmatæ of uterus, 1317

pharyngo-epiglottic, 1126

pubo-resical, 1237

recto-uterine, 1226,1238

salpingo-palatine, 1143

salpingo-pharyngeal, $11+3$

semilumar, of the colon, 1212

of the conjunctiva, 821

sublingual, 1108

synovial, of the patella, $3 \pm 8$

transversales of rectum, 1226,1230

triangular, of the tonsil, 1146

tubari, 1315

umbilical, lateral, 1235

medial, 1235

ureteric, 127 .

urogenital, 1334

rentricular, 1070

vesical, transverse, 1238

vocal, 1070

Plugging the posterior nares, 1385

Pogonion, 286

Point, alveolar, 285

jugal, 286

occipital, 285

subnasal, 285

supra-auricular, 286

Polar bodies, 15, 19

projection, 15,20

first, 15,20

second, 15, 20

Poles of lens, 820

Polymasty, 1338

Polymorphic cells, 645

Polyphyodont dentition, 1248

Polythely, 1338

mammary gland, derelopment of, 1339

lymph ressels of, 1338

nerves of, 1339

vessels and nerves of, 1338

Pons hepatis, 1192

(Tarolii), 540, 548, 567

acoustic area of, 551,604

auterior medullary velum, 549

brachium of, 566

conjunctivım, 549, 569

pontis, $5 \pm 8$

central tegmental tract of, $56 \pm$

cereliro-pontine fibres of, 566

commexions of longitudinal and transverse fibres of, 566

corpus ponto-bulbare of, 5.5.)

trapezoideum of, 567

development of, $33,514,592$

dorsal or tegmental part ol, 567

eminentia meclialis of, 551

external arcuate fibres of, 5.5 .5

fasciculi longitudinalis of, 56.5

fasciculus olbliquus of, $549,5.5$

cireumolivaris promidis, $5 . \overline{5}$

forea superior of, 551

gray matter of, 564

internal arcuate tilıres of, 556

internal structure of, 56.5 et seq.

lemniscus fibres of, 566,570
Pons (Varolii), lingula of, 549

locus cocruleus of, 551

medial longitıdinal bundle in, 558, 568

mesencephalic root of trigeminal nerve in, 569

nuclei of, $565,566,567$

arcuate of, 555

olivary nuclei of, .555

accessory, 556

dorsal, 5ั56

medial, 5.56

origin of, $516,567,569$

pars basilaris of, 56.j

position and comnexions of, $5 \pm 0,541$

pyramidal tract in, 565

raphe of, 558, 567

recessus lateralis, 549

restiform body in, 567

reticular formation of, 567

spinal root of trigeminal nerre in, 567

substantia ferruginea of, 370,551

sulcus basilaris of, $5 \pm 8$

tegmental part of, 567

transterse fibres of, 566,567

veins of, 971

ventral portion of, 56.5

Ponticulus, 829

Pontine flexule of brain, 514

Popliteal artery, 9.51

fascia, 405

fossa, surgical anatomy of, $143 \vec{i}, 1457$

groore, 243

line of tibia, 249

lymph glands, 1014

surface of femur, 242

rein, 986

abnormality of, 1059

Popliteus fascia, 420

muscle, 429

action of, 42.9

minor, 429

Pore, gustatory, 854

Porta hepatis, 1190

Portal canals, 1200

system, development of, 1036, 1037

vein, 990

Portio supravaginalis cervicis uteri, 1316 vagiualis cerricis uteri, 1316

Porus sudorifurus, 861

Position of kidneys, 1257, 1258

of urethral orifice in bladder, 1274

Post-anal gut, $\$ 8$

Pust-auditury process, 132, 133

Post-auricular point, 1359

Post-branchial borlies, 43

Post-central anastomosis, 1044

arteries, 1014

gу1т, 662, 663

line, 1360

Post-coronal depression, 166

Post-costal anastomoses, 1045

Posterior commissure of brain, 821

cutaneous nerve of thigh, surgical anatomy of, 1457

rami of lumbar nelves, 691 morjlutugr of, 691

of sacral aud coeygeal nerves, 691

of spinal nerves, 687

of thoracic nerves, 690

Posteru-lateral tract of spinal merlulla, 534

Post-glenoid tubercle, 126 
Post-menral auastomoses, 1044

Post-pharyngeal lympl glands, 1000

Post-splienoid bone, 138

Post-trausverse auastomoses, 1045

Post-rertebral reuous plexus, 976

Pouch of Douglas, 12:6

relation of, to uterus, 1319

surgical auatomy of, 1435,1436

branchial, 42

duodenal, 1185, 1186

pliaryngeal, 42

of Prussak, 84:2

of Rathke, 49

recto-genital, 1226

recto-vesical, 1226

surgical anatomy of, $143 \pm$

utero-vesical, 1238, 1317

ressels, 42

Poupart, iuguinal ligament of, 477 surface anatomy of, 1458

line of, 1411

plane of, $1 \pm 11$

Præcentral sulci, 665

sulcus, surface auatomy of, 1360

Præcordial area, outline of, 1403

Præcuneus, 662

Præ-interparietal bone, 277

Prielaminar arteries, 926

Præputium clitoridis, 1324, 1326 penis, 1299

Prævertebral fascia, 448 muscles, 467

Pre-aortic lymph glands, 1012

Pre-auricular lymph gland, 998 point, 1359

Pre-basi-occipital bone, 278

Precentral line, 1360

Precervical duct, 43 sinus, 43,76 sulcus, 43

Prechordal part of basis cranii, 291 portion of skull, 291

Precoracoid, 295

Precostal anastomoses, 1044

Prehallux, 295

Prelaminar anastomoses, 926

Prelaryngeal lymph glands, 1001

Premaxillæ, 150 ossification of, 150

Premaxillary suture, 150

Premolar teeth, 1117

Preneural anastomoses, 1044

Prepatellar bursa, 1460

Prepollex, 295

Prepuce, 1326

Preputial glands, 1299

Presphenoid bone, 291

Presternum, 107

Pretracheal glands, 1001

Prevertebral arteries, 896 fascia, $448,467,1386$ muscles, 467

Prickle-cells, 857

Primary optic vesicle, 33

Primitive alimentary canal, 41 aoltre, 67

branches of, 1027

morphology of, 1040

brain, fate of eavities of, 36

cerebral vesicles, 33

groove, 23

heart, 1026
Primitive streak, 26

vascular system, 1025

Primordial bones, 292

Princeps cervicis artery, 895

pollicis artery, 921

Prismata adamantina, 1245, 1247

Pro-atlas, 278

Process or Processes; Processus-

accessory, of the vertebræ, 96

acromion, 203, 204

alar, of ethmoid, 140

alveolar, of maxilla, 148

absorption of, 197

angular medial, of frontal bone, 115 surface anatomy of, 1360

anterior mallei, 840

articular, 89

of cervical vertebræ, 91

of liumbar vertebræ, 96

of sacrum, 97

of thoracic vertebræe, 93

basilar, 120, 123

of calcaneus, 259

capitular, of vertebra, 284

ciliary, 812

clinoideus anterior, 135

medius, 135

posterior, 135

cochleariformis, 128

surgical anatomy of, 1368

conchal, of ethmoid, 141

surgical anatomy of, 1378

condyloid, of mandible, 156

coracoid, 201

morphology of, 295

ossitication of, 204

surface anatomy of, 1445

variations in, 280

coronoid, 156, 210

surface anatomy of, 1325

dens, 92

ossification of, 10.5

epicondylic, of humerus, 280

surface anatomy of, 1449

ethmoidal, of inferior concha, 143

facial, of parotid gland, 1136

talciformis, of sacro-tuberous ligament, 337

frontal, of maxilla, 145, 148

of fiontal bone, 117

medial, 49

fronto-nasal, 49

fronto-sphenoidal, of zygomatic bone, 153

funicular, of peritoneum, 1409

globular, 49

hamulns, of lacrimal, 143

of os hamatum, 221

of sphenoid, 138

surgical anatomy of, 1385

intermaxillary, 49

intrajugular, 122

jugular, 172, 177

lacrimal process of inferior concha, 143

lateralis mallei, 840

nasalis, 49

tali, 254

tuberis calcanei, 259

lenticularis incudis, 840

mamillary, of the vertebra, 96

marginal, of zygomatic bone, 153

mastoid, 128

maxillary, of inferior concha, 143

of mandibular arch, 48, 49, 50, 149 
Process or Processes, maxillary, of mandiĺnlar. arch, first appearance of, 48,149

maxillary, of palate bone, 152

medial tuberis calcanei, 259

muscular, of vertebræ, 89

muscularis, 1065,1074

olecrano11, 210

surface anatomy of, 1449

orbital, of palatine bone, 152

palatine, 50, 148, 149

paramastoid, 278

paroccipital, 278

petrosal, 135

phalangeal, of lamina reticularis, 851

of rods of Corti, 851

post-auditory, 133

pterygoid, 137, 174

pterygo-spinous, 137

pyramidal, of palate bone, 152

reticularis, 524

sphenoidal, of palate bone, 152 septi cartilaginous, 801

spinous, of cervical vertebre, 90

of iumbar, 95

of sacral, 97

serial homology of, 283

surface anatomy of, 1436

of thoracic vertebræ, 93

styloid, 177

of radius, 216

surface anatomy of, I 150

temporal, 127

ossification of, 132

relation of, to jugular foramen, 177 root of, 177

of third metacarpal bone, 225

of third metatarsal, 225

of ulna, 213

temporal, of zygomatic bone, 153

of Tomes, 1247

transverse, of atlas, 1391

of the cervical vertebrie, 90

lumbar, 95

sacral, 98

serial homology of, 284

surface anatomy of', 1437

thoracic, 93

trochlear, 260

of calcaneus, 260

tubarius, of pterygoid process, 838

tubercular, of rertebræ, 284

uncinate, of etlimoid, 14 I

pancreatis, 1203

vaginal, of the peritoneum, 1295, 1319 surgical anatomy of, 1409

of sphenoid bone, 177

of temporal bone, 127

vermiform, 1215

vocal, 1070

xiphoid, 108

zyomatic, of frontal, 115

maxilla, 148

temporal, 126

Proctodieum, 42

derivative of, 50

Profunda artery of the tongue, 892, 1130

brachii, 918

branch of ulnar artery, 918

cervicis artery, 914

clitoridis artery, 942

femoris artery, 949

abnormalities of, 1050
Profunda femoris artery, branclies of, 949 penis artery, 942

Proguatlious skull:, 287

Projection filures of cerebrum, 651

Prominentia canalis facialis, 833

laryngea, 1062, 107\%

surface anatomy of, 1387

spiralis, 819

styloidea, 834

Promontorium cochlere, 1368

of sacrum, 98

surgical anatomy of, 1444

tympani, 832

Pronation, 328, 401

Pronator quadratus muscle, 390 action of, 391

teres inuscle, 385 action of, 385

Pronephros, 1327

Pronucleus, female, 16

male, 20

Pro-otic part of temporal bone, 131-132

Prophase, 9

Prosencephalou, 514, 607 development of, 33,514

dienceplialon of, 608

development of parts of, 608

telenceplialon of, 608

Prostate, 1301

anterior surfaces of, 1301

apex of, 1302

base of, 1301

capsule of, 1429

development of, 1335

ducts of, 1303

fibrous sheath of, 1302

glandular part of, 1301, 1203

lateral lobes of, 1302

surfaces of, 1301

middle lobe of, 1302

nerves of, 1304

posterior surfaces of, 1302

pudendal plexuses of, 1302

senile hypertrophy of, 1429

sheath of, 1429

structure of, 130:)

surgical anatomy of, 1429

vessels and nerves of, 1:301

Prostatectomy, 1429

perineal, 1430

supra-pulicic, 1429

total, 1430)

Prostatic urethra, 1305

development of, 1335

utricle, 1306

Prostatico-resical venous plexus, 985

Prosthion, 288

Protoplasm, 8

Protoplasmic process of Deiters, 507

Protovertebral somites, 28

Protuberance, mental, 155

occipital, exterul, 121 internal, 121

Prussak, pouch of, 842

Psoas alsicess, 1439

majur muscle, 410 actions of 411

minor, 410

actions of, 411

Pterion, 166, 179, 285

surface anatumy of, 1360

Pterotic piat of tempolal lone, 13:2 
Pterygoid artery of internal maxillary, 900 of internal caroticl, 902

canal, 138, 175

fosะa, 174

lamina, lateral, 137

medial, 13 ‘

muscles, 455-457

actions of, 458

nerves, 457

notch, 137

plexus, venous, 968

process, 137

ridge, 137

tubercle, 138

venons plexus, 968

Pterygo-palatine fossa, 138 artery, 899

canal, iti

index, 287

nerre, 777

sulcus, 138

vein, 968

Pterygo-spinons ligament, 313 process, 137

Pubic, 945

branch of inferior epigastric artery, 945 of obturator artery, 940

crest, 233

sexual difference of, 238

surface amatomy of, 1458

ligaments, 337

lymph glands, 1015

sinus, 197

tubercle, 233

surface anatomy of, 1458

vein, 988

Pubis, 232

morphology of, 296

Pubo-capsular ligament, 340

Pubo-cavernosus muscle, 488

Pubo-coccrgeus muscle, 494

Pubo-prostatic ligaments, 493, 1429

Pubo-rectalis muscle, 494

Pudendal artery, accessory, 1056 extermal, deep, 948 superficial, 948

internal, 940

nerve, 738

surgical anatomy of, 1428

plexus, 766

reins, 985

venous plexus, 735,1439

branches of, 736

morphology of, 740

Pudendum muliebre, 1324

Pulled elbow, 1449

Pulmonary artery, 882, 1037, 1405

abnormalities of, 1050

development of, 68

morphology of, 1046

surface anatomy, 1408

nerves, 786, 788, 791

orifice, 878

surlace anatomy of, 1405

plexus, 786,788

anterior, 788,791

posterior, 786,791

valve, 877

vascular system, 882,958

vein, 958,1097

orifices of 875

vessels, 1099
Pulp cavity of spleen, 1353 of tooth, 1114

Pulvinar of thalamus, 611

Puncta lacrimalia, 825 surgical anatomy of, 1377

Pupilla, 814 dilator of, 814

sphincter of, 814

Pupillary border, 814 membrane, 813

Purkinjé, cells of cerebellum, 580, 581 fibres of, 879

Purple, visual, 815

Putamen of lentiform nucleus, 639

Pyloric antrum, 1169

artery, 930 morphology of, 1046

canal, 1169

clıanges in, during digestion, 1173

ligaments, 474

portion of stomach, 1165, 1166, 1169, 1173

sphineter, 1163, 1166, 1173

valve, 1173,1174

rein, 992

ligaments of, 1174

morphology of, 1048

Pylorus, 1169

surgical anatomy of, 1416, 1417

Pyramid of cerebellum, 576

of medulla oblongata, 545

Pyramidal cells, 645

lobe of thyreoid, 1347

process of palatine bone, 152

Pyramidalis abdominis muscle, 481

Pyramids of medulla oblongata, 545, 557, 558

decussation of, 557

renal, 1265

tract, 538, 545, 565

of tympanic cavity, 834

of vestibule, 843

Pyrenin, 8

Quadrate lobe of liver, 1193, 1194

muscle (of upper lip), 450

angular head, 450 action of, 454

infraorbital head, 451 action of, 452

Quadratus femoris muscle, 418 action of, 418

labii inferioris muscle, 451

lumborum muscle, 485

Quadriceps (extensor) femoris muscle, 406 action of, 409

Quadrigeminal bodies, 585, 586

derelopment of, 34,592

Racemose glands, 1132

Radial artery, 919

fossa, 211

groove in upper arm, 207

nerve, 710

surgical anatomy of, 1448

variations, 742

Radiale, os, 295

Radialis indicis dorsalis artery, 920

Radiatio or Radiation-

acoustic, 643,656

of corpus collosum, 631

pars occipitalis of, 631 
Radiatio or Radiation, of corpns striatum, 639 occipito-thalamic, $620,6+3,658$

optic, $620,643,658$

thalamic, 610

thalamo-occipital, 658

thalamo-temporal, 656

Radicular cells, 528

veins of medulla oblongata, 972

Radii lentis, 820

Radio-carpal joint, 328

movements at, 329

surgical anatomy of, 1450

synovial stratum of, 329

Radiography of stomach, 1417

Radio-humeral joints, 323

Radio-ulnar joint, distal, 3ə7 proximal, 326

Radius, 214

architecture of, 272

connexions of, 213

homology of, 295

movements of, on ulna, 213

ossification of, 217

surgical anatomy of, 1449,1450

variatious in, 272

Radix or Root, anterior nervorum spinalium, 685

arcus vertebræ, 88, 90, 93, 95, 97

brevis ganglii ciliaris, 759

cochlearis nervi acustici, 604,852

dentis, 1114

descendens mesencephalica n. trigemini, 569, 601,602

lateralis tractus optici, 378,384

linguæ, 1125

longa ganglii ciliaris, 773

medialis tractus optici, 378,574

mesenterii, 1208

nasi, 799

nervi facialis, 781

penis, 1299

pili, 859

posterior nervorum spinalium, 685

pulmonis, 1096

sympathica ganglii ciliaris, 759 submaxillaris, 757

unguis, 858

Rami communicantes, gray, $69-1,754$ cervical, 694, 759

development of, 681

functions of, 755

lumbar, 719

of plexus, brachial, 700

cervical, 694, 7.59

lumbo-sacral, 719

pudendal, 736

of thoracic nerves, $716,71 \%, 761$

Rami communicantes, white, 680, 69.-

cervical, 697

development of, 680

lumbar part of, 762

of lumbo-sacral plexus, 719, 762

of pelvic plexus, 76:2

of pudenclal plexus, 737

of sacral plexus, 719

of solar plexus, 762

of thoracic sympathetic, $759,760,761$

Ramus, Rami or Branches (of arteries)acetabuli, $9 \pm 9$

acromialis, 916

transverse scapular artery, acromial branches of, 912
Ramus, Rami or Branches, ad pontem, 90anterior A. thyreoidea superioris, 892 ascendens $\mathrm{A}$. circuntlexie femoris lateralis, 949

A. transversic colli, 911

auriculares anteriores, 896

auricularis arterice occipitalis, 895

posterioris, 896

bronchial, 92.5

calcanei, 953

medial, 955

ca rotico-tympanicus, 902

carpeus dorsalis $\mathrm{A}$. radialis, 920

dorsalis A. ulnaris, 923

volaris A. radialis, 920

volaris A, ulnaris, 922

circumflexus A. coronarice sinistra, 887 cochlearis $A$. auditive interne, 853,907 communicans A. tibialis posterioris, 9.53 communicans A. peronea, 953

cricothyreoideus, 892

cutanei anteriores (pectorales et abdominis), 926

deltoideus, 916

descendens anterior $A$. coronarix sinistre, 887

A. circumflexæ femoris lateralis, 949

A. occipitalis, 895

A. transver'sæ colli, 911

posterior A. coronarize sinistre, 887

dexter A. hepaticæ, 930

dorsalis A. costo-cervicalis, 914

A. lingux, 892

A. lumbalium, 935

duodenales A. gastroduodenalis, 930

epiploici A. gastroepiploica dextre, 930

fibularis, 956

frontalis A. temporalis superficialis, 897

glandulares A. maxillaris externx, 893

A. thyreoider inferioris, !11

hyoideus A. thyroidese superioris, 892

hyoideus A. lingualis, 892

iliacus A. iliolumbalis, 938

intercostales A. nammarice internce, 913

intestini tenuis, 932

mammarii externi A. thoracalis lateralis, 916

mammarii A. mammarice internic, 913

mammarii laterales A. intercostalium, 926

mediales $\mathrm{A}$. intercostalium, 926

mastoideus $A$. occipitalis, 895

A. auricularis posterioris, 895

mediastinales aortie, 925

meningeus accessurius, 899

A. occipitalis, 895

A. vertebralis, 907

mylohyoidens, 899

occipitalis A. auricularis posterioris, 896 asophagei aortie, 925

d. yastricue sinistrite, 9:9

ovarii A. nterince, 940

pancreatici A. lienalis, 929

A. pancreaticoduorlenalis superioris, 930 parotidei A. temporalis superticialis, 896. parietalis $A$. temporalis stperticialis, 897

jectorales A. thoracuacromialis, 916

perfurans A. tibialis posterioris, 553

A. Lnammarice internic, 913

A. metacarjalium volarium, $92+$

A. metatursalium plantarium, 955 
R:umus, Ramior Branches, pericardiaciaortæ, 925 petrosus superficialis A. maxillaris interma, 898

pharyngei A. pharynged ascendentis, 896 posterior A. thrreoidea superioris, 892

A. olituratorix, $9 \pm 0$

A. intercostalinm, 926

pterrgoidei A. maxillaris internæ, 899

pubic A. epigastrice inferioris, 945

pubicus A. epigastricæ inferioris, 945

pubicus A. obturatorice, 940

saphenus, 951

sinister $\mathrm{A}$. hepaticæ, 930

spinalis A. iliolumbalis, 938

A. intercostalis supremæ, 914

A. intercostalium, 926

A. lumbalium, 935

A. sacralis lateralis, 938

A. vertebralium, 907

stapedius A. stylomastoideæ, 895

sternomastoideus A thyreoidex superioris, 892

suprarenales superiores, 933

tonsillares A. maxillaris externæ, 893

tracheales A. thyreoider inferioris, 911

tubarius A. nterince, 940

restibular A. auditivæ internæ, 853

volaris profundus, 923

superficialis, 919

Ramus or Rami or Branches (of nerves) -

alveolares superiores anteriores, 777

posteriores, 775

alveolaris superior medius, 777

anastomotici cum nervo faciali, 780

hypoglosso, 780

anastomoticus cum chorda tympani, 781

nervo auriculo-tempoiali, 781

N. facialis cum nervo glossopharyngeo, 782

N. vagi cum nervo glossopharyngeo, 788

cum nervo laryngeo inferiore, 789

ulnari, 707

cum ramo auriculari nervi vagi, 788

anastomoticus peronæus, 730

anterior nervi obturatorii, 722

anterior nervorum spinalium, 692

rami cutanei lateralis (pectoralis et ab(ominalis), 692, 714, 716, 717

anteriores $\mathrm{N}$. thoracalium, 692, 713, 714-717 nervorum cervicalium, 692

lumbalium, sacraliım, coccygeorım, 719 auricularis $\mathbf{N}$. vagi, 788

buccales $\mathrm{N}$. facialis, 784

calcanei mediales, 734

cardiaci inferiores $\mathrm{N}$. vagi, 789

superiores N. vagi, 789

cœliaci N. vagi, 789

colli N. facialis, 784

communicans nervorum spinalium, 687

communicantes ganglii submaxillaris cum nervo linguali, 780

cutanei anteriores nervi femoralis, 724

cruris mediales, 724

cutaneus anterior (pectoralis et abdominalis), $692,714,716,717$

cutaneus anterior nervi ilı-hypogastrici, 720

lateralis (pectoralis et abdominalis), 720

nervi ilio-hypogastrici, 720
Ramus or Rami or Branches, cutaneus, lateralis, nervorum thoracalium, posterior rami of, lateral cutaneous branch of, 716, 717

medialis nervorum thoracalimm, 690

medial entaneous branch of, 690

nervi obturatorii, $7: 33$

volaris nervi ulnaris, 709

dentales inferiores, 780

superiores, 775

descendens N. hypoglossi, 794

digastricus $\mathrm{N}$. facialis, 783

dorsalis manus nervi ulnaris, 709

externus, nervi accessorii, 793

laryngei superioris, 788

frontalis nervi ophthalmici, 772

gastrici $\mathrm{N}$. vagi, 789

hepatici $N$. vagi, 789

inferior nervi oculomotorii, 770

inferiores nervi cutanei colli, 618

infrapatellaris, 726

internus, nervi accessorii, 793

laryngei superioris, 788

isthmi faucium, 780

labiales inferiores $\mathrm{N}$. mentalis, 770

superiores N. maxillaris, 777

laryngo-pharyngei, 756

lateralis ramorum posteriormm nervorum cervicalium, 688, 690

N. lumbalinm, 690

nervorum sacralium et coccygei, 691

lienales nervi vagi, 789

linguales N. glossopharyngei, 786

N. hypoglossi, 795

N. lingualis, 780

marginalis mandibulæ, 784

mediales ramorum posteriorum $N$. cervicalium, 688, 690

medialis ramorum posteriorum N. lumbalium, 690

nervorum sacralium et coccygei, 691

membranæ tympani $\mathrm{N}$. auriculo-temporalis, 780

meningeus nervi vagi, 788

nervorum spinalium, 686

mentales nervi mentalis, 780

musculares nervi axillaris, 710

femoralis, 724

ilio-hypogastrici, 720

ilio-inguinalis, 721

ischiadici, 728

mediani, 705

musculo-cutanei, 704

peronæi, 730

profundi, 730

superficialis, 731

raclialis, 633

tibialis, 732

uluaris, 709

nervorum thoracalium, 716,717

plexus lumbalis, 720

nasales externi N. naso-ciliaris, 773

interni N. naso-ciliaris, 773

laterales N. naso-ciliaris, 773

mediales $\Lambda^{\top}$. naso-ciliaris, 773

occipitalis $\mathrm{N}$. auricularis posterioris, 783

œsophagei N. vagi, 788

orbitales ganglii spheno-palatini, 778

palmaris nervi mediani, 705

palpebrales inferiores nervi maxillaris, 777

palpebralis inferior nervi infra-trochlearis, 773

superior nervi infra-trochlearis, 773 
Ramus or Rami or Branches, parotidei nervi auriculo-temporalis, 780

pericardiacus nervi phrenici, 699

perineales nervi cutanei femoris posterioris, 737

pharyngei nervi glosso-pharyngei, 786

nervi vagi, 788

phrenico-abdominales nervi phrenici, 699

posterior nervi obturatorii, 723

nervorum spinalium, 687

posteriores nervorum cervicaliım, 688, 690

lumbalium, sacralium, coccygeosum, 690, 691

thoracalium, 690

profundus nervi plantaris lateralis, 734 radialis, 712

ulnaris, 709

pulmonalis partis thoracalis sympathici, 761

renales N. vagi, 789

renalis nervi splanchnici minoris, 765

stylohyoideus, 783

stylopharyngeus, 786

submaxillares ganglii submaxillaris, 780

superficialis N. plantaris lateralis, 735

nervi radialis, 712

N. ulnaris, 709

superior $\mathrm{N}$. oculomotorii, 770

superiores nervi cutanei colli, 696

temporales $\mathrm{N}$. facialis, 783

superficiales $N$. auriculo-temporalis, 780

thyreohyoideus N. hypoglossi, 795

tonsillares $\mathrm{N}$. glossopharyngei, 786

tracheales nervi recurrentis $\mathbf{N}$. ragi, 789

tubæ plexus tympanici, 786

ulnaris nervi cutanei antibrachii medialis, 710

volaris nervi cutanei antibrachii medialis, 710

zygomatici $\mathrm{N}$. facialis, 784

zygomatico-facialis, 776

zygomatico-temporalis, $7: 6$

Ramus anterior ascendens fissurac cerebri lateralis, 653

anterior horizontalis fissuræe cerebri lateralis, 653

posterior fissuræ cerebri lateralis, 653

Ramus bronchialis eparterialis, 1097

bronchialis hyperarterialis, 1097

Ramus ossis ischii inferior, 232 superior, 232

mandibulæ, 156

surgical anatorny of, 1375

pubis inferior, $23 \pm$ superior, 233

Raplie medullæe oblongata, 55., 561

palati, 1110

phar'yngis, 464, 1149

pontis, 558

scroti, 1297

of tongue, 1129

Rathke, pouch of, 49

Recess or Recessus, aqueductus restibuli, 813 cochlearis, 843

duodenojejunal, 1185

ellipticus vestibuli, $8 \pm 3$

epitympanic, 83:2

ileocæcal, 1218

inferior, 1218

superior, 1218

infundibuli, 618

intersigmoid, $12: 3$

labyrinthi, 853
Recess or Recessus, lateral, of fossa rhomboidea, 571

lateral, of pharynx, 1141

naso-palatine, 802

optic, 618

paracolic, 1219

parotid, 1133

pharyngeus, 1144

pinealis, 618

piriformis, 1069, 1147

retrococalis, 1219

sacciformis articulationis radio-ulnaris distalis, 327

splhæricus vestibuli, $8 \pm 3$

spheno-ethmoidalis, 802

supra-pinealis, 618

utriculi, 846

Recesses of Tröltsch, $8+2$

Rectal examination, 1430, 1431

fascia, 1228

of female, 1436

lymph glands, 1015, 1016, 1017

triangle of perinæum, 1427

Recto-coccygeus muscle, 1229

Recto-genital folds, 1317

pouch, 1226

Recto-uterine fold, 1317

muscle, 1238

Recto-vaginal fold, 1317

Recto-resical fascia, 493 pouch, 1226

surgical anatomy of, 1434

Rectum, 1224

ampilla of, 1226, 1227

anal orifice of, 1230

in child, 1228

columns of, 1:30

cotrise of, 1224

curvatuxes of, 1221

development of, 1252 ?

general relations of, 1228

lateral flexures of, 1224

nerves of, 12:3:3

pars analis of, 1228

peritoneal relations of, 12206

pits of, 1230

plicæ trausversales of, 1225, 1230

remoral of, 1433

sphincter of, 1229

structure of, $12: 29$

surgical anatomy of, 1430

valyes of, $1: 30,1231$

variations in, 1233

ressels of, 1232

Rectus abdominis muscle, 481

capitis anterior muscle, 468 lateralis muscle, 470 posterior major muscle, 444

femoris muscle, 407 minor muscle, 444

action of, 109

muscles of orbit, inferior, 453

liateral, 453

inedial, 453

silperior, 4.53

actions of $45 \frac{1}{4}$

Recurrent artery, 924

nerve, surgical anatomy of, 1394

Red marrow, 83

nucleıs, 613

origin of, 516

Refracting media of the eje, 819 
Region, frontal, 667 of brain, 665

hypothalamic, 613

prizcentral, 660

Regiones abdominis, 1158

Reichert, cartilage of, 159

Reid, base line of, 1360

Reil, island of, 654,655

Reissner, membrane of, 849

Renal artery, 927 corpuscles of kidney, 1266 development of, 1331

fascia, 1425

impression on liver, 1194

plexus, 765

vein, 982

Reproduction of cells, 8

Reproductive cells, 11

organs, female, 1310

male, 1286

bulbo-urethral glands, 1286

duct, ejacula tory, 1286

ductus deferens, 1286

epididymis, 1286, 1287

penis, 1286

prostate, 1286

serotum, 1286

testis, 1286

vesicula seminalis, 1286

Reserve gerns of teeth, 1244

Respiration, movements of, 474

muscles of, $470,47 \pm$

organs of, 1061

Respiratory system, 1061 development of the, 42,44

Restiform body, 547, 562

development of, 562

functions of, 563

structure of, 562

Rete testis, 1288 venosum dorsalis manus, 978

vertebrarum, 976

$$
\text { pedis, } 989
$$

Reticular process, 524

substance, 524

structure of, 564

Retina, 814

bacillary layer of, 817

bipolar cells of, 816

blind spot of, 815

blood-ressels of, 818

cone-granules of, 817

cones of, 817

development of, 827

excavatio nervi optici, 815

forea centralis of, 815

ganglionic layer of, 816

granule layer of, 817,818

horizontal cells of, 817

inner molecular layer of, 816

nuclear layer of, 816,817

macula lutea, 815

membranæ limitantes of, 817

nervous lamina of, 814

optic cup of, 815

disc of, 815

ora serrata of, 815

papilla nervi optici, 815

pars ciliaris retinæ, 815

iridica retinx, 815

optica retinæ, 81 อ

pigment of, 817
Retina, relation of optic fibres to, 620

rod-granules of, 817

rods of, 817

spongioblasts of, 817

stratum opticum of, 815

pigmenti of, 817

structure of, 815

of macula lutea, 818

of ora serrata, 818

sustentacular fibres of, 815,817

ressels of the, 818

visual purple of, 815,817

Retinacula cutis, 856

of hip-joint, 340

Retinaculum superior peroneal, 422

Retinal layer of optic vesicle, 825

Retro-cæcal fossæ, 1218

Retro-colic fossæ, 1219

Retro-pharyngeal abscess, 1386

Retzius, space of, 493, 1429

striæ of, 1122

Rhinencephalon, 627, 682

development of, 33

Rhinion, 285

Rhinoscopy, anterior, 1378 posterior, 1385

Rhodopsin, 815

Rhombencephalon, 514, 515

development of parts of, $51 \tilde{0}$

isthnus of, 515

Rhombic lip, 554

Rhomboideus major muscle, 368

minor muscle, 368 actions of, 369

Rib, eleventh, 113

first, 109

second, 112

tenth, 113

twelfth, 113

surface anatomy of, 1437, 1442

Ribs, 109

angle of, 109

architecture of, 109

cartilages of, 113,315

cervical, 90, 104

false, 109

floating, 109, 112

head of, 109

lumbar, 104, 277, 284

movements of, 317

ossification of, 112

peculiar, 109

shaft of, 109

surface anatomy of, 1401

true, 109

tubercle of, 109

typical, 109

variations in, 276

vertebral, 109

vertebro-chondral, 109

vertebro-sternal, 109

Ridge, epicondylic, 207 surface anatomy of, 1449

interosseous, of fibula, 252 of tibia, 248

intertrochanteric, 240

pectoral, 206

pterygoid, 137

superciliary, 116

surface anatomy of, 1374

temporal, 116

trapezoid, 199 
Ridge, Wolffian, 39

Riedel's lobe of liver, 1195

Rima glottidis, 1070 surface anatomy of, 1388

oris, 1106

palpebrarum, 821

pudendi, 1324

vestibule, 1070

Ring, abdominal inguinal, 1408

femoral, 405

hypocartilaginous, of membiana tympani, 834

subcutaneous inguinal, 477, 1408

crura of, 477

intercrural fibres of, 477

tympanic, 133

Riolan, muscle of, 823

Risorius muscle, 451

Rivinus, ducts of, 1139

notch of, 831

Rod-bipolars of retina, 816

Rod-granules of retina, 816

Rods of Corti, 850

head-plate of, 850

phalangeal processes of, 851

retinal, 817

Roof of fourth ventricle, 578

Roof-nucleus, 577

Roof-plate, 31, 502

Root of lung, 1096

surface anatomy of, 1442, 1410

Roots of aortic arch, 1027, 1028

of nerres, 519

of vertebral arches, 88

cervical, 90, 92

lumbar, 95

thoracic, 93

Rosenmiiller, fossæ of, 1144 surgical anatomy of, 1434 organ of, 1315

Rostrum of corpus callostum, 630 of sphenoid, 135

Rotation of joints, 303

Rotator humeri muscles, 373,377

Rotatores dorsi muscles, 445

Round ligament of liver, 1197 of uterus, 1319 surgical anatomy of, 1434

Rubro-spinal tract, 534, 588

Rudiment of the processus vaginalis, 1296

Ruffini, corpuscles of, 865

Rugre of palate, 1110,1111

of scrotum, 1297

of stomach, 1165

vaginales, 1323

Running, movements of, 437

Sac, lacrimal, 825

development of, 49

surgical anatomy of, 1377

tooth, 1245, 1246

Sacculus of membranous labyrinth, $846, £ 48$ development of, 52 , 854

ductus endolympliaticus of, 847

reuniens of, 847,854

utriculo-saccularis of, 847

macula acustica of, 847

siuus utricularis of, 847

Saccus endolymphaticus, $8+7$

development of, 52

Sacral arteries, lateral, 938 middle, 935
Sicral canal, 99

and coccygeal nerres, first three sacral, 691 posterior rami of, 691

crest, 97,98

ganglia, 763

index, 99, 289

lymph glauds, 1016

nerves, 691, 702, 727, 735

notch, 96

plexus, 727

anterior branches of, 727

articular branches of, 728

branches of, 727

communications of, with srmpathetic, 727

formation of, 727

muscular branches of, 728

nerves of distribution from, 728

position and constitution of, 727

sympathetic, 766

terminal branches of, 729

veins, 983

Sacro-coccygeal joint, 308

nerves, 691, 738

Sacro-genital fold, 1283, 1318

Sacro-iliac joint, 335

surface anatomy of, 1455

ligaments, 336

Sacro-spinalis, muscles, 439

actions of, 442

surface anatomy of, 1437

Sacro-rertebral angle, 109

sexual differences in, 238

Sacrum, 96

ala of, 98

auricular surface of, 99

canal of, 99

lateral part of, 96

ossification of, 106

posterior surfice of, 97

promontory of, 98

level of, 1443

serial homology of, 284

sex ditferences of, 99

variations in, 275

Sagittal fontanelle, 194

plane, 5

sulcus, 117, 119, 121

suture, 118, 119, 171

Salivary glands, 1113

development of, 1249

structure of, 1140

Salpingo-palatine fold, 838, 1143

Salpingo-pharyngeal fascia, 8.38

fold, 838,1143

musele, 465

Santorini, cartilages of, 1065

lucts of, 1108, 1138, 1207

tubercle of, 1069

Saphenous artery, 951

nerve, 726

sufface anatumy of, 1461, 1463

reins, 988,989

Sartorius muscle, 406 action of $406^{\circ}$

Scala tympani, 845

vestibuli, 845

Scalene tubercle, 111

Sualemis anterior muscle, 467

medius muscle, 467

posterior muscle, 467 actions of these, 468

Scallp, 448 
Scilp, arteries of, $894,895,897$

lrmph ressels of, 1003, 1357

inutsicles of, 448

surgical anatouny of, $135 \%$

veins of, 967,1357

Seapha auriculie, 828

Scapula, 200

acromion, 200

architecture of, 271

axillary margin, 201

conmexions of, 201

glenoid cavity of, 201

homology of, 295

ligaments of, 320

morements of, 319

notch of, 201, 202

ossification of, 204

surface anatomy of, 1436, 1444, 1445

variations in, 280

Scapular arteries, circumflex, 917

subscapular, 917

transverse, 911

index, 288

line, 1397

notch, 201, 202

Scapulo-clavicular joint, 318

Scarpa, fascia of, 1427

foramina of, 149,174

ganglion of, 853

Scheme of the nervous system, 498

Schindylesis, 300

Schneiderian membrane, 804

Schreger, lines of, 1123

Schultze, comma tract of, 533

Sciatic foramen, greater, 229, 337 lesser, 232, 337

foramina, 229, 232,335

ligaments, 337

nerve, 728

surgical anatomy of, 1456

notch, 229,252

greater, 229, 232

lesser, 232

Sclera, 807

canal of Schlenm of, 808

development of, 743

foramina of, 808

lamina cribrosa of, 808

fusca of, 808

sinus renosus of, 808

spatium perichorioideale of, 808

structure of, 808

sulcus of, 807

vascular and nerve-supply of, 808

venre vorticosæ of, 808

Scleratogenous segment, 29

Sclero-corneal junction, 809

Scrotal arteries, 1298

Scrotum, 1297

development of, 1295

raphe of, 1297

tunica dartos of, 1298

Sebaceous glands, 861

Sebum cutaneum, 861

Secondary bones, 292

chorionic villi, 53

tympanic membrane, 833

Secretory nerves of salivaly glands, origin of, 598

Sectiones cerebelli, 579

corporum quadrigeminorum, 584, 586

medullæ oblungatæ, 555, 565
Sectiones, medullæe, spinalis, 523, 539

pontis, 565, 570

telencephali, $633,636,638,641$

Segmental arteries, 66, 1043

anastomoses of, 1044, 1045

somatic, 1043, 1045

splanchnic, 1046

type, 2

veins, 1048, 1049

Segmentation cavity, 21

nucleus, 21

Sella turcica, $13 \pm$

of ovum, 15, 21

Semicanalis m. tensoris tympani, 834

tubæ auditivæ, 834, 838

Semicircular bony ducts, 844 ampullæ of, 847

crista ampullaris of, 848

crus commune of, 844

cupola terminalis of, 848

development of, 854

lateral, 844

membranous, 847

osseous, 844

posterior, 844

superior, 844

ducts, 847

development of, 52

Semilunar ganglion, 722

space of Traube, 1418

Semimembranosus muscle, 420 action of, 421

bursa, 1458

surface anatomy of, 1458

Seminal vesicles, 1292, 1294

development of, 1335

structure of, 1294

vessels and nerves of, 1295

Seminiferous tubules, 1288

Semispinalis muscle, 442 capitis, 442 dorsi, 442

Semitendinosus muscle, 419 action of, 420

surface anatomy of, 1450

Senses, organs of the, 799

Sensory area of the brain, 662

cells, 497

decussation, 562, 566

tracts of brain, 657

Separation of proximal epiphyses of humerus, 1445

Septal artery of nose, 805

Septo-marginal tract, 535

Septula testis, 1288

Septum or Septa, of aortic bulb, 1035

of aorto-pulmonary artery, 1035

atriorum, 1033

of auricles, 1032, 1033

development of, 1033

canalis musculo-tubarii, 833

cartilagineum nasi, 802

corporum cavernosorum, 1300

femoral, 405

glandis penis, 1298

intermuscular, of arm, 378

of foot, 423

of leg, 422

of thigh, 403

intermusculare femoris lateral, 404 medial, 404

fibulæ anterius, 422 
Septum or Septa, intermusculare fibulæ posterius, 422

humeri laterale, 378

mediale, 378

interventricular, 1035

linguæ, 1129

mediastinal, 1083

membranaceum Tentriculorum, 878

musculare rentriculorum, 878

nasi, 185 , 802

cartilage of, 800

development of, 40, 1033

surgical anatomy of, 1378

orbitale, of eyelids, 822

pectiniform, of penis, 1300

pellucidum, 628,632

posterior median of, 521

posterins of arachnoid, 672

primum, 1033

scroti, 485

secundum, 1033

sinumm frontalium, 270

sphenoidalium, 271

spuirium of heart, 1032

of tongue, 1129

transversum, 68, 74

of semicircular ducts, 848

tubre, 833

of uterus, 1320

of vagina, 1320

ventricular, 878

development of, 1035

Serial homology, 3

of vertebræ, 283

Serous glands, 1132

Serratus anterior muscle, 372 action of, 372 surgical anatomy of, 1446

posterior inferior muscle, 439

superior muscle, 438 actions of, 439

Sesamoid bones, 228, 269

patella, 245

of short muscles of thumb, 228

cartilages of larynx, 1062

of nose, 800

Sexual eminence, 1336

Shaft of the femur, to expose the, 1456

of humerus, exposure of, 1449

Sheath, axillary, 1447

carotid, 447

dentinal, 1123

digital, 384 surgical anatomy of, 1453,1454 of toes, 424

femoral, 405,475

of thexor longus pollicis, 1453

medullary, 508, 532

mitochondrial, 18

primitive, 508

of prostate, 493

of rectus muscle, 483

Shin, 248

Short bones, 82

Shoulder, bony parts of, 1444

fascix of, 373

muscles of, 373

surgical anatomy of, 1444

Shoulder-b]ade, 200

girdle, 317

movements of, 319

joint, 320
Shoulder-joint, bursæ connected with, 323 movements at, 323,377 nerres of, 703

Shrapnell, membrane of, 835

Sigmoid artery, 933

colon, 1223

mesocolon, 1223

Sigmoidoscope, examination by, 1433

Sinus, air, 84

aortic, 884

of Arlt, 825

cavernous, 975

circularis, 974

coronary, 959

abnormalities of, 1057

development of, 1032

morphology of, 1049

tributaries of, 959

costo-mediastinal, 1094

of dura mater, 972

of epichidymis, 1287

ethmoidal, 185

frontal, 186, 137 I

surgical anatomy of, 1371

great oblique, of pericardium, 882 transverse, of pericardium, 882

intercavermosus anterior, 974 posterior, 974

lactiferi, $1: 338$

lateral, 974

morphology of, 1040

surgical anatomy of, $135 \%, 1358$

longitudinal vertebral, 976

of Maier, 825

maxillary, 149, 186

surgical anatomy of, 1379

oblique, of pericardium, 882

occipital, 183, 974

of palate bone, 186

parasinoidal, 974

petrosal, inferior, 975

superior, 975

phrenico-costal, 1093

piriform, 1069, 1147

of portal rein, 990

precervical, 43

rectal, 1231

rectus, $97 . t$

renalis, of kidney, 1265

rhomboid, 550

sagittal inferior, $668,669,974$ abnormalities of, 1058

superior, 668,973 surgical anatomy of, 1364

sphenoidal, 135, 183, 185, 1373

extent of, 133

opening into, 135

relation of, to nasal fossie, 18.5

to orbit, 163

spheno-parietal, 975

squamo-petrosal, 1058

straight, 974

superior, of utricle, $\$ 46$

tarsi, 3.5.

tonsillar, 1145

transverse, 974

tympani, 833

urogenital, 13:R

utricular, 763

of Talsalva, 79 \%

venosus, 1031, 1033

sclerre, 808 
Sinuses, lymph, 99ł, 995 renous, of cranium, 808

Skein, chromatin, 10

Skeletal muscles, development of, 495 structures, 81

Skeleton, 81

appendicular, 82 morphology of, 294 axial, 82,87

development of, 28, 29, 102, 106 splanchnic, 43, 81, 1062

Skin, 856

appendages of, 858

corium of, 857

derelopment of, 861

of embryo, 78, 79,862

epidermis of, 857

papillæ of, 857

pigment of, $85 \mathrm{~s}$

retinacula of, 857

tactile corpuscles of, 865,866 discs of, 865

Skull, age differences in, 197

akanthion, 285

akrocephalic, 286

alveolar point, 285

apertura piriformis, 163

asterion, 285

base of, 172, 179

basion, 285

at birth, 194

bones of, 115

brachycephalic, 171, 285

brachyfacial, 286

brachyuranic, 287

breadth of, 286

bregma, 285

capacity of, 284

chamæcephalic, 286

chordal, 290

cryptozygous, 171,286

dacryon, 285

dermic, 292

development of, 290

dolicho-cephalic, 171, 285

dolicho-facial, 286

dolicho-uranic, 287

facial angle of, 286

fixed points of, 285

floor of orbit, 168

fontanelles of, 194

frontal sections of, 186

front of, 160

glabella, 285

height of, 286

female, 194

horizontal circumference, 286 section, 192

hypsicephalic, 286

indices of, 284

alveolar index, 287

dental index, 287

gnathic index, 287

nastl index, 287

orbital index, 287

orthocephalic index, 286

palato-maxillary index, 287

superior facial index, 286

total facial index, 286

vertical index, 286

infra-temporal fossa, 168

inion, 285
Skull, interior of, 179

lambda, 285

lateral aspect of, 164

wall of orbit, 162

length of, 285

leptoprosopic, 286

leptorhine, 287

ligaments of, 312,313

longitudinal arc of, 286

macrodont, 288

measurements of, 286

medial sagittal section of, 183

wall of orbit, 163

megacephalic, 284

megadont, 288

megaseme, 287

mesaticephalic, 285

mesocephalic, 284

mesodont, 288

mesognathous, 287

mesorhine, 287

mesoseme, 287

mesuranic, 287

metopic, 172

metriocephalic, 286

microcephalic, 284

microdont, 288

microseme, 287

morphology of, 293

nasion, 285

obelion, 285

ophryon, 285

opisthion, 285

orbital fossæ, 160

orthocephalic, 286

orthognathous, 287

phænozygous, 171, 286

platyrhine, 287

posterior aspect of, 171

prechordal, 291

primordial, 292

prognathous, 287

pterion, 285

pterygo-palatine fossa, 170

rhinion, 285

roof of orbit, 160

in section, 179

sexual differences in, 193

skeleton of face, 163

stephanion, 285

sub-nasal point, 285

surgical anatomy of, 1358

tapeinocephalic, 286

temporal fossa, 166

trabecular portion of, 290,291

upper aspect of, 171

vertebral portion of, 293

vertebrate theory of, 293

vertex, 285

as a whole, 159

Smegma embryonum, 79 præputii, 1299

"Snuff-box," anatomical, 400

Soleus muscle, 429

action of, 429

surgical anatomy of, 1461, 1462

Solitary glands, 1179,1181

Somæsthetic area, 645

Somatic mesoderm, 25, 27 segmental arteries, 1043, 1044

Somites, mesodermic, 28, 29, 75, 76

Sounds of heart, 1405 
Space of Burns, 967

epidural, 669

intercostal, 114, 470

interpleural, 1089

mediastinal, 1089, 1090

of Yuel, 852

of Retzius, 1410, 1429

subarachnoid, 671

cisternce of, 671

communications of, with ventricles, 553,671

fluid of, 671

ligamenta denticulata of, 672,675

septum posterius of, 672,675

spinal, 672

trabecular tissue of, 671

subdural, 670

surgical anatomy of, 1362

Spaces of Fontana, 810

interglobular, of ivory, 1247

lymph, 867

perilymphatic, 846

perivascular, 870

Spatia anguli iridis, 810

intercostalia, 114, 470

perichorioidealia, 811

perilymphaticum auris internæe, 846 zonularia, 819

Sperm cells, 11, 12, 16, 1288

Spermatic fascia, 475, 477

funiculus, 1290, 1296

surgical anatomy of, 1430

internal artery, 928

abnormalities of, 1052

morphology of, 1046

rein, 983

abnormalities of, 1058

development of, 1040

mor'pliology of, 1048

surgical anatomy of, $1 \neq 27$

Spermatids, 17

accessory body of, 17

centrosomes of, 17

development of, 18

Spermatocyte, 12

of first order, 12, 16

of second order, 17

Spermatozoa, 17

axial filament, 17, 18

body, 18

centrosomes, 17

head, 17

neck, 17

sleath, mitochondrial, of, 18 sivilal, of, 18

tail, end-piece, 18 end-ring, 18

Spheno-ethmoidal recess, 802

Sphenoid bone, 133

alce, developnent of, 138

angular spine of, 13.5, 136

architecture of, 271

body of, $1: 33$

connexions of, 138

crest of, 133

great wings of, 1:34

orbitil fissure, inferior, 137

ossification of, 138

pterygoid liminie of, 137

small willgs of, 135

variations in, 278

Sphenoidal angle of parictal bone, 119 conchie, 139
Sphenoidal crest of sphenoid bone, 135

process of palate, 152

sinuses, 271

skiagraphs of, 1372

surgical anatomy of, 1372

Spheno-mandibular ligament, 312

Spheno-palatine artery, 900

foramen, $185,192,152$

ganglion, $775,77 \%$

nerves, 775

notch, 152

roots of, 777

rein, 968

Spheno-parietal sinus, 975

suture, 164, 166

Spheno-petrous fissure, 176

Spheno-squamous suture, 176

Spheno-romerine canal, 279

Spheno-zygomatic suture, 163

Sphere, attraction, 20

Sphincter ani externus, 486, 1232 action of, 1232

pupillæ, 814 internus, 1232

pyloric, 1166,1174

recti, 1229

vaginæ, 487

vesicre, 1284

Spina or Spine, angular, of splienoid, 136, 167

frontal, 116

helicis, 828

iliaca anterior inferior, 229

superior, 228

posterior inferior, 229

superior, 229

surface anatomy of, 1455

ischiadica, 232

sexual differences of, 237

surface anatomy of, 1456

mentalis, 156

nasal, 116

nasalis anterior, 146,164

posterior, 174

peroneal, 260

rariations in, 282

pubic, 233, 1458

scapulæe, 202

sphenoidal, 136, 167

suprameatal, 126, $1366^{\circ}$

of tibia, 246

trochlear, of frontal bone, 117

tympauica major, 831

minor, 831

Spinal arteries, 938

formation of, 1029

of intercostals, 926

of lateral sacral, 938

of vertebral, 907

canal, 90, 92, 102

columin, 100, 102

toramen of cervical vertebre, 90

of lumbar vertebræ, 9.)

of thoracic vertebre, 93

ganglia, 685

medulla, 517, 539

anterior merlian fissure of, 521

surgical anatomy of, 1443

antero-lateral column, 5.99

antero-mexlian columm of, 529

apex of , 523

arrangement of, emliryological methoxl, 532

experimental method, 532 
Spinal medulla of nerre-fibres of white matter in tracts, 532

caput of, 523

cauda equina of, 519,526

cell column, intermedio-lateral, 530

central canal of, 521, 523, 526

cervical enlargement of, 519, 524

cervix of, $5 \geq 3$

changes in gray matter of, 524

columns of, $22,520,523,528$

anterior, 523, 528

antero-lateral, 529

ceutral, 529

intermedio-lateral, 530

lateral, 523, 529

posterior, 522, 523, 525, 529

postero-lateral, 529

retro-postero-lateral, 529

commissure of, anterior white, 523, 539

gray, 523,539

posterior, 523

component parts of white matter of, 531

conus medullaris of, $518,524,525$

development of, $31,33,35,520$

dorsal nucleus of, 531,538

enlargements of, 519,524

surgical anatomy of, 1443

fasciculi of, anterior proprius, 535, 537, 538

lateral, 535

bulbo-spinal, 537,538

collateral fibres of, 534, 535, 539

lateralis proprius, 538

olivo-spinal, 538

fasciculus cuneatus of, 526,533

gracilis of, 526,533

solitarius of, 598

(fasciculus of) posterior proprius, 535

rubro-spinal, 537,538

septo-marginal, 535

spino-cerebellar anterior, 537,538 posterior, 537,538

spino-tectal, 537

(fasciculus of) spino-thalamic, 535, 537 anterior, 537, 538

posterior, 537

tecto-spinal, 537, 538

restibulo-spinal, 537, 538

filum externum, 526

internum, 526

terminale of, 518,526

fissures of, 522

antero-median, 522

intermedius posterior, 522

lateralis posterior, 522

postero-median (septum), 522

funiculi or tracts of, 535

anterior, 522, 525, 528, 539

antero-lateral, 522

of Burdach, 522

of Goll, 522

lateral, 522, 525

posterior, 521, 522, 525

postero-lateral, 584

solitarius, 598

gray matter of, 523, 525

inferior limit of, in child, 517

internal structure of, 523

intersegmental association fibres of, 535,538 length of, 517

ligamenta denticulata of, 518, 675

longitudinal commissural fibres of, 537,538

lumbar enlargement of, 519, 524
Spinal medulla, membranes of, 518, 669, 675 nerve-cells of, 528 et seq.

nerve-fibres in gray matter of, 531

nerve-fibres of, 531 et seq.

neturoglia of, 527

origin of nerves from, $519,529,533$

posterior paramedian sulcus of, 522

postero-lateral column, 529

sulcus of, 522

postero-median column, 529

processus reticularis of, 524

regional differences in, 519, 527

regions of, 519

relation of, to vertebræ, 517,1422

segments of, 519

sensory and motor distribution of various segments of, 744, 752

septa of, 521,522

substantia gelatinosa Rolandi, 523, 528 grisea, 520

substantia grisea centralis of, 528 reticularis of, 564

sulci of, 522

sulcus lateralis posterior of, 522

summary of chief characters, 527

surgical anatomy of, 1443, 1444

theca of, 518

tract or tracts of Burdach, 526,533

anterior cerebro-spinal, 536, 539

cerebello-spinal, 531, 536

comma (fasciculus interfascicularis), 533

of Goll, 526, 533

of Gowers (fasciculus antero-lateral superficial), 536

lateral cerebro-spinal (crossed), 536, 538

of Lissauer (postero-lateral), 534

trigeminal root-fibres in, 601

veins of, 977

rentriculus terminalis of, 526

white matter of, 524,531

Spinal nerves, 519, 678

anterior rami of, 692

anterior root, 520

development of nerve-roots, 679

distribution of the, 687

distribution of, to muscles and skin of the limbs, 744

lower limb, cutaneous nerves, 747 muscular nerves, 748

upper limb, cutaneous nerves, 744 muscular nerves, 745

white rami communicantes of, 687

divisions or rami of, 686

formation of, 680

posterior rami of, 687

roots of, 520,533

splanchnic parts of, 680

venous plexus, anterior, 976

posterior, 970

Spinalis dorsi muscle, 442

Spindle, achromatic, 10, 13

Spine, somatic parts of, 680

Spino-glenoid ligament, 320

Spino-thalamic tract, 537,538

Spinous process of cervical vertebræ, 90, 93

of lumbar vertebræ, 95

of sacrum, 97

homology of spinons processes, 283

surgical anatomy of spinous processes, $1436,1442,1443$

of thoracic vertebræ, 93 
Spiral fasciculi of cochlear nerve, 852 ganglion, $785,845,852$

line of femur, 242

organ of cochlea, 849,850

tubules of kidney, 1266

Splanchnic ganglion, 761

mesoderm, 27

nerve, 761

greater, 761,764

lowermost, 761,764

segmental arteries, 1027, 1046

skeleton, 81

Splanchnology, 3

Spleen, 1352

accessory, 1353

angles of, 1352

blood and lymph vessels of, 1353

borders of, 1352

development of, 1253, 1353

excision of, 1442

hilus of, 1352

lymph nodules of, 1353

nerves of, 1353

notches and tissures of, $13 \tilde{2} 2$

peritoneal relations of, 13.53

pulp of, 1353

structure of, 1353

surfaces of, 1352

sustentaculum of, 1353

Splenic artery, 929

lymph glands, 1020

plexus, 765

vein, 922

Splenium of corpus callosum, 630

Splenius capitis muscle, 439 action of, 439

Spongioblasts, 503, 817

Spongioplasm, 8

Spongy bone, 83

Spur of malleus, 839

Squama occipitalis, 120, 121

temporalis, 125

Squamo-petrosal sinus, 1369

Squamosal bone, 292

Squamoso-mastoid suture, 125

Squamous suture, 127

Stalk, allantoic, 38

body, 38

optic, $682,825,826$

of thalamic radiation, 610,612

Stapedial artery, 841

Stapedius muscle, 841

Stapes, 840

annular ligament of, 841

development of, 841

foot-plate of, 840

ligaments of, 841

movements of, 842

surgical anatomy of, 1368

Staphylorrhaphy, 1385

secondary hæmorrhage after, 1385

Stenson, canals of, 149

duct of, 1136, 1137

foramen of, 149,174

Stephanion, 166, 172, 285

Sternal angle, 107

articulations, 317

furrow, 1397

line of pleural reflexion, 1085, 1086

lines, 1397

lymph glands, 1010

veins, 963
Sternalis muscle, 370

Sterno-clavicular joint, $\$ 17$

movements at, 319

muscle, 372

Sterno-cleido-mastoid muscle, 458 action of, 458

surgical anatomy of, 1390

Sterno-hyoid muscle, 459 action of, 460

Stermo-mastoid artery of occipital, 895 of superior thyreoid, 892

muscle, 458

Sterno-pericardial ligaments, 881

Sterno-thyreoid muscle, 459 action of, 460

Sternum, 106

architecture of, 270

body of, 107

infrasternal angle, 114

manubrium, 107

movements of, 317

ossification of, 108

surgical anatomy of, 1397, 1405

variations in, 276

xiphoid piocess of, 108

Stigmata of capillaries, 867

Stilling, canal of, 819

Stomach, 1163

anterior surface of, 1167

areæ gastricæ of, 1176

arteries of, 1176

bed of, 1170

body of, 1168

capacity of, 1171

cardia, 1164

cardiac orifice of, 1164 surgical anatomy of, 1416, 1417

portion of, 1163

of child, 1171

curvatures of, 1166, 1167

development of, 47, 1249

displaced, 1171

in temale, 1171

form of, 1163

foveolæ of, 1176

fundus of, 1168, 1163

surgical anatomy of, 1416

gastro-phrenic ligament of', 1170

glands of, 1176

greater curvature of, 1167 surgical anatomy of, 1417

hour-gliss, 1171

incisura angularis of, 1166 cardiaca of, 1165

lesser curvature of, 1166 surgical anatomy of, 1417

lymph vessels of, 117

mucous memibrane of, 1179

muscular coat of, 1174

nerves of, 1177

partial resection of, 1418

peritoneal relations of, 1170

pit of, 108, 114

plicæ villosæ of, 1176

position of, 1063,1172

posterior surface of, 1167

pyloric antrum of, $1161,1167,1169$

canal of, 1169

ligaments of, 1170

orifice of, 1169,1173

surface anatomy of, 1416,:1417

surgical anatom $y$ from the back, 1439 
Stomach, pyloric portion of, 1169 surgical anatomy of, 1416, 1417 position of, 1416

sphincter of, 1166, 1174

valve of, 1174

pylor'ss, surgical, 1165

radiography of, 1417

relations of, 1416

rugæ of, 1165

serous coat of, 1174

size of, 1171

at birth, 1171

structure of, 1174

submutcous coat of, 1173

sulcus intermedius of, 1167

surfaces of, 1163

surgical anatomy of, 1416-1418

topography of, 1416, 1417, 1439

uncorered area of, 1170

reins of, 1991

I-ray examination of, 1173

Stomach-bed, 1170

Stomach-chamber, 1169

relations and connexions of, 1169

Stomata of capillaries, 867

Stomatodæum, 25, 27, 41

derivatives of the, 48

separation into nose and mouth, 49

Straight sinus, 974

Strand fronto-pontine, 653

Stratum bacillare retinæ, 816,818

circulare membranæ tympani, 835

musculare ventriculi, 879

compactum, 57

corneum epidermis, 857,859

$$
\text { unguis, } 859
$$

cutaneum membranæ tympani, 835

filamentosum, 858

germinativum epidermis, 857 unguis, 859

granulosum cerebelli, 581 epidermis, 858 ovarii, 1314

grisetum centrale pedunculi cerebri, 584 colliculi superioris, 586

interolivary, 556

lemnisci, 586

longitudinale musculare ventriculi, 879

lucidum, 858

mucosum epidermis, 857

membranæ tympani, 835

opticum, 586, 815

colliculi cerebelli, 580

superioris, 586

papillare of skin, 857

pigmenti retinæ, 816,817

radiatum membranæe tympani, 835

reticulare of skin, 857

spongiosum, 57

synovial, 302

development of, 304

of ankle-joint, 353

of carpo-metacarpal joints, 333

of elbow-joint, 325

of hip-joint, 341

of intercarpal joints, 331

interosseutus, of leg, 350

of intertarsal joints, 358

of knee-joint, 348

of mandibular joint, 312

of metacarpo-phalangeal joints, 333

of radio-carpal joint, 329
Stratum, synovial, of radio-ulnar joint, 327 of shoulder-joint, 322

zonale cerebri, 585

sectionum corporum quadrigeminorum, 586

thalamencephali, 611

Streak, primitive, 23,26

Strength of bones, 83

Stretching the sciatic nerve, 1457

Stria or Striæ medullares, 550, 605

of Gennari, 644, 659

longitudinalis lateralis, 630

of corpus callosum, 629

medialis, 630

medullares, 615

fossæ rhomboideæ, 550

of thalamus, 611

olfactorii lobi intermedia, 624

lateralis, $6 \mathbf{z} 4$

of Retzius, 1122

terminalis, 610, 635, 636, 642

transversæ corporis callosi, 631

vascularis auris internæ, 849

Striate arteries, 905

veins, 970,971

Stripe of Hensen, 850

Stroma of iris, 813

ovarii, 1313

vitreum, 819

Structure of bones, 83

cerebral hemispheres, 644

teeth, 1122

urethra, 1428

Stylo-auricularis musele, 830

Styloid process of fibula, 250

of metacarpal bone, 225 variations in, 280

of radius, 216

surgical anatomy of, 1450

of temporal bone, $127,168,177$ development of, 43, 44, 159 ossification of, 132

of ulna, 213

surface anatomy of, 1451

Stylo-glossus muscle, 463

Stylo-hyals, 132, 159

Stylo-hyoid ligament, 313, 1134

muscle, 461

action of, 462

Stylo-mandibular ligament, 313, 1134

Stylo-mastoid artery, 895

foramen, 129, 177

Stylo-pharyngeus muscle, 465

Subacromial bursa, 323

Subanconeus muscle, 382

Subarachnoid fluid, 671

space, 671,672 surgical auatomy of, 1227

Subarcuate fossa, 130, 131

Subclavian artery, 909 abnormalities of, 1054

branches of, 910

development of, 1027-1028

ligature of, 1394

morphology of, 1045, 1046

surgical anatomy of, 1252, 1255

groove, 111

loop, 759

lymph trunk, 998

plexus, 759

vein, 965,966

abnormalities of, 1058

danger of injury to, 1394 
Subclavian vein, morphology of, 1048, 1049 surgical anatomy of', 1395

Subclavius muscle, 371 action of, 371

Subcoracoid centre, 204, 296

Subcostal angle, 1397, 1407

artery, 926

groove, 110

line, 1407

muscles, 470

plane, 1407

Subcrureus (O.T.), 408

Subdeltoid lunsa, 323

Subdural space, 670 surgical anatomy of, 1362

Subinguinal lympl glands, 1459

Sublingual artery, 893 gland, 1138 developinent of, $12+3$ surgical anatomy of, 1383 region, 1383

Submalleolar apophysis, 282

Submaxillary artery, 893

duct, 1138

fossa, 155

ganglion, 780

gland, 1137

development of, 1243

duct of, 1138

surgical anatomy of, 1391

lymph glands, 1000

Submental artery, 894

triangle, 1387

Subnasal point, 285

Suboccipital nerve, 688

triangle, 444

boundaries of, 444

Subphrenic abscess, 1412

Subpleural plexus, 913

Subscapular artery, 917 of transverse scapular, 912

bursa, 377

fossa, 203

lymph glands, 1008

nerve, inferior, 713

superior, 713

Subscapularis muscle, 377 action of 377

minor muscle, 377

Substantia adamantina, 1122

corticalis lentis, 820

lympho-glandulæe, 995

sectionum cerchelli, 576 telencepliali, 644

elumea, 1122

ferruginea, 570

gelatinosa (spinal medulla), 528

grisea centralis (spinal meclulla), 528

lentis, 820

medullaris lymplio-glandulie, 995

nigra, 614

perforata anterior, $34,541,62 t$ relation of, to olfinctory tract, 624

posterior, 541, 615

relation of, to third ventricle, 616

propria cormere, 810

suctorial prad, 446, 1109

sucloriferous rlands, 861

Suleus or Silci, 646,653

alar, 799

alreolo-glossa 1, 1383

angular, 665,666
Sulcus or Sulci, anthelicis transversus, 829

arteriæ intermedius, 1167

occipitalis, 128

temporalis media, 125

vertebralis, 89

auris anterior, 828

basilar, of pons, 548

bicipital, lateral, 1448

merlial, 1446,1447

calcanei, 259

calcarine, 659

lateralis, 659

posterior, 659

carotic, 135

central, of brain, 663

insulæe, 654

of cerebral cortex, 646

axial, 646

development of, 646

operculate, 646

terminal, 646

hemispheres, 653

chiasmatis, 135

chorioidal, of eye, $621,637,675,826$

cinguli, 666

circular, 654

collateral, 661, 662

transverse, 662

costæ, 110

cruris helicis, 829

diagonal, 566

ethmoidalis ossis nasalis, 145

firmbrio-dentate, 627

floccular, of cerebellim, 572

frontal, of brain, 665

inferior, 665,668

middle, 665

sulci (of frontal bone), 116

superior, 665,668

surface anatomy of, 1360

fromto-marginal, 665

hamuli pterygoidei, 138

hippocampi, 626

horizontal, of cerebellum, 5 73

hypothalamicus, 618

inferior interventricular, 8.2

intermedius posterior medulle oblongate, 544

intertubercular, of liumerus, 206

interventricular, 618

intraparietal, 661, 644, 664

lacrimal, of maxilla, 147

ossis lacrimalis, $14 \mathrm{~T}$

lateral, of lirain, $653,1359,1360$

lateralis mesencepliali, $58 t$

posterior medullie oblongatie, 544,547 spinalis, 522

limiting, of Reil, $65 \pm$

longitudinal, of cerebrum, 540,676

longitudinalis, of heart, 618

lunatus, 660

malleolitis, 253,249

medianus posterior medullo spinalis, 522

mento-labial, of lips, 1108

musculi flexoris hallucis longi calcauei, 260 tali, 257

peronsi calcanei, 260

ossis cuboidei, $26: 3$

mylo-liyoilteus, 155

naso-lacrimal, 49

laterialis, of lips, $110 \mathrm{~s}$

nervi oculo-motorii, 584 
Sulcus or Sulei, nervi petrosi superficialis majoris, 130

radial, $20 \%$ minoris, 130

ulnaris, 207

obturatorius, 234

occipitalis lateralis, 661

anterior, $66{ }^{\circ}$

paramedial, 661

transverse, 611

oculn-nasal, 49

olfactory, 666

orbital (of brain), 666

paracentral, 664

para-cingular, 665

paramedial, 661

para-pyramidal, 573

of parietal region, 662

parital superior, 665

parito-occipital, 661

paroccipital, 644,661

peronæi, 253, 260, 263

petrosus inferior ossis occipitalis, 123 temporalis, 128

superior, 128

polares, 660

post-central, 662

inferior, 664

superior, 664

surface anatomy of, 1360

post-]unar, 573

post-nodular, 571

præcentral, 665

inferior, 664,665

superior, 664,665

surface anatomy of, 1360

præcunei, 665

precervical, 43

primary, of cerebellum, 572

of promontory, 832

pterygoid, 138

pterygo-maxillary, 168, 192

pterygo-palatine, 138,192

rhinalis, 624

sagittal, of frontal bone, 118, 119, 171

of occipital, 121

of parietal, 119

secundary, of cerebellum, 572

sigmoid, 123

simial, 660

of spinal medulla, 522

spiralis externus cochleæ, 849

internus cochleæ, 849

subclavian, 111

subclavius pulmonis, 1093

subjuarietal, 665

suprapyramidal, 573

tali, 256

temporal, inferior, 658

middle, 658

superior, 657

surface anatomy of, 1360

topography of, 1360, 1361

terminalis atrii dextri (His), $87 \pm$

significance of, 874

lingux, 1125, 1126

of heart, 873

transverse (of brain), 674

of occipital, 121

of parietal, 119

tubæ auditivæ, 128, 838

of vallecula, 574
Superciliary ridge, 116, 160

sexual differences of, 116, 193

surface anatomy of, 1358

Superficialis volæ artery, 919

Superior temporal sulcus, 657 topography of, 1360,1361

rena cava, 1405

Supination, 328, 401

Supinator muscle, 398 action of, 399

Supra-auricular point, 286

Supraclavicular nerves, 696

Suprahyoid artery, 892

lymph glands, 1002

muscles, 460

Supramandibular nerve (O.T.), 784

Supramarginal triangle, 1360

Supramastoid crest, 125

Suprameatal spine, 126, 1366, 1369 surgical importance of, 1366, 1369 triangle, 126

Supranasal bone, 277

Supraoccipital bone, 124 development of, 292

Supraorbital artery, 903

foramen, 116, 160

margin, 115, 160

nerve, 772

notch, 116, 160

surface anatomy of, 1358

ridge, 116

rein, 968

Suprarenal artery, 927, 933

gland, 1343

development of, 1341, 1343

forms and relations of, 1344

in fotus, 1343

hilus of, 1345

medullary portion of, 1343

nerves of, 765,1346

relations of, 1340

structure of, 1346

surgical anatomy of, 1425

impression of liver, 1192

plexus, 765

vein, 982

abnormalities of, 1058

development of, 1040

morphology of, 1048

Suprascapular nerve, 703 region, 1436

Suprascleral lymph space, 808

Supraspinatus muscle, 375 action of, 375

Supraspinous artery, 913

fossa, 202

ligament, 308

Suprasternal artery, 912

noteh, 107

region, 1397

Supratonsillar fossa, 1145, 1147

Supratrochlear foramen, 280

lymph glands, 1007

nerve, 778

Sural arteries, 952

nerves, 730, 732

Surface and surgical anatomy, 1357

of abdomen, 1407

of abdominal aorta, 1426

of abdominal wall, 1407

of accessory nerve, 1393

of ankle, 1411, 1463 
Surface and surgical anatomy of arm, 1447 of axilla, $1446^{\circ}$

of back, 1436

of bregma, 1358

of buttock, 1455

of ceutral sulcus of biain, 1359

of cranium, 135;

of ear, 1360

of elbow; 1449

of face, 1374

of female pelvis, 1434

of foot, 1463

of forearm, 1450

of hand, I450

of head and neck, 1357

of heart, 1403

of inferior end of central sulcus, 1359

of junction of motor areas, arm, and face, 1359

of knee, 1460

of lambda, 1358

of lateral fissure of brain, 1359

of lateral ventricle, 1362

of leg, $146 \mathrm{I}$

of limgs, 1398

of meningeal arteries, $136 t$

of middle meningeal artery, 1359

of neck, 1385

of perineum, 1427

of popliteal space, 1457

of scalp, 1357

bloorl-supply of, 1357

of shoulder, 1444

of thigh, 1458

of thorax, 1395

of transterse sinus, 1365

Surgical neck of humerus, 206

Suspensory ligament of clitoris, 1326

of lens, 819

of ovary, 1312

of peuis, 1299 muscle of duodenum, 1187

Sustentaculum lienis, 1353

tali, 260

architecture of, $2 \mathrm{it}^{\mathrm{t}}$

position of, 1464

surface anatomy of, 1465

variation in, 282

Sutural bones, 145,146

Suture or Sutura, 300

coronal, 164,172

synostosis of, 197

dentate, 300

devulopment of, 304

frontal, 160

fronto-maxillary, 160

fronto-2y:gomat ic, 160

lıarmonia, 300

infraorbital, 279

intermaxillary, 163

internasal, 145

lambdoid, 165, 171

surgical anatomy of, 1360

limbosa, 300

masto-sifnamosal, 128

metopic, 118, 277

naso-frontal, 160

notha, 300

occipito-mastoid, 165, 171

orbitu-maxillaly-frontal, 27

palatine, 174

transverse, 174

parieto-mastoinl, 164
Suture or Sintura, petro-squamous, 125, 126 surgical anatomy of, 1366

premaxillary, 150

sagittal, 119, 171

ser'rata, 300

spheno-parietal, 164

spheno-squamous, 168

spheno-zygomatic, 163

squamosa, 164,300

squamoso-mastoid, 125, 126

vera, 300

zJgomatico-frontal, 160

zygomatico-maxillary; 160

Swallowing, movements in, 467

Sweat glands, 861

development of, 862

ducts of, 861

glomerulus of, 861

orifice of, 861

Sylvian (O.T.) (lateral cerebral) fissure, 653,654 development of, 655,656

surgical anatony of, 1359,1360

fossa, $62 t$

point, 1360

veins, 971

Symmetry, 4

Sympathetic nervous system, $678,753,1342$

cephalic and cervical parts of, 756

central communicating branches, 762

peripheral branches of distribution, 762

commissural cords of, $755,756,759,761$, 762,763

development of, 681

functions of, 755,762

ganglia of, 504,753

gangliated cord of, 753

general structnre of, 753

gray rami communicantes of, 678,681

lumbar, 761

medullated, 754

morphology of, 766,795

medullated nerve-fibres of, 754 noll-merlullated, 754

peripheral branches of, 755

plexuses of, 763

rami communicantes of, $754,756,759$, $761,762,763$

sacral, 762

central conmunicating branches of, 763

peripheral branches of distribution, 763

thoracic part of, $759,76 \mathrm{~L}$

alortic lianches, 761

central communicating brancles of, 761

functions of, 761

peripheral lianches of distribution, 761

julmonary brinches, 761

splauchnic blanches, 761

white rami communicantes of, 678 , tis0, 681

Symplysis of jaw, 155

ossium pul,is, 337

sacro-cocevirues, 308

lulis, $3: 3 \overline{4}$

("wvity of, 33T

filiro-cintil.ıge, interpubic ol; 3337

ligaments of, 3337

Sruarthrusis, 299 
Synchond rosis, 299

cranii, 300

epiphsseos, 300

neuro-central, 104

petro-jugular, 300

spheno-occipital, 300

sternal, 317

Srndesmologr, 299

Syrudesmosis, tibio-filutlar, 35̃ 1

ligaments of, 351

Srnoria, 301, 304

Synovial bursæe, 302

fat-pads, $302,325,341,348$

ponches posterior to the condyles of the femur, 1461

sheaths at wrist, 388,389

strata of joints of lower limb, 341, 348, 350, 351,353

of pelris, 336

of thorax, $314,315,316$

of upper limb, 322, 325, 327, 329

of mandibular joint, 312

stratum of the knee-joint, 1461

System, blood-rascular, morphology of, 1042

primitive formation of, 64

Systema lymphaticum, 993

nerrorum centrale, 497

periphericum, 677

sympathicum, 753

Systematic anatomy, 3

Systemic circulation, 882, 959

Table of relations of structures to rertebral spines, 1442, 1448

Tactile corpuscles, 863 discs, 864

Tænia coli, 1211

pontis, 615

thalami, 610

Tail, 48

fold, 38

gut, 48

Talo-calcaneal joint, 354

ligaments, 355

Talo-calcaneo-navicular joint, 355

Talo-fibular ligaments, 352

Talo-navicular joint, 355 surgical anatomy of, 1464 ligaments of, 355

Talo-tibial ligaments, 353

Talus, 254

architecture of, 274

articular surfaces of, 255

development of, 265

facets of head, 257

head of, 257

homology of, 295

ossification of, 265

Tapeinocephalic skulls, 286

Tapetum, 631, 812

cellulosium, 812

of chorioid, 812

fibrosum, 812

Tarsal arches of eyelids, 823

glands, 822,823

surgical anatomy of, 137

lateral artery, 957

ligaments of eyelid, 822

tarsi, 1378

Tarsale, os, 295

Tarso-metatarsal joints, 359 surgical anatomy of, 1464
Tarso-metatarsal, line of, 1464

Tarsus, 254, 821

architecture of, 274

ossification of, 265

palpebral lateral raphe of, 822

medial ligament, 822

transverse articulation of, 357

variations in, 282

as a whole, 264

Taste buds, 854, 1128

fibres, course of, 598

gustatory hair, 855

pore of, 854

nerres of, 855

nuclei of, 598

organs, 854

structure of, 854

supporting cells of, 854

Tectorial membrane, 851, 852

Tectum, 516

Teeth, 1112

adamant, 1113, 1122

composition of, 1122

prisms of, 1122

alveolar periosteum, 1115, 1123

alveoli of', 1115

apical foramen of, 1114

arrangement of, in jaws, 1119

auditory, 850

canine, 1117

cavity, 1114

cingulum of, 1116

contact surface of, 1115

crown of, 1114, 1116, 1118, 1119, 1120

cuticle of, 1122

composition of, 1123

dental canaliculi, 1123

deciduons, 1113, 1114, 1121

dental arches, 1119

index of, 1248

lamina of, 1026

dermal, 1244

development of, 1244

eruption of, 1120, 1246

eye, 1117

fangs of, 1114

follicles of, 1245,1246

general form and structure, 1114

germs of, 1245

grinding surfaces of, 1115

gubernaculum of, 1247

incisor, 1115, 1116

irory of, $1113,1122,1123$

lingual tuluercle of, 1116

Jymph ressels of, 1005

molar, 1117

lower, 1118

roots of, 1118

upper, 1118

morphology of, 1248

multitubercular, 1248

Nasmyth's membrane of, 1122

neck of, 1114

nerres of, alveolar anterior superior of, 777 inferior, 780

middle, superior, 777

osseous sulostance, 1123

posterior superior, 775

papilla of, 1244

parts of adamant, 1113

ivory, 1113

period of eruption of the permanent, 1120 
Teeth, permanent, 1115, 1119

descriptive terms for, 1115

premolar, 1117

pulp of, 1114,1123

cavity of', 1114

relative sizes of, $1116,1117,1118,1119,1120$, 1121

reserve gerns of, $12+6$

root of, 1114, 1116, 1117, 1118, 1119

canal, 1114, 1115

serotinus, 1113, 1118, 1119

structure of, 1122

substantia ossea of, 1113,1123

tartar of, 1115

tubercles of, 1114, 1116, 1118, 1119, 1128

of crown, 1114, 1118, 1119

variations in number of, 1121

Tegmen tympani, 192, 271, 832 surgical anatony of, 1366

ventriculi quarti, 549

Tegmental region, hypothalamic, 613

Tegmentum, 586

Tela chorioidea ventriculi quarti, 571 tertii, 617

of the fourth ventricle, 674

submucosa intestini, 1179

serosa, 1178

ventriculi, 1175

sulbserosa, 1158

parts derived from, 620

of the thind ventricle, 617,674

Telencephalon, 608

derelopment of, 34

Telolecitlial ova, 11

Telophase, 10

Temporal area, 656,658

artery, deep, anterior, 899

middle, 897

of posterior cerebral, 908

of retina, 818

superticial, 896

bone, 125

angles and petrous part of, 128

architecture of, 271

articular tubercle of, 167

at birth, 133

connexions of, 131

ussification of, 131

parts of, at lirth, 125

petromastoid jart of, 128

petrous part, anterior surface, 130

inferior surface, 129

squamous part of, 125

tympanic antrum of, 832 part of, 127

variations in, 278

zygomatic process of, 166

canal, 154

crest, 116, 118, 166

external neoustie meatuss ol, 127

fascia, 455

fos:a, 145,166

gyri, $65 \overline{7}, 658$

latelisl wall, 167

line, $116,118,166$

medial wall, 166

untscle, 455

nerve of auriculo-temporal, 780 deep, 779

of facial, 783

of orbital, 776

of maxillary, $7 \mathrm{ic}$
Tenıjoral plane, 118

process, 153

region, 656, 658

surgical ana tomy of, 1360

ridge, 118,166

sulci, 958

veins, $96 ;, 968$

Temporo-mandibular arch, 279

joint, 312

surgical anatomy of, 1366,1375 vein, 965

Temporo-pontine tract, 643

T'endinun inscriptiones, 1407 .

Tendo calcaueus (Achillis), 428, 429

surgical anatorny of, 1463

Tensor fascixe latæ muscle, 415 action of, 416 surgical anatomy of, 1459

tarsi muscle, 450

tympani muscle, 841 canal for, 128

veli palatini muscle, 466

Tentorium cerebelli, 669

Teres major muscle, 376

ligament of liver, 1196

minor muscle, 375 actions of, 376

Terms in use in limbs, 5

Testicular artery, 928

Testis, 1286

appendices of, 1287

conus vasculosus of, 1289

descent of, 1295

development of, 1333

ductuli efferentes, 1288

dudus deferens of, 1289

development of, 1296

efferent ductules of, 1288

epididymis of, 1286, 1287

gubernacnlum of, 1295

lobes of, 1288

lymph ressels of, 1289

mediastinum of, 1288

mesorchium, 1295

nerves and vessels of, 128 ;

paradidymis of, 1287

processus raginalis of, 1295

rete of, 1288

seminiferous tubules of, 1288

septula of, 1288

sinus epididymidis, 1287

structure of, $1 \geq 88$

tubuli recti of, 1288

seminiferi contorti, 1288

tunica albuginea of, 125s

vaginalis of, 128 ;

vasetulusa of, 1 요 88

undescended, 1296

ressels and nerves of, 1289

Thalamencephalon, 608, 609

Thalanic radiation, $610,612,613$

Thalamo-cortical tibres, $61: 2,613$

Thalamo-striate fibres, $612,641,642$

'Thalamus, 541, 609

anterior nuclens of, 612

tubercle of, 611

central nucleus of, 612

comnexions of, 612 , 641

with cerebral eortex, $61: 2,613$

with hippocimpus, 625

with optic tract, 658

cortico-thillanie tibres of, 612, 613 
Thalamus, development of', 35

grey matter of, 611

inferior sturfice of, 610

internal medullary lamina of, 611

intimate structure of, 611

laminia medullaris, exterior of, 611 interior of, 611

lateral gemiculate body of, 611,613

medullary lamina of, 610

nuclens of 611

surface of, 610

lemniscus fibres of, 586

massa intermedia of, 611

medial nucleus of, 611

nuclei of, 611,612

origin of, 517

position and connexions of, $610,611,612,613$

pulvinar of, 611

radiation of, $610,612,613$

stallis of, 612

stratum zonale of, 611

stria medullaris of, 611

superior surface of, 610

surfaces of, 610

tænia of, 610

thalamo-mamillary of, 612

tuberculum, anterius of, 611

Thebesius, valve of, 874

Theca folliculi, 1314

of spinal medulla, 518

Theory of nerve components, 505-506

Thigh bone, 239

Third ventricle, 616 development of, 36

lateral ventricle, 36

Thoracic aorta, 884

branches of, 924

surface anatomy of, 140

duct, 993, 996

abnormalities of, 1059

course of, 997

length and diameter, 997

relations of, 997

tributaries of, 997

surgical anatomy of, 1394

ganglia, 759

part of sympathetic, 759

lateral arteries, 916

supreme, 916

nerves, 713 .

anterior rami, 713

posterior rami of, 690

first thoracic, 713

communications of, 713

intercosto-brachial, 714, 716

second thoracic, 714

communications of, 716

third thoracic, 716

fourth to sixth thoracic, 716

lranches of, 716

seventh to eleventh thoracic, 717 branches of, 717

twelfth thoracic, 717 branches of, 717

vertebræ, 93

Thoraco-acromial artery, 916

Thoraco-dorsal nerve, 713

Thorax, 113

anterior wall of, 113

aortic area of, 1405

apertures of, 114

at bixth, 114
Thorax, cavity of, 1083

division of, into regions, 1397

fœetal condition, 114

in fœetus, 114

joints of, 313

lateral walls of, 114

lines of, 1089

lymph ressels of, 1013

mediastinum of, 1089

mitral area of, 1405

muscles of, 470

posterior wall of, 113

precordial area of, 1403

pulmonary area of, 1405

regions of, 1397

sexual differences in, 114

sternal fur'ow of, 1397

surgical anatomy of, 1395

tricuspid area of, 1405

walls of, 113

T'hrombosis of femoral vein, 1427

Thumb, movements of, 402

muscles of, 392, 393

Thymus gland, 1350

blood-vessels of, 1351

development of, 44, 1351

structure of, 1351

vestiges, cervical, 1351

Thyreo-arytænoid ligaments, 1067 muscle, 1073

action of, 1076

Thyreo-epiglottic ligament, 1068

muscle, 1075

action of, 1076

Thyreo-glossal duct, 44, 1348

surgical anatomy of, 1348

Thyreo-hyal, 146

Thyreo-hyoid areh, 42, 43

bar, 44, 159

membrane, 1066

muscles produced from, 460

action of, 460

nerve of, 796

Thyreoid artery, inferior, 910

abnormalities of, 1037

morphology of, 1046

superior, 891

cartilage, 1062

development of, 1100

incisura of, 1062

inferior cornua of, 1063

laminæ of, 1062

linea obliqua of, 1063

ossification of, 1065

prominentia of, 1062

strperior cormua of, 1063

tubercle, inferior, of, 1063 smperior of, 1063

fascia, 1389

gland, 1347

accessory, 1348

blood and lymph vessels, 1348

capsule of, 1388

development of, $43,44,1348$

fascial comnexions of 1388

isthmus of, 1347

size of, 1347

surgical anatomy of, 1388

lateral lobes of, 1347

levator of, 460, 1347

pyramidal lobe of, 1347

structure of, 1348 
Thyreoid gland, surgical anatomy of, 1388 variations in, $13 \pm 7,1348$

rudiments, 1348

veins, 964,965

Thyreoidea ina arter'y, 888

Thyreotoms, 1388

Tiljia, 246

anterior crest of, 248

architecture of, 274

condyles of, 246

connexions of, 249

fibular notch of, 249

fossie of, 247

homology of, 295

intercondyloid eminence of, 247

interosseous crest of, 248

malleolus medial of, 249

mutrient foramina of, 249

ossification of, 250

platyknemia, 281

popliteal line of, $2+9$

shaft of, 248

surgical anatomy of, 1461

tubercles of, 247

tuberosity of, 248

variations in, 281

Tibial artery, anterior, 955

posterior, 952

recurrent, 956

nerve, 729,732

articular branches of, 732

cutaneous suræ lateralis, 732

Tibiale, os, 295

Tibialis anterior muscle, 424

action of, 424

surface anatomy of, 1465

yosterior muscle, 431 action of, 431

surface anatomy of, 1465

Tibio-fascialis anterior muscle, 424

Tibio-femoral index, 289

Tibio-fibular ligament, interosseous, 349 transverse, 349

syndesmosis 351

artieulation, 349

movements at, 349,350

Tibio-navicular ligament, 353

Toes, digital sheaths of, 430 movements of, 436

Tomes, filurils of, 1247 processes of, 1247

Tongue, 1124

anterior glands of, 1382

arteries of, 1130

development of, 45,1249

Jorsum of, 1124, 1125, 1126

folia of, 1124

foramen cactum of, $45,1126,1249,1381$

fremum of, 1128

sumprical antomy of, 138:3

glands of, 1130

inferior surfice of, 1128

lateril mincrin, 1125

lingual duet of, 1139

lympli follicles of, 1126

vessels of, $1005,1130,1383$

mucous nembrane of, 1129

muscles of, 462

surgical anatomy of, $13 \mathrm{~s} 2$

nerves of, 1131

oral part of, 1126

lapillice of, 1126
Tongue, pharyngeal part of, 1126 plicie fimbriatie of, 1128

raphe of, 1129

septum of, 1129

structure of, 1129

sulcus terminalis of, 1125

surgical anatomy of, 1381

taste-buds of, 854

thyreo-glossal duct of, $42,46,1348$

surgical anatomy of, 1381

vessels of, 1130

Tonsil or Tonsilla, arteries of, 1147

of auditory tube, 838

cerebelli, 575

develojment of, 1249

lingual, 1126

palatine, 1145

development of, 1249

lymph ressels of, 1147

nerves of, 1147

plica triangularis of, 1146

relations of, 1147

surgical anatomy of, 1383

pharyngea, 1143

surgical anatomy of, 1385

Tonsillar arteries, $114 \overline{7}$

lymph gland, 1392

nerve, 786, 1147

plexus, 1147

Tooth-band, 1245

Torus levatorius, 11 t 3

oceipitalis transversus, 27\%

palatinus, 279

tubarius, 1143

uretericus, 1277

Touch, organs of, 858, 863-866

Trabeculie lienis, 1353

carneæ, 877

corportum cavernosorum, 1300

cranii, 290

Trachea, 1078

bifurcation of, 1076, 1402

cartilaginous rings of, 1081

development of, 1100

fibro-elastic membrane of, 1081

mucous glands of, 1082

membrane of, 1082

muscle of, 1081

relations of, 1079

structure of wall of, 1081

surface and surgical anatomy of, 1388, 1402

thoracic part of, 1080

Tracheal arteries, 911 cartilages, 1081

Tracheotomy, high, 1388 low, 1388

Tract, antero-lateral, 535

bulbo-spinal, 537,538

bulbo-thalamic, 591

cerebro-pontine, 566

eircum-olivary, 557

ilio-tibial, 404

surface intitomy of, 1461

olivo-spinil, 538

proprius, $5: 37$

sino-lectal, 537

tecto-spinal, 5:37, 562

thatamo-olivary, 556

vestibulo-spinal, 537, 538

Tracts or 'Tractus, See also under Spinal mednllis

Burlach, 53], 53:3, 537, 547, 5.59 
Tracts or Tractus, callosal, crossed, 631 central tegmental, of puns, 568 cerebellar, 536, 537, 546, 563, 578 sensory, 538 sensory cerebellar, 538,546 cerebello-olivary, 556, 560 of corpus trapezoideum, 567 cortico-pontine, 653

frouto-pontine, in internal capsule, $6 \pm 2$ of Gowers, 535, 536, 546 gracilis, 533, 547, 559 interfiscicular, 533, 587

lateral cerebro-spinal (crossed jyramidal), $338,545,557,565$

anterior cerebro-spinal (direct pyramidal), 536, 539, 545

in cerebral hemispheres, 642,643

in internal capsule, 642

in medulla oblongata, 538,545

in pons, 565

of lemniscus, $568,570,585,586$

medial longitudinal, 562, 568, 570, 588

myelinisation of, 532, 533

olfactory, 623

lateral root of, 624

medial root of, 560

structure of, 623

optic, 619

cerebral connexions of, 620

commissural fibres of, 619

efferent fibres of, 619

lateral root of, 620

medial root of, 619

postero-lateral (of Lissaner), 534

rubro-spinal, 538, 588

septo-narginal descending, 535

solitarius, 597

spinalis of trigeminal nerve, 547,601

spino-thalamic, 535, 537, 562, 591

spiralis foraminosus, 844,845

superficial antero-lateral, 536, 546

temporo-pontine, 653

Tragicus muscle, 829

Tragus, 828

Transpyloric plane, 1411

Transverse artery of basilar, 907 cervical artery, 911

carpal articulation, 330

fissure of brain, 604

humeral ligament, 321

intermetacarpal ligament, 332

ligament of acetabulum, 339 of knee, 348

metacarpal ligaments, 333

metatarsal ligament, 360

perineal ligament, 338

processes of vertebræ, cerrical, $90,92,93$ lumbar, 90

sacral, 98

surgical anatomy of, 1393

thoracic, 93,94

scapular artery, 911

ligaments, superior and inferior, 320

vein, 911

tarsal articulation, $35 \%$

vesical fold, 1283

Transversalis fascia, 475

Transversus abdominis muscle, 480 auriculæ muscle, 830

perinei profundus muscle, 488

superficialis muscle, 487

thoracis muscle, 470
Transyersus of tongue, 463 vaginæ muscle, 489

Trapezius muscle, 365 sulgical anatomy of, 1437

Trapezoid ligament, 319 ridge of clavicle, 199

Traube, semilimar space of, 1418

Triangle of auscultation, 367

carotid, 1390, 1391

digastric, 1390, 1391

epigastric, 1397

femoral, 414

of Hesselbaclı, 483, 1235, 1408

lower carotid, 1393

lumbar, 478

of Petit, 367

of Macewen, 126, 168

medial supracondylar, 1447

of Petit, 1437

surgical anatomy of, 1437

rectal, of perineum, 1427

submental, 1387

suboccipital, 444

supramarginal, 1359

suprameatal, 126, 168

urogenital, 1427

Triangles of neck, 1387

Triangular ligament of liver, left, 1196

Triangularis (oris) muscle, 451 right, 1196

Triceps brachii muscle, 381 surgical anatomy of, 1437

suræ muscle, 428

Tricuspid a rea, 1405

orifice, 874,877

surface anatomy of, 1405 valre, 877

Trigeminal nerve, 771

development of, 683

main sensory nucleus of, 600

mesencephalic root of, 601

nature of, 602

motor nucleus of, 601

sensory root of, 600

tractus spinalis of, 601

Trigonum acustici, 551

collaterale, 636,637

femorale, 414, 1291

habenulæ, 614

of thalamus, 611

hypoglossi, 551, 594

of lateral ventricle, 636,637

olfactorimm, 623

vagi, 551

vesicæ, 1277

Triquetral bone of hand, 219 morphology of, 295 ossification of, 223

Trochanter major, 241, 1455

minor, 242

tertius, 242, 281

Troclılea, 206

of humerus, 208

of superior oblique muscle, 453

tali, 254

Trochlear fossa, 117

nerve, 770

development of, 683

mincleus of, 602

spine, 117

surface, 204, 208

Trochoid rotatory joint, 301 
Trolard, anastomotic vein of, 971

Tröltsch, recesses of, 842

Trophol,last, 21

Trunci lumbales (lymphatic), 997

Truncus corporis callosi, 630

costo-cervical, 914

intestinal, 997, 1210

jugular lymphatic, 998

lumbo-sacral, 727

suluclavius, 998

sympathicus, 753

Trunks of brachial plexus, 700, 742

of sacral plexus, $720,727,742$

Tubal artery, $9 \geq 8$

Tube, anditory, 44, 50, 52, 176

neural, 33

uterine, 1314

Tuber-- Tuberculum - Tulserositas - Tubercle or Tuberosity

accessory, 96

adductor, 242,245

surgical anatomy of, 1461

amygdaloid, 636

anterior of the atlas, 91

lielicis, 52, 828

thalami, 611

vertebrarum cervicalium, 90

anthelicis, 52, 828

antitragicum, 52,828

articular, of jaw, 125

of atlas, 91

of the auricle, 828

auricule Darwinii, 828

calcanei, 259

caroticum, 1395

cinereum, 541, 547, 615

development of, $3 \pm$

cloacal, 1328,1336

coracoid, of clavicle, 199

corniculate, of laryux, 1069

of Wrisberg, 1069

costal, of clavicle, 199

of cuboid, 263

cuneate, 547

cuneiform, 1069

deltoid, 207

of clavicle, 198

dental, 1114

dentis, 1114

dor'sal, of radius, 1450

epiglottic, 1069

of femur, 241, 242, 243

of fifth metacarial bone, 226, 1451

of fifth metatarsal, 267

frontal, 115

genital, 78, 1328

of humertus, 204, 206, 207

iliaca, 230

impar, 45,46

infraglenoidal, 201

intercondyloid lateral, 24

medial, 247

intermedium helieis, $S: 28$

intervenosum, 875

of ischium, 232

surgical anatomy of, 1455

jugular, 122

labial, 1109

lubular, 52, 828

majus humeri, 206

maxillary, 147,148

mental, 155
Tuber-Tuberculum - Tuberositas - Tubercle or Tuberosity, minus humeri, 206

of navicular bone of hand, 218 surgical anatomy of, 1451

of foot, 261 surgical anatomy of, 1464

obturatorium anterius, $23 \pm$ posterius, 234

olfactory, 623

omentale hepatis, 1193

pancreatis, 1206

of palate bone, 152

papillare hepatis, 1192

parietal, 118

peroneal, 1464

pharyngeal, 123, 176, 179

posterius atlantis, 91

vertebrarum cervicalium, 90

post-glenoid, 126, 278

pterygoid, 138, 175

pubicum, 233, 237

for the quadratus, 240

of radius, 215

of rib, 109, 111, 112

of Santorini, 1069

scalene, 111

supraglenoidal, 201

supratragicun, 52, $\$ 28$

of talus, 254

of tibia, 246,248

tragicum, 52, $82 \mathrm{~S}$

uluæ, 210

vermis cerebelli, 575

vertebrarterial, 1395

of Wrisberg, 1069

of zygoma, 153

Tubercular point of hip, 1455

process of vertebra, 284

Tubes, bronchial, in lung, 1097

dentinal, 1045, 1247

Tubular glands, 1132

Tubules of kidney, 1266

of par-oüphoron, 1316

Wolthian, 1328

Tubuli recti testis, 1288 renales, 1266

seminiferi contorti, 1288 recti, 1288

Tunica albuginea, 1288, 1300 of corpus cavernosum penis, 1300 conjunctiva lualbi, 8으 palpebrarum, 823

dartos, 1298

exterina or adventitia of arteries, $86 S$ of lymph ressels, 994 of veins, 869

filorusa of lidneys, 1255

interna or intima of artelies, 868 of lymph vessels, 994 of veins, 869

media of arteries, s6is

of lymph ressels, 994

of veins, 869

mucosa linguie, 1129

tubie auditivie, $8: 38$

tymparica, 8.2

serosa, 1234

vaginalis, 1287

vaseulo:i veuli, 810,814

Tumnel of Corti, 850

'Tymu'anic antrum, 834, 8:36, 1:36?, 1:371 aditus of, 834,1369 
Tympanic antrum, development of, 133

relation of, to supra-meatal triangle, 1369

to tympanum, 834

surgical anatony of, 1369

arteries, anterior, of internal maxillary, 898

inferior, of pharvngeal ascending, 896

of internal carotid, 902

posterior, of stylo-mastoid, 895

superior, of middle meningeal, $89 \mathrm{~s}$

attic, 136s, 1369

surgical anatomy of, 1368

canal, 129

cavity, 52, 191, 192, 832

atrium of, 832

danger of injury to lateral semicircular duct in, 1371

development of, 842

facial nerve in, 1371

formation of, 842

membrana tympani secundaria of, 833

mucons membrane of, 842

muscles of, 841

nerves of, 842

opening of, 1371

of the molar teeth into, 1113, 1119

orifice of auditory tube in, 750

pouch of Prussak, 842

promontory of, 832

pyramid of, 834

recesses of Tröltsch, 842

recessus epitympanicus of, 832

relation of, to tympanmm, 834

surgical anatomy of, 1368

vessels of, 842

walls of, 832

carotic, 834

jugular, 832

labyrinthic, 832

mastoid, 834

membranous, 834

tegmental, 832

groove, 834

membrane, 834

folds of, 835

paracentesis of, 1368

surgical anatomy of, 1367

triangular cone of, 835

nerve, 836

ossicles, 838

part of temporal bone, 127, 132, 133

ossification of, 132, 133

sexual difference in, 194

plate, fibrous, 831

plexus, 759

ring, 133

Tympano-hyal, 132

Tympano-mastoid fissnre, 127

Typical segmental nerve, 692

Ulna, 210

architecture of, 272

connexions of, 213

homology of, 2.95

ossification of, 213

surgical anatomy of, 1449, 1451

variations in, 280

Ulnar artery, 921

collateral artery, 899

furrow, 213

nerve, 708

notch, 216

veins, 977
Ulnare, os, 295

Ultimo-branchial body, 44, 1352

Umbilical arteries, 65, 939

cord, 55

fissure, 1191

fossa, 1191

notch, 1191

region, 1411

vein, 1036, 1037

vesicle, 22,53

zone, 1411

Umbilicus, development of, 39 primitive orifice of, 38

Umbo membranæ tympani, 835

Uncinate process of ethmoid, 141 of pancreas, 1205

Uncus, 629

Ungual phalanges of fingers, 227 surgical anatomy of, 1444 of toes, 268

Ungues, 858

Urachus, 48, 1283, 1332

Ureter, 1268

abdominal part of, 1268

calibre of, 1270

development of, 1331

in female, 1270

surgical anatomy of, 1434

orifice of, 1277, 1278, 1428

pelvic part of, 1269

position of, 1426

posterior position of, 1437

structure of, 1270

surgical relations of, 1426

variations in, 1271

vessels and nerves of: 1271

Ureteral artery of internal spermatic and ovarian, 928

of renal, 927

Urethra, 1284

bulb of, 1308

cavernous part, 1304,1308

portion of, 1308, 1309

crista urethralis of, 1284, 1303, 1306 male, 1306

development of, 1333, 1334

external orifice of, 1284 surface anatomy of, 1427

female, 1284

development of, 1333

fossa navicularis nrethræ, 1308

glands of, 1285, 1304, 1309

internal orifice of, 1277,1278

lacunæ of, 1285, 1309

male, 1304

surgical anatomy of, 1428

masculinus, 1306

membranous part, 1304, 1307

surgical anatomy of, 1427

para-urethial duct of, 1285

prostatic part, 1304, 1305

rupture of, 1427

structure of, 1285, 1309

surgical anatomy of, 1427

utriculus prostaticus, 1306

Urinary bladder, 1271, 1278

capacity of, 1277

development of, 1328, 1332

distended, 1276

empty, 1275

in female, 1278

in infant, 1279 
Urinary bladder, interior of, 1277 urachus of, 1280, 128:3

ureteral orifices of, 1278

urethral orifice of, 1273,1274

Urogenital canal, 1329

cleft, 1336

diaphragm, 489, 491

relation of, to fascia of pelvis, 489,491

fissure, 1336

organs, development of, 1327

space, 1335

system, 1257

triangle of perineum, 1427

Uterine artery, 928

of orarian, 928

surgical antatomy of, 1435

decidua, 57

glands, 1230

plexus, 765,766

tube, 1310,1314

abdominal ostium of, 1314 .

ampulla of, 1314

appendices vesiculosi of, 1316

development of, 1335

fimbriae of, 1314

infundibulum of, 1314

isthmus of, 1314

mesosalpinx of, 1314

nerves of, 1315

ovarian fimbria of, 1314

pars uterina of, 1315

plice of, 1315

structure of, 1315

surgical anatomy of, 1436

uterine ostium of, 1315

ressels of, 1315

veins, 985

venous plexuses, 985

Utero-sacral ligaments, 1318

Utero-vesical fold, 1317

pouch, 1238, 1317

Uterns, 1316

age differences in, 1320

anteflexed, 1319

anteverted, 1319

arbor vitie of, 1317

body of, 1316

broad ligaments of, 1238

surgical anatomy of, 1431

cavity of, 1317

cervical callal of, 1317

ganglion of, 1321

cervix of, 1316

commexions of, 1317

development of, 1335

at different ages, 1320

external orifice of, 1316

fundus of, 1316

glands of, 1320

horns of, 1320

internal orifice of, 1317

intestinal surface of, 1316

lips of cervix, 1316

lymph vessels of, 1321

masculinus, 1306

in menstruation, 1320

nerves of, 1321

orifice, exterual of, 1317

internal of, 1316

periodic changes in wall of, 1320

peritoneal relations of, 1317

plice palmatie of, 1317
Uterus, position of, 1319

pregnant, 1321

relations of, 1319

retrorerted, 1319

round ligament of, 1319

septum of, 1320

structure of, 1320

supra-raginal part of cervix, 1316

surgical anatomy of, 1434,1435

vaginal part of cervix, 1316

variations in, 1320

resical surface of, 1316

vessels and nerres of, 1321

Utricle, 846

development of, 52

macula acustica of, 816,857

recessus of, 846

sinus superior of, 846

Utriculus prostaticus, 1292, 1306

Uvula cerebelli, 576

palatina, 1111

vesicæ, 1277

Vagina, 1321

bulbs of, 1326

carina urethralis of, 1323

carunculæ hymenales of, 1322

columns of, 1323

development of, 1335

digital exploration of, 1435

fornix of, 1321

hymen of, 1322

introitus of, 1325

lymph vessels of, 1324

mucous membrane of, 1323

muscular coat of, 1323

nerves of, 1324

orifice of, 1325

relations of, 1322

rugæ of, 1323

septum of, 1320

structure of, 1323

variations in, 1320

ressels and nerres of, 1321

vestibule of, 1325

Vagina mucosa intertubercularis musculi bicipitis brachii, 380

musculi recti abdominis, 482

nervi optici, 808

opening of, 1325

processus styloidei, 127

tendinis musculi extensoris carpi ulnaris, 384 digiti quinti, 384 hallucis longi, 431 pollicis longi, 384

flexoris hallueis longi, 431 pollicis longi, 390

peronei longi plantaris, 426

tibialis anterioris, 424 posterioris, 431

tendinum digitalis, 388,389 perlis, 430

musculi extensoris digitorum perlis longi, 425

flexoris digitor'um pedis longi, 430

musculorum abcluetoris lungi et extensoris brevis pollicis, 383

extensoris digitorum communis et extensoris indicis, 38 .

extensorum carpi radialium, 384

jeronieorum communes, $4 \cdot 23$

Taginal artery, 939, 1324 
Taginal, examination of, 1435

ligaments, 354

persistence of, 1409

plexus, 766,985

process of temporal bone, 127,177

sphenoid bone, 17 .

reins, 985

venous plexuses, 985

Tagus nerre, 786, 788

aldominal brauches, 789

auricular branch of, 788

cardiac nerves, inferior, of vagus, 789

recurrent, of vagus, 789

stiperior, of vagus, 789

commmications of, 788

derelopment of, 684

external branch of, 788

internal brauch of, 788

lingual branch of, 788

meningeal branch of, 788

nuclei of, 596

pharrngeal branch of, 788

superior laryngeal nerve, 788

thoracic branches, 789

Vallate papillæe, 1127

vallum of, 1127

Tallecula, 574

cerebelli, 1126

epiglottica, 1068

of larynx, 1068

Talve or Valves, anal, 1230, 1231

aortic, 878

cusp of, 878

of Beraud, 825

coli, 1214, 1215

lips of, 1214

position of, 1214

structure of, 1214

of the coronary sinus, 875

fossæ navicularis, 1309

of Hasner, 825

of heart, positions of, 1405

ileo-cæcal, 1215

surface anatomy of, 1421,1443

of the inferior vena cava, 875

limule of, 877

of lymph ressels, 994

mitral, 878

nodule semilumar of, 877

pulmonary, 877

processus vermiformis, 1216

pyloric, 1166, 1173, 1174

rectal, 1230, 1231

sinus coronarii, 875

spiral, of gall-bladder, 1201

structure of, 1202

tricuspid, 871

valve of fossa navicularis, 1308

of reins, 869

of the vena cava, 874

venæ cavæ inferioris, 875

venous, of heart, 1032

V as afferens renis, 1267

efferens renis, 1267

prominens, 849

spirale, 849

Vasa aberrantia, 1055

efferentia testis, 1288

intestini tenuis, 932

sanguinea retinæ, 818

vasorum, 870

Vasenlar area, 64
Tascular system, 64, 867

abnormalities of, 1049

blood, 867

development of primitive, 63

divisions of, 870

lymph, 867

morphology of, 1042, 1047

primitive, 65,1025

Vastus intermedius muscie, 409

lateralis muscle, 407

medialis, 408

Vein or Veins; Vena or Venæ, 958

abnormalities of, 1057

advehentes, 1037

allantoic, 68

anal, 984

anastomotic, posterior, 971 great, of Trolard, 971

angular, 965

anonymæ dextra et simistra, 962

anterior pyloric of Mayo, 1416

appendicular, 1421

aqnæductns vestibuli, 853

arciform of kidney, 1267

auditory internal, 853

anricular anterior, 830, 967

posterior, 967

axillary, 977

abnormality of, 1447

development of, 1042

relations of, 977

surface anatomy of, 1447

tributaries of, 978

azygos, 960

abnormality of, 1057

development of, 1040

morphology of, 1048

hemiazygos, 961

abnormalities of, 1057

development of, 1040

morphology of, 1048

accessoria, 961

abnormalities of, 1057

development of, 1040

morphology of, 1048

tributaries of, 961

basal, 971

basilic, 979

abnormalities of, 1058

development of, 1042

morphology of, 1049

surface anatomy of, 1447,1418

basis of vertebræ, 976

of bones, 87

brachial, 977

of brain, 970

bronchial anterior, 961 posterior, 961

morphology of, 10 18,1049

canaliculi cochleæ, 965

canalis pterygoideæ, 968

capillary, 867

cardiac, anterior, 960

great, 959

inferior, 960

middle, 960

oblique of left atrinm, 960

small, 959

smallest, 960

cardinal, anterior, 69, 1038

morphology of, 1048

posterior, 69, 1040 
Tein or Veins-continued

cava inferior, 980, 983

abnormality of, 1058

development of, 70,1040

fossa of, 1192, 1195

morphology of, 1048

orifice of, 873,875

surface anatomy of, 1426

superior, 960

abnormality of, 1057

development of, $70,1035,1036$

morphologs of, 1048

orifice of, 873,874

surface anatomy of, 1405

centralis retinæ, 818

cephalic, 978

abnormality of, 1058

development of, 1042

morphology of, 1049

surface anatoms of, 1448

cerebellar, 971

deep, 971

cerebral, 970,971

anterior, 971

basal, 971

deep, 971

middle, 971

inferior, 971

magna Galeni, $976^{\circ}$

superficial, 971

middle, 971

superior, 971

cervical, transverse, 967

cervical deep anterior, 963

posterior, 963

transverse, 967

chorioid, 970

ciliary, 814

circumflex ilii deep, 988 superficial, 989

colic, right, 992

middle, 992

left, 992

comitans, 959, 1049, 1059

conjunctival, 824

coronaria ventriculi, 991, 998

of corpus striatum, 970

of cranium, 969-976

cystic, 990,992

deep, of trunk and limbs, 963

dental, inferior, 968

superior, 968

development of, 1035

digital, of foot, 988 morphology of, 1049

of hand, 978

diploic, 969

frontal, 969

occipital, 970

temporal, 969

dorsal, of clitoris, 9.12

linguæ, 965

of penis, 985

deep, 985

superficial, 985

duodenal, 992

elastic layer of, 869

emissary, 975

parietal, 968

endothelium of, 869

epigastric, inferior, 988

superficial, 986
Vein or Veins-continued

epigastric, superior, 968

of extremities, development of, 1042

facial, anterior, 965

surface anatomy of, 1391

common, 965

surface anatomy of, 1392

posterior, 968

deep, 965

femoral, 986

morphology of, 1049

tributaries of, 987

of forearm and arm, superficial, 978

frontal, $96 \bar{\tau}, 969$

gastric, right, 992

gastro-epiploic, 992

gluteal, inferior, 984

superior, 984

great cerebral, 970

hæmorrhoidal, inferior, 984

(media), 984

superior, 992

of head and neck, 964

of heart, 959

morphology of, 1048

hemiazygos, 961

accessoria, 961

hepatic, 982

abnormalities of, 1058

development of, 1037

interlobular, 1200

morphology of, 1049

sublobular, 1200

hypogastric, 984

development of, 1040, 1041

morphology of, 1048

ileo-cæcal, 990

ileo-colic, 990

iliac, common, 983

abnormalities of, 1058

derelopment of, 1040

left, 983

morphology of, 1048

right, 983

surface anatomy of, 1427

tributaries, 983

external, 986-988

ilio-lumbar, 983

infra-orbital, 968

innominate, 962

left, 962

development of, 1040

morphology of, 1048

right, 962

development of, 1040

intercostal, 961

anterior, 961

left superior, 961

derelopment of, 1040

morplology of, 1048

posterior, $96 \mathrm{i}$

first left, 961

first right, 961

right superior, 963

morphology of, 1048

right superior, 961

intercosto-brachial, 714

interdigital, of foot, 954

of hand, 924

interlobar, of the kidney, 126 -

interlobular hepatic, 982 of the kiclney, 1267 
Tein or Teins-continued internal cerebral, 970 interosseous, of hand, 978 interventricular, inferior, 960

intervertebral, 976

intestinal, 99:, 1210

jugular, anterior, 967 abnormalities of, 1057

external, 966

abnommalities of, 1057

derelopment of, 1010 surgical anatomy of, 1391

internal, 964

abnormalities of, 1057

bullb of, 964

development of, 1040

morphology of, 1048

surgical anatomy of, 13.)1

jugular, posterior external, 966 primitive, 1040

labial, 1109

of large intestine, 992,993

lingnal, 965,1130

surgical anatomy of, 1382

of liver, 980,990

of lower limb, 985

abnormalities of, 1059

deep, 986

derelopment of, 1042

morphology of, 1049

superficial, 988,990

lumbar, 982

development of, 1042

abnormalities of, 1058

ascending, 961, 982

development of, 1041

morphology of, 1048

lymph vessels of, 870

magna cerebri, 970

mammary, internal, 962, 977

mandibular, 993

masseteric, 965

maxillary, internal, 968

morphology of, 1048

median, of bulb, 972

anterior, 972

antibrachii, 980

abnormalities of, 1058

development of, 1042

surgical anatomy of, 1450

basilic, 980

surgical anatomy of, 1450

cephalic, 980

abnormalities of, 1058

basilic, 979

cubital, 979

surgical anatomy of, $1 \pm 50$

of forearm, 980

posterior, 972

mediastinal, 961, 963

of medulla oblongata, 972

meningeal, 970

mesenteric, inferior, 992

morphology of, 1049

superior, 992

tributaries of, 992,993

morpliology of, 1049

metacarpal, dorsal, 978

of mid-brain, 971

minimæ cordis, 960

morphology of, 1047

muscle-fibres of, 869
Vein or Veins-continued

musculo-phrenic, 963

nasal, 806

nerves of, 870

of the nose, 988

obliqua atrii sinistri (Marshalli), 70, 872, 960

obturator, 984

occipital, 967,970

œsophageal, 1155

ophthalmic, inferior, 968

superior, 968

of orbit, 968

orarian, 1048

abnormality of, 1058

morphology of, 1048

palatine, posterior, 965

palpebral, 824

pancreatic, 1208

pancreatico-duodenal, 1208

parotid, 965, 1137

pharyngeal, 965

canal, 968

phrenic, 982

of the pons, 971

popliteal, 986

abnormalities of, 1059

portal, 990

branches of, 991

capillaries of, 990

development of, 1037

morphology of, 1048

primitive development of, 1026

sinus of, 990

surgical anatomy of, 1416

tribntaries, 991

primitive head, 69

profunda clitoridis, 984

penis, 984

proper dor'sal digital, 978

volar digital, 978

pterygoid, 968

of pterygo-palatine region, 968

pterygo-palatine, 968

pubic, 988

pudendal, internal, 985

superficial, 988

pulmonary, 109, 958

development of, 1049

morphology of, 1049

orifices of, 875

relations of, 958

pyloric, 992

morphology of, 1048

radial, 919

abnormalities of, 1058

development of, 1042

morphology of, 1049

radicular, of bulb, 972

ramine, 965, 1130

surgical anatomy of, 1383

of rectum and an us, 1233

renal, 982

abnormalities of, 1058

development of, 1040

morphology of, 1048

revehentes, 1037

sacral, 983

middle, 983

saphena magna, 988, 989

abnormalities of, 1059

development of, 1042 
Vein or Veins-continued

saphena magna, morphology ot, 1049

parva, development of, 1042 morphology of, 1049

surgical anatomy of, 1459, 1463

of scalp, 967

surgical anatomy of, 1357

scapular, transverse, 967

sciatic, 984

of scrotum, 1298

segmental, 1048, 1049

sigmoid, 993

spermatic, 983

abnormalities of, 1058

development of, 1040

morphology of, 1048

surgical anatomy of, 1430

spheno-palatine, 968

spinal, 977

longitudinal anterior, 977 posterior, 977

of spinal medulla, 977

splenic, 992

sternal, 963

of stomach, 991, 992

striate, inferior, 971

structure of, 869

subcardinal, $10 \pm 1$

subclavian, 965

abnormalities of, 1058

development of, 1040

morphology of, 1049

relations of, 965

surgical anatomy of, 1395

tributaries of, 966

superficial, of trunk and limbs, 978, 988

superior vena cava, 960

relations, 960

tributaries, 960

supra-orbital, 967

suprarenal, 982

abnormalities of, 1058

development of, 1040

morphology of, 1048

systemic, general arrangement of, 959

temporal, deep, 968

anterior, 969

posterior, 969

superficial, 967

temporo-mandibular, 965

abnormalities of, 1058

morphology of, 1048

terminalis, 970

testicular, 983

thyreoid, inferior, 964

morphology of, 1049

surgical anatomy of, 1389

middle, 965

superiores, 965

tibial, anterior, 986

posterior, 986

tonsillar, 1147

transverse cervical, 967

scapular, 967

tunica externa of, 869

intima of, 869

valves of, 869

media of, 869

tympanic, 842

nlnar, $97 \%$

development of, 1042

morphology of, 1049
Vein of Veins-continued

umbilical, 68

impar, 66, 68, 1036

lateral, 66,1036

subcardinal, 70

development, 1036

of upper limb, 977

abnormalities of, 1058

deep branches of, 977

development of, 1042

morphology of, 1049

superficial branches of, 978 abnormalities of, 1058

uterine, 985

vaginal, 985

valves of, 869

of vertebræ, 976

vertebral, 963,976

vesical, 1284

vessels of, 870

restibular, 853

visceral, 1048

morphology of, 1048

vitelline, 56

vitello-umbilical, 69

vorticosæ, 808

Velum, 549

anterior medullary, 569

development of, 33

palati, 1111

posterior medullary, 576

Vena azygos, 960

cava, inferior, 980

relations of, 980

tributaries of, 981

Venous arch, dorsal, of foot, 988 of hand, 918

transverse, of foot, 989

ligament (Arantius) of liver, 1196

sinuses of cranium, 969

system, portal, 990

primitive development of, 68

valves of heart, 874,875

Ventral aorta, 1026, 1027

Ventricles, cerebral, development of, 514, 517

fourth, 36,549

acoustic area of, 551

area postrema of, 551

calamus scriptorius of, 550

chorioid plexuses of, 674

eminentia medialis, 551

floor of, 550

fossa rhomboidea of, 550

fovea, inferior, of, 550

superior, of, 551

funieulus separans of, 551

lateral apertures of, 553

recess, 549

locus corrulens of, 551

medial apertures of, 553

obex of, 579

roof of, 549,578

striæ medullaris of, 550

substantia ferruginea of, 551

tegnen of, 549

trigonum acnstici of, 551

liypoglossi of, 551

vagi of, 551

lateral, 621,632

anterior cornu of, 632, 634

body of, 633

bulb of, 635 
Teutricles, cerebral, lateral, calcar avis of, 635 chorioid plexus of, 636

cornu posterius, 633, 635

derelopment of, 621

eminentia collateralis of, 636

floor of, 636

foramina of, 621,632

hippocampus of, 636

horns of, 633,635

surgical anatomy of, 1359

inferior cormu of, 633,635

nuclei of, $635,636,637,638,639$

pars centralis of, 633,634

shape of, 633

trigonum of, 636

third, 616

chorioid plexus of, 674

floor of, 616

foramina of, 618

front wall of, 617

infundibulum of, 616

derelopment of, 616

lateral wall of, 617

massa intermedia of, 617

recessus opticus of, 618

pinealis of, 618

roof of, 617

suprapinealis of, 618

sulens hypothalamicus, 618

tela chorioidea of, 617

walls of, 617

of heart, 876

development of, 1032

left, 877

aortic orifice of, 878 valve, 878

mitral cusps of, 878

orifice of , 878

valve of, 878

muscle of, 878

right, 876,877

atrio-rentricular orifice of, 877

chordæe tendineæ of, 877

conus arteriosus of, 876

infundibulum of, 876

moderator band of, 877

muscular papillares of, 877

pulmonary orifice of, 877 valve, 877

trabeculæ carmeæ, 877

tricuspid ralve, 877

septum of, 876

abnor'mality of, 1050

of larynx, 1071

development of 1032

Ventricular septum of heart, 876,898

Ventriculus, terminalis of spinal medulla, 526

Tera cerebri magni, 674

terminalis (of brain), 674

Vermiform process, 1215

in animals, 1217

blood-ressels of, 1217,1421

cavity of, 1216

development of, 48

at different ages, 1216

lymph nodules of, 1217

vessels of, 1217

mesenteriolum of, 1216

morphology of, 1217

orifice of, 1216

position of, 1421

size of, 1216
Termiform process, structure of, 1217 surgical anatomy of, 1421

valve of, 1216

vessels of, 1217

Vermis cerebelli, 572, 574

Vernix caseosa, 862

Vertebra or Vertebræ, 87 accessory process of, 96 anticlinal, 101

arch of, 88

architecture of, 81

articular processes, 89

cervical, 90, 91

characteristics of, 90

coccygeal, 88, 99

ossification of, 106

common characters of, 88

epiphyses of, 104

false, 85

fifth lumbar, 96

fixed, 88

furcalis, 276

laminæ, 89

lumbar, 95

characteristics of, 95

mammillary processes of, 96

movable, 88

ossification of, 104

prominens, 93

psendo-sacral, 284

relation of, to spinal medulla, 519

important structures to spines of, 1442 , 1443

to spinal nerves, 678

sacral, 96-98

ossification of, 104

serial homology of, 283

special 9th, 10th, 11th, 12th, 94

thoracic, 93

characteristics of, 93

true, 88

typical, 88

variations in, 275

veins of, 963

Vertebral aponeurosis, 365

arch, 88

arterial tubercle, 1395

artery, 910

border of scapula, 199

bow, 103

canal, 88

development, early, of, 29

membranous, 29

column, 87

articulation of, with cranium, 310

canal of, 102

cartilaginous, 103

curves of, 100

development of, 102

intervertebial foramina, 102

length of, 102

ligaments of, 305

membranous, 29, 102

movements of, 309

surgical anatomy of, 1442, 1443

variations in, 275

as a whole, 100

foramen, 88

formula, 88

line of pleural reflexion, 1086

plexıs, 759

roots of arches, 88 
Vertebral vein, 963

Vertebrarterial foramen, 88, 89, 90 serial homology of, 283 variation in, 275

Vertebrate theory of skull, 293

Vertebro-chondral ribs, 109

Vertebro-sternal ribs, 109

Vertex, 285

Vertical plate of palate bone, 150

Vesalius, foramen of, 136

Vesica fellea, fossa for, 1191

urinaria, 1271

body of, 1274

fundus of, 1274

internal urethral orifice of, 1273

peritoneal relations of, 1272

position of, 1272

vertex of, 1274

Vesical arteries, 939

inferior, 939, 1284, 1295

middle, 939

of obturator, 940

superior, 1284, 1295

plexus of nerves, 766

venous, inferior, 985 superior, 985

Vesicle, anditory, 506

cerebral, 514

germinal, 22

optic, 825

otic, 51,853

recessus labyrinthi of, 853

umbilical, 55

Vesico-vaginal artery, 939

Vesicula seminalis, $1286,1290,1295$ development of, 1327,1336

structure of, 1286

vessels of, 1289

Vestibular area, 846

ganglion, 785

gland, larger, 1326, 1327

smaller, 1326

nerve, 8.53

Vestibule or vestibulum, aortic, 843 aquæductus vestibuli, 843

bulb of, 1326

of labyrinth, 843

aqueduct of, 843

bursæ omentalis, 1239

crista of, 843

development of, 853

fissnra of, 844

lamina spiralis ossea of, 844 secundaria, 844

macula cribrosa of, 84

of mouth, 1107

pars intermedia of, 1326

pyramis vestibuli, 843

recessus cochlearis of, 843

ellipticus of, 843

spliericus of, 843

of larynx, 1069

nasi, 802

oris, 1106

vagina, 1325

bulb of, 1326

glands of, 1326

Vestigial fold of Marshall, 882

of pericardium, 872,88 ?

Vibrissæe, 802

Tilli, absorbent, 59

anchoring, 59
Villi, arachnoideal, 672

chorionic, 54

intestinal, 1179

primary chorionic, 53,58

secondary chorionic, 58

Vincula accessorius, 430

brevia, 389

digitorum profundus, 389

sublimis, 388

of flexor digitorum longus, 430

longa, 389

tendinum, 388

Visceral arches, 42

clefts, 42,46

intermediate arteries, 1043, 1046

veins, 1048

Visual areas and fibre tracts, 658 purple, 815

Vitelline body, 14

duct, 48,55

membrane, 13

veins, 66

Vitello-intestinal duct, $38,48,55$

Vitellus, 14

Vitreous body, 819

arteria hyaloidea, 819

canalis hyaloidens of Stilling, 819

composition of, 819

development of, 826

fossa patellaris of, 819

hyaloid fossa of, 819

membrane of, 819

spatia zonularia, 819

suspensory ligament of lens, 819

zonula ciliaris of, 819

Vocal folds, 1070

Voice, organs of, 1061

Volaris profunda artery, 923

superficialis artery, 922

Vomer, 144

alæ of, 144

architecture of, 271

connexions of, 147

ossification of, 144

variations in, 279

Vomerime cartilage, 801

Vulva, 1324

anterior commissure of, 1324

bulbus vestibuli of, 1326

clitoris of, 1326

development of, 1335

fossa navicularis of, 1325

frenulum clitoridis of, 1326

labia majora of, 1324

minora of, 1324

mons Veneris of, 1324

nerves of, 1324

posterior commissure of, 1324

præputium clitoridis of, 1326

surgical anatomy of, 1436

urogenital space of, $1325,1328,1336$

ressels of, 1326

vestibular glands of, 1326,1327

vestibule of, 1326

Wagner, corpuscles of, 865

Walking, movements of, 436

Wallerian degeneration, 532

Weight of the brain, 667

of the heart, 880

Wharton, duct of, 1138

surgical anatomy of, 1383 
White line of anus, 1232 of pelris, 491, 493

White matter of cerebellum, 516 of cerebral hemispheres, 647,653 development of, 503, 505 of medulla oblongata, $557,560,562$ of spinal medulla, 531, 539

Willis, circle of, 908

Wind pipe, 1078

Wing, of sphenoid, orbital, 135 temporal, 136

Tirsung, duct of, 1206

Wisdom teeth, 1114, 1118

Wolffian body, 1329

duct, 1329

glomeruli, 1329

ridge, 39

tubules, 1329

Tomb, 1316

Tormian bones, 145, 277, 278

Wounds of the scalp, 1357

Wrisberg, ganglion of, 790

Wrist, arterial arches of, 920, 922, 923

bones of, 217

ligaments of, 329

movements at, 334

synovial sheaths at, 388,389

IVry neck, 1390

I-ray examination of the stomach, 1173

Iiphisternal joint, 316 surface anatomy of, 1397, 1407

Xiphoid artery, 914 cartilage, 108

Y-shaped ligament of Bigelow, 340

Yellow marrow, 83

Yolk, 14

nutritive, 14

sac, $38,48,55$

Zahnleiste, 1245

Zona arcuata, 850

fasciculata of suprarenal gland, 1346
Zona, glomerulosa of suprarenal gland, 1346 orbicularis of hip-joint, 340

pectinata, 850

pellucida, 11

reticularis of suprarenal gland, 1346

striata, 11

Zones, abdominal, 1411

costal, 1158

epigastric, 1159

hypochondriac, 1159

hypogastric, 1158, 1159

iliac, 1159

lumbar, 1159

umbilical, 1158, 1159

Zonula ciliaris, 819

Zygapophyses, 283

of vertebræ, 89,284

Zygomatic arch, 167, 169

surface anatomy of, 1364, 1365, 1367 1375

bone, 153

architecture of, 271

connexions of, 154

ossification of, 154

relation of, to orbit, 162,164

variations in, 279

centre, 150

crest, 137,154

fossa, 168,175

head of quadratus labii superioris muscle 451

lymph glands (anterior auricular), 998

nerves, of facial, 784

of maxillary, 778

process, 148

processes of, 153

tuberosity, 153

Zygomatico-facial canal, 154

Zygomatico-orbital artery, 897 canal, 154

Zygomatico-temporal canal, 154

$Z$ ygomaticus muscle, 451

actions of, 452

Zygote, 13, 16 



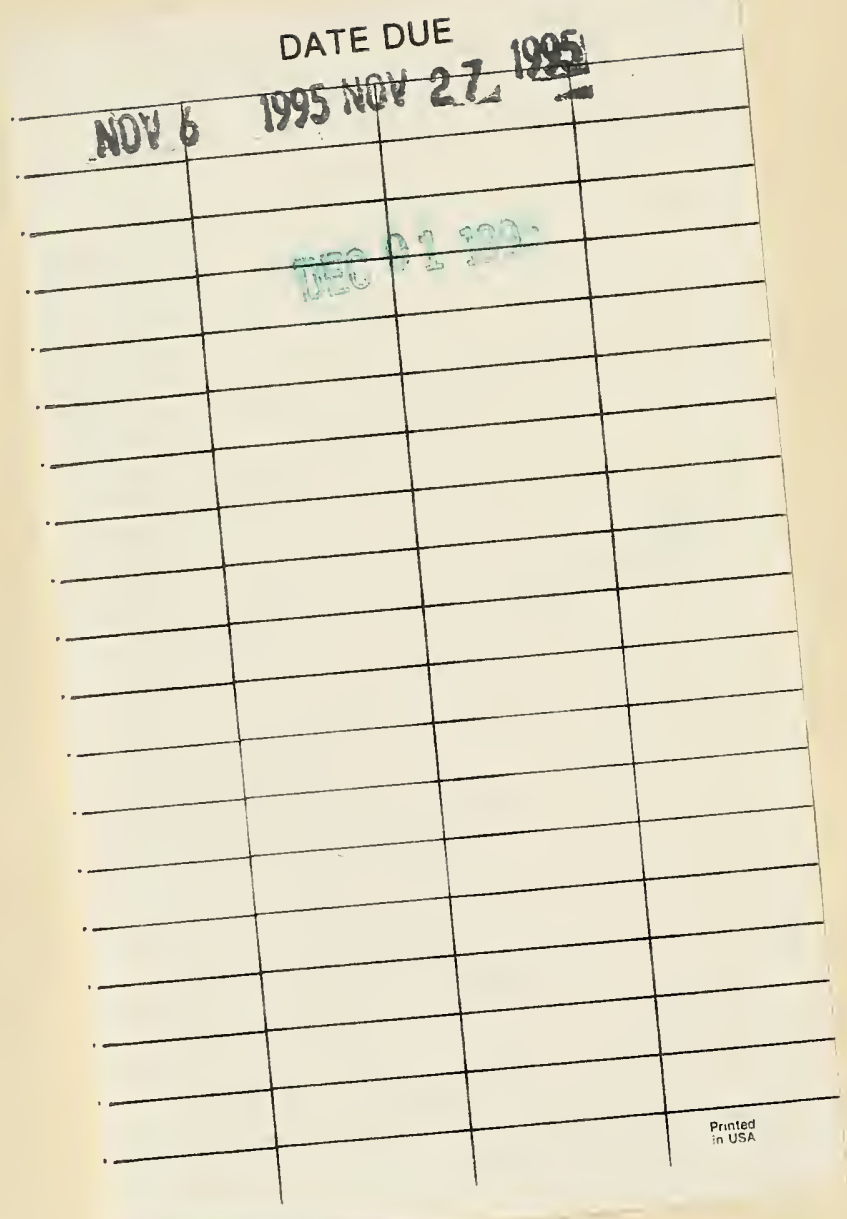




\section{COLUMBIA UNIVERSITY LIBRARIES (hSI, StX \\ QM 23 C91 1914 C. 1 \\ Cunningham's Text-book of anatomy.

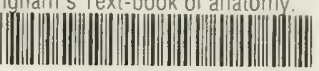 \\ 2002145464}

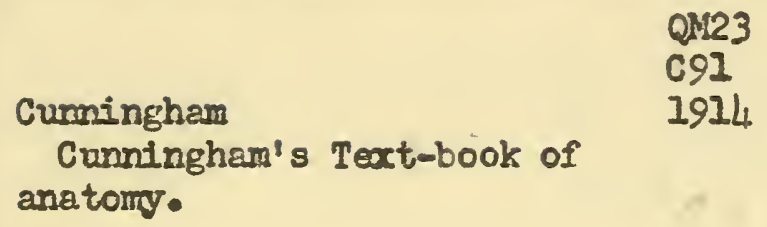


